


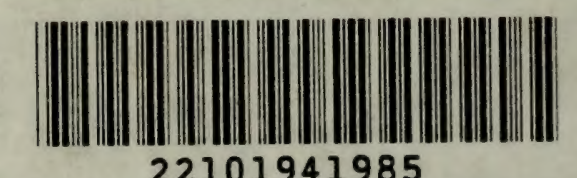

22101941985 

$\mathrm{B} / 3 \mathrm{O}^{-2} \mathrm{C}^{2}$ 

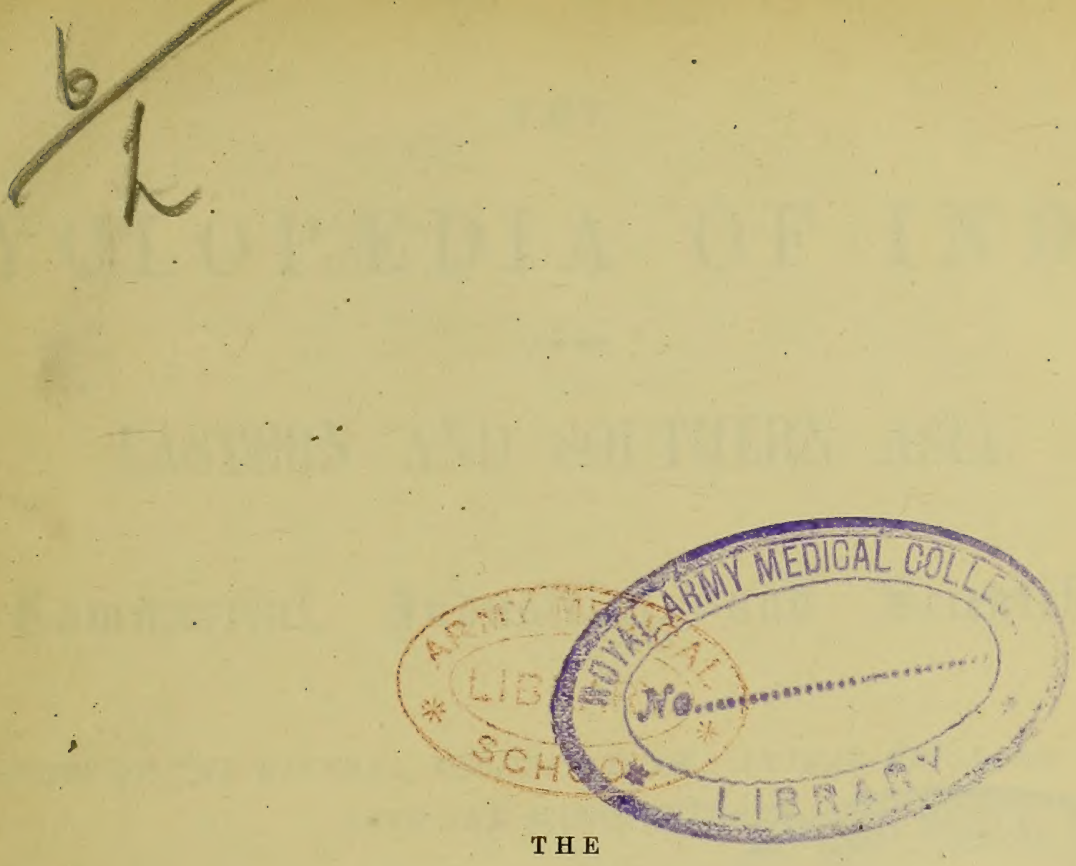

C Y CL.OP EDIA OF INDIA

AND OF

EASTERN AND SOUTHERN ASIA.

THIRD EDITION 


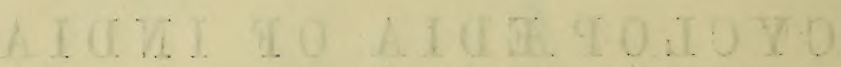

MORRISON AND GIBB, EDINBURGH, PRINTERS TO HER MAJESTY'S STATIONERY OFFICE. 


\section{CYCLOPADIA OF INDIA}

AND OF

\section{EASTERN AND SOUTHERN ASIA,}

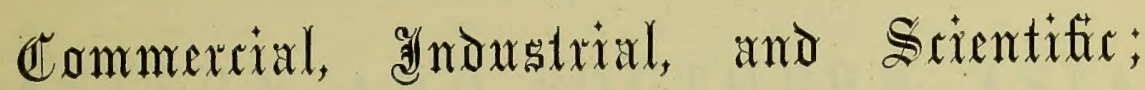

PRODUCTS OF THE MINERAL, VEGETABLE, AND ANIMAL KINGDOMS, USEFUL ARTS AND MANUFACTURES.

BY

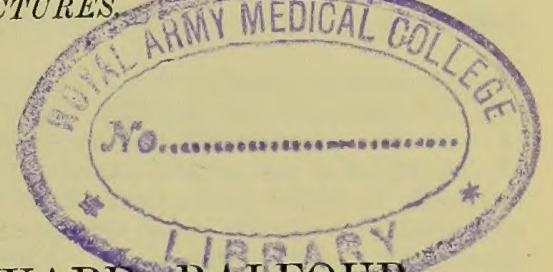

\section{SURGEON GENERAL EDWARD BALFOUR,}

CORRESPONDING MEMBER OF THE IMPERIAL-ROYAL GEOLOGICAL INSTITUTE, VIENNA; FELLOW OF THE MADRAS UNIVERSITY;

AUTHOR OF

'THE TIMBER TREeS OF INDIA AND OF EASTERN AND SOUTHERN ASIA,' ETC.; FOUNDER OF THE MADRAS MUHAMMADAN LIBRARY ; OF THE GOVERNMENT CENTRAL MUSEUM, HADRAS; OF THE MYSORE MUSEUM, BANGALORE.

IN THREE VOLUMES.

VOL. II. H-NYSA.

THIRD EDITION.
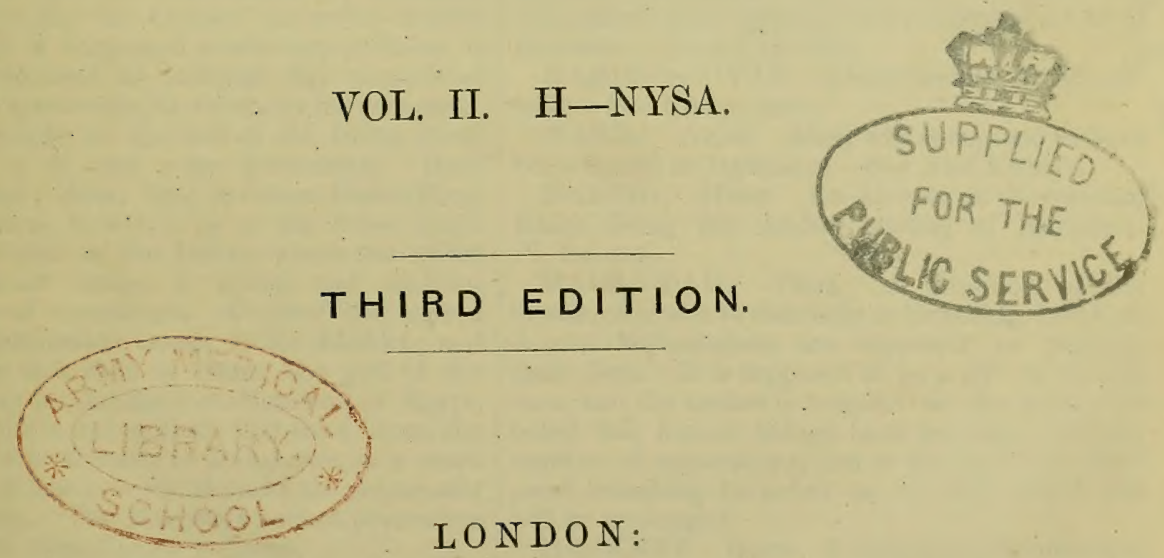

LONDON:

BERNARD QUARITCH, 15 PICCADILLY. 


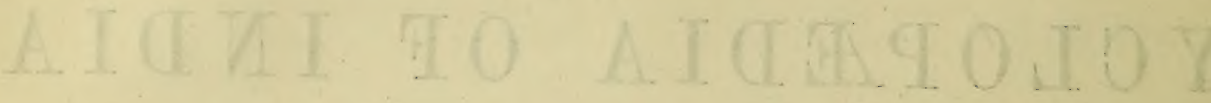

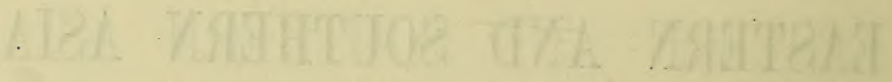

[All Rights Reserved.]

TRO RAMC coll. $\operatorname{lin}$ 


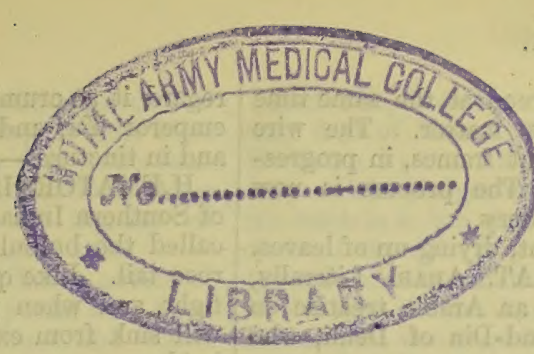

\section{CYOLOPADIA OF INDIA}

AND OF

\section{EASTERN AND SOUTHERN ASIA.}

\section{$\mathrm{H}$}

H. This letter in the English language, as an aspirate, shows that the vowel following it must be pronounced with a strong guttural emission of voice, as in hammer, house, humidity, helm, history, hyson; but in a few English words it is quiescent, as in hour, honour. There is no letter $\mathrm{h}$ in the Tamil alphabet, and in foreign words introduced into it, the $\mathrm{h}$ is changed to $\mathrm{g}, \mathrm{q}$, or $\mathrm{r}$; but this English letter is represented in the Arabic, Persian, Urdu, Sanskrit, Hindi, Mahrati, Bengali, Uriya, Telugu, Karnatica, and Malealam, though the sounds are mere modifications of the simple breathing. Two of the sounds derived from the Arabic are not very nicely distinguished in Indian pronunciation. One may be something harsher than the other, and so far it agrees with the strong Sanskrit aspirate, whilst the softer breathing of the Nagari alphabet, the Visarga, or sign of the nominative case, may be regarded as peculiar. Sir William Jones distinguishes the harsher forms by an accent, as Ah'med. Gilchrist and Shakespear distinguish it by a dot underneath it; Professor Wilson places the dot beneath the softer Arabic aspirate. In a suggested missionary alphabet, it has been proposed to indicate the unmodified flatus by an apostrophe, as ve'ement for vehement. With the people on the line of the Indus river, the letters $\mathrm{s}, \mathrm{h}$, and $\mathrm{z}$ are permutable. Hind becomes Sind; Zalim Sing becomes Halim Hing. The difficulties, however, as to the letter $h$ are not greater than in the Italian, where the initial $\mathrm{h}$ is quiescent before a vowel, and modifies the sounds of consonants. Colonel Tod says s and $h$ are permutable letters in the Bhakka; and he supposes that Sam or Sham, the god of the Yamuna, may be the Ham or Hammon of Egypt. He also thinks it not unlikely that the Chaora, the tribe of the first dynasty of Anhalwara, is a mere corruption of Saura, as the ch and $\mathrm{s}$ are perpetually interchanging. The Mahrattas cannot pronounce the ch; with them Cheeto is Seeto.

HAÁSIA WIGHTII. Nees. This good-sized tree is not uncommon in the moist woods on the Tinnevelly and Travancore range of ghats, at 2000 to 3000 feet elevation, and Animallays 4000 feet.
H. oppositifolia, Thw., occurs in Ceylon.-Beddome.

HAB, a river on the western frontier of Sind, and for some distance the boundary between British territory and Baluchistan. It rises in Kalat, falls into the Arabian Sea in lat. $24^{\circ} 52^{\prime} \mathrm{N}$., long. $66^{\circ} 42^{\prime} \mathrm{E}$., after a total length of about 100 miles. Except the Indus, it is the only permanent river in Sind. It abounds in fish. It has been proposed to supply Karachi (Kurachee) with drinking water from the Hab.-Imp. Gaz.

HABAKKUK. This sacred writer says (i. 16), 'They sacrifice unto their net, and burn incense unto their drag; because by them their portion is fat, and their meat plenteous ;' from which it would seem that the Jewish idolaters had a custom like that of the Hindu, who annually worship the implements of their trades.

HABARUM, a mount close to the Dead Sea, on which Moses died, in the fortieth year of the exodus. In this interval the whole land of the Emorites had been taken, the Midianites overthrown, and the country of the king of Basan conquered, the river Jabbok crossed, and the western country on the Jordan (Batanæa and Aulonites) taken eastward and northward as far as Hermon,-Bunsen, iii. 252.

HABIB-us-SIYAR. A book written by Khondamir. See Khond-amir.

HABIL. ARAB. Abel, who is suposed to have been buried at Damascus. See Abu Kubays.

HABSHI. HrND. An African or Abyssinian, Habsh being the Arabic reading of Abyssinia. Pl. Habush.

HABZ-i-DAM. PERs. A retention of the breath, or power to discontinue breathing, by which devout Mahomedans are supposed to prolong their lives. It is supposed to be a gift to devout men, and the notion is founded on the erroneous belief that human beings have to take a certain number of respirations, and if the power to suspend breathing be acted on, to that extent life will be prolonged.

HACKERY. HIND. A cart drawn by bullocks, from Akra, a cart. It may, however, be from the Portuguese Carro or Acarretai, to carry.- $W$.

HACKLES, upright pointed wires, through which the stems of flax are drawn to disentangle 
or comb them out, being freed at the same time from remaining extraneous matter. The wire pins are arranged on different frames, in progressive degrees of fineness. The process is now performed by special machinery.

HADA. HIND. A blight, drying up of leaves.

HADAYK-ul-BALAGHAT. ARAB. Literally, the Gardens of Eloquence, an Arabic treatise on eloquence by Mir Shams-ud-Din of Dehli, who lived at the end of the 18th century.

HADI, a helot race, spread over all Bengal, who take their name from the original Santali word for man, Had, and who have supplied such terms as Hadd, base, low-born; Hadduk, a sweeper; Hunda, hog, blockhead, imp; Hudduka, a drunken sot, etc. Also, Hadi, in low Bengali Hadikath, is the name of a rude fetter or stock, by which landholders used to confine their serfs until they agreed to their terms. It means literally the helot's log. It was also used for fastening the head of the victim in the bloody oblations which the Aryan religion adopted from the aboriginal races, especially in the human sacrifices to Kali, to which the low castes even now resort in times of special need. In an account of such a human offering to Kali, during the famine of 1866, it was mentioned that the bleeding head was found fixed on the 'harcat,' i.e. helot's log. $-D r . W . W$. Hunter, p. 30.

HADIAH. ARAB. A maiden of good family and courage, who precedes in battle the Bedouin Arab, mounted on a camel, in the fore ranks. She has to shame the timid and excite the brave by taunts or praise.-Palgrave.

HADIS. ARAB. (Pl. Ahadis.) The traditions of the sayings and practice of Mahomed. They are 5266 in number, and are considered a supplement to the Koran. They are also called Sunna or customs, also Ahadis Nabaweya, the Apostolic Acts. The Sunni, the Shiah, and the Wahabi sects all acknowledge traditions as binding on them; but the Shiah sect do not acknowledge the same collection as binding on them which the Sunni adopt, and the Wahabi recognise six Sunni books as correct.

HADIWICKE, a moderately hard, fine, closegrained, rather heavy Ceylon wood.

HADRAMAUT, a province of Arabia Felix, on the sea-coast between Yemen and Oman. The chief products are frankincense, gum-arabic, dragon's blood, myrrh, and aloes.

HADROSPHERUM, Mesospherum, and Mierospherum are terms applied by Pliny to varieties of nard; perhaps a mistake of his, as Dioscorides observes that some people made the mistake of regarding malabathrum as the leaf of Indian nard. -Yule, Cathay, i. p. cxlv.

HAMADIPSA CEYLANICA. Blain. The land-leech of Ceylon. Another is the Hæmadipsa Boscii, and another is Hæmopsis paludum.

HAMATIN, a colouring substance obtained from the Crsalpinia sappan tree.

HAMATITE. Tai-che-shih, Chin.

Yu-yu-liang, . . CHIN. / Red hæmatite, . ENG. Brown hæmatite, . ENG. Hydrated oxide of iron, ,"

A name given to certain forms of native peroxide of iron. When of a red colour it is called red hæmatite; and when brown, brown hæmatite. According to Hanbury, it resembles the old lapis ætiles. It occurs in British India and China in many places; and the Chinese regard it as crumbs from the table of the great emperor $\mathrm{Yu}$, and use it medicinally in powder and in tincture.-Smith.

HEMATORNIS CAFER is one of the bulbuls of Southern India. It is not a song bird, and is called the bulbul-i-gul-dum, or bulbul with the rose tail. Like quails and cocks, it is trained to fight, and when pitted against an antagonist it will sink from exhaustion rather than release its hold.

HEMATOXYLON CAMPECHIANUM, the logwood tree; has been introduced into India, where it grows readily and seeds abundantly. It is used only as a dye, and the bark is astringent. It is a low spreading tree, seldom thicker than a man's thigh.-Cleghorn in Madras $E . J . R$.

H无NKE. The Reliquiæ Hænkianæ of Presl is a folio volume, with plates, devoted to the materials collected by Hænke, who was employed in the Spanish service, and collected in America and Manilla. The Indian plants described are few, and the descriptions and identifications far from satisfactory.-Hooker $f$. et Thomson.

HAE-NUN, called by Europeans Amoy, an island on the S.E. of China about 22 miles in circumference. The town of Amoy is situated on the S.W. part of the island, opposite the small island of Ko-lan-soo, which affords protection to the town anchorage or inner harbour. On the western side of the island is that of Woo-seushan, also that of Woo-an. Amoy was delivered over to the British, after the first Chinese war of $1841-2$, and forms one of the consulates thereof, Shang-hai and Hong-Kong being others.

HAE-TAN, a large and irregularly-shaped island on the E. coast of China, near the mainland, between lat. $25^{\circ} 24^{\prime}$ and $25^{\circ} 40^{\prime} \mathrm{N}$. Its northern part, Hae-tan peak, is in lat. $25^{\circ} 36^{\prime} \mathrm{N}$., and rises to an elevation of 1420 feet; but its eastern and western shores are low, and indented with deep sandy bays.-Horsburgh.

HATUMAT, a land mentioned in the Vendidad of the Zoroastrians, as the eleventh of which the Aryans took possession. It is the valley of the Helmand to the west of Arachosia.-Bunsen.

HAFIZ, ARAB., from the Arabic Hifz, he did remember, is a literary title given to a Mahomedan who can recite the whole of the Koran from memory. It is generally earned by lads, sometimes of very tender years, and in large towns there are always several of the Hafiz. Where so many are actual Hafiz, multitudes have almost attained thereto, and remember vast portions of their religious book; and every Mahomedan with any education can indicate almost any passage under discussion. The Koran is not, perhaps, a third the size of the Old and New Testaments, and the feat of committing it to memory is comparatively easy, which may explain why we so seldom hear of a Bible Hafiz. Recently, however, in 1860, a religious gentleman in Massachusetts having offered several prizes of Bibles to those, old or young, who should commit to memory and repeat the largest portion of the Bible, Mrs. Betsy Conant, who had been residing in Melrose, a lady sixtyeight years of age, committed to memory the entire Bible, Old and New Testament, reciting each day in the week. This was certified by her daughter, and also by the superintendent of the Sabbath school. An Irish servant girl repeated nearly 10,000 verses; three other women repeated 
above that number; and a list was appended of some 20 more who were able to repeat from 3000 to 9000 verses. It is noticeable that more than two-thirds of the successful competitors were women, showing how strong the faculty of memory is among the sex as a general rule.

HAFIZ, a lyric poet, native of Shiraz, author of the Dewan-i-Hafiz. Many of his poems have been translated; one by Sir William Jones, and which perhaps surpasses the original, commences with

'Sweet maid, if thou wouldst charm my sight,

And bid these arms thy neck enfold;

That rosy cheek, that lily hand,

Would give thy lover more delight

Than all Bokhara's vaunted gold-

Than all the gems of Samarkand.'

Hafiz is his takhallus, or poetical appellation. His own name was Muhammad Shams-ud-Din. Very little is known of his life; and it appears to have been in no degree remarkable for incident. He was born at Shiraz in the beginning of the 14th century, and died and was buried near there in A.D. 1338. He is now regarded as a holy man, and oblations are offered at his shrine. $\mathrm{He}$ is buried in a small garden about half a mile outside the walls of the town. The tomb over his remains was erected by Karim Khan. It is a block of white marble in the form of a coffin, on which are cut, in the most exquisite Persian characters, two of his poems, and the date of his death. A copy of his works is kept in an adjoining house. The white material with which the tomb is formed, has become, from exposure to the weather, very much discoloured, and adds to the sombre effect produced by the cypress trees that surround it. Four well-known distichs of $\mathrm{Hafiz}$ inculcate the return of good for evil :

'Learn from yon orient shell to love thy foe, And store with pearls the hand that brings thee woe Free, like yon rock, from base vindictive pride, Emblaze with gems the wrist that rends thy side: Mark where yon tree rewards the stony shower With fruit nectareous, or the balmy flower: All Nature calls aloud-Shall man do less Than heal the smiter, and the railer bless?

-Pottinger's Tr.pp.241-2; Ouseley, pp.241-2; Sir William Jones; As. Res.iv.; MacGregor, iv. p. 557. HAFT. PERS. Seven :-

Haft-Aklim, the seven climates, into which Mahomedan geographers divide the earth. The term is meant to include the whole world, and kings have sometimes assumed the title of King of the Seven Climates. It applies, however, to the northern hemisphere, which they partition into zones of various breadth, from east to west. Haft-Kishwar has the same meaning and allusion as Haft-Aklim; and the sovereignty of the world is sometimes assumed under that title.

Haft-Dhat, literally seven metals, corresponding to the planets, each of which ruled a metal: hence Mohar, the sun, for gold ; Chandra, the moon, for silver.

Haft-Hind, the seven rivers of the Panjab.

Haft-Khaneh, or Satgurh group of caves, is one of the Behar caves in the neighbourhood of Rajagriha, the most ancient caves in India, about 200 B.C. The others are the Milkmaid's cave, the Brahman Girl's cave, the Nagarjun cave, and in the neighbourhood are the Karna chapara and Lomas Rishi caves.

Haft-Rang, a beautiful variety of the rose.

Haft-Lang, a tribe of the Bakhtiari.
Haft-Tan, literally seven persons who, in the early days of Mahomedanism, were worshipped in Kurdistan by the Ali Ilahi sect as the incarnate deity. Baba Yadgar was one of the seven persons. His tomb is in the pass of Zardah, and is the holy place of the Ali Ilahi sectarians, who believe in upwards of a thousand incarnations of the godhead. At the time of the Arab invasion of Persia, the Zardah pass was regarded as the abode of Elias.

HAFT-AKLIM. Amin Ahmad, Razi, author of a history of the Persian poets, entitled Haft-Aklim, or the Seven Climates, has illustrated his work with much geographical matter. Ahmad was surnamed Razi, being a native of Rai. Amin Ahmad said the cuneiform character was then unintelligible to the learned of all religions.-Ouseley's Tr. ii.402, iii. 10 .

HAGENIA ABYSSINIA, the kosso or kousso, a moderate-sized tree of Abyssinia. Its flowers are largely used in tapeworm. It is a drastic purgative, and is largely used by the races who eat raw flesh.

HAGGIS. Sultan Baber compares the jackfruit to a haggis. 'You would say,' quoth he (p. 325), "that the tree was hung all round with haggises.'-Yule, Cathay, ii. p. 362.

HAIGA, a clan of Brahmans in Canara.

HAIHAYA, son of Yadu, and grandson of Nahusha. The Haihaya are mentioned as a powerful nation, who defeated and killed Jamadagni, and are supposed to be the same with the Persians. In Colonel Tod's time, a tribe of this race were occupying the top of the valley of Sohagpur in Baghelcund. They were aware of their ancient lineage, and though few in number, they were still celebrated for their valour.

HAIL. In Exodus ix. 24, it is mentioned that there was hail, and fire mingled with the hail, very grievous, such as there was none like it in all the land of Egypt since it became a nation. Hailstorms of India occur in very limited patches, and seldom last above 15 or 20 minutes; but falls of hail occur simultaneously in places many miles apart. The hail occasionally consists of masses of ice, destroying houses, men, cattle, goats, and sheep. At the end of the 18th century, a mass: fell at Seringapatam the size of an elephant, which took three days to melt.

On the 10th April 1822, at Bangalore, 27 bullocks were killed.

In May 1823, a violent hail-storm, with stones of considerable size, occurred at Hyderabad in the Dekhan. Sufficient quantities were collected to cool the wine for several days.

At Dharwar, in May or June 1825, a hail-storm occurred, with hail in size from that of a filbert to a pigeon's egg.

In 1826, a mass, nearly a cubic yard in size, fell in Kandesh.

At Kotah, on the 5th March 1827, 6 persons were killed, 7 others severely injured, and animals and birds killed and hurt.

In April 1838, a mass of hailstones, 25 feet in its larger diameter, fell at Dharwar.

On the 22d May, after a violent hail-storm 80 miles south of Bangalore, an immense block of ice, consisting of hailstones cemented together, was found in a dry well.

On the 12th May 1853, in the Himalaya, north of Peshawur, 84 human being and 3000 oxen were killed by masses of ice, nearly a foot in leircumference, hard, compact, and spherical. 
On the 11th May 1855, ice-pieces fell at Naini Tal of the dimensions of cricket balls, and birds were killed.

A hail-storm occurred at Futtehghur on the 13th April 1878, when much injury to buildings resulted.

In Ceylon hail has fallen at Kornegalle, at Badulla, Kaduganawa, and Jaffna. On the 24th September 1857, during a thunder-storm, hail fell near Matelle in such quantity that in places it formed drifts upwards of a foot in depth.

One year a heavy fall of hailstones took place near Ashteh (the village where Bapoo Gokla fell), which caused severe injuries to people working in the fields, and the death of a girl about ten years of age. Many of the hailstones were larger than a good-sized wood-apple; they fell in an oblique direction, and so accumulated at the foot of walls that it took two days in some places for them to melt away. One piece was larger than a man's head, and took two days to dissolve; the wheat crops, which were then nearly ripe for taking down, were quite destroyed by it. A hail-storm of exceptional severity passed over Tiperah in Eastern Bengal on the evening of the 12th March $1879 ; 17$ persons were killed and 10 wounded. Native reports stated that 29 were killed and 141 injured. Houses were blown down and unroofed, the storm being accompanied by a strong wind.

Hail-storms of India occur in each month of the year, but chiefly in the dry months. Of 127 such hail-storms, 102 occurred in the four months February to May inclusive :-

January, . 5 5 May, . . . 17| September, . 2 February, : 20 June, : 4 October, : 3 March, . 31 July, . . 2 November, : 4 April, . . 34 August, . 0 December, . 5

In the first fortnight of March in one year, on the $3 \mathrm{~d}$, a violent hail-storm occurred at Bolarum, which dashed right through the roofs of the houses, and stripped the trees of their leaves and branches; it was experienced at Secunderabad, but did not extend to Hyderabad itself. A hailstorm occurred at Cawnpur on the 8th, and two violent hail-storms happened at the same time near Meerut, many of the fragments being the size of ostrich eggs. A violent squall, with hail, occurred at Hurryhur on the $12 \mathrm{th} ; 270$ birds, which had been killed by it, were picked up in a single garden, and the river was found covered with dead fish, which seemed to have been attracted to the surface, and fell victims to the gratification of their curiosity. In Berar and in the parts of the Mahratta country there is a caste of hail-conjurors, the Garpagari, who pretend to have the power of preventing hail falling on fields.-Dr. Buist's Physical Research; Dr. Turnbull Christie, Jam. Ed. Jo. ii. of 1830.

HAILEYBURY COLLEGE, an institution near London, of the English E. I. Company, at which its civil servants were trained to be writers in India, for magistexial, revenue, and judicial offices. It was abolished on the assumption of India by the Queen of Great Britain.

HAINAN, an island bounding the Gulf of Tonquin to the eastward, extends 165 miles in a N.E. and S.W. direction, and is about 75 miles in breadth, between lat. $28^{\circ}$ and $31^{\circ} \mathrm{N}$., and long. $110^{\circ}$ E. Viewed from the sea, it presents many high and uneven appearances, but inland there are many level districts, cultivated with rice, sugar- cane, tobacco, and betel-nut trees. These level tracts are separated by lofty mountains and impenetrable forests, through which paths are opened. The island is subject to the Chinese. The fishing boats are built of a hard, heavy wood, and sail fast. Their fishing voyages, commencing in March, last for two months, and they navigate to 700 or 800 miles from home, collecting beche de mer, dry turtle, and sharks' fins amongst the numerous shoals and sandbanks in the S.E. of the China Sea.-Horsburgh. See Tonking.

HAINES, SIr FREDERICK, G.C.S.I., served in the Sutlej campaign of 1845-46, including the battles of Moodkee and Ferozeshah, at the latter of which he was severely wounded; also in the Panjab campaign of 1848-49, and more recently in the Crimea, including the battles of the Alma, Balaclava, Inkermann, and siege of Sebastopol. He was, in 1871, appointed to the command of the Madras army, and in 1876 succeeded Lord Napier of Magdala as Commander-in-Chief in India. He was created a G.C.B. in 1877.

HAIQ. The populations to whom the term Armenian is now applied, call themselves Haiq. Their chief occupancies are the Turkish province of Erzerum, and the Russian district of Erivan, and the patriarch resides in Erivan. They are now under the sway of Russia, Persia, and Turkey, but they are found in all Eastern countries. 37,676 are in European Russia alone; and one important settlement of them is in Venice, that of the Mechitarist monks, on the island of St. Lazarus. In figure the Armenians have been likened to the Jew, the Turk, and the Afghan. They evince great commercial aptitude, and are bankers and merchants. In Armenia, however, they cultivate the soil. Before their conversion they were fire-worshippers. Many of them now are Nestorian Christians, some are Romanists. The language of the present day has affinities with the Iron, and Persian, Syrian, Arabic, and Turki. General tradition and the formation of language point alike to the mountains of Armenia as the birthplace of the Arab and Canaanitish races, and there is especial native evidence to the same effect as regards Fdom, consequently the Phonicians.

\section{HAIR.}

Haar, . DA., DU., GER. Voloss, . . . Rus. Cheveux, Poil, Fr. Kesa, : : SANsk. Bal, . GUJ., Hind. Cabellos, : : . SP. Pelo, : . IT., SP. Har, . : : SW. Capilli, Pelles, . Lat. Mairu, . . TaM. Ruma, Rula, Malay. Ventrukulu, . . TEL. Ranbut, Tailhan, ", Sach,. . . : TURK. Cabello,. . . Pör.

With the exception of man, the exposed parts of the bodies of mammals are covered with hair. Hair is a considerable article of traffic. Goats' hair is largely exported from Bombay to England. The hair of the elephant's tail and the bristles of the wild boar are utilized in India. The value of the exports of hair from India amounts to about $£ 2000$ annually, about 200 to 300 tons.

A remarkable command is given to the Israelites in Leviticus xix. 27 : "Ye shall not round the corners of your head,' or, literally, 'Ye shall not go round, i.e. with a razor, 'the sides of thy head.' The Septuagint renders this, "Do not make Sisoen of the hair of your head.' Greek lexicographers say that Sisoen, though not a Greek word, means a lock, or circular portion of hair left unshaven, 
and consecrated to Saturn; the grandfather of Bacchus, who is thought to correspond with Siva. In some respects Saturn also resembles Siva. A recent commentator says on the above text, "It seems probable that this fashion had been learned by the Israelites in Egypt, for the ancient Egyptians had their dark locks cropped short, or shaved with great nicety, so that what remained on the crown appeared in the form of a circle surrounding the head. Frequently a lock or tuft of hair was left on the hinder part of the head, the rest being cut round in the form of a ring, as the Turks, Chinese, and Hindus do at the present day.'

Poole says 'the Gentiles cut their hair for the worship of devils or idols, to whom young men used to consecrate their hair, as Homer, Plutarch, and many others write.' Professor Vitringa looks upon this manner of trimming the hair in a circular form, while the rest of the head is shaven, as a symbol of the sun equally diffusing his rays, which the ancients called his hair. The Romans are said to have worn the hair of the head uncut, either loose or bound behind in a knot, and consecrated it to Apollos.

Herodotus says that the Arabians cut their hair in such a manner, that the circumference of their head is found to be round all about as if they had been cut with a bowl, in imitation of Bacchus, and in honour of him. He says also that the Macians, a people of Sybia, cut their hair round so as to leave a tuft on the top of the head. We learn from Homer that it was customary for parents to dedicate to some god the hair of their children, which they cut off when they came to manhood. Achilles, at the funeral of Patroclus, cut off his golden locks, which his father had dedicated to the river-god Sperchias. From Virgil it appears that the topmost lock of hair was dedicated to the infernal gods. In Athens it is said Hercules and Apollos were the chief deities selected for dedicating the hair, - to the first by the humbler part of the community, and the latter by the more wealthy. Tertullian speaks of an extraordinary rite about the dedication of the hair of infants, which was practised even before they well had any hair, and that cut off when they were named.

The ancient Greeks, in laying out their dead, placed an obolus, a Greek coin, in the mouth to pay Charon's fare across the rivers Styx and Acheron, and a cake made of flour and honey to appease Cerberus. Greek men cut off their hair when they obtained the age of puberty, and dedicated it to some deity. 'Theseus is said to have repaired to Delphi to perform this ceremony, and to have consecrated his shorn locks to Apollo. After this it was again allowed to grow long, and only cut off as a sign of mourning. Thus, at the funeral of Patroclus (Iliad, xxiii.) the friends of Achilles cut off their hair, and

'On the corse their scattered locks they throw.'

In some parts of Greece, however, it was customary to wear the hair short, and to allow it (Cassandr. 973) to grow long when in mourning.

' Neglected hair shall now luxurious grow,

And by its length their bitter passion show.'

Hindu men, on the death of a relative, abstain from shaving, and the Burmese dead have a coin placed with them for the spirit-world.

The women of nearly all the oriental races wear long hair, differently braided. The men of Baluchistan and Afghanistan shave the front, but wear hair long on the back and sides of the head. Mahomedans of India as a rule shave their heads. Hindu men also shave, leaving only a scalp-lock on the crown. This scalp-lock is noticed by Martial, Seneca, and Tacitus as worn by German races. Brahman women, on the demise of their husbands, have their heads shaved.

In Luristan, the women, on the death of their men relatives, cut off their hair, and hang the locks around the tomb. The hair of Hindu women, and often also that of men, is frequently made a votive offering to their gods. Crowds of the Hindu pilgrims to Triputty and other holy places, both men and women, return with heads shaved, Hindu lads have their heads shaved. Nero placed his first beard in a jewelled box, and dedicated it to Jupiter. Herodotus mentions (Melp. iv. c. 34) that the Delian maidens used to cut off a lock of their hair before marriage, in memory of the Hyperborean virgins who died in Delos. In some tribes of the Orang Benua of the Malay Peninsula, and among the Malay, it is customary to cut off a part of the bride's hair.

The Somali of the east of Africa change their hair into red by mixing it with lime. Amongst the Romans, blonde auburn tresses were most admired, and to obtain these, men steeped their hair in a powerful alkali, as the Somali now do. Mahomedans of India have black hair, occasionally dye it red with henna or mehndi. The tuft of hair, or scalp-lock, Shik'ha, SANsk., D'zutu, TEL. Kudi mai, TAM., is worn by all who profess Hinduism, and it has been a subject of much discussion with Christian missionaries, whether, on conversion, the new Christian's scalp-lock should be removed.-De Bode, ii. 218-19; Newbold; Postans ; Lubbock.

HAIR POWDER.

Poudre à poudrer, : FR. $\mid$ Polvere di cipri, . IT. Puder, . . . Ger. Polvos de peluca, : SP.

Hair powder is generally made from pulverized starch, and perfumed with various scents. Faulkner:

HAI-TSAI. CHIN. Literally, sea vegetable. Hai-tsai, Hai-wan, and Kwan-pu are Chinese names for several species of Laminaria, Rhodomenia, Iridæ, etc., used in China for food, for size, and for jelly. Kwan-pu is the tangle.

HAI-YANG is the Neptune of the Chinese. In $\mathrm{Hi}$-ching-mian is a temple of the sea-god. At Ta-coo, in one hand he holds a magnet as emblematic of security, and a dolphin in the other, to show his sovereignty over the inhabitants of the sea; his head, beard, and hair are evidently intended as a personification of water.-Macartney's Embassy, i. 31.

HAIYU, Haioo, Haya, or Vaya. The Haiyu, the Chepang, and the Kusundu are three uncivilised Bhot tribes, who dwell amid the dense forests of the central region of Nepal, to the westward of the great valley, in scanty numbers, and nearly in a state of nature. They live in huts made of the branches of trees, on wild fruits, and the produce of the chase. The Chepang are slight, but not actually deformed, though with large bellies. Mr. Hodgson says they are of Mongol descent. Their language is akin to that of the Lhopa. The Chepang, Haiyu, and Kusunda seem to belong to the Rawat group 
of frontier populations. They are named by Mr. Hodgson as Durre, Denwar, and Bramho. They occupy the districts where the soil is moist, the air hot, and the eflluvia miasmatic. They dwell in Nepal as the fragments of a tribe of great antiquity, with peculiar traditions, language, and appearance, all tending to isolate them from the people amongst whom they dwell.

HAIZA. ARAB., Hind. Cholera. Haiza-kapatta, Kalanchoe varians.

HAJ. Arab. A pilgrimage by a Mahomedan to Mecca, Medina, Jerusalem, Sinai, etc.; hence the title Haji, a pilgrim. Hajjat, a woman pilgrim. The pilgrimage of Mahomedans to Mecca-enjoined by the Koran (Sura, xxii. 28)-is incumbent on all men and women who have sufficient means to meet the expenses of the journey, and to maintain their families at home during their absence. Its ceremonial continues during three days of the month Zi-ul-haj. The day of the ceremony is the 10th $\mathrm{Zi}-u l-h a j$, on the Eed-ül-Kurban or Bakrid festival. The setting forth of the pilgrims from the distant parts of the world is generally attended with great show. The Persian Shiah sect resort in pilgrimage to three places. The town of Meshid is reckoned the least in the scale of sanctity; and those who have been there to the tomb of Imam-Raza, obtain the title of Meshidi. The next after them are the Karbalai, who stand a degree higher in estimation; while those only who have visited the Kaba at Mecca and the tomb of Mahomed at Medina, can lay claim to the title of Haji. A Persian will feel offended if you call him Meshidi, when he has a right to the superior degree of Karbalai, or the still higher and more pompous appellation of Haji. Thus Meshidi, Karbalai, and Haji become titles of distinction. Haj-ul-Asghar, the lesser pilgrimage. Haj-ul-Akbar, the greater pilgrimage. About 70,000 annually visit Mecca.

The Indian Haj is the most numerous of all the pilgrimages which arrive every year at Jeddah. In 1880 it consisted of 15,000 souls, the next most numerous being the Malay Haj, which numbered 12,000. The latter consists mostly of Dutch subjects. The Dutch encourage their subjects to visit the holy places in Arabia, on the principle that the experience which is gained on the journey of the tyranny and extortion of the Musalman government in Hejaz tends to increase in a Haji the sense of the advantages he enjoys at home.

Haj Darwazah, or Mecca Darwazah, the pilgrim gate of the eity, from which the pilgrims issue when proceeding on pilgrimage.

HAJAM, HIND., the Nai of the Hindus, a barber, who shaves, bleeds, cups, cleans the ears, pares the nails, etc., usually included among the members of the village establishment.

HAJAR. ARAB, A stone, any stone:-

Hajar-ul-Akab, eagle - stones of the ancients. One of them was probably the bonduc nut of the Guilandina bonduc. The Greeks believed that the eagle-stones or atiles were only found in the nests of eagles; and the Arabs describe them as resembling tamarind stones, but hollow, and found in eagles' nests, and they believed that the eagles bring them from India.-King.

Hajar-ul-Musa, asphalte.

Hajar - us - Siah, also Hajr - ul-Aswad, a celebrated black stone which is built into the Kaba at Mecca, an object of the greatest veneration.
This stone is set in silver, and fixed in the south-east corner of the temple. It is deemed by Mahomedans one of the precious stones of paradise that fell to the earth with Adam, and, being preserved at the deluge, the angel Gabriel brought it to Abraham when he was building the Kaba. It 'was, they say, at first white, but its surface has become black from coming in contact with those who are impure and sinful. It is semicircular, about six inches in height, and eight inches in breadth. It is in the wall of the Kaba in the east outer corner, about four feet from the ground, its surface undulating and polished. Burton, on reaching the stone, despite popular indignation, testified by impatient shouts, monopolized the use of it for at least ten minutes. Whilst kissing it, and rubbing hands and forehead upon it, he narrowly observed it, and came away persuaded that it is a big aërolite. Ali Bey calls it, 'mineralogically,' a black volcanic basalt, whose circumference is sprinkled with little crystals, pointed and strawlike, with rhombs of tile-red feldspath upon a dark background, like velvet or charcoal, except one of its protuberances, which is reddish. Burckhardt (p. 137) thought it was 'a lava containing several small extraneous particles of a whitish and of a yellowish substance.'

Hajar-ul-Yahudi is encrinite, sold in Peshawur at Rs. 10 the maund.-Burton's Mecca, iii. p. 210; Malcolm's Persia, ii. p. 336.

HAJONG, a section of the Bodo tribe who dwell in the plains of Cachar.

HAJRAH or Hajirah. ARAB. Hagar, the kept woman of Abraham, the mother of Ismael, generally called the Bibi Hajirah.

HAKARI, a tribe of N. Kurdistan inhabiting the mountains on either bank of the great Zab river above Amadia. They have 14 subdivisions, also 94 Christian villages, with 15,520 souls. Their country is precipitous and difficult, the people wilder than any Kurds. They have 25,000 fighting men.-MacGregor.

HAKIM. ARAB, A doctor of philosophy, a doctor of medicine, a learned man, pronounced Hakeem. The Hakim or Tabib of British India is of the Mahomedan faith, and, like the Vydian Baid or Vaid, is usually a physician purist. The Hakim as a rule claims to be a follower of the Yunani or Grecian school of medicine. He designates the Hindu Vydian as of the Misri or Egyptian school, but recognises also a Suryani or Syrian school. General Ferrier says that the influence which the Hakim Sahib has generally exercised in the British embassy at Teheran, and the employment of such men as Jukes, Campbell, M'Neill, Riach, Bell, Lord, and others, in various important duties in those countries, led the chiefs of Harat to suppose that physicians occupy a higher place in the councils of the British than is accorded to them. - Ferrier, Journal, p. 149.

HAKLUYT, RICHARD (Archdeacon), Bishop of Westminster, in 1601 was appointed Historiographer of the East Indies, by the first Chairman of East India Directors. He held constant communication with the seamen, and lectured at Oxford to the students. He died 1616, and his successor was the Rev. Samuel Purchas. $-E . J$. Murray, Surveys, 1871.

HAKODADI was a small town of Japan. Within sight of Hakodadi, and at the distance of about 25 miles, is an active volcano. The orater forms 
nearly a circle, from 1500 to 2000 yards round. The ground is in some places so hot that the hand could not touch it. This volcano throws up a hot sulphur spring at about 20 miles distant, and 5 from Hakodadi, the heat of its water being $109^{\circ}$ in the warmest part. The natives regard it as almost a certain cure in cases of skin disease. Men, women, and children, all nude, bathe together.

HAKRA, a name of the river Caggar.

HAL. ARAB., HIND. Present, present state, condition, current, as Ibrahim Khan-i-hal, the present Ibrahim Khan; Hal-ki-waste, for the occasion; Hali-sikkah, current coin. It occurs frequently in combination, and is used in revenue accounts to represent the existing state of collections.-Elliot, Supp. Gloss.

HAL or Har. HrND. A plough. Hali, a ploughman. It has been suggested that as the Aryans were originally and essentially an agricultural and therefore a peasant race, they may have derived their name from their plough, and words of a similar sound relating to agriculture are found in several tongues. In Latin it is Aratrum, from Aro, I plough. In Egyptian (in Nefruari), Ar is said to mean a plough. In Tamil it is Er, in Telugu Araka, in Sanskrit, along with Nagala or Nagara, it is also called Hala or Hara; and the Aryan race may possibly have obtained their name from this implement of husbandry. The Hal is a pointed beam in a plough, which serves as the ploughshare.

Hala-Ketana, SANsK., the plough-ensign, one of the insignia of royalty of the great Chalukya dynasty, when ruling at Kalian. Hali, a ploughman.

HALA, also Halla Kandi, a ruined city on the Indus, 30 miles above Hyderabad. The Hala deputy collectorate is between lat. $25^{\circ} 8^{\prime}$ and $26^{\prime} \mathrm{N}$., and between long. $68^{\circ} 16^{\prime} 30^{\prime \prime}$ and $69^{\circ}$ $17^{\prime} \mathrm{E}$.

HALA, a range of mountains, called also the Brahuic range. It is the great mountain system of Baluchistan, extending from the Suliman Hills, in lat. $30^{\circ} 30^{\prime} \mathrm{N}$., by the curved Bugti and Mari (Murree) chain to the north of Shawl, and thence in a generally S.S.W. direction to the ocean, which it reaches at Ras Mowari (Cape Monze), in long. $24^{\circ} 46^{\prime}$. Its breadth and height vary. The Chahl-tan is 11,000 to 12,000 feet, 7000 feet being the highest part at Kalat. Shawl is 5900 feet. In the northern part is the Bolan pass, and the Moolla pass is near Gandava. It throws out to the $W$. and S.W. numerous offshoots, which traverse Makran, and either sink into the ocean or the desert plains of Eastern Persia, or into the mountain system of Persia. - MacGregor.

HALAILI, a cotton stuff with long stripes of white silk, a favourite material amongst the city Arabs At Constantinople, where the best is made, the piece, which will cut into two shirts, costs about thirty shillings.

HALAL. ARAB. The new moon. It is a favourite symbol in Mahomedan standards as a crescent, indicating continuous increase.

HALAL. HIND. Lawful food for Mahomedans, as opposed to Haram, unlawful food. The lawful animals are such as chew the cud, and are not beasts of prey; birds that pick up food with their bills, and do not seize their prey with their claws, or wound them with their bills; fish, but no other

marine animals, and locusts. Reptiles and wine and all intoxicants are unlawful.

HALAL KHOR. Hind. PERs. A sweeper, a house scavenger. The words are Arabo-Persic, and mean a lawful eater, i.e. one to whom everything is lawful. Scavengers are usually Mahomedans, and are also called Mahtar, Bhangi, Toti, Lal-Begi.

HALAR, a principality in the Gulf of Cutch, of which Nowanagar is the capital, ruled over by the Jam of Nowanagar. See Rajputs.

HALAS, a branch of the Sakai population of the Malay Peninsula. They tattoo their face and breast, pierce their ears and nose, and insert porcupine quills. See Kedab.

HALAYA PAIKA, or Old Paik, a race in Mysore. Wilson says Halepaik, KARN., is a term applied in Mysore to the drawers of tari, who speak the Tuluva language.

HALAYUDHA BHATTA, author of the Abhidana Ratnamala, a Sanskrit dictionary. He lived about the 7th century.-Dowson.

HALBA. GOND. Immigrants into the Central Provinces from the south, and their principal colony is in the S.W., where they hold 37 flourishing villages. They gain their living chiefty by distilling spirits, and worship deified distillers, at the head of whom is Bahadur Kalal, which merely means the 'bold distiller.' They are, next to the Teli, the best cultivators; except in the jungles, they have generally become Hinduized. All that is necessary for a good Halba is that he should sacrifice once in his life three goats and a pig, one to each of the national deities, called Narayan Gosain, Burha Deo, Sati, and Ratna.

HALCYONID Æ, the kingfisher family of birds, of the tribe Fissirostres, order Insessores. It has two sub-families, the Alcedininæ and Halcyoninæ. Sub-Fam. Halcyoninæ.

Halcyon amauropterus, Pearson, the brownwinged kingfisher of Bengal, Arakan, and Tenasserim.

Halcyon fulgidus, Gould, is a very beautiful kingfisher of Lombok. It lives in thickets away from water, and feeds on snails and insects picked from the ground, like the great laughing jackass of Australia.

Halcyon fuscus, Bodd.

H. Smyrnensis, Sykes, | Alcedo fusca, Bodd.

Sade-buk, . BENG. Vichuli, . . TAM. Match-ranga, : : ", Lak-muka, : : TEL. Kilkila, . : * HIND. Buche-gadu, : : " The white-breasted kingfisher; inhabits all India, Ceylon, and eastwards to China.

Halcyon leucocephalus, Gmel.

H. gurial, Pearson.

H. Capensis, Linn. $\quad$ Alcedo leucoeeph., Gmel.

H. Javana, Gray.

Gurial, . . BENG. / Male pojma, . MaL.

The brown-headed kingfisher, is over all India and the Archipelago.

Halcyon saurophaga, a very fine kingfisher, with white head, neck, and lower parts, green scapulars, and blue wings and tail, from New Guinea, is a very shy bird, frequenting the margin of the island, usually seen perched on some detached or solitary branch, as if sunning itself, and darting off into the dense bush upon being approached.-Macgillivray, Voyage, i. p. 245.

Halcyon atricapillus, Gmel.

Alcedo atricapillus, Gm. A. pileata, Bodd.

A. brama, Less. 
The black-capped purple kingfisher; is rare in India, but more common in the countries eastwards to China.

Halcyon Coromandelianus, Scop.

H. Coromandel., Blyth. $\mid$ H. lilacina, Sw.

H. calipyga, Hodgs.

The ruddy kingfisher of the Himalaya, Nepal,

Sikkim, and the east coast of the Bay of Bengal.

Besides these, are $\mathrm{H}$. cyaniventris from Java, H. concreta from Sumatra, H. pulchella from Malacca and S. Tenasserim.

Todiramphus collaris, Scopoli.

A. chlorocephala, $\mathrm{Gm}$. A. sacra, $\mathrm{Gm}$.

The white-collared kingfisher of the Sunderbuns, Arakan, Tenasserim, Malayana, and Archipelago. Its feathers are largely prized by the Chinese, who buy the skins at 24 for a dollar.

There are other species in the Nicobars and Archipelago.

Ceyx tridactyla, Pallas.

A. erythica, Pall. I A. purpurea, Gmel.

The three-toed purple kingfisher, is found in Sikkim, Malayana, and the islands.

Sub-Fam. Alcedininæ.

Alcedo Bengalensis, Gm., common Indian kingfisher.

Alcedo euryzona, Temm., great Indian kingfisher.

Several species occur east of the Bay of Bengal, viz. A. Beryllina from Java, A. Moluccensis from Moluccas, A. Meningting of Java.

Ceryle rudes, Linn.

Ispidia bicincta, $S w$.

Phutka-match-ranga, ",

The pied kingfisher; occurs in Africa and most parts of South Asia and south of Europe.

Ceryle guttata, Vigors.

Matchi bag, HIND. Ung kashiya, LIP.

The large-crested black and white kingfisher, is a native of the Himalaya.-Jerdon, i. pp. 221-235.

HALDA or Harda, HIND., is a mildew affecting the cerealia, in which the plant turns yellow and withers.

HALDA or Haldi. Hind. Among Mahomedans, the ceremony of smearing a couple with turmeric between the period of their betrothal and marriage.

HALDAR or Holdar, a name borne by some Bengal families of the trading castes.-Wilson.

HALDIA MOORA and Singia moora are roots brought to Ajmir mixed with haldi; they are acrid and poisonous, and are carefully separated. Genl. Med. Top. p. 151.

HALEBID, a village in the Hassan district, Mysore, lat. $13^{\circ} 12^{\prime} 20^{\prime \prime} \mathrm{N}$., long. $76^{\circ} 2^{\prime} \mathrm{E}$. ; population (1871), 1207 ; the site of the ancient city of Dopasamudra or Dvaravatipura, the capital of the Hoysala Ballala dynasty. It was apparently rebuilt in the 13th century by King Vira Someswara. To him is assigned the erection there of two magnificent temples in honour of Siva, which rank among the masterpieces of Hindu art. The larger, Haisaleswara, rises 25 feet high above the terrace on which it stands. The ornamentation consists of a series of friezes one above another, each about 700 feet long, and carved with the most exquisite elaboration. One frieze alone represents a procession of not less than 2000 elephants. The Ballala kings ruled from about A.D. 950 to A.D. 1310 . It was plundered by Ala-ud-Din's general Kafur, a eunuch and con- verted Hindu leader of a Mahomedan army, and it was finally destroyed by Mahomed III., in A.D. 1326. Jonur, also called Moti-talao, twelve miles from Seringapatam, was afterwards made the capital. The entire walls of the Halebid Saiva temple are covered with carvings in stone, forming a Hindu pantheon. There are also two Jaina temples with colossal idols. The roofs are supported by splendid columns, said to be of potstone, beautifully turned, and so highly polished as to be used as a mirror when wetted with water.

HALFA. ARAB. The Stipa tenacissima, a plant of North Africa, largely utilised as a paper material.

HALHED. Nathaniel Brassy Halhed in 1776 published a code of Gentoo laws or ordinations of the Pandits, from a Persian translation made from the original, written in the Sanskrit language; author of a Grammar of Bengali, A.D. 1778.

HALI, in Kamaon, one of the Dom race who has been bought as a slave. In Surat, the Hali slave was a voluntary bondsman, who had temporarily sold himself for a sum of money.-Wils. Gloss.

HALI ETUS, the sea eagle genus of birds, of the sub-family Aquilinæ, family Falconidæ, and order Raptores.

H. fulviventer, Vieill., ring-tailed sea eagle.

Falco Macei, Temm. I H. unicolor, Gray.

Haliætus Macei, Blyth. H. lanceolatus, Hodgs.

H. albipes, Hodgs.

Macha rang, . BENG. Bala, . . . BENG.

Mach-manga, . " Kokna, . . KoL.

Mach-korol, koral, " $\mid$ Ugus,. . . . ",

The ring-tailed sea eagle is found throughout the $\mathrm{N}$. of India, along the Ganges and Indus up to Kashmir. It lives on fish, tortoises, and snakes.

H. leucogaster, Gmel., grey-backed sea eagle.

Blagrus leucogaster, Blyth. $\mid$ F. dimidiatus, Raffles. Ichthyætus cultrungus, ," F. maritimus, Gmel.

Falco blagrus, Daud.

This sea eagle is found throughout India, in Burma, Malayana, and Australia, chiefly on the coast and near the mouths of rivers. It lives on sea-snakes, crabs, rats, and on fish which it picks up on the beach.

H. leucocephalus is a bird of $\mathrm{N}$. America and N.E. Asia.-Jerdon, Birds,

HALIASTUR INDUS. Bodd.

Falco Indus, Bodd. Haliætus ponticerian., Syk. M. rotundicaudus, Hodg. Sunker chil, . . BENG. Ru-mubarik, . HIND. Dhobia chil, . . ", Kheman kari, . SANSK. Garuda,. : . CAN. Ratta Ookab, . : SIND. Brahmany kite, : ENG. Garudalawa, : TEL Pis-gender, • GOND. Shemberrid, Y YRRKALA. Bahmani chil, - HiNd. Garuda mantaru, "

Europeans have given the name of the Brahmany kite to the Haliastur Indus, probably from observing the feelings of the Hindus regarding it, who revere it as Garuda, the eagle vahan of Vishnu, and believe that when two armies are about to engage, its appearance prognosticates victory to the party over whom it hovers. The Brahmany kite is very useful in the populous seaport towns of India, in removing carrion and refuse, and is never killed. Major Moor mentions as an instance of this bird's boldness, of which he was a witness, viz. its stooping and taking a chop off a girdiron standing over the fire that cooked it. The religious Hindu feeds these birds on holidays, by flinging up little portions of flesh, to which they are attracted by the call Hari! Hari! meaning Vishnu, Vishnu. 
It is found throughout all India. In Bengal, the kites and Brahmany kites breed chiefly in January and February, and disappear during the rains.

HALICACABUM of Pliny, supposed to have been Physalis somnifera, var. flexuosa.

HALICORE DUGONG. Cuv.

Trichechus dugong, Gmel. $\mid \mathbf{H}$. Indicus, Owen.

Halicore cetacea, Ill. $\quad$ Dugungus Indicus, $\boldsymbol{H} \alpha \mathrm{m}$.

H. Indica, Desm.

Indian dugong, . . ENG. Duyung, . . MaLAY. Dugong Lamantin, ", Talla-maha, . SINGH. Le dugong des Indes, FR.

The dugong is an inhabitant of the narrow seas of the Eastern Archipelago; and Professor Owen denominated it Halicore Indicus, in distinction from that of the northern coast of Australia, at a time when the former had not been ascertained to frequent (as a dugong of some kind is now known to do) the Malabar coast and Gulf of Calpentyn in Ceylon. It inhabits the shallows of the Indian Ocean and about Ceylon, where the water is not more than 2 or 3 fathoms deep. It does not appear to frequent the land or the fresh water. Its flesh is delicate. The dugong was noticed as occurring in Ceylon by the early Arab sailors, by Megasthenes (Fragm. lix.) and Elian, and subsequently by the Portuguese. It is this creature which gave rise to the tales about mermaids, which have till the present day occupied the world, and doubtless had their origin in the tales of the Arab sailors. They are phytophagous, or plant-eaters. The species named by authors are-

H. Indicus, Owen, the Malay dugong, an inhabitant of the narrow seas of the Eastern Archipelago.

H. tabernaculi, Ruppell, the dugong of the coral banks of the Red Sea, has a feeble voice, and feeds on algæ. It is about ten feet long. In February and March bloody battles occur between the males. Its flesh, teeth, and skin are utilized. Their skins, called tun, are used for sandals.

H. Australis, the manate of Dampier, and whitetailed manate of Pennant, is a native of the west coast of Australia.

H. Indicus, F. Cuvier.

Trichechus dugong, Erx- $\mid$ Halicore tabernaculum, leben.

Halicore cetacea, Illeger.

Halicore dugong, Cuvier apud Raffles.

Dugong of Buffen.

Dugong, . . Malar.
Ruppell.

Dugungns marinus, Tiedemann apud Schinz. H. Hemprichii, Ehrenb.

Parampuan laut, MaLAY.
Under these synonyms Dr. Theodore Cantor unites all the above, which he says inhabits the Red Sea, the seas of the Malay Peninsula, Singapore, Sumatra, the Philippine Islands, Moluccas, Sunda Islands, and New Holland-Eng. Cyc.; Blyth in B. As. Soc. Journ.; Tennant's Ceylon; Cantor in B. As. Soc. Jour., No. clxxii. of 1846.

HALIFAX, LORD, better known as Sir Charles Wood, Secretary of State for India in the middle of the 19th century, and during the time of the revolt and mutiny. During his tenure of office, in 1854 , the plan of educating the people of India was promulgated.

HALIOTID无, a family of recent and fossil shells, belonging to the class Gasteropoda, of the mollusca. The genera include the haliotis, earshell, sea-ears ; deridobranchus ; stomatia; scissurella; ianthina, violet snail. One species, the haliotis or sea-ear mollusc or ear-shell, is largely used as food by the people on the coast of Manchuria. They are also dried and exported to China, and sell at 300 for a dollar.-Adams.

Haliotis funebris, Cumming and Reeve.

$$
\text { H. iris, Auctorum. }
$$

Shih-kiueh-ming, . CHIN. | Fu-yu-kiah, . . Chin.

This molluse is found on the coasts of Shantung, Foh-kien, and Kwang-tung; they are 4 or 5 inches long, and are smooth and iridescent on their inner surface ; the pearly interior is levigated, and applied to opacities of the cornea. Shells with 7 or 9 foramina are most prized.-Smith.

HALLI. KARN. A small village or hamlet; written Hully, and added frequently to other names, as Harpan-hully. It is the Telugu Palli.

HALLIKAR, also Hal-wakkal, a tribe of the agricultural Sudra in Mysore.-Wilson.

HALTVA, a hill race in Bustar, Bandara, and Raipur, who wear the sacred thread, which privilege those in Bustar purchase from the raja.

HALWA. HIND, A kind of sweetmeat, specially that made of honey and camel's milk, and brought from the Persian Gulf, via Bombay, in saucers. Halwai is a sweetmeat seller. Halwarang means colour of sweetmeat, pale drab, first dyed with naspal, pomegranate rind, then with catechu.

HALWAHA. HIND. In Oudh, a predial slare, employed as a ploughman. See Hal.

HAMADAN, a town of Persia, in the province of Irak-i-Ajam, 180 miles S.W. of Teheran. It is the ancient Ecbatana. It is said to have been founded by Jamshid, a king of the Peshdadian dynasty. The population is about 50,000 souls. It has a delightful neighbourhood, many beautiful bazars. The mountain streams contain gold. In the centre of the town is the tomb of Ali Ben Sina (Avicenna); and not far from it are those of Esther and Mordecai, which are revered by the Jews, and kept in repair. An inscription on the tombs is that, on Thursday, the 15th of the month Adar, the building of this temple over the tombs of Mordecai and Esther. was finished by the hands of the two benevolent brothers, Elias and Samuel, sons of the late Ismail Kachan. The town people make felt carpets largely.Kinneir; Menteith; Morier; Rich; MacGregor, iv. p. 172 ; Ferrier, Journ. p. 35 ; J. B. Fraser, p. 221 ; Porter's Travels, ii. p. 91.

HAMAL, or Haml. ARAB, Lit, he carried. Hāmilah, a pregnant woman. Hamāl, a porter, a bearer of a palanquin or tonjons. They carry it by means of the pole on their shoulders, the first man on the right shoulder, the second on the left, and so on, thus always keeping the pole steady. Frere, Antipodes, p. 197.

HAMAM DASTAH. HIND. A mortar; from the Persian Hawan. See Hawang-dastah.

HAMAMELIDE $Æ$, witch hazels, a very small group of woody exogenous plants of N. America, Japan, China, the central parts of Madagascar, S. Africa, the Khassya mountains, and Upper Assam. Some of the species are large forest trees, affording good timber. Bucklandia populnea tree is found from Cherrapunji to Surureem. Altingia excelsa, Noronha, is a large tree of Assam and Burma; the Liquidamber cerasifolia, Griff., occurs in the Malay Peninsula; and L. orientale, Miller, is the storax tree of Asia Minor. Hamamelis Chinensis is of China and the Jaintia Hills. Hooker, Him. Jour. ii. p. 318 ; Gambier. 
HAMD-ALLAH. ARAB. An abbreviation of the ejaculation Al-hamd-ul-illah! The praise be to God. It is as commonly used by Mahomedans as the Thank God! of the English.

HAMILTON, CHARLES, Author of a Historical Account of the Rohilla Afghans, London, 1787.

HAMILTON, DR. FRANCIS, formerly Buchanan, a Bengal medical officer, who published papers in the Linnæan Society's Transactions, author of a Journey through Mysore; An Account of Nepaul; Account of the Fishes found in the river Ganges and its Branches, with a volume of plates. He was the first after Rheede to explore the botany of Malabar.

HAMILTON, CAPTAIN, visited Cambay in A.D. 1681, and gave an account of its quartzose minerals.

HAMILTON, WALTER, author of a Geographical, Statistical, and Historical Description of Hindustan and the Adjacent Countries, 1820.

HAMILTON, WILLIAM, surgeon to the embassy sent from Calcutta under John Surman and Edward Stephenson, which reached Dehli on the 8th July 1715. He was successful in his treatment of the emperor Ferokhsir, who on recovery married the daughter of Jye Singh (Ajit Singh). Hamilton died 4th December 1717, and his epitaph is of historical interest :-

'His Memory ought to be dear to his Nation, for the Credit he gained the Engliah in Curing Ferrukseer,

the present King of Hindustan, of a Malignant Distemper,

by which he made his own name famous at the Court of that Great Monarch ;

and without doubt will perpetuate his Memory as well in Great Britain as all other Nations in Europe."

-Orme, ii. p. 20 ; Hough, p. 4.

HAMILTONIA SUAVEOLENS. Roxb.

Kanera, Pudari of BEAs. | Niggi, Tulenni, . RAvI. Muskei, Kantalu, Chenab. Phul, Golunla of .

Fisanni of.

Pudaxi of

TLES,

A common shrub in the Panjab Himalaya, up to near the Indus, at from 2500 to 6000 feet. Its wood is very small ; but in Chamba it is said to be used for making gunpowder charcoal.-Dr. Stewart; Roxb. i. 554 .

HAMIR. The Balla race were of sufficient consequence in the thirteenth century to make incursions on Mewar, but the first exploit of the celebrated rana Hamir was his killing the Balla chieftain of Choteela.

HAMIRA. There were four distinguished leaders of this name amongst the vassals of the last Rajput emperor of Dehli; one of them, who turned traitor, and joined Shahab-ud-Din, was a Scythian of the Ghiker race, which maintained their ancient habits of polyandrism even in Baber's time. The Haoli Rao Hamira was lord of Kangra and the Ghikers of Pamir.-Tod's Rajasthan, i. 560.

HAMIRPUR, a district in the N.W. Provinces of India, lying between lat. $25^{\circ} 5^{\prime}$ and $26^{\circ}$ $10^{\prime} \mathrm{N}$. and long. $79^{\circ} 22^{\prime} 45^{\prime \prime}$ and $80^{\circ} 25^{\prime} 15^{\prime \prime} \mathrm{E}$. Area, 2289 square miles. It encloses the Native States of Sarila, Jigni, and Banda. There are 62 clans of Rajputs, and the Pariahar, Chauhan, and Bais have been specially guilty of infanticide. The Chandel and Bundela, the old dominant classes, now sunk to 548 and 612 respectively, mostly still cling to the neighbourhood of Mahoba, the seat of their former supremacy. The Bais are far the most numerous of the Rajput classes in the district. Among the Sudras the most numerous are the Lodhi, the Chamar, and the Kori. The Mahomedans are the descendants of converted Hindus, who were originally Thakurs. -Imp. Gaz.

HAMITE. Mr. Logan says (J. E. Ar., May to June, 1854) the earliest Hebrew ethnography indicates that the Semitic region was jointly occupied by Shemites and Hamites. Four branches of the Hamites are enumerated, viz. (1) the Cushites, embracing the tribes of Sheba, Havilah, Raamah, etc., in Southern Arabia ; (2) the Ethiopan and Euphratan tribes of Nimrodians.

HAMMA-i-JOUR, literally 'joining of hands,' a Parsee ceremony practised in Pappati, similar to the English greeting of a 'Happy New Year.'Parsees, p. 61.

HAMMAM. ARAB. A bath. Hammam lena, to take a bath. Public baths, usual in Turkey, Egypt, Persia, and Kābul, are unknown in India. In the middle of the 19th century there were a hundred of them in Cairo alone,-Lane, ii. 43.

\section{HAMMER.}

Chakuj; Matripat, AraB. |Martillo, . . . . IT. Marteau, . . FR. Martillo, : : SP. Hathora, : : HIND. Chekij, : : TORK.

The native sledge-hammer of Bombay is employed in breaking trap, granite, limestone, and other rocks. Its handle is generally of male bamboo, about two feet long. Its head is something like that of an ill-shapen axe,-thick all along. It weighs about $18 \mathrm{lbs}$. In the face or striking portion is a bluntish wedge of steel, fastened in with a piece of leather. With this the native quarryman will break up the most obdurate trap into slabs or blocks of almost any size or form, from a pavement flag 3 inches thick and 2 feet square, to a block 2 feet cube. He looks narrowly at the grain of the stone, and then with a series of blows, of no great force, apparently, the stone falls in pieces, seemingly without effort. Similar varieties of this, of exactly the same pattern, are used as hand hammers; they are called Sootki. The blasting, or rather the boring, tool, or jumper, is a plain round rod of iron, about three feet long, pointed at both ends with steel. No hammer is ever employed in boring. The jumper is raised and struck in with both hands, and a man will penetrate some inch or two in an hour. The native punch is a short, dumpy, lancetpointed tool; it is sharpened by being turned point up, and struck with a piece of flint. When used in stone-dressing, it is held in the left hand, and struck with a hollow-faced iron hammer, the cavity being about an inch in depth and as much in diameter.-Dr. Buist, Bombay Times.

HAMPI, a ruined city, in lat. $15^{\circ} 19^{\prime} 50^{\prime \prime} \mathrm{N}$., long. $76^{\circ} 30^{\prime} 10^{\prime \prime} \mathrm{E}$., on the S. bank of the Tumbudra, 36 miles N.W. of Bellary. It is the site of an ancient capital of the Vijayanagar kings. The ruins cover nine square miles, including Kamlapur on the south, and Anagundi, a later seat of the dynasty. Hampi was founded, on the fall of the Ballala dynasty, about 1336 A.D., by two brothers, Bukka and Harihara, whose descendants flourished here till the battle of Talikot, 1565 A.D., and afterwards at Anagundi, Vellore, and Chandragiri for another century, until finally 
overwhelmed by the advancing powers of Beder, Ahmadnaggur, Bijapur, and Golconda. The Vijayanagar rajas extended and beautified Hampi with many palaces and temples.-Imp. Gaz.

HAMPSAGUR, lat. $15^{\circ} 9^{\prime} \mathrm{N}$., long. $76^{\circ} 4^{\prime} \mathrm{E}$., on the right bank of the Tumbudra. The level of the Tumbudra is here 1647 feet above the sea.

\section{HAMS.}

Hammen, . . DUt. / Presuntas, . . PORT. Jambons, : : . FR. Okoroku, : : RUS. Schinken, . . GER. Jamones, . . . SP. Proseiutti, : : Ir. But, . : : TuRk.

They are largely imported into India for the use of Europeans. Many Mahomedan shopkeepers will not even sell them.

HAMSA, the god of the Druse race.

HAMSAYA. HIND. A neighbour, dependant, vassal.

HAMUN, a name for the lake of Seistan, Hamun is an Old Persian word signifying expanse. - Ferrier, Journ. p. 429. See Ab-Istadah.

HAMZA, uncle of Mahomed, slain by Wahsha, a negro slave. See Masailma-el-Aswad.

HAN, the 5th dynasty of China, began B.c. 206, and lasted to A.D. 264. Most of the Han princes were munificent patrons of literature. During the reign of Ming-ti, the 15th of the Han dynasty, considerable intercourse was carried on between the princes of India and China. This had obtained from the earliest period, but particularly during the dynasties of Sum, Leam, and Tam, from the fourth to the seventh centuries, when the princes from Bengal, Malabar, and the Punjab sent embassies to the Chinese monarchs. The Han dynasty of China reformed the Chinese calendar.

HANAFIYAH, a large vessel of copper, sometimes tinned, with a stopcock in the lower part, and generally with a ewer, or a basin, to receive the water.-Burton's Mecca, ii. 43 .

HANBALI, a commentary of the Koran. The commentator was bom at Baghdad A.H. 164, and died there A.H. 241 , nearly 70 years old.

HAND.

Yadd, . . . ARAB. Manus, . . . LAT.

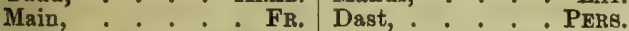
Hat'h, : : HIND. Kai, : : TaM., TeL. Mano, : : IT. SP.

The figure of the hand, amongst all nations, is utilized as an emblem.

The band is an emblem for $\nabla$., with the three central fingers folded in; and by placing the symbol below, the cardinal $\mathrm{X}$. is produced. In India, amongst Mahomedans and Hindus, the right hand is more honoured than the left; in China the left hand is more honourable than the right; in Siam the right more than the left.

In British India, a person to whom you make a present, a servant to whom you do a kindness, will rush to your hand and press it to his lips. To seize a man's hand is to crave his protection, to profess yourself his servant; hence the act is one of obedience and devotion, almost of servility. The person advancing to seize the hand always does so in a stooping posture, in an attitude of humility. The giving the hand amongst all nations (Prov. xi. 21) has been considered as a pledge for the performance or ratification of some act of importance, and it was the custom amongst the Scythic or Tartar nations of transmitting its impress as a substitute; the hand being immersed in a compost of sandal-wood, is applied to the paper, and the palm and five fingers (panja) is the signature. In Carne's letters from the East is given an anecdote of Mahomed, who, as erroneously supposed, unable to sign his name to a convention, dipped his hand in ink, and made an impression therewith, but Mahomed only followed an ancient solemnity, or custom, for all Mahomedans occasionally stamped or sealed their epistolary communications with the print of their hand. Hyder Ali often did it. It was considered a solemn form of signature. The panja, or palm and five digit form hand, of the Mahomedans, is used at the Maharram in erect Panjah flags or Alam, in the name of Husain and other martyrs.-Tod's Rajasthan, i. p. 362.

HANDI. HIND. A cooking-pot or kettle made of pottery, of the same shape as a deghcha, which is of brass.

\section{HANDKERCHIEF.}

Mouchoir, . . Fr. Fuzzoletto, . . . IT. Tuch, Schnupftuch, GER. Panullo, : : : SP. Rumal, . . HIND. Mendil, Mahrama, Turk. Handkerchief pieces form a considerable article of manufacture and traffic in Southern India. Handkerchiefs, coloured, from Madras, red from Sydapet and Ventapollem, are much admired for the harmony and richness of the colours, and the superiority of texture. Nellore pocket-handkerchiefs of jean deserve unqualified approbation. The silk handkerchiefs manufactured in Bengal are known in the market as Bāndana, Kora, and Chapa. They are generally figured, and of different colours. They are exported chiefly to the Burmese territories, and sold at from $1 \frac{1}{2}$ to 5 rupees each. The coloured cotton handkerchief's manufactured at Ventapollem, on the east coast, are well known in foreign markets, were formerly highly prized for their superior qualities and colours, but they have been driven from the markets by the Madras and Pulicat manufactures, which the community prefer for their superior qualities and colours. Madras handkerchiefs of superior kinds are sold at $1 \frac{3}{4}$ rupee each, and inferior sorts at 4 annas to 12 annas; the colour of the last description is very perishable. The ordinary colour of the Madras handkerchiefs is red, and Mahomedans and Hindus prefer them to those of other countries. The principal site of the manufacture of silk handkerchiefs for the head is Seringapatam in Mysore; they are of superior quality, and of red and pink colours; they are in squares of 6 cubits, and are, in consequence of their gold lace borders, sold at 35 to 100 rupees each.Mad. Ex. J. Rep.

HAND-MILL.

Meula,

Fr. |Mola, . . . . . I IT.

Chakki, : : Hind.

The grinding at the hand-mill is noticed in Exodus xi. 5, Isaiah xlvii. 2, and Matthew xxiv. 41. It is the quern of the Gael. In all the south of Asia, in small families, the labour of one person suffices to grind enough for the day's consumption; but where the inmates are more numerous, two people sit on the ground with the hand-mill between them. A single person, to cause the upper stone to revolve, has to pull it towards and to push it from her; but when two are working, each pulls towards her side. The Old and New Testaments notice the process, but it is well described in the 47th chapter of Isaiah. It is a heavy task, but they lighten 
it by their labour-songs, and they work from the earliest morning hours, 2 or 3 A.M.

HAND-PLANT, Cheirostemon platanoides, $H$. $B$. $K$., venerated by the ancient Mexicans, from the singular resemblance to a clawed hand presented by the curved stamens of the flower.

HANDRO. HIND.? A tree of Chutia Nagpur, with hard, red timber.-Cal. Cat. Ex. 1862.

HANGI. HIND. A large horse-hair sieve, used by silk-dyers.

HANGRANG PASS, lat. $31^{\circ} 47^{\prime} 7^{\prime \prime}$, long. $78^{\circ}$ $30^{\prime} 6$, in Kanawar, W. of the Sutlej, leads over to Spiti. The top of the pass is 14,530 feet above the sea, according to the G. T. S.

HANG TUAH, a celebrated champion of Java, called the Laksamana. He must not be confounded with the Laksamana of the Portuguese writers, as the latter lived several generations after the first, who accompanied king Mansur to Majapahit.

HANIA. Arab. An Arabic salutation, meaning, May it be good to you.

HANIF, an expression employed in the Koran by Mahomed, to signify that he followed the pure and catholic faith of Abraham. One Mahomedan theological sect is called Hanif. The Hanifi theology chiefly holds by the religion of Abraham.

HANIFAH, a commentator of the Koran, was born at Kufa А.H. 80, and died at Baghdad, in prison, A.H. 150, nearly 70 years old.

HAN JIN and Tan Jin, men of Han or of Tang, from the dynasties of those names.

HANKA, also Anküs. HiNo. The elephantdriver's spear-goad.

HAN-KOW, CHIN., means mouth or port of the Han. See Yang-tze-kiang.

HANLE TSO, a fresh-water lake in Ladakh, in lat. $32^{\circ} 48^{\prime} \mathrm{N}$., long. $78^{\circ} 54^{\prime} \mathbf{E}$., at the monastery of Hanle, 14,600 feet above the sea. This is the largest sheet of fresh water in Ladakh.-Cunningham's Ladakh, p. 142; Schlagentweit.

HAN-I,IN-YUEN, the Imperial Academy of China, founded by Kablai Khan. For 600 years the small body of Han-lin scholars have held their sessions undisturbed by dynastic revolutions or political outbreaks. No learned society in the world can compete with it in age or in its intense exclusiveness. The examinations being open to all, and forming as they do the only recognised channel to official rank, every man in the empire who aspires to end his days as something more than a plebeian, enters the lists. At the first competition, which consists of five sessions separated by intervals of a few days each, and which is held annually in the chief city of each district, about 2000 candidates generally present themselves. Out of this number from 20 to 80 of the best are chosen, and on these are conferred the degree of Siu-ts'ai, or 'budding genius.' Every third year the budding geniuses from every district in each province-and there may be 70 or 80 -go to the provincial capital to appear before an imperial examiner as candidates for the next degree of $\mathrm{Ku}$ jin, or 'promoted scholars.' On this occasion 5000 or 6000 competitors contest the bonour of being the one in each 100 who, as the ripest scholar, is admitted to the further degree of $\mathrm{Ku}$ jin. In company with all those who have won similar honours in the capital of the 18 provinces of the empire, the successful $\mathrm{Ku}$ jin goes, in the succeeding spring, to Pekin, where, if fortune attend him, he wins the distinction of becoming a Tsin shi, or 'one ready for office.' In agreement with this descriptive title, the new Tsin shi may, if they please, ballot for the vacant junior mandarinates, for which they have now shown themselves qualified, and from which they may rise by their own exertions to seats in the Grand Council of State, or to places in the imperial cabinet. But, if desirous of still further distinguishing themselves as scholars, and of obtaining the honour of places in the Imperial Academy, the 200 or 300 survivors of so many contests present themselves at the palace, where they are examined by the emperor in person. Out of this number about 20 are chosen whose scholarship is the ripest, whose penmanship is the best, and whose literary style is the most perfect, and to these are given seats among the Immortals of the Han-lin. On one only of these 20, chosen out of the 300 million inhabitants of the empire, la crême de la crême, is conferred the signal title of Chwang-yuen, or model scholar of the empire. Once in three years is this degree granted; and so supreme is the prize, that provinces contend for it, and the birthplace of the victor becomes famous for ever. The instant that the imperial award is given, heralds carry the news at express speed to the friends of the laureate. We have, says Dr. Martin, seen them enter a humble cottage, and, amid the flaunting of banners and the blare of trumpets, announce to its startled inmates that one of their relations had been crowned by the emperor as laureate of the year. And so high was the estimation in which the people held the success of their fellow-townsman, that his wife was requested to visit the six gates of the city, and to scatter before each a handful of rice, that the whole population might share in the good fortune of her household.

Members of the Han-lin are appointed the official poets and historians of the reigning dynasty, and every imperial compilation undertaken is the work of these men. It was they who edited the famous dictionary of the language which added a lustre to the reign of K'ang-he (1661-1721), and who, at the bidding of the Emperor K'een-lung (1755-1795), compiled the celebrated encyclopædia in 5020 volumes, one of the few existing copies of which is now in the library of the British Museum. To act as examiners at the competitive examinations, and as literary chancellors in the provinces, form part also of their duties, as well as composing prayers for the use of the emperor on occasions, writing inscriptions for the temples of various divinities, in acknowledgment of services, and choosing honorific titles for members of the imperial household.

The holders of hereditary titles are so few, that their existence cannot be said to impair the assertion that the holders of official rank form the only aristocracy in China. Unlike the aristocracy of other lands, this charmed circle is, according to law, only to be entered by winning distinction at the examinations; and as these are open to every man in the empire, of whatever age and of whatever station in life, except the very outcasts, the highest prizes are as freely accessible to the peasant or shopman, as to the sons of the loftiest dignitaries. China may thus be said to be a democratic empire, tempered by an ariatocracy of talent. $-D r . W . A$. P. Martin, The Chinese, 
their Education and Letters; Huc, Chinese Empire, i. pp. 19,95 .

HANNAMANTU'S PILLAR. About 50 feet west of the high road from Kurnool to Gooty, 50 t miles from Kurnool town, stands this natural pillar of gneiss rock. There is scarcely such another in the world. Amongst a few smaller pillars of a similar kind, it towers 25 feet high, averaging 6 feet square. This average width is exceeded in the middle, and tapers off towards both ends; so that the top is 4 or 5 feet square, and the base about 3 feet square. It is all solid, except that the upper 4 or 5 feet is separated from the rest of the pillar by a tine horizontal crack. The most striking part of it is, that it does not stand on its base fully, nor even upon half of it. A string 10 feet long will encircle the whole of the bearing points of the base, which all lie within a space about 3 feet long and 2 feet wide, in the form of a truncated right-angled triangle. This is a small base for a pillar weighing as much as a couple of locomotive engines with their tenders complete. Yet even on this small base, if, as appears likely, the centre of gravity falls about the centre of the base, it will require a wind-pressure of $80 \mathrm{lbs}$. on the square foot to overturn the pillar. Years ago, some Hindu enthusiast painted a figure of the monkey god on this pillar. Recently some iconoclast has been removing the figure, by flaking off the stone in a very destructive way.-Traveller.

HANNO, according to Pliny, a native of Carthage. When that city was at the height of her prosperity, he circumnavigated the continent of Africa, sailing from Gades (Cadiz) to the extremity of the Arabian Gulf. He wrote all the details of his voyage in the Punic language.

HANOMOREY, betle-box bearers of Oovah in Ceylon, a race or caste held to be more degraded than the Rodiya. - Tennant.

\section{HANSA or Hanasa.}

Gans,

Xnv,
Anser,

Gangsa,
PALI. PORT. SP.

A swan, a goose. When the followers of the first crusade issued from England, France, and Flanders, they adored a goat and a goose, which they believed to be filled with the Holy Ghost. Salu, translated quails in Numbers xi. 31, are supposed to be red geese. Brahma is styled the Hansa rider, it being his vahan or vehicle. The figure on many Buddhist monuments is the Casarca rutila, or Brahmany goose. The goose is emblazoned on the national standard of Burma.

HANSI, a municipal town of Hissar district, Panjab, and headquarters of the Tahsil, lat. $29^{\circ}$ $6^{\prime} 19^{\prime \prime}$ N., long. $76^{\circ} 0^{\prime} 19^{\prime \prime}$ E., population (1868) 13,563. Dr. Hunter says it was founded, according to tradition, by Anang Pal Tuar, king of Dehli. Colonel Yule says it was founded by Raja Pethora of Dehli. It was captured by Mahmud of Ghazni, A.D. 1035. The well within the lower fort, or fausse braye, is 120 feet deep. In the centre of the upper fort is a cistern capable of containing 184,000 gallons. It was the capital of George Thomas, who raised himself from being a sailor before the mast to be ruler of a small Indian principality.-Yule, Cathay, ii. p. 406 ; Imp. Gaz.

HANSRAJ. HrND. Adiantum caudatum, A. capillus veneris, $\mathbf{A}$. venustum, the pari-soosa or mu-i-pari, fairy-hair ferns, the leaves of which are deemed by the natives of India beating and febrifuge.-Gen. Med. Top. p. 127.

HANTU. Malay. A spirit, a ghost.

HANUMAN, a Hindu deity. From Hanu, the cheek, Hanuman means long jaw. His figure is that of a man with a black monkey face and a long tail. Hanuman or Hanumat, in Hindu mythology, is son of Pavana, the wind, by Anjana, wife of a monkey named Kesari, called also Lanka-dahi, also Yoga-chara, Marut-putra; and he has the patronymics Anili, Maruti, and the matronymic Anjaneya. His images are set up in temples, sometimes alone, and sometimes in the society of the former companions of his glory, Rama and Sita. He is supplicated by Hindus on their birthdays to obtain longevity, which he is supposed to have the power to bestow. As the god of enterprise, offerings are made at his shrine by night. Hanuman is said to be a son of Siva. He is fabled to be the son of the wind, and is called Maruti, from Pavana being chief of the Marut, or genii of the winds. $\mathrm{He}$ is also called Muhabar. As the monkeygeneral who assisted Rama in his war with Ravana, he is regarded and worshipped as a demigod. Both Hanumanji and Boosundi are said to have their lives protracted through the four yuga of Hindu chronology. Boosund was a crow who had more blood than he could drink in the wars of Sambhu and Nesambhu. He just quenched his thirst with blood in the wars of Rama. But in the wars of the Mahabharat he broke his beak by striking it against the hard dry earth, which had soaked in the little blood shed on the occasion. In 1868, Bala, potail of Assaye, who was five years old when Sir Arthur Wellesley fought the battle, was the pujari of the temple in which the editor put up. Bala daily walked in and poured water on the lingam (Abishegam), also on Hanuman and on the bull (Basava); then put rice on all these, then walked around five times, then put rice on the tulsi, and the worship concluded.-Tr. Hind. ii. p. 207 ; Col. Myth. p. 59 ; Dowson.

HANUMAN, the Bengal langūr, Presbytes entellus of Bengal and Central India. The males live apart from the females, whom they visit at seasons. See Presbytes.

HANUMAN NATAKA, a long drama on the adventures of Hanuman, by various hands, completed by Damodara Misra, by request of King Bhoja, in the 10th or 11th century.

HANXLEDEN and Paulinus a Sancto Bartolomeo whose real name was Philipp Wesdin, in 1790 published the first Sanskrit grammar.

HAOU? TSING! TSING! The Chinese salutation on meeting, meaning literally, Are you well? hail ! hail! See Chin.

HAPTA HINDU, of the Vendidad, is the modern Panjab, the Hapta Sin or Hapta Hin, or the seven rivers, called in the Vedas the Sapta Sindhava. These consist of the Sindhu or Indus, with its six eastern confluents, viz.:

Vitasta or Hydaspes.

Asikni or Ascesenes.

Parushni or Hydraotes.

Vipas or Hyphasis. Satadru or Hesydrus. Kubha or Kophen.

In the journeying of the Aryan race, their fourteenth settlement was in Hapta Hindu (Panjab, vi. 19), the land of the seven Hinda, that is, the country between the Indus and Sutlej. In the Vedas, the country of the five rivers is also called the land of the seven rivers. The traditional Greek names also are seven. The Indus 
and the Sutlej are each formed by the junction of two arms, which in their earlier course were independent. According to this view, it stands thas:-
1. Kophen (Kubha), . .?
2. Indus, Upper, : . :
3. Hydaspes (Bidaspes), - II. Hydaspes.
4. Akesines (Asikni), . III. Akesines.
5. Hyarotis (Hydraotis, $\}$ IV. Hydraotes.
6. Hyphasis (Vipasa), $\left.\begin{array}{l}\text { 7. Saranges (Upper Sata- } \\ \text { dru, Sutlej, Ghara), }\end{array}\right\}$ V. Hyphasis.

Ritter supposes that the country extended as far as the Sarasvati, but such a supposition is at variance with history. It is now ascertained from the Vedas that the Aryans passed the Sutlej at a very late period, and settled in what is now India. It was not till their fourteenth settlement, after the migration from the primitive country in the north, that they passed the Hindu Kush and the Indus. The previous resting-places form an unbroken chain of the primitive abodes of the Aryans.-Bunsen, iii. 465, 487. See Aryans.

HAQ. ARAB. Right, truth; also an attribute of the deity, Al Haq, the true God, a word in frequent combination. Haq also means any right or due to which a person is entitled. Haq-dar, a person entitled to any right. See Sufi.

HAR. HIND. A necklace; a necklace of honour.

HAR, the Rajput god of war, is Kumara. In the Hindu mythology he is represented with seven heads; the Saxon god of war had six. The six-headed Mars of the Cimbri Chersonese, to whom was raised the Irmanseul on the Weser, was worshipped by the Sacasenæ, the Catti, the Siebi or Suevi, the Jetæ or Gete, and the Cimbri, evincing in name, as in religious rites, a common origin with the martial warriors of Hindustan. The Rajput delights in blood; his offerings to the god of battle are sanguinary, - blood and wine. The cup (cupra) of libation is the human skull, the calvarium. He loves them because they are emblematic of the deity he worships; and he is taught to believe that Har loves them, who in war is represented with the skull to drink the foeman's blood, and in peace is the patron of wine and women. With Parvati on his knee, his eyes rolling from the juice of the p'fool and opium, such is this Bacchanalian divinity of war, who is a perfect analogue of the manners of the Scandinavian heroes. The Rajput slays buffaloes, hunts and eats the boar and deer, and shoots ducks and wildfowl (cookru); he worships his horse, his sword, and the sun, and attends more to the martial song of the bard than to the litany of the Brahman. In the martial mythology and warlike poetry of the Scandinavians, a wide field exists for assimilation; and a comparison of the poetical remains of the Asi of the East and West would alone suffice to suggest a common origin. The cupra of Har, a human skull, the calvarium, in the dialects pronounced cupar, is the cup in Saxon. The cup of the Scandinavian worshippers of Thor, the god of battle, was a human skull, that of the foe, in which they showed their thirst of blood; and Har, the Hindu god of battle, leads his heroes in the 'red field of slaughter' with the cupra in his hand, with which he gorges on the blood of the slain. The Gosain are the peculiar priests of Har or Bal; they seem all to indulge in intoxicating drugs, herbs, and drinks.-Tod's Rajasthan, i. 67 .
HAR, Terminalia chebula, and other three species, furnish all the discarded myrobalans of old pharmacopoeias. The whole are much used in dyeing. The myrobalan from Dehli and Harowti, Hindustan and the Dekhan, are of four kinds, namely, Gural harra, astringent and purgative, used in mesalihs, given in medicine to children, 4 seers for 1 rupee; Juwal harra, used in the same way, 8 seers for 1 rupee; Chaipel harra, used only in dyeing, 10 seers for 1 rupee. According to the size of the myrobalan, its value augments, so that it very large one may be worth 100 rupees or more, the natives believing that the very large ones have the virtue of causing purging by being merely retained in the hands, and is esteemed to possess wonderful general deobstruent and purgative qualities, etc. etc., but is in reality worthless.-Genl. Med. Top. pp. 136, 153.

HAR. HiND. A plough; enters into the composition of many words. See Hal.

HARA, a name of Siva or Mahadeo.

HARA, a mountain range. See Hala.

HARA, a branch of the Chauhan Rajputs, who give their name to Haraoti, which includes Kotah and Bundi. The Hara Rajputs have held Haraoti through all dynastic changes. Bundi is their capital, and they claim descent from the family that ruled in Ajmir before the Mahomedan conquest in 1342. The Hara Rajput is above the middle height, with graceful and well-proportioned limbs. He is wiry, upright, with a commanding presence; with an air of pride and haughty superiority over all men, but devoted to their chiefs. The face is well shaped; nose and mouth finely cut; eye small and long, bright and clear, but not indicative of high intellect. The Hara Rajput partakes freely of tobacco, spirits, and opium, fish, and flesh of all kinds, except that of the cow or buffalo; but thick and coarse cakes of flour form the chief food, with regetables and milk. This Hara branch of the Chauhan dynasty are descended from Anuraja, a son of Visaldeva, or more properly of Manakya Rai (Tod, ii. p. 454), who in A.D. 695 founded Sambhur, hence his title of Sambri Rao. In A.D. 1024 Anuraja took possession of Asi or Hansi, in Hariana. The Bundi branch of this family reckon from Rao Ratan, who built Ratanpur, the name of the chief town, in 1578 to 1821 , in which year was Ram Sinh. The Kotah branch reckon from Madhu Sinh, son of Rao Ratan, in A.D. 1579, to Kiswar Sinh, Madhu Sinh, regent, in A.D. 1819. Thomas' Prinsep, p. 249 ; Captain W. H. Beynon, in vol. vii., People of India.

HARA. ARAB. A quarter of the city in Cairo. Every quarter has its shaikh, called Shaikh-ulHara. The whole city is also divided into eight districts, over each of which there is a shaikh.

HARAI is the most important of the hill chiefships or zamindaris in the north of the Chindwara district.

HARAKAT. ARAB. Trouble, inconvenience. Under British rule in India, Harakat na hui, barakat hui, Trouble there has been none, blessing hath there been.-Burton's Mecca, i. 11 .

HARA KIRI is from Hara, JAPANESE, the belly, and Kiri, root form of Kiru, to cut; a self-immolation by disembowelling, a mode of self-execution adopted in Japan. Practically, they make only a small wound in the belly, and in the act of so doing a relative or other person, whom they have 
selected, cuts off their head with a sweep of a sword. In 1869 , when Taki Zenzaburo was permitted by the Mikado so to die, because he had ordered the Europeans to be fired upon at Kohe, he wore a dress of ceremony and a zimbaori coat. He advanced to the high altar and prostrated himself twice, with his pupil on his left to act as the kaishaku or beheading friend. He was presented

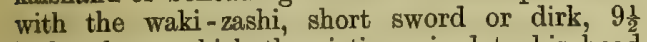
inches long, which the victim raised to his head and placed in front of himself. He then confessed aloud, 'I, and I alone, unwarrantably gave the order to fire on the foreigners at Kohe, and again as they tried to escape. For this crime I disembowel myself, and I beg you who are present to do me the honour of witnessing the act.' Bowing again, he let his clothes fall to the waist, then took the dagger, and, stabbing himself below the waist on the left side, he drew it slowly across to the right side, and, turning the dirk in the wound, he gave it a slight upward turn. He then drew out the dirk, leant forward, and stretched out his neck. At that moment the kaishaku sprang to his feet, and with one blow severed the head from the body, made a low bow, wiped his sword, and retired. The stained dagger was then solemnly borne away as proof of the execution. The Samurai, or gentlemen of the military class, are trained from infancy to regard this self-execution as an honourable form of expiation. In some parts of Japan, as the victim criminal stretches out his hand to take the wooden dagger, the kaishaku strikes off his head; or a Daimio disembowels himself and cuts his own throat.Mr. Mitford in Cornh. Mag., Nov. 1869; Oliphant, ii. 147 ; Manners and Customs of the Japanese, 193.

HARAM. ARAB. Sacred; the most sacred place of a temple or a palace; the seraglio of a great man. Harmain, the holy cities of Mecca and Medina. In Arabia, Egypt, and Turkey, the Hărăm or Harm means the female part of the family, and the word is used to avoid the indecorum, in the eyes of a Mahomedan, of mentioning his wives or daughters. It is likewise the name for that part of the house where the females dwell. Mahomedans are so scrupulous to avoid speaking personally of their female relations, that, when obliged to refer to them, they say, ' $\mathrm{My}$ house is sick,' or ' $\mathrm{My}$ house sends compliments to your house.' The haram in India means a purchased woman associating with her master. In Arabia, the haram woman would be a slave woman taken in war.-Rich's Kurdistan, i. p. 2.

HARAM, in India, unlawful, forbidden ; whatever the Mahomedan law disallows; unlawful food, such as pork, wine, mushrooms, etc., hence Harāni and Haramzädāh, a vicious, wicked man or beast.

HARA-MUK or Gunga bul, TIB., means literally place of the Ganges, and is a sacred lake on the mountain of Haramuk, in Kashmir. It lies under the wildest and most lofty peaks of the mountain, is $1 \frac{1}{2}$ mile long and 200 or 300 yards wide, and is about 12,000 feet above the level of the sea.-Vigne.

HARAN, the present Karra, a day's journey south of Odessa, to which Abraham went from Ur of the Chaldees. It is the capital of a Turkish pashalik, which extends in a north-west direction from the mouth of the Shat-ul-Arab to the rocks of Merdin, the Baghdad frontier towards Con- stantinople. In an east and west line 1t stretches from the confines of Persia to the banks of the Khabour, which separates it from the pashalik of Orfa, the Osrhoene of the Romans, and that part of Mesopotamia which contained the Haran of Abraham, and the famous Edessa of the crusades. -Bunsen, iii.

HARAND, a district in Eastern Baluchistan bordering on the Indus. It is one of the three eastern sections of Baluchistan. Harand and Dajil, in Cutch Gandava, are inhabited by the Gurchani tribe of Rinds, and have the Muzari on their south.

HARAQUAITA is the Arachosia of the classics, the country of the Rachos, with whom the immigrant Aryans came in conflict, and who have been turned into the fearful Rakshasa of popular Hindu belief. According to General Ferrier, Arachosia can be distinctly shown by the Greek measurements to have been at the ruins of Shahr-Zohak, or Olan Robat, between Kilat-i-Ghilji and Mokoor. According to Ch. Bunsen, Haraquaita is south of $\mathrm{Ka}$ abul, and is the Harauwati of the cuneiform inscriptions, and the Arachosia of the classics. It was the ninth settlement made by the Aryans (verse 13 ) in a country which they conquered, and it was here that they commenced to inter their dead, which the Zendavesta strictly prohibits, as being the greatest desecration of the sacred earth-an apostasy, therefore, from the true faith. The Arachotia mentioned on the coins of the Indo-Greek rulers was Kandahar. The Haraquaita of the Zend language is the Saraswati of Sanskrit writers, the Greek Arachotos, and the Chinese Tsaukuta. - Bunsen, iii. 464 to 485 ; Ferrier's Journ. p. 323.

HARAWAL. TURK. The advanced guard of an army; the officer commanding it.

HARB. ARAB. Battle. Harbi, martial, valiant. In Mahomedan law, Dar-ul-Harb is a nonMahomedan state, not subject to Mahomedan rule, and, although at peace, an incessant object of hostilities. Dar-ul-Islam is a Mahomedan state.

HARB, an Arab tribe who warred with Mahomed. Mahomed is fabled to have resuscitated those killed in the war by the application of balsam of Mecca.

HARBOURS. Captain Taylor gives a list of 656 ports and harbours in British India, the chief of which are-Karachi in Sind; on the. west coast of India are Poshetra and Serai, in the Gulf of Cutch; Chuch Bandar or Shalbet, on the south coast of Kattyawar, 30 miles east of Diu Head. It is formed by Shalbet Island. Bombay harbour is the best on the west coast. Jyghur and Viziadrug is south of Bombay; Karwar is the port of $\mathrm{N}$. Canara. Cochin harbour is kept clear by its splendid backwater, which acts as a tidal reservoir. Kolachul, on the Travancore coast, has some outlying rocks, and large ships can ride at anchor to leeward of them in still water. Tuticorin, in the Gulf of Manaar, is the port for all the large trade of Tinnevelly, but vessels have to lie $2 \frac{1}{2}$ miles from the shore. Chittagong harbour or port is $\mathbf{1 0}$ miles up the river Karnfuli. It is one of the best ports in India. The Hoogly, the Irawadi, and the Moulmein rivers are much resorted to.

HARBURENNI and other places in Ceylon have numerous rock inscriptions in the Pali language, from 104 B.c. to twelfth century, in the Lat to the modern Tamil character. Religion 
mentioned is Buddhist. Sir Vilmot Horton says there are thousands of these inscriptions in Ceylon, and they exhibit the Deva Nagari in all its transitions. The inscriptions would appear to be much defaced, and little is yet made of them. -Vol. v. p. 554 .

HARDAUL-LALA, a chief of Bundelkhand, whose spirit, according to the natives of Northern India, visited the camp of Lord Hastings with cholera in consequence of the slaughter of cows in the grove where the chief's ashes were interred. Hardaur or Hardaul is the name given to the earth mounds on which a flag is placed, raised to avert epidemic disease from the villages of $\mathrm{N}$. India.-Wilson.

HARDEHA. HIND. A tribe of the Koch'hi.

HARDINGE, Viscount, G.C.B., a general officer of the British army, who distinguished himself in the Peninsula under the Duke of Wellington. He took the office of GovernorGeneral of India, 23d July 1844, and held it till the 12th January 1848. He endeavoured to preserve peace, but, after the death of the Maharaja Ranjit Singh, the Sikh nation had been agitated, and anarchy followed. On the death of Kurruck Singh, the Sikh army freed themselves from all control, and 50,000 men invaded British territory, and they began to cross the Sutlej on the 11th December 1845. Lord Hardinge had left Calcutta on the $22 d$ September, and placed himself under the orders of Sir Hugh Gough; and on the British Indian army arriving at Moodkee on the 18th December, they found the enemy advancing in order of battle, and the battle that ensued lasted from three in the afternoon until nightfall. The Sikh army lost seventeen guns and several thousand men. In this battle Sir Robert Sale fell. The Sikhs retreated to Firoz Shahar, where for three days they were throwing up entrenchments around their camp. On the 21st December Sir Hugh Gough attacked their entrenchments, and the British army and its generals bivouacked on the field, exposed throughout the night to the fire of the enemy. The battle was renewed next day, and terminated in the success of the British, the camp being taken, after a long and bloody conflict. Prince Vladimir of Prussia was present in this engagement, and his physician, Dr. Hoffmeister, was killed.

The Sikh army retired to the right bank of the Sutlej opposite Lodhiana, which Major-General Sir Harry Smith was sent to protect; and in the subsequent movements the Sikh army opposed him at Aliwal on the 28th January 1846, but were defeated with great loss, and the left bank was cleared. Sir Harry Smith rejoined the commander-in-chief, and on the 10th February 1846 the battle of Sobraon was fought and won, but with great loss on the part of the British, thirteen officers were killed and above one hundred wounded, A treaty was signed, transferring all the country between the Sutlej and Beas, and afterwards modified to the Beas and Indus. Raja Dhulip Singh was reinstated on the throne, and Raja Gulab Singh made independent, and granted Kashmir and other territory. Sir Henry Hardinge was created a viscount, Sir Hugh Gough a baron, and Sir Harry Smith a baronet. Lord Hardinge returned to England, and was succeeded by Lord Dalhousie.
HARDTVAR, ancient historical town and place of Hindu pilgrimage in Saharunpur district, N.W. Provinces, lat. $29^{\circ} 57^{\prime} 30^{\prime \prime}$ N., long. $78^{\circ} 12^{\prime} 52^{\prime \prime}$ E. ; population (1872), 4800 . It was originally known as Kapila or Gupila, from the sage Kapila, who passed his life in religious austerities at the spot still pointed out as Kapilasthana. Hardwar, or Hari-dwara, literally Vishnu's Gate, seems to be of comparatively modern origin, as both $\mathrm{Abu}$ Rihan and Rashid-ul-Din mention only Gangadwara, or the Ganges gorge (literally, gate). Tom Coryat visited the place, and described it as 'Haridwara, the capital of Siva.' The level of the Ganges at Hardwar is $\mathbf{1 0 2 4}$ feet. The Ganges falls rapidly to Hardwar, which is 1300 miles from the mouth. It is a great place of pilgrimage, the pilgrims often occupying the valley of the Ganges to a length of nine and a depth of two miles from the village of Doodea past Hardwar and Myapore to Kunkul and Jooalapore. Its celebrity is owing to the proximity of the Rikikase gorge, from which the Ganges escapes from the Siwalik Hills of the Himalaya mountains, thirteen miles above Hardwar. It was a scene of sacred rites long before either Sivaism or Vishnuism developed in their present forms. As the spot where the Ganges issues forth on its fertilizing career, Hardwar obtained the veneration of each of the great religions of India, and preserves the memorials alike of Buddhism, Sivaism, and Vishnuism, and of rites perhaps earlier than any of them. A dispute exists to this day between the followers of Siva and Vishnu as to which of these deities gave birth to the Ganges. The Vishnu Purana is cited by both, as it ascribes the Ganges to Vishnu, and the Alaknanda, or eastern branch of the Ganges, to 'Siva's Gate;' the Vishnuvites maintain that it is Hari-dwara, "Vishnu's Gate." The great object of attraction at the present day is the Hari-ke-charan, or bathing ghat, with the adjoining temple of Ganga-dwara. The charan, or footmark of Vishnu, is imprinted on a stone let into the upper wall of the ghat, and forms an object of special reverence. Each pilgrim struggles to be the first to plunge into the pool after the propitious moment has arrived, and stringent police regulations are required to prevent the crowd tramping one another to death, and drowning each other under the sacred water. In 1819,430 persons, including some sepoys on guard, lost their lives by crushing in this manner, after which accident Government constructed the present enlarged ghat of sixty steps, 100 feet in width. Riots and bloody fights were of common occurrence amid the excited throng. In 1760 , on the last day of bathing (10th April), the rival mobs of the Gosain and Bhairagi sects had a longcontinued battle, in which the almost incredible number of 18,000 are said to have perished. In 1795 the Sikh pilgrims slew 500 of the Gosains. In 1829, Gosains fought their way to the Ganges, and many were killed. The great assemblage of pilgrims takes place on the first day of the month of Baisakh, the commencement of the Hindu solar year (March-April), and the anniversary of the day upon which the Ganges first appeared upon earth. Every twelfth year, the planet Jupiter, being then in Aquarius, a feast of peculiar sanctity occurs, known as a Kumbh-mela, and is attended by an enormous concourse of people. The ordinary number of pilgrims at the annual 
fair amounts to 100,000 , and at the Kumbh-mela to 300,000 .

Pilgrims come to Hardwar from all parts of Hindustan and Bengal, from the Dekhan, the Panjab, from Kashmir, Afghanistan, Tartary, Tibet, and China, some as religious devotees, some as worldly tradesmen. For miles around the place it is one immense encampment. Colonel Yule has seen Buddhist pilgrims at Hardwar who had crossed the Himalaya from Maha-Chin, as they said, to visit the holy flame of Jawalamukhi in the Panjab. A great attack of epidemic cholera occurred at Hardwar in 1783 , when 20,000 people died in eight days.-Yule's Cathay, p. 411 ; Taylor's Visit, p. 177 ; Imp. Gaz.

HARDWARE.

Isenkramvarer, . DAN. Chincaglio, . . . . IT. Yzerkramery, . DUT. Quincalharia, : PoRT. Clinquallerie, . . Fr. Mjeloizchnue Towar-

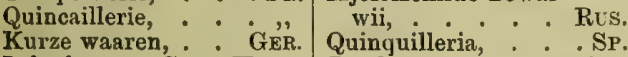
Kurze waaren,
Loha kam, .GUJ., HIND.

In commerce, goods of every kind made from metal.-M'Culloch.

HARDWARI PEORI, or Indian yellow, is the dried deposit precipitated from the urine of cows that have been fed on the leaves of the mango (Mangifera Indica). It consists principally of magnesia and purreic acid, as it has been called by Sir R. Kane. On treating a solution with weak muriatic acid, after evaporation, yellow scaly crystals of purreic acid are obtained. Hardwari peori is usually met with in the bazars in lumps. Wilayiti peori is chrome yellow, in lumps (chromate of lead). Hardwari indicates the locality where it is obtained. A dye made of the Harsinggar is sold under the same name.-Powell, Ec. Pr: Panj. p. 195.

HARDW ICKE, MAJOR-GENERAL, a distinguished zoologist, who was employed in Northern India in the early part of the 19th century. His collection was described by Dr. Gray of the British Museum, in one volume.

HARDWICKIA BINATA. Roxb.

Caratchu, Kamra, . CAN. | Kar-atchi, Kat-udugu, TA. Anjun, . . MAHr. Epe, Nara epe, . . TeL. Atcha, Attimaram, TAM.

This large leguminous tree grows in the forests of the Godavery, in the Nullamallay, on the mountains of the Coromandel coast, in some parts of Kandesh, in the Padshapur jungles, in the Guzzelhutty pass, common in Lulling pass between Malligaum and Dhoolea, and on the hills of the Sone valley. It is a most elegant tree, tall and erect, with an elongated coma, and the branches pendulous. On the Godavery it is often hollow in the centre. Yields a timber of an excellent quality for beams, and a variety of uses. The wood is red or dark-coloured, very hard, very strong and heavy. As the shoots grow up very straight, it is also valuable for rafters. The bark yields a strong fibre, and the people of the island of Siva Samudram use it without further preparation.-Roxb.; Voigt; Mr. Rohde's MSS. ; Hooker's H. J. i. $50 ; W$. and A.; Beddome; Dr. Gibson.

HARDWICKIA PINNATA. Roxb. This very large tree is very conmon on the $\mathrm{S}$. Travancore ghats (Asambu Hills), in the dense moist forests, up to 3000 feet elevation, and is also found on the Tinnevelly side, just above Courtallum (between

the $2 \mathrm{~d}$ and $3 \mathrm{~d}$ falls), and on the new Manjerabad ghat (S. Canara), about 1500 feet up from Siradi. The tree yields a dark red balsam, which is used medicinally. A deep notch is made into the heart of the tree, and after a time it begins to flow. The tree flowers in March and April, and the legumes ripen in July. The wood is much used by the coffee planters and others for building purposes.-Roxb.; Beddome, Flo ra Sylv. p. 255.

\section{HARE.}

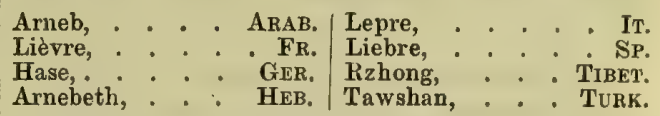

See Lepus; Mammalia.

HARGILA, the Bengali name of the adjutant bird, said to be from Har or Hur, a bone, and Nigalua, to swallow.

HAR GQVIND, a Sikh guru. See Guru.

HAR-HAR, a subdivision or part of an estate. In Saugor it means the cultivated space immediately round a village, which is quite opposed to the meaning it generally bears in the N.W., where it is applied to the land most distant from the site of the village, i.e. beyond the Mungha. In Bundelkhand and some other places it signifies a tract of land, but the term in no way indicates separate possession of the tract designated.Elliot, Supp. Gloss.

HARI, the ancient Arya, the country of Herat, is the western province of Khorasan.-Belleu.

HARI, a name of Krishna as an avatar of Vishnu. Hari, Hari-bol, amongst Hindus, a shout of applause.

HARI. The great harvests are called in Hindi rabi and kharif, or by the Northern Hindu vil. lagers hari and sawani, from the names of the months in which the crops are ripe. Rabi is the spring harvest, kharif the autumn; but it is not all land that bears two harvests. Land that does so is called do-fasli, and land that only bears once, ek-fasli; but there are certain tracts of country where two or even three harvests are taken off the soil. The principal crops of the rabi are the cold-weather crops of wheat, barley, gram, mattar (Vicia), lentils, tobacco, linseed, sarshaf or sarson, rai, etc. The kharif sowings are jawar, bajra (millet), maize, rice, moth, mung, mash, and other pulses, sugar-cane, and cotton.Powell, Handbook.

HARIALI GRASS, Cynodon dactylon. All its stems which lie near the ground take root, and by this means, though an annual plant, it increases and spreads very wide. It yields abundance of seed, of which small birds are very fond. It has been found very successful to allow the seed to ripen before the hay is cut, as it then propagates itself by seeds, in addition to the runners. This grass is also found in Great Britain, but in that country its produce and nutritive properties are comparatively insignificant, while here it constitutes three-fourths of the pasture. It is the most nutritious grass, indigenous to all parts of India, and, when cultivated, of most luxuriant growth in the hottest time of the year.

HARIANA, a municipal town in Hoshiarpur district, Panjab, lat. $31^{\circ} 38^{\circ} 15^{\prime \prime} \mathrm{N}$., long. $75^{\circ} 54^{\prime}$ E. ; pop. (1868), 7745. The Hariana tract of country is in the Hissar and Rohtak districts, Panjab. It consists of a level upland plain, interspersed with patches of sandy soil, and largely overgrown with brushwood. The Western Jumna 
canal now fertilizes a large number of its villages. During the troublous period which followed the decline of the Moghul empire, Hariana formed the battle-field where the Mahratta, the Bhatti, and the Sikh met to settle their territorial quarrels. In 1783 , the terrible famine known as the San Chalisa devastated almost the whole surrounding country, which lay waste for several years. In 1795, George Thomas took possession of Hissar and Hansi. By the close of 1799 he had extended his power as far as Sarsa, and the Sikh chieftains of the Cis-Sutlej States began to fear his dangerous encroachments. In 1801 they combined in requesting General Perron, Sindia's general at Dehli, to attack Thomas; and a force under Bourquien in 1802 drove him out of Hariana into British territory.-Imp. Gaz.

HARI CHANDRAGARH, a mountain and hill fortress, about 20 miles S.W. from Ankole. It is the culminating point of the watershed of the Bhima and Godavery drainage systems, 4700 feet above the sea. The cap or plateau on its summit is about three miles in breadth. There are Jaina or Buddhist caves in its centre, with a vihara of 750 A.D. according to Fergusson, and 1234 A.D. according to Wilson.

HARIDAS, a disciple of Chaitanya. The name is given to the reader or reciter of the Ramayana, and preacher of the Kirtan during the Ram Naomi. The Haridasari of Mysore recite to music songs and tales from the ancient Hindu writings. See Yugbyasa.

HARIGOLU. TEL. A basket boat.

HARIHAR, a town on the right bank of the Tumbudra river, in the Chittuldrug district of Mysore, lat. $14^{\circ} 30^{\prime} 50^{\prime \prime} \mathrm{N}$., long. $76^{\circ} 50^{\prime} 36^{\prime \prime} \mathrm{E}$. ; pop. (1871), 6401. Written Hurryhur.

HARI-HARA, or Hari-Hara putra, a name of the Hindu deity Ayenar.

HARI-MARIAH, a sacrifice of a live kid in front of the village god of the Mahrattas.

HARINA and Sorendip, or Serandah, are Raneh and Madagascar.

HARINAGHATTA, the Trinacacha, one of the mouths of the Ganges.

HARINESWARA or Harinesa, a title of Siva.

HARIPORE, about 12 miles from the Ravi on the eastern bank, supposed to be the Sangala of Alexander. It is west of Pakpatan.

HARISCHANDI, a Vaishnava sect of Hindus, amongst the Dom or sweeper race of the Western Provinces of India. The founder was HarisChandra. See Hindu.

HARIS-CHANDRA, the 28th king of the Solar dynasty. He was son of Tri-Sanku, and was celebrated for his piety and justice. There are legends about him in the Aitareya Brahmana, the Mahabharata, the Markandeya Purana, the only intelligible one being in the Aitareya Brahmana, that of his purchasing Suna Sepha to be offered up as a vicarious sacrifice for his son. He was a descendant of Ikshwaku. He is fabled to have had a hundred wives, but no son; and he visited Varuna, offering, if a son were born to him, to sacrifice him to Varuna. A son was born, and named Rohita, and Varuna claimed the sacrifice, but was put off with excuses, until Rohita grew up and began to travel in the forests. There he met a starving rishi, who had three sons, and Rohita offered him 100 cows for one of his sons, to serve as a sacrificial ransom. To this the rishi and his wife agreed, and the middle son, Suna Sepha, was given, and for another hundred cows was bound to the sacrificial post by Ajigarta, son of Suyavasa ; but Suna Sepha prayed to Indra, to Agni, to Savitri, to Visva Deva, to the Aswina, to the Ushas, and the deities released him from Varuna's bond.-Garrett.

HARIT, in Hindu mythology, the coursers of the sun, the analogue of the Greek Charites, from the root Ghar, to shine or glisten. The Harita in the Rig Veda are 7 or 10 mares of the sun, typical of his rays.-Dowson.

HARIVANS, founder of the Radha Vallabhi sect of Hindus, whose special deity is Rad'ha, the mistress of Krishna.

HARIVANSA, a poem of 16,374 verses, giving the genealogy of Hari or Vishnu. It is in three parts. It is thought to have been written in the S. of India in the time of the Puranas. The Harivansa is a comparatively modern sequel to the Mahabharata.-Growse, p. 50 ; Douson.

HARIIVA, named in the cuneiform inscriptions, is the Aria of the Greeks, the Haroyu of the Vendidad, the modern Herat.-Bunsen, iii. 481.

HARKARA. Hind., PERs. A messenger.

HARM, ARAB., means sacred, and is applied to the Mahomedan women's apartments, also to women captives and purchased women. The words Harām, unlawful, Hurmat, chastity, Harāmi and Haramzadah, a wicked person or animal, and Maliarram, the first month of the Mahomedan year, come from this word. See Haram.

\section{HARMALA RUTA. - ?}

Peganum harmala, - ? | Ruta sylvestris, -

Harka, . . CAN. / Viragu, . . TAM.

Kodar, Harmal, : HIND. Arkalu, . . . TEL

Grows plentifully at Lahore. The ruins of the old city are covered with this weed and Asclepias gigantea. Harmal, in Lahore, is looked upon as the plant sacred to the Pariah caste; yet though a Sikh or Hindu would not touch harmal, the seeds are in common use among the natives to fumigate the rooms of the wounded. The natives regard a person suffering from any discharge, as hæmorrhoids, menses, etc., as unclean, and think that the exhalation proceeding from such person may be prejudicial to the wound; therefore it is customary, on the entrance of every stranger, to strew a few grains of harmal upon a charcoal fire. The natives, with the exception of Sikls and Hindus, use these seeds internally against weakness of sight and retention of urine-Honig. p. 281 ; O'Sh.

HAR-MANDUR, a celebrated Sikh temple at Amritsur. It was destroyed in 1762 by Ahmad Shah.

HARMOZIA. This ancient town, in a bay of the Gulf of Ormuz, was subsequently called Gombroon, but now Bandar Abbas. It is a seaport town in the province of Kirman, in a barren country. It is fortified with double walls. Bussora did not long benefit by the fall of Hormuz, but appears to have been nearly ruined during the reign of Nadir Shah, whose tyranny extended its baneful influence even to this extremity of the Persian empire ; so that in $1750 \mathrm{Mr}$. Plaisted found there nine houses out of ten deserted. In the year 1639 there seems to have been an English factory at Bussora, subordinate to that at Gombroon, and protected by firmans.-Ouseley's Tr. i. p. 155 ; A Journal from Calcutta to Aleppo, etc. p. 11, Lond. 1758; Kinneir's Memoir, p. 201. 
HARMUZI. HIND. A deep red earth.

HARPAIID E, a family of insects, found dispersed in nearly all the countries of the globe: they abound more in the arctic than antarctic regions. The following genera are recorded as belonging to India, viz. Harpalus, Platymetopus, Selenophorus, Cyclosomus, and many others. Some species of Ophonus from Bengal and Poona closely resemble British species.

HARPEGNATHOS SALTATOR, one of a genus of ants of the Peninsula of India, in Malabar and Mysore. It has the name ealtator from its making most surprising jumps when alarmed or disturbed. It is very pugnacious, and bites and stings very severely. It makes its nest under ground, generally about the roots of some plant. Its society does not consist of many individuals. It appears to feed on insects, which it often seizes alive.

HARPOCRATES, the ancient Egyptian god Aurora or Day-spring, is often represented seated on the lotus.

HAR-PUJAH. HIND. The worship of the plough on the day which closes the season of ploughing and sowing, usually in Kartik. See $\mathrm{Hal}$; Har; Husbandry.

HARPUI,IA IMBRICATA. Blume.

Otonychium imbricatum, Bl., Rumphia, iii. 180.

Streptostigma viridiflorum, Thw.

This tree is common in the western moist forests of the Madras Presidency, from Canara to Cape Comorin, and ascends the mountains to about 3500 feet elevation; it is also found in Ceylon. When covered with its brilliant orange fruit, it is a beautiful sight on the ghats in Malabar and Canara. The tree flowers in the cold season, and ripens its fruit in March and April. The stigma is sometimes not at all twisted.-Bedd. Fl. Sylv.

H. cupanioides, Roxb., is a small tree of the hilly parts near Chittagong; it flowers in April, and the fruit ripens in July. - Roxb. i. 64.̄.

HARRIER, species of birds of the genus Circus.

HARRIS, GENERAL LORD, commanded at the siege and fall of Seringapatam, A.D. 1799.

HARRIS, LORD, grandson of the first Lord Harris, was born in 1810, and was educated at Christ Church, Oxford, where he took his degree in 1831. The first post that he held under Government was that of Lieutenant-Governor of Trinidad, of which island he was afterwards made Governor and Commander-in-Chief. In 1854 he was made Governor of Madras, and he held the post till 1859 , when he was succeeded by Sir Charles Trevelyan. He made a re-valuation of the lands in $\mathrm{N}$. and $\mathrm{S}$. Arcot, from which great advantages resulted to the people and to the State. He sent to Northern India all the Madras soldiers, and, dismantling his own presidency of both men and guns, enabled Lord Clyde and Lord Canning to reconquer Northern India.-Z'hurlow, Company and the Crown, pp. 32, 33.

HARRIS, SIR WILIIAM CORNWALLIS, an officer of the Bombay Engineers, who entered the service in 1823, and died at Poona on 9th October 1848. He wrote on The Wild Sports of Southern Africa, London 1844 ; and afterwards went to Shoa as an ambassador, of which mission he published a narrative, named The Highlands of Etbiopia, London 1844 .

HARSHA DEVA, a king of Kashmir, who reigned A.D. 1113 to 1125 , author of the drama called Ratnavali, or the Necklace.
HARSHA VARDDHANA was a paramount sovereign of 36 different states, comprising nearly one-half of India in extent, and including all its richest and most fertile provinces. He was defeated by the Chalukya of Kalyani.-Cunningham, Ancient Geog. of India, p. 14.

HAR-SULA. Sacrificial pillars are termed Sura or Sula in Sanskrit, which, conjoined with Har, the Indian god of -war, would be Har-sula. The Rajput warrior invokes Har with his trident (tri-sula) to help him in battle, while his battle shout is Mar! mar !-Tod.

HARTAL. HIND. Yellow sulphuret of arsenic, orpiment. Two varieties occur, - the hartal-iwilayiti and hartal-warki, the last so called from its bcautiful glittering lamellar texture; varieties of hartal-i-warki are called hartal pili and gulabi. -Powell, p. 63.

HART'H. PANJ. A Persian wheel for raising water. See Irrigation Wells.

HARTIGHSEA, $s p$, in Java yields a fruit used as garlic. Hartighsea spectabilis, the Kohekohe, or New Zealand cedar, is a good timber tree.

HART'S EAR, Cacalia kleinia, Linn.

Lisan-us-saur,. . ARAB. / Yerrimai naku, . TAM. Gao-zaban,. . PERs. Y Yennapa nalika, . TRx.

The leaves resemble the tongue of the cow (hence its Asiatic names); the stalks are prickly, and covered with white spots. While fresh, the leaves have a strong smell like hemlock, and are given by native practitioners, in the form of decoction, in rheumatism, syphilis, leprosy, and in all other cases in which sarsaparilla is usually employed by European physicians. It is brought to Bombay from the Persian Gulf, and is procurable throughout India in most native druggists' shops.-Faulkner.

HARTSHORN, the Luh-koh, Luh-jung of the Chinese, in China used medicinally, in the form of powder, as a jelly, and in tincture.

Hartshorn shavings, Luh-jung-p'ien and Luhkoh-shwang of the Chinese, is used in China in hæmaturia, spermatorrhoea.-Smith.

HARUN-ur-RASHID, khalif of Baghdad from A.D. 786 till A.D. 808 . He was famed throughout the world for his valour, love of justice, zeal for literature and the arts, and his encouragement of commerce. He placed all public schools under John Mesue, a Nestorian Christian. His household physicians were Manik and Saleh, two Hindu physicians. He is said to have caught the illness of which he died, on his way from Baghdad to Khorasan, whither he was going in order to suppress the revolt of Rafi. At that time the empire of the khalifah was one of the most powerful that ever existed, and extended from the confines of India and Tartary to the Mediterranean, including also all Northern Africa. The reign of Harun-ur-Rashid was prosperous and splendid. Although he has been famed for liberality and justice, his bloody cruelties throw an eternal stain on his memory. He died at Taos in Khorasan, after a reign of 22 years. The Daoudputra, the reigning family at Bahawulpur, claim to be descended from Harun-tur-Rashid.Vambery, Bokhara, p. 53.

HARUT, in Mahomedan belief, the name of an angel who, together with another named Marat, having severely censured mankind before the throne of God, they were sent down to earth in human shape to judge of the temptations to 
which man is subject. They were seduced by women, and committed every sort of iniquity, for which they were suspended by the feet in a well in Babylon, where they are to remain in great torment until the day of judgment.

\section{HARVEST.}

Hisal, Moisson

Arab. Mietitura, . IT. Erute, Herbst, : : GRR. Bichun, Hossad, : TURK. Fasl, . . HIND.

In British India there are very generally two harvests in a year,-the summer crop, sown in the spring, being reaped in the end of summer, and known in Northern India as the kharif. The other harvest, known as the rabi, is sown after the autumn, and reaped in early spring. In some localities there are three harvests, known to the Hindus as that of the spring (arit), asu or autumn, and paush or winter. The emperor Akbar introduced into India the harvest, or Fasl, as an era. See Fasli ; Rabi.

HARIVAHA. HrND. Predial slaves of N. India. HARWUN, HiND. A pulse equal to rawan.

HASAINZAI, an independent tribe on the N.W. frontier of India. In 1852 the British moved against them, to punish them for the murder of Mr. Carne and Mr. Tapp ; and again, in 1868 , to punish them for an inroad on British territory at Agror. A force 14,762 strong, with 20 guns, was moved under Major-General Wilde. -MacGr. N.W. F. I. pp. 248-268. See Agror.

HASALE or Hussulleeru, KarN. One of the aboriginal tribes of Mysore, occupying the hill districts of Nagar, woodmen, but serving as agricultural labourers.

HASAN and Husain, two sons of Ali by his wife Fatima, daughter of Mahomed. After Ali's death, Hasan and Husain went to reside at Medina. Hasan was poisoned there, A.D. 659, by an emissary of the khalif. The poison was placed in Hasan's way by his wife Zainab. And several years afterwards, on the 10th of the Maharram, A.H. 46, Husain was slain at Kirbala, his eldest son, Zain-ul-Abidin, alone escaping. These events are commemorated in India by the ceremonies of the first ten days of the Maharram. Annually, as this season of mourning returns, the Shiah Mahomedans recite the melancholy story of the deaths of these martyrs.

The deaths of this family, with the assassination of the khalif Omar in the mosque at Jerusalem, caused the great division into the Sunni and the Shiah sects, which continues amongst Mahomedans to the present day throughout all the Mahomedan world. After the death of the third successor of Mahomet, Ali ascended the throne; but after a short reign of six years, during which he had to encounter a serious rebellion headed by Ayesha, he was at last assassinated. For this reason Ali is regarded as a martyr, and the first of the twelve Imams. Of the Shiahs Hasan and Husain, the two sons of Ali and Fatima were grandsons of Mahomet; as boys they had been his darlinge, and as men they received much of that warm personal devotion which had been bestowed on the great founder of Islam. Hasan succeeded his father on the throne for a short time, but yielded to the pretensions of a Sunnite khalif. He was afterwards carried off by poison, and was thus in his turn regarded as a martyr, and the second of the twelve Imams.
Husain and his followers rose in arms to assert his right to the throne of the khalifs. Near the banks of the Euphrates the enemy pressed against him in overpowering numbers. Nearly all his followers were slain, and his child was killed in his arms. He himself was fainting from thirst and fatigue; but when the hour of prayer arrived, he performed his religious duties in the face of the enemy; for there were few, even in that hostile host, who were prepared, under such circumstances, to draw the sword upon the grandson of the prophet. At last, exhausted by thirst, he bent his steps towards the Euphrates; his adversaries now rushed forward to intercept him. Husain, however, had already thrown himself on his breast over the stream, and was beginning to taste the refreshing water, when an arrow pierced his mouth. A confused crowd of warriors now closed around him, and began to assail him with their swords. A long and desperate struggle followed, but he was at last overpowered, and his head was carried away as a trophy. Husain was thus regarded as, if possible, the greatest martyr of the three; and not only is he reverenced as the third Imam, but his representatives of the niue succeeding generations are reverenced as the nine Imams who make up the number to twelve. His death, or martyrdom, was followed by a cry of grief wherever men had embraced the faith of Islam; and even in the present day the Shiah Mahomedans are afflicted with the profoundest sorrow throughout the days of the Maharram, and shed tears for their beloved and martyred Imams; it is a melancholy sight.

HASAN ABDAL, a village in the Rawal Pindi district of the Panjab, forming a part of the remarkable group of ancient cities which lie around the site of the ancient Taxila, lat. $33^{\circ}$ $48^{\prime} 56^{\prime \prime} \mathrm{N}$., long. $72^{\circ} 44^{\prime} 41^{\prime \prime} \mathrm{E}$. Hiwen Thsang in the 7 th century visited the tank of the serpent king Elapatra, which has been identified with the spring of Baba Wali, or Panja Sahib. Successive legends of Buddhist, Brahman, Mahomedan, and Sikh origin cluster around this sacred fountain. The shrine of Panja Sahib crowns a precipitous hill, about a mile east of the town ; and at the foot stands the holy tank, a small square reservoir of pure water, generally full of fish. It is so called from its being the burial-place of Baba Hasan Abdal, a Sayyid of Sabzwar, in Khorasan, who came to India with Mirza Shah Rukh, son of Timur, and died at Kandahar, and whose tomb is much resorted to by pilgrims. Jahangir, in his memoirs, says: "To-day I arrived at Baba Hasan Abdal. About a cos east of the town is a waterfall, the water of which rushes down with great rapidity. There is none like it in Kābul, but there are two or three like it in Kashmir. In the middle is a tank, from which the river flows. Raja Man Singh has built here a little villa. There are a great number of fish in the tank, half a yard and a quarter yard long. As the place is so nice, I stayed here for three days, and drank wine with my friends. I also enjoyed fishing. The fishes are caught with peculiar nets, which are difficult to be used. I caught twelve, had pearls strung through their snouts, and set them free.'

HASAN GANGA. In A.D. 1347, four years before the death of Muhammad Taghalaq, Hasan Ganga, an officer of high station in the Dekhan, 
headed a successful revolt against his master, and established what was known as the Bahmani dynasty of the Dekhan, fixing his capital at Kulburga. His descendants reigned for thirteen generations, for 174 years, from A.D. 1347 to 1518. He is said to have been an Afghan of low rank, a native of Dehli. He farmed a small spot of land belonging to a Brahman named Ganga, who was in favour with the king; and Hasan, having accidentally found a treasure in his field, he gave it to his landlord. The Brahman, struck with his integrity, advanced his fortunes. Hasan rose to rank in the Dekhan, where he became a leader in the revolt. He had before assumed the name of Ganga, and now added that of Bahmani, by which his dynasty was afterwards distinguished. During the reign of Ala-ud-Din II., in A.D. 1437, dissensions broke out between the native Dekhani and foreign Mahomedan troops, but towards the end of the dynasty the Dekhani troops gained the ascendency. Yusuf Adal Khan, a Turk, and chief of the foreign troops, retired to his government of Bijapur, where he subsequently (A.D. 1489) took the title of king, and founded the dynasty of Adal Shahi. Nizam-ul-Mulk, the Dekhani chief, being afterwards assassinated by Kasim Barid, a Turk, his son Ahmad set up the dynasty of Nizam Shahi at Ahmadnaggur, in the Dekhan. Kasim Barid was now the master of the court of the Bahmani king, Mahmud II. (A.D. 1482), at Beder; and two other great chiefs became independent, and after a time each took the title of king. These were Kutub-Kuli, a Turkoman from Persia, and Imad-ul-Mulk, descended from a Hindu convert. The former (A.D. 1512) founded the dynasty of Kutub Shahi at Golconda, near Hyderabad, and the latter that of Imad Shahi at Ellichpur, in Berar. Ahmad Barid, son of Kasim, governed for some time under a succession of pageants, but at length assumed the title of king, as the first of the Barid kings of Beder, the Bahmani family being thenceforth no longer mentioned.

A temporary union of the kings of Bijapur, Golconda, and Ahmadnaggur, in 1564, enabled them to subvert the empire of Vijayanagar, and reduce the power of its chief to that of a petty raja. -Elphinstone's India, 416, ii. app.; Briggs, The Nizam; Shahab-ud-Din's Hist. MSS.

HASAN-ibn-SABBAH, or Hasan-us-Sabbah, was the founder of the sect known as the Assassins. He was brought up at Nishapur, under the then renowned saint, the Imam-ulMuwakkaf, and had for his schoolmates the Persian freethinking poet, Omar-ul-Khaiyam, and another, afterwards known as Nizam-ul-Mulk, 'Marshal of the Empire,' prime minister to Alp Arslan. The three lads had made a compact that whichever of them attained to rank and fortune should share his advantages with the other two; and when the most successful of the three was established in his position as marshal-minister, the other two claimed fulfilment of the promise made in youth. Omar-ul-Khaiyam asked only for the means of devoting himself to literature and science, and has left $a$ name as the most original poet and the greatest astronomer of his time; Hasan-us-Sabbah asked for and obtained an important political post, but devoted his energies to endeavouring to supplant his schoolfellow and benefactor. Failing in this, he turned rebel, and, collecting round him a band of fanatics, took possession of the fortress of Alamut, a mountain on the shores of the Caspian, and spread terror through both Islam and Christendom by the fierce bravery with which he and his followers encountered all opposition, and by the terribly insidious manner in which he removed his enemies by secret assassination, Nizam-ul-Mulk being among his many victims. One of the numerous stories told of him is that, having been summoned to surrender, he called two of his followers to him, and bade one to stab himself, and the other to throw himself from the highest battlements of the fortress. This order the 'Devoted Ones'-Fidwi, as they were called-at once obeyed, and Hasan derisively asked the envoy what his master's troops could do against a chief who commanded such men as those. He was pitiless and inscrutable. It is said that he slew his own son because he drank wine. This does not seem to coincide with the belief that his followers were addicted to the use of the resin of Cannabis Indica, or Indian hemp, called hashish, whence some have derived their name of Hashishin, the 'Assassin' of European languages. Hasan-usSabbah was generally known as 'Shaikh-ul-Jabl,' from his mountain fortress; and it is from the title Shaikh, which means both a 'chief' and an 'old man,' that he is known to European history as the 'Old Man of the Mountain.' He gave his name to the Al-Hasani, a heterodox sect, now variously known as the Ismaili, Bathenians, or Assassins, who are spread through Asia from Persia to Western India, and during the crusades he or one of his successors was known as the 'Old Man of the Mountain,' a mistranslation of the Shaikh-ul-Jabl. His career was from A.D. 1090 till his death in A.D. 1124, at Alamut, where he had lived 35 years. The political power of the sect was destroyed by Hulaku, grandson of Chengiz Khan, A.H. 654.Porter's Travels, i. 286; Osborne's Islam, p. 357.

HASAN KHEL, (1) A section of the Gadaizai Bunerwal; (2) of the Adam Khel Afridi; (3) of the Mahmud Khel Utmanzai Vaziri.-MacGr. N.W. F. I. i. p. 578 .

HASAN NIZAMI, author of the Taj-ulMaasar, or Crown of Victories, was born at Naishapur. Mir Khond and Haji Khalfa call him Sadr-ud-Din Mahomed-bin-Hasan Nizami. He left his home during the troubles that overtook it, and went to Ghazni, and on to Dehli. His book gives the history of Kutub-ud-Din Aibek, with portions of the life of his predecessor, Muhammad Ghazi, and of his successor, Shams - ud-Din Altamsh.-H. Elliot.

HASHIM - bin-HAKIM, born at Gaza, near Merv, is known as Mokanna, or the Veiled Prophet of Khorasan, because he was one-eyed, deformed in feature, and bald, and concealed his features. $\mathrm{He}$ claimed to be the deity; his most numerous converts were near Samarcand and Bokhara. He was joined by hordes from Turkestan. He had a hundred of the loveliest women of Transoxiana. About the year 163 Hijira, he destroyed himself.

HASHIYA. HIND. A border or edging.

HASHM. ARAB. Train, retinue. Pl. Ahsham. HASHMEE MAUND, equal to 16 Tabreez maunds of $7 \frac{1}{4} \mathrm{lbs}$, each, or about $116 \mathrm{lbs}$. English.

HASHT-ANGA. SANsK. Literally, eight limbs. A reverential prostration of the Hindus, in which they touch the ground with the belly, breast, forehead, and both sides of the face successively, 
kiss the earth, half rise up, then pass the left over the right forearm, and vice versa; and finally, after again saluting mother Hertha, stand erect.

HASHTNAGAR ('Eight Cities'), a Tahsil of the Peshawur district, Panjab; lat. $34^{\circ} 3^{\prime}$ to $34^{\circ}$ $25^{\prime}$ N., and long. $71^{\circ} 37^{\prime}$ to $71^{\circ} 57^{\prime}$ E. General Cunningham believes the modern term to be a corruption of Hastinagara, the city of Hasti.

Hasti, Tod says, sent forth three grand branches, Ujamida, Deomida, and Poormida. Ujamida's progeny spread over all the northern parts of India, in the Panjab, and across the Indus; the period, probably 1600 years before Christ. From Ujamida, in the fourth generation, was Bajaswa, who obtained possessions towards the Indus, and whose five sons gave their name, Panchalica, to the Panjab, or space watered by the five rivers. The capital founded by the younger brother, Kampila, was named Kampilnagara. The descendants of Ujamida by his second wife, Kesunee, founded the Kusika kingdom and dynasty, celebrated in the heroic history of N. India.-Tod.

HASHU or Hashwi occupy the watershed between the Thoukye Khat and Poung-loung.

HASISH. ARAB. Tender tops of Cannabis sativa, after flowering, the Bhang of India and Persia, and Fasukh of Barbary. It is indulged in to some extent by Mahomedans of India. Egypt surpasses all other nations in the variety of compounds into which this drug enters. The Hottentots use it; and the Siberians intoxicate themselves with the vapour of the seed thrown upon red-hot stones, as the Scythians of old did.

HASORA, a town in Central Asia, 7198 feet above the sea, on the banks of the river which runs northwards to the Indus. The Hasora country is west of Deotsu, and lies to the south of Rongdo. The people speak the Tibetan language. Moorcroft gives it the name of Zungari. It is partially a Bhot district. According to Ad. Schlagentweit, Hasora, or Astor, or Tsunger, in lat. $35^{\circ} 12^{\prime} \mathrm{N}$., and long. $74^{\circ} 53^{\prime} \mathrm{E}$., is a fort in the valley of Astor or Hasora.-Moorcroft; $A d$. Schl.; Latham.

HÁSSAN, a mountain forming part of Taurus and Zagros, between Diarbakar, Palo, and Moosh. The Kurd race, who inhabit all that part, are called Zaza, which means stuttering, mouthing, or speaking unintelligibly, and seems to be a nickname.-Rich's Kurdistan, i. p. 376.

HASSAN, a district of Mysore State, forming the north-western portion of the Ashtagram division, and lying between lat. $12^{\circ} 30^{\prime}$ and $13^{\circ} 22^{\prime}$ $\mathrm{N}$, , and between long. $75^{\circ} 32^{\prime}$ and $76^{\circ} 58^{\prime} \mathrm{E}$ The Jains have been numerous at Sravan-Belgola and other places since the $3 \mathrm{~d}$ century B.C.; and a Jaina image of Gomateswara, 60 feet high, is on a peak of Chandrabetta. The census of 1871 ascertained the population to be 669,961 . Of inferior castes, by far the most numerous are the Wakliga $(238,780)$, who are agricultural labourers; next come the Kuruba $(55,341)$, shepherds; and the Neyige (15,972), weavers. The Lingaets, who have always been influential in this part of the country, number 70,168 . Out-castes are returned at 128,913 ; wandering tribes, 5109 ; wild tribes, 3602. The village of Sathalli is the centre of an agricultural Christian community, founded by the Abbe Dubois. The total number of this community is about 1000 , and they are known as 'Caste Christians,' - that is to say, they retain all the social observances of their Hindu ancestors. The Malnad is greatly dreaded for the malarious fever which prevails after the early rains.-Imp. Gaz

HASSANDHUP. HIND. A hard, white clay, supposed to be a deposit from a mineral spring containing sulphur. But it is also a medicinal compound.

HASSANIYEH, an Arab tribe, who have a very curious form of marriage. The woman is legally married for three days out of four, remaining perfectly free for the fourth.-Lubbock, Orig. of Civil. p. 54.

HASSELTIA ABOREA, a handsome tree growing near Jampiam, in Java, with flowers large, yellowish-white, in axillary fascicles. The milk obtained from the trunk by incision, mixed with honey and reduced with boiling water, is employed as a powerful drastic for destroying the tape-worm ; it is, however, apt to produce inflammation of the intestines, and in some cases has proved fatal._Lindley, Flora Medica, Eng. Cyc.

HASSKARL, JUSTUS CHARLES, a botanist, Superintendent of the Gardens at Java, 18521854. Collected cinchona plants and seeds in South America, and took them to Java. He was created Knight of the Netherlands Lion, and Commander of the Order of the Oaken Crown. He was author of the Hortus Bogoriensis, a catalogue, with occasional notes and descriptions, of new species of the plants cultivated in the Government Botanical Garden of Buitenzorg, near Batavia, published in Batavia in 1844 ; also author of an octavo volume of descriptions, entitled Plantæ Javanicæ Rariores.-Hooker f, et Thomson; Markham, Perıv. Bark.

HASTINAPUR, an ancient city of the Meerut district, N.W. Provinces, lying on the bank of the Burha Ganga, or former bed of the Ganges, 22 miles north - east of Meerut, lat. $29^{\circ} 9^{\prime} \mathrm{N}^{\circ}$, and long. $78^{\circ} 3^{\prime} \mathrm{E}$. ; pop. (1872) 77 . Its remains can still be traced on the banks of the river, but it was destroyed by the river encroaching on it. Hastinapur formed the capital of the great Pandava kingdom, celebrated in the Mahabharata. The legends of the Mahabharata centre around this city.

HASTINGS, FRANCIS, second Earl of Moira, afterwards created Marquess of Hastings, G.C.B., assumed charge of the office of Governor-General of India, 4th October 1813, and held it till his re-embarkation, 9th January 1823. During his tenure of office, he took the field in person, on the 18th October 1817, against the Pindara. The forces under his command in the field were over 100,000 horse and foot, besides 20,000 irregular cavalry. He allotted several positions to the brigades, and closed in upon the Pindara. One leader, Karim Khan, fell into the hands of Sir John Malcolm; another, Sita or Chetu, was killed by a tiger, whilst sheltered in the forests near Asirgarh. While the Governor-General was encamped in the part of the country formerly ruled by a noted chief, Lalla Hurdi, cholera broke out in the camp, and in ten days carried off 764 fighting men and 8000 camp - followers. He broke up his camp, and marched S.E. from the Sind across to the right bank of the Betwa, and encamped at Erich, where the cholera disappeared. The natives of India attributed that outbreak to the malignity of Lalla 
Hurdi's ghost, who had been poisoned under extraordinary circumstances. The Marquess induced the Government of Great Britain to extend the Order of the Bath to officers of the E.I. Company's service, and before the conclusion of the third Mahratta war fifteen of them were created Knights Commander. He invested the first of these, Sir David Ouchterlony, on the 20th March 1818, at Terwah. The E. I. Company acknowledged their sense of his services, bestowing on his family two grants of money, in sums of $£ 60,000$ and $£ 20,000$ respectively. His long rule of 9 years, from 1814 to 1823 , was marked by two wars of the first magnitude, namely, the campaigns against the Gurkas of Nepal, and the last Mahratta struggle.

HASTINGS, WARREN, the first GovernorGeneral of India. He was born in 1732 , and came to India as a writer in 1749 . He returned to England in 1763; but in 1769 he was appointed to be $2 \mathrm{~d}$ Member of Council at Madras, in 1772 President of Council, Bengal, and in 1773 Governor-General, and on the 1 st February 1785 he made over the keys of the fort to the next senior Member of Council, and left India on the 6th of the same month. He carried with him a modest fortune of $£ 80,000$. On his arrival in England in 1785, he was well received by the King, Queen, and Court of Directors, and was about to be made a peer, when Mr. Pitt opposed this, and, seven days after his arrival, he was impeached by Messrs. Burke, Fox, and Sheridan, accused of acts of oppression. His trial commenced on the 13th or 15th February 1788 , in the presence of the King and Queen. It proceeded for seven years, and at length, after an honourable defence, on the 23d April 1795 Hastings was acquitted; the verdict of an impartial posterity has long since affirmed the award (Marshman, i. p. 427). He passed out at the gate of Westminster Hall ignorant whence the funds were to come by which the weekly bills of his household were to be discharged; but the Court of Directors paid his costs, and granted him an annuity. From all parts of the empire, from men of various creeds and colours, from officers of renown, from Hindus and Mahomedans alike, poured in addresses of congratulation. The Prince Regent made him a Privy Councillor, and hinted at bigher honours. Happy in his family life, blest with the healthy old age which is the appropriate reward of a pure and temperate manhood, farming and writing little poems, studying Malthus, and following with delight the rising genius of Walter Scott, the great proconsul glided by an easy road into euthanasia and immortality. He died on the $22 \mathrm{~d}$ August 1818, in his 86th year; in which year also Sir Philip Francis, his opponent, died. He was the administrative organizer, as Clive had been the territorial founder, of the British Indian Empire. He rested his claims as an Indian ruler on his administrative work. He re-organized the Indian service, reformed every branch of the revenue collections, created courts of justice, and some semblance of a police. In 1781 he founded the Madrassa for Mahomedan teaching, and he extended his patronage alike to Hindu pandits and to European students.-Imp. Gaz. iv.

HASYARNAVA. SANSK. Ocean of Laughter, a modern comic piece, by a pandit named Jagadisa.-Dowson.

HAT. HIND. A periodical market day, a fair.
HATA or Saif is a long gauntleted weapon used in athletic exhibitions.

HATCHING FOWLS' EGGS by artificial heat, though only obscurely described by ancientauthors, appears to have been common in Egypt in very remote times. The building in which the process is now performed is called Maamal-el-Tirakh. In Chusan the hatching-house of ducks is a shed, the roof thickly and compactly thatched with paddy, the walls plastered over with mud. There are a number of straw baskets, thickly besmeared with mud to prevent them from igniting; a tile is so placed as to form the bottom of the basket, and a lid fits closely over the top. A small earthen firepot being placed under each basket, the eggrs belonging to different folks are put into the baskets as soon as they arrive. The baskets are kept closely shut for five days, a uniform heat being maintained under the basket by means of the before-named earthen fire-pot, and at the expiration of that period they are taken out and carefully examined; the good are placed in holes, which have been cut in a board for their reception, and the bad are laid aside to be returned to their owners. Before the eggs have become cold, they are replaced in the baskets and kept there for nine or ten days; that is, the eggs remain altogether in the baskets about a fortnight or fifteen days, the heat of the hatching-house ranging from $93^{\circ}$ to $100^{\circ}$. In the middle of the shed broad shelves are placed, on which the eggs are laid when taken finally from the baskets, being carefully covered over with a thickly wadded coverlet, and the little birds issue from their fragile domicile in about a fortnight or three weeks, - the whole process of hatching an egg occupying one month or five weeks. In the Philippines incubation is performed by placing warm paddy husks under and over the eggs, which are deposited in frames. A canvas covering is spread over the husks. The art is to keep up the needful temperature; and one man is sufficient to the care of a large number of frames, from which he releases the ducklings as they are hatched, and conveys them in little flocks to the water-side.-Pococke's East, i. 260; Bowring's Philippines, 104; Sirr's Chinese, i. 249.

HATHIKRA-GILLI. HIND. An earthenware pestle, weighted, used for crushing gram.

HATHILI, a reputed saint, one of five held in veneration by the lower orders in the N.W. Provinces. He is buried at Barech.

HAT'HPHOR, a tunnel on the northern face of Ramgarh Hill, Sirguja State, Chutia Nagpur. At its mouth it is about 20 feet in height by 30 in breadth, but at the inner extremity of its course of 150 yards it is not more than 8 feet by 12 . On the southern side of the recess rises a sandstone cliff, which contains two caves, the larger being 44 feet long, 10 feet wide, and about 6 feet high. It was here, according to the legend, that Sita was carried off by the demon Ravana; and two deep grooves in the rock, in front of the larger cave, are said to be portions of the enchanted circle which Rama drew around her for her protection. - Imp. Gaz.

HATIM TAI, an Arab chief, famed amongst Mahomedans for his generosity. Many Persian and Hindustani romances have been written regarding him. He lived about a century before Mahomed. In all Mahomedan countries he is quoted as a model of generosity. Al Maidah says, when he 
fought, it was to be triumphant; when he had acquired spoils, he gave to the spoiled; when he besought, he gave ; if he contested with the powerful, it was to overcome; when he took captives, he released them.-Major J. Daklon, p. $162 ;$ Palgrave.

HATKAR, a cowherd race of Berar.

HATRAS, formerly highly predatory, under British rule became one of the busiest and most thriving places in Upper Hindustan, and a principal mart for the cotton and indigo of the neighbouring districts.-Tr. of Hind. ii. p. 122.

HAUDA. Hind. The howdah or chair for riding on an elephant. It is in various forms. The Hauda-amari is a howdah with a canopy.

HAUDIGA. CAN.? A Mysore wood used for furniture; polishes and turns well; is useful for the cabinetmaker, and would do for veneering.

HAUG. Martin Haug, Doctor of Philosophy, in early life assisted Chevalier Bunsen in preparing his Bibelwerk. He was afterwards appointed Professor of Sanskrit at Poona, an office which he held from 1859 to 1865 , and during this time he devoted himself to the study of the Zend. He published his Funf Gatha in the Journal of the German Oriental Society. In Bombay there appeared his essays on the Sacred Language, Writings, and Religion of the Parsees; and he also edited a translation of the Aitareya Brahmana. He returned to Germany in the beginning of 1866 , and was almost immediately afterwards appointed Professor of Sanskrit and Comparative Philology in the University of Munich, which he held up to the time of his death. He and dastoor Hoshang Jamasp published two valuable glossaries of the old Zend-Pehlavi, and an edition and translation of the Arda-Visaf. He died in Switzerland, 2d June 1876.

HAUL. ARAB. Power. La haul wa la quwat ila ba Allah, There is no power nor virtue but in God,-a solemn invocation of Mahomedans.

HAURAN is a term applied to any solitude, whether barren or fertile, and sometimes applied to extensive pasture lands. Hauran is the Auranitis of Josephus, and the Iturea of St. Luke. The countries south of Damascus, viz. the Hauran, the rocky wilderness of the Ledja, and the mountainous district lying east of the Jordan, collectively speaking, formed the country which was first conquered by the Israelites before the subjugation of the land of Canaan, and was allotted to the tribe of Reuben, Gad, and the half tribe of Manasseh. In the time of the Romans, nearly the whole was comprised under the district called Peræa, which was itself divided into the six cantons of Abilene, Trachonitis, Iturea, Gaulonitis, Batanæa, and Peræa, strictly called; to which some geographers have added Decapolis. Abilene was the most northern of these provinces, being situated between the mountains of Libanus and Anti-Libanus, and deriving its name from the city of Abila or Abela. Trachonitis was bounded by the desert on the east, Batanæa on the west, Iturea on the south, and the country of Damascus on the north, and included the rocky district now called El Ledja. Iturea, on the east of Batanæa, and to the south of Trachonitis, derived its name from Ietur, the son of Ishmael, and was called Auranitis, from the city of Auran, which latter appellation it still retains, under that of Hauran. Gaulonitis was $a$ tract on the east side of the lake of Gennesareth and the river Jordan, which derived its name from Gaulan, the city of $\mathrm{Og}$, king of Bashan. Batanæa, the ancient kingdom of Bashan, was situated to the north-east of Gaulonitis, and was celebrated for its excellent breed of cattle, its rich pastures, and for its stately oaks. A part of it is now called El Belka. Peræa, in its strictest sense, included the southern part of the country beyond Jordan and Samaria.

In May the whole of the Hauran plain is covered with swarms of Bedouin wanderers from the desert, who come for water and pasturage during the summer months, and to obtain a provision of corn for the winter; they remain till after September. If they are at peace with the pasha, they encamp generally amongst the villages near the springs or wells; if at war with him, confine themselves to the district to the south of Boazra, towards Om-e-jaml and Jadheins, extending as far as Zerka. The Arabs of the Jabl Hauran (called the Ahl-ul-Jabl) and those of the Ledja seldom encamp beyond their usual limits; they are kept in more strict dependence on the pasha than the other tribes. The Abl-ul$\mathrm{Jabl}$ are the shepherds of the people of the plains, who entrust them with their flocks during the winter to pasture amongst the rocks and mountains. In spring the Arabs restore the flocks to their proprietors, receiving for their trouble one-fourth of the lambs and kids, and a like proportion of the butter made from the milk during the spring months. Those which are to be sold are taken to Damascus. The soil of the Hauran consists of a fine black earth, of great depth, but little cultivated.-Burckhardt; Robinson's Travels.

HAUZ. Arab., Hind. A fountain, a tank.

HAVELOCK, Sir HENRY, K.C.B., one of three brothers, officers in the British army, who served in India. William was killed in charging the Sikhs at Ramnuggur. Henry, born 1795 at Bishopwearmouth, in 1815 entered the army in the 95th Regiment, and afterwards exchanged into the 13th Light Infantry, and in January $1823 \mathrm{em}$ barked for India. He served in the first Burmese war as Deputy Adjutant-General, and published his Experiences of Campaigns in Ava. On the 9th February 1829 he married Hannah Shepherd, youngest daughter of the Rev. Dr. Marshman. He was with his regiment whilst it was cooped up in Jalalabad. He was present at the battles of Punniar and Maharajpur. In 1857 he commanded a division in the Persian war. When the mutiny and rebellion of 1857 occurred, Havelock suggested the formation of a moveable column at Allahabad, which was immediately formed, and among the troops were Neill's Madras Fusiliers. From this time he commanded in many battles, on the 11th July 1857, at Futtehpur; on the 15th he fought at Aong; on the 16th he fought and took Cawnpur. His last great effort was the first relief of Lucknow, on the 25th September 1857. The second relief of Lucknow was effected by Sir Colin Campbell, on the 17th November 1857. Sir Colin Campbell had arrived in India, and the Government had superseded Havelock, putting Outram in command of the force in Oudh; but that noble soldier refused to supplant his brave comrade, preferring rather to act under him than deprive him of his well-earned right to relieve Lucknow, and the two together adrancing 
effected the relief. The Blue Caps (Fusiliers) charged the Char Bagh bridge, but Maude's two guns could not silence the superior artillery of the enemy in their front. Almost every man at them was either killed or wounded, when General Neill, who commanded the first brigade in Sir James Outram's absence, allowed a charge, and the first Madras Fusiliers were ordered to advance. Lieutenant Arnold, a young officer ever conspicuous even among the daring spirits of that noble regiment, had been impatiently watching for the signal. At the first word, and without waiting for the regiment to rise and form, he dashed on to the bridge with some ten of his men. Arnold himself fell, shot through both legs, and his devoted followers were swept down almost to a man. Lieutenant Havelock, the Deputy Assistant Adjutant-General, alone remained on the bridge, the mark for a hundred bullets. The Fusiliers dashed forward with a cheer, without giving the enemy time to reload, advanced over the prostrate bodies of their comrades, and, rushing on the guns amidst a storm of bullets, wrested them from the enemy, and bayoneted the gunners. It was a second Lodi! Poor Arnold died. 'At length,' writes the general, 'we found ourselves at the gates of the Residency, and entered in the dark in triumph.' General Havelock's career was finished. He fell sick, and died in perfect peace and hope, attended by his aide-de-camp, Hargood of the Fusiliers, and his son. Calling the latter to him, he said, 'I die happy and contented.' 'See how a Christian can die." And when Outram came to visit his dying comrade, he said, 'I have forty years so ruled my life, that when death came I might face it without fear.' A statue has been erected to his memory in Trafalgar Square, London.

HAVILDAR, in the British Indian armies, a non-commissioned otticer of native soldiers equal to a sergeant.

HAVVAH or Hawa of the Arabs, the Eve of the Bible, the mother of the human race, and recognised under different names in all cosmogonies. The Astarte of the Assyrians, Isis nursing Horus of the Egyptians, the Demeter and the Aphrodite of the Greeks, and the Scythian Friya. Baltis, in Byblius called Beuth or Behuth, i.e. void of genesis, is identical with space, and means the mother's womb, the primeval mother,the fundamental idea being the mother or source of life, which is the meaning of Havvah, and the Eve of Genesis. The tomb of Eve is pointed out in several places. Mecca is bounded on the east by a kill called Abu-Kubays, and, according to many Mahomedans, Adam, with Eve his wife and son Seth, lie buried there. Also, at less than a mile from the Medina gate of Jedda, is a tomb said to be of our common mother Eve. It is surmounted by a cupola and surrounded by walls, enclosing a pretty cemetery, in which many of her children lie around her.-Bunsen's Egypt; Hamilton, Sinai.

HAWAIGAR, in Hindustan, firework manufacturers.

HAWK EAGLE, species of the genera Nisætus and Limnætus.

HAWKING is a pastime to which several Asiatic races are addicted. The employment of trained hawks may be traced to an exceedingly remote antiquity; and $\mathrm{Mr}$. Layard found a basrelief at Khorsabad, in which a falconer is bearing a hawk on his wrist. The Bedouins of Mesopotamia are attached to the sport, and especially so with reference to their food supply; and the Arabs may possibly have introduced it, together with the creed of Mahomed, among the Malays of the Archipelago. In Africa this sport is confined to a few of the Mahomedans of the north. In Europe it seems to be first distinctly mentioned by authors about the fifth century; but the garniture of the trained hawks would appear to have been unknown prior to the crusades. In the famous Bayeux tapestry, for instance, falcons are represented as carried upon the wrist unhooded. Trained ospreys were formerly employed in Europe for fishing; and Colonel Montague cites an Act passed in the reign of William and Mary, by which persons were prohibited at a certain period of the year from taking any salmon, salmon peal, or salmon kind, by hawks, racks, guns, etc. There is at least one great hawk fair or sale in the Himalaya, at which Indian falconers, many of whom come from immense distances, congregate for the purpose of buying, selling, and comparing their hawks.

The bawks commonly used are-

1. Goshawk.-Astur palumbarius, Linn. Baz, Shah. baz, female; Jurra, male. Europe, Himalaya, Sind, Neilgherries.

2. Crested Goshawk.-A. trivirgatus, Temm. Gorbesra, Manik-berra, Kot-eswar. All the hilly wooded regions of India.

The Shah-baz, or hawk-king, a large grey goshawk with yellow (gulab) eyes, caught in the hills of Afghanistan and its surrounding regions, is brought down to the plains, and sold, when well reclaimed, trained, and in good condition, for $£ 5$ or £6. The tiercelet or male is, as usual, much smaller than the female, and is called Jurra in Persian, 'the active.' Both are uncommonly strong and ferocious. They are accounted the noblest birds; the Sher-baz (lion-hawk), or peregrine of Bokbara and the snowy regions, being all but unknown in Sind.

3. Peregrine Falcon,-Falco peregrinus, Gm. Bhyri, female; Bhyri bacha, male. Native of Europe, N. Asia ; visits India from October to April.

The Bhyri or Bhairi, Falco peregrinus, so celebrated amongst Indian falconers for her boldness and power, and her tiercel, in Sind improperly called the Shahin, are found in some parts of Sind. They fly at partridges, hares, bustards, curlews, herons, and the saras; being long-winged hawks, or birds of the lure, they are taught to fly high, to wait on the falconer, and to make the point; not greatly prized.

4. Laggar:-Falco jugger, (tray. Laggar, female Jaggar, male. Common over all India, Sind, Panjab.

The Laggar, and her mate the Jaggar, is the only long-winged hawk generally used in Sind; she is large and black-eyed, with yellow legs, black claws, and a tail of a cinereous white colour. She is a native of Sind, moults during the hot months from April to October, and builds in ruined walls and old mimosa trees. The Laggar is flown at quail, partridge, curlew, bastardbustard, and hares. The best sport is undoubtedly afforded by crows, only she is addicted to carrying the quarry, and is very likely to be killed by her angry enemies. She is trained for the season, and then let loose.

5. Shahin Falcon.-Falco peregrinator, Sund. Shahin, female; Kohi, Koela, male. Native of all India, Afghanistan, and Western Asia. 
The Shahin is the female of the Falco peregrinator. and is esteemed the first of all the falcons for hawking. It is trained to hover and circle in the air over the falconer and party.

6. Saker or Cherrug.-Falco sacer, Schl. Chargh, female; Charghela, male. Africi, Himalaya,

Nepal, Europe.

The Saker or cherrug falcon, F. sacer, is trained for striking hares, antelopes, florikin.

7. The Merlin,-Hypotriorchis osalon, $\mathrm{Gm}$.

8. Turumti, or Redheaded Merlin.- H. chicquera, Daud. Turumti, female; Chetwa, male. Europe, all India, and Sind.

Both these have been trained in Europe and Asia.

9. The Hobby.-Hypotriorchis subbuteo, $L$. Doureli, Regi. Native of Europe; a winter visitor to all parts of India.

10. Indian Hobby.-H. severus, Horsf. Dhuti, female; Dhuter, male. Inhabits the Himalaya, Malay Peninsula, Java, and the Philippines.

11. The Kestrel. - Tinnunculus alaudarius, Briss, Narzi, female; Narzanak, male. A native of Europe; a cold-weather visitor to India.

12. Lesser Kestrel. - Erythropus cenchris, Naum. Kashmir, Neilgherries.

13. Red-legged Falcon.--E. vespertinus, $L$. S. Europe, N. Africa, Western and Central Asia, India.

14. Shikra.-Micronisus badius, Gm. Shikra, female; Chipka, Chipak, male. Afghanistan, all India, Ceylon, Assam, Burma, Malayana.

15. European Sparrow-hawk. - Accipiter nisus, $\boldsymbol{L}$. Basha, female; Bashin, male. Visits India, October to March

16. Besra Sparrow-hawh.-A, virgatus, Temm. Besra, female; Dhoti, male. All the large forests of India, Assam, Burma, and Archipelago.

The Shikra and her tiercel the Chipak are flown at partridges, and by their swiftness and agility afford tolerable sport. At the same time they are opprobriously called dog-birds by the falconer, on account of their ignoble qualities, their want of stanchness, and their habit of carrying the game,-carrying being the technical word for flying away with the wounded bird. They could formerly be bought ready trained in most parts of Sind for a shilling or two.

The Shikra, Micronisus badius, is more commonly trained in India than any other hawk.

The European sparrow-hawk, Accipiter nisus, and the Besra sparrow-hawk, A. virgatus, are both largely trained.

The Bashah sparrow-hawk, A. nisus, and her mate the Bashin, a small, short-winged, low-flying bird with yellow eyes, and dark plumage in her first year, which afterwards changes to a light ash colour, marked with large grey bars, are very -much valued on account of the rapid way in which they fill the pot, especially with partridges. As they remain in Sind during the cold weather, and retire in summer to the hills around, those trained are passage-hawks, or birds of the year. Their low price, $8 \mathrm{~s}$. or $10 \mathrm{~s}$, made it scarcely worth while to mew them, so they were let loose when the moulting season commenced.-Jerdon's Birds; Burton's Falconry in the Valley of the Indus.

HAWKINS, an English captain who landed at Surat in the year 1608, in the reign of the emperor Jahangir. He proceeded to Agra to the court of the emperor, where he was well received.

HAWKS, Kites, etc.

Fancon,.... FR. Halcon, . . . SP. Habicht, Falke, : GER. Atmaja, : : TURK. Falcone,
Eagles, hawks, kites, etc., are all classed by naturalists under the sub-families Accipitrinæ or hawks, Aquilinæ or eagles, Buteoninæ or buzzards, Falconinæ or falcons, and Milvinæ or kites, etc., all of the family Falconidæ. They fly well, take their prey on the wing, feed on small mammals, birds, reptiles, fishes, and insects; almost all are solitary and monogamous. Many of them are common to Great Britain and the E. Indies, as the peregrine and other falcons, the merlins, and kestrel. Astur trivirgatus, the goshawk, occurs in the hilly parts of Nepal, India, and the Malay countries. A. palumbarius is a native of Europe and the Sub-Himalaya. The kestrel is occasionally observed in extraordinary abundance, and harriers (Circus) are often seen beating over the open ground. In Lower Bengal, kites quit Calcutta and neighbourhood during the rains and return in the cold weather. It is supposed that they go to the N.E. to breed. The kestrel, baza, and Indian hobby are most frequent in Bengal during the rains. In Bengal, the kites and Brahmany kites breed chiefly in January and February, and disappear during the rains; but adjutants appear as soon as the rains set in, and, becoming in fine plumage towards the close of the rains, depart at that time to breed in the eastern portion of the Sunderbuns, and along the eastern coast of the Bay of Bengal, upon lofty trees and rocks. In the island of Bombay, on the approach of the monsoon, nearly all the kites, hawks, vultures, and other carrion birds disappear from the sea-coast; but the crows begin to build their nests and hatch their young just at the season that seems most unsuitable for incubation, when the eggs are often shaken out, or the nests themselves are destroyed, by the violence and inclemency of rain and tempest. Carnivorous birds, as the rains approach, betake themselves to the comparatively dry air of the Dekhan, where they nestle and bring forth in comfort, and find food and shelter for their little ones. The scenes which follow the conclusion of the rains are curious enough. While the Mahomedans bury, and the Hindus burn their dead, the Parsee race expose their dead in large cylindrical roofless structures, called towers of silence, where birds of prey at all times find an abundant repast. Their family cares and anxieties over for the season, the carrion birds, which had left in May for the Dekhan, return in October to Bombay, and make at once for the usual scenes, now stored with a three months' supply of untasted food. As they appear in clouds approaching from the mainland, the crows, unwilling that their dominions should be invaded, hasten in flocks to meet them, and a battle ensues in the air, loud, fierce, and noisy; the fluttering of the wings, the screaming and cawing of the combatants, resounding over the island, till the larger birds succeed, and, having gained the victory, are suffered henceforth to live in peace.

In Ceylon, the beautiful peregrine falcon, Falco peregrinus, Linn., is rare, but the kestrel, Tinnunculus alaudarius, Briss., is everwhere found; and the bold and daring goshawk, Astur trivirgatus, Temm., is seen wherever wild crags and precipices afford safe breeding places. In the district of Anaradhpura, where it is trained for hawking, it is usual, in lieu of a hood, to darken its eyes by means of a silken thread passed through holes in the eyelids. The ignoble birds of prey the kites, 
Milvus govinda, Sykes, keep close by the shore, and hover round the returning boats of the fishermen, to feast on the fry rejected from their nets. Accipiter trinotatus is a beautiful hawk of Celebes, with elegant rows of large round white spots on the tail.-Tennant's Ceylon, p. 246 ; Dr. Buist in Bombay Times; Mr. Blyth, 'Z.,' in Indian Field. See Eagles.

\section{HAY.}

Hovi, . . . . Dut. /Feno, . . . . Port.

Foin, : : : FR. Syeno, : : : RUS?

Hew, , . . GER. Heno, . . . . SP.

Ghans, : : GuJ. Hö, : Sw., DAN.

Sukha ghans, : HıND. Wolanda pillu, . TAM.

Fieno, . . . IT. Endu pachika, . TEL.

Foonum, : : LaT. Kuru ot, . . TURK.

Any kind of grass cut and dried for the food of horses, cattle, etc. $-M^{\prime}$ Culloch; Faulkner.

HAY, LORD ARTHUR, afterwards Marquess of Tweeddale, author of numerous contributions on the botany and natural history of India.

HAYOBANS, a Rajput tribe in the province of Benares, who once were dominant on the banks of the Nerbadda. $-W$.

HAYWARD, GEORGE W., a scientific explorer, who was endeavouring to reach the Pamir steppes and the country north of Peshawur, in the interest of the Royal Geographical Society of London, but was murdered, in A.D. 1870, in Chitral by Mir Wali, the nephew (sister's son) of Aman Malik, chief of Chitral, the valley north of Swat and Bajour and west of Gilghit. The Kashmir authorities urged him repeatedly to abandon the expedition, in which his life would not be safe. Mr. Hayward resolved to persevere, although he was aware that beyond the Gilghit frontier the Maharaja of Kashmir would be absolutely unable to protect him.

HAZAR. Arab. Present. Hence also Hūzür, the presence, an appellation of royalty; also Hazrat, a respectful address ; Hazari, breakfast.

HAZARA, according to Bellew, is from Hazär, a thousand; it means a division, a disposition by thousands, and is so applied by the Persians, by the mountaineers of Ghor, and by the Afghans, to the Mongol tribes occupying the mountain country of Ghor, lying between Kābul and Herat in one direction, and Kandahar and Balkh in another. He says (p. 205) it is the equivalent of the Tartar toman or tuman. Hazara tribes occupy the whole range of the Paropamisus, or the mountains extending between the Hindu Kush or Caucasus and the city of Herat, to within a few days' march of Kandahar. The Hazara districts between Käbul and Bamian are collectively called Bisut, and mallia or tribute is enforced from them by the authorities of Kābul. In the mountainous country between Kābul and Herat, the habitations of the Hazara tribes are at heights between 5000 and 10,000 feet above the sea. Some of them claim to be of Turk origin; others in appearance very much resemble the Gurkha. They have the same high cheek-bones, the same small eyes, very little beard, and these no doubt are of Tartar origin. Some profess the Sunni, others the Shiah form of Mahomedanism. A tribe inhabiting the country to the east of the Taemuri of Khaff, between it and the great range from Khairabad to Rosanak, are violent Sunni. These are of Tartar origin, and are predatory, selling their captives to the Turkoman, and plundering up to Herat. Of the
Hazara between Kābul and Herat, some claim descent from Toghiani Turk.

The Deh Kundi Hazara assert their origin from a Koresh tribe of Arabs. The Deh Kundi muster 12,000 fighting men.

The Froladi of Gujaristan are said to be so called from a daughter of Afrasiab.

The Deh Zangi Hazara, who were reduced by Murad Bey of Kunduz, are Shiahs, and from them most of the Hazara slaves are procured. They are rich in flocks, and their cavalry have been estimated at from 12,000 to 28,000 .

The Jaguri Hazara, who can assemble 5000, occupy the country bounded north by Gujaristan and Gul-Koh, east by Karabagh, Mukur, and Resana, south by Arghandab and Warazan, and west by Mahstan, 60 miles by 40 miles of beautiful and fertile valleys, and number about 50,000 souls. They are a short but well-made race, beardless, with flat nose, and some of their tribes follow the custom called Kooroo-bistan, which consists in lending their wives to strangers for a night or a week.

The Faoladi Hazara number 1000 families. They dwell between Kābul and Bamian.

The Deh Chafran or Zard-alu, near Karabagh, are about 3000 families.

The Shaikh Ali, east of Bamian, from 3000 to 5000 families, occupy between Bamian, Ghorband, and the Helmand.

About forty other tribes are mentioned by Elphinstone, Burness, Wood, Leech, Lumsden, who estimate their numbers up to 300,000 souls.

The Hazara assume as their titles, Ikhtiar, Khan, Mehtar, Sadiq, Sultan, Turkhan, and Vali. Grain is scarce; their bread is tasteless; and their food consists of the flesh of their sheep, oxen, and horses, with cheese. In years of scarcity they voluntarily sell their children to the Uzbak slave dealers. The Shiah Hazara detest and persecute the Sunni Afghan, Aimak, and Uzbak, yet revere Ali and all Syuds. They speak a Persian dialect, and are friendly with the Kazzilbash and Parsivan. Almost every tribe is at war with their neighbours, and with the Aimak and Urbak, and even the chiefs of their own race carry off many into slavery. Hazara do all the labouring work of Kābul. Their country yields lead and sulphur. They breed dumba (tailed) sheep and horses. Their animals have the fine shawl-wool with which they manufacture carpets and the fabric called Burrick. Hazara Zeidnat was a tribe in the fertile Kala Nao district, at the Murghab and Panjdeh rivers, who claim to be the original Hazara, and assume the title of Sar-i-khana. Their chief has jurisdiction over 28,000 tents. They are supposed to be Aimak. They had immense flocks and herds of sheep, goats, buffaloes, and camels. In 1847, Yar Muhammad marched against and defeated Karimdad, the chief of this tribe, and removed 10,000 families to Herat; and the Persians, after the capture of Herat in 1857, removed the whole tribe within Persian territory; and deprived them of all their baggage and cattle. They could assemble 4000 cavalry and 3000 infantry. Ferrier, in his Caravan Journeys (pp. 194-237), mentions that he fell among the Aimak Hazara on the Murghab river, and other tribes about Dev-Hissar, more to the north and east. He says their women take part in every war, manage the horse, the sword, and the fire- 
lock. Their courage amounts to rashness, and they are more dreaded than the men for cruelty and fierceness. It is, and, so far as they know, has always been, a national custom. Here we have an intelligible explanation of the Amazons of Alexander, and the 'female hosts' of Nemuchi. In an attack by the Firoz Kohi on a Hazara tribe near Singlah, in which he was engaged, he says it was a remarkable sight to see brave and energetic Tartar women under fire amongst, and as forward as, the men ; they fight also on horseback, and ride or act under any circumstances as well as the other sex. He says 'more than one of them would, I have no doubt, meet any European horseman on more than equal terms : the dexterity with which they manage their horse is extraordinary, and their courage is not less great. They take part in every war, and the ranquished dread their cruelty more than that of the men.' -Cal. Rev. No. 64, p. 433; Vigne's Personal Narrative, pp. 113-171; Masson's Journeys, ii. pp. 217-295; E. I. Parl. Papers, Cabool and Afghanistan, pp. 135, 136; Yule's Cathay, ii. p. 540 ; Ferrier, Journeys, pp. 194, 222, 237 ; MacGregor; Bellew, p. 205 ; Campbell, p. 54.

HAZARA, a British district in the Panjab, lying between lat. $33^{\circ} 45^{\prime}$ and $35^{\circ} 2^{\prime} \mathrm{N}$., and between long. $72^{\circ} 35^{\prime} 30^{\prime \prime}$ and $74^{\circ} 9^{\prime}$ E. ; area, 2771 square miles. It is bounded on the north by the Black Mountains, the Swati country, Kohistan, and Chilas, on the east by Kashmir, on the south by Rawal Pindi district, and on the west by the river Indus. It consists of a long and narrow valley, shut in on either side by lofty mountains, whose peaks rise to 17,000 feet above the sea. A group of ancient mounds, extending into the southern portion of this district from that of Rawal Pindi, have been identified by General Cunningham with the site of Taxila. Under the successors of Ranjit Singh, the Hazara people declared for independence, and Syud Akbar of Sitana was elected king by the assembled chieftains. Enumeration over a total area of 2835 square miles disclosed a total population of 367,218 . The Hindus amount to 5.06 per cent. The Pathan tribes were-Jadun, 15,711; Swati, 21,334 ; 'others,' 16,748. Other Mahomedans are-Syuds, 11,700; Dhund, 14,412; Kharal, 10,734; Awan, 50,564; Gujar, 54,420. Hindus or Sikhs-Kshatriyas, 12,320; Brahmans, 3009. The Swati occupy the Khagan gorge; while the other tribes of Pathan origin inhabit the western frontier of the district. The Dhund and Kharal hold the south-eastern hills; the Awan and Gujar are scattered over the whole country, occupying inferior social positions. The Dhund, Kharal, and Swati in particular are of small stature, and deficient in strength.-Imp. Gaz.

HAZARIBAGH, a British district in Bengal, lying between lat. $23^{\circ} 25^{\prime}$ and $24^{\circ} 48^{\prime} \mathrm{N}$., and long. $84^{\circ} 29^{\prime}$ and $86^{\circ} 38^{\prime}$ E. ; area, 7020 square miles; population in $1872,771,875$. A central plateau, about forty miles in length, has peaks rising from 2463 to 3445 feet above the sea. Its aboriginal tribes are-Santal, 35,306; Kol, 7307 ; Bhoi, 5835; Munda, 5664; Birhor, 132; Bhuiya, 73,824 ; Chamar, 26,112 ; Ghatwal, 31,134 ; Bhogta, 20,546. The agriculturists are -Kurmi, 40,538; Koeri, 27,550. The traders are-Banya, 13,669; and Teli, 29,876. The Rajputs, known as the Panwar or Ujjaini, formerly supplied the Bhojpuria sepoys to the native army ; and the Nagbansi, who are peculiar to Chutia Nagpur, are Rajputs of pure blood. The Srawak or secular Jains are well-to-do merchants, and occupy a high social position. The religious Jains live at the foot of Parasnath Hill, and are custodians of the temples in the village of Madhuban, from which pilgrims ascend Parasnath. The Birhor of Hazaribagh and Lohardagga live in the jungles or hill-sides in huts made of branches of trees. They have hardly any cultivation, and never touch a plough. The men spend their time in snaring hares and monkeys, and also trade in various jungle products. They worship female deities and devils, and it is supposed that they at one time practised cannibalism. The wealthier Ghatwals are considerable landholders in the N.E. of Hazaribagh, and claim to be zamindars under the permanent settlement of 1793.-Imp. Gaz.

HAZAR KINIAN, or the Thousand Springs, are in Kurdistan, in the district of Aalan, an alpine spot where innumerable springs start from the ground.-Rich's Kurdistan, i. p. 262.

HAZEL NUT, Corylus avellana.

Bindik, . . . Beng. A Avellane, . . LAT. Tsin, : ChIN. Fenduk, : : Pers. Noisettes aveilenes, FR. Avellaas, . . PORT. Haselnusse, . GER. Avellanas, . . . SP. Naccinole, aveline, . IT.

The fruit of different species of the Coryli or hazel trees. The kernels have a mild, farinaceous, oily taste, agreeable to most palates. A kind of chocolate has been prepared from them, and they have been sometimes made into bread. They are grown in Europe, are produced abundantly in China and in the Himalayas; and hazel nuts are imported into Bombay from the Persian Gulf. - M'Culloch.

HAZIRAT. HIND. In Mahomedan divination, in India, the flame of a charm-wick.

HAZIR ZAMIN. HIND. A personal bail.

HAZRAT. Arab. An honorific appellation, equivalent to lord, reverence, Mr., worship. Lord Jesus, Hazrat Isa. Hazrat Ali, the lord Ali.

HAZRAT IMAM, a town on the south bank of the Oxus, producing good silk.

HEAD.

Ras, . . . Arab. Sar, . Hind., Pers. Tête, : : Fr. Talle, : TAM., TeL.

The Mahomedan races of $\Lambda$ rabia, Persia, and India, in acknowledging an order, stake their head on obeying it. The Arab will say, Dala rasi, On my head be it; and the Persian and Indian Mahomedan, Ba-sar-o-chashm, On my head and eyes be it. Horses are numbered by their head, as Bis ras asp, 20 head of horses.

Head cloths, or roomals, of cotton are manufactured in the Madras districts. They are always in squares of $5 \frac{1}{2}$ and 6 cubits, with lace borders, and are always red-coloured, printed with white spots. These are worn by Hindus as turbands, and are of value from Rs. 8 to 250 .

Head-dress. The Turks of Turkey and of Egypt wear the turband and the red Fez cap. The Jews of Syria, Egypt, and Persia wear the turband (sar-band). All the Mahomedans and many Hindus of India use turbands. Many Persians wear caps. The Chinese history ascribes wing-like appendages to their emperor's cap. But wings attached to the cap are rather an ancient Hindu 
feature, and are remarkably preserved in the state costume of the kings of Burma and the sultans of Java.-Yule, Cathay, i. p. lix.

HEAT. Poo hgying, BurM. The heat in S. Asia is sometimes very great. Major Sander's thermometer, on the Farrah-Rud in 1840, rose to $175^{\circ}$ in the sun, a heat which enabled him to poach eggs in the burning sand. The mean heat at Bombay is $84^{\circ}$, at Madras $83^{\circ}$, Calcutta $79^{\circ}$, Delhi $72^{\circ}$. The gunpowder in the factory of Madras is dried on blackened platforms in the sun's rays, and the thermometer rises to $164^{\circ}$ Fahr.

HEAVEN, the Assama, Al-Fardūs, and the Jannat of the Arab, Bihisht of the Persians, Himmel of the Germans, and Paridesh of the Hindus, with all is the place to which the souls of the virtuous dead are translated. Paridesh means the other world; Himmel is from Himalaya, the abode of snow. Mahomedans and Jews have seven heavens. The seven heavens of the Jews are-(1) the vellum or curtain, (2) the expanse or firmament, (3) the clouds of ether, (4) the habitation where the temple of Jerusalem and altar are situated, and (5) where Michael offers sacrifice; (6) fixed residence, (7) Araboth or special place of glory. The celestial place of the Saiva Hindus is Swerga, said to be on Kailasa, a mountain in the Himalayas north of Lake Manasa, also on Mount Meru. It is also called Sairibha, Misraka vana, Tavisha, Tridivam, Tripishtapam, and Urdhwa-loka. The heaven or paradise of Vishnu is Vaikuntha, also called Vaibhro, and sometimes described as on Mount Meru. The Saiva regards Vaikuntha, and the Vaishnava regards Kailas as merely a second Swerga. Each sect believes that the heaven of their opponents passes away with Indra's paradise at the Maha Prulay, but that their own heaven is not so much destroyed as re-created, Kailas merging into Maha Kailas, and Vaikuntha being elevated into Go Lok.

HEAVY SPAR or sulphate of baryta is found near the village of Pudoor, on the banks of the Tumbudra, about 7 miles from Kurnool, on the slope of a low range of hills. Dr. Royle found it near the convalescent depot at Landour.

HEBEL, the vanishing, Abel of the Bible.

HEBER. The passage. A historical term connected with the race of Arphaxad, indicating their passage near the Upper Tigris in a south-western direction.-Bunsen. See Joktan.

HEBER, REGINALD, bishop and metropolitan of India, an eminent writer. He was found dead in his bath at Trichinopoly on the $3 \mathrm{~d}$ April 1826 . He visited many parts of India, and consecrated most of the churchyards and churches, which led to after regulations. His narrative was published in London in 1828.

HEBREW. The language of Tyre and Sidon was pure old Hebrew. Abram was a Hebrew, who spoke Aramaic as his mother tongue, but migrated from the Trans-Euphrates country, and adopted the language of Canaan. His first-born son was Sidon. 1400 years after Joseph, Canaan was occupied by the Israelite, Edomite, and Canaanite as separate nations. In the old Testament (Isaiah xix. 18) the language of the Bible is called the language of Canaan, - in no instance Hebrew. The Hebrew language is used by the small colony of Jews residing in Cochin and its neighbourhood. Hebrew is a branch of the Semitic family of languages. Yemen and Arabia are considered by Jewish mediæval tradition as the land of the Ten Tribes, where powerful Jewish kings fought against infidels; this belief exists even now among Eastern Jews. About the middle of the 19th century, Rabbi R. Jacob Saphir visited Yemen. After R. Jacob Saphir, Joseph Halévy was sent to Yemen by the French Government, in order to copy Himyaritic inscriptions, and brought back manuscripts, which were partly acquired by the Bodleian Library. Mr. Shapira of Jerusalem revisited the Jews in Yemen, and through him the British Museum now possesses a considerable number of manuscript Bibles, many of them provided with the superlinear punctuation (usually called the 'Assyrian" vowel-points, while the punctuation used in our Bibles is called the 'Palestinian'), as well as with the Massorah. The Yemen manuscripts also contain a collection of Agadic books, called Midrashim, which embody many lost passages, known only from quotations by Maimonides and others. In Persia the Jews have adopted in their writings the native language, though still using Hebrew characters, just as their brethren have done in the Arabic-speaking countries, in Greece, Spain, France, and Germany, and as the Karaitic Jews have done among the Tatars. The Persian translation of the Bible to be found in manuscripts of the National Library at Paris is, according to Solomon Munk, not earlier than the 13 th century and not later than the 14th; but Bishop Theodorus in the 5th century mentions a Persian translation of the Bible. So does Maimonides in the 12 th century, who refers to a translation of the Pentateuch made several centuries before Mahomed. If this translation is not based on an early translation, the Jews in Persia must have kept up the ancient Persian dialect, just as the German Jews still speak in the ghettos the pre-Lutheran German, or as the Spanish exiles in the East speak ancient Spanish, -in a word, the 'langue des exilés,' as Voltaire styles the French of the Huguenots at Berlin. We know, in fact, that in the time of the second temple the Pentateuch lessons read in the synagogues (Acts xv. 21) were interpreted by the Methurgeman in the vernacular; hence the origin of the Targum or Chaldee translation. In Persia this rule was observed as late as the 13 th century, for it is stated on the margin of Genesis $x \times x v .22$, "The translation of this verse ought not to be read publicly.' The same is said in the Talmud, 'The history of Reuben is read (in Hebrew), but not in the translation.' In the synagogues of the Greek rite, the practice of reading the translation of the Haftarah (section of the Prophets, Luke iv. 16 ; Acts xiii. 14) was still kept up in the 12th century, according to a ritual manuscript in the Bodleian Library, which contains the Greek translation of the book of Jonah in Hebrew characters with vowel points. This book forms the prophetical lesson of the afternoon service (called Minhah) on the Day of Atonement, and it is the oldest piece in prose written in modern Greek. Besides the Hebræo-Persian manuscripts in Paris, the Imperial Library of St. Petersburg possesses a fragment of a Hebræo-Talmudic dictionary, written at Djorjan in 1339 , and the British Museum an astronomical treatise, transcribed in Hebrew characters from a Persian 
manuscript. This is about all that is known of Jewish writing in Persia.

Recently, Mr. Neubauer acquired in Paris a Pentateuch and Psalms, written at Koom in the year 1483, to which a Jewish calendar in Persian is attached. Another manuscript contains a translation of the Psalms, which is missing in the Paris collection. The copyist states that it was written for the great king, Kibleh-i-Alam (the Kibleh of the world), possibly Kablai Khan, who was the great protector of art and science in that dark age, about 1294. Indeed, at that time, when Argun was the vassal king of Persia, the Jewish physician Saad-ud-Daula was his minister of finances, who not only restored order to- the finances of the kingdom, and forced the Mongol generals to obey law and justice, but also attracted learned men and poets to the court of his master. The most curious of the manuscripts is a fragment of an epopee, which has for its subject the whole of the biblical history, and is simply an imitation of Firdausi ; its author, however, remains at present unknown.

HEDERACE , the ivy tribe of plants, the Araliaceæ of A. Rich. Species of the genera panax, paratrophia, and hedera occur in India. $H_{\text {. }}$ heterophylla occurs in Penang, P. palmata in Nepal and Arakan, P. terebinthacea in Penang, and $\mathrm{H}$. exaltata, $T h w$, is a large tree growing in the central province of Ceylon, at an elevation of 4000 to 6000 feet. H. umbellifera, the Sarura of Amboyna, has a shrubby, unarmed stem, and yields a blackish or dull-brown resin with a very powerful aromatic camphorated smell.-Eng. Cyc.; Voigt; Thw.

HEDERA HELIX, the ivy.

Lablab kussus, - ARAB. Arbambal, - JHELUM. Brumbrum of . BEAs. Karmora,Mandia,KAGHAN Dakari, : Kural, Kuril of ChenAB. Karur, . . RAvi, Harbambal of . JHELUM. Karbaru,Kaniuru, SUTLEJ.

This ivy has a climbing stem, with root-like fibres. It is found between the Canaries and Europe on the west, and the northern parts of China on the east. In the north of India, and indeed occasionally in Italy, the berries, instead of being black as in Britain, are bright yellow, and it is supposed that this is more particularly the Hedera of the Roman poets. The flowers are yellowish, and appear late in the season, and, in consequence, are much resorted to by bees at seasons when little other food is to be had. It is common in the Panjab Himalaya, at places from 3200 to 8000 feet; occurs in the Salt Range and Trans-Indus ; and Dr. Bellew got it at 9000 feet near the Safed Koh. It is stated to be a favourite food of goats, and in Kullu the leaves are said to be added to the beer of the country to make it strong.-Dr. J. L. Stextart, Eng. Cyc.

HEDGEHOG, the genus Erinaceus of the maminalia. There are in India two species, E. collaris and E. mentalis. E. dealbatus, Swinhoe, is Chinese.

HEDGES are not used for the cold-weather crops of India. For the garden crops, sugar-cane, betel vine, and others, the large species of saccharum are used. Quick hedges are formed in Japan of the Lycium Japonicum, Citrus trifoliata, Gardenia, species of Viburnum, Thuja, Spirza; and arbours are made of the Dolichos polystachyos. Dr. Cleghorn gives the following as the wild and eultivated hedge plants of India :-
1. Plants adapted for field enclosures.

Opuntia Dillenii, Haw. | Epicarpurus orientalis, Agave Americana, $L$. Blume.

Euphorbia tirucalli, $L$. Jatropha curcas, $L$.

E. antiquorum, $L$. Pisonea aculeata, $R$ ox.

\begin{tabular}{l|l} 
E. nivulia, Buch. & Capparis sepiaria, $L$. \\
Cæsalpinia sepiaris, Rox. & C. aphylla, $R o x$.
\end{tabular}

C. sappan, $\boldsymbol{L}$.

Pterolobium lacerans.

Guilandina bonduc, $\boldsymbol{L}$.

Parkinsonia aculeata, $L$.

Poinciana pulcherrima, $L$.

Mimosa rubicaulis, Lam.

Inga dulcis, Willd.

Acacia Arabica, Willd.

A. concinna, $D$. $C$.

Vachellia farmesiana, $W$.

Hemicyclia sepiaria, $W$.

II. Ornamental plants for

Lawsonia inermis, Wall.

Lonicera ligustrina, $L$.

Citrus limetta, Riss.

Morus Indica, $L$.

Punica granatum, $\boldsymbol{L}$.

Phyllanthus reticulata.

Hibiscus rosa Sinensis, $L$. Scutia Indica, Brong.

Azima tetracantha, Lam.

Gmelina Asiatica, $L$.

Balsamodendron Berryi, Arn.

Toddalea aculeata, Pers.

Bambusa arundinacea.

Bambusa spinosa, $R o x$.

B. nana, $\boldsymbol{R} o x$.

Dendrocalamus tulda, Nees.

Pandanus odoratissimus.

III. Plants used for edging garden walks.

Pedilanthus tithymaloides, . Rosa semperflorens, Curtis. Poit.

Vinca rosea, Willd.

Rosa Indica, $\boldsymbol{L}$.

Heliotropium Curassavicum, $L$.

The Cacti, Agaveæ, and Euphorbiæ are adapted to the arid districts, their structure enabling them to exist, when refreshed with only occasional showers; the Mimoseæ and Cæsalpineæ seem to enjoy the somewhat more cold and noist climate of the Balaghat districts; while the Bambusez and Pandaneæ luxuriate in the rich loamy soil of the Mulnad (i.e. rain country). Plants for railway fences ought to differ as the line is continued through various districts, in accordance with the conditions under which particular plants thrive best between certain limits of temperature and moisture.-Thunberg's Tr. ii. 8; Cleghorn in Rep. Brit. Ass. 1850 , p. 311.

HEDUNG of Java, the chopping knife of the Tenger mountaineers.

HED-YA. MAHR. A drover or cattle-dealer.

HEDYCHIUM, a genus of plants belonging to the natural order Zingiberaceæ. 28 species occur in the East Indies, some of them with sweetsmelling flowers.

Hedychium coronarium, Linn.

Doolal champa, BENG. | Ganda suli, . MaLay. Fhet-lan-thæ, BurM.

The garland flower, much cultivated. The fiowers are fragrant; colours, orange, scarlet, yellow, and white. The yellow and white rarieties are both common. This is the most charming of all the plants of this natural order; the great length of time it continues to throw out a profusion of large, beautiful, fragrant blossoms, makes it particularly desirable. The plants are increased by dividing the roots.

Hedychium spicatum, Royle.

Ban-haldi ; Shlui of BEAs. I Bazar Roots.

Sidhoul, 3 HiNd. San-na, San-lah, CHIN. Ban-kela; Saki of RAvi. Kapur kachri, HiND. Khor; Shalwi, . Sutues. Kachur, Seer, Rutti, ",

This grows throughout the East Indies, in Nepal, in the Panjab Himalaya, up to near the Jhelum, at least, at from 3500 to 7500 feet, and also in China. Its large broad leaves are twisted, and made into coarse mats for sleeping on, etc. The root is fragrant, warm, and aromatic; and $D r$. 
Royle thinks it may probably be the ritte, or lesser galangal of Ainslie. The root, capoor cutchery, in China, is cut into small pieces and dried for exportation: has internally a whitish colour, but externally it is rough and of a reddish colour; it has a pungent and bitterish taste, and a slightly aromatic smell. It is exported to Bombay, and from thence to Persia and Arabia ; it is said to be used in perfumery and for medicinal purposes, and also to preserve clothes from insects. In Garhwal they are used in washing the newly married; and Madden states that they are pounded with tobacco for the hookah.-O'Sh; Marsden; Roxb.; Voigt; Stewart.

HEDYOTIDE E, a section of plants of the natural order Cinchonaceæ, containing species of Wendlandia, Dentella, Hedyotis, etc. There are ten known species of Hedyotis.

Hedyotis Burmanniana, $R$. $B r$.

Oldenlandia biflora, Lam.

Gerontegea biflora, Cham. and Schl.

Khet-papra, . Beng. | Purputi, Papra, . Hind.

Two-flowered Indian madder, is a plant of Ceylon, both Peninsulas of India, and Bengal. Appears in moist ground in the rainy season. The whole plant is used in infusion as an excellent tonic and febrifuge in chronic fever. Dose 1 to 2 drachms ; price 8 annas per $\mathrm{lb}$. Other species also occur, and are called Ganda badalee and Poonkha.

Hedyotis Heynei, $R$. Br.

H. herbacea, Willde. |Oldenlandia herbacea, Rox. Tella nela vemu, ... TEL.

A plant of the Peninsula of India.-Irvine.

Hedyotis umbellata, Lamarck.

H. hispida, Roth. $\quad$ Oldenlandia umbellata, H. Indiea, Rom. and Sch. Linn.

Chay-root, ANGLo-TAM. Saya, . TAM. Indian madder, ENG. Emburel cheddi, : , Choya, , SINGH. Cherivelu, . . TEL. Sayan ; Sayan mul, ",

This dye plant grows in sandy soils on the Coromandel coast. The root of that which grows wild is reckoned the best, but it is also cultivated to some extent. For the cultivation of the plant the finest sandy soil is required, as being the most favourable to the free growth of the root, on the length of which the value of the article greatly depends. The cultivation commences in the end of May or beginning of June, with the first falls of the south-west monsoon. During the space of three months the sand is subjected to repeated ploughings, and is thoroughly cleaned from all weeds. Between each ploughing it is manured, and after the last ploughing it is levelled with a board, and formed into small beds of about six feet by three. The seed, which is extremely minute (so much so that it is impossible to gather it except by sweeping up the surface sand into which it has fallen, at the end of the harvest), is then sown by spreading a thin layer of sand over the prepared beds. They are then kept constantly moist, and are watered gently with a sieve made of palmyra fibres, five or six times a day; care being taken that the water is quite sweet and fresh, for which purpose it is obtained from wells newly dug in the field. At the end of a fortnight the seeds under this treatment will have germinated freely, after which the young plants are only watered once a day, in addition to which, liquid cow-dung, greatly diluted with water, is daily sprinkled over them. In about four months more, or at the end of six months from the time of sowing, provided the season has been good and the falls of rain regular, the plants will have reached maturity, and the roots be ready for digging. But no artificial irrigation will compensate for a failure of the natural rain ; and when this happens, the plants must be left for three or even four months longer, in which case the produce will be deficient both in quantity and quality. But in an ordinary season the produce of a podu, or plot containing an acre and threequarters, will yield from 5 to 10, averaging about 8 , candies of $500 \mathrm{lbs}$. each.

The plants are dug up with a light wooden spade tipped with iron, and are tied into bundles of a handful each, without cutting off the stocks. They are then left to dry, the leaves wither and fall off, and the bundles are weighed and removed. Before the digging begins, the seeds, which have now ripened, are shed, and, being exceedingly minute, become inextricably mixed with the sand, the surface of which is therefore carefully scraped up, and reserved for future sowings.

It is largely used by the Indian dyer in the south of India. It furnishes a red dye similar to manjith. Experiments in Great Britain with the chay-root have hitherto failed, in consequence, it is supposed, of deterioration during the voyage. In the case of this and of some other Indian dyestuffs, the colouring matter could be extracted similarly to indigo before it is exported.-O'Sh.; Ains.; R. Mad. Ex. 1857. See Chay-root; Dyes.

HEDYSARUM. Ti-yu, Chrn. Several occur in China, where the roots are employed as a styptic or vulnerary. The leaves are used as a vegetable, and as a substitute for the proper tea-leaf.

H. lineare is used in Cocbin-China as a stomachic, and $\mathrm{H}$. alpinum in Siberia for the same purpose.

H. junceum grows in vast quantities in Shekhawatti and elsewhere, near Jeypore; the small branches are sweet, and eaten by camels and other cattle. This becomes a considerable bush, and has no thorns.

H. edysarum tuberosum, Roxb.

Pueraria tuberosa.-Bank's 1c. Kemp. tab. 25.

Kudsumi, . . Hinv. | Daree goomodee, . TEL.

A rare species, a native of the valleys far up amongst the mountains. It flowers during the hot season, at which time it is perfectly naked of leaves, being deciduous about the beginning of the cold season. The root, peeled and bruised into a cataplasm, is employed by the natives of the mountains where it grows to reduce swellings of the joints.-Roxb. ii. 863 ; Gen. Medl. Top. p. 205 ; Snith.

HEEL. This part of the body is often alluded to by oriental nations. The only vulnerable part of Krishna's body was his heel, in which he was shot by a Bhil.

HEEMACHA. HrND. A bag made of the skin of a lamb, used by fakirs.

HEEN. Every Chinese province is divided into a certain number of districts, called Fu, Ting, Chow, or Heen. A Fu is a large portion or department of a province under the general control of a civil officer, immediately subordinate to the head of the provincial government.-Sirr, Chinese.

HEERA-KASSEES. HrND. Dry persulphate of iron, used in dyeing, in making ink, blacking 
leather; also in medicine, and made into missi to apply to the teeth. To make-

Black missi.-Heera-kassees, chaipal harra, choonigond, lila tootiya, iron filings, kuth, equal parts, pounded and mixed; rubbed on the gums.

White missi. - Sufaid soorum (crystallized carbonate of lime, double refracting spar) and cinnamon pounded together; used as tooth-powder.

Sada-kassees.-Impure sulphate of iron, the refuse from the manufactory of the sulphate of copper : four seers for one rupee.

HEERA-KHOND, a place in Assam where diamonds occur. See Diamond.

HEERANA or Hirana, in E. Oudh, manuring a field by penning a herd of cattle or flock of sheep in it for several hours. K'hhutana is used in a similar sense in Rohilkhand. This practice is known in England under the name of fold-course or foldage, and formerly meant a privilege which several lords reserved to themselves of setting up folds within their manors for the better manurance of the same.-Elliot, Supp. Gloss.

HEGGADE. KARN. The headman of a town or village, but especially applied to one of the Jain religion. It is also used by certain castes as an affix to proper names, to intimate respectability, corresponding with Sahib or Mian in Hindustan. -Wilson's Glossary.

HEI-MIN, in Japan, all below the nobles; the commonalty.

HEJAZ, ARAB., is a large province of Arabia, containing the two sacred cities, Mecca and Medina. But geographers differ much as to its limits. Burton says that the Arab of the Hejaz still uses heathenish oaths and heathen names, few being Mahomedan. Their ordeal of licking red-hot iron, their practice of the salkh or scarification as a sign of manliness, and their blood revenge, their eating creatures which have not been made lawful by the usual formula, and their lending their wives to strangers, he indicates as showing how little Mahomedanism has influenced the uncivilised parts of the country.-Burton's Mecca, iii. 79 .

HELA, a man of a low caste; an inferior division of the Bhangi, engaged in the lowest menial offices. The Hela pride themselves on eating the leavings of Hindus only.

HELEOCHARIS TUBEROSA, Rœm. and Sch., the Ma-tai or Pe-tsi of the Chinese, is a rush which is cultivated in ponds for its edible tubers. $H$. fistulosa and $\mathrm{H}$. plantaginea of Australia and India and H. sphacelata are allied plants.-Smith.

HELFER, DR., of the Bengal medical service, and a celebrated botanist, was murdered by the natives of the Andamans, in January 1839. See As. Jour. 1840, vol. xxxiii. Author of Notice of the Mergui Archipelago, ibid. vol. xxxiii.; Report on Tenasserim and the surrounding Nations, Bl. As. Trans, vol, viii. Along with Lieutenant Hutchinson, he reported on the new coal-field of Tenasserim in Bl. As. Trans. 1839 , vol, viii. 385 . Author of Researches on the Tenasserim Coast, in Friend of India, 165, 638.-Dr. Buist, Catalogue.

HELIANTHUS ANNUUS. $L$. Sun-flower.

Shooria mukti, - BENG. Aditya bhakti chettu.

Suraj mukhi, : HrNo. Poddu or Proddu

Suria mukhi,: : SANsk. tirugudda chettu, TEL

It is indigenous in Mexico and Peru; it was early introduced into Europe after the discovery of America. It is one of the cistaceæ, or rockrose tribe. An acre has been known to yield
50 bushels of seed - like nutlets, from which 50 gallons of oil have been pressed, useful for the table, for machinery, soaps, and for painting. The seeds are valued for feeding fowls, also as a substitute for coffee. The large flower-heads yield much honey, the stalks a useful textile fibre, and the blossoms a brilliant, lasting yellow dye The absorbing and exhaling powers of this plant are great, and it is valuable for raising quickly vegetation around fever morasses. A sun-flower. according to Laccupidan, will exhale $1 \frac{1}{2} \mathrm{lb}$. of water in a day. Its products are yielded in a few months.-Roxb.; Von Mueller.

HELIANTHUS TUBEROSUS. Linn.

Bheamoka, . . BENG. | Jerusalem artichoke, ENG. A native of Brazil, but the plant is cultivated throughout India as a vegetable in gardens. Jerusalem artichoke is a corruption of the Italian Girasole. It was introduced into Europe at the Farnese Garden at Rome, whence it was originally distributed. The roots are composed of a number of oblong tubercles, very large and fleshy, reddish outside and white within, resembling a potato; the stems are herbaceous, and upright. In France it is also known by the name of topinambour and poire de terre. According to Braconnot and Payen, the tubers do not contain fecula, but a vegetable principle called inulin or dahlin. These tubers, when cooked, form a good substitute for potatoes, and by some are even preferred. The foliage and tubers increase the milk of cows; the stem is rich in textile fibre. Its yield is as plentiful as potatoes, with less labour; and in fair land, rich in potash, continues uninterruptedly from year to year.-Roxb.; Von Mueller.

\section{HELICIA ROBUSTA. Wall.}

Rhopala robusta, Roxb. | H. Travancorica, Bedd.

A very handsome, good-sized tree, not uncommon on banks of streams on the Travancore and Tinnevelly mountains, above Panpanassam, at about 4000 feet elevation; it also inhabits Eastern Bengal and Burma.-Beddome, Fl. Sylv.

HELICID $\mathbb{E}$, a family of Gasteropodous mollusca, the land snails. See Mollusca.

HELICTERES ISORA. Linn. Screw-plant. Isora corylifolia, Sch. and End.

Dhamni, . . Dukr. Avurtunni, . . SANsk. Murad sing?.. ", Leeviya-gaha, . SINGH. Kewun? Kewanni, ", Valambirikai, : TAM, Maror-phalli, HIND. Syamali, : TEL. Kupaisi, Joa-ka-phal, ", Ada syamali, Kavanchi, ,, Kisht, Bur-kisht, . PERS, Nooli-tudda, . . ",

This planit has a singular-looking contorted capsule, consisting of five fibres closely twisted in the shape of a screw, of various lengths, from 1 to $2 \frac{1}{2}$ inches. A liniment is prepared from the powder of it, which is supposed to be a valuable application in cases of offensive sores inside of the ears. The Telugu name means that the juice of the root is a powerful stomachic. The powder of the fruit has also been used in griping pains of the bowels, but solely because the twisted fibres of the capsule were considered to stamp it as a remedy, according to the ancient doctrine of signatures. The fibre of the bark makes good ropes.-Powell; Steuart; Ains. Mat. Med. p. 118; O'Sh. p. 228.

HELICTIS. Gray. A genus of the mammalia, belonging to the order Carnivora and family Felidi. The species inhabit Eastern Asia, and have the general appearance and colouring of Mydaus, combined with a dentition resembling 
that of Gulo or Mustela, but differing from both the latter genera in the large internal lobe of the upper carnivorous tooth. There are three species, -H. moschata of China, H. Nepalensis, the Nepal wolverine, and $\mathrm{H}$. orientalis, Horsficld, from Malayana. They have long claws, adapted for burrowing.-Jerdon, Mammals, p. 80 ; Eng. Cyc.

HELILAH. ARAB., PERs. Myrobalan of Terminalia chebula, Roxt. Of these there are six kinds,-Helilah zirah, the young fruit, dried, of the size of cunin seed; Helilah jaoi, size of a harley-corn; Helilah zengi, size of a raisin, and black like a negro; Helilah chini, larger than Helilah zengi, and greenish; Helilah asfer, fruit near maturity and yellow; Helilah kabuli, the fruit at full maturity, called also Sarwarri hirda. Helilah-i-siah, Pers., Helilaj-ul-aswad, ArAB., Helileh-i-kalan, PErs., Helilaj-ul-kabuli, Aras., Terminalia chebula, myrobalan.

HELIOPOLIS or Baalbec, the Baalith of Scripture, and Heliopolis or temple of the sun of the Greeks, is now a ruin. It is on the lower slopes of the Anti-Libanus, 43 miles north-west of Damascus, in lat. $34^{\circ} 1^{\prime} 30^{\prime \prime} \mathrm{N}$., and long. $36^{\circ}$ $11^{\prime} \mathrm{E}$. The date of its origin is unknown; but Antoninus Pius built a great temple there. It was sacked in A.D. 748 by the Mahomedans, and finally pillaged in A.D. 1400 by Timur, and now contains about 100 Arab families, cultivators, and herdsmen, who reside in a quarter surrounded by a modern wall. The great temple of the sum and its buildings are at the western end, outside the modern walls. There were rows of pillars in the Corinthian order of architecture, almost all of which have now fallen, as also have the roofs of great courts, one of them 144 feet square, and vaulted passages. On the east is a court 230 feet by 118 feet, which had arches on its western and northern sides. See Baalbec.

HELIOS. The sun-god. See Aditya Ra; Heri.

HELIOTHIS ARMIGERA, an insect of the family Noctuidæ, which in innumerable hordes attacked the poppy crops of Shahabad and Patna in the season 1877-78; it is equally destructive to the cotton crops. It eats into the capsules of the poppy and cotton; careful hand-picking is the sole remedy. The pupæ become entrapped in the capsule. In February and March it attacks the coffee plant.

HELIOTROPE or Bloodstone, a quartzose mineral, which occurs abundantly in the trap rocks of the Dekhan.

HELIOTROPIUM, a genus of flowering plants of the natural order Boraginaceæ; several species are known in India. They should be grown in a soil more approaching to sand than clay. They are easily cultivated in pots, or the flower beds; propagated by cuttings in sand under glass. They require to be protected from the hot winds.Roxl.; Rieldell.

Heliotropium Brevifolium, Wall.

Chiti mirak, . Derajat. / Chittiphub, . PanJ.

The herb is said to be laxative and diuretic; the seeds are emenagogue-IWallich; Powell.

HELIX, a genus of land-snails very numerous

in India.

HELL.

Enfer, .... Fr. Narakan, . . SANSK.

Hölle,
L'inferno, : : : : GEr. YOL. II.

Christians, Mahomedans, and
Hindus, a place of after pumishment, to which the souls of wicked people are sent. Mahomedans call it by the Hebrew and Arabic term, Jahanam, but also Dozakh; the Hindus, Narakam. Amongst the Japanese, Gokuja, or hell-or, as it is otherwise called, Roja-is their cage. By this they mean their prison, which stands about the middle of the town, at the corner of a descending street. The Hindus have seven or eight hells, named A tala, Nitala, Gabhastimat, Mahatala, Sutala, and Patala, each under a regent. The Siva Purana enumerates eight; other names not enumerated above, being Tala, Vidhi Patala, Sarkara-bhumi, and Vijaya.-Hist. of Japan.

\section{HELLEBORUS NIGER, black hellebore.}

Khertik, Kherbeck, ARAB. Kuddu, . GUJ., HIND. Kurbec-ul-aswad, . Helleboro, . PORT, Neiswurtel, . DAN. Kataka-rohini katuruni, Kalikutki, Dú, HIND. SANSK., TAM., TEL. Schwartz Neisswargel, . . GER.

Under the native names, two kinds of hellebore are commonly met with in the Indian bazars, brought from Nepal and the Red Sea. The roots of both plants are used in medicine; they are much used by farriers, and occasionally by native practitioners, as a powerful cathartic in maniacal and dropsical cases. The roots of one kind occur in pieces of 4 to 6 inches, are black all through their substance, externally of a greyish colour, with numerous joints. The second variety is in similar pieces, but of a whiter colour internally. -Faulk:; O'Sh. p. 168.

HELL-WATER, a narcotic spirit, distilled in Java from the fleshy part of the fruit of Arenga saccharifera.

HELMAND RIVER is the Etymander of the classics, and the Hrtumat of the Vendidad. It rises at Fazindaz, in the west slopes of the mountains of Paghman, about lat. $34^{\circ} 40^{\prime} \mathrm{N}$., and long. $68^{\circ} 2^{\prime}$ E., and, flowing generally to the S.W., after a course of 700 miles falls into the lake of Seistan. It is fordable at fourteen places. It is capable of being navigated by steamers. Its banks are fertile and well wooded, and an industrious population at one time occupied it, but left it, disgusted with the insecurity that prevails; and the accounts of it by travellers, writing at different times, have greatly varied.-MacGregor, p. 335; Malculm's Persia, i. p. 3 ; Pottinger's Tr. p. 316 ; Ferrier's Journey, p. 428. See Aria Palus.

HELMSIIAN, the Sikani, HiND., Jurumudi, MalaY. Sikani is from Sukhan, a helm. Sukhani, a helmsman.

HELOT. Modern India is largely inhabited by Hindus proper and Helot races, who have become completely or partially amalgamated into Hindu society. The superior Helot classes, all over Northern India, cultivate to a considerable extent either on their own account or as the servants of others. In the south of India are the Pariah, who are represented in the Canarese Karnatica by the Holar, and amongst the Mahrattas by the Mhar and Dher, and by the Malla in Telingana. The leatherworkers, the Chakili of the Tamil people, are the Madiga of the Teling race, and the Whang of the Mahrattas. In Northern India, the Dom, Dam, and Dumi; in Central India, the Kharwar or Kheroar, or ancient Santal, and the present Kheria. In the Panjab are the Chura serfs, descendants of 
Throughout India are the Coolie or Kuli; and the Hadi is a Helot race in Bengal.- $\boldsymbol{M} r$. Campbell.

HELWINGIA, a very anomalous genus of Himalaya and Japan, having the unisexual flowers sessile upon the middle of the leaf, owing to the adhesion of the flower-stalk to the leaf-stalk and midrib. H. Himalaica, Hook, grows at 7000 feet.

HEMA. SANsK. Gold. Hemadai, golden mountain, i.e. Meru. Hema-Kuta, golden peak, a range between the Himalaya and Meru.

HEMA CHANDRA, a great Jaina teacher who lived in the 12th century. He gained over to the Jaina faith the Hindu kings of Gujerat, shortly after which these princes disappeared before the Mahomedan conquests. Hema Chandra seems to have been the author of Abhidana Chintamani, a useful vocabulary, and of a life of Mahavira, printed under Mr. Colebrooke's superintendence.

HEMADRI, a Brahman of the Madhyandiniya Sakha, of the Sukla Yajur-Veda. He wrote several books, the Chaturvarga Chintamani on law, the Muktaphala on religion, and a Commentary on Wagbhata, called Ayur Veda-Rasāyana.

HEMBAKO, the Tibetan name of the territory in Ladakh which the Kashmirians call Dras.

HEMEROCALLIS, a genus of plants belonging to the natural order Liliaceæ, called day-lilies. H. flava is a native of Germany, and $H$. fulva of Italy; H. disticha from China; H. Sieboldii from Japan. H. speciosa and H. graminea are cultivated in gardens.

Hemerocallis fulva, Willde., Nargas, Gool-nargas, HIND, the narcissus of India, cultivated as a flowering plant.

Hemerocallis graminea, Tatavinov, Hiuen-tsau, CHIN. In China this is regarded as a charm for dispelling grief, and is worn in women's girdles to favour the birth of sons. The young leaves are eaten, and intoxicate slightly. The flowers of this day-lily, when dried, are called the Kin-tsints'ai.-Smith; Roxb. ii. p. 168; Gen. Med. Top.

HEMICYCLIA, a genus of moderate-sized trees of Ceylon and the Peninsula of India. H. Gardneri, Thw., not very abundant; H. lanceolata, Thw., grows at Caltura, Ceylon; and $H$. sepiaria, $W$. and $A$., Weera-gass, SINGH., is abundant in the hot, drier parts in the peninsula of the island.

H. Elata, Bedd., is a lofty, straight, glabrous tree, very common in the dense moist forests of the Wynad (2000-4000 feet elevation), also in the Animallays and Tinnevelly mountains. The leaves are less coriaceous than in $\mathbf{H}$. venusta, but have exactly the venation and shape of that species, which is a small drooping tree with a different inflorescence. H. sepiaria has much more coriaceous, differently-shaped leaves, and is scarcely more than a shrub; the timber is strong, and much valued for building purposes. - Thucrites; Wight, Icones; Beddome, Fl. Sylv. p. 279.

HEMIDACTYLUS TRIEDRUS, a pretty little white and spotted lizard of Labuan. It is one of the Geckotidæ.

\section{HEMIDESMUS INDICUS. R. Brown.}

Smilax aspera.

Periploca Indica, Willde.

Asclepias pseudosara, Rox.

Ununtamul, BENG., HIND.

Kural,

Muckwy,

Muckwy, : : D Hкн, Nab, Pala Sugandhi, : ",

DÜКн.

Nunnari,

TAM

Naru nindi, : Mraleal. Suganda-pala, : ",

Shadipa, . . SANsk, Pala Chukhanderu, ",

Iri musu, . . SINGr. Tella Sugandhi-pala, ,
Indian Sarsaparilla, or Country Sarsaparilla, is a common plant all over the Indian Peninsula. The root is long and slender, with few ramifications, covered with rust-coloured very fragrant bark, the odour remaining after drying, and strongly resembling that of new-mown hay. The roots have long been employed in the Madras Presidency as a substitute for sarsaparilla, and have been also used in England, and very highly spoken of. It can be purchased of good quality at from 2 to 4 annas the seer. It occurs in bundles about a foot and a half long. Much of its virtues depend on a volatile principle; and it should not be employed in decoction, as long boiling dissipates the active ingredient. The infusion is a fragrant and highly effectual alterative and diuretic, of great service in secondary venereal affections and chronic rheumatism. It is in every respect a perfect substitute for sarsaparilla.-O'Sh. Disp.

HEMIGYMMA MACLEODII. Griff.? Cordia Macleodii, Hooker.

Deyngan of . Jubbulpur. | Botku, . . . TkL.

This tree is abundant in the Godavery forests near Mahadeopur, and near Warangal, and it is also indigenous to the Jubbulpur forests, where it is called Deyngan. It yields a very beautiful wood, which would answer as a substitute for maple for picture frames, etc.-Captain Beddome.

HEMIGYROSA CANESCENS. Roxb.

Molinæa canescens, Roxb. Sapindus tetraphyllus, Cupania canescens, $W . A . \quad D, C$.

Kurpa, . . . MAHR. Koriai, . . TEL. Nekota, . . TAM.

A common tree in jungles on the eastern side of the Madras Presidency, Salem, Cuddapah, Mysore, etc.; also found in Bombay and Ceylon. It does not ascend the mountains much above 3000 feet. The wood is whitish, and is occasionally used by the natives for building purposes.Beddome, Fl. Sylv. p. 151.

HEMIGYROSA DEFICIENS. W. $A$.

Sapindus deficiens, $W, A$.

A small or middling-sized tree of the Tinnevelly ghats, common at 2000 to 4000 feet elevation, Animallays (head of the ghat from Palghat up to the Neliampatty coffee estates) 2500 feet elevation, and towards the higher ranges at 5000 feet elevation. It appears to be in flower all the year round.Beddome, Fl. Sylv. p. 231.

HEMIGYROSA TRICHOCARPA. Thw. A moderate-sized tree. One variety grows in the central province of Ceylon up to an elevation of 3000 feet, another in the hot, drier parts of the island.-Thw. En. Pl. Zeyl. i. p. 56.

HEMILEIA VASTATRIX, the coffee-leaf disease, or leaf-fungus, has for several years seriously affected the coffee trees of the island of Ceylon. Though requiring careful inspection for its detection, it was present upon all the coffee trees examined about 1879. With the help of the microscope, it is found at all times to pervade the greater part of the stems and older leaves, in the form of very fine branching filaments, its effects being apparent in numerous somewhat translucent spots, which may be observed when holding one of the older leaves against the light. The direet injury so caused to the coffee tree is, however, very slight, as compared with the effect produced when the fungus attacks the young leaves, causing them to fall prematurely. The presence of the fungus-filaments in such abundance on the outer 
surface of the tree is quite sufficient to account for phenomena which it was first thought must be attributable to a poisoning of the juices of the tree, by an absorption of the fungus matter through its roots. The latter idea must therefore be given up, and the disease considered as external, except when it appears within the tissue of the young leaves. Subsequently, from these enclosed masses of filaments short branches are produced, which emerge from the pores, and bear the conspicuous orange-coloured spores or reproductive bodies. Some of these spores have been observed to germinate on the outside of the leaf, producing branched filaments of exceeding tenuity, which grow with marvellous rapidity all over the: surface of the leaf, and beyond to the stems. The ends of some of these filaments, too, have been observed to enter the pores of the leaf, to form fresh diseasespots and fresh crops of spores. The true Liberian coffee is said to be of hardy habit, and more able to resist the ravages of this disease.

HEMIONITIS CORDIFOLIA. In Tenasserim, near the sea-shore, this species of mule fern, with cordate fronds, is sometimes seen.-Dr. Mason.

HEMIPTERA, an order of insects; several genera occur in India ; amongst them-

Fam. Pachycoridx, Dall. Cantuo, Bymot and Serv. Callidea, Lap.

Fam. Eurygasteridæ, Dall. Trigonosoma, Lap.

Fam. Plataspidæ, Dall. Coptosoma, Lap.

Fam. Halydidæ, Dall. Halys, Fabr.

F'am. Pentetamidæ, St. Pentatoma, Olive.; Catacanthus, Spin.; Rhaphigaster, Lap.

F'am. Edessidæ, Dall. Aspongopus, Lap.; Tesseratoma, Lep. and Serv.; Cyclopelta, Am. and Serv.

Fam. Phyllocephalidæ, Dall. Phyllocephala, Lap.

Fcm. Mictidx, Dall. Mictis, Leach.; Crinocerus, Burm.

Fam. Aniroscelidæ, Dall. Leptoscelis, Lap.; Serinetha, Spin.

Fam. Alydidæ, Dall. Alydus, Fabr.

Fam. Stenocephalidæ, Dall. Leptocorisa, Latr.

Fam. Coreidx, Steph. Rhopalus, Schill.

Fum. Lygæidæ, Westw. Lygæus, Fabr.; Rhyparochromus, Curt.

Fam. Aradidæ, Wlk. Piestosoma, Lap.

Fam. Tingidæ, Wlk. Calloniana, $W l k$.

Fam. Cimicidæ, Wlk. Cimex, Linn.

Fam. Reduviidæ, Steph. Pirates, Burm:; Acanthaspis, A m. Serv.

Fan. Hydrometridæ, Leach. Ptilomera, Am. Serv.

Fum. Nepidæ, Leach. Belostoma, Latr.; Nepa, Linn.

Fam. Notonectidæ, Steph. Notonceta, Linn.; Corixa, Geoff.

Of the aquatic species, the gigantic Belostoma Indicum attains a size of nearly three inches. Some of them are most attractive in colour. A green one, often seen on leaves, is quite inoffensive if unmolested, but if irritated exhales an offensive odour. Insects known as coffee bugs have occasioned to the coffee planters great losses, against which, seemingly, at present they have no means of protecting themselves. The whole order emit a powerful odour, and they present a very large proportion of gay-coloured and conspicuous insects. The ladybirds (Coccinellidæ) and their allies the Eumorphidæe are often brightly spotted as if to attract attention, but they can both emit fluids of a very disagreeable nature; they are certainly rejected by some birds, and are probably never eaten by any. The genera of Homoplerous Hemiptera, cicada, lystra, monophlebus, polyneura, and cyrene have several species in the $E$. Indies.-Tennant. See Insects.

HEMIRAMPHUS, a genus of fishes of the family Scombresocidæ, which includes the genera Belone,
Scombresox, Hemiramphus, Arrhamphus, and Exocœtus.

Hemiramphus macrorhynchos of the Bay of Bengal, near Pondicherry, has an elongated body, and proboscis-like member procceding from its mouth.

H. Russelli, Cui. and Val., Toda pendek (Pendek, short). The Malays thus denominate all the species of Hemiramphus, to distinguish them from those of Belone ('Toda of the Malays). At Penang this species is numerous at all seasons, but larger individuals occur at irregular intervals. They appear at European tables under the appellation of guard fish.-Cantor: Hartwig.

HEMIT'RAGUS HYLOCRIUS. Jerdon.

Kemas hylocrius, Ogilby. I Capra warryato, Gray. Ibex, . . . . ENG. Warri-adu, . . TAM Neilgherry wild goat, " Warri-atu, : : ,

This is found on the Neilgherry and neighbouring' hills, extending along the Western Ghats nearly to Cape Comorin; also on the Pulney Hills, and is called ibex by the Madras sportsmen. They are very wary, feed like a flock of sheep, and flee to the precipices when alarmed. Length, $4 \mathrm{ft} .2 \mathrm{in}$. to $4 \mathrm{ft}$. $8 \mathrm{in}$. to root of tail ; tail, 6 or $7 \mathrm{in}$; height at shoulder, 32 to 34 in.; horns occasionally 12 to $15 \mathrm{in.-Jerdon,} \mathrm{pp.} \mathrm{288-90.}$

HEMITRAGUS JEMLAICUS. Jerdon.

Capra jharal, Hodgs.

C. quadrimamis, Hodgs.

Himalnyan wild goat, ENG. Kart of . . . . KULU.

Tehr, Tare, Tahir, HrND. Jharal of : . NEPAL.

Jhula (male), Kanawar. Jehr of . ' SimLa.

Thar, tharni (fem.), "Esbu, Esbi of . . SUTLEJ.

Kras; Jagla, . KASHM.

It is found throughout the whole of the Himalayas, generally in flocks, feeding on the grassy spots among the rocks. Length, $4 \mathrm{ft} .8 \mathrm{in}$. to root of tail ; tail, $7 \mathrm{in}$; height, 36 to $40 \mathrm{in}$.; homs 12 in. long, very thick at the base.

HEMP. Cannabis sativa, Linn.

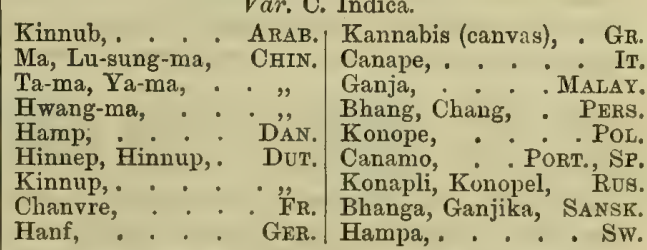

In the export commerce of India, hemp is a term applied to the fibres of several distinct plants, all valuable as cordage materials ; and the Chinese terms, Ho-ma, Ta-ma, Ya-ma, and Hwang-ma, are fibres of urticaceous, malvaceous, and tiliaceous plants. But the true hemp of Europe is the fibre of the Cannabis sativa of botanists. It possesses a remarkably tough kind of woody tissue, capable of being manufactured into linen and cordage. It is an annual plant from 3 to 10 feet high, with the males and females on separate stems. It is difficult to say of what country the true hemp plant is a native, - Willdenow says Persia, Gmelin says Tartary, Thunberg found it in Japan; so that the varieties produced by climate have by some been thought to be distinct species, the European being called C. sativa, and the Indian C. Indica. Herodotus mentions it as a Scythian plant. Bieberstein met with it in Tauria and the Caucasian region. It is well known in Bokhara and Persia, and is grown everywhere throughout India, and in the Himalaya up to 10,000 feet. In European countries 
it is cultivated only for its ligneous fibre, so extensively employed in the manufacture of ropes, and of coarse but strong kinds of cloth. It is cultivated in oriental countries to obtain the intoxicating leaves, called Ganja, from which bhang and subji or sidhi are produced, and for the resinous product called charras. The mode of cultivating is, however, different for each of its products. The plant requires exposure to light and air, and is therefore sown thin or transplanted out, when it is cultivated for its resinous and intoxicating secretion; while the growth of fibre is promoted by shade and moisture, which are procured by thick sowing.

In Arabia, Egypt, and Turkey, the leaves used as an intoxicant are known as Hashish, and Hashāsh is a term of obloquy; the plural Hashasin has been supposed by some writers to be the source of the word Assassin. For its fibre it is chiefly grown in Russia, and is sent to the other European countries for cordage, canvas, and towelling. The finest quality of hemp, and that which brings the highest price, being sold at $50 \mathrm{~s}$. per cwt. when the best Russia brings only 47s., comes from Italy; though French, English, and Irish hemps are much esteemed. The Russian hemp grows best in a friable soil of moderate richness. At St. Petersburg hemp is assorted into clean hemp, or firsts; outshot hemp, or seconds; halfcleaned hemp, or thirds; and hemp codilla. Riga hemp is classed as rein or clean, outshot, and pass hemp. Particular care is taken to ship hemp and flax in fine dry weather, and to preserve it from damp by packing with mats; for if either get wet, they are apt to heat, and to be totally spoiled.

The hemp imported into Great Britain from all countries, from 1877 to 1880 , ranged from $1,204,036$ to $1,320,731$ cwt. of value from

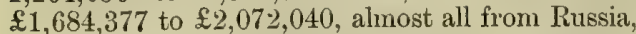
Germany, Italy, and the Philippines; from India, between the years 1874-1879, the raw fibres exported under the commercial designation of hemp, in quantity and in value only ranged thus, -

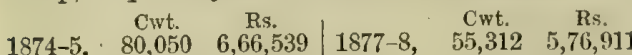
\begin{tabular}{lll|llll}
$1874-5$, & 80,050 & $6,66,539$ & $1877-8$, & 55,312 & $5,76,911$ \\
$1875-6$, & 75,878 & $6,28,604$ & $1878-9$, & 45,628 & $4,62,334$
\end{tabular} \begin{tabular}{lll|lll}
$1876-7$, & 85,207 & $7,58,856$ & $1879-80$, & 42,202 & $4,03,076$
\end{tabular}

But during the same period the annual exports from. India of coir, hemp, and jute averaged about 280,000 tons, value $£ 3,500,000$, the coir and hemp being valued about $£ 20$ a ton, and jute $£ 12$ the ton.

Sunn hemp (Crotalaria juncea), called also Brown hemp, Madras hemp, Indian hemp, Konkani hemp, Salsette hemp, Bombay hemp, Travancore flax, and by the vernacular names, Sana, Ghore-san, Sunn, Shanamoo, Kenna, Ambari, Taag, Wuckoo-nar, and Janapa-nar. It is the kind most generally cultivated all over India, on account of its fibre, and is that usually mentioned in the exports from Calcutta under the name of hemp, but also as sunn. The plant may be distinguished by its flowers being of a bright yellow colour, and of the form of the pea and of the laburnum, while the leaves are entire and lanceolate.

Ambari or Delihani hemp (Hibiscus cannabinus), called in the languages of India, Mesta-pat, Nalkee, Pulooa, Sunni, Valaiti Sumn, Garnikura, Gongkura, Pooley-nammajii, Pundey, Pundrika, and Palungoo of Madras, is very generally cultivated all over India, and exported of very good quality from the west side. 'The fibre is like that of jute. It is often confounded with that of the sunn, as it is one of the brown hemps of Bombay, though the two plants differ much from each other.

Jubbulpur hemip is established as an article of commerce in India, and highly esteemed by good judges in Britain.

Manilla hemp is from the Musa textilis, grown in the Philippines, and introduced into S. India by Major (now Sir George) Balfour. It is being imported into Great Britain in increasing quantities and value.

\begin{tabular}{l|l|l}
$1877,332,304$ cwt. $£ 488,069$ & $1879,337,687$ cwt. $£ 434,037$
\end{tabular} $\begin{array}{ll}1878,421,160, " 551,856 & 1880,407,431, \text {, } 622,776\end{array}$

A gigantic species of Cannabis hemp, growing from ten to fifteen feet in height, is in China a staple summer crop. This is chiefly used in making ropes and string of various sizes, such articles being in great demand for tracking the boats up rivers and in the canals of the country.

Jute is the fibre of Corchorus capsularis, and C. olitorius, and also known to the people as Pat, Koshta, Bhungee pat, Ghanalita pat, Putta, Singin-ganasha. It is now imported as jute, being largely used in Dundee.

Hemp seed and Oil, Ta-ma, Ho-ma-jin, Hwang-ma, CHIN. The small, shining, brittle achænia of the Cannabis sativa, are albuminous and oily, and entirely devoid of all narcotic properties. They are crushed for oil, the Ganja yemmai, TAMr, in many parts; in Russia, much used for burning in lamps.

HEMROO. HIND. A satin fabric of India, value two rupees the yard. See Kimkhab.

HENBANE SEED, Hyosciamus niger.

Bung, Buzir-ul-bung, AR. | Khorasani ajwain, Hind. Sikran, Urmanikou,. ," Adas, Adas pedas, MALAT. Jusquiame, . . . Fr. Khorasani omam, TAM. Bilsenkrout, . GER.

The seeds of the henbane plant have the odour of the plant, and an oily, bitter taste; an oil is obtained from them. See Hyosciamus.

HENDERSON, Dr., a Bengal medical officer, who travelled in disguise as a Syud from Lodhiana in 1835, and passed by way of Mundi, Sanskar, or Lahul, to Ladakh and Iskardo, descending over the dangerous pass of Alunipilah, and by Burzel or Astor to Guryo and Kashmir. He again travelled to Dir and Bajwara, but was there plundered, and he returned to Lahore, where he died of fever in February 1836. He was the first projector of the Agra Bank.

HENERY, properly Ondari, one of the Bombay islets, $1 \frac{3}{4}$ miles due E. of Kenery Island, and surrounded by reefs. It is joined on the $\mathrm{N}$. to Trombay and Salsette, as these are united to each other by bridges and embankments.

HENLE. In $18+4$ there was issued at Berlin the Systembong der Plagiostomen by Dr. Henle, which included several of the genera and species of the fishes of the seas in the $\mathrm{S}$. and $\mathrm{E}$. of $\Lambda$ sia.

HENNA, HiNd., PERs., is the leaf of the Lawsonia alba, Lam., the camphire of Scripture, the Yen-chi-kiah of China, and the Cyprus shrub of the Greeks and Romans. It is a fragrant plant when in flower. The fresh leaves, when beat up with catechu,

The fingers' ends with a bright roseate hue,

So bright that in the mirror's depths they seem

Like tips of coral branches in the stream!'

This use of the leaves is as old as the era of the 
Egyptian mummies, and is still followed by the Arabs, Persians, and people of British India, the last of whom know it as the mehndi. The leaves, beaten up into a soft mass with rice water, are applied to the nails, finger-ends, palms, and soles of the feet overnight; on being washed off the next morning, these parts are found stained a deep red colour. Men use it to stain their moustaches and beards, and for dyeing the manes and tails of their horses. In China, the leaves or flower of Lawsonia alba, of the Impatiens balsamina, and of the Terustroemia Japonica are mixed with lime or alum, and applied to stain the fingers, the mane, tail, and hoofs of horses, red. Chinese children, especially girls, often have a circular spot of rouge or henna placed between the eyes. It is also used as an ordinary dye-stuff. A decoction of the leaves is used in skin diseases, lepra, etc. The flowers when distilled are used as a perfume.-Smith.

HENSLOIVIA PANICULATA. Migu. Anambo, Burm. A reddish - coloured wood of British Burma, used occasionally for cart wheels. The average length of the trunk to the first branch is 50 feet.-Dr. Brandis, Cal. Cat. Ex., 1862.

HENZA. BURy. A large golden figure of the sacred bird is in front of the throne of the king of Burma. The word is of Sanskrit origin,-Hanza, a goose. The Henza is regarded as the king of birds. It is perhaps a mysticized swan. Amongst the Burmese, the bayet, an emblem of nobility, is a pretty necklace of several strings or chains of filigree work joined together, and sewn with little figures, in red gold, of the Henza, which hangs low down on the breast.-Yule's Embassy, p. 85.

HENZADA, Myanoung, and Tharawaddy, three districts in the Pegu division of British Burma, with a population of about 500,000 . The number of Burmese in the district in 1876 was greatly in excess of Talaings. On the conquest of the lower country by Aloungbhura (Alompra), every effort was made to destroy the Talaing nationality; and now it is said that scarcely any one of Talaing descent calls himself anything but a Burmese, so completely has the national spirit been extinguished.-Imp. Gaz.

HEPHASTUS MUICIBER, or Vulcan, the analogue of Visvakarma.

HEPTAPLEURUM RACEMOSUM. Wight. Hedera racemosa, $W . I c$.

A large tree, common on the Neilgherries and Animallays, etc., at elevations from 3000 to 7000 feet; grows also in Ceylon.-Beddome, $\mathrm{Fl}$. Sylv.

HERA, a Babylonian goddess, the prototype of the Roman Juno and of the Egyptian Hora.

HERACLEUM, a genus of plants of which several species grow in the Himalaya; one of these, the padalli or poral, is collected for the winter fodder of goats, and is supposed to increase the milk. Wight, in Icones, gives H. pedatum.

HERAT is also called Heri ; and the river on which it stands is called Hari-Rud. This river Hari is called by Ptolemy Apros, by other writers Arius; and Aria was the name given to the country between Parthia (Parthuwa) in the west, Margiana (Marghush) in the north, Bactria (Bakhtrish) and Arachosia (Harauwatish) in the east. It is the Haroya of the Vendidad, and is supposed to be the same as the Haraiva (Hariva) of the cuneiform inscriptions, though this is doubtful. The importance of its situation is very great, and it has always exercised considerable influence over the affairs of Central Asia, and has endured more than forty sieges in ancient and modern times. It is one of the most ancient and most renowned of the cities of Central Asia. It gave its name to an extensive province at the time of the expedition of Alexander, and is supposed by some to be Alexandria in Ariis. Before the invasions of Chengiz Khan, the city could boast of 12,000 retail shops, 350 schools, 144,000 occupied houses, and 6000 baths, caravansaris, and water mills. It was for some time the capital of the empire which was transmitted by Timur to his sons. Under the mild and genial rule of his son, Shah Rukh Mirza, it recovered all it had lost. The restored prosperity continued till the beginning of the 16th century. Up to that period Herat was not only the richest city in Central Asia, but the resort of the greatest divines, philosophers, poets, and historians of the age. From the house of Timur it passed in the beginning of the 16 th century to the Suffava dynasty of Persia, from whom it was taken by the Daurani in 1715 . It was retaken by Nadir Shah in 1731, and it fell into the hands of Ahmad Shah in 1749. When the Daurani empire, created by Ahmad Shah, was lost by his grandsons, and parcelled out among the Barakzai brothers, Shah Kamran managed to maintain a precarious footing at Herat. He was the son of Mahmud, and therefore nephew of Zaman Shah, Shah Shuja-ul-Mulk, and Firoz - ud - Din, and the last remaining representative of the Saddozai princes in Afghanistan. Herat was all that remained to him of the empire of his family. Kamran was cruel and dissipated, and his minister, Yar Muhammad Khan, was even worse. Dost Muhammad was ruling at Kābul, and his halfbrother, Kohun-dil Khan, ruled at Kandahar. Dost Muhammad was the son of Phound Khan, Barakzai. On the 23d November 1837, Muhammad Shah, king of Persia, laid siege to Herat, in pursuance of his ambitious policy for the reconquest of Afghanistan. It was on this occasion that Herat sustained a memorable ten months? siege, and all the efforts of the Persian king to capture it, aided by the advice and direction of Russian officers, were defeated, principally by the efforts of Iieutenant Pottinger, of the Bombay Artillery. Shah Kamran and his minister, however, continued intrigues with Persia, and the envoy, Major d'Arcy Todd, withdrew. On the occurrence of disasters in Kābul, Yar Muhammad was relieved of all apprehension of the interference of the British Government, and in 1842 strangled his sovereign, Shah Kamran, usurped the government of Herat, and professed himself a dependent of Persia. On his death in 1851, his son Syud Muhammad Khan succeeded him, only to be deposed in 1855 , and succeeded by Muhammad Yusuf, grandson of Firoz, grand-nephew of Shah Zeman. Muhammad Yusuf was afterwards deposed, and Isa Khan succeeded; but under him Herat fell to the Persians, and he was murdered within a few weeks by a party of Persian soldiers. By the treaty of Paris, concluded between Britain and Persia on the 4th March 1857, the Persians were required to evacuate Herat. Before they withdrew, they installed Sultan Ahmed Khan, better known by the name of Sultan Jan, as ruler of Herat, and the British Government did not refuse to recognise him as de facto ruler. Shortly after, 
Sultan Jan attacked and took Furrah, but the Amir of Kābul retook Furrah on the 29th June, and on 28th of July laid siege to Herat. After a siege of ten months, during which Sultan Jan died, the Amir Dost Muhammad took Herat by storm on 27th May 1863. He died eleven days afterwards, and was succeeded in the government of Kābul by his son, Sher Ali, who placed his own son, Muhammad Yakub, in charge of the captured city. Herat was thus again annexed to the Afghan dominions. Herat was visited by Mr. Forster in 1783, by Captain Christie in 1810, by Arthur Conolly in 1831, and by Eldred Pottinger in 1837. It is a city of great political importance; and in the strivings of the Persians and Afghans to obtain its possession, it has undergone great changes, but quickly recovers from the effects of war.

Herat is on the high road between India and Persia, the centre spot of an extensive and fertile valley, well watered by channels made from a perennial stream. The climate is the finest in Asia. There are two hot months in the year, but the thermometer even then rarely stands higher than 85 degrees (Fahrenheit) in the shade. The nights are always cool, often cold. The Heratis have a proverb, "If the soil of Isfahan, the cool breezes of Herat, and the waters of Khwarizm were in the same place, there would be no such thing as death.' Herat is on the same level with the rest of the table-land of Western Afghanistan, and may be regarded as forming part of it, but it is just beyond the ridge which divides the waters that run to the south from those that flow northward to the Oxus. The winter is tolerably mild; on the plain the snow melts as it falls, and does not lie long even on the summits of the mountains.

The districts of Herat boast of extensive mines of iron and lead. The scimitars made at Herat are considered the best in Central Asia. The breed of Herati horses is scarcely less renowned; they are very cheap, and are exported in large numbers. Herat, too, is famous for its carpets, worked in silk and in wool, and in both combined, they are made of any size, and command large prices. Hitherto the difficulty in the way of transport has prevented their being so well known as they deserve. Silk is spun in large quantities in the districts. The districts likewise produce largely asafoetida, saffron, pistachio nuts, gum, and manna. These and horses constitute the principal exports. Of skins, only those of the sheep and the lamb are used in Herat. Sheepskins are made up into coverings. The people are Mongol, Parsivan, Tajak, and Hazara. - Bellew; Elphin. India, 629; East Ind. Park Papers, 133 ; Treaties, etc. vii. 165 ; Müller's Lectures, 234.

HERBA BENGALO. Mention is made in several old works relating to India, of cloths having been made of a plant called Herba Bengalo, which appears to be now unknown as a material of manufacture. Linschoten, who visited Bengal in 1599, is one of the earliest travellers who notice it (vide Navigatio ac Itinerarium Johan. H. Linscotani, A.D. 1599). Mandelso speaks of it as ' a certain herb having on the top of its stalk (which is about the compass of a man's thumb) a great button like a tassel: this tassel is spun out, and there are excellent stuffs made of it. The Portuguese eall it Herba Bengalo, and make of it hangings and coverlets, in which they represent all sorts of figures' (vide Mandelso's Travels, A.D. 1639, translated by J. Davies, book ii. p. 94). A similar description is given of it by the Abbé Guyon in his History of the East Indies:-'On trouve encore à Bengale une espèce singulière des toiles qui n'est ni fil ni coton, dont on fait des tapis et des couvertes. On les nomme simplement herbes. La tige de l'herbe, dont elles sont faites, a un pouce d'epaisseur et au haut une espèce de houppe qui contient une sorte de bourrée que les femmes du Paris filent on prendroit ces etoffes heure de loiser: mais elles sont sujettes a se couper dans les plis' (vide Histoire des Indes Orientales, par M. I'Abbé Guyon, A.D. 1744, iii. p. 19). Fitch, about the year 1586, and Hamilton in 1744, both refer to it in their accounts of Orissa. The latter calls it Herba, a sort of tough grass of which they make ' ginghams, pinascos, and several other goods for exportation' (New Account of the East Indies, by Captain A. Hamilton, A.D. 1744, i. 393).

HERBEIOT, D', author of the Bibliotheque Orientale, or the Oriental Library, was born at Paris, 4th December 1625 . He was Oriental Secretary and Interpreter to the court. He began the work at first in Arabic, but afterwards continued it in French. He died at 70 years of age, before the work was printed; but it was continued by Antoine Galland, the translator of the Arabian Nights Entertainments. D'Herbelot understood critically the Latin, Greek, Hebrew, Chaldaic, Syriac, Arabic, Persian, and Turkish. It was history arranged alphabetically._-Oriental Herald. HERBERT, CAPTAIN J. D., wrote on the Mineral Productions of the Himalayas, in As. Res., 1833, viii., part 1, p. 216; Course and Levels of the Sutlej, ibid., 1825, xv. p. 339 ; Coal within the Indo-Gangetic Mountains, ibid., 1828, xiv. 397; Gypsum in the Indo-Gangetic Mountains, ibid., 1833, xviii. part 1, p. 216 ; Tour through Kumaon and Ghurwal, in Bl. As. Trans., 1844, xiii., part 2, p. 734 ; Geological Map of Himalaya Survey, ibid., 1844, xiii. part 1, p. 171. -Dr. Buist.

HERBERT, SIR THOMAS, a cadet of the Pembroke family, who travelled as secretary to the English embassy to Persia from 1627-29. In his book, entitled A Description of the Persian Monarchy now beinge, the Orientall Indyes, Isles, and other parts of the Greater Asia, and Afrik,' was published in 1634 . He contends that Prince Madoc ap Owen Gwynedd discovered America 300 years before Columbus. The third edition, 1665 , contains a beautiful etching of Persepolis by Hollar.

HERCULES is supposed by Colonel Tod to represent Baldeva, a prince of Mathura, nephew of Koonti, the mother of the Pandua, and who, as in the days of Alexander, is still worshipped at Buldeo in Vrij, his club a ploughshare, and a lion's skin his covering. Megasthenes (iii. pp. 525531) mentions the Indian tradition of Hercules as reigning in India fifteen generations after Dyonysus; that he built Palibrotha and other cities; had numerous sons, to each of whom he left an Indian kingdom; and a daughter Pandæea, to whom he likewise bequeathed a realm. Bunsen, following Lassen, says he was chiefly worshipped in the Suras-Sen country, and identifies him with Krishna; says he founded Mathura. But there were many to whom this name was applied: 
Varro enumerates forty-four, Diodorus says three, and Cicero six. Hercules Belus of Cicero is supposed to be the Osiris who invaded up to the Indus.-Tod, Rajas. i. 30 ; Buns. iii. 525, iv. 210.

HERDSMEN in Central Asia, and south to the Arabian Sea, are a large mass of the populations of their respective regions,-many of them in Arabia, Persia, Afghanistan, Baluchistan, being purely nomades, dwelling in tents, and migrating with the seasons; others of them in British India camping out only in the dry season. Numbers of Ahir or Gopa in Central India and Western Bengal cling to the nomade life of their ancestors, but Sad'h Gop, or pure Gopa, are settling down to husbandry. The Gareri herdsmen founded the Holkar dynasty. In the S. of the Peninsula are the Dhangar, the Kurumbar, also shepherds, who were once dominant, but now only pasture great flocks of sheep. Amongst the Hindus of Bengal, the Goali are numerous; after them, the Brahman and Kaist races, are the Bagdi, an aboriginal people, and a class of cultivators called Kyurto. See Ahir; Dhangar; Gadaria; Gaola; Gopa; Kurumbra.

HERI, a name of Krishna, familiarly Kaniya, was of the celebrated tribe of $\mathrm{Yadu}$, the founder of the fifty-six tribes who obtained the sovereignty of India, and descended from Yayat, the third son of Swayambhuva Manu, or the man, lord of the earth, whose daughter Ella (Terra) was espoused by Budha (Mercury), son of Chandra (the moon), whence the Yadu are styled Chandravansi, or children of the moon, the Lumar race.

The coincidence between the epithets of the Apollos of Greece and India, as applied to the sun, are striking. Heri, as Bhan-nath, the lord of beams, is Phœbus, and his heaven is Heripur (Heliopolis), or city of Heri. Helios, of Greece, was a title of Apollo, whence the Greeks had their Elysium; and the Heripur or Bhan-t'han (the abode of the sun) is the highest of the heavens of the Rajput. Hence the eagle (the emblem of Heri as the sun), was adopted by the western warrior as the symbol of victory.-Tod's Rajasthan, i. pp. 532-545.

HERI, a tribe of Mahomedan Rajputs, chiefly found in Juspur, a pargana of Moradabad.

HERI-RUD, written also Hari-Rud, a river of Afghanistan, which rises in lat. $34^{\circ} 50^{\prime} \mathrm{N}$., and long. $66^{\circ} 20^{\prime} \mathrm{E}$., at that point of the Koh-i-Baba range of mountains where it branches off into the Koh Siah and Safed Koh, at an elevation of 9500 feet. It flows west through Shahrek, Obeh, and Herat. After leaving Herat, it flows through Persian territory, dividing into two branches, the smallest of which runs towards Mashad. Its plains are harried by Hazara and Turkoman. It is said to have formerly joined the Murghab. The united stream is ultimately lost in the desert of Khorasan. At Herat it was formerly crossed by a brick bridge.-MacGregor.

HERITIERA LITTORALIS. Ait., D. C:

Balanopteris tothila, Gert. | Ka-na-zo, . . BurM. Sundri, . . . BENG. Kon-zo-za-loo, : ",

A species of the Sterculiacer. Grows in the Mauritius, the Peninsula of India, the Sunderbuns, is common in the Rangoon district, and along the sea-shores in the Mergui Archipelago and Amherst province. Its wood is used for boats, boxes, planks of houses, etc. ; is very light, scented, durable, and tough, - Roxb, i. p. 142 ; Voigt; M'Clelland; Captain Dance.

\section{HERITIERA MINOR, Lam.}

H. fomes, Willde. | Balanopteris minor, Gertn. Sundri, . . BENG. Ka-na-za, . . BurM.

A gloomy-looking tree, distinguishable from all others many miles distant. Wherever the tides occasionally rise and inundate the land, this tree is sure to be found, throughout the whole Tenasserim coast, but is never found at home, either on the high, dry lands on the one hand, or in the wet mangrove swamps on the other. It grows in the Sunderbuns, is used in Calcutta for firewood, furnishes the sundri wood so well known in Bengal for its strength and durable qualities, and gives its name, as Captain Munro thinks, to the Sunderbuns. IVhen seasoned, it floats in water, and is the toughest wood that has been tested in India. When Rangoon teak broke with a weight of $870 \mathrm{lbs}$, sundri sustained $1312 \mathrm{lbs}$.

It is used for boats, piles of bridges, boxes? and many other purposes. It is recommended for helves, but should be killed a twelvemonth before being cut down, or otherwise should be seasoned by keeping, after it has been cut down. Dr. IVallich says it stands unrivalled for elasticity, hardness, and durability. He adds that the charcoal made from it is better than any other sort for the manufacture of gunpowder. $-M^{\prime}$ Clelland, in Records, Foreign Dept. ix. p. 43 ; Di. Mason; Captain Dance; Voigt.

HERITIERA PAPILIO. Bedl. A very lofty evergreen tree, common in the dense moist forests above Courtallum (Timnevelly) at about 3000 feet elevation, also about Peermede (Travancore), 3500 feet; in flower in August and September; it yields a very valuable, tough timber.Beddome, Fl. Sylv. p. 218.

HERIYA RAYAT, or chief rayat, also called Buddhavant, the wise, in Mysore; a person of importance, who takes the lead in all affairs of the community.

HERMANN, PAUL, a medical man who furnished the materials of the Thesaurus Zeylanicus of the elder Burmann, published in Holland, and afterward of the Flora Zeylanica of Linnæus.$H$. et $T h$. p. 46.

HERMES or Mercury, the analogue of Buddha. The worship of Hermes was established in Italy, Greece, Egypt, and Syria, and his ruined temple is 6 miles from Zahle, and a mile from Fursul.

HERMIPPUS, according to Pliny, translated the Zendavesta into Greek about the same time as the Septuagint translation of the Bible. Hermippus is supposed to have been the peripatetic philosopher, the pupil of Callimachus, and one of the most learned scholars of Alexandria.

HERMIT CRAB, the well-known Pagurus crustaceans that occupy the empty turbinated shells of testaceous molluscs. The fore part of the body is armed with claws, and covered with a shield, but it ends in a long, soft tail, provided with one or two small hooks. Some of them carry large shells to considerable heights and distances from the sea. The genus Cœnobita inhabits the land; and in Kandavu, one of the Fiji group, they climb the bills and go far inland, bearing their shells with them. - Hartwig; Moseley, p. 304.

HERMODACTYL. Pei - mu, CHIN. This medicinal plant of the later Greeks and Arabs forms the sweet and bitter Surinjan of the Arabs, and both are supposed to be species of the genus 
Colchicum. The Persian name of the sweet is Surinjan shirin, and Surinjan talkh is the bitter. In India, the Surinjan talkh, or bitter, and Surinjan shirin, or mild, are both identical with the Hermodactyls of the ancient Arabian and Greek writers. The tasteless variety is about one inch long and the same in breadth, heart-shaped, rather flattened, grooved at one side, convex at the other. They are not wrinkled, are easily broken, and form a white powder. The bitter kind is smaller, and has a striped appearance. In some trials which Dr. O'Shaughnessy made with an acetous tincture of the Surinjan talkh, he was led to believe it possessed all the virtues of the dried Colchicum of Europe.-O'Sh. p. 661 ; Irvine.

HERNANDI, a martial branch of the Koresh tribe of Mecca. Many of them in Syria are employed as irregular horse.

HERNANDIA PELTATA. D. C. Palati, SingH. This is a large tree, common on the seacoast in Ceylon between Galle and Colombo; also in Australia, and on the sea-coasts in the South Pacific and Eastern Archipelago, westward to the Mascarene Islands, and northward to the Philippines and Loo-Choo. Its wood is very light, and takes fire so readily from a flint and steel, that it might be used as tinder. The juice is a powerful depilatory, removing the hair without any pain; the bark, seed, and young leaves are cathartic.Bedilome, Fl. Syl. p. 300.

HERNANDIA SONORA. Limn. Bong-ko, JAVAN. A tall, erect tree of the Moluccas and the Fiji Islands; in the last, forming one of the sacred groves, - a complete bower. The genus was named after Hernandez, a naturalist sent out to Mexico by Philip II. of Spain, and obtained its name 'sonora' from the noise made by the wind in whistling through its persistent involucels. The bark, the seed, and the young leaves are slightly cathartic. Rumphius says that the fibrous roots, chewed, and applied to wounds infected with the Macassar poison, act as an effectual cure. The juice of the leaves is employed as a depilatory. It destroys the hair wherever it is applied, and this without producing pain. The wood of this species is very light; and Aublet says it takes fire readily from a flint and steel, and may be used as tinder. - Ains.; O'Sh.; Voigt; Seeman's Fiji; Eng. Cyc.; W.Ic.; Thw. Zeyl. p. 258.

HERODOTUS, a Greek historian who travelled in Egypt and Persia, and visited Tyre, B.C. 460. He never gives us to understand that he was able to converse in any but his own language. He is called the father of history. He relates that, after Cyrus had conquered a large portion of Asia, his third successor, Darius Hystaspes, extended his conquests towards the Indian Peninsula.-Bjornstjerna, p. 93.

HERONS are classed by naturalists in the family Ardeidæ, gen. Ardea, Ardeola, Herodias, Nycticorax. Those of the E. Indies are-

Ardea Goliath, Temm, the great heron.

A. Sumatrana, Ruffles, the dusky grey heron.

A. cinerea, Linn., the blue heron.

A. purpurea, Linn., the purple heron.

Nycticorax griseus, Linn., night heron.

Ardeola leucoptera, Bodd., pond heron.

Butorides Javanica, Hor'sf., little green heron.

Herodias alba, the Ardea alba, large egret, or great white heron of Europe, Asia, N. Africa, very rare in Britain, is very common in India, though the race is considered different by some.

H. bubulcus, the Ardea russata, or buff-backed beron or egret of Europe, Asia, N. Africa, exceedingly rare in Britain, is very common in India.

H. egrettoides, Temm., the smaller egret, Patang-kabagla of India, Burma, and Malayana.

H. garzetta, the Ardea garzetta, or little egret of Europe, Asia, N. Africa, exceedingly rare in Britain, very common in India. Three specimens observed of an egret in winter dress seemed to differ only from ordinary Herodias garzetta in having black toes.

Herons are plentiful in Kashmir, and a heronry is protected in the Shalimar Gardens. About 50 miles S.E. from Madras, and 12 miles from Chingleput, is a small village called Vaden Thangul, which means literally Hunter's Rest, from Vaden, hunter, and Thangul, rest. To the south of the village lies one of the small tanks called Thangul by the Tamil ryots, implying a water-rest or temporary reservoir, with an area of about $4 \frac{1}{2}$ acres ( 30 cawnies). From the N.E. to the centre of the bed of the tank there are some 500 or 600 trees of the Barringtonia racemosa, from about 10 to 15 feet in height, with circular, regular, moderate-sized crowns, and when the tank fills during the monsoons, the tops only of the trees are visible above the level of the water. This place forms the breeding resort of an immense number of water-fowl; herons, storks, cranes, ibises, cormorants, darters, paddy birds, etc., make it their rendezvous on these occasions. From about the middle of October to the middle of November, small flocks of 20 or 30 of some of these birds are to be seen, coming from the north to settle here during the breeding season. By the beginning of December they have all settled down; each tribe knows its appointed time, and arrives year after year with the utmost regularity, within a fortnight later or earlier, depending partly on the seasons. They immediately commence building their nests or repairing the old ones. When they have fully settled down, the scene becomes one of great interest. During the day the majority are out feeding, and towards evening the various birds begin to arrive in parties of 10,15 , or more; and in a short time every part of the crown is hidden by its noisy occupants, who fight and struggle with each other for perches. Each tree appears like a moving mass of black, white, and grey; the snowy white plumage of the egrets and curlews contrasting with, and relieved by, the glossy black of the water-crows and darters, and by the grey and black plumage of the storks. The nests lie side by side, touching each other, those of the different species arranged in groups of 5 or 6 , or even as many as 10 or 20 , on each tree. The nests are shallow, and vary in inside diameter from 6 to 8 inches, according to the size of the bird. The curlews do not build separate nests, but raise a large mound of twigs and sticks, shelved into terraces as it were, and each terrace forms a separate nest; thus eight or ten run into each other. The storks sometimes adopt a similar plan. The whole of the nests are built of sticks and twigs, interwoven to the height of 8 or 10 inches, with an outside diameter of 18 to 24 inches; the inside is slightly hollowed out, in some more and in others less, and lined with grass; reeds and quantities of leaves are laid on the nests. In Jamuary the callow young are to be seen in the nests. During this time the parent birds are constantly on the wing in search for food, now returning to their young loaded with the spoil, 


\section{HERONS.}

and again going off in search of a further supply. About the end of January or early in February, the young are able to leave their nests and scramble into those of others. They begin to perch about the trees; and by the end of February or the beginning of March those that were hatched first are able to take wing and accompany their parents on expeditions; and a week or two later, in consequence of the drying up of the tanks in the vicinity, they begin to emigrate towards the north with their friends. Thus, in succession, the different birds leave the place, so that it is completely deserted by the middle of April, by which time the tank also becomes dry, and the village cattle graze in its bed, or shelter themselves under the trees from the scorching heat of the midday sun, while the cow-boys find amusement in pulling down the deserted nests. The villagers hold an agreement from the Nawab's ancient government, which continues in force by a renewal from the British Government, that no one is to shoot over the tank, and this is strictly enforced. When the tank becomes dry, the silt of its bed is taken up to the depth of a foot, and spread over the ricefield.

Dr. Shortt visited the trees on the 8th March 1864 , on a raft pushed along by two fishermen swimming one on either side, their heads only visible above. As he got near the birds rose en masse overhead, and, uttering piercing cries, some, with threatening gestures, rested a moment on the adjoining trees, and then took to their wings again. Although so crowded, they performed their evolutions with the greatest nicety and dexterity, never interfering with each other's movements. Some ascended to a great height, and were hardly perceptible in the air, while others gyrated immediately above their heads; many crowded on adjoining trees, and witnessed the intrusion with dismay.

The small grey and black stork, Leptoptilos Javanica, Hor:sf., - Tamil name, Nutha cootee narai; literally, shell-fish (Ampullaria) picking crane,-were the most numerous. Their nests were 2 feet in diameter, and contained three eggs or young. The eggs were of a dirty white colour, of the same shape, but not quite so large, as those of the turkey. The flesh is eaten by Mahomedans and Pariahs. The bird keeps entirely to marshy fields, edges of tanks, etc. Some half-dozen or more may often be seen in the morning sunning themselves with outstretched wings in the dry fields. They nest early, and the young are firm on the wing in the month of February.

The ibis or curlew, Ibis falcinellus,-Tamil, Arroova nooken; literally, sickle-nosed, which name they take from their long curved beaks. The nests of this bird contain from three to five eggs, resembling in size and shape a mediumsized hen's egg, but are of a dirty white colour. The birds are white, with black head, feet, and neck, and have a long curved black bill. The young are fully fledged in March, and take to the wing in April.

The grey heron, Ardea cinerea, Linn.,-Tamil, Narai, sometimes Pamboo narai, or snake crane,has a similar nest, built of twigs, containing sometimes two, sometimes three eggs. They are fledged from January to April, according to the time of depositing their eggs, which some do earlier than others. The eggs are of a light green colour; they are not so large in circumference as a largesized hen's egg, but are longer, with the small end sharp.

The purple heron, Ardea purpurea,-Tamil, Cumbly narai, or blanket crane. Nest the same; deposits two to three eggs, of same size and colour as last; seems to rear only two young. The young are fully fledged in A pril.

Nycticorax griseus, Linn.,-Tamil, Wukka. Nests are built after the same fashion, but smaller in size, and contain five eggs the size of a bantan's, and of the same shape. The young are fledged in April.

The cormorant, Graculus Javanicus, Horsf.,Tamil, Neer cakai, or water-crow. Nest built of sticks; rears three or four young, which are fledged and on the wing in January; eggs like those of a small-sized bantam's, rather sharppointed at small end, with a slight greenish tinge.

The large cormorant, Graculus Sinensis,-Tamil, Peroon neer cakai, or large water-crow,-builds a very rude nest, chiefly formed of sticks; lays four eggs the size of a medium-sized hen's egg, and have a slight greenish tinge; the young are fledged sometimes in January, sometimes in March. These birds, as well as G. pygmæus, are to be seen fishing in the tank itself; and the rapidity with which they find their prey, by diving, is wonderful.

The darter, Plotus melanogaster,-Tamil, Pamboo thalai neer cakai, or snake-headed watercrow. Nest same as last; three, sometimes four, eggs of same size and colour; young fledged and on the wing, some in January, others not till April.

The villagers of Vaden Thangul told Dr. Shortt that the pelican sometimes breeds here, as also the black curlew. Occasionally different kinds of teal, widgeons, etc., are said to nest in the rushes that bound the inner surface of the tank bund. The egrets, or Herodias garzetta, bubulcus, and intermedia, were congregated in very large numbers, and roosted on the trees at night; but they do not nest, which seems singular, for of all the birds that assemble here, these occur in the greatest number. Ardea alba, or Herodias alba, and $\mathrm{H}$. intermedia are also found here; and the natives say that they breed.-Dr. Shortt, in Limn. Soc. Jo.

HERPESTES. Illiger. Mungoose, Mangouste. Ichneumon, Lacepede. | Mangusta, Oliver.

The Herpestes is a genus of digitigrade carnivorous mammalia; and the Egyptian species, the ichneumon, has been noticed by writers from the earliest times, its combats with snakes and its alleged attacks on crocodiles having been mentioned by Aristotle, Diodorus Siculus, Pliny, Strabo, Ællian, and others. The mungoose of India and ichneumon of Egypt are frequently domesticated, and their search for snakes for food is continuous. Jerdon gives 12 species belonging to British India and the E. Archipelago, viz. H. brachyurus, exilis, fuscus, griseus, Javanicus, Jerdoni, Malaccensis, monticolus, Nipalensis, Smithii, and vitticollis, and retains as synonyms of other authors, Auro-punctatus, Elliotti, nyula, pallidus, pallipes, and rubiginosus.

Herpestes fuscus, Waterhouse, the Neilgherry brown mungoose, occurs in the Neilgherries.

Herpestes griseus, Gcoff., Madras mungoose. H. pallidus, Schinz. |Mangusta mungos, Elliot. Mungli, . . . CaN. Newul, Newara Koral, : : GoND nyul, . . HIND. Mangus, : HiNd, MAAR. / Yentawa, : : TrL。 
Spread through most parts of S. India, in the open country, thickets, hedgerows. It eats eggs, and kills snakes, and their poison is believed not to affect the mungoose. It is very destructive to domestic fowls, pigeons. The plants Ophiorhizon mungos and 0 . serpentinum are said to be eaten by it when bitten by a snake.

Herpestes Malaccensis, F.Cuv., Bengal mungoose. H. nyula, Hodgs.

Nwal, Newara, Nyul, Hind. | Baji biji, . . Hind. Inhabits Bengal, N. India, Assam, Burma, and Malayana; lives in burrows made by themselves.

Herpestes monticolus, W. Elliot.

Long-tailed mungoose, ENG. | Konda yentawa, . TEL. Its tail is long, and tip dark coloured; occurs in the E. Ghats.

Herpestes Nipalensis, Gray.

H. auro-punctatus, Hodgs. | H. pallipes, Blyth.

The gold-spotted mungoose is found in the Panjab, all over the Lower Himalaya from Sikkim to Kashmir and Afghanistan; also southwards in Bengal, Assam, Burma, and Malay Peninsula.

Herpestes Smithii, Gray, ruddy mungoose.

H. Elliotti, Blyth.

I H. rubiginosus, Kelaart.

Oceurs near Madras, at the foot of the E. Ghats and Neilgherries, also in Ceylon.

Herpestes vitticollis, Bennet, the stripe-necked mungoose of the W. Ghats, from near Dharwar to Cape Comorin.

HERPESTRIS MONNIERA. $\mathrm{H} . \mathrm{Br}$ :

H. Brownei, Nutt.

H. procumbens, Spreng.

H. cuneifolia, $\boldsymbol{P}$ ursh.

Bramia Indica, Lam.

Calytriplex obovata, Roiz and Pav.

Shwet chamini, Bevg Beami,. : MALEAL. Sambrani chettu, TEL. Jelabrimmi, . . SANSK.

This creeping plant grows in many parts of India, near streams and tanks, in moist places; and the jointed root, stalks, leaves, and blue-bell flowers are all used in the medicines of the native physicians._Roxb.; Ainslie; Voigt; Useful Plants. HERRINGS.

Haringen, Harengs,. FR. Seldi, . . Rus. Haringe, Heringe, GER. Arenques, . . SP. Aringhe, . . . . Iт. Sill, . . . . . Sw,

A well-known fish, 8 to 12 inches in length and about $5 \frac{1}{2}$ ounces. It dies almost the instant it is taken out of the water. Herrings are met with in three different forms. Fresh herrings are the condition in which they are taken from the sea; white or pickled herrings are merely salted, and put into barrels; and red herrings are gutted and salted, and afterwards hung up and fired with the smoke of green wood. On the Tenasserim coast are flat-bellied herrings, thryssa anchovies, Tenasserim sardines, bristle-finned sprats, shads, chatæsi, fresh-water herrings, flying fish, half-billed gar-fish, pikes, plagusia, soles and brachirus-turbots.-Mas.

HESSING, ColONEL. His tomb is a model of the taj. He was a Dutchman in Sindia's service, who rose from a common soldier to be the governor of Agra.-Tr. of Hind. i. p. 436.

HESTIA JASONIA, the sylph, floater, spectre, or silver-paper butterfly, is found only in the deep shades of the damp forests of Ceylon, in the vicinity of pools of water and cascades. Temant, i. p. 263.

HESUDRUS, the ancient name of the Sutlej river, the Hesydrus of Alexander, and the Satadru of the Vendidad. In the oldest hymns of the Veda, about 1500 B.c., we find a war-song referring to a battle fought on the banks of this river. -Bunsen.

HETEROPA ASAROIDES. Birthwort. The Si-sin plant of China; the dried root is used medicinally.

HETEROPANAX FRAGRANS. Scen. A tree of Lakhimpur in Assam. The cocoons and silk of the Eria silk-worm feed on its leaves.

HETEROPHRAGMA ROXBURGHII. D. $C$. A large timber tree of Chanda, the Godavery forests, and the Malabar coast. S. adenophylla, Seem., and S. sulphurea, Kurz, occur in Burma.

HETEROPODA, a class of nucleobranch oceauic molluses, of anomalous forms, with the foot variously modified for swimming. Amongat these, Pterosoma plana, Less., is a transparent, delicatelytinted, winged animal, thick and gelatinous, and almost invisible in the water; it is found in the seas of the Eastern Archipelago. The Firola, of the same class, is a transparent creature, with a long proboscis, and swims by means of a fin below. The Sagitta, or arrow-fish, one of the same class, darts through the water by sudden instantaneous jerks; it resembles a minute arrow. Its body is so transparent that its whole organization may easily be observed. Atlanta, a pretty little curly shelled nucleobranch of this class, Heteropoda, has both its shell and body transparent. All these range through the Mediterranean, Atlantic, and Indian Oceans.-Collinguiood.

HET-HER, a name of Aphrodite, called also Hather, Athyr, and Hathor, an Egyptian goddess, fabled to be the daughter of Ra or the sun.

HETKARI. MAHR. Signifying down; as applied to country, down the coast to the south, a native of the country southwards of the Savitri river; a native of the Southern Konkan, serving in the Mahratta infantry.-Wils.

HEUMA or Shendu tribe inhabiting the hills north of Arakan. They occupy the Yeoma-toung hills, on the watershed between the Meeyk-young and the drainage of the Manipur rivers. The Heuma are placed by Captain Tickell in the higher hills to the $\mathrm{N}$. and $\mathrm{N}$. $\mathrm{E}$. of the Kun tribes, between lat. $21^{\circ}$ and $22^{\circ} \mathrm{N}$., and long. $93^{\circ}$ and $94^{\circ}$ E. Their chiefs are called Aben, and their villages have about 50 to 400 houses. They use the trap-bow for shooting the elephant, but firearms are superseding the ruder weapons. They. regard the sun and moon as deities.

HEVEA BRAZILIENSIS yields the caoutchouc of commerce. H. Guianensis, the eaoutchouc plant, its trunk 17 to 20 yards high, scaly like a pine-apple; very straight, branched at the summit. Incisions in the bark cause the discharge of a juice which concretes into the well-known and very valuable caoutchouc of commerce. This is a product, however, of many other trees in this and allied families, - for example, of Jatropha elastica, Ficus Indica, Artocarpus integrifolia, Urceola elastica, etc. The juice when first obtained is white and milky, sp. gr. 1.011; spread in thin layers, it quickly dries into a colourless and often transparent solid substance.-O'Sh. 560.

HEWANT. HIND. The autumn harvest of 
Northern India, intermediate between rabi and kharif, including bajra and juar. Hemanta in Bengal is a rice crop growing in the months Agrahayana and Pausha (November-December), ripening in December.

HEY NE, BENJAMIN, M.D., a Madras medical officer, author of Mode of Manufacturing Uatechu, Bl. As. Trans. vii. p. 108; Travels in India, ibid. ; On Copper at Nellore, ibid, ; Tracts, Historical and Statistical, on India, with an Account of Sumatra, London 1814.

HEYNEA AFFINIS. Juss. H. trijuga, Roxb. This is a very ornamental middling-sized tree of Nepal, common in many localities on the western mountains of the Madras Presidency, from 2000 feet upwards; at Conoor, 6000 feet, abundant; Bolampatty valley, 3000 feet, very abundant. $H$. quinquijuga, $R_{\text {. }}$, is a native of the Moluccas, with the perfect habit of a Melia.-Roxb.; Bedd.

H'HAVIRA-PATI, i.e. resolute prince, also styled Shora-pati, lord of the oxen, a ruler who opposed Semiramis and drove her back across the Indus. The whole country on the right bank of the Upper Indus, the site of the present Peshawur, opposite Attok (Taxila) and still higher up, was tributary to the Assyrians, as it afterwards was to the Medes and Persians. Pliny tells us that Semiramis capitulated here, on the Kophen (the Kabul river, the Kubha of the Rig Veda); and on the black obelisk from Nineveh in the British Museum, which is at least of the 9 th century B.C., the Bactrian camel is found side by side with the Indian rhinoceros and Indian elephant. According to Diodorus (ii. 16-19), Semiramis fitted out an armament in Bactria, and between B.c. 1235 and 1225 she crossed the Indus with a vast force. At first she drove back the opposing maharaja from the strong position that he had taken up with a vast force, especially of archers; but, rallying his retreating forces, he soon drove back the Assyrians in total disorder to the river, which they had great difficulty of crossing, and only after immense loss. Semiramis concluded an armistice, made an exchange of prisoners, and retreated into Bactria with a third of the army which she had brought against India. At that time there must have been a supreme ruler in India, a sami raja, with a capital in the district to the south of the Saraswati, in the Jumna and Ganges Doab.-Bunsen, iii. 549.

HIA, the first Chinese dynasty, descendants of Yu, from B.c. 1991 to 1559 , ruled 432 years. Its first emperor was $\mathrm{Yu}$, beginning B.C. 1991.

HIATILLA, or the White Huns, a Tartar tribe who issued from the plains near the north wall of China, and made themselves masters of the country of Transoxiana. Some years afterwards, Turkish tribes expelled the Hiatilla from the lands that they had taken from the Sacæ or Seythians. There is every ground to conclude that it was an army of the Hiatilla that invaded Persia in the reign of Bahram-Gor, and that it was to one of their kings that Firoz fled.-Malcolm's Persia.

HIBAVINIA OIL. CANARESE. Under this name there was exhibited at the Madras Exhibition of $1857 \mathrm{a}$ solid oil from the Sampajey district, of a clove-brown colour. A small phial priced at $4 \frac{1}{2}$ rupees.

HIBISCUS, a genus of plants belonging to the Malvacer or mallow tribe; above 30 species of the genus are known in the E. Indies. Several furnish useful commercial products, and most of the
Indian species might be employed for the same purposes as hemp, as the bark is tough, and may almost always be stripped off in long slips.

Hibiscus collinus, Roxb. (Eriocarpus of $D . C$.), a native of the mountainous parts of the Northern Circars and of Peninsular India, where it is called Kanda-gang, and where the natives use the bark as a substitute for hemp. Dr. Roxburgh states that there are three varieties of this plant, the double red, double yellow, and double flesh red.

Hibiscus ficifolius, Roxb. In the Moluccas, an annual, growing straight, very tall, often 12 to 14 feet high, with few branches. The fibres described as uncommonly beautiful, and rather stronger than the sunn fibre.

$$
\begin{aligned}
& \text { Hibiscus furcatus, Roxb., W. and } A \text {. } \\
& \text { H. bifurcatus, Roxb. | H. aculeatus, } R \circ x b \text {. }
\end{aligned}
$$

Konda gongura, TEL.

A very prickly plant, growing in India to a height of from 6 to 8 feet. It yields abundance of strong, white, flaxy fibres, but from the prickliness of the plant it is very troublesome to handle. The stems are cut when in flower, and steeped immediately.-Poxb.; W. and $A$.

Hibiscus punctatus, Dalz., Gibson, an annual fibrous plant of Sind and Multan.-Von Mueller.

Hibiscus vesicarius, CAv., a plant of the Peninsula. Good samples of its fibre were exhibited as wild Ambari at the Madras Exhibition of 1855 .

HIBISCUS CANNABINUS, L., Dekhani hemp. Kudrum of . BeHAR. Ambari, . . DUкн. Mesta pat, Nalki, BeNG. Sankokla patsan, PANJ. $\begin{array}{lll}\text { Punday, Pundrica, CAN, } & \text { Vatsan, Sunni of } \\ \text { Hiang-ma, . . CHIN. } & \text { Palungo, . . TAM. }\end{array}$ \begin{tabular}{l|l|l} 
Hiang-ma, & CHIN. & $\begin{array}{l}\text { Palungo, } \\
\text { Pulacha, }\end{array}$
\end{tabular} Pula namaji, . . Coimв. Ghongu kuru, . T' TEL,

Hibiscus cannabinus is an erect growing plant, to about 4 to 6 feet. It is slightly prickly over the stem. There is a dark, purplish - coloured species. Both are grown all over India for the acidulous leaves, and also for the fibres of its bark, called one of the hemps of India, which are used as cordage; the cultivators sow a small quantity along the edges of the usual crops for their own use. In the beginning of the rains, and when it commences to flower, it is cut and treated exactly as the sunn hemp from Crotalaria juncea. The proportion of fibre is about half the weight of the plant. It is used for making rope, sackcloth, twine, paper, etc. The price of the prepared fibre is from 3 to 4 rupees per maund, according to its strength, length, and cleanliness. The fibre, like that of jute, is sometimes called Pāt; also, in Bombay, Dekhani hemp, to distinguish it from Taag or Konkani hemp; also Indian hemp. Also, it is one of the brown hemps of Bombay, and is often confounded with the fibre of sunn, though the two plants greatly differ,-the sunn, Crotalaria juncea, being known in Bombay as Taag. The length of the fibres of carefully cultivated Ambari is from 5 to 6 feet; they are of a paler brown than ordinary brown hemp of the Crotalaria juncea, harsher in feel, and stick more together; but they are divisible into fine fibrils, possessed of considerable strength, well calculated for rope making, as also for coarse fabrics. Though esteemed by some of the natives of Western India, the hemp of the $H$. cannabinus is not, either in strength or durability, so good as the true hemp of Europe, or as the sunn or brown 
hemp of the Crotalaria juncea. The strength of this tibre was tested by several scientific men, and breaking weight found to be-

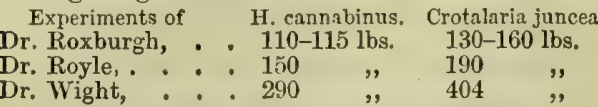

The exports of this fibre are not distinguished from other hemps. An excellent substitute for tow might be profitably supplied from it. The rope made of the fibre is used in the Karnatic as a substitute for the jute of Bengal, the produce of Corchorus capsularis, a plant comparatively unknown in the Peninsula. Dr. Riddell strongly recommended this fibre as a paper material.M. Ex. Jur. Rep.; Royle; Roxb.; Voigt; Steurart. HIBISCUS MUTABILIS. $L$.

Thalpadmo, . Beng. Gul-i-rjaib, . HIND, Fu-yung, Mu-fu-yung, $\mathrm{CH}_{\mathrm{H}}$.

The changeable rose is a large shrub, native of China, remarkable for the changes which occur in the colour of its flowers, bearing white flowers in the morning, but changing in the course of the day, and in the evening to red; easily propagated by cuttings. The flowers and leaves are used in China medicinaliy, and its fibre is there made into cloth.-Drs. Roxb., Riddell, Mason, Stewart.

HIBISCUS ROSA-SINENSIS. $L$, Shoe-flower. Uru, Joba, Juva, Beng. Jaba, . . . SANsk. Chu-kin, Fuh-sang, CHIN. Sapata cherri,. . TAM. Fu-sang, Liu-hwa, ," Dasana japa pushJasun, . . HIND. pamu,. . . TEL. Shem pariti, . MaleaL. Jova pushpamu, . , Kambang saptu,

This plant is common in India; the leaves are used as emollients, anodyne, and gentle aperients; the flowers are deep scarlet, and yield a very mucilaginous juice, which turns rapidly to a dark purple. Applied to soft, unsized white paper, this colour is nearly as sensitive a test for acid as the celebrated litmus. Shoe flowers are sometimes employed for dyeing lilac colour, but it does not appear to be a permanent dye ; they are also occasionally rubbed on leather for the purpose of blackening and polishing. The natives make pickles of the flowers, and they are used for giving a red tinge to spirituous liquors. The petals furnish a black liquid to dye the eyebrows. - Roxb. iii. p. 194 .

HIBISCUS SABDARIFFA. $L$. Roselle.

Mesta, BENG. Patwa, PANJ.

Thrm-bau-khyen- $\quad$ Pulychay kire, TAr.

boung, . BurM. Shimay kashli kire,

Oseille, - MAunitius, Yerra gogu, . T"

There are five varieties, cultivated in most gardens for the calyces, which, as they ripen, become fleshy, are of a pleasantly acid taste, and are much employed for making palatable tarts, as well as an excellent jelly. The stem, if cut when in flower, and the bark stripped off and steeped immediately, displays a mass of fibres of a fine silky nature. The leaves are used as greens, alone or mixed with others; often cultivated in flower-beds for its very pretty flowers. In the French West India Islands, a kind of cider or wine is prepared from it, termed Vin de ozeille.Ains.; Roxb.; Von Mueller.

HIBISCUS STRICTUS. Roxb. A native of the Rajmahal Hills, with a straight stem of from 6 to 14 feet in height, and a very smooth bark. It is in blossom about the termination of the rains, and the seed ripens in December and
January, soon after which the plants perish. The bark abounds in flaxen fibres, beautiful, long, glossy, white, fine, and strong. Sow in the beginning of the rains in beds, and when about six inches high transplant out in rows about nine inches asunder, and about as much from each other in the rows. In 1801, 40 square yards planted in this manner yielded 33 pounds weight of very clean fibres. Dr. Roxburgh's original specimens are 9 and 10 feet in length, a fibrous mass apparently easily stripped off, and composed of fine and easily divisible fibres.-Roxb.; Royle.

HIBISCUS SURATTENSIS. Linn., Roxb.

Kashlikire, . . TAM. | Mulu gogu, . . TEL.

A herbaceous plant, with speckled prickly stems, and yellow flowers; the leaves are used as greens.-Roxb. ; Jaffrey.

HIBISCUS SYRIACUS. Linn.

Muh-kin, . . CHIN. / Oodha godhul, Hiso.

There are four varieties of this plant cultivated for ornament in India, two purple, a single and a double; and two white, a single and a double. The flowers are used to blacken the eyebrows and shoe leather. It is a common hedge plant of $\mathrm{Hu}-$ peh in China.-Roxb. iii. p. 195.

HICK. SingH. A Ceylon wood, very hard, fine, close, very uniformly grained; heavy, in colour resembling pencil cedar.

\section{HIDES.}

Hud,

Huiden,

Peaux, .

Haute,

Chamra, Cuoja, Pelle, : : IT. Toll, Tolu, TAM., TEL. Pellis, : LAT. Deri,. ' TURK

Hides and skins, raw, dressed, and tanned form a large item of the exports from India, and since the year 1851 the quantities and values exported have largely increased, while amongst the millions of India they are largely used. In every part of $\mathrm{S}$. India extensive tanneries have been established, chiefly by the Labbai Mahomedans. The value of the exports from India have been as under, for hides and skins, raw and dressed :-
1851-52, . £303,089
$1860-61$, . $£ 656,629$
$1852-53, \quad: 337,849$
$1853-54, \quad \cdot 402,365$
$1854-55$, - 402,386
$1855-56$, : 431,729
$1856-57, \quad 572,530$
$1857-58$, - 639,702
$1858-59$, : 544,680
$1874-75$, : $2,677,765$
$1875-76, \quad \cdot 2,943,573$
1876-77, - 2,991,022
$1877-78$, : $3,756,887$
$1878-79,: 3,186,845$
$1879-80, \quad$ * $3,733,005$
$1880-81,: 3,733,565$
$1859-60, \cdot 444,537 \quad 1881-82$, . $3,948,792$

About the year 1850 , nearly 40,000 tons of leather, hides, and skins were annually imported into Britain; the total imports into Great Britain of hides and skins, in 1880 , was 83,397 tons, value $£ 6,910,817$.

All untanned leather is classed under the denominations of hides, kips, and skins. From these there are various kinds of leather tanned. Butts and backs are selected from the stoutest and heaviest ox hides. The butt is formed by cutting off the skin of the head for glue, also the cheeks, the shoulder, and a strip of the belly on each side. In the back, the cheeks and belly are cut off, but the shoulder is retained. The butt or back of the ox hide forms the stoutest and heaviest leather, such as is used for the soles of boots and shoes, for most parts of harness and saddlery, for leather trunks and buckets, hose 
for fire - engines, pump - valves, soldiers' belts, and gloves for cavalry. Hides consist of cow hides, or the lighter ox hides and buffalo hides; they are the same as butts with the bellies on. Hides are sometimes tanned whole, and are struck for sole leather, in which case they are called crop hides. Skins are used for all the lighter kinds of leather.

Bull hide is thicker, stronger, and coarser in its grain than cow hide. The hide of the bullock is intermediate between the two.

Calf-skin is thinner than cow's. It is tanned for the bookbinder, and tanned and curried for the upper part of shoes and boots.

Sheep-skins are tanned and employed for bookbinding, leathering for common bellows, whiplashes, bags, aprons, etc.; also for the cheaper kinds of wash-leather for breeches, gloves, and under-waistcoats ; and are also coloured and dyed leathers and mock morocco, used for women's shoes, for covering writing-tables, stools, chairs, and sofas, lining carriages, etc.

Lamb-skins are dressed white or coloured, for gloves; are very extensively used with the hair on in the N.W. Himalaya, Afghanistan, Hazara, Kafiristan, Tartary, Tibet, China, and Persia, as articles of dress for the head, and for mantles.

Goat-skins form the best dyed morocco of all colours. Kid-skins supply the finest white and coloured leather for gloves and ladies' shoes.

Deer-skins are all shamoyed, or dressed in oil, chiefly for riding breeches. Shamoyed leather of sheep, goat, and deer-skins was formerly a lucrative branch of the leather trade, for breeches, white or dyed.

Horse hide is tanned and curried for harness work, for collars, etc. Enamelled horse hide, split or shaved thin, is used for ladies' shoes, in imitation of seal, but does not produce so good a leather as seal.

Dog-skin is thin, but tough, and makes good leather. Most of the dog-skin gloves are really made of lamb-skin.

Seal-skin makes a valuable leather, but a large proportion of seal-skins is used as fur.

Hog-skin affords a thin, porous leather, which is used for covering the seats of saddles.

Iguana skins can be tanned and dyed black, or left of their natural colour. They are thin, even, soft, tough, elastic, and granular or shagreen-like in external appearance. It bids fair to be a durable article for light slippers, and a good covering for the commoner kinds of instrument boxes, such as are still done over with shagreen. Python skin, when tanned, makes excellent boots, much prized for their strength, pliability, and great beauty, as they are handsomely marked. The skins of young alligators are tanned, converted into leather, and the leather manufactured into boots.

Wash-leather skins are prepared with oil, in initation of chamois, for household purposes, such as cleaning plate, brasses, and harness.

Leather is made from the skin of salmon and other fish.

HIDIMBA, a wife of Bhima. Her brother was a cannibal, and was killed by Bhima.

HIERONIMO DI SANTO STEFANO, a Genoese; visited India about $1494-99$ as a merchant adventurer. At Cairo he laid in a stock of coral beads and other wares, and passed down the
Nile to Cane (Keneh), from which he travelled by land through the Egyptian desert for 7 days to Cosir (Cosseir) on the Red Sea, where he embarked on board a ship, which in 25 days carried him to Mazua (Massouah) ' off the country of Prester John;' and in 25 days more, during which he saw plenty of boats fishing for pearls, to Aden (Aden); and in 35 days more to Calicut. 'We found that pepper and ginger grew here,

and the nut of India ' (cocoanuts). From Calicut he sailed in another ship, and in 26 days reached Ceylon, 'in which grow cinnamon trees, . . . many precious stones, such as garnets, jacinths, cats'eyes, and other gems, .... and trees of the sort which bears the nut of India.' Departing thence, after 12 days he arrived at a port on the coast of Coromandel, 'where the red sandal-wood grows ;' and, after a long stay, departing thence in another ship, after 27 days reached Pegu in Lower India. 'This country (Pegu) is distant 15 days' journey by land from another, called Ava, in which grow rubies and many other precious stones.' From Pegu, where he suffered many and great troubles, he set sail to go to Malacca, and, after being at sea 25 days, one morning found himself in a port of Sumatra, 'where grows pepper in considerable quantities, silk, long pepper, benzoin, white sandalwood, and many other articles.' After further and greater troubles suffered here, he took ship to Cambay, where, after 6 months' detention among the Maldives, and subsequent shipwreck, he at length arrived, but stripped of all his goods. He notices that Cambay produced lac and indigo. In his destitution he was assisted by a Moorish merchant of Alexandria and Damascus, and after a time proceeded in ship of a sharif of Damascus as supercargo to Ormuz, in sailing to which place from Cambay he was 60 days at sea. From Ormuz, "in company with some Armenian and Azami (Irak-Ajemi) merchants,' he travelled by land to Shiraz, Isfahan, Kazan, Sultanieh, and to Tauris; whence he went on with a caravan, which was plundered by the way, to Aleppo, and finally to Tripoli.-India in the 15th Century; Birdwood's India Office Records.

HIE-SHAN, a group of three islands and eight rocks on the east coast of China, which extend 4 miles long. The southernmost is the largest, and the inhabitants are fishermen.

HIGH PLACES. Sacred edifices were often erected by the Hebrews, Greeks, and Romans upon elevated sites. The custom is of very high antiquity. Hector, according to Homer, sacrificed upon the top of Ida. Abraham was commanded to offer up Isaac on Mount Moriah; and Balak is represented as selecting three elevated stations, where he sacrificed with Balaam.-

First station.-Numbers xxii. 41: 'And brought him up into the high places of Baal.' 'And he led him to the high places of his god' (Chaldee and Samaritan). "And he made him ascend Bemoth Baal' (Syriac). 'He made him ascend to the pillar or mound of Baal' (Greek). 'And he led him up to some temples of his god' (Arabic).

Second station,-Numbers xxiii. 14: 'And he brought him into the field of Zophim, to the top of Pisgah.' 'To the field of observation, to the top of the hill' (Chaldee). 'To the field of the watchers, to the top of the hill' (Syriac). 'To the field of the watchers, to the peak of observation' (Samaritan). 'To the field of observation, 
on the summit of a levelled place' (Greek). 'T'o an high place, on the top of a citadel' (Arabic).

Third station.-Numbers xxiii. 28: 'And Balak brought Balaam unto the top of Peor.'

Numerous Hindu temples are erected on the summits and slopes of mountains, notably at Triputty and Srirangam, in the Madras Presidency.Archrogia; Milner's Seven Churches.

HI-HYA, a tribe of the Lumar race, brave and valorous; their remnants exist in the line of the Nerbadda at the very top of the valley of Sohagpur in Baghelcund. See Sehestra; Arjuna; Ha-Haya.

HIJILI, a small marshy district on the western side of the mouth of the Hoogly river. It is the sea-coast division of the Midnapur district of Bengal; a considerable quantity of salt is now produced by private persons under Government supervision.-Imp. Gaz.

HIJRAH. ARAB. A flight, but applied as relating to the flights of the disciples of Mahomed, and of Mahomed's own flight, to escape persecution. The first flight oonsisted of 15 disciples of Mahomed, who, at his recommendation, to avoid persecution, took refuge in Abyssinia. The Koresh wished them to be delivered up, but the Nagashy of Abyssinia refused. The second flight is that most generally known, and has given rise to the Mahomedan era of the Hijrah. It was the flight of Mahomed to Medina, which took place on the night of Thursday the 15th July, A.D. 622. In the khalifat of Omar, this was constituted the commencement of the Mahomedan era.

The Mahomedan Hijrah year consists of twelve lunar months, each of 29 days 12 hours and 44 minutes; and the year, 354 days 8 hours and 48 minutes.

The months of the Mahomedan year, -

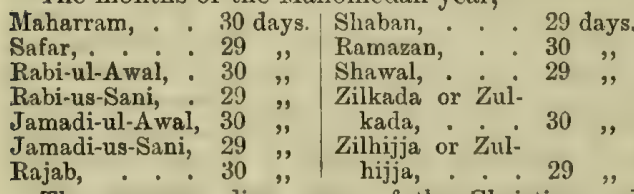
The corresponding" years of the Christian and Hijrah cras may easily be calculated by the following formula,-it being remembered that the Christian are solar and those of the Hijrah lunar years, and that 521 solar are equal to 537 lumar years:

Ex.-That is the year of Christ 1734, according to the Hijrah?

From 1734 A.D. subtract 621, the difference of the two eras; result, 1113 of the Hijrah in solar years.

Then, 521 : 537 : : 1113: 1147 Hijrah.-Playfair's Yemen.

HII.LAH; a town $5 \pm$ miles from Baghdad, on the site of the ancient Babylon; about two-thirds of it is on the right bank of the Euphrates and the remainder on the left bank, the two parts being connected by a bridge of 28 boats, and 450 feet in length. It is inhabited by Arabs, Persians, Turks, and Jews. It has numerous gardens. Basket boats ply at the ferry.

Hillah lies in lat. $32^{\circ} 31^{\prime} 18^{\prime \prime} \mathrm{N}$. and $\mathrm{V}$. of Baghdad. According to Turkish authorities, it was built in the fifth century of the Hijira, in the district of the Euphrates which the Arabs call El-arad-Babel, lying on a spot of the west site of Babylon. The ruins near Hillah are still by the Arabs designated Babel, and all historical records as well as traditions agree in representing these as the remains of the first city of Nimrud, the Babylon of Herodotus, Diodorus Sicults, and other historians.-MacGregor.

HILL STATES is a term by which the British designate several independent and feudatory kingdoms in the Himalayas. Nepal is the largest of these; it is independent, but has treaties with British India.

Sirmur or Nahan.-In recognition of the services rendered by raja Shamsher Purgass during the 1857 mutiny, he received a khillat of Rs. 5000 , and a salute of 7 guns. The family is Rajput. Revenue of Sirmur, a lakh of rupees a year. 'The raja maintains a small force of drilled sepoys, numbering 250 men. Population, 75,595. The raja pays no tribute, but is bound to render feudal service. Gross revenue, Rs. 2,10,000.

The Kahlur or Bilaspur raja had estates on both sides of the Sutlej, but the sunnud given to raja Mooher Chand in 1815 confirmed to him the eastern portion only. The family is Rajput. In acknowledgment of his services during the mutinies of 1857 , the raja received a dress of honour of Rs. 5000 value, and a salute of 7 guns. Revenue, Rs. 1,00,000 ; population, 66,848 .

The Hindur or Nalagarh chief belongs to a Rajput family. A sumnud was granted in 1815. Population, 60,000 ; revenue, Rs. $90,000$.

Bashahr, a tributary state, gave Rs. 3945 as tribute. Rawaun, on the left bank of the Pabur, was transferred to Keonthal. The thakuri of Kotgurh and Kumharsain were declared independent of Bashahr. The raja is of a Rajput family. Population (1872), 90,000; revenue, Rs. 70,000.

Keonthal.-After the Gurkha war, a portion of the territory of Keonthal was sold to the maharaja of Patiala. The chief claims a Rajput origin. He is bound to render feudal service. In 1858 the chief was created a raja, and received a dress of honour worth Rs. 1000 for his services during the mutinies. Revenue, Rs. 60,000, and population (1875), 50,000.

The Baghal family is Rajput, Revenue, Rs. 60,000 ; population, 22,305 .

$J u b b u l$. - Originally this Rajput state was tributary to Sirmur, but after the Gurkha war it was made independent, and the rana received a sunnud from Lord Moira on 18th November 1815. Revenue, Rs. 30,000 ; population, 40,000 souls. The rana pays $\mathrm{Rs} .2520$ tribute, and is bound to render feudal service.

Bhaji pays tribute, Rs. 1440 . Revenue, Rs. 23,000 ; population, 19,000 .

Kumharsain state, formerly a feudatory of Bashahr, was declared independent at the Nepal war; pays Rs. 2000 as tribute. Revenue, Rs. 10,000 ; population, 10,000 . The family is Rajput, of not very high pretensions.

The Kuthar sunnud bears date the $3 \mathrm{~d}$ September 1815 , and confirms to rana Bhoop Singh and his heirs the hereditary possessions of his ancestors, subject to the performance of feudal service, and supplying a contingent of 40 begar, but subsequently commuted to a tributary payment of Rs. 1080. Revenue, Rs. 5000 ; population, 3990. The family is Rajput.

Dhami.-This old Rajput state became independent of Kahlur after the Gurkha war. The state was bound to supply 40 begar, but this was commuted to a tribute of Rs. 720 . Revenue, Rs. 8000 ; population (1875), 5500. 
Baghat, a hill state, the chief of which acted unfriendly during the Nepal war. He died without issue on 11th July 1839. The state was treated as a lapse, and pensions to the extent of Rs. 1282 were assigned to the family. Gazetteer says population, 10,000 ; revenue, Rs. 8000 .

Balsan.-This state was originally a feudatory of Sirmur, but a separate sunnud was granted to it in September 1815. Its tribute payment is Rs. 1080. Its chief is of Rajput origin. Thakur Jograj was created a rana in 1858 for services rendered during the mutiny. Revemue, Rs. 6000 ; population, 4892 .

Mailog.-The sunnud of this Rajput state is dated 4th September 1815. The tribute is Rs. 1450. Revenue, Rs. 9000 ; population, 1000.

Bija.-This petty state pays a tribute of Rs. 180 . Revenue, Rs. 1000 ; population, 981.

Taroch.-Revenue, Rs. $6000 ;$ pop. 6000. Jt pays Rs. 280 in lieu of begar.

Kunhiar state pays Rs. 180 in lieu of begar. Revenue, Rs. 4000 ; population, 2500.

Mangal was an ancient dependency of Kahlur, but was declared independent on the expulsion of the Gurkha. Its tribute payment is Rs. 72. Revenue, Rs. 700 ; population, 917.

Darkuti.-This pretty chieftainship pays allegiance to the British Government, and is exempted from all pecuniary liability. Revenue, Rs. 600; population, 700 .

In 1847 transit duties were abolished throughout these states. A yearly sum of Rs. 13,735 is paid in compensation by British India. To all the hill chiefs the right of adoption has been granted. -Aitcheson, Theaties, etc. p. 323.

HILL TRACTS of Arakan, or N.E. Arakan, are regarded as a revenue district, extending N.E. to Independent Burma and to Manipur, with an area of 4000 or 5000 square miles, and a population of 12,442 souls. The country, wild and beautiful, consists of parallel ridges of sandstone, clothed with dense forests ; its chief river the Kuladan (Koladyn) or Yam Pang. The tribes are the-

Ra-Khaing or Khyoung - tha, or sons of the river; profess Buddhism, and have paper books.

Shandu are polygamic, and bury their dead.

Kha-mi, meaning man, homo, or Khwe-myi, meaning dog's tail, their dress hanging down behind like a tail. They trade.

Mro, 2162, live on the Mi, Anu, or Khoung-tso, dwell on the banks of the Tsala river.

Khyeng inhabit the Arakan Yoma Hills, E. of the Le-Mru; they are shy, and tatton their women's faces.

Khyaw, in a village on the Tsala river, are a Kuki clan. They speak different dialects of the Arakanese and Kha-mi, but have many religious beliefs, domestic customs, and laws in common. Twice annually they worship the spirits of the dead, Ka-nie-hpa-law. Chastity before marriage is not required, and crimes are punished by fines.

HILL TRIBES is a general term by which the British designate collectively the numerous uncivilised tribes who inhabit the mountain ranges and higher hills in British India and along its borders. Most of them are wholly illiterate. Dr. W. W. Hunter has mentioned that-

In the North-West Provinces there are wandering and wild tribes, named Bur, Damak, Kanjar, Pasi, Kumboh, Nat, Saussee, Gond, and the Tharoo in the Terai ; the Pasi also occurring in Oudh.
The Chinese Frontier and Tibet have the Gyami, Gyarung, Takpa, Manyak, Thochu, Sokpa, Horpa.

Nepal (East to West) has the Serpa, Sunwar, Gurung, Murmi, Magar, Khaksya, Pakhya, Newar, Iimbu.

Kiranti Group, East. Nepal, have the Kiranti, Rodong, Rungchenbung, Chingtangya, Nachhereng, Waling, Yakha, Chourasya, Kulungya, Thulungya, Babingya, Lohorong, Limbichlong, Balali, Sang-pang, Dumi, Khaling, Dungmali.

The Broken Trities of Nepal are the Darhi. Denwar, Pahri, Chepang, Bhramu, Vayu, Kuswar, Kusunda, Tharu.

Lepcha of Sikkim.

Lhopa of Bhutan.

In N. E. Bengal are the Bodo, Dhimal, Kochh, Garo, Kachari.

In the Eastern Frontier of Bengal are the Munipuri, Mithan Naga, Tablung Naga, Khari Naga, Angami Naga, Namsang Naga, Nowgong Naga, Tengsa Naga, Abor Miri, Sibsagor Miri, Deoria Chutia, Singpho.

Mishmi, Chulikata Mishmi.

Abor group, viz. Padam and other Abor, Miri and Hill Miri, Dophla, Aka or Hrusso.

Naga of Upper Assam, the lower Naga group.

Naga west of the Doyang river.

Kuki, Manipur, and their neighbours Kouponi. Mikir, Jaintia and Khassya.

Arakan and Burma, Khyeng or Shou, Ka-mi, Ku-mi; Mru or Toung, Sak.

Siam and 'T'enasserim, Karen, Toung-thu, Ahom, Kham-ti, Laos.

Central India, Ho (Kol); Kol ; (Singbhum), Santal; Bhumij Rajmahali, Gond, Khond, Saora, Chentsu, Bhil, Patooa.

Broken Tribes, Cheroo, Kharwar, Parheya, Kisan or Nagesar, Bhuiher, Boyer, Nagbansi, Kaur or Kaurava, Mar.

Southern India, Toda, Kota; Badaga, Irular, Kurambar, Mali-Arasar, with many broken tribes in the plains, Yerkala, Pariah, Chakili, Mhar, Mhang, Okkalu, Holar.

Ceylon, Veddah.

HILL TROUT of Hindustan is no trout, but a large bony fish of a silver-grey spotted with black ; will eat everything he can swallow; is often taken with an infant brother while spinning for his high-caste neighbours, with an artificial minnow of glass, with a piece of rag or news paper, with bees, or dragon-flies caught off the bushes by the river, with a morsel of cabbage leaves boiled, but in general with the orthodox spinning, the minnow, or the artificial fly, made very large and showy. In Kashmir, five bags of these fish have been caught, some weighing 7 lbs. each. One seen in the market was 12 lbs. The Walur Lake, the Dhul Lake, and the Jhelum all swarm with them about the mulberry trees, the fallen fruits of which seem to afford them in legions a sweet and pleasant diet, if one may judge by the mighty rush ensuing on a shaking of the boughs. Boatmen avail themselves of this, cover a bent pin with a plump mulberry, and drop it amid the shoal. This fish is widely distributed; abundant in the backwaters of the Ganges, in the great rapids of that river far above Hurdwar, and in Dehra Doon, in lat. $27^{\circ} 28^{\prime} \mathrm{N}$., in the upper branches of the Brahmaputra, and in the Mishmi and Abor backwaters, also in most 
of the small rivers of the Panjab, in which latter locality it does not seem to grow very large, though plentifully, owing perhaps to its being the common food of numerous fish of prey. Is abundant, though small, in Central India, in Bundelkhand and Jhansi districts. That it is eatable, is all that can be said, but giving good sport in its way, and yielding subsistence to the monsters of the deep, and useful in diverting their attention from mischief to their own breed. The Europeans in Northern India apply the name of trout to three spotted carp, species of Barilius. B. bola, which takes a fly well, is said to attain $5 \mathrm{lbs}$. weight. It is found in Northern India, Assam, and Burma. B. tileo, smaller, is of Assam and Bengal; and B. bendilisis is a third small species. See Chiliva; Fish : Fisheries.

HILSHA or Ilisha, Clupea ilisha, shad, sable fish of Southern India.

Nga-tha-louk, . BunM. | Palasa, . . . TAM. Pulla, . . Sind. Ulumoolum, : TEL.

This is a migratory sea fish of the herring tribe, which enters the Ganges and Irawadi and Indus rivers to deposit its eggs. It is the shad of Bengal and the sable fish of Trichinopoly. In one of them 1,023,645 eggs were counted. The females are more numerous than the males. It is best preserved in tamarinds or vinegar.-Dr. $F$. Day.

HIMALAYA MOUNTAINS comprise a system of stupendous ranges, with the loftiest peaks in the world. They extend continuously for a distance of 1500 miles along the northern frontier of British India, from the Indus to the gorge where the Dihong bursts through their main axis, thus embracing the meridians $75^{\circ}$ to $95^{\circ} \mathrm{E}$. On the west, the Himalaya, with the Kouen Lun, converge towards the Pamir table-land, whence the Tian Shan and the Hindu Kush radiate, and the Kouen Lun and the Himalaya form respectively the northern and southern escarpment of the lofty Tibetan plateau, which has an average level of 15,000 feet. The average breadth of the Himalaya is computed at 150 miles, with a mean elevation of 18,000 to 20,000 feet; but there are solitary mountains and peaks rising higher,-for instance, in the Western Himalaya, Jumnotri, 20,038 feet: Kedarnath, 22,790 feet; Badrinath, 23,210 feet; Nanda Devi, 25,661 feet;-and in the Eastern Himalava, Dhawalgiri, 26,826 feet; Daya bang, 23,762 feet; Mount Everest, 29,002 feet; Kanchinjinga, 28,156 feet.

The Himalayan system is composed of a northern, a central, and a southern range.

The northern range is naturally divided into a western and an eastern section. Its westerm section is known as the Kara-korum or Mustagh, and it forms the water-parting between the basins of Lob-Nor and the Indus. The Kara-korum pass is on the real line of water-parting, and the streams north of it join the Tarim basin, while those on its southern slope discharge into the Indus.

Several of the peaks along this western section of the Himalaya attain a height of 25,000 feet, and the chief one, ' $\mathrm{K} .2$,' 28,265 feet, is second in altitude to Mount Everest. This section of the range extends from its junction with the Hindu Kush near the Baroghil pass to Mount Kailas, near Lake Manasarowar in Tibet, and the best known passes across it are the Kara-korum and the Changchenmo, exceeding 18,000 and 19,000 feet respectively in height, But there are also the
Karambar uass, the Mustagh pass, and a pass on the road between Rudok and Kiria. The southern slopes of the Mustagh range in its northerm portion are covered with enormous glaciers, one of them 35 miles long. These glaciers are the source of streams which flow southwards between bare craggy mountains and join the Indus or its tributary the Shayok. The collective name applied to the various districts which comprise the valleys of the Indus, Basha, Braldu, Shigar, Shayok, etc., is Baltistan. The inhabitants are Mahomedanized Tibetans of Turanian stock, and there is a small body of Aryans called Dards.

To the E. of Lake Manasarowar, a saddle which is crossed by the Mariam-la pass, connects the northern and central ranges of the Himalaya. On its eastern side rises the Tsan-pu (To-choktsang-pu), of which the northern range forms the northern watershed as far as to the south of the Sky Lake (Tengri-nur in Mongolian, and Nam-cho in Tibetan). Hence it appears to curve round the lake in a north-easterly direction for 150 miles, after which its further course is unknown.

The subsidiary chain between the northern and central ranges runs from Mount Kailas, near Lake Manasarowar, to the junction of the Indus and the Shayok. Majur Cunningham called it the Kailas or Gaugri range. It is 550 miles in length. Its peaks average between 16,000 and 20,000 feet in height, and it is crossed in its nortbern portion by a number of passes, which lead from the valley of the Indus into that of the Shayok. About lat. $33^{\circ} 12^{\prime} \mathrm{N}$., the Indus deviates at right angles, and pierces right through this granite range to resume a north-westerly course beyond. The southern portion of this range lies in Tibetan territory, and has been crossed at four points by native explorers.

The central range has its commencement in the Nanga Parbat, 26,629 feet high. It towers conspicuously on the extre ne verge of the Kashmir frontier above the Indus valley, and has been seen by General Cunningham from Ramnagar, in the Panjab, a distance of 205 miles. Proceeding from this point towards the south-east, we find that for the first 50 or 60 miles the central range forms the water-parting between the Indus and the Jhelum. Two roads, joining the Kishenganga and Astor rivers, go over passes of upwards of 13,000 feet, and others lead into the Dras valley. At the point where the Dras pass (11,300 feet) affords access from the Kashmir valley to the high table-land of Ladakh, a minor range branches off and separates successively the Sind valley, the northern part of the vale of Kashmir, and the Jbelum valley, on the south, from the Kishenganga on the north. A little south of the same pass, another ridge branches off, and, rumning north and south, forms the eastern boundary of the vale, till, near Banihal, it joins itself to the Pir Panjal range, which again runs east and west for about 30 miles, then turns N.N.W., and continues for some 40 miles more till it dies off towards the valley of the Jhelum. This range completes the mountainous girdle which encircles the valley of Kashmir. About the vicinity of the Dras pass, the range increases in beight, and the peaks are high enough to form glaciers, two of thern, Nun and Kun, being each over 23,000 feet in height. The north-eastern slope of the range drains into 
the Indus, the Suru and Zanskar being the chief rivers. A little farther to the south, the Bara Lacha pass (16,200 feet) affords a route from Lahul and Kangra to Leh.

Farther to the south-east, the central range becomes broken by the precipitous gorge of the Sutlej (the classic Hesudrus), which, rising in the sacred lakes of Rakas Tal and Manasarowara on the southern side of the Tibetan Kailas, takes a northwesterly course for 280 miles, till, joined by the waters of the Spiti river, it turns and cleaves through the two outer ranges, emerging on the plains of India at Ropar, after a course of 560 miles. The junction of the Sutlej and Spiti rivers is marked by the Lio Porgyul peak, which rises sheer 22,183 feet high from the edge of the two streams, 13,000 feet below its summit. Further to the S. E., numerous passes lead from British territory over the central range into Hundes. The Niti pass (16,676 feet) leads across it to Khotan, by way of Totling, Gartokh, Rudokh, Noh, and Kiria, and is the best and easiest route between Eastern Turkestan and India. Eastward of this point, the central range is occupied by the Native States of Nepal, Sikkim, and Bhutan. On its northern side the range has enormous glaciers, which drain into the Isan-pu river; while its southern slopes give rise to many large rivers, which burst through the southern range, and eventually discharge their waters into the Ganges or Brahmaputra. The source of the Ganges lies a few miles beyond Gangotri ; and the Kali, Karnali, Narayani, Buri Gandak, Tirsuli Gandak, Bhutia Kosi, Arun, all flow through Nepal. To the east of the Mariam-la pass, only three Europeans have ever crossed the central range. An imposing view of the long line of glaciers and peaks of the central range was obtained by Dr. Hooker from the Donkia-la pass in Sikkim. Two of the most remarkable of the inland lakes are the Palti and Chomtodong. The former (14,700 feet above the sea) is about twenty miles long and sixteen broad, without an outlet. This lake is situated north of the Arun basin, and, like the Palti lake, is encircled by spurs from the central range. The Palti or Yam-dok-cho lake is also without an outlet, and is ring-shaped; it is supposed to be about 45 miles in circumference. An island in its centre rises into rounded hills from 2000 to 3000 feet high.

The southern range, at its north - western extremity, appears to spring from the southernmost point of the Pir Panjal range. At its outset it is pierced by the waters of the Chenab, the main stream of which rises in Lahul far to the south-east, under the name of Chandra-bhaga, and for 180 miles drains the south-western and north-eastern slopes of the central and southern ranges respectively. The peaks of the southern range gradually increase in height from 1300 to 20,000 feet, and its outer slopes are washed by the Ravi and Beas, the feeders of which rise on the southern side of the culminating range. Passing the Sutlej, the road up the gorge of which is connected with Simla by the great Hindustan and Tibet road, we meet the Bhagirathi, Alaknanda, and a variety of rivers, which rise in the space between the two southern ranges.

The western terminal portion of the Himalaya chain comprises a number of great ranges, which are commonly known as the Mustagh or Kara- korum, Ladakh, Zanskar or Baralacha, and Pir Panjal, all of which have a N.W. to S.E. direction. The Baralacha separates the Indus river from its first affluents, as the Eastern Himalaya separates the Tsan-pu from the Ganges. The average elevation of Kashmir valley is between 5000 and 6000 feet above the sea; Huramuk Mount, 13,000 feet; Pir Panjal, 15,000 feet; average of the valley of Indus (north of Kashmir valley), 6000 to 7000 feet.

Major Cunningham gave the following summary of the information he collected regarding the great mountain chains in the north of the Panjab :-

\begin{tabular}{|c|c|c|c|c|c|}
\hline \multirow[b]{2}{*}{ Name of Chain. } & \multirow{2}{*}{ 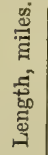 } & \multirow{2}{*}{ 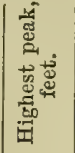 } & \multirow{2}{*}{ 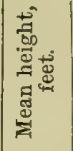 } & \multicolumn{2}{|c|}{ Snow line. } \\
\hline & & & & North & South \\
\hline Kara-korum or Tr.-Tibetan, & 450 & 24,000 & 20,000 & 18,000 & 18,500 \\
\hline $\begin{array}{l}\text { Kallas or Gangri, or Mla- } \\
\text { Tibetan, }\end{array}$ & 550 & 20,700 & 20,000 & 18,500 & 19,000 \\
\hline Tr.-Himalaya or Tsho-moriri, & 350 & 21,000 & 19,300 & 19,500 & 20,000 \\
\hline W. Himalaya or Bara Lacha, & 650 & 25,749 & 20,000 & 19,000 & 18,000 \\
\hline Mid-Himalaya or Pir Panjal, & 407 & 21,786 & 17,000 & 17,000 & 16,000 \\
\hline Outer Himalaya, or Daola & & & & Thesnc & ow dis- \\
\hline Dhar, . . . . & 300 & 16,174 & 15,020 & $\begin{array}{l}\text { appe } \\
\text { annu }\end{array}$ & $\begin{array}{l}\text { ared } \\
\text { lally. }\end{array}$ \\
\hline
\end{tabular}

Peaks.-Some of the peaks on the Kara-korum range, along which runs the boundary between Ladakh and Yarkand, are very high, the highest being 28,278 feet above the sea. This mountain is called K. 2, and towers above all the surrounding ranges, being probably the second highest in the world. The heights to the south of the Sutlej range from 20,103 feet to 25,749 feet, and the heights of the passes vary from 16,570 feet to 18,331 feet. In the Western Himalaya the snow limit ranges are from 17,500 to 20,106 feet. The highest peaks of the Western Himalaya are,Nanda Devi or Jawahir, 25,749 feet; Gyu peak, 24,764 feet; Mono Mangli, 23,900 feet; Porgyal, 22,700 feet.

The Giant's Peak and the Eastern Dal-la are occasionally called Gemini by residents of Assam who have seen the Himalaya panorama from Nanklau in the Khassya Hills.

Eastern Dal-la, lat. $27^{\circ} 52^{\prime} 1^{\prime \prime} \mathrm{N}$., long. $92^{\circ} 38^{\prime}$ $6^{\prime \prime} \mathrm{E}$., in Bhutan, in the immediate vicinity of the Giant's Peak top of the peak, is 21,435 feet according to Herm. Schl., and 21,476 feet, Pemberton.

A line of high snow peaks can be traced running nearly parallel to the plains of India, and extending from the places of passage of the Indus on the west and Brahmaputra on the east. These snowy peaks are separated from each other by deep ravines, along which flow large and rapid rivers. Every pre-eminent elevation is not, however, so much a peak as a cluster of peaks, springing from a huge sustaining and connected base. Between lat. $27^{\circ} 16^{\prime} 23^{\prime \prime}$ and $31^{\circ} 6^{\prime} 8^{\prime \prime} \mathrm{N}$., and long. $78^{\circ} 32^{\prime} 32^{\prime \prime}$ and $89^{\circ} 18^{\prime} 43^{\prime \prime} \mathrm{E}$, are seventy-nine peaks, ranging from 14,518 feet, to that of Mount Everest, 29,002 feet above the sea. The Pir Panjal, a great snow-clad range, shuts in the valley of Kashmir on the south. With that exception, the ranges covered with perpetual snow are first met with on the southern slope of the great Indo-Tibetan table-land, along a line between 80 and 90 miles from the foot of the outer mountains, and 20 or 30 miles south of the Indian watershed; and from this line northward snowy peaks abound everywhere over the 
summit of the table-land. The average elevation of the crest of the Indian watershed, between the points where the Indus and Brahmaputra cross it (1500 miles), probably exceeds 18,000 feet. The heights of the following peaks are given by $\mathrm{Mr}$. Trelawney Saunders in Geog. Mag., July 1877 :-

\begin{tabular}{|c|c|c|c|c|c|c|c|}
\hline & & & & Lat. & & Long. & Ht., Ft. \\
\hline Aku, , . & & & $\overline{28^{\circ}}$ & $23^{\prime} 25^{\prime \prime}$ & 85 & $10^{\prime} 12^{\prime \prime}$ & 24,313 \\
\hline arathor, . & & & & 320 & 84 & 932 & 26,069 \\
\hline drinath, & & & 30 & 4416 & 79 & 1920 & 23,210 \\
\hline Srikan & & & 30 & 5725 & 78 & $50 \quad 50$ & 149 \\
\hline Poonc & & & 31 & 012 & 78 & 3545 & \\
\hline $\mathrm{k} \mathrm{Gu}$ & rea & & 27 & 347 & 88 & $48 \quad 39$ & 17,572 \\
\hline lari, & & & 27 & 4937 & 89 & 1843 & 944 \\
\hline akoo 0 & or Che & & & 2728 & 88 & 4938 & \\
\hline ng, E. & & & 27 & 4627 & 87 & 121 & 020 \\
\hline . & & & & $\begin{array}{ll}4516 \\
49\end{array}$ & 86 & 5156 & 215 \\
\hline isi, & & & 98 & $\begin{array}{l}4933 \\
1517\end{array}$ & $\begin{array}{l}82 \\
85\end{array}$ & $\begin{array}{l}3933 \\
33 \quad 35\end{array}$ & 415 \\
\hline bang, & & & 20 & 4143 & 83 & 329 & \\
\hline Mour & & & 27 & 5912 & 86 & 586 & $\begin{array}{l}20,820 \\
29,002\end{array}$ \\
\hline Hovi & & & 27 & 4052 & 88 & 513 & 25,304 \\
\hline ia, & & & 28 & 213 & 85 & 4921 & 305 \\
\hline & & & 30 & 5118 & 78 & 5353 & 21,672 \\
\hline otri, & & & 31 & 025 & 78 & 346 & \\
\hline 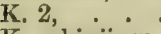 & - & & & & & & 28,278 \\
\hline injinga, & & & 27 & 425 & 88 & 1126 & \\
\hline & & & 27 & 3626 & 88 & 915 & 015 \\
\hline Ibi & am & & 30 & 5513 & 79 & 384 & \\
\hline th, & & & 30 & 4753 & 79 & 634 & 790 \\
\hline adi, & & & 28 & 3538 & 83 & 51 & 522 \\
\hline & & & 27 & 3036 & 88 & 1928 & 146 \\
\hline$i$ & & & 28 & 4539 & 83 & 2552 & \\
\hline ut, & & & 30 & 1651 & 80 & 639 & 22 , \\
\hline evi 0 & 1. Lat & & 30 & 2231 & 80 & 0 & 661 \\
\hline & & & 30 & 416 & 79 & 4453 & 22,093 \\
\hline & & & 30 & 4352 & 70 & 2656 & 21 , \\
\hline ri or $]$ & Donk & kia & 27 & 5652 & 88 & $53 \quad 5$ & \\
\hline & & & & 3434 & 88 & 1535 & 22,017 \\
\hline & & & & 1251 & 80 & 289 & 22,673 \\
\hline & & & 27 & 5318 & 87 & 754 & \\
\hline & & & & 5813 & 86 & 2832 & 23,570 \\
\hline Sargoroen, & & & 31 & 68 & 78 & 3232 & 20,405 \\
\hline Trisool, E., & * & & & 3056 & 79 & & \\
\hline & & & & & $\begin{array}{l}79 \\
79\end{array}$ & $\begin{array}{r}49 \\
2\end{array}$ & \\
\hline Yassa, ? & . & & & 3255 & & 36 & 26,680 \\
\hline
\end{tabular}

Watershed.-The Himalayan watershed lies at a very considerable distance to the north of the great Himalayan peaks, which, from the side of Hindustan, seem to form the watershed. The greater part of the giant peaks, which rise to an elevation of 25,000 to 29,002 feet, are situated not on the central axis but to the south of it. Viewed from a distance of about 150 miles, these mountains present a long line of snow-white pinnacles, which on a nearer approach are seen towering above the dark line of lower but still lofty mountains. The steep face is toward the plain, and to the north the chain supports the lofty table-land of Tibet. Deep narrow valleys, separated by ranges running either parallel or at right angles with the main ridge, contain the numerous sources of the rivers flowing into the Ganges, the Indus, and the Brahmaputra.

Rivers, - The great rivers issuing from the Himalaya from west to east in succession, are the Jhelum, the Chenab, the Ravi, the Beas, the Sutlej, the Jumna, the Ganges, the Gogra, the Gandak, the Kosi, the Tista, the Monas, and the Subansiri. The Indus, the Kābul river, the Jhelun, the Chenab, the Ravi, the Beas, and the Sutlej form seven large rivers, which flow through fertile valleys. The Jhelum runs in the valley of Kashmir. The course of the Ravi and Chenab is short, and their valleys small. The Beas in its upper portion is in the Kulu valley, but lower down it becomes entangled amongst the lower ranges west of Mundi, whence it opens on the plains of the Sutlej. The Sutlej has a tortuous entangled course in its upper parts, but enters the valley west of Simla, in Sukeyt and Balaspur. The Brahmaputra, Indus, Sutlej, and Kurnali or Gogra are called by the Tibetans, Tam-jankhamba, or Horse's Mouth ; Shingh-gi-khamba, or Lion's Mouth; Langchan-khamba, or Bull's Mouth ; and Mabja-khamba, or Peacock's Mouth. These four great rivers drain the Kailas group of mountains. They rise close to the great Kailas Purbut. Eastward of the meridian marked by the Sanpu falling into the plain of Assam, the rivers descending from the eastern part of the Tibetan highland cut up the plateau into a succession of lofty ranges and deep gorges running north to south. These rivers include the Dihong and other affluents of the Brahmaputra, also the great Yang-tze-kiang with its tributaries, which flows southwards to lat. $26^{\circ} \mathrm{N}$., then turns eastward, to traverse the whole of China proper.

Passes. -The Himalaya present almost insurmountable obstacles to communication between the countries which they divide, thereby separating the Boti or people of Tibet from the Hindu family of India. The distinction of climate is not less positively marked, the ranges forming the lines of demarcation between the cold and dry climate of Tibet, with its dearth of trees, and the warm and humid climate of India, with its luxuriance of vegetable productions. There are, however, many passes. In Kanawar there are fifteen, at elevations varying from 15,000 to 17,000 feet. From the peak of Mono-mangli to the sources of the Gilghit and Kunar rivers, not less than 650 miles, the chain is pierced by the Sutlej and Para at the base of Porgyal, and by the Indus at the foot of Dyamur.

Between Gilghit and Chittagong there are a hundred passes; but of all these, the basins of the Ganges and its four great feeders, the Gogra, the Gandak, Kosi, and Tista, are the great mountain passes of the Himalaya.

The following are the heights of passes over the Outer Himalaya range :-

\begin{tabular}{|c|c|c|c|c|c|}
\hline & & & Lat. & Long. & Ht., Ft. \\
\hline Barga, & & & $31^{\circ} 16^{\prime}$ & $78^{\circ} 19^{\prime}$ & 15,000 \\
\hline Ghusul, . & 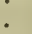 & : & 3121 & 788 & 15,851 \\
\hline Gunas, . & . & . & 3124 & $\begin{array}{ll}78 & 8\end{array}$ & 16,026 \\
\hline Kinulia, . & . & . & $31 \quad 15$ & 7825 & 17,000 \\
\hline Lumbia, & . & . & 3116 & $78 \quad 20$ & 16,000 \\
\hline Marga, . & . & . & 3116 & 7821 & 16,000 \\
\hline Nibrung, & . & . & 3122 & $\begin{array}{ll}78 & 10\end{array}$ & 16,035 \\
\hline Nulgun, & 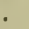 & . & $31 \quad 19$ & $78 \quad 13$ & 14,891 \\
\hline Rupin, . & . & • & $31 \quad 2$ & 7810 & 15,480 \\
\hline Shatul, & . & . & 3125 & 7758 & 15,555 \\
\hline Siaga, & • & . & 3116 & 7820 & 16,000 \\
\hline Sugla, . & & , & $31 \quad 13$ & $78 \quad 29$ & 16,000 \\
\hline Sundru, . & $\bullet$ & • & 3124 & $78 \quad 2$ & 16,000 \\
\hline Yusu, . & & 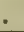 & 3124 & 78 & 15,877 \\
\hline
\end{tabular}

Sub-Himalayas or Siualik. Along the southern base of the Himalaya, and parallel with the general direction of the mountains, a series of comparatively low ridges extends, formed of tertiary rocks. In the Panjab, the transition from the plains to the outer hills is marked by a belt of dry, porous ground, seamed by numerous gullies or ravines, from 100 yards to a mile wide, partly covered with long, tufty jungle grass. To the east the Terai occupies the same position. This is a belt of waste, marshy ground, a malarious region 


\section{HIMALAYA MOUNTAINS.}

of varying breadth, lying below the level of the plains. This tract affords pasture to innumerable herds of cows and buffaloes. Beyond lies a dry belt of rising ground, called Bhavar, chiefly of a gravelly and sandy nature, with abundance of the sal tree (Vatica robusta). Next intervenes a range of fossiliferous sandstone, which almost uniformly edges the Himalaya from the Jhelum to Upper Assam. The space between these and the slope of the Himalayas themselves is occupied by the Duns, the Maris (in Nepal), and Dwars (in Bhutan), longitudinal valleys of rising ground, either cultivated or yielding a plentiful forest growth. Streams issuing from the Himalayan ranges lose a great part or the whole of their water by percolation through the gravel in the Bhavar region. At the base of the slope, much of the water that has percolated the gravel re-issues in the form of springs, the ground is marshy, and high grass replaces the forest. This tract is the Terai, a term not unfrequently applied to the whole forest-clad slope of the Himalayas, known also in Nepal as Morung:

Sivalaya (Sivalik) is the local name of the range separating the Dehra Doon from the plains east of the Jumna, and this has given the term Siwalik. It was in the Siwalik Hills that Lieut. (General Sir Proby) Cautley, in the early part of the 19th century, discovered the presence of fossils; and the collections made by him and Dr. Falconer were described by the latter in the Fauna Antiqua Sivalensis and Palæontological Memoirs. The great fossiliferous deposit of the Siwaliks is near the valley of Markanda, westward of the Jumna, and below Nahun. By the joint labours of Lieut. Cautley and Dr. Falconer, and of Lieutenants Baker and Durand, a sub-tropical mammalian fossil fauna was brought to light, unexampled for richness and extent in any other region then known. It included, amongst the Primates, species of macacus (2), and semnopithecus (2); of the Carnivora, species of felis, canis, ursus, hyæna, meles, mellivora, lutra, machærodus, enhydriodon, etc. ; of the Proboscidea, elephas (7), euelephas loxodon (1), stegodon (5), mastodon (4), tetralophodon (6), trilophodon (7); of the Ungulata perissodactyla, rhinoceros, acerotherium, listridon, equus, hipparion ; of Ungulata artiodactyla species, hippopotamus, hippopotamidon, tetraconodon, sus, cervus, camelopardalis, sivatherium, bos, bison, bubalus, antilope, capra, ovis, camelus. Of the Rodents, species of mus (1), rhizomys and hystrix. Among the Reptilia, monitors and crocodiles of living and extinct species, the enormous tortoise, Colossochelys Atlas, with numerous species of emys and trionyx. And, along with fossil fish, Cyprinidæ and Siluridæ, no less than 25 species of shells were found, all of which but 4 are now extinct. The general facies of the extinct fauna exhibited a congregation of forms participating of European, African, and Asiatic types. T'hey are beautifully arranged in the London Natural History Museum. Himalaya, as a name, is from the Sanskrit words Hima, snow, and Alaya, an abode. The range is also called Himadri, and Himavat; also Himachala (snowy mountain), and also Himadaya, the place of appearance of snow (Adaya, appearance), whence the classic name Kmodus. Himavat, the Western Himalaya, where it bifurcates and embraces the country occupied of old by the Sakr, was the
Emaus of ancient geographers, the Himin of the Mcso-Gothic, the Hemel (Himmel) of the German, and the Heven of the Anglo-Saxon. Pliny was fully aware of the signification of the name, for he says (Hist. Nat. vi. p. 117), 'Imaus in colarum lingua, nivorum signiticans.' Hindus call all the high snowy peaks of the Himalaya by the generic name Kailasa ; and, in the mythology of the Hindus, Mount Kailasa is the heaven of Siva and of Vishnu; another fabled Himalayan mountain, Meru or Su-meru, being the site of Swarga, the heaven of Indra; and in Hindu mythology the sacred Ganges is fabled to spring from the feet of Vishnu.

Races. - The habitable parts of the range are occupied by Mongoloid races, and to a small extent by tribes of Aryan descent; and many of the tribes are supposed to have occupied their present localities before the 4 th or the 7th centuries A.D. A sparse Aryan population lies scattered among the valleys.

The Bhot area is bounded on the south by India and Kashmir, on the north by Chinese Tartary, and on the west by Little Bokhara and Kafiristan. Amongst them may be mentioned the Mahomedan Bhot of Baltistan or Little Tibet, of Rongdo, Skardo, Parkuta, and Khartakshi, of Shigar, Chorbad, etc.; (2) the Buddhist Bhot of Ladakh, Hungrung and Kanawar, the Bhot of the Chinese empire, the Tibetans of Rudok, Garo, Goga, etc., of Lhassa and TishuLumbu, the Si-Fan, the Lhopa of Bhutan, the Tak, the Bhot of Garhwal, Kamaon, and Nepal; the Chepang, and probably the Rhondur, the Chak, the Drok, the Hor, the Kolo; and (3) in the further east are the Koch'b, the Dhimal, the western Bodo of Sikkim; and (4) still farther are the Bhutan frontier, and still farther are the eastern Bodo or Boro of Assam and Cachar, the Garo, the Khassya, and the Mikir. To the central region are similarly confined, each in their own province, from west to east, the Dunghar (west of Nepal), the Dardu, the Gakar, the Bamba, the Kakka, the Dogra, the Kanet, the Garhwali, the Kohli, the Kas or Khasia (in Nepal), the Magar, the Gurung, the Kusunda, the Chepang, the Sunwar, the Newar, the Murmi or Tamar, the Khombo or Kiranti, the Yakha, the Limbu or Yak-thumba, the Lepcha or Deunjongmaro (in Sikkim), the Lhopa (in Bhutan), the Dafla (east of Bhutan), the Abor and Bor, the Miri, and the Mishmi. The Cis-Himalayan Bhotia (called Palusen, Rongbo, Serpa, Kath - Bhotia, etc.), extend along the whole line of the ghats, and with the name have retained unchanged the lingual and physical characteristics, and even the manners, customs, and dress, of their transnivean brethren. The passes through the Snowy Range are occupied by the Bhoti, who have a monopoly of the trade across the Himalaya, are carriers, loading the goods on the backs of sheep. Most of the traders of the snow valleys have some members of their families residing at Daba or Gyani, on the Nuna khar lake.

The men of all races in the hills are short and of poor physique; they look wom, and get deep-lined on the face at a comparatively early age. The young women are often extremely pretty, those living in the higher and colder villages having, at 15 or 16 , a complexion as fair as many Spaniards or Italians, and with very regular features. But they grow darker as 
they advance in years, and become very plain. As a general description of the Mongoloid tribes there, the head and face is very broad, usually widest between the cheek-bones, sometimes as wide between the angles of the jaws; forehead broad, but low and somewhat receding; chin defective; mouth large and salient, but the teeth vertical, and the lips not tumid; gums thickened; eyes wide apart and oblique; nose long, pyramidal; hair of head copious and straight; of the face and body deficient; stature low, but muscular and strong; character phlegmatic, goodhumoured, cheerful, and tractable. Polyandry yet exists partially, but is disappearing. Female chastity is little heeded before marriage. Crime rare, and they are truthful. They sacrifice, and are little Hinduized. Their craftsmen are stranger helot races, located amongst them from time immemorial, as smiths, carpenters, curviers, potters. The Newar alone have any literature, and that wholly exotic.

To the lower range, again, and to similarly malarious sites of the middle region, are exclusively confined the Koch'h, Bodo, Dhimal (Sikkim and east of it), the Kichak, Pallas, Hayu, Tharu, Dhenwar, Kumba, Bhramu, Dahi or Dari, Kuswar, the Bhotia (in Nepal), the Boksa (in Kamaon), the Khatir, the Awan, the Janjoh, the Chib, and the Bahoa (west of Kamaon to the Indus).

The Khas, Magar, Gurung, Newar, Murmi, Lepcha, and Bodpa, etc., are dominant unbroken tribes. The broken tribes are all the Awalia, the Chepang, Kusunda, and Hayu, and there are tribes of helot craftsmen, blacksmiths, carpenters, curriers, etc., who are regarded as unclean. The unbroken tribes are the more recent immigrants from the north; their languages are of the simpler Turanian type, whereas those of the broken tribes are of the complex or pronomenalized type, and the phenomena of ethnology in the Himalaya warrant the conclusions that they were peopled by successive swarms from the great Turanian hive, and that its tribes are still traceably akin alike to the Altaic branch of the north, and to the Dravidian of the south. The Khas, the Kanet, the Dogra, and several other tribes of the Western Himalaya, are clearly of mixed breed, descended from Tartar mothers and Aryan fathers.

The Himalayan mountains thus form the meetingground of the Aryan and Turanian races. The two stocks are in some places curiously intermingled, though generally distinguishable. To the extreme north-west are found the Dard, an Ayran race of mountaineers, abutting on the Pathans or Afghans on the west, and the Balti. a race of mahomedanized Tibetans of the Turanian stock, on the east. To this latter stock also belong the Champa, a race of hardy nomades, wandering about the high-level valleys of Rupshu, and the Iadakhi, a settled race, cultivating the valleys of their country. The other Aryan races are the Pahari or 'mountaineers,' the Kashmiri, the Dogra, and Chibhali, who inhabit the outer hills. In Garhwal and Kamaon we find the Kanawari (inhabitants of Bashahir), the Nilang people, who differ in no respect from those of Hundes, and the inhabitants of the Bhotia Mahals of Kamaon and Garhwal, who are of mixed Tartar and Indian origin.

A number of the hill-men are Rajputs, and there are a few villages of Brahmans. The Dom are hereditary bondsmen to the Rajputs. Basgi men and women are singers at the temples. From Kashmir eastwards, all the easily accessible portions of the Himalaya are occupied by Aryan Hindu as far as the eastern border of Kamaon and the Kali river, separating Kamaon from Nepal, - the Tibetans being here confined to the valleys about and beyond the snow. People of Tibetan blood have migrated into Nepal throughout its whole length, and have formed mixed tribes, whose appearance and language is more Tibetan than Indian, but whose religion and manners are Hindu. East of Nepal, in Sikkim and Bhutan, the Hindu element almost disappears, and the Tibetans are altogether dominant. Between the Kali and Dhansri, in Nepal, Sikkim, and Bhutan, the ordinary population consists of the following:-

1. Cis-Himalayan Bhotia or Tibetans, called Rongbo ; Siena or Kath Bhotia ; Palu-Sen.

2. Serpa. 3. Gurung. 4. Magar. 5. Murmi.

6. Newar. 7. Kiranti. 8. Limbu or Yak-thumba. 9. Lepcha or Deunjong Maro.

10. Bhutanese, or Lhopa, or Dukpa, or Brukpa.

Gurkha, Gurung, Magar.-In Nepal, in the west are the Gurung and Magar tribes, short, with features of an extreme Mongolian type, full of martial ardour and energy. They are famed as the Gurkha soldiers. They have considerable intellectual ability.

The Newar of the valley of Nepal are the cultivating peasantry, have Tibetan features, with a fair and ruddy complexion. The language of the Magar, Gurung, and Newar is chiefly Tibetan. Farther east are the Keranti, Murmi, and others. Some mixed races are found to the south of each chain, as the Lahuli and Kanawari in the west, and the Gurkha and Bhutani in the east.

Highest Permanently Inhabited Villages.

1. Bhutan, Sikkim, Nepal. 2. Kamaon and Garhwal. Yangma Guola, 9,279 feet. Ussilla, . . 8,940 feet. Lamteng, . . 8,883 ", Tsobta, . . 8,842," Bumdangtang, 8,668 ", Mukba, : . 8,600" Lachung, . 8,630 ", Kathi, . . 7,410",

\section{Simla and Kulu. 4. Lahol, Kanaur.}

BambhoraGarh,9,844 feet. Darcke, . 11,746 feet. Janglik, - 9,257 , Rarik, . . 11,685 , Jatvar, : : 8,177 ", Kunu, : : . 11,683 ," Kot,

5. Kishtwar and Kashmir.

Sukne, . . 9,122 feet. Daver, . . 7,718 feet. Bara Banghal, 8,535 , Kullan, . . 7,175 ", Pashmin, . 8,351 ", Shapion, : : 6,672",

II. Highest Summer Villages of Kamaon and Garhwal. They do not occur in the Himalaya west of Garhwal.

Kedarnath, . 11,794 feet. Niti, . . 11,464 feet. Goh, . . 11,561, Nelong, - 11,350, Loa,. : : 11,510 ", Milum, : . 11,265 ",

III. Western Tibet.

A. Highest Permanently Inhabited Villages.

Hanle, a Buddhist Puling, in Gnari monastery, 15,117 feet. Khorsum, . 13,953 feet. Chushul, a small number of Stone Houses. Pananuk, a shep- $\quad$ Muglab, . . 13,847 feet. herds' settle- Kibar, . . 13,607 ment, : 14,146, Gya, : : 13,548 ", B. Highest Summer Villages.

Norbu, . . 15,946 feet. Puga, . . . 15,264 feet. Chabrang, : 15,588 " Gartok, . 15,090 , Korzog, . . 15,349 ", | Gartok, . .15,090 C. Highest Pasture Grounds in Summer.

Larsa, . . . 16,349 feet. Rukchin, . . 15,064 feet. Zinchin, : 16,222, Amlung, : 15,300, Kiangchu, : 15,781 ", Jugta, : : 15,058 ", 
IV. Kouen Lun.

Highest villages, 9,400 feet. | Highest pasture

Highest summer

villages, . 10,200,

grounds, . 13,000 feet.

V. Andes. Highest Towns and Villages.

Authorities : Burkart; Humboldt; Pentland; Wislizenus, \begin{tabular}{l|l} 
Cerro de & Turche, \\
Pasco, 10,641feet(H.)
\end{tabular} Potosi, . 13,665, (H.) Zacatecas, 8,051 , (B.) Cuzco, . 11,380 ", (P.) Mexico, . 7,469 ", (H.)

Sanatory stations and convalescent depots for British troops have been formed on spurs from the Himalayas, as well as on other of the hill ranges of British India, as on Mount Abu, Mababaleshwar, Ramanmallay, the Neilgherries. In 1877 the mortality at the hill stations was only 6.49 per 1000 ; in Bengal proper, $9 \cdot 11$; in Meerut and Rohilkhand, $10^{\circ} 16$; in the Panjab, 10.68 ; Gangetic provinces, $13 \cdot 24$; Agra and Central India, $14: 36$.

Almorah in Kamaon, .

$5300-5500$ feet.

Chinee, on the Sutlej, 150 miles from Simla, 9096 ,

Dailhousie, on the Chamba Hills, - . 5700 ",

Darjiling, • ' •

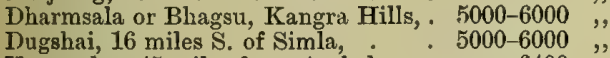

Kussowlee, 45 miles from Ambala, : $7300-7572$,"

Landour adjoining Mussoori, . . 7300-7572 ,

Murree, in the Hazara Hills, : . $6400-7200$,"

Mussoori near Landour, 22 miles S.W. of Almora, .

Simla, 77 miles from Ambala, and 22 miles N.E. of Subathu,

6409-7400

Subathu, 9 miles from Kussowlee,

$6500-8000$ 4000

Languages.-In the Himalaya, according to Mr. Aitcheson, the various dialects are mixed together in great confusion. On the northern Assam frontier are found, in the following order from $\mathrm{E}$. to W., the Aka, Abor, Dafla, Miri, and Mishmi ; next to these is Bhutia, which carries us as far E. as the Tista; Sikkim, or the country between the Tista and the Singhaleela range, contains the Lepcha and Limbu dialects. The Sikkim Terai gives us the Dhimal, Bodo or Mechi, and Koch'h, which latter also occupy the plains of Koch-Bahar, and the northern parts of Runjpur, Dinajpur, and Purniah. In Nepal, according to Mr. Hodgson and Dr. Campbell's researches, we find a perfect maze of dialects. Beginning from the Singhaleela range, we find Limbu or Kiranta, which goes WV. as far as the Dudkusi river, in long. $86^{\circ} 44^{\prime}$. Sherwill found the Gurung in the higher parts of Singhaleela, closely connected with whom are the Murmi. Along the lower hills are the Magar, who extend to the W. as far as Palpa. Somewhere about here we should apparently place the Brahmu, Chepang, Hayu or Vayu, and Kusunda. In Central Nepal are the Newar, Pahri, and Brahmo, a dialect of Magar, also the Darahi or Dorhi, Danwar, and Paksya. The Tharu live in the Terai between Chumparum and the Khatmandu valley, as far W. as the river Gandak. These last four are classed among Indo-Germanic languages. The rest are Turanian, with more or less infusion of Hindi. The Parbatia or Paharia, a dialect of Hindi, is spoken all over Nepal, and is the court language. West of this again comes the Palpa, then the Thaksya, Sunwar, and Sarpa, the dialects of Kamaon and Garhwal, which carry us on to the Milchan of Kanawar, the Hundesi, and Tibarskad north of it. West of this come the Dogra dialects of the Panjab hills.
Valleys.-The Dehra Doon is a winter valley. Its length is about 45 miles and its breadth about half that. It is shut on the north by the Siwalik range, rising 3000 feet high. On the E. are numerous mountains rising 7000 or 8000 feet, amongst them Mussoori and Landour; the Asun and the Sooswa rivers drain it. It is clear of jungle, and well cultivated. The tea-plant thrives, and the village of Dehra is large and thriving:

In the Kangra valley, some places like Bhagsu (Dharmsala), and the road from Kangra town, Haurabagh and Fouta-Kal, are beautiful, as also are the views of the Snowy Range. Kot Kangra or Kangra town was the capital of a powerful hill state, which was conquered by the Sikhs. It is 2500 feet above the level of the sea. Bhagsu, above Dharmsala, is 7000 feet above the sea. Haurabagh is 7000 feet, and Fouta-Kal 9000 feet above the sea. The Kangra people are sturdy, honest, and independent.

The Sutlej valley commences a few miles above Mundi, and continues up for about 40 miles, almost to Simla and Subathu, and has the sanatoria of Simla, Kussowlee, Nagkunda, and Chor. Mundi is the chief town of the Mundi state. The Sutlej people are amiable and gentle, free of low cunning, having the appearance of a mixed race between the Tartar and the common hillmen. They are fair, well made, and strong, but are filthy and indigent. The women have a toga fastened round the waist. Nagkunda is estimated at 9000 feet above the level of the sea. Chor is 12,000 feet.

The Beas valley exceeds in beauty that of Kashmir. It runs from the Bajaora mountain on the north, to the Snowy Range on the south, a length of about 60 miles, and its heights range from 4500 feet at the foot of the Bajaora pass, to 9000 feet at Ralha at the foot of the Rotang pass. Sultanpur is 4584 feet. It is the only town in the valley, and trades with Ladakh, Central Asia, Mundi, and Kangra. Polyandry prevails in the Beas valley, but the general immorality is ascribed to the large numbers of Yarkandi traders.

$\widetilde{K} u l u$. The poorer Kulu people wear only a blanket, wound around the waist, and one end flung across the shoulders and pinned across the chest; men and women often dress alike, but the long hair of the women is plaited in one tress.

Animal Life.-The partridge has been observed 16,080 feet above the sea, and crows and ravens 16,500. The Khalij pheasants never descend below 12,000 feet; and high over the Kinchinghow $(22,756$ feet), flocks of wild geese are seen to wing their flight. The wild yak, the existence of which in the wild state has been doubted, and the kiang, five to six species of wild sheep and goats, hares, and mice, are found as high as 16,000 to 17,000 feet. The highest permanent village occupied by man is at 11,746 feet (Darcke), but in summer the herdsmen go higher up the mountains. On the southern slope the cultivation has not risen higher than 10,000 feet; but on the north side are the cultivated valleys of the Baspa river at 11,400 feet, and advancing farther, the habitations of man are to be seen as high as 13,000 feet, and cultivation 13,600 feet. There are many shrines and sacred spots within the ranges to which Hindu pilgrims resort, and numbers of them perish amidst the perpetual snows. Amongst them is Badarinath, in Garhwal, a temple dedicated to an 
incarnation of Vishnu, 10,294 feet above the sea. Kedarnath is another Vaishnava temple within the Himalayas, 11,794 feet above the sea; Gangotri also, in Garhwal, at 10,319 feet of elevation, is another shrine, its vicinity being sacred to Hindu thought, as near it, at 13,800 feet, the Bhagirathi issues, no puny stream, from beneath a glacier.

Florc, - If we commence with the bases of these mountains, and pass successively through the several belts, we first find a vegetation similar to that of the southern provinces of India: the agricultural products consist of rice, millet, amaranth, an esculent arum, ginger, turmeric, a little cotton, and sugar, at the season, succeeded by wheat, barley, and buckwheat, in the cold-weather months. Along with plantains, oleander, and some of the orange tribe, we meet also with some species which were long considered peculiar to China, as Marlea begonifolia and Houttuynia cordata, with species of Chloranthus, Incarvillea, and others. On ascending higher, we pass through different gradations of vegetation until reaching the regions of the oaks and rhododendrons, which is immediately succeeded by that of pines.

Trees grow very generally in the Himalaya up to heights of 11,800 feet, and in most parts there are extensive forests covering the sides of the mountains at but a little distance below this limit. In Western Tibet, however, there is nothing at all corresponding to a forest. Apricot trees, willows, and poplars are frequently cultivated on a large scale; poplars, indeed, are found at Mangnang in Gnari Khorsum at a height of 13,457 feet, but they are the objects of the greatest care and attention to the lamas. On the northern side of the Kouen Lun are no trees at all, owing to the considerable height of the valleys. In the Andes they end at about 12,130 feet; in the Alps, on an average, at 6400 feet, isolated specimens occurring above 7000 feet. The cultivation of grain coincides in most cases with the highest permanently inhabited villages; but the extremes of cultivated grain remain below the limit of permanent liabitation. In the Himalaya, cultivation of grain does not exceed 11,800 feet, in Tibet 14,700 feet, and in the Kouen Lun 9700 feet. For the Andes the limit is 11,800 feet. In the Alps, some of the extremes are found near Findeler, at a height of 6630 feet, but the mean is about 5000 feet. The upper mean limit of grass vegetation in the Himalaya is at 15,400 feet; in Western Tibet, nearly the same level as for the highest pasture grounds, 16,500 feet, may be adopted. in the Kouen Lun grass is not found above 14,800 feet. Shrubs grow in the Himalaya up to 15,200 feet; in Western Tibet as high as 17,000 feet; and in one instance, at the Gunshankar, even to 17,313 feet. On the plateaux to the north of the Kara-korum, shrubs are found at 16,900 feet, and, which is more remarkable, they occasionally grow there in considerable quantities on spots entirely destitute of grass. $A_{s}$ an example may be mentioned, amongst several others, the VohabChilgane plateau $(16,419$ feet), and $\Delta$ Bashmalgun (14,207 feet). In the Kouen Lun the upper limit of shrubs does not exceed 12,700 feet. Above this height grass is still plentiful, and shrubs being here, as generally everywhere else, confined to a limit below the vegetation of grass, the range presents an essential contrast in this respect to the characteristic aspect of the Kara- korum. The number of species of plants, as well as the number of individuals, is exceedingly limited in the higher parts of the Kouen Lun. Lichens are completely wanting in the dry angular gravel covering the high plateau, and the slopes of the mountains in their neighbourhood.

Snow is a phenomenon which varies extremely with the latitude, longitude, humidity, and many local circumstances. In Ceylon and the Madras Peninsula, whose mountains attain 9000 feet, and where considerable tracts are elevated above 6000 to 8000 feet, snow has never been known to fall. On the Khassya mountains, which attain 7000 feet, and where a great extent of surface is above 5000 feet, snow seems to be unknown. In Sikkim snow annually falls at about 6000 feet elevation, in Nepal at 5000 feet, in Kamaon and Garhwal at 4000 feet, and in the extreme West Himalaya lower still. In the Sikkim Himalaya, the giant peaks of Donkiah, Kinchinghow (22,756 feet), and Kanchinjinga, the third greatest mountain of the world $(28,156$ feet), only surpassed in altitude by the Kara-korum (28,278 feet), and Mount Everest (29,002 feet), form the culminating points in this magnificently wooded region. The truly temperate vegetation supersedes the sub-tropical above 4000 to 6000 feet; and the elevation at which this change takes place corresponds roughly with that at which the winter is marked by an annual fall of snow.-Outer Mountains of Kemaon, by Capt. Herbert, in Bl. As. Trans. xi, xii.; Royle, Ill. Him. Bot.; Herm. Schl.; MacG.; Campbell, pp. 47, 147-8, 168; Thomson's Travels; Hooker f. et Thom. pp. 189, 190; Hooker, Him. Jour.; Universal Review, No. 3, p. 359 ; Major Cunningham ; Captain Strachey, Report, Brit. Association, 1847; Annals, Indian Administration; Medlicott and Blanford's Geology of India; Trelawney Saunders; Magnetic Survey of India, p. 9; Fraser's Himalaya Mountains; H. H. Wilson's Hindoo Sects; Imperial Gazetteer.

HIMIS, a Buddhist monastery near Leh in Ladakh, 12,324 feet above the sea.

HIMMARGUJERATI, one of the eighty-four Gachchas of the Jaina sect.

HIMMAT BAHADAR, the pupil of Rajendra Gir, a Dasnami ascetic.

HIMYAR was the fifth monarch from Kahtan, and gave his name to a dynasty which ruled over Yemen for many centuries, with varying fortune and different degrees of magnificence. Himyar was the first of the descendants of Kahtan who reigned over the whole of Yemen. This dynasty terminated on the conquest of Yemen by the Abyssinians in A.D. 525; and Dthoo Nawaz, the last of them, was the tyrant who destroyed the Christians of Nejran by burning 20,000 in a pit, noticed in chapter 85 of the Koran as the martyrs the brethren of the pit. The dynasty had ruled in Yemen for 2000 years, and its downfall was accelerated by the intolerance of the Jewish Tobbas. For a short time prior to A.D. 595, assisted by the Persian monarchs, Nushirwan and Khusru Parwez, the dynasty again ruled over Yemen, but was ultimately put aside by Persia declaring Yemen to be a satrapy. The devotions of the Himyarites were addressed to a multitude of deities, of which the principal were the sun, the moon, and the planets. The most powerful of this dynasty was Abu Karib, commonly called Tobba. In A.D. 206 he covered the 
Kaba with a tapestry of leather, and supplied its door with a lock of gold. The Beni Himyar of S. Arabia claim to be descendants of that dynasty. Himyaritic inscriptions were found by Lieutenant Cruttenden in the town of Senaa. They are likewise met with at Aden. The language appears to lean more to Hebrew than the Ethiopic, while the Gara language, called also Ekkbili or Mahrah, is more akin to Ethiopic. - Playfair's Yemen; Niebuhr's Tr. ii. 178; Wright's Christ. in Arabia.

HINAYANA, a form of Buddhism which prevailed in India east of the Indus. It was put aside by Kanishka, who introduced the Mahayana schism. The Hinayana was the purer sect of the Buddhists, followers of the lesser vehicle.

HIND. The term India, by which this country, as far as it was known, is distinguished in the earliest Grecian histories, appears to be derived from Hind, the name given to it by the ancient Persians; through whom, doubtless, the knowledge both of the country and its name were transmitted to the Greeks. Mr. Wilkins says that no such word as Hindu or Hindustan are to be found in the Sanskrit dictionary. The people among whom the Sanskrit language was vernacular, styled their country Bharata.-Rennell's Memoir.

HINDI is a term used all over Northern India, to denote the vernacular tongue of the districts. Speaking generally, the whole of Upper India, including the Panjab, but exclusive of Bengal, may be said to be possessed by one language, the Hindi. This range, therefore, would include all the Rajput states, Jeysulmir, Ajmir or Rajasthan, Mewar, Marwar, Bikanir: and also the N. and E. in Lahore, Multan, Dehli, Agra, Malwa, Gujerat, Oudh, Allahabad, and Behar. Indeed, in the entire tracts lying between the Vindhya on the south, the Himalaya on the north, the Indus on the west, and Bengal and Assam on the east, are spoken what are called Hindi dialects, some of which contain Sanskrit words to the extent of nine-tenths of their entire vocables. The languages spoken in the north-western border of India, between it and Afghanistan, and those of India adjoining Afghanistan, are dialects of Hindi, but sufficiently distinct to be called Sindi, Panjabi, and Kashmiri. Lieut. Leech, indeed, has given vocabularies of seven languages spoken on the west of the Indus. According to Colebrooke, Hindi owes nine-tenths of its vocables to Sanskrit roots; but when it is spoken by Mahomedans, who added to it Arabic and Persian roots, it became converted into Hindustani or Urdu, literally the camp tongue. It is that which the Mahomedans generally, and the Indian army everywhere, speak, and has hitherto been the language employed in personal intercourse by the British in their communications with the people of the country, though only formed into a written tongue since the beginning of the nineteenth century by Dr. John Borthwick Gilchrist of the Bengal Medical Service. The learned and the great retain Persian for epistolatory correspondence. When, however, Hindi is spoken by Hindus, who draw on Sanskrit for enrichment or embellishment, it appropriately retains the name of Hindi. Modified in these various ways, it is found not only on the plains of Hindustan, but also on the southern slope of the Himalayas, for Mr. Trail informs us that the language of Kamaon and Garhwal is pure Hindi, Indeed, generally, along the Sub-Himalayan range as far as the Gogra river, the impure Hindi dialect introduced by the Gurkhas from the plains appears to be extirpating the vernacular Tibetan tongues of the aboriginal mountaineers. Mr. Masson made himself understood throughout the whole of Kohistan ; and it will thus be seen that the term is used to bring under one common designation the various dialects of a language essentially one, but which has received no great cultivation in any of its forms. According to the Brahman pandits of Benares, there are hundreds of dialects equally entitled to the name. The Brij Basha (or Bhaka, as it is pronounced on the Ganges) and the Panjabi are the two most cultivated varieties of it; but the Panjabi passes into Multani, which a good philologist has shown to be a corrupted form of Panjabi; whilst Jataki, again, farther to the south, is a corrupted form of Multani ; Sindi, according to Lieut. Burton, is a perfectly distinct dialect, though directly derived from Sanskrit. When the Mahrattas extended their conquests into Hindustan, they saw Hindi everywhere prevalent, from the limits of the desert to the frontiers of Bundelkhand, and, finding it different from their own tongue, they called it contemptuously Rangri Basha, quasi barbarous jargon. Sir John Malcolm extends the Rangri Bhaka as far west as the Indus, and east as far as the frontier of Bundelkhand, where, as in all the country to the Indus from the western frontier of Bengal, dialects of Hindi prevail. The Marwari and other dialects of Rajputana are evident varieties of Hindi introduced by the Rajput races.

The great variety of the Hindi dialects is doubtless owing to the absence or non-use of any common book, as the Bible or New Testament; and from the prolonged dominance of the Mahomedan rulers, and the encouragement given by them, by the ruling Hindu courts, and by the British, to the study of Persian, Hindi has been less studied than the Persian or modern Urdu. In 1872, in eight districts of the N.W. Provinces, the Urdu or Persian reading pupils in the Tahsili and Halkabandi schools largely exceeded the Hindi and Nagri reading scholars, ranging from $\frac{2}{5}$ ths to $\frac{3}{4}$ ths.

The people speaking these Hindi dialects are of different races. Amongst the races in this tract are the Mhairs of Ajmir, the Rajputs, the Hindus of the eastern counties, called Purbhiahs, and the descendants of the Aryan conquerors who have been residing there nigh two thousand years, men of large physical frame, proud, vain, self-reliant, and abstemious.

HINDIAN, a small town in Khuzistan, on the Tab river, 35 miles from its mouth, navigable to this town for bagla and boats.-MacG.p. 176 .

HINDIKI, a name by which the Hindus are designated in Afghanistan and westwards to Russia. In Astracan there are about five hundred families. Mr. Mitchell says that the reputation of these Hindu colonists stands very high, and that they bear a preference over all the merchants of other nations settled in this great commercial city. The Hindiki in Afghanistan are described by Bellew as descendants of Arab fathers with Hindu mothers. The Indian born Habussh, slaves of the Nawabs of the Karnatic, were styled Hindi.

HINDU is the ordinary name by which the 
idol-worshipping people of British India are at present known, but the term is only of recent use. The races to whom it is applied are only now fusing, under the firm rule of the British, and never, hitherto, could have had one common designation. Bharata or Bharatavart'ha is an ancient Sanskrit name for part of the countries which Europeans include in the term India. Hindu for the people, and Hindustan for the country, now so generally applied by natives as well as foreigners, are possibly of Persian or W. Aryan origin, and may have relation to the seven rivers of the Panjab, the Sabp'ta-Sindhu, which the Aryans met with in their course to the south, the river Indus being still known as the Sind hu or Sind'h (Hitopadesa, p. 333). With the Persians, Ind or Hind and Hindu, as synonymous with black, has long been applied to the dark-coloured populations in the territories which are now comprised in British India. The Arab, the Persian, the Afghan, and Sikh, when speaking of the people of India, only call them 'black men;' and even in India the Mahomedan descendants of the Arab, Persian, Moghul, and Afghan conquerors use the same designation. 'Kala Admi,' literally black man, is ever in their mouths; and Hindus themselves, in their various tongues, likewise so distinguish themselves from all the fair foreigners amongst them. The African races, who were formerly brought to India as the household slaves or guards of native princes, invariably, when alluding to such of their own people as are born in the country, style them Hindi; and the Hindu merchants trafticking throughout Afghanistan, Central Asia, and Russia, are known to the people as Hindiki. Therefore, though a large part of the idol-worshipping people now-a-days call themselves Hindu, in this they are merely following the names given to them by their Arab, Persian, Afghan, Turk, Moghul, Tartar, and British rulers. Even Europeans have only of late habitually used this term, for at the beginning of the 19th century Gentoo was the everyday name employed, though it has since gradually fallen into disuse. It, also, was derived from a foreign people, the Portuguese, and was applied to the idol-worshippers, like the Gens of the Romans and Gentile of the Scriptures. It never, perhaps, reached much beyond the seaport towns, and if the better educated amongst the natives ever employed it, their doing so was merely in imitation of Europeans. And now, too, similarly, Brahmans and others, when alluding to the Teling race of their ow n countrymen, likewise style them Hindus.

Hindu is thus almost entirely a European conventional term, and does not represent a nation, a race, or a religion. The great bulk of the people known by this appellation are the descendants of Turanian, Scythian, and even Aryan immigrants, who in bygone ages are supposed to have left the cold north, some offshoots moving westward, and others to the south ; for remnants of Turanian languages are found in Baluchistan, and the seat of the great Sanskrit-speaking people was long in Kashmir, proving that one great highway to the south had been down the valley of the Indus, through Kashmir and the Panjab. But between the valley of the Indus and that of the Brahmaputra, there are 20 or 30 passes in the Himalaya through which the northern races could stream to the genial south. Amongst the first of these immigrants seemingly were Kolarian and Dravidian races, belonging to the Turanian family of mankind, bodies of whom seem to have spread themselves over the Peninsula. As to the date of their advent, however, history is silent, but there seems no doubt that great branches of the Scythic stock were occupants of India at the time that it was to a considerable extent conquered by the Sanskrit-speaking tribes of the Aryan family. In the north, the subjugation or ousting of the Turanians from all rank and power was so complete, that Sanskrit forms of speech became the languages of the country; and now, in the north, Kashmiri, Panjabi, Sindi, Gujerati, Mahrati, Hindustani, and the Bengali, all of them with a large admixture of Sanskrit, are sister tongues known as forms of Hindi. South of the Nerbadda, however, it is otherwise. Throughout the Peninsula the languages in use differ from the Sanskrit in grammar, and only admit Sanskrit words in the same way that the Anglo-Saxon admitted terms of law and civilisation from the Norman-French. At the present day, the south of India more largely represents the Turanian, and the north the Aryan race. The fair, yellow-coloured Aryans are, however, to be met with south even to Cape Comorin but though mixing with the various Dravidian nations, races, and tribes for at least 3000 years, in physical form, complexion, intellect, and manners, the Brahmanical and other Aryan families are as distinct as when their forefathers first came from the north, it may be three or four thousand years ago. The great Aryan migration seems to have received its first check at the Vindhyan range, between the 14th and 8 th centuries before the Christian era.

This powerful branch of the Aryans passed into Northern India between the 14th and 8 th centuries before Christ. They brought with them the language of the Vedas; and as all Brahmans profess alike to recognise the authority of these sacred books, we witness the modern worshippers of Siva, Vishnu, and the maintainers of the Sankhya or Nyaya or Vedanta doctrimes, all considering themselves and each other to be orthodox members of the Hindu community. It is this common recognition of that one set of religious books which is the sole bond of union amongst the descendants of the various races and tribes professing Hinduism or Brahmanism, who now people India. The Aryans seem to have brought with them a servile race, or to have had amongst them a social distinction between the noble and the common people, which has ever continued. As they conquered southwards, amongst the Turanian races whom they found in the country, they reduced the less civilised tribes to a state of predial slavery. They named them in fierce contempt, Dasa or slaves, and these formed the true servile race of Menu and other writers. Where the races who had preceded them retained their independence, these proud immigrants styled them M'hlecha, a term which even to the present day is intended to comprise everything that is hateful or vile. But the immigrant Aryans found along the coasts of India also other races, different alike from the Scythic tribes and from the Aryans of the Vedas, - earlier colonizers or immigrants, probably from the west, - who had a civilisation of their own, and with whom the Pharaohs, and Solomon and Hiram, and the Cushite Arabs of Yemen 
and the people of E. Africa, carried on a lucrative trade by sea. This people had extended down the coast to Cape Comorin, had crossed over to Ceylon, and crept up the Coromandel coast, till stopped by the Godavery and Mahanadi. All the Bengal Presidency and Central India was at that time thinly inhabited by a Turanian, Sakyan, or Mongol race, coming down from Tibet and Nepal. But so sparse was the population whom the Aryans encountered, that, in the Vedas, Agni is represented as the general of Nahusha, the first settler, that is, they cleared the ground by burning the forests, and some fine descriptions are given of the grandeur and terror of the sight. Up to the present day the religions of the prior occupants have never been other than local cults, and many of them even yet continue very barbarous. The higher civilisation of the East Aryans has enabled them to propagate their changing views, but the phases of their religious beliefs have been marked by four great epochs:-

I. The Vedic age, which was characterized by the worship of the gods of the elements, Agni, Indra, Varuna, and appears to have been current in the Panjab prior to the disappearance of the Saraswati in the sand.

II. The Brahmanic age, characterized by the worship of Brahma, and which seems to have prevailed between the disappearance of the Saraswati and the advent of Sakhya.

III. The Buddhist age, which was characterized by the pursuit of Nirvana, and seemingly prevailed from about B.C. 600 to A.D. 800 or 1000 .

IV. The Brahmanical revival, which is characterized by the worship of incarnations of deities, and has prevailed from about A.D. 800 till now.

Vedic Age.-Among the gods whom the Vedic Aryans worshipped were Indra and Agni. Indra was the firmament, with all its phenomena. $\mathrm{He}$ alone held the thunderbolt, and was king over gods and men. Agni was the element of fire. All the other gods were but manifestations or other forms of these two. The relationship is evident between Agni and the sun, the Surya or Sura Savitri of the Vedas, and a female divinity. But Indra also is frequently identified with the sun: indeed, the twelve great deities, or Aditya, are but other names of the same god as presiding over the twelve months of the year. The Aditya most frequently invoked are Mitra, Varuna, Aryaman, and, in a lesser degree, Ansa, Daksha, Pushan, Bhaga, Vishnu, and Twashtri. Pushan watches over roads and travellers; Twashtri is the Vulcan or smith of the gods. Slight mention is made of Vishnu; but we have the germ of the legendary three steps, being apparently simply the rise, culmination, and setting of the sun. Among the inferior deities, the Marut or winds hold the first place; and next to them the Aswini, apparently twins or brothers, and sons of the sea (Sindhu), so that the Vedic Aryans evidently had settlements near some water, which they called a sea. The Aswini are almost invariably represented as having a triangular car with three wheels, drawn by asses; while their name appears to be derived from Aswa, a horse, which would seem to identify them with the two horses of the sun. The sakta or hymns addressed to them are richest of all in legend. Their connection with Indra (Jupiter), their patronage of mariners, their twin brotherhood, the two horses and stars found on their coins, identify them with the Grecian Dioscuri. In the Vedas, heaven, earth (Aditi and Pritivi), and ocean are rarely invoked, and the sun has com- paratively few saktas. Occasional laudations are given to rivers, especially to the Saraswati; and this nature-worship extends to the cow, the wood used in the oblations, and even the vapa or sacrificial post. To Ushas, or the dawn, some of the most beautiful hymns in the Veda are addressed. All these deities are expressly declared to be 'the progeny of the heavens and the earth' (IVilson's Vedas, i. p. 276). No mention is made of the planets,- for Brihaspati is not a planet, but ' the lord of prayer,'-and the moon has not even a sakta.

The worship of the Vedic race is briefly but comprehensively described by themselves (Asht. I. Adhy. I. Sakta 6), where it is said the standers around associate with (Indra) the mighty (sun), the indestructive (fire), the moving (wind), and the lights that shine in the sky. The blessings they implore, says Professor Wilson, 'are for the most part of a temporal and personal description, -wealth, food, life, posterity, cattle, cows, and horses; protection against enemies, victory over them, and sometimes their destruction.' 'There are a few indications of a hope of immortality and of further happiness, but they are neither frequent, nor, in general, distinctly announced.' The only notice of an after life is found in the legend (for nothing is founded on it) of three brothers called Ribhus, who for their meritorious actions were made gods. Also, in one or two passages, Yama and his office of ruler of the dead are obscurely alluded to (Dr. Wilson, i. p. 25). Yama is usually connected with the Yamuna river. So monotonous and irreverent are the great bulk of their prayers (to Indra especially), that Professor Wilson could scarcely believe them to be in earnest. An instance of this is the hymn addressed to the goddess Anna (Anna devati, known in Bengal as Anna Purna), personified as Pitu, or material food, by the rishi Agastya (see Wilson's Veda, ii. p. 192; Calcutta Review, No. 64, p. 412); and in a similar strain the soma plant is addressed. This plant, the Sarcostemma brevistigma, is found all the way from the mountains of Mazenderan to the Coromandel coast, and Viswamitra is described as passing the Sutlej and Beas to gather it. Bruised between two stones, mixed with milk or barley juice, and fermented, it formed a strong inebriating spirit. 'The purifying soma, like the sea rolling its waves, has poured forth songs, and hymns, and thoughits.'

The ritual of these old Aryans, as described in Professor Wilson's epitome of the saktas, comprehended offerings, prayer, and praise. The former are chiefly oblations and libations of clarified butter poured on the fire, and the expressed and fermented juice of this soma plant, presented in ladles to the deities invoked. It seems to have been sometimes sprinkled on the fire, sometimes on the ground, or rather on the kusa sacred grass strewed on the floor; and in all cases the residue was drunk by the assistants. There is no mention of any temple, or any reference to a public place of worship; the sacrificial chamber was always in the house of the worshipper, and it is clear that the worship was entirely domestic. The worshipper himself does not appear to have taken any part personally in the ceremony ; and it was by priests - seven and sometimes sixteen-by whom the different ceremonial rites are performed, and by whom the mantras, or prayer and hymns, were recited (i. p. 24). The soma juice was the obla- 
tion or libation of the Vedic worship (the homa of the Parsee), and allusions to it are met with in almost every page.

The following tabular statement of the number of saktas in the 500 hymns translated by Professor Wilson, addressed to each deity, sets their actual and relative worship clearly before us:-

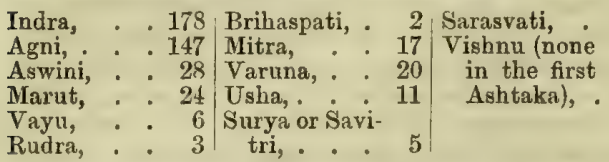

This leaves less than sixty hymns for all the other members of the Vedic pantheon. Some of the divinities worshipped in Vedic times are not unknown to later systems, but at first perform very subordinate parts; whilst those deities who are the principal objects of worship of the present day are either wholly unnamed in the Veda, or are noticed in an inferior or different capacity. The names of Siva, of Durga, of Kali, of Rama, of Sita, of Krishna, of Radha, the present gods, so far as research has gone, do not occur in the Vedas. And the practice of the conquered races seems to have been to represent or regard local deities as identical with, or avatars or incarnations or other names of, the Vedic gods, who had already become objects of Aryan worship. The Vedas mention Rudra as the chief of the winds, collecting the clouds as a shepherd's dog does the sheep, and attending on his master Indra ; in the Vedas he is the father of the winds; even in the Puranas he is of a very doubtful origin and identification; but in the present day everywhere amongst the Saiva Hindus he is identified with Siva. With the single exception of an epithet Kapardi, 'with braided hair,' of doubtful significance, and applied also to another divinity, no other name applicable to Siva occurs, and there is not the slightest allusion to the lingam or phallus form in which, for the last ten centuries at least, he seems to have been almost exclusively worshipped in India; neither is there the slightest hint of another important feature of later Hinduism, the trimurti, or triune combination of Brahma, Vishnu, and Siva, as typified by the mystical syllable $O^{\prime} \mathrm{m}$ ( $\left.a-u-m\right)$, although, according to Creuzer (i. p. 26), the trimurti was the first element in the faith of the Hindus, and the second was the lingam. In this view Creuzer must have intended the mixture of creeds now current in India, for the whole Vedic faith was essentially a sabaistic and nature worship.

Religious Books. - Aryan Hindus have been remarkable amongst civilised races as abstaining from all historical writings; and a knowledge of the changes that have occurred in their beliefs has been obtained from their books of religion, philosophy, and fiction.

The Rig-Veda Sanhita is a collection of hymns of the ancient Aryans, addressed to the elements and powers of nature. Their age is various, prior and subsequent to the 15 th century B.C. The Rig-Veda is of primary importance in the Hindu religion and mythology. The Yajur and Sama Vedas consist of hymns derived from the Rig, but re-arranged for religious purposes; and the fourth Veda, the Atbarva, is of later date. The Brahmana are ritualistic and liturgical compositions, chiefly in prose, and attached to the different mantras. They are later than the Vedic hymns, and recognise one Great Being as the soul of the universe. Of a still later age are the Aranyakas and Upanishads, which form part of the collective Brahmanas, and are principally philosophical. The Brahmanas recognise one Great Being as the soul of the universe. A golden egg was produced in the universal waters, from which in course of time came forth Prajapati, the progenitor, or the quiescent Universal Soul. Brahma took a creative form, as Brahma the Prajapati. From the Prajapati, or great progenitor, there was produced a daughter, and by her he was the father of the human race. The Upanishads, of which above 150 are known, are later, the oldest being about the 6 th century B.c. They contain an examination of the mystic sense of the Vedas, and are free from Brahmanical exclusiveness. They have a monotheistic tendency.

The age of Menu was after that of the Brahmanas. Menu follows the golden egg theory, and he calls the active creator who was produced from it, Brahma, and Narayana. The latter name became subsequently exclusively applied to the Vishnu deity. The institutes of Menu show a great advancement of the Brahman caste.

The Mahabharata and the Ramayana are epic poems, which deal with the actions of men. Indra is mentioned; but Brahma, Siva, and Vishnu have become the gods, Brahma being but little mentioned; while in some passages Siva, in others Vishnu, is supreme, and the incarnations of Vishnu assume a permanent place. The Ramayana, by Valmiki, is supposed to be of the 5th century B.c., and its hero the royal Rama and his faithful wife Sita have been deified as incarnations of Vishnu and his consort. It is the older epic. The age of the Mahabharata is supposed to be in some of the six centuries B.C. ; but it contains an interpolated episode, the Bhagavat Gita, which has been supposed to be of the $2 d$ or $3 d$ century A.D. In it Krishna is the Supreme, and bhakti or faith is enjoined.

These books belong to the Brahmana age. But a great reformer arose in the 6th century B.C., and the religious sects formed after him were prominent in India for about 1500 years, and are still the faiths of Burma, Tibet, Mongolia, Manchuria, Siam, Annam, and largely of Ceylon, China, and Japan. The reformer was Sakya Sinha, son of king Suddhodana of Magadha, and is known to history as Buddha.

Buddhism.-The valley of the Ganges was the cradle of Indian Buddhism, and Sakya Muni the founder of the new doctrines. As the champion of religious liberty and social equality, Sakya Muni attacked the Brahmans in their weakest and most vulnerable points, -in their impious assumption of all mediation between man and his Maker, and in their arrogant claims to hereditary priesthood. His boldness was successful, and before the end of his long career he had seen his principles zealously and successfully promulgated by his Brahman disciples, Sariputra, Mangalyana, Ananda, and Kasyapa, as well as by the Vaisya Katyayana and the Sudra Upali. At his death in B.C. 543, his doctrines had been firmly established, and the holiness of his mission was fully recognised by the eager claims preferred by kings and rulers for relics of their divine teacher. His ashes were distributed amongst eight cities, and the charcoal from the funeral pile was given to a ninth. He 
had lived and preached from Champa and Rajagriha in the east, to Sravasti and Kausambi in the west. In the short space of 45 years, this wonderful man succeeded in establishing his own peculiar doctrines over the fairest districts of the Ganges, from the Delta to the neighbourhood of Agra and Cawnpur. This success was perhaps as much due to the early corrupt state of Brahmanism, as to the greater purity and more practical wisdom of his own system.

From his time until the end of the long reign of Ajatasatra, 519 B.C., the creed of Buddha advanced slowly but surely. This success was partly due to the politic admission of women, who in the east have always possessed much secret though not apparent influence over mankind. To most of them the words of Buddha preached comfort in this life, and hope in the next. To the young widow, the neglected wife, and the cast-off mistress, the Buddhist teachers offered an honourable career as nuns. Instead of the daily indignities to which they were subjected by grasping relatives, treacherous husbands, and faithless lords, the most miserable of the sex could now share, although still in a humble way, with the general respect accorded to all who had taken the vows. The Bhikshuni were indebted to Ananda's intercession with Sakya for their admission into the ranks of the Buddha community; and (see Csoma's Analysis of the Dulva, Res. As. Soc. Bengal, xx. p. 90 ; also Fo-kue-ki, chap. xvi. p. 101) the Pi-khieu-ni, or Bhikshuni, at Mathura, in token of their gratitude, paid their devotions chiefly to the stupa of Anan (Auanda), because he had besought Buddha that he would grant to women the liberty of embracing ascetic life. The observances required from the nuns are recorded in note 23 , chap. xvi. of the Fo-kue-ki. The female ascetic even of a hundred years of age, however, was bound to respect a monk even in the first year of his ordination. It is related that Sakya's wife, after the first outburst of grief on seeing his return to her as an ascetic, herself became a Bhikshuni.

From its rise in the 6th century B.C., the doctrines of Buddha gradually spread over the whole of India. It was extended by Asoka to Kashmir and Kābul shortly after Alexander's invasion, and it was introduced into China about the beginning of the Christian era by 500 Kashmirian missionaries. In A.D. 400, when $\mathrm{Fa}$ Hian visited India, Buddhism was still the dominant religion, but the Vaishnava sect of modern Brahmanism, with a mixture of the old Aryan creed and the Buddhist faith, were already rising into consequence. In the middle of the 7 th century, although the pilgrim Hiwen Thsang found numerous temples of the Saiva, whose doctrines had been embraced by Skanda Gupta and the later princes of Pataliputra, yet Buddhism was still the prevailing religion of the people. But though the faith of Salcya lingered about the holy cities of Benares and Gaya for two or three centuries later, it was no longer the honoured religion of kings and princes, protected by the strong arm of power, but the persecuted heresy of a weaker party, who were forced to hide their images under ground, and were ultimately expelled from their monasteries by fire. In 1835, Major Cunningham excavated numerous Buddhist images at Sarmath near Benares, all of which had evidently been purposely hidden under ground. He found quantities of ashes also, and there could be no doubt that the buildings had been destroyed by fire; and Major Kittoe, who subsequently made further excavations, was of the same opinion. The Buddhist religion has long been extinct in British India. Its last remnants were extinguished, in blood and violence, about the 14th century, dying out about Trichinopoly and along the coast-line from Vizianagram to Masulipatam. But it still flourishes in its Hinayana and Mahayana forms, in the countries on its north and north-east borders, in Nepal and Tibet, in Mongolia and Manchuria, in Ava, Ceylon, and China, and amongst the Indo-Chinese nations of Annam, Siam, and Japan; and its followers far outnumber those of all other existing creeds except the Christian.

The Buddhist faith was pre-eminently a religion of mercy and peace, of charity and benevolence. In the topes dedicated to the celestial Buddha, Adinath, the invisible being who pervaded all space, no 'deposit was made; but the divine Spirit, who is 'Light,' was supposed to occupy the interior, and was typified on the outside by a pair of eyes, placed on each of the four sides either of the base or of the crown of the edifice. But in ages of strife and violence, of deifying mortals and of arrogant assumptions of an ignorant priesthood, a creed that taught gentleness and meekness and kindness to living creatures must have exercised a great influence over the community,must early have gained many converts amongst the peaceable and good, and largely leavened the minds even of those who did not openly become converts; and amongst this class must be included the entire populations from the primevai land east of the Oxus to China and Japan in the farthest east, to Singapore and Ceylon in the extreme south. For ten centuries it had been the prevailing religion of India; but when the unwritten Tartar faith became corrupt and feeble, Brahmanism was revived, mixed with the worship of new gods, a Siva and a Vishnu, and every form of absurd fetishism gathered from local idolatries and superstitions. It is this mixture of several creeds which Europeans now style Hinduism, and its followers Hindus. It is found amongst the people in every variety of belief,-from the mildest spirit and demon worship and recognition of numerous forms of gods and their idols, to a distinct theism; from the grossest ignorance and superstition, to the most refined speculativeness; performed and associated with bloody and most inhuman rites, and again followed with the greatest tenderness for animal life.

Brahmanic Revival.-In the later hymns of the Vedas can be traced the origin of the Vishnu worship, and the setting aside of Indra. But the foreign Siva and Bhavani had come in with the Sakæ, and mingled in their worshippings, until the doctrines of Buddha, himself a Sakyan, were promulgated, and held their own for more than a thousand years, until, between the 5th and 12th centuries of the Christian era, a host of new divinities, Vishnu, Siva, Durga, Kali, Rama, Krishna, Ganesha, Kartikeya, prevailed over a better faith than their own, and up to the present day enslave and degrade the Hindu mind.

The Puranas, eighteen in number, are more recent books. Their age has been supposed to be from the $2 d$ to the 16 th century A.D., though their name means old. These are all in verse; give a 
cosmogony, celebrate the powers and works of the gods, and give the history of the Solar and Lunar dynasties who ruled in Northern India; and to them have been appended 18 Upa Puranas. Later than these are the Tantras, which are religious and magical works, that give prominence to the female energy of the deity, his active nature being personified in the person of his sakti or wife, each of whom has a gentle and a fierce form, as Radha, Devi, Uma, Gauri, Durga, and Kali, and these are worshipped both symbolically and in the actual woman.

In the Puranas the Vedic deities are forgotten, and marvellous legends have gathered round the favourite divinities, full of wild imaginings, and evidencing a corrupt state of society and religion. Vishnu and Siva have obtained respective sects as followers. Krishna has become the object of a sensuous, joyous worship; the worship of Devi, the consort of Siva, has become established, and the foundation has been laid of the obscene and bloody rites afterwards developed in the Tantras. The Puranas and the Tantras are the religious books of the Hinduism of the present day. The Veda is a mere name: its gods, and rites, and language are only known to the learned, and the modern system is quite at variance with the Vedic writings, - the Puranas and later writings being the great authorities of modern Hinduism. Their mythology and legends fill the popular mind, and mould its thoughts. The great epic poems, the Mahabharata and the Ramayana, with their heroes, the Pandava, the Kaurava, Rama and his wife Sita, Hanuman, and Ravana, are listened to with delight; and the stories about Krishna, from his infancy till his death, are the never-ending source of joy to the young. The mild and gentle Rama, 'the husband of one wife,' pure in thought and noble in action, and his faithful wife Sita, are, however, objects of the devotion of many, and theirs is the least degrading of the many forms of Hindu worship.

Philosophies. - Concurrent with the ritualistic worship of the modern Hindu gods and goddesses, there are six schools of philosophy, - the Nyaya, the Vaiseshika, the Sankhya, the Yoga, the Yurva mimansa, and Uttara mimansa. All of them have the same final object, - the emancipation of the soul from future birth and existence, and its absorption into the supreme soul of the universe. They are supposed to have had their origin between the 5th and $3 d$ centuries B.C. The Nyaya and Vaiseshika recognise a Supreme Being; the Yoga is theistical; the Sankhya, atheistical; the two Mimansas are the Vedanta. The object of these two Vedanta schools is to teach the art of reasoning, with a view to aid in the interpretation of the Vedas. The Purva mimansa is generally known as the Mimansa, and the Uttara mimansa as the Vedanta; and the principal doctrines of the latter are that the Supreme Being is the omniscient and omnipotent cause of the existence, continuance, and dissolution of the universe. The Vedanta or Mimansa philosophy is treated as a scholastic philosophy, which, basing itself on the sacred books and the popular religion, seeks for unity of thought only as a means of introducing order amid the divine personages and legends, and has sought to give a spiritual import, a sort of new birth, to the gods of Brahmanism. In the Vedanta philosophy, Brahma is placed in the foreground as the soul of the universe, the primal being, which alone has true existence. To this school, not matter only was a semblance, even the soul was a transient phenomenon. The Sankhya philosophy is contrasted with it, as a purely pantheistic system. In this view this philosophy has broken completely with the popular creed, and with the doctrines of the Vedas and the Brahmanas. The Sankhya philosophy occupies itself more with life in manifestation, therefore especially with the life of the individual spirit connected by its body to the outward world. Both of these leave the Vedas unassailed, nay, the whole Brahmanic religion, in so far as it concerns rites and customs.

A census was taken of the people of British India in 1881, and the numbers following these creeds were found to be $187,957,450$, out of a total population of $253,891,821$ souls :-

Hindu Population, census 1881.

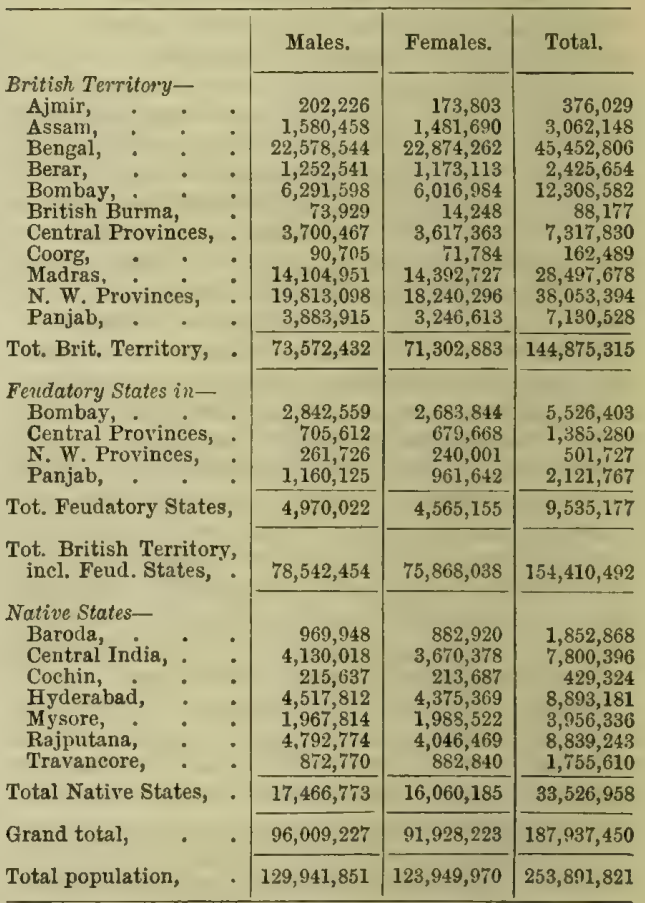

Christianity and Mahomedanism have modified the doctrines of the Aryan Hindus. Since Buddhism disappeared from India, its nations have been conquered by races professing creeds with followers nearly as numerous as Buddhism had ever acquired. Rapid as was the progress of Buddhism, the gentle but steady swell of its current shrinks into nothing before the sweeping flood of Mahomedanism, which in a few years spread over one-half of the civilised world, from the Atlantic Ocean to the swampy fens of the Oxus, to China, and to the Eastern Archipelago. From the 11th century, when the inroads into India of Mahomedans began, up to the present time, when they too, as a ruling race in India, have in their turn almost disappeared, Semitic Arabs, Aryan Persians, Scythic Tartars, Turk and Mongols, and Anglo-Saxons, have successively swayed the destinies of the Hindu races, and each of the new-comers has to some extent 
modified the beliefs and social customs of the conquered. Legislation by the Mahomedan rulers, and after them by the British, has effected many changes. Repulsive forms of fanatical penance are phenomena seldom seen; the immolation of widows is a criminal occurrence; ghat murder, or the exposure of the sick and dying upon the banks of sacred rivers, is matter of past history; open infanticide has been in a great measure suppressed. Further changes have been retarded by the circumstance that the Mahomedan and the Christian came amongst them as soldiers, with all the licence to be found in camps, and the contempt for strange things which youth engenders. Nevertheless the great bulk of the 23 millions who follow Mahomedanism in Bengal and Assam, as also its followers who speak the Malay language, are descendants from idol-worshipping races; while in N.W. India many Rajput and Jat tribes have also embraced the faith of Islam; and the Hindu Nanak, the founder of the Sikh faith, and Kabir and other reformers, drew their views prominently from the Mahomedans. Christianity has been preached in India since the early years of the era, and there has lately been a belief that parts of the ritual of the worship of Krishna had been taken from Christian texts, but the Christians throughout the E. Indies, China, and the Archipelago may not as yet exceed three millions.

Since the 15 th century, Christian missionaries of all sects have been labouring in their vocation, with some success. But this has been largely owing to the steady increase of schools for secular instruction, which have every year been on the increase, and, since the middle of the 19th century, are crowded with the youth of all races, sects, castes, and ranks. In this respect every teacher of English is a missionary, for it is impossible for the youth of India, if educated under Christian teachers by means of a Christian literature, to be otherwise than embued with the doctrines of Christians, whatever their professions may be. In the 19 th century, the first reforming sect that arose was a theistic body in Calcutta, and many who have received the bigher education have joined it, or have formed other sects with similar views. But even in the case of Hindus who have had no English education, and have never heard the voice of the missionary, such are receiving instruction from others of their own people who have been so taught; and the mass has been so leavened, that the great tendency amongst youthful inquiring minds is to accept some form of monotheism,-either to acknowledge one of their own deities, whether Vishnu or Siva, as the Lord of all, or adopt an ideal Supreme Being of their own creation, whom they clothe with attributes, purer, more just, and more worthy of reverence than any god which their religious books possess.

Hinduism as it is. - In approaching this part of the subject, it may be mentioned that the mythology of India has done much to explain that of Greece and Scandinavia, as will be seen by the following list of the more prominent Hindu deities of the present day and their principal analogues:Agni, : - Vulcan, fire, ignis.

Swaha, : Vesta, his wife.

Aswini-Kumara, Castor and Pollux.

Aruna, . Aurora.

Atadeva, : : Diana

Kuvera, : : Plutus, the god of riches,
Indra, . . God of firmament,-Jupiter.

Varuna, . . God of water, -Neptune, Ouranos. Prithivi, : : Goddess of earth, - Cybele.

Viswakarma, Architect of gods, - Vulcan.

Surya or Arka, - The sun, $\rightarrow$ Sol.

Heracula, : A Hindu deity, $\rightarrow$ Hercules.

Aswiculapa, , Esculapius?-Genii.

Vayu, . . Eolus.

Vaitarini, . The river Styx.

Durga, . . Juno.

Narada, : : God of music, - Mercury.

Krishna, . . Apollo.

Bhawani, - Venus or Minerva Musica.

Kali or Durga, : Proserpine.

Ganesha, - A male Minerva.

Kartikeya or

Skanda,

Kama, .

God of war, - Mars.

Hanuman, son of

Pavana, .

Rama, .

Sri, Lakshmi

Anna Purna,

God of love, - Cupid.

The monkey god, - Pan.

The god of wine, - Bacchus.

Ceres.

Sects. - The changes in the religions of the Aryan Hindus during the past nineteen centuries have been continuous. Perhaps the earliest indications of coming changes were given in the third division of the Vedas, known as the Upanishads, which discuss the nature of the deity, the nature of the soul, and the connection of mind and matter. They contain the beginnings of the metaphysical inquiry, which ended in the full development of Hindu philosophy. The oldest of these books is supposed to be about the $2 d$ century B.C.

The great Saiva reformer was Sankaracharya, who lived in the 8th or 9th century. He was the teacher of the Vedanta philosophy; he founded the sect of Smartha Brahmans, and has been regarded as an incarnation of Siva. His follower, Anandagiri, wrote the Sankara Vijaya about the 10th century. The worshippers of Siva regard that deity as the Supreme : and his consort Parvati, in her numerous forms of Devi, Durga, Bhawani, etc., has many worshippers. These two are preeminently designated Mahadeo and Mahadevi.

Vishnu and his consort Lakshmi are equally regarded by their followers as Supreme, and might have the same designations, but neither under these names nor in any of their many incarnations are they so honoured. A few of the gods of the times prior to the Christian era continue to be invoked,-amongst them, Indra the god of the firmament, Agni the god of fire, Kama the god of love, and Kuvera the analogue of Pluto; but the Diti, Aditi, Aditya, Rakshasa, and others of the Vedas have become myths, and the chief deities of the modern Hindus are Siva and Vishnu with their consorts; Rama and Rama-Chandra, and Bala Rama, Ganesh, Garuda, Hanuman, Jaganatha, Kandoba, Krishna, Kartikeya, god of war, the phallic lingam, Nandi the bull, Virabadhra, and Vitoba.

Ramanuja was a Vaishnava philosopher, who put forward the Viseshtadwaita system, and the sect who follow his teachings worship Rama and Sita. The Adwaita is a monad doctrine, which acknowledges the reality of spiritual existence only. Dwaita, or the doctrine of duality, distinguishes two principles in creation, spirit and matter.

Ramanand (A.D. 1350 ?), the follower of Ramanuja, was the first to admit low caste people as his disciples, one of whom was Rai Das, another was Kabir, and the Kabir Panthi sect gave rise to the Nanak Shahi about A.D. 1449. 
Chaitanya, a Vaishnava reformer in Bengal in the 16th century, was deemed an incarnation of Krishna. He too admitted all classes as his disciples.

Charandas, a merchant of Dehli, lived in the time of the 2d Alamgir (A.D. 1757). His first disciple was his sister, Sahaji Bai, who was a distinguished writer. The sect worship Krishna and Radha.

Mira Bai, wife of Lakha, rana of Udaipur in the reign of Akbar, was of the Vaishnava sect, and a distinguished writer.

Jayadeva, of the 12th or 13th centuries, wrote the Gita Govinda, an erotic poem on the early life of Krishna.

Five great sects exclusively worship a single deity, and one recognises the five divinities; these are-

1. Saiva, worshippers of Siva in his numerous forms, who, however, worship Siva and Parvati or Bha wani conjointly.

2. Vaishnava, who worship Vishnu.

3. Surya, who worship Surya or the sun.

4. Ganapatya, who worship Ganesha.

5. Sakta, who exclusively worship Bhawani or Parvati, the sakti or female energy of Siva.

6. Bhagavata, who recognise all divinities equally.

The fourth and fifth are subdivisions or ramifications of the first, or Saiva, of which may be traced these distinctions:-1. Saiva proper, meaning the worshippers of Siva and Parvati conjointly. 2. Lingi or Lingaet, the adorers of Siva or his phallic type separately, and these are a very.strict and rigid sect. 3. Sacta, the adorers of the yoni of Bhawani or her symbol separately. 3. The Ganapatya, the exclusive worshippers of Ganesha, the first-born of Mahadeva and Parvati.

The second grand sect, or Vaishnava, is variously divided and subdivided. First, or division of Gocalast'ha, or worshippers of Gocal or Krishna, is subdivided into three :-

1. Exclusively worship Krishna as Vishnu himself: this is generally deemed the true and orthodox Vaishnava.

2. Exclusively worship Radha, as the sakti of Krishna or Vishnu: this sect is called Radha Valabhi.

3. Worship Krishna and Radha conjointly.

Second, or division of Ramanuj, or worshippers of Ramachandra, is in like manner subdivided into three :-

1. Worship Rama only.

2. Worship Sita only as his sakti.

3. Worship both Rama and Sita conjointly.

The Vaishnava of the present day, though nominally worshippers of Tishnu, are thus in fact votaries of deified heroes. The Gocalast'ha (one branch of the sect) adore Krishna, while the followers of Ramanuja worship Ramachandra. Both have again branched into three sects; one consists in the exclusive worshippers of Krishna, and those only are deemed true and orthodox Vaishnava; another joins Krishna's favourite, Radha, with the hero; a third, called Radhavalabhi, adores Radha only, considering her as the sakti or active power of Vishnu. The followers of these last-mentioned sects are said to have adopted the singular practice of presenting to their own wives the oblations intended for the goddess; and those among them who follow the left-handed path are said to require their wives to be naked when attending them at their devotions.

Among the Ramanuj some worship Rama only, and others both Rama and Sita; none of them practise any indecent mode of worship. And they all, like the Gocalast'ha, as well as the followers of the Bhagavata, delineate on their foreheads a double upright line with chalk, or with sandal-wood, and a red circlet with red sanders wood, or with turmeric and lime; but the Ramanuj add an upright red line in the middle of the double white one.

The Saiva sect are all worshippers of Siva and Bhawani conjointly; and they adore the linga or compound type of this god and goddess, as the Vaishnava do the image of Lakshmi-Narayana. The exelusive adorers of the goddess Bhawani are the Sakta sect. In this last-mentioned sect there is said to be a right-handed and decent path, and left-handed and indecent mode of worship; and both Major Moor and Professor Wilson allude to the licentious character of the latter form, a feature certainly quite unknown in the Southern India of the present day. The left-handed form of worship of the several sects, especially that of the Sakta, is founded on the Tantras, which are for this reason held in disesteem.

Sectarian Differences.-The great point of difference amongst the sectaries is as to the claims of respective deities to be regarded as the first cause. Few Brahmans of learning, if they have any religion at all, will acknowledge themselves to belong to any of the popular divisions of the Hindu faith, although, as a matter of simple preference, they more especially worship some individual deity as their chosen or Ishta Devata. They refer also to the Vedas, the books of law, the Puranas, and Tantras, as containing the only ritual which they recognise, and regard all practices not derived from those sources as irregular and profane. These deities have their different avatars or incarnations, in all of which, except that of the sakti themselves, they have their sakti (wives) or energies of their attributes. These have again ramified into numerous names and forms. The following is an enumeration of the several sectaries of each class, and to them we refer for separate notices of their origin and tenets :-

\section{Vaishnava Sects.}

1. Ramanuja, or Sri Sampradayi, or Sri Vaish. nava.

2. Ramanandi or Ramawat.

3. Kabir Panthi.

4. Khaki.

5. Maluk Dasi.

6. Dadhu Panthi.

7. Raya Dasi or Rai Dasi

8. Senai or Sena Panthi.

9. Valabhachari or Rudra Sampradayi.
10. Mira Bai.
11. Madhavachari or Brahma Sampradayi.
12. Nimawat or Sanakadi Sampradayi.
13. Vaishnava of Bengal,
14. Radha Valabhi.
15. Sak'hi Bhava.
16. Charan Dasi.
17. Harischandi.
18. Sadhna Panthi.
19. Madhavi.
20. Sanyasi, Vairagi, Naga.

Saiva Sects.

1. Dandi and Dasnami.

2. Jogi or Yogi.

3. Jungama or Sri Saiva.

4. Paramahansa.

5. Urdhaba'hu, Akas Muk'hi and Nak'hi.
6. Gudara.

7. Ruk'hara, Suk'hara, and Uk'hara.

8. Kara Lingi.

9. Sanyasi, Brahmachari. Avadhuta Naga.

\section{Sakta Sects.}

1. Dakshini or Bhakta. 2. Vami or Vamachari.
3. Kanchuliya.

4. Karari. 
1. Ganapatya Miscellaneous Sects.

2. Saurapatya or Saura.

3. Nanik Shahi, of seven olasses, viz. :

a. Udasi.

b. Ganjbakshi.

c. Ramrayi.

d. Suthra Shahi.

e. Govind Sinhi.

f. Nirmala.

g. Naga.
4. Jaina.

a. Digambara.

b. Swetambara

c. Yati.

d. Sravaka.

5. Baba Lali.

6. Pran Nathi.

7. Sadb.

8. Satnami

9. Siva Narayani.

10. Sunyavadi.
Most of these comprise a number of subdivisions, and, besides acknowledged classifications, many individual ascetics are to be found all over India, who can scarcely be included within the limits of any of them, exercising a sort of independence both in thought and act, and attached very loosely if at all to any of the popular schismatical sects. Some of the popular works of the Hindus adopt a different classification, and allude to 96 prashada or heresies, which are thus arranged, viz.:-Amongst the Brahmans, 24 ; Sanyasi, 12 ; Viragi, 12 ; Saura, 18; Jangama, 18; Jogi, 12 . Also, new gods or objects of worship are in constant formation, and are believed in by great masses of the people, though only a bit of paper, a cart-wheel, and other oddities. There is a temple of the goddess Elamma about a mile distant from the town of Jat, in the Jat jaghir. An annual fair is held in honour of this idol, at which about 10,000 people assemble. About the year 1860, a Mali or gardener set up the idol, stating that it had appeared there of its own accord. Both men and women visit the temple and worship the idol. The worshippers, before commencing the worship, strip naked, apply powdered sandal-wood to their whole bodies, put on the ornaments they may have, hold a small branch of the nim tree in their folded hands, and leave their places of residence to visit the idol. After visiting the idol, they go round the temple for a certain number of times. They then leave the temple to bathe in a neighbouring tank. After bathing, they return to the temple, worship the idol, and return home. When Mr. Chapman was collector of Satara, he punished some of the naked worshippers.

Sakti.-The Hindu goddesses are uniformly represented as the subordinate powers of their respective lords. The term is from the Sanskrit, meaning power, strength; thus Lakshmi, the consort of Vishnu, the preserver, is the goddess of abundance and prosperity; Bhawani, the wife of Siva, is the general power of fecundity; and Saraswati, whose husband was the creator, Brahma, possesses the powers of imagination and invention, which may justly be termed creative. She is therefore adored as the patroness of the fine arts, especially of music and rhetoric; as the inventress of the Sanskrit language, of the Devanagri writing characters, and of the sciences which writing perpetuates; so that her attributes correspond with those of Minerva Musica of Greece or Italy, who invented the flute, and presided over literature.

Mixings.-Saivaism and Vaishnaism described above are the common everyday religions of the bulk of the Hindu populations. But the internal beliefs of the worshippers have no such community, and their various tenets must be sought for under the history of their several sects. A Saiva sect, the Satnami, profess to adore the true name, the one God; but they nevertheless recog

nise the whole Hindu pantheon, and pay reverence to what they consider manifestations of his nature visible in the avatars, particularly Rama and Krishna. The Sadh, on the other hand, utterly reject all kinds of idolatry; are pure deists, with a simple worship. Between these unitarian sects and such as adore every deity, there is the utmost diversity of theory and practice; and the fusing of their creeds, doctrines, and customs is continually going on. Major Moor tells of a Mahomedan butcher at Poona, who occasionally supplied the Residency with meat. Being asked if he would kill a calf, he started back with horror at the proposal, ejaculating a prayer to be forgiven for having even heard it. Many Mahomedans of India borrow from the Hindus ceremonies that are celebrated with festivity. They take an active part in the gambols of the Holi, and even solicit the favours of the Indian Plutus at the Diwali. Many Hindus, on the other hand, join in the festival of the Maharram. The bridal procession of the Mahomedans on the fourth day, with all the sport and gambols of the Chaut'hi, is evidently copied from the similar custom of the Hindus. The Mahomedans have adopted the premature marriage of infants, and Hindus largely imitate the Mahomedan seclusion of their wives (Colebroke, As. Res. vii. p. 307). A Mahomedan is forbidden to eat meat which has not been killed by one of the faithful, who is directed to 'halal' or sanctify the animal by turning its face toward Mecca, and, while the blood is ejected, to repeat a short prayer. Many Mahrattas and other Hindus, pleased with the ceremony, bring their sheep, fowls, etc., to Mahomedans to be made 'halal,' and then eat them with increased satisfaction.

Vahan or Vehicles.-Several animals are appropriated as the vahan or vehicles to the mythological personages of modern Hinduism. The swan, the eagle, and the bull appertain respectively to Brahma, Vishnu, and Siva, and are severally denominated Hanasa, Garuda, and Nandi. Ganesha, eldest son of Siva and Parvati, the elephant-headed god of prudence and policy, rides a rat, supposed to be a very sagacious animal; Kartika, their second son, generalissimo of the celestial armies, mounts on a peacock. Indra, the powerful regent of the firmament, the Jupiter Pluvius of the Hindus, rides the elephant Airavata, symbolical of might. Varuna, genius of the waters, bestrides a fish; as doth also Ganga, the prime goddess of rivers. Kama Deva, the god of love, is carried by a lory or parrot; Agni, god of fire, by an ardent ram.

Village Deities. - Every hamlet has its own object of adoration, always supposed to be a goddess, and the idol is generally a black stone or piece of wood. Amongst names given to it in Southern India are-

Ai.

Ankal-Amma.

Poni-Amma, gold mother. Kani-Amma,

Yegatal.

Mutialamma, pearl mother.

Tripura-sundari, the beautiful of three cities.

Paleri-Amma, or PeriyaAnma, or great goddess. Dandumari, Mallamma.

Chinnamma. Ammannamma.
Osuramma,

Sellamma.

Yellamma.

Padavettu-Amma.

Tulukan-Amma.

Muttumari.

Mari-Amman.

Potearamma

Karikatta.

Tanthoniamma.

Choundeswari.

Vadivatta.

Nagattamma. 
A pujali or pujari, a worshipping priest of the Sudra caste, is appointed for her daily worship. He anoints her daily, and puts ashes on her head, -really on the top of the stone, for it is not an image, being entirely without shape, a mere stone from the neighbouring brook or river. In a small pot he cooks rice, which he collects from the villagers in turn, presents it to the idol, and then takes it to his own home. He breaks a cocoanut in front of the idol, to which he offers it. But the one half he keeps for himself, and gives the other to the families from whom he collected the fruit. The villagers make vows to their goddess to offer up to her fowls and sheep in sacrifice, if she will fulfil their desires. Once a-year they collect money by subscription, and celebrate a feast in honour of their goddess, during which sheep and fowls are largely sacrificed. The Sudra Hindus and the entire servile and predial tribes in the south of India have the fullest faith in their respective village goddesses. When they or their children are overtaken by sickness, they seek the idol and consult the pujari, who sings hymans, affects to hear the Amman's voice, and then announces to the worshipper the offering that must be presented. If cholera break out, it is not unusual for some neighbouring village deity suddenly to rise into great importance, and the sacrificial rite is then almost unceasingly performed. The Hindus, too, have even personified this pestilence into a goddess, whom they name Maha-Kali, and believe that if they neglect her worship she destroys them by the disease. Indeed, gods are everywhere in process of establishment, and smallpox as well as cholera have thus been personified. Maha-Kali of Ujjain is a cholera goddess, and Mari-Amman or Amur of the Tamils is a smallpox deity. When a person is attacked with smallpox, they believe that the goddess has taken possession of the sick man. While in the house, the sexes remain apart until the sick person has recovered, and been purified by ablution. They place the leaves of the margosa tree beside the sick person, because the goddess is supposed to delight in this tree. They give cooling food, but employ neither internal nor external remedies, in reverence for the divinity. The women of the household offer rice-flour mixed with jagari or coarse sugar and black gram (Pairu, TAM.; Yesalu, TEL.) before the patient in honour of the goddess, and afterwards distribute offerings to Sudras and others. On the seventh day, i.e. what medical men call the fifteenth day, the invalid is bathed in cold water, and the whole body rubbed with a pasty mixture of leaves of the margosa (melia and azadirachta) mixed with turmeric, and on the same day rice mixed with curds are distributed to Sudras. If in the virulence of the disease an eye be lost, it is attributed to something having been done displeasing to the goddess. The goddess, indeed, is supposed to appear in three forms,--as Tatta amavaru or Chinnamavaru, i.e. small goddess or measles; Peddamavaru, or great goddess or smallpox; and Pairamavaru, or goddess of green grain (Phaseolus mungo), - the two first of which are most feared.

Devil and Spirit Worship.-Every Hindu work containing allusions to native life, says Dr. Caldwell, and the dictionaries of all the Hindu tongues, prove the general prevalence of a belief in the existence of malicious or mischievous demons, in demoniacal inflictions and possessions, and in the power of exorcisms. Spirit houses of Mysore are little sheds erected over white-ant hills. In Berar, when theGonds fell a wood on a hill-side, they leave a little clump to serve as a refuge for the elf or spirit whom they have dislodged. The Brahmanic worship of the spirit of the dead is shown by their bringing back to the house the dead person's soul, supposed to have lost its home by the body's death. A stone or some such object is picked up at the grave, and carried reverentially back to the house, where it is worshipped for a few days, and then decently disposed of. The demons worshipped are multitudinous. Chand Khan of the Dekhan is one of them. His tomb is worshipped on one bastion of every mud fort. The legend regarding him is to the effect that there was a difficulty encountered in the erection of a bastion, and he was sacrificed and buried to appease the obstructing demon. See Demon; Devil; Shanar.

Unions of any sort, especially of waters, are held sacred by Hindus, and above all the union of the Ganga and Jumna near Allahabad,- - the latter river having previously received the Saraswati below Dehli, so that in fact all three unite at this famed sangam or confluence. But the Hindu poet feigns a subterrane flow of the Saraswati, and a mystical union at the sacred point, where bathing is deemed peculiarly efficacious. Major Moor once saw (p.429) at Poona a well-modelled group in clay, where Radha's locks, tripartite, were plaited into the mystical Triveni by the amorous Krishna, who sat rapturously admiring the work of his hands. The Triveni, or three-plaited locks, in Hindu mythology, is the mystical union of these three sacred rivers, the Ganges, Jumna, and Saraswati, severally the consorts or energies of the three great powers. Coleman also says (pp. 394, 398) that the Triveni, or three-plaited locks, is allegorical of the holy rivers Ganga (or Ganges), Yamuna (or Jumna), which join near Allahabad, the Saraswati being supposed to join the other two under ground. A Hindu dying near the imagined confluence of the three streams, or even of those of the Ganga and Yamuna, attains immediate beatitude; consequently self or self-permitted immolation, sati, etc., were meritorious on this peculiarly holy spot, and multitudes of pilgrims annually resort there to bathe. Other rivers are held sacred by Hindus, viz. the Godavery, the Sindhu or Indus, the Krishna or Kistna, the Cauvery, and the Brahmaputra. It is, however, the Ganges that is most revered. The Hindu longs to perform his ablutions in its streans; its waters are carried to remote distances, to be sold to persons who wish to perform with it their sacred rites; many men and women formerly drowned themselves in the sacred stream, hoping by that means to reach their heavenly abode; the bodies of those dying far and near are sent to be committed to its bosom; and from still greater distances Hindus send incremated bones of deceased relatives to be cast into the waters.

The union of the palmyra and the Urostigma religiosa is deemed holy, and their orchard is married to its adjacent well before its fruit can be partaken of.

The Hindus also reverence the impressions of feet. On the top of Adam's Peak in Ceylon is a natural hollow, artificially enlarged, said to be the impression of a foot of Buddha, as Buddhists 
say, but called by the Hindus, Sripada or Sripad, meaning the divine footstep, Vishnu having, they say, alighted on that spot in his avatara of Rama; although Mahomedans and Christians have also claimed that footmark as of their religious relics. Hindus make pilgrimages to the Sripad in Ceylon, and in other places where similar proofs of an avatar or descent have been discovered.

The Mahrattas make images in honour of deceased ancestors, and of their guru or spiritual instructors, as Lares, or Penates, or Lemures. Nat and Vira (Nat'ha, lord; Vira, brave) and Bharava are epithets applied to such domestic images.

Their leaf-platters, used as plates, are usually made of the leaves of the mango, the jamoon, Syzygium jambolanum, the banyan, and pipal trees. Part of the ceremony of a vow of friendship, amongst Hindus, consists in dividing a bel or larger wood-apple, half of which is kept by each party, and from this compact is called bel bandar. Every Hindu, whatever his avocation, on his new year's day worships the object or implement by which he obtains his living, or, in western phrase, blesses and consecrates it. During the Durga puja, Durga is worshipped in the form of a water-pot. It is called Ghita-puja, also Ghatasthapana. The water-pot being placed after certain invocations, Durga is supposed to enter it, and she is then worshipped. The bamboo is worshipped by the Tiperah people, the Cachari, and the Garo. They stick a bamboo in the ground during one of their religious festivals, and worship it. The Kol of Central India worship the sal tree (Vatica robusta).

Many trees are held to be sacred, some to Siva, some to Vishnu, some to both.

To both are the Artemisia austriaca, Calophyllum inophyllum, Chrysanthemum Indicum, Euonymus tingens, Gracillara spinosa, Guettarda speciosa, Ixora bandhuca, Jasminum undulatum, Nerium odorum, Origanum marjorana, Sarcostemma brevistigma.

Sacred to Vishnu, Azaderachta Indica, Ocimum sanctum.

Sacred to Lakshmi, Nelumbium speciosum.

Sacred to Siva, Bauhinia parviflora, Azaderachta Indica, Cæsalpinia pulcherrima, Cratæva religiosa, Jonesia asoca, Phyllanthus emblica.

Kama Deva, god of love, tips his arrows with the flowers of the Mangifera Indica, Michelia champaca, Mesua ferrea, Pandanus odoratissimus, and $\mathrm{Pa}$ vonia odorata.

The Egle marmelos leaf represents Brahma, Siva, and Vishnu. The Euphorbia ligularia is sacred to Manesha, the snake goddess, and is worshipped by an Assam tribe.

The C'ow.-Hindus regard the cow as sacred. Every morning the Hindu wife or maid-servant spreads the floor with cow-dung mixed with water, partly as a religious duty, partly for cleanliness. She sprinkles the urine of the cow over her head, and sprinkles it about the house in purification, when anything has occurred to make it, in their religion, unclean. Every morning, on rising from bed, every Hindu is enjoined to cast a glance on the objects mentioned in the following slokam:A kapalam (brindled) cow, a mirror, the sun, a rich man, a king, a priest, a giver of rice (in charity), and a chaste woman. It is not, however, the cow's face, but its tail, on which they cast their look. Protecting the cow is meritorious. When a Hindu is dying, his relations give a cow to a Brahman, and repeat the gift on the 11th day after the demise. When a Brahman is married,

the father of the bride always gives a cow, Surabhi, to his son-in-law, along with other presents. Every Friday the Hindu wife washes her cow. She smears its face with turmeric, and ornaments the animal's forehead with a round mark from the red powder prepared from lime and turmeric. Some Hindus call the cow Kama-duh, or Kama-dhenu, the servant of Indra; other Hindus believe that the cow is Lakshmi, the goddess of prosperity, whom they thus propitiate by their worship. Those who do not possess a cow will buy some grass and give it to that of their neighbour. Amongst the five deadly sins is that of killing a cow; the other four are killing a Brahman, a pregnant woman, a child, and killing one's mother.

The Bull is not reverenced equal to the cow, but it is the vahan or vehicle of Siva. In all saiva temples may be seen the image of this animal, called Nandi, made of black stone, kneeling before the lingam and yoni, the symbols of Siva and Parvati. In pictures, Siva is invariably represented riding on his vahan or vehicle, a bull. A bull, both in the saiva and vaishnava temples, carries the kettledrums which are sounded for worship three times daily. When a cow or bull falls sick, Hindus will vow that if the animal recover, it shall be left in the temple; and every Friday the Brahmans employed in the services of the temple, when they lave Siva's symbol and the Nandi with milk, in the ceremony called Palu Abhishekam, the devoted bullocks are likewise thus washed.

Daily Life of the Hindus. - Having briefly sketched some of the various rites now forming the religion called in Europe Hindu, and the differences in the forms of idol-worshipping which are to be found, it may be interesting to conduct one of this faith from the cradle to the grave.

Childhood and Adolescence.-The ceremonials observed on the birth of children, at the commencement of their education, on investiture with the sacred thread, communication of a gayatri or initiatory sentence, in their marriage ceremonies, and those adhered to on the occurrence of a death in a family, have now a general resemblance among, or are more or less imitated by, all castes, classes, and ranks. On the birth of a Brahman child, the ceremony called Putrotsavam is performed, and on this occasion the father presents sugar and sugar-candy to relatives and friends. On the 11th day the mother is anointed with the oil of the oriental sesamum. On the same day (11th) the Punyahavachanam, or the purification rite for the mother and house, is performed. It is then that the child receives its name-that of some one of its grand or great-grand parents-by the father writing it three times with a golden ring, in unhusked rice, spread on a plate. This naming is called Namakaranam, and is followed by the guests bestowing blessings on the young one, as they scatter rice, coloured with turmeric, over it and the mother, who are seated in the midst of the assembly. The father then distributes money to the poor, and entertains relatives and friends. On this night, for the first time, the child is put into the cradle by the female guests, some of whom sing religious songs, while others rock the little one, and at the close the assembly are dis. missed, after being presented with betel-nut, plantains, and boiled pigeon-pea (Cajanus Indicus). The birth of a girl is less a source of rejoicing, because of that part of the Hindu creed which 
lays down that parents and other ancestors attain Swarga-locum or Indra's heaven through a son's efforts. Each new moon, as also on the occurrence of an eclipse, either of the sun or moon, also at the summer and winter solstices, their Utrayanam and Datchanayanam, every caste Hindu, whether Brabman, Kshatriya, Vaisya, or Sudra, offers the Tharpanam, or water sacrifice, in the names of his deceased father, grandfathers, great-grandfathers, and their wives, consisting of seeds of the oriental sesamum mixed with the water. It is as a means of continuing this ceremony that Hindus long to have a son born to them, as in their creed-books it is taught that the manes of ancestors are gratified by the Tharpanam. At five months of age, the Choulam ceremony occurs, and the lobes of the ears are pierced with a small, thin gold ring. When six months old, Anaprasanam, or giving the child rice for the first time, is a social and sacred rite, at which, as also at the Choulam, relatives and friends are entertained. On the first occurrence of the birthday, the child is anointed and decorated with jewels, relatives and friends are entertained; and in the evening the child is carried to a temple, and presented to the deity of their sect. As the second anniversary draws near, or about that time, the boy's head is shaved on a propitious day, which affords another opportunity for feasting friends.

Boyhood.-When five years old, the father ascertains an auspicious day, and entrusts his son to a teacher. The instructor engraves the alphabet with an iron style, sometimes set in silver or gold, on a leaf of the palmyra tree, which is then coloured with turmeric. The leaf is placed on unhusked rice spread over the floor, and the teacher, whatever the sect or caste of the pupil be, invokes the god Vigneswara to smooth the difficulties in the way of the child's studies. Then, holding the boy's forefinger, he thrice traces with it the forms of the vowels in the rice, teaching the boy their sounds. The pedagogue is presented with a new cloth and some money, and dismissed, after which relatives and friends are entertained. On the seventh or ninth year, the Upanayanam is performed, on which occasion the family priestUpad'hay-ya, SANSK., Upa-dhialu, TeL.-causes the boy to offer a burnt-offering, Homan, to the entire pantheon of gods, by pouring ghi (clarified butter) over the fire. He then invests the youth with the zandiyam, the zonar or sacred cord, letting it fall from over the left shoulder to the right side. He subsequently teaches the gayatri to the boy, if he be of the Brahmanical order, as also the morning, noontide, and evening prayers, the due attention to which is considered sufficient to remove all sins committed during the day and night. The gayatri or gayatri mantrum of the Brahmanical or priestly order is never pronounced aloud, and it is exceedingly rare that any Brahman can be induced to divulge it. Its literal translation is : ' $O$ 'm! earth, air, heaven, $O$ 'm! Let us meditate on the supreme splendour of the divine sun; may he illuminate our minds." It is considered the most sacred text of the Vedas; and the common belief in and reverence for it is the bond of union amongst the entire Brahmanical order. With this ceremony the boy is considered to be born again, and he is of the Punar Janma, or twice born. This is the spiritual birth of the Hindu, or his regeneration, for until this time the uninitiated youth, though of the Brahmanical class, so far as his right to perform religious ceremonies is concerned, is only regarded in the light of a Sudra. If the Vaishnava youth, who has now been initiated into the mysteries of the Brahmanical order, be set apart for the sacerdotal office of the priesthood, he is further marked, by being branded on the muscular part of both arms with the sanku or chank, and the chakram or disc of Vishnu. This is called the Chakrankitam. From this time he is ranked as a Brahmachari, or of the order of bachelors, for he has now entered on his religious life,the whole of the days of a spiritual Brahman being apportioned into four religious stages, viz. that of the Brahmacharyam, or bachelorhood; Grahastasramam, or the married state; Vanaprastam, the living in solitude with his family ; and Sanyasam, or the abandonment of all worldly matters. A bachelor's dress differs from that of a married man, in so far as he does not wear the dhoti, but only a wrapper round the lower part of the body; he is prohibited from eating betel, and continence is enjoined. Among other Hindu castes, the Brahmachari ceremony is performed at any time prior to the celebration of marriage, but their gayatri is from the Puranas, not the Vedas.

Marviage.-There is no time fixed for the marriage of sons. It is performed at any time from infancy, as the parents may please. But amongst the priestly and mercantile orders, the Brahmans and Vaisya, as also among the goldsmiths, girls must be married before they attain puberty. The Brahmans believe that they would be as if guilty of murder if they allowed a girl to grow up before being married. This is founded on correct physiological knowledge. And in Southern India, they, as also the goldsmith tribe or race or caste, regard such a possible occurrence with so great horror, that they say it would be incumbent on them if it happened, but which is invariably guarded against, for all the family to drown themselves. Children have no voice in the matter of their marriage. When parents are desirous of having their sons married, they institute inquiries amongst their relatives or friends not of their own gotram or tribe. They visit the girl's parents in a propitious hour, and request their daughter in marriage for their son. The parents of the girl make inquiries as to the character of the boy, and if satisfied, they promise their daughter for him. It is not customary for a girl's parents to go seeking for a husband for their daughter. When so far arranged, if the girl's parents be poor, they may perhaps stipulate that jewels and money shall be presented to their daughter at the marriage time. But this practice, which is a remnant of the ancient custom of purchasing a wife, is gradually dying out with all but the humbler people. Now-a-days, a rich Hindu would disdain to receive money from the parents of their son-in-law for giving their daughter to him, and many tribes-for India contains the descendants of numerous distinct races-repel with disdain any insinuation of their readiness to sell their daughters. Indeed, sons-in-law do now occasionally receive some dower of money or property with their brides. In a recent instance, so much as five lakhs of rupees $(£ 50,000)$ are said to have been given to a son-in-law who had already four wives. But the former practice of disposal of their female children is clearly marked in their marriage law, in which a girl, who quits her father's 


\section{HINDU.}

house for her husband in another family, ceases to be an heir of her own parents, though she acquires rights in the property of her new home.

Marriage Ceremonies. - When all the preliminary arrangements are settled, a day is fixed for the performance of the marriage; preparations are made by the father of the girl, who invites relatives and friends to be present on the occasion, the invitations being usually communicated verbally, but sometimes by letter. On the day preceding that of the marriage, by the Snat'haka Varattam, the youth is relieved of his bachelorhood, the ceremony on this occasion consisting in the homa or fire-sacrifice, and giving of charity. On the marriage eve, the bridegroom, accompanied by his parents, relatives, and friends, goes in procession to the bride's house, and presents her with a new cloth of some value, with any jewels that may have been before agreed on; betel-nut is handed to the guests, and friends and relations are entertained. The poor Brahmans, too, are remembered on the occasion, the money-gifts to whom are called Datchana. The wedding-day at length arrives, but with emotions very different from those of the principal actors in ancient Hindu times, for now-a-days both bride and bridegroom are usually quite infants, - - and if not both, the bride with most tribes certainly is so. Tribes of Sudras, however, and a fair, intellectual literary race called Kait or Kayasth, who claim their origin from a deified mortal called Chatr-gopuitr, also many of the Pariah tribes, allow their girls to grow up and remain in their father's house, without any feeling of shame being associated with the practice. And the Vedas teach us that in their times virtuous maidens remained unmarried in their father's house long after they had grown up. On the wedding-day, the bride and bridegroom are anointed with oil (the Abhiangana-s'nanam), are dressed in their best, and decorated with jewels. 'the father of the bride has erected a temporary canopy in the court of his house, beneath which she is seated beside her groom, and the family priest commences the ceremony by causing them to make a burnt-offering, by the homa sacrifice of pouring ghi into the fire, whilst the priest utters a mantra. At the same instant, by the Navagraha Aratanam and Asht'ha dik palaka Aratanam, a series of incantations, they bring Indra, Varuna, Agni, Yama, etc., from Swarga-locum and locate them in any casual article, in some part of the house.

When seated, the girl is formally given to the husband (Kania-danam, literally spinster-giving); a priest blesses some water in a small vessel, and the father of the girl, taking this and his daughter's right hand, places them together in the bridegroom's right hand, saying, 'I do this, that my father, grandfathers, and great-grandfathers may attain Swarga' (heaven). The bridegroom then rising, and standing before the bride, amidst the deafening din of tomtoms, ties round her neck the mangala sutram, a thread coloured with turmeric, to which a golden jewel called Bottu or Tala is attached. Sanda]wood paste, perfume, and flowers are presented to the guests, betel-nut is offered to all relatives and friends, and money-presents are made. The married couple receive Asir-vadam (benedictions and congratulations) from the assembly, and as they prostrate themselves at their parents' feet their parents bless them. The prostrations are

\section{HINDU.}

also occasionally made at the feet of other near relatives, who likewise bestow a blessing. Amongst the Brahmans, the ceremonials of the marriage are continued for fire successive days, and for three days, or one day, or seven days, with other castes. On the fifth or last day, the gods who were brought from Swarga into the bride's home, and have been daily worshipped there, are released. Four earthenware pots, placed beneath the pandal or canopy, are filled with rice highly coloured with turmeric, and a Brahman sitting near, by motions from his hands, affects to feed the located gods (Navediam), and then to release them. This is the Naka balli, or offering of victims, to the gods of Swarga-locum. And now the parents of the newly-married couple, as also relatives and friends, interchange presents, and make gifts to the young people. In the evening of that day the bridegroom takes his wife home. This is done in a procession, in which parents and relations join, and is treated as a religious ceremony, called Grahapravesam, or house-entering, immediately after which the bride and bridegroom are seated in the middle of the floor, the father of the girl presents them with new clothes, and the relations and friends are feasted. After remaining three days in her husband's home, the girl-wife is taken back to the house of her parents, with whom she lives, making only occasional visits to her husband's residence, until puberty. On this event her father sends word to her husband, who presents gifts to the bearer of the happy tidings, fixes on an auspicious day to bring his wife home, and intimates the date to his father-in-law. The latter prepares a cot or bed, candlestick, cooking utensils, chairs, boxes, and other household fittings, also buys new clothes for his daughter, whom they convey to her husband's house for good, and an entertaiument is given to all relatives and friends. Her parents remain in the house with their daughter and son-in-law for two or three days, and before taking leave of them they give them some advice for their guidance.

Married Life.-From this time the young wife lives with her husband, in subservience to her mother-in-law or sister-in-law, whichever be the head woman in her new home. As a young thing she cannot have much to say; but her little ways and tiny talk are at an end, and it is even, on many occasions, considered highly indecorous for her to speak at all. She cannot speak to her husband in the presence of his father or mother or other people, and partly from shamefacedness, partly from fear of them, her busband rarely speaks to his wife in their presence. This intense reserve goes off greatly as they grow older; but in no instance, perhaps, does the Hindu wife ever attain to the same freedom of speech with her husband as marks the intercourse with the young wife in a Mahomedan family, where they are sometimes married equally young, and where their innocent prattle is the very life of the household. At home, however long she be a wife, a Hindu woman never eats till her husband finishes his meal; she rises and stands in a respectful attitude if her husband or his parents or brothers enter the house, and at all times addresses them in a low tone of voice, and speaks slowly. And so long as the husband's mother or his sister is the head of the house, the husband communicates his wishes as to what he wants his wife to do, not to ber 
directly, but through his mother or sister. Abroad from home, the Hindu husbands and wives may at all times be seen walking along the roads, but the wife never presumes to walk at the side of her partner. She is always a pace or so behind, and a little at the side. If they be out on matters of business, the wife continues, all along the road, to prompt her husband as to what he is to say or do, but the instant that the place of business is reached, she falls off to a distance, and never presumes to take any part in the discussion. In a poor family, the wife, as in all countries, has to perform the entire domestic duties of the household, but with richer people who keep servants the wife's labours are restricted to superintendence, attention to her children, sewing, and other female occupations. They are in this social respect much in the position that Europe was a few hundred years ago ; but there is this difference, that scarcely a Hindu wife is able to read or write, or even permitted to learn. Since the middle of the 19th century, in the presidency towns, a few female schools have been established by the bettereducated Hindus, who are desirous that the next generation shall receive educated partners in their homes. But in all India, out of a population of nearly $200,000,000$ of Hindus, there are not, perhaps, in 1883, 3000 girls of the higher Hindu castes under tuition. The younger men are averse to the continuance of the intense restraint hitherto imposed on their homes, and are breaking through it, but these are almost solitary exceptions to the vast mass. Brahman girls are forbidden to be educated at all; and those who urge education on them are opposed by the women themselves, who will exclaim, 'What! would you make us as dancing-girls!' the educational efforts having only hitherto been directed to such unfortunate sisters, from the fear-and it is shared with many men of the Hindus and Mahomedans - that education may tempt, by giving facilities, to vice. In this they evidence a great ignorance of human nature, a more enlarged knowledge of which would convince them that only the training of the moral faculties can uproot vice, which, where the evil desire prevails, no restrictions can restrain. The ntmost that a Brahman woman learns, are the songs and hymns sung by women in their own houses during marriages and other festivals. The Hindu wife - bred from her childhood in the strictest seclusion, consigned at an early age to the care of a husband of whom she can have previously known little or nothing, and who is often as dependent upon others as herself-leads a life of mysterious quietude, varied only by the rites of religion and the ordinary events of the family. Of the world around her she knows nothing. All her thoughts and feelings, joys and sorrows, desires and affections, are imprisoned within the little circle of her own household. Her mental faculties are either altogether undeveloped, or wasted upon toys, ornaments, idle tales, family gossip, or similar frivolities. Her moral powers, too, are overlaid by superstition and prejudice. Yet these ladies are the mothers of the rising generation, who are acquiring the language and the literature of Europe, and fondly imagining that its members are as capable of exercising the rights of self-government and self-control as those who have sprung from the free and independent women of the western world, whose mothers in the warlike ages took part in the counsels of their nations, and accompanied their warriors to the field. Hindu wives are only allowed to speak to their nearest relations, fathers, brothers, etc., and are never trusted from home alone. Married women, when at the daily bath, smear their bodies with turmeric, and place on their foreheads the round mark with the red colouring matter from the turmeric? and, like many other orientals, paint their eyelashes with lamp-black. Married women also wear a bodice. Though their religious books (Shastras) permit the Hindu widow to re-marry, custom, which is more rigorous, forbids it; and once widows, except with a few tribes, - the Jat, the Gujar, and others, - they ever after remain single. See Marriage Customs.

Death and Future State.-Then a Hindu dies there are the inevitable tokens of grief amongst relatives; but women evince their emotion with great demonstrations and noise, proclaiming aloud the good qualities of the deceased, as they beat their breasts and mouths. The death-wail is heard far distant, and once heard is never forgotten. 'Naked he came, and naked has gone; this dwellingplace belongs neither to you nor to me." Relatives and friends, on learning the melancholy tidings, go to the house of mourning to condole with the bereaved family, and the women join in the death-wail, which rises loud above all the other sounds of the busy world around. As death is drawing near, however, the attendants, after purifying the house with cow-dung, perform the Jiva Praias-chittam, by laving the dying man's body with water, placing in his mouth or causing him to drink a little milk, buttermilk, honey, treacle, and plantains (panchakavia), and then releasing a cow. Such an ordeal few men in weak health could withstand, and it may not be doubted that it is never performed without hastening the fatal event, for the attendants force the five things into the dying man's mouth. After demise the corpse is washed and dressed. The family priest pronounces certain mantra of purification over it, for every household has its own Brahman teacher. It is borne on a bier to the burning ground by four men, and followed by relatives and friends, both men and women. A large heap of firewood and dried cow-dung cakes has been already gathered together there, which are stacked up over the remains, and the son sets the pile on fire. It is their belief that as death parts the soul from the body, the god of justice, Yama, sends two angels with an invisible form to receive into it the flitting spirit, and convey it to Yarna-locum, his hall of justice, to be tried there, and awarded its sentence of future punishment or reward. The secretary, Chatr-gopūtr, records the decree, and the disembodied spirit takes up its abode in Swarga, or in Narika, or revisits earth to be re-born, and afforded another opportunity of gaining release from mortality. The day following the demise and incremation, they revisit the spot. They pour milk or water, or milk and water, over the ashes, and make an offering of rice to the Preta, the departed soul. On the second, third, or fifth day, the son selects any small black stone, or three back stones, which he places against a pipal tree, Ficus religiosa, on the bank of a pond or tank. This represents the deceased, or rather his Preta is supposed to be located in the stone, and where three stones are used, those also of his grandfather or great-grand- 
father; and each day, for ten days, the son offers to the stone or stones a water-sacrifice to quench the thirst of the departed. $\mathrm{He}$ also cooks rice there, and offers it to a crow, to satisfy the hunger of the deceased; he continues this every morning till the tenth day, because it is the Hindu belief that the soul of the departed hovers about the house for ten or twelve days, and then takes up that future habitation which, according to their view of the transmigration of souls, may be its lot. On the tenth day the stone is thrown into the water. The object of all this is their belief that the shade of the departed is occupying five separate beings and places,- - one descends upon his son, a second rests on the place of incremation, a third in the house he has left, a fourth in the stones that are raised to represent him, and the fifth in the crow to which the food is thrown. And if the crow refuse the food, the beholders deem it an augury of the ill life of the departed, or that some object of his life remained incomplete.

Widowed State. - If the deceased was a married man, the mangala sutram, or sacred thread, which was tied round the neck of his bride on the wedding day, is now broken by other widows of the family. She ceases to wear a bodice or jewels, or flowers in her hair. She discontinues the use of turmeric when at the bath; the red mark is no longer placed on her forehead, and in many cases the long black tresses are removed, for some classes of Brahman women have their head shaved. From this time their lives are one continued scene of misery. Restricted to the meanest of the household avocations, they are treated by their nearest relatives with contumely and neglect. Their very loneliness and bereavement, instead of being occasion for sympathy and endearment, only calls forth harsh, often brutal, treatment. Their very condition is a term of abuse; and, denied it on earth, many a Hindu widow seeks peace in the grave, for there the wicked cease from troubling, and there the weary be at rest.

After - Death Ceremonies.-On the 11th day, among Brabmans, the son of the deceased selects two or three relatives, or several Brahmans, to be in the place, or representatives, of his parent. They are anointed with the oil of the oriental sesamum. The son presents them with flowers, the sandal perfume, and new cloths, and then entertains them. Until they finish their meal, no member of the household is allowed to partake of food. So soon as they rise, however, a morsel of rice is thrown to the crows, and the representatives of the deceased are dismissed with betel-nut, new cloths, and presents of money, according to the son's means. All other relatives present are then entertained. For one year from this time this becomes a monthly ceremonial on the day of the deceased's demise. On the first anniversary of the deceased person's samvatsarikam, a Hindu, however poor, must, with much display, perform the ceremonies which are then required. This necessity is a great tax to all of them; but where several deaths have occurred in a family, it is a ruinous burden, for the rules of their faith compel their performance, and if a person have not money of his own with which to perform this, he must beg for it or borrow it for the purpose. The religious importance to the deceased of the performance of this anniversary rite is considered very great, and it is this which occasions the great desire to have a son. If the family be what in law is called a united Hindu family, the ceremonial is conducted by the eldest son, but where they have separated, each son must perform it separately. For those who have no sons, the widow can perform it, and the widower husband can do the same for his wife. On the future anniversaries the sradha only is performed.

Burial and Burning.-Before the body is taken to be burnt, it is anointed with ghi, or clarified butter. Arrived at the side of the water, the nearest relation sets fire to the pile, which is soon in a blaze. It takes three cwt. of wood to consume the body of an adult. At the present day, the general practice of the Vaishnava Hindus is to burn their dead, but they also launch the bodies into the stream of the Ganges, or expose them on the open plains. After the incremation, using a branch of sami, and another of palasa (Butea frondosa), instead of tongs, the son or nearest relative first draws out from the ashes the bones of the head, and afterwards the other bones successively, sprinkles them with perfumed liquids and with clarified butter (ghi) made of cow's milk, and puts them into a casket made of the leaves of the palasa (Butea frondosa). This he places in a new earthen vessel, covers it with a lid, and ties it up with a thread. Selecting some clear spot where encroachments of the river are not to be apprehended, he digs a very deep hole, and at the bottom spreads the cusa grass (poa), and over the grass a piece of yellow cloth. He places thereon the earthen vessel containing the bones of the deceased, covers it with a lump of mud, moss, and thorns, and plants a tree in the excavation, or raises a mound of masonry. Subsequently, the son or nearest relative repairs to the cemetery, carrying eight vessels filled with various flowers, roots, and similar things; he walks round the enclosure containing the funeral pile, with his right hand towards it, successively depositing at its four gates or entrances, beginning at the north gate, two vessels containing eight different things, with this prayer: 'May the adorable and eternal gods, who are present in the cemetery, accept from us this eightfold imperishable oblation. May they convey the deceased to pleasing and eternal abodes, and grant to us life, health, and perfect ease. This eight-fold oblation is offered to Siva and other deities; salutation to them.'

In the south of India, the ascetic followers of both Siva and Vishnu bury their dead; so do the Vaishnava, Vairagi, and Sanyasi in the north of India, and the Saiva Jogi. The class of Hindu weavers called Yogi have adopted a similar practice, as also have all the castes in Southern India who wear the lingam. All infants and unmarried persons are interred, as also all the artisan tribes. At the Sanyasi devotee's interment no wailings or expressions of grief are allowed. The corpse, seated in a litter, is borne to the grave, preceded by musicians, and attended by persons who cast rose-coloured powder into the air, or demonstrate in other modes their joy. It is placed in the earth in a sitting posture, instead of being consumed on the pile. A small platform raised over the spot, and exbibiting the sculptured feet of the deceased, commemorates his sanctity.

Ceremonials of Worship. - A Brahman who attends to his religious duties, bathes before sun- 
or libation from his hand. He prays in this wise :

'He who meditates on Pundri kachă (he with the lotus eye), though a very great sinner, will be forgiven.

'If he sprinkle over his head water which is pure and holy, he will be purified and strengthened.

All sins committed during the night, by word, deed, mind, mouth, hands, feet, belly, organs, or in anger, will be forgiven by Surié jotishi' (the light of the sun).

The next part of the ritual is the ceremony called Arg'hiam, which is performed to free the sun from the Rakshasa, who is striving to hinder its appearance. This consists in offering, four times, a water sacrifice or libation, by taking water in the hands and pouring it on the ground, as he four times pronounces the Vedic Gaitri, viz. 'O'm! Bhürbhuvă ssuvâhā, O'm! Tatsa vit'hru varēnnyâm, B'hargo devâsyâ dhimahi dhiyo yonaha pracho dayath.'-'O'm! earth, air, heaven, O'm! Let us meditate on the supreme splendour of the divine sun. May he illuminate our minds.' After this he prays, at length or briefly at will, in the form of a commenting or expounding of the above Gaitra.

He then prostrates himself (to Vasu deva or to Krishna, or to Vishnu if a Vaishnava) to Sarvantariami, a god who pervades all creatures, and prays him to bless all the Brahmans and cows within the four seas, mentioning his own name, his got'hram or tribe rishis. At the close he offers to Narayana his deeds by body, mouth, heart, and senses.

At noon, prayers are repeated, and he prays to Suria (the sun).

In the evening, prayers recur, and he implores Varuna (the god of the sky and regent of the west) in sacred words.

Hindu Society.-Hindus are classed as Vaidikam and Laokalam or Lao-kikam, clergy and laity. It is a common notion that the Brahmans of India are the priests of the Hindus, but this is not correct. Though of the priestly or sacred order, the vast bulk of this class are employed in lay pursuits, as soldiers, merchants, lawyers, clerks, perhaps in every avocation of daily life except such as involve manual labour, though they are even agriculturists in Northern India and Orissa. Various sects of Hindus have priests of the Sudra caste, and many aboriginal races employ members of their particular tribe or race. Speaking in a general way, it may be stated that where the people of India are followers of the Puranas and Vedas, their priests are invariably Brahmans; but the extensive Lingaet sect, and the Jain, and all the sects or tribes who worship the village deities, or adhere to spirit or devil worship, select priests from their own classes. Also the Kansallar, or artificer tribes of Sudras, all of whom wear the sacred cord, select an ascetic member of their own caste as their priest, and have also family priests from their own circle. Indeed, they claim for themselves a superiority to the entire Brabmanical order, asserting their origin to be older; and no one of the Kansallar would accept of water from a Brahman. But, in the usual discrepant character of the Hindu people, although the Kansallar claim that their caste possess this superiority, and though they possess the Brahmanical Vedas, yet their manner of conversing and dressing, and their wornen's clothes and ornaments, resemble those of nonBrahmanical castes. In paying respect to Brahmans, they say and use the Dandam, and not, as from an inferior to a superior, the Namaskaram, as one Brabman will to another. Amongst the Saiva sect, who have Brahman priests, the guru is styled Sankarachari, and is invariably a Sanyasi or ascetic. He resides in a matham or monastery along with other Brahmans, to whom he imparts religious instruction or preaches. He is greatly reverenced by his disciples, who regard him as almost equal to a god. The monastery is supported by the disciples' gifts. The members of these monasteries are charitable to all the poor, and erect temples out of surplus receipts. But the head of the establishment, the Mat'hadi-padi, when he travels to superintend his followers, does so with vast pomp and display, in a litter of a peculiar form, often richly ornamented, and accompanied by a great concourse of people, with elephants, horses, and conveyances for bis property. Like all Sanyasi and Brahmans engaged in religious duties, the members of the matham bathe thrice daily. Twice daily the chief worships the Saligrama, a fossil ammonite from the Gogra or Gandak, or a gold, silver, or copper idol of Krishna or of Siva. After washing the idol with water, he decorates it with the sectarian mark, and worships it with offerings of flowers and tulsi leaves; he sips a little of the water used in the worship, and the rest is carefully preserved in a silver cup along with tulsi leaves, and dropped from a small spoon, 'Voodharni,' into the hands of disciples, who esteem the gift as cleansing from all sin. The head monk only eats once a-day, and before taking his meal he invariably presents it to the deity. Disciples, when they approach the head monk, prostrate themselves before him. Their mode of caring for the idol is in all its forms identical with that of caring for a living human being,--bathing and anointing it, offering it food, offering it praise and reverence in song, in danciug, and in prayer, and periodical, in some cases daily, and seasonal airings and processions. In exploring the great theatre in Ephesus, Mr. Wood discovered an inscription containing information as to the endowments and worship of the temple of Diana, and laying down the route by which, on the birthday of the goddess, her silver shrines and other treasures were to be carried in procession from the temple to the great theatre through one city gate, and back to the temple through another city gate, which was called the Magnesian. And this is a perfect representation of the customs of the Hindus of the present day, and precisely as noticed in Isaiah xlvi. 7 : 'They bear him upon the shoulder; they carry him, and set him in his place.'

Position and Religion of Hindu Wumen.-A great defect in their social system seems to be the unequal conditions of the sexes. In European households there is almost as little real mixing of different grades of society, as occurs amongst the different castes of India. But among the Hindus, although their creed permits the women to attain heaven on their demise, so long as they are here on earth, whatever secret influence a wife may have, it is not shown to the community. Speculative as are the entire Brahmanical populations, and to a large extent also all the races called Hindus, 
many of them diving into the mysteries of their theology, except a Vedantist occasionally make a remark to the women of his household as to the inutility of worshipping their ordinary images, the Hindu wife has little or no instruction in religion, and takes no part in all that array of ceremonial which occupies so much of the daily time of a Hindu, particularly if religious. The Hindu prays morning, noon, and night a somewhat long prayer. T'he wife's prayer, if she pray at all, is very short, a Saiva woman merely mentioning the name of her deity in the three words-'O'm! nama Saiva!' -'Hail! name of Siva!' Amongst the Smart'ha Brahmans and Mad'hava sect of Vaishnavas, each household keeps a tulsi plant in the middle of its little parterre or courtyard. A small pedestal is erected, in the hollowed centre of which the plant is placed. Daily the women of the house resort to it, circle, 'pradatchanam,' and prostrate themselves six times before it, pour water over, and then, standing before it, pray to Lakshmi. A similar worship to the pipal tree, with a sculptured cobra at its foot, is offered both by men and women to whom offspriug have not been given. This pipal tree is always on the bank of a tank, in which the devotees bathe, dressed in a silk garment used only when performing sacred rites. Places where cobra snakes have formed colonies are largely resorted to by women longing for children, and they make to the cobras offerings of sugar and milk, for the cobra is deemed an $\alpha \gamma \propto \theta 0 s \Delta \varepsilon \mu \alpha \nu$, guarding the symbol of the reproductive organ. The prayer of the Brahman of every caste and sect includes the Gaitri invocation to the sun.

Legal Rights of Husband and Wife.-A girl is accounted by law marriageable at the age of eight. Girls are, however, given in marriage at the age of two and upwards, till they attain their maturity. A Brahman girl attaining maturity without having contracted marriage, forfeits her caste. The girl, when married, remains with her own family until she reach maturity, when her husband can claim her and remove her to his house. The right of choosing a husband for the girl rests first with her father. Should he have demised, it devolves in succession upon her paternal grandfather, brother, paternal uncle, male paternal cousins, and lastly upon her mother. If these relatives should have neglected the duty of choosing a husband for the girl up to three years after she may have attained the age of eight, she is at liberty to choose for herself. The lads of the three superior classes, namely, the Brahman or the sacerdotal order, the Kshatriya or the military tribe, and the Vaisya or the mercantile body, may not contract marriage until they have completed the stage of studentship (Menu, iii. 4), the opening of which period is marked by performance of the Upianayanam, or investiture with the sacred thread, and the close by a ceremony termed Samavasthana. For the Sudras or the servile class, who have no stage of studentship, there is no limitation as to the time for marriage. There are eight recognised kinds of marriage, viz. Brahma, Daiva, Arsha, and Prajapatya, which are appropriate for Brahmans, and are based upon disinterested motives; the Gandharva and Rakshasa, which are appropriate for Kshatriyas, and are founded, the former on reciprocal desire, and the latter on conquest; the Asura, which is practised by Vaisya and Sudras, wherein the consent of the party giving away the girl is obtained by a pecuniary consideration; and the Paishacha, where the marriage may have been effected through fraud or force practised upon the girl, and which is reprobated for all classes. Though each class has its characteristic description of marriage, there is nothing to bind them to the rites appropriate to them. A Brahman, for example, may contract an Asura marriage, and a Sudra a Brahma one. The Brahma and Asura are the most usual forms of marriage. The former is an approved one, and the latter, as a sordid proceeding, is discouraged (i. 42, 43; Macnaughten junr, i. 60). The binding circurnstances essential to the completion of a marriage are gift and acceptance of the girl, and the ceremony termed Saptapathi, or the seven steps. This is performed by the bridegroom placing the bride's foot successively on seven lines drawn on rice in a platter. From this observance has followed the practice of any two persons pledging mutual friendship by taking seven steps together, so that the term Saptapathinam has come to be synonymous with friendship. The ceremonial in question accomplishes the marriage. The other ceremonies observed, including sacrifice by fire (homam), are of minor significance. The tying the tali or nuptial token by the bridegroom round the neck of the bride, is a practice sanctioned by usage, but not prescribed in the Shastras. The above matrimonial contract in itself fixes the condition of the parties as married, irrespective of the consummation of the marriage, when the girl, on reaching maturity, is taken home by the husband. It brings the girl, should her husband die, to the state of widowhood, with its attendant consequence, and gives her right of inheritance in her husband's family. When either party ineurs forfeiture of caste, intercourse between them ceases: and should the loss of caste be on the side of the woman, and she be sonless, she is accounted as dead, and funeral rites are performed for her (Smruti chandrika, on text of Vasista and Yajna vulkia). If she have a son, he is bound to maintain her; and in this way, under such circumstances, her existence is recognised notwithstanding her loss of caste. Infidelity in the female, save in certain of the lowest classes, occasions forfeiture of caste, and puts an end to the marriage (Smruti chandrika). The husband, however, is not entitled to damages from the adulterer, - the Hindu law not providing for discretionary damages upon any account. Impotence in the man, and confirmed barrenness in the woman, as also loathsome or incurable disease in either, justify separation (i. 47), but will not sever the marriage.

Akbar, emperor of India, forbade marriages before puberty, and sanctioned the re-marriage of widows. The British Indian Government in 1856 by an Act sanctioned this, but up to this time (1883) very few Aryan Hindus of the higher castes have dared the superstitious dread of the gods, and the anger of their caste-fellows, which hinder this act of justice towards their widows.

Murli; Basava. - Many young women all through India are married to their gods, and thenceforward are allowed to associate with the temple attendants or others. Girls of the Virasaiva sect and of some of the aboriginal races are married to a knife or other object, and become common. With some of the Hindu sects a: 
widower cannot re-marry, but such a bridegroom with his bride are each married to a tree with all the customary ceremonies of a wedding, each clasping their respective trees, and they then live together as husband and wife. The weaver castes near Madras devote their eldest daughter to the gods to serve in the temple; and instances occur of temple girls being educated in Christian mission schools.

Hindu Inheritance.-Adoption is legal with the Hindus, and sons are often adopted. If a son be adopted, he succeeds to his adopted father; he loses all claim on the inheritance of his original father, and is entitled to a sixth of the property of his adoptive one, even if after his adoption sons of the body should be born. In Hindu law there are ten descriptions of sons, - one of them the son of a man's wife by an uncertain father, begotten when he himself has been long absent. When a Hindu dies, the sons may either continue to live together with the property united, or they may divide it according to certain rules. If they remain united, the eldest brother takes possession of the property, and the others live under him as they did under their father. In this case the acquisitions of all the sons (who have not formally withdrawn) go to augment the common stock. If they divide, the eldest takes 1-20th; the youngest, 1-80th; and the intermediate sons, 1-40th. Unmarried sisters live with their brothers.

Sectarian Marks. - Amongst the peculiarities which first attract the eye of a stranger on seeing the Hindu religionists, are the red and white marks on their foreheads. Their prominence is often so glaring as to be unseemly. When the theistical Sikh religionists hastened from the Panjah in 1857 and 1858 to aid in quelling the mutiny and rebellion in India, in their wild enthusiasm they named all the Hindus contemptuously 'Matha Din,' literally, carrying their faiths on their foreheads; and a more expressive term could not perhaps have been coined, for all that ordinary Hindus know of their religion are the differences in these marks, which indicate differences of religious sects, not of castes, and the sectaries have a superstitious regard for such distinctions. It is held necessary, where convenient, or no especial objection or difficulty exists, for these marks to be daily renewed. A Brahman cannot perform any of his daily sacrifices, etc., without the completion or contemplation of this distinction; and it is irreverent in one of an inferior tribe to approach a holy man, or to ask his blessing, or to partake in the benefit of any religious rite, without or in view to this sectarial decoration. The Saiva, worshippers of Siva, called Siva-bakht, and the Vaishnava, otherwise Vishnu-bakht, worshippers of Vishnu, are to be known, the former by the horizontal position of their forehead lines, and the latter by their perpendicularity. One perpendicular mark, centrally between the eyes, is generally referable to one of Vishnu's sectaries; it is not common. Two upright parallel lines, with a black or open circlet between or under them, are the commonest distinction of Vaishnavas, whether seen on pictures of Tishnu himself, or on Rama and Krishna, or others of his avatars. In general, perpendicular lines appertain to Vaishnava sects, and horizontal lines appertain to Saiva sects. The marks on the forehead are ordinarily called namam ; the customary substances used are earths, tirumannu, or white ashes from a sacred fire, saffron, sanders wood, sandal-wood, white clay, etc. It is a very ancient mode of distinguishing religious sects, and is alluded to in Ezekiel ix. 4. The Sakta sect, when they avow themselves, mark either with saffron or with turmeric and borax. The Saura or Suria are true worshippers of the sun; and some of them adore the dormant and active energies of the planet conjointly. This sect, which is not very numerous, is distinguished by the use of red sanders for the horizontal triple line, as well as for the circlet on their foreheads.

Superstitions.-Hindus believe in omens, good and bad, and look for them as encouragements or warnings on most occasions, such as in journeying from one place to another, or when a marriage is on the tapis. It is considered a favourable omen, if, when proceeding on business, a crow fly from left to right; or the traveller meet two Brahmans, or a married woman, or a Sudra with a stick in his hand, or a jackal be seen. If these good omens occur, they believe that they will certainly succeed in the object of their journey. It is a bad omen to meet a single Brahman, or a widow, or if a crow fly from right to left, or a cat cross their path. On seeing any of these evil omens, almost every Hindu will postpone his journey, however emergent; though in this latter case he may return home for a little and start again. It is a good omen, if, when a marriage is under discussion, the toll of a bell be heard or the neigh of a horse; but a person sneezing or the sudden extinguishing of a light are bad omens.

No Hindu ever takes any important step without first consulting the stars, by referring to a Brahman astrologer or to the astrological almanac. If business will not admit of delay; he will consult the Sivagyanmut or Advices of Siva, or the buchuns or sayings of Khona, wife of the great astronomer Varahamira, to ascertain whether the time be auspicious. With many Hindu and aboriginal races, the snake is reverenced; and if a cobra be killed, they inter it or burn it with all the ceremonies usual for a human being.

When an epidemic disease seems to be approaching a village, the village tutelary divinity is carried in procession to meet the god of the pestilence, and with shouts, execrations, and defiant gestures they deter the advance.

The names, both of men and women, and of their towns, are frequently those of their gods and their avatars, or of their deified heroes, - as Siva, Ananda, Eswara, Gopala, Narayana, Rama, Bhawani, for men; Durga, Kali, Ganga, Lakshmi, Radha, Saraswati, for women; and Bhima, Yudishtra, Draupadi, Kunti, their ancient heroes and heroines.

Charity and Alms. - Almsgiving is expressly enjoined by the Brahmanical religion, as conferring merit and power over the unseen world, not for compassion or brotherly love, or for doing as we would be done by. Hindu charities consist in feeding Brahmans and pilgrims ; building choultries, and houses, and temples, and bridges; in planting trees, and groves, and gardens; making roads; in supplying water to travellers; in digging wells or tanks. It is, however, an oriental idiosyncrasy for every man to desire, not to found a family or restore an old 
ancestral residence, but rather to leave some residence exclusively commemorative of himself, and to repair nothing which his predecessors have left, lest they should have the credit of it with posterity. If they give alms, it is to persons of their own or of a higher caste. For a Hindu to bestow alms on a Pariah, however urgently in need the latter may be, is almost an unknown act.

Food, and Cooking, and Hospitality.-Yike that of the bulk of the human race, the food of the Hindu is obtained almost wholly from the vegetable kingdom. But with the Hindu the adherence to this kind of diet forms part of their religious belief. Unlike the Hebrews (Deut. xiv.; Leviticus xi.) or the Mahomedans, to whom only certain creatures were forbidden, several Brahmanical tribes do not touch animal food at all, and no. Hindu of the four great castes can partake of the flesh of the cow, much less avow that he had so done. They also require their food to be prepared by people of their own or a higher caste, or, in their dread of pollution, even by their own hands. With some sects this dread is carried to such an extent, that they do not permit any unconverted eye to see them cooking, and if accidentally overlooked, will bury or give away the materials under preparation, however hungry they be. Many Hindus likewise cook within a sacred circle, and if any lower caste or no-caste person enter it, the cooking is suspended, and the article destroyed. Many Hindus eat their meals dressed in silk clothes used only for sacred rites, and waited on by their wives or female relations, who do not presume to eat until their husbands have finished. They eat off metal dishes, of gold, or silver, or brass; but the ordinary platter is made of leaves of the plantain, banyan, lotus, or palasa, pinned together with grass stalks in the form of a dish. These are sold in every bazar. They are employed to ensure safety from pollution, being thrown away after the meal. The custom mentioned in John ii. 8, of appointing a governor of the feust, is one followed by Hindus at a large feast. There is a continued stream of their hospitality, such as it is, but castes will rarely eat with one another; and at meals each Brahman sits with his own leafy platter apart from his neighbour, to prevent the possibility of even accidental pollution by his own food touching that of another, or vice versa. Where such stringency exists as regards people of their own faith, their associating at meals with people of other creeds is of course an impossibility. These remarks apply to the Brahmanical Hindus in general; but the members of many of their reformed sects eat with each other, without regard to former caste distinctions. In like manner, as followers of one faith, all individuals are equally entitled to the prasad'ham, or food which has been previously presented to a deity; and it is probably the distribution of this in all temples, and, for instance, annually at Jaganath, that has given rise to the idea prevalent in Europe, that at this place all castes of Hindus eat together. A Hindu in general eats twice daily, in the forenoon and after sunset; but a Brahman widow eats only once daily, at noon. The food of the Hindus along the seaboard of India is rice,--when they can afford it,-partaken of with vegetable curries or pickles as condiments. In the higher lands of the interior, and in the more northern portions of India, the pulses and millets, with wheat and maize, are the articles in common use, in the form of cakes. The prior processes which in Europe fall to the miller and the baker, are got through in the Hindu household. The pestle and mortar is with Hindu families a very important domestic implement, and few are without it. The mortar is generally of stone, but often a block of wood, the lower part shaped like an hourglass stand, and in the upper is a conical cavity of the contents of about two gallons. The pestle is of hard wood, about four feet long, and two inches in diameter, with the ends tipped or ferruled with iron, to prevent their splitting or wearing. It is usual for two women, to whose lot beating rice out of the husks and similar domestic operations generally fall, to work together. The pestle is raised perpendicularly by the right hand of one, and as it falls is caught by the right hand of the other, she who raised it quitting it in its fall; when tired with their right hands, they use the left, relieving them. A song is frequently chanted during the work. The stone mill, so often alluded to in the Old and New Testament, consisting of two flat stones worked by one or two women, is in use in every house. The religious restriction to vegetable diet is doubtless of Buddhist origin. Buddhism had the effect of inspiring a great respect for life ; and all orthodox Hindus regard the inviolability of animal life as the most sacred of laws. In whatever degree sanguinary rites may be practised by any portion of these people, such are directly opposed not only to the influence and example of almost all the Brabmans, but to the practice of the immense majority of the more cultivated and the higher castes. Myriads of Hindus have lived and died without ever partaking of animal food; and amongst the Jains, every precaution is taken to prevent themselves involuntarily destroying or swallowing even insect life. Their priests never partake of stale food, lest living creatures should have been generated in it, keeping a cloth over their mouths lest an insect unconsciously enter; and they walk with a small soft broom in hand, with which they gently sweep the ground on which they are to tread or sit. With all this, there is occasionally witnessed amongst some one or other of the races following Hinduism an apathy and indifference as to the preservation of the lives of their fellow-creatures which Europeans fail to understand. An instance of this occurred in 1820 at the fair at Hardwar, in which 700 persons are stated to have lost their lives. It was calculated that not less than two millions of people had assembled on the occasion, when, at the opening of the fair, the rush was so great towards the steps of the bathing-place as to cause this melancholy catastrophe. Dreadful as it was, the exertions of the British officers only prevented its being infinitely greater. An eye-witness remarked that the Brahmans looked on not only with apathy, but with joy depicted in their countenances; and women at a short distance were bathing in other parts of the sacred water, with as much indifference as if the utmost serenity prevailed around them. After the fair, the roads for miles round Hardwar were strewed with dead bodies of men, women, horses, camels, and dogs.

Dress and Clothing. - The dress of Hindu men is of white muslin or cotton cloth, and their upper coat is now generally sewed. The under 
garment for the lower part of the body, the dowati or dhoti, is a loose, unsewed wrapper. Women of all classes wear unsewed wrappers of green, red, or yellow coloured cotton, edged with silk or gold embroidery, and a bodice of cotton or silk.

Scalp - lock. - All Hindu men retain only the tuft of hair on the crown of their heads, which is familiar to Europeans from the pictures and descriptions of the Indians of North America as the scalp - tuft, the most glorious trophy, if not the sole reward, of their victor. The Hindu practice of wearing this scalping tuft (Shik'ha, SANsk. ; d'Zutu, TeL. ; Kudimai, TAM.) was doubtless brought with them from Central High Asia; for, like the Indians of N. America, the Scythians cleaned the scalps they took, and hung them to their horses' bridles. The Decalvare of the ancient Germans was nothing other than the scalping mentioned in the laws of the Visigoths, capillos et cutem detrahere. According to the annals of Flude, the Franks still scalped about the year 879, and also the Anglo-Saxons; and head-hunting is only now being suppressed among the Khassya and Garo races of the N.E. frontier, and arnongst the Dyaks of Borneo.

Titles. - One amongst the honorific social distinctions of the Hindus is that of Acharya, a religious teacher, properly a Brahman who instructs religious students of the Vedas, of the Brahman, Kshatriya, and Vaisya castes, but is in use as relating to any religious instructor. In the south of India the term is applied to the head of a religious society, equivalent to the Mahant of Hindustan, and the Panda or head priest of a temple. But it is assumed also by Brahmans engaged in secular pursuits, by carpenters and other artisans, and amongst the Mahrattas by cooks.

Caste.-A great object with Hindus in general is to preserve their social position in caste. The divisions and subdivisions of their different castes are very numerous, - the Sudra are said to have nearly fifty; but with all Hindus purity of caste is held of the highest consequence, and its loss may occur from various causes.

The division into castes or sects of the Aryan races whom we style Hindus, was known to the Greeks, and seems to have been early known to the Arabs. The Grecian authors, on the authority of Megasthenes, divided the tribes into seven, and Ibn Khurdadba (obiit A.D. 912), an officer of the khalifs, also arranges them into seven classes, but the occupations differ which these authors attributed to them :-

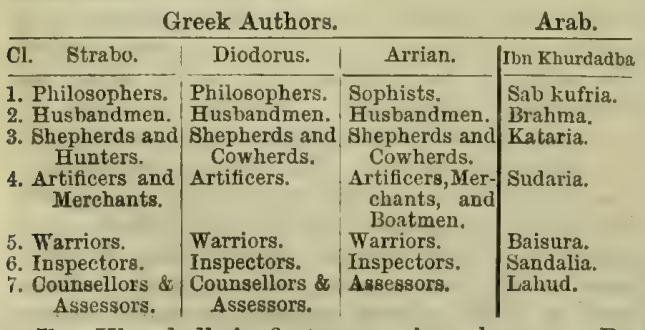

Ibn Khurdadba's first name is unknown. By the others he seems to indicate the Brahman, Kshatriya, Sudra, Vaisya, the Chandala, and jugglers.

Dr. Caldwell tells us that in all ordinary cases where illegitimate children are bom, if there

be no great disparity in rank or caste between the parents, the child takes that of the two parents which is the lower. Where considerable disparity exists, and particularly when the woman is of the higher rank, -as, for instance, when a high caste woman, or even a woman belonging to the middling castes, has formed an intimacy with a Pariah man,--the mother either procures abortion or commits suicide. The child never sees the light. Caste has its chief relations with race descent. There are historical instances of sovereigns creating Brahmans in great numbers from amongst other races; the Mahratta Brahmans are said to have been so made from amongst fishermen; and a great body of Rajputs were consecrated of the Kshatriya caste.

To escape possible defilement, the servile races - Pariah, Mhar, Mhang, Chamar-are compelled to dwell outside the village walls, and in the larger towns Christians have their own quarters; and the higher Aryan castes require the predial races not even to approach their dwellings, but to stand at a distance and call aloud what they wish to communicate. A Hindu may lose or be expelled from his caste for many social acts, but no meritorious deed can raise a Hindu from one caste to another, nor does immorality or crime degrade him from his caste. Many castes eat and drink together, but intermarriages of persons of different castes are almost prohibited in the higher castes, and are rare even in the very lowest. It is a hedge over which many persons desire to leap. Chaitanya and other reformers have founded sects which have abandoned caste distinctions; and the lower tribes, as the Chamar or shoemaker, the Dhobi or washerman, have largely joined antiBrahmanical sects, as the Kabir panthi, Satnami, etc. The aboriginal races, of Turanian descent, as a rule, by origin and nature are averse to caste distinctions and Brahmanism.

Avocations.-The races following Hinduism, and the converts from amongst them to Mahomedanismı and the Sikh faith, are, almost exclusively, the owners and tillers of the soil of India; and as agriculturists in Northern India are in village proprietory communities, those of Central India are village proprietors, and those of Western and Southern India are joint holders under Government. The entire banking interests in India, moneyed men and capitalist class, smaller merchants, traders, and carriers, are Hindus ; and Hindus are settled for merchandise in Arabia, in Afghanistan, all through Persia and Turkestan; they are in Astracan, in the southern provinces of Russia, even as far as Moscow; also in Eurther India, throughout Burma, Tenasserim, south wards to Singapore; and, from unknown antiguity, one Hindu tribe of the north-west of the Peninsula have been located on the east coast of Africa southwards to Mozambique, and have been the willing agents of slave-dealers.

The more famous amongst their writers :-

Agastya.

Anandagiri.

Angirasa.

Apastambha.

Arya Bhatta.

Aswalayana.

Atri.

Bharata.

Bharavi.

Bhartrihari.
Bhaskara.

Bhatti.

Bhava Bhuti.

Brahmagupts.

Charaka.

Charandas.

Dandi.

Devi Mahatamya.

Dhanwantri.

Dya Dwiveda. 
Gopinatha.

Gotama.

Gritsamada.

Halayudha Bhatta.

Hema Chandra.

Jaya Deva.

Kabir.

Kalhana.

Kalidasa.

Katayayana.

Kautsa.

Kavi Karnapura.

Kavi Raja.

Krisbna Dwaipa Yana.

Krishna Misra.

Kulluka Bhatta.

Madhavacharya.

Magha.

Mallinatha.

Mamatta Bhatta.

Manu.

Markandeya.

Mira Bai.

Murari Misra.

Nanak.

Panini.

Parasara.

Patanjali.

A knowledge of reading and writing is very widely diffused, but those who cannot write use trade-marks as their sign-manual, of which the following may be mentioned:-

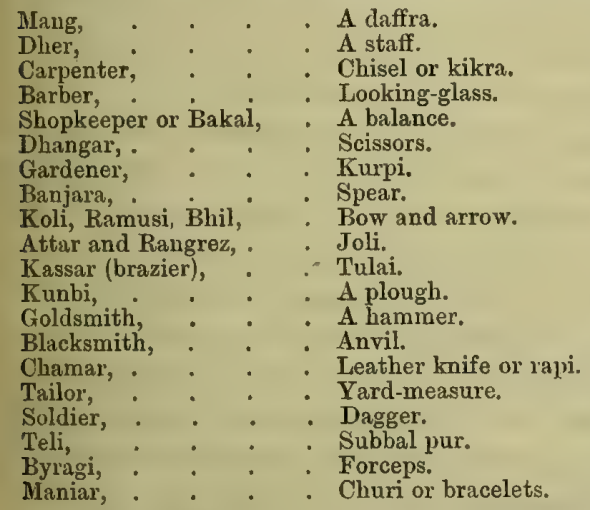

Religious Liberty.-From the oldest times, succeeding rulers of Travancore and Cochin, and seemingly those of Gujerat, have ruled their dominions with the most entire religious liberty; and Arab races, Jews, Parsees, Romans, Africans, Egyptians, Portuguese, Dutch, and British have traded and settled there. At Patna, the little Christian church, or Mut'h, as it is inserted in the village dufturs, was endowed its portion of land exactly as any other religious establishment.

In the changes between Buddhism and Hinduism, and with the occasional forcible proselytizing by the Mahomedans to their faith and by the Portuguese at Goa to their views, there has been much cruelty; and, generally speaking, Hindu and Mahomedan sovereigns favoured those of their subjects who were of the rulers' faiths. But, by an Act passed in 1840 , a discontinuance was put to all interference on the part of British functionaries in the interior management of native temples ; in the customs, habits, and religious proceedings of their priests and attendants; in the arrangement of their ceremonies, rites, and festivals; and generally in the conduct of their interior economy; the tax on pilgrims was abolished; and in 1841, salutes and the attendance of troops or military bands were forbidden at such festivals.

Hindu Morality.-Major Moor remarks that it is some comparative, though negative, praise to the Hindus, that the emblems under which they everywhere exhibit the elements and operations of nature are not externally indecorous. Unlike the abominable realities of Egypt and Greece, we see the phallic emblem in the Hindu pantheon without offence, and know not, until the information be furnished, that we are contemplating a symbol whose prototype is indelicate. The external decency of the symbols, and the difficulty with which their recondite allusions are discovered, both offer evidence favourable to the moral delicacy of the Hindu character. Temples are nevertheless commonly to be seen, on which are represented, in statues even of life size, figures which only the mind of man in all its corruptness and wickedness could conceive. However recently erected, these are perhaps but remnants of the period succeeding the asceticism and austerities of Buddhism. Books then came to be written about heroes whom they deified, some of whose lives, as painted, are a continuous outrage of decency. But the people generally never followed such licence. To have done so, society must have ended. At the present day, undoubtedly, the morality of the Hindus is far above the stories in their books, the statues on their shrines, or the licence which prevails amongst the few who associate with the Devadasa at their temples; and it is only their patience under such grossness, their not rising in wrath to reform it, their worship of fire and the elements, of the sun and moon, of the lingam and yoni, of the saligrama, the binlang, the tulsi, and the poa; their reverence for, almost worship of, the cow, the kite, and the cobra; their worship of Nandi, of idols with unnatural or hideous forms, of shapeless blocks of wood or stone, in which the educated have no faith, and which are often treated with irreverence by all; their respect for books of the contents of which they are ignorant, and which are not worthy of their present civilisation,-it is their adherence to all these confused amalgamations of the coarse Vedic creed, Scythic worship, fetishism, the austerities and sacredness of life of Buddhism, and the licence of Vishnu as Krishma, which excites the wonder and the contempt of all educated men. And their indifference is the more remarkable, because two thousand years ago they had a religion 'less disgraced by idolatrous worship than most of those which prevailed in early times. They had a copious and cultivated language, and an extensive and diversified literature; they had made great progress in the mathematical sciences, they speculated profoundly in the mysteries of man and nature, and they had acquired remarkable proficiency in many of the ornamental and useful arts of life. In short, whatever defects may be justly attributed to their religion, their government, their laws, their literature, their sciences, their arts, as contrasted with the same proofs of civilisation in modern Europe, the Aryan Hindus were in all these respects quite as civilised as any of the most civilised nations of the ancient world, and in as early times as any of which records or tradition remain. In the re-ascendency of Brahmanism after the overthrow of Buddhism, the prime defect 
of which was a want of knowledge of the true God, and to which was subsequently added a relic worship, and an over-fondness for asceticism, the writers who are now regarded by the Hindus as authorities, introduced the outrageous matters which at the present day are the shame and degradation of the followers of this extraordinary faith. Major Moor observes that, with a little alteration, the first part of Juvenal's fifteenth satire, beginning 'Quis nescit,' might be applied to the teachers of Hinduism as now seen, as happily as to the Egyptians, the objects of Juvenal's severity. It is a picture of the Hinduism of the present day:-

'Who knows not that there's nothing vile nor odd, Which brain-sick Brahmans turn not to a god? Some of those blockheads bulls and cows adore ; Fish, reptiles, birds, and snakes, as many more; A long-tail'd ape some suppliants admire, Or man-like elephant, a god the sire ;

One race a god, half-man half-fish, revere, Others to unsightly moieties adhere;

Hosts to a stone's high deity bend down,

While others sticks with adoration crown;

Nay, vegetables here hold rank divine, -

On leeks or mushrooms 'tis profane to dine.

$O$ holy nation, where the gardens bear

A crop of gods throughout the tedious year!'

It has been remarked that the characters of many of the Hindu deities are faintly indicated by the term immoral. Everything that is gross and sensual and wrong is to be found as ordinary acts of their deities; and the followers of these faiths present the extraordinary spectacle of a people with purer lives than is to be found in the idolatrous or demonolatrous systems of religion which they follow. They have a proverb amongst themselves, - 'Yatha devas, Tatha bhaktah, i.e. As is the god, so is the worshipper,-happily not applicable to their own conduct. For in their domestic lives they are gentle, not aggressive; modest, reverent, respecters of authority, temporal and spiritual ; desirous of knowledge, seekers of the truth, patient under mental or bodily labour ; diligent in their callings, frugal, temperate, and chaste; living with one wife, though Hindu law permits a plurality; amongst the entire Hindu races offences against the person are rare, and it is only amidst the licence of the temples that gross polygamy is common, and is even there confined to the habitues of the shrines.

In all these remarks, however, it is necessary to bear in mind that the Hindus comprise many races, and dwell in many different climates. Amongst some of the races, and particularly amongst the non-Aryan tribes, there is much drinking of alcoholic fluids, which with other of their races is almost unknown. Mountstuart Elphinstone says their most prominent vice is want of veracity. They do not even resent the imputation of falsehood. The same man would calmly answer to a doubt by saying, "Thy should I tell a lie?' who would shed blood for what he regarded as the slightest infringement of his honour. Hindus are not ill fitted by nature for intrigue and cunning, when their situation calls forth those qualities. Patient, supple, and insinuating, they penetrate the views of the persons with whom they have to deal. I,ike all that are slow to actual conflict, they are very litigious, and much addicted to verbal altercation. "The manner in which often,' Dr. Chevers writes at p. 451, 'a crowd of Bengalis fall upon a viction of their displeasure, and beat and tear him into pieces with sticks, fists, feet, bands, and any weapon which may happen to have been brought or caught up, until the body lies in the midst of them a mere bloody, featureless, disjointed, broken mass, is scarcely characteristic of the reputed mildness of the national character.'Abbé Domenech's Deserts of N. America; Bunsen's Egypt; Brown's Teloogoo Dictionary; Caldwell's Comparative Grammar, also Tinnevelly Shanars; Calcutta Review; Coleman's Mythology; Cunningham's Bhilsa Topes; Cunningham's History of the Sikhs; Elliot's History of India; Elliot's Supplemental Glossary; Elphinstone's Hist. of India ; Hodgson in Bengal As. Soc. Transactions; Latham's Descriptive Ethnology; Marsden's Marco Polo; Max Müller's Chips; Marshall's Stat. Rep.; Moor's Pantheon; Mullen's Hindu Philosophy; Sherring's Castes and Tribes; Strange's Hindoo Law; 'T'nnant's Ceylon; Tod's Rajasthan; Tod's Tracels ; Vigne's Travels ; Ward's Hindoos ; Wilson's Glossary; Wheeler's Mahabharata; Wheeler's Rantayana; Wheeler's Travels of $a$ Hindoo; Wilson in Royal As. Soc. Transactions; Williams' Story of Nala.

HINDUSTAN is a term which the people of Europe apply to British India generally. To the people of India, however, and to Europeans residing there, the name is restricted to that part of the country which lies between the Himalaya and the Vindhya mountains, and from the Panjab in the N.W. to Bengal in the S.E. This was the Aryavartha or Aryan country of the Sanskrit writers, who also called it Punya bhumi, or the Sacred Land. Jutting to the south of this portion is a triaugular promontory or peninsula, known to the Hindus as the Dekhan (Deccan), meaning the south; and these two portions form the region which is briefly to be noticed here.

Rivers and Mountains. - The northern portion is watered by the Gauges and the Indus and their tributaries, and it is known as the Indo-Gangetic plain. It is an immense extent of flat country, stretching from sea to sea, is entirely composed of alluvial deposits of very late geological age, and it separates the hilly ground of the Peninsula from the mountain ranges of Sind, the Panjab, the Himalaya, Assam, and Burma. Several of the southern rivers are large, - the Nerbadda, Tapti, Mahanadi, Godavery, Kistna, and Cauvery; but none of them equals in importance the Ganges, or the Indus, or the Brahmaputra, which, with the Irawadi of Further India, are the only rivers navigated by steam flotillas, though the Godavery has boats trafficking on it. The marine lagoons, on the east and west coasts, connected by canals, are available for inland navigation, and most of the rivers and their affluents are utilized for irrigation. The east const of the Peninsula is washed by the Bay of Bengal, and its west coast by the Arabian Sea; but the great Indo-Gangetic plain is mountain girt. To the west are the Khirtari, the Suliman, and the maze of mountains separating India from Afghanistan; to the south are the Vindhya; and on all the north Hindustan proper is bounded by the stupendous Himalayas.

The Aravalli bills are connected by lower ranges with the western extremity of the Vindhya mountains, on the borders of Gujerat, and stretch northwards to a considerable distance beyond Ajmir, in the direction of Dehli, forming the 


\section{HINDUSTAN.}

division between the desert on the west and the central table-land. It would be more correct to say the level of the desert, for the south-eastern portion, including Jodhpur, is a fertile country.

Amarkantak, a great plateau, forms the watershed of the Mahanadi, Son, Tons, Johilla, and Nerbadda. These rivers, though large and full of water even half-way from their mouths, are very irregular in the slopes of their beds, and are disturbed by frequent rapids, so that, owing to these impediments, increased still further by the rocky character of the river beds or their banks, navigation is limited for the most part to the lower portions of their course.

Central India is a table-land of unequal surface, from 1500 to 2500 feet above the sea, bounded by the Aravalli mountains on the west, and those of the Vindhya on the soutb, supported on the east by a lower range in Bundelkhand, and sloping gradually on the north-east into the basin of the Ganges. It is a diversified but fertile tract. The plateau is known as the Patar, and many parts are covered with jungle. The Aravalli hills have afforded protection to the most ancient sovereign race in the east or west, - the ancient stock of the Suryavansa, the Heliadæe of India, or children of the sun, the princes of Mewar, who, when pressed, were wont to retire to its fastnesses, only to issue again when occasion offered.

The Vindhya mountains north of the Nerbadda river, and the Satpura range south of that river, run east and west, and separate Hindustan proper from the Dekhan.

In that peninsular Dekhan or southern portion are two mouu tain ranges, known as the Easteru and Western Ghats. These ghats run in wavy lines southwards towards Cape Comorin, approaching and receding from the coast, and leaving, between them and the sea, low, alluvial, fertile tracts from 50 to 100 miles broad. The region enclosed within the ghats has several extensive plateaus, rising 1200 to 3000 feet above the sea, as in the Ceded Districts, Coimbatore, Hyderabad, and Mysore; and in the more southern parts are spurs rising higher, with particular names. For instance, to the north of Coimbatore the chain rises abruptly to 8000 feet, as the Neilgherry range, and continues northward as the mountains of Coorg. The rainfall, which is great on the western coast, is less on the Neilgherries, being 82 inches at Dodabetta, and 48 inches at Ootacamund. Farther north, in the Nagar district of Mysore, where are many rounded or table-topt ed hills 4500 feet high, often cultivated to that height, and rising in some places to upwards of 6000 feet, the climate of the western part is very humid, and particularly so at the town of Nagar or Bednur, 4000 feet high, on a spur of the western chain, where inclement rain is said to last for months.

The Trazancore group presents a striking ana$\log y$ to the island of Ceylon. The hills are loftiest at the extreme north of that district, where they stretch east and west for 60 or 70 miles, separating the districts of Dindigul and Madura.

The Pulney mountains are west of the Dindigul, the Animallay south of Coimbatore, and the Sheragiri south-west of Madura.

Climate and Seasons.-A country with such varied features, and extending through 28 degrees of latitude $\left(8^{\circ} 8^{\prime}\right.$ to $36^{\circ} \mathrm{N}$.), has climates and products commensurately varied. In Hindustan the people usually arrange the year into three periods, - the Choumasa or Burk'ha, which is the rainy season of four months' duration; after which is the Seeala, or Jhara, or Mohasa, the cold season. followed by the Dhubkala or K'hursa, or hot season. This division indicates generally the course of the seasons in all Hindustan, though in one locality or another the rains or the hot or cold seasous may be somewhat more or less prolonged.

Winds and Rains. -The S.W. monsoon blows from the Southern Ocenn, and is loaded with vapour. This is deposited largely along the sea-face of the Western Ghats, and between them and the sea, from 70 to 100 inches at the sea-level, and as much as 250 inches on the mountain face. At Mahabaleshwar it amounts to 260 inches annually. In the Southern Konkan, especially in the Sawant. wari district, the rains are as heavy as in Canara. At Bombay the rains last from June till the end of September, and the fall is only 71 inches, which is considerably less than at any point farther south on the west coast. At Tanna, however, the average fall is more than 100 inches. This monsoon wind passes over the plains of Bengal, and strikes on the Khassya mountains and the whole length of the Himalaya, discharging itself in heavy rains. From April till August it blows from the east of south, in August S.S.E., and in September more easterly, lowering the temperature of Bengal and of the northern plains, though the plains of the Panjab continue excessively heated.

From the vernal till the autumnal equinox, the heat of a great part of India continues great; but after the autumnal equinox, the great mass of the Himalaya becomes intensely cold, and the plains of India generally become cool. Where the N.E. monsoon prevails, it is everywhere a land wind, except on the east coast of the Karnatic, the Malay Peninsula, and the Archipelago. In Malaya it blows over a great extent of sea, and is therefore very rainy; but in the Karnatic the width of sea is not great, so that the rainfall, though well marked, is less, and terminates Jong before the end of the monsoon, probably from the wind acquiring a more directly southerly direction, after the sun bas reached the southern tropic. The amount of rain varies prodigiously in different parts of India, from almost none to 555 inches at Cherrapunji; but the rainfall affords no direct criterion of the hunidity of any climate, for the atmosphere may be saturated with moisture without any precipitation taking place. Thus, while in Sikkin $1^{\circ}$ for 300 feet is the proportion for elevations below 7000 feet, on the Neilgherry Hills it is about $1^{\circ}$ for 340 feet; in Khassya, $1^{\circ}$ for 380 feet; and the elevations of Nagpur and Ambula produce no perceptible diminution in their mean temperature, which is as great as that which would normally be assigued to them were they at the level of the sea. The chief fall occurs during the S.W. monsoon, between May and October. On the more southerly part of the Coromandel coast, on the east of the Peninsula, heavy rain falls in the months October to December, at the opening of the N.E. monsoon ; and in all the more northerly provinces, a wellmarked season of winter rains occur, commencing about Christmas, and extending to February. At this season, in the south of India, showers occur, but they have little effect on agricultural operations, - often, indeed, are injurious to cotton when 
grown as a cold-weather crop. Subject to these exceptions, it may be said generally that the portion of India east of the 80th meridian has a rainfall of more than 40 inches, while the portion west of the same meridian has less than 40 inches. The region in which the fall is less than 30 inches includes almost the whole of the Panjab, a considerable part of the N.W. Provinces, a large part of Rajputana and Kattyawar, as well as almost the whole of the Dekhan and.Mysore. In Sind, and in the southern portion of the Panjab, the rainfall is less than 15 inches, and is extremely irregular; but in Sind the agriculture almost wholly depends on artificial irrigation from the Indus. The parts of the country most subject to droughts are-(1) the W. and S. parts of the N.W. Provinces, the Panjab E. of the Sutlej; (2) the W. and N. States of Rujputana and of the Central Plateau, which border on the N.W. Provinces; (3) the districts of Bombay and Madras above the ghats, together with the southern and western regions of Hyderabad and all Mysore, except the strip lying close along the Western Ghats; and (4) the Madras districts along the east coast, and at the southern extremity of the Peninsula.

Dr. Royle gives the following arrangement of the countries of which the plants will grow in the different parts of India :-

Tropical and East Indian islands, tropical Africa, Brazil, Guiana, West Indies, and Florida.

East and west coast of Africa.

S. States of N. America, Egypt, N. of Africa, Syria.

Mexican highlands, lower mountains of Spain.

S. of Africa, extra-tropical New Holland,S. America beyond $23 \frac{1}{2}^{\circ} \mathrm{S}$. lat.

Mediterranean region.

Chino-Japanese region, Middle Andes, Peru, and mountains of Brazil.

North of Europe, north of Asia, \& North America.

Arctic regions, mountains of Europe, Elevated Andes.

Travancore, Cochin, Mala bar, Ceylon, Malay Peninsula, Chittagong Bengal, Lower Assam.

Coromandel coast, Northern Circars, Konkan

Gujerat, Behar, Doab, Dehli, Malwa.

Mysore, hilly ranges in Dekhan, Rajoutana.

Saharunpur and Northern Doab.

Dehra Doon, and Himalayan valleys to moder ate elevations.

Neilgherries, Upper Assam, Himalayan moun tains.

Himalayan mountains, regions of oaks and pines.

Himalayas above region of forest.

Crops.-Many parts, alike of the northern and southern districts, have two crops during the year, - one called the kharif or rain crop, sown in June, and reaped in October; the other, sown in October, and reaped in March and April, called the rabi or spring or cold-weather crop. The latter, embracing the months which approximate in temperature to those of the season of cultivation in colder countries, corresponds with them also in the nature of the plants cultivated, as for instance wheat, barley, sorghum, oats, and millet, peas, beans, vetch, tares, chick-pea, pigeon-pea, and lentils; tobacco, safflower, and chicory; flax, and plants allied to mustard and rape, as oilseeds; carrot, coriander, and cummin, and other seeds of a similar kind, as ajwain, sonf, soya, and anison. In the rainy season, a totally different set of plants engages the agriculturist's attention, as rice, cotton, indigo, and maize, with sorghum, pulse, paspalum, most of the tropical legumes, as well as several of the cucumber and gourd tribes, together with the sesamum for oil, and the varieties of the egg plant as a vegetable. The sunn and sunni species of Corchorus and Crotalaria cordage plants are also cultivated at this season. In the extreme N.W. countries, as, for instance, throughout Afghanistan, the climate is excessive. The cold of the winter is intense, the spring is damp and raw, and the summer, during which hot west winds prevail, is intensely hot at all elevations. The crops are chiefly wheat and barley, even up to 10,000 feet elevation. Rice is cultivated in great quantity at Jalalabad, 2000 feet; at Kābul, 6400 feet; and to a considerable extent at Ghazni, 7730 feet. Poplars, willows, and date-palm trees are extensively planted, as well as mulberry, walnut, apricot, apple, pear, and peach trees, and also the Elragnus orientalis, which bears an eatable fruit. The vine abounds as in all warm and dry temperate climates. The majority of the Afghan and Tibetan plants are also, on the one side, natives respectively of the Caspian steppes and N. Persia, and of Siberia on the other.

The date is cultivated in Baluchistan up to 4500 feet; and a dwarf palm, Chamærops Ritchieana, Griffith, occurs abundantly in many places, but with a somewhat local distribution.

The area of the entire region nuder notice is $1,308,332$ square miles, and its population 253,891,821. Excluding Assam and British Burma, both of which are beyond Hindustan in Further India, the British administer $876,972 \mathrm{sq}$. miles of territory, with a population of $193,270,700$ souls; and the states in alliance, feudatory and mediated, have an area of 573,772 square miles, with a population of $52,002,924$.

Races. - The British territory is chiefly in the plains, and its population at the census of 1871 comprised $73 \frac{1}{2}$ per cent. of Hindus and Sikhs, $21 \frac{1}{2}$ per cent. of Mahomedans, and 5 per cent. of all others, including under this title Buddhists, Jains, Christians, Jews, Parsees, Bramhoes, and Hillmen. As this page is passing through the press, portions only of the 1881 census have been made public, and the figures are to some extent not up to date. Under the designation Hindu are included almost all who profess, in some form, the Brabmanic religions, or who are worshippers of local deities, of whom about $10 \frac{1}{8}$ millions are Brahmans, $5 \frac{5}{8}$ millions are Kshatriyas and Rajputs, $105 \frac{1}{2}$ millions of other castes; $8 \frac{3}{4}$ millions do not recognise caste; and $17 \frac{3}{4}$ millions are aboriginal tribes or semi-Hinduized aboriginals. In 1881 the numbers were as under:-

Hindus, . . 187,937,450|Jains, . . 1,221,896 Sikhs, . 1, 1,853,426 Christians, - 1,862,634 Mahomedans, 50,121,585 Aborigines, : 6,426,511 Buddhists, : $3,418,884$ Others,. : $1,049,435$

The Buddhists are almost all inhabitants of Burma, and not of Hindustan, but with the incomplete census reports the residence respectively cannot be distinguished.

The ancestors of the present inhabitants, during the bygone ages, either as immigrants or as conquerors, have been entering India from the north and west. How little these have amalgamated, may be judged of by mentioning that out of 1030 villages lying here and there between the Jumna and Sutlej, and which were under British management in 1844, there were found to be 41 different tribes of agriculturists. And as a characteristic of the rebellion of 1857 and 1858 , 


\section{HINDUSTAN.}

it was observed that certain classes of villagers attacked and destroyed other classes ; - the powerful hand of a regular government being temporarily removed, the ancient antipathies of race at once came into play. Dwelling amongst each other, door to door, but yet never mixing, neither eating together nor intermarrying, most of the races remain as distinct as when, $10,15,20,30$, 40 , and 50 centuries ago, they came to the south. It is this separating system which has kept the stocks of Aryan and Turanian races of India pure. On the slightest suspicion as to descent, all intercourse ceases, and the descendants, in different lines from the same recognised ancestor, form new

Population of India accoring to Census of 1881, -classified under Sexes and Religion, and distinguishing British Territory from Native States.

\begin{tabular}{|c|c|c|c|c|c|c|c|c|c|c|c|}
\hline \multirow{2}{*}{$\begin{array}{l}\text { Province or } \\
\text { State. }\end{array}$} & \multicolumn{3}{|c|}{ Total Population of all Religions. } & \multirow{2}{*}{$\begin{array}{l}\text { Hindus. } \\
\text { M. \& F. }\end{array}$} & \multirow{2}{*}{$\begin{array}{l}\text { Mahomm. } \\
\text { M. \& F. }\end{array}$} & \multirow{2}{*}{ Aborign. } & \multirow{2}{*}{$\begin{array}{l}\text { Buddh. } \\
\text { M. \& F. } \\
\end{array}$} & \multirow{2}{*}{$\frac{\text { Christ. }}{\text { M. \& F. }}$} & \multirow{2}{*}{$\begin{array}{c}\text { Sikhs. } \\
\text { M. } \& \mathrm{~F} .\end{array}$} & \multirow{2}{*}{ Jains. } & \multirow{2}{*}{$\begin{array}{l}\text { Others. } \\
\text { M. \& F. }\end{array}$} \\
\hline & Males. & Females. & Total. & & & & & & & & \\
\hline Territory. & & & & & & & & & & & \\
\hline Ajmir, . . & 248,844 & 211,878 & 460,722 & 376,029 & 57,809 & & & 2,225 & 182 & 24,308 & 169 \\
\hline Assara, . . & & & 4,8 & & 1,317 & 488,251 & 6,563 & 7,093 & 14 & 158 & 177 \\
\hline Bengal, . . & & & 69,536 & $\left.306\right|^{2}$ & 21,7 & $2,055,822$ & 155,809 & 128,135 & 549 & 1,609 & 37,407 \\
\hline ar, & & & 2,6 & $2,425,654$ & 187,555 & 37,338 & 1 & 1,335 & 525 & 20,020 & 245 \\
\hline Bombay, . . & & & 16,4 & $12,308,582$ & $8,021,131$ & 562,678 & & 138,317 & 127,100 & 216,224 & 80,382 \\
\hline British Burma, & & & 3,7 & $88,17 \pi$ & 168,881 & & $3,251,584$ & 84,219 & & 5 & 3,905 \\
\hline ntral Prov.,. & & & 9,83 & 7,317 & 773 & $1,533,599$ & $1 i$ & 11,949 & 97 & 45,718 & 653,808 \\
\hline Congr, . . & & & 302 & 489 & 12,541 & $\ldots$ & & 3,152 & ". & & \\
\hline dras, . . & 43. & 15,7 & 31,1 & 28,4 & $\mathbf{1}, 933,5$ & . & 1,535 & 711,080 & & 24,973 & $\mathbf{1}, 804$ \\
\hline P.\& Oudh, & & & 69 & 38 & & . & 103 & & 3,644 & & 221 \\
\hline Panjab, . . . & 10 , & & & 528 & 10,5 & $\ldots$ & 2,864 & 33,420 & $1,121,004$ & 35,826 & $\begin{array}{r}1,645 \\
\end{array}$ \\
\hline Total,... & $102,850,879$ & $99,038,018$ & $201,888,897$ & $144,875,315$ & $45,127,033$ & $4,677,688$ & $3, \overline{418,476}$ & $1,168,589$ & $1,253,115$ & 448,897 & 919,784 \\
\hline Feudatory St. & & & & & 229 & & 12 & & 30 & & 3.303 \\
\hline Central Prov., & 87. & 33 & $\begin{array}{l}0,94 \\
1,70\end{array}$ & $\begin{array}{l}0,020,405 \\
1,385,280\end{array}$ & 9,914 & $\begin{array}{l}369,216 \\
220,318\end{array}$ & 12 & $\begin{aligned} 837 \\
24\end{aligned}$ & $\begin{array}{r}30 \\
2\end{array}$ & $\begin{array}{r}82,219 \\
193\end{array}$ & $\begin{array}{r}3,303 \\
93,989\end{array}$ \\
\hline N.W.P.\& Oudh, & 384 & & 750 & 501,727 & 014 & .. & & 9 & & & . \\
\hline Panjab, . . & $2,112,303$ & 380 & 3,86 & 2,121 & $1,137,284$ & & 387 & 279 & 595,110 & 6,852 & \\
\hline Total, . . & $6,937,044$ & $6,317,358$ & $13,254,402$ & $9,535,177$ & $2,140,441$ & 589,534 & 399 & 7,149 & 595,142 & 289,264 & 97,296 \\
\hline Tl. Brit. Terxi. & $109,787,923$ & $105,355,376$ & $215,143,299$ & $154,410,492$ & $47,267,474$ & $5,267,222$ & $3,418,875$ & $1,175,738$ & $1,848,257$ & 738,161 & $1,017,080$ \\
\hline Dheres. & & & & & & & & & & & \\
\hline & 1,139 & & & & & & $\cdots$ & 771 & & & 8,146 \\
\hline India, & 4,882 & & 9,26 & 7,80 & 718 & 891,424 & & 7,065 & 1,455 & 49,824 & 1,025 \\
\hline bad. & 815 & & 278 & 4 & 33,344 & . & - & 136,361 & & & 1,249 \\
\hline $\begin{array}{l}\text { erabad, } \\
\text { ore. }\end{array}$ & 137 & & 9,84 & 8,89 & 925 & . & . & 13,614 & 3,664 & 8,521 & 685 \\
\hline ing, & 665 & $\begin{array}{l}346 \\
27\end{array}$ & $\begin{array}{r}4,1 \\
10,2\end{array}$ & $\begin{array}{l}3,9 \\
8,8\end{array}$ & & 166,343 & & $\begin{array}{r}29,249 \\
1,294\end{array}$ & 41 & & \\
\hline Travancore, & 1,15 & 204,024 & 2,40 & 1,75 & 146,909 & $100,0 \pm 0$ & & 498,542 & & $\begin{array}{c}518,012 \\
\ldots\end{array}$ & $\begin{array}{r}21,084 \\
97\end{array}$ \\
\hline Tl. Native St & $20,153,92 \mathrm{~S}$ & $18,594,594$ & $38,748,522$ & $33,526,958$ & $2,854,111$ & $\overline{1,159,289}$ & 9 & 686,896 & $\overline{5,169}$ & 483,735 & $\overline{32,355}$ \\
\hline & & & & & & & & & & & \\
\hline
\end{tabular}

Many of the aboriginal tribes, now under the British or feudatory rulers, are broken nationalities, as the Gond, the Bhil, the Kathi, the Gujar, the Mair, the Meena, the Bhar, the Kurku, the Maria, the Khond, the Santal, the Kol. There are smaller tribes in Chutia Nagpur and the Tributary Mahals, wild mountain races in Julpiguri, with more compact clans of Mongoloid tribes in the Garo, Khassya, Jaintia, and Naga Hills, and in Tiperah and the Chittagong Hill tracts. On the hills and in the plains in the extreme south of Peninsular India, are the Nair, the Coorgs, the Beder, the Male Arasar, the Kadar, the Yanadi, the Irular, the Badaga, the Toda, the Kotar and Kurumbar, and the Saura, the Chenchwar of the Eastern Ghats.

The Kallar, Maravar, Teer, and Shanar occupy the plains in the very south of the Peninsula. Some of the predial tribes, the Dom, Pariah, Mhar, Holiyar, Mhang, Dhor, Chamar, Veddar, Puller, Cherumar, are settled in the outskirts of the villages; but the Wadawar, Banjara, Lambari, Korawa, Bhaora, Bhatu, the Yerkala, some of the Kurumbar, and others, are homeless wanderers, moving amid the civilised settled dwellers of the plains, or secluded in the hills and forests, and are largely predatory, as are also the Sansi, Baori, Harni of the Panjab, and the Nat of Northern Hindustan. The Dravidians are in several great castes. In this way almost every family of a few hundred years' duration is now broken up. The cause of the origin of this exclusive propensity is unknown, further than that the system of caste and the forms of Brahmanic worship commenced amongst the East Aryans after their passage of the Sutlej, and now every Aryan and most Turanian households are guided by its rules. The tribes and castes are everywhere numerous. It has been estimated that in Bengal alone, if their subdivisions and septs and clans be taken into account, they would amount to many thousands. The Bombay Census Report of 1881 enumerates 1245 . 
Rajput, Hindu, and Mahomedan rule. The principal of the allied states are those ruled over by Hindu sovereigns, and the Rajput families of Udaipur or Mewar, of Jodhpur or Marwar, of Jeypore in Rajputana, by the Rao of Cutch, and the Hindu sovereigns of Mysore, Travancore, and Cochin. The Mahratta rulers are of Kolhapur, the Gaek war, Sindia, and Holkar; the Malsomedan states are Bhopal and Hyderabad. The French have possessions in Hindustan, with an area of 178 square miles, and 271,460 souls; and the area of the Portuguese possessions is 1086 square miles, with 407,712 souls, chiefly in towns or suburban.

The chieftains of Rajputana have about 93,000 armed retainers, mostly undisciplined.

The Hyderabad state is composed of portions of Telingana, Karnatica, Maharasthra, and Gondwana. Its ruler, styled the Nizam, is a Mahomedan, and most of its territorial nobility and its soldiery are of the same sect. The area, including Berar, is about 98,000 square miles, and its population $11,226,496$.

In the Hyderabad state there are three large armed forces, - one body, the subsidiary force, at Secunderabad, of about 5000 of all arms; the other, the contingent, also of all arms, about 5000 , at Ellichpur, Bolarum, Aurangabad, Hingoli, and Mominabad; and the Nizam has a large body of disciplined and undisciplined troops, stated in 1879 at 38,000 infantry, 8200 cavalry, and 725 guns.

The dominions of the Mabaraja Sindia are 33,119 square miles in extent, with a population of $2,500,000$, and revenue, 1 million.

The Maharaja Sindia can, under treaty agreements, maintain a regular force of 5000 men, and 36 guns. The fortress overlooking the town of Gwalior is held by British troops, who occupy also the neighbouring cantonment of Morar.

The Maharaja Holkar of Indore and Malwa rules over about 8400 square miles of straggling territory in Central India, with a population of about 750,000 .

Bhopal adjoins Holkar's dominions to the eastward. Its ruler and the court are Mahomedans, of Pathan descent, as are likewise a large number of the population of the chief town. The territory contains 6760 square miles, and nearly 700,000 inhabitants. The number of armed retainers maintained is about 6000 , with 39 guns of sorts. Bhopal has, from the earliest times, displayed an nnswerving friendship for and loyalty to the British. In the most trying times of the Mutiny, when other states wavered, Bhopal stood true. The dynasty which rules it has never shown any love for aggression. A small colony of Mahomedans planted in the midst of a large Hindu community at the time of the break up of the Moghul empire, the descendants of that colony have been satisfied to mairtain the dominion of their fathers. Pathans in Central India are as much foreigners to the Hindu population as are the British. The present and preceding ruler have been ladies, eminently just and devout.

The Native States of India can dispose of 64,172 cavalry, 241,063 foot soldiers, and 9390 trained artillerymen, working 5252 guns.

The Mewar state, of 11,614 square miles, and a population of $1,161,400$ souls, was founded about A.D. 144. It is also called Udaipur from its capital. It is ruled over by a family of Surya- vansa or Solar descent, Sissodia Rajputs, the Heliadæ of India, the highest in social rank and dignity of all the Rajput chiefs of India, descendants from Rama, king of Ayodhya.

The states of Doongurpur, Sirohi, and Partabgurh are offshoots from it; and Sivaji, the founder of the Mahratta power, was descended from the Udaipur family. By treaty in 1818, the British Indian Government undertook to protect thisstate.

The Jeypore state, of 15,000 square miles, and a population of $1,900,000$ souls, is ruled by Cuchwaha Rajputs (Kachwaha), who also claim descent from Rama. It was founded amongst the Meena race, A.D. 967. The family furnished to the Moghul emperors some of their most illustrious generals; and Jey Singh II. (A.D. 1699) was a distinguished mathematician and astronomer. In 1803 the state entered into a treaty of alliance with the British.

The Marwar or Jodhpur state was founded about A.D. 1459 by Jodha, a descendant of the Rahtor Rajput kings of Kanouj. Among the Rajput states it ranks next to Mewar and Jeypore. Its area is 35,672 square miles, and population, $1,783,600$.

Bundi is ruled by a family of the Hara tribe of Rajputs. Its area is 2291 square miles, and population, 220,000; revenue, Rs. 5,00,000. Raja Oneda, in 1804, gave efficient assistance to Colonel Monson when retreating before Holkar; and in 1818, Maha Rao Bishen Singh concluded a treaty with the British, acknowledging the British supremacy.

The Kotah principality was formed in the beginning of the 17th century by the chief of Bundi, who was forced by the Maharana of Udaipur to cede half his territory to his younger brother. Its treaty with the British is in 1817, and this was the first of the Rajput states to cooperate with the British in suppressing the Pindaris. During the mutiny of 1857 , however, the Maha Rao made no attewpt to assist the P.litical Agent, who with his two sons was murdered. Area, 5000 square miles; population, 433,000; revenue, Rs. 25,00,000; tribute, Rs. 1,84,720.

Jhallawar was formed in 1838 , when the Kotah principality was dismembered, and (8th April) British supremacy was acknowledged by $\mathrm{Raj}$ Rana Mudun Singh undertaking to pay Rs. 80,000 annually as tribute. Its area is 2500 sq. miles; population, 220,000 ; and revenue, Rs. 14,50,000.

Tonk is ruled by a Mahomedan ruler with the title of Nawab, descendant of Amir Khan, a famous predatory leader. Its area, 1800 square miles; population, 182,000 ; revenue, Rs. 8,00,000.

Kerroulce is a Hindu state, with an area of 1878 square miles; population, 188,600 ; revenue, Rs. 3,00,000. Its mabaraja, Muddun Pal, did good service during the mutinies.

Kishenyarh is an offshoot of Marwar. Its area, 720 square miles; population, 70,000 souls; and revenue, Rs. $6,00,000$.

Dholpur is ruled by a Jat family. Its chief in 1803 co-operated with the British during the second Mahratta war, and its chief in 1857 aided the fugitives from Gwalior. Its area, 1626 square miles; population, 500,000 ; and revenue, Rs. $6,00,000$.

Bhurtpur is also a Jat principality. It was founded by Birj, a freebooter, and was largely extended in 1763 by his grandson, Suraj Mull. 
In 1803, Ranjit Singh was ruling when Holkar, after the battle of Deeg, pursued by Lord Lake, took refuge in the fort. Ranjit Singh refused to surrender Holkar, and withstood four assaults before capitulating, and a new treaty was then formed. On the occurrence of a disputed succession, the fort was stormed by the British, 18th January 1826, and the young maharajah settled on the throne. Area, 1974 square miles; population, 650,000 ; revenue, Rs. $21,00,000$.

The Uluar chiefship in Rajputana is under British protection, has an area of 3300 square miles; population, $1,000,000$; and revenue, 16 lakhs. The state in 1771-1776 was carved out amongst the Meo and Rajputs by Pratap Singh, a Naruka Rajput.

Bikanir was founded about the close of the 15 th century amongst small tribes of Jat, Bhatti, and others, by Bika Singh, son of Raja Jodh Singh of Jodhpur. He died A.D. 1505. In 1857, his successor greatly aided the British, and 41 villages were bestowed on him. Its area is 17,676 square miles: population, 539,000 ; revenue, 6 lakhs.

Jeysulmir, a Rajput state, entered into alliance with the British in 1818. Its chief's name was Moolraja. Area, 16,447 square miles ; population, 73,700 ; revenue, Rs. 5,00,000. The people are chiefly Yadu Bhatti Rajputs, who claim a very ancient descent, and its ruler, the Maharawal, is head of the clan. Like the Rahtor Rajputs, they are supposed to be descended from one of the Indo-Scythic tribes who penetrated into India at very remote times.

Dungurpur chiefship, formed by an offshoot from the Mewar family. Area, 1000 square miles; population, 100,000 ; revenue, Rs. 75,000.

Sirohi, a state in Rajputana, is ruled over by the Deora, a branch of the Chauban clan. They claim direct descent from Deo Raj, a descendant of Prithivi Raj, the Chauhan king of Debli. The earliest inhabitants were Bhils, succeeded by Rajputs of the Gehlot Pramara, and the present Deora Chauhan. Area, 3000 square miles ; population, 158,000. Its ruler in 1845 transferred Mount Abu to the British as a sanatorium. During them utiny of 1857-58, its ruler, Rao Sheo Singh, did good service.

Baroda is a Native State in alliance with British India. It includes all the territories of the Maharaja the Gaekwar in different parts of Gujerat, lying between lat. $21^{\circ} 51^{\prime}$ and $22^{\circ} 49^{\prime} \mathrm{N}$, and long. $72^{\circ} 53^{\prime}$ and $73^{\circ} 55^{\prime} \mathrm{E}$., with an area of 4399 square miles, and population, 2,000,225. Its chief rivers are the Nerbadda, Mahi, Sabarmati, and Saraswati. Its people are Hindus, Jains, Parsees, and Mohamedans. Revenue, Rs. $1,02,64,820$.

Cutch is a Native State in political relation with the Bombay Presidency, ruled over by a Jhareja Rajput prince. Population, 512,084; but there are many broken tribes amongst them.

Kolhapur is ruled by the representatives of the younger braneh of the family of Sivaji, as the rajas of Satara were of the elder. The Kolhapur family long struggled to head the Mahratta power, until, in 1731, Sahoji by treaty recognised Kolhapur as an independent principality. In 1760 , the descendants of Sambaji became extinct, and one of the Bhonsla family was adopted. In the mutiny of 1857 the raja remained faithful, but his younger brother, Chimma Sabib, joined the rebels.
Area, 3184 square miles; population, 546,156 ; revenue, 10 lakhs.

Mysore is a Hindu state in the southern part of the Peninsula, with an area of 27,078 square miles, and, in 1881, a population of $4,186,188$. Its Mulnād or hill country adjoins the Western Ghats; its plain country is well cultivated, but the rainfall is not abundant and is irregular, and in 1876-77 it failed, and above a million of the inhabitants were lost. Its aboriginal tribes are Bedar, Kurubar or Kurumba, Lambani, Koracha, and Pariahs. The languages are three dialects of Canarese.

The Cochin Rajas claim descent from an ancient dynasty who once ruled from N. Canara to Cape Comorin. The state was conquered by Hyder Ali, and retained by Tipu, until, in 1792 , it was released by the British. In 1809, the family rebelled against the British, and, by a treaty then made, a subsidy of Rs. 2,76,037 per annum was exacted. Area, 1131 square miles; population, 399,060 ; revenue, Rs. $10,57,497$.

The Travancore rulers are of the Kshatriya race, and of the Hindu religion, but, with many of their subjects, Nairs and others, they follow the descent by the female line. At the commencement of the 18th century, the territory now known as Travancore had a number of chiefs, who were constantly at war, but they were gradually brought under the authority of the Raja of Travancore, Wauji Baula Perumal, 1758 to 1799 . He was a stedfast ally of the British, who aided him in return; and in 1789, being attacked by Tipu, the British declared war, and, on the conclusion of peace in 1792, Tipu restored all the territory he had wrested from Travancore. A treaty was agreed to in 1795. Any failure in the direct female descent requires the selection and adoption of two or more females from the immediate relatives of the family, who reside at certain places in Travancore. The maidens adopted for this purpose become Tumbruttis, and are styled Ranis of Attingah on certain ceremonies performed publicly at Attingab, and in the chief temple of Trevandrum. Area, 6653 square miles; population, 1,262,647; reuenue, Rs. 42,85,000.

The family of the Zamorin of Calicut and the Bibi of Cananore also follow uterine descent.

The Puducottah chieftain is styled the Raja Tondaman Bahadur. At the siege of Trichinopoly in 1753 , the British army greatly depended on the Tondamaus' fidelity and exertions for provisions. They and most of their subjects are of the Kollar race. Area, 1037 square miles; population, 268,750 ; and revenue, Rs. $3,24,136$.

The Sundur Raja is a Mahratta of the Ghorpara family. The territory is small, in a valley between two hills, 35 miles west of Bellary. In 1817 , the chief Shevo Rao submitted to BrigadierGenl. Munro, but his state was restored to him in June 1818, and a formal sunnud issued in 1826.

Banaganapilly is a jaghir held by a Syud family with the title of Nawab. Its, area, 500 square miles; population, 35,200 ; revenue, Rs. $1,66,175$. It has been in the family under successive grants from Mysore and Hyderabad, and formed part of the territories ceded to the British by the Nizam under the treaty of 1798 , and it was confirmed by sunnuds in 1849 and 1862 in perpetuity for all legitimate successors.

Bengal is an administrative division of British 
India, comprising Bengal proper, Behar, Orissa, including the Tributary Mahals, Assam, Chutia Nagpur, and the Native States of Hill Tiperah and Koch-Bahar. It extends from the meridian $82^{\circ}$ to $97^{\circ} \mathrm{E}$. long., and lies within the parallels of $19^{\circ}$ $40^{\prime}$ and $28^{\circ} 10^{\prime} \mathrm{N}$. lat. On its N.W. is the Native State of Rewa in Central India, also the districts of Mirzapur, Ghazipur, and Gorakhpur, belonging to the N.W. Provinces. On the north of Bengal, from the Chumparun district as far east as the Bhutan Doars, the Himalaya range, running through the Independent States of Nepal, Sikkim, Tibet, and Bhutan, forms its northern boundary. Farther east, along the northern frontier boundary of Assam, lies a tract inhabited by the Akka, Dofla, Miri, Mishmi, Naga, and other wild tribes. Along its eastern frontier lies a part of Independent Burma; below that is the Munipur state; still farther south are various hill tribes,- the Naga, Lushai, Khyen, Mikir, etc. ; and at the extreme south-east (south of Chittagong, which is the south-eastern district of the Bengal Province) is the Akyab district of Arakan.

On the south-west of Orissa is Ganjam in the Madras Presidency; on its west are the Tributary Mahal estates, and also the Sumbulpur and Balaspur districts of the Central Provinces.

In 1881, the population of Bengal was 69,536,861. About two-thirds of its population profess Hinduism in various forms, and about one-third are Mahomedans, with a small number of Christians. It is ruled by a Lieutenant-Governor. Many of the higher caste Hindus are recognised as former immigrants, but the origin of the vast bulk of the Mahomedans is obscure.

Assam is a province of British India, with an area of 41,798 square miles, and a population, in 1881 , of $4,881,420$. It is the valley of the Brahmaputra, but is east of the Ganges, and beyond the bounds of Hindustan.

Madras city is built on the western shore of the Bay of Bengal. It is the chief town of a British province of same name, with an area of 138,318 square miles, and a population, in 1881 , of $31,170,631$, comprising several distinct ethnic divisions of races speaking Canarese, Tamil, Telugu, Uria, and Tulu, with several uncultivated tongues of searcely civilised aboriginal tribes.

The Bombay Presidency embraces an area of 197,875 square miles, and a population, inclusive of Feudatory States, of $23,395,663$. The Fendatory States of this presidency have an area of 73,753 square miles, and, in 1881 , a population of $6,941,249$. Their names are Khairpur, Cutch, Cambay, Mahikanta, Narukot, Palanpur, Kattyawar, Rewakanta, and Surat. In the Konkan are Janjira, Jauhar, and Sawantwari; and in the Dekhan, Akalkote, the Dangs, Satara Jaghirs, Kolhapur, S. Mahratta Jaghirs, and Savanur. The languages spoken are Canarese, Mahrati, Gujerati, Konkani, and Sindi, and denoting distinct races. The more prominent of the aborigines are the Bhil, Koli, Ramusi, Mhar, and Mang.

Central Provinces, a British district lying between lat. $17^{\circ} 50^{\prime}$ and $24^{\circ} 27^{\prime} \mathrm{N}$., and long. $76^{\circ}$ and $85^{\circ} 15^{\prime}$, with an area of 112,912 square miles, and $11,548,511$ inhabitants. The British districts comprise Ch'hattisgarh, Jubbulpur, Nagpore, and Nerbadda; and there are thirty native principalities, viz. fifteen in Chutia Nagpur, with Bamra, Bastar, Kankar, Karond, Kawarda, Khairagarh,
Khondka, Makrai, Nandgaon, Patna, Raigarh Bargarh, Rairakhol, Sakti, Sarangarh, and Sonpur. It lies south of the Vindhya mountains, and the Nerbadda river flows through it. Its aboriginal peoples are chiefly Gond, Bhil, and Kol tribes.

Coorg, a British province, in lat. $11^{\circ} 56^{\prime}$ to $12^{\circ}$ $50^{\prime} \mathrm{N}$., was conquered in 1833 . Its dominant race are brave mountaineers, 27,033 in number, the total population, in 1881 , being 178,302 . They are demon-worshippers. Canarese, Kodaga, Malealam, and Tulu are spoken.

Ajmir and Mairwara form a British province in Rajputana, of $2,710,680$ square miles, and a population of 460,722. The chief aboriginal races are Mair and Gujar, the languages Hindi and Urdu. Mairwara is inhabited by Mair, Gujar, and other aborigines.

The North-West Provinces and Oudh are in the centre of Hindustan, in the valleys of the Ganges and the Jumna, and their affluents. They are ruled over by an officer, who is LieutenantGovernor of the N.IT. Provinces and Commissioner of Oudh. The combined territory has an area of 105,395 square miles, and a population of $44,849,619$. The N.W. Provinces part is the Hindustan proper of the Mahomedan classification, and three-fourths of its inhabitants are Hindus.

The Panjab province, in the extreme N.W., is ruled over by a Lieutenant-Governor. Its population, including the feudatories, number $22,712,120$ souls, in an area of 219,714 square miles. The Hindus, Mahomedans, and Sikhs form the bulk of the population.

Central India is a political division, under the superintendence of a Political Agent. It has an area of 81,140 square miles, with a population of $7,699,502$. In this political division there are 71 feudatory or mediated rulers, of whom 4 are Mahratta, 7 are Mahomedans, 17 are Bundela, 33 are Rajput, 6 are Brahman, and 4 belong to other races. 'The 6 feudatory states are Gwalior, Indore, Bhopal, Dhar, Dewas, and Jowrah.

The Native States under the political agencies for Central India, Bhopal, Baghelcund, and Western Malwa, are given in detail at page 458, British India.

This Feudatory Territory has three grand divisions. The N.E. division comprises the Native States of Bundelkhand and Rewa. The northeru division consists of the northern and central districts of the Gwalior States. The S.IV. division comprises the table-land known in modern times as Malwa, though far within the ancient limits of the province of that name, and the submontane territory between it and the Nerbadda, as also a considerable tract south of that river, extending to the Kandesh frontier. The 1st or N.E. division, extending from the Bengal Presidency in the $\mathrm{E}$. to the Gwalior State in the W., includes Rewa and 35 other states and petty chiefships. Its area is about 22,400 square miles, its population about $3,170,000$ souls, and its public revenues aggregate about Rs. $63,58,000$. The $2 \mathrm{~d}$ or N. division extends from Bundelkhand ancl the Saugor district, and has an area of about 19,505 square miles; its population is about $1,180,000$ souls, and its public revenue about Rs. $67,65,000$. The $3 \mathrm{~d}$ or S.IV. division goes on westward to the Bornbay Presidency, and contains the remainder of Gwalior, Holkar's States, Bhopal, Dhar, Dewas, and other small 
states. The area of this division is about 41,700 square miles, its population about $3,320,000$ souls, and its public revenues about Rs. 1,30,00,000.

Bhil.-The desolate wilds and jungles of the western Satpura range, and parts of the country which extend from them to the Vindhya Hills, are occupied by Bhil tribes, who abhor field labour or manual labour of any kind.

Malva. - Adjoining this are the richly-cultivated plains of Malwa, with occasionally intervening tracts of hill and jungle, from the Myhee on the west to Bhilsa on the east, -a stretch of nearly 200 miles, and from the crest of the line of the Vindhya to Mundissore and Oomutwarra, a distance of 100 to 120 miles, and occupied by a thrifty agricultural people.

Hilly Tract.-This is succeeded by the more hilly and jungly tracts of Oomutwarra, Seronje, and Keechiwarra, with a scanty population.

Gualion: - Northwards towards Gwalior the country becomes more open, except on the wild border tracts of Kotah and of Bundelkband, till we come to the carefully-cultivated plain of Gwalior, stretching for a distance of 140 miles between the Chambal, Pahuj, and Sind rivers.

Bundelkhand is ruled by the Bundela race. A vast portion of Bundelkhand is billy and unproductive, forming the northern slope of the tableland of the Vindhya.

Rew $a$ is ruled by the Baghela race. The plains of Rewa are fertile, but the valley on the Sone to the south of the Kymore range is desolate. The people are indolent and untrustworthy. Though widely different in other respects, there is one characteristic common to the Baghel of Rewa, the Bundela of Bundelkhand, and the Rajput of Gwalior and Malwa,-a dislike to labour or service away from their homes. They generally leave tilling of the soil to the inferior and servile classes, and are regarded as the heads of the local society. Many of the Rajputs in the states of Central India give themselves up to sloth and the immoderate use of opium.

Malwa and Gwalior are great centres of trade. In Malwa, the towns of Indore, Bhopal, Ujjain, Mundipur, Rutlam, Dhar, Jowra, Augur, Nemuch, Shujawulpur, and Bhilsa are the principal marts. Indore is the capital of the Maharaja Holkar. Gwalior is the capital of the Maharaja Sindia.

Rajputana Agency.-Rajputana stretches from lat. $23^{\circ} 15^{\prime}$ to $30^{\circ} \mathrm{N}$., and from long. $69^{\circ} 30^{\prime}$ to $78^{\circ} 15^{\prime} \mathbf{E}$., containing an area of 128,000 square miles, with a population estimated at $10,268,392$, and includes twenty principalities, viz.:-

15 Rajput, viz. -$$
\text { J }
$Bikanir.

Sirohi. Jeypore. Kotah. Marwar(Jodhpur). Kerrowlee. Bundi.
Lawa.

Lawa.

Shahpura. Ulwar.

Dungurpur. Banswara. Partabgurh. Jhallawar.

2 Jat, viz. Bhurtpur, Dholpur. 1 Mahomedan, viz. Tonk.

In 1881 , there were in Rajputana $8,839,243$ Hindus, 861,747 Muhomedans, and 378,672 Jains, the aboriginal races being Ahir, Balal, Bhil, Chamar, Dhakur, Gujar, Jat, Kanta, Mina, and Sondhia. The Bhils are-in Dungurpur, 66,952 ; Udaipur, 51,076 ; Banswara, 48,045; and Partabgurh, 270.

Frontiers.Arond the borders of Hindustan are many independont states, repullies, theocracies, and democracies, with most of which the British Government, as a paramount power, have treaties or agreements. Commencing in the S.W. on the shores of the Arabian Sea, and enumerating the states in succession northwards, and again turning to the S.E., are-

Lus Beila, Baluchistan, Sewistan.

Near the Dehra Ghazi Kilan district are the Bugti, Murree, Gurchani, Lughari, Kosah, and Khutran.

Near the Delra Ismail Khan district are the Bozdar, Kusrani, Oshterani, Sheorani, and Waziri.

Near the Kohat district are Turi, Zymukht, Orakzai, Sepah, Buzoti, and Afridi.

Near Peshaveur are the Momund, Usman-Khel, Ranizai, Swati, Bunurwal, and Judun.

Near the Hazara district, the Husanzai.

On the north are Ruka, Nari-Khorsam, Garhwal, Hundes, Nepal, Sikkim, Bhutan, Towang: Beyond Hindustan, in Further India, many tribes on the Assam borders, Manipur, Tiperab, and numerous Shan, Karen, etc., tribes in native Burma, Chittagong, and Arakan, with Burmese and Talaing in British Burma.

People.-Several civilised nations are found within the above space, in the Indiau plains, but differing from each other, in manners and language, even more than those inhabiting any corresponding portion of Europe. The inhabitants of the dry countries in the north of Hindustan, which in winter are cold, are comparatively manly and active. The Mahratta, inhabiting a mountainous and fertile region, are hardy and laborious; while the Bengali, with their moist climate and their double crops of rice, where the cocoanut tree and the bamboo furnish all the materials for the construction of their houses unwrought, are more effeminate than any other people in India, and a love of repose, though not sufficient to extinguish industry or repress occasional exertions, may be taken as a characteristic of the whole people of the Bengal Province. Akin to their indolence is their timidity, which arises more from the dread of being involved in trouble and difficulties than from want of physical courage; and from these two radical influences almost all their vices are derived.

The men of Hindustan on the Ganges are the tallest, fairest, and most warlike and manly of the natives of Hindustan proper; they wear the turban, and a dress resembling that of the Mahomedans; their houses are tiled, and built in compact villages in open tracts; their food is unleavened wheaten bread.

Food.-Along the lowlands of the southern Peninsula, as in similar districts of Further India and China, rice is the favourite article of food with all whose means afford it; but the multitudes use it only as an occasional meal, and subsist on the pulses and millets and wheat. They are skilled cultivators of the soil, and by irrigation channels, canals, and tanks of every size, have supplemented the natural rains, producing largely for domestic use and for export, cinchona, cotton, coffee, hemps, indigo, jute, lac, opium, salt, silk, saltpetre, tea, and wheat; and, since the arrival of the British, coal has been largely worked, and tea and coffee have become great industries. Their domestic animals are the oxen and buffalo horned cattle, with camels, horses, asses, mules. 
goats, and sheep, and they have domesticated the elephant and the yak, and have trained the various hawks used in falconry; they are brave and skilful fishers, and the sea could supply millions with food if the salt laws could be framed to permit its use for curing. Much loss of human life and domestic animals is caused by crocodiles, snakes, leopard, panther, bear, and tiger. Hindustan yields alum, gold, silver, iron, lead, precious stones, in which, as also in the copper and brass wares, they are skilled workers, and in much of their art they continue unrivalled. The raw materials for glassmaking are abundant, and they produce beautifully-tinted bangles for the wrist. Their weavers supply the whole labouring community with the useful cotton and woollen cloths; though Europe and America have been sending to Hindustan the cotton fabrics now used by the well-to-do classes, the strong cottons of the labouring classes are still holding their own. The British have introduced spinning mills, they are weaving by steam-power. In the finest muslins, they still surpass all other nations; and in their silks, silk and cotton fabrics, carpets, mushru, kimkhab, and shawls are producing articles the admiration of the world.

Languages.-There are two learned languages, Sanskrit and Pali, in which the religious books of the Hindus and the Buddhists are written. The Buddhist Scriptures of Tibet, Mongolia, Pegu, Ava, Siam, Kambogia, Cochin-China, and Ceylon, are all in the Pali, and the Vedas of the Hindus are in a form of the Sanskrit tongue. The Koran and the Hadis are religious books of the Mahomedans. Though the Koran has been translated into most languages, it is still retained in the Arabic by most of the people of that religion, but neither Arabic, Sanskrit, nor Pali are vernacular, and are understood only by the very learned. Throughout Northern Hindustan, the Hindi is the language of the people, but it has numerous dialects, designated by the names of the districts in which they are spoken, Panjabi, Multani, etc. One of these, the Brij-Basha or Brij-Bhaka, is the form spoken near Mathura, and takes its name from Brij, the tract about Mathura and Brindaban, where, in the Hindu mythologies, Krishna sported with the Gopin. The Rangari or Rangri dialect is bounded by the Indus on the west, Bundelkhand on the east, the Satpura Hills on the south, and Jeypore, Jodhpur, and Jeysulmir on the north. A language of mixed origin is in use amongst the Mahomedans of India, and employed by all races as the ordinary lingua franca in their intercourse with the people of the country. It was first reduced to writing and grammar by Dr. John B. Gilchrist of the Bengal Medical Department. It is called Hindustani, also Urdu, and is essentially Hindi, with large admixtures of words of Sanskrit origin or of Persian and Arabic, according as the speakers or writers are Hindu or Mahomedan. At present the Hindustani or Urdu, the Panjabi, and the Persian are written and printed in the same character; but the Arabic, Bengali, Burmese, Canarese, Chinese, Gujerati, Hindi, Mabrati, Malealam, Malay, Siamese, Singhalese, Tamil, and Telugu are all distinct tongues, each written and printed in a separate character. In the south of India, the Arabic numerals as used in Europe have been generally introduced into Government accounts. This was on the recommendation of Sir Erskine Perry ; and it has been supposed possible to use the Roman and Italian character for the other tongues.

Religion.-In Hindustan, amongst races ordinarily classed as Hindus, including 20 millions of non-Aryan aborigines, there is practised every form of idol-worship, nature-worship, spirit-worship, fetishism, and demon-worship ; but the great mass follow what Europeans designate as Brahmanism, which is a reverence for deities described in the Vedas, Puranas, Tantras, religious books written by the Brahman teachers. The ancient history of India shows that there were four great religious eras. The Vedic, in which Agni, Indra, and other personifications of spiritual existences were propitiated with feasts and invoked in the hymns of the Rig Veda, and in which maidens selected their husbands in the Swayamvara, and monarchs sacrificed in the Aswa Medha. In the Brahmanic period the Ksbatriya feasts were converted into sacrifices for the atonement of sins against Brahmanical law, and divine worship was reduced to a system of austerities and meditations upon the Supreme Spirit as Brahma. It was in this era that the Brahmans assumed the character of a great ecclesiastical hierarchy, and established that priestly dominion which still extends over the minds and senses of the Hindus of India. Thirdly, the Buddhist period, in which Sakya Muni appeared; and fourthly, the Brahmanical revival, during which Brahmans abandoned the worship of their god Brahma, and, with books styled the Puranas, reverted to the old national gods and heroes of the Vedic Aryans. In this era Vishnu came to be regarded as the Supreme Being, and Rama and Krisbna as his incarnations. Followers of this form of belief are known as the Vaishnava, of whom there are numerous sects. Another deity, Siva, of whose origin nothing definite is known, is now largely worshipped by the Saiva religionists, of whom also there are many sects; and there are besides these, many smaller, active monotheistic sects. Mahomedans of Hindustan, 50,121,585 in number, are mostly of the Sunni sect, the Shiah sectarians being few in number. Christians, of all sects and denominations, do not number two millions ; Jains, fire-worshippers or Zoroastrians, known as Parsees and Sikhs, are over three millions, and aboriginal races, with local cults and others, are 7,575,946 souls--Treaties, Engagements, Sunnuds, etc.; Annals of Indian Administration; Census Reports for 1871 and 1881; Elphinstone's History of India; Hooker and Thompson's Flora Indica; Royle's Productive Resources of India; Wils. Gloss.

HINDYAN, a town in the province of Fars, at the mouth of the Kheirabad river, the Ab-i-Shereen of 'Timur's expedition, and perhaps the Arosis of Nearchus. It is navigable from the sea up to Zeitun, which latter town is only a day's journey (five farsangs) to Behbehan,-De Bode.

HINGINGHAT, a town in Wardha District, Central Provinces of British India, 21 miles south. east of Wardha, in lat. $20^{\circ} 33^{\prime} 30^{\prime \prime} \mathrm{N}$., long. $78^{\circ}$ $52^{\prime} 30^{\prime \prime} \mathrm{E}$. ; population (1877), 9415. The cotton grown in the Wardha valley is esteemed one of the best indigenous staples of India-Imp. Gaz.

HINGLAZ, a town in Makran, 12 miles inland from the Arabian Sea, and about 80 miles W. from the mouth of the Indus. It is a place of 
Hindu pilgrimage, but is little visited, from the difficulties which attend the journey when made from most parts of Hindustan. It is at the end of the range of mountains dividing Lus from Makran. A small temple on the summit of a mountain is dedicated to Nani or Maha Mari, a form of Kali. Hinglaj Devi or Hingula Devi is the red goddess.-Postans' Western India.

HINGOLI, lat. $19^{\circ} 43^{\prime} \mathrm{N}$., long. $77^{\circ} 11^{\prime} \mathrm{E}$, in the Dekhan, south-east of Aurangabad, and 185 miles north-west of Hyderabad; the mean height of the village is 1495 feet according to Scott, and 1478 feet according to Wilson. It is a military station of the Hyderabad contingent.

HINNOM. At the union of the vales of Hinnom and Jehoshaphat, there is a basin of water where the fire of the Hebrew temple was preserved; and beyond it, where a clear stream runs through a very narrow inlet between the Mount of Olives, and that where Aceldama and the other sepulchres stand, are many olive trees. -Skinner's Overland Journey, i. p. 218.

HIOUNG-NU, the Hun. De Guignes places Attila and the greater part of his army among the Turk race.

HIPPALUS, a Greek of Alexandria, the commander of a trading vessel in the Red Sea, some time prior to or during the reign of the Emperor Claudius, or about A.D. 47. He took advantage of the steady blowing of the monsoon winds, and sailed direct to the coast of India, at which he arrived at Musiris or Barace, somewhere between Goa and Tellicherry. His name was given to the S.IF. monsoon. A few years before this, as a freedman of Annius Plocamus was collecting tribute on the coast of Sabæa, he was carried out to sea, and across the Arabian Sea to the port of Hipporos in the island of Ceylon, where he was kindly treated, was presented with a larger ship, and on his return the king of the country sent four ambassadors to the Roman emperor, and a raja or chief to be the captain to manage the ship. Mr. Roberts supposes the port of Hipporos to be the Greek words Hippos and Oros, or horse mountain, a Greek translation of KuthriMalei, a hill on the N.W. coast of Ceylon.Roberts, p. 81; India in the 15th Century. See Musiris.

\section{HIPPOBOSCA EQUINA. Linn. Horse-fly.}

HIPPOCAMPUS, a genus of fishes of the family Syngnathidx. H. mannulus and $H$. comes of the Indian Seas, when drying, assume the figure of a horse's head, and are known to all as the sea-horse, which the name Kuda in Malay implies. The body is tapering and curled near the tail.

HIPPOCRATEA ARBOREA. Roxb. Kathapahariya, Hind. A tree of Assam, Chittagong, Tiperah, and Morung, also of the Kotah jungles. H. Indica, obtusifolia, Grabamii, and viminea are also known in India.

HIPPOCRATES, B.C. $460-361$, the Bu-krat of the Arabs, was a learned physician, born B.c. 460 at Cos, an island in the Ëgean Sea. He was the son of Heraclides and Phænarete, of the Asclepiadæ family. He travelled in Greece, Scythia, Colchis, and Asia Minor; also, it is supposed, in Egypt and Asia. It is to him that Galen attributes the theory of the four elements in the body, air, earth, fire, and water. He wrote 'On the Nature of Man,' and to him is due the important doctrine of crises. Hippocrates, and after him Galen, held a knowledge of astronomy to be essential to physicians. He is supposed to be the Charaka of the Hindus.

HIPPOGLOSSUS, a genus of fishes of the family Pleuronectidæ. $\mathbf{H}$. olivaceus is the Japanese balibut.

HIPPOLYTE, a genus of the crustaceæ of the tribe Palemoniens, of Milne Edwards, as under :H. ventricosus, Edw., Asiatic Seas. H. quoyanus, Edw., New Guiner. H. spinifrons, Edw., New Zealand. $\boldsymbol{H}$. spinicaudus, $\boldsymbol{E} d w$., New Holland. $H$. gibberosus, Edw., New Holland. H. marmoratus, $E d w$, Oceanica.

HIPPOLYTUS, a Christian bishop who resided in Arabia, and is supposed to have written the treatise concerning the Peregrinations of the Apostles.

HIPPOPHAE RHAMNOIDES. Linn. A spiny strub of the Panjab and N.W. Himalaya, in Kangra, Lahore, and Ladakh, with many vernacular names. Its stem is sometimes 5 or 6 feet in girth, with diœcious flowers, small, round, orange-coloured, acid berries, and narrow leaves like those of rosemary. Its acid fruit makes a good jelly with half its weight of sugar. Its stem gives a good fuel and charcoal.-Stewart; Cleghorn.

\section{HIPPOPHAE SALICIFOLIA.}

Lhala, . . Bнот. |Buckthorn, . . Ešg. Tarwa, : : CHUk. Tser-khar, Soorch, PANJ.

A willow-leaved shrub of the N.W. Himalaya. It is found in the Sutlej valley between Rampur, and at an elevation of 10,000 feet. Near the Chenab it is a stout shrub with spinous branches, and frequent in the valleys. The small yellow berries are extremely acid, but when ripe and boiled with sugar form an agreeable and wholesome preserve. The people use the branches for dry hedges and fuel, and they are considered village property. A species of Prunus, Litsi, ripens here in September, with a tolerably sweet fruit, something like the cherry. A gooseberry, Bilitsi, with small, woolly, sour berries, is common here also. A black-fruited Ribes, Rasta, resembling in taste the European red currant, is largely eaten by the people.-Clegh. Pan. Rep. pp. 67, $150 ; D r$. J. L. Stewart.

HIPPOPOTAMUS, the Behemoth of the Old Testament, is found in Africa in great numbers, and the existence of two species is suspected. The natives kill it with spears after enticing it into a pitfall. The flesh is delicate and succulent; the layer of fat next the skin makes excellent bacon, technically denominated hippopotamus speck at the Cape. The curbaj whip (hence the Spanish Corvacho and French Cravache) is made of the hide. The ivory of the great canine teeth is highly valued by dentists for making artificial teeth. No other ivory keeps its colour equally well; and the canine teeth are imported into England for this purpose, and fetch about $30 \mathrm{~s}$. per pound. One of the specific distinctions pointed out by M. Desmoulins is the comparative abrasion of the canines in the supposed two species.

The people of Rome several times had opportunities of witnessing hippopotami, amongst other wild beasts, collected for the triumphal exhibitions of their emperors. But for 1500 years, until 25th May 1850, Europe had not seen one. The Zoological Society of London then obtained a male, and afterwards a female, which bred. That received in 1850 was the first living seen in Great Britain since the Triassic age of the world. 
The hippopotamus has been discovered in a fossil state in Ava and in the Sub-Himalaya, where there is an admixture of extinct and existiug forms, well preserved,-remains of hippopotamus, rhinoceros, mastodon, peculiar forms of elephas, and very remarkable bovines, dissimilar from those now in India; also, of animals still existing in India, are found the fossil Emys (Pangshura) tecta. The embedded shells are all of species still living in the valley, and indicate that the changes have been gradual from the time that the hippopotami wallowed in the muds, and rhinoceros roamed in the swampy forests, of the country where mastodons abounded, and where the strange forms of the sivatherium, dinotherium, and camelopardis existed.-Eng. Cyc.; Hamilton's Sinai, p. 339.

HIPPOSIDEROS, a genus of the mammalia of the order Cheiroptera. The following Indian species may be named:-

H. apiculatus, H. fulvus,

H. armiger.

H. ater.

H. bicolor.

H. diadema.

H. galeritis.

$H$. insignis.

H. Lankadiva.

H. murinus.

H. nobilis.

H. speoris.

H. penicillatus.

H. Templetoni.

H. cineraceus, Blyth, the ashy horseshoe bat, has only been found in the Panjab Salt Range.

H. murinus, Jerdon.

Rhinolophus murinus, Ell. | Rhinolophus fulgens, Ell.

The little horseshoe bat is of a mouse colour. It inhabits S. India, Ceylon, Nicobars, Burma, aud Malayana.

H. speoris, Jerdon.

lihinolophusspeoris, Schn., | H. apiculatus, Groly. Blyth, Ell.

R. Dukhanensis, Sykes. H. penicillatus, Grou.

The Indian horseshoe bat has a variably coloured body. It inhabits all India, Ceylon, and the Archipelago east to Timor.

Voulha is the Singhalese word applied to all bats.-Mr. Blyth's Report.

\section{HIPTAGE MADABI,OTA. Giertn.}

$$
\text { Grertnera racemosa, Roxb. }
$$

Benkar, Khumb, BEAS. Ati muktamu,

Findra, Chenab. Madhavitige,

Bokhi or Utimukta, Duk. Potu-vadla,
Madmalti, . PANJ. Vadlaya rala,

Chabuk, Churi,

PANJ. Vadlaya rala,

'TEL.

Delight of the woods, is a large climbing shrub, with very beautiful white and yellow flowers in terminal racemes; petals fringed, four white, one yellow; one of the stamens is much longer than the rest; fruit unequally three-winged. The bark is a good sub-aromatic bitter. H. obtusifolia, D.C., is a plant of China. It grows over all India, and is cultivated at Lahore.-Riddell.

HIRACLIUS, successor of Phocas, was taken prisoner by Khusru.

HIRAN, king of 'I'yre, was contemporary with Solomon, whom he assisted in building the teuple of Jerusalem. He received from Solomon 20 villages of Galilee, and was a partner with Solomon in the Indian trade. He reigned B.C. 1025 to 992 .

HIRANYA. SANsK. Gold or golden; henceHiranya or Svarna, supposed to be Ireland.

Hiranya-Garbha, from Hiranya and Garbha, the wounb.

Iliranyabalar, the river Sone. Its E. branch is also called Gujjhabate or Coli.

Hivanya Kasipa, in Hindu mytholngy, Adaitya, an enemy of the Hindu gods, a king destroyed by Vishnu as Narasimha. He is the same with Vijaga, son of Kasyapa and Diti.-As.Res.iii. p. 393. Hiranyaksha, from Akshi, the eye.

HIRLO. MAHR. Any warrior slain in battle. Cairns are accumulated over their remains.

HIRNEOLA AURICULA JUD E. Fr. Jew'sear, a fungus of Britain, and widely distributed. It is the Teria iore of Tahiti, and is known at Singapore as an article of commerce used as food.

HIRN PARDI, also Hirn-Shikari, a fowler race of the Peninsula of India, who call themselves Bhaora.

HIRUDO, the leech, one of the class Annelidæ, many of which occur in the south and east of Asia; they were early employed therapeutically by the Hindus, and the Arabs adopted their practice (Royle, Hindu Med. p. 38; and Wise, Hindu Medicine, p. 177). Herodotus alludes to one kind, Bdella Nilotica. Dr. Pereira infers that Sanguisuga Egyptiaca, the species from which the French soldiers in Egypt suffered, is that referred to in the Bible (Proverbs $x x x, 15)$ by the name of Olukch or Aluka. The latter, or Aluk, is also the Arabic name for leech. Six kinds of useful and six venomous leeches are mentioned in Susruta, and by Avicenna. But Aristotle makes no mention of them, and they do not appear to have been used in Greek medicine in the time of Hippocrates. Pliny, however, describes them very clearly, under the name of Hirudines and Sanguisugæ, and distinguishes two species. Eight species of medicinal leeches have been enumerated; the most common is the Sanguisuga medicinalis, Hirudo medicinalis, Lim., which is a native of all the stagnant fresh waters. $H$. officinalis is distinguished by its unspotted olive-green belly and by the dark-green back. H. medicinalis is the kind usually employed in Britain. Its belly is of a yellowish-green colour, but covered with black spots, which vary in number and size, forming almost the prevailing tint of the belly, the intervening spaces appearing like yellow spots. On the back are six longitudinal reddish or' yellowish-red bands, spotted with black, and placed on an olive-green or greenish-brown ground. Other species, figured by Brandt, are H. provincialis, $H$. verbana, $H$. obscura, and $\mathbf{H}$. interrupta. In the United States they use $\mathbf{H}$. decora. In India, leeches are extremely abundant, procurable in the tanks. Hirudo tagalla, also called $\mathrm{H}$. Ceylonica, a land leech, lives in the thickets and woods of Ceylon, the Philippine Islands, and at clevations of 11,000 in the Himalayas.-Eng. Cyc. p. 212.

HIRUNDINIDA, a family of birds of the order Insessores, tribe Fissirostres, comprising the sub-family Hirundininæ, with the genera Hirundo, Cotyle, and Chelidon, and the sub-family Cypselinæ, with the genera Cypselus, Acanthylis, Collocalia, and Dendrochelidon.

Hirunto rustica, the rustic swallow of Europe, Asia, Africa; is migratory, and common in the plains of India during the cold season; chiefly seen over water.

H. domicola, Jerdon, is the Neilgherry house swallow of S. India, Ceylon, Penang, Malacca, and Java.

H. filifera. This is a beautiful wire-tailed swallow, with prolonged middle tail feathers, and is found throughout India, N.W. Himalaya, and Kashmir.

$H$. daurica, mosque swallow or red-rump swallow, is found in N. and Central Asia, over all India from Nepal to Ceylon, and N. China. 
H. Llaviculla, Blyth, belongs to the group of republican swallows (Petrochelidon of the prince of Canino), and has similar habits to the $H$. fulva of $N$. America.

H. Japonica, H. striolata, occur in Japan.

H. hyperythra, Layard, Ceylon.

Cotyle Sinensis, the ordinary Indian sand martin, occurs together with $H$. riparia.

C. urbica, the martin of Europe, Africa, Asia, and Siberia, is somewhat rare or local? in India, and migratory.

C. riparia, the sand martin of Europe, Asia, Africa, N. America, is migratory in India, and local, and mostly replaced by $\mathrm{H}$. Sinensis.

C. rupestris of S. Europe, is common in the high mountains of India, and there is a diminutive of it also in the $\mathbf{H}$. concolor of Sykes.

C. subsoccata, Hodgs., the dusky martin of Kashmir, Ladakh, Nepal, and in the cold weather, Panjab.

( : concolor, Sykes, the dusky crag martin of all India.

Chelidon urbica, Linn., the English house martin, has been found in the Neilgherries.

Ch. Casbmiriensis, Gould, the house martin of Kashmir, where it is abundant.

Ch. Nipalensis, Hodgs., the little Himalayan martin.

Ch. dasypus, Bonap., of Borneo.

Sub-Fam. Oypselinæ, Swifts.

Acanthylis sylvatica, Tickell, the white-rumped spinetail of all India, inhabits the jungles.

A. leucopygialis, Blyth, of Japan.

A. coracinus, $M$ ull., of Borneo.

A. gigantea, Temm., brown-necked spine-tail of Neilgherries, Wynad, Malabar, and Ceylon. It is a magnificent swift.

1. caudacuta, Lath., white-necked spine-tail, a splendid powerful swift of the Himalaya, Nepal, Sikkim and Bbutan, and China.

('ypselus melba, Linn., the alpine swift of Soutliern India.

Cy. apus, Linn, the European swift, is found throughout W. Asia, N. Africa, and Europe; is common in Afghanistan, Kashmir, and visits the Panjab in the rains.

C'y. affinis, Gray, the common Indian swift of the Panjab, Sind, all India ; breeding in colonies.

('y. leuconyx, Blyth, the white-clawed swift of all India, but rare.

C'y. vittatus, Jard and Sebly, of all China, Malayan.

Cy. Batassiensis, Gray, the palm swift, abounds in all the districts of India, Ceylon, Assam, Burma, wherever the palmyra and cocoanut palms grow; nest very small, and always placed on the leaf of the palmyra.

C'y. Sinensis, Bonaparte, of China.

Collocalia nidifica, $L$ ath.

Hirundo nidifica, Lnth., | H. unicolor, Jerdon.

Blyth., Horsf.

H, brevirostres, $M^{6}$ Clell. C. concolor, Blyth.

This, the Indian edible nest swiftlet, is found in the Neilgherries, Ceylon, Western Ghats, Coorg, Wynad, Malabar, Sikkim, Himalaya, Assam, Java, Malay Peninsula, Andamans, Siam, Cochin-China, and other islands of the Archipelago. The nest, when pure and of the first make, is composed entirely of inspissated mucus from the large salivary glands of the birds. It is very small. When these first-make nests are removed, the second make are inferior.

Co. linchi, Jerdon, C. fuciphaga, Hirundo fuciphaga, edible nest swift of the Nicobars, on the rocky coast of the Bay of Bengal from Arakan south to Java. Its nest is more valuable than that of the C. nidifica.

Other species of Collocalia are found in the Eastern Archipelago as far as New Guinea, one from the Mauritius, and one or more from the Pacific islands.-Jerion, pp. 155-185.

HISLOP, Rev. STEPHEN, born 8th September 1817, at Dunse; Berwickshire. He joined the liree Church in 1844, and a muniticent donation of Rs. 25,000 having been offered by Captain (General Sir William, K.C.B.) Hill, on condition of founding a mission at Nagpur, Mr. Hislop) went to it. He devoted his spare time to examination of the geology of Nagpur, and his writings appeared in the Journals of the Bombay As. Society for July 1853, the Royal Geological Society for 1855 , on the Connection of the Plantbearing Sandstone of Nagpur with the Coal Beds of Central India and Western Bengal; and the Bengal Asiatic Society's Journal, No. iv. 1855 , contains another on the Age of the Carbonaceous Strata just referred to. In those papers $\mathrm{Mr}$. Hislop described some of the numerous fossils which had been found in the tertiary deposit, and the sandstone, coal, and shells of the province of Nagpur. He employed his leisure in making a geological collection of the antiquities of the provinces around him; they now form the nucleus of the collection in the museum at Nagpur. He was drowned crossing a river.

HISSAR, municipal town and administrative headquarter's of Hissar district, Panjab, lat. $29^{\circ}$ $9^{\prime} 51^{\prime \prime} \mathrm{N}$., long. $75^{\circ} 45^{\prime} 55^{\prime \prime} \mathrm{E}$. ; population (1868), 14,133. The district, lying between lat. $28^{\circ} 36^{\prime}$ and $29^{\circ} 49^{\prime} \mathrm{N}$., and long. $75^{\circ} 16^{\prime}$ and $27^{\circ} 22^{\prime} \mathrm{E}$.; area, 353,973 square miles; population, 484,681 . Hissar forms the western border district of the great Bikanir (Bickaneer) desert. It consists for the most part of sandy plains dotted with scrub and brushwood, and broken by undulations towards the south, which rise into hills of 800 feet, like islands out of a sea of sand. The soil is in places hard and clayey, difficult to till, but when sufficiently irrigated, highly productive. In these spots water is only reached at a depth of from 100 to 130 feet; the cost of a masonry well

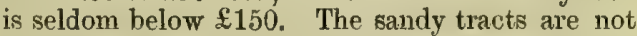
unfrequently swept by storms, which greatly altex the face of the country, The jhul (Salvadora oleoides), the kavi or leafless caper (Capparis aphylla), and the jharberi (Zizyphus napeca) abound; their berries serve as food in times of scarcity. It has been much harried. After Nadir Shah ravaged the land, the Sikhs began their inroads; the Bhatti of Bhattiana struggled for superiority; and from 1795-1802, George Thomas, an Irishman, fought for dominion. Early in the mutiny of 1857 , the local levies at Hansi and Hissar revolted, and all Europeans were either murdered or compelled to fly. The Bhatti rose under their hereditary chiefs, and the majority of the Mahomedan population followed their example, but were suppressed by a force of Panjab levies, aided by contingents from Patiala and Bikanir, under General Van Courtlandt.

The Tuar Rajputs $(13,921)$ possess five or six villages. The Bhatti, now Mahomedans $(22,008)$, trace their descent from Jesal, of the Yadubansi stock. Both Tuar and Bhatti were marauding desert tribes. The Pachada, or men of the west, now Mahomedans, are also of Rajput descent. A religious sect known as Bishno worship their founder, Jambhaji, as an incarnation of Vishnu, and bury their dead in a sitting posture, in the floors of their houses or cattle-sheds. They consider even the touch of tobacco polluting. At their marriages, passages from the Mahomedan Koran and the Hindu Shastras are indiscriminately recited. They avoid destroying life, and inter any animal accidentally killed. The decayed town of Agroha is interesting, as being the original seat of the great mercantile class of Agarwala. 
There are rock-cut inscriptions at Tosham.-Imp. Gaz.

HISSAR, a hill state north of Badakhshan, whose chief claims a Grecian origin. It yields copper ore, micaceous sandstone, inferior marble.

HISTA, a Malay measure of arbitrary length, the fourth of the dippa, about half a yard.-Sinmonds' Dict.

HISTIOPHORUS, the sword-fish or fan-fish, is the Ikan-layer of Amboyna, the Dutch Zeyl-fish or Sail-fish, and the Sailor-fish of seamen. It is from 10 to 14 feet long, and is said to raise its dorsal fin and use it as a sail.-Bennett.

HIT, in lat. $33^{\circ} 43^{\prime} \mathrm{N}$., and long. $42^{\circ} 27^{\prime} \mathrm{E}$., is on the right bank of the Euphrates, has 1500 houses. It has bitumen springs on the left bank at Gasar Sadi. The people are boat-builders, prepare salt, bitumen, and naphtha, and burn lime. There is a bridge of boats here. It is the usual place where caravans cross the Euphrates between Baghdad and Damascus. With the smell of bitumen and naphtha outside the town the whole water and air is infected. It is undoubtedly the place mentioned by Herodotus under the name of Is, as furnishing bitumen for the building of Babylon. Near this, on the Euphrates, and a little below Samara on the Tigris, the country is mere alluvium. The works of salt and bitumen around Hit give a singular appearance to the country. The Euphrates near Hit has an average width of 350 yards, with a depth of 16 feet, and a current of three knots per hour in the season of the floods, when there are fourteen islands, on some of which are small towns. See Iran; Karej.

HITOPADESA, SANSK., from Hita, good, and Upadesha, teaching,-Good Advice, is the title of an ancient Sanskrit work, though it is but a rearrangement of an older one, called Pancha Tantra, or the Five Books, which itself has been translated several times and printed. But it has never attained the fame of its offspring, the Hitopadesa, and there are few, if any, of the vernacular languages of India into which the Hitopadesa has not been translated. It is classed by Hindu writers as a work on Niti, or polity, and it was designed for the instruction of princes, to prepare them for the duties of their future lives. The scene of the Hitopadesa is the ancient city of Pataliputra, situated at or near the present Patna. The king of that place, deploring aloud the wild and heedless lives of his sons, was overheard by a pandit named Vishnu-sarma, who undertook to make his sons versed in the principles of polity within the space of six months. To accomplish this he prepared the Hitopadesa, and accomplished his task of instructing and training the princes. The book consists of a series of fables, story within story, according to an oriental fashion. But the greater part of the work is occupied by verses cited from ancient writers in illustration and proof of the positions maintained by the interlocutors.

The Hitopadesa is divided into four books, entitled Mitra-labha (Acquisition of Friends), Suhrid-bheda (Separation of Friends), Vigraha (War), and Sandhi (Peace). The first two have a general interest, and are applicable to all classes of people. The last two books apply especially to kings and ministers. The stories are mostly concerned with animals, but there are a few in which human beings are concerned. These are not edifying, and display a contempt for chastity, and a disposition to make merry over the misfortunes of easy-tempered husbands with intriguing wives. The nature of them may be inferred from such titles as The Old Man and his Young Wife, and The Farmer's Wife and her Two Gallants.

In the 6th century of A.D. era it was translated into Old Persian, by order of the emperor Nushirwan. From the Persian it was translated into Arabic in the ninth century, under the title of Kalila o Damna, a work which obtained great celebrity, and is still popular, Kalila o Damna being the Arabic representations of the Sanskrit names Karataka and Damanaka, two wily jackals who appear in the work, and are proverbial throughout the east for their craft and cunning. It was afterwards translated into Hebrew, Syriac, and Greek. The Hebrew version was made by John of Capua, towards the end of the fifteenth century, and from his work translations were made into the chief modern languages of Europe, and it became familiar to British youth under the designation of Pilpay's Fables. Two versions of the work were made into modern Persian by authors whose names are known, but their translations have been eclipsed, and their productions are obsolete. There is also a translation in Turkish. The most celebrated Persian translation is that of the renowned rhetorician, Husain Vaiz Kashifi, whose work, Anwar-i-Suhaili (Lights of Canopus), is famous throughout the Mahomedan world, and is scarcely less famous among the orientalists of Europe. Elegant versions of it were printed by Messrs. Eastwick and Woollaston, and that of the latter is published in an ornamental style. The Anwar-i-Suhaili has borrowed some stories from the Hitopadesa, but has greatly added to their number. The identity of the borrowed stories is palpable enough when pointed out; but nothing can well be more dissimilar than the two works, the one all plain and terse simplicity, the other florid, fanciful, ornate, and abounding with far-fetched hyperbole. The stately sententious roll of the verse of the Hitopadesa and the light and airy couplets of the Anwar-i-Suhaili are at the very opposite extremes of composition. Yet another distinguished Persian author bestowed his labours upon the Arabic edition of the work. Abul Fazl, the celebrated minister of the Emperor Akbar, made a new translation. Though a professed rhetorician himself, and the author of several important works in the high style, he considered Husain Vaiz's version too florid and difficult for such a work; and he made a more simple translation in an easy narrative style, which became popular under the title of Jyar-i-Danish, Touchstone of Wisdom. This has again been translated into Hindustani, under the title Khiradafroz, Enlightenment of the Understanding. The Hindus have thus had brought back to them, first in a Persian, and then in a modern Urdu form, the stories told by their ancestors in ages long gone by.

The text has been frequently printed in Europe, but the most esteemed edition is that of Professor Francis Johnson of Haileybury.

HITTI'TE, a dominant race mentioned in 1 Kings $x .29$ and 2 Kings vii. 6 . They held mastery in Syria in the era of the Hebrew judges and earlier kings. They were called Kheta 
by the Egyptians, and Khatta by the Assyrians. In B.C. 835 , Shalmaneser received tribute from all the kings of the Hittites. Their last monarch, Pirsiris (Pisiri), was defeated and slain B.c. 717, and Carchemish was made the seat of an Assyrian governor. But at one time the Hittite empire stretched from the Euphrates to the Dardanclles, and they disputed for several centuries the sway of Central Asia with Ramesside Pharaohs on the one side, and with Assyria's mightiest monarchs on the other. The Hittites were defeated, and their city Ketesh destroyed, by an Egyptian king (Rameses II. of Egypt?), about 1340 B.c. A great battle, figured in Sir G. Wilkinson's Ancient Egyptians, was fought between Rameses II. and the Hittites, near their sacred city of Kadash, which is shown as a city with a double moat, crossed by bridges beside a broad stream running into a lake. The lake has been generally identified with the Baheiret Homs, through which the Orontes passes south of Homs. 'Ihe site of the city, as important in Hittite records as the northern capital of Carchemish, Lieutenant Conder has identified with the ruins known as the Tell Neby Mendeh. They lie on the left bank of the Orontes, four English miles south of the lake. The modern name belongs to a sacred shrine on the highest part of the hill on which the ruins lie, and the name of Kadesh still survives, an instance of the vitality of prior names lingering in the minds of the people long after they have forgotten the Roman, Greek, or Crusaders' names. Lieut. Conder writes, - ' Looking down from the summit of the Tell, we appeared to see the very double moat of the Egyptian picture; for while the stream of the Orontes is dammed up so as to form a small lake 50 yards across on the S.E. of the site, a fresh brook flows in the $\mathrm{W}$. and $\mathrm{N}$. to join the river, and an outer line of moat is formed by earthen banks, which flank a sort of aqueduct parallel with the main stream.' He gives a full account of the ruins, the position of the place, and the disposition of the Egyptian forces before the battle.

Their writing character was displaced by the Assyrian cuneiform. The Assyrian King Sargon (13.C. 722-705) is mentioned in the Hebrew Bible. It was in the time of Sargon that Assyrian culture first gained a permanent footing in the W. ; while the overthrow of Carchemish and the last relies of Hittite power in B.C. 717 naturally led to the disuse of the Hittite mode of writing, and the spread of the cuneiform characters employed by the Assyrian conquerors. The well-known passage in Pliny (H. N. vii. 57), 'Literas semper arbitror Assyrias fuisse; sed alii apud $\mathrm{Egyptios}$ a Mercurio ut Gellius; alii apud Syros repertas volunt.' Mr. Sayce sees in this an allusion to the Hittite graphic system. In this case, he remarked, the passage in Pliny would be a record of the three independent modes of writing which the east invented, and would contain a half-forgotten tradition of that strange system of hieroglyphics from which in all probability the syllabary of Asia Minor and Cyprus was derived. Hittite monuments have been found at Kiz Hissar, which is supposed to represent the Dana or Tyana of Xenophon, built, according to Strabo, on the tomb of Semiramis.

HI-UL, or Hi-el, the grand festival of the German tribes of the Baltic.
HIUNRA of the Byansi, an avalanche.

HIWEN 'IHSANG', a Chinese traveller who passed 17 years (from A.D. 629 to 645 ) in travelling through the countries lying to the $W$. of China, and especially in India, through countries which few had visited before him, and he describes some parts of them which no one has since explored. His chief object was to study the religion of Buddha, but his observations, geographical, statistical, and historical, are characterized by great minuteness and precision. He started from Pekin, and made his way, amidst hardships and difficulties, through Chinese Tartary to the region where Buddha had laboured. Near Talas, on his way to India, he fell in with the Great Khan of the Turks, a successor of Dizabulus, whom the Chinese traveller calls Shehu. His account is very like that of Zamarchus. The Khan occupied a great tent adorned with gold flowers of dazzling richness. The officers of the court sat in two long rows on mats before the Khan, brilliantly attired in embroidered silk, the Khan's guard standing behind them. Although he was but a barbarian prince under a tent of felt, one could not look on him without respect and admiration. He appears to have regarded the Wakhsh branch as the main Postu or Oxus.-Stanislas Julien, Histoire de la vie de Hiwan Thsang, pp. 55, 56 ; Yule, Cathay, i. pp. 165 and 234.

HLAINE, an elongated valley of Pegu.

HLA-PET. Burm. Literally, wet-tea. To the eastward of Bamo and Koung-tuno, hills are visible, peopled by cateran Kakhyen, and by breeches-wearing Paloung, employed peaceably in growing tea for pickling. This is the hla-pet, which is made up with a little oil, salt, garlic or asafcetida, etc., into a sort of pickle, and is essential to the comfort of every Burman, being partaken of on all ceremonial occasions. It is floated to Ava on bamboo rafts, so as to be retained always partially wet. It is eaten by the Burmese in small quantities after dinner, as Europeans eat cheese: They say it promotes digestion, and they cannot live in comfort without it. Colonel Burney mentions that the Burmese Resident, proceeding to Calcutta in 1830 , took a large supply of hla-pet with him, as a necessary of life, not to be had where he was going. Hla-pet is partaken of on many ceremonial occasions; and on the conclusion of law-suits, the bill of costs is always rounded off with a charge for pickled tea, as European agents' accounts are still rounded off with a charge for postages.-Fytche, p. 270 ; Mason's Burma; Yule's Eimbassy, p. 101.

H'LIVOT-DAU. BurM. The cabinet and high court of the realm of Burma, in which there are foux woon-gye or chief ministers, assisted by as many woondouk. -Y Yule's Embassy, p. 3.

HNAU. Burm. A boat of Burma.

HNAU-BEN. BuRM. A large tree, of pale yellow wood, preferred for making combs. It bears a large fragrant fruit, but worthless.Crawfurd, i. p. 192.

$\mathrm{HO}$, a Chinese measure of capacity, about $7 \frac{3}{4}$ gallons,-Simmonels' Dict.

HO. Arab. He, He is ; the name of God. Ho ul Aziz, He is glorious.

$\mathrm{HO}$, Hore, Horo, in the $\mathrm{Kol}$ tongue, a man. In the mountains S. IV. of Calcutta are the Dhangar, Oraon, the Kol, the Larka $\mathrm{Kol}$ or Ho, and the Khond. The Ho are a comparatively small tribe 
of the Kol race. Their country proper is the part of the Singbhum district called Kolehan, a series of fair and fertile plains studded with hills. It is about 64 miles from $\mathrm{N}$. to $\mathrm{S}$. and 124 from $\mathrm{E}$. to W., and has to the S. and S.E. the tributary estates Mohurbhun, Keonjur, Bonai, and Gangpur, inhabited by Uriya-speaking Hindus; to the east and north the Bengali pargana of Dhulbhum and district of Manbhum, and to the N. and N.E. the Hindi district of Lohardaggah.

The $\mathrm{Ho}_{0}$ is the most compact, the purest, most powerful and interesting and best-looking division of the whole Munda nation. The more civilised Ho have an erect carriage, and dignified, fine manly bearing, with figures often models of beauty. The occupants of the less reclaimed parts are more savage-looking. Their tradition is that they came from Chutia Nagpur, and that they brought with them their system of confederate governments of Purha, which they call Pirhi or Pir. The Ho have a tradition that they once wore leaves only, as the Juanga women till 1871 did, and not long since threatened to revert to them unless cloth-sellers lowered their prices. The Ho of the border-land have probably much intermixed with the Uriya. They are agricultural, but change their localities. A Ho bridegroom buys his bride, or rather his father buys her for him, the price being so many head of cattle. The Kol and Larka Kol are cognate with the Khond. The Ho language differs so little in phonology and glossary from the Munda, Bhumij, and Santal, that Captain 'Tickell's account of its grammar may be taken as that of the Kol language generally. The Ho are addicted to suicide; they have no endearing epithets. They erect menhir or slabs, and dolmen or tablets, over the graves of their dead. The dance of the Ho and Santal is not that of the Munda, though the last have something resembling it, and it can be unade to assume a mournful cadence, as the same step and drum-beat is used at their funeral ceremonies. Colonel Dalton says (p. 106) the youths and maidens of the Ho mourn as they revolve, and lock up, keeping admirable time both in the movements of the feet and undulations of the head to the monotonous beat of the drums. They believe that the souls of the dead become bhoots (spirits), but no thought of reward or punishment is connected with the change.-Captain Tickell, As. Soc. Jour: ix. pp. 783, 997, 1063 ; Lubbock, Origin of Civil, p. 268; Dalton's Ethnology of Bengal, pp. 106, 184.

HOANG-HO, a great river in China, 3040 miles long, in lat. $39^{\circ} 40^{\prime} \mathrm{N}$, and long. $98^{\circ} \mathrm{E}$., undoubtedly one of the finest rivers in the world. It takes its rise in the mountains of Tibet, and, after traversing the Koukou-Noor, enters China at the water province of Kan-su; it leaves it again to the sandy plains at the foot of the Alechan mountains, surrounds the country of Ortous, aud, after having watered China from south to north, and then from west to east, throws itself into the Yellow Sea. The waters only assume their yellow tint after passing the Alechan and the Ortous. The river rises almost always to the level of the country through which it flows ; and to this is to be attributed the disastrous inundations which it occasions, which are so fatal to China, but are of little consequence to the nomadic Tartars, who have only to strike their tents and move off elsewhere. In ancient times its mouth is said to have been in lat. $39^{\circ} \mathrm{N}$; at present it is in $34^{\circ}$. The Chinese Government is obliged annually to expend enormous sums to keep the river within its ber. In the year 1799 it cost $£ 1,682,000$. - Huc's Journey.

HOANG-TI is the first historical Chinese emperor (B.C. 2698); and the Chinese historians allege that in his reign the inventors of sundry arts and sciences arrived from the western kingdoms in the neighbourhood of the Kouen Lun mountains. -Yule, Cathay, i. p. 35.

HOCKEY. A game of Tibet resembling hockey, and called Chaughan, is played on horseback, on a plain about 60 yards broad and 350 long, with a stone pillar at each end as the goal. The ball is somewhat larger than a cricket ball, and in Tibetan is called Pulu. The stick or Byntu is of the strong and straight bough of the almond tree, about 4 feet long, and let in at the top and passed quite through to the other end of a curved piece of solid birch-wood, about the size and shape of a drenching horn. The game is mentioned by Baber. It is played in every valley in Little Tibet, Ladakh, Yessen, Chitral. The Persians, who wanted to play on horseback, were the first who found a long stick necessary. This stick they

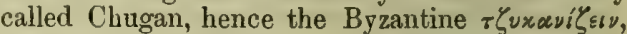
and the French Chicane, in which lawyers bandy about the unlucky clients. From the Chugan came the croquet-mallet, the golf-club, with all the family of spoons, drivers, cleeks, bunker-irons, putters, and niblicks; came also the hockey-stick, and probably the bat, which was at first a thick club with a curved foot, a terrible weapon in the hands of a 'slogger.' The Chugan may have been the father of the racquet. In Byzantine descriptions of the game, a staff ending in a broad bend, filled in with a network of gut-strings, is mentioned. The Munipuri call it Kango-jai. They select a turfy piece of ground 400 yards in length by 200 in breadth. The ponies used are small, swift for their size, and obedient mouths. The club consists of a rattan as thick as an ordinary-sized walking-stick, and 5 feet long, and its lower end has attached, at an angle of 45 degrees, a cylindrical piece of hard oak-wood, 1 foot in length, and 1 or $1 \frac{1}{4}$ inch in diameter. The whole weighs about $1 \mathrm{lb} .10 \mathrm{oz}$. The ball is a globe 3 to 4 inches in diameter, cut out of the light bulbous root of the bamboo. The suppleness of the cane, the weight of the club, and the elasticity of the ball is such, that a well-delivered stroke will lift the latter about a hundred yards. Two sides are formed, 5 to 7 to a side. The ball is thrown up in the centre of the ground, and each party strives to drive it to the opposite goals. The club is held in the right hand and the reins in the left. All the skill of horsemanship and dexterity in the use of the club are called into full play. It is beautiful to see the game played by men expert in the exercise, and by ponies well trained, for the animals in the course of time acquire a perfect knowledge of the play, and enter into the excitement of it as well as the riders.

HOCOMLIA MONTANA. Gibson.

Sampga, . . CAN. Kudkee, . . . MAHr. Tambut, : Mahr.

Grows in Camara and Sunda, on and close to the head of the ghats. Wood seldom runs large; is white, hard, and tough ; used for agricultural insplements. $-D$ r. Gilks's. 
HODADIN, a peaceable shepherd tribe of Bedouins.

HODAIDA, on the east coast of the Red Sea, in lat. $14^{\circ} 47^{\prime} \mathrm{N}$., and long. $42^{\circ} 53^{\prime} \mathrm{E}$., a town of Yemen, with lofty buildings. It is on the N.E. side of a sandy bay, and sheltered by a point of land rumning N.W. About A.D. 1836 it was made the seat of government of that part of Yemen.

HODGSON, CAPTAIN J. A., author of Journey to the Source of the Jumna, Hot Springs at Jumnotri, etc., in As. Res. xir. p. 128; On a New Form of the Hog Kind in Sind, in Bl. As. Soc. Traus. xiv. p. 423 ; Journey to the Head of the Ganges, in As. Res. xiv. p. 60 ; Survey to the Heads of the Ganges and Jumna, ibid.; Latitudes of Places in Hindoostan, ibid. p. 153 ; Heights and Positions of the Himalaya Peaks, ibid. p. 187 ; Route from Katmandu to the Chinese Frontier, ibid., 1832, xiii. p. 513. Captain Hodgson and Lieutenant Herbert published Astrononical Observations in Hindustan, with a Journal of the Survey of the Sources of the Rivers Ganges and Jumna, and an Account of the Positions and Heights of the Principal Peaks of the Himalaya Mountains.-Dr. Buist's Catalogue.

HODGSON, BRYAN H., of the Bengal civil service, widely known for his researches into the natural history of the Eastern Himalayas, and the ethnology of the races and tribes dwelling in British India and its bordering countries. He was appointed Resident at the court of Nepal in 1821. He wrote on the Sheep inhabiting the Himalayan Region, in Bl. As. Trans, 1841, x. p. 320 ; On the Literature and Religion of the Buddhists, Serampore 1841; On the Buddha Literature of Nepaul, As. Res. xvi. p. 409 ; Route from Katmundu to Tazedo, ibid. xvii. p. 513 ; On a New Species of Buceros, ibid. xviii. p. 178; Description of the Aquila Nepalensis, ibid. part ii. p. 13 ; Description of the Circaetus Nepalensis, ibid. p. 21; Migration of the Natatores and Grallatores in Nepaul, ibid. p. 122 ; On the Wild Goat and Wild Sheep in Nepaul, ibid. p. 127 ; Description of the Ratwa Deer, ibid. p. 170; Of the Buceros Homrai, ibid. p. 139 ; Of the Wild Dog of the Himalayas, ibid. p. 221 ; On the Antelope of the Himalayas, Gleanings in Science, iii. p. 152 ; On a Species of Felis, ibid. p. 177 ; On Scolopacidæ, ibid. p. 233 ; On the Musk Deer, ibid. p. 329 ; On the Cervus Jaral, the Ratwa Deer, and the Tharai Goat, ibid, p. 371; On the Chiru, ibid. p. 387 ; On the Mammalia of Nepaul, ibid. p. 442; On the Manufacture of Nepaul Paper, Bl. As. Trans. i. p. 8; On the Nepaul Military Tribes, ibid. ii. p. 217 ; On the Aborigines of Nepaul Proper, ibid. iii. p. 215 ; On European Speculations on Buddhism, ibid. pp. 382,425 , 499 ; Synopsis of Mammalia of the Himalayas, ibid. v. p. 231 ; On Nepaul Ornithology, ibid. p. 358 ; On the Language of Buddhist Scriptures, ibid. ii. p. 682 ; On the Cuckoo of the Himalayas, ibid. viii. p. 136 ; On the Thibetan Type of Mankind, ibid. xvii. p. 222 ; On the Aborigines of Central India, ibid. p. 550 ; Relics of the Catholic Mission in Thibet, ibid. p. 225 ; Route from Katmandu to Darjeeling, ibid. 1\% 634; On the Aborigines of Soutbern India, ibid. xviii. p. 350 ; On the Aborigines of North-Eastern Iudia, ibid. P. 451 ; Note on Indian Ethnology, ibid. p. 238 ; Un the Aborigines of the North-Eastern Frontier, ibid, xix. p. 309 ; Aborigines of the South, ibid. p. 461 ; On the Law of Legal Practice and Policc of Nepaul, Lond. As. Trans. i. pp. 45, 258. It was his opinion that the Tamulian, Tibetan, IndoChinese, Tangus, Chinese, Mongol, and Turk are so many branches of the Turanian family. $-D r$. Buist's Catalogue.

HODGSONIA HETEROCLITA. Hooker. Trichosanthes het., Roxb., is the most magnificent plant of the jungles in the valley of the Tista in Sikkim. It is a gigantic climber, allied to the gourd, bearing immense yellowish-white pendulous blossoms, whose petals have a fringe of buffcoloured curling threads several inches long. The fruit is of a rich brown, like a small melon in form, and contains six large nuts, whose kernels (called Katior-pot by the Lepcha) are eaten. The stem when cut discharges water profusely, from whichever end is held downwards. It is a new cucurbitaceous genus, found in the Terai, clinging in profusion to the trees, and also 5000 feet up the mountains. It grows also in the forests east of Chittagong. The long stem, like almost all woody climbers, is full of large vessels; the juice does not, however, exude from these great tubes, which hold air, but from the close woody fibres.-Hook. H. J. i. p. 395 , ii. p. 350 .

HODHAD, king of Yemen, father of Balkees, queen of Sheba; lived about the beginning of the Christian era. See Balkees.

HOD'HU, an ancient name of India.

HOE, a secret society of the Chinese, into which the members are initiated. The concluding ceremony consists in pricking the middle finger of the right hand, dropping the blood into a bowl of arrack, from which each of the candidates drink, and are then saluted as brethren.

HOE is the digging implement of the labourers of India; its forms are called in Hindi, hat'hia, kalpi, kharpa, mamati, rambha, and ramp.

HOEI-HOEI. The Chinese and Manchu call by the name of Hoei-hoei all the Mahomedan tribes who live under Chinese dominion. This word, therefore, has ceased to designate a nation. As the Uigur Hoei-hoei, called simply Hoei-hoei under the Mongol dynasty of Yuan, were Mahomedans, this name is applied by the Chinese to all those of the same religion, in the same manner as the Russians are often called Greeks, because they are of the Greek Church. The inhabitants of the towns of Little Bokhara are in part descendants of the ancient Uigur or Hoei-hoei, and consequently Turk; in part Sarti, or Bokharians, who are scattered as merchants all over Central Asia, and who are Iranians. There are many of them at Pekin, Hang-chu-fu, Canton, and other commercial cities of China, Their mother-tongue is Persian, but they also speak the oriental Turki, which is the general language of Turkestan, and the most diffused in Little Bokhara.

HOEI KING, a Cbinese Buddhist traveller in India, Khotan (Yu-than), and Tibet, in A.D. 399-400, along with Fa Hian, the Fo-kue-ki of Remusat, Klaproth, and Landresse. Fa Hian, with Hoei King and other Chinese pilgrims, reached Yu-than or Khotan in A.D. 399-400. Fa. Hian then travelled by Tsu-bo and $Y u-h o e i$ and over the Tsu-Ling mountains southwards to Kie-Chha, the moderu Ladakh, where he rejoived Hoei King. From Kie-Chha the pilgrims proceeded westward to Tho-ly, which they reached in one month. They came to Iudia orerlaud by way of Tartary 
and Kābul, visited Ceylon, and sailed thence to Java. On his return, Fa Hian left behind him an account of his travels, called Fo-kue-ki, or an account of the Buddhist countries. At the time of his visit Buddhism was still the dominant religion, though Vaishnava doctrines were gaining ground.-Cunningham, Ladakh; Cal. Rev.

HOFFMEISTER, author of Travels in Ceylon and Parts of the Himalayas to the Borders of Thibet.

HOG, Indian wild boar, Sus Indicus.

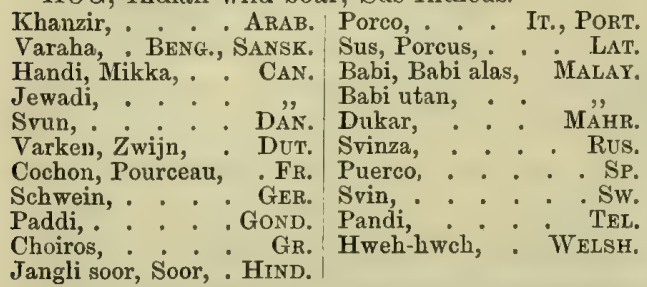

The wild hog abounds in many parts of India, and the males attain to a very large size. It is generally believed that there is no specific difference between the wild hog of Europe and India. The adult males dwell apart from the herd. The wild boar is constantly hunted by Europeans on horseback, with the spear; natives of India hunt the boar with dogs. Spearing the wild hog is one of the favourite sports of British officers in India.

All the wild hogs in the Archipelago are small animals compared with the wild boar of Europe, or even with that of continental India.

Sus verrucosus, so called from the fleshy excrescence on the sides of the cheeks, has a grotesque and a formidable appearance, but is in reality a timid animal. Their number in Java is immense in particular districts.

Sus Andamanensis, Blyth, a small race in the Andamans.

Sus Zeylanensis, Blyth. Mr. Blyth distinguished this from the hog common in India. The skull approaches in form that of a species from Borneo, the Sus barbatus of S. Muller.

The genus Babirussa of F. Cuvier takes its name from two Malay words, Babi, hog, and Rusa, a deer. It is the Sus babyrussa of Linnæus, and the $B$. alfu'us of Lesson, and occurs in the island of Buru or Bourou, one of the Moluccas, also in Celebes and Ternate.

Sus Papuensis is a New Guinea hog.

Porcula sylvania, Hodg., the pigmy hog of the sal forests of N. India, is the Sano banel and Chota sur of the natives of India, and confines itself to the deep recesses of primeval forest. The adult males abide constantly with the herd, and are its habitual and resolute defenders.-Sykes' Cat. Dec. Mam. p. 11 ; Crawfurd, Dict. p. 152; Ternant's Ceylon, p. 59 ; Catalogue of Mammalia in the India House Museum.

\section{HOG-DEER.}

Hyelaphus porcinus, Sund. Axis niger, B. Ham. Cervus porcinus, Zimmerm. Cervus niger, B. Ham. C. dodur, Royle.

Axis porcinus, Jerd.

Para, . . . HIND. Sugoria, . . HrND. Khar, Laguna, - " $\mid$ Nuthrin haran, . ,

The hog-deer inhabits Central India, Bengal, the Gangetic valley, Panjab, Sind, Assam, Sylhet, Burma. It frequents chiefly long grass and tamarisk jungles, grassy grounds and open glades in forest openings, rarely seeking the forest shade.
It is not gregarious, both sexes living solitary in general. The young are beautifully spotted. The buck drops his horns in April, and ruts in September._Jerdon, p. 263.

HOGENDORP. Le Compte C. S. W. de Hogendorp, author of Coup d'CEil sur l'île de Java et les autres possessions Neerlandaises dans l'Archipel des Indes, 1830.

HOGG, SIR JAMES WEIR, BART, took a prominent part in discussions relating to Indian affairs in Parliament. He was a Director of the East India Company, and twice was Chairman. He was born at Stoneyford, in the county Antrim, in 1790, and was called to the bar in Ireland. At Calcutta he held the office of AdministratorGeneral. He returned to England in June 1833. At the abolition of the old Court of Directors he was named one of the Political Military Committee. He was raised to the baronetcy in 1846 .

HOG-GUM, a resin abundantly afforded by Moronobæa coccinea, $A u b l$, a fine tree of Jamaica. Negroes dig it from among the roots of old trees. It is used in medicine, and is inflammable, burning with an agreeable odour. This might be introduced into India. The false hog-gum of Jamaica is yielded by Rhus metopium, Linn.

HOGLA. BENG. Typha angustifolia, Typha elephantina, Roxb., elephant grass, cat's-tail grass. HOG'S LARD.

Sur-ki-charbi, . . Hind, | Adeps suillus, . . . LA'T.

This is the fat about the loins of the hog, Sus scrofa. It is purified by melting and straining. Its melting point is from 78 to 88 degrees Fahr. In Europe, hog's lard is much employed in ointments, but in India it is desirable to exclude it from all pharmaceutical preparations.-O'Sh.

HOISALA BELLALA, a dynasty who had supreme sway in Mysore from A.D. 1000 to 1300. They built three groups of temples, one at Somnathpur, S. of Mysore, by Vinaditya Bellala (1043), another at Baillur by Vishnu Verddhana (1114), and the greatest at Dwara Samudra or Hullabid (1145) by Vijaya Narsinha, the building of which was stopped by the Mahomedan invasion in A.D. 1310-1311.

Some of the Hoisala Bellala kings were Jains; but their buildings at Somnathpur, Bellur, or Hullabid belong to the Vaishnava or Saiva faiths. The Basti temples of the southern Jains, like the Jaina temples of Northern India, always have a tirthankara as the object of worship. The Bettu temples of Southern India are open courtyards, containing images of Gomati, who possibly may be Gautama Buddha. There are two hills at the village of Sravana Belgola, 33 miles N. by $W$. from Seringapatam. On one of these, a mass of syenite 500 feet high, a Jaina image, 70 feet 3 inches high, has been carved out of the solid rock. The expression of its features is pleasing, with curly hair ; and at Karkala, the image, 41 feet 5 inches, and weight 80 tons, has been moved to its present site, and was erected A.D. 1432. The third, and supposed oldest, at Yannur, is 35 feet high. They belong to the Digambara sect of the Jains, being entirely naked, but with twigs of the Bo Tree twisted round their legs and arms, with sexpents at their feet. In the Jaina cave at Badami, the figure has two snakes twisted around its legs and arms, and the Bo Tree is placed behind. On a shoulder of the other hill at Sravana Belgola, called Chandragiri, are the Basti temples, fifteen 
in number, all of the Dravidian style, raised into storeys. The Jaina temple at Moodbidri, and all others in Canara, resemble the temples of Nepal, and many of them are built of wood. The interiors are richly and variedly carved, with massive pillars. A large number of the tombs of the priests, some of them five to seven storeys in height, each with a sloping roof, like the temples of Khatmandu, Tibet, and China. The stambhas or free-standing pillars of the Jainas in Canara, are very graceful.-Fergusson, p. 393. See Architecture.

HOLAR, also Holiar or Holaru, in the Canarese districts of the Peninsula, the Pariah or Dher race. Professor Wilson describes the Holar as a. man of a low or out-caste tribe, by profession a musician, which answers to the Mhang race, but there is no doubt but that the Holar is the Dher. The Morassi Holiyar are the same as the Halle Makkalu, old adopted sons of the Morasi Wakaliga. They are labourers and weavers. See Holiyar.

HOLARRHENA ANTIDYSENTERICA. Wall. Echites antid., Roxb. Kogar of . Chonemorpha antid., Don. \begin{tabular}{l|l} 
Kyura (seed) of: KANGRA. & Kawar of \\
KanJ. RAvi, BEAS. & Istaraku pala, . TEI.
\end{tabular} Indarjao,

A large surub or small tree of Malabar, Siwalik Hills, up to the Chenab in the N.W. Himalaya, Sylhet, and Chittagong. It bears a white flower. Its bark (Tellicherry bark) is used in medicine as an astringent. The leaves are used as fodder or as litter. The wood is white, light, and closegrained, and is used by carvers.

HOLARRHENA CODAGA. W. I. Kooda palli maram, TAs. A small-sized white wood, very fine grained, employed in cabinet-making. Dr. Wight gives also H. Malaccensis in Icones, 1298.

HOLARRHENA MITIS. $R . B r$. Kirri-wallagass, SingH. A moderate-sized tree of Ceylon, not uncommon up to an elevation of 1500 feet.

HOLARRHENA PUBESCENS. O'Sh. Reora, HrND. Wood light. This species and the $H_{\text {. }}$ antidysenterica yield the Indurjuo talkh of the bazar.-O'Sh.; Roxb. ; Voigt; Thw. Zeyl. p. 194.

HOLDNA. HIND. In Kangra, the process of destroying weeds in a rice crop.

HOLI, a popular Hindu festival, called in Sanskrit Holikha, or Phal gotsava, or Hutasham, or Hutasavi, also Dola or Dolavatra, or the Swinging Festival. It is supposed to relate to the vernal equinox, and to be similar to the Persian New Year's day. It is held about the 19th March, or ten days before the full moon of Phalgun. It is in honour of Krishna, and is quite a saturnalia, red powders being thrown and red fluids squirted at passers-by, and licentious songs sung. At the close of the festival, a pile is lighted, and a wheaten cake or Poli offered on it. The analogy between the goddess of the spring, Saturnalia, Phalguni, and the Phagesia of the Greeks, will be recognised. The word is not derived from eating, with the Rajput votaries of Holica as with those of the Dionysia of the Greeks, but from Phalguni, compounded of Guna, quality, virtue, or characteristic, and Phala, fruit, - in short, the fructifier. The Egyptian Phallica is the Holica of the Hindus. Phula and Phala, flower and fruit, are the roots of all Floralia and Phalaria, - the phallus of Osiris, the thyrsus of Bacchus, or lingam of Iswara, symbolized by the Sriphala, or Ananas, the food of the gods, or the Sitaphala of Sita, the Helen of
Ayodhia. It is much observed by the cowherd castes of Orissa.

HOLIDAIS of the several races dwelling in India chiefly occur at seasonal changes, but also at the anniversaries of certain occurrences connected with their religions or historical events. The dates of the public holidays vary with the lunar months, and those below are approximate :-

\section{Christian.}

New Year's day, Jan, 1. | Easter holidays, March.

Good Friday, April. 1 Ascension day, May. Christmas day, Dec. 25. $\quad$ Pentecost holidays, June. Hindu.

Makar Sankranti, about | Janm Ashtami, about Aug. January 11.

Maha Shivaratri, about Ganesh Chaturthi, about February 24.

Huli, about March 10-11.

Ram Naomi, about April 4.

Shravani purnima, Cocoa:

nut day, about August 6.

$$
\text { Parsee-Rasami or Shahanshahi. }
$$

Jamshidi navroz, about/Gatha Gahanbars, about March 21.

Aban feast, about end of Pateti or New Year's day, April.

Adar feast, about June 8.

Farvardin Jasan, about June 8. about September 23.

Kurdad feast and valava, about September 28-29.

Atishbehram SaIgeri, about November 8.

Parsee-Kadmi.

Aban feast, about end of Pateti or New Year's day, March.

Farvardin Jasan, about September 24. May.

Gatha Gahanbars, about August 29-30. Atishbehram Salgeri,about September $\mathbf{9}$.

Mahomedan-Suni (lunar months).

Shab-i-Burat.

Lailat-ul-Kadar.

Ramadhan 'Id.

Ashura.

Bari Wafat.

Ghilan.

Bakr 'Id, or 'Id Kurban. | Miraj-i-Mahomerl.

Mahomedan-Shich (lunur months).

Katl-i-Imam Ali.

Shaha Kadir.

Ramadhan 'Id.

Bakr 'Id.

'Id Gadir.

Ashura.

Chahlam.

'Id Maolud.

Jevish.

Purim, or day of Queen Esther, March 13.

Pesach or Passover, April 11-17.

Shabuoth, or the Delivery of the Law, May 31.

Tishabaiab, or the day of Lamentation, August 1.

Rosh Hosana, or New Year's day, September 21-22.

Kipur, or the days of Atonement, September 29-30.

Succoth, or the Feast of Tabernacles, October 5-13.

Hindus have many other festivals. Their names differ in the several languages; but there may be named here Bali-Pratipada, Basant'h-Panchami, Nag-Panchami, Kartiki Ekadasi, and others.

Mahomedans have also the Maharram, AkhiriChar Shamba, Chiraghan - i - Banda Nawaz, and Zinda Shah Madar, Pir Dastagir, and Urüs-iKadar Wali.

Parsees have in addition, the Amardad, Jamshidi-Naoroz, Ardibehesht-Jasan, Meher-Jasan, and others.

HOLIGARNA LONGIFOLIA. Roxb.

Kagira, Biba-biba, Can. | Katu-jeru, . . MaleaL. Holgeri, . .'MAHR.

One of the trees yielding the well-known black lacquer varnish. It grows in Travancore, in Malabar, in Canara, and Sunda, mostly above the ghats at Nilgund, in the Konkan, Assam, Chittagong, and in the forests of Tenasserim. Wood good for houses and beams. Its danger- 
ously acrid exudation is used by the natives to varnish shields and for other purposes. A fine black varnish from its fruit is brought from Manipur. This turns of a beautiful black colour when applied to a surface, owing, according to Sir D. Brewster, to the fresh varnish consisting of a congeries of minute organized particles, which disperse the rays of light in all directions; the organic structure is destroyed when the varnish dries, and the rays of light are consequently transmitted. There is brought also from Manipur a varnish made from the Semecarpus anacardium (marking nut), and a remarkable black pigment resembling that from Melanorrhoea usitatissima, which is white when fresh, and requires to be kept under water.-Roxb. ; Voigt ; Gibson ; O'Sh. ; Mason; Hooker's H. J. ii. p. 331; Beddome.

HOLIGARNA RACEMOSA. Roxb. A tree of Assam, Sylhet. Leaves alternate, linear-obloug. Flowers racemed, juice of the wood acrid.-Roxb.

HOLIYA or Holayar, in the Canarese-speaking country, in Mysore, and in Coorg, an agricultural labourer. In the Canarese-speaking country, like the Pariah or Dher; in Coorg he is one of three principal classes of slaves, Holayaru, Yewaru, and Paleru. Their subdivisions are the Mari, Byr, Murtha, Bulgi, Baday, Rookh, and Kembatta Holayaru. The last is a native of Coorg. The Mari Holayaru follow the custom of descent through the female line, the descensus ab utero. The Holeya race of labourers in Coorg, ill-favoured, with coarse, stupid features, short in stature, but strong built, with dark and black skin, and black, straight hair. They practise demonology, and are said to have no guru.-Wils. See Holar.

HOLKAR, the family name of the Mahratta rulers at Indore and its territories. The family name is taken from the village of Hull, on the Nira river in the Dekhan, where they were shepherds and farmers. Mulhar Rao Holkar, son of Khundaji Holkar, was born about the year 1693, and his mother, in consequence of some dispute, took him to Kandesh to his uncle Narainji, where, as a lad, he herded his uncle's sheep. When grown up he took service, and distinguished himself under Kudum Bande, a Mahratta leader, but subsequently (1724) under Baji Rao Peshwa as a commander of 500 ; and in 1728 was sent to administer Malwa, where he died A.D. 1769. Mulhar Rao was present at the battle of Panipat, and shared in the common overthrow of the Mahratta armies. Sindia's forces were almost annihilated, and Madhaji Sindia was lamed for life; but Holkar's division alone drew off with serried ranks and little loss, and Sindia thought that he had not been well supported by Holkar. He was succeeded by his grandson, Mali Rao, who died insane, nine months after his ascension. The pious Abalya Bai, the mother of Mali Rao, then took the management of affairs, and appointed as the commander of the army, Tukaji Rao Holkar, a chief of the same tribe, but in no way related to Mulhar Rao. This chief for many years served Ahalya Bai with the most devoted fidelity. Ahalya Bai died in 1795 , and was not long survived by Tukaji Rao Holkar, after whose death the power of the house of Holkar was nearly extinguished by quarrels in the family and amid the dissensions which distracted the Mahratta confederacy at the close of the eighteenth century. The fortunes of the family, however, were restored by Jeswunt
Rao, an illegitimate son of Tukaji Rao Holkar, who in 1802 defeated the united forces of Sindia and the Peshwa near Poona. The conclusion of the treaty of Bassein, between the Peshwa and the British Government, defeated Jeswunt Rao's hopes of possessing himself of the person of the Peshwa. In the following year, when Sindia and the raja of Berar combined against the British, Jeswunt Rao Holkar promised to join the confederacy, but on the actual outbreak of hostilities he kept aloof, and apparently intended to take advantage of the war to aggrandize himself at Sindia's expense. His schemes, however, were rendered hopeless by the treaty of Surji Anjengaum ; and Jeswunt Rao Holkar, after making a series of inadmissible proposals for an alliance, seems then to have hastily determined, unaided and alone, to provoke hostilities with the British. In the war which followed, Holkar was completely overthrown. He was pursued by Lord Lake across the Sutlej, whither he retired in the hopes of forming a combination with the Sikhs against the British Government ; and on 24th December 1805 he signed a treaty on the banks of the Beas, by which he was stripped of a large portion of his territories. Soon after the conclusion of the treaty, Jeswunt Rao Holkar became in $\mathbf{1 8 0 5}$ insane. He died in 1811, leaving an illegitimate son, named Mulhar Rao Holkar, during whose minority the state was torn by the most violent dissensions. The lad's mother, Toolsi Bai, the favourite concubine of the late ruler, secured herself in the regency. She was, however, subsequently barbarousiy murdered, and Holkar's army having sustained a complete defeat at Mehidpore, on 6th January 1818 the treaty of Mundisore was concluded, by which the supremacy over the Rajput princes of Udaipur, Jeypore, etc., was transferred to the British Government, the engagement between the British Government and Amir Khan was confirmed, four districts rented by Zalim Singh of Kotah were ceded to him, Holkar lost all his possessions within and to the south of the Satpura Hills, and his remaining territories came under the protection of the British Governınent. Mulhar Rao Holkar died in October 1833 , at the age of 28 . He left no issue, but his widow and his mother adopted Martand Rao Holkar, a child between three and four years of age, who was said to be of the same tribe and lineage as Mulhar Rao Holkar. The child was publicly installed on 17th January 1834, under the name of Martand Rao Holkar. The adoption of Martand Rao, however, proved to be a device of the mother of Mulhar Rao Holkar, for the purpose of keeping the power in her own hands during a long minority. It was not acceptable to the people, who were in favour of the succession of Hari Rao Holkar, a cousin of the late Maharaja. Hari Rao since 1819 had been kept in rigorous confinement, but he was released on the night of $2 \mathrm{~d}$ February 1834 , by a powerful body of his partisans, and received a ready welcome from the troops and people. The policy of non-interference prevented the Resident from giving active support to Martand Rao, although the installation of Martand Rao had been formally acknowledged by the British Government. This indifference on the part of the British Government as to who should rule, gave rise to most serious disturbances. The wealthy merchants fled from Indore, trade 
was suspended, and Bhil tribes infested the roads and destroged many villages. Martand Rao was banished from the country, and gianted an allowance of 500 rupees a-month, on condition of his resigning all claims to the succession. On 8th September 1835, an attack was made on the palace for the purpose of assassinating the Maharaja and his minister. The attempt was unsuccessful, and resulted in the slaughter of the whole of the assailants. Martand Rao Holkar died without issue at Poona, on 2d June 1849, and with his death ended the intrigues which from time to time endangered the peace of the country, both during the rule of Hari Rao Holkar and his successor. When the attack was made on his person in 1835, Hari Rao applied to the British Government for aid, but it was refused, on the ground that the engagement to maintain the internal tranquillity of the country depended on the condition that the measures of its government were not directly or indirectly the cause of disturbance; and because the grant of assistance would require a continual interference in the internal affairs of the state, inconsistent with the position of Holkar and the policy of the British Government.

In 1841, Maharaja Hari Rao adopted as his heir and successor, Khundi Rao, a boy of 13 vears of age, son of an obscure zamindar, and very distantly related to the reigning family ; and I Iari Rao died on the 24 th October 1843 , aged 49. Warned by the evils which resulted from the vacillating policy pursued on the accession of Martand Rao, the British Government took inmediate ineasures to proclaim Khundi Rao as the acknowledged successor, and to make it known that no other claims would be recognised. But Khundi Rao died on 17th February in the following year. He was never married. On this, Sir Robert Hamilton selected and installed the younger son of Bhao Holkar, who took the title of Tukaji Rao Holkar. In a letter to the young chief, the Governor-General laid down the conditions on which the state was conferred on him. This letter (No. lxxvii.) was declared to have the force of a sunnud, and the Maharaja was required to present a nuzzer of 101 gold mohurs on its delivery.

The young chief, Tukaji Rao Holkar, attained his majority in 1852, and was entrusted with the entire management of the affairs of the state, and was granted a sunnud guaranteeing to him the right of adoption.

An annual payment of 30,000 rupees is made to Holkar by the British Government as compensation for his share of the district of Patan, which was made over to Bundi in 1818. The Maharaja also receives through the British Government a tribute of 72,700 Salim Sahi rupees, on account of Partabgurh, but he has no feudal supremacy over that state. He receives credit for this tribute as part of his contribution towards the Malwa contingent, and it is realized from Partabgurh one year in arrears.

In the war with Jeswunt Rao Holkar, Lord Lake gave many lessons how to deal with the less coherent forces of Asiatic rulers. Jeswunt Rao Holkar, when he opposed the British in 1803, had 100,000 regular troops, amongst whom were 60,000 light horse, and 130 guns, with the fortresses of Chandore and Galingurh. From the tactics he adopted, this moveable force baffled the
British commanders and all the military power of India, from April 1804 till the 15th February 1805. But on the 2d April 1805, Lord Lake marched all night, and at daybreak entered Holkar's camp, which he completely broke up; in this, in going and coming, Lord Lake marched 50 miles. Lord Lake subsequently, in December 1805 , marched in his pursuit 405 miles in 43 days, from Secundra to the Beas river at the Rajghat. In Jeswunt Rao Holkar's final overthrow, Iord Lake marched 350 miles in a fortnight. Sir D. Ouchterlony was defending Dehli against the Mahrattas; but, on 'their abandonment of Dehli on the 14th or 15th October 1803, Lord Lake followed them, and at length, with a small body of 3000 British horse and artillery, amongst which were the 8th and 27th Dragoons, made a forced march of about 48 miles, defeated the forces of the Mahrattas, about 60,000, near Farrakhabad, followed 10 miles in pursuit, and returned to camp, making a journey of about 70 miles in 24 hours, with a loss of 22 dragoons killed, and 20 Europeans and natives wounded.

At that time, Amir Khan, the Rohilla chieftain of Rohilkhand, forsook the Bhurtpur raja, but was followed by General Smith, whom Lord Lake sent in pursuit. After a march of 700 miles in 43 days, Amir Khan's army was overtaken, and defeated at Afzalghur, at the foot of the Himalayas, on the 2d March 1804, and Amir Khan was conveyed across the Ganges and Jumna in March, but he rejoined Holkar's camp under Bhurtpur. At Laswari, in Central India, in 1803, Lord Lake and General Fraser fought and won a battle against the battalions of Sindia and Perron.

The Indore State maintains 3300 cavalry, 5250 infantry, and 340 artillery, with 24 field guns.

In 1832, the Maharaja (1883) Tukaji Rao Holkar was born, and in 1843 he was placed on the throne by the intervention of the British. He has displayed much capacity as a ruler. His estates are somewhat scattered, and he has wished to connect then. Area, 8075 square miles, and population in 1878 was 635,000 . He has earnestly encouraged all commercial and trading transactions. The $a b-$ original race is the Bhil.--Treaties and Sumnuds.

HOLLAND, a country in Europe with great possessions in the Eastern Archipelago, which are designated Netherland India, also the Dutch Possessions in India; and Holland formerly held parts of Ceylon, also parts of what is now British India, and likewise Malacca in the Malay Peninsula. Holland is situated along the southeastern coast of the North Sea, and extends in its greatest length, from N.F. to S.IV., about 190 English miles. lits greatest breadth, from $\mathrm{E}$. to W., is about 123 English miles. The superficial area is 7,614,252 English acres, or 11,897 English square miles. Holland has had a severe contest with the ocean, which has ended in the country being brought into a high state of cultivation and comparative safety. The canals are very numerous, and of the greatest utility in draining off the waters, and in facilitating the internal trade. They are lined with trees, which tend greatly to improve the country, in itself so flat, that to those approaching it along the rivers and some part of the coast the trees and spires seem to rise out of the water. Along the coast of the North Sea there is a line of broad sandhills and downs, in some parts so very high as to 
shut out the view of the sea even from the tops of the spires. In some parts of Zealand and of North Holland the defensive war against the encroachments of the sea is kept up with great difficulty and at an immense expense. The province of Friesland, which has no sandhills, is protected against the sea by stupendous dykes and palisadoes, the repair of which costs upwards of half a million sterling yearly. The industry of the people has multiplied cattle and pasturegrounds. Laws passed in 1857 and 1863, and based on a system of religious equality, and a total separation of church and state, ensure for every child in the country an education in the simple branches of secular knowledge. The three universities of Leyden, Utrecht, and Groningen contain upwards of 1400 students. The population in 1865 was $3,529,108$. Protestants, $1,942,387$; Catholics, 1,234,486; the remainder are Jews. Several dialects are spoken in Holland. The Dutch, which is an offspring of the Low German or Nieder Deutsch, is the language of two-thirds of the inhabitants. Flemish is spoken on the Belgian frontier. See Dutch.

HOLLY, Ilex aquifolium, Linn., a favourite European evergreen. Its hard white wood is nsed in making Tumbridge ware, for the stringing or lines in cabinet work, calico-printers' blocks, etc. Birdlime is the juice of holly bark extracted by boiling, mixed with a third part of nut-oil. 21 species are known as natives of the Himalayas, Nepal, Southern India, Khassia Hills, and Burma. Several species of holly-Kau-kuh and 'Tsz'-shu -grow in China; Ilex cornutum, near Ningpo; I. agnifolium, near Canton. The berried holly tree, called Miau rh-tsze and Luh koh-tsze, grows along the valley of the Yang-tse; a tea, called Luh koh-ch'a, is made from the leaves, and the wax insect sometimes feeds on them. The wood is turned into small boxes, and the bark is boiled to produce birdlime.-Smith, $M$. $M$. See Ilex.

HOLLYHOCK is a plant of the genus Althea, and its varieties well worth cultivating on the plains during the cold months of India.-Jaffrey.

HOLOCANTHUS INSPERATOR, $C$. and $\check{V}$., Kulloo koli min. TANr., is a fish frequently taken at Madras. H. semicircularis, $C$. and $V$., also a Madras fish.

HOLOCENTRUS ARGENTEUS is the Pookoorowah, a very delicious fish of Ceylon and the Bay of Bengal. H. ruber, a beautiful red fish of the New Hebrides, is poisonous at certain seasons.-Bennett.

HOLONG. Hind. ? A tree of Chutia Nagpur, furnisbing a hard red timber.-Cal. Cat.

HOLOSTEMMA RHEEDIANUM. S s $r$.

Holostemma adakodien, $R$. et Sc.

Asclepias annularia, Roxb.

A. convolvulacea, Herb., Heyne.

Sarcostemma annulare, Roth.

Apoong, . . . KoL. Istara'kula palem, Ada modien, : Maleal. Vistara'kula pala, Palla-gurgi,. . TEL. Palagurugu, .

This plant grows throughout India. It has large flowers of a red, green, and white colour; is very abundant in the hills about Purulea, and is also found in the neighbouring plains of Chutia Nagpur. The fibre is said to attain its best condition after the rains.-Royle, $F i h . P l, p$. 306.

\section{HOLOTHURIA.}

Hoy-shun, . . CHIN. | Swala, . . JAPAN. Sea cucumber, - ENG. Holothurion, - LAT. Sea slug, - . ", Trepang, MALAY, JAPAN. Cornechu, : : Fr. Biche-da-mar, . SP. Beche-de-mer, .

There are thirty-three species or varieties, and several of them are used as food. They are found in the Mediterranean, in the Eastern Archipelago, Australia, Mauritius, Ceylon, Zanzibar, etc., and are occasionally brought to Bombay from the latter place, and re-exported to China. The great sea cucumber of Europe is the largest of all the known species, and is probably a foot in diameter.

H. oceania, Lesson, is about 40 inches long, and secretes from the surface of its body a fluid which causes an intolerable itohing.

H. lutea, Quoy and Gaimard, is the Styohopus luteus, Brandt.

H. tubulosa, Blainville, of the Mediterranean. The Fierasfer Fontanesii, a parasite fish, dwells within it. It is eaten at Naples.

In the Ladrones, H. Guamensis, Quoy and. Gaimard, is preferred as food.

H. edulis, the trepang of the Malay, is black. It is found in all the islands from New Holland to Sumatra, and also on most of those in the Pacific: but is produced in the greatest abundance on small coral islands, especially those to the south of the Sulu group. The Chinese at Canton call it Hoy-shun, which means sea ginseng.

The holothuria of Raffles Bay is about 6 inches long and 2 inches thick. There are six sorts, the best lying about 12 feet deep. It is an unseemly - looking mollusc. Upwards of 8000 cwt. are yearly sent to China from Macassar; about $9000 \mathrm{cwt}$. are exported from Java. It is fished for in April and May, and is relished in China and in Malay countries. They are boiled in water, then flattened by stones, dried on mats in the sun, and then smoked. It is for the most part caught by the hand, for it has little power of locomotion; but in deep water, sometimes by diving or by harpoons. It sells at Singapore at 8 to 115 dollars per pikul of $133 \frac{1}{3}$ lbs. Trepang, although an article of considerable importance in the trade of the Indian islands, is seldom dealt in by Europeans, which arises from nice or rather capricious distinctions in their quality, which no European is competent to appreciate.

New Caledonia exports annually, to the value of $£ 4000$, the white bellied, red bellied, small black, large black, and brown, with teats, selling at

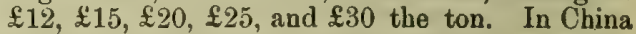
the first quality sells at $£ 90$ to $£ 200$ the ton. In $1871,274^{2}$ pikuls were received at six Chinese ports. H. scabra, of the Philippine Islands, regularly lodges in its interior, species of fierasfer and of pinnotheres.

Many of the Holothuridæ have anchor-shaped spicules embedded in their skin, as the Synapta; while others (Cuviera squamata) are covered with a hard calcareous pavement. Many of these are of a bright red or purple colour, and are very conspicuous; while the trepang which is not armed with any such defensive weapons, is of a dull sand or mud colour, so as hardly to be distinguished from the sea-bed on which it reposes. See Fierasfer.

HOLU. CAN. Pollution. See Holar; Holayar. HOLWAN. In A.H. 16, when the Arabs had 
taken this city, 300 horsemen returning from this enterprise, under the command of Fadhilah, towards the end of the day encamped between two mountains in Syria. Fadhilah (Fazl Allah) having intimated that it was time for evening prayer, began to repeat with a loud voice the usual form, 'God is great,' etc., when he heard his words repeated by another voice, which continued to follow him to the end of his praver.Rich's Kurdistan, i. 51.

HOLWELL, Mr., the chief of the settlement of Calcutta, when, on the 18th June 1756, it was taken by Suraj-ud-Dowla. Mr. Holwell and 146 of his people were thrust into a guard-room 20 feet square, from which in the morning only 23 re-issued alive. This guard-room was known in Indian history as the Black Hole of Calcutta. It was in the corner of Tank Square, near where, in 1834, was Messrs. Lyell, Mackintosh, \& Co.'s office, but it was removed about the beginning of this century. See Black Hole; Calcutta.

HOLY FIG - TREE, Urostigma religiosum, Mig. Holy Grail or Sangreal, see Jataka. Holy Star Anise, Illicium anisatum.

HOM, of the Zendavesta, is the Soma of the Vedas, and supposed to be the Sarcostemma brevistigma; but possibly is the vine of Bacchus, the ampelos, and identical with the Gaogird tree, which enlightened the eyes.

HOMA, a sacrificial burnt - offering of the Hindus. It consists of clarified butter or ghi, presented to the fire in sacrificial ladles. The word is Sanskrit from Hoo, to offer. The devout of all eastern races have offered to the deity articles of the foods by which life is sustained. The Hom or burnt-offering of Abel was of the first of the flock. The modern Rajput tenders the first portion of the repast to Anadeva, the nourisher, the goddess of food ; and all Hindus make similar oblations. The Homa burnt-offering can be made ouly by Brabmans. While prayers (mantra) are being said, five kinds of consecrated wood, together with the dhurba grass, rice, and butter, are kindled and burnt, and the fire is fed so long: as the ceremony lasts.

HOMAGE is shown in Rajputana by offering of water. The kallas is a household utensil of brass. A female of each family, filling one of these with water, repairs to the house of the head of the village, when, being all convened, they proceed in a body to meet the person to whom they render honour, singing the suhailea, or song of joy. The presenting of water as a token of homage and regard is especially common in Mewar.-Tod's Rajasthan, ii. p. 98.

HOMALIUM CEYLANICUM. Gardn.

Blackwellia Ceylanica, Gardn.; B. tetrandra, W. Ic.

This large tree, the Lee-yang of the Singhalese, is not uncommon throughout the western forests of the Peninsula up to 4000 feet; is also found on the N. Arcot Hills, near Madras, also in Ceylon. The timber is very strong, and in use for building and various other purposes.

Homalium tomentosum? Myouk-kyan of the Burmese, a tree of Moulmein, with a strong wood. H. Travancoricum, Bedd., is a very handsome middle-sized tree of Travancore and Tinnevelly. H. Griffithianum, minutifolium, Nepalense, propinquum, and Schlichii are also known, large trees.-Cal. Cat. Ex., 1862; Beddome, Fl. Syll:

VOL. II.
HOMALONEMA AROMATICUM. Schott. Calla aromatica, Roxb. | Zantedeschia arom., Spr. Kuchu gundubi, BeNG.

A peremial plant, native of Chittagong; tubers covered with the dried sheaths of the leaves, with long white fibres proceeding from every part. When cut they exhale an aromatic scent like ginger. As a stimulant it is highly esteemed in India. Dr. Wight figures also $\mathrm{H}$. calyptratrum and H. rubescens. - Roxb. iii. 513; W. Ic.; O'Sh.

HOMALOPSID $\mathbb{E}$, a family of harmless freshwater snakes, order Ophidia, sub-order Serpentes colubrinæ nonvenenati, species as under:-

Fordonia unicolor, Gray, Penang.

Cantoria elongata, Gthr., Singapore.

Cerberus rhynchops, Schneid., from Ceylon to Siam.

Hypsirhina plumbea, Boie, Eastern India.

H. enhydris, Schneid., Bengal, Eastern India.

H. Jagorii, Peters, Siam.

H. Bennettii, Gray, China.

H. Chinensis, Gray, China.

Ferania Sieboldii, Schleg., Bengal, Province Wellesley.

Homalopsis buccata, L., Malayan Peninsula, Gamboja.

Hipistes hydrinus, Cant., Penang.

Herpeton tentaculatum, Lacep, Siam.

HOMARARI, a Baluch tribe who occupy

Tambu. See Kalat.

HOMERIT $Æ$ of Ptolemy; the Himyar of

Arabia.

HOMONOYA SYMPHYLLIAFOLIA, Kurะ.

A timber tree of Darjiling Terai.

HOMOPTERA, an order of insects. Amongst them, in the East Indies, sec. Trimera; family Fulgoridæ:-

Fulgora (Hotina) clavata, Westuv, Assam.

F. gemmata, Westw., Himalaya.

F. guttulata, Westw., N. India.

F. virescens, Westw., Sylhet.

F. viridirostris, Westw., Assam.

F. spinolæ, Westw., Mysore, Assam.

F. oculata, Westru., Malabar, Penang.

Aphæna scutellaris, White, Java.

A. imperialis, White, Sylhet.

Ancyra appendiculata, White, Moulmein.

HONAIN-bin-ISHAQ, a Christian, a uative of Hira, who lived in the 9th century. He was one of the most ancient of the Arabian medical writers. After travelling in Greece and Persia, he settled in Baghdad, where he translated into Arabic the elements of Euclid, the Almagest of Ptolemy, and the works of Hippocrates and Aristotle. He appears to have commented on the works of Galen. One of his treatises is on the eyes, and another on sleep and vision.

HO-NAN is bounded on the N. by Peh-chi-li, on the S. by Hu-peh, on the E. by Ngan-hoei, and on the W. by Shen-si; it is also called by the Chinese, Tong-hoa. The capital is situated ou the south bank of the Hoang-ho, which flows through the whole breadth of the province. Its population is turbulent, and generally found inimical to foreign travellers. Ho-nan means south of the river.-Sirr's Chinese, i. p. 431.

HONAWAR, a seaport town in the N. Canara district of the Bombay Presidency; situated in lat. $14^{\circ} 16^{\prime} 30^{\prime \prime} \mathrm{N}$, and long. $74^{\circ} 29^{\prime} \mathrm{E}$. On the decay of the Portuguese power in India, Honawar was acquired by the sovereigns of Bednor; and, on the conquest of Bednor by Hyder Ali, this town also submitted to him. In 1783 it was taken by assault by a British force, despatched from Bombay, under the command of General Matthews; and in 1784 successfully defended by 
Captain Torriano against Tipu Sultan, to whom, however, in the same year, it was ceded by the treaty of Mangalore. On the overthrow of that prince in 1799 , it again came into the possession of the British. It is the Honor and Onor of Deb and Cesar Frederici; Hinawar, Hannaur of Abulfada; Hanor and Hunawur of Abd-ur-Razzaq; and probably the Nandor of the Catatan map; Abul Fazl describes it as a fine place, with pleasant gardens and a Mahomedan population, with a great export trade of rice, and much frequented by shipping. It was long a nest of pirates.Imp. Gaz.; Cathay, ii. p. 451.

HONE, a stone used for sharpening or setting cutlery. The best is of a greenish colour, inclining to yellow, often marked with thin dendrical lines, and is moderately hard, having a fine close texture, resembling indurated clay. Hones of good quality are obtainable in the Cuddapah and Kurnool districts of India,-Waterston; M. Ex.

\section{HONEY.}

Asal-ul-nahl, Injubin, AR. Mel, . . . . . LAT Pya-ya, . . Burm. Madu, Ayer-maddu

Fung-mih, . ChIN, manisan labah, MAtay.

Honig, Honing, DUT. Shahad, Pers, HIND. Dibs, Asal, . .EGYPT. Med, . . . Rus. Miel, . . Fr, Sp. Madha, . . SANsk Debash, : : HEB Mipanny, . : Singh. Madb, : Hind Haning, : : Sw Mele, Miele, : . Ir. Tayn, Teyna, TAм., Té.

Honey is obtained from the honeycomb of the Apis mellifica, Linn., and other species of honeybee, of the order Hymenoptera, Linn. Honey is secreted by the nectaries of flowers, sucked by the bee into its crop, where it undergoes some slight changes, and is then stored up in the comb for the food of its community. 'The finest honey is that which is allowed to drain from the comb; and if obtained from hives which have never swarmed, it is called virgin honey. In some localities it is poisonous, owing to the deleterious nature of the plants from which it is collected. Dr. Hooker has stated that in some parts of Sikkim the honey of rhododendron flowers is believed to be poisonous. Azalea pontica, the Anabasis informs us, poisoned the soldiers of Xenophon in the retreat of the ten thousand. Honey diluted with water undergoes the vinous fermentation, and hydromel or mead is produced. A wild shrub, jeneda, appears to intoxicate the bees. The aborigines take a piece in their hand, and, biting through the bark, they get the pungent white juice into their mouths; this they spit out at the bees, which either fly away or become intoxicated. The honey of the Eastern Archipelago is a thin syrup, very inferior in flavour to that of temperate climates. The comb is chiefly sought on account of the wax, which forms a large article of exportation to Europe, India, and China. The honeys of the Aravalli and of Kaslimir are praised, selling at tenpence the pound. There are wild bees in the woods of Kashmir, but the zamindars have also hives in the walls of their houses. The bees are quite domesticated. In the Shevaroy Hills honey is largely collected by the Mallaiali race, and is seemingly the product of three species of bees. Mr. Fischer had some hives of bees from Europe, but by day the beeeater birds and king-crows largely destroyed them, and moths at night stole the honey. Once, on examining the hive, he found a moth had succeeded in forcing its way into the hive. The bees had killed it there, but as they could not cast it out, they enclosed it in a wax tomb.

The honey-yielding Apis dorsata, A. bicolor, A. Indica, A. nigripennis, and A. socialis, occur in the south of India and Ceylon.

Sir Samuel Baker, in his book, Eight Years in Ceylon, refers to the Bambera (A. dorsata) as follows :- "The largest and most extensive honeymaker is the Bambera. This is nearly as large as a hornet, and it forms its nest upon the bough of a tree, from which the comb hangs like a Cheshire cheese, being about the same thickness, but five or six inches greater in diameter. The honey from this bee is not so much esteemed as that from the smaller varieties, as the flavour partakes too strongly of the particular flower which the bee has frequented; thus in different seasons the honey varies in flavour, and is sometimes so highly aperient that it must be used with much caution. The wax of the comb is the purest and whitest of any kind produced in Ceylon.' It is supposed to range the Archipelago, Siam. A. dorsata and A. Indica have been introduced into Europe, and the Cyprian bee into Ceylon. In Europe, the gold-banded Ligurian is prized.

HONEY DEW, a secretion on plants, from species of Aphides.

HONEY-EATERS of the South Sea Islands, are species of Melithreptes, in Australia and neighbouring islands, of the family Melliphagidæ.

HONEY-GUIDE, birds of the sub-family Indicatorinæ, genus Indicator, of Sikkim and the Malayana.

HONEY OF RAISINS is the Sher of the Persians. It is the juice of the unripe grape, boiled to a syrup and formed into a solid mass, like congealed honey out of the comb. It is supposed to be this honey to which Ezekiel, writing of Tyre, alludes (xxvii. 17): 'Judah and the land of Israel traded with thee; corn of Minnith, honey of raisins, and (in some editions honey alone) oil, and balm gave they to thee for thy wares.' It is made in Syria, and is exported to Egypt.-De Bode's Tr. ii. p. 146.

HONEY-SUCKERS, the name of a family of birds, the Nectarinidæ or Cinnyridæ, of which several species are common to India and the Archipelago. They are also called the sun-birds, and they take the place in the $\mathrm{E}$. Indies of the humming-birds of S. America. Humming-birds have straight bills, while the bill of the sun-bird is curved. The species are all of small size, with some feathers of a bright metallic lustre. They hover over flowers, and extract the honey with their tongues. Dr. Jerdon notices the Arachnothera magna and A. pusilla, the large and little spider-hunter, 正thopyga miles, $\mathbb{E}$. Vigorsi, $\mathbb{E}$. Gouldiæ, સ. ignicauda, Æ. Nipalensis, E.. Horsfieldii, and E. saturata; Leptocoma Zeylanica and L. minima; Arachnechthra Asiatica and A. lotenia. The sub-family Dicæinæ, flowerpeckers, has Dicæum coccineum, D. chrysorhæum, D. minimum, D. concolor, Piprisoma agile, Myzanthe ignipectus, Pachyglossa melanoxantha. In the Moluccas, in Bouru and Ceram and Timor, and Australia, species occur of Tropidorhynchus and Mimita.-Jerdon: Tennant.

HONEYSUCKLE. Jin-tung and Kin-yin-hwa, CHINESE, species of the genus Caprifolium, with few exceptions natives of cold countries; require rich vegetable soil.-Jaffrey. 
HONG, a word used in Malay invocations, unhallowed, of great power, and so panas (hot), that if any man use a Hong invocation three times, nothing that he undertakes for himself will succeed, and be will live powerful but miserable, able to afflict or assist others, but unable to assist himself. It is perhaps the Sanskrit Hom. It appears to be considered as a recognition of an essence or first principle beyond God, and an appeal to it for power which God has not granted to man. It is used in Javanese invocations; and a Javanese explains it to mean embryo of being, primeval essence; so that Sir T. S. Raffles' conjecture, that it is the Buddhist and Hindu O'm (Aum), is probably correct.-Jour. Ind. Arch.

HONG. ChIN. A united firm, a mercantile corporation.

HONGAY. CAN.

Hip-pe, . : . CAN. Moha, Hind, MaHr. Kuranj, . Hivb., MAHR. Nella kalavalu, . TEL.

Under these names are known two different trees growing in the woods of Mysore. Oil is obtained from the seeds of both. Hip-pe trees are extensively planted in topes in front of villages, for the purpose of obtaining oil. They seem to be species of Bassia, or perhaps Pongamia glabra.IT. Ex. of 1857.

HONG-KONG, a large island at the entrance of the Canton river, about 22 miles in circumference, but very mountainous and generally barren. The highest peak has 1825 feet of elevation. The island was ceded to the British in the beginning of 1841, and Victoria Town is on the north side of the island. The houses of the European residents are built terrace-like, on the face of the hill. Hong-Kong is the Heang-Keang of the Chinese, and the name signifies the valley of fragrant waters. It is one of the group of islands which lie north of the estuary leading to Canton, in lat. $22^{\circ} 17^{\prime} \mathrm{N}$., and long. $114^{\circ} 12^{\prime} \mathrm{E}$., and is distant from Macao 42 miles, and from Canton 105 miles. Hong-Kong is about 10 miles in length, and $4 \frac{1}{2}$ in breadth; the noble harbour is nearly 4 miles in length, and rather more than $1 \frac{3}{4}$ in width. Hong-Kong is one of that cluster of islands called by the Portuguese the Ladrones, or piratical islands.-Lay's Chinese as they are, p. 280.

HONHAR. HIND. Fate; that which is to be. HONIGBERGER, Dr., a German physician at the court of Ranjit Singh; author of a work on the medicinal products of the Panjab.

HONOVER, the most sacred prayer of the Parsees. It is very ancient, and has been translated from the Zend into German by Professor F. Spiegel, and into French by J. Oppert. D. Framjee of Bombay sent its words to the editor in 1871. He considers it to be a theistic prayer to the Supreme Being. Its words are,-

'Yathā ahü vairyō

Athā ratus ashāat chit hachā

Variheus dazdā mananhō shyaothénanām

Ariheus Mazdāi, Khshathremeh Ahurāi

Ayim darigubyơ dadhat Vaçtārem.'

-Bunsen's God in History.

HOODED, in natural history, a term applied to describe several animals. The hooded chameleon is the Chamæleo cucullatus; the Corvus cornix is the hooded crow of Europe, Asia Minor, Afghanistan, Japan, and Barbary; and the hooded presbytes is one of the Simiadæ.

HOOKAH. HiNd. The Indian pipe and appar- atus for smoking: In Bengal generally, and in Persia, pure tobacco is rarely smoked; but various compounds are made and smoked in hookahs of various forms, the ghalyun of Arabia, nargyle of Persia, hubble-bubble of British India generally, and the highly ornamental hookah. The nargyle is doubtless a word derived from Narel, a cocoanut, for the primitive form of hookah is the narel, a hollow cocoanut shell half-filled with water. On one side of the shell is inserted a pipe, which is connected with the fire-pan and tobacco-holder (chillam), and on the other side is inserted another tube, which goes into the mouth of the smoker. When the smoker draws, the smoke from the first pipe (the end of which is under water), is drawn up with a bubbling noise through the water (hence the term hubble-bubble), and is thus cooled and purified. The flexible tube (necha) of the more elaborate hookah is made of a long coil of iron wire covered with cloth and ornamented. This was invented in Akbar's time. A hookah for smoking madhan (opium), with a peculiar shaped chillam, is called Madhaki. In Lower Bengal the lower orders frequently smoke in companies, with one hubble-bubble or narel or kalli, which are the most ordinary and cheap forms. All sitting round in a ring, the pipe passes from one to another, each taking a few whiffs as it passes. This is never done by the higher orders, nor is it done in Hindustan. The Sulfah form of hookah is the commonest in Kābul and Peshawur. The hookah has almost ceased to be used by Europeans in India, but natives continue to use it with gurako or prepared tobacco. Some hookah-snake tubes are very costly, the precious metals and precious gems being largely employed in their manufacture. The snake or pliable ornamental tubing lengthens out into several coils, and the smoke passes through a water-vase, while the mouthpiece is of amber, silver, etc.-Simmonds' Dict.; Robinson's Travels, ii. p. 226.

HOOKER. Sir Joseph Dalton Hooker, K.C.S.I., I.D., F.R.S., D.C.L., LL.D., was born 30th June 1817. In 1839 he entered the navy as AssistantSurgeon, and up till 1843 he was Botanist of the antarctic royage of exploration by the Erebus and Terror under Captain (Sir) James Clark Ross ; and between that year and 1860 he published the Flora Antarctica, Flora Novæ Zelandiæ, and the Flora Tasmauica, in six quarto volumes. Between 1847 and 1853 he visited the N.E. of India, and published in two volumes a journal of his travels in the Nepal and Sikkim Himalayas. When on the frontier with Dr. Campbell, the raja of Sikkim seized and imprisoned both of them for some weeks. He published in a folio volume the Rhododendrons of the Sikkim Himalayas, and several communications in the journal of the Bengal Asiatic Society; and he and Dr. Thomas Thomson commenced a Flora Indica, of which one volume appeared; but later on he renewed the publication of the Flora of British India, and up to 1883 three volumes were completed. He also wrote On the Structure of the Balanophorer, On the Origin of the Pitchers of Nepenthes, On the Distribution of Aretic Plants, in 1860; Essay on the Flora Tasmanica, A Memoir on the Welwitschia Mirabilis ; also Students' Flora of the British Islands, and Primer of Botany for the use of Beginners; and along with Mr. Bentham, Genera Plantarum ad exemplaria imprimis in Herbarriis 
Kewensibus servata definita. On the death in 1865 of his father,Sir William Hooker, he succeeded to the office of Director of the Royal Gardens, Kew.

HOOLOCK GIBBON, Hylobates hoolock, the white-handed gibbon ( $\mathrm{H}$. lar.). The long-armed apes or gibbons constitute a very distinct section of quadrumanous animals, confined to the Malay countries of Southern Asia and the adjacent islands. They do not usually bear captivity well,

HOOLOOGOO, grandson of Chengiz Khan. See Hulaku.

HOOLY, a Hindu festival in honour of Krishna, which takes place in the month Phalgun, February-March, at the commencement of the joyous spring. The amusements on this occasion consist in dancing, singing, and play. Their songs are called Kavir, or extempore stanzas, principally in allusion to the charms of Krishna and his amours with the Gopia, and are not marked by an excess of delicacy. One of the dances is the favourite Tipri dance, or Rasa mandala, in which 20,30 , or more form a ring, each having a short stick in the band, with which the dancer strikes alternately those of the persons before and behind him, keeping time with it and his foot; the circle moves round, keeps time to a drum and shepherd's pipe of three or four siveet and plaintive notes. In Major Moor's Hindu Pantheon is a beautiful plate on this subject, in which Krishna (with Radha) in the centre is described as the sun, and the circle of dancers as the heavenly bodies moving round him. In the hooly, the players throw a red powder, sometimes mixed with powdered talc to make it glitter, into the eyes, mouth, and nose, or over the persons of those who are objects of the sport, splashing them well at the same time with an orange-coloured water. The powder is sometimes thrown from a syringe, and sometimes put into small globules, which break as soon as they strike the object at which they are aimed. The Hindu women are expert in throwing these. The hooly among the Hindus reminds one strongly of the Saturnalia of the Romans : people of humble condition take liberties with their superiors in a manner not admissible on other occasions. The chief fun in public is throwing the coloured powders above alluded to on the clothes of persons passing in the streets, and squirting about the tinted waters. Dignified personages avoid as much as they can appearing abroad while these jocularities are passing, unless with the view of gaining popularity they condescend to partake in them; in general they confine themselves to their houses, and amuse themselves with their families. In pictures, belonging to a series illustrating the domestic occupations of the Indians, the family diversions of the hooly appear like those more publicly exbibited,-scattering yellow and red powders, and squirting coloured water. Sending simpletons on idle errands contributes also to the delights of the hooly ; this is performed exactly similar to our ceremony of making April fools on the first of that month, and is common to all ranks of Hindus; and Mahomedans, indeed, join in this, as well as in other items of hooly fun and humour. Another opportunity of merriment, similar to the May-day gambols of England, is afforded to the Hindus in a festival in honour of Bhawani, that always falls on or near that day.-Cole. Myth. Ilind. p. 382 ; Moor's Hindu Pantheon. See Holi.

HOOPOE, birds of the genus Upupa, of which in India are U. epops, Limn., U. nigripennis, Gould., $U$. longirostris, Jerdon. U. epops is common in Southern Asia during the cold season, and on the table-lands at all seasons. It is to all appearance a bird of fluttering and feeble flight, but has repeatedly been observed, during the seasons of migration, at altitudes considerably above the limits of vegetation. On the western side of the Lanak pass, about 16,500 feet, Major Cunningham saw a hoopoe ; also at Momay (14,000 to 15,000 feet elevation), under the lofty Donkia pass in Northern Sikkim.

HOORMUZ, the name of one of those Parthian kings known to the Romans as Artabanus. There were five of the name Artabanus, the first in B.C. 216 , and the last about A.D. 235 , and with whom ended the Arsacidæ, he having been slain by one of his officers, Ardeshir Babegan (Artaxerxes) who became the first of the Sassanidæ. It is supposed by Malcolm that Artabanus III, was the Shahpur of the Greeks. His son Vonones reigned; for a short period. His name is sometimes written Pollas. He was the Volageses of the' Greeks, whose war with the emperor Nero and embassy to Vespasian are related in the Roman history. Hoormuz appears to have been Artabanus IV. of the Romans.-Malcolm's Persia, i. p. 85.

HOPEA, a genus of plants of the natural order Dipterocarpaceæ. The Thin-ga-do of the Burmese, a species of Hopea, is a large tree which abounds in the same localities of British Burma as $H$. odorata, but the wood is not equally valued. A cubic foot weighs $52 \mathrm{lbs}$. It sells at 12 annas per cubic foot. H. decandra, Buch., called Ooroopa in Malayala, is a tree which the natives of Canara prefer to teak for building ships, being more durable and close grained. $\mathbf{H}$. discolor, Thw., is a large tree of Ceylon, growing in the Saffragam and Ambagamowa districts at no great elevation. The under sides of the leaves are of a rich brown colour. H. faginea, Wall, is a tree of Penang. H. floribunda? The-ah,also Tan-the-ya of the Burmese, is a very large tree of Tavoy.-Thw. Zeyl.

HOPEA ODORATA, $R n x b$.

Then-gan,. . . . BURM. i Then-gan-pha-yung,BurM.

This species grows in Chittagong and Burma, and is considered the most valuable indigenous timber tree in the southern provinces of Tenasserim, and at Tavoy and Mergui is sawn up for building purposes. The then-gan trees grow to a height of 250 feet; they are found near Moulmein in laterite and sandstone chiefly. The best canoes are made of it, and it is used extensively in native boatbuilding. It is a light-brown wood, is used extensively by the Burmese in the construction of boats carrying 3 or 4 tons, formed from the trunks of these magnificent trees. The trunk is scooped or burnt out, and stretched in the centre, whilst warm, by means of cross pieces of wood. When the required breadth is obtained, the sides are built up to obtain a greater capacity. These treeboats, if they may be so called, are from 7 to 8 feet beam. The breaking weight of $\mathrm{H}$. odorata may be stated at $800 \mathrm{lbs}$., with a specific gravity of 45 to 46 lbs._Drs. Mason, M'Clelland, lioxb.

HOPEA PARVIFLORA. Bedd.

Kiral boghi, Ghats ofS.CAN. Iru-bogum, . MALABAR. Tirpu, - Plains "

A large, handsome tree, common both in the moist and dry forests in Malabar and $S$. Canara, up to an elevation of 3500 feet. The 
wood is hardly known commercially as yet, but it is much valued by the natives in S. Canara; and Colonel Beddome believes it will be of great value for gun-carriage purposes, and will also answer well for sleepers. In S. Canara it is much valued for temple-building purposes.-Beddome.

HOPEA SUAVA. Wall. Engyin, BurMr. A valuable tree found in the Eng forests of British Burma, but large trees are not common in Pegu. Wood tough and hard, but heavy, used in housebuilding, for boats, and a variety of other purposes, and said to be as durable as teak. A cubic foot weighs $55 \mathrm{lbs}$. In a full-grown tree, on good soil, the average length of the trunk to the first branch is 60 feet, and average girth measured at 6 feet from the ground is 7 feet.-Dr. Brandis.

HOPEA WIGHTIANA. Wall. A variety of this tree is the $H$. glabra, $W$. and $A$, very common in many of the western Madras forests. The timber is very valuable, and very similar to that of Hopea parviflora. One variety, the Kong of Tinnevelly, is par excellence the timber of that district. Another variety is abundant in the S. Canara district, where it is called Kalbow and Hiral bogi; it is a first-rate coppice firewood, and large tracts in this state are met with in the plains of that district, never apparently flowering, but abundantly covered with the abortive fruit-like echinate excrescence, much like the young fruit of a Spanish chesnut; it is probably the formation of some insectin the bud of the panicle. A somewhat similar formation occurs in Hopea parviflora. -Wall.; Beddome, Fl. Sylv. p. 96.

HOPPER, the Appa of the Singhalese, and Apum of the Tamils. In Southern India, cakes made of wheaten flour and cocoanut milk. The Appas of the Bombay Presidency are made from the Sorghum vulgare, and are of rice-flour in Ceylon. HOPS.

Humle, . . DA., Sw. Luppoli, . . . . IT. Hoppe, . . DUT. Humulus lupulus, . Lat. Houblon, . . Fr. Chmel, . . Rus. Hopfen, : GRr. Oblon, SP. Bruscandoli, . : : Iт. Lupulo, : : SP., PoRT.

The hop plant has been introduced into India, grows well at Kaolagir in the Doon, but flowers eparingly. It has yielded enormously in Australian colonies, in Victoria, along the valleys of Gippsland, and other localities, to the extent of 1500 lbs. an acre. The properties of hops, of giving the bitter to beer and preventing acetous fermentation, enable it to be kept much longer. To it, no doubt, is owing a portion of the stomachic properties of malt liquor, as we see exemplified in the bitter, often called Indian, ales. Hops are hypnotic, especially when stuffed into a pillow, but they should be first moistened with spirits, to prevent the rustling noise. Fomentations also have been used. Hops are thought to be diuretic (as is also the root), and to be useful in correcting lithic acid deposits.-Royle; Von Mueller.

HOR or Hor-pa. TIBeTan. Kao-tsze, Chin. This race call themselves Ighur. They seem to be Bhot. They dwell on the north-western frontier of Tibet, on the confines of the Turk districts of Little Bokhara. Some of them are Mahomedans, and Mr. Hogdson considers them to be Turks.Latham's Ethnology.

HORA. SANSK., LAT. The 1-24th part of the natural day, answering to a European hour.

The Vara or solar day in Hindu almanaes is reckoned from sunrise to sunrise, and is divided into 24 hora or hours, and each hora of the day is ruled by one of the planets in turns, the rotation being the Sun, Venus, Mercury, Moon, Saturn, Jupiter, and Mars.-Kala Sankalita. See Tithi ; Vara.

HORA, a goddess of Byblus, worshipped at Babylon as Hea, the equivalent of Juno. Her name in Tyre was Itea.-Bunsen.

HORA-ALIA. Singr. A rogue or must elephant.

HORA-BORA, a tank, now in ruins, in the Bintenne district of Ceylon. Its length is 8 or 10 miles, and breadth 3 or 4 . The embankment is from 50 to 70 feet high, and its base is 200 feet broad.-Tennant's Ceylon.

HORANAWA, a shrill musical pipe in use with the Kandians. Its tones have some resemblance to those of the bagpipe. Its mouthpiece is made from the talipot leaf, and its other parts of jackwood and brass.-Sirr's Ceylon.

HORDE, an introduced English word from the Turkoman word Urdu, a camp.

HORDEUM, a genus of plants of the natural order Panicaceæ, furnishing the barley so much used by the more northern nations of the world.

H. distichon, Linn., 2-rowed barley.

H. deficiens, Stendel, of Red Sea, 2-rowed barley.

H. hexastichon, Linn., 6-rowed barley.

H. vulgare, Linn., 4-rowed barley.

H. zeocriton, Linn., 2-rowed barley.

To this species belong the sprat, battledore, Fulham, Pultney rice, and Turkish barley, and the Dinkel.

English barley is that with 2-rowed ears, and its botanical name is Hordeum vulyare distichon. The Scotch bere or bigg is the Hordeum vulgare hexastichon. It has two rows of ears, but three corns come from the same point, so that it seems to be 6-eared. The grains of bigg are smaller than those of barley, and the husk thinner. The kinds of barley especially cultivated for making pearled barley or malt, are Hordeum perlatum, $H$. distichon B., Zeocriton commune, Hordeum mundatum. These are technically known as Scotch and French pearl barley, battledore barley, German rice, sprat barley. Fero de ozzo is made from sprat barley.

Professor Einhof analyzed 1000 parts of barley flour, and found it to contain 720 of starch, 56 sugar, 50 mucilage, 36.6 gluten, 12.3 vegetable albumen, 100 water, 2.5 phosphate of lime, and 68.0 of fibrous or ligneous matter.

The specific gravity of English barley varies from 1.25 to 1.33 ; of bigg, from 1.227 to 1.265. The weight of the husk of barley is $1 / 6$, that of bigg 2/9. Professor Ure states 'specific gravity of barley is 1.235 by my trials.'

H. ægiceras, Royle, MSS., bas ears cylindrical ; florets arranged in a confused manner, not in rows ; awns soft, short, hooded, and bent downwards; grains loose in the husk. It is found in the northern parts of India, and probably in Tartary, as its grains have been sent to England under the name of 'Tartarian wheat.' Its appearance is more that of wheat than of barley, and its naked grains assist the resemblance. It is, however, a genuine species of Hordeum. It appears to be a productive plant, but little is as yet known of its quality in the climate of England.

H. gymnodistichum has the ear cylindrical; 
awns almost parallel with the ear; grains loose in the husk. Naked barley, a species but little cultivated now, is of unknown origin. It is said to have been introduced into England in the year 1768 ; but it is reported to have preserved its characters unaltered from time immemorial in some parts of Europe.

H. gymno-hexastichon has the ear cylindrical; awns very long, rough, and rigid, rather spreading away from the ear; grains loose in the husk. The original of this, the naked 6-rowed barley, is unknown. It is extemely productive, and in some parts of Europe it is reckoned the most valuable of all. The French call it, on account of its good qualities, Orge celeste.

\section{HORDEUM COELESTE.}

Chama, - • Внот. Elo, _. . Chexab. Grimnas (husked),. ", Ua-jo, Ua, KHAS, SUTLEJ.

This is found in the Sutlej valley between Rampur and Sungnam up to 15,000 feet. The beardless variety is most esteemed. Barley ripens in the end of May, several weeks before wheat. The dough made of it is called 'ampe' in Ladakh.

HORDEUM DISTICHON. Linn.

Zeocritum distichon, Beauv.

Shair,. . . ARAB. Shoreh, . - HEB. Mu-yau, : : Bursr Jao, HiNd, PERs. Krithe of Dioscorides, GR. Barley arisi, . . TAM.

Barley of Exodus ix. 31, the summer barley of England. This is commonly stated to be a native of Tartary. Colonel Chesney found it wild in Mesopotamia, upon the banks of the Euphrates. It is much cultivated in Europe, and is the common summer barley of England, and that which cultivators seem to prefer. Its ears are not so large as those of $\mathrm{H}$. hexastichon, but the grains are heavier. Ear cylindrical ; awns almost parallel with the ear; grains adhering to the husk.

HORDEUM HEXASTICHON. Limn.

Shair, . . . ARAB, Yoa of . KaNGRA, JAV, Juvo, : : : BeNG. Soa, Jhotak, . LADAKH. Mu-yau, : Bury. Shiroka of

Thanzatt, Nai, - ChenaB. To-sa of : NePdL. Jaw, jawa, : "Tro, Ne, of : PANGRA. Sa-too, : Dukr. Situs-hooka, . Rus. Ijoir, : EGYPT. Chak of SutLEJ, SW. Krithe of Dioscorides, Gr. Yava, Yava biy-yamyuTEL, Shoreh, . . . HeB. Pachcha yava, Yavalu, , Jao,. : Hind., Pers.

Common or winter barley is grown in N. India. It is frequently cultivated as a cold-weather crop in the plains of the Panjab, as it requires less labour and gives more produce than wheat even in inferior soils, and where the water is deep below the surface. Above 8000 feet of elevation it is much more common than wheat, while at lower heights it is less grown. In Lahoul and Ladakh it is abundantly cultivated with Fagopyrum up to 13,000 feet in Ladakh. Some kinds of barley may be seen up to 14,000 feet about Hanle, near the Tsomoriri lake, and this is found in the Sutlej valley between Rampur and Sungnam at an elevation of highest limit 15,000 feet, and much cultivated. Barley is cultivated much in the same way as wheat, but is ready for cutting somewhat sooner; it is grown much on 'sailaba' aud 'barani' lands. In the Panjab it is much less esteemed than wheat, and sells much cheaper, though it produces much more, and requires worse lands and less watering than wheat. The varieties are Jau-desi (common country barley) and Jaupaighambri. Ghoni jau is barley that has scarcely any liusk at all, but only a fine skin. Barley is one of the cheapest of the grains found in the bazars of Kaira, in Gujerat. - Powell; Cleg. Panf. Rep.; Stcuart, p. 256 ; Eng. Cyc., quoting Loues Elements of Agriculture, p. 238; Voigt.

HOREB and Mount Sinai are part of the Jabl-ul-Tur range, with Hor or Seir, now called Jabl Harun, or Aaron's mountain.

HOREHOUND, BLACK, Ballota nigra ; white, patch leaves.

Horehound, white; Marrubium vulgare, Linn. Pucha pat, . . BENG. | Marrubium Indicum, LAT.

This plant grows at elevations of 2000 to 7000 feet in the N.W. Himalaya, in Kashmir, the Salt Range, on the Chenab and Trans-Indus. The leaves are of a whitish-grey colour, having a woolly appearance, and possessing a faint agreeable odour, and a sharp, bitter taste. That met with in Bombay is imported from Singapore, and is used in various ways by the natives, but chiefly as an ingredient in Guraku, and, when combined with other herbs, for scenting the hair of women. The essential oil is in great request among the superior classes of natives, for imparting the peculiar fragrance of the leaf to clothes.-Faulkner; J. L. Stewart.

HORINGHATA, one of the moutbs of the Ganges.

HORMARA, a section of Baluchistan, adjoining the Arabian Sea. The Hormara tribe say they came originally from Sind.

HORN.

Hoorn, . . . . Dut. | Tanduck sungu, Malar.

Corne, : . FR. Rogg, . . . RUs. Sing, GuJ., Hinv., KarN. Cuerno, : : : SP. Corno, . . . IT., PoR. Kombu, . . . TAM. Cornu, : : Lat. Kommu, : : Tel,

The horns of animals are largely utilized in the manufactures of the south and east of Asia; and those of the bison, buffalo, elk, ibex, goat, antelope, deer, oxen, and rhinoceros are largely inported or re-exported. Horn of kinds is extensively used in the manufacture of handles for knives, walking-sticks, spoons, combs, lanterns, snuff-boxes, powder-flasks, buttons, hairpins, etc. In China, buffalo horns are worked into lanterns, some of which are highly elegant. Chessboards, work and knitting boxes, tea-chests and teacaddies, inkstands, baskets, etc., which are lined with sandal-wood, are generally very neatly made at Vizagapatam. But they are far surpassed, both in cheapness and workmanship, by articles of a similar description, the produce of German industry, which are largely imported into England.

In China, lanterns made of horn shavings are largely used. Horn is softened by very intense heat, and then extended into thin laminæ of any shape. The best sort of rhinoceros horns come from Cochin-China, and sell at times for 300 dollars a-piece ; an inferior sort is imported into China fron India, of which some probably arc from Southern Africa, which are sold for 30 dollar's and upwards a-piece. The Chinese work the finest of these horns into elegant cups and other articles, but the most of the importation is used as a medicine. It also forms an article of commerce in the Chinese junks trading to Japan. The deer-horns and antlers exported from India are the dense antlers of the sambur (Cervus hippalephus), of the barking deer (Cervus muntjac.), of the axis (Cervus axis), the nil-gai 
(Damalis rusa), and other species; also the horns of the thar, gural, and yak. Horns exported from India, -

Year. Cwt. Rs. Year. Cwt. Rs.

\begin{tabular}{lll|lll}
$1874-75$, & 58,175 & $7,62,399$ & $1877-78$, & 88,783 & $19,42,009$
\end{tabular}

\begin{tabular}{rrr|rrr}
$1875-76$, & 55,755 & $8,06,652$ & $1878-79$, & 67,828 & $13,78,667$ \\
$1876-77$, & 71,890 & $12,80,051$ & $1879-80$, & 57,204 & $12,68,321$
\end{tabular}

Horn-bows are sometimes used in the armainent of some Chinese troops.

HORNBEAM, Carpinus viminea.

Shirash of . . BEAS. Imar of . . SUTLEJ. Charkre of: : RAVI.

A moderate-sized tree growing in the N.W. Himalaya, at from 5500 to 6000 feet up to the Ravi. Its wood is esteemed by carpenters.- $D$ r. J. L. Stewart.

HORNBILL, birds of the family Bucerotidæ, genera anorhinus, berenicornis, buceros, homruius, hydrocissa, meniceros, tockus, aceros, cranorhinus, rhyticeros, and rhinoplax, the shapes of whose bills arrest attention. Their food consists of fruits, berries, flesh, and even carrion.

B. cavatus, body and wings black, greater coverts and quill-feathers tipped with white; thighs, upper and under tail coverts, white. It is a native of India, the Himalaya mountains, Java, and most of the islands of the Archipelago.

B. pica, Scopoli, is the B. coronata, Boddzert. The female is built up in the nest and fed by the male during incubation. This hornbill abounds in Cuttack, and bears there the name of Kuchilakhai, or Kuchila-eater, from its partiality for the fruit of the Strychnos nux vomica.

B. rhinoceros, the rhinoceros hornbill. The bill about 10 inches long, and of a yellowish-white; the upper mandible red at the base, the lower black; the horn or casque varied with black and white; the body black, of a dirty white helow and posteriorly; tail about 12 inches, the feathers white at the base and tip, black in the middle. It is a native of India and the Indian islands.-Eng. Cyc.; Goold; Tennant's Ceylon. See Birds ; Buceros.

HORNED HOG, the babirussa, inhabits the woods of Java, Celebes, and others of the larger Sunda isles. Its upper tusks are of great length and curved form, and grow upwards and backwards like the horns of the Ruminantia. It is probably the Sus tetraceros of Alian.-Eng. Cyc. p. 359 .

HORNET, Tsireah, HEB, ; Crabo, LAT.

HORPA, Turkish tribes, so called by the Tibetans, and known to the Mongols as Bada Hor.

HORRE. SINGH. A hard, though coarse, open-grained, heavy Ceylon wood, Dipterocarpus lævis.

HORSBURGH, JAMES, whose name is indissolubly connected with the history of the Marine Surveys of India, was a native of Scotland. He began life as a cabin boy, but soon rose to the command of a vessel in the eastern seas, and gave rein to his innate love of surveying. After many years, he returned to England, and a set of his charts, engraved by Walker, placed him at once in the first rank of hydrographers. About 1804 he published the first edition of his East Indian Directory, and on the 10th November 1810 he was appointed to examine the journals of the East India Company's ships, and became Hydrographer. From that time till his death in 1836 , all charts passed under his scrutiny, and were published under his superintendence. Fourteen chart's actually; compiled by himself, were published by the East India Company, from the N. and S. Atlantic to the Archipelago. His Directory went through six editions, in 1809, 1836, 1841. After the middle of the 19th century, Mr. Findlay printed one on that of Horsburgh, and in 1871 Captain Taylor printed another.

In his honour a lighthouse was erected on Pulo Aor, near Pedra Branca. His sailing directions are reckoned indispensable in navigation. The island of Pedra Branca is called Batu Putih by the Malays, both these terms signifying white rock. Prior to the quarrying operations on it, it was covered by the dung of the numerous sea-birds that frequented it as a restingplace. The rock is situated at the extremity of the Straits of Singapore, nearly in mid channel; and as it advances beyond the mouth of the Straits considerably into the China Sea, it has for ages served as the principal leading mark to vessels passing out of, or into, the Straits.-Dr. Buist's Catalogue ; Journ. Ind. Archipelago, 1852; E. I. Marine Surveys, P. P., 1871.

HORSE.

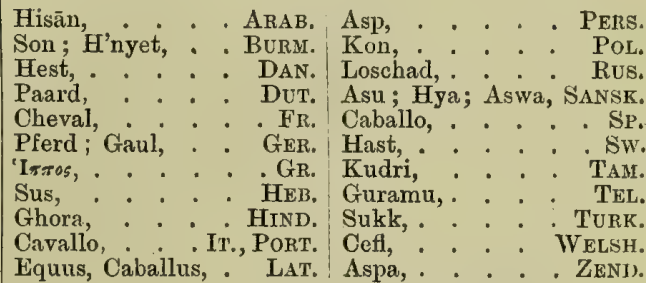

The king Sesonchosus of Egypt is supposed to have been the tamer of the horse. But, from time immemorial, the horse has been domesticated and subservient to man, and been largely used in war. An ancient eastern prince (Job xxxix. 19-25) describes the horse as a creature which

'Mocketh at fear, and is not affrighted;

He saith among the trumpets, Ha! ha!

And he smelleth the battle afar off,

The thunder of the captains and the shouting.'

Judging by its varied names, the horse seems to have been very generally diffused over the central parts of the old world, some of the terms being derived from its neigh. Amongst every nation of the old world its use and beauty have made it a favourite. Supernatural powers have even been attributed to it by some nations. It was sometimes considered the most acceptable sacrifice that could be offered to heathen deities; and we read in 2 Kings xxiii. 11 that Josiah took away the horses that the kings of Judah had given to the sun. According to Herodotus, the horse was the most appropriate offering that could be made to the sun, on account of its great swiftness. The Persians dedicated horses to the sun: and Sextus Pompeius sacrificed to Neptune by throwing horses into the sea.

During the Hindu rule in Hindustan, prior to the advent of the Mahomedans, the horse was offered in sacrifice by sovereigns claiming paramount power. See Aswa Medha.

The sacred horses of the Germans were white, and the device of the Saxons was a white horse. Marco Polo tells us that 100,000 white horses were presented to the Great Khan on New Year's 
day; and the Tartar chiefs continued at least to the time of Kan-ghi to present a tribute of white horses to the emperor. Native princes in all parts of India continue fond of white horses, and generally have one or more favourites of this colour in their stud. A favourite colour for state occasions is cream-colour. The royal carriage of Britain on state occasions is drawn by six creamcoloured horses. The horse represented on Greek and Roman bas-reliefs was a small, compact, and spirited-looking little animal, not larger than what we would call a pony, but he must have been perfectly trained, for neither bridle nor bit nor saddle was used by his rider, who guided him by a small stick, tapping him on either side of the neck as he wished to turn.

Naturalists generally believe that the varieties of all horses have descended from one species, but there are at present numerous varieties, presenting great differences in size, shape of ears, length of mane, proportions of the body, form of the withers and hind quarters, and especially of the head, and the pedigree of a racehorse is generally more to be relied on in judging of its probable success, than its appearance.

The horse can bear both intense heat and intense cold. In Siberia are wild horses in lat. $56^{\circ} \mathrm{N}$, and he comes to the highest perfection in Africa and Arabia. Much humidity seems more unfavourable to the horse than heat or cold; and this, perhaps, will explain why, to the eastward of the Bay of Bengal, over a humid area of enormous extent, in Burma, Siam, Malayan Archipelago, the Loo-Choo Islands, and a large part of China, fullsized horses do not occur. In Japan, farther east, they recur. The range of colour in horses is very great. The English racehorse is said never to be dappled; cream-coloured, light and mouse-coloured duns are occasionally dappled. Horses of varied colours, of diverse breeds, and from various parts of the world, have a tendency to become streaked, and racehorses often have the spinal stripes, the stripe being generally darker than the other parts of the body; they occur across the shoulder and on the legs. Darwin considers the whole horse genus to have had for a progenitor an animal striped like a zebra (but perhaps otherwise very differently constructed), the common parent of our domestic horse, whether or not it be descended from one or more wild stocks of the ass, the hemionus, quagga, and zebra. He says that the spinal stripe in the English racehorse is more common in the foal than in the grown animal. 'The ass not rarely has distinct transverse bands on its legs, like those on the legs of the zebra. The spinal stripe occurs on horses of all colours, but on the mouse duns and on duns the transverse bands occur on the legs, and sometimes also a faint shoulder stripe. In the Kattyawar breed, a horse without stripes is not considered purely bred. The spine is always striped and the legs barred, and a shoulder stripe is common, and sometimes is double or treble. The ass has almost always a dark stripe or band on the shoulder, which is sometimes even double, but is always variable in length and breadth. The koulan of Pallas has been seen with a double shoulder stripe. The hemionus has no shoulder stripe, but their foals' legs are generally striped.

The prevailing belief amongst the Europeans in
India, is that the native breeds of horses have decreased under British rule. Up to the beginning of the 19th century, there were several horse fairs in Rajputana, especially those of Bhalotra and Poshkur, to which the horses of Cutch and Kattyawar, the Lakhi jungle, and Multan, were brought in great numbers. Valuable horses were then bred on the western frontier, on the Looni, those of Rardurro being in high estimation. But after the successes of the British over the Mahrattas and the Pindara, the breeding studs of Rardurro, Cutch, and the jungle became almost extinct, and the horses from the west of the Indus were carried to the Sikhs. The destruction of the predatory system, which had created a constant demand, lessened the supply. The Lakbi jungle was well known in India for its once celebrated breed of horses, which became extinct in the early part of the 19 th century.

Colonel Henry Shakespeare thinks that the cause of the decline of the native horse in India, arises from the fact that Government has encouraged the supply of a larger description of animal than the country naturally produced, and the hardy small breeds of native horses have thus been neglected. Perhaps, however, the chief causes of the decline in their numbers, is their non-requirement for the predatory. bands and Parthian-like cavalry, since the contentions of the princes of India have been suppressed; also cultivation has been extending over grazing lands; and as the former governments of India and their military servants were the largest buyers of horses, though the British continue to buy extensively, the soldiers and the guns of the British Indian army are larger than those in use by former native powers, and the British admit only horses into the ranks of their armies, and even in their equipage a mare is rarely seen.

Panjab. - Under native rule, the Panjab maintained an enormous cavalry force, mounted chiefly, if not entirely, on horses bred in the country, but that territory is now unable to meet the demands of its irregular force, which is numerically insignificant compared with that kept up by the Sikh Government. The reasons assigned for this are three in number:-1st. Large numbers of brood mares were withdrawn from the Panjab at the time of the annexation; 2d. Extensive demands were made on the province for both horses and mares during the mutiny; and $3 \mathrm{~d}$. A large proportion of the re-mounts of the Sikh army were mares, which were regularly bred from; but under the British system, which requires re-mounts to be available for service at all times of the year, this cannot be done. It has therefore occurred that mares introduced into irregular cavalry corps, on account of their tractable nature, are not permitted to breed; and the result is that every one bought up for military purposes, and even every one bought up by the European community, may be regarded as a brood mare lost to the country. It has also been ascertained that breeders are parting with their best mares. The Dhunni caste, of the Rawal Pindi districts, the best in the province, is almost extinct from this cause. Yet many excellent brood mares were left, especially in the Rawal Pindi, Jhelum, Gujerat, Gugaira, and Lahore districts. There were also very good mares in the frontier districts, such as Bunnu, Kohat, Dehra Isunail Khan, and Dehra Ghazi 
Khan. Although small, they possess good blood and great powers of endurance, which is everything in the horse.

Palanpur has a really good breed, the mares of which are justly and highly esteemed, and command considerable prices even among natives.

In Rajputana, few of the princes have generally good horses in their territories. The Marwar horse contains apparently much Kattyawar blood, and, bred with great care in many places throughout the country by the thakurs and others, is a valuable animal in every respect. Good mares are also scattered, but the generality of horses met with are inferior animals in every respect.

The breed of horses in Jeypore is exceedingly poor, as little care has been taken to improve the country animal in any way. Some few of the thakurs possess and breed good animals. The horses of Shikawutti are said to be good.

Bunni Singh, raja of Ulwar, founded a fine breeding stud, consisting of well-selected Arabs and Kattyawar horses, and in Ulwar the troopers were better mounted than native cavalry generally, and a better stamp of horses was met with than in any other Rajput state. The finest of his cavalry were, however, almost annihilated on meeting with the rebels in superior numbers in 1857 .

In Bhurtpur, also, some attention was given to the breed of horses, but they are inferior to those of the Ulwar district.

The Dekhan breed of horses was highly improved about the beginning of the 19 th century by crosses with the Arab horse. The small blood-horse of the Bhima valley or Terai are of this breed, and the mares are beautiful. The horse very rarely grows above 14 to $14 \cdot 1$ hands in height, but has the fine limbs, broad forehead, and much of the docility and all the enduring properties of the Arabs, and has been mistaken for them. $\mathrm{He}$ is not so fiery as the small and blood Arab, and more manageable in the ranks. Malligaum, about 25 miles from Ganga Kheir, on the Godavery, is a great mart for the Dekhan horse, and purchasers from all parts of the Peninsula annually resort to the fair. Some of the horses are really very fine. In the Dekhan, the larger horses are bred about the Gor river and Aligaum, between Poona and Ahmadnaggur.

The Hyderabad territory in the Dekhan can breed about 2000 horses a-year, and 500 good colts could be purchased at lower rates there than are paid for Arabs or Cape or Australian horses.

The low-statured horses of the Bhima and Man rivers, the Bhima Terai and Man Terai, are good. The Bhima horse has all the best points of the high-bred Arab, without his very fine skin, irritable temper, and rather long pasterns, and has generally better feet. The marches of the Mahratta and Pindari horsemen during the early part of the present century are well known, and the Mahratta pony to this day, when of the proper breed, commands a high price in the Indian markets. The little ponies used in Madras in the Jatka carriages, are brought from Poona, Sholapur, Hubli, and Dharwar. A few are brought from Kangayam in the south of the Peninsula. A good pony costs 150 rupees.

The Tattu, or pony of the Dekhan, is a wonderful animal, often with great speed, or great strength and much endurance. Their colours are generally bay, or brown, or chesnut; grey seldow, and dun still more so. They are generally taught to amble four or five miles an hour.

The Kathi or Kattyawar horse is a large and powerful blood animal. They have fine leau heads, and make admirable cavalry chargers; commonly of a dun colour, with black points and black manes and tails. All have the shoulder stripe. It has been said, but not seemingly with correctness, that few of the Kattyawar horses of the present day are of the real Kattyawar breed, being much crossed with Arabs and half-bred horses of sorts. The pure bred Kathi are fine powerful horses, with one great deficiency in shape, - a want of bone below the knee, and a fiery screaming temperament. This breed is specially preferred by native chiefs, who give very large sums for handsome Kattyawars.

The Ghoont or Khund is a breed of the Himalaya mountains, generally small, strongly made, hardmouthed, and sometimes almost unmanageable. In ascending hill faces, or passing along the declivities of mountains, it is best to let them bave their own way, for in an intricate passage they often show more sagacity than the rider. Their common pace is a kind of amble, and they stop every now and then to breathe, when no application of the whip will move them. They are surefooted, and sometimes halt at the edge of a precipice, to the terror of the rider; they are not so quick in ascending hills as the low-country horses, but they descend with double the speed, and endure great fatigue. The ghoont, though a useful ànimal, seidom carries any burden but a man. In Spiti they are bred chiefly for sale. They have two breeds, one a small ghoont, never above 12 hands high, peculiar to the country; and the other, a large breed from 13 to $13 \frac{1}{2}$ hands high, is bought from the Chinese, and usually comes from Choomoortee; for a Chinese ghoont two years old they give a Spiti ghoont four years old. All are equally hardy, and are kept out the whole winter, except the yearlings, which are housed. During winter the ghoont live on the roots of the stunted bushes, and are very expert at scraping the snow from off them with their fore feet. The breed of ghoont might be improved with a little care. Many are killed during winter by wolves and leopards.

The Yarkand pony is a hardy little animal, and fetches a high price, being in request for the hillstations in the North-Western Provinces of India. The variety called the Tangun piebald is common. They are shy and timid at tirst, and evince a strange dislike to Europeans, but soon get accustomed to their new masters; and for their strength. endurance, and sure-footedness, are well adapted for alpine travelling. While crossing the Karakorum mountains, whole caravans are sometimes overwhelmed by snowstorms; and Billah Shah, a chief merchant of Leh, mentioned that in many places the route to Yarkand was only traceable by the bones of horses.

The Tangun of Tibet are wonderfully strong and enduring. They are never shod, and the hoof often cracks, and they become pigeon-toed. They are frequently blind of one eye, when they are called Zemik (blind ones), but this is thought no great defect. They average $£ 5$ to $£ 10$ for a good animal in Tibet, and the best fetch $£ 40$ to $£ 50$ in the plains of India, where they becomc acclimated and thrive well. Giantchi (Jhansi- 
jeung of Turner) is the best mart for them in the eastern part of Tibet, where some breeds fetch very high prices. The Tibetans give the foals of value messes of pigs' blood and raw liver, which they devour greedily, and it is said to strengthen them wonderfully; the custom, Dr. Hooker believes, is general in Central Asia. Humboldt (Per. Nar. iv. p. 320) described the horses of Caraccas as occasionally eating salt meat. In India, sheep's head is often given in mesalih. The Tibetan pony, though born and bred 10,000 to 14,000 feet above the sea, is one of the most active and useful animals in the plains of Bengal, powerful and hardy, and when well trained early, docile, although by nature vicious and obstinate.

In China, the horse commonly seen is not much larger than the Shetland pony. It is bony and strong, but is kept with little care, and presents a worse appearance than it would if its hair were trimmed, its fetlocks shorm, and its tail untied. This custom of knotting the tail is an ancient practice, and the sculptures at Persepolis show that the same fashion prevailed among the Persians. The Chinese language possesses a great variety of terms to designate the horse. The differences of age, sex, colour, and disposition are all denoted by particular characters. They are chiefly reared in the province of Kiang-si.

In the north also, in the vast plains, the Mongol, Tartar, and Manchurians rear horses, a docile, handsome, and intelligent breed, but do not generally exceed 10 or 12 hands; usually chesnut, bay, and grey. These are generally bred in a wild state, the stallions and mares being allowed to form herds in the plains at their will. Piebald or skewbald horses marked with patches of white and bay are to be seen. Horseflesh is eaten both by the Chinese and Mongolians, as also the flesh of mules and asses in many parts of China.

The horses of Japan average only 13 hands.

In the Archipelago, the horse has been immemorially domesticated by most of the more advanced nations, wherever it could be made use of. The chief exceptions are the Malay Peninsula, the eastern seaboard of Sumatra, and nearly the whole of Borneo,-countries in which the people dwell on the marshy banks of rivers, in which there is not even a bridle-path, and fit, therefore, only for the boat and the buffalo. The native horse is always a mere pony, seldom reaching 13 hands high, and more generally of about 12 hands. There are many different breeds, every island having at least one peculiar to itself, and the large islands several.

Sumatra has at least two distinct races, - the Acheen and Batubara, both small and spirited, but better adapted to draught than the saddle. The small but excellent breed of horses reared in Acheen excel all those of the Archipelago, excepting those of Bhima in Sumbawa. Those of $\Lambda$ cheen have fine crests and good strong shoulders; in which latter particular, as also in height of wither, they differ very much from the horses of Java and the islands to the eastward, which are generally deficient in these points. They are exported to Penang and Singapore, and are driven in small carriages. They are occasionally sent to British India.

Of all the countries of the Archipelago, Java is that in which the horse most abounds, and here we find several different breeds, as those of the hill countries, and those of the plains. Generally, the Java horse is larger than that of Sumatra, but, in the language of the turf, has less blood and bottom. The lowland horses, the great majority, are somewhat coarse and sluggish, but the upland are spirited, smaller, and handsomer.

The horse, although of a very inferior breed, is found in the islands of Bali and Lombok; but the next island to these eastward, Sumbawa, produces the handsomest breeds of the whole Archipelago. They are the Arab of the Archipelago; yet the blood is not the same as the Arab, for the small horse of Sumbawa, although very handsome, wants the fine coat and the blood head of the Arabian. There are in this island and adjacent islets three different races, that of Tambora, of Bhima, and of Gunong Api, the last being most esteemed.

Next to Java, horses are most abundant in Celebes. These are inferior in beauty to those of Sumbawa, but excel all others of the Malayan portion of the Archipelago, in combining the qualities of size, strength, speed, and bottom.

A very good breed is produced in Sumba, called in the maps Sandal-wood Island.

But perhaps the best breed of the whole Archipelago, although still but a pony, is that of the Philippines. It is superior in size to any of the breeds of the western islands, which it may owe to the superior pastures of the Philippines, and possibly to a small admixture of the Spanish horses of America, although this last is by no means an ascertained point.

Generally, the horses of the Archipelago are hardy, sure-footed, and docile. The horses are all entire, and the mares used only to breed and as beasts of burden. By the natives of the Archipelago, the horse is only used for the saddle or to carry burdens, and never for draught, either for plough or wheel-carriage. To see horses drawing a native carriage, except in imitation of Europeans, we must go to the sculptures on ancient temples in Java, where they are thus represented.

In two islands only of the Archipelago is the horse found in the wild state, Celebes and Luzon, the only ones that are known to have extensive grassy plains fit for its pasture, and in these it is caught by the lasso and broke in, as in the Llanos of America. In such situations it is certainly far more likely to have become wild from the domestic state than to be indigenous. In so far as Celebes is concerned, this view is rendered probable by the name being a corruption to the Javanese from one language of that island, the Wugi; while in another, the Macassar, the horse is called the 'buffalo' of Java. In the Philippines it is not even alleged that the wild horses are anything else than domesticated ones become so. In Pigafetta's enumeration of the domestic animals of Cebu, he makes no mention of the horse. In the city of Manilla, a pair of good riding horses cost from 100 to 120 dollars, and a pair of carriage horses from 120 to 130 . Of course they are much cheaper in the provinces where they are reared. The borses of Sumbawa, Celebes, and Sumba are largely exported to Java, to the British settlements in the Straits of Malacca, and even as far as the Mauritius. In Batavia, a good Bhima or Batak horse is worth from $£ 10$ to $£ 15$.

The Barl, so famed in Europe, was never brought to India; reared by the Moors of Barbary and Morocco, during their dominion in that country, 
the barb was introduced into Spain, where, however, it has been suffered to degenerate greatly since their expulsion. The noble barbs are of rare occurrence even in their own country. The common horse of Barbary is a very inferior animal. In the beauty and symmetry of their forms, however, even the barbs are far from excelling; their valuable qualities - and in these they are perhaps unequalled by any other breed in existence-are unrivalled speed, surprising bottom, abstinence, patience, and endurance under fatigue, and gentleness of temper.

Arabian horses are now-a-days comparatively little seen in India. A larger horse, with greater power, has been needed, to meet the wants of the British Government for its heavier ordnance and heavier soldiers, and for the larger carriages now in use by Europeans and the wealthier natives. $\Lambda$ lso, the prices demanded for the Arab horses are beyond the means of ordinary purchasers, and the Arab never was in great request in India, except as a riding hor'se. The chief, Abd-el-Kadir, speaking of Arab horses, said, 'A thoroughbred horse is one that has three things long, three things short, three things broad, and three things cleau. 'The three things long are the ears, the neck, and the fore legs ; the three things short are the dock, the hind legs, and the back; the three things broad are the forehead, the chest, and the croup; the three things clean are the skin, the eyes, and the hoof. He ought to have the withers high and the flanks hollow, and without any superfluous flesh.' These are very nearly the words which writers use in describing perfection in horses, and in these matters, therefore, they seem to have borrowed their ideas from Arabian writers.

The best Arab horses are bred in the desert by the Anazah tribe, in whose territory, before the conquest of the Wahabees, the district of Nejd was included, where the richest pasture of Arabia is found. That name, in India, used to procure a high price at all times for a horse. The Anazah is one of the largest and most extensively subdivided of the Bedouin tribes. They have the best horses. They visit Nejd as well as Syria. Some of the Anazah Arabs have a great prominence in the foreheads. The marks at the base of the ears of the Anazah and other horses, have their origin in the custom of the Bedouin, of stitching the new-born foal's ears together, to make them take what is thought the proper shape. Purveyors of the Indian market, knowing that the Indian purchasers look for such marks, frequently counterfeit them on the baser born breeds which they buy for India, by branding them in the right place with the firing-iron.

In the Arab horse, says Colonel Shakespeare, the favourite colours in India are greys of kinds. The nila, i.e. a grey with a blue skin, is generally more hardy that the sabza, a grey with a lightcoloured skin, and the feet of the nila are more generally black than the sabza. The other colours are bay and brown of different shades, and chesnuts. Black is very rare. Arab roans are common. The high-caste Arab is phlegmatic and wearisome to ride when unexcited; trips in his walk, and does not step out; but when roused by emulation in the hunt or race, will go at full speed over rock and stone, when the soil is not visible, or up and down the sides of a precipice, and, if properly handled, never make a mistake.
The Arab people do not keep any long pedigreès of their thoroughbred horses. The certificates which they furnish merely give the names of the clans, under the assumption that the purity of blood is notorious throughout the tribe. Of all their domestic animals, Arabs put the greatest value on their horses.

The time to see the horses and horsemen of Damascus in their glory, is about sunset on the Merj and the neighbouring road, where they are regularly exercised. If the master does not ride, a groom is sent out, and the young foals gambol loose by their dam's side, till they are old enough to be ridden, which is at an early age. Their education begins often with learning the rahwan pace, which is much esteemed. It is generally taught by tying the feet on the right and left side together, each to each, - the right front to the riglst hind, and so with the left. An animal who excels in this kind of amble is worth a large sum, be he ever so ill-bred or poor in appearance. The value of the accomplishment lies in its comfort to rider and ridden, for so smooth is the pace, that a brimming: cup of water may be held at full speed without spilling; and so easy is it for the horse, that a well-trained one is supposed to cover the distance between Damascus and Beyrout in eight or nine hours. When we consider that the actual length of road is 72 miles, twice ascending and descending several thousand feet in crossing the ranges of Lebanon and Anti-Lebanon, the performance is certainly creditable.

The pedigree of one of their horses of the blue blood is as well known throughout the districts traversed by the tribe he belongs to, as that of any royal family of Europe. The Bedouins of Syria have five principal breeds, known as the Khamsa, or five,-(1) The Kehilan (fem. Kehileh or Kehilet) is the fastest, but not the hardiest. They are bred chiefly by the Bedouins settled between Basra, Merdin, and Syria. That of Dsjulfa seems to be the most numerous. They are highly esteemed, and consequently are very dear. (2) The Seglawi (fem. Seglawieh), of which the Seglawi Jedran is considered the best in all the desert. (3) Abeyan (fem. Abeyeh) is a small, but generally the handsomest breed. (4) The Hamdani (fem. Hamdanieh), not a common breed. (5) The Hadban (fem. Hadbeb), not common.

Mr. Robinson says these five principal races diverge into many ramifications. Every mare particularly swift and handsome, belonging to any one of the chief races, may give origin to a new breed, the descendants of which are called after. her, so that the names of different Arab breeds in the desert are innumerable. The horses of the Bedouin of Syria are mostly small, seldom exceed. ing fourteen hands. They ride, almost exclusively, their mares, having the advantage over the horses in speed and good temper. The latter they sell to the town's people, or to the fellahs. They object to them, not only because they are more vicious than the mares, but because they neigh, which in an expedition by night might be the means of betraying them. They are first mounted after the second year, from which time the saddle is seldom taken off their backs. They are kept in the opeu air during the whole year, never entering the tent, even in the rainy season. In summer they stand exposed to the mid-day sun. In winter a sackcloth is thrown over the saddle. Like his master, 
with very little attention to his health, he is seldom ill. Burning is the most general remedy, and as this is done with a hot iron, it has given rise to the erroneous notion that the Arabs mark all their horses.

More than half of the Arab horses exported to Bombay are shipped from the seaport of Koweyt. Palgrave says they are generally brought from the north of Arabia or the Syrian desert. There are good horses of this kind at Hayel and Jabl Shomer. Those of Shomer or Anazah breed are high blooded, and often very perfect in all their points. The best of the Nejd horses are small, few reaching fifteen hands, and fourteen being about the average, but their small stature is not observed in their excellent shape. The genuine Nejd breed is obtainable only in Nejd; and the distinctive points of the Nejd horse are, the full rounded haunch, the slope of the shoulder, and the extreme cleanness of the shank. In Nejd breeding, care is taken to select a good stallion and good mare. The total number is about 5000 ; and horses are kept only for war or parade, all travelling and other drudgery being performed on camels, or on asses. The Nejd horses are esteemed for their great speed and endurance; and in the latter quality, indeed, they are unequalled, bearing up through abstinence and labour for 48 hours, under an Arab sky. They are often ridden without bit or bridle, saddle, rein, or stirrup, but they yield to the pressure of the knee or thigh, and to the voice; can be wheeled and turned and brought to a dead stand in mid career of full gallop. Mares are never parted with, and good stallions rarely so. 'Those of Hayel and Jabl Shomer are a fine breed, and horses from them often find their way to Europe, where they are sold at high prices. These are generally the produce of a Jabl Shomer mare with Nejd stallion, or the reverse. Their height varies from 14 to over 16 hands; but their shape is less elegant than the Nejd, and often indicates some defect, such as a heavy shoulder, small rump, shelly or contracted hoof, or small eye.

To the east and south of Toweyk, the Arab horse loses in beauty and perfection, in size and strength; and in Oman they resemble the tattu of India.

In the south of Arabia, the horses are mere rats, short and stunted, ragged and fleshless, with rough coats and a slouching walk, but with fine snakelike head, ears like reeds, wide and projecting mostrils, large eyes, fiery and soft alternately, broad brow, deep base of skull, wide chest, crooked tail, limbs padded with muscle, and long elastic pasterns. It was told to Captain Burton (Pilgrimage, iii. p. 269) that the $\mathrm{Zu}$ Mahomed and the $\mathrm{Zu}$ Husayan, sub-families of the Beni Yam, a large tribe living around and north of Sanaa in Yemen, have a fine large breed, called El Jaufi, and that the clan El Aulaki rear animals celebrated for swiftness and endurance. The other races are stunted; and some Arabs declare that the air of Yemen causes degeneracy in the first generation. In Solomon's time the Egyptian horse cost 150 silver shekels, which, if the greater shekel be meant, would still be about the average price, $£ 18$; and Wellsted tells us (i. p. 306) that several of the Imam's horses in his time were of the noblest breed in Nejd, some of his mares being valued at from 1500 to 2000 dollars.

Persian-The Bakltiari have a hardy race of horses, of a middle stature, about the usual size of the Arab horse, and a good deal of the blood of the latter runs in their veins. They are exceedingly fleet, sure-footed, and soft-mouthed, very manageable also, and capable of climbing up mountains with the agility and fearlessness of mountain goats. Among the richer Bakhtiari are many Chab-Arab horses, which are taller than the Nejd-Arab, and resemble more those of the island of Bahrein. The Chab-Arab horse is justly prized in Persia; and Baron de Bode never witnessed a greater display of beautiful Arab blood horses, than on the plains of Mal-Amir, at the camp of the Bakhtiari chief, Muhammad Taghi-Khan, for at the court of the Shah of Persia the Turkoman horses are preferred to the Arab; and among the former, the Tekke breed is the most esteemed for its size, power, and faculties of endurance.

Arabian horses are not very common in the north of Persia; but the breed between them and a Persian mare is all elegance and elasticity, being of a rather stronger mould than the Arab of Nejd, the best race of the country. The Persian horses never exceed 14 or $14 \frac{1}{2}$ hands, yet certainly on the whole are taller than the Arabs, and have been much improved of late. Although neither so swift nor so beautiful as those of Arabia, they are larger, more powerful, and, all things considered, better calculated for cavalry. Of the several breeds of horses in use in Persia, the most valuable is that called the Turkoman. In the eyes of an English jockey, however, these horses would hardly seem to possess a single good point. They are from $14 \frac{1}{2}$ to 16 hands high, have long legs and little bone under the knee, spare carcases, and large heads. But what renders the Turkoman horses so valuable to the natives, is their size and extraordinary powers of supporting fatigue; for they have been known to travel 900 miles in 11 successive days. The Arabian blood has also been introduced into Persia, and some horses bred in Dashtistan, in point of speed and symmetry, emulate the most admired coursers of Nejd. Their usual food is chopped straw and barley; the bed is made of dung, which is dried and beat into powder, and regularly erery morning exposed to the sun. No people are fonder or take more care of their horses than the Persians. They are clothed with the greatest attention, according to the climate and season of the year, and in the warm weather are put into the stable during the day, but taken out at night. The horses in Persia are not so subject to internal disorders as in England, but their heels are invariably contracted, from badness of shoeing.

Persian horses brought to Bombay from Basrah and Bushahr, and those bred on the shores of the Gulf, are in use with the British Government, and some are of great power, strong, and enduring. The Gulf horses are out of Persian mares by Arab horses.

Turkoman horses, of excellent breed, are found amongst the Turkomans, who export the finest to Afghanistan, Persia, and India. The Akhal and Yomut horse is little inferior to the Arab in swiftness, endurance, and beauty of form. The Turkoman horse is a fine animal, between fifteen and sixteen hands high. He is bred from the Arabian, but the cross of the breed of the country, and the fine pasture, have given him great size and strength. There are probably no horses in 
the world that can endure so much fatigue. Sir J. Malcolm ascertained, after minute examination of the fact, that the small parties of Turkoman who ventured several hundred miles into Persia, used both to advance and retreat at the average of nearly one hundred miles a-day. They train their horses for these expeditions as sportsmen train for a race; and the expression they use to describe a lorse in condition for a chapao or forage is, that ' his flesh is marble.' The Turkoman horse stands high, and the reports as to his feats show him to be a very superior animal, but they are almost unknown in India.

The Turkoman horse around the Hindu Kush is carefully reared. It is a large bony animal, more remarkable for strength and bottom than symmetry and beauty. Its crest is nobly erect; its lead is not so small, or its coat so sleek, as the brood of Arabia, and the length of its body is greater. They will perform six hundred miles in 7 or even 6 days. Those that reach India are reared about Balkh, and Andkhu, and Maimana.

The horses of the Turko-Tartar races are,-

The Turkoman horse, or Argomak, chiefly in the weatern and southern parts of the khanate.

The Urbak horse, more especially in the north of Bokhara, and in Miankale; and lastly,

The Khokand horse, in the neighbourhood of Samarcand and the east of it. There are two more, which are, however, inferior to the former; these breeds are the following, - the Kirghiz horse and the Karab Airi, the latter being a cross-breed from the Turkoman stallion and an Uzbak mare, and vice versa. All these breeds differ from each other by their coat, as well as by other qualities.

The Argomak is usually tall, well-shaped, with slender legs and a swan-like neck, carrying its head proudly and with ease aloft. But its great beauty consists in the peculiar lustre of its coat, which is especially observable in the bay-coloured Argomak. Their defects are, a narrow chest, and a scanty tail and mane, in addition to which, some have the defect of being saddle-backed. These defects incapacitate the Argomak for undertaking long journeys; and it would be above all things unadvisable to make use of them in travelling over the steppes of the Kirghiz, because they are so much spoiled by the excessive care which is taken of them, that they are almost incapable of finding: food for themselves, not only in winter, but even in summer.

The $U z b a k$ horses, which are smaller than the Argomak, and inferior to them in point of external beauty, have nevertheless many redeeming qualities, of which the principal is their strength. Some of their defects arise in consequence of their being badly broken in by the Uzbaks. With these horses the pace is neither a walk nor a proper trot, but what the Cossacks term a grana or short trot. Baron de Bode here seems to mean the amble. The second defect is that the Uzbaks never geld their horses, which renders it impossible to picket them together, but each horse is obliged to be attached to a separate stake,-a circumstance which, although trivial at first sight, is one of the reasons why the Uzbak camps take so much room, and are therefore more exposed to sudden attacks.

The strongest race of the Turko-Tartar horses is undoubtedly that of Khokand; hence they are usually employed by carriers for transporting goods from one place to another. Five batman is the usual weight of a loaded cart, although they increase the weight sometimes to seven and eight batman from Bokhara to Samarcand. The power of these horses becomes still more apparent when they are used as pack horses. Baron de Bode had seen a horse loaded with two large tents, some kettles flung over the back, and a man sitting astride. It accompanied him in this fashion the whole way from Samarcand to Karshi, and from thence to Bokhara.

The Karab-airi is a very handsome race of horses, in size equal to the Uzbak horse, but in the shape of the head and legs resembling the Argomak. They are reckoned good racing horses in Bokhara, but as they are trained for the game of kukbari, in which, after running a certain distance, the riders rest, these horses cannot hold out a protracted race, especially as they exhanst their strength from the very outset.

The horses of the Kirgliz Kazak are trained to run races, in distances sometimes from twentyfive and thirty to forty and fifty versts. Every Kirghiz, in setting out on a journey, fastens to his saddle a bag of kurut or curd made from sour milk. He soaks some of it in water, and thus appeases his hunger and thirst together.

Two wild horses are found in the Russian steppes, the Tarpan and the Musin. The latter is supposed to be a steppe horse run wild; but the younger Gmelin, Pallas, and Middendorff think that the tarpan is a descendant of the pristine wild stock. Darwin and Wallace, however, are of opinion that the tarpan also is a steppe horse run wild.-Rolleston, p. 50.

The Muss of the Kirghiz is the wild horse of the Asiatic plains. This animal is not like the wild horse of S. America, which undoubtedly sprang from those taken into the country by the Spaniards. He is of a distinct race from the Asiatic horse, very small (not so large as an ass), beautiful in form, having a small head and short ears, and varying in colour from black, bay, grey, and white, the latter being the most rare. His sense of smell is very acute, which renders him most difficult to approach. He is exceedingly fleet, and few horses can run him down. In hunting him, a great number of Kirghiz assemble, and when the scouts have found the herd, the horsemen form an extended line at a considerable distance towards the steppe. When so much has been accomplished, they gradually ride up, forcing: the herd towards a pass in the mountains. As they approach near to the ravine, the hunters draw closer, forming a crescent, and proceed with extreme caution till the stallions enter the pass. While this has been going on, another party of hunters have made their way into the pass, taking their stand in the narrowest part, and waiting till the herd appears. Having signalled to the hunters on the plain that the pass is secured, the whole body close up, and the wild animals are in a trap. They are now driven onward till stopped by the hunters above, when the work of slaughter begins, and vast numbers of these beautiful creatures are killed by their battle-axes. The Kirghiz consider their flesh the greatest delicacy the steppe affords.

Dr. Jerdon, however, says wild horses of a truly feral type are at present unknown. The Gor Khar, Equus onager, Pallas, is the wild ass of Cutch; the Kyang or Dzightai, or wild ass of Tibet, is 
Fquus hemionus, Pallas; the E. hemippus, Is. Geoffroy, which inhabits Syria, Mesopotamia, N. Arabia, is the wild ass of Scripture; and E. asinus is of N.E. Africa and S. Arabia.

Since 1840, British India has received small batches from the Cape of Good Hope, of good figure and good temper, suitable for riding horses and for draught, but, like the Arab horse, higher priced than can easily be afforded. Australia has since taken a hold on the Madras and Calcutta markets, and its imports are termed Walers. What number of new horses of all sorts are needed for British India annually, is not known. The imports have been-

$$
\text { Australia. Other Places. }
$$

1874-75, 2072 476

$1875-76, \quad 2075 \quad 175$

$1876-77, \quad 23555 \quad 507$

$1877-78, \quad 1938 \quad 487$

$1878-79, \quad 2079 \quad 1271$

$1879-80,2133 \quad 1473$

Australia, Other Places, Rs.5,29,270R. 1,44,325 $7,06,850 \quad 37,025$ $7,25,700 \quad 1,19,550$ $5,99,000 \quad 2,32,820$ $7,07,300 \quad 5,50,525$

$6,89,600 \quad 4,78,350$

-Huc and Gabet, p. 229 ; Yule's Cathay, i. p. 143 ; Daruin, Animals and Plants; Tod's Rajasthan, ii. pp. 162, 227 ; Powell ; Gerard's Koona"ur, p. 112 ; Adams, p. 269 ; Hooker, Him. Jour. i. p. 118, ii. p. 131; Williams' Middle Kingdom; Crawfurd, Eng. Cyc. p. 383 ; Skinner's Journey, ii. p. 70 ; Niebuhr's Travels, ii. p. 301 ; Shakespeare's Wild Sports; Palgrave, i., ii. p. 97 ; Robinson's Tr. ii. pp. 167, 356; Wellsted's Tr. i. p. 306 ; Kinneir's Persian Empire, p. 38 ; Malcolm's Persia, ii. p. 241 ; De Bode's Bokthara, p. 198; Vigne's Personal Narratize, p. 455 ; Athinson, Amoors, p. 326 ; Porter, ii. p. 536 ; Gray.

HORSE CHESNUT, Esculus hippocastanum. An Asiatic tree, long planted for shade and oruament on the Continent and in Britain. The wood is soft, and not durable. The fruits are used in Switzerland and Turkey for feeding sheep, horses, etc.

HORSE - FLY, Hippobosca equina, Lim., attacks horses and man. Its bite, like the scorpion sting, affects individuals variously.

HORSE GRAM, Dolichos uniflorus. This pulse, Madras gram, is largely used in the Peninsula of India for feeding horses. In Northern India, Chenna, or Bengal gram, Cicer arietinum, is the pulse used. The composition of horse gram in 100 parts is,-moisture, 11.40 ; nitrogenous matter, 23.25 ; starchy matter, 61.43 ; fatty or oily matter, 0.81 ; ash, $3 \cdot 10$.

HORSE HIDE is tanned and curried for harness work, for collars, etc. It has of late years been substituted for seal-skin, but does not produce so good a leather. Enamelled horse hide, split or shaved thin, is used for ladies' shoes, in imitation of seal.

HORSE LEECH is the Shwui-chih and Mahwang of the Chinese. Horse-mango, Mangifera foetida. Horse-almond, Sterculia foetida. Horsecassia, Cathartocarpus Javanicus. Horse-cat, civet.

HORSE-RADISH, Lah-kan, CHIN.

P'eberrod, - . DAN.| Raphanus rusticanus, LAT Rammenas, . . Dut. Rabao de Cavallo, . Port Rava, Raifort, . FR. Khren, . . . RUS Cran de Bretange, . ", Rabano, Picante, - SP. Meer-settij, : GER. Pepparrot, . Sw. Rafano, : : Iт.

The Cochlearia armoracia, Linn., a perennial plant, common in moist places of Europe, and grown in India. Its root is used as a condiment, and is, besides, an article of the materia medica.

\section{HORSE-RADISH TREE.}

Hub-ul-ban (seeds), ARAB. Hyperanthera moringa, L, Sujna, . . BeNG. Sagul, . . MAHr. Sohunjana, . DUKH. Moriaben, . Pers. Munga-ke-jhar-ki-jar,HIN, Sigrumalla sohanjana, SA. Sagul-ke-jhar-ki-jur, . , Muranghai ver, . TAs. Moringa pterygosperma, I. Munaga veru, . : TeL.

This tree grows easily from seeds, in gardens, only requiring watering for the first few months. The scraped roots are very like horse-radish, and are served up as a substitute. The long pods are boiled and used as a vegetable, also made into curry. The flowers and leaves are used as a vegetable, and its gum is used medicinally.-Faulkner.

HORSE TAIL. The tails of the horse and of the yak are used as standards. Tupha, Tugh, or Tau, according to Remusat, is the Turki naine of the horse-tail standard, but is applied also by the Chinese to the yak tail, which, respectively with those nations, mark the supreme military command. -Rech. sur les langues Tartares, p. 303 ; D'Ohsson, i. p. 40, in Yule, Cathay, i. p. clxxiv.

HORSFIELD, Dr. Thomas Horsfield and Mr. Moore's Catalogue of Birds, in the India House Museum, appeared in 1856 and 1858. Dr. Horsfield was one of the earliest naturalists labouring in the East Indies, though the extent of his labours in Java and Sumatra is but little known. His researches in Java and the neighbouring islands began in 1802, and were continued till 1819. During that time he collected upwards of two thousand species, the most copious and interesting of which have been published by Messrs. Brown and Bennett in the Plantre Javanica Rariores, one of the most profound and accurate botanical works, and one most important for the Indian botanist to study with attention. He wrote Zoological Researches in Java and the Neighbouring Islands, 1824 ; Descriptive ('atalogue of the I epidopterous Insects in the Museum of the East India Company, 1828-9; with Bennett and Brown, Plantæ Javanicæ Rariores, descriptæ Iconibusque illustratæ, 1838-44; and an Essay on the Cultivation and Manufacture of Tea in Java, 1841.

HORTON PLAIN, a few miles from Newara Elia, in Ceylon, is the highest table-land in that island. The pitcher plant, Nepenthis distillatorin, grows in great luxuriance on it.

HORTUS MALABARICUS, a botanical work undertaken at the suggestion of Henry van Rheede, a Dutch Governor of Malabar. The specimens were collected in 1674 and 1675 by Brahmans, and sent to Cochin, where drawings of them were executed by Mathæus, a Carmelite missionary; corresponding descriptions were at the same time made in the Malabar language, which were afterwards translated into Portuguese by Emanuel Carneiro, a Cochin interpreter, and from that into Latin by Hermann van Douep, the secretary to the city of Cochin; the whole was under the superintendence of Casearius, a missionary there. The work was at length published at Amsterdam between 1686 and 1703 , in 12 volumes folio, with $79 \pm$ plates, and was edited by Commelyn, who has occasionally added remarks on the plants.-Wight's Prod. i. p. 7.

HORUS, a god of the Egyptians. One of the most remarkable fictions in the Egyptian and Syrian mythologies, is that of the annual disappearance and resurrection of Horus, or the solar Osiris, and the lamentations for Adonis and the 
joy at his restoration. These, as well as the Deot'han of India, bear evident reference to the sun's annual motion.-Elliot, Supp. Gloss.

HOSHANGABAD, a town in the Central Provinces of India, in the Sagur and Nerbadda territories, lat. $20^{\circ} 45^{\prime} 30^{\prime \prime} \mathrm{N}$., and long. $77^{\circ} 46^{\prime} \mathrm{E}$., its district forming a portion of the Nerbadda valley, lying entirely on the left bank of the river, and including some large tracts in the Satpura Hills. The district is bounded on the north by the territories of Bhopal, Sindia, and Holkar, from which it is separated by the Nerbadda, the Central Provinces lying between lat. $21^{\circ} 40^{\prime}$ and $22^{\circ} 59^{\prime} \mathrm{N}$., and long. $76^{\circ} 38^{\prime} 30^{\prime \prime}$ and $78^{\circ} 45^{\prime} 30^{\prime \prime} \mathrm{E}$. Population in 1872, 440,186 ; area (1877), 4376 square miles. Four Gond rajas, in 1870 , held the eastern portion of the district. The aboriginal tribes number 89,029 ; Hindus, 364,676 ; Mahomedans, 21,765; Buddhists and Jains, 1132. The most numerous of the aboriginal tribes are the Gond (57,946 in 1872), and Kurku $(19,295)$; the remainder consisting of Bharia, Maria, etc. Among the Hindus, the Brahmans in 1872 numbered 25,393 , and the Rajputs, 28,689 ; the mass of the Hindu population consisting of Dhers or Mhars, 39,173 ; Kunbis, 17,215; Lodhis, 13,323 ; Gujars, 24,759; Chamars, 15,117, and others inferior castes. -Imp. Gaz.

HOSHIARPUR, in lat. $31^{\circ} 32^{\prime} 13^{\prime \prime} \mathrm{N}$., long. $75^{\circ} 57^{\prime} 17^{\prime \prime} \mathrm{E} .$, a large civil and military station, in the Panjab, N. of Ludhiana, 1066 feet above the sea. It gives its name to a British revenue district, lying between lat. $30^{\circ} 58^{\prime}$ and $32^{\circ} 5^{\prime} \mathrm{N}$., and between long. $75^{\circ} 31^{\prime}$ and $76^{\circ} 41^{\prime} 15^{\prime \prime} \mathrm{E}$. Area, 2086 square miles, pop. (1868) 938,890. Brahmans numbered 76,821; Rajputs, 47,464; Kshatriyas, 21,784; Banya, 1493 ; Arora, 386 ; Jat, 112,789 ; Gujar, 21,543 : 3977 Sayyids, 843 Moghuls, 8733 Pathans, 145 Baluch, 37,522 Malomedan Rajputs, 31,262 Jats, and 45,893 Gujars. The Jats form the most numerous tribe in the district, composing 42 per cent. of the proprietary body, and paying 38 per cent. of the land revenue. $-I m p$. Gaz.

HOSPITAL. There was an hospital at Rai and another at Baghdad, of which Rhazes, A.D. 923 or 932 , was the superintendent; and about the same time, between A.D. 905 and 920 , the first European hospital was founded by the Saracens at Salerno in Italy. Hospitals existed in China during the Sung dynasty, between A.D. 960 and 1278. The pinjrapol of Bombay and of Surat are hospitals for sick and lame animals, established by Hindus. The East India Company established many civil hospitals tbroughout India, and Hindu and Native States have followed in this line.

HOTA, SANSK., or Hotri, the priest who directs the Homa or burnt-offering, from Hu, SANsk. to offer. The Hota pours the clarified butter on the fire in the burnt-offering, repeating the proper formulas. Hutsava or fire-food is the name of the oblation.-Ward's Hindoos; Wilson, Glossary.

HO-TSING, the artesian fire-springs of the Chinese, which are sunk to obtain a carburetted hydrogen gas for salt-boiling, far exceed the European artesian springs in depth. These firesprings are very commonly more than 2000 feet deep ; and a spring of continued flow was found to be 3197 feet deep. This natural gas has been used in the Chinese province Sze-chuen for several thousand years; and portable gas, in bamboo canes, has for ages been used in the city of Khiung-tscheu. More recently, in the village of Fredonia, in the United States, such gas has been used both for cooking and for illumination.Curiosities of Science, p. 118; Imbert.

HOT SPRINGS and sulphurous springs are numerous on the shores of the Dead Sea, and also in its basin, and in other parts of the Jordan valley. The hot springs of Callirhoe were the favourite resort of Herod. There are others at Um Keis (Gadara), where are the ruins of baths; and the hot springs of Tiberias have been famous ever since the time of Joshua (B.C. 1426), when they gave name to the place. Most of these are strongly mineral. The hot water of Elisha's Fountain is sweet.

The hot springs of Bosher and Ghullas in Oman are inland from Muttra, situated at the foot of rocks. Their temperature ranges from $83^{\circ}$ to $112^{\circ}$. Hot springs occur also at Maculla in Arabia, likewise $1 \frac{1}{2}$ miles inland from Muscat.

In Shoa, hot springs occur at the village of Gossamee in Morabeitee; at Kowut, in the province of Gidem; at Korari, about 10 miles S.E. of Alioamba; at Makfood, in the bed of the Jowahah river; at Metak, about 3 miles S. of Ankober; at Finfinni, in the Germama plain ; in the bed of the river Kassam, in the district of Aden, and in the neighbourhood of the extinct volcano of Fontali.

Hot springs occur at Jumnotri, Gungootri, Kedarnath, and Badrinath, in Garhwal; also near Nutpa, Bukti, and Jauri, in the valley of Sutlej (Gerard), opposite Soni banks of Sutlej (Prinsep). Hot spring at Silol, Kangra (G. T. Survey). Kulat in Kullu (Gerard). Munnikarn, in Kullu, and a hot spring farther up the Parbati. Mr. Edgeworth informs us that the water where it issues from its source is of the temperature of $207^{\circ} \mathrm{Fahr}$. It is therefore one of the hottest known springs. Some of the hottest of these are the Geysers $180^{\circ}$, Surajkund $190^{\circ}$, the Petersquelle in the Caucasus $195^{\circ}$, spring on Paluk river $196^{\circ}$, and what Humboldt discovered and describes as the hottest spring in the world, Guanaxuata in Mexico, $207^{\circ}$. The boiling point of water at the elevation of Munnikarn is much below that point. Rice is cooked in the spring at Jumnotri $194^{\circ}$, at about 11,000 feet above the sea, and in many others of inferior temperature. Munnikarn is on the right bank of the Parbati (or Parub) river. There is a large village here, and high mountains covered with snow environ the place. There are several hot springs, three or four of which boil furiously. The latter issue out of rocks near the edge of the river, and dense steam rises out of them in considerable volumes, heating the air all round, absolutely darkening the path for a few yards, and the heat is very distressing. All the inhabitants of Munnikarn cook their food in these boiling springs, and wood is never used by them for culinary purposes.

In Ladakh many hot springs occur, but the best known are those of Nubra, Puga,and Chushul; the two first have clear water, and a temperature of $167^{\circ}$, with beds of soda below the springs. Those at Puga occur in the bed of a rivulet, where they bubble out at temperatures from $80^{\circ}$ to $140^{\circ}$. The hottest contain chloride of sodium and sulphuretted hydrogen in solution; and those of low teinperature chloride and borate of sodium. 
The hot spring of Chushul has a temperature of $96^{\circ}$, without taste or smell, but is said to have medicinal properties.

A hot spring occurs at Bebitsil in the Basha valley in Little Tibet, from which a deposit of sulphur occurs. Two hot springs, sulphureous and chalybeate, also occur near the village of Duchin, in Little Tibet. The temperature of one visited by Mr. Vigne was $154^{\circ}$ Fahr. One occurs 12 miles east of Rajawur, the temperature about $140^{\circ}$. It is sulphureous, and deposits sulphur in its course.

Between $U$ and Tsang, in Tibet, are some hot springs, which are also numerous in the mountains lying east of the Ma-p'bam lake, and at one place hot water is thrown twelve feet high. Hot springs issue from the flats near a stream at Chung-leng, 16,170 feet above the sea, the temperature $122^{\circ}$ to $130^{\circ}$. The hot springs of India are resorted to by the people for the cure of lingering ailments.

The hot spring at Ab-i-Garm at Chitral, in Afghanistan, is also called Talab-i-Nil, also Chattiboi. Lower range of Suliman mountains.

In Baluchistan a hot spring occurs at Basman, in the Kohistan of Baluchistan, 44 miles N.W. of Banpur. Lieutenant Pottinger halted at Basman, and found the hot well upwards of twelve yards in circumference, and two or three feet in depth ; in the centre of it was a circular pipe built of red burnt brick, about eight inches in diameter, and within as many of being level with the water, which boiled out of it as thick as a man's thigh, with considerable violence, and at noon so heated that he could not venture to put his hand into the ebullition. One side of the well had been gradually worn away by the incessant gushing of water over it, and thence a limpid brook flows past the village, and suffices the husbandmen for the irrigation of their grounds. He bathed in this stream about five yards from its source, and found the water pleasantly tepid, with a strong sulphureous smell and taste, which unfit it for culinary purposes; but the Baluchi regard it as aperient in its effects, and an excellent specific in cutaneous disorders.

Pir Muggen, Alligator Tank, is 13 miles from Kurachee (Carless). Juggen and Deyrah, N. Sind (Kirk). Springs at the base of the Halla mountains, Sind (A. Young).

The following means of temperature of the hot springs at Pir Mangal, or Munga, or Mungear, were taken in September 1844 by Major Baker and Lieutenant Maclagan :-

1st spring, 4th Sept., 11.30 A.M., Water, $119^{\circ}$ Air, $89 \cdot 25^{\circ}$

," "4.45 P.M., , 118.29, 86

", $\quad 9.5$ P.M., ", $117, \% 86$

, 5th Sept., 5.45 A.M., ", $119 \quad$ ", 78

", 9.5 A.M., ", 119 ", 83

21 spring, 4th Sépt, 11.45 A.M., ", 127.5 ," 91

" , 4.55 P.M., ", $126.25,86.5$

," " 9.25 P.M., ", 126.05", 80

" $\quad$ 5.50 А.M., " $128.25,78$

5th S'ept., 9.15 A.M., ," 128 ", 83

$3 d$ and principal spring, which is the saint's shrine, and which feeds the Alligator Ponds.

4th Sept., 5.30 P.M., . . Water, $99^{\circ}$ Air, $85^{\circ} 5^{\circ}$

The water of these springs, where it first issues, has a slightly sulphureous smell and taste, but, after a short exposure to the air, becomes perfectly sweet and pure; it leaves a slightly blackish deposit on the pebbles. The rocks in the vicinity consist of an upper cap of coarge limestone, overlaying coarse soft sandstone.

The other hot springs of Sind are the Lukki and Gazi Pir springs. Of the latter, Lieutenant Maclagan gave the following account:- "There is a hot spring on a considerable elevated plateau upon the hill called Bhil, above Gazi Pir, a saint's shrine, a few miles west of Shah Hasan, on the Meunchar Lake. I could not hold my hand in the spring for any length of time. The water fills a small reservoir under a clump of trees, then escapes in a narrow stream which flows along to the edge of the plateau, and throws itself over the rock in a white cascade.' The sulphur springs near the village of Lukki, like the springs at Mangal Pir, are three in number, but are much more highly impregnated with sulphur, though their temperature, as under, is not so great, -

1st spring, at 12 A.M., water $102^{\circ} \mathrm{Fahr}$; air in the shade, $82^{\circ} \mathrm{Fahr}$.

$2 \mathrm{~d}$ spring, at $12.12 \mathrm{~A} . \mathrm{M}$, water $103^{\circ} \mathrm{Fahr}$. ; air in sun, $86^{\circ} \mathrm{Fahr}$.

3d spring, at 2 P.M., water $105^{\circ}$, in shade $68^{\circ} \mathrm{Fahr}$.

Water boiled at third spring by thermometer at $212^{\circ}$ $75^{\prime}$, and at Kurachee by same thermometer at $214^{\circ}$; difference, $1^{\circ} 25^{\prime}$.

At Devakl Unei is 50 miles S.E. from Surat, at the foot of some hills, the temperature being $111^{\circ}$ to $120^{\circ}$.

One at Oonai or Oonari, in the jungle between Bansda and Boharee, in Gujerat, has a temperature of $120^{\circ}$ to $124^{\circ}$; but it is said to vary at seasons (Dr. A. Gibson). Oonai is a small hamlet in the territory of the raja of Bansda, near the hills east of the Surat district. Also one at Tooee, near Ruttenpur, on the Mhye xiver, in Gujerat, between lat. $22^{\circ} 49^{\prime} \mathrm{N}$., and long. $73^{\circ} 30^{\prime} \mathrm{E}$. There is a sulphurous hot spring at Tulsiram, in the centre of Geer, in Kattyawar.

A line of thermal springs traverses the Southern Konkan; and there are hot wells at Veijrabhoy, 48 miles $\mathrm{N}$. of Bombay.

Hot springs occur between Dasgaon and Souther'n Rajapur, between the Ghats and the sea, generally from 16 to 24 miles inland from the sea. At Rajapur there is one spring; near Mhar, on the Bancoot or Fort Victoria river, 75 miles S. of Bombay, there are severa], their temperatures being $98^{\circ}, 105^{\circ}$ and $109^{\circ}$. They are midway between Dasgaon and Mhar, and about 75 yards from the river.

There are ten places with hot spring between Rajapur and Saksee, viz. in the Viziadrug taluk, village Oonglee (Oonale) near Rajpur, about 20 miles from the Ghats and 12 miles from the sea. It is largely used. There are three in the taluk Ratnagherry and in the mahal Sangameshwar, at the villages Rajwari, Tooril, and Sungmairi, about 14 to 16 miles from the Ghats and 26 miles from the sea. That at Tooril is exceedingly hot. One at the village Arowli, in the Konedewri mahal one said to increase the appetite, at the village of Mat in the Hatkumbe mahal. Three at Oonari village in the Severndrug taluk and the Natoe Palwan mahal. One at the village Oonari, in the Jafferabad mabal. One at the village of Savi, in the Ryeghur taluk and Mhar pargana, between Mhar and Dasgaon; and one at the village Oonari, taluk Sankse and Pali mahal. Oonali or Oonari is the Mahratta term for hot springs, which will explain why so many villages bear this name.

Hot springs, about 150 in number, occur near Wujerabaee, in the Bhewnday taluka of the Tanna 
collectorate. The district in which they occur borders upon the river Tansa, on the Duganel side of the Bhewnday taluk, and is seemingly confined to the villages of Akulkolee, Ganeshpuri, Gorad, and Nimbawullee, in a tract about 3 miles long and a mile broad. The Argurd Kund spring, which is the hottest, has a temperature of $130^{\circ} 60^{\circ}$. Hot springs, having a temperature of $87^{\circ}$, rise through the limestone near the Pindi hills, and globules of gas escape from round holes in the debris and mud covering the bottom of the ravine. About five miles north of the hot springs of Urjunah, and four miles south of those of Kair, sandstone caps a gently rising ground covered with basaltic soil. Near the last-mentioned town many hot springs rise in the argillaceous limestoue, which has been remarkably broken up and altered by the globular basalt protruding through it in different places. The principal springs issue at the foot of the rising ground, where the rock is most remarkably altered. Their temperature $\left(87^{\circ}\right)$ was the same as that of Urjunah, on the other side of the Pindi Hills, and it did not vary during the hot and cold months of 1831 and 1833 .

Hot springs occur in the Satpura Hills, at Nizardeo, also at its sister spring at Unabdeo, about 3 miles to the north of Adawad, right under the Satpura Hills. Here the hot water issues from an oblong aperture in what appears to be a solid block of masonry, forming the lower part of an old Hindu temple, and flows into a tank 25 feet square. Four miles west of the Unabdeo spring is another hot spring, called Ram talao, or Sunabdeo. It is in a narrow gorge or glen formed by two low projecting spurs of the Satpura; the temperature, $140^{\circ}$. It contains 8.4 per cent. of silica and iron. There is another hot spring at Nizardeo, at Wirwada.

Near Bagin river in Pana district, Bundelkhand (Franklin). Two hot springs in Alwar country, one 15 miles $W$. by $S$. from Alwar, one 20 miles N.E of Jeypore (Capt. Bellew's Survey). Mineral springs at Machery? (Col. Tod). At Sitabari, in Harowtee; also cold springs (Col. Tod).

Birthum.-Hot springs occur at Buklesur in Birbhum. There are about eight of these, each being enclosed by little walls of sandstone in the form of wells, and known by different names, taken from those of the Hindu gods. The spring that has the highest temperature is the Surajkund, in which, says a Hindu traveller, we could not dip our band, and in which an egg may be boiled, but not rice, of which we threw in a handful to try the experiment. A few paces from the Surajkund is a cold spring. There are springs in the bed of the Paphara, the washer-of-sins. The water of the Satgunga has a milky whiteness, whence the origin of its name.

Confervæ abound in the hot springs of Surajkund; and two species, one ochreous brown and the other green, occur on the margin of the tanks themselves, and in the hottest water; the brown is capable of bearing the greatest heat, and forms a belt in deeper water than the green. Both appear in broad luxuriant strata, wherever the temperature is cooled down to $168^{\circ}$, and as low as $90^{\circ}$.

The water of one hot spring at Pachete near the Damuda is $190^{\circ} \mathrm{Fahr}$. in the cold weather. The spring is chalybeate. Hot springs near Monghir, on the Ganges, are known as the Seeta
Kund ; temperature, $163^{\circ}$. Hot springs at Rishi Kondah and Bhimband, in the trap mountains of Rajmahal. A thermal spring occurs in trap rock between lat. $23^{\circ}$ and $24^{\circ}$ N., and long. $86^{\circ}$ and $87^{\circ} \mathrm{E}$.

Kaljhurni,Maharu,Hatbulleah,Noubhil, between Rajmahal and Suri (Sherwill). Lacarakunda, 21 miles S.W. of Suri, in Birbhum (Sherwill). Tantlooee, 16 miles N. W. of Suri, on Sidh nullah, (Sherwill). Springs at Katkamsandi, Old Benares road (Everest). Pinarkun, Ramgur (Breton). Pabarpur, Kurruckpore Hills (Sherwill). Rajgir and Guriuk, N. by E. of Gyah (Sherwill). Utteer, 30 miles from Puri (Brander).

There are two warm springs in the bed of the Godavery, one in the middle of the river near Badrachellum, about one hundred miles west from Rajamundry. At Kair and Urjunah, Dekhan (Malcomson). At Byorah (Malcomson).

Bum Buklesir is a pretty and curious spot, easily accessible, in a well-cultivated country, with a little jungle to its south. It is one mile from the large town of Tantipara, on the banks of the Buklesir, a small nullah. There are five or six hot springs, the whole group called Bum Buklesir. The hot wells have been surrounded with masonry walls, and are immediately on the north or right bank of the nullah. There are numerous hot springs in the bed of the nullah, only to be seen in the dry season, giving out sulphuretted hydrogen, with which the air is tainted. Near the hot springs are several cold ones, all flowing from a tough gneiss rock. The hot and cold springs are only separated by a few feet from each other. The body of water ejected from the hottest well is very considerable, being about 120 cubic feet per minute; it runs from innumerable small orifices in an accumulation of mud and dirt, the rock being nowhere visible within the masonry of the tank. In the hottest water, $162^{\circ}$, a green shiming conferva thrives. Another spring is $128^{\circ}$, and the coolest $83^{\circ}$. Some 300 or 400 feet from the bank of the river, among the dilapidated temples, there is a large built tank, which is supplied by two springs, one hot and the other cold, so that at one end the water is warm, at the other cold, and in the centre tepid. The stream of the nullah is about 50 yards across, with a brisk current, and it retains its heat below the springs for a considerable distance; its temperature was $83^{\circ}$ in the month of December, when the temperature of the air was in the shade $77^{\circ}$. The sand of the stream some little way from the spring, and at the depth of six inches, is intolerably hot to the hand. Extending for about 200 yards along the right bank of the stream, are 320 small brick and mortar vihara or temples, built by various pilgrims, each containing a lingam or emblem of Mahadeo. Only one temple has any pretension to architectural elegance. Numerous attendant Brahmans, most importunate beggars, loiter about the temples, engaged in bathing in the hot stream, or watching the cremation of dead bodies, which operation is constantly being carried on. Tantipara is a fine substantial village, with most of its inhabitants engaged in preparing silk for the Calcutta market. There is an indigo factory, besides a police choki and abkari station. A short way off is the large town of Dobrajpore, offering a good market for English piece-goods, and producing a large supply of fish from its 


\section{HOT SPRINGS.}

numerous tanks. Between it and Bum Buklesir, and in the town of Dobrajpore, large naked and picturesque masses of granite and gneiss protrude through the soil, occupying altogether about a mile square. The scene is a very curious one. In the opposite direction, but farther away, is Nagpore, or Jye Nuggur, a large town ; the greater part of it has gone to decay, as is shown by its falling mosques, half - filled and weed-choked masonry tanks, and ruined buildings which almost approach to palaces in extent. The famous Nagore wall or entrenchment extends in an irregular and broken figure round the town of Nagore, at a distance of about 4 miles; its length is about 32 miles. At Lakarakunda, about 5 miles off, is a warm spring, temperature $85^{\circ}$. Near the feeble stream which carries away its waters is a curious cut stone Hindu temple.

The hot springs of Momay (temp. $110^{\circ}$ ), at 16,000 feet, produce a golden-brown Coenocoleus, representing a small form of $\mathrm{C}$. cirrhosus, and a very delicate Sphœrozyga, an Anabaina, and Tolypothrix ; and at 17,000 feet, a delicate green Conferva, with long even articulations. With the latter is an Odontidium, allied to or identical with 0 . turgidulum; and with the former a fine species of Epithemia, resembling in form, but not in marking, E. faba (E. zebra); a fine Navicula, perhaps the same with $\mathrm{N}$. major and Fragilaria virescens. In mud from one of the Momay springs there was Epithemia Broomeii, n.s., and two small Naviculæ; and in the spring two other species of Epithemia.

In the hot springs of Surajkund, and on their banks, at temperatures varying from $80^{\circ}$ to $158^{\circ}$, at which point vegetation entirely ceases, a minute Leptothrix abounds everywhere, varying a little in the regularity of the threads in different specimens, but searcely presenting two species. Between $84^{\circ}$ and $112^{\circ}$ there is an imperfect Zygnema, with very long articulations; and where the green scum passes into brown, there is sometimes an Oscillatoria, or a very minute stellate Scytonema, probably in an imperfect state. Epithemia ocellata also contributes often to produce the tint. An Anabaina occurs at a temperature of $125^{\circ}$, but the same species was found also in the stream from the springs, where the water had become cold, as was also the case with the Zygnema. Mr. Thomas Brightwell found in a portion of the same specimen, Epithemia alpestris. The Diatomacer consisted of-

Epithemia Broomeii, n. $s p . \mid$ E. inæqualis, $n . s p$.

E. thermalis, $n . s p$. Novicula Beharensis, $n . s p$.

The vegetation in the three sets of springs was very different. As regards the Confervæ, taking the word in its older sense, the species in the three are quite different, and even in respect of genera there is little identity; but amongst the Diatomaceæ there is no striking difference, except in those of the Behar springs, where three out of the four did not occur elsewhere. In the Pugha and Momay springs, the species were either identical with, or nearly allied to, those found in neighbouring localities, where the water did not exceed the ordinary temperature.

In Ceylon, hot springs occur in two places in the Kandyan province, at Badulla, at Kitool near Bintenne, near Yaviutu in the Veddah country, and a fourth at Kannea, 7 miles beyond Trincomalee; and there are two in the province
HOT SPRINGS.

of Uva, and one at Batticaloa. Their waters are considered efficacious in cutaneous ailments and rheumatism. A fifth is said to exist near the Patipal Aar, south of Batticaloa. The water in each is sufficiently pure to be used by the natives for domestic purposes.

In the hot springs of Kannea, the water flows at a temperature varying at different seasons from $85^{\circ}$ to $115^{\circ}$. In the stream formed by these wells, M. Reynaud found and forwarded to Cuvier two fishes, which he took from the water at a time when his thermometer indicated a temperature of $37^{\circ}$ Reaumur, equal to $115^{\circ}$ of Fahrenheit. The one was an apogon, the other an ambassis; and to each, from the heat of its habitat, he assigned the specific name of Thermalis. Also a loche, Cobitis thermalis, and a carp, Nuria thermoicos, were found in the hot springs of Kannea at a heat of $40^{\circ}$ cent., $114^{\circ} \mathrm{Fahr}$; ; and a roach, Leuciscus thermalis, when the thermometer indicated $50^{\circ}$ cent., $122^{\circ}$ Fahr.

Fish have been taken from a hot spring at Puri when the thermometer stuod at $112^{\circ} \mathrm{Fahr}$, and as they belonged to a carnivorous genus, they must have found prey living in the same high temperature.

Fishes have been observed in a hot spring at Manilla, which raises the thermometer to $187^{\circ}$, and in another in Barbary, the usual temperature of which is $172^{\circ}$; and Humboldt and Bonpland, when travelling in South America, saw fishes thrown up alive from a volcano, in water that raised the temperature to $210^{\circ}$, being two degrees below the boiling point. The springs of Kannea are situated in low ground abounding in quartz, surrounded by low jungle, in an unbealthy country.

Of the twowarm springs in the province of Ouva, one is at Badalla, in Upper Ouva, about 1861 feet above the level of the sea, where the mean annual heat is about $69^{\circ}$; the other is about a mile and a balf from Aliputa, in Lower Ouva, near the path on the way to Kotahowa, about 1061 feet above the level of the sea, where the mean annual temperature is probably about $76^{\circ}$.

Hot springs also occur as under :-

On Ranjit river.-Darjeeling Guide.

Between Meeaday and the Arakan Hills.-Phayre.

Sitacund, near Chittagong.

Springs at Numyan, near Prome.

Hot-water fountain at Tavoy; at Lunkyen, in Tavoy ; and at Sienli in Martaban,-Prinsep.

Near Kaline Aurig, Martaban.-Low.

Hot spring on Attaran river, Tenasserim.-Piddington. Hot springs on the Palouk river and at Pee, between Mergui and Tavoy, some sulphuretted.-Major W. $M^{6}$ Leod.

There is a hot spring near Chirana Puteh, and another at Salanama in Rambu. Tin has been procured near Taba, and also near Chirana Puteh.

Ayarpanas (hot water) spring near Malacca ; its water, $115^{\circ}$, is said to be useful in rheumatism.

Hot springs, some of interest, exist at Yommack, in lat. $22^{\circ} 24^{\prime} \mathrm{N}$., long. $113^{\circ} 28^{\prime} \mathrm{E}$., about 15 miles N.W. of Macao, with a temperature from $132^{\circ}$ to $190^{\circ} \mathrm{Fahr}$. The springs are three in number, and are near a rivulet, 100 yards from the river.

Hot springs occur in the Shan-tung province of China at Âi-sban, about 12 miles from Chefoo; also at Loong-chwen, $60 \mathrm{li} \mathrm{E}$. of Ning-hai ; at Wun-shih-ting, 70 li S. of Tung-chow; near Yichow-foo, and at Chau-yuen, $60 \mathrm{li}$ W. of Whang- 
hien. The water is sulphurous, and baths have been established there.-Forbes, Ceylon, ii. p. 49 ; Bengal As. Soc. Journal, 1848 ; Mrs. Hervey's Tartary, i. p. 94 ; Patterson's Zoology, part ii. p. 211 ; Yarrell's British Fishes, i. part xvi. ; Tennant's Ceylon, p. 59 ; Davy's Ceylon, pp. 42-46; Carter's Wester'n India, p. 21 ; Pottinger's Beluchisten, p. 179 ; Hooker, Him. Jour. ; Tr. of Hind.; Dr. W. Hibbert, in Jam. Ed. Journ. xxiv., 1837; Dr. R. Kirk, in Jo. B. Med. Soc. No. vi. ; Fleming; Dr. A. Duncan, Bo. Medl. Pro., 1836 ; Briggs ; Dr. Macpherson, in Indian Annals of Med. Sc., 1854 ; Mr. Livingstone, in Jam. Ed. Jour.

HOTTENTOT, a race occupying a part of the extreme south of Africa, near the Cape of Good Hope.

HOUGH, MaJor W., author of A Narrative of the March and Operations of the Army of the Indus in the Expedition to Afghanistan in 1838-39, and History of the Dooranee Empire to the Present Time, London 1811.

HOURI. In Mahomedan belief, a woman in paradise. It is translated in Sale's Koran, chap. lv., 'beauteous damsels, having fine black eyes.

\section{HOUSE.}

Bait,

Maison,

Haus, .

Khana,

\begin{tabular}{cc|l} 
- Arab. & Casa, \\
: Fr. & Oor, \\
\hline & Ger. & Illu,
\end{tabular}

Hind, Pers. $\{$ Ev, Konak,
IT., SP. TAM. TEL. Turk.
In the granitic country of Telingana, the houses are usually built of adhesive earth or clay, of a square or rectangular form, smeared often with red earth, and picked out with perpendicular bands of slaked lime, with a pyramidal roof of palmyra leaves or grass. Houses in the Karnatic are of mud walls, with roofs thatched with grass or palm leaves. Houses on the banks of the Kistna, near its debouchure, have circular walls of adhesive earth.

In the Tamil and Telugu country, the walls are usually of mud, with thatch or tiles for the roof. The humbler races have circular houses; their houses in Telingana are detached from each other, outside the gharri or fort. In the Canarese tract about Hurryhur, the back of the house is formed by raising a very high wall, on which a long sloping roof rests.

In Arabia and Mahomedan countries of Persia and India, houses have a common courtyard, with numerous rooms leading from it.

The circular form of hut is the only style of architecture adopted among all the tribes of Central Africa, and also among the Arabs of Upper Egypt; and although these differ more or less in the form of the roof, no tribe has ever yet sufficiently advanced to construct a window. Their houses are circular and conical, with onfy one opening for a doorway.

The Yezdy, a Kurd race settled near Aleppo, build a stone wall, and erect over it a goat-hair roof.

In Persia, the cottages of the villagers and peasuntry are of mud, or rough stones cemented with mud, and mostly consist of two rooms. The walls, which are usually about seven feet high, are very thick, and full of niches and recesses, which serve as cupboards for depositing all manner of miscellaneous articles. The roofs of the larger Persian houses are flat, and many have tall bad-gir or wind towers rising high above. The bad-gir is a large square tower, covered on the top, but opening below into the apartment above which it is erected. The four sides are laid open in long perpendicular apertures like narrow windows, and within these are partitions or walls intersecting each other, so as to form four channels in the tower. By this contrivance, from whatever quarter the wind blows, it is caught in the tower and conveyed into the room below, so that a constant current of air is kept up, except when it happens to be a dead calm.

The cottage of Bengal, with its trim, curved, thatched roof, and cane or bamboo walls, is the best looking in India.

The houses of Hindustan are built of clay or unburnt bricks, and tiled.

In the greenstone tract of the Dekhan, Berar, and the Mahratta country, where wood is scarce and of high price, the walls are mostly of mud, with flat roofs. The houses are huddled close together, surrounded by a wall, often with a central gharri or fort.

Houses with a flat roof have a parapet (Deuteronomy xxii. 8 ) to prevent any one falling into the street.

Acts $x .9$ tells us that 'Peter went upon the housetop to pray.' All the flat-roofed houses of India would admit of this; but some of the rich Hindus have a room on the top of the house, in which they perform worship daily.

2 Samuel xi. 2 says, 'And it came to pass in an evening-tide, that David arose from off his bed, and walked upon the roof of the king's house.' It is common in India with Mahomedans and Hindus to sleep in the afternoon. The roofs of houses are flat, and it is a pleasing recreation in an evening to walk on the flat roofs.

In Tibet, the peasant's house much resembles a brick kiln in shape and size. It is built of rough stones, without cement, and has two or three small apertures for ventilation. The roof is flat.

Houses in Burma, Arakan, the Straits Settlements, and all through the Archipelago, are raised on piles; some on the river side are built over the river on piles several feet high, with wooden or bamboo matting walls. The whole frontage on the left bank of the Moulmein river is built over, as also in Mergui. Some of the tribes of Further India live in great houses, communicating in their entire length. This is for defence.

Houses in many eastern countries are built as a quadrangle, the four outer walls being dead, or pierced with loopholes; in one of the halls is the entrance to an open unroofed courtyard, surrounded by chambers or open verandahs. This arrangement explains the circumstances of the letting down of the paralytic into the presence of our Lord, in order that he might heal him (Mark ii. 4, Lnke v. 19). The paralytic was carried by some of his neighbours to the top of the house, either by forcing their way through the crowd by the gateway and passages up the stairs, or else by conveying him over some of the neighbouring terraces; and there, after they had drawn away the awning, "they let him down along the side of the roof, through the opening or impluvium, into the midst of the court before Jesus.'

Matthew x. 12-14 says, "And when ye come into an house, salute it. And whosoever shall not receive you,' etc. It is the custom amongst Hindus of a stranger to go to a house, and as he enters it to say, "Sir, I am a guest with you to-night.' If the person cannot receive him, he 
apologizes to the stranger.-Horn's Critical Stuly of the Scriptures, i. p. 385; Shaw's Travels, i. pp. 374-376; Hartley's Researches in Greece, ii. p. 240; Robinson's Tr. ii. p. 351; Ward's Hindoos.

HOUSE - LEEKS, King - t'ien, CHIN. The plants Umbilicus malacophyllus, Sedum acre, and Sempervivum tectorum, are grown on Chinese housetops, with the idea that they ward off fires. -Smith, M. M. C.

HOUSHA, in Bengal, a village authority.

HOUTMAN, CORNELIS, in A.D. 1595, as supercargo, was entrusted with the cargo of four ships to sail by the Cape of Good Hope to the East Indies, a company having been formed, entitled 'Het Maatschappy van verre Landen,' to carry out the Dutch enterprises in the east. He left the Texel 2d February 1595, crossed the line 14th June, doubled the Cape 2d August, landed at Sumatra 11th July 1596, and entered the harbour of Bantam 22d July. He purchased pepper and spices in the Sunda Islands and Java, and returned to the Texel in 1597.

A second expedition, in which he was slain, went out in 1598, and returned in 1600-1601. This seems to have been commanded by Admiral Vanneck, who formed an establishment at Java and in the Molucca Islands; and he was followed by Admiral Warwyk, who fortified the factory at Java, and formed alliances in Bengal. In 1624 the Dutch settled on Formosa, which soon attained a high degree of prosperity, but was ultimately wrested from them by a Chinese patriot. They have had a factory in Japan since 1640, where they submitted to very degrading treatment. The Dutch subsequently expelled the Portuguese and Spaniards from Malacea and from the Moluccas, and afterwards formed settlements at Timur, Celebes, Macassar, and Sumatra.

Spielbergen was the first Dutch navigator who touched at Batticaloa in Ceylon, in March 1602. He went to Kandy, where he was well received, entered into alliances with the king of Kandy in the year 1638, and for the next twenty years their wars with the Portuguese were incessant. The Portuguese finally departed on the 24th June 1658.

HOVA. The tombs of the Hova race of Madagascar consist of stone vaults, made of immense slabs of stones, flat inside, forming a subterranean grotto. They also erect stone pillars similar to menhir. The supposed aborigines of Madagascar were the Vasimba, whose tombs are small tumuli or cairns, surmounted by an upright stone pillar.

HOVENIA DULCIS. Thunb. \begin{tabular}{l|l}
$\begin{array}{l}\text { Chih-ku, Ki-ku-tsze, CHin. } \\
\text { Coral, Honey, and }\end{array}$ & $\begin{array}{l}\text { Sicka, . . . . Hind, } \\
\text { Kempokonass, : JAPAN. }\end{array}$
\end{tabular}

White stone tree, ENG. Ken, Kimponass, . ",

This tree grows in India, Nepal, China, and Japan. Its fruit are small, dry, and pea-like, pendent upon the fleshy peduncles, like the casbew nut. They greatly increase in size at the time of their maturation. The fruit-like thickened branches are of a russet colour, and filled with a pleasant, yellowish, pear-like pulp. The fleshly peduncles are said to counteract the immediate and after effects of wine. - Smith, M. M. C.; Roxb. i. p. 630; Von Mueller.

HOIVA. ARAB. Eve, the mother of the human race.

HOWDAH, a seat, pad, or open litter fixed on the back of an elephant.
HOWLER, a name given to the Gulshaniyeh darvesh. See Darvesh.

HOWRAH or Haura, sub-district of Hoogly district, Bengal, with independent magisterial jurisdiction, lying between lat. $22^{\circ} 13^{\prime} 15^{\prime \prime}$ and $22^{\circ}$ $47^{\prime} \mathrm{N}$., and between long. $87^{\circ} 47^{\prime}$ and $88^{\circ} 24^{\prime} 15^{\prime \prime}$ E.-Inzp. Gaz.

HOW-TSAO. CHIN. A bezoar stone, used in China for the treatment of Cynanche tonsillaris.

HOYA, a genus of plants of the natural order Asclepiacex. The species in Southern Asia are, - H. carnosa, fusca, lanceolata, linearis, ovalifolia, pallida, parasitica, Pottsii, pauciflora, pendula, and viridiflora. Several of the species, under the name of wax plants, are cultivated on account of their elegant flowers. H. imperialis, Lindl, of Borneo, is highly beautiful, its large and rich purple flowers being relieved by the white, ivory-like centre; it is epiphytal. H. carnosa, $R$. $B r$., the flesh-coloured wax plant, is a native of China.Voigt; Wight; Eng. Cyc.; Low's Sarawak, p. 67.

HOYA PENDULA. Wight and Arnott.

Asclepias pendula, Roxb. | Hoya revoluta, Wight.

A. Rheedii, $\boldsymbol{W}$. and $\boldsymbol{A}$. Nasjera patsja, MALEAL.

This plant grows in the Circar mountains, Malabar, and Neilgherry Hills, and is used in medicine. Its flowers are middle sized, white, and fragrant. -Voigt.

HOYA VIRIDIFLORA. $R . \quad B r$. Asclepias viridiflora of Roxburgh. A native of Coromandel, Sylhet, and the Neilgherry Hills. The root and tender stalks produce nausea, and promote expectoration. The leaves, peeled and dipped in oil, are used by the natives of India as a discutient in the early stages of boils, and in the more advanced stages to promote suppuration.

HSU SHEN, author of the Shuo Wen, a Chinese dictionary. It consisted of 10,000 separate characters, in the tablet and stylus form. Commonly called the 'Lesser Seal.' He lived in the time of the Han dynasty.

H'TEE, BURM., is the umbrella or canopy of gilt iron filigree which crowns every pagoda in Burma. Now-a-days, generally, a bottle is put on the H'tee, and a similar practice is said to be pursued in Ceylon, originating, as it is surmised, from the knowledge that glass is a uon-conductor. The H'tee of the Shooay Dagon pagoda at Rangoon was renewed by the king of Burma in 1871 at a cost of $£ 62,000$, and about 50,000 people assembled to assist in putting it up. It was 47 feet high and 13 in diameter. Kings of Burma in 1755, and again in 1774, had asserted their sovereignty over Rangoon by thus crowning the great pagoda. - Yule's Embassy.

HUAKI. MAORI. A fabric of New Zealand used in clothing.

HUC and GABET, two French missionaries, who, by a route till then quite unexplored by any European, passed among the mountains north of Bhutan and Ava, and so made their way due east to the plains of China (Central Flowery Land). M. Huc wrote an account of his travels.

HUD. At Hasek is the tomb of the prophet Hud, the fourth in descent from Shem.

HUDDART. Captain Joseph Huddart, F.R.S., author of the Oriental Navigator, which first appeared in 1785 , with an atlas of 108 charts. A second edition of it appeared in 1797, a third in 1801 , and a fourth in 1808 , of 755 pages. Its plan was adbered to by Captain James Horsburgh 
(obiit May 1836), under the title of India Directory, the first part of which appeared in 1809, the second part in 1811, and it has since gone through several editions. Its place has now been largely taken by two similar works, one under the editorship of Mr. Findlay, and "another by Captain Taylor of the Indian navy.

HUDDEEAROO. HIND. A kind of ring used at Nahomedan marriages.

HUDIGAR. KARN. A low caste in Mysore.

HUE or Fue. Chin. A secret society.

HUGEL. Baron Charles F, von Hugel, author of Kaschmir und das Reich der Siek, Stuttgart 1840 , describing his visit to the Himalaya mountains and the valley of Kashmir. The Fische aus Caschemir were described by MM. von Hugel and von Heckel. Baron Hugel met other two travellers in Kashmir, and they agreed to carve the following inseription on a black marble tablet, and set it up in the little building on the Char Chunar island:- 'Three travellers in Kashmir on the 18 th November 1835, the Baron Ch. Hugel from Jamu, Th. G. Vigne from Iskardu, and Dr. John Henderson from Ladakh, have caused the names of all the travellers who have preceded them in Kashmir to be engraven on this stone. Bernier 1663 ; Forster, 1786; Moorcroft, Guthrie, and Trebeck, 1823 ; Victor Jacquemont, 1831; Joseph Wolff, 1832.' Two only of these, the first and the last, ever returned to their native country. In the list they did not include Catholic missionaries. Forster did, strictly speaking, return home, but he came out again and died at Madras. When Char Chunar island was visited by Dr. Adams in 1854, the tablet had been removed.-Hugel's Tr. p. 144; Buist's Cat.; Adams' Naturalist in India.

HUGH LINDSAY was the name of the first steamer that conveyed an overland mail from Bombay to Suez. She was the first steamer that entered the Persian Gulf. She was lost coming out of the roads of Bassidore, a port on the island of Kishm, in the Persian Gulf.

HUGLI or Hoogly, a town in Bengal, in lat. $22^{\circ} 54^{\prime} 44^{\prime \prime} \mathrm{N}$., long. $88^{\circ} 26^{\prime} 28^{\prime \prime} \mathrm{E}$. It has the town of Chinsurah adjoining it on its south, and their joint population in 1872 was 34,761 . A fort is said to have been built here by the Portuguese in 1537, and a population gathered around it. About the year 1629 it was taken by storm, under the order of the emperor Shah Jahan; but in 1640 the English East India Company, under a firman granted to Dr. Boughton, opened a factory here, and two years afterwards another at Balasor. Between 1685 and 1688 , disputes arose between the Nawab of Bengal and the Coinpany's servants ; but peace was restored, and in the treaty permission was given to build a factory at Sutanati, the present site of Calcutta. Hoogly is the head station of a British revenue district, with an area of 1467 square miles, and a population in 1872 of $1,488,556$ souls, the most numerous Hindu castes being the Bagdi, Kaibartta, Brahmans, Rajputs; and Mahomedans, 299,025. When Hoogly fort was taken by the troops of Shah Jahan by assault, after a siege of $3 \frac{1}{2}$ months, more than 1000 Portuguese were slaughtered, and 4400 men, women, and children were made prisoners of war. The best-looking young persons were sent to Agra, and circumcised and made Mahomedans. The girls were distributed among the harams of the emperor and his nobility. In Hoogly the first press was set up in India in 1778, by Messrs. Halhed and Wilkins, on the occasion of the publication of a Bengali grammar by Halbed. The Bandel church is the oldest Christian church in Bengal, built, according to the inscribed date, in 1599. Prior to Hoogly, the royal port of Bengal was Satgaon. The Ganges formerly flowed by this place, and came out near Andool, and the remains of wrecked vessels have been turned out beneath the earth, which has overlaid the bed of the deserted channel. Satgaon is of great antiquity, having been known to the Romans under the name of Ganges Regia.

The Hoogly river is formed by the junction of the Bhagirathi and Jelinghi, two branches of the Ganges. It runs into the sea at Saugor roadstead, by an estuary 15 miles wide. Its length is 160 miles by winding of stream. It receives the Damodah, 350 miles; Dalkissore, 170 miles ; Cossy, 240 miles; Mor, 130 miles; and about 49,000 square miles are drained. The river has on its banks Calcutta, Serampur, Chandernuggur, Hoogly, and Murshidabad. The rivers forming it are offsets from the western branch of the Ganges delta. The eastern or Saugor channel is the principal entrance. From Middleton Point light to Fort William at Calcutta is $83 \frac{1}{2}$ miles in length, following the windings of the river. It is the most westerly, and, for commercial purposes, the most important channel by which the Ganges enters the Bay of Bengal. Proceeding south and a little east from Santipur, the Hoogly river divides Murshidabad from Hoogly district, until it touches the district of the Twenty-four Parganas in lat. $22^{\circ} 57^{\prime} 30^{\prime \prime} \mathrm{N}$., and long. $88^{\circ} 27^{\prime}$ $15^{\prime \prime} \mathrm{E}$., close to the village of Bagherkhal. It then proceeds almost due south to Calcutta, next inclines to the south-west, and finally turns south, entering the Bay of Bengal in lat. $21^{\circ} 41^{\prime} \mathrm{N}$., and long. $88^{\circ} \mathrm{E}$.

The Saraswati, now a muddy channel, enters the Hoogly at Satgaon, about 30 miles above Calcutta, and the Adi Ganga, now little more than a series of pools, which diverges south-east from it just below Calcutta, are both rivers of great sanctity. They are supposed to represent the original Ganges, Holy Mother Ganga, who takes her divine source in the Himalayas, and pours her waters into the Bay of Bengal at Sagor (Saugor) island. In August 1856, neap tide rose $15 \frac{1}{2}$ feet above the datum sill of the Kidderpore dock; and upon the 18th August 1856, spring tide rose to $22 \frac{1}{4}$ feet above the same datum, the greatest rise of the salt lakes being 12 feet. This is on the western side of the delta. On the eastern side the tides rise from 40 to 80 feet. The silt held in solution, earthy matter, carbonate of lime, magnesia, sulphates of lime and iron, at 3 feet of depth, varies at Calcutta and in the Gasper Channel from 7:34 to $18 \cdot 92$.

The Hoogly is difficult to navigate. The tides run rapidly. The James and Mary Sands, 30 miles below Calcutta, used to be reckoned so perilous, that until well into the nineteenth century East Indiamen lay at Diamond harbour, just below their dangerous currents. A minute supervision of the channels, with steady dredging and a constant readjustment of the buoys, now renders the Hoogly a safe waterway to Calcutta for ships of the largest modern tonnage, drawing up to $26^{\circ}$ feet. These sands are shallows formed 
at the entrance into the Hoogly, from its western bank, of the Damodar and Rupnarayan rivers, which bring down the drainage of South- TVestern Bengal. These rivers discharge at sharp angles into the Hoogly, at a distance of only a few miles apart, nearly opposite Falta, which lies 27 miles by water from Calcutta. Their waters check the flow of the Hoogly, and lead to the deposit of vast quantities of the silt with which the Hoogly, Damodar, and Rupnarayan are loaded. If a ship touch the bottom of the sands, she is immediately pushed over by the current; and cases are known in which only the yards of a great three-masted ship have remained above water within half-an-hour after the accident; vessels become covered over with the sand if not promptly blown up. The sands extend upwards from Hoogly Point, $33 \frac{1}{4}$ miles from Calcutta, opposite the mouth of the Rupnarayan, to about Falta, 27 miles from Calcutta, opposite the mouth of the Damodar.

Fishermen, who have sea-going boats, inhabit villages near the entrance of the Hoogly.

A bore is caused by the head-wave of the advancing tide becoming hemmed in where the estuary narrows suddenly into the river, and often exceeds 7 feet in height. It is felt as high up as Calcutta, and frequently sinks small boats or dashes them to pieces on the bank. The tide itself runs as high up as Hoogly town.-Tr. of Hind. i. pp. 13, 15.

HUGONIA MYSTAX. Linn. Modera kanni, Maleal.; Agur, Tas. A shrub growing in Malabar, the Coromandel coast, and Ceylon, with large blossoms of golden-yellow colour. It is employed in native medicine.-W. Ill.; Voigt.

HUJERI. ARAB. A term applied to one of the servile races of Arabia. Qu. Khijra?

HUJRA. Pers. A place of assembly, a cbamber. In Afghanistan, a house set apart for the accommodation of travellers, and where, in the evenings, the old and the young assemble to converse and smoke the chillam.-Masson's Journeys, i. p. 119.

HUJRA, a small town of 3000 inhabitants in the Montgomery district of the Panjab; residence of a branch of the Bedi Sikhs, descendants of guru Baba Nanak. It was conquered by Bedi Sahib Singh during the reign of Ranjit Singh, and held by him in jaghir from the Mabaraja. His descendants still hold extensive revenue grants in the neighbourhood, and exercise considerable local influence.-Imp. Gaz.

HUJULOHA. Hind. An epithalamium.

HUKKA. Hind. A pipe used in India, in which smoke is made to pass through water. Hukka bardar, a pipe-bearer. Hukko charsee Pattani, used by Patans for smoking charras, resin of bemp, or Cannabis sativa.

HUKMCHIS. HiND. A dark-coloured gum obtained from the date palm.

HUKUM or Hukung, a valley in Assam, about 1000 feet above the level of the sea. It is surrounded on the north and east by mountains elevated 5000 and 6000 feet, and is traversed by numerous ranges of low bills.

HULAETA. Hind. In Hindustan, the first ploughing of the season, which is generally preceded by the taking of omens, and other superstitious ceremonies. The note of the koel bird, amongst other auguries, is considered very favourable, and its utterance is of such authority as to enable the cultivator to dispense with a formal application to a Brahman.-Ell. See Hal ; Har.
HULARI, a mountainous district near Shiraz, with fine vineyards, from which the choicest Persian wine is prepared, both red and white. This wine has much body; it resembles the strong Cape wines, and is fit to be exported.

HULASWAR, a division of the Holeyar of the Canarese-speaking race.

HULDI or Haldi. Hind. Turmeric ; Curcuma longa, $R o x b$. It takes an important place in many of the customs of the people of India. Haldi mehndi is a Mahomedan betrothal ceremonial, as also are Haldi or Nunja baithna, Haldi chor, and Haldi saoo. The Hindu races use it largely for smearing their bodies, and to dye with it portions of their new clothes to avert the evil eye.

HULKA-BUNDI or Halka-bandi. Hind. A system of schooling, embracing those of the circle of villages in which they were established.

HULL. E. C. P. Hull, author of Coffee Planting in Soutbern India and Ceylon, London 1877.

HULLAH or Nimboli. HIND. A neck ornament worn by Mahomedans.

HULLAR or Hulla, a district which forms the chief part of the southern shores of the Gulf of Cutch. The land near the sea is low, but all well watered. Nowanagar is the principal place of the district. The Roje temple is in lat. $22^{\circ} 32$ $50^{\prime \prime} \mathrm{N}$., and long. $70^{\circ} 1^{\prime} 30^{\prime \prime} \mathrm{E}$.

HULLE MUKKALU, a caste in Mysore who. live by begging, and by fees from goldsmiths' shops, blacksmiths' shops, and at marriage ceremonies.

HULUGU, grandson of Chengiz Khan, founded the Mongol dynasty of Persia. On the $22 \mathrm{~d}$ of January 1258 , he appeared with his army before Bagbdad. On the first of February he took the city by storm, and put an end to the power of the khalifs. He had made the khalif Mostassim believe that he was willing to give his daughter in marriage to the khalif's son. But when the principal people were thus all got together, the Tartars set on them, and put them all to death. Baghdad, the city of seience, learning, and pleasure, was given up to pillage and slaughter, and more than 800,000 persons were mercilessly destroyed. Sanut declares that Hulugu killed the khalif by pouring molten gold down his throat. Whilst the Mongol were covering Poland with blood and ruins, Hulugu, in the east, was completing the conquest of Syria. After the capture of Baghdad, he entered Mesopotamia, seized on Merdin and Harran, passed the Euphrates, and made himself master of Aleppo and Damascus. The Tartar general had sent orders to Nasir, the sultan of Aleppo, to submit at once, and come in person to meet him. Not being complied with, Hulugu laid siege to Aleppo. Twenty catapults played for five days against the town, and it was taken by assault on the 18th January 1260. An incredible amount of treasure was found in it, and the carnage was still more horrible than at Baghdad. The streets were choked up with corpses, and it is stated that 100,000 women and children were sold for slaves in Little Armenia or in the territories of Europeans. He was succeeded by his son Abaka, who married a daughter of Michael Palæologus, the Greek emperor. His brother Nicolas, who succeeded him, became a Mahomedan; but Arghun Khan, son of Nicolas, was hostile to the people of that creed. Arghun sent embassies, conducted by a Genoese named 
Buscarelli, to the Pope, and to the kings of France and England, proposing an alliance against the Saracens and Turks; and in 1290 Edward I. of England sent Geoffrey de Langley on a return nission to him. Arghun having lost his favourite wife in 1286, sent Kublai Khan to select another for him, and the Polo relatives were commissioned by Kublai Khan to escort the new bride he had chosen for his nephew, to the Persian court. - Huc's Christianity, i. p. 268.

HUMA, a fabulous bird, the phonix of classical writers, also the hoopoe, Upupa epo.

HUMAYUN, emperor of India, twice reigned in that country, viz. from the death of his father Baber, 26th December 1530, till he abdicated on the 9th July 1543, and again from re-accession, A.D. 1555, till his death. Humayun was the eldest of four sons of Baber. Of these, Kamran was governor of Kābul and Kandahar at the time of their father's death, but Hindal and Mirza Akbari were unemployed in India. Humayun on accession ceded the Panjab and the country on the Indus to Kamran, in addition to his former territories; gave the government of Sambal to Hindal, and that of Mewat to Mirza Askari. Humayun's first operations were against Bahadur Shah, king of Gujerat, and he was one of three hundred chosen men who, at night, in August 1535, scaled the almost perpendicular rock on which the hill fort of Champaner is built. Sher Shah's revolt, however, recalled him to Hindustan and the banks of the Ganges; but, after gaining temporary adrantages, in a general action in April 1840, near Canouj, Humayun's forces were defeated and driven into the Ganges, Humayun himself escaping to the other side with great difficulty. He sought protection from Kamran at Lahore, then, failing in an invasion of Sind, he sought and found an asylum with Maldeo, raja of Marwar, but finding Maldeo likely to deliver him up to his enemies, he moved to Amerkot, a fort in the desert not far from the Indus. The journey through the desert was calamitous; many of his companions died miserably from thirst; Humayun, with only seven mounted attendants, entered Amerkot, and was received kindly by the chief, Rana Parshad. Here, on the 14th October 1542, was born his son Akbar. His fortunes still varied, and he sought protection with Shah Thamasp, king of Persia. He sent his confidential officer, Babram Khan, to meet the king, and followed afterwards on a visit, but found himself a prisoner, was compelled to accept the Shiah doctrines and forms, and promised to introduce it into India, to wear the Kazzilbash cap, and to cede the kingdom of Kandahar. At length he was allowed to depart, and, arriving at Seistan, he found 14,000 horse awaiting his arrival, under the command of Morad Mirza, king Thamasp's son.

He took Bast on the Helmand, besieged and took Kandanar, March 1545. Mirza Askari took Kābul, and recovered Akbar, but only again to sustain reverses in Balkh, during which he fled with only eleven attendants to Badakhshan. Recovering somewhat, he overthrew Kamran (1547), and all the brothers (1548) were reconciled, and took food together; only again for Humayun to meet with further reverses, for Humayun marched against the Khalil, but in a night attack he was defeated by these mountaineers, and his brother Hindal killed. Humayun again took the field, defeated the Afghans, and compelled Kamran to fly to India, where he took refuge with Sultan Selim, and afterwards with the Sultan of the Ghakkar, who in September 1553 betrayed him to Humayun. He was blinded, and allowed to proceed to Mecca, where he soon after died. Humayun passed a year at Kābul and Kandahar ; and on the death of Selim Shah he set out from Kābul with 15,000 horse in January 1555 , to Lahore, overthrew Sikander Shah at Sirhind, and took possession of Dehli and Agra. In less than six months after his return to the capital, when descending the stairs from his library, hearing the muazzan's call to prayers, he repeated the creed, and sat down on the steps till the azan was finished. As he rose with the belp of his staff, it slipped on the polished marble step, and he fell over the parapet, and was stunned. On the fourth day of the accident he expired, A.D. 1556, A.H. 963, in the 49th year of his age and 26th of his reign, including the 16 years of his banishment from his capital. $\mathrm{He}$ was succeeded by his son Akbar, then thirteen years and four months old; and in Akbar's reign India was formed into one empire. Humayun in all his military operations had shown no want of personal courage, but great deficiency in enterprise, and he had gone through bis subsequent calamities with cheerfulness that approached to magnaminity._Elphin. pp. 384-413.

HUMBOLDTIA UNIJUGA. Berdd. Ic. A handsome middling-sized tree, growing abundantly on the Travancore Ghats, in the dense forests a little below the Attraymallay, 3000 to 4000 feet elevation; timber very hard and durable. Wight gives also H. Brunonia, laurifolia, and Vahliana. -W. Ic. ; Beddome, Fl. Sylv.

HUME, ALLEN OCTAVIUS, C.B., a civil servant of the Bengal Presidency, and author of The Game Birds of India. While magistrate of Etawa, by force of will and mild obstinacy of purpose, he overcame much resistance from the natives, and for years continued toiling at schools and Christianity, and all that elevates the human heart. $\mathrm{He}$ was an instance how much can be done in India by the influence of one man. It is in India where such influence attains its highest sway. A place more desert-looking and hopeless of growth for any European seed could hardly be selected; yet this one pale Englishman, of slender frame and ascetic habits, developed upon that fiery soil a caste of natives unsurpassed in firm allegiance and educational distinction.-T. J. Hovell-Thurlow, The Company and the Crown, p. 89.

HUMEA ELATA. Roxb. Masjot, Beng. A tree of Chittagong which attains a great size. Humea elegans is an ornamental plant of N. S. Wales, grows to the height of 5 or 6 feet; colour of the flower red, and well adapted for borders; it requires a good soil. - Roxburgh, ii. p. 640 ; Riddell.

HUMEANA. HIND. A waist-belt to carry money.

HUMPI, a ruined city in the Bellary district of the Madras Presidency, known formerly as Bijanagar, also written Vijayanagar and Vijianuggur, properly Vidianuggur, or the town of learning. There is a tradition that there was a town here about A.D. 1100, but it first acquired a name from being occupied or founded by two fugitives from Telingana, or, according to Prinsep, 
in 1338 by Bilal Deo of Karnata, who resisted Muhammad Taghalaq, and founded Vijayanagar. In 1347, Krishna Rai ruled there; in 1425, Deva Rai ; in 1478 , Siva Rai. Vijayanagar sovereigns claimed to be of the Yadu race. Towards the 15th century, the city had become the capital of a great Hindu power, which ruled over the Hindu chiefs to the south of the territories of the Adal Shahi, Nizam Shahi, and Kutub Shahi, kings of the Dekhan. In the middle of the 16th century, these three Mahomedan kings, fearing the growing power of Ramaraja, the sovereign, made war against him. Rama was then in his 70th year. He met the confederates at Talicottah, on the 25th January 1565 , with a great army of 70,000 horse, 90,000 foot, 2000 elephants, and 1000 pieces of cannon; but he was defeated with a loss of 100,000 men, and was taken prisoner. The authors Khafi Khan and Shahabud-Din state that the elephant on which he was mounted ran away with him into the confederates' camp. He was beheaded at Kala Chabutra, in the Raichore Doab, and his head remained for 200 years at Bijapur as a trophy. Vijayanagar sank into an insignificant place, and is now known as the ruins of Humpi. The raja's brother, however, took refuge in Peniconda, and subsequently at Chandragiri, whence the English merchants obtained the grant of the ground on which Madras was built, and engraved on a gold plate, which was lost in 1746, when Madras was captured by the French under Labourdonnais. The descendant of Ramaraja is the raja of Anagundi, whose title is Sri Mudrajadhi Raja, Raja Parameswara Sri Virapratapa, Sri Vira Terumala, Sri Viravenkata Ramarawya, Dava Maharawya Sumstan Vedaya Nagarum.-Wh. H. I. p. 459.

HUMULUS LUPULUS. Linn. The hop plant; has been extensively distributed in the Himalayas. At 2500 feet, in the Dehra Doon, it grows well, and at an altitude of 6000 feet in the Government gardens, Mussoori, but in those regions the highest limit appears to be 4000 or 4500 feet. It has been successfully cultivated in Dehra Doon for many years, so far as mere growth is concerned; but heavy rain at the flowering period prevents the flower from reaching perfection as to quantity and quality of the powder on which its value depends, and the results have, on the whole, been unsatisfactory.-Stewart, P. Pl. p. 217. See Hops.

HUN. Hind. A gold coin of S. India, worth $31 \frac{1}{2}$ rupees, called pagoda by the British. It is about 50 grains weight.

HUN, a race who have secured for themselves a niche with the 36 races of India. D'Anville, quoting Csoma de Koros, informs us that the White Hun occupied the north of India; and it is on the eastern bank of the Chambal, at the ancient Barolli, that tradition assigus a residence to the Hun; and one of the celebrated temples at that place, called the Sengar Chaori, is the marriage hall of the Hun prince, who is also declared to have been possessed of a lordship on the opposite bank, occupying the site of the present town of Bhynsror. In the 12 th century the Hun must have possessed consequence, to occupy the place they hold in the chronicle of the princes of Gujerat. The race is not extinct. One of the bards pointed out to Colonel Tod the residence of some in a village on the estuary of the Myhie, though degraded and mixed with other classes. There are also two tribes in the Himalaya who have preserved this designation,-the one in Gnari Khorsum, who call themselves Hunia; the other being the Limbu in Nepal and Sikkim, a large division of whom are called Hung. Arrian, Strabo, and Ptolemy state that a race known as the White Hun were established in the Panjab and along the Indus about the beginning of the Christian era. They are mentioned in the Mahabharata and Markandea Purana; Dr. Fergusson says (p. 39) the White Hun or Ephthalites are the Jat.

The Hun are known in Chinese history as Heungnoo, meaning boisterous slaves. The Hiatilla or White Hun iesued from the plains near the north wall of China, made themselves masters of the country of Transoxiana and Khorasan, and anticipated the irruption of those Turkish tribes who afterwards expelled the Hiatilla from the lands that they had taken from the Sacæ or Scythians. There is every ground to conclude that it was an army of the Hiatilla that invaded Persia in the reign of Bahram-Gor, A.D. 420, and that it was to one of their kings that Firoz fled, A.D. 475.

The Hun who appeared in the west, dated their empire from one of the princes of the Hia (Hya) dynasty. Their country was of great extent, situated on the west of Shen-si, of which they possessed the western parts ; and their posterity still inhabit a part of that territory, the present Ele or Ili. They were one of those extensive tribes which the ancients comprised under the name of Scythians.

It was from Ili valley and town in Central Asia that Lassen supposes the Szu Tartars were expelled by the Yue-tchi or White Huns, B.c. 150. The Szu Tartars he supposed to be the Sacæ, and the Yue-tchi to be the Tochari. After occupying Tahia or Sogdiana for a time, they are stated by the Chinese to have been driven thence by the Yenger some years afterwards, and to have established themselves in Kipen, in which name Lassen recognises the Kophen valley in the Kohistan. The great Kirghiz horde is adjacent to Ili and Tarbagatai. It is under the dominion of China, and exchanges large quantities of eattle on the frontier for silk goods.

HUNDE. KARN. A name of the Kuru-baru, Mysore shepherds.

HUNDES or Gnari Khorsum is a part of Chinese Tibet comprising the upper basin of the Sutlej and headwaters of the Kamali river. For the name, Professor Wilson gave Hiun, snow, and Des, country ; but Captain H. Strachey derives the name from the Sanskrit Hun, meaning the aborigines of the country north of the Himalaya, who are mentioned in the Mahabharata and the Markandeya Purana. This latter explanation commended itself to the Hungarian scholar, Csoma de Koros, who thought that be might find in these parts the origin of his own people. Mr. Ryall's derivation is from a Sanskrit word meaning gold, Hun-des being the gold country. The Hunia people of Hundes are chiefly nomades, owning large flocks of sheep, and herds of cattle and goats. They are a good-natured race; ugly, simple, and, like most dwellers in cold regions, extremely dirty. They practise polyandry, and in their customs are like the Bhot of Ladakh described by Cunningham. There are five principal passes leading into Hundes from British 
territory. The traffic is only open between the 15th of June and 15th October, and not even then without the express permission of the Chinese authorities at Lhassa, who carefully satisfy themselves that no epidemic prevails in the Ghats in British territory. The gold-fields of Hundes lie chiefly in the neighbourhood of Thok Jalang, 100 miles N.E. of Gartok. Washing operations are carried on under the supervision of a gold commissioner, who is called Sarpan, and takes a royalty of $\frac{2}{5}$ ths of an ounce yearly from each digger. At Gartok, fine gold-dust sells at Rs. $1 \frac{1}{8}$ in weight for Rs. 16. The greatest demand for gold is at Lhassa. In the early part of the 19th century, the goldfields round Lake Manasarowar were worked rather extensively; but an epidemic breaking out amongst the miners, the authorities at Lhassa interposed, and the operations were stopped. The Hunia all drink tea, and travel great distances, living on it and sattu, the flour of a parched grain. The Hunia only grow small patches of uwa, a kind of barley, and obtain their other grains from the bill territories of British India. They keep three years' supply of grain in store, to obviate the stoppage of the roads. Their villages are mere tents.-Tod's Rajasthan; Gutzlaft's Chinese History: Malcolm's Persia; Chatfield's Hindustan; Ritchie's British World.

HUNDI, an Indian draft or bill of exchange, drawn by or upon a native banker or sirraf, commonly written shrof.-Simmonds' Dict.

HUNGARY, a kingdom of Europe, divided by the river Danube into Upper and Lower Hungary, and subdivided into 46 counties. The Hungarian, Lapponian, and Finish dialects are now classed as members of the great Turanian or Tartar family of tongues, which is spoken by all the tribes from the Himalaya to Okotsk and to Lapland, and includes the Hungarian, Crimean, and Turkish tongues.

HUNG KIAO. CHIN. The Red Church, also known as Brug-pa, the designations of the Sakya priesthood of Tibet.

HUNGRUNG, a district adjoining Ladakh, belongs to the raja of Bisatun, its villages lying from 9500 to 12,000 feet above the sea.

HUNG SING-WONG, with the Chinese, the god of the Southern Ocean, and a state deity of China.

HUNSUR, a town in Mysore, on the right bank of the Lakshmantirtha, in lat. $12^{\circ} 17^{\prime} 40^{\prime \prime} \mathrm{N}$. long. $76^{\circ} 19^{\prime} 5^{\prime \prime}$ E. ; population (1871), 4293. It has the breeding establishment of the Amrita mahal, a select breed of draught cattle, said to have been formed by Hyder Ali for military purposes, and still kept up by the British Government.

HUNTER, ALEXANDER, M.D., a medical officer of the Madras army, who about A.D. 1851 founded the first school of industrial arts seen in India, and, with much devotion and self-sacrifice, by the year 1871 he had taught one or other branch of art-drawing, pottery, etc.-to upwards of two thousand young men, all of whom had found ready employment. His success led to the formation of several other schools of art in other parts of India. He devoted much of his attention to the manufacture of fibres from the plants of the south of India, and to the discovery of minerals useful in the arts.

HUNTER, Dr. W. W., LL.D., C.I.E., a Bengal civil servant, author of Rural Life in Bengal,
Comparative Dictionary of the Non-Aryan Lamguages of India, London 1868 . He was Statistical Officer to the Government of India, compiled in 18 volumes the Statistical Report of Bengal, and, after years of labour, issued the Imperial Gazetteer of India, in 9 volumes. The work is one of administration, and is the necessary complement of the transfer of India from the Company to the Crown. During the E. I. Company's rule it had several times been projected. Dr. Hunter in his preface names ten persons who were his assistants. He wrote also Orissa in 2 volumes, and also a life of Lord Mayo. His varied talents were utilized by being nominated a member of the Council of the Governor-General of India, and was employed in 1882 to ascertain the state of education amongst the people.

HUNTERIA CORYMBOSA. Roxb. A tree of Penang. This and H. Zeylanica, Thw. (Maddeya, Singr., the Cameraria Zeylanica of Retz), are supposed by Colonel Beddome to be the same. The timber is very fine and close-grained, and very similar to boxwood; it answers well for engraving.-Beddome, $F l$. Sylv. part xxiii. p. 265.

HUNTING LEOPARD, or Hunting Cheeta, Felis jubata. These animals live mostly in the plains, where they hunt deer or antelope in parties of four or five together, in the same manner as the wolves do, secreting themselves in bushes at different points, while one of their number chases the buck. On its passing the ambiscade, they pounce out on the little gazelle, or take up the running in turns as it races past them.

HUNZA-NAGER are two adjoining towns, and include a small tract of country on the upper course of a large feeder of the Gilghit river, having an area of 1672 square miles.

$\mathrm{HU}-\mathrm{PEH}$ is the northern division of the ancient province of Hu-kwang, and is bounded on the N.W. by Shen-si, on the S.E. by Ho-nan, on the E. by Ngan-hoei, and the W. by Sze-chuen. Its population is about 27 millions. Hu-nan is the southern division of $\mathrm{Hu}-\mathrm{kwang}$, and is larger than the northern portion just described, but it is not so thickly populated.

HURA CREPITANS. Linn. The sand boxtree, a middle-sized tree of rapid growth, native of tropical America. The trunk is strongly armed, the wood light and useless. The sap of the leaves and trunk is so very poisonous, as to produce blindness in a few days after touching the eye. Seeds a violent, drastic, dangerous purgative.-M. E. J.R.; Voigt.

HURALA. CAN. Four sorts of Hurala, lampoil seed, are grown in Mysore-M. $E$. of 1857 .

HURDAH. HIND. A parasitic fungus in the form of an orange-coloured rust. It is of the genus Trichobasis; it attacks growing wheat and barley.

HURDI-MURDI, in Persia, is a term employed to designate all the trifling but necessary articles which travellers fling in small bags, and carry across the saddle on a journey, in order to have them at hand.

HURDOUR or Hardaur is the name given in Hindustan to the oblong mounds raised in villages, and studded with flags, for the purpose of averting epidemic diseases, and especially the cholera morbus. It is called after Hurdoul Lala, the son of Bursing Deo, from whom are descended the rajas of Duttea. The natives have a firm persua- 
sion that the cholera broke out in Lord Hastings' camp, in consequence of beef having been killed for the European soldiers within the grove where repose the ashes of this Bundelkhand chief. His worship prevails throughout the Upper and Central Doab, a great part of Rohilkhand, and to the banks of the Sutlej. To the eastward the worship of Hoolka Devi (the goddess of romiting) has been prevalent since the same period.--Elliot.

HUREE-HARA. SANSK. Both words are derived from Rhree, to take away, possibly the source of the English word to harry.

HURINGATTAH, an entrance to the Ganges, on the west of Rabnadab Island.

HUR KI PAIRI, sacred steps leading down to the Ganges.

HURMUL SEED, Lahuri hurmul, HiND. The Harmalæ semina are seeds of Peganum harmala, grey, small, pyramidal, and triangular, and used as rue.-O'Sh.

HUR-PUJA or Har-puja, amongst the agricultural races of India, the worship of the plough. This takes place on the day which closes the season of ploughing and sowing. It generally occurs in the month of Kartik, but in some places is held both after the kharif and rabi sowing, i.e. in the months of Sawun and Kartik. The plough is washed and decorated with garlands, and to use it or lend it after this day is deemed unlucky. The practice reminds of the Fool-plough in England, a ceremony observed on the Monday after Twelfth Day, which is therefore called PloughMonday, on which occasion a plough adorned with ribbons is carried about, and the peasants meet together to feast themselves, as well as wish themselves a plentiful harvest from the great corn sown (as they call wheat and rye), as well as to wish a God-speed to the plough, as soon as they begin to break the ground to sow barley and other corn.-Br. Ap. ii. No. 92, Elliot's Sup. Gloss.

\section{HURRICANES.}

Tufan, - ARAB., Hind. Tund-howa, . . Hind. Mou being, Burv. Gird-bad, : . Pers. Typhoon, Tyfoon, E ENG. Huracm, . . SP. Orkun, . Gersr. Kyar, . : Terk.

Hurricanes have been investigated by Colonel Capper, Quartermaster - General of the Madras army, Mr. W. C. Redfield of New York, Dr. Thom of the British army, Colonel Reid, Mr. G. T. Taylor of Madras Observatory, and Captain Piddington of Calcutta. A hurricane means a turning storm of wind blowing with great violence, and shifting more or less suddenly, so as to blow half or entirely round the compass in a few hours. The present state of our knowledge seems to show that, for the West Indies, the Bay of Bengal, and the China Sea, the wind in a hurricane has two motions, the one a turning or veering round upon a centre, and the other a straight or curved motion forward, so that it is both turning round and rolling forward at the same time. It appears also that, when it occurs on the north side of the equator, it turns from the east, or the right hand, by the north towards the west, or contrary to the hands of a watch; and in the southern hemisphere, that its motion is the contrary way, or with the hands of a watch. Piddington's first memoir, with the charts and diagrams, showed that this rule held good for the storm of June 1839 off the Sandheads, and that the wind was really blowing in great circles in a direction as described, i.e. against that of the hands of a watch. He assumed, then, that the hurricanes in the Bay of Biscay always follow this law.

The tyfoons and storms of the China Sea and eastern coast of Asia appear to be similar in character to the hurricane of the West Indies and the storms of the United States coast, when prevailing in the same latitudes. A tyfoon which occurred in the China Sea in 1831, affords probable grounds for connecting the hurricane at Manilla, October 23-24, with that of October 31 at Balasor, on the shores of the Bay of Bengal.

Of 61 hurricanes that occurred north of the equator, from 1830 to 1854 , their numbers werein the month of October, 12; May and November, 9; September, 8; April, August, and December, each 5; July, 4; June, 2; and March, 1 . In the Bay of Bengal the hurricanes usually occur at the changes of the monsoons, in April and May, and in October, November, and December.

The S.W. monsoon prevails north of the equator, and when it prevails, the S.E. trade-wind acquires additional strength from the demand made upon it to supply the S.IV. monsoon, these two winds being apparently one system under the influence of the earth's rotation and the high temperature which prevails in the northern hemisphere.

Gales and hurricanes occur in the Indian Ocean south of the equator. Trade-wind gales occur at all seasons, but chiefly in June, July, and August. In these the wind veers but little. In the extratropical gales, between lat. $30^{\circ}$ and $45^{\circ} \mathrm{S}$., the wind veers much, and in the tropical burricanes the winds veer and shift.

South of the equator, hurricanes occur in November and May, and travel to the W.S.W., and afterwards, but not always, to the S. and S.E., the wind invariably moving round a central space (which is usually characterized by a calm) from left to right, or with the hands of a watch; while the storm, which has a diameter of 1 to 1500 miles, moves onwards at the rate of 1 to 20 miles, but more frequently 4 to 7 miles an hour, for a period varying from a few hours to ten days, attended with torrents of rain, and its northern half often with lightning. Dr. Thom showed that south of the equator these rotatory storms are always generated between the N.W. monsoon and S.E. trade-wind. They occur only during the S.W. monsoon months, and their rise and progress are intimately connected with the S.E. trade-wind and N.W. nonsoon, two opposing winds. With ships, the safest course is to lie to and watch the barometer and wind, till the bearing of the centre be known with some certainty.

Of those who have resided at Mauritius, who have earnestly studied and discussed the laws which govern these storms, may be mentioned Dr. Thom, Lieutenant Fryers, Royal Engineers, Mr. Sedgewick, who published a little work, which he called The True Principle, and Mr. Bosquett, of the Observatory at Mauritius, who translated into French Piddington's Hornbook, with annotations of his own, and who claimed to be able, by careful and constant meteorological observations, to foretell the occurrence of hurricanes in the Indian Ocean, and to describe the course they will take. The chart in Piddington's Hornbook shows that these cyclones never extend to the northward of $10^{\circ}$ or $12^{\circ}$ south latitude in the meridian of Mauritius. Therefore vessels leaving the island in the 
hurricane season for any part of India, should steer to the northward, passing well to the westward of the Cargades, a most dangerous group, thus keeping a clear sea open to the westward, that there may be nothing in the way should it be desirable to run to the northward and westward, which would be the true course to take in case of encountering the south-western or northwestern quadrants of a cyclone (of which in the hurricane season a vessel from Mauritius is in danger), and this course she should keep until she is sufficiently far north to be beyond its influence.

Of the more remarkable occurrences, that at the mouth of the Ganges, on the 7th October 1737, was attended by a violent earthquake, and extended 60 miles up the river; 20,000 craft of all descriptions were destroyed, - amongst them, 8 English ships and all their crews,-and 300,000 souls are said to have perished in Lower Bengal, or in the bay. The river rose 40 feet above its usual level. An English church and steeple sank into the earth the next morning.

On 4th October 1739 , a cyclone occurred at Ganges mouth, in which 30,000 lives were lost.

Madras has been subjected to severe hurricanes, generally in the early part of May or the end of October. They seem to travel up from the E.S.F., and progress rapidly in a W.N.W. direction till they touch the land, and then they assume a westerly or sometimes W.S.W. course. Their centres generally come right on to the port of Madras. A hurricane has seldom been known to extend south of Porto Novo, 120 miles from Madras (out at sea they are met with as far south as Ceylon), or north of Nellore, 100 miles from Madras. Their diameters are about 150 miles, and they revolve in a direction contrary to the hands of a watch. When the hurricane's centre comes right on to Madras, and there takes a west course, the wind is first at $N$., increasing in violence for a few hours, and then a lull or perfect calm for half an hour or so, when the hurricane recommences furiously from the exactly opposite quarter, south. This is in accordance with the theory of cyclones. Usually the gale commences about N.N.W., showing that the vortex of the cyclone bears about E.N.E. Vessels, therefore, warned by the barometer, the hollow breaking surf, the threatening sky, and the signals of the master attendant, should at once put to sea (having previously close-reefed and sent down top-hamper). The course to steer, and fortunately it is one which the wind assists, is S.S.E. to S.E. In a few hours the vessel will probably have the wind moderate at west, and may-in fact it has been done-sail round the cyclone, the wind veering to south and then to east. Vessels at first steering east to get away from the land have run right into the vortex of the hurricane. The only danger in a southerly course is from the stormwave setting the ship on shore. If the lead give notice of this, the ship must be hauled up more to the eastward.

If the gale commence N.N.W. at Madras, and end at S.E., as has often happened, it shows that the centre has taken a W.S.W. course, and passed a little to the south of the town; but if it end at S.W., it shows that the centre has taken a W.N.W. course, and the vortex passed to the north of Madras.

In the earliest notices that we have of hurri- canes on the Madras coast, - at least of those of which we have any record, - was that of the $3 d$ October 1746, twenty-three days after the surrender of Madras to $M$. de la Bourdonnais. On the $2 \mathrm{~d}$ of October the weather was remarkably mild during the whole of the day, but about midnight a most furious tempest arose, which continued with great violence till noon of the following day. When it began there were six large French ships in the Madras roads, and some smaller ones. The Duc d'Orleans, Phonix, and Lys put to sea and foundered, and in them upwards of twelve hundred men were lost. The Mermaid and Advice, prizes, shared the same fate. The Achille (the flag-ship of M. de la Bourdonnais) and two other vessels of war were dismasted; and they had shipped so much water that the people on board expected them to go down every minute, nothwithstanding they had thrown overboard the lower tier of guns. Of twenty other vessels belonging to different nations in the Madras roads when the storm began, not one escaped, being either wrecked or lost at sea. The ships which were at anchor in the road of Pondicherry felt nothing of this hurricane.

Another hurricane occurred off Cuddalore on the 13th April 1749. (It is rare to meet with hurricanes before May.) The English army were then on their march to Tanjore, to set Sahoji on the musnud and depose Pretaub Singh. Admiral Boscawen had agreed to send some ships to escort the troops, cannon, and stores to the place at which they designed to disembark them, which was at Devicottah, south of the Colerun river. A dreadful hurricane at N.N.W: came on on the night of the 12th of April, and continued all the next day. Its greatest violence was between eight at night of the 13th, and at two the next morning, shifting round from the northward to the east, till it came to the south, where it ended. In this storm H.M. ship the Pernbroke (one of those appointed for the above service) was driven ashore and wrecked on the Colerun shoal, a little off Porto Novo. The captain, all the officers (except the captain of marines and purser, who were ashore on leave), and 330 men were drowned, only 12 men being saved. In the same storm the 74 gun ship Namur (Boscawen's flag-ship) foundered in shoal water, not far from Devicottah. The first, second, and fourth lieutenants, master, gunner, two lieutenants of marines, and 520 men were drowned; only two midshipmen and 24 men were saved. The admiral, captain, and some other officers were on shore. The Lincoln and Winchelsea, E.I.C. ships, were likewise wrecked off Fort St. David, but the crews were saved. Almost all the small vessels that were near Fort St. David were lost. H.M. ships Tartar and Deal Castle, together with the Swallow sloop, being at sea, and more to the southward, did not feel the tempest in that violent degree with which it raged near the coast, but they were all dismasted. The rest of the fleet were fortunately at Trincomalee. The English camp was at that time some miles from Porto Novo, and was so devastated that the army were obliged to march to Porto Novo for equipage.

Orme mentions a hurricane on the 31 st October 1752 , as the most violent that had been remembered on the coast.

The new year of 1761 was ushered in with a most violent hurricane at Pondicherry. At this 
time the British were laying siege to that town, and the fleet were in the roads intercepting all succour by sea. When the storm began, Admiral Stevens had with him eight sail of the line, two frigates, a fire-ship, and a ship with stores. From 8 P.M. of the 31st December, till 10 P.M., there was a constant succession of very heavy squalls. About 10 P.M., Admiral Stevens, in the Norfolk (having for his captain the gallant and unfortunate Kempenfelt), was forced to cut his cable, and made the signal for the squadron to do the same. But the noise and violence of the gale was such that no guns could be heard or signals observed. The other commanders accordingly obeyed previous orders, and continued at anchor, till at length their vessels parted, and then with the greatest difficulty they got their ships before the wind, with scarce any sail set. The gale continued to increase until midnight, by which time the wind had veered from N.N.W., where it began, to the N.E., and in an instant it was succeeded by a calm, attended by a thick haze. This was of short duration, for in the space of a few minutes the storm burst from the S.S.E., and raged with redoubled fury. Had the squadron got under sail and proceeded to sea early, they would have had an opportunity of gaining sufficient sea-room before the storm came from the S.E. The first gust of this fresh hurricane laid the Panther on her beam-ends, when, the sea breaking over her, Captain Affleck ordered the mizzen-mast to be cut away. This not relieving the ship, he ordered the main-mast to be cut away likewise; it broke below the upper deck with such force that it tore it up, and the mast and rigging hanging over the side, continued to encumber the ship for a considerable time, until a heavy sea cleared them. The ship then righted, and, the reefed foresail having withstood the violence of the gale, by means of it they got back in fourteen fathoms water, and there let go the sheet anchor; but not bringing up, they cut away the fore-mast, the fall of which carried away the bowsprit, when the ship came round, and in this manner rode out the storm. The America, Meduay, and Falmouth were dismasted, and, after much distress, came to an anchor near the Panther. But it did not fare so well with the Nevcastle, the Queenborough frigate, and the Protector fire-ship, who, scudding before the S.E. gale, mistook their soundings, and drove towards the shore without endeavouring to come to an anchor. The roaring of the wind prevented them from hearing the noise of the surf till it was too late. All three came ashore about two miles south of Pondicherry. Of their crews only seven perished, who were dashed overboard by the violence with which the ship struck when they took the ground. A more miserable fate attended the Duc d'Acquitaine, the Sunderland, and the Duke store-ship. Their masts withstood both hurricanes, but they were driven back by the S.E. tempest, and were under the necessity of anchoring; when, bringing up with all their masts standing, they broached to, and either capsized or foundered. The crews, in number eleven hundred, perished, except seven Europeans and as many lascars, who were next day picked up floating on pieces of wreck.

On 21st October 1763, a cyclone occurred at Madras, which lasted 14 bours; all the ships driven on shore were stranded.
On the 21st October 1773, a violent hurricane visited Madras. It began at N.W., and ended with the wind easterly. (It must have travelled S.W., and the vortex passed south of Madras.) The men-of-war put to sea early, but all the vessels that remained at anchor were lost, with the crews.

The next hurricane of which we have to notice, is that of 1782. The weather had been threatening, and when it came on to blow, on the 20th October, the boats belonging to Sir E. Hughes' squadron (then in the roads) were on shore with their crews, on duty. The gale commenced at N.W., and every vessel that could bear canvas, put to sea. Most of the men-of-war boats put off to their ships, which were getting under weigh, and were reached with difficulty by the larger boats, and some of the smaller; but some boats were unable to reach their vessels, and were lost. The Superb was dismasted, and the Exeter was almost rendered a wreck. Sir Edward Hughes was obliged to shift his flag to the Sultan. Both the Superb and the Exeter got to Bombay with jury-masts. The Neckar (a country vessel) lost her main-mast, and some vessels foundered at their anchors. The morning following the hurricane presented a sad spectacle,-upwards of a hundred small country vessels stranded on the beach, the whole remaining stock of rice in the warehouses washed away, famine raging, and pestilence threatening! For the ravages of Hyder had driven thousands from the country to Madras, where already there had been great suffering for want of food. Upwards of 1000 corpses were buried every week for several weeks, in large trenches outside the town. The Governor (Lord Macartuey) used noble endeavours to mitigate the calamity, and set an example by sending away all his own horses and servants. Hyder was at Pondicherry, and the admiral's fleet gone! Ships, however, came in laden with grain from Bengal: Hyder Ali died in December, and the hopes of the British revived.

The records of the Madras Observatory notice a heavy gale on the 27 th October 1797. The barometer did not fall below $29 \cdot 465$.

A hurricane occurred at Coringa and Masulipatam on the 28th October 1800.

On the 4th December 1803, H.M.S. Centurion (of 50 guns, bearing the flag of Admiral Rainier), on her passage from Trincomalee to Madras, experienced a violent hurricane, which left her with nothing standing but the bowsprit, and had nearly proved her destruction. The gale commenced about midnight; at 11 A.M. on the 5th, the wind flew round in a violent gust to the southward, and till 6 P.M. it was blowing a hurricane. H.M.S. was so severely strained, that she had 8 feet of water in her hold, and her upperdeck guns were obliged to be hove overboard. Jury-masts were rigged, and on the 11 th the Centurion anchored in the Madras roads. H.M.S. Albatross was dismasted in the same storm, and put in at Negapatam to refit.

Madras suffered from another hurricane on the 10th December 1807. Fortunately there was only one vessel in the roads when the storm commenced, and she put to sea. To show the effect of the storm-waves, it may be mentioned, from the testimony of an eye-witness (Captain Biden) that the bottom of a ship of 800 tons, supposed to 
have been burnt in the roads about ten years before (in 1797), was washed high and dry on the beach near Parry's office; the whole of her floor was perfect, with a large quantity of her ballast (pigs of iron kentledge). The devastation along the beach and in the town and suburbs of Madras was very great. It was during this hurricane that there occurred an extraordinary rise of the tide, which inundated the whole of Black Town.

Another very disastrous hurricane occurred on the $2 \mathrm{~d}$ of May 1811. Providentially the fleet, with the troops for the attack of Java, had just sailed. The Dover frigate and Chichester storeship remained in the roads; they parted, and were lost. Ninety country vessels went down at their anchors. Only two vessels that were in the roads when the hurricane set in, were saved, and these put to sea. During this hurricane the surf broke in 9 fathoms of water, four miles from shore!

On the 24th October 1818, Madras again suffered. The wind commenced at north, and, after increasing in violence, suddenly lulled, and as suddenly flew round furiously to south. This hurricane travelled west, and its vortex passed over the town. The barometer fell to $28 \cdot 78$.

On the 9 th October 1820 , there was a hurricane commencing at N.W., veering to W. and S.W. The barometer fell to 28.50 . Here the cyclone travelled west, and passed to the north of Madras.

On the 30th October 1836, a gale set in from north. At 4 P.M. it blew a regular hurricane from N.N.W. and N. After an ominous lull of half an hour, it flew round with redoubled violence from the south, at half-past seven P.M. At this time the barometer was $28 \cdot 285$.

On the 29th October, at noon, it had been 30.050 30th October, at 6 A.M., . . . . 29:940 30th October, at noon, : : : 29707

30th October, at 5 P.м., . . . . 28.891

30th October, at 7.30 P.M., . . . 28.285

At" midnight, when the gale broke, : : 29415

A storm causing great loss occurred at Bombay on the $15 \mathrm{th}$ June 1837 .

In November 1839 , a hurricane occurred off Coringa, when a storm-wave laid the shore 8 feet under water. 70 ships and 700 people were lost at sea, and 6000 perished on shore.

In October 1842, there was a heavy gale at Madras, but hardly considered a hurricane.

In May 1843, another hurricane occurred at Madras. On this occasion the brunt of it was felt out at sea, and several vessels were lost. Those that remained at their anchors rode it out.

The next hurricane at Madras took place on the 25th November 1846; during it the pressureplate of the Observatory anemometer broke, at a pressure of $40 \mathrm{lbs}$. registered; and the force of one heavy gust was computed at $57 \mathrm{lbs}$. per square foot! The large iron wind-vane of the Observatory was bent to a right-angle; and one of the lat piers on the Elphinstone bridge blown over. These formed the data for computation. The previous month there had been an unprecedented fall of rain ( $20 \frac{3}{4}$ inches in 24 hours). Had the hurricane set in before the soil had dried, not a single building or tree in Madras would have remained upright.

On 19th April 1847, a violent hurricane extended from the equator to Sind. It was severe at Ratnagherry; the Maldives were submerged, followed by severe famine. The Cleopatra was lost in this.

A destructive storm occurred at Bombay on the 2d November 1854.

In July 1780 , during a tyfoon in the China Sea, about 100,000 people perished.

A tremendous hurricane, with an inundation caused by a storm-wave, occurred at Cuttack and around Culcutta, on the 30th November 1831.

On the 31st October 1831, 300 villages and 11,000 people were swept away in Lower Bengal by inundations, followed by a famine; and the loss of life was estimated at 50,000 souls.

On the 21st May 1832,8000 to 10,000 people perished in the delta of the Ganges.

On the 8th October 1832, a furious storm and disastrous inundation occurred around Calcutta, followed by great sufferings at Balasore-- $\boldsymbol{M r}$. Meldrum in Pro. Brit. Assoc., 1867 ; Pharoah's Gazetteer of S. India; Dr. Buist in Bo. Geo. Tr., 1856 ; Piddington, Law of Storms, p. 524; American Expedition to Japan, p. 137. See Cyclone.

HURTAL. Persulphuret of arsenic, orpiment. There are two kinds, viz. gobhari hurtal, in yellow flakes, used in oil-painting; one seer costs Rs. $1 \frac{1}{4}$. Tabki hurtal, greenish, crystallized, given by fakirs in fumigation. One ruttee of it is wrapped up in a leaf of muggar-bel, and smoked in a hookah. It is evident that the smoker only escapes dangerous consequences, owing to the heat volatilizing most of the arsenic; as it is, the little inhaled often makes the person senseless. Salt is then given to restore the senses. Thus employed, tabki hurtal is considered a most powerful aphrodisiac. It is also used in ointment; costs three rupees for one seer.-Genl. Med. Top. p. 137.

HURUT or Harat, a Persian wheel for drawing water from a well; a corruption of Ruhut or Arhut.-Elliot, Supp. Gloss.

HUSAIN ALI KHAN, KIRMANI, author of History of the Reign of Tipu Sultan, translated by Colonel W. Miles, London 1844.

HUSAIN - bin - ALI - ul - VAIZ, surnamed Kashif. He translated the fables of Bedpai from the Arabic of Ibn Makaffa, and named them Anwar-i-Sohaili, or Lights of Canopus.

HUSAIN GORI, the first of the Gori dynasty, succeeded to the throne of India in A.D. 1157 (other authorities say 1151 or 1155 ), by deposing Khusru Shah, the 13th and last of the Ghaznavi kings. Mahmud, the nephew and successor of Shahab-ud-Din, was the fifth and last of the Gori dynasty. He imparted little influence on India. He had attacked the king of Kharasm at Takash, and subdued the Ghikar tribe; but in A.D. 1206 , while returning to Ghazni, he was assassinated by two of his own tribe,-according to Orme in 1212, and another authority gives 1214 .

HUSAINI. HIND. A kind of grape, the large sweet kind that are packed in boxes, and sent from Kābul in the cold season.

HUSAINI BULBUL, also called the Shahbulbul, is of the sub-family Myagrinz, and is known also as the paradise fly-catcher. It is of a chesnut colour for many months, but becomes white in the breeding season, in its plumage des noces. It is a very graceful bird, with very long tail feathers, and it is a pretty sight to see it flitting from tree to tree; how the birds prevent the long tail feathers from becoming entangled in the thorny trees, is difficult to understand. 
In Ceylon, the bird in its chesnut dress is called the fire-thief, and the white bird the cotton-thief; it is also called the sultana bulbul. Its colouring is chaste. Mr. Layard has often watched them, when seeking their insect prey, turn suddenly on their perch and whisk their long tails with a jerk over the bough, as if to protect them from jnjury. It is common about Madras. It is the Tchitrea paradisi, Linn.; and Europeans call it also the bird of paradise.Tennant's Ceylon, p. 249.

HUSAN YUSUF of Lahore is the silicious frustule of one of the Diatomacer. It is of a pyramidal form with a convex base, and on each triangular face is a prominent rounded knot; these markings are not affected by acids, and remain after heating to redness. When heated in a reduction tube, it gives off a peculiar smell and combustible gas, showing that it is quite in a fresh state, otherwise it appears somewhat similar to a fossil. Husan Yusuf is collected in lakes and ponds in the hills around Srinuggur in Kashmir. It floats on the surface, and is skimmed off and dried.-Powell's Handbook, p. 320.

HUSANZAI. Between the extreme northern frontier of the Hazara district and the Indus, there lies a somewhat narrow strip of rugged and mountainous territory; this is inhabited by the Husanzai, who therefore dwell in Cis-Indus, that is, on the left bank of the river. They could number, perhaps, 2000 fighting men. The principal bill is known as the Black Mountain, from its dark and gloomy aspect. In the adjoining tract, within the Hazara border, lies Western Tournouli, the fief of a chief politically dependent on the British.

HUSBANDRY, Agriculture, Tillage.

Zarāat; Fallahat, ARAB. | Kheti bari, . . BENG. Amongst the Chinese, and with several of the races in India, husbandry is considered an honourable avocation ; but Rajputs, Brahmans, and Mahomedans in India deem manual labour derogatory. Husbandry and silk-weaving were the earliest of the arts cultivated by the Chinese people. The former was introduced by Shin-nong, the immediate successor of Fo-hi, and the silk-weaving by an empress: and to both of these benefactors the Chinese perform annual sacrifices on their festival days. With them, husbandry is still bighly honoured; and annually, at a grand festival in honour of the spring, the emperor ploughs and sows part of a field. The ancient Egyptians, Persians, and Greeks held games and festivals, mingled with religious ceremonies, at seed-sowing; and in Enyland, formerly, the festival of Plough Monday was held, during which the plough-light was set up before the image of the patron saint of the village.

The Chinese annual ceremony at Pekin consists in ploughing a sacred field with a highly ormamental plough kept for the purpose, the emperor holding it while turning over three furrows, the princes five, and the bigh ministers nine. These furrows were, however, so short, that the monarchs of the present dynasty altered the ancient rule, ploughing four furrows, and returning again over the ground. The ceremony finished, the emperor and his ministers repair to the terrace, and remain till the whole field has been ploughed. The ground belongs to the temples of heaven and earth, on the south of the city, and the crop of wheat is used in religious services. The rank of the actors renders the ceremony more imposing at Pekin, and the people of the capital make more of it than they do in the provinces. A clay image of a cow is carried to the spot, containing or accompanied by hundreds of little similar images; after the field is ploughed it is broken up, and the pieces and small images are carried off by the crowd, to scatter the powder on their own fields, in the hope of thereby ensuring a good crop. The heads of the proviucial governments, the prefects and district magistrates, go through a similar ceremony on the same day. In Ningpo, the principal features of the ceremony consist in a solemn worship, by all the local officers, of a clay image of a buffalo, and image of a cowherd. The prefect then ploughs a small piece of ground, and he and his associates disperse on the morrow. They come together in another temple at dawn, where a series of prostrations and recitals of prayers are performed by the fathers of the people in their presence. So soon as this is over, the clay ox is brought out, and all the officers pass around it repeatedly in procession, striking the body at a given signal, and concluding the ceremony by a heavy blow on the head. The crowd then rush in and tear the effigy to pieces, each one carrying off a portion to strew on his fields.

In British India, until after the middle of the 19 th century, the Kandh race sacrificed human beings to the earth goddess, with ceremonies identical with those practised by the Chinese and their clay bullock.

Most races have had some religious ceremonies at seed-time or harvest; and to the present day, amongst most of the Hindu races of British India, at the close of the ploughing and sowing season, either in the spring or autumn, the plough is worshipped. It is their Har-puja.

The Kuur-mundla of the Hindus in Northern India, meaning the closing of the furrows, is a naine given to the day on which the sowing is completed, but also called Kuur-boji and Hariur, and in the north-west Dulia jhar or Pulia jhar, meaning the cleaning out of the sowing basket,-Kuur-boji meaning the filling of furrows. The day is a festival. The plough is decorated; the residue of the seed-corn is made into a cake, which is partaken of in the open field, and part of it given to Brahmans and beggars. It is the seed-cake of the farmers of England, mentioned by Tusser:-

"Wife, some time this weeke, if the wether hold cleare, An end of wheat sowing we make for this yeare:

Remember you, therefore, though I do it not,

The seed-cake, the pasties, the fermenty pot.'

The plough, the hoe, and from time immemorial the drill, have been the chief agricultural implements of the Hindus, of whom about 70 per cent. are engaged in husbandry. Their ploughs for breaking up new ground are very heavy, and are drawn by two to eight team of bullocks, as the nature of the soil demands; but one pair of bullocks, with a very light plough, suffices for cultivated land. In rice-fields buffaloes are used.

The plough of the Hindus for their lighter soils is a naturally crooked branch of a tree, with an iron plate as a share or coulter. The cow is never put to labour by the agricultural Hindu, the only race who so employ it being the homeless wandering 
Brinjari. In Malay countries the plough is usually drawn by one or two buffaloes, which are peculiarly adapted for the wet land culture of rice, to which the use of the plough is almost exclusively confined, the chunkal or large hoe being employed in turning up the soil in plantation culture. When the light plough of the Hindu farmer is used, there is a mere seratching of the soil, but it is finely pulverized by repeated cross traversing. This form of cultivation has been denounced by most of the Europeans who have written on the subject; and Mr. Robertson, of the experimental farm near Madras, constructed a light plough of the shape in use in Britain, to be substituted for that of wood which is now in use. But in all such substitutions the point which presents itself as difficult to meet, is the feebleness of the dranght cattle. The plough of India is doubtless defective, but it is suited to the draught cattle at their command; and by going over and over the ground and making repeated stirrings, they eventually get down to a depth of $4 \frac{1}{2}$ inches, or about half an inch less than an average lea ploughing in Britain.

The Chinese have a machine which cuts up both the soil and the trefoil roots. It consists of a strong wooden frame with three cross bars, into which are fixed two rows of strong concave knives. A bullock is yoked to the machine, and, with the driver standing upon it, it is urged through the soil in all directions.

The drill husbandry of Mysore cannot be excelled. Their drilling-machine sows thirteen rows at a time, with the greatest regularity; and their bullock hoe, with blades which pass between the drills, eradicates weeds when the plants are a few inches high, and freely and effectually stirs the soil.

In British India, the arable land is held by three distinct tenures. Sir William Muir has described three broad distinctions in the title under which land was found by the British originally, to be owned or managed throughout various parts of India, viz. ryot occupancy or proprietorship, official zamindarship, and village proprietorship.

The first signifies that the ryot is the hereditary occupant or owner of his own individual bolding. 'The last, village proprietorship, signifies that one or more persons, or a body of coparceners, possess proprietary rights over all the lands (including waste) contained within the boundaries of their village or estate; village proprietors may be either talukdars, zamindars, pattidars, or members of a proprietary and cultivating brotherhood. At the time that the British assumed supremacy, ryot proprietorship prevailed in the south of India, official zamindarship in Bengal, and village proprietorship in the N.W. Provinces.

It may be added, that on the N.W. Frontier are tribal tenures; and in Hazara, Peshawur, and partly in Dehra Ismail Khan, there is a periodical redistribution of the holdings amongst the tribes, known as Waish or Vaish. In Bannu, the island is held in tals, the area of the tribe; in darra, the holding of a group of families; and lich'h, one family holding. In Dehra Ghazi Khan, each member of the tribe holds his own share.

From the time of the census of 1871 , husbandry of India has been attracting great attention, because the population has been increasing more rapidly than the means of subsistence. Also, two-fifths of the revenue of British India are derived from the land; and as the Govern- ments of India and the cultivating tillers of the soil are to a great extent joint proprietors of the land, it is felt to be the duty of the state to instruct their partners, and within their state rights to prevent exhaustion of the soil. So far as experience of a century teaches, there are, taking the entire country, two bad years to every seven good ones; the average population affected in each instance is about twenty millions; and the result may accordingly be said to be equivalent to a famine over the whole country nearly twice in a century. Each of the great provinces, except Bengal, is visited with drought at intervals averaging eleven or twelve years, and with famines of exceptional magnitude at intervals of about fifty years. Bengal enjoys far longer periods of immunity, and, except in one or two localities, is wholly exempt from this visitation. Judging from the past, the largest population ever likely to be simultaneously famine-stricken is about thirty millions; and of these, $4 \frac{1}{2}$ millions will need assistance during the months of greatest distress, and an average of $2 \frac{1}{2}$ millions for an entire year.

How to prevent the soils of India being: exhausted, is becoming an increasing subject of thought. With the exception of irrigated lands, little manure is employed in India. The principal food-crops are neither manured nor irrigated, and so long as moderately good soils were being tilled, a rude system of husbandry sufficed to meet the wants of cultivators; but now that by the pressure of population inferior soils are being taken up, it is necessary that an improved system of agriculture should be adopted. At present the farm cattle not at work are rarely if ever fed; the cows and calves are half-starved, and little milk is obtained. Draught bullocks are partially fed. But fodder grasses are never cultivated; and the want of power in the draught cattle is a great cause of defective tilling. It is acknowledged that with care produce can be greatly increased. Messrs. Lawes and Gilbert at Rothamsted, for 24 years grew wheat on unmanured and manured land. Unmanured land yielded only 12.4 bushels per acre, weighing 57.4 lbs. the bushel; land receiving yearly 14 tons of farm-yard manure yielded $34 \cdot 1$ bushels per acre, weighing $59 \cdot 3 \mathrm{lbs}$. But the average produce per acre, on a series of observations extending over ten years, in several districts of the Bombay Presidency, was found to be as follows :- Wheat, 9 bushels, 585 lbs. ; juari, 10 bushels, 650 lbs. ; bajri, 6 bushels, 390 lbs.

In the Dehra Doon the produce from wheat cultivation was found to average $1260 \mathrm{lbs}$. per acre; and at the Sind experimental farm, bajri (Penicillaria spicata) has yielded as much as 1420 lbs. per acre.

In the Nile valley the yield of wheat is from 8 to 20 fold; barley, 4 to 18 fold; maize, 14 to 20 fold; Sorghum vulgare, 36 to 48 fold.

The Famine Commissioners in their report (ii. p. 72) give the following as the produce of food-grains per acre in several parts of British India :-

Panjab, N.W. Provinces and Oudh, and Bengal, 13 Central Provinces, . 8 Berar, * 6 Bombay, excl. Sind and N. Canara, Madras and Mysore, 11 1 busliels, or 0.29 of a ton per acre.

8
6
7
11

$\begin{array}{llll}\text { " } & 0.36 & , & , \\ \text { " } & 0.21 & , & , \\ & 0.16 & , & , \\ , & 0.19 & & \\ , & 0.3 & , & ,\end{array}$


Mr. Morris, Chief Commissioner of the Central Provinces, in his report for $1872-73$ (p. 6), gives the following as the average produce per acre:-

\begin{tabular}{|c|c|c|c|c|}
\hline Rice. & Ibs. & Wheat. & lbs. & \\
\hline Raip & .602 & Sagar, . & 324 & pur, \\
\hline ir. & . 426 & Hoshangabad, & & Wardha, . \\
\hline Balaghat, & - 360 & Jubbulpur, . & 600 & Nagpur, . \\
\hline ara, & $\begin{array}{r}672 \\
448\end{array}$ & $\begin{array}{l}\text { Narsingpur, } \\
\text { Raipur, }\end{array}$ & $\begin{array}{l}400 \\
432\end{array}$ & \\
\hline eoni, & .654 & natpur, & & \\
\hline
\end{tabular}

The area under cultivated crops in India is equal to one acre per head of the population, which increases at the rate of 1 per cent. per annum, equal to two millions yearly. To provide for this increase of numbers, two methods of increasing the production present themselves, viz. progressively to increase the area of cultivated land, and gradually to increase the produce from the land at present cultivated. The equivalent of the two methods are an extension of cultivation by two millions of acres anuually, or an increased produce by one-tenth of a bushel annually from the present acreage. In coming to a decision over these two methods, it is necessary to remark that in British India, the best and most available land has long been occupied. The cultivable area still untouched is great, but is in places remote from population, and requiring much beyond the ordinary capital of an Indian cultivator to bring it into a state of production. The second method has therefore to be chiefly relied on. One bushel of increase per acre, obtained gradually in ten years from the present cultivated area, would meet the demand of a gradual increase in the same time of 20 millions of people. The produce would then have gradually risen from 10 to 20 bushels an acre.

The population in British India is at present, one part with another and one year with another, barely raising more than sufficient food for their requirement, and the Indian Government, in 1883, arranged with the railways to carry grain from one district to another at the lowest remunerative rates; because from certain districts it was being exported, while the population in some parts is even now pressing on the means of subsistence, and is increasing at a rate which is causing anxiety. The increase in Great Britain from 1851 to 1861 was 0.56 per cent. In India it has been stated at from 0.52 in the N.W. Provinces, 0.54 in Bombay, and 0.74 in Madras, and it has been supposed that the normal may be 0.5 and 0.6 . P.P. 1880 , p. 29 .

The population per square mile has been given as under :-

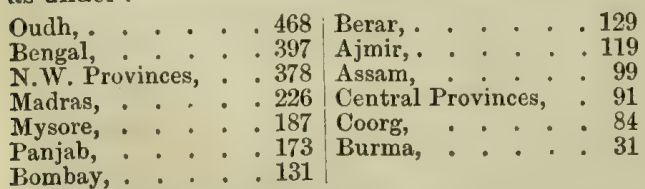

On the average, in all British India, 211 to the square mile,-agricultural, 56 per cent. ; traders, 18 per cent. ; labourers, 16 per cent. ; professional and service, 10 per cent., the labourers being mostly employed on the land.

Between 1850 and 1880,18 millions of acres of waste land had been brought under cultivation in the Madras and Bombay Presidencies, a quantity amounting to 80 per cent. of the area under cultivation in 1850. In the N.W. Provinces, from 1840 to 1880 there was an increase of 6 millions of acres, or 30 per cent. of the area under cultivation in 1840. In British India, the cultivated area for food-crops is a little more than one acre for each individual; in the Panjab, 0.76 of an acre; in the N.W. Provinces and Oudh, and in Bengal, 0.81 ; in Central Provinces, 1.8 ; in Berar, 1.75 ; in Bombay, 1.4 ; in Madras, 0.93 ; in Mysore and Burma, each 1 acre.-F. Rep. p. 73 .

The Famine Commissioners, in their report of 1880 (i. p. 50), assuming the population of British India at $181,350,000$, estimated the area uuder food-crop at $166,250,000$ acres, yielding an outturn of $51,530,000$ tons of food. The ordinary consumption is estimated at $47,165,000$ tons, leaving a surplus of $5,165,000$ tons. The estimated consumption includes food, $37,980,000$ tons; seed, $3,450,000$ tons ; cattle food, 309,000 tons ; and wastage, $2,555,000$ tons.

The famine of 1876-77 affected a population of 36 millions in the Peninsula of India, and in that yeur the crop in Bombay was short of the average by $1 \frac{1}{2}$ million tons, in Madras by $3 \frac{1}{2}$ millious, and in Mysore by 1 million tons.

The subject of Indian husbandry is one of much difficulty. The climates, the rains, and the soils of British India widely differ, and demand from the husbandman the most varied treatment. The lands in the deltas of the Ganges and Indus are annually strewed over with the fine silt which the floods of these rivers bring down in their course from the Himalayas, and cereals and the great millets are grown with little labour; and by varying the crops, the soil in those districts is made to yield three crops in the year. The great volcanic tract of the Dekhan, in provinces reached by the moist winds and rains of the south-west monsoon, and covered for ten and twenty feet deep with the regur or black cotton soil, from unknown times, has yielded once a-year, without manure, one luxuriant erop of wheat, sorghum, or cotton, grown in the open fields, without other care than the ploughing, sowing, and reaping.

The earth nowhere else yields agricultural produce in return for so little labour as in Lower Egypt, and gives back the seed so plentifully. In the lands which the Nile overflows, when the water is partially withdrawn, the fellah, without previous labour, throws the seed from his boat into the wet mud. Their present yield of wheat is from 8 to 20 fold ; of barley, from 4 to 18 ; of maize, from 14 to 20 ; of Sorghum vulgare (darrah), from 36 to 48 fold. A like fertility is repeated in the flats of the deltas of the Indus and the Ganges, where rice crops are grown defying the inundations.

In India, crops known as the kharif are sown from the latter part of May and beginning of June to the early part of August, and are reaped from the latter part of October to the early part of December. And in districts watered by the N.E. monsoon and winter rains, rabi crops are sown from the latter part of August to the early part of November, and are gathered in the spring from the end of February-March to the beginning of April, being brought on by the heavy dews and cool nights and winter showers that prevail during the cold-weather months of India.

The Rice varieties of the Peninsula of India are sown and ripen at different periods. Some of them are sown in July, but most in August. Some 
ripen in four months in November, some in five months in December, and some in six months in January or February.

Of the Oil-seeds, Sesamum orientale is sown in May and gathered in August, and Arachis hypogea is sown in September and gathered in February.

Of the Pulses, Lablab vulgaris, Cajanus Indicus, $P$ haseolus radiatus, and Dolichos catiang are generally grown on lands depending on the natural rains, and their seeds are sown along with the millets. Phaseolus mungo and $\mathrm{Ph}$. max. are sown in July and gathered in January. Cicer arietinum is sown in October and gathered in March. Dolichos cultratus, Phaseolus aconitifolius, and Pisum sativum are sown in December and gathered in February.

For Millets, the ground is ploughed up, and the seeds sown broadcast, in July or August, and reaped in November or December, -

Panicum miliaceum, Willde, or varagoo, in six months ;

Penicillaria spicata, or cumboo, in four months ;

Panicum miliare, or shama, in three months;

Sorghum vulgare and its allies ripen in five months;

Setaria Italica, or tennay, in four or five months.

In Kandahar, the spring or rabi harvest produces wheat, barley, pulses, beans, lentils, madder, etc. The autumn or kharif harvest crops are maize, pulse, rice, beans, carrots, turnips, eggfruit, beetroot, love-apple, tobacco.

In most parts of Afghanistan and in the extreme N.W. of India the crop sown in the end of autumn, and reaped in spring, consists of wheat, barley, Ervum lens (addus), Cicer arietinum (nukhud), with some peas and beans. The other crop is sown at the end of spring, and reaped in autumn, and consists of rice, Panicum Italicum, and P. miliaceum, Sorghum vulgare, Penicillaria spicata Zea mays, and Phaseolus mungo.

The former, the spring harvest, is the most important in the countries west of the Suliman range. The latter, the autumn harvest, called by the Afghans Paniyeh or Tirmani, is on the whole the most considerable. But there are modifications, according to climate. In the Hazara country, and also in all the coldest parts of Afghanistan and the neighbouring states, they sow their only harvest in spring, and reap it in the end of autumn.

In the Kharaoti (Karoti), the Kattiwaz, and some other elevated countries in that neighbourhood, they sow their only crops at the end of one autumn, and reap it the beginning of another.

In Bajawar, Panjkora, in the country of the Upper Nomunds and that of the Utman Khel, wheat is the principal grain sown, and their most important harvest is that which is reaped in summer.

In Peshawur, the Bangash, Jaji, Daman, and Isa Khel countries, the harvests are nearly equal; but in the eastern countries, that which is reaped in autumn is the more important. Wheat is the chief food of the people, though in several parts the millets, Panicum, Sorghum, and Penicillaria spicata are also made into bread. Indian corn heads are eaten roasted as a luxury.

About towns the food - grains mentioned are largely supplemented by their pālez harvest, of musk melons, water melons, various kinds of cucumbers, pumpkins, gourds, grown everywhere in open fields like grain. And in the gardens are grown carrots, turnips, beetroot, lettuce, onions, garlic, egg-plant, spinage, and greens of all kinds, cabbage, cauliflower. Barley is given to horses, and turnips are sown for cattle.

Rice is grown in most parts of Afghanistan, but in very different quantities. In Swat and Peshawur it is most abundant.

Berar is a province in the centre of the Peninsula, which receives the rains of the S.W. monsoon from June to August, and the winter rains of December and January, and its seed times and harvest times are as under. The plants with an asterisk (*) are irrigated :-

\begin{tabular}{|c|c|c|c|}
\hline & & Sown. & Harvested. \\
\hline Abrus precatorius," & & June & November \\
\hline Allium sativum, ${ }^{*}$. & .. & November & March \\
\hline A. cepa,* ${ }^{*}$. & • & Trune" & " Feh \\
\hline $\begin{array}{l}\text { Cajantus Indicus,. } \\
\text { Capsicum annuum, * }\end{array}$ & & $\begin{array}{l}\text { June } \\
\text { June }\end{array}$ & $\begin{array}{l}\text { Jan., Feb. } \\
\text { January }\end{array}$ \\
\hline Chavica betle, * . & & May & in a year \\
\hline Cicer arietinum, & . & October & February \\
\hline Convolvulus batatas, & . & September & February \\
\hline Coriandrum sativum, & & June & January \\
\hline Crotalaria juncea, & & June & October \\
\hline Curcuma longa, & . & July & January \\
\hline Ervum lens, . & . & October & January \\
\hline Gossypium Indicum, & & June & January \\
\hline Hibiscus cannabinus, & & June & Nov., D.ec. \\
\hline Indigofera tinctoria,* & & June & August \\
\hline Lathyrus sativus, . & & October & January \\
\hline Linum usitatissimum, & . & October & February \\
\hline Morinda citrifolia, . & . & June & in 3 years \\
\hline Nicotiana tabacum,. & . & July & December \\
\hline Oryza sativa,* & . & June & Oct., Dec. \\
\hline Panicum pilosum, . & & June & October \\
\hline Papaver somniferum & & October & Feb., March \\
\hline Penicillaria spicata, & & July & October \\
\hline Phaseolus mungo, & . & June & November \\
\hline Pisum sativum, . & & October & January \\
\hline Ptychotis ajwain, & & June & November \\
\hline Sesamum Indicum, & , & $\begin{array}{l}\text { Jan. or lia } \\
\text { August }\end{array}$ & $\begin{array}{l}\text { In } 12 \text { month } \\
\text { January }\end{array}$ \\
\hline Sinapis ramosa, . & . & November & February \\
\hline Sorghum vulgare, & ${ }^{\circ}$ & May, July & July, Dec. \\
\hline Triticuin estivum, & - & $\begin{array}{l}\text { Norember } \\
\text { June }\end{array}$ & \\
\hline & & & \\
\hline
\end{tabular}

In India, diseases and wild beasts cause heavy losses to the agriculturists. On this form of loss the Mysore Administration Reports for 1873-74 to 1875-76, have shown the losses in cattle sustained by their owners, -

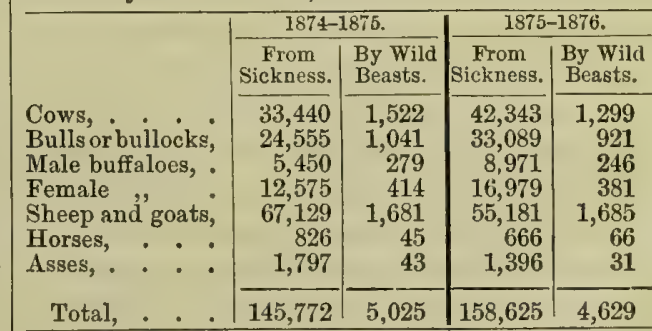

In 1873-74, the cattle of all kinds numbered $2,911,684$, and the deaths 138,759 . In 1874-75, the respective numbers were $2,921,962$ and 150,797 , the increase of 12,038 deaths having been due to cattle disease in the Mysore and Hassan districts.

Irrigation.-The crops are liable to great injuries from insects and fungi, which will be found mentioned under Insects. Rats, locusts, hyænas, elephants, also cause losses; but that which is most dreaded is droughts, for the rainfall fluctuates from year to year as much as 50 per cent. on either 
side of the average, and failure of the rains results in scarcity and famine. The rains on the seaward sides of the Western Ghats and of the Arakan Hills never fail, the inundations and the cauals of Sind and Lower Bengal protect the crops from all fear of drought; but in Mysore, the Ceded Districts, Ongole, Orissa, Hyderabad, Rajputana, Oudh, N.W. Provinces, and the Panjab, the rains have often failed, and millions of the inhabitants and their cattle have perished. The Tamil, Teling, and Gond races have evinced much ingenuity in constructing tanks wherever the slope of the ground admitted, and the races along both banks of the Lower Indus have laboriously formed inundation canals. With water, in tropical countries, plants of some kind may be grown. But much injury results from profuse supply of canal water swamping the lands. Land is destroyed unless there be perfect drainage made before the irrigation is adopted. The water must be able to get out of the land as well as to get into it with equal facility. Of all the supplies, river water is the best, as it brings with it a large proportion of silt; after that comes water from tanks, then the natural rains; and worst of all are the waters of-wells and canals, for they contain much saline matter in solution, and chiefly soda. Salts in undue proportion render soils sterile. Mr. Robertson of the Sydapet farm says that soil which contains more than a balf per cent. of salts, capable of being washed out by water, cannot possibly be productive. Mr. E. C. Schrottky says that the remedy for this is subsoil drainage.

Manure.-Next to water in agricultural value comes manure. The Chinese, of all the eastern races, are the most successful appliers of manures, utilizing them from the animal, vegetable, and mineral kingdoms, and applying them in a skilful manner, growing green crops for manure, which they plough down into their fields, and using recent animal refuse in a greatly diluted state. Throughout British India, the husbandmen are thoroughly acquainted with the value of manures, both fresh and decomposed, but the quantity obtainable is barely sufficient for their garden cultivation. Even if all the cattle refuse could be had, it would still be insufficient; but in most parts, owing to the scarcity of firewood, dried cow-dung cakes are the chief fuel. Also, with every increase of irrigation, manure is necessarily more and more needed, the soluble parts of the soils being more easily taken up, and are more frequently so by the more frequent cropping. The soils of many parts of British India are thus in danger of becoming atterly barren. Learned men from ancient times have been warning agriculturists on this point. In the first century of the Christian era, L. Junius M. Columella, in a letter to Publius Silvinus, pointed out that the sterility of their fields is to be attributed to their own doings. Mr. H. C. Carey of Philadelphia has shown that in the States, in the beginning of the 19th century, 25 to 30 . bushels of wheat per acre were to be got, but latterly only 12 bushels. In Virginia and Kentucky, tobacco was grown until the soil was completely exhausted, and had to be abandoned. In a late Settlement Report in the Hoshangabad district, it was stated that in the Nerbadda valley, fifty years before, the rate of produce had been tenfold, but only sixfold at the date of the report.
Liebig; in his letters on Modern Agriculture (pp. 176-77), remarks that 'there are fields that may yield without manuring, for $6,12,50$, or 100 years successively, crops of cereals, potatoes, vetches, clover, or any other plants, and the whole produce can be carried away from the land, but the inevitable result is at last the same: the soil loses its fertility, the fields will ultimately be brought to a state of exhaustion, the corn will only yield an amount equal to the seed, the potatoes will no longer produce tubers, and the vetches or clover will die away after barely appearing above the ground.'

These remarks are admonitory to the cultivators, the State, and the people. If the land be only half tilled, and be starved as regards manure, the share of the produce falling to the State will appear large; but the more produce it can be made to yield, the more easily will the land-tax be paid. Throughout India the ground around the village site is always resorted to by the inhabitants, and tobacco is there the most frequent crop. It is almost the only open field that receives animal refuse, four-fifths of the cattle droppings being dried and used as fuel. The average daily weight of cows' droppings is 4 or 5 lbs. daily, equal to $15 \mathrm{cwt}$. per annum; two-thirds are consumed as fuel, excepting during the rains. How little the fields receive, is known from the fact that there is one head of horned cattle to every two cultivated acres,-plough cattle, milch cattle, and buffaloes. Even the small portion retained for manure is wasted, no care being taken to prevent loss by drainage or evaporation. Mr. Buck mentions that at Farrakbabad night-soil has been utilized for ages past, as much as Rs. 15,000 to 20,000 being paid there by the cultivators to the sweepers.

In the general non-use of manure, the prevailing practice has been to throw the exhausted fields out of cultivation for periods of years, after which it is again broken up into great masses by iron bars. Full crops are not immediately obtained. In the Chanda district, it has been observed that where fresh soil is broken up for rice cultivation, the ground can never be got into proper order during the first year, and the yield is less than in the old fields. In the second year the return rises to about an eighth above that of the old fields, and increases gradually year by year until the fifth, when it reaches 50 per cent. above the yield of the old fields. It then commences to decline, and in about another five years has subsided to the level of the old fields. Land yielding dry crops seems also to reach its highest point of fertility in the fifth year of cultivation, but it falls more slowly to the condition of old fields than is the case with rice lands, and in a field twenty years old will be more productive than one which has been twenty years under the plough. When a cultivator sees a field becoming sterile, he allows it to be fallow for from two to five years, in the meanwhile pasturing his cattle thereon; and when the land is again sown, it is found to give a yield equal to its neighbours.

Green manure, ploughed in, has several advantages. It saves transport, rapidly decomposes, saves all the constituents of the manure; while decomposing, raises the temperature of the soil, protects the soil from the effect of solar heat, prevents evaporation, retains fertilizing gases, and 
pulverizes the soil. The jute and cassia leaves and exhausted indigo plants are largely utilized in this way. Bone-dust is only employed in places superintended by Europeans.

Progress. - The British have been very desirous of improving the husbandry of the people, and have succeeded to a small extent. Millions sterling were expended in experiments to improve the staple of cotton; much encouragement was given to the silk and lac industries; unsparing and successful efforts have been made to establish tea, tobacco, cinchona, hop, and caoutchouc plants; opium cultivation has been brought to the highest pitch of perfection; the indigo manufacture has attracted many Europeans, though the manufacture of the last two products has been left entirely to native skill; tobacco varieties have been introduced; an attempt was made to introduce the fine cochineal insect; a little has been done to introduce improved breeds of cattle and sheep; much has been done for fibrous plants; and by agricultural exhibitious, agri-horticultural societies, farms, fairs, and agricultural banks, forests have been protected, planting of trees encouraged; great canals constructed for irrigation; loans have been made for well-digging; while railways, harbours, and improved ocean steamers have aided in the distribution, and emigrants have been encouraged and protected. These have been regarded by the British rulers as their duties.

Ninety per cent. of Indian exports are raw products, and steady efforts have been made to improve the means of transit and distribution on rivers, canals, ocean ships, roads, and railways. In scarcities and famines, perhaps, no efforts can stave off the destruction of the cattle needed for carriage, and a meteorological department has been formed to watch and give warning of climatic changes. The countries adjoining Further India, still sparsely inhabited, can be looked to for years to come as food granaries, but early effort should be made to encourage and develope the arts. Railway workshops, spinning and weaving companies, tea, cotton, coffee, and cinchona planters have done inuch, but the fishermen need to have facilities afforded for salting their fish captures, which is the sole animal food that almost all the races eat; and the climates of the western coast of India and of Burma are inimical to cattle and sheep.

Much is still capable of being accomplished in the way of improving existing and adding new varieties of fruit and timber trees, root plants, vegetables, cereals, pulses, and millets, condiment plants, truffles, mushrooms, with herbage and fodder plants for cattle.

Trees should be planted in groves and lines, to afford shelter from drying hot winds. They are a powerful engine in the production of coolness and moisture, and their leaves furnish manure. Prizes and payments should be made to persons who successfully raise trees in exposed situations, for a tree cannot be raised by Government employés under three to five rupees. Sir George Campbell, when in the Panjab, issued an order that every man who cut down a tree should plant five in its place. The breed of stock, cattle, sheep, and goats could be further improved, and better varieties imported and they may be persuaded to rear fowls of kinds, and to add to their stock by domesticating bees. The preservation of fodder crops by ensillage might be introduced, and greater care taken, in storing manure, to arrange for the preservation of its fluid parts, under-draining being adopted to bring fresh soil under tillage.-Sir Henry Elliot's Supplement; $M r . R . H$. Elliot and Mr. F. C. Danvers in Jo. Soc. of Arts; Carnegy's Kachahri Technicalities; B. H. Baden Powell, Econom. Prod. of the Panjab; Manual of the Land Revenue Systems of India; E. C. Schrottky, Rational Agriculture; Mr. F. N. Wright, Agriculture in Cawnore; Mysore and Central Provinces Administration Reports; Baron von Mueller's Select Plants; MacGregor, pp. 35, 36; Wils. Gloss.; Williams' Middle Kingdom, ii. p. 109; Ward, p.101; Peschel on Man, p. 492.

HUSE, a transparent fabric of Manilla, of which the shirts of the coloured population are made. It is made from the fibre of the Musa textilis.-Oliphant.

HUSKS, on which the prodigal son desired to appease his bunger, were the pods of the Ceratonia siliqua.

HUSN and HASN, pl. Hasnein, sons of Ali, a cousin of Mahomed, by Fatima, Mahomed's daughter. Husni Syud, a descendant of Hasnein. HUSN - ABDUL is a town between Rawal Pindi and Peshawur. It has a sacred tank, supplied by many rivulets, and crowded with fish. A stone there has a rude bas-relief, said to be an impression of a foot.

HUT or Hoth, a small Baluch tribe in the Debra Ghazi Khan district.

HUT-GAR or Hat-gar, a weaver caste in the Canarese-speaking country about Belgaum.

HUT'HEELE or Hat'hile, one of the Panchpiri, or five noted saints of the lower orders of Hindustan. He is said to have been the sister's son of Ghazi Meean, and lies buried at Bahraich, near the tomb of that celebrated martyr.

HUT-HU, SANSK., in Hindu asceticism, signifies the external meaus used to fix the mind upon the One Spirit. These means are, sitting in a particular posture, keeping the eyes fixed on the end of the nose, repeating a particular name, and many other practices equally ridiculous.

HUTTON, MAJOR, author of Note on the Culture of Silk at Kandahar; on the Wool and Woollen Manufactures of Afghanistan; Zoology of Kandahar.

HUTTON, Dr., a Bombay medical officer, author of a History of the Kooria Mooria Islands in the Royal and Bombay Geographical Society's Journal; East Indian Marine Survey.-P. $P$.

HUWANA, CAN., the flower fish, occurs in a curious small lake of fresh water close to the sea, near Cundapur in N. Canara. They are considered a delicacy, and used to be sent by runners to Tipu Sultan. They are caught by a number of boatmen moving from one end of the lake.

HUZUR. HIND. A respectful form of address to persons of rank, equivalent to 'presence,'-the presence, the royal presence.

HUZURASH, name of the translation of the Zendavesta into Pehlavi, a mixture of Semitic and Iranian, made in the time of the Sassanidæ. Pehlavi was the language used by the Sassanian dynasty.-Bunsen; Max Muller. See Honover.

HWA-KEA-TSZE, the Chinese cycle of 60 years. The Chinese year commences from the conjunction of the sun and moon, or from the nearest new moon to the 15th degree of Aquarius. It has 12 lunar months, some of 29 , some of 30 
days. To adjust the lunations with the course of the sun, they insert, when necessary, an intercalary month. Day and night are divided into 12 periods, each of 2 hours.-Gutzlaff's Chinese History, p. 73 .

HIVANG-te-wang, and Teen-tsze, are titles which have been held by Chinese emperors. Wang is commonly translated king; the other emperor. See China, 684.

HWOH-FU, Chinese living Buddhas.

HWUI - HWUI KEAOU. CHIN. The Mahomedan religion.

HYACINTH, a mineral used as a precious stone, consisting of silica and zirconia, transparent, and of a red colour.

HY ENINA, a sub-family of the Felidæ, digitigrade carnivorous mammalia, distinguished by having their fore legs longer than their hind legs, by their rough tongue, great and conical molar, or rather cutting-and-crushing, teeth, projecting eyes, large ears, and a deep and glandular pouch beneath the anus. In general form, hyænas resemble dogs more than cats; and Linnæus classed them with the former, to which they appear united by the Lycaon pictus of S. Africa. There is one species in India,-

Hyæna striata, Zimmer., H. vulgaris, Demarest. Naukra-bagh, . BENG. Taras; Hundar, . HrNd. Har-vagh, : . "' Lakhar-baghar, . ", Kirba ; Kat-kirba, CAN. Lakar-bag'h, . . , Korna-gandu, : " Lakra-bag'h, Hi. ",

The striped hyæna is of a pale, yellowish-grey colour, with transverse tawny stripes, neck and back maned, and ordinary length is 3 feet 6 inches to root of tail; tail 17 inches. It prefers open country, and generally digs a hole for its den on the side of a hill or mountain, or lurks amongst ruins. It is quite a nocturnal animal, sallying forth after dark and hunting for carcases, the bones of which it gnaws, occasionally catching some prowling dog or stray sheep. It generally returns to its den before sunrise. Its call is very unpleasant, almost unearthly. The young are easily tamed, and show much attachment to their keepers or masters, uttering sounds not unlike human laughter.

The spotted hyæna (H. crocuta) and the brown hyæna, which is a third species of the genus, are restricted to Africa. Their jaws are enormously strong, and when they bite they hold on obstinately, and can with difficulty be made to let go their hold. The voice of the spotted hyæna when excited resembles a laugh, whence it is commonly known as the laughing hyæna. The hyæna and lion are eaten by the Arabs.-Jerdon's Mammals.

HYALAA TRIDENTATA, Lam., of the seas of the E. Archipelago, has the power of expanding its keel appendices into the form of large, oval, semi-transparent leaves of a light green colour.Collingwood.

HYALONEMA LUSITANICUM, the glass rope; a vitreous sponge of the Japanese seas. It is small and cup-shaped, pierced through the centre by a number of clear glass fibres, twisted together into a column 8 or 12 inches long. It roots itself in the mud by a twisted wisp of strong flint needles, somewhat on the principle of a screw pile. So long as there were only Japanese specimens to study, which was top and which bottom, which the thing itself and which para. sites growing on it, whether it was a sponge or a zoophyte, or something else, -could not be settled. But the discovery of the same or a closely-allied species in abundance, from the Butt of Lewis down to Setubal on the coast of Portugal, where the shark fishers call it seawhip, has given savans specimens enough on which to make up their minds, and has added another form to the list of those common, strangely enough, to European seas and to those of Japan.-Capt. St. John, p. 77.

HYAT. Arab. Life, said by Mahomedans to have been created on the $10 \mathrm{th}$ day of Maharram.

HYAT QALANDAR, also Baba Booden, or Bawa Booden, a Mahomedan devotee, who settled on the Baba Booden Hills, on the Nuggur district of Mysore. On his arrival or return from Arabia he brought with him some coffee berries, since which time the plant has continued to be grown in that district.

HYDASPES or Bedaspes, the ancient Greek names of a river of the Panjab, called in Sanskrit the Vitasta; it is the Jhelum or Behut of the present day.

HYDERABAD, in lat. $17^{\circ} 21^{\prime} 45^{\prime \prime} \mathrm{N}$., and long. $78^{\circ} 30^{\prime} 10^{\prime \prime} \mathrm{E}$., on the right bank of the river Musa, is the capital of an independeut inland kingdom of the same name, in the centre of the Peninsula of India. The territory lies between lat. $15^{\circ} 10^{\prime}$ and $21^{\circ} 41^{\prime} \mathrm{N}$., and long. $74^{\circ} 40^{\prime}$ to $81^{\circ} 31^{\prime} \mathrm{E}$., and has an area of 98,000 square miles, with a population of $11,250,000$; and since the 15 th century, it has been under Mahomedan rulers of the Bahmani, Kutub Shahi, and Azof Jahi dynasties, the second of whom ruled from the adjacent fortress of Golconda, and was overthrown by Aurangzeb, 1687 . The Hyderabad country is in the table-land of the Dekhan, from 1250 to 1800 feet above the sea, and is surrounded by British provinces. It has been formed by the preceding and present dynasties out of several nationalities, viz. part of Gondwana on the N.E., Telingana on the E. and S.E., Maharastra on the N.IV., and the Canarese or Karnatica speaking country on the S.W. and S.; and the four languages of these races are current in their respective limits, that of the dominant Mahomedan race being the Urdu or Hindustani, with Persian as the epistolary language of the court.

It comprehends the seats of some of the greatest and most powerful ancient sovereiguties of the Dekhan:- Kalyan, the capital of the western Chalukya and Bijala Raya dynasties; Devagiri or Deoghur, the capital of the Yadava; Warangal, that of the Kakateya; and the great Mahomedan principality of Kulburga, which subsequently split into the subordinate powers of Bijapur (the Adil Shahi), Ahmadnaggur (Nizam Shahi), Golconda (Kutub Shahi), Berar (Inad Shahi), and of Beder (Birud Shahi). In the tract lying between the Mysore, Hyderabad, and the Mahratta country, were several smaller chieftaincies, such as that of the Nawab of Banagauapilly, a Syud family in the east of the Ceded Districts; the Pathan nawabs of Kurnool, on the right bank of the Tumbudra river; farther west, the Reddi chief of Gadwal; the Mahratta ruler of Sundur, one of the Ghorpara family; the Kshatriya raja, Narapati of Anagunda, the representative descend. 
ant of the great king Rama of Vijayanagar, who was overthrown by the combination of the Mahomedan kings of Golconda, Kulburga, Bijapur, and Ahmadnaggur; the Pathan nawab of Shahpur, the Ghorpara chieftains of Ganjandergarh and Akalkote; and at Ghurguntah and Beder Sholapur are the descendants of Pid Naik, a Beder soldier, to whom Aurangzeb granted a small territory in the Raichore Doab, for the aid given at the siege of Bijapur.

The rulers of the reigning Asof Jahi dynasty have been:-

1. Kamr-ud-Din, styled Asof Jah, Nizam- 1713-1748 ul-Mulk, subahdar of the Dekhan.

2. Nasir Jang, eldest son of Asof Jah, mur dered by Pathans.

3. Muzafar Jang, grandson of Asof Jah, and nephew of Nasir Jang, killed during a mutiny of his troops.

4. Salabat Jang, third son of Asof Jah, deposed by his younger brother in 1761 , and died in prison two years afterwards.

5. Nizam Ali, younger son of Asof Jah,

6. Secunder Jah, son of Nizam Ali,

7. Nasir-ud-Dowla, son of Secunder Jah,

8. Afzal-ud-Dowla, son of Nasir-ud-Dowla,

9. Mir Mahbub Ali Khan, Br., infant son

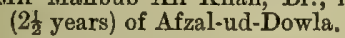

The founder of the present dynasty was a distinguished officer of Aurangzeb. He was a Turani noble, whose name was Chin Kilich Khan. He succeeded Daoud Khan in the government of the Dekhan. After various intrigues during the weak reigns of Ferokhsir and of the Syuds, Mir Hasan Ali and Mir Abdallah, after the assassination of Ferokbsir in 1718, in the reign of Muhammad Shah, Asof Jah, in 1720, when governor of Gujerat, revolted, overran Kandesh, and captured Asirgarh. He was subsequently appointed vizir, but, disgusted with the vicious courses of the emperor, he returned to the Dekhan, defeated Mubaraz-ud-Dowla, and in 1724 re-established the Hyderabad kingdom near Golconda, where the Kutub Shahi family had ruled till overthrown by Aurangzeb.

In 1748, Nizam-ul-Mulk died, aged 104 years. His second son, Nasir Jang, assumed the government; but Muzafar Jang, a grandson of Nizam-ulMulk, took the lead, declared himself subahdar of the Dekhan, and joined Chanda Sahib and Dupleix, and in 1749 fought and won the battle of Ambur. Various intrigues occurred, in which Nasir Jang formed friendships with the three Pathan chiefs of Cuddapah, Kurnool, and Savanore; but he was attacked by the French before Ginjie, where one of the Pathan chiefs shot him. On this Muzafar Jang was released from prison and declared Nizam. He joined Chanda Sahib and the French under Dupleix, but he was assassinated by the Nawab of Kurnool on his way to Hyderabad, in 1751, when M. Bussy declared Salabat Jang, the youngest uncle of the deceased, to be the Nawab of Arcot.

Salabat Jang alternately combined with and opposed M. Bussy, was deposed in July 1761, and was shortly after assassinated by his brother, Nizam Ali.

In 1763, Nizam Ali met the army of Madhava Rao, Peshwa, under Raghoba, on the banks of the Godavery, and was completely routed. From that time till the beginning of the 19 th century the French and British influence alternated, until, under a treaty of date the 1st September 1798, the British surrounded and disbanded the French battalions. Since the treaty of the 1st September 1798, under renewed treaties, the Hyderabad Government has subsidized a brigade of the British Indian army. It has consisted of all arms, and has varied in strength from above 4000 to over 15,000 . In 1798 they numbered 6801 ; in 1820 , 15,489 ; in 1867,4494 ; and in 1882,5683 . To provide for their pay by the treaty of the 12 th October 1800, the Nizam ceded all the territories he had acquired by the Mysore treaties of 1792 and 1799 , yielding about $17,58,000$ pagodas. These Ceded Territories comprise the collectorates of Bellary, Cuddapah, and Kurnool; and from $1800-1$ to $1880-81$, the receipts have been $\mathrm{Rs}$. $47,47,53,951$, and charges Rs. $16,24,65,997$, net Rs. $31,22,87,954$ in the 81 years, or annually Rs. 38,55,406. In addition to the subsidiary force, the Hyderabad Government has, since 1811, kept up another armed force, known as the Hyderabad Contingent. It had its origin in the inefficiency of the Nizam's troops, and has been commanded by European officers, some of whom were lent from the Indian army; but, after the treaty of 21st May 1853, the officers became entirely of the latter class, and until that change it was styled the Nizam's army. In 1811, the strength of its cavalry was 9000 , and of the infantry and artillery 8000 , with 25 guns and 20 European officers. From 1815, there has been a gradual reduction of the Contingent. In 1853-54, when the change to the present system was made, the strength was 9799 , with 37 guns and 881 camp followers; and in 1880-81 the artillery and infantry numbered 5432 , cavalry 2200 , with 69 European officers, 20 warrant and non-commissioned officers, 16 guns, and 1040 camp followers. The total military force of the Nizam has been returned as consisting of 71 field and 654 other guns, 551 artillerymen, 1400 cavalry, and 12,775 infantry, besides a large body of irregulars. The state is entirely enclosed within British territory, and, with its good police, a very small armed force is needed. After the third decade of the 19th century, from the want partly of financial skill on the part of Chandoo Ial, Peshkar-i-Dewan, and partly from his general extravagance and retention of large bodies of foreign mercenaries, the pay of the Nizam's Contingent fell into arrears, and the Nizam assigned the Raichore Doab and Berar valley to provide funds for the pay. Raichore was early restored, but during all the minority of Mir Mahbub Ali Khan, the Dewan Regent, Sir Salar Jung, Bahadur, strove to recover Berar. This province was administrated by Commissioners, under the Resident of Hyderabad. In 1871, it had 17,334 square miles, with a population of $2,231,565$. In 1881, the population of Berar was $2,672,673$ persons, and the population of the remainder of Hyderabad territory is estimated in the same table at $9,000,000$.

Berar is, in the main, a broad valley running east and west, lying between the Satpura range on the north and the Ajunta range on the south. The area of Berar may be reckoned at a little more than 17,711 square miles. The principal rivers are the Tapti, the Purna, the Wardha, and the Pain-Ganga or Pranhita.

Of the Berar towns, Ellichpur is the largest, Oomrawati, Akola, and Akote (in the Akola distriot) follow. 
The principal divisions of the people of Berar as to creed and caste were :-

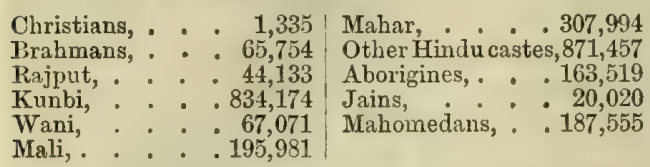

The chief numbers of the other Hindu castes in 1881 were as follows:-

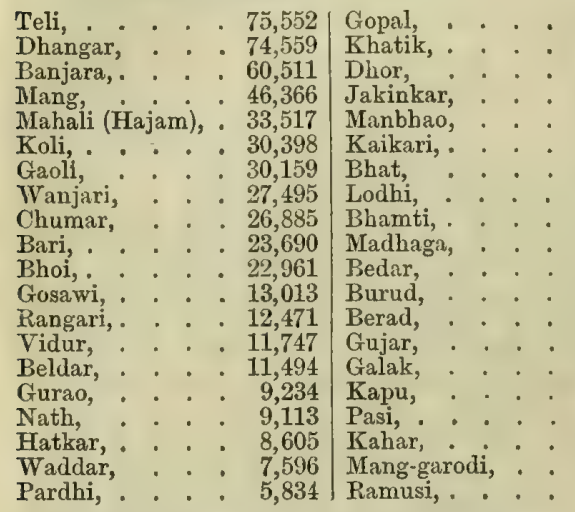

4,904

4,487

4,477

4,347

4,111

3,103

2,520

1,773

1,693

1,595

1,273

1,201

330

967

356

256

247

218

118

The Aborigines are detailed as under:-

Andh,

Arakh,

Balai,

Gond,

Kolam,

\begin{tabular}{r|l}
37,010 & Koilabhute, \\
371 & Korku, : \\
803 & Lajar, : \\
4,183 & Moghe, : \\
64,817 & Nihal, :
\end{tabular}

12,163 Pardhan,

The Hindu religious mendicants are,-Byragi, Bharadi, Dangat, Gondhali, Gosain, Manbhao, Nath, Sanyasi, and Vasudi. The Mahomedan fakirs are of the tribes Kadari, Banawa, Madari, Chisti, Nakshbandi.

All of the Bhil race who live along the skirts of the Satpura range appear to have embraced Mahomedanism, though they do not intermarry with the purer Mahomedans.

The Kshatriya class contains mostly a set of very dubious pretenders to the honour of Rajput descent. Mahrattas of no particular family usually call themselves Thakur; even a Kunbi will occasionally try to elevate himself thereby; while the Purbho, Kayasth, and other castes of mixed origin and good social status are constantly invading the Kshatriya military order. The distinction is also claimed by the rajas of the Satpura Hills, who assert that they are Rajputs depressed by the necessities of mountain life, whereas they are Gond or Kurku elevated by generations of highland chieftainship.

The Sudra caste in Berar, as in Mysore, all eat together, although they do not intermarry. The Kunbi and Mali eat flesh, drink liquor moderately, and their widows may always re-marry if they choose, excepting the widows of Deshmukhs, who ape high caste prejudices. The Koshti is a weaving caste. The Banjara are comparatively numerous in Berar; their occupation as carriers is gone, and during their transitional stage they gave a good deal of trouble to the police. The Dhangar are sheep farmers, and the Hatkar, one of their clans, still hold much land on the border of the Nizam's territory, and were until A.D. 1853 notorious for pugnacity and rebellion. The Bhoi has recently been supposed to belong to a widely-spread primitive tribe; the Garpagari live by the profession of conjuring away hailstorms. Any one who has watched the medicine man at work has witnessed a relic of pure fetishism, possibly handed down from the pre-Aryan races and their earliest liturgies. The Vidur and Krishnapakshi are the same; they are descend. ants of Brahmans by women of inferior caste ; and Krishnapakshi is only an astronomical metaphor for describing a half-breed, the term meaning literally 'dark-fortnight,' and referring to the halfdarkened orb of the moon. The Mhar have been taken to be the same with the Dher, a very useful and active tribe. The Mang appear to be the lowest of all in the social scale. The paucity of the Khakrob or Bhangi, who are so numerous in Northern India, is a serious sanitary difficulty. The Kaikari are a tribe formerly well known for their thieving habits. Of the aborigines, the Gond, Korku, and Bhil are the only completely preserved specimens of tribes. The two first retain their languages, while the Bhil tongue seems to have become extinct very recently in Berar, its disuse being probably expedited by their general conversion to Mahomedanism. The Ramosi, a predatory race, speak Telugu in their families, and are doubtless from Telingana. The original Pardhan among the Gond answered to the Bhat among the Hindus, but many seem to have settled in the plains as a separate class of Gond.

The chief towns are Hyderabad, Secunderabad, Aurangabad, Beder, Mominabad or Amba Jogi, Ellichpur, Warangal, Oomrawati, and Nandeir.

Mahomedans, though of the dominant class, are not numerous in any district of the Hyderabad dominions. They dwell in considerable numbers in Hyderabad, Beder, Kulburga, Aurangabad, Karinjah, and Ellichpur,-places where rulers formerly resided; but in other places they are few, and everywhere they look to state employ. They have no lands, but several of them have the state revenues in jaghir. Out of 158,721 of these religionists in Berar, only 1296 are professional. The Syuds of Kulburga and Gogi and Hyderabad seem inpoverized; the Pathan, Moghul, Arab, Persian, and Habshi Mahomedans are soldiers, and those of Berar are noted for their idleness and profligacy, seldom taking to the plough.

The Godavery, rising on the eastern declivity of the Western Ghats, disembogues in the Bay of Bengal. The total length of this great river, along the Hyderabad border and through the territory, is about 600 miles, for about 200 of which it is navigable from June to February. The Wardha rises in the hills of Betul and Ch'hindwara. Near the junction of the Pain-Ganga with the Wardha, and in the valley of the latter river, there are coal-fields. Those which have been examined over a small area near Sasti and Paoni show an average of 40 feet in thickness.

Except in the city of Hyderabad itself, no effort or attempt had been made to educate the people of the Hyderabad Territories, though education is making enormous strides in Berar and in British Maharastra. There was no proper school met with in all the Editor's journeys, in 1866-70, amounting to about 7000 miles, and only occasionally a few lads, children of foreigners, were to be seen learning in a verandah the elements of the Hindi or Mahrati. 
The Dewan, Sir Salar Jung, in 1868, made changes in the administrative machinery, and five Sudder Talukdars or Divisional Commissioners were appointed, for Aurangabad, Bir, and Purbhani ; for Nandeir, Naldrug, and Beder; for Nulgonda, Khummum; for Lingsugur and Raichore; and for Indore, Meduck, Yelgundul, and Surapur. The first three commissioners on Rs. 1500 a montb, and last two on Rs. 1000.

The people in the first two divisions speak Mahrati, the next two the Telugu, and the last are the Canarese districts of the Nizam's Territories. Each of the above fourteen districts is presided over by a talukdar on from 400 to 600 rupees a month, assisted by deputy talukdars, who control and superintend the work of naibs or tahsildars of talukas. The commissioners go on circuit within their respective jurisdictions during eight months of the year, spending the remaining four at some central locality. The commissioners communicate with the Minister through the Malguzari or Civil Secretariat. There is a separate department of police, with a Suddur Mohtamim or inspector-general. Immediately under his orders are placed five naib mohtamim or deputy inspectorgenerals, to whom the Zillah Mohtamim or the district superintendents are directly subordinate. Each district has its Zillah engineer. There is a Conservator of Forests, and chief inspector of the medical department.

HYDERABAD, in Sind, in lat. $25^{\circ} 23^{\prime} 5^{\prime \prime} \mathrm{N}$., and long. $68^{\circ} 24^{\prime} 51^{\prime \prime} \mathbf{E}$., was built in 1768 on the site of the ancient Patala or Patalene by Ghulam Shab, Kalhora. It was the chief town of the territories ruled by the Talpur dynasty, until 14th February 1843, when, after the battle of Miani (Meeanee), it surrendered to the British, and the capital was transferred to Karachi (Kurachee). The Hyderabad country was conquered from the Talpur dynasty, Amirs of Sind, by a British Indian army under Sir Charles Napier. The ancient name of Hyderabad was Neroon or Nirun, and Abulfada described it as almost equidistant between Dabul (Dewul or Tatta) and Mansura, Sehwan, or Minagara, the latitude of which is $26^{\circ} 11^{\prime}$. Its territory is of great ethnic interest, having been a refuge of Aryan, Baluch, Jat, Moghul, Pathan, and Rajput races for centuries before the birth of Christ; and Assyrians, Bactrians, Greeks, Arabs, and Rajputs have ruled up to and within its borders. The territory is now a British revenue district, under the Commissioner of Sind, between lat. $24^{\circ} 13^{\prime}$ and $27^{\circ} 15^{\prime}$ N., and long. $67^{\circ} 51^{\prime}$ and $69^{\circ} 22^{\prime} \mathrm{E}$. The population consists of Mahomedans, 560,349; Hindus, 118,652 ; with other creeds and tribes, 44,882 . total, 723,883. Of the Mahomedans, more than three-fifths, or 373,705 , are Sindi, chiefly Sunni of the Halpotra, Junijo, Dul, Powar, Thebo, Sumro, Sand, Katiyar, and other clans, descendants of the original population converted to Islam during the Ummayid dynasty of Khalifas.

The Baluchi Mahomedans $(128,785)$ are in a great number of tribes, the chief being the Rind, Bhugti, Chang, Talpur, Jatoi, Laghari, Chandio, Kaloi, Khaso, Jakrani, Lashari.

Pathans are found chiefly about Hyderabad and Upper Sind, along with Bokhari, Matari, Shirazi, and Lekhiraji Syuds. Together they number 15,815 persons.

The Sind Memons were formerly Kachhi
Hindus, who emigrated to Sind under the Kalhora rule, and devoted themselves to agriculture and cattle - breeding. The Khwaja are descendants of fugitives from Persia when their creed (the Ismailyeh heresy) was persecuted by Hulaku Khan. The Memons and Khwajas aggregate 13,000. Sidi, natives of Maskat (Muscat), Zanzibar, and Abyssinia, who until the British conquest were bought and sold as slaves. The Shikaris or Daphers of Tanda number 1353. They are Mahomedans, but they eat carrion, and are excluded from the mosques. Among Hindus the most numerous caste is the Vaisya or Baniya, aggregating about 85,000 , and of these nearly four-fifths belong to the Lohano tribe, and the majority of Hindu shopkeepers and traders also belong to the Lohano caste. In their complex subdivisions, they are mixed up with the Mahomedans. Although wearing the thread, they become the disciples of Mahomedan teachers, assume their dress, eat meat, drink spirits, and disregard all the customs of orthodox Hindus with regard to receiving food from inferiors, etc. Their marriage ceremonies are so expensive that many of them remain single till late in life.

The canals begin to fill about May, in proportion to the annual rise of the Indus, and are again dry by October. None are perennial in the Tando deputy collectorate, and in Hala only one, - the Mahmuda._Imp. Gaz. See India.

HYDER ALI, an officer of the Mysore Hindu sovereigns, whom he set aside and then ruled over the country as an independent prince. His greatgrandfather, Muhammad Bablol, came from the Panjab, and settled in the district of Kulburga, about 110 miles S.W. of Hyderabad. He was accompanied by two sons, Muhammad Ali and Muhainmad Wali, who both married in the Kulburga district, but left it for Seera, in Mysore, where they were employed as revenue peons; and here Fatteh Muhammad, son of Muhammad Ali and the father of Hyder Ali; was born, A.D. 1702. Fatteh Muhammad fell in battle, leaving two sons, Shahbaz and Hyder, at the age of nine and seven years respectively. Hyder grew up wholly illiterate, but was a brave soldier, and, after the fall of Devanahully, he was promoted to the command of 50 horse and 200 foot. Hyder shared in all the wars in which Nunj Raj and Deo Raj were involved; and when Muhammad Ali and Chanda Sahib were striving for the sovereignty of the Karnatic, he assumed the Mysore Government, A.D. 1761, the raja Nunj Raj taking a jaghir of three lakhs of pagodas. Hyder Ali's great success was the taking of Bednore, or Nuggur in 1763, in which he is said to have found twelve kror of rupees: .Raja Nunj Raj died childless, and a distant relative named Cham Raj was selected by Hyder. Bartolomeo (p.8) mentions that Hyder Ali in early life stood sentry at the west gate of Pondicherry.

Hyder Ali was severely curbed by the Mahrattas, and entered into an alliance with Nizam Ali to attack the British, but the allies were defeated at Changama in August 1767, and again at Trincomalee. The war continued, however, and Hyder Ali, in March 1769, arrived within ten miles of Madras, but on the 4 th April a treaty was concluded. Hyder Ali conquered Coorg in 1772, and in 1773 and 1774 he recovered all the territories which the Mahrattas had seized. In 1775 he captured Bellary from Bassalut Jang. In 
1776 he extinguished the power of Morari Rao and the independence of Savanore; and in $\mathbf{1 7 7 9}$ he annexed all the dominions of the Nawab of Cuddapah. On the 21st July 1780 he invaded the Karnatic, plundered Porto-Novo, laid siege to Arcot, and on the 10th September 1780 totally destroyed the force of Colonel Baillie at Perambaukum. Sir Eyre Coote arrived from Calcutta on the 5th November 1781. While Hyder was surrounding five forts, Coote captured Carungally and overthrew Hyder's forces in a general battle at Porto-Novo, on the 1st July 1781, on which Hyder's investment of Trichinopoly, and that of Wandiwash by his son Tipu, were abandoned. Coote met Hyder at Pollilore, but again, on the 27th September 1781, at Sholingur, Coote completely defeated Hyder, and compelled him to raise the siege of Vellore. Hyder Ali died, aged 80 , on the 7th December 1782. His death took place in camp at Chittore, near Arcot, but was concealed until his son Tipu could arrive. At his father's demise, at the close of a virtual reign of thirty years, the army consisted of a hundred thousand well-trained men, with about five millions sterling of money in the treasury. He left at his death a compact kingdom, and was succeeded by his son Tipu, known as Tipu Sultan. He was interred at Seringapatam, and a dome was erected over the tomb.

HYDER MIRZA, DOGHLAT, author of the Tarikh-i-Rashidi, an active, bold, adventurous officer, who held high commands under the emperor Babar; and his book, the Tarikh-i-Rashidi, a history of Central Asia, shows that he was a learned and accomplished man. $\mathrm{He}$ was the son of Muhammad Husain Mirza, who was the eldest son of Hyder Mirza, Doghlat, Amir of Kashgar. Muhammad Husain Mirza married the younger sister of Baber's mother, and he was put to death at Herat, A.H. 914 (A.D. 1508), under the orders of Shaibani Khan.

HYDNOCARPUS ALPINUS. W. Ic. tab. 942. One of the natural order Pangiaceæ, the Maratatti of the Neilgherries, a very handsome tree with a beautiful foliage, cornmon on the Neilgherries up to nearly 6000 feet, and at 1500 feet on Calcad Hills, Tinnevelly, and in Ceylon. On the Neilgherries the wood is much used as beams and rafters for native houses; it answers as deal for general purposes, packing-cases, etc.; it splits readily, and is a good firewood. The tree flowers in July and August.-Beddlome, $F l$. Sylv. p. 77.

HYDNOCARPUS INEBRIANS. Vahl.

$$
\text { H. venenata, Gertner. }
$$

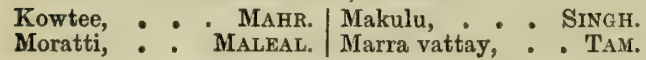

A large tree, growing in Ceylon on the banks of rivers up to an elevation of 2000 feet, also in Malabar, in Tinnevelly, and Travancore. It is a conmon tree on the west coast, not so in the Coimbatore jungles. The tree is hardly found in the Bombay northern jungles on the coast; more frequently in those south of the Savitri river. The wood is not used for any purpose. Flowers small, white. Fruit used for poisoning fish. The seeds of the fruit afford the Thortay oil of Canara, called also Neeradimutu oil. It is a very valuable vegetable solid oil, of the consistence of ordinary hard salt butter, and is used as a remedy in scabies and ulcers of the feet, also internally.-Thwaites; Voigt; Gibson; Wight.
HYDNUM CORALLOIDES. Scopoli. A mushroom, called the Koho khur in Kashmir. It grows in the hollow trunks of Pinus Webbiana. When cooked, its taste is excellent. There are many European species.-Von Mueller.

HYDRANGEA, a genus of hardy shrubs. One species commonly cultivated for the sake of its beautiful flowers, is a native of China and Japan. Loureiro took it for a primrose, and called it Primula mutabilis ; and Commerson subsequently named it Hortensia, in compliment to Madaine Hortense Lepleaute. $\mathbf{H}$. hortensis is the Guelder rose. It is from 'Udor, water, and Aggion, a vessel, in allusion to some of the species growing in water, and the resemblance the capsule bears to a cup.

$\mathrm{H}$. paniculata is the Nori-nori of Japan; a gummy matter is obtained from its bark, by decoction, used in sizing paper.

H. Thunbergii, Siebold. Yan-siu-kiu, ChIN. ; Amats-ja, JAPAN. A shrub of E. China, Japan, and Java, is used as tea, and called in Java tea of heaven.-Sir J. E. Reed, p. 43.

HYDRAOTES, the ancient Greek name of a river in the Panjab, the modern Ravi; known also as the Rhoas. Two separate words forming the Greek name are 'Udor and Raotes; its Sanskrit name is Airavati.

HYDRAULIC CEMENT, the finer kinds of lime and cement on the coast of the Peninsula of India are made from shells. A piece of ground about ten feet square is laid down even and floored over with clay; an upright pole is placed at each end of this, and a sheet stretched out with back stays spread between the poles, which are steadied with strings. On the floor a bed of shells and rice-chaff alternately, about ten inches thick and eight feet by six, is spread neatly out. Some firewood is placed along the windward side of this, and when the sea-breeze sets in the wood is kindled. As the heat extends to leeward, and the shells become calcined, the lime-burners draw off the fore parts of them with a stick, and so soon as they have cooled on the floor sufficiently to allow them to be handled, they are placed in a scoop basket, and the dirt and epidermis winnowed from them. The shells, now white and pearly, are next thrown into a small-sized vat partially filled with water; here they for some time boil from the effects of the heat and slaking. The whole in a short time settles down into a fine semi-fluid mass, which is taken out and slightly dried, and is now ready for use. A good hydraulic cement is formed of the blue clay of Madras and shell-lime. Bitumen or asphalte seems to have been employed in Babylon as a cement.

HYDROCERA TRIFLORA. W. and $A$. Water oleander. This is the Domuti of Bengal, the Noli me tangere, one of the Balsaminacex. It expels its seed at a mere touch. The Turks regard it as a symbol of ardent love.

HYDROCHARACEÆ, a natural order of floating or water plants; six genera with eleven species occur in the East Indies, viz. species of Ottelia, Vallisneria, Hydrilla, Blyxa, Enhalus, Boottia, and Hydrocharis. Hydrilla verticillata, along with similar plants, is employed by sugar refiners for covering the surface of their sugars, to permit the slow percolation of water. Enhalus acoroides has a sulphurous smell. Its fruit is eatable, raw, boiled, or roasted; if boiled, the nuts acquire the taste of boiled chesnuts. The natives 
of the Moluccas make nets of the tough threads which remain after the putrified leaves; these nets are said to be very durable in sea water. Blyxa octandra, Rich, grows all over India ; Boottia cordata, Wall., a plant of Prome and Taong-Dong. Enhalus acoroides, Linn. (Acorus marinus, Rumph., Stratiotes acoroides, $\operatorname{Linn}$.), grows in the Konkans and Moluccas.

Hydrilla verticillata, Linn.

Serpicula verticillata, $L$. $f$. | Udora vexticillata, Spreng. Vallisneria verticillata, $R$. Hottonia serrata, Willde. Kurelee, . . Hind. | Jhangh, . . PANJ. Jala,. . . PANJ. Punachu, . . TEL.

This, with other aquatic plants, is used by the sugar-refiners of Saharunpur for covering the surface of sugar, in order to allow the slow percolation of water when refining it. It is common in water in parts of the Panjab plains up to Peshawur. It is used east of Sutlej for refining sugar, but at Multan, west of that river, it is not obtainable.-Stewart, Panj. Plants, p. 241.

Hydrocharis cellulosa, $H . B$.

Ottelia alismoides, Pers.

Stratiotes alismoides, Linn. Damasonium Indicum, Hymenotheca laxifolia, Willde

Salis. $\quad$ D. alismoides, $R . B r$.

It is the Panee-kula of Bengal, and grows in most parts of India.

Vallisneria alternifolia, Roxb., the Rusnojhangi of Bengal, grows there and in the Konkans and Coromandel. V. physicum, Juss., is a plant of Cochin-China.

Vallisneria spiralis, Linn.

V. spiraloides, Roxb. IV. Jacquiniana, Spreng.

A plant of Europe, America, and India.

HYDROCOTYLE ASIATICA. $L$. Pennywort. Hydrocotyle rotundifolia, Wall.

Thulkuri, . . Beng. / Munduka brummi, TeL. Kodagam, : MaLeal. Bokkudu, : . .", Munduka purni, . SANsk. Pinna yelaki chettu,. ", Heen-gotu kola, . SiNGH. Babbasai elaka, . ", Vullari kire, : TAM. Elika chavi kura, . .

A small herbaceous creeping plant with little purplish red flowers, a native of Africa and America, and in moist shady places all over Southern Asia. It has long been employed in medicine, its leaves applied to bruises, and its virtue in leprosy has been latterly again much lauded. An infusion of the toasted leaves is given to children in fever and bowel complaints. - Ainsl.

HYDROCY ANIC ACID, Prussic acid. Several species of the rose order of plants contain a considerable amount of Prussic (hydrocyanic) acid; the oil of the common laurel and bitter almond is, owing to its presence, a virulent poison.

HYDROLEA ZEYLANICA. Vahl.

Nama Zeylanica, Linn. | Steris aquatica, Burm.

A herbaceous plant, grows in water and marshy ground in the East Indies. The leaves beaten into a pulp and applied as a poultice are deemed useful in cleaning and healing ill-conditioned ulcers in which maggots have formed.-Voigt.

HYDROPHID As, the family of sea-snakes. A principal babitat of sea-snakes is the ocean between the southern shores of China and the northern coast of New Holland. They frequent the seas that separate the islands of the Pacific, but they have never yet been found in the Atlantic.

They are found on all the coasts of the East Indies within soundings, and are supposed to live on sea-weed. Sir J. E. Tennant says he has sailed through large shoals of them in the Gulf of Manaar, close to the pearl banks of Aripo. The fishermen of Calpentyn, on the west of Ceylon, live in perpetual dread of them, and believe their bite to be fatal. In the course of an attempt to place a lighthouse on the great rocks of the southeast coast, known by seamen as the Basses or Baxos, the workmen who first landed found that portion of their surface liable to be covered by the tides, honeycombed and hollowed into deep holes filled with water, in which were abundance of fishes and some molluscs. Some of these cavities also contained sea-snakes from four to five feet long, which were described as having the head hooded like the cobra di capello, and of a light grey colour, slightly speckled. They coiled themselves, like serpents on land, and darted at poles thrust in among them. The Singhalese who accompanied the party said that they not only bit venomously, but crushed in their coils the limb of any intruder. About the year 1834, a midshipman, the boatswain, and a seaman of one of H.M. war ships at Madras were all bitten by a sea-snake, and died.-Tennant's Ceylon.

HYDROPHOBIA. Dr. A. Gibson says the Notonia corymbosa, native name Wandur Rotee, is useful as a prophylactic in hydrophobia. It grows rather plentifully on the stony parts of the high hills near Jooner, and also in some parts of the Northern Dekhan, Kandesh, etc.

HYDROPHYLAX MARITIMA. Linn. A straggling herbaceous plant, native of the shores of Coromandel and Malabar, where it shows its pale lilac blossoms a great part of the year. The branches run over the sand, sometimes under the surface, and strike root at the joints. It answers well as a sand-binding plant where the sand is moist.-Roxb. i. p. 373 .

HYDROSAURI, or water lizards, live on the margins of springs and on low river banks. Hydrosaurus salvator, Lour., occurs in Bengal, Assam, Ceylon, Malacca. Tail compressed, fingers long, nostrils near the extremity of the snout. A black band on each temple, round yellow spots disposed in transverse series on the back; teeth with the crown compressed and notched. H. marmoratus, a huge lizard of the Philippines.-T'ennant.

HYKSOS, or shepherd kings, were Semitic tribes from the N.E. of Egypt, that is Canaanites, associated with Bedouin tribes of Northern Arabia and the peninsula of Sinai. They held Memphis, but their stronghold was a fortified camp on the border of the Syrian desert.

HYLOBATES AGILIS, the gibbon, one of the Simiadse, occurs in the Malay Peninsula, and several other species in the Archipelago.

Hylobates Hoolook, the Simia Hoolook, Harlan; H. seyrites and H. coromandus, Ogilby; H. Houloch, Lesson, a native of Assam, Sylhet, Cachar, and Khassya Hills. Its howlings are very extraordinary.

Hylobates Lar, Homo lar, Linn.; Simia longimana, Schreb.; S. albimana, Vigors and Hors.; Le grand gibbon of Buffon. A native of Tenasserim and Malacca, where it is known as the white-handed gibbon. The contrast which this animal offers with $H$. hoolook is very remarkable. The body is proportionally much shorter, and it is quite incapable of walking in the erect attitude commonly assumed by $\mathrm{H}$. hoolook, always creeping forward when on the ground in a crouching position. 
Hylobates Leuciscus, the silvery gibbon, the Wow-Wow or Wa-Wa, Simia leucisca, Schreb., Moloch, Audeb., native of Malacca. The Wa-Wa, or long-armed ape, is the most beautiful of all the monkey tribe. The fur of this gentle little animal is grey; its face, hands, and feet are jet black; in features it more resembles those of the human race than the orang-outang. - Low's Sarawak, p. 80 ; Jerdon.

HYLOBII, a sect of ascetics mentioned by Megasthenes as living in the woods, clothed with the bark of trees, and living on fruits and leaves. Hylobios is a literal translation into Greek of Vanaprashtha, SANsK., dweller in the woods, which is the usual designation of a Brahman in the third stage of his life.

HYMEN AA COURBARIL. Linn. The locust tree, gum-anime tree, or courbaril locust tree, is a fine colossal spreading tree, growing in the tropical parts of America, in Jamaica, and in Tenasserim, where it was introduced by Major Macfarquhar. The tree is easily propagated. The timber of the old trees is very hard and tough, and is in great request for wheel-work, particularly for cogs. The wood is so heavy that a cubic foot is said to weigh a hundred pounds; it takes a fine polish, and is used by cabinet-makers. When in a sickly state, the resin called Western anime, also W. Indian copal, exudes from between the principal roots. It is fine and transparent, of a red or yellowish-red colour, and in large lumps. It resembles amber, is very hard, and sometimes contains leaves, insects, or other objects imbedded in it. It burns readily, emitting a very fragrant smell. Dissolved in rectified spirits of wine, it makes one of the finest kinds of varnish.-Eng. Cyc.; O'Sh.; Mason's Ten.; Voigt; Von Mueller.

HYMENODYCTION EXCELSUM. Wall.

Cinchona excelsa, Roxb. Cedar wood.

Kala bachnak, Duk, HinD. Burja ; Burija, . Tex. Barthoa; Thab, . PANs. Chetippa, : . ", Sagapu maram, . TAM. Bandaru, Pundaru?

A very large tree belonging to the Cinchonaceæ, common all round the foot of the Neilgherries, and in the mountainous parts of the Circars, but chiefly in the valleys. The wood is firm, close-grained, of a pale mahogany colour, and very useful for many purposes; much used and esteemed for jnside work, such as drawers, etc. The bark, Dr. Roxburgh informs us, possesses both the bitterness and astringency of the Peruvian bark, and, when fresh, even in a stronger degree. The two inner leaves of the bark possess great bitterness and astringency; the bark is used by the tanners, and also as a medicine among the Hindus, in eases requiring astringents. Dr. O'Shaughnessy analyzed the bark from the Botanic Garden of Calcutta, but could detect no alkaline ingredient. Nevertheless the trees of hilly regions may furnish the valuable desideratum. The stamina being contained within the tube, affords much ground for expecting the discovery of a febrifuge alkaline in this species - Roxb.; $O^{\prime} S h$.

HY MENODYCTION OBOVATUM. Wall.

Karwai ; Karwye, MAHr. Malay tansh, . TAM. Yella mala,. . TAs.

This large, beautiful tree is not uncommon in the sub-Alpine forests from Canara down to South Travancore, up to elevations of 4000 feet. It is less common, however, than the H. utile, Wight. Dr. Gibson says this and H. utile grow on the
Bombay side of India, but that the wood of neither is fit for anything but fuel. Colonel Beddome says the timber is used by the natives for a variety of purposes, and is probably equal to that of H. excelsum.-Wight; Gibson; Beddome.

H. thyrsiflorum, Wall., grows at Rajmahal, Chittagong, and at Rangoon.-Drs. Wight, Gibson, and Voigt.

HYMENODYCTION UTILE. W. $T c .1159$.

Kurwye, . - MAHR. | Pirunjolay maram, TAM.

This tree attains a large size, and the heartwood is red. Dr. Wight was informed that it furnished the wood called bastard cedar, and he afterwards found two other trees similarly reported. Dr. Gibson says the wood of this tree is never used in Bombay except for firewood. The tree is common enough, in rocky slopes, mostly in or near thick forests. It does not stretch inland beyond the limits of the ghat ravines.Wight; Gibson.

HYMENOPTERA, an order of insects characterized by the majority of them having stings. See Insects.

HYOBANS. The raja of Huldee or Hurdee in Ghazipur is of this conspicuous clan, which once held large dominions on the banks of the Nerbadda.-Elliot, Supp. Gloss.; Jour. Beng. A. S.

HYOSCIAMUS NIGER. Linn. Henbane.

Bunj, . ARAB., Pers. 'Sapht, . . . EGYPT. Siekran, . . ", Uoskuamos, . . . GR. Dandura, : CHenab. Adas-pedas,. . Malay, Bazr-bang, . . ", Dentura of . . RAvr. Yang-chih-chuh, . CHIN. Khorasani omum,. TAM, Nau-yang-hwa,

The Seed.

Khurasani ajwain, HIND. | Tukhm-i-bunj-i-Rumi, Bazr-ul-Bunj, . Pers.

PERS.

The henbane plant is a native of Europe and of Asia Minor, and in the Panjab Himalaya is frequent in waste ground near houses from 5000 to 10,000 feet. The seeds are officinal in India for their narcotic effects, and it is cultivated in several parts of India. In physiological action this plant and its preparations seem intermediate between belladonna and opium, combining great soothing and anodyne power with the property of dilating the pupil. An alkali has been obtained termed hyosciamia, which differs little, if at all, from atropia. A dry inspissated juice of the leaf was prepared by exposing the juice in thin layers on a shallow earthen vessel to the intense heat of the sun in April and May. Dr. O'Shaughnessy deemed this extract far superior to any imported from Europe or prepared in India by other processes. In three-grain doses its soporific and anodyne effects were most decisive, and its use rarely if ever followed by any headache or other unpleasant symptoms.-O'Sh.; Stewart; Spry.

HYPERICUM CHINENSE. Smith. Kin-szets'au or Kin-sze-t'au, CHIN. A beautiful flowering plant of China.

HYPERICUM PERFORATUM. Linn. St. John's wort. Bassant of Ravi, Bassant dendlu of Beas. Common in the Kashmir mountains. In Arabian medicine it is recommended to expel intestinal worms and to cure piles, prolapsus uteri et ani. In European practice St. John's wort was regarded as a mild stimulant tonic, diuretic, emenagogue, etc. The dried herb boiled in alum water communicates a yellow or yellowish - red colour to wool, silk, etc. St. John's wort plants 
all bear yellow flowers, with one exception from Cochin-China-Riddell; Stewart; Honigb.

HYPH ENE, a genus of dicotomous palms of Africa, but growing in India. H. argun, Martins, grows in Nubia. H. coriacea, Grertn., the Doum palm of equatorial E. Africa and Upper Egypt, attains a height of 80 feet. It is common at Multan. H. crinita, Grertn., of Egypt and Abyssinia. H. thebaica, Mart., the Doum palm, or gingerbread tree of Egypt, grows at Okamundel and on Diu Island. Exceptional in the palm order from its branching trunk.

HYPHANTIDIUM SERICARIUM. Bennett. A lepidopterous insect of Australia. Its larvæ weave a beautiful silken web.

HYPHASIS, the ancient Greek name of the river of the Panjab, called in Sanskrit Vipasa. It is the modern Gharra.

HYPOLITE DESIDERI, a traveller who set out from Goa on the 27th November 1713 , and reached Lahore in October the following year.

HYRCANIA, the hilly region south of the Caspian Sea, the country about Mazenderan, which has much forest. It is the Greek corruption of the word Korken or Gorghen, the name of a river which rises in the Kurdish mountains, traverses this region, and falls into the Caspian Sea.Ouseley's Trav. i. p. 188, ii. p. 59.

HYSSOPUS OFFICINALIS. $W$. Hyssop. Zufaiy yeabus, . Arab. Hyssope, . . . . Fr. Zufæ yabis, . : ,, Isop, . : : Ger. Ushnaz Daoud,

",

Used, in infusion, for coughs and asthma ; also in toothache, uterine or vesicle affections, and indurations of the liver or spleen. Hyssop that cometh out of the wall, alluded to in 1 Kings iv. 33 , was probably a lichen or moss, probably the Gymnostomum fasciculare, a moss common in the Holy Land.-Powell, i. p. 365.

HYSTRICID $E$, a family of mammals of the order Rodentia. The sub-family Hystricinæ embraces the animals familiarly known as porcupines, of the genus hystrix of Linnæus. They are rodents, whose covering consists for the most part of offensive and defensive armour, in the shape of spines or quills, instead of hairs.

Hystrix Bengalensis, Blyth.

H. Malabarica, Sclater. I Bengal porcupine, . ENG.

This is smaller than H. leucurus, the head and body being about 28 inches, and tail 8 inches. It is found in South Malabar, Lower Bengal, Assam, and Arakan; doubts, however, exist as to the identity of $H$. Bengalensis and H. Malabarica. Dr. Day states that he procured specimens of the orange porcupine from various parts of the ghats of Cochin and Travancore, and that the flesh of this kind is more highly esteemed for food than the common variety. The native sportsmen declare that the aroma from these burrows is quite sufficient to distinguish the two species.

Hystrix Leucura, Sykes. Indian porcupine. H. hirsuti-rostris, Brandt. H. Zeylanensis, Blyth. $\mathrm{H}_{\text {. cristata Indica, Gray. H. cauda-alba, Sykes. }}$

Sajru, . . . BENG. Sahi, Sayal, Sarsel, Hind. Yed, : : : CAN. Salendra,. . MAHR. Hoigu, : : GOND. Dumsi, Saori, : : : GoJ. / Yeddu pandi, : . TEL
The white-tailed or Indian porcupine is found over a great part of India. It forms extensive burrows, often in societies, in the sides of hills, banks of rivers, nullahs, and tanks, or old mud walls. Its length is about 32 inches, tail 7 inches. In some parts of the country they never issue forth till dark; dogs take up the scent readily, The porcupine charges backwards on its assailants, with erected spines, and dogs frequently get severe wounds, the strong spines being driven deeply into them. The meat of the porcupine is white, tasting something between pork and veal, and is not bad eating.

Hystrix Longicauda, Marsden. \begin{tabular}{l|c} 
H. alophus, Hodgson. & Acanthion Javanicum, \\
H. Hodgsonii, Gray. & $F$. Cuv.
\end{tabular}

Crestless porcupine, ENG. O'e of . . . . LIMBU, Sathung of IEPCHA. Achotia dumsi, NEPAL

The crestless porcupine is found in Sikkim, in Nepal, at Darjiling; up to 4000 and 5000 feet. In the Eastern Himalaya it is about 24 inches long, tail 4 and quills $5 \frac{1}{2}$ inches. They are very numerous and very mischievous, committing great depredations in the edible root crops.

Atherura fasciculata is of the Tiperah Hills and southwards to the Malay Peninsula. The tail is much longer than in the true porcupines, and ends in a tuft of long bristles, and the spines of the back are less elevated.-Jerdon; Mason.

HYSUDRUS, the name by which the Greeks designated the Sutlej river.

HYTA-BASHI, a leader of the Hyta troops, Turkish irregular cavalry, called Hyta along the valley of the Tigris and at Mosul, and Bashibazouk in Roumelia and Anatolia. They are collected from all classes and provinces. A man known for his courage and daring is named HytaBashi or chief of the Hyta, and is furnished with tazkara or orders for pay and provisions for so many horsemen, from four to five hundred to a thousand or more. He collects all the vagrants and freebooters he can find to make up his number. They find their own arms and horses, although sometimes they are furnished by the Hyta-Bashi, who deducts a part of their pay until he reimburses himself. The best Hyta are Albanians and Lazes, and they form a very effective body of irregular cavalry. Their pay at Mosul is small, amounting to about eight shillings a month ; they are quartered on the villages, and are the terror of the inhabitants, whom they plunder and illtreat as they think fit. When a Hyta-Bashi has established a reputation for himself, his followers are numerous and devoted. He wanders about the provinces, and, like a condottiere of the middle ages, sells his services and those of his troops.

HYUGOR. Внот. A mantle of sheep-skin or goat-skin.

HYUL or Jiul, of the northern European nations, is the Hindu sacranta, and is supposed in Tod's Rajasthan (i. p. 24) to be derived from Hya, SANsk., a horse, El, sun, whence $i \pi \pi 0 s$ and

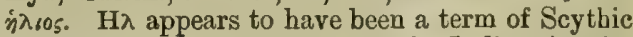
origin for the sun; and Heri, the Indian Apollo, is addressed as the sun. Hyul may be the Noel of France.Tod's Raj. i. p. 24 . 


\section{I}

I. This letter of the English alphabet has, in Englaud, four sounds. As an initial and medial letter, it has a long sound, as in iron, fine, isinglass ; a second is short and acute, as in sit, infant, indigent; a third sound is that of the letter $u$, as in stir; and the fourth sound is close and slender, though long, like ee, as in fatigue, intrigue. The three first sounds are peculiar to the English language, but the last long sound, as of ee, is represented in all the tongues of the south-east of Asia.

IANTHINA, the violet snail, a genus of molluscs, of the family Haliotidx. There are six recent species, widely distributed in the four quarters of the globe. They are seen floating on the ocean, but are often driven on the shores by tempests. The beach at Madras is strewn with them after a gale. The Ianthina has occurred on the coasts of Britain. In warm climates it is very plentiful-_Eng. Cyc.

IARVINI. TAM.?

Crawn, . . Dut., Port. / Yarvaney, . . . . TAM.

A Ceylon tree which grows tall and straight, from 20 to 45 feet high, and from 12 to 30 inches in diameter. It answers many purposes in ship and house work.-Edye, Timber of Ceylon.

IBADIYAH, a Shiah sect of Mabomedans which was founded in Oman by Abdullah-ibn-Abad. They elect their own imam.

IBERIA. This ancient kingdom is the modern province of Kartelania in Georgia. Ptolemy describes it as bordered on the north by the Sarmatian mountains, to the south by a part of Armenia, to the east by Albania, and to the west by Colchis, the present Immeretia. He mentions many of its towns and villages. Strabo, who travelled in these countries, speaks of this being a flourishing and even luxurious state. In western emigration, the Iberians and Cantabrians preceded the Celts, and their language is preserved in the Basque (Biscayan).-Porter's Tr. i. p. 110 ; Latham in Brit. Assoc. Journ., 1845, pp. 77, 78.

IBEX. This name is given in India to several animals of the genus Capra or goat. C. Sibirica (I. Himalayana, Blyth) is the Himalayan Ibex, the Skeen, Skyn, Sakeen or Sikeen of the Himalaya, the Kyl of Kashmir, Jerdon. These are the names of the male; that of the female, in Tibet, is L'danmo. It inhabits Ladakh and Kashmir east to Nepal. It is agile and graceful in its movements. They are hunted and shot in the winter for the sake of the soft under-fleece, which in Kashmir is called Asali tus, and is used for lining shawls, also for stockings, gloves, and is woven into a fine cloth called Tusi. No wool is so rich, so soft, and so full. The hair is manufactured into coarse blanketing for tents, and twisted into hair ropes. The sportsmen of Southern India give the name of Ibex to the Neilgberry wild goat, Hemitragus hylocrius. See Goat.

IBI-GAMIN, a glacier in Eastern Tibet, in height 22,260 feet English = 20,886 French feet.

IBIS, a familiar name applied to species of birds of the tribe Cultirostres; the Pelican Ibis is Tantalus leucocephalus, extremely common throughout India, Ceylon, and Burma. The Shell Ibis is the Anastoma oscitans, Boddaert, very abundant in the lake and river districts. The Ibisinæ or true ibis, of which three species occur in India, and are there called curlews, from which, however, they differ in breeding on trees, and feeding their young till full grown.

The White Ibis is the Threskiornis melanocephalus, Limn, and is found throughout India ; the Warty Black Ibis, Geronticus papillosus, Temm., also of all India, feeds chiefly on dry land; and the Glossy Ibis, the Falcinellus igneus, Gmelin, occurs in vast numbers in India in the cold weather. It occurs throughout the whole world, and is very common in India. It is called in Tamil, Arroova mooken, literally sickle-nosed, from its long curved beak. The nest contains from three to five eggs, which resemble in size and shape a medium-sized hen's egg, but are of a dirty-white colour. The birds are white, with black head, feet, and neck, and have a long curved black bill. The head and neck are naked, and the tail-feathers of rather a rusty-brown colour; the lower sides of the wings, from the axillæ to the extremities, are naked, and the skin in the old birds is of a deep scarlet colour; in the young this is absent, although the part is naked. The young are fully fledged in March, and take to the wing in April.

The Sacred Ibis, Ibis religiosa, had great honours paid to it by the ancient Egyptians. It extends across the whole African coutinent in the same latitude, and is found on the west coast also.-Jerd.

IBLIS. ARAB, The devil, one who despairs of God's mercy.

IBN ASIR, author of the Kāmil-ut-Tuarikh, a general history of the Ghaznavites.

IBN BATUTA, born A.D. 1304, died 1377-78, was one of the great travellers of the Arab race. He spent 24 years (from 1325-49) in travelling throughout the east, from Tangiers across Africa to Alexandria, and in Palestine, Syria, and Arabia ; down the east coast of Africa to Quiloa; across the Indian Ocean to Muscat, Ormuz, Kish, Bahrein, and El Catif ; through Central Arabia to Mecca and Jiddah; and again in Egypt and Asia Minor, and across the Black Sea to Caffa or Theodosia, and by Azov or Tanna, on past the bills of the Russians, to Bolgar on the Volga, - but not daring to penetrate farther northwards into the 'Land of Darkness.' Returning south to HajTarkhan (Astracan), he proceeded, in the suite of the wife of the Khan of Kipchak, the daughter of the Greek Emperor Andronicus, westward to Soldaia and Costantiniah (Constantinople; he mentions Istambul as a part of the city); whence, returning to Bolgar, he travelled on eastward to Bokhara, and through Khorasan to Käbul, Multan, and Debli, where he remained eight years, 1334-42. Being sent by the Sultan Muhammad Taghalaq on an embassy to China, he embarked from Kinbaiat (Cambay), and, after many adventures at Calicut (where he was honourably received by the Samari or Zamorin) and Hunawar (Onore), and in the Maldive Islands, and Ceylon and Bengal, he at last took his passage toward China in a junk bound for Java, as he calls it, but in fact Sumatra. Returning from China, he sailed direct from the coast. of. Malabar to Museat and Ormuz; and, travelling by Shiraz, Isfahan, Bussora, Baghdad, Tadmor, Damascus, Aleppo, Jerusalem, and (for the fourth time) Mecca, Egypt, and Tunis, at last reached Fez again, after an absence from Morocco of half his 
lifetime. Subsequently he spent six years in visiting Spain and Central Africa, where he was the guest of the brother of a countryman of his own from Ceuta, whose guest he had been in China. 'What an enormous distance lay between these two!' he exclaims. He says that in his time Cairo was the greatest city in the world out of China, and that the finest trading ports he had seen were Alexandria in Egypt, Soldaia or Sudak in the Crimea, Koulam (Quilon) and Calicut in India, and Zayton (Chinchau) in China. $\mathrm{He}$ also describes Aden as a place of great trade, to which merchant ships of large burden resorted from Cambay, Tauna, and all the ports of Gujerat and Malabar. Among the productions of the Indian Archipelago, he describes gum-benjamin, aloes-wood, cloves, camphor, and sandal-wood; and enumerates also cocoanut palms, areca-nut palms, jack trees, orange trees, mangoes, and jamuns (Eugenia jambolana). Porcelain, he says, is made in China nowhere except in the cities of Zayton and Sinkalan (Canton). It was exported to India and elsewhere, passing from country to country until it reaches Morocco. The first detailed account of his travels was published in Europe in 1808. They were translated from the Arabic, with Notes by S. Lee, London 1829. He enumerates many large and populous towns, and gives a high opinion of the state of the country. He speaks of Madura as a city like Dehli, and that through the whole of Malabar, for two months' journey, there was not a span free from cultivation; everybody had a garden, with his house placed in the middle of it, and all surrounded by a wooden fence. And the ports were frequented by ships from China, Persia, and Arabia, and other neighbouring countries.-Lee's Ibn Batuta; Birdwood's Report; India in the 15th Century; Tr. of a Hindoo; Yule's Cathay.

IBN HAUKAL, an Arab traveller who visited India a short time after Masudi. He wrote the Ashkal-ul-Balad, or Kitab-ul-Masalik-0-uIMamalik, or descriptions of countries, in which occur notices of most of the Mahomedan kingdoms of his day. His real name was Muhammad Abu-1-Kasim, and he was a native of Baghdad. He left Baghdad A.D. 943 (A.H. 331), and he continued travelling till A.D. 968 . He notices his obligations to Ibn Khurdadbah, and he copied likerise from Istakhri. He finished his book A.D. 976, and it was translated in 1800 by Sir William Ouseley.-Ind. in 15th Cent.; Elliot; Hist. of India.

IBN HISHAM, A.D. 833 (A.H. 218), author of Sirat-ur-Rasul, translated by G. Weil, Stuttgard 1864. It contains the earliest and most authentic history of Mahomed, and was founded on a book by Ibn Isbaq.

IBN ISHAQ, died A.D. 768 (A.H. 151). He wrote traditions of Mahomed.

IBN KHALLIKAN. This well-known work has formed the basis of almost all that has been written on the personal history of remarkable men of Islam.

IBN KHURDADBAH, died A.D. 912 (A.H. 300 ), wrote a work on roads and kingdoms. $\mathrm{He}$ attained high office under the khalifs. He was a Zoroastrian. He is the first who makes mention of galangal and kamala, and he also mentions porcelain, sugar-cane, pepper, aloes-wood, cassia, silk, and musk.-Elliot.

IBN SAAD, A.D. 844 (A.H. 130), secretary of

Waqidi (Katib-ul-Wakidi), died A.H. 130-114. He wrote a life of Mahomed.

IBN-ZAIN-ul-TABARI, a physician of Baghdad of the early part of the 10th century.

IBN ZOHAR, the name of two distinguished Arab physicians, father and son, who flourished in Spain during the 11th and 12th centuries, and who are known to Western Europe by the name of Avanzoar. They were Jews by descent and profession. The father was born at Seville about A.D. 1072-73, and died there A.D. 1162. He was physician at the court of Cordova, and had charge of an hospital. His most celebrated book, the Tasir, is one of the most valuable in the possession of the Arabian physicians. It displays much originality and discrimination. It contains a compendium of medical practice, including many facts and observations not found in preceding writers. He also wrote on Calculus and on Regimen, and some of his books were translated into Hebrew and Latin. He was the teacher of Averhoes. The son, 1114-99, also wrote several medical works, one of them on Diseases of the Eye. He died at Morocco, A.D. 1199.

IBRAHIM, founder of the Roushenai sect of Mahomedans; died at Cairo, A.D. 1529.

IBRAHIM KHAN of Gour had 7000 families of Taymuni under his rule; but about the year 1838 Yar Muhammad of Herat completely devastated the country which they occupied, and removed them to Herat, where he established some of them in the city, and some in the suburbs. In 1846, however, they took advantage of Yar Mubammad's absence on the Murghab, to decamp into the Persian territory.

IBRAHIM LODI, king of Dehli, was defeated at Panipat by Baber.

ICE.

lis, . . . . DaN. | Glacies, . . . LAT. Ijs, : : : Dut Gelo, Caramelo, : Port. Glace, . . . Fr. Teodt, . . : Rus. Eis, . : . GRR. Hielo, . : : SP. Yakh, : : HIND. Is, . : : S SWED. Ghiaccio, . . . IT.

In many countries, the command of a proper supply of ice or snow for cooling water or other liquids in summer, has long been regarded as one of the necessaries of life. There are even allusions to it in the Proverbs of Solomon:- As the cold of snow in the time of harvest, so is a faithful messenger to them that sent him; for he refresheth the soul of his masters' (xxv. 13).

The Chinese in the north of their country form ice-houses, about Ningpo, 60 feet long, 42 feet broad, and 12 feet high.

Ice is of great importance to the Chinese, who depend much for their food upon the fish which are caught in their waters. They are enabled by its means to keep their fish during the hottest weather for a considerable time, and transmit them in this way to different parts of the country. Ice has become an article of commerce. This traffic commenced in Wenbam Lake, about 18 miles from Boston, in the United States of America, and subsequently some of the Norwegian lakes have furnished abundant supplies.

Between 1874 and 1880, the imports into India ranged from 147,360 to $268,011 \mathrm{cwt}$., and value Rs. $2,11,675$ to $12,51,902$, from all quarters. The Rubattino Company tried to convey Alpine ice from Genoa to Bombay. 
Ice is now largely made in India by machines. The Peninsular and Oriental Ice Company at Bombay, in 1868 made five tons at a cost of five pie the $1 \mathrm{~b}$. Private manufacturers sell it at two annas a lb. at a profit. The smaller machines turn it out in cylinders, the larger machines in slabs. On the recommendation of Colonel (Sir George) Balfour, C.B., the Indian Government sanctioned an ice machine, value $\mathrm{Rs}$. 7000, for each European regiment.-Tumlinson ; Fortune.

ICELAND MOSS is the lichen (Cetraria Islandica), $A c h .$, common in the north of Europe and North America. It yields a nutritive starchy substance, sometimes employed to make bread and gruel.-Waterston; Faulkner.

ICELAND SPAR, a variety of calcareous spar found in rocks near Kābul, and is extracted and broken into crystalline rhombohedral fragments, more or less opaque. It is employed by the natives as an astringent in ophthalmia, gonorrhoea, and other fluxes, in doses, internally, of 7 grains, and also externally as a local application. It is called Surma safed, or white antimony, from being thought to be similar to black antimony, the common tersulphide of that metal. Price 3d. per lb.-Cat. Ex., 1862.

ICHNEUMON, a genus of insects which belong to the order Hymenoptera, section Terebrantia, and family Pupivora, in the classification of Latreille.

The species are many. They have a slender shape. The female, by means of its ovipositor, deposits its eggs into the body of a caterpillar, previously stupefied, so that the larvæ find food as soon as they are hatched, and devour the interior bit by bit. They are also often deposited into the larvæ of coleoptera; hemiptera, aphides, and weevils. The ichneumon forms small nests of clay, into.which they deposit the infected insect. -Eng. Cyc.

ICHNEUMONS, a group of carmivora, spread over Africa and Southern and Eastern Asia. The Egyptian ichneumon very closely resembles the European species. It was one of the animals held sacred in ancient Egypt. It is of common occurrence throughout North Africa, and particularly abundant on the Nile, where it is said to attack the crocodiles, and where, without doubt, it destroys great numbers of eggs. The Ichneumons are all extremely fond of eggs, whether of reptiles or of birds. They break them very cleverly, by tapping one end on the ground; and through the small aperture thus effected they suck out the whole of the contents. There are several species of Herpestes in India, called Mongoose or Mungus; H. 'Javanicus of Java and Sumatra; H. griseus, Geoff., of continental India and neighbouring countries; $H$. Nipalensis, Gray, of Nepal; H. neyula, Hodgson, of the Terai; $\dot{H}$. Malaccensis, Jerd., of Bengal; H. monticolus, Jerd., hills of Eastern Ghats; H. fuscus, Jerd., of Neilgherries; H. vitticollis, Jerd., of Western Ghats; $\mathrm{H}$. brachyurus and $\mathrm{H}$. exitis of Malay Archipelago. The Egyptian species, Herpestes ichneumon, celebrated for destroyiug serpents and crocodiles, was called Ichneumon Pharaonis. See Mongoos.

ICHNOCARPUS, a genus of plants belonging to the order Apocynaceæ. I. fragrans, Wall, is grown in Nepal and Kamaon. It has large handsome flowers; I. Loureirii is a native of Zanzibar.
ICHNOCARPUS FRUTESCENS. $R . B r$. Echites frutescens, $R o x b$. | Apocynum frutescens, $L$. Shyama luta, . BENG. Nalla tige, . . . TEL Shama-lata, . * " Illukatte, . . . . , Pal-vulli,. - MaleaL. Munta gajjanamu, . ", Nalla tiga, . . TEL.

Grows all over India. According to Royle, it is sometimes used in India as a substitute for sarsaparilla; 12 annas per lb.-O'Sh. p. 442 ; Cal. Cat. Ex., 1862 ; Don; Lindley.

ICHTHYOCOLLA, a named derived from เ $\chi \theta \cup \varsigma$

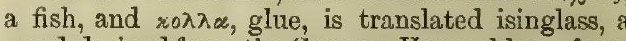
word derived from the German Hausenblase, from Hausen, the great sturgeon, and Blase, a bladder, being one of the coats of the swimming-bladder of fishes, chiefly of the genus Acipenser on sturgeon, and of which the best. qualities are exported from the rivers of Russia, flowing into the Black and Caspian Seas, but also from the Sea of Ural and the Lake Baikal.-Royle. See Air-bladder; Fish-maws ; Isinglass ; Sounds.

ICHTHYOPHAGI, a fisher race of the ancients, on the coasts of Persia, the Sir Matsya or Sermahi. Fish to this day is the staple article of food of the inhabitants on the sea-coast of Baluchistan. In the Shatt-ul-Arab, fish are caught and cured, and sold at one shilling the cwt. ; for six months the people of Basra live on almost nothing else, and also from Basra to Hormuz, the sea-coast people principally live on fish; and manuscript dictionaries describe the bread or food called Mahi-abah on Mahi-ashnah, used chiefly among the people of Lar, as prepared from fish (more particularly n small kind found near Hormuz), dried by exposing it to the sun. Strabo and Arrian relate that the ancient Ichthyophagi made into bread the fishes, which they had dried and roasted in a similar manner. The region of the Ichthyophagi commenced at Malana, near Cape Arabah, and ended between the ancient Dagasira and the place now called Cape Jask, or more properly Jashk. Churchill's Collection of Vovages mentions that 'the coastes of Persia as they sailed in this sea, seemed as a parched wildernesse, without tree or grass; those few people that dwell there, and in the islands of Lar and Cailon, live on fish, being in manner themselves transformed into the nature of fishes. So excellent swimmers are they, that seeing a vessel in the seas, though stormie and tempestuous, they will swimme to it 5 or 6 miles to begge almes. They eate their fish with rice, having no bread; their cats, hemes, dogges, and other creatures which they keepe have no other dyet.' Nieuhoff, who travelled in 1662, says that about Gambroon 'the common people make use of dates instead of bread or rice; for it is observ able that the ordinary food of the Indians all along the coast from Basora to Sind is dates and fish dried in the air ; the heads and guts of the fishes they mix with date-stones, and boil it all together with a little salt water, which they give at night to the cows after they come out of the field, where they meet with very little herbage.'- $A$ s. Res. ix. p. 68; MacGregor; Taylor's Travels from England to India, i. p. 266 ; Churchill's Collection of Voyages, ii. p. 230 (first ed.); Ouseley's Tr. i. p. 228 ; Townsend's Outram and Havelock, p. 297.

ICHTHYOPHIS GLUTINOSUS, an immense earth-worm, common in Sikkim. It is a native of the Khassya mountains, Singapore, Ceylon, and Java.-Hook. Jour. p. 25. See Reptiles. 
ICICA INDICA. $W$. and $A$.

Bursera serrata, Wall. $\mid$ Schinus saheria, $\boldsymbol{H} . \boldsymbol{B}$. Schinus Bengalensis, $\boldsymbol{H} . \boldsymbol{B} . \quad \mathrm{S}$. Niara,

\section{",}

The Nayor tree of Assam and Chittagong, growing 70 feet high; timber close-grained and hard, as tough as oak, but heavier, and used for furniture by the natives. In South America are several species of Icica, all of which yield a transparent fluid, resembling turpentine in many of its properties, and they might be introduced into India. In Guyana, I. altissima, I. heptaphylla, I. heterophylla, I. decandra; and I. icecariba in Brazil.

'ID, ARAB., written Eed, a religions holiday of the Mahomedans. Of these, two Eidein are farz or absolute, being enjoined by texts in the Koran; these are the 'Id-ul-Fitr and the 'Id-us-Zoha. The 'Id-ul-Fitr, called also the 'Id-us-Saghir and Ramazan-ki-'id, is held on the 1st day of the month Shawal, in commemoration of breaking the thirty days' fast of the Ramazan. It is held with prayers and rejoicings and distribution of alms to the poor.

The 'Id-us-Zoha, or'Id-ul-Kurban, or Bakr-eed, the meanings being the festival of the forenoon, of sacrifice, or the bull-festival, is observed in commemoration of Abraham's sacrifice of his son, whom the Jews and Christians say was Isaac, but Mahomedans say was Ishmael. It begins on the 9 th of the 12 th month, Zulhijja, with prayers and offerings, and is continued on the morning of the 10 th with public prayers, after which a sheep, an ox, or a camel is sacrificed, and the meat of the sheep and oxen eaten by the offerers, or distributed to their friends and the poor.

IDA, one of the daughters of Dakșa, who was married to Kasyapa.

IDAAN, called also Merut or Murut, a race in Bormeo who inhabit the more hilly districts towards the north, in the vicinity of Kina Balou. They resemble the Kadyan, some of their tribes are near the capital; they are said to have sacrificed human victims, like the Kyans. The Idaan of different places go under different denominations and have different languages, but in their manners and customs they seem to be nearly alike. The name Idaan is in some measure peculiar to those of the north part of Borneo; the inland people of Passir are called Darat; those of Benjar, Biajoos; the Subano of Magindanao appear to be the same people. The Idaan are reckoned fairer than the inhabitants of the coast; this has given rise to an opinion, seemingly wholly unfounded, that they are the descendants of the Chinese. The custom obtained of arranging human skulls about the houses of the Idaan as a mark of importance. Journal Indian Archipelago, 1849, p. 557.

IDA CHETTU. TEL. A very small variety of orange, growing in all the hilly country of the Circars, both cultivated and wild. Perhaps the original of the Citrus aurantium, Linn., C. variatro, Heyne, p. 57, musk orange, Chota kichili, HIND., Kiri kittali, CAN.-Fl. Andh.

IDAIN, Idankai or Iddakai, TAM., Idagai, KARN., the left side; the left-hand castes of the Hindus.

IDAIYAN. TAM. Cowkeeper. The cowherd race in the southern districts of the Peninsula of India. They have as their tribal titles, Khone, Kone, or Konar, meaning king, also Karialan meaning landlord, and Servakaren meaning captain; but those in the northern districts adopt that of Pillai, The race are very numerous, but take a lower place in social life than the agricultural Vellaler, who generally take the title of Mudali.

IDIGA. KARN. A toddy-drawer; a caste who sell toddy, the ferrnented palm wine, etc., also employed as palanquin bearers. -Wils.

\section{IDOLS.}

Idole, . . - Fr. Ímagen, . . Sp. Bild, Gotze, : :GER. Vigraham, Salai, "TAM, Ebenbild, : : " Vikramu, Vigram, TeL. But, . Hind., Pers. Prattima, . . : ", Imagine, : . . IT. Put, Surat, ' " TuRk. Idolo, . . . IT., SP.

The idols of the Hindus are made of gold, silver, and copper, or their alloys,-one alloy of frequent use being that called panchalaka, of gold, silver, copper, tin, and lead; but iron, brass, crystal, stone, earth, cow-dung, and wood are also often employed, the red sanders wood and the woods of the Cupressus torulosa, Macrotomia euchroma, and Melia azedarach. Many of the idols in India are monsters, many are mere shapeless masses of stone with a smearing of red lead, or a $\log$ of wood without shape or form, or a stone from the river-bed; others, like the bull Nandi or Basava, the vahan of Siva, are beautifullyformed models of that quadruped. The forms of Siva and of his wife Parvati and of the cobra serpent are usually well portrayed, as also of the peacock in the Saiva temples. The horse is formed of wood, plated with silver and gilded; occasionally well-made figures of the elephant are to be seen.

The images made of gold are generally those of Durga, Lakshmi, Radba, Krishna, and Saraswati ; they are kept in private houses, and worshipped daily, and weigh from one to four tolas.

The image of Sheetula, of 10 or 12 tolas, is often made of silver, kept in the house, and worshipped daily. Ward mentions that at Kidderpur, adjoining to Calcutta, was a golden image of Puti-tupavuni, 2 cubits high. Near Sarampur was a golden image of Jagadhatri, about $1 \frac{1}{2}$ cubits high. Very small copper images of Surya, and of Siva riding on a bull, are preserved in private houses, and worshipped daily.

The images of all the gods and goddesses may be made of stone, generally of a black, but some of a white colour; the greater number are placed in temples; a few small ones are found in private houses. All images of stone are worshipped daily; the greater number are of the lingam, or the various forms of Vishnu. A few exist of the lingam, nine or twelve cubits high. Throughout Lower Bengal and all the south of India, every village has its guardian idol, generally one or more rough stones smeared with red lead, and placed under an aged banyan or pipal tree. In one single street of Calcutta there are more images of Krishna and emblems of Siva than perhaps in the whole length of the Doab. A lingam at Benares requires six men. to encircle it. The clay and composition images made in the vicinity of Calcutta for the annual festivals (some of which have a very splendid appearance, and are of large dimensions), after the ceremonies are over are cast into the river. The modern manufacturers of the deities are artisans in gold, silver, and other metals, stone-cutters, and potters. Some of the modern casts are handsome, but the modern sculptures are commonly contemptible. Some of the ancient Hindu sculptures are magnificent, and in minute ornamental and floral decorations almost unrivalled. 
In Burma the images of Gaudama are made of wood, marble, and the precious metals. In Siam, Japan, etc., images are made of the ornaments, precious metals, etc., collected from the ashes of the funeral pile of a deceased person; and others again from the pulverized fragments of the bones kneaded with water into a paste, baked, and afterwards gilded.

Images of snakes are common: The idea of their curative virtues is very old in India : a Hindu attacked by fever or other diseases, makes a serpent of brass or clay, and performs certain ceremonies to its honour, in furtherance of his recovery. Such ceremonies are particularly efficacious when the moon is in the Nakshatra (mansion, sign, or asterism) called Sarpa or the serpent, called also Ashlesha. Dhanwantari is the Esculapius of the Hindus, but has not an attendant serpent like his brother of Greece; the healthbestowing Dhanwantari arose from the sea when churned for the beverage of immortality. He is generally represented as a venerable man with a book in his hand.

Every Hindu house has at least a picture; many have idols; and every man of the Vira Saiva or Jangam sect, of whom there are many millions in India, always wears the lingam in a silver or gold casket, suspended from his neck or tied round his arm. The lingam inside is a small stone cylinder embedded in the yoni. The ordinary lingam, of which there are millions in India, is a stone cylinder rising from the yoni, a stone platform marked with circular markings; usually in front of it is a figure of the bull Nandi in stone. Ganapati or Ganesa, with the head of an elephant and the body of a fat man, is an idol frequently to be seen. As the god of wisdom, he is worshipped at the beginning of every undertaking by almost all Hindus. When a Hindu boy or girl begins to read, they make a Ganesa in the form of a small cone of cow-dung, which they place on a purified spot, and ornament it with flowers and naragam and red kanganu, and offer a sacrifice by burning camphor and frankincense, also offering betel-nuts and plantains, cocoanuts and jagari, then bow reverentially and pray for the god's aid. The pyramidal figure is then kept for a time or thrown into the water. Any person may see them.

In a Hindu temple, the idol is kept in the centre of the temple, called Sanadi. Daily the Brahman servants anoint it with oil, cleanse it with sikaia, wash it with water, then with curds, milk, lime-juice and hovey, and cocoanut water. Before it the dancing girls of the temple, the devadasa, dance and sing to music morning and evening. On certain festivals, the idol is taken from the temple in a palanquin or on a car, and made to perambulate the squares and the streets.

Idols are frequently objects of litigation, and sacrifices of human beings are occasionally made to them. In a village called Kishnagur, some 30 miles from Bikanir, there lived one Maya Ram, a Jat by birth, in whose house was an image of stone, which Maya Ram and his family used to worship. It was a tradition in the village that the idol had been kept formerly in several other houses, one after the other, but that all who worshipped it had come to a violent end; and Maya Ram one day was seen behaving very strangely before the idol, dancing frantically, says the report. $\mathrm{He}$ then forbade the other villagers to enter the house.
He seemed under the influence of some religious homicidal mania, attacking his kinsmen, and threatening to kill them unless they conformed to his worship of the stone image. He killed the child of his elder brother. Suddenly the contagion of madness seemed to seize the whole family: Maya Ram, with two male kinsmen and seven women, threw themselves into a well all together, and shouting 'Swarga chalo!'-Come to heaven! - the whole ten were drowned.

The Jain idols are usually naked figures of men and women, of gigantic proportions, often erect, but in every attitude. The Buddhist idol is usually Buddha or Gaudama, reclining, or sitting in the attitude of preaching. Some of the figures of Gaudama at the great Shooay dagon temple at Rangoon are of vast dimensions.-Moor; Ward's Hindus; Tr. of a Hind.; Coleman.

IDRISI or $\mathrm{Al}$-Idrisi, the surname of $\mathrm{Abu}$ Abdullah Muhammad, author of the geographical work Nuzhat-ul-Mushtak-fi-Ikhtirak-ul-Afak. He was born at Ceuta, in Morocco, towards the latter part of the 11th century. He travelled in Europe, and eventually settled in Sicily at the court of Roger II. He describes the countries in the S. and E. of Asia.-Elliot.

IFTAH. ARAB. The evening meal of the Mabomedans during the Maharram.

IGHIR. ARAB. Acorus calamus.

IGNATIA AMARA. Linn. The K'u-shih-pa-tau of the Chinese. Ignatius bean, syn. of Strychnos sancti ignoti.

\section{IGUANA.}

Zib, . . . ARab. Manawak, Manuwak, Mat. Iguana or Inguana, ENG. Ghoda-sala, . SANSK. Lizard, . . . Talla-goya, . : SINGH. Ghorepore, HIND, DUK. Udumu,. : : TAM. Biyawak, Bewak, MaLAY, Udumbu, : T TEL.

Iguana is the popular name for species of reptiles of the genus Varanus, family Varanidæ, order Sauria, of the section of scaled reptiles. Baron Cuvier classed them under his Iguaniens; others have arranged them under the Agamidæ. Varanus flavescens, Gray, inhabits Bengal; V. dracæna, Linn., Bengal and Agra, and also V. nebulosus, Dum. et Bil.

Varauus Dumerilii attains a length of 7 feet; it frequents the neighbourhood of houses, to rob hen roosts.

The Basilisk of the Eastern Archipelago is the Basaliscus Amboiensis, Daudin, one of the Iguanidæ. Messrs. Dumeril and Bibron, in their Erpetologie (1837), treat of these reptiles under the name of Lizards, Iguaniens, or Sauriens Eunotes. In the catalogue of the specimens of lizards in the British Museum, the Iguanidæ with the Agamidæ constitute the tribe Strobilosaura.

The Iguana of India, generally found about old walls and ruinous buildings, is about two feet long; tail long, round, and tapering; back, tail, and throat are serrated ; and its whole surface is covered with shining scales. The flesh is eaten by the Mahomedans of India, and in the West Indies it is salted and barrelled for exportation. In India the body of the dried Iguana is made into an electuary, with a certain portion of ghi, and used as a strengthening medicine in consumptive complaints. An animal oil is obtained from it. The Iguana of the Europeans of Ceylon, the Talla-goya of the Singhalese, is the Monitor bracena, Linn. It is 4 to 5 feet long. The Singhalese and 
Tamil races of Ceylon believe the tongue of the Iguana to be a specific for consumption, if plucked from the living animal and swallowed whole.T'ennant's Ceylon; Faulkner; Eng. Cyc.

IHRAM. ARAB. The dress worn by Mahomedan pilgrims at Mecca. See Harm. Lane says (Mod. Egypt, i. p. 131), during his performance of the required ceremonies in Mecca, and also during his journey to Arafat, and until his completion of the pilgrimage, the Muslim pilgrim wears a peculiar dress called Ehram (vulgarly Heram), consisting generally of two simple pieces of cotton or linen or woollen cloth, without seam or ornament, one of which is wrapped round the loins, and the other thrown over the shoulders; the instep and heel of each foot and the head must be bare. After the recitation (a Khutbah on Mount Arafat), the sacrifice, and other ceremonies on the return journey to Mecca, in the valley of Mena, every one resumes his usual dress, or puts on a new one, if provided with such.

I.H.S. This sacred monogram, arranged in cypher, is the Chinese Buddhist's sacred symbol of Buddha.

IJARA. HIND, A contract. Ijaradar, a contractor. - W.

IJMA. ARAB. Lit. collecting or assembling, in Mahomedan theology, means the unanimous consent of the Mujtahadin or learned doctors. See Jama.

IJTIHAD. ARAB. Carrying on war against non-Mahomedans and infidels. See Jahad.

IJU, also written Eju, the horsehair-like substance which grows on the gomuto tree, the Arenga saccharifera, Labill. This substance is also called gomuto; part of it is a stiff bristle, but the bulk more resembles horsehair, and it is largely made into cordage. See Arenga; Gomuto.

IKAN. MALAY. A fish; also a crab. The word is always prefixed or added to the specific name of the fish, as ikan-bawal, the pomfret; tulor-ikan, fish-roe ; sirip-ikan, fish-fins ; sisekikan, fish scales.

Ikan dori, a small dark-coloured fish, of about a pound weight. Great caution is necessary in handling it, because it is armed with poisonous spikes under the pectoral and dorsal fins, the wounds from which are extremely painful. It is not much esteemed.

Ikan mimi, the king-crab.

Ikan saladu and Ikan surdudu, Arius Arius.

Ikan sambilang, literally fish of nine, from the nine barbs on its head. It is found in the ponds of the Malay Peninsula, and is largely eaten.Earl ; Cantor; M'Nair, p. 83 ; Simmonds.

IKAUNA, a pargana in Bahraich district, Oudh. The Brahmans, 13,986 , are the most numerous caste; the Ahirs and Kurmis coming next, with 9740 and 7615 respectively. The village of Tandwa is identified by General Cunningham with the Tu-wei of $\mathrm{Fa}$ Hian and Hiwen Thsang, where Kasyapa Buddha was born and lies buried; while a statue of the mother of Sakya Buddha is now worshipped in the village as Sita. -Imp. Gaz.

IKRAR. ARAB. A promise, an agreement. Ikrar-namah, a deed of settlement.

IKSHWA'CU, one of the ten sons of Manu Vaivasvata, considered to have been the first of the Solar dynasty, offspring of the sun. He reigned at Ayodhya, the capital of Kosala, in the second or Treta Yuga. As the offspring of the sun, his VOL. II. posterity was called the dynasty of the Solar princes, in the same manner as Budha was reputed the head of the Lunar line. Modern commentators bring the time of his accession down to the year 1320 before Christ. A passage in the Agni Purana indicates that the line of Surya, of which Ikshwa'cu was the head, was the first colony which entered India from Central Asia. But the patriarch Budha was his contemporary, he being stated to have come from a distant region, and to have been married to Ila (Ella), the sister of Ikshwa'cu. Max Müller says this name is mentioned only once in the Rig Veda, and he and others suppose it is the name not of a king, but of a race occupying the northern or north-western part of India.

The lineal descent from Brahma Bharata was Bramha, Marichi, Vaviswat, Manu, Ikshwa'cu, Kukshi, Vikukshi, Vanu, Anaranya, Prithu, Trisanku, Dhundumar, Yuvaneswa, Mandhata, Sisandhi, Dhruvasandi, Bharata.

Nimi, one of Ikshwa'cu's hundred sons, founded the Mithila dynasty.-Dowson.

IL pronounced also Ilhat or Iliat, a term applied to the nomade tribes of Persia. It is also a Semitic for $\mathrm{m}$ of Grod. See Iliyat.

ILA, sister of Ikshwa'cu, of the Solar race, was married to Budha of the Lunar race, and these were the ancestors of the Lunar line of kings. In Hindu mythology, Budha, son of Atri, son of Brahma, was husband of Ila, the earth, daughter of Spatembas. Budha was Mercury, son of the moon.

ILA or Ilita, mentioned in the Vedas as a goddess, may possibly be the same as the Babylonian goddess Ili or Bilat Ili, queen of gods.

ILA, in the Rig Veda, is food personified as the goddess of speech. According to Sayana, she is the goddess presiding over the earth. The Satapatha Brahmana represents her as springing from a sacrifice which Manu performed to obtain offspring, and she had offspring to Manu. According to the Puranas, she was the daughter of Manu Vaivaswata, wife of Budha (Mercury), and mother of Pururavas; but, through the favour of the gods, her sex was changed to a man, but again became a woman, and she married Budha, to whom she bore Pururavas.-Dowson.

ILACHI. HIND. A generic term for the fruits of several plants producing cardamom, viz. :

Bari-ilachi or Ilachi-kalan, Amomum cardamomum, the large rough-shelled variety.

Choti or Khurd-ilachi, Elettaria cardamomum, the small cardamom.

ILAH, the name of an old Arabian deity, and is more properly and more usually applied to a pagan god, than to Allah, God supreme over all, -composed of $\mathrm{Al}$, the, and Ilah, God. Hence the Mahomedan profession of faith says, La Ilah il-Allah, etc., which in the ordinary translation of 'There is no god but God,' conveys no precise meaning, and involves an obvious truism, which Mahomed would never have enunciated. The true reading would be, 'There is no deity but God.' From some passages in the early Indian historians, it would appear that they supposed the famous Somnat to be the Arabian Ilah or Ilat. Notices of it occur in the Rauzat-us-Safa, Habib-usSair, and Ferishta, the passage quoted from Farid-ud-Din Attar; Sale's Koran, i. p. 23, i. p. 390 ; Hyde, de Rel. Vet. Pers. p. 130; Pococke, 
Spec. Hist. Arab. pp. 4, 92, 110 ; Bird's Gujerat, p. 39 ; D'Herbelot, Voce Lat.; Al-Makkari, Mahomedan Dynasties in Spain, i. p. 346; and Herod, iii. Alihat, the gods; Ilahat, a goddess; Ilahi, divine.-Elliot.

ILAHABAD or Allahabad, a city of the N.W. Provinces of British India. Before Akbar's time, this place was known as Preag or Prayag; by him it was denominated Allahabas, which subsequently became Allahabad. The name is more correctly Ilhabad or Ilahabad, but the usual practice of writing it is Allahabad. The article 'al' coalesces with the substantive in Allah, and represents the Almighty.-Elliot.

ILAHI. ARAB. The title of an era, now obsolete, invented by the emperor Akbar, commencing with the first year of his reign, A.H. 963 or A.D. 1556. It was on his coins. The Ilahi gaz is the standard gaz, or yard, of forty-one fingers, instituted by Akbar. After much controversy respecting its length, it was authoritatively declared by the British Indian Government to be 33 inches long; and the declaration has been attended with considerable convenience to revenue officers, as a bigha measured by this yard constitutes exactly five-eighths of an acre--Elliot.

ILAKA. ARAB. A dependency. Ilaka-dar, a person in possession.

ILAKA-BAND. HiND. A silk fringe, silk girdle, and tassel maker. Ilaki, a square scarf of Multan.

ILA KURA. Tel. Salsola Indica, Wille. This is occasionally used as a vegetable, and, being naturally salt, has given rise to the Teling saying, 'The carping husband (finding fault without cause) says to his wife, There is no salt in the Ila kura.'

ILAM, said by some authors to be the Tamil name of Ceylon, and to signify gold; but gold in Tamil is Ponnu.

ILAMBADI. TAM. Corruption of Lambady, the Banjara race, so called in the south of India.

ILA-PANANKI JANGU MAVU. TEL. A farina is obtained from this root by treating it the same as in manufacturing manioc. It is very nourishing.

ILAVRATA. In an ancient Hindu geography, one of the divisions of the known world; its mountains are called Tien-chan, Kiloman, Tangrah or Tangla.-As. Res. viii. p. 311.

ILCHI, a town in High Asia, with 40,000 inhabitants.

ILEX, the holly genus of plants. Dr. Wight mentions I. Gardneriana and I. Wightiana. Mr. Thwaites names, as growing in Ceylon, I. denticulata, a large, and I. Walkeri, a small tree. Mr. Hodgson, in his Nagasaki, mentions eight species in Japan, viz. crenata, Thbg., microphylla, Bl., integra, $T h b g$., latifolia, $T h b g$., rotunda, $T h b g$., serrata, $T h b g$., aquifolium, $L$, var. heterophylla.

Ilex denticulata, Wall., is a very large timber tree, not uncommon on the higher ranges of the Neilgherries and Animallays at 6000 to 8000 feet, and at similar elevations in Ceylon; its timber is much valued, and is said not to warp or crack; it has serrated leaves.-Bedd. Fl. Sylv.

Ilex dipyrena, Wall. Himalayan holly.

Dodru, Dinsa,. . Beas. | Kanjru, Karelu, . Ravr. Krucho,

Kimelu, . Kanjru, Karelu, . Ravi
Drunda, . . . Shangala, Cंü Drunda, CHENAB.
This moderate-sized tree grows at Mussoori and everywhere in the Himalayas to 5000 or 9500 feet. The wood is heavy, hard, and fine grained, much like common holly, and used for various purposes of carpentry. It bears a very close resemblance to the holly, especially in November and December, when it is covered with clusters of scarlet berries.-Stewart.

Ilex Malabarica, Bedd., a large species growing in the Wynad.-Bedd. Fl. Sylv.

Ilex serrata is a lofty species found in Mussoori, and I. excelsa in Nepal.-Royle, Ill. p. 167; $O ' S$.

Ilex Walkeri, Wight, Gardn., is a small tree in the Central Province of Ceylon, growing at an elevation of 5000 to 8000 feet.

Ilex Wightiana, Wall., is a large umbrageous tree, with small white flowers and red berries, growing in the Neilgherries and in the southern and central parts of the island of Ceylon up to an elevation of 4000 feet.-Thw. Zeyl. p. 183.

III, a valley and town in Central Asia, from which Lassen supposes the Szu Tartars were expelled by the Yue-tchi or White Huns, B.C. 150. He supposes the Szu Tartars to be the Sacæ, and the Yue-tchi to be the Tochari. After occupying Tahia or Sogdiana for a time, they are stated by the Chinese to have been driven thence, also, by the Yengar, some years afterwards, and to have established themselves in Kipen, in which name Lassen recognises the Kophen valley in the Kohistan. The great Kirghiz horde is adjacent to Ili and Tarbagatai. It is under the dominion of China, and exchanges large quantities of cattle on the frontier for silk goods. The Tsiankiun has authority over the Eluth and Chahar of his own central province of Ili, who have also Chinese ministers; also over the Eluth, Chahar, and Hassack, under the Tsantsan minister resident at Tarbagatai, and over the Mahomedans of the eight cities in Ili, south of the Tien-shan, who are under resident ministers of different degrees.

ILIYAT are tribes in Persia and Khiva, some of whom are nomade, dwelling in tents, and others reside in towns. The word lliyat is derived from Il, a Turki word signifying tribe, equivalent to the Arabic Kabilat, to which 'aut,' an Arabio termination of the plural, was added, - a combination not uncommon. The Iliyat tribes in Persia are mostly of Arab, Kurd, and Turkoman descent; along with tribes from the Bakhtiara mountains, who are of a race totally distinct from the northern hordes, and probably something more indigenous to the soil than any of the other wanderers, but all lead the same manner of life, and bear the common name of Iliyat, their pastoral habits little distinguishing them from the Bedouin Arab or the nomade Tartar. The subjects of the Persian empire therefore appear to consist of the stationary inhabitants of towns and cities, and the wandering dwellers in tents and temporary villages. The Iliyat comprise a very large portion of the population of the country, though their actual numbers are not well known. They are Mahomedans of the Sunni sect. Many of the best families in Persia are of Iliyat origin. The present royal family is of the Kajar tribe, a Turkish Il, which came into Persia with Timur. The principal Iliyat tribes are said by Morier and MacGregor to be- 
Afshar.

Aimak.

Arab.

Bajiban.

Bakhtiari.

Baluch.
Bayat.

Feili.

Hazara.

Kajar.

Khuda Bandi.

Kurd.
Lak.

Mama Senni.

Shah Sevan.

Shekagi.
Kurd Buchel.

Frazer mentions that in his time 195,000 Iliyat families were tributary to Khiva, viz. :-

Yamut, . . . 15,000 Kazak, . . 40,000

Goklan, . . 20,000 Ilkdar, . 15,000

Chudar,. . . 2,000 Sarokh, . . 15,000

Kalpak, . . . 30,000 Uzbak, . . 40,000

The Chudar are said to have been brought from the farther borders of the Oxus by Muhammad Rahim Khan. In the 10th century, they are said to have comprised 500,000 families within the province of Fars alone. Although much inferior in numbers, many of the present Mliyat tribes are very considerable; and since the destruction of Rai, and the decay of Isfahan, Shiraz, and all the other great cities throughout the empire, they constitute a principal source of population, and the best nursery of its soldiers. Some of their chiefs are men so powerful that the king attaches them to his court by honourable and lucrative employments, or detains them about his person as hostages for the loyalty and good conduct of their respective clans. We find them, as they were 800 years ago, unmixed with the Persians who inhabit cities; retaining their pastoral and erratic habits, and using among themselves a dialect different from the language of the country, which, however, most of them can speak and understand. They are an independent and hardy race, inclined to hospitality. Two or three families in little groups, preparing or enjoying their simple meal by the roadside, or proceeding on their journey, the wife carrying one child, two or three others packed in baskets on an ass, which the husband drives before him, are usual pictures to be seen.

Iliyat tribes have each their own history. They change their places of encampment with the season and climate, going in the summer to the Ailak, or quarters where pasturage and water are to be found in abundance; and when the cold of winter sets in, adjourning to the Kishlak or warmer region, in which their flocks and herds, as well as themselves, are better sheltered. The tribes adhere to their respective districts, but the distances that some of the tribes have to perform in their annual migrations are really wonderful. From the southern shores of Fars, the Kashgoi arrive in spring on the grazing grounds of Isfahan, where they are met by the wandering Bakhtiari from their warm pastures of Arabistan, near the head of the Persian Gulf. At the approach of winter both these tribes return to their respective Kishlak or Garm-sair. In each province of Persia there are two chiefs, elders, acknowledged by all the tribes who roam in that province. In their conduct and morals the Iliyat women are vastly superior to those of the towns and settlements. They are chaste and correct in their lives, and faithful to their husbands. They are Sunni Mahomedans, but are by no means particular in their religious observances, and are not ruled or influenced by the maula as townsmen are. They are all, in a greater or less degree, professional robbers,-some tribes living solely by rapine and plunder, and others resorting only occasionally to such means. They have large flocks and herds, which they often augment by taking possession of their neighbours'. The eivilised population hold them in great dread on this account. The Il-khani of Fars is the chief of the Kashgoi tribe.

The nomades breed camels, cattle, and horses, mules and asses. Their tents are made of goats' hair. Often on approaching an Iliyat encampment, the stranger is met by the women of the tribe, who burn aromatic herbs in honour of the guest, and as a token that he is welcome to their hearth. Mr. Bickmer observed a similar practice among the Kuldi in Kurdistan. This custom must be very ancient, for we find Fardusi alluding to it in his descriptions of the early heroic ages of Iran.

The usual drink of the Luristan Iliyat consists of buttermilk weakened with water; a little salt is added to it, and it is then called Ab-i-dhung. It is generally sour. There is nothing so efficacious for the purpose of slaking thirst on a hot summer's day as this $\mathrm{ab}$-i-dhung.-De Bode's Travels; Ouseley's Travels; Rich's Kurdistan; Frazer's Travels; Morier; MacGregor.

ILLAM. Maleal. A house, a dwelling, a household.

ILLANUN, also Lanun, a maritime race of the Archipelago, formerly addicted to piracy. In the year 1837, the schooner Maria Frederica, Captain Gregory, was cut off in Ampanam roads; and in 1840, the English whaler Mary, Captain Blosse, while at anchor at the North Islands, near the N.W. point of Lombok, was surprised and taken by a fleet of Lanun prahus (See Moniteur des Indes for 1847-48, pp. 17-21); but the vessel and crew were soon afterwards ransomed for a large sum in Spanish dollars by Mr. King, who subsequently, finding that the pirates still remained there, fitted out an English merchant brig, that was then loading rice for England, with guns and men supplied by the king of Lombok, and succeeded in driving them away for a time. Traders visiting any of the ports east of Java should take every precaution to prevent surprise. Their course along the north-west coast of Borneo to the coasts of Sumatra and the Malay Peninsula is now obstructed by the settlement of Labuan, which they cannot pass without some intelligence being received of their motions, and this being conveyed speedily to Singapore, would inevitably lead to their being sought out and destroyed.

ILLECEBRACE $E$, the knot-grass tribe of plants, comprises thirty-nine genera. Of these, three species are found in Arabia, one in Persia, one in China and in continental India. Seventeen forms have been discovered in the $\mathbf{E}$. Indies of Herniaria, Hapalosia, Illecebrum, Polycarpœa, Drymaria, Mollugo.

ILLICIUM, a genus of plants belonging to the order Winteraceæ of Lindley. The order contains four genera and twelve species, shrubs or small trees; one of them, the Illicium anisatum, grows in Japan and China ; one on the Khassya mountains, and one in New Zealand. The general properties of the order are stimulant and aromatic.-Voigt, p. 13.

ILLICIUM ANISATUM. L. Star anise tree. Badian-i-khatai, . ARAB. Chinese anise, . BNG. Hwai-hiang, : CHIN. Skimmi, : JAPAN. Ta-hwui-hiang,. . " San-ki, . Manilla. Pah-koh-hwui-hiang, " Anasi pu, . . . TAM Anas phal, DokH., HIND. Marati mogga, : TEL

Aniseed tree, - ENG. 
The star anise tree is a native of the countries extending from lat. $231^{\circ}$ to $35^{\circ} \mathrm{N}$., or from Canton to Japan. The designation star is applied to the fruit from the manner in which they grow, the pods being in small clusters, joined together at one end, and diverging in five rays. They are prized for the volatile oil obtained from them, and for their aromatic taste. The barks have a more aromatic flavour than the seeds, but they are not so sweet. In China, their most common use is to season sweet dishes. In Japan they are placed on the tombs of friends, and presented as offerings in the temples. They are chiefly exported direct to India, England, and the north of Europe, at the average value of $8 \frac{1}{2}$ dollars per pikul. In India they are used in seasoning curries and flavouring native dishes; and large quantities are used in Europe in the preparation of liqueurs. The capsules constitute in India a rather important article of commerce, and are sold in all the bazars. Both capsules and seeds evolve a powerful odour of anise; the taste is similar, very mild, sweet, and somewhat acidulous. The capsules and seeds abound in an essential oil, easily procured by distillation with water; this oil is rather brown, lighter than water, more difficultly congealed than the true aniseed oil, but in other respects exactly of the same properties. The powdered capsules are used by the Mahomedan practitioners as stimulant carminatives. For the colics of children, the essential oil is given with advantage. The tree might be introduced into India.-O'Shaugh.; Thunberg's Tr. iii. p. 227 ; Morrison's Comp. Summ.; Simmonds; Faulkner; O'Sh. Beng. Phar. p. 412; Royle, H. B. p. 58.

ILOCO, one of the languages spoken in the island of Luçon. In the Philippines are many separate nations or tribes, speaking distinct languages, unintelligible to each other. The principal tongues of Luçon are the Tagala, the Pampanga, the Pangasinan, and the Iloco, spoken at present by a population of $2,250,000$ people; while the Bisaya has a wide currency among the southern islands of the group, Leyte, Zebu, Negros, and Panay, containing 1,200,000 people. Mr. Crawfurd says that it does not appear, from a comparison of the phonetic character and grammatical structure of the Tagala with those of Malay and Javanese, that there is any ground for fancying them to be one and the same language, or languages sprung from a common parent, and only diversified by the effects of time and distance, and that an examination of the Bisaya dictionary gives different results. See India.

ILOL, a native state within the political agency of Mahikanta, in the province of Gujerat, Bombay. Pop. (1872), 5511.

IMAD SHAHI, a dynasty of Berar, founded by Fattah Ullah, a descendant of a Hindu convert.

Fattah Ulah, .

Ala-ud-Din,

Deria,

Burhan,

Tufal.

Merged into that of Ahmadnaggur, A.D. 1572, A.H. 980.-Elph. p. 676 .

IMAM. ARAB. A leader; the president of a mosque; the person who leads the daily prayer and is in receipt of the revenues of the mosque; also the title of the four great dpctors of the four orthodox Sunni sects; also the title of the twelve great leaders of the Shiah sects; but it is also given to any great religious leader, head, or chief in religious matters, whether the head of all Mahomedans as the khalif, or the priest of a mosque, or the leader in the prayers of the congregation. Imam answers to the Latin Antistes. In the Koran (chap. ii. vers. 118-20), 'God said unto him, Abraham, I constitute thee Imam unto men, 'that is, a model of religion.

After the death of Mahomed, his successors, the khalifs, became his delegates or lieutenants, and were also termed Imam or leader. When Mahomedans meet together for prayer, an Imam is chosen who leads the prayer, and the congregation regulate their attitudes by his, prostrating themselves when he does so, and rising when he rises. In like manner the khalif is set up on high as the Imam or leader of the faithful in all the business of life. He must be a scrupulous observer of the law himself, and diligent in enforcing it upon others. The election of an Imam is imperative ( $p .229$ ). The fourth Sura says, 'Obey God and his prophet and those of your people who exercise government over you.' The qualities of an Imam are knowledge, integrity, mental and physical soundness.

Imam is a sacred title with the Shiahs, and is given only to Ali and the immediate successors of the Prophet, who were twelve in number, their Bara-Imam. The last of these, the Imam Mahdi, is supposed by them to be concealed (not dead), and the title which belongs to him cannot, they conceive, be given to another. Among the Sunni Mahomedans, however, it is a dogma, that there must be always a visible Imam or father of the church. It was long maintained that the Imam must be descended from the Arabian tribe of Koresh ; but the emperors of (Oonstantinople (who are of a Turk family) have assumed the sacred title, which they claim on the ground of the formal renunciation of it by Muhammad the twelfth, the last khalif of the race of Abbas, in favour of Selim the first. The acknowledgment of this title renders the emperor of Turkey the spiritual head of all orthodox Mahomedans.

The sect of Mahomedans who believe that the Imam Mahdi has come and gone, are the Mahdavi, or, as others call them, Ghair Mahdavi, i.e. people without Mahdi. About the year 657 A.D., or some twenty-five years after the death of Mahomed, his son-in-law Ali met Muavia, and fought the battle of Siffin. Displeased at the conduct of Ali on that occasion, about twelve thousand men deserted him. Some years after, they were nearly all destroyed by Ali ; but a few survivors fled to various parts. Two men settled in Oman, and there preached their distinctive doctrine of the Imamat, that is, they taught that the office of 'Head of the Faithful' was elective, and not hereditary. They thus differed from the ordinary Shiahs, who hold the doctrine of divine right in its entirety, and never can acknowledge any khalif or chief who is not descended from Ali. Some fifty years̄ after this, one Abdullah-ibn-Abad vigorously preached the doctrine of the right of the people to elect the khalif, or, as they would call their head, the Imam. It is from him that the sect of the Ibadiyah, an offshoot of the Shiahs proper, takes its rise. They elected their own Imam, and thus arose the jurisdiction of the Imam of Oman. From 
this potentate came the Sultan of Zanzibar. This shows how entirely free they are from any allegiance to the Sunni khalif. No Ibadiyah ever acknowledged the khalif of Baghdad as his spiritual chief, much less is he likely to recognise one in such a doubtful successor to the office as the Ottoman Sultan. It is not known that the ruler at Muscat has ever laid claim to the title of Imam, though Europeans invariably confer it on him. Imam is, however, said to be now adopted as a royal or dignatory title by several Arab and African sovereigns. The successors of Mahomed continued to exercise their religious functions in proof that they enjoyed spiritual as well as temporal power, and took the title of khalif; but various Arab princes, who dared not aspire to the title of khalif, took that of Imam, to which they frequently added that of Amir-ul-Mominin, or prince of the faithful, and, like the khalifs, observed the precaution of changing their name when they ascended the throne. The custom seemed to typify that their whole nature underwent a change, on being invested with an office to which a certain amount of sanctity was attached.

Of the twelve Imams of the Shiah sect, one was Imam-Ali, cousin and son-in-law of Mahomed, who married Fatima, Mahomed's daughter; the two sons of Ali, the Imam Husain and Imam Hasan, neither of whom were successful leaders, though since their deaths they have by some sects been deified and believed to be incarnate (Ali, Ilahi).

In every Sunni mosque, at the appointed prayers, there is a leader of the devotions, who is called the Pesh-Imam, because he remains in front (Pesh) of the worshippers, leading them in the successive parts of their worship.

The four learned doctors of the faith were Malik ibn Anas, Imam Abu Hanifa, Imam us Shafi, and Imam Ahmad bin Hanbal.

Malik ibn Anas, a native of Medina, born A.D. 713-14, A.H. 95, died A.D. 795 , A.H. 179, in his 84th year. He wrote the treatise called Muwatta, the Beaten Path, classifying the oral traditions. It formed a system of jurispruadence which prevailed throughout Spain and Northern Africa, its extension in Spain having been aided by Yahia ibn Yahia, a Berber, who had visited Medina to sit under the teaching of Malik ibn Anas. He returned to Spain, where he had much influence.

Imam Abu Hanifa, a Noman of Persian origin, was born at Basra, in the Hijira year 80 (A.D. 699-700). He was a learned and devout man, humble in spirit. He passed most of his life in Kufa, and was famous as a lawyer. He refused to be kadi of Kufa, on which Ibn Omar ibn Hobaira, governor of the two Iraks, ordered him to be daily flogged until he consented. Ten strokes of a whip were consequently inflicted daily for twelve days, and, being still a recusant, he was set at liberty. He died in prison A.H. 150, A.D. 767.

Imam us Shafi, of the tribe of Koresh, was born A.H. 150 , A.D. $767-68$, and was brought up in Mecca, but at the age of 45 went to Baghdad, and afterwards to Old Cairo, where he remained till his death in A.H. 204, A.D. 820. He was an eclectic. His doctrines were taught in the schools of Cairo, Irak, Khorasan, and in the regions beyond the Oxus. Between the Hanifa and Shafi sects there were controversies and animosities, and when the Mongols of Chengiz Khan appeared before Rhe, the Shafi sect offered to deliver up the city on the condition that all the Hanifi were slain. This was acted on, but a few days afterwards the Mongol slew also all the Shafi, and the bodies of the members of the two sects were thrown together.

Imam Ahmad bin Hanbal was the fourth and last of the great orthodox Imams. He was born A.H. 164, A.D. 780, at Merou or Baghdad. His teachings differed from those of Shafi in that he did not allow the principle of deductions. His system never extended beyond Baghdad, and is now obsolete.-Osborn's Islam; Pottinger's Travels, Burton's Scinde; Malcolm's Persia, ii. p. 345.

IMAM ALI, a town in the vicinity of the Shatt ul Arab, in Ur of the Chaldees.

IMAM BARA. HIND. A building in which are conducted the ceremonies of the Maharram, in commemoration of the deaths of Ali and his sons Hasan and Husain. The Tazias or shrines are sometimes retained in it.

Imam-bari, a building over an imam or Mahomedan saint, or other holy Mahomedan. The imam-bari at Lucknow is a magnificent palace. Its most remarkable part is an immense hall, containing the tomb of Asof-ud-Dowla, the greatgrandfather of the last king of Oudh.

IMAMI. HIND. A kind of Kābul silk.

IMAM MASHUDI, the religious guide of Akbar. His tomb is to the west of the Masjid-i-Kutubul-Islam.-Tr. Hind. ii. p. 201.

IMAM RAZA is buried at Mashid. In his name whole bazars and streets have been bestowed in Mashid, and outside that town, as also in other parts of Khorasan, fields, vineyards, and caravansaris. He is styled Hazrat, also Sultan-ul-Ghriba, king of the poor, and is always mentioned as if still living; a poor person applying at his shrine receives three days' provisions.-Vambery, p. 286.

IMAM-ul-MUWAKKAF. See Hasan ibn Sabbah.

IMAMZADAH means the descendants of an imam; but, it is said, generally applied in Persia to the mausoleums built over the bodies of such descendants, which are to be found scattered in great abundance all over the country.-Fraser's Khorasan, p. 303.

IMAN. ARAB. Faith. In Mahomedanism, the belief of the heart and the confession of the mouth.

IMAUS, a name by which part of the Himalaya was known to the Greeks and Romans. Pliny was fully aware of the signification of the name, for he says (Hist. Nat. vi. p. 117), "Imaus in colarum lingua, nivorum significans.' A great part of the mountains N.W. from India was also called the Paropamisus or Hindu Kush; and Imaus and Hindu Kush seem to have been identical. The true Imaus, however, is the ridge which separates Kashmir from Little Tibet. It appears to incline in its northern course towards the continuation of the Hindu Koh, and even to join it. The term Hindu Koh or Hindu Kush is not applied to this ridge in its whole extent, but seems confined to that part of it which forms the N.W. boundary of Kābul; and this is the Indian Caucasus of Alexander. There is, however, much confusion from the Tibetan, Chinese, and Persian names of that great mountain mass.-As. Res. iii. p. 389. See Himalaya.

IMMOLATION. Self-immolation is not uncommon in India. It is generally performed by persons lingering under incurable disorders. It is 
done by leaping into fire, by burying alive, by plunging into a river, or by wading into the river with earthen pots at the side, and filling them until they sink, dragging the victim down with them. -Elphin. p. 191. See Sati.

IMPATIENS, Balsams.

Fung-sien, . C ChiN. Tatura, . Kanara. Kih-sing-tsze, . ", Pallu, Tilphar, RAVI. Bantil, . . Jhelum. Hulu, Juk, . SUtLeJ.

A genus of plants belonging to the East Indies. Single species extend into Europe, Siberia, and North America. Not less than 100 species are known, and almost entirely from the mountains of the Peninsula of India or the Himalaya, from Sylhet as far north as the Sutlej, and in lat. $30^{\circ}$ N., at as great elevations as 7000 feet, but chiefly at elevations of 4000 and 4500 feet, where there is moisture combined with a moderate but equal temperature. They are abundant on the mountains of the Western Ghats, but absent from the plains of India, though some are found on the Malabar coast, little elevated above the sea, but only during the monsoon. They are largely cultivated in Indian gardens as handsome flowering plants ; coloursrose-pink, white, blue, and variegated. In the middle of the rains, the whole line of the Western Ghats is covered with them. The ripe capsules, on being touched, fly open and scatter their seeds, whence they get the name of Noli me tangere.

\begin{tabular}{l|l|l|l} 
albida. & Goughii. & ornata. & sylvestris. \\
bracteata. & inconspicua. & oppositifolia. & trilobata. \\
campanulata. & insignis. & Rheedii. & tomentosa. \\
cuspidata. & Jerdoniæ. & rivalis. & tripetala. \\
dasysperma. & Kleinii. & rosmarinifolia. & triphylla. \\
fasciculata. & latifolia. & rufescens. & umbellata. \\
filiformis. & Leschenaultii. & scabrida. & uncinata. \\
fomentosia. & modesta. & scapifiora. & verticillata. \\
fruticosa. & Munroni. & setacea. & viscida. \\
Gardneriana. & Mysorensis. & &
\end{tabular}

IMPERATA ARUNDINACEA, Cyrillo, of S. and $\mathrm{E}$. Asia, the lalong grass of India, almost a sugar-cane in miniature; valuable for binding sand, especially in wet localities.-Mueller.

IMPERATA CYLINDRICA. Beauv.

I. arundinacea, Cyrit. | Saccharum cylindricum, Lagurus arundinaceus, $\boldsymbol{L}$. Lam.

The Ooloo plant of all India, Ceylon, Moluccas, and Australia. Much used as thatch. - Voigt.

IMPERATA KCENIGII. Beauv.

Sir, Sil, Bharwi, . PANJ. | Alang-alang, . . MALAY.

A silky-headed small grass, abundant at low spots in many parts of the Panjab plains.

IMPHI, the Chinese sugar-cane, Sorghum saccharatum, Pers., is said to have long been grown in India, but was re-introduced in 1860 by Surgeon-Major Balfour, of the Madras medical department. With careful cultivation in a rich, well-watered cotton soil, it attains the height of eight feet, and it yields in three months a crop of plants very similar to sorghum, except in the appearance of the heads. The natives consider it a variety of sorghum, and are favourably impressed with the plant, as it yields a large quantity of sweet juice which produces good jagari, and the crushed stalk is excellent food for cattle.

INAM. ARAB, A gift, a grant, of which there are many kinds. Inamdar, a holder of a rent-free grant of land. A revenue term introduced by the Mahomedans. Hindus have no word to denote rent-free lands, or freehold property, except Suwusthan, one's own place ; but with them that is never found in less quantities than a whole village. Rent-free lands under the Hindus were merely designated by terms signifying the purposes to which devoted, as Dewasthan, the idols' place; Pasodi, a shawl, the Patel's grant; Choli, 'a bodice' for the Patel's wife; Hadola, a row or collection of bones; Hadki, a little bone; Domni, a dish, - the last three being grants to the Mhar tribe. Deo Shet, a grant to a person who has been successful in a trial by ordeal, such as that of determining a village boundary. In Mahomedan countries, it is customary to call inam grauts to religious orders grants of land, although they include only the rents thereof; for there is no seising of the land itself, which is the proprietary right of the cultivator only. In the tamba-patra, copperplate patent (by which such grants are designated in Rajputana) of Yasovarma, the Pramara prince of Ujjain, about the 12th century, commanded the crown tenants of the two villages assigned to the temple to pay all dues as they arise, money-rent, first share of produce. In India, where the cultivating proprietor has always paid a feu-duty to the state, the grant of an inam is, like the grant of a jaghir, merely the transfer of the state dues. According to practice, a jaghir is a reward for past or a retaining fee for future services, or a means of support, and is resumable at pleasure. The inam for religious purposes has been a more permanent alienation; but even the Madras Government about the middle of the nineteenth century re-examined all the inam grants, and up to a late date decisions had been given on 396,815 cases.

Under the Mahomedan sway, inam became a revenue term, which the British adopted, but was inquired into when peace pernitted the examination of the inams. The religious merit attached among Hindus to the grant of land to the Brahmanical class, the facility afforded by the period of anarchy which followed the overthrow of the native dynasties for irregular alienations by inferior authorities, the acceptance by the 'Mahomedan rulers of the existing condition of things, the further opportunity for irregular grants which was given under the political confusion occasioned by the struggle between the British and French for Indian supremacy during the latter half of the 18 th century, and the system of rewarding meritorious service by alienations of Government revenue, either in perpetuity or for a stated number of lives, which was in force during the earlier years of British rule in the Madras Presidency, from the enormous sacrifice of state revenue involved, attracted the attention of the administration at a very early period, and caused a recognition of the importance of a general inquiry into titles to rentfree lands.

Inam tenures were found divisible into nine general classes. The first three classes are inams for religious and public service. They consist of grants for the support of pagodas, muttums, village headmen, mosques, and durgas, kazis, Christian churches, chuttrums, water pandals, topes, tanks, wells, anicuts, schools, and miscellaneous works of utility.

In the Madras Presidency the basis of Sir Charles Trevelyan's inquiry was that possession for fifty years was to give a good title, no matter what the origin of the possession might have been. This being established, religious service inams were all to be confirmed on existing tenures, and 
to be resumed only when the object for which they were held had ceased to exist. Other service inams were to be continued on the same terms when such services were still required; but when they could not be made available for any useful public purpose, the value of the public claim upon the land was to be added to any existing quit-rent payable thereon, the owner being thus enfranchised from service. All other inams held for personal benefit were either to be retained on existing tenure, subject to liability to lapse and without power of alienation, or were, at the option of the holder, to be converted into an absolute property by the imposition of a quit-rent representing the annual value of the reversionary right of Government in the property. This reversionary right was estimated in terms particularly favourable to the inamdars, in order to induce them to take advantage of the privilege offered.- $W$.

INCENSE-WOOD, eagle-wood. Incense was burnt in ancient heathen temples to neutralize the offensive odour arising from animal sacrifice.

INDERABIA, of some English navigators, is also written in different charts, Andervia, Anderipe, Indervea. Dr. Vincent (Nearch. p. 375) thinks it the Caicandrus of Arrian, but a corresponding name is not found in oriental manuscripts.Ouseley's Travels, i. p. 174.

INDERJAO. HIND. Wrightia antidysenterica. Its seeds are very largely used medicinally, being boiled in milk, and given in hæmorrhoids and dysentery, and in docoction in fever and gout; also used as an anthelmintic. Dose, gr. $\nabla$ to $Э$ j. Price 5 annas per $1 b$. The bark of the root is astringent and febrifuge, and is used as a specific in dysentery and bowel complaints. Dose, $3 \mathrm{j}$ to ziij in decoction.

Inderjao-i-Sherin is Wrightia antidysenterica. Inderjao-i-Talq is Holarrhena antidysenterica, also H. pubescens.

INDIA is supposed to have obtained its name from the Indus, the Sin, Sinda, or Hinda, the Abu-Sin of the Arabs, the first great river met in the routes from Western and Central Asia. It is true that so far back as the reign of Darius Hystaspes, B.C. 521, writers placed Indians on both sides of the Indus, and made India extend westward to Kandahar (Gandhara), embracing perhaps the fourteen Iranian provinces or nations enumerated on the Naksh-i-Rustum as lying between Sogdiana and the Panjab, and subject to Darius. But eastward of the Indus, the country was always India. But this term seems to have been chiefly used in the south of Asia, for it first occurs in the book of Esther (i. 1, viii. 9) as the limit of the territories of the king Ahasuerus in the east, as Ethiopia was on the west, and the names are similarly connected by Herodotus (vii. 9). The term Hoddu, used by the Hebrews, is an abbreviation of Honadu, which is identical with the names of the river Indus, for to the present day all along the course of that river the letters $\delta$ and $h$ are interchanged. In the Vendidad, the Panjab is described as the Hapta-Hindu, and the other native form, Sindus, is noticed by Pliny (vi. 23). The India of the book of Esther is not, however, the Peninsula of Hindustan, but the country surrounding the Indus, - the Panjab, and perhaps Sind, - the India which Herodotus deseribes (iii. 98) as forming part of the Persian empire under Darius, and the India which at a later period was conquered by Alexander the Great. The name occurs in the inscriptions of Persepolis and Naksh-i-Rustum, but not in those of Behistun. Masudi mentions that at the time of the Muhammadan conquest, the country about Basrah was called Arz-ul-Hind, the Land of India.

There were other three names by which India was known to the western Asiatics. One of them originated from most of the traffic with India having at one time been by way of the Persian Gulf and the Red Sea. The Tyrians established depôts on the shores of the Persian Gulf, and the course of trade being through the land of the Cushdi, the races in India came to be included under the ethnological title of Cush (Genesis x. 6 ); and hence the Persian, Chaldæan, and Arabic versions of the Bible frequently render that term by India (Isaiah xi. 11).

Another ancient but local term for India is stated to have been Kolaria, and numerous Kol tribes are scattered through the country to the present day. Bharata or Bharata-varsha is likewise mentioned as an ancient local appellation.

In recent times success in wars and diplomacy has placed under the dominion of the United Kingdom of Great Britain, or in alliance; nearly all the territories lying between the Indus and the Himalaya on the N.W., to Cape Comorin and Singapore on the S.E., and that part of Southern Asia has come to be spoken of as British India, and the British Empire in India also as Her Majesty's Eastern Empire. But British India, Netherland India, the Spanish Indies, Portuguese and French India, are but portions of the region in Eastern and Southern Asia known to Europe as the East Indies, and which include all the countries from Arabia and Persia eastwards through Baluchistan, Hindustan, the Malay Peninsula, Siam, the Indian Archipelago to New Guinea, China, and Japan. With the Portuguese, the northern part of Hindustan held by the Moghul sovereigns was styled Mogor, and Goa and the western coast of the Peninsula was to them India. With the Dutch, India means Java, Sumatra, and other Netherland possessions in the Archipelago. French India is in the Western Peninsula, and in Annam and Tonquin in Ultra-India; and the Spanish Indies are in the Philippine Islands in the far east.

The ancients termed the Ultra-Indian region India beyond the Ganges. Leyden included it and the Indian Archipelago under the name of the Hindu-Chinese countries. Malte Brun calls it ChinIndia. Ritter, the greatest of geographers, prefers the German name Hinter-Indies. But instead of Further India, Trans-Gangetic India, the Eastern Peninsula of India, etc., the single words UltraIndia and Trans-India have been proposed by Mr. Logan, as they admit of the ethnic and adjective forms of Ultra-Indian or Trans-Indian; and for the insular region of the Eastern or Indian Archipelago, Mr. Logan proposed the term Indonesia. Mr. Logan's names are well chosen, because several of the islands have been occupied by Indian races. Java was long under a race from Hindustan, and Bali still professes Hinduism. The whole of the East Indies, therefore, consisting of the continental portions bisected by the Bay of Bengal, and the eastern islands, may be comprised under the three names of India Proper, Ultra-India or Trans-India, and Indonesia. 
Populations. - The regions thus defined are occupied by races of Negroid, Mongoloid, Aryan, Turanian, and Semitic descent, and this article is restricted to the ethnic relations of the populations.

It is generally accepted that a great part of the inhabitants of Hindustan and the Peninsula are of Seythic, Mongoloid, or Turanian race, and were the earlier occupants of the country. This conclusion has been come to from their linguistic and physical affinities. Some of them seem to have been pastoral tribes from the north and north-west, who were subsequently pushed aside or pressed farther on by races in possession of a higher civilisation and a knowledge of agriculture. The successive arrivals have been supposed by Dr. Caldwell to have been-first and earliest, the Kol, Santal, Bhil, etc., who, he supposes, may have entered British India from the north-east. After them, but from the north-west, came the Dravidian races, who now occupy the south of the Peninsula, into which they voluntarily migrated or were driven by the pressure of subsequent hordes. Then there came Scythian or non-Aryan immigrants, also from the north - west, whose language afterwards united with the Sanskrit to form the Prakrit dialect of Northern India; and lastly came the Aryans.

From time immemorial the region between the Euphrates and the Indus has been held by successive Turanian, Iranian, and Semitic conquerors. In historic times Scythic tribes have invaded India,-Getæ, Takshak, Sakæ, Su, Yu-chi, Naga, Ghakar, Jat, Asi, Kathi, Rajpali, Hun, and Kamari. They seem to have brought with them a worship, out of which ultimately was formed the Buddhist religion as promulgated by Sakya Muni. These Indo-Scythic tribes also brought with them their northern custom of using tribal designations, taken from the names of animals, Varaha, the hog; Numri or Lumri, the fox; Takshak, the snake; Langaha, the wolf; Cutchwaha, the tortoise; Aswa or Asi, the horse; Sisodya, from Sisoo, the hare, etc., - and several of them still hold large possessions in the western parts of Central India, Sind, and Baluchistan. Some of them even carried their names into Europe. Asi was the term by which the Getæ, Yeut, or Jat were known when they invaded Scandinavia and founded Yeutland or Jatland; and the Asi and other nomades who took Bactria from the Greeks, Mr. Prinsep considers to have been Scythians of Azes, who overpowered the Greek dynasties in Sogdiana and Northern Bactria, between 140 and 130 B.C. And Asia seems to have been so called in ancient times from this great Asi race, whose name is said by Remusat to have been applied by the Chinese almost promiscuously to the nations between the Jaxartes and Oxus, as far south as Samarcand. In one of his quotations it is applied to the people of Khokand, and in another to the people of Bokhara, Kanishka, B.c. 40, formed a powerful Scythic dynasty in the N.W. But Vikramaditya, king of Ujjain, B.C. 57, stemmed one Scythic invasion, and in A.D. 78 Salivahana checked another inroad; yet during the next seven centuries the Sah, the Gupta, and Valabhi established dynasties in Northern and Western Indies.

The Dravidian race preceded the Ultra-Indian, Tibetan, and Aryan, and their language prevailed everywhere to the southward of the Himalayas.
Their route seems to have been from the north-west, where, Chevalier Bunsen says, the two great nations once centred, the one in the Altai and the pasture land towards the Himalaya, the other having its centre in the Ural mountains, and now appear in Asia as the subdued or primary element, as the subdued substratum of Iranian civilisation; and the aboriginal languages of India which attained their full development in the Dekhan dialects belong to that stock. Also Dr. W. W. Hunter's philological investigations permit the conclusion that the fragmentary peoples still to be seen in India, who have preserved their ethnical identity in sequestered wilds, or have merged as helots or low castes into the lowland Hindus, form the débris of a widely spread primitive race; and from the northern shores of the Indian Ocean and the China Sea, traces have been exhumed by him of ethnical evolutions, and the ebb and flow of human speech far more ancient, and on a grander scale, than the pre-historic migrations of the Indo-Germanic stock.

Successive Turanian and Irano-Semitic races have in turn influenced all the great outlying southern provinces in Africa, India, and UltraIndia; but from the formation of the language, the older intrusive people, the Scythico-Semitic and pastoral, found India less Scythic and more African than it became under their influence. And the land routes from the north-east, north, and northwest were not the only highways to the East Indies. Mr. Logan is of opinion that several of the races now dwelling in the south and east of Asia, in British India, Ultra-India, and Indonesia, reached their present localities by sea. Certainly, amongst all the foreign influences acting on the south of India proper, of which the presence can be clearly traced, two are of the widest extent. The first is entirely African and Indo-African in its character. It embraced the whole Indian Archipelago, Australia, and Papuanesia, and the races to which it must be referred appear to have prevailed along the shores and islands of the Indian Ocean from Africa to Polynesia, their limits being those of the monsoons.

There was prolonged commercial intercourse between the western and eastern parts of the Indian Ocean, from the Arabian Sea, Persian Gulf, Red Sea, and Africa, to the Mozambique channel on the west, to the Indo-Australian seas on the east. And when they were spreading over E. Africa, India, and the Indian Archipelago, there could have been no civilised Semitic, Iranian, Burmese, or Siamese races to binder them. The strong Africanism observable in some of the lower South Indian castes is seemingly the remnant of an archaic formation of a more decided African character. India proper lies between two great Negro countries, that on the west being still mainly Negro, even in most of its improved races, and that on the east preserving the Negro basis so near India proper as the Andamans and Kidah. It is therefore highly probable that the African element in the population of the Western Peninsula has been transmitted from an archaic period, before the Semitic, Turanian, and Iranian races entered India, and when the Indian Ocean bad Negro tribes along its northern as well as its eastern and western shores.

In the southern parts of the Western Peninsula, amongst the races speaking the Tamil language, are many who have African features in all their 
variety. The mixed Labbi and Moplah races of the extreme south of the Peninsula may be of African and of Arabian descent. But the Sidi of Janjirah are recent arrivals; the Negroes of the Dandilli Hills of $\mathrm{N}$. Canara are of unknown origin; the African slaves of the Muhammadans of Baluchistan, Sind, the Dekhan, and Karnatic are classes regarding whose African and Arabian origin there are no differences of opinion; also the Kader of the Animallay Hills file their teeth to a point like some African tribes; the Mincopi of the Andaman Islands, the Semang of the Eastern Peninsula, the Negrito and Papuan races of Indonesia and Papuanesia are recognised branches of the Negro race; while farther to the north, the Kisan or Nagesar, a broken tribe in the Jashpur highlands, have Negroid features; and the Bhuiher of Palamau and Jashpur reminded Colonel Dalton of the representations be bad seen of the Andamanese.

The vernacular of a people can only be taken as a test of descent along with their physical characteristics. The languages of conquered races, and of such conquering races as become associated with a higher civilisation, are liable to disappear. There cannot be any doubt that physically the Tamil Pariah, the Mhair of the Mahratta country, the Dher of the Dekhan, the Holiar of the Canarese, the Paravan of the Malealam territory, and the Malla of Telingana, are of the same Dravidian stock, though they now speak five different tongues. Some broken tribes of Bengal speak a dialect of Hindi; but their physical characteristics, some of their customs, the remnants they have preserved of their primitive paganism, and in some cases their traditions, lead to the conclusion that they are the residue of a people who, together with the Kolarian races, occupied India proper prior to the appearance of the first Aryan invaders. It is now known that there are many Oraon villages in Chutia Nagpur in which the Oraon language is quite lost, but the inhabitants nevertheless speak two tongues, Munda and Hindi. The languages of the Hinduized aborigines of Chutia Nagpur appear to have followed their religion. All the tribes that have became Hindu in faith have lost their old language, and speak a rude dialect of Hindi. The Oraon in Chutia Nagpur follow the Munda paganism, and adopt the Munda languages; while the Munda, Ho, Santal, and other Kolarian tribes, who adhere to their ancient faith, have preserved their old language, or at all events a pre-Aryan tongue. Alaung Phra (Alompra) subdued the Mon or Talaing race in $1757-58$, from which time the Burmese strongly discouraged the Mon language; and after the first war between the British and the Burmese in 1824-26, the Burmese forbade the Mon to be taught in the monasteries or elsewhere. The result has been that in little more than a century, the language of a million people has become extinct. In 1870 , there were not one hundred families in Pegu in which it was used as their vernacular tongue, though still spoken in Martaban and in Mamlam-yang by the descendants of immigrants who reappeared there when the British became supreme. But it is not merely the language that is disappearing, - the Talaing people themselves are being absorbed by the more powerful Burmese race.

History. - No one of the races who were occupy- ing India and South-Eastern Asia prior to the Muhammadan invasions, retain any strictly historical record of the routes by which they reached their present localities, or of the date of their respective advent. From the geographical distribution of the $\mathrm{Kol}$ and Dravidian languages, Mr. Hislop formed the opinion that while the stream of Dravidian population, as evidenced by the Brahui in Baluchistan, entered India by the north-west, that of the Kol family seemed to have found admission by the north-east; and as the one flowed south towards Cape Kumari (Comorin), and the other in the same direction towards Cape Roumania, a part of each appears to have met and crossed in Central India. The Karen of UltraIndia have a tradition of crossing a sea of sand, which is supposed to mean the desert of Gobi ; but they have no knowledge as to the date of their migration. That the Mongoloid races have made great efforts to reach more hospitable climates, is shown by the presence of many tribes wedged into the mountainous region on the frontiers of India. On both sides of the Indus, in Baluchistan, Lower Sind, in Nepal, Bhutan, and Sikkim, are many hundred tribes, some of almost similar origin, yet forming distinct nations and using dialects unintelligible to each other, though of the same family of languages.

The linguistic affinity of many of the non-Aryan peoples of India, is shown by the fact that they take their tribal designations from their word for man in their respective dialects, - thus Bala-li, Mola-li, Dhima-li, Santa-li, Banga-li, the people of Bala, Dhima, Banga, etc. ; and the very general term Mi (man) supplies the basis of the race name to not less than forty ascertained tribes,thus the Du-mi, Ka-mi, Anga-mi, Mi-than.

The prior immigrants from the north have been termed Scythic, Turanian, Mongolian, Kolarian, Tamulian, and Dravidian. All these designations distinguish them from that branch of the Aryan races (Iranian, Indo-Atlantic, Cancasian, Mediterranean) now dispersed through India proper, called by Humboldt East Aryans or Brahmanic Indians. The West Aryans or Persians had separated and migrated into the northern country of the Zend, where they combined a belief in Ormuzd and Ahriman with a spiritualized veneration of nature. But the East Aryans came through the Panjab into India proper, and they have continued up to the present time to exert a great influence on the people. It was an immigration on the borders of historic times. Much connected with this people remains in obscurity, for they have been a non-recording race. Chevalier Bunsen supposes that they reached the land of the Five Rivers some time between 4000 and 3000 B.C.; but we have no standard whatever, from our present point of view, by which to estimate the length of the period from their immigration into the country of the Indus down to their farther advance to the land of the Saraswati. All we can say regarding them is, that peculiar habits of life were contracted in the land of the Five Rivers, and that, out of the elemental religion there instituted, allusions to which are found in the oldest Vedic hymns, the Brahmanical system, with a new mythology and the introduction of castes, gradually grew up on the eastern side of the Sutlej. That author is, however, of opinion that the period of the passage of the Sutlej and immigration to- 
INDIA; ITS ARYAN, RAJPUT, AND JAT IMMIGRANTS.

wards the Saraswati occurred from B.C. 3300 to B.C. 3000 . Whilst they dwelt in the country of the Five Rivers, from B.C. 4000 to 3000 , little change in their habits and belief seems, in his opinion, to have occurred. But about B.c. 3100 or 3000 their power on the Indus appears to have been broken, in consequence of some war with one of the surrounding kingdoms, and from the latter date India east of the Sutlej up to the extent of the Aryan conquests adopted Brahmanism. From that time the religious views, forms, and habits of Bactria were for ever abandoned by the East Aryan immigrants, and between B.C. 3000 to B.C. 1900 they extended their Brahmanical religion from the Saraswati to the Doab. It was this race who called the portion which came under their own rule by the name of Aryavarta, the abode of the Aryans. In classical Sanskrit it was also known as Bharata and Bharata-varsha, and also Jambu-Dwipa. But by the western nations, India east of the Indus was always India, and was never called Arya by any writer.

This Aryan or Sanskrit speaking colony of Brahmans, Kshatriyas, and Vaisyas found the greater part of Northern India peopled by rude tribes, whom they designated M'hlecha, Dasya, Nishada, etc., and it is the received opinion that many of those prior occupants were of Scythian, or at least of non-Aryan origin. . But to a much later period, and when the Aryans were in full occuption of the country from the Indus to the Ganges and iuto Bengal, all to the south of the Vindhya mountains continued to be occupied by Turanian races. An immigration into Ceylon of a colony of Aryans from Magadha took place about B.C. 550 (B.C. 543); and Wajeya, the leader of the Ceylon expedition, is said in the Mahawanso to have married the daughter of the king of Pandu. But now, unless Travancore be an exception, there is no large Aryan colony in any part of the south of the Peninsula of India, individual members of that race alone appearing scattered amongst the nations occupying it. There is nothing in history to show, nor is there in the physical appearance of the races to the east of the Ganges and of the Bay of Bengal anything to warrant, the belief that these East Aryan immigrants ever advanced, in masses, beyond their present locality north of the Vindhya range.

Brahmanic Life. - They brought with them views as to the gradations of social rank, against which, up to the present day, all other races and even their own reformers have been repeatedly striving ; but they likewise brought larger intellect, letters, and a higher civilisation, not only enabling them to hold a position of superiority, but to inspire the prior races with the desire to be enrolled amongst the Aryan classes of Brahmans, Kshatriya, Vaisya, and Sudra. These East Aryan immigrants throughout all India proper possess the lands best suited for tillage, and in Travancore they are the sole landlords. When they first reached the Panjab, they depended on their horses. Arrived in India, they tamed the elephant, which finally rivalled the chariot. In the time of the Mababharata, B.C. 1400? Bhagadatta, Uttara, Duryodhana, Anvinda, and others fought on elephants. At the time of Alexander's invasion (B.C. 327) elephants had almost completely superseded cars. And in their wars they placed the infantry in the centre, and the horse and elephants on the flanks of their armies.

The date of the Rajputs' appearance in India proper is even more obscure. The Lesser Sind river now marks the eastern boundary of Rajputana, as does the river Indus that to the west, its limits being lat. $23^{\circ} 15^{\prime}$ to $30^{\circ} \mathrm{N}$, and long. $69^{\circ} 30^{\prime}$ to $78^{\circ} 15^{\prime} \mathrm{E}$., an area of 123,000 square miles, inhabited by a population of ten millions of souls. The north - eastern Panjab and CisSutlej district seems to have first been a Brahman before it became a Rajput country, and subsequently to have been advanced upon by the Jat. The great seat of Rajput population and ancient power and glory was, however, on the Ganges. When vanquished there by the $\mathrm{Mu}$ hammadans, after the 12 th century, the principal Rajput families retired into the comparatively unfruitful country to which they give their name. But even in Rajputana proper, though it has Rajputs for the dominant race, the population is much more Jat than Rajput, the Jat extending continuously from the Indus to the Ganges. Before the Rajputs were driven back from Ayodhya and the Ganges, Northern Rajputana had been partitioned into small Jat republics, and the Jat still form the most numerous part of the population and possess the largest share in the cultivation, though they share the more open parts with the Mina, the remains of the Saraswati Brahman population, and the dominant Rajput. The southern and more hilly parts of Rajputana are much occupied by the Mina, the Mhair, and the Bhil, and Malwa is occupied by Rajput, Kunbi, and Jat, the Charun and the Bhot races being also there. Rajputs and Jat occupy the plains south of the Salt Range. In the valley of the Ganges, the body of the Rajput population lies next to the Jat race to the east; in the Middle Doab, Rohilkhand, and Oudh, and still farther east, the country is shared by a Brabman population. In Lower Rohilkhand, where they are called Thakur, as also in Western Oudh, Rajput communities are strong and numerous; in Eastern Oudh, especially on the broad tracts between the Gogra and Ganges, there is a great Rajput population, and they are pretty numerous to the east of Oudh, in Azinghur and Ghazipur. They are also numerous in Mynpuri, Futtehghur, and Etawa; and Baiswara, the country of the Bais Rajputs, lies almost parallel to the Brahman country of the Lower Doab.

The Getæ, the Jat, Jut, or Jit, and the Takshak, from the Sakatai or Chaghtai region, now occupy places amongst the 36 royal races of Rajputana. The Puranas furnish certain points of information regarding their earliestmigrations, and the histories of Mahmud and Timur acquaint us with their later efforts. They expelled the Greeks who remained after Alexander's departure. Between the time of Cyrus, six centuries before Christ, when Tomyris fought for independence, and the rise of Timur (A.D. 1330), although twenty centuries had elapsed, the great Getic nation was little circumscribed in power. Under this last prince of the Getic race, Taghalaq Timur Khan, the kingdom of Chaghtai was bounded on the W. by the Dhasht-i-Kipchak, and on the S. by the Jaxartes or Jihun, on which Timur, like Tomyris, had his capital. Kojend, Tashkand, Ootrar, Cyrapolis, and the most northern of the Alexandrian eities, were within the bounds 
of Chaghtai. The Massagetæ, Getæ or Goths, seem gradually to have advanced from their ancient limits into the more fertile districts of Asia, and to have been driven in successive wars across the Sutlej. They are now spread throughout the Indus valley, from the mountains of Joud, through Sind, to the shores of Makran, and up to the valley of the Ganges. They long preserved their ancient habits; appearing as desultory cavaliers under the Jit leader of Lahore, they made a brave stand for independence against the British under the Jat ruler of Bhurtpur and the successors of Ranjit Singh, while Dholpur state is still Jat. In Bikanir and the Indian desert, in the desert tracts E. and W. of the Indus, they are camel and cattle breeders, but cultivate in the valleys and fertile oases wherever tillage is possible.

The Kathi, another ancient Scytbic race, are the ruling tribe in Kattyawar. The Malli and the Katheri of Multan opposed Alexander's advance; 1300 years afterwards, Mahmud was opposed by a race of the same name, and they must have preserved their ancient spirit to have been so long able to offer a front to the formidable armies of so furious an enthusiast. Their laureate bards still style them 'Lords of Multan and Tatta,' and they repeat couplets descriptive of their emigrations from Multan, their temporary settlement in the tracts called Pawin, N. of the Runn, and telling of their leader, Megum Rao, conducting the first Kathi colony across the gulf into Saurashtra, eight hundred years ago ; and so predominant was their power, that it changed the ancient name of the Peninsula from Saurashtra to Kathiwar.

Parsees occupy a prominent place in the $W$. of India. In the eighth century (A.D. 717), a small body of W. Aryans emigrated from Ormuzd, and landed at Sanjan, 25 miles S. of Damaun. They were a mere remnant of the ancient followers of Zoroaster, and though still few in number $(69,000)$, they have distinguished themselves in W. India by commercial enterprise.

The information regarding the more important immigrations into W. India, as will have been observed, is still so vague as to justify Mr. Elphinstone's remark (i. p. 19), that until Alexander's conquests, the dates of events are all uncertain; and again, from that time till the Muhammadan invasion, a connected history of this country cannot be given.

A Bactrian dynasty for nearly a hundred years held a considerable portion of the Indus territory, but in the early centuries of the Christian era there was a great upheaving of the nations in India proper. During the khalifat of Umar, history records an expedition from Arabia by the route of Baluchistan. From the eleventh to the eighteenth centuries there were repeated inroads of Moghuls, Turks, Persians, Afghans, and Arabs, led by Mahmud, 'limur, Baber, Nadir Sbah, and Ahmad Shah. Their military followers seized on kingdoms, provinces, and royalties, and in British India, in 1881, their descendants and those of their converts numbered $50,121,585$ souls.

As the Muhammadans' power declined, the Mahrattas, a Turanian race, led by Aryan Brahmans, rose to full, though brief, dominion, and have been succeeded by Christian races from W. Europe. The Danes have ceased to retain any territory in the E. Indies. The French, however, in India proper still hold Chandernuggur, Kari- kal, Pondicherry, Yanaon, Mahe, with eight other smaller settlements, comprising an area of 178 square miles, and a population of 285,022 souls, and they are now dominant on the Mekong river in Ultra-India. Portugal, on the W. coast of the W. Peninsula, at Goa, Damaun, and Diu, has 1066 square miles, with a population of 369,788 souls, and that nation occupies Macao in China. The Dutch have left India proper for In.. donesia, where their great possessions amongst the Archipelago islands from Sumatra to New Guinea occupy 455,411 square miles, with a population of $17,952,803$ souls,-Malay, Negrito, Papuan, Muhammadan, Christian, and Pagan. The Spanish Indies are likewise in Indonesia, in the Philippine Archipelago, most of the population being of the Negrito race, and almost all proselytes to Christianity. Nothing is known of the date of advent of the multitude of peoples of Mongoloid origin occupying the region from the N.E. part of the Himalaya, southwards to the seas of the Archipelago.

Language.-Dr. Hunter, at page 20 of his Comparative Dictionary, has put forward the opinion that the aboriginal races of the E. Peninsula, Burma, and India N. of the Vindhya range derived their speech from a source common to them and the Chinese (p. 22), - not only the terms for common natural objects and for the civil institutions of a primitive race, but also a part of the nomenclature of tillage, and even such terms of civilisation as road; yam, etc.

The Jaina and Buddhist religionists number in British India $4,640,780$; the great bulk of them $(3,251,584)$ being in British Burma. The Sikh religionists, converts from the Jat race, are almost two millions $(1,853,426)$, and are nearly all in the Panjab; and of the Christians, 1,862,684 in number, 711,080 are in Madras, in which tradition asserts there have been converts since the days of St. Thomas the Apostle. The small body of Parsees, and a still smaller number of Jews (7600), are mostly in the west parts of the Peninsula.

Amongst most of these eastern races, the birth of a boy is greatly more prized than that of a girl. Their daughters are occasionally neglected, and, amongst some of the Rajput tribes, even destroyed. The proportion of girls to boys was found by the census of 1871 to be low. Amongst Hindus the range in the several provinces was from 72.95 to $97 \cdot 37$ girls to 100 boys, and amongst Muhammadans from 80.92 to $95 \cdot 18$.

It is quite an oriental custom for the population to arrange themselves into separate communities, each with an independent life, and intermeddling as little as possible with events that do not disturb its internal condition. Under this system a man's country is the guild or community in which he is born, and the people recoguise as the supreme authority whoever happens to be de facto ruler. Such race and communal isolation is common to all the populations of British India proper, but it has been widely extended by the system of minute castes which the East Aryans brought into India. Many of the prior races, while continuing the race guild, or clinging to a religious sect, resent the Brahmanical arrangement, and the census of 1871 showed in British India 8,712,998 persons not recognising caste, or designated out-castes. The geographical, historical, and economic notices of 
INDIA; ITS AFRICAN RELATIONS.

the countries in Eastern and Southern Asia will be found under their alphabetical arrangement. This article relates solely to their ethnic features. - Logan in Journ. Ind. Archipelago; Bunsen; Max Muller; Hunter's Comparative Dictionary; Tod's Rajasthan; Humboldt's Cosmos; Dalton's Ethnology; Yule's Cathay; Rawlinson's Herodotus; Dr. Caldwell ; Sir Walter Elliott; Prinsep's Antiquities; British India Census; Elphinstone's Hist. of India.

AFRICA. From pre - historic times, Iranian, Turanian, Mongol, Turk, Hamite, Semite, and Negro races have been continuously adding to the inhabitants of India and the Eastern Archipelago. Of the races occupying Africa, ethnologists recognise three distinct ethnical divisions, - that of the woolly fleecy-haired, woolly tuft-haired, and lank curly-haired; and six linguistic divisions, Semitic, Hamitic, Fulah-Nuba, Negro and Negroid, Bantu, and Hottentot Bushman.

The Fulah of Senegal and the Upper Niger, as well as the Nuba of the Nile region of Darfur and Kordofan, are considered of indigenous African race; but they are very superior to the Negroes, and seem to be the intermediate agents of Muhammadan civilisation. South-Western Asia is the original home of the Hamite and Semitic branches of the Caucasian race; but they have intruded into Africa, and now occupy the whole of its northern part as far as the Soudan and the east coast districts north of the equator. Of the two, the Hamite were the first to become dominant there, but they are in no way akin to the pure African.

The Semitic populations in Asia are the Arabians, Syrians, and Samaritans; in Africa, the Abyssinians of Tigre and Amhara, Agow, Falasha, and Gafat. Several branches of this race have played a distinguished part in the history of the world. Conquest and commerce, but chiefly the former, have greatly diffused them. They have gone northward and eastwards into Persia, Central Asia, India, and China; small parties are located in India proper, Ultra-India, and Indonesia. In Asiatic Turkey, there are about 1.500,000 Arabs and others of the Semitic group. They conquered and migrated westerly along the north of Africa and into Europe, and they ruled in Spain for 700 years, but were again driven back into Africa; and now representatives of the Semites and Hamites are found differently mixed in Egypt and Abyssinia, all over the Sabara, and in the Arab and Moorish states; and the races in Morocco have been stated as under :-

Berber and Tuarik, 2,300,000|Jews, Shelluk or Shellook, 1,450,000 Negroes, Mandingos, 120,000 Moor and mixed Arab, 3,555,000 Christians, : : $\quad 300$ pure Arabs, . 740,000

The Berler include the Libyan, the Moor, the Numidian, and Gaetulian of the old geographers.

The Berber and Shelluk are untamed, warlike tribes, dwelling in the mountains; when possible, rovers of the sea; claiming fanciful origins, but impatient of any subjection. They are the same race as those whom the French call Kabyle and Zouave. The Moors are little idle men, who grow fat from indolence; they are lowlanders, traders, dwellers in cities, avaricious, perfidious, cowardly, cringing, and insolent. The Riff-dwellers of Kalhiya, Cape Tres Forcas, corre- spond to the Arab Suaheli on the Red Sea coast, the names being from Ripa, a bank, and Sahilah, a sea-shore.

In Morocco, the Berber continue pure, free from Arab blood, and still call themselves Mazig. Their language is termed Shelluk, or Tamashigt. The Algerian Kabyle or Qabail are pure Berber. They are the old Numidians, and differ in language, form, and habit from the Arabs of the plains. Their number is about 700,000 ; they have a federal republic, the old Quinque-gentes who gave so much trouble to the Romans, who tried the soldiership of Maximilian, and sixty years afterwards again revolted.

In Tunis the Berber are called Suawua, and south-east of Tunis they receive the name of Jabaliya. The inbabitants of Suiva, the oasis of Jupiter Ammon, the Garamantes of ancient geography, are likewise of Berber origin, as also are the Teda or Tibbu of the Eastern Sahara.

The Sanhadsha of the Western Sahara are Berber. The Tuareg of the central region of the great African desert, who call themselves Imoshag, are Berber.

The Tuareg nomade in the Great Desert are very fair, with long hair, aquiline noses, high foreheads, and thin lips. They say their prayers in Arabic, and speak a Semitic tongue. Their arms consist of a long lance with a broad head, javelins 6 or 7 feet long, with jagged hooks at the pointed end, a round buckler (darega) of buffalo or elephant hide from Soudan, and a poniard and broad-bladed scimitar.

The Arabs of Morocco are the Moors of Spain, the Saracens of France,-tall, graceful sons of the desert, courteous, brave, hospitable, and confiding,-descendants of the conquerors who in the first ages of the Hijira propagated the religion of Mahomed, crossed the Straits of Gibraltar, destroyed the Gothic chivalry, reigned in Spain for 700 years, invaded France, devastated Italy, and pillaged the suburbs of imperial Rome. When the last Arab king submitted to Ferdinand and Isabella, and the Moorish palaces of Granada were surrendered to the Christians, the old conquerors went back to Africa, and resumed their nomade life. In Tripoli, the Arab has monopolized the country. In Tunis, the native reappears in a smaller proportion, and in Morocco he is very scarce.

Abyssinia was peopled by Southern Semites, who crossed the Red Sea from Yemen and Hadramaut before the Arab conquest of Egypt. They were converted to Christianity in the 4th century of the Christian era, and in the 6th they re-crossed over to Arabia, to avenge the persecution of Christians by a Jewish ruler, conquered Yemen, and marched to the gates of Mecca, where they were overthrown two years before Mahomed was born. Such partial migrations and conquests have left tribal bodies from other races in the land.

The Adal tribes, also said to be a Semitic race, dwell on the west of the Red Sea. They call themselves Afer, but by the Arabs they are called Danakil, from their chief tribe Ad-Alli; and Dr. Krapf was of opinion that this Afer is the Ophir of Scripture.

The Danakil, pl. Dankali, are a Hamite race who inhabit the most southerly African shores of the Red Sea as far as the Straits of Bab-el-Mandeb. 
The Eloikob or Wa-kuafi and the Masai, also Hamite races, are the terror of all Negro tribes in equatorial East Africa, on account of their wars and kidnapping expeditions.

The Somali, another Hamite race, occupy the eastern promontory of Africa from near Bab-elMandeb to the Juba on the Indian Ocean, and they border on the Galla district on the west. They have a woolly head of stiff thick hair from 6 to 8 inches long, and which is said to be always crimped.

The Fellaheen peasantry of the Lower Nile, and the Coptic Christians of the towns of Egypt, represent the ancient Egyptians. These are also represented by the Berabra or Berber of the Nubian Nile districts, who were Christians until the fall of the Berber-Nilitic empire of Dongola in A.D. 1320. Between the Nubian Nile and the Red Sea are the Bisharin, the Hadendoa; and some of the Beni Amer, who, in addition to a corrupt Arabic, speak Tobedauie, a more ancient Hamite language with three genders.

The inhabitants of Shoa are about 2,500,000, of whom one-half are Christians, the Amhara, and the remainder partly Muhammadan and partly Galla. The Christians are a stout, well-formed race, from 5 feet 7 inches to 5 feet 9 inches in height, with luxuriant silky black hair.

The Galla, a Hamite race, call themselves Orma or Oroma. The word Galla means immigrants, and Orma means strong, brare men. They are partly distributed in Abyssinia, and partly in a compact body in the east of the interior of Africa. They live in a beautiful country, extending from lat. $8^{\circ} \mathrm{N}$. to $3^{\circ} \mathrm{S}$., with a climate not surpassed by that of Italy or Greece, and speak a language as soft and musical as pure Tuscan. They are from six to eight millions in numbers. They are one of the finest races in Africa, of a dark-brown colour, with strong hair, and well limbed. They are a warlike, manly people, conscious of their own strength, and of a moral and noble character. Their beards are tolerably luxuriant, and their features regular and agreeable. With the exception of the southern tribes, they and their wives always appear mounted either on horses or on oxen.

Amongst them are scattered Christian tribes, but the religion of the race in general is fetish, and the seren tribes of the Wollo Galla are Muhammadans. The fetishists worship the serpent as the mother of the human race, and hold their religious services under a tree. They acknowledge a supreme being, whom they call Mulungu, and have a notion of a future state. There seem to be three natures or attributes in their supreme being, viz. Wak or Waka, supreme; Ogli, a masculine, and Ateli, a feminine, power or embodiment. They have two holy days in the week, viz. Saturday, which they call Saubatta kenna or little Sabbath, and Sunday, which is their Saubatta gadda or greater Sabbath.

The Negro race families inhabit Africa from the southern margin of the Sahara as far as the territories of the Hottentots and Bushmen. They extend from the Senegal across to the Upper Nile, including the Upper Guinea coast; but they have been driven from the extreme eastern parts of Africa by intruding Hamite and Semitic families. The Negro tribe speak a number of apparently distinct languages, which cannot be reduced to one system; but the people themselves are of one type, and that type quite different from those dwelling north and south of them.

The majority of the Negroes have high and narrow skulls, a prominence of the upper jaw, prominent lips, and an oblique position of the teeth. But the variations are very great. The colour of the skin ranges from ebony black, as in the Joloffer, to the light tint of the Wa-kilema ; and Dr. Barth even mentions a copper colour of Negroes in Marghi. Winwood Reade says the typical Negro is rare even among Negroes. In many tribes the jaws are not prominent, the lips are not swollen, and the nose is pointed straight or hooked.

The Bantu Negro family occupy Central Africa, from lat. $5^{\circ} \mathrm{N}$. Its eastern tribes are the people of Zanzibar, the Suabeli, the Mozambique nations from the coast to Lake Nyassa, the Betshuan inland, and the Kafir, with other little known tribes farther to the west.

The Soudan Negro family occupy from the Niger to the White Nile. The tribes are numerous,-Ibo, Nuffi, Ewhe, Otshi, Joloffer, Sererer, Fulke, Sourhay, Hausa, Kanuri, Bagrimma. In the towns of Darfur and Kordofan, both Arabic and Barabric are spoken. The lowest of all Negro tribes inhabit the district of the White Nile.

From lat. $11^{\circ}$ southwards, we find the Shelluk, the Nuebr, the Dinka; and west of the last are the Luoh (Djur), the Bongo (Dohr), and the Sandeh (Niam Niam). The Luoh and Bellanda are offshoots from the Shelluk. The Dinka and Shelluk Negroes closely resemble the Fundi Negroes on the Blue Nile, the founders of the kingdom of Sennaar in the 16th century, which they maintained for three centuries. The Fundi and the Bertha Negroes are directly allied in physical characters, language, and manners.

The Zanzibar dominions comprise that portion of the coast included between Magdashoa, in lat. $2^{\circ} \mathrm{N}$., and Cape Delgado in long. $10^{\circ} 42^{\prime} \mathrm{S}$. Beyond them, to the N., are the independent Somali tribes, which extend almost to the Red Sea, where they meet the Dankali race; and on the S. they are bounded by Mozambique. The extent of coast under the dominion of the Sultan of Zanzibar is about 1100 miles, but the most valuable parts of his sultanate are the islands of Zanzibar (containing the capital of the same name), also called Ungujo, Pemba, and Monfia. The first is situated at a distance of from 20 to 30 miles from the mainland, and is in size about equal to the Isle of Wight. It contains none but small streams.

The coasts of the mainland are called Us-Suahil, and its inhabitants, without distinction, Suahili. The population of Zanzibar island is about 250,000 souls, comprising (1) the Arab landed proprietors, the ruling race, who are enterprising and intelligent, but dirty, ignorant, and bigoted, dishonest and unprincipled; (2) a race of mixed descent ; (3) natives of the Comoro islands, brave and industrious; (4) natives of the W. coast of Madagascar; (5) Arabs from the coast of Hadramaut, patient and industrious; and (6) Arabs from Oman, a troublesome, turbulent, and plundering race. Southwards from this,

Indians.-About 4000 Muhammadans and Hindus from British India have settled at Zanzibar, Baamoyo, Pemba, Quiloa, Dar-u-Salam, on the E. coast of Africa, also in Madagascar, at Nossi Bei, 
and Marotta. The Muhammadans are of the Khoja, Bohra, and Mehman sects, thrifty and industrious races, who have their families with them. The Khojas settled in Zanzibar about the middle of the 17th century, and are chiefly from Cutch, Jamnaggur, Surat, and Bombay. They number 535 families, governed by a council of five elders, and they annually remit about $£ 6000$ for religious purposes to the head of their sect in India. There are 2000 in Zanzibar, 137 in Baamoyo, and a few in Pemba, Quiloa, and Dar-u-Salam.

There are 250 families of the Bohra sect of Muhammadans in Zanzibar, 142 at Mombas, 51 at Pemba, 42 at Lamu, and 21 at Malinda. Their ancestors emigrated from Surat in the 17 th century, and settled on the N.W. coast of Madagascar for trading purposes. They are guided by a maula in spiritual affairs.

The Hindu merchants there are of the Bhatti and Banya castes, from Cutch and Jamnaggur. They are engaged in business in all the towns and villages in the mainland, also at Mozambique, Eboo, and other Portuguese settlements; they never bring their families with them. Their number in 1872-73, in Zanzibar, was about 474 .

Lieutenant-Colonel C. P. Rigby, writing in 1860 , mentioned that 19,000 slaves had been brought to Zanzibar from the adjoining coast of Africa; the adults were sold at from $£ 2$ to $£ 7$, and boys or girls from $£ 1,5$ s. to $£ 2,10$ s., the majority being from the great tribes of M'Nyassa, Miyan, and Magindo. The tribes to the $\mathrm{N}$. of Mombassa were too fierce and warlike, and the Somali and Galla are never made slaves. In Zanzibar, in 1872-73, African slaves formed the greater part of the population. Slavery since abolished.

The language spoken in Zanzibar is Ki-Suaheli, called by the Africans Maneno Ungoja, and dialects of it are spoken over a vast extent of $\mathrm{E}$. Africa, from the limit of the Galla and Somali country, in about lat. $3^{\circ} \mathrm{N}$., to as far S. as the Zambesi. It is soft and pleasing to the ear, without any guttural sounds. It is written with Arabic letters. A corrupt Arabic is also current.

Mr. R. Cust adopts the opinions as to African languages of M. F. Miiller of Vienna. He says that among the Semitic, some, like the Old Punic and Old Abyssinian, are dead; others, like the Arabic, Amharic, and Tigree, are living vernaculars. Among the Hamitic, Old Egyptian and Coptic are dead; but Berber, Kabyle, Tuareg, Galla, Somali, and others are spoken by millions. The Fulah-Nuba languages are spoken by conquering races, some of whom have adopted Muhammadanism; they stretch from the Atlantic on the $\mathrm{N}$. fringe of the Negro races, across the continent to the basin of the middle Nile. The Fulah have extended into the heart of Negroland, and are found everywhere. The Negro race extend across the continent S. of the Sahara desert and N. of the equator, and reach from the Atlantic to the equatorial lakes. Their languages are numerous, totally distinct from each other, and of many we know little or nothing. The great Bantu race occupy the peninsula of Africa from the equator southward, leaving a corner for the last family. The diverse languages of these numerous and powerful races, of whom the Zulu and Kafir are so well known, can be traced back to one common mother language, which has perished. The Hottentots and Bushmen represent all that remains of the original earliest inhabitants of the continent, They have been pushed forward by the Bantu. and nearly destroyed; their languages are totally distinct from each other.

Religions.-In Africa, the Semitic race are found as fetish-worshippers, Christians, Muhammadans, and Jews. Abyssinia is Christian, with the chief truths of the Bible blended with merely human notions. The early Arab religion was Sabæanism, a worship of the heavenly bodies, mixed witl idolatry, but with Mahomed commenced the Arab conquests, the creed, science, and literature, and now all N. Africa is Muhammadan. When the Arab conqueror Akbah had overrun the states of Barbary from end to end, and, after passing through wildernesses in which he or his successors were one day to found the literary and commercial capitals of Fez, Kairoan, and Morocco, had reached the point where the Atlantic and the Great Desert meet, spurring, so it is said, his horse into the waves of the Atlantic, and raising his eyes to heaven, he exclaimed, ' $O$ Allah! if my course were not stopped by the sea, I would still go on to the unknown kingdoms of the west, preaching the unity of thy holy name.'

Throughout Central Africa fetishism prevails. The Bantu Negroes have ancestor-worship, shamans, and trial by ordeal.

Suahili offer food to the demon of disease. They do not eat it themselves, but place it on some footpath that a passer-by may consume it, and thus take the pestilence on himself.

TURKEY IN ASLA may be taken to include Syria, Mesopotamia, parts of Armenia, Asia Minor proper, and the Arabian peninsula. These regions are occupied by three distinct races, - the Ural Altaic, the Aryan, and the Semitic.

The Ural Altaic, in addition to a few Kazzilbash, comprise twelve millions of Turk who speak Turki, and are Mubammadans; also three millions of the Turkoman tribes who speak a Turk tongue.

The Aryan races are the Hellenes or Greeks, the Armenians, and the Kurd. The Armenians, three millions in number, are of the Orthodox and United Armenian sect, and speak the Armenian tongue; the Hellenes, two millions in number, speak the modern Greek, and are of the Urthodox and United Greek Church; and the Kurd, one million in number, speak the languages of the Kurd and Zaza, and are chiefly Muhammadan in faith.

The Arab $1 \frac{1}{2}$ millions, the Maronite 300,000 , and the Druse 40,000 , are the races of Semitic origin who speak Arabic, but the Arab are Muhammadans, the Maronite are of the United Syrian Church, and the Druse are pagan.

The Anatolian Turk are a lusty, stalwart race, of rude manners and harsh utterance, but frugal, patient, much enduring, kindly, hospitable, and tolerant in religious matters. They have an earnest, taciturn temperament, with much sound understanding and shrewd observation, but are defective in foresight and business habits. Hence they make, as a rule, indifferent merchants, and most of the wholesale trade has thus fallen into the hands of the rival races. In the country districts they are agriculturists and stock breeders, and in the towns, dealers in smallwares or craftsmen. Military service weighs heavily on them, and with polygamy prevents their increase.

The Greeks or Hellenes are industrious traders, 
shrewd, calculating merchants, excellent seamen, intelligent agriculturists, and monopolise the learned professions. The Greek race in modern times everywhere displays a praiseworthy zeal for the spread of education.

The Armenians still exist as a distinct nationality in the N.E. highlands of Anatolia, and are sparsely diffused throughout Southern Asia, from Constantinople to Ultra-India. They are constitutionally timid and reserved; rarely appealing to arms in self-defence, they yield submission to the strongest. But they are, intellectually, almost on a level with the Greeks, outrivalling them in commercial enterprise, ruling the money market, and are keen, perhaps cunning, traders. They habitually speak Turkish like a second mother tongue, their own language belonging to the Iranian branch of the Aryan family.

Armenia has no political existence. Its ancient bounds were between lat. $36^{\circ} 50^{\prime}$ and $41^{\circ} 41^{\prime} \mathrm{N}$., and long. $36^{\circ} 20^{\prime}$ and $48^{\circ} 40^{\prime} \mathrm{E}$., but it is now divided between Persia, Russia, and Turkey. The people live in good houses, are industrious traders, and its peasantry are powerful and robust. Their women are on equality with the men. On marriage, the women are silent till the birth of a child. They became Christians in the 4th century, but separated from the Greek Church in A.D. 526, and are now under a Catholicus or Patriarch. Their language, the Haik, is written with an ancient and modern character.

The Kurd highlanders are the descendants of the fierce Carduchi of Xenophon. They belong to the Iranian branch of the Aryan stock, and linguistically approach nearer to the Persian than to the Armenian subdivision. They are undoubtedly brave, but restless and unruly, often treacherous, lawless, and bloodthirsty. Halfsavage Kurd tribes occupy the uplands about the head-streams of the Tigris and Euphrates. They form a disturbing element in Asiatic Turkey, which is continued from Kurdistan southwards to Arabia by the restless nomade Bedouin Arabs of the Syrian desert, and of the plains watered by the Tigris and Euphrates. Nominally they are subjects of the Sultan of Turkey, but the Shamara, the Beni Lam, and other powerful tribes maintain an ill-disguised standing feud with the authorities, often disturbing the right bank of the Euphrates, from about the parallel of Aleppo all the way to the Persian Gulf. If united, they might easily bring from ten to twenty thousand formidable mounted warriors into the field, but tribal dissensions neutralize their power, and enable the Turks to keep them under.

Yezdi or Dasseni and Jacobites, a religious sect in Armenia, but chiefly in the Basheka province, in the pashalik of Musal and the Sinjar Hills. Their religion is a mixture of devilworship, with the doctrines of the Magi, Christians, and Muhammadans. Their greatest saint is Shaikh Adi, who is supposed to have lived about the 13th century, and is believed to have written a sacred book, 'Aswad,' or the 'Black.' They consider the devil the chief agent in executing the will of God. They reverence Moses, Jesus, and Mahomed, as also the HChristian and Muhammadan saints and prophets. They adore the sun as symbolical of Jesus. On the 10th of the moon in August they hold a meeting at the tomb of Shaikh Adi for a day and a night. All men and married women are present, and the intercourse is said to be promiscuous. At the village of Shaikh Adi is the brass figure of a peacock, which they call Malik Taus, king peacock, and they venerate it as representing David and Solomon. They circumcise on the eighth day. They place the body of their dead on its feet, touch the neck and shoulders, and strike with their palm the palm of the deceased, saying, 'Ara-Bihisht,' Away to paradise.

Tiari, a tribe, about Sulamary, of Nestorian Christians, with about 10,000 men.

Mendajaha, disciples of John, a religious sect in small communities in Basra, Kurnah, Mahamra, and Shaikh-ul-Shayok. Their religion is a mixture of paganism, Hebrew, Christian, and Muhammadan. They have a book called Sidra, and also the Psalms of David. They respect the town of Mecca, and more so one of the pyramids, beneath which they say their great progenitor, Saba son of Seth, is buried. The priests baptize, and use the Ohaldee language in all their ceremonies.

BLACK SEA, CAUCASUS, AND ARMENLA. The great Asiatic highland south-east of the Black Sea and south-west of the Caspian has ever been remarkable for its numerous races, and is now a well-head of nationalities, where the people promise at no distant period to combine into new nations. This region is enclosed on the west by the torrent river Kizil Irmak, the Halys of the ancients; on the south it has the Tigro-Euphrates valley and its border-lands; on the east are the desert tracts of Central Persia; and on its north, the Black Sea, Russian Georgia, and the Caspian Sea. The highland is formed by several entangled mountain chains, apparently belonging to, but somewhat apart from, the Caucasus, from which it is separated by the wide valley of Georgia, and the plains watered by the Rion or Phases and the Araxes. These highland mountains run N.W. and S.E. from the Anatolian coast beyond Trebizond, to the lofty peak of Demavend, and the neighbourhood of Tabreez or Taurus. It comprises parts of Turkey, Russia, and Persia, the whole east of Anatolia, with Northern Kurdistan, both of which belnng to Turkey, the Russian provinces of Erivan and Karabagh, with the Persian province of Azerbijan, and in their central point is the double cone of Ararat, covered by never-melting snows. The soil is fertile up to 6000 feet, and produces all kinds of cereals, with the 'yaila' or pasture lands of vast extent, and clothed with excellent grass, rising still higher. In the valleys below are the vines, fruit trees, maize, rice, tobacco, and varied cultivation, alternating with forests in which grow the ash, walnut, box, elm, beech, oak, fir, and pine, and amongst its minerals are iron, copper, silver, and lead. From its valleys flow the great rivers Choruk, Araxes, Tigris, and Euphrates, with all their countless tributaries, with other water-courses, some for the Black Sea, some to the Caspian, some to the Mediterranean, and some to the Persian Gulf. The population of that mountain tract is made up of Armenians, Turkomans, and Kurds, and until recently did not exceed fifteen to the square mile. But to avoid the pressure of Russian rule, many of the Turkomans from the N.E., and many Circassians, have crossed into the Turkish dominions, and many Turkomans also have joined from Persia. 
CAUCASIA consists of the narrow neck of land separating the Euxine (Pontus) from the Caspian Sea, and connecting the S.E. corner of Europe with S.W. Asia. It is inhabited by highland tribes of various races, dwelling in the closest proximity, hemmed in on the north by Russian Slav, and southwards by the Armenian, Kurdish, and Persian Iranians. In comparatively recent times, Tartars and other immigrant races have penetrated into the Kura, Terek, Kuma, and Kuban basins.

In the Southern Division are upwards of a miltion of people,-the Georgian, Imerian, and Rachan in Imeria; the Mingrelian, Gurian, and Lechgum in Mingrelia ; the Laz in Lazistan; the Svan in the Upper Ingur; and the Pshav and Khevsur near the sources of Alazan and Yora.

In the Western Division, on the left bank of the Kuban, on the coast of the Euxine, and N. and E. of the Elburz, are the Cherkess, Abkhasi, and Kabard, 138,000 souls.

In the Eastern Division, the Chechenz, 164,000, occupy the right bank of the Terek, and the Lesghi, 517,000 in number, dwell in Daghestan.

The Oss or Osseti, 110,000, hold both slopes of the Great Caucasus about Kazbek.

The Georgians alone are of historical interest.

Caucasia Inhabitants.

Kartvelian stock-Georgians, Imerians, Mingrelians, Svans, Pshavs, Khevsur,

$1,150,000$

Laz (Sunni), .

20,000

West Caucasian stock-Cherkess, Abkhasian, Kabard,

East Caucasian stock-Chechenzes, Lesghi, . Semites-Jews,

138,000

164,000

30,000

Slav stock-Great Russians, Little Russians, Bulgarians, Bohemians,

$1,500,000$

Iranian stock -

Ossi,

Armenians,

Kurd, Tat, and Talish,

Greeks and Germans,

110,000

720,000

380,000

50,000

Mongolo Tartar stock-Tatar, Nogai, Turkoman, Kumik, Kirghiz, Turk, Kalmuk, .

Christians,

$1,550,000$

$3,560,000$ $2,200,000$

Of all the Turki peoples, the Uzbaks are the most civilised, and, besides the Usmanli, they are the only Turki people who possess a written language and a literature. The Chaghtai, in which Baber wrote his memoirs, is still the standard literary language of all the Central Asiatic Turki peoples.

Kara Kalpak, or black caps, are a fertile race.

Kara Kirghiz are the Burut of the Chinese and Kalmuk. They live partly in Zangaria and Turkestan, and partly in the Western Altai. They speak an almost pure Turki dialect. Kara Kirghiz and the Kazak or Kirghiz Kazak represent respectively the highland and lowland nomade elements all along the northern and eastern border-lands of the Aralo-Caspian basin. The Kazak do not acknowledge the appellation of Kirghiz, which the Russians affixed to their name to distinguish them from the other Kazak.

Tajak are the original Iranian element, settled In all the arable land.

Sart is the term applied to the settled inhabitants. ots meaning is not known

CIRCAssia is the Cherkess of Asiatics. It is a mountainous country in the S.E. corner of
Europe, on the northern face of the Caucasus, lying between lat. $41^{\circ} 50^{\prime}$ to $45^{\circ} 20^{\prime} \mathrm{N}$., and long. $37^{\circ}$ to $47^{\circ} 20^{\prime}$ E., about 550 miles long and 75 miles broad; area, 40,000 square miles. The highest summits for nine months are covered with snow. In a small tract not less than seventytwo dialects are spoken. The Cherkess and the Che Chen are the two great tribes. They take the common name of Adighe; but the Cherkess include amongst them the Kabard, Abkhas, Uiche, and other clans, and number 400,000 to 500,000 souls. The $\mathrm{Che}$ Chen number 150,000 souls. Their religion is a mixture of Christianity, Muhammadanism, and paganism. They reverence Merem, a benevolent deity, and Tschible, the spirit of thunder. There are three social classes, -Usdi or nobles, Tschfokot or freemen, and Pschilt or slaves,-and these are hereditary, like the castes of India. On occasions when their forts or villages have been surrounded, they have destroyed their women and children, set fire to their dwellings, and perished in the flames rather than surrender.

Their young women are famed for their beauty, and are sought for in the neighbouring kingdouns. They are brought up in simple and domestic habits by their mothers, are taught the use of the needle in decorative works, and to make their own clothes, and those of the men of their family, and are otherwise very carefully reared. They are sold to the bridegroom and to traders.

The Cherkess or Circassians were typical representations of the West Caucasian races. They were the most powerful and warlike of all the western nations. Since their fual reduction in 1864 by Russia, most of their lands on the left bank of the Kuban have been occupied by their conquerors, the great bulk of the Cherkess having withdrawn into Turkish territory, and dispersed over Armenia, Asia Minor, Syria, and the Balkan peninsula. Similarly, 20,000 Abkhasians emigrated to Turkey at the close of the last Russian war, and both races have become predatory. Cherkess are to be found in Asia Minor along with Lazi, where also are the Yuruk, a nomade Turk race occupying the uplands between Erzerum and the plains of North Syria. Kazzilbash also are there, and are scattered over Anatolia, Persia, and eastwards to Kābul. They call themselves Eski-Turk or old Turks. The fertile plains of Raz Ova and Ard Ova near Tokat, and the villages between Angora and Amasia, and between Kara Hissar and Tokat, are the Kazzilbash headquarters. They profess Islam, but avoid all inquiry into their doctrines. The Circassians and Ábkhasians have never found a suitable home in Asia Minor, and are a serious disturbing element, being indolent and predatory. The Cherkess and Abkhasians of West Caucasus are Sunni Muhammadans; the Kabard are Christians; and these three races number 138,000 .

Georgians have a tall, slender figure, a noble bearing, regular features, aquiline nose, finelyformed mouth, dark complexion, black eyes and hair.

Arbiches, a daring, brave tribe in the mountains on the E. coast of the Black Sea.

Abasia, a trans-Caucasian province, in the government of Immeretia, Russia. The Abases are of the Caucasian race, rude, and are predatory.

Khersuri, a half-savage predatory tribe neav 
the crest of the Caucasus. They are surrounded by the Ghondmakar, Kist, Boghasser, and Didyen.

Kistes, a brave pagan Caucasus tribe, a branch of the Lesghi, and bordering on the military road from Tiflis to Mozdok. They are governed by elected elders.

Kosakint, a powerful tribe of the Caucasus, of 10,000 families, who can bring above 4000 excellent cavalry into action.

Lazi, a brave race occupying the head of the great range of Taurus district of the province of (Trebizond) Tarabazun, to the east along the shores of the Black Sea, in the neighbourhood of Batoum. At the census they numbered 18,000 men. During the Russo-Turkish war of 1828-29, they brought 12,000 fighting men into the field.

Lesghi. The country of this race is about 12,000 square uniles, the N. and S. slopes of the Cancasus. Narrow valleys and lofty mountains are occupied also by their tributaries, the Avar, Zerker, and others. Menteith says there are four tribes,-Kajar Kumak, 20,000 families; Kafir Kumak, 25,000 ; Avar, 32,000; and the AkKuscha, 12,000. The Lesghi are the bravest but most turbulent of all the tribes of the Caucasus; most of them are Muhammadans. Nadir Shah lost 30,000 of his best soldiers in a campaign against the I esghi, but they were totally defeated by the Russians in 1788. Their government is democratic.

Avar, a predatory tribe of the Lesghi, occupying the north slope of the Caucasus between the rivers Absai and Koisu. They are of Tartar descent.

Osset, a tribe dwelling on both sides of the Caucasus, numbering 16,000 to 20,000 families, partly Christians and in part pagans. They belong to the Indo-Germanic race, with many customs similar to the Germans. They are of slender and light form, some with brown or red hair. They sit on chairs or benches, never cross-legged like orientals. They are cleanly, brew and drink beer, using horns, and drink healths. They show the grave of the prophet Elijah (Asiljalegat) in a grove near the village of Lamadan. They pay money for their wives. Until the married woinan bear a child, she must, as with the Armenians, be silent. A widow who has borne children may be re-married to the father or brother of her deceased husband. There are nobles, freemen, and slaves. They adhere to the vendetta. They are short, 5 feet 4 inches, and thick-set, with haggard features, usually blue eyes, and red or light-brown bair. The women are seldom pretty.

Pehavi, a tribe of the Caucasus, living in fifteen villages, and numbering 3698 souls. They hold the mountains between Kakhetiaus and Chechenz.

ARABIA. - The Arab has been a migrating, conquering race. The first emigration from Arabia is supposed to have taken place about 700 years before the time of Solomon. Arabia is described in the Periplus as a country filled with pilots, sailors, and merchants. In Pliny's time Arabs were the carriers of the Indian trade; their settlers have occupied the north and east of Africa, have filled the western shores of Ceylon, have established themselves on the coast of Malabar, and they are prominent in Sumatra in the Archipelago. In all parts of the south of Europe, W. Africa, W. and S. and E. Asia, are to be seen descendants of Arab conquerors. They occupy Khuzistan and the whole of the Persian littoral, and also that of Persian and Baluch Mekran. Their armies have overrun the valley of the Lower Indus, have been dominant in Samarcand, Oudh, and Arcot, on the east have reached the Chinese territories, and on the west the Atlantic, Malta, Italy, and Spain.

The present Arabians, according to their own historians, are sprung from two stocks: Kahtan, the same with Joktan or Yoktan of the Bible, the son of Eber, whose descendants occupy the south; and Adnan, descended in a direct line from Ishmael, the son of Abraham and Hagar, who occupy the north. Yoktan, according to Ch. Bunsen, was one of the two sons of Nimrud, and was the chief of the first Arabian emigration that proceeded southwards. Tradition points to the mountains of Armenia as the birthplace of the Arab and Canaanitish races, and it is supposed that they travelled along the banks of the Tigris into Mesopotamia, from which a portion of them commenced a great migration southwards, the result of which was the foundation of the primeval kingdoms of $\mathrm{S}$. Arabia, the kingdoms of the Adites in Yemen, who believe that they came from the sacred north, and once lived in a glorious garden of the earth, which they are to restore. In the matter of their present locations, Dr. Latham, in his Ethnology, considers that Hejaz is peopled by the descendants of Ishmael, but the inhabitants of Mecca and Jedda consist of pilgrims and their descendants of African, Persian, and Turk blood. In S. Arabia, Yemen, Hadramaut, and Oman, the people are more or less Himyarite in blood, history, and civilisation. Those of the towns of Mocha, Sanai, Rodda, and Loheia are the more civilised, and the desert and hill Arabs are rude and ignorant, one of them so rude in speech as to be named the Bin-i-Kalb, children of dogs : and the Berekede, a branch of the Asir, are said to lend their wives. The Asir tribe occupy between Mecca and Medinah. They have six kabileh, -Bin-ul-Asmar, Bin-ul-Akmar, Charaan, Asir, Roufeida, and Ahida, and muster about 44,500 fighting men.

The people now occupying the Arabian peninsula are, however, regarded by Captain Burton as of three distinct races, viz. the aborigines of the country, who have been driven, like the Bhils and other autochthonic Indians, into the eastern and south-eastern wilds bordering upon the ocean; second, a Syrian or Mesopotamian stock, typified by Shem and Joktan, that drove the indigenæ from the choicest tracts of country; these invaders still enjoy their conquests, representing the great Arabian people. And, thirdly, an impure Egypto-Arab clan, well personified by Ishmael, his son Nebajoth, and Edom (Esau, the son of Isaac), that still populates the Sinaitic peninsula. The indigens or autochthones, he says, are those sub-Caucasian tribes which may still be met with in the province of Mahrah, and generally along the coast between Muscat and Hadramaut. The Mahrah, the Jenabah, and the Gara especially show a low development. These are Arab-ulAribah, for whose inferiority oriental fable accounts as usual by thaumaturgy. Dr. Carter also has remarked on the similarity between the lowest type of Bedouin and the indigens of India, as represented by the Bhils and other jungle races. The principal immigrant race, he says, are the 
Noachian, a great Chaldæan or Mesopotamian clan, which entered Arabia about B.C. 2200 , and by slow and gradual encroachments drove before them the ancient race, and seized the happier lands of the peninsula. This race would correspond with the Arab-el-Muta-Aribah or Arabicized Arabs of the eastern historians. The third family, an ancient and noble stock, dating from B.c. 1900, and typified in history by Ismael, still occupies the Sinaitic peninsula.

In Arabia there are several powerful nations, practically independent, though the emperor of Turkey claims to be their suzerain. But the great bulk of the population are in tribes, ruled by shaikhs or chiefs of their own election, chiefly pastoral and nomade, many of them predatory, with smaller tribes clinging around the larger for protection. Around Jerusalem are the Anezi, Shammar, Mowali, and Salhan.

The Shamr or Shammar is a great and powerful tribe of Bedouin Arabs who inhabit the N. part of the Al-Jazira province of the pashalik of Baghdad, and extend all over Mesopotamia. They pay no tribute, are greatly predatory, and bave so tbrown the beautiful lands of the Al-Jaziras out of cultivation, that it is literally a desert. They came from Nejd, about the beginning of the 19 th century, under the leadership of Farez-ibn-Unr-ibn-Muhammad-ibn Abdul Aziz, and the country they occupy is now called Jazirat-ibn-Farez. They have ten divisions, which have 1000 tents. There are also ten Bedouin and Fellaheen tribes subject to them, mustering 13,500 tents, with 81,000 souls.

The Shammar Jerbeh tribe wander in Irak, all over N. Mesopotamia, from S. of Sinjar and the Khabur river to the Saklawiyeh canal, W. of Baghdad. They are the terror of the Turkish authorities and people.

The Shammar Togha tribe wander about the Diyaleh river, as far as Kut-ul-Amareh, and from the E. bank of the Tigris to Nahrwan. They have ten families, have about 200 matchlocks or guns, and 700 horsemen. Their war-cry is Sinaaish.

The Daasur families have 210 tents.

The Daour tribe number 300 guns and 300 horsemen, and, when at feud with the Shammar Togha, they cross to the W. of the Tigris, and settle near Shirsh and Shedhayf.

In Mesopotamia are the following tribes :-

Abdeh, a Bedouin tribe in N. Mesopotamia, with 2000 families. They are under the Shammar.

$A l$ bu Asi, a Fellaheen Arab tribe of 500 tents in the N. part of Mesopotamia, round Nisibin.

Near the Zab river are the Ash Shawan, Al Bakr, and Al Tai, with 700 tents. They are pastoral and predatory.

Amud, a Bedouin tribe of Arabs of about 700 tents, in the $N$. part of Mesopotamia, on the banks of the Jaghjagha river.

Khureseh, a Bedouin Arab tribe near Nisibin, in N. Mesopotamia, with 800 tents and 13,500 souls, tributary to the Shamr.

Thabet, a tribe of Bedouin Arabs who inhabit the N. portion of Mesopotamia. They have 1000 tents, and are subject to the Shamr.

Kikia, a Turkoman tribe in N. Mesopotamia, from Mardin to Veran Shahr, numbering 1000 tents. They are the descendants of the old Artokide kings.

Milia, a Turkoman tribe occupying the extreme N. part of Mesopotamia, from Mardin to Veran
Shahr. They number 600 families. They are subject to the Shamr Arab.

The Baiat or Al-Beyat, a Turkoman tribe of 300 tents, W. of Kifri, who can turn out 1000 horsemen. Nadir Shah swept away the bulk of the Baiat to Khorasan.

$A l$ bu Sehnan, 200 tents, of Zab al Kabir and the $\mathrm{Al}$ bu Hamad of Eski Mosul, are pastoral and predatory.

Beni Zid, 100 tents, of Eski Kifri, are pastoril and agricultural.

The Zobeid is a great and powerful tribe in Mesopotamia, S. of the Saklawiyeh canal as far the Ajaf marshes, partly nomade and predatory, partly settled and agricultural, on the E. and W. of the Euphrates, about the Hindiyeh. They have 1750 tents, and can muster 500 horse and 600 foot with fire-arms. Their war-cry is Jeheysh, and their chiefs are descended from Abdallah, of Himentæ descent, the Himentæ of Ptolemy.

Dhiffyr, a tribe of Bedouin Arabs, in the desert about the Montafik territory W. of the Euphrates. They are predatory, and cross the Tigris to levy contributions as far as Badrai and Mendali, and aid the Montafik.

Near the rivers Tigris, Euphrates, and Hye are the following tribes:-

Kojami, a savage, ferocious, wild tribe of 1000 families, WV. of Urumia and Selmast, in the mountainous country at the source of the Tigris. They are Christians.

Tokali, a wild tribe about the source of the Tigris. They are Christians.

Abbu Muhammad, an Arab tribe in the marshes N. of Kurnah and the banks of the Tigris, as far as the Hud stream. They rear buffaloes; are neither courteous nor brave.

$A l$ bu Deraj, a tribe of 500 tents, wander between the Tigris and Euphrates, S.E. of the Hye. Ashair Beni Laam tribe occupy both banks of the Tigris, from the Hye river to the $\mathrm{Hud}$, and have about 4500 tents. They are proud, and do not marry their daughters into other tribes; when pressed by the Government, they migrate into Persian territory. They could, if united, bring 15,000 horsemen into the field.

Ashereh Kut al Amareh is a small Bedouin family on both banks of the Tigris, around the Hye stream. They have about 60 guns and a few flocks. They are chiefly guides, and are quiet and useful.

Al Deriya, Al Mayoof, and Al Mariyan are great pastoral families S.E. of the Hye. They do not cultivate.

Al Hamid Bedouins have 300 tents, and dwell in Irak, $N$. of the Hye.

Arfiyd family dwell from Shumli to Hye in Irak. They have 400 tents. They are Bedouins, and can muster 300 horsemen with spears.

West of Baghdad, as far S. as Musserib, there wander several families, the Al-Abu-Aamer, the Beni Timim, the Az-Zoba, the Al-Tedagheh, and Al-Berghut, agricultural and pastoral, in all about 1200 tents; and to the N.W. of Baghdad are the pastoral Al-bu-Sagr, the agricultural Al-Meshahedeh, and the Aj-Jeburur (300 tents). Near the Dijeil canal, N.W. of Baghdad, are the tribes Al-Khasrij (100 tents), Al-Majma, Al-Makadmeh, Beni Timim, Al-bu-Hujaza, and Aj-jeneyleh. They are pastoral and agricultural, and predatory. 
In the Baghdad pasbalik are the following tribes :-

Abeyd, an Arab tribe, $\mathrm{N}$. of Baghdad. They comprise six families, with 1050 tents. They occupy the lands opposite the Dijeil canal, around Samara and the Katuls, and extend from the E. bank of the Tigris to the Hamorin Hills. They are styled Al bu Shahr, or illustrious. They are predatory, have good horses and camels.

Adeil, an Arab tribe dwelling in Baghdad eity; another part of this tribe are in Nejd.

Al Bakr, an Arab tribe of about 200 tents, N. of the Zab river, in Baghdad pashalik.

Al Beyath, an Arab tribe of 300 tents, between Tuz, Kharmati, and Kifri, in Baghdad pashalik. They may be the Al Beiyath, an Arab nomade tribe of 130 tents and 130 matchlocks, who wander about Nahr Kathwaniyeh in the Baghdad pashalik.

Al bu Hamad, a predatory Arab tribe of 150 tents near Eiski Mosul, province of Baghdad.

Al bu Sakr, a pastoral tribe of Arabs with about 300 tents and 300 matchlocks, N.W. of Baghdad, above the Saklawiyeh canal.

Al bu Salman, an Arab tribe of 200 tents, partly agricultural, in part predatory. They dwell at Zabl Kabir in the Baghdad pashalik.

Aj Jebur, 300 tents, and the Khasrej, 100 tents, both cultivate in Dholoiyeh Hawis.

Al Kherkhiyeh, 300 tents, cultivate in Keshkul and Syedelan.

Al Kerwiyeh, 300 tents, cultivate in Kara Teppeh. Al Mashahedeh, a nomade tribe of Arabs to the N.W. of Baghdad, above the Saklawiyeh canal.

Amareh, an Arab tribe in the pashalik of Baghdad. They have 27 divisons and about 2520 tenits. In the early part of the 19 th century this tribe was the most powerful in Irak-i-Arabi. They have about 500 matchlocks. Their war-cry is Akhuyet Saadeh.

An Naim, a tribe of Arabs of about 100 tents near Hamrin, in the pashalik of Baghdad. They profess great sanctity, and wander about as Syuds and Darvesh. They have camels and horses.

An Nedeh, a tribe of agricultural Arabs near Mend Ali, in Baghdad pashalik. They have 300 tents.

As Seraj, an Arab tribe in the pashalik of Baghdad in Mesopotamia. They have 1480 tents, wander over Mesopotamia, S.E. of the Hye, as far as the Hud river. They can muster 800 horse with spears, and 400 foot with fire-arms.

Azzoba, a tribe of Bedouin Arabs near Nuhi Abu Gharib, W. of Baghdad. They number 300 tents ; are partly pastoral, partly predatory.

Baij families are of Bedouin habits. They have 600 tents; they are good horsemen.

Beni Lam, a powerful tribe of Arabs in the S.E. portions of the province of Baghdad, with 68 clans. They occupy the frontiers of the Turkish and Persian empires, are continually engaged in plundering expeditions, are most treacherous, dishonest, and greatly feared. They are estimated to have 40,000 families. The Montafik Arabs have repeatedly defeated them. They can muster about 5000 horse and 10,000 infantry.

Beni Timim, two small Arab tribes in the Baghdad province, engaged in cultivation. They have 150 tents, and dwell between Sindiyeh and the Atbeim, and in Balad Ruz.

Dellim occupy both banks of the Euphrates, from west of Baghdad northwards as far as the town of Hit. They have thirteen families and 1700 tents, and are warlike and agricultural. If united, they could muster 10,000 fighting men.

Khezail, a large Arab tribe in the Lamlun marshes near Baghdad; fierce and independent. They are stout, fair, and comely ; their women very beautiful. They are the only Shiah tribe of Arabs.

Madan, an Arab tribe settled in small reed huts in the province of Baghdad. They have buffaloes, sheep, and goats. They are of uncouth and brutal habits, and thievish. They use scant apparel. Captain Jones says they have nine families, with 1900 tents and huts. They are strong in guns.

Majma, a collection of small Arab tribes on the left bank of the Tigris, in the province of Baghdad, partly pastoral, partly settled. They are very thievish.

Montafik, a powerful Arab tribe near the banks of the Euphrates from Korna to Samvat, in the province of Baghdad. The shaikh can bring into the field 4000 horse and 4000 foot. About A.D. 1744 , they obtained the right of dominion over a small tract of country above and below Suk-uShaikh, paying tribute to the Sultan. But, on one of their shaikhs refusing to pay, a Mameluk officer attacked and destroyed them. They have since then again risen.

Anizeh and Dhiffyr are Bedouins. They generally locate themselves in the desert about the Montafik territory to the west of the Euphrates, and make occasional forays into Mesopotamia.

Sherabin, a tribe of Fellaheen Arabs who inbabit the neighbourhood of Nisibin, in the province of Baghdad. They number 600 tents, and pay a money tribute to the Shamr.

The Mahrah, a sea-coast tribe, dwell in the S.E. part of Arabia, from the opening of the great Wadi Masilah on the S.W., in long. $51^{\circ} 13^{\prime}$ $\mathrm{E}$, and the town of Damkot, in the Bay of AlKamar, on the N.E., in long. $52^{\circ} 47^{\prime} \mathrm{E}$., with a coast-line of about 135 miles. Their country contains many Himyaritic inscriptions. They are descended from the ancient Himyari of Hadramaut. They have their divisions, subdivisions, or families, i.e. bait. They are of sinall, almost diminutive, stature, and are always at war with each other. They are not a handsome race; their features are short and irregular, eyes small, black, sunken, and piercing, with a cunning expression. They and the Gara touch each other's fingers in saluting, but instead of kissing them afterwards, as the Gara do, the Mahrah place each other's noses side by side, and audibly sniff in the air. Inland they live on milk and flesh, with dates and sorghum millet; on the coast, on fish and dates. They are said to have no religion. Their language is very soft, and they sry of it, Kalam d'Mhari misl Kalam-ul-tair, "The Mahrah tongue is like the singing of birds.' The Mahrah dialect, as spoken by the Mabrah themselves, is described by Dr. Carter as the softest and sweetest language that he had ever heard. A dialect of the Mahrah, called Shehri, is spoken by a tribe around Morbaat, and with this the language of the Curia Muria islanders is almost identical, and that of Socotra appears to resemble it.

The maritime part of Hadramaut is known as Joor Shihr. The Mahrahs to the westward are 


\section{INDIA AND ITS ARAB NEIGHBOURS.}

said to be descended from the more ancient and original tribes of Gara, and both declare they are descended from the Himyari race.

The Gara or Hakili race, in the S.E. of Arabia, occupy exclusively the Sabhan mountains, which extend from Marbat to Hasek. They claim descent from the Himyari. They border on the Mahrah race, but near them are remuants of the Afar tribe of the Hassarit, and the Barama, while in most of the towns in Dofar are the Al-Kathivi, who originally came from Hadramaut, and are at war with the Gara. The Kabtan family is the head of the Gara tribe.

At Hasek is the tomb of the prophet Hud, the fourth in descent from Shem.

The language of the Gara, called Hakili, or Ekhili, or Ehkyly, appears to be a purer or more archaic dialect than Mahrah. Dr. Carter says the Gara is the Bedawi dialect of the south-east of Arabia, and, like that spoken by the Socotrans and the Curia Muria islanders, is intensely guttural. They understand the Arabic of the towns only after much intercourse. It is spoken at Marbat and Zafar, and throughout the district of Shajr, by the Hakili (Gara of the Arabs), and Barama tribes, whose coast is from Damgut to Nus.

The Southern Arabians say that the Gara has a much less proportion of modern Arabic than the Mahrah. It is spoken along the S. coast of Arabia from Sehut to Damgut, and extends far inland amongst the mountains.

Aden is British territory, but several tribes occupy the region around.

The Abdali or $A l$-Abadil occupy Lahej, which has an agricultural population, all Arabs. They have 66 sub-tribal divisions. The Jews are the goldsmiths, money-changers, and masons.

The Khadmi and Hijri are of African descent, resembling the Suahili, and are menials.

The Mouludi are of mixed descent,-Arab fathers and African mothers,-and are more honourably employed. There are few. slaves. The principal grain grown is the white and red varieties of the Sorghum vulgare.

The Fadhli or $A l$-Fadhl have about 100 miles of hilly sea-board. They have 24 sub-tribes, with about 6000 fighting men. They are proud, warlike, and independent, ready to take offence, treacherous and vindictive, grasping and avaricious, and lax in morals. The Murchasha subtribe hold a zanoo or base-born son in bigher honour than a legitimate son. They claim descent from the ancient Himyarites.

The Akrabi tribe (AI-Akarib) have a small territory on the coast-line, inland to the desert. They have about 250 or 300 fighting men.

The Howshati (Al-Howashib), with 10 subdivisions, dwell in a marshy, unhealthy tract. They cultivate sorghum and sesamum.

The Alawi tribe are united and powerful. They have about 700 fighting men. Their hilly district is N.W. of the Howshabi country, and little cultivated.

The Amir tribe dwell N.E. of the Alawi, on the high road to Sanna. The majority of the cultivators are Jews. Their fighting men are 2000.

The Subaihi (us-Subaiha) is a large sea-board tribe, from Ras Imram to Bab-ul-Mandeb. They are typical Bedouins; are 18 petty sub-tribes, few of which cultivate or trade, and only one has any fixed habitation; but live by plunder, which they do unrestrainedly. They eat the sorghum; are spare of frame, but brave and enduring, though treacherous. They have not any horses, and but few camels, but these of a high breed, usually equal in speed to that of horses.

The Yaffai (ul-Yaffaa) have more than 35,000 fighting men, in 15 sub-tribes; brave, but peaceably disposed. Their country is said to be mountainous in the interior. It begins at Khanfar, on the left bank of the Banna river, and has several towns. Many parts are well cultivated. They have several sub-tribes, one of them, the Yeber, of Himyarite descent. Their country is fertile, producing coffee, safflower, cotton, wheat, barley, and wax ; the exports being from Shoogra to Hadramaut.

The Aulaki (Al-Awalik) country is on the seaboard between the Fadbli country and the Hadramaut. The population, 15,000 in number, are herdsmen and cultivators. Some of this tribe have taken service with the Nizam of Hyderabad.

The Arabian Sea, that part of the Indo-Afric Ocean on the south of Arabia, including the Red Sea and Persian Gulf, has 6000 miles of sea-coast. The southern tribes of the peninsula of Senai are more or less fishermen. The littoral Arabs of the Persian Gulf obtain almost all their means of livelihood from the pearl fisheries on the banks off the Arabian coast. The inhabitants of the Persian littoral are Arabs, more or less mixed, but in many places pure. The Persian rulers, however, regard all who reside below the raised table-land of Persia as aliens, and the Alab settlers on their coast retain the habits of their parent tribes.

Women.-The Arabs are not so scrupulous as the Turks and Persians about their women; and though they have the haram, or women's part of the tent, yet such as they are acquainted with come into it.

Customs.-It is necessary, when considering the Arabs, to distinguish between a series of grades towards civilisation, in which they are at present to be found. The Bedouin is wandering, pastoral, tent-loving, disdaining to trade, yet avaricious, and willing to sell his ghi, his mutton, or his horse, and always found in wide and open wastes, unpressed upon by adequate exterior power. Yet even the Bedouin bends to circumstances. He accepts the region allotted for his pasture grounds. Plunder has its laws, and vengeance its chivalry. If he will not trade, he has still wants, and he suffers the presence of a Jew or Saleebah as the Afghan sufiers that of the Hindu. A little higher in the scale, as with the Cha'ab, is the original wanderiog pastoral Arab, in a district where he is pressed upon from without, and where boundless plunder and roaming are restrained by exterior force. The Arab then partly turns to agriculture, and for this he must in some degree settle. Society harmonizes to this level. Trade is possible. Corn is sold. The abba cloaks are woven and exported. Date trees are plauted. Huts of reeds replace tents; and one sees in their feeble efforts at reed ornamentation, and in their rough twisting of their reed rope for their bunds, the possible germ of some architectural efforts. Yet higher in the scale is the Arab flourishing as an experienced and wealthy merchant in a town, or administering a well-ordered and comfortable rural district. Passing anong these 


\section{INDIA AND PERSIA.}

people, society is seen in its transitional state towards civilisation.

PIRATE COAST.-The littoral within the Persian Gulf between the mountain range and the sea-shore, and extending in that direction from Kasab to the island of Bahrein-a distance of 350 miles-bears the designation of the Pirate Coast. Ibn Haukal, in his rersion of the Koran, informs us that before the deliverance of the children of Israel from Egyptian bondage, the subjects of a pirate monarch in these parts seized on every valuable ship which passed. The possession of a few ports within and near the entrance of the Persian Gulf, where it is not more than thirty miles across, enabled them to perceive and sally out on all passing vessels. To the Portuguese, during their brief career in India, they proved quite as troublesome as they did in the latter part of the 18th century to the British. The imans of Maskat have been repeatedly at war with these tribes. In 1809, an expedition was sent against them under Captain Wainwright, in His Majesty's ship Chiffonne. Their principal stronghold, Ras-ul-Khaimah, was stormed and taken, and fifty of their largest vessels burnt or destroyed. Leit, on the island of Kishm, and several other ports, were reduced, but they soon returned to their old practices. The inhabitants of the Pirate Coast consider themselves to be far superior to either the Bedouin or town Arab. The latter, especially those from Oman, they hold in such contempt, that a Maskatti and an arrant coward are by them held to be nearly synonyinous. They are taller, fairer, and in general more muscular, than either of the above classes, until they attain the age of thirty or forty years, when they acquire a similar patriarchal appearance.

The Arab Caliphs were eminently literary. The Arab invasion of Europe first dispelled the darkness which had spread over that continent. They brought with them the knowledge of the East, and in a measure, also, the then forgotten learning of Grecian antiquity. About the 8th century they gave to Europe their numerical figures, and the art of determining their rank in the decimal arrangement by their positional value.

The Arabic language, as written in the Koran, is the most developed and richest of the Semitic tongues. It is not now spoken in any part of Arabia, as there written. Probably it never was so, any more than the Latin, the English, the German, or Italian, have ever been spoken as written in their respective bounds; and Burton quotes from the Arabic Grammar of Clodius, that the dialectus Arabum vulgaris tantum differt ab erudita, quantum Isocrates dictio ab hodierna lingua Græca. Indeed, the Arabs themselves divide their spoken and even written language into two orders, - the Kalam Wati, or vulgar tongue, sometimes employed in epistolary correspondence; and the Nahwi, or grammatical and classical language. Every man of education uses the former, and can use the latter. 'And the Koran is no more a model of modern Arabic (as it is often assumed to be) than Paradise Lost is of English. The Koran has been translated from the Arabic into English, French, Persian, Urdu, Malay, Javan, Tamul. In Socotra, the language in use is undoubtedly derived from the Ghiz or Ethiopic. At present the Arabic alphabet is in use amongst the Turks, Persians, Malays, some of the people of India and Africa. It was, however, of Syrian origin. The Arab family is Muhammadan, except the Christian Arabs of Malta. Nejd or Central Arabia is Syriau, and arranged into divisions called Suk. - Lane's Koran; Peschel, Races of Man; Latham's Ethnology; Captain Felix Jones in Boy. Geogl. Socs. Trans., xii.; Colonel MacGregor; Dr. Carter in Boy. As. Soc. Jour.; Pelly; Rawlinson; Wellsted's Travels ; Burton's Mecca, iii. p. 330 ; Bunsen's Egypt, iii. and iv. ; Fontanier; Layard's Nineveh; Mignan's Trav.

PERSIA. - The regions through which the Euphrates and Indus rivers run, and the countries intervening, have, since remote ages, been occupied by races who have taken a prominent place in Indian history. When Chengiz Khan in the early part of the 13th century overthrew Kharasm, and its ruler fled, only to die on an island in the Caspian, and his son, Jalal-u-Din, was defeated on the banks of the Indus, which he swam with seven followers (A.D. 1221) amidst a shower of arrows, but he conquered Sind and established his power in Persia, and was killed in Mesopotamia about A.D. 1233. After Shams-u-Din Altamsh had established himself firmly at Dehli (A.D. 1211, April 1236), he received investiture from the khalif of Baghdad, and at his court dwelt the author of the Jama-ul-Hikayat, a collection of historical anecdotes in Persian. The grandson of Altamsh, Nasir - $u$ - Din Muhammad, reigned at Dehli from A.D. 1246 to 1266 . He was an eminent patron of Persian literature, and the Tabakat-i-Nasiri, a general history of Persia and India, was written at his court. In A.D. 1544 , the Dehli emperor Humayun, driven from India, was received in Persia by Shah Tamasp, who sent an army to restore Humayun, and it took Kandahar. After the accession of the house of Timur, notwithstanding the hostile feelings felt towards the Persians from religious prejudices, the court of Dehli long continued to have two parties, one using Turki, the other Persian; and although Aurangzeb treated the Persians (the original models of Indian Muhammadans) as rude and barbarous, and never mentions their names without adding a rhyming dislike, to the present day (1883) the Persian continues to be the court language of Indian rulers, and used by the learned in their literary and epistolary writings. Till the middle of the 17 th century (1648), Kandahar was usually in the power of Persia; but early in the 18th century (1720-1722) Persia fell to the Ghilji. A few years later, Nadir Shah's victories in Herat (1731) led to his election as king. In 1738-39 he invaded India and sacked Dehli. During the first half of the 19th century, the British from India and the Persians have alternately been interchanging friendly embassies and been at war. British officers of rank and eminence have been lent to discipline the Persian army, and that army has been repulsed from Herat by Lieutenant Eldred Pottinger, and been defeated at Mahammerah by British Indian forces. The region intervening between the Euphrates and the Indus is thinly peopled. It is now occupied by races who are subjects of the king of Persia, the bulk of whom are nomade and of varied origin; also by the races known to Europe as Afghans; by the Brahui mountaineers, and the Baluch races of Baluchistan, and by races on the 
sea-coast the period of whose arrival there is unknown, but who are largely Arab.

The Arab conquest (A.D. 632-38) permitted many of that race settling in Persia and to occupy prominent positions in it; but there are considerable numbers of maritime Arabs in its seaboard provinces, extending eastward as far as Sind, and who have probably been dwelling in their present localities long prior to the time of Mahomed. The people of Karak are Arabs, as also the Tangistani tribes S. of Bushahr near the sea; likewise the inhabitants of the Rohila district of the Fars province, who rear horses of mixed Persian and Arab breed, and export them to Bombay.

The population of Persia has been variously estimated. Sir John Malcolm estimated six millions, and latterly about five millions have been named. The people are partly settled in towns and partly pastoral nomades, and this joint occupation of the South-West Asian lands, from the Mediterranean and the Red Sea to the Indus, by fixed civic nations and nomadic tribes of herdsmen, sometimes of the same and sometimes of different races, is a standing etbnic phenomenon.

The nomade tribes are all predatory, and giory in their pursuits. They are brave and hospitable, but rude, turbulent, and grasping. They move with the seasons to summer and winter quarters. The men of Kasvin, Tabreez, Hamadan, Shiraz, and Yezd are as remarkable for their courage as those of Kum, Kashan, and Isfahan are for their cowardice. From time inmemorial, Persian or Pehlavi, Arab and Turkoman, have been contending for mastery. But the Persian inhabitants of towus, and those engaged in cultivation, are not warlike, and the contest has been between the Persian nomade and the Turkoman nomade, - the two great martial classes of the population. The Persian nomades all belong to the Pehlavi stock, though their dialects are different. They inhabit Kirman, nearly all Fars, a part of Irak, and the whole of Kurdistan, a region stretching through the ranges of highlauds from near the entrance of the Persian Gulf in a N.W. direction, along the left bank of the Tigris as far as Armenia. The Turkoman nomades entered Persia with conquering armies; they had come from the banks of the Tolga, from beyond the Oxus, and from the plains of Syria. Their habits are the same as the Persian nomades, but they speak a different language, and from the Arab couquest till the death of Nadir Shah, the rulers of Persia had cither been Arab or Turkoman. No member of the Persian nomades had ascended the throne. It was this, probably, that gave rise to the bloody strife between the Zand and the Kajar. The Zand are the most illustrious of all the Persian tribes, and one of their chiefs, Karim Khan, after the death of Nadir Shah, succeeded in establishing himself in Isfahan and the Southern Provinces. The Kajar was a Turkish tribe brought by Timur from Syria, A.D. 1398, A.H. 805, and settled between Elburz and the Caspian, where they rapidly increased. After the death of Nadir Shah, a fierce war raged between Karim Khan, Zand, and Muhammad Hasan Khan, Kajar, which ended in Karim Khan's accession. The Kajar tribe is a Turkish Il, and from the accession of Fatah Ali Shah (obiit 1834) they have been dominant. They have two sections, the Yokaribash and Ashagabash, each of which has six subdivisions or clans. The
Ziadoglu were settled at Ganjab, in Russian Armenia, where they still remain. The Azdanlu clan were removed to Merv in the reign of Shah Tamasp I., and held it until conquered and nearly annihilated by the Uzbak under the khan of Bokhara.

$L a k$, a very large nomade tribe spread over Persia, though chiefly in Fars, Mazandaran, and Kasvin. They claim descent from the Kaianiau kings. The Zand, the tribe of Karim Khan, were Lak. They have 20,000 families, all of them predatory. The principal are the Beiranawand, Khojawand, Nadawand, Nakawand, Jalalawand, Abdul Maliki, and Sujah Vaksan. They are of the Ali Ilahi sect.

The Abiul Maliki reside partly near Shiraz and partly in Mazandaran, but chiefly around Sarmi Kala. They are said to be about 3000 or 4000 families. They have villages aud cultivate, but are constantly on the move. They are professed thieves, living on plunder of passengers and small caravans, but seldom murder. They are liable to furnish 500 mounted fighting men for the Shah.

Iliyat is the general designation of the nomade tribes of Persia. They comprise a very large portion of the population of the country. Many of the best families are of Iliyat origin. The term is derived from the Turkish word Il, signifying a tribe, and the Arabic termination 'at.' All of them, Zand or Pehlavi, Arab or Turk, lead the same manner of life, their pastoral habits little distinguishing them from the Bedouin Arab or the nomade Tartar on the banks of the Tedzen. Each lliyat tribe has its own history, and the principal nomade tribes are the Afshar, Aimak, Arab, Bajiban, Bakbtiari, Baluch, Bayat, Feili, Hazara, Kajar, Khuda Bandlu, Kurd, Kurd Bucheh, Lak, Mamaseni, Shah Seven, Shekagi. Some of them grow small quantities of grain, but their chief avocation is to breed camels, horses, cattle, mules, and asses.

They change their places of encampment with the season and climate, going in the summer to their Ailak, or quarters where pasturage and water are to be found in abundance; and when the cold of winter sets in, adjourning to their Kishlak or warmer region, in which their flocks and herds as well as themselves are better sheltered. Their summer abodes consist of large black tents, made of woven horse-hair, the sides being matting or dried rushes. They are usually pitched in a quadrangular form on the banks of their hereditary xivers, and under the brow of the mountains which have shadowed their forefathers for unknown generations. Hence, though they wander, it is yet within bounds. They have a country, and only change their place in it. The nomade tribes of Arabia and of Tartary bear the same character, possessing an extended inheritance, though it be only a desert. The Iliyat chiefs, to whom the tribes are entirely devoted, are the hereditary nobility of the kingdom of Persia. Those in the southern provinces, the Bakhtiari, Feili, and Mamaseni, trace their origin to the most remote antiquity, and are probably the descendants of the warlike bands who inhabited the same country in the days of Alexander. The Kashgoi are a nomade Turkish tribe of about 12,000 families, whose chief is the Il-khani of Fars. They and the Bakhtiari from the warm pastures of Arabistan and the head of the Persian Gulf arrive in spring 
on the grazing of Isfahan. At the approach of winter, both the tribes return to their respective Garm-sair or wintering lands. The entire southern region of Fars, bordering on the Persian Gulf, is called the Garm-sair or hot region. It extends from the sea to the latitude of Kazerun, and runs parallel with the Persian Gulf, from the banks of the Tab to the confines of Luristan. From Bushahr eastward, as far as Kangoon, the tract is named the Dashtistan, or land of plains. The Tungistan, commonly pronounced Tungistun, or narrow land, is a small tract of land east of Bushahr. The greater portion of the people of the whole of that Garm-sair consists of an independent, lawless set, many of the tribes being robbers by profession.

The Garm-sair of Sijistan is a narrow tract along the lower course of the Helmand. The Baluch races seem to pronounce it Gurm-sehl or Garm-sail, and one of their wintering places is about 75 miles north-west of Nooshky. Each lliyat tribe has a separate grazing ground for its flocks; and this land, from long and undisputed possession, is considered as the property of the different chiefs. In the fine season they are continually on the move in search of pasturage; but in the winter, several of the tribes, amongst which may be numbered the Karagoosli and Afshar, settle in villages. In Dashtistan, Asterabad, and the northern parts of Khorasan, instead of tents they live in small portable wooden houses. They principally subsist on the produce of their flocks, and consequently grow but a very small proportion of corn. They manufacture cloth, as well as several other little articles for their own use; and the most beautiful Persian and Turkish carpets, so much admired in Europe, are the work of the Jliyat. Inured from their infancy to arms, to danger, and fatigue, and tenacious at the same time of the honour of their tribe, they are at once the prop and the glory of their country. Each tribe is divided into tira or branches, and each tira has a particular leader, all of whom are, however, subservient to the chief. These chiefs are, both from birth and influence, the first men in the empire; they are always mutually jealous and hostile; and the king, by nicely balancing the power of the one against that of the other, insures his own safety and the peace of his dominions. It was also the custom to detain at court, either the chief himself or some part of his family, as hostages for the fidelity of the tribe. Iliyat women are chaste and correct in their lives, and faithful to their husbands, and in their conduct and morals are vastly superior to those of the towns and settlements.

Turk Tribes. - The Afshar tribe is one of the Kazzilbash, spread over Kirman, Fars, Luristan, and Khuzistan, in great numbers at Abiverd, and round the lake of Urumia. They are said to be of Turk origin, and to speak a Turki tongue. Their two sections are Shamlu and Karklu, and they number 20,000 families. They were one of the seven Turkish tribes to whom Shah Ismail owed much of his success, and whom he designated Kazzilbash. Abiverd was the birthplace of Nadir Shah, who was of this Karklu branch.

Layard says the Gunduzlu, a Turk tribe of Khuzistan, have 1500 fighting men. It is a branch or clan of the Afshar tribe. Nadir Shah found them occupying the plains of Khuzistan to the foot of the great chain of mountains, and also in the country now held by the Cha'ab Arabs. They were sufficiently powerful to restrict the Bakhtiari to the mountains. Nadir Shah deported them to the north of Persia, but they returned to Kliuzistan on his death. The Gunduzlu Turk in winter reside near Boleti, and in summer and autumn on the Ab-i-Gargar.

The Baharlu is one of the Kazzilbash Turkish tribes whom Shah Ismail brought from Syria. They have 2000 houses in Azarbijan. The other Kazzilbash tribes were the Ustajulu, Chamlu, Nikalu, and Zu-ul-Kadar, but whether any of them now remain is not known.

Chardaoria tribe from Luristan and the Afshar occupy Sain Kala in Azarbijan.

Kasvin is a town in Irak-i-Ajam, 97 miles from Teheran. Its inhabitants amount to about 25,000 souls. They are chiefly descendants of the Turk tribes who have long pastured their flocks and herds in the neighbourhood. They are hardy and robust, but rude and ungovernable.

Kar'a Papa is a Turk tribe of several hundred families, in the Solduz district of Azarbijan. They were settled in Georgia until A.D. 1826, and on war breaking out between Persia and Russia they moved into Solduz district, and Abbas Mirza gave them lands on military tenure. They found the occupants of the country chiefly Kurds, with a few Mokaddam Turk. They are prosperous. They have a high reputation for valour, and are skilful horsemen.

The Khuzistan province, in the extreme S.W. corner of Persia, has on its south the province of Fars and the Persian Gulf. Its population consists of nomade tribes, dwelling in tents, pastoral and agricultural. In its northern part are Feili, Bakhtiari, Kobgelu, and Mamaseni ; in its south are the Arab tribes Anafijab, Ali Kathir, Cha'ab, and Beni Lam. The Dinaruni and their subdivisions dwell in Khuzistan. The Dinaruni are predatory, ignorant, and barbarous, and can muster 3000 men. They are overawed by the Bakhtiari.

The Feili, Bakhtiari, Kohgelu, and Mamaseni occupy also Luristan, where the Feili have two sections, the Pesh Koh and Pusht-i-Koh, cismontane and trans-montane as regards the Zagros chain. The Pesh Koh are notoriously predatory, and single travellers and caravans cannot travel in safety. They are a branch of the Ali Ilahi Muhammadans, holding to many local superstitions. The Feili pretend to bave more respect for an oath than the Bakhtiari, and to be less bloodthirsty, but there is little difference between them. The Silah Silah section of the Feili Lur are of similar bad character.

The Bakhtiari are a large, martial, valorous tribe, who occupy the mountains, and move to summer and winter quarters. They have a tradition that they came originally from Syria. The Haft Lang and Char Lang are their two sections, between which from time immemorial there has been the greatest eumity, and when they approach, blood is spilt. They can muster 6000 cavalry and 13,000 infantry. They have a national dance called chapi, and they have rejoicings over their dead, especially over those who fall in battle. Nadir Shah took a number of them into his army. The Janeki are the chief branch of the Char Lang. The Bakhtiari have been supposed to have given the name to Bactria. 
The Binduni are a small tribe dwelling amongst the Bakhtiari.

The Malah-Madi tribe of Bakhtiari accompanied Nadir Shah against Herat.

The Alaki, a branch of the Haft Lang, make their summer quarters in the mountains near Teheran, and in winter go to the sea-coast near Bushahr.

The Kohgelu inhabit the mountains at the source of the Jarahi river, between lat. $50^{\circ}$ and $51^{\circ}$. They adjoin the Bakhtiari, and are the same in language, manners, customs, character, and religion, but they consider themselves different; they are under the Behbehan governor, whilst the Bakhtiari are under that of Shiraz. They have about 20 clans, with 15,500 families.

Arab Tribes.-The Cha'ab Arabs are a tall, martial race, strong-limbed and muscular, active and healthy. They occupy the lower part of Mesopotamia, the southern portion of the plain of Khuzistan, in Persia, with the Hindiyan river on the east and the Karun river on the west, extending along the banks from Ahwaz till its junction with the Shat-ul-Arab. Their divisions are the Ali Bu Nasir, the Idris, Nasara, Mohaisen, Bawi, Beni Jemim, and Haidari Haidar, with about 50 subdivisions. Their adults are stated at 68,000 , but about 10,000 are supposed to be fighting men. They are agricultural, and have irrigating canals. They protect trade. They are Shiah Muhammadans. They are tributary to Persia.

Albu Ali is a tribe of the Cha'ab Arabs, residing in Khuzistan. They number 2500 adult males.

Abu Ghesh, a tribe of the Cha'ab Arabs, residing at Buziah, in the province of Khuzistan. They have 6000 adult men.

Ali Bakard is an Arab tribe settled in the plain of Ram Hormuz, in Khuzistan. They have good matchlockmen, and a few expert horsemen.

Ali Kathir, a large Arab tribe in the Dizful district of Khuzistan. They have 19 branches, of about 14,000 to 15,000 families, and can furnish a good body of cavalry.

Ali Khamis, a nomade tribe of Arabs, a branch of the Maedan, inhabiting the plain of Ram Hormuz, in Khuzistan.

Al Kuniferah, a clan of the Cha'ab, are located on the road from Mohamra to Dorak, in Khuzistan.

Al Mukadam, a tribe of Cha'ab Arabs, near Dorak, in Khuzistan.

The Amur clan wander about in the southern parts of Kluzistan. They number 10,000 adult males.

Anafijah, a nomade clan of the Maedan Kluzis$\tan$ tribe of Arabs, are a powerful tribe under the authority of a shaikh, who retains 300 horse and 400 foot. They occupy in Khuzistan the right bank of the Karun below Band-i-Kir. They possess large flocks of camels and sheep.

The Asar Kirah clan reside near Oushar, near Buziah, in the Falahiyah district of Khuzistan.

The Bawi are a large and powerful tribe of Arabs, who can turn out about 1000 horsemen and about 2000 footmen. They inhabit both banks of the river Karun, and are tributary to the Cha'ab shaikh, though its chief considers himself more under the protection than under the absolute authority of the shaikh of the Cha'ab Arabs, against whom they frequently appear in arms. They are notoriously treacherous.
Dinaruni, a predatory, barbarous, and ignorant tribe of the mountains of Khuzistan. They can muster 3000 men. They are overawed by the Bakhtiari. The Ali Mahamdi in Khuzistan is one of the largest subdivisions of the Dinaruni.

The Sadat and Sadir and Saki tribes dwell near Hawizah in Khuzistan, and numbers of the Saki are in Luristan.

The Sharifat tribe las about 10,000 families. They occupy the vicinity of the right bank of the Hindian river in Khuzistan and the Zaitun Hills. This tribe has 2000 foot and 700 horse, and has frequently opposed the Cha'ab shaikh.

Teheran, the capital of Persia, is built in the very lowest part of an immense desert plain. It has 100,000 inhabitants. Colonel Shiel gave the following tribes of the neighbourhood and district of Teheran.

Turk, viz. Shah Seven, 9000 tents; nomade in Kum, Teheran, Kasvin, and Zanjan.

Kharekanlu, Bajmanlu, Kundeshlu, Khellij, Khoda Bandehlu, 400 houses in Teheran city.

Afshari, 900 houses and tents, between Teheran and Kasvin.

Usanlu, 1000 tents at Demavand, Kehleku, and Gavbaz, 150 houses.

Abul Hasani, Jahan Beglu, and Shadlu, 320 tents and houses.

Tuyuj, a base tribe, dwelling in 300 tents near Teheran. They are very poor, are thieves and fortune-tellers.

Turk and Lek, viz. Turk-i-Mafi, 100 houses; Pazeki, 2000 tents and houses; Kengerlu, Kara Churlu.

Lek, viz. Nine tribes near Kasvin, 1500 tents; Hedawand, Burbur, and Sylsipur, 1000 tents and houses.

Zargar, thieves and coiners.

Khurd Bacheh, 400 tents.

Shah Sarwari, 250 tents, and Nana Kelli, 650 tents, S. of Teheran.

Kurlistan lies between lat. $34^{\circ}$ to $39^{\circ} 30^{\prime} \mathrm{N}$., and long. $40^{\circ} 48^{\prime} \mathrm{E}$.; 500 miles long, and 150 miles broad; but near Van its breadth is about 300 miles. The Kurds inhabit the whole of both sides of the main range, which, running out south from Mount Ararat, divides Asiatic Turkey from Persia from Bayazid to near Hamadan. The limits comprise portions of the provinces of Bayazid, Arzrum, Mush, Van, Diarbakr, Musal, and Turkish Kurdistan in Asiatic Turkey, and of Ardelan or Persian Kurdistan, Azarbijan, and Kirmanshah in Persia. It is a succession of steep and rugged mountains, with fertile but narrow strips of valleys at their base. The mountain system consists of the great southern spur of Mount Ararat, which divides the drainage of the Tigris from that of Persia, and from which several spurs project. The western part of Kurdistan gives rise to the Batman Su, Bitlis Chai, Diala, Khabur, Sert Chai, Tigris, Yezdikhaneh Su, Zab greater and lesser, and Lake Van is in Kurdistan. The people are greatly nomade, with large flocks of sheep and goats. Their horses are good, and 60,000 to 80,000 could be annually supplied.

A. Pizhder district.-The Sekkir and Nur-udDini have 100 villages and 1000 fighting men; Shinki, 200 families; Ghellali, 150 families; Siwell, an agricultural tribe.

$B$. Nomade. - Jaf and its tributaries could 
furuish 1000 infantry and 300 horses. The Jaf protect all the tribes of Luristan and Persian Kurdistan, increasing their strength to several thousands. There are fragments of about seventeen tributary tribes, comprising nearly 3000 families, formerly part of the Balbassi, Lak, and Feili. Amongst these are the Zend, to which belonged Karim Khan, king of Persia, whom the Kajar overthrew.

In N. Kurdistan, the four great tribes are the Bahdinan, Bohtan, Hakari, and Rowandez, the Hakari having 27,840 souls.

The Kurd are the Carduchai of the Greeks. They are partly nomade, partly settled. They are brave, hospitable, robust, hardy, and temperate ; are long-lived, but uncivilised, averse to settled habits, delighting in war and rapine, and hardly regarding murder and parricide as crimes. They are seldom taught to read or write, but are carefully taught to manage horses and arms. The wali of Ardelan and wali of Sulimania are their greatest chiefs, he of Ardelan claiming to be the lineal descendant of Salah-ud-Din; is tributary to Persia. The features of the Kurd are sharp; face oval, nose prominent, mouth and chin receding; brow ample, eyes deep set, dark; mouth well formed, and teeth fine. Kurd or Kerad seems to mean speech. The people call their country Karmanj. They are invariably mounted; are armed with bows and javelins. Their tents are black.

The Kurd in Asia Minor are thievish, predatory, revengeful, untruthful, and irreligious. The working and industrious portion of the population in N. Kurdistan are Armenian and Nestorian Christians, all serfs, known as Zar Kharidi, gold purchased, and they are bought and sold as predial slaves with the land.

Suimanial is the capital of Turkish Kurdistan. Bebbeh, a Kurd clan, now dominant in Sulimania, and formerly very powerful. They claim descent from a European princess who married their ancestor Fahib Ahmad.

The Mendimi number 300 families. They are under the Pasha of Sulimania.

Millis, a Kurd tribe, inhabit the Abdul Aziz range in the Sulimania district of Asiatic Turkey. The Kurd are widely spread. They are found in Kurdistan, on the east of Persia, also in the west of Persia, in Asia Minor, and in Syria; they also possess Merv, they are numerous in Khorasan, are also met with in Baluchistan, on the Dasht-i-be-Daulat, and in Takari (Tirkari), in Cutch Gandava, two miles $\mathrm{N}$. of Cutchi ; they say they can muster 500 fighting men. A few of the Kurd are on the Russian territory, some are well within the Turkish, others within the Persian frontier. The nucleus of the Kurd family, however, lies south of Armenia, along the mountain ridge which separates Asiatic Turkey from Persia. They have many tribes, a few agricultural, but most of them pastoral and nomade. They are hardy, brave, and rapacious. The Mikri Kurd occupy the south of Azarbijan. They are agricultural; they are brave horsemen, and on one occasion, in the early part of the 19 th century, drove the whole Russian cavalry off the field.

The Bilba tribe, in Lahijan in Azarbijan, are nomade, roaming about the borders of Persia and Turkey. They are the most predatory, turbulent, and treacherous of all the border tribes of Kurd- istan, and have been ruthlessly hunter down by other tribes. They number about 5000 families, in three divisions,-Pirall, Mengur, and Marnish.

Mikri, Hakari, Afshar, and Zerza are found in the Urumia district of Azarbijan.

The Kurd in Persian Khorasan were brought from Kurdistan by Shah Ismail, and settled on the eastern frontier of Persia, to check the inroads of the Turkomans. There were 4000 families, who have since increased to 50,000 , and they are formidable, both on account of their numbers and their valour. They continue predatory, and retain much of the Kurd language, though adopting the Persian dress.

The Amberlu Kurd, who occupy the Zetunabad district in Azarbijan, were settled there by Nadir Shah.

Urumia in Azarbijan, on the borders of Kurdistan, has 20,000 to 30,000 inhabitants of the Mikri, Hakari, Afshar, and Zerza. The plain is highly productive, but the people are poor and oppressed.

South of Urumia is the town of Ushnai, in lat. $36^{\circ} 55^{\prime} 29^{\prime \prime}$, at the foot of the great Kurdistan mountains of Turkish Kurdistan. The inhabitants are Kurds of the tribe of Zerza, formerly 4000 , but now only 800 houses, the plague having carried off numbers of them.

The Mengur, a division of the Balbas Kurd, are uomades who pasture their flocks in summer upon the Persian frontier, between Sardasht and Ushnae, and in winter retire far within the Turkish line.

The Bera-Dust, a celebrated tribe, inbabit the district of Kamresh, west of lake Urumia, in the Persian province of Azarbijan. They formerly gave chiefs to Sumai and Terkur.

Baban, a tribe of Kurds between lake Urumia and Kerkuh.

The Kurds of Guran of Kirmanshah are frank and hospitable, of the Ali Ilahi religion, mixed with doctrines of Judaism, Christianity, and Shiah Muhammadanism. They are supposed to be of Hebrew origin. Major Rawlinson raised a regiment amongst them. The Sharaf Bayene tribe, between Zohab and Sulimani, are supposed to be Guran Kurd.

The Baho and Dastiari districts of Persian Makran are occupied by the Jagdal, Hot, Latti, Raisi, Kosagi, and Shahzadah.

Adian, a tribe of Kurds claiming descent from Shaikh Adi, the Kurd saint. They dwell on the banks of the Bohtan.

Ali Arus, a nomade tribe of Arabs dependent on Hawizeh district of Kurdistau.

Babdiman, a Kurd tribe in the valley of Amadia and left bank of the Tigxis. The chiefs of Amadia claim descent from the Abbassi khalifs, and assume a saintly character. Some of the chiefs have imitated the latter khalifs by covering their face with a veil, so that no one may see their face.

Bulbassi is a Kurd tribe composed of the following sections:-1. The Kabaiz, the reigning family; 2. Manzoor ; 3. Mamash; 4. Piran; 5. Rummook; 6. Sinn; and 7. Taafah. The chiefs of tribes are called Muzzin. The Bulbassi will not bestow a girl in marriage on a person of another tribe or people. They have courtship among them, and carrying off a girl by the lover is common. When a chief dies, he is succeeded by the best or bravest of his family, with the common consent of his tribe. If his eldest son be incapable, the best of the brothers succeeds. In 


\section{INDIA AND PERSIA.}

their own country the Bulbassi do not willingly acknowledge any superior, either Turkish or Persian; but when they descend into the regions of Karatchuk, they pay a tribute of sheep to the Bey. Most of the principal people among them possess a complete suit of mail. They sew a wounded man in the skin of a bullock fresh stripped off the animal, leaving only his head out; and they leave him in it till the skin begins to putrefy. They say this never fails to cure the most desperate spear or sabre wound.

Baliki, a large Kurd tribe of 10,000 families, occupying a strong secluded country which forms the prolongation of the Ushnai mountains. They claim descent from Sharezer or Sanaser, son of Sennacherib. They mix up a belief in Moses, Christ, Mahomed, and Ali.

Kelowski or white caps, called also Guran, are scattered all over Kurdistan. They are deemed ignoble.

Khazanli, a Kurd tribe in the Kharzandagh mountains, formerly predatory.

Khoshnav, a Kurd tribe in the north part of the country. They have three branches. Their language partakes of the Bebbeh and Bahdinan dialects. Khoshnav and Rowanduz Kurd are brutally savage. They rigidly follow their prayer times, but do not scruple to kill their enemy, even in their mosque.

Luristan, a province of Persia, of 19,500 square miles, extending for 270 miles westward from the borders of Fars to those of Kirmanshah. It has a population of 56,000 , composed of the Feili. It is divided into Luristan Buzurg and Luristan Kuchak (greater and lesser). The former is the mountainous country of the Bakhtiari, stretching from the frontiers of Fars to the river Dizful; and Luristan Kuchak is situated between the river and the plains of Assyria. From the 12th to the 17th century, Luristan Kuchak was ruled by a race of independent princes who were styled Atabeg, the last of whom, Shah Verdi Khan, was displaced by Shah Abbas the Great, and the country, with the title of Wali, granted to Husain Khan, a rival chief. The Feili clan is that of Husain Khan. When the whole of the Luristan Kuchak was under the dominion of a wali, all the tribes were designated Feili, but it is now applied only to those of the Pasht-i-Koh behind the great Zagros chain. Major Rawlinson gives Luristan Kuchak to six tribes and twenty-seven clans. The women perform all the labour. Their religion is an offshoot of that of the Ali Ilahi sect, with many local superstitions. The Lur do not revere Mahomed or the Koran. They wership Baba Buzurg, and regard several holy men amongst them with little short of adoration. And many of their observances are traceable to a time long prior to Mahomed. Macdonald Kinneir had noticed their midnight orgies of Chiragh Kushan, which are probably not now continued, but they were common till the beginning of the 19th century, and are supposed to have been a remnant of the physiological worship of Anaitis and Mithra, from the time that Sesostris ereeted the emblems of the worship, and Semiramis followed them in practice.

Mahmaseni, properly Muhammad Huseui, one of the most turbulent and lawless tribes of Persia, are settled to the north of Kazerun, in the province of Fars. They claim descent from Rustam. They have six clans,-Rustami, Gavi, Zali, Bekesh,Dushman, Ziari, and Zoi. Their families have been estimated at from 400 to 12,000 . They dispossessed the former inhabitants of Fehlian from all the arable land. Regular troops were sent against them after the death of Fatah Ali Shah, on which they threw themselves and children over a precipice and destroyed themselves.

The Rustami of Sarab-i-Silah and Digar, in the plain of Bairam in Fars, are esteemed the bravest of the tribe. They can bring 200 well-mounted and well-armed horsemen into the field.

Laristan, a province of Persia, in lat. $26^{\circ} 30^{\prime}$ to $28^{\circ} 35^{\prime} \mathrm{N}$., and long. $52^{\circ} 30^{\prime}$ to $55^{\circ} 30^{\prime} \mathrm{E}$., extending along the north shore of the Persian Gulf, and is 210 miles long and 120 miles broad. The coast is in the possession of different Arab tribes, all predatory. The interior has an aboriginal race who speak a dialect of the Pehlavi.

Azarbijan province is in the extreme N.W. corner of Persia. Colonel Shiel gave the numbers of their tents at 65,000 , as under :-

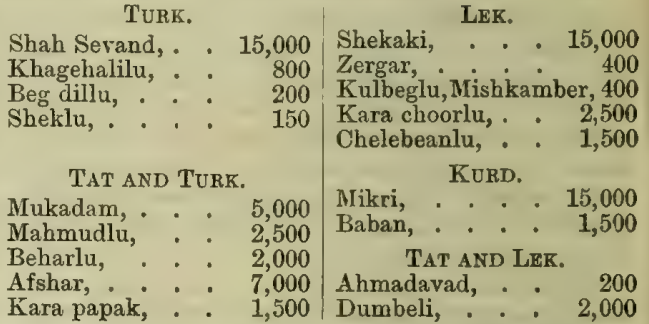

The Azarbijan people have an aptitude for war, and could supply 60,000 men, viz. 20,000 cavalry, 3000 artillery, regular infantry 12,000 , irregular infantry 25,000 .

The Chardaori tribe from Luristan and the Afshar, occupy Sain Kala in Azarbijan. Tabreez, its chief town, has a population estimated from 80,000 to 140,000 . It has been repeatedly taken and sacked by the Turks, Persians, and Russians.

Shahgagi is a large but rough and lawless tribe of about 50,000 families, in Azarbijan, in the distriets of Hasht-Rud, Garm-Rud, Miana, and Ardebel. They use Turkish and Leki. They make excellent soldiers, and British officers in 1833 formed three battalions from them.

Shah Sevand are nomade Iliyats in Irak and Azarbijan. They form a very large tribe of 15,000 families; they do not cultivate, but are wealthy from their herds of cattle and flocks of sheep. They are predatory. Their winter quarters are at Mishkin, and they occupy Ardebil and Khemseh.

Fars, a provinee of Southern Persia, is bounded on the N. by Irak, E. by Kirman and Luristan, W. by Khuzistan, and S. by the Persian Gulf. It lies between lat. $27^{\circ} 20^{\prime}$ and $31^{\circ} 41^{\prime} \mathrm{N}$., and long. $49^{\circ} 20^{\prime}$ and $54^{\circ} 20^{\prime} \mathrm{E}$., with an area of 44,335 geographical square miles. Its plains are in general fertile. It has the seaports of Tauri, Kongun, Reshahr, Bushahr, Bandar Reg, and Bandar Dilam. It is sparsely peopled. Its tribes are Persians-Lek, 9000 houses; Turk, 40,000; and Arabs, 10,000 .

Kash Kayi is a collection of tribes in the province of Fars, whose ancestors are said to have been deported from Kasbgar by Hulaku. They have thirty divisions, with about 15,000 families. They have sheep, goats, horses, horned cattle, and asses, and they make up wool into carpets and 
those of Turkish Kurdistan on its IV., E. by Irak$\mathrm{i}$-A jam, and S. by Luristan. It is a highly productive region. The Kurds supply sheep to Teheran and Turkey; its fine horses have much Arab blood, and its carpets are celebrated. Its tribes are :-

\begin{tabular}{|c|c|c|c|}
\hline LEK & Families. & & Familie \\
\hline Guran, & - $\quad 3,500$ & Zuleh, & 250 \\
\hline $\begin{array}{l}\text { Kalhur, } \\
\text { Zanganah, }\end{array}$ & $\begin{array}{r}.11,500 \\
: \quad: 10,500\end{array}$ & $\begin{array}{l}\text { Nanu Killi, } \\
\text { Ahmadawand, }\end{array}$ & i) \\
\hline Surjahea, & . . 2,000 & Pyrawand, . & \}$. \\
\hline (branch of the & Zanganah.) & Bahtui, . & .9 \\
\hline Jalalawand, . & - 300 & Filehgiri, & )$. \\
\hline Balawand, & - 6 & Sufehwand, . & \\
\hline Panjinawand, & - . $\int 1,000$ & Vermezgar, . & .) \\
\hline Zohinawand, & - - 1,000 & Kusiawand, . & . 1,500 \\
\hline Iersini, . & : $\quad \begin{array}{r}2,000 \\
-\quad 400\end{array}$ & & \\
\hline
\end{tabular}

Jalilawand, : : 600 Khuda-bandalu,

200

Kirmanshah, the chief town, is in lat. $34^{\circ} 18^{\prime}$ $45^{\prime \prime} \mathrm{N}$., and long. $46^{\circ} 3 \overline{7}^{\prime} \mathrm{E}$., and 250 miles S.S.W. from Teheran.

The Kalhur is a large and powerful tribe, in the district of Harunabad. They number from 7000 to 11,500 families. The men are tall, well made, and good marksmen. The women are handsome, They are of the Ali Ilahi sect, and they worship at the shrine of Baba Yadgar in the pass of Zardah.

The Sinjani tribe in the plain of Mahi-dasht number 4000 tents, and have considerable strock of camels, horses, oxen, mules, and asses. They are very lax Muhammadans.

Mazandaran, province of Persia, lies between S. shores of the Caspian Sea and the Elburz ravge of mountains, about 2000 miles long and 60 miles broad, from lat. $55^{\circ} 45^{\prime}$ to $57^{\circ} \mathrm{N}$., and long. $50^{\circ} 15^{\prime}$ to $54^{\circ} \mathrm{E}$. The climate is very unhealthy. They are the most warlike of the Persians; the men are brave and expert in the use of arms. They are required to furnish to Government about 12,000 infantry. The wandering tribes, estimated at 50,000 souls, have settled, and provide 5000 cavalry. The tribes named by Colonel Shiel and Mr. Holmes are Lek, Kurd, Turk, Afghan, Baluch.

\begin{tabular}{|c|c|c|}
\hline $\begin{array}{l}\text { Abdul Malaki. } \\
\text { Afghan. } \\
\text { Afshar. } \\
\text { Baluch. } \\
\text { Gerailu. }\end{array}$ & $\begin{array}{l}\text { Imamlu. } \\
\text { Imranlu. } \\
\text { Jan beglu. } \\
\text { Kajar. } \\
\text { Kelidgeli. }\end{array}$ & $\begin{array}{l}\text { Khojevand. } \\
\text { Modanlu. } \\
\text { Talish. } \\
\text { Usanlu. }\end{array}$ \\
\hline
\end{tabular}

Modanlu is the largest tribe, and contributes 1000 horse; the Khojevand and the Abdul Malaki are the vext in importance.

Gondar, a small tribe of 500 souls, who inhabit the wild country near Ashraf in Mazandaran: good marksmen with the bow and matchlock. They are said to eat the flesh of the wild hog, and place no restriction on the intercourse of the sexes.

Firoz Koh, a village of 300 houses in Irak-iAjam in Persia, 90 miles $\mathbf{N}$. of Teheran. It is built on the bank of a stream, towered over by perpendicular rocks 1000 feet high. The houses rise on the mountain side, but others of the people dwell in caves on the mountain side.

The religion of the bulk of the inhabitants of Persia is Muhammadanism of the Shiah sect. But Persia has always been fertile in sects. The earliest known to modern Europe was promulgated from the Alamut, a solitary, bare, and steep rock, 32 miles from Kasvin, which Hasn Sabah, chief of the Assassins, made his fortress. He was the Shaikh-ul-Jabal which the crusaders translated Old Man of the Mountain.

The Ali Ilahi believe in the incarnation of Ali and his descendants. They have long taken a place among the sects of Persia. They extend eastwards into Bombay, but are now chiefly found among the genuine Persian tribes of Lak descent; also among the Guran Kurd, and around the higher parts of Zagros. They are said to practise rites which they conceal from the uninitiated. A similar rule of retaining secrecy to their customs is attributed to a sect called Adami, whose meetings at night, in caves, are said to be conducted with rites like those of the Mylitta of the Assyrians, of the Alitta of the Arabs, and of the Persian Mithra; but such are the usual form of accusations made in Asia by opposing sectarians. The same is said of the Lur.

The Majusi or Gaor Yezdi are said to worship the cow.

The Sufi doctrines current in Persia are various forms of philosophy. Many of the most learned and best read of the community are Sufi sectarians, amongst whom there are both atheists, theists, and pantheists. The Kaimur and Mitanli are Sufi sects of freethinkers, who deny everything they cannot prove. The Dheri sect of the Sufi believe the world to be uncreated and indissoluble.

The Babi sectarians were followers of Syud Ali Muhammad, who, after repeated imprisonings, was at last shot at Tabreez. His doctrines were atheistic, under the guise of pantheism, but many of the religious men, mulla and mushtahid, joined him. He gave to himself and his doctrines the title of Bab (door, porte), to imply that his doctrine was the gate of heaven. Persia has many religious mendicants, darvesh or fakir, some of whom designate their sects by the names of holy men; some of them permit marriage, others are celibates. The Adhumian or Ajumian sect take their name from Sultan Adhum, who resigned his throne to become a mendicant; they do not marry, are wanderers, and are seen constantly moving their lips in silent prayer.

The Christian sects in Persia are of the Armenian and of the Nestorian Churches. The Nestorians elaim to be Kaldani; they inhabit the district of Urumia in Azarbijan, and the mountains to the south. They live amongst Kurd; and their patriarch has dwelt at Kojamis near Julamerk, in the heart of the Kurd nountains. Their number in Persia, Turkey, and Kurdistan is about 200,000,wild, brave, and grasping. About the year 1870 they were attacked by the Kurds, and numbers massacred. There are throughout Persia, as in Afghanistan, Turkish Arabia, Turkey, and the west coast of India, small bodies of Jews, who are occupied in petty traffic and as distillers.

Fire-worshippers, followers of the doctrines of Zertusht (Zoroaster), are still to be found in different parts of Persia. Yezd is a town of 30,000 souls, of whom 1000 are Jews and 4000 fire-worshippers, there designated Gabr (Gaour), but styled Parsee in British India, after their original home. The merchants of Yezd visit Bombay, the Mauritius, Java, and China.

Hindus are met with in many parts of Persia, engaged in financial and mercantile transactions. The town of Turshez, 36 miles N.E. of Turbat Haidari, is occupied by Hindus from Multan and Jeysulmir.

Karbala, in Turkish Arabia, and in Persia, Mashad, and Kum, are sacred towns. Kum is in Irak-i-Ajam, 80 miles from Teheran. The sister 
of Imam Raza is buried there, and the town is the most celebrated of the sanctuaries (Bast) of Persia. In Mashad, the capital of Khorasan, the Imam Raza was interred; his shrine is a sanctuary even for murderers, and the people from very great distances send the bodies of their dead relatives to be interred near the saint's tomb. Formerly the whole mabalah, or quarter of Bidabad, was reckoned sacred, like the Kedesh of Galilee, and the Shechem of Samaria and Hebron in Judea. The town of Ardebil (lat. $38^{\circ} 14^{\prime} \mathrm{N}$., and long. $48^{\circ} 21^{\prime}$ E.) has the tombs of Shaikh Safi-ud-Din, and of his descendant Shah Ismail, the founder of the Saffavi dynasty, and on their account it is a place of pilgrimage.-Porter's Travels, i. p. 475; Kinneir's Geographical Memoir; Malcolm's History of Persia; Pottinger's Travels, Beluchistan and Sinde; Rich, Pesidence in Kurdistan; Chesney's Euphrates and Tigris; Fontanier; Taylor; Layard; Burnes; Conolly; Ferrier; Baron de Bode, Travels; Colonel MacGregor, Central Asia, iv., quoting Abbot, Chardin, Clerk, Eastwicke, Fraser, Grant, Holmes, Monteith, Morier, Ogilvy, Ouseley, Pelly, Pasley, Rawlinson, Stewart, Stanton, Shiel, Tod, Wagner, Wilson.

CENTRAL ASIA, as here to be noticed, is known to the natives of Persia as Turan. Its western boundary may be taken as the Caspian Sea and the Ural; on the east is the lofty table-land of the Bolor mountains, which form the western boundary of Chinese Turkestan and Zungaria; on the S. and S.E. are Persia, Kashmir, Kafiristan, and Afghanistan; and its northern boundary is western Siberia. The northern half of Central Asia consists of the Kirghiz desert, which is mountainous and rugged on the east, and full of saline steppes on the west. In the midst of the southern half lies the Sea of Ural, on the western side of which up to the Caspian Sea there stretches a broad tract of desert. But on the eastern side of Central Asia is the fertile tract watered by the Syr Darya and Amu Darya, - the Jaxartes and the Oxus, -and which was conquered by Russia in 1864 and 1868.

The countries north of the Hindu Kush, which lie in the valley of the Oxus and its tributary rivers, from Balkh upwards, have several designations. Eastwards of that city lies Kunduz, and Badakhshan is farther eastward. To the north of this territory are the hill states of Wakkan, Shughnan, Darwaz, Kulab, and Hissar, whose rulers claim a descent from Alexander the Great. To the eastwards of Badakhshan lies the plain of Pamir, inhabited by the Kirghiz, and beyond the Belur Tagh mountains are Chitral, Gilgit, and Iskardo, which extend towards Kashmir. South of Badakhshan is the country of the Siah Posh Kafir, who occupy part of the range of Hindu Kush and a portion of Belut Tagh.

Central Asia has a hardy peasantry, dwelling in the mountain region with its vast upland downs, well suited for summer pasture, partly descendants of the original inhabitants, and in part nomade races. At the foot of the mountains, in the tracts of surpassing fertility, Turk, Bokhariot, Kalmuk, Kirghiz, Uigur, Mancbu, Chinese, and Iranian dwell in the well-watered plains.

The regions from the Polar Sea to the Hindu Kush, and from the interior of China to the shores of the Danube, have been occupied by nomade races from pre-historic times, along with descendants of Semitic and Iranian conquerors from the south. The more ancient occupants of Central Asia belong to the Iranian family. The later immigrants are from Mongoloid races. From amongst these came the warrior nations known in the west as the Hun, the Avar, the Uigur, the Kutrigur, and Khazar. And the manner of living, the customs, and physical conditions of the tribes, whose arms reached from the Jaxartes to the heart of Rome and Gaul, had much resemblance to those of the present inhabitants of Central Asia, nomades, who are in their habits the same as they were 2000 years ago. In the tent of many a nomade chief a similar life is observable as that described by Priscus as prevailing at the court of the king of the Huns. Attila, Chengiz Khan, and Timur, in historical characters resemble each other; and Vambery was of opinion that energy and good fortune could now almost produce on the banks of the Oxus and Jaxartes one of those warriors, whose soldiers, like an avalanche carrying everything before it, would increase to hundreds of thousands, and would appear as a new example of God's scourge, if the powerful barriers of European civilisation, which has a great influence in the east, did not stop the way.

Considerable portious of the region are occupied by the Turk race. These are usually recognised to be in ten tribes,-Uigur, Uzbak, Usmanli, Yakut, Turkoman, Nogaian, Basian, Kalmuk, Kara-Kalpak, and Kirghiz.

The Uigur occupy part of the region known to Europe as Chinese Tartary, and the Uzbak are their western neighbours under the Chinese. They at present occupy Kashgar. They are called Hiung-nu by the Chinese, and in Europe are known as the Hunigur, Hongre, or Hun. About B.C. 200 they dispossessed the $\mathrm{Yu}$-chi, but were in turn subjugated by the Chinese before the Christian era.

Uigur, according to Professor A. Vambery, are the most ancient of the Turkish tribes, and formerly inhabited a part of Chinese Tartary, which is now occupied by a mixed population of Turk, Mongol, and Kalnuk. They were the first who reduced the Turkish language to writing, borrowing the old Syriac characters from Nestorian Christians, who had come to their country as early as the 4th century of the Christian era. The manuscripts of this language, written in the characters mentioned, afford, therefore, the most ancient and valuable data in investigating the history not only of Central Asia, but of the whole Turkish race. He believeshe had collected all that has been discovered of the Uigur language, though the Uigur had a literature, and were very fond of books, at a time when the western world was involved in ignorance and barbarism. The most valuable manuscript he obtained bears date 1069 , and was written in Kashgar; it treats of etluics and political subjects, and forms a kind of manual of advice to kings how to govern with justice and success. It reveals the social condition of this people, and forms the basis of the later regulations by which all Turks are governed. The Uigur writing character was the original source of those still used by the Mongol and Manchu. The modern Tartar characters are written (and, it is presumed, read) in vertical lines from top to bottom of the page, the lines 
succeeding each other from left to right. What Uigur meant with Mongol authors is doubtful, but the people and language so called by the western Asiatics were Turki. Captain Valikhanoff speaks of the language now in use at Kashgar as being Uigur, but it is not clear whether he means that this term is known to the natives.

Uzbak are now dominant in Khiva, and are spread through the Bokhara khanate. Their early history is obscure, but prior to Chengiz Khan's time all Mawar-u-Nahr was occupied by a Turk race, with whom the modern Uzbak claim identity, and many names of their tribes, as Kungrad, Naiman, Kipchak, Jalair, etc., are identical with those of the Kirghiz, Kara Kalpak, and Turkoman. Their prominence in the khanate of Bokhara dates from the times of Chengiz Khan, whose grandson Shaibani, brother of Batu Khan of Kipchak, son of Jogi (eldest son of Chengiz), ruled over a number of Turk and Mongol tribes occupying the country between the river Ural and Sea of Ural, and also the regions watered by the river Jaik, which flows into the Caspian. With these he founded the khanate of Tura; and one of his descendants, $\mathrm{Uz}_{\mathrm{z}}$ bak KLan, was so beloved, that his people gave his name to the nation. One of his descendants, a powerful ruler named Abul Khair Khan, advanced towards the S.E., under whom the Uzbaks were composed of a number of Turki and Mongol tribes to whom others joined, attracted by their prestige. Their genealogical list, Nasalnamah-i-Usbakia, enumerates 97 tribes, one-third of whom are settled in the khanate, viz. Aimak, Arabet, Chagatai, Chiljuyut, Buzachi, Byagrin, Byatash, Jid, Juyut, Galiachi, Gurlyat, Durmen, Khitia, Kir, Kirkit, Karlik, Kipchak, Kalmuk, Katagann, Kanchin, Kungrad, Kunigaz or Kanigaz, Kureme, Lakaye or Lokbai? Manghit, Naiman, Sarai, Tatar, Turkomans, Uigur, Ung, Ungachit, Uzoi, Yabu, Yuikhun.

The Manghit is the chief and dominant tribe, some of them being settled in towns, others nomade near Karshi and Bokhara. The settled portions cultivate by means of their Persian slaves. Intercourse for ages with Persian women, and of other Turki tribes who have joined them, attracted by their prestige, has largely modified their physical appearance. Burnes, Abbott, Elphinstone, Fraser, Vambery, Khanikoff, Collett, and others have noticed them variously; but they may be described as haughty and overbearing in demeanour towards all the other races of the khanates, averse to labour, rather given to acts of violence, but brave, simple, manly, straightforward, and comparatively honest. The simpler though ruder Uzbak of Khiva is the better.

Urganj, or Yengi Urganj, the modern Urganj, formerly the capital of Khiva, is a flourishing commercial but walled city on the banks of the Oxus, about 18 miles $\mathrm{N}$. of Khiva. The inhabitants are chiefly Tajak. Old Urganj, the ancient capital of Kharazm, is in ruins.

Usmanli are descended from a pastoral band of Oghuz Turk, who were migrating under the leadership of Ertoghrul. The tribe, A.D. 1224, had left Khorasan, and rested for a time in Armenia, and, during their progress westward, Ertoghrul aided successfully a small army of Alaud-Din, the Seljuk sultan of Iconium. They take their present tribal name from Ertoghrul's son Usman, and their numbers are about 11 or 12 millions, seattered over the whole Turkish empire in Europe, Asia, and Africa. They form the landed proprietors, the aristocracy and bureaucracy of Turkey ; and their language, the Usmanli, is spoken by all persons of rank and consideration, and by all government authorities in Europe, Syria, Egypt, Tunis, and Tripoli. In the southern provinces of Asiatic Russia it is the language of the people along the borders of the Caspian, and through the whole of Turkestan. It is heard even at the court of Teheran.

The Turkoman group of tribes has been known from the early ages as a distinct branch of the Turkish race. They were first known historically as having come from the neighbourhood of Mangishlak on the Caspian, but they have traditions which assert that they lived originally far to the east, and travelled thence in a N.W. direction; and isolated groups are indeed found located on the supposed line of route, in the district of Jizikh, north of Karmina and Samarcand, which, although living for ages apart from the rest of the race, still retain all the characteristic features of the race. Soon after the death of Timur, the tribes overran and occupied Persia, and Azun Hasan, chief of the Turkomaus of the White Sheep, overthrew and killed in battle Abu Said Mirza, the most powerful of Timur's descendants. The last chief of this dynasty, Murad Beg, was driven out of Baghdad, A.H. 908, by Ismail Shah of Persia, and was finally defeated and slain by the Persians, A.H. 920, A.D. 1514.

At present the various tribes, entirely nomade, have no political connection with each other, nor any common head, and the power and importance of the race has greatly fallen. But the Mameluk of Egypt were of Turkoman origin; and the Turki races in the N. and W. of Persia and adjoining districts are of this stock. For a long time past they have been employed as mercenaries by Khiva and Bokhara, and they will serve any master who will pay them well. Nadir is said to have had the whole race in his pay; and Aga Muhammad Khan, the founder of the Kajar dynasty, is said to have employed them.

They extend from the Caspian eastwards to Balkh, in the south of the Amu (Oxus), and from that river southward as far as Herat and Asterabad, a tract almost all desert, excepting the districts watered by the Atrak, Amu, Gorghan, and Murghab, where they cultivate the soil.

They are chiefly uomade (charwar), but partly settled (chumur). The latter cultivate, have large flocks and herds, and keep fowls, but have few camels ; the nomades have numerous camels, sheep, and goats. Both classes rear horses. The Turkomans have nine tribes,-Ali-ali, Arsari, Chandora, Goklen, Kara, Salor, Sarika, Tekke, and Yomut,-each of them with several taifa or tira, clans or branches. The Russians estimate their numbers at 600,000 , in an area of 21,000 square miles.

The Ali-ali, about And-khui, have 3000 tents $=15,000$ souls. The Arsari are on the banks of the Amu, about Charjui and Lab-i-Ab, and northwards as far as Kirkinjuk and Karakul. In the end of the 18th century they arrived from Mangashlak. Those on the Amu produce silk, the finest in the khanate. They have 20 clans, 
and have 50,000 to 60,000 tents $=250,000$ or 300,000 souls.

The Chandor, seven or eight clans, have about 12,000 tents. They frequent the country lying between the S. shores of the Caspian and the Lower Amu.

The Goklen are agricultural, settled, and the most peaceable and civilised of the Turkoman; dwell in the rich country about Garjan; most of them are Persian subjects. They have ten clans, and about 10,000 tents.

The Kara, a small but very savage tribe, at war with all their neighbours, are found about And-khui, and near wells between And-khui and Merv.

The Salor have been famous for their martial qualities ever since the Arab invasion. The Constantinople dynasty is said to belong to them. At present they have three clans, with 8000 tents. The Sarakhs near Merv are said to be of this tribe. They are rich in cattle, and cultivate. They and the Saribs early left Mangishlak. The Sarakhs are equally brave; they are occupying about Panjdik, on the Murghab, but are at war with most of the other tribes. They have about 10,000 tents, in five clans.

The Tekke have their principal stations at Akbal and Merv. They are the most numerous and powerful tribe. They have less than the other tribes of cultivable land within their borders, and are more dependent on plunder. Their incursions are much dreaded in the N.E. of Persia, as well as in the direction of Herat. Their principal taifas are the Bakshi, Otemisch, and Totamish, with numerous subdivisions, and they are said to number 60,000 tents $=300,000$ souls. In 1881 they submitted to Russia.

The Yomut are said to have 31,000 families, of which 16,000 are subject to Khiva, and 15,000 to Persia. They themselves allege that their tents are 40,000 to 50,000 . They are settled on the eastern shores of the Caspian and on some of its islands, also in the Khiva desert near the Oxus. They have four clans; one, the Ogurjali, are under Persia, and are peaceable traders.

The purest type of the Turkomans is found amongst the Chandor and Tekke in the remoter deserts, are of middle height, small head, oblong skull, a rather long chin, and snub nose; cheekbones not high; eyes remarkably bright, sparkling, and fiery; feet usually turned inwards ; and usually fair in colour. The women are unveiled, have a ruddy, healthy look, and of ten considerable beauty. They are chaste, devoted to their families, and do all the hard work, the men confining their work to the care of their horses. The women make beautiful carpets; a long shift is their usual dress, to which they add a shawl and boots, with many silver triukets, chains, amulets, etc.

The chief expeditions of the Tekke were to seize slaves in Herat, Khorasan, Seistan, W. Afghanistan, and Persia, whom they sold in Bokhara and Central Asia ; while the Yomut infested the southern shores of the Caspian. The Ali-ali and Kara captured caravans on their way to Bokbara. The Chandor ill-treat their slaves, so as to be a scandal to the neighbouring races. The slaves are mostly Persians of the Shiah faith; but they take the Sunni from Khaf and Herat, also capture Jamshidi and Hazara, occasionally an Afghan and a Hindu. The slave trade is regularly organized.
The Kara Kalpak is an industrious tribe of Bokhara and Khiva. They inhabit the delta of the Oxus, to which they migrated from the delta of the Syr-i-Darya in the beginning of the 19th century, in consequence of continual fights with the Kirghiz. They are supposed to be the race whom the Russians call Tchernie Kobluki. Their traditions are to the effect that about the 15 th century they occupied the territory about Kazan, which they built. Afterwards Tartars came there. Subsequently, the city was taken by the Russians, on which the Kara Kalpaks left, and the Tartars remained. The Kara Kalpaks then led a nomade life for 130 years, but afterwards settled for about 30 years in Turkestan. About A.D. 1690, a war occurred, on which they again left Turkestan, and settled, part of them on the Lower Syr-i-Darya (Jaxartes) and Yani Darya, others on the right bank of the Zar-afshan, and 60,000 kibitkas on the Upper Oxus. Small numbers dwell on the right bank of the Zar-afshan, not far from Samarcand.

In appearance and dress they are intermediate between the Kirghiz, Kazak, and Kalmuk. They are tall, vigorous men, with more powerful frames than any of the Central Asian tribes, but clumsy, and with coarse features. They have large head, flat full face, large eyes, flat nose, slightly projecting cheek-bones, a coarse and slightly-pointed chin. Trotter says they bave 10,000 to 15,000 tents in the Khiva districts; their tents are large and strong, and guarded by a breed of large dogs.

Kirghiz proper are called Burut by the Chinese, Kara Kirghiz by other Asiatics, and by the Russians, Diko-ka-mennyi. (i.e. wild mountain people). They must not be confounded with the people called by the Russians Kirghiz or Kirghiz Kazak, a distinct nation, differing from the Kirghiz proper in appearance, in language, and in many of their habits and customs. Their name and origin are said by them to be derived from Kirk-kiz, forty maidens, the male ancestor being a red dog. Vambery, however, says the name is from Kir, a field, and Giz, root of the verb Guzmak, to wander. They call themselves simply Kirghiz. Their principal quarters are in the mountains around Lake Issyk$\mathrm{kul}$, and in the valley of the Chu; this valley and the Ala-tagh or Kirghiz-tagh mountains being' their boundary to the north, from whence they wander into Chinese territory on the one hand, or into Khokand and Samarcand on the other, while to the south they range over the Pamir, Karatagin, and as far as Badakhshan and the eastern parts of the kbanate of Bokhara. They are divided into two great sections, the On (right) or eastern Kirghiz, and the Sol (left) or western, both from a grandson of Kirghiz Beg. The tribes of the On are the Sary Bagnish, Bogu, Saltu, Cherik, Sayak, Adygive, Monandyr, Jadygyr, and Tungstar; those of the Sol are the Kokche, Soru, Mundu, and Kitai. They are ruled by their elders, styled Manap. Their chief wealth eonsists in cattle, sheep, and camels. They intermarry with the Kirghiz Kazak. They profess Muhammadanism, but retain some of the customs of the fire-worship. Few can read, and their women have much freedom, are unveiled, and there is a curious absence of jealousy. They trade in felts and pelts, skins of the martin and fox, and deer horn. Love of travel and war have often brought together the most distant branches; but whether 
on the shores of the Emba, or of the Sea of Ural, whether in the environs of the Balkash and Alatan, there is little difference to be found in the dialects spoken by them.

The Kirghiz between the Ural and Lake Balkash, including the Buriat, are, of all Turks, most nearly allied to the Mongols. The great Kirghiz steppe is the eastern portion of a belt of low-lying country which stretches from Europe into Asia, along the frontier of southern Siberia, and is divided by the upheaved chain of the Ural mountains, which run in a north and south line. The Kirghiz hordes occupy the low plain which, commencing from the north-eastern shores of the Caspian, and continuing along the Eruba steppe, passes across the country north of Lake Ural, directly to the eastern end of the Balkash. They also inhabit the banks of the middle and lower courses of the Syr-i-Darya (Jaxartes), as well as the Kizzel Koom (red sand) deserts, which are localities taken possession of by them in more recent times.

Tungus are widely distributed; there are Tungus in China and on the Frozen Ocean. Manchu, who conquered China in A.D. 1644, and founded a dynasty, belonged to the Tungus. The Tshapodgir occupy between the Yenisei and Tunguska. Mongol and Tungus are few in number, and many of the tribes are dying out. Since the 8th century, the Chinese have known the Mongol as the Mung-ku, but they applied to them the nickname of Tata. This is the origin of the term Tartar, Tatar, or Tahtah, a designation used at the present day as vaguely as Scythia was by the Greeks. By a dialectal change in the Persian language, Mongol becomes Moghul, a term applied to emperors of India, successors of Baber, though Baber was not a Mongol, but a Turk, who wrote and spoke Jaghtai Turki.

The Hazara spoke the language of the Mongol so late as the time of the Baber. The two hordes of the eastern Mongol inhabit the eastern half of Gobi. The Mongols sometimes bury their dead; often they leave them exposed in their coffins, or cover them with stones, paying regard to the sign under which the deceased was born, his age, the day and hour of his death, which determine the mode in which he is to be interred. For this purpose they consult some books, which are explained to them by the Lamas. Sometimes they burn the corpse, or leave it exposed to the birds and wild beasts. Children who die suddenly are left by their parents on the road.

Kalmuk call themselves Olot, 'the peculiar people.' They have four hordes, - the Zungar, the 'I'urget, the Khoshod, and the Turbet. They also call themselves Durban-Oirad, the four allies. The meaning of the term Kalmuk is uncertain. The Turget tribe of the Kalmuk, feeling oppressed by the continually increasing power of the Zungar, emigrated to Russia in A.D. 1636, and were granted pasturage on both banks of the Lower Volga by the Czar Michael Feodorovitch. After the destruction of the Zungar power by the Chinese in 1756, in the reign of the Emperor Tsian Lung, the remnants of the Kalmuks rejoined their compatriots in Russia; but on the 5 th January 1770 , the great portion of the tribe, 150,000 souls of them, in 30,000 kibitkas, set out from the Lower Volga to return to China. They were beset on their route by the Kirghiz Kazak, by the Cossacks of the Ural, and by the Burut or Black Kirghiz, and by other Turk tribes; but 70,000 of the emigrants eventually reached their ancient pasturages, - about half the number of those who started from the Lower Volga.

At the present day, from 80,000 to 100,000 Kalmuk, following the Buddhist religion, are found in the Government of Astracan.

The Kalmuk in Bokbara are descendants of followers of Chengiz Khan, and of stragglers left by the Turget Kalmuk in 1771, in their migration from the Volga to Eastern Turkestan. The latter speak their own language.

Kazak. - The territory occupied by this race extends from the Caspian to the rivers Ural, Tobal, and Irtish, and the Altai mountains on one side, and to the Tian Shan and Hindu Kush and the Amu on the other. Their numbers are computed at 400,000 families, or between 2 to $2 \frac{1}{2}$ millions of souls, viz. the Great Horde, 75,000 families; Middle Horde, 165,000; and Little Horde, 160,000. At present the Middle Horde is more in contact with Russia, and is the most civilised, and three divisions roam within Russian territory. They have Mongol features, with black hair; are strong, bealthy, and well made; slow, heavy, and ill-favoured. They are morose, vindictive, and revengeful ; passionate, but not brave, greedy and avaricious; but are attached to their country, are grateful for kindness, and respect the aged.

Kazaks are chiefly nomades, with great flocks of sheep. They speak a corrupt form of Turkish.

Kazaks roam over the desert steppes that lie between Siberia, China, Turkestan, and the Caspian Sea. Russia, China, Khokand, Bokhara, and Khiva levy tribute on portions of this race; but they are true nomades, and cannot be said to be subjects of any particular power. They subsist on the milk and flesh of their flocks and herds. At the commencement of winter, when forage fails, the Kazak kills the old horses, camels, etc., and salts their flesh for winter food. They are Sumni Mubammadaus.

In manner of life and language the Kazak is hardly to be distinguished from the Burut. In colour, the Kazak women and young men have white, almost a European complexion, which darkens by exposure. 'The Kazak have the short neck of the Turanian race, so different from the long-necked Iranians; and they have thick-set, powerful frames, with large bones; head not very large, crown round, and more pointed than flat; eyes less almond-shaped, but awry and sparkling; prominent cheek-bones, pug noses, a broad flat forehead, and a larger chin than the Burut; beard on chin thin, only hairs on both ends of upper lip. They deem a Kalmuk woman more beautiful than their own. The men in summer wear the Kalpak head-dress, and in winter the Tumak cap of fur, covered with cloth and flaps. They are almost all Muliammadans, but, like all nomade tribes, are lax in their observances, for they retain much of the Shamanist belief which they held prior to their conversion some centuries before. Cheiromancy, astrology, casting out devils, are conimon to all Muhammadans, but the Kazak draw omens from the burnt sacrifice of the shoulder-blade and the twisting of the entrails.

Iranians.-From the Vendidad opening chapters there seems in ancient times to have been a great kingdom in Central Asia, —an eastern branch, with 
INDIA, AND THE CENTRAL ASIA TRIBES.

its primeval seats on the Oxus. The Iranian people, who were settled between the Oxus and the Jaxartes as early as the times of the Judges of Israel, still, however, hold their ground in the country, under the names of Tat, Tajak, Sart, Galsha, and Parsivan. A primitive and not impure Iranian population might still be found in almost every district, from the Indus to the Jaxartes, and throughout the valleys of the Oxus. And Persian, Kurd, Armenian, Osset, and Tajak are dwelling in the countries to the W. and N.W. of India.

Iranian races have always been known for their refinement and high civilisation, from which Europe borrowed through the Byzantine and Greek culture, and the Persians have long and faithfully retained the features of its national characteristics. Though overrun by the Semitic and Turanian races, the Iranian has borrowed little or nothing from them, but has exerted over them powerful influence. According to Khanikoff (Sur l'Ethnographie de la Perse), the Iranian of Persia came from the east of modern Persia, about Segestan and Khorasan, and moved to the west in pre-historic ages; and, though altered by the attacks of the Turk tribes from the north, or from contact on the west and south with Turanian and Semitic elements, the Mede is everywhere recognisable as the same as described by Herodotus and later Greek writers. The arrow-headed writing at Persepolis enumerates the Iranian people of that day. The form of the Iranian is spare but elegant, even noble, but there have always been differences between the Eastern and Western Iranians.

The East Iranians are-(a) the Segestani or Khafi, (b) Char Aimak, (c) Tajak and Sart; each of which counts many subdivisions. The principal number of the Segestan people occupy Khaf and its neighbourhood, Ruy, 'T'ebbes, and Birjan.

The people of Khorasan are greatly intermixed with Turk elements. The language of modern Iran is laden with Arabic and Turkish words; but in the east the language is much like that in which Fardusi wrote his poem, free from words of Arabic origin.

The Char Aimak consist of four peoples, the Tremuri, Taemuni, Firoz Kohi, and Jamshidi, all of them of Iranian origin, and all speaking Persian. The Aimak, who graze their flocks in the Paropamisus, are brave and relentless; and Afghans, when travelling, whether proceeding from Balkh, Kābul, Kandahar, or Herat, never enter into the mountain districts of these intrepid nomade tribes.

The Taemuri dwellat Gorian and Kub'sun, on the western boundary of Herat, and in the villages and towns situated east of Iran, from Tarbat Shaikh Jam as far as Khaf. About a thousand of their families dwell near Herat.

The Taemuni dwell in the Jolgha-i-Herat, from Kerrukh to Sabzawar, the few who have extended to Farrah being styled by the Afghans, Parsivan. Each member of the Char Aimak knows no greater enemy than the Afgban, and all attempts to form Afghan colonies amongst them have failed. The Taemuni are of a wild, warlike nature, though agricultural.

The Firoz Kohi, a small number of people, about 8000 , dwell on the steep hill N.E. of Kala Nao, and from their inaccessible position afflict their whole neighbourhood with their robbing and plundering. Kala $\mathrm{Nao}$, on the summit of the mountain, and the fortified places of Darz-i-Cutch and Chaksaran, are

VOL. II.

considered similar to whole nests of the Bakh tiari and Luri in the environs of Isfahan. They have a resemblance to the Hazara, but their forehead, chin, complexion, and figure are less Turanian. They are decidedly Iranian. They take their name, the Firoz Kohi, from Teheran. Timur settled them by force in Mazandaran, but they soon returned to their own country. They have a few cattle, and they sow a little, and plunder the caravans travelling on the Maimani road, or make inroads on the scattered tents of the Jamshidi.

Jamshidi are the only tribe of eastern Iranians who are exclusively nomades. They derive their descent from Jamshid, and moved out of Segestan to the shores of the Murghab, which they have occupied from pre-historic times. They live in the neighbourhood of the Salor and Sarik Turkoman, and they use the round conical tent of the Tartars, surrounding it with felt and a reed matting; and their clothing and food are Turkoman, as also their occupation, for they are as great manstealers. They excel the other Aimak as horsemen, and for a chapao, band themselves with men of Herat or with the tribes of Turkomans. It was this cause that led Allah Kuli Khan to transport them from Khiva to the banks of the Oxus, after he had conquered them with the allied Sarik. After a residence of 12 years, they fled, and returned to the town of Murghab. The Jamshidi is polite in word and manner. They still retain parts of the Zoroastrian faith, reverence fire, and pitch their tent door to the east.

The Tajak is Iranian. He is met with in largest number in the khanate of Bokhara and in Badakhshan, but many have settled in the towns of Khokand, Khiva, Chinese Tartary, and Afghanistan; some even to the south, in Baluchistan. The Tajak is of a good middle height, has broad, powerful frame of bones, and especially wide shoulder bones; but they diverge from the Iranian; they have the Turanian wider forehead, thick cheeks, thick nose, and large mouth. The Tajak originally came from the sources of the Oxus in the steppe of Pamir. The term is from Taj, a crown, the fire-worshipper's head-dress. The Tajak, however, does not so style bimself, but regards the term as derogatory. The Turks style the Tajak, Sart. The Tajak is covetous, unwarlike, and given to agriculture and trade, but fond of literary pursuits, and polished; and it is owing to their preponderance in Bokhara that that city has been raised to the position of the headquarters of Central Asiatic civilisation, for there, from pre-Muhammadan times, they have continued their previous exertions in mental culture, and, notwithstanding the oppressions which they have sustained from a foreign power, have civilised their conquerors. Most of the celebrities in the field of religious knowledge and belle lettres have been Tajaks; and at the present day the most conspicuous of the Mullah and Ishan are Tajaks, and the chief men of the Bokhara and Khiva court are Tajaks, or, as the Turks style the race, Sart. Professor Vambery considers the Tajak and Sart identical, but he recognises that in their physiognomic peculiarities the Sart differs greatly from the Tajak, being more slender, with a larger face, and a higher forehead; but he attributes these changes to frequent intermarriages between Sart men and Persian slaves. The Tajak 


\section{INDIA, AND THE CENTRAL ASIA TRIBES.}

have two branches, - the Galcha and the Tajak of the plains. The Galcha inbabit some of the mountainous districts of Badakhshan, Wakhan, Shighnan, Karatagin, and other Hill States to the east of the khanate of Bokhara. They are also said to be found on the Upper Zar-afshan, in the mountain S.W. of Tashkand, and to the E. of Panjkand; and in the latter locality they are called Karatagin. Some, in the secluded alpine valleys of Afghanistan, have preserved their Irani type and language better than the Tajak of the west, who have been exposed to the waves of the Turkish and Mongol conquerors, and who, though obviously Persian, have more or less the heavy cheeks, thick nose, large moutb, and wide forehead of the Turk race.

The language of the Galcha resembles Persian, but has many words of an older Aryan type. The dialects of the Hill States also are known as the Wakhi, Ishkashimi, Shighnani. The Galcha are brave, more than a match for the predatory Kara Kirghiz. The different states are each ruled by a hereditary monareh, most of whom claim descent from Alexander the Great. In their states they form separate communities. In all the others they are dispersed amongst the Turks and Uzbak races, and are following agricultural and commercial pursuits. They have little feeling of nationality, and Khanikoff and Vambery describe them unfavourably for courage, morals, or honesty. The Tajak of the plains are zealous Sunnis.

Ishkashim is a small Tajak state on both sides of the Upper Oxus, tributary to the Mir of Badakhshan. It contains the ruby mines for which Badakhshan is famous.

Wakhan is a small territory in a portion of the valley of the Upper Oxus, or Darya-i-Panj, extending about 94 miles from the fort of Ishkashim, in about lat. $36^{\circ} 45^{\prime} \mathrm{N}$., long. $71^{\circ} 38^{\prime} \mathrm{E}$., on the Pamir Kul branch of the Oxus, 42 miles beyond Kala-Panj. It is N. of Hindu Kush, between the Chitral country and the Pamir khanate of Shighnan. It has always been subject to Badakhshan, which it touches in the west. Its inhabitants are of purer Aryan stock than the Tajak, and their language is akin to Sanskrit or Takri. It holds the southern route of the caravan between Turkestan and Afghanistan. To the $\mathrm{N}$. and $\mathrm{S}$. the valley is bounded by high hills, on whose slopes the Wakhan people pasture their flocks. They are Shiah Muhammadans, disciples of Aga Khan of Bombay (died 1881), to whom they sent contributions. They dress in thick trousers and choghas. The valley is ruled by a hereditary chief, whose revenue is derived from the slave trade in which he engages.

Eastern Turkestan rulers have been Muhammadan from the time of Taghalaq Timur, who was, we are told, the first Muhammadan sovereign of Kashgar of the lineage of Chengiz. Buddhism, indeed, was found still prevalent in the cities of Turfan and Kamil at the time of the embassy of Shah Rukh in 1419, and probably did not become extinct much before the end of the century. But in the western states Muhammadanism seems to have been universal from an earlier date, and maintained with fanatical zeal. Saintly teachers and workers of miracles, claiming descent from Mahomed, and known as Khaja or Khoja, acquired great influence, and the sectaries attached to the chief of these divided the people into rival factions, whose mutual hostility eventually led to the subjugation of the whole country. For late in the seventeenth century, Khoja Appak, the leader of one of those parties called the White Mountain (having been expelled from Kashgar by Ismail Khan, the chief of that state, who was a zealous supporter of the opposite party or Black Mountain), sought the aid of the Galdan Khan, sovereign of the Eleut or Kalmuk of Zungaria. Taking the occasion so afforded, that chief in 1678 invaded the states south of the Tian Shan, carried off the Khan of Kashgar and his family, and established the Kliaja of the White Mountain over the country in authority subordinate to his own. Great discords for many years succeeded, sometimes one, sometimes another being uppermost, but some suprenacy always continuing to be exercised by the khans of Zungaria. In 1757 the latter country was conquered by the Chinese, who in the following year, making a tool of the White party, which was then in opposition, succeeded in bringing the states of Turkestan also under their rule.

The Turk, wherever met with, is ever heavy and lethargic in his mind and body, but in his resolves firm and stedfast, not from principle, but from apathy and aversion to change; and it is from these characteristics that his appearance is earnest and solemn, $-a$ profound seriousness, a marked cold expression of countenance, with a great inclination to pomp and magnificence. An Uzbak or Turkoman has a proud bearing, as if possessed with a self-consciousness of greatness and power. The Usmanli Turk's love of independence is boundless. He considers himself born to rule; that hunting and war alone are worthy of him, and husbandry ignominious. In Central Asia, agriculture is exclusively in the hands of the Persian slaves, commerce and business with the Tajak, Hindu, and Jew. The Turk is intellectually the inferior of the Iranian and Semitic nations. This defect is noticed by other nations, who apply the terms Turkluk (Turkdom), Kabalik (coarseness), and Yugunluk (thickness), Sadeluk (simpleness); and with these qualities, as the Usmanli is easily taken in by the Armenian, Greek, and Arab, the Turk is as easily so by the Tajak and Hindu. In transactions the Turk are regarded as possessing more honesty, frankness, and confidence, plainness, simplicity, and uprightness. Compared with the Persians, the Turk is a faithful servant, attached soldier, and upright man. They are more brave, persevering, and love more to rule than any other Asiatic people. They are unpolished, wild, and uncultivated, but seldom cruel out of malice. They crave riches, but only to expend them. They exact much labour from their subordinates, but protect and deal liberally with them. The Turk is innately a nomade, and, like other nomades, is distinguished for hospitality. The Burut is the wildest aud most savage and most superstitious of them, but less malicious than the Kirghiz and Turkoman. The Burut has not wholly abandoned Shamanism, and knows little of the Muhammadan religion.

The Kazak Kirghiz are less brave and warlike, though readily engaging in a pillaging expedition. They form the bulk of the Turkish nomades, and are for the most part devoted to a wandering life; in very few instances have they settled.

The Kara Kalpak are considered dull and foolish. 
They are even less warlike than the Kirgbiz, they have seldom appeared as conquerors, and are even less employed as mercenaries. They are largely occupied as cattle-breeders, and they are active, benevolent, and faithful.

Many of the Turkoman dwell in a half-settled state along the left bank of the Oxus as far as Char Jui, and in Khiva. They are notorious amongst all the races of Central Asia as the most restless adventurers. Throughout the whole globe it would be difficult to find a second nation with such a restless spirit and untameable licentiousness as these children of the desert. To rob, to plunder, to make slaves, is to the Turkoman honourable; they are always poor, and are dirty and avaricious. Their country is the wildest and most savage, where even keeping a few cattle gives only a scanty income.

The $U z b a k$ are honest, upright, and have much Turkish open-heartedness ; they are proud of their education, and represent all the best side of the national character of the Turks.

In Central Asia, the warrior, the shepherd, the priest and the layman, youth and old age, equally affect poetry and reciting of tales. The literature of the Muhammadans or settled nations, brought from the south, is filled with exotic metaphor and illustration. In the three khanates, the Mullah and Ishan have written much on religious subjects, but its mystical allusions are beyond the reach of the people. The Uzbak, the Turkoman, and Kirghiz esteem music as their highest pleasure, and often break out in song, singing soft minor airs. The Uzbak poetry on religious subjects is exotic, derived from Persian or Arabic sources. The Tartar compositions are tales, and relate to heroic deeds similar to the romances of Europe.-Trotter's Central Asia, Bokhara; Collett's Central Asia, Khiva; Major Wood's Lake Aral; H. W. Bellew, C.S.I. Kashmir and Kashgar ; Fraser's Travels; Professor Vambery, Russians in Central Asia, p. 67; Vambery, Sketches of Central Asia, pp. 283-338; Yule's Cathay, and the Way Thither, i. p. 206, ii. p. 547 ; Timkouski, Journey to Pekin, i. pp. 378, 379, ii. p. 312; Surveyor-General's Report; Peschel, Races of Man; Winwood Reade, Savage Africa; Anthropological Review; Barth, Travels in the Interior of Africa; Von Maltzan, Tunis and Tripoli; Livingstone's Travels; Cameron's Walk across Africa; Stanley, Through the Dark Continent; Burton, Zanzibar; Dr. Kirk; Liext.-Col. Rigby; C. Markham in Moral and Material Progress; Mr. R. Cust in Philological Institute.

AFGHANISTAN, in all historic times, seems to have been an arena in which powerful races bave been striving for dominion,-Scythian, Mede, Greek, Persian, Moghul, and Turk races, Ghilzae, Saddozai, and Barakzai tribes; even the British have ruled there, and the limits of the ruler's sway have been continuously on the change.

Little is known of the occurrences up to the invasion by Alexander the Great. After that conqueror's death, his lieutenant Seleucus succeeded to the sovereignty of the Asiatic conquests. But under Seleucus' grandson, Afghanistan was taken from the Seleucià by aboriginal chiefs, and soon after formed, with Bactria, an independent state, which existed through 150 years. Subsequently Scythians made themselves masters of Afghauistan, and appear to have held possession of it up to the death of Mansur, when one of his officers, Sabaktagin, established an independent dominion over all the $\mathrm{S}$. parts of Afghanistan, making Ghazni his capital. His son Mahmud, who died A.D. 1028, enriched Afghanistan with the spoils of India; but in the reign of Bahram, one of the Tartar's descendants, the Sabaktagin dynasty were deprived of all but the Panjab, and this too, in A.D. 1160 , they lost. Afghan rulers at different times have laid claim to the region embraced between lat. $30^{\circ}$ and $37^{\circ} \mathrm{N}$., and long. $61^{\circ}$ and $70^{\circ} \mathrm{E}$. ; but the whole of the country of the Yusufzai clans, of Kafiristan, of Chitral, of the Afridi, of the Waziri, and much of the Hazara country are essentially democracies, and pretend as little to owe allegiance as the Amir of Kanbul cares to claim it; while Badakhshan, Kunduz, the Char Vilayat, the Aimak country, the Hazara, the Ghilzae, and the Kakar, as also Kuram, Khost, and Dawar, only yield obedience when the demand is backed by force. So little have the tribes amalgamated, that the region which Europeans designate Afghanistan is not even known by that name to the people who inhabit it. The term Afghan is hardly known to any of the Muhammadans of Asia, and the original countries of the various tribes is equally unknown. It has, however, been satisfactorily ascertained that the lower valleys of the Kâbul country were once occupied by Buddhist and Hindu religionists, and that the present Afghan tribes have advanced into the N.E. corner of Afghanistan within comparatively recent historical times; the peaks of the Safed Koh, between Jalalabad and Kābul, bear such Hindu names as Sita Ram. The Yusufzai and other tribes in the $\mathrm{N}$. are comparatively recent conquerors of the N. hills and valleys, where they have mixed with a free Hindu people, and are fairer than the other Afghan tribes.

There is the certainty that within the three last centuries there were people styled Gabar in the Kābul countries, particularly in Lughman and Bajor, also that in the days of Baber there was a dialect called Gabari. We are also told that one of the divisions of Kafiristan was named Gabrak. That in former times fire-worship existed to a certain, if limited, extent in Afghanistan, is evidenced by the pyrethræ, or altars, still crowning the crests of bills at Gard-dez, at Bamian, at Seghan, and at other places. Near Bamian also is a cavern, containing enormous quantities of human bones, apparently a common receptacle of the remains of Gabar corpses. At Murki Kbel, in the valley of Jalalabad, and under the Safed Kol, human bones are so abundant in the soil that walls are made of them. There is every reason to suppose it a sepulchral locality of the ancient Gabar; and coins are found in some number there.

According to Captain Raverty, the people who dwell about Kābul and Kandahar, Shorawak and Pishin, designate themselves B'r-Pushtun or Upper Afghans; and those occupying the district of Roh, which is near India, are called L'r-Pukhtun or Lower Afghans; and Major Fosberry suggests (J.E.S.) that the term Pathan, by which the Afghan races are generally known throughout British India, has been derived from Pushtun or Pukhtun. Although the tribes known by these names speak the Pushtu as a common language, they are not all of the same origin, but are dis- 
tinguished by marked characteristics, moral as well as physical. One tribe repudiates another, and denies its Afghan origin. The names of Pathan, Rohilla, Afghan, which serve at the present time to designate the Indian Afghans, are really those of so many distinct races little blended together. In their own country they make no matrimonial alliances except amongst themselves, indicating their feelings as an original race. Afghan has been said to be only an Arabic plural of the word 'feghan,' which was applied to them about the time of Sultan Abu-Seid, of the race of Chengiz Khan, because of their constantly disunited state amongst themselves. The primitive tribe of the Afghans is called 'taifah, " a word which corresponds with that of nation. The first division of this primitive tribe are called 'firqa,' a tribe; and the subdivision of this, 'tirah' or branch.

Mr. Campbell supposes them to be Aryan, and probably of similar origin to the Jat. Several writers consider them to be descendants of one of the ten tribes of Israel, and seven books bearing on this subject were placed at the disposal of Surgeon-Major Bellew, and his examination of them showed their own belief to be that they are descendants from Saul, whose history in these books is in the main like that in the Hebrew Bible. Saul's two grandsons, Asaf and Afghana, served under Solomon.

In its physical features, Afghanistan is a star of valleys radiating from the Koh-i-Baba, and everywhere bounded by very rugged and difficult mountains: the two great ranges, leaving the Bam-i-Danial in the N., being the Mustagh and the Hindu Kush, with numerous offshoots from the latter. The Siah Koh is the S. branch of the Koh-i-Baba, from which the Helmand, the HariRud, the Murghab, Balkh-ab, and Kunduz rivers rise.

The Hindu Kush range is traced from the S.W. corner of the Pamir in Central Asia, in about lat. $73^{\circ} 30^{\prime} \mathrm{N}$., whence rise the Amu Darya, the Yarkand Darya, the Kunar, and the Gilgit rivers. It extends $W$. as far as the spur which divides the Ghorband valley from that of the Helmand, in long. $68^{\circ} 30^{\prime} \mathrm{E}$., from which point it is called the Koh-i-Baba. In these limits it forms the watershed of the Oxus (Amu Darya) to its N., and the Kābul river to its $S_{\text {. }}$; and its ramifications or breadth may be said to extend from lat. $34^{\circ} 30^{\prime}$ to $37^{\circ} 30^{\prime} \mathrm{N}$., nearly 200 miles. The passes from Chitral to Badakhshan across the Hindu Kush are Chitral, Jshtirab, Kagram, Nuksan, Kharteza, and Dara; from Deh Parian in the Panjsher valley a pass leads by Anjuman to Bamian; the other passes are the Thal, Khawk, Bazarak, Shatpal, Parwan, Saralang, Kaoshan, Gwalian, Gwazgar, Chardar, Gholalaj, Farinjal, and Ghorband.

The Kohistan region commences from Kaghan, which is a narrow glen stretching upwards from the northernmost point of the Hazara district for a distance of nearly 90 miles, and separating the maharaja of Kashmir's territory from the independent mountaineers. It is a district $\mathrm{N}$. of that city, and has the valleys of Tagao, Nijrao, Panjsher, Ghorband, Charikar, Alishang, Alighur, and the Lower Kuner. The villages are small, but numerous; the Kohistani, 40,000 in number, have always been independent; their country is strong for defence. They are bold, violent, and unruly, and reckon it a disgrace to die in bed. They are prone to individual assassinations ; their arms, a carbine, a firelock, a pistol, and short sharp dagger, a few bows and shields. In 1840 the British Indian forces had engagements at Parwandarra, Tutamdarra, Jalgah, Kahdara, Charikar, and Istalif.

Amongst them mulberry flour is the staff of life; and, in their perpetual quarrels, the mulberry plantations of the valleys have, to their credit, always been spared.

The Suliman range is thrown off to the S. from the Allah Koh ridge between Kābul and Ghazni, in lat. $69^{\circ} 30^{\prime}$, and thence running southwards without a break, but throwing off many spurs, it forms the system of mountains of E. Afghanistan and Baluchistan. Takht-i-Suliman is the name given to two peaks on the spur of the Suliman range, which forms the S. watershed of the Zhob river, and ends in the Gomal river at Ghwalari. The N. peak is in lat. $31^{\circ} 41^{\prime} \mathrm{N}$., long. $69^{\circ} 58^{\prime} 40^{\prime \prime}$ E., and rises 11,298 feet above the sea. The S. peak is in lat. $31^{\circ} 35^{\prime} 40^{\prime \prime} \mathrm{N}$., long. $70^{\circ} 0^{\prime} 40^{\prime \prime} \mathrm{E}$., and rises 11,070 ft. No European has ascended it.

As will have been seen, the Afghanistan country is entirely mountainous, but it has numerous flatbottomed valleys hemmed in by the mountains. These valleys are so large as to permit the evolutions of an army, and this feature explains why these mountaineers carry on most of their warfare on horseback, and are proud of their cavalry and its elan. The region has many rivers of small size, and many irrigation canals. From its high elevation above the sea, the climate is very severe. The people are chiefly pastoral nomades, and even when settled, live in tents. The towns are of no great size. Kibul, the present capital, has a population of 50,000 or 60,000 souls. The Kandahar population was estimated by Dr. Bellew at from 16,000 to 20,000 houses, or from 60,000 to 80,000 souls. Herat has from 6000 to 10,000 inhabitants; Maemana, 40,000; Kunduz, about 6000 or 7000 ; and Shibbargham, 12,000 .

In calling their country Walayat, the Afghans distinguish two portions of it as-(1) Kābul or Kābulistan, N. of Ghazni and the Safed-Koh, as far as the Hindu Kush; and (2) Khorasan and Zabalistan, S. and W. from Ghazni to Persia and the desert of Seistan. Its greatest length is 750 miles, and greatest breadth 550 miles. Afghanistan is further recognised by its people as comprising the provinces of Kābul, Jalalabad, Ghazni, Kandahar, Herat, and Balkh, or, as the last is now called, Afghan-Turkestan. To these are sometimes added the districts of the Ghilzae and of the Hazara. Its ruler is known as the Amir, and his revenues are estimated at forty lakhs of rupees, or less than half a million sterling.

$K \bar{a} b u l$ is the name of a province, a city, and a river. The city is in lat. $34^{\circ} 30^{\prime} 30^{\prime \prime} \mathrm{N}$., long. $69^{\circ}$ $6^{\prime} 8.31^{\prime \prime} \mathrm{E}$, and is 6396 feet above the sea. On the right bank of the Kanbul river, near the junction of the rivers Käbul and Logar, and at the west extremity of a spacious plain, is an angle formed by the approach of two inferior ridges, the Koh Takbt Shah and Koh Khojah Safar. The town is about 3 miles in circumference. The population, as has been said, amounts to 50,000 or 60,000 souls in about 9000 houses. Kābul is well situated as a site for commercial intercourse between India and Turkestan, being at the gorge of the nearest and most practicable passes connecting the two 
countries. It is the seat of government of Afghanistan. The thermometer maximum in August is $90^{\circ}$, the minimum in October $30^{\circ}$.

The Kazzilbash dwell in the Chandol quarter, without the city, on the W. It is fortified. A brigade of the British Indian army occupied Kābul in the years 1839 to 1841 , but had a series of reverses from the $2 \mathrm{~d}$ Noyember 1841 till the 6th January 1842 .

The province of Käbul has the Koh-i-Baba on the N.W, the Hindu Kush on the N.; the Panjsher river is on the N.E., and on the E. it extends as far as Jagdalak. On the S. it has the Safed Koh and Ghazni, and on the $\mathbb{W}$. the country of the Hazara. Much of this province is mountainous, but it contains a large quantity of arable land, rich along the base of the mountains. Wheat is the chief product, and after it barley and peas, the two last being largely consumed by the poor. Sheep, corn, rice, ghi, horses, and ponies are imported. The annual revenue amounts to $£ 180,000$.

The Käbul river rises by two heads, the northern from a copious spring at Sar-i-Chashmah, in lat. $34^{\circ} 21^{\prime} \mathrm{N}$., and long. $68^{\circ} 20^{\prime} \mathrm{E}$., at an elevation of 8400 feet. ' At a short distance beyond Kābul it receives the Logar river from the S., and thence assumes the form of a large stream, which becomes of importance at Jalalabad, and finally falls into the Indus at Attock, after a course of 300 miles.

Kandahar, a town and fortress in Afghanistan, is in lat. $31^{\circ} 37^{\prime} \mathrm{N}$., and long. $65^{\circ} 28^{\prime} \mathrm{E}$., and 3484 feet above the sea. It is situated between the Argandab and Tarnak rivers on a well-cultivated plain. It is 233 miles S.W. of Ghazni, 380 miles S.E. of Herat, and 144 miles N.W. of Quetta or Shal. It is an ancient city, supposed to have been one of those built by Alexander the Great, since whose time it has been successively in the hands of the Seleucides, the Arabs for 600 years, the Persians from A.D. 1535, the Chaghtai Turks, the Uzbaks, the Persians again, the Afghans (1747), the British (1839), again the Afghans, again the British (1880), and again (1881) the Afghans. A brigade of the army of British India held it from the 20th April 1839 to the 8th August 1843. It is surrounded by a mud wall 27 feet high, with six gates, and a ditch 10 feet deep and 24 feet wide. Its districts are occupied by separate tribes, -Barakzai, Nurzai, Alekozai, Popalzai, Bamezai, Bardurani, and Alizai. The houses are stated by Hough to be 40,000 , by Bellew 16,000 to 20,000 , and the population has been estimated at from 15,500 to 100,000 . The citadel is on the N., and the tomb of Ahmad Shah is near. The place has many sickly people, and also many poor beggars and idiots (houlliad), who are reverenced. The trade to Herat and Mashad is in the hands of Persians. Wine is made at Kandahar. The summer is hot, but the winter pleasant.

The Herat province contains the districts of Ghorian, Sabzawur, Farrah, Bakwa, Kurak, and Obeh, in which there are 446 villages, with about 70,000 fighting men. The tribes are the Turkoman Tekke, Sarakh, and Salor, the Irsali, Charsanghi, the Persian Hazara, Jamshidi, Taemuni, Taemuri, and Firoz Kohi, and the Berbari Hazara. The city of Herat is in lat. $34^{\circ} 22^{\prime} \mathrm{N}$, long. $62^{\circ} 9^{\prime} \mathrm{E}$., and 2650 feet above the sea. It is built on the right bank of the Hari-Rud, and is distant as under:-
Kandahar, N.W., miles 369 Peshawur, by KandaGhazni, . . . , 602 har and Kăbul, miles 881 Kābul thro' Hazara, ," 550 Dehra Ismail Khan, ,, 892 ," Ghazni, , 691 Sakkur, . . . , 762 Teheran, . . ", 700 Yeza, . . . " ", 357 Khiva, . . " "700 Mashad, : :" 215 Bokhara, . " 600 Balkh, . : 370

It is situated in a fertile and well-watered valley, surrounded by lofty mountains. The population has fluctuated from 6000 or 7000 to 100,000 , as war or peace reigned. The people are mostly Shiah Muhammadans, but Afghan, Persian, Indian, Tartar, Turkoman, and Jew are there, all carrying weapons. Herat is the emporium for trattic between Kābul, Kandahar, Hindustan, and Persia. Carpets are made there of great beauty, ranging in prices from 10 to 1000 rupees. Its fortifications are nearly of a square form, 1600 yards by 1500 yards. It has been besieged oftener than any city of Asia. It fell to the Turkoman in the reign of Sultan Sanjar in 1157, who left not one stone upon another. In 1232 it was twice taken by Tuli Khan, son of Chengiz Khan. On the first occasion he put all the garrison to death, and on the second he massacred 160,000 of the population, only 40 persons escaping. Centuries afterwards it again revolted, and Miran Shah, son of Timur, entered the city with a large force and decimated the inhabitants; a similar fate overtook it when taken by Olong Beg, grandson of Timur. In 1477, Jahan Shah, a Turkoman prince, ravaged it. In 155 1 , Abad Khan, an Uzbak prince, burned and pillaged up to its gates. In 1607 it was sacked by the Uzbaks. In 1730 it was taken by Nadir Shah; in 1750 it fell to Ahmad Shah, Daurani. In 1823 it was besieged by the Persians; in 1824, by Kamran; from November 1837 to the 9th September 1838, it was besieged by the Persians, while Lieutenant Eldred Pottinger was within the walls, and his conduct and influence made the defence successful. On the 24th October 1856 it was surrendered to the Persians. But since then, in 1863 (27th May), it was taken by the Amir Dost Muhammad Khan, and after his death was again fought for by his sons and descendants.

Seistan province was formerly a separate dominion. In recent times it has been claimed by rulers of Persia, Afghanistan, Kandahar, and Herat. It is situated between lat. $30^{\circ} 30^{\prime}$ to $32^{\circ}$ N., and long. $60^{\circ} 30^{\prime}$ to $64^{\circ} \mathrm{E}$. ; and at present it has the four districts of Lash, Shaikh-Nasur, Sehkuha, and Kandahar-Seistan, under four chiefs. In Lash are the Ishaqzai Daurani Afghans; in Sehkuha are Kayani and Towki Baluch; in ShaikhNasur are Sarbandi Baluch; and the Garm-sel has Baluch and Afghans mixed,-the total population being about 127,000 . Numerous rivers from the N. and N.E. enter it, and at one period of the year overflow their banks. The most important of them are the Helmand, Farrah-Rud, Harut-Rud, and Khash-Rud. The Seistan lake is more a marsh than a lake, and wild hogs abound in its reedy parts, with clouds of insects, wasps, mosquitos, fleas, and flies. The bite of one of the flies is painful, and horses suffer much from them.

Afghan-Turkestan is a name that has been applied to all the Afghan dominions of North Hindu Kush and Koh-i-Baba. It comprises the Uzbak states of Maemana, Andkhui, Sar-i-Pul, Shibbargham, Balkh, Khulm, Kunduz, and Badakhshan.

Kunduz is the name of a district, a river, and a 
town. The town is wretched, and is on the right bank of the river just before it joins the Farkhan river. It is 650 miles from Yarkand, 370 miles S.S.E. from Samarcand, 390 miles S.E. from Bokhara. The other fortified towns in the district are Hazrat Imam, Talikhan, and Rustak.

Maemana is a walled town 172 miles N.E. from Herat, and 28 miles S. of Bokhara. The inhabitants are Uzbak, with some Tajak, Herati, and a few Jews, Hindus, and Afghans. They are the bravest of all the Uzbak, and are renowned throughout Central Asia for their fearless and determined disposition. The district is 18 miles broad and 20 niles long, and the population is estimated at 40,000 families.

Khulm is the name of a river, a district, and a town. The town is 307 miles N.N.W. of Kābul, and 310 miles S.E. of Bokhara. The population of the district is estimated at 700,000 souls. Since the early part of the 19th century, Khulm has been visited by Moorcroft, Burnes, Lord, and Ferrier.

Shibbargham, 60 miles W. of Balkh, has 12,000 souls of the Uzbak and Parsivan races.

Shaghnan district is on the left bank of the Amu Darya, between Vakhan and Rashan.

Vakhan is a district of Badakbshan-Afghanistan, which consists of the portion of the valley of the Amu Darya from Kala Khojah upwards, and includes the valleys of Sarhad and Sar-i-Kol, the last being a dreary, uninhabitable waste for the greater part of the year. The population is about 1000 . The Mir claims descent from Alexander. It produces shawl wool.

\section{i. Daurani tribes, 600,000 , viz:- a. Popalzai. |d. Atchakzai. b. Alikuzai. c. Barakzai. d. Atchakz
e. Nurzai. \\ f. Ishakzai. g. Khugiani.}

ii. Tarin, 38,000 , viz. :-

$$
\text { a. Spin Tarin, viz. :- }
$$

1 Shadizai. | 2 Marpani. | 3 Lasran.

4 Adwani.
1 Batezai.

2 Haikalzai.

3 Malizai.

4 Kadazai.

5 Khanazai.

6 Khamzai.

b. Tor Tarin, viz. :-
7 Alizai.

9 Kalazai.

10 Naezai.

11 Musizai.
12 Abdur Rahmanzai.

13 Habilzai.

14 Hamranzai.

15 Karbela.

16 Khidarzai. iii. Kakar, 72,000, viz. :-

a. Jalazai. |d. Usman Khel. g. Hamzazai.

b. Musa Khel. e. Abdulazai.

c. Kadizai.
iv. Ghilzae, 276,000, viz. :-
1 Zabr Khel.
a. Tbrahim, v
2 Ahmadzai.
3 Umar Khel.
4 Adamzai.
6 Chinzai.
7 Shahmomalzai. 11 Ali Khel.
8 Kaisar Khel. 12 Andar.
b. Turan, viz, :-
1 Ohtak.
12 Tokae.
3 Hotaki.

v. Povindah, 30,000, viz. :-

Lohani. | Nasir. | Nazai.

Kharoti.

vi. Waziri, 127,500 , viz, :-

Mahsud.

| Utmanzai.

| Ahmadzai.

vii. Sheorani,

viii. Turi, 21,000 , viz. :-

1 Gundi Khel. 3 Mastu Khel.

2 Alizai.

4 Mastu Khel.

ix. Zaemukht, 21,000, viz, :-

1 Mamuzai. 12 Khwahdad Khel.

x. Orakzai-Ali Khel,

xi. Dawari,

,

xii. Khostwal,

xiii. Afridi, 85,000 , viz, :-

1 Kuki Khel. 4 Kamr.

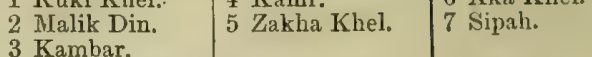

xiv. Jaja (Jaji), 7000, viz. :-

1 Kehwani. 4 Ahmad Khel.

2 Ada Khel. 5 Ali Khel.

3 Petla. 6 Jamu Khel.

xv, Mangal, 3000, viz.:-

1 Miral Khel. 3 Zab.

\begin{tabular}{l|l}
2 Khajuri. & 4 Margae.
\end{tabular}

xvi. Jadran,

xvii. Shinwari, 50,000, viz. :-

1 Khoja Khel. |3 Murdad Khel. 5 Syud Khel.

2 Shekhmal Khel. 4 Ashkbel Khel. 6 Sngu Khel.

xviii. Momand, 80,000 , viz. :-
1 Tarakzai.
3 Baizai.
5 Utmanzai.
2 Alamzai. $\quad 4$ Khwaizai. 16 Dawezai.

xix. Yusufzai (Kohistan), 400,000, viz.:-

1 Baezai.

2 Khwazozai.

3 Malizai.

4 Turkilani.

5 Utmanzai.

$\begin{array}{ll}5 \frac{1}{2} & \text { Hasnzai. } \\ 6 & \text { Akazai. } \\ 7 & \text { Mada Khel. } \\ 8 & \text { Iliazai. }\end{array}$

xx. Badakhshan, Darwaz, .

xxi. Kunduz, Khulm, Balkh,

xxii. Char Vilayat,

xxiii. Aimak,

xxiv. Hazara,

xxv. Chitral, Nimcha, Lughimani,

xxvi. Kafar, .

xxvii. Kohistani,

xxviii. Seistani,

xxix. Bangash,

xxx. Kazzilbash,

xxxi. Tajak,

xxxii. Hindki and Jat,

xxxiii. Mixed population of towns,

Of these races and tribes, it may be mentioned that, physically, the Afghan people are among the fimest on the earth, with a broad, robust, ruddy, manly look, and they are bardy and bold. They have a pleasant, frank, simple, unaffected way. About Kābul they are fair, many with red hair and blue eyes, but some of the tribes in the lower and hotter hills and valleys near India have rather dark skins. The majority are astute, intriguing, ambitious, and faithless; avaricious, fickle, uncertain, and crafty; and in bold, unblushing lying a Hindu is a mere child to an Afghan. But, since the middle of the 19 th century, the eastern Independent and British tribes have been largely, and in increasing numbers, employed in the native army of British India. General Ferrier describes their black eyes as full of fire; the lids are tinged with antimony, for this, in their opinion, gives force and adds beauty and a dazzling brilliancy to them; their black beard is worn short; and their hair, of the same colour, is shaved off from the front to the top of the head, the remainder at the sides being allowed to fall in large curls over the shoulders. Their step is full of resolution, their bearing proud, but rough.

Every Afghan, writes Colonel MacGregor, is born a soldier; and their army, though in a miserable and confused state, moves with great rapidity, and over immense distances.

The mass of the army is cavalry. This form is adopted from the national character, and the nature of the climate and soil. Their love of war exceeds that of all other eastern nations; they are excellent skirmishers, and experienced foragers. 
When he wrote (1876), the Afghan army, 71,000, was in three divisions :-

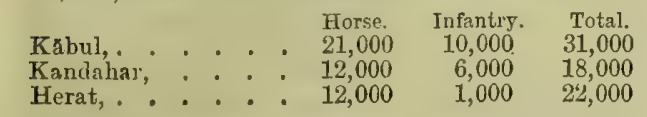

The horse was composed of Afghans, Kazzilbash, and Hazara ; their infantry of mountaineers, Uzbak, Parsivan, Hazara, and Baluch. There were, besides, many Jazailchi and matchlockmen, all excellent skirmishers.

North of the Hindu Kush is the country of the Uzbak, which includes Maemana, Andkhui, Akcheh, Sar-i-Pul, Balkh, and Kunduz.

The Aimak and Hazara occupy the upper portions of the valleys of the Murghab, Hari-liud, Helmand, and Arghandab, known as the Hazarajat.

The country of the Daurani extends for 30 miles north and south of a line drawn from Herat through Kandahar to Shal-kot (Quetta).

The Baraich Afghans are great camel breeders. They occupy Shorabak, due east of Seistan, on the banks of the Lora. Seistan lies on the rivers Helmand and Farrah-Rud, and the Seistan people occupy the lower portion of all the rivers running to the Seistan lake. They eat wheat and maize, and mutton, fowls, and hares. Their women are not pretty; their language is Persian mixed with other words.

Seistan has been at times Persian, and at times under the Afghans. Its adult male population has been variously estimated at from 20,000 to 30,000 families by EIphinstone, Taylor, Conolly, Ferrier, Leech, and MacGregor, and is supposed to amount to 127,500 souls, with 30,000 fighting men. Elphinstone supposes the original population to have been Tajak. Its inhabitants now consist of the Kayani, Sarbandi, Towki, Ishaqzai, and Shahreki, all of whom are shiahs, and of Baluch, who are sunni Muhammadans. Ferrier estimated the fighting men of the Baluch of Seistan at 30,000 or 35,000 . Contrasting them with Afghans, he says, Afghans are good for a rush, but do not meet the shock of an attack or stand the fire of artillery. The Baluch surpass them in tenacity and bravery; they attack in small parties of ten or twelve, are bold in the advance, and remain firm under the fire of an enemy, tying their tunics together.

The great clan of the Ghilzae, once dominant and still powerful, occupy, on the $N$. and $E$. of the Daurani, the upper portion of the rivers Logar and Tarnak, and all the plain country between the $\mathrm{E}$. and $\mathrm{W}$. watersheds of these rivers.

The Siah Posh, and the kindred race in Chitral, are in a triangular tract bounded by the Panjsher river, the south range of the Kunar, and the Hindu Kush.

The Yusufzai occupy all the valleys which drain the Laspisar range and its ramifications. This tribe are involved in domestic strife, but are united against foreign aggression.

Southwards, fringing the eastern spurs of the Safed Koh, are the independent Momand, Afridi, Orakzai, Shinwari, Turi, Khatak, and Bangash tribes.

Still farther south are the Waziri, stretching across the debouchure of all the valleys from the Kuram to the Gomal, and shutting off from the plains the small tribes of Jaji, Permuli, Dawari, and Khostwal.
The Povindah occupy a triangular tract bounded by the districts of the Ghilzac, Waziri, and Kakar.

The Kakar extend N.E. from the Shal valley to the 'Takht-i-Suliman.

The Uzbak in Afghan-Turkestan are supposed to amount to 350,000 , viz. :-

\begin{tabular}{|c|c|c|c|}
\hline $\begin{array}{l}\text { Kunduz, } \\
\text { Maemana, } \\
\text { Sar-i-Pul,. } \\
\text { Khulm, }\end{array}$ & & $\begin{array}{r}170,000 \\
80,000 \\
60,000 \\
15,000\end{array}$ & $\begin{array}{l}\text { Shibbargham, } \\
\text { Akcheh, : : } \\
\text { Balkh, : } \\
\text { Andkhui, : }\end{array}$ \\
\hline
\end{tabular}

In their advance from the north, the Uzbak have been stayed by the Hindu Kush, and by the equal, if not greater, valour of the Afghan. The Kataghan tribe in the Kunduz province, north and south of the Amu Darya (Oxus), number 42,000 families.

Sar-i-Pul town is 100 miles S.W. of Balkh, and has about 18,000 souls, dwelling in houses and tents. The chief and most of the population are Uzbak.

The Saharai, literally people of the plain, is a tribe who call themselves Mongol. They inhabit the plain on both banks of the head-waters of the Murghab, and claim to have been settled there by Chengiz Khan, and to have ever since preserved their independence. They are a small patriarchal republic. 'They are idol-worshippers, but recognise a good (khuda) and an evil (shaitan) principle.

The Aimak are a Mongoloid race inhabiting the western portion of the Paropamisan mountains between Kābul and Herat. They are bounded on the north by the Uzbak, on the south by the Daurani, on the west by Persia and the Turkomans, and on the east by the Hazara. They acknowledge relationship with the Mongols, Chaghtai T'urks, and Kalmuks, and intermarry with these nations. They are shepherds and cultivators, are brave and savage, plundering wherever an opportunity occurs. They speak a dialect of Persian, but Baber mentions that in his time many of them spoke the Mongol language. Their wars are carried on with great cruelty. They have four sections,- the Firoz Kohi, Taemuni, Taemuri, and Zuri. Aimak, in Turki, means a tribe.

The Taemuri and Hazara, west of Herat, are subject to Persia, dwelling in sandy tracts interspersed with barren hills.

The Taemuni inhabit the S. slopes of the Siah Koh branch of the Hindu Kush about Ghor, to the N. of Girishk and Sabzawur. They could collect 20,000 fighting men. They are a powerful tribe of brave men. They have a lead mine at Sharak.

The Firoz Kohi Aimak unsuccessfully defended themselves against Timur, and were deported to the neighbourhood of Herat. They now occupy the mountainous country between Herat and Maemana, extending up the Hari-Rud. They are estimated at from 20,000 to 30,000 families.

The Zuri inhabit Sabzawur or Isfazar, which is an extensive plain to the east of the road from Farrah to Herat, and situated among mountains.

The Aimak and the Hazara bave been supposed to be of the same race, separated from each other by the sectarian views they have assumed, the Aimak being rigidly sunni, and the Hazara violently shiah. They resemble each otber in their Tartar features and habits, and in the 
despotic character of their government. Their chiefs are absolute, levy taxes, keep soldiers in their pay, and dwell in castles. The Aimak live in canps, in Khirgah tents, which they call Urd, each governed by a Ket Khuda.

The Hazara, or Hazarajat, are so called from the innumerable Taifah, or tribes, into which they are divided,-Hazar signifying in Persian a thousand. Their principal subdivisions are (1) Deh Zangi, (2) Deh Kundi, (3) Jaguri, (4) Faoladi, (5) Deh Chopān, (6) Shaikh Ali. They occupy the whole range of the Paropamisus, or the mountains extending between the Hindu Kush and the city of Herat, to within a few days' march of Kandahar. The inhabited parts are 5000 to 10,000 feet above the sea, and the highest peaks rise to 20,000 feet. Their numbers have been variously estimated at from 50,000 to 300,000 souls by Elphinstone, Bellew, Burnes, Wood, Leech, and Lumsden. They are supposed to be of varied origin. The Hazara of the hill country near Ghazni and Kandahar are Turanian in a marked degree, and are without doubt of Mongolian blood. They seem to be in many ways like the Brahui, and at one time they possessed the country on the Kalat side of Kandahar, and were then nearer to the Brahui than they now are. In appearance, these very much resemble the Gurkha; they have the same bigh cheek-bones, the same small eyes, very little beard, and no doubt are of Turanian origin.

The Hazara are a middle-sized race of stout make, with small grey eyes, high cheek-bones, and wanting in beard. They are of harsh aspect, and are asbamed of their beardless Tartar appearance. They are simple, mild mannered, and industrious, but unblushing beggars and thieves. They are, as a tribe, weak, vacillating, and disunited, very passionate, -at one moment fickle and capricious, and again merry, conversable, and hospitable. Their women are slender, handsome, engaging, and immoral. The Jaguri tribe' follow the 'Kooroo Bistan 'custom of lending their wives for a night or for a week, and do this to so large an extent that they are said to be losing their Tartar form of features, to which they have a great aversion. Broadfoot, however, limits his remarks on this part of their character to the observation that the women are ugly and not very chaste. The men do all out-door labour, and the women manage the house. They are never beaten. They sing and play on the guitar, and many of them are poets. Their out-door amusements are hunting and racing. Their clothing is made of the coarser camelhair cloth called 'barak,' their boots of rough goatskin, and they twist rolls of cloth around their legs. The women go unveiled; twist two or three lungi on their bead like a tiara; they wear long woollen frocks, and boots of soft deer-skin, which reach to their knees. The weapons of the men are sword and matchlock, the latter being most trusted to. They manufacture excellent powder, and are good shots. Some of the clans bave a military repute; they would make good soldiers, and might have risen to distinction, but they are disunited. Their food consists chiefly in the flesh of their sheep, oxen, and horses; grain is scarce, and their bread is tasteless, as few of them can afford to use salt. They are poor, and in times of scarcity they voluntarily dispose of some of their children to the Uzbak slave-dealers. Each village is defended by a high tower capable of containing ten or twelve men, loop-holed, with a kettle drum, and in time of peace a single man remains in the tower to sound an alarm if necessary. They are violent shiahs, reverence Ali and his Syud descendants, but practically they have no religion, observe no forms or fasts, and have no form of prayers. They speak a kind of Persian; they are very ignorant and illiterate. Their titles are Khan, Sultan, Ikbtiar, Wali, Mir, Mehtar, and Turkhan. They barter men, women, oxen, cows, sheep, ghi, carpets, sulphur, and lead, with merchants from Kābul, Herat, Turkestan, and Kandahar, in exchange for coarse cotton cloth, chintzes, tobacco, felts, carpets, dye-stuffs, iron spades, plough coulters, molasses, and raisins. Alinost every tribe is at war with its neighbours; and they are constantly exposed to inroads of Uzbaks from the north, who sweep away whole villages into slavery. The Aimak also carry off as many of them as they can conquer or kidnap; and the chiefs of their own race in their petty wars steal each other's subjects and sell them to Turki merchants. All the unskilled labour in Kābul is done by Hazara, some of tbem slaves and some of them free; and in winter there are not less than 10,000 of them residing in the city, earning a livelihood as porters and by clearing the snow from off the house-tops. The Hazara pay tribute to the Afghans. Their property consists in dumba (big-tailed) sheep, and a small, hardy breed of horses. Their country has lead and sulphur; they make 'barak' or hair cloth and good carpets.

The Jamshidi Hazara are of undoubted Iranian extraction. These are estimated at only 8000 to about 12,000 families, and are very poor. They inhabit the country north of the range of mountains which bound Herat. They live in black felt tents; they assist the Turkoman in their slaving raids. The women make fabrics of wool and goat'shair, which sell well in Persia.

The Hazara Zeidnat are a rashly brave, ferocious mannered tribe, occupying the country at the sources of the Murghab river in Afghanistan, and could muster 12,000 fighting men. They number 28,000 tents. They make large quantities of cloaks from 'barak' hair-cloth, rear horses, and have great flocks of sheep, goats, and herds of camels and oxen. In 1847, Yar Muhammad defeated Karimdad, and deported 1000 of their families to Herat ; and in 1857, the Persians, after their capture of Herat, removed the whole tribe within the Persian territory, taking from them all their baggage and cattle to prevent them running away. There are no better horsemen in Asia. Their women pride themselves in their ability, when necessity requires, to mount a horse, and use a matchlock and sword with an intrepidity equal to that of their warlike husbands and brothers. They are not pretty, but are well made, enjoy perfect liberty, and their husbands are not jealous of them. In time of peace they do all the bousehold and field work, and with their children weave the 'barak' cloth.

The section of the Zeidnat inhabiting the country 100 miles N. of Herat are sunni Muhammadans. They are renowned for their courage, are considered the most noble of the Hazara, and have the title of Sar-i-Khana, literally chief of the race. They have 28,000 tents. They have numerous flocks of sheep, camels, and buffaloes, and rear 
excellent horses. They make 'kourk ' or 'barak' hair-cloth from the fine silky wool that grows on the belly of the camel. A piece of barak costs from Rs. 5 to Rs. 40, and suffices for a robe. These are worn in the winter by Afghans and Persian nobles. The wool on the other parts of the camel's body makes a coarser cloth. Their horses are of the Turkoman breed, smaller and not so well formed as those of the Teki, but steadier, and their powers of endurance are unequalled.

The Pusht Koh Hazara dwell S. of the Hindu Kush and its Safed Koh branch. They are divided amongst themselves, and constantly at war with the Afghans.

The Daulat Pah section of the Hazara inhabit a portion of the plain of Urt and valley of Siah Sang to the south of Bamian.

The Deh Zangi Hazara is a great tribe occupying the country N.W. of Bamian. They have four sections, and 10,500 families. They are Shiahs. Most of the Hazara slaves in Turkestan are of this tribe.

Timur seems to have been the last who held the Hazara in subjection. After his death they resumed independence.

The Daurani Afghan tribe occupy the country N. and S. of the road between Herat and Kandahar, 800 miles long and from 80 to 150 miles broad. It has the Paropamisan mountains on the north, inhabited by the Aimak and Hazara. On the west it has a sandy desert, which separates it from Persia ; on the S.W. it has Seistan and another desert that separates it from Baluchistan; its southern boundary is formed by Shorawak and the hills of Khojah Amran, and it joins the Ghilzae country on the east. The tribe has two great divisions,-Zirak, with four clans-Popalzai, Alikuzai, Barakzai, and Atchakzai ; and Panjpao, with five clans-Nurzai, Alizai, Ishabzai, Khugiani, and Maku. The whole population of their country is estimated at 600,000 souls, of which the Daurani themselves are one-half. They hold their lands on military tenure. They are partly pastoral and partly agricultural, and they speak with delight of the pleasures of their camp life. They term their summer and winter grounds Eilak and Kishlak, dwelling in their coarse black camlet tents, called Kishdi, the same with the Kara-ulli of the Turks and Siah-chadar of the Persians.

Each of the great clans of the Daurani is ruled by a sirdar chosen out of the head family, and the spirit of revenge for blood is much controlled. They have no feuds, and never go armed except on journeys. There are shops in their towns kept by Hindus. The Kishdi or black tents of the shepherds are 20 to 25 feet long, 10 or 12 feet broad, and 8 or 10 feet high. The inclement tracts are left by the shepherds in winter for the plains. They treat their wives kindly, are conspicuously hospitable; like other Afghans, do not abstain from plunder, but they have a consciousness of superiority and II sense of natural dignity, and are respected by all Afghans. They are extremely attached to their country, and have a reverence for Kandahar, to which the bodies of their great men are carried for interment, even from Kashmir and Sind. They travel little, and have never come to British India as merchants or adventurers.
The Saddozai is the chief branch of the Popalzai clan of the Daurani; Abmad Shah was a Saddozai. He thrice invaded India, and on the third occasion he fought and won the battle of Panipat (6th January 1761), when about 300,000 Mahrattas fell, amongst them the son and the cousin of the Peshwa, and the Mahrattas as a nation ruled by the Peshwa were broken up.

The Nurzai section of the Panjpao Daurani are a martial tribe of about 30,000 families, most of them shepherds. They occupy, along with Iliyat, the district of Sabzawur, which town is 93 miles from Herat and 286 miles from Kandahar. They hold a congeries of forts with their pasturage and cultivated fields around.

The Khugiani tribe of the Panjpao Daurani have three divisions, - Waziri, Khairbun, and Sherzad. The Waziri have given the Panjab province of the British Indian Government much annoyance. The Khugiani reside chiefly in the Gandamak valley of Jalalabad, and have now about 5312 houses.

The Alikuzai number 10,000 families, and are mostly agricultural. The Alizai are pastoral ; their numbers are stated to amount to 15,000 families.

The Atchakzai Daurani are entirely nomades, living in black tents in the ranges of Khojah Amran. They say they can muster 14,800 families, in 32 divisions.

The Daurani are stout and well made, with long hair and beards, many of them being above the standard of the Indo-Germanic races of Europe. Some have round and plump faces. With others, the countenance is strongly marked, and with most the cheek-bones are prominent. When a family is by itself, the men and women eat together; but few restraints are put upon the female, and her influence is considerable. The Daurani tribes, all but the Atchakzai, about 5000 in number, are religiously given, but not intolerant. They are of the sunni sect. Their national dance, called Attun, is danced almost every evening, with songs and tales to accompany it. They are fond of tales and fond of the chase.

The Daurani and the Ghilzae clans, from their numerical strength, have exercised greater power than other of the Afghan tribes. The Daurani are known also as the Sulimani, from the mountains whence they came, having dwelt in the Tobeh Maruf district.

The Kufelzai, more geverally known as the Popalzai, numbering 20,000 families, are an offshoot of the Abdali, one of the branches of which, the Saddozai, gave sovereigns to the Afghans in the 17 th and 18 th centuries.

Their name Daurani is titular. Abmad Khan, of the Saddozai branch of the Abdali, about the close of 1747 was crowned at Kandahar under the title of Ahmad Shah, Daurani, which Elphinstone says means pearl of pearls, but is commonly understood to refer to the dominion of the world (Dauran). From his time up to 1820 , his descendants have ruled; but since the last-mentioned date the Barakzai, a great clan of the Zirak branch of the Abdali, have been furnishing the ruling family in Kābul. Their numbers are about 30,000 families. The great bulk are pastoral, a few engage in tillage in the country S. of Kandahar, in Arghesan, and on the banks of the Helmaud.

The Tarin are a tribe in Afghanistan who have 
two divisions, viz, the independent Safed or Spin Tarin, and the Tor Tarin in the valley of Peshin, who are subject to the Kandahar Government. The Safed Tarin (White Tarin) could muster 6000 fighting men, and the Tor Tarin (Black Tarin) about 3000 .

Peshin is the middle portion of the valley of the Lora river, Barshor being the upper and Shorawak the lower part. Peshin is inhabited by the Tor Tarin, by families of Syuds, and a ferv Kakar.

The Spin or White Tarin tribe reside in the valley of Zawura, and in the open plains of Tull and Chutialli. They stretch into Cutch Gandava and nearly touch the British frontier. The Tor and Spin form two factions on the Banu frontier in which all the neighbouring tribes became involved, seventeen of them being for the Tor and sixteen for the Spin faction.

Writing of the Tarin, Lieutenant-Colonel MacGregor says: 'I have given them credit for the character of general peacefulness which they hold among their neighbours. There are comparisons among thieves, and in a country like Afghanistan, where an honest man is seldom or ever met with, one can only speak comparatively; for the best of them would in a civilised country be considered as scoundrels of the blackest dye, and consigned to the common hangman.'

The Ghilji or Ghilzae is next in importance to the Daurani tribe. The names and numbers of the several clans are variously enumerated by Mountstuart Elphinstone, Lumsden, Leech, Masson, Broadfoot, N. Campbell, Gerard, and MacGregor, and the estimates of the strength range from 35,000 to 100,000 families, with about 30,000 good fighting men. The names of the clans usually recognised are Ohtak, Thoki, Suliman Khel, Ali Khel, Sabrak, Tereki, and Kharoti. Of these the Suliman Khel is the most important, their numbers being 30,000 or 35,000 . The Ghilzae inhabit the country bounded on the south by Kalat-i-Ghilzae, on the west by the Gulokh range, on the east by the Suliman range, and on the north by the $\mathrm{K}$ abul river, but in many places extending beyond these boundaries.

The Ghilzae tribe occupy the principal portion of the country between Kandahar and Ghazni, and are the most numerous of the Afghan tribes. These people are also found between Farrah and Herat, and again between Kābul and Jalalabad, but in either position, being under due control, they are little heard of. The Ghilzae between Kandahar and Ghazni comprise the great families of the Ohtak, the Thoki, the Tereki, and the Andari, with their subdivisions. The Ohtak are acknowledged the principal of the Gbilzae families, and furnished the chief in the period of their supremacy.

Between A.D. 1715 and 1724, the Ghilzae were dominant under Mir Wais, his son Mir Mahmud, and relative Mir Ashraf, who was finally put down by Nadir Shah; but in that interval Isfaban had been twice taken by the Ghilzae, and Persia had lost a third of its population. When Nadir Shah overran Herat and Kandahar, he is said to have deported to Teheran 18,000 Gbilzae with their families, and to have given the Kandahar lands to his Persian followers. But in Ahmad Shah's time there was a fresh distribution, and again another when the Kandahari brothers arrived at power.

The Khojah section are next to Jadran in the extreme east of the Ghilzae country. They murdered Colonel Herring of the 37th Bengal Native Infantry, and were punished by Captain Outram. Their women took part in that fight, handing powder and ball to their husbands, and throwing down on the assailants incessant showers of stones.

Between the years 1839 and 1842, the British Indian army was continuously engaged with the Ghilzae, and Sir John Keane, Captains Outram, Anderson, Macan, and Woodburn, Colonels Chambers, Wymer, and Sale, Generals Nott, Pollock. and M'Caskill, were at different times employed against them. The Suliman Khel attacked the army in its advance to Kābul, and when Kābul was abandoned, the Ghilzae hung upon and destroyed the retreating force. The force moved from Kābul on the 6th January 1842. It numbered then 4500 fighting men, of whom 690 were British, 970 were native cavalry, and 2840 native infantry, along with whom were 12,000 followers. Of all that body, Assistant-Surgeon William Brydon, of the Bengal army, alone reached Jalalabad, and 95 men, women, and children taken prisoners were afterwards released. From Butkak the Ghilzae surrounded thern, attacking, plundering, and massacring. On the 8th January, about 3000 of the retreating force and its followers were slain at the head of Khurd Käbul defile.

On the 11th January 1842 , a remnant arrived at Tezin to the number of 4500 ; but at Gandamak, 20 officers and 45 British soldiers, the last survivors, fell. The Ghilzae indeed drank deep of blood.

In 1848 and 1849 they were engaged against the Amir Dost Muhammad Khan, who suppressed them with an army of 25,000 veteran Abdali.

The Ghilzae, although considered and calling themselves Afghan, and, moreover, employing the Pushtu or Afghan language, are undoubtedly a mixed race. The name is evidently a modification or corruption of Khalji or Khilaji, that of the great Turki tribe, mentioned by Sharif-ud-Din in his history of Timur. The testimony of Ferishta, while clearly distinguishing the Ghilzae tribes from the Afghan, also establishes the fact of their early conversion to Muhammadanism. Still there is a tradition that they were at some time Christians of the Armenian and Georgian churches. This tradition is known to the Armenians of Kābul; and they instance, as corroborating it, the practice observed by the Ghilzae of embroidering the front parts of the gowns or robes of their women and children with figures of the cross, and the custom of their housewives, who, previous to forming their dough into cakes, cross their arms over their breasts, and make the sign of the cross on their foreheads after their own manner. In the 10th century they still spoke Turki

East of Ghazni, in the province of Zurmat, are the Suliman Khel Ghilzae, exceedingly numerous, and notorious for their habits of violence and rapine. These have no positive connection with the Thoki or other tribes, neither have they one acknowledged head, but are governed by their respective Malik, who are independent of each other. Dost Muhammad Khan reduced them to the condition of tributarieg, after having destroyed a multitude of their castles. 
The Ghilzae women cannot boast of beauty, which they strive to supply by ornament. The girls from the age of eight to twenty are not much veiled, but they twist their hair, and tie it like a cake, which hangs over their forehead, and a little below their eyebrows. The centre of the lock (or hairy cake) is adorned by a gold or silver coin, which in black hair shines prettily. This is the sign of virginity amongst the Ghilzae. The women allow their twisted locks to hang upon their ears, even as far as their arms.

Moorcroft met with a party of wandering Ghilzae; their tents were nothing more than flimsy black blankets, stretched over forked sticks about four feet high; within, they had some more blankets, sacks, and pack-saddles; and without, a few loads of mats, ropes, and netting, for the formation of their packages; both men and women were robust, with strongly-marked features.

The Ghilzae are both an agricultural and a pastoral people, and dwell in villages and castles, as well as in tents. They are a remarkably tall, fine race of men, with marked features, the Ohtak and Thoki peasantry being probably unsurpassed, in the mass, by any other Afghan tribe for commanding stature and strength. They are brave and warlike, but the generality of them have a sternness of disposition amounting to ferocity, and their brutal manners are not discountenanced by their chiefs. Some of the inferior Ghilzae are so violent in their intercourse with strangers that they can scarcely be considered in the light of human beings. They irrigate by the Karez aqueducts and by wells, growing wheat, barley, lucerne, clover, and madder. The bridegroom gives a feast to the neighbours, costing a poor man about Rs. 100 ; and men often remain unmarried till 28 or 40 years old. When the engagement is arranged, the bridegroom is admitted to see his engagee once or twice alone at night, and, in general, without a breach of chastity. The women frequently fight by the sides of the men. The pastoral Ghilzae are all robbers, often murdering. They are hospitable, and respect elders. The Andar Ghilzae are expert Karez diggers.

Bar Daurani is a name sometimes applied to the Pathan tribes enclosed between the range of the Hindu Kush, the Indus, the Salt Range, and the Suliman range. It was applied to them by Ahmad Shah, and includes the Yusufzai, Utman Khel, Turkolani, Mohmand, Afridi, Orakzai, and Shinwari, also the tribes of the plains of Peshawur and those of Bangash and Khutak.

Povindah. - A great part of the inbabitants of Arabia, Persia, Asiatic Turkey, Afghanistan, and Baluchistan consist of nomade pastoral races, who are continually on the move to and from their winter and summer quarters. But from the most ancient times there have been travelling merchants traversing these regions, carrying the products of the varied climates from one nation to another. The prophet Ezekiel, who lived B.c. 574, tells us in the 27th chapter, that the Ashurites made benches of the ivory brought from the Chittim islands; that the men of Tarshish traded with Tyre in silver, iron, tin, and lead; Javan, Tubal, and Meshech brought slaves and brass vessels; horses and mules were brought by the house of Togarmah; the men of Dedan trafficked in ivory, ebony, and precious clothes for chariots; and precious stones, spices, and gold were the products sold in Tyre by the people of Sheba and Raamah. At the present day, the great trading race of Central Asia are the Povindah. They conduct all the traffic between British India and the Amu Darya valley. They are a pastoral race, but portions of their tribes and some of their clans carry goods to Dehli, Cawnpur, Benares, and even to Calcutta, Bombay, and the Dekhan, and return with the spices and produce of the East to Ghazni, Kalat-i-Ghilzae, Kābul, Kandahar, and Herat. Their chief clans are the Lohani, Nasir, Niazi, Kharoti, with subdivisions Daotani, Mian Khel, Miani, Kundi, and smaller clans, Miti, Suliman Khel, and Mashuni.

They bring to India dried fruits, drugs, spices, silks, woollens, pashminas, felts, horses, cattle, camels, and carry away British and Indian manufactures of every kind. Camels are their ordinary means of carriage. The imports and exports at the Indus ferries of the Dehra Ismail Khan district are valued at 59 lakhs, or half a million sterling.

They are wealthy, have fine horses, and can muster about 14,000 fighting men. In a region so full of wars, the perseverance with which they continue their successful enterprise merits all praise. Between Kābul and Katiawaz, the Kafila can travel separately, but from Katiawaz to British territory they have to move for mutual protection in one great body. They are in truth soldier merchants, moving in bodies 5000 to 10,000 strong, heavily armed, under an elected chief with the title of khan, marching like an army, with advanced guard and rear guard, and flanking parties, in some parts with daily skirmishes, occasionally pitched battles, and when halting at night, posting sentries and throwing out pickets. Major Edwardes says he hardly ever saw a Povindah who had not one or more wounds on his body; and the loss of an eye, broken noses, scarred skulls, lame legs, and mutilated arms are almost as common as freckles in England.

The Kharoti section to the W. and N.W. of the Waziri have 1500 tents. Their climate in winter is very severe. Many of them are quite fair. In spring they live on milk, ghi, kooroot, and cheese.

Only militant merchants of this description could ever have made a profit out of a commerce which had to traverse difficult mountain ranges, through savage robber tribes, and the countries between them seamed with the customs lines of greedy, short-sighted chiefs. Besides the demands of the governments, they are subjected to the exaction of the officials and petty chiefs at every stage of their route, and the blackmail of the various tribes through which they pass, - the Turkoman on the Oxus, the Uzbak robbers of Muzar Sharif, the Tartars of the Dasht-i-Safed, the Hazara of Syghan and Bisut, the Wurdak between Käbul and Ghazni, the Hotuk between Ghazni and Katiawaz, the Suliman Khel of Katiawaz, and the Waziri between them and the Indus valley. Sorely harassed, at every step losing men, horses, camels, bales of merchandise, bribing, cajoling; bullying, defying, and fighting, twice every year the caravans of these martial traders, seeking their precarious gains, battle their desolate way through the deserts of Bokhara, the defiles of the Paropamisus, the Ghilzae plateau, and the passes of the Suliman range, across the Indus to the Panjab. Their 
Kafila have to pass the Suliman mountains in one great company for mutual protection. Every year they lose a hundred or more men, and at least two per cent. of their camels, besides some hundred loads of goods. If the routes were made safe, they might make four trips annually. They leave their families at the foot of the hills, and enter British India in October, the largest body moving by Multan, and the smaller by Bahawalpur and Sirsa to Dehli, Benares, and Calcutta. They bring the wool of Kerman to Amritsar and Ludhiana, raw silks, gold and silver wire, fruits; and carry back cotton and woollen fabrics, scarfs, the gold thread of Dehli, the brocades of Benares, drugs, indigo, etc. The passes from which they emerge are the Gomal, Manjbi, Shekh Haidar, and Zarkani. They undertake the safe custody of the passes on the border of the Dehra Ismail district south of Tank limits for six months in the year, without any special considerations being granted them by the Indian Government.

The Nasir are the strongest of all the sections. They have been estimated to number from 1850 to 12,000 families. They are migratory, dwelling in summer among the Tokhi and Ohtak Ghilzae, and moving in winter to the Derajat. They trade less than other sections, but depend on their flocks and herds for food, clothing, and tents. Their sheep and camels are numerous. They are small of stature, ugly, and black ; are rude and squalid in their general appearance, and barbarous in their manners. They are one of the chief trading clans between Hindustan and Khorasan.

The Lohani section have three branches, Daulat Khel, Pani, and Mian Khel. The first two and part of the Mian Khel have settled to agriculture. The remainder of the Mian Khel are traders, the men in summer visiting Bokhara, Samarcand, and Kābul, a guard being left to protect the women in their felt tents; in the winter they move through the Gomal pass to the Derajat, when some of them proceed to Lahore and Benares, and return in April to revisit Karabagh and Pana.

The Aka Khel are a poor tribe of the Povindah. Three of their divisions visit British territory for trade, bringing fruits and cloths. They have a considerable number of camels.

Lohani, a section of the Povindah, are descended from Nub, son of Ismail, and are rightly called Nuhani. Nuh had two wives,-Sbiri, from whom are sprung the Maorat and the Tori; Tori had five sons,-Mama, Mian, Talor, Hod, and Palakh. Mana's descendants are the Daulat Khel of Tank, Isa Khel, and Mian Khel. The Daulat Khel, agriculturists in the Debra Ismail Khan district, form the predominant tribe in Tank, which is a semiindependent portion of the Dehra Ismail Khan district. Kati Khel, a section of Daulat Khel Lohani Povindah, also reside at Tank.

The Ali Khel are a poor branch of the great Ghilzae tribe; a few trade on their own account, but the majority hire out their camels to the Suliman Khel, with whom they travel. A camel load is about $3 \frac{1}{2}$ maunds, and they charge $R_{5} .5$ to Rs. $5 \frac{1}{2}$ a maund from Khorasan to the Daman.

The Daotani tribe of the Povindah have nine sections or khel, viz. Badin, Hasan, Ibrahim, Madu, Nuso, Rana, Sado, Sankizai, and Usmanzai. They live at Wana, and come down in three Keri after the Kharoti. They bring silk, pashm, carpets, charas, and are one of the richest of the Povindah tribes.

The Kharoti tribe in Afghanistan inhabit the district of Karabagh and the table-lands of Dur Tselae, Saroba, and Sar-Afzai on the E. borders of Khorasan; their khel are three,-Zadu, I, and Adu, with numerous subdivisions, about 15,000 to 20,000 souls. The Povindah and agricultural Kharoti are of the same clan; the Povindah Kharoti are Ghilzae. They are friendly with the Lohani and Ghilzae Povindah, with the exception of the Suliman Khel, with whom they have an old and very bitter blood feud; they are at enmity with the Waziri.

Purmuli, or Fermuli, or Hurmuli, a brave and warlike race, about 8000 in number, residing south of the Kanbul river near Orglum in the Kharoti country, and to the west of Kābul. They carry on an unceasing hostility with the Kharoti tribes around them. Some are soldiers in the Amir's army, and some engage in trade. They occupy the lands at the head of the Waziri country.

The Pashai race, in Afghanistan, were formerly very numerous, but are now greatly reduced, their remnants being found in the districts of Mundal, Chitela, Parena, Koondee, Seva Koolman, Nijrao, Lughman, Koh Karinj, Kunar, Bajawar. The Panjsher people are probably Pashai, though calling themselves Tajak. They and the Nijrao inhabitants speak the Pashai dialect. The Safi of Taghai and the Dara Mir are also probably Pashai. The Pashai are mentioned repeatedly by Lieut. Leech as one of the most numerous tribes in the Panjsher valley and adjoining passes. These are supposed to be Muhammadans, but as the name is mentioned also by Elphinstone as that of one of the Kafir tribes, part of them in the mountains may have retained their heathenism and independence.

The Saf, with about 2800 fighting men between Pashut and Shewa, occupy the north side of the hills on the left bank of the Kunar river. The Safi understand Pukhto, but speak the Pashai. They inbabit the valley of Dara Nur, the hills to the north of Jalalabad, and between that division and the Kafir country, also the valleys of Barhot and Daminj to the west of Dara Nur. They are a straightforward, manly race, with florid complexion, light eyes and hair. They have bee-hives, and make wine and vinegar.

The Safi occupy Dara Nur, Dara Mazar, Dara Pech, and the valleys opening on the Khonar river, and in a district called Surkh Khambar, south of Bajawar. In Baber's time they were Kafirs. They were expelled by the Ghilzae from the lands to the south of Taghow, and between Kābul and Jalalabad. Nadir Shah cultivated a friendship with them.

South of the Safi, at Bahi, the first march from Goshter, on the Jalalabad river towards Bajawar, are a people called Yeghani, who consider themselves Afghans, but are probably converted Kafir, for they speak a dialect which no Afghan can understand.

The Buruki race, who claim to be of Arab origin, occupy Logur and Butkak, in the Ghilzae portion of the Afghan country, and are said to have been settled there, south of the Käbul river, by the Sultan Mahmud in the 11th century. Their 
number is about 8000 families, but they arrange themselves into tribes with chiefs. They are good soldiers.

The Jaji tribe dwell in the valleys of the Hariab and its tributaries. They have about 700 or 800 families. They are much at feud with one another; each house is separate, and in the form of a square. They form a circle for their wild war-dance.

The Mehrani tribe inhabit the slopes of the Takht-i-Suliman next to the Shirani; they are great marauders.

The Kakar inhabit the extreme S.E. corner of Afghanistan. They claim to be descended from a man named Sharif - ud - Din, whom Mahomed converted and gave the name of Abdur Rashid, with the title of Pret Khan. He is said to have had five sons,-Shirani, Tarin, Miuni, Barechi, and Umar-ud-Din, all founders of clans. From the extreme antiquity of the Kakar clan it has branched largely, and the Arabi Khel or race of Mulla, the Taemuni of Ghor, the Firoz Kohi Hazara, the Kayani tribe of Seistan, the Utman Khel, and the Gakar, all claim connection with them. The Kayani tribe are commonly called Baluch, but they acknowledge themselves and are recognised descendants from the Saugor Khel Kakars. They are scattered all over Afghanistan ; a branch is in Kashmir on the banks of the Jhelum, and the asafoetida trade of Herat is in their hands. They number 14,000 to 20,000 fighting men, viz. :

Jalazai, . . . $2000 \mid$ Kahizai, . . 1000 Musa Kbel, : : 3000 Hamzazai, : : 1100 Kadizai, . . 2000 Shahozai, Alizai, and Usman Khel, : : 200 Tenizai, . . . 900 Abdulazai, . : . 2000 Khidarzai and others, 200

The Kakar country in the headwaters of the Lora is wild and inaccessible. It forms a square of about 180 miles between the Atchakzai country, the Spin Tarin, the Suliman range, and Baluchistan. But Kakars named Casia occupy in part the valley of Shal. The Punni clan, in Sewi and Sewistan, is Kakar.

The Jalazai section number only about 110 fighting men. The Alizai clan is agricultural and pastoral, and are said to number 10,000 fighting men. They are peaceably inclined, and every winter large numbers come to Dehra Ghazi Khan to labour as wood and grass cutters and roadmakers.

The Musa Khel branch are in the hills beyond the Baluch, to the west of Dehra Ghazi Khan district and the Kala Roh range, three or four days' journey from Mangrota or Vihowa. Their sections are Balel, Umas, and Lahar. They could assemble 3000 fighting men.

The Shahozai, said to be an offshoot of the Kakars, number 200 fighting men.

The Bar Namai Kakar are about twenty miles south-west of Mekhtar, and the Khojah are an offshoot from them.

Among the widely-distributed Kakar race there are many differences in manners and in personal appearance. At the time of Mahmud of Ghazni, a warlike tribe of Ghakkar, Gukkar or Kahkar were in the Salt Range or Jhow mountains between the Indus and Behut (Hydaspes), and at an early period of their history they would seem to have been given to infanticide. They are supposed to be the descendants of the mountaineers whose chief, Ambisaces, sent ambassadors with presents to Alexander. Baber writes the name Guker, but it is also written Ghuka and Khaka.

The Khostwal is a Pathan tribe occupying the valley of Khost in Afghanistan, for 40 miles along the Shamil or Kheti river. Their five divisions or Khel are the Ismail, Matun, Manduzai, Shamal, and Lakan, and they number 6000 to 8000 souls.

The Abdul Rahman Khel, of Khost, inhabit the Matun district of that valley, also, therefore, called Matuni. They are a branch of the Karani clan, and are also Mamuri. They number about 1000 fighting men, and are mostly agricultural.

The Makbal is a quiet, peaceable tribe living to the north of the Mangal and west of the Jaji. Some of them dwell in the Khost valley.

Vanicha, a Pathan tribe of 300 fighting men. Their Zargwal section dwell near Bahian, and the Khorasani in the hills bordering Khorasan.

The Tajak are the aborigines of the country, and are not Afghans. Alexander probably found them there, as fire-worshippers, speaking Sanskrit or Pehlevi. They form the industrial part of the population of the khanates of Uzbak, Khiva, Bokhara, Khokand, and Kashgaria, also in Farghana, in Khorasan and in Baluchistan, all over Afghanistan from Jalalabad to Herat, and from Kandahar to Balkh, also in Persia, Turkestan east and west, scattered and unconnected, mixed with the Uzbaks, Afghans, Persians, Baluch, and Brahui, but with independent governments in in Darwaz, Karatagin, Vakhan, and Badakhshan. They seem to have been the aboriginal inhabitants of all these countries, and to have been pushed aside by more martial, advancing, and conquering races. They speak Persian, and in Turkestan and Afghanistan, Tajak and Parsivan are synonymous terms; but in the west they are also called Sart. Tausik or Taujik is the name applied to the Arabs in all Pehlevi writings; but they themselves at present derive their name from Taj, a crown or head ornament. They are supposed to be of the same race as those of Kafiristan, Chitral, Shagbnan, and Roshan. The Tajak are a handsome race, athletic, tall, with fair complexions, and lively, sociable temperaments. They wear the costume and follow the customs of the races amongst whom they are dwelling; but they are of settled habits, mostly agriculturists, or engaged in all the industries of towns. They are sunni Muhammadans, and are quiet, orderly, frugal, and industrious people. Some of them, under the term Turk, serve in the army of the Amir of Käbul and in the Panjab Irregular Force. They are, next to the Afghans, the most powerful race in that country, and compose the principal part of the population round Kābul, Kandahar, Herat, Balkh, the Kohistan of Kābul, Chitral, Gilgit, Shaghnan, Badakhshan, Karatagin, Vakhan, Darwaz, the small states north of the Hindu Kush, of Doshi, Khinjan, Indarab, Khost, Firing, and Versukh; the Baraki of Logar, the Fermuli of Urghun, the Sardehi of Zurmet, and the Shahregi and Sarbandi of Seistan are Tajaks. The Baraki inluabit Barak, Logar, and part of Butkak, mixed with Ghilzae. In 1809 they had 8000 families. The Logar branch speak Persian, those of Butkak speak a language called Baraki. They are more respected than other Tujaks. The river of the Panjsher valley in Afghanistan rises on the south of the Hindu Kush in the Khawak pass. The orchards and mulberry plantations furnish the staple 
support of its inhabitants. The Panjsheri, like the rest of the Kohistani, are Tajaks. They are sunni Muhammadans and bigoted. They form peace leagues with the Kafirs, exchanging hostages, They have been independent since the time of Timur, but every man is for himself, and the whole valley is filled with turbulence and strife. They could assemble 10,000 men. They are good soldiers.

The Tajak in the Surkh Rud district of Jalalabad division have 2827 houses. The Parsivan who came with the army of Nadir Shah and settled in towns, are merchants and in various trades; in villages they are shepherds and agriculturists.

Kazzilbash formed part of one or more of the seven Turkish tribes that embraced the party of Shah Ismail, the founder of the Saffavi dynasty. This sovereign, to distinguish them from the others, gave them a kind of red cap, hence their name of 'Red head,' Kazzilbash. The seven tribes were Oustajalu, Chamlu, Nikalu, Baharlu, Zoolkaddar, Kajar, and Afshar. When Nadir Shah marched towards Dehli, he had twelve thousand fighting Kazzilbash with him. When he quitted that city, on his return, he left behind him three hundred of these, who, with other troops, were directed to bring away his treasure, and follow him. They passed through Käbul; but when within two days' march of Kandahar they heard of his death, and a few days afterwards, Ahmad, Nadir's lieutenant, arrived, attended by five or six hundred Daurani; he seized the treasure, and took the Kazzilbash into his service, and his kind treatment of them induced others to come from the neighbourhood of Tabreez, Mashid, Kirman, and Shiraz, in Persia, where the true Kazzilbash exercise the profession of horsebreeders, shepherds, and cultivators. There are now perhaps about ten thousand Kazzilbash in the city of Käbul, who are ever ready to serve as mercenaries. Their leaders are by far the most wealthy, the most intelligent, and the most influential men at Kābul. Under the Amirs of Kābul they have served as body-guards, and still retain their own language. They are known in that city as Ghulam Khani or Ghulam-i-Shah, lit. household or royal slaves. They have three sections, the Jawansher, Afshar, and Morad Khani. The Jawansher are of Turk descent from Shisha, have several sections, and form the principal part of the Kazzilbash.

The Kazzilbash are good horsemen; they constitute the bulk of the cavalry and artillery of the Amir of Kābul. They are also found in the Indian army irregular cavalry. In Afghanistan they are also merchants, petty traders, scribes, physicians, secretaries, and stewards. They speak Persian and Turki.

The Jat in Afghanistan, about 300,000 in number, are Sunni Muhammadans; they are mostly very poor, - farm servants, barbers, musicians, and sweepers.

The Hindki are Hindus of the Khatri class, residing all over Afghanistan, even amongst the wildest tribes, who could not get on without them. They pay a capitation tax, are not allowed the open worship of their religion, nor to give evidence in a court of justice, nor to appear on horseback. The Parancheh Hindki are found in the Panjsher valley at the head of the Swat valley, also in the Banu district in British territory, in Peshawur, Kohat, and in the Hazara country. They are traders, and of recognised integrity.

Arabs have colonies in the Jalalabad district, Bajawar, Peshawur, and Pughman. The Jalalabad Arabs are well conducted, they are pastoral and agricultural. They speak Persian, and belicve that their ancestors came with Timur.

Jews are found throughout the country in small numbers.

A few Baluch tribes pasture their flocks and herds in the southern parts.

Kawal (Qu. Khawal) are a tribe of thieves and fortune-tellers, who wander about the Pughman mountains.

The Sadu tribe, in the Pughman hills, much resemble gipsies in habits and mode of life; they are fortune-tellers and thieves.

The Afghan are all Muhammadans, having been converted to this creed within half a century from the first promulgation of that religion. The majority of the tribes are of the sunni sect. The shiah sectarians are the Badakhsi, Vaki, Seistani, Tajak, Kazzilbash, Hazara, Turi, Bangash. Some of the Orakzai, Dawari, Khostwal, Jaji, Chitrali, and some Kohistani.

The Parsivan and Aimak, who are subject to the Afghans, profess Muhaminadanism. Besides the two sects just mentioned, some are of the Ali Ilahi schism.

The government of the tribes is a democracy, their representation and self-government being by their Jirgah and Ulus, but, like most rude people, no man's nationality extends beyond his own clan.

The mother of a betrothed girl connives at the engaged couple meeting; this is called Nam-zadbazi, literally betrotbed happiness.

The Afghan are the only people of Central Asia who in comparatively recent times have come to reside to any considerable extent in British India. They have never, however, migrated in large bodies, but have accompanied the Muhammadan rulers of India, all of whom have entered from Afghanistan, and brought bodies of the Afghan with them. They are known in India by themselves and others by the name of Pathan. Some of these have settled in many places throughout Northern India and in some parts of the south, as far south as Hyderabad, Kurnool, and Cuddapah, some of them in villages, where they own and cultivate the soil. These have been in considerable numbers in the native army of British India, and particularly in the corps of irregular cavalry, and in Northern India, in the civil service of Government. A few Pathan settlements are found in the Panjab and about Dehli, and they are numerous in the Upper Doab and Rohilkhand. Pathan principalities, jaghirs, and families are met with all over India, and the Begum of Bhopal is of Afghan descent.-Bunsen; Calcutta Review; Campbell; Chesney; Elphinstone's Hist. of Caubul; Ferrier's Hist. of the Afghans; Latham's Ethnology; Mohun Lal's Travels; Colonel MacGregor's High Asia; Peschel; Tud's Rajasthan.

BALUCHISTAN, as known to Europeans, is partly Persian territory, and in part under the rule of the Khan of Kalat. Its territorial divisions have been already noticed under that heading; what remains to be described here are the multitudinous races who have found refuge in its 
mountain valleys. According to the most recent authorities, it has an area of 140,000 square miles; 60,000 are under the Shah of Persia, in the Sarhad and Baluch, two mountain plateaux, and 80,000 under the Khan of Kalat, in the provinces of Saharawan, Jhalawan, Cutch Gandava or Cutchi, Las, and Makran.

The territorial boundary between Brahui or Kalat Baluchistan and Persian Baluchistan has been defined; but the inhabitants, particularly those in Makran and the Kohistan, are occupants of the two divisions.

Mr. Masson arranged the portion of Baluchistan subject to the Khan of Kalat into four subdivisions:-

\begin{tabular}{|c|c|c|c|}
\hline Western. & Maritime. & Central. & Eistern. \\
\hline $\begin{array}{l}\text { Nushki. } \\
\text { Kharan. } \\
\text { Mushki. } \\
\text { Panjghur. } \\
\text { Kej. } \\
\text { Kolwah. }\end{array}$ & $\begin{array}{l}\text { Las. } \\
\text { Hormara. } \\
\text { Persani. }\end{array}$ & $\begin{array}{l}\text { Saharawan. } \\
\text { Kalat. } \\
\text { Jhalawan. }\end{array}$ & $\begin{array}{l}\text { Cutch Gan- } \\
\text { dava. } \\
\text { Harand on } \\
\text { the Indus. } \\
\text { Dajil on the } \\
\text { Indus. }\end{array}$ \\
\hline
\end{tabular}

Kolwa

The people are partly pastoral and nomade, partìy dwellers in towns, and, as indicated by their physical appearance, are of widely different races, who have pushed or been pushed forwards from the S., the W., and the N.W., into their present sites. In the khanate of confederate tribes are the Baluch tribes proper, the Rind, the Brahui, the Lumri, the Dehwar of the capital, the Jet or Jat of Cutch Gandava, the Babi, Arab races occupying the maritime provinces, the Afghans of Shal, and the Hindu residents of villages.

Baluch traditions trace their origin to Aleppo in Syria, from which they emigrated, passing through Persia to Cutchi, Makran, and Seistan. They entered Sind through the Bolan pass, and then broke into two factions, Lishari and Rind, and the Lishari successfully disputed the rights to the water of the Jhool river.

Dr. Cooke was inclined to the opinion that the Brahui were Tartar mountaineers who had gained a footing in the country, ultimately becoming the ruling race; and that the Baluch came from the westward, but whether they were Seljuk Tartars or Arabs from Aleppo, he thinks is a matter of doubt. He considers the Hindus to have been the first colonizers of the upper part of the Brahui mountains, and that the Brahui gradually settled amongst them; that Sehwa, a Hindu raja, called in the aid of these mountain shepherds against a horde of depredators from the western parts of Multan, Shikarpur, and Upper Sind; and that the Brahui, having defeated and driven off these invaders, seized the government for themselves, a chief of the name of Kumbar becoming Khan of Kalat, of whom the present khan is a lineal descendant.

The other race, the Baluch, he says, ascribe their origin to the earliest Muhammadan invader of Persia, and are very desirous of being supposed to be of Arab extraction. They spurn the idea that they are derived from one stock with the Afghans. The affinity of the Baluchiki to the Persian language favours their tradition that they came from the westward; to support which, also, we see that the majority of the Baluch still dwell on the western frontier.

Sir Henry Rawlinson says the Persians regard the Baluch as descended from Belus, king of
Babylon. It has been said that Baluchistan was first applied to the territory by Nadir Shah; but Ibn Haukal, in the 10th century? says, "The Balonjes are in the desert of Mount Kefes, and Kefes, in the Parsi language, is Kouje, and they call these two people Koujes and Baloujes.'

The Brahui are the dominant race. From their physical appearance, their language, and the sites which they occupy, together with their traditions, they appear to have been a nation of Tartar mountaineers, who settled at a very early period in the southern parts of Asia, where for many centuries they lived an ambulatory life in khels or societies, headed and governed by their own chiefs and laws; and at length they became incorporated, and obtained their present footing at Kalat and throughout Baluchistan. Their pursuits and ways of domestic life afford reason for believing that they were originally mountaineers; and some amongst them affirm that the very name demonstrates this by its signification, being a compound of an affix Boan, and Roh, a word said to mean a hill. This tradition is supported by the collateral evidence of the Baluch being called in one quarter of the country Narui, 'lowlanders,' i.e. literally 'not hillmen,' a name they received from the Brahui when they came amongst them, and evinced a preference for the champaign districts.

The Khan of Kalat's dominions extend from Shal or Quetta in the N. southwards to the sea on the coast of Makrau, and from the frontier of Persia beyond Kharan and Panjgur on the T. eastward to British Sind, a length and breadth of about 400 miles. This territory, varied in character to no ordinary degree, consists of lofty, rugged table-land and level ground, and their climates exhibit the severest heat and most intense cold. When the plains of Cutchi are intolerable in the month of May, by reason of the intense heat, dust-storms, and poisonous winds, the weather about Quetta and Mustung resembles an English spring-time.

A mountainous table-land, running north and south, comprises the proviuces of Saharawan, Jhalawan, and Las. It extends from the Afghan mountains N. of Quetta southwards to Cape Monze, or from lat. $40^{\circ}$ to $25^{\circ} \mathrm{N}$., a length of 340 miles. In breadth it extends from the level plains of Cutchi eastward, to Nushki on the borders of the Seistan desert westward, extending thus about 150 miles, widest about the centre, but it gradually narrows southwards until, at Cape Monze, the range is only a few miles in width. The height also varies. The greatest altitude is attained at Kalat, about 7000 feet, where the climate is European; southward it rapidly declines, until in the province of Las the elevation is little above that of Sind. In this mountain range here and there are long and meandering valleys, but it is the natural boundary of Westeru India.

The Kohistan of Balucbistan is the part lying to the westward. On its N.E. and IV. it has sandy deserts, and on its south are various districts of Makran. Its principal mountains are those called the Sarhad between lat. $29^{\circ}$ and $30^{\circ}$ N., visible from a distance of 80 or 90 miles. In several places are brooks of liquid salt; pools of water covered with naphtha, stulphur, muriate of ammonia, and hot springs. It is occupied ex- 
clusively by Brahui, in a number of petty republics.

The Badozai and Bari tribes of Baluch inhabit the district of Past-i-koh west of Sibi in this Kohistan.

The Memaseni tribe of Seistan and Luristan, west by north from Shiraz, occupy still farther west in the valley of Mushki. They are the bravest but the most savage of the tribes, and lead a wild, disorclerly life, frequently at feud with their neighbours. They are the powerful tribe encountered by Alexander in Upper Bactriana.

Bashkurd is the most western district of the Kohistan; it is extremely mountainous, and is separated by a desert from the Persian province of Nurmanshahr. It is occupied by a tribe of Kurds who have advanced out of Luristan. They are pastoral, and prefer the uplands. There is a hot spring at Basman, a hamlet in the Kohistan.

The Baluch and Brahui take their tribal names from the chiefs under whom they serve, the district or country to which they belong, or the traditions as to whence they derive their descent. Between the numerous clans, blood-feuds have at times been long continued. The authority of the Khan is acknowledged by the greater portion of the tribes and races in Baluchistan, and the khanate has treaties with British India. Quetta is now (1883) garrisoned by a British force.

Pottinger, writing early in the 19 th century, enumerated 74 principal tribes of Brahui, and gave 106,760 as their fighting strength; but he added that he could have given twice as many more names.

The more important of the Baluch, Brahui, and Afghan tribes in the khanate occupy the following districts:-

Nusherwani (Baluch) in Kharan and Washak and partly in Maskai.

Mirwari (Brahui) in Maskai.

Gitchki (Brahui) in Panchgur and Kej.

Lumri or Numri in Las. They are connected by blood with the Batti of Jeysulmir, and trace their ancestors to Samar, the founder of Samarcand.

Kassi (Afghan) in Shal.

Minghal tribes and Bizanju, Zahri, Haidarani, Kaidrani, and Kambarani occupy the Jhalawan districts of Wad, Nal, Sohrab, Zahri, and Kozdar.

Raisani, Sherwani, and Bangalzai (Brahui) in Mustang. Rakshani (Baluch? Brahui?) in Nushki.

Kalat by Dehwar, Brahui, Babi, Hindu, Afghan, and slaves. The Brahui is the dominant tribe.

Pind (Baluch) and Jat are in Cutch Gandava, w th Rind and. Bugti (Rind) in the hills beyond. Garchani (Rind) occupy Harand.

Baluch inhabit the hills to the IV. of the N.W. British frontier from the Vihowa pass on the N. to the extreme limits of Jacobabad on the south and west. The khanate tribes own the authority only of their respective chiefs, but several of them occupy partly khanate and partly British territory.

Major John Jacob, C.B., writing in the year 1854 , gives the following three lists of -

i. Tribes residing beyond British territory, and de facto independent of any other state.

$\left.\begin{array}{l|l|c}\text { Khetrani. } & \begin{array}{c}\text { Kujjuk and } \\ \text { Lashari }\end{array} & \begin{array}{c}\text { Bugti } \\ \text { and } \\ \text { Gurchani. }\end{array} \\ \text { Sibi. } & \text { Mari. }\end{array}\right\} \begin{gathered}\text { Predatory bill } \\ \text { tribes. }\end{gathered}$

ii. The Border Baluch, who are partly within and partly without British territory, are as under:

Burdi.

Durdi.

Jakrani.

Jettui.

Jamali.

Khybiri.

Jat.

Nizamani.

Khanavi. iii. Border Tribes living within British territory. These are the Mazari, Burdi, Khosa, Jemali, Jettui, Dumki, Jakrani, and others.

Baluch have no written tongue, but Persian is used, and in their traditions they claim to be Arabs who left Aleppo after the death of Imam Husain, and to have settled in Kirman and afterwards in Makran, while subsequently some of them went to Kalat and Khorasan and other places.

The great Rind tribes are subdivided into 44 branches. Their traditions affirm them to have emigrated ages ago from Damascus and Aleppo. Their language is the Jatki, in common with that of the other inhabitants of Cutch Gandava, and Mard-i-Rind means a brave man. The Rind of Cutch Gandava are of the Utanzai division.

The Utanzai dwell at Suran; the Dumki and Jakrani dwell at Lehri; the Doda Mari at Kahan; the Bugti, in the hills east of L,ehrat, Sing Saloh, and Teriki; the Homarari dwell at Tambu; the Jamali dwell at Rojan. The Dumki, Jakrani, Bugti, and Doda Mari were distinguished by their predatory habits. They indulged these in attacks on the British armies west of the Indus. The Mari tribe inhabit the eastern hills of Cutch Gandava, and were notorious for their lawless habits and frequent inroads on the plains. A peaceful and submissive portion of the tribe are in the hills west of the province below Jell. A large portion are at Adam Mari, on the S.E. frontier of Sind. They and the Maghazzi seem to have emigrated from Makran to Cutch Gandava at different periods, and to have become incorporated with the Jat cultivators.

The following minor Rind tribes reside in the N.E. hills of Saharawan:-Kallui at Lup; Kuchik at Kirta; Pushh at Johan; Mandarari at Rodbar; and Puzh at Kajuri.

The Rind on the western banks of the Indus are of two great tribes, the Gurchani, who inhabit Harand, and south of these the predatory but nearly independent Mazari tribe. Their subdivisions are-

A. Dwelling in the hiliy region N.W. of Cutchi. \begin{tabular}{l|l|l|l} 
Bugti. & Gurchani. & Lurd. & Mazari. \\
Chachri. & Lashari. & Mari. & Mundastri. \\
Dirishk. & & &
\end{tabular}

Dirishk. B. Dwelling in Cutchi.

Ghulambulk | Tharani. Changia. Jalambani. $\quad$ Kosa. $\quad$ Puzh. Dinari. Jatui. $\quad$ Nusherwani. Rindani. \begin{tabular}{l|l|l|l} 
Doanki. & Kalui. & Omrani. & Utanzai.
\end{tabular}

The Rind section of Baluch are in small groups or singly all over Sind, though more numerous in the north near Jacobabad, or southwards in the Thur and Parkur districts. Rind, under Chakur, attached themselves to the emperor Humayun's fortunes. They got a grant of land in the Bari Doab, and settled at Sat-gharra, on the banks of the Sutlej near Gogaira, and are still there, though not so designated. Some Baluch settled in the N. W. of India, to as far as Dehli, where they are scattered about in various capacities, and are often camel-drivers. They are large, powerful, swarthy men. They serve as mercenary soldiers in Arabia; and latterly, in Bombay, they became labourers at the harbour and on the quays.

The Maghazzi have only four families, the Butani at Jell being the chief. They are the deadly enemies of the Rind, but are probably of the same race. The Maghazii are subdivided 


\section{INDIA, ITS BALUCHISTAN NEIGHBOURS.}

into four principal families or clans, of which the Butani of Jell are the most illustrious, and gave the chief or sirdar to the whole. They boast of being able to muster 2000 fighting men; and between them and the Rind a blood feud long existed. The Magbazzi and Rind are alike addicted to the use of ardent spirits, opium, and bhang.

The Baluch are in tribes or tomans, each under a hereditary tomandar. The tomans are subdivided into clans or para, each clan with a hereditary Makadam or headman. Each clan has sections or pali. They are a hardy, martial race, truthful and faithful to their engagements. They dismount and fight on foot with sword and shield. They are Muhammadans of the Sunni sect, but are not bigoted nor fanatical, and have no hatred to the British on religious grounds. Their courage is open and stern; 700 Bugti refused to surrender to Colonel Merewether's horsemen, though escape was hopeless, but allowed themselves to be shot down till two-thirds had fallen. They are averse to labour and to all instruction, considering it an indignity to learn to read or write. They are averse to regular service or to wear uniform. In their internal wars and blood feuds they never molest women or children, though they carry on their contests with the most implacable enmity.

The lads who have not put on trousers are regarded as children. Their women move fearlessly about the hills, gathering the fronds of the dwarf palm, or collecting fullers' earth. Widows are remarried to their deceased husband's brother. The men wear their beards, and have bushy whiskers. Their turban is of cloth twisted like a rope; they have a sort of shirt reaching to the knees and plaited at the waist behind, with loose trousers, and a white sheet as a plaid. The ornaments of the women are necklaces (hassi) a torque of stiff solid metal; a necklet (chamkalli, a string of twisted silk with pointed gold beads), armlets, bracelets, and anklets.

Their houses are mean, their flocks are small. They are bad riders, though they have a good breed of mares, $13 \cdot 2$ to 14.1 in height, well built, wiry, and hardy, able to carry their rider 50 to 70 miles, with his bedding, food for man and horse, with matchlock, -in all about 13 stone; they are never shod.

Their arms are sword and shield and matchlock. They are hardy, endure severe privation. They have blood feuds,--Khun-bawur, satisfaction in blood.

The Narui section of Baluch are a tall, handsome, rctive race, with good features and expressive countenances, not possessing great physical strength, but inured to changes of climate aud season, and nccustomed to undergo every kind of bardship nud fatigue. They fight with great gallantry, fearless of deatb, ouly requiring a lcader to direct their impetuous valour. They are the most savage and predatory of the Baluch. The Rind and Maghazzi Baluch resemble the Narui Baluch in size and stature, and, like them, have good features and expressive countenances, but are less able to support hardships and labour. They are of a darker colour than the Narui. They are hospitable. They are almost pastoral ; usually reside in (ghidan) tents of black felt or blanket, stretched over a framework of tamarisk (guz). The VoL. II.
Narui prefer snud houses to tents. The Baluch are indolent, and only rouse themselves to some favourite amusements. They are sober, using flesh meat, wheat, and barley, cakes, rice, dates, cheese, sweet and sour milk, and soup made of dal or peas, seasoned with pepper. The Narui principally inhabit that portion of Baluchistan which lies to the westward of the desert, and there are likewise clans or khel of them at Nushki and in Seistan.

The sections Rind and Maghazzi are settled in Cutch Gandava, to which fertile plain they have migrated at different periods from the province of Makran, and have become incorporated with the Jat, or cultivators of the soil, as the subjects of the Kban of Kalat; a few of these likewise reside in the hills to the N.E. of Cutch Gandava, and on the skirts of the deserts north of Kalat. The Baluch, in all the east of Baluchistan, are but the upper stratum of the population; and there, as also in Seistan and Cutch Gandava, the Jat race form the greatest portion of the agricultural population.

Baluch tribes think much of good blood and the claims of long descent. Baluch mothers, like those of the Armenians, Hebrews, Chinese, and Afghans, see the proofs of their daughter's marriage.

Baluch have a code of honour, to which they scrupulously adhere, and have far more nobility of character and manliness of disposition than Afghans. The Afghans swore not to molest British troops when retiring from Kābul, nevertheless destroyed the brigade. The Baluch swore to keep faith with Captain Browne and his garrison in Kahun, and escorted them safely to the plains, though quite at their merey and dependent on them even for water. The Baluch closes with his enemy in the fight, sword and shield in hand; the Afghan engages with matchlock, firing from a distance, if possible under cover, and seldom closing with his enemy.

Baluch women generally wear the gagh-gho, a long shift resembling an English night-shirt, but opening behind between the shoulders, and with half arms. It is usually made of red or white stuff, and reaches almost down to the ankles. Red is the fashionable colour, and elaborately worked at the breast.

The men wear their hair long and flowing over the shoulders, whilst a luxuriant beard falls over the breast. The women tie their hair in a knot behind, brushing it smooth in front, and keeping it in place by a fixature. The colour of the hair is frequently brown or red.

Baluchistan grows whent, barley, millet, and rice, but mutton and milk preparations are the staple articles of food; asafœetida is largely used.

Jaloh is a scorching hot wind of the Baluchistan desert. It is frequent in the eastern low-lying province of Cutch Gandava or Cutchi ; it blows also in the sandy deserts bordering on Southern Afghanistan, and is often fatal to animal life.

Lead mines are worked at Kappar or Sekran in Central Baluchistan.

The Brahui are confined to the mountain districts, in which also are tribes from several sources; for instance, Jhalawan has Rajput descendants, the Boledi is of Arab descent, and the Kamburani claim to be Abyssinian.

The typical Brahui are certain tribes in Sabarawan and Jhalawan. They have, both in feature 3 


\section{INDIA, ITS BALUCHISTAN NEIGHBOURS.}

and speech, indications of a Mongoloid or Turanian origin. They are hardy, often migratory. Their political chief is the Khan of Kalat. They are Sunni Muhammadans.

The more unsettled and wandering Brahui reside in one part of the country during summer, and migrate for the winter season. They likewise change their inmediate place of resort many times, in search of pasturage for their flocks, - a practice rare among the Baluch tribes. They differ so much from the Baluch in external appearance, that it is almost impossible to mistake one for the other. The Brahui, instead of the tall figure, long visage, and raised features of their fellow-countrymen, are stout and squat, have short, thick bones, with round faces and flat lineaments. The title Kamburani is a general one for all the Brahui. The Kamburani are subdivided into distinct gradations of rank, called Ahmadzai and Khani. The first supplies the khan, and the Khani are of the secondary rank of chiefs; while the Kamburani include all the remainder of the tribe, though in common use is applicable to the whole body. They receive wives from, but do not marry their daughters into, other tribes.

Brahui are found throughout Baluchistan, but chiefly occupy the mountainous regions of Jhalswan and Saharawan, while Kalat, the capital, is their headquarters. They are hardly to be surpassed in activity, strength, and hardiness, being alike inured to the cold of the mountains of Baluchistan and to the heat of Cutchi. The women of the Bizanju tribe, and those of the Nichari near. Kalat, are esteemed very handsome; but the exposure to which they are subjected during their migrations soon bronzes the face, and they acquire a hardy, masculine appearance. At the commencement of the winter months, all migrate to the plains, and many leave the hill country as early as the middle of September. On a march they sustain incredible labour.

The Gurganani Brahui take their name from the Persian Gurg, a wolf.

Kamburani Brahui are estimated to have 1000 fighting men. They are supposed to have como from Abyssinia, Kambur in Baluchi meaning an Abyssinian. It is said also to mean a tortoise.

Brahui and Baluch are equally hospitable, but the Brahui are the more quiet and industrious race, with habits averse to the rapine and violence to which the Baluch tribes are addicted. In personal bravery and endurance of privations and hardships, the Brahui are esteemed superior to all the neighbouring races. Their gratitude is lasting, and their fidelity conspicuous. They are mild and inoffensive in manner, though uncouth and uncivilised. Their women are not secluded.

The tribes, especially the Brahui mountaineers, reside in tomans, or collections of tents. These tents are made of goats' hair, black or striped; the furniture is very simple, -a few metal cooking pots, a stone band-mill, and some rough carpets and rugs, with a distaff for spinning wool, and a hookah, are all that are usually found in a Brahui tent. That of the chief may perhaps be better furnished, and he is richer than his neighbours in flocks and herds. The dress of the lower orders is made up of a long tunic, trousers loose at the feet, and a black or brown greatcoat or cloak, usually of felt, kamrband, and sandals. They wear a small cap, either fitting tight to the out- line of the head, or dome-shaped, with a tassel on the top. Those of the higher classes are elaborately ornamented with gold thread. A few wear turbans; and the Baluch have them preposterously large, of white muslin. The higher classes are somewhat better dressed, and carry loongees or scarfs, which they throw around their shoulders in exactly the same manner as a Scotchman wears his plaid, and as the ancient Irish wore them long ages ago.

Saharawan province, in Central Baluchistan, is about 10,000 square miles. The population does not exceed 50,000. This elevated plateau is the more northern of the Baluch confederate provinces, and runs with the Afghan districts of Peshin and Toba, and is separated on the east by a range of hills from Dadar and Cutch Gandava. It has only the Bolan river and a few rivulets, but the climate is cool, and the rains ensure good grain harvests. Quetta, Kot, or Shal is one of its districts, and snow lies there for two months of the year. The population cousists of the Kassi (Kassye) tribe of Afghans, who claim affinity with the Safi clans; but in spring and summer numerous Brahui tomans range over its plains. Its capital, called Shal by the Baluch, by the Afghan is called Quetta, an equivalent for ' $k$ ot' or fort, sometimes Shal-Kot.

The Shal valley was ceded to Nasir Khan of Kalat by Ahmad Shah, the first Daurani sovereign. It has many small divisions and villages. Its capital, Shal or Quetta, is very unhealthy from July to September.

Part of the Sherwani Brahui dwell in Shal. The Sherwani occupy also exclusively Khad and Kishna, but reside with other tribes in Shal and Mustung. They take their name from their belief that they came from Sherwan on the Caspian.

Mustung has a healthy climate and fertile soil. It contains no Afghans, the fixed inhabitants are Dehwar, mixed with the Raisani, Sherwani, Mahmud Shahi, Bangal-zai, Lari, and Sirphera tribes of Brabui.

The Raisani, the most respectable of the Saharawan tribes (from Rais, Arabic for ruler), are able to raise 500 fighting men. The Raisani furnish the chief of Saharawan, whose place on all state occasions is on the right of the Khan of Kalat, the chief of Jhalawan being on the left. They are traders, horse-dealers.

The Lari Brabui occupy the valley of Nermuk in Sabarawan, but reside also at Mustung and Shal, with other tribes.

Sirphera, literally head-shearers, dwell in Saharawan and Cutchi. They reside in summer in Gurchani, and during winter in Cutch Gandava. Pliny mentions the Saraparæ near the Oxus.

Mangachar has a few dispersed hamlets. It is well irrigated with canals, and the whole plain is intersected with dams to preserve the rain. The tomans are scattered over the plain. Many brood mares are kept. It is separated from Mustung by a lengthened valley termed Khad, in which the Sherwani tribe of Brahui dwell. The Brahui tribes on the east border with the Mandawari, Kuchik, and Puzh Rind tribes and the Ghazghi Brahui, adjacent to Cutch Gandava. The Langhao are in Mangachar.

Dasht-i-be-Daulat belongs to the Kurd Brabui tribes. It is in the northern part of Saharawan and west of the Bolan Hills, and is about 15 miles 


\section{INDIA, ITS BALUCHISTAN NEIGHBOURS.}

in length and breadth. In spring it is clothed with lovely flowers and grasses, and is then covered with the tomans of the Kurd, who retire to Merv after the harvest of autumn, and then predatory bands of Khaka roam over the ground. The Kurd possess also Tikari in Cutch Gandava. Their sections are the Made-zai, Shadan-zai, Zirdad-zai, Shadi-zai, and Massutari. A pastoral tribe of Kurd occupy the Kohistan.

The Kharan province, in which lie two small towns, is occupied by a Rind tribe of Persian origin, called the Nusherwani, of whom the Alifzai are one branch. They cultivate a little wheat and barley, but insufficient for their own wants. They claim a descent from Nusherwan similar to the Udaipur Rajputs. They are the dominant tribe in Kharan. The Dagari and Hijbari tribes are said to be the original owners.

The Rodani Rind are at Ashi Khan and Puden, the Ghazghi and Samalari are in the hills west of Khanak, and the Sunari in Dasht-iGoran.

Jhalawan province has that of Saharawan on the north and west, Las-Beyla on the south, and Cutchi and Sind on the east. It lies between lat. $26^{\circ}$ and $29^{\circ} \mathrm{N}$., and long. $65^{\circ}$ and $67^{\circ} \mathrm{E}$., and comprises the districts of Sohrab, Zahri, Baghwan, Khozdar, Zidi, Kappar, Wad, and Nall, together with the hills occupied by the Mingal, Bizanju, and Samalari Brahui. The inhabitants are pastoral, and have large flocks of sheep. Jhalawan has less elevation than Saharawan. Many of the tribes are supposed to be of Rajput origin; and, until lately, the practice of infanticide was prevalent amongst them. Near Bagwana Dr. Cook saw a cave in the rock filled with the dried mummy-like bodies of infants, some of which when seen had a comparatively recent appearance. The fixed population in their little towns does not exceed 10,000, and are greatly exceeded by the pastoral tribes. The great Brabui tribes of Mingal and Bizanju give them the preponderance. The Bagwana valley is all well cultivated.

Bizanju Brahui inhabit the districts of Nall, Urnach, and Kolwah, also Ormara in Makran. They have 10 sections,-Tamarari, Muhammadari, Gabarari, Umarari, Nindowari, Ludani, Lotani, Chanal, Baduzi, and Siapad. Many of the sections occupy the Urnach valley. The two great divisions, the Umarari and Tamarari, are west of, but on the same hills as, the Mingal. They are a violent people, and much addicted to rapine.

Boharzai is a predatory tribe in the Chiru Nal valley in Jhalawan.

Khozdar, a sub-district of Jhalawan, has the Mardui Brahui tribe. They smelt lead from a carbonate ore.

The Mingal, a powerful Brahui tribe, dwell in the southern hills of Jhalawan, from the limits of Kliozdar to Bela in Las. Their manners are rude and their habits predatory. The Shahi-zai and Phailwan-zai are their two great divisions. They pretend to be able to raise 18,000 fighting men.

Ziggar Mingal dwell in Nushki to the west of Salharawan. They are hospitable, and adhere to their promises. The Ziggar Mingal and Rakshani of Nushki have no proper towns or villages, but reside in tents, though not migratory. Their river, the Kaisar, is useless for irrigation, and is lost amongst the sands. They cultivate wheat at the skirts of the hill ranges supporting the plateau of Saharawan. Snow seldom falls. The Ziggar Mingal at one time occupied the Dasht-i-Goran near Kalat, but their increasing numbers compelled them to emigrate into Nushki, dispossessing the Rakshani, of whom two tomans or clans still reside at Nushki. They have a much-valued breed of horses, called Tarji. Their flocks are very numerous.

The Nusherwani, the ruling tribe in Kharani, extend into Nushki, others into Baluch Makran, Panjgur, and Kolwah.

Sageti (Sajadi ?) have about 700 adult men. They inhabit the valley of Graisha in Jhalawan. They are supposed to be descendants from a portion of the force that marched southwards with Alexander. The chief family of the tribe are the Saki, distinctly of Scythian origin. They are of those Sakæ who formed part of Alexander's army, and whose country is stated by Dr. Wilson to have been that lying between the Paropamisan mountains and the Sea of Ural. It is not improbable that they accompanied Alexander as far as the south of Sind, and, returning with Craterus up the Moolla pass, settled in their present position. Sakæ still occupy the borders of the Caspian.

Zahri or Jahri, a Brahui tribe in Jhalawan.

Nushki is an extensive province west of Jhalawan. It has several towns and castles, and is inhabited by Mehmasani, Nusherwani, and Mirwari.

Mirwari Brahui are in Nushki, Jao, and Kolwah in Baluchistan.

The Mehmasani have branches in Seistan and in the hills of Luristan.

Kalat town, in lat. $29^{\circ} \mathrm{N}$, and long. $66^{\circ} 40^{\prime}$ E., is the capital of Baluchistan. It is 7000 feet above the sea, in a narrow valley, with the hills of Cutch Gandava on its east. Its soils are rich, and it has one permanent stream, with several of the karez aqueducts. Kalat district is the principal district of the Brahui race. The town was taken by storm by the British Indian army on the 13th November 1839, from the northern or Mustung gate. The population consists of the dominant Brahui, and of Baluch, Dehwar, Babi, Afghans, Ghilzae, and slaves. The miri or citadel has the palace of the khan. The Babi suburb is on the south side ; Brahui, Ghilzae, Afghans, and others dwell in the Past-i-Shahr, and Afghans are in all the suburbs. The number of the inbabitants has been stated at 12,000, and that of its houses at 800 . The Abmadzai branch of the Kamburani is the section of the Brahui to which the Khan of Kalat belongs. It is said to be descended from Kambur, son of the Imam Kambar; but Kambur, in Baluchki, means an Abyssinian, and the dominant tribe is believed to have come from that country, and to have been ruling since the middle of the 17th century.

Gadad are the slaves (Khanazad, household guards) of the Brahui rulers. Every family of consideration in Baluchistan has slaves either of African origin or of captives taken in predatory excursions.

Dehwar speak pure Persian. They are the settled inhabitants of towns and on culturable lands. They are called Tajak in Persia, Sart in Bokhara, and Dehgan in Afghanistan, Dehwar and Dehgan meaning villagers. They are a quiet, orderly people. In Baluchistan they have about 
INDIA, ITS BALUCHISTAN NEIGHBOURS.

thirty sections, in fire grand divisicns. Dr. Cook s.lys their language is nearly pure Persian; they inluabit the Deh or villages, and do not migrate, are an agricultural people, hard-working and poor.

The Babi or Ababi are a wealthy trading class in the Shal district and at Kalat. They are stout, well-made men, with good features and pleasant manners. They appear to have come originally from Afghanistan. They have four khel or sections,-Umar, Hija, Chur, and Ganga.

Cutch Gandava for brevity is generally called Cutchi. It is bounded on the N. and N.E. by the M urree and Bugti countries, on the WV. by the Hala mountains, ou the E. by Sind, but is separated from Sind in the S. by a desert strip 20 miles broad. From these bounds it will be seen to extend from the town of Dadar, near the mouth of the Bolan pass in the N., to near Khyree Gurree in British Sind in the S., a distance of 100 miles, and from the Hala mountains on the WV., 150 miles eastwards to the Panjab. The surface is nearly uniformly flat, and is mostly a waste, for although the streams of the Bolan, the Narra, the Shari, and the Teywaugh run through it, - and wherever water is obtained Cutchi can be cultivated, and bajra (Penicillaria spicata) and juari (Sorghum vulgare) grown,-the air is arid, the average annual quantity of rain being about two inches, and for two or three years at a time there may even be no rain. When it does fall, a severe form of fever follows, from which no one escapes. Except within the influence of irrigation or after successive seasons of favourable downfalls, Cutchi may be termed a desert waste. Bagh, the principal town, in lat. $28^{\circ} 56^{\prime} \mathrm{N}$, and long. $67^{\circ}$ $54^{\prime}$ E., about 38 miles from Dadar, has a population of 8000 to 10,000 ; the neighbourhood is positive desert or Pat. Gandava is the second town.

Dadar, in lat. $29^{\circ} 28^{\prime} \mathrm{N}$., and long. $67^{\circ} 34^{\prime} \mathrm{E}$., and 743 feet above the sea, is also a town of some importance. It is 5 miles from the $E$. entrance of the Bolan pass, and is well supplied with water from the Bolan river, but it is almost surrounded by hills, and the closeness and great heat have given rise to the Persian saying, ' $\mathrm{Ai}$ Allah! Dozakh chira sakhti chon Dadar hasti !'-O Lord ! why did you make hell, when you have Dadar? The Bolan pass is 54 miles long reckoning from its mouth, 5 miles W. of Dadar, through the Hala mountains to the Karlaki, $2 \frac{3}{4}$ miles to the $\mathbf{E}$. of the Dasht-i-be-Daulat, 5900 feet above the sea, where the fertile, well-watered valleys of Mustung and Shal occur. From April to August, the climate of Cutchi is proverbially sultry, and the desert blast, the bad-i-simum or jaloh, sweeps across it. In winter the climate is temperate, and the Khan of Kalat, and all the wealthier Brahui, as also the Rind Baluch, resort to it. The khan takes up his residence at Gandava, but Bagh is the more important town. The several tribes in Cutchi number in all about 100,000 souls. It is inhabited by very distinctly marked races, - the Jat, Rind, Maghazzi, and Brahui. The Jat seem the original race, and occupy the centre of the province. The Rind, lawless sub-tribes, Jakrani, Dumki, Bugti, and Murree, are n more recent intrusive race dwelling on the skirts. The Doda, a division of the widely dispersed great Murree tribe, for the last three centuries have cccupied the hill ranges $\mathbf{E}$. of the plain of Cutchi. The Murree are a brave race, long distinguished as daring depreda- tors. In 1880 they harassed the British in the advance to Kandahar.

Harand and Dajil, in Cutch Gandava, but bordering on the Indus, are inhabited by the Gurchani, and have the Mazari on their south.

The pastoral and agricultural tribes are the Jat, the Khosa, Jamali, Jettui, Machee, Oomrani, Ramdani.

The Dumki sub-tribe of Rind claim a Persian origin; they are a hardy, brave, and martial race.

The Jat, distributed thronghout Baluchistan, are all Muhammadans. Those of Cutchi have $2 \cdot 2$ sections engaged in tillage; also 18 section of camel-breeders.

The Jat of Cutchi dwell in villages.

The Guruwani tribe in Cutchi follow Muham. madanism, but are descendants from former Hindu rulers in the highlands of Baluchistan.

The Kaihiri is a strong but peaceable tribe in Chatar and Pulaji in Cutchi, who claim to be Shaikhs from Afghanistan. They rendered good service to the British. They suffered defeats in 1828 from the combined Murree, Bugti, Dumki, and Jakrani, and were driven out of the country, but were restored by Sir Charles Napier after his hill campaign in 1845 . He enrolled eighty of their number as irregular horse, and stationed them in the Cutchi side of the desert. These are still kept up, at Rs. 14,580 per annum of pay.

The Langao tribe is of Hindu origin, and retain the Hindu titular appellations. They dwell S. of Bagh in Cutchi, and in the valley of Mangachar between Kalat and Mustung. Their Maidizai offshoot reside in Gwadar.

The Magheri tribe have four subdivisions,Hajizai, Bambirani, Bhond, and Arbani. Their chief town, Jalal-Khan, is N.W. of Bagh.

The Jatui is a small agricultural sub-tribe of Rind Baluch between Shikarpur and the Indus, also in Cutchi. They were formerly predatory, but are now peaceable. They have eleven subdivisions.

The Tarin, a Pathan tribe furnishing about 700 fighting men, inhabit the country to the north of Cutchi.

The Jakrani tribe is Baluch; they occupy the portion of Cutch Gandava to the E. of Chutar and Shahpur. They are a section of the Maghazzi. They have nine subdivisions,-Salivani, Majani, Sujapaz, Suwanani, Sudkani, Solkani, Mulkani, Karokani, and Dirkani, and have 300 fightiny men well mounted. They and the Dumki before British annexation were largely predatory, but after Sir Charles Napier's campaign in 1845 , the best portion of this tribe was removed to fertile land near the Kashmir desert in the Jacobabad district. They used to unite with the Dumki, and could muster for plundering about 1500 hor'semen well armed, with about 500 more able-bodied armed men on foot. The Jakrani carried on their forays on horseback, and levied black-mail on all merchants. They are now peaceful cultivators of their own and Government lands.

The Kojah are a section of the Kakar Afghans who have settled in the district of Sibi in $\mathrm{N}$. Cutchi. They have attained to great power, and in 1840 had 700 fighting męu. Their country is richly cultivated.

The Barozai or Barozhi, a clan of Pathans, reside in the town of Kurk in Sibi, a semicircular bay 25 miles across, in the hills N.E. of Dadar, and 
irrigated by canals from the Narra river. They number 700 men. They are living between the Brahui, Murree, and Kakar, and have adopted the Baluch manners and customs. They pay tribute yearly to Kandahar.

The Bugti is a sub-tribe of Rind Baluch who occupy the hilly country to the W. of the Rajanpur border. Their six divisions, and the number of their fighting men, have been stated as under :-

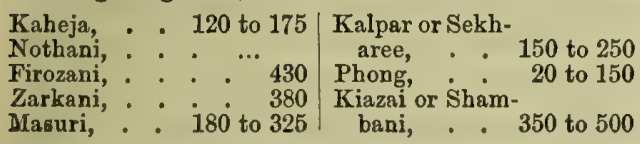

Thus the total number of the Bugti fighting men bas been variously estimated at from 1300 to 4000. Their country is chiefly rugged and barren, but contains much good pasture land and some fertile valleys. They sell cattle and sheep to the people of Sind. Their Kaheja, Kalpar, Notbani, and Phong clans inhabit the hills on the N.W. frontier of Sind and Cutchi and the S. part of the Mazari country on the Panjab. The lands of the Shambani and Masuri clans extend along the Panjab frontier, between the British military posts of Banduwala and Sabzil-ki-Kot on the E., adjoining the Mazari and Dreshuk, with the Gurchani on the N., and the Loharani Murree on the W. The Bugti and Murree were in cessantly at war through a prolonged period. In 1839 the Bugti made predatory attacks on the British army as it advanced on Afghanistan, and were then defeated by Major Billamore. In 1844-45, Sir Charles Napier moved against them with a force of 7000 of all arms, besides a number of Murree Baluch auxiliaries, but only about 3500 Bugti seem to hare opposed. The campaign lasted fifty-five days, with little loss to the Bugti. Major Jacob, in 1847, was subsequently engaged against them, and they suffered much distress for food; and on the 1st October 1847, Lieutenant Merewether killed 600 of them, with a loss on his side of 9 killed and wounded. They have since made several inroads on British territory; but they were broken up, and removed to lands near Larkhana. Such of them as wished returned in 1851 to their own country, and are now orderly, industrious, and contented. Their valley of Mutt is well cultivated, and produces excellent wheat and millet, and they sell their sheep and wool. The original Hindu inhabitants of the Mair and Bugti hills were driven out by their present occupants, but the natives of Barkhan (the Khetran), inhabiting the more mountainous district to the northward, were able to hold their own. The whole are nominally subject to the khan as chief of all, but his power appears to vary with his popularity. Dehra Dibrak, or Dehra Bugti, is the capital of the Bugti. It is in the Siaf valley, and is their only town, for they are essentially nomade. Major Billamore's force captured it in 1839, and again in 1845 General Simpson's column. Bugti occupy also the southern portion of the Suliman mountains, a tract of extremely hilly, stony, and barren country beyond the British frontier on the west, and southwest of Mithenkot in the Panjab, and north of Shikarpur in Sind. They acknowledge the Khan of Kalat. Their valleys are numerous and fertile, with streams flowing through them. They have nine sub-sections. They can muster 1000 fighting men.
The Mazari, a sub-tribe of Rind Baluch, occupy the tract of country on the right bank of the Indus, between Mithenkot and Burdeka, partly in the Panjab, partly in Sind. They are south of the Dreshuk. The adult males are about 2500 . They long continued predatory, and were the most expert cattle-stealers on the border. They are now orderly, and sided with the British in the Indian mutiny of 1857 . They have 39 sub-sections.

The Murree sub-tribe of Rind Baluch inhabit the outer hills which surround Cutchi on the east, north, and north-west sides. They are subjects of the Khan of Kalat. They have the Tarin and Luni on the north, the Khetrani and Bugti on the east, the Bugti on the south, and Kalkar on the west. Their districts are Kahun, Mundabi, Jantali, Phailawar, and Nisao. Their four sections are Ghazani, Loharani, Bijarani, and Mazarani. They number 8000 souls, with about 2000 to 3000 fighting men. They are predatory. Their opposition to Captain Browne of the 5th Bombay N.I., who defencled Kahun, and to Major Clibborn in 1839, is maiter of history. In 1859, an expedition under Najor Henry Green was sent against them. Many of this clan settled in Lower Sind, in the Khyrpur country, and in the districts near Sukker, but these have not for several generations harl communication with the independent hill Mari. The country of the hill Murree is mostly barren hill, with many extensive valleys and fertile spots; it extends from the neighbourhood of the Bolan jass. on the west to the Bugti and Khetrani country on the east about 100 miles, and from Surtoff on the south to the Afghan territory on the north about 80 miles. The Narra river and its large tributary the Lar, also the Lharee, run through it. Their chief town is Kahun.

The Shum plain formerly belonged to the Shumbani tribe, but they have been driven from it by the Murree, who devastated all the country around their own district. - The Dauggati or will ass roams over the elevated plain.

Gurchani dwell south of the Lughari. They are said not to be pure Baluch; the tradition being that Doda of the Deh caste was banislied from his tribe, and, mounting his mare, he rode into the desert, lost his way, wandered on and on, until at last he was found by the Rind more dead than alive. After trying all other means to revive him, a young virgin was sent to lie with him, that the warmth of her body might restore him to life, which was effectual, and he married her. His family rejoined him from Tatta or Sewerton in Sind. The Gurchani have 49 suo-sections.

The Dreshuk is a Baluch tribe dwelling Eouth of the Gurchani. They are large landowners, but all their lands are cultivated by the Jat 1ace. They have ten sub-sections.

The Khetrani or Khuttran tribe, about 18,000 in number ${ }_{3}$ are in a district in the hills of Baluchistan to the north of the Bugti country, which their district adjoins. Its greatest extent is about 120 miles N. and S., and 70 miles $\mathrm{E}$. and W. The chice town is Barkhan, which is about 160 miles N N.E. from Shikarpur. N. of the Khetrani are the Afghans, to their W. the Murree (Baluch), and on their $\mathrm{E}$. are the Lashari and Gurchani tribes. The Khetrani are not Afghans nor Baluch, but they intermarry with both these races. They follow agriculture, and are of peaceable habits, their country being sufficiently fertile to supply their 
wants ; and though brave and ready to fight when attacked, they abstain from plundering their neighbours. The river Lar runs through their country.

The Lashari and Gurchani dwell in a barren and unproductive strip of country between the Khetrani and Multan. They are shepherds and herdsmen.

The Jamali is a small, poor clan of Baluch cultivators and shepherds, who reside at Rojhan at the N.W. of Shikarpur, and on the edge of the Barshori desert, also in E. Cutchi. They dwell in Upper Sind along with the Jettui, a similar tribe. They are principally in Khyra Garhi in Larkhana. They are not predatory, and some are artisans. A tribe of the same name is found in Lower Sind.

The Dumki tribe occupy the territory between the Mazari on the $\mathrm{N}$. and the Burdi on the S. They were the most martial and formidable of all the Baluch tribes. General Jacob disarmed them, and they subsided into peaceable and industrious cultivators.

Burdi are a small tribe of Baluch, residing mostly in the Burdeka district on the western bank of the Indus, with the Mazari district on the north and Sind canal on the south. They continued predatory until the year 1860 , combining with the predatory Dumki, Jakrani, Khosa, etc. ; but on General Jacob disarming all the population of Sind, and cutting a road through the forest, this sufficed to render the Burdi peaceable and well-disposed cultivators. Several small branches dwell in Sind and Cutchi.

The Khosa tribe is scattered all over the country between Nuggur Parkur and Dadar, and have several villages on the Sind border. They are said to have been originally Abyssinians. The tribe is found in many parts of Upper Sind, Cutchi, and on the southern frontier of the Panjab. Major Pollock, writing in 1860 of the Khosa in the plains of Dehra Ghazi Khan, said a Khosa who has not been in jail for cattle-stealing, or deserved to be, who has not committed a murder, or debauched his neighbour's wife, or destroyed his neighbour's landmark, is a decidedly creditable specimen ; and if, added to this, he is out of debt, he is a perfect marvel. They have 35 sub-sections.

The Maghazzi are subdivided into four principal families or clans, of which the Butani of Jell are the most illustrious, and give the chief or sirdar to the whole. They boast of being able to muster 2000 fighting men; between them and the Rind a blood feud long existed. The Maghazzi and Rind are alike addicted to the use of ardent spirits, opium, and bhang. They are one of the principal Baluch tribes in Cutchi. Their chief town is Jhal, 24 miles from Gandava, at the foot of the western hills. They can raise a formidable force of wellmounted men. They resemble the Narui in sizo and stature, and, like them, have good features and expressive countenances, but are not capable of bearing so much fatigue. A small number of them in 1830 defeated the Rind. Pottinger included amongst the Maghazzi, the Abrah, Burdi, Isobani, Jakrah, Jakrani, Jalani, Jataki, Kalandarani, Lashari, Matihi, Musani, Kakrani, Nari, Turbandzai, and Unar. Postans considered them to be of Jat origin.

LAS. - Las and Makran are two seaboard provinces. Their coasts are arid and sterile, with sandbills and other rugged hills near the sea.
The Las province lies between lat. $24^{\circ} 50^{\prime}$ and $26^{\circ}$ $15^{\prime} \mathrm{N}$., and long. $65^{\circ} 28^{\prime}$ and $67^{\circ} 18^{\prime} \mathrm{E}$., with an area of 5000 square miles. Las means the plain country. Las extends from the Hingor river to the river Hubb (by Ras Muari), and is separated from Lower Sind and the delta of the Indus by the Hala mountains. Its chief town is Bela (Beyla), and is the residence of its chief, the Jam. The houses of this town are mean, but ancient coins, trinkets, and funereal jars are exhumed near it.

The Chandra kup or basins of Rama Chandra are in the province of Las, near the Phor stream, on the road to the temple of Hinglaj, and between the greater and lesser Hara mountain ranges. The kup are seven small truncated conical hills of very lightcoloured earth, rising two to four hundred feet somewhat abruptly from the plain, with numerous fissures at their base. They are saline mud volcanoes, the mud constantly bubbling up, and sometimes overflowing. There are similar mud volcanoes in Makran.

Shahr Roghan is a deserted town of caves resembling those of Bamian. It is about 9 miles north from Bela in Las, on either bank of the Purali river, in a wild, broken ravine, with cliffs rising perpendicularly 400 or 500 feet. The excavations, about 1500 in number, are in the form of rooms 15 feet square. The legend connected with it resembles that of Tobit and the seven friends. It relates to a beautiful but demonharassed princess, Buddul Tumaul, who slew her seven lovers, and was at length rescued by Saif-ul-Mulk, son of the king of Egypt.

Hinglaj in Las is famous for its Hindu temple. It is on the Hara range, near the Aghor or Hingor river, about 30 miles from the seaport of Ormara, and 150 from Kurachee. It is one of the fifty-one pita or spots on which, according to Hindu belief, the dissevered limbs of Sati or Durga fell. Muhammadans regard it as the shrine of Bibi Nani, the Nanaia of the old Babylonians, Bactrians, and Persians.

It has many subdivision, such as Jamhot, Gungah, Angariah, Chuta, also the Gadur, Masorah, Manghia, Shekh, Shahoka, Sur, Vahreh, Sabrah, Mandarah, Runja, Burah, Dodah, etc. The population of Las province has been estimated from 30,000 to 60,000 souls. Their tribes are the Lumri or Numri, the Chuta, Med, Jokia, and Barfat. The people are Muhammadans, many of them of the Mehman sect. The seaport Sonmiani contains numbers of the Mehman sect or race, and part of the fixed population of Bela is called Jaghdal.

The Lumri or Numri is the dominant tribe, and is commonly termed the Lassi branch of the Lumri tribe. The Lumri or Numri are believed to be descendants of the Samma and Sumra Rajputs. They trace their origin to Samar, who founded Samarcand, and acknowledge a consanguinity to the Bhatta of Jeysulmir. Lumri have obtained possession of all the hill tract lying between the Pubb mountains and the Indus, east and west, and between the Mallir and Bharun rivers on the north and south, from which, about A.D. 1780, they ultimately drove the Khosa. Their features resemble those of the Rajputs. They wear arms, but they are peaceful shepherds and cowherds: They form the bulk of the population of Las. The Jamhot or Jamot are the dominant tribe of the Lumri, and furnish the Jam or ruler 
of the province. The Dodeh are a section of the Lumri in Las. The Lumri are an active, hardy, pastoral people ; their wealth consists in flocks of goats, with fewer buffaloes and camels. They despise agriculture; wild Lumri are found grazing on the rocky banks of the Hab river. Their language varies little from that current in Sind. They manufacture coarse fabrics from the wool of their goats and camels. The Lumri eats meat almost raw, and is greatly addicted to the use of opium.

The Biruvi tribe dwell near Bela; they sell their children when in want. They are better looking than the Sidi, and, as they speak Sindi, Hindus prefer them as domestic servants.

Hormara, a sterile district with a port of same name, is subject to Las. Near Jabal Malan is a tribe called Gujur; at Garuki, the Saugor tribe ; and at Hormara in Makran, with four hundred houses, is a tribe of this name. The Hormara tribe say they came originally from Sind. Persani, west of Hormara, is a small port of two hundred houses.

Chuta, a small tribe of 2500 souls, occupy a district of the same name, on the river Hub, which falls into the sea at Cape Monze. They are said to be of Sumrah, but also, it is said, of Brahui origin, and seem to occupy the Pubb hills of Kurachee, on both banks of the river Hub, and separated from British territory by the Kurter, Mihi, and Mol hills. The Chuta say that when Dodeh, their ruler, fell in the battle by Allah-udDin, the Chuta tribe left Sind and joined the Brahui. They are pastoral, cattle graziers. They are of smaller stature than the Sindians. Their huts are of mat or of coarse blanket, drawn over a rough framework of sticks. They wake their dead. They are quarrelsome, and so addicted to thieving as to have an alliteration of their name Chuta Buta, Chuta Rogue. They have 14 clans.

Las has two or three places for receipt of custom.

MAKRAN is a province which extends from Jashk to the Hingor river. Makran has Persia on the west, the provinces of Las and Jhalawan on the east, Persia, Afghanistan, and the Kharan district on the north, and the Arabian Sea on its south. Its western portion is under Persian rule, and its eastern under the Khan of Kalat; the boundary being at long. $62^{\circ} \mathrm{E}$. Its name is supposed to be the combination of two Persian words, Mahi-khoran, Ichthyophagi. It was also known to the ancients as Karmania altera. From Cape Jashk on the Purali river, a distance of 500 miles, the shores of the coast of Makran are washed by the Arabian Sea. It is a district of hills and valleys, in parallel ranges running east and west, but almost rainless. On many of the hills are beds of clay, 50 to 150 feet thick, containing fossil shells of the miocene formation. Between Gwadur and Ras Kucheri are many of the mud volcanoes called Chandra kup, and near Ras Jashk is a hot spring with a temperature of $128^{\circ}$. One group of the Chandra kup, consisting of three cones, is a mile to the westward of Huki and about 60 miles from Sunmiani. The other group, consisting of two cones, is about 10 miles north of Ormara.

It is the most westerly of the Kalat territories, and is sometimes called Kej Makran. It is the Gedrosia of the Greeks. It is inhabited by many tribes, of whom the Gitchki is the most numerous, but about half the population is of a sect of Muhammadans called Zigger. Its chief town is Kej; Gwadur and Ormara are seaports, and Panjgur is an inland town. The Makran and Las region has been familiar to Europeans ever since the trying march across it of Alexander the Great. He left Patala in Sind (presumed to be Tattah on the Indus) some time in March or April, and proceeded in the direction of Bela, crossing in his route the lower ranges of the Brahuik mountains. Thence he marched in the direction of Jao (Jhau) in Makran, forcing a very difficult pass some distance south of the ancient town of Gwajak, where he was opposed by the natives. He then kept nearer the coast, traversing the present Kolwah district, experiencing much difficulty in obtaining water, and suffering from fatigue, hunger, and thirst, until he reached the fertile valley on the western border of Gedrosia, the present Banpur, from which he passed into Karmania, the present Persian province of Kirman.

The names of the places mentioned by Arrian on the Las and Makran shores, viz. Malana, Araba, Kalama, Derembosa, and Kophas, are still retained in the modern designations Malan, Araba, Kalamat, Darambab, and Kophan. The Asthæ of Ptolemy and Kamina of Nearchus, is the small island of Satadip, called Asthilal by Arabs and Baluch, lying a short distance off the Makran coast, between Ormara and Pasni, its other names being Astola Island, Haftala, Sataluh, and Sangadip. It was much resorted to by the Juasmi pirates. Hindu pilgrims visit it.

In the time of Marco Polo traffic seems to have been directed through Makran, whose people, he says, "live by merchandise and industry, for they are professed traders, and carry on much traffic by sea and land in all directions. And you must know that this kingdom of Kes Makran is the last in India as you go towards the west and north-west.'

The babits of the people on the coast seem to be identical with those of the races who are known to have dwelt there two thousand years ago, and described by the ancients as the Ichthyophagi. From Basrah to Hormuz, and eastward to the Indus, the sea-coast people still principally live on fish. The Mahi-abah and Mahi-ashnah, literally fish-bread and fish-soup, used among the people of Las, is prepared from fish (more particularly a small kind found near Hormuz), dried by exposing it to the sun. Strabo and Arrian relate that the ancient Ichthyophagi made into bread in a similar manner, the fisb, which they dried and roasted. The region of the Ichthyophagi, as known to the ancients, commenced at Malana, near Cape Arabah, and ended between the ancient Dagasira and the place now called Cape Jashk. Churchill's collection of voyages mentions that 'the corstes of Persia, as they sailed in this sea, seemed as a parched wildernesse, without tree or grass ; those few people that dwell there, and in the islands of Las and Cailon, live on fish, being in manner themselves transformed into the nature of fishes. So excellent swimmers are they, that seeing a vessel in the seas, though stormie and tempestuous, they will swimme to it five or six miles, to begge almes. They eate their fish with rice, having no bread; their cats, hennes, dogges, and other creatures which they keepe have no other dyet.' Nieuhoff, also, who travelled in 1662 , says that 
about Gambroon, the common people make use of 'dates instead of bread or rice; for it is observable that the ordinary food of the Indians, all along the coast from Basora to Sinde, is dates and fish dried in the air; the heads and guts of the fishes they mix with date-stones and boil it altogether with a little salt water, which they give at night to the cows after they come out of the field, where they meet with very little herbage.' At the island of Kharak, also, at the present day, fish and dates are the chief articles of the people's food, and fish is still the staple article of food of the inhabitants on the sea-coast of Baluchistan.

There are, in Makran, cyclopean structures raised by some unknown prior race. They are called Ghorbasta or Ghorband, and bear a resemblance to the cyclopean remains of Europe. They are built across ravines and on the declivities of mountains, to form tanks and to distribute the water. They must have been constructed by a race who had, on entering it, foreseen that the country would not otherwise support them, and the race is supposed by Dr. Cooke to have been Pelasgi, or a people with kindred habits.

Ras Jashk, or Cape Jashk, is the western limit of the Makran seaboard. The inhabitants of the village near it are Baluch and Arab fishermen.

The present population of Makran, about 200,000, consists, -1st, of Gitchki, Boledi, and Malikah, who furnished the ruling chiefs in Makran; 2d, the second class are great and powerful tribes, some of them of Brahui origin, viz. the Bizanju, Nusherwani, Mirwari (Brahui), and some Narui or Baluch, viz. Hot and Rind; $3 d$, tribes of respectability, viz.:-

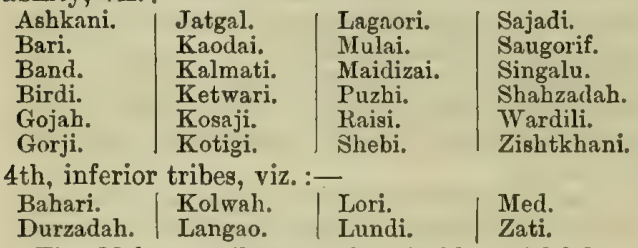

The Makran tribes are hospitable, faithful to their agreements, and courageous. Though averse to European discipline, they take service with Sindhia, Holkar, the Gaekwar, and the Kattyawar chiefs. The Makrani is capable of great fatigue and endurance, though not of large frame. Their language is a branch of ancient Persian. Their houses are mean, chiefly of matting.

The Saugor, a tribe of Baluch, are fishermen.

Gwadar town is occupied by 4000 or 5000 inhabitants,-Biadhiah, Arab, Hindu, Khojah, Med, and Korawa.

The small seaport village of Chaobar or Charbar, belonging to the Imam of Muskat, has 560 inhabitants, consisting of Med, Bosdar, Keji, Tizi, Shirik, Khojah, Bania, and Hamali.

The Raushani Narui, in Upper Makran, aro numerous and influential, and have the following sections:- Arbabi, Khasoji, Kurd or Shahidi, Malika, Ming or Mind, Rakshani, Sajadi. The Rakshani give the chief to the tribe.

The Mand district is occupied by a lawless portion of the lind tribe.

The Jagdal, Jalgal, Zodgal, or Zadgal tribe, in Makran, are of Lumri or Numri origin, immigrants from Sind and Las. They wrested power from the Boledi, and now hold the Baho Dashtiari district under the Persian Government.
The Kalmati or Karmati tribe in Baluch Makran are immigrants from Sind.

The Hot, a Baluch tribe, is widely spread over Central Makran, in Tump, Dasht, Baho, and Geh. They are the most numerous in the province, and are held in high consideration.

The Mirwari tribe dwell in Mushki, Jhao, and Kolwah. Pottinger in 1810 said their fighting strength was 7000 . Masson says they are of the Kamburani family now ruling at Kalat.

Ashkani Baluch are settled in the hilly districts north of Kej, in Baluch Makran.

The date trees of Makran flower in February and March, and the fruit ripens in August and September. When in full flower, a stalk of the male flower is inserted into a small incision made in the core of the top of the female tree.

The maritime and fishing population of the little ports on the coast of Makran, from Sonmiani to Charbar, are often denominated Med, and comprise four divisions, - the Guzbur, Hormari, Jellarzai, and Chelmarzai. Med fishermen are boat-owners. Padiharee have no boats. The other fisher races are the Korawa and the Raisi. The Kaodai or Khudai, a tribe in the Dasht and Kolwah districts of Makran, are a well-to-do and respectable people. Lagaori tribe in Persian Makran are perhaps the Laghari.

The Birdi is a tribe scttled in Makran.

Zati or Sati occupy chiefly Baho and Dashtiari.

The Shabzadah are of Arab descent. They first settled in Sind, but migrated afterwards to Juni, Dasht, and Baho, in Makran.

The Boledi also is an Arab tribe, which has taken its name from that of a town in the $\mathrm{Kej}$ district. In the 17 th century they seem to have subverted the power of the Malika, only to be, in their turn, put aside by the Gitchli.

The Kolwah dwell only in Gwadar, in Makran, to which they came from Juni, where they were slaves or servants to the Shabzadah. They are a seafaring people, superior to the Med in social position; but, like the Med, superstitious and immoral, with peculiar religious rites.

Panjgur (or Panchghar) is a district of Baluch Makran about 100 miles to the N.E. of Kej. It is a rich and fertile tract, with a cluster of forts and villages amongst groves of date trees, for which it is celebrated. It is occupied by the Gitchki tribe of Brahui, of peaceful and agricultural habits, and also by the Nusherwani tribe of Persian origin, the two tribes being at feud.

Kolwah is an extensive valley of Baluch Makran, immediately west of the Jhao district. It is separated by a sterile hilly tract from the maritime district of Ormara. It is four or five days' journey from the coast, has several villages and castles, and is occupied by the Bizanju, Kaodai, Mirwari, Ormarari, Rakshani, and Nusherwani tribes, who interchange their commodities with the coast, sending wool, ghi, hides, and bdellium. Wheat is largely grown here.

The Homarari occupy Balor. Ormarari may mean the people of Ormara.

The Banpur valley is a province in the Kohistan of Baluchistan. It was annexed by Persia about 1845, and now forms part of Persian Baluchistan. It was at this valley that Alexander emerged from the arid tract he had followed through Bela, Jhao, and Kolwah.

Jhao or Jao, a valley to the west of Las, and 
east of Kolwah, is sparsely inhabited by Bizanju, Halada, and Mirwari (Brahui), who are rich in herds of cattle, buffaloes, and camels, and in flocks of sheep and goats. It is well wooded, without cultivation. The valley has but one village, Nandaru. Numerous mounds, here called dam or 'daim,' exist, where coins and trinkets are found, remnants of some former civilisation. These daim occur in other parts of Baluchistan. There is also the site of an ancient city, which Masson has suggested may be that founded by Alexander the Great amongst the Oritæ.

$K e j$ is a division of Makran, and properly included the districts of Dasht and Kolanch.

The Kolanch district has a population of 2000 of the Puzbi, Band, Wardili, Jagdal, and Biznnju tribes.

The Dasht district extends from Gwetar Bay, N.E. to the vicinity of Kej, a distance of about 100 miles. The inhabitants are members of Bar, Birdi, Hot, Kaodai, Sbabzadah, and Rind tribes, in all probably 3000 or 4000 persons.

Kej town was the former capital of Makran, and is now the residence of a deputy of the Khan of Kalat. It is a cluster of small villages and forts in the great valley which traverses Makran from east to west. The population consists of Gitchki of much importance, the Raisi, the Mulai, the Sangura, Durzada, Leri, Lundi, and Kutwari, about 10,000 souls. The name of the district of Kej Makran is written by Mandelelo Getsche Macquerono. Marco Polo names it Kesmacorono, which is supposed to be Kej mahi-khoran, fish-eating Kej. Ibu Haukal (p. 140) says ' the Baloujes are in the desert of Mount Kefes, and Kefes in the Parsee language is Kouje, and they call these two people Koujes and Baloujes. The Baloujes are people who dwell in the desert.'

The Gitchki tribe are settled both in the Baluch and Persian portions of Makran, but have their chief residence in the town of $\mathrm{Kej}$. They are said to be descended from a Sikh named Mar Singh, son of Pana Singh of Lahore, who in the early part of the 17th century settled with his companions in the Gitch district. One branch resides in Kej and Tump, and another at Panjgur. Since the beginning of the 18th century, they have been at feud with the Boledi, but intermarry with them. Some are of the Zikri, some of the Dai sect.

Mulai or Mullai, a Baluch family settled in $\mathrm{Kej}$; it is not numerous, but is respectable, and some of them seem to belong to the Zikri sect.

Ketwari is a Brahui tribe in the Kej district.

Kosaji, a tribe occupying Baho and Dashtiari in Persian Makran. Baho and Dashtiari are under the superintendence or rule of two Jagdal chiefs. The inhabitants are Jagdal, Hot, Latti, Raisi, Laghari, Kosagi, and Shahzadah.

RELIGION.-The people of Makran are Sunni Muhammadans, but have amongst them the Dai, Mazhabi, or Zikri, the Biadhiah, and Khojah sectarians. The Khojal are often opprobriously designated Lutiah. The Dai or Zikri sect are in Baluch Makran, in Kej, Kolanch, and Kolwah. The Dai, met with at Gajer, resemble the Brahui in appearance, and wear the same dress. Portions of certain Brahui tribes are Dai, such as the Sageta, Saki, Shadu, Shahduzai, Marbrow, etc. They say that they originally came from the westward near Kej, where there is a city called Turbot. The sect abounds in Makran, and has extended east. At Turbot is a little hill of circular form, called by them Koh-Murad, on the summit of which is their principal masjid, where they meet at stated times to perform their rites. Their book is said to enjoin them to curse Mahomed, and in derision to say God is God, but the mother of Mahomed is His prophet. Their ritual services are conducted at night; men and women assemble, and revolting acts are said to be practised during the wild state of excitement into which they work themselves. Their prophet is Mahdi, and they date their origin from A.D. 1591 in the Panjab. At marriages their priest is said to see the bride, but all these may be caluminies, as they are of the kind usual amongst Asiatics when alluding to other sects. At the siege of Kej they conducted its unsuccessful defence against Mihrab Khan's son, and the assailants killed or captured all its defendants, exhumed and burned the remains of their patron saints.

Professor Wilson, in his Ariana Antiqua, p. 141, mentions the Dai amongst other Seythian tribes as associated with the Massagetæ; and in a map attached to Digby's translation of Quintus Curtius, their position is fixed a little south of the Jaxartes. This coincidence of association with the Sageta and Sakæ, both then and now, is worth remarking.

The Biadhial sect are Arab immigrants from Oman, residing in the town of Gwadar in Baluch and Persian Makran. They reject both Osman and Ali, and are regarded as heretics (Kharji) by both Sunni and Shiah. Like the Shiah, they practise dissimulation (takiya) in speaking of their faith. They drink wine.

Hinglaj or Nani is a hill in Baluch Makran 1800 feet high, and has one of the most ancient Hindu shrines existing. It is sacred to a goddess said to be Parvati, or Mata, or Kali. The Mubammadans regard the hill as sacred to Bibi Nani, probably the goddess Nanaia of the Babylonians; and the shriue is a well, the water of which at times rises up with a bubbling noise, and pilgrims reverence the rising bubbles by salaaming and throwing in their offerings. If an interval occur between the rising of the bubbles, the pilgrims call on Mata to appear. Animals are sacrificed at the shrine to Kali.

LANGUAGES in use in Baluchistan, are Brahuiki or Kur-Gali, Baluchki, Jatki, and Persian, but only the last-named is a written tongue. Considered as a whole, Dr. Caldwell regards the Brahuiki language as derived from the same source as the Panjabi and Sindi, but it unquestionably contains a Dravidian element, derived, in his opinion, from a remnant of the ancient Dravidian race baving becn incorporated with the Brahui. From the discovery of this element beyond the Indus river, he adopted the opinion that the Dravidians, like the Aryans, the Græco-Scythians, and the Turco-Mongolians, entered India by the north-west route. The Brahuiki language, according to Mr. (Sir George) Campbell, is mainly Arvan (Indo-Persic), with a Turanian element. The Brahuiki or Kur-Gali is spoken by the tribes of Suharawan and Jhalawan, from Sbal or Quetta in the north to Jhalawan in the south, and from Harrand in the east to Kohak in the west. Baluchki is spoken by several of the Jhalawan and Rind tribes, as the Minghal and Bizanju, also by the Brahui Khan of Kalat, and by his sirdars or chiefs, who consider Brahuiki as vulgar. 


\section{INDIA, THE NORTH-WEST FRONTIER TRIBES.}

The structure of the modern Baluch language does not seem to warrant belief that any other than Persian was the parent stem. Philologists concur in opinion that the Baluchki is a tongue of the Aryan or Sanskrit stock, in which Persian, Sindi, Panjabi, and Sanskrit words recur; and that the Brahuiki belongs to the Scythic or Turanian, or Tamulian, or Dravidian stock. Lieutenant Pottinger mentions that the Baluch tongue partakes considerably of the idiom of the Persian, being at least one-half of its words borrowed from that language, but greatly disguised under a corrupt and unaccountable pronunciation. Dr. Latham classes the Baluch language with the Persian, but considers it as a modified form.

The Jat, who form the principal part of the population of Cutch Gandava, speak the Jatki language. Indeed, from Herat, Käbul, Kandahar, the Panjab, to Sindh and Cutch Gandava, between the Sutlej and the Ganges, the Jat everywhere preserve their own, the Jatki tongue.

The NORTH-WEST FRONTIER of British India, both beyond and within the British border, has many martial tribes, many of them with democratic forms of government. They may be thus shown :-

Independent Tribes along the outer face of the N.W. Panjab Frontier, and inhabiting hills-

Adjoining Hzzara district-Hasanzai, 2000.

Adjoining Peshawur districts - Judoon, Bunnorwal, Swati, Ranizai, Usman Khail, Upper Mohmand, 16,000 to 19,700 .

Adjoining Peshawur and Kohat districts-Afridi, 15,000 to 20,000 .

Adjoining Kohat district-Buzoti, 500; Sipah, 300; Orakzai, 20,000 to 25,000; Zymukht, 5000 ; Turi, 5500.

Adjoining Kohat and Dehra Ismail Khan districtsWaziri, 20,000 to 30,000 .

Adjoining Dehra Ismail Khan distriot - Sheorani, 10,000 ; Oshterani, 1000 ; Kusrani, 1200 ; Bozdar, 4000.

Adjoining Dehra Ghazi Khan district-Khutran, 3000 ; Kosah, 5600 ; Lughari, 5120 ; Gurchnni, 2000 ; Murree, 3000 to 4700 ; Bugti, 1200.

The independent tribes are estimated to have about 128,000 fighting men, but there have been few instances of anything like combination among them, and the mountain hosts can only be kept together for a few days at a time, as each one has to carry his own four or five days' supply of provisions. After annexation of the Panjab, several independent tribes harassed the border tribes of British India, and expeditions were undertaken for their repression; but their leading men have, in later years, been able to retain their tribes to their agreements, and the British frontier is enjoying rest.

Barechi, a simple, inoffensive clan, numbering about 3000 families, who occupy the valley of Shorawak. Their camels are numerous. They are at enmity with the Baluch on their south.

Jadran, a Pathan tribe of Sunni Muhammadans who inhabit the eastern slopes of the main Suliman range. They are slightly made, but hardy, and small parties annually visit Banu and work as coolies. They are nomades, little above the savage state; have no cattle, tents, nor large towns, but travel with all their goods on their backs.

Kajakzai are descended from a Kakar chief, who fled to the vicinity of Sibi in Baluchistan. They number 700 to 1000 fighting men.

Khuttuk tribe, with 15,000 fighting men, occupy the hills south of Peshawur to Kushalghar and Kalabagh on the Indus.

The Mangal is a considerable tribe in the southern and upper portions of the Kuram valley, and also those of the Zurmat. They are said to possess 200 forts, 500 black tents, and 8000 fighting men. They are said to be thievish. They have several sections.

Marwati or Maorati, a brave tribe of Pathans in the Marwat division of the Banu district, numbering 42,725 souls in 1868 , with fighting men estimated at from 5500. They are one of the finest races, Trans-Indus, tall, muscular, fair, and often rosycheeked. They are of pure Afghan blood, a branch of the I ohani tribe. Their khel or sections are the Bahram, Dreplara, Musa, Tapi Nuna, and Jhandu. They are bold, manly, simple, and upright, deeply attached to their sandy villages and reed huts, frank and friendly with strangers. Their country is arid; they have few wells, but form tanks, and one village has to go $14 \frac{1}{2}$ miles for water.

Kafiristan, called by its own people Wamastan, is a country on the north of Afghanistan, bounded by the crest of the Hindu Kush between Kashkar ridge and the Farhan ridge, and occupying the valley of the Chigar Sarae. The race occupying it are known as the Siah Posh, lit. black clothes, and in the Chigar Sarae are independent. No European has visited the race. The soil of the valley is fertile, producing wheat and barley, and the mountains are clothed with foreat trees, the growth of ages. Cultivation is carried on by the men and women, who till, sow, and reap, using a pointed stick of hard wood, and a three-pronged fork; they have oxen where the country is open, but the hill tracts are terraced, and the soil is turned with hand labour. The principal crops are sown in spring and reaped in autumn. They export a few slaves and forest products, and import small-wares. They levy a tax (Kalang) on the Muhammadans and Nimchah on their borders. Kafir slaves are much prized for their fidelity and courage, and the Barakzai family retained them as their confidential body-servants. The labouring tribe amongst them is called Bari. They erect rope bridges across the streams and ravines, of ropes made of goats' hair. The form of government is that of patriarchal republic. They practise the vendetta, they make forays, and kill all Muhammadans whom they encounter.

The Siah Posh have been conjectured to be descendants from the Greek followers of Alexander, also from the Arab tribe of Koresh, but Lumsden supposes them to be aborigines driven from the plains. Their language is of Sanskrit origin. They have several tribes, amongst whom are the Katti, Kamoz, Waegal, and the Kam or Kampar. They are fair, some of them with blue eyes, but others with Mongoloid features. They are social, drink wine freely. They are polygamists. The ages for their marriages are, for men, 20 to 25 years; and women, 16 to 20 . Women are kept in a separate building periodically, also on childbirth, both of these being Hindu customs. The dead are placed in a box, which is left on the top or side of a hill, which is a Tibetan and Zoroastrian practice. They are idol-worshippers, the figures being those of a man or woman. Dogan is their chief deity; and Mahadeo, Bruk, Kantaar, Pane Truskai, and Eumrai are his incarnations. 


\section{INDIA, THE NORTH-WEST FRONTIER TRIBES.}

The Utah is a priestly class, and the Dil are soothsayers. They sacrifice sheep, goats, and cattle. They eat everything except carnivorous animals. They sit on chairs and atools, like the people of Lughman and the Khugiani. They ornament their houses with carvings. Timur in A.D. 1398, Sultan Muhammad Mirza in A.D. 1453, Baber A.D. 1507, and others, made inroads against them, but with only doubtful successes. Some of them, in the time of the Emperor Jahangir, were converted to Muhammadanism. The Chanak tribe inhabit the valley of Mukah, west of Islamabad in Lamghan, and S. of Dubmiah in the Sakal Dara; they have become Muhammadans. The Duhtuk principally occupy the country on the borders of Chitral.

The Kafir race occupy the most inaccessible portions of the Indian Caucasus between the Bajawar, Kashgar river, and Bamian, in the mountainous region of Northern Afghanistan, with Bajur and Kuner on the south. Kafiristan is bounded on the west by the Belut Tagh, on the east it touches Chinese Turkestan and Little Tibet, to the south lies Afghanistan, and to the north Khokand or Farghana, where the population is Chaghtai Turk. They are independent, have defied all attempts at reduction, their enmity to Muhammadans has been inveterate and unceasing, and they give no quarter; but of the Kafir clans, 18 in number, 8 have now become Muhammadans.

The Kafir are fond of honey, wine, and vinegar, music and dancing, the sexes dancing apart. They have no written character, and are said to speak a language resembling Pushtu. They wear a lock of hair on the right side of their heads. They are persecuted by all the surrounding nations, who seek to capture them as slaves. Their women do all the out-door work, and follow the plough. The exposure of the deadadopted by the Siah Posh has contributed probably to their being suspected to be a remnant of the reformerZertusht, but in no account is the least mention of fire-worship amongst them. The marriage ceremonies are extremely simple, consisting merely of procuring two twigs or rods, of the respective height of the bride and bridegroom, and tying them together. They are then presented to the couple, who preserve them with much care, so long as they find it agreeable or convenient to live together. If desirous to separate, the twigs are broken and the marriage dissolved. The Siah Posh build their houses of wood, of several storeys in height, and much embellished with carving. These accounts are trustworthy, as we witness that the Safi of Kaziabad, in the hills west of Lughman, and who have been converted, actually reside in such dwellings. Their arms are bows and arrows, long knives and daggers.

Khaibar District.-One of the most northerly of the passes beyond the British frontier leads through the Khaibar mountains. It is 18 miles in length, leading from Peshawur towards Kābul. As it approaches the northern outlet, it becomes more formidable. The pass is of an inegular form, but the average breadth is about 1500 paces; the hills which border it may be about 700 feet high. The Afridi, Shanwari, and Mohmand are the chief tribes in its vicinity. Nadir Shah paid a sum of money to secure his passage through it. The Daurani rulers of Kābul also acknowledged certain of the Afridi and Shanwari to be real passmen, and paid five Afridi clans, Zakha Khel, Sipah, Kuki Khel, Malik Din Khel, and Kambar Khel, also paid the Loargi and Singu Khel of the Shanwari. The British, likewise, from their first invasion of Afghanistan, have paid the passmen to keep the Khaibar clear.

The Shanwari inhabit a portion of the Khaibar mountains, some of the eastern valleys of the Safed Koh, and are also found on the borders of Bajawar. They have five sections-Abdul Rahim, Ali Sher, Sangu, Sipai, and Manduzai. They have been continuously predatory since the British approached their borders. They are the most industrious carriers between Peshawur and the other marts on the way to Kābul, using mules and camels for carriage. They are stalwart and hard-working, but inveterate thieves.

The Lowaghar Shanwari have three sections near the British territory, with 1050 fighting men.

The Tirai tribe live among the Shanwari; they speak a language differing from that of their neighbours.

The $A$ fridi are a large and very important tribe. They inhabit the lower and easternmost spurs of the Safed Koh range, to the west and south of the Peshawur district, including the valley of the Bara and portions of those of Chura and Tira. To their east they are bounded by the Khatak of Akora and the Mohmand and Khalil divisions of the Peshawur district; the Mohmand are on their north; to their west are the Shanwari ; and the Orakzai and Bangash are on their south. They claim descent from Khalid ibn Walid, a Jew who embraced Muhammadanism, but take their name from Afrid, who, in the 10 th century, at the time of the advance of Mahmud, fled for refuge to the wilds of Sheratala.

Their clans or khel, and the strength in fighting men, are as under:-

Kuki, . . . . 3500 /Zakha, . . . . 4000 Malik Din, : : 3500 Aka, : . . : 1200 Kambar, : : 3500 Sipah, . : . 1500 Kamr, : : : 1500 Adam, : : : 3500

These give their names to the divisions of their country. In the northern portion of their country is the Khaibar range, barren, rugged, and inhospitable to the last degree; to the south is the watershed of the Bara river.

The Afridi is the most important tribe of all on the Panjab frontier. Their country is about 80 miles long, and, on the average, 8 miles in breadth, and mountainous throughout. One or two thousand of them are serving as soldiers in the Bengal army and Panjab Irregular Force. The Afridi in appearance are fine, tall, athletic highlanders, whose springy step, even in traversing the dusty streets of Peshawur, at once mark their mountain origin. They are lean but muscular, with long gaunt faces, high noses and cheek-bones, with fair complexions; they are brave and hardy, and make good soldiers, but are subject to home-sickness. They are careful shots and good skirmishers, but their speciality is hill fighting. Lieutenant-Colonel Edwardes, detailing the occurrences in the Peshawur district during the Mutiny, mentions as an instance of the strange things that happened in those days, that one morning 500 Afridi of the Malik Din Khel (who were in disgrace and under blockade) marched from the hills into the cantonment, armed to the teeth, and said they had come to fight for the British and be forgiven. He accepted them at once, and they repulsed the first assault of the 51st Bengal N.I. when it rose, and then formed the nucleus of one of the Panjab regiments. 
INDIA, THE NORTH-WEST FRONTIER TRIBES.

The Afridi round the Kohat pass are carriers and traders, and cut and sell firewood. They occupy the mountains in summer, living in moveable mat huts; but, as winter draws near, they descend to the Khaibar, Bazar, Kajurai, Bagiara, and Lower Bara districts, and the low valleys and hills bordering on the west of the Peshawur basin, in order to avoid the snows of Maidan, which is 7500 or 8000 feet above the sea; Dwatawi and Tordara being about 6000 feet. None of the Afridi clans are found west of the Safed Koh or Rajgal ranges. They have the command of the Khaibar and Kohat roads. The Adam Khel Afridi are located in the hills and glens westward of Jalala Sar; and in the glens on each side of the defile leading from the Peshawur valley to Kohat, it holds the entire pass in its grasp. They are permanent residents in villages, strengthened by towers, possess many camels, and are large carriers of salt.

The Adam Khel Afridi is their largest and most powerful clan, has always been quite independent, and has never acknowledged any authority. Their possession of the Kohat and Jawaki passes have given them great importance. They are separated from the great body of the Afridi. Their sections are the Gali, Jawaki, Hasn, and Asha Kbel, who can muster 4540 fighting men.

The Hasn Khel, of the Adam Khel Afridi tribe, are in two great sections, the Akhorwal or Tatar and the Janakhori, and can muster 1900 fighting men from their five villages. After the punishment of the Bori in 1853 , they submitted; they subsequently gave annoyance, and again, in 1867, tendered submission.

The Jawaki Afridi live in 22 villages in the hills to the east of the Kohat pass, and from time to time, up to the year 1878, have given great trouble to the British. They have, according to Major Cavagnari, $18 \mathrm{khel}$, according to Major Coke 7 khel, with about 1000 fighting men. They are almost the sole wood carriers of Kohat; they possess many camels. Their importance is increased by the circumstance of their holding the Jawaki pass, for which they get Rs. 2000.

In 1853, after the assassination of Colonel Mackeson, an expedition was sent against the village of the Bori section, 33 miles N.E. of Kohat. The force was 1532 strong, under Brigadier Boileau, and that village was destroyed, with a loss of eight killed and twenty-nine wounded on the British side.

The Kambar Khel, in the Maidan of Tira, have two divisions, with ten subdivisions. The Kamr Khel are mostly scattered about the hills south of the Dwatawi pass to Tira Maidan.

The three sections of the Malik Din Khel are in the central portions of the Tira Maidan.

The Zakba inhabit the Khaibar pass from Gargora to Garhi Lal Beg. They are the most important and most powerful of all the Afridi clans, and can muster between 4000 and 5000 fighting men, and have eight subdivisions, viz. Bari, Khasrozai, Mohib, Paendah, Pakhai, Zaodin, Nasr-uDin, and Shan. They move in summer to Maidan and Bara, and in winter dwell in the caves and hamlets of Bazar and Khaibar. The Kin Khel have their summer quarters in Bar Bara and Tordara, and winter in the caves of Kapirai, and to the mouth of the Khaibar.

The Ashu Khel are located to the south of Fort
Mackeson, on the first range of hills, and in the Uchalgada valley. They live in five villages, and can muster 700 matchlocks.

The Afridi of Janakhwar are the best of the Afridi, bold and intrepid in action.

The Aka Khel are in the dreary hills to the S.W. of Peshawur, from the Bara river to near Akhor, going to Tira in summer, in winter living in caves. 'They are of a reddish-white colour, with strong physique, and are notorious for theft and robbery.

The Sipah section of the Afridi have three clans, - the Abu Bakr, Hormaz, and Landi Khel, and can muster about 1500 fighting men. They have nine villages in Bara, between the Kamr and Zakha Khels, but separated from the Zakha by the long range of the Surghar hills. They winter in the caves of Kajurai, near Gandao and Mehmani.

The Mohmand tribe are partly British subjects, occupying a subdivision of the Peshawur district immediately south of Peshawur. When the Mohmand tribe immigrated from the west, the ancestors of this Peshawur clan advanced and dispossessed the Dilazak, and have since had no further connection with the main body, who located themselves in the hills to the N.W. of the Peshawur valley, between the Kābul and Swat rivers. This main body are independent, and have six clans,- the Baizai, Tarakzai, Halimzai, Khwazai, Utmanzai, and Dawezai, each with many subdivisions. The strongest in fighting men is the Baizai, who are estimated to have 12,000 , while the total strength las been stated at 19,700 ; and Ahmad Sher gave their numbers at 35,000 , but it is probable they could never bring 16,000 into the field. The Mohmand country is rugged and unfruitful, the natural resources few, and mats are the sole manufacture. Like all Pathans, they boast of Pathan honour, but it is believed that they would sell, or prostitute, or kill any one for gold. They have no literature. They do not take service in the British army so readily as the other tribes. Three of their clans are known to the British, 一the Pindi Ali, the Alamzai, and the Michni Mobmand. The last of these, the Michni Mohmand, after annexation, were allowed to holit from the British Government a fief or jaghir in Doaba, the fertile triangle near the junction of the Swat and Kābul rivers, of which they collected the revenue. A portion of the lands they themselves cultivated, and farmed out the remainder to other tribes of the plains as tenants. Many of their clansmen dwelt in the neighbouring hills, and others traded in the Peshawur valley.

The Alamzai Mohmand, whose headquarters are at Gandao in the hills, also held a fief of Panjao, in British Doaba, chiefly cultivated by tenants. A few of their clan lived on the plains, but the majority in the hills.

The Pindi Ali inhabit a very strong locality in the hills ; at a former period, prior to British rule, they had held a similar jaghir in Doaba, which, like other fiefs, had been granted by preceding Governments as black-mail, to buy off depredation. They belong to the Isa Khel and Barhan Khel subdivisions of the Tarakzai clan. They were the worst behaved of all the Mohmands, and for eleven years after the British occupation of the Panjab, they worried the British border. They could muster about 2000 fighting men. For the first 
right years, the Mohmands gave more trouble than any other of the Peshawur border tribes. In December 1850 , they made an inroad on the village of Shabkadr; in March, August, and October 1851, the Michni Mohmands were aggressors; and on the 25th October, a force, under Sir Colin Campbell, was sent against them, and was variously engaged till the middle of December, by which time a fort had been erected to hold them in check, and the force returned to cantonments. In the following July (1852) the Michni and Panjao Mohmands, having been exiled from house and lands, and cut off from trade and all c mmunication with the plains, tendered their submission, and their fiefs were restored. In the mutumn of 1854, the Michni Mohmands again misbehared, and in September Colonel Boileau lal a force against them, and destroyed some of the villages, which fired on the troops as they moved along the open ground. They continued to misbehave, and made eighty - three raids and atracks on British territory between 1855 and 1860 ; but they at length submitted to LieutenantColonel Edwardes, whohad written to Saadat Khan that he desired the honour and welfare and strength of himself and family. From that time until the Ambela expedition of 1863 , the Mohmands abstained from troubling the border. But Sultan Khan, son of Saadat Khan, then collected about 3000 Mohmand, Safi, and Bajawari, and they were met at Shabkadr by Captain Earle with 55 of the 6th Bengal Cavalry and 100 Native Infantry. Lieutenant Bishop charged and fell, but the enemy lost about 28 killed and wounded, and retired to liagmena and Gandao. But by the 1st January 1864, Sultan Muhammad had gathered around him about 4500 Mohmands, and advanced beyond Shabkadr. Here, Colonel Macdonell, C.B., met them with 3 guns, 477 cavalry, and 1272 infantry, and defeated them with a loss of about 100 killed and wounded, and they dispersed to their homes. One of the wives of Sher Ali Khan, the Amir of Kubul, was a daughter of Saadat Khan. The Michni Mohmand murdered Lieutenant A. Boulnois, R.E., near the fort of Michni, on the 14th January 1852, and near that place Major Macdonald was murdered by them on 21st March 1873, for which there was no motive. The numbers of the fighting men the Mohmand clans could turn out have been given as 19,700 , viz. the Baizai clan, 10,000 to 12,000 ; the Khwazai, 800 ; the Tarakzai, 2500; the Halimzai, 3000; the Utmanzai, 500 ; and the Dawezai, 900.

The Shalmani race inhabit the village of Shalman, on the Tartara hill in the Khaibar range. Elphinstone says they are originally from Kuram, were afterwards in Tira, and again in Hashtnuggur.

The Mula Guri tribe of 500 families, on the north slopes of the Tatara mountain, on the Peshawur frontier, are notorious thieves.

The Black Mountain is at the N.Wr. extremity of the Hazara district. It is a long narrow granite ridge of nearly uniform height, with higher peaks at intervals, and occasional deep passes. Numerous large rocky spurs project from the sides, which are often precipitous; the routes to ascend the mountain being along the spurs from British territory, are those of Tanawal and Shunglai, Chata, Agror, Chajri, Barchar, Khun, and Gali. The more prominent passes and peaks are as under:-

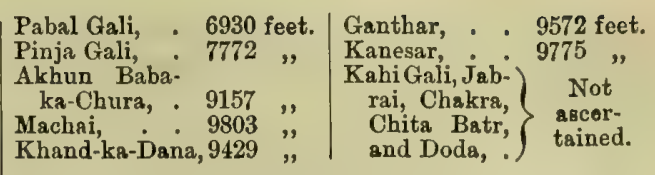

The view from Machai is grand. The jungle on the lower S.E. slopes consists of Berberis and Acacia modesta; at 6000 feet the Pinus longifolia and Pinea Tebbiana begins, Abies deodara and oaks. The poplar and plane grow in the valleys. The Indus runs deep and rapid under the western foot of the mountain, and is there from 70 to 300 yards wide. In its course there are eleven ferries, with boats large enough to carry twenty to thirty passengers, and the natives all along cross it on inflated skins (Shina in Pushtu). The tribes of the mountain (from $N$. to $\mathrm{S}$.) are the Hasanzai, Akozai, Chagharzai; N. of Agror, on the E. face, are the Syud of Pariari and the Swati of Deshi. The Hasanzai and Akozai, the bravest, belong to the Isazai branch of the Yusufzai ; and the Chagharzai, the most numerous, to the Malizai branch. The Hasanzai adjoin the frontier of the Hazara districts of the Panjab. They reside on both sides of the Indus, those Cis-Indus living on the Black Mountain, and those Trans-Indus immediately opposite to it. They have ten khel or clans, who could furnish 1115 fighting men; and the other races who are living amongst them-the I'illi, the Gujar, and craftsmen-could furnish 600 more. Every man possesses a sword and shield, and there are said to be 1100 matchlocks in their tribe. In 1851, Mr. Carne and Mr. Tapp, two officers of the customs, were led into an ambuscade formed by the Hasanzai, near the Jhandrani ravine. Mr. Carne parleyed with their leader, who swore that if they delivered up all their property, their lives would be safe; but though agreed to, the Hasanzai bound the two officers, and, taking them a little off the road, cut their throats in cold blood. In December 1852, a force marched to punish the Hasanzai. It was in three columns, under Lieutenant-Colonel Napier (now I.ord Napier of Magdala), Major Abbott, and Major Davidson; and from the 20th December to the 2d January, the British forces were engaged. The Hasanzai behaved bravely, defending their ground step by step, and gaining temporary advantages, but inflicting little loss on their British assailants. In August 1863,500 or 600 Hasanzai made a raid on the Tanawal villages of Shushi, Chumiar, Bandi, Nawashah, Jrabu, Dargarian, and Bai, burning them and carrying off some cattle. But they entered into agreements to be peaceful, and they adhered to their promises, until a section of them attacked the Oghi Thannah on the 30th July 1868. They were afterwards parties in all the Agror attacks during August, but submitted when General Wilde's force advanced up the Black Mountain.

The Chagharzai and Hasanzai are the first Pathan neighbours of the British to the north, inhabiting a mountain tract on the east bank of the Indus, known as the Black Mountain. The Chagharzai inhabit both banks of the Indus above Buner. They are said to have above 7800 fighting men, and are in three clans, - the Nasrat, Firozai, and Basi Khel. Their spring (rabi) crops are wheat, barley, masur, and tobacco, and their kharif or autumn crops, maize, rice, and mat'h beans. Their 
INDIA; THE NORTH-WEST FRONTIER TRIBES.

wealth is in cows, buffaloes, and goats. They are thorough mountaineers, hardy and brave above all the neighbouring tribes.

Passing to the west of the Indus are the Mudah Khel and Amazai. The Mudah Khel are to the north of Amb, the principal town of the Tunawal chief.

The Mahaban mountain infringes on the Indus, where it washes the British frontier district of Hazara. The Mahaban has many tribes around it. It is a peak in the extreme corner of the Yusufzai country. It is on the right bank of the Indus, at the east end of the spur of the Ilam range, which divides the drainage of Buner from that of the Yusufzai plains. It is clothed with forest trees, chiefly fir, with luxuriant herbage, and is generally suited to the requirements of a pastoral race; it is also terraced and cultivated.

The Amazai inhabit the eastern slopes of the Mahaban mountain.

The village of Malka, in the Amazai country, is situated on a plateau on the N.W. of the Mahaban mountain, and was selected by Hindustani fanatics as a settlement. On the inner side of Mahaban it has easy communication with the Amazai, the Mada Khel, Chagharzai, and Hasanzai ; and the Khudu Khel, Utmanzai, and Jadun are close at hand and easily reached. In 1863 an expedition was sent to destroy Malka, from which resulted a campaign in Ambela, and the Bunerwal ultimately undertook to burn Malka, and expel the fanatics from Buner, Chamla, and the Amazai lands.

Following the west bank of the Indus to the Pihur ferry, we come to the amphitheatre of hills which environ the Peshawur district, in which are a considerable number of tribes. The Jadun or Gadun are the first nearest to the Indus, cunning and intriguing. After them are the Buner or Bunerwal, the Swati, the Mohmand, and Bajauri, who opposed the British in the Ambela campaign.

The Jadun or Gadun of Gadunia dwell south of the Hasanzai, partly on the slopes of the Mahaban mountain, partly in the Hazara district. They are supposed to have been a clan of Kakar Afghans who had been driven to take refuge in the Safed $\mathrm{Koh}$, and afterwards in Hazara and Chach. They have two divisions, - the Salar, who possess 12 villages of 2530 houses, and the Mansur of 18 villages. None of the villages are walled, but a few have towers. The tribe are cultivators and cattle-owners, and their buffaloes are celebrated. They boast of having 12,000 fighting men, but about 2800 is the supposed true number they could turn out. In 1861 they annoyed the British frontier by sheltering Hindustani fanatics at Satana, but they entered into an agreement to live peaceably. Subsequently, however, they invited the fanatics to return, and on the 15th July 1863 they were subjected to a blockade; and Colonel Wilde, C.B. led a force against them, arriving at Maini on the 30 th December, and on the 5th January 1864 fresh agreements were entered into. Their conduct continued to be so unsatisfactory, that on the 15 th June 1870 they were again blockaded. During July and August they kept the border in agitation, but on the 10th September they came to terms, their Jirgah or council agreeing to pay a fine of Rs. 3285 , and give security for Rs. 1500 more. A few of the Jadun are serving as soldiers in the British Indian army.
Satana. $\quad$ Swat Races, viz.:- $\mid$ Ranizai. Ambela Pass. Panjkora. | Malizai. Deshi. Laluaui. Akrozai. $\quad$ Baizai. Garwi. Swat River. Khwazozai.

, Kohistan. Osman Khel. - Musa Khel

, Passes. Bajawar. Nakbi Khel

Satana is a village on the right bank of the Indus river, at the east foot of the Mahaban mountain, 13 miles above Topi. The village was originally made over by the Utmanzai to Syud Zaman, from Takhta-band in Buner. His descendants allied themselves to Syud Ahmad, who settled in Satana, and they aided him in all his ambitious struggles to establish a Wahabi empire of Muhammadan reformers on the Peshawur border. The ablest of the Satana Syuds was Syud Akbar, who, in 1849 or 1850 was chosen to be badshah or king of Swat. He died in May 1857 ; and two leaders rose, viz. Syud Mubarak Shah, a son of the deceased Syud Akbar, and Syud Umar, who kept a gang of thieves. The refugees from Hindustan had one or two mulvi, but no one of reputation. Not content with the church lands, the Syuds of Satana demanded tithes from the Utmanzai, who resisted their attempt to cut their grain crops. Syud Umar was shot, and Syud Mubarak was wounded in the foot, and the Syuds and men of Hindustan were expelled. After the destruction of the Hindustani settlements at Mangal Thana, a force under Sir Sydney Cotton, in 1858 attacked and defeated them, destroying Satana. Also, in 1863, on its removal to Malka, on the opposite slopes of the mountain, on the 26 th of August 1868, a large body of the Swati attacked and defeated the Wahabi Hindustani, and drove them into the country of the Chagharzai, TransIndus, east of the Buner valley.

The Ambela or Surkhawi pass leads from the Sudum valley, Peshawur district, into that of Chamla. Steep mountains rise 1000 feet, absolutely precipitous. In 1863, General Chamberlain's brigade, 5000 strong, was opposed on the pass by nearly all the fighting strength of the Yusufzai clan, 15,000 strong, under the Akhund of Swat, the chief of Panjkora, and other leaders. The object of the British was to drive the Hindustani fanatics from Malka. The operations lasted from the 20th October to the 25th December 1863. The loss to the British was 227 killed, amongst whom were 15 British officers, and 620 wounded, of whom were 21 British officers. Generals Chamberlain, Wilde, and Garvock commanded.

The Laluani is a Baluch tribe inhabiting the village of Lalu, on the crest of the Ambela ridge, 3 or 4 miles east of the pass.

The Swat river runs through the Swat valley. This valley is about 70 miles long, but its breadth varies from a few hundred yards to 10 miles. Its three subdivisions are Ranizai, Kuz or Lower Swat, and Bar or Upper Swat. The valley is highly cultivated and densely peopled, producing rice, beans, barley, wheat, Indian corn, fruits, sugar-cane, cotton, and tobacco. The people are bigoted Sunni Muhammadans, with as many factions as there are villages. Their religious leader for many years was Abdul Ghafur, styled the Akhund, who was revered from the Indus to the Kuram. Swat valley is intersected by ravines and glens, bringing down the drainage of the bounding ranges. It is unhealthy in summer. The occupants are Afghans, Mulla, and Syuds. The total population is estimated at 96,000 souls, and 


\section{INDIA, THE NORTH-WEST FRONTIER TRIBES.}

consists almost entirely of Baizai, Khwazozai, and Akozai. The Kohistan of Swat is above Chaorari. The head of the Swat valley is occupied by the Torwal and Garwi tribes, who speak a language different from Pushtu, which, however, they understand. They are probably allied to the Kafir, Chitral, and Gilghit races. Beyond Swat and Bajawar is Kafiristan.

Towards the lower extremity of the Swat valley, a formidable range of hills bounding the valley runs for many miles from east to west, nearly parallel to the British frontiers; and at the eastern extremity of this range stands the Mora mountain, Between this range and the frontier, however, intervene two tracts, named Ranizai and Lower Osman Khel, both quasidependencies of Swat.

The best of the passes leading into Swat is one named Mullakund, which opens from Ranizai. A little farther to the eastward of Ranizai also there are some passes leading into the Lunkhor valley, which belongs to British Yusufzai. These latter passes are not available for passage from Swat to British territory, because leading into Lunkhor they can be stopped by any party holding that valley. The passes viâ Ranizai and Osman Khel, if the people of those tracts accord a passage, lead straight on to the British plains of Hashtnusgur. Above the Lunkhor valley, just beyond the British frontier, is the strong village of Pullee.

The subdivisions of the Peshawur district, adjoining the tribes above described, are Lunkhor or north-west corner of Yusufzai, and then Hashtnuggur.

Of the Swat, Ranizai, and Lower Osman Khel tribes, the two latter are subordinate to the former.

The Swati race inhabit portions of the Swat valley and of the valleys of Tikri, Alahi, Deshi, Nandihar, Pakli, Konsh, Bogarmang, and Agror, Balakot, and Garhi Hahib-ullah, north of Hazara. They are sometimes called Dehgan, and seem to be of Indian origin, and to have formerly ruled between the Hydaspes and Jalalabad, but they have been dispossessed of their lands by the Pathans. They have no connection with the Yusufzai Pathans who now occupy the Swat country. They are of poor physique and of low courage; they appear to have all the vices of the Pathans, and, as with them, cold-blooded murder and grinding avarice are the salt of life. They are all Sunni Muhammadans, and very bigoted.

Panjkora consists of a number of narrow and hill-bound valleys, inhabited by the Malizai, Khwazozai Akozai, and Yusufzai. The climate is severe in the north, but mild in the south, and the district fertile. The Panjkora river divides it from north to south.

The Akozai are a grand division of the Yusufzai tribe, comprising the Baizai and Khwazozai clan, who inhabit the Swat valley. The Akozai are estimated at 90,000 souls.

The Khwazozai are a section of the Akozai Yusufzai.

The Malizai section of the Khwazozai Akozai and Yusufzai occupy the country of Panjkora, which also takes their name. They can muster 8000 fighting men.

The Kohistan of Malizai is a glen at the head of the Malizai drainage. The people are supposed to have been Kafirs, converts to Muhammadanism.
The British Baizai district is a bay about 20 miles long and 12 miles broad, which runs into the hills between the Paja and Malakhand ranges at the extreme N.W. of the Yusufzai division of the Peshawur district. It is inhabited by Baizai, Swati, Utman Khel, and Khatak, with some Mohmand, Rowanri, etc. The last of these claim to be Pathans, and there is no great family of khans in Baizai. On the 11th and 14th December 1849, Colonel Bradshaw led an expedition against those in British territory, in which he attacked and destroyed the villages of Sangao in British Baizai, and Pali Zormandai and Sherkhana in Swat Baizai.

The Baizai division of Swat is south of the Mora range and north of Lunkhor. It is called Sam Baizai, to distinguish it from Baizai in the Swat valley, and comprises the villages of Pali, Sherkhana, Jalalpur, Zormandai, Bazdara, and Mora Banda, each with its separate khan.

Gujar herdsmen are in hamlets scattered over the Mora mountain.

The Osman Khel or Utman Khel are a Pathan tribe who occupy the hills north of Peshawur, between the Mohmand and Ranizai, on both sides of the Swat river, from the Koh-i-Mora to the Khanora mountain. They are descendants of Utman Baba, who accompanied Mahmud of Ghazni on his expedition into Hindustan in the year 997 , and settled in this country. They have five khel or sections, descendants from his five sons. They are a powerful tribe, and, according to Turner, can muster 17,000 fighting men; Mountstuart Elphinstone says 10,000, and Bellew 5000 . Their country is very hilly generally. They are all at feud with the people of Bajawar; in 1827 and 1850 they engaged the Mohmands. They are a tall, stout, and fair race, are sober but uncivilised, and have frequent quarrels amongst themgelves. At first they gave much trouble to the British frontier, and in 1852 afforded an asylum to and aided the fugitive Khan of Tangi; on which a force under Sir Colin Campbell proceeded against them in May, and their principal villages, Pranghar and Nawadand, were taken and destroyed after a determined resistance. Since then the Utman Khel have never given any trouble.

The Utman Khel or clan who inhabit the northern portion of the Baizai division of Yusufzai are probably a section of the above tribe. They have three clans,-Ismail, Daulat, and Sehsada. Their villages are strongly situated in the nooks and corners of spurs running down from the Paja and Mora ridger, and the people are as wild as the hills they inhabit. Their conduct has been, on the whole, more consistently mulish and refractory than that of any other village along the whole border from Abbottabad to Jacobabad. They began to give trouble in 1847 , and up to 1872 they continued in it. In 1849 a force under Colonel Bradshaw destroyed the village of Sangao belonging to the Dawat Khel. In 1855 the same village was fined Rs. 200 , on account of some robberies and molestations of travellers, and the village was removed from its bill position, and its two sections located respectively in the more accessible villages of Pipal and Miam Khel; but during the troubles of the mutiny they crept back again. In 1859 they sheltered some crimiuals, and opposed the attempt made to seize them. In 1863 six of their villages furnished men to oppose 
INQDIA, THE NORTH-WEST FRONTIER TRIBES.

the British force which was sent on the Ambela campaign, and they were fined R8. 2500 ; after which they were disturbed by intestine factions, with regular fights on the 21st August, 25th and 29 th September, 3d and 21st Oetober 1864, in which the British did not interfere. In November and December Lieutenant Ommaney unsuccessfully endeavoured to induce them to make peace; but in February 1865 Captain Monro was more successful, and fines were imposed. In 1865 quarrels broke out afresh among them, and on the 16th January 1866 a force of 4000 men and 12 guns, under Brigadier - General Beresford, C.B., was sent amongst them. The villages of Mian Khel and Sangao, and other villages, were destroyed, and new sites fixed for them. In 1872 , however, some of the clans evacuated the villages of Kui, Barmul, and Mian Khan, and as they refused to return or to obey the authorities, the houses of the Kui ringleaders were pulled down.

The Ranizai are a subdivision of the Baizai Akozai division of the Yusufzai clan. The country they inhabit is divided into the Sam Ranizai and Bar or Swat Ranizai. 'The latter is the lowest or most westerly part of the Swat valley, in which they have thirty-five villages. Sam Ranizai is an extensive district, stretching over the Totai Hills, and includes the whole of the lower end of the Swat valley, in which there are about thirty khel or clans. On the annexation of the Panjab in 1849, it was found that the Sam Ranizai country was being made a refuge for malcontent criminals of every description, who periodically made raids on British territory. In 1852 the Ranizai Swati attacked a detachment of the Guide Corps, and a force under Sir Colin Campbell was marched to their village, on which the Ranizai maliks of Shahkot submitted, were fined Rs.5000, and gave ten hostages. The force then marched towards the British territory; but as the Ranizai refused to pay the fine, and repudiated the hostages, whose families they expelled from their territory, on the 18th May Sir Colin returned to Shahkot, and found his force opposed by about 4000 infantry and $\overline{2} 00$ cavalry, all from Swat, in addition to the armed villagers. The king and the akhund of Swat had stationed themselves on the crest of the Malakand pass to witness the fight. After a slight resistance, the Swat troops broke and fled, leaving 300 of their number dead on the field. The village and its granaries were then destroyed, and from the 20 th to 24 th twelve other villages were similarly destroyed, and the British force returned through Lunkhor to Gujargarhi. In June they tendered submission, and all that was required of them was to behave peaceably. Since that time the Ranizai people have fulfilled all their engagements, and have evinced an anxiety to maintain peace.

The government of Swat, like that of all Pathan tribes, is a most complete democracy. The country is split up into as many factions almost as there are villages, and even in these there are often several sections. But the late akhund, Mullah Abdul Ghafur, working on their religious feelings, was able to induce them to combine, and he used all his power to prevent collision with the British Indian Government.

Abdul Ghafur, the akhund, was born in the village of Syedasam in Buner. He was poor, and for twelve years studied for the priesthood in the village of Beka in Yusufzai, living on shamak and milk, and he subsequently became a disciple of the Mian of Kaku Khel. He returned to Buner, and afterwards went to Swat, where he was revered for his sanctity, and was always consulted by the Swat people. He recommended them to select Syud Akbar of Satana as their king. When that ruler died, on the 11th May 1857, his son, Syud Mubarak Shah, made unsuccessful efforts to succeed him, and, being expelled from Swat, he, with mutineers of the Bengal N.I., settled in the valley of Panjtar, which adjoins the Yusufzai side of the valley of Peshawur, where they founded a Wahabi colony, headed by Mulvi Muhammar Inayat.

The Pathans of Swat are hospitable; the men are spare and apparently feeble; the women are strong, stout, and buxom, and enjoy more liberty and rule the men to a far greater degree than is known amongst other Pathans.

Deshi, a clan of the Swati on the eastern face of the Black Mountain. They have 720 fighting men. Other tribes, Zizrari, Syud, Mula, Akhun Khel, and Gujar, have settled amongst them.

Garwi, a Kohistani tribe inhabiting the head of the Swat valley, and numbering about 3000 adult males. They are not Afghans, and have a distinct language.

Maturizai, a section of the Baizai Akozai Yusufzai on the east bank of the Swat river. Their two sections are the Balol Khel and Ala Khel.

Musa Khel, a section of the Baizai Akozai Yusufzai on the left bank of the Swat river.

Naikbi Khel, a section of the Khwazozai Akozai Yusufzai on the right bank of the Swat river. They have 6000 fighting men.

Orakzai, Bazoti, Sipah, Zaimusht, and Turi adjoin the Kohat district of the Panjab. The Orakzai inhabit the mountainous country to the north and west of the Kohat district. Their country is called Tira. It consists of the Khankai and Mastura or Tira Toi valleys. The Tira mountains are spurs from the Samana range and from the Safed $\mathrm{Koh}$, and of 5000 to $\mathbf{7 0 0 0}$ feet of elevation. The people are all Orakzai mountaineers, wiry, martial, deceitful, cruel, and avaricious. They migrate for the winter with their flocks to the low levels of the Kohat and Tiri hills about Miranzai.

The Orakzai have the Afridi on their north and east, the Kohat district bounds them on the south, and the Safed Koh on the west. Their chief sections are the Daulatzai, Ismailzai, Laskarzai, and the Hamsaya, and they can furnish 28,870 fighting men. In 1855 they caused trouble in the district adjoining them. On the 30th April, 1500 or 2000 of the Afridi and Orakzai were driven off from an attack on General Chamberlain's camp at Darsamand. In 1868 and 1869, they again gave trouble, till Colonel Keyes advanced against Garo in February 1869, and destroyed it on the 25th February, since which time they have been quiet. Garo was a mere collection of caves.

Rabia Khel section of the Ismailzai Orakzai was the most prominent of all the Orakzai in the disturbances on the Miranzai border in 1855. From April to August 1855, they committed eighteen raids. They occupy the crest and north ridge of the Samana range. Fighting men, 600 . They were punished by a force under General Chamberlain. 
The Daulatzai section of the Orakzai inhabit the corner of the Afridi hills, near the Afridi and the Kohat district. Their sections are the Bazoti and the Usturi Khel, each 500; the Utman Khel, 600; the Mani Khel and Firoz Khel, each 800 ; the Sipah, 300; the Abdul Aziz Khel, 400 ; and Bar Muhammad Khel, 1000.

Bazoti inhabit the corner of the Orakzai country between the Afridi and the Kohat district. They have several khel or clans, which are said to number 500 fighting men. In the cold weather the Bazoti live in the Bazoti valley; but in summer, from April to November, they go to the head of the Mastura glen in Tira, where they sow their wheat before leaving, and their rice crop in the Bazoti valley before their return to Tira. At the commencement of the British rule west of the Indus, the Bazoti were always cattle - lifting on the British border, and they organized and headed the attack on the Kohat pass which led to Sir Charles Napier's expedition of 1850. But they were quiet till the 15 th January 1868 , when they joined with others in again making raids. On the 11th February, a small force of 2 guns, 80 cavalry, and 480 infantry, were sent against them, but were unsuccessful, retiring with the loss of 9 killed and 27 wounded; and on the 13th February 1869, the Utman Khel attacked the Kohat Kotal, supported by the Bazoti. Colonel Keyes, 25th February, moved against them with 4 guns and 2000 men, but retired with a loss of 2 killed and 34 wounded; the enemy were about 200 strovg, and lost 17 killed and wounded.

The Utman Khel number about 600 fighting men. They are the most predatory clan of all the Orakzai tribe.

Sipah inhabit from the west of the entrance to the Bazoti valley. They are Shiah Muhammadans. They share, since 1853 , the allowance granted by the British for keeping open the Kohat pass.

The Abdul Aziz Khel touch on British territory. They are Shiah sectarians, and Gar in politics. The family of the Begum of Bhopal are said to be of this clan.

Another clan of Orakzai, the Mula Khel, are Hamsaya, located on the outer spurs of the Samana Garh, S.W. of Hangu ; they can muster 1000 fighting men. The Mamuzai, a branch of the Lashkarzai, 3000 men. The Ali Sher section of the Lashkarzai, also 3000 men; they bring cotton.

The Bar Muhammad Khel of the Daulatzai, in the upper part of the Tira valley, can muster 1000 fighting men. They are Shiah sectarians, Gar in politics, and winter in British territory.

The Shekhan dependents (Hamsaya) of the Orakzai inhabit the hills of Drand, beyond Gaoz Dara, and to the west of Samalzai.

The Mishti Khel of Hamsaya, also a dependent section, occupy the hills from the exit of the Kohat river to Kasha. They have about 3000 fighting inen.

Buner is a valley bounded N.W. by Swat, N.E. by the Puran valley, S.W. by the Yusufzai plains, and S.E. by the Indus. It consists of a hill-girt plain, about 18 miles by 12 miles, but encroached upon by spurs upon all sides from the boundary hills. It is inbabited by the Iliazai and Malizai division of the Yusufzai, who have in Buner 94 to 100 villages. They are Pathans, or Afghans, and are usually called Bunerwal. They are rich in cattle, especially buffaloes, but they have to

VOL. II. import grain. Buner communicates with Swat by the Karakar, Jawarai, and Katel passes, all difficult, and only used by footmen; and the passes that communicate with British territory are the Spirzai, Malandri, Surkhawi or Sherdara, and Buner. On the east the Barando defile leads into it.

Occupying parts of the Buner valley are the Alisher khels of the Gadazai Iliazai and Nurzai Iliazai, and two sections of the Iliazai Yusufzai named the Ashazai and Panjpai.

The Gadazai occupy the south slopes of the Ilam and Dosira mountains in villages. Their sections or khel are the Ibrahim, Hasn, Seni, Ali Sher.

The Bunerwal of the Buner valley, in 1849 backed up some British subjects in Lunkhor who had refused to pay revenue, and they also aided the Swati in attacking Pali, and threatening the villages in British territory to which the Paliwal had fled for safety. When the British in 1863 adranced to take possession of the Ambela pass, the Bunerwal were the most determined of the British opponents. During some negotiations, in which, unfortunately, their suspicions were aroused, they attacked the British camp on the 22d October. Further negotiations ensued, and on the 17th December they undertook to dismiss all their fighting men on the Buner pass, to destroy Malka in the presence of British officers, to expel the Hindustani fanatics from Buner, Amazai, and Chamla, and to give hostages till the above were carried out. Accordingly, on the 19th, a party advanced to destroy Malka, in which they were aided by the Amazai. Colonel MacGregor, when noticing these events, observes tbat 'their conduct throughout cannot but be regarded with some admiration: they fought us like men throughout the defence of the heights of Ambela, and when they made peace they stuck to their engagements like gentlemen. British loss was 847 killed and wounded; that of the Bunerwals is not known, but it must have been heary.' In the operations in the Ambela pass, the force of the enemies opposed to the British by the 18 th November bad increased to 15,000 men, composed of Bunerwal, Hindustani, Swati, the Amazai, Ranazai, Mada Khel, the Utman Khel of Lunkhor, and others.

The Chamla valley is immediately north of the Mahaban range. Its breadth varies from 1200 yards to nearly 3 miles. It is near to and politically part of the Buner country

The Chamla valley is separated from Buner by a spur of the Guru mountain, and from the Khudu Khel by a spur of the Mahaban, but it is inhabited by Bunerwal, and the meaning of Chamla is said to be tenant-holders. The valley and the central plain of the Yusufzai are comnianded by hills that descend from the Hindu Kush.

The Zainusht are Afghans who inhabit the hills hetween Miranzai and Kuram. They have two great divisions, - the Khwaidad Khel and the Malıamadzai or Mamuzai. Their villages are open, but with towers. Cultivation is only seen close to their villages, owing to the number of internal blood feuds in this tribe, which necessitate their agricultural operations being near to obtain support. Their country is a tract about 15 miles long, between two ranges of mountains, and generally covered with jungle. They remain in their villages throughout the year. They were at feud with the Bangash. There was a bitter blood feud between 
INDIA, THE NORTH-WEST FRONTIER TRIBES.

their own two clans. It arose about the year 1840 from their joining opposite sides in a dispute between the Käbul Khel Waziri and the Turi and Bangash ; but in 1866, Captain Cavagnari, aided by the Miranzai people, induced them to conclude a truce for ten years. Their fighting men have been largely over-estimated at 400 cavalry and 5000 infantry.

In the Daman or skirt of the Suliman range are the Shiah Turi, the Jaji, and the Isa Khel. The Jaji dwell in houses with a teh-kbana or excavation in the earth. The Isa Khel occupy the banks and islets of the Indus, engaged in the cultivation of wheat, but are also robbers.

The Turi Afghans inhabit the valley of Kuram. They and their neighbours the Jaji are said to be descended from two Moghul brothers, Tor and Jaji ; but Lieut.-Colonel Edwardes was of opinion that the Turi are Khatar Hindki in origin from the Rawal Pindi district. They have five great divisions or khel, termed Panjpadri or fivefathered, viz. Gandi, Alizai, Mastu, Hamza, and Dopazai, and 53 subdivisions, and can turn out 5000 fighting men. Their ordinary covering is a blanket shirt; they are dark-complexioned men, strong, hardy, and courageous, and are superior horsemen. A mounted Turi is a perfect model of a mosstrooper. His horse is small, but active and enduring, and he carries his own clothing under the saddle; while, at the saddle-bow, in leather wallets, hang food for man and horse, spare shoes, nails, and a hammer, in case of accident, and an iron peg and rope to picket the horse anywhere in a moment. The object of horsemanship with them is to commit daring and distant raids. A profusion of arms cover every horseman. One or two short brass - bound carbines at his back, two or three pistols and knives of sorts and sizes all round his waistbelt, and a sword by his side. Major James, however, considered them far inferior to the Waziri in courage and all manly qualities, and says, with coarse sensual features, there is much of the savage in them. On scenting their prey, their eyes dilate, and they evince all the greed and ferocity of wild beasts. In their raids they are ruthless, and spare neither age nor sex. They are generally short, compact, and sickly-looking, mean, with a skulking or cunning look about them. They are at feud with the Waziri, Zaimusht, Mangal, and Jaji, and they joined General Chamberlain in the Kābul Khel expedition against the Waziri, and served as spies and plunderers. They were formerly nomade, but about the end of the 18 th century settled in Kuram, which they purchased from the Bangash, and afterwards also obtained Pewar; and the Bangash have now only the villages of Zeran and Shilofzan in the hills, and Isa Khel in the plains. The Bangash are dependents of the Turi, but there was war between them. On one occasion the Turi killed 500 Daurani on the Jaji border, and only ceased slaying on the intercession of a Kazzilbash chief. At first they gave much trouble to the British on the Kohat border, and in 1853 and 1854 made eight raids on British territory. In June 1856 they made thirteen raids; and on the 21st October 1856 a force of 14 guns, with 4500 men, under Brigadier Neville Chamberlain, marched against them, and reached Thal, the frontier village, on the 5 th November, and he fined them Rs. 8630 ; but the feud between the
Turi and Waziri has since then given a great deal of trouble. Part of the Turi are nomade, moving with their flocks and herds between Nilab on the Indus and Kābul, wintering about BaI Yamin, and pasturing in summer near the Safed Koh. They are Shiahs, and revere the shrine of Fahm-i-Alam, the father of Nadir Shah. Their war-cry is that of the Shiah sectarians, Ya Ali! Ya Haidar!

The Waziri or Vaziri are a large tribe of Pathans, with 43,980 fighting men, who inhabit the hill country to the $\mathrm{W}$. of the British frontier, W. of the Indus, adjoining the Kohat district and the district of Dehra Ismail Khan, and extending from Thal in Miranzai to the Gomal pass. Their great clans and their fighting strengths are,-the Utmanzai, 17,200 ; Ahmadzai, 9580 ; Mahsud, 14,500; Gurbaz, 1500 ; Lali or Lelai, 1500 . They are the most united body on the N.W. Frontier of British India; they have shown a more hostile spirit and kept more aloof from the British than any other tribe. Their proper settlements are among the higher spurs of the Suliman range, where they pass the summer months. In October the greater portion of the tribe descend with flocks and herds to the lower hills bordering on the Kohat and Banu districts. The Mahsud district is rugged. The northern Waziri cultivate broad tracts on both banks of the Kuram river. They claim descent from Vazir, son of Suliman, from whose grandsons and great-grandsons, Utman, Ahmad, Mahsud, Ali, Balol, Iali, and Gurbaz, the great clans of this tribe take their names. They are tall, muscular highlanders, with considerable courage. They have warred with all their neighbours, from all of whom, except on the British side, they have made conquests. They usually go on foot, and are most active in the mountains, generally attacking at night. A Waziri when caught by any of the surrounding tribes was never spared. On the other hand, the Waziri never injure women, nor take their jewels, but all men they invariably kill. Their neighbours admit their truthfulness and courage. They are haughty and bloodthirsty towards strangers. They are a fine race, prone to plunder, and careless about bloodshedding; but bold, plain spoken, true to their friends, and inclined to be boastful and rough in council. They have never owned any allegiance to Käbul.

The Mahsud Waziri number about 15,000 fighting men; they inhabit the hills on the Tank and the South Banu borders. Their sections are the Alizai, 5600; the Shahman Khel, 3000; and Balozai, 8100 . They have always been highly predatory, especially the Alizai branch, and are at enmity with all around them. On the British occupation, they resumed their habits, and in 1860 the tribe was overcome by a force under General Chamberlain, 5196 strong. The British lost 63 killed and 166 wounded; the Mahsud Waziri lost more, but nevertheless have continued troublesome. They occupy the vast and lofty mountain range to the $\mathrm{S}$. of the Banu district, and to the $W$. of the Dehra Ismail Khan district. Its principal hills are the Ghubur, about 7000 feet above the level of the sea; the Pirghul, 11,500; the Shuvi Dhur, 11,000 feet; and behind and above all, beyond the Mahsud territory, towers the Takht-i-Suliman, 14,000 feet above the sea level.

The Ahmadzai have about 9580 fighting men. 


\section{INDIA, THE NORTH-WEST FRONTIER TRIBES:}

The Hati Khel are the most numerous of all the Ahmadzai. They are very much employed in the salt trade, but had many idle hands, some of whom in a band of robbers murdered Captain Mecham on the 5th November 1859 . Before the Sikh conquest of the Panjab, about the beginning of the 19th century, the Abmadzai nomades had occupied the Banu country in winter, and at length took permanent possession of the lands nearest the Thal. The Bizan Khel section of the Ahmadzai are responsible for the passes of Pinza, Khurd, Kalani, Kilhoi, Ghlosin, Tangi.

The Utmanzai are the most northerly clan, and can muster about 17,000 fighting men. Of their sections, the Kābul Khel are wild and lawless, with three subdivisions, the Miami, the Saefali, and the Pipati, numbering 3500 fighting men. The Käbul Khel, between 1850 and 1854, committed over twenty petty raids on British territory, and the British blockaded the whole tribe.

Although the Waziri are a united tribe, the clans have not joined each other on the occasions of the British expeditions into their territories. The blood feuds are not extensive, the actual murderer only being permitted to be slain in avenging a murder. They have no poor amongst them, the tribe subscribing to re-establish any family who are in need. They have cereals as their chief food, but use mutton. All graveyards are sacred to the Waziri, who in their yearly migrations to the hills never hesitate to deposit on the family tombs any property they wish to leave behind them. This is left untouched even by professional robbers. They have amongst them great numbers of fakirs, and they hold the tomb of Darvesh Musa in great veneration. In cases of adultery, they kill the woman and cut off the man's nose. Like all Pathan tribes, marriages are entered into after puberty. Childless widows are re-married to a relative of the deceased. The bridegroom buys his bride.

The Batani Pathans inhabit the outer spurs of the Waziri Hills, adjoining the S. of Banu and N. of Dehra Ismail Khan districts, from the E. slopes of the Gabr mountain at the Shamla Khurd pass to the Hisara pass. They trace their lineage through Batan to Kais, the founder of the Afghan race. Captain Maclean's list of their sections gives the Dana with 1400 ; the Tata, 1600; and the Uraspun, 1000 fighting men. Captain Norman gives the sections of the Dana as the Bobak, Bobar, Voraka; and the Uraspun, as the Tsaplai Shakhai. Captain Carr gives ten sub-sections of the Tata, 16 of the Dana, and 13 of the Uraspun. The Batani country is bare, stony, and uncultivated, resembling the Doon of the Himalaya. There are numerous passes into their hills; their principal settlements within the hills are those of Jandula, Siragar, and Gabr. They have flocks of sheep and herds of cattle, and cultivate wheat and bajra (Penicillaria spicata). They are of middle height, spare and wiry, are agricultural but predatory. They number 4600 fighting men at the outside. They were for years troublesome. They bring to British territory, grass, wood, wool, ropes, malu, camels, bullocks, sheep, goats, hill rice, ghi, and honey, and take back grain, sugar, oil, salt, donkeys, piece goods, and sandals.

Dawar is a rich, open, and fertile valley, in lat. $33^{\circ}$ $7^{\prime} \mathrm{N}$., and long. $32^{\circ} 57^{\prime} \mathrm{E}$. It is called Rodh by the inhabitants, who style themselves Dum or Marasi ; it is entirely surrounded by the Waziri Hills, and the Waziri settlers on the British border. The Banuchi are its nearest neighbours, and its communications with its neighbours are through the mountain tracts of the Suliman range. The tribal divisions are Tapizai and Malai, with many subdivisions; and the entire population has 25,000 souls, all of them Sunni Muhammadans. All their villages are walled; fever prevails, and goitre is a common disease. Lieutenant-Colonel Edwardes described them as great blackguards, and they are depraved and vicious, and are addicted to great crimes. They shave one eyebrow, half the moustache, and half the beard, and apply antimony above and below the eye. On the 6th March 1872 , a force of 1650 cavalry and infantry with two guns was sent against them under Brigadier-General Keyes, C.B., and after a brief action on the 7 th they submitted, the British loss being 6 wounded, and the Dawari loss 43 killed and 30 prisoners.

Chamkani, a tribe who inhabit the base of the Safed Koh, said to have 3500 fighting men. They are very poor.

Shirani or Sheorani are a Pathan tribe who inhabit the hill country to the W. of the British frontier, from the Shekh Hyder pass on the N. to the Ramak on the $S$. They thus adjoin the subdivisions of British Tank, Kolachi, Draband, and Chaodwan. Their fighting men have been variously estimated at from 3000 to 10,000 . They have three great sections, - the Chua Khel, Uba Khel, and Sen Khel,-with numerous clans. A great part of their territory is occupied by the Takht-i-Suliman and the hills which surround its base. Many parts of it are nearly inaccessible; one road in some places is cut out of the steep face of the hill, and in others supported by beams inserted in the rock, and is still impracticable for loaded bullocks. The population is scattered in villages of from 20 to 40 houses through the valleys and lower part of the mountains. The sites of their houses are cut out of the slopes of the hills, so that on three sides the earth forms the lower part of the wall. Each cottage has only one room and one entrance, which is closed at night by the branch of a thorny tree. The Shirani are of middle stature, spare, but stout; have bold features, grey eyes, high cheekbones, and their general appearance is wild and manly. They are hardy and active. The clothing of a common Shirani consists of a coarse black blanket tied round their middle and another thrown over their shoulders; a few yards of white cotton cloth is loosely twisted round their heads; and their feet are protected by sandals made of leather prepared by the tamarisk. Their usual food is bread made of Indian corn, with butter and kurut, and wheaten bread; their luxuries are milk, wild olives, pomegranates, and pine seed. Mutton is occasionally eaten. They never kill horned cattle for food, but when a bullock happens to die, they cut its throat in the Muhammadan manner, and eat it. They marry late, and the women have only domestic work, except at their two harvests. The principal employment is agriculture, the valleys being largely irrigated. The common stock consists of small bullocks, but they have asses, a few goats, and a very few horses. They are punctual in their prayers. They were at war with all the surrounding tribes that pass 
through their country in the annual migrations. 'I'he passes into their country are the Chaodwan, Draband, Gajestan, Guioba, Isparikat, Kuram, Ramak, Shekh Haidar, Shirani. Prior to the British annexation of the Dehrajat, the Shirani were the terror of the whole border, and were generally the aggressors. From 1849 to 1853 they annually made inroads on the British territory, but in the last-named year they were met and defeated and followed up by Brigadier Hodgson, and their fort of Kotki mined and blown up. Mr. Elphinstone gives a very favourable account of them, but Colonel MacGregor commenting on it observes that ' a Pathan obeys no one, and, except the dictates of his own revengeful and avaricious nature, nothing has any influence with him.'

The Babar tribe inhabit the Koh-i-Daman of the Dehra Ismail Khan district, opposite the Saugor and Dahina passes. Between them and the Mian Khel, on a boundary dispute, a blood feud raged for upwards of a hundred years, each year renewed. They are a brave but scattered tribe. They are of Shirani descent. They number 600 or 700 fighting men. They are of mercantile habits, and are the richest of all the tribes of the Daman. They are very fair, and are the most superior race in the Trans-Indus districts. The proverb, 'A Babar

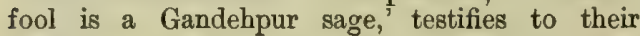
wisdom.

The Ushtarana or Oshterana is an Afghan tribe who inhabit the outer hills opposite the extreme south portion of the Dehra Ismail district. They are conterminous of the Dehra Ismail Khan and Dehra Ghazi Khan districts. They are largely engaged in trade, and have been supposed to be a division of the Lohani tribe. They are in two clans, the Gagalzai and the Ahmadzai, each of which has about 450 fighting men, but there had long been a blood feud between them, and they were hardly on speaking terms. Nothing can be more miserable than the whole of the Ushtarana country. They are not predatory, and are the bravest tribe of the Suliman range. They possess a large tract of land in British territory. On the outbreak of the Sikh war in 1848, 200 of them followed Major Edwardes to Multan. The Vooch or Korah pass, on the border of the Ushtarana hills, and nearly opposite to Dehra Fattah Khan, constitutes the boundary line between the Pathan and Baluch tribes. It is faced by the British outposts of Doulalwalla and Vihowa.

The Kasrani are a Baluch tribe who dwell in the extreme north of the Dehra Ghazi Khan district, a portion of the south of the Dehra Ismail district, and in the hills to the immediate west of these tracts. Their hills extend from the Korah pass downwards for a distance of about fifty miles. They have many subdivisions, and their fighting men are estimated at about 668 . There are about 3314 of this tribe in the plains of the Dehrajat, and they graze large herds of cattle on the sandy plains between Kot Kasrani and Vihowa. They are the most northerly of all the Baluch. They made an inroad on British territory in 1852 , and were punished by the police; and in 1853 Brigadier Hodgson moved against them with 1000 sepoys and police, and destroyed some villages. The hill Kasrani and their neighbours the Bozdar long had a bitter feud, but by British influence a truce was arranged. In 1868 Lieut. Gray attempted to seize Jahangir Khan, but he was himself made a prisoner and carried off, and only released after a force of the Bozdar and the Panjab cavalry had been sent in pursuit.

Khastai, a small tribe of Pathans beyond the Dehra Ghazi Khan border. They are peaceful and quiet, agricultural and pastoral.

Luni, a Pathan tribe west of the Dehra Ghazi frontier. Their neighbours on the north are the Kakar and the Musa Khel, on the south are Murree Tarin, with the Khetran on the east. Their adult men are 1200. They speak a mixture of Pushtu and Baluch. The Chumalang range of hills produces a valuable coal, also sulphur.

Bozdar, a Baluch tribe who occupy the hills on the Dehra Ghazi Khan frontier. Their country extends on the north as far as the Saugor pass and Drug, where they touch the Kasrani, Esot, and Jafar; on the east to the foot of the hills on the Saugor border; on the south to the Vidor pass and the Majvel Sham (plain), where they weet the Hadiani and Khetran; and on the west to the crest of the Kala Roh, where they are bounded by the Luai and Musa Khel Pathans. Their country is about 40 miles long by 30 broad, and is entirely mountainous, formed of the outer spurs of the great Suliman range. They number about 2720 fighting men, as under :-

Dulani, . . $850 \mid$ Chakrani, . $400 \mid$ Jalani, . . 120 Ladwani, . 360 Sihani, . 150 Jafarani, . 300 Gholamani,. 300 Shahwani, . 140 Rustamani, . 100 and they have numerous subdivisions,-according to Major Minchin, 64, with 3776 fighting men. Their country is a series of bare and sterile ridges, divided by bare ravines with small patches of cultivation. They are friendly with the British. Their greatest enemies were the Ushtar ana Pathans, and at times the Khetran. They fight with matchlocks. They have few horses, and about 100 horsemen. They purchase the coarser grains, cloth, tobacco, and oil in the markets of British India. They claim to be of Rind Baluch origin; and their name, from $\mathrm{Boz}$, a sheep, was given because of their possession of large flocks of sheep. From 1850 to 1856 they were frequently troublesome to the British, and in 1857, an expedition, 2369 strong, under General Chamberlain, was moved against them. The Bozdar numbered 1700 , and lost 20 to 30 killed and 50 to 70 wounded. More than all the frontier tribes, the Bozdar had for years previously plundered and murdered in the plains and the hills. They recommenced plundering in 1861, but later on they behaved better.

Esot, a small tribe of Afghans near the Dehrajat frontier. Balfarat, a small clan of Esot Pathans on the Vihowa border of Dehra Ghazi Khan.

The Jafar is a tribe of Pathans with 500 fighting men. They dwell to the N.W. of the Bozdar hills, between the Buj spur of the Suliman and the Bozdar tribe. They have twelve branches, and possess a few camels and horses.

The Khutran or Khetran are a Baluch tribe inhabiting the hills to the west of the Dehra Ghazi Khan district. The Khetran are curiously intermixed with the Baluch tribes, and farther south are the Kosa, Laghari, Gurchani, Murree, and Bugti, occupying the frontier line of the Dehra Ghazi Khan district down to its point of junction with the Sind border; on the north the Musa Khel and Luni Patban, the Bozdar on the N.E., the Hadiani Laghari on the east, and the Durkani section of 
the Gurchani occupy the high crests of the Kala Roh and the Morunj plain. The Murree are on the W. and S.W. West of the Kolu valley is the small tribe of Zarkhan Pathans, west of whom again are the large tribe of the Tarin, and N.W. are the Ushtarana and Shahdozai. It is a large extent of country. Their boundaries can with difficulty be marked out, and they lay claims to portions of the adjoining lands. Their sections are the Ganjura, Chacha or Dariwal, Hasani, and Nahr, with many clan subdivisions, and their fighting men have been stated at from 3000 to 6000. They all live inside forts. They are the wealthiest of the Baluch tribes, are not warlike, do not plunder, and are largely engaged in cultivation, but are recipients of all the plunder on the border. They seem to have been formed by branches of other broken tribes. They are at feud with the Murree, Bozdar, and Durkani, and with the Luni and Musa Khel Pathans. They carry on a large trade with the British territory. A branch of the Khetran live round Tihowa in the Dehra Ghazi Khan district, who can raise 300 fighting men.

Hasani, a tribe in the Khetran country near Laghari Barkhan, also in the Shahdozai country.

Zar Khan, a small but very martial tribe of Pathans inhabiting the Kolu valley, and separated from the Khetran by the Jandran range. They number 600 men. They have good horses, and their arms are swords, shields, and matchlocks.

The Laghari tribe on the border of the Dehra Ghazi Khan district occupy from the Dalana on the north to the Kura pass on the south. Their sections are the Aliani, Hadiani, Boglani, and Haibatani, with numerous clans. They have been variously estimated as capable of furnishing from 1900 to 5250 fighting men. In the Dehra Ghazi Khan district, in 1868, there were also 11,311 Laghari and 904 in the Dehra Ismail district. At the opening of the Sikh rebellion they sided with Mulraj.

The $K o s a$, in the Dehra Ghazi Khan district, is a Baluch tribe with seven divisions, - Balelani,Jangel, Jandani, Jarwar, Isani, Tomiwala, and Mehrwani, estimated capable of furnishing from five to six thousand fighting men. They are among the bravest of the Baluch, and formerly were very powerful. They live almost wholly in the plains, which they cultivate. They are likewise graziers, and have numerous flocks. There have been difficulties in securing the succession, but the tribe has twice aided the British.

Gorchani, Gurchani, or Gorishani tribe are Baluch, but mixed, who inhabit the Jampur division of the Dehra Ghazi Khan district in the immediate vicinity of Harand. They have thirteen sections, - Shikani, Hotwani, Khalilani, Alikhani, Bazgir, Jaskani, Pitafi, Lishari, Durkani, Chang, Surani, Joqiani, and the Helwani. Their fighting men are estimated at 1100 to 1200 . The Pitafi and Lishari sections had been inveterate thieves, and until 1866 continued to give trouble; but in recent years there has been no complaint against them. Their population is 3938 souls, of whom 1100 or 1200 are adults. In 1867 , a raid on Harand by 1200 Murree, Bugti, and Khetran, was met by the Gurchani and the 5th Panjab Cavalry, and defeated with great loss.

Murree or Mari, a brave Baluch tribe who inhahit the outer hill which surrounds Cutchi on the east, north, and north-west sides. They are subject to the Khan of Kalat, and nowhere touch on British territory. They possess the districts of Kahan, Mundahi, Jantali, Phailawar, and Nisao, and their four main sections are the Ghazani, Loharani, Bijarani, and Mazarani. Their country extends from the Bolan pass to the Phailawar plain, about 120 miles, mostly barren hills, but with many fertile valleys. They are nomades, and rich in cattle, but their habits were altogether predatory, and they can furnish about 4000 fighting men. The portion who inhabited the eastern hills in Cutch Gandava were notorious for their lawless habits, and for making frequent inroads on the plains. They and the Maghazzi seem to have emigrated from Cutch Gandava at different periods, and to have become incorporated with the Jat cultivators. A peaceful and obedient portion of the tribe are in the hills west of the province below Jell. A large portion are at Adam Murree on the S.E. frontier of Sind; the Doda Murree occupy Kahan. In April 1840, Captain Lewis Browne of the 5th Bombay Native Infantry occupied Kahun, and held it till the 28th September, when he retired with his arms and a gun,-all efforts to relieve him having failed. In one of these disastrous efforts under Major Clibborn at Nufusk, the British lost 179 killed and 92 wounded; they subsequently met with many calamities. On the $23 \mathrm{~d}$ May 1849 , in a fight with the Brahui at Bibi Nani, they lost 750 men out of 1300 . In August 1849 , they plundered the village of $\mathrm{Mal}$, and attempted predatory incursions on British territory. In 1852 (24th January), the fort of Kahun andmany of its houses were destroyed by an earthquake, and many lives and much property lost. A cave in a hill, in which many were dwelling, was filled up by the fall of the hill, destroying 260 Muhammadans, 80 Hindus, and many cattle. On the 11th December 1852, a large body of Murree attacked the town of Pulaji, and killed 40 of the Kaihiri. Major Jacob then remonstrated with the Khan of Kalat, and urged him to restrain his subjects; but on the 30th January 1853, a party of 200 Murree horsemen left their hills, and attacked some Bugti shepherds on the Mazardan plain. On the 23d March of that year they fell on the village of Trihar, killing several of the Dumki, and carrying off a very great number of camels and other cattle. On the $3 \mathrm{~d}$ April they had carried off cattle from Kasmir, and were followed by the Sind Horse, and, coming up with them near Hirpani, a hand-tohand fight ensued, in which the British lost ten killed and wounded. They made raids on the 17 th and $23 \mathrm{~d}$ June, the 10th and 17th September, 28th October, 26th November, and 28th December 1853, and 24th February 1854. On the 21 st January 1859 , the Khan of Kalat assembled 8000 horse and foot to punish them, and was accompanied by a British force under Major Malcolm Green, and Sir Henry Green was present, and the Murree tendered their submission. But in December 1862 the khan was obliged to take another force into the hills. In their attacks on the Panjab border, between the 25th September 1850 and 1869 , they made about twenty raids, killing people and carrying off cattle. On the 1st February 1869, the Murree chiefs met Colonel Phayre, in the presence of the Bugti, Dumki, and Mazari chiefs, and the Murree agreed to live peaceably. 
The Bugti tribe are Baluch who inhabit the hilly country to the west of the Rajanpur border, and it has been estimated that they can muster from 1200 to 4000 fighting men. Their six divisions are the Kaheja, Nothani, Musuri, Kalpar, Phong, and Kiazai. Much of their country is rugged and barren, but it contains good pasture lands and some fertile valleys. They claim to be allied with the Rind Baluch. They and the Murree were unceasingly at war, but the Bugti were also at feud with the Mazari, Dreshuk, Dumki, Burdi, and others. They made predatory attacks on the British army when advancing towards Afghanistan. In 1844-45 Sir Charles Napier advanced against them with 2500 men, and was opposed by about 3500 Jakrani, Dumki, Bugti, and Khetran. The campaign lasted from the 15 th January to the 4th March 1845 , on which the chiefs submitted, after 54 days of incessant exertion. They again, on the 10th December 1846, assembled a force of 1500 armed men, and made an inroad to within 15 miles of Shikarpur, and returned to their hill with 15,000 head of cattle, without the loss of a man. On the 1st October 1847, the whole Bugti force entered the plain, but were met by Lieutenant Merewether of the Sind Horse, with 133 men. The Bugti formed a solid mass to receive the attack, but were overthrown at the first onset, retired, and were again defeated, and at last threw down their arms and surrendered. Out of 700 , only two horsemen regained the hills, while the loss of the British was nine killed and wounded; and the tribe, broken and dispersed, fled for refuge to the Khetrans. Nevertheless petty inroads occurred, and on the 7 th April 1869, 500 Bugti attacked the post of Kasmir, and were repulsed, and, as they retreated, a native officer and party came on a party of 300 or 400 Bugti driving off 1000 camels. He immediately charged them, killing many, and recovering all the camels.

The BRITISH TRIBES on the N.W. frontier of India inhabit partly hills and partly dwell in the plains. They may be enumerated as follows :-

i. Hazara district-

a. Turnouli of Darwazai.

b. Syuds of Kaghan and Agror.

c. Ghakar.

ii. Peshawur district-

a. Yusufzai.

b. Khalil.

d. Swati.

e. Dund or Doond or f. Sutti. Dhund.

c. Mohmund of the plains.

iii. Kohat and Peshawur district- $a$. Khatak.

iv. Kohat district-a. Bangash.

v. Dehra Ismail Khan districta. Banuchi.

b. Marwati

c. Butani.

d. Chiefs of Tank.

e. Chiefs of Kolachi f. "Dehra Ismail Khan.

a. Dreshuk,

Nutkani.

h. Lund.

The British Hazara is a Cis-Indus district of the Panjab. It is a mountainous country, bounded on the north by various independent tribes, on the S. by Rawal Pindi, on the E. by Kashmir, and on the W. by the Indus. Its greatest length is 130 miles, and breadth 40 miles, with an area of 2994 square miles. It has four revenue subdivisions,-Haripur,Mansera, Tanawal,and Kaghan. In the last are Gujar ryots, and Swati occupy Kunbar as far as the Black Mountain. In its south portion are the Bomba, Dhund, Karal, and Ghakar, and in the tracts on the Indus are the Utmanzai, Mashwani, and Tarkheli.

The Tanaoli and Jadun are in Tanawal. They are fair cultivators. The Gujar, Awan, and other Muhammadan converts are hard-working and thrifty ; the Syud, Swati, Utmanzai, and Tarkheli are careless, lazy races. The Mashwani are very thrifty.

Agror is a subdivision of the Hazara district, 10 miles long and 6 broad, consisting of three main valleys in the upper portion of the Unar river, bounded on the north by the Mana Ka Dana spur of the Black Mountain. Its beautiful mountain glens, Unar, Arbora, and Kathai, are one mass of luxuriant vegetation, and open into several minor glens, -Chulandarian, Kabl, Bazdara, and Kanjara Dara. A great spur comes down from Nanga Parbat, and another range comes from above Kabl. The inhabitants, 8721 in number, are Swati and Gujar of low physique and debased morality. The Swati have all the vices of the Pathan without his courage, and they do not care to fight even for their own fields. There are a few Tanaoli, Awan, Pathan, Koreshi, Syud, and Dasht, bigoted Muhammadans, who speak Pushtu, all ruled by a khan. The Koresh tribe claim Arab origin, and are in all the Trans-Indus districts.

There are also in Agror portions of upwards of twenty Afghan tribes, with the usual artisans of eastern villages, and a few Khatri and Brahman Hindus, living in 45 small villages. In July and August 1868 a small force was sent into Agror; the Swati submitted, but others held out, and a large force under Major-General Wilde advanced to the Black Mountain. In July 1869 two hamlets in the valley were burned by raiders of the Hasanzai, Parari Syud, and Akozai, on which a British force destroyed the Akozai village of Shahtut. On the 5th and 15th April 1870 and 4th June 1871 other villages were attacked by raiders, but after 1872 the Agror valley and Hazara border were free from any hostile attacks.

Suati.-The Alahi valley, to the north of Hazara, drains into the Indus nearly opposite Ghorband. The inhabitants are Swati.

The Kohistan is a valley on the Hazara border to the N.E. of Alahi, along the west and north of Kaghan. It has an area of 500 or 600 square miles. The Kohistani claim to be of Arab descent, but their neighbours say they were idol-worshippers up to the last quarter of the 18th century. This seems correct, as their divisions are the Rana proprietors, the Yeshlsan vassals, Kamin artisans, and Dum musicians. The Kohistani are a physically fine race, free spoken and very united. They trade in timber and other produce. Their divisions or khel are the Bara, Kali, Galoch, Shandar, and Gatar.

The Kaghan valley or glen forms the most northern part of the Hazara district. It has a population of about 22,000 , Syuds and Gujar. It consists of the inner slopes of two parallel mountain ranges, clad with perpetual snow, and ranging in height from 12,000 feet at the $\mathrm{S}$. entrance of the valley to 15,000 feet at its northern head. It stretches upwards till it nearly reaches Chilas. The Gujar are quiet and peaceable cultivators. The Syuds are proprietors, having received it 
from the Sikhs. They are lazy, disunited, and intriguing. They were proceeded against in 1852 , and they surrendered to the British.

Gujar are found in the frontier districts of the Peshawur division, and amongst the independent tribes. They profess Muhammadanism, are cultivators and rear cattle. They are a fine healthy race, quiet, industrious, and frugal. They are of Jat descent, but are now subdivided into clans and khel like the Afghans. They are very numerous, and form the entire population of many villages. They are not owners of the lands beyond British limits, but lease from the Patban proprietors.

The Bambar tribe of Hazara inhabit the range of mountains behind Raragoli, N.E. of the Jadun. They are a portion of the Bambar tribe of Muzaffarabad. They have no sympathies with any other Hazara tribes.

Mashwani are a tribe of Syuds in the Hazara district in the N. portion of the Gangdar range, also about 400 families in the Koh-Daman of Kābul. They are of fine physique, manly, brave, and truthful. They are large carriers.

The Utmanzai inhabiting the Torbela and Khalsa tracts of Hazara are a branch of the Utmanzai of Yusufzai. The population of Khalsa is 8567 souls, and of Torbela 7088.

The Jadun or Gadun is a Pathan tribe partly on the slopes of the Mahaban mountain, partly in the Hazara district, and in part Trans-Indus. They are surrounded by tribes of Yusufzai origin. Their country is called Gaduna. They have two divisions, - Salar and Mansur. They claim to have 12,000 fighting men, but may have a sixth part of that number, and these are badly armed. The British have several times blockaded them in their valleys.

Dalzak is a tribe of Afghan descent, part of them inhabiting a portion of the country on the right bank of the Indus, but are chiefly on the left bank in Hazara.

The Dhund is a very handsome race, inhabiting the Boi tract of Hazara, especially between the Jhelum and the main range, numbering 18,518 souls, living in villages on plateaux about 1000 feet above the river. They are improvident, lack energy, and have been badly affected towards the British.

The Tanawal district on the Hazara border is the most wild, mountainous, and rugged part of Hazara, and is peopled with armed and warlike peasants. It is divided by the river Siran into an eastern and a western part. The Palal are British subjects, and the Hindwal are in an independent principality, and occupy an actual area of about 720 square miles in the Doaba of the Indus and Siran, with a revenue of Rs. 28,000 . Bahingra, a rugged, steep mountain, is in independent Tanawal. The Pakli plain in the Hazara district is occupied by the Swati, Awan, Syuds, and Tanaoli.

The Karāl are a poor, humble tribe, 16,615 in number, dwelling in the Nara tract of the Hazara district and in the Jadun tract. Some of their villages on the spur of a ridge in Hazara are 5000 feet above the sea. They are agriculturists. They are of Hindu origin, converts to Muhammadanism.

The Awan are the most numerous and the best of these frontier tribes, and there is no better people in India. They are settled in large agricultural communities on the Chach plain, on the eastern side of the Indus, and in smaller bodies farther east, on the Jhelum, Gujerat, and Sealkot districts. They are scattered in Yusufzai and the Kohat district, as well as in Hazara and other districts on the left bank of the Indus. In Yusufzai they are said to number 3000 souls. They have enlisted in the Panjab force and in the regular infantry. They are good soldiers. The Awan of the lower lands, and Dhund, etc., of the higher lands, have democratic village institutions.

Gakkar, Ghakar, or Kakar, a tribe inhabiting portions of the Hazara, Jhelum, and Rawal Pindi districts of the Panjab. They claim to have come into their present position from Seistan with Mahmud of Ghazni ; but they are one of the oldest and most powerful of the Hindu dynasties of the Panjab. They opposed Mahmud on the plains of Peshawur, but they seem soon afterwards to have adopted Muhammadanism, and their. country was a jaghir to them from the times of the first emperor of Dehli, for which they paid the annual tribute of a horse, and rendered military service at first to Dehli, afterwards to Kābul, and subsequently to the Sikhs. About 1783 they suffered from a severe famine.

In 1847, when the British came into contact with the Hazara, they took the British side; they aided in the siege of Multan, and again sided with the British in the mutiny of 1857. Their chiefs have borne the titles of Sultan, Mirza, and Raja. The Gakkar are not distinguishable from the Awan in personal appearance, both being very large, fine men, but not very fair.

They are supposed to be descendants of the mountaineers, whose chief Ambisaces sent ambassadors with presents to Alexander. In the time of Mahmud they inhabited the Salt Range or Jhow mountains between the Indus and the Behut (Hydaspes). Baber names them Gakar; but it is also written Ghaka and Kakha. At an early period of history, old writers tell us that they were given to infanticide and polyandry. It was a custom, says Ferishta, 'as soon as a female child was born, to carry her to the market place, and there proclaim aloud, holding the child in one hand and a knife in the other, that any one wanting a wife might have her; otherwise she was immolated.' By this means they had more men than women, which occasioned the custom of several husbands to one wife. When any one husband visited her, she set up a mark at the door, which, being observed by the others, they withdrew till the signal was removed.

The Dhund, Tanaoli, Alpial, Kurral, Awan, and Gakkar tribes are known only by their tribal names, without any common appellation; they live north of the Salt Range. They are described by Mr. Campbell as the finest and handsomest men in India, perhaps in the world. They profess Muhammadanism, and have fanciful Muhammadan genealogies, but are wholly Indian in their language, manners, habits, and constitutions. Their language is Panjabi. They have no connection with the Pathan races, and they claim none with the Jat and Rajput, the Dilzak alone claiming to be of Hindi origin. Their features would seem to show that they have kindred with the Kashmiri, or with the pre-Hindu congeners of the earlier Indians found in the hills far west, but their language and character, dress, and the architecture of their houses, would indicate that they are nearly allied to the Panjabi. 
Peshau:ur, in the Panjab, is the name of a proince, a district, a city, and military cautonment. It is British territory, in India proper. The city is in lat. $34^{\circ} 1^{\prime}$ N., and long. $71^{\circ} 37^{\prime}$ E., and 1200 feet above the sea. The district lies between lat. $33^{\circ} 50^{\prime}$ to $34^{\circ} 30^{\prime} \mathrm{N}$, and long. $71^{\circ} 30^{\prime}$ to $72^{\circ} 50^{\prime}$ E. The cantonment in 1868 had 21,720 inhabitants ; the city, 60,974 ; while that of the district was 523,152 , principally various tribes of Afghans, with Paracha, Khojah, Tajak, Kashmiri, and Brahmans, giving 271.2 souls to the square mile, the chief races as under :-

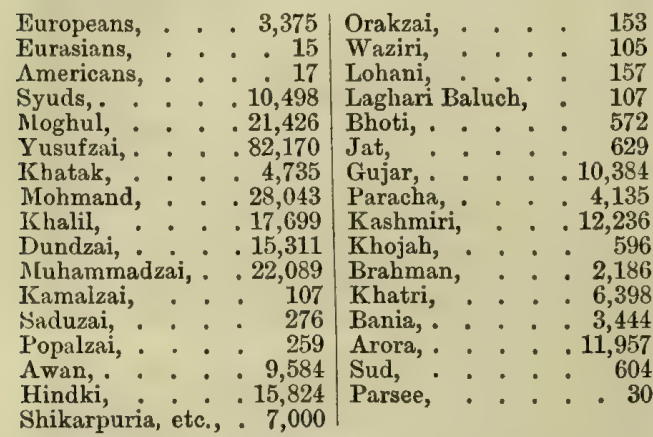

The tribes on the Peshawur and Kohat borders are in two political factions, - the Gar and the Samal. The tribes who are of the Gar faction are the Abdul-Aziz, Adam, Afridi, Akhel, Alikhel, Bazoti, Firoz, Kambar, Kuki, Manu, Masuzai, Sipah, Turi, Ustura, Utman. The Samal faction are the Afridi, Aka, Ali-Sherzai, Bar-Muhammad, Kamr, Khadarzai, Malik Din, Mishti, Mamazai, Orakzai, Rabia, Shekhan, Sipah, Soda, Waziri, Zaimusht, and Zakha. The factions arose two hundred years ago, in the quarrels of two Hindu brothers.

Peshawur is said to be a corruption from Purshawur. Major James thinks it means the seat of Purrus or Forus, the name of a king or dynasty, as similarly Lahawar means the seat of Lawa.

The Peshawur valley is at the extreme north of the Trans-Indus territory. On its north are the hills of the Molimands, Utman Khel, Swat, Buner, and the Mahaban tribes. It is bounded on the E. by the Indus, S. by the Khatak and Afridi hills, and W. by the Khaibar mountains. Its area is 1928 square miles; the valley is closed on the N.W. and S. by a more or less continuous range of high hills. To the east for about 20 miles is a gap occupied by the plain of Chach. The northern boundary is a continuous range of hills extending in an arc from the Indus, opposite Torbela to the Swat river, where it debouches on the plains at Abazai Fort. The highest points in this range are Mahaban, 7471 feet, Tatara, 6862 feet, Mulagarh, 7060 feet. Its N.E. is inhabited by Yusufzai ; the Khatak, Khalil, Mohmand, and Vaudzai occupy districts with these names; the Muhammadzai and Miana inhabit Hashtnuggur, and Lunkhor has the Khatak and Utman Khel; while many tribes are in Doaba and Khalsa. It is highly fertile and well peopled. Its rivers are the Indus, the Swat river, the Käbul river, which divides into streams. The Yusufzai have the best climate and are the finest people. In this district Lieutenant-Colonel Mackeson was wounded on the 10th September 1853. Major Adams, wounded on the 15th January 1865 , died on the 26 th of that month, and on the $3 d$ October 1865 Lieutenant Ornmaney was killed.

The Yusufzai Pathans inhabit the hills north of the Peshawur district, and the Yusufaai division of that district lies between lat. $34^{\circ}$ to $34^{\circ} 3^{\prime} \mathrm{N}$. and long. $71^{\circ} 55^{\prime}$ to $72^{\circ} 40^{\prime} \mathrm{E}$.; area, about 2000 sq. m. ; population, 98,977. They claim that their ancestor Mandai had two sons, Umar and Yusuf. Umar left one son named Mandan, from whon and Yusuf the tribe are descended. Mandan hal seven sons, from whom sprang the Usmanzai, the Utmanzai, and the Rajār.

Yusuf had five sons, viz. Uria surnamed Badi, the founder of the Badi Khel, Isa of the Isazai, Musa of the Musazai, whose son Ilias founded the Iliazai, Mali of the Malizai, and Ako of the Akozai. There is also a Yusufzai clan called Ramzai.

The total population of the Mandan branch is 140,000 souls with 30,000 fighting men, and of the Yusufzai, 106,000 souls with 43,200 fighting men. About the year 1873 there were 793 Yusufzai serving in the Bengal army and 364 in the Panjab force. Besides the Yusufzai, thei district had in its population, Gujar Awan 3000. Kashmiri 6000, Hindki 10,000, Mula slaves and Hindus. The Gujar are Mubammadans ; they form the entire population of many villages; they cultivate the lands, paying rent, and are also cattle graziers. They number about 75,000 souls, and are a fine athletic race.

The Hindki are mechanics, artisans, and traders, and have the following guilds amongst others, Charikar, ploughmen; Dum or Mirasi, musicians ; Gadba or Rawanri, shepherds, graziers ; Musalli, sweepers; and Shahkail, cotton cleaners. All the Hindki are termed Hamsaya (neighbour) or Fakir (beggar). The Ghulam slaves were descendants of war prisoners; the men are called Mrai and the women Windza. They are beyond the British frontier.

The Mula number 34,000. They have two sections, Astanadar or Buzurg and the Mula, both of them holy classes. The Hindus are nearly all Khatri, and number 22,000.

The Yusufzai, formerly nomades, are now agriculturists and traders. They are superstitious, proud, greedy, and revengeful; they observe their religious rites of prayer and pilgrimage, almsgiving (Zakat, Khairat, and Ashar) and fasting. They are boastful of their descent and prowess, and demand, Am I not a Pukhtun? They are hospitable; but so soon as the guest leaves he might be robbed or murdered by his late host. Their honour, Nang-i-Pukhtana, is satisfied with Badal or retaliation; Nanawati, sheltering a guest; and Mailmastai, feeding a stranger.

They are suspicious and jealous of their women; the abuse or slander of one's female relatives was only to be washed out by blood; and not unfrequently the slandered one, whether guilty or innocent, was murdered to begin with. They do not treat their women with respect or confidence. Elopements (Matiza) are one of the most fruitful causes of feuds. They are dirty in their persons and clothes. They are fond of field sports, and in disposition are lively, merry, fond of music and recitations. The women are uneducated, and coarse and obscene in their conversation. On a death occurring, the women of the quarter | assemble for the vir or wuzar lamentation. 
The Mandan division of the Yusufzai number 4000 souls, with 80,000 to 100,000 of other races settled amongst them. They can muster 25,000 to 30,000 armed men. They have seven khel or clans.

The Utmanzai is a division of the Mandan.

The Razar section of the Mandan comprises five of the seven sections of that division. They all reside in the British district of Yusufzai, and give their names, Ako Khel, Malikzai, Manizai, Khidaizai, and Mamuzai, to their respective subdivisions. The Mamuzai rebelled during the mutiny of 1857 , but were subdued.

The Akozai is a division of the Utmanzai clan of the Mandan Yusufzai. They are located beyond the British frontier, and occupy the south spurs of Mahaban, on the right bank of the Indus.

The Khudu Khel section of the Saddozai division of the Utmanzai Mandan Yusufzai inhabit the north slopes of the Sar Patai mountain. They are said to have 1500 or 1800 fighting men. 'They gave trouble to the British in 1857, and a force under General Cotton moved against them in 1858 .

Isazai is a division of the Yusufzai clan.

The Akozai division of the Isazai clan of Yusufzai inhabit the western slopes of the Black Mountain on the Hazara border. They have four sections or khel, Barat, Aziz, Tansan, and Painda, and can muster 1165 fighting men. They have been troublesome on the Agror border.

The Mada Khel section of the Isazai Yusufzai inhabit the northern slope of the Mahaban. They number about 2000 ; their clans are the Mada, Hasan, and Bazid, but Dalazak, Gujar, and boatmen live in their country.

The Hasanzai section of the Isazai Yusufzai dwell on both sides of the Indus; those Cis-Indus on the Black Mountain, and those Trans-Indus immediately opposite it. They have ten sections, and 1115 fighting men. They murdered Messrs. Carne and Tapp in November 1851, and Colonel (now Lord) Napier led an expedition against them.

The Malizai division of the Yusufzai occupy the lower portion of the Buner valley. They number 16,000 souls, and can muster 3500 or 4000 matchlockmen.

The Nurizai section of the Malizai Yusufzai are in the south-west corner of the Buner plain.

The Daulatzai section of the Malizai Yusufzai inhabit a portion of the valley of Buner. They have between 3500 and 4000 matchlockmen.

The Nasrozai section of the Iliaszai Yusufzai has the Panjpao and Makhozai as subdivisions. The Makhozai inhabit the country to the north-east of Buner, in a glen through which a tributary of the river of the Puran valley flows.

'The Amazai section of the Usmanzai clan of the Yusufzai are partly within and partly beyond the British border, and are divided into two portions by a northern spur from the Mahaban. Their country is well wooded with pines, but is rough and narrow. Their fighting men have been estimated at from 1500 to 8000 , the former probably correct. Malka, burnt in 1863 by General Chamberlain, is in the Amazai territory, and in 1864 (11th January) they excluded the Hindustani fanatics from their limits.

Daulatzai is a division of Amazai Usmanzai
Yusufzai in the Pewawur district, in the Sudhum valley, enclosed on three sides by hills. Their subdivisions are the Bazid Khel and Hasan Khel.

The Ismailzai, a section of the Amazai Usmanzai Mandan clan of Yusufzai, are in the Yusufzai plain.

The Akozai is a grand division of the Yusufzai, comprising the Baizai and Khwazozai, who inhabit the Swat valley; they number about 90,000 souls.

Paindah is a section of the Malizai Khwazozai Yusufzai.

Adingzai is a section of the Khwazozai Akozai Yusufzai, who inhabit the right bank of the Swat river, and a glen running north from it about 10 miles long, from the Swat river to the Laram hill. A hill on their east separates them from the Shamozai. They have forty-four villages. Their sections or khel are the Mir-Hasan, Babu, Utmanzai, Shergha, Marjan, Baram, and Umar Khel. The Utmanzai and Babu Khel redistribute their lands amongst themselves every ten years. They communicate with the Malizai by the Laram pass.

Ashi Khel, also called Shamizai, is a section of the Khwazozai division of the Akozai Yusufzai.

Malizai is a section of the Khwazozai Akozai Yusufzai who occupy the country of Panjkora. They number 8500 fighting men. They opposed the British in the Ambela campaign.

The Khadakzai section of the Akozai Yusufzai reside north of the Ranizai, on the right bank of the Swat river.

The Baizai section of the Akozai clan of the Yusufzai are mostly on the south bank of the Swat river, beyond British border.

The Jinki Khel section of the Baizai Akozai Yusufzai are on the left bank of the Swat river, with the Kohistan on their north.

The Babuzai section of the Baizai Akozai Yusufzai are on the left bank of the Swat river. They have four sub-sections, and about 1000 fighting men.

The Barat Khel is a section of the Babuzai Baizai clan of the Akozai Yusufzai.

The Azi Khel is a section of the Baizai Akozai Yusufzai dwelling on the left bank of the Swat river.

The Ranizai Yusufzai is a subdivision of the Baizai Akozai division of the Yusufzai clan, and are further subdivided into the Sultan Kban, Usman, Burhan, Utmanzai, and Ali Khels. They all reside beyond the British border. They can muster about 3000 matchlockmen. The Ranizai country is divided into Sam Ranizai and Bar or Swat Ranizai. Sir Colin Campbell moved against them in 1852 .

The Aba Khel division of the Baizai Akozai Yusufzai is located on the left bank of the Swat river. They have five khel, viz. Ismail, Khasai, Zaman, Khalai, and Skhalo. The Abazai are on the right bank.

The Chagharzai tribe of Yusufzai Afghans inhabit both banks of the Indus above Buner. Their three subdivisions are the Nasrat Khel, with 800 fighting men; Firozi and Basi Khel, with 4150 fighting men. The Trans-Indus Chagharzai have 1950 fighting men.

Ghoria Khel is a name sometimes used to designate the five Peshawur tribes, Mohmand, Daudzai, Khalil, Chamkani, and Muhammadzai. 
They are descended from four sons of Ghoria, son of Khar Shabun, son of Saraband. The Ghoria Khel came from Kandahar, and settled for many generations in Ghazni, from which they removed to Kābul, and afterwards to Nangrahar and Peshawur in the reign of Kamran, son of Baber; they fought with the Dilazak, and gradually got possession of the country, which they still retain, the Chamkani excepted. Their chiefs are called Arbab, lords. They are said to be more treacherous than other Pathans.

The Daudzai tribe of the Ghoria are located in the Peshawur valley, between the Khalil and Khalsa divisions and the Kābul river. The population in 1868 was returned at 37,671 , almost all Muhammadans, Syud, Moghul, Daudzai, Gujar, Khojah, Kashmiri, Khatri, and Arora. The three Daudzai sections are the Mandaki, Mamur, and Yusuf. In 1881, there were only 5898 of the Daudzai tribe returned in the Panjab.

The Khalil inhabit a portion of the Peshawur district in the plain between the Khaibar Hills and Peshawur. They are of Afghan descent. Their chiefs have the titular name of Arbab (the Arabic plural of Rab, lord). They numbered 13,595 souls in 1881. About 100 serve in the Bengal army and Panjab force.

The Mohmand tribe are partly independent, but a portion of them colonized in the south-western lands of the Peshawur district, and in 1881 numbered 44,009 souls. They are now respectable cultivators, have been lukewarm supporters of the British, and have maintained friendly relations with their neighbours, the Afridi. They have not, however, fraternized with their fellow Mohmands of the rugged, sterile, hilly country N.W. of Peshawur, against whom in 1851 a force under Sir Colin Campbell was sent; in 1854 another force was sent under Colonel Boileau; and in 1864, a third time, under Colonel Macdouell. The Pendi Ali Mohmand worried the border for the first eleven years of British rule. The six clans of the Mohmands can turn out 19,700 fighting men; Tarakzai, 2500; Halimzai, 3000 ; Khwaizai, 800 , Baizai, 12,000 ; Utmanzai, 500 ; and Dawezai, 900. The Halimzai section includes the chiefs who hold the Panjpao lands in the British territory near Shabkadr, and inhabit the Kamal district north of Pindi Ali. They are considered the best fighting men of the Mohmand. By 1873 only 272 Mohmands had entered the Panjab force and Bengal army.

In the Hashtnuggur division of the Peshawur district are two tribes meriting notice,-the Mian, a branch of the Kaka Khel Kbatak, who are carriers, and the Muhammadzai or Mamanzai, a mixed population of 25,000 souls, who have about 5000 matchlockmen.

The Gagiani tribe of Pathans in the Doaba division of the Peshawur district are said to have come from the valley of the Kabul river, and to have ousted the Dilazak. Some of them settled at first in Bajawar, but were soon driven out by the Tarkolani.

The Parancha is a mercantile tribe of about 500 families, who are said to have come from Baghdad and settled in various parts of the frontier districts of Kohat and Peshawur. They claim descent from Nusherwan. They trade from Bombay and Calcutta with ter, indigo, chocolate, and cloth, about September, to Bokhara, and from Bokhara they start afresh for Yarkand, Tashkand, and Orenburg, and go also to the fair at Nijni Novgorod, which they call Makraia, and bring back wrought silk, Tilla and Ratiska coins.

The Kohat district of the Panjab is on the right bank of the Indus, between lat. $33^{\circ}$ and $33^{\circ} 35^{\prime} \mathrm{N}$., and long. $70^{\circ} 35^{\prime}$ and $71^{\circ} 55^{\prime} \mathrm{E}$. It extends 120 miles from Darwazai on the right bank of the Indus in the Khatak country, five miles below Atak, to Biland Khel on the Kuram river, at the head of the Miranzai valley. The breadth of the Kohat district is from Darwazai to Rokwan in the Shakrdara estate, where it joins the Banu district; the distance is 72 miles, a labyrinth of barren rocks and ravines of the most impracticable nature intersecting it in every direction. Its area is $1,816,000$ acres, of which $1,497,760$ are absolutely barren. Its rivers are the Kohat Toi and Tiri Toi. It produces sulphur, alum, and has rock-salt mines. The population of 145,419 souls consists of Sikh, Hindus, Bangash, and Khatak Muhammadans. The Kohat defile in the Afridi hills between Kohat and Peshawur runs for miles from Fort Mackeson to Busti Khel. The Kobat district is divided by tribes into two unequal parts, viz. the northern and more fertile but smaller part, consisting generally of the system of the Kohat Toi ; this is inhabited by the Bangash, while the southern, which is the larger and more desolate portion, belongs to the Khatak; it consists of the system of the Tiri Toi and the south spurs of the Khatak Hills. The British administrative divisions of Kohat are Kohat Khas (proper), Miranzai, and Tiri. The total population is 145,419 souls ; of this 1808 are Sikhs, 6544 Hindus, 136,565 Muhammadans, comprising Yusufzai, Bangash, Khatak, Orakzai, Baluch, Waziri, Syud, Moghul, Mohmand, and other Pathans, with Jat, Ranghar, Bhatti, Arora, Gakkar, Parancha, Brahmans, Khatri, Bania, and Sikh.

The Kohat pass in the Afridi hills leads from Kohat to Peshawur. It runs down the bed of a stream, with a level roadway. Its width varies, and the tribes interested in it are the Bangash, Jawaki Afridi, Adam Khel Afridi, Bazoti, Firoz Khel, Utman Khel, and Sipah Orakzai, Gali Khel, Akhorwal, and Hasn Khel. In 1850 a force under Sir Colin Campbell moved against the Afridi, and since then the pass has been occasionally blockaded.

The Miranzai division of the Kohat district is forty miles long and three miles broad, consisting of numerous small well-cultivated valleys, with 26 villages. The people are wealthy in cattle, goats, and sheep. They were settled in 1855 by Brigadier-General Chamberlain, and again in 1856 and 1859. The Miranzai district comprises the valleys of the rivers Hangu and Shkali. The tribe have 26 villages, and a population of about 24,000 .

The Land tribe occupy Land Kamar in the Kohat district. They have three khel or families, -Gari, Khwazi, and Tarki. Their country is famed for its Ber fruit (Zizyphus jujuba).

The Banuri are a family of Syuds who have resided in the town of Kohat since the time of Aurangzeb, and the people of Swat have since paid 'ooshur' to them. They have been devoted 
servants of the British, and Mir Mubarak Shah fell at the siege of Dehli.

The Waziri, who occupy the hill country to the west of the Trans-Indus frontier from Thal in Miranzai to the Gomal pass, claim descent from Vazir, son of Suliman. They are nearly all independent. Their total fighting strength is 43,980, viz. Utmanzai, 17,100; Abmadzai, 9580; Mahsud, 14,500 ; Gurbaz, 1500; and Leila, 1500. The Ahmadzai seem to have emigrated to the Banu district about the close of the 18th century, and gradually dispossessed the Banuchi owners, coming into undisputed possession of some of the best tracts on the left bank of the Kuram. They have never allied themselves to the Banuchi. Nearly all the Ahmadzai have now settled down in the plains as good cultivators, and pay their revenue regularly. In British territory (20,743) the Ahmadzai hold 15,572 acres, paying Rs. 5864 ; the Vazir, 21,420 acres, paying Rs. 7670 ; and the Utmanzai, 5848 acres, with a rental. of Rs. 1806.

Khatak, a tribe of Pathans, 118,050 souls, who inhabit the S.E. portion of the Peshawur district, and $S$. and $E$. of the Kobat district, in a desolate region, stony and barren. Karlanrai, of the Sarban branch of the Afghans, had four grandsons, -Lukman, Utman, Zadran, and Usman, from whom tribes are sprung. Lukman's descendants are named Khatak, from a Pushtu expression, $\mathrm{Pah}$ Khatar, meaning ' he has come to grief,' in allusion to his having had Sabäka, a very ugly woman, saddled on him as a wife. Their descendants formed the Bolak, Taraki, and Tari clans of the Khatak tribe. Their country may be said to extend 120 miles along the right bank of the Indus, from Hund to Kalabagh, with a breadth varying from 7 to 65 miles. The Darshi, Kundi, Seni, Uria Khel, and Jaluzai tribes have at various times attached themselves to the Kbatak. The Akora Khatak inhabit the extreme S.E. portion of the Peshawur district, and there is a Khatak colony in Lunkhor. Of 72,723 returned in the census of $1868,56,260$ were in the Kohat district, 11,400 in the Banu district, and 4735 in Peshawur. Mr. Elphinstone estimated the Akora divisions at 10,000 families, and the Tiri at 14,000; Lumsden estimated the Akora branch at 38,000 souls; Dr. Bellew gave 14,000 souls as the number of the Khatak in Yusufzai, and thinks they could turn out 3000 matchlockmen. Mr. Elphinstone described the Khatak as tall, good-looking, and fairer than any of the tribes of Peshawur. Colonel Lumsden, writing shortly after annexation, described the hill tribes as a wild, turbulent, impoverished set; but Coke noticed the Baraki and Bangi Khel Khatak as a fine hardy race, notoriously plucky, and better suited for infantry soldiers than any Pathans he knew of. During the 13th century the Khatak are supposed to have left Shal, in the Suliman range, where they resided with their kinsmen the Waziri, and settled in Banu with the Shitak, the ancestors of the present Banuchi, and they were allotted the Sadr Awal canal from the Kuram river near Adhami, which is now in possession of the Bizan Khel section of the Ahmadzai Waziri located on the Banu Thal. Towards the end of the 15th century they quarrelled with the Shitak, and left Banu and settled in the hills and plains as far as the Nilab
Ghasha on the right bank of the Indus. Malik Akhor in the time of Akbar took up his residence in the Gaozdara, a pass near Shaikh Aladad leading to the Jawaki country, and the country northwards towards Atak, and the district thus occupied is known as Akhora Khatak. Malik Akhor aided Akbar, and had grants of land conferred on him, which enabled him to become chief of the Khatak, whom he governed for 41 years, until murdered by the Balak clan. His eldest son, Yakia Khan, ruled 61 years, and was murdered. Yakia Khan's son, Shabbaz Khan, reigned 31 years, and was killed by an arrow wound in the head at Kamalzai in Yusufzai. The son of Shahbaz was the celebrated Khushal Khan, who served the emperor Shah Jahan, but was long imprisoned by Aurangzeb. When released, he abdicated in favour of his son, Ashraf Khan, after ruling 50 years. Subsequently the family continued engagements with Ahmad Shah Abdali, with the Kābul rulers, and with the Sikhs. On the British annexation of the Panjab, Khojah Muhammad Khan was confirmed in the chieftainship of Tiri, the chiefs of the Akhora Khatak obtained grants of land as jaghir and cash allowances. The Khatak as a rule have been very good subjects to the British, and in particular Khojah Muhammad, K.C.S.I., Nawab of Tiri, was uniformly loyal and well intentioned, and an unsullied example of fidelity, gallantry, and merit. The Khatak in Yusufzai are the Shabat Khel, the Mamuti, and the Mishak of Kasima and Lunkhor; the Hote of Tazagram and Lunkhor ; the Yakub Khel in Lighani and Miasar; the Huseni in Charchar and Lunkhor; and the Makor in Alu and Lunkhor.

On occasions of betrothals, marriages, circumcision, they have great rejoicings, and perform the martial Khatak dance. A number of men with drawn swords revolve to the music of the pipe (Surnai) and drum. Their movements at first are slow and in measured time, their swords being alternately held aloft above their heads, or sweeping down towards the ground, as if to cut an enemy. These movements become quicker, the music more spirited, the dancers shout their war-cry, and swords flash through the dust and smoke as they revolve wildly round the fire, keeping it up until quite exhausted. It is worth seeing. The Khatak were mixed up with the fortunes of Akbar, Shah Jahan, Aurangzeb, Ahmad Shah, and since the 15th century the strife amongst themselves has been incessant. They are a warlike but turbulent race, but, as mentioned, have been uniformly loyal to the British. A branch of Khatak are in Yusufzai.

The Barak is a large and important branch of the Kbatak, living S. of the Tiri Toi, and W. of the Sagri and Bangi Khel. They are of the Tari section, and under the British rule are all managed by the Nawab of Tiri. They possess the lands of Daresh Khel, Bahadur Khel, and Latammar, the valley of Nari, all Chaontrah, the Loeghar mountains, and the country of Gudi. Khel, between the Spinghar and Shinghar ranges and the tract of LaLd Kamar. They are a wellbehaved, fine hardy race; are the swiftest footmen and best mountaineers in the country, famed for their courage. They number 5000 fighting men.

Bangi Khel are of the Bolak branch of the 


\section{INDIA PROPER, ITS PESHAWUR PROVINCE.}

Khatak, who inhabit the hills to the north of Kalabagh, on the Indus, in the Banu district, lying between the Tiri Khatak and the Sagri Khatak. They are wild in their habits, their hills are barren and often without water; they were in old days noted robbers, but are now peaceable and well-behaved; they are fine active, athletic mountaineers, and of a frank bearing, grazing cattle and cutting wood for the markets of Kalabagh. A few are in the Panjab Frontier Force. Their sections are the Abi Khel, Tarka Khel, Tapi Khel, and Maraj Khel. Their inhospitable country has caused them much inconvenience, and led to disputes between them and the Sagri Khel of the Khatak.

Ano Khel, a section of the Tari division of the Khatak, to which the Khatak chiefs belong.

The Nasrati is a small, high-spirited tribe of Khatak, who dwell in the valley below the Shinghar range, and also pasture and cultivate the Thal.

The Babar section of the Khatak reside chiefly in Kani, on the left bank of the Indus. They have large flocks of sheep and goats, and they eat the flesh and drink the milk of camels.

The Bangash is a Pathan tribe who inhabit the Miranzai valley, the Kohat defile in British territory, and also the valley of the Kuram river in Afghanistan. They are said to be descended from a person named Ismail, who was surnamed Bankash or Bangash. Their subdivisions are the Garu, with the sections Amir, Jamshidi, and Miranzai; and the Samalzai, with the sections Tuzi, Namani, and Alizai. They are said to have come from Gardez in the Ghilzae country, from which they were driven by the Ghilzae about the 14th century. They then settled in Kuram, where they remained for another hundred years. Another account is that they came from Seistan, and are of the same race as the Jat. The emperor Baber (A.D. 1504) found them located in Kuram, which was formerly divided into Bangash-i-Bala and Bangash Pain, Upper and Lower Bangash. Since the middle of the 18th century the Turi have been gradually dispossessing the Bangash from Bangash-i-Bala, and now every Bangash attaches himself to a Turi as his Naik or protector. Their numbers in Kuram are 5600. The three main divisions of the clan are the Miranzai, with three clans; Baizai and Samalzai, with five sections. The Miranzai took up the lands of Nariab, Upper Miranzai; the Baizai inhabit the Kohat valley proper, and the Samalzai are in the wild jungle district of the same name. They are not deemed courageous by British officers. They are hospitable. They have behaved well to the British. In 1853 they claimed the right of occupying the Kotal of the Kohat pass, and their share of the pars emoluments was settled at Rs. 3200. Other accounts describe the Samalzai clan as noted for their bravery, and that they could turn out 700 fighting men.

Bangash are of the Shiah sect. The 1868 census showed 31,774 Bangash in British territory. Sultan Muhammad, Barakzai, up to 1848 held Kohat as a fief from the Kābul government. It was then taken possession of by the British on account of hostility evinced during the second Sikh war. The Khan of Hungu, in the Bangash country, was in the British service as revenue collector, when he was murdered by one of his own relatives. The khanship descended to his son. The Bangash tribe have suffered much from the raids of their hill neighbours, Waziri, Orakzai, Turi, and Käbul Khel. The Miranzai valley belonged to the fief of Sultan Mubammad, but, being an outlying locality, was overlooked when Kohat was taken possession of. The Kābul government then lost no time in arranging for the occupation of Miranzai, which appeared to have been vacated; so Sirdar Azim Khan, the governor of the Kuram province, in 1851 summoned the Miranzai to surrender, but they petitioned the British to include them in Kohat. Under the circumstances this request was acceded to. They were in their hearts hostile to the British Government, as indeed they were to any government whatever. They offered to guard the Kotal, and asserted that they had a hereditary claim, stronger than that of the Afridi, to occupy the ridge. The Kotal was then made over to them, and as the Afridi refused to open the pass, it was resolved to establish a blockade, and the Afridi were debarred from entering the Kotal and Peshawur valleys. While these arrangements in 1853 were progressing, the Guli Afridi suddenly attacked the Bangash people on the Kotal, and seized that post. Several Bangash chiefs were killed in the encounter, and Major Coke, who was present, was slightly wounded. Upon this check, the Bangash people obtained the alliance of the small though warlike tribes, Bazoti and Sipah. These were independent, and dwelt in the hills near the pass. The southern section of the Jawaki Afridi also joined the league.

The Marwati or Maraoti tribe of Pathans give their name to the Marwat division of the Banu district; they are a branch of the Lohani tribe, being descended from Loh and his first wife Shiri. They have five khel or clans, - Bahram, Dreplara Musa, Tapi, Nuna, and Jhandu. They were formerly pastoral, and traders in the Katawaz district of the Ghilzae country, but left it from a quarrel and tried to settle in Tank, from which the Daulat Kbel ousted them, and they came on to Marwat. They are tall, muscular, and fair, often rosy-cheeked, and evidently of pure Afghan blood, forming a striking contrast to their mongrel neighbours the Banuchi; they are a bold, manly, simple, and upright people, deeply attached to their sandy villages and reed huts. They are proud, but dignified, and frank and simple in their manner with strangers, and are distinguished from all the Pathan tribes by a more generous treatment of their women.

Their country is excessively arid; the water is so far below the surface, they cannot afford to sink wells to it. Their women are the watercarriers. At the census of 1868 they numbered 42,729 souls, and their sections in former days could turn out 5500 fighting men,-Bahram, 2000; Dreplara, 2000; Musa Khel, 1500.

Banu, in lat. $32^{\circ} 15^{\prime}$ to $33^{\circ} \mathrm{N}$., and long. $70^{\circ}$ $20^{\prime}$ to $71^{\circ} 20^{\prime} \mathrm{E}$., a district in the Panjab, 60 miles long and 55 miles broad, with an area of 2036 square miles. Its Trans-Indus portion is bounded N. by the Khatak hills, W. and N.W. by the hills of the Waziri, S. by the Batani and Masrot ranges, and $\mathbf{E}$. by the Indus. It is surrounded by barren hills, but is a highly fertile valley; 


\section{INDIA PROPER, THE DEHRAJAT PROVINCE.}

in spring a vegetable emerald, and in autumn clothed with crops growing from lacustrine calcareous clay often 40 and 50 feet deep. The climate is feverish. The population is about 200,000 , mostly agricultural - Baluch about 70,000 ; other Muhammadans, 100,000 ; and Hindus, 200,000. The chief towns are Edwardsabad, Laki, Isa Khel, and Kalabagh; their houses built of mud, with a Chouk or place of assembly, and a guest-room. The people are dirty. They are strict Muhammadans.

Isa Khel is a division of the Banu district, enclosed between the Indus and the Khatak hills. Most of the inhabitants are Niazi; but the Awan, and Jat, and Hindus are intermixed. Many of the Niazi are migratory.

The sanatorium of Shekh-Budin, in lat. $32^{\circ} 17^{\prime}$ $49^{\prime \prime} \mathrm{N}$., and long. $70^{\circ} 50^{\prime} 49^{\prime \prime}$ E., and 4516 feet above the sea, is on the Mohar range in the Banu district, 64 miles south of Banu.

The Banuchi or Banuwal is a mixed tribe occupying the Banu subdivision of the Banu district. The people have come from all the surrounding lands, and their stature and appearance are of the most varied kind; most of them are spare, without much muscular development, attributable to the malarious climate. They are morally a low, vicious race, very litigious and untruthful. The Waziri, the Marwati, and Isa Khel are as different from them in character as in race.

The Umar Khan Khel, one of the clans of the Bairam Maorat, occupy the Agzar Khel village in the Banu district.

The Niazi is a tribe of Afghans settled in the Banu district, descendants of Niaz Khan, son of lodi, king of Ghor, by his. second wife Takia. Lodi was the Lohani chief who invaded Hindustan, A.D. 15 (A.H. 955), and conquered the Daman; and the Isa Khel districts were allotted to Niaz, whose descendants still occupy it. The Niazi, like most of the Lohani, are divided into an agricultural and a Povinda portion. The agriculturists are all in British territory; their sections or khel are the Isa, Kamar, Kundi, and Sarhang. The Povinda have five branches, and trade between Khorasan and the Dehrajat. Their sections or khel are the Mamrez, Nur Khan, Mahsud, Ali, and Mala. The Niazi are good loyal subjects. They have no money expenditure at their marriages. The Michan Khel section of the Niazi hold villages in the Banu district. They are Shaikhs, and very wealthy.

Tor and Spin are two factions on the Banu fruntier. They originated from the quarrels of two Banuchi, Sarke and Ibrahim, in which all the tribes got involved. Those who sided with Sarke were called Sarke Gundidar, subsequently Kohna Gundi, and afterwards Tor Gundi; they comprise 32 sections. The Spin faction embraces 27 sections; ticy were first called Jan-behdar, afterwards Noya Gundi, and lastly Spin Gundi.

The Dehrajat is a portion, about two-thirds, of a narrow strip of land which extends along the west bank of the Indus river, about 300 miles from the Kalabagh range to the $N$. boundary of sind, and hemmed in between the Suliman range and the Indus. The three $p$ srtions of the Dehrajat are the Dehra Ismail Khan, Debra Ghazi Khan, and Dehra Fattah Khan. A thin fringe of cultivation and jungle extends along the bank of the great river, and terminates, as you advance into the interior, in a flat desert country, where a precarious supply of water from the hills affords a poor cultivation in the vicinity of the thinly-scattered villages. Lower down, the hill streams become smaller, and the aspect of desolation still greater, so that for miles not a human being is visible, nor can a drop of water be procured to quench the thirst produced by these scorching plains. The Pathan and Baluch tribes who inhabit the hills, have the same attachments to their chiefs, internal hereditary feuds, dislike to combination, and predatory habits, which distinguish so many mountain races, but have withal a martial bearing and love of independence. The scarcity of water limits cultivation, and their wealth consists in their herds, which find a scanty pasturage at the foot of the hills. Amongst the mountains occur a few fertile patches. The country being traversed by footpaths known only to themselves, the hill tribes were accustomed to issue from it in raids on their wealthier neighbours in the plains, harrying their cattle, and retreating in safety to their impracticable mountains. To stop this, in the beginning of 1857, after one of such inroads, the Panjab Government sent an expedition from amongst the troops of the Panjab irregular force, to reduce the Bozdar tribe; and names kuown to fame in the Indian mutinies-Chamberlain, Coke, Nicholson, Hodgson, Probyn, Watson, Wylde, and Green-were all trained in this school of warfare, involving severe marches, incessant fights, and exposure to all the seasons of the year.

Baluch tribes extend along the lower half of the Dehrajat frontier; they are less warlike, and are more or less migrant and predatory, particularly in the west. In habits they resemble the Iliyat and Kurd. They have dark skins; live in mud houses, in forts, and in-their black felt tents called gedaun, stretched over a tamarisk framework. An assemblage of gedaun forms a toman or village, inhabited by a khel, and a tribe consists of a certain number of $\mathrm{khel}$. The headquarters of Baluch tribes, and the majority of the clansmen, are in the independent hills beyond the British territory, the boundary line of which runs along the base of the hills; but a large number of each tribe also hold lands in the plain, and are British subjects, some of the chiefs also residing there. The Baluch of the plains, for the most part, after annexation, behaved as well-disposed subjects, but the Baluch of the hills continued their old habits of plundering. All the tribes were at feud with each other; they not only fought in the hills, but they carried their contests to the plains, where they attacked all villages except those belonging to their own tribe. The men of the plains usually resisted the attacks with spirit at the time, but they were not allowed to retaliate afterwards, as they used to do under the Sikh rule. To guard British villages and people from their constant aggression, a strong cordon of military posts was fixed along the base of the Suliman range. The marauding parties were 50 , $100,200,300$, occasionally even 500 strong. They were often mounted, and fled, if hotly pursued, for 15, 20, and even 30 miles. Many of the villages and much of the cultivation being close to the hills and in front of the posts, the plunderers carried off their booty to the hills before the detachment could come up. 
Dehra Ismail Khan is a British district lying between lat. $31^{\circ}$ and $32^{\circ} 15^{\prime}$ N., and long. $70^{\circ} 20^{\prime}$ and $71^{\circ} \mathrm{E}$. On the south it joins Dehra Ghazi Khan, and the boundary marks the separation of the Pathan and Baluch frontier tribes. The eastern boundary is the river Indus. The general aspect of the country is that of a dry alluvial plain, destitute of all vegetation, and intersected by the ravines of the hill feeders of the Indus. The irrigation canals are small. The area is 3777 square miles. The cultivators are Patbans or Jats. The Multani Pathans have been logal to the British; the others are the Gandapur, Mian. Khel, Daulat Khel, and Babar. Pushtu and Panjabi are spoken. Its population comprises Christians, Syud, Moghul, Saddozai, Alizai, Popalzai, Waziri, Pathan, Laghari, Baluch, Bozdar, Kosah, Kasrani.

Dehra Fattah Khan, a small town in lat. $31^{\circ} 7^{\prime}$ $9^{\prime \prime} \mathrm{N}$., and long. $70^{\circ} 46^{\prime} 39^{\prime \prime} \mathrm{E}$., is 532 feet above the sea. It is on the right bank of the Indus, and 53 miles south of the capital of the district. The rainfall is very precarious.

Daman-i-Koh is a tract of country stretching along the foot of the mountains west of the Dehrajat, inhabited by Afghans, Jat, and Baluch.

The Mandu Khel is a small peaceable agricultural tribe to the west of the Dehra Ismail district, numbering 3000 souls. The Multani Pathan tribe are in Multan, Dehra Ismail Khan, and Dehra Ghazi Khan. They are descended from the Abdali, who came in the times of Alamgir and Aurangzeb. They have been friendly with the British.

Gandapur, a tribe who inhabit the Daman of the Dehrajat in the vicinity of Kolachi, Takwara, and Lumi. They are peaceable British subjects, in the Dehra Ismail Khan district. They numbered 5945 in 1868 . The Kolachi division and town of the Dehra Ismail Khan district are occupied by the Gandapur, the Mian Khel, Babar, and Baluch, along with Syud, Koresh, and Hindus. The Gandapur clan were formerly in Afghanistan, but abandoned it and settled near Kolachi. They are hospitable.

The Kundi is a quiet agricultural tribe of Pathans, in the N.W. corner of the Dehra Ismail Khan district. They claim descent from Lodi, the founder of the Lohani tribe, whom they accompanied into the plains. They have about 1000 fighting men.

The Mian Khel tribe, in the Dehra Ismail district, are a section of the Lohani. Their two sections are named Isot Khel and Sein Khel.

Isot or Sot are nomade Pathans on the hills to the west of the Dehra Ismail Khan frontier. They are said to be of Kakar origin. They have no towns or villages, and have about 300 fighting men. They remain about the slopes of the Tiri hill in summer, and in winter migrate to Kaliwahin, on the western slopes of the Nara. They have four sections.

Khar Sin or Ghar-shin tribe are harmless and inoffensive Syuds, who reside among the Ushtarani on the frontier of the Dehra Ismail district, also among the Kakar of Peshin, and among the Murree. They are pastoral and agricultural. They are a branch of the Khar Sin of Uch and Ahmadpur, in the Bahawulpur territories, with whom they came from Bokhara in the 18th century.

The Hari Pal tribe on the Dehra Ismail frontier, on the borders of Spasta. They are fakir, and about 800 in number.
The Kapip are a poor agricultural tribe to the west of Draband on the Dehra Ismail frontier. They are peaceable, and sow sorghum and maize, and have fruit-trees.

Zmara, a small tribe of the Dehra Ismail frontier. They have the Ushtarani on the east, the Isot on the south, the Shirani on the north, and the Musa Khel on the west.

The Miani tribe are in the Gomal valley, in the Dehra Ismail Khan district.

Belot, in lat. $32^{\circ} 15^{\prime} 20^{\prime \prime} \mathrm{N}$., and long. $71^{\circ} 11^{\prime}$ $51^{\prime \prime}$ E., has the shrine of Shah Abdul Wahab. It is in the Dehra Ismail Khan district, on the right bank of the Indus. Two Hindu shrines are near.

The Butani is an Afghan tribe dwelling in the Dehra Ismail Khan district in the hills near the Peyzu pass. They were predatory until they became British subjects.

The Dehra Ghazi Khan district of the Panjab is situated between lat. $69^{\circ} 20^{\prime}$ and $71^{\circ} \mathrm{N}$., and long. $28^{\circ} 20^{\prime}$ to $31^{\circ} 10^{\prime} \mathrm{E}$. Its area is 6530 square miles, or, according to Captain Barron, 5256. It has four divisions, viz. those of Saugor, Dehra Ghazi, Jampur, and Mithankot. It has Sind lands, or those along the banks of the river, and Pachad lands, or those within the influence of the hill streams. The mountain peaks rise to 7640 feet. It has many mountain streams, and 13 canals. Its population in 1868 was 308,840 souls.

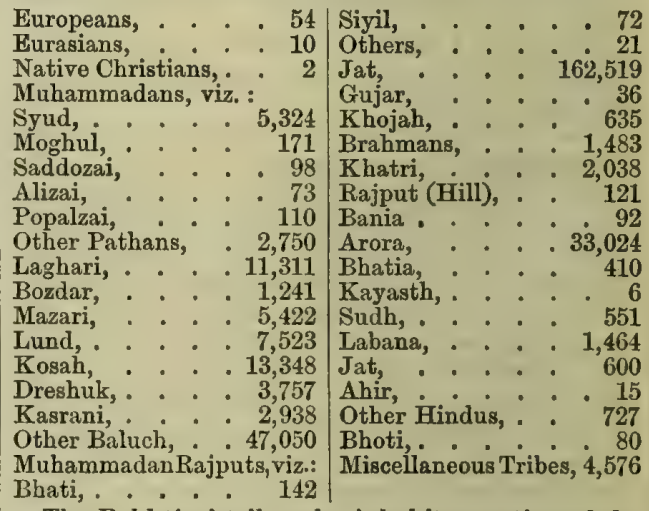

The Bakhtiari tribe who inhabit a portion of the Dehrajat round Draband, are said to be a branch of the Bakhtiari of Persia. They have about 1300 houses.

Dehra Din Panah is in the Saugor division of the Ghazni district, 44 miles north of Ghazni. It is two miles from the right bank of the Indus. Abdul Wahab, canonized as Shah Din Panah, is buried there, and his shrine is visited. He was a native of Uch in Bahawulpur. He died in the 16th century.

The Pastrani, according to Major G. Jacob, a well-educated, peaceable tribe, who inhabit the hills at the extreme north of the Dehra Ghazi Khan district.

The Nutkani is a Baluch tribe in the Dehra Ghazi Khan district, inhabiting the country S. and E. of Mangrota. They have been estimated to have from 800 to 3000 adult fighting men. Their country is fertile. They claim to have come from Aleppo.

The Mazari, a Baluch tribe, is in the extreme S. of the Dehra Ghazi Khan district. Their four sections are the Baluchani, Rustamani, Masidani, 
and Sargani; some of them are in Sind, and they number 5422 souls. They have even been notoriously predatory, and up to 1870 gave trouble to the British.

Lund of Tibi is a Baluch tribe in the Jampur division of the Dehra Ghazi Khan district. They have Gorchani plain on the N.E. and S., and Durkani on the W. Their three sections are the Lund, Rind, and Kosa. They are a compact tribe, with about 952 fighting men.

Lund of Sori is a Baluch tribe who inhabit the extreme northern portion of the Dehra Ghazi Khan district. Their six divisions are Hyderani, Bakrani, Zarani, Gar Surani, Kilani, and Gurchani. Their number in 1868 was 7523 , and their fighting men about 2000. They received from the British Rs. 300 monthly to protect the passes.

Iaghari, a tribe on the frontier of the Dehra Ghazi Khan district, from the Dalana on the N. to the Kura pass on the S. Their four sections are Aliani, Hadiani, Boglani, and Haibatani, in all 11,311 in 1868 , with about 3770 adult males. They claim relationship with the Talpurs of Sind.

Kosah, a Baluch tribe scattered through the Dehra Ghazi Khan border, with seven divisions, viz. Balelani, Jangel, Jandani, Jarwar, Isani, Tomiwala, and Merwani. The population is about 13,348 , with about 1500 fighting men. The tribe is brave, but the chief's house much divided against itself.

Khetran is a Baluch or a Pathan tribe, and are about 13,746 in number, who inhabit the hills to the west of Dehra Ghazi Khan, and have a branch within the district. They have the Musa Khel and Luni Pathan on the north, the Bozdai on the north-east, the Laghari and Gurchani on the east, with the Murree on the south-west and west. Their country drains into the Kaha river, and is of large extent. They have four sections, - the Ganjura, Dariwal, Hasani, and Nahr, -with many subdivisions. They have about 4582 fighting men. They live inside forts, and are not warlike, but are expert riders and swordsmen. Their country is a succession of picturesque fertile valleys with barren mountains.

The Kasrani Baluch tribe are in the extreme north of the Dehra Ghazi Khan district, also in the southern portion of the Dehra Ismail district, and the hills to the immediate west of these tracts. Its divisions are the Lashkarani, Khubdin, Bhada, Wasusani, Laghari, Jarwar, and Rustamani, with numerous subdivisions, with about 1549 fighting men. A force under Brigadier Hodgson was sent against them in 1853 .

The Adamani section of the Kasrani is settled at Jok Budhu in the Dehra Ghazi Khan district. They are now peaceable.

Gurchani, a Baluch tribe who inhabit the Jampur division of the Dehra Ghazi district near Harand. They have twelve sections, with about 3938 souls, and 1312 fighting men. They gave much trouble since annexation.

Dreshuk, a Baluch tribe of Dehra Ghazi Khan. Their divisions are Kirmani, Mingwani, Gondfaz, Saryani, Arabani, Jaskani.

Nahar, a tribe who live partly round Harand in the Ghamni district, and partly round Nahar ka Kot in the Khetran hills. They say they came from Afghanistan.

Of the other Baluch tribes in the Dehra Ghazi Khan district, a mere mention will suffice. are the Amdani, Chandia, Giskoria, Ghoramani, Gopang, Hut or Hoth, Laskani, Malkani, and Mastui. Beyond the Dehra Ghazi Khan border are the Pathan tribes Khastai and Luni. The Khastai are little numerous, are peaceful and quiet; they are agricultural and pastoral.

The Luni speak a mixture of Pushtu and Baluch, and have 1200 men. The Chum, a long range of hills, produces a valuable coal, also sulphur. Their neighbours on the north are the Kakar and the Musa Khel, on the south are Murree and Tarin, with Khetran on the east.-Aitcheson's Treaties; Asiatic Researches; Bellew; Burnes' Cabool; Burton's Scinde; Calc. Rev.; Campbell's Eth. of India; Chesney, Euphrates Expedition; Chronicles of Kashmir; Collett's High Asia, Bokhara, and Baluchistan; Cunningham's Sikhs; De Bode's Tr.; Elphinstone's Caubul; Ferrier's Travels; Fusberry, in Journ. Eth. Soc.; Hist. of Afghans; Latham's Ethnology; Leach, Vocabulary; MacGregor's High Asia and N.W. Frontier; Masson's Journeys; Medley's Year's Campaigning; Mohun Lal's Travels; Moorcroft's Travels; Peschel's Races of Man; Panjab Frontier, by an Official; Panjab Report, in Records Gov. of India; Pottinger's Beluchistan; Prinsep's Antiquities by Thomas; Raverty's Afghan Language; Rennell's Memoirs; Taylor and Watson's People of India; Thomson's Travels; Tod's Rajasthan; Townsend's Outram and Havelock; Vigne, a Personal Narrative; Wood's Lake Aral; Fule's Cathay; Census of 1881.

SIND is a province of British India, between lat. $23^{\circ}$ to $28^{\circ} 32^{\prime} \mathrm{N}$., and long. $66^{\circ} 43^{\prime}$ to $71^{\circ} 15^{\prime}$ E. It is on both sides of the lower course of the Indus and the delta of that river, and is bounded on the north and east by the Panjab and Rajputana, on the south by the Arabian Sea and Runn of Cutch, and on the west by Baluchistan. Its maximum length is 350 miles, and greatest breadth 280 miles. Its area is 48,014 square miles, and population in $1881,2,413,823$. It is under the Bombay Government, and is arranged for administration into the five collectorates of Kurachee, Hyderabad, Shikarpur, Thar and Parkar, and the Upper Sind Frontier. But a good deal of the province is hill and desert, the fertile plains being in the valley of the Indus. The density of the population varies greatly, being 2.19 per square mile in the Kohistan of the Kurachee collectorate, 15.9 in Thar and Parkar, 85.2 in Shikarpur and in that of the Hyderabad taluk of the Hyderabad collectorate, - the average being 50.3 to the square mile.

It has been repeatedly overrun by conquering armies,-by Alexander of Greece, B.C. 327, by the Bactrian Greeks, by Indo-Scythic tribes, by Hindu or Rajput dynasties, by the Arabs of the khalifat, and by Mahmud of Ghazni. After his time it was subject to perpetual incursions from the Ghori, Khilji, and Taghalaq dynasties of Dehli and the Panjab, and the Moghul rulers of India, descendants of Baber; Persian, Afghan, Baluch, and the British, have each in succession had dominion over it, and it is now a British province.

Three thousand years of continuous changes of races and of dynasties have peopled Sind with multitudinous tribes and clans, many of them till lately predatory, numbers of them handing down blood feuds for generations, the bolder and stronger striving with the sword to win more fertile lands, and all of them being pressed forwards by ever 
INDIA PROPER, ITS SIND PROVINCE.

succeeding conquerors, till stopped by the great river Indus or the sea.

The first task of the British was to establish follows:-

\begin{tabular}{|c|c|c|c|c|c|c|c|c|c|}
\hline & Hindus. & Muhammadans. & Christians. & Jains. & Parsees. & Jews. & Sikhs. & Aborigines. & Total. \\
\hline Kurachee, . . & 68,975 & & 4674 & 9 & 960 & 106 & 10,819 & 3,050 & 478.688 \\
\hline Hyderabad, & 89 & & & 144 & 2 & 31 & 42 , & 27,460 & \\
\hline Shikarpur, . . & 93,341 & 75 & 736 & & 64 & 9 & 68,655 & 5,892 & 986 \\
\hline Thar and Parkar, & 43,755 & & 14 & 1038 & & 4 & 898 & 48,440 & 203,344 \\
\hline Upper Sind, . & 9,894 & & 230 & & 9 & 3 & 3,664 & 1,198 & 124,181 \\
\hline Total Sind, . & 305,079 & $1,887,204$ & 6082 & 1191 & 1063 & 153 & 126,976 & 86,040 & $2,413,823$ \\
\hline
\end{tabular}

One of the races still present, the Med or Medi or Mand, is noticed, B.c. $40-30$, by Virgil, who calls the Jhelum Medus Hydaspes. They were not one of the five tribes of Yuchi or Tochari mentioned by Chinese writers, but seem to have belonged to the great horde of Su or Abar, who entered India B.C. 126, and gave their name of Indo-Scythia to the province. They seem to have been forced to migrate from the Upper Panjab to Sind. The earliest of the Muhammadan writers notice that they were firmly established in Sind by A.D. 250 , along with their ancient rivals the Jat. Ibn Haukal describes them in his time (about A.D. 977) as occupying the banks of the Indus from Multan to the sea; and there can be no doubt that they are now represented by the Mer of the Aravalli range to the east of the Indus, of Kattyawar to the south, and of Baluchistan to the west. Edrisi describes the Mand as a numerous and brave tribe who occupied the desert on the borders of Sind and India, and extended their wanderings as far as Alor on the north, Makran on the west, and Mamehel (or Umarkot) on the east. Ibn Haukal records that "the Mands dwell on the banks of the Mihran, from the boundary of Multan to the sea, and in the desert between Makran and Famhal (or Umarkot). They have many cattlesheds and pasturages, and form a large population.' Rashid-ud-Din locates them in Sind at a still earlier period. According to his account, Med and Zat, two descendants of Ham, the son of Noah, were the progenitors of the people of Sind, prior to the Mahabharata. The name is variously written as Mer, Med, Mand, in all of which forms it is found even at the present day. To these General Cunningham would add Mind, which is the form of the name given by Masudi. He identifies this people with the Mediand Mandrueni of the classical writers; and as their name is found in Northern India from the beginning of the Christian era downwards, and not before that time, he concludes that the Mandrueni must be the Saki Indo-Seythians who occupied the Panjab and Sind, and who, under the names of Mand and Zat of the early Muhammadan authors, were in full possession of the valley of the Indus. Lastly, Wilford's surveyor, Mogal Beg, writes Mandyala, which is also a form that he received from two different persons; while in General Court's map it is spelt Mamriala. To this people General Cunningham refers the name of Minnagar, or ' city of the Min,' which was the capital of Lower Sind in the second century of the Christian era. That Min was a Scythian name in use is known from its occurrence in the list of Isidor of Kharax as one of the cities of Sakastene or Sejisthan. The actual position of Minnagar is unknown, and there are but few data to guide us in attempting to fix its site. If he be right in identifying Minnagar, or the 'city of the Min,' with
Manabari, or the 'place of the Mand,' he thinks there can be little doubt that the great IndoScythian capital was at Thatha.

The following list of the tribes and races in Sind was prepared by General Merewether, and it is believed to be very accurate:-

\section{Kurachee Collectorate, 478,688.}

Syuds.-Shirazi, Shakrur, Alavi, Mashedi, Maiindrani, Arifi, Rezuri, Bokhari, Amirkhani, Lukalivi, Mutalivi, Istrabadi, Khabroti. Their forefathers came to Sind from different places on the Asiatic continent.

Kureshi, viz. Alvi, descended from Ali, from Iran.

$A$ basi, derived from Abas, from Irak.

Sidiki, ", " Ababakr Sidik.

Faruki, ", "Umar.

Usmani,", Usman.

Baluch. - Rind, Juttoi, Chandia, Nuhani, Khosa, Ohang, Lushari, Kupri, Julbani, Gungani, Nizamani, Almani, Gopang, Mungwani, Dluwani, Sunjrani, Jamali, Jurwar, Kolachi, Pitabi, Mugsi, Murree, Khowad, Daruck, Laghari, Muhesur, Talpur, Bugdi.

The Rind tribe is the head of all the Baluch from Baluchistan, and from them the several tribes are said to have descended. The Talpur, however, became rulers in Sind, while the Rind remained dependents. The Baluch generally are said to have come originally from Aleppo in Syria. They have all the characteristics of Arabs, - sharp, well-defined features, and well-knit limbs. All their divisions merely denote families or descendants of men of renown, whose names the families bear.

Karamati.-Pubrani Muhammadans, Bighad, Gubole, Bayi, Kachri, Kumba, Mugra, Ahmadani, Ruzida, Supad, Murwa, Ladia, Muheri, Sahtia, Allura, Jingiani, Morsur, Biramani, Khirturi, Thuani, Rajwani, Sotiani, Parwari, Chirani, Gocha, Rahwani, Gorewani, Sherikhani, Mindiar, Goramani, Kulri, Mochir, Sholani, Bunbani, Dewani, Jamali, Said, Durayai, Toremani.

These have descended from Baluch tribes, but are subdivided into several sections named.

Assundi, descendants of a tribe from Multan.

Moghul, ," , Persia.

Turuk or Turks, ," ", Khorasan.

Afghan, sections are Kumirpota, Mitopota, Budipota, and Norungpota. 'Samra' has been corrupted into 'Sumra,' and under this the several tribes are found in the Kurachee collectorate. They came to Sind about Hijira 445 , and became the rulers of the province in 609 , from which year they were in power up to 751 , when they were overthrown by the Summa.

Summa.-Buda, Shora, Suhta, Agil, Ottur, Amra, Hajana, Rathor, Puria, Janspuwar, Nalica, Charshu, Sind-Summa, Chugra, Butti, Koraja, Notiar, Udhar, Udha, Lukba, Muhur, Sutia, Potor, Lund, Unur, Babria, Dungua, Guba, Phul, Lukkha, Munapya, Munabiya, Kaka, Tukhra, Pulli, Randbhir, Musra, Summa, Sumaja, Notia, Abra, Wahud, Nahia, Phulnabia, Koria, Dissur, Mindra, Ludia, Odbaja, KidriPota, Lund-Summa, Kakaja, Nara, Jaraja, Hingora, Jugsia, Virriah, Hingoja, Derra-Sumani, Halla, Udbahingora, Jasingora, Ramabey, Sahad-Summa, Tellaruja, Nuria, Hapra, Rahuja-Juna, Granoe, Rahawa, Lukhatia, Sumra, Jamlakha, Sudaria-Summa, Juna-Summa, Budio, Saheb-Summa, Oto-Summa, Shekbab-Summa, Biya, Bodia-Chellaria, Mungra, Abraja, Cur-Hingora, Sultanote-Numria, Jokia, Jutt, and other sections.

Summa now claim to be descendants of Ham, son of 
Noah. They were the early inhabitants of Sind, and were in power as rulers, from Hijira 752 to 927 , when they were overthrown by the Arghuni.

Arohuni came to Sind during the reign of the Summa, whom they overthrew. They succeeded the Summa as rulers of Sind about the year 927 Hijira, and continued so until their defeat by the Turkhani in Hijira 962.

The Turhluni came to Sind about the same time. They succeeded the Axghuni as rulers of Sind about the year 962 Hijira, and were in power until Hijira 1021.

Foreign Tribes. - Tukzi, Tumini (Thainr), Alt Mogelra (now known as Moria), Powanhar, Jubisia, Alutba, Binwalla, Sufean, Koral, Bayar, Supias

Descendants of Havun.-Mukrani, Ludi (now known as Luclia), Hubsha, Sidi, Jungiani.

Sindi Musalmans, viz. Nakhuda, Machi, Solangi, Mochi, Memon-Khowaja, Memon-Sayata, Gudi, Chuwan, Awan.

Brohmans. - Kokanist and Deshast from the Dekhan, Gujerati and Nuggur from Gujerat, Gowar, Sarsat (Sindi), Pokarna from Jeysulmir.

Khatri or Khastria, containing the tribes Wania, Kanuga, Amil, Merani, Gadi, and Mahajan.

Miscellaneous Hindus, viz. Doghra, Rahtor, Meghwar.

\section{Hrderabad COLlectorate, 754,624.}

Buluch. - Talpur, Rind, Lasharri, Laghari, Jamali, Murree, Chandia, Hajana, Nizamani, Khosa, Gubole, Gadi, Mugsi, Kunbhiri, Kuppri, Nuhani, Buglani, Chulgri, Hote, Nadani, Chang-Juttoi, Porkhurri, Lund, Julbani, Kurmi, Dewani, Mubrani, Rusmani, Mushori, Kulloi, Zore, Kolachi, Buldi, Mungalja, Ruse, Bhurgri, Jiskani, Mari, Surgani, Lakhani, Hisbani, Gubchain, Khatrian, Sanjarani, Rustomani, Bozdar, JanwariShaer, Amandani, Karmatti, Zindpuri, Shahoni, Korai, Dulwani, Sukrani, Nath-Koni, Gurchani, Daidano, Dreshuk. The same remarks apply here as to the Baluch in Kurachee.

Peers. - Nakshbandi, Jublani.

Sumra. - Cultivators and oil manufacturers.

Syuds.-Ruzvi, Bokhari, Barawala, Mutalavi, Cutehi, Sunaimi, Lukiyari, Nagori, Qurani, Shirazi, Khabrati.

These are the landowners and extensive cultivators. Originally came from Arabia and Persia 700 years ago. The several divisions derive their names from some distinguished ancestor, or from the place where they originally lived, or where they settled down when they came to Sind. Razvi from Imam Musa Raza, Shirazi from Shiraz, Lukiyari from Lukki.

Kureshi.-Abasi, Usdi, Kalhora, Qazi, Insari, Dukhiya, Sidiki, Faruqi, Alavi, Humzori. The Qazi are cultivators and scribes. Originally came from Syria.

Sumatra or Summa. - Summa, Unar, Abra, Gandhai,

Sahta, Dhera, Mitira, Bhawwar, Sethore, Bhata, Daliar, Bhawwari, Setharua, Nangor, Mangria, Gangra, Kiria, Haliah, Hariah, Gundall, Nulipotra, Udyan, MTailiar, Pima, Tunia, Depar, Lakha, Paribar, Chana, Agara, Chachok, Patu, Sadar, Phail, Dahari, Bihan, Wagan, Buriara, Detha, Manlahan, Mahisar, Bughia, Kakepotra, Dahraja, Bhan, Malak, Laujara, Pali, Waria, Theba, Hathipotra, Sukhra, Gaba, Hingora, Rahu, Kaka, Juneja, Kaurija, Vistara, Wasan, Aradinja, Chanika, Juna, Kanreja, Sirachaja, Maira, Bhanoja, Mamar, Dokeja, Manahin, Buga, Bhurt, Halliputa, Powahar, Suheja, Shora, Sumra, Numriah, Jokhia, Kalur, Pullija, Jugsia, Thora, Sama, Chunchur. The above are cultivators-Aborigines.

Shaikh or Memon, -- Hudokut, Qazi, Khebrana, Surha, Akhund, Patoli, Katiyar, Puggir, Lusi, Bandru, Kussabi, Mirzapuri, and Khowaja.

These, originally Hindus, are cultivators, shopkeepers, workmen, etc. Distributed throughout the collectorate. The Khwaja descended from the Memons, but are Shirhs, and call themselves descendants of Khwilja Suliman Pharisee.

Gola. - Shidi, Habshi, Khaskeli, Sindi, and Zemghur. These were slaves in former days.

Khowaja were also converted Hindus.

Khaskeli are the descendants of slaves purchased by the Baluch and others from foreign countries.

Raza, Lohar, and Wadha or Dahkan, are different tribes, and are called from the trades they follow, Dhobi, Pinjara, are of varied origin.

VOL. II.
Kalri, Kori, Mochi, Sonard, and Thathara. Some foreigners and some Sindi.

Muhana, Baleshahi, and Machi. Machi and Shikari are the lowest of the Sindi tribes, and are generally cultivators and fishermen.

Miscellaneous Races, viz. Gurji, Mungri, Khokur, Hore-wala, Dubgur, Puri, Patan, Silawut, Sati, Pinjora, Chaki, Lakhati, Dhobi, Kumagur, Nukash, Solungi, Raza, Lohar, Matchi, Zurdoze, Dhingai, Bazai, Nagori, Khudhari, Buthora, Hajjam, Siyil, Bura, Girana, Ghuryalchi, Kunjur, Gabi, Marwai, Korai, Siyil Kudra, Sahita, Maganhar, Hulya, Rajpur, Chabuk, Dahirri, and Bubbur, Dyatra (Canzat), Syal, Baber, Julwar, Samtra Mushori, Naich, Subag, China, Buk, Dul, Panihar, Subaki, Jora, Lishari, Goracha, Pifera, Isran, Setar, Bhangir, Watia, Tagar, Ghanga, Dashk, Motimal, Zurdori, Naneal, Dridona, Majdona, Vidyola, Dangroj, Nougraj, Jokhia, Khokhar, Hatar.

Brahmans. - Gowar, Drawar, Barhi, Bawanjali, Seikar, Silar, Kawunchundra, Sarsad, Pokarna, Kitri, Sydpar, Dukhni, Purbi, Maharashtra, Tilung, Carnatic, Kokunt, Gujur, Surisali, Pokumi, Purli, Gund, Sarsedh, Canouj, Kankubh, Mital, Brahmput, and Bhuchak.

Khastra.-Mangoh, Munijan.

Waish.-Lohana, Bhatia, Bhabira, Amil, Panjabi, Mahesirri, Usuwar, Suhwani, Khalsa, Shahdadpuri.

Khitri.-Gurupota.

Sudur.-Khutti, Sonara, Sutar, Bagoi, Sochi, Lohar, Mochi, Tumbuli, Kalal, Jakhiri, Jeysulmirani, Kurmi, and Ode.

Lohana and Sarsut Brahmans, descended from Sri Ramchund, Pokurna, Babra, Panjabi, Khudabadi, Sehta.

Udasi and Sunncsi.

Sonaras, descended from Deni.

Hindu Ascetics, viz. Sunnasi, Byragi, Jogi, Jangam, Udasi, Bhagat, Barra, Thukur, Bhut, Jajak, Brahma chari.

\section{SHIKARPUR COLLECTORATE, 852,986}

1. Syud; 2. Pathan; 3. Moghul; 4. Brahui ; 5. Baluch; Rind, Juttui, Talpur, Chandia, Khosa, Laghari, Mugsi, Buldi, Lashari, Julbani, Lund, Jamali, Bunglani, Bugti, Mazari, Gadi-Dundki, Nizamani, Bang-Jakrani, Dumki.

Jhut, Surrai.

Sindi, Abra, Kallora, Pholpota, Gopang, Mussem, Porrur, Syal, Soda, Bugia, Budda, Sukta-Turrio, Machi, and Bhutto.

Hindus.-Brahman, Chuttri, Bunya, Amil, Thakkur. UpPer Sind Frontier, 124,181.

Baluch. - Tribes the same as given above, viz. Rind, Dumki, Jakrani, Murree, Bugti, Lashari, Gurchani, Mazari, Burdi, Cosah, Jamali, Mugzi, Chandia. These people have all the characteristics of Arabs, both in features and customs. They are restless and unwilling to labour, but will undergo the most wonderful fatigue for the purpose of stealing a camel or bullock. They have sharp, well-defined features, and very spare but well-knit bodies and limbs. All their traditions agree that they originally came from Syria, probably about 1200 years ago.

Khyheri are a priestly set who attached themselves to the Baluch on their way eastwards from Aleppo, joining them from Tabreez. In importance among themselves, the Baluch rank as follows :-

1. Rind ; 2. Lashari ; 3. Jutoi ; 4. Dumki ; 5. Jakrani ; 6 , Murree; 7 , Bugti ; etc.

Bruhui.-These have a different origin from the Baluchi, and have remained for the most part in the mountains of Baluchistan, giving the khan to the country. The traditions of the Brahui are not so clear as the Baluch, but they came also from the west, entering Baluchistan from Kirman, by Makran.

Shut.-This is a wandering race, but attaching themselves to Baluchi and other tribes. They were generally Hindus ; are squarer and stouter in their build, and have broader features than the Baluch. They are all camel breeders and dealers.

Hindus.-Are principally of the Bunya caste.

Thor ANd PArkur, 203,344.

The Thur and Parkur district is inhabited by Hindus and Musalmans, more equally divided than in any 225 
other part of Sind. Each of these include several tribes which are divided into classes. Their manners and customs resemble those of Cutchi. They are naturally inactive. The chief occupation is breeding and grazing cattle, for which they evince greater preference than for agricultural pursuits. The language in use is a combination of Sindi, Marwari, and Gujerati, and is called Dati. In some parts of the district they carry on business in Gujerati, but the generality use the Dati, with which they are more familiarized.

1. Syuds ; 2. Baluchi, viz. Rind, Chandia, Gurgage, Kullohi, Bunglani, Dulwani, Sugrani, Dhownki, Laghari, Nattikani, Murree, Kuppri, Bhurgi, Khosa, Numrial, Butrani, Lashari, Bubber, Koriah, Nora, Kolachi, Zindpuri, Berohi. Arie.

Thut.-Chacher, Kalru, Kokur, Syal, Pusiah, Thyme,

Summat.-Summa, Summaja, Dull, Roahma, Ưmur Bumbra, Gailra, Pulli, Saita, Rajur, Nukry, Powur. Powhore, Hallapotra, Molla, Diary, Durs, Sukkerdeonpotra, Kotriah, Vikiah, Dadpotra, Keriah, Sungrasi, Thabba, Nori, Seahra, Joga, Jinji, Junaja, Hingorja, Hingora, Bahun, Kullur, Bakur, Durpar.

Hindus.-Brahman, Puskurna, Vias, Ackaraj, Cavata, Josi, Basu, Changangri, Jundria, Prohut, Masara, Dhowra, Lora, Mahdave, Viasurra, Takur, Hirow, Panah, Kullah, Hojah, Sarsud, Nuriajur, Sanichurri.

Soda. - Sultan, Bhojraj, Gungdass, Bijara, Sadur, Bhujbur, Kalun, Sungrasi, Virjuid, Bhar-Mull, Askaran,

Uda, Bhowta, Gagilra, Sutta, Muddat.

Commercial Tribes, viz. Lohana, Kerar, Uswur, Kutri, Chepa, Sonara, Darzi, Malli, Sutar, Uda, Barber, Raj put, Dohut, Balwaro, Kavrio, Charni, Bhatti, Rhye Dhur, Jessore, Chowan, Jaraja, Purwar, Vurhun, Joga

Broken Tribes, viz. Mengwar, Bhil, Koli, Balashahi and Shikari.

Miscellancous Races, viz. Shaikh, Memon, Kumbrani Gudda, Bujir, Mohana, Jokiah, Dukur, Koliah, Amunda Bhopa, Mahur, Hakra.

These multitudinous tribes can be summarived from the 1881 census as follows in the total Sind population of $2,413,823$ :-

Brahman, . . 13,531 | Shaikh, . . 32,888 Rajput, . 10,534 Sindi, $1,273,761$ Lohana, . . 211,926 Other Muham.

Other Hindus, : 69,088 madans, - 119,080 Baluch, * . 409,012 Aboriginals and

Pathan, . . 14,729 forest races, : 86,040 Syud, : : 37,734 Others, . 135,500

Most of the races dwelling in Sind designate themselves by tribal names, either assumed by themselves or applied to them. These names indicate the country or town from which they came, or the ancestor or distant race from whom they have sprung.

The tribes are so mixed up one with another, that, excepting just on the borders, no part of the country can be marked off as occupied by any particular tribe; even on the borders there is much intermixture. The great Murree tribe of Baluch, for instance, has a large, and the strongest, part of its clans in the hills to the north, and outside of the Sind border; but there are a great many of the Murree located in different parts of Sind, even down to 100 miles south of Hyderabad.

The $A r a b$ is numerously represented by Syuds, who claim descent from Mahomed, through his daughter Fatima and her husband Ali. There are, of them, 13 tribal designations in Kurachee, and 11 in the Hyderabad collectorate, - landowners and extensive cultivators, who say they came from Arabia and Persia about the 12th century. The Hasani and Husaini Syuds (which is properly written Sayyid) are numerous; the former class have the title of Pir, as Pir Bhawan Shah; the Husaini race is termed Sayyid, as Sayyid Jendal Shah. As, is usual in the Sind province, these two families are subdivided into clans, called after their previous place of residence, as Bokhari, Mathari, Shirazi, Lakhirai, Lakrulai, etc. Most of them are of the shiah or rafizi persuasion, and therefore they suffered severely during the various Afghan invasions. Many of these Sayyids are learned men, much respected by the commonality, in spite of the differences of belief. Under the Kalhora dynasty, they became possessed of large landed estates, granted as inam (or free gift) in perpetuity. When the Talpurs came into power, the priesthood declined.

The Koreshi was the Arab tribe to which Mahomed belonged. They have in Sind many tribal names; they are cultivators, kazi, and scribes, originally from Syria, Iran, and Irak, and claim descent from Ali, Abbas, Abubakr, Umar, and Usman, styling themselves Alavi from Ali, Abbasi from Abbas, Sadiqi from Abubakr, Faruqi from Umar, Usmani from Usman.

The Sadiqi are sufficiently numerous, and have the title of Makhdum, or master, as Makhdum Nuh, Sadiqi.

The Faruqi names usually begin with Miyan (master), as Miyan Ibrahim, Faruqi.

The Alavi, the posterity of Ali by any of his numerous wives except Fatima, are all shiahs, are not often met with, and bear the title of Khwajo, e.g. Khwajo Murad Ali.

The Abbassi, descendants of Abbas, are very numerous in Sind. They are called Mullo (priest), or Buzurg (the great), e.g. Buzurg Maaruf, Abbassi.

Other foreign tribes are descendants of Harun, also Mukrani, Ludi (now known as Ludia), Habshi, Sidi, and Jungiani.

The Afghans are generally found about Hyderabad, and in the north of Sind. Many of them have been settled in the country for some generations, and have become possessed of considerable landed property. The Kakar are the most aristocratic of the Afghans.

Gola, formerly slaves, principally from Africa, are the Sidi, Habshi, Khaskeli, Sindi, and Zemghur.

Baluch,-All the tribes who have come from Baluchistan are known in Sind by the general term Baluchi. The Rind tribe is, in Sind, the head of all those from that region, and from them have descended other sub-tribes. The Talpur, however, became rulers in Sind, and the Rind remained their dependents. The Baluch are generally said to have come originally from Aleppo in Syria. They have all the characteristics of Arabs,-sharp; well-defined features, and wellbuilt limbs. In Sind, many of their divisional appellations merely denote families of descendants of men of renown, whose names the families bear. There are 28 tribal names in the Kurachee district, 60 in that of Hyderabad, and 13 in Upper Sind. They are averse to regular labour, and restless, but they will undergo the most wonderful fatigue for the purpose of stealing a camel or bullock. All their traditions point to Syria as their original site, and the date of their advent as about 1200 years ago. Amongst themselves, the Rind rank first in importance, then the Lashari, Jutui, Dumki, Jakrani, Murree, Bugti.

The Brahui have mostly remained in the mouutains of Baluchistan. General Merewether says that the Brahui traditions are less clear than those of the Baluch, but are to the effect that they also 
came from the west, entering Baluchistan from Kirman by Makran.

Jacobabal, a frontier district of Sind, between lat. $27^{\circ} 56^{\prime}$ and $28^{\circ} 27^{\prime} \mathrm{N}$, , and long. $68^{\circ}$ to $69^{\circ}$ $44^{\prime}$ E., which comprises the tract of country bounded by the Bugti Hills on the north, by Kalat on the west, the Bigari canal on the south, and the river Indus on the east. The district ranges from 170 to 257 feet above the sea. From 1865 to 1870 the rainfall ranged from $1 \cdot 11$ to 8.80 inches. At the extreme north is desert plain. The Sind Hollow, a former bed of the Indus, traverses onethird of the district, and between it and the river the country is split up into numerous 'dhund" and 'dhoree.' On its north is a range of barren hills with fertile valleys, occupied by the Murree and the Bugti. Baluch tribes, Jamali, Dumki, Jakrani, Khosa, Mazari, form the population, with Burdi, Sindi, Jumma, the nomade Jat, who rear camels, cattle, sheep, and goats, and Hindu cultivators. The Jat are a hardy, good-looking, industrious race, and their women are very comely; they drink largely of camels' milk. The Baluch use jowari (sorghum) flour, and bajra (Penicillaria spicata), and milk. The cultivation is by irrigating canals.

Chanduka is a fertile tract 60 miles long, in Upper Sind, formerly occupied by the Chandia Baluch. It extends to the desert of Cutchi on the north, has the Hala range for its western boundary, and the river Indus on the east. Its principal town is Larkhana, so called from the Larak, a tribe formerly settled there. The tombs of Shah Muhammad Kalhora and of Shah Baharah are there. Hindus and Muhammadans comprise the population. The Muhammadans are Baluch and Sindi, the latter are agriculturists and artisans. The principal tribes are the Chandia, the Jamali, the Abra, and the Jat, with the Lahori, the Hukrah, and the Chujrah. The Chandia and Jamali are poor. The Jat are cultivators, and r'tar cattle. They are migratory; their subdivisions are the Darudgar, Junejah, Kohawar, Wagun, and others. The settled portion are not called Jat.

The Sindi are a quiet, industrious race, tall and handsome, and can undergo much fatigue, but are not very noted for activity. They are nearly all cultivators. They are untruthful, illiterate, and superstitious.

Languages. - The Larayi dialect of Sind is spoken in Chanduka; it differs much from the Sarhaiki spoken north of Larkhana. Persian is the polite language.

The Kalhor $a$ and Talpur tribes furnished the last dynasties, and though the one deduced its origin from the Abbassides of Persia, and the other advanced pretensions to descent from the prophet, both were alike Baluch.

Yar Muhammad, Kalhora, assisted by the Rind Baluch, overthrew the Puar Rajputs, who held dominion in Sind. He directed that a number of clubs should be suspended in front of his tomb, as a memorial of the ease with which the conquest was effected. The clubs were still hanging in 1847 in front of his tomb at Khodabad.

The Talpur have their name from the town (poora) of palms (tal or tar), and are said to amount to one-fourth of the population of Lohri or Little Sind, which misnomer they affixed to the dominion of Hyderabad. There are none of the Talpur in the t'hul. They emigrated from Chot to
Sind about A.D. 1760 , and, after attaining power, ruled from A.D. 1799 to 1843 , when they were overthrown by the British. The family have four principal branches, - the Shahwani, the Shahadani, the Khanani, and the Munikhani. A minor branch is the Jumidani. The Talpur are of the Shiah sect, and claim to be Syuds.

The Lughari family is a subordinate branch of the Talpur. The Lughari of the Dehra Ghazi Khan plain dwell south of the Khosa, extending from Viddore to Gungehur, between Choti Bala and Hurrund. The Lughari joined Lieutenant Edwardes' camp in his advance against the dewan Mulraj. The Talpur of Sind was one of their sections. The Lughari claim to be able to trace their pedigree up to their departure from Arabia. They have 55 sub-sections, of whom a large number reside in the hills.

Burgari, a minor tribe of Baluch in Sind, are also connected with the Talpur family.

The Daoudputra inhabit generally the country of that name in the north, but are to be met with in various parts of Sind.

The Desert of Sind lies between the frontier of Rajputana and the valley of the Indus, and from Daoudputra on the north to Buliari on the Runn, 220 miles long and 80 broad, or 17,600 square miles. It is one entire t'hul, with few villages and a few shepherds; 50 miles without water, the wells 70 to 500 feet deep, and the sand-hills little mountains. It was through this tract that Humayun sought refuge to the Dhat country and its capital, then Omarkot, where Akbar was born. Arora, there, is a ruined town. Omerkot was wrested from the Soda race by the Rahtor tribe of Marwar, and since then the chiefs of the expelled clan have dwelt in Chore, 15 miles N.E. of Omarkot. At one time, every third year brought famine. The Soda women of this desert tract of Dhat are proverbially handsome. In this desert, and in the valley of the Indus, are the Soda, Kat'ha, and Mallani, descendants of the Sogdi, Kat'hi, and Malli, of Gete and Yuti, many of whom call themselves Baluch, or keep the ancient name of Numri, whilst the Zj'hut or Jat retain their primitive appellation. There are also remains of a Johya and Dahya, who, with Gete, Jat, or Hun, hold places amongst the 36 royal races of ancient India. The Baraha and Lohana tribes are there; the Sahrai, the great robber of the desert; the Bhatti, Rahtor, Joda, Chauhan, Mallani,Kaorwa, Joshya, Sultano, Lohana, Arora, Khumra, Sindil, Maisuri, Vishnavi, Jakhur, Shiag, Ashiag, and Puniah. Jakhur, Shiag'h, and Puniah, harmless, industrious, in the desert and the valley, are denominations of the Jat race, but most of these sections have become Muhammadans, and call themselves Zj'hut.

The Nyad or proselytes from Rajput or other Hindu tribes are-Zj'hut, Rajur, Unra, Sumra, Mair, Mer, Mor or Mohor, Baluch, Lumria or Luka, Sumaicha, Mangulia, Baggreah, Dahya, Johya, Kairui, Jangurea, Undur, Berowi, Bawuri, Tawuri, Chrendea, Khosa, Sndani, Lohana. These converts are ferocious and intolerant.

The Soda is scattered over the desert, some are Muhammadans.

Kaurwa, a peaceable nomade race, chiefly in the t'hul of Dhat, rear cattle.

Dhote or Dhatti, like the Kaurwa, a pastoral race of Dhat ; their cows give 8 or 10 seers of milk daily. 
Lohana, numerous in Dhat and Talpura; they are scribes and shopkeepers.

Arora, a thrifty race, tradesmen and farmers.

Bhatti, formerly martial, now traders, and, like the Arora, have commercial agencies all over India. Brahman Bishnavi, cultivators and graziers, numerous in Dhat, some in Chore, in Omerkot, Dharnas, and Mitti.

Rebarvi, a race who in Hindustan profess Muhammadanism and rear camels; here, are a tribe who rear camels, or, with the Bhatti, steal them.

Sahra $i$ is the most numerous of the Muhanmadan tribes of the desert, of which he is the terror. Masson says the Sabrai once ruled in Kalat. They preceded the Sewah, a Hindu dynasty, which in turn the Brahui displaced.

Khosa, a section of the Rind Baluch settled in Upper Sind between Sukker and the Sind canal towards Shikarpur. They have four clans. The Khosa become a predatory tribe on the eastern confines of Sind, verging towards the Cutch territories, where Rajputs are located. They were very troublesome. They are also in the eastern boundaries as wandering herdsmen.

Sumaicha are converts to Muhammadanism, from the Soda race; some are pastoral, some are plunderers. They are dirty, and never shave.

Rajur, converts from the Bhatti, are cultivators, shepherds, and thieves, and evil-livers.

Umra and Sumra, converts from the Puar or Pramara race, have mixed largely with Muhammadans.

The Jat, Zj'hut, Jet, Jut, or Jhat, in religion partly Hindu, partly Sikh, and partly Muhammadan, occupy the north-west and bordering provinces of British India, also the Panjab and Sind. They all refer to the west of the Indus and of Ghazni as their original seats. They are the principal cultivating and pastoral classes in Sind.

The Jat on the Upper Sind frontier are converts to Muhammadanism; they are a wandering race, but attach themselves to Baluch and other tribes. They are squarer and stouter in their build, and have broader features than the Baluch. In Lower Sind they are camel-breeders and dealers. The Jat is as inseparable from the camel throughout Sind as the Arab from his horse in Arabia, and are consulted on every occasion where the health or efficiency of this invaluable animal is in question. The Jat, like all the tribes in the Sind districts, have innumerable subdivisions, called Koum. They are I hard-working, quiet race, occupying themselves in rearing camels, feeding flocks, or cultivating the soil. They are invariably found in large communities, often living in temporary huts or 'wands,' and migrating all over Sind and its confines, as shepherds, in search of pasture. Where this is not the case, they are farmservants either of the Baluch chiefs or wealthy zamindars, who repay their labour with a modicum of the produce. The Jat in Sind are exceedingly valuable subjects. Their women throughout the country are noted for their beauty, and, to their credit be it also spoken, for their chastity. They work as hard as the men, and the labour of tending, driving home their flocks, milking the cattle, etc., is fairly divided. They form a large division of the population of Sind, though seldom found in its towns, being dispersed over the whole face of the country, particularly eastward to the desert tract which separates Sind from Cutch, known as the Runn, on which this tribe rear large flocks of camels. Other pastoral Wuhammadans are the Khosa in Upper Sind, Sikh Lohana in the Delta, and emigrants from the Panjab, who have in many instances become amalgamated with the people of the country.

The Sindi is taller, more robust, more muscular, and stronger than the native of Western India. His hands, feet, and ankles are large. The features are regular, and the general look of the head is good. His beard, especially among the upper classes, is handsome, though not equal to that of the Persian or Afghan. The brave and hardy hill tribes have always treated the Sindi like a serf, and his morale is low. He is idle, immoral, and apathetic, unclean in his person, and addicted to intoxication, notoriously cowardly in times of danger, and proportionately insolent when he has nothing to fear. The Sindi women (not the Baluch) are fond of intrigue, fond of flattery, but are grave and sedate in society. The indoor games are pachisi, cards, cowries ; most all smoke tobacco; they are fond of snuff, and many use ganja. The Sindi men are fond of fighting (Ghata) rams. The best breed is the large and strong black animal of the hills. The women of Sind dress gaily, in bodices worked over with various coloured silks in many patterns, into which they frequently insert pieces of lookingglass. Sindi women are of fairer complexion and finer features and form than those of Western India; the latter, however, are superior in grace and delicacy of make. Sindi women are most indecent in their language, especially in abuse; they have very few expressions peculiar to their sex, but deliberately select the worst words used by the men.

The Gabole clan of Baluch, dwelling in Sind, have marked and peculiar features. Under the Sind Amir's rule they garrisoned hill forts in the western mountains, and held rent-free lands for their military service.

The Nizamani, a Baluch tribe in Sind, follow settled pursuits. They take their name from Nizam, a common ancestor, though now subdivided into separate clans or houses. They are well educated in Persian, Sindi, and Arabic.

The Kahiri are a small tribe of peaceful herdsmen aud cultivators, occupying lands in the Cutchi district of Sind.

The Lund have 30 sub-sections or families.

Amrani, a Baluch tribe on the northern margin of the district between Upper Sind and Cutchi ; they have eleven clans.

Jamali, a poor Baluch tribe; cultivators and shepherds at Rajhan on the edge of the Barshari desert in Upper Sind.

Jatei, a small Baluch tribe in Upper Sind.

The Mohanna are deep-sea fishermen and sailors, a thriving class, fish maws and shark fins being largely exported. They also fish with large handnets in the Manchar, Maniyar, and Kinjur lakes, resting on an inverted pot as a float. They are Muhammadans, supposed to have been converts from Hinduism. They have four sections, - the Kurachee, Lara, Bundri, Wungura, the last named being foresters in the salt-water jungle. They are dark in colour. The men are industrious and hardy, though addicted to the use of bhang. Their women when young are handsome, but even when 
married are immoral and unchaste, and use gross language. Their headmen are styled Changa Marisa.

Outcastes. - The ceremonial or professional uncleanness of certain races, which in India takes the form of caste inferiority, is continued into Sind as regards the Dapher, the Kori or weavers, the Dher and Chamar, curriers, tanuers, and shoemakers; and the Chahru and Bala Shahi, sweepers. All these are deemed unclean. The Dapher is a hunter, fowler, or shikari; many of them profess Muhammadanism, and are styled Machhi, but are not allowed to enter a mosque, possibly because they eat carrion. They occupy separate hunting grounds, and are skilled hunters. Their name is taken from the 'dapho,' their favourite weapon, a broad-headed javelin, with a shaft six or seven feet long.

The Langhan or Mirasi and the Kalwat are musicians. The Langhan are of Jat or Sindi extraction, and are considered a vile race. The Kalwat are respectable singers. There are some charming Sindi poems; amongst them is that of Sasani and Punha, the history of whose love and death much resembles that of Romeo and Juliet.

Luri, bards or troubadours, who attach themselves to high Baluch families in Baluchistan and Sind. They are musicians, tinkers, vagabonds, and fortune-tellers. They are in troops, with a chief in each. They profess Muhammadanism, but are really pagans.

The Agari is a race of low degree, employed in the manufacture of salt.

The Rangeli or Khobli is a low courtesan of the Jatki race, from the districts of Ubbo and Jhangsiyal. They inhabit villages on the main roads, and support themselves and the men by receiving travellers. Some of these women have very fine features and forms, particularly in early youth. A more respectable class is the Kanyari, who, like the nautch girl of India, generally unites the occupation of dancing with the immoral part of her profession.

Kulmutti, a well-conducted, intelligent tribe on the western part of the Kurachee collectorate, clain to be of Arab origin. They appear to have established themselves on the Makran coast, whence they pushed their way into sind, and acquired by conquest possessions on both banks of the Hubb, and in the Sakra taluk. Their chief wealth consists in camels.

The Muhammadan religion has been largely accepted by the races who have been occupying Sind, but the numbers professing the Hindu and the Jaina faith are still considerable. Immigration from the Panjab, from Amritsar and Multan, and from the western parts of India, keep up the numbers.

Hindus are dispersed over the whole of Sind; in the wildest fastnesses of the Baluch mountains, in the deserts and smallest collection of huts, in the jungles of the plains, a Hindu and his shop of tobacco, spices, groceries, or cloths, is sure to be found; but their principal localities are in Northern Sind at Shikarpur, and in Southern Sind at the port of Kurachee. In Lower Sind, in the Kurachee collectorate, are Brahmans from the Konkan and Mahratta country, Gujerat and Nuggur; also Gour Brahmans, and the Sarsat and the Pokarna from Jeysulmir. In the Hyderabad district, they are even of more distant countries, the Dekhan,
Telingana, Dravida, the Camatic, and Kanouj. Khatri occur both in. Hyderabad and Kurachee. The Vaishnava sectarians seemingly embrace all who engage in traffic and banking. In Kurachee are the Amil, Godi, Kanuga, Mahajan, Merani, and Wanhia; in Hyderabad, the Lohana, Bhatti, Bhabera, Panjabi, Mebisirri, Usuwar, Sehwani, Khalsa, and Shahdadpuri. The Sudra are the Bagoi, Jakhiri, Jeysulmiri, Khutti, Kalal, Kurmi, Lohar, Muchi, Ode, Socbi, Sonara, Sutar, and Thumbuli. The Hindus in Sind, Afghanistan, Arabia, Persia, and Africa, are merchants, bankers, shopkeepers. The Hindu merchants and bankers have ageuts in the most remote parts of Central Asia, and could negotiate bills upon Kandahar, Kalat, Kābul, Khiva, Herat, Bokhara, or any other of the marts in that region. Shikarpur merchants are found all over India and Central Asia, some as financiers with bills of exchange, others selling cloths. The places of Hindu pilgrimage are Hinglaj, the Makli hills near Tatta, and the Dhara Tirt'h in the Lukki hills near Seluwan. Women of the Hindus of Sind possess a considerable share of personal beauty, appear to be fond of intrigue, but seldom if ever become prostitutes.

Converts. - Though the older residents in Sind have become Muhammadans, down to modern times Muhammadan converts have been allowed to retain their Hindu names. Under this custom, the Jat Muhammadans have some communities in the northern part of Sind; those in Lower Sind are camel-drivers. The Sumra or Summa Rajputs adopted the Muhammadan religion while ruling, and remained in Sind after their deposition by the Muhammadans. Another section have remained in Cutch, whose chief also takes the title of Jam.

Nareja is one of the oldest of convert Sind tribes, and is found in Lower and Upper Sind or Khyrpur, and became converts to Muhammadanism of the Hanafi Sunni sect. The race is broad, fat, lethargic, and sensual, and the gait heavy and shambling. Sindi is the language that they speak, read, and write.

Ponhav, Muhammadan converts from Hinduism, form one of the most ancient, and formerly most powerful, of the local Sindi tribes, whose influence was destroyed by the Kalora in the beginning of the 18th century. Their present principal residence is at Mehar and Sehwan, in Central Sind.

Abra, an old and influential tribe in Sind, the records of whose prowess and reputation are still preserved in the songs and traditions of the country. They give their name to the Nushira Abra district of Upper Sind. The Oonur tribe is an offshoot from the Abra; is numerous in the Larkhana and Sukkurkund districts. Oonurpur is on the right bank of the Indus.

Mhar, a very ancient tribe inhabiting the skirts of the desert south of Bahawulpur. They were converted from Hinduism to Muhammadanism. They are ignorant but peaceable herdsmen, breeding camels and sheep. About A.D. 1541, while Shah Beg Arghun was ruling, they came from Oobara, near the present Bahawulpur frontier, and dispossessed the Jatui. Subsequently, the Daoudputra dispossessed the Mhar, who never regained their former position.

The Babra, a Jaina sect, numerous in Jodh- 
pur in Rajputana, are found in Sind. They form part of the mercantile body usually styled Marwari. They are enterprising bankers, financiers, and in Sind merchants, also petty traders and shopkeepers.

Jokia, a tribe in the western part of the Kurachee collectorate, claim a Rajput origin, and their chiref takes the title of Jam.

The Lohana of Sind are Vaishnava and Saiva Hindus. Some of them worship the river Indus deity and his wazir under the names Jenda Pir and Udhero Lall. They engage in trade and in agxiculture. The suffixed titles of their subdivisions are-Mul, Chund, Rae, Ram, Das, Lal. They are the principal number of Hindus in the country, but, like the Saraswati Brabmans, they eat meat, fish, and onions, and drink spirits, buying the flesh from the Muhammadans, it being unlawful for them to kill. They are not highly educated, but in the time of the Talpur Amirs they were largely employed as revenue collectors, and were described as scheming and crafty. Under British rule they have shown an earnest application and devotion to duty, able and energetic, honest and upright. They are financiers, bankers, merchants, and shopkeepers.

Tradesmen are the Raza, Lohar, Wadha or Dakhan, Dhobi, Pinjara, Katri, Khori, Mochi, Sunara, Thattiara, Muhana, Baleshahi, and Machi.

There are, besides, in the Hyderabad district, 78 races of miscellaneous origin.

Religion.-The Muhammadans are 78 per cent. of the population; many of them claim to be Syuds; and besides the great sects of Shiah and Sunni, there are several prominent smaller bodies.

The Ismaili are chiefly in Sind, where they take the title of Khajah (Khoja, Khowaja). They are numerous in Bombay city, and in the Sind collectorates of Kurachee, Ahmadabad, Hyderabad, and Tanna. In Bombay city, on the date of the census, 8451 , or $6 \cdot 15$ per cent. of the Muhammadans there, returned themselves under that designation, and about 18,000 were residing in other parts of that presidency. They are petty dealers and merchants, are quiet, peaceful people, and have never given any annoyance to the British.

The Ismaili acknowledge Ali, Hasan, and Husain as rightful imams; some hold that the line closed with Ismail, son of Jafar Sadiq, who was their seventh and last imam. From him they take the name Ismaili, and also from him the 'seveners.' The Ismaili put a metaphorical interpretation on the Koran, which tended to explain away and supersede its doctrines, leaving only a negative religion, and substituting licence for morality. They were sometimes called Mulāhida, heretics, and have been deemed to include the Karmatians, and the Assassins, and others, but these are merely offshoots from the Ismailian heresy. The doctrines were largely spread by Abdallah, son of Maimun, a native of Persia. In the middle of 1878 , Killu Khutu, a young Muhammadan, murdered the Mukhi or headman of the Khojahs in the open street in broad daylight at Umercurry in Bombay. $\mathrm{He}$ was hanged on the 20th July 1878.

The Bora or Bohorah Dr. Wilson describes as corresponding in many respects with the Ismaili, the Ansari, the Mutawilah, and the Druse of Syria. They pay particular regard to the tenets of Ismail, son of Jafar, the sixth imam, and hold, like the Shiah. but in a more exaggerated form, the mystical doctrine of the umion of the deity with Ali. The mercantile Bora are divided into three sects, - the Sulimani, the Aliyah, and the Dawudiah, from certain lines of the mullas or pontiffs, to which they adhere. In Bombay city they form $7 \cdot 8$ per cent. of the Mubammadans there; but it is in Kaira, Surat, Broach, Ahmadabad, and other cities of Gujerat, that the sect are principally numerous. They are pedlars, shopkeepers, workers in iron and tin, and many of the men are long absent from their families following their professions. The Bombay census returns show in that presidency about 10,000 .

The Karmati or Karamata is a sect founded about 278 A.H. (891 A.D.) by Ahmad, a follower of Abdallah. He taught that everything desirable was allowable. He endeavoured to carry out his views by violence, and began an open war against the ruling powers. In 290 A.H. (903 A.D.) the Karmat sect made a fearful inroad into Syria; and in 311 A.H. (923 A.D.) they plundered Basra and Kufa. In 319 A.H. (931 A.D.), led by Abu Tahir, they took Mecca, with terrible slaughter, plundered the temple, and carried away the Black Stone (Hajr-ul-Aswad), which they retained for twenty years. Ar Razi, the twentieth khalif, paid them a subsidy to secure the safe passage of pilgrims to Mecca. The Fatimite dynasty of Egypt was founded in 297 A.H. (909-10 A.D.) by an Ismailian, in rivalry of the Arabian khalifat. It grew rapidly into power, and became a source of great trouble and jealousy to the rulers of Baghdad, and the wars were most savage and unrelenting. They appear to have pushed eastward into the valley of the Indus, and to have sought a country in Sind about 375 A.H. (985 A.D.), and seem to have been ruling there at the time of Mahmud's return from the fall of Somnath. They destroyed the great idol at Multan, and the chief whom Mahmud of Ghazni drove thence was one of this sect. But they re-obtained power there, for in 571 A.H. (1175 A.D.) Muhammad Ghori again delivered Multan from the hands of the Karmatians. In 634 A.H. (1237 A.D.) we find them in some force at Dehli, where they made a concerted assault on the Muhammadans in the great mosque, and slew a considerable number, but they were finally overpowered, "and every' heretic (mulahida) and Karmatian was sent to hell.' Their name was given to them from their use of the Karmata or Karmat style of writing Arabic, in which very small letters are used with very close lines. General Merewether's returns show 39 sections of Karmati in the Kurachee collectorate in Sind, but whether or not they belong to the Karmati sectarians, there is no information.

The Assassin sect known to the Crusaders also sprang from the Ismaili. The founder was Hasan-us-Sabāh, a native of Re. He was schoolfellow and companion of Nizam-ul-Mulk, the well-known wazir of the Saljuki dynasty, and author of Majma-ul-Wasaya. The forcible removal of all foes and rivals by the dagger was the distinctive practice of this sect. Nizam-ul-Mulk fell under their dagoers, and the author of the Jahan Kusha nearly became a victim to them. In 483 A.H. Hasan-us-Sabāh obtained possession of the strong fortress of Alamut or Alah-amut (the eagle's nest) in the province of Rurbar, about 
eleven parsang's north of Kazwin. Here he and his descendants maintained themselves for nearly two centuries, when the fortress and many others fell to the Mongols. Mangu Khan determined to exterminate the whole of the Ismaili sect; and under him and his successor Hulaku, their fortresses were taken, and many thousands of their men, women, children, and babes at the breast were put to the sword.

The Memon sect of Muhammadans are numerous in the Kurachee and Hyderabad collectorates of Sind, and have spread into all the Bombay districts. The number given in the returns of the census taken in 1872 is about 50,000 , but others of the sect must have merely styled themselves Musalman. In Bombay city they numbered 8825 . In the returns received from General Merewether there are entered Memon Khojah and Memon Sayata, and are placed among the Shaikh or Memon sections. Dr. Wilson says they take their sectarian name from Mihman, a Persian word for a guest, a stranger, and that they are converts to the Sunni form of the Muhammadan religion, principally from the agricultural and mercantile classes of Hindus in Sind, Cutch, and Kattyawar. In Sind they have many learned and respectable men amongst them, but the bulk are engaged in trade, agriculture, and cattle-breeding.

Slaves.-There was in Sind in the time of the Amirs, a system of slavery common to it and all the countries to the north-west, viz. that of fathers selling their daughters as wives when very young, as also of the sale of girls for the zananas of the wealthy. The Afghans were particularly notorious for this traffic in Sind, but it was after all very limited. Under the former rulers, many slaves were brought from Africa and Arabia, and employed as domestics. They were known as Habshi ( pl. Habūsh), also Sidi.

The Guda, a mixed race between Sindians and Sidi women, were equally slaves with their mothers, and could be bought or sold at will.

Languages. - Sindi is the prevailing vernacular tongue, but the Sindi people and language are more confined to Lower Sind, and there the Sindi has much Arabic mixed with it. It is, however, spoken from the northern boundary of Kattyawar northwards to Bahawulpur, and from the hills on the west to the desert which separates Sind from the western portion of the Indian Peninsula. The Arabic character is used in writing. The language of Lar is purest. Sindi is of Hindi origin, being a still greater variation from the Sanskrit than the Gujerati. It is often written in a peculiar character, called the Khuda Wadi, and the Hindus keep all their own accounts and correspondence in it. This tongue has the dialect of the Siraiki of Upper Sind, containing numerous Jataki words.

Cutchi has in it elements of the Gujerati. That of the hunters and tanners, Dedh, is another dialect.

The language in use in the Thur and Parkur is called Dati. It is a combination of Sindi, Marwari, and Gujerati. In some parts of the Thur district they carry on business in Gujerati, but the Dati, with which they are more familiar, is in more general use.

Jataki is the language of the wide-spread Jat race, from the northern regions of the Panjab southwards to the Arabian sea.
The Persian and the Urdu are also to some extent in use.

The few Afghan zamindars settled in the north of the province still use the Pushtu of their forefathers; but the dialect is not sufficiently diffused among the people to be included in the languages of Sind. The same is the case with pure Panjabi; it is confined to the small number of Sikhs who are settled in the different cities and towns.

Baluchi is spoken by the tribes who have migrated to the plains of Sind. One-half of its words appear to be Persian or dialectal variations from that tongue. Like Brahuiki and Pushtu, the Baluchi vocabulary contains a few Sanskrit and Arabic roots, together with a considerable proportion of other words. As must happen among a people divided into clans, and separated from each other, the dialect abounds in diversities of words and idiom, and, being naturally poor, it borrows many vocables from the neighbouring countries. Its literature is confined to a few tales, legends, war songs, and the productions of the Bhat or Baluch bards.-Sir Henry Elliot's History of India; Mi. (Sir George) Campbell's Ethnology of India; Census Reports, 1872, 1881 ; Dr. Forbes Watson's People of India; Aitcheson's 1reaties; Tod's Rajasthan; Elliot's History of the Panjab; Postans' Personal Observations ;'Postans' Sind; Masson's Tourneys; Burton's Scinde; Ouseley's Travels; Hindu Infanticide; Pennant's Hindoostan; Remell's Memoir; Rawlinson, Herod.; Smith's Dictionary of the Bible; Cunningham's Ancient India; Genl. Merewether in Literis.

PANJAB, a great province in the extreme N.W. of British India, with an area of 142,449 square miles, and a population of $22,712,120$ inhabitants. It takes its name, literally the Five Rivers, from five of the great streams which intersect it,-the Sind or Indus, the Jhelum or Hydaspes, the Chenab or Ascesines, the Ravi or Hydraotes, and the Gharra or Hyphasis. In many parts the rainfall is scant, and droughts and famines occur. In 1859 there, was drought; famines recurred in 1860,1868 , and 1869 , severely in the last-named year, and the year 1878 was calamitous: Wheat, their great food grain, has been selling at 25 to $63 \mathrm{lbs}$. for a rupee.

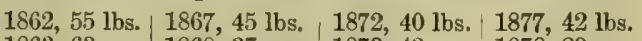
\begin{tabular}{l|l|l|l|l}
1863,63 & 1868,37 & 1873,43, & 1878,29 & 187
\end{tabular}

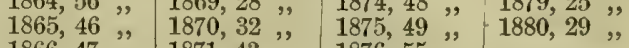
\begin{tabular}{l|l|l}
$1866,47, "$ & $1871,43, "$ & $1876,55, "$
\end{tabular}

It is a frontier country in the route of the conquerors who have invaded India,-Aryan and non-Aryan, Scythi and Gete, Turk and Mongol, - who have occupied the plains, and have pushed broken tribes into the mountain and desert tracts. Conquest and occupation have been facilitated by the democratic institutions of the inhabitants, and Alexander, Timur, Baber, Nadir Shah, and Abmad all entered from the west.

At the time of Alexander's expedition, the Greeks heard of 118 different kingdoms in the N.W. of India, all more or less hostile to each other; and the many martial tribes in and around this province, and the variety of languages spoken within its bounds, attest the accuracy of the Greek historians; also thirty-six native chiefships are still interspersed in British territory. 


\begin{tabular}{|c|c|c|c|c|}
\hline & Area. & $\begin{array}{l}\text { Both } \\
\text { Sexes. }\end{array}$ & Males. & Females. \\
\hline ory, : & $\begin{array}{r}106,632 \\
\mathbf{8 5 , 8 1 7}\end{array}$ & $\begin{array}{r}18,850,437 \\
3,861,683\end{array}$ & $\begin{array}{r}10,210,053 \\
2,112,303\end{array}$ & $\begin{array}{l}8,640,384 \\
1,749,380\end{array}$ \\
\hline
\end{tabular}

The Feudatory States are as under-

\begin{tabular}{|c|c|c|c|c|c|c|}
\hline & & Area. & $\begin{array}{c}\text { Popula- } \\
\text { tion. }\end{array}$ & & $\begin{array}{l}\text { Area. } \\
\text { Sq.m }\end{array}$ & $\begin{array}{l}\text { Popula- } \\
\text { tion. }\end{array}$ \\
\hline Bhajji, & & 96 & 12,106 & Kapurthala, & 620 & 252,617 \\
\hline Dujana, & • & 114 & 23,416 & Kunhar, . & 7 & 3,648 \\
\hline Bilaspur, & & 448 & 86,546 & Kuthar, . & & 1,923 \\
\hline & & 124 & 20,663 & Kumharsein, & 90 & 9,515 \\
\hline lat & & 36 & 8,339 & Loharu, . & 285 & 13,754 \\
\hline wulp & ur, & 1500 & 573,494 & Mailog, . & 48 & 9,169 \\
\hline & & 51 & 5,190 & Maler Kotla, & 164 & 71,051 \\
\hline & & 3320 & 64,345 & Mangal, . & 12 & 1,066 \\
\hline & & & 1,158 & Mand & 1000 & 147,017 \\
\hline aba, & & 3180 & 115,773 & & 928 & 261,8 \\
\hline & . & 26 & 3,322 & Nahan, & 1077 & 112,371 \\
\hline & & 5 & 590 & Nalagarh, & 252 & 53,373 \\
\hline & & 612 & 97,134 & idi, : & 48 & 17,847 \\
\hline Dac & & 1 & 170 & Rawa & 3 & 752 \\
\hline & & 1232 & 249,862 & Sang & 16 & \\
\hline & & 288 & 19,196 & Tarhoch, . & 67 & 3,216 \\
\hline & & 178 & 67,708 & Suket,. . & 474 & 52,484 \\
\hline & & 116 & 31,154 & & & \\
\hline
\end{tabular}

Around the borders, also, are eminently warlike tribes, independent, and kept separate by unending feuds. Every grown-up man is available for their wars, and the numbers of their fighting men have been estimated at 170,200 , as follows:-

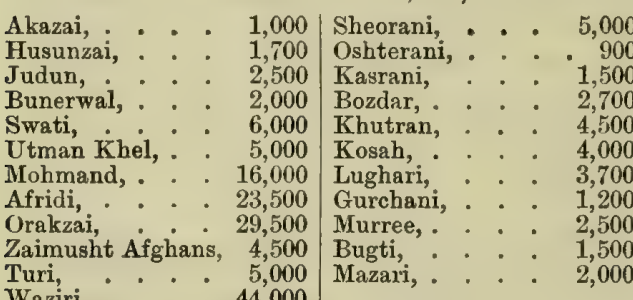

Waziri, . . 44,000

Language. - The race distinctions observable there will be understood by the above statements, but the subject may be further illustrated by showing the languages spoken in the province-

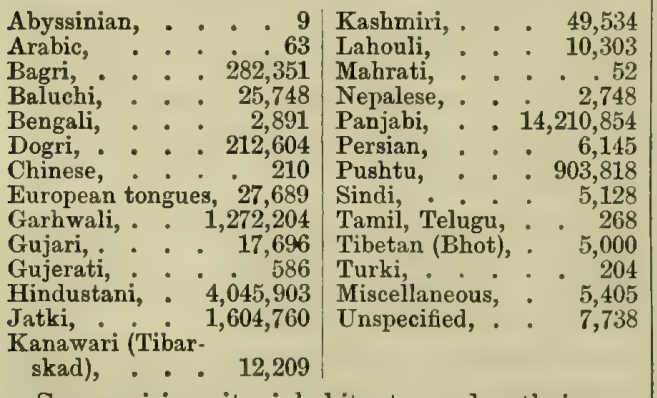

Summarizing its inhabitants under their respective religions, the numbers are-

Muhammadans, 11,662,434 Buddhists,

Hindus,

Sikhs, : : : 1,716,114 Jews, : : : 465

Jains, . . 42,678 Others, . . . 1,153

It is the only province of British India in which the Muhammadans preponderate; but the mass of the people are of Jat origin, and have only in comparatively recent years accepted the Islamic faith. The great sects of Mubaumadans are as under-

Sunni, . . 11,306,855 Farazi, . . . . 165 Shiah, : 102,256 Others, . . 250,627
Tribes.-The more prominent of Muhammadan tribes belong to three great nations, - the Ghilzai, the Pathan, and the Afghan. The Ghilzai tribes, 23 in number, have combined with tribes of Persian origin, but all claim descent from the Pathan progenitor Kais. Pathans proper number 23 tribes, comprising Karlanri, who are Indian in the mass (Afridi, Khatak, Waziri, etc), with a large admixture of Turk tribes, also Bangash. The Ghurghushti Pathans claim descent from Ghurghush, son of Kais. Of the Afyhans proper, 29 tribes are represented in the Panjab. They are recognised to be of Jewish or Arab stock, who have fused into a nation with the Gandhari, an ancient Indian race. They have two divisions, the original Afghans from Ghor, of Jewish or Arab descent or both, with whom are blended the ancient Gandhari immigrants from Peshawur to Kandahar. There are also 14 tribes of the Kākar, a Scythic stock, with affiliated tribes of Indian origin. Baluch claim to have come to their present territory, west of the Indus, from Aleppo. The three nations may be shown as under-

\section{A. Ghilzai Nation.}

\section{a. Lodi Section. Niazai, viz.}

Lodi,. . . . 13,161 | Niazai, . . . 36,371 Khasor, : : : 2,099 Kundi, : : : 3,667

Datanini, . : 1,363 Baluch, viz.-

Daulat Khel, . 1,387 Suliman Khel, _ 5,205

Mian, . . . 5,561 Nasir, . . 9,005

Marwat, : : 47,546 Kharoti, : : 7,169

B. Pathan Nation.

\section{Bhitanni, . 3,574 b. Karlanri Section}

a. Kakar Section. Waziri, . . . 20,743

Shirani, : 1,316 Banuchi, : : 20,307

- Miani,. : 2,211 Khatak, : . 118,050

Babar, : : 2,431 Afridi, : : 17,426

当 Oshterani, : 1,646 Utman Khel, : : 6,924

¿s Gundupur, : 8,095 Orakzai, . . 7,157

Kakar, : 4,759 Bangash, : : 17,565

क्षี $\begin{array}{ll}\text { Musa Khel, : } & 1,998 \\ \text { Ghorezai, : } & 1,809\end{array}$

$\left\{\begin{array}{l}\text { Ghorezai, : } 1,809 \\ \text { Panni, } 1,241\end{array}\right.$

C. Afghan Nation.

Muhammadzai, . 19,604 Abdali, . . . 9,738

Yusufzai, . . 98,977 Tarin, . : : 5,812

Utmanzai, : : 5,547 Zaimusht, : : 1,335

Mulliagori, . . 1,249 Khetran, . . 1,558

Mohmand, : : 44,009 Urmar, : : : 3,737

Daudzai, . . . 5,898 Sargani, . . . 3,940

Khalil, . . . 13,595

Several of the independent tribes are barbarous savages. The Census Report of 1881 mentions that 'the true Pathan is perhaps the most barbaric of all the races with which we (the British) are brought into contact in the Panjab.' He is bloodthirsty, cruel, and vindictive in the highest degree; he does not know what truth or faith is.

The border tribes within British territories are largely Pathans, similar in origin and in customs to the independent tribes occupying the mountains and valleys intervening between British and Afghan territory, many of the tribes, indeed, being partly independent, and in part under British rule. Afghan rulers have avoided interfering with these tribes, but they have become somewhat civilised since they have seen the British rule.

The Syud Mubammadans are descendants of Mahomed and of Ali. They are distributed through all the province. The Moghul are chiefly in Peshawur and Hazara, Yusufzai, Mohmand, 
Khalil, and Muhammadzai are almost entirely in the Peshawur district; Klatak are in Bunnu and Kohat; Bangash are almost all in Kohat; Waziri and Lubani are chiefly in Bunnu.

The Baluch in the Multan division are said to have arrived in the Panjab about the 16th century. They are strong-built men, with forbidding features, ignorant, rough, and boorish in manners, pugnacious and thieving. They breed camels, grazing them in the jungles of Guyaira near Lahore, selling them in Lahore and the N.W. Provinces. Camels' milk forms one of their chief articles of diet. In 1881, 51 of their tribes were represented in the Panjab, numbering 355,238 souls.

The Jat, Rajput, and allied castes number $6,275,294$, as under-

\begin{tabular}{|c|c|c|c|c|c|c|c|}
\hline & & & & & British. & Feudatory & Total. \\
\hline Jat, & & & & & $3,564,519$ & 868,231 & $4,432,750$ \\
\hline Rajpout, . & - & & . & & $1,436,058$ & 241,511 & $1,677,569$ \\
\hline Thakur, & . & & . & & 24,984 & 7,782 & 32,766 \\
\hline Rathi, & & & . & & 53,002 & 32,190 & 85,192 \\
\hline Rawat,. & - & & . & & 9,994 & 7,206 & 17,200 \\
\hline Dhund, . & . & & . & & 20,315 & & 20,315 \\
\hline Kohat, : & & & : & & 9,468 & 34 & 9,502 \\
\hline
\end{tabular}

Jat.-There are 81 Jat clans, 26 of them nimbering over 10,$000 ; 16$ over 20,$000 ; 8$ over 50,000 ; and 3 over 100,000 .

Colonel Tod formed the opinion that many of the Jat and Rajput clans are alike of Getic origin; and at the present day we find 31 clans in the Panjab over a million strong, classifying themselves indifferently under the two headings. The Jat race are conspicuous for their industry; their well - fenced and well - worked fields are always distinguishable from the slovenly and illcared-for lands of Gujars and Brahmans. The wife of the Jat works cheerfully in the field with him in every kind of agricultural labour.

Broken Tribes.-Dwelling amongst the settled races of the Panjab are nearly three millions of broken tribes, mostly non-Aryans, and whom the settled races deem unclean. Their avocations are scavengers, leather-workers, fowlers, etc. A few of them are regarded as wholly unclean; others are homeless migrants, dwellers in tents, mostly predatory; but all of them possess a kind of monotheism, mixed with shamanist and totem rites. Many of these remnants have adopted Islam; some have taken the Sikh pahul; others have adopted the new Ram-dasi faith. Some inter their dead, while others cremate the remains. $2,012,000$ are of Hindu origin; 173,000 follow the Sikh faith; 492,000 are Muhammadans, and some are Buddhists.

Minor Dominant Tribes-landowners and agriculturists-

$$
\begin{aligned}
& \text { Aw } \\
& \text { Bor } \\
& \text { Dao } \\
& \text { Doo } \\
& \text { Gak } \\
& \text { Guj } \\
& \text { Kan }
\end{aligned}
$$$$
\text { Gad }
$$$$
\text { Ghos }
$$$$
\text { Kachbi }
$$$$
\text { Kamboh, }
$$

532,855 40,731
18,163

63,437 25,789 627,304 10,413
Khanzada, Kharral, Khattar, $\therefore \quad 1,245$ $\mathrm{Me}, 36,137$ Taga, * * 116,227

\section{Minor Agricultural and Pastoral Tribes-}

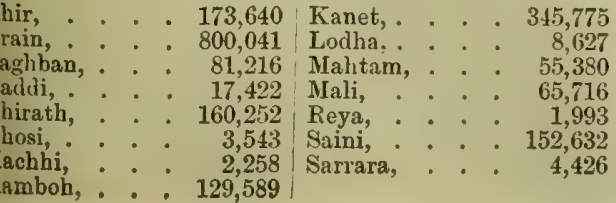

\begin{tabular}{|c|c|c|c|c|c|c|c|}
\hline heri, . & 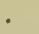 & & & Julaha; & & & \\
\hline ria, & & & & lera, & & & \\
\hline Bazigar, & & & 13, & Kanjar, & - & & 2,872 \\
\hline Beldar, & & - & - 3, & Kehsal, & . & & \\
\hline mar, & & & $1,072,6$ & Khatak, & . & & 14,181 \\
\hline rang & & & - $\quad 5,0$ & Kori, . & . & & 10,739 \\
\hline ar o & & hubr & 28 & Kurmi, & . & & 4,017 \\
\hline a & or & & & Mina, . & & & 1,116 \\
\hline & & . & $1,078,739$ & Muchi, . & . & & 349,272 \\
\hline & & . & & Nat, & & & \\
\hline & & & 66, & Od or Oulh & & & 15 , \\
\hline & & & 20 & iwara & & & \\
\hline & & & & $\mathrm{Pa}$ & . & & \\
\hline ila, & & & 1,4 & Perna, . & & & \\
\hline & & & & $\mathrm{Pu}$ & & & 2, \\
\hline i, . & & & & Qalaniari, & & & \\
\hline Hess & & & & i, . & . & & 21 , \\
\hline & & & $\begin{array}{l}3,4 \\
8,0\end{array}$ & & & & \\
\hline \multicolumn{8}{|c|}{$\begin{array}{l}\text { Watermen, Boatmen, Cooks, Blacksmilhs, Car- } \\
\text { nters, Potters- }\end{array}$} \\
\hline & & & - $\quad 7,194$ & & & & \\
\hline & & & 11,9 & Ma & & & 168 \\
\hline ri, & & & 1,716 & Mallah, & & & 67 \\
\hline & & & 433,884 & & & & 11,290 \\
\hline gar & & & 3,158 & Saiklgar, & & & 1,48 \\
\hline & . & & 1,004 & han or & & & , 596, \\
\hline mhar, & & & 486,025 & $i$, . & . & & 1,904 \\
\hline \multicolumn{8}{|c|}{ Hill Tribes- } \\
\hline & - & & & & & & 1,726 \\
\hline & & & & $\mathrm{Has}$ & & & \\
\hline & & & 18,7 & Koli, & & & 123,171 \\
\hline & & & 52,9 & Meg, . & & & 38,467 \\
\hline & & 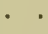 & 70,533 & Rehar, . & . & - & - 814 \\
\hline & & - & & & . & & 10,813 \\
\hline
\end{tabular}

Impure and Outcaste Tribes-

Foreign Races-

Arab,

2,342 Kazzilbash,

Ghulam, : : 3,446 Shaikh, : . 372,335 Moghul, . . 102,979/ Turk, : . . 3,535

Minor Professional Castes-

Bhand, . . . 2,775| Mirasi, . . . 204,941

Bhat, : : 30,022 Nal, : : : 342,123

Bhaurupia, . . 386 Rawal, . . 17,853

Jogi, . . . 72,733

Mercantile and Shopkeeping Castes-

Arora ; Bhatia; Banya, sar; Khatri; Mahajan; including the Agarwal, Dasa, Mahesri, Oswal, Saralia; Bohra; DhunPahari; Paracha; Sud; Bhabra; Khaka; Kho. jah.

Carriers and Pedlars, Cattle Dealers-

Banjara, . . . 11,217| Maniar, . . . 7,574

Bhabra, . . . 919 Rahbari, : : 3,881

Kangar, : . 653 Tamboli, : : 1,146

Kunjra, . . 5,001 Untwal, : : : 2,100

Labana,

48,489

Wandering and Criminal Tribes-registered-

Baluch, . . . $530 \mid$ Mina, . . . . 740

Bawuri, . . 1,312 Pakhiwara, : :1,020

Gurmang, . . . 43 Sansi, . . . . 9,563

Harni, * : 2,721

Gypsy Tribes-

Baddun, . . $1,736 \mid$ Kanjar, . . . 2,872

Bazigar, . . 13,841 Nat, . . . 11,740

Gandhila, . : 1,449 Perna, : : : 1,157

Garri, . : . . 685 Qalandari, . . 3,895

Hesi, : : 1,110

Scavenger Castes-

Chubra, . . 1,078,739| Klatak, . . 14,181

Dhanuk, . . 66,059

Miscellaneous-

Bengali,

1,044

1,014 Kanchan,

8,576 Kashmiri, . 179,020

Chahzang, : : 2,624 Kayasth, . : 13,420

Dogra, . . . . ${ }_{1912}^{397}$ Parsee,. . . . 462 
Sikks.-The Panjab was the birthplace of the Sikh religion. The chiefs of this creed were dominant when the British fought the battles of Moodkee, 18th December 1845; Ferozeshah, 21st and 22d December 1845; Aliwal, 28th January 1846 ; Sobraon, 10th February 1846; Kussoor Fort taken, 11th February 1846; Lahore occupied, 20th February 1846 ; and the Panjab was annexed 30th March 1846.

Nanak, the founder of this faith, was born near Lahore in the latter half of the 15th century, and died at Dehra Nanak on the Ravi in 1539. He taught a form of monotheism, and was followed by other leaders, to whom the title of guru was conceded. A hymn composed by Nanak is recited among other parts of the ritual morning and evening. It is repeated three times in the Granth. Its train of thought resembles the hymn by Milton, sung by Adam and Eve in Book v., Paradise Lost.

Parts of it run-

'To thee sing th' angels who men's deeds record,

And note and weigh their faith in thee Supreme;

To thee sing regions, orbs, and universe,

Created, cherished, and upheld by thee;

To Thee sing those whose deeds delight the eye,

The hosts that wear the colours of thy faith.

All things beside which sing thy glorious name

Could ne'er be told by Nanak's lowly song.'

In 1675 , Guru Govind, the tenth spiritual chief from Nanak, formed the Sikhs into a religious and military commonwealth. In the wars that occurred between them and the Moghuls, there were cruel barbarities on either side; but the destruction of the Dehli empire, and the dissensions amongst the Mahratta leaders, allowed the rise of a Sikh leader, Ranjit Singh, from whose officers the country was conquered.

The Bedi, descendants of Nanak, rank first among the followers of this faith. They are wellto-do, but from pride of birth were so notoriously addicted to the crime of infanticide, as to have been designated by the opprobrious title of Korimar, daughter-slayer. They number only 6804 souls.

The Sikh are secular and religious. Of the latter are three classes,-Akali, Nihang, and Nirmalla.

The Akali were armed religious devotees of the Sikbs, established by the Guru Govind, and they zealously supported him against the ascetic Banda, the Byragi. In Raujit Singh's time they moved about almost in a state of nudity, and were very insolent.

No one is a Sikh by descent, - a Sikh must be installed. The institutionary discipline of a young Kbalsa Sikh is very compendious: when he can bend a bow, wield a sabre, and mount a horse, his instruction is completed.

The followers of Govind, the tenth and last guru, are styled Singh or lion. The followers of Nanak and of his eight successors are known simply as Sikh, but there are several sects, Udasi, Nanak Shahi, Ganj Bakshi, Ram Rayi, Nirmala, Naga, Suthra Shahi, and Govind Singhi. They all believe in the Adi Granth, or first volume compiled by Arjan, but not in the volume compiled by Guru Govind.

All orthodox Sikhs must have the five K's, five accompaniments whose names begin with the letter $\mathrm{K}$,-the kes, or long hair ; the kirpan, a small knife with an iron handle, round which the kes is rolled and fastened into the hair of the head; the kach'h, or drawers; and the kara, an iron bracelet. No part of the person must be shaved, and smoking is prohibited.

The Daoudputra are on the left bank of the Sutlej river. In the beginning of the 18th century the Daoudputra were weavers and cultivators. and displayed no martial character, but local convulsions enabled the head of the tribe to assume power at Bahawulpur, and they have since then maintained themselves there. They now claim descent from the Khalif Abbas. They are a tall, strong race, of somewhat dark complexion, but with good features, and wear their hair hanging on their shoulders in masses like the people of Sind and Baluchistan. They have been friendly with the British, and in the battles of the 18th and 28th June 1838, a contingent aided General Cortland and Major (afterwards Sir Herbert) Edwardes in the contest with Mulraj, who had revolted at Multan.

Converts.-Of the Rajput converts to Muhammadanism, the Bhatti are chiefly in the Central Division : the Janjua, Siyal, and Gheba are in the Rawal Pindi Division; and Rangar in the Dehli, Hissar, Ambala, and Hazara districts.

Of the other converts to Muhammadanism, the Jat are few in the Peshawur Division. Ghakkar. are in Rawal Pindi, Jhelun, and Hazara districts; Dhund, in Rawal Pindi and Hazara; Kharral, chiefly in Montgomery; Karral, in Hazara; Wuttu, chiefly in Sirsa and Montgomery; Meo, chiefly in Gurgaon; Gujar are in all the districts, though mostly in the Chenab, Sutlej, and Hazara; Paracha, in Peshawur and Rawal Pindi; the Khojah, in Amritsar and Rawal Pindi ; the Kashmiri are in Amritsar, Lahore, Rawal Pindi, Peshawur, and Hazara.-Census Reports of 1868, 1871, 1884; Mr. (Sir George) Campbell's Ethnology of India; Dr. Forbes Watson's T'ribes of India; Powell'sHandbook; Major-General Sir C. M. MacGregor's Frontier.

\section{NORTH - WEST PROVINCES AND OUDH.-}

Hindustan, in Europe, is a geographical term applied to British India generally. By the people, however, and by the Enropean residents, the name is restricted to that part of India which lies between the Himalaya and the Vindhya mountains, and the N.W. Provinces and Oudh occupy a large part of that expanse. Hindustan was the Madhya-desa of the ancient Aryans, the middle region or Aryavarta, the Arya country. In a slokam in the Sanskrit work, the Amarakosha, the ancient boundaries of it are thus defined:-

'Ariavartahā punia bhūmi hī,

Mad'hiam Vindhya Himāva yoho,'

i.e. the Aryan country, the sacred land (lies) between the Vindhya and Himalaya, in this way indicating both the dominant race and the boundaries of the country held by them at the time that Amara Sinha wrote.

In 1877 the N.W. Provinces and Oudh were placed within one jurisdiction. The N.W. Provinces lie between la.t. $23^{\circ} 51^{\prime} 30^{\prime \prime}$ and $31^{\circ} 5^{\prime} \mathrm{N}_{\text {., }}$ and between long. $77^{\circ} 3^{\prime}$ and $84^{\circ} 43^{\prime} 36^{\prime \prime}$ E., seven degrees of latitude and seven of longitude, its area being 81,403 square miles; while Oudh lies between lat. $25^{\circ} 34^{\prime}$ and $28^{\circ} 42^{\prime} \mathrm{N}$., and long. $79^{\circ} 44^{\prime}$ and $83^{\circ} 9^{\prime} \mathbf{E}$., three degrees of latitude and three of longitude, with an area of 23,992 square miles. They together, including also the. 
order that they may follow a lazy life. Nearly half of the fakir sects of the N.W. Provinces and Oudh are in Allahabad and Gorakhpur. Badi-udDin, styled Shah Madar or Zindah Shah Madar, is said to have been a Jew, born at Aleppo, and to have visited India in the reign of Sultan Ibrahim Sharqi, and resided between Cawnpur and Farrakhabad. $\mathrm{He}$ died A.D. 1433, and Ibrahim erected a handsome tomb over him. Muhammadan tradition is that he was born A.D. 1050 , and that he is still alive, hence the term Zindah, living. A great fair is held at his tomb for the first 17 days of Jamadi-ul-Awal.

They reverence five pirzadah, viz. Ghazi Mian, a pirzadah who was slain, and is regarded as a martyr ; his tomb is at Baraitch in Oudh. Pir Hathili, a pirzadah, was sister's son of Ghazi Mian; monuments have been erected, and fairs are held in his honour. Pir Jalil, a pirzadah of Lucknow. Pir Muhammad, a pirzadah of Jounpur; and another.

The great bulk of the Muhammadans are engaged in humble avocations, - cotton cleaners, weavers, spinners, dairymen, greengrocers, glass bracelet makers, butchers. It is believed that most of these are descendants of converts from Hinduism. This is the ordinary explanation of the numbers of Muhammadans in the different parts of the country; but since the first Muhammadan invasion of Oudh by Syud Salar Masa'ud, a relative of Mahmud of Ghazni, many armies, each with camp followers, have entered it, and each have left remnants behind.

Muhammadans from their first coming into India took a liking to the mild climate and rich soil of Bijnour, and many of them settled in it. Even in later times the jaghirdars were more numerous in Rohilkhand than anywhere else. They were styled Rohi or mountaineers, and gave their name to the district. They made many proselytes.

The chief castes in the two provinces are-

Ahar, cultivators, 257,670 Ahir, herdsmen, $3,584,185$ Arakh, labourers, 64,713

Bahelia, fowlers, 67,360

Banya, Mahajan, trader, banker, 1,204,130

Banjari, carriers, 41,846

Ban Manus, ropemakers,

33,213

Bans phor, bamboo workers,

Bari, leaf-plate sellers,

68,817

Barhai, Kharadi,

Kuka, carpenter, 497,207

Bhangi, Hela, scavenger,

426,243

Bhar, cultivator, 349,113

Bhat, Jaga, Jachak,

Rajbhat, bard, 129,921

Bhuinhar, landlord, cultivator,

Bhurji, grainparcher,

Bind, toddydrawer, . . 72,581

Boria, cuitivator, . 21,335

Bralimans, Ojha, Padha, Panda, 4, 6.55, 204

Chamar, . . 5,360,548

Dhanuk, village watchinen,. - 119,341

Dhobi, washermen, . . . 518,872
Meo, cattle-breeder, 13,246

Nai, barber, . . 639,957

Nat, acrobat, : 36,810 Orh, trader, : 18,983

Pasi, watchman, 1,033,184

Patwa, tape-

weaver,

29,860

Rajbhar, pigherds, 11,157

Rajput, land-

owner,

$3,027,400$

Ronia, trader, . 38,105

Setwar, cultivator, 36,498

Sonar, goldsmith, 247,485

Taga, landholder, 101,615

Tamoli, betel-leaf
seller, 209,775

Tharu, cultivator, 27,172

Teli, oilman,

grocer,

685,123

Others, $1,981,690$

uhammadans-

Gujar, . . . 39,858

Jat,. : $: 10,401$

Mewati, . . 26,666

Kajput, . . 122,055

Taga, . . . 26,070

225,050

Each of these castes has a history, but the limits of this work preclude notices. The Arakh, Bhar, and Cheru, now small broken tribes in very humble avocations, were dominant even since the Muhammadan times. The Chamar aboriginals have largely adopted the Satnami monotheism, and the Taga or Tyagia claim to have been cultivators of the lands before the Jat settled.

The Gujar, now a predatory race, once ruled, and gave their name to Gujerat.

The Kshatriya, in Oudh, are the chief landholders. About 160 talukdars hold under direct grant from the British Government, and are entitled to seats in the viceregal darbar; and the first 45 or so of these claim the royal Hindu titles of raja, rana, or rao. They follow only arms or agriculture, or serve as semi-military personal retainers, peons, overseers, bailiffs, rent collectors.

The Khussia generally call themselves Rajputs. They are the oldest inhabitants of Garhwal, in which district they form half the pupulation. They are peculiar to the hills. Their name is derived from Khusdes, the ancient name of Kamaon.

Bisnoi or Beshnoi, a sect of Hindu religionists who worship only Vishnu. They were originated about A.D. 1460 in Bikanir, in Marwar, by a reformer named Jhamji. They do not now make any converts, are exclusive as to their food, abstaining from eating food touched by any other sect. Until recently they saluted each other with the Muhammadan greeting, Us-salam alaikum, and had such Muhammadan names as Ghulam Muhammad, Faiz Muhammad. They bury their dead.

The Bisnoi of Garhwal are turbulent, and disliked by the other inhabitants of the N.W. Provinces. The caste is common in the Moradabad district, where they combine Muhammadan and Hindu customs. They are there a quiet, industrious people, generally carpenters.

Mewati, a predatory tribe of cultivators who seem to have come from somewhere in Rajputana, and are found here and there along the S.W. borders of the N.W. Provinces of India. The Alwar country near Dehli seems of late to have been called Mewat, but they extend farther east than the Gujar, and in Malwa are common as regular soldiers and depredators. They are supposed to be mostly Muhammadans.

Boksa, a forest tribe in Western Rohilkhand, and in part of the forests or Siwalik Hills of Debra Doon and Terai. They are of short stature and spare habits, with broad faces, depressed noses, proguathous jaws, thick lips, very scanty beard and moustaches, but not darker in colour than the ordinary Hindus of the country. They are reputed to be skilful in witcheraft. They are 
very ignorant and indolent, but simple, inoffensive, and good-humoured. They have a scanty, rude cultivation, and collect forest produce and wash for gold, but they have no caste, eat almost anything: They have no separate language. They are supposed to be dying out. They are said to enjoy a wonderful immunity from the effects of malaria.

In the Terai they claim to be Powar Rajputs, and clain to be addressed as Thakur. They seem to have come from Dharanuggur about the 11th century. Tharu or Tarooa state they came from Chitore, after its third sack, that by Akbar about A.D. 1560 . They rear fowls.

The Boksa and Tharu are alike superstitious, truthful, addicted to drink, not very chaste. Both are to an extent migratory, exbausting the land, and moving to fresh soil. They frequently consult their medicine men, who are called Barara.

The Gaharicar and Dungra are other occupants of the Terai.

Atith, Saiva sectarians, followers of the doctrinal teachings of Sankaracharya (A.D. 850). He had ten disciples, each of whom founded a house, and are known as the Dasnami; $6 \frac{1}{2}$ houses have since dissented (atitha, passed away from worldly cares); the remaining $3 \frac{1}{2}$, known as the Dandi, because they carry a staff, adhere to Sankara's views.

The vagrant, mendicant, and predatory races are the badhak, bawari, bhand, bhantu, bharthi, bhat, bhaurupia, birjbasi, dalera, gandhila, gujar, kaparia, khangar, nat, natak, sunoria.

The forest and hill tribes and fowlers are the bahelia, bandi, bhotia, boksa, chuyar, dhanuk or dosadh or darkar, dom, dungra, gaharwar, khunjar, passiah, raji or rawut, and sansia.

The religious mendicants are the aghora, atith, bisnoi, fakir, gosain, joghi, paramahansa, sanyasi, and satnami.

Infanticide of female children has been a crime amongst several of the races of the south and east of Asia from prehistoric times. Mubammad denounced it among the Arabs; and in the 19th century, in India, the British have striven to put it down. It has been practised by the Bedi amongst the Sikhs, by Rajput races of Rajputana, by the Jharijah Rajputs of Cutch, by the Toda mountaineers of the Neilgherries, but notoriously to a large extent by Rajput tribes in the N.W. Provinces and Oudh, and the Government of India published Act viii. of 1870 for its suppression. In this Act, certain tribes, chiefly Rajputs, were proclaimed. The total number of persons belonging to castes suspected of the practice is

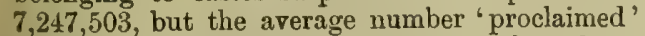
amounts only to 357,419 . These latter have been carefully watched for the last five years, and a census taken annually. The present percentage of females is 39.3 , and of males 60.7 , while the general return for the whole population shows 48 per cent, of females. The present census shows an increase in the proportion of females, but this is due, Mr. White says, to the superior accuracy of the present report, and not to the suppression of the practice of female infanticide. There is little beyond surmise known as to the laws regulating the production of the sexes; but it has been suggested (Report, p. 45) that in the N.W. Provinces and Oudh more boys are begotten than girls, and the following are the births registered among the proclaimed castes:-

$\begin{array}{rrrrr} & & \text { Mille. } & \text { Fomale. } & \text { Total. } \\ 1875, & \text { : } & 8,701 & 7,914 & 16,615 \\ 1876, & \text { : } & 8,893 & 8,539 & 17,432 \\ 1877, & \text { : } & 8,722 & 8,304 & 17,026 \\ 1878, & \text { : } & 5,838 & 5,504 & 11,342 \\ 1879, & \text { - } & 7,830 & 7,295 & 15,125\end{array}$

Also, the 1881 census report gives the males and females of 193 castes in the N.W. Provinces and Oudh, 164 of whom had more males than females.

It is not solely among the proclaimed castes of this province that females are fewer than the males; all the races and sects have fewer women :-

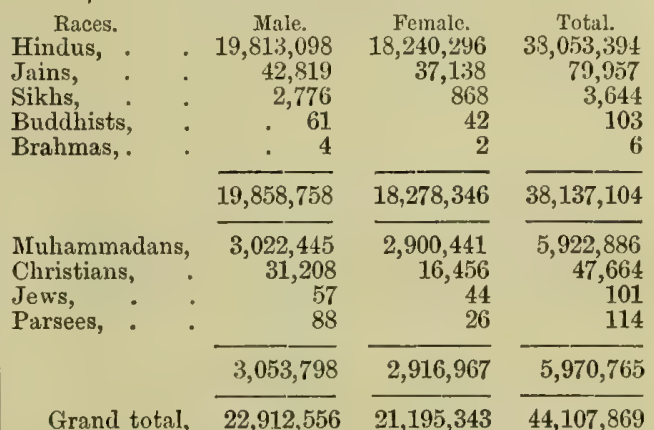

It is only in the Madras Presidency and Bengal Province that the females exceed the males. Ratio per 1000 to total population :-

\begin{tabular}{|c|c|c|c|c|c|}
\hline & Males. & Females. & & Males. & cmales. \\
\hline W. Pro & & & $\begin{array}{l}\text { Central Pro } \\
\text { vinces, }\end{array}$ & 505 & 495 \\
\hline vinces, & $519 \cdot 5$ & $480 \cdot 5$ & Bengal, & 498 & 502 \\
\hline Berar & $516 \cdot 5$ & 483.5 & Panjab, . & $542 \cdot 5$ & $457 \cdot 5$ \\
\hline Bombay, & 516 & 484 & Hyderabad, & 50 & 492 \\
\hline Burma, & 533 & 467 & England an & & \\
\hline Coorg, & 563 & 437 & Wales, & & \\
\hline Assam, & 513 & 487 & 1881, & 486 & 514 \\
\hline
\end{tabular}

The census report (p. 35, par. 46) puts forth the opinion that the increase in the proportion of females at the 1881 census is not due to the decrease of female infanticide, and this seems a legitimate deduction from the following details :-

\begin{tabular}{rrrrr}
\multicolumn{3}{c}{ Under ten years old. } & \\
& Males. & Females. & Percentage of \\
Suspected clans, . & 946,591 & 833,565 & $46 \cdot 8$ \\
Rest of population, & $4,929,176$ & $4,699,254$ & $48 \cdot 8$ \\
\cline { 2 - 2 } & $\frac{5,532,819}{40}$ & $\overline{48 \cdot 4}$
\end{tabular}

Above ten years old.

Suspected clans, . $\quad 3,004,682 \quad 2,512,665 \quad 45 \cdot 5$

Rest of population, $14,032,107 \quad 13,149,829 \quad 48 \cdot 4$

Total population, $\overline{17,036,789} \overline{15,662,494} \quad \overline{47 \cdot 9}$

In the 1872 census, it is supposed that there had been a large concealment of girls under twenty years of age. In 1872 , the girls under ten were $4,135,097$, and in 1881 they numbered $4,094,684$, a decrease of 40,469 .

In the feudatory province of Garhwal, the males are returned as 170,755 , and the females 174,874 .

RAJPUTANA, a region to the west of Hindustan, is chiefly ruled by feudatory princes, mostly of Rajput descent. These have twenty states, with an area of 129,750 square miles, and a population of $10,102,049$. The British portion, consisting of Ajmir and Merwara, has an area of 
2710 square miles, and a population of 460,722 , the totals being in area 132,460 square miles, and population $10,729,114$, or 80.9 to the square mile. The country is little productive; one part of it, indeed, Marwar, embracing the Indian desert, takes its name from Mri, death; and the people mostly consist of races who have been driven from the more open plains, and found shelter in this inhospitable region.

Rajputana lies in the centre of a circuit all round the edge of the more compact mass of the Jat people,-from the Salt Range, through the Northern Panjab and adjoining hills, to Rohilkhand, Oudh, and the Centre Doab, thence by Bundelkhand, through Sindia's territory, Malwa, Mewar, Gujerat, and Kattyawar, into Lower Sind. They are not found in any number to the north of the Salt Range. nor are they in any of the hill country west of the Jhelum. A large proportion of the Rajputs scattered about the Eastern Panjab, Cis-Sutlej territory, and Dehli districts, are now Muhammadans, as are occasional Rajput villages all over Hindustan, and a good many Rajput rajas, their conversion having been influenced by the Moghul emperors. But east of Dehli, conversion is quite the exception. A small Rajput tribe, called Jan-jua, now Muhammadans, is, however, found about the Salt Range.

The North-Eastern Panjab and Cis-Sutlej districts seem to have first been a Brahman, then a Rajput country, and subsequently advanced upon by the Jat. The Jat country is just such as would be occupied by a large stream of people issuing through the Bolan pass, in lat. $28^{\circ}$ or $30^{\circ} \mathrm{N}$., and the Rajputs are ranged in a semicircular form around the eastern and northern and south edge of the Jat nrea, the mass of them occupying the richer valley of the Ganges. Mr. Campbell's conjecture is that the Rajput are an earlier wave from the same source as the Jat, who came in by the same route, have advanced farther, and been completely Hinduized; while the Jat have come in behind them.

From Mahmud to Aurangzeb, the Indian conquerors were contented with the nominal subjection of the hardy Rajput tribes of Rajputana, among whom military enthusiasm, grafted on religious principles, was added to strength and agility of body. Sir John Malcolm, writing of them, remarks that it was not easy to subdue Rajputs. Such men, though broken by their own dissensions, before and after the Muhammadan conquest, into a thousand petty states, almost every one of which was an object of contest between brothers, yet still every individual was a soldier who preferred death to disgrace, and though ready to be the servant, scorned to be the slave of any monarch upon earth.

Akbar allied himself with the Rajput royal houses, and for a hundred years, high civil and military posts were bestowed on them. The most brilliant conquests of Akbar, Jahangir, and Aurangzeb were by their Rajput allies. But the Rajputs were alienated from the Moghul family by the bigoted conduct of the emperor Aurangzeb, who reimposed the poll tax on Hindus which Akbar had abolished, and by his destroying Hindu temples everywhere. Aurangzeb alienated the sympathies of a race who, when rightly managed, had encountered at command the Afghan amidst the snows of Caucasus, and made the furthest Chersonese tributary to the empire of Assam. Raja Maun of Jeypore took Arakan, Orissa, and Assam. Raja Jeswunt Singh of Marwar retook Kābul for Aurangzeb, and was rewarded by poison. Raja Ram Singh Hara of Kotah made several important conquests, and his grandson Raja Eswari Singh and his five brothers were left on one field of battle.

The love of country and the passion for possess. ing land are strong throughout Rajputana. While there is a hope of existence, the cultivator elings to the bapota ; and in Harauti this amor patriæ is so invincible, that, to use their homely phrase, 'he would rather fill his part in slavery there, than live in luxury abroad.' There are, however, amongst the Rajputs 84 mercantile tribes.

Rajputs have been little prominent since the early part of the 18th century. Besides the continuous strivings amongst their own tribes, following the crushing defeat of Prithi-raj, A.D. 1193, by Shahab-ud-Din, for several hundred years they had to sustain the shocks given by the Muhammadan invaders. On the decline of the house of Timur, they became the dupe and then the prey of the Mahrattas, and they, were only saved from utter annihilation by becoming the loyal allies of Great Britain. The armies they furnished had exhausted the material, infanticide has diminished their numbers, and their wives, shut up like those of Muhammadans, give no aid in agriculture. Misfortune and compulsory inaction has led to the excessive use of opium, and the 19th century has heard nothing of the independent chiefs of this once warrior race.

Of late years, Rajputs, as they have become under Brahmanical influence, have more and more strictly been denying themselves animal food and the flesh of the wild boar, and the greatest number are vegetarians, subsisting upon farinaceous food, with vegetables, pulse, ghi, butter, and milk.

The names of the states are Ajmir, Banswara, Bhurtpur, Bikanir, Bundi, Dholpur, Dungerpur, Jeypore, Jeysulmir, Jhallawar, Jodhpur, Kerrowlee, Kishengarh, Kotah, Lawa, Merwara, Oodeypur, Partabgarh, Shahpura, Sirohi, Tonk, and Ulwar. Ajmir and Merwara are British territory, Bhurtpur and Dholpur are ruled by Jat princes, and Tonk by a Muhammadan chief, the other seventeen states being under Rajput sovereigns. But Rajputs nowhere form a majority of the population, though they are strongest numer. ically in the northern states and in Mewar.

At the census of 1881, the religions of the people were found to be-

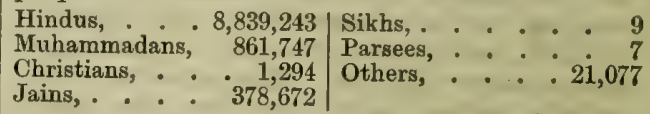

And the castes were found to be-

Brahman, . . 906,463 Chamar, . . . 567,098 Rajput, : : 479,554 Dhakar, : : 75,008 Mahajan, : : 634,440 Sondhia, : : 43,740 Kayasth, . : 19,118 Balal, : : 61,530 Gujar, : : : 402,709 Other Hindus, : 3,344,167 Jat, : : : 425,598 Sikh, . . : : 9 Ahir, . : 130,653 Parsee, . : 7 Mina, : : 427,672 Muhammadan,: 861,747 Bhil, : : : 105,870 $\mathrm{Meo}^{2}$. . . 45,946

The Khanzadah, in Ulwar (Alwar) and North Jeypore; the Kaimkhani in the same neighbourhood; the Meo, who are an indigenous tribe, 
very strong in Ulwar and Bhurtpur; the Merat section of the Mairs in Mairwara; the Sodhas of Rajput descent, in the far west, towards the borders of Upper Sind, have adopted Muhammadanism, but continue to regulate their marriages by their own rules of genealogy and consanguinity.

The Baori and Moghya are predatory tribes, the former north of the Aravalli, and the latter south of that range. They are professional thieves.

The Bhat or Bards are a prominent race, the genealogists of the Rajput races.

Jaina are of Rajput descent, though now financiers and merchants. The Gujar, Jat, Mina, and Mair are the principal agriculturists.

Rajputs have spread into every part of British India, but wherever found they clain to belong to certain tribes and clans, and, like the people of Europe and the Mahrattas of the Dekhan, they have also surnames, though the families are too extended for these names to be utilized.

Rajputs claim to have three origins, - (1) the descendants of the Suryavansa or Solar race, the ancient dynasty of the Sun; (2) the descendants of the Chandravansa or Indravansa or Lunar race, the ancient dynasty of the Moon; and (3) the Agnicula, the family initiated at a sacred fire said to have been kindled on Mount Abu by the saint Agastya, From these three, thirty-six primary royal races are said to have sprung, of whom the following may be enumerated:-

A. 36 Solar or Suryavansa dynasties.

1. Grahilot or Gehlot, 24 branches. The Sesodia is the most distinguished. The rana of Udaipur is a Grahilote.

2. Rahtor, descended from Rama by Kusa, his second son, 24 branches. The raja of Jodhpur or Marwar belongs to this tribe.

3. Kachwaha, also sprung from Kusa, 12 branches. The raja of Jeypore is of this tribe.

B. Yadu or Chandravansa or Jadu or Lunar dynasty, sprung from the moon.

1. Yadu or Jadu, descendants of Krishna, 8 branches. The Jharija and Bhattya in Cutch and Jeysulmir are the most powerful.

2. Tuar. Vikramaditya was a Tuar.

C. Agnicula or Fire race have four tribes and 87 branches, viz.-

1. Pramara, west of Malwa and the desert of the Indus, 35 branches. The Mori, Soda, Sankla, Khair, Umra, Sumra (now Muhammadans), Vehil, Mairawat, Balhar, Kaba, Omata, Rebar, Dhundia, Sortla, Harir little known.

2. Parihara, 12 branches.

3. Chalukya, of great power in the $11 \mathrm{th}, 12 \mathrm{th}$, and 13th centuries, 16 branches. The Bhagel branch is their chief representative.

4. Chauhan or Chaumana, 24 branches. The Hara of Harawti, the rajas of Kotah, Bundi, the Khichi of Ragughar, the Deora of Sirohi, the Sonagarba of Jhalore and Pawaicha of Pawaghar.

The unnamed progenitors of the four Agnicula tribes of Rajputs-the Chauhar, Chalukya, or Solunkee, Puar or Pramara, and the Pariharaseem to have been invaders who sided with the Brahmans in their warfares, partly with the old Khatri, partly with increasing schismatics, and partly with invading Græco-Bactrians, and whose warlike merit, as well as timely aid and subsequent conformity, got them enrolled as 'Fire-born,' in contradistinction to the Solar and Lunar families. The Agnicula are now mainly found in the tract of country extending from Ujjain to Rewah near Benares, and Mount. Abu is asserted to be the place of their miraculous birth or appearance.
Colonel Tod was inclined to regard the Agnicula race as of Scythic origin, but Mr. Elphinstone (p. 229) points to the difference in their physical appearance and habits from the Rajputs.

The seat of the Pramara or Puar was amongst the Vindhya, at Ujjain, Dhar, and Mandu. Vikramaditya, the champion of Brahmanism, was, according to common accounts, a Puar Rajput.

There are several races in Rajputana on whom the surrounding civilisation has made no apparent impression.

The Blil, an aboriginal race, are entered as numbering 105,870 . They are in clans under chiefs, inhabiting long stretches of wild and hilly tracts, where they live almost independent, holding together under their own petty chiefs and headmen, paying irregular tribute or rents to the chief of the state, or to the Rajput landowner upon whose estate they may be settled. There are also, of course, a good number of Bhils, as of all other half-tamed tribes, who have mixed with the general population. At the 1881 census they rose in rebellion on the attempt to number them; but their numbers have been supposed to be, in Udaipur, 51,076 ; Partabgarh, 270 ; Dungarpur, 66,952 ; Banswara, 48,045.

The Dadu Panthi sect, who have their headquarters in Jeypore, have the armed Naga as one of their sections; the Ram Sin'h sect prevails in Ulwar and Mewar, and have their headquarters at Shahpura.

Mair have been supposed to have at one time dwelt in the Upper Panjab and in the Indus valley, and they have been conjectured to be a relic of the Med, an Indo-Scythic tribe that crossed into India from Central Asia.

Mewat. - The fierce and turbulent mountaineers of Mewat, though their frontier was within 20 miles of Dehli, were never entirely quieted until the establisbment of the British Government.

The Parihara Mina until recently carried out the destruction of their female infants. They traced the practice to an injunction of a woman who became a sati, also to a curse of Mahadeva. To be a father-in-law is to ensure contempt, and he is looked upon by the bridegroom as an inferior. Their daughters are, however, eagerly sought after by the other tribes of Mina. They worship Siva as Mahadeo, whom they usually designate Baba Adam, father Adam. The Mina are undoubtedly aboriginals.

One of the Mina race puts the tika of investiture on the forehead of the Rajput raja of Nerwar. It is of blood drawn from the face of another Mina.

The tika of investiture put on the forehead of the rana of Udaipur is of the blood of a Bhil.

The Hinduized chiefs of Central India have the tika of investiture of the blood of a pure Kol; and the head of the Cheri, formerly a great tribe, but now a few families, is invested with the blood tika of the non-Aryans and the title of raja.

Rajput women, even more so than the Musalmani, are kept strictly concealed, termed gosha or pardah nashin, rarely appearing abroad, and even then, on the necessity occurring, carefully veiled. A woman exposing her face is understood to proclaim herself immoral. They are, as a rule, entirely uneducated; but occasionally a queen or the wife of a Thakur may have a smattering of Hindi. Many of them drink spirituous liquors, and most of them indulge freely in tobacco and 
opium, the latter drug being given even to infants. They possess great influence over their husbands, and evince the deepest interest in all that redounds to their husband's name and fame. Family pride with them appears the chief motive of every action, and they are at all times ready to brave danger, even to sacrifice their lives, in support of it. This spirit has on occasions led to their affording examples of daring which have placed them as high in the songs of the bards as their fathers and husbands, but at others has led them into long-continued family quarrels, the wives being in constant dispute with each other.

Their daughters are married to men of the best tribes, and their widows are not permitted to remarry; and it is the point of honour as to their danghters' marriages, that led to the practice of infanticide. Their practice is not to marry into their own but into another tribe, and this has assimilated the tribes to each other. A marriage ceremony is not considered completed until ' teeag' or distribution of presents to charuns and bards has been made, which formerly were disgracefully high.

The Rajputs were long notorious for encouraging their widows to immolate themselves as sati, with the dead bodies of their husbands, and there are many chattri or domed cenotaphs erected, where chiefs or men of mark have been burnt after death, often with their wives and female slaves.

Several of the tribes were notoriously guilty of destroying their female infants, and this criminal tendency has not, it is supposed, been eradicated. At the 1881 census, in every one of the twentytwo States the males are in excess of the females, the totals of their numbers being $5,710,337$ males and $4,852,434$ females.

Rajputs are little advanced in high education, though the celebrated astronomer Jye Singh earned a European fame.

Some of the tribes follow the Scythic custom of adopting the names of animals as the titular appellations of the clans. The Sesodia have their designations from Sissu, the hare; the Lumri are the fox; the Kachwaha, the tortoise; the Gurgbansi and the Langa are the wolves.

The better known of the tribes and clans are-

\begin{tabular}{l|l|l|l|} 
Agarwal. & Dahuna. & Kaim-khani. & Rajwar. \\
Agnicula. & Dhakara. & Kamara. & Rangar. \\
Bach. & Dhundia. & Katti. & Rebar. \\
Baghel. & Doba. & Khair. & Sadhani. \\
Baihar. & Dogra. & Khanzada. & Sama. \\
Bais. & Gaddhi. & Khatri. & Sankla. \\
Bhali- & Gaurua. & Langa. & Sengar. \\
Sultan. & Gerhwal. & Lumri. & Sesodia. \\
Bhat. & Gohil. & Macheri. & Sikerwal. \\
Bhatti. & Gor. & Maldot. & Sirni. \\
Bhayel. & Grahilot. & Meo. & Sirwaya. \\
Bilkhuria. & Guhurwar. & Mer. & Sodha. \\
Bir-gujar. & Gurgbansi. & Mina. & Solunki. \\
Bujgoti. & Hara. & Mohil. & Sorila. \\
Bundela. & Harir. & Nikumba. & Sundhia. \\
Bundi. & Hun. & Oomat. & Sumra. \\
Chahil. & Jat. & Oswal. & Tak. \\
Chandela. & Jetwa. & Parihar. & Thaori. \\
Charan. & Jhala-Muk- & Pramara. & Tilak- \\
Chauhan. & wahana. & Puar. & Chandra. \\
Chaunhar. & Jharija. & Rahtor. & Tuar. \\
Choura. & Johya. & Rajbansi. & Umra. \\
Dahi. & Kaba. & Rajkumar. & Vehil. \\
Dahiria. & Kachwaha. & Rajput. & Yadu. \\
\hline
\end{tabular}

The Ajmir and Merwara provinces are under British jurisdiction, although parts of Merwara belong to the Marwar State and part to that of
Mewar. The area is 2710.68 square miles, and the population 460,722 , of which number 57,309 persons are in British Merwara, 5611 are in Marwar Merwara, and 38,514 in Mewar Merwara. Mer means a hill, and the saying is,-Mer aor mobr, ūnché păr rāzi hain,-Mer and peafowl love the heights.

Ajmir city in 1881 had a population of 48,735 souls. In Ajmir villages three or four families live together in one house. In towns, particularly in Ajmir city, families differing from each other in caste and connection are seen living in separate compartments in the same enclosure, and three or four strangers take a house jointly.

Jain.-The principal mercantile tribes are the Agarwala, Bija Bargi, Khandelval, Mahesri, Oswal, and Saraogi, in all 39,641 in number. The head priests or Sri Paj of the Saraogi Digambara Jains are celibates, and are greatly reverenced. The Swetambara head priests are the Jati. They carry a stick, dress in white or yellow, some of them marry.

The Jati of the Dhundia, a sect of the Oswal tribe, are ascetics, both male and female. They seldom wash their bodies, do not shave the head, and keep their mouth covered with a cloth to prevent incurring the sin of swallowing minute insects. The Tera-panthi are a like sect among the Saraogi. Both sects abhor the killing of animals.

The Digambara neither eat nor drink when the sun is below the horizon. The Swetambara are less strict.

The aboriginal castes and tribes are as under:

\begin{tabular}{|c|c|c|c|c|}
\hline \multirow{4}{*}{\multicolumn{2}{|c|}{$\begin{array}{l}\text { Mer, } \\
\text { Merat Gorat, } \\
\text { Barar Rawat, }\end{array}$}} & \multirow{4}{*}{$\begin{array}{r}\text { Ajmir. } \\
. \quad 15,764 \\
\cdot \quad 377 \\
. \quad 1,636\end{array}$} & \multirow{2}{*}{$\begin{array}{c}\text { Merwara. } \\
17,182\end{array}$} & \multirow{2}{*}{$\begin{array}{r}\text { Total. } \\
32,946\end{array}$} \\
\hline & & & & \\
\hline & & & 7,334 & 7,711 \\
\hline & & & $\begin{array}{r}18,400 \\
789\end{array}$ & $\begin{array}{r}20,036 \\
6,549\end{array}$ \\
\hline $\begin{array}{l}\text { Ehul, } \\
\text { Mina, }\end{array}$ & : & $\begin{array}{r}4,7100 \\
\cdot \quad 4,389\end{array}$ & 35 & 4,424 \\
\hline Chita, & . & 86 & 46 & 132 \\
\hline Total & . & 27,012 & $44,78 \hat{0}$ & $\mathbf{7 1 , 7 9 8}$ \\
\hline
\end{tabular}

The Chita and Barar, according to tradition (Tod, i. p. 680), are descended from Jodh Lakhun, son of Prithi-raj, and a Mina girl who had been seized in a marauding expedition, whom he married, supposing her to be a Rajputni. Discovering her race, he sent her away, and her two sons, Ahul and Anup. One day, while resting beneath a banyan tree (băr), the brothers prayed that, as a sign, if their race was to continue, the trunk might rend asunder, and the event is handed down in a distich-

' Charar se Chita bhayo, aor Barar bhayo băr ghat, Shakh ek sé do bhayé ; jagat bakhāni jāt.

'From the rending noise, the Chita are called, and the clan Barar from the splitting of the bar tree.

Both are descended from one stock; the world has made this tribe famous.'

CENTRAL INDIA is occupied by 69 Native States or semi-independent holdings. The rulers of Bhopal and Jaora are of the Muhammadan faith, the other chiefs profess some form of Hinduism. These states are spread through two irregular and detached tracts stretching from west to east across the middle of the continent of India. A straight line drawn from Nemuch, in long. $74^{\circ} 54^{\prime} 15^{\prime \prime}$ E., to the capital of the Bhopal State, in long. $77^{\circ} 25^{\prime} 56^{\prime \prime}$, would pass through portions of Givalior, Jaora, Gwalior, Jhallawar 
(Rajputana), Gwalior, Dewas, Narsingarh, Rajgarh, Gwalior, to Bhopal. These Native States are in political relation with the Government of British India, conducted by an agent to the Governor-General for Central India and his assistants.

The total area of Central India is 75,229.64 square miles, with a population of $9,261,907$ souls, or 123.12 persons per square mile. 94 per cent. profess some form of Hinduism, 5 per cent. Muhammadanism, and Jain, Parsee, Christians, Sikhs, and Jews form the other 1 per cent.

Hindus, . . 7,800,396 Sikhs, . . . . 1,455 Muhammadans, $\quad 510,718$ Aborigines, . 891,424 Jains, : . . 49,824 Jews, . . . 38 Parsee, : : 916 Unspecified, . . . 71 Christians, . . 7,065

The population can best be shown in detail by arranging them as Hindus and Aborigines-

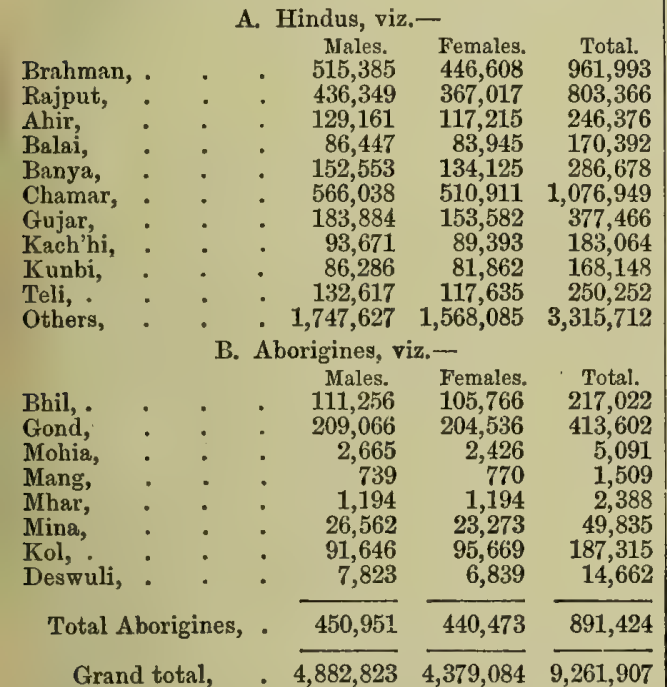

The proportions thus being $87 \cdot 23$ females to 100 males.

The race descent is various in the nations, even in the chiefs. The rulers of Rewa, Sohawal, and Koti are Baghel. Bundela princes rule in Ajaigarh, Bijawar, Charkhari, Dattia, Panna, and Urch'ha, and other less important though powerful families in Bundelkhand are Bundela. The maharaja of Urch'ha is the acknowledged head of the Bundela tribe.

The chiefs of Rutlam, Sailana, and Sitamau are Rahtor Rajputs, and have a common ancestry, claiming descent from the Jodhpur family. Khichi and Umat Rajputs are in the west from Bundelkhand, and there are small scattered numbers of Paribar, Kachwaha, and Sesodia Rajputs, with Puar Rajputs, in Dhar and Dewas.

Rewa, with an area of about 10,000 square miles, has no roads or means of internal communication.

The Jaina, 49,824 in number, are a wealthy commercial people, dwelling in towns, and exercising much influence over their fellow-townsmen in all matters bearing on the sanctity of animal life. Instances have occurred of their depriving a whole community not only of animal food, but also of clean clothes, during periods sacred to their special faith. They admit of proselytes from the higher Hindu castes.

VOL. II.
The Chamar are deemed unclean; to touch them is pollution, and they are rarely allowed to reside within the village.

Baghelkhand and Bundelkhand in the eastern parts of the region include in their population a considerable number of Gond, Kol, and semi-independent Baghel.

The Bhils in Central India are in the S.W. corner of the Agency.

$K o l$ of Central India occupy the hilly country of Chutia Nagpur, Mirzapur, Rewa, and Punna. Kol wives eat with their husbands; the Kol are passionately fond of dancing, which they cultivate as an accomplishment. They have a peculiar dread of witches, and are very superstitious. The custom of marrying by capture is current amongst them. The young man waylays the girl he has selected to carry off, and brings her to his house. Her relations soon appear, but are satisfied by presents of cows and goats.

The Moghia, 5091 in number, correspond to the Banrior of Rajputana. They are a predatory race, for whose reclamation a special officer has been appointed by Government.

Languages, 19 in number, are spoken in cantonments by 90,811 persons, chiefly Urdu or Hindustani (71,560), Mahrati (6011), English (5646), and Marwari (3023). The rest are Arabic, Bengali, Afghani, Baluchi, French, German, Gujerati, Hindi, Canarese, Panjabi. Mahrati is the court language at Indore, Gwalior, Dewas, and Dhar, but at the other states Hindi and Rangri.

CENTRAI PROVINCES form an administrative division of British India, under the jurisdiction of a Chief Commissioner, lying between lat. $17^{\circ} 50^{\prime}$ and $24^{\circ} 27^{\prime} \mathrm{N}$., and long. $76^{\circ}$ and $85^{\circ} 15^{\prime} \mathrm{E}$. The area is 113,279 square miles, and the population 11,548,511. To the north extends the Vindhyan table-land, which sheds its waters northwards into the valley of the Ganges; south of this are the valleys of the Nerbadda and the Tapti; farther south are the extensive highlands constituting the Satpura table-land; and still farther to the south extends the great Nagpur plain, formed by the valleys of the Wardha and Wain-Ganga.

In this expanse there are 18 British districts, Balaghat, Baitul, Bhandara, Bilaspur, Chanda, Chindwara, Dumoh, Hoshangabad, Jubbulpur, Mandla, Nagpur, Nimar, Narsingpur, Rajpur, Saugor, Sumbulpur, Seoni, and Wardha. Enclosed in these are the following 15 Feudatory States, comprising about a fourth part of the entire area, with a population of 36 to the square mile:-

\begin{tabular}{|c|c|c|c|c|c|}
\hline & Area. & Pop. & & & \\
\hline andi. & $\begin{array}{r}13,062 \\
3,745\end{array}$ & $\begin{array}{l}196,248 \\
224,548\end{array}$ & $\begin{array}{l}\text { Makrat, } \\
\text { Chhuikhidan }\end{array}$ & $\begin{array}{r}215 \\
-174\end{array}$ & 16,76 \\
\hline & 1,486 & 128,943 & Kanker, & 639 & 63,610 \\
\hline agarh, & .540 & 71,274 & Khairagarh, & 940 & 166,138 \\
\hline 8 & 2,399 & 257,959 & Nandgaon, & 905 & 164,339 \\
\hline npur, & - 906 & 178,701 & Kawardha, & 887 & 86,382 \\
\hline & 83 & 17,750 & Sakti,. . & 115 & 22,819 \\
\hline & & & & & \\
\hline
\end{tabular}

Races.-The territory is peopled by Aryan and Turanian races. The Dravidian and the Kolarian, two great branches of the Turanian family, are believed to have entered India from the north, at different points, and, when pressed southwards, they decussated and intermingled in the hilly forest tracts of these Central Provinces. Few of their dialects are cultivated, and several of their clans are little above barbarism.

In the entire province, 6,058,300 speak the Hindustani, and $1,967,881$ speak Mahrati; but 
INDIA; THE CENTRAL PROVINCES.

amongst the Dravidian clans, 967,502 speak Gondi, and 588,914 of the Kolarian branch speak the Munda tongue. The more open parts of the country have been occupied by intruding civilised races, for 16 Indian tongues are spoken, viz. Bengali, Bhuin, Bygāni, Canarese, Dhangar, Goanese, Gujerati, Kaikari, Kashmiri, Malealam, Uriya, Panjabi, Sindi, Tamil, Telugu, and Yerkal; as also 7 Asiatic non-Indian tongues and 10 nonAsiatic. The cultivated languages are the Hindi, Urdu, Mahrati, Ch'hattisgarhi, Uriya, Telugu, and Gondi; and the 11 unwritten tongues, Gondi, Gayeti, Rutluk, Naikude, Kolami, Madi or Maria, Madia, Kuri or Muasi,.Keikadi, Bhatrain, and Parja.

\section{Non-IFindu or Aboriginal Tribes.}

A. Dravidian.

Gond, cultivators and field Gond, Ch'hirkia, . 8 labourers (clan not Dholi, . . 3,508 specified), . 1,617,250 Gaiki,. . . . 293

Worshipping 3 deities, 64 Ghasia, . . 5

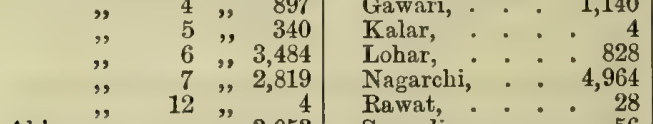

Ahir, ". 12, . . 3,053 Rawat, : * : 28

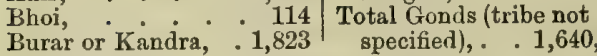

Gond, Bharia, . 29,820|Gond, Manne,. . 1,098 Bhatra, . 13,869 Marai, . . 2,269 Bhima, . . 28 Maria, . . 48,715 Darwe or Naik, ‘4,017 Mooria, . . 31,573 Deogarhia, . . 3 Nagbansi, . 202 Dhur,. . . 34,288 Ojha, . . . 2,794 Halba, . . 62,451 Pardhan, . 50,664 Jhoria, - 3,204 Pathari, . 11,207 Khatulwir, : 1,047 Raj Gond, : 67,325 Koilabhuti,. 974 Rawanbansi, . 5,852 Kulbhut, .. . 254 Thakur, . . . 62 Koitur, : 8,610 Thoti,. . . . 991

Koi, 13,128 Turi, . . 3,712

Kolam, . . 1,516 Total Gond, $\overline{2,040,355}$

Agaria, - 3,396 $\mid$ Bhaina, . 7,698 Kamär, . 7,666 Arak,. : 2,142 Bhuiyan, 5,929 Khond, 147,768 Bentkar, . 90 Bhuian, 7,644 Oraon, 1,130 Bhumhar, : 279 Dal, : 1,979 Parja, - 7,920 Bhoyar, : 70 Dalbhuiya, 10 Rautia, 5,744 Bhuyar, : 660 Dal Kand, 11 Sabara, 104,506 Bhuiyar, . 8 Dhangar, 1,225 Saonra, . 26,123 Bhoina, 5,771 Dhanwar, 17,849|'Taala, . 1,443 Total Dravidian tribes, . . $\overline{2,397,216}$ B. Kolarian Tribes.

Baiga, . 18,514 Ganjhu, . . 5 Manjhwar, 1,783 Bhil, : 17,583 Khaira, : 8,890 Manjhi, . 1,580 Bhilala, : 13,097 Khairwar, 16,030 Muasi, : 1,456 Bhogta, : 94 Kharia, 8,890 Munda, : 1,919 Bhumia, 13,594 Kol, : 76,119 Nagesar, . 1,757 Bhunjia.. 4,453 Kol-katia, 29 Nahal, . 7,230 Binjhwal, 83,868 Korku, 83,438 Nahar, : 560 Birjia, 1,395 ,Gaulan, 15 Pahari (reBopchi, : 529 Korwa, - 563 ligion, Cherwa, : 423 Kura, : 31,044 Nahal), . 6 Gadba, : 199 Mahto, 1,231 Saota . . 70 Total Kolarian tribes, . . . 510,301

C. Unclassified.

\begin{tabular}{r|r|} 
Moghia, : : : $\quad 702$ & $\begin{array}{c}\text { Others, Sumbulpur } \\
\text { district, . } \quad 1,253\end{array}$
\end{tabular} Total Aboriginal tribes, . . $2,909,402$

The races who have most numerously immigrated are the Brahmans and Rajputs. The former number 359,886 , and the latter 212,515 . By immigrants from all the surrounding races, the territory has over five hundred castes, omitting the washermen, barbers, potters, and similar classes, the more important being as under:-
Agharia * 19,539 Gosain, • 27,533 Ahir, : : : 509,526 Gujar, : : : 44,289 Balahi, . . 45,317 Kach'hi, . . 116,677 Banya, : : 76,447 Kalar, : : 156,297 Banjara, . . 52,570 Kewat, . . .165,591 Barai and Tamboli, 26,305 Kolta, . . . 92,827 Beldar, . . 10,246 Kori or Koli, . 48,826 Bhat, Jangra, Rao, 26,621 Kunbi and Kurmi, 740,528 Bhoer, . . . 39,840 Lodhi, . . . 265,147 Bhoi,. : : : 12,446 Mali, : : : 115,821 Biraự, . . : 33,427 Mānā, . . : 39,454 Chamar, . .760,101 Manbhau, . . 776 Dangi, . : 23,180 Mang, : : 19,535 Dhanuk (fowlers), 6,313 Marar, . . 200,900 Dher, . . 15,995 Mehra, : : . 242,304 Dhimar, . : 194,453 Mehtar, : : 13,712 Ganda, . . 250,133 Mhar, . . 321,724 Gaur, . . 214,936 Paik, . . . : 13,804 Gawari, . . 110,363 Puar, . . 106,086

Rajputs are here whose ancestors arrived before Hinduism was established. Amongst the Rajput clans there are portions of nations and tribes, with whom, up to the present day, Brahmanism has never been accepted; and many of the non-Aryan races are preferriog the theistic doctrines of Nanak and Kabir.

The Rajputs from Malwa seem to have pushed their conquests into the country, and intermarried with them, and their descendants are still known as Rajputs or Gond Rajputs. They established governments, one of which ruled the Narmada valley, and had its capitals at Mundala and at Garha near Jubbulpur. It was founded by Jadu Rai, who succeeded his father-in-law Nagdeo, the Gond raja of Garha (A.D. 358). Mundala was conquered by his descendant, Gopal Sa (A.D. 634). Sungram Sa, the 47 th in descent from Jadu, inherited only three or four districts in 1480 , but at his death, in 1530, he ruled over fifty-two. Ferishta tells us that when Asif Khan invaded Garha in 1563, Bir Narayan was raja. Hirdi Sa, the 54th raja, built the temple at Ramnagar, near Mundala; and Seoraj, the $59 \mathrm{th}$, began to reign in 1742, when Balaji Baji Rao invaded the country. A second kingdom bad its seat on the southern slope of the Satpura Hills, at Deogarh in Chindwara, one of the rajas of which, Bakht Baland, was either taken prisoner by one of Aurangzeb's generals, or visited Dehli of his own accord, where he was converted to Muhammadanism, and then permitted to return to his country, where 'his descendants,' says Mr. Hislop, 'though adhering to this change of creed, have not ceased to marry into Gond families, and hence the present representative of that regal house is not only acknowledged by the whole race about Nagpur as their head and judge, but is physically regarded a pure Raj Gond.' A third Gond principality had its capital at Kherla in Baitul, to which belonged the famous forts of Gawilgarh and Narnallah. In 1433, its raja, Narsingh Rai, who is represented as powerful and wealthy, was slain in battle by Hoshang Gori, king of Malwa, and Kherla taken. At a later date it appears to have become subject to Pandu Gauli, the raja of Deogarh, and continued so under his successors. Not far from Kherla we find a hill raja at Saoligadh, in Aurangzeb's time, who seems to have maintained bis independence till swept away by the Mahrattas between 1760 and 1775. A fourth Gond kingdom was that of Chanda on the Wardha, which extended far to the east and south-east. The four dynasties arose before the ascendency of the Moghuls in India, and have left architectural and 
other monuments of great interest. "The princ:pal architectural remains are at Mandla, at Garha near Jubbulpur, at Chauragadh near Narsingpur, at Deogarh near Chindwara, at Kherla near Baitul, and at Chanda.' There was a fifth Gond Rajput dynasty at Warangal or Orankal, in the Dekhan, to the south of the Godavery, which is said to have been founded by Kakati of the Ganapati fanily, about A.D. 1088. The kingdom became very powerful about the end of the 13 th century, and the raja of Orissa, becoming jealous of his neighbour's power, solicited the aid of Ala-ud-Din, who sent an army in 1303, through Bengal, to attack Warangal, but his expedition failed. Malik Kafur was then despatched with 100,000 horse into the Dekhan, and, after a siege of some months, he took Warangal in 1309 , and made the raja Ladderdeva tributary. In 1321 it was again besieged by Alif or Jema Khan, the son of Ghaiasud-Din Taghalaq, but he was obliged to retreat with the loss of nearly his whole army. He returned, however, and in 1323 reduced the place and carried the raja prisoner to Dehli. It is said he was afterwards released and restored; at all events Warangal reasserted its independence in 1344, and assisted Hasan Ganga Bahmani in his revolt. From this time the Bahmani kings of Kulburga involved the native rajas in continual wars. Firoz Shah (1397-1422) especially obtained great successes over the raja of Kherla; and finally Amad Shah Wali took permanent possession of Warangal, forcing the raja to relinquish his ancient capital and flee northward across the Godavery, where he established bimself in wild independence among the inaccessible forests. The Gond rajas still maintained their independence, however, and in 1513 we find them joining in a powerful confederacy on the side of Medon Rai against $\mathrm{Mu}$ hammad II. of Malwa. At the close of the 16th century, Akbar reduced the western portion of Gondwana, but it was not till the middle of the 18th that permanent progress was made. About 1738, Raghoji Bhonsla interfered in a disputed succession in Deogarh, and secured half the revenues; but in 1743 the Gonds raised an insurrection, which Raghoji quelled, and annexed the principalities of Deogarh and Chanda to his own dominions; and in 1751-52 he took the forts of Gawilgarh, Narnalla, and Manikdrug, with the districts dependent on them. From this period large numbers of Mabrattas settled in these districts, and the Gonds became more restricted to the hills.

The great husbandmen and gardener races, the Kachi, Kolta, Kunbi, Kurmi, Lodhi, Mahdela, Mali, and Marar, number 1,531,900 persons, a seventh part of the population of the Central Provinces. They are all immigrants.

The Kunbi $(451,712)$ came into the province from Poona, Kandesh, and Maharashtra generally. They are the oldest settlers, and, as in the Mahratta country, Kunbi has come to mean a farmer. They are the backbone of the agricultural community; they distinguish their origin as Mahratta Kunbi, Dekhani Kunbi, and Deskar Kunbi, and those who came from Berar were Mahratta horsemen who accompanied the first Raghoji.

The Kurmi are the cultivators north of the Kunbi, but to the south of the Rajput and Jat. They form the bulk of the population in the part of Manhhum near the Damuda river (Dalton, p.
157), and are a very industrious class of quiet cultivators in considerable numbers in all the central and eastern parts of the N.W. Provinces, and in Hindustan generally, and there attend to the finer garden style of cultivation much more than the Jat and Rajput, but, like the Jat race, are assisted by their industrious women, while the Kunbi women's industry has passed into a proverb: Bhale jat, Koonbin ki, K'hoorpi hat'h, K'het nirāwen apne pi ke sat'h.

The Kurmi have villages of their own, and are also spread in detached families or groups. Colonel Tod and Mr. Campbell consider them to be identical with the Kunbi, and to occupy from $16^{\circ}$ to $23^{\circ}$ or $24^{\circ} \mathrm{N}$., and from the western frontiers of Gujerat to the countries watered by the Wainganga, the Middle Ganga, and upper streams of the Nerbadda. Very few of these became soldiers, and in the valley of the Ganges they are looked down upon as mere humble tillers of the soil. They are more numerous towards the Jubbulpur and Saugor territories, where they mingle with the Lodha. Thence westwards, as on both sides of the Nerbadda, in Malwa, where they meet the Jat, and throughout the southern borders of Hindustan, there are numerous Kurmi who speak Hindi. Those in Hindustan are darker and less goodlooking than Brahmans and Rajputs ; but Mr. (Sir George) Campbell states (p. 93) that they are quite Aryan in their features, institutions, and manners. Other authorities, however, think that there is no similarity in the physiognomy of the Kurmi and Kunbi. The Kurmi subdivisions are-Jeshwar, Dhaviai, Patan, Adhonda, Patrihu, Ghora Charhao; but Sir H. Elliot says the seven subdivisions are usually enumerated as K'hureebind, Puturya, G'horchurha, Jyswar, Canoujia, Kewut, and Jhooneya. Wilson also says they have seven sections.

The Ghameta of Behar are a subdivision of the Kurmi. They form, says Elliot, a large class of the cultivators in the eastern and central portion of Bengal; few in Dehli and the Upper Doab.

The aboriginal races to a large extent $(1,753,917)$ adhere to their peculiar religions, and their tendency is towards some form of monotheistic cult. A summary shows-

Hindus, . . 8,703,110 A Aboriginal, . . 1,753,917 Sikh, - 31799 Religions-

- 317,094 Parsee, . . . . 399

Satnami, . : 398,409 Jew, : . . . 63 Kumbhipathia,: . .913 Christian, : : 11,973 Brahmo, . : : 7 Muhammadan, 285,687 Jaina, : : 45,911 Unspecified, . . 12 Buddhist, : 17

The Kabirpanthi, followers of Kabir, and their sect the Dadupanthi, have departed from Kabir's monotheistic teachings; the majority continue to worship their own gods, but invoke Kabir as an additional deity. The chief guru of the sect resides at Kawardha, in the Bilaspur district. The system of caste has been introduced, and all ceremonies are performed by Hindu priests according to established ritual.

The Sad'h mendicants, who beg from door to door in pairs, own allegiance to the chief guru at Kawardha. In the Central Provinces, most of the Kabirpanthi are married people, whereas in Northern India they are celibates.

The Nanakpunthi, and its sect the Nanakshahi, continue to follow the inculcations of Nanak.

The Singhapani, followers of Singhaji, a holy 
man, have temples in the Hoshangabad and Nimar districts, which are frequented by people of all castes.

The Satnami sect was founded by Ghasi Das, a Chamar, between the years 1820 and 1830 , amongst the people of his own tribe in Ch'hattisgarh. Their title means the True Name. They are theistic sectarians, with some rules as to diet and narcotics.

In the 15th century, in Rewah, Rohi Das, a Chamar, had put forward similar views, but that reform had not taken a permanent hold of the people. Ghasi Das has been more successful, and the entire Chamar tribe are carrying out his injunctions with more or less strictness. Their widows re-marry. They have no tradition as to the date of their arrival in this province, nor as to the cause of their being designated Chamar, meaning leather-worker. They have active, wellset figures, of a brownish colour, with features less marked than those of the higher castes. They are fair cultivators, industrious, tenacious of their rights, and numbers of them are in easy circumstances. Their women are strong and sturdy, and many of them are fair and comely. The Kabirpanthi and Satnami theists are being daily added to.

The Dhami sect of the Damoh and Saugor districts combine the reading of the Koran with the observances of the Hindu religion.

The Aghori are Hindu beggars, who extort money from people by eating loathsome substances in their presence.-Tod's Rajasthan, ii. p. 371; Elliot's Supp. Glossary.

GONDWANA.-Between lat. $18^{\circ} 40^{\prime}$ and $23^{\circ} 40^{\prime}$ N., and long. $78^{\circ}$ and $822^{\circ} \mathrm{E}$., an area of 135,000 square miles, is a mountain and forest region which was known to the Moghul geographers as Gondwana. It was held by the Gond chieftains who were dominant until overcome by the Mahrattas in the early part of the 18th century, and they are now under the sway of the British in Jeypore, Berar, Chutia Nagpur, and the Central Provinces, and under the Asof Jahi dynasty of Hyderabad.

Gonds are amongst the most numerous of the tribes of the Central Provinces. They are found in thenorth, about Saugor and the source of the Hasdo. On the east they cross that river into Sirguja, where they border on the $\mathrm{Kol}$, and are found with the Khand and Uriya in Nowagudda, Kareal, and Kharond or Kalahandi. In the south they form the mass of the population of Bastar, and a portion of the inhabitants of Jeypore in the Madras Presidency, and occupy the hills along the banks of the Godavery, about Nirmul, in the Hyderabad country; and on the west they are intermingled with the Hindus of Berar for 30 miles from the right bank of the Wardha, and along with the Kur extend along the hills both north and south of the Nerbadda to the meridian of Hindia, where they give place to the Bhil and the Nahal.

The Gonds divide themselves into twelve and a half castes, viz. Raj Gond, Raghuwal, Dadare, Katulya, Padal, Dholi, Ojhyal, Thotyal, Koilabhutal, Koikopal, Kolam, Madyal, and an inferior sort of Padal as the half caste. Mr. Hislop says the first four, with the addition, according to some, of the Kolam, are comprehended under the name of Koitor, the Gond par excellence. This term, in its radical form Koi, is the name given also to the Meriah sacrificing tribes of Orissa, and to the wild tribes skirting the left bank of the Godavery, from Rajamundry to near the mouth of the Indrawati. The Koitor, as a rule, resent with no small vehemence the imputation of belonging to any portion of the Hindu community. The first three classes generally devote themselves to agriculture; the fourth includes those who have begun to conform to the Hindu religion and ape Hindu manners. The Padal, Pathadi, Pardhan, or Desai, called Raj Pardhan to distinguish them from the Mahrati-speaking half caste, who play on wind instruments of brass and spin cotton thread, are the religious counsellors or bhats of the upper classes. The Dholi are musicians, and a subdivision of them in jungly districts are employed as goatherds. The Ojhyal are wandering bards and fowlers. The Thotyal (i.e. maimed) or Pendabarya, 'minstrels of God,' are also called Matyal, because their songs are chiefly in honour of Mata, the dreaded goddess of small-pox. They make baskets also. The Koilabhutal are the third wandering caste, and their women are dancing girls. They follow their profession chiefly among the Hindus, it being reckoned disreputable by the people of their own race. The Koikopal, i.e. Gondi Gopal, are a settled class devoted to cow-keeping. The Madya, called Jhodia in Bastar, are savages on the Beila Dila Hills and in the remoter parts of Chanda; the only clothing the women wear is a bunch of leafy twigs fastened with a string round their waists to cover them before and behind. In this they resemble the Juanga to the south of the Kol country, the Chenchi near the Pulicat lake and to the north of Ellore; and till about A.D. 1830 a similar custom existed among the Holier near Mangalur. The Kolam extend along the Kand'hi Konda or Pindi Hills, on the south of the Wardha river, and along the table-land stretching east and north of Manikgad'h, and thence south to Danttanpalli, running parallel to the right bank of the Pranhita. They do not intermarry with the common Gond, but the one attend the nuptials of the other, and eat from their hands. Connected with the Gonds, though not included in the preceding classes, are the Badiya between Chindwara and the Mahadeva Hills, who have conformed to the Hindus in their language and some religious observances; the Halica, pretty numerous in Bastar, Bhandara, and Raipur, who covet the distinction of wearing a sacred thread, a privilege, till recently, sold to those in Bastar by the raja; the Gaiti Gonds in Bastar who call themselves Koitor; the Moria Gond, who are the principal agriculturists in Bastar; and the Naikude Gond, inhabiting the jungles on both banks of the Pain-Ganga, and especially the tracts between Digaras and Umarkhed, and found about Aparawapet, and as far as Nirmul, who have adopted the Hindu dress, and will not eat beef, but they live by the chase, or cut wood and grass, and are a terror to their neighbourhood by their depredations.

Marriage.-The Gond of Nimar serve for a wife, but practise forcible abduction of the bride, with a mock fight. They are polygamic.

Dulha Deo is a favourite deity in Bundelkhand and amongst the Gond of Central India. It is the apotheosis of a bridegroom (dulha) who died in the marriage procession, and whose death so affected the people that they paid him divine 
INDIA; THE BENGAL PROVINCE.

honour's. The worship of Adonis is similar, and also that of Thammuz, whose annual wound in Lebanon allured the Syrian damsels to lament his fate.

The Gond of Mandla have the Lamjina Shadi, in which the betrothed lad serves an apprenticeship for his future wife. A Gond girl, however, may exercise her own will and run off with a man, but it is quite allowable for her first cousin or the man whom she has deserted to abduct her from the man whom she has chosen. The Shadi Bandhoni is a compulsory marriage. In the Shadi Baitho, a woman goes to a man's house. Widows re-marry either to a younger brother of their deceased husband, or to some other man.

The leaf ordeal, in Bastar, is followed by sewing up the accused in a sack, and letting her down into water waist-deep; if she manage, in her struggles for life, to raise her head above water she is finally adjudged to be guilty. Then comes the punishment. The extraction of the teeth is said in Bastar to be effected with the idea of preventing the witch from wuttering charms, but in Kamaon the object of the operation is rather to prevent her from doing mischief under the form of a tiger, which is the Indian equivalent of the loup-garow.

Religion.-The Gond clans are generally spiritworshippers; all of them bring the spirit back to the house. If a man of the Bygah of Raipur die, three days afterwards bis son throws grain before a fowl. If it eat any of the grain, he believes that the spirit of the father has entered the house, and the fowl is sacrificed thereto. Similarly with the Binjwar of Raipur, on the third day the relatives take a pot of water to the village tank, and bring back the spirit of the deceased to his house, where he is thenceforward worshipped. The Bunjia bring the dead man's spirit back to the house in a pot of flour.

The Bilaspur Gond worship a raised earthen mound, under the name Bura Deo. They worship also a branch of the Saj plant, a species of euphorbia. Pharsapend, the god of the Gond of Chanda, is represented by pieces of iron in an earthen pot, and suspended from a tree remote from the village and from the high road.

BENGAL PROVINCE occupies the lower part of the valleys of the Ganges and the Brahmaputra, but gives its name to an administrative circle, with an area of 193,198 square miles, and a population of $69,536,861$, part of the area, 36,634 square miles, comprising the hilly districts of Koch-Bahar, Hill Tiperah, the Tributary States of Orissa, Chutia Naypur, and Behar.

In Sind, conquering and fleeing races bave been stopped by the Indus, the ocean, and the Indian desert; in the Panjab, the furtber southern progress of advancing tribes has been barred by the many rivers, and by the fronting nations of Aryans, Jat, and Rajput settled in the Gangetic plain; and, similarly, many great tribes who are distinct from the races in other parts of India, and who keep aloof from each other, have been cooped up into the river and hill regions of Bengal. Amongst such may be mentioned the Babhan, Baori, Barui, Bhumia, Bhumij, Bind. Dosadh, Gareri, Kandara, Kapali, Karan, Khandait, Kharwar, Koch, Kol, Madak, Mal, Pan, Pod, Rajwar, Sadgop, Santal, and Tiar. There are even now in Bengal 38,319 Asiatics other than natives of India and British Burna.
Bengal is under the jurisdiction of a LieutenantGovernor, and comprises the four provinces of Bengal proper, 76,406 square miles; Behar, 14,139 square miles; Orissa, 9053 square miles; and Chutia Nagpur, 26,966 square miles; with 36,634 square miles of Feudatory States. These great provinces are arranged for administrative purposes into nine revenue circles, each under a British officer; their respective areas, in square miles, and population, being as under :-

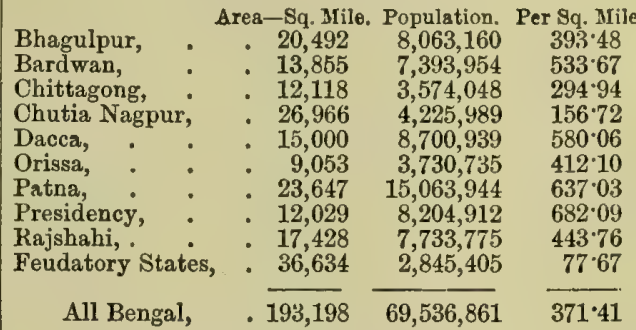

Religion. - The Census return for 1881 has classed the religions of these millions under ten headings, as under:-

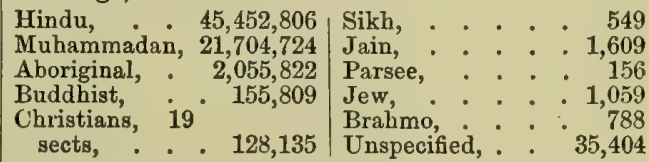

A remarkable feature in this summary is to be seen in the great numbers who profess Islam. The total number in all India of this persuasion is $50,121,585$, and almost one-half of that number is in Bengal. Many of them are found in Eastern Bengal and the adjoining districts of Sylhet and Cachar, and in the two districts of Bogra and Rajshahi, and there they comprise the bulk of the cultivating and labouring class; while in Chittagong and Noakhali they follow a seafaring life. When they embraced this religion is not known, nor is it known from what race of aborigines they were converted, and few of them present any peculiar features. The Malik or Mullak of Behar are supposed to have been converted Rajputs. They cultivate land, and the wealthy possess considerable landed property, but generally they are employed as land-agents and peous. They use toddy freely, and are turbulent when under its influence. They do not intermarry with other Muhammadans; their marriage ceremonies are kept secret, and are conducted by women. Others of the Muhammadans retain portions of their former creeds. Many of the Bedi tribe of Bengal, for instance, have adopted Islam and are circumcised, but continue to worship the Hindu goddess Kali.

The Hindus have all adopted that caste system which is so intimately bound up with other parts of their religious and social life. The number of their castes is supposed to be about 1000 , and the more prominent among them are the Adhikari, Babban, Baidya, Bhat, Brahman, Deswali, Dogla, Ghatwal, Karan, Kayasth, Khandait, Khandwal, Kishnpachi, Mahanti, and Rajput. There are 265 minor castes, numbering $1,371,260$ persons.

The trading castes, 963,159 in number, are the Banya, Komati, Muniyara, Nuniyar, Panwaria, Suratwala, and Vesya, but the vations of all parts of Asia, Europe, and America have bere their representatives engaged in commerce.

The pastoral castes, in number $4,115,377$, com- 
INDIA; THE BENGAL PROVINCE.

prise the Bhartia, Gandhari, Gareri, Gordha, Gujar, and Goala.

\begin{tabular}{|c|c|c|c|c|c|c|}
\hline & \multicolumn{6}{|c|}{47 Aboriginal Tribes, $1,365,215$, viz.- } \\
\hline & & & . . 225 & Korwa, & & \\
\hline & & & - 20,870 & & & \\
\hline & & & . 226,167 & ba, . & & \\
\hline & & & - 1,539 & & & \\
\hline & & & 1,874 & & & \\
\hline & & & 3,926 & & : & \\
\hline & & & 15 & & & \\
\hline & & & 15,665 & & & \\
\hline & & & & & & \\
\hline & & & . 971 & & & \\
\hline & & & 1,327 & & - & \\
\hline & & & - 198 & & . & \\
\hline & & & $1,601,722$ & & : & \\
\hline & & & . 529 & & & \\
\hline & & & 36,911 & & & \\
\hline & & & 10 & & & \\
\hline & & & 27,109 & & & \\
\hline & & & . 481 & & . & \\
\hline & & & & & - & \\
\hline & & & - 22,356 & aria, & . & \\
\hline & & & 1,227 & Tha & & \\
\hline & & & & & & \\
\hline & & & & Tiper & & \\
\hline
\end{tabular}

53 Semi-Hinduized Aborigines, 10,618,451, viz.-

\begin{tabular}{|c|c|c|c|}
\hline & & & \\
\hline Baheliya, & $\therefore:$ & adara, . & \\
\hline Balai, ? & . 8,317 & Keora, . & . \\
\hline Bari, & 27,758 & Khaira, & \\
\hline atar, : & $\begin{array}{r}., 548 \\
\end{array}$ & Kharwar, & 195 \\
\hline Bathudi, & 24,210 & Khoria, & \\
\hline auri. & 481,493 & Khyen, & \\
\hline & & Koo & 1,648 \\
\hline İali, & 54,094 & Kodmal, & \\
\hline nya, & 483,656 & Koranga, & \\
\hline & 136,812 & & \\
\hline & 48,469 & & \\
\hline & & & 1,251 \\
\hline & . 95,3 & Maler, : & \\
\hline & $1,408,0$ & Mal Paharia & \\
\hline Cha & $1,576,076$ & & 12 \\
\hline Chik & $\begin{array}{r}. \quad 29,084 \\
\end{array}$ & de, & 13 \\
\hline & . 2,633 & & 65, \\
\hline ii, & . 4,843 & & \\
\hline & & & . \\
\hline h, : & 1,134 & & . \\
\hline ntah, & - $\quad 88,123$ & & . \\
\hline & . $\quad 41,781$ & Pandit, & \\
\hline & . 4,811 & & \\
\hline & 16,407 & Shikari, & - 2,0 \\
\hline & . 286,109 & Turi, : & . $\quad 30,7$ \\
\hline & . . 337 & & \\
\hline & Beng̨ & & \\
\hline & & & \\
\hline & 129 & & \\
\hline & 376 & & \\
\hline & $\begin{array}{l}\text {. } 5,766 \\
\end{array}$ & & \\
\hline & - 4,835 & ia, . & \\
\hline$W$ & - 6,888 & lik, & \\
\hline & . 44 & Santal, & 1,087, \\
\hline & $\begin{array}{r}112 \\
0\end{array}$ & Uraon, & \\
\hline & & & \\
\hline
\end{tabular}

Hill Tribes of the Northern Frontier, 39,023.

Garo, . . . . 27,450| Manipuri, . . . 8,813 Khassya, : : . 26 Naga, . : : 1 Kuki, $: 2,733$ Tribes of the Assam Valley.

Tribes of the Assam Valle
Mal

Nagar,

Orha,

Raju,

Sadgop,

Beldar

15 Labouring Castes, 546,839, viz.-

Chuniya, : : 99,788 Khattik, : 11,519

Dhuliya, . 88,020 Matia, . . 18,570

Kora, . . 43,565 Pandari, . . 23,904

Naik, : . 33,442 Tursha, : : 78,284

Nuniya, . . 279,861

23 Boating and Fishing Castes, 2,131,433, viz.-

Goklia, . . 32,302 Mallah, . . 470,676

Gonhri, . 86,217 Manjhi, : 65,361

Jaliya,. . 381,540 Patuni, . . 72,013

Jhalo, : 19,454 Pod, : : 325,755

Kewat, . 254,873 Tiar, . . 349,117

Koral, . . : 46,120 Others, : . 16,520

Let,. : : : 11,485

9 not recognising caste, 683,227 , viz. -

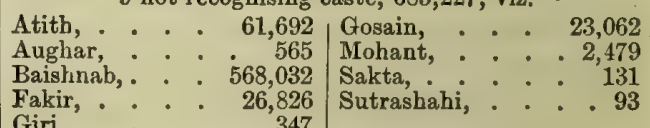

Languages in Bengal.

Arabic, . . . 905 Finnish, . . . 1

Armenian, : 737 Garo, : : : 24,949

Bengali, . 36,416,970 Gondi,. . . . 1,294

Burmese, . . 1,584 Hungarian, : : 11

Canarese, . : : 34 Irish, . : : 89

Chinese, . . 850 Japanese, . . . 1

Dutch,. : . . 55 Kandh, : : 52,357

English, : . 37,464 Kharria, : : . 1,893

French, : : : ${ }_{372}^{414} \mathrm{Khasi}_{\mathrm{K}_{1}}: \mathrm{K}_{1,026,775}$

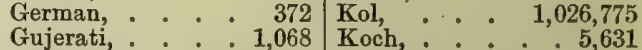

Hebrew, : : 1,450 Lap, : : : 5,631

Hindustani, : 21,799,081 Lepcha, $\vdots \vdots \quad:$ 4,611

Kashmiri,. . . 91 Limbr, . . . 277

Mahrati, . . 344 Madrasi, . . . 632

Malealam, . . 65 Malay,. . : 8

Marwari, . . 3,363 Maler, . . 57,777

Nepalese, : : 89,855 Manipuri, : : ${ }_{127}$

Panjabi, . . 608 Mech, . . . 11,101

Pushtu, : : 381 Mughi, . : 15,709

Persian, : : 2,336 Murmi, : : 652

Portuguese, . 297 Norwegian, , . 84

Tamil, . . . 1,623 Roumanian, . . 6

Telugu, . . 11,310 Russian, . . . 60

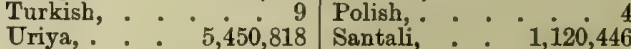

Uriya,
Welsh, : $5,450,818$
S

Italian, $: 2_{255}$ Swiss, $: \vdots \vdots$

Greek, : : 94 Siamese, $: \vdots \vdots 1$

Unspecified, . 335,129 Singhalese, : . . 2

Assamese, . . 399 Swedish, : : : 133

Bhil, . . . . 19 Tibetan, . . 11,850

Danish, : : 51 Tiperah, : $: .95$

Dhangar, : : 4,119 Uraon, $\vdots 38,982$

The races and castes are thus summarized :-

20 Asiatics, other than natives of British India, 38,319

47 Aboriginal tribes of Indin

53 Aboriginal tribes, semi-Hinduized, . $\quad$ 10,618,451

6 Hindus, superior castes, $\quad .4,897,426$

13 " intermediate castes, . . . 2,777,124

$7 "$ trading castes, . : : 963,159

7 pastoral castes, * . 4,115,377

3 cooks, . . . . 924,984

38 Agricultural castes, : : • • • $6,875,197$

14 Serving castes, . . . 2, . 204,003

22 Artisan castes, . . . . . $4,482,471$

19 Weaver castes, $\quad$. $\quad$ : $\quad$. $\quad .1,619,344$

15 Labouring castes, 546,839

23 Boating and fishing castes, $\quad \vdots \quad \vdots 2,131,433$

15 Dancer, musician, beggar, and vagrant 43,253

9 not recognising caste, $\vdots \vdots \quad \vdots \quad 683,227$

$683,2,7$
48,114 
Sex.-Bengal is, for India, in the unusual position of having more of the female than of the male sex, the respective numbers being $34,911,270$ and $34,625,591$, but they largely continue the Hindu practice of giving their young girls in marriage to full-grown or even middle-aged men. The necessary result follows in a great number of widows, and while there are in Bengal 1,375,217 widowers, there are 7,401,629 widows.

The races in the Bengal, Behar, Chutia Nagpur, and Orissa provinces in their mental and physical characteristics are widely dissimilar. The Bengali of Bengal proper lives amid a network of rivers and morasses. He presents a weak and puny appearance, but he is able to endure an amount of exposure to which a native of the Upper Provinces of Hindustan would soon fall a victim. In active pursuits, the Bengali is timid and slothful, but in intellect he is stubtle and sharp-witted; and these qualities, combined with a plodding industry and a fondness for sedentary work, have enabled the race to obtain employment in all the offices of the Indian Government, and to rise to some of the highest judicial posts in the land.

On the south-west of Bengal are the Uriya people of Orissa. They are even more timid than the Bengali race. They are conservative to a degree, are wanting in enterprise, contented to follow the practices of their forefathers, and evincing a thorough dislike of all modern improvements. They are the most bigoted and priestridden race in British India.

On the north-west is the province of Behar. It is occupied by a hardier and more manly race, who speak Hindi, the language of Upper India, and are usually called the Hindustani. They are more decidedly Aryan than any other of the races found in Bengal. Even the semi-aboriginal tribes of Behar are of a better build and of a nobler mien than similar tribes in Lower. Bengal.

Besides these three distinct nationalities, the Province of Bengal contains several tribes who have been but partially subjected to Aryan influence, and have hardly as yet come within the pale of civilisation. They are evidently of prior arrivals in the districts which they now occupy, but wave after wave of immigration has poured into India in bygone ages, and no one can say who were the real first comers. These tribes are found in masses throughout the province, and, though much mixed up together, they retain their customs and habits distinct. Besides these, there are within each nationality numerous tribes and castes of various origin and race, and in various degrees of civilisation. . Amongst them, the Aryan Brahman, who traces his lineage back to the time when Kanouj was dominant, and the half-civilised Koch or Poliya of Dinajpur. These are probably the representatives of two perfectly different stocks; but even where no distinction of race can be traced, there are frequently found tribal subdivisions with ethnical peculiarities of their own.

The number of separate tribes and castes in the Bengal Province probably do not fall short of one thousand. If their respective subdivisions and septs or clans be taken into account, they would probably amount to many thousands. The aboriginal tribes alone are very numerous; while those for whom, though Hinduized to a certain extent, an aboriginal origin may be claimed would swell the number by a very large amount.

The Babhan $(1,031,501)$ are a fine, manly race, who claim to be Sawaria Brahmans. They adopt from the Rajputs the honorific terms singh and rai, and take those of tewari, misr, and panre from the Brahmans.

Baisnab $(568,032)$ is not a race, but a Vaishnava sect in Bengal, where the letter ' $v$ ' is changed into $\mathrm{a}$ ' $\mathrm{b}$;' and they are also called Boistab. 'The sect claim to be followers of the tenets of Chaitanya. They are reformers, admit with initiatory rites all comers into their number; they have no separate caste distinctions, but have Brahmans as gurus. They abstain from animal food and from intoxicating liquors. Many are married, and the lives of those who are single are generally said to be immoral. The doctrines of Chaitanya enjoined the living heart worship of Vishnu (Bhagat or Bhakte), and the putting aside of symbols and ceremonies. Much of the finest portion of the poetical literature of Bengal almost wholly originated with the Baisnab sect.

The Baori $(481,493)$ take the heron as the emblem of their tribe, and must not be eaten by them. The dog is sacred to them.

The Bhar afford an illustration of the vicissitudes of nations. At present are largely swineherds, but before the arrival of the Aryans they were rulers over the country from Rhotas to Rewah. The Bharata of the Puranas are supposed to have been Bhar, and the Amethia and Purihar Rajputs are said to be Bhar. The goddesses at Patna and Gya are supposed to have been erected by this race. Many stone forts remain in the country formerly ruled by the Bhar, and are said to have been their handiwork. The Bhar, the Cheru, and the Pasi have given their daughters in marriage to Rajputs.

Birhor (1539) are said to have, till lately, been given to cannibalism. A Birhor whose end was approaching would invite his clan to assemble to feast on his body.

Brahmans are a numerous and influential race, most of them of Aryan origin, but they are kept apart by social and clan distinctions, and are distributed throughout all India, in number 7,123,909, a third part of whom $(2,754,100)$ being in Bengal. They are to be seen in every station in life, and in every avocation, as office-holders, learned men, fortune-tellers, guides to pilgrims, musicians, astrologers, beggars, funeral performers, cultivators, priests in all parts of the country, and even coolies in Nepal. Brahmans of Orissa have two great divisions, the Vaidik or learned class, and the Laukik who engage in business, in husbandry, as gardeners, and even as bricklayers.

Butia or Bhotea amongst the people of Hindustan is applied to any Tibetan. Many are employed in the $\mathrm{N}$. of Bhagulpur as coolies. Butia of Bhutan burn their dead, and throw the ashes into the nearest stream. They are Buddhist and shamanist.

Chandal or Charal $(1,576,076)$ are a hardy race, capable of enduring considerable exposure and fatigue. In the Ramayana, the powerful prince of Oudh is represented as courting the alliance of Gohurka, a Chandal chief. They are now, throughout all Northern India and Bengal, in a subordinate position, nsually as labourers.

Cheru $(15,665)$, like the Bhar, were once 
dominant. They have a tradition that, starting from Moorung, they took Kamaon; thence they made themselves masters of Bhojpur. Subsequently (1611) they took possession of Chumparun, and in 1613 occupied Palamow. According to another legend, they ruled in Behar, whence they were expelled by the Sivira, who were again thrust out. They claim to be descended from the great serpent, an indication of their Mongoloid origin. They eat flest. Their women assist in the field labours.

The Dom, in Bengal 343,246, and in all India 721,655 , are widely dispersed throughout the northern parts of British India, dwelling outside the towns and villages apart from the settled population; they have several sections. They work as blacksmiths, carpenters, masons, weavers, are miners and musicians, fan and basket makers, gravediggers, and executioners. They. serve Europeans as sweepers, cooks, and their women as ayah ladies'-maids. Dom women are famed for their good looks, and are notoriously uncbaste. They perform in the women's apartments. The Hindus do not permit them to draw water from the same wells. They construct the funeral pyres of the Hindus, and supply the fire. They worship stones, to which they sacrifice fowls and goats.

Dosadh $(1,138,651)$. - Nearly all in Bengal claim to be descendants of, and they worship as a demon, the astronomical umbra Rahu, the moon's ascending node, which they say causes eclipses.

Gaola in Bengal number 3,992,949. They are a pastoral race, following the same pursuits as the Ahir and the Gopa. They are as far south as Hyderabad in the Dekhan, but many have settled down in villages as dairymen, with large herds of cows and buffialoes. They are of strong, powerful frames. In Behar are turbulent, so greatly so, that Patna Gaola is a term of reproach.

Ghatwal $(113,173)$. - Nearly all in Bengal are descendants of men who were employed in Behar in keeping the passes open.

Juanga, chiefly of Orissa, number only 529 in Bengal. Their women, until 1871, had as their sole covering a string of beads around their waists, into which they stuck a bunch of leaves before and another behind.

Kaibartha, in Bengal 2,100,379, and in India $2,137,540$, are the great cultivators of Bengal, and many take Khasiya as their designation.

Kayasth, in Bengal 1,450,843, and 2,159,813 in all India, have twelve sections. They are essentially a caste of scribes, and are to be seen in the service of all the native courts, and in the offices of the Indian Government. They eat and drink freely. Their women are strictly secluded.

Khandait $(617,017)$, from Khauda, a sword, are descendants of military retainers, who had their lands on a strictly military tenure, but are now undistinguishable from other husbandmen. They and the Paik are of a similar position.

Koch $(1,878,884)$ are chiefly in Koch-Bahar, with numbers of them in Matsya-des and Kamarupa, i.e. in Rangpur, Lower Assam, and Purnia. The Koch kingdom was founded by Haju, about A.D. 1550. The Koch, Mech, and Bodo are often classed together, but Colonel Dalton regards these as distinct races. The Pali or Paliya are supposed to be of Koch origin. They have several sections. With the Pani-Koch women, when they marry, property vests in the wife, and descends to her daughters; the husband goes to the wife's house, and is subject to her. They sacrifice to the sun, moon, and stars, also to the deities of the woods, bills, and rivers, and to the manes of their progenitors.

The Koeri $(1,204,884)$, called also Muari and Murao, are the best spade husbandmen, and largely engage in poppy cultivation and the manufacture of opium, with other garden produce.

$K o l$ is a term said to be of Sanskrit origin, and to have a derogatory meaning, but applied by Hindus to aboriginal tribes of Chutia Nagpur, of two distinct families, the Kolarian and the Dravidian, whom Colonel Dalton thus classed :A. Kolarians who speak the Munda language or allied

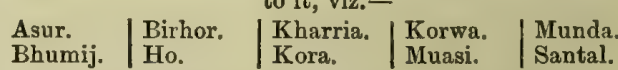

Kolarians who have lost their own original languageCheru. | Kharwar. | Kisan. | Saont. B. Dravidians.

Bhuiya. |Gond. \begin{tabular}{l|l|l|l}
$\begin{array}{l}\text { Bhuiya, } \\
\text { Bhuiher. }\end{array}$ & $\begin{array}{l}\text { Gond. } \\
\text { Kandh. }\end{array}$ & $\begin{array}{l}\text { Mal. } \\
\text { Oraon. }\end{array}$ & $\begin{array}{l}\text { Sabar, and } \\
\text { many } \\
\text { others. }\end{array}$ \\
Kauthia. & Kaur. & Rautia. &
\end{tabular}

In the census of 1881 they are arranged by $\mathrm{Mr}$. Bourdillon somewhat differently :-

\begin{tabular}{|c|c|c|c|c|c|c|c|}
\hline & & Kolarians, 3 & 0,244, viz. $_{0}$ & & & & \\
\hline Munda, & • & . . 14,310 & Bhumij, & - & & & $12 ?$ \\
\hline Karwa, & 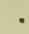 & 6,888 & Kharwar, & • & & & 112 \\
\hline Chuar, & - & 5,766 & Bhil, : . & - & & & 87 \\
\hline Mahili, & & 2,510 & Kharria, & • & & & 44 \\
\hline Brijia, & & Dravidians, & $\begin{array}{l}\text { Korwa, } \\
25,948 \text {, viz.- }\end{array}$ & - & & & 22 \\
\hline Oraon, & - & $\begin{array}{r}21,115 \\
\text { Indefinite, } 4\end{array}$ & Dhangar, & - & & & 4,835 \\
\hline $\begin{array}{l}\text { Poithalik, } \\
\text { Paharia, }\end{array}$ & & $\begin{array}{rr}\text {. } & 362,521 \\
. \quad & 50,906\end{array}$ & Nagpuri, & - & & & \\
\hline
\end{tabular}

The following is Mr. Bourdillon's distribution :-

Chutia Nagpur, . 791,750 | Orissa, . . . 1,062 Behar, . . 15,644 Feudatory States, 62,635 Bengal, : : : 575

Kurmi are largely occupied as gardeners and husbandmen. They number $4,065,075$ in Northern India, and of these $1,213,422$ are in Bengal.

Mal, 125,238 in Bengal, and 16,876 in Assam, are supposed to have long occupied the districts near the Ganges and bordering on the Bay of Bengal. Pliny writes of 'Gentes Calingæ proximi mari, et supra Mandei Malli, quorum Mons Mallus, finisque ejus tractus est Ganges.' Also, ' $\mathrm{Ab}$ is (Palebothris) in interiore situ Monedes et Suari quorum Mons Maleus.' Mr. Beverley thinks that the Mal take their name from the Dravidian word Mallai, a hill, and that they were driven eastward over all Bengal, where they fell into their present position of society.

Mech (9288) stretch along the base of the mountains of the Sikkim, Bhutan, and Nepalese Hills, from the Kauki river to the Brahmaputra. The malaria of the forest, so deadly to strangers, has no effect on them. Their fentures are of a strong Mongolian caste. They call themselves Bodo or Boro.

Mugh are in the south of Chittagong and in the hill tracts, and they settled in the Sunderbans about A.D. 1780, when they fled from their homes on war breaking out between the king of Burma and the rajas of Arakan, but they love to revisit their homes in the fair weather season of the year. Their general physique is strongly Mongolian. They are Buddhists. The 
term Mugh was applied to the fire-worshippers of Persia by the Arabs, and to any non-Muhammadan.

Nat $(26,560)$ are a vagrant, wandering race, with habits and occupations assimilating to those of the gypsies of Europe.

Oraon $(45,638)$ call themselves Khurnkh, and the younger men of the tribe Dhangar. They are honest, industrious workers, are a merry, lighthearted people, excessively fond of dancing, which is their great national amusement. They are known to Europeans as part of the Kol, but they are not Kolarians. Oraon have a Dumkuria, or Morang hall, in which the unmarried men and some of the married sleep. Any absentee is fined. In this hall are kept all the flags and instruments used in their dances. In some Oraon villages also there is a sleeping - house for the unmarried girls, with an elderly woman to look after them. The names of the Oraon clans are taken from animals, which are sacred to the particular tribe.

Pasi, 164,595 in Bengal, and $1,033,184$ in the N.W. Provinces, are watchmen, fowlers, swineherds, labourers, and agriculturists, and spread throughout the N.W. Provinces and Behar, but they too, like the Bhar and the Cheru, were formerly rulers in the land. They were owners of the pargana of Khyrabad in Oulh, in the time of Prithi-raj in the 12th century, and they fought on the side of the Chandal against the Chauhan. Since then they have been highly predatory.

Puran of Orissa assert that they and another race were produced from a peafowl's egg, - the Puran from the white, and the Kharria from the shell.

Rajwar have many clans, some of them cultivators, others predatory. They are of mixed origin, but chiefly aborigines.

The Santal (in Bengal 1,128,190, and in Assam 7744 ) say of their origin that a wild goose came from the great ocean, and alighted at Ahiri-pipri, and there laid two eggs, from which issued the first parents of the Santal. The Santal have twelve clans, one of them is the Murmu, which is their name for the Portax pictus antelope, and the clan must not kill it, nor eat its flesh.

The Santal parganas are 140 miles N.W. of Calcutta, in a wild and sparsely populated country. For revenue and administrative purposes, these are arranged into four sub-districts. The Santal and Paharia have regular village institutions, with a manjhi or headman, and similar to the Munda and Maniki among the Kol and Ho. Over the Santal manjhi are headmen of hundreds called parganas. The Santal have no written language of their own; very few of them can write either Hindi or Bengali, and they aided in the census operations by tying knots on strings of different colours to distinguish males from females, and children from adults. In Bengal proper, Santals are mostly in the Midnapur and Bancoorah districts, others are in Orissa. They have six domestic ceremonies, viz. (1) Admission into the family, (2) into the tribe, (3) into the race, (4) betrothal. (5) cremation, (6) placing three fragments of the skull into the Damodar gods and demon. They are exogamic.

Dosadh are constitutionally brave. A number po them fought in Clive's army at Plassey.
CALCUTTA, the capital of Bengal, metropolis of all India, and the seat of the Government of India, is built on the left bank of the Hoogly, a branch of the river Ganges.

\begin{tabular}{lrrrr} 
& & Males. & Females. & Total. \\
Town proper, : & : & 257,778 & 143,893 & 401,671 \\
Fort-William, : & 3,002 & 346 & 3,348 \\
Suburbs, : : & 147,205 & 104,234 & 251,439 \\
Port, : & 28,037 & 163 & 28,200 \\
\hline \multicolumn{1}{c}{ Total, : } & 436,022 & 248,636 & & 684,658
\end{tabular}

It has a large Muhammadan population, 221,013 , chiefly men, 147,788 , with 73,225 females. There are 89 Hindu castes, the more important beingAgarwala, . . 2,460|Kamar, . . . 4,873 Aguri, : : : 1,373 Kansari, . : : 2,009 Bagdi, : : 3,760 Kaora, $:$ : $_{1,113}$ Baidya, : . . 2,684 Kayasth, . . . 37,474 Baisnab, : : 7,026 Khandait, : .913 Banya, : : : 3,168 Khetri, : : : 1,233 Brahman, : : 38,763 Kumhar, : : 1,193 Chamar, . . 8,569 Kurmi, . . 2,620 Chetri, . . 5,892 Koeri,. . . .545 Dhopa, : : 4,053 Madah, : : : 3,849 "Khasa-Dhopa, 435 Mehtar, : : : 7,124 Dom, . . . i, 674 Napit, : : : 5,842 Dosadh, . . 3,385 Rajput, . . .720 Gandabanik, : 6,879 Sarnakar, : : 2,414 Gawala, : : 14,364 Satgop, : : 8,626 Jelia, : : : 2,086 Subarnabanik, : : 14,567 Jogi, : : .292 Sunri, . . . 3,468 Kahar, : : : 8,727 Sudradhar, : : 3,604 Kaibartha, : : 12,680 Tambuli, . : : 2,411 Kalu, . . : 2,878 Tanti,. . : : 12,928 Kalwar, . . .502 Teli, . . 8,393

A mixed race, known as Eurasians, are not numerous, only 9410 , and there are representatives from the nations of Europe speaking twenty European languages. The 26 Asiatic tongues spoken are as under:-

Arabic.

Arabic. Hebrew.

Hindustani,87,526. Pushtu.

\begin{tabular}{|l|l|l} 
Assamese. & Khassi. & Santali. \\
Bengali, 417, 234. & Madrasi. & Siamese \\
\hline
\end{tabular}

$\begin{array}{lll}\text { Burmese. } & \text { Malay. } & \text { Singhalese. }\end{array}$

\begin{tabular}{l|l|l} 
Chinese. & Mahrati. & Tamil.
\end{tabular}

$\begin{array}{lll}\text { Cutchi. } & \text { Malabari. } & \text { Telugu. }\end{array}$

\begin{tabular}{l|l|l} 
Garo. & Malay. & Uriya, 15,151. \\
Gujerati. & Panjabi. &
\end{tabular}

with 20 European languages.

ASSAM has an area of 46,341 square miles, and a population of $4,881,426$. It is in the extreme north-east of British India, being bounded on the north by the eastern section of the Hinalaya mountains, which portion is inhabited by the Bhutia, Dafla, Aka, and other hill tribes. On its west and south lies Bengal proper, and on the east it has the feudatory Native State of Manipur and the wild regions of Upper Burma.

Assam is naturally divided into three portions, viz. the valley of the Brahmaputra on the north, that of the Surma on the south, and between these two valleys are mountain regions running east and west, which form the watershed of the two basins, and help, with numerous streams, to swell the waters of two of the largest rivers which at the present day form the chief means of communication. On the night of the census, there were 3899 boats on the rivers, with 20,301 persons on board. The people are thus distributed :-

Surma valley,

Brahmaputra valley,

Cachar Hill tracts, : $2 \dot{4}, 433$

Garo " " : 85,635

Khassya and Jäintia do., 169,360

Naga Hills,

1,380

$2,258,434$

$2,249,185$

, "tracts,

93,000 $-373,807$ 


\section{INDIA;-ASSAM; THE BOMBAY PRESIDENCY.}

There are 105.34 persons to the square mile; but there is much waste land; the density ranged from 9.91 per square mile in North Cachar Hills to 361.95 in Sylhet.

The Brahmaputra valley has been the scene of frequent revolutions, by which one tribe has succeeded to another, and each has left its traces on the character and physique of the present inhabitants, who have Ahom, Chutiya, Koch, Bodo, and Aryan blood largely in their veins. They are a proud, haughty, and indolent people, and have been inclined to use opium in excess.

Hindu missionaries are largely and actively engaged in proselytizing. The chief of the propaganda are Gosains from Nadya and Kanouj. A few of the Kamrūp Gosain marry, but those of Upper Assam are celibates of the Vaishnava sect, living in monasteries (shatra) with their temple in the centre, and the cells of their chief followers, to the number sometimes of several hundred, disposed in order around it. There are also some Kolita missionaries.

The Chutiya, Koch, and Rajbansi have accepted Hinduism. The Madhahi, Mahalia, Rabha, Sarania, Totila are semi-Hinduized; but the Garo, Hajong, Kachari, Lalung, and Mech remain in their own faiths.

The Kachari chiefly worship the Bathau or the Siju (Gharbura), a species of euphorbia (E. antiquorum). A plant of it is kept in every courtyard as their tutelary deity, called Siju-Gohain, and is carefully protected by a fence of split bamboo. Offerings are made of rice, eggs, chickens, and goats. Other of their deities are Mainau, who provides food and drink; Khober (? Kuvera), the god of wealth; Hasung Madai, the traveller's god; with Dalah, Gabang, Hagrani, Madāi, sylvan deities ; and Daini Madāi, gods of the waters.

The Deori or Deoshi is their divine, who in sickness and peace makes offerings of salt, rice, pulse, eggs, chickens, pigeons, goats, pigs, to the wrathful deity, and works himself up into a state of hysteria.

Other tribes named are the Aka on the borders, the Kolita and Kaibarth in the valley.

The Muhammadans also are actively proselytizing, and their numbers are 1,317,022.

\section{Bodo Tribes, viz. -}

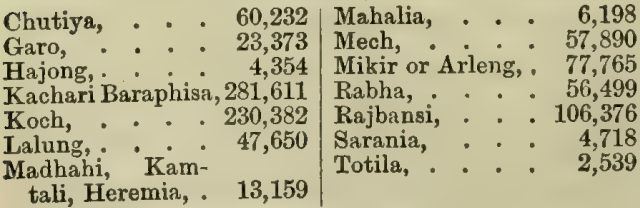

$$
\begin{array}{r}
\text { tali, Heremia, . } 13,159 \\
\text { II. Shan Tribes, viz.- }
\end{array}
$$

\begin{tabular}{|c|c|c|c|c|c|c|}
\hline $\begin{array}{l}\text { Abor, } \\
\text { Ahom, } \\
\text { Borahi, } \\
\text { Dafla, }\end{array}$ & Deori & $\begin{array}{r}821 \\
179,314\end{array}$ & $\begin{array}{l}\text { Khamti, K } \\
\text { Aitonia, } \\
\text { Nora, Ph } \\
\text { Miri, } 50 \mathrm{cl} \\
\text { Shan, }\end{array}$ & $\begin{array}{r}\mathrm{P} \\
\mathrm{P} \\
\text { ans }\end{array}$ & $\begin{array}{l}\text { jang } \\
\text { Pani- } \\
\text { ial, : } \\
\text { : }\end{array}$ & $\begin{array}{r}2,883 \\
25,636 \\
. \quad 275\end{array}$ \\
\hline $\begin{array}{l}\text { Bhutia, } \\
\text { Khassi, } \\
\text { Kuki, } \\
\text { Langam, } \\
\text { Malla, } \\
\text { Man, } \\
\text { Manipuri, } \\
\text { Matak (M }\end{array}$ & $\begin{array}{l}: \\
: \\
\dot{0} \\
\dot{\operatorname{ran}})\end{array}$ & 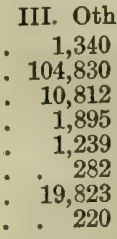 & $\begin{array}{l}\text { Tribes. } \\
\text { Mishmi, } \\
\text { Naga, } \\
\text { Nepalese, } \\
\text { gantal, } \\
\text { Santeng, } \\
\text { Singpho, } \\
\text { Tiperah, }\end{array}$ & $\dot{0}$ & $\dot{0}:$ & $\begin{array}{r}685 \\
104,650 \\
3,991 \\
7,397 \\
47,815 \\
1,774 \\
3,984\end{array}$ \\
\hline
\end{tabular}

Most of the other races in this province are represented in other parts of India.
On the Northern Assam frontier are found, in the following order from east to west, the Aka, Bor, A bor, Doffla, Miri, and Mishmi.

On the Southern Assam frontier we have the numerous Naga and Singpho dialects, the Mikir and Angami, the languages of the Khassya and Jaintia hillmen, the Boro in Cachar, and the Garo in the hills of that name.

Abor and Bor-Abor tribes occupy the hills between the Subansiri and Dihang rivers, and extend to the east. They are powerful tribes. The Abor have a Morang or town hall in each of their villages, which is occupied nightly by all the bachelors, and a proportion of all the married men; that at Membu was 200 feet long, and had 16 or 17 fireplaces. They call themselves Padam. The term Abor is said by Colonel Dalton to mean barbarous. It is applied particularly to the hill races on the southern slopes of that portion of the great Himalayan range between the Dihang and Subansiri rivers.

The Manipur State has an area of 8000 square miles, and a population numbering 221,070 . It is a hill country, sparsely occupied, with 27 inhabitants to the square mile. The bulk of the Manipuri of the valley claiming a Kshatriya descent $(130,892)$ have embraced Hinduism. The men are indolent, and leave the out-door work to the women and to slaves. The Koi are of slave descent. The hill tribes number 85,288. The non-Hindu tribes have about 300 deities to whom they sacrifice.

BOMBAY. - The Bombay Presidency of British India is under the rule of a Governor and Council, composed of natives of Great Britain, and for legislation there is a Council in which Europeans and natives of India assemble. These two bodies have jurisdiction over an area of 124,516 square miles, in provinces extending between lat. $13^{\circ} 15^{\prime}$ and $28^{\circ} 12$ N., and long. $66^{\circ} 43^{\prime}$ and $76^{\circ} 28^{\prime}$ E., and over the fortified promontory of Aden in Arabia, 1600 miles away to the west, in lat. $12^{\circ} 45^{\prime} \mathrm{N}$., and long. $45^{\circ} 4^{\prime}$ E. The physical features of the provinces in the area here indicated are of a widely different character, and they include portions of British territory mixed with several possessions of Indian princes.

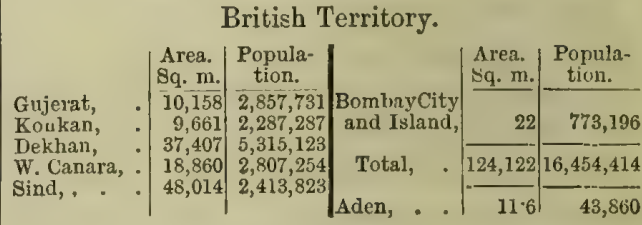

Feudatory States.

\begin{tabular}{|c|c|c|c|c|c|}
\hline & Area. & $\begin{array}{c}\text { Popula- } \\
\text { tion. }\end{array}$ & & Area. & $\begin{array}{c}\text { Popula- } \\
\text { tion. }\end{array}$ \\
\hline Cutch, & $\begin{array}{l}6,500 \\
8,000\end{array}$ & $\begin{array}{l}512,084 \\
576,478\end{array}$ & Satara & 3,314 & 318.687 \\
\hline ahikanta, & 11,049 & 517,485 & Akalkot, & 498 & 58,040 \\
\hline Kattyawar, & 20,559 & $2,343,899$ & Kolhajur, & 2,816 & 800,189 \\
\hline Rewakanta & 4,792 & 543,452 & S. Mahratta & & \\
\hline Cambay, & 350 & 86,074 & Jaghirs, & 2,734 & 523,753 \\
\hline arukot, & 143 & 6,440 & Savanur & & $\mathbf{1 4 , 7 6 3}$ \\
\hline arat, ? & 1,220 & 77,633 & Khairpu & 6,109 & 129,153 \\
\hline & 325 & 76,361 & Tot. Feus & 73,753 & 6,941 \\
\hline & 000 & 174,433 & Tot British & 124,122 & $16,454,414$ \\
\hline & 3,84 & 60,2 & and & & \\
\hline
\end{tabular}

Bombay city, with its great population, is on 


\section{INDIA; THE BOMBAY PRESIDENCY.}

an island which has been joined to the mainland by means of a causeway.

The Konkan and North Canara districts are chiefly in the lowland between the ghats and the sea, with an ample rainfall of 100 inches. The seaboard has several small harbours, and the people are fishing and seafaring races. In the Northern Konkan, the country between the hills and the coast is a mass of low ranges, and cultivation is carried on on the steep slopes of the hills and in the intervening valleys. In the southern part of the Konkan, the hills approach the sea, leaving little room for agriculture, but there are many small harbours with fisher races.

Gujerat, with the valleys of the Sabarmati and the Mahi, and the lands in the lower course of the Tapti and Nerbadda, excepting in its east and north-east, is a flat country, with a good soil. Its rainfall, 37 inches, is scant. Its people, in their castes and occupations, differ more than in any other part of India. There are numerous aboriginal races, some of them landowners, some in a servile condition, with several aboriginal and forest tribes of whom there is no tradition. The area of Gujerat is 10,158 square miles, arranged into the five districts of Ahmadabad, Baroach, Kaira, Panch-Mahals, and Surat. The low-lying alluvial tract around the coast of Gujerat is occupied by Rajput tribes, and by Gujar, Kathi, Koli, and Kunbi. In its southern districts the inost numerous of the aboriginal classes are the Chaudria, the Duria, and the Bhil of the Dang.

The Dekhan province is wholly on the tableland of the Peninsula plateau, 1500 to 1800 feet above the sea, and is occupied largely by the Mahratta race. It is covered with the regur or black cotton soil, of inexhaustible fertility, but in its eastern part the rainfall is always so scant and uncertain that the tract is known as the famine belt. Its districts are Ahmadnaggur, Kandesh, Nasik, Satara, Sholapur, and Poona, 37,081 square iniles. Bombay Dekhan is the name applied only to all that part of the tableland stretching from the ghat range eastward to the Hyderabad and British possessions.

The Karnatic is partly above and partly below the ghats; the greater portion of it is included between the river Kistna and the Tumbudra. Its inhabitants speak the Canarese language, and irrigate with the aid of tanks. In its south-west corner there are valuable forests, and cultivation is carried on in patcbes interspersed with forest. It includes the revenue districts of Belgaum, Canara, Dharwar, and Kaladgi, 18,860 square miles.

Sind is in the valley and delta of the Indus. It is the most northerly portion of the Bombay Presidency, is a highly arid region, but is fairly cultivated by means of canals led from the Indus river. Its population is of a very mixed character, differing in race, in religion, and in customs and habits.

In this presidency are some of the largest towus of India-

Ahmadabad, . . 124,000 Nadiad, . . . 28,000 Ahmadnaggur, : 39,000 Nasik, : $: 2_{24,000}$ Belgaum, : : 32,000 Poona, : : : : 129,662 Bijapur, : : 12,000 Satara, : : 29,000 Bombay, : . 773,196 Sholapur, . 59,000 Baroach, : : : 37,000
Dhulia, : Surat, : : 18,000 107,000

Bombay city is a creation of the British people.
The island formed part of the dower of Catherine of Briganza, queen of Charles II, who in 1668 transferred it to the English E. I. Company, on an annual rent of $£ 10$. But from prehistoric times, people from the S.W. of Asia, of Egypt, and of Southern Europe have in succession been trafficking in territories which are now under the jurisdiction of this presidency. Besides the aboriginal races whose advent is unknown, this presidency has descendants of Kathi, Getæ, Parthians, and Huns from High Asia.

From the early years of the Christian era until the middle of the third century A.D., the Sinha or Sah were ruling at Sehore; they were displaced by the Gupta, who in their turn fell before a native race ruling from Balabhi or Wullubhi, at the foot of the hills of Chamardee. In 770, Wullubhipur, the present Wulleh, fell to a foreign race. From this time parts of this region were held by the Chaura (746-942), by the Solunki Rajputs, and Mahmud of Ghazni (1024), Shahab-ud-1in (1174-1179), and Kutub-ud-Din (1194) harassed the northern parts. The Wagela dynasty was ruling in the 12 th and 13 th centuries; in A.D. 1297, Alif Khan, brother of Alaud-Din, suddenly appeared with a large force, defeated Kurun of the Wagela race, took Anhilwara, sacked Cambay, and destroyed Sidhpur and Somnath. Anhilwara had been to the west of India what Venice became to Europe; but in 1411 Ahmad Shah abandoned Anhilwara, and occupied as his capital Kuranawati, on the left bank of the Sabarmati. From that time till the opening years of the 19 th century, the region has been an arena on which Dehli rulers, the Rajputs, the Portuguese, the Mahratta dynasties, the Asof Jahi of Hyderabad, and the British have been striving for victory and dominion, each leaving some of its followers in the territories.

Its princes and chiefs in alliance with the British are about 363 in number. Their states have an area of 73,753 square miles, and a population of $6,941,249$; and the region between Kandesh and Sind, a distance of 400 miles, nearly all belongs to feudatory rulers.

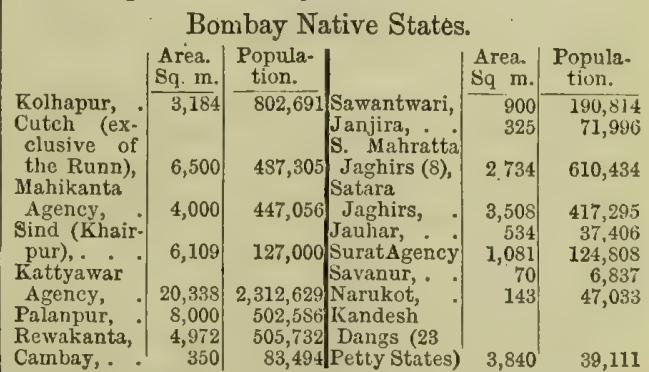

Amongst these feudatories are their Highnesses the Gaekwar of Baroda, the Rao of Cutch, the Jam of Navanagar, the Thakur of Murvi, the Jetwa Rana of Porebandar, the Gohil Rawul of Bhownaggur, the Jhala ruler of Hulwud-Drangdra, the Bhonsla raja of Kolhapur, the Nawabs of Cambay, Junaghar, Janjira, and Savanur, with many great families in the Southern Mabratta country whose ancestors held high offices under the Peshwa.

The 1881 census of the Hindus shows 716 castes in $11,438,033$ persons. There are 147 
Wania or Banya, 391,288 in number, have 68 subdivisions. The Jains, who number 215,033 souls, have 81 sub-sections; and $1,133,927 \mathrm{Mu}-$ hammadans are said to have 233 sections.

\section{Main Castes, Bombay British Territory.}

\begin{tabular}{|c|c|c|c|}
\hline & British. & Feudatory & Total. \\
\hline & 664,411 & & $1,011,198$ \\
\hline & 196,906 & 252,688 & 449,594 \\
\hline Agria and Mithagria, & 170,302 & 271 & 170,573 \\
\hline Berad (Beder), & 118,335 & 23,428 & 141,763 \\
\hline Bhandari, & 134,656 & 23,376 & 158,032 \\
\hline Chamar or Khalpa, & 163,102 & 40,015 & 203,117 \\
\hline Dhangar, . & 472,167 & 118,393 & 590,560 \\
\hline Dubla, & 106,332 & 2,723 & 109,055 \\
\hline Kunbi, Mahratta, & . $2,403,059$ & $1,082,509$ & $4,485,568$ \\
\hline Kunbi, Lewa, & . $\quad 215,928$ & 166,746 & 382,674 \\
\hline Kunbi, Kadwa, . & 100,365 & 59,252 & 159,617 \\
\hline Koli, Mahratta, . & 244,146 & 22,384 & 266,530 \\
\hline Koli, Talabda, . & 639,141 & 637,208 & $1,276,349$ \\
\hline Koli, Konkani, . & 120,006 & 5,943 & 125,949 \\
\hline Koshti, & 78,586 & 20,258 & 98,844 \\
\hline Potter (Kumhar), & 124,405 & & \\
\hline Lingaet, & 261,799 & 210,280 & 472,079 \\
\hline Lohana, & 234,303 & 114,211 & 348,514 \\
\hline Mali, . & 252,141 & 25,258 & 277,399 \\
\hline Mhang, & 161,970 & 32,703 & 194,673 \\
\hline Mhar, . & 852,523 & 345,207 & $1,197,730$ \\
\hline Panchamsali, & 288,875 & 2,371 & 291,346 \\
\hline Parit,. · & 58,107 & 11412 & \\
\hline Reddi, Roldsmith, : $_{\text {Gold }}$ & $\begin{array}{r}58,382 \\
130,486\end{array}$ & $\begin{array}{l}11,312 \\
39,306\end{array}$ & $\begin{array}{r}169,792 \\
1692\end{array}$ \\
\hline $\begin{array}{l}\text { Goldsmith, } \\
\text { Teli and Ghanchi, }\end{array}$ & 175,841 & 12,791 & 188,632 \\
\hline Wanjari (Brinjari), & 105,885 & 2,474 & 108,359 \\
\hline Other Hindus, & $2,346,332$ & & \\
\hline Aborigines, viz. Bhil, & - 341,634 & 200,972 & 542,606 \\
\hline Foresters, Thakur, & 302 & 7,776 & 8,078 \\
\hline Warli, & 8,397 & 54,787 & 63,184 \\
\hline Kathodi, . & 4,478 & 4,497 & 8,975 \\
\hline Other Aborigines, & . . 207,867 & 101,184 & 309,051 \\
\hline Muhammadans, . & $3,021,131$ & 753,329 & $3,774,460$ \\
\hline
\end{tabular}

Other castes, viz.-

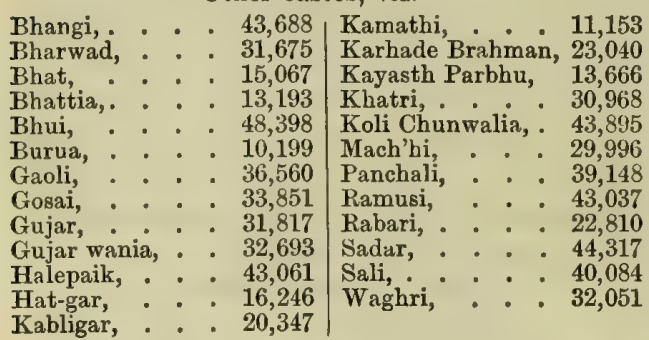

The trading classes of the Bombay Presidency are the Bhattia, Gujar wania, Gujerati, Jain, Konkani wania, Lohana, Mahrati wania, Lingaet, Marwari wania. The Lohana are chiefly in Sind, with a small number in Gujerat. The home of the Bhattia is in Cutch, a few in Gujerat, and in some numbers in Bombay city. Wania is a general term applied to all traders, and there are Gujar traders from Gujerat. The Gujerati merchants are the most widely spread of all this trading class, and are styled Wania, Khedayada, Lad, Modb, Marwari, and Srimali. The Bhattia, Jain, and Parsee are keenly engaged in trade; as also are the Bohra, the Khoja and Mehman Mubammadans.

Agriculturists are Kunbi, Koli, Jangam, Agria, Bhandari, Dubla, Lingaet, Panchamsali, Halepaik, Raddi, Mali, Mahratta, and Sadar. The Kadava Kunbi are very particular as to their intermarriages. But when a suitable match for a girl cannot be found, she is married to a bunch of flowers, which are afterwards thrown into a well. She is then a widow, and can be married with the natra rites. Or she is married to a married man, on the agreement that he divorce her on completion of the ceremony, and she can then be re-married by the natra cereinony.

Under the native governments, each of the village communities in the Dekhan had a portion of ground attached to it, under the control of the inbabitants. They were paid from different sources, in some from Meras lands, in others from Gairan or Gutkooli and Inam lands. In the Dekban and Carnatic table-land, the offices of the headman and accountant, as also those of the minor members of the municipality, are hereditary; but in North Konkan and Gujerat, the appointments are by selection. The village system has a deep root among the Mahrattas.

In Kolaba, the village menial, he who watches the gates and preserves the boundary marks, is the chief. The usual members of the village staff are the sonar, kasar, sutar (carpenter), teli, darzi, lohar, kumhar (potter), chamar, muchi, hajam (barber), parit (washerman), mhar, and mhang.

The shepherd races are the Bharwad, Brinjari, Dhangar, Gaoli, Gol, Gras, Kumbar, and Rabari.

The seafaring and fisher tribes are the Ambi, Bhoi, Gabit, Kharwa, Mach'hi, Mangala, and Moger.

'l'be chief forest tribes are returned as under:-

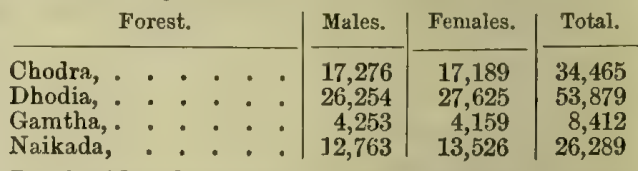

But besides there are the Bhil, Kathodi, Thakur, and Warli.

The aborigines, returned as numbering 562,678, are chiefly in the Panch Mahal district, where they form 30 per cent. of the population; in the Thar and Parkar they are 23 per cent.; in both Thana and Surat they form 19 per cent.; in Kandesh, $14 \cdot 6$ per cent. ; in Nasik, 10 ; and in Baroach, 9 per cent. Of their total number, 561,317 are illiterate, viz. 284,507 illiterate males, and 276,810 illiterate females.

Famine, Rainfall.-The rainfall in the Dekhan districts, always scant, at uncertain intervals even fails, and dearths and famines result. About the year 1801, aggravated by wars, a severe famine occurred, and in 1877 another occurred, owing to another failure in the rains. In the latter year the famine area extended over nine districts in all. Three of these districts - Kandesh, Nasik, and Satara-showed some increase in 1881 on the population return of 1872 ; but the decrease in Ahmadnaggur was 3.48 per cent. ; in Poona, 2.45 per cent. : in Sholapur, 19.02 per cent.; in Belgaum, 8.56 per cent. ; in Dharwar, 10.78 per cent. ; and in Kaladgi, 21.77. The natural growth of the population, had it not been for the famine, should have been about 8 per cent. on the population of 1872 .

\begin{tabular}{|c|c|c|c|c|}
\hline \multirow{8}{*}{$\begin{array}{l}\text { Ahmadnaggur, } \\
\text { Poona, : : } \\
\text { Sholapur, : } \\
\text { Belgaum, : } \\
\text { Dharwar, : } \\
\text { Kaladgi, . }\end{array}$} & \multirow{8}{*}{ 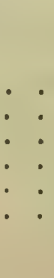 } & \multirow{2}{*}{$\begin{array}{c}1872 . \\
778,337\end{array}$} & \multirow{2}{*}{$\begin{array}{c}1881 . \\
751,228\end{array}$} & \multirow{2}{*}{$\begin{array}{c}\begin{array}{c}\text { Actual } \\
\text { Decrease. }\end{array} \\
27,109\end{array}$} \\
\hline & & & & \\
\hline & & 921,353 & 900,621 & 20,732 \\
\hline & & 719,375 & 582,487 & 136,888 \\
\hline & & 944,985 & 864,014 & 80,971 \\
\hline & & 989,671 & 882,907 & 106.764 \\
\hline & & 816,273 & 638,493 & 177,780 \\
\hline & & $5,169,994$ & $4,619,750$ & 550,244 \\
\hline
\end{tabular}




\section{INDIA; THE BOMBAY PRESIDENCY.}

There was thus an actual decrease of 550,244 on the population of 1871 , and a decrease of 963,843 on what the population should have been had it increased as in ordinary times.

The Languages current in this presidency are about forty in number, but the following sixteen cultivated tongues are the vernaculars of twentyone out of the twenty-three millions which form the total of the population:-

Hindustani, . 1,074,127 Goanese or Konkani,46,742 Nahrati, $9,286,608$ Tamil, . . 8,971

Gujerati,: : $7,535,100$ Hindi, . : : 20,274

Canarese, 498,234 Tulu, . . : 595

Sindi, . . 2,095,703 African, . . . . 2,088

Marwari, : : 192,974 Turkish, : . : 225

Baluchi, . : 151,326 Cutchi, . . . 11,715

Arabic, : . . 10,498 Panjabi, . . . 24,301

Persian, : . 4,308 Pushtu, . 8, 825

Portuguese, . . 4,260 Telugu, . . . 123,367

The other tongues spoken are Chinese, English, French, German, Somali, Spanish, Swedish, Bengali.

Religion.-The Hindus of the Bombay Presidency recognise themselves as worshippers at particular shrines, and the only prominent sects are the Walabha-Chariya, the Swami-Naraiyan, and the Lingaet.

The village deities are Kandi Rao or Kandoba, Venkoba, Vittoba, Ganpati, Hanuman, and Bhyroba. The Nag serpent and Hanuman images are in every village south to the Tumbudra. But the Mahratta are largely spirit-worshippers, and blood sacrifices are frequent. At Chinchor, near Poona, a Brahman family claim to be an incarnation of Ganesa. Krishna was accidentally killed near Pattun. His ashes are entombed there, and with the temples at Dwaraka are largely visited. The sun-worship continues there, and with it that of the lingam. The Jaina sect have the holy sites of Shatrūnji, near Palitana, Gorakhnath, A bu, Sita, Girnar, Gop-nath, etc. At Somnath or Someswara is a famed lingam temple, which was lately rebuilt by Ahalya Bai, widow of Holkar. The Parsee temples are chiefly at Bombay and Surat. They are mean structures compared with those of the Jaina sect, who delight in raising beautiful fanes for their sainted Tirthankaré.

On the Girnar mount is the Bhairava J'hap rock, from which devotees were wont to throw themselves; and the rock on which Asoka's edicts are cut is at the entrance of the valley which leads to the base of the mountain, from the Junagarh side.

The Brahmans are largely of Aryan descent, and differ chiefly in their lineage from founders of families. They might therefore be supposed to incline towards assimilation. Yet the Gujerati Brahmans alone have eighty subdivisions.

The Brahmans of Maharashtra are Deshast or Dekhanist, Kokanist, Karhadé, and Deorukha.

Those of Gujerat are the Audich, Anãwala, Mewāda, Modh, and Nagar.

The Gaur Brahmans are the Saraswat, Sashtekar, Shenvi, and Kanaujia (Kanyakubja).

The Havik are Canara Brahmans, and cultivate.

Deshast or Dekhani Brahmans include mostly those of the table-land in the Dekhan and Canara above the ghats. The Matrayani and Madbyandini are of Kandesh and Nasik, and the Palsé Brahmans of N. Konkan.

The Konkanist Brahman, also called Chitpawan, who rose to fame in the times of the Pesh was, mostly belong to the Konkan and Poona. They are a highly in tellectual race.

Jain religionists are proportionally numerous in Cutch, in the northern states of Gujerat, particularly in Ahmadabad. In Kolhapur and the Southern Mahratta country, many of the peasantry belong to this sect. The sect have about eighty subdivisions. The Oswal or Humbad, the Porwal and Shrimali are the chief. Jain husbands in Gujerat marry into Hindu families, The Hindu wife, while in her husband's home, conforms to his ritual; but on the many occasions on which she revisits her father's family, she reverts to the rites of her ancestors.

The Muhammadans number $3,021,112$. They are known as the Shaikh, Sayyid, Pathan, and Moghul; but in their religions they are of Sunni and Sbiah sects. The Sunni are followers of the four commentators of the Koran, Hanafi, Shafai, Hanbali, and Maliki. There are several Shiah sects, the more prominent of its branches being the Khoja, Bohra, and Mehman. One section of the Khoja follows the representative of Hasan-usSabbah, the Shaikh-ul-Jabl, or Old Man of the Mountain of the times of the Crusaders, whom they regard as an incarnation of Ali. About A.D. 1480 , a large body of Hindus of Cutch adopted this religion. Their leader, Aga Ali Shah, resides in Bombay, and succeeded his father, Aga Khan, a claimant for the Persian throne, who, after being driven from Persia, was long a Bombay resident.

The Bohra are a numerous, widespread, and wealthy sect. Their chief apostle, Dai or Mallab, resides in Surat. He names his successor. Those of Ahmadabad are of the Sunni sect.

The Shiah Bohra of Surat, those trading in Bombay, and a few others, are highly trained in the vernacular language of their own locality, and also in Urdu and Arabic.

The Mehman are cultivators, shopkeepers, artisans. They are believed to be converts from Hinduism. They are distributed through the Kurachee district.

In Sind, the Malik and the Mol Islam are other divisions, and in Aden are the Imamya and Zaidiya.

Fakirs are Muhammadan devotees; among them the fakir or darvesh belong to several schools, the Azad, Banawa, Chishti, Iraq, Rafai, Jalalia, Kadaria, Kalandaria, and Madāria. The founder of the last-mentioned school, Shah Madār, lived in Makhanpur, 60 miles from Lucknow. The Kadaria take their name from Abdul Kadar, Jalani, of Baghdad; Jalal Bokhari of Bahawulpur founded the Jalalia, and the Azad are a section of the Jalalia, and are celibates; and the Kalandari claim as their founder $\mathrm{Bu}$ Ali Kalandar, whose tomb is held in great reverence.

More than 60 per cent. of the Muhammadans reside in Sind. The Muhammadans are largely converts from some of the Hindu tribes, and descendants of immigrants from the adjoining districts of Baluchistan, Afghanistan, the Panjab, and the Indian clesert.

The Parsees are a prominent, though not a numerous body of the population. They have separated, on very unimportant points, into two sects, one of these, the Kadimi, or old firm, reckon by the old Persian era, which is a month earlier 
than that used by the Shahanshahi, Shensoi, or Rasini, who form 92 per cent. of the sect.

The Jews take a humble position, largely artisans, masons, carpenters. They came from the Persian Gulf or Arabia in the 15th or 16th century. They call themselves Ban-i-Israil.

The homeless broken tribes and predatory sections of the Dekhan population have received much attention from several writers.

In 1843, the Editor furnished to Jameson's Edinburgh Journal notices of the homeless tribes of the Southern Mahratta country. In 1852 , Captain Harvey, of the Bombay police, described seventy-one races wandering in that presidency; and in the following year, Major Douglas Graham enumerated thirty-eight of the moving communities in the Kolhapur territory, additional to those described by Captain Harvey. Little more than the names of these can find room here.

The Beder extend along the western part of the Dekhan plateau in all its extent, from the Tapti to Mysore. The Beder attained their highest power about the 16th century. Harponhully, in the Bellary district, was founded by two brothers, one of whom married a daughter of the Polygar chief of Chittuldrug. In A.D. 1517, Raidrug was given to a Beder chief who built the present fort. There are now two Beder chiefships, Zorapur and Gurgunta, to the south of Sholapur. Until early in the 19th century, the Beder in the Southern Mahratta country were under a Naik, who held the fortified village of Chikuldini, at the foot of the western hills; they were eminently predatory, tillage extending no farther than around their houses. They are a simple-mannered race, civil and good-humoured, and communicative, but very poor. The ancestor of the Zorapur chief aided Aurangzeb in the siege of Bijapur, for which he was rewarded with the title of raja, and was made a mansabdar of 5000 . They number 118,335 in the Bombay Presidency, and in all India 171,269 is the return. The Berad, 263,896.

The Bhaori, or Hirn Shikari, or Hirn Pardi, are a migratory race of fowlers and hunters, who are to be seen in most parts of the Peninsula. They snare game and wild animals of all kinds, jackals, foxes, wolves, leopards, tigers. They are of short stature, black and shrivelled, greatly wanting in intelligence, and timid in their intercourse with people in the towns to which they bring their captures for sale. The wornen earn a little by selling antidotes for snake-bites and scorpion stings,simple roots and parts of the animals they kill; and the jackal's horn, a projecting part of the frontal bone, is eagerly purchased from them as a charm against the evil eye. They are in all parts of India, but chiefly in Marwar. They have several tribes, Rathor, Mewar, Chauhan, Sawandia, Korbiar, and Kodiara. They dwell in distinct hunting-grounds, generally with rivers as boundaries, and have hereditary chiefs, termed Haulia, who assembles the tribe on occasions. One portion of the reward for capturing tigers is allotted to the river deity; the forest deity has another. They are wretchedly poor, with a few rags for clothing, but they steal from fields and grain-pits; and the settled population think they are wealthy, When the beard first appears, it and the hair of the head is cut once annually, for five successive years, but afterwards it is left unshorn. Their girls are married about the time they grow up; the rejoicings last five days, during which the couple, smeared with turmeric, remain seated on the ground. They burv their dead.

The Bhatoo, Doomur, or Khelati are a wandering race of acrobats, who arrange themselves into twelve sections, and move about in the districts of Aurangabad and Ahmadnaggur southwards to Hurrihur in Mysore. The men seldom exceed five feet in height, and the women proportionally smaller. At the period of adolescence, the young men and women are perfect models for the sculptor. Besides performing as athletes, the men exorcise demons from those possessed, and the young women are devoted to the gods, Kandoba at Chinchor, near Poona, being usually resorted to. When the girl is about five years old they lay her at the feet of the deity, and she becomes a Mūrli devotee. Most of their feats consist of leaping over or climbing up a bamboo. They sustain severe injuries; an old man of 60 years of age recollected having actually seen four people killed, and innumerable injuries of others, by falls from the bamboo. His own right elbow-joint bad been crushed. They usually take a partner from amongst the devoted women, who have grown too old to perform. They profess to worship Narayan, but the bamboo with which they perform is the chief object of their adoration; when cut down they have it consecrated, and term it Gunnichari or chief, and in their assemblies or Panchaits it is erected in their midst. They have no other idols, but they visit the shrines of Ellama, Tulsidas, Bhawani, Dawal Malik Peer, and Nursoba. They bury their dead, place food at the head of the grave, and draw favourable omens.

The Bhattia and Banya of Mandavi and other parts of Cutch have been trading since many centuries in Africa and Arabia, and were largely engaged in the African slave trade. The sailors of Mandavi are bold and skilful, and their pilots famed for their skill and daring.

The Bhil of Ajmir, Central Provinces, Hyderabad, and Rajputana number 141,972; and in the Bombay Presidency 341,634, chiefly in Kandesh, Panch Mahal, Nasik, Thur and Parkar, and Ahmadnaggur. In the western districts they are known as the Kale Puruj (black men), also as the Dubla (slender). North of the Nerbadda, in the Bhil marriages, the groom takes the bride on his shoulder and dances round a fire; it is called the Ghora-natch. Bhil clans are in a state of great moral transition. They were bold plunderers, their national weapon the bow. Those located between the Tapti and the Satpura Hills are known as the Wah-wih or Wa-sa-weh. The Bhil worship the image of a horse, named Baba Deo Ghora.

The Bhoi, fishers, palanquin-bearers, and seamen, extend across the Peninsula from Bengal to Bombay, wedged in between Aryan and Kolarian races in their north, and Gond, Teling, Mahratta races in the south. Mr. Plowden supposes them to be the Besta of Madras, 367,904; states 11,019 are in Berar, and 46,134 in Hyderabad, but does not mention the 48,398 whom Mr. Baines returns from Bombay.

The Chamar, 163,102 souls, are tanners, curriers, and shoemakers. Their name is derived from the Hindi word for leather. The Chamar are known as the Sultungar, Huralbukht, Dubali, Woji, Chour, 
Paradosh. The Sultungar dye and sell sheepskins; the Paradosh work in tent-making, etc. The higher rank Chamar make shoes; the Huralbukht dye skins red, and make shoes ; the Dubali, Woji, and Chour make bridles, pakhals, waterbags, and eat animals that have died of disease.

The Dubali section of the Chamar are 10,224 according to the 1871 census, but the memorandum placed before Parliament showed 73,000 Dubali in the Surat district.

Dohor or Dhor, Kutai, or Duphgar, dye skins of horned cattle, and are leather-workers, make pakhals, mot or well buckets, dol or hand buckets; the Kutai are cobblers, tent-workers, and eat diseased animals, as also do the Duphgar, who make leather oil bottles.

The Chamar of Bombay reckon as sections, the Chour, Dubali, Huralbukht, Paradosh, Sultungar, and Woji. They are all tanners, curriers, shoemakers, and saddlers, and all of them eat animals that have died of disease.

The Dher are the great labouring class of the Dekhan, and seem to have been its first proprietors. They were returned in 1881 as 110,040 , and the Mhar and Dher $1,197,730$, and these two are supposed to be identical. In physical appearance Dher, Mhar, Mala, Parayan, Chandal, Kahar, and Holar are identical, and number in all India $10,069,739$.

Gujar.-Dekhan people designate as Gujar all persons from Gujerat. The Duria race of Gujerat make their temples of cotton trees, around which they raise upright stones in rows or in circles.

The women of the Chaudria race of Gujerat dispose immense strings of cowries around their head and neck. They are dreaded as witches, and in 1836 numbers of them were to be seen deprived of their noses as a prevention of witchcraft.

Jharija, a Rajput clan ruling in Cutch, are spread through Cutch, Gujerat, and Kattyawar. They have until recently been largely given to infanticirle. They get wives from the daughters of the Jhala, Wagel, Sodha, and Gohil Rajputs. In 1818, Captain M'Murdo estimated the numbers of the Jharija in Cutch at 12,000 persons, of whom only 30 were women. They killed girls to avoid paying for them heavy marriage portions. In the Bombay Feudatory States, the females were 120,357 to 132,331 males. In British provinces, 93,722 to 103,184 males. The Rao of Cutch, the Jam of Navanagar, and Thakur of Murvi are Jharija, and it was the Murvi chief who, in Colonel Walker's time, 1818 , was the first to discontinue infanticide.

Kaikari, Hind., Mahr., Tam., TeL., Kaikadi, are makers of baskets from stems of cotton plants and palm leaves, but are all predatory.

Kattyawar people consist of Ahir, Koli, Kunbi, Lohana, Mher, Mehman, Rajputs, Rebari, and numerous Muhammadan tribes from Sind, Makran, Baluchistan, Arabia, Miana from Cutch, Badhel, Wagher of Okamundel and Sindi called Bawur. The Wagher of Dwaraka with the Badhail of Aramra were long the terror of these seas. In 1803,1858 , and 1859 they repulsed British troops, but in 1868 (8th May) the place was stormed, and their chief fell.

Kattyawar Babria, a peasant tribe, give their name to the Babria district.

The Koli, 2,219,540, are scattered from Raj- putana to the southern part of the Mahratta country :

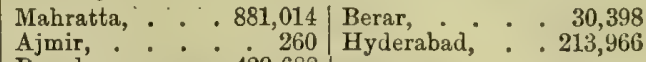
Baroda, . . 429,688

Koli are spread from the Thur and neighbourhood of Sind to Goa, and eastward to the Bhima. The Koli of Gujerat, up to the early part of the 19 th century, were a restless, turbulent race, despising agriculture, and living by plunder. Their chiefs were Rahtor, Chauban, Mukwana, etc., Rajputs who intermarried with the aborigines. The Dubla Koli, up to 1836 , were mostly hereditary slaves. One proprietor in S. Gujerat had 300 of them. Their owners employed them in fishing and husbandry, and hired them out. The Dubla are now chiefly in the Broach and Surat districts, and in the latter district were largely Hali or predial slaves, hereditary serfs to families of colonizing Brahmans of the Anawala section. They are a little higher than the Dhodia in the social scale.

Kayasth, the great scribe and writing class of all India, 2,159,813. More than half the writers of Bombay claim to be Kayasths.

The Maddikpor, as they call themselves, are a migratory race in the Southern Mahratta country, who are known to the people as the Kili Kyuntur, the Kotabu. 'They are in general tall, well-made men, of an olive-yellow colour. They arrange themselves into ten branches, - Avoti, Atōk, Naknar, Pachungya Ram, Sinda, Sarwar, Saskene, Mohrkar, Sengan, and Durwia, - and claim to be allied to the Koli or Barkar. They are beggars and fishers; their women earn a little by tattooing the foreheads of Hindu women, from which the tribe are called Putcha, and by knitting; but the chief occupation of the men consists in exhibiting transparencies painted on deerskin in bright colours, representing the story of the Mahabharata, which they relate to admiring crowds. They have also dancing puppets. They dwell in closelywoven grass huts. Every morning they worship the transparencies. The bamboo box is placed on a spot freshly covered with cow-dung, the lid is opened, and a prayer made for daily food. They are not restricted to one wife. They catch fish.

Mhang $(161,970)$ of Kolhapur were long notorious for their wild, untameable habits, their great cunning, hardiness, and predilection for outrage and robbery. They have been known to refuse an offer for their daughter's band because the young man was not an expert thief. They are illiterate, and make as their mark the figure of a knife. Many of their young women were devoted to the deity Kandoba as Murli, or attached as Jogini to the goddess Yellama, and on the 3d of ManghWud (February) they were accustomed to parade the streets in a state of nudity in honour of the goddess. Their tutelary deity is Jagadamba.

The Mhar and the Dher $(852,523)$ of the Bombay Dekhan, the Parwari race of the lands below the ghats, the Holar of the Canaresespeaking district, the Chandal of Bengal, the Pariah of the Tamil country, the Kahar and the Mala of the Teling nation, assimilate in physical appearance. The Dher is the great labouring class of the Bombay Dekhan, and seem to have been its first owners. The numbers returned of these races are $10,069,739$, viz, :- 
Mhar, . 1,434,446| Chandal, Dher, : : 110,040 Kahar, : : $1,840,856$ Dher and Mhar, 1,197,730 Holar, : * . . 447,421 Parayan, . 3,290,038

None of all these have accepted Brahmanism, but adhere to shamanist rites. They reside outside the villages, are labourers, weaving in the intervals of agricultural operations, are village servants and watchmen. They have several sections, and the Wusydong Mhar, the Tilwun, Wun, and Aduwun claim to have come from near Benares, and to be descended from a race whom they call Dong. They are nearly all illiterate.

The Miana of Mallia in Mucha Kanta, on the banks of the Muchu river, have a Thakur, but own allegiance only to their own Chowhattia or heads of tribes. They are of a turbulent disposition.

Murli.-Several of the Indian races, the Dhangar, Dher, Mhang, Koli, Mhar, and Manurwara, and occasionally even the bigher Hindu castes, under various vows, devote their girls to the gods. The deity to whom the girl is more frequently vowed, is some incarnation of Siva or his consorts. Amongst the Mahratta people on the western side of India, Kandoba is the usual Siva avatar to whom the girls are devoted, and his chief shrines are at Jejuri, Khanapur near Beder, and at Malligaon; but other deities, or even a dagger, are objects for their vows. The ordinary people believe that from time to time the shadow of the god comes on the devotee (deo ki chaya ati, ang par), and possesses the devotee's person (Murli ke ang ko bhar deti). These devotees are called Murli in Mahrati, Jogini or Jognidani in Canarese, and Basava in Telugu. They at times affect to be or really are possessed, during which they rock the body, and people occasionally make offerings to them as to an oracle or soothsayer, laying money at their feet, and await the possessing to hear a decision enunciated. The female deity to whom those near the Bhima river are devoted, is Yellama; the Bhuili race devote their Murli to Mata. Boys also are devoted, and styled Waghia, from Wag, a tiger. Near Amraoti it is to Amba and to Kandoba that the Murli and the Waghia are devoted. The Waghia does not associate with the Murli. At Amraoti, the people say that Kandoba moves on Sunday particularly, and selects a clean tree (clean Murli), whose body he fills.

Paggi of Gujerat must not be omitted. Their skill in tracking footınarks has acquired for them great fame.

The Ramusi, 43,037, are found in all the districts westward from Telingana to the edge of the Western Ghats. They call themselves Boyill or Boiggia. They claim to have three sections, as under:-

1. Bhaka.

a. Chauhan.

b. Jadu.

c. Roray.

2. Holga.

3. Behdar.

Though they have adopted Mahrati, they preserve a few words of their original Telugu for purposes of crime.

The Ramusi have continued predatory for about 500 years. When Ala-ud-Din Husain Gangui Bahmani (A.D. 1347-1358), heading the revolted troops of the empire, assumed sovereignty, and made war on the Hindu countries that encircled the kingdom of Kulburga, the Ramusi seem to have been detached from the Teling nation, and to have at first settled among the fertile valleys of Maharashtra around Kuttow, Musswur, Malloura, Nalgund, the hill fort of Maimanghar in Mandesh, and east of Satara and the town of Phulton, and now they are found scattered from Hyderabad westwards; and the valleys of the Maun, Neera, Bhima, and Peera rivers, with the hills and plains in the vicinity, the districts of Satara, Poona, and Ahmadnaggur, give shelter to their desceudants, who are thus scattered through a region lying between lat. $17^{\circ}$ and $20^{\circ} \mathrm{N}$., and long. $73^{\circ} 40^{\prime}$ and $75^{\circ} 40^{\prime} \mathrm{E}$. But in this wide extent 40,000 is perhaps the utmost number of their people. They are generally ill-favoured, but not dark coloured, short statured, but muscular and capable of untiring labour. The women are even more ill-favoured than the men, but are active and hardy, are very much attached to their children, and are strictly virtuous. They are pantheistic, but their favourite deity is Kandoba or Kandi Rao, named also Martinda, to whom, as also to Bhawani and Rama, they made their vows on their plundering expeditions.

The Bhaka Ramusi are hardy, active, and enterprising, covetous, rapacious, and treacherous. From the time of Sivaji they plundered and were the ready instruments of rebellion, and successive rulers retaliated by massacring them on every opportunity. They were finally put down in 1832 by the British, when their leader Oomiah was hanged on the $3 \mathrm{~d}$ February. During the unquiet times of the Mahratta rule between 1790 and 1818, they had gained head, and kept the country disturbed. They have now settled down to husbandry, and some of them are employed as watchmen, an office which in several towns is hereditary, the Rakhwala being one of the municipality. The Holga branch arrange themselves in 13 sections; their language is nearly Canarese. Though not hereditary robbers, many of them are decoits, highwaymen, and burglars, and often commit murder when engaged in robbery. They are part of the commune, as village watchmen, with shares of the village fees, and some are cultivators. In olden times they undertook to track up all robbers, and if they failed they had to make good half the value of the property plundered.

HYDERABAD is a principality in the centre of the plateau of Peninsular India. It is ruled over by a Muhammadan sovereign, whose ancestral title, Nizam of the Dekhan, was bestowed on the founder of the family by the emperor of Dehli, but the dynasty is known as the Asof Jahi. The territory has been gathered under one sway from portions of four great nationalities, - Telingana in the east, Karnatica in the south, Maharashtra in the N.W., and Gondwana in the N.E., all of them peopled by non-Aryan races, amongst whom are some Aryans, with Muhammadans, and many fragments of broken, homeless, wandering tribes. The area is 81,807 square miles, and its population $9,845,594$, being 120 to the square mile, the great bulk of them professing some form of Hinduism.

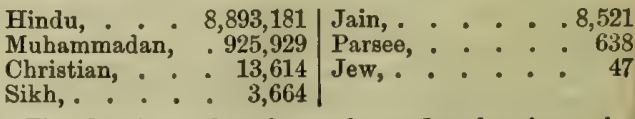

The dominion has been formed only since the 


\section{INDIA; THE HYDERABAD STATE.}

middle of the 18th century, and there is not yet any approach to a fusion of the masses into one nation, the rulers and their officers and their army being all alike foreigners. There has never jet been any Teling, Mahratta, or Canarese who has been placed in a high office of the State, although 85 per cent. of the population belong to these three races. The existing position of the races will be seen from the languages now spoken :-

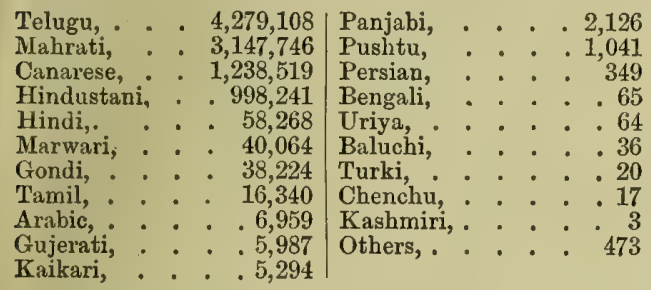

Since 1784, an ambassador, styled a Resident, has been to this court, but they have been frequently changed; from 1784 to 1797 inclusive, there were $4 ; 1805$ to 1853,17 ; and 1856 to 1884,15 .

Since the middle of the 19th century, the Berar portion of the Nizam's dominions of 17,711 square miles has been assigned to the British, in order to provide from its revenues funds for the pay of the Hyderabad contingent of artillery, cavalry, and infantry, which the Hyderabad State by treaty enrol for mutual defence. A census has been taken in 1881 of each of these two portions of the Hyderabad territory, but only that for Berar is to hand. Mr. Plowden, however, in his general report for all India, has given the following as the castes and races of the Hyderabad part:-

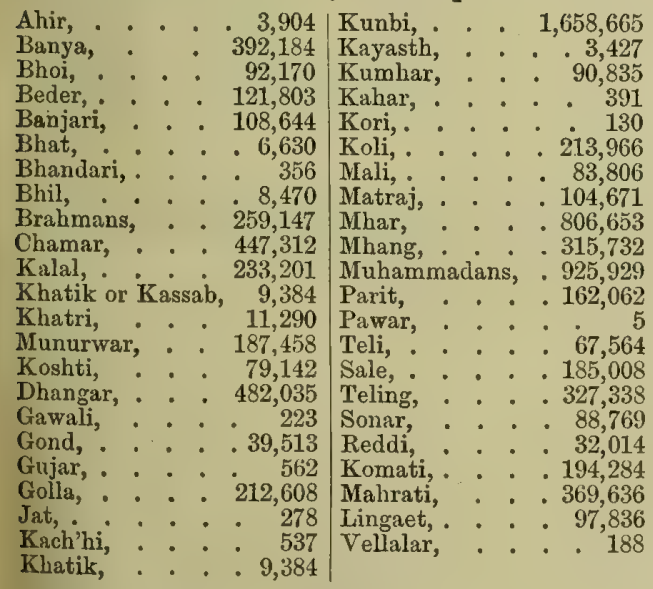

The Gadaria, Jogi, Kamma, Pasi, and Uriya make an additional number.

On the boundary line in the middle course of the Tumbudra and the Kistna rivers, and in the valleys of their affluents, the Bhima, the Gatpurba, and Malpurba, are several chiefs meriting notice. Until the year 1839, a family of Pathan Muhammadans ruled at Kurnool on the right bank of the Tumbudra, with the title of Nawab. In that neighbourhood a Syud family still rule as nawabs of Banaganapilly. Farther west are the Reddi chief of Gadwal, the Mahratta chief of Sundur, one of the Ghorpura family; the Kshatriya raja Narapati of Anagunda, claiming to be a descendant of the great king Rama of Vijayanagar, who was overthrown by the combined armies of the four Muhammadan kingdoms of Golconda, Kulburga, Bijapur, and Ahmadnaggur; the Pathan nawab of Shahnur, the Ghorpura chiefs of Gujundargarh and Akalkot, and at Gurgunta and Beder Sorapur are descendants of thatBeder soldier Pid-Naek, to whom Aurangzeb, for aid given at the siege of Bijapur, granted a small territory in the Raipur Doab, and who are now feudatories of the Hyderabad Government. The Beder of Sorapur drink spirits, eat the hog, crocodile, porcupine (sarsal), manis (uli), iguana (ghorpara), cow, buffalo, cat, rat, bandicoot (Mus gigantea), and jerboa rat. Eminently predatory, they gave their name to the Pindara who for nearly a century kept all India in commotion, and in the mutiny and rebellion of 1857 the Beder of Sorapur rose, but were suppressed, and their chief, sentenced to transportation, destroyed himself en route. The descendants of Pid-Naek are tall, handsome, fair men, fond of the chase, hunting the wild boar with powerful dogs. The town of Sorapur is in the centre of a rocky amphitheatre, admirably suited for the location of a predatory band.

The Muhammadans of Hyderabad are not cultivators, but several of them have State revenues in jaghir. Of those in Berar, only 1296 are professional. The Syuds of Kulburga, Gogi, and Hyderabad seem impoverished; those of Pathan, Moghul, Arab, Persian, and Habshi origin all prefer military employ, and rarely take to the plough. Before and after the fall of the great Hindu kingdom of Vijayanagar, several Muhammadan dynasties had ruled in parts of the lands now forming the Hyderabad territories, amongst others, the Nizam Shabi of Ahmadnaggur, the Adal Shahi of Bijapur, the Bahmani dynasty of Kulburga, the Imad Shabi of Ellichpur, the Kutub Shahi of Golconda, and the Asof Jahi, who are now ruling, and the greater part of the Muhammadans are now to be found in the cities which since the 14th century have formed the capitals of these rulers. They may be about 7 per cent. of the population.

Goolar or Baid, about 2000 in number, are dwelling in the villages between Hyderabad and Poona, but a very considerable number reside in Seroor, 10 miles from Kulburga, and near Hiraphool, and between Kulburga and the Bhima. They call themselves 'Gol,' also Hanam-Gol, from Go, cow, and claim to be of the cowherd race. The people, however, designate them Adavi Goolar and Gaddha Goolar, that is, country or wild Goolar and donkey Goolar. The Adavi Goolar are also designated Bai-Mandel-Wanlu, also Dowai-Darman, also Dowa-Dene-Walé, because the men are travelling herbalists, collecting medicinal roots and plants for the native physicians. They are poor, and the young people and the women beg. Their physical appearance and colour are strikingly similar to those of the Rajputs, only they are not so tall, and are more slender. They have no resemblance to any other of the races in Southern India. They do not eat the cow or bullock, but use the goat, sheep, hare, and other creatures; like the Beder, they eat the crocodile. They do not intermarry with the Gaddha Goolar. The latter dwell in the outskirts of towns and villages; the men wear beards, and rear dogs and asses; 
INDIA; TIE BERAR ASSIGNED DISTRICTS.

they hunt for wild animals, and eat the jackal, the crocodile, the porcupine, and the iguana. They are goatherds, and the wornen beg.

The Goorao, the Vidur, and the Krishna pakshi are offspring of Brahmans and women of the lower castes. Some of the Goorao are employed in temples, others are clerks.

BERAR has an area of 17,711 square miles, with a population of $2,672,673$, being 151 to the square mile; the females are 88,311 fewer than the males. It is also designated the Hyderabad Assigned Districts, and is administered by the Indian Government, arranged for revenue purposes into the six districts of Amraoti, Akola, Basim, Ellichpur, Buldana, and Wun. A considerable portion of its eastern districts belonged to Gondwana, and there are still there many small broken tribes of that race; but since the latter years of the 15th century, it has had a succession of Muhammadan and Mahratta rulers, the Imad Shahi of Ellichpur, Nizam Shahi of Ahmadnaggur, the Dehli emperors, the peshwas of the Mahrattas, the Azof Jahi of Hyderabad, and now the British.

How the followers and the agricultural tribes of the surrounding nations have taken advantage of these changes to occupy the arable lands, will be seen from the current languages, viz.Mahrati, . 2,207,514 English, . . . 571 Hindustani, : 302,601 Panjabi, . . . 189 73,344 Pushtin,

'T'elugu, : : . 39,435 Arabic,

Korku, : : 29,039 Sindi,

Gujerati, . . 17,043 Bengali,.

Kaikari, : : 1,496 Persian, Baluch,

Canarese, . . 1,487 German, French,

Tamil,

792 Chinese,

Out of the whole number of inhabitants, there are only 73,344 speaking Gondi and 29,039 of the allied Korku, the others are foreigners.

In 1881 the more important of the trades, tribes, castes, and sects were as under :-

Banjari,. . . 27,495|Koli, . . . 30,398

330 Komati,

Bhat, : : : 2,520 Kori, : * : 68

Bhoi-Besta, . 22,961 Koshti, 14,785

Brahmans, . . 65,754 Kumhar, . . 20,066

Chamar, . . 26,885 Kunbi, . . . 834,174

Dhangar, : . 74,559 Lingaet, . : : 9,859

Gaoli, : : . 30,159 Lodhi, : : $\begin{array}{r}1,773 \\ \text { Mali, : } 195,981\end{array}$

Gujar, : : : 6,329 Mhang, : : 46,366

Jain, : : : $\quad 6,329$ Mhang, : 89 Mhar, : 307,994

Jogi or Nat'h,. . 9,113 Pasi, . . . . 256

Kahar, . . . 247 Rajputs, . . 44,133

Kalal, : : 14,943 Salé, . . . 9,126

Khatik, : . 4,487 Sonar, . . 27,548

Khatri, : : 2,015/Teli, . . : 75,552

The chief aborigines of Berar are 164,941, as under :-

Andh,

Arakh,

Balai,

Bhil, .

Kollam,

Kolabhuté,

Ahir. - Berar is the most southerly part of British India in which this designation is found; even the Gaola race may be said to cease here, although in Hyderabad there are a small number of Gaola who keep cows and buffaloes; but the Dhangar, being the shepherd race, occupy the central Dekhan as herdsmen, and farther south the Kurubar, shepherds, from Kurı, a sheep.
The Ahir, before the Christian era, were in the N.W. frontier of India, from which they passed to Lower Sind and on to Gujerat. When the Kathi arrived in Gujerat in the 8th century, they found the Ahir there, and part of the Ahir had advanced to the east, and into Kandesh. An inscription in one of the Nasik Buddhist caves shows that early in the 5th century that country was under an Ahir king; and in the Puranic geography, the region from the Tapti to Deogarh was called Abhira, or the country of herdsmen. The Ahirs held dominion over the wild tracts of Gondwana, parts of Kandesh and Berar, and possessed the fortresses of Asirgarh, Gawilgarh, and Narnala; and in the 12 th and 13 th century they were rulers of Deogiri or Dowlatabad. Those of them who moved towards the WainGanga have become Gawari, and in the Mailghat they are the Gaolan.

In Berar, the Dhangar sheep farmer race are of two sections, the Kota Pullia Dhangar, who keep sheep, and the Barji Hatkar, or 'shepherds with the spear.' The latter still hold much land on the borders of the Nizam's territory, and, until the British domination, were notorious for pugnacity and rebellion; they even still continue a quarrelsome and obstinate race. They are supposed to have come from Hindustan in twelve tribes, and been impelled by the Gonds towards Hingoli and Basim, which locality got the name of Barah Hatia, or the twelve tribes. They are found from Basim, on the north of Hingoli, into East Berar, where they occupy the hills on the north bank of the Pain-Ganga. The Hatkar are fine, able-bodied men, independent but arrogant; many of them never shave or cut the hair of their face.

The Hatkar arrange themselves into the Poli, Gurdi, and Muski clans, all of whom eat with the Kunbi. They burn the dead who die in battle or in the chase, but inter those who die of disease, seating the body cross-legged, with a small piece of gold in its mouth.

Gaoli have been settled from time immemorial along the Satpura range, and once were dominant in the hill country around Baitul.

The Bhil of Berar occupy the eastern slopes of the Gawilgarh range to its western extremity, and stretch far westwards into Kandesh. They belong to the Turvi clan; all now are Muhammadans. Those who live along the outskirts of the Satpura have embraced Muhammadanism. All along the Gawilgarh skirts, the Kurku, the Gond, and the Bhil bave settled down to agriculture wherever the country has been cleared, and are now honest, peaceful, and inoffensive.

Gharpagari, of the Amraoti district, profess to have power to prevent the fall of hailstones on a field.

Mailghat is a strip of country along the course of the Wardha river, occupied by the Raj Gond races, the Agarmunde, Bhoya, Pardhan or Bard, Ballai, and Nihal; also by the Mugi, who are fishers and fowlers.

Gond occupy the Mailghat and the southern skirts of its bills, extend in the north-east into Sirguja; they are found along with the Khand and Urya in Karal and Kalahandi or Kharond; in the south they form the mass of the population in Bastar, form part of the population of Jeypore, and occupy the hills along the left bank 
of the Godavery about Nirmul, and on the west are intermingled with other inhabitants of Berar for 30 miles from the right bank of the Wardha. Gondi is spoken by $1,079,565$ of people :-

Bengal, . . . 1,294 | Hyderabad, . . 38,224 Berar, : . 72,344 N.W. Provinces, . 201 Central Provinces, 967,502

Andh, along with the Gond, the Korku, and the Kolamb, inhabit the Mailghat and the southern skirts of the hills. These four tribes each speak a separate language, but resemble each other in their physical appearance, and all have features quite distinct from the inhabitants of the villages. They reside also in the Maiker, Amraoti, and Wun districts, but in that last mentioned are a wild and uncivilised race. Andh are also called Pardhan, and are said to be helot Gond, but they are cultivators. They eat meat, but not the flesh of animals which have died of disease.

Banjara have the three sections, Charan, Labhana, and Matturiah. They eat together, but do not intermarry. Their war and love songs and their language are in a form of Hindi. They are illiterate.

Kaikari of the Mahratta country and Berar and Central Provinces are supposed to be the same as the Korcha of Bellary, the Korawa of N. Arcot, the Koragar of the Canara jungles, and the Yerkuala of Madras, all skilful thieves. They have 1272 divisions.

Kaikari, in Berar, are a migratory and predatory race, ostensibly basket-makers, using the midrib of the fronds of palms, also cotton stalks. In 1867 an effort in Berar was made to compel them to settle, but they preferred expatriation.

The Kolam extend along the Kandi Konda or Pindi Hills, on the south of the Wardha river, and along the table-land stretching east and north of Manikghar, and thence south to Dantanpalli, running parallel to the right bank of the Pranbita. They eat with the other Gond, but do not intermarry.

The twelve Gond clans are-Padal, also called Pathudi; Pardhan, Raj Pardhan or Desa ; Dholi ; Ojhyal; Thotyal; Koilabhutal; Madya, called Jhodia in Bastar ; Kolam ; Badiya Hullwa ; Gaiti Gond; Moria Gond; Kur or Muasi.

They are also said to arrange themselves into 13 sections, viz.-

\begin{tabular}{|c|c|c|}
\hline $\begin{array}{l}\text { Manes. } \\
\text { Gowari. } \\
\text { Raj Gond. }\end{array}$ & $\begin{array}{l}\text { Kahilwar. } \\
\text { Thotli. } \\
\text { Pardhan. }\end{array}$ & $\begin{array}{l}\text { Jaduwan. } \\
\text { Kohalin. } \\
\text { Andh. }\end{array}$ \\
\hline
\end{tabular}

The Madya are savages on the Beila Dila Hills and in the remoter parts of Chanda; the sole covering of the women is a bunch of leaf twigs in front and behind, kept in position by a string round the waist.

The men and women of the Gond never associate at work, but labour apart. A Gond desirous of having a wife, and having resolved on a particular girl, takes with him a band of his comrades to the field where the women are at work, and he suddenly, alone, runs towards and attempts to capture her. His comrades will not, however, aid him to carry off the girl unless he succeed in touching her hand before she reach the village shelter. By touching the girl's hand, the marriage contract is sealed and cannot be broken; nevertheless the women often fight every inch of the ground, inflict the most serious hurt and some-

times shameful defeats, continuing the contest even after the bridegroom has touched the bride's hand, and if the village skirts be reached, the men turn out to aid the women, and pursue the attacking party back to their own village.

Koli, of Berar, are the Mahadeo Koli, Bunkar Koli.

Kunbi constitute a large part of the cultivators in all Maharashtra, in the north-western parts of Hyderabad, in Berar (681,368 souls), in the Central Provinces.

The Kunbi, in Berar, allot themselves into 11 classes-

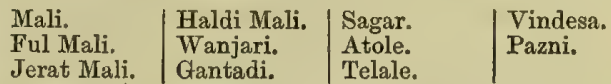

With the exception of the Haldi Mali and Pazni, they have Roti vya whar amongst each other but not Beti vya whar, i.e. they eat with each other but do not intermarry. The Kunbi and Mali alone, of the Sudra people, are 834,588 souls. The Kunbi and Mali eat flesh, drink liquor in moderation, and their widows may all re-marry if they choose, except those of the deshmukh, who follow the high caste custom.

Since Berar came under British rule, many immigrants have added to its people, and the revenue has greatly improved. Receipts, Rs. 1,01,73,849; expenditure, Rs. 87,83,350; and there are now 896 schools, with 35,891 scholars.

The prominent religious sects are the-

Lingaet.

Jain.

Vaishnava.

Muhammadan.

Sikh.

Manbhao.

Sanyasi.

Rai Dasi.

Nanik Shahi.

Byragi.

Jogi.

Religious mendicants-

Bhat.

Thakur.

Gurao.

Manbhao.

Many deified persons-

Krishna.

Siva.

Ganpati, Ganesh.

Bhawani.

Surya.

Rama.

Parasurama.

Vithoba.

\section{Gosawi. \\ Byragi. \\ Nath. \\ Gondhali.}

Hanuman.

Rukmini.

Kandoba.

Bhairava.

Ram-das.

Tukaram.

Maneshwar.
Kandoba is largely worshipped in the Mahratta country, and is assumed to be an incarnation of Siva. In Berar, until lately, women used to swing themselves by iron hooks fastened into their flesh, after first naming their petition to the priest; in his honour, also, men drew strings of heavy carts by means of iron hooks fastened into their bodies. The Wagher beg in his name, and the Murali are devoted to him. Many houses have a silver image of him, sword in hand, on horseback, before which, on the Champa Shasti, they wave a copper platter, bearing cocoanut, jagari, turmeric, and sixteen small lamps made of dough. His votaries offer him brinjals and onions, which they may not use themselves before this day. He rides on a black dog, which is worshipped. He is worshipped on Sunday, and is also called Martand (the sun).

The Kunbi and Mali worship at Muhammadan shrines. No non-Hindu is allowed to approach a temple; his touching it is pollution. They have as deities, stones daubed. Sikhs are few in 
Hyderabad or Berar, and are mostly of mixed descent. The sect have a college at Nandeir, on the left bank of the Godavery. On the 10th day of the Dasara, in Berar, a married girl is worshipped.

Some Mhar worship Vithoba, the god of the Pandarpur temple. Others worship Varuna's twin sons, Meghoni and Deghoni, and his four messengers, Gabriel, Azrail, Michael, and Anadin. They worship also Kali Nik, Wackach, Sari, Gari, Mai Kans, Dhondiba; likewise the four Bhairava, Kal, Bhujang (snake), Samant, Andhut; the heroes Bhima, Arjuna, Lachman, Ch'hatrapati (Sivaji), and others; and the demons Aghya and Jaltia Vital. In their worship, some are said to officiate naked; others with their clothes wet and clinging. The statues of Vithoba and Rukmini are nude. The Mang worship Mahadeo; he swears by the dog. The Dukar Kolhati hunt the wild boar, and kill a boar when they worship Bhagwan every year or so.

The Manbhao are a small order of Conobites. They admit both sexes, who are celibates, though they form one community. They wear black clothes, and shave their heads. One of their principal mat'h or monasteries is at Rithpur, near Ellichpur. They are all over Maharashtra; some have married and settled down in villages. They worship Krishna and Datatri; they are of quiet, inoffensive manners, and their nuns and monks wear black clothes. Their number in Berar is only 3519 . The sect was founded about the 17th century by Kishn Bhut, a Brahman, who is said to have had four sons by a woman of the Mhang or leather-worker race. At the present day celibacy is professed by the men and women, and both wear a black cloth tied round their waist, forming a skirt, to indicate that they do not recognise any distinction as to sex. Their name is said to be Maha Anubhao, great understanding, abbreviated into Manbhao. The Gharbari are laymen, and the Byragi, who wear black clothes, are both monks and nuns. They are hated by the Brahmans. They do not admit the low-caste Mhar.

Datatri is a son of the rishi Atri (supposed to have been a triune incarnation of Brahma, Vishnu, and Siva). The Gharbari are lay members; the monks and nuns wear clothes stained with lamp-black (kajal). They are admitted into the order by the chief monk cutting off a portion of the hair; the monks and nuns are clean shaven. They are prohibited drinking the water of any village in which there is a temple to any goddess; they are not to drink the water of a village in which a man has been murdered or poisoned, or been killed by falling into a well. If a man die a natural death, they must visit a graveyard before they eat or drink. They will not cut or break down a tree, large or small. Tulsi Bai, the mistress of Jeswunt Rao Holkar, was a Manbhro woman. The Gosawi, Manbhao, and Gondhali recruit their ranks from Sudras of any caste.

Trees. - In Berar, certain families hold in honour certain trees and plants; and at marriage times branches of those trees are set up in the house.

Maroti is a deity of the people of Berar, to whose guardianship they confine their boundaries. Numberless temples, shrines, and images are erected to him, but no specific rites are celebrated to his honour. He is nowhere styled Hanuman, and only the educated are acquainted with the legends which suppose him to have been chief of the Langur monkey tribe.

Marriage.-In Berar, a widow is married by the 'pat' form, an inferior ceremony. The groom is not married to the woman, but to the swallowwort plant, or to a ring or a pitcher. The twigs of five plants are used, - the mango, the shami, jambul, apata, and swallow-wort. The trees are worshipped, a twig is cut from each; in the bride's house they are placed in an earthen pot, around the mouth of which is bound a strip of yellow cloth, torn from a woman's bodice. They are subsequently worshipped at the Deokundi ceremony. After death, when the corpse bas been washed, dressed, and anointed, a sprig of holy basil is placed on the dead man's mouth or ear.

In Berar, most Hindu women are allowed to make a second marriage. Ahir, Gujar, Jat, the younger brother marries the widow of the elder brother.

Vidur and Krishnapakshi are the same. They are the offspring of Brahmans with women of inferior caste.

MYSORE.-The great central plateau of the Peninsula of India includes the Mysore territory, the British districts of Salem, Bellary, Cuddapah, Kurnool, the Hyderabad dominions of the Nizam, the British districts of Belgaum, Dharwar, Sholapur, Poona, Aurangabad, and the assigned province of Berar. They present vast undulating plains, of various elevations from 1400 to 3000 feet above the sea, almost entirely devoid of trees, and with but little low jungle. Here and there low ranges of hills appear, and isolated rocks, hills or drugs, mostly bare or springled with a low brushwood. Towards the north and west of this plateau region large steppes occur. The surface is more broken by hills and ravines than in the south, with a greater abundance of low jungle and stunted trees. In many of the ravines are timber trees, and towards the more northern portions there are considerable tracts of long grass lands or 'rumnabs.' The whole of this tract was formerly named the Dekhan, from the Sanskrit Dakshina, meaning the south. The prevailing character of the soil in the Salem and Mysore portion of this region is a reddish loam overlying gneiss and granite rocks; in the Ceded Districts, in the eastern part of Hyderabad, and in the Southern Mahratta country, it is mostly regur or black cotton soil, overlying sandstone, limestone, and claystone strata, with patches of red soil, but regur is the only soil visible over all the great volcanic outburst of greenstone that covers Berar, Poona, and the west of Hyderabad, and north to the Nerbadda.

When Tipu Sultan fell at the storm of Seringapatam, the British placed on the throne a descendant of a former Hindu ruler, but his administration was not successful, and in 1832 Mysore was placed under a British officer as commissioner. On the 25th March 1881, on the present ruler coming of age, the country was restored; but, by treaty, Bangalore and its outskirts, 12 miles square, was assigned to the British. It is the British cantonment in Mysore.

Mysore, Maisur, or Maheshwar, as a State is in alliance with the British. Its ruler, H.H. the Maba raja Chamarajendra Wodayar Bahadur, is a Hinau prince, and was adopted by his childless pre- 
INDIA; THE MYSORE STATE.

decessor. The territory has an area of 24,723 square miles, and in 1881 there was a male population of $2,085,842$, and females $2,100,346-$ total, $4,186,188$, being 169 to the square mile. Ten years before, in 1871, a census was taken, which showed males 2,535,924, - females $2,519,488$-total, $5,055,412$, or 204 per square mile. Loss of males, 450,082 ; loss of females, 419,142 ; total loss, 869,224 . The loss of the male population was 18 per cent., and that of the female 16 per cent.

The loss in the Hindu and Buddhist population was 864,343 souls in $4,820,688$, or at the rate of 18 per cent. on the population of 1871 .

The Muhammadan loss was 8517 in 208,991, being at the rate of 4 per cent.; but Christians increased 3573 upon 2566.

The Mysore people recognise 101 castes in their country, but in the census of 1871 the enumerators returned 413. The more important are as under:-

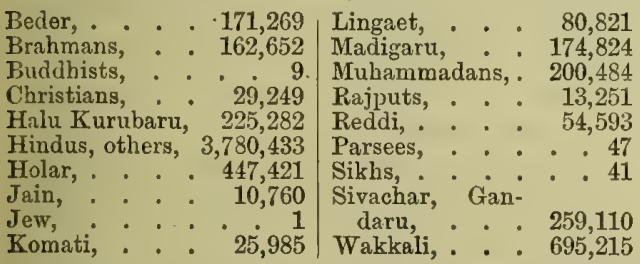

The Banajiga (29,866), Idiga Nagarta (4888), and Tiglar, market gardeners $(28,780)$, are also named. The Idiga in Coorg collect the palm wine.

In 1871 the principal tribes were named as under :-

Brahman, . . . 169,637|Lumbana, . . . 33,000

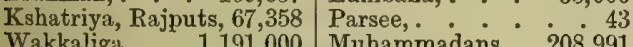
$\begin{array}{lr}\text { Wakkaliga, : } .1,191,000 & \text { Muhammadans, . 208,991 } \\ \text { Kuruba, : } 371,000 & \text { Buddhists, Jains, } \\ 13,263\end{array}$ Kuruba, : : : 371,000
Baidara, : 262,000 Christians, . . 25,676 Korawa, . . 36,600

There have been many immigrants from surrounding nations, as the languages current in 1881 will show, but the country is essentially Canarese:-

Hindustani, . 231,450, Konkani, . . . 4,370 Telugu, . . 637,230 Coorgi,. . . . . 21 Mahrati, . 67,871 Persian, . . 118 Tamil, : : 130,569 Arabic,. : : :40 Gujerati, . . . 1,181 Pushtu, . . . . 87 Canarese,. . .3,095,647 English, . . . 8,148 Mnlealam, : . 332 Sindi, : : 17 Tulu, . . . . 8,941 Other ten tongues, . . 30

Many of the Muhammadans are descendants of immigrants, and others are of Hindu origin. During the reigns of Hyder Ali and of his son Tipu Sultan, numbers of Hindus were forcibly converted to Muhammadanism.

The Labbai are commercial. Colonel Wilks says that in the 8th century, during the administration of a cruel governor of Irak, Hajaj Bin Yusuf, members of the house of Husain abandoned their native country, and settled in the Konkan and to the east of Cape Comorin, and were the ancestors of the Labbai. See Labek.

The social customs of many of the Hinduized and aboriginal tribes differ from those of other parts of India.

Brahmans.-Among the Smartta and Madhava the mother will not eat anything cooked by her daughter until the birth of her daughter's first child, as she only then becomes ceremonially pure. The Sanketa or Sanketi Brahmans of Mysore are an offshoot from a Smartta colony in the Madura district, and speak a corrupt Tamil. Their women tie their saree cloth tight round the body.

The Wakkali or Wakkaliga is the great agricultural body throughout the Canarese-speaking districts. Their number in Mysore is 695,215. There are eight sections, - Nonaba, Gangadikara, Maliya, Morasa, Lalgunda, Reddi, Kamme, Kunchatiga, and Nadavar. They eat together, but only marry in their own respective clans. Some of the women of the Morasa section of the Akaliya had to sacrifice a finger of their right hand previousiy to piercing the ears of the eldest daughter, preparatory to her betrothal. Placing the finger on a block, the blacksmith with a chisel and hammer strikes it off at a single blow. If the girl to be betrothed be motherless, and the mother of the boy to whom she is to be betrothed have not before undergone the amputation, she has now to permit the sacrifice. See Wakalu.

The Holar or Holiyar is the great servile race of all the Canarese-speaking countries, taking the place of the Mahratta Mhar, the Hyderabad Dher, the Teling Mala, and Tamil Parayan.

The Kulawadi, village policeman, beadle, henchman of the headman of the village, boundary commissioner, is invariably a Holiyar. The Holiyar are farm labourers, watch the herds, and one of their number is generally priest of the village goddess. Every village has its Holigeri or Holiyar's quarter outside the village boundary hedge, and they object to and prevent Brahmans passing through their hamlet. If attempted, they turn out in a body, slipper him, in former times even to death. Other castes may approach to the door, but must not enter. If by chance a person do get in, the owner tears the unwelcome intruder's cloth, ties up some salt in a corner of it, and then turns him out. This is supposed to avert any evil which his presence might have brought on the owner of the house. At Melkot, the chief locality of the followers of Ramanuja, and at Beleru, where there is also a deity worshipped by Brahmans, the Holiyar bave the right of entering the temples on three appointed days of the year. At Melkot they have the privilege of dragging the car. Captain Mackenzie mentions that all castes in the village recognise the Kulawadi as the rightful owner of the village. If a question be raised as to the village boundary, the Kulawadi is the only one competent to take oath as to how the boundary ought to run. The old custom was for the Kulawadi to place on his head a ball of earth, with some water in the centre, and to march the boundary. If he march wrongly, the ball falls to pieces, the Kulawadi dies in fifteen days, and his house becomes a ruin. On a death occurring, the Kulawadi receives a fee from the family, who thus 'buy from him the ground for the dead.' The fee is called Nela-Haga (in Carnatica, Nela, earth, and Haga, a coin worth one anna two pie). The Kulawadi, however, is not supreme; he again pays annually one fowl, one hana ( 4 annas 8 pie), and a handful of rice to the agent of the Sudagãdu Sidda (or lord of the burning grounds), who resides in the Baba Booden Hills, and appoints agents for the tracts of country to collect his dues.

The skins of all animals dying within the village boundary are the property of the Kulawadi, and 
this one fact often settles a village boundary dispute. The Karu Kallu is the village boundary stone; it is a plain menhir, and the village Patel once a year makes an offering to it, which the Kulawadi at the conclusion of the ceremony carries off. Where there is no Patel, the Kulawadi performs the annual ceremony. The ordinary attire of all the Holiyar, and of the Mhar, is the narrow lungoti strip of cloth passing between the thighs, with a coarse hair blanket or cumbli for covering. The ancient Mysore Holiyar, ViraBaraka, is said to have been cursed by the gods thus :-

'An old cumbli for clothing, a stick in your hand,

The leavings of betters you'll eat in this land.

And these words paint the present condition of the Kulawadi.

Washermen of Mysore worship Basava-devaru or Ubbe in a temple with a shapeless stone, and to this they sacrifice animals, to prevent the clothes being burned in the Ubbe or steaming-pot. They also worship Vishnu. Basava lived in the 12th century, at Kalian, where he was minister to Bajal, the king, and he introduced there the worship of the lingam. But the Mysore washermen, though worshipping Basava as a deity (devaru), nevertheless are Vaishnava.

Beder or Nayik.-Their clans are called Kiratika, Barika, and Kannaiya in different parts of Mysore. They have two other divisions, Karnata in the south, and Telinga in the north, who neither eat together nor intermarry. The former wear the lingam. Most of the Pallegar of Mysore are of this race. They are a brave, martial, but predatory race, and have two small principalities at Beder Zorapur and Gurgunta, between the Kistna and the Bhima rivers. The Beder are said to have formed part of the armies of Tipu.

Pindari (Beder) tribe of Muhammadans, converts from the Beder race, and were formerly predatory, have now settled to agriculture, and take employ in the Mysore horse.

Idiga, or toddy-drawers of Mysore $(80,715)$, worship all the Hindu deities, but especially evil spirits, and they adore pots full of toddy. In the Nagar division they are called Hale Paika, and were soldiers under the Pallegars. They eat animal food, and drink largely. Their widows do not re-marry, but are concubines, and, their children become an inferior division of the caste.

Kuruba of Mysore have two sections, -Betta Kuruba and Hande Kuruba. The Kuruba worship Bire-devaru, also a box containing the wearing apparel of Krishna under the name of Junjuppa. They are agricultural, herdsmen, labourers, and blanket weavers.

Betta Kuruba or Hill Kuruba are met with in the forests along the S.W. boundary of Mysore, and amongst the hills at the foot of the Neilgherry range, living in small, rudely-built villages called Hadi. They earn a livelihood by felling timber, at which they are very expert. They are a diminutive race, the men averaging about 5 feet 2 inches in height; but they are very active, and capable of much endurance. Of late years they have been seeking employment in the neighbouring coffee estates. The Jenu or Honey Kuruba (1094) gather honey and other forest products. They are shorter and darker than the Betta Kuruba, and in Coorg are migrants, Iraliga collect forest produce, and differ from the Jenu Kuruba only in name. See Kuruba.

Badaga, of the Neilgherry Hills, regard the Kuruba as sorcerers, and at the beginning of the ploughing season they get a Kuruba to turn the first furrow, and to bless the first handful of the seed corn, otherwise they imagine the harvest would be a failure, and they give the Kuruba a small portion of the crop.

Soliga (1069) dwell in the Beligiri-rangam Hills on the S.E. frontier of Mysore. They live in small communities of five or six huts in the midst of the forests. They speak old Canarese. They cultivate with the hoe small patches of ground to grow a coarse plantain, vegetables, and a little ragi, which they eat with edible roots and the flesh of animals they catch. They avoid strangers as much as possible, and visit the plains only to purchase necessaries.

Natwa (Natya, SANSK., dancing), or dancing women attached to temples, are also called Kunda Golaka. They are drawn chiefly from the Sudra classes, Banajiga, Beder, and Besta; are born in the caste, or adopted or devoted by their parents even before birth.

Waddara are earth and stone masons, but give information largely to robbers. They are polygamists on a large scale, and widows and divorced women are re-married.

Hasular occupy the ghats in the N.W. part of Mysore. They are a short, thick-set race, very dark slinned, and with curled hair. They fell timber, work in betel-nut gardens, and gather wild cardamoms, pepper, etc. They speak a dialect of Canarese.

Yerava, in the southern taluks of the Mysore district, are said to have been slaves to the Nairs in the Wynad district. They resemble the African in features, having thick lips and a compressed nose. They speak a language of their own.

Nagarta call themselves Vaisya Hindus, but this claim is not admitted by the Brahmans or by the Komati. They engage in agriculture, but never till the ground with their own hands, nor even follow any mechanical profession.

Of mendicant sects in Mysore, the more important are the Dasa, Jangama, Satani, Domba, Jangalaga, Budabudiki; Pichakunte, Hale or Pansu, Makkalu, and Helva or Paknati Jogi.

In 1871 there were 12 wild tribes, 44 servile tribes, and 16 of homeless migrants. Omitting mere trade and country designations, the remaining castes and tribes are the Agamudi, Agasa, Besta or Bhoi, Bilwa, Golla, Koracha, Lumbana, Murka or Hale Kanadiga, Namadhari, Palli, Rachwar, Rajpindi, and Uppara.

Many of the Christian sects of Europe have missionary bodies in Mysore,-English, French, German, Scotch, Roman Catholics; but the French bave been prominent since the days of the Abbe Dubois in the 18th century, and they have now a vicar-apostolic, with 13 European missionaries and native priests.

Mr. (Sir) Walter Elliot mentions in the Journal of the Ethnological Society that the Canarese race of Mysore and the Southern Mahratta country believe that the spirits of unmarried persons, of the unchaste, of those who have died a violent death, etc., become malignant ghosts, called Viraka, who are appeased by offerings.

COORG or Kodaga is a British province to the 
INDIA; THE TRAVANCORE STATE.

west of Mysore, between lat, $11^{\circ} 55^{\prime}$ and $12^{\circ} 50^{\prime}$ $\mathrm{N}$., and long. $75^{\circ} 25^{\prime}$ and $76^{\circ} 14^{\prime} \mathrm{E}$. It is 60 miles long by 40 broad, and its area is 1583 square miles, with a population of 178,302 , of whom 77,863 are females. It is a hilly country, culminating in mountain ranges, the highest being 5375 feet above the sea. Kodaga is said to mean west.

In 1834 it was ruled over by a raja of the Lingaet sect of Hindus; but his cruelties, carried on for a long series of years, brought on a war with the Indian Government, and, after a battle on the 8th April 1834, the country was annexed. Since then, the general population has largely increased by settlers from surrounding districts, but the Coorg are believed to be diminishing.

The numbers speaking the current languages perhaps best show the original nations of the present inhabitants:-

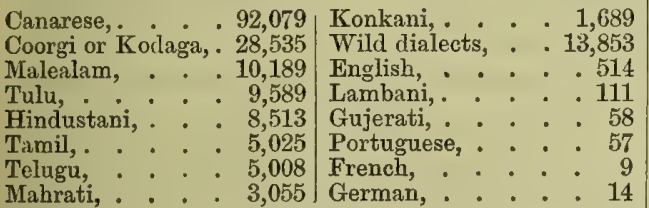

The Coorg race have 13 clans, but they arrange themselves into Coorg and Amma Coorg. They are a tall, muscular, broad-chested, well-favoured race of mountaineers, 5 feet 8 inches to 5 feet 9 inches in height, handsome and well made, far superior in physique to the inhabitants of the plains, whom they greatly despise. They are also far advanced in civilisation, and are very intelligent. They have a Caucasian head, regular features, aquiline nose, with chiselled lips, black eyes, and dark hair. They wear whiskers and moustache, but no beard, have a fair complexion, with intelligent countenances, and general bold, independent deportment. They follow agriculture, and a few seek other employments; but, as a rule, they eschew military employ. They believe themselves to be descendants of the daughters of Chandra Varma, king of Matsa Desha, obtained by the intercession of Parvati. Chandra Varma is said to have come originally to Coorg. The vice of drinking has a deep and widely-spread hold upon them. They marry at a ripe age, but the wives of brothers are in common. They are a compact body of mountaineers, who have been lords of the soil from time immemorial. They live in farmhouses far apart. The Amma Coorg take among the Coorgs a place similar to that of the Brahmans among Hindus.

The Coorg despise manual labour, and cultivation is carried on by the immigrants, the Tamil Vellalar, the Teling Reddi, the Canarese Wakala, and the Malabar Nair, while the Teling Sudra are labourers. The Aranbagaru are agriculturists, and the Arambada Kikartiru are dependents on the Arambagar.

The 1881 census return classifies the people as under:-

Coorg", . . 26,558 i Non-Hindus, . . 56,030

Amma Coorgs, : : 475 Muhammadans, : 12,541

Brahmans, : 2,445 Native Christians, 2,637

Rajputs, : : 480 Europeans, . . .228

Other Hindus, . 56,801 Eurasians, : : . 287

Inferior castes and

Jains, : : : : 99

tribes, . . 21,100 Parsees, . . . . . 21

The following tribes have not accepted Hindu-
Balagai Holeya, agricul- | Malaya Holeya.

turists.

Kembati, natives of Coorg. Parava do.

Mari Holeya or Moringi, Kukka, coolies from coolies from Malabar. Canara.

Other aboriginal and jungle tribes are-

Adigarai, labourers, speak Malealam.

Ajala, , from Canara.

Betta Kurubä, a fowler tribe from Malabar and Canara Jenu Kuruba, foresters.

Palay, agricultural labourers, speak Tulu.

Yarava, of 2 sections, Paniyar and Panjira, from Wynad.

Holeya, labourers in Coorg, number 32,450 .

They are ill-favoured, with coarse, stupid features, short in stature, but strong built, with dark or black skin and black, straight hair. They practise demonology. Some of them, as the Badagu, speak Canarese. Others, as the Kembati, speak the Kodaga tongue. They are of small stature, eat beef and other flesh meats. They worship Ryappadevaru and Jamauts.

The Yarava of Coorg number 11,894. They came from the Wynad and settled in the Yedenalknad and Kiggatnad taluks. They have thick lips, woolly hair, and black complexion. They are labourers. Their language is said to resemble Malealam; they worship evil spirits, and have no priests.

The Betta Kuruba are well proportioned, with good features. They are fowlers, mat and basket makers. They have a central hut, around which other huts are erected, like the nave of a wheel. All adult males sleep in the central hut. People approaching the huts have to take off their shoes.

Hegade, a small tribe of cultivators in Coorg, of small stature, who follow Coorg customs, but do not eat or intermarry with them.

In the S.W. part of Coorg are the priests of Amma, the goddess of the river Cauvery. They generally retain the old devil-worship of the Dravidian race, of which they are a branch. They chiefly worship the goddess Cavare Amma or Parvati ; but demon and ancestor worship are common.

The languages prevailing are Coorg, Canarese, Malealam, Tamil, Tuju or Tulu, Urdu, and English. The Coorg or Kodaga language has generally been regarded by some as Canarese, modified by the Tulu. But Mr. Moegling states that it is more nearly allied to the Tamil and Malealam than to the Canarese. It is generally recognised as between Old Canarese and Tulu. It is admirably suited for expressing easy-flowing poetry of a humorous or solemn strain.

TRAVANCORE has an area of 6730 square miles, and a population of $2,401,158$, being 357 to the square mile; the males, in 1881 , were $1,197,134$, and females 1,204,024. The Travancore dominion is also called Kerala, a term which is supposed to be derived from its dense forests of cocoanut palms. It is also called Veynād, also Tirupapur Swarupam, likewise Karma-Bhumi, the eastern coast being Jnana or Punnea-Bbumi. Trividam Code is the original of the Travancore of the English. The people know it as part of the Malealam, which means literally hill and dale. In the native parlance, the term comprises the districts of Malabar, South Canara, and the Native States of Cochin and Travancore. By Europeans, however, Malabar is the name given to the coast region of the extreme $\mathrm{S} . \mathrm{W}$. of the Peninsula of 


\section{INDIA; THE TRAVANCORE STATE.}

India. Its inhabitants have not been often disturbed by foreign war, but the external influences of foreign races engaged in commerce have been largely felt.

Parasurama, in his invasion from the nortb, overran the provinces below the ghats, overcame the races which he found there, exterminated the higher classes, and introduced foreigners. His march probably extended to Cape Comorin, whence he drove Ravana, the native ruler, and many of his followers, into Ceylon, from which, at a later period, the ancestors of some of the castes of Tinnevelly and of the Tiyars of Malabar returned. He was not a Brahman, but seems to have been an aboriginal chief whom the Brahmans employed in their schism with the Kshatriya; he is represented as exterminating the Kshatriya with his battle-axe (parasu), which is the distinguishing weapon of the Kond. He has been deified as one of the incarnations of Vishnu.

Sects. - From Bombay to Cape Comorin are many indications of long-continued intercourse with western nations, and from prebistoric times coins of Augustus, Tiberius, and later emperors have been found in Malabar and Coimbatore. A colony of Nestorian Christians from Antioch early settled to the south of Goa. The Jews of Cochin possess copper s'asanams of a king of Kerala, attested by witnesses signing their names in Archaic Hebrew, Cufic, and Pehlavi, about the 6th or 7th century. Many families professing Judaism are scattered through the Southern Konkan, but they are not Jews, more probably Samaritans, who call themselves Ban-i-Israel. In Cochin there are two classes of Jews, one of them very fair, and of pure descent from the parent stock, the other dark, and probably proselytes or slaves.

Rulers. - Since the 14th century, portions of this coast region have been under the control of the dynasty of Bijanagar, of the Adal Shahi of Bijapur, of the Portuguese and Dutch from Europe, of Muhammadan rulers of Seringapatam, and of the British; and in the wars of these races many ancient chiefs have disappeared, and amongst them the Zamorin of history has lost nearly all his ancestors possessions. These changes and immigrations have introduced many castes and customs peculiar to this region. Amongst the former are Namburi Brahman, Tiruvappaud, Tamban, Koil-Tamburan, Samunthaken, Pundala, Unniathiri, Kurthavu, Nedungadi, Eliathu, Mut'hathu, Adicul, Chakiar, Nambiar, Oonnee, Psharodi, Pushpaken, Varier, Alat'hi, Nambidi, Thyambadi, Plapulli, Nair, and many others.

Inheritance.-Many of these have adopted the custom of the descensus ab utero, the descent by the female line, which they designate Marumakkatayam. The Ponan, a branch of the Tir or Ilivar, have not adopted this. Also amongst the Namburi Brahmans, only the eldest brother marries, the unmarried girls being carefully secluded, and many never marry at all; but even the Moplah Muhammadans follow this law of inheritance. Along with and dependent on it is the existence of polyandry amongst the Nairs of Malabar, which also in a household form prevails amongst the people of Coorg, as also amongst the Toda of the Neilgherries, amongst the Kapilli tribe on the Dindigul valley, amongst the Totti, a Pariah race in Mysore, also amongst the people of the Tibet passes.
Kerala or Malealam, also written Malayarma and Malayama, from Mala, a mountain, and Alam, a dale, is a long tract of land extending from Gocurnum near Goa to Cape Comorin, and includes within it the British districts of South Canara and Malabar, and the Feudatory Cochin, Calicut, and Travancore under Hindu rulers, with the Muhammadan Bibi of Cananore. The country is a succession of hills and valleys. Kerala is supposed to be a dialectal change from Malikeram. cocoanut, dense forests of that palm growing in the country; but it is also said to have been derived from a prince of that name who is famed for wisdom, benevolence, and moderation. The total area of that united Malealam or Kerala tract is 16,634 square miles, with a population of $5,490,991$. The most distinctive part of the tract is Travancore, which has an area of 6730 square miles, and in 1881 a population of $2,401,158$.

Languages.-From its position in the extreme south, with a seaboard the first to be touched by voyagers from the west, races are there of the most diversified origin, and the languages current are Arabic, Hebrew, English, French, Portuguese, Sanskrit, Urdu, Hindi, Mahrati, Gujerati, Sindi, Konkani, Malealam, Tulu, Tamil, Telugu, and Canarese, though Malealam and 16.8 per cent. of Tamil are the tongues used by 99.2 per cent. of the population, Malealam principally to the north of Trevandrum, and Tamil south of that city. Adjoining the Malealam district on the north is the S. Canara district, in part of which, around Mangalore, the Tulu language is spoken, Canarese being the tongue in general use.

The Malealam language is spoken in the low country and along the Western Ghats, from Cape Comorin to the Chandragiri river, or more strictly, perhaps, to Nileshwar (Nileswara), where a Nair raja, conquered by Hyder Ali, formerly ruled.

The people occupying that tract are mostly settled, but it has had several dynastic races; the Zamorin of Calicut, the Bibi of Cananore, the raja of Cochin, the raja of Travancore, and the Dutch, have all held sway there; but the present rulers are the maharajas of Travancore and of Cochin, the Zamorin of Calicut, and the Bibi of Cananore; and the present paramount power is the British.

Tulu, Tuju, or Tulava, a cultivated Dravidian tongue, is an idiom which holds a position midway between the Canarese and the Malealam, but more nearly resembling the Canarese. Though once generally prevalent in the district of Canara, it is now spoken only in a small tract of country in the vicinity of Mangalore, by not more than 100,000 or 150,000 souls. It has been encroached upon by many languages, and is likely soon to disappear. The Tulu has a strong resemblance to Malealam, though the Tuluva-speaking race are unable to understand their Malealam neighbours. The people speaking the Tulu shrink from contact with foreigners, even from people of their own caste, retreating from the great roads, cities, and bazars as eagerly as the Tamil flocks to them; and the Tulu-speaking race are to be found isolated with their families in their high walled parambu, in parts where the lines and centres of communication are entirely occupied by the more enterprising Tamil people. Tulu is the original language of 
the Canara collectorate, but has been largely displaced by Canarese, the language of the conquering power about the 15 th century. It now prevails (though not exclusively) from the north border of Malabar (Kavai), where it is much mixed with Malealam, to Udapi in the north. Mangalore, Mulki, and Udapi are the chief places where it is spoken. The Tulu people belong to the same race as the Tamil and Telugu family, now conventionally called the Dravidian race. There is no doubt that Tulu is a dialect of the Canarese, and rlosely allied to the 'Toda, Badaga, and Coorg dialects. There do not seem to be any dialects of Telugu. Malealam is a dialect of Tamil. By dialect is meant that these languages were, many centuries ago, the same as the Canarese and (in case of Malealam) as Tamil, but that long separation and different influences have caused the variations we now see. Tulu, Toda, etc., are far more closely allied to Canarese, and Malealam to Tamil, than Canarese, Tamil, and Telugu are to one another. The Tulu people have no literature, cxcept a few translations by German missionaries.

\section{Travancore Castes.}

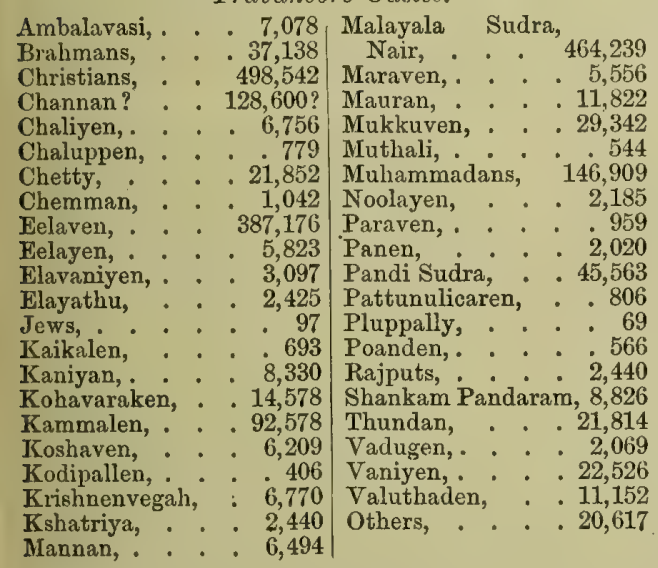

Mannan, Non-Hindu Aborigines.

Koraven, . . . . 54,828| Parayen, . . . .66,454 Malarayen, : : 17,627 Poolayen, : : 196,539 Oolladen,. : : $: 2,840$
Pallen,
: :

The ruling families in Travancore and Cochin claim to be of the Kshatriya race, of whom in Travancore there are fourteen clans all regarding themselves to be of the Lunar line, and of one gotram or stock, descendants from one chief. They do not therefore intermarry. Their daughters, with one exception amongst the clans, are usually married by Bralumans, and the offspring are called Samanthar or Murdhavasikthar. The exception to this is the Koil Pandala subdivision, from which consorts are chosen for the Ranis of Travancore.

The Malayala Sudras are the Nairs of Malabar. They are the agriculturists of the country, cultivating as temants of the Namburi, who are the landlords or Janami of Malealam, and who are looked up to as the 'suzerain master, their household deity, their very god on earth.'

The titular designation given to nearly all the Brahmans of Travancore (except to the Papi caste) is Namburi (from $\mathrm{Nam}=$ Veda, and Pureppika, to complete), meaning an expounder of the Yedas. Among the varied clans of Brahmans in
India, these Namburi take a very high position for sanctity. With the object of retaining their landed property unbroken, succession is from father to son, but it is strictly entailed on the eldest son. The younger sons are not allowed to marry, but visit the Ambulavasi (temple) and Sudra women, who receive them more for the honour than for any gifts they bring. The Namburi are unboundedly hospitable to Brahman strangers, and are charitable. They are of a fair colour, their women are considered beautiful, and the race are remarkable for cleanliness of person and neatness in dress.

Their women often remain unmarried after they have grown up, and even to an advanced age. Numerous daughters are considered a misfortune, the dowry and marriage expenses bearing heavily even on the wealthiest Namburi. Infanticide, however, is unknown. But a Namburi, anxions to see his sisters married, will give them to a family from which he takes one or more wives. The Namburi women are guarded with a more than Muhammadan seclusion. At home they dress like the Nair women, with a cloth from the waist downward. When they move abroad they are covered over with cloths, and attended by a Nair servant woman, who commands all men on the road to stand aloof.

There are 27,138 Bralimans, mostly immigrants from the districts of the Madras and Bombay Presidency. The Travancore people style these foreign Brahmans 'Putter,' a corruption of Bhatta, devout; but they are also distinguished by affixing the localities whence they came, as Mabratta, Telugu, Tamil, Gujerati, Pandy. Karnatica, Choliar, Gowda, Mukkani, Pataya, Vanchi, Iyengar, and Sanati Brahman.

Inheritance Lau's. - The peculiar marriage customs of the bulk of the races in Travancore originated the existing law of inheritance. That law is called Marumakkatayam; it is the descensus ab utero of the Locrians, under which a sister's children inherit. Parasu Rama urged all his Brahman colonists to adopt it, but those of Panuiar alone complied. All the Kshatriya families, however, follow this law of inheritance.

The Marumakkatayam law of inheritance is, however, followed by all the Brahmans who serve in temples, by all the Malealam Sudras, most of whom have the titular designation of Nair ; by the five artisan castes, the goldsmith, brazier, stonemason, blacksmith, and carpenter; also by the Maran Sudra, who eat rice prepared by a Varier, and whose women receive Variers' visits; by the old Kshatriya race, amongst whom are the sovereigns of the country; and by the Nanjanad sections of the Vellalar race.

Nair girls are all married at an early age, before they grow up, and the ceremony is attended with much display of wealth, but the husband or person who ties on the marriage string (the tali) has no claim to possess her then or in after life. But when she attains maturity she chooses the person with whom she is to associate, who presents ber with a cloth. The union agreement, however, on either side is dissolvable at pleasure, the sole restriction on the Nair woman being that she must not admit any mian of a class below her own. Accordingly a Nair household has no husband, but consists of its owner, and the maternal uncles, the uterine brothers and sisters, 
and the sisters" children. Women may rule the state, and, under the Marumakkatayam law, in nearly half the houses in the country, women are the sole proprietors of their households.

Among those who follow the Marumakkatayam law, a female child is more highly prized than a boy, and the ratio of adult women to 100 men in Travancore is higher than in neighbouring districts, as under :-

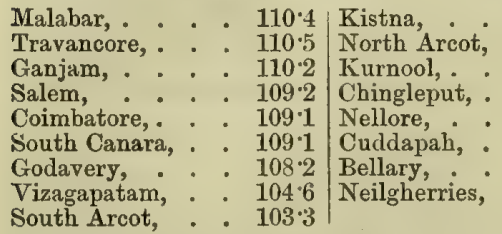

$103 \cdot 2$

$102 \cdot 2$

$101: 5$

$101 \cdot 4$

$99 \cdot 3$

$99 \cdot 2$

$98 \cdot 6$

$80 \cdot 1$

Northwards from Travancore the marriage and inheritance laws vary. The Tuluva people are remarkable for the law of succession called Aliya Santana. This is the law of the so-called Sudra tribes, and a tribe that practises it is probably Tulu. But the race does not include Brahmans or low castes, who are mostly settlers from other parts of S. India, though in some cases they have adopted the custom. In South Malabar, descent is to sons-in-law; but in N. Malabar, the Nair, the artisans, carpenter, brass-smith, blacksmith, and goldsmith, also the Tiar, who are toddydrawers, and the Mookwa fishermen, are all polyandrists, and the descent of property goes in the female line. In North Malabar, this law of descent is called Marumakkatayam, and the Muhammadan Moplah has conformed to this usage. In Canara, a similar law, called Aliya Santana, or nephew inheritance, prevails, and is in practice more strictly carried out than in $\mathrm{N}$. Malabar. In N. Malabar, the adherents to Marumakkatayam form united family communities, termed Tarwaad. The senior member of whatsoever branch is the head of the family, is termed Karnaven; the other members are styled Anandraver; the remotest nember is acknowledged as one of the family, and entitled to maintenance if living under subordination to the head of the family and taking part in their religious observances. For the women there is nothing analogous to the state of widowhood as existing elsewhere. Whether in alliance with men or not, they reside in their own families. The Nair marries before he is ten years of age; but though he supports, he never associates with his wife, who receives, at her pleasure, any men, provided they be not of lower birth. Consequent on this form of descent, a Nair does not know who his father is. In law, property is held to vest in the females only; practically the males are co-sharers with the females. In default of males, females succeed to the management of the family property. In some families the management devolves on them preferably to the males, and the senior female takes it. There is, however, a growing tendency to convey property from father to son, arising from the gradual abandonment of polyandry. The connubial connection in question is called in Malabar Goona-dosham, Goona, good, Dosham, evil (for better or worse). In Travancore it is styled Mundu-vanga, viz. Mundu, cloth, Vanga, receiving, and the girl taken is of ripe age, and her consent must be obtained. Personal acquaintance thus precedes the union. The hour selected for the ceremony is 8 P.M. There is an assemblage of friends; the man presents the woman with a mundu or white muslin cloth, in a corner of which, in North Malabar, a small sum of money is tied. The girl either goes to the man's house, or remains in her own, and is visited by him there. Each party is unrestricted as to the number of such connections that may be formed, but these ordinarily do not exceed two or three. The descent being in the female line, the parentage of the father is immaterial. The Marumakkatayam law is not followed in North Malabar by the Aka Podwal, a class of pagoda servants, nor by the Brahmans of North Malabar or of Canara. But in Travancore law, as only the eldest brother of a Brahman family is allowed to marry with his equal, the other brothers form other connections, and their children, therefore, do not inherit. In the Tuluva country, the Brahman widow can devote herself to the temple, and reside outside or inside its walls. If within the walls, she is a servant of the idol, and receives the visits of men of her own caste only; the offspring of such, if boys, are called Moylar, and the girls are married to them. But if she elect to reside outside the walls, she must pay a monthly sum to the pagoda, and may cohabit with any man of pure descent.

The Nair women do not cover their bosoms when at home, and, in North Travancore, not even when abroad. With the well-to-do Nairs, reading and writing are essential in the education of the women, and singing and instrumental music are accomplishments. Eighty per cent. of the educated native women are of the Malealam Sudra (Nair) and native Christian classes.

Religion.-In Travancore, the superior divinities are Vishnu, Siva, Bhagavati, and their incarnations. The inferior objects of worship are in the Paikoil or devil-temples and other places. But all the latter, and many of their female gods, owe their origin to Tamil immigrants, the true Malealam population invariably resorting to the higher idols. There have been white and black Jews in Travancore from very ancient times, and Cbristians from the earliest days of Christianity. At present there are-of the church of Rome, 153,815; Protestants, 57,318; Syrians, 287,409. Mubammadans are 146,909 in number.

The Ambalavasi (Ambalam, pagoda or temple, and Vasi, he who lives), 7078 in number, are peculiar to Malabar. They have fourteen large and numerous small subdivisions, but all are employed in the Hindu temples, of which there is one to every 248 of the population. They abstain from animal food of every kind.

Amongst the Sudra castes in Travancore are the Vellalar, the Mudali, and the Pandi Sudra.

The Vellalar in 1872 were 24,125 in number, and in every district in the kingdom. In the adjoining provinces of British territory, where Tamil is spoken, the great body of the cultivators claim to be Sudras of the Vellala stock, and when well to do they receive the honorific suffix of Mudali.

The Idayan, Edaga, or Yadava is the shepherd race scattered over Southern India. In Travancore they are known as the Konan, Kangayen, Valayadaiyen, and Vaduk-idayen, and are 6319 in number. The Gopa, Gaola, Gorakh, and Satgop of Northern India, Bengal, and Orissa, and 
the Gaoliga of Mysore, and some of the Dhangar, are cowherds, but are not identical with the Kurubar, and some of the Dhangar of the Dekkan, and some of the Ahir of Northern India. The shepherd race of Southern India are spreading out into all available employments. They are classed as Sudra Hindus, and usually styled Pillai, in distinction to the Vellalar cultivators, who add Mudali, or first man, to their names; and the shepherds, Idayan, take a lower social position.

The races in Travancore who were held in servile positions are upwards of 30 per cent. of the population, and may be shown as under :-

\begin{tabular}{|c|c|c|}
\hline Chemman or & & Shannan, - 128,600 \\
\hline $\begin{array}{l}\text { Chakler, } \\
\text { Kshowraken or }\end{array}$ & . 1,042 & Mookooven or fisher- \\
\hline barber, & 14,578 & Malayaraen, : \\
\hline $\begin{array}{l}\text { Kanian or sooth- } \\
\text { sayers, }\end{array}$ & & $\begin{array}{l}\text { Vaden and Oolladen, } \\
\text { hunters, }\end{array}$ \\
\hline & - 959 & Puller, . . : \\
\hline $\begin{array}{l}\text { Thundan, : } \\
\text { Noolian, }\end{array}$ & 21,814 & $\begin{array}{l}\text { Koravar, } \\
\text { Pariah, }\end{array}$ \\
\hline Elaven, : & 387,176 & Pullayar, : : \\
\hline
\end{tabular}

The Pullayar or Pulian are a hard-working and extremely useful race, noted for their truthfulness and integrity. Until recently they were bought and sold like other property, but they all have been freed by the present maharaja. They have remained on the lands they were cultivating. In social life they are lower than the Pariah. They speak Malealam. They are unknown in the British provinces.

The Elavar or Elaven are numerous. They aggregate 387,176 , and are engaged in cultivation and in manufacturing the produce of the cocoanut tree, which forms a staple of the country.

The Shanar or Channan race, in number 128,600 , are also found in the neighbouring British districts. They are chiefly engaged in the manufacture of the produce of the palmyra palm, Borassus flabelliformis, which is only inferior in value to the cocoanut tree.

Some of the Elavar and Paravar are amongst the most respectable cultivators in the Travancore kingdom. The Shanar of S. Travancore are even a more enterprising class; and the Pariah, throughout Southern India, is the chief labourer in the fields, and in other out-door work.

The Kummalar, or artisans of Travancore, - the goldsmith, the coppersmith or brazier, the stonemason, the blacksmith, and the carpenter. In Travancore, however, the Chembu-thatti or coppersmitbs claim to be a distinct caste, but this is not conceded to them.

The Chetty of Travancore, of whom there are fifteen subdivisions, most of which seem mere nationalities.

Tiyar, from the Singhalese Twar, an islander the Ponan race in Malabar. They are a branch of the Ilivar or Tir from Ceylon. They inherit from the father.

Parayer, also Pula Parayar, also Todinvar, a low-caste predial slave race of Malabar, who are stone-cutters, who are supposed and believe themselves to be wizards and witches. Vengeance and fear have occasionally led to their being cruelly treated.

Paniker, a race dwelling amid the forests and jungles of Malabar, who roughly clear the ground, and raise crops of coarse rice and other grains

during the monsoon, and move to another place. They also collect forest products, - cardamoms, beeswax, gums. Their sole implement is a kind of adze. They are of diminutive stature. There is a small race called Kaniar Panikar, who practise astrology and necromancy. They calculate eclipses, cast horoscopes, and foretell the times and seasons, sell charms for all purposes, love philters, discover treasure, cure disease.

Cheramar, one of the predial slave races of Malabar. They are supposed to be descendants of the race conquered by the Chola kings. They are of very diminutive stature, very black skin, and not unfrequently woolly hair. Wilson derives the name from Chera, the soil. They follow the rule of Marumakkatayam.

Nagadi, an abject race in Malabar, beggars and thieves. They are of diminutive form, of the deepest black in colour, features brutish, hair thick and curly.

Bakadara and Betadara, two rude slave races in Tulava, who worship a benevolent deity named Buta, represented by a stone, kept in every house. They, too, believe that the spirits of the dead become Paisachi, and they offer sacrifices to Buta to restrain the Paisachi from troubling them.

Holier women, until towards the middle of the 19th century, used to visit Mangalore with no other covering than thick bushy branches before and behind, hung from their waists.

Bant, a tribe in Canara who worship the Paisachi or demons, and believe that persons who die a violent death become Paisachi.

Bunter, a race in Canara, the original landowners, who follow the rule of female descent. They marry, and the wives reside with their husbands, but do not interfere in the house management.

The Kurumbalen are a slave race who worship the hill god Malai-deva, and the spirits of deceased ancestors. They burn their dead if good men, and bury them if bad; and they believe the latter to become demons, requiring to be conciliated by sacrifice.

Languages spoken in Travancore:-

\begin{tabular}{|c|c|c|c|c|c|c|c|}
\hline Hindustan & & & an & & & & \\
\hline Telu & & 3,352 & Cutchi, & & & & \\
\hline Mahrati, & & 1,383 & Nagaram, & & & & \\
\hline Tar & & 439,565 & English, . & & & & \\
\hline Gujerati, & & 571 & Arabic,. & & & & \\
\hline & & $\begin{array}{l}774 \\
454\end{array}$ & guese & & & & \\
\hline & & $\begin{array}{l}70 \pm \\
664\end{array}$ & orew, & & & & \\
\hline
\end{tabular}

Maleali is spoken by about $4,847,681$ people along the Malabar coast, on the western side of the ghats or Malaya range of mountains, from the vicinity of Chandragiri near Mangalore, where it supersedes Canarese and Tulu, to Trevandrum, where Tamil begins to be spoken; but all along that coast Tamil intertwines with Maleali, which is a very ancient form of Tamil. The Rama Charita is the oldest existing Maleali poem.

Tulu or Tuluva is destitute of a literature in the proper sense of the term, and never had any character of its own. The only books printed in Tulu have been by the Basle missionaries. It is one of the most highly developed languages of the Dravidian family. It is spoken by about 300,000 people between the Chandragiri and Kalyanapuri rivers. It is written with the Malealam characters; it differs widely from Tamil, 


\section{INDIA;-THE COCHIN STATE; THE MADRAS PRESIDENCY.}

less so from Canarese, and less again from Coorg. Tulu is said to mean meek, humble.

COCHIN, a small territory on the seaboard of the western side of the Indian Peninsula, in treaty with the British. Its area is 1361 square miles, population 600,$278 ; 301.815$ are males. The Bibi of Cammanore and H.H. the Zamorin of Calicut may also be named.

MADRAS CITY is on the east coast of the Peninsula of India, in lat. $13^{\circ} 4^{\prime} 6^{\prime \prime} \mathrm{N}$., and long. $80^{\circ} 17^{\prime} 22^{\prime \prime} \mathrm{E}$. In 1881 its population was 405,848. It is the capital of a presidency, to which it gives its name, and which is under the jurisdiction of a Governor and Council.

Famine.-In 1871 there was in this presidency a population of $31,597,872$, but in 1881 only $31,170,631$. Between the census taking of 1871 and that of 1881 , in the years 1877 and 1878 , in consequence of drought, there was famine in several districts, and many died. It pressed most heavily on Bellary, Coimbatore, Cuddapah, Kurnool, Madura, Nellore, North Arcot; and Mr. M'Iver calculated the total loss at three and a half millions. In the districts most severely affected the decrease of the population was $1,751,327$, or 12.8 per cent. In those not affected or but slightly affected by famine, there has been an increase of $1,288,430$, or $7 \cdot 19$ per cent. The age returns of the census of 1881 show that the effects of the famine had been most severely felt among the very young and the very old; and besides causing deaths, it prevented births. The children who were born in 1878 and 1879 , and who were begotten in 1877 and 1878 , were short of 700,000 as compared with 1871; and in 1881, of the ages up to 20 , there were $1,947,950$, or $12 \cdot 04$ per cent., fewer than in 1871.

Parts of the districts now comprising the Madras Presidency were known to Europe in times prior to the birth of Christ. Dynasties known as the Pandya, Chola, and Chera were then ruling, and merchants from the west were trading; a Pandyan prince sent two embassies to Augustus, who received the first at Tarragona, and the friendship of the Romans was sought by O Kerobothros, a king of Chera or Kerala. The Chola, the इapas of Ptolemy, were in power from B.C. to the 11th or 12th centuries A.D.; but in 1113 , and again about 1150 , parts of the Chola territory were overrun by the Singhalese.

The Kurubar, a shepherd race (kuru, a sheep), the $\Sigma$ woos voн a $\delta \varepsilon_{s}$ of Artakur (Arcot) of Ptolemy, formed a federal community of 24 states, with castles, which were destroyed by one of the Chola kings of Tanjore in the 5th and 6th centuries, and he established a new capital at Conjeveram; but to the present day the country people point out the Kurubar-Kot or forts which that shepherd-race had constructed. Since the Chola fell, this southern region has seen a Hindu dynasty at Bijanagar, the Muhammadan Adal Shahi of Bijapur, the Hindu Mahrattas who succeeded to Tanjore, with Hindu princes in Cochin, Calicut, and Travancore; and from the 15th to the 18th century, several races were striving for dominion. Muhammadan rulers, Mahratta armies, Polygar chieftains, and the Dutch, the Portuguese, the French, and the British, all took part in the strife, till the Britisl, the Mubammadan dynasties of Hyderabad and Banaganapilly, and the Hindu rajas of Mysore, Travancore, Cochin, Puducottah, and Sandur alone remained as dominant powers. The Pandiya, the Cheru, the Chola, and the Kandya kings of Ceylon have all disappeared.

The north-east parts of the Peninsula have also had many dynastic changes. The Andbra dynasty ruled at Chicacole and Rajamundry prior to the Christian era. Pliny says they had 30 fortified towns, an army of 100,000 men, and 1000 elephants. The Kesari, lion kings, ruled in Orissa. The Chalukya Rajputs of Rajamundry succeeded a Buddhist dynasty, and subsequently the Ganapati of Warangal, the Vema Reddi, the Rayel of Bijanagar held stray; and the Chalukya of Kalian were overthrown during a time of religious war, when the people adopted the Lingaet teaching of the Jangams.

This presidency has an area of 141,001 square miles, with a population of $31,170,631$, viz. $15,421,043$ males, and $15,749,588$ females, being 221 to the square mile. The most numerous races under Madras rule are the Tamil and Teling, with parts of the nations speaking Malealam, Canarese, Tulu, and Uriya ; all of these are occupying ancestral lands, many from unknown times, and to them have to be added a quarter of a million of landless people speaking Mahrati, and over half a million speaking Hindustani.

Tamil was the language of three of the ancient dynasties who have been named. The Chola of Tanjore and Combaconum were settled on or near the Cauvery and Colerun rivers, and gave their names to the Coromandel or Cholamandel coast. The Pandiya capital is now occupied by the inhabitants of Madura; and the Chera ruled at Kerala on the Malabar coast. The Kurumbar, also, about the commencement of the Christian era, was briefly dominant in Southern India, and the Idayan herdsmen race still form a numerous portion of the Tamil-speaking people.

Mr. Taylor is of opinion that Tamil was cultivated in its purity in the ancient Pandiya kingdom. It is now spoken in the extreme south, south-east, and in Ceylon, throughout the vast plain of the Carnatic or country below the ghats, termed the Carnatic Paen Ghāt by the Muhammadan sovereigns and by the British who have succeeded them. The Tamil-speaking country extends from Cape Comorin to Pulicat, 30 miles north of Madras, and inland from the Bay of Bengal to the Eastern Ghats. The Tamil skirts all the eastern frontier of Mysore, is also spoken over the Bara Mahal, Salem, South Arcot, Chingleput, Tanjore, Trichinopoly, Madura, Tinnevelly, Coimbatore, and Combaconum, meeting with the Malealam at the Gap of Palghat. It is spoken also in the southern part of the Travancore country, on the western side of the ghats, from Cape Comorin to the neighbourhood of Trevandrum; also in the northern and north-western parts of Ceylon, where Tamilar formed settlements prior to the Christian era, and from whence they have gradually thrust out the Singhalese.

The Tamil was the earliest developed of all the Dravidian idioms, is the most copious, and contains the largest portion of indubitably ancient forms. It includes two dialects, the classical and colloquial, the ancient and the modern, called respectively the Shen Tamil and the Kodun Tamil, which so widely differ that they may almost be regarded as different languages. The people at present speaking Tamil are, as regards 


\section{INDIA; THE MADRAS PRESIDENCY.}

social customs, the least scrupulous or superstitious, and the most enterprising and persevering race of Hindus, and swarm wherever money is to be made, or wherever a more apathetic or a more aristocratic people is waiting to be pushed aside. 'The majority of the Hindu religionists found in Pegu, Penang, Singapore, and other places in the east, where they are known as Kling, are Tamil. All throughout Ceylon the coolies in the coffee plantations are Tamil; the majority of the money-making classes, even in Colombo, are 'Tamil; and ere long the Tamilar will have excluded the Singhalese from almost every office of profit and trust in their own island. The majority of the domestic servants, and of the camp-followers in the Madras Presidency, and the half of its army, are Tamil; and the coolies who emigrate so largely to the Mauritius and the West India Islands, are mostly of the Tamil people. Including the Tamil in the military cantonments and distaut colonies, and those in South Travancore, Northern Ceylon, and excluding all Muhammadan, Teling, and Brahman residents of the Tamil country, who amount to at least 10 per cent. of the whole population, the people who speak the Tamil language are estimated at about 16 millions. The Tamil people are, generally speaking, dark coloured and short statured, energetic, fiery, and quarrelsome, but not vindictive. Many of them have embraced Brahmanism, but the low castes and fragmentary tribes have a spirit and a devil worship, and worship the local deities called Ammun.

Telugu is spoken on the eastern borders of the Peninsula by about 17 millions. The people are a taller and fairer race than the Tamil, many of the more northern of them being equal in stature to the Aryan Hindus of the north. They are more Brahmanical than the Tamil races, and are as energetic as the latter, though less restless.

Canarese people are about 7 millions in number, chiefly in the centre of the Peninsula; they are a tall and dark but singularly graceful race.

The Teling and Canarese are almost of similar physical frame, but, as a rule, the Teling are fairer. The great similarity of the two languages Canarese and Telugu justifie's the opinion that the people are of the same stock, and that circumstances bave modified their characters and personal appearance. The table-land occupied by the Canarese, from the southern part of the Mysore country, through Bellary in the Ceded Districts up to the Tumbudra, is arid, and the soil yields as food crops small millets,-Eleusine corocana, Setaria Italica and Germanica, Panicum Italicum, and Penicillaria spicata,--wbich even the labourers of the south of India only use on pressure when scarcity or dearth prevails.

Malealam is spoken in the south-west of the Peninsula by about 4 millions; Tulu, on the west seaboard somewhat to the north, by about 30,000 .

Kodaga is spoken by the people of Coorg, 150,000 in number.

On the Neilgherry Hills are the Kota, about 1000 in number, the Toda about 1360 in number, the Badaga, another small tribe, and Kurumbar and Irular who dwell on the slopes of the mountains. In the interior of the Peninsula are the Gond, and or its N.E. border the Khond, Kund, or Ku. ali of whom are estimated at half a million of souls. Amongst these larger nations smaller tribes are intermixed, some of them living in forests or migratory; some have preserved their ethnical identity in sequestered wilds, othere have merged as helot castes of the lowland Hindus, and these now fragmentary peoples form the debris of widely-spread primitive races.

Seventy-three languages are enumerated in the schedules, of which 48 are Asiatic and 25 nonAsiatic. Those principally spoken are five Dravidian tongues, Tamil, Telugu, Malealam, Canarese, and Tulu, viz. $28,853,267$, or 92.56 per cent. Uriya, Urdu or Hindustani, and Mahrati are spoken by Uriya, 1,128,495 ; Hindustani, 696,103 ; Mahrati, 230,006 .

\begin{tabular}{|c|c|c|c|c|c|c|}
\hline \multicolumn{7}{|c|}{ Madras Presidency Languages. } \\
\hline Hindustan & & . 695,510 & Chentsu, . & - & & \\
\hline & & $11,754,946$ & Singhalese, & . & . & \\
\hline & & $12,382,220$ & Kodagu, . & - & - & \\
\hline ti, & & - 229,777 & Bengali, . & - & . & 30 \\
\hline se, & & $1,299,839$ & Burmese, & - & . & \\
\hline Uriy & & - 773,159 & Sindi, . & - & - & \\
\hline $\operatorname{lam}$ & & $2,366,181$ & Pushtu, & - & - & \\
\hline & & $\begin{array}{r}6,638 \\
35,636\end{array}$ & ari, & - & - & \\
\hline Hin & & $\begin{array}{r}35,6 \\
\cdot \quad 2,6\end{array}$ & chi, : & • & : & \\
\hline & & : $\quad 426,222$ & lese, : & & : & \\
\hline & & - 366 & miri, : & $\dot{0}$ & : & \\
\hline & & 21,984 & Panjabi, . & $\cdot$ & - & \\
\hline & & - 1,306 & Arabic, & • & . & 72 \\
\hline ? & & 61,735 & Persian, & . & . & . $1,80^{\prime}$ \\
\hline & & 58,2 & Chinese, . & - & - & \\
\hline & & 31,9 & Portuguese, & . & . & 3,641 \\
\hline & & 21,9 & Fre & . & . & . \\
\hline & & 12,0 & aan, & - & - & \\
\hline ba, & & - . 3,886 & Hebrew, & & & - 2 \\
\hline & & - 1,499 & & - & & \\
\hline & • & . 1,019 & Dutch, : & & & \\
\hline & & 316 & pecified & . & . & 2,07 \\
\hline & • & . . 206 & Swedish, . & - & . & 15 \\
\hline & & 148 & & - & . & \\
\hline & & 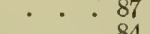 & African, & - & • & \\
\hline & & & & & & \\
\hline
\end{tabular}

There were 19,044 different caste names returned. The Vellalar alone were returned of 54 subdivisions and 3389 caste names. The Satani, a Hindu sect of the 16 th century, have already seventeen divisions.

Since the middle of the 19th century, the tendency with the Tamil and Teling Hindus has been to mark themselves as belonging to particular families, in imitation of the Brahmans of Southern India, all of whom know the got or founder of the section to which they claim to belong. The following are the more numerous of the castes and races in the Madras Presidency:-

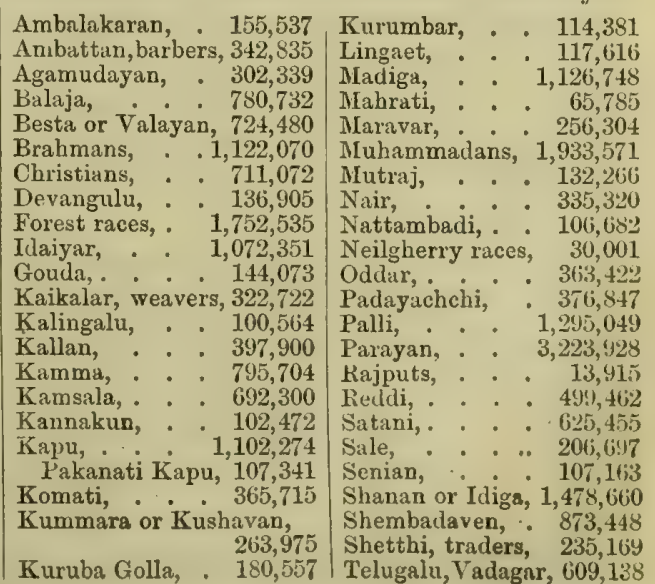


Uparavan, . 104,985, Vannian, . 1,075,505

Vaniyan, Gandla, 316,694 Vellalan, : ‘ $1,625,895$

Vannan, washermen, Kongado, . . 143,010 528,535 Yadavalu, : : 105,426

Neilgherry Hill tribes, in 1871 , were 30,001 .

Badaga, . . . 24,130|Kurumbar, . . . 3,185

Toda, . . . 675 Irular, .

Kota, . . . .1,065

Forest, etc., races.

Jatapu, . . . 63,337 Oddar,

Koravar, : 55,645 Kodulu,

Kondulu, hillmen, 63,249 Savaralu,

Malayali, . 69,396 Uparavan

Vedan, hunter, :51,854 Uriya,

Yenadi,. : : 66,099

The agriculturul races in Telingana are the Velama, the Reddi, the Kamma, the Kapu, the Balija, the Pakanatti, the Naidu. The Tamil cultivators are the Vellalar and a smaller number of the pastoral Idaga; those of the Mahratta districts are the Kunbi, and further north Kurmi.

In Malabar and Malealam the Nair are the chief husbandmen, but in the Canarese districts the Wakkali, and in Canara the Bant and Nadavar. The Teling cultivators have spread into all the western and southern lands. These follow the Brahmanical doctrines, maintain the caste observances of purity and impurity, and have adopted the early marriage customs and other institutions of Menu. They are essentially agriculturists, but they take military service, engage in mercantile transactions, or enter the civil service of Government. Tamil and Vallalar were brought from the Cauvery river by the Chola kings, who conquered the Kurumbar and eradicated Buddhism. They now occupy the whole of the Coromandel coast in its southern part, and have many agrestial slaves. They had many slaves before leaving the Cauvery, and doubtless added to them during the persecution of the Kurumbar race.

The religious sections of the people are as under:Hindus, $28,497,666$ Jews,

Muhammadans, 1,933,571 Theists, 13

Christians, . . 711,072 Kodaga, . . . . . 2

Jains, . : : 24,962 Agnostics, : : : 1

Buddhists, . . 1,546 Others, . . . . 69

Parsee, . . . 143 None, . . 5

Brahmo, : : 132 Not stated,

The Hindus are returned as under:Saiva, . . 15,399,686 | Lingaet,

Vaishnava, 10,494,408 Others, - ; 64,580

The Saiva Brahmans arrange themselves asAradhya, Namburi, Smartta, Velnati, Vaighnasulu, and Uriya. The Vaishnava Brahmans are-Madhava, Sri Vaishnava, Andhra, and Golconda. The Telugu Brahmans-Murikinati and Niyogulu. Others-Bengali, Gouda, Konkana, Gujerati, and Maharashtra.

The Muhammadans $(1,933,571)$ are largely descendants of the soldiers that have overrun the Peninsula, but a large number belong to Arab and Persian traders who have settled in the country, and many of the Labbai and Moplah section are from the offspring of Hindu mothers.

Arab, • • $\cdot 3,736$ | $3 y, 182$ Syud, * * 23,386

Moplah, : 495,714 Others,. : 217,238

Moghul, : : : 1,235 Not stated, : 1,092,037

Pathan 15,373

They are almost all of the Sunni sect.

The Christians of the Madras circle are numer- ous. One of the primitive Christians seems to have arrived in the south of India in the early years of the Christian era; the Portuguese fleets brought from Europe many missionaries, amongat them St. Francis Xavier; Robert de Nobilibus, Britto, Beschi, Dubois, and others have been striving to convert the people. The Romish church has several vicariates, and the Portuguese priests attend to much of the coast line ; the French have a vicar-apostolic in Mysore, and their priests are also in the Northern Circars and in the N.W. Provinces; while the Italians occupy Hyderabad and Native Burma. Since the closing years of the 17th century, Protestant Christians of all denominations from Europe and America, amongst them Ziegenbald,Schwartz, Rhenius, Caldwell,Duff, Mason, Anderson, have been zealously endeavouring to educate and to proselytize, and these efforts have resulted in 1,862,634 Christians in all India:Madras, . . . $711,080 \mid$ N.W. P. and Oudh, 47,673 British Burma, 84,219 Central Provinces, 11,973 Coorg, . . 3,152 Central India, ? 7,065 Bombay, : 145,154 Ajmir, . : 2,225 Pengal, . . 128,135 Baroda, . . . 771 Panjab, : : 33,699 Cochin, : : 136,361 Assam, : 7,093 Mysore, : : 29,249 Hyderabad Dekhan, 13,614 Rajputana, . : 1,294 Berar, . . . 1,335 Travancore, : 498,542

The Vellalar are shorter and darker than Brahmans, shorter and darker even than the Teling people, but they have in general well-formed countenances and graceful forms, though amongst them also occur the decidedly African lip and nose and forehead. They believe that they came from the north. They are now classed by the Brahmans as Sudra Hindus, but Southern India only became Brahmanical about the 8th to the 10 th centuries, and when the Vellalar adopted Hinduism is unknown. They claim to be Vaisya, of the Buvansa or agricultural section, a claim which the other races do not admit. They are very largely agricultural, and take the honorific appellation of Mudali or first man, pl. Mudaliar. Under former native rule in Tonda-Mandalam, the Vellalar alone were allowed to hold landed property. The Vellalar are eager in their study of English, have largely obtained employment, civil and military, under the British Government, and are an honourable, moral, and peaceful race, intelligent and thrifty, and respectable in their domestic life. The designation Vellala means charitable; but their name has been supposed to have been derived from Valaumi, the Tamil word for the act of regulating irrigation. In the present day, in Tinnevelly, they will not touch a plough, the Puller race doing everything for them. They do not use animal food or intoxicating liquors; they marry before puberty; their women are chaste; polygamy is almost unknown, the widows do not re-marry, and they burn their dead.

Vellalar as farmers and peasant-proprietors, in the cultivation of rice, betel, and tobacco, are perbaps not excelled in any part of the world. They rarely accept $a$ menial occupation. They are mostly of the Saiva sect, but the chief objects of their worship are village gods, and they keep the Pongal and Dipawali festivals.

The Karakatan Vellalar of the Madura 'Hills occupied their present locality before the Vellalar of the plains adopted the customs of the Aryan immigrants. And now, amongst them, when an estate is likely to descend to a female, in default 
of male issue, she is forbidden to marry an adult, but goes through the ceremony of marriage with some male child, or, in some cases, with a portion of her father's dwelling-house, on the understanding that she may receive any man of the caste. Her children inherit the property, which is thus retained in the woman's family, the child-husband being the supposititious father. Amongst the Tamil races who have adopted Brahmanism, the Vellalar, alike in numbers and in social rank, take the chief place. The Christian converts of the Vellalar retain their Kudmi or scalp-lock of hair.

The Teling races following agricultural pursuits, have very distinct characteristics. Several of them seem to be of Aryan origin, and all of them are taller and fairer than the races in the south.

The Ailma, or Velama, or Yelmi $(258,698$ in number) in the Teling country are a prominent agricultural tribe, with military proclivities, and claim to be Rajputs. They are soldiers and agriculturists.

The Rachwar or Rajwar of the Northern Circars also claim to be descendants from the Kshatriya race; they are a brave tribe, with a high sense of honour. They have been long established in the Northern Circars, and have been remarkable for the desperate acts by which they expiate a real or imaginary insult. Their name is variously written and pronounced by others, but the Teling "style them Racha and Racha-vadu, doubtless a variation from raja, often corrupted to Ratsawar, Raiswar, or Rowar. They were military retainers in Mysore and in Kamaon, where they speak Telugu; they practise medicine. The Rachwar chiefs are a remarkably fine, handsome race. There are defects in their genealogy, but they are permitted to intermarry with the Rajputs of Rajputana.

In the middle of the 18th century, zamindar Rangaru of Bobbili had a feud with a neighbouring polygar named Vizeram Rauze, and the latter persuaded the French commander, M. Bussy, to espouse his side of the quarrel, and Rangaru was obliged to retire to his stronghold. It succumbed to the army brought against it by M. Bussy on the 24th January 1757, consisting of 750 Europeans, of whom 250 were horse, 4 field-pieces, and 11,000 peons and sepoys, the army of Vizeram Rauze, who commanded them in person. Rangaru believed it hopeless to maintain the fort against so overwhelming a force, and, calling his principal men together, he declared that it was immediately necessary to preserve their wives and children from the violation of the Europeans, and the still more ignominious authority of Vizeram Rauze. The stern determination was carried out to the fullest; the habitations in the niddle of the fort were indiscriminately set fire to, and every woman and child either perished in the flames or was remorselessly stabbed in endeavouring to escape. Then those who accomplished the deed returned to die on the walls, and fell almost to a man. Rangaru himself, hastening to the defence of a tower, was killed by a musket-ball. After the capture of the fort, four of Rangaru's soldiers concealed themselves in a thicket, and three days afterwards two of them succeeded in penetrating to the tent of Vizeram Rauze, and, having stabbed him in thirty-two places, were themselves immediately cut to pieces.

The great bulk of the Teling people engaged in agriculture retain their tribal designations; thus-

The Balijavadu, pl. Baljawanlu, in Telingana, are a Sudra tribe of husbandmen.

The Sudra Pakenatti, Muttatti, and Vellanatti are village authorities, and take the designation of Reddi. A peaceful and innocent migratory race bearing the name of Pakenatti were found in Mysore and the Telugu country, about the beginning of the 18th century, driven from their homes by oppression.

In the Ceded Districts, the Peracoonta Kapalu and Gungeddi Kapalu are husbandmen of the Sudra grade.

The Gumpa Kumalu, or Kama-waru, or Kamavaru, are Sudra husbandmen, who do not permit strangers to enter their houses, and regard their tribe as pure Sudras.

The Naek or Naidu are honorific terms applied to masters or chiefs of tribes, and many of the Teling Sudra take this honorific appellation. They are tall, robust men, fair complexioned, who are in good positions as merchants and as servants of the British Government.

The Kapu in the Cuddapah district do not allow the re-marriage of their widows, nor concubinage, but the latter is generally winked at to prevent the family disgrace of their becoming common; and even adultery is but little regarded so long as the offenders belong to the same caste or subcaste.

The Palli race of the Cuddapah district pledge their wives as security for loans of money, and if not repaid, the woman is re-married to another man. A case of this bigamy was tried in $\mathbf{1 8 7 6}$ at the Session of Cuddapah, and all the parties were fined. The husband had borrowed some money from his mother-in-law, and left his wife with her till he could repay. Having failed to pay within the prescribed period, the wife was remarried to another man. The twice-married wife, her mother, and a third party who was present at the second marriage, were held to be equally punishable as principals, all having been present at the re-marriage.

Paik of Vizagapatam are military; a fine brave race, and good shots with the matchlock. They have ten sections, viz. Suathro, Bellama, Noula, Kalgina, Kampu, Kunu, Uriya, Binnakurya, Bosuntea, and Guri.

The Mutraj subdivide into Bhui and Mutraj, and the Bhui of Telingana is classed as a Teling Sudra, who occupies himself as a palanquinbearer; but where settled, away from his fields and agricultural pursuits, the Bhui is engaged in eatching fish by the net.

The Ur-bhoi-wanlu are mercenary soldiers who serve native sovereigns. They are never found in the ranks of the British army. There are a few of them in every large town in the south.

The Yerra Walleroo are a Dhangar or herd tribe in the Northern Division.

The Palalu, of the Northern Circars, are agricultural labourers who are regarded as slaves to the ryots, and were hereditarily attached to and transferable with the land.

The Agari of Cuttack are said to be domestic slaves.

Gaita is the name of a barbarous Gond tribe in the Rajamundry district.

Nackar and Reddi, in 'Tinnevelly, claim to have 
been there ever since Rama's advance on Ceylon, and to have formed part of that leader's army. 'They call themselves Oudh Reddi.

The Reddi and Kamma Teling came from the north, and are styled by the Tamil people Varuga or Vadaga, meaning northern. According to Dr. Caldwell, they had been previously settled on the Ganges. They are a taller, finer race than the Tamil, Canarese, or Mahrattas. The Reddi are bulky, fair, handsome men, energetic and enterprising. They have advanced along the Kistna, and the rajas of Gudwal and Wanparti are Reddi. They have pushed colonies of Reddi into the Canarese and Tamil districts, and are found in small scattered communities west to Bellary, and south-west to Tinnevelly, and west to Poona.

The Teling or northern agriculturists think themselves superior to the Tamil cultivating castes. In the Madura district, soon after the establishment of the Nayakan dynasty, the Teling immigrants became so numerous and so influential that the Jesuit priests of Madura regarded them with the Brahmans as constituting the chief part of the people; and at the present day the poorest and most ignorant Teling bangle seller is disposed to give himself airs, and to affect a superiority over Tamilar of considerably better position than himself.

The Kavare are a Telugu-speaking race, part of whom have migrated into the Tamil country, where they have 18 clans. Most of them are farmers, but the Baliji section are also petty traders, hawkers, and sailors. They were primarily an agricultural people, holding lands on military tenure, and working their farms by means of inferior castes.

'The Reddi of the south of India are divided into 24 clans, who marry in their own clans. The temples of the Reddi and the Naekar are of a rude form; they are of the Vaishmava sect, but a brass lamp seems to be the only utensil they contain, and flowers and cooked food and spirits are offered before it; they worship demons like the Shanar. Some, also, at one place, worship a lingam. Their emblem of the Brahmanical Vishnu is an octagon pillar, and they call Vishnu Perumal or Senna Rayer Perumal. They eat all but cow's flesh. As a law, the men marry their sister's daughter, but an aunt does not marry her nephew. Sometimes the bride is a mere child of 5 or 6 years old ; sometimes the bridegroom's age is no more, while the wife to whom he is married is a full-grown young woman, who, by the time her husband has grown up, has a young family of 4 or 5 children. Property descends through the issue of a son and granddaughter, uncle and niece. If a man refuse to marry his own sister's daughter, his father's property descends not to him, but to the man who marries the rejected woman.

The Reddi are married on the field, the Naekar are married in the house; a cotton thread is fastened round the woman's neck. If no son be born, they marry younger wives in the hope of male progeny, and the Rev. J. F. Mearns had known a man with five wives. They burn their dead, and offer rice to the manes. If the crows eat the offering, the state of the deceased is augured as happy. The Reddi are exclusively farmers. They speak a corrupt Telugu, but read and write Tamil. The Naekar are mostly clerks and farmers, but are also tradesmen, brokers, shopkeepers, and the hawkers of the Peninsula are almost all Naekar.

The Naekar seem to have invaded the south of India during the reign of the Pandiyan dynasty, which they overthrew ; and they held the country by allotting it into 72 portions, each under a polygar chief with military followers. The dynasty reached its highest under Tirumali Naekar. Some of the polygars appointed by them were of the Totier caste or race, and one of the chief polygars is of the Totier caste, but they consider the designation reproachful. They are known collectively as the Kombelathar, but they consist of nine families or clans, descendants of a common ancestor. They are a bold, martial race, robust and tall in stature.

Khandait were granted lands on military tenure. They resided in fortified houses, and held their lands at a quit-rent on condition of acting as a feudal militia, and protecting the lowlands from the incursions of barbarous mountain tribes. Their name is from Khanda, a sword.

The Mala race are the Teling Pariah, but the derivation of the word is not known. In the Brahmanical Puranas there is mention of a race called Mala in the N.E. of Bengal, and their country in the Midnapur district still bears the name of Mal-bhum, and it may be that the Mala were slaves whom the. races now in Telingana brought with them from the Gangetic valley.

The Tamil herdsmen call themselves Yadava or Idayan, also Go-vansa or cowherd race. They are darker and more slender than the Vellalar, and are less engaged in cultivation. They usually take the honorific appellation of Pillai, or son of the gods, as Gurusami Pillai, s designation which is, however, also adopted by other races. In Tinnevelly the Idayan take the honorific title of Konan. Pillai or Pilly means a son, but is applied to the god Vigneswara, the son of Siva and Parvati, known as Pilliar; and it has been said that three or four centuries ago Brahmans of Tinnevelly took the title of Pillai, sons of the gods. The larger number worship Vishnu. A smaller part are of the Saiva sect, but in the south the village deities and evil spirits or devils are the chief objects of their worship. In some districts widows are re-married to the brothers of the deceased husband.

Kurumbar:- In the Peninsula, in the Ceded Districts and Hyderabad, the Kurumbar are dark, almost black men, of slender and spare forms; they are quite dissimilar from the Gaoli in personal appearance, wholly distinct also from the Idayan or Yadava Tamilian herdsman race, who are known in all the Tamil country as Pillai or son, and in all probability the dispersed Kurumbar or Dhangar of the Peninsula of India, some of them in towns and others almost nomade, are the fragments of the great shepherd race who held sway in the soutbern districts in the early centuries of the Christian era. The life of the shepherd Kurumbar is passed at a distance from towns and villages, in the open plain, or in the glens and forests, night and day watching their flocks. The Handi Kurubar are Kurumbar who take service in towns.

Kurumbar have caste clans, but they are not rigid in theobservance of caste rules nor as to food. They marry grown-up women, which Brahmans never 
do; they sacrifice to ancestors, and they have a god called Bhyrava, but have no demon-worship. They are shepherds, gardeners, labourers, weavers. Some engage in Kumari cultivation. They are quiet, inoffensive, industrious, honest, and sincere. The Kad or Red or Jungle Kurubar are mentioned by Buchanan as a poor, dwarfed tribe, employed as watchmen.

The Dhangar are of the Mahratta and Telugu countries, are in twelve tribes, who do not eat together nor intermarry. In the bill country of Ramgarh and Chutia Nagpur the Oraon tribe take this name, and descend periodically into the plains for labour. The Dhangar, in Calcutta, are labourers (Campbell, p. 33). Mr. Hodgson describes the Dhangar as of Mongol origin. In the south of India they are cowherds and weavers in wool. Many are settled in towns, occupied as labourers, kitchen gardeners, and dairymen, and the Dhangar in the south of India arrange themselves accordingly. The Teling Dhangar are milkmen and weavers of coarse woollens; the Mahratta Dhangar graze cattle and sheep, and clarify their butter into ghi ; the Bangar Dhangar are purely cowherds.

The landless labourers of the Madras Presidency (Parayan, 4,439,253 ; Vannian, 3,751,093) number about a fourth of the entire population. They chiefly comprise the Vanniar, the Pulliar, and the Pariah; the Oddara and the Uppara, road, salt, and tank makers.

The Vanniar and the Pulli or Palli are the chief labouring agricultural classes of the southern districts of the Madras Presidency, particularly numerous in Tricbinopoly and Tanjore. The Tanniar are good field labourers and excellent farm servants and cultivators. Before the British became paramount, they were predial slaves on the lands of the Vellalar and Brahman proprietary, but a large number of them are now farming on their own account, or work the lands of the higher castes on the principle of sharing half the net profits with the proprietor; others of them are simply labourers, and by taking advances from their employers are still practically serfs of the soil, from inability to extricate themselves from their indebtedness. They are, as a rule, very dark skinned, and have all the characteristics of a non-Aryan race. They now rank, however, as Sudra Hindus, and, like other Sudras, are claiming to be of the higher social rank of the Vaisya, but this is not conceded to them. The honorific suffix of Naik is used with their names. It is supposed that in former times several of the semiindependent polygar chiefs in the south were Vanniar.

Kanakkan in Tamil, Shambog in Canarese, Adigari in Maleali, Karnain in Telugu, are designations of the race who follow accounting and clerking in the Tamil, Telugu, Canarese, and Teling districts. They correspond in their avocations to the Kayasth of Northern India. The Kanakkan recognise four subdivisions, - Sir K., Saratu K., Minadu K., and Mattuvali K. And the 1881 census report showed 102,472 of the Kanakkan and Karnam race, most numerous in Ganjam, N. and S. Arcot, and Chingleput. In the early days of the E. I. Company's progress they were their brokers, agents, and interpreters. They are the hereditary village accountants.

Polygar chiefs were known in Madras as Men-
Kavalgar, and the village watchmen as SthalaKavalgar, whom the British call Talliyar, from Sthaliyar, or local guardians. Of these tribes none have risen to general power, but they established many small principalities in secluded places, and by siding with the larger powers they retained their petty sovereignties, - the Beder rajas of Bednore or Nagar in Mysore, of Harponhalli in the Ceded Districts, of Beder Zorapur in the Doab of the Bhima and Tumbudra, the Matta Rachawar of Carvatinagar; the Kallar chief of the S. Arcot district, styled H.E. the Tondaman Raja of Puducottah; the Maravar chiefs of Ramnad and Siva Ganga in Madura, and others in the south, some of whom claimed the privilege of coining money. Towards the close of the 18 th and beginning of the 19th century, the British Government required to reduce several of the polygar chiefs. In 1802-3 Kotta Bomma Naik, the dumb chief of Panjalam Kurchi in Tinnevelly, thrice beat back British detachments, and was at last subdued by a small army with Europeans and guns. If the British arms were otherwise engaged, these tribes would instantly rise as the Gujars and the Beders of Zorapur did in the revolt of 1857.

Shanar or Shanan. - Three palms of British India, the cocoanut tree, palmyra tree, and date tree, furnish the greater part of the palm wines, which are largely fermented and drunk by the people, or from which sugar and an alcoholic spirit, as also vinegar, are prepared. The palm-tree cultivators of the Madras Presidency in 1881 were $1,478,660$ in number,-Billava, Eruvan, Gavundla, Hale Paika, Idiga, Indra Kavisian, Shannan, Segadi, Sondi, and Tiyar. Those of the Travancore State were 508,692 in number, -all the Paraven, Nulian, Thundan, Elaven, and Shannan. The dry, rainless tracts of Tinnevelly bring to perfection the palmyra tree (Borassus flabelliformis). Western India and Ceylon produce the cocoanut tree (Cocos nucifera), which grows with most luxuriance within reach of the salt air of the ocean; and the date tree (Phoenix sylvestris) is seen all over the south of India in patches, and extensively in parts of the Dekhan, of Northern India, and of Bengal.

The Shauar race in Tinnevelly and the south of the Peninsula have a tradition that they came from the north of Ceylon. They are everywhere a hard-working, industrious people, traders, cultivators, toddy-drawers, distillers, eating freely of fish and flesh, and drinking the toddy or palm wine. They are dark skinned, with low foreheads, sunken eyes, and prominent cheek-bones, timid and superstitious; are not so good-looking even as the Maravar, either as to physique or features. In the sandy sea-coast wastes of the south of the Peninsula they have widely extended the cultivation of the palmyra tree; they claim a seigniorage over these tracts, and they are largely occupied in extracting the palm wine. A man will attend to about 50 palm trees. Travancore Shanar women lately wished to cover their bosoms, and their attempt to do so was interfered with by the Nair race. More than one-half of them profess Christianity of the Protestant or Romish Churches, and the other half follow demonology, with the usual bloody sacrifices and devil dances. In Tinnevelly and Canara they are largely devilworshippers. In Malabar they worship some local deities; but in Tinnevelly very many of 


\section{INDIA; THE MADRAS PRESIDENCY.}

them have become Christians. Some of them from Tinnevelly have graduated in the Madras University, and the position of the race is improving. Of the Travancore palm cultivators, the Elaven and Paraven are also called Shogan, also Valen and Elava Panikar. These correspond to the Teyar of Malabar, and members of this community are amongst the most respectable of the Travancore people. The Shanar of S. Travancore correspond to the Elaven of N. Travancore, and are even a more enterprising class. The Shogan appear to be the Chego race of Malabar, noticed by Wilson as the Chegavan or Chekavan, whom he describes as a man of low caste, commonly a Teer, one whose occupation is drawing toddy. In civil war or rebellion, the Chego were bound to take up arms for the sovereign; and some princes employed them as soldiers if they had not a sufficient force of Nairs. The Chego are subdivided into two sections, the Chego and the Twen Chego.

The Shanar have many of the characteristics of the aboriginal tribes, worship devils or local deities; but in Tinnevelly, where many of them have become converts to Christianity, the contrast is great between 'Martha,' the native Christian Shanar girl of to-day, with her neat attire and good education, and poor 'Chodalee" of former times, before Rhenius and his fellowlabourers Christianized Tinnevelly. Sir Walter Elliot considers the Hala-Paik of Sirci in Upper Canara, ard the Bilawari below the ghats, to be nearly allied to the Shanar.

Teer, Teyar, Tiar, Eeyoover, or Juver, the toddy-drawers of Malabar, follow the rule of descent a matrice. The women are polyandrous, and admit all comers. Till recently treated as unclean, and compelled to move from the road when a Nair approached, they are now being educated in the Goverument schools, obtain service, are acquiring land, and are very well to do. They are fairer and more refined looking than the Nair. Teer is said to mean island, and the Maldives and Ceylon have been named as their original country. Dr. Caldwell thinks they came from Ceylon, but a Teyar race occurs in the Sunderbans. The Teyar of Malabar and Travancore have one wife between several brothers, but plurality of wives is also common. Physically they are a fine and haudsome race, the women being particularly fair.

Kallar, Kallan, or Colleri are a tribe in the Tondaman country, in the Vasanga district, in the eighteen palliams or districts, and throughout the Madura, Tinnevelly, Salem, Tanjore, Chingleput, and Coimbatore districts. Calicoil was the stronghold of the lord parumount, the raja of Tondaimandalam, the country of the Tondaman, which was an ancient division of the Peninsula of India, of the part now occupied by the Arcot and Chingleput collectorates. The country of the Tondaman, H.E. the raja of Puducottah, a feudatory chief, is now only a small tract near Trichinopoly.

Until late years they were so predatory that in the south of the Peninsula of India Colleri became the designation of a thief, and their tribal name is derived from Kallara, thieves, plunderers. In ancient times they seem to have inhabited the woods from Trichinopoly to Cape Comorin. Orme describes them in the middle of the 18 th century as expert thieves and plunderers, and the Jesuit Father Martin says they were very cruel. Pennant, writing of them in the 18 th century, says the adjacent countries are covered with thick forests, and little cultivated by reason of the savage inhabitants, the Polygars and Colleri, who may be truly styled 'sylvestres homines.' The Colleri, he adds, were predatory, and their government, as also that of the polygars, feudal. They generally sided with the Muhammadans and the British in the wars against the French in the times of Clive and Dupleix; but, as with the Maravar, they have now settled down to peaceful occupations. They are small statured and dark skinned, and their monkey-like features afforded to Valmiki the illustration of Rama's advance to Ceylon being aided by the monkeys.

The Ramayana describes the forest (or wilderness) of Dandaca as covering the whole extremity of the Southern Peninsula, and the rude inhabitants are designated rakshasha (monsters) or vanara. Vanara is from Vana, a wilderness, and Nara, a man, that is, a wild or uncivilised man; and to this sense, as to the wild races in the extreme south, Mr. Taylor thinks may be reduced the fable of Hanuman, the chief monkey, and that of his army. He says that those who have seen the Colleri and Marava will readily consider them to differ from all family likeness of the Aryan Hindus; and as their visages often resemble baboons more than men, it would require even less than the ardent poetical imagination of a Valmiki to induce the employment of an equivalent word, which would so aptly seem to convey the idea imparted by their appearance. In 1871 they numbered 354,554 , the population of the Puducottah State alone being then 316,695 .

The monkey-faced races in the south of India are all brave and martial people, with much physical power and endurance. Their habits and customs are entirely aboriginal. Nominally of the Saiva sect, they are mostly devil-worshippers. They usually bury their dead. They have a first and second marriage, like the Maravar of Ramnad. The titular surname of all Kallar is Ambalakaren, and they returned 155,537 in 1881. Divorce and re-marriage of widows are allowed. Marriage of near relatives is usual. The Westerm Kallar of Madura are polyandrists. It constantly happens that a woman is the wife of either ten, eight, six, or two husbands, who are held to be father's jointly and severally of any children that may be born of her body. And when the children grow up, they style themselves the children not of ten, eight, or six fathers, as the case may be, but of eight and two, or six and two, or four and two fathers.

The Maravar of Tinnevelly are employed as Kavalgar or watchmen, but almost every case of highway robbery in that district is traced to this race. They were formerly the most martial tribe of the south, and held their lands under military tenure. They were numerous and powerful in Madura and Tinnevelly even after British occupation, but they are said to be disappearing. Their widows re-marry; divorce is easy. In their daily life they use all flesh meats except that of the cow, and drink spirits. They were long predatory, but they have settled down to agriculture, and some of them have property. The zamindar of Ramnad is a Maravar. They also occupy Shiva- 
ganga. Their district has been surmised to be the Marullo of Cosmas Indicopleustes, which was on the continent opposite Ceylon.

The Maravar men wear ear-rings, and by pulling; elongate the lobes of their ears. The women insert massive ornaments in the lobes of the ear till a perforation is made an inch wide, and the eal' sometimes comes down to the neck.

They worship local deities, demons, and evil spirits, to whom they offer liquor, flesh, and fruits, and practise divination and sacrifice; and, on the occurrence of a small-pox or cholera epidemic, the whole village is excited, and devil dances are common. They are a robust, hardy, dark-skinned, stalwart race, athletic, with well-developed muscles, active, of moderate height, the cranium rounded, narrow in front, forehead low, eyes large and full. They are employed as village watchmen, and are honest to their employers, but have been largely given to thieving and gang robbery. The men do not wear turbands. They wear their hair long; and arranged like the women of the Dekhan.

The Naravar women of Ramnad and Sivaganga wear cloths of 25 or 30 cubits in length, folded in plats, which they fasten behind. This is unlike other Hindu women, whose cloths do not exceed twenty cubits, and are fastened on the right side in front. In their marriages, disparity of ages is not considered, nor is the presence or assent of the bridegroom necessary, - a blade of wood in his absence serving as proxy. They intermarry, some of the subdivisions not marrying into the father's family ; but Hindus in general intermarry with the mother's relations. In Ramnad and Tinnevelly, the titular surname of all Maravar is Dever.

Beder.-In the tract lying between the Mysore, Hyderabad, and Mahratta territories are several petty sovereignties, such as the nawab of Banaganapilly, a Syud family, in the east of the Ceded Districts. Until 1839, the Pathan nawabs of Kurnool ruled on the right bank of the Tumbudra river. Farther west, the Reddi chief of Gadwal, the Mahratta chief of Sundur, one of the Ghorpara family; the Kshatriya raja Narapati of Anagoondah, who claims to be the descendant of the great king Rama of Vijayanagar, who was orerthrown by the combination of the Muhammadan kings of Golconda, Kulburga, Bijapur, and Ahmadnaggur; the Pathan nawabs of Shabnoor, the Ghorpara chieftains of Gujundargarh and Akalkot, and at Ghoorgontah and Beder Zorapur are the descendants of that Beder soldier Pid Naik, to whom Aurangzeb, for aid given at the siege of Bijapur, granted a small territory in the Raichore Doab. The Beder race have only these two small sovereignties, and some of them in Zorapur are tall, well-made, robust men.

The Beder of Beder Zorapur drink spirits, eat the hog, crocodile, porcupine (sarsal), manis (uli) iguaua, bullock, cow, buffalo, cat, rat, bandicoot (Mus gigantea), and jerboa rat.

Prior to the Muhammadan invasion of the Peninsula, the Beder race seem to have been settled in the northern part of Mysore under successive dynasties, and they do not appear to have advanced north of the Bhima river. They were numerous in the doab between the Krishna and Tumbudra rivers, and the Beder principalities of Gurgunta, Jaliballi, and Deuhüg protected the line of the Krishna. In the Raichore Doab also were Beder principalities, at Kankgari, Adoni, and south of the Tumbudra at Chittuldrug, Harpanhalli, and Zorapur, the last of which rose to considerable power during Aurangzeb's reign. The Beder of Zorapur rose in the rebellion of 1857.

The Beder race in parts of Mysore, 260,000 in number, form a considerable part of the population, and have many polygarships, and 26,761 in the Madras districts. Some of them have become Muhammadans. Their name is variously written, and pronounced Beder, Baida, Baidera, Waida, Vedda, Vedar, Veddar, Vedan, Bedan, and Berad. They are the race who gave their name to the Pindara who harassed Central India for nearly 100 years.

The Pindari are mentioned in Indian history as early as the commencement of the 18 th century. Several bands followed the Mahratta armies in their early wars in Hindustan. They were divided into durrah or bands, commanded by sirdars or chiefs, and people of every country and of every religion were indiscriminately enrolled in this heterogeneous community, a horse and sword being deemed sufficient qualifications for admission. A common interest kept them united. Some of the chiefs acquired wealth and renown in the Mahratta wars; they seized upon lands which they were afterwards tacitly permitted to retain, and transmitted, with their estates, the services of their adherents to their descendants. The predatory Pindara bands were all broken up and the members dispersed at the close of the third Mahratta war, during the Marquess of Hastings' administration.

The Kammalar, or artisans, are also called in Telugu Kamsala or Panchala, the last name being given to them because of their five trades, - goldsmith, coppersmith, blacksmith, carpenter, stone-cutter. Those of the Tamil and Telugu country respectively intermarry with their own country artisans. They number in Madras, 602,300. The Brahmanical caste system rauks them as Sudras, but in the Madras Presidency they wear the sacred thread, and maintain that they are of higher origin than the modern Brahmans, and many of them add "Achari," religious teacher, to their names. According to Mr. Sherring, the Mahratta goldsmiths also claim to be allied to Brahmans; and in the south of the Madras Presidency, some Kammalar call themselves Visva Brahmans. They do not, however, have Brahman teachers. They are nearly all of the Saiva sect, but they worship Kamatchi Amma, $\mathrm{Kali}$, and village gods. They bury their dead in a sitting posture; to obtain which, as deatly comes on, they raise the upper part of the body against a wall, to which by a peg or nail they secure the head. The Vaishnava artisans burn their dead. Most of the artisan races are skilful workmen, and, since the opening of railways and other public works in India, they have all been earning double their former wages. They are quiet, docile, and respectable men, but they detest Brahmans, have their own guru or priests, and their own books. They have as an idol a figure like a sitting Buddha. Sir W. Elliot supposes them to be the descendants of Buddhists, partially converted under persecution to an ostensible Brabmanism. They form the chief of the left- 
hand castes, and their followers are the Pallar, with the leather-workers and tanners. The righthand castes are led by the Brahmans, and their followers the Pariahs lead the van, and beat their drums when they come to blows. The points on which they now differ or stickle for are trifles.

Chetty, Chettiar, Setti, or Chitty, of the Telugu and Tamil districts, number nearly a quarter of a million $(235,169)$. Their designations are dialectal variations from the Sanskrit Sreshthi, and Hindi and Mahrati Seth, Seti, and Shet. It is applied in the south of India to all the races engaging in trade, banking, or mercantile transactions, though many of them enter Government offices. They claim to be the Vaisya section of the Hindus, but they are of varied origin, few of them eating together or intermarrying; some of them large, bulky, xanthous-coloured, intellectual men, and others short statured and of mean physical appearance. This may be judged of by mentioning that there are ninety different clan designation of the Chetties of the Madras Presidency. one of which is again subdivided into upwards of one hundred sections. In 1871 there were 16.948 Chetties in Travancore, divided into sixteen sections. They all add the honorific term Shet or Seth, or Chetty or Chettiar, to their names, as Jagat Shet, Vencata Kistnamah Chettiar, as indeed do the Parsee and the trading Bohra, Mehman, and Khojah Mubammadan.

In the Madras Presidency they are essentially traders, and take their designation from their origin, as Marwari Chetty, Gujerati Chetty, etc. The Komati Chetty claim to be Vaisya Hindus; the meaning of Komati, their designatory name, is not known. They wear the sacred thread. They are of the Saiva and Vaishnava sects, but many worship the goddess Kamatchi Parameswari. Many are landholders.

Natu-Kothiar, of the south, all speak Tamil, and follow Brahmanism; are large spice merchants, and all of them have the marked African protruding lips and nose sharply cut at the forehead. They are keen, active traders, but grasping, with no public spirit. They seclude their wives.

Weavers.-The Tamil castes of weavers are the Kaikalar or Kaikilan, and they numbered in 1871 above a million. About half the men are employed in the construction of textile fabrics and dress, in which they are aided by their families. The number of looms continues steadily to increase. The great number of the agricultural labourers weave coarse cottons and woollens in the interval of their field work. The designation Kaikkil means to undertake, but those engaged in special branches of their trade are in Tamil called Seringar, Jendraver, Saliyar, Sedan, and Silupan. Their names in Telugu are Salay, Padmay-Salay, Jendrar, Thokata, and Devangalu, about 400,000 in number. These have, however, numerous subdivisions, and the weaver colonists from northern countries who are settled in the south hold no intercourse with the southern weavers. In every large town there are colonies of silk weavers, Patnulkar, whose ancestors originally came from Gujerat, fair, handsome men and women, their chief men dealing in raw silk, and well to do. 62 per cent. of the soutbern weavers profess the Saiva religion, but worship village deities and demons. They are addicted to drink.
The women and children all work at the loom; the fly-shuttle is not as yet in use. Their numbers are increasing; some allow widows to re-marry. The weavers of the Chingleput district devote their eldest daughter to the service of the temple.

Shembadaven or Fishermen.-Several races in the Madras Presidency follow this occupation. They number 873,448. The Tamil people call their chief race Shembadaven, but in the Canarese language and in Maleali they are called Mukkava or Mukwa, and in Telingana the fishing tribes are the Boi, the Besta, Chapakulam, Patnavar, Mogivlu, Paravar, and Valaiyan. They fish along the seashore, in the marine lagoons, and they spread along the larger rivers.

The Muku'a fishermen in North Malabar follow the rule of descent a matrice, but those in the south permit of descent of property to sons.

Paracur are a dark-skinned, almost black, race in the extreme south of the Indian Peninsula, living in villages along the sea-coast, and earning their bread as fishermen, with nets, lines, and hooks. They own canoes, which they take to sea before daylight, and return about noon. Their ancestors are said to have been converted by Xavier, and they still profess the Romish religion, but they are drunken and dissolute. Mr. Nelson mentions that the Portuguese on coming to India found the Paravar greatly oppressed by the Muhamwadans, and they assisted the Paravar on the agreement that they should become Christians.

The Bii race, 414,810 , from the northern part of Telingana, are fishermen, palanquin bearers, domestic servants. They mostly profess to be of the Vaishnava sect.

The Pulli have about thirty subdivisions, according with their various occupations, but these all eat together and intermarry. In Tinnevelly, the Pullans are loathed by all caste races. They live by ploughing, sowing, and reaping the fields of the wealthy caste men. They are also employed as coolies in road-making and building, etc. They are not permitted to live within a Hindu village, but apart, and their hamlet is called the 'Pullacherry.' Their women never cover the upper portion of their bodies, and to do so in the presence of any other caste would be considered a gross insult. Their religion is the worst kind of devil-worship.

The Puller, Pallar, or Pali race in the south of India were formerly in a state of slavery, but their position is now solely dependent on their means. Both men and women work well, take part in all agricultural labour, the women in this particular vying with the men. The Puller women as a rule cannot be induced to cover their breasts. Previous to British rule, the Puller who inbabited the forests and mountainous districts of the Malabar coast were regarded by the settled inhabitants as inferior to the beasts of prey, and were not even permitted to erect houses for themselves. A shed supported on four bamboos, and open on all sides, sheltered them from the rain, but not from the inclemency of the weather. They dared not venture on the public road lest their steps should defile it; and when they perceived any person approaching them from a distance, they were required to utter a loud cry and make a wide circuit to let him pass.

In Travancore, the Pullayar, about 188,916 in 
number, are described as the lowest in the scale of society. They are, however, a truthful, honourable, hard-working, useful race, and are labourers in the rice lands. They speak Maleali, and are scarce in the Tamil-speaking taluks of Nanjanad and Shencottah. Until lately they were bought and sold as chattels, but are now free men, though they prefer to remain on the lands of their former master. A few of them are wandering in the Warsanad and other jungles of the Madura district.

Pariahs are supposed to be identical in race with the Malavadu of Telingana, the Holiyar of Carnatica or Canarese-speaking . race, the Dher of Hyderabad and Berar, the Mhar of the Mahratta, and the Poliyar of the Maleali. The Vetti, the village servant of the Tamil people, is a Pariah. The Pariah name is supposed to be derived from Parai, TAM., a drum. Pulaiyar is the term by which they are known in Shen Tamil, and is said to be from Pulai, TAM., flesh, hence vileness ; but it is more probably from Pulam, TAM., land. The Canarese term Holiyar, and the Hala-Kannadi Poliyar, are supposed to be from Hola, a field or land. But in the Kapurdigiri inscription of Asoka, which is engraved also on the rocks at Girnar in Kattyawar, and of Dhauli in Cuttack, are the words, "In all the subjugated territories of king Priydasi, and also in the bordering countries, as (Choda) Palaya (or Paraya), Satysputra, Keralaputra, Tambi pani,' etc., the Paraya are named in the centre of the Dravidian group, with the Chola or Sora, Kerala or Malabar, and Singhalese.

The Holiyar of the Canarese believe that they were once an independent people, and had kings of their own. The Pariah of the Tamil countries also believe that they were once the most important race; and Ellis states that those of Tondamandalam in the province of $\mathrm{S}$. Arcot consider themselves the real proprietors of the soil. The head Vetti Pariar at Trivalur in Tanjore carries the chouri or fan of the god Tiyaragar or Siva, and in Madras, at the festival of Eggutal (the sole mother), it is a Pariah who puts the tali or marriage cord around the neck of the goddess.

The Holiyar of the centre of the Peninsula where Canarese is spoken, and in Canara, seem to be identical with the Pariah or Dher race of the other districts, and, like the latter, are predial slaves. In Coorg, the Holiyar has three branches, the Holeyaroo, Yewaroo, and Paleroo. Both in Canara and Coorg, however, they lave other designations prefixed, such as Mauri Holeyaroo, Byr Holeyaroo, Murtha, Bulgi Holeyaroo, Rookha Holeyaroo, Badaya Holeyaroo; and in Coorg, Kembatta Holeyaroo. Amongst the Mauri Holeyaroo, property descends through the female line.

The Komati, or Hindu shopkeepers of Madras, before contracting marriage send an offering of betel to the Chakili or shoemakers; and in Vizagapatam, Brabmans go through the ceremony of asking the consent of the Malavanlu to their marriage.

The Patel or head-municipal authority is occasionally found to be a Pariar in the Mahratta country. The Editor has seen one of them. The Pariar of the Tamil country are unable to enunciate some of the true Tamil vocables; they either mispronounce or omit them. The Pariar of the Tanil countries are never called Adumai or slaves.
The Pariah clans are found in every village and town in the Peninsula. They are settled in houses, their quarter being usually apart from other residents, and outside the walls of fortified places, and called Parcherry in the Tamil country. Their history is altogether unknown; they are almost wholly landless; they are often, in the villages, predial slaves, and escape from this position only in the largest towns, where labour is available.

They are labourers, servants, grooms, never are scavengers; eat dead cattle, dedicate their girls to the gods; are shamanists, fetishists, and polytheists. The Mhar are regarded by Hindus as lower in social rank than the Dher. The Mhar are not numerous, but are to be met with throughout the Mahratta country, dwelling. apart outside the village, and, like the Pariah, are often part of the Baluth, being the village messenger and watchman. The mark for their signature is a staff. The Pariah are wholly different in race and appearance from the leatherworking race, the Chakili, Madaga, Dhor, Chamar, or Mhang, whose mark signature is a knife. The Pariah are a willing, ready people, obliging, grateful for any little kindness, and, for the traveller, whether at midnight or midday, in sun or rain, or cold or heat, they take up their staff and move cheerfully along to show the road to the next village. Indeed, in the great tract of country forming the Peninsula, the Pariah races and the Mhar are the chief free labourers. Hindu farmers rigidly prevent their holding land, and with equal tenacity prevent those of the hamlet leaving it, lest the village lose its labouring hands. They have been really village slaves throughout the Hyderabad country. The Pariah amongst the Tamil people arrange themselves into many tribes.

Their women, in the Tamil country, are married at all ages, their widows re-marry, concubinage and bigamy are not rare, and they marry near relatives. They are addicted to drinking. Many of them are educated. Auvaiyar, a Pariah woman, is famed throughout the Tamil nation for her poetry. Also, the Kural, the most popular poem ever produced in the Tamil country, was written by Tiru Valluvar, the divine Valluvar, a Pariab. It is read and admired by Tamil Hindus of every class and creed. The author addresses himself to mankind in general, witbout reference to caste or creed. He enunciates a monotheism embracing all bumanity. $\mathrm{He}$ rises above the puerilities of castes, and preaches a pure morality to the human race as a whole. Though a Pariah, he was deemed to be worthy of election to the academy of Madura, an honour usually reserved exclusively for Brahmans of learning and piety. Another Pariah poet, Kapila, author of the Agaval, has been supposed to have been a brother of the author of the Kural, and his works still hold a high place in public esteem.

Pariahs are permitted to marry into each other's families. They are regarded by caste Hindus as unclean, but they are not out-castes or men who have been expelled from other castes, but a race of non-Hindus. They are usually the serfs of the Sudra agriculturists. Those in the large towns in Southern India, in the employ of Europeans, are quick, intelligent, and active. They are emigrating with great rapidity to the West Indies, Mauritius, 
Cape Colony, and the Burmese provinces, etc., where sectarian or social distinctions are unknown. There are ten castes who are lower in the social scale than the Pariah, and from these are excluded the Pallar, who dispute precedence with the Pariar. The Pariar constitute a well-defined, distinct, ancient race, independent of all others, and has its own subdivisions, its own peculiar usages, its own traditions, and its own jealousy of the encroachments of the races which are above it and below it. And the Pariah, whom St. Pierre's romance has fabled as a mild, benevolent, subdued being, whenever he has an opportunity, is as severe on other sects as from the custom of the world we would surely expect. Some of them devote their young women to the gods, but the practice is followed for money, and is generally regarded as vile.

The Dher of Hyderabad worship all the heathen deities; they are eminently polytheists, but they also worship the elemental rain water, as the Meghoba (probably Mrigh), as a deity; and at stated times make a lamp-stand of dough, on the top of which they place the ghi pipkin as a lamp, with ghi or clarified butter and a cotton wick, which they light and worship, putting cakes before it. Many of them worship departed spirits, most of them evil, some of them good spirits, and others which they designate devils, and which appear only at night, as saya or shades. All believe in transmigration, and one man mentioned his hope to be re-born as a Muhammadan. They are monogamic.

The Pariah aid in cultivation and reaping, yet if they touch cooked food it becomes unclean.

The Pariah of the Panjab are fine powerful men, and tolerably good looking. Native governments recognised in them a material for soldiers useful in desperate enterprises. The early Sikh reformers tried to proselytize these men, but with very partial success, though a few, as Sikhs, obtained a respectable position. Christians also have almost failed in converting them. Mr. Campbell regards those of the Panjab as Aryans.

Every Jat village in the Panjab has a Pariah quarter, where the low-caste people reside along with the Choora. They are the ordinary labourers, who do the inferior coolie work.

The Dher are few north of the Satpura range, south of the Nagpur road. The Berar Dher class themselves as Andhwan, Somassi, Wad, Larwan, Laryan or Larron, and Tirwan. The Somassi and Wad intermarry. The Somassi and the Laryan Dher eat together, but do not intermarry. The Somassi Dher ride on horseback in their marriages, the Laryan on a bullock.

These ancient races have been in their present servile position for two or three thousand years. In this interval they have been the predial slaves and servants of Christians, and Buddhists, and Muhammadans, and Hindus, but they retain their shaman and fetish customs, into which they have infused little, if any, of the creeds of their successive masters.

Koragar are described as a race in South Canara who are still sold as slaves. They are physically strong, with a forehead of moderate size, and black skin. There are three clans, - the Ande Koragar, Vastra Koragar, and Sappu Koragar. Under Hindu rule, the Ande Koragar were considered so unclean; they were not per- mitted to spit on the ground, but had a pot suspended from the neck into which they expectorated. The second clan wear the shrouds taken from the dead, and the Sappu have leaves as a covering. The women cover their breasts with the leaves woven together, to which they were condemned because one of them in authority asked a high-caste girl in marriage. Their marriage ceremony consists in having water poured over them, and rice sprinkled. The Aliya Santanam law seems to guide them, but that of the Makkala Santanam is also in force, and the children are allotted accordingly. The destined slave has new clothes given him. The master takes a plate into which he pours some water, and drops into it a piece of gold. The slave takes a sip of the water, and pours the remnant on a spot of ground, which is then given over for his use.

The Cherumar or Chermar are lower in the social scale than the Tiyar. Should a Cherumar be walking along a public path, he must run into the jungle on the approach of one of the superior castes, nor can he come within 32 feet of the Nair or 64 feet of the Brahman. Some of the hill tribes of Malabar are required by Brahmans to remain a hundred paces distant; and in trade or barter he must lay down his goods, retire to the prescribed distance, and leave the payment to be adjusted by the higher rank man. The Cherumar were returned as 99,009 in 1871 , and 64,725 in 1881.

Leather-worker:s are amongst the most humble of all the settled races in the south of India. They are the Chamar, Madigaru, Chakili, or Mhang. They dwell outside the village walls, are tanners, workers in raw hides and in leather, shoe and harness makers, messengers, scavengers, and executioners. They are never grooms. A very few have ever been known to have the ability to read or write. The race, as a rule, are of a dark black hue, short in stature, and of very slender frame; lower limbs particularly slight, and calf and foot delicate. They still eat creatures that most races regard as unclean. In villages, where they perform the lowest menial offices, they are paid by portions of the crops and some small privileges.

In Northern India and in Bengal, the Chamar form the great bulk of the labourers, taking the place of the Pariah of the Peninsula. There are many sections throughout the Hyderabad country, and in Berar they are part of the Baluth of the village system of Maharashtra. The Mhang worship the leather ropes which they make. They also make cakes, which they place on the ground, and over them five stones and a lamp. and worship these. They also worship the spirits of departed men who have led evil lives. They claim the right to have for food, cattle and camels and horses that die of disease; but in the village of Dangopura, in 1866 and 1867, this point was for twenty months under litigation, the ultimate decision being in favour of the Dher. In the Northern Dekhan are the sectious Mhang Garoro, Hollar Mhang, Dekhan Mhaug.

The Mhang Garoro are also styled Pharasti or migrants, as they have no settled abode, but move from place to place begging. Their men and women assume other clothes, and smear theix foreheads with the red kuku, a mixture of tur- 
meric and safflower. They also are conjurors and sleight-of-hand adepts, from which they bave their name Garoro. The men also beat the dholak when practising their conjuring tricks.

The Hollar Mhang are village musicians. At marriages, play on the sannai, a musical wood instrument, and beat the dafra. They are also labourers, and go messages.

The Dekhan Mhang make brooms and mats from the date palm; are also labourers, bring wood, marry girls under age, fall at the foot of Hanuman, but worship at a distance, being not allowed to approach. They, like the Pariah and the humble native Christian, are also prohibited approaching the house of any Hindu, but stand some yards off and intimate their presence by calling out baba, or mabaraja, or ayer, and, as with the Dher, everything they have brought, and everything they touch, and the place they touch, is unclean. If it be a metal dish it is passed through fire, and if of cloth or other material it is washed, or sprinkled with water, or placed on the ground for earth purification.

They mount on horseback in procession to their marriage, a right which they probibit the Dher and Teli or oilmen. In some parts they do not usually claim dead creatures as a right, but beg portions from the Dher.

They worship generally all the local deities or village gods, - the Ammun, the $\mathrm{Ai}$, the Mata, Musoba, Mariai, Devi, Kandoba, and the Mangir or ghosts of deceased relatives. Mangir is in the form of a human being engraved on silver or copper, intended to represent a deceased father or mother; sometimes it is a casket of copper containing a silver figure of a man. The Mangir is worshipped at the Dewali and Dassara, and at Amas and full moon and anniversaries. The figure is worshipped by washing and burning frankincense. They bury or burn their dead. They place the corpse in the ground, then bring a potful of water from the river, pour it on the body, and cover the dead with earth; after three days they take food and place it over the dead.

The Dhor, Hind., TEL., Dhoria, CAN., Dhorata, MAHR., are found in most of the larger villages of the Dekhan. They are tanmers, but are regarded as Hindus, and, unlike the Dher and Mhang, reside within the villages. They worship the earthen jar in which the hides are steeped, placing red lead on it. They do not partake of mimals that die of disease. They never devote their young women to the gods. They are looked on by the Pariah or Dher as vile, and are not associated with in eating or intermarrying. The Dhor are robust, fair, short men, with welldeveloped chests, wide faces, light-coloured eyes, many of them with a light moustache, and in all their features they present evidence of a Mongoloid origin. They never eat the large horned cattle, the cow, buffalo, or bullock, nor do they eat dead animals, but fowls, fish, deer, goats, and sheep are lawful. They marry in their own tribe, making the marriage procession on a bullock, and say that they are not entitled to proceed on a horse. Like almost all the races of India, they worstip, at anniversaries, the chief implements of their trade, which in their case is the tan-pit; but they weekly cowdung a small spot in their house, on which they burn incense, place flowers and wherten cakes covered with rice, bow down, worship, and eat. The deity thus invoked one family at Oodghir said was Bawa Adam, whom they consider to be Mahadeva (Siva), and inquiry elicited the information that about 60 or 80 miles west of Punderpore is a stone named Bawa Adam or Father Adam. It is doubtless the phallic lingam of Hindus. They also worshipped $\mathrm{Ai}$, mother, whom they designate as the Bhawani at Taljapore, but Kandoba at Malligaum also receives their worship. The temple guardians, however, do not permit the Dhor to approach near to the idols, as their trade of workers in skins and hides makes them unclean. They bury the dead who have fallen victims to small-pox and cholera, but those from some other diseases are burned; a pregnant woman dying is burned. They make leather from hides, and manufacture such articles as are used for water purposes, the mot bucket, the d'hol or drum, and pakhal or water bags. In Berar, workers in leather consist of $12 \frac{1}{2}$ clans, amongst whom are the Dhor and Kullar Bandela Chamar. The Katai make shoes and sandals, and labour in the fields at seed and harvest times. The Katai are identical in personal appearance with the Chuckler (Chakili) of the very south of India.

The Chamar in Aurangabad worship Mariamma and Sitla. They marry when under age, amongst themselves, proceeding on foot to the goddess Sitla, whose shrine they circumambulate five times. The expense is about a hundred rupees. They speak Hindi. They burn their dead.

Agambadyar, a rude tribe in the most southern part of peninsular India. Their ordinary surname is Servikaren.

The Totti of the Tamil people is a village servant who waits upon the villagers. The domestic Totti does the humblest part of the house work.

Kurchayer, a race in the Wynad forests, skilful bowmen, dexterous in destroying wild animals.

Wild Races.-In the mountainous parts of the Ganjam district, in Jeypore, and in all the hill tract which lies between the Bay of Bengal and the Central Provinces, are numerous races who have not attained to the civilisation reached by nearly all populations of the plains. They speak their own tongues. Their tribal names are Agurtu, Balija, Erikulu, Gadabalu, Gartulu, Golla, Gonda, Jannalu, Jatafi, Jond, Konda-Doralu, Konda-Rajalu, Loddi, Pano, Pittola, Pydelu, Telega, and Yenadi.

The Khond occupy parts of the Ganjam district and of Orissa, between the Mahanadi and the Godavery. The Khond lie between the Kol and the Soura. They are the most numerous of the hill tribes of Ganjam. They own and cultivate the soil, and hunting game is their only other avocation. The men are of medium height, stout, strong, and not uncomely, with aquiline noses, high cheek-bones, and receding foreheads. The women are short statured, coarse featured, and not cleanly. They wear a scanty kilt-like piece of cloth reaching from the waist to the middle of the thigh. Both men and women wear a profusion of brass rings and armlets. Sir Walter Elliot says they call themselves Kuinja; their neighbours in Orissa call them Khand, and the Telugu people call them Ku, Kod, and Gond. Khand is said to mean mountaineer. The Khond, the Kol, and the Soura races have held the same 


\section{INDIA; THE MADRAS PRESIDENCY.}

position as now since the 4 th century, though some intermingling has occurred on their borders. The Kolarian races of that region have been arranged as Gadaba, Kerang Kapu, Bhumiga, Bhunijiga; and the Dravidians as Parja, Dhurwa Gond, Batra, Koi, Matiya, Konda Kapu, Konda Dora, Khond, Kottiya, Pentiya, Muriya.

The Khond of the northern and central parts of the Mahal or mountain country of Ganjam are skilful, energetic, and well-to-do farmers. They are in tribes, speaking different dialects, and in varying degrees of civilisation and lawlessness. The Kuttiah Khond on the Kalahundy and Jeypore borders are perhaps the most fierce and martial. The tribes occupying the hills bordering on Ganjam, with the exception of the Simili Khond tribe of Bodagada, are somewhat more civilised; and in the Gumsur Mahal, where many of them speak Uriya, there is not much perceptible difference between the Khond tribes of the hills and those living in the jungle villages at the foot of the ghats.

It became known in 1838 that the Khond race were addicted to the sacrifice of human being's (Meriah) to the earth goddess, and ever since then the British. Government have made continuous efforts to suppress this rite. Since 1857 . the Khond of Kimedy have been surging up from time to time, but the true reasons are not known, though those alleged are their hopes of renewing the Meriah. The Khond who occupy the eastern parts of the highlands between the Godavery and the Mahanadi, were notorious for their human sacrifices. Those near Berhampur average in height 5 feet $5 \frac{3}{4}$ inches, and in weight 8 stone, with well-developed muscles and tendons standing out hard and firm. They are wiry and active, have an upright gait, carry their heads erect, straight noses, narrow nostrils, thin lips, black eyes, not high cheek-bones, slightly projecting lower jaw, white and regular teeth, with oval faces, as if of a mixed Caucasian aud Mongolian origin.

The Khond in the Eastern Ghats, south of the Mahanadi, have the face round, the cheek-bones somewhat prominent, the forehead full and expanded, the nose flattish and broad at the point, the mouth large, with lips full but not thick. The eye is quick and brilliant, the general expression of the face intelligent, determined, and good-humoured. In person they are muscular, neatly formed, and about the beight of the races of Hindus of Southern India. The skin is clear and glossy, and it varies little in colour from a light bamboo to deep copper. Like the Gaugetic tribes, they have little or no beard. They are social, and more truthful than natives of the plains, but easily excited. Animal food and palm wine, and the spirit from the Bassia latifolia flower, are only used on festive occasions. The deities of the Khond are the same as those of the S.E. Gond. Pen and Pennoo are common to Khond and Gond.

In the Kotiah country and round about Baliguda, buffalo sacrifices have taken the place of the Meriah. The buffalo is tied to a sacrificial pole (Bassa-kumbo), and the chief pujari or worshipper places his tungi seven times on the baffalo's neck, and on his giving it a final heavy blow, each of the pujari, sacrificial priests of all the other villages, who have all been standing ready with knives in their hands, rush on the buffalo, slice off pieces from it, and, with some of its blood, each darts to his village and buries the sacrifice in the sacred grove, sprinkling the blood to the four quarters of the earth. On the following day ail return to the place of sacrifice to eat the remainder of the flesh, and drink toddy to excess. The Khonds of the Boria Mutah do not follow this practice. The other Khonds sacrifice two or three buffaloes every two or three or four years, but do not bury any portions.

Khonds in the Gumsur Mahal were about 54,290. The headman of a village is styled Majji, and Patta-Majji is the designation of the headman of a number of villages. They are a finer race of men than the Soura. The Ippa tree (Bassia latifolia) flowers in the months of March and April, and the whole country is then given up to drinking. The Government's agent presents cloths to the Majji and to the Meriah victims rescued from the sacrifice. The family is the basis of their society, and Khond sons have no property during their father's life. On failure of male issue, the land passes to the village. The Khond are faitbful and brave, boundlessly hospitable, and a guest's safety and care are paramount duties. Agriculture and war are deemed the sole honourable avocations.

A boy is married in his tenth year to a girl four or five years older than himself. In the middle of the marriage feast, at night, while the dancing goes on, the girl's uncle lifts her on his shoulder, while one of the boy's uncles does the same with the bridegroom. Suddenly the uncles exchange burdens, and the boy's uncle makes off with the bride. In a moinent the festivities cease, the kinsmen range themselves into two hostile tribes, the girl's friends trying to recapture the bride, the boy's to cover her flight. The two parties carry the fight to great lengths, and the conflict exhibits an ancient custom of marrying by capture.

The Pano race in the Purla Kimedy and Gumsur Mahals are hill Pariahs, and each Khond village has a Pariah low-caste hamlet attached to it. Their total number in the Madras Presidency was stated to be 34.683 in 1872 . The Kandara and Pana are chiefly found as agriculturists and weavers in Orissa.

Gondwana, besides the great portion under the Nizam, includes Korea, Sirguja, and Udaipur. But Gond colonies extend as far east as the Katak (Cuttack) Tributary Mahals, where they blend with the Khand and the Saura or Savara, and they extend to Kandesh and Malwa on the west, where they touch the Bhils. A considerable portion of this tract are Gonds. The Maria are the wildest and purest of the 12 tribes, all of whom call themselves Koitor, plural of Koi.

The $K o i$ in the hill country of the Godavery district is a numerous hill race. The Koi of Jeypore are a listless, drunken set, and bad cultivators. They are found from Jeypore southwards to the Godavery river, and westwards to Kummumet in Hyderabad.

The Matiya cultivators of Jeypore say their ancestor sprang from the soil, and point to an opening from which he came.

In 1868 disturbances rose in Keonjur in the early part of the year. It is one of the Tributary Mahals of Cuttack. The Juanga, the Kol, and 
Bhuiya joined them, and at one time 20,000 were in insurrection, and it was not until August that it was put down.

Sourah, Saur, Sabar, Sar, Savara. These varied names arise from the circumstance that in Bengal $\mathbf{v}$ is pronounced as $\mathrm{b}$, and is constantly softened into au and u. Their principal habitat is in the mountainous country, about 200 miles long, which rises from the Bay of Bengal, and, stretching southwards from the Mahanadi, runs down from the Chilka lake to the Gedavery river. They are a branch of a widely-dispersed race, who are found in Central India, in Gwalior, and Marwar, and even as far as Southern Rajputana. The name is identical with Sairea, applied to populations occupying the fastnesses of the Eastern Ghats, along with the Khand and Kol. The Purla Kimedy Mabals are principally inhabited by Sowrah, and the Jalantra Mahals both by Sowrah and Khand. These two are the chief races in the Mabals, but the Uria, the Soondi, and the Pano are interspersed amongst them. The Soondi are arrack sellers, and the Pano are a degraded race of Uria origin. These Sowrah and Khand are rude and unciviliser, and live by tillage and the barter of sundry forest articles. Sir Henry Elliot has suggested that the Siviri, the Seori, and the Cheru may perhaps be the Saurasena. In the Harivansa is the following passage:- 'From this race caune the Sauravira and Saurasena. The great king Saurasena has given his name to the country over which he reigned.'

The Sowrah have also been supposed to be the Suari of Pliny and the Sabaræ of Ptolemy. The Sabar and Sahar of Pooree, Cuttack, and Balasore in Orissa, are possibly one branch, as also are perhaps the Chensuar farther south; these are savages armed with bows and arrows and battle-axes. The hilly tract which extends from Purla Kimedy to Berhampur in Ganjam, is bounded on the east by the narrow belt which separates the hill tracts from the sea, and on the west by the Khand clans of Chinna Kimedy and Jeypore. The Sowrah are believed to be prior occupants, but in habit and barbarism they bear a strong resemblance to the Khand. The Sowrah are wholly within Telingana, and extend from the Godavery to the southern froutier of the Khand. Their country is one of the most difficult in the world, - a hilly tract corered with a jungle as deadly to sepoys as the lowest swamp in the Santal parganas. They are small, mean, and very black. According to Major Macpherson, the hill tribes south of the Khand, and running up to near the Godavery, are Sowrah. Dr. WV. W. Hunter says the Sowrah also now live with the Oraon or Odaon of the Bengal frontier. An insurrection in 1858 was neither aided nor led by Khand, the principal actor in the affair was a man named Danda Sina, of Garbah Goomah, a village occupied by the Sowrah tribe. Danda Sina had some time before been apprehended by the authorities of Ganjam on a charge of dacoity. He was convicted and sentenced, but the sentence required confirmation, and in the interim he contrived to effect his escape. Flying to his own village, he collected a large body of his clansmen, and with 10,000 followers attacked the manager of Purla Kimedy. Seven peons were killed upon the spot, and though the manager escaped, the whole country was immediately in a state of excitement. The Sowrah had previously been irritated by the execution of two of their number for murdering the headman of a village, and had openly threatened vengeance for their deaths. An old device was also employed to stimulate them to action, and give additional coherence to the movement. As in the Santal rebellion, an avatar descended, though he was not, as with the Santal, in the shape either of a cart-wheel or of a piece of paper. The Sowrah appear to be advanced beyond that point in theology, and their idol was a little brazen image. But in all other respects the device was identical with that employed among the Santal. The avatar issued commands, the active leader was sole interpreter of them, and the commands authorized armed resistance to regular authority.

The Sowrah race who occupy the hills near Chicacole, near Kalahundy, and southwards as far as Badrachellum, bury their dead with their weapons. The headman of a village is styled Gomango. The Sowrah in the Purla Kimedy Mahals are about 16,398 , and 15,193 in the Pedda Kimedy Mahals. Half the villages are situated below the hills, and their occupants are in constant intercommunication; even the bill Sowrah frequent the markets of the plains, and the people of the low country no longer fear to trust themselves amongst the hills. They pay their rents to the raja of Jeypore.

The Sowrah who occupy the Pedda Kimedy, Surangi and Purla Kimedy Mahals to the south of the Khand tribes, have little in common with the Khand. In agriculture they are on a par with the Khand tribes.

The Chensuar, Chenchwar, or Chentsu, a wild, half-savage forest tribe inhabiting the Eastern Ghats of the Peninsula. They are known to their settled neighbours as the Chenchu kulam, Chenchwar, and Chensuar. Wilson names them Chenchuvadu (Vadu, TEL., a man; Wanlu, Vanlu, pl. men). They dwell in the tract of jungle covering the westernmost range of the Eastern Ghat line, between the Pennar river and the Kistna, known locally as the Nullamallay and the Lankamallay. Those of the Nullawallay range seldom visit the plains, their time being occupied in the search for forest produce, roots, on which they subsist, honey, tamarind, wood-apple, game, and herbs, which they barter for grain. In the Cumbum district some of them earn a livelihood by guarding the crops and cattle of the farmers on the hill tracts. 'They are generally peaceable, but a few who live near the plains are given to petty thefts of grain. Their weapons are the bow and arrow, a bill-book, and sometimes a matchlock. They inhabit clearings in the forest, and live in beebive-shape huts like the African, Nicobarian, and many of the ruder Asianesian tribes. These are of wickerwork, with walls about three feet high, and a conical straw roof, with a screen for a door. The men are almost nude, and have in general only a rag for covering, with a leather cap on their head. The women dress like the wandering female basket-makers, whom they resemble in features. The features of the meu are small, but the expression is animated, cheek-bones higher and more prominent than those of the Hindus in general, nose flatter, and nostrils more expanded; their eyes black and piercing; in 


\section{INDIA; THE MADRAS PRESIDENCY.}

stature they are a little shorter than their neighbours, and they are slightly but well made, except about the knee, which is large, and the leg. The colour of the skin is darker, and there seems a tendency to cutaneous eruption. They have large dogs, and a few are employed as hill police in the pass from the Cumbum to Badwail. The Nandial Chenchwar have no images. They are polygamists; they bury their dead, but sometimes burn, and, like the Tatars, they carry the deceased's weapons to the grave. They use the spear, batchet, the matchlock, or a bamboo bow and reed arrow tipped with iron. They look on weaving and other manufacturing arts with contempt. They are patient and docile. Vocabularies of six of these non-Aryan tongues, the Khand, Savara, Gadaba, Yerukala, and Chentsu, are given at p. 39, No. of 1856 , of Beng. As. Soc. Journal.

The Patuah or Juanga are a forest race inhabiting the Tributary Mahals to the south of Singhbum in Cuttack, scattered in the mahals or killahs of Keonjur, Pal Lehra (30 villages), Dhenkanal ( 6 villages), and Hindole ( 6 villages). The stature of the men does not exceed 5 feet 2 inches, and that of the women 4 feet 3 inches or 4 feet 4 inches. Their forms are slight, witb little muscular development, and physique weak. Their face is shorter and broader than that of the Uria, nose is flat and nostril wide. Their colour is not darker than the Uria peasant. The men are not handsome, but the women are repulsively ugly. The men dress like the peasantry of the neighbourhood; but till 1871 all the covering of the women consisted of two bunches of twigs with their leaves attached, one before and one behind, which were changed daily, kept in position by a strip of bark or a string of glazed earthenware beads passed twenty or thirty times round the waist and over the stems of the twigs; hence the name of the tribe, Patuah, literally people of the leaf, but they call themselves Juanga. The women also wear necklaces of the same kind of beads, and their hair is gathered. together in a knot at the back of the head, fastened by a string with a silver or brass button at each end of it. The women wear no blanket or covering at night, but sleep between two fires. Their traditions are to the effect that they were formerly vain of fine dress, and were wont to lay aside their good clothes to prevent them being soiled, and wear such leaves when attending to the cleaning of the cow-house or other duty, when one day a thakurani, or, according to some, Sita, appeared, and commanded them as a punishment for their vanity always to wear such leaves. Dr. Shortt mentions that the legend of Killah is that a rishi commanded them to wear the leaves. They believed that if they violated these commands they would be devoured by tigers. Women dance in a circle to the sound of a large drum beaten by the men, moving round and round in the same measured step, occasionally advancing towards the musicians and then retreating, but keeping the body inclined towards the musicians. Their villages are in some clearing or opening in the forest; are small, with about six or eight families, in poor and mean thatched huts of wattle and daub, each family in its own dwelling. They have no lands, but sometimes assist in the cultivation of the neighbourhood. Their avocations are chiefly those of the chase, using the bow and arrow and dogs ; they kill deer, hogs, and not unfrequently snakes, of the flesh of which, especially that of the Python molurus, they are very fond. Except the cow, they are omniverous. Their usual food is insipid and nauseous roots (tunga, kurba, and panialu), and the seeds of the jungle grasses. They all call themselves Pudban, and have no system of caste. They pay homage to nameless spirits who inhabit the woods and mountains, and make offering to the genus loci of a fowl, a goat, or rice, or spirits. In the month Baisakh they offer libations to the manes of their deceased ancestors. They bury their dead. Marriages are arranged by the parents, and are scenes of revelling and drunkenness. They adhere to one wife, unless she prove unfruitful. Like many Hindus, they will not pronounce their wives' names. Their language is not similar to Uriya, and it shows that they are connected with the Mundah of Chutia Nagpur, and that their nearest kinsmen are the Kheriah. But in their present position they are isolated from all other branches of the family, and they have no suspicion that they are connected with them.

The Juanga have been said to extend into Bastar, and to be there called Jbaria, and farther north to have the name of Madia; but these points need confirmation. The Juang of Keonjur and the Malhar or Patuah of Dhenkanal are identical in manners, dress, language, and habits. Hitherto, any person wearing a cotton cloth became, by so doing, an out-caste from his people. But in 1871 the maharaja of Dhenkanal and the British revenue officer induced the women to discard their leaves and use cloths. They rebelled in April 1868 , but were subdued by the month of August. The Juanga or Jowang dwell apart from the agricultural population, and have a language of their own. They cultivate patches in the forest clearings, but they like to wander in the forest and gather its wild products.

The Vedan, Vedar, Verldar, or Bedan of the Malabar forests are predial slaves, who cut timber and do not cultivate. In Travancore and Cocbin are the Vedan and the Oolladen; both tribes are hunters, and are most numerous in the mountain taluks.

The Kaclar, a hill race, occupying the Animallay Hills in the collectorate of Coimbatore. They are open, independent, straightforward men, simple, and obeying their Mopens or chiefs. They are strong built and active, with woolly hair and something of the African features, and file their front teeth to a point. The women wear enormous circles of pith in the lobes of their ears, which they distend down to their shoulders. A black monkey is the Kadar's greatest dainty. A small number are employed by the Forest Department in forest conservaney and in felling timber, and others collect forest produce, which they barter for grain. They also cultivate for thenzselves, on the hills, patches of ragi (Eleusine coracana), which they supplement as a food supply with roots, herbs, etc., found on the hills.

Maleali, a race in the Shevaroy Hills, in South India and in Malabar. They inhabit the mountain tracts of the Salem district. A small body of the Maleali occupy the hills in the Kallakurchi taluk of the South Arcot district, and are engaged in cultivation and felling timber. 


\section{INDIA; THE MADRAS PRESIDENCY.}

There are two small hamlets of them above Papanassam in the mountains dividing the Tinnevelly district from the Travancore territories. A few in the Salem district have a rude kind of kumari cultivation, breaking up patches of land, which they abandon when the soil becomes exhausted, but residing in villages, with none of the wild habits of the people of the jungle. They have their own social rules, and their headmen are all-powerful. On bills twenty-five miles S.IV. from the town of Vellore, there are thirty small villages, with a rude and uncivilised population. who do not clothe themselves properly. They speak a language scarcely intelligible, but believed to be a Tamil patois. They are addicted to thieving, but live by cultivation and exchanging wheat.

The Ariyan or Malai Arasar or Malai Arayan, literally Hill Kings, are a community of 15,000 or 20,000 people in the southern mountains of Travancore. They are nomade or semi-nomade, shifting their locations to suit their kumari cultivation. Many of them live in huts constructed on trees, above the reach of wild beasts. But there are others with villages beautifully situated amongst the mountaius, from 2000 to 3000 feet above fever range. They worship the dii loci residing in peaks, trees, and great rocks, and also the spirits of ancestors. Their priest worships the hill deity, and works himself into a state of possession. They bury their dead in cromlechs, constructed, like the cromlechs in Coimbatore, of four stones and a covering one, like those now in use amongst the Gotta tribe of Gond, on the Godavery; and in the cromlech is deposited a metal image, or an oblong stone in which the spirit of the deceased is supposed to dwell. They have sacred groves, where the greatest reverence and silence is observed. They are great hunters. They are innocent in character, are truthful and chaste in language, but are great drunkards. Their language is Dravidian. The Malai Arasar, in the range of ghats between Tinnevelly and Travancore, are in small communities of five or six families. Those of the Coimbatore district live in the low jungles of the Pollachy and Oodalempetta taluks, and in the Bolumpetta jungles. Their huts consist of a few sticks covered with bark and thatch. They live on wild forest products, but, since A.D. 1850 , they have been cultivating potatoes for their own use. They have a few fowls and dogs. As a race they are diminutive and pot-bellied, their crania small and pear-shaped, rising to a point about the junction of the occipital bone with the sagittal suture; a low retreating forehead; long; tangled, black hair, flat nose, and small eyes. They are averse to intercourse with strangers. They catch wild animals in pits and traps, and use bows and arrows. They are low in the scale of civilisation. Their principal occupation is hunting, but some of them are engaged in the cultivation of forest land. Coffee planters have been dispossessing them of their lands.

Malai Kudi, or plural Malai Kudiar, a hill tribe living in the jungle tracts of South Canara, in the Uppanangadi taluk, in the cardamom forest tracts, etc., bordering on the ghats. The Malai Kudi Kunalie, Malai Kunalie, Nad Kunalie, Kari Kunalie, Kumri Mahrati, and Koragar, formerly, when kumari cultivation was unrestricted, may have had their abodes permanentl 5 in the heart of the jungles, but they have long since taken to the plains, and are now to be found everywhere, though in secluded localities.

A Negro race occupy the hills at Dandilli in North Canara.

The Neilgherry Hills are situated between lat. $10^{\circ}$ and $12^{\circ} \mathrm{N}$., and long. $76^{\circ}$ and $77^{\circ} \mathrm{E}$., bounded on the north by the table-land of Davarajpatnam, S. and $\mathrm{E}$. by the open country of Coimbatore, S.W. by the Manaar river, a branch of the Bhowani; W. by the chain of ghats, and N.W. by the district of Wynad. The base of these mountains, including that of the Kunda Hills, covers a circumference of 200 miles. Their greatest length is from E. to W. 46 miles, and medium breadth 15 miles; the surface is composed of ridges of different elevations. The country is divided into three districts, the Peringa Naad, Malka Naad, and Thodawar Naad. The first two are mountainous, but the third is of sloping hills and gently undulating surface of table-land. Dodabetta is 8700 feet above the level of the sea. The races occupying these Naad,- the Thodawar, Buddaga, Kothur, Kurumbar, and Erular, - until the early part of the nineteenth century, remained secluded amongst their forests and on the mountain summits.

The Toda or Tlodawar, properly Tuda or Tudavara, live in hamlets or 'mund' on the hill plateau. Motta and Mund are words meaning a Toda hamlet. They never could have exceeded a few thousand, but they have diminished through opium eating and polyandria, and, at a former period, the prevalence among them of female infanticide. It is said that no girl has been destroyed since 1819. Before marriage, young people associate. After marriage, the Toda wife, or if there be more than one, all the wives, in a family of brothers are common to all the brothers. They claim to be aborigines, and other classes recognise the claim, and regard them as the lords of the hills, and pay them in kind, as tribute, one-sixth of the produce. They occupy the Todawar Naad and Malka Naad. Their villages are in the depths and on the skirts of the forests. Their houses are built in the form of a parallelogram, 10 feet by 6 , roof semicircular, and door $1 \frac{3}{4}$ to 2 feet high, and 14 to 18 inches wide, and it is the only aperture. Their appearance is calm and dignified, and carriage graceful. Their colour is a deep copper hue. Their numbers in 1825 were-men, 145 ; women, 100 ; boys, 45 ; and girls, $36=326$. Their men average in height 5 feet $32 \frac{2}{3}$ inches, and average weight $121 \frac{1}{4} \mathrm{lbs}$. Nose long, large, and well formed, generally aquiline. The women average in height $60 * 25$ inches, in weight $110.80 \mathrm{lbs}$. They are handsome and comely in feature.

The Toda have five sections-(a) Peiki, (b) Pekkan, (c) Kuttan, (d) Kenna, and (e) Todi, who eat together but do not intermarry. Todawar or Torawar, in Tamil, means herdsmen. The men carry a small axe and their cowherd staff. Toda women tattoo their arms, legs, and chest with dots. The men wear a piece of stout cotton cloth about 5 lbs, in weight thrown around them as a toga or mantle, descending to the knee, and their feet and head are always bare. The women have a similar mantle, but falling to the ankles, with the loin cloth (Mundu, TAM.) of Hindu women below it. The Toua do not bathe, but anoint their bodies with ghi, which soon becomes rancid. 


\section{INDIA; THE MADRAS PRESIDENCY.}

They are dirty. The Toda women have metal and shell ornaments, with brass armlets weighing 6 lbs. The Toda lead a quiet, peaceful life. They are fond of feasting and dancing on festive occasions ; all use tobacco, many use opium, and in latter years the use of arrack has largely increased. Their cemetery and piace of funeral sacrifice is a pretty green spot, partially enclosed by a stone wall, and rendered very gloomy by a thick wood on one side and lofty hills on the other. It is their practice to sacrifice buffaloes on the demise of a Toda, and a strongly-walled area is set apart for the reception of these animals, whose bones and horns are strewed on the ground. At the demise of a Toda chief, the funeral procession entered the green and moved towards the centre. The deceased was dressed in a new garment and mantle, and arrayed in all the ornaments which he had worn during life. He was carried on a bier formed of branches and herbs, and followed by a number of mourners, male and female, who chanted the lament, whilst others carried wood for the funeral pile and provisions for the evening meal. A herd of buffaloes was driven into the walled area, and the men, armed with clubs, entered with exulting shouts, and performed a wild dance amongst the buffaloes. These soon became excited to the highest pitch, and, at a signal, a bell was attached to the neck of each infuriated animal. Two young men would throw themselves on the animal's neck, seize it by its horns, and others would run to their assistance, and eight or ten men would be seen hanging on the neck of one animal, whilst others increased its rage by blows of their clubs, and goaded it on with hideous yells and gestures. Three or four animals were thus attacked at one time, and the bell attached to the neck of each. But meanwhile the general assemblage which lined the walls were weeping, exulting, or sending forth shrieks of horror whenever a man was wounded, a buffalo overpowered, or a lover or a husband in imminent danger. On the next day, the victims were finally sacrificed. The men struck the animals behind the horns with a wood-cutter's axe. But sometimes the blow was indecisive, and an infuriated animal escaped and drove madly amongst the multitude. After the sacrifice, several wild dances followed, during which the men feigned to cut and lacerate themselves. On the third day, the deceased was burned on the funeral pile.

The Kotar tribe ranks next to the Toda in priority of occupation of the hills. They have no caste, and as a body are the most industrious of the bill tribes, giving much of their time and attention to agriculture, handicraft, etc. When not required at agricultural operations, they employ themselves as carpenters, smiths, basketmakers, etc., making and repairing their ploughs, bill-hooks, hoes, etc. They are also curriers, and are highly esteemed in the plains for the excellent leather they make. They perform all the menial offices required by the Toda and Badaga, supplying them with barbers, washermen, etc. They acknowledge the Toda as lords of the soil, and accordingly pay the tribute demanded by them as Goodoo. At the same time they exact from each hamlet of the Badaga within a certain distance of their own village, certain annual fees, which they receive in kind, for services rendered as handicraftsmen, etc., in addition to that of ceremonial or festive occasions for menial services performed. They hold the best lands, and they have the right to select the best whenever they wish to extend their holdings. They are well made and of tolerable height, rather good featured and light skinned, having a copper colour, and some of them are the fairest skinned among the hill tribes. They have well-formed heads, covered with long black hair, grown long and let loose, or tied up carelessly at the back of the head. An average of 25 men gives the following measurements, etc.:-

Age, years,

Men. Woinen.

Height, inches,

Circumference of head, inches, - $\quad 62.61 \quad 57.98$

Circumference of meck,

$\begin{array}{llll}\text { Circumference of chest, ", } & \text {. } & \text {. } 30.68 & 1197 \\ 29.3\end{array}$

Circumference of arms, , . 8.76 8.2

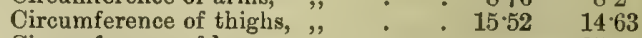

Circumference of legs,,$\ldots \ldots . \quad \ldots 5^{\circ}$

Length of arms

Length of hands,

Breadth of hands,

Length of feet,

Breadth of feet,

30

7. $\quad 26 \cdot 52$

3.25

10 .

$3 \cdot 5$

3.

$9 \cdot 25$

$2 \cdot 25$

Weight, avoirdupois, lbs., . . . $105 \cdot 2 \quad 96 \cdot 24$

They have a slightly elongated face, with sharplydefined features; the forehead narrow but prominent, and occasionally protuberant; ears flat. and lying close to the skull. The women are of moderate height, of fair build of body, but not nearly so good-looking as the men. Their arms are tattooed, having nine strealis, with four dots on each arm and four circular marks on each forearm. The women assist the men at their work in the fields, aud make baskets and earthen pots, etc. Their number at the last census was 1065. They form large communities, each village containing from 30 to 60 or more huts of tolerable size, walls built of mud, and covered with the usual thatch grass. The station of Kotagherry takes its name from the Kotar villages in its vicinity. The Kotar, as a body, are unclean. All the dead cattle and carrion in the vicinity, of every kind, find acceptance among them as food. Oxen and buffaloes which perish from old age or disease belong to them of right, and they carry home and greedily devour the tainted carrion which they find on the highways and in the fields. Some rude images of wood or stone, a rock or tree in a secluded locality, form their objects of worship, and to these sacrificial offerings are made; but the recognised place of worship at each village consists of a large square piece of ground, walled round with loose stones, 3 feet high, and containing in its centre two pentshaped sheds of thatch open before and behind, and on the posts that support them some rude circles and other figures are drawn. They hold an annual feast in honour of their gods, which comprises a continuous course of debauchery and licentiousness, extending over two or three days. On these occasions they clothe and ornament themselves in their best, and make as grand a show as they can, and to witness which the other tribes are invited. Much indecent dancing takes place on these occasions between the men and women, and frequently the spirit of their deity is supposed to descend on some of them, when their frantic deeds seem to form but a branch of demonology. As a rule, they marry and live with one wife, and have a number of 
INDIA; THE MADRAS PRESIDENCY.

children. The Kotar possess a small breed of cows, but bave no buffaloes. They never, as a rule, milk their cattle, but leave it all to the calves. The Kotar keep up an annual feast in memory of their dead, when a few cattle are slain on a rude kind of altar constructed for the purpose, and on it a portion of the flesh of the animal is laid, with a little of each of the different kinds of grain they cultivate, and is consumed as a burnt-offering to their gods, in memory of their dead relatives and friends. During this ceremony the young men and maidens dance around the altar together. Whilst the younger members are thus engaged, the elders busy themselves in preparing a grand repast for their friends, whom they invite from the adjacent villages on the occasion of this annual festival. More cattle are now slaiu, and the flesh mixed with small portions of every kind of grain grown in their fields; a great fire is raised, and the scene becomes one of confused riot and mirth, with blowing of the kollera horn, mingled with yells and shrieks and beating of tom-toms, the confusion continuing from morning. till night.

The Kotar language is a very old and rude dialect of Canarese, having the same Tamil roots, but differently pronounced, without the guttural or pectoral expression of the Toda. They are believed to be descended from some of the lowcaste tribes of the plains, who in former times sought refuge on these hills from the persecution practised on them by the invaders of India. There is scarcely a useful implement connected with the mechanical arts, trade, agriculture, or husbandry, that they are not conversant with.

Every Kotar village has belonging to it a circle of Badaga hamlets or villages, from which they claim at periodical seasons the payment in kind of certain fees or dues, and for which they in return furnish the Badaga with, or rather make for them (the latter supplying the material), their implements of woodcraft and husbandry. These fees are generally paid in a certain quantity of whatever grain the Badaga has cultivated, for each plough of land, besides incidental dues on marriages, etc. The Kotar always attend the funerals and obsequies of the Toda, etc., receive from them the carcases of the buffaloes that are offered in sacrifice, allowing from a half to a quarter of a rupee for some; and others they receive in return for the assistance they afford on these occasions, or for services which may have been perforned for the family of the deceased. If they cannot supply themselves with flesh by any of these means, they kill some of their own herd, or purchase for that purpose from the other tribes. The Kotar burn their dead, collect the bones on the following day, and bury them in a hole, marking the spot where they have done so. This they do in order to the performance of the obsequies. On the night of the first Monday after the first new moon in the month of March, all the friends of the deceased assemble, and, preceded by music, go to the place of burning.

Brdaga are the most numerous tribe on the Neilgherry Hills, are also called Badakar and Vadakar, meaning Northerner, but their Toda name is Marves, the term for a labourer. They state that about the 15 th century their ancestors came from the Malusal Hills, sixty miles south-east of the town of Mysore. Their name is supposed to be a modification of the Canarese word Vuddaca or North, and they undoubtedly speak an ancient but organized dialect of the Canarese ; but whether famine or persecution drove them from their own country is not known. They are of fair complexion, and handsome.

Both men and women worls in the fields, but of late years a large number of men find employment as labourers and artisans. The other hill tribes on the hills live in isolated communities, but the Badaga dwell in villages on a rising ground, in streets running in parallel lines, in thatched houses built of stone and mud, and divided into separate compartments, with a double tier of lofts, and with a wide terrace in front as a drying, thrashing, and winnowing floor. The doorway, 43 inches high and $26 \frac{1}{2}$ broad, is their only opening.

The cattle are penned in an adjoining cowhouse or shed. Dr. Shortt says they have eighteen sects. The arrangements on betrothal are made by the parents, but the marriage only takes place when grown up. Polyandry does not prevail, but divorce is easily obtained. The women look like mummies. They wrap a cloth round their bodies from below their arms to their knees, and fasten it with a cord below their arms and around their hips; the arms and shoulders and their legs below the knees are bare. A scarf goes round the head, and is let fall behind. The women are of domestic habits, are simple, modest, and retiring, and kind and affectionate mothers. Formerly they claimed as their deity Hettee-du, an old man, and Herear-du, who, they said, conducted them to the mountaius; and they still have numerous deities. A chief deity is in Rungasawmy peak, where men of the Irular tribe officiate as priests, and offerings of ghi and fruits are made; another deity is on a droog: near the village of Hollikul, where a Badaga priest officiates; and there are other male and female gods. Many are comparatively wealthy. They can neither read nor write; they are timid and superstitious, haunted with a dread of evil spirits, and are deceitful, ungrateful, and false. They are in perpetual fear of the Kurumbar, to whose sorcery and witchcraft they attribute all accidents and ailments which befal themselves, their cattle and crops, and in their delusions they have killed Kurumbars and suffered for it. Nevertheless they get the Kurumbar to officiate as priests at all social ceremonial occasions. They both burn and bury their dead.

Irular or Erular in the Tamil districts are most numerous in N. Arcot, Chingleput, Salem, and Coimbatore. In the Neilgherries they are a low type of the Dravidian race occupying the lower skirts of the forests at the base of the hills. They arrange themselves into two clans, the Urali and the Kurutalei, meaning rulers and serfs. They dwell in the clefts of the mountains and in the little openings of the woods. 'The word Eruli means unenlightened or barbarous, from the Tamil word Erul, darkness. It is the term applied to them by their neighbours, and they speak a rude Tamil dialect. They sacrifice be-goats and cocks to their deity Mahri, which is a winnowingfan, and they have minor fetish objects, mere stones, that they call Moshani and Konadi Mabri. They inter their dead in great pits, 30 or 40 feet square, thatched over and planked across, with an opening about a cubit square in the centre of 
the planking; across this opening are laid pieces of wood, on which the dead are placed, and covered with earth, and are left so till another person die, when the former remains and the earth are turned into the pit and replaced by the newly dead. They are scattered in small communities, practising a rude system of agriculture, which scarcely furnishes them with sufficient food, so that, when pressed for sustenance, they resort to the jungles and live on such products as they can collect. They make use of animal food of every description, not even excepting vermin and reptiles. They collect for their immediate wants as food, the wild fruits, herbs, and roots; also honey, beeswax, gums, and dyes of various sorts, and medicinal herbs and drugs, which they barter with the people of the plains in exchange for food and clothes. They are intrepid as regards the wild beasts they meet in the jungles, and in their search of honey they sometimes suffer severely from contact with wild bears. They hunt and take game of every description. The Irular in the Salem district wander through the jungles, collecting forest produce, and living upon roots and whatever they can kill, snakes, rats, and lizards even being used as food. They are simple and superstitious to a degree, and the people of the plains believe them to be sorcerers. They rarely come out of the jungle, and their headmen arrange the barter of the forest produce for grain, salt, trinkets, tobacco, and sheep, with the people of the plains. They are employed by the Forest Department in the forest conservancy and in felling timber, and those so occupied live in hamlets of bamboo and daub huts. Polygamy is allowed, and they have many children, but they die off largely from fever.

The following is the result of the weight and measurements of an average of 25 men :-

Age, . . 26.68 years. Length of arms, $300^{\circ}$ in. Height, 61.78 in. Hands,. . 6.5 ,"

Head, circumf., 19.83 ", Breadth of hands, 3.25", Neck, . . 11.59 ", Length of legs, . 34.5 ," Chest, . . . $29 \cdot 91 "$ " Feet, . . 9.0 Arms, . : 8.42 " Breadth of feet, . 325", Thighs, : : 15.17 " | Weight (avoir.), 96.2 lbs.

The women are strong and stoutly built, anything but prepossessing in appearance, and very dark skimned. Their feet, of those of all the S. Indian races, are the most beautifully formed. They are fond of ornaments, and wear heaps of red and white beads about their necks, thin wire bracelets and armlets, with ear and nose rings.

In their habitats the men wear no clothing but the lungooti, but when working on plantations they wear cloths like other natives. The women wear a double fold of a wrapper cloth, which extends from the waist to the knees; the upper part of their bodies with their bosoms are nude.

Ku'umbar.-Above the Irular, at heights varying from one to two thousand feet, in the clefts of the mountains and in little openings in the woods, with which at this elevation they are girt, live a race calling themselves Kurumbar. They occupy the highest range bordering on the Neilgherries. Their neighbours, when speaking of them, usually prefix to their name the term Mullu, a thorn; in Tamil they are called Kurumbar, in Canarese Kurubaru. The Toda do not consider the Irular as forming a part of the inhabitants of the hills, but they allow this designation to the Kurumbar, whom they call Kurb, their term for a cleft or glen, and from them they receive certain services. Swarthy and unhealthy-looking in countenance, small of stature, the head but thinly covered with sickly-looking hair, the only covering it has; little or no eyelash, small eyes, always bloodshot and apparently much inflamed, potbellied, and with water running from their mouths, they have in most respects more the semblance of savage than of civilised man. Their women and children have much the same squalid appearance, though on their necks and wrists they wear ornaments made of the different kinds of wild seeds and of berries. Many of the men also wear ornaments in their ears, of yellow straw, plaited with some degree of ingenuity. They have no marriage ceremony; but occasionally, when two have been living together for some time, they will enter into an agreement, in the presence of friends, to remain united for life; and in a family where a succession of such unions has taken place, they will, once in two or three generations, perform a ceremony, and hold a festival in celebration of them. This is done by pouring pots of water over one another, the pairs seating themselves together for this purpose, the ablution commencing with the seniors. They then put on new cloths, and end the day in feasting and merriment. Kurumbar on the eastern slopes of the Neilgherry Hills and below Segur obtain a livelihood by timber - felling. The Kurumbar of the Wynad forests on the western side of the Neilgherry mountains have two sections, the Jani and the Mulli, and the Gurchea, Panniar, and Pulliar races live along with them. The Jani Kurumbar live entirely in the forest; they are the only axemen, and without them it would be difficult to work a forest, and the wood contractor and planter alike employ them. They are very docile, quick of imitation, and slavishly submissive to their mudeli or head. Those employed by the coffee planters are a little civilised, appreciating the comforts of life in a slight degree higher than their more savage brethren. They erect rude huts for the habitation of themselves and family, which are built on elevated ground, surrounded by jungles, and about six in number; they touch one another, and the whole present the form of a crescent. One larger than the rest, styled the cutcherry, is erected in the middle in the shape of a hall, for the sojourn of casual strangers. It is dedicated to their household deity, and the place cannot be contaminated by a shoed foot. They may be said to be ephemeral residents in these habitations; the presence of a suspected stranger in their vicinity, sickness, or other trifling but natural cause, will make them migrate from one place to another, but generally within the same district.

Yenadi.-This term is said to be a dialectal variation from the Tamil word Anathan, meauing a poor man who has no guardian, guide, help, or protector. The race are also called Villi, Irular, and Maraver. Villi and Vader are synonymous, and mean hunters or uncivilised men who dwell in the woods. Irular or Iroolar means unenlightened or ignorant men. The Villi and Irular are less rude than the Yenadi.

Villi dwell in hamlets of five or six huts on the outskirts of most of the villages in the district of Chingleput, and are sometimes called Yenadi. They are herbalists. They have Mongol features; 
the men have scant hair on the lip or chin, and no whiskers. They are polygamists. They eat all animal food, except the flesh of the cow. They dig up the wild chay root. The average height of the men was 5 feet 5 inches, and weight S3 lbs.

The Enadi or Ianadi race dwell in the Sriharicottah jungles, and in the hills and forests northwards to Nellore; they numbered 67,935 at the census of 1871. In 1867, in the Nellore district, they were estimated by Dr. Lloyd at 20,000. A similar race occupy the neighbouring forests on the hills at Naglawaram. In 1871 a number of the Enadi were living in Madras at the Vasarapad serpent temple as its priests, and were finding employment as labourers. The Sriharicottah estate lapsed to the British Government in 1835. Till then, the Enadi were in a state of complete barbarism, did not know the use of money, were rarely seen, and lived on fruits, roots, and other jungle produce. In order to civilise them, Government employed them to gather jungle produce, and gave them in exchange rice and clothing. Also a register of marriages, births, and deaths was established, and at each birth of a boy $2 \frac{1}{2}$ annas were given, and of that of a girl $1 \frac{1}{4}$ anna. The residents inland are more robust than those of the Sriharicottah jungles.

The Yanadi live in huts over all the town of Nellore; but in 1871 those residing in a wild state in the hills separating Nellore and North Arcot were supposed to be few, sickness and civilisation having tended to remove them from that wretched condition. Those wild Enadi are small in stature, have poor attenuated frames, with no reverence for human life. 'They have been known, in removing a cloth from a sleeping man, to kill the unresisting owner first. Those in the hills live upon roots and grain obtained in exchange for forest produce, medicinal herbs, and honey. They steal sheep, and use violence if necessary, but they readily take employment with a civilised man, and rarely return to their old life.

$$
\text { Yerkal }
$$

Yerkullevar, . . TEL. : Yerakellu, . . . TEL. Eruku, Eruku-vadiz, Thu, Yerkal-vadi,

Erukulu-vadu, . . ", Yerkel-wanlu,

Erukuvanlu (pl.), : " Yerlan, Erlan, Kond"̆A.

Kurshi-wanlu,

Yerra-wanru,

Yerkal, Xerakedi,

call themselves 'Kurri.' They are wanterers, living in grass, mat, or reed huts, make and sell mats and baskets, and tell fortunes. Where Canarcse is spoken in the Peninsula, they occupy themselves ostensibly as basket-makers and in fortunetelling; but they are notoriously predatory, and steal girls, whom they devote to prostitution. They are found on the outskirts of most towns.

The Yerkala of the Nellore district are migratory mat and basket makers, using the midrib and leaflets of the date palm. They also make wooden combs, work as labourers, and a few who have settled engage in cultivation. They rear pigs, poultry, donkeys, and dogs, and eat the flesh of most animals. They are usually of a dark-brown colour, the men are spare and light made, but hardy, with low forehead, small eyes, short nose. They wear only a strip of cloth, and they tie their hair in a knot above their brow. They admit polygamy, but do not're-marry their widows They seem to be identical with the Yevaru, Yerra- wanru of Coorg, a class of predial slaves, amongst whom are several subdivisions,-Panay.Yewaru, Punjay - Yewaru, etc. The Yerrakula in the Kistua district are settled in villages.

The Korawa, in 1872, 60,255 in number, and Erukala, 54,163, in the Madras Presidency, aresupposed to be the same race, known by the former name amongst the Tamil people, and as the Erukala in Telingana and amongst the Canarese. They are certainly of similar habits. The Korawa subdivisions are-(1) the Bajantri or Gaon Korawa or Souai Kolawaru, (2) Teling Korawa or Kasbi Korawa, (3) Kolla Korawa, and (4) Soli Korawa. The clan called Kunchi or Kunsi Korawa, also known as the Kuaebra Katta Kulwaru, seem the same as the Kasbi Korawa, and the Pattra Korawa or Patr Pallu have their name from the dancing girls having bells on their feet and ankles.

The Yerkal, Korawa, or Kunchi Kori are wanderers, of whose original country they themselves retain no knowledge. They are darker than the usual tinge of Hipdus around them. In their own communities they style themselves Yerkal, and they give the same appellation to the language in which they hold communication with each other. With the exception of the cow, almost all animals are used by them as food.

They worship a goddess called Poler Amma. Polygamy is common; and if a man owe money to his neighbour, he pledges his wife or daughter to his creditor, who mav either live with them or transfer them to another person. On the release of the debtor, he reclaims his wife and any children that may have been born in the interval. In $\mathrm{N}$. Arcot, Chingleput, and Tanjore, the Korawa mortgage their unmarried daughters, who become the absolute property of the mortgagee until the debt is discharged. In Madras, the Korawa when in want of money sell their wives outright for about Rs. 50. In Nellore they all purchase their wives at from Rs. 30.to Rs. 70, making payment in asses or cattle. Their various clans do not intermarry. They bury their dead. In Travancore there are about 56,274 Korawa; and there is a race of this name in Cutch of similar babits.

The Bajantri Korawa are musicians (Baja, music); they are also called the Gaon or village Korawa. They are found in the Bijapur, Bellary, Hyderabad, and Canara district, residing in small tents (pal) or in grass huts outside the walls. The men are more robust than the settled population, but the women are shorter and darker than the Canarese. They abstain from cow's flesh, but eat deer, wild hog, tigers, jackals, and por'cupine. They are thieves; they will not labour; the men are musicians, and with their women make grass screens (tatties); at harvest times they beg and pilfer from the reapers; the women tattoo the arms and foreheads of the Hindu women. They marry when the bride and bridegroom are about eighteen years of age; polygamy is allowed, and they live virtuously, never prostituting their children. 'They keep in their houses idols of the figure of Hanuman, and mark their foreheads with the marks of the Taishnava sect.

The Teling Korawa are known as the Kasbi Korawa, i.e. prostitute Korawa, also Aghare Pal Wale, sitters at the door of their tents, as Tamar sat in an open place, and was seen by Judah (Genesis xxxviii. 13-21). They differ in appear- 
ance from the Bajantri Korawa, but resemble in figure and countenance the Teling people. They are found throughout the Dekhan, are basketmakers and sell brooms; but their chief subsistence is from their young women. one of whom from their earliest infancy they devote to the gods. The devoted women are the Murli of the Mahratta, the Bassai of the Canarese, the Basava or Lingallu of the Teling races. The goddess to whose service their lives are dedicated is Madda Elama, also Hülgiwa, near Bellary, and Chatwai, a divinity of their own creation by sprinkling red lead on the tarwar tree, the Cassia auriculata. The devoted women sometimes bear children, who are admitted into their caste. The colours seen amongst them vary from the fairness of the Bralmans to that of the darkest of the Sudra races. No one can read or write. They abstain only from cow's flesh and pork. The women dress with the choli or bodice and saree. They are rarely permitted to reside inside towns, or only then at some ruined spot remote from respectable people. They bury their dead, and place the deceased's usual food at the head of the grave, anguring most favourably if it be eaten by a crow and next if by a cow; if rejected by crow and cow, they deem the deceased to have lived a very depraved life, and fine the surviving relatives.

Religion.-The Satani are a Vaishnava sect; are frequently religious mendicants, priests of inferior temples, minstrels, sellers of flowers for offerings to the idols. They are followers of Chaitanya, a Vaishnava reformer of the 15th century, and of his disciple Sanatana. Chaitanya was a person of low caste, but became distinguished as an author and expounder of the doctrines of his master. The sect admit all classes and all castes into their sect, and many common women join them. In 1872 they numbered 194,777 in the Madras Presidency, and 714,000 in number in all India. They have views similar to the Baisnab (Vaishnava) reformers of Bengal.

The Jaina period in the Tamil country extended from the 8 th or 9 th to the 12 th or 13 th centuries A.D. Sandara Pandiya, who expelled the Jaina sect from Madura, was ruling when Marco Polo visited India at the close of the 13 th century. Saudara Pandiya is also called Kun Pandiya or Kubja Pandiya. Nearly all the Jaina in the Madras Presidency are in N. and S. Arcot and in S. Cauara.

Non-Hindus. - In British India, the people following the Brahmanical religion restrict the term Hindu to the Sudra races; the Brahman, the Rajput, and the Chettiar being distinguished by these appellations respectively. On the other hand, all whom they regard as low castes are styled by them Chandal or M'hlecha, which latter term indeed they extend to Christians and Muhammadans. The non-Hindu races of British India are about seventy millions,--Buddhist and other races not recognising caste, - - aboriginal tribes, semi-Hinduized aborigines, Christians, and Muhammadans. Also such races as the Kol, the Bhil, the Gond, the Khand, the Beder, the Dher, Mhar, Mhang, Chakili, Waddaru, Malla, Madaga, and the Pariah, the leather-worker, and fragments and small tribes scattered anongst the communities, occupying forests and mountain fastnesses, dwelling on the outskirts of towns, or migratory and nomade.
These are largely shamanist and fetish-worshippers. The shaman and fetish-worshippers, in general, bury their dead.

The deities to whom their worship is more specially directed are beings whose anger is to be feared. Pieces of wood or stone are made to represent these deities, a shapeless stone from a river bed, or a piece of the Erythrina tree, or of the margosa wood; but the institution of a prominent idol seems invariably to be accompanied by some sacrificial rite, sometimes a goat in kid, but more frequently the buffalo or bullock is the victim. A cart is made, on which, after sacrifice, the stone is placed, daubed with red lead, and taken to the site appointed for it. Poch Amma or Kokli Amma is the goddess who sends smallpox, and Mari or Marai Amma, the goddess from whom cholera cornes, the epithet Mari or Marai being brought seemingly from the root relating to deatb, derivatives from which have branched into many of the old-world languages.

Throughout the south of India, each household of the Hindu and non-Hindu races, and each hamlet and town, have their particular personal and local deity. Eg-gath Amma is the guardian deity of the city of Madras, and once a year the idol representing her is taken around the town, halting for some days at particular spots. Wilson says that Mari Amma and Eg-gath Amma are goddesses adopted from the Virgin Mary and St. Agatha. Bal Amma, a shapeless mass of wood, is a goddess much dreaded, as are all who keep such an idol in their houses, and they are obliged. to intermarry amongst themselves. Mari Amma seems the same as the Ai of the non-Aryan races in the Mahratta country.

The goddesses Mhang-kali, Ujla Mhang-kali, Jul Amma, Yeli Amma, Poch Amma, and Madri Heri of the Central Dekhan, are all supposed to be related, to be, some elder, some younger, sisters of the same brood. To all of them are offered the sacrifice of blood of sheep, or goats, or horned cattle, and when the people are excited by an outbreak of a pestilence, the numbers of sheep and buffaloes sacrificed before an Ammun idol are numerous, so many as forty sheep in a night. The worshippers move in procession under loud cries, accompanied by the Murli women, who frequently become hysterical, who are then believed to be possessed by the god, and the onlookers exclaim, Deo ka ch'baya aya, ang'h b'har lia, The shade of the god has come, and filled the body. All of them adhere to the worship of spirits, and to such fetish and shaman cults as the above, in which indeed many of the uneducated Hindus, and more particularly the Mahratta Sudra people, share. But these forms of fetishworship are most observed amongst the Pariah race, the leather-workers, the predatory races, the races that have been or continue to $b^{\circ}$ predial, by domestic slaves, the forest races, and migratory homeless fragments of broken tribes.

The village god, the Gramma-deva, is everywhere worshipped by bloody sacrifices. The name in the centre of India is Bhim Sen, or Bhum Sen amongst the Gonds, Bhum supposed to be from Bhumi, earth. Bhum pen of the Gonds is usually a shapeless stone, covered with vermilion, and it is worshipped over all Gondwana and from E. to W. Berar.

The Asaga race of washermen of Mysore 
INDIA; THE MADRA9 PRESIDENCY.

worship a shapeless stone, which they call Bhumadevaru.

The Hari Mariah of the Mahratta races is a sacrifice of a live kid in front of their village god, and probably has its name from the Hindi word $\mathrm{Har}$, a plough.

Amongst all the aboriginal and Aryan races of the Peninsula, serpent-worship and spirit-worship prevail. In the more southern parts, and among the less civilised races, new objects of worship are being constantly selected. In 1868 , the raja of Wanparti died at Hyderabad, in the Dekhan. He had passed through a life of storm and turbulence, and his spirit was worshipped in Secunderabad on each occasion that cholera broke out. In the extreme south, the Pai or Pei or Paisachi are disembodied spirits, demons, and are worshipped by all the heathen Shanar race of Tinnevelly. The Bant race of Canara believe that persons who die from violence become Paisachi. In the Telingana villages are many small temples dedicated to the Perintala, the spirits of women who have been deified, Perintala meaning a wife, a domestic woman. Amongst other female deities is Polimera, the goddess of boundaries, from Pola in Telugu, meaning land.

The village of Perriapollium, 25 miles north of Madras, on the bank of a small river, is famous for a temple dedicated to a goddess known by several names, Amma, Ellai Amma, Mari Amma, who is claimed by Hindus to be their Kali, or Durga, or Bhawani. An annual festival is held there, and about 100,000 persons assemble, and sheep, goats, and buffaloes are largely sacrificed, their heads being severed by one blow of a billhook. At the close of the festival, men, women, and children bathe in the river, and afterwards array themselves solely with the leaves of the Azadirachta Indica, not a particle of clothing nor of cotton is allowed to remain on the body, even the waist-string worn by men, and the thali or marriage neck-string worn by women, are laid aside. With the men, leafy twigs of the tree fastened to a straw rope are tied round the waist, and the leaves reach to the lower part of the thighs or knees. The women as their sole covering hold a cluster of the twigs in their hands, and cross their arms over their breasts. In this state they rush up to the temple door and salute the image within, then circumambulate the temple two or three times, bowing to the idol each time they pass the doorway, and then return to the river, where they bathe and resume their clothing. Occasionally devotees, in fulfilment of their vows, lie down near the temple, and roll themselves round and round it. Cattle, also, covered with the leaves, are led around the temple.

The Vira-Saiva sect of Lingaet and their Jangam priesthood are Hindus; are most numerous in Mysore and in the Canarese-speaking. parts of the Madras, Hyderabad, and Bombay districts. They are not a moral sect, are bigoted and exclusive, and the men wear the emblem of Siva, in silver caskets, suspended from the neck or fastened around the arm. They are strict vegetarians, are engaged in all the avocations of civil life, and rarely enter the army.

The Moplah, written also Mapillai, from $\mathrm{Ma}$, mother, Pillai, a son, are all Muhammadans, and are descendants of Arabs who visited or settled in Malabar. Wilson supposes that the Malabar women who bore children to them, ignorant of the race of foreigners who were the fathers, styled the children 'sons of mothers;' but the probability is that the law of descensus ab utero, Marumakkatayam, prevailing there from prior ages, was followed by the mothers of the children born of casual or permanent intercourse. The Moplah are all large men, active and enterprising, and possess much landed property. They have been restless under British rule, and have repeatedly risen in insurrections, but these have been very local, and seem to have sprung from agrarian grievances, the result of being unacquainted with the Hindu proprietary rights in the lands. They are a devout, God-fearing race, inclined to puritanism, are occasionally fanatical and prone to religious excitement, but they have never been rulers in India, have no dynastic recollections or longings, and are well worthy of being encouraged by their British rulers. Under the influence of religious excitement; they are reckless of their own lives or those of others, and the presence of European troops in the district has always been considered necessary to secure peace. There were outbreaks about the years 1837,1849 ? 1873. They are a hard-working, plodding, and frugal people, temperate and simple in their lives, and striving their best to live honestly and decently. They all speak the Maleali language, but they use a modified form of the Arabic alphabet to write in. The Moplah women are secluded. They number over 500,000 in the Madras provinces, principally in the Malabar and S. Canara districts. They prefix to their names the word Jonakan, a dialectal variation from Yavana, Grecian, to distinguish them from the Nestorian Christians, who are also called Mapillai, but have the word Nasrani, Nazarene, prefixed to the term.

Labbai, a race of Muhammadans in the Madras Presidency, where they number over 300,000 , hardworking, intelligent, upright men, entering keenly and enterprisingly into all branches of trade, and extending their mercantile connection over all the Peninsula. They are merchants, tradesmen, pedlars, leather manufacturers, fishermen, boatmen, and sailors. They are numerous in Tanjore, Tinnevelly, Madura, N. Arcot, and Madras town. They are liberal, large-minded people, yet frugal and thrifty in their personal expenditure. They use the Tamil langunge in their families, and have the Koran in that tongue. They take their name from the Arabic word Labek! meaning my lord, equivalent to the English expressions, 'I beg pardon,' 'That did you say?' Like the Moplah of the western coast, they are supposed to be descendants of Arab fathers by women of the southern parts of the Tamil country. They are mostly Sunni.

Christians have been in the south of India from soon after the time of Christ. During the past four centuries, Xavier, Robert de Nobilibus, Beschi, and Britto all laboured to convert the people of the south of India to the Romish forms ; while Schwartz, Kohloff, Rhenius, and others have laboured for the Protestant Church.

Eurasians in the Madras Presidency at the census of 1871 were 26,374 , of which 13,584 were in Madras or the neighbouring district of Chingleput, and 5409 in Malabar, where the Portuguese and Dutch had formerly settlements. 
Their women in Madras are married when very young.

Cairns are observed in every part of the Peninsula of India from Nagpur to Tinnevelly. There are immense numbers on the Animallay Hills. There are six different kinds of cairns and cromlechs at the Neilgherry Hills. The Todas use the Azaram, a small stone circle, within which they burn their dead. Mr. Metz says the kistvaens are termed Moriari mane. These contain pottery with a rich red glaze, and many of the clay figures found in them have a high Tartar head-dress. They contain a very large urn or jar, filled with human bones, partially charred, with a number of beautiful little vessels of various shapes, made of glazed pottery, and with relics of iron weapons.

In the cairns of the Dekhan have been found skeletons on their faces, some with arms and utensils; other cairns have had ashes and charred bones.

BRITISH BURMA has an area of 87,220 square miles, and in 1881 a population of $3,736,771$. It extends from lat. $10^{\circ}$ to $22 \frac{1}{2}^{\circ} \mathrm{N}$., 950 miles, from the Pakchan river to near the sources of the Koladyn river.

The province has five natural divisions. In Arakan, the narrow strip of lowland between the Yoma and the sea; the valleys of the Irawadi, Sitang, and Salwin, separated from each other by the Pegu Yoma and Poungloung ranges; and, in the south, in Tenasserim proper, a narrow lowland strip between the Siamese frontier and the Bay of Bengal. The coast line is upwards of 1000 miles.

The country is very thinly occupied, only 42.8 to the square mile. The inhabitants are composed of numerous tribes of the Mongoloid family, but owning no connection with each other, and they have entered the districts, some from the north, some from the east, and some from the south. Every year 80,000 to 100,000 immigrants enter Burma, more than one-half of whom are from Upper Burma, the others from Madras and Chittagong. Most of those who come from Buddhist countries settle in the province, but the bulk of the persons from India make a little money, and in three or four years retire. The Chinese who come to it are, more than others, inclined to settle, most of them being familiar with the Buddhist form of religion, which the races in Burma largely follow.

In the census of 1881 , it was shown that 541,743 persons were born outside the provinces; of these 316,000 were vatives of Upper Burma. The immigrants are mostly men, consequently the females are very few.

\begin{tabular}{cc|cc} 
Males. & Females. & Males. & Females. \\
$1872,1,435,518$ & $1,311,630$ & $1881,1,991,005$ & $1,745,766$
\end{tabular}

The Burmese women readily intermarry with the immigrants.

There seem to have been two great branches of immigrants from the great bend of the Brahmaputra, one of these, Naga, Kuki, Shandoo, Lushai, Khyen, Mru, and Kum-wi, bending westwards. Another branch moved to the east, and are now known in the upper valley of the Irawadi as Kakhyen, who, on the watershed of the Irawadi and Salwin, merge into Karen, with the Karen-ni as an offshoot, and advanced into the delta of Pegu as the Karen cultivator; and of these the Toungthu are probably a fragment, Subsequent to the descent of these tribes, a great people seem to have entered from the head-waters of the Irawadi, occupying its splendid valley, and driving back the prior occupants into the mountains on either side. These last comers are now represented by the Burmans, from whom the Arakanese branched soon after the occupation of Burma proper.

The tribes that have been exposed on the seaboard of Arakan or in the basin of the Irawadi, to the influence of the Chinese, Shan, Mon, Bengali, and more distant commercial nations, have attained a comparatively high civilisation. The Singpho, although much behind the Burmans, are greatly in advance of the Kuki, and the Burmese seem at a very ancient period, when their condition was similar to that of the Kuki, and perhaps in many respects more barbarous, to have spread themselves from the Upper Irawadi to the south and west as far as the highlands of Tiperah on the one side, and Pegu on the other. Wherever the stock from which they have been derived was originally located, they probably first appeared on the Ultra-Indian ethnic stage as a barbarous Himalayan tribe, immediately to the eastward of the Mishmi, if indeed they were not identical with the Mishmi of that era. The Upper Irawadi was probably then occupied by the ruder and inland tribes of the Mon-Annam alliance.

Dr. Mason, writing in 1860 , classed the races of Burma as follows :-

\section{a. Burmese Tribes, viz.-}

\begin{tabular}{|c|c|}
\hline $\begin{array}{l}\text { 1. Burmese. } \\
\text { 2. Arakanese. } \\
\text { 3. Mugh. } \\
\text { 4. Kanyan. } \\
\text { 5. Tounghoo tribe. }\end{array}$ & $\begin{array}{l}\text { 7. Yau, Yo, Jo, or Quoi. } \\
\text { 8. Ze-baing or Ye-bain. } \\
\text { 9. Pyu. } \\
\text { 10. Kado. } \\
\text { 11. Danu. }\end{array}$ \\
\hline
\end{tabular}

b. Talaing, Peguan or Mon. c. Shan Tribes, viz. -

\begin{tabular}{l|l} 
1. Shan or Tai. & 3. Paloung or Paloa.
\end{tabular} 2. Lao, Lau, Lawa, or Wa. 4. Phwon or Mwoon.

\section{d. Karen Tribes, viz.--}

i. Sgau Karen, viz.-

1. Sgau.

2. Man-ne pghe.

3. Pa-ku.

4. We-wa.

ii. Bghai Karen, viz.-

1. Tunic Bghai.

2. Pant

3. Lay May."

4. Manu-manau.

5. Red Karen.

iii. Pwo Karen, viz. 1. Pwo.

\section{Shoung.}

3. Kay or $\mathrm{Ka}$.

4. Taru or Ku-hta.

5. Mop-gha or Ple-mau.

6. Ha-shwie?

7. Toungthu.

8. Khyen, Kyn, or Chin. iv. Shan Karen, viz.-

1. Yen or Yein.

2. Yen-seik.

3. Ying-bau.

4. Pandung.

5. Toung-yo.

6. Black Karen.

\section{c. Miscellaneous Tribes, viz.-}

1. TKa Khyen or Kaku.

2. $\mathrm{Ka} \mathrm{mi}$ or $\mathrm{Ke} \mathrm{mi}$.

3. Kyan.

4. Koon.

5. Sak.

6. Mru.

7. Shandoo,

8. Selung.

In Burma, in 1881, the chief races were as under:-

\begin{tabular}{|c|c|c|c|}
\hline & & 274 & Chinese, \\
\hline & & . 18 & Bengali,. \\
\hline & & .58 & ustani, \\
\hline & & & Tamil, . \\
\hline & & 3 & \\
\hline & & . & \\
\hline & & - & C F \\
\hline & & . 59,723 & icans, . . \\
\hline
\end{tabular}


Their religions were as under :-

Buddhists, . . 3,251,584 |Jews, . . . . . . 204

Nat worshippers, . 143,581 Parsees, . . : . 83

Hindus, . . . 88,177 Brahmans, . . . 37

Christians, : 84,219 Jains, : : . 5

Muhammadans, . 168,881

The great Mramma family are known to the British as Burmese. They include the Arakanese, Burman, Tavoy, Choung - tha, Yau, Ya - bein races. The people and their speech are of common origin.

The Arakanese differ but little from the Burmese in feature or form, and though the Arakanese spoken language is so dissimilar from that of the Burmese, as to be almost unintelligible, when written it is the same in almost all respects. They preserve the letter $r$, which the Burmese pronounce $\mathrm{y}$ in sound. The Arakanese also retain with its natural sound the inherent vowel a, which on the east of the Arakan Yoma range is pronounced in several different ways.

In Tavoy are descendants of an Arakanese colony, planted there before the Burmese had conquered the intervening Talaing or Mon. The principal inhabitants of Amherst province are Talaing, Karen, and Toungthu, with small numbers of Arakanese, Shan, Burmese, Hindus, Chinese, Muhammadans, and Malays.

The Yau live on a western tributary of the Irawadi, about the latitude of Pagan. They do not differ much from the Burmese either in race or language. They are the pedlars of Upper Burma.

The $Y a$-bein are almost indistinguishable from the Burmese. Their language is a dialect of the Burmese. They rear silk-worms, which is never done by the pure Burman.

Choung-tha, or children of the stream, are a part of the Arakanese nation who have remained in the hills. They are gradually descending into the plains. They speak Arakanese, and are Buddhists.

In the Tibeto-Burman family, and belonying by origin to the same great Mranma group as the Burmese, are classed the hill tribes of Arakan,the Sak, Chaw, Kway-mi, Koon, Mru, and Shandoo tribes, - who live near the Koladyn and its tributaries. Their languages are marked by differences sufficient to entitle them to be separately named.

The Burmans proper occupy the valley of the Irawadi, mixed with Karen, from lat. $18^{\circ} \mathrm{N}$. to the delta. They are Buddhists. Their language, the Burmese, is spoken in Arakan, in the valleys of the Irawadi and Sitang, and in Tenasserim to the south of Taroy. There are numerous Shan States far to the north-east, but they generally owe fealty to the Burmese monarch. The tribes and natives under the sway of the respective rulers are numerous.

The Burmans are lively, inquisitive, active, irascible, and impatient. The men have long bodies, with short, stout thighs. They are of a reddish-yellow colour, are not fond of continuous daily labour. Both men and women wear a jacket, and a wrapper for the lower part of the body.

The Burman woman's lower garment is a narrow cloth of various colours, of a pleasing contrast, which descends generally from the waist or from below the arm to the feet. It is made to overlap, and is tucked in in front, at the waist, but it is so narrow that most of the inner thigh is shown at each step. The young people are little restricted in their intercourse, and the marriage ceremony, and that of divorce, are simple; the women are naturally affectionate, very intelligent, engage largely in market and shopping business, and even undertake extensive mercantile transactions.

Every male Burman is tattooed in his boyhood from the waist to the knees; in fact, he has a pair of breeches tattooed on him. The pattern is a fanciful medley of animals and arabesques, but it is scarcely distinguishable, save as a general tint, excepting on a rather fair skin. Erskine, in his Course in the Pacific, mentions that the natives of the Samaon or Navigators' Islands have exactly the same fashion.

The Burmese are spirit worshippers. They propitiate the Naides, they reverence the suake. Almost every Mon village has a Nat sin or Nat shed.

They believe in astrology, alchemy, and witchcraft, the evil eye, philtres. The Hman Tsaya is the witch-finder. Diseases are supposed to be the work of evil-disposed Nats. The Kyat or Jat are elfs or goblins, who live in the earth-mounds found in the forest.

Pungyi or Phoungye, meaning Great Exemplar or Great Glory, is the name by which the members of the monastic rule of Buddhism are commonly known in Burma.

Mugh is a term which the Muhammadans and British have given to the Arakanese, but that people restrict it to the descendants of Arakanese by Bengali mothers. The Mugh form six-tenths of the native population of Arakan, one-tenth being Burmese and the remainder Hindu. In Arakan, and in the basin of the Irawadi, are several tribes of the same stock with the Burman, and their languages are in their present form so much akin to it that they may be almost considered as forming, with Burman, dialects of one tongue.

Karen is a term by which the Burmese designate most of the mountaineers of $\mathrm{Pegu}$ and Southern Burma. The Shan call them Yang, which is pronounced by the Burmese Yen, and there are tribes known as Yein, Yen-seik, Yenbau. Some of the Karen tribes wear white clothing, some black, and some red, and these colours have been used to designate them. But as some of their tribes wear a frock or tunic, while others have short trousers as a costume, the forms of their clothing have been employed as designations.

Red Karen call themselves Ka-ya; some of the Bghai clans, Ka-yay. They have traditions pointing to the north as the region whence they migrated, and of having crossed a river of sand (shamo), a desert where the sands rolled before the winds, also of having once been in the possession of books of religion, which they had lost. This tradition may refer to Gobi desert, which is intersected from $\mathrm{E}$. to $\mathrm{W}$. by a depressed valley, the Shamo or Sea of Sand, which is also mixed with salt. West from it lies the Hau Hai or Dry Sea, a barren plain of shifting sand blown into high ridges. But they are an impressionable race, and it will be difficult to localize the place to which they allude.

The Karen preceded the Burmans in the delta of the Irawadi, and are now the joint occupants with the Mon. They are also found in the lower plains of the Salwin, the deltas of the Sitang 
and Irawadi, the middle basin of the Sitang as far as Tonga, and in Tenasserim. In Martaban there is also a remnant of an allied tribe, the Toungthu. Both the Karen and the Toungthu belong to the Yuma branch of the Tibeto-Burman family.

The long and narrow hill tract between the valley of the Irawadi and the Salwin as far north as $23^{\circ}$ is occupied by cognate tribes called Karenni (Red Karen), who are said to speak a very ancient dialect of the Yuma family. This branch has a parallel range on the western side of the Irawadi, and in their traditions they assert that they preceded the Burmans as the dominant people of the basin, and they seem from very ancient times to have occupied the whole of the valley southward from the valley of the Banak on the west to the borders of Yunnan.

No trace of the Mon is left along the Yuma range, - tribes of the Karen family being the exclusive holders of its inner valleys. Some of the very imperfectly described tribes on the eastern side of the Irawadi, to the north of the Karen-ni, viz. the Ze - baing, Ka-Khyen, etc., may belong to the older immigration. But the Mon is the only remnant within the ancient Karen province, and its earlier preservation is doubtless owing to the same causes, its arts, civilisation, and wealth, which have enabled it to hold its own against the Tibeto-Burman horde of the Irawadi.

The Karen in British Burma are over half a million $(581,294)$. Their language differs widely from those of the hill tribes of Arakan, and ethnologists class them by themselves, separate from the members of the Mramma family. They are supposed to have come from the N.W. of China, moving towards Yunnan, and thence along the hills on either side of the Sitang and Salwin rivers into their present positions, about the 6 th century of the Christian era.

There are three great groups, - the Sgau or Burman Karen, the Pwo or Talaing Karen, and the Bhgeh or Bweh, to one or other of which linguistic groups all the clans are referred.

The Karen languages are monosyllabic and tonic, and show unmistakeable evidence of Chinese influence in their vocabulary. The Bweh Karen are in the Salwin and Martaban district. They include the Karen-ni or Red Karen.

The Karens paint the two posts of their doorways, the one red and the other white. Karens walk round the dead to make a smooth path, like the Bhotani in procession round the shrines of Buddha, and like Jews, who walk seven times round the coffins of their friends. The Jewish priests, in offering oblations, Psalm xxvi. 6, walked round the altar seven times. The Assam hill tribes, like Karens, consider the touch of the dead pollution, as in Numbers xix. 13: "Whosoever toucheth the dead body of a man, and purifieth not himself, defileth the tabernacle of the Lord: because the water of separation was not sprinkled upon him, he shall be unclean.' Karens are smaller than the Burmans. The White Miaou-tse, who occupy the hill country of Central China, present many points of resemblance to the Karens. They are brave, independent, and at certain intervals sacrifice an ox without blemish to the great Fatber. It is amongst the Mirou-tse that the Old Testament is said to have existed from time immemorial, which they say came to them from heaven 2000 years ago.

The first convert to Christianity was Ko Thah Byu, who was baptized at Tavoy in 1828 ; but before his death in 1841, there were 1300 native disciples. The missionaries amongst them have been Mr. Boardman, Miss Macombe, and Messrs. Mason, Wade, Bennet, and Abbot. Several of their dialects have been reduced to writing, some in Roman, some in Burman character, and the Scriptures translated.

Sgau tribes speak the Sgau dialect. Sgau is their own designation for themselves, but they likewise claim to be Pgha-ka-nyo, or men. As the seaboard is approached, the Sgau and the $\mathrm{P}_{w 0}$ are found mingled together from Bassein to Mergui. They are, however, found from Mergui, in lat. $12^{\circ}$ $\mathrm{N}$., to Prome and Tounghoo, in lat. $19^{\circ} \mathrm{N}$.; a few have passed westerly into Arakan, and on the east they have wandered to the east of Zimmay over the watershed that separates the Meinam from the Salwin. They are the most numerous of all the Karen tribes. They wear a white tunic, with a few horizontal bands of a red colour near the bottom, and from this they are called White Karen. Where the population is sparse, they cultivate the most favourable spots, first, before hewing down the trees, abjuring the departure of all evil, and then dibbling in the rice seed, which they do not sow broadcast like the Burmese; planting also cotton, capsicum, Indian corn, vegetables of all kinds, and Job's tears between the rows. They also fish largely, for they eat all creatures, lizards, snakes, deer, wild hog, elephant, rhinoceros, wild ox, buffalo; they gather the wild cardamom, or wash for tin. They have no mechanical art, but some of the women weave and embroider. Their betrothals are in infancy, and the married couple early associate, but there are frequent separations. All the Sgau and the Pwo burn their dead, but a bone is taken from the ashes, and in the dry season is buried with a festival, with music and dancing. The bone is placed in a booth, and around it the articles belonging to the deceased are hung, with a torch at the head and another at the foot to represent the morning and evening stars. They make offerings to evil spirits, the $\mathrm{Na}$, and to a good spirit, whom they style grandmother.

Bghai or Bweh.-From the mouth of the Thoukye-Khat creck to near the British boundary and the Shan State of Mo-bya, the whole country from the Sitang to the Salwin is peopled nearly exclusively by tribes to whom the Sgau and the $\mathrm{Pa}-\mathrm{ku}$ give the name of Bghai. The Bghai or Bweh are met with immediately north of the Sgau and Pwo, on the left bank of the Sitang, and on the watershed between it and the Salwin.

Lushai. - The high mountain range called Moduting, Mranidong, and Yomdong, forms a natural boundary between Chittagong and Arakan. The Koladyn flows about 16 miles distant on the east, and the country there is mostly uninhabited. To the west are the Lushai.

The Shandoo are a recently intruded tribe. They are the most warlike tribe, and exist in large numbers outside the boundary of British Burma, and are said to be pressing the Kway-mi and Mru southwards. They are probably the same race as the Kuki, who, according to Colonel Dalton, stretch from the valley of the Koladyn to the 
border of Manipur and Cachar. Their language belongs to the Tibeto-Burman family.

The Kway-mi or Ka-mi (dog-tail) differ but little from the Mru. Both these races are moving southwards. Sir Arthur Phayre believed them to form a branch of the Myam-ma race, from which the Burmese and Arakanese spring, and he considers the hill tribes to be prior occupants. They number about 19,000, two-thirds of whom are in the hills of $\mathrm{N}$. Arakan, the rest having settled on the Akyab plains. They have black, straight hair, high cheek-bones, oblique eyes, and scanty beards. They appear, like the Rakhaing-tha, in a more rude state of existence, and the traditions of the latter people refer to the $\mathrm{Ka}$-mi as prior occupants.

The Toungthu in personal appearance and dress somewhat resemble the Shan. They are short of stature, and thickly built. Their language is tonic, and closely connected in vocabulary and syntax with the Pwo Karen. They are a.clannish, taciturn people. Their name signifies hillman, but they call themselves $\mathrm{Pao}$, and are divided into many local clans. In British Burma they number about 30,000 in the Amherst district, on the banks of the Salwin, and along the Thatone range of hills, and about 5000 east of Kyi Keto.

Northern Arakan hill tracts comprise a district about 60 miles long and 40 broad. There are six distinct clear ranges, and two important rivers with their affluents pierce the mountains. Till recent years the whole of this region was the home of many wild and lawless clans, who lived amidst constant rapine and disorder, and the British policy has been to mark a boundary for the more civilised possessions. In 1875-76 there were four tribes within the British territory, numbering 12,442 souls. Rakhaing or Khyoungtha, sons of the river, 1219; Khami or Rhwe-myi, 7172 ; Anu or Khoung-tso-Khyeng, 2162; Khyaw or Kuki Mro, 2126. The Mru outside the boundary are the worst of the marauders.

The Khyen are the largest of the numerous hill tribes of Arakan. They occupy the Yoma range of mountains between Pegu and Arakan, are numerous in the hill tracts of Northern Arakan, and on the eastern side of the Irawadi, in the uplands of Prome and Myedai, and on the watershed between the Irawadi and Sitang. There are also some 5000 in Sandoway. Captain Hannay says they are identical with the Naga. Colonel Yule thinks they are nearly allied to the Kuki. Dr. Mason classes them with the Pwo Karen. They are a retiring, timid race ; are migratory, but are settling down under British rule, following the practice of jhoom or toung-ya cultivation. In British Burma they number over 50,000, partly in Arakan and in Pegu, chiefly in Thayat-Myo and Prome, with settlements on the north of Pegu as far as Tounghoo. The Chin or Khyen are widely extended in British Burma, being on both sides of the Arakan Yoma, also in the Thayat-Myo and Prome districts to the east of the Irawadi river, and are in large numbers in Upper Burma. They point to the Chindwin river as their ancient home. They tattoo the faces of their young girls so as not to leave even an eyelid free from hideous blue-black deformity. Their language has affinities with the Pwo Karen.

The Chaw are a small tribe of 587 souls in
North Arakan. They are connected with the Kuki.

The Sak or Thek are in the Akyab district.

Shan of the Burmese are the Po-yi of the Chinese, and the Tai of the Siamese. Po-yi means White Barbarian. The Shans are behind the Chinese in the arts, but in Burma every article of husbandry of iron, brass, or silver is from the Shan States N. and E. of the capital, also the best of the lacquered ware, the last principally from Monai to the E. of Lower Pagan. The Shan States also manufacture silk, and the Shans of the N.E. and the Cathay Shans or Munipuri know the art of dyeing both cotton and silk. The silks are exceedingly rich, and of varied check patterns.

The Shans in British Burma in 1881 were 59,723 immigrants and their descendants, chiefly from the Shan States. Outside the boundary they are very numerous from the N.E. of the kingdom of Ava to Bankok. They are of the same origin as the Ahom and Khamti of Assam. Their language is monosyllabic, and has, like the Chinese and Karen languages, more numerous tones than the Burmese. They are hard-working and careful cultivators.

Mon or Talaing. - The tracts about the mouths of the Irawadi, Sitang, and Salwin were anciently called Savarna Bhumi or Ramanya, and were inhabited by the Mon. The language of the Talaing is monosyllabic and tonic, with a sprinkling of polysyllabic words, and had a common origin with those of Cambodia and Annam; and Captain Forbes has suggested that the Assamese, Mon, and Cambodians moved down the IndoChinese Peninsula about the same time, and occupied contiguous tracts of country until the Siamese intruded themselves between the members of the Mon Annam family. It has been suggested that the Mon language is connected with that of the Munda or Kolarian tribe in Chutia Nagpur, and a few words in both languages are more or less alike.

There are in British Burma 154,553 pure Talaing, and 177,939 persons of mixed Burmese and Talaing parentage.

The Burmese call them Talaing. The Siamese appellation is Ming-mon. The ancient capital of the Talaing was called Thadung, Thatung, or Satung. Its ruins are still to be seen between the mouths of the Sitang and Salwin rivers, and the colonists seem to have been of Hindu origin, possibly arriving several centuries before the Christian era. They seem to have extended their empire to Pegu and Arakan in the early centuries of the Christian era, and to have held sway for sixteen centuries. Part of this population dwell on the delta of the Irawadi, Mon being the name used by themselves for the native populations of Pegu, Moulmein, Amberst, and Martaban; but their neighbours call them Talaing, and the same names, Mon or Talaing, are given to the vernacular language of Pegu. The alphabet, like that of the T"hay and Burmese, is of Indian origin, being essentially that of the Pali form of speech; and, like all alphabets of this kind, its language embodies a Buddhist literature. The Mon language is quite unintelligible to a Burmese or Siamese.

The Talaing language has the intonations characteristic of the Chinese family, but to a 
INDIA; ITS CASTES AND TRIBES.

much less extent than the Chinese itself, the Tai, or the Karen. The roots are principally monosyllabic, but this language is remarkable for its numerous compound consonants. Like all other Indo-Chinese languages, grammatical distinctions are made by particles prefixed or suffixed. In its vocables it is the most isolated language in Further India, but it has a radical affinity with the language of the Ho or Kol. The Talaing people call themselves Mon, which has this bearing on their origin, that a Ho or Kol tribe are called Munda and Mon. Mr. O'Riley thinks that the Mon are only distinguishable from the Burmans by their less Mongolian and more Rakhoing aspect. They appear to have been considerably modified by the Indian element, which has always been very powerful at the head of the Bay of Bengal.

The Daingnet or Dinet, 1995 in Akyab, are in features somewhat like the Gurkha of Nepal. They do not tattoo their bodies, dress in white, and do not intermarry with other races. They dwell among the hills of the Yet-thay-doung township, near the Chittagong frontier. A few speak the Nepal tongue, some talk Bengali, and some Arakanese.

Salone, 894 in number, are a tribe of sea gypsies, living in the dry weather in their boats, wandering about the islands of the Malay Archipelago, and during the monsoon taking shelter in huts built on the lee side of the islands. Their clans keep to their respective fishing grounds. They have peculiar wicker boats, and were formerly exposed to the attacks of Malay pirates. They are in personal appearance between the Malay and the Burmese. Their language has affinities with the tongue of the former, and belongs to the Malay Polynesian group of agglutinating languages. They visit Mergui to dispose of the beche-de-mer.

$2,245,125$ persons speak the Burmese language proper. Amongst these are included many of mixed race, such as the Burmese-Talaing.

There are 362,988 Arakanese, chiefly in the Akyab and Kyouk-pyu districts of Arakan, with large numbers in Sandoway. The whole number speaking Burmese therefore is 2,612,274.

All the languages that have been included under the head of Burmese belong to what is sometimes called the Tibeto-Burman family, are monosyllabic, and are spoken by races possessing the Mongolian type of countenance.

The Burmese women readily intermarry with the immigrants. The principal mixed races are as under:-

\begin{tabular}{|c|c|c|c|}
\hline & $.1,554$ & Chin-Karen, & \\
\hline "ר & Chinese, & Shan-Chinese, & . 1,213 \\
\hline, & Karen, . & ", Karen, . & . 1,323 \\
\hline , & Shan, & Tounghoo-Karen & $.2,48$ \\
\hline " & Tounghoo, 1,076 & Burman, & 3,968 \\
\hline la & Shan, $\quad .9,517$ & English-Burman & \\
\hline
\end{tabular}

Total indigenous and allied mixed races, . 230,484

Total Indo-Burman races, .

10,620
762

Total European-Burman races, .

Total Christians returned as Europeans, - 6,808
Castes and Tribes.-In British India proper the following are the castes returned in the census of 1881 as exceeding 100,000 in any one province :-

Agamudian, . . 302,338| Ahir, . . . 4,639,167 Agria, Mith-Agria, 170,573 Ahom, : : 179,314 Ahar, . . 272,863 | Ambalakaran, : 155,537
Ambattan,

Araikulam

Arora,

Babhan

Bagdi,

Balai, .

Banjari,

Banya,

Barhai,

Barhi,

Bauri,

Beder,

Berad, .

Bhandari,

Bhangi, Mihtar,

Bhar,

Bhat,

Bhil, (Dubla)

Bhoi, Besta,

Bhuinhar,

Bhuinya,

Bhumij,

Bhurji,

Bind,

Boisnab,

Brahman,

Chamar Khalpa, $10,474,686$

Chandal, Changa, 1.,749,608

Channan, . . 128,600

Chasa, . . 534,061

Christians, - 1,862,634

Chuhra, - . 629,412

Das, . . 102,426

Devangulu, · $\quad 136,901$

Dhanuk, . 661,269

Dher, . . 110,040

Hyderabad, 2, 660,087

Dhimar, . . 193,58

Dhobi, .

Dom,

Dosadh,

Dubla,

Elaven,

Gadaria,

Gareri,

Gauda,

Gaudaru, Sivachar,

Ghatwal,

Ghiriat

$1,331,190$

721,655

$1,138,651$

129,241

387,176

920,220

112,400

233,991

Kuruba, 180,535

Golla, Gaoli, . 242,767

Gond, . . 646,277

Gonda, . . . 144,063

Gosain, : : 147,998

Gour, . . . 214,818

Gowari, · . 110,579

Gujar, . . 1,213,113

Hajam, Barber, . 237,919

Hari,

297,643
447,421

Idayan

$1,071,882$

Jain,

189,493

Jaliya,

381,540

Jandra,

Jangam,

Jat, .

Jhinwar,

Jugi,

Kachari,

Kach'hi,

Kahar, .

Kaibartha

107,169
320,856

320,85
630,994

269,111

340,342

281,611

Kaikalar,

$2,258,769$

$1,840,856$

$2,137,540$

323,788

Kalar, : . : 153,070

Kalingalu, . . 100,564

Kalita,. . . 253,860

Kallam, : : 397,857

Kalu, . . . 170,782

Kalwar, : : 535,819
Kamma, : * 795,732

Kandara, Bengal, 120,906

Kandu, . . . 608,919

Kanet, : : 344,814

Kapali, : . 130,240

Kapu, . : 1.07,341

Karan, . . . 106,332

Kawa, * . 1,102,255

Kawar, . . . 115,078

Kayasth, . 2,159,813

Kewat, . . . 521,053

Khandait, . . 617,017

Kharwar, . . 195,242

Khatak, : : 168,829

Khatri,. . . 393,199

Khond,. . . . 135,960

Koch, : : $1,878,804$

Kodula, $\quad 244,090$

Koeri, . : 1,207,951

Kol, . : . 299,961

Koli, Konkani, - $\mathbf{1 2 5 , 9 4 9}$

Mahratta, : 881,014

Baroda, . . 676,661

Talabda, . 661,865

Kolita, . . . 253,860

Komati, . 591,639

Kori, . . 884,871

Koshti, . . . . 315,424

Kumbar, . . 114,378

Kumhar, : 2,053,080

Kummalen, . . 784,998

Kunbi, . . 7,146,555

Lewa, . . 568,038

Kadawa, 334,881

Kura Varu, . . 225,282

Kurmi, . . 4,065,075

Kurubar, . . 225,282

Kusavan, . . 263,975

Lingaet, • . 457,168

Jangam, - 320,856

Lodh, . . 1,040,724

Lodhi, . . 264,667

Lohanna, . . 348,514

Lohar, . . $1,595,858$

Lonia, . . . 378,619

Madigaru, . . 174,824

Maduk,. - 308,821

Mahajan, . . 634,440

Malayala Sudra, $\quad 664,260$

Mal, . . 142,114

Mali, : : 1,209,019

Mallah,. . $\mathbf{1 , 0 8 4 , 9 3 1}$

Mang, . . . 556,771

Marar, . . . 184,519

Maravan, : 256,304

Mehra, . - 231,624

Mhar, Dher, : 2,742,216

Mina, . . 432,096

Munurwar, : 187,458

Mussahar, . . 549,524

Mutrasi, . . 104,671

Mutsatta, . . 133,141

Nahambadi, . 106,682

Nai, . . . 2,283,641

Nair, . . 336,227

Nat, Jugi, . . . 121,901

Nath worshippers, 143,581

Nunnia, . . 282,090

Oddan,. . . 363,289

Ooria, . : 101,199

Padiyroi, . . 376,847

Pan,. : : 241,487

Panchamsali, . . 291,246

Paraet, . . 162,062

Parayen, : $3,290,038$

Pasi, . . 1,199,505

Pillai, . . 1,294,982

Pod, . . . 325,755

Powar, . 106,081

Pulaven, . . 196,539

Rajbansi, . . 106,376

Rajwar, . . 131,364

Reddi, . : 654,700

Sadgop, : : 557,947

Saini, : : 137,380 
INDIA; THE NORTHERN AND N.E. FRONTIER.

\begin{tabular}{|c|c|c|c|c|c|}
\hline Sakkili, & - & $.1,126,837$ & Tarkhan, & & \\
\hline le, & & - $\quad 206.794$ & Tatwa,. & & 245,904 \\
\hline lewara, & & . 194,134 & Teli, & & $2,953,939$ \\
\hline Santal, . & & - 210,661 ? & Teli and Gh & nel & i, 200,183 \\
\hline Saora, : & & - 103,490 & Telinga, . & - & 327,338 \\
\hline aralu, & & - 131,469 & Telugalu, . & & 613,090 \\
\hline Sembadav & en, & - 100,019 & Tiar, . . & & 349,117 \\
\hline Setti, . & & - 235,286 & Uapparavan, & & 104,959 \\
\hline Shanan, & & . 1,478,690 & Uriya, . · & & 101,199 \\
\hline $\begin{array}{l}\text { Sonar, } \\
\text { Sudra, }\end{array}$ & & $\begin{array}{l}\text { - } 979,709 \\
-\quad 339355\end{array}$ & Vanan, & & $\begin{array}{l}528,458 \\
339136\end{array}$ \\
\hline & & 589,021 & Vanian, & & $1,075,264$ \\
\hline r, & & 363,198 & Velamá, & & \\
\hline & - & 101,615 & Vellalar, & . & $1,770,669$ \\
\hline Tamoli, & - & 320,266 & Wakkaliga, & . & 695,21 \\
\hline & • & 679,875 & Yadavalu, & & \\
\hline
\end{tabular}
Religions.

Hindu, . 187,937,450 | Nat worship, . 143,581 Muhammadans, 50,121,585 Parsee, . . . 85,397 Aborigines, - .6,426,511 Jew, . . . . 12,009 Buddhist,. . . 3,418,884 Bramho, . . . 1,147 Christian,. . .1,862,634 Kunbipatia, . 913 Sikh, . . 1,853,426 Others and unspeciJain, : . . 1,221,896 fied, . . . 59,985 Satnami,
Kabirpanthi, : : 347,994 All religions, $\overline{253,891,821}$ -Dr. Calduell's Comparative Grammar and Shanars; Mr. (Sir George) Campbell's Ethnology of India; Dr. A. Campbell in Journ. Ethnological Society; Sir Walter Elliot in Jo. Eth. Soc.; Sir Henry Elliot's India ; Captain Forbes, N.E. Frontier; Fraser's Himalaya Mis.; Gerard's Kunawar; Dr. W. W. Hunter's Non-Aryan Languages and Imperial Gazetteer; India Administration and Census Reports; Journals Asiatic and Ethnological Societies; Marshall's Todas ; Mason's Burmah; Samuells, in Beng. As. Soc. Jo., 1856 ; Dr. John Shortt on Leaf Festival, on the Yenadi, on Neilgherry Tribes; Turner's Embassy; Dr. F. Watson's People of India; Dr. H. H. Wilson's Hindoo Castes; Dr. Thomson's Travels in N.W. Himalaya; Mr. Trelawney Saunders in Geog. Soc. Journ.

On the NORTHERN AND NORTH-EASTERN FRONTIER OF INDIA the principal races may be enumerated as under :-

Chinese Frontier and Tibet. - Tibetan, Bod, Gyami, Gyarung, Takpa, Manyak, Thochu, Sokpa, Horpa.

Nepal, W. to E. - Serpa, Sunwar, Gurung, Murmi, Magar, Thaksya, Pakhya, Newar, Limbu.

E. Nepal.-Kiranti, Rodong, Rungchenbung, Chingtangya, Nachhereng, Waling, Yakha, Chourasya, Kulungya, Thulungya, Bahingya, Lohorong, Lunbichhun, Balali, Sangpang, Domai or Dumi, Khaling, Dungmali.

Ncpal Broken Tribes.-Darhi, Denwar or Dhenwara Pahri, Chepang, Bhramu, Vayu or Hayu, Kuswar, Kusunda, Tharu, Bhramah, Bhotia, Brahman, Ekthariah, Gallia, Kami, Khas, Margi, Mungar, Murung, Nimbu, Parbattiah, Sarki, Yakha.

Sikkim.-Lepcha

Bhutan.-Lhopa.

Bengal, N. E.-Bodo, Dhimal, Koch, Garo, Kachari.

Bengal, $E$., is Assam.

The valleys of the Himalaya are occupied by many tribes, who carry on traffic and intercourse over the mountain passes, amongst the highest of which (above the sea) are the Baralacha, 16,500 feet; Niti, 16,800 feet; Baleh, 17,700 feet; Umasi, 18,000 feet; Lankpya, 18,000 feet ; Kuibrang, 18,300 feet; Lakhur, 18,400 feet; Mana, 18,760 feet.

Mr. Hodgson, Dr. Campbell, and Mr. Aitcheson have all noticed the maze of languages spoken in the Himalaya; and the ethric phenomena in the Himalaya warrant the conclusion that they were peopled by successive swarms from the great Turanian hive; that its tribes are yet traccably alike to the Altaic branch of the north and to the Dravidian of the south, and that the Khas, the Kanet, the Dogra, and several other tribes of the Western Himalaya are of mixed breed, descended from Tartar mothers and Aryan fathers.

The Nimcha are a half-breed race on the southern slope of the Indian Caucasus, between the Afghans and the higher peaks. They speak a language related to the Indian tongues, with some curious affinities to Latin.

The northern region of the Himalaya is occupied exclusively by the Cis-Himalayan Bhotia (called Palu Sen, Rongbo, Serpa, Kath Bhotia, etc.), who extend along the whole line of the ghats, and who, with the name, have retained unchanged the lingual and physical characteristics, and even the manners, customs, and dress of their transnivean brethren.

To the central region of the Himalaya are confined, each in their own province, from west to east, the Dunghar, west from Nepal; the Dardu, Gakkar, Bamba, Kakka, Dogra, Kanet, Garhwali, Kohli, the Kus, Khas, or Khasia in Nepal ; the Magar, the Gurung, the Kusunda, Chepang, Sunwar, Newar, Murmi or Tamar, Khombo or Kiranti, the Yakha, the Limbu or Yakthumba, the Lepcha or Deunjong-maro in Sikkim; the Lhopa in Bhutan.

In the lower region of the Himalaya, and in similarly malarious sites of the middle region, dwell the Bahoa, west of Kamaon to the Indus; the Chibh, the Janjoh, the Awan, the Khatir, the Boksa in Kamaon; the Bhotia in Nepal; the Kuswar, the Dahi or Dari, the Bhramu, the Kumha, the Dhenwar, the Tharu, the Hayu, the Pallas, the Kichak, the Dhimal of Sikkim and east of it; the Bodo and the Koch'l. Of these, the Khas, Magar, Gurung, Newar, Murmi, Lepcha, and Bodpa, etc., are dominant unbroken tribes.

The broken tribes are the Awalia, Chepang, Kusunda, and Hayu; and there are located amongst them from time immemorial tribes of helot craftsmen, blacksmiths, carpenters, curriers, potters, etc., who are regarded as unclean.

The unbroken tribes are the more recent immigrants from the north; their languages are of the simpler Turanian type, whereas those of the broken tribes are of the complex or pronominal type.

West of Nepal comes the Palpa, then the Thaksya, Sunwar, and Serpa; the dialects of Kamaon and Garhwal, which carry us on to the Milchan of Kanawar; the Hundisi and Tibarskad north of it.

In Nepal, the Parbattiah or Paharia, a dialect of Hindi, is spoken all over the state, and forms the court language.

Between Leh and Dras, three distinct dialects of the same language are in use. The people and their language are called Bhot by the Kashmiri. It is entirely different from Kashmiri and its cognate dialects of Dardistan and Kafiristan, or of Badakhshan and Wakkan, and bears no resemblance to the Turki and Kalmaghi spoken in Kashgar.

In the lower country, the people near the debouchure of the Kashgar river speak a mixed tongue, called Lughmani.

The men of all castes in the hills are short and of poor physique; they look worm, and get deep lined on the face at a comparatively early age. 
The young women are often extremely pretty, those living in the higher and colder villages having, at 15 or 16 , a complexion as fair as many Spaniards or Italians, and with very regular features. But they grow darker as they advance in years, and become very plain.

Most of the traders of the snow valleys have some members of their families residing at Daba or Gyani on the Nuna-khar lake.

The natives of Sukeyt, Mundi, and Kulu, in the Kohistan of the Jalandhar, have sallow complexions, and appear to be of the same race as the inhabitants of Bussahir. In fact, many of the coolies employed as carriers between Simla and Kalka are men from these states, who are attracted there by the wages, which average one anna a day in their own districts, but from four to six annas on the left bank of the Sutlej. The men are generally tall and strong, but few of them are handsome. Many of the young women are pretty, but at the age of 20 or 25 become coarse and stout. The dress of both sexes is nearly the same. It consists of a drab-coloured woollen frock, trousers of the same or of leather, and a flat skull-cap, generally black, with sandals made of coarse grass. The woollen cloth called puttoo is manufactured by themselves, and resembles thick coarse blanketing. It is sold in pieces of 10 inches in width and about 21 feet in length, at 2 rupees 8 annas or 3 rupees a piece, according to the quality. Both sexes wear a girdle around the waist, and the men generally go bare-legged during the hot weather. They seldom, if ever, wear shoes; the richer classes, however, wear worsted stockings and shoes when they go out. The women, instead of the cap, sometimes have a coloured piece of cloth tied round their head, and occasionally twist their hair into one long plait, the end of which is ornamented with slips of coloured cloth or shreds of worsted.

Sati was greatly followed in Mundi by the rajas, and by the principal Rajput families, but by the treaty with the British in 1846 it was discontinued. When raja Tori Sain died in 1826, 17 women, mostly slaves, were burned with his body, and 18 with that of Zalim Sain, who died in 1839. Infanticide also was very common.

The Chumba-gaddi race of the Chumba Hills say they are Rajputs, and of the Gaddi-jat. They are somewhat short, but strong, and cleanly in their habits. They are sharp, and able to impose on their less knowing neighbours. Most of the witch-finders are of the Chumba-gaddi race, and the race may always be known by their peculiar conical caps, with lappets to turn down over their ears, like an English travelling cap. When Europeans made their first appearance in the Kangra valley, these men had very slight notions of caste, and would eat or drink anything the Europeans gave them, but since their contact with the natives of the plains they have become as bigoted as any Hindu. The Gaddi are hill shepherds about Kangra and elsewhere.

The Lahuli people are a race distinct from the people of Kulu or of the Chumba range. The Lahuli men are short, but sturdy, very ugly and very dirty. Their women are decidedly plain. The dress of both sexes is a black woollen frock with drawers, and a woollen plaid, with black circular caps of felt. The women let their hair fall from the back of the head in long plaits.
Chitral, Upper and Lower.-An independent state, consisting of the upper part of the Kunar valley, Afghanistan. It is bounded on the $\mathrm{N}$. by the Hindu Kush, dividing it from Wakhan and Badakhshan; a crest on the E. separates it from Gilgit and the parallel tributary valleys of the Indus; on the $\mathrm{S}$. it is separated from Panjkora, and on the W. from Katiristan. The population is Muhammadan, Kafirs of the Kamuz, Askin, and Ashpin tribes. They are the Dhangar race. The men are tall and well made, but exceedingly cowardly; the women are remarkable for their beauty and their immorality. They bear a strong resemblance in their features and colour to the hill people of Chumba and Kaugra, symmetry of form, black eyes and hair. They speak a dialect of Dardu, but generally use Persian, Pushtu, and Turki. The soil is fertile, climate severe in winter. The rulers of both Chitrals are Sunni in faith. They capture their own Shiah subjects and the Siah Posh, and sell them as slaves; sometimes whole families are sold. Boys and girls are the most prized of all the slaves brought to the Turkestan market, and fetch from Rs. 100 to Rs. 500 ; but the more comely women, Rs. 500 to Rs. 1000 . The exports are korah kashkari or unbleached silk; choga, made of shawl-wool, with which all animals, dogs, and particularly goats, are provided.

The Rawat or Raji of Kamaon lead a wandering and uncivilised life in the forests on the eastern borders of the district. They are a remnant of a prior population, whom Mr. Traill thinks are of the same race as the Dom. The Rawats appear to have been a knightly and equestrian order among the Bhils, and they bave a tradition that their ancestors were the aboriginal princes of Kamaon. The terms Dom and Rawat are not peculiar to Kamaon. The Dom is found in many parts of India, and Rawat is the name of another widely disseminated race. The Rajivaru of Kamaon speak Telugu. They practise medicine. The tongue spoken as the hill dialect of Kamaon is in the main Hindi, but has affinities to the Bengali in some of the popular terminations, in the verb to be, and in some other particulars.

The Chumang, Chamar, or Kohli of the adjacent Himalayan province on the west, evidently belong to the same race. They are a degraded class, usually darker than the Kanet (or, proper, Kanawari), and some are said to have woolly hair.

Bhuksa.-In the hills of Kamaon, in the forests from Sabna on the Sarda to Chandpur on the Ganges, is a tribe called Bhuksa. They claim to be descendants of the Powar Rajput, to have been expelled from Dhar, and taken refuge first in Oudh, and then in their present location.

The Kanet is an agricultural race in the Simla Hills and east of the Sutlej. They are a local tribe, holding most of the land on the Simla Hills. They are inferior in position to Rajputs, more perhaps of the level of the Kurmi and Lodhi, but they are often educated, and are generally ministers to the Rajput chiefs. Their women are very nice looking, and all the tribe who are not (in the upper hills) in contact with Tartars are quite Aryan, though not very large. They follow a corrupted Hinduism; their villages contain Hindu and Buddhist temples, and the people worship at both; and their marriages are conducted by Lama priests according to the Buddhist 
ritual, and the Hindu and Buddhist Kanets intermarry. The northern Kanets are polyandrists, but one brother remains at home while the others are away on business, and the women are often childless. The southern Hindu Kanets are not polyandrists.

The Tibetan colony at Mohasu, just above Simla, are powerful, ruddy - looking people, entirely unlike Indians; their women are industrious, but very unattractive.

In Lower Kunawar the preponderating language is Hindi, and is called Milchan, but the Bhot preponderates in Upper Kunawar. The Lubrung or Kanam, and the Lidung or Lippa, are varieties of the Milchan. In Sungnam the word Theburskud is used to designate all variations from the regular form of speech. In Kunawar, Buddhism decreases in the central districts, and disappears in the southern, where Brahmanism in an impure form occurs with local gods and irregular priests, every bill having its deota or genius. Polyandry is general in Kunawar, from the higher classes and lowest Chamars, one family having one wife, the elder brother being the more special husband. It is called Kürpa. The mean number of inhabitants to a house in various parts of Kunawar is $\operatorname{six}$

The Kuncwari or Kanet are the principal race in Lower Kunawar. They are physically Aryans, but are Tibetans in disposition and manners.

In the upper valleys of the Sutlej, in Spiti and Kunawar, are mixed races exhibiting much Tibetan blood, and in religion apparently more Buddhist than Hindu.

The Kohli of Kunawar are a distiuct and degraded class, darker than the Kanet, and some are said to have woolly hair. Colonel Cunningham thinks it probable that they belong to the ancient Sudra or pre-Aryan race. They seem allied to the Doms of Kunawar. Indeed, Kohli of Simla, Garhwal, Kunawar, and the plains of Northern India call themselves indifferently Kohli or Chamarai. They are an aboriginal race. They are distinct from the Kanet, who regard the Kohli as out-castes, and neither eat nor intermarry with them. In the Himalaya the Kohli are polyandrists. They are porters and labourers and weavers, village musicians, playing on the pipe and tabor, each tune with a marked character of its own. Every Kunawar village contains a portion of them. The Kohli are not Chamars or curriers, but are cultivators, weavers, palanquin-bearers, village servants, fishermen. They worship snakes, also the Gramma-devata or village lares et penates, and are occasionally pujaris. They are cleanly; they drink, but in moderation. In Gujerat many hold petty chieftainships, with estates attached to them. They are not allowed to enter temples or make offerings except by the hands of priests.

The Bhotia race occupy Darma, Chandans, and Byans jn the N.W. Himalaya.

Sipal is the name of the men of Siba in Darma. In Byans a dialect of Hindi is spoken. Byans Rikhi is a mythical saint, who is supposed by the people of Byans to be dwelling on the top of the Kelirong mountain. He is supposed to represent the rishi Vyasa.

Captain W. C. Hay describes the Bhotias of Spiti in the N.W. Himalaya as a physically robust race, with strongly - marked, weather - beaten countenances, of middling height, with flat faces and noses, and in general small eyes, the skin of a light-brown colour, with a ruddy hue derived from the reflection of the sun from the snow. The smallness of the eye is particularly mentioned by observers in other localities, as in Bhutan.

The Sutlej people are amiable and gentle, free of low cuuning, having the appearance of a mixed race between the Tartar and the common hillmen. They are fair, well made, and strong, but are filthy and indigent. The women have a toga fastened round the waist.

The Kulu province consists of the mountain basin of the Beas, and the west bank of the Sutlej. Sultanpur, its capital, is elevated 4584 feet. The chain bounding the Sutlej on the west is considerably higher than that on its east bank, and is crossed into Sukeyt by the Jalauri pass, elevated 12,000 feet. The province of Chumba bounds it on the west, and the physical features of Kulu and Chumba are similar. The poorer Kulu people wear only a blanket wound around the waist, and one end flung across the shoulders and pinned across the chest; men and women often dress alike, but the long hair of the women is plaited in one tress. The women of Kulu and the adjoining states are inordinately fond of ormaments. Both men and women suspend round the neck several amulets of mother-ofpearl engraved with mystical figures. Polygamy is common.

Dogar, an uneducated, ignorant tribe, originally Hindu or Chauban Rajputs, but converted to Muhammadanism at some unremembered date. They dwell on the borders of the Panjab, chiefly along the banks of the Sutlej river. They are indifferent farmers and cultivators. Like the Pachada, the Dogar wears a waist-cloth or loongee.

The Chilas country is bounded on the north by the Indus river, on the south by the watershed of the ridge over Lülussur lake, on the east by the watershed of the same ridge as above Lūlusur lake, culminating in the lofty peak of Munga Parbut. The Aslor boundary marches with Chilas here on the west to a point beyond the village of Sazeen, where the Indus takes a turn to the south-west. Chilas affords good pasturage, but lies under snow for a considerable portion of the year.

The Sheen, claiming an Arab descent, are the proprietary and governing class. Crime is rare, women have more liberty and power than among Muhammadan tribes, but breaches of chastity are punished by death. They were visited in 1866 by Dr. Leitner at the request of the Bengal Asiatic Society. Their language seems distinct from Pushtu, Persian, and Hindi, and is not understood by their neighbours the Syud race, who inhabit Dareil and Tankir to the west of Gilgit. According to their own traditions, the inhabitants of Chilas were conquered about the middle of the 18th century, and converted to the Mulammadan faith. Up to about 1840 the Kaghan Syuds received quantities of gold dust as religious dues from the people of Chilas; but when the Syuds, aided by the Sikhs, failed in an attack on Chilas, the dues were abandoned. A second attack by the Sikh nation was successful, and a small annual tribute of 3 tolas of gold dust and 100 goats is paid to the Kashmir durbar.

The Gilgit territory is in lat. $35^{\circ} \mathrm{N}$. and long. 
$74^{\circ} \mathrm{E}$. The Indus river runs through it from N.E. to S.W. It is on the southern declivity of the Hindu Kush, between Chitral on the west and Baltistan (Little Tibet) on the east. In the Bannu valley there are races intermixed, of whom may be noticed the Dardu of Gilgit and Chilas. Gilgit, in Tibetan Gyilgyid, has an area of 2500 square miles on the right bank of the Indus.

The Dard race, lying along the Indus to the westward of Ladakh, speak three distinct dialects, and use the Persian character in writing. The three dialects of Dardu are called Shina, Khajuna, and Arniya. The Shina dialect is spoken by the peoples of Astor, Gilgit, and lower down in Chilas, Dareil, Kohli, and Palas, on both banks of the Indus; the Khajuna by the people of Hunza and Nager, and the Amiya in Yasan and Chitral. Astor has an area of 1600 square miles on the left bank of the Indus. The Dard or Durd are supposed by Vigne to be the Dadicæ $\left(\Delta \alpha \delta_{6} x_{\alpha}\right)$ of Herodotus, and the people who now occupy the country called Dardu. According to Burnes, the mir of Badakhshan, the chief of Darwaz in the valley of the Oxus, and the chiefs eastward of Darwaz who occupy the provinces of KulubShughnan and Wakkan north of the Oxus, also the hill estates of Chitral, Gilgit, and Iskardo, are all held by chiefs who claim a Grecian descent. The whole of the princes who claim descent from Alexander are Tajak, who inhabited the country before it was overrun by Turki or Tartar tribes. The Kashmir people have their own peculiar language. The Balti people of Little Tibet say that Ladakh, Iskardo, Khopalu, Purik, Nager, Gilgit, and Astor are distinct Tibets.

Chaprung, in lat. $31^{\circ} 27^{\prime}$ N., and long. $79^{\circ} 33^{\prime} \mathrm{E}$., is described as a large populous place. When any man of property dies, they bruise the body to pieces, bones and all, and form it into balls, which they give to a large species of kite, which devour them. These birds are sacred, kept by the Lamas, and fed by them, or by people appointed for that purpose, who alone approach them; others dare not go near them, perhaps from superstitious motives, for they are held in great fear. This ceremony is very productive to the priesthood, an expenditure of very large sums being made on the decease of any great man, and the Lamas receiving presents of very fine and expensive caps. Poorer people are sometimes buried, and at others thrown into the river.-Fraser's Himalaya Mountains, p. 338.

The number of the houses of Ladakh is estimated at 30,000 , with 210,000 inhabitants, or 433 persons in the square mile. In Ladakh the nuns and monks bear a large proportion to the population. It was subject to Lhassa until A,D. 1834, when it was seized by Zorawar Singh, general of the raja of Jamu. The Ladakh race call themselves Bot-pa, speak Tibetan, and profess the religion of Buddha under a hierarchy of monks called Lamas. The term Tibet is unknown to the people, as also to the Indians, who call them Bhotia, and their country Bhutan. Ladakh belongs partly to the Jamu raja, and partly to the British, and is Bhot along the banks of the Chandra and Bhaga, but Hindu after their junction. To the north of the Ladakh country the people of Yarkand and Khoten speak Turki. To the west, beyond Balti, the people of Astor, Gilgit, and Hunza-Nager speak different dialects of Dardu, while the Kashmiri have their own peculiar language. To the south, the people of Chumba, Kulu, and Bussahir speak a dialect of Hindi, and to the east and south-east the people of Rudok, Chang-Thang, and Ngari speak Tibetan only. In the Ladakh frontiers of the Western Himalaya, the Bhots salute by raising the back of both hands to a height even with the forebead, and then repeatedly describing a circle in the air with them by dropping the fingers downwards, and turning the paim inwards. This is similar to the Muhammadan practice of Billaen-lena, where a woman is supposed to take upon herself all the evils which would befal the person whom she addresses. Polyandry prevails in Ladakh. The brothers of one family have a single wife in common, and the children take name and obey, as head of the family, the eldest husband.

Beas.-Polyandry prevails in the Beas valley, but the general immorality is ascribed to the large numbers of Yarkandi traders.

TIBET is called by the Chinese Tsang, also Si Tsang. The Tibetans call their country Bod-yul, and the Chinese also call it Fuh-kwoh, or the land of Buddha. The term Tibet is from Tu-pehteh (Tu-bod). It has four territorial provinces, viz. Tsien Tsang or Anterior Tibet; Wei or Chung Tsang, Central Tibet; How Tsang, Ulterior Tibet; and Gnari or Western Tibet. Tibet is now governed by China through the Buddhist hierarch, the Dalai Lama, and in this manner it is a dependency of China. (See Dalai Lama; TsongKha-ba.) The Dalai Lama and Panshen Lama are aided by a council of four laymen, entitled Kalon or Kablon, i.e. Minister of State, under the direction in chief of the two Imperial Commissioners or Residents appointed from Pekin. The authority of the Chinese administration being rendered the more complete by the long minorities which are entailed at each successive re-embodiment of the two supreme ecclesiastical dignitaries.

China (Gyanak, TIв.) is on the east, India (Gyagar, TrB.) is to the south. A man of the country is called Bod-pa, and a woman Bod-mo. The Turk and Mongol races on the north of Tibet are called by the Tibetans Hor and Sok-po (HorSok). The hill people of India who dwell next to the Tibetans are called by them by the general name of Mon or M'hon; their country, Mon-yul; a man, Mon or Mon-pa, and a woman, Mon-mo. Khapolor, Chorbad, and Keris on the Shayok river, Khartakshe, Totte, and Parguta on the Sing ge chu, Shigar on the Shigar river, and Balti and Rongdo on the Indus, are Tibetan districts. Little Tibet or Baltistan contains about 12,000 square miles, is about 170 miles long, and lies between $74^{\circ}$ and $76^{\circ} 35^{\prime} \mathrm{E}$. Little Tibet is called by the Kashmiri Sri Butan.

The Hun or Turk for 2000 years, up to the $3 d$ century of the Christian era, predominated in the eastern part of the great plateau of Tibet. It was not, however, until B.C. 313 that the chief Tibetan tribes, the Hun or Ngari, Dzang, H'lassa, Wei or $\mathrm{U}$, and Khan, were for the first time united with the State. In the 7th century of the Christian era its sway had extended from Kashmir on the one side to the Yo-long on the other. It continued to flourish for some centuries, frequently waging war on China, and compelling the emperor to accept ignominious conditions of peace. From the 7 th to the 10th century of this era the 
Tibetans extended their dominions along the whole length of the Himalayas, and into Kashmir at the one end, and into Assam and Bengal at the other. Bhutan is so completely Tibetanized, that it may be said to advance the Tibetan frontier near to the plains of Assam and Bengal. For a period of five or six centuries, up to the 12th century, Tibet held a large portion of the Himalayas, and seemingly their dominion extended also into the plains, in the sub-Himalayas, in Assam, and in Bengal. Chinese historians, indeed, relate that the Tsang dynasty, from the 7 th to the 10th century, extended their conquests to the Bay of Bengal, to which they gave the name of the Tibetan Sea. Bengal appears to have been conquered about the middle of the 7 th century.

In the 12th century the Chinese conquered Eastern Tibet, and towards the end of the century Independent Tibet was shorn of its power and prestige, and reduced within narrow limits. When Chengiz Khan, early in the 13th century, conquered Northern China, he overran Tibet, and brought to a final close the era of its political greatness. But though the West or Middle Tibetan so early in the Christian era crossed the snowy range, and occupied a considerable portion of the sub-Himalayas, and more or less modified their Gangetic inhabitants, their physical influence on most of the Gangetic tribes-Himalayan, Lowland, and Vindhyan-appears to have been so slight that it is now mostly imperceptible. It is certain that a great influx of them took place some centuries after Christ.

Tibetans do not seem to have dislodged the ancient tribes in the tract along the foot of the hills from Gauhati to Sylhet, but only to have conquered and modified them; and the Changlo and Abor languages appear to place it beyond doubt that it was chiefly through the partially Tibetanized tribes and languages along the northern margin of Assam, and in contact with the dominant Tibetan population behind them, that an ethnic Tibetan influence was maintained in the valley of Assam and the countries to the south of it. The races in this region are chiefly Bhot, Turk, and Mongol. The Balti people, the people of Little Tibet, the Byltæ of Ptolemy, though Tibetan in language and appearance, are all Muhammadans, and differ from the more eastern Tibetans of Leh (who call themselves Bhotia or inhabitants of Bhot) by being taller and less stoutly made. Their language differs considerably from that of Leh, but only as one dialect differs from another. The Bhot have been extending westward. As a general rule, the Himalaya divide Hindustan from Bhotland, but there are Bhot in several parts south of the crest of those mighty mountains in Garhwal and Kamaon. From Simla, for several hundred miles to the east, all the passes through the snowy range are occupied by the Bhot. They have a monopoly of the trade across the Himalaya, are carriers, loading the goods on the backs of sheep.

The Tibetan element is absent beyond the Kali, i.e. in Kamaon, but in Bussahir it is strong where Tibetans occupy the higher tracts.

Garhwal is a non-regulation district under the N.W. Provinces of British India. It is a country of very great extent, though of small comparative value. Many of the larger rivers of Upper India, and all those which form the origin of the Ganges, have their rise in its mountains, and hold their course through its territory. Srinuggur, the chief town, is on the south bank of the Aleknanda, about 20 miles above its junction with the Bhagirathi at Deo Prague, where a strip of level ground stretches along for 3 or 4 miles, forming the valley known by the same name as the town. The people of Garhwal are Bhot, dwelling in the passes and their neighbourhoods at heights above 6000 feet. The pass-men state that ridges which within the memory of man were covered with forest and pasture lands are now covered with snow, showing the extension of the snow zone. The Bhot here, as elsewhere, is an agriculturist, and is assisted by slaves, who live under the roofs of their masters. The people in the Mana, Niti, Juwar, and Byanse passes are supposed to be immigrants from Tibet who drove out an earlier body of Hindus, and many of the chief families trace their origin to a Tibetan locality. The inbabitants of the Darma pass are said to be a body of Mongol left in Kamaon by Timur. The Darma inter their dead for a time, and in the month Kartik exhume and burn them, but the other pass-men burn their dead on their demise. The Darma practise divination, taking their omens from the warm livers of sheep sacrificed for the purpose. The women of the Darma and Byanse pass dress alike, and these two clans eat the yak, and would eat the cow; while those of Mana, Niti, and Juwar abstain from beef of all kinds, and look down, as on an inferior caste, on the Darma and Byanse. The Juwar nearest India have the largest trade, and resort to an annual fair in September at Gartogh, the residence of the Lhassa viceroy. These passes are the roads from India to Nari or Gnari, Tibetan provinces of the Chinese empire. The Garhwal people have a passionate love of country and home.

The Bhot of Ladakh is strong, hardy, short, and square, with a decidedly Mongol physiognomy,by which is meant a flat face, broad cbeek, depressed nose, very large ears, oblique and narrow eye curtailed at the corners, black hair, and low stature, their average height being 5 feet 6.1 inches ; the skulls are less Mongolian, having a capacity of 72 cubic inches, 80 cubic inches being a fair capacity for a European.

Towang-raj. - Proceeding from Kokonor to Yunnan, going from north to south, are the Sokpa, the Amdo, who now speak Tibetan; the Thochu, the Gyarung, and Manyak. These bear the Chinese designation of Sifan or Western Aliens, whilst the Tibetan call them Gyarang-bo. Turning westward, after passing through the Kham districts of Gyarung and Khwombo, we come to the region of the Takpa and Tak-yul, which is the Tow-ang-raj of the British in India. Of these the Gyarung are the most important tribe. They reckon 18 banners under 18 chiefs. In Tibetan, 'Gya' and Chinese 'Fan' have the same meaning, viz. foreign or alien.

In Southern Tibet, also, there are numerous scattered Horpa and Sokpa, as there are many Bodpa in Northern Tibet. Po or Pha means man. In Tibetan and several other cognate languages, po, pa, is restricted to the male sex, and mo, ma, to the female.

The Sok occupy the eastern part, and also the wide adjacent country called Koko-nor and Tangut by Europeans, and Sok-yul by the Tibetans. 
The northern part of Tibet, lying beyond the Nyen-chhen-thangla range of mountains, and between it and the Kwan-leun or Kouen Lun chain, is occupied by two tribes, the Horpa and Sokpa. The Hor occupy the western part of that region, also a portion of Little Bokharia and of Zangaria, where they are designated Kao-tse by the Chinese, and Uigur or Ighur by themselves. Mr. Hodgson considers them to be Turk.

The eastern part of Tibet, between the elevated lake plateau and the Yun-long mountains, appears to be occupied by Mongol tribes called Sok. This word is said to mean pasture, and to be the root of the term Scythia.

The lake plateau is occupied by Turki tribes called Hor, a term which is said to mean highland.

The Sifan region is from 40 to 60 miles broad; it is a rugged, mountainous declivity from the lofty plateau of Khum to the low plain of Szechuen. Within it are the Takpa, and outside are the Gya-mi.

Horsok is a compound word used by the Tibetans to designate the nomades who occupy the whole northern part of Tibet, viz. that lying beyond the Nyen-ch'hen-thang-la range of mountains. These two races are the Hor or Horpa and the Sok or Sokpa. The Hor lying on the western half also occupies much of Little Bokharia and Zangaria, and the Sok dwell on the eastern half and the wide adjacent country called Koko-nor and Tangut by Europeans, and Sok-yul by Tibetans. South of the Tluang - la chain are numerous scattered families of both tribes, $\mathrm{d}$ welling amongst the Bodpa or Tibetans proper. The Chinese call the Horpa Kao-tse. The Horpa are a Turk race.

The term Kao-tse, used by the Cbinese to designate the Horpa, is supposed by Mr. Hodgson to be the Khach'he of the Tibetans, literally 'wide mouths.' Mr. Hodgson thinks the Sokpa of the Tibetans the same as the Olet and Kalmuk of Remusat and Klaproth.

The Chakpa or Jagpa and the Drokpa or Brogpa are Bhot occupants of the central part of Northern Tibet. Mr. Hodgson supposed them a mixed race joined together for predatory purposes. They are robber bands between the Horpa and Sokpa, recruiting from the Bodpa (Tibetans proper), Horpa, Sokpa, and Drokpa. The Drokpa also dwell between the Horpa and Sokpa. They are distinct from the Dukpa or Brukpa of Bhutan.

KASHMIR DOMINION, as at present formed, comprises the provinces of Jamu, Kashmir, Kishtwar, Zanskar, Ladakh, and Balti, an area of 68,000 square miles. The territory is ruled by a Rajput sovereign of the Dogar clan; but the people of the vale of Kashmir are of Aryan descent. The hills westward from Kashmir are inhabited by Kukka and Bumba, but towards the river are Afghan tribes. In the hills south of Kashmir and west of the Jhelum to Attock and Kalabagh on the Indus, are Gukkar, Gujar, Khatir, Awan, Junjooh, and others. Eastward of Kashmir are the Bhot race, Balti, and Ladakh. The races and broken tribes of the region will be found noticed under 'Kashmir;' it will suffice here to mention that the more prominent are, Kashmiri, Dogra, Brahman, the Bamba, the Khatri, the Thakur, the Ch'hib, Jat, Gukkar, Gaddi of Jamu, Dard, Dom, Megh, Batal.

Skardo or Iskardo.-Little Tibet is so called by the people. It was conquered in 1840 for the raja Gulab Singh, by his general Zorawar Singh, with his Dogra troops. Skardo is called by the Lamas of Ladakh, Skarma-m Do, meaning the enclosed place or the starry place. Skardo is also designated Balti, Balti-yul, Balor, Palolo, and Nang Kao. Iskardo is a Muhammadan corruption of the Tibetan name Skardo, or Kardo, as it is very commonly pronounced. The Muhammadans of Asia, as a rule, are unable to pronounce two consonants together, but prefix a vowel, as Mr. i-Smith, Mr. i-Stewart.

rGylfo, the title of the ruler of Iskardo or Little Tibet, is derived from two Balti words, rGyl, powerful, and Fo, a man. The queen is styled rGyl-mo. Mr. Vigne points to this as the origiual of the title of Guelph, belonging to the royal family of Great Britain, and of the term Gylfekoniger, still used to designate the old kings of Denmark.

The mountains which surround the Iskardo plain rise at once with great abruptness, and are very steep and bare. The houses of Iskardo are very much scattered over a large extent of surface, so that there is no appearance of a town. The people occupying Little Tibet are the Byltæ of Ptolemy. They have on the east the Khor country, which is inhabited by a people supposed to be the Chauranœi-Scythæ of Ptolemy.

The Balti of Iskardo also dwell in the valley of the Indus, above the junction with the Gilgit river. Skardo is a Bhot tract, but the people are Shiah Muhammadans. Their features indicate a Tibetan origin, and their language is decidedly so. They are a quiet people, and the Kashmir ruler has enlisted many of them. The people are strong and hardy; they grow corn and cut water-courses like the people of Rongdo, irrigating the land and using manure. They are fond of out-of-door manly games.

Khor, a territory S.E. of Ladakh and eastward of the Byltæ. Its people are supposed by $A$. Cunningham to be the Chauranœi-Scythæ of Ptolemy.

Nubra, Pangong, and Rodok districts, in the basin of the Shayok river and its affluents, lie on the S. flank of the Kouen Lun, from Balti to Nari, and have Ladakh as their southern boundary. With the exception of Nari, this is the most lofty and most sterile part of Tibet, the axis of the Kouen Lun being probably upwards of 18,500 feet, the valleys 16,000 to 17,000 feet, and numerous peaks rise 20,000 to 23,000 feet. The Kara-korum pass is 18,300; the salt Pangong lakes, 13,400 feet. The Changpa are a semi-nomade tribe near the Pangong Tso pass. They dwell, in their grazing grounds, under huts (galkol) made of the yak's hair. The people there call themselves Bhot.

Chango are a tribe of Hungrung Tartars occupying 378 square miles.

Chang-Thang dwell on the northern plains, to the north of Ladakh, supposed to be the ChatæScythr of Ptolemy.

The Dras district extends from Zojila to Channagund. Dras adjoins Kashmir, the intercommunication being by the Zoji pass, a remarkable depression of 11,300 feet, through which flow the moist winds of Kashmir, and Dras is the most humid and fertile province of Tibet. Dras, its capital, is 10,150 feet above the sea, and consists of balf a dozen hamlets dispersed over the inequalities of a spacious basin in the close-set hills. 


\section{INDIA ; -NEPAL; BHUTAN.}

Parang and Zanskar, Piti and Guge, are Tibetan districts; Piti and Hungrung are two valleys. That of the Piti river is entered from Kanawar by the Hungrung pass, elevated 14,800 feet; the Parang pass is 18,500 , and leads over the range dividing the Parang from the Piti rivers. All east of Piti is Tibetan.

Zanskar occupies the north slope of the main Himalayan chain, parallel with Kishtwar on the south. Padum, the capital, is 12,000 feet above the sea.

NEPAI is an independent kingdom in the Central Himalaya, extending for 500 miles along the Himalaya, from the western extremity of Sikkim to the eastern border of Kamaon, from which it is separated by the river Kali. Its capital, known as Khatmandu, is called Yi-des by the Newar, and by the Parbattiah or Pariah race it is known as Kultipur. It is situated at the junction of the Bhagmutty and Bishmutty, is 4000 feet above the sea, and about 30 miles from the plains of India. The valley of Nepal intervenes between the snowy range and the valley of the Ganges, and has been a refuge in which Aryan and Bhot tribes have found a shelter, and notice of them will be found under Nepal, sufficing it here to mention that the ruling tribe, the Khas or Sahi, form part of the martial Gurkha race.

BHUTAN, on the N.E. of British India, is situated between lat. $26^{\circ} 30^{\prime}$ and $28^{\circ} \mathrm{N}$., and long. $88^{\circ} 45^{\prime}$ to $92^{\circ} 25^{\prime} \mathrm{E}$., and occupies from the southern declivities of the great central ridge of the Himalaya mountains to the foot of the inferior heights which form a talus at their base, and constitute the natural northern boundary of the Assam valley eastwards from the Sikkim to where the Brahmaputra passes through the mountains. Bhutan is one of the long narrow states lying upon the southern slopes of the Himalaya; the territory consists of a number of rough transverse chains of hilis at right angles to the parent range, which forms the backbone of Asia, with precipitous valleys and glens, at the bottom of each of which runs a mountain stream, and the overlooking mountains are covered with snow in June and July.

In TV. Bhutan, the mountain ranges are lofty and rugged, and the river courses very deep and generally narrow. At Panaka, the Pachu is only 3700 feet above the sea. The mountain mass, however, which descends from the axis of the Himalaya, to separate the Monas from the Subansiri, attains an elevation of at least 24,000 feet, as far south as latitude $28^{\circ}$. Three peaks upon this are visible from the Khassya mountains, and spurs descending from it were ascended to an elevation of nearly 12,000 feet by Mr. Booth in 1849, in a district north of Bishnath, in Upper Assam, which is inhabited by the Dophla race.

Bhutan is from Bhutant, the end of Bhot. Its capital is Tassisudon. The dominion is known to the Tibetans by several names,-Lho-pa-to, Lhomon-k'ha-zhi, and Lho-bruk-pe-yul, or simply Lho, the south. Lho-pa therefore means a native of Bhutan, and this is the name by which the Bhutanese call themselves; but they are also known as the Duk-pa and the Bruk-pa. Duk means the sect of Lamaism prevalent, and ba or $\mathrm{pa}$, of or belonging to. The Hindu shastras or sacred writings call the Bhutanese Pla-va, the Lepcha call them Pra. Dharma raja is the title of the spiritual head of Bhutan, and he is supposed to be an incarnation of Buddha.

Bhotia is the Sanskrit, and Tibetan the AngloPersian, name of the people who call themselves Bod-pa or native of Bod. The Newar of Nepal proper call the cis-nivean Bhotia, those south of the snows, by the name of Palu-sen, and the trans-nivean, those living beyond the snows, Thasen. The Chinese call the Mongol Tha-tha. Bhotia generally occupy Cachar, though some families are planted in the lower lands.

The population bas eight principal and a few minor classes, all pure Mongolian, and in addition there are the Khampa, who live in tents and booths, and a vast number of Assamese and Bengali slaves. They are Buddhist, but eat the flesh of goats. sheep, and cattle. The poor people use wheat and barley. All classes use intoxicating liquors. The favourite drink is chong, prepared from wheat, barley, or rice; it has an agreeably acid taste.

The Lhopa is the dominant race, but they have a tradition that before they entered it, Bhutan, or at least the eastern part of it, was occupied by the Koch'h. The Lhopa areagriculturaland industrious, employing artificial irrigation on their patches of soil in the valleys. They are also distillers, and make paper from the bark of the Diah tree. The Lhopa are tall, many being more than 6 feet high, and fairer than the people of the south of Europe. Hair black; eye small, black, with pointed corners, as if artificially stretched; eyebrow slightly shaded; eyelashes scarce; below the eyes, the face is broadest, and rather flat, but narrow from the cheek-bones to the chin; this character of the countenance being more developed in the charac. teristic Chinese farther east, to whose features this is the first approach. Their skins are remarkably smooth, and most of them arrive at a very advanced age before they can boast even the earliest rudiments of a beard; they cultivate whiskers, but the best they produce are of a scanty straggling growth.

The Lhopa are quarrelsome and cruel, but not brave; and Dr. Hunter says the rude, unlettered part are aimless, both morally and intellectually.

The higher classes are the Kham-pa, the Bhot-pa, and the Kushi.

The Kampa or Kham-pa are properly the Eastern Tibetans; but this nomadic tribe is spread widely over Tibet and a portion of China, and their name is also applied in Bhutan to the adjacent division of Tibet to the south of Tsang-po. The present royal family of Sikkim is a Kham-pa importation. A previous dynasty was the T'sang. Wang is a Chinese title equivalent to reguius, which has been adopted in Tibet, and the Bhutan class who bear it may probably be the descendants of the original Tibetan rulers during the Tsang dynasty.

The Sangla, the Ramtang, and the Tebula are inferior classes, who are not eligible for the higher offices of government. They are supposed to be remnants of the pre-Tibetan tribes of Bhutan, and to have been originally of the same stock with the Abor, etc., that is, the Gangetic race, although they have become assimilated to their Tibetan conquerors.

There are four dialects of Tibetan in use,viz, the Sangla, which is spoken south of Tassgong; the Brambi in the north as far as Tongso; and the Galong and Bom-dang beyond the Bramhi, to the west. 
INDIA;-SIKKIM; DARJILING.

The Bhutanese Lhopa, Dukpa, or Brukpa are an undoubted branch of the Tibetans in form, customs, and language, although they differ slightly from their trans-Himalaya relations. True Tibetans are spread over the higher habitable baud of the mountains from Bhutan to Kamaon, or from the Dhansri to the Kali. They are called Rong-po, Siena, or Kath-Bhotia, Serpa, etc., but Rong-bo or lowlander is the name now applied by the Tibetans to the Bhotias or Tibetans on the southern side of the Himalaya, and it seems to have been formerly applied by the early Tibetan conquerors to some or all the Gangetic or TibetoGargetic tribes.

The Lhopa or Bhutanese, from their unscrupulous marauding habits, are on bad terms with every one of their neighbours. Though nominally subject to Tibet, were the annual tribute withheld, it would not be inquired after, so anxious are the Tibetans to bave no dealings with the Bhotia. For years all Bhotias eutering Tibet were disarmed at the frontier, beyond which the tributebearers were permitted to proceed. The British annexed the Doars of Bhutan from the Lhopa in 1865; and the Sikkimese have, lesis than the Tibetans, to do with the Bhotia, whom they look upon as unscrupulous robbers, while to the east the Towang raja bas to keep up a frontier force for the especial purposes of preventing Bhotia raids.

$T a k$ or Tak-pa or Tak-poni is a district enclosed within the great bend of the Brahmaputra; it lies in a line from Lhassa to Jorhat in Assam, and overlies the north-eastern part of Bhutan. It is the country of the Tak race.

The Tak-pa language seems to be spoken only in the country of the Towang raja, on the upper habitable portion of the southern side of the Himalayas, to the east of Bhutan. It is more Sifan than Bhotian, though it has dialects of the latter at least on two sides of it. This province was conquered by the Tibetans.

SIKKIM, with 1600 square miles, consists of the valley of the Tista river, which with its tributaries drain the whole territory. Its great tributary is the Ranjit river, which, at first separated by a mountain range, joius it from the west, flowing for a short distance parallel to the plains, through a deep ravine not 1000 feet above the sea, to the north of an elevated transverse range. Being opposite to the Gangetic valley, it is open to the full force of the monsoon; its rains therefore are heavy, almost uninterrupted, and are accompanied by a dense fog and a saturated atmosphere. The rainy winds sweep almost without interruption up to the base of Kanchinjinga (28,178 feet), the loftiest mountain and most enormous mass of snow in the world. The snow-level is here 16,000 feet. The two principal sources of the Tista river are the Lachen and the Lachung; these run in two valleys, which are separated by a lofty snowy range projected to the south-west; the valleys are somewhat sheltered, and the perpetual snow-line rises to above 18,000 feet. From the level of the sea to an elevation of 12,000 feet, Sikkim is covered with dense forest of tall umbrageous trees. At 10,000 feet, on the summit of Tanglo, yew appears. There are in Sikkim about 2770 species of flowering plants, and 150 ferns. In the Darjiling district, in addition to the Europeans, Hindus, and Muhammadans from the plains, the population consists of Nepalese; of the Bhotia from Bhutan, Tibet, and Sikkim; of the Lepcha and Mechi, who are considered the prior occupants of Sikkim. The Rajbansi of Sikkim are the Koch or Kooch race, of the same descent as the raja of Koch-Bahar, on which account they call themselves Rajbansi. In the plains of Sikkim, the Rajbansi and Bengali are in equal numbers. The Mechi inhabit that portion of the Terai which lies under the hills. They are a migratory race, who live by cultivating the virgin soil. They have no caste distinctions.

The Bhotia race of Sikkim dwell in the valleys approaching the snowy range.

The Mech are the occupants of the Terai or sub-Himalayan range, who retain the manners of the mountaineers. Firing the forest is so easy in the drier months of the year, that a good deal of cultivation is met with on the spurs, at and below 5000 feet, the level most affected by the Lepcha, Limbu, and Sikkim Bhotia. The mountain slopes are so steep that the spurs or little shelves are the only sites for habitations between the very rare flats on the river banks and the mountain ridges, above 6000 feet, beyond which elevation cultivation is rarely if ever carried by the natives of Sikkim. The varieties of grain are different, but as many as eight or ten kinds are grown without irrigation by the Lepcha, and the produce is described as eighty fold. Much of this success is due to the great dampness of the climate; were it not for this, the culture of the grain would probably be abandoned by the Lepcha, who never remain for more than three seasons on one spot. The average rainfall at Naini Tal is 88 inches. Naini Tal is elevated 6500 feet on the last spurs of the Gogar, overhanging the plains of Rohilkhand. Almora is 15 miles farther than Naini Tal from the plains, and it is 5500 feet, but only 34 inches of rainfall. The fall at Darjiling is 165 inches. Oak trees, maple and other mountain trees, throw out great knots in the places to which the Balanophora attach themselves. These knots are hollowed out into wooden cups by the Lepcha of Tibet. Some of the Lepcha cups are supposed to be antidotes to poison; they are of a peculiar pale-coloured wood, and cost a great sum, but common cups cost only $4 \mathrm{~d}$. or $6 \mathrm{~d}$. They are all imported into Tibet from the Himalaya.

Darjiling, on the eastern end of the Himalaya, in lat. $27^{\circ} \mathrm{N}$., and long. $88^{\circ} \mathrm{E}$., is about 7168 feet above the sea. The tribes in and around Darjiling consist of Amatti, Bahir, Bhotia, Brahman, Chepang, Dhanuk, Dhanwar, Dhimal, Dom, Garo, Kewant, Koch, Lepcha, Limbu, Maralia, Mech, Murmi, Nepalese, Oraon, Rajput, Sanwar, Tharu.

The Khu, the Magar, and the Gurung, with a markedly Mongolian physiognomy, stature low, 5 feet 3 inches to 5 feet 8 inches; small hands. The Khu speak a Parbattiah or Sanskritic dialect of Hindi. The Magar and Gurung have separate dialects of their own, which are not Sanskritic. They are mountaineers, and make good soldiers.

The Bhotia, the Lepcha, and the Murmi have strongly-marked Mongolian features. The Bhotia and Lepcha are fair in colour, with powerful frames, feet and hands well developed, and they are active.

The Murmi are smaller in stature than the Bhotia and Lepcha. They speak languages of Tibetan origin.

The Limbu, the Kiranti, the Haiu, the Sanwar, 
and the Chepang are mountaineers, of small stature, all of Mongolian type, which is most marked in the Limbu.

The Michi, the Dhimal, and the Garo inhabit the Terai or low lands at the foot of the mountains, and withstand the most deadly malaria. Their physiognomy is Mongolian, with a yellowish skin. They are not of the Hindu, Buddhist, or Muhammadan religions. They are not fond of soldiering.

The Tharu and Dhanu:ar live in the Terai. They are of a dark colour, are scarcely Mongolian in features, and they are either Buddhist or Mubammadans.

The Batur, Kebrut, the Amath, the Maralia, the Dhanuk, and the Dom live in the Terai, are dark coloured, and not Mongolians. They speak Hindi and Bengali, and follow Hinduism, but are deemed unclean.

The Koch'h or Rajbansi inhabit the Terai, Nepal, and Sikkim, and spread into the adjacent districts of Purniah, Rangpur, and Assam. They are of a dark colour, and follow Hinduism, but are deemed unclean castes.

Lepcha.-Sikkim and Darjiling is the land of the Lepcha, a Bhot race who are hemmed in between the Newar and other Nepal tribes and the Lhopa of Bhutan on the east, the Lepcha area being barely 60 miles in breadth, but they occupy an extent of about 100 miles from N.W. to S.E. along the southern face of the Himalayas, to the east and west of Darjiling, extending i.e. into Bhutan on the east and into Nepal on the west. Lepcha are also called the Deun-jong-maro. They are divided into two families, the Rong and the Khamba, but in physical appearance, in all essentials of lauguage, religion, customs, and habits, they are now so amalgamated that they are to be regarded as the same people. Their traditions are that the Rong has always been in Sikkim, but there is no doubt that the Khamba came across the snowy range from Tibet into Sikkim in the beginning of the 17th century. Dr. A. Campbell believes that the Rong are of the same tribe and from the same locality in Tibet, but had emigrated long prior to the Khamba. The Khamba say they came from 'Khain,' a province of China, which they describe as about 30 days' journey to the east and north of Lbassa, and on the main road from that city to Pekin. The Lepcha are Buddhists, following the Lamas of Tibet and of their own tribe.

The Lepcha lama or priest can marry, and many of them engage in business. The Lepcha have a written character. The Lepcha have no caste distinctions, but they speak of themselves as belonging to one or other of the following sections:-Burphung Phucho, Udding Phucho, Thurjokh Phucho, Sundyang, Sugut, Tungyeld, Luckson, Therim, Songme. They are gross feeders, eating all kinds of animal food, pork, beef, goat's flesh, mutton, the monkey, elepbant, rhinoceros, the flesh of the cow, birds, and all kinds of grain and vegetables, fern tops, fungi, nettles, and mountain spinacl. They are fond of fermented and spirituous liquors, a beer from the murwa, but are not given to drunkenness.

The Lepcha women perform all the field and house labour. The Lepcba man is idle, abhors all craft labour, but recently they have worked as chair-bearers, and in the tea plantations. The Jepcha do not marry young. They intermarry with the Limbu and Bhotia. The Lepcha bury or burn their dead. Their ailments are smallpox, rheumatism, and remittent fever, and goitre is known amongst them.

The Lepcha physiognomy is markedly Mongolian, stature short, from 4 feet 5 inches to 5 feet; face broad and flat, nose depressed, eye oblique, chin beardless, skin sallow and olive, with a little moustache on the lips; broad chested and strong armed, but small boned, with small wrists, hands, and feet. The Lepcha is honest, timid, and peaceful, with mild and frank features; a dirty, good-natured people, resembling in cha:racter the Mongol beyond the Chinese wall. The Lepcha throws over him loosely a cotton cloak with blue, white, and red stripes, and uses an overcoat with sleeves in the cold weather; a broad umbrella-shaped hat of leaves and a penthouse of leaves in the rains. The women dress in silk skirt and petticoat, with a sleeveless woollen cloak. The Lepcha man carries a long, heavy, and straight sword, serving for all purposes to which a knife or sword can be applied. They drink the fermented juice of the Eleusine coracana, murwa, an acidulous, refreshing, and slightly intoxicating drink, not unlike hock or sauterne in its flavour. They marry before maturity, the brides being purchased by money or service. The Lepcha, like the Borneo Dyak, kindle a fire by the friction of sticks.

The face is round, and the expression is remarkably lively and soft, which is the reverse of that of the Lhopa and West Tibetans, and their lively and inquisitive character does not belie it. The men have less muscular development than the Magar, Gurung, and Murmi, and other Parbattiah. They are fair, ruddy, and with Mongolian features, and have no beard. The women are proportionally short. They are poor agriculturists, and move from place to place, staying two or three years. The sword worn by every Lepcha is called Ban. It is the Chipsa of the Bhotia, a straight sword with a wooden scabbard, open along the side.

The Limbu is a border race in Sikkim and Nepal, but the Kirata, Kiranti, or Kichak as well as the Eaka and Rai are often included under this name; and Dr. Campbell informs us that in appearance they are very much alike. Limbu has therefore become the common appellation of the whole population of the mountainous country bordering between the Dūd Kosi and Konki rivers in Nepal, and they are also in small numbers eastwards to the Mechi river, which forms the coterminus of Nepal and Sikkim. The name is a dialectal variation from Ekthümba. The Lepcha call them 'T'sang, in the belief that their original country was T'sang. The Limbu, Sanwar, and Chepang possess a small Mongolian type, strongest in the Limbu. The Limbu resemble the Rong, but are a little taller and more musculerr, with the eye rather smaller; the nose also is somewhat smaller, with a somewhat high bridge. They are a hardy, hard-working race, engage in the cultivation of grain, and breed cattle, pigs, and poultry. They drink to excess. Their huts are made of split bamboo, and the roofs of leaves of the wild ginger and cardamom, guyed down with rattans. They have martial proclivities, and occasionally enlisted in the native army of British India. According to Dr. Campbell, the Limbu is 
more pleasing to the ear than the Lepcha, being labial and palatal. If they ever had a written character it has been lost. They are partly Brahmanical and partly Buddhist; their great deity is called Shammung, but they have many minordeities. As a Limbu expires, the friends fire off a gun to give intimation to the gods; the body is burned, but they do not sacrifice or make offerings to the manes.

CEYLON ISLAND has an area of 24,702 square miles, and in 1881 a population of $2,759,738$, of whom $1,469,553$ were males and $1,290,185$ females. It is under the rule of a Governor and Council, whose jurisdiction extends to Dependent Islands, with an area of 1060 square miles, comprising the Maldives, west of Ceylon, and the Cocos Islands, S.IV. of Sumatra,-total area, 25,762 square miles. The population in 1844 was estimated at $1,442,062$; in 1857 it amounted to $1,697,975$, besides about 30,000 soldiers and foreigners. In 1871 the total population in the island was $2,406,262$.

The mountain zone in the centre of the island is about 4000 square miles, its summits rising to between 3000 to 7000 feet, the highest mountain being Piduratalla galla, 8296 feet; Adam's Peak being 7353 feet; Neueraellia, 6200. The Mahaveliganga, the Ganga of Ptolemy's map, has a course of 150 miles to its embouchure at Trincomalee. The rich and well-watered delta between Colombo and Galle is an overgrown waste. The Singhalese, whose property it is, have covered it with cocoanut, bread-fruit, and jack-fruit trees, and on those they are content to live, or rather exist, passing the greater part of their time in sleep, while the women of their household work.

The races in 1881 -

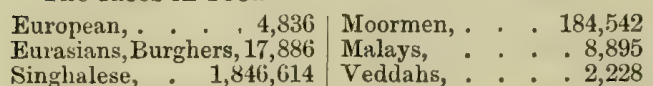

\begin{tabular}{lr|l} 
Singhalese, & $1,846,614$ & Veddahs, : $: ~$ \\
Tamils,
\end{tabular}

Arranged according to religion-

\begin{tabular}{|c|c|c|c|c|}
\hline & & & Male & Females. \\
\hline Christians, & & & 139 , & 128,319 \\
\hline Buddhists, & - & & 888,3 & 809,713 \\
\hline Hindus, & . & & 328,779 & 264,851 \\
\hline Muhammadans & & & 111,339 & 86,436 \\
\hline Others, & & . & . 1,420 & 866 \\
\hline
\end{tabular}

Ceylon island has long been known to the people of the west, to Arabians, Africans, Jews, and Greeks. It is the Taprobane of the Greeks, which name appears to have been derived from Tamraparni (iu Pali Tambapanni), a place said to have been near Putlam, where the Magadha colonists under Vijaya, B. c. 543, had landed, and afterwards it applied to the whole island. Tamraparni is also, however, the name of the principal river in Tinnevelly, opposite Ceylon. Milton writes of this people-

- From India and the Golden Chersonese

And utmost Indian isle Taprobane,

Dusk faces with white silken turbands wreathed.'

It has been several times overrun by conquering nations, and has also been aggressive. It was conquered by Vijaya B.c. 543 ; but in the early centuries of the Christian era there were wars with the Chola of the Peninsula, with alternate fortunes, and in the 12 th century A.D. king Prakraina Bahu defeated the kings of the Southern Inclia States, and also conquered Cambodia. In the 15 th century A.D. a Chinese army penetrated to the hill country, defeated the Singhalese forces, and captured the king, whom they carried to China. Its northern portion was twice captured by the Tamil race; and in A.D. 1505, when the Portuguese arrived, it was divided under seven separate rulers. In 1656 the Dutch finally expelled the Portuguese, and the British landed in Ceylon in 1796. In 1815 the last king of Kandy, Vikrama Simha, a cruel monster, was deposed and banished to India by the British.

The Singhalese are comparatively few in the north of the island, in Jaffna, Vanni, and Manaar, but increase to the south, where they are 90 per cent. of the population. On the other hand, the Tamil race are most numerous in the northern districts.-Jaffna 271,000, Eastern Province 69,243; on coffee estates 115,092, and scattered through the island 78,314. The Singhalese are 69.40 per cent., and the Tamil $22 \cdot 21$ per cent.

Kandyans inhabit the hill country, and are a hardy, robust race, only recently intermingling with the low country. Their language is made up of three component parts,-Elu (or Singhalese pure), the Pali, and the Sanskrit. They possess an extensive literature, and their religion is Buddhism. The low country Singhalese are either Buddhists, Roman Catholics, or Protestants.

Among the Kandyans polyandry was prevalent till 1861, and the wife had the possession of all the brothers. The children call the eldest brother fatber. A man could bring in another, not a relation, to bave joint marital rights with himself ; indeed, the first husband could so introduce as many as the wife consented to receive as husbands. According to Polybius, polyandry was practised in ancient Greece, and in Book xii. we read that it was an old and habitual practice in Sparta. In Kandy, in the Beena marriage, the husband resided in the wife's house, and the woman shared the family inheritance with ber brothers. The husband, in this marriage, could be dismissed summarily by the family of the wife. In the Diga marriage, the wife left her own house for that of the husband,--forfeited all claim on the property of her parents, but acquired some claim on that of her husband, and the wife could not obtain divorce, unless with the full consent of the husband. Divorces were constantly sought for by women on trivial pretences. A child born within nine months of the divorce, must be maintained by the husband. The Kandyans are larger men than the Singhalese of the coast provinces. They are exceedingly indolent and thriftless.

Tamil people have been residing in Ceylon from unknown times, but many are recent immigrants. Their main occupation is agricultural. The (coolie) labourers, who come over in large numbers from the continent during the coffee season, are Tamilar.

Tenuent describes the Veddah as miserable objects, active but timid, athletic thongh deformed, with large heads and misshapen limbs. Their long black hair and beards fall down to the middle in uncombed lumps; they stood before him with their faces bent towards the ground, and their restless eyes twinkled upwards with an expression of uneasiness and apprehension. The children were entirely naked, with misshapen joints, huge heads, and protuberant stomachs; the women were the most repulsive specimens of humanity he had ever seen in any country.

The forest Veddah dwell in hollow trees or caves, 
subsist on game, which they kill with rudelyformed bows and arrows, wandering from jungle to jungle, as the game becomes scarce. They will not hold the slightest intercourse with any natives but those of their own tribe. The village Veddah dwell in certain districts, hold but slight intercourse with the other inhabitants of the island, will not intermarry nor mix with them, but can make themselves understood to the Singhalese.

The forest Veddah are dexterous hunters, and especially skilful in snaring the wild elephauts. The two sections of the tribe do not intermarry, as they mutually distrust each other. They have their own headmen, whom they elect and obey. They use bows and arrows, and clubs of iron and wood. In 1871 their number was reduced to 534 , of whom 459 were in the Central Province. They occupy a district abont 90 miles long and 45 broad in the south-eastern side of Ceylon, lying between the sea and the base of the Badulla and Oovah Hills. According to Mr. Sirr, they are a remnant of the Yakko, the original inhabitants of Ceylon, who, 2000 years ago, after the conquest of the island by Vijaya and his followers, returned into the wilds, as the Koli in Gujerat, the Bhil in Malwa, the Patuah in Cuttack, the Khond in Gondwana, and the Beda in Mysore retired before conquerors. The Bisadæ or Besadæ, which in mediæval Greek is called Vesadæ, are alluded to in the tract of Palladius de Moribus Brachmanorum, written about A.D. 400 ; and the same name is applied by Ptolemy to a similar race inhabiting Northern India. The Veddah, in drawing the bow, employ their hands and their feet. They are onnivorous, and eat carrion and vermin, roots, grain, monkeys, fruit, birds, bats, crows, owls, and kites, but refuse the bear, elephant, and buffalo. Their language is a dialect of Singhalese, free from Sanskrit or Pali, but the vocabulary is very limited, and they have recourse to gestures and signs. They have no temples, idols, altars, prayers, or charms, but have a devil and spirit worship. They cover their dead with leaves in the jungle.

Phodia, according to one tradition, were hunters who, on the eve of a solemn occasion, failing to obtain game, etc., murdered a child and sent its dismembered body to the king; another and more probable tradition is to the effect that this caste persisted in eating beef after its use as food had been prohibited. Their own traditions make them descendants from a daughter of King Pera-kumba, who in anger with his daughter gave her to a scavenger. They are mentioned in the Rajavali, written B.C. 204 , and in ch. xlii. of Mahawanso, A.D. 589. The tenth chapter of the Mahawanso mentions that, B.C. 437 , the king Pandukabhaya employed them in Anuradhapura as scavengers. The native laws forbade a Rhodia to approach a temple of Buddha or the Hindu gods; to build houses, or to live in any abode enclosed within walls, nor even to cultivate the soil or possess land; and, even to this day, their dwellings are mere sheds. They were forbidden to approach, much less to touch or breathe upon, a caste man, and all things they touch are unclean. The men wander about in parties or tribes seeking their precarious subsistence. Their women perform feats of legerdemain, and tell fortunes, and their want of chastity is proverhial.
Their numbers do not exceed a thousand, and they are principally in the Kandyan province, at Saffragam, Dombera, Wallepane, etc. Nominally Buddhists, they are also spirit-worshippers. Rhodia, Rodeya, or Rodda, in Singhalese, literally means filth. In their social degradation they resemble the Cagot and Caqueax, who from time immemorial have been held in abhorrence in the valleys of the Pyrenees and the plains of Bretagne, Poitou, and Guienne.

The Rhodia is of tall stature, head well formed, features straight and regular, nose long and not flattened, lips thin, and appearance intelligent. The features and head of an average Rhodia and Kinnaraya are nearly identical with those of the European races. The Rhodia's head is dolichocephalic. They are Buddhists and devil-worshippers, but are not admitted inside the temples. They are polygamists and polyandrists. They are all uneducated, and cannot count above 50. Their language, containing about 350 words, is peculiar. They bury their dead.

Gialcalaya are a low-caste predatory race, near Matelle in Ceylon, who acter as executioners in the times of the Kandyan kings.

Gattaroo, a low caste race in Ceylon.

Moorman is the designation in Ceylon for all persons professing the Muhammadan faith, other than Malays and Arabs. The costume of the men is a long petticoat, fastened round the waist and reaching to the heels. Tortoise-shell combs are worn by men as well as women. In the numerous excesses into which European costume is carried, the size of the back comb worn by ladies has never attained that of the Singhalese men, who also wear a narrow long bent comb across the forepart of the head; the lighter-coloured shell is most esteemed by them. Five pounds is a moderate price for a tortoise-shell back comb, which increases in value according to the size and quality of the shell. Hair-pins of tortoise-shell are worn by the women, gold and silver being substituted for full dress. These hair-pins are among the articles purchased by passengers in the steamboats.

The European population consists chiefly of British immigrants employed in the civil and military services or on the coffee and tea plantations. Burgher is a term properly applicable only to white persons of pure Dutch descent, of whom there are now but very few in Ceylon; but the name has, by courtesy, been given to all those who in India are styled Indo-Britons, Eurasians, Anglo-Indians, East Indians, or, now rarely, halfcastes, namely, the descendants of Europeans by native women, therefore a race of mixed European and native origin. In 1871 they numbered only 5771.

The Singhalese or Elu language, according to Rask, belongs to the Turanian family of speech, but Aryan and Dravidian elements are intermixed, and in Ceylon a remnant of Buddhists is still to be found who use the Pali scriptures.

Maldive Islands, Zabiyah-ul-Mohli, form a vast group, estimated at twelve hundred, extending southward from lat. $7^{\circ} 6 \frac{1^{\prime}}{2} \mathrm{~N}$. to $0^{\circ} 42^{\prime} \mathrm{S}$. These multitudinous islands and rocks have about 470 miles in length from $N$. to $\mathrm{S}$., and 70 miles in breadth, the islands being formed into large groups which the natives call atoll or atollon. Sir Charles Lyell says the word is Malay. Of these atolls there are nineteen, and they appear to be the 
summits of coral mountains. The inhabitants are Muhammadans, governed by a sultan or king, and engaged in trade and navigation. Their ships are from 50 to 200 tons, and they visit Penang, the continent of India, and Arabia. They became Mubammadans in the 16 th century, but their wives are not strictly secluded. They are a timid, inoffensive people, using a language different from those of the mainland or Ceylon, and they possess three written characters, - the Dewihi and Hakura, written from left to right, and the Arabic, written from right to left. The men are rather short, of a dark-copper colour. They are expert navigators and sailors, have schools for teaching navigation, make and repair nautical instruments, such as the astrolabe and quadrant, and translate into their own language from the English books, the rules of navigation.

The Laccadive Islands are so called from two Hindi words, Laksha dwipa, hundred islands. They are also called the Divi or Amin divi islands, are off the coast of Malabar, and extend from lat. $8^{\circ} 30^{\prime} \mathrm{N}$. to the parallel of $13^{\circ} 52^{\prime} \mathrm{N}$. Most of the islands are low and surrounded by steep coral reefs. They form a group of fourteen small islands, partly under the British and partly under the Bibi of Cannanore. The people are of Malayala origin, but are now Muhammadans, and mostly adhere to the Aliya Santana law of inheritance, or that of maternal descent. They are poor, quiet, and inoffensive. They are taught Arabic and Bal-tite, a dialect of Malayalam. They carry on a small trade with all the coast of Western India, which they visit in boats up to fifteen tons burden, carrying tortoise - shell, sea-slugs, mats, shells, shark-fins, cocoanuts, and coir.

Five islands, Amini, Kadamat, Kiltan, Chetlat, and Bitra, with a total area of $6 \frac{1}{2}$ or 7 square miles, are attached to the South Canara district ; and other five, Agathi, Kowrathy, Kalpeni, Androt, and Minekoi, with an area of $7 \frac{1}{2}$ to 8 square miles, are under the Bibi of Camnanore. All the islands have lagoons. The population numbered, in 1871, 13,495 ; a few read the Koran in Arabic. According to Lassen, the language of the Laccadives and Maldives belongs to the Turanian family. It is Malayalam written in the Arabic character. They catch fish, turtle, and the holothuria. Grave crime is almost unknown. Rats swarm on the islands, and a revenue officer introduced the mungoose, species of Herpestes, and large owls to keep them down, as the rats were destroying the grain crops on the ground and the cocoanuts on the trees. In 1871 the islands were flooded dur.. ing a storm, and a steamer laden with rice was sent to them, and in 1875 an hospital assistant and midwife were sent.

Andaman Islands have an area of $880^{\circ} 2$ square miles, and a population in 1881 of 14,628 , of whom 7440 were convicts on the penal settlement. The Andaman Islands lie in the direct track of ships navigating the eastern side of the Bay of Bengal, and have been twice actually occupied by a British establishment. Their inhabitants, the Mincopi, had the feeling of hostility and aversion towards strangers which is common to all the wilder Papuan tribes. They long continued to be bitterly hostile to the colony of 1855 . They are savages of a type lower than that of any of all the other races in the south and east of Asia, or even of the whole world. Few of them exceed five feet in height. Their lower limbs are spare and illproportioned, their bellies protuberant, the complexion deep black, and the hair woolly. They have also a taste, so characteristic of the wilder Papuans, for daubing their heads with red ochre. They have canoes, but use small rafts when they wish to visit the islets. Both sexes go entirely naked, for the pieces of fringe that they wear about them are rather intended for ornament than as a covering. They obtain fish by descending to the shore at low water and spearing those that are left among the reefs by the receding tide, also shooting them with bows and arrows, and catching them with small hand-nets, and depositing them in long wicker baskets which they carry slung from their shoulders. All these are characteristics of the wilder coast Papuans, especially those who formerly occupied Tasmania, to whom, indeed, the Mincopi bear a resemblance so striking as to excite surprise that two tribes who must have been separated during many ages, and who reside in clinates so different, should be distinguished by precisely the same characteristics. The only point of difference that can be detected consists in the knowledge on the part of the Andamans of the use of the bow and arrow, which was either never known to the Van Diemen's Land natives, or had been neglected in favour of the dart or throwing spear, which is far better adapted to the open nature of their country.

A large number of Mincopi who visited Ross Island during the Editor's stay in 1863 evinced great facility in imitating vocal sounds. They (Mincopi) roam in tribes, who speak different dialects unintelligible to each other; one of their dialects has been called Bojingijida. The tribes are at enmity with each other. The inhabitants of the Southern Andaman erect no houses, those of the Little Andaman erect beehive huts of the rudest character. Their marriage ceremony is extremely short and simple; their dead are interred immediately after death, or placed on a raised platform, and the site where the death occurred is abandoned. After two months, the bones of the deceased are cleaned and distributed, to be suspended round the neck, seemingly as charms. Women have sometimes a slight cincture of leaves, a bunch of which is suspended from the waist-belt behind. There are kitchen middens, some of great dinensions, one being 300 yards long, 50 yards broad, and 10 feet high, composed of shells and the bones of birds. The zoology is identical with that of Burma.

The Malay Peninsula is also known as the Eastern Peninsula, to distinguish it from the Western Peninsula of India. It is a long, narrow, mountainous tract, varying in breadth from 50 to 150 miles, and about 700 miles in length, on the east from Bankok at the head of the Gulf of Siam, in lat. $13^{\circ} 58^{\prime} 30^{\prime \prime} \mathrm{N}$., and long. $100^{\circ} 34^{\prime} \mathrm{E}$., and on the west from the Tavoy river to Cape Ramunia, in lat. $1^{\circ} 22^{\prime} 30^{\prime \prime} \mathrm{N}$. The mountains of the interior rise 5000 and 6000 feet in height above the sea, one of them, Ladang, which the Portuguese named Mount Ophir, being 5600 feet high. The metallic ores obtainable are gold and tin, the latter in great abundance, and it is probably from the gold obtainable that the Peninsula has been supposed to be the Aurea Chersonesus. Newbold says (i. p. 431) that the 
gold obtained from the Malay Peninsula amounted in one year to 19,800 ounces.

The Portuguese and the Dutch have at times held possessions there, but the former were driven out by the latter nation, who ceded all to Great Britain by the treaty of London of 17 th March 1824, Britain undertaking not to hold any of the islands south of Singapore. The dominant powers at present are the British on the west and south, and the Siamese on the east and south.

Kalantan, Quedah, Tringanu, Perak, Kemaman, Jellabu, Sunjie Ujong, Jompole, Srimananti, Rumbowe, Johole, Nanning, Sejamet, and Johore are native states, over which Siam claims supremacy, and the British territory comprises the southern part of Tavoy, Mergui, Province Wellesley, and Malacca, with the islands of Singapore, Penang, the Andamans, the Nicobars, and the Mergui Archipelago. Lieut. Newbold furnished an estimate of their populations in 1839 :-

\section{Exterior-}

Quedah and Ligore, 50,000 Rum

Perak,

Salangor and

Kalang,

Johore with Sejamet

and Muar,

Pahang, .

Kemaman,

Kalantan,

Tringanu, Interior-

Patani,

35,000 Sunjie Ujong, : :
Johole, : :

12,000

Jompole,

25,000 Jellabu,

40,000
1,000 Aborigines scattered over

50,000 British-

30,000 Malacca and Penang

10,000 (1836), .

Pro. Wellesley (1835), 46,880

It was estimated that Quedah had 100,000 souls and Patani 90,000 before the Siamese invasion, when they were reduced to one-eighth of their former numbers.

The more southern states are Malay, interspersed with small colonies of Chinese, mostly men, and of Chulia and Kling emigrants from the Peninsula of India. There are four British districts styled the Straits Settlements. These were occupied in the early part of the 19th century, and attracted numbers of Chinese, Malay, and Kling. A census taken in 1881 shows their population as under :-

\begin{tabular}{|c|c|c|c|c|c|}
\hline \multirow{6}{*}{$\begin{array}{l}\text { Arabs, } \\
\text { Boyanese, } \\
\text { Bugis, } \\
\text { Chinese, } \\
\text { Javanese, } \\
\text { Jaweepahan }\end{array}$} & \multicolumn{2}{|c|}{ Singapore. } & \multicolumn{2}{|c|}{$\begin{array}{c}\text { Penang and } \\
\text { Pro. Wellesley. }\end{array}$} & Malacca. \\
\hline & M. & $\frac{F}{191}$ & M. & $\mathrm{F}_{175}$ & $\begin{array}{ll}\text { M. } & \text { F. } \\
152 & 151\end{array}$ \\
\hline & 1,377 & 257 & 7 & & 118 \\
\hline & 1,014 & 978 & 6 & 8 & 47 \\
\hline & 46,631 & 7,467 & 30,168 & 6,214 & $9,850 \quad 3,606$ \\
\hline & 2,155 & 1,084 & $\begin{array}{r}804 \\
778\end{array}$ & 283 & 246 \\
\hline Kling, & 7,664 & 1,633 & 5,136 & 1,687 & 1,556 \\
\hline Malay, . & 10,041 & 9,209 & 35,501 & 34,963 & $28,10229,372$ \\
\hline Siamese, & 25 & 19 & 266 & 183 & 3 \\
\hline
\end{tabular}

Two distinct races are in that peninsula and its adjacent islands, the Mongoloid, Mon, Siamese, and Malay, with the Negroid, Mincopi, and Semang. The tribes of the Mongoloid race are numerous, but are in places so few in numbers that a hut or two form a nation. They are of little political or ethuical importance. In the states bordering on Siam, the bulk of the population consists of the Malay, Siamese, and Samsam, the latter being Siamese converts to Muhammadanism, who have adopted the language, the habits, and manners of the Malays.

All but the Malays are engaged in mercantile, artisan, or agricultural avocations, making a little money and returning to their native countries. This is evident from the disproportion of the sexes. The Malays have 73,644 men and 73,544 women ; but the Chinese men are 86,649 , with only 17.287 women; and the Kling 14,356 men and 4638 women.

Quedah, between lat. $5^{\circ}$ and $6^{\circ} 50^{\prime} \mathrm{N}$., and its several islands are occupied by the Malay, Siamese, Samsam, and Semang. In the Salangor State, from lat. $3^{\circ} 50^{\prime} \mathrm{N}$., the mass of the population is Malay, but the ruling race are Bugis from the Celebes. This small state, up to the earlier part of the 19 th century, was more addicted to piracy than any other of those in the Peninsula.

Tringanu, a maritime state on the east coast, is peopled by Malays. Patani has Malays and Siamese.

The four inland states of Rumbowe, Sunjie Ujong, Johole, and Srimananti, as also the province of Nanning (4000 square miles), are peopled by the descendants of a Malay colony direct from the ancient empire of Menangkabau in Sumatra.

The Johore Archipelago embraces several hundreds of islets, and the considerable islands of Battan, Bintang, Krimun, Gampang, Gallat, and Sinkep, in the line of the plutonic zone of elevation of the Malay Peninsula from Singapore to Billiton. Banka and Billiton may also be included in it ; they are so geologically and ethnologically, though not geographically. The more important of the tribes in this Archipelago are those termed collectively Orang Pe-Sukuan, literally the people divided into tribes. They are all vassals of the king of Johore. The tribes of highest rank are the Orang Bentan under an Ulubalang, the Orang Singgera under a Batin, the Orang Kopet under a Jumang, the Orang Bulo, and the Orang Lingga. There are other tribes of the creeks and the sea, and some in the interior of the larger islands are wild.

Johore, formerly the chief city of the empire of that name, and residence of the sultan, is situated about 20 miles up the river so called. The town was founded in A.D. 1511 or 1512 by Sultan Muhammad Shah II. of Malacca, who, after his expulsion from that place by the Portuguese, fled to the river of Johore. From that time the town of Johore has been the capital of the empire, which took the name of the empire of Johore instead of that of Malacca. It is in the extreme southern part of the Peninsula, with numerous islands. Johore is the residence of a Panghulu, who is appointed both by the sultan of Johore and by the Tumungong of Singapore. It is now the generally received opinion that Johore derived its population from Menangkabau. The Johore Archipelago was probably inhabited from a very remote period, anterior even to the existence of any race in Sumatra, by a maritime branch of the same people, radically Malayan, who are now found in the interior of the Peninsula and of the southern half of Sumatra. Several tribes in various stages of civilisation still possess the Johore Islands. Though little known to Europeans, they can never have been without Malay or Indo-Malay visitors, for it was by the great rivers of Palembang, Jambi, Indragiri, and Kampar, before whose embouchures these islands lie, that the natives of Ceylon and Southern India must have gradually carried civilisation into the interior of Southern Sumatra.

Kalang, Jellabu, Ulu Pahang, Jellaye, and Srimananti are also Malay, subject to Johore. 
The smaller tribes of the interior and of the seacoast have their own names, but are known generally by Malay designations, of local signification, with the word Orang prefixed, - Orang Binua, men of the soil; Orang Bukit, men of the hills; Orang-Utan, men of the woods; Orang Slitar, men of the strait; Orang Laut, men of the sea. Occasionally the Arabic word Rayat, or subject, is used, as Rayat Utan, Rayat Laut.

Also, among the forests and mountains of the interior are several barbarous tribes, who subsist chiefly by hunting and by shooting game, using the blowpipe and poisoned arrows. Amongst them are the Semang, the Sakai, or Orang Bukit, men of the hills; the Jakun, or OrangUtan, or Rayat Utan, men of the woods. The wild tribes are chiefly in the mountain chain running down the centre of the Peninsula from Quedah to Point Ramunia. The Rayat Utan, the Jakun, the Sakai, the Hala, the Belanda, and Besisik, are in the forests in the south.

Pahang territory extends from Sadile, in lat. $2^{\circ} 15^{\prime} \mathbf{N}$., to Kamamang or Kemaman. The population of Kemaman consists of Malays and Chinese; but in the interior of Pakaa, between Kemaman and Tringanu, is an aboriginal race termed Pangan, said to have the frizzled hair of the Papuan.

Orang Binua, literaliy men of the soil, is a name applied by the Malays indiscriminately to all the uncivilised scattered tribes,-Semang, Bela, Jakun, Hala, and Udai. In the States of Sunjie Ujong and Johole there are twelve such tribes, besides the Besisik and the Belanda, and others in Salangor. The Binua have been supposed by some to be of Negro origin, but others regard them as Mongoloid races.

Newbold says it is stated by the Binua, and admitted by the Malays, that before the Malay Peninsula had the name of Malacca, it was inhabited by the Orang Binua. In course of time, the early Arab trading vessels brought over priests from Arabia, who made a number of converts to Islam; those of the Orang Binua who declined to abjure the customs of their forefathers, in consequence of the persecutions to which they were exposed, fled to the fastnesses of the interior, where they have since continued in a savage state. He says their general physical appearance, their lineaments, their nomadic habits, and a few similarities in customs, point to a Tartar extraction.

In the Binua, the cheek-bones are broad in all directions and prominent, giving to the face below the base of the forehead a marked lateral development, beyond it or to the forehead an appearance of being compressed. The lower jaw is massive, spreads out, and does not rise rapidly, thus producing an obtuse chin and the anterior maxillary projection considerable.

The ruder Binua dialects of the Peninsula are rapidly disappearing. There are Binua on the Simrong and other branches of the Indau, which are in Johore. The southern part of Pahang is inhabited by the same tribe of Binua who are found in Johore. Some of them, indeed, have habitations, which can scarcely be called houses.

The Jakun are scattered through the interior, and are often called Rayat Utan. They do not differ materially from the Malay in colour and physiognomy.

The Bodoanda Jakun and Bodoanda Jawa are two tribes in the Rumbowe State. In Rumbowe Ilir are the Battu Ampar, Munkal, Paya Kumba Barrat, and Tiga Nenik tribes, and in Rumbowe Ulu are the Battu Ballang, the Paya Kumba Darrat, the Sa Melongang, and the Sri Lummah; also the Tiga Battu, Anak Malacca, Anak Achi (children of Malacca and Achin), and Tannah Dattar.

The Jakun are proud, impatient of control, but honest, fond of music. Both men and woinen, in their forests, have only a strip of the tarap tree for covering. The features of the Jakun or Sakai, the Belanda, the Besisik, and the Akkye bear a common resemblance to the pure Malays ; they have the same sturdy legs and breadth of chest, the small depressed, though not flattened nose, with diverging nostrils, and broad, prominent cheek-bones, which distinguish that race of men.

Udai are little known. Many Malays believe they are a class of Jakuns, while others affirm that they are a colony from some foreign country. The Tuanku Puteh of Rumbowe informed Newbold that the Udai are a race of savages, thinly scattered over the states of Jellabu, Pahang, Tringanu, and Quedah, and resemble in feature the darker variety of Jakuns. Their size is represented as smaller, and their habits more savage, going nearly naked, dirty in person, rarely constructing huts, and subsisting on forest products, using the sumpitan and poisoned arrows, and sbarp stakes as spears.

The Semang and the Udai dwell in the forests in the north, and are met with in Quedah, Perak, Tringanu, and Salangor. To the north of the province of Ligore, the Semang seem to be called Karian. Malays class the Semang as the Semang Paya, Semang Bukit, Semang Bakowe, and Semang Bila, meaning the Semang of the marsh, of the hills, of the coast, and the civilised. Sir Stamford Raffles and Mr. Anderson described the Semang as having a black skin, woolly hair, thick lips, flat nose, receding forehead, and protuberant belly; and subsequent authorities regard them as of the Papuan race. Newbold (ii. p. 378) says that those around Quedah are scarcely to be distinguished from the Jakun, having the same curly and matted, though not frizzled hair, but with a complexion generally a little darker. They use poisoned arrows with the blowpipe sumpitan. They are said to write on the leaves of the "stebbal.' Many have been converted to Muhammadanism. They will be further noticed along with the Papuans.

The Orang Sabimba is a small tribe of forest nomades who hunt the wild hog with dogs, and use the sumpitan blowpipe as their weapon. Rice is their chief food, but they eat the hog, monkey, snakes, birds of all kinds, except the domestic fowl. They abstain from agriculture. They bury their dead, depositing all the deceased's utensils along with the body. They speak the Malay language, but with a peculiar accent.

The Mintira believe that all diseases are caused by spirits, each ailment having its own spirit, who haunts in caves, in woods. They have wishing rocks to which they resort to gather the Chinkwi flower, which gives them supernatural power over others. Amongst their marriage ceremonies is that of the bride and bridegroom eating from the same plate. The Mintira, and all the tribes 
of the interior, have a dread of the sea, and never venture on it.

The Chinese scattered over the principal islands of the Archipelago were estimated in 1839 at nearly a million in Siam, Tonquin, Cochin-China, Kamboja, Laos, and the Malay Peninsula. In the year 1871, in the British Settlements in the Straits, there were 103,936. Facilities for travel have allured a great influx of that intelligent race, who are largely engaged in mining operations, in garden cultivation.

The Orang (Slitar) Selat, literally people of the straits, the Cellates of Valentyn, are a wild tribe, living in boats near the old Straits of Singapore, using small boats 20 feet long. With the Biduanda, they are joint occupants of Singapore. They speak a Malay dialect with a guttural accent. They gather shell-fish; they fish and collect forest produce. They are liable to a leprous affection of the skin. They are supposed to be uncivilised Malays.

The Sakai is a pagan population in the Malay Peninsula, divided into the Sakai Jina and Sakai Bukit, the latter being hillmen and mountaineers, the former more settled and civilised. They are strict worshippers of the elements. Sakai is the Pahang word for an aboriginal.

The Hala, a branch of the Sakai, tattoo their face and breast, pierce their ears and nose, and insert porcupine quills. The Sakai tongue of Perak appears to resemble in its phonetic character the ruder dialects of the Burman group. This character is intermediate between that of the Semang on the one side, and that of the ruder Sumatran, Javan, and Borneon on the other. The Johore Binua is more guttural, aspixate, and harsh, remarkably broad and slow.

Rayat Laut and Orang Laut literally mean seafaring people. The Malays distinguish them from the localities they occupy, as the Orang Rawang, the Orang Selut or Orang Slitar. Their principal haunts are Galang, Selat, Muru, Baru, Kalang, Timiang, Liugga, Tambusa, Sooghi, Mantang, Akik, Murabu, and Ratas. They resemble the Jakun and Malay in appearance, but are of darker colour, and more savage and uncouth in aspect. They are proud and restless, impatient of control, and fond of music. They live in their boats, in which they make long voyages. They are expert divers and fishers, and collect agaragar, trepang, wood, oil, etc. The Akkye or Payat Laut, of the shores and islets, dwell apart from the Malay, from whom they differ in habits and religion. They are thinly scattered, living upon fish, and are probably identical with the Ichthyophagi mentioned by Herodotus, Diodorus, and Pliny.

The Selong or Selone sail all through the islands of the Mergui Archipelago, south of Tavoy. They are a mild, honest, intelligent, and peaceful race, timid, reserved, and difficult to approach. They number about 1000 . They reside in their boats, which are good; are decently clad, and are inclined to settle in villages and cultivate. They are fishers for the sea-slug, which they pick up at the low water of spring tides during the N.E. monsoon. They bring to the ports of Tenasserim and of the Malay Peninsula, tortoise-shell, the larger shells of the triton and nautilus, valuable for their mother-of-pearl; the gigantic tridacna, and pearls found in a species of meleagrina in the deep bays of the Lampee Island; also bechede-mer, sharks' fins, dried fish, and edible birds' nests. They believe that Nat or spirits dwell in the land, the sea, the air, and the forest, but they do not invoke or sacrifice to them. They subsist entirely on fish, turtle, and shell-fish.

Perak; on the west coast, south of Quedah, is 75 miles long. It is tributary to Siam. Its inhabitants consist of the Malays ; also the Batta, Barak, Rawa, Mandeling, and Korinchi people of Sumatra; the Bugis and wild tribes in the interior, with settlers from Europe and China. The Bugis are much respected. They at one time overran Quedab, but are now of little importance. The Korinchi are strict Muhammadans, dress always in white. They have the Malay manners and language, but use a writing character of their own. The Rawa and Mandeling people are labourers.

The Orang Binua, literally men of the country, are called Sakai by the Malays of Perak, also Orang Bukit or hillmen, or Orang Laut or sea men, or Jakun, Besisik, from the localities or rivers they occupy. The Sakai or Jakun of Perak are smaller in size than the Malay. The Semang of Perak are of the same size as the Malay, in complexion of a dark-brown more than black, with flat nose, thick lips, large mouth, and hair not lauk and black like the Malay, nor woolly like the Ethiopian Negro, but long and in tufts. The Perak population has been estimated at 30,000 to 80,000 , and its wild tribes at 5000 or 6000 .

Salangor runs for 120 miles south of Perak, from lat. $3^{\circ} 50^{\prime} \mathrm{N}$. The mass of the population is Malay, but the government was held by Bugis from Celebes. In the early part of the 19th century, it was more addicted to piracy than any other of the states of the Malay Peninsula.

Until the earlier part of the 19 th century, the Malays on the E. and W. coasts of the Peninsula were largely piratical.

Rhio-Lingga is the name given to two groups of islands, the Rhio and Lingga, forming the Archipelago of innumerable islands and reefs stretching between Sumatra and Borneo, and which, till 1824 , were a part of the formerly powerful kingdom of Lingra, wbich extended over a great part of the Malay Peninsula, and over the maritime provinces on the east coast of Sumatra from Palembang to the territory of Siak. The Rhio group includes Bintang, Battam, Gallat, Bulan, Chumbol, Sugel, Durian (Dryon), Karimon, and Segupong; that of Liugga including Lingga, Sinkep, Timian and Roding; Saga and the Seven Islands. On the cession from the Netherlands to the British Government of the Dutch possessions on the Malay Peninsula, Rhio (pronounced Ree-ow) became of some importance.

ANNAM, COCHIN-CHINA, KAMBOGIA, LAOS, SIAM. - Around the borders of British India, in the N.IV., the N.E., S.E., and E, is an ethnical group, which contains the Tibetans, the Nepal tribes, several nationalities of the subHimalayan range, the Burmese, the Siamese, the natives of Pegu, the Kambogians, the CochinChinese, and the Chinese, in populations which cover perhaps one-fifth of Asia. They have a general similarity, they are somewhat fair in complexion, with what are called Mongolian features. There are Christians, Mubammadans, and shamanists among their religious sects, but the Buddlist, Confucian, and Taouist philosophies are used as 
religions, and almost all believe in the transmigration of souls towards a final absorption. The first migrants from the northern side of the Himalaya, now represented by the Annam, Kambogian, Mon, and Laos tribes, appear to have been at a later period gradually pressed to the eastward and southward by the Tibeto-Burman tribes.

The Mon-Annam or East Himalaic tribes occupy the territory bounded on the north by the left side of the valley of the Brahmaputra as far as the head of Assam, and a line drawn thence eastwards along the range in which the Irawadi bas its sources, and across the converging meridional chains, beyond to the most eastern, the Mangli, which separates the Kiang from the Mei-kong.

On the south-east of Assam are numerous tribes, many of them subject to the Burmese. These belong to the Siamese or T"hai group, and are composed of the Siamese proper, the Khamti, the Laos, and the Shan, who each speak a dialect of their own, none of which are like the Burmese.

The Laos or Shan race speak a language which was primarily East Himalaic, like Mon, Kambogian, Annam, and $\mathrm{Pa}$-long. Like them, it was carried at some remote period into the BrabmaputraGangetic province, and received some Dravidian roots. Subsequently it shared in the great eastern movement of the Himalaic dialects, from the basin of the Ganges into that of the Irawadi, where it was intimately connected with some of the intrusive West Himalaic or Tibeto-Burman dialects. It was then pressed farther into the east, into the basin of the Upper Mei-kong and Tonkin, and became the language of Yunnan. During the Han dynasty, Chinese colonies began to occupy the valleys of Yunnan, and from that time the Laos language was exposed to the influence of Chinese, and began to receive the modified form it possessed when the pressure of that great race on the older tribes of Yunnan caused the Laos people to swarm to the westward and sonthward. When they re-entered the basin of the Irawadi, they had acquired from their partially Chinese civilisation a superiority over the Tibeto-Burman tribes of Northern UltraIndia, which made the Laos clans predominant along the central belt of Ultra-India from the Himalaya to the mouth of the Menam.

The Shan or Shyan call themselves T'hi or T'hai, and occupy great part of Laos and Siam, and bordering districts of Burma. In personal appearance, customs, and languages, the Shan and Karen are but offshoots of the same stock. The Laos, the Shan, and the people called Ahom were originally the same, and once held Assam and Bhutan under their dominion, Assam, indeed, being a dialectal variation of Ahom. The Sban race swarm in numerous tribes over the countries stretching from the valleys between China and Tibet on the north, to the Gulf of Siam in the south, and if united would form the most formidable state in Eastern Asia. They occupy all the territories between the Irawadi and the mountains of Annam. At Bhamo, to the north, east, and south-east of which they are numerous, the language of the Shan corresponds with that of the Siamese. Their babits, mode of living, cultivation of the ground, correspond with those of the Khyen and Karen. People of the T'hai group have a superior physical development, and resemble the Balinese.

Perpetual aggressions and frequent conquests, extirpations of villages and migrations, mark the modern history of nearly all the Tibeto-Burman tribes, and of the different branches of the same tribe. In recent ages, the Laos have settled in the lands of the Singpho, the Bodo, the Burman, the Peguan, the Kambogian, and the Malay, and have originated communities having no connection with each other. The Singpho at a late period forced their way from Burma into Assam. The Bodo have occupied the country of the Mikir, and the Arung Angami and Kuki bave intruded on both. The same tribes also, separated into clans and villages, are permanently at war with each other; Kuki flees from Kuki, Singpho from Singpho, Abor from Abor.

The Mon, called by the Burmans Ta-lain, and Peguans or Peguers by Europeans, long successfully contested with the Burmans the sway over the basin of the Irawadi. They were annexed to Burma in the middle of the 16th century, but again threw off the yoke in the beginning of the 18th century, and subjugated all Burma. Their range embraces the delta of the Salwin, where Moutama or Martaban was their chief port. They loug preceded the Siamese in the Tenasserim Provinces, and the languages of the Semang and Binua of the Malay Peninsula retain deep traces of their ancient influence to the south. A colony is also found in the basin of the Menam. Before the great southern movement of the Laos, the Mon appear to have occupied that basin also, and to have marched and intermixed with the closely-allied Kambogians of the Lower Mei-kong. They seem to have been at one time the chief traders eastward of the Bay of Bengal.

The Nicobar Islanders appear to have been an early colony of the Mon race in its pure or more west Chinese and less Indian condition. They are flatter faced and more oblique eyed than the Rakhoing and Mon, in this resembling the more sequestered hill tribes of the Burman race. In some islands they have been much mixed with Malay colonists. Nicobar phonology is allied to that of the Selong and Semang. The entire population has been estimated at 6000 souls. They eat the pig, yam, and plantain. They dread evil spirits. They bury the dead, and deposit with the body all the small articles of property of the deceased. They are monogamic, but divorce is frequent.

Ka-Khyen.-In the Irawadi and Mei-kong basins, there are remnants of tribes strongly distinguished from the predominant races, and tending, with the evidence of language, to show that the ethnic history of Ultra-India is very ancient, and has undergone repeated revolutions. One of the most remarkable is the Ka-Khyen. They are described as being in their appearance not Mongolian, and totally different from the surrounding races of Shan, Burmese, and Chinese.

The Palong, $\mathrm{Pa}$-on, or $\mathrm{Ze}$-baing are partially subject to, and located to the east of, the Mo Meit (Mung Myit, Moung-m-ri), beyond the Karen-ni, and along the Chinese frontier, as far as the latitude of Bamo (Mang-mo). They are good carpenters, dyers, and blacksmiths. Their dha or swords are exclusively used in and around 
Bamo. They approximate to the Shans, of whom they are probably an offshoot; they wear the same dress, and are Buddhist, but they have affinities with the Ka-Khyen. The Palong seem to resemble the Annamese in some respects.

A race of the same name (Panong), but to which the Siamese apply the generic name of Ka or Kha, inhabit the mountains of Laos, bordering on Kambogia. They are a coarse and debased variety of the Annam and the Kambogian type.

Chong.- - On the same side of the Mei-kong basin, but towards the sea, between lat. $11^{\circ}$ and $12^{\circ} \mathrm{N}$., a hill tribe called Chong preserve more of the ancient Australo-Tamilian character than the surrounding tribes. In the Chong, the hair, instead of being stiff or harsh, as in the Mongolian, Tibetan, and prevalent Ultra-Indian and MalayaPolynesian race, is comparatively soft, the features are much more prominent, and the beard is fuller.

The Muong or Muang, who inhabit the mountains on the west of the Tonkinese province of Thank-Hoa-noi, and stretch into China, are evidently an extension of the aboriginal or uncivilised Laos of Yumnan. The name is the Laos term for town or village which is scattered over so large a portion of the Chinese maps of Yumuan, indicating the present limits of Laos in that province.

The Annamese, or Annamitic group of peoples inhabiting Cochin-China and Tonkin, are a section of the division to which the Chinese belong. The Chinese designate the Annam people Ngannam. The Tonkinese call the Cochin-Chinese Kuang and Kekuang, names probably the same as Khyen and Ka-Khyen. The Cochin-Chinese, on the other hand, call the Tonkinese Kepak.

The Annamese group, amongst whom are the Moy, are found in Cochin-China and Tonkin, and two centuries before Christ the Chinese found the Annamese in possession of the basin of Sang Koi. The Annam race (comprehending under this name both the Cochin - Chinese and Tonkinese, for there is very little difference between them) are fair, but are a short, squat, and ill-favoured people, with long arms and short legs. They are probably lower in stature than any people of Central Asia. Their limbs are strong and well formed, and they are active and hardy. In point of features they bear a nearer resemblance to the Malay than to any other people; their countenances exhibit an air of cheerfulness and goodhumour. The women are, to a remarkable degree, fairer and handsomer than the men, their hands, arms, and feet are well formed, and the carriage even of the lower orders is graceful. The hair of the head is worn long, and put up in a knot at the back of the head, as was practised by the Chinese before the present fashion was imposed upon them by the Manchu; and the dress of both sexes is becoming; it is the old costume of China, before the Chinese were compelled to adopt that of the Manchu conquerors. Both sexes dress nearly alike. For the lower part of the body, the covering consists of a pair of loose trousers, secured at the waist by a sash. The main portion of dress consists of two or more loose frocks, reaching half-way down the thigh. Its sleeves are loose, and with persons not compelled to labour, they dangle a foot, or even a foot and a half, beyond the extremities of the fingers; but the labouring classes from necessity wear them short. With the women, the inner frock reaches below the knee, and the outer down to the ankles. When a Cochin-Chinese is in full dress, as when he makes visits or is engaged in the performance of religious rites, he always wears over the frocks now inentioned a loose silk gown reaching to the ankles. Both sexes wear turbands, which are put on with much neatness; and the form of this article of dress, which is always determinate, distinguishes the civil from the military order of public officers.

Cochin-China is the name given in Europe to a kingdom occupied by an Annam people. The derivation of this European name is obscure: Kachao is the name given by the Annam people to the capital of Tonkin; and Cochin-China is known to the Malay navigators as Cutchi, but they give the same name to Cochin on the Malabar coast. Cochin-China has probably been so called from the alliteration or reduplication so common with easterns, aided by the proximity of China, and may be derived from Kachao, the capital of Tonkin and China, so that Cochin-China may mean China-Cutchi. Cochin-China is bounded on the west by the Laos country. It extends between lat. $10^{\circ}$ and $11^{\circ}$ to $18^{\circ} \mathrm{N}$. The laws and modes of punishment of the CochinChinese are nearly the same as those of China. Their language, termed the Annamite, is monosyllabic, and evidently derived from that of China. Their written language, indeed, is merely borrowed in whole or in part from the Chinese, though the two languages have become so different that persons of the two nations cannot communicate either in reading or writing. Chinese, however, is the learned language of Cochin-China, with the pronunciation of the Cochin - Chinese. The Annamite language, from its monosyllabic character, presents but a small variety in the sound of the words, and a great number of significations, all indicated by the tone, are given to words spelled alike. The religion of the common people is the religion of $\mathrm{Fo}$, which they call Phat; but the people readily embrace Christianity. The common language is spoken in Cochin-China, Tonkin, Ciampa or Tsampa, Kambogia, Siam, and in Laos.

The Moi or $K a-m o i$, who occupy the broad. expansion of the Annam chain towards Kambogia, and appear to extend northwards along these mountains, marching with the Laos people on the westward, are said to be black savages, with Negro features. The Kambogians style them Kha-men. They are the Kho-men of Leyden and the Kha-men of Gutzlaff. They are very black, and resemble in their features the Caffre.

Kwanto are the aborigines of Tonkin, and must not be confounded with the Annamese.

Kambogia, lying between Siam and CochinChina, contains about $1,000,000$ people, of whom four-fifths are the native Kho. It contains the four provinces, Potisat, Kampong Suak, Kampong, and Kampot Son. Kambogia was anciently called Kamphucha. The people call themselves Khmer, and their country Sroe-Khmer, the country of the Khmer. They are called by the Siamese, Kammen; by the Cochin-Chinese, Komen; by the Chinese, Tang - po - cha; and by the Malays, Kamboja. Kambogia is the lower portion of the valley of the Mei-kong river. 
The ancient territory of the Kambogians appears to have embraced all the country lying west and south of the river of Saigun, extending on the Gulf of Siam as far north as the twelfth degree of latitude, and in the interior at least to the fifteenth. The eastern part of their territory having been subjugated by the Cochin-Chinese, and the western fully taken possession of by the Siamese, the latter, with the co-operation of the Kambogians under their rule, have retaken Pennom-pen, on the great river Mei-kong, called by the Burmese Meh-kwan-mit (Moor, p. 190), but which probably receives several names in its long course of 1500 miles, till it enters the sea by several branches.

Sovereignty over the kingdom of Kambogia was claimed by Siam and Cochin-China, and the Kambogian prince, unable to resist either of the sovereigns, paid tribute to both. The Government of Siam compelled the young princes of Kambogia to reside as hostages at Bankok. It is now under the protection of France, which has formed a colonial government over six provinces of Cochin-Cbina, which were formerly part of the kingdom of Kambogia. The population of French Cochin-China, principally of Chinese descent, is about three millions. The provinces were obtained from the emperor of Annam by a treaty signed at Hue in $\mathbf{1 8 6 2}$.

The whole of the coast from Kamas in Kambogia, quite up to what is called by the Siamese Lem Samme-san, the Cape Liant of Europeans, is an uninterrupted archipelago of beautiful islands. The Kambogians who are subjects of Siam occupy the southern districts of the Meikong down to the frontiers of Cochin-China. The river of Kambogia is one of the largest in Asia. It falls into the sea by three mouths, between the ninth and eleventh degrees. These three embouchures are known to European navigators by the names of the Western or Basak river, the Eeastern or central branch, and the Northern or Japanese river. The first of these is the largest, and the more suitable for navigation, and is said to have from 14 to 18 feet of water on the bar at its mouth at high-water or springtides.

The capital was visited by a Madras officer in the year 1854, at which time the king, besides his four married wives, had three hundred other women. The women of Kambogia shave their head, leaving only a short tuft of hair. They also blacken their teeth. The Kambogians speak a language distinct from those of all their neighbours; but in physical form, manners, laws, religion, and state of civilisation, they bear a closer resemblance to the Siamese than to any other people. A few of its people have embraced Christianity.

In Kambogia, it is stated by a writer in the Journal of the Indian Archipelago that Buddha is there styled Sāmonacudom. But there prevails amongst them a pantheism, in which all nature is deified, but above all they place Buddha, and worship him daily. The Sa tra Trayphum and the Sa tra Papithum are mentioned as two of their religious books.

The Kho occupy the delta of the Mei-kong in Kambogia, between Siam and Cochin-China, the remaining population being Chinese, CochinChinese, Siamese, Malays, Portuguese, and mixed races. The Kho are the aborigines of Kambogiá. Their language and that of the Mon in Pegu are said to be much more nearly allied to each other than to the T'hai language, which is spoken in the intervening country. The Kho and Siamese languages are mutually unintelligible.

Champa is a narrow mountainous tract between Cochin-China and Kambogia. The only part of the continent of Asia, the Malay Peninsula excepted, in which the Malays have settled, and to which their language has extended, is Kambogia. In that country they established the little independent principality called Champa, well known both in Malay and Javanese story. Both the Malays of the Peninsula and the Javanese appear to have carried on a commercial intercourse with Champa, and the same commerce still goes on between Champa and the British settlement of Singapore. The people are known in Kambogia as the Tsiam, and to the Annamese as the Loi Thuan or Thierg. Colonel Yule says a number of them are settled near the Great Lake.

The Maung T'hai or Siam people consist of the Siamese proper, the Khamti, the Laos, and the Shan. The valley of the Menam, throughout its whole course, is exclusively T'hai, and the T'hai attain their highest civilisation on the alluvial delta of their river. The old capital, Ayuthia, founded in 1351, was abandoned in 1751 for Bankok, lower down the river, and Siamese now dominate that part of the Peninsula which extends from the Siam Gulf to lat. $7^{\circ} \mathrm{N}$. Kambogia, the Laos of the Lu country, Luang, Phra Bang, and Nan, are also tributary to Siam. The Siamese are a Mongoloid race, as are those of Ava, Pegu, Kambogia, Cochin-China, and the Malays. The Siamese have large, straight faces, flat occiputs, lowness of the hairy scalp, comparatively small and firm mouth, hard staring eyes, and a grave expression. The Siamese are pliysically superior to the natives of the Indian Archipelago, if we except those of Bali; indeed, the Balinese and Siamese bear a striking resemblance to each other. Some natives of Siam attain a height about the middle size, and are generally well made; but their average height is 5 feet 3 inches. The hue of their skin is a shade darker than that of the Chinese, but they have fairer complexions than the Malays and Javanese. They are a bnsy, industrious, and enterprising people, but vain, deceitful, and cruel. T'hai is the native name of the Siamese, and their chief divisions are the Laos, Shyan (Shan or Ahom), and Khamti.

The Laos nation are in the interior of Siam, and their language is a variety of that of the T'hai. Burma, Siam, and Tonkin received their first culture from India, along with Buddhism, and their ancient buildings all bear the stamp of Indian origin and Indian taste of a post-Christian age; Siam in recent times has added Chinese methods of improvement to the Indian ones; while Tonkin mainly from China. De Carne mentions (p. 129) that at the close of the 18th century, when the king of Siam made himself master of Palembang on the Kambogia, he drove out all the inhabitants, and replaced them by others. Many foreigners, Chinese and CochinChinese, reside in Siam, also Portuguese, French, British, and Dutch. The Siamese marriage approaches more to a civil contract than to a 
religious institution. The bridegrooms are from 16 to 20 years of age, and the brides about 14 years. In Siam polygamy and concubinage are allowed. There are four classes of wives recognised, the first being those received from royalty. Relatives of the same blood do not intermarry. In Siam, the kings marry into their own family, even with their own sisters and daughters.

The wives of the Burmese and Siamese engage largely in business, take an active part in their lusband's affairs, and enter into personal transactions. The wives of men of rank advise and issue orders; those of humbler station make trading voyages in boats up the river on their own account and on that of their husbands. The women of Burma and Siam attend public festivals and theatrical representations. They go abroad on foot without ostentation or affectation.

The dress of both men and women consists of a cloth wrapped round the waist, one end being brought between the legs and fastened behind, which gives this portion of their attire the appearance of a pair of trousers. In addition, women wear a cloth wrapped round the body, under the arms. Both men and women have the hair shaved from their heads, with the exception of a small round patch which is left between the crown and the forehead. This, being brushed up, is made to stand on end, which gives them a scared appearance. Paternal authority is strongly enforced.

The Chinese and Siamese have an annual ploughing festival. The Siamese kings formerly attended, and personally held the plough; but in later years it is the duty of the Phonlat'hep, or superintendent of the rice granaries, who proceeds in great pomp to a field beyond the town, where he ploughs ground sufficient to yield a crop of five measures of grain. On the second month he revisits the field, and stands on one foot for three solar hours, in invocation of the Devata.

The Siamese and the Burmese Buddhists, though they avoid killing any creature for food, eat the flesh of animals which other people have killed, as also that of creatures, cattle, and sheep that have died of disease.

Slavery exists in Siam, but only war captives are kept with severity. Gambling in every form, as with the Chinese and Malay, is common, and cock-fighting, fish-fighting, cricket-fighting, and lotteries.

Siamese appears by far the most widely spoken language of Ultra-India. It was at one time the lingua franca of Quedab, almost as much as the Malay, and even that wandering Negro tribe the Semang spoke it in some places. It was also current in Assam and Yunnan, at the opposite extremities of Ultra-India. No dialect of the T'hai is intelligible to a Burmese. The alphabets also differ, but on the whole the essentials of their civilisation are the same, the cbief difference being in the language. The Laos alphabet slightly differs from that of the Siamese proper, but, practically speaking, the language is spoken with remarkable uniformity over the whole T'hai area, and the Siamese proper, the Laos, the Shan dialects, and the Khanti are one. From Assam to Bankok, the difference in the language is merely that of pronuncintion.

Pali is the sacred literature of the Siamese, and is called Pali, Bali, and Pasa Makata (Bhasha
Magadha), the language of Magadha. The tala poin or priests are enormously disproportioned to the rest of the inbabitants. In Bankok alone their numbers exceed 30,000 . The Pheek'ho, or priests of Siam, are taken from the mass of the people. They can revert to the laity at pleasure.

With the richer classes, the body, after the bowels have been extracted, is laid in a wooden coffin, externally lacquered and gilt, and this is placed for some days on a high table. In the meantime the priests light up tapers, burn perfumes under the coffin, and chant funeral hymns at night. A procession of relatives and friends, dressed in white and covered with white veils, follow the corpse. Beside it are borne figures of various animals or singularly-shaped monsters carved out of bamboo, and the accompanying talapoins exclaim, "We must all die, we are all mortal!' The mourners attest their sorrow by their tears, and often hire women for the express purpose. The body is then taken from the coffin and placed naked on the pile, which is set fire to, and the remains are scorched. The body is then replaced in the coffin, and deposited under one of the pyramids erected about the temple. Graves are held sacred among the Siamese, and their violation is considered as a heinous offence. The bodies of persons killed by accident, by lightning, the still-born, those who die in child-birth or from small-pox, and suicides, are either thrown iuto the water or exposed to the beasts of prey. When a person dies absent from home, his heir writes his name and age on slips of paper, and burns them along with an effigy or a portrait of the deceased.

Zimmay, also written Chang-mai and Xiengmai, is due north of Siam proper, on the Menam river, between lat. $19^{\circ}$ and $23^{\circ} \mathrm{N}$. It is tributary to Siam. Its capital has a population of 50,000 . The Laos form the humbler population. The Miaotse or Miautsi are said to belong to the T'hai group.

The mountain races in Siam are the Kariang, the Lawa, the $\mathrm{Ka}$, and the Chong.

The Kariang inhabit the mountains on the N.W. frontier of Siam, as far as lat. $20^{\circ} \mathrm{N}$.

The Lawa dwell in the same mountain range, but to the S. of the Kariang.

The $K a$ are in the range of mountains between the valleys of the Menam and Mei-kong. The Ka and the Chong (the Gueo of the Portuguese) are rude tribes, elephant hunters.

Chong are a hill tribe on the side of the Mei-kong basin, but towards the sea, between lat. $11 \frac{1}{2}^{\circ}$ and $13^{\circ} \mathrm{N}$., in the hilly region at the N.E. angle of the Gulf of Siarn. They preserve more of the Australo-Tamilian character than any of the neighbouring tribes. Their hair, instead of being stiff or harsh as in the Mongolian, Tibetan, and prevalent Ultra-Indian and Malaya-Polynesian race, is comparatively soft, the features are much more prominent, and the beard is fuller.

Luang Praban, Sien-kan, Muong-Nan are also tributary to Siam. The last named is probably Mruang Loon, a small state S.E. of Zimmay; and Muang Phre Bang, on the Mei-kong, is a larger state which acknowledges the supremacy of Siam.

EASTERN ASIA and its inbabitants have received the attention of many eminent ethnologists, Bennett, Bikmore, Burns, Crawfurd, Earl, Keane, 
Jagor, Giglioli, Hogendorp, Lesson, Logan, Lubbock, Huxley, MacGillivray, De Marne, Marsden, Moor, Newbold, Norris, Peschel, Raffles, St. John, Temminck, and Wallace,-almost all of whom have resided there, some of them for long terms of years. The names which they applied to this region have been based partly on geographic, partly on ethnic, grounds; the more generally accepted being-

Indonesia, or the Indo-Pacific insular region.

Melanesia, comprising New Guinea, Australia, and all the eastern Papuan islands.

Micronesia is all the islands between Melanesia and the Loo-Choo and Japanese chain.

Polynesia, all the islands of the Pacific to the east of Micronesia and Melanesia, as far as Easter Island.

Papuanesia has been occasionally used to distinguish the northern Melanesian islands, inhabited chiefly by spiral-haired races.

Oceanica includes all the Indo-Pacific islands.

Asianesia is a comprehensive term, including the S.E. insular region, viz. Indonesia, Melanesia, Micronesia, and Polynesia.

The region embraced by these terms extends through 80 degrees of longitude and 80 degrees of latitude, from lat. $40^{\circ} \mathrm{N}$. to $40^{\circ} \mathrm{S}$., and long. $100^{\circ}$ to $180^{\circ}$ E.; and Behm and Wagner's enumeration for 1881 give as under :-

China, viz.-

China proper,

China Tributaries - Manchuria, Mongolia, Tibet, Zangaria, East Turkestan,

\section{Total,}

Corea

Japan and its Dependencies (Kuriles, Loo - Choo, Benin Islands),

Himalaya States (Nंepal, Bhutan, etc.),

Burma, British,

Burma, Native,

Manipur,

Siam,

Annam,

French Cochin-China,

Cambodia,

Malacca Peninsula, Independent States,

Straits Settlements, British, . Andamans,

Nicobars,

Sunda Islands and Moluceas,

Philippine Islands,

Dutch Possessions, including New Guinea and the Papuan Islands,

North Borneo, British,

Australasia, viz.-

New South Wales,

Victoria,

Queensland,

South Australia,

West Australia,

Tasmania,

New Zealand, .

New Guinea,

New Guinea - Neighbouring Islands, Square

$4,024,690350,000,000$

$7,531,074 \quad 21,180,000$

$11,555,764371,200,000$ $236,7848,500,000$ ?

$382,447 \quad 36,357,212$

$234,000 \quad 3,300,000$ $229,351 \quad 3,707,646$ $457,000 \quad 4,000,000$ $19,675 \quad 126,000$ $726,850 \quad 5,750,000$ $140,500 \quad 21,000,000$ $59,456 \quad 1,597,013$ $83,861 \quad 890,000$ $81,500 \quad 300,000$ $3,742 \quad 390,000$

$6,497 \quad 14,500$

1,772

$1,693,757$ $28,867,000$

\section{$1,462,400 \quad 27,962,000$} $57,000 \quad 150,000$

751,468

62,346

213,525

279,865

31,000

115,705

489,953

785,362

22,594

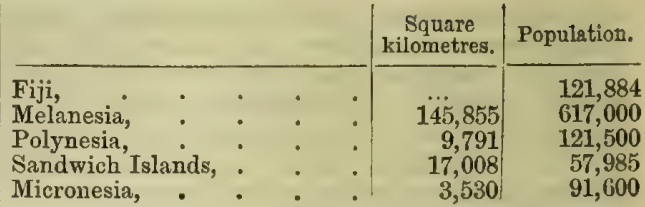

The Eastern Archipelago lies entirely within the tropics. It overspreads an area from lat. $10^{\circ} \mathrm{S}$. to $10^{\circ} \mathrm{N}$. of the equator, and forty-five degrees of longitude $\left(95^{\circ}\right.$ to $140^{\circ} \mathrm{E}$.), measuring upwards of 4000 miles from east to west, and about 1300 miles from north to south. Three of the islands, Borneo, Sumatra, and New Guinea, are larger than Great Britain; Java, Luçon, and Celebes are about the size of Ireland. The region here indicated is known usually as the Archipelago, also the Eastern and the Malay Archipelago. This Archipelago is marked by a chain of active and extinct volcanoes through the whole length of Sumatra and Java, and thence by the islands of Bali, Lombok, Sumbawa, Flores, the Servatty islands, Banda, Amboyna, Batchian, Makian, Tidore, Ternate, and Gilolo to Morty Island. Here the belt is broken and shifted 200 miles to the west, to North Celebes, from which it passes on to Siau and Sanguir, to the Philippine Islands, along the eastern side of which it continues in a curving line to their northern extremity. From the extreme eastern bend of this belt at Banda, for 1000 miles, to the north-east coast of New Guinea, is a non-volcanic district. But there, on the north-east coast of New Guinea, another volcanic belt can be traced through New Britain, New Ireland, and the Solomon Islands to the farthest eastern limits of the Archipelago. The united length of these volcanic belts is 90 degrees, their width about 50 miles; but for about 200 miles on either side of them, evidences of subterranean action are to be seen in recently elevated coral rock or in the barrier coral reefs, which indicate recent submergence.

Five European powers, Spain, Portugal, Holland, France, and Britain, have sought dominion in the Archipelago. Portugal has now only Macao and the Dilly settlement in Timor. France is directing her attention to Annam and Tonkin on the mainland. Great Britain claims possession, including Hong Kong, of 1400 square miles; Holland, 600,000 square miles, and rules over 26,000,000 of Asiatics; and Spain, 116,000 square miles, with eight millions of Asiatic subjects.

Mr. George Windsor Earl, in the middle of the nineteenth century (1855), made known to geographers that a continuous submarine bank stretches out from the Malay and Siamese peninsulas, embracing Sumatra, Borneo, Java, and as far as the Philippines. It extends all along the east side of Asia, from lat. $8^{\circ} \mathrm{S}$. to $6^{\circ} \mathrm{N}$., 1200 miles from $N$. to $S$. and 1500 from $E$. to W. The soundings in this vast area are all under 100 fathoms, but the greater part from the Gulf of Siam to Sumatra and Java is under 50 fathoms. East of this succeeds the seas of the Straits of Macassar and Lombok, more than 100 fathorns deep. Then begins another bank which unites New Guinea and other Papuan islands, the Celebes, the Timor group, the Moluccas, as far as Aru Islands, Mysol, and Waigiou, with Australia.
Oceanic islands, riz. the Society Islands (Tabiti, Moorea, etc.), Tua-motu group, Gambier group, etc. - 
It is now the opinion of naturalists that the Asiatic continent once included Java, Sumatra, and Borneo, probably also at an earlier period the Philippine Islands ; also that the Australian continent included the Timor group, the Celebes, the Moluccas, and the Papuan Island, and that the islands of the Asiatic division on the one hand, and those of the Australian on the other, have been disrupted from their original continents by the violence of their respective volcanoes; that the phenomena of volcanic action have been all of comparatively recent occurrence, and have not wholly obliterated the traces of the ancient distribution of land and water.

These views have been arrived at from the fact that the natural productions of the Asiatic islands and those of the Australian islands widely differ. The elephant and tapir of Sumatra and Borneo, the rhinoceros of Sumatra and Java, the wild cattle of Java and Borneo, belong to the same genera which inhabit part of Southern Asia. Similarly with the birds and insects, every family and almost every genus found on any of the Asiatic islands occurs also on the Asiatic mainland, and in a great many instances even the species are identical.

On the other hand, neither Australia nor the Australo-Malay islands have ape or monkey, cat or tiger, no wolves, no hyænas, no bears, no elephants, horses, sheep, deer, or oxen. But Australia and the Australo-Malay islands have the opossum and the wombat; and the kangaroo, long supposed to be peculiar to Australia, is found both in the Aru Islands and in the southern part of New Guinea.

The Asiatic division has woodpeckers, pheasants, barbets, and fruit thrushes, but no cockatoos or brush-tongued lories. Australia and the AustraloMalay islands have none of the former, but are the natural home of the latter.

Lastly, Mr. A. R. Wallace formed the opinion that all the peoples of the various islands can be grouped either with the Malay or the Papuan, two races differing in their physical, mental, and moral characters. In this view he carries out Mr. Earl's idea, and he is of opinion that a line can be drawn which shall so divide the islands as to indicate the one-half which truly belong to Asia, while the other with no less certainty is allied to Australia, and he designates these respectively the Indo-Malayan and the Austro-Malayan divisions of the Archipelago.

The races occupying the islands, speaking broadly, are Malays or Papuans; but Mr. A. H. Keane has classed them as Malays, MoluceaMalays, Malayo-Papuans, and Papuans, as under :-

$$
\text { i. The Asiatic Malay Islands. }
$$

Group 1. The Indo-Malay Islands, viz. Sumatra, Java, and Borneo, with Malay inhabitants.

\section{ii. The Australo-Malay Islands.}

Group 2. The Timor Islands, viz. Lombok, Sumbawa, Flores, and Timor, with Malayo-Papuans.

Group 3. Celebes, Sulu Islands, and Bouton, with Malay inhabitants.

Group 4. The Moluccas, with Molucca-MIalays in Bouru, Ceram, Batchian, Gilolo, Morty, Ternate, Tidore, Makian, Kaioa, Amboyna, Banda, Goram, and Matabello.

Group 5. The Papuan Islands, New Guinea or Papua, Aru Islands, Ke Islands, Mysol, Salwatty, Waigiou, and others.

Of dark and brown types, Mr. Keane (p. 593) recognises four distinct stocks, - one of various shades of brown, and three of a distinctly dark type, physically different, speaking languages which belong to radically distinct linguistic types, while the varieties of the brown stock are one in speech aud physique. The three dark races are the Austral of Australia, the Negrito, and the Papuan.

The Negrito occur in Luçon and other of the Philippine Islands, the interior of Malacca, and the Andamans. Those in the Philippines are the Aètas, Aitas, or Itas of Spanish writers, a term in Tagala meaning black, the same as the Malay Hiss, hetam. Those of the Andamans are the Mincopi, and those in the Malay Peninsula are the Semang and Bila. The Papuans, another of the black type, Papua, from Malay s, papuwah, meaning curly, have also been called Melanesians. They are found in a pure state, or mixed with other races, in all the islands stretehing from about the meridian of Flores eastwards to Fiji. They have sometimes been called Alfuro and Harafora, which some writers apply to heathen, i.e. the nonMuhammadan and non-Christian tribes interspersed in Bouro, Ceram, Flores, Gilolo, and simply means non-Muhammadan.

Malayo-Polynesian, Indo-Pacific, Micronesian, and Maori are names which have been applied to the three types of the brown races; but $\mathrm{Mr}$. Keane prefers that of Malay for the western branch, Micronesian for the north-western group, and Maori or Polynesian for the large brown races of the Eastern Archipelagoes. He says that the Papuans are pure only in the interior and western parts of New Guinea, Aru, Waigiou, Salwatty, and other islands. On the N. coast of Australia, they are mixed with the Austral stock.

In the Admiralty, New Britain, and all the Archipelagoes, from New Guinea east to Fiji, they form the basis of the population intermingled with the Maori race. These are Maori-Papuans. In the Indian Archipelago, from Timor Laut westwards to Flores inclusive, they are blended with Malayan elements. These are Malayo-Papuans. New Guinea, he says, has at least two, but probably three tribes, viz. Papuan, Negrito, and Maori, but the presence of Maori there needs confirmation.

The races and their varieties present marked differences in their physical formation, even as to the mere heights, as will be seen by their measurements in millimetres, as under:-

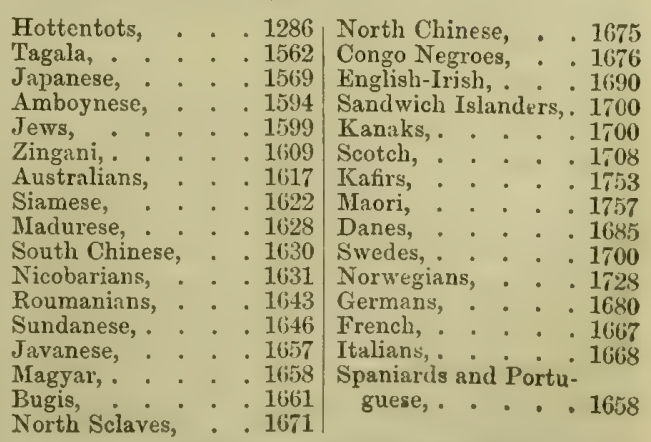

Negrito.-The Malay race, in stature, are inter. 
mediate between the Papuan and the Negrito. The Papuan are taller than the Malay, but the Negrito are about 4 feet 6 inches or 4 feet 8 inches, or 8 inches shorter than the Malays. The Negrito nose is small, flattened, or turned up at the apex, while the Papuan nose is large and prominent, with the apex prolonged downwards. The Negrito hair is the same as that of the Papuan and also of the African. The Negrito of the Philippines, the Semang and Bila of the Malay Peninsula, and the Mincopi of the Andamans, agree with each other. The Negrito are living in Luçon, Negros, Panay, Mindoro, and Mindanao to the number of 25,000 , but are also in Palawan and Formosa. They are small in stature, but well made.

Of the Malay race, there are three broad ethnic divisions, viz. the Orang Malayu, the Orang Laut, and the Orang Binua.

The Orang Malayu are civilised communities in Sumatra, Malacca, Borneo, etc., are all Muhammadans, and speak High Malay, with a literature written in the Arabic character.

The Orang Laut, literally sea people, are known as the Baju Laut of Celebes; and Mr. Keane supposes them to be akin to the Lanun of Borneo and Illanos of Mindanao. They live in their boats on the water, engaged in fishing and addicted to piracy, or, as De Barros says, "Cujo officio he rubar e pescar.'

The Orang Binua, or men of the soil, known also as Orang-Utan or wild men, as Orang Gunong or hillmen, likewise as Orang Darat or landsmen, are wild, savage, and unlettered tribes of the interior of Malacca, parts of Sumatra, RbioLingga, and other islands in the Straits of Malacca. They speak in rude but pure Malay dialects, are in numerous tribes, with names given from the rivers and the districts they occupy.

The Malay language proper, wherever current in the Archipelago, is spoken with remarkable uniformity; and that spoken even by the ruder uncivilised tribes in Malacca and Sumatra, known as the Low Malay, does not differ from the High or Literary Malay.

Malay proper is vernacular in Malacca, in a large part of Sumatra, in the islands of Billiton, Banca, Panjor, Penang, Singapore, Rhio-Lingga, Banda, in parts of the Moluccas and Timor, and generally round the coast of Borneo.

Orang Laut.-The custom of living on the water is common in various parts of Southern Asia ; it is in some countries occasioned by necessity. But the people who are called Rayats on Banca and in the neighbouring seas, adopt it by choice, and preserve it in situations which would afford a more comfortable mode of life. They are probably dispersed through all the countries where the Malay language is current. They always formed part of the subjects of the Malay princes during their prosperity at Malacca and afterwards at Johore. Those of them who have preserved their manners pure, dwell in small prahus, which carry their possessions and families. These are of the size and class of the vessels distinguished among the Malays by the name of prahu kakap, probably from their supposed resemblance to a fish of the same name in their form and motion; they are equally adapted to rowing and sailing. Their after part is the kitchen, and here a small stove is permanently fixed; the central space serves for their usual occupations during the day, and for their rest at night; several large mats, which are rolled up in the day time, form its principal furniture; their fore parts contain a small chest, in which they preserve their articles of value. During the night, and in bad weather, the vessel is covered by a light mat (or kajang), which, when not in use, is folded over the posterior part. The furniture of each prahu is very simple. One harpoon with a shifting point, and a spear-like implement for searching for crabs in the sand, some empty cocoanut shells, with oar and paddles in proportion to the size of the vessels, are always found; besides these, a drum and a comb of uncommon size ; most prahus carry a favourite cat. A number of long wooden lances, as their common weapon of defence, are always placed in conspicuous parts. These they wield with much dexterity. The larger prahus (especially those intended for warlike purposes) are provided with rantakkas, firelocks, spears, and Malay cutlasses.

Each prahu carries a large sail. The day is spent in small excursions on the ocean; at night the vessels are anchored near the shore or fixed to a pole. Smaller vessels are generally drawn upon the beach. When opportunities allow, they seek the shelter of small bays or the outlets of rivers. They often subsist for many days, successively on fish, crabs, oysters, or mussels, which they consume indiscriminately, but they are extraordinarily fond of vegetable food, and whenever they have an opportunity all of them devour double the quantity of rice that will suffice another Malny. The places they occupy or have lately visited are easily known by the remnants of fish, by piles of shells, etc., and are also indicated at a great distance by a nauseous odour. Cleanliness is by no means one of their qualities; they are rarely exempt from eruptions on the skin, and they complain of diseases of the bowels.

They spend their time chiefly in fishing or in preparing fishing-tackle of various kinds. The preparation and arrangement of the leaves of a species of pandanus for sails is the business of the females. Those who have attached themselves to a particular spot sell and barter dried fish, trepang, agar-agar. In the year 1825 the Carimon Islands (Krimun) were occupied by Orang Laut, who plundered when they could do it with impunity. The Carimons, from their central position, were a favourite haunt of pirates, and the strait separating the two islands was seldom without some of their boats.

Sumatra is between 128,500 and 140,000 square miles in area. Its inhabitants have been estimated at from 2 to $4 \frac{1}{2}$ millions. Among the people of the Archipelago generally, the island is known as Pulo Purichu, also Pulo Indalas; the Javanese term it Tana-Palembang, the land of Palembang. The origin of the term Sumatra is unknown. The Malay races proper occupy about half the area of the island. Their chief tribes are the Korinchi, the Orang Rawa, Orang Palembang, Rejang, Serawi, Lampong, Batta, the Orang Kubu or Orang Lubu. Marsden mentioned the Orang Gugu, and in the southern belt the Orang Abung, described as a head-hunting race.

Excepting Menangkabau, the whole coast of Sumatra is nominally under five sovereignties, viz. Palembang, Jambi, Indragiri, Siak, and Acheen. Menangkabau province is the plateau in the in- 
INDIA; THE EASTERN ARCHIPELAGO, JAVA, ETC.

terior, north of the town of Padang. Palembang is nearly all Muhammadan.

The Achi or Achinese are the most civilised, and through them Mubammadanism, with such arts and civilisation as accompanied it, were directly or indirectly communicated to the other islands in the Archipelago. They are supposed to be a mixture of the Batta and Malay with the Arab, and with the Chulia natives of the west of India. During the latter half of the 17 th century, four queens reigned iu succession over Acheen.

The Batta are partly under the Dutch, partly independent, and the latter continue cannibals. They do not allow marriages between people of the same clau.

In Sumatra there were formerly three perfectly distinct kinds of marriage, - the Jugur, in wbich the man purchased the woman; the Ambel-anak, in which the woman purchased the man; and the Semando, in which they joined on terms of equality. In the Ambel-anak marriage, the father of a virgin makes choice of some young man for her husband, generally from an inferior family, which renounces all further right to or interest in him, and he is taken into the house of his father-in-law, who kills a buffalo on the occasion, and receives twenty dollars from his son's relations. After this, the buruk baik'nia (the good and bad of him) is invested in the wife's family. If he murder or rob, they pay the bangun or the fine. If he be murdered, they receive the bangun. They are liable to any debts he may contract in marriage, those prior to it remaining with his parents. He lives in the family in a state between that of a son and a debtor. He partakes as a son of what the house affords, but has no property in himself. His rice plantation, the produce of his pepper garden, with everything that he can gain or earn, belongs to the family. $\mathrm{He}$ is liable to be divorced at their pleasure, and though he has children, must leave all, and return naked as he came.

A Sumatran scrupulously abstains from pronouncing his own name, merely as a punctilio in manners. It occasions him infinite embarrassment when a stranger, unacquainted with their customs, requires it of him. As soon as he recovers from his confusion, he solicits the interposition of his neighbour. He is never addressed, except in the case of a superior dictating to his dependent, in the second person, but always in the third, using his name or title instead of the pronoun; and when these are unknown, a general title of respect is substituted, and they say, for instance, 'Apa orang kaya punia suka,' 'What is his honour's pleasure?' for 'What is your or your honour's pleasure?' When ignominious persons are spoken to, use is made of the personal pronoun kau (a contraction of angkau), particularly expressive of contempt.

People of rank allow their finger nails to grow to a great length. Both sexes file their teeth, and blacken them with the empyreumatic oil of the cocoanut shell. The Lampong women have their teeth rubbed down even with their gums. Others have them formed into points, or have the ends rubbed off and the stumps blackened. Their chiefs sometimes set their teeth in gold, by casing the gums with a sheathing of that metal.

Java is supposed to have had early intercourse with races trading down the Red Sea. From the 12th to the close of the 15th century, it was ruled by sovereigns professing the Hindu religion, and many architectural remains are to be seen throughout the island. In 1478, the Majo Pahit dynasty was overthrown by the Arabs. Subsequently, in 1511, the Portuguese reached Java, followed a century later, 1605 , by the Dutch, who since 1609 have partially occupied it, except for the years 1811 to 1816 , when the British captured it. In 1880, Java and Madura had an area of 2380.7 geographical square miles, with a population of $19,797,077$ inhabitants, viz.-

\begin{tabular}{l|l|l} 
Javanese, . . 19,542,835 & Europeans, . . 33,703
\end{tabular} Chinese, . . 206,915 Others, . . . 3,092 Arabs, . . . 10,528

The Javanese are a Mongoloid race, with mild, placid, prepossessing features, and lank hair. They are taller than the Bugis. Their limbs are slender, and wrists and ankles small, and the colour of their skin is yellow. They are enthusiastically fond of poetry, and have a delicate ear for music.

Until the middle of the 19 th century there was a remnant of an aborigiual race in the Tengger mountains following Hinduism, and the Kalang and Bedui are hill and forest tribes. The Arabs are religious teachers, the Bugis are settled on the sea-coasts. In the western part of the island, the Malays speak the Sunda language, but the bulk of the people speak Javanese, which has a high and low dialect, with many Sanskrit words.

Madura is separated from Java Island by a strait not more than a mile wide. Many of the Madurese have settled on Java. The people are of martial tendencies, but victims of cruel and degrading superstitions. Its population is 810,135 , of whom 3932 are Chinese, 1516 Arabs, and 509 Europeans.

Bali Island is immediately to the east of Java, of which it looks like a continuation. In parts of Java, in Lombok, in parts of Sumatra, amongst the Dyak of Borneo, and the Philippine islanders, there are remains and customs indicative of a Hindu origin; but in Bali, since A.D. 1478, the entire population, amounting to about one million, profess the Hindu religion, and the burning of widows amongst them is carried to an extent never known even in continental India. The slaves of a great man are also consumed upon his funeral pile; and when the immense annual loss of life produced by these frightful practices is considered, it is surprising that the island possesses so large a population. They are fairer in complexion, stouter in frame, and more energetic in their dispositions, than the Javanese, and in appearance and dress bear a great resemblance to the natives of Siam. The Balinese entertain a great aversion to a maritime life, and are more rarely to be met with at the European ports than the natives of the other islauds to the eastward. Bali women, like the Burmese, attend to the selling of goods and merchandise.

Women take precedence, not only by custom, but by law ; if unmarried, according to the rank of their fathers, and if married, according to the rank of their husbands. The men are indolent, and abstain from labour, and men of all ranks receive great assistance in their households, and in conducting their public duties, from the skill, activity, and zealous intelligence of their wives. The Balinese abduct their intended partners, 
running away with them into the woods, where they remain concealed until the friends of the young man are able to compensate the family of the girl, when they return and live together as man and wife. The amount paid ranges from Rs. 100 to 200,20 per cent. of which falls to the king. The language of Bali is of the same family as the Javanese, from which, however, it differs in its terminations. The court language (Bhasha Dalam), the ancient Kawi, is spoken by the king. There is an active volcano in the island, and earthquakes occur from time to time.

Banca Island in its interior has a hill race or Orang Gunong, but its littoral is occupied by cultivators, and around the coasts a maritime people, the Orang Laut, dwell in their prahu boats. These are similar in their habits to the Baju Laut of Borneo and Celebes. They subsist entirely by fishing. This island abounds in tin, and many Chinese have been working the mines.

Borneo is the principal island of the Sunda group. After Australia, it is the largest island on the globe, as large as France and England combined. Stein estimated it at 210,107, and the Penny Magazine at 286,000 square miles, with 3 to 4 millions as its population. Its many tribes take their tribal names from the river basins or the districts they inhabit, and thus we have the Dyak clans, Orang Duson, and the Orang Sampit from these rivers; and in the north of the island are the Sarebu Dyaks, Sakarran, Lundu, Sibnuw, established on the rivers which bear these names. Other rivers are the Borneo, Banjarmassin, Passir, Coti, Pontianak, and Sambas.

The better known tribes are Malay, Suluk, Baju, Balagnini, Dusun or Duson, Illanun, Kadayan, Bisaya, Murut, Kalamut, Tutung, Kyajao, Kayan, Dyak, Tatao, Kanawit, and Melando. The sea-coast has tribes totally unconnected with each other, each with its own manners and customs, and governed by its own laws. The west is occupied by Malays and Chinese; the north-west by the half-caste descendants of the Muhammadans of Western India; the north by the Cochin-Chinese; the north-east by Sulu; and the east and south coasts by the Bugis tribes of Celebes. There are, besides, numerous seafaring tribes, who live in prahus in islands near the coast; amongst others, the Lanun from Magindanao, and the Orang Baju and Orang Tidong, source unknown.

Since A.D. 1244, Malays from Malacca, Sumatra, and Java have been settled along the coast. On the east coast there is a great admixture of Bugis blood. All the rajas and principal men are Bugis, or have Bugis relatives in Celebes, and there are also many Bugis in the Western Residency. The greater part of the coast is dotted, rather than peopled, with Malay settlements.

The Dyak inhabit thatched bamboo houses, erected on piles 18 or 20 feet high, those belonging to each family or petty tribe being joined together by means of a stage or verandah running along the front, and reached by ladders, which are pulled up at night. Many of the smaller villages are defended by stockades. The Jangkang Dyaks dwelling on the Sakiam, a branch of the Sadong river, are said to be cannibals. The men of this tribe file down their teeth to a point, like the teeth of a saw. Until after the middle of the 19 th century, the Dyak tribes were constantly at war with each other, making forays for heads, which they suspended in their houses. A man could not marry until he procured a head, and distant voyages and every stratagem were adopted to obtain these.

The Kyan, a powerful tribe, about 100,000 in number, occupy the country from the south of the kingdom of Brunei, right away into the interior. They are the most martial tribe in Borneo, fierce, hot-blooded, and reckless of life. The Kyan have eleven tributary clans, several of whom, both men and women, tattoo. The Kyan and the Idaan or Murut are said to be addicted to human sacrifice; and they arrange skulls about the houses.

Mr. Burbidge (Gardens of the Sun) has given the latest and best account of the present state of the inhabitants. He tells us that the Kadyans are a peaceable and well-disposed tribe of aboriginals, who, living along the coast near to the capital, have mixed a good deal with the Malays, and speak their language. Some of the older and more intelligent men of this tribe are well acquainted with the Murut, Duson, and the Brunei dialects. Although the Kadyan people are nominally Muhammadans, their women enjoy the greatest freedom, and are never secluded, as is the custom of the Malays of the coast; indeed, many Kadyan houses consist of one very large room only, there being no private apartments of any kind. This is a rather singular trait of these people, since even the Murut and the Duson have one side of their houses partitioned off so as to allow of a separate private room for each family.

The Duson villagers keep bees and export wax in quantity, and most of the tribes collect the varied natural products of the sea or of the forest in their respective districts.

The physique of the inland tribes, especially of the Dyak, Kadyan, and Murut, is superior to that of the Malays.

Murut women, whether in boats or afield, appear to be as active as the men. Their hair is often very gracefully wreathed up with a string of red or amber-coloured beads, sometimes with a strip of the pale-yellow nipa leaf in its young state, and the colour contrast is then very effective. In Borneo and elsewhere in the Malayan islands, Orang-Utan (literally wild man) is applied not only to the large red monkey, but also to the aboriginal inhabitants of the interior. The Murut are frequently spoken of as Orang-Utan, not only by the Malays, but also by the Kadyans, a tribe of aboriginals converted to the Muhammadan faith. The Murut have a great love for gong music; and now and then a cheap German gun or old Tower musket is obtained from Chinese traders. Spears, blowpipes, krisses or parongs (swords), and their ghastly baskets of human skulls, form their only accumulated wealth.

With the Murut, one enormous house is built, sufficiently large to accommodate from twenty to fifty families. These houses vary from 30 to 100 yards in length, and, like those of the Kadyan, are built on piles, so as to be better prepared for resistance in case of a sudden attack. The Murut and the Kadyan who live in the vicinity of the Baram river, and one or two other tribes. of the aboriginal Borneans, still continue the practice of head-hunting, although the custom is now fast dying out here, as it has in the case 
of the Dyak of Sarawak and other places farther south. Long after the middle of the 19 th century, a youth was not allowed to marry until he had taken the head of an enemy, and if any ill-luck or death occurred in the tribe, head-hunting raids were indulged in at once to appease the malignant spirits which were believed to have been the cause; or if a chief's favourite wife or child died, he at once took to head-hunting in a bloodthirsty spirit of revenge. The Murut and other aboriginals are great believers in omens, and whether on head-hunting or pig-killing expeditions, they pay great regard to the cries of birds and animals.

The Baju, Lanun, Balagnini, and Sulu tribes, who inhabit the north of Borneo and the islauds to the north-east, are given to piracy. The Lanum or Illanun long infested about 300 miles of the north-west coast, by eruising to other parts of the Archipelago, plundering villages, and often carrying off whole populations into slavery. The Lanuus on the coasts north of Menkabong are petty traders or cultivators. The Duson, who live in the hills farther from the coast, give them a bad character.

The Orang Baju or Baju Laut profess Muhammadanism. They live in boats at the mouths of most of the rivers on the east coast. Their boats are 8 or 10 tons each, and when in harbour are covered with a roof of matting. They are fishermen and collect trepang.

The Orang Tidong, a hardy, seafaring race, occupy to the north of the Baju Laut. They cruise among the Philippine and Sulu Islands, disposing of sago, which is their principal food. They are said to be occasionally cannibals.

The Chinese settlers are largely engaged in working the gold mines. Coal, diamonds, iron, antimony, mother-of-pearl, caoutchouc, guttapercha are also products. The elephant, rhinoceros, leopard, ox, hog, orang-utan, and others of the monkey tribe.

The Bornean Malays may be said to have but little literature; the Koran, a few MS. poems, prayers, and tales are the only books generally seen in the island; but the people possess a vast amount of traditional lore, and many of their songs refer to the bistory of the country, the beauty of their women, or to the personal attributes and prowess of their former rulers. Malayan romances and minstrelsy are alike rich in imagery. Malay is the court language at Brunei, but the inhabitants generally use a dialect similar to that of the aboriginals who live near the capital. Slavery, although not yet abolished in Borneo, is not nearly so common as was formerly the case.

Amboyna, Bauda, Ternate, Tidore, and others in the neighbourhood are small volcanic islands, fertile in tine spices. The clove tree grows spontaneously in Ternate, Tidore, Motir, Makian, and Batchian.

The Amboyna people are of the Malay race, short, squab, and darker than the Javanese; they are gentle, sober, brave, easily managed, make good mounted or infantry soldiers, and a considerable number of them have embraced Christianity.

The Buro people consist of Malays of the Celebes type, often exactly similar to the Tomore people of East Celebes who are settled in Batchian. These form the bulk of the population. Another race, in smaller numbers, resemble the Alfuro of Ceram.

Ternate, Tidore, Motir, and Makian are only trachytic cones, standing on the same great fissure of the earth. The Ternate people consist of Malay, Orang Sirani, and Dutch.

Celebes Island is in the Molucca Sea. It extends from lat. $2^{\circ} \mathrm{N}$. to $6^{\circ} \mathrm{S}$, and from long. $125^{\circ}$ to $129^{\circ} \mathrm{E}$. It is composed of four peninsulas, forming gulfs. Some of the mountains rise to 7000 feet above the sea, Klabat in the Northern Peninsula being 6500 feet. In the north of Celebes there are several active volcanoes.

The population is over a million, and is composed of several of the Malay nations. Of these, the Wugi, Bugi or Bugis are the most advanced in civilisation.

In 1512, Celebes was taken possersion of by the Portuguese, who were displaced in 1660 by the Dutch, and the British kept it from 1811 to 1816. One of the Dutch Residencies is at Mang Kasara, which has been modified into Macassar, and Macassar men is a common name for the Bugi. Many of them have adopted Christianity. They are the great traders and navigators of the Archipelago. At the beginning of the western monsoon they go in great numbers to the Aru Islands, which is the principal rendezvous for the people of Ceram, Goram, the Ki Islands, Tenimber, Baba, Kilwaru, and the adjacent coast of New Guinea, a distance from Macassar of upwards of 1000 miles. They are of the Malay family, but, although exposed to the same temptations, they have never been pirates; they defend themselves against the Malay prahus with the most heroic and desperate valour, and if overpowered will blow up their vessels rather than submit. They are the Phonicians of the Archipelago, and are to be seen on every coast from the northern parts of Australia to the Malay Peninsula. With the eastern monsoon, they sail westwards until they reach Singapore. The Alfuro race thinly occupy the elevated woody parts.

The Minahassa people, of the Malay family, up to the early part of the 19 th century were head-hunters like the Dyaks of Borneo, and, like them, built their houses on posts 20 feet or more above the ground, and 90 to 200 feet long, and 48 feet broad, to contain 16 or 20 households.

Around the coasts, a fishing and seafaring race, the Orang Laut, dwell in boats.

The languages current are the Bugi, Macassar, Bouton, Salayer, Tomore, Tomohow, Langowen, Ratahan, Belang, Tanawauko, Kema, Bautek, Menado, and Bolanghitam.

Batchian, in lat. $0^{\circ} 30^{\prime}$ S., and long. $127^{\circ} 30^{\prime} \mathbf{E}$., כ4 miles long and 20 miles broad, is separated from Gilolo by a narrow channel. Its inhabitants profess Muhammadanism. The interior is uninhabited, there are only a few villages on the coasts. The Batchian Malays differ very little from those of Ternate. Their language, however, has more of the Papuan element in it, with a mixture of pure Malay, showing that they are formed from stragglers of various races, almost homogeneous. The Orang Sirani (qu. Nasrani or Suryani) are Christians of Portuguese descent, like those of Ternate. Many of these have a Portuguese physiognomy, but their skin is generally darker than that of the Malays. They speak Malay, with a large number of Portuguese 
words and idioms. The Orang Sirani are very fond of dancing. In 300 years, they have changed their language and lost all knowledge of their nationality, but in manners and appearance they are almost pure Portuguese. Everywhere in the east, where the Portuguese have mixed with the native races, the offspring are darker in colour than either of the parent stocks. This is the case with the Orang Sirani, and with the Portuguese of Malacca and Goa. This is not the case in South America, where the Mameluco, the offspring of the Portuguese and Indian, is often fairer than either race, but always fairer than the Indian. The Orang Sirani are as civil, obliging, and industrious as the Malay, but they consider themselves of a superior order, and are inclined to trade and commerce rather than to manual labour.

The Galela men from Giloln is a third race, and a fourth race is a colony from Timor, in the Eastern Peninsula of Celebes, who were brought there many years ago, at their own request, to aroid extermination by another tribe. They have a very light complexion, open Tartar physiognomy, low stature, and a language of the Bugis type. They are an industrious agricultural people, and supply the town with vegetables. They make a good deal of bark cloth, similar to the tapa of the Polynesians. A cylinder of bark is taken off and soaked and beaten till it be as thin and as tongh as parchment. It is used for wrapping up clothes; also dyed with a bark dye, and sewed into jackets.

Gold has been washed for in the island of Batchian ever since 1774. Batchian and Tawali Islands are separated by a narrow strait.

The Keffing Islands is a little group of 17 islands, in the Molucca Sea, encircled by very extensive reefs projecting into deep water, aod renderiug them difficult of approach. The cachalot or spermaceti whale abounds in the ocean, and might support an extensive fishery. Some of the islets are low, sandy, girdled by reefs, and, as in Ghissa, with a lagoon in the centre, absolutely swarming with fish, while the shores are peopled by ducks and snipes. Their inhabitants resemble those of the S. coast of Ceram, and are not of the Papuan or Negro race. They are great traders, and constantly visit New Guinea, and purchase birds of paradise, luri, crows, pigeons, megapodiidæ, and scented woods.

Pulo Manok, or Bird Island, lies midway between Ceram and the Serwatty group. It is a high solitary mountain resting on the bosom of the sea, with a truncated cone, desert, and the refuge only of myriads of birds, which deposit such vast quantities of eggs, that many of the natives of the neighbouring islands visit the place and subsist for whole days on this wholesorne food. Sulphur is also found on the rocks.

The little communities existing in these scattered groups present curious phases of social life. Dwelling in houses erected on posts, they in many instances surround their villages with rough walls of coral, occasionally carrying a similar fortification all along the shore. Many of them, apparently peaceful traders, were secretly addicted to piracy, though some bore a character for innocence and love of industry altogether inconsistent with this pursuit. Among these are the inhabitants of Motir, a trachytic cone south of Makian, a gentle, tranquil, sober tribe, following the occupation of potters, and supplying the neighbouring islands with vessels and utensils of various kinds made of red clay, elegantly moulded and of good quality. These compete in the markets of the Molucca Sea with the plates and pans brought by the traders of Keffing from the $\mathrm{Ki}$ Islands.

Savu Island, one of the Sunda group, is on the south of Flores. Mr. Wallace says (ii. p. 277) that Savu and Rotti have a handsome race with good features, distinct from the Timorese or Papuans, and whom he classes with the Malays of the western islands of the Archipelago.

The Negroid tribes of the S.E. of Asia have been variedly classed by Lesson, Macgillivray, Earl, Logan, Bikmore, and Wallace. There are two very distinct varieties amongst them,a diminutive statured, who have been styled Negrito, with a larger, even stalwart people, who are equally black, but called by the Malay term. Papua, from their curly woolly hair, which, however, is a characteristic alike of Negrito and Papua. Also on the coasts of the more westerly islands, and on those of the islands to the eastward, Malay and Polynesian tribes have settled, and intermarried with the Negrito and Papua, and their descendants appear in modified forms of the two aboriginal races. The pure but less martial Negrito have taken refuge in the mountain fastnesses of their islands. Also Peschel arranged the Papuan race into an Australian and an Asiatic group, comprising in the latter the Alfur, Mincopi, Negrito, and Semang, but there is no marked difference between these. The Andaman islanders, called Mincopi, are decided Negrito, as also are the Semang and Bilo of the Malacca States of Quedah, Perak, and Kalantan; and there was said to be a tribe in the neighbourhood of the Timboro mountain in Sumbawa. The known tribes of the Mincopi are said to be the Akakol, Arokojuwai, Balawa, Bogijiab, Bojingijida, Jarawa, and Yerewa, speaking different languages.

In a N.W. direction from New Guinea, the Papuan race extends through the Moluccas to the Philippines, but in those islands they only appear in small and scattered tribes, occupants of the mountain fastnesses. From New Guinea to Timor, again, the small islands, with the exception of the Aru, are occupied by a race whom Earl designated Malaya-Polynesians; but at Timor, especially near the N.E. end, a Papuan race reappears, though not, in his opinion, in a pure state. Some on the island of Flores or Mangarai assume a more decided Papuan character. Mr. A. R. Wallace (ii. p. 104) describes the Papuan face as compressed and projecting, brow protuberant and overhanging, mouth large and prominent, the nose very large, the apex elongated downwards, the ridge thick, and the nostrils large,- the nose is an obtrusive feature, the beard is twisted, and the hair of the head is frizzly. In mental and moral characteristics the Papuans differ remarkably from the Malay races. They are much more impulsive, and do not conceal their emotions and passions. They are inquisitive, talk much and loudly, and laugh boisterously, reminding one of the Negro character as much as of the Negro form and aspect.

Gilolo or Halmahera is one of the Molucca 
islands. Its north end is in about lat. $2^{\circ} 23^{\prime} \mathrm{N}$. It lies between lat. $0^{\circ} 50^{\prime} \mathrm{S}$. and $3^{\circ} 10^{\prime} \mathrm{N}$., and is in length 220 miles. Like Celebes, it consists of four peninsulas, separated from each other by a deep bay. Its area is 6500 square miles. Tidore, which was discovered by Magellan, and taken into the possession of the Portuguese in 1527 , and by the Dutch in 1607, as also Ternate Island, are on the west coast of Gilolo. Gilolo has a long mountainous coast; high bold land, with three remarkable peaks. The Negro indigenes called Alfuro live in the north of the island. They are an industrious and enterprising race, cultivating rice and vegetables, and indefatigable in their search after game, fish, trepang, pearls, and tortoise-sbell. They are radically distinct from all the Malay race. Their stature, their features, as well as their dispositions and habits, are almost the same as those of the Papuan. Their hair is semi-Papuan, neither straight, smooth, and glossy like all true Malays, nor so frizzly and woolly as the perfect Papuan type, but always crisp, waved, and rough, such as often occurs among the true Papuans, but never among the Malays. Their colour alone is often exactly that of the Malay, or even lighter. Of course there has been intermixture, and individuals are seen whom it is difficult to classify, but in most cases the large somewhat aquiline nose with elongated apex, the tall stature, the waved hair, bearded face, and hairy body, as well as the less reserved manner and louder voice, unmistakingly proclaim the Papuan type. Here is the exact boundary between the Malay and Papuan race. It is only in the Northern Peninsula that these Papuan indigenes exist, the whole of the rest of the island, with Batchian and the other islands westward, being exclusively inhabited by Malay tribes like those of Ternate and Tidore. This would seem to indicate that the Alfuro are a comparatively recent immigration, and that they have come from the north or east, perhaps from some of the islands of the Pacific, though it is difficult to understand why so many fertile islands should possess no indigenes. It has, indeed, been stated that Obi, Batchian, and the three Southern Peninsulas of Gilolo possess no true indigenous population. The Galela race are natives of a district in the extreme north of Gilolo, but they are great wanderers over the Archipelago. They are a very fine race, remarkably energetic and industrious, of light complexion, tall and with Papuan features, coming near to the drawings and descriptions of the true Polynesians of Tabiti and $\mathrm{Owyhee.}$ They build large and roomy prahus, with outriggers, and settle on any coast or island they take a fancy for. They catch turtle and trepang, hunt deer and wild pigs, and dry the meat, and cut down the forest and plant rice or maize. The Tebello tribe is similarly described. Bikmore, however, states, seemingly erroneously, that the Alfuro are strictly of the Malay type, and have not the dark skin and frizzly hair of the Alfuro of Ceram and Buru, though representatives of that people may exist in Gilolo. The population of Gilolo is supposed to be 75,000 ; all but 5000 of them are under the sultan of Ternate. It has been suggested that the Alfuro seem to have affinities with the Tagala race of the Philippines, through the Sangir islanders.

Lombok Island is about 53 miles long and
45 miles broad, lying between lat. $8^{\circ} 12^{\prime}$ and $9^{\circ} 1^{\prime} \mathrm{S}$, and is intersected by the meridian of $116^{\circ} 15^{\prime} \mathrm{E}$. The Bugis call it Sassak, which is the name by which the inhabitants designate themselves, but its proper name is Selaparan. It is separated from Bali by the Straits of Lombok, and from Sumbawa by the Straits of Allass. It is mountainous, well covered with wood; a volcanic peak in the N.E. corner of the island has an altitude of 11,134 feet. The island has been peopled from the neighbouring islands.

The Sassak are a Malay race, hardly differing from those of Malacca or Borneo. They had been converted to Muhammadanism, but the island was conquered by the Balinese, and the ruling race are Brahmanical from $B$ ali, and the raja of Lombok has the title of Anak Agong, which means son of heaven. A Sassak accepting Hinduism enjoys the privileges of the Balinese, and is exempt from taxation. An extensive commerce is carried on with all the Malay islands, particularly with Java and Borneo. The people frequently do a-mok, and it seems to be deliberately done. On one occasion, a person doing a-mok killed seventeen people before he could be killed. In war, a whole regiment will agree to a-mok, and then run on with such desperate resolution as to be very formidable to men less excited than themselves.

The men are strict with their wives; infidelity is punished by the couple being tied back to back and thrown into the sea, where crocodiles devour the bodies. Even a married woman accepting a flower or betel from a stranger has been punished by death with the kris; and any one found without leave within the grounds of a house is krissed, and his body thrown out to the street. The people of Lombok believe that some men can turn themselves into crocodiles, which transformation they adopt in order to devour their enemies.

Sumbawa, a large mountainous island, 160 miles $E$. to $W$. aud 20 miles broad, with an area of about 3200 square miles, separated on the TV. from Lombok by the Strait of Allass, and by the Supia Strait on the east from Flores and Commodo. Ithas six native states, -Sumbawa, Bhima, Dompo, Tomboro, Sangar, Pekat, under the supremacy of Netherlands India. It produces wax, birds'nests, sulphur, pearls, gold-dust, tobacco, horses, rice, timber, sandal-wood. The (fire mountain) Gunong Api is at the N.E. end of Bhima harbour. In Sumbawa, in $1815,12,000$ people were destroyed by the great eruption of Tomboro. Three languages are current in this island, one of them spoken by the people of Bhima. Their alphabet, once distinct, has been displaced by that of the Celebes.

Ceram Island, next to Celebes, is the largest island of the Moluccas. It is situated between lat. $3^{\circ}$ and $4^{\circ} \mathrm{S}$. on the meridian of $130^{\circ} \mathrm{E}$., and is 180 miles long, but its greatest breadth is only 42 miles. The island is one long mountain chain that sets off transverse spurs, and some of the peaks are 5000 or 6000 feet in height, all of them sending down innumerable streams to the sea. The vegetation is everywhere luxuriant, and the trees gigantic. The northern peninsula of Gilolo, and the great island of Ceram, are inhabited by tall and well-made people, with Papuan features and curly hair. They are bearded and hairy limbed, but they are quite as light in colour as 
the Malays. They are an industrious and enterprising race. The people of Ceram approach nearer to the Papuan type than those of Gilolo. They are darker in colour, and a number of them have the frizzly Papuan hair; their features are harsh and prominent, and the women are far less engaging than those of the Malay race. The Papua or Alfuro man of Ceram gathers his frizzly hair into a flat circular knot over the left temple, and places cylinders of wood, as thick as one's fingers and coloured red at the ends, in the lobes of the ears. They go almost naked, but armlets and anklets of woven grass or of silver, with necklaces of beads or small fruits, complete their attire. The women have similar ornaments, but wear their hair loose. All are tall, with a darkbrown skin, and well-marked Papuan physiognomy. Ceram has on its western side the three islands Bonoa, Kelang, and Manipa. The commercial products from these islands consist of tortoise - shell, mother - of - pearl, beche-de-mer, wild cinnamon, wild nutmegs, and birds of paradise. Of 28 words of the language of Ceram, nine of the words are Malay, two Javanese, and 17 are common to these two languages.

Goram is a group of three islands at Manowolko, east of Ceram; a slight infusion of Papuan on a mixture of Malay and Bugi has produced a good-looking people. The Goram people are wholly traders; every year they visit the Tenimber, $\mathrm{Ki}$, and Aru islands, the whole N.W. coast of N. Guinea, from Oetanata to Salwatty, and the islands of Waigiou and Mysol. They also extend their voyages to Tidore, Ternate, Banda, and Amboyna. Their trade is in trepang, medicinal Mussoi bark, wild nutmegs, and tortoise-shell, which they sell to the Bugi traders at Ceram Laut and Aru. Their prahus are all built by the $\mathrm{Ki}$ islanders, who annually turn out hundreds of neat boats.

S.E. of Goram is a high group composed of raised coral reefs 300 or 400 feet, with a volcano on the island of Teor, which broke forth in 1659 .

Sangir and Siau Islands are two groups between Celebes and the Philippines. The inhabitants resemble the people of Menado, whom Mr. Wallace (ii. pp. 292-95) describes as Negrito. Christianity has made progress among the Sangir islands, the Christian population in the middle of the 19th century having been 20,000. There are several extinct volcanoes, and some still in full action, in the Sangir group; the devastations which they have caused from time to time have been disastrous to the inhabitants. The eruption of Duwana, in 1808 , completely annihilated the village of Tagalando, destroyed all the surrounding forests, and suddenly deprived the inhabitants of all means of livelihood, by the destruction of their fields. The Gunong Api causes numerous ravages in the island of Siau; its peak, 6000 feet above the level of the sea, forms the culminating point of this group. Gunong Api covers with its base all the northern part of Sangir-besar; this volcano was active in 1812, when the torrents of lava destroyed the extensive forests of cocoanut trees with which this part of the island was covered, and caused the death of many of the inhabitants. These islands furuish more than 25 kinds of wood suited for building and furniture. Two harbours, sheltered from all winds, exist in the larger Sangir, one in the Bay of Taruna, the other called Midelu on the eastern side.

Floris or Flores is an extensive island of the Archipelago, 201 miles long from E. to W., and from 34 to 45 miles broad. It was so named from the Portuguese word Flor, a flower, but is called Ende and Mangerye, from its chief south and west ports. It is in lat. $8^{\circ}$ and $9^{\circ} \mathrm{S}$., and in long. $123^{\circ} \mathrm{E}$. The inland parts are very mountainous and woody, and it contains several active volcanoes of considerable height. The Portuguese early visited and named this island, but they do not appear ever to have settled on it, and in 1812 the Bugi expelled all European settlers. But on the east of the island many profess Christianity, and hoist the Portuguese flag. Its chief trade at Ende is with Sumba or Sandal-wood Island; the Mangerye port trades with the Bugi and Malay. According to the statements of Bugi traders who had settled in Flores, that island is inhabited by six different tribes or races speaking as many different languages, the Ende, the Mangarai, the Kio, the Roka or Rakka, the Konga, and the Galeteng, names derived from the principal places of their residence. The coast is occupied by the Malay or brown race, but in the interior is a people with frizzled hair, and a similar frizzledhair people live in the mountainous parts of Solor, Pintar, Lombatta; and Ombay. On the south coast is the Rakka or Roka tribe, who are reported to be cannibals, accustomed to eat their enemies and their own relatives who die. Captain Keppel says that the natives captured from the island used to be much esteemed by the Celebes pirates as slaves.

Solor island is about 70 miles in circumference, lying south of Celebes. Its N.E. extremity is in lat. $8^{\circ} 26^{\prime} \mathrm{S}$., and long. $123^{\circ} 10^{\prime} \mathrm{E}$., and it is separated from Flores by the straits of that name. The mountaineers appear to be the original inhabitants. Up to 1837 they were perfectly savage, subsisting on and bartering forest products with the coast tribes. The latter are said to be of the Malay race, are called by Moor the Baju Laut or Orang Laut, are remarkable for their skill in managing their prahus and canoes, and are the most expert fishermen in these seas, frequently capturing the black fish, a small variety of the cachalot or sperm whale, which no other fishermen in these seas will venture to attack. The blubber or fat obtained from them is used as food, and also as an article of barter with the inland inhabitants; and the oil and spermaceti is sometimes disposed of to the Bugi and Macassar traders, who prefer it to cocoanut oil for burning in their prahus. Several Solor fishermen are always to be found at Coupang, the Dutch settlement on Timor, chiefly in the service of the Netherland Government, from whom they obtain a fixed allowance of rice and maize. These are relieved by others every year, in compliance with an old treaty, by which the coast natives of Solor agreed to furnish an annual quota of men for the public service. As all the youths have to take their turn, the system makes them accustomed to intercourse with Europeans. Their religion is Muhammadan, but many on the north coast have been converted to Christianity.

The neighbouring islands of Sebrao, Pantar or Alao, Ombay, and Wetter are inhabited by the same race as the mountaineers of Solor, and are 
said to be caunibals (Moor, p. 11), constantly on the watch to surprise the unwary.

Timor is the most southerly and the largest of the Molucca Islands, extending from lat. $8^{\circ} 21^{\prime}$ to $10^{\circ} 23^{\prime} \mathrm{S}$., and long. $123^{\circ} 30^{\prime}$ to $127^{\circ} 15^{\prime} \mathrm{E}$. ; it is about 300 miles long and 60 broad, and has high undulating mountains in the interior. Timor seems to form the N.E. end of the great range of volcanic islands, which extends N.E. and S.W. from Timor to Sumatra. It has only one active volcano, Timor Peak, near the centre of the island, which was blown up during an eruption in 1638, and has since been quiescent. Earthquakes occasionally recur. Timor means the east. The Portuguese settlement of Dieli or Diely is in lat. $8^{\circ} 34^{\prime} \mathrm{S}$., and long. $125^{\circ}$ $40^{\prime}$ E., and on the north side of the island. Koepang or Coupang, in the west end of the island, is the chief Dutch town. These two nations claim between them the entire sovereignty of the island. The coast is largely occupied by Malays and Chinese, but in the interior are tribes much nearer to the true Papuan than those of the Moluccas, The Timorese are dusky-brown or blackish, with bushy frizzled hair, and the long Papuan nose. They are of medium height and of rather slender figures, are constantly at war with each other, but they are not very courageous or bloodtbirsty. In their excitable disposition, loud voices, and fearless demeanour, the Timorese closely resemble the Papuan people of New Guinea. In the islands west of Timor, as far as Sumba or Sandal-wood Island and Flores, a very similar race is found, which also extends eastward to Timor Laut, where the true Papuan race begins to appear. The inbabitants of the southwestern part of Timor, in the neighbourhood of Coupang, are an exceedingly dark, coarse-haired people, and travellers have found difficulty in coming to a conclusion as to whether they belong to Malayan or Papuan races, so equally balanced are their characteristics. The anonymous author of an excellent Account of Timor, Rotti, Sivu, Solor, etc., in Moor's Notices of the Indian Archipelago, says the natives are generally of a very dark colour, with frizzled, bushy hair, but less inclining to the Papuans than the natives of Ende (on the island of Flores). They are below the middle size, and rather slight in figure. In countenance they more nearly resemble the South Sea islanders than any of the Malay tribes. The S.E. coast of Timor near Mount Allas is, according to Bikmore, occupied by the Papuan race with frizzled hair in tufts on the head. Mr. Earl says that the short tufted hair of the mountain Papuan is found in Timor, and it is possible that the races are there mixing, as its position is next to Papua. There are Malays and Chinese, but the native Timorese preponderate; they have nothing in common with the Malays, and are closely allied to the true Papuans of the Aru Islands and New Guinea. The women talk to each other and to the men with loud voices, and with a self-assertion quite different from Malay women. The mountaineers of Timor are of Papuan type, have rather slender forms, bushy frizaled hair, the skin of a dusky-brown colour, and have a long, somewhat aquiline nose, with the overhanging apex, which is so characteristic of the Papuan, and so absolutely unknown among races of Malayan origin on the coast. There has been an admixture of Malay, and the coast occupants have wavy, not frizzled hair, a lower stature, with less prominent features, and the houses are built from the ground. The houses of the Papuan mountaineers are raised on posts. The dead of the Papuan Timorese are laid on a stage six or eight feet above the ground, sometimes open, sometimes covered, and are retained there till money for a feast can be obtained, when they are burned. The 'Pomali,' exactly resembling the taboo of the Pacific, is in full operation here, and a few palm leaves stuck outside of a garden will preserve it from any thief.

The land mammals in Timor are only seven in number,-Macacus cynomolgus, common all over the Indo-Malayan Archipelago; Paradoxurus fasciatus, a civet cat; Felis megalotis, a tiger cat; Cervus Timorensis; Sorex teais; and Cuscus orientalis.

Semao Island is near Timor. The natives of this place have been named by Mr. Crawfurd of the Negro-Malayan race. The people are like those of Timor, with frizzly or wavy hair and a copperybrown colour. Semao Island has abundance of monkeys, one of them, the Macacus cynomolgus, or hare-lipped monkey, which is found all over the western islands of the Archipelago.

Rotti Island lies off the S.W. end of Timor. It is about 60 miles long and 38 miles broad, and is in lat. $10^{\circ} 53^{\prime} \mathrm{S}$., and long. $123^{\circ} 5^{\prime} \mathrm{E}$. It is a succession of low hills and narrow valleys, the soil is stony but fertile. In the early part of the 19 th century it had 18 rajas over as many districts. who could bring 10,000 fighting-men into the field, sometimes opposing, sometimes aiding the Dutch, but always at enmity with the Timor raja. The inhabitants are below the middle height, and are considerably darker than the people of Celebes, but are remarkable for having long lank hair, whilst nearly the whole of the inhabitants of the surrounding islands have frizzled hair. Their features are more prominent, and they bear a stronger resemblance to the natives of India than to those of the eastern islands. The women are much fairer than the men, and many of them have very pleasing countenances. They are a mild-tempered people, and not of jealous disposition; polygamy and divorce are allowed. Their religion and belief in auguries are nearly the same as in Timor. They inter their dead under their houses, which, as in Celebes, are always raised several feet from the ground, whilst those of Timor are always built on the ground. Their language has many words in use in Timor, but the natives of the two islands do not understand each other. The slave trade up to the early' part of the 19th century was carried to a great. length in this island, several hundred slaves having been exported to Batavia, Amboyna, and other Dutch settlements in the course of one year. Ansus Island is Papuan. The houses, built on posts, are placed entirely in the water. At very low water only is the beach partially uncovered. This beach consists of mud, in which mangroves grow luxuriantly, and completely obstruct a landing. The gardens, from this cause, are situated on the surrounding islands, principally on an island with a high beach lying opposite to the kampong. The Ansus Papuans' hair is in tufts. Their appearance is good-natured, faces regular, eyes beautifully black, the mouth broad, with 
beautiful regular teeth, and the forehead high but narrow. Many have thin lips and finely curved noses, which give them a more European physiognomy. The men are generally handsome and well formed, stout, without being too thick, strong and muscular; the women very good looking; and some children with very regular soft faces and long pendent curling hair.

$B o$ Island is inhabited by a mixed race of Papuans and the brown race.

New Guinea is known to the Malays as the Tanna Papua. Its approximate area is 275,000 square miles, and it is, after Australia and Borneo, the largest island of Australasia. It is essentially the Papua land, its people being partly of the diminutive and partly of the stalwart Negro race. The island was discovered in 1525-26 by the Portuguese, and up to the present time its coasts and seas have often been visited by ethnologists, surveyors, and Christian missionaries; but the sickly nature of the climate, and the repellent character of the Papuans, have prevented investigation.

Captain Moresby says the coast north of Torres Straits, as far east as Yule Island, appears to be occupied by the black Papuan race, naked and hostile. It is an unbroken level of swampy, mangrove-covered ground, and probably malarious; its shores have no protecting barrier reef.

He speaks of the fierce and bloody nature of the black Papuans of West New Guinea. But he also mentions that from Red Scar-Head to the extreme east of New Guinea, the coast is peopled by a mild Malayan race of inoffensive manners. Red Scar-Head is 35 miles east of Yule Island; outside from 4 to 10 miles from the shore is a great barrier reef. Some of their houses are 30 to 40 feet long. They are a small, lithe, copper-coloured people, with clean, well-cut features and a pleasing expression of countenance. They wear their hair frizzled out, mop fashion, and are tattooed with stars and small figures on the breast and shoulders. They wear a leaf girdle; the young men have cowrie shell ornaments on the legs and arms, and plumes of paradise birds on the head. The cartilage of the nose is pierced, and bits of bamboo or shells inserted. According to the same author, in Robert Hall Sound the people are of the Malay type, shorter, coarser in feature, and thick lipped, almost beardless. They have high cheekbones, like the Malay, but their noses are well formed and inclined to be aquiline. Their eyes are dark and beautiful, with good eyebrows. The men's hair is frizzled into a mop form, but that of the women is cut short, and their bodies are tattooed with graceful patterns. The men do not tattoo. Their race joins the black Papuan in the vicinity of Cape Possession; but Captain Moresby also says both races were present at Robert Hall Sound, and the natives varied in stature and cast of feature.

Dori harbour or bay is formed by a long, low promontory, curving round towards the Arfak range, which rises abruptly from the opposite side of the bay. Towards the extremity of this promontory is situated the village of Dori, and opposite, at about a mile, is the inhabited island of Mansinam, and a smaller one uninhabited. The inhabitants of Dori build their houses at or below low-water mark, raised on posts, and reached by a rough and tottering causeway from the beach. The natives of the interior do not differ perceptibly in physical character, but have a distinct language, and are called Arfaki by the Dori people. Their houses are very similar, but are raised 12 or 15 feet high, on a perfect forest of thin poles, a few of which are put diagonally, and prevent the whole from falling with the first wind. The people of Dori are fishers and traders, the Arfaki are agriculturists. The former catch turtle and trepang, which they sell for beads, knives, and cloth, and purchase of the Arfaki their rice and yams, plantains, and bread-fruits, and numbers of tame cockatoos and lories, which they sell again to the Ternate and Tidore traders. All these natives have the characters of the Papuan race very strongly marked,- - the fiat forehead, heavy brows, and large nose, with the apex bent downwards, are almost universal, as well as the harsh curly hair, which often forms an enormous stiff mop, and is then highly esteemed. It has, in fact, a very grand and imposing effect. The colour of the skin varies greatly. In general it is a dirty black or sonty colour, but varies to a fine brown, which is often quite as light as that of the pure Malay races. The natives of Dori possess the rude artistic genius of the Oceanic tribes, decorating their household utensils and the prows of their canoes with elaborate carving, and the posts of their council-house with obscene caryotides. The language of the Dori people resembles that of the Aru and Ki Islands in containing a large number of monosyllabic words, as well as others excessively polysyllabic, offering a remarkable contrast to the striking dissyllabic character of the whole Malayan group of languages.

Papuans of Sorong, on the N.W. coast of New Guinea, are said to drink the blood which drops from a newly-cut-off head of an enemy killed in war, provided he had been a man of valour; they believe thus to inbibe his courage.

The Papuan idols called Karwar are the effigies of the distinguished men. They are similar to the Tikki of the Maori and other wooden figures of the Polynesians.

Brumer.-The women of Brumer Island, on the south coast of New Guinea, are tattooed on the face, arms, and front of the body, but generally not on the back, in rertical stripes less than an inch apart, and connected by zigzag markings. On the face these are more complicated, and on the forearm and wrist they are frequently elaborate as to resemble lacework. The men are more rarely tattooed, and then only with a few lines or stars on the right breast. Sometimes, however, the markings consist of a double series of large stars and dots stretching from the shoulder to the pit of the stomach.

Warrior Island is in Torres Straits. The men are powerful, are armed with six-foot bows; their war canoes are 50 and 60 feet long.

Aiou or Yowl is a group of islands situated about 70 miles W.N.W. from the Cape of Good Hope, on the W. coast of New Guinea, and 30 miles N.E. from the island of Waigiou in the Gilolo Passage. The group consists of circular low isles, 16 in number. The largest lies in about lat. $0^{\circ} 25^{\prime} \mathrm{N}$., and long. $131^{\circ} \mathrm{E}$. The group is surrounded by an extensive coral reef, nearly a degree in circumference, the south-western portion 
of which is separated from the main reef by a narrow but deep channel. Aiou Baba, the largest of the group, lies on this detached portion of the reef, and is about 7 miles round, and 500 feet in elevation. The north-eastern or larger reef, which contains the islands of Abdon and Konibar, with several coral islets, is said to have an opening on the N.W. side which admits large vessels within the reef. The inhabitants are Papuans, are few in number, and occupy themselves almost exclusively in fishing and in catching turtle, with which the lagoons within the reef abound. The chief exports are tortoise-shell of good quality, which is obtained here in large quantities, and trepang. These are purchased by Chinese from Ternate, the king of which place assumes supreme authority over all those parts of the coast of New Guinea which his subjects have been in the habit of visiting for purposes of trade. The traders to Aiou all employ small vessels, which alone are adapted for going within the reef of Aiou Baba, their chief resort. They bring red and white calicoes, thick brass wire, old clothes, glass beads, and all sorts of ornamental finery which the Negroes of New Guinea delight in as much as those of Africa. The natives are tolerably friendly to strangers, but must not be trusted too much, as they are inclined to be treacherous and revengeful, which is the case, indeed, with all the Papuan tribes.

Modera is about 25 miles in length, lying to the N.N.E. of the Great Ki, distant about 60 miles, and is the south-westernmost of a group of high islauds, which until lately were considered as forming a part of New Guinea. The inhabitants are Papuans, and do not bear a high character among their neighbours. Wild nutmegs, trepang, and tortoise-shell are obtained here. Red calico, parang or chopping knives, coarse cotton shawls and handkerchiefs, with iron, Java tobacco, muskets, and gunpowder, are the principal articles in demand. The chief traffic was in slaves, which are distributed among the neighbouring islands of the Archipelago, and are sometimes carried as far as Bali and Celebes.

Waigiou Island lies between New Guinea and Gilolo. Its inhabitants are Negroes, with features more regular, an expression of countenance more agreeable, and complexion less black, than the Negroes of New Ireland. Their persons are delicate and slender, and their stature short. The hair differs in texture among individuals, some having it woolly like the African Negroes, some lank like the European, and others again of a texture between the two. The highest facial angle was $69^{\circ}$, and the lowest from $63^{\circ}$ to $64^{\circ}$. Paradisea rubra, the rare red paradise bird, and Ptilonopus pulchellus, a lovely little dove, occur here.

Gebe Island is between New Guinea and Gilolo. It is occupied by the Negro race, with nose flat, the lips thick and projecting, the complexion a dark olive, the eyes deep seated, and on an average the facial angle $77^{\circ}$, but as high as $81^{\circ}$. In Gebe, Waigiou, and in some parts also of the coast of New Guinea, the Malayan race may have become intermixed with the Negro, as the complexion is lighter and the peculiar texture of the Negro hair altered or obliterated. The language spoken at Waigiou is entirely Papuan, being that which is used on all the coasts of
Mysol, Salwatty, the N.W. of Guinea, and the islands in the Great Geelvink Bay. Waigiou, Gebe, Poppa, Obi, Batchian between New Guinea, and the Moluccas, as well as the south and east peninsulas of Gilolo, possess no original tribes, but are inhabited by people who are evidently mongrels and wanderers.

Arroe or Aru Islands extend from lat. $7^{\circ}$ to lat. $5^{\circ} 52^{\prime} \mathrm{S}$., and in long. $133^{\circ} 56^{\prime} \mathrm{E}$., run for upwards of 100 miles N. and S., and between 40 and 50 miles in breadth. They lie between the Timor Laut group and the S.W. coast of New Guinea, distant about 60 miles. They are a closely-packed group. Some of the southern islands are of considerable extent, but those to the north, lying close to the edge of the bank, are rarely more than 5 or 6 miles in circumference. The land is low, being only a few feet above the level of the sea, except in spots where patches of rock rise to the height of 20 feet, but the lofty trees which cover the face of the country give to it the appearance of being much more elevated. Coral reefs extend from the shores of all the islands, and in the eastern parts of the group these are often of great extent. The Aru islanders have had much intercourse with strangers. They purchased from the Bugis the Papuan slaves brought from New Guinea, who were employed in diving for pearls and in the beche-de-mer fishery. The Aru islanders are excessive in their use of intoxicating liquors, imported from Java and Macassar. In personal appearance the people are between the Malayan and Polynesian Negro. In stature they surpass the civilised natives of Celebes. The dress of the men is a piece of matting or cloth girded round the loins, and drawn tight between the thighs, and a salendan or shawl. No fillet is worn round the head. The hair is woolly and frizzled out like that of the Papuan. The men are jealous, and easily roused to anger by abuse of their women or ancestors; otherwise they are of mild disposition. Christianity was introduced into the Aru Islands many years ago by the Dutch of Amboyna, and nearly all the principal people profess this creed, but some are Muhammadans. The Aru islanders bear a strong personal resemblance to the aborigines of Port Essington; indeed, on several occasions in which natives from the neighbourhood of the late settlement visited the islands in European vessels, they were considered by the Aruans as belonging to some remote part of their own group. But the Aruans also possess many characteristics in common with the Outanata of the opposite coast of New Guinea. One of their most singular peculiarities, however, consists in the value which they attach to elephants' tusks, brass gongs and trays (dulam, talam), and huge porcelain dishes. A man's goods on his death, all the chattels which he has collected during his life, including tusks, gongs, and precious china dishes, are broken in pieces and thrown away; and in the villages may be seen heaps of these fragments of property which custom or some singular superstition has deterred the living from appropriating. The natives are Papuans, with black or sooty-brown skins, woolly or frizzly hair, thick-ridged prominent noses, and rather slender limbs; most of them wear nothing but a waist-cloth. The Papuan talks, laughs, shouts without intermission. Papuan boys sing cheerily as they walk along, or talk 
aloud to themselves, which is quite a Negro peculiarity. They have as food, sago, vegetables, fish, and molluses; and tobacco, betel, and arrack are their luxuries. Their houses are rude sheds. There are some mixed races amongst them. The women have only a mat of plaited strips of palin leaves worn tight round the body, andr eaching from the hips to the knee, or suspend a mat in front and one behind. Their frizzly hair is tied in a bunch at the back of the head. They delight in combing it or forking it, using a large wooden fork with four diverging prongs, to separate and arrange the long, tangled, frizzly mass. They and the men wear ear-rings, necklaces of silver, brass, shell. The Aru Papuans told Mr. Wallace that some of their tribes kill the old men and women when they can no longer work, but he saw many old folk. Their hair is usually black, and strongly curled. Like the African Somali, they wash it with wood-ashes or lime-water, which impart to it a lightish colour, and cause it to appear rough, both these peculiarities being considered very tasteful by the Alfoer as well as by the Papuans. The usual height of the men is from 5 feet 4 inches to 5 feet 8 inches, and there is a great inclination to slimness about the lower extremities among the taller men, some of whom attain the height of 6 feet.

The Baju or Baju Laut, meaning the Sea Baju, are a maritime people in the Aru Islands, who venture far to sea. Many of the Baju remain throughout the year near the. Dutch Settlement of Macassar, on the south end of Celebes, where they are found very useful in carrying despatches. They are chiefly employed by the Chinese in fishing for trepang or sea-slug, and, according to the policy invariably adopted by the latter in their dealings with the natives, are generally involved in debt, from which extrication is nearly hopeless. The demand against each boat or family usually averages about four hundred guilders (twenty-five pounds sterling), and, extraordinary as it may appear, no instance is on record of their ever having absconded to avoid the payment of their debts. About Sulu and the circumjacent islands, the Baju Laut are the most industrious and useful race, and to them Sulu is indebted for bringing its submarine wealth. A hundred sail of ten to twenty tons burden have been seen at one time at Bontian under Dutch colours. They are a different race from the Orang Laut of the Malay Peninsula and the Straits of Malacca. They are the Orang Solok of the east of Subanas and Lutas. They speak the language of Sulu, and profess Muhammadanism.

The Kei Group of ten islands adjoins the Aru Islands. Ke, Kei, or $\mathrm{Ki}$ is prefixed to the names of all their villages. The Great $\mathrm{Ki}$ is about the size of Tanakeka, an island near Macassar. The $\mathrm{Ki}$ group form the northern of the south-easterly islands. The natives are industrious, and great boat-builders. The islands, covered with luxuriant forests, are occupied by two races, one of them the Papuan, who make cocoanut oil, build boats, and make wooden bowls; their boats are from small planked canoes to prahus of 20 to 30 tons burden. They build the skin first and fit on the knees and bends and ribs. Money is not used, but every transaction is in kind. The Papuan wears a waist-cloth of cotton or bark. The Papuan women of $\mathrm{Ki}$ are not secluded, the children are merry, noisy, and have the Nigger gxin, and amongst the men is a noisy confusion of tongues and excitement on every occasion. The other race are Muhammadans who were driven out of Banda, and wear cotton clothing. They are probably a brown race, more allied to Malays, but their mixed descendants have great varieties of hair, colour, and features, graduating between the Malay and Papuan tribes. The men profess Muhammadanism, but eat hog's flesh. The islands produce Maratigo and Banyaro woods, well adapted for masts.

Carpophaga concinna occurs in the $\mathrm{Ki}$ and in Banda, where it is called the nutmeg pigeon. Cyphogastra calepyga, a beautiful species of the Buprestidæ, occurs here; also the butterfly Orchis, Phalænopsis grandiflora, two large beetles, Therates labiata and Tricondyla aptera. T. labiata is ever on the watch, and from time to time emits an odour like otto of roses. Tricondyla aptera of the Malay Islands resembles a large ant, more than an inch long, and of a purple-black colour. It is wingless.

The PHILIPPINE ISLANDS were discovered in 1521 by Magellan, and they were named after Philip Ir. of Spain. There are ten principal islands, 400 of medium size, and 800 islets, running 900 miles from worth to south, and 500 miles from east to west, from lat. $5^{\circ} 40^{\prime}$ to $18^{\circ} 47^{\prime} \mathrm{N}$., and between the meridians of $120^{\circ}$ and $125^{\circ} \mathrm{E}$.

The larger islands are traversed by chains of lofty mountains, in which are active rolcanoes, amongst others, Dabao in Mindanao, Albay and Taalen in Luzon. Earthquakes recur apparently three times in a century, and hurricanes frequently sweep across the islands. The population is about four millions, in many distinct nations or tribes, speaking distinct languages unintelligible to each other. They are sometimes called the Manillas, and their inbabitants Manillamen.

Spanish territory is nearly 116,000 square miles, and population about 8 millions, and a trade exchange of 12 millions sterling. The three great outlets into the Pacific lead from the Philippines, viz. the Sulu channel, leading direct to New Guinea; the Bernardino strait opposite the Pelew and Mariana Islands, and in the north the Bashi passage, the nearest outlet from China. In 1833 , the population of the principal islands was estimated-

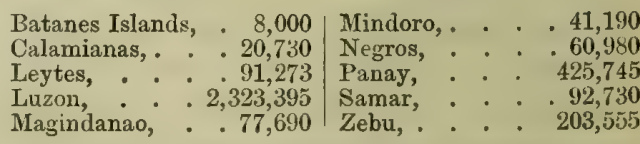

A writer in the Quarterly Review (No. 314 of 1884) says their southern half is tenanted by the Visaian (Bisayan), who resemble the Dyak of Borneo. Many of them have adopted Christianity. They are fond of music and gaiety.

The Tagala subdivisions are the Kosan, Bicol, Igorrotes, and others in the northern part of the Philippines. They are darker than the Visaian, are excellent agriculturists, ingenious artificers, and daring seamen. Chinese bave married with the Tagal. The total number of Spaniards does not much exceed 5000 .

The Negrito are believed to have been the prior occupants, and to have retired into the mountain districts before invaders. They are a black, woolly-haired race, of diminutive stature, 4 feet 
6 inches to 4 feet 8 inches high, with hair like that of the Papuan and many Negroes of Africa. But of the central group of the Philippines, consisting of Panay, Negros, Samar, Leyte, Masbate, Bohol, and Zebu, only in the first two were Negrito tribes remaining, the crest of the mountain range of Negros, which extends for 120 miles throughout the length of the island, being almost exclusively occupied by scattered tribes of Negritos.

Magindanao or Mindanao, the most southerly island, is partly under Spain, and in part under feudatory chiefs, with Muhammadan subjects of Malay race, whose women at the age of 13 (probably on marriage) have their teeth filed thin, stripped of the enamel, and blackened. The Negrito sparsely occupy the interior. Mindanao people were addicted to piracy, using prahus 96 feet in length, 26 in breadth, and $8 \frac{1}{2}$ feet of hold, with 40 oars, 2 rudders, and a crew of 90 men. Some of their prahus are long and narrow, 50 feet long, and only 3 in breadth, but with outriggers to enable them to carry sail. They use the tripod mast, and sail with great speed.

In Mindoro Island, the Negrito occupy the Bengan, a mountainous district, living on friendly terms with the Manguianes, wild tribes of the brown race, by whom they are surrounded.

The principal tongues of Luçon are the Tagala, the Pampanga, the Pangasinan, and the Iloco.

The islands produce gold, sulphur, amber, pearls, tortoise-shell, mother-of-pearl, sappanwood, and ebony ; and rice, cocoa, coffee, indigo, and pina fibre are grown.

Negros. - The woolly - haired tribes are more numerous in the Philippines than in any other group of the Indian Archipelago, with the exception of New Guinea. The Negrito population in 1842 was 25,000 . The island on which they were first seen was named by Magellan 'Isla dos Negros,' to distinguish it from the adjacent island of Zebu, where his ships remained for some months. Negros still contains a large population of Papuans, while Zebu is altogether free from them, and no record exists of their having ever been found there. Samar and Leyte are similarly situated with Zebu, but Mindanao and Mindoro contain several tribes of Negritos, and they form the chief population of the less accessible parts in the mountain ranges of Luçon, the largest island of the Philippine group. The accounts of the Negritos given by the early Spanish navigators perfectly apply to their present condition. They are described as being smaller, more slightly built, and less dark in colour than the Negroes of Africa, and as having features less marked with the Negro characteristics, but as having woolly hair. The Indian races are in general superstitious, credulous, fond of gaming, and particularly addicted to cock-fighting. The Negrito are said to be the original inhabitants of the islands, who retired before the invading Indians. The extent of this Archipelago is 300 leagues from north to south, and 180 leagues from east to west. Its islands are traversed by a mountain range, and partially fertilized by the overflow of spacious lakes. This Archipelago received its name after Philip II. of Spain, in whose name they were finally conquered, pacified, and peopled. The Negrito of the Philippines are polytheists, but without temple or ritual. They believe in omens, invoke Camburan (God) the moon and stars, and adore the rainbow after a storm. They have also a worship of ancestors, a god of the harvest, of the fisherman and hunter, and a remnant of fetishism in a grotesque native devil. Iloco is one of the languages spoken in the island of Luçon. In the Philippines are many separate nations or tribes, speaking distinct languages unintelligible to each other. The principal tongues of Luçon are the Tagala, the Pampanga, the Pangasinan, and the Iloco, spoken at present by a population of $2,250,000$ people, while the Bisaya has a wide currency among the southern islands of the group, Leyte, Zebu, Negros, and Panay, containing $1,200,000$ people.

Negros or Buglas Island extends from lat. $9^{\circ}$ $4^{\prime}$ to lat. $9^{\circ} 50^{\prime} \mathrm{N}$. Of the central group of the Philippines, consisting of Panay, Negros, Samar, Leyte, Masbate, Bohol, and Zebu, the two former are the only islands in which Negrito tribes exist. to the present day, and even as regards Panay, the fact must be considered doubtful. Negros, however, contains a considerable Negrito population, the crest of the mountain range, which extends throughout the length of the island, a distance of 120 miles, being almost exclusively occupied by scattered tribes.

The SULU ARCHIPELAGO is that chain of islands, about 60 in number, which stretches across from the N.E. point of Borneo to the island of Mindanao. Sulu Island, from which the Archipelago is named, is high and of considerable extent, being 35 miles long and from 5 to 10 broad; it lies in long. $121^{\circ} \mathrm{E}$., near the centre of the Archipelago. Sulu was called Felicia by the Spaniards. It was also called Banjar Kulau, Little Banjar, to distinguish it from Banjar Massing in Borneo; and the word Sulu has been surmised to be from the Chinese $\mathrm{Su}$ and Lao, the island of the Laos. The ruling race are Malays. The occupants were Papuans, who have been driven to the mountains by subsequent races. A people called Orang Dampuwan, or by the Chinese Sonpotualan, held Sulu and all the sea-coasts for a short time. Chinese and Spaniards have several times taken and lost ground. A race is named who are called Orang Duson, and another as the Orang Sulok or Bisayan. The religion of the ruling race is Muhammadanism, but part of the Papuans are pagans and part Muhammadan, and there are remains of Buddhism and Hinduism. There are Christian freemen in the interior. The Bisayan language of Luçonia is in general use, but many of the people speak Malay, others Chinese, and others Spanish. Marsden mentions the existence of dictionaries of the Bisayan, Tagala, and Pompanga tongues. In the middle of the 18 th century the British sent to Sulu Mr. A. Dalrymple and others on commercial missions, which led to no permanent results. The houses are, like those of the Malays, raised 4 or 5 feet from the ground, the ascent being by a ladder, which is pulled up at night. The Macassar men of Celebes determine many disputes by single combat, but never avenge themselves by personal assassination. On the contrary, the Sulu race have no idea of putting themselves on a footing with their antagonist, but always attack him in the dark, or off guard. It would scarcely be possible to scrape up a more infamous race than the Sulu. The only virtue they boast is courage, which, unaccompanied with principle, is at best 
but negative, and in this instance doubtful. Honesty, industry, or hospitality are unknown to the mass of them, at least in practice, but they are distinguished by civil dissensions, treacherous assassinations, vain-boasting, theft, laziness, dirt, envy, and dissimulation, or rather unconnected falsehood.

The Sulu do not, like the Muhammadans of Hindustan, seclude their women; on the contrary, they mix in society as in Europe. The women wear a close, short baju of cotton of various colours, with kanchings on the back part of their arm; trousers (saluar) of fine white cloth or of flowered silks or kimkhabs, with two sarongs, one put on as a petticoat, the other thrown over their shoulders. They tie their hair in a bunch at the fore part of their head; wear krabows in their ears, rings on their fingers, and Chinese shoes on their feet. In their houses, however, their sole apparel is their trousers, remaining nude from the waist upwards. They arch their eyebrows with the razor, shave off the short hairs round their foreheads, and their teeth, like those of the men, are filed and stained black.

Mr. Hunt says the Baju of the Sulu Archipelago are really the Orang Sulok of the east of Subanos and Lutas. Authorities, however, have considered them to be from Johore, from China, from Japan, or a Bugi tribe. They speak the Bisayan language of Sulu, profess Muhammadanism, and are, as the word 'Baju' indicates, fishermen. They made Macassar their headquarters, to escape from the oppression from which they suffered at the hands of the Datu chiefs of Sulu. The Lanun or Illanun race, from the provinces of Illano and Melana, in the island of Magindanao, long carried on piratical expeditions, making Sulu their chief headquarters and entrepot for the sale of their plunder. They moved in large fleets of small prahus in the straits of Macassar, among the Moluccas, and in the southern islands of the Philippines. During a six months' residence at Sulu, about the year 1830, Mr. Hunt heard of many ships being captured. Their twelve establishments in the Sulu dominions in his time had upwards of 8000 pirates, with prahus manned by 30 to 60 . In 1851 the Governor-General of the Philippines took the fortress at Sulu, and since then Spain has been dominant over the Sultan, to whom they allow 2400 dollars per annum. In 1883 they assumed a more direct control.

FIJI group consists of numerous islands between lat. $15^{\circ} 30^{\prime}$ and $19^{\circ} 30^{\prime} \mathrm{S}$., and long. $177^{\circ}$ and $178^{\circ} \mathrm{W}$. They are in three divisions, an eastern, northern, and western, in a semicircle, with the base, about lat. $19^{\circ} 30^{\prime}$, in great part surrounded by coralline reefs. The population amounts to about 150,000 souls. They are of a Negroid race. Beyond the Fiji, the brown Polynesian race, or some intermediate type, extends over the Pacific. The descriptions of these latter agree exactly with the characters of the brown indigenes of Gilolo and Ceram.

AUSTRAIASIA embraces Australia, Tasmania or Van Diemen's Land, New Caledonia, New Hebrides, Queen Charlotte's Islands, Salomon Archipelago, New Britain, New Zealand, and others.

AUSTRALIA lies between lat. $10^{\circ} 39^{\prime}$ and $39^{\circ} 11^{\prime}$ S., and long. $113^{\circ} 5^{\prime}$ and $153^{\circ} 16^{\prime} \mathrm{E}$. Its coastline is about 7750 miles, within which is an area of three millions of square miles. The com plexion of the natives is chocolate-coloured, the lips thick, teeth white and even; eyes deep set, small, and black; hair long and black, generally straight, but sometimes slightly curled; beards thick and bushy.

SANDWICH or Hawaii or Owyhee Islands group, eleven in number, were discovered in 1778 by Captain Cook, and on the 14th February 1779 he was killed on the shore of the Bay of Kealakekua, on the west side of the island of Hawaii. They lie in the N. Pacific, between lat. $18^{\circ} 50^{\prime}$ and $22^{\circ} 20^{\prime} \mathrm{N}$, and long. $154^{\circ} 55^{\prime}$ and $160^{\circ} 15^{\prime} \mathrm{W}$. Maunakea mountain, in Hawaii Island, rises to 13,953 feet above the sea. The population in 1849 was supposed to be about 80,000 souls. There has been a large influx of foreigners from Asia, America, and Europe. The inhabitants are nominally Christians. The male population are a good height, athletic, and well proportioned; but neither men nor women are prepossessing in appearance, although they have the reputation of being good tempered and not easily aroused into anger. The ruins of an old temple are still to be seen about six miles from Honolulu, near Diamond Hill. It is said to have been built by Ka-me-hameha the First, after the conquest of the island. It is called Heiau. Here, in the days of heathenism, were offered human sacrifices. The victim was chosen either by the priest or king. The messenger of death entered his abode while he slept, and he met his end by strangling. He was then dragged off as an offering to the sanguinary god.

SAMOAN group, or Navigators' Islands, in the S. Pacific, eight in number, situated between lat. $13^{\circ} 30^{\prime}$ and $14^{\circ} 30^{\prime}$ S., and long. $168^{\circ}$ and $173^{\circ}$ W., were discovered in $1768^{\circ}$ by Count de Bougainville. The population is about 60,000 . The people are taller and better formed than any other of the Polynesians.

NEW ZEALAND consists of two large and several smaller islands in the Southern Pacitic Ocean, between lat. $35^{\circ}$ and $46^{\circ} \mathrm{S}$, and long. $166^{\circ}$ and $179^{\circ} \mathrm{E}$. They were discovered by Tasman in 1642. The area is about 86,000 square miles. There is an active volcano in the Bay of Plenty, and many conical hillocks, seemingly extinct volcanoes. The native population is estimated at 100,000. The men are tall, well-formed, strong, athletic, and active. Many of the chiefs are upwards of six feet high. The women are likewise well formed. The eyes are black, strong, and piercing; hair black and commonly straight, but sometimes thick, bushy, and curly; that of the women fine, soft, and silky. The men who can afford it tattoo the skin. The principal chiefs and their wives wear green talc stones, called Heitiki, suspended from their necks, on which is carved a human figure sitting cross-legged. Cannibalism and infanticide were formerly very common.

LADRONES. - Two groups of islands are so designated. The group near the S. coast of China, 18 miles S.E. of Macao, in lat. $21^{\circ} 57^{\prime}$ N., and long. $113^{\circ} 52^{\prime} \mathbf{E}$., at the entrance of the Bay of Canton, consists of two islands. The Grand Ladrone, called by the Chinese Tyman Shan, is in lat. $20^{\circ} 56^{\prime} \mathrm{N}$., and long. $113^{\circ} 44^{\prime}$ E., 12 miles east of Macao, and 29 miles east of Canton factories. It is steep and bold, and 2 miles in circumference. On its west side is the Little Ladrone. 
The pirates who infested the Archipelago consisted of the inhabitants of the free Muhammadan states in Sumatra, Lingin, Borneo, Magindanao, and Sulu; those natives who have remained uncontaminated by the doctrines of the Arabs never being known to engage in the like pursuits. The Europeans who were unfortunate enough to fall into their hands were generally murdered, while the natives who composed the crews of the captured vessels were sold for slaves. The term Ladrone is of Portuguese origin, and is applied by the Portuguese to the Chinese pirates, who commenced to gain power by the close of the 18 th century.

Ladrones, also called the Marianne Islands, were the first islands seen by Magellan in 1521 . From these he sailed to the Philippines, where, in the island of Mactan, near Zebu, he was killed, as also was Barbosa. Magellan's companions then visited Timor in 1522 , and returned to Lisbon, making the first circumnavigation of the globe. They are a large archipelago, stretching from N. to $\mathrm{S}$., from the southern extremity of China into the $\hat{N}$. Pacific for 450 miles, between lat. $13^{\circ}$ and $21^{\circ} 35^{\prime} \mathrm{N}$., and nearly under long. $145^{\circ} \mathrm{E}$. The islands are 20 in number. When the Spaniards arrived, the inhabitants, in manners, government, colour, and speech resembled the Tagala of the Philippines, - a tall, robust, well - proportioned race, olive-complexioned, with well-grown beards and long black hair; both sexes stained their teeth black, and some painted their bodies red. But that race has disappeared, and only about 2000 people of foreign origin now inhabit the islands.

CHINA has an area of $11,555,764$ square kilometres. Its emperor rules over 371 millions of Mongoloid races, viz. Chinese proper 350 millions, and 21 millions Tibetaus, people in Formosa, T'ungus, Manchu, Mongol, Kalmuk, Buriat, and Uzbak, in Manchuria, Mongolia, Tibet, Zangaria, and East Turkestan; and he claims tribute from several semi-independent states. Its dynasties have ruled through 4000 years, and the territorial distinctions-China proper and the Chinese empire -have existed from the earliest periods of their history.

Among the tributaries are those of Inner and Outer Mongolia, of Ulia-Sutai and Tsing-Hai, or Koko-Nor; and the tribes acknowledging the sway of China are classed as Inner and Outer Mougolians. Inner Mongolia lies between the desert of Gobi and the continuous frontier of Manchuria and China. The Outer Mongolians are Kalkas of different tribes. Among the tribes and remnants of tribes are the Shumet of Shan-si beyond the wall; Chahar, Bargou, Eluth, Solon, Taguri, Orunchun, Oilar, Hassack, Yu-muh, Tasang or T'sang, and Sang-ting.

The Chinese proper are of a yellow colour, but brown and sometimes a maroon tint are seen. Their face is broad and flat, the cheek-bones projecting, irides black, eyes oblique, beard scanty, stature above that of the Malay and Tibetan. They are skilful, enterprising, and self-reliant; emigrate with confidence, and are numerous in the islands of the Archipelago, the Indian Ocean, and America.

They have made many great discoveries in the arts, but they do not advance beyond a certain grade of intellectual development.

Their many millions belong to about 400 sing or clans, and those of the same sing are relatives, descended from the same ancestor, and bound to help one another. With the nation, the idea of the family is the grand principle that serves as the basis of society, of which the emperor is the head. The poor, and all who are not well-to-do, rarely use any kind of animal food. In the midland and southern provinces, the diet consists of plain boiled rice, with a relish of pickled fish or vegetables, salted eggs, and curd made of lentils, etc. When meat can be afforded, pork is always the favourite dish, and amongst the higher classes, mutton, poultry, venison, or game; with such delicacies as beche-de-mer, seaweed, sharks'-fin jelly, fish, the edible swallow's nest, ducks' tongues, pigeons' and plovers' eggs. Weak tea is their great liquid. Spirits are rarely used.

Yunnan province, in the extreme S.W., is inhabited by many tribes. Ainongst them, the Lolo of different clans, the Pai-yi, the Pen-ti, the Min-kya. Also, in the mountain ranges which separate China and Burma, are the Mousso, whose women wear huge silver ornaments. To their west are the Lissu tribe, in the tract between the Lan-tsang-keang and the Lo-keang or Salwin. And in addition to these, on the borders, are the Sifan, Meau-tsze, Pa-e, Ho-nhi, Khato, Lo-pé, Shen-tsen, and other tribes.

Within the borders lying in the southern and western provinces, parts of the Chinese empire,Hu-kwang, Sze-chuen, Yunnan, Kwei-chau, and Kivang-si, - are various tribes, known as the Miut, Yau, Tung, and Keh-lau, who are reckoned by the Chinese as Miau or barbarians. Some of them in the recesses of the mountains, still unsubdued, are styled the Sang Miau; but the subdued tribes paying tribute are called Shuh-Miau. Many of the wild Miau live in Kai-li, Tai-hung, Hwangnit, and Shi-ping.

Sifan, Kham, Miau, Tzu, Yeh, Jen Mantzu, and Ichia, in Chinese phraseology all mean various degrees of savagery or barbarity. The rude Tibetan tribes of nomade and predatory habits are chiefly known in Tibet under the generic name of Kham ; it corresponds to the Sifan of China.

The Miao-tse or Miau-tse, occupying the highlands of the southern half of the Chinese empire, nearly a hundred in number, are regarded as aborigines, and are said to belong to the Thai group. They are cultivators, rear the silk-worm, forge iron, and work in other metals, are weaver's. traders, fowlers, fishers, herdsmen, and some of them highly predatory.

The Kih-mang-ku-yin live in excavations made in high cliffs in the Kwang-shun-chau district. The King-kia of Li-po-hien have a festival on the last day of the tenth month, at which they sacrifice to demons. In the eleventh month, the unmarried folks have a dance, at which they choose life partners for themselves.

The Luh-ngeh-tsze of the Wei-ning district, in Ta-ting, inter their dead in coffins, but after a year, and for seven successive years, re-open the graves, wash and clean the bones, and replace them.

The Lang-tsze-Miau of Wei-ning follow the Couvade practice. On the birth of a child, the husband takes to bed, and is cooked for aurl waited on by the wife, who suckles the child and works in the fields; not till after a month does the husband go abroad. When a parent dies, so soon as life becomes extinct, they twist the head round 
backwards, so that, as they say, he can see behind him.

Tungus, a general name applied to a population common to a rast area in Siberia and China. Their physiognomy connects it with the tribes of Northern Asia in general, and their language forms a transition between the monosyllabic and agglutinate forms of speech. The Tungus, under the name Manchu, constitute the dominant population of China itself. The tribes under Chinese rule, in Manchuria, on the watershed of the,Amu, are termed Manchu. The Manchu proper have a literature, with an alphabet modified from the Mongol. They are agricultural and industrial. They conquered China in 1644, and founded a dynasty. The Tungus on the shores of Okotsk call themselves Lamut, from Lamu, the sea. Some Tungus call themselves Boji or men, others Donki or people.

The Mongol, properly Mang-ku, have four branches, viz. the Eastern Mongol, the Kalmuk, the Buriat, and the Hazara or Aimaq. Originally the Eastern Mongol got from the Chinese the nickname of $\mathrm{Ta} \mathrm{Ta}$, but since the 8th century they have been called Mang-ku (Mongol). They inhabit the eastern half of Gobi, and are divided into the two borders, the Schara towards the south, and the Kalka, their northern neighbours.

The Chinese are now spreading through the Archipelago, east of Asia, and America. The immigrants evince great physical strength and endurance, much intellectual energy and perseverance. They have great power of organization, and give each other mutual assistance and support. Wherever bodily strength and manual dexterity have to be combined, the Chinese in the east of Asia have no equal, and they are seen wherever mines have to be worked, new agricultural products introduced, or factories erected and put to use; expert in all artisan and handicraft work. While the British and German settlers refuse to marry the native women with whom they associate, and leave the offspring in bastardy, the Chinese invariably raises his Burmese, Cambodian, Malay, or Siamese helpmate to the full rank of wife, treats and honours her as such, and bestows on her children all the advantages to be conferred by acknowledged legitimacy, backed by strong parental affection.

There are three prominent philosophies in China, following the views of Kung-tsze (Confucius), of Laou-tse, whose religion is known as the Traou, and the Buddhists who adhere to the teachings of Sakya. The doctrines of Confucius are based on the moral consciousness of right and wrong, which he believed to be inherent in all men. The Taouist morality is based on the Kanyong-peen, or book of retribution, in which it is inculcated that the punishments of sin and rewards of good doing fall in this life. Sakya's followers teach a strictly moral code, but in Tibet there is a hierarchy which exercises political power. The Woo-wei-keaou is a sect of China. Muhammadanism and Christianity have made progress. In the state religion there are sacrifices to the heavens (Teen), to Te, the earth, and to Tae-meaou, the great temple of ancestors; and education of the people is regarded as essential to the welfare of the state. Women are rarely educated. Marriage is universal; polygamy is allowed. Infanticide and sale of children are practised.
FORMOSA, called Tai-wan by the Chinese, is a large island in the China Sea, separated from China by a stormy strait, 80 or 90 miles wide. It stretches as far north as lat. $25^{\circ} \mathrm{N}$., and this is the most northerly limit of the Malay language, Malay words being found in the language of the aborigines, and the inhabitants of the interior, who are supposed to be of Malay origin, are in several groups, each speaking a dialect of their own. On the easterly side of the island is a belt of level land near the sea, but it is rugged and mountainous in the interior. The Chinese occupied it about A.D. 1430. The Dutch took possession of it in A.D. 1634, but were dispossessed by a Chinese adventurer in 1661 , though a small body of men claim to be their descendants. The Chinese colonies are mostly on the $\mathrm{N}$. coast. The central and southern districts are inhabited by the aborigines. The Formosa tribes are Favorlong, Jakih, Pepukhwan or Peppohoan, Sideia, Tilloi, Yukan.

The barbarian tribes worship a good and evil spirit, with women priestesses termed Inib. They are, fond of out-of-door merry-makings, and during the annual nine days' festival, they drink and play and give themselves up to sensual pleasures. Marriage of men is not allowed until they be 21 years of age. Libations to the earth and sky are poured out, and they are married, but the wife remains in her father's house, and until the husband reach the age of 40 , he can only visit the wife by stealth at night, and daylight sees the signal for his quitting it. It is said that divorces are very frequent, and children born before the mother is 37 years of age are allowed to live.

The Peppohoan race of this island are descendants of the savage tribes who inhabited the plain country, and, being conquered by the Cbinese, have mixed with them to a great extent. They are a promising race, and accept Christianity readily. The Chinese residents prefer Peppohoan women for wives, being finer and stronger women, prettier and more useful, than those of the Chinese. The savage tribes of Formosa tattoo their faces; the maen wear a tunic of coarse grass-cloth, and the 'fighting women' a tunic and a short petticoat or piece of grass-cloth. Their huts are neatly built of bamboo and palm leaves. Over some of the doors are seen rows of the skulls of wild animals, the deer, the boar, the monkey; and one of them displayed the tails of six Chinamen tied up in a bunch, which he said had belonged to men he had killed.

COREA or Korea the Manchu call Solgo ; Kao-li is the Chinese name. Its area has been stated at 236,784 square kilometres, and its population at from $7 \frac{1}{2}$ to 15 millions. The people use rice, barley meal, and flour of millet. 'The Coreans were driven out of East Tartary into the peninsula which they now occupy. Their country was subsequently invaded by the Mongols, on which occasion the Siogour Yoritomo defeated Kablai Khan. They have since been conquered by the Japanese. Its people are supposed to be a mixed race, descendants from Tartars, Chinese, and Japanese. They have flat faces, oblique eyes, broad cheek-bones, strong black hair, and scanty beard; they are strongly made, their skin varies from tawny or yellow to brown, wheat, or straw colour, and reddish-yellow. They have a mixture of the Chinese and Japanese physical features. Their religion is Buddhist; their alphabet and language differ from the Chinese. 
JAPAN and its dependencies (the Kuriles, Loo-Choo, and Benin Islands) are in area 382,447 square kilometres, and population $36,357,312$. The Japanese are a short-statured Mongoloid race, intelligent and progressive, ruled over by an emperor. The Aino were the aborigines of the Japanese islands, but only a remnant of them now exist in the island of Yezo. The Aino, the Ghiliak, and Yenesei Ostiak respect the bear. The true Ostiak hang the skin on a tree, pay it homage, and beg the animal's pardon for having killed it. They also swear by the bear. Their severe treatment by the Japanese has Ied them to other countries. They occupy the southern part of the island of Saghalin, which is in possession of the Japanese. The Aino are of short stature, with broad faces of the Mongol type. They are a timid race, their limbs are hairy ; they have bushy beards and long tangled hair, large heads and clumsy figures; the expression of their faces is that of good-nature combined with stupidity. According to M. Rosney, their language is dissimilar to Japanese, and that spoken in the Kuriles and in the island of Yezo is also different from Japanese.

The Loo-Choo or Lieu-chen Islands lie to the N.E. of the Patchu group, and consist of one large island surrounded by smaller ones, the large island being of considerable size and well peopled. It extends from lat. $26^{\circ} 3^{\prime}$ to $26^{\circ} 53^{\prime} \mathrm{N}$., and long. $127^{\circ} 34^{\prime}$ to $128^{\circ} 25^{\prime} \mathrm{E}$, , being 58 miles long, and about 10 or 12 miles broad. In language and physical form the Loo-Choo islanders resemble the Japanese, their Buddhism being more imperfect, and their manners more simple.

SAGHALIN, SAGHALIEN, or TARAKAI, long believed to be a peninsula, is an island lying between lat. $45^{\circ} 54^{\prime} 2^{\prime \prime}$ and $54^{\circ} 24^{\prime} \mathrm{N}$., and long. $141^{\circ} 40^{\prime}$ and $144^{\circ} 46^{\prime} \mathrm{E}$. It is about 600 miles in length, and from 20 to 100 broad. It is well wooded and fertile, and coal is found in many places, especially about Jonquiere Bay. Two-thirds of the northern part belong to Russia, and is peopled by Ghiliak.-Aitcheson's Treaties; Asiatic Researches; Mr. F. H. Batten's British Garhwal; Behm and IVagner; Dr. Bennett; Bikmore's Travels; Burbidge, Gardens of the Sun; Miss Bird's Chersonese; Census, 1872, 1881; Dr. Collingwood in Journ. Ethn. Soc.; Crawfurd's Archipelago and Malay Dictionary; Dalton's Ethnology of Bengal; G. W. Earl's Papuans and Physical Geography; Edkins' China; Hooker and Thomson's Flora Indica; Horsburgh's Directory; Mr. Hunt in Morr's Archipelago; Journal Ind. Archipelago; Keane's Asia; Keppel's Archipelago; Peschel; Sir S. Raffles' Memoirs; Raja Brooke's .Journal; Logan in Journ. Ind. Archipelago; Lubbock, Origin of Civilisation; Macgillivray's Voyage in the Rattlesnake; Major-General Sir C. M. MacGregor's Gazetteers; Mallat's Les Philippines; Marsden's Sumatra; M'Nair's Perak; Melvill de Carnbee, in Journ. Ind. Achipelago; Le Moniteur des Indes Orientales; Moresby's Now Guinea and Polynesia; Newbold's Malacca; Trel. Saunders in Geng. Soc. Journ.; St. John's Indian Archipelago; J. D. Vaughan in Journ. Ind. Archip.; A. R. Wallace, Eastern Archip.; F. Watson's People of India; Williams' Cruise of the Pearl.

INDIAN NAVY. In A.D. 1609, in the early years of the English East India Company's trade with India, the need for the protection of their shipping led to Sir Henry Middleton being sent with three ships to Surat. His flag-ship ran aground at Mocba, and he was detained more than a year by the Arabs, and, after reaching Surat, he withdrew, under the advice of both the native and the English merchants, and drove a kind of filibustering trade in the Red Sea. Afterwards be was joined by Captain John Saris, who was sent out with three more vessels to protect the Indian trade. Captain Hippon, who was despatched about the same time in a single ship, the Globe, founded the factories in the Bay of Bengal which developed into the Presidencies of Calcutta and Madras. The victory of Captain Best over the Portuguese fleet in the roadstead of Surat, October 29,1612 , which two years later was eclipsed by the operations of Captain Downton, followed up by exploits in the Persian Gulf, crowned by the capture of Ormuz, disposed of all fear of Portuguese ascendency in the east, and firmly established this East India Company's trading privileges. In 1615 a local marine force of ten grabs and galivats was established, which, added to the small home squadron, formed the nucleus of the future navy of the Company. The right of trial by common and martial law, as in the royal service, was in 1624 conceded to the Company's commanders and agents abroad, to which was added that of building forts for the security of their trade, the earliest of these being that of Fort St. George at Madras, erected in 1640. The acquisition of Bombay in 1668 gave the Company a valuable port and naval station, and their service, -thenceforth known as the Bombay Marine,now amounting to a respectable fleet, was not long in distinguishing itself in the defence of Surat and Bombay against the Mahrattas, as well as in repelling the threatened attack of the Dutch in 1672. On the pacification which ensued, the English Company's ships were entrusted with the police of the Southern Indian seas, the protection of the Red Sea being assigned to the Dutch, and that of the Persian Gulf to the French. The suppression of piracy became from the first one of the prominent duties of the service. Surat, where the larger vessels had originally been constructed under native foremen, gave place in $\mathbf{1 7 3 5}$ to Bombay as the depôt for building purposes. The Company's fleet then numbered more than 20 vessels, one of them, the Revenge, mounting 28 guns, 20 of which were twelve-pounders. This fine frigate was lost, with all hands, in a gale, April 20, 1782, after having done good service in the war with France and Hyder Ali. In the reduction of Pondicherry, August 23 , 1793 , the capture of Ceylon in 1795, and the attack upon the Dutch in the Moluccas in 1801, the services of the Bombay Marine were of the utmost value; nor were they less conspicuous in the taking of Mauritius in 1809, in the reduction of Java in 1811, in the attack upon Mocha in 1820 , and in the operations against the Joasmi pirates in the Persian Gulf, who, from the year 1797 , had given unintermitting trouble to the protective cruisers of the Company. The Burmese war, from 1824 to 1826 , gave occasion to many a brilliant display of skill and valour, for which the thanks of the Directors and of both Houses of Parliament were tendered at the conclusion of peace. Remodelled under the charge of Sir Charles Malcolm, brother to the Governor of 
Bombay, as superintendent, the service was constituted as a marine corps, with the title of the Indian Navy, under an order dated May 1, 1830.

Under Sir Henry Leake, the naval expedition, $1852-53$, which aided in the reduction of Burma, was ably planned and carried out, followed up by no less successful operations in the war with Persia in 1856-57. The latest and not the least brilliant of the warlike services of the Indiau navy was that rendered by the detachment which, after aiding in the suppression of panic in Calcutta, pushed up the country to the relief of the beleaguered Europeaus. But no officer of the service was ever honoured with knighthood or with a military order. Until the final hauling down of the flag in Bombay harbour at noon of the 30th of April 1863 , its duties-faithfully, zealously, and often brilliantly discharged-brought with them little more reward than that which is proverbially said to be conferred by virtue upon itself. Nevertheless its band of skilled officers had given to the world a body of charts the value of which it is impossible to overstate, and the hydrography of the Indian coasts and seas had been carried to a degree of perfection which is beyond all proportion to the slenderness of the means under command. Among the most notable are the surveys of the Red Sea by Elwon and Moresby, those of Mesopotamia by Lynch, Campbell, and Felix Jones, those of the Coromandel coast by Lloyd and Fell, those of the south-east coast of Arabia by Haines and Saunders, with the more recent charts of the Persian Gulf by Constable and Stiffe, and those of the Kattyawar and Malabar coasts by Commander Dundas Taylor. To the last-named officer maritime interests are indebted for the Wind and Current Charts, which give so much security to the navigation of the Indian seas; and above all, for a Sailiug Directory, founded on Ilorsburgh. To the impression produced by Captain Taylor's memoraudum on the existing state aud deficiencies of the Indian marine surveys, was due the seasonable establishment, about 1873 , of a special department of that nature at Calcutta, of which Commander Taylor was made superintendent, with a staff of well-chosen assistants. In the year 1858 the whole service had been summarily broken up, the vessels were condemned to be sold, the officers pensioned off, the official records disposed of as waste-paper. In his anniversary address to the Royal Geograplical Society in 1863, Sir Roderick Murchison said its services had been varied, useful, and honourable : the beneficial and enduring results of its suppression of piracy and the slave trade are well known, and the widespread and lasting utility of the excellent surveys made by its officers hold an equally prominent place.-East India Marine Surveys.

INDIAN OCEAN is bounded on the west by the coast of Africa to the meridian of Cape L'A gulhas, continued to the antarctic circle. 'The antarctic circle is its southern limit as far as the meridian of Tasmania, but strictly the western coast of Australia, continued northwards to the larger islands of the Asiatic Archipelago and the Bay of Bengal. One of the large currents of water which have their origin in the Indian Ucean, is the well-known Mozambique current, called at the Cape of Good Hope the L'Agulhas current. Another makes its way through the Straits of Malacca, and, being joined by other warm streams from the Java and China Seas, flows out into the Pacific, like another Gulf Stream, between the Philippines and the shores of Asia. Thence it attempts the great circle route for the Aleutian Islands, tempering climates and losing itself in the sea on its route towards the N.W. coast of America. There is a counter current of cold water between it and the China shore.-Findlay.

INDIAN YELLOW, a dye procured from the urine of the cow, after eating decayed and yellow mango leaves; other authorities refer it to camels' dung. Analysis show's it to be composed chiefly of purreic acid, combined with magnesia. Its Hindi name is Purree.-Simmonds' Dict.

\section{INDIGO.}

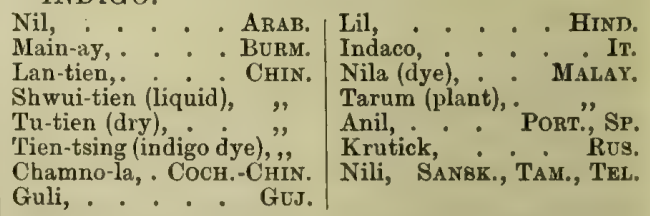

The plants which afford indigo dyes are grown chiefly in the East and IV est Indies, in the middle regions of America, Colombia, and Florida, in Africa, and in Europe, and are mostly species of the genera Indigofera, Isatis, 'J'ephrosia, and Nerium. Indigofera tinctoria furnishes the chief indigo of commerce; produced in Bengal, Madagascar, the Isle of France, and St. Domingo. The Indigofera disperma, a plant cultivated in Spain and America, grows higher than the preceding, is woody, and furnishes a superior dyestuff. The Guatemala indigo comes from this species. Indigofera anil grows in the same countries, and also in the West Indies. The Indigofera argentea, which flourishes in Africa, yields little indigo, but it is of an excellent quality. I. glauca is the Egyptian and Arabian species. There are also the I. cinerea, I. erecta (a native of Guinea), I. hirsuta, I. glabra, and several other species. Indigo of an excellent quality has been obtained in the East from Gymnema tingens, or Asclepias tingens, a twining plant. Species of Ruellia furnish the well-known room dye of Assam, and the Chinese obtain a blue dye from the Ruellia indigotica, as also from the Isatis indigotica. Wrightia tinctoria, an evergreen with white blossoms, affords some indigo, as do the Isatis tinctoria, or woad, in Europe, and the Polygonum tinctorium, with red flowers, a native of China. Baptista tinctoria furnishes a blue dye, and is the wild indigo of the United States. Plants of other genera are also employed for obtaining indigo, as Marsdenia tinctoria, Galega tinctoria, but especially the former. Dr. Bancroft (i. p. 190) also adduces Spilanthes tinctoria, Scabiosa succisa, Cheiranthus fenestralis, also a species of Bignonia and a Tabernæmontana, on the African coast, with Anorpha fruticosa and Saphora tinctoria, as all yielding a blue dye, or coarse sorts of indigo. It is obtained in Nubia from the Tepbrosia apollinea, and on the banks of the Niger from the 'T. toxicaria; and Indigofera Australis of Australia produces a good indigo. A small quantity bas been produced by chemists in the laboratory.

Indigo is produced largely in Bengal and $\mathrm{N}$. India, from the 20 th to the 30 th deg. of north latitude; also in the provinces of Tinnevelly, Cuddapah, and the two Arcots of the Madras Presidency; in Java, in the largest of the Philippine 
equal value in sugar and rum, would probably cost about $\mathfrak{E} 4000$.

The indigo of the Indigofera tinctoria is obtained by subjecting the plant to a fermentive process, in large masses, in tanks. After its removal, the water is stirred and beaten by paddles, its colour passes to a blue, and the suspended particles settle to the bottom, forming a blue sediment, which, after the water is drawn off, is dried in the sun and cut up into cakes. The time for sowing varies in Bengal proper, Tirhut, and the several districts of the N.W. Provinces. In Bengal, sowings prevail in the month Kartik (October), hence called Kartiki. In Tirhut, Sarun, and Champarum, in which there is rich alluvial land and a natural moisture, the sowings are in February (Phalgun), and the factories are known as Phalguni. The preparation of the land in Tirhut is much more elaborate than in Bengal proper or the N.W. Provinces, and altogether a more advanced system prevails there, and the work is regularly spread over the whole year. In the N.W. Provinces and in Oudh, the sowings chiefly take place on the first fall of rain in June (Asarh), hence the factories are known as Asarhi, but these have sowings also called Jamowa, which is a sort of compromise between the Phalguni and Asarhi periods. An artificial moisture is secured in February and March by irrigation, and small patches of indigo are sown near every available well.

In the $N . W$. Provinces the planter's work comes on him all in a heap in June or July (Asarh and Sawan). He has sowing, cutting the stumps left of the past year's crop, manufacture of the new crop, packing and despatch of the indigo. The fresh plant is filled into steeper vats, and pressed down with beams of wood interlaced with bamboos; water is then let in from the reservoir, and steeping or fermentation allowed to go on for ten or twelve hours, according to the state of the atmosphere. After fermentation is complete, the liquor is drawn off into a lower beating vat (hauz mahye). Ten or twelve men now enter the vat with shovels; they are called mahunean or beaters; they beat (mabye) from one and a half to two hours, and by this means a great quantity of carbonic acid gas is disengaged, and the particles of indigo get thoroughly exposed to the atmosphere, and obtain their requisite supply of oxygen, after which they granulate. The vat is now allowed to settle, the indigo gradually subsides, and the water, which separates, is drawn off, and is of the colour of dark sherry. A sediment is left at the bottom of the vat, which is collected and discharged into a cistern alongside, and runs through a strainer (channah) into the boiler (karah), when it is heated to boiling point. From the boiler the liquid indigo (mal) is run on a table on which is spread a sheet, and allowed to filter through until the liquid runs clear. The day following, the indigo, fully drained, is of the consistency of curds, when it is removed to the press-house, put into presses, and subjected to severe pressure. With the aid of nuts and screws, a solid mass is thus obtained, which is taken to the drying-house (bari khana), placed on a cutting frame, and cut with brass wire into cubes or cakes (goti or bari). The cakes are placed on wicker-work frames to dry. A whitish efflorescence soon covers the cakes, and a strong smell of ammonia prevails throughout the drying-house. When quite dry, the cakes are taken down, brushed, assorted according to colour and quality (rang milan), and packed into boxes for export, after which the N.W. planter has nothing to do till the following June.

In Tirhut the preparation of the land is commenced in October. All the old stumps are dug out, the land is twice ploughed (somra or docha), and a flat roller (henga) passed over, to break the clods and keep in the moisture. If the sith or jhuthi, or refuse indigo stalks (a rich manure), has not already been spread on the land, and allowed to decompose, it is now spread, and, to save time, set fire to, and the ashes well ploughed in; then all the smaller clods are pulverized, and all grass and refuse removed. The land is then finally ploughed and rolled, and allowed to rest till the end of January. In the beginning of February, sowings begin and last to the end of March. In April and May, the young plant is weeded. About the middle of June or first week in July, manufacturing begins, and lasts without interruption till the end of September. In October the cakes are taken down from the shelves where they have been drying, brushed, packed in boxes weighing about three factory maunds each, marked and numbered, and finally sent down to Calcutta for sale and shipment to Europe, China, Persia, and America.

In Bengal proper, indigo is cultivated at a season when nothing else is on the ground. It occurs intermediately between the two great crops of the year, and it has puzzled Boards of Revenue before now to decide whether it is a rabi or kharif crop. It is cleared off the ground in time for another crop, and it is far from being an exhausting crop. The ryots know this well, and all they get for their indigo is additional to their income, though, at a strict calculation, it would not cover the expense of the cultivation.

After having ploughed the ground in October, November, and the beginning of December, they sow the seed in the last half of March and the beginning of April, while the soil, being neither too hot nor too dry, is nost propitious to its germination. A light mould answers best, and sunshine, with occasional light showers, are most favourable to its growth. Twelve pounds of seed are sufficient for sowing an acre of land. The plants grow rapidly, and will bear to be cut for the first time at the beginning of July; nay, in some districts so early as the middle of June. The indications of maturity are the bursting forth of the flower-buds and the expansion of the blossoms, at which period the plant abounds most in the dyeing principle. Another indication is taken from the leaves, which, if they break across when doubled flat, denote a state of maturity. But this character is somewhat fallacious, and depends upon the poverty or richness of the soil. When much rain falls, the plants grow too rapidly, and do not sufficiently elaborate the blue pigment. Bright sunshine is most advantageous to its production. The first cropping of the plants is the best; after two months a second is made, after another interval a third, and even a fourth ; but each of these is of diminished value.

The plant is sold in Bengal by the bundle, which is measured by a chain. In the Doab it is 
sold for 1 rupee for 5 to 6 maunds. 200 to 225 maunds of plant to a maund ( $75 \mathrm{lbs}$.) of indigo, is a fair average produce. Therefore it would cost about 36 to 40 rupees for the plant necessary to make $75 \mathrm{lbs}$. of indigo. The expense of manufacturing would be but little.

The finest quality of dye is produced by factories in the Jessore and Kishnagar districts. An ordinary plantation there comprises 4000 acres of land, which may yield on an average 1000 maunds of $82 \mathrm{lbs}$. each. The annual outlay for labour, seed, etc., on this one branch of industry, is seldom less than a million and a half sterling, of which fully nineteen-twentieths are expended by Europeans. The cultivation is generally one of hazard, as the fields are always liable to be swept of their produce during any heavy or sudden fall of rain. The plant often suffers from long drought. With a few good seasons, favourable soil, a thorough knowledge of the business, and a certain degree of industry, an indigo planter may reckon on realizing an independence in less than a dozen years, supposing him to have started with ample means.

In South Arcot, Kurnool, and Cuddapah, indigo is largely cultivated, and especially in the lastnamed district, which is well suited for the cultivation of the staple. The average growth in the Madras Presidency covers 304,676 acres, twothirds of which are in the South Arcot, Cuddapah, Nellore, Kistna, and Kurnool districts. Cuddapah indigo is grown by ryots on contract to deliver so much indigo plant at the factory at a fixed rate per bundle. The agents of the Madras firms aroid occupying the same taluks, so that there is no system of forcing the cultivation upon the ryots, who are much too independent to submit to such a process. The trade is quite free, and the system of advances to the tenantry has done a great deal to improve their condition, as well as facilitated the collection of the revenue. The cultivation of indigo is not fixed; it extends or contracts with the demand for the article. It has, however, been steadily increasing of late years ; many of the richer ryots cultivate it, and manufacture it on their own account. Native capitalists also engage in the trade. Mr. Wedderburn estimated the cultivation and manufacture of indigo by natives, without European superintendence, in the ratio of 10 to 1 of that produced under European management. Eight lakhs of rupees were drawn by bills in 1859 , on the Cuddapah Treasury, by Madras mercantile houses. And eight lakhs scarcely represent one-half of the sum paid for indigo, the out-turn of which, on 36,000 acres, cultivated in the year 1860 , at an average profit of 50 rupees per acre, will show a value of 18 lakhs of rupees.

Mr. Rohde (MS.) mentions that two methods of preparing indigo are in use in the Madras territories. That called Karpa indigo, and which is known in the market as Madras indigo, is prepared from the dried leaves; the Bimlipatam indigo is from the recent leaves upon the Bengal plan. He says that in the indigo factories of Bengal, using the recent leaves, there are two large stone-built cisterns, the bottom of the first being nearly upon a level with the top of the second, in order to allow the liquid contents to be run out of the one into the other. The uppermost is called the fermenting vat or the steeper, its area is 20 feet square, and its depth 3 feet; the lowermost, called the beater or beating vat, is as broad as the other, but one-third longer. The cuttings of the plant as they come from the field are stratified in the steeper till this be filled within 5 or 6 inches of its brim. In order that the plant during its fermentation may not swell and rise out of the vat, beams of wood and twigs of bamboo are braced tight over the surface of the plants, after which water is pumped upon them till it stands within three or four inches of the edge of the vessel, and an active fermentation speedily commences, which is completed within fourteen or fifteen hours, a little longer or shorter according to the temperature of the air, the prevailing winds, the quality of the water, and the ripeness of the plants. Nine or ten hours after immersion of the plant, the condition of the vat must be examined, for then bubbles appear, which rise like little pyramids, are at first of a white colour, but soon become grey, blue, and then deep purple red. The fermentation is at this time violent, the fluid is in constant commotion, innumerable bubbles mount to the surface, and a copper-coloured dense scum covers the whole. As long as the liquor is agitated, the fermentation must not be disturbed, but when it becomes more tranquil, the liquor is to be drawn off into the lower cistern. It is of the utmost consequence not to push the fermentation too far, because the quality of the whole indigo is thereby deteriorated; but rather to cut it short, in which case there is, indeed, a loss of weight, but the article is better. The liquor possesses now a glistening yellow colour, which, when the indigo precipitates, changes to green. The average temperature of the liquor is commonly $85^{\circ} \mathrm{Fahr}$; its specific gravity at the surface is 1001.5 , and at the bottom 1003. So soon as the liquor has been run into the lower cistern, ten men are set to work to beat it with oars or shovels four feet long, called basquets; paddle-wheels have also been employed for the same purpose. Meanwhile two other labourers clear away the compressing beams and bamboos from the surface of the upper vat, remove the exhausted plant, set it to dry for fuel, clean out the vessel, and stratify fresh plants in it. The fermented plant appears still green, but it has lost three-fourths of its bulk in the process, or from 12 to 14 per cent. of its weight, chiefly water and extractive matter. The liquor in the lower vat must be strongly beaten for an hour and a half, when the indigo begins to agglomerate in flocks, and to precipitate. This is the moment for judging whether there has been any error committed in the fermentation, which, if so, must be corrected by the operation of beating. If the fermentation has been defective, much froth rises in the beating, which must be allayed with a little oil, and then a reddish tinge appears. If large round granulations are formed, the beating is continued, in order to see if they will grow smaller. If they become as small as fine sand, and if the water clear up, the indigo is allowed quietly to subside. Should the vat have been over-fermented, a thick fat-looking crust covers the liquor, which does not disappear by the introduction of the flask of oil. In such a case the beating must be moderated. Whenever the granulations become round and begin to subside, and the liquor clears up, the beating must be discontinued. The froth 
or scum diffuses itself spontaneously into separate minute particles, that move about the surface of the liquor, which are marks of an excessive fermentation. On the other hand, a rightly fermented vat is easy to work; the froth, though abundant, vanishes whenever the granulations make their appearance. The colour of the liquor when drawn out of the steeper into the beater is bright green, but so soon as the agglomerations of the indigo commence, it assumes the colour of Madeira wine, and speedily afterwards, in the course of beating, a small round grain is formed, which on separating makes the water transparent, and falls down, when all the turbidity and froth vanish. The object of beating is threefold: first, it tends to disengage a great quantity of carbonic acid present in the fermented liquor; secondly, to give the newly-developed indigo its requisite dose of oxygen by the most extensive exposure of its particles to the atmosphere; thirdly, to agglomerate the indigo in distinct flocks or granulations. In order to hasten the precipitation, limewater is occasionally added to the fermented liquor in the progress of beating, but it is not indispensable, and has been supposed capable of deteriorating the indigo. In the front of the beater a beam is fixed upright, in which three or more holes are pierced a few inches in diameter. These are closed with plugs during the beating; but two or three hours after it, as the indigo subsides, the upper plug is withdrawn, to run off the supernatant liquor, and then the lower plugs in succession. The state of this liquor being examiued, affords an indication of the success of both the processes. When the whole liquor is run off, a labourer enters the vat, and sweeps all the precipitate into one corner, and empties the thinner part into a spout which leads into a cistern alongside of a boiler 20 feet long, 3 feet wide, and 3 deep. When all the liquor is once collected, it is pumped through a bag for retaining the impurities into the boiler, and heated to ebullition. The froth soon subsides, and shows an oily-looking film upon the liquor. The indigo is by this process not only freed from the yellow extractive matter, but is enriched in the intensity of its colour, and increased in weight. From the boiler the mixture is run, after two or three hours, into a general receiver, called the dripping vat or table, which, for a factory of twelve pairs of preparation vats, is 20 feet long, 10 feet wide, and 3 feet deep, having a false bottom 2 feet under the top edge. This cistern stands in a basin of masonry made water-tight with, chunam hydraulic cement, the bottom of which slopes to one end in order to facilitate the drainage; a thick woollen veil is stretched along the bottom of the inner vessel to act as a filter. So long as the liquor passes through turbid, it is pumped back into the receiver. Whenever it runs clear, the receiver is covered with another piece of cloth to exclude the dust, and allowed to drain at its leisure. Next morning the drained indigo is put into a strong bag and squeezed in a press. 'ithe indigo is then carefully taken out of the bag, and cut with a brass wire into bits about 3 inches cube, which are dried in an airy house upon shelves of wicker-work. During the dryiny, a whitish efflorescence comes upon the pieces, which must be carefully removed with a brush. In some places, particularly on the coast of Coromandel, the dried indigo lumps are allowed to effloresce in a cask for some time, and when they become hard, they are wiped and packed for exportation.

In preparing indigo from dried leaves, the ripe plant being cropped is to be dried in sunshine from 9 o'clock in the morning till 4 in the afternoon during two days, and thrashed to separate the stems from the leaves, which are then stored up in magazines till a sufficient quantity be collected for manufacturing operations. The newly-dried leaves must be free from spots, and friable between the fingers. When kept dry, the leaves undergo, in the course of four week, a material change, their beautiful green tint turning into a pale blue grey, previous to which the leaves afford no indigo by maceration in water, but subsequently a large quantity. Afterwards the product becomes less considerable. The dried leaves are infused in the macerated steeping vat, with six times their bulk of water, and allowed to macerate for two hours, with continual stirring, till all the floating leaves sink. The fine green liquor is then drawn off into the beater vat; for if it stood longer in the steeper, some of the indigo would settle among the leaves and be lost. Hot water, as employed by some manufacturers, is not necessary. The process with dry leaves possesses these advantages, that a provision of the plant may be made at the most suitable times, independently of the vicissitudes of the weather, the indigo may be uniformly made, and the fermentation of the fresh leaves, often capricious in its course, is superseded by a much shorter period of simple maceration.

Dr. Walker mentions, in his Account of the Productions of Humamkunda in the Dekhan, that only one species, Indigofera tinctoria, is there used for the preparation of indigo, and it is collected in the rains, when the dye is commonly made. A strong decoction is made of the plaut, -leaves, flowers, pods, and twigs being all iudiscriminately thrust into a pot; when this is hot an infusion of Eugenia jambolana (rose-apple tree) is added, the indigo is immediately precipitated, and, the superincumbent water being drawn off, is dried in the sun.

The native plan of mounting the indigo vat merits attention. A potash ley is prepared from the ashes of the Euphorbia tiruculli (milk bush hedge) and lime, by mixing them together and then filtering; in this ley seeds of the Trigonella fœnum-grecum and Cassia tora are boiled, and, the liquor being strained, is poured into the water drawn off after the precipitation of the indigo, and the indigo itself is then put in, and some more potash ley is added.

In three or four hours the fermentation is perfected, and the vat filled for the purposes of the dyer. The theory of this vat is very obvious: extractive matter derived from the liquor in which the indigo was first boiled, with the sugar, starch, and mucilage of the two leguminous seeds, cause a fermentation by which the indigo is rendered soluble in the alkaline solution. The process is more simple than that usually followed by dyers in Europe, and is in perfect accordance with every rule of practical chemistry. There is no superfluity and no waste, and on the whole it is a most favourable specimen of native ingenuity and skill.

The indigo plant is cultivated in China to a great extent, as well as a species of polygonum, 
from the leaves of which a colour is produced which nearly equals the blue obtained from indigo.

With the Javanese, who of all the Malayan race have certainly made the highest progress in all the useful arts, there is a specific term for dyeing or tinting,-madall; but the Malays express it only by Chalup, the word for dipping. Yet the only generic words which either of them possesses for colour, are the Sanskrit Warna and the Portuguese Tinta. Their colours are usually sombre,-little varied, but generally fast. Blues are always produced from indigo, yielded for the most part by the Indigofera tinctoria, as in other parts of India, but in Sumatra occasionally from the Marsdenia tinctoria, a plant of the natural order of the Asclepiaceæ. Kulaf or vasma, in the Panjab, is the pounded dried leaves of the indigo plant, used principally as a hair-dye after the previous application of henna (Lawsonia inermis). 'The powdered leaf of Indigofera anil is used in the cure of hepatitis.-Capper's Three Presidencies; Powell's Handbook; Mr. Rohde's MSS.; Simmonds; Royle's Him. Botany; Annals of Indian Administration, 1870 ; Bonynge, America; Tomlinson's Dict.; Sivr's China; Cal.Cat. Ex., 1862 ; Carnegy. INDIGOFERA, a genus of plants, some of them of great economic value, of the natural order Fabaceæ. About 150 species are known, many of which grow in the East Indies; amongst others-

anil.

arborea.

argentea.

aspalathoides.

atropurpurea.

brunonia.

cinerascens.

coerulia.

\begin{tabular}{|l} 
disperma. \\
dosua. \\
echinata. \\
elliptica. \\
enneaphylla. \\
flaccida. \\
glanduloss. \\
hirsuta.
\end{tabular}

linifolia.

tinctoria. mucronata. trifoliata. pauciflora. trita. pedicellata. uncinata. pentaphylla. uniflora. polygonata. violacea. pulchella. viscosa.

There are also several undetermined species, the dug kenti and the kenti of Kaghan (qu. I. arborea), the doun-daloun of Burma, the latter a tree four or five feet in girth, found both in the Rangoon and Tounghoo districts, though it is scarce. Its white-coloured wood is adapted to every purpose of house building. An indigenous species of indigo is sometimes in Tenasserim used in forming a blue dye, and a wild iudigo is found abundant in the Sutlej valley between Rampur and Sungnam, at an elevation of 7000 feet, in rocky hills. The species are indigenous in the equinoctial parts of Asia, Africa, and America; but there is some difficulty in ascertaining all the cultivated species, as the subject is usually neglected both by naturalists and cultivators.

Indigofera anil is said by De Candolle to grow wild in America, and to be cultivated in both Indies, as also along the Gambia in Africa. Drs. Wight and Arnott state they have not sufficient materials to determine if $\mathrm{I}$. anil be a distinct species. According to Dr. Honigberger, I. anil is cultivated in some provinces of the Panjab, but more for dye than for medicine, the leaf (Vishaso danie, SANsK.) being used by the natives in hepatitis.-O'Sh. p. 292 ; Honigb. p. 289.

INDIGOFERA ARBOREA, Roxb. iii. p. 381. Manthu of Chamba Hills. Dug, Hast, Kast of PANJ. Jand of . Murree HILls. Hathi, Kainti, . . ",

A shrub of no value as a timber tree; elevation 7000 feet.-Roxb.; Powell.

INDIGOFERA ARGENTEA, $L$, is I. cœrulea and I. colorata, Roxb. Drs. Wight and Arnott

YOL. II,

state that it is the species cultivated in Egypt and Barbary for the sake of its indigo, and, according to Humboldt, also in America. I. argentea is shrubby, with round branches, which appear of a silky whiteness from appressed pubescence.Voigt.

INDIGOFERA ASPALATHOIDES. Vahl.

I. aspalathifolia, Roxb. Lespedeza juncea, Wall. Aspalathus Indicus, Linn.

Manili,. . . Maleal. Shiva nimba, . SANgk. Manneli, : :"

A shrubby, low-growing plant of the Peninsula of India. The small leaves, flowers, and tender shoots being supposed to possess cooling demulcent and alterative properties, are prescribed in decoction in leprous and cancerous affections. Rheede tells us that from the root of it an oil is extracted which is of use in erysipelas.-Ainsl.; Voigt.

INDIGOFERA CERULEA. Roxb.

I. brachycarpa, $D . C$. | Kar-nili, . . . . TEL.

This plant grows in the Dindigul Hills and the Rajamundry Circars, and Dr. Roxburgh states that it comes near to I. argentea, Linn. De Candolle inquires whether this be sufficiently distinct from I. tinctoria. It is an erect shrubby species, growing in dry, barren, uncultivated ground to the height of three feet, and higher in good garden soil. It flowers during the wet and cold seasons. The leaves are pinnate. Dr. Roxburgh states that he extracted a most beautiful light indigo from the leaves of this plant, and in greater quantity than he ever could from the common indigo plant, or even from Nerium tinctorium. The process he adopted was similar to that practised with the leaves of Nerium tinctorium, or the scalding process. - Roxh.

INDIGOFERA ENNEAPHYLLA. Linn.

I. cæspitosa, Wight. | Hedysarum prostratum, $L$.

Chepu-naringi, . TAM. Chala pachchi, . TEL. Cherra gadan, . TEL.

Grows at Dindigul, Saharunpur, Prome, Segain. The expressed juice is given as an alterative by the native physicians in old syphilitic diseases. O'Sh.; Roxb. iii. p. 376 ; Voigt.

INDIGOFERA GLANDULOSA. Willde. Barugadam, TeL. A small shrubby species, a native of moist rich lands amongst the Circar mountains. Flowers and ripens its seeds during the wet and cold seasons. The natives of the hilly countries make meal of the seeds, which they bake into bread, and use as an article of diet, when more agreeable food is scarce. Cattle are fond of the plant.-Roxb.

\section{INDIGOFERA HETERANTHA. Wall.}

Kathi, Kati, . . BEAs. Kanti, Khenti, . HiND, Kathewat, . . ", Kiitz of KAGHAN. Shagali of : CHENAB. Katsu, Kaskei of . RAVI.

This, the commonest of the Himalayan species, is a shrub which is abundant in many places in the hills and the eastern skirts of the Suliman Range from 2500 to 8000 feet. In Kashmir and elsewhere the twigs are largely used for making baskets, etc., and they form part of some of the twig bridges. In Kangra the flowers are used as a pot herb.-Drs. Stewart, Cleghorn.

INDIGOFERA LINIFOLIA, Retz, vegetates in both Peninsulas, in Bengal, and in the lower mountains of the Panjab. There the root is used in febrile eruptions. - Honig.; Stewart. 
INDIGOFERA TINCTORIA. Linn.

I. Indica, Lam.

Lan-tien,

Tayung,

Mai-nay, Shan-maysAYA.

Nil,

Tom, Tarum, Talum, MaL.

I. sumatrana, Gcert.

Ameri, . Maleal. Wasma, Basma, . PANJ. Nili, Tayum, 'I'AG. India, whence it las been introdur and America, and in the W. Indies is sometimes called Indigo Franc, or French indigo. It is said to be found wild along the sands of Senegal. It is grown occasionally by Karens and Burmese, and is cultivated in the Panjab. Indigo from the Indus is mentioned in Arrian's Periplus, and many traces of an export of it by the same river to Europe are found in the historical records as early as the middle of the 17 th century. At present the chief tracts for its cultivation are in the Southern Panjab, near Multan, largely in Lower Bengal, in the Northern Circars, and throughout the North Arcot and the Cuddapah collectorates of the Peninsula of India._Roxb.; Stew.; Mason's Tenasserim ; Eng. Cyc.

INDIGOFERA TRITA, Linn. Indigofera cinerea, Roxb. A common herbaceous plant, with trifoliate leaves, and small, reddish-green flowers. -Roxb. iii. p. 371.

INDO-ATLANTIC, a designation of the Caucasian race of mankind, and of their language, usually styled Indo-European. Indo-Australian, a name applied by Mr. Logan to the Negroid race occupying the southern shores of Asia. Indo-Briton, a term by which the mixed races of European descent are known in British India. They are also called Eurasians, East Indians, and half-castes. Many, however, who so call themselves are Creoles of pure descent, but Creole is not used in India. Indo-Chinese races occupy the low lands near the Brahmaputra; but the term is applied strictly to the people occupying the countries between India and China. Indo-European, a term applied by Dr. Prichard to a dynasty of languages, sometimes called IndoGermanic, and by later writers also Aryan or Iranian. Indo-Germanic, a term employed to designate the Indo-Atlantic, Indo-European, or Caucasian race of man, and the family of languages spoken by them. Indo-Getic, a term in use to designate the Scythic Getæ race who settled in India and on its N.W. borders. Indonesia, a geographic and ethnic name suggested by Mr. Jogan to designate the Eastern Archipelago.Campbell, p. 49.

INDORE, a city on the left bank of the Katki, in Malwa, in lat. $22^{\circ} 42^{\prime} \mathrm{N}$., and long. $74^{\circ} 54^{\prime}$ $\mathrm{E}$., and 1998 feet above the sea. It is the capital of the dominions of the maharaja Holkar. The state has an area of 8075 square miles, and population about 635,000 souls, lying between lat. $21^{\circ}$ $24^{\prime}$ and $24^{\circ} 14^{\prime} \mathrm{N}$., and long. $74^{\circ} 28^{\prime}$ and $77^{\circ}$ $10^{\prime} \mathrm{E}$. It is nearly bisected by the Nerbadda river, and has the Chambal and its tributaries on the northern part. The state consists of many isolated tracts, and within it is the British cantonment of Mhow (Mau). It is bounded on the north by part of Sindia's dominions, on the east by the states of Dewas and Dhar and the district of Nimar, on the south by Kandesh district, and on the west by Barwani and Dhar. Like the rest of Malwa, the soil of Indore is fertile, consisting largely of the rich black loam known as cotton soil. The principal crops are wheat, rice, millets, pulses, oil-seeds, sugar-cane, cotton. The revenue of the state in $1878, £ 512,300$; the expenditure, $£ 416,600$. The Residency or Rajkumar College at Indore, for the education of the sons of the chiefs and gentry of Central India, is affiliated to the Calcutta University.

Indore was captured by the British on the 24th August 1804. As a city, it is of modern date. That part of the Holkar capital called Old Indore was a small village, the site of which pleased Ahalya Bai, who encamped at it after the death of Mulhar Rao Holkar. The dominant race in Indore are Mahrattas, and there are a considerable number of Gonds and Bhils. There are several cotton mills in the state of Indore (one belonging to the Maharaja), which are in constant work. Opium manufacture is another important industry, and in 1877-78, 16,243 chests were exported from Indore.

INDO-SCYTHI and Indo-Scythian are terms employed to designate races who became early occupants of N.W. India. The Yuchi, established in Bactria and along the Jihun eventually bore the name of Jeta or Yetan, that is to say, Getes. Their empire subsisted a long time in this part of Asia, and extended even into India. These are the people whom the Greeks knew under the name of Indo-Scythi. The period allowed by all authorities for the migration of these Scythic hordes into Europe, is also that for their entry into India. The sixth century is that calculated for the Takshak from Sehesnagdes; and it is on this event and reign that the Puranas declare that from this period no prince of pure blood would be found, but that the Sudra, the Turshka, and the Yavan would prevail. All the IndoScythic invaders held the religion of Buddha, and hence the conformity of manners and mythology between the Scandinavian or German tribes and the Rajputs increased by comparing their martial poetry. The Indo-Scythi of Arrian were a Scythic tribe who had settled alony the Indus. They attempted to penetrate eastward by way of Kandesh and Malwa, but were opposed by Vikramaditya. The Indo-Scythia of the Greeks was therefore the valley of the Indus, Northern IndoScythia being the Panjab proper, and occupied by the Med race, and Southern Indo-Scythia being Sind, occupied by the Jat, a tribe of the Abar hordes. Pliny calls the western region of the Caucasus, Scythia Sendica; and about this were congregated the Maidi, next to the Sindi and Kerketæ; a tribe of Arii or Arichi, who gave their name to an island of Aria, or Arietas, or river Arius; a tribe of Maetes or Mæotai, with towns named Madia and Matium; a tribe of Matiani, with a town of Mateta; a tribe of Kottæ, with a country called Kutais, and cities called Kuta and Kutaia; a tribe named Kolchi, with a mountain and a district called Koli ; a tribe of Iberes, with a town called Iberia; a tribe called Buonomai, a district of Minyas, a city of Male; and a tribe of Baternæ, with a river called Bathys, and a port named Bata;-these names reminding the investigator of the Med, Kathi, Kol, Abhir, Mina, Mallina, and Bhatti of the valley of the Indus. See India.

INDRA, the Hindu god of thunder, a personification of the sky, the chief of the Devata or Sura, the name being from the Sanskrit root Id, to be 
glorious (vide Devata). The attributes of Indra correspond to those of the Jupiter Pluvius and Jupiter Tonans of the Greeks and Romans, and the Thor of Scandinavia, and as such he is the impersonation of the phenomena of the skies. He is represented as a white man sitting upon his celestial vahan, the elephant Airavati, produced at the churning of the ocean, and holding in his hand the vajra or thunderbolt. One of the Rig Veda hymns describes the contest of Indra, the lord of thunder, with Vritra, otherwise called $A^{\prime} h i$, the personification of the rain-cloud; and those who know how important rain is to countries like India, can appreciate the joy that welcomes descending showers upon the parched and heated fields, and understand how the cloud which is supposed to imprison the waters is regarded as a demon, while the lightning that cleaves it, and sets them free to descend on earth, is worshipped as a beneficent deity. The following is Professor Wilson's translation of the hymn in the 32d Sakta :-

'I declare the former valorous deeds of Indra, which the thunderer has achieved: he clove the cloud; he cast the waters down (to earth); he broke (a way) for the torrents of the mountain.

'He clove the cloud, seeking refuge on the mountain; Twashtri sharpened his far-whirling bolt; the flowing waters quickly hastened to the ocean, like cows (hastening) to their calves.

'Impetuous as a bull, he quaffed the soma juice; he drank of the libations at the triple sacrifice. Maghavan took his shaft, the thunderbolt, and with it struck the first-born of the clouds.

'Inasmuch, Indra, as thou has divided the first-born of the clouds, thou hast destroyed the delusions of the deluders, and then engendering the stun, the dawn, the firmament, thou has not left an enemy (to oppose thee).

"With his vast destroying thunderbolt, Indra struck the darkling mutilated Vritra; as the trunks of trees are felled by the axe, so lies A'hi prostrate on the earth.'

Indra takes a different position in each of the three periods of Hindu mythology. In the Vedic period he is the great being who inhabits the firmament, guides the winds and clouds, dispenses rain, and hurls the tbunderbolt. In the Epic period he is still a principal deity, taking precedence of Agni, Varuna, and Yama. In the Puranic period he is inferior in rank to Brahma, Vishmu, and Siva. His heaven is called Swargaloka or Indra-loka, and his pleasure-garden or elysium, his city (sometimes placed on Mount Meru, the Olympus of the Greeks), his charioteer, his thunderbolt, his elephant, his bow (the rainbow) are all famed.

Nature-worship, with Indra as its chief deity, seems to bave been holding its place until about B.C. 1500 ; but, in later mythologies, he is even vilified, and described as extremely licentious. And in the present state of Hinduism, in which every Hindu has a separate belief, and heroworship, devil-worship, and lingam-worship are the prevailing forms, Indra is almost unheard of and unknown, is never invoked, and has been replaced by Vishnu and Siva, their wives and children and incarnations.

Amongst the earliest dissenters from Indra were the Yadu race under Krishma's influence. The Mahabharata makes Krishna say to Nanda, his adopted father, "Why worship Indra as the Supreme God? O father! we are Vaisyas, and our cattle live upon the pastures, lct us thcrefore cease to worship Indra, and pay our devotions to the mountain Govardhana.' Up to that time, it was to the heaven of Indra that the good who died were believed to proceed.

These changes indicate the strife between sects as the present forms of Hinduism were being eliminated. In one myth, Indra is depicted, like Argus, covered with eyes, and is thus called the thousand-eyed god. Having become enamoured of Ahalya, wife of the rishi Gautama, the rishi discovered his intentions, and bestowed on the god his curse that his body should be covered in a very extraordinary manner, which, on the contrition of the offending deity, he changed into eyes.

It is related that on one occasion, in the form of a shepherd boy, Indra robbed the garden of a peasant. In this theft he was detected. The story is told in a hymn-

'The sage musician chose ;

He told how Sachi, soft as morning light,

Blythe Sachi, from her lord Indrani hight,

When through clear skies their car ethereal rose,

Fixed on a garden trim her wandering sight,

Where gay pomegranates, fresh with early dew,

Vaunted their blossoms new ;

Oh! pluck, she said, yon gems, which nature dresses

To grace my darker tresses.

In form a shepherd's boy, a god in soul,

He hastened, and the bloomy treasture stole.

The reckless peasant, who those glowing flowers,

Hopeful of rubied fruit, had fostered long,

Seized, and with cordage strong

Shackled the god, who gave him showers.

Straight from seven winds immortal Genii flew,-

Varuna green, whom foamy waves obey,

Bright Vahni, flaming like the lamp of day,

Cuvera, sought by all, enjoyed by few,

Marut, who bids the winged breezes play,

Stern Yama, ruthless judge, and Isa cold,

With Nairit mildly bold;

They with the ruddy flash, that points his thunder, Rend his vain bands asunder.

The exulting god resumes his thousand eyes,

Four arms divine, and robes of changing dyes.

To understand these allusions, it must be remembered that the Hindus have assigned regents to each cardinal and intermediate point of the compass. Indra being esteemed the first of firmamental deities, and especially the ruler of the east, that point is reckoned first, and the others are thus ruled:-Agni, south-east; Yama, south ; Nairit, south-west; Varuna, west; Vayu, north-west; Kuvera, north; Isa or Isani, northeast. To which are sometimes added three other quarters or points, viz. above, governed by Brahma; below, by Naga or Sesha Naga, the king of serpents, otherwise named Vauki; and the centre, ruled by Rudra or Siva.

Indra is called Sakra in conseciuence of bcing the evil adviser of the demous or asura, by whom he was so often driven from heaven; but also, with mythological inconsistency, Pakushasani, he who governs the gods with justice; Shatkratu, he to whom a hundred sacrifices are made; Vitraha, Bularati, and Numuchisadana, the destroyer of the giants ; Urisha, the holy; Meghusadana, he who is borne on the clouds, etc., etc. Indra possesses the following blessings, produced at the churning of the ocean:-Kamdenu, the allyielding cow; Pariyataka, the tree of plenty ; and Uchisrava, the eight-headed horse. The princes of Kangti, the rajas of Assam, and otber chiefs in the eastern parts of India, claim to have derived their origin from Indra.

One of his numerous names is Dyupeti, or, in 
the nominative case, before certain letters, Dyupetir, which means the Lord of Heaven. He may be considered as the Jove of Ennius, in his memorable line-

'Aspice hoc sublime candens, quem invocant omnes Jovem,' where the poet clearly means the firmament, of which Indra is the personification.

Indra is fabled to reside in the celestial city of Amravati, where his palace Vaijayanta is situated in the garden Nandana, which contains the allyielding trees Pariyataka, Kalpadruma, and three others similarly bountiful. He rides the elephant Airavati, driven by his charioteer Matali, and be holds the weapon Vajra or the thunderbolt, and he is hence named Vajrapani. His chief musician is named Chitra-rat'ha, who rides in a painted car, which on one occasion was burned by Arjun, the confidential friend and agent of Krishna or the sun. The water-spout is said to be the trunk of his elephant, and the iris is appropriately called his bow, which it is not deemed auspicious to point out. Menu says, 'Let not him who knows right from wrong, and sees in the sky the bow of Indra, show it to any man.' His consort is Indrani, or Aindri, or Mahendri, also named Pulomaya, sometimes Powlumi and Sachi, and she is very virtuous as well as beautiful.-Williams' Nala; Coleman; Menu; Moore; Cal. Rev.; N. Br. Rev. ; Sir W. Jones' Hymn to Indra, xiii. p. 275.

INDRABHUTI, son of Vasubhuti, one of the Ganadharas or masters of the Jain schools, the same with Gautama.

INDRADWIPA or Gandharvachanda, a division of the Old Continent. Has been supposed to be the Orkney Islands, but also Japan.

INDRAGIRI, a hill at Sravana Belgola in the south of India, has the oldest known Jain inscription. It records an emigration of Jains from Ujjain, under the leadership of Swami Bhadra Bahu, the last of the Sruta Kevalis, who was accompanied by Chandragupta, king of Pataliputra. Its date is supposed to be about the $3 \mathrm{~d}$ century B.C.-Growse, p. 49.

INDRAJIT, in Hindu legends the conqueror of India. The term is Sanskrit, from Jee, to conquer. He was the bravest and most powerful of the sons of Ravana. In the war which Rama carried on against Ravana, Indrajit's bravery was very conspicuous, but at the close of the war he was slain by Lakshmana.

INDRA-LOKA, called also Swarga, the heaven of Indra, built by Visvakarma, a son of Brahma, and architect of the gods.

INDRAPRASTHA, an ancient town of Pandava, Kaurava, and Yadava times. Its ruins are pointed out half-way between Dehli and the Kutub. Indraprastha and Dehli were about five miles apart, the one on the Jumna, and the other on a rocky hill to the $\mathrm{S} . \mathrm{W}$. in the interior. Indraprastha does not appear to have been a famous place in the history of Buddha. The historians of Alexander and Seleucus also make no allusion to the princes of Indraprastba, which, however, was one of the five pat or prastha which had been demanded by Yudishthra as the price of peace between the rival Kuru and Pandava races, and which old Dhrita Rashtra gave away from his kingdom to his turbulent nephews. The principality assigned to them was a bit of forest land, then known under the name of Khandava-vana. The existence of Indraprastha in the $2 d$ century A.D. may, however, be recognised in the Indabara of Ptolemy; and Dehli may possibly be found in Ptolemy's Daidala, which is placed close to Indrabara (perhaps Indrapat), and midway between Modura or Mathura and Batan Kaisara or Sthaneswara. The date of the occupation of Indraprastha as a capital, by Yudishthra, may be attributed, with some confidence, to the latter half of the 15 th century B.C. Posterity can now hardly trace its site. The only spot that has any claim to have belonged to that ancient city, is a place of pilgrimage on the Jumna called the Negumbode Ghat, immediately outside the northern wall of the present city. Popular tradition regards this ghat as the place where Yudishthra, after his performance of the Aswa Medha, or the horse sacrifice, celebrated the Hom, and a fair is held at the ghat whenever the new moon falls on a Monday. Local tradition, however, in this instance, contradicts the Mahabharata, which states the Aswa Medha to have been performed at Hastinapura on the Ganges. The Negumbode Ghat may be the spot where Prithi-raj celebrated his Aswa Medba, but it had acquired a sacredness from before the time of that prince, and was a place of resort where his grandfather, Visal Deva, had put up an inscription to transmit the fame of his conquests. Humayun tried to do away with the aame of Indrapat, and substitute that of Deenpana. None but pedantic or bigoted Muhammadans make use of this name. The common people either call it Indrapat or Purana Killa. Neither could Sher Shah have it called after him as Sherghar, - the voice of tradition is not easily silenced. The Purana Killa, as it now stands, is nearly rectangular in shape, and its walls are over a mile in circuit. In the interior of the Purana Killa is the Keelar Kona mosque, said to have been commenced by Humayun, and completed by Sher Shah. It has five horseshoe arches, decorated with blue tiles and marble, and is a favourable specimen of the architecture of the Afghan period. It is, perhaps, one of the most tasteful mosques in or near Dehli, and is remarkable for its richly inlaid work and graceful pendentives. The prevailing material of the centre arch is red cut sandstone and black slate, and towards the ground white marble and black slate, the carving throughout being very ornate. The two side arches are composed of simple red-stone, picked out with yellow glaze and black slate finely carved, the outermost arches are still plainer in construction, the outer walls changing from red to grey stone. -Tr. of Hind. ii. p. 130-145. See Dehli.

INDUR LATIB. PERS. A drug importer? from Persia into the Panjab, supposed to be Nardostachys jatamansi.

INDUS.

Sam-po-ho, . . Chin. Sind'hu, the adjective

Sin-tow, : : , Saind'hava, SANSK. Sinthus, : : Gr. Sing-ge-chu or Lion Tsang-po, : LADAKH. river, TIBETAN. Aba-Sin, . . ., Sinh-ka-bab or Lion'sSindus, : : : 'LAT. $\begin{gathered}\text { Sinh-ka-bab or Lion's-" } \\ \text { mouth-descended, ", }\end{gathered}$ Nil-ab, : : Pers.

The source of the Indus is in lat. $31^{\circ} 20^{\prime} \mathrm{N}$, and long. $80^{\circ} 30^{\prime} \mathrm{E}$., at an estimated height of 17,000 feet, to the N.W. of Lakes Manasarowara and Rawan H'rad in the southern slopes of the Gangri or Kailas mountains, a short way to the eastward of Gartop (Garo). The Garo river is the Sing-ge-chu or Indus. From the lofty moun- 
tains round Lake Manasarowara, spring the Indus, the Sutlej, the Gogra, and the Brahmaputra. A few miles from Leh, about a mile above Nimo, the Indus is joined by the Zanskar river. The valley where the two rivers unite is very rocky and precipitous, and bends a long way to the south. From this point the course of the Indus, in front of Leh and to the S.E. for many miles, runs through a wide valley, but the range of mountains to the north sends down many rugged spurs. A little lower, the Indus is a tranquil but somewhat rapid stream, divided into several branches by gravelly islands, generally swampy, and covered with low Hippophae scrub. The size of the river there is very much less than below the junction of the river of Zanskar. The bed of the Indus at Pitak, below Leh, has an elevation of about 10,500 feet above the level of the sea, but the town is at least 1300 feet higher. From the sudden melting of accumulations of ice, and from temporary obstacles, occasioned by glaciers and avalanches in its upper course, this river is subject to irregularities, and especially to debacles or cataclysms, one of which, in June 1841, produced terrific devastation along its course, down even to Attock.

At the confluence of Sinh-ka-bab with the Shayok, the principal river which joins it on the north from the Kara-korum mountains, the river takes the name of Aba-Sin, Father of Rivers, or Indus proper, and flows then between lofty rocks, which confine its furious waters, receiving the tribute of various streams; and at Acho, expanding into a broader surface, it reaches Derbend, the N.W. angle of the Paujab, where (about 815 miles from its source) it is 100 yards wide in August, its fullest season. From Derbend it traverses a plain, in a broad channel of no great depth in Attock, in lat. $33^{\circ} 54^{\prime} \mathrm{N}$., long. $72^{\circ} 18^{\prime}$ E., having, about 200 yards above this place, received the river of Kābul, almost equal in breadth and volume, and attains a width of 286 yards, with a rapid boiling current, running (in August) at the rate of six miles an hour. The breadth of the Indus at Attock depends not only upon the season but the state of the river upwards, and varies from 100 to 260 yards. The whole length of its mountain course, from its source to Attock, is about 1035 miles, and the whole fall is 16,000 feet, or 15.4 per mile. From Attock to the sea the length is 942 miles, making its whole length, from the Kailas mountain to the Indian Ocean, 1977 miles. Its maximum discharge, above the confluence of the Panjab or Five Rivers, occurs in July and August, when it is swollen by the seasonal rains, and it then reaches 135,000 cubic feet, falling to its minimum of 15,000 in December.

In the Tibetan of Ladakh it is commonly designated Tsang-po, or the river, and is the Sampo-ho of the Chinese Pilgrim Hiwen Thsang, who travelled in the middle of the seventh century.

Below the junction of the Panjab rivers down to Sehwan, the Indus takes the name of Sar, Siro, or Sira ; from below Hyderabad to the sea it is called Lar; and the intermediate portion is called Wicholo (Bich, HrNDI), or Central, representing the district lying immediately around Hyderabad, just as, on the Nile, the Wustani, or Midlands of the Arabs, represents the tract between Uppe and Lower Egypt. Sir A. Burnes mentions that Sar and Lar are two Baluch words for north and south. The Indus or Sind has been called by that name from time immemorial to the present day, by the races on its banks. The ancients knew that this was the native appellation. Pliny (lib. 6, vi.) says, 'Indus incolis Sindus appellatus.' The Chinese call the river Sin-tow.

From Attock the course of the Indus to the sea, 940 miles, is S. and S.W., sometimes along a rocky channel, between high perpendicular cliffs, or forcing its way, tumbling and roaring, amidst huge boulders, the immense body of water being pent within a narrow channel, causing occasional whirlpools, dangerous to navigation, to Kalabagh, in lat. $32^{\circ} 57^{\prime} \mathrm{N}$., long. $71^{\circ} 36^{\prime} \mathrm{E}$., situated in a gorge of the great Salt Range, through which the river rushes forth into the plain. In this part of its course it has acquired the name of Nil-ab, or Blue Water, from the colour imparted to it by the blue limestone hills through which it flows. There are some remains of a town on the bank of the river, named Nil-ab (where Timur crossed the Indus), supposed to be the Naulibus or Naulibe of Ptolemy. At Kalabagh the Indus enters a level country, having for a short time the Khusuri Hills, which rise abruptly on the right. It now becomes muddy, and as far as Mittunkote, about 350 miles. the banks being low, the river, when it rises, inundates the country sometimes as far as the eye can reach. Hence the channels are continually changing, and the soil of the country being soft,a mud basin, as Lieutenant Wood terms it, - the banks and bed of the river are undergoing constant alterations. These variations, added to the shoals, and the terrific blasts occasionally encountered in this part of the river, are great impediments to navigation. The population on its banks are almost amphibious; they launch upon its surface, sustained by the inflated skins or mussaks, dried gourds, and empty jars used for catching the celebrated pulla fish, the Hilsa of Bengal.

At Mittunkote the Indus is often 2000 yards broad, and near this place, in lat. $28^{\circ} 55^{\prime} \mathrm{N}$., long. $70^{\circ} 28^{\prime} \mathrm{E}$., it is joined, without violence, by the Panjnad, a large navigable stream, the collected waters of the Sutlej, Beas, Ravi, Chenab, and Jhelum. Its true channel, then a mile and a quarter wide, flows thence through Sind, sometimes severed into distinct streams, and discharges its different branches by various mouths into the Indian Ocean, after a course of 1977 miles. The Indus, when joined by the Panjnad, never shallows, in the dry season, to less than 15 feet, and seldom preserves so great a breadth as half a mile. Keeled boats are not suited to its navigation, as they are liable to be upset. The Zoruk, or native boat, is flat-bottomed. Other boats are the Dundi, Dund, Kotal, and Jumpti. Gold is found in some parts of the sands of the Indus.

The shore of its delta, about 125 miles in extent, is low and flat, and at high tide, to a considerable distance inland, overflowed; and generally a succession of dreary, bare swamps.

In the mouths of the Indus, the tides rise about 9 feet at full moon, and flow and ebb with great violence, particularly near the sea, when they flood and abandon the banks with incredible velocity. At 75 miles from the ocean they cease to be perceptible. 
Between the Seer and Kori mouths, at the S.E. of the delta, it is overspread with low mangrove jungle, running far into the sea, and from the Seer is a bare, uninhabited marsh. The main stream of the Indus has discharged its waters at many points between Cape Monze, immediately west of Kurachee and the Gulf of Cutch, if not even that of Cambay. Pitti, Hajamri, and Kediwari, now sea-channels and tidal creeks, shut off from the river, except during the monsoon, are all former mouths of the Indus. The Buggaur or Gharra is still a considerable stream during the inundation; it takes off from the Indus close to Tatta.

The languages spoken on the N.W. border of India are dialects of Hindi, but sufficiently distinct to be called Sindi, Panjabi, and Kashmiri. Lieutenant Leech, indeed, has given vocabularies of seven languages spoken on the west of the Indus. The western border tribes are still mostly under patriarchal governments. In the more southerly are the rarious Baluch tribes in the territories to which they give their name, and whose language is said by Captain Raverty to be a mixture of Persian, Sindi, Panjabi, Hindi, and Sanskrit. The Brahui tribes in Saharawan and Jhalawan, whose great chief is the khan of Khilat, ethnologists consider to be of the same Scythic stock as the Dravidian races in the Peninsula, and infer from this that the passage of some of the Dravidian tribes from Turan was along the valley of the Indus. The Brahui physical type is Scythic, and the language has strong Dravidian affinities. The Brahui is a genuine representative of the preIranian population of S.E. Irania or Baluchistan. The Jat of the Lower Indus appear to be of the same race as the Brabui, and are almost black.

The principal towns on the banks of the Indus river are Leh, Attock, Kalabagh, Dehra Ismail Khan, Dehra Ghazi Khan, Mittunkote, Hyderabad.-Captain Carless; Lieut. Wood; Dr. Lord; Cunningham ; Findlay; Elliot; Hist. of the Panjab.

INDUVANSA, also known as the Lunar race, a race who, in pre-historic times, were dominant in Northern India. In the Raj Tarringini and Rajaoli, the Induvansa family are shown to be descendants of Pandu, through his eldest son Yudishthra. These works, celebrated in Rajwara as collections of genealogies and historical facts, were compiled by the pandits Vedyadhra and Ragonath, under the eye of the most learned prince of his period, Siwai Jai Singh of Amber, and give the various dynasties which ruled at Indraprastha, from Yudishthra to Vikramaditya. The Tarringini commences with Adinath, or Reshabdeva, being the Jain theogony. Rapidly noticing the leading princes of the dynasties discussed, they pass to the birth of the kings Dhrita Rashtra and Pandu, and their offspring, detailing the causes of their civil strife, to that conflict termed the Mahabharata or great war. On the death of Pandu, Duryōdhana, nephew of Pandu (son of Dhrita Rashtra, who from blindness could not inherit), asserted their illegitimacy before the assembled kin at Hastinapur. With the aid, however, of the priesthood, and the blind Dhrita Rashtra, his nephew Yudishthra, elder son of Pandu, was invested by him with the seal of royalty, in the capital of Hastinapur. But Duryodhana's plots against the Pandu were so numerous, that the five brothers determined to leave for a while their ancestral abodes on the Ganges. They sought shelter in countries about the Indus, and were first protected by Drupdeva, king of Panchalica, at whose capital, Kampilnagara, the surrounding princes had arrived as suitors for the hand of his daughter Drupdevi. But the skill of Arjuna in archery obtained him the fair, who 'threw round his neck the burmala or garland of marriage.' The disappointed princes indulged their resentment against the exile; but from Arjuna's bow they suffered the fate of Penelope's suitors, and the Pandu brought home his bride, who became the wife in common of the five brothers; manners decisively Scythic. This marriage is glossed over, admitting the polyandry, but, in ignorance of its being a national custom, childish reasons are interpolated. In the early annals of the same race, predecessors of the Jeysulmir family, the younger son is made to succeed; also a Scythic or Tartar custom.-Tod's Rajasthan, i. pp. 17, 48 .

INFANTICIDE.

Kindermord, . . GER. | Infanticidio, . IT., SP.

Down to comparatively recent historic times, the Phœnicians, Carthaginians, Aramæans, Syrians, Babylonians, and even Israelites, and their neighbours on both sides of the Jordan, sacrificed their children with the hoped-for object of averting any great and serious misfortune. There is a Phonician legend of El, the strong, offering up his son Yedud or Yedid, the beloved. El being the Kronos (Bunsen iii. 286), Malekh Bel was the same as the Tyrian Hercules, or Moloch, or BalMoloch, to whom, as also to Hecate and Melekhet Artemis, dogs were sacrificed. The principal sacrifices offered to Hercules Usu, as well as to his mythical companion, were human beings, which, in Laodicea of Phœnicia, might be ransomed by a doe. At Carthage, the practice of sacrificing their favourite children, and those of the highest rank, in honour. of Hercules, continued down to their latest wars. The legend of the Grecian Hercules is, that he became insane, burned his own children, as well as those of his twin-brother Iphicles, and murdered his guest Iphitus (Bunsen iv. 212, 213). The Greeks exposed their children on the highways to perish with hunger, or to be devoured by beasts of prey, and that barbarous practice was sanctioned by some of their most celebrated lawgivers. Among the Romans, the custom of infanticide also prevailed. It is probable, says Malthus, that when Solon permitted the exposing of children, he only gave the sanction of law to a custom already prevalent. Of all the states of Greece, the Thebans are mentioned by Elian as the only exception to the general practice of exposing infants at the will of their parents. By the other states of Greece, infanticide was sanctioned and regulated by law, under legal provisions for the regulation of this practice. Malthus (vol. i. p. 291) in a note says: How completely the laws relating to the encouragement of marriage and of children were despised, appears from a speech of Minucius Felix, in Octavio (cap. 30): "Vos enim video procreatos filios nunc feris et avibus exponere, nunc adstrangulatus misero mortis genere elidere: Sunt qux in ipsis visceribus medicaninibus epotis originem futuri hominis extinguant et parricidium faciant ante quam pariant.' This crime, he adds, had grown so much into a custom 
in Rome, that even Pliny attempts to excuse it: Quoniam aliquarum fecunditas plena liberis tali venia indiget (iv. xxix. cap. iv.).

Among the Canaanites, the Phonicians, and the Carthaginians, the sacrifice of children was prescribed as a propitiation to their sanguinary deities Moloch and Kronos.

Moses forbade, under penalties of death, the ceremony of passing children through the fire to Moloch ; but down to the time of Manasseh it was nevertheless practised among the Jews, and the king sacrificed his own son. Jephthah consecrated a victory by burning his daughter. The Greek fleet was detained at Aulis till Iphigenia had been murdered. And when Tacitus tells us of the German childreu being embarked in a shield on the face of the river, he is probably referring to the same act. Female infanticide was common over all Arabia in the time of Mahomed, and is frequently reprobated in the Koran. It was Mahomed who put a stop to the inhuman custom, which had been long practised by pagan Arabs, of burying their daughters alive, lest they should be reduced to poverty, or else to avoid the displeasure and disgrace which would follow if they should happen to be made captives, or to become scandalous by their behaviour; the birth of a daughter being for these reasons reckoned a great misfortune, and the death of one as great a happiness. The manner of their doing this is differently related; some say that when an Arab had a daughter born, if he intended to bring her up, he sent her clothed in a garment of wool or hair, to keep camels or sheep in the desert; but if he designed to put her to death, he let her live till she became six years old, and then said to her mother, Perfume her and adorn her, that I may carry her to her mothers; which being done, the father led her to a well, or a pit dug for that purpose, and having bid her look down into it, pushed her in headlong as he stood behind; and then filling up the pit, levelled it with the rest of the ground. But others say that when the woman was ready to fall in labour, they dug a pit, on the brink whereof she was to be delivered, and if the child happened to be a daughter, they threw it into the pit, but if $u$ son, they saved it alive. This custom, though not observed by all the Arabs in general, was yet very common among several of their tribes, and particularly those of Koreith and Kendeh, the former using to bury their daughters alive in Mount Abu Dalama, near Mecca. In the time of ignorance, while they used this metbod to get rid of their daughters, Sasaa, grandfather to the celebrated poet Al Farazdak, frequently redeemed female children from death, giving for every one two she-camels big with young, and a he camel ; and hereto Al Farazdak alluded when vaunting himself before one of the khalifs of the family of Meya, he said, I am the son of the giver of life to the dead; for which expression being censured, he excused himself by alleging the following words of the Koran:- 'He who saved a soul alive shall be as if he had sared the lives of all mankind.'

Europeans, at their settlement in America, found female infanticide still practised among some of the tribes; and the Abbé Dubois mentions that it was customary to expose or put to death children born under stars supposed to possess a particularly malignant influence.
Dillon, who went in search of La Perousc, mentions that the women of Tucopia were at least treble the males; all the male children, except the two eldest, being strangled on their birth, whilo all the girls were allowed to live.

When Captain Wallis visited Otaheite and the neighbouring islands in the South Sea, the practice was unhesitatingly avowed by the lascivious Eereeoie societies in these islands.

Dr. Bennett tells us (i. p. 122) that infanticide was practised by the women of Australia and New Zealand, on infants born after a severe labour, and on half-caste infants.

Infanticide of female infants has been practised in India from unknown times amongst the ancient Gakkar race in the Panjab, and it has been a constant custom, and has continued in several parts of India down to the latter third of the 19th century. It was long supposed to have been confined to the clans of the Rajkumar or Rajavansa tribe, who inhabit districts in the neighbourhood of Benares; but a larger knowledge disclosed the existence of a similar practice "among several tribes in Gujerat, all through Rajputana, also in the N.W. Provinces, in Oudh, Cutch, and west of the Indus in Baluchistan. Mr. Duncan was the first who brought the prevalence of infanticide to the notice of the British rulers of India. He became acquainted with its existence in 1789 while at Juanpore, and he induced the Rajkumar tribe, who practised it, to enter into a covenant to discontinue the horrid practice, which the covenant recognised to be condemned in the Brahma Bywar Purana as a great crime. The races with whom it has been customary to sacrifice their female children, are the Jut or Jat, the Rahtor Rajputs of Jeypore and Jodhpur, the Jahreja Rajputs of Cutch, and the Rajkumar race, the Sourah of Ganjam, and the polyandric Toda race on the Neilgherries.

The Rajkumar and Rajavansa, in a portion of the territories of Oudh and the adjoining provinces, and the Jahreja, in the countries of Cutch and Gujerat, on the western side of the Peninsula of India, alleged that the practice of female infanticide had existed for 4900 years ; and the late General Walker, in an account published by Major Moor early in the 19th century, estimated the number of deaths of female children annually, in Cutch and Gujerat only, at no less than 30,000.

The Government of India, during the Marquis Wellesley's administration, in 1802 , declared it to be punishable by law. But this proclamation was only partially successful.

In 1821, all surplus of fines levied on the Kattyawar chiefs, was thrown into a fund to provide dowers for unmarried girls, and this was followed by the Gaekwar in 1825. Little success resulted; and in 1834, Mr. J. P. Willoughby arranged to take a census and to put in force measures to prevent the Jahreja and others from destroying their female infants. The practice as a recognised custom ceased, the last conviction having been in 1854 , and in 1872 there were in Kattyawar 10,461 males to 9513 females.

After the conquest of the Panjab by the British, Mr. C. Raikes called a public meeting of the sirdars and chiefs at Amritsar; the meeting recognised as the causes for killing their female children, the expenses of marriage, for dowers, and for the exactions for the Bhat, the Rai, the Dut, the Bhand, 
the Nai, the Merasi, and other beggars; and the meeting resolved to discontinue and suppress the practice. Indeed, among the many pressing measures of reform stopped by the inutiny, was the passing of an Act, actually draughted, to prevent and punish the crime of female infanticide. In 1856, Mr. Moore, a special commissioner, had made the most startling revelations as to the prevalence of the crime in the Busti district. The subject was overlooked till 1867, when Mr. Hobart was sent into the same district to report whether, as was supposed, the practice had abated since 1856 . Instead of this, he discovered that the houses of certain Rajput clans were floored with skulls, and the tanks choked with infants' bones. Sir William Muir at once put repressive measures in force, and applied to the Government of India for immediate legislation. Mr. (Sir John) Strachey accordingly moved for leave to introduce a Bill.

In Cutch in 1840, at the request of the Rao, the chiefs bound themselves to measures of repression. In 1840 there were 4912 males and 335 females, but in 1873 the Jahreja males were 8371 to 4272 females, and the Rao expressed his determination to repress this crime. In Palanpur and Mahikanta, and among the Kumbi of Gujerat, the success was great. In 1840 there were only three girls alive amongst 35 clans residing in 95 villages in the southern portion of the Allahabad district. In 1843 it was found that not a single daughter existed amongst the great dominant clan of Chauhan Rajputs at Mainpuri. In the latter ease, shortly after the determined efforts of a collector to put down the vice at any cost, there was a wonderful change effected; and it was found that in the year 1864 there were 1284 Chauhan girls living.

In March 1870 an Act was passed for the repression of infanticide. 'The rules sanctioned by this Act are very simple and precise. Certain districts or clans are proclaimed. A careful census is taken, and a nominal register is prepared, showing the names of all the members of a family. In this register, each birth, marriage, and death is recorded, the midwife, head of the family, and village night-watchman being responsible for the accuracy of such a record, and for duly reporting any event to the police. A tribe or district is to be held guilty if the female children do not average 40 per cent. -10 per cent. being allowed for certainty's sake, although of course a higher ratio would be more strictly in accordance with the natural proportion. Further, the report tells us, 'the minimum number to which the ratio might safely be applied, was fixed at 25 ; and where out of that number of children only 40 per cent. are females, -i.e. where there are 10 girls to 15 boys, - the ratio may be accepted as a prima facie indication sufficient to warrant the surveillance contemplated by the rules.'

But as it was found in some districts that the average of the female population of girls was only 25 per cent., stronger rules were to be at once enforced, every pregnancy was to be reported by the village midwife and night-watchman, and the police were ordered to be on the alert to detect even the attempt to commit crime. Even the heads of families could be obliged to report pregnancies to the Local Government, were such a step necessary to uproot the evil.

In the $N$.W. Provinces, in 1874-75, girls were only 30.9 per cent. of the total infants.
In Oudh, from a census of 649 villages in 187576 , infanticide seems to have been discontinued amongat Rajput children; but in the N.T. Provinces there were 3113 villages, with a population of 393,529 souls, and there were birth reports of 4.08 per cent. more boys, showing a supposed concealment of girls born.

In Kattyawar, in the year 1875-76, taking all the Rajput tribes, there were 90.70 females to 100 males. The Jahreja tribe in 1872 had 90.93 females, and in 1875-76, 91:39. The death-rate among male infants in $1875-76$ was $15 \cdot 59$ per cent. on the total number of male births, and among females, $15 \cdot 19$ per ceut. The number of unmarried Rajput girls in $1874-75$ was $15^{\circ} 08$, and in $1875-76$ it was 15.45 .

In Cutch, however, in 1875-76, the percentage of infant deaths to births among males was 18:30, and among females, $31 \cdot 13$, against 25.47 and 30.05 in 1874-75.

In Palanpur the percentages were 10.52 and 12.90 respectively, against 7.69 and 26.47 in 1874 75 ; and in Mahikanta, 16.32 and 36.66 , against $6 \cdot 45$ and $27 \cdot 45$.

In the first half of $1872-73,150$ persons were punished in India under the Infanticide Act. In 1875,27 districts in the N.W. were under the infanticide rules. On the 1st of April 1875, there were found in the proclaimed villages 80,235 boys to 32,759 girls, in the proportion of $71 \cdot 1$ to 28.9 . The returns on 1st September 1874 showed 82,400 boys to 35,137 girls (not including arrivals and removals), in the ratio of $70 \cdot 1$ to $29 \cdot 9$. The minor population has risen from 12,994 to 117,537 , the boys having increased by $2 \cdot 7$, and the girls by 6.9 per cent., in the ratio of 28 to 72 per 100.

Female infanticide, by violent measures, has greatly decreased among the Jat tribes, but many children are allowed to die by neglect. With them the great cause of the crime was the excessive expenditure for their marriage, but this has been greatly curtailed.

The pliase which the crime once presented in Southern India was quite different from that which is now presented by the same crime amongst the northern Rajputs. Infanticide in Southern India, it is believed, used to be practised chiefly amongst the caste of temple dancing-women, and, strange to relate, led to the murder, not of female, but of male children. This was remarkable. Infanticide in India has always, generally speaking, meant the murder of girls, so that the expense (so crushing to Hindus, to whom marriage means feasting and lavish expenditure) of wedding them to the sons of neighbours might be avoided by poor parents. But in the case of the caste of temple women, females were profitable, whilst male children were useless. So the new-born male infant used to be cast into some particular well or secret receptacle, whilst the girls were trained from infancy to read, sing, dance, adorn themselves, enjoy the emoluments of the temple, and take part in the worship of the god.

It was the custom of the T'alpur dynasty of Sind to put to death all children born to the princes of slave women. Dr. James Burnes was informed that one member of the family alone had destroyed 27 of his illegitimate offspring.

Dr. Cooke saw mummy-like bodies of infants in a cavel in Bhagwana in Baluchistan, some of which had a comparatively recent appearance. 
Infanticide of girl infants was common in Saurrada, by entombing them alive, or wrapping them in cloth, and so burying them. It was put an end to by Colonel (Sir John) Campbell about the year 1848. The Kandh killed their own girls, and then purchased wives from other parts of the country.

Infanticide was greatly condemned by the Sikh Guru Govind, who says, "With the slayers of daughters whoever has intercourse, him do İ curse.' And again, 'Whosoever takes food from the slayers of daughters, shall die unabsolved.' Nevertheless, the Bedee race of the Sikhs, the hereditary priesthood, who are to be found all over the Panjab, adopted this mode of disposing of their daughters, from religious pride leading them to regard with horror the idea of giving their daughters to persons of inferior rank.

In the total population of British India of $255,891,821$, the males, in 1881 , numbered $129,941,851$, and females $123,949,970$, or six millions less.

In four provinces or states the females were in excess, viz. :-

\section{Bengal,}

Madras,

Mysore,

Travancore,

Males. Femnles.

$34,625,591 \quad 34,911,270$

$15,421,043 \quad 15,749,588$

$2,085,842 \quad 2,100,346$

$1,197,134 \quad 1,204,024$

In every other province the males were more numerous, and in the following four greatly so:-

\section{Coorg,}

N.W. Provinces and Oudh, Panjab,

Rajputana,
Males.

100,439

$23,297,255$

$12,322,356$

$5,544,665$

Females.

77,863

$21,552,364$

$10,389,764$

$4,723,727$
Under Act viii. of 1870 for the suppression of female infanticide, small sections of the Ahir, Ahar, Taga, Jat, Rajput, Gujar, and Mina, aggregating about 350,000 persons, were proclaimed in various parts of the N.W. Provinces and Oudh.

The suspected castes consist mostly of well-to-do agriculturists, amongst whom the 1881 census shows the following proportion of females to 100 persons :-

\begin{tabular}{|c|c|c|c|c|c|c|}
\hline \multirow{3}{*}{ Age. } & \multicolumn{4}{|c|}{ Absolute Numbers. } & \multirow{2}{*}{\multicolumn{2}{|c|}{$\begin{array}{l}\text { Percentage of } \\
\text { Females to Per } \\
\text { sons in same } \\
\text { Age Group. }\end{array}$}} \\
\hline & \multicolumn{2}{|c|}{ Males. } & \multicolumn{2}{|c|}{ Females. } & & \\
\hline & $\begin{array}{l}\text { Susp. } \\
\text { Castes. }\end{array}$ & $\begin{array}{c}\text { Other } \\
\text { Hindus. }\end{array}$ & $\begin{array}{l}\text { Susp. } \\
\text { Castes. }\end{array}$ & $\begin{array}{c}\text { Other } \\
\text { Hindus. }\end{array}$ & $\begin{array}{l}\text { Susp. } \\
\text { Castes. }\end{array}$ & $\mid \begin{array}{c}\text { Othel } \\
\text { Hindus }\end{array}$ \\
\hline $\begin{array}{r}0 \text { to } 9 \\
10,19 \\
20,1,29 \\
30 \text {, ete. } \\
\end{array}$ & $\begin{array}{r}946,591 \\
834,350 \\
717,686 \\
1,452,646 \\
\end{array}$ & $\begin{array}{l}3,997,556 \\
3,137,475 \\
2,730,553 \\
5,502,975 \\
\end{array}$ & $\begin{array}{r}833,565 \\
599,857 \\
605,541 \\
1,307,267 \\
\end{array}$ & $\begin{array}{l}3,800,626 \\
2,438,194 \\
2,709,161 \\
5,484,251 \\
\end{array}$ & $\begin{array}{l}46 \cdot 82 \\
41 \cdot 83 \\
45^{\cdot} \cdot 76 \\
47 \cdot 36 \\
\end{array}$ & $\begin{array}{l}48 \cdot 74 \\
43 \cdot 75 \\
49 \cdot 81 \\
49 \cdot 91 \\
\end{array}$ \\
\hline Total, & $3,951,2 \pi 3$ & $15,368,559$ & $3,346,230$ & $14,432,232$ & 4 & 48.43 \\
\hline
\end{tabular}

The census report of 1881 shows, as under, the percentage of females in age group:-

Caste. 20 and up. Under $5 . \mid$ Caste. 20 and up. Under 5. \begin{tabular}{l|l|l|l} 
Mina, & $46 \cdot 25$ & $52 \cdot 72$ & Jat, \\
$44 \cdot 6$ & $44 \cdot 9$
\end{tabular}

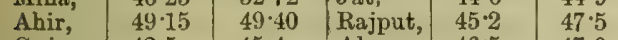
\begin{tabular}{l|l|l|l|l|l} 
Gujar, & 42.5 & $45 \cdot 4$ & Ahar, & 46.5 & 47.0
\end{tabular}

Among the last five castes there still is neglect of female infants, though during the last ten years the high mortality amongst the Rajput, Taga, and Gujar must have considerably abated; but among the Ahar and the Jat there has been little, if any, improvement. During the five years 1875 to 1879 inclusive, the birth-rate of the proclaimed castes fluctuated from $32 \cdot 7$ to $48 \cdot 3$ per 1000 of the population.

Infanticide at one time was prevalent in the
Kandyan country, from poverty, being boru under an evil star, and illegitimate children.

The Chinese have complete power over their offspring, even to life. In China, and also in Japan, infant murder is at the present time prevalent. In the great cities of Pekin and Canton, Sir George Staunton found the exposure of children to be very common. Among the Chinese, however, it is ascribed to their extreme poverty, and it is more prevalent in the southern coast provinces than in the northern and midland. There are towns and districts in China where infauticide is practised, in some instances to an infamous extent, in others to a less degree. There are others, again, where it is not known at all as a habit, and $M r$. Medhurst believes that in the majority of cities it is a crime no more frequent than in some European towns, and then only to conceal frailty. The Government of British India, and their officers engaged in the census-takings of 1872 and 1881, have been directing much attention to this subject, and the present position will be found described at p. 237 of article India, and p. 354 of Rajputs.-Medhurst, Far. Cathay, p. 90 ; Browne on Infanticide; Cormack's Fenale Infanticide; Cole. Myth. Hind.; Malcolm's Persia; Burnes' Sind; Calcutta Revieu, 1871; Govind Rechet Nameh, extra to the Grunth; Cunningham's Sikhs; Sale's Koran, p. 54 ; Abbé Dubois; Chatfield's Hindustan; Census Reports; Oriental Herald, xv. p. 479 ; Pr. R. A. Suc. iii. p. 263 ; Mor. and Mat. Proq., 1874-75, 1875-76.

INFANTS. Sons are greatly longed for by all the races inhabiting the south and east of Asia. A prevailing feeling regarding them is such as is expressed in Psalm cxxvii. 4, 5, 'As arrows are in the hand of a mighty man, so are the children of the youth. Happy is the man that hath his quiver full of them; they shall not be ashamed, but they shall speak with the enemies in the gate;' for most persons will hesitate to attack a large united family. But the desire in Asia is for male children. Amongst Hindus and Chinese, with both of whom spirit-worship largely prevails, sons are particularly longed for, in order to obtain from them duties to the manes of their parents. The eastern custom of nursing a child from the hip or side, as in Isaiah $l x .4$, is still continued, and a child born after vows, is still, as in Proverbs xxxi. 2 , called the son of a vow. As in Genesis $x \times v .6$, the children of Muhammadans, born of a wife of humbler birth, or of a haram woman, are not deemed equal in social rank to the children of a high-born wife. Luke xviii. 15 says, "They brought unto him also infants, that he would touch them.' When a Hindu spiritual guide (guru) visits a disciple, the latter takes his child to him for his blessing; placing the infant before the guru, and forcing its head down to his feet, the parent solicits his blessing, which he gives in some such words as these- 'Live long; be learned; be rich.' The usual blessing of a Muhammadan fakir, man or woman, is Jio-baba, Live, my child; Jio, sahib, Live, sir; Jio-bibi, sahib, hazrat Maryam ka saya, Live, lady, under the protection of the Lady Mary. ING. BUrM. A lake. Ing-khun, lake revenue. Ing-tha-ma, lake fisher.

INGA BIGEMINA. Willde. Iron-wood. Mimosa bigemina, Linn. | M. lucida, Roxb. Bung-mai-zah, . . BURM. / Katur konna, . . Burss. 
This tree grows in the Konkaus, Nepal, Assam, and Pegu. It is of smaller girth than the I. xylocarpa, but grows to a great height, and has a black wood. Like the I. xylocarpa, it is called iron-wood by the English in Pegu and Tenasserim. In uative gardens it is an ornamental tree, with sweet-scented blossoms, and affording a thick, beautiful shade. Its seeds are poisonous when taken internally, notwithstanding which they are sold at a high price in the bazar, and are used by Burmese and Karens as a condiment to their pre-

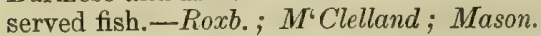

INGA DULCIS. Willde.

Mimosa dulcis, Roxb. | Pithecolobium dulce, Benth

Manilla tamarind, . ENG. Sima chinta, . . TEL. Curkapulli maram, . TAM. Sima chinduga, . . ",

This small tree from the Philippines is now grown in India, attains to 12 to 18 inches in diameter, and resembles the hawthorn in general appearance. It was introduced into the Philippine Islands, but was a Mexican tree, which the Spaniards introduced into the Eastern Archipelago. It furnishes a hard wood. It is a most valuable hedge plant, perhaps the best in India, and is now sparingly used along some of the railway lines of the Peninsula. The pulp of the fruit is edible. Pods curiously twisted.-Voigt.

INGA XYLOCARPA. D. C. Iron-wood. Mimosa xylocarpa, Roxb. $\mid$ Acacia xylocarpa, Willde. Xylia dolabriformis, Benth.

Pyen-ka-do, . B৫RM. Jamboo, . . Hind, Yerool, . CAN., MAHR. Eruvalu, : . . TAM. Jamba, . . ," Malei averei, . . ., ?? Partridge wood," . ENG. Tangedu, . . . TEL. Boja of the . GoDA very. Konda tangedu, . . ",

This valuable and stately timber tree blossoms during the hot season, at which period it is nearly destitute of foliage. It is abundant in the Walliar forests of Coimbatore, also in $\mathrm{N}$. Canara, between Sircee and Yellapore, and is not uncommon in the seaboard forests of the Bombay Presidency, south of Panwell. In Canara and Sunda it is chiefly above the ghats in Soopeh and Dandelee, where it grows large, and is very useful in house-building. It is met with in the Godavery forests, where it grows very large on the mountains, and there is much of it in the Vizagapatam district. In the southern forests of Pegu it is a plentiful large tree, 15 to 18 inches in diameter, very lofty and straight, with 6 to 9 feet in girth, and very abundant in Amherst, Mergui, and Tavoy.

The heart-wood of full-grown trees is of a dark colour, very hard and dense, strong and durable, etc. It is used for house and bridge posts, ploughs, boat anchors, for naves of cartwheels, crooks for ships ; knees and bends, posts, piles, and bridges; and is excellent for railway sleepers, etc. A cubic foot weighs 60 to $66 \mathrm{lbs}$. $\mathrm{An}$ inch bar of the Coimbatore wood sustained 550 lbs. Nails cannot be driven into it. It is as impervious to white ants as teak, and is even more durable in the ground. In the Madras Gun Carriage Manufactory it is used for poles, axle cases, and braces for transport limbers, poles and yokes for water-carts, cheeks, axle cases for transport carriages, light mortar carts. On the Madras Railway it has been employed extensively for piles, transoms, and walling pieces. In small scantlings, it is liable to split and warp under exposure to the weather.-Drs. Roxb., Wight, $M^{\circ}$ Clelland, Brandis, Mason, Gibson, Cleghorn; Captain Dance; Mr. Rohde; Cat. Ex.; Voigt.
INGIE or Engie. Burm. A white linen jacket used by Burmans.-Winter's Burma.

ING-LEET-MEN. BURM. An ambiguous expression adopted by Burmese as a salve to their pride, for use when compelled to hold intercourse with a dignitary who is not in their view an anointed king. It may apply to the Queen of Fngland or to the Governor-General.-Yule's Embassy. Qu. Englishmen.

INGLIS. HIND. A pensioner. The word is a corruption of 'Invalids.' Wilson says it is meant for English.

INGOT, a small wedge-shaped mass of tin, copper, gold, or silver, etc., of an indefinite size and weight. About 40 ingots of tin go to the ton. In some countries ingots of the precious metals pass current, as silver in China. In Burma, gold and silver ingots, of half an ounce weight avoirdupois, form part of the local currency.-Simmonds' Dict.

INGOULETZ. On leaving its banks and travel-. ling eastward over the steppe, are to be observed innumerable tumuli, which vary greatly in size; and one of unusual magnitude is generally surrounded by several of smaller dimensions. There can be no doubt that the larger tumuli are raised over the bodies of princes and heroes, and the minor sort cover the remains of the followers of their armies, or of their state. The expanse occupied by these monuments of the dead extend regularly to the very farthest stretch of sight. Herodotus declares these remote regions of sepulture to be regular places of interment for whole nations, and particularly mentions, that whenever the Scythians lost a king or a chief, they assembled in great multitudes to solemnize his obsequies; and, after making the tour of certain districts of the kingdom with the corpse, they stopped in the country of the Gerrhi, a people who lived in the most distant parts of Scythia, and over whose lands the sepulchres were spread. A large quadrangular excavation was then made in the earth (in dimensions more like a hall of banquet than a grave), and within it was placed a sort of bier bearing the body of the deceased prince. Daggers were laid at various distances around him, and the whole covered with pieces of wood and branches of the willow tree. In another part of the same immense tomb were deposited the remains of one of the late sovereign's concubines, who had been previously strangled; also his favourite servant, his baker, cook, horsekeeper, and even the horses themselves, all followed him to the grave, and were laid in the same tomb, with his most valuable property, and above all a sufficient number of golden goblets. This done, the hollow was soon filled and surmounted with earth; each person present being ambitious to do his part in raising the pile that was to honour his departed lord. About six miles from the ancient city of Sardis, near the lake Gygæus, was to be seen the great tumulus erected in memory of Alyattes, father of Crosus. It is described by Herodotus as of prodigious height, having a base of stones, on which three classes of people were employed to heap up its enormous bulk. In the time of Strabo, the remains were 200 feet high, and the circumference three-quarters of a mile. Several other tumuli surrounded it. This form of sepulture may be found all over the world; and how 
lasting it is, as a monument, may be gathered from the date of this very mound of Alyattes, which could not have been erected much less than 2400 years ago, Alyattes having been contemporary with Nebuchadnezzar, the king of Babylon who destroyed. Jerusalem about 600 years before the birtl of Christ. In some parts are found tumuli in distinct groups wide of each other; and in other places they appear singly, like solitary and silent watch-towers, at distant stations. About 7 miles S.E. of Hyderabad, in the Dekhan, is an immense plain covered with cairns and kistvaens. -Porter's Travels.

INGUVA, also Ingya, and Hingupatri. TEL. Ferula asafœida; also applied to several Gardenia, some of which yield a medicinal gum, particularly G. gummifera, from which is produced the resin called Dikamali.

INITIATORY rites are practised by Brahmanical Hindus for the admission of a youthful member into their circle, the Gaitri being the sacred and secret words imparted. The Sikh religionists and Muhammadan pirs and fakirs also have their modes of initiation. The Chinese secret societies likewise use sacred rites. Many of the Australian tribes are similarly initiated amongst the men of their clans.-Macgillivray's Voyage, i. p. 14. See Tun Surana.

INJADRI, or Satpura, range of low mountains runing east and west to the south of the Nerbadda river.

INK, BLACK.

Bloek, DA. Mashi, MALEAL. Ink; Inkt, : : DUT. Tinta, : PoRT., SP. Encre, . : FR. Tschernilo, . S RUS. Dinte, Seahi, GuJ., HiNd., Pers. Blak, Schrif black, . Sw.
Inchiostro, . . Tam. Atramentum, : LaT. Sira, . . . TEL. Mangsi, Dawat, . Malay.

Printing ink, writing ink, marking ink, India ink, etc., are composed of different ingredients, gall-nuts, copperas, gum, and logwood,-according to the purposes to which it is to be applied. That which is used by the Tamil writers in the Cutcherries is thus prepared. Half a seer of rice, burnt black, is well boiled in a seer and a half of water, till but one seer remains, then strain off the dregs. To this seer of burnt rice water is to be added two pollams of lac; boil them well together, and strain off the dregs. Half a seer of carpoo varnam or lamp-black, and half a pollam of vullam pisin or gum-arabic, are then to be well rubbed into a fine powder, and gradually added to the mixture of lac and burnt rice water, when the whole is rubbed together and well shaken at different intervals for the space of three days.

Muhammadans take of lamp-black and gumarabic equal quantities, and pound them together into a very fine powder. This powder is then moistened with the juice of the pulp of the kuttalay or small aloe, and well rubbed at intervals for two days together, after which it is formed into little cakes, and dried on plantain leaves in the sun for use.

For a good writing ink, take of nut-galls 2 lbs., sulphate of iron $13 \mathrm{oz}$., gum-arabic $13 \mathrm{oz}$.; pound the galls, and take 14 bottles of water, of which take three-quarters and boil the galls in it for three hours in a large pot; cool and pour off the clear liquid, and strain the remainder (careful and repeated straining is the great secret of successful ink-making) ; take the remaining fourth of water, and dissolve the iron and gum, boil cloves in it to prevent fungi; make all to 15 bottles of fluid. Strain everything well. Black ink for printers is made of lamp-black, linseed oil, rosin, brown soap, and a small quantity of indigo. Blue ink is made with indigo. Red ink, Segapoo mye, TAM., is prepared by adding a little water to Shem pungie (red cotton), Luttooka doodi, TEL., also by steeping and afterwards boiling chips of red dye-woods in vinegar.

Indian ink or China ink is a solid ink from China. That used in Eugland by artists is made in Canton and Ngan-hwui; the best is made at Hwui-chau-fu, in the latter province. Pine branches are burned under a moveable roof of thatch, and the soot is carefully mixed with isinglass or boiling glue. Oil and rock-oil have also been burned to form a finer soot. It is always scented with musk. Corean ink is good. Good Indian (China) ink is put up in plain patterns ; the best kinds are gilt all over. It should be bright when broken, free from grittiness when rubbed on the ink-stone, emit a strong scent, and render the writing glazed when dry. Chinese written documents may be soaked in water for some weeks without being washed, and linen marked with Indian ink will bear several washings.-Ainstie, Mat. Med. p. 175; Smith; M. M. C.

INLAID WORK is an art which dates from a remote period. It has been carried on in Bombay since the commencement of the 19th century, having been originally introduced from Hyderabad in Sind. It is said to have been introduced into Sind about twenty years earlier from Persia; its native seat is supposed to be Shiraz. From Bombay the work has been carried to Surat. The materials used in the work are:-A mineral green dye for dyeing the stag's horn. Tin wire (Kylacenotur), used in the ornamental veneering. Sandal-wood, ebony, and sappanwood, used in the frame work, and sometimes entering into the ornamental veneer; ivory, always white. Stag's horn, dyed green with mineral dye, verdigris. Glue, for binding; Ahmadabad glue being esteemed far above all other kinds, including English. The tools employed are a wheel for drawing the tin wire into different shapes for the preparation of the ordamental patterns, saws of different kinds, files, chisels, drills, planes, and a square. The only mystery is in the portion of the work which appears inlaid, but which is not inlaid in the first sense of the term. The patterns are veneered on, and may be applied to any fiat or gently rounded surface. The ornamental veneer is prepared by binding together rods of ivory, tin, sappau, ebony, and green-dyed stag's horn, of different shapes, often geometric. These rods are usually three-sided, cylindrical, and obliquely four-sided. They are arranged so as when cut across to exhibit definite patterns, and in the mass present either the appearance of rods or of thin boards, the latter being to be sliced down into borders. The primary rods are sometimes bound together before being sliced, so as to form more complex patterns. The patterns commonly found in Bombay ready prepared for use are:-

1st. Chakra (i.e. wheel), the smaller being of the diameter of a fourpenny bit, and the larger of a shilling. 
$2 \mathrm{~d}$. Kutkee or hexagonal, being composed of obliquely four-sided rods, of ivory, ebony, or sandal-wood, and of ebony, tin wire, puttung, and green-dyed stag's horn mixed.

$3 \mathrm{~d}$. Trenkoonia gool (i.e. three-sided flower), a three-sided pattern composed of tin wire, ebony, ivory, puttung, and green-dyed stag's horn.

4th. Gul (flower), obliquely four - sided, and compounded as last. These are all for the central veneer. The border patterns are :-

5th. Teekee, round, and varying in size from a twopenny bit to a large pin's head, and used for the central patterns, as well as for bordering.

6 th. Gundeerio (plumb, full), composed of all the materials used in this work.

7th. Ekdana (one grain), having the appearance of a single row of tin beads set in ebony.

8th, 9th, and 10th. Poree lehur, Sansoohansio and Porohansio, varieties of border ornaments not easy to distinguish from one another by mere description.

In 1860, about fifty manufacturers were established in Bombay; six had been settled there from periods varying from twenty-five to fortysix years. A few employ workmen, but the majority work for themselves, with the aid in many cases of a brother or son. The inlaid work resembles 'Tunbridge ware.

At Vizagapatam, in Madras, similar articles are made of ivory and stag's horn, with scroll-work edged in to suit European taste. At Manipuri, in the North-Western Provinces, wooden boxes are inlaid with brass wire. The chief seats of ivory-carving are Amritsar, Benares, Murshidabad, and Travancore, where any article can be obtained to order, from a full-sized palanquin to a lady's comb. Human figures in clay, dressed to the life, are principally made at Krishnagar, in Bengal, Lucknow, and Poona._Imp. Gaz. iv.; Dr. (Sir George) Birdwood.

INOCARPUS EDULIS. Linn.

South Sea chestnut, ENG. Maipe, Otaheite chestnut, ., Kata,

TAHITt

A native of the Molucca Islands, and from thence introduced into the Botanic Garden at Calcutta in 1798, where in ten years the largest of them was 25 or 30 feet high. They blossoin during the hot season, and ripen their fruit in August and September.-Roxb. Fl. Ind.

INSCRIPTIONS.

Aufschrift, Inscrizione, $: \therefore$ IT.

We read in the Old Testament of writings, engravings, pens, and books, -in Exodus xxiv. 7, xxv. 16, and xxxii. 15, 16, at least 1500 B.c. ; in Job xiii. 26, xix. 23, 24, perhaps about the same age; and subsequently in Psalms xl. 7, xlv. 1, lvi. 8 , and lxix. 28, and in Proverbs iii. 3, at least 1000 years B.C.; but the first authenticated inscriptions in India are those of the 3d century before Christ, engraved at Kapurdigiri, Dhauli, Girnar, etc. In the ten books (Mandala) of 1017 hymns in the Rig Veda, the art of writing is not even alluded to. At the time when the songs of the Rishis were collected, there is no allusion to writing materials, whether of paper (papyrus) or bark (liber) or skins, nor is there any allusion to writing during the whole of the Brahmana period of Vedic literature. Even during the Sutra period all the evidence obtained from them but leads to the supposition that though the art of writing then began to be known, the whole literature of India was still preserved by oral tradition. The statements of Megasthenes, and Strabo, and Nearchus, however, show that, in their times, the art of writing was known in India, and that it was practised before the time of Alexander's conquest; nevertheless the origin of the Indian alphabet cannot be traced back much beyond the date of Alexander's invasion. The Lalita Vistara, however, one of the canonical books of the Buddhists, describes Sakya Sinha's entry into the writing school (li-pi-sala), and the alphabet that he is described as learning is the common Sanskrit alphabet. But in the times even of Nearchus and Megasthenes, letters do not seem to have been a vehicle of literature. Nearchus describes the people as writing on compressed cotton, Megasthenes as making inscriptions on mile-stones, and Curtius says they wrote on the soft rind of trees. The inscriptions generally supposed to have been engraved by Asoka, 300 years before the present era, with a view to promulgate the doctrines of Buddba, are therefore the oldest literary remains of India, but are upwards of 1000 years later than the era when the tablets were engraved on Mount Sinai, and when the Assyrians and Babylonians had formed great libraries, and were recording on tablets their military and civil transactions.

Nearly all that we know of ancient Iudia, and of the countries on its north-western borders, with their former conquerors and rulers, has been obtained by the investigations of learned men into the legends on the numerous ancient coins found in Afghanistan, the Panjab, and India ; and from the inscriptions found engraved on rocks and pillars, and in caves, in various places in India, in Kābul, and throughout the ancient empires of Iran and Assyria; through Hadramaut and Oman, in several districts of N. Arabia, and through the north of Africa. These, with the more celebrated remains of Egypt, prove that literature was cultivated in those countries at a time when Europe was inhabited by painted or tatooed barbarians. Amongst others who have laboured to decipher these may be mentioned Wilkins, Jones, Colebrooke, H. H. Wilson, J. Prinsep, Dr. Mill, Norris, Dowson, Thomas, Bayley, Bhau Daji, Rajendra lal Mittra, Rawlinson, Sir Walter Elliot, F. W. Ellis, Colonel Mackenzie, C. P. Brown, General Cunningham, James Fergusson, Dr. Burnell in the Asiatic Researches, and Journals of the Royal Societies, with Grotefend, Lassen, Burnouf, and Oppert.

Many facts in history have been made known by the coin legends and rock inscriptions, and among others the extension of a Macedonian empire over a great part of North-Western India, and the conquest of the island of Ceylon by a Buddhist sovereign of India, three centuries before the Christian era.

Not less interesting are the inscriptions in the ancient Persian language, in the Assyrian or cuneiform character, spread through the empire of the great Cyrus, which throw an important light on sacred as well as profane bistory. The clue to the discovery of the sense of these Persian records was obtained by Grotefend, Lassen, and Burnouf; and, partly aided by it, though much more by his own ingenuity, Sir Henry Rawlinson was able to decipher many of these ancient historical engravings. 


\section{INSCRIPTIONS.}

It was Champollion who laid the foundation of the decipherment of the hieroglyphics; Anquietil, Duperron, and Burnouf are the fathers of Zend studies; Arabic and Syriac scholars in Germany are the direct or indirect pupils of Sylvestre de Sacy and Quatremere; in Chinese, Stanislas Julien stands alone; Assyrian was cultivated in France and in England, and subsequently taken up by German scholars. About 1868 the Academie des Insciptions et Belles-Lettres decided to have its 'Corpus Inscriptionum Semiticarum' to collect in one work the Semitic inscriptions scattered throughout various books and periodicals, and more especially the Phœnician and Punic inscriptions. The first part of this Corpus contains fifty Phœnician inscriptions, with Latin translation and commentary by MM. Renan and J. Derenbourg. Of larger and complete inscriptions, one was found by M. de Vogue at Gebel (Byblos), in which it is reported that the King Yehomelek erected an altar in the temple in the 4 th century B.C. Another is the Sidonic inseription on the sarcophagus of King Ashmonezar, which is one of the best preserved; it is also of the 4th century B.C. Most of the inscriptions (ten to fifty) are those found at Cyprus, the greater part of which are now in the British Museum. We find mentioned in them the following kings,-Pumyaton and Melekyaton, kings of Kitti (Cyprus), and Adil (Idalion), and Ptolemy, probably Soter (312 B.C.), to whom the monuments are consecrated, the god Resheph, probably identical with the biblical bené Resheph (Job v. 7), known on Egyptian monuments as the god Raspu. Esculapius is called in some of those inscriptions Baal Merappe, 'Baal Sanator,' analogous with the Hebrew Raphael.

The inscriptions in Western Media on the Bebistun or Baghistan tablets, record the political autobiography of Darius Hystaspes in the old Persian language, in the Babylonian, and also in the language of the Scythians in the MedoPersian empire; and the translation of the Scythian portion of those inscriptions is distinctly of the Scythian, that is, Turanian group, as spoken in the 5th century B.C., though the people by whom it was spoken are believed by Professor Oppert and Mr. Norris to have been Medians. This Scythian part of the Behistun inscriptions bears a special relationship to the Ugro-Finnish family, which Dr. Caldwell considers to resemble the Dravidian dialects. He thinks that the ancient Scythic race, by which the greater part of Central Asia was peopled prior to the irruption of the Medo-Persians, belonged to the Ugrian stock, and not to the Turkish or the Mongolian.

1. Rock Inscriptions have been found, amongst other places, at Shahbazgarhi, Khalsi, Girnar, Dhauli, Jangada (two separate edicts on Dhauli and Jangada rocks), Sahasaram, Rupnath, Bairat, Khandagiri, Deotek slab.

2. Cave Inscriptions have been found at Barabar, Nagarjuni, Khandagiri, Ramgarh.

3. Pillar Inscriptions have been found :-

Dehli pillar from Siwalik (Firoz Shah's Lat), five inscriptions, one called Queen's edict, and one the Kosambi edict.

Dehli pillar from Meerut.

Allahabad pillar.

Lauriya-Araraj pillar (Radhia).

Lauriya, Navandgarh pillar (Mathia).

Sanchi pillar.

The inscription at Junagarh, discovered by $\begin{aligned} & \text { rock inscriptions contain the na } \\ & \text { Ptoleny, Antigonus, and Magas. }\end{aligned}$
Colonel Tod in 1822, has three paragraplis more than that at Dhauli in Katak (Cuttack), discovered by Iieutenant Kittoe. Others have been discovered at Kapurdigiri and at Ganjam.

The fourteen edicts into which the Junagarh inscription is divided cover considerably over 100 square feet of rock. They are inscribed on the uneven surface of a huge rounded and somewhat conical granite boulder.

The records on the rocks and pillars and caves north-west of India, and in India itself, are in two characters, styled the Aryan or Bactrian, and the Lat or Budh. The term 'Lat' has been given because found on certain pillars (Lat, SANSK., a pillar) in Dehli, Allahabad, etc. The Lat or Budh or early Pali character is the same as the Aryan, but the forms of the letters differ from the Aryan, and the letters are larger. Inscriptions in these characters are engraved on rocks at Kapurdigiri in Afyhanistan, at Cuttack, at Dehli on a pillar; also on pillars at Allahabail, Betiah, Muttiah, and Radhia.

A pillar near Dehli has been called the pillar of Firoz, after Firoz Shah, who reigned in Dehli A.D. 1351 to 1388 . It has a more ancient inscription, and one with a more recent character below in Sanskrit, to the effect that Raja Vigrah or Visala Deva had, in A.D. 1169, caused this pillar to be inseribed afresh to declare that the said raja who reigned over the Sikambari had subdued all the regions between the Himavat and Vindhya. This pillar was erected to enjoin the doctrines of Buddha, but the reading of it somewhat differs from that of the others. Though resembling the Girnar inseription in general purport, these inscriptions differ considerably in the structure of certain sentences. Both Mr. James Prinsep and Professor Wilson attempted translations of it.

The same Lat or Budh characters found on the pillars at Dehli, Allahabad, and elsewhere, are also found engraved on rocks. The ancient Budh alphabet is really the simpler and more elegant form of the refined Sanskrit.

The Allahabad inscription is similar to that at Dehli, but has four short lines additional. A stone lodged in the museum of the Asiatic Society at Calcutta, found at Bairath near Bhabra, between Dehli and Jeypore, has an inscription in the Budh character.

The same character is also found in two inscriptions at Junir, of which one is on the Naneh Ghat. It is in keeping with the inscription on the Dehli pillar and on the rock at Girnar.

The Girnar inscription was supposed by $\mathrm{Mr}$. James Prinsep to be in the Pali language.

The inscriptions on the pillars at Dehli and Allahabad, and on the Tirhut pillars at Mathya and Radhia, on the rocks at Junagiri in Gujerat, and at Dhauli in Cuttack, were deciphered and translated by the remarkable ingenuity of $\mathrm{Mr}$. James Prinsep. A supposed third version of the rock inscriptions (but in the Ariano-Fali character), which was found at Kapurdigiri, near Peshawur, has been carefully collated with the others by Professor Wilson. Many short inscriptions from Gaya, Sanchi, and Birat, as well as from the cave temples of Southern India, have also been published at different times. The edicts in the rock inscriptions contain the names of Antiochus, 
The Aryan or Bactrian character is that used in the inscriptions at Jellalabad, Mavikhyala, and Kapurdigiri on topes or tumuli, which are numerous for about 300 miles around.

Jalalabad is in the valley of Käbul, and contains many sepulchral topes, which also occur at Daranta and at Hidda or Idda in its neighbourhood. That at Jalalabad was opened by Mr. Masson, and the inscription makes mention of Kadiphes. It is in the Aryan character.

Manikhyala is situated near Jhelum, on the banks of the river of that name, called by the Greeks the Hydaspes. Many topes are there, one of which is 80 feet high, with a circumference of 320 feet.

These topes or tumuli, it is now admitted, are only cairns regularly built, and this mode of sepulture is supposed to be alluded to in the heaps and graves and tombs spoken of in Job xxi. 32, also xxx. 24, and in Jeremiah xxxi. 21; and cairns are still found scattered over all the northern parts of Europe and Asia, and down to Cape Comorin in Peninsular India.

Inscriptions on stones and on copper plates have also been met with all over Southern India, but few of them are of a date prior to the year 1000 of the Christian era, and the larger portion are much later. Some give valuable facts and the names of kings, but the bulk of them record matters of little importance. The Lat character occurs rarely in the sonthern part of the Peninsula, still it is the only one used on the sculptures at Amaravati, which have been described by the Rev. William Taylor and Mr. J. Fergusson; and Surgeon-General Balfour, while in charge of the Government Central Museum at Madras, advised the despatch to London of most of the sculptures which are now placed against the wall in the staircase of the British Museum.

An extensive collection of inscriptions was made by the late Colonel Mackenzie, SurveyorGeneral, which also the Rev. W. Taylor described.

In Malayala, as in other parts of Southern India, inscriptions occur in various ancient characters as well as in modern letters. The translation of the copper plate grant to the Syrian Christians, which is still in their possession, has been given in the Journal of the Madras Literary Society.

The inscriptions found in the south of India are in three alphabets, - the Chera, Chalukya, and Vengi. The first appears in Mysore in the second half of the 5th century; the oldest specimen of the Chalukya is of date about the first half of that century ; the third is more modern.

The Portuguese at Goa took some inscriptions on stone to their native country, but Sir Charles Wilkins was the first to explain one (at Cintra), about the end of the 18th century. The earlier volumes of the Asiatic Researches contain several interpreted by Wilkins, Jones, and Colebrooke, and in the later volumes $\mathrm{H} . \mathrm{H}$. Wilson contributed many valuable articles on this subject. The Journal of the Asiatic Society of Bengal about 1830 (by the articles by J. Prinsep, Dr. Mill, and others) made immense progress; and of later years the same journal, the Journals of the Royal Asiatic Society and of the Bombay Society, have often done much to advance the study of the Sanskrit inscriptions of India; and Mr. Norris, Professor Dowson, Mr. Thomas, Mr. Bayley, Dr.
Bhau Daji, and Babu Rajendralal Mittra have been decipherers. In the south of India an immense number of inscriptions exist in the Dravidian languages, many of which are not inferior in antiquity or interest to most of the Sanskrit and Prakrit inscriptions of the north, though, with the exception of a few articles (in the Madras Journal), published by Sir W. Elliot, and containing the results of his own researches, and those of Mr. F. W. Ellis, nothing has been as yet made public. Colonel Mackenzie, however, at the beginning of this century, made an immense collection of copies of inscriptions, and to the disinterested labour of Mr. C. P. Brown we owe the existence of copies of this collection, which, though purchased by Government for an enormous sum, had been neglected and suffered to rot from want of a little care. Copies of inscriptions collected by Sir W. Elliot in the Canarese country were presented by him to the R. A. Society of London. General Cunningham has made large collections of copies of inscriptions in the north of India. His Archæological Reports contain the result of his inquiries.

To copy inscriptions on stone, brush off all dust or mud, and take a mould by applying to the surface stout unglazed paper, uniformly wetted with water, and forced into the irregularities by repeated and forcible strokes with a hard clothes brush. - Dr. Burnell, A Few Suggestions; Fergusson. See Architecture; Dehli ; Sculpture.

INSECTIVORA, an order of mammals which in India is represented by genera of the families, Talpidæ, Sorecidæ, and Erinaceidæ. Talpa micrura, macrura, and leucura of Nepal, Sikkim, Sylhet, Tenasserim, and Japan; Urotrichus talpoides of Japan; Sorex cærulescens, murinus, nernorivagus, Griffithii, serpentarius, heterodon, saturatus, Tytleri, soccatus, niger, leucops, Hodgsoni, Perroteti, micronyx, melanodon, Sikkimensis, oligurus, homourus, macrurus, and holosericeus, of various parts of India. The order may also be thus shown :-

Fam. Talpidæ, Moles. Talpa, $4 \mathrm{sp}$. ; Urotrichus, $1 \mathrm{sp}$. Fam. Sorecidæ, Shrews. Sorex, $20 \mathrm{sp}$.; Soriculus, $1 s p$. Crossopus, $1 s p$.; Corsira, $1 s p$; C. Feroculus, 1 $s p$.; C. Myogalea, $1 s p$.

Fam. Erinaceidæ, Hedgehogs. Erinaceus, $7 s p_{0} ; \mathbf{E}$. Tupaia, $2 s p$

See Erinaceidæ; Mammalia; Sorecidæ; Talpidæ. INSECTS.

Hasharat, Hainat, AraB. Dadadam, Dadah, Pers, Insecte, . . . . FR. Khast, Khashasat, * ", Entoma, : : GR. Zad, . . :

Kira, Kirm, Ghun, Hind. Insecto, . . . : 'SP Sursuri, . . . . , Puchi, . . : TAM. Insetto, . . . . IT. Purbu, . . . TEL, Insecta, . . . LAT. Bujek, : : TURK.

Insects are a class of invertebrate articulated animals, forming one of the four divisions comprised in the Arthropoda of naturalists, the four divisions being-

1. Crustacea.-Respiration by means of gills, or by the general surface of the body; two pairs of antennx; locomotive appendages more than eight, borne by the segments of the thorax, and usually of the abdomen also. Examples-Crabs, lobsters, shrimps, wood-lice, etc.

2. Arachnida.-Respiration by pulmonary vesicles, by tracheæ, or by the general surface of the body; head and thorax united; antennæ absent; legs, eight; abdomen without locomotive appendages. Examples-Spiders and scorpions.

3. Myriopoda,-Respiration by tracher; head distinct; 
the remainder of the body composed of nearly similar segments; one pair of antennæ; legs numerous. Excumples-Centipedes and millepedes.

4. Insecta.-Respiration by tracher ; head, thorax, and abdomen distinct; one pair of antennæ; three pairs of legs borne by the thorax; abdomen without limbs. The adult form (with a few exceptions) winged. Examples-Beetles, bees, wasps, flies, butterflies, locusts, cockroaches, earwigs, dragonflies, ant-lions, May-flies, bugs.

The Insecta are divided by naturalists into the following sub-classes :-

I. АMmTABotA.- Young not passing through a metamorphosis, and differing from the adult in size only ; imago destitute of wings; eyes simple, sometimes wanting.

II. HRMтMTABOLA, - Metamorphosis incomplete ; the larva differing from the imago chiefly in the absence of wings, and in size; pupa usually active, or, if quiescent, capable of movement.

III. HoLometa BOLA. - Metamorphosis complete; the larva, pupa, and imago differing greatly from one another in external appearance. The larva vermiform, and the pupa quiescent.

I. The AMETABOLA are divided into the following orders:-

Order I. Anoplura. - Minute aptera, with the mouth formed for suction; two simple eyes, or none.

This order comprises insects which are commonly parasitic, and are known as lice (Pediculi).

ORDER II. MALLOPHAGA. - Minute aptera, in which the mouth is formed for biting, and is furnished with mandibles and maxillæ.

These insects are usually known as bird-lice, being generally parasitic upon birds, though sometimes upon inammals.

OrDer IIr. Thysandra. - Apterous insects, usually with a masticatory mouth, and having the extremity of the abdomen furnished with locomotive appendages.

The most familiar members of this order are the Podurce, or spring-tails.

II. The Hemmetabola are divided into the following orders:-

OrDER IV. HEMIPTERA.-Mouth suctorial, beakshaped, consisting of a jointed rostrum, composed of the elongated labium, which forms a jointed, tubulan shenth for the bristle-shaped styliform mandibles and maxillæ. Eyes compound, usually with ocelli as well Generally provided with two pairs of wings; but these are sometimes wanting.

This order is divided into the following two sub-orders :-

Sub-Order a. Homoptera.-The anterior pair of wings of the same texture throughout (membranous) The wings do not fold over one another when the insect is at rest. The three segments of the thorax are united in a mass, and the pro-thorax is generally shorter than the meso-thorax. There are ocelli between the com pound eyes, and the antennæe are small, and composed of few joints. The females have an ovipositor of threetoothed blades.

In this section are the aphides, the scale insects (Coccidce) ; the cicadas, the lantern-flies (Fulgora), etc Sub-Order $b$. Heteroptera. -Anterior wings membranous near their apices, but chitinous towards the base, overlapping each other at the apex when at rest The antennx are modernte in size, and composed of a few large joints. The pro-thorax is the largest segment of the thorax. They are divided into two groups of the Bydrocorisce (water-bugs), and Geocorisa (land-bugs).

ORDER V. ORTHOPTERA, - Nouth masticatory; wings four, sometimes wanting; the anterior pair mostly smaller than the posterior, semi-coriaceous, usually with numerous nervures, the interspaces between which are filled with many transverse reticulations; sometimes overlapping horizontally (cockroach), sometimes meeting like a house-top (grasshoppers). Posterior wings usually having their front portion of a different texture from their hinder portion, this latter bein almost always more transparent, and when not in use. folded longitudinally, resembling a fan. Posteriol wings mostly wanting in the females of the Plattida. Antennæ usually filiform. Metamorphosis semi-incomplete (sometimes, however, the adult is apterous, when it is difficult to distinguish the lava ,pupi, and imago). This order includes the crickets (Achetina), grasshoppers (Gryllina), locusts (Locustina), cockroaches (Blattina), etc.

ORDER VI. NEUROPTERA, - Mouth usually masticatory; wings four in number, all membranous, generally nearly equal in size, traversed by numerous delicate nervures, having a longitudinal and transverse direction, and giving them a reticulated lace-like aspect. Metamorphosis generally incomplete, rarely complete. The larva active, hexapod, rarely with pro-legs.

This order includes the dragon-flies (Litrellulida), caddis-flies (Phryganeidce), May-flies (Ephemeridce), the ant-lion (Myremeleo), termites, etc.

ORDER VII. APHANIPTERA. - Wings rudimentary, in the form of plates, situated on the meso-thorax and meta-thorax; mouth suctorial. Metamorphosis complete.

This order comprises the fleas (Pulicidce).

ORDER VIII. DIPTERA. - The anterior pair of wings alone developed ; the posterior pair of wings rudimentary, represented by a pair of clubbed filaments, called halteres or balancers. In a few the wings are altogether wanting; mouth suctorial. The metamorphosis is complete, the larvæ being generally destitute of feet. In some cases (e. $l$, the gnats) the pupæ are aquatic, and have the power of moving rapidly. In most cases, however, the pupæe are quiescent. The Diptera constitute one of the largest of the orders of the Insecta; the house-flies and flesh-flies (Musca), gaats (Culex), forest-flies (Hippobosca), crane-flies ( $T$ ipulida), and gad-flies (Tabanid(c), constituting good examples.

ORDER IX. LERINOPTERA.-Mouth suctorial, consisting of a spiral trunk. Wings four in number, covered with modified hairs or scales; wanting in the females of a few species. Nervures not very numerous, mostly longitudinal. Antennæ almost always distinct, and composed of numerous minute joints. This well-known and beautiful order of insects comprises the butterfilies and the moths.

ORDER $x$. HYMENOPTERA.-Wings four, membranous, with few nervures; sometimes absent. Mouth always provided with biting-jaws, or mandibles; the maxilla and labium often converted into a suctorial organ. The metamorphosis is complete, but the various parts of the pupa are visible through the delicate enclosing membrane.

The Hymenopterc form a very extensive order, com. prising the bees, wasps, ants, ichneumons, saw-flies, etc.

ORDER XI. STREPSIPTERA.-Females without wings or feet; parasitic. Males possessing the posterior pair of wings, which are large, membranous, and folded longitudinally like a fan. The anterior pair of wings rudimentary ; jaws abortive.

The Strepsiptera are a limited order of parasitic insects of small size, found on bees and other Hymenoptera, generally between the segments of the abdomen.

Order xiI. Coleoptera. - Mouth masticatory, furnished with an upper lip or labrum, two mandibles, two maxillæ, with maxillary palpi (generally four-jointed), and a moveable lower lip or labium, with jointed labial palpi. The four wings are usually present, and the anterior pair are not adapted for flight, but are hardened by chitine, so as to form protective cases (elytria) for the posterior wings. The inner margins of the elytra are generally straight, and when in contact they form a longitudinal suture. The posterior wings are membranous, and when not in use are folded beneath the elytra. The antennæ variable.

This order comprises all the beetles properly so called.

With insects, the principal parts attached to the head are two antennæ, an upper lip (labrum), a lower lip (labium), bearing the labial palpi; a pair of jaws (mandibles), an inner pair of jaws (maxillæ), to which are attached the maxillary palpi. The thorax is divided into three segments, the pro-thorax, meso-thorax, and meta-thorax. The 
pro-thorax bears the front pair of legs ; the mesothorax bears the front pair of wings and second pair of legs; the meta-thorax bears the second pair of wings and the third pair of legs. The legs consist of the following principal parts: the coxa, trochanter, the femur, tibia, and tarsus.

The diversified elevations of the countries of the East Indies, with their varied temperatures, cause in localities a greater or less abundance of particular forms ; but numerous genera of tropical and temperate climates are everywhere associated together, and the range which the genera enjoy is very considerable.

But the pervading character of Indian entomology is uniformity. We meet with numerous genera, both of tropical and temperate climes, associated together. There is a great intermingling of forms, and the range which genera enjoy is considerable. In part of the Himalayas, at the extreme southern points of India, in the west, and even in the Archipelago, there is one pervading character, evincing everywhere the prevalence of tropical genera. In Nepal and the southernmost extremity of the Mysore, in Ceylon, at Bombay, at Madras, and at Calcutta, also at Singapore, in Japan, and in Java, with the rest of the Polynesian Isles, the majority of the same types abound; and what is of more consequence, a great majority of the same species also occur in most of the abovementioned regions. Also, if we turn to Africa, we find a considerable similarity in its entomology with that of Asia. Among the Carabidæ occur Anthia, Orthogonius, Trigonodactyla, and Siagona ; among the Lamellicornes, Epirinus, and Popillia, the conical Buprestidæe and the extraordinary Paussidx; and to these may be added the genera Melyris, Megalopus, Sagra, and Adorium; Dorylus among the Hymenoptera, and Diopsis among the Diptera. $\mathrm{We}$ find precisely the same species in both continents. Among the most conspicuous are Copris sabæus and C. pithecius, Cetonia cornuta and Lytta gigas. Even supposing that no identical species occurred common to Asia and Africa, a very remarkable similarity exists in the representatives of each; one example of which is Ateuchus sanctus, which very closely resembles the celebrated sacred beetle of the Egyptians, the object of their worship, by some regarded as an emblem of fertility, but more probably that of eternity.

This branch of natural history has been largely cultivated by many eminent writers, both in its scientific and economic relations; and among those who are quoted in this article may be named J. C. Fabricius, 1775 and 1803 ; Donovan; J. O. Westwood, Drury, Exotic Entomology; J. C. Farmer, F. IV. Hope, 1837 and 1851; Thomas Horsfield and Frederic Moore; Sir James Emerson Tennent, A. R. Wallace, John Nietner, J. WoodMason, Charles Darwin, Sir John Lubbock, Albert Muiller, W. H. Benson, R. Thompson, and Miss Eleanor A. Ormerod. John Curtis, in 1824 and 1860, wrote on Farm Insects and the Turnip Crop; and in 1877, and again in 1882, Miss Ormerod produced a very valuable work on the Insects attacking Field and Garden Crops.

The principal authors who have written on the insects of Eastern and Southern Asia, are Horsfield, F. Moore, Drury, Nietner, Wallace, Westwood, Wood-Mason.

Himalayan entomology in character is both
Asiatic and European, and the intermingling of forms of temperate and tropical climes is one of its most distinguishing peculiarities. In its valleys southern forms predominate over northern; and to the uninterrupted belts of jungle stretching along the mountain ranges, we may trace several tropical phytyvorous genera far beyond their apparent natural limits. Some carnivorous insects are also found ranging far to the north in the Himalayas, an example of which is Anthia 6-guttata, a wellknown native of the tropics; the specimens, however, are mere dwarfs compared with those of Peninsular India. Among the Cicindelidæ, Colliuris appears; among the Carabidæ, we find Desera, Omphra, and Cyclosomus; among the Lamellicornes, Euchlora, Mimela, and Dicranocephalus; and to these may be added Anisotelus belonging to Telephoridæ, and Podontia and Phyllocharis to the Chrysomelidæ; all of these are attached to warm countries, and some, indeed, are seldom found but within the torrid zone. Many genera from the Himalayas evince an affinity to European types; various Himalayan genera closely approximate Siberian forms; and some of the species described by Dr. Gebler from the Altaic chain of mountains, particularly some Chrysomelidie, are believed to be indigenous in both regions. Some few, however, are worth noticing, such as Broscus and true Carabus, Geotrupes and Pimelia. Several species of the following genera of Coleoptera occur in the Himalayas, as well as in Europe, namely, Elater, Melolontha, Chrysomela, Cassida, and Coccinella. Among the carnivorous insects, Dermestes lardarius and vulpinus, Corynetes violaceus and rufipes, and some of the Staphilinidæ, are essentially the same in Europe and the Himalayas. Of Lepidoptera, Papilio machaon is evidently the same as that met with in England; the same remark will apply to Vanessa Atalanta and Cynthia cardui.

A greater number of species of Lepidoptera are disseminated throughout the world than of any other order. In Asia and Europe, we meet with Papilio machaon, Gonepteryx rhamai ; with some species of Colias and Pontia, with Vanessa Atalantaland Cynthia cardui; and to these may be added several identical Sphingidæ, particularly Acherontia Atropos, Deilephila, and Celerio. Among the Noctuidæ, Geometridæ, Tortricidæ, and Tineidæ, many species will also be found inhabitants of both continents. In the Orthoptera, some Gryllidæ are common to countries remotely situated, which may partly be accounted for by their migratory habits. Among the Blattidæ, several tropical species range widely; some of them have become naturalized even in a northern climate; and Indian, Brazilian, and New Holland species live in the bouses of London. Among the eastern Neuroptera there occur various Libbelulinæ and Hemerobiidæ, closely resembling English species.

Among the Hymenoptera may be noticed the universal ranger, Evania appendigaster, ever attendant on Blatta, some Ichneumonidæ, Crabronidæ, Apidæ, and Vespidæ,-all of them presenting identical species with those of Britain.

In referring to the Diptera may be mentioned the orange-fly, the same in England, India, and America; the gnats and mosquitoes, common to the four quarters of the globe, alike the pest 
of the Indian and Laplander; and, lastly, various species of musca. Passing by the Aptera, and the various parasites of birds, quadrupeds, and of nian himself, we find among the Hemiptera several identical species of Pentatoma, Reduvius, Tetyra, besides Cimex lectularius, the scourge of all countries and climates.

Chinese insects were described by Fabricius and Dunovan. Mr. Hope, in March 1842, published Iialf a century of the Coleoptera of Canton and Chusan, collected by Dr. Cantor. Part of Mr. Bowring's Coleoptera and Homoptera of HongKong and neighbourhood, were published in the Annals of Natural History, 1844, by Mr. Adam White.

The following list, although necessarily incomplete, will give an idea of the families and genera occurring in Southern India. It is based on Sir J. E. Tennent's list of Ceylon insects :-

\section{Order Coleoptera,} Linn.

Fam. Cicindelidæ, Steph.

Cicindela, Linn.

Therates, Latr.

Collyris, Fabr.

Tricondyla, Latr.

Fam. Carabidx, Leach

Omophron, Latr.

Calasoma, Weber.

Pselaphonax, $W i k$.

Casnonia, Latr.

Ophionea, Klug.

Euplynes, Niet.

Heteroglossa, Niet.

Zuphium, Latr.

Pheropsophus, Solier.

Cymindis, Latr.

Anchista, Niet.

Dromius, Bon.

Lebia, Latr.

Creagris, Niet.

Elliotia, Niet.

Catascopus, Kirby.

Scarites, Fabr.

Clivina, Latr.

Leistus, Frcehl.

Isotarsus, Luferte.

Panagæus, Latr.

Chlienius, Bon.

Anchomenus, Bon.

Agonum, Bon.

Colpodes, $\mathrm{Macl}$.

Argutor, Mer.

Simphyus, Niet.

Bradytus, Steph.

Curtonotus, Steph.

Harpalus, Latr.

Calodromus, Niet.

Megaristerus, Niet.

Platysma, Bon.

Morio, Latr.

Barysomus, Dej.

Oodes, Bon.

Selenophorus, $D e j$.

Orthogonius, $D e j$.

Maraga, $W l k$.

Helluodes, Westw.

Physocrotaphus, Parry.

Physodera, Esch.

Omphra, Latr.

Planetes, Macl.

Cardiaderus, Dej.

Distrigus, $D_{e j}$

Drimostoma, Dej.

Cyclosomus, Latr.

Ochthephilus, Niet.

Spathinus, Niet.

Acupalpus, Latr.

Bembidium, Latr.

Trechus, Clairv.
Lathridius, Herbst.

Corticaria, Marsh.

Monotoma, Herbst.

Fam. Dermestidæ, Leach.

Dermestes, Iinn.

Attagenus, Latr.

Trinodes, $M e g$.

Fam. Histeridæ, Leach.

Hister, Linn.

Saprinus, Erich.

Platysoma, Leach.

Dendrophilus, Leach.

Fam. Aphodiadæ, Macl.

Aphodius, Illig.

Psammodius, Gyll.

Fam. Trogidre, Macl.

Trox, Fabr.

Fam. Copridæ, Leach.

Ateuchus, Weber.

Gymnopleurus, rilig.

Sisyphus, Latr.

Drepanocerus, Kirby.

Copris, Geoff.

Onthophagus, Latr.

Onitis, Fabr.

Fam. Dynastidæ, Macl.

Oryctes, Illig.

Xylotrupes, Hope.

Phileurus, Latr.

Fam. Geotrupidæ, Leach.

Bolboceras, Kirby.

Geotrupes, Latr.

Orphnus, $\mathrm{Macl}$.

Silphodes, Westw.

Dineutes, Macl.

Porrorhynchus, Lap.

Gyretes, Brulle.

Gyrinus, Linn.

Orectochilus, Esch.

Fam. Staphilinidæ, Leach. Ocypus, Kirby.

Philonthus, Leach.

Xantholinus, Dahl.

Sunius, Leach.

Edichirus, Erich.

Pœderus, Fabr.

Stenus, Latr.

Osorius, Leach.

Prognatha, Latr.

Leptochirus, Perty.

Oxytelus, Grav.

Trogophlœus, Mann.

Omalium, Grav.

Aleochara, Grav.

Dinarda, Leach.

Fam. Paussidæ, Westw.

Cerapterus, Swed.

Pleuropterus, Westw.

Paussus, Linn.

Fam. Pselaphidre, Leach. Bryaxis

Fam. Scydmænidæ, Leach. Erineus, $W l k$.

Scydmænus, Latr.

Fam. Trichopterygidæ.

Trichopteryx, Kirby.

Ptilium, Schupp.

Ptenidium, Erich.

Fam. Phalacridæ, Leach. Phalacrus, Payk.

Fam. Nitidulidæ, Leach.

Nitidula, Fabr.

Nitidulopsis, Wlk.

Meligethes, Kirby.

Rhizophagus, Herbst.

Fam. Colydiadæ, Woll.

Lyctus, Fabr.

Ditoma, Ilig.

Dastarcus, Wlk:

Fam. Trogositidæ, Kirby . Trogosita, Olive.

Fam. Clicujidre, Steph.

Læmophlous, Dej.

Cucujus, Fabr.

Silvanus, Latr.

Brontes, Fabr.

Fam. Lathridiadæ, Woll.
Fam. Melolonthidæ, Macl.

Melolontha, Fabr.

Rbizotrogus, Latr.

Serica, Macl.

Plectris, Lep.

Isonychus, Mann.

Omaloplia, Meg.

Apogonia, Kirby.

Phytalus, Erich.

Ancylonycha, Dej.

Leucopholis, Dej.

Fam. Rutelidæ.

Anomola, $\mathrm{Meg}$.

Mimela, Kirby

Parastasia, Westw

Euchlora, Macl.

Phyllopertha, Kirby.

Popillia, Leach.

Adoretus.

Singhala, Blanch.

Fam. Cetoniadæ, Kirby.

Glycyphana, Burm.

Clinteria, Burm.

Tæniodera, Burm.

Protætia, Burm.

Agestrata, Erich.

Coryphocera, Burm.

Macronota, Hofin.

Fam. Trichiadæ, Leach.

Valgus, Scriba.

Fam. Lucanidæ, Leach.

Lucanus.

Odontolabis, Burm.

Dorcus.

Egus, Macl.

Fam. Passalidæ, Macl. Passalus, Fabr.

Fam. Sphæridiadæ, Leach. Cercyon, Leach.

Fam. Hydrophilidæ, Leach. Hydrous, Leach. Hydrobius, Leach. Philydrus, Solier. Berosus, Leach.

Hydrochus, Germ.

Georyssus, Latr.

Fam. Buprestidæ, Steph.

Sternocera, Esch.

Chrysochroa, Solier.
Chrysodema, Lap. Sphæridium, Fabr.

Belionota, Esch.

Chrysobothris, Esch.

Agrilus, $M e g$.

Fam. Elateridæ, Leach.

Lacon, Lap.

Campsosternus, Latr.

Agrypnus, Esch.

Alaus, Esch.

Cardiophorus, Esch.

Corymbites, Latr.

Athous, Esch.

Ampedus, $\mathbf{M e g}$.

Legna, Wlk

Fam. Lampyridx, Leach.

Lycus, Fabr.

Dictyopterus, Latr.

Lampyris, Geoff.

Colophotia, Dej.

Harmatelia, Wlk.

Fam. Telephoridæ, Leach.

Telephorus, Schaff.

Eugeusis, Westw.

Fam. Cebrionidæ, Steph.

Callirhipis, Latr.

Fam. Melyridæ, Leach.

Malachius, Fabr.

Malthinus, Latr.

Enicopus, Steph.

Honosca, Wlk.

Fam. Cleridæ, Kirby.

Cylidrus, Lap.

Stigmatium, Gray.

Necrobia, Latr.

Fam. Ptinidæ, Leach.

Ptinus, Linn.

Atractocerus, $\mathrm{Pal}$.

Fam. Diaperidæ, Leach. Diaperis, Geoff.

Fam. Tenebrionidæ, Leach.

Zophobas, Dej.

Pseudoblaps, Guer.

Tenebrio, Iinn.

Trachyscelis, Latr.

Fam. Opatridæ, Shuck.

Opatrum, Fabr.

Asida, Latr.

Crypticus, Latr.

Phaleria, Latr.

Toxicum, Latr.

Boletophagus, nlig.

Uloma, Meg.

Alphitophagus, Steph

Fam. Helopidæ, Steph.

Osdara, Wlk.

Cholipus, Dej.

Helops, Fabr.

Camaria, Lep.

Amarygmus, Dalm.

Fam. Meloidæ, Woll.

Epicauta, Dej.

Cissites, Latr.

Mylabris, Fabr.

Fam. Cistelidæ, Steph.

Cistela, Fabr.

Allecula, Fabr.

Sora, Wik.

Thaccona, Wlk.

Fam. Mordellidæ, Steph. 
Dendropemon, Schon. Dendrotrogus, Jek.

Eucorynus, Schon.

Basitropis, Jek.

Litocerus, Schon.

Tropideres, Schon.

Cedus, Waterh.

Xlyinades, Latr.

Xenocerus, Germ.

Callistocerus, Dohrn.

Anthribus, Geoff.

Aræocerus, Schon.

Dipieza, Pasc.

Apolecta, Pasc.

Arrhenodes, Steven.

Cerobates, Schon.

Ceocephalus, Schon.

Nemocephalus, Latr.

Apoderus, Olive.

Rhynchites, Herbst.

Apion, Herbst.

Strophosomus, Bilbug.

Piazomias, Schon.

Astycus, Schon.

Cleonus, Schon.

Myllocerus, Schon.

Phyllobius, Schon.

Episomus, Schon.

Lixus, Fabr.

Aclces, Schon.

Alcides, Dalm.

Acionemis, Fairm.

Apotomorhinus, Schon.

Cryptorhynchus, Illig.

Camptorhinus, Schon.

Desmidophorus, Chevr.

Sipalus, Schon.

Mecopus, Dalm.

Rhynchophorus, Herbst.

Protocerus, Schon.

Sphœenophorus, Schon.

Cossonus, Clairy.

Scitophilus, Schon.

Mecinus, Germ.

Fam. Prionidæ, Leach.

Trictenotoma, Gray.

Prionomma, White.

Acanthophorus, Serv.

Cnemoplites, Newm.

Egosoma, Serv.

Fam. Cerambycida, Kirby .

Cerambyx, Linn.

Sebasmia, Pasc.

Callichroma, Latr.

Homalomelas, White.

Colobus, Serv.

Thranius, Pasc.

Deuteromma, Pasc.

Obrium, Meg.

Psilomerus, Blanch.

Clytus, Fabr.

Rhaphuma, Pasc.

Ceresium, Newm.

Stromatium, Serv.

Hespherophanes, Muls.

Fam. Lamiidæ, Kirby.

Nyphona, Muls.

Mesosa, Serv.

Coptops, Serv.

Xylorhiza, $D e j$.

Cacia, Newm.

Batocera, Blanch

Monohammus, Meg.

Cereopsius, Dup.

Pelargoderus, Serv.

Olenocamptus, Chevr.

Praonetha, Dej.

Apomecyna, serv.

Ropica, Pasc.

Hathlia, Serv.

Iolea, Pasc.

Glenea, Newm.

Stibara, Hope.

Fam. Hispida, Kirby.

Oncocephala, Dohrn.
Leptispa, Baly.

Amplisba, Baly.

Dohrnia, Baly.

Estigmena, Hope.

Hispa, Linn.

Platypria, Guer.

Fam. Cassididæ, Westw.

Epistictia, Boh.

Hoplionota, Hope.

Aspidomorpha, Hope.

Cassida, Linn.

Laccoptera, Boh.

Coptocycla, Chevr.

Fam. Sagridæ, Kirby. Sagra, Fabr.

Fam. Donacidæ, Lacord.

Donacia, Fabr.

Coptocephala, Chevr.

Fam. Eumolpidæ, Baly.

Corynodes, Hope.

Glyptoscelis, Chevr.

Eumolpus, Fabr.

Fam. Cryptocephalidæ, Kirby.

Inclica, Wlk.

Cryptocephalus, Geoff

Diapromorpha, Lac.

Fam. Chrysomelidx, Leach.

Chalcolampra, Baly.

Lina, $M$ eo.

Chrysomela, Linn.

Fam. Galerucidæ, Steph. Galerucr, Geoff.

Fam. Halticidæ.

Graptodera, Chevr.

Monolepta, Chevr.

Thyamis, Steph.

Fam. Coccinellidæ, Latr.

Coccinella, Linn.

Neda, Muls.

Coelophora, Muls.

Chilocorus, Leach.

Epilachna, Chevr.

Scymnus, $K u g$.

Fam. Frotylidw, Leach.

Fatua, Dej.

Dacne.

Triplax, Payk.

Tritoma, Fabr.

Ischyrus, Cherz.

Fam. Endomychidæ, Leach.

Eugonius, Gerst.

Eumorphus, Weber.

Stenotarsus, Perty.

Lycoperdina, Latr.

Ancylopus, Gerst.

Saula, Gerst.

Mycetina, Gerst.

\section{ORDER ORTHOPTERA,} Iinn.

Fam. Forficulidæ, Steph. Forficula, Linn.

Fam. Blattidæ, Steph.

Panesthia, Serv.

Polyzosteria, Burm. Corydia, Serv.

Fam. Mantidæ, Leach.

Empusa, Illig.

Harpax, Serv.

Schizocephala, Serv.

Mantis, Linn.

Fam. Phasmidæ, Serv.

Acrophylla, Gray.

Phasma, Licht.

Phyllium, Illig.

Fam. Gryllidæ, Steph. Acheta, Linn.

Platydactylus, Brall.

Steirodon, Serv.

Phyllophora, Thunb.

Acanthodis, Serv.

Phaneroptera, Sern.

Phymateus, Thunb.
Truxalis, Linn.

Acridium, Geoff.

\section{ORDER NEUROPTERA,} Linn.

Fam. Sericostomidæ, St. Mormonia, Curt.

Fam. Leptoceridæ, Leach.

Macronema, Pict.

Molanna, Curt.

Setodes, Ramb.

Fam. Psychomidæ, Curt. Chimarra, Leach.

Fam. Hydropsychidæ, Curt Hydropsyche, Pict.

Fam. Rhyacophilidæ, St. Rhyacophila, Pict.

Fam. Perlidæ, Leach. Perla, Geoff.

Fam. Siliadix, Westw. Dilar, Ramb.

Fam. Hemerobidæ, Leach. Mantispa, Illig.

Chrysopa, Leach.

Micromerus, Ramb.

Hemerobius, I inn.

Coniopteryx, Hal.

Fam.Myrmeleonidæ, Leach Palpares, Ramb. Acanthoclisis, Ramb. Myrmeleon, Linn. Ascalaphus, Fabr.

Fam. Psocidæ, Leach. Psocus, Latr.

Fam. Termitidæ, Leach. Termes, Linn.

Fam. Ernbidæ, Hagen. Oligotoma, Westw.

Fam. Ephemeridx, Leach. Baetis, Leach.

Potamanthus, Pict.

Cloe, Burm.

Cænis, Steph.

Fam. Libellulidæ. Calopteryx, Leach.

Euphæa, Sclys. Micromerus, Ramb. Trichocnemys, Sclyg.

Lestes, Leach.

Agrion, Fabr.

Gynacantha, Ramb.

Epophthalmia, Burm.

Zyxomma, Ramb.

Acisoma, Ramb.

Libellula, Linn.

\section{ORDER HYMENOPTERA} Iinn.

Fam. Formicidæ, Leach.

Formica, Linn.

Polyrhachis, Smith.

Fam Poneridx, Smith.

Odontomachus, Latr.

Typhlopone, Westw.

Myrmica, Latr.

Crematogaster, Land.

Pseudomyrma, Quen.

Atta, St. Farg.

Pheidole, Westw.

Meranoplus, Smith

Cataulacus, Bmith.

Fam. Mutillidæ, Leach.

Mutilla, Iinn.

Tiphia, Fabr.

Fam. Eumenidæ, Westw.

Odynerus, Latr. Scolia, Fabr.

Fam. Crabronidæ, Leach. Philanthus, Fabr. Stigmus, Jur.

Fam. Sphegidæ, Steph. Ammophila, Kirby. Peloprus, Latr. Sphex, Fabr.

Ampulex, Jur.

Fam. Larridæ, Steph.

Larrada, Smith.

Fam. Pompilidæ, Leach.

Pompilus, Fabr.

Fam. Apidx, treach.

Andrena, Fabr.

Nomia, Latr.

Allodaps, Smith.

Ceratina, Latr.

Colioxys, Latr.

Crocisa, Jur.

Stelis, Panz.

Anthophora, Latr.

Xylocopa, Latr.

Apis, Linn.

Trigona, Jur.

Fam. Chrysidæ, Wlk.

Stilbum, Spin.

Fam. Dorylidæe, Shuck.

Enictus, Shuck.

Fam.Ichneumonidæ, Leach

Cryptus, Fabr.

Hemiteles, Grav.

Porizon, Fall.

Pimpla, Fabr.

Fam. Braconidæ, Hal.

Microgaster, Latr.

Spathius, Nees.

Heratemis, $W l k$.

Nebartha, $W l k$.

Psyttalia, Wlk

Fam. Chalcidiæ, Spin.

Chalcis, Fabr.

Halticella, Spin.

Dirrhinus, Dalm. 
Mycalesis, $\boldsymbol{H} u b n$. Crnonympha, Hubn. Emesis, Fabr.

Fum. Lycænidæ, Leach. Anops, Boisd.

Loxura, Horsf.

Myrina, Godt.

Amblypodia, Horsf.

Aphnæus, $H u b n$.

Dipsas, Doubl.

Lycæna, Fabr.

Polyommatus, Latr.

Lucia, Westw.

Pithecops, Horsf.

Fam. Hesperidæ, Steph. Goniloba, Westw.

Pyrgus, Hubn.

Nisoniades, Hubn.

Pamphila, Fabr.

Achylodes, Hubn

Hesperia, Fabr.

Fam. Sphingidæ, Leach.

Sesia, Fabr.

Macroglossa, Ochs.

Calymnia, Boisd.

Chorocampa, Dup.

Pergesa, $W l k$.

Panacra, Wlk

Daphnis, Hubn.

Zonilia, Boisd.

Macrosila, Boisd.

Sphinx, Linn.

Acherontia, Ochs.

Smerinthus, Latr.

Fam. Castniidæ, Wlk.

Eusemia, Dalm.

Egocera, Latr.

Fam. Zygænidæ, Leach.

Syntomis, Ochs.

Glaucopis, Fabr.

Enchromia, Hubn.

Fam. Lithosiidæ, Steph.

Scaptesyle, $W l k$.

Nyctemera, $\boldsymbol{H} u b n$.

Euschema, $\boldsymbol{H} u b n$.

Chalcosia, Hubn.

Eterusia, Hope.

Trypanophora, Koll.

Heteropan, $W l k$.

Hypsa, $\boldsymbol{H} u b n$.

Vitessa, Moor.

Lithosia, Fabr.

Setina, Schr.

Doliche, $W l k$.

Pitane, Wlk.

Emene, Wlk:

Dirade, $W l k$.

Cyllene, Wlk.

Bizone, Wlk.

Deiopeir, Steph

Fam. Alope, Wlk

Tinolius, Wlk.

Creatonotos, Hubn.

Acmonia, Wih.

Spilosoma, Steph.

Cyonia, Hubn.

Antheua, $W l k$.

Aloa, Wik:

Amerila, $W l k$.

Ammatho, $W l k$.

Fam. Liparida, Wlk.

Artaxa, Wlk.

Acyphas, WVlk

Lacida, WTh.

Amsacta, $W l k$.

Antipha, Wlk:

Anaxila, $W l k$.

Procodeca, $W l k$.

Redoa, Wlk:

Euproctis, Hubn,

Cispia, Wlk.

Dasychira, $\boldsymbol{H} u b m$.

Lymantria, Hubn.

Enome, Wlk:

Dreata, $W l k$.
Pandala, Wlk.

Charnidas, Wlk.

Fam. Psychidæ, Brw.

Psyche.

Metisa, Wlk.

Eumeta, Wlk.

Cryptothelea, Templ.

Fam. Notodontidæ, St.

Cerura, Schr.

Sauropus, Germ.

Nioda, Wlk:

Rilia, $W l k$.

Ptilomacra, Wlk.

Elavia, Wlk.

Notodonta, Ochs.

Ichthyura, Hubn

Fam. Limacodidx, Dup.

Scopelodes, Westw.

Messata, Wlk.

Miresa, Wlk.

Nyssia, Schr.

Neæra, Schr.

Narosa, Wlk.

Naprepa, Wik.

Fam. Drepanulidæ, Wlk.

Oreta, Wlk.

Arna, Wlk.

Ganisa, Wlk

Fam. Saturinidæ, Wlk.

Attacus, Linn.

Antheræa, $\boldsymbol{H} u b n$.

Tropæa, Hubn.

Fam. Bombycidæ, Steph.

Trabala, Wrk.

Lasiocampa, Schr.

Megasoma, Boisd.

Lebeda, Wlk.

Fam. Cossidæ, Newm.

Cossus, Fabr.

Zeuzera, Latr.

Fam. Hepialidæ, Steph. Phassus, Steph.

Fam. Cymatophoridæ, Schr

Thyatira, Ochs.

Fam. Bryophilidx, Guen. Bryophila, Treit.

Fam. Bombycoidæ, Guen Diphtera, Ochs.

Fam. Leucanidæ, Guen. Leucania Ochs.

Brada, Wlk.

Crambopsis, Wlk.

Fam. Glottulidæ, Guen.

Polytela, Guen.

Glottula, Guen.

Chasmina, Wlk.

Fan. Apamidx, Guen.

Laphygma, Guen.

Prodenia, Guen.

Calo-gramma, $W\urcorner k$.

Heliophobus, Boisd.

Hydræcia, Guen.

A pamea, Ochs.

Celæna, Steph.

Fam. Caradrinidæ, Guen. Amyna, Guen.

Fam. Noctuidæ, Guen. Agrotis, Ochs.

Fam. Hadenidæ, Guen.

Eurois, $\boldsymbol{H} u b n$.

Epiceia, Wlk.

Hadena, Treit.

Ansa, $W l k$.

Fam. Xylinidx, Guen.

Ragada, Wrk.

Cryassa, Wlk:

Egelista, $W 7 k$.

Xylina, Ochs.

Fam. Heliothidæ, Guen. Heliothis, Ochs.

Fam. Hæmerosidæ, Guen. Ariola, Wlk.

Fam. Acontidæ, Guen. Xanthodes, Guen.
Acontia, Ochs.

Chlumetia, Wlk.

Fam. Anthophilidæ, Guen. Micra, Guen.

Fum. Eriopidæ, Guen. Callopistria, $\boldsymbol{H u b n}$.

Fam. Eurhipidæ, Guen. Penicillaria, Guen.

Rhesala, Wlk.

Eutelia, Hubn.

Fam. Plusiidæ, Boisd.

Abrostola, Ochs.

Plusia, Ochs.

Fam. Calpidæ, Guen.

Calpe, $T_{\gamma} \cdot i t$.

Orcesia, Guen

Deva, Wlk.

Fam. Hemiceridæ, Guen. Westermannia, Hubn.

Fam. Hyblæidæ, Guen.

Hyblæa, Guen.

Nolasena, $W l k$

Fam. Gonopteridæ, Guen. Cosmophila, Boisd.

Anomis, $H u b n$.

Gonitis, Guen.

Eporedia, Wlk.

Rusicada, Wlk.

Pasipeda, Wlk.

Fam. Toxocampidæ, Guen. Toxocampa, Guen. Albonica, Wlk.

Fam. Polydesmidæ, Guen. Polydesma, Boisd.

Fam. Homopteridæ, Boisd.

Alamis, Guen.

Homoptera, Boisd.

Diacuista, $W l k$

Daxata, Wlk.

Fam. Hypogrammidx, Guen.

Briarda, Wik

Brana, Wlk.

Corsa, Wlk.

Avatha, Wik.

Gadirtha, $W l k$.

Ercheia, Wlk.

Plotheia, Wlk.

Diomea, Wlk.

Dinumma, Wik.

Lusia, Wlk:

Abunis, $W l k$.

Fam. Catephiidx, Guen.

Cocytodes, Guen.

Catephia, Guen.

Steiria, $W l k$.

Auclia, Wlk.

Asgilia, W7k.

Maceda, $W l k$.

Fam. Hypocalidæ, Guen. Hypocala, Guen.

Fum. Catocalidæ, Boisd. Blenina, $W l k$.

Fam. Ophideridæ, Guen. Ophideres, Boisd.

Potamophera, Guen.

Lygniodes, Guen.

Fam. Erebidæ, Guen. Oxyodes, Guen.

Fam. Ommatophoridæ, Guen.

Speiredonia, Hubn.

Sericia, Guen.

Patula, Guen.

Argiva, Hubn

Beregra, $W l k$.

Fam. Hypopyridæ, Guen Spiramia, Guen.

Hypopyra, Guen.

Ortospana, Wlk.

Entomogramma, Guen.

Fam. Bendidæ, Guen.

Homæa, Guen.

Hulodes, Guen.

Fam. Ophiusidæ, Guen.

Sphingomorpha, Guen.

Lagoptera, Guen.

Ophiodes, Guen.

Cerbia, Wlk.

Ophisma, Guen.

Achæa, Hubn.

Serrodes, Guen.

Naxia, Guen.

Calesia, Guen.

Hypætra, Guen.

Ophiusa, Ochs

Fodina, Guen.

Grammodes, Guen.

Fam. Euclididæ, Guen

Trigonodes, Guen.

Fam. Remigidæ, Guen.

Remigia, Guen

Fam. Focillidæ, Guen.

Focilla, Guen.

Fam. Amphiganidæ, Guen.

Lacera, Guen.

Amphigonia, Guen.

Fam. Thermisidæ, Guen.

Sympis, Guen.

Thermesia, Hubn.

Azazia, Wlk.

Selenis, Guen.

Ephyrodes, Guen.

Capnodes, Guen.

Ballatha, Wlk.

Daranissa, Wlk.

Darsa, Wik.

Fam. Urapterigidæ, Guen. Lagyra, Wlk.

Fam. Ennomidæ, Guen. 
Dichromia, Guen. Hypena, Schr. Gesonia, Wlk.

Fam. Herminidæ, Dup. Herminia, Latr. Adrapsa, Wlk. Bertula, Wlk. Bocana, Wlk. Orthaga, Wlk. Hipoepa, Wlk: Lamura, Wlk. Echana, Wlk. Dragana, $W 7 k$. Pingrasa, $W l k$. Egnasia, $W l k$. Berresa, $W l k$.

Imma, $W l k$. Chusaris, Wik. Corgatha, $W l_{k}$. Catada, Wlk.

Fam. Pyralidæ, Guen. Pyralis, Linn. Aglossa, Latr. Labanda, Wlk.

Tam. Ennychidæ, Dup. Pyrausta, Schr.

Fam. Asopidæ, Guen. Desmia, Westw. Addiodes, Guen. Samea, Guen. Asopia, Guen. Agathodes, Guen. Lencinades, Guen. Hymenia, Hubn. Agrotera, Schr. Isopteryx, Guen.

Fam. Hydrocampidæ, Guen Oligostigma, Guen. Cataclysta, Schr.

Fam. Spilomelidæ, Quen. Lepyrodes, Guen. Phalangiodes, Guen. Spilomela, Guen. Nistra, Wlk. Pagyda, Wlk. Massepha, Wlk.

Fum. Margarodidæ, Guen. Glyphodes, Guen. Phakellura, L. Guild. Margarodes, Guen. Pygospila, Guen. Neurina, Guen. Ilurgia, $W l k$.

Fam. Botydx, Guen. Botys, Latr. Ebulea, Guen. Pionea, Guen. Scopula, Schr. Godara, Wlk. Herculia, Wlk. Mecyna, Guen.

Fum. Scoparidæ, Guen. Scoparia, Haw. Davana, Wlk.

Darsania, Wlk Dosara, Wlk.

Fam. Choreutidæ, Staint. Niaccaba, Wlk. Simæthis, Leach.

Fam. Phycidæ, Staint. Myelois, $\boldsymbol{H u b n}$. Dascusa, Wlk. Daroms, Wlk. Homosoma, Curt. Nephopteryx, Hubn. Pempelia, Hubn. Prionapteryx, Steph. Pindicitora, $W l k$. Lacipea, Wlk. Araxes, Steph. Catagela, Wlk

Fam. Crambidæ, Dup. Crambus, Fabr. Darbhaca, $W l k$. Jartheza, Wlk.
Bulina, $W l k$. Bembina, Wlk. Chilo, Zinck.

Dariausa, $W l k$. Arrhade, $W l k$.

Darnensis, $W l k$.

Fam. Chlœphoridæ, Staint. Thagora, Wlk.

Earias, 'Hubn.

Fam. Tortricidæ, Steph.

Lozotænia, Steph.

Peronea, Curt.

Lithogramma, Steph.

Dictyopteryx, Steph.

Homona, Wlk.

Hemonia, Wlk.

Achroia, Hubn.

Fam. Yponomeutidæ, Steph.

Atteva, Wrk.

Fam. Gelichidæ, Staint.

Depressaria, Haw.

Decuaria, Wlk.

Gelechia, $\boldsymbol{H} u b n$.

Gizama, Wlk.

Enisipia, Wlk.

Gapharia, Wlk.

Goesa, Wlk.

Cimitra, $W l k$.

Ficulea, $W l k$.

Fresilia, Wlk.

Gesontha, Wlk.

Aginis, Wlk.

Cadra, Wlk.

Fam. Glyphypterigidæ, Staint.

Glyphyteryx, Hubn.

Hybele, Wlk.

Fam. Tineidæ, Leach.

Tinea, Linn.

Fam. Lyonetidæ.

Cachura, $W l k$.

Fam. Pterophoridæ.

Pterophorus, Geoff.

Order Diptera, Linn.

Fam. Mycetophilidæ, $\mathrm{Hal}$. Sciara, Meig.

Fam. Cecidomyidæ, $\boldsymbol{H} a l$. Cecidomyia, Latr.

Fam. Simulidæ, Hal.

Simulium, Latr.

Fam. Chironomidæ, Hal. Ceratopogon, Meig.

Fam. Culicidæ, Steph. Culex, Linn.

Fam. Tipulidæ, Hal. Ctenophora, Fabr. Gymnoplistia, Westw.

Fam. Stratiomidæ, Latr. Ptilocera, Wied. Pachygaster, Meig. Acanthina, Wied.

Fam. Tabanidæ, Leach. Pangonia, Latr.

Fam. Asilidæ, Leach. Trupanea, Macq. Asilus, Linn.

Fram. Dolichopidæ, Leach. Psilopus, Meig.

Fam. Muscidæ, Latr. Tachina, Fabr.

Musca, Linn.

Dacus, Fabr.

Ortalis, Fall.

Sciomyza, Fall.

Drosophila, Fall.

Fam. Nycteribidx, Leach. Nycteribia, Latr.

ORder Hemiptera, Linn.

Fam. Pachycoridæ, Dall. Cantuo, Bmyot and Serv. Callidea, Lap.

Fam. Eurygasteridæ, Dall. Trigonosoma, Lap.

Fam. Plataspidæ, Dall. Coptosoma, Lap.

Fam. Halydidæ, Dall. Halys, Fabr.

Fam. Pentatomidæ, St. Pentatoma, Olive. Catacanthus, Spin. Rhaphigaster, Lap.

Fam. Edessidæ, Dall. Aspongopus, Lap.

Tesseratoma, Lap. and Serv.

Cyclopelta, Am, and Serv.

Fam. Phyllocephalidx, Dall.

Phyllocephala, Lap.

Fam. Mictidæ, Dall.

Mictis, Leach.

Crinocerus, Burm.

Fam. Aniroscelidæ, Dall. Leptoscelis, Lap.

Serinetha, Spin.

Fam. Alydidx, Dall.

Alydus, Fabr.

Fam. Stenocephalidæ, Dall.

Leptocorisa, Latr.

Fam. Coreidæ, Steph. Rhopalus, Schill.

Fam. Lygæidæ, Westw. Lygæus, Fabr.

Rhyparochromus, Curt.

Fam. Aradidæ, $W l k$.

Piestosoma, Lap.

Fam. Tingidæ, Wlk. Calloniana, $W l k$.

Fam. Cimicidæ, Wlk Cimex, Linn.

Fam. Reduviidæ, Steph.

Pirates, Burm.

Acantbaspis, $A m$. and Serv.

Fam. Hydrometridæ, Leach.

Ptilomera, Am. and Serv.

Fam. Nepidæ, Leach. Belostoma, Latr.

Nepa, Linn.

Fam. Notonectidæ, Steph. Notonceta, Linn. Corixa, Geoff.

ORder HOMOPTERA, Latr.

Fam. Cicadidæ, Westw.

Dundubia, $A m$. and Serv.

Cicada, Linn.

Fam. Fulgoridæ, Schaum.

Hotinus, Am, and Serv.

Pyrops, Spin.

Aphæna, Guer.

Elidiptera, Spin.

Fam. Cixiidæ, Wlk.

Eurybrachys, Guer.

Cixius, Latr.

Fam. Issidx, Wlk.

Hemisphærius, Schaum.

Fam. Derbidæ, Schaum.

Thracia, Westw.

Derbe, Fabr.

Fam. Flatticla, Schaum. Flatoides, Guar.

Ricania, Germ.

Pociloptera, Latr.

Fam. Membracid $x, W l k$. Oxyrhachis, Germ.

Centrotus, Fabr.

Fam. Cercopidæ, Leach.

Cersopis, Fabr.

Ptyelus, Lap and Serv.

Fam. Tettigoniidæ, $W l k$ :

Tettigonia, Latr.

Fam. Scaridæ, Wlk.

Ledra, Fabr.

Gypona, Germ.

Fam. Iassidæ, $W l k$.

Acocephalus, Germ.

Fam. Psyllidx, Latr.

Psylla, Geoff.

Fam. Coccidæ, Leach.

Lecanium, Illig.

Coccus.

Some insects are useful to man and his industries, but some are hurtful, even ruinous; some are of wonderful beauty, and others are of interest from peculiarity of structure or of habits. They are gifted with such senses as love, touch, taste, smell, sight, hearing, and the commanding and governing senses, and in this state the two sexes meet and the propagation of their kind is effected. After impregnating, the males usually die. The females live a short space longer, until they lay their eggs. Their fecundity is generally very great, but their numbers are kept under by many insectivorous creatures, - amongst birds by woodpeckers, by the Sittinæ or nuthatches, by Certhias or true creepers, and by the Parrinæ or titmice. The hard-bodied beetles and other Coleoptera are eagerly seized while on the wing by the shrikes, drongas, crows, rollers, bee-eaters, thrushes, and others. Many bats, carnaria, and civets are insect feeders. The ants, the acari, and ichneumonidæ, among insects, destroy caterpillars and grubs, and some of the ichneumons destroy the larvæ of many species of gall-flies. Genera of the family Mordellidæ are mostly parasites of the Hymenoptera. They abound in tropical climates, and check the increase of the Vespidæ (wasps), and Bombidæ (bees). The lizards, the chameleons, and the geckos eat up great numbers of the 
Very few insects are edible, and from their small size they add little to the food supplies of man. The Greeks ate grasshoppers; even now the aborigines of New South Wales eat them raw, first taking off their wings. Elian relates of an Indian king, who for a dessert, instead of fruit, set before his guests a roasted worm taken from a plant (probably the larva of an insect), which was thought very delicious. Mites in myriads are consumed in cheese. Negroes in Jamaica eat the Bugong butterflies, after removing the wings, and they store them up by pounding and smoking them.

The Chinese, it is said, thriftily eat the chrysalis of the silkworm, after making use of the silk; the larvæ of a hawk-moth are also relished.

The Palolo viridis or sea-worm, and the grub of the Cordylia palmarum or palm-weevil, are used as food articles. The grub of the palm-weevil is the size of a thumb, and is a favourite with some races of India. The palm-weevil of Burma, quite a large insect, is, according to Dr. Mason, a species of Calandra. Its larva is an odious-looking grub, which is eaten by the Burmese, and esteemed by them a great luxury.

The grub of a species of Cicada of the Homoptera is eaten by the Karens as a great luxury. It is domiciled in a clay tube several inches high, from which the Karens extract it by a thorny branch of a bamboo.

Humboldt mentions ants as being eaten by the Marivitunos and Margueratares, but he does not specify the genus or species. Hottentots and races in the East Indies eat the termites, or white ants, boiled, fried, and raw. Broughton, in his Letters written in a Mahratta camp in 1809, tells us that they were carefully sought after, and preserved for the use of the debilitated Lurjee Rao, prime minister of Sindia. They are delicate eating. The natives mix them with flour, and make a variety of pastry; or they parch them in pots over a gentle fire, with or without ghi, stirring them about as is done in roasting coffee. White ants, at their season of pairing, about the commencement of the rains, take wing, and pour into houses that are lighted up. They almost instantly cast their wings, and are then mere creeping insects, easily caught.

The peasants of Languedoc hold the Mantis religiosa almost sacred; they call it Prega Deori or Prie Dieu.

For man and his industries insects furnish many valuable materials. Galls are employed in dyeing and in tanning and ink-making, and are also used medicinally. They are produced on different species of oak, one of them by the female of the Cynips or Diplolepis piercing the buds of Quercus infectoria, and, it is said, also of Q. ballota; another gall, also, on the tamarisk, Tamarix Indica, is largely gathered on the N.W. borders of India, in Central Asia, and Kurdistan. In China, a gall, which is said to be produced by an aphis, is more bulky than the oak galls, and of very irregular shape, and hollow.

The cochineal insect, the Coccus cacti, is of great value in the arts. There are two species, one yielding the fine cochineal of commerce, the other the Grana sylvestris or wild cochineal. The latter is naturalized in India, but it is of little commercial value, being enveloped in a thick cottony down, which cannot be separated from the insect for the preparation of the dye. The fine cochineal insect lives on several cultivated kinds of thornless Opuntia, and $\mathrm{O}$. cochinilifera, which is employed in the W. Indies for rearing the insect, has been introduced into India. The fine insect will not settle on the wild prickly pear, O. Dillenii. The females alone yield the dye. The young are viviparous; cvery cochineal mother produces above a hundred young ones. Whilst within the mother they appear to be all connected, one after the other, by an umbilical cord to a common placenta, and in this order they are, in due time, brought forth as living animals, after breaking the membrane in which they were at first probably contained as eggs. The fine cochineal, the Grana fina, is brought to Europe chiefly from Central America, and sells in England at 3s. 6d. It yields a valuable red, crimson, scarlet dye for wool and silk, and colouring material. The best rouge is made from it, and its imports into Britain in 1881 were valued at $£ 355,924$.

Another species of Coccus, C. maniparus of Arabia, punctures the Tamarix gallica, and causes the exudation of the Arabian manna. But, in India, the most valuable of the species of Coccus is $\mathrm{C}$. lacca, the female of which becomes the lac of commerce. It is a product of British India, and in the year 1877-78 the exports were,-

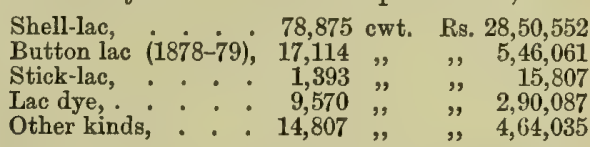

This forest product varies in quantity from year to year.

The trees on which the female Coccus lacca chiefly settle are the Ficus Indica, F. religiosa, Butea frondosa, the cotton trees, Bombax ceiba, Salmalia Malabarica, Gossampinus Rumphii, and Zizyphus jujuba. Lac lake was first made in Calcutta in the beginning of the 19 th century, and the lac dye was manufactured afterwards. Another Coccus, C. Sinensis of China, secretes a wax (Peh-la?) from which candles are made; and the Coccus polonicus of High Asia and Europe is also used in its native regions for dyeing wool, silk, and hair of a red colour.

Bees are useful in producing honey, and in Afghanistan they are semi-domesticated, as in Europe. The races on the N.W. frontier of India make openings in the walls of their houses for the bees to sheiter in, and their honey is much valued. The Langeh bee of Borneo, and one of smaller size called Nuang, produce valuable honey. They generally place their nests underneath the larger branches, and the Dyaks ascend the trees by means of a rail of bamboos to reach them. A small bec of Borneo is esteemed for the wax of its honeycomb. The Trigona læviceps gathers the pwai ngyet resin of Burma. Bees are not the only insects which produce wax. The Flata limbata, Hutton, an insect of the Himalaya related to the Pœciloptera, produces a wax which dissolves readily in water.

Still more valuable than the species of Coccus are the domesticated and wild insects which produce the silks of commerce. They are of the families Saturniidæe and Bombycidæ, of the Lepidoptera. All the Saturniidæ are silk spinners, -Actias, Antherea, Attacus, Caligula, Cricula, 
Loepa, Neoris, Rinaca, Rhodia, Salassa, and Saturnia ; and there are about 400 species known to naturalists, but only some of the BombycidæBombyx, Ocinara, Theophila, and Trilocha-produce it. The silk industry has been fostered in China from the most ancient times, the empress taking a personal interest in it, as the emperor does in that of agriculture; and in British India the wild insects yielding tasar are carefully watched. About four million pounds weight of raw silk, value about $17 \mathrm{~s}$. the pound, are annually imported into Great Britain, chiefly from China. The exports from India in 1877-78 were 1,512,819 lbs., value Rs. $70,35,493$, to Great Britain, France, and Italy. In 1881, Great Britain imported silk to the value of $£ 15,092,201$, comprising knubs, or husks, waste, raw, thrown, and manufactured.

The blistering flies, species of Cantharis, Mylabris, and Meloe, though used only in medical practice, are not to be forgotten in the enumeration of insects valuable to man. Cantharis vesicatoria is the Spanish blistering fly. The Indian flies are Mylabris chicorii, Meloe trianthema, Cantharis gigas, and $\mathrm{C}$. violacea; but Mylabris chicorii is that exclusively used.

The beautiful wing-cases or elytra of Chrysochroa, a species of Buprestis of a brilliant metallic green colour, are used in India, and exported to Europe, to ornament cuscus fans, baskets, etc., to be worked on muslins, and to enrich the embroidery of ladies' dresses. A species of Buprestis occurs in Burma of variable copper and green, burnished with transparent golden bronze. They are liring gems, and Sgau Karen maidens use the wingcases for necklaces and chaplets. The Kyen adorn themselves with the elytra of B. ignita. Westwood estimated the species of Buprestis at 1500 .

The excreta of animals which would be injurious to man, are buried deep in the earth by the dungbeetles, the useful Copridæ and Dynastidæ. Some of these are of great size, with immense horn-like protuberances on the head and thorax of the males. Some of them cut the masses into round balls, which they roll to a distance, and bury an inch or two deep in the ground.-Wall. Tr. of $a$ Nat. p. 95 .

The Necrophaga are carrion feeders; and species of Necrophorus, Necrodes, Silpha, and Oiceoptoma occur in the East Indies.

A brown-black scavenger beetle of Burma, and very common, resembling Scarabæus stercorarius or Geotrupes stercorarius, selects for its burrow a bed of ordure, which it excavates two or three feet deep, and at the end of the passage forms a chamber of several inches in diameter. It is not a pellet roller.

Nature protects the otherwise helpless animals in varied ways. They are to be found on leafy plants, on withered branches, or amidst dried grasses on the ground, and so closely resembling the surrounding objects, that even when pointed to they cannot be made out by an unaccustomed eye. One mode or other of protection is followed through all the insect world. Beetles that imitate other Coleoptera of distinct groups are very numerous in tropical countries. The insects which others imitate always have a special protection, which leads them to be avoided as dangerous or uneatable by small insectivorous animals; some have a disgusting taste (analogous to that of the Heliconidæ) ; others have such a hard and stony covering that they cannot be crushed or digested; while a third set are very active, and armed with powerful jaws, as well as being provided with some disagreeable secretion.

The Phasmidæ abound in Asia, Africa, S. America, the Eastern Archipelago, and Australia. They are numerous in British India. Their varied shapes have obtained for them curious names,spectres, phantoms, devils' horses, soldiers of Cayenne, walking sticks, walking leaves, or leaf insects (Phyllium), animated sticks, and, like the Bacteria sarmentosa, they mostly are inoffensive leaf-eating creatures, some being broad and leaflike, while others are long and cylindrical, so as to resemble sticks or bits of withered grass. The imitative resemblance of some of these insects to the plants on which they live, and to the bits of straw and wood around them, is marvellous.Wallace, Tr. Nat. p. 92.

The praying insects, the Mantidæ, are so called because of their habit of sitting with their long fore feet held up as if in prayer. In reality they are real tigers amongst insects, taking that position in wait for their prey, which they seize with their powerful serrated fore feet. They stand motionless, and so closely resemble the leaves as not to be easily perceived.

The true leaf insects of the East Indies are species of the genus Phyllium. They are the size of a moderate leaf, which their large wing-covers, and the expanded margins of the head, thorax, and legs, cause them exactly to resemble. Their green colour and the veining of their wings precisely correspond to that of their food plant.

Hymenoptera comprise the gall insect, ichneumon flies, sand wasps, mason wasps, mining wasps, stinging ants, common ants, wasps, hornets, carpenter bees, honey bees, and dammer bees. They mostly have stings with which to protect themselves, and the pain from the thrust of that of the wasp, the bee, the hornet, or the ichneumon is considerable, death even resulting from the attacks of a multitude of bees. Even large birds like the myna carefully fly off to aroid the hornet's attacks.

Bugs belong to the family Hemiptera, several genera of which occur in India. Amongst others are Cantuo ocellatus, Leptoscelis marginalis, Callidea Stockerius, etc. Of the aquatic species, the gigantic Belostoma Indicum attains a size of nearly three inches. Yet some of them are most attractive in colour; a green one is often seen on leaves. They are quite inoffensive if unmolested, but if irritated exhale an offensive odour.

The larvæ of the genus Adolia are hairy, and sting with virulence.

Another Ceylon caterpillar of the moth Necra lepida, Cramer, the Limacodes graciosa, West., short, broad, pale-green, with black spines, which feeds on the Carissa jasminifiora, stings with fury. It occupies also the Thespesia populnea, and at a certain stage of its growth descends by a silken thread and burries away.

A species of the Hister family, of British India and Further India, a small glossy black'beetle, when touched draws up its limbs and counterfeits death to admiration.

One of the Brachinides of Burma, when seized, 
emits, with slight snapping noises, successive discharges of aeriform vapour, which blackens the fingers like a strong acid.

Latrodectes lugubris; the kara kurt or black worm of the Kirghiz, is about the size of a finger nail. It can jump several feet, and its bite is very venomous.-Schuyler, ii. p. 123.

The running spiders and some of the water beetles, species of Hydrophilus, secure their progeny by carrying their eggs in a cocoon under the abdomen.

The object for which some insects are furnished is not apparent. Many species of the Cerambycidæ beetles emit an odour resembling attar of roses.

Scolopendra phosphorea, Mason, of Burma, is a small centipede, which when touched suddenly becomes a living blaze, each lobe glowing like a mass of phosphorus.

All Hindus reverence the cow amongst mammals, also the Brahmany kite amongst birds, and the tulsi (Ocimum sanctum) amongst plants, but to no insect do they attach religious importance. In ancient times, however, the Ateuchus Egyptiorum was the sacred beetle of the Egyptians. It is found in Egypt and Western Asia. It has almost an exact representative of India in Ateuchus sanctus. It was regarded by the Egyptians as an emblem of fertility, or more probably that of eternity.

The most remarkable and gigantic insects of the old world are species of the Scarabæus. S. atlas, $F a b r$, is said to be a native of Java, and there are four species indigenous to Nepal.

Luminous insects were styled by the Romans Noctiluca and Luciola. They are numerous in the tropics, and greatly so in some parts of the S. and E. of Asia.

The names glow-worm and fire-fly are applied to the Lampyrides, a tribe of the Malacodermous Coleoptera, also to the South American Elateridæ, of the genus Pyrophorus, and to the Homopterous insect Fulgora oculata, which occurs in Penang, and F. spinolæ of Assam. Fulgoræ of Burma are said not to be luminous. F. laternaria is of S. America. F. candelaria is said to be of S.E. Asia.

Lampyris fire-fly, the Mouche lumineuse of the French, delights in the warm damp of the jungle. The fire-flies assemble around particular trees. Elater cœnosus, Hope, and other species, in Nepal, frequent the oak, the alder, and the willow.

A species of Epeira, a large red and black spider, about Monghir on the Ganges, form gigantic webs, stretching across the paths, sufficiently strong to offer considerable opposition to a traveller. The reticulated part of the webs are of a bright yellow colour, and about five feet in diameter, but have a stretch of ten to twenty feet, including the great guy ropes, by which it is fastened to some neighbouring tree or clump of bamboos. The spider sits in the centre waiting for its prey. One of them when expanded measured six inches across the legs; and Captain Sherwill found a species of Nectarinia entangled in one of their webs.

The beetles which most attract attention from their size and beauty are the Buprestidæ and Longicornes. The Anthribidæ abound in the Malay Archipelago, and, like the Longicornes, have very long antennæ. The Eupholi of the Papuan Islands and the Pachyrhynchi of the Philippines are living jewels.

The butterflies, moths, and sphynxes belong to the Lepidoptera, of which a greater number of species are disseminated throughout the world than of any other insect order, and many of them are of great beauty. Phalena patroclus of Burma is a magnificent moth.

The larvæ of Dipsas isocrates, a lepidopterous insect, occupy the interior of a pomegranate, which they enclose in a woven web to prevent it falling.

Deiopeia pulchella, an insect common in British India, feeds on the kernel of the seed of Phyrostigma venenosum, which contains a poisonous principle, and the excrement of its larvæ contains the principle of the bean unaltered.

The curious wood-moth, the Sack Trager of the Germans, the dalone kattea of the Singhalese, and kundi puchi of the Tamil people, are species of Eumeta, E. Cramerii, Westwood, and E. Templetonii, Westwood. They gather and cement around them a bundle of thorns, which they bind together by threads so as to form a secure case. The male at the close of the pupal rest escapes from one end of the case, but to the female it is a covering for life.-Tennent's Ceylon.

Deticus, an insect of the grasshopper tribe, is kept by the Chinese in cages for fighting. They live for months in captivity. $-G$. Bennett, p. 271.

Crickets are pitted against each other by the Chinese, and largely betted on.

The skip-jack beetle is a species of the Elateridæ, which flies into the houses in the evening. When laid on its back, it suddenly turns itself over with a clicking sound.

The activity, intelligence, and ingenuity displayed by ants have attracted attention in all ages. The curious ant, Drepanognathus saltator, Jerdon (or Harpegnathus saltator, Jerdon), one of a genus of the Peninsula of India, in Malabar, and Mysore, has the name saltator from its making most surprising jumps when alarmed or disturbed. It is very pugnacious, and bites and stings very severely. It makes its nest underground, generally about the roots of some plant. Its society does not consist of many individuals. It appears to feed on insects, which it often seizes alive.

Ecophylla smaragdina is a green ant of the Malay Archipelago. It is rather large, and a long-legged, active, and intelligent-looking creature. They live in large nests, formed by glueing together the edges of leaves, especially of Zingiberaceous plants. When their nest is touched, a number of the ants rush out, apparently in a great rage, stand erect, and make a loud rattling noise by tapping against the leaves.

The three families of ants, Formicidæ, Poneridx, and Myrmicidæ, comprise many genera and a large number of species. Their stages of life, egg, larva, pupa, imago, are the same in all, and they have workers, imperfect females (which constitute the great majority), males, and perfect females.

Ants kill off a great number of caterpillars and other small insects.

Forel, examining one large nest, found more than twenty-eight dead insects brought in per 
minute, which would be 100,000 destroyed in a day. Many ants collect seeds.-Sir J. Lubbock on Ants, p. 60.

Pheidole providens, Sykes, collects large stores of grass seeds, on which it subsists from February to October. Colonel Sykes observed these ants bringing up their stores of grain to dry, and they utilize species of aphis, coccus, cercopis, centrotus, membracis.

Ant-lions are not ants, but the larvæ of species of Myrmelon. Their form at the lower part resembles that of a spider, but the head is armed with a sharp, strong pair of claws. These excavate in gardens, and fields, and roadways, small coneshaped cavities, with exquisitely smooth edges and sides, at the bottom of which the ant-lion lurks, so that any insect approaching the lip of the cone immediately falls to the ambush below, and is seized and destroyed. In its perfect state it resembles the dragon-fly, but it is seldom seen.

The trap-door spider is abundant in many parts of British India, and particularly so about Ghooty in the Ceded Districts. It is a species of the genus Cteniza, and is of considerable size. It excavates for itself a house in the ground, of dimensions quarter the size of this page, and forms a trap lid, which fits with great nicety, and closes the instant the prey falls inside.

No country is exempt from the injuries inflicted by insects. In Great Britain, in 1881, the turnip crop suffered heavily from various insect pests. The ' $\mathrm{fly}$ ' attack proved a heavy visitation over a large area of both England and Scotland. In some parts of Scotland, a small weevil, the Ceuthorhynchus contractus, was quite as injurious as the fly, and in the south of Scotland this weevil and another closely allied joined with the fly, the result being a very heavy destruction. A ground caterpillar, the caterpillar of the turnip-moth, Agrestis segetum, was very mischievous in Suffolk and Kent. Cabbage also suffered from fly in Kent and Essex. In Scotland, the maggot of the cabbage-fly (Anthomyia brassica, and possibly in some cases Anthomyia radicum) was unusually and seriously injurious to garden crops of cabbage. The beet-fly (A. betæ), which first appeared to any serious extent in 1880, still holds its own. Hops suffered from the froghopper, or cuckoofly, Euacanthus interruptus. Planters round Alton made a machine of tarred boards on which the creatures stuck when taking their tremendous leaps, and the damage was checked. Daddy long-legs' attacks in 1880 were disastrous. The customary corn pests are wireworm, red maggot, and aphides. A wheat saw-fly made its appearance, and near Rochdale grass saw-flies of some species of Dolerus appeared in great numbers. The Oscinis frit or frit-fly is at times exceedingly destructive in Sweden. The oak suffered from the leaf-rollers and other caterpillars. Saw-fly caterpillars were injurious to pines; and near Berwick, a small beetle, Orchestes fagi, caused much damage to the beech leaves. Their presence is a constant source of anxiety, not unfrequently of ruin, to the farmers and planters in all parts of the world, but particularly in tropical climates. The injury from insects is not less than that from the several diseases, caries, must, and ergot, which infest the cereal grains, produced by minute cryptogamic plants (mushrooms), which alter the perisperm, and sometimes destroy it altogether. (See Cereals.) Insects in their perfect state are not long-lived, and it is in the early stages of their existence that they cause most destruction.

The Diptera order has many insects which irritate and greatly annoy man, although not destroying life.

The Peepsa is one of these; it is a very small black fly, which floats like a speck before the eye. Its bite leaves a small spot of extravasated blood under the cuticle, very irritating if not opened. In British India they cling in myriads to any hanging thread, and can be destroyed by encircling them by an open cone of paper, and setting fire to its edges.

Midas ruficornis is a dipterous insect of the S.E. coast of the Peninsula of India. But the most troublesome of the mosquitos on the east coast and in Ceylon, is a species of Culex (C. laniger).

Wasps, scorpions, and centipedes often inflict painful stings and bites, which rarely prove fatal, but, except the hornets and wasps, they are rarely aggressive, only attacking man in selfdefence, or when alarmed. Some of the scorpions are black coloured, but the usual tints are varions shades of brown, and in the forests of the Malay Islands they occur of a green colour, and 8 to 10 inches long. Their numbers in some parts of India are great. On the plain at the Gor Naddy, in 1840 , they were multitudinous.

Amongst the insects which infest books in India are two genera, which are usually regarded as accomplices in the work of destruction, but which, on the contrary, pursue and greedily feed on the larvæ of the death-watch and the numerous acari, which are believed to be the chief depredators that prey upon books. One of these maligned genera is a tiny tailless scorpion (Chelifer), of which three species have been noticed in Ceylon,-the C. librorum, Temp., C. oblongum, Temp., and C. acaroides, Hermann, the last of which, it is believed, had been introduced from Europe in Dutch and Portuguese books. Another genus of book insects is the Lepisma, the fish insect genus, and called so by Fabricius from its fish-like scales, tiny silvery creatures, which feast on the acari and soft-bodied insects that infest books. There have only been two species described, viz. the L. niveofasciatus and L. niger, Temp.; it has six legs. As insects are very destructive to books in India, and the pastes or gums employed in the bindings form special objects for the attacks of certain tribes, it may be useful to know that insects refuse to attack the gum of the cashew-nut fruit.

Mother insects deposit their eggs in localities suitable for their reception and future development, selecting the object or substance to which instinct directed them as being the best adapted to serve those ends. Water for a few, and the soil of the earth for very many, but the vegetable kingdom for vastly the greatest number, serve insects as suitable habitations for rearing their young. It is while in the state of larvæ that they consume the greatest amount of food. Those living in the interior of timber or on vegetables, or other hard substances requiring manducation, are furnished with a pair of powerful mandibles or jaws, and another and less powerful 
pair of masticatory jaws or maxillæ. Those which chiefly inhabit water are of carnivorous habits, and prey upon insects smaller and softer than themselves, are furnished similarly with jaws, but adapted for seizing and destroying their prey. Such as inhabit the soil are either vegetable feeders, and conform in their structure to that section, or are carnivorous, and are hence provided with the means of obtaining their food similar to those which inhabit the water. A few have suctorial mouths, but these feed upon the juices of aninal and vegetable substances, especially when such are in a state of decomposition.

The larvæ of butterflies and moths are known as caterpillars. They remain in the larva state for very varied periods; some for a brief time, others for a fortnight, a month, or several months, and in the larger Coleoptera from three to four years. During this period they are solely occupied in eating, and their voracity is immense. After passing through the pupa state, the perfect insects come forth. They can walk and fly, but have not the same voracious appetite, and do not use the same food as in the larva state. Such is the case with all butterflies and moths, but not with all beetles. Grasshoppers and dragon-flies form a general exception, for they are as voracious and as capable of devouring much food in their perfect state as they were when in the larva condition.

The locust tribe, as defined by Westwood, includes all the grasshoppers, the females of which are destitute of an exserted ovipositor, and which have the antennæ short, filiform, and with twenty or thirty joints. Locusts, at intervals of years, appear in myriads in Central and Southern Asia, Persia, and in Northern India, often after droughts, and eating up every green thing. When their larvæ are advancing along the ground, it is customary in some parts of Northern India to dig a trench in front of the advancing army, and as they tumble in, earth is shovelled in over them.

In Burma, where caterpillars appear at intervals in the paddy fields in immense numbers, devouring plants down to the roots, grass as well as paddy, moving on daily a few miles, the plan adopted in Hindustan could be usefully applied.

The itch insect (Acarus, $s p$. ) and other parasites are a plague to man. See Louse.

Estrus equi, of the south of Europe and Persia, is a dipterous insect. Its eggs are deposited on the hair of the horse, and licked into the stomach, and when complete, the insects pass through the canal.

Cephalremia ovis (syn. CEstrus ovis), of Europe and the E. Indies, lays its eggs in the nostrils of the sheep, and the worm from it occupies the frontal simuses, and gives rise to fatal diseases.

Weevils and their allies are in immense numbers, and many species are of extreme beauty, but occasion much loss by their attacks on the cereal grains.

The scarlet mite, Acarus telarius, called also red spider, envelopes the leaves of a plant in u delicately woven web, which so checks the respiration that the plant becomes dry and withered.

The insects in India which are the most destructive to living and dead vegetable substances belong to five families of Coleoptera, or beetles; to two families of Hemiptera, or bugs; to one of the Neuroptera, or lace wings; and to three of the Hymenoptera.

The larva of the Coleoptera are armed with formidable jaws for the manducation of the solid portions of wood upon which they feed.

The larvæ of the Buprestidæ, beetles of brilliant colours, after acquiring maturity, bore into the timber to the depth of two or three inches, and then undergo their metamorphosis. These beetles often render timber unfit for use. They have been found in the living Acacia catechu, the Vatica robusta, mango trees, and the Pinus longifolia. They commence underneath the bark.

The larvæ of a species of Buprestis was found by Mr. R. Thompson boring two or three inches into felled logs of sal (Vatica robusta), in the Kotree Doon. He found also another buprestis in the dead timber of a living Acacia catechu tree, and another in the trunk of a living mango tree. A small buprestis of a shining colour is frequently found in the timber of the Cheer pine, Pinus longifolia, quite destroying the logs. It is only in the bark that the females can deposit their eggs, the sapwood and newly-formed bark affording the larva nourishment; and to protect fellerl timber, the bark should be removed as soon as the tree is felled.

The stag-beetles, species of Lucanus, in Indir are numerous, and common as to individuals, and are, of the whole order of wood-beetles, the most destructive to living trees. Their larvæ live for three or four years in the interior of trunks of oak, and about Naini Tal barely one in ten of the trees escape their ravages. These and the larvæ of Prionus beetles seem exclusively to attach themselves there to the oak as their habitation. They bore to the heart of the stem, in winding passages. In felled logs they are easily killed by immersing the logs in water, or by pouring boiling water into the apertures.

The Lucanus cervus males often fight for the possession of the female. 'Their mandibles are prolonged into long horns. Two males will approach, and, entwining their mandibles, try to lift each other off their feet. Accomplishing this, the victor carries off the conquered to a distance of several feet, and then returns to the female.

Male stag-beetles have been found feeding on the renewed bark (after shaving) of Cinchona succirubra trees, in Maskeliya, Ceylon. The female has much shorter mandibles, and is said to use them in forming a hole in the trunks of trees for the reception of its eggs. Westwood says (i. p. 187) the perfect insect feeds on the honey-dew upon the leaves of the oak; they also feed upon the sap exuding from the wounds of trees, which they lap up with their finely-ciliated maxillæ and lower lip. It has been supposed that the larva of this insect, which chiefly hides in the willow and oak, remaining in that state several years, is the animal so much esteemed by the Romans as a delicacy, and naned cossus. The injury which it causes is often very considerable, boring not only into the solid wood, but also into the roots of the tree. The stag-beetle received from Maskeliya was a male with immense mandibles, and greatly resembled Lucanus cervus, the common stag-beetle of Europe.

The Euchirus beetles, species of the Lamellicornes, are said to have habits similar to their congener the stag-beetle, Lucanus cervus.

Euchirus longimanus, the long-armed chafer of Amboyna, drinks the sap of the sugar-palms. It is a sluggish insect. 
The Xylophagi, xylophagous beetles or woodeaters, Bostrichus, Tomicus, and species of Hylesinus, called Ghoon or Ghūn by the natives of $\mathrm{N}$. India, live inside wood even in their perfect state, and the timber attacked by them becomes perfectly unsound. The Tomicus monographus is a minute cylindrical beetle of Northern Europe, of a very destructive character to felled oaks. An allied Indian species (Tomicus perforans) bores through the staves of beer and water casks. In 1860-62, it attacked the beer barrels of the Commissariat Department in Lower Bengal and Burma, and caused great loss. A witty subaltern styled it Tippling Tommy. Mr. Thompson has known, in Dehra Doon, a species of Hylesinus attack and so entirely eat the poles and rafters of houses, made of the sal tree, as to cause the roofs of the buildings to fall in; and a similar occurrence in a building in the hills, in which the Cheer or Pinus longifolia was used. The insect in this case resembled the Hylesinus piniperda of European forests, one species of which attacks the elm trees around London. The insects called ghoon in Northern India are omnivorous, eat bamboos, dried drugs, cheroots, pasteboard, books, and even furniture made of the lighter woods. The Calandra granaria is one to which the term ghoon is applied. The species of Botrichus affect chiefly the dead wood of forest trees. They are the largest of the Xylophagi. Other genera, as Scolytus, Hylesinus, and Tomicus, are smaller but more numerous. The Tomici are very destructive to bamboos, which the Hylesini also attack. The powdery excrementitious particles which their larvæ throw out, make their presence known. The injury to the coffee plants, in Ceylon and the Peninsula, from species of Xylotrechus, has been often ruinous. $\mathrm{X}$. quadripes, Chevrolat, is the most destructive, and whole estates in Coorg have been ruined by it. It is popularly called the worm or coffee-fly. Under the word 'Coffee' are given the known enemies to that plant.

Cerosterna gladiator, a longicorn beetle, eats the bark of the Casuarina trees, and has caused heavy losses to their planters. Cocoanut trees have great enemies in the shape of two beetles. One of these is a large Curculio (Rhynchophorus, Sach.), called the red beetle, nearly as big as the stag-beetle of Britain; the other is the Oryctes rhinoceros, so called from its projecting horn. The red beetle is so called from the red mark on the upper part of its breast. Its attacks are said to be on the nut, but those of the rbinoceros beetle are on the terminal bud of the palm stem. When so injured, the bud dies, and, the crown of the leaves falling off, leaves the cocoanut tree a mere bare stem. The same result occurs to other palms, the palmyra, the betel, in which the top bud or cabbage, as it is called, is destroyed.

Batocera rubus, the Curuminga beetle of Ceylon and S. India, penetrates the trunk of young cocoanut trees near the ground, and deposits its eggs near the centre. The grubs, when hatched, eat their way up through the centre to the top, where they pierce the young leaf-buds, and destroy the trees.

Sphænophorus planipennis, a weevil of Ceylon, is destructive to cocoanut trees.

Dr. Mason mentions that he found the young leaves of a Lagerstræmia Indica half devoured every morning, yet could not discover a single insect throughout the day; but, on visiting it at night with a light, he found dozens of a small cockchafer beetle, species of Melolonthidæ, eating with great avidity.

The many dialects of Hindi, and the languages and dialects of the Dravidian and Kolarian branches of the Turanian, offer a great obstacle to any attempt to trace through their vernacular names the injurious insects of British India, but some of them may be named. The sursuri of Hindustan is bred in grain, the ghoon is destructive to wood and grain, and the rig is a bird-louse.

Mr. Wright mentions that in the district of Cawnpur, a spider, known as the Agia or Makari, attacks the bud of the Sorghum vulgare before the flower forms, and no grain follows; he says it is chiefly due to want of rain. In the month Bhadon, the pith of the stem is attacked by the thuntha, also due to want of rain, and in drought the lassi attacks it.

The Bangka, also called Katua in Hindustan, is a water-beetle which eats rice plants. It is said to take a leaf for a boat and to paddle itself from stalk to stalk. It is barmless when the water is let off from the field.

The larva of the Heliocopis cupido attacks the cotton plant in its bud.

The larva of the weevil Deprescaria gossipiella, the toka of the natives of Hindustan, attacks the cotton seeds in harvest.

The larva of Heliocopis cupido is dispersed by sprinkling ashes over the plant. That of the Deprescaria gossipiella can be checked before storing.

As the rainy season approaches, the Bhüngo, a hairy caterpillar, preys on the stem leaves. The myna eats and the starling (tilie) destroys multitudes of these insects.

The t'hela disease is caused by a viviparous wingless parasite, the Aphis lanigera, with a flaskshaped body, six feet, two antennæ, two tubes at abdominal extremity, a haustellum for puncturing, and a sucker for extracting, and within this transparent sucker a perfect apparatus resembling a hand-pump; the sucker is fixed, the miniature piston plays, and the sap-the life-blood of the plant-is absorbed, and its leaves are destroyed.

The oily (t'hela) honey-dew on the leaves is greedily eaten by the red and brown ants, Formica rufa and F. fusca; and should the exudation be scanty, the ants, with their antennæ, stroke and fondle the aphis until a supply be secreted. Both sexes only exist in August, and one congress yields the young for six generations. After pairing, the female deposits eggs, which in four days animate. Immediately from every pore in their bodies springs a cottony substance, which covers and protects them, and they eat the leaf. As they grow their white cover vanishes, and pale-orange, wingless insects appear, the Koongnee of the Jats.

The Aphis lanigera does not attack cotton plants growing near hemp. They are destroyed by the lady-bird (Coccinella) and by the lace-wing (Chyrosopus).

The cucumber family of plants is largely preyed upon by a twelve-spotted beetle like a lady-bird, which, alike in the grub and the perfect state, feeds on the leaves and flower-buds.

Some of the Hylesini bore to the centre of the felled Cheer (Pinus longifolia) to the depth of a foot, attacking in vast numbers, but only if the 
bark be left on. Ghoon of Hindustan secms a generic term for all beetle-like insects which attack timber, grains, etc. Timber and bamboo traders destroy the timber ghoon by depriving them of air, by immersing the affected articles in water for a few weeks. They are also killed by being buried. Tar or paint have no effect on them. The Hylesini are the genus Apate of Fabricius.

The genera Tomicus and Bostrichus are largely distributed over all India.

A Burna species of the Bostrichidæ, with its larvæ, is exceedingly destructive to bamboos. In the course of one rain they will sometimes utterly destroy a dwelling the bamboos of which had been felled in the preceding dry season, while bamboos felled at the close of the rains remained unharmed.

Saw-flies, Tenthredo, and their pseudo-caterpillars, never attack wood. They do comparatively little damage.

The longicomes are a highly-diversified family of beetles. They attack dead vegetable matter. A remarkable larva, thought to be one of the Prionii, was found in the stem of the tea plant in Northern India. The mother beetle punctured the main stem of the plant near the ground, and inserted the egg, and the larva, when hatched, bored into the pith of the stem, and then bored down and up, destroying the plant. Mr. Thompson offers no suggestion how to destroy them.

The beetle Cerambyx vatica, Thompson, attacks the sal or Vatica robusta when felled. These insects grow to a great size, but never attack the tree when its bark has been removed. This and the little buprestis are the only beetles which attack the Vatica robusta. The larvæ, soft-bodied grubs, of the Cerambycidæ and Buprestidæ can easily be destroyed by pouring scalding water into their holes, or by immersing the logs in water for a couple of days. Hot winds which dry the timber, and also much rain, kill them. In their larva state these insects are open to the attacks of both the parasitical ichneumons and acari, the larvæ of which feed upon the young grubs. Toon (Cedrela toona) and sissoo (Dalbergia sissoo) are both attacked by a larger and more powerful Cerambyx than that found on the Vatica robusta.

Rottlera tinctoria, the rewneah of Northern India, is constantly attacked by another Cerambyx, the larva of which is over four inches in length, and as thick as a man's thumb.

'The larvæ of the capricorn beetles are called, in Hindi, Mukora. There are four kinds of Mukora recognised in Northern Iudia, and they attack the Vatica robusta and the pine.

A minute species of the Cerambyx attacks the living bark of the Acacia catechu, and their presence may always be detected by the gummy exudation which their presence within the tree occasions. Cerambyx vatica, or sal-grub, burrows in the wood of that tree, and is sought for by the woodpeckers.

A small species of Leptura, in Northern India, attacks the harder woods. They have been found in the wood of the goug-creeper, a species of Robinia.

Species of Saperda also occur in the northern forests of India.

Monochamus soongna, Thompson, is one of the
Cerambycidx. It is a magnificent bcetle, and its larva is very destructive to the Bombax heptaphyllum (or seemul), also the Soongna or Moringa pterygosperma, and the roongra or Erythrina suberosa. Its larva is very large, and armed with powerful mandibles.

Another Monochamus beetle enters the trunk of the Salix tetrasperma, and bores it in all directions.

A Monochamus attacks the Butea frondosa. Leptura has been found on the Robinia macrophylla, Vatica robusta, the bamboo, and species of Dalbergia.

Pupæ of another Monochamus beetle were discovered underneath the bark of the Butea frondosa, and in logs of the Odina wodier and Bombax heptaphyllum. They were found in solid cocoons made of a substance resembling lime. The shell was fully one-sixteenth of an inch in thickness, quite hard and firm.

Hemiptera are exemplified in the common house bug and all the aphides or plant lice.

Hemipterous insects do not undergo a complete metamorphosis. After being hatched from eggs laid by the parent insect, the larvæ and pupæ remain much alike. Their fecundity is enormous. In the Kamaon forests a large and magnificent red bug, two inches long, has been observed sucking the stones of the Cordia myxa. By piercing the soft stems of young plants, they cause thousands to perish in a single day.

A green bug of Burma, one of the Tingidæ, is very injurious to fruit. They suck the juice of oranges through the skin. The paddy bug of Burma sucks the paddy before the kernel has become hard. It is a species of Cimex, or one of the Scutelleridæ, and whole fields of rice are sometimes abandoned in consequence of the devastation it commits.

Some bugs are beautifully and brilliantly coloured, but bugs, both field and house, emit usually a disagreeable odour.

The Aphides, or plant lice, when in large numbers, injure young shoots and twigs. A very pretty little one is found in Kamaon on the dabree tree. They excrete a white substance of a sweet taste, which cakes on the leaves. Another aphis is found on the sal or Vatica robusta.

Aphis Coffer, the coffee louse, is found in small communities on the young shoots, and on the underside of the leaves of the cocoanut tree, but occasion little injury.

Neuropterous insects, like the dragon-flies, are carnivorous or herbivorous. The fecundity of the white ant is enormous, and they have males, females, and neuters. They will not touch fresh Huldu timber, but, on drying, the wood will be attacked.

Hymenopterous insects are exemplified in the bees, wasps, black ants, and flies. Many live in societies, and are divided into three classes,-males, females, and neuters. Of their larva, some are carnivorous, some herbivorous; the perfect insects, however, live chiefly upon flowers and honey. A few are carnivorous and omnivorous, as, for example, black ants.

The Xylocopa, or carpenter bees, bore tunnels in timber, where they gather in honey and the farina of flowers, leaving a lump of this compound in a divided cell for the nourishment of the young larvæ, sub-cylindrical, whitish worms, when they are 
hatched. Each cell has, with the egg, a separate supply of this food. In the Kamaon forests there are three species of $\mathbf{X y l o c o p a , -} \mathbf{X}$. purpurea, Xylocopa ficea, Thompson, and a species found on the Nauclea cordifolia. This geuus lives in colonies. They will not attack wood smeared over with tar, and will leave their habitations if it be applied to the canals.

Of the weevil family, the Rhynchophora, the genera Bruchus, Calaudra, Curculio, and Rhynconus are extremely injurious to vegetables, boring into the young stems of plants, and living upon their juices. The Curculio also injure felled timber by boring into it. One species or variety of Curculio, one inch in diameter, was found by Mr. Thompson several inches deep in a log of the Butea frondosa. His observations satisfied him that these were bred in the wood. A Burma species of Curculio makes great harock among the mangoes.

The ravages of some of the smaller weevils, Bruchus and Rhynchites, are highly detrimental to the productiveness of the northern forests of India. In 1863, entire seed crops of the Vatica robusta were destroyed. This family insert their eggs into the stigma of the flower, and the young larva becomes developed in the fruit or pericarp, and the fruit ultimately falls. The common gram beetle is a good illustration of the genus Bruchus. The species of this genus attack most leguminous seed-pods, peas, beans, gram, etc.

Brarrah, a wood-louse in Swat, which infests mosques and houses where old mats are lying about; the place bitten by them becomes red and inflaned. The insect is of the shape of a bug, but larger.-Lt.-Col. MacGregor.

Two species of the genus Bruchus attack the poppy seed when stored.

A longish weevil, seemingly a species of Lixus, one of the divisions into which the Longirostres have been made, was constantly found by Mr. Thompson under the bark of felled logs. It bores with facility through the softer parts of wood.

Calandra granaria is known to the people as the Ghoon, also the Ch'heda and Makora; it is a weevil very destructive to grain. Ghoon and Ghoongi in Hindustan seem to be applied as names to several insects destructive to grain and wood.

The enemies of the coffee plant are numerous, and notices of most of them will be found under the word 'Coffee.'

Mr. Haldane, in a pamphlet entitled 'All about Grubs,' mentions several beetles which injure coffee trees. The most important is the Big Patna cockchafer (Lepidista pinguis, Burm.). The female of this beetle is nearly white; the male is brown, and was named Melolontha rubiginosa by Mr. F. Walker. Another smaller brown species of chafer mentioned by Mr. Haldane is Ancylonycha pinguis, Walker. A third species, pale green with yellow margins, is Mimela xanthorhina, Hope.

Lecanium coffer, a genus of the order Hemiptera, appears on the young shoots and buds, like small, wart-like bodies. Each of these warts is a transformed female containing about $700 \mathrm{eggs}$, which are hatched within it. When the young ones come out of their nest, they may be observed running about and looking like wood-lice. Shortly after being hatched, the males seek the undersides of the leaves, while the females prefer the young shoots as their place of abode. The larvæ of the males undergo transformation in pupa beneath their own skins; their wings are horizontal, and their possessing wings may probably explain the fact of the comparatively rare presence of the male on the bushes. The female retaius her power of locomotion until nearly her full size, and it is about this time that her impregnation takes place. Each tree on which this bug makes its appearance should be well dusted with a mixture of pounded saltpetre and quicklime in equal parts; by sponging the parts affected with a mixture of soft soap, tar, tobacco, and turpentine. Another species of Lecanium, in another country, put a stop to the cultivation of the orange as an article of commerce. - Tennent's C'eylon, pp. 4,46 .

The coffee tree is supposed to have been brought to Ceylon about the middle of the 17th century. The first regularly worked estate was opened in 1825 ; but the bug does not seem to have appeared in large quantities till 1845 , when, however, it began to spread with such rapidity that in 1847 a very general alarm was taken by the planters, about the same time that the potato, wine, and olive diseases began to create alarm in Europe. The coffee bug seems, however, to be indigenous in Ceylon, for the white bug has been found in orange, guava, and other trees, as also on beetroot and other vegetables; and the brown bug attacks the guava, hibiscus, Ixora, Justicia, and orange trees,-indeed, every plant and tree and even the weeds on a coffee estate, particularly such as are in gardens.

Heliothis armigera is an insect of the family Noctuidæ, which, in the seasons $1877-78$, in innumerable hordes attacked the coffee crops of Shahabad and Patna. It is equally destructive to the cotton crops. It eats into the capsules of the coffee and cotton. The pupæ become entrapped in the capsules. Its attacks on the coffee plant are principally in February and March. Careful band-picking is the sole remedy.

Heliocopis cupido or Deprescaria gossypium attacks the cotton plant; it is the Toka of Hindustan.

The larva of the Gracillaria coffeifoliella mines the coffee trees. It is very common.

Hemileia vastatrix, the coffee leaf disease, or leaf fungus, has for several years seriously affected the coffee trees of the island of Ceylon. Though requiring careful inspection for its detection, it was present upon all the coffee trees examined about 1879. With the help of the microscope, it is found at all times to prevade the greater part of the stems and older leaves, in the form of very fine branching filaments, its effects being apparent in numerous somewhat trauslucent spots, which may be observed when holding one of the older leaves against the light. The direct injury so caused to the coffee tree is, however, very slight, as compared with the effect produced when the fungus attacks the young leaves, causing them to fall prematurely. The presence of the fungusfilaments in such abundance on the outer surface of the tree is quite sufficient to account for phenomena which it was first thought must be attributable to a poisoning of the juices of the tree, 
by an absorption of the fungus matter through its roots. The latter idea must therefore be given up, and the disease considered as external, except when it appears within the tissue of the young leaves. Subsequently, from these enclosed masses of filaments short branches are produced, which emerge from the pores, and bear the conspicuous orange-coloured spores or reproductive bodies. Some of these spores have been observed to germinate on the outside of the leaf, producing branched filaments of exceeding tenuity, which grow with marvellous rapidity all over the surface of the leaf, and beyond to the stems. The ends of some of these filaments, too, have been observed to enter the pores of the leaf, to form fresh disease spots and fresh crops of spores. The true Liberian coffee is said to be of bardy habit, and more able to resist the ravages of this disease.

The caterpillars found on the coffee trees of Ceylon are Orgyia Ceylanica, Euproctis virguncula, Trichia exigua, Narosa conspersa, Limacodes graciosa, and a species of Drepana, but they do not cause much injury. One caterpillar, however, the Zeuzera coffer, destroys many trees, both young and old, by eating out the heart. It resembles the caterpillar of the great moth of England, and is as thick as a goose quill. It generally enters the tree 6 to 12 inches from the ground and makes its way upwards. The sickly drooping of the tree marks its presence. Caterpillars of the Boarmia leucostigmaria and B. Ceylanica, also those of Eupithecia coffearia, are found on coffee and other trees in Ceylon from September to December. Some Ceylon caterpillars sting. A greenish one, that occupies the Thespesia populnea (Suriya, Singh.), at a certain stage of its growth, descends by a silken thread, and hurries away. The moth of this is supposed to be a Bombyx, named Cnethocampa, Stephens. Another, short, broad, and pale-green, with fleshy spines, that feerls on the Carissa jasminiflora, and stings with fury, is of the moth Neora lepida, Cramer (the Limacodes graciosa, West.). The larvæ of the genus Adolia are hairy, and sting with virulence. Many exactly resemble in tint the leaves they feed upon, others are like little brown twigs, and many are so strangely marked or humped, that when motionless they can hardly be taken to be living creatures at all.-Tennent's Ceylon. See Larva.

Bakoli is a small green caterpillar that destroys rice crops.

Many caterpillars avoid cabbages if dill be grown in their beds, others keep aloof from gooseberry bushes if broad beans be grown near, and the use of pyrethrum is said to protect vines from the Phylloxera; and other insects aroid places sown with hemp.

White ants and crickets are the inveterate enemies of the tea plant. Whole acres of young plants have been known to be destroyed by these destructive insects. It has therefore been considered advisable to fire, instead of fell, jungle required to be reclaimed for the purpose of teaplanting.

A beetle, supposed to be one of the Melolonthidæ, about the middle of the 19 th century infested the tea plantations in the Dehra Doon. Ten or twenty of them lay concealed two or three inches deep in the earth beneath the bush, and emerged at night to feed on the leares. The existence of the plantation was threatened. But a party of labourers was told off, each with a hoe, twice daily to dig around the plants, and the beetles were seized and destroyed by boiling water. Bushels of beetles were gathered and destroyed, and the plantation freed from them.

The following insects injurious to the poppy and other crops were collected in the gardens at Deegah, Dinapore, and Bankapore :-

A. Attacking the young poppy plant in November and December, viz. :

Acheta campestris and A. domestica; also other species of Acheta.

Gryllus species, called in Hindi ghudya and phunga.

Gryllotalpa vulgaris, the goorghooria in Hindi.

\section{B. Attacking the maturing poppy in February and} March, viz. :

Heliothis armagera.

Noctua species.

Bombyx species, the Buro-bhooa

Gryllus species,

C. Attacking poppy seeds in granaries:

Tetranychus papaveræ, the poppy seed mite.

Tipula species.

Bruchus ",

Sitona ",

Calandra,"

D. Attacking cold weather or rabi crops :

Species of Aphis, Cassida or tortoise bettles, lady-birds ; Haltica, $s p$.; Coccinella, $s p_{.}$; Thyka eucharis; Locusta, $s p$.

Of these, it may be mentioned that the crickets, Acheta, A. campestris, A. domestica, and other species called the Jhengur or Jhanga of Hindustan, attack the poppy plants from November to January, until the stem begins to shoot. A large species of this genus attacks the Casuarina trees. It lodges at the foot of the tree, and at nightfall ascends the tree, and cuts off the young top shoots. The crickets are very destructive to garden and field crops.

The cranefly, a species of Tipula, is allied to a gnat. Its grub is a pest of the young poppy plant, both on and under the surface of the soil.

Bala, HrNo., is a grub which eats the young shoots of wheat or barley when about six inches high.

The Girwa or Girwi, HIND., an insect? which turns the grain crop of a brick-dust colour.

Gindar, HIND, an insect very destructive to growing crops of pulse.

Ecidium Thomsoni infests the fir tree Abies Smithiana.

About the year 1879-80, an insect in Monghir threatened to become very destructive to the rice crops. Mr. Wood Mason identified it as belonging to the genus Cecidomyia, and as related to the Hessian fly which ravaged the wheat fields in the United States. This genus, Mr. Wood Mason says, had never before been found in India, and he proposed to call the species Cecidomyia oryzæ, or the rice-fly. He considered it as likely to prove a most formidable pest, and recommended that the district officers should be instructed to make further inquiries, and carefully watch its progress.

The common rice weevil of India is the Sitophilys oryzæ. 
The Barar, HnND., is a disease? which attacks the rice crops.

Badhiya, Hind., is a disease? attacking growing sorghum, penicillaria, and zea, which prevents the ear filling.

A species of Cetonia is very destructive to roses and other flowers.

An insect, known as the nutmeg insect, attacks that nut, and to aroid it they are dried in the shells.

The stores of soldiers' coats were much damaged in India by a little beetle, Anthrenus vorax, Waterhouse.

The Honourable Mr. Morrison mentions (Compendious Summary) that eargoes of salt cod were brought to China from England, but only for two years, as it was found to breed an insect which bored through the ship's timbers.

The ravages of the Doorkhee or Durkhi insect are very destructive to the young indigo plant.

Gryllotalpa vulgaris is the mole cricket.

The Goorghoorgah or Goorghooriah, Hind., occurs in the temperate and tropical regions of the Old World; it is of nocturnal habits, and is a destructive creature to all vegetable products. In Dinapore and Bankapore it attacks the young poppy plant in November and December.

The most troublesome of the mosquitos on the coast of Ceylon is the Culex laniger.

Two species of Gryllus, called ghudya and phunga in Hindi, in Lower Bengal attack the young poppy plant in November and December.

Of the locusts which at intervals devastate some countries, the Acrydium (Gryllus) migratorium is that of Africa and the south of Asia, and G. gregarius that of Sinai. The migratory locust, Acrydium (or Kidipodium) migratorium, which occurs in Africa and the south of Asia, is greenish, with transparent elytra of a dirty grey, whitish wings, and pink legs. They have the power of inflating themselves with air, and of travelling about eighteen miles a day. They are bred in the deserts of Arabia and Tartary. Cajaput oil protects books.

Insects are easily killed by kerosine emulsion. Pure kerosine, 1 gallon; condensed milk, $1 \frac{1}{2}$ pint; water, 3 pints. Mix the water and milk before adding the oil, and churn until the whole solidifies and forms a butter. In using it, difute the butter with from 12 to 16 times its weight of water, and then apply immediately. If allowed to stand, the butter separates and rises to the surface.Bengal As. Soc. Journ., No. xxxi. p. 426; Bennett; Buckland's Curiosities of Natural History, 1857; English Cyclopxdia ; Figuier, Insect Life; Hooker, Himalayan Journal; Mr. Hope in Madras Lit. Soc. Journ., 1840 ; Kirby and Spence; Huxley, Introduction to the Classification of Animals; O'Shaughnessy, Mat. Med.; Royle, Mat. Med.; Royle on the Productive Resources of India; Tennent's Sketches of the Natural History of Ceylon, pp. 442-446; Tennent's Ceylon; Thompson on Insects destructive to Woods and Forests; Wallace, Tropical Nature; Crawfurd's Dictionary; Ceylon Observer.

INSESSORES, an order of birds, known also as the Perchers, very numerous in India. They form the great bulk of the feathered creation, nearly three-fourths of all known birds belonging to this order, in the tribes dentirostres, conirostres, tenuirostres, fissirostres, and scansores,swallows, martins, swifts, night-jars, bee-eaters, rollers, kingfishers, wagtails, some of the pipits and larks, stonechats, several warblers, and the thrushes.

INULA CHINENSIS. Smith. Sinen-fuh-hwa, CHIN. Grown in China since the 6th century. It has a beautiful, golden - yellow, composite flower. I. Royleana grows in the Kashmir Hills; but the plant is considered poisonous, and is not used.-Honigberger, p. 290 ; Smith, Mat. Med. Chin.

INUNDATIONS are of frequent occurrence in India from rainfalls and from storm-waves, and have been noticed under the headings 'Floods' and 'Cyclones.' The most calamitous have been from storm-waves striking the Coromandel coast and the islands at the delta of the Ganges. The cyclones have been examined by Colonel Capper of Madras, Mr. Redfield of the United States, Professor Dove, Lieutenant-Colonel Reid, Mr. Piddington of Calcutta, who suggested the term cyclone; also by Mr. Espy of Philadelphia, and by Messrs. Meldrum, Blanford, Wilson, and Elliot. Those of the Laccadive Islands, in a hurricane of April 1847, were described by Captain Biden in Madras Spectator, 1st, and Bombay Times, 4th October 1817, and in the Bombay Times, 13th August 1850. An account of remarkable inundations in India in 1849 was given by Dr. Buist in Bl. As. Trans., 1851, and Edin. Phil. Jl., 1851; and inundations of the Brahmaputra in Assam were described by Dr. $\mathrm{M}^{6} \mathrm{C}$ Cosh in Topography of 1837 . Inundations occurred of the Ganges on 21st August 1838, when it rose at Allababad 43 feet, and did immense damage at Benares. Hoshangabad was on the same occasion flooded by the rise of the Nerbadda. One of the Indus, in 1841, supposed to have been occasioned by the bursting of a glacier, was described in Bl. As. Trans., 1848, xviii. Those of the Tapti, for the past thirty years, were described in Bombay Times, 1851. Inundations at the mouth of the Ganges, occasioned by hurricanes, occurred in May 1823 and May 1830, Bl. As. Trans. i. p. 25 ; and the great storm-wave which struck the coast at the estuary of the Megna at 3 A.M. of the 1st Novenber, in which 215,000 persons perished, was described by Mr. J. Elliot.

INVOCATION. The eastern Christians commence their writings with the words, 'In the name of the Father, the Son, and of the Holy Ghost;' the Jews, 'In the name of the Great God;' the Arabs, 'In the name of God, the Compassionate, the Merciful.' The Muhammadans in India, in all letters or memoranda, place the Alif letter, for Allah, God, at the top of the first page of their writings. Hindus invoke the deity Ganesh under the title of Sri. The Persian magi used to begin with 'In the name of the Most Merciful, Just God.'-Lane's Koran, p. 86.

IODINE-Iode, Fr., Iod, Ger., from "wòns, violet, the colour of its vapour-was obtained by M. Courtois in 1812 in the residual liquor of the process for obtaining soda from kelp. It is found in sea and several mineral waters, and in sponge, corals, some molluscous animals, and amongst the seaweeds in Fucus vesiculosus, Linn., F, nodosus, 
Linn., and others. The leaf of a seaweed (a species of Laminaria, Dr. Falconer) employed in the Himalaya is called goitre-leuf, gulur-ka-patta. In S. America, the stems of a seaweed are sold by the name of goitre-sticks, because they are chewed by the inhabitants wherever goitre is prevalent. Iodine could be procured by burning large quantities of seaweed, or of the conferva of the salt-water lake near Calcutta; but the process is only economical where the weeds yield enough of impure carbonate of soda to cover the general expense of this operation.-Beng. Phar.

IONIA. This name occurs in ancient Sanskrit writings, and is supposed to refer to the Bactrian Greeks. See Javan; Kābul; Veda.

IONIDIUM SUFFRUTICOSUM. $W$. and $A$. Viola suffruticosa, Roxb., Linn.

Nunbora, . . Beng. Nela kobbari, . TrL. Ruttun puruss, Duk. Purusha ratnam, " Urela-tamara, MAL., TAM. Surya kanti chettu, ," Charati, . SANSK.

A rugged and somewhat prickly reclining herb, having a small crimson flower. It is common over the Peninsula of India, and is used as a demulcent.

\section{IPECACUANHA.}

Amerikanische brechGer. Raiz de Oro, . . SP.

Cephaelis ipecacuanha, a herb indigenous in the shady forests of E. Brazil, southwards to San Paulo. The root (rhizome) affords the valuable emetic medicine.

IPOMCEA, a genus of plants of the natural family Convolvulaceæ. The species and varieties in India are about fifty, pretty creepers flowering in the morning. In China, many beautiful species are cultivated. Dr. Honigberger received the seeds of I. dasysperma from Hindustan as an antidote to hydrophobia. It is called Kut'te-kibinj, i.e. the seeds for dogs. In October, as soon as the rains close, I. pileata, a pretty little twining species, is seen blushing through every hedge and bush in Tenasserim. It is peculiar for its concave bonnet-shaped involucre, in the midst of which half-a-dozen tiny blossoms hide their rosy lips. I. reniformis, Perretay-keeray, TAM., is a perennial creeper with yellow flowers; the leaves used as greens mixed with tamarind; very common during the cold months. I. sepiaria, Thalee-keeray, TAM., is a climbing perennial plant with rose-coloured flowers, found in hedges ; the leaves are eaten mixed with others as greens. I. sessiliflora, Roth., Bhanwar, HiND., occurs sparingly in the Panjab plains, up to the western frontier. It is eaten in India in famines. I. triloba grows both wild and planted in Japan. The roots are either white or black; the latter are used as laxatives. - Honigberger, p. 291 ; Mason; Jaffrey; Stewart; Thunb. Tr. iii. p. 63.

IPOMCEA PES-CAPRAE. Sweet.

I. maritima, $R . B r$.

I. orbicularis, $E l l$.

I. carnosa, $R . B r$.

I. Brasiliensis, Meyer.

I. biloba, $F_{0} * s k$ :

Chagul khuri, . BENG.

Convolvulus pes-capræ, Linn.

C. maritimus, Desr.

C. bilobatus, Roxb., $R h$.

C. bauhiniæfolius, Salisb.

Goat's-foot a BENG. | Beda tige, . . TEL Do-patte-luta, . HIND. Chevulla pilli tige, "

This is a useful sand-binding plant on the shores of the south and east of Asia, and has the widest range, trailing over the sandy beaches along the coasts of India, and from Hainan to the Chusan Archipelago.-Williams' Middle Kingdom. IPOMGEA PES-TIGRIDIS. Linn.

Tiger's-foot ipomcea, ENa. Pora batul, . . . Hinn. Kunra, . . . HIND. Mekamu adugu, . TEL.

In Tenasserim, the tiger-footed ipomoa, with large palmated leaves, is not uncommon; very common in the rains everywhere in Rajputana.

IPOMAEA REPTANS. Poir.

Ganthian, . . Hind. | Vari, Nali, . . TAM. Vellay-keeray, : TAM. Tota-kura, : : TEL.

A creeping annual with rose-coloured flowers, found about the borders of tanks and moist places. The leaves are used as greens, and in some places its root also appears to be eaten.-Jaffrey.

IPOMCEA TUBEROSA, Linn., the Malabar creeper, a native of tropical America, is a climbing plant with a woody stem; leaves palmated, seven parted. Flowers yellow and showy, appear in October and November. It is in general use for covering old walls, trellises, etc.-Riddell.

IPOMCEA TURPETHUM. R. $B r$. Turbeth. Convolvulus turpethum, Linn.

Hud-ul-zangi, . ARAB. Chita-bansa of . PANJ. Teori, Dud kalmi, Beng. Trivurta, - SANsk. Nag-putta, Turbad, HiND. Trasta-walu, : SINGH. Tarwai, Tirwi,. . " Shevadi, . . . TAM. Nasut, Niswut, : ", Tegada, : . : TEL.

A native of all the E. Indies, Archipelago, Australia, Polynesia, Tinian, etc. Its root is perennial, and has long been employed in India as a purgative, rubbing up a slip of the bark with water or milk on a stone, and swallowing the emulsion thus formed. A strip 6 inches in length from a root as thick as the little finger, is deemed a sufficient dose. The action of the medicine is extremely uncertain. It is considered beneficial in diseases of the mucous membrane, in leprosy, and paralysis. It contains a purgative resin resembling that of jalap.-O'Sh.; Steu. ; Powell.

IRAK, a geographical term for part of Persia and part of Arabia, the Irak-i-Ajami and Iraki-Arabi. The Euphrates and the Tigris have a generally parallel course. At Baghdad they approach most closely before uniting, not far above the outlet in the Persian Gulf, giving the included land the shape of an hour-glass. This included land is the Mesopotamia of the ancients; the northern half being now known to the Arabs as Al Jazirah or the island, and the soutbern as Irak Arabi, to distinguish it from the neighbouring Persian territory, the Irak Ajami, the ancient Media.

IRAN, a region to the south-east of the Caspian Sea, which extends for 1280 miles from Sumeisat on the Upper Euphrates eastward to Taxila on the Indus, and nearly 900 miles in breadth from the shores of Gedrosia, in lat. $25^{\circ}$ $\mathrm{N}$, to the banks of the Oxus near Samarcand, in lat. $40^{\circ} \mathrm{N}$. The latter river and the Caspian Sea form the northern limit of this great division; the Persian Gulf is on the southern, whilst the rivers Indus and Eupbrates constitute the eastern and western extremities. In this wide expanse of territory, stretching, with various elevation, at least $25^{\circ}$ from north to south, such extremes may be looked for as will bear out the remarkable description of the younger Cyrus. "In the dominions of my father,' said the prince, 'people perish with cold at the one extremity, whilst they are suffocated with heat at the other' (Xenophon's 
Anabasis, Book i. pp. 67, 68, Ed. Hutch, 1735). Thus the northern and central portions of the plateau of Iran and Arabia, as well as a great part of Asia Minor, enjoy a temperate climate, whilst an intense cold occurs in the northern parts of Afghanistan, in nearly the whole of Kurdistan, and on the elevated mountain ranges and high valleys on both sides of Ararat. Yet, notwithstanding this difference of climate, throughout the whole a great similarity prevails in the vegetable and animal worlds. The surface of Iran nay, in a general way, be described as consisting of a wide-spreading plateau, flanked by mountainous countries on the east and west, and bounded to the north and south by two mountain chains, outside of which are two extensive plains on a much lower level. Of these, Turkomania, with the continuous plain westward of it, between the Caspian Sea and the Elburz mountains, form that which is on the northern extremity; Arabian Irak and Khuzistan, with the rest of the level tract outside the Zagros, form the plain at the southern extremity. In the space intervening between the great mourtain chains, the surface in most places is largely impregnated with salt and saltpetre, which prevail to some extent on the plains of Fars and the conterminous provinces of Irak and Kirman. Between Abushahr and Dalaki, crystallized sulpbate of lime is found; and a little westward, in Khuzistan, an abundant supply of sulphur; while rock-salt, alum, antimony, and orpiment, as well as mineral waters, are found in abundance in different states, also petroleum and naphtha. Iron is met with in Masandaran, Khorasan, and Bactria, and, with copper and lead ores, more abundantly in the pashaliks of Diyar-Bekr and Sivas, with the addition of gold, silver, and precious stones. Copper and other ores abound in Kurdistan, the Julamerik, and other mountain districts. In the Dumbu Tagh mountains, the granite abounds with topaz, beryl, schorl, and disseminated gold. Extensive salt lakes and streams, impregnated with the same substance, occur. Amongst the former way be mentioned the Caspian Sea, the picturesque Urumiyah, and Van Zerrah or Durrah in Seistan, Bakhtegan in Fars, and others; the fresh-water lakes are only met with in the tracts below Babylon, and again between the Elburz range on the shores of the Caspian.

The language of modern Iran is laden with Arabic and Turkish words; but in the E. the language is much like that in which Ferdusi wrote his poem, free from words of Arabic origin.

There are four distinct kinds of horses in Iran: 1st, the original Turkoman breed, a large, powerful, enduring animal; $2 \mathrm{~d}$, the yaboo, or common carrying hack, which is stouter and rather larger than the galloway; then the smaller Arabian breed (first introduced by Nadir Shah); and lastly, a fourth, between the Arabian and the Turkoman horse, the badpai (wind-footed), which, being the most prized by the Persians, is almost always among the horses of a great man's retinue. Mules, though small, are much used for caravans. This animal seldom goes less than 30 miles in a day, though carrying a load of about $3 \mathrm{cwt}$., and passing over such kotals or passes as would appal even a Spanish muleteer. Perhaps one-third of the inhabitants of Iran are nomadic, and this section, by its habits as well as mode of life, constitutes a race "separate from the other or fixed portion, which consists of Persians, Kurds, Armenians, Arabs, Jews, and Parsees.

IRANIAN RACES, called also Indo-Atlantics, also Caucasians, have always been known for their refinement and high civilisation, from which Europe borrowed through the Byzantine and Greek culture, and the Persians have long and faithfully retained the features of its national characteristics. Though overrun by the Semitic and Turanian races, the Iranian has borrowed little or nothing from them, but has exerted over them a powerful influence. According to Khanikoff, Sur l'Ethnographie de la Perse, the Iranian race of Persia came from the E. of modern Persia, about Segestan and Khorasan, and moved to the W., in pre-historic ages, and though altered by the attacks of the Turko-Tartar tribes from the north, or, where in contact, on the W. and S., with Turanian and Semitic elements, the Mede is everywhere recognisable as the same as described by Herodotus and later Greek writers. The arrow-headed writing at Persepolis enumerates the Iranian people of that day.

The form of the Iranian is spare but elegant, even noble, but there have always been differences between the $\mathrm{E}$. and $\mathrm{W}$. Iranians.

The E. Iranians are- (a) the Segestani or Khafi, (b) Char Aimak, (c) Tajak and Sart; each of which counts many subdivisions.

The principal number of the Segestan people occupy Khaf and its neighbourhood, Ruy, Tebbes, and Birjan.

The people of Khorasan are greatly intermixed with Turko-Tartar elements.

The Char Aimak consists of four peoples, the Taimuri, Taimuni, Firoz Kohi, and Jamshidi, all of them of Iranian origin, and all speaking Persian. The Aimak, who graze their flocks in the Paropamisus, are brave and relentless, and Afghans, when travelling, whether proceeding from Balkh, Kābul, Kandahar, or Herat, never enter into the mountain districts of these intrepid nomade tribes. Each member of the Char Aimak knows no greater enemy than the Afghan, and all attempts to form Afghan colonies amongst them have failed.

The Taimuri dwell at Gorian and Kuh'sun, on the western boundary of Herat, and in the villages and towns situated E. of Iran, from Tarbat Shaikh Jam as far as Khaf. About a thousand of their families dwell near Herat.

The Taimuni dwell in the Jolgha-i-Herat, from Kerrukh to Sabzwar, the few who have extended to Farrah being styled by the Afghans Parsivan. The Taimuni are of a wild, warlike nature, though agricultural.

The Firoz Kohi, a small number of people, about 8000 , dwell on the steep hill N.E. of Kala-i-No, and from their inaccessible position aftlict their whole neighbourhood with their robbing and plundering. Kala-i-No, on the summit of the mountain, and the fortified places of Darz-i-Cutch and Chaksaran, are considered similar to the uests of the Bakhtiari and Luri in the environs of Isfahan. They have a resemblance to the Hazara, but their forehead, chin, complexion, and figure are less Turanian. They are decidedly Iranian. They take their name, the Firoz Kohi, after the city of that name, about 63 miles from Teheran. Timur settled them by force in Masandaran, but they soon returned to their own 
country. They have a few cattle, and they sow a little, and plunder the caravans travelling on the Maimani road, or make inroads on the scattered tents of the Jamshidi.

Jamshidi are the only tribe of E. Iranians who are exclusivsly nomades. They derive their descent from Jamshid, and moved out of Segestan to the shores of the Murghab, which they have occupied from pre-historic times. They live in the neighbourhood of the Salor and Sarik Turkoman, and they use the round conical tent of the Tartars, surrounding it with felt and a reed matting; and their clothing and food are Turkoman, as also is their occupation, for they are great man-stealers. They excel the other Aimak as horsemen, and for a chapao, band themselves with men of Herat or with the tribes of Turkomans. It was this cause that led Allah Kuli Khan to transport them from Khiva to the banks of the Oxus, after he had conquered them with the allied Sarik Turkoman. After a residence of 12 years, they fled, and returned to the town of Murghab. The Jamshidi are polite in word and manner. They still retain parts of the Zoroastrian faith, reverence fire, and pitch their tent door to the east.

The Tajak is Iranian. He is met with in largest number in the khanate of Bokhara and in Badakhshan, but many have settled in the towns of Khokand, Khiva, Chinese Tartary, and Afghanistan. The Tajak is of a good middle height, has a broad, powerful frame of bones, and especially wide shoulder bones; but they diverge from the Iranian; they have the Turanian wider forehead, thick cheeks, thick nose, and large mouth. The Tajak originally came from the sources of the Oxus in the steppe of Pamir. The term is from Taj, a crown, the fire-worshipper's head-dress. But the Tajak does not so style himself, and regards the term as derogatory. The Tajak is covetous, unwarlike, and given to agriculture and trade; fond of literary pursuits, and polished; and it is owing to their preponderance in Bokhara that that city was raised to the position of the headquarters of Central Asiatic civilisation, for there, from pre-Islamic times, they had continued their previous exertions in mental culture, and, notwithstanding the oppressions which they have sustained from a foreign power, have civilised their conquerors. Most of the celebrities in the field of religious knowledge and belles-lettres have been T'ajaks, and at the present day the most conspicuous of the Mullah and Ishan are Tajaks, and the chief men of the Bokhara and Khiva court are Tajak, or, as the Turks style the race, Sart. Vambery considers the Tajak and Sart identical, but he recognises that in their physiognomic peculiarities, the Sart differs greatly from the 'lajak, being more slender, with a larger face, and a bigher forehead; but these changes he attributes to frequent intermarriages between Sart men and Persian slaves.

In Central Asia, the warrior, the shepherd, the priest, and the laymen, youth and old age, equally affect poetry and reciting of tales. The literature of the Muhammadans or settled nations brought from the $S$. is filled with exotic metaphor and illustration. In the three khanates, the Mullahs and Ishans have written much on religious subjects, but its mystical allusions are beyond the reach of the people. The Uzbak, the Turkoman, and Kirghiz esteem music as their highest pleasure,

VOL. II.

and often break out in song, singing soft minor airs. The Uzbak poetry on religious subjects is exotic, derived from Persian or Arabic sources. The Tartar compositions are tales, and relate to heroic deeds, similar to the romances of Europe.

Mr. Farrar (p. 70) gives B.c. 2000 as the period of the Aryans leaving their common home, but in this he differs greatly from Chevalier Bunsen and other authorities. The E. Iranian race came down the valley of Indus and into India, and Central Hindustan or Central India became the Madhyadesa of the ancient Aryans - the middle region or Aryavarta, the Arya country; and a slokam in the Sanskrit work, the Amara Kosha, defines its ancient boundaries thus :

'Ariavartaha punia bhumi hi,

Mad'hiam Vindhya Himava yoho ;'

i.e. the Aryan country, the sacred land (lies) between the Vindhya and Himalaya; in this way indicating both the ruling race and the boundaries of the country held by them at the time that Amara Sinha wrote the Amara Kosha.

There would seem to have been two migrations into India of the Aryans, viz. the Earlier Aryans, the ancestors of the most ancient Hindus, a people acute, literary, skilled in arts, but not very warlike, and rather aristocratic than democratic in their institutions. The Later Aryans, a warlike people, probably once Scythians, democratic in their institutions, and rather energetic than refined and literary. The Aryans of India have caste and marriage laws, with strict rules of inheritance resulting from their sacred form of marriage, and subject to none of the caprices of Muhammadan and similar laws. Aryan is the private property in land, as distinguished from the tribal; the property first of the village, then of the family, then of the individual, and a consequence is the attachment of the Aryan to his native soil. Especially Aryan is the form of what we call constitutional, as opposed to patriarchal and arbitrary, government. The Indian village or commune is a constitutional government, common to all the Aryans; but there are two great classes of Indian Aryans, one with aristrocatic communes, and one with democratic, and recognising as equal all free citizens, to the exclusion of helots only. Among the non-Aryans the rule of the chiefs seems to be patriarchal and arbitrary. Property in the soil is tribal rather than individual. There is little local attachment to the soil.-Vambery's Sketches of Central Asia; Bunsen, Eyypt's Place in Universal History; Reverend Mr. Farrar; Dr. Pritchard, in the Report of the British Association. See Aryan; India.

IRAVAN or Ilavan. Malealan. A caste whose occupation is the extraction of palm wine or tari from palm trees.

IRAVATI, the same with the river Hydraotes or Ravi.-As. Res. ix. p. 53.

IRAWADI, the principal river of Burma and Pegu, rises in the S. slopes of the Patkoi mountains, -one branch in lat. $27^{\circ} 43^{\prime} \mathrm{N}$., long. $97^{\circ}$ $25^{\prime} \mathrm{E}$., and another in the same hills a few days' journey farther eastward. These two, known as the Myit-gyi or large river, and the Myit-nge or small river, respectively, unite to form the Irawadi in about lat. $26^{\circ} \mathrm{N}$. The springs are reported to be fed by large snow beds and a few glaciers. In I arch the river begins to rise, and gradually increases its volume till its waters are forty feet 
above their lowest level. They rapidly subside in October, when the rains cease and the N.E. monsoon begins.

It runs nearly $\mathrm{N}$. to $\mathrm{S}$. through Burma and Pegu, and discharges itself by nine different mouths into the Bay of Bengal, after a course of 1060 miles. It receives the Khyendwen, 470 miles; Shwely, 180 miles; and the Moo, 125 miles; and it drains 164,000 square miles. The chief tributaries of the Irawadi, in British territory, are the Ma-htun (or Meng-dun), the Ma-de, and Thai-lai-dan from the W.; and the Kyeni, Bhwotlay, and Na-weng from the E. Its tide is felt as far up as Henzada, and at Puzwondoung it rises $18 \frac{1}{2}$ feet at springs. The Bassein branch affords a passage for the largest ships for 60 miles from its mouth. No river of similar magnitude presents so few obstructions to navigation. Amongst the high mountains at its source the rainfall is considerable; at its centre, the fall of rain is comparatively small, but much rain falls at its delta. From the entrance of the Nam Yang downwards, the valley of the Nam Keng is generally very flat, and of some considerable width, and numerous marshy tracts appear on either side of the river. The average length of the Nam Kang, from the mouth of the Nam Yang down to its junction with the Irawadi at Katikyo Nainmo, including the numerous curves, amounts to 52 miles. From the entrance of the Nam Keng to Amarapura, the river has a real length of 269 miles; from Amarapura to the head of the delta at Sakkemun, 370 miles. The delta forms a triangle, nearly equilateral, with sides of 160 miles, the enclosed area consequently amounting to 9742 square miles. Towards Pegu and Sitan the Irawadi widens considerably, in consequence of the accession of the Pan-lan river, and its limits become less sharply defined. The valley of Hukum is stated to be 1000 feet above the level of the sea. The central branch of the Irawadi, at Manchi, in lat. $27^{\circ} 20^{\prime} \mathrm{N}$., where it was visited by Wilcox, has an elevation of 1800 feet, and runs over a pebbly bed. Its elevation at Bhamo, in lat. $24^{\circ}$, is estimated by the same authority to be about 500 feet. The valley of Manipur is drained by the most westerly tributary of the Irawadi, and it is separated from Cachar by a mountain range, which is 6000 or 8000 feet high, and is pine-clad towards the summit. The valley of Hukum or Hookoom was visited by Griffith; it is more open, but is surrounded on the $\mathrm{N}$. and $\mathrm{E}$. by mountains elevated 5000 and 6000 feet, and is traversed by numerous ranges of low hills. Griffith's own account of the Irawadi above Bhamo is, that it keeps up its magnificent character, as far as he went, to the mouth of the Mogoung river, where it is 900 to 1000 yards across, and he describes the appearance of its vast sheet of water as really grand. At the beginning of the first defile, about five miles above Bhamo, the river is about 1000 yards across, and its course is defined by low-wooded hills which run close to its banks. About two miles farther on, the channel narrows to 500 yards, and the hills become even closer and hang more abruptly over the stream than before, and about another mile beyond, a higher range of hills from the S.W. comes in behind the former one, and both terminate on the bank as two headlands. Upon the right bank of the Irawadi, the mountains opposite Than Yun Yova, in lat. $24^{\circ} 36^{\frac{1}{2}}{ }^{\prime} \mathrm{N}$., long. $96^{\circ} 31 \frac{1}{2}^{\prime}$ E., have an average height of from 6000 to 7000 feet. One of the highest, the summit of which is visible from the valley, reaches apparently 8000 feet. Westward of Let-pan Zin Yova, at a little distance from the right bank, lat. $24^{\circ} 27^{\prime} 2^{\prime \prime} \mathrm{N}$., long. $95^{\circ} 56^{\prime} 15^{\prime \prime} \mathrm{E}$., the summits of the mountains attain a height of 2000 feet. Heights of 800 and even 1000 feet are also numerous on the right bank of the river, only 20 to 23 miles N. of Shue-mut-thophya, lat. $23^{\circ} 4^{\prime}$ N., long. $96^{\circ} 15^{\prime} \mathrm{E}$.

The character of the whole river district, including the elevations not above from 3000 to 4000 feet, presents a thoroughly tropical appearance. The declivities of the hills, as well as the valley of the river, are covered with the wildest and most diversified vegetation, in the shape of dense tree and grass jungles.

The bore in this river is occasionally severe, but in the neighbouring Sitang river its fury is great, and occasions much loss of life. Burmans name thirty feet as the height to which it occasionally rises, and this may perhaps be the case in the bends of the river, where the rush has attained its full speed, before being deflected to the next bend. Even in the Hoogly, near the bend at Chandpal Ghat, the pointed curling wave may be seen several feet high. In the Irawadi and Mekong basins, there are remnants of tribes strongly distinguished from the predominant races, and tending, with the evidence of language, to show that the ethnic history of Ultra-India is very ancient, and has undergone repeated revolutions.

Its delta extends for $\mathbf{1 3 0}$ miles from Porian point to Rangoon river. Through its delta run nine principal branches, the names of which are, the Bassein or Negrais, the Thek-ngay-thoung, the Kyun-tun, the Peah-ma-lau, the Irawadi, the Dallah, the Pyapun, the China Buckeer or Tdoo, and the Rangoon rivers. Their mouths are fronted by extensive shoals, formed from the detritus brought down by the rivers. The amount of water which the Irawadi pours into the sea is about two-thirds that of the Ganges.

In the delta there is a maritime vegetation of mangroves, Sonneratia, Heritiera, Excoecaria, and other saline plants, just as in similar salt-marshes along the coast of the tropics. Irawadi is derived from Airavati, the elephant of Indra. - Schlagentweit, General Hypsometry of India, ii. p. 101; Oldham in Yule's Embassy; Hooker and Thomson's Flora Indica.

IRAWARA, in Mysore, the total produce, before division under the 'batai' tenure.

IRDHI, amongst the Buddbists of Ceylon, a state embracing ten supernatural powers.-Hardy.

IRIACEE, the Iridacer of Lindley, the iris tribe of plants. They are chiefly herbs, and are more remarkable for their beautiful fugitive flowers than for their utility. This order, however, contains the saffron (Crocus sativus) and the iris, more than one species of which affords the orris root of commerce. I. Florentina, Linn., grows around the Mediterranean Sea, and is one species furnishing the orris root of commerce. Many species are grown in Indian gardens. The rhizomes of the Tseh-lan of Hunan in China, and of other species, are eaten or added to the infused tea-leaves to flavour it.-Roxb. See Iris.

IRIARTEA, a genus of palms peculiar to the farests of S. America, and might be introduced 
into India with advantage. I. Exorrhiza, Mart., the Pashiuba or Pasciuba of Brazil, produces an edible fruit. Iriartea setigera, Mart., is fabricated into blow-pipes. I. Anticola, sp., is the wax-palm of the Andes and Brazil. Its former name was Ceroxylon. See Paims.

IRIS FLORENTINA. Linn. Florentine iris. Sosan, . . Arab., Heb. | Peh-chi, . . . Chin. Shoti of . . BEAs. | Orris root, : : ENG.

A native of Italy and Asia Minor, furnishes the orris root of European shops. It is a favourite ingredient in hair and tooth powder. Excellent orris root is procurable in the bazars under the name of Bekh-banafsha or violet root, but Royle under this head very confidently refers the putchuk of commerce to this article. A species of iris is cultivated in India, and its roots are used in the same manner as those of the Florentine kind. A broadish-leaved species occurs at various places throughout the Panjab Himalaya from 2500 to 9500 feet. Mr. Powell says the Iris Florentina is entirely distinct from the Kashmir variety, which luxuriates over every grave, and blooms on many a house-top in the far-famed valley, a custom resembling that of the ancient Greeks, who venerated the iris as the messenger between God and man.-Powell ; Winter; O'Sh. ; Stewart.

IRISH MOSS, or Carrageen moss, is the Chondrus crispus, Lngb., and C. mammillosus, Grev., of the W. of Ireland. It is used for cattlefeeding and for dietetic purposes.

IRON. W. of Armenia, on the borders of the Caspian Sea, we find the ancient name of Albania. The Armenians call the Albanians Aghovan, and as gh in Armenian stands for $r$ or 1 , it has been conjectured by Boie that in Aghovan also the name of Arya is contained. This seems doubtful. But in the valleys of the Caucasus we meet with an Aryan race speaking an Aryan language, the Os of Ossethi, and they call themselves Iron.Muller's Lectures, p. 230. See Elburz; Hindu.

IRON.

Mars of the Alchemists.

Hedeed,

Than,

\section{ARAB.}

Ferrum,

Basi, Besi,

LAT.

Tieh, Tee, .

BURM.

Ahan,

Malay.

Pers.

Jern CHIN.

Yzer, Jizer,

Aos-panah,

PoL.

$$
\text { DAN, SW. }
$$

DuT. Scheleso,

PUSHT.

Fer; . : : FR. Ayas, Hyam, : SANsK.

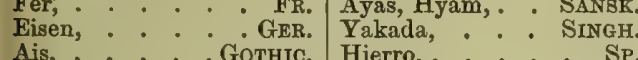

Ais,

Sideros,

Gотніс.

Gr.

HTR, Irmbu, .

Ferro, - . Ir, Por. Deymir, Timur, Turk.

Ferro, : : IT, Por, Deymir, Timur, 'TuRK.

Iron when found native is supposed to be generally of meteoric origin, but extensively in combination with oxygen or sulphur, as a salt of various acids, as carbonate, sulphate, etc., mixed with earths or other metals.

The iron of commerce is extracted from iron ores. Some of the oxides, as magnetic and specular iron-ore, are heated only with charcoal, as in Sweden, Russia, and the E. Indies, when the carbon combining with the oxygen the iron is set free and melted. The carbonate, iron pyrites, clay iron-ore, red and brown hæmatites, and spathose iron, are first roasted, and then exposed to a fierce heat in contact with charcoal, coke, or sunall coal, and a flux, either lime or clay, according as the ore is argillaceous or calcareous. These earthy matters become vitrified, and form a slag at the surface, while the heavy particles of iron, falling down, run out by a hole at the bottom into moulds, and form pig or cast iron. This is still impure, from the presence of charcoal, sulphur, and portions of silicon and aluminum. It is again twice fused in the refining and puddling furnaces, and exposed to the influence of a current of air at a high temperature, when the whole of the charcoal and sulphur are burnt out, and the other impurities form a slag at the surface. The metal is taken out, beaten or pressed, and then drawn into bars, which form the malleable or wrought iron of commerce.

Iron has long been known in India. From a passage in Kalidasa's drama of the Hero and the Nymph (p. 218), it is clear that the art of welding it was known to the early Hindus.

'You tell me, gentle Nymph, your fair friend pines

With amorous passion. But you do not see

The ardour that consumes this heart for her.

Alike our glowing flame. Then quickly aid

Our union to cement, as close combines

Iron with iron, when each fiery bar

With equal radiance glows.'

The iron-smelters of India are low caste, and humble, poor people. They have small clay furnaces, with charcoal for fuel, and the blast is caused by foot or hand bellows of sheep or goat skins, or even of leaves. The smelting process lasts from 6 to 10 hours, but at 3 or 4 separate charges, at the end of which time from 10 to 20 lbs. weight of iron is produced.

Iron-ores abound in almost every district of India, and the prevailing ore is the oxydulous iron, often magnetic, and with polarity; but specular iron-ore, hæmatite, clay iron-ore, and sulphuret of iron also occur abundantly. Many of the ores are noted for their singular purity, especially the magnetic oxides. Some are distinctly titaniferous, being in this respect similar to the Taranaki ironsand of New Zealand. But the bulk of the ores of Beypur, Salem, Palamcottah, Penatur, Puducottah, are rich magnetic oxides, and when freed from earthy matter, and ready for the blast furnace, contain about 72 per cent. of iron. They are found in mountain masses, and are obtained by quarrying with a crowbar. They are quite free from sulphur, arsenic, and phosphorus, and upon a large average have been found to yield 68 per cent. of metal in the blast furnace. The Punpara and.Honore ores were used for the production of steel by the Bessemer process.

The plan adopted for the production of Indian cast-steel at the Beypur works, by the Bessemer process, was similar to that pursued in Sweden, but differed essentially from the Sheffield method. At Sheffield and elsewhere in Great Britain, where the process was in operation, pig-iron was melted in a reverberatory furnace, and run thence into the converter or Bessemer vessel, which was mounted on axles. But in Sweden, and at the Beypur works in Madras, the crude metal was run direct from the blast furnace into an ordinary founder's ladle, raised to a sufficient height by means of a travelling crane, and then poured into the converter, which is a fixed vessel, lined with a mixture of native fireclay and sand and pulverized English firebrick. Steam was raised to about $50 \mathrm{lbs}$. in the boilers, giving a pressure of blast of about $6 \frac{1}{2}$ or $7 \mathrm{lbs}$. per square inch, and the air was driven into the converter through 11 tuyeres of $\frac{3}{4}$ inch diameter, placed horizontally at the bottom of the vessel. No manganese or other metal was added 
to temper the steel, the quality of the metal required being regulated by the pressure of blast and the time of blowing. As soon as the metal was sufficiently decarbonized, the vessel was tapped, and the fluid steel run into a ladle provided with an outlet in the bottom. This ladle was swung round over the cast-iron ingot moulds, the fireclay plug withdrawn, and the steel allowed to flow in a clear stream into the moulds beneath. These ingots were then cogged down under a Nasmyth hammer, and drawn into finished steel bars of various sizes.

The iron-ore of the Salem districts of the Madras Presidency is a rich magnetic oxide, very heavy and massive. The yield averages 60 per cent, of metallic iron. Much of the ore being a pure black magnetic oxide, would doubtless yield 73 per cent. The ore is, however, often mixed with quartz, which is a very refractory material in the blast furvace. Limestone, and in some places shell-lime, is employed as a flux; and the charcoal of some kind of acacia is the fuel. It occurs there in immense beds 50 to 100 feet thick, and its outcrop can be traced for miles. On one hill six miles from Salem are five bands of magnetic iron-ore from 20 to 50 feet thick.

Magnetic iron-ore of fine quality occurs in Coimbatore, Cuddapah, and Vellore; magnetic hæmatites and magnetic iron-sand also in Cuddapah, in the North Arcot district, in the Vellore taluk, at the villages of Pankam, Pulleputt, Anchenamput, Vannanthangal, Vennembutt, Catharercoopum, Vaniembaddy, Satghar, and Strevelliputur; and magnetic iron-ores occur in the Bellary, Masulipatam, and Mysore districts. Manganese was detected in the iron-ores of Hyderabad, Kurnool, Bellary, the Baba-Booden hills, Mysore, and Vizianagram. Ores of Hyderabad are magnetic. In the Salem district two varieties of iron are obtained, one remarkable for its softness and malleability, the other for its steel-like hardness, which adapts it for the formation of edge-tools, cold chisels, etc. The following names are given to this metal in process of adaptation to its finished manufacture:-Culties or blooms of iron, Palms or bars of iron, Vuttoms or pieces of cast-steel as it comes from the clay crucibles, Oollies or bars drawn out from the clay crucibles, iron beads which ooze out from the blooms in the blast furnace. Bloom iron from Palghat is readily malleable, and furnishes a hard steel-like iron. It is necessary to subject the bloom to a second fusion and much hammering before they can bring it to the state of the soft malleable iron in which it is met with as an article of commerce.

The iron-ores of Coimbatore are of very fine quality, particularly rich in the metal, and highly magnetic.

Dr. Heyne, describing the manufacture of iron in the Karnatic to the south of the Pennar river, says, when first smelted, it is extremely brittle, requiring several operations to bring it into a malleable state. There are two varieties of ore used in the district in which he observed the processes. The one, an iron-sand, collected in the beds of rivers, consists of the protoxide, mixed with much of the peroxide; the other, a red schist, is almost entirely composed of red oxide, but in the centre of the mass it affects the magnet.

The woods used in Southern India for making charcoal for the iron works at Beypur were the vella-marda, karra-marda, Indian-gooseberry, Poohum, nux vomica, and cassia.

Iron-glance of the hills of Cupputral, in the Ceded Districts, furnishes an excellent malleable iron. Specular iron-ore occurs in the Sandur hills, about 30 miles W. from Bellary.

The Bellary district yields a variety of ironores, some of them very rich in the metal, and several of them are associated with manganese. The prevailing ores of iron of this district are the black and grey ores alternating with sandstone, liver-coloured ore (which has been repeatedly seut to Madras as copper-ore), and red jaspery clay iron-stones. They are also associated in the same district, and in the vicinity of Kurnool and Ghooty, with magnesian limestone, grits, conglomerates, aluminous shale, fireclay, and black dolomite.

The principal ores of the Cuddapah district are red, brown, and purple in colour, which yield iron of excellent quality and very malleable. Some of the magnetic iron-ores of the same district are particularly rich in iron, and a few of them contain traces of manganese. Of those from Chemur and Pulevendalah, the latter is magnetic, although earthy and dull red in the fracture, and bright red in the streak. The steel-grey and granular iron-ores of Chitwail, Camalapur, and Gurumcondah are all rich in the metal, and more or less magnetic. The yellow ochre and rusty ores of the Muddenpully taluk are said to yield good malleable iron. The steel-grey iron-sand Comarole and Yandapully in the Doopaud taluk are highly magnetic, and contain a little manganese. The micaceous iron-ore and iron-glance of the Doopaud taluk are also rich in the metal.

Gunnygull bill ridge, south of Kurnool, is seamed with great veins of very pure specular iron-ore. A great cone-like mass of almost pure specular iron-ore rises out of the base of the northern slopes. Then S.E. of Ramulkota there is a ridge a 'perfect mine of iron;' but the great local drawback is the scarcity of fuel, of which only a small supply is obtainable from the low and thin jungle in the hilly regions to the southwards. Smelting is carried on at Ramulkota. The ore which is brought from an adjacent hill is massive, roughly granular, coarsely crystallized, and very brilliant. Usually the iron-ore is smelted once in a month, during 24 hours. The furnace is charged seven times during this day and night; when seven lumps of smelted metal are obtained. The furnace is charged first (a fire being at the bottom) with powdered charcoal. Two large baskets (six or seven large Madras measures) of charcoal are thrown on the fire; then a small basket of pounded ore (74 seers) and six small baskets of charcoal, that is, about a handful of iron and a bandful of charcoal alternately, at about an interval of a minute. Nothing else is put in the furnace. The bellows are kept at work for about two or three hours. Then the soft mass of metal is raked out, beaten for a short time with heavy hammers until it assumes the rounded wedge-shaped form usually given to the lump of iron at native furnaces, a deep cut being made in the mass. This lump of metal is about three-quarters of the weight of pounded ore placed in the furnace, and it is worth three rupees. Afterwards it is reduced to bars of workable iron, by being heated four times in the 
forge, and beaten between each heating. The furnace is a small dome-shaped edifice, almost exactly like the furnaces of the Salem district, both in shape and size.

Numerous iron villages and hamlets are found along the western flanks of the Nullamallays, and several of these furnaces are always at work, the metal being in demand for ploughshares and other agricultural implements, though not for tires of wheels, for which it is found unsuitable. Besides Nerjee stone, the district abounds in serpentine.

Iron-ore, hard and compact, of a light bluish colour, and of excellent quality, occurs in great abundance at Tinmericottah; brown iron-ore near the Guticondah; iron-ore in crystals and parallelipods on the surface of rising ground about three miles from Gurjal.

From the neighbourhood of Bomalapur, six or eight miles north of Dorenal in the Guntur district, and all the way to Gompedala near Doopaud for seven or eight miles, the ground is nearly all iron-sand. It is washed and smelted at Ramapoliam near Dorenal.

The most prevalent iron-ores of the Hyderabad territories seem to be the rusty brown, red, and yellow ochres; iron or steel sands with manganese, and specular or glance ores, - none of the latter, however, are magnetic. The black, brown, and red cellular iron-ores are abundant. Red hæmatite is found in the iron clay near Kondapur, and is used in the manufacture of the Wootz steel.

The magnetic iron-ore employed for ages in the manufacture of the damask steel used by the Persians for sword-blades, is obtained from schist near Kono-Samudram around Deemdoortee, where the ore is extensively distributed. The minute scales of iron are diffused in a sandstone-looking gneiss or micaceous schist, passing by insensible degrees into hornblende slate, and sometimes containing amorphous masses of quartz. The strata are much broken up and elevated, so that the dip and direction are in no two places the same, and bear no relation to the mountains in the north. The iron has the remarkable property of being obtained at once in a perfectly tough and malleable state, requiring none of the complicated processes to which British iron must be subjected previous to its being brought into that state. Mr. Wilkinson found it to be extremely good and tough, and considered it superior to any English iron, and even to the best descriptions of Swedish. The Persian merchants, who frequented the iron furnaces of Kona-Samudram, are aware of the superiority of this iron, and informed Dr. Voysey that in Persia they had in vain endeavoured to imitate the steel formed from it.

Ores, powerfully affecting the magnet, exist in great quantity at Taygur, a village of the Konkan.

The iron-ore of Rewa Kanta was in former times abundantly worked in the Zillahs of Narukot, Palanpur, Simudra, and Bhilod.

The Azuria mines in Jubbulpur are situated on a hill consisting of iron-ore found at $1 \frac{1}{2}$ feet from the surface, and extending over an area of about 60,000 yards square and 30 feet deep. The ore exists in thin flakes of a grey-iron colour and metallic lustre. The ore and charcoal are thrown in small quantities every half-hour into an earthen furnace 5 feet high and 3 feet diameter. A part of the bottom of the furnace is filled with fuel only; this being kindled, a pair of bellows is applied to raise the heat, and a passage made at the side of the furnace for the melted metal to run out. Four maunds (320 lbs.) of ore and $2 \frac{1}{2}$ maunds of charcoal are daily used in a furnace; the fuel is used in the proportion of 5-8ths or 62 per cent. of the ore for smelting, and 1-5th more for refining the metal. A furnace furnishes daily 2 maunds $(160 \mathrm{lbs}$.) or 50 per cent. of the crude iron from 4 maunds of the ore; this, when forged, yields 30 seers, or nearly 19 per cent. of wroughtiron. The entire cost of the pure metal obtained amounts to Rs. $1 \cdot 13$ per maund, including labour and materials.

Iron-ore, in the form of silicious peroxide, occurs at Tendukhera, Narsingpur. The ore actually worked is a large vein or lode in the limestone of the great schist formation, and the only rock in its immediate vicinity is hard grey and blue crystalline limestone. It occurs to the north of the Nerbadda, in the open flat country between the river and the Vindhya Hills, and at one or two other places in the neighbourhood, also at Mohpani, not far from Tendukhera. The iron is smelted in small clay furnaces, blown by goat-skin bellows, worked by the hand. It is obtained in small lumps or blooms called cutcha or raw iron, and is afterwards reheated and hammered, and then sold as pucka or finished iron. Intermixed with the raw iron as it comes from the furnace, is a sort of crude steel, which is carefully selected and used for the manufacture of tools and agricultural implements. The ore is largely smelted at Tendukhera, about two miles from the mines, where, during the eight dry months of the year, about sixty furnaces are worked. About 5 tons $3 \mathrm{cwt}$. of iron-ore and 5 tons $12 \mathrm{cwt}$. of charcoal are used for the manufacture of two tons of pucka or finished iron. The ore contains, upon an average, about 40 per cent. of iron; it is very fusible. The ore is obtained by means of pits sunk from 30 to 40 feet, through the alluvium of the valley, to the ore. They are washed in during the rains, and require to be resunk yearly. The pucka iron sells at from 5 to 6 rupees (10 shillings) per goan or bullock-load of 3 maunds, equal to 24 bundles, or from $£ 4,10$ s. to $£ 5,8 \mathrm{~s}$. per ton. From the iron of these mines, about 1840 , a very good suspension bridge was built near Saugor.

At Lohara (Loha, Hind, iron), in the Chanda district of the Central Provinces, there are two localities, five miles apart, where hæmatite abounds. At the eastern one there is a mass of dense red hæmatite, forming an isolated bill 120 feet above the level of the surrounding country, which would probably yield 300,000 to 500,000 tons of iron without going below the surface. The other mass is smaller in extent.

Iron-ore, in the form of magnetite or granulated, is found lying on the surface of almost all the high grounds in Chutia Nagpur.

In Bundelkhand and in the Nerbadda valley are large quantities of hæmatite.

An iron-ore called Dbaoo is produced in the land lying between Mouzah Sathu Nurwari of the Gwalior district and Punehar, also in the hills adjoining. The ore is taken to Dhoa and Bugrowlee and other places, where it is smelted. The ironores of Gwalior are remarkable for their purity and richness. They are chiefly red iron-ores and mag- 
netite, containing sometimes manganese, but there are also brown iron-ores and silicious hæmatite. The magnetites contain 70 per cent. of metallic iron, the red iron-ore from 60 to 71 per cent. of iron, the brown iron-ores from 42 to 54 per cent., and the silicious hæmatites from 45 to 48 per cent. of metallic iron. Of sulphur there are but few traces, and of phosphorus none. The red ironores near Suntoro, Maesora, and Dharoli occur in enormous quantities on the surface of the ground. These ores, it is stated, are especially serviceable for the production of Bessemer cast-steel for rails. There is a large forest in the immediate $\mathrm{N}$.W., which may be calculated to yield $56,000,000$ tons of wood, and which, it is estimated, would feed an iron work producing daily twelve tons of finished iron during 900 years.

Abundance of iron-ore is found in the district of Sumbulpore, and it is plentiful in the Cuttack tributary states of Talcher, Dhenkanal, PalLohara, and Ungool, and, indeed, throughout the hilly country bordering the settled districts of this province on the N.W. In Sumbulpore the broken iron-ore is mixed with charcoal, and put into the furnace, about 4 feet high, and made of clay. The fire is maintained by a blast, introduced through a fireclay pipe, which is sealed up with clay after the insertion of the nozzle of the bellows. The slag is raked out, through an aperture made in the ground, and which runs up into the centre of the furnace base. Three men-one to serve the fire, and two to work the bellows-are required to tend each furnace. Talcher and Dhenkanal ores are said to produce very excellent metal, without the aid of a flux. The charcoal used is made from the sal or Vatica robusta. The price of the crude iron in Ungool. is a trifle less than one anna per seer.

In S. Mirzapore, Palamow, Singrowlee, and Rewa the ores yield 70 to 75 per cent. of pigiron. Each furnace is kept in full play all day. Each day, if the smelters have wives and children to break up the ore into $\frac{1}{2}$ or $\frac{1}{4}$-inch cubes, and bring charcoal, they will charge the furnace four times, and the day's work will be 4 or 5 small malleable pigs of 2 or $2 \frac{1}{2}$ seers each, or in all 12 annas to a rupee's worth of iron. They employ no flux. The furnace is emptied at each charge. The metal never runs liquid from the furnace, but falls to the bottom, below the blast tube, from whence it is taken in a flaming mass by a pair of iron tongs, and while incandescent it is hammered on a hard stone or rough iron anvil into a double wedge-shaped pig, the labour being divided between the smelter and his family.

The fuel employed in the Ulwar district in smelting the ore, is charcoal obtained from the dhak tree (Butea frondosa), and costs about 1 rupee for 6 maunds. To smelt 16 maunds of ore, 24 maunds of charcoal are required, and this will yield 4 maunds of iron, valued at 3 rupees per maund.

The part of the Vindhya Hills forming the southern portions of Shahabad, and of Mirzapore, N. and N.W. of the Sone river, together with Mirzapore, south of the Sone, Rewa, Palamow, and, in fact, the whole chain and spurs of the Vindhya range in this neighbourhood, is full of mineral wealth of various kinds. Quarries of the peroxide and proto-peroxide of iron, as also of iron pyrites, abound in the most accessible portions of the Kymore range. The Kymore range is the north-easterly spur of the Vindhya range, and fills all Southern Mirzapore and Shahabad. Some of the ores yield 70 to 75 per cent. of pigiron. Some of the best iron in India is produced in Palamow, Rewa, Bidjugghur, and Singrowlee. The iron from the latter place in particular bears a high character in the market, being tough, flexible, and easily worked.

In Bengal, about 6 miles N.E. of the town on the road to Bugodhur, a place on the Grand Trunk Road, is the Silwar Hill, which almost deserves to be called an iron mountain. It stands at the bed of a valley, through which runs the Kunbur river, all along the course of which stream good iron-ore is found in large quantities. About 5 or 6 miles north of Hazaribagh, on the Burbi road, is Sedgua, and here, close to the road, is coal of a very good quality. Iron-ore has been traced in the Kunbur valley for a distance of nearly 30 miles, and the ore is said to have yielded 75 per cent. of the finest metal. So plentiful is the ore, that the Kol and Santal, who work it to procure the material for making kodalies, hatchets, etc., for exportation to the neighbouring districts, never do more than dig a hole to the depth of two, or it may be three feet. Coal, although found near the station, can be procured in any quantity from the banks of the Damuda, and wood can be drawn from the forests and jungles of the Ramgurh plateau.

Hazaribagh iron-ore appears to be of the finest quality, and contains not less than 80 per cent. of pure metal. It also contains a slight admixture of manganese, which would be very useful as a flux where the finest steel, such as would be required for guns, is manufactured. There is a surface of 500 square miles of this ore in the Damuda coal-fields, extending from ten miles south of Hazaribagh on to Turi, and underneath this rich deposit is a layer, supposed to be about 20 feet in extent, of the finest coal in India.

The Agaria, Kol, Santal, and other jungle races smelt with charcoal only, and make no use of the enormous deposits of coal ; their out-turn perhaps amounting to about a maund in a couple of days. A very large quantity of iron of a very fine description is found near Chuttra, one of the principal towns in the Hazaribagh district. Coal is often found within 5 or 6 miles of this place, viz. in the Mahanadi river.

The iron-ores of the Panjab are produced along its N.E. mountain frontier, as well as in the lower hills of the Sulimani and Waziri ranges, and those to the S.E. of the Bunnu district, and to some extent in the Salt Range on the other side of the province, in the hilly portion of Gurgaon district, and in the districts of Simla, Kangra, Dehra Ismail Khan, and Hazara in the Dehli district.

The Mahruli Hill, which yields iron-ore, is one of that group of outliers that forms a continuation as it were of the Aravalli range.

Along the Himalaya frontier, the principal places of production are the Hill States of the Simla district, Jubal, Dhami, Bashahr, and Rampur. At Suket, Chamba, and Mandi, iron is largely produced, and the mines at Shil, Kot Khai, Futtehpur, and Bhir Bangal of Kangra are famous. Mines are worked along the whole range, both on the north and south faces, from the Sutlej to the Ravi. Under the Sikh rule, this iron was extensively used for gun-barrels. 
At Kanigorum, in the Waziri Hills, it is found also as a hæmatite in several parts of the Salt Range, and in the Chichalli range, on the other side of the river. The cutlery of Nizamabad and Gujerat is, however, exclusively manufactured with imported steel.

The Kamaon ores are from an argillaceous band containing large quantities of red hæmatite, the ore-bed being 10 to 20 feet thick, and extending for a long distance. The surface deposits supply the greater proportion of ores used by the smelters, but much labour is necessary in the collection.

Magnetic iron-ore is found in considerable quantity about 30 miles N.E. of Dharmsala, Kangra district, close to the sanatorium of Dalhousie. Of the ores of the Chamba Hills, and in the divisions up to the Hazara district included in the Kashmir territories, the best is found at Reyasi in Jammu; the ore found at Sonf and Kutyar, in Kashmir proper, is not so good.

In the hills due north of Peshawur is the source of the fine Bajaur iron which is used in the manufacture of the gun-barrels of Kohat and Jammu, and in the formation of steel for the blades of Bokhara and Peshawur.

At Sikbhar, in the Darjiling district, is a valuable magnetic iron-ore.

Iron is obtained from the ore found in Shoru Cacharri Mehaul, in Gholagat Sub-division, in Assam, about 15 or 18 feet under the surface of the ground.

In Pegu, ore is found in the slope of a mountain called Popah, about 3000 feet in height, 15 miles inland from the river Irawadi, on its left bank. The ore is found in large quantity in nodules, and is collected and smelted by the inhabitants of the neighbouring villages. They use no flux of any description in smelting. Price 4 rupees per ton, delivered at the neighbouring furnaces.
There is a large variety of ores of iron in the Tenasserim Provinces, some of which are uncommonly rich in metal.

Iron-ore abounds in the Shan states, and to the south of Mandalay in the district of Pagang. To the west of Sagaing, for miles up the Irawadi river, the ore abounds, a rich hæmatite. Tin is found in the Shan States to the south of Mandalay.

Many of the provinces of China yield an excellent iron, equal to the Swedish metal, from red hæmatite; limonite, black magnetic iron-ore, and specular iron-ore occur, but the trade in Chinese iron is petty.

Europeans, in private companies, under Government patronage, and also by Goviernment departments, have made several unsuccessful attempts to establish iron works of the form adopted in Great Britain. The chief of these have been the attempts at Beypur and Porto Novo in 1833 and 1859, in 1874 in the Madras Presidency, with a complete loss to the shareholders; at Dechauri in the N.W. Provinces, and in Bengal. In 1855 the iron works at Dechauri, in the N.W. Provinces, possessed a well-constructed high furnace; forest for the supply of charcoal was growing all round them; they had fair, brown iron-ore at hand, and excellent rich hæmatite and magnetic ores only 25 miles off, but the work was abandoned. In 1882, the Government of India took the Bengal ironworks off the proprietors' hands, paying the shareholders Rs. 4,30,761. Surgeon-General Balfour, in 1855 , reported on the iron-ores of the south of India, and showed that in the competition, to be successful, Indian iron must vie with the iron of Sweden and Russia, and that it is the convenient forms of hoop, and bar, and pig-forms in which wrought-iron is imported-which give British the preference.

Iron imported into India-

\begin{tabular}{|c|c|c|c|c|c|c|c|c|c|c|}
\hline & & & & & \multicolumn{2}{|c|}{ Cast or Pig. } & \multicolumn{2}{|c|}{ Wrought. } & \multicolumn{2}{|c|}{ Total. } \\
\hline & & & & & Cwt. & Value, Rs. & Cwt. & Value, Rs. & Cwt. & Value, Rs. \\
\hline $1874-75$ & & & & & 52,262 & $1,15,457$ & $1,482,604$ & $1,23,13,095$ & $1,534,866$ & $1,24,73,485$ \\
\hline 1875 & & & & & 8 & & & & $2,023,8$ & 978 \\
\hline $1876-77$ & & & & & 49,0 & & 6,758 & & $2,251,743$ & 473 \\
\hline 1877-78, & & & & & 127,443 & $3,01,128$ & $2,286,790$ & $1,38,76,782$ & $2,437,721$ & $1,43,55,611$ \\
\hline 1878-79, & & & & & 51,313 & $1,22,497$ & $2,291,483$ & $1,41,78,434$ & $2,365,306$ & $1,44,60,151$ \\
\hline $1879-80$ & 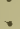 & & & & 100,994 & $2,27,384$ & $1,972,3$ & $1,18,87,6$ & $2,111,156$ & $1,22,94,217$ \\
\hline & & & & & 58,179 & $\mathbf{1}, \mathbf{4 5}, 901$ & $2,579,741$ & $1,51,80,589$ & $2,665,604$ & $\begin{array}{r}1,54,75,409 \\
0\end{array}$ \\
\hline $1881-8$ & & & & & 104,095 & $2,58,053$ & $2,291,745$ & $1,36,72,463$ & $2,450,690$ & $1,41,38,144$ \\
\hline
\end{tabular}

About 120,000 tons of iron are imported into India, of annual value about $1 \frac{1}{3}$ kror of rupees, and almost entirely from the United Kingdom.

The native furnaces throughout India are of the same pattern, small circular structures $4 \frac{1}{2}$ to 5 feet high, built of earth, and the product brings in the villages a higher price ( $\$ 23$ the ton) than iron from Europe (£18 the ton). The Kutub near Dehli, 23 feet 8 inches, is a remarkable illustration of what the ancient blacksmiths could do; and the great gun on the ramparts of Bijapur, cast at Ahmadnaggur about the 16 th century, is another.

Iron, Red Oxide.

T'sze-jen-tung, . . Chin. / Roth eisen oxyde, . Grr. Sesquioxide of iron, ENG. Ferri sesquioxidum; LAT. Peroxide of iron, . F. peroxidum, . " Colcothar, ENG., L̈̈. F. oxydum rubrum;" ", Peroxide de fer, . . FR. Crocus martis, . " ",

This occurs native in the Chinese provinces of Shen-si and Kiang-si.
Iron Rust.

Sadid ul hadid, . . ARAB. Karatan basi, . . MAlay. Than khya, : BuRM. Irambu tapu, : TAut. Tai basi, : : MaLAY. Tuphu, . : : ", Iron, Sulphate of, Ferri Sulphas.

Bala-dokta, . BENG. Hara tutia, . HIND. Luh-fan, T'sing-fan, CHr. Solfato di ferro, : IT. Tan-fan, Tsau-fan, ," Ferrum vitriolatum, LAT. \begin{tabular}{l|l} 
Green vitriol, \\
Green copperas, : ENG.
\end{tabular} Green copperas, : . Fr. Tarusi,
Sulfate de fer, . . Mankur madni, : PERs. Schwefelsaures eisen, ", Tutiya subz, : PERs. \begin{tabular}{|l|l} 
Oxydul, Eisen vitriol, GHR. & Unna, Anna baydi, TAM.
\end{tabular} Hera kasis, . . HuND.

Sulphate of iron is the sulphate of the protoxide of iron, and occurs in the form of green crystals, soluble in water. The salt is formed abundantly by natural oxidation of the sulphuret of iron, a mineral especially common in coal districts. The sulphuret, absorbing oxygen from the atmosphere, is converted into the sulphate of the protoxide of iron; this is apt to be changed into the red- 
coloured sulphate of the sesquioxide. It is made artificially on a large scale, for use in the arts, by exposing moistened pyrites to the air. It occurs in the Indian bazars in large masses of green crystals, and in a state of considerable purity. It was known to the ancients, is mentioned in the Amara Kosha of the Hindus, and it is used by them, as by the Romans in the time of Pliny, in making ink. A very cheap green copperas in China is largely used in the mission hospitals as a disinfectant, also in dyeing black, and as an emetic in cases of poisoning. The natives of India have long known the use of acetate of iron, which they prepare by macerating iron in sour palm-wine, or in water in which rice has been boiled.-Royle, Mat. Med.; O'Sh., Beng. Phar. p. 325 ; Royle, Hindu Medicine, p. 44; Smith, M. M. C.; Local Committee, Jubbulpur; Captain Strover, 1873; Smith; Balfour's Report on the Iron Ores, Iron and Steel of the Madras Presidency; Prof. Max Muller's Lectures, p. 223; M'Culloch's Commercial Dictionary; Powell's Handbook; Madras Ex. Jur. Reports; Cat. Ex., 1862; Carter's Geological Papers; Voysey; Moral and Material Progress of India; Cat. and Jur. Report, Exhibition of 1851.

IRON - BARK TREES, a commercial name applied in Australia to several species of Eucalyptus. E. sideroxylon is a valuable timber tree, possessing great strength and hardness, and much prized for its durability by carpenters, shipbuilders, for top-sides, trenails, the rudder stock, and belaying pins; by waggon builders, for wheels, poles, etc.; and by turners for rough work. It is much recommended for railway sleepers, and is extensively used in underground mining work. It somewhat resembles the red gum tree, but it is more difficult to get large trunks of it sound in the heart. See Eucalyptus.

IRON-WOOD.

Pya of

Pieng,

Jerntræ,

Yserhout, .

Bois de fer,

Eisenholz,

Legno di ferro, .

AKYaв. / Lignum ferreum, LAT. D̈AN. Pao de ferro, : : PoRT

DUT. Tverdodrevnik,. . RUS.

Fr. Naw, . . : Singh.

Ger. Palohierro, . . SP.

Iron-wood is a commercial term applied to variety of woods, in consequence of their hardness, and almost every country has an iron-wood of its own. One, the product of an evergreen tree, Sideroxylon, remarkable for the hardness and weight of its timber, which sinks in water, receives this name; it is of a reddish hue, and corrodes like iron. This tree grows chiefly in the West India Islands, and is likewise very common in South America. Mesua ferrea, a tree furnishing one of the iron-woods, and which, also, has received its specific name from the hardness of its wood, is a native of Ceylon and of the two Peninsulas of India, of Northern India, Malacca, and of the islands. M. pedunculata likewise furnishes part of the timber known under this name. That of Arakan is the Xylia dolabiformis; but in Ceylon, the Maba buxifolia and Mimusops Indica also furnish the iron-woods of that island. The Ceylonese have also an iron-wood tree known under the name of Naw, of the western provinces of Ceylon, perhaps the $M$. ferrea. It is described as used for bridges and buildings. The timber of the Metrosideros vera of China is called true iron-wood. The Chinese are said to make their rudders and anchors of it, and, among the Japanese, it is so scarce and valuable, that it once was only allowed to be manufactured for the service of their king. The iron-wood of southern China, however, is Baryxylon rufum; of the island of Bourbon, Stadmannia sideroxylon; and of the Cape of Grood Hope, Sideroxylon melanophleos, which latter is very hard, close-grained, and sinks in water. That of the Canara forests is from two species of Memecylon (ramiflorum, umbellatum), and on the Coromandel coast the term is occasionally applied to the wood of the Casuarina equisetifolia. In Tenasserim, the term is applied to the woods of Inga xylocarpa and I. bijemina, and to that of a species of Diospyros. The ironwood of Australia is from a species of Eucalyptus, E. sideroxylon, and that of Norfolk Island from the Notelæa longifolia. The iron-wood of Guiana is from the Robinia panacoco (of Aublet), that of Jamaica is the Fagara pterota, and Erythroxylum areolatum is also called red-wood. Egiphyla Martinicensis and Coccoloba latifolia are other West Indian trees, to the timbers of which the name of iron-wood has been applied; and Ostrya Virginica, called American hop hornbeam, has wood exceedingly hard and heavy, whence it is generally called iron-wood in America, and in some places lever-wood. Under the name of ironwood, two specimens were sent by the Calcutta Committee to the Exhibition of 1862. One of them, Pya, Vern., a tree of Akyab, grows to a moderate size, and is plentiful in the Sandoway and Ramree districts. The other iron-wood, Pieng, Vern., also a tree of Akyab, grows to a large size, and is very plentiful in Arakan; its wood is very hard, and used for posts. One of these is perhaps the Xylia dolabriformis, Benth. The iron-wood of the South Sea Islands is the timber of the Casuarina equisetifolia. The ironwood of New Zealand is the Vitex littoralis. The Aki or Lignum vitæ of New Zealand, the Rata and the Pohutu kawa of the same country, are all hard-wooded trees belonging to the genus Metrosideros, Lindley; and several other species of Metrosideros have been described, natives of Australia and the South Sea Islands, as furnishing iron-woods of commerce. The Metrosideros buxifolia of Allan Cunninghain is the New Zealand plant called Aki, and is a rambling shrub, adhering to trees, and climbing by means of its lateral roots to the summits of the loftiest trees in the forests of Wangaroa and the Bay of Islands.Eng. Cyc.; Holtzaptfel; Faulkner; Macgillivray; Dr. Bennett; Mr. Mendis ; Dr. Mason, Cal. Cat. Ex. of $1862 ; M^{\prime}$ Culloch.

IRRIGATION.

Wasserung, . . GER. | Regamiento, . . IT. Befeuchtung,

Generous as the Indian soils usually are, and favourable as are the seasons in the plains and valleys of British India, the amount of the rainfall, one year with another, varies by fifty per cent. above and below the average. Rain is frequently absent for many weeks, and without some artificial means of supplying the soil with moisture, no crops could at those periods be taken off the ground. Something can be grown with water, nothing can be obtained without it; and throughout the south and east of Asia the efforts of the rulers and the people have been directed to obtain and hoard the water supply. Of the seven 
regions into which British India has been divided for hygrometric purposes, two only have their fill of water from natural sources. In the drier regions the rainfall is precarious as well as scanty, and wide expanses of good soil lie permanently untilled and tenantless. A good part of the Panjab and the whole of Sind would be scarcely habitable without irrigation, and in the southenstern quarter of the Madras Presidency it is indispensable. The natives of these regions have, from unknown times, been forming tanks, digging canals, and leading off channels from rivers, some of them betokening great skill and great labour; and in the 18th and 19th centuries the labours of British engineers, especially of those of the Madras Presidency, have been conspicuously successful in irrigation. Sir Arthur Cotton, in Tanjore, reconstructed and enlarged the ancient irrigation works with such effect, that during the first sixteen years 50,000 acres of land, previously waste, were brought under tillage, the average produce per acre was increased by one-eighth, and the selling value of the land was doubled. In the delta of the Godavery, where Sir Arthur Cotton next went, notwithstanding its rich alluvial soil and fostering climate, alternate flood and drought had brought famines. The territory is now a luxuriant garden, 265,000 acres having been brought under humid cultivation, and the population is prosperous. The Ganges Canal, which diffuses irrigation over an area 320 miles long by 50 broad, is the most magnificent work of its class in the whole world, having a main channel 348 miles long, primary branches of $\mathbf{3 0 6}$ miles, and minor arms of an aggregate length of 3000 miles. In one place this canal is carried over a river 920 feet broad, and thence for nearly three miles along the top of an embankment 30 feet high.

The irrigation canals of the Tigris and Euphrates have not retained their ancient magnificence, but the oases around Bokbara and Khiva owe their value to the irrigation channels led from the Oxus. In Persia, Karez aqueducts are largely in use for irrigation, and the Nizam Shah dynasty of Abmadnaggur formed several of these on the north of their capital.

In India, irrigation is carried on from wells and from tanks, and largely from channels led from its rivers, well irrigation being employed for garden culture, and to supplement the rainfall. The efforts made by several of the races to preserve and utilize the water from the rains and rivers, have been gigantic, as in the cyclopean Gorbasta structures of Baluchistan, where dams of huge stones have been drawn across the valleys by a race of whose history nothing is known. In India both Hindus and Muhammadans have made great artificial lakes, with dams or bunds, often highly oruamental. One of the most beautiful is that of Kankroli or Rajnagar in the Mewar or Udaipur State. Its retaining wall is about 2 miles long, and the area is about 12 square miles. It is 376 paces in length, is covered by white marble steps, $-a$ fairy scene of architectural beauty.

The great tank at Cumbum, in the Ceded Districts, is 8 miles in circumference, and covers an area of nearly 15 squares miles; that at Ulsoor, near Bangalore in Mysore, is of equal size. The magnificent lake constructed by Mir
Alam, near Hyderabad in the Dekhan, as a famine work, has a steamer on it.

Wells or reservoirs, known as the Bai, Baori, or Baoli, have been formed in many parts of India, with flights of steps and a succession of platforms, enclosed by arches, leading down to the water.

Most of the waterworks constructed by the Muhammadans in India were undertaken to obtain water for their parks and palaces. It is to the Hindu races, Aryan and non-Aryan, and in recent times to the British, that India is indebted for the great tanks and irrigation canals which are now to be seen. The smaller tanks in the south of the Peninsula of India, all of Hindu origin, are multitudinous, and some of them are of great size. To Hindus also India is indebted for the great anicuts or dams which head back the waters of the Cauvery and the Colerun.

Some of the great irrigation works, both in Northern and Southern India, have been so constructed as to be available also for navigation. Navigation on the Orissa canals in 1877-78 yielded $£ 3384$; on the Midnapur canal, $£ 10,692$; and on the Sone canals, $£ 5965$, the aggregate being larger than was derived from irrigation. In Madras, boat tolls in the Godavery delta brought in $£ 4496$, and in the Kistna delta (Madras canals), £1718. The works of the Madras Irrigation Company on the Tümbūdra were not made available for navigation until 1879 . The canal was projected for irrigation and navigation, which should extend from Sunkesala, 17 miles above Kurnool, to the Kistnapatam estuary on the sea-coast of Nellore, and the Madras Irrigation Company undertook that part of it between Sunkesala and the Pennar river at Sumaiswaram, and subsequently to the town of Cuddapab. It was completed in 1871, but it has been financially a failure, attributable to the heavy charges for maintenance and establishment, to the unprofitable outlay on the navigation works, and the scarcity of labour.

In the Bombay Presidency, near Poona, the British have erected a masonry dam to form Lake Fife, one of the finest reservoirs in the world.

The British have drawn one great canal from the Ganges at Hardwar; they have improved and enlarged an old canal which the Muhammadans brought to Dehli from the Jumna; a great canal has been led from the river Sutlej, in the Sirhind division of the Panjab, another from the river Ravi north of Lahore, for the Amritsar district; with many lesser streams for Multan, and for the inundation canals of the Derajats. In Behar a great canal has been taken from the Sone river; in Orissa the Mahanadi has been dammed farther south, as has also the Krishna river at Bezwara, and the Cauvery and Colerun river near Trichinopoly. But what is there accomplished on a very large scale by the British India Government is, throughout many parts of the country, performed by the villagers themselves. For miles the Hindu cultivator will carry his tiny stream of water along the brow of mountains, round steep declivities, and across yawning gulfs or deep valleys, his primitive aqueducts being formed of stones and clay, the scooped-out trunks of palm trees and hollow bamboos. And sometimes, in order to bring the supply of water to the necessary height, the pe-cottah or the bucket-wheel is employed, worked by men, by oxen, by buffaloes, or by elephants, 
and in the more level tracts of the south of the Peninsula every little declivity is dammed up to gather the falling rain.

And, independent of the general benefits to the people, great profits have been made by the British Government in several cases, by restoring or repairing tanks and channels which had become ruined, such net profits amounting to from 10 to 45 per. cent., and in one instance to 250 per cent. And it is believed that the construction of large storage reservoirs would return a high percentage on the outlay. The smaller tanks constructed by the people themselves well repay the labour employed, though to the Government the construction of flat country tanks of the second class, or even of the third class, offer a very doubtful return.

The value of water to the' cultivator is shown, first, by contrasting the yield of dry crops with that of rice and sugar-cane, from actual experiments. From these it appeared that the net profit per acre on dry crops was $8 \mathrm{~s}$. $2 \frac{1}{4} \mathrm{~d}$.; on rice, $\mathfrak{E} 4$, 16s. $10 \frac{1}{2} \mathrm{~d}$; ; and on sugar-cane, $£ 18,6 \mathrm{~s}$. $6 \mathrm{~d}$. In the two last cases a very low rate for the water was assumed, viz. 12s. per acre for each crop of rice, and 24s. per acre for each crop of sugar-cane, as provisionally fixed by Government. A comparison was made between dry crops and rice, and dry crops occasionally flooded, based on the average price of grain extending over five years, and deducting one-fourth from the gross value of the crop in the case of dry crops, and one-sixth in the case of wet crops, to cover loss in bad years. Without deducting the water rate, the difference in the net value of the crops was as follows:-Between dry crops and rice, taking the most unfavourable comparison, 258. 7d.; between dry crops and the same occasionally irrigated, $30 \mathrm{~s} .8 \mathrm{~d}$. ; and between two dry crops and sugar-cane (which occupied ten months of the year), $\mathfrak{L} 8,2 \mathrm{~s}$. $8 \mathrm{~d}$. But if water be stored, so as to allow a second crop of rice to be grown, the advantages are nearly doubled. Provided a water rate proportioned to the value of the water were fixed, irrigation would benefit the cultivator to the extent of $8 \mathrm{~s}$. $6 \mathrm{~d}$., or 50 per cent., and yield a gross return on the outlay of $14 \mathrm{~s} .9 \mathrm{~d}$. per acre; and if water were stored for a second crop, the gain to the cultivator would be $19 \mathrm{~s} .9 \mathrm{~d}$., or more than 100 per cent., and the return to the agency supplying the water $37 \mathrm{~s}$. 3d. per acre, the cultivator not having to expend any capital in improvements. Of the $37 \mathrm{~s}$. $3 \mathrm{~d}$. per acre profit, $22 \mathrm{~s} .6 \mathrm{~d}$. was about the sum due to the storage of water, supposing such storage works to be added to distribution works already constructed. The cost of large works of irrigation might be safely reckoned at $£ 7$ per acre on an average, or $\mathfrak{£} 8,15 \mathrm{~s}$. if 5 per cent. on one-half the capital for ten years during construction were added. If the profits made by the application of the water were divided in the proportion of one-third to the cultivator and twothirds to the agency supplying the water, works of channel irrigation would benefit the cultivator, as above stated, to the extent of 50 per cent, and yield a net return of $7 \cdot 4$ per cent. on the capital expended. It appears probable that, in the most favourable localities, 7000 cubic yards of water could be stored for $\mathfrak{E} 1$, and in others 4250 cubic yards.

A committee was appointed by Lord Canning to consider the views as to irrigation held by
Colonel Sir Arthur Cotton and Colonel Crofton, and they decided in favour of Colonel Crofton's views against those of Sir A. Cotton. Of the reasons given for its decision one was their objection to the construction of a weir across the Ganges, below the confluence of the Solani, at the estimated cost of $£ 1,128,631$, to pass a volume of water over the Ganges of $30,000,000$ cubic yards. But the Godavery weir, to pass above $200,000,000$, only cost $£ 90,000$; the Cauvery weir, to pass the same volume as the Ganges, $30,000,000$ cubic yards, only cost $£ 15,000$; the Kistna weir, to pass 180,000 cubic yards, only $£ 100,000$; the Tumbudra weir, for about double the volume of the Ganges, only $£ 30,000$. The average estimate for weirs on similar rivers in Madras is about $£ 500$ per million cubic yards of volume per hour; while the estimate of the Ganges Canal Committee was nearly $£ 40,000$ per million.

Only rivers of the larger class, which have a continuous flow for several months, are available for extensive irrigation projects. The smaller rivers are merely torrents, which quickly carry off beavy falls of rain, and then become dry again. The water, however, is in many cases intercepted by chains of tanks, of the second or third class, built across these torrents.

The deltas of large rivers, being the most easily irrigated lands, bave been so treated for ages, and the works have been much extended and improved under the British Government, by the construction of permanent weirs of great lengths at the heads of the deltas, such weirs being built on the sandy beds of wide rivers subject to heavy floods. This seemed to have been beyond the skill of the ancient native rulers. They, however, built many weirs on the large rivers in the middle part of their courses, the situations being skilfully chosen, but the construction was rude and imperfect. They were generally built on a reef of rocks, with loose rubble, faced with large blocks of granite laid dry, and sometimes fastened with iron clamps. The modern weirs in similar situations are of masonry, with a vertical or slightly battering face on the down-stream side, and with heavy copings. In rivers having sandy beds, it is usual to build the body of the weir on a foundation of brick wells, sunk to the low-water level, and filled with concrete. On the lower side there is an apron, having a slope of 1 in 12 from the crest, with a toe wall ; and if the slope be long, intermediate walls are also built on wells, and below all there is a broad layer of rough rubble of large dimensions.

The ancient irrigation channels were generally defective in design, being too small, and having much too great a fall. In consequence of these channels being so near the river, they irrigated only a narrow strip of land; and the current being too great, excessive annual repairs were required. This system necessitated numerous offtakes from the river, involving the expense of many weirs, and a great aggregate length of unproductive channel, from the offtake to the point where the channel reached such a level as to com. mand the surface of the country. On the other hand, a canal of large dimensions, taken off from one head, having a slower current and less fall, would soon so gain on the level of the river that it would reach districts remote from it, and con- 
sequently more in need of artificial supplies of water ; and it would also command a much larger extent of country than it could supply entirely with water. This was an advantage, because it would be many years before a district could be completely changed from dry to wet cultivation, as it would require to have its population trebled. It also afforder means of assisting dry crops in years of drought, and thus preventing famine. In many districts complete failure of the crops now grown occurred every few years, and a good crop was a rare occurrence. There should therefore be facilities for completely irrigating detached areas at considerable intervals, and of giving occasional irrigation to dry crops.

Distribution was effected from the second class of tanks directly, by means of sluices in the bund. From the third, and more especially from the first class, it was commonly effected indirectly; thus the natural channel of the river or rivers, which had been dammed to form the tank, were used to carry part of the water for irrigation, weirs being built across them at suitable places, and artificial channels taken off from above them. By these means the surplus of the water, which was generally wastefully used by the ryots, was saved, being collected by drainage into the stream, and redistributed at the next weir. Distribution was most economically effected from a canal, when the latter ran along a ridge; but as this could rarely be accomplished in the case of a canal taken off from a main drainage, it was next best effected by leading the main distribution channels down the ridges crossed by the canal. Distribution could be carried out in the Ceded Districts for $5 \mathrm{~s}$. per acre, including sluices in the main canal, and all necessary road and water crossings, but excluding the coast of terracing the land to prepare it for wet cultivation, this being done by the occupier. The nature of the ground was occasionally such that the drainage was effected naturally, no works being required for that purpose beyond small open trenches in the rice fields.

Ordinary agricultural works in the Madras Presidency irrigate an area of about 3,365,157 acres, yielding a revenue of approximately Rs. $1,31,04,126$. They consist of two kinds, viz. (1) rain-fed tanks or reservoirs, generally of minor individual importance, each deriving its supply directly from rainfall distributed over an area of land, which is called the catchment basin; and (2) channels from rivers and streams providing direct irrigation, or supplying tanks, together with the tanks supplied. In the first case, the rainfall is caught and retained before it reaches natural lines of any importance. In the last, it is diverted from the drainage lines while pursuing its course, and led away by artificial means. In connection with these last are the anicuts or weirs which have been constructed by former governments and under British rule. About 1876, there were in the Madras Presidency 1212 weirs across rivers or streams, 769 of which were in the three districts of Madura, Salem, and S. Arcot. There were 33,318 tanks and irrigation canals, of which the districts of Coimbatore, Vizagapatam, Kistna, Kurnool, and Nellore had only 2590. The irrigated area from all these was approximately $3,365,157$ acres, and the revenue Rs. 1,31,04,126. Besides these, there were irrigation works belonging to landlords, also others belonging to the Government irrigation systems, for which capital and revenue accounts are kept. Of these last, the principal are the anicuts or weirs across the rivers Godavery, Kistna, Pennar, Cauvery, Vellar, Palar, and Tambrapurni, and the great reservoir of Chembrumbakam.

It was Lord Canning's opinion that the construction of great irrigation works might be entrusted to private companies; but the Madras Irrigation Company and E. I. Irrigation Company formed at that time (1861) for the Tumbudra and Mahanadi, have been pecuniarily unsuccessful. For the Mahanadi river scheme, for instance, the capital raised in June 1861 , nearly a million sterling, was intended to be utilized in certain initiatory parts, amounting to about one-half of the complete scheme, which was estimated at two million sterling. To meet the second half of the scheme a second million was to be raised when wanted, by a second issue of shares. The works began in December 1863. Irrigation was first available in December 1865 , but was first taken up in April 1866, giving returns in October 1866. Navigation began to pay in March. 1863, but eventually the scheme was bought up by Government in December 1867. The initiatory half of the works was not then perfectly completed, but was nearly so. The estimates having been exceeded, the first issue of one million was very nearly spent. The navigation returns from March 1863 to August 1867 amounted to $£ 5922$. The cultivators refused to pay for the water. In the year 1872-73 the total acreage of irrigation was only 4753 acres, yielding $£ 4263$ in water rates, and the navigation returns on a tonnage of 154,422 tons amounted to $£ 4750$; the total receipts, including $£ 1481$ from other sources, amounted to $£ 10,293$ for that year.

Mr. Latham, chief engineer of the Madras Canal and Irrigation Company, reported that the expectation, based upon the experience of the north-western canals, that irrigation would not fall off much after its value had once been felt during the famine, has proved delusive. Yet the increase caused by the famine had been but moderate :-

1875-76 (before the famine), . . 13,928.45 acres. 1876-77 (the year of failure of rain), $24,545 \cdot 08$," $1877-78$ (a year of famine and late rain), $27,922 \cdot 17$ ", 1878-79 (a year of excessive rain), . . 14,731 49 ,

The Tumbudra canals were led from a weir, 4500 feet long, across the rocky bed of the river at Sunkesala, and it was intended to reach 250,300 acres of rice cultivation up to the year 1865 . The Madras Irrigation and Canal Company had realized less revenue than sufficed to cover the working expenses. Up to the end of 1877-78, the total outlay was Rs. $1,52,73,352$. The attempt to make it suitable for navigation added Rs. $36,80,584$ to its cost. The canal was designed to irrigate 200,000 acres of wet crops, or a corresponding area of other crops. But the largest area irrigated was in the famine year 1876-77, when it reached 82,477 acres, viz. wet crops 24,545 , dry crops 67,932 . It is now recognised that canals for traffic must have the same width and depth from their commencement to their termination; but that irrigation canals, by giving off channels along their course, should gradually fine away to their end.

Between 1862-63 and 1872-73 the acreage irrigated by the Western Jumna Canal was from 
331,037 to 496,542 acres ; in the Eastern Jumna Canal, from 160,355 to 274,101 acres; the Bari Doab Canal, from 126,016 to 287,079 acres; and the Ganges Canal, 205,605 to $1,078,399$ acres.

In 1869 , the Eastern Jumna Canal irrigated 102,322 acres; in $1877,103,632$ acres; and in 1878 it was 110,722 acres, yielding a revenue of Rs. $18,56,440$.

Panjab.-Of the twenty-one million acres under cultivation in an average year in the Panjab, only five and a half million acres (of which four and a half millions are under food crops) are irrigated by artificial means. One and a half million acres more are situated in the beds of the Panjab rivers, and require little rain to bring their produce to maturity. Of the remaining twelve and a half

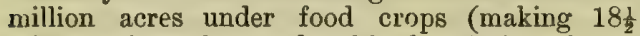
millions altogether under this description of produce), six and a half are pretty safe, being grown under an abundant and a reliable rainfall in the submontane districts, and six millions produce a more precarious crop, being wholly dependent on the less certain rainfall of the tract farther south. It is roughly estimated that on an average for the whole province an acre of irrigated land produces half as much again as an acre of land wholly dependent on rain. This ratio gives one-third of the total yield of food grains as the produce of irrigated land, and two-thirds as dependent on rainfall or rain-floods. Following out the comparison into more detail, it is calculated that 36 per cent. of the whole supply of food grains is produced by land artificially irrrigated, 43 per cent. by land more or less protected by floods or abundant rainfall, and only 21 per cent. by land dependent on a more precarious rainfall. The chief means of artificial irrigation are wells, which irrigate three millions of acres; inundation canals, chiefly from the rivers of the Panjab proper, irrigate one million; and perennial canals, of which the Western Jumna and Bari Doab Canals are the chief, protect only three-quarters of a million of acres.

There are several plans by which, in British India, water is lifted. One of these, from wells, is by means of the 'mot' or 'pur,' a flexible leathern bucket containing from $2 \frac{1}{2}$ to $12 \frac{1}{2}$ gallons, which is attached by a strong rope to a pulley. In masonry wells in the north of India, from 4 to 20 runs can be worked at one and the same time, and at unbricked or Kach'ha wells more than two runs are seldom worked. The runs-called 'lao,' from Lana, to bring - are worked by men or women, bullocks, and buffaloes, but generally bullocks. Whatever power may be employed in a garden or field of any size, one person is needed to receive and empty the bucket at the mouth of the well, another to drive the bullocks, and a third to distribute the water. In a small patch of land two persons will suffice. Human labour is the most expensive, but is the quickest. About two standard bighas can in one day be irrigated in the above manner by one set of labourers.

Irrigation is sometimes effected by hand labour, two men raising the water by means of a bamboo or leather bucket or basket, swung from ropes. In the Doab of the Ganges and in Rohilkhand, it is called beri, lehari, ch'hapa, boka ; in Benares and Oudh, dauri ; and in Debli and Bundelkhand, dal, dugla, dulia. In Sind and in the Panjab; the Persian wheel, a series of earthenware buckets on the periphery of the wheel, is largely used.

In Dehli and the Doab, dal is the name applied to the basket or bucket used for raising water from a deep well. It is made sometimes of leather, but generally of munj (Saccharum munja) or jhau (tamarisk). It is more expensive than the "tor" irrigation, which consists in merely breaking down the field ridge. Sugar-cane, poppy, and garden crops are irrigated, where possible, from wells only, even when the expense of drawing water from a deep well is fourfold that of shovelling it out of a hollow on the earth's surface; and practical agriculturists entered rates one-fifth higher on lands irrigated from wells than those watered from jhils or ponds.

Where the natural rains are the sole means of irrigating the lands, only one crop can be raised annually, and even that, in difficult seasons, is unobtained. But with artificial irrigation two and three crops can be raised, - a monsoon, a coldweather, and a hot-weather crop.

In Farrakhabad, where three crops are obtained, Indian corn sown in June-July, and harvested in August and September, is the first crop. In October - November, potatoes or carrots are planted as a second crop, and taken up in February or March ; and the third crop is tobacco or melons, sown in April, and gathered in May or June.

Cost. - From the commencement of the Godavery delta irrigation system of works up to $1877-78$, the sum of Rs. $78,77,781$ had been expended. The area irrigated under the anicut was 541,892 acres, in 1876-77, yielding a revenue of Rs. $22,98,423$, divided into a water tax of Rs. 15,91,767, and land assessment Rs. 7,06,656. The total expenditure for the Kistna delta system has been Rs. $48,40,546$. This system is intended to irrigate 470,000 acres. Of that extent, 246,000 were irrigated in 1875-76, yielding a revenue of Rs. $10,98,978$, viz. water tax Rs. $7,32,756$, and land $\operatorname{tax} R$ s. $3,66,222$. Out of 321 miles of canal proposed for navigation in this delta, 267 miles had been opened for traffic up to 1877-78.

From the upper parts of the Cauvery river, channels have been conducted through the Trichinopoly and Tanjore districts, and the portions within the reach of the waters are cultivated like gardens. The great Colerun channel, quite like a great river and about a mile broad, is led off from the Cauvery, aids to form the sacred island of Srirangam, and is exhausted in irrigating the lands to the east. The Cauvery delta irrigation system irrigates 796.968 acres, yielding a revenue of Rs. $33,78,442$. Up to the end of $1873-74$, the sum of Rs. $13,39,641$ had been expended on it by the British Government, which outlay has been estimated to yield a return of 85.81 per cent. The total expenditure on the Srivai Kuntham anicut in the Madras Presidency up to 1877-78, was Rs. 9,20,510. In Mysore, there are anicuts or dams at Nundur, Sri Ramadwara, and Maseehully, and a great reservoir is to be established at Mauri Conwai.

IRULAR. At the foot of the Neilgherry mountains, and for a short distance within the forests extending from their base into the plains, live a race commonly known by the name of Irular. They are in two classes, - one called Urali, the other Kurutalei. Iruli means unenlightened or barbarous, from the Tamil word Irul, darkness, 
and is a term applied to them by their neighbours. Urali signifies the rulers of the people, and Kurutalei the common people. Captain Harkness met with a group of Irulars all but naked, -men, women, and children dancing, jumping, and amusing themselves. The bair of the men, as well as of the women and children, was bound up in a fantastic manner with wreaths of plaited straw ; their necks, ears, wrists, and ankles decorated' with ornaments formed of the same material ; and carrying little dried gourds, in which nuts or small stones had been placed, they rattled them as they danced, and, with the rustling of their rural ornaments, gave a sort of rhythm to their motion. His unexpected visit disconcerted them at first, but this was soon got over, and the dance again resumed, in front of a little thatched shed, which was their temple. When it was concluded, they sacrificed to their deities a he-goat and three cocks. This was done by cutting the throats of the victims, and throwing them down at the feet of the idol, the whole assembly at the same time prostrating themselves. Within the temple there was a winnow or fan, which they called Mahri, and in front of the temple two rude stones, which they called, the one Moshani, the other Konadi Mahri, but which are subordinate to the mahri or fan occupying the interior of the temple. No great distance from this, he passed their places of sepulchre, there being one for the Urali and another for the Kurutalei. These sepulchres are pits, about thirty or forty feet square, and of considerable depth, over which are placed large planks; above is erected a shed, covering in the whole, and protecting it from the weather. In the centre of the planks is an opening about a cubit square, over which are placed other pieces of wood, and on these is raised a small mound of earth in the form of an altar, the surface being decorated with pebbles, placed there both as memorials of the departed, and as objects of future worship. When a death occurs, the mound of earth is removed, and the body thrown in. Some ten or twelve days after, a mound of fresh earth is raised, in room of the one which had been removed; the pebbles, which in the first instance had been carefully put aside, are again replaced, and another one added to them in memory of the deceased. All this is done with much ceremony, the pebbles being anointed with oil, perfumed with frankincense, and decorated with flowers. Food is also distributed to the assembly, according to the ability of the relatives of the deceased. The Irulars speak a rude Tamil.-Captain Harkness' Neilgherry Hills.

IRVINE, ROBERT H., a medical officer of the Bengal army, who rose to the rank of Deputy Surgeon-General. He wrote (1841) an Account of the General and Medical Topography of Ajmir.

IRWIN. Lieut. Irwin accompanied Mountstuart Elphinstone to Afghanistan ; the amount of multifarious information he collected is altogether surprising.

IRWIN, EYLES, an officer of the East India Company, author of a Series of Adventures in the Course of a Voyage up the Red Sea, on the Coast of Arabia and Ligypt, in the year 1777.

ISA, also called Isana, the Hindu deity, presiding over the N.E. quarter of the heavens; a name of Siva.
ISA KHEL, a town and division in the Bant district on the N.W. frontier of India, 42 miles from Banu, and $28 \mathrm{~S}$. of Kalabagh. The town, with 7440 inhabitants, is 9 miles $W$. of the main branch of the Indus, opposite the Rokri Ferry. The Isa Khel division is enclosed between the Indus and the Cuttack Hills, and has a population of 46,000 souls, mostly clans of the Niazi, descendants of Niaz Khan, second son of Lodi, the son of Shah Husen, king of Ghor, from whom the Lohani and Ghilzai claim descent. With the Isa Khel, money is never given to the bride's father, as is the custom of all other Pathan tribes, and every woman of the Isa Khel branch, however humble, is strictly Gosha. The other tribes and races are Awan, Baluch, Hindus, Jat, Cuttack, Khudzai, Koreshi, Pathan, Shaikhs, Syuds, Khatak. The Niazi are trusty allies of the Britisb.-MacGregor.

ISANI. Colonel Tod describes a lofty threepeaked mountain, on which is a temple dedicated to Aya - Mata, also called Isani, the tutelary divinity of the Kol. This and the effigy of the horse are there the only objects of adoration among this aboriginal race. This was the first time he had seen a personification of mother earth, for such is Isani, from Isa, goddess, and Anani, eartb, the universal nurse-mother (Aya-Mata). In their worship of the horse they resemble the other forest tribes, the Bhil, the Gond, and the Surya. Among the many remarkable festivals of Rajasthan kept with peculiar brilliancy at Udaipur, is that called Gangore, in honour of Gouri or Isani, the goddess of abundance, the Isis of Egypt, the Ceres of Greece. Like the Rajput saturnalia, which it follows, it belongs to the vernal equinox, when nature in these regions proximate to the tropic is in the full expanse of her charms, and the matronly Gauri casts her golden mantle over the beauties of the verdant Vassanti. Then the fruits exhibit their promise to the eye, the koil fills the ear with melody, the air is impregnated with aroma, and the crimson poppy contrasts with the spikes of golden grain to form a wreath for the beneficent Gauri. Gauri is one of the names of Isa or Parvati, wife of Siva, Mahadeva, or Iswara, who is conjoined with her in these rites, which almost exclusively appertain to the women. The meaning of Gauri is yellow, emblematic of the ripened harvest, when the votaries of the goddess adore her effigies, which are those of a matron painted the colour of ripe corn; and though her image is represented with only two hands, in one of which she holds the lotus, which the Egyptians regarded as emblematic of reproduction, yet not unfrequently they equip her with the warlike conch, the discus, and the club, to denote that the goddess, whose gifts sustain life, is likewise accessary to the loss of it ; uniting, as Gauri and Kali, the characters of life and death, like the Isis and Cybele of the Egyptians. But in the Gangore festival she is only seen as Anna-purna, the foodfiller, benefactress of mankind. The rites commence when the sun enters Aries (the opening of the Hindu year), by a deputation to a spot beyond the city, 'to bring earth for the image of Gauri.' When this is formed, a smaller one of Iswara is made, and they are placed together; a small trench is then excavated, in which barley is sown; the ground is irrigated and artificial heat supplied till the grain germinates. By rites known only to 
the initiated, having been performed for several days within doors, they decorate the images, and prepare to carry them in procession to the lake. During these days of preparation, nothing is talked of but Gauri's departure from the palace,whether she will be as sumptuously apparelled as in the year gone by; whether an additional boat will be launched on the occasion, though not a few forget the goddess altogether in the recollection of the gazelle eyes (mirg-aeni) and serpentine locks (nagni zoolf) of the beauteous handmaids who are selected to attend her. At length the hour arrives, the martial nakāra give the signal to the cannonier without, and the guns on the summit of the castle of Ekling-garh announce that Gauri has commenced her excursion to the lake. The cavalcade assembles on the magnificent terrace, and the rana, surrounded by his nobles, leads the way to the boats, of a form as primitive as that which conveyed the Argonauts to Colchis. The scenery is admirably adapted for these fêtes, the ascent being gradual from the margin of the lake.

At length the procession is seen winding down the steep, and in the midst, borne on a pat'h or throne, gorgeously arrayed in yellow robes, and blazing with 'barbaric pearl and gold,' the goddess appears, on either side two beauties wave the silver chamra over her head, while the more favoured damsels act as harbingers, preceding her with wands of silver, the whole chanting hymns. On her approach, the rana, his chiefs and mimisters, rise and remain standing till the goddess is seated on her throne, close to the water's edge, when all bow, and the prince and court take their seats in the boats. The females then form a circle around the goddess, unite hands, and with a measured step and various graceful inclinations of the body, keeping time by beating the palms at particular cadences, move around the image singing hymns, some in honour of the goddess of abundance, others on love and chivalry, and embodying little episodes of national achievements, occasionally sprinkled with double entendre, which excite a smile and significant nod from the chiefs, and an inclination of the head of the fair choristers. The festival being entirely female, not a single male mixes in the immense groups, and even Iswara himself, the husband of Gauri, attracts no attention, as appears from his ascetic or mendicant form begging his dole from the bounteous and universal mother. It is taken for granted that the goddess is occupied in bathing all the time she remains, and ancient tradition says death was the penalty of any male intruding on these solemnities; but a late prince deemed them so fitted for amusement, that he even instituted a second Gangore. Some hours are thus consumed, while easy and goodhumoured conversation is carried on. At length, the ablutions over, the goddess is taken up and conveyed to the palace with the same forms and state. The rana and his chiefs then unmoor their boats, and are rowed round the margin of the lake, to visit in succession the other images of the goddess, around which female groups are chanting and worshipping, as already described, with which ceremonies the evening closes, when the whole terminates with a grand display of fireworks, the finale of each of the three days dedicated to Gauri.

Gauri, Anna-deo or Anna-devi, and Anna-purna, 'filling with food,' or the nourisher, are the names applied to 'the mother of mankind,' when she places the repast before the messenger of heaven. Considerable resemblance is to be discerned between this festival of Gauri and those in honour of the Egyptian Diana at Bubastes, and of Isis at Busiris, within the delta of the Nile, of which Herodotus says, "They who celebrate those of Diana embark in vessels; the women strike their tabors, the men their flutes, the rest of both sexes clap their hands and join in chorus. Whatever city they approach, the vessels are brought on shore, the women use ungracious language, dance, and indelicately throw about their garments.' Wherever the rites of Isis prevailed, we find the boat introduced as an essential emblem in her worship. Bryant furnishes an interesting account from Diodorus and Curtius, illustrated by drawings from Pocock, from the temple of Luxor, near Carnac, in the Thebaid, of the ship of Isis carrying an ark; and from a male figure therein, this learned person thinks it bears a mysterious allusion to the deluge. Colonel Tod, however, was inclined to deem the personage in the ark Osiris, husband of Isis, the type of the sun arrived in the sign of Aries (of which the rams' heads ornamenting both the prow and stem of the vessel are typical), the harbinger of the aunual fertilizing inundation of the Nile, evincing identity of origin as an equinoctial festival with that of Gauri (Isis) of the Indo-Scythic races of Rajasthan.

\section{' Heavenly stranger, please to taste}

These bounties, which our nourisher, from whom

All perfect good, unmeasured out, descends

To us for food, and for delight hath caused

The earth to yield.'-Paradise Lost, book v. pp. 397, 401.

The German Suevi adored Isis, and also introduced a ship in her worship, for which Tacitus says he has no materials whence to investigate the origin of a worship denoting the foreign origin of the tribe. This Isis of the Suevi was evidently a form of Ertha, the chief divinity of all the Saxon races, who with her consort Teutates or Hesus (Mercury) were the chief deities of both the Celtic and early Gothic races, the Budha and Ella of the Rajputs; in short, the earth, the prolific mother, the Isis of Egypt, the Ceres of Greece, the Annapurna (giver of food) of the Rajputs. On some ancient temples dedicated to this Hindu Ceres are sculptured on the frieze and pedestal of the columns the emblem of abundance, termed the cumacumpa, or vessel of desire, a vase of elegant form, from which branches of the palm are gracefully pendent. Herodotus says that similar water-vessels, filled with wheat and barley, were carried in the festival of Isis; and the Egyptian god Canopus is depicted under the form of a water-jar or Nilometer, whose covering bears the head of Osiris.-Tod's Rajasthan i. p. 570 .

ISATIS INDIGOTICA. Fortune. A perennial, almost shrubby, dye plant of $\mathrm{N}$. China. It furnishes a product almost similar to I. tinctoria, or dyers' woad. In China, colouring matter for dyeing blue is derived from two species of plants, the Polygonum tinctorium at the south, and the Tien tsing or Isatis indigotica, cultivated at Shanghai and Chusan, and largely in the $\mathrm{Ke}$ wang-meow district, a few miles to the south.

Isatis tinctoria, Linn., the dyers' woad, is a tall herb of two years' duration, growing from the Mediterranean to Japan, succeeding best in rich limestone ground. Its fermented leaves furnish 
a blue dye. The species of Isatis are numerous. -Williams' Middle Kingdom. See Dyes.

ISFAHAN, a chief town of Persia, formerly the capital of the country. It is built on the banks of the Zand-rud, and has about 60,000 inhabitants and 100 neighbouring villages. Isfahan occupies the central part of an oval plain, which is enclosed by a range of mountains, presenting a singularly serrated outline. The lowest part is on the N.E. and the highest on the S.W. side of the city. From an elevated pass leading through the rugged and rocky belt on the latter side, there is obtained a fine view of this mountain basin, whose circumference is about 30 miles. A distance of about 12 miles separates the mountains on the western side from those of the eastern; the shorter diameter being about 8 miles. It is well watered by the tortuous Zend-rud, which flows through it rather southward of its centre.

Mir Wais, chief of the Ghilji, died in 1715 , and was succeeded by his brother, but shortly afterwards Mahmud, son of Mir Wais, became chief of the tribe. He left Kandahar with 25,000 men, marched to Kirman and on to Yezd, from which place he moved directly on Isfahan. He was opposed at Gulnabad, near that city, but obtained a complete victory, and he surrounded and blockaded the city, and soon the inhabitants suffered all the horrors of famine. The miseries endured are described by most writers as surpassing the greatest extremities ever known on such occasions.

The horrors of this siege have been described by the Polish Jesuit Krusinski, who personally witnessed them, and they are noticed in the Histoire de Perse Depuis le Commencement de ce Siecle (the eighteenth) of M. la Mamye Clairac, on authorities which cannot be disputed. The inhabitants of Isfahan were compelled by famine to devour not only mules and horses, but dogs and other creatures, which their religion taught them to consider as unclean. A woman endeavouring to strangle a cat, was heard to exclaim at every scratch or bite that she received, "Thou strivest in vain, I'll eat thee notwithstanding.' The leaves and bark of trees were ground into a kind of meal, and sold by weight; shoe leather was boiled and used as food; at length human flesh became the chief support of many miserable wretches, who for a while were content with what they could collect from bodies that filled the public streets; but some were induced to murder their fellow-citizens, and it is even said that parents killed and devoured their own children. From the MS. memoirs of Ali Hazin, we learn that ' a crust or lump of bread was sold at so high a price as four or five gold ashrafi.' A pound of bread, according to Krusinski, attained, in September, the price of thirty shillings; and, in October, of above fifty. Among the calamities of this memorable siege, Ali Hazin laments the destruction of his library, which comprised about 5000 volumes, Arabic and Persian, many enriched with the marginal notes of his learned ancestors.

After a protracted siege, the king, Shah Husen, the last of the Safavi dynasty, went forth with all his principal courtiers in deep mourning, surrendered himself to Mahmud, and with his own hand placed the crown on the head of the conqueror (October 1722). The authors differ as to the numbers who perished, and also as to those whom Mahmud ordered to be slain after the submission.
Mahmud, after a brief reign of two years, became insane, and either died or was put to death (A.D. 1724), and was succeeded by his nephew, Nadir Namah. - Sir W.Jones; Balfour's Memoir of Hazin, p. 122 ; Malcolm's Persia, i. p. 644 ; Elphinstone's Hist: of India, pp. 631, 632; History of the Revolution of Persia, published by the Pere du Cerceau; Ouseley's Travels, iii. pp. 44, 45 .

ISF ANDYAR, the brazen-bodied; his son Bahman, surnamed Ardeshir, a prince of great renown, is one of the most conspicuous names amongst the heroes of the Shah Namah. See Persian Kings.

ISHA. ARAB. Evening prayer. Ishrak, prayer at sunrise.

ISHAA. JAP. A learned race of Japan, practising medicine.

ISHMAEL, son of Abraham, is supposed by $\mathrm{Mu}$ hammadans to have been the son whom Abraham took to offer up in sacrifice. His lineal descendants were called Arab-ul-Mostaraba, or mixed Arabs. They occupied the Hejaz, and amongst', their descendants was the tribe of Koresh. See Adnan.

ISHTAR, a goddess of the Babylonians, the biblical Ashtoreth.

\section{ISINGLASS.}

Loo-pa, . . . CHIN. Hausblase, . . . GER. Yu-kiau, Yu-piau-kiau, , Hausenblase, . . ." Husblas, : DAv, SW. Ichthyocolla, : : GR. Sounds, Swim, ENG. Cola di pesce, . . IT. Air-bag, . . . ", Palogpong ikan, . MALAY. Swimming bladder, . ", Ari-ikan,

Fish-maws, . . ", Colla de peixe, : P’orT Fish sounds, : ." Klei rubui, Karluk, RUs, Colle de poisson, : Fr. Colapez,. . . . SP. Carllock,

The Greek name Ichthyocolla, is from $\iota x, \nu \varsigma$, a fish, $x_{0} \lambda \lambda \alpha$, glue. Isinglass is from the German Hausenblase, from Hausen; the great sturgeon, and Blase, a bladder, being one of the coats of the swimming-bladder of fishes. Fish-maws or fishsounds of commerce, exported from Calcutta, Madras, Penang, Mergui, Malabar, and Sind, are the sac-like membrane, slit open; some small, thin, and transparent, others three and four inches across in both diameters, something of the shape of short purses with spring clasps, of a light colour, and semitransparent, resembling in appearance the ordinary qualities of isinglass, especially some of the Brazilian kinds. Fish-maws, under the names Singally and Sozille, had long been carried away by the Chinese from Calcutta, Madras, and Bombay, at the rate of about a shilling a pound, without its being generally known that it was isinglass which was thus exported.

The swimming-bladder of fishes consists of three membranes, the outer or peritoneal coat, the middle membranous and muscular one, and the inner, glossy, highly vascular coat, which has a pulpy appearance, and is the membrane which forms the best isinglass. The fish which yield the European supplies are the great sturgeon, osseter, sevruga, and sterlet, also the Silurus glanis, barbel, Cyprinus brama and C. carpio and Perca lucioperca, which do not belong to the tribe of sturgeons. In the fisheries of the Caspian and Volga, where the system is most complete, and the division of labour the greatest, the sounds and roes of the sturgeon are extracted immediately the fish are caught, and delivered over to the isinglass and caviare makers. The fresh sounds are first split open, and well washed to separate the blood, and any adhering extraneous matter. They are then 383 
spread out, and exposed to the air to dry, with the inner silvery white membrane turned upwards. This, which is nearly pure gelatine, is carefully stripped off, laid in damp cloths, and left in the outer covering, and forcibly kneaded with the hands. It is then taken out of the cloths, dried in the form of leaf isinglass, or rolled up and drawn in a serpentine manner into the form of a heart, horseshoe, or lyre (long and short staple), between three pegs, on a board covered with them; here they are fixed in their places by wooden skewers. When they are somewhat dried thus, they are hung on lines in the shade in well-arranged rooms till their moisture is entirely dissipated. The oblong pieces sometimes are folden in the form of book isinglass. Though isinglass of the finest quality, and in the largest quantities, is yielded by, it is not confined to, the sturgeon tribe ; for even in Russia, the Silurus glanis, species of Cyprinus and barbel, yield it, and are met with in commerce with Brazilian, New York, and Hudson's Bay isinglass. The fishes which produce it on the coast of Brazil, Mr. Yarrell informed Dr. Royle, are probably several species of the genera Pimelodus and Silurus, or of closely-allied genera. The Brazilian isinglass is imported from Para and Maranham. It is very inferior in quality for domestic purposes to the best imported from Russia, which sells for 12s. per $1 \mathrm{~b}$, and the other from $9 \mathrm{~d}$. to $3 \mathrm{~s}$. $6 \mathrm{~d}$. It is in the form of pipe, block, honeycomb, cake, and tongue isinglass, the last formed of a double swimming-bladder. The isinglass obtained from North America in the form of long ribbons, is produced, according to Dr. Mitchell, by Labrus squeateague, at New York, called weak fish, which is about 15 inches in length, and above $6 \mathrm{lbs}$. in weight, forming one of their most abundant fish, and furnishing the principal supply for their tables.

An anonymous correspondent in Parbury's Oriental Herald, in 1839 , stated that the Chinese had long been engaged in a trade with Calcutta in isinglass, afforded by a fish called Sulleah in Bengal, from half a pound to three-quarters of a pound being obtained from each fish. Dr. M ${ }^{\circ} \mathrm{Clel}$ land (June 1839, J. As. Soc. vol. viii. p. 203) then mentioned that the fish yielding the isinglass is Polynemus sele, Buch., sele or sulea of the Bengalese, common in the estuaries of the Ganges, and often found weighing from 20 to 24 pounds, and that Palogpong ikan or Ari-ari ikan of the Malays, Loo-pa of the Chinese, appears to have formed an article of exportation from the islands of the Indian Archipelago as early as they became visited by the Chinese.

Arius arius, Buch. Ham.

Pimelodus arius, $B . H$. | Iknn surdudu, . MaLay. Ikan saladu, . MALAY.

Total length, 1 foot 10 inches. This fish inhabits the sea and estuaries of Penang, Malayan Peninsula, Singapore, Pondicherry, and Gangetic estuaries. At Penang, small individuals of this species are very numerous at all seasons. They form an article of food, and contribute more than any other of the Siluridæ to the exportation of isinglass.

Arius militaris, $L$.

Silurus militaris, Linn. | Osteogeniosus, $\boldsymbol{B} . \boldsymbol{H}$.

Length, 1 foot 6 inches. Inhabits the sea and estuaries of the Malayan Peninsula, and of its islands, of Malabar, Coromandel, the Ganges, and Irawadi. Their air-vessels are preserved.
Arius truncatus, $C$. and $V$. Length, 112 inches. Inhabits sea and estuaries of Penang, Malayan Peninsula. Its air-vessel is small, but very thick, and is transversely divided into two compartments. The fish is held in esteem by the natives, but at Penang it occurs so rarely that its air-vessel does not contribute much to the general stock of isinglass.

Capoeta macrolepidota, $K u h l$. Length, 11 inches. Inhabits Penang, Java, and Tenasserim (fresh water). The air-vessel is very large, thin, white, consisting of two elongated oval portions, of which the anterior is truncated in front.

Corvina chapta, Bola chapta. The Bola inhabits the Malay coast ; furnishes isinglass.

Corvina coitor, $H . B$. , Whiting. Inhabits the estuaries of the Ganges and Irawadi. Its airbladder makes excellent isinglass.

Johnius maculatus, Bloch., Schneirler, var.? Sari kulla, TAM., Russell. | Corvina maculata, C. andV. Inhabits sea of Penang. The form of its airvessel resembles that of Johnius belengeri.

Johnius diacanthus, Lacepede.

Lutjanus diacanthus, Lac. Corvina catalea, Belanger Johnius catalens, Cuv. and Bleeker.

Nalla katchelee, Russell. Corvina nalla katchelee, Katchelee, Russell. $\quad$ Richardson.

Sciæna maculata, $C$. and $V$. Ikan tambareh, MaLAY.

This fish grows to 2 feet 9 inches. It inhabits the seas of Penang, Malay Peninsula, Singapore, Malabar, Coromandel, Bay of Bengal, Gangetic estuaries, Tenasserim, Canton, China seas, Madura, and Java, The air-vessel, $\frac{1}{3}$ of the length of the fish, is of a broad lanceolate shape, tapering behind into a very elongated point. This fish is valuable as an article of food, and its isinglass sells in the China market at from 40 to 45 Spanish dollars per pikul.

Johnius Dussumieri, $C$. and $V$. Corvina Duissumieri, $C$. and $V$. Length, $6 \frac{4}{3}$ inches. It inhabits the Sea of Penang, the Malayan Peninsula, Singapore, and Malabar. The length of the airvessel is about one-fourth the total length. The isinglass is reputed good, but, owing to the small size of the fish, little is procurable.

Lates heptadactylus, Lacepede.

Perca maxima, Sonnerat. Coius vacti, Ham.

Holocentre heptadactyle, Lates nobilis, $C$. and $V$., Lacepede.

Pandoo menoo, Russell. Ikan Siyakup, MLALAY.

This fish inhabits the sea and estuaries of Penang, Malayan Peninsula, Singapore, and Madras. It yields isinglass, of which, however, in the Straits of Malacca, but little is collected, partly on account of the comparative scarcity of the fish, and partly owing to the thinness of the air-vessel. That of a fish, when dried, weighs upwards of one ounce. At Penang, this kind sells at the rate of 25 to 30 dollars per pikul.

Lobotes erate, Cuv and $\mathrm{Val}$.

L. Farkarii, $C$. and $V$. Ikan batu, Ikan pichat

Length, 2 feet 5 inches. It inhabits the seas of Penang, Malay Peninsula, Singapore, Java, Madura, Malabar, Ceylon, Bay of Bengal, and estuaries of the Ganges. The air-vessel is very large, about one-third of the total length, silvery white, and of a lanceolate shape. It is excessively thin, and so firmly adhering to the back, that but a small part can be removed. The isinglass is considered by the Chinese dealers to be of good 
quality, but the small quantity procurable renders the fish less valuable in this respect.

Mugil cephalotus, Cuv. and Val.

Mugil our, Forskitl. $\quad$ Sole bhanggan, Ham.

M. cephalus, Russell.

Boutali, TAM., Russell.

Jumpul, . MilaY.

Length, 2 feet. It inhabits Penang, Malayan Peninsula, Singapore, Macao, Lancavy, Chusan, Madura, Coromandel, Bay of Bengal, Gangetic estuaries, Malabar. The air-vessel is large, elongated; its parietes very thin, pearl-coloured.

Otolithus biauritus, Cantor, Ikan salampæ. Total length, 3 feet. Inhabits seas of Penang, Malay Peninsula, Singapore, Lancavy, Tenasserim Province, and, according to Jerdon, the Malabar coast, where it is called Sille-kora in Malealam. The air-vessel is nearly one-half of the total length, and in shape might be compared with an elongated antique urn with two handles. From the anterior part of each of the latter proceed five branches, four of which give off smaller ones to each side, and the fifth is tortuous and smaller than the rest. It yields a large quantity of isinglass, which in the Chinese market is considered to be of the best quality, and fetches 40 to 50 Spanish dollars per pikul.

Otolithus maculatus, Kuhl and Van Hassel. Jaran-gigi, MALAY. The total length of this fish is 2 feet 9 inches. It inhabits the seas and estuaries of Penang, Malay Peninsula, Singapore, and Batavia. It is highly valued for the sake of its air-vessel, which yields a considerable quantity of the best kind of isinglass.

Otolithus ruber, Bloch and Schneider. Jarangigi, Malay. Total length of this fish is $2 \frac{1}{2}$ feet. It inhabits the seas and estuaries of Penang, the Malay Peninsula, Singapore, Coromandel, and Malabar. The air-vessel is large, flattened, broad, lanceolate, terminating behind in a single point. The isinglass is considered very good, and sells in the Chinese market from 40 to 45 Spanish dollars per pikul.

Otolithus versicolor, Cuv, and Val., Russell, 109. Panna, TAM. The total length of this fish is only $6 \frac{1}{8}$ inches. It inhabits the sea of Penang. Its air-vessel is one-fourth of the total length. Jerdon says this fish is one foot long, and very oommon at Madras.

Pempheris molucca, C'ur. This fish grows to $3 \frac{1}{2}$ inches. It inhabits the seas of Penang, the Moluccas, Batavia, and Japan. Its air-vessel is large and thick.

Platax arthriticus, Cur. and Val.

Ikan bonna, Bell. | Chotodon arthriticus, $C . \& V$.

Total length, 1 foot 7 inches. It inhabits the seas of Penang, Sumatra, Java, and Singapore. The flavour is excellent, but the large air-vessel is too thin, and yieldis too little isinglass to become of value.

Polynemus heptadactylus. Total length, $4 \frac{1}{2}$ inches. Inhabits Penang, Batavia, Cheribon, and Samarang.

Polynemus Indicus, Shaw, Roe Ball.

P. sele, Buchanan.

P. lineatus, $M^{\prime}$ Clelland.

\begin{tabular}{l|l}
$P$. & P. gelatinosus, $M^{6}$ Clelland.
\end{tabular}

P. ploteus, $\boldsymbol{M}^{\prime}$ Clelland.

Lukway, . ARAKan. Ikan kurow, . MLLLAY. Ira-tha,. . Burar W Walan kala,. . TAsr.

Total length, 3 feet. It inhabits the seas of Penang, Singapore, Malay Peninsula, Sourabaya, estuaries of the Ganges, Vizagapatam, Madras, and Pondicherry. The air-vessel is silvery, its membrane thick, the general form oval. It occupies the whole length of the abdomen, terminating behind in a very sharp point, which penetrates the thick of the tail over the first interspiual of the anal. At Penang single individuals occur at all seasons; but numbers are taken from June to August. The weight is commonly from 4 to $6 \mathrm{lbs}$, seldom exceeding 20 lbs. The air-vessel of a goodsized fish, when dried and ready for the market in China, weighs upwards of $2 \mathrm{oz}$, is considered very good isinglass, and fetches 25 to 30 dollars per pikul. The fish itself is valued as an article of food, though less so than P. tetradactylus. Mr. O'Riley estimated that $2000 \mathrm{lbs}$. of isinglass from this fish might be obtained annually off Amherst alone. Mr. Blundell said that the largest sounds were exported from Rangoon, and that they sell there at about 8 annas a pound. Major Bogle wrote that about 10,000 of the fish, large and small, were taken annually in Arakan, and that the sounds sold there for about 5 annas per pound to the Chinese, who exported them to Penang, where they are said to bring more than a rupee a pound.

Polynemus plebius, Broussonet, $L_{*}, C^{\prime}$ and $V$.

P. lineatus, Lacepede. $\quad$ P. Commersonii, Shaw.

P. niloticus, Shaw. $\quad$ Bynni, Bruce. Pole kala, TAM.

Length, 4 feet. It inhabits the Coromandel coast, Otaheite, Isle of France, and Isle of Tanna. Its value as a fish yielding isinglass unknown.

Pristipoma hasta and Pristipoma olivaceum, of the family Percidæ, are common round the coasts of India, and their air-bladders are largely exported to China.

Umbrina Russelli, C. and V., Richardson. Ikan gulama, . MALAT. | Qualar katchelee, . TAsr.

Total length, 6 inches to 1 foot? Inhabits seas of Penang, Malay Peninsula, Singapore, Vizagapatam, Indian and China seas. Its isinglass is considered of good quality.-Russell.

The Indian isinglass is not prepared with anything like sufficient care to obtain a place in the markets of Europe. Good isinglass cannot be made without considerable attention being paid during the processes of washing, beating, scraping, and drying, all of which have a very important influence on the goodness of the finished isinglass. The imperfect solubility of some, and more especially of the thick pieces, is occasioned by the presence of a considerable quantity of albumen, or insoluble nembranous matter having most of the properties of albumen, which is not only itself insoluble, but in addition renders much of the gelatine with which it is associated likewise insoluble. It is more than probable that the greater part of this albuminous substance might be readily removed by sufficiently scraping the isinglass during its preparation. Attention should also be directed to the process of drying, as, if not properly dried, it might possibly undergo a slight change or decomposition, and become partially converted into a more insoluble form of gelatine. A more important objection is the smell, which, however, may likewise, to some extent, be traced to the preparation. Much greater care is bestowed on the preparation in Russia than in India. Boiling with fresh-made charcoal would probably have the effect of depriving inferior isinglass of some of the smell and colouring matter when required for the purposes 
of a jelly. Isinglass cut into threads is unsuitable for the English commerce, notwithstanding that isinglass for retail is cut into fine threads, as more convenient for general use, and for making jellies and soups, in consequence of the extensive surface which is exposed rendering it more easily and quickly soluble. But there is a great prejudice in the wholesale market to buying things in a cut or powdered state, in consequence of the innumerable methods adopted for falsifying and adulterating almost every drug. Machinery is used in London for cutting the isinglass into threads of any degree of fineness; and as it is impracticable at present to rival this in India, besides having to contend against prejudice if sent in this state, it is preferable, and will be cheaper, to prepare the article and send it as sheet isinglass, that is, the form of the slit sounds themselves, or their purest membrane, washed, cleaned, and dried in the best manner. The Indian isinglass, as at present prepared, is complained of as too thick if intended to come into competition with the superior varieties of Russian isinglass. Some of it may, without difficulty, be rendered thinner, for even in the dried state, layers of membrane which display a fibrous structure may be stripped off, and which no doubt contain the greater portion of the insoluble albumen. It might also be made thinner by beating, or pressing between iron rollers or marble slabs, as is done with American and some kinds of Brazilian isinglass. The extra labour which this would require might be profitably saved, by not tearing it into fibres, in which state it is disapproved of in the market; but it might still be cut or rasped into a state fit for domestic use. The refuse should be turned to account; the soluble parts of the sounds separated from the insoluble, and poured out into thin plates, and dried on nets, as is done with some of the gelatine of commerce. In order to ascertain the value of the article (merely stripped of all impurities calculated to injure its quality, without any regard to appearance), a considerable quantity was sent to England by Dr. M'Clelland. From the account received of the sale, it appears that this isinglass realized only 1s. 7 d. per pound, which was considerably under its prime cost.-Dr. Royle on Isinglass, p. 11; Cantor, Malayan Fishes in J. B. As. Soc.; Mason's Tenasserim; Dr. Day on the Air-bladder of Fishes; Jerdon, Fishes.

ISIS, a goddess of the Egyptians. Macrobius tells us that Isis is worshipped in every religion, being either the earth or universal nature, under the influence of the sun. For this reason the whole body of the goddess is covered with breasts (in this respect resembling the Diana multomamma of Ephesus), because the universe is nourished by the earth of nature. Over the door of the minor temple of this deity at Pompeii, are wreaths of lingam and yoni.-Milner's Seven Churches, p. 79 ; Tod's Rajasthan. See Cumbha; Gauri; Isani.

ISKARDO or Skardo, principal town of Balti state, Kashmir, in lat. $35^{\circ} 12^{\prime} \mathrm{N}$., and long. $75^{\circ}$ $35^{\prime} \mathrm{E}$. It is on a plain 7700 feet above sea-level, at the bottom of a valley surrounded by lofty mountains. The fort occupies a rock of gneiss at the confluence of the Indus with its great tributary the Singpar.

Baltistan or Balti (called by British geographers Little Tibet), is a country a good deal to the north-east of Kashmir, and north-west of Ladakb. Gilgit, conquered by Gulab Singb, is to the west-north-west of Iskardo. The Chorbat district is a dependency of the government of Iskardo, which, like that of Jeh, is subject to Kashmir. The desert country by which Nubra and Chorbat are separated, has, for the present, acted as a barrier to the further extension eastward of the Muhammadan religion, which is now universally that of the people of the whole of Iskardo (or Balti) district, as well as of Dras. On the Indus, and in the valley south of it, there is no uninhabited tract between the two, so that the Muhammadan and Buddhist populations are in direct contact. The result is, that Muhammadanism is in that part gradually, though very slowly, extending to the eastward. Iskardo is a Muhammadan corruption of the Tibetan name Skardo, or Kardo, as it is very commonly pronounced. The mountains which surround the Iskardo plain rise at once with great abruptness, and are very steep and bare. The houses of Iskardo are very much scattered over a large extent of surface, so that there is no appearance of a town.-Thomson's $T r$. pp. 204-219; Mrs. Hervey's Tartary, i. p. 213.

ISLAM, the Mubammadan name of the Muhammadan religion, derived from the Arabic verb Salm, he gave safety; other parts of the verb being in use, as salam, taslim, salāmat, mūslim. Its followers style themselves mūsalmān, the Arabic plural of mūslīm; and in India, muslinı or nao muslim, lit. new saved, is applied to all converts. They also call themselves Mubammadi, also Momin, and style their faith the Din-i-Islam, the saving faith.

Islam is the name that was given to the Muhammadan religion by its founder. Surat-ulImran, verses 78,79 , says it is the belief in God, and in what was sent down to Abrahan, Ishmael, Isaac, Jacob, and the tribes, and given to Moses, Jesus, and the prophets from their Lord.

The followers claim for it to be regarded as the true faith, comprising obedience to the will of God, submission, humbling one's self. Their sacred book, the Koran, is the foundation of the laws and religion of the Muhammadans. The Shaikh-ulIslam is the chief legist and jurist of the T'urkish empire. Ahl-ul-Islam are the people of the faith.

The doctrine is termed Islam. Faith is termed Iman, and religion, in its practical sense, Din. Muhammadanism enforces the dogma of unity in creed, by the phrase 'ul-Islam malleti wahidun,' All Islamites are one nation. Islamism is regarded by the Jews as the second great heresy of their faith.-Cal. Rev., Feb. p. 387 ; Malcolm's Persia, ii. p. 322.

ISLAMABAD is the ancient capital of Kashmir. Five miles to its west is the temple of Martand. It is built on the Jhelum, and is the seat of the shawl manufacture.

ISM. ARAB. A name or attribute. In exorcism, amongst Muhammadans, certain names (Ism, sing. ; Isma, pl.) are used, such as the Ism-jallali, or fiery or terrible attribute of the deity, also the Ism-jamali, the watery or air or amiable attribute, and with these they pretend to cast out devils, and command the presence of genii and demons. Ism-i-Azam is the great attribute of the deity. Ism, a noun; Ism-u-nisbah, an adjective; Asma, plural, names or attributes of God.

ISMAIL, called Samani, a Turk, the founder 
of the Samani dynasty, A.D. 862. He conquered Transoxiana, Khorasan, and Afghanistan, and fixed the seat of his government at Bokhara. The Samani dynasty ruled for 120 years. It was the fifth of this dynasty who possessed a Tartar slave named Alaptagin, who was made governor of Gbazni and Kandahar, and on the death of his patron assumed independence. Alaptagin was succeeded, A.D. 970, by his purchased Turki slave Sabaktagin.

ISMAIL, the first king of the Suffavean race, ascended the throne of Persia in A.D. 1499, and proclaimed the Shiah faith to be the national religion of that country.

ISMAIL, son of Jafar Sadaq, was the seventh Imarn of the Shiah Muhammadans. The Shiab sect look on Ali as the first rightful leader of the Muhammadans, and say that from him and his wife Fatima, Mahomed's daughter, have alone sprung the rightful heirs to the Imāmat. In this view, Abubakr, Umar, and Othman, who preceded Ali, and Muāwiyah, the fifth khalif, and his son Yezid, are all alike regarded as usurpers. Ali, Hasan, and Husain were first, second, and third. Jafar, the sixth of the Shiah Imams, was a man of superior sanctity, wisdom, and learning. He was the author of the Book of Faith which is still in use. A tradition exists that he did not die, and will reappear. His son Ismail was, during his lifetime, nominated his successor, but, dying before his father, and leaving none but young children, his half-brother Musa Kasim, whose mother was a slave, was elected to the Imumat. Musa's son Ali was eighth Imam; Muhammadbin-Ali was ninth; Ali, son of Muhammad, tenth; Hasan, the eleventh, was poisoned, and his son Muhammad, born A.H. 255 at Sermenrai, and who was a mere infant at his father's death, was his successor, but disappeared mysteriously at the age of twelve years. According to a legend, he entered a cave at Sermenrai, near Baghdad. On the accession of Musa Kasim, many of Ismail's followers espoused the cause of his children, and formed a sect, who became notorious in history as the Assassins, their ruler being styled the Shaikhul-Jabl, or Old Man of the Mountain, whose fortress was Alamut; but with the defeat of Kahir Shah, Ala-ud-Din's son, the demolition of his strongholds, and the slaughter of over 12,000 of his adherents by Hulaku, the power of the Ismaili family came to an end.

ISMAIL ABULFADA, Prince of Hamah in Syria, A.I. 733, which was translated by John Gagnier, Professor of Arabic at Oxford, A.D. 1723, and into English by the Rev. W. Murray, Episcopal clergyman at Duffus in Scotland.

ISMAILI, also Ismailiah, are Shiah sectarians, who take their name from the Imam Ismail, son of the Imam Jafar Sadaq. In Bombay they are known as the Khoja sect. The Ismaili are the sect of the chief known to the Crusaders as the Old Man of the Mountain, the Shaikh-ul-Jabl. The sect in its original form was a branch of the Shiah, but was called Ismailian, from Ismail, the eldest son of the sixth Imam, whom they recognised as his father's successor in opposition to the mass of the Shiahs. Their doctrine took the form of a sort of gnosticism, giving a uon-natural sense to all revelation, from which they had the name also of Bathenians, from Batin, ARAB., within, a word gignifying esoteric. Hasan Sabah, son of an Arab at Rai, one of their converts in Persia, put himself at the head of the sect in that country, and about A.D. 1090 made himself master of the mountainous part of Irak Ajami, immediately south of the Caspian. This region included many strong castles, and at one time the power of his successors extended to the gates of Isfahan. From its character the country was called by the Arabs Balad-ul-Jabl, the hill country, and hence the chief's title. This was also applied to the head of a branch society which had its seat in Syria, and became well known to the Crusaders. The name of Assassin has been by many supposed to be derived from Hashish, the hemp drug, under the influence of which the emissaries of the society are imagined to have acted, but it is more probably obtainable from Hasan Sabah, hence al-Hasani.

In the western side of India, members of the Ismaili sect are designated Khoja, about 1400 families in and around Bombay, 5000 in Kattyawar, 3000 in Sind, and 800 or 900 in Zanzibar. They are descendants of converted Hindus of Sind, who about 400 years ago were won over by Pir Surd-u-Din, a Dai of the Ismaili.

Aga Khan, a chief of one of the branches, claiming indeed to be a descendant from or the representative or incarnation of $\mathrm{Ali}$, died, aged eighty-one, at Bombay, in April 1881. He had failed in an attempt to obtain the kingdom of Persia, and returned to India, where he obtained fees from all his sect from Zanzibar to Central Asia. The Khoja sect of Bombay alone gave him a lakh of rupees a year, and the Government of Bombay allowed him 12,000 rupees annually, for services rendered during the Afghan war of 1842. His son has since been recognised as his successor.Malcolm's Persia, i. p. 347 ; D'Ohsson, book iv. ch. iv.; Yule, Cathay, i. p. 154.

ISOETES COROMANDELINA. Linn.

Ghi-ka-gadda, . Duкн. | Gitti gadda, . . . Ter. Nechatty kalangu, . TAM.

Found in great abundance along the edges of tanks in the Karnatic. The tender white shoots immediately above the spore-bearing involucres are a favourite article of diet, and are sold commonly in the bazars after the monsoon.

ISONANDRA, a genus of plants belonging to the natural order Sapotaceæ. The genus consists of large trees growing in Ceylon, and in the two Peninsulas of India. Dr. Wight, in Icones, has I. candolleana, lanceolata, percha, Perottetiana, polyandra, and villosa. In Ceylon, I. canaliculata, $T h w$. , is a middle-sized tree in the Caltura district; I. grandis, Thw., a large tree of the Central Provinces and Saffragam districts, from the seeds of which an oil is extracted, and which is used similarly to that of the Bassia longifolia. I. lævifolia, $T h w$. is a moderate-sized tree of the Saffragam district of Ceylon and at Reigam Corle. I. pauciflora, Thw., is a moderate-sized tree at Ratnapura, in Ceylon. I. obovata, Griffith, is an evergreen tree of Tenasserim, yielding a sort of gutta-percha. I. rubiginosa, Thw., is a large tree of the Saffragam district and Hinidun Corle, in Ceylon, growing up to an elevation of 4000 feet.

-W. Ic.; Thw. Zeyl.

ISONANDRA ACUMINATA. Lindl.

Isonandra Cullenii, Drury. | B. elliptica, Dalzell. Bassia acuminata, Bedd.

Indian gutta tree, ENG. Pashonti, . MLLLal. Pachonti, . Maldal. Pali, .. Tas. 
Grows in the forests of Coorg, the Wynad, Travancore, and in the Animallay mountains. It attains a height of 80 or 90 feet, and furnishes a good wood, and capable of receiving a good polish. It exudes from the trunk a substance having similar characters to the gutta-percha of commerce; this is procured by tapping, but the tree requires an interval of rest of some hours, or even of days, after frequent incision. In five or six hours, upwards of $1 \frac{1}{2} \mathrm{lbs}$. was collected from four or five incisions in the tree. When fresh, this is of a milk colour, the larger lumps having a dull-red colour. The gum is hard and brittle at the ordinary temperature, but becomes sticky and viscid on the increase of heat, such as that from friction in a mortar; and when this condition is reached, it does not, until after the lapse of several days, resume its original consistence. Boiled with water it becomes of a reddish-brown colour, rendering the water turbid and slightly saponaceous. With some chemical re-agents, the behaviour of the gum was exactly like that of the gutta-percha, while with others only a slight similarity was observed. After solution in naphtha or turpentine, gutta-percha resumes its original condition, but the pachonta continues viscid and sticky, and if again much cooled becomes brittle and friable as at first. It is not found applicable to all the purposes for which gutta-percha is used, but 20 to 30 per cent. of it may be mixed with gutta-percha, without destroying the qualities of the gutta.-Surgeon-General Balfour in Report of Madras Government, Central Museun; Madras Conservator's Report, 1858, p. 6; Year Book of Facts.

ISONANDRA GUTTA. Hook.

Didropsis gutta, Benth. |Gutta-percha tree, . ENG. Mazer wood tree, . ENG. ! Taban, Niato, . Malar.

The gutta-percha tree is a native of the Malay Archipelago, Sumatra, and Borneo. In 1812 the discovery was made that its gum was suited for an infinite number of applications; and now there is scarcely any vegetable product more extensively useful, or one more generally sought after for mercantile purposes. Dr. Montgomerie observed in the hands of a Malay woodsman at Singapore, the handle of a parang, made of a substance quite new to him, and which he found could be moulded into any form, by simply dipping it in boiling water until it was heated throughout, when it became plastic as clay, and when cold regained, unchanged, its original hardness and rigidity. Dr. Montgomerie transmitted specimens of this substance to England on the 1st March 1843, and received the gold medal of the Society of Arts for its introduction, 'as a new and hitherto unknown substance, likely to be useful for various purposes in the arts.'

Gutta-percha, in its crude state, differs in many particulars from caoutchouc; it is of a paleyellowish, or rather dirty white colour; it is contained in the sap and milky juice, which quickly coagulates on exposure to the air, -from 20 to 30 $\mathrm{lbs}$. being the average produce of one tree. For collecting the sap, the trees are felled, barked, and left dry and useless. Hence forests are soon cleared of the gutta trees, whereas it is believed that a constant and moderate supply might be secured by incisions in the bark, as in the case of caoutchouc. The gutta is received in blocks, or in rolls of thin layers, being, in the first place, freed from impurities by kneading in hot water, when it is left soft, plastic, and of a whitish grey. When thus prepared, the gutta has many curious properties. Below the temperature of fifty degrees it is as hard as wood, but it will receive an indentation from the finger nail. When softened in hot water, it may easily be cut and moulded, and it will harden, as it cools, to its former rigidity; and it may be softened and hardened any number of times, without injury to the material. Unlike caoutchouc, it has little elasticity, but it has such tenacity, that a slip oneeighth of an inch substance sustained $42 \mathrm{lbs}$. weight, and only broke with a pressure of $56 \mathrm{lbs}$. When drawn out, it remains without contracting. It has been made subservient to the manufacture of tubings, mouldings for picture-frames, catheters and other surgical instruments, whips, thongs, cricket balls, driving bands or straps for mechanic purposes, soles for boots and shoes; in solution, also, like caoutchouc, for waterproofing cloth. It is likewise employed in mastics, cements, and is burnt and made into printing ink and paint. -Tomlinson; Cat. Exhib., 1862.

ISONANDRA WIGHTIANA. $A . D . C$.

I. Perottetiana, A. D. C. I. lanceolata, W. Ic.

I. Candolleana, W. Ic. Kiriwarala gass, . SiNGH.

A moderate-sized Ceylon tree and of the Western Ghats. One variety is extremely abundant at an elevation of 2000 to 5000 feet, another variety grows near Galagama, and a third variety is at Newera Ellia.-Thw. Zeyl.

ISORA CORYLIFOLIA. Sch. and End.

Helicteres isora, Linn. | H. Roxburghii, Rheede.

Antumora, . . Beng. Valumpiri, . Maleal.

Thu-gnay-khyæ, BuRM. Valambiri kaya, : ThL. Indian screw plant, ENG. Nuliti ; Syamali, : ", Marori, . . HIND.
Isora Marri,. : MALEAL.

Good white fibres, called Googul in Tamil, are obtained from its bark, and are made into excellent ropes; various parts of this plant are employed in medicine; its wood is employed to obtain fire by friction. - Mad. Ex. Jur. Rep.

ISPAND. PERs. The seed of the Lawsonia inermis, in Persia burnt at marriages.

ISPRINJI, a town of Baluchistan, occupied exclusively by the Bangolzai Baluch, who also spread into Shal and Mustang, and in winter repair to Talli, near Lehri.

ISPRUK, a coarse powder made from a species of Delphinium, growing in Afghanistan; used in dyeing.-Simmonds' Dict.

ISRAFIL, according to Muhammadan belief, the angel who will sound the trumpet at the last day.

ISREE, a cotton fabric. Vizagapatam Isree, Nellore white Percalah, and Jyempettah Soocey are of accurate workmanship.-Jur. Rep. M. E.

ISSYKOL LAKE, in parts is 5000 feet above the sea. It is 300 versts in length, and 50 in breadth. Bones are found there, and submerged ruins and statues of men and women.

ISTAKHR, an isolated hill north-west of Persepolis, having a fort which seems to have served as a state prison. This isolated hill is the key of the pass which opens into the plain of Persepolis, from the hilly country of Ardekan. Istakhr or Persepolis was always a favoured spot with the ancients. It was the cradle of the Abmed race, and it was in its vicinity that Yezdejird, on his return from Khorasan, placed himself for the 
last time at the head of his subjects, and was defeated by Abdullah, son of Omar, A.D. 650 . The Sharf Namah, a History of Kurdistan, represents the castle of Istakhr as a state prison in which Ahmed was confined during the space of ten years. Among the celebrities of Istakhr may be mentioned Mazdac, who propagated the doctrine of the conmunity of women, which in the early part of the 19 th century was renewed by the Saint Simonians. Mazdac was a native of that town, and flourished in the reign of the Kaianian monarch Kobad, in the 6th century of the Christian era.-Ouseley's Tr. ii. 404; De Bode's Tr. 165.

ISTALIF, a town in the Koh-i-Daman of Kābul, 20 miles W.N.W. of Kābul. The inhabitants are Tajak; they are turbulent and vindictive, but are deemed the best foot soldiers in Afghanistan. It was carried by assault by the troops under Sir John $M^{\circ}$ Caskill on the 29 th September 1842 , and totally destroyed. It is one of the most picturesque spots which can be conceived; all that a combination of natural beauties can achieve are beheld here in perfection. The hills produce good pasture. The houses are erected along the skirt of the mountain. Near this place is a beautiful village called Istarghich, on the way to Charikar. This latter place is larger than any other town in the valley, but is not handsome.Mohun Lal's Tr. p. 560; Masson's Journeys, iii. p. 120; MacGregor, pp. 392, 393.

ISTAQBAL. ARAB. The Muhammadan courtesy of advancing to receive a distinguished guest. A deputation is usually sent forward to meet, welcome, and conduct to the lodgings prepared for him, any stranger or guest to whom it is designed to pay high respect; and the more numerous and higher in rank the persons of whom this deputation is composed, the greater is the honour conferred. In the courtesies of Muhammadans, a host advances to receive a visitor, and on his departure convoys him (murajāt) to the same spot.-Fraser's Khorasan.

ISTAWA. ARAB. In the Bombay revenue accounts, the land rent levied at progressively increased rates, until it reaches the full sum imposable on land brought into cultivation.Wilson

ISTIMRAR. ARAB,, HiND, TEL. Land granted in perpetuity at a stipulated rent. $-W$.

ISTIOPHORUS GLADIUS, the flying swordfish of the Cape, has a large dorsal fin.-Hart.

ISIVARA. SANSK. Lord, master; but is a designation by Hindus of the particular god, Brahma, Vishnu, or Siva, whom they may regard as the Supreme Being. Generally, however, in Southern India, it is accepted as applied to Siva, who is also called Maha-deva. Colonel Tod sees the Osiris of Egypt in the Iswara of India.

ISWARA. In Hindu astronomy, the 11th Jear of the cycle of Jupiter.

ITALY, a country in the south of Europe, its southern shores washed by the Mediterranean Sea and the Gulf of Venice. Its chief cities are Rome, Milan, Florence, and Turin. 'The old Italic languages comprehended the Latin, Umbrian, Oscan, and Siculian. The modern Italian is an offishoot from Latin ; it is remarkable for its smootbuess, and is spoken in its greatest purity at Florence. In 1881-82, Italy sent to India merchandise to the value of Rs. $52,44,334$, and received Indian produce of value $\mathrm{Rs}_{\mathrm{s}} 3,10,23,810$.
ITIHASA. SANSk. Epic poems of the Hindus, as the Ramayana and the Mahabharata legends of heroes, some of them pictured to have been related by Bhima-sena, as he lay wounded on the field of battle.-Dowson; Growse.

ITO, a tree of Tahiti, furnishing a strong, heavy timber, used for posts and the framework of houses.

ITR. HiND. Also written Atr, Otto, and Attar, any strong-scented essential oil.

ITZABU, a square silver coin of Japan, worth about $1 \mathrm{~s} .6 \mathrm{~d}$. or $1 \mathrm{~s} .8 \mathrm{~d}$. It is the common coin of Japan by which prices are fixed.

IVES, EDWARD. A medical officer of the British Navy, who wrote a Voyage from England to India in 1754, and an Historical Narrative of the Operations of the Army in India under Admiral Watson and Colonel Clive, Lond. 1773.

IVORY.

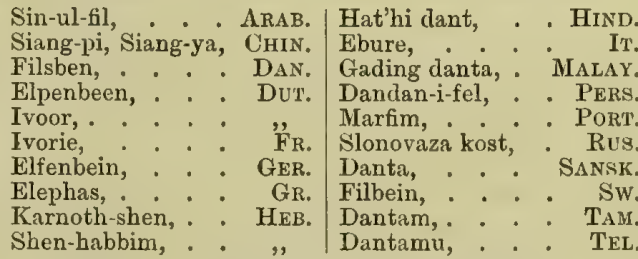

Ivory is mentioned in Homer and Hesiod. The great throne of Solomon was made of ivory (1 Kings x. 18-20, xxii. 39; 2 Chronicles ix. 17-19; Canticles vii. 4). The ivory of commerce is obtained from the tusks and teeth of the elephant, the narwhal, the walrus, and the hippopotamus. The best and largest supply is, however, from the elephant, and that of the slain elephant is preferred. The male elephant, when full grown, has two tusks, varying very greatly in size in different animals, but most valued when they are large, straight, and light in colour. These tusks are hollow at their insertion into the jaw, and for a considerable space therefrom, but become solid as they taper towards the extremity. The principal sources whence they are obtained are the western coast of Africa and the E. Indies; but the African tusks are most esteemed, as being denser in texture, and less liable to turn yellow. By an analysis, the African show a proportion of animal to earthy matter of 101 parts to 100 ; while in the Indian it is 76 to 100 .

Unmanufactured Ivory.

\begin{tabular}{|c|c|c|c|c|c|}
\hline & \multicolumn{2}{|c|}{ Imported. } & \multicolumn{2}{|c|}{ Exported. } \\
\hline & & Lbs. & Value, Rs. & Los. & Value, Rs. \\
\hline $1874-75$ & & 567,214 & $12,11,517$ & 8,288 & 39,183 \\
\hline $1875-76$ & & 568,588 & $22,92,471$ & 12,300 & 59,473 \\
\hline $1876-77$, & & 546,769 & $24,15,314$ & 10,731 & 52,566 \\
\hline 1877-78, & & 456,662 & $19,39,549$ & 11,211 & 56,653 \\
\hline $1878-79$ & & 405,988 & $16,73,742$ & 12,148 & 57,458 \\
\hline $1879-80$ & & 431,740 & $17,92,609$ & 12,255 & 55,624 \\
\hline 1880-81, & & 471,689 & $20,54,332$ & 9,194 & 43,970 \\
\hline 1881-82, & & 511,829 & $21,89,672$ & 9,994 & 50,046 \\
\hline
\end{tabular}

The largest pair of elephant's tusks sent to the 1851 Exhibition weighed 138 lbs.; they were obtained from a wild elephant killed in the Travancore forests. One tusk weighed 71 lbs., the other $67 \mathrm{lbs}$, and showed a fine white compact kind of ivory; of these two, one measured 6 feet 8 inches in length, and the other 6 feet 6 inches, the circumference at the base being 17 inches in each case. The domestication of the elephant is usually attended by deterioration of 
the length and quantity of the ivory. At Zanzibar, and on the east coast of Africa, tusks weighing $100 \mathrm{lbs}$. each are common; those of $175 \mathrm{lbs}$. are not rare, and a pair has been seen whose joint weight was $560 \mathrm{lbs}$.

The tusks of the hippopotamus afford a very hard and white ivory. These are usually short and much curved, hollow at the place of insertion, and covered with a glossy enamel. They vary in weight from 3 or 4 to 30 lbs. These are highly prized by the dentists, and are better adapted than any other ivory for making artificial teeth. The thick coat of enamel which covers them has first to be removed, for this entirely resists steel tools, and under it is found a pure white ivory, with a slight bluish cast. The parts rejected by the dentists are used for small carved and turned works.

The horn or tooth of the narwhal is also hard and susceptible of a fine polish. The largest size is 10 feet long; at the lower extremity it forms a slender cone of a twisted or spiral figure.

Fossil ivory at one time supplied almost the whole of the ivory-turner's work made in Russia. Along the banks of the larger rivers of Further Siberia, thousands of tusks were annually dug up, which once constituted the weapons of defence of a species of mammoth now extinct. Their substance was as well adapted for use as the ivory procured from living species. One measured 10 feet in length, and was solid to within 6 inches of the root, weighing no less than $186 \mathrm{lbs}$. ; this was cut up into keys for pianofortes. African ivory, when first cut, is mellow, warm, and transparent, almost as if soaked in oil, and with very little appearance of grain or fibre; the oil dries considerably by exposure, and a permanent tint then remains, a few shades darker than writing paper. Asiatic ivory is more dead-white at first, but is more disposed of the two to turn yellow afterwards. Ivory is brought to China, principally from Cochin-China, and from Africa via Bombay, and always finds a ready sale at Canton; the largest and best tusks weigh from 16 to $25 \mathrm{lbs}$. each, decreasing to 5 or $6 \mathrm{lbs}$. The cuttings and fragments also form an article of trade, as the workmen can employ the smallest pieces. Bones and horns, especially the long horns of buffaloes, are in China worked into handles, buttons, etc. Rhinoceros' horns are taken from Burma, from Sumatra, and from Africa through Bombay; they are highly valued by the Chinese, from a notion that cups made from them sweat whenever a poisonous mixture is poured into them. A perfect horn sometimes sells as high as 300 dols., but those that come from Africa do not usually rate above 30 or 40 dols. each. The principal use of these horns is in medicine and for amulets, for only one good cup can be carved from the end of each horn; and consequently the parings and fragments are all preserved. The hard teeth of the walrus, lamantin, and other cetaceous animals also form an article of import into China from the Pacific, under the designation of sea-horse teeth; they weigh 1 or 2 lbs. a-piece, and the ivory is nearly as compact, though not so white, as that of the elephant.

Ivory of the teeth of the sperm whale is hard, heavy, elegantly marked, and takes a good polish, but is somewhat variable in quality, and often deficient in purity of colour. $-F . D$. Bernett, p.
11; Tomlinson; Holtzaptfel; Hon. Mr. Morrison's Compendious Description; Madras Exhibition Juries' Rep.

IVORY CARVINGS of different parts of India are admired for the elaborateness of detail and for the truth of representation. A set of chessmen from Berhampur at the Exhibition of 1851, carved from the drawings in Layard's Nineveh, were excellent representations of what the workmen could only have seen in the above work, and showed that they are capable of doing new things when required; their representations of an elephant and other animals were true to nature. At the Madras Exhibition of 1855, a very interesting and complete series of carvings in ivory was exhibited by the raja of Travancore. It comprised many of the common animals, reptiles, fruits, and flowers of the country, all carved with taste, and carefully finished. There was a good deal of grace and spirit in the action of the animals, some of which were in natural attitudes, particularly a bull and cow, two deer, a cheeta, and a rabbit. A frog and lizard were well represented, and a pair of paper-cutters with ornamental handles were particularly deserving of notice, one for the judicious adaptation of a common garden flower to the design, and the other of a lizard in a spirited attitude. The whole series evinced a perception of the natural beauties of the objects represented. The delicate carving of Chinese workmen is well known. Few products of their skill are more remarkable than the balls, containing ten or twelve spheres cut out one within another. The manner of cutting these is simple. A piece of ivory or wood is first made perfectly globular, and then several conical holes are bored into it in such a manner that their apices all meet at the centre, which is usually hollowed out an inch or less after the holes are bored. A long crooked tool is then inserted in one of the conical holes, so bent at the end and stoppered on the shaft that it cuts the ivory at the same distance from the surface when its edge is applied to the insides of the cone. By successively cutting a little on the insides of each conical hole, their incisures meet, and a sphericle is at last detached, which is now turned over and its faces one af ter another brought opposite the largest hole, and firmly secured by wedges in the other holes, while its surfaces are smoothed and carved. When the central sphere is done, a similar knife, somewhat larger, is again introduced into the holes, and another sphere detached and smoothed in the same way, and then another, until the whole are completed, each being polished and carved before the next outer one is commenced. Fans and card-cases are carved of wood, ivory, and mother-of-pearl in alto-relievo, with an elaborateness which shows the great skill and patience of the workmen, but at the same time his bad taste in drawing, the figures, houses, trees, and other objects being grouped in violation of all propriety and perspective. Beautiful ornaments are made by carving roots of plants, branches, gnarled knots, etc., into fantastic groups of birds or animals, the artist taking advantage of the natural form of his materials. Models of pagodas, boats, and houses are also entirely constructed of ivory, even to representing the ornamental roofs, the men working at the oar, and women looking from the balconies. Baskets of elegant shape are 
woven from ivory splinths; and seals, paperknives, chessmen, counters, combs, etc., exceeding in finish and delicacy the same kind of work found anywhere else in the world. The most elaborate coat of arms, or complicated cypher, can also be imitated by these skilful carvers. The national taste prefers this style of carving on plane surfaces; it is seen on the walls of houses and granite slabs of fences, the woodwork of boats and shops, and on articles of furniture. Some of it is pretty, but the disproportion and cramped position of the figures detract from its beauty. When bones are subjected to the action of hydrochloric acid, the phosphate of lime, which forms one of their component parts, is extracted, and thus bones retain their original form, and acquire great flexibility. In the course of drying, the ivory returns to its original hardness, but its flexibility can be easily restored by surrounding it with wet linen, or by placing wet sponges in the cavities of the pieces. The decay of articles in ivory can be effectually checked, even when its progress has advanced so far as to cause the specimens to crumble away under the hands. Some of the works in ivory forwarded by Mr. Layard from Nineveh, were found on their arrival in England to be in a state of rapid decomposition. Professor Owen was consulted on the subject, and he suggested a remedy, which has proved entirely successful, thereby preserving to this country these curious relics of ancient art. Concluding that the decay was owing to the loss of gelatine in the ivory, he recommended that the articles should be boiled in a solution of gelatine. Under this process they became apparently as firm and solid as when they were originally entombed. Williams' Middle Kingdom; Yule's Embassy; Hodgson's Nagasaki; Hon. Mr. Morrison's Compendious Description; Mad. Ex. Jur. Rep. See Carving.

IVORY PALMS.

Palme de marfil, - SPAN. Homera, Indians of PerU. Tagua, Indians of Darien. Pullipunta,

The ivory palms are the Phytelephas macrocarpa and P. microcarpa, trees of S. America, between lat. $9^{\circ} \mathrm{N}$. and $8^{\circ} \mathrm{S}$., and long. $70^{\circ}$ to $79^{\circ}$ W., inhabiting damp valleys, banks of rivers, and rivulets on the lower coast region in Darien, and on mountains 3000 feet above the sea in Ocana, growing generally in separate groves, seldom intermixed with other trees or shrubs. The fruit, a collection of from six to seven drupes, forms clusters which are as large as a man's head, and stand at first erect, but when approaching maturity, its weight increasing, and the leaf - stalk which had up to that period supported the bulky mass having rotted away, it hangs down. A plant bears at one time from six to eight of these beads, each weighing when ripe about twenty-five pounds. The drupes are covered outside with hard woody protuberances. Vegetable ivory was exported chiefly from the river Magdalena, and in some years no less than 150 tons of it were imported into England. The Indians employ the leaves of this most beautiful palm as a covering to their cottages. The fruit at first contains a clear insipid fluid, with which travellers quench their thirst; this fluid afterwards becomes gradually sweet and milky, and at length acquires solidity, so as to be as hard as ivory. If the fruit be gathered while the juice is fluid, the latter soon becomes acid; but when allowed to attain perfection, the kernels are of sufficient hardness to be employed by the Indians as knobs for walking-sticks, reels of spindles, and little toys, which are white, and perfectly hard while dry; if they are put under water they soften, but on drying, their hardness is restored. Bears eagerly devour the young fruit. The vegetable ivory is, in fact, the albumen surrounding the embryo, and which in some other palms, as the cocoanut palm, constitutes a beautiful and firm substance lining the shell. This useful plant might be introduced into India.Seeman in Botanical Magazine, May 1856, p. 192.

IXORA, a genus of plants belonging to the tribe Cinchonaceæ, and the genus is so named, it is supposed, from the Hindu god Iswara. They form shrubs or small trees, with opposite leaves, and stipules arising from a broad base, but acute at the apex. The species are numerous, and chiefly confined to India and the Eastern Archipelago.

IXURA BANDHUCA. Roxb. Jungle geranium. Bandhooka,. . HIND. | Buckolee, . . Hind. Kuktuka,

A spreading shrub, smaller than I. coccinea, but equally common; in flower almost during the whole year; of a pale crimson colour. In the Kotah gardens and jungles it is a beautiful bush, covered with numerous scarlet flowers all the year, and would be very ornamental.

IXORA COCCINEA. $L$. Flame of the forest. I. grandiflora, $R . B r$.

Pan-sa-yeik, . BurM. | Thetti, . . TAM. Shetti, : : MALEAL.

This species of Ixora is sometimes called by the European residents of Tenasserim, the country geranium.

IXORA PARVIFLORA. Vahl. Torch tree.

I. alba, Roxb.

I. pavetta, Andr.

I. decipiens, $D$. C.

Henna gorivi, . CAN. Shulundu, . . TAM, Gandhul? : HiND. Karang cottay, : ", Ruughun? . . " Korivi pala, . . TEL. Jilpai,. . . " " Komma chettu, : ", Koora, Koorat, "MAHr. Putta pala, Tedda, " ",

A small tree, common in the jungles of the $\mathrm{S}$. of India. The flowers are very sweetly scented, and it blossoms in the hot weather. The wood is of a reddish-brown colour, the grain hard, very close, and easily worked. It gives a smooth surface and stands a good polish, is well adapted for the lathe, and is in use for furniture and building purposes. A cubic foot, unseasoned, weighs 78-84 lbs, and 66 lbs. when seasoned, and its specific gravity is $1 \cdot 056$. It burns very readily and clearly, and on that account its branches are often made into torches by people travelling at night.-Voigt; Gibson; Ainslie; Irvine; M. E.J.R.; Beddome.

IXOS LEUCOGENYS? the bulbul of Kashmir, is about $7 \frac{1}{2}$ inches length bill, head and legs black; plumage generally olive greenish brown, with a white spot behind the eye, and white tips to tail feathers. Crest black and curved forwards. It is quarrelsome and noisy. Its note resembles that of the English blackbird, but is less full and musical. - Vigne.

IYAR-i-1)ANISH is the Persian version of the Pancha-Tantra.-Dowson.

IYAVAN. TAM. An out-caste, a worker in leather.

IYEN, and Puther or Bhutter, in Travancore, 
are titles of Tamil Brahrnans. Iyengar, properly Aiyangar, amongst the Tamil people an honorific title to Brahmans.

IYER means sir, master, lord, and is added to the names of Brahmans as a distinetion. Iyer is immediately derived from the Tamil Aiyar, father, more reverentially pronounced Aiyangar. Iyer is used by a Hindu woman to attract her husband's attention, - no Hindu woman ever allowing herself to pronounce her busband's name. In Southern India it is used in the form of Ayah, as a lady's maid or child's maid. It is also assumed by Smartta and other Brahmans, and also by the Satani, a Hindu monotheistic sect who follow the doctrines of Chritanya, and do not wear the punul or sacerdotal thread. Iyer is also adopted by Christian missionaries, and the Tamil equivalents Kanani and Sangi are added to their names, in addition to that of Iyer.

IZAR. HIND. Trousers; hence Izar-band, the trousers waist-string.

IZNEE, a fakir who acts as a messenger. Iznee Shah, a mohurrum fakir.

IZ-ud-DIN HUSAIN, the founder of the Ghori dynasty, was a native of Afghanistan. The origin of the house of Ghor has, however, been much discussed, - the prevailing opinion being that both they and their subjects were an Afghan race. Ala-ud-Din Ghori, A.D. 1152, completed the overthrow of the Ghaznavi dynasty, by the defeat of Bahram, the last king, who fled into India. The founder of the Ghori dynasty at Dehli was Shahāb-ud-Din, who took the title of Muhammad.

\section{J}

In the English alphabet this letter has only one sound, as in jam, jelly, job, just; and, the Tamil excepted, each of the oriental languares of $\mathrm{S}$. Asia has a Ietter with a similar sound. But the letter $\mathrm{j}$ has a different sound in the languages of the other European nations from that of the English tongue; and the French obtain the English sound by prefixing the letter d, thus, djam'l for jam'l, a camel ; djab'l for jab'1, a moun. tain. The Germans and Dutch give to this letter the sound of $\mathbf{y}$, and have proposed to obtain the sound of the English letter $\mathrm{j}$ by using an accented $g$, or writing it dsch. The people of Egypt often give to this letter the sound of $s$, and those of Yemen give it the sound of hard g, so that jab'l is pronounced gab'l, and jam'l is pronounced gam'l. Several of the Hindu races give to the letter $z$ the sound of the English $\mathbf{j}$, as jaban, jabti, jor, for zaban, zabti, and zor.

JABAL. Arar. A mountain.

Jab'l-ul-Ballad, Media, Persian Irak.

Jab'l-ul-Makatib, Mount Sinai.

Jab'l Karim, Mount Olympus.

Jab'l-Sus, Mount Atlas.

Jab']-ush-Shaikh, Anti-Libanus, the Hermon of the Hebrews.

Jab'l-ul-Taraq, Gibraltar.

Jab'l-ut-Tarush, Mount Nebo.

JABAL-ARAFAT, anciently called Jabal-Ilal, the Mount of Wrestling in Prayer, and now Jabalur-Rahmat, the Mount of Mercy, is a low pointed hillock, of coarse granite split into large blocks, with a thin coat of withered thorns, about one mile in circumference, and rising abruptly from the low gravelly plain-a dwarf wall at the southern base forming the line of demarcation-to the height of 180 or 200 feet. It is about 12 miles on the Taif road, due east of Mecca. Near the summit is a whitewashed mosque with a minaret, looking like a small obelisk; below this is the whitened platform, from which the preacher, mounted on a dromedary, delivers the sermon, to be present at which it is an essential part of the Muhammadan pilgrimage to Mecca.-Hamilton's Sinai, p. 131 ; Burton, iii. p. 252.

JABAL HAOURAN. The waters of the Nahr-uz-Zerka, the Jabbok of the Scriptures, first collect to the south of Jabal Haouran; at this point they enter the Jabal Belka, and, after winding through the wadis in a westerly direction, finally empty themselves into the Shariat-ul-Kabir (the Jordan). -Robinson's Tr. ii. p. 171.

JABAL MIA ALLY, or Quoin Hill, 865 feet high, is near Bab-ul-Mandab.

JABAL MUSA, the Mount of Moses, is the name given by the Arabs to all that range of mountains which rises at the interior extremity of the valley of Faran; and, to that part of the range on which the convent of St. Catherine stands, they give the name of Tur Sina. The hill on which stands the convent of St. Catherine is supposed to be the Sinai of the Jews, on which Moses received the law.-Niebuhr's Tr. i. p. 191.

JABAL NAKKOUS, or Mountain of the Bell, is about 400 feet in height, and the material of which it is composed is a light-coloured friable sandstone; but an inclined plane of almost impalpable sand rises at an angle of $40^{\circ}$ with the horizon, which, when put in motion, raises musical sounds. At their commencement, the sounds might be compared to the faint strains of an Alolian harp when its strings first catch the breeze; as the sand becomes more agitated by the increased velocity of its descent, the noise more nearly resembles that produced by drawing the moistened fingers over glass. The sounds sometimes fall quicker on the ear, at other times are more prolonged; but this swelling or sinking appears to depend upon the Arabs increasing or retarding the velocity of the descent. It is about $4 \frac{1}{2}$ hours' journey from Tur. The same is told of the Goz-ul-Hannan or Moaning Sand-heap in the Wadi Urnub; also of the Reg Rawan in Afghanistan.-Wellsterl's Tr. ii. pp. 24-26.

JABALPUR or Jubbulpur, a town and district in the Central Provinces, lying between lat. $21^{\circ}$ $12^{\prime}$ and $23^{\circ} 56^{\prime} \mathrm{N}$., and between long. $76^{\circ} 40^{\prime}$ and $81^{\circ} 35^{\prime} \mathrm{E}$. During the minority of Prem Naraiu (1550?) the Gondqueen Durgavati administered the government; and Asof Kban, the viceroy of Kara IIanikpur on the Ganges, conquered the Gurkha principality. The decisive battle was fought under the castle of Singaurgarh. Stung by her defeat, Durgavati put an end to her life.

The district is one of the largest and most populous in the Central Provinces. T'he main part of the district is a large plain of rich soil watered by the Nerbadda, the Paret, and the Hiran. About nine miles from Jabalpur on the south - west, a considerable extent of tolerably pure and beautifully saccharine white limestone is seen; the river cuts a deep channel through the mass of this rock, exposing sheer vertical surfaces of the white limestones in places 220 feet high; it 


\section{JABALPƯR FEMP.}

is scarcely possible to exaggerate the picturesque effect of the varied outline and colour of the whole. The locality is well known as the Marble Rocks. Coal is found at Ramghat, Lametaghat, and near Singapore on the Mahanadi. The latter seam is 18 inches thick, and is said to be poor and unworkable. The Lametaghat coal promises well. Iron is found in more than a hundred places, of which the principal are Simra, Gogri, Bolia, Agaria, Dalrora, Jauti, Panagar, and Lameta. The iron is worked entirely by native processes. The people are for the most part Gond, Gond Rajput, Kol, Bharia, Baiga, Lodhi, Ponwar, Kurmi, Kahar, Dhimar, Dher, and Chamar. There are also Brahmans, both from Maharashtra and from Mathura; Kayasths from Farrakhabad and elsewhere, and Muhammadans. There are now no Gond landholders of any importance, but there are some Lodhi chiefs who once possessed a local celebrity.

JABALPUR HEMP, Crotalaria tenuifolia, is a perennial plant, native of Coromandel, which grows to 6 or 9 feet high, and yields this fibre. It is considered equal to Russian hemp, and bears a heavier weight.

\begin{tabular}{|c|c|c|c|}
\hline Kind and quality of rope. & Size. & $\begin{array}{c}\text { Govern- } \\
\text { ment } \\
\text { Proof. }\end{array}$ & $\begin{array}{l}\text { Breaking } \\
\text { weight. }\end{array}$ \\
\hline $\begin{array}{l}\text { Oiled Jabalpur hemp, artil- } \\
\text { lery traces, }\end{array}$ & $\begin{array}{c}\text { Inches. } \\
3\end{array}$ & $\begin{array}{l}\text { Cwt. } \\
36\end{array}$ & $\begin{array}{c}\text { Cwt. } \\
432\end{array}$ \\
\hline $\begin{array}{l}\text { Untarred do, superior four } \\
\text { strand, plain laid, }\end{array}$ & $3 \frac{1}{2}$ & 42 & 83 \\
\hline $\begin{array}{l}\text { Untarred Dhunchee (Eschy- } \\
\text { nomene cannabina, Roxb.), } \\
\text { Sesbania aculeata, }\end{array}$ & $3 \frac{1}{2}$ & 49 & 75 \\
\hline Pine-apple fibre, & $3 \frac{1}{4}$ & 42 & $57 \quad 0$ \\
\hline
\end{tabular}

A good deal of the value of this plant is supposed to be the result of the climate and soil in which it is grown.

JABAL SHAMSAM, the highest wall of the Aden crater, where Cain is supposed to have been buried; elevation, 1775 feet.

JABAL TEER, a small islet with two peaks in the Red Sea, in lat. $15^{\circ} 32^{\prime} 30^{\prime \prime} \mathrm{N}$., and long. $41^{\circ}$ $50^{\prime} 30^{\prime \prime}$ E., 34 miles N.W. from Jabal Zebayer, and 900 feet high. It is supposed to be rolcanic, as smoke is said to have been issuing from it at the time of its survey.

JABAL TUR, a mountain near Mount Sinai, or Jount Sinai itself.

JABAL TUR, a spur of the great Taurus range, which forms the watershed of the Tigris, from Mardin to its south bend opposite Jazirah-ibnUmar. It is a continuation of Karajah Tagh, and continues into the Sinjar Hills.-MacGregor.

JABAL-ul-JUDA, Aghri Dagh, or Mount Ararat, the Ararat of modern geographers, in the province of Erivan, is in height about 16,200 feet. In the last volume of Cosmos, Humboldt records the height of Demavend at 19,715 feet, which is 1785 feet under the height attributed to it. According to some authorities, Ararat is only 17,112 feet high. General Monteith made it 16,000 feet above the level of the Araxes. Agridagh is the name given to it by the Turks; but all unite in revering it as the haven of the great ship which preserved a father of mankind from the waters of the deluge. Ararat is called by the Armenians, also, Massissinsar, or Mountain of the Ark. Berosus and Alexander both declare that in their time it was reported that some planks of the ark remained on this hill at the date of the accession of the Abbasside khalif s, A.D. 749 .

The usual Muhammadan tradition places the grounding of the ark, not on Armenian Ararat, but on the Jabal Judi in Kurdistan, whence Benjamin of Tudela says (p.93), Omar bin Khatab removed the ark from the summit, and made a mosque of it. Demavend is believed to be fully 4000 feet higher than Ararat.-Yule, Cathay, i. p. 467; Purter's Tr. i. 183; General Monteith.

JABAL ZABARAH, the Samaragdus Mons of the ancients. It has the famous emerald mines which were worked B.C. 1650 , in the time of the great Sesostris Ir., by extensive galleries. It was again worked in the early part of the reign of Muhammad Ali. The mines were on the Cosseir road from Koptos to Aennum (Philoteras). Wellsted thinks (Trav. ii. p. 323) that the locality indicated by Bruce was the island of Wadi Jemal, and that the Arabs had so called it because of its proximity to the only emerald mines on the adjacent continent.-Bunsen's Egypt; Wellster.

JABER, the Killa Husn Jaber of the Arabs, the ancient Roman town of Beles, about two miles from the Euphrates. It is the Ezion-geber of Scripture (1 Kings ix. 26-28). - Catafayo.

JABRAL. At Amraoti in Berar, the deities worshipped are named as under:-

$\quad$ Male deities.
Jabral Abral.
Massoba.
Babram.
Mahadeo.
Shadawal.
Kandoba.
Worba.
Yetoba, Vittoba.

Female deities. Asra or Asrai. Meskai. Amba. Marri. Satwai. Agachi Panna. Jana Bai.

Jabral is worshipped at and near Ellichpur, and seems to be the angel Gabriel, whom Muhammadans style Jabrail. In the alliterative habits of the orientals, the term Jabral Abral is commonly used, and the silver figure, that of a man, is worn around the neck. Near Amraoti, also, is a rag tree, with incense on altars of mud at its foot, which the Dher of Balgaon said was a Jabral. Sakinath is a deity of Amraoti, whose worship protects from suakes. In the Chauki pass, in the Lakenwara range, which forms the watershed between the Godavery and the Tapti, about 10 miles north of Aurangabad, there is a shrine of the deity called Massoba, to which people of all castes resort, from a circle of a hundred miles, Brahman, Sudra, and Dher, but chiefly the Mabratta Kunbi. The Jatra is held in the month Cheita, and lasts for four days, during which many sheep are offered in sacrifice. It is in the southern side of the pass, a mere block of stone, with smaller blocks at its foot, all smeared with red lead. The objects of thcir visits are wholly personal, beseeching the deity to give, or preserve, their children, their flocks, or their food.

JABRANG, a coarse description of silk, made by a wild tribe, who are the only people in Yegu that rear the silk-worm and cultivate the mulberry. -Local Committee, Rangoon.

JABU or Zhobu, a hybrid between a male yak and a cow. It is more valuable than the pure yak or the garjo hybrid between a bull and female yak. It is used for riding, also for carriage, and will carry from two to three maunds; is very surefooted, hardy, and docile. Its price in Kamaon 
is Rs. 20 to Rs. 50 ; both varieties breed freely together, and also with the pure stock. None of them bear the heat of the plains.

\section{JACANA.}

Parra ænea, Cuv. | P. superciliosa, Horsf. Dal-pipi, Jal-pipi, Beng. | Kattoi, Karatiya, BENG.

This singular bird, the Metapodius Indicus, Latham, is a native of all India, of N.W. Himalaya, and of China, and is distinguished not less by the grace of its form than by its adaptation to the localities for which nature has allotted it. Formed for traversing the morass and lotus-covered surface of the water, it supports itself upon the floating weeds and leaves by the extraordinary span of the toes, aided by the unusual lightness of its body. Like the moor-hen, of whose habits and manners it largely partakes, it is doubtless capable of swimming, the long and pendent tailfeathers being elevated so as not to dip in the water. It may be seen in the N.W. Himalaya squatting on the broad leaves of the Iotus, Nelumbium speciosum, and marsh marigold (Calla palustris). Its flight is not strong, and is composed of many flaps; the call is rough, like that of the water-hen. The curved tail-feathers, the brilliant yellow patch on the hind part of the neck, and shining brown of the back, white wings more or less tinged with black, at once serve to distinguish it.-Adams; Williams' Middle Kingdom, p. 263 ; Jerdon, p. 708.

JACK. Dr. William Jack was appointed to the Bengal Medical Service in 1813. During the Nepal war of 1814-15, he was attached to the army under General Ochterlony. In 1818, Sir Stanford Raftles, Governor of the British Settlements in Sumatra, offered him an appointment on his staff, promising him every facility for the exploration of the natural history of that island. Jack's descriptions of Malayan plants were published in the Malayan Miscellanies, and were reproduced by Sir William Hooker in the companion to the Botanical Magazine, and by Dr. M'Clelland in the Calcutta Journal of Natural History. He died 15th September 1822, on board the ship on which he had embarked on the previous day to proceed to the Cape of Good Hope.-H. and T. Fl. Indica.

\section{JACKAL.}

Canis aureus, Linn.

C. aureus Indicus, Hodg.

Shaghal, . . ARab. Alopex, . . . GR. Shigal, AR., Dur., Pers. Shu'al, : : : Heb. Siar, Sial, . BENG. Ghidar, . . HIND. Amu, . - Bнот. Kola, : HiNd., MAHR. Nari, : CAN., TAM, Srigala, : : SANSK. Jackhals, . . Dut. Nakka, . . . TEL.

The jackal is found in Syria, Arabia, Persia, in all India west of the Brahmaputra, and over S.E. Europe. Both the jackal and the hyæna are more or less plentiful, affecting even the mountainous regions to pretty high altitudes. Along the line of the Ganges, in Lower Bengal, they move in packs and eat indiscriminately. In the Peninsula, they are of larger size, are often seen singly or in pairs, and in the Dekhan live much on wild fruits; the coffee-bean of the plantations is largely eaten by them. Their cry when moving at night is very disagreeable, and even when clicketing, their call is unpleasant. Among mammals, the jackal, hyæna, domestic swine, and dog; and among birds, vultures, kites, crows, minas, and the adjutant bird Leptoptilos argala, Gmel., are the chief carrion eaters of S.E. Asia. The swine, the buffalo, the cow, the bullock, and even sheep, in many parts of India, are driven daily to the purlieus of the towns. The jackal and hyæna are of nocturnal, bold, and stealthy habits, and though the hyæna hunts generally singly, the jackal does so in packs, and anything in the way of flesh, putrid or otherwise, is acceptable. The cry of the jackal is peculiar; it is composed of a succession of half-barking, half-wailing cries, on different notes. When properly pronounced, there is no better illustration of it than the following words, set to the tones of the animal's voice :-

\section{'A dead Hindu ! a dead Hindu !}

Where-where? where-where?

Here-here ; here-here.'

The jackal in the Peninsula of India and in the low country of Ceylon sometimes hunts in packs, headed by a leader, and they have been seen to assault and pull down a deer. The small number of hares in the districts they infest is ascribed to their depredations. When a jackal has brought down his game and killed it, its first impulse is to hide it in the nearest jungle, whence he issues with an air of easy indifference, to observe whether anything more powerful than bimself may be at hand, from which he might encounter the risk of being despoiled of his capture. If the coast be clear, he returns to the concealed carcase, and, followed by his companions, carries it away. But if a man be in sight, or any other animal to be avoided, the jackal has been seen to seize a cocoanut husk in his mouth, or any similar substance, and fly at full speed, as if eager to carry off his pretended prize, returning for the real booty at some more convenient season.

The following anecdote may be told of a jackal: - 'Going homewards I shot a fine buck chitul (or spotted deer), and while following up his prints and blood, as silently as possible, in the hope of getting another shot upon our again starting him, we heard a great stamping and crashing of bushes about forty yards ahead; soon we saw the buck trying to shake off a large jackal that had pinned him by the throat. The chitul in vain tried, by swinging his head backwards and forwards violently, to dislodge the jackal, who, doubled up like a ball, held on as well as the best bull-dog could have done, nor did he lose his hold until, after watching this strange scene for some minutes, I dropped the chitul with another shot. The jackal hastily retreated. Often when walking after. a wounded black buck or antelope in the plains, I have seen one or two jackals trotting along in the exact direction the wounded antelope had gone off. There is very little chance of any wounded small animal escaping such watchful creatures.'

The kole balloo is an aged jackal which accompanies a tiger, and feeds on the tiger's prey. Jackals are subject to hydrophobia, and instances are frequent of cattle being bitten by them and dying in consequence. An excrescence or small horny cone, about half an inch in length, and concealed by a tuft of hair, is sometimes found on the head of the jackal. This the Singhalese call narricomboo; and they aver that the possessor of this can command by its instrumentality the realization of every wish, and that if stolen or lost by him, it will invariably return of its own accord. Those who have jewels to conceal rest in perfect 
security, if, along with them, they can deposit a narri-comboo, fully convinced that its presence is an effectual safeguard against robbers. The words of Psalm lxiii. 10, "They shall be a portion for foxes,' appear obscure; but if they be rendered, 'They shall be a portion for jackals,' the anathema becomes plain and striking to a Hindu, in whose country the disgusting sight of jackals devouring human bodies may be seen every day.-Tennent's Ceylon; Eothen's Tr:; Wav'd's Hindoos; Adams' Naturalist in India.

JACKDAW, Corvus monedula, of Europe, Siberia, Barbary, W. Asia, Peshawur valley, and Kashmir, may be seen in flocks in winter in the northern frontier of the Panjab, associated with the Cornish chough and the rook. - Adams.

JACKETS, coats, and vests are worn by Hindus and Muhammadans in India. They are called koorta, angarkha, nuna, anga, mirzai, kufcha, kuba, jama, chupkan, dagla, tabada, jora.

JACK-FRUIT IREE, Artocarpus integrifolius. Some varieties bear a fruit from 10 to $60 \mathrm{lbs}$. in weight, much esteemed as an article of food by the natives in India. The dye obtained from its heartwood, as prepared by the natives, is a brilliant orange-yellow, and is obtained by the addition of an infusion made from the leaves of the Don-yat, producing a brilliancy of colour not excelled by the best English dyes. The tree is of value for its fruit and its timber. In many places it is found $2 \frac{1}{2}$ feet in diameter, and from 30 to 35 feet high. In Canara it was preferred by Tipu Sultan for the grab ressels built at his naval depot, Honore. In Ceylon it is used by the furniture-makers for chairs, couches, etc., for which purpose it answers well; and, if polished with care, its brilliant colour is superior to that of mahogany.

Jackwood is imported into Bombay from the Malabar coast, and was at one time in great request there for making furniture. Of late years, however, it has been entirely superseded by blackwood for this purpose. It is imported into Britain in logs from 3 to 5 feet diameter, and also in planks; the grain is coarse and crooked, and often contains sand. The wood is yellow when first cut, but changes to a dull red or mahogany colour. It is used in India for almost every purpose of house carpentry and furniture, and in England for cabinet-work, marquetry, and turning; and also for brush-backs. Jackwood is sometimes misnamed orange-wood from its colour.-Baker's Papers; Holtwaptfel; Edye, Forests; Faulkner.

JACOB, grandson of Abraham, the Yakub of the Arabs, a patriarch of the Israelites. Jacob was father of twelve sons, who founded the twelve tribes of the Hebrews; he went to Egypt B.C. 2747-46.-Bunsen.

JACOB, GeNeral LE GRAND (1851), Resident at Bhooj. Author of an Account of Gumli or Bhumli; Report on the Iron in Kattyawar, its comparative Value with British Metal; Mines and Means of Smelting Ore, Lond. As. Trans. v. p. 73 , viii. p. 98; Brief Historical, Geological, and Statistical Memoir on Okhamandul, in Bom. Geo. Trans. v. p. 157; Report on the District of Babriowar, ibid. vii. p. 700 ; Inscriptions from Palitana, in Bom. As. Trans. i. p. 56 ; on the Asoka Inscriptions, Girnar, ibid, p. 257.-Dr. Buist's Catalogue.

JACOBABAD, a frontier district of Sind, between lat. $27^{\circ} 56^{\prime}$ and $28^{\circ} 27^{\prime} \mathrm{N}$, and long. $68^{\circ}$ to $69^{\circ} 44^{\prime} \mathrm{E}$., which comprises the tract of country bounded by the Bugti Hills on the north, by Kalat on the west, the Bigari canal on the south, and the river Inclus on the east. The district attains to from 170 to 257 feet above the sea. From 1865 to 1870 the rainfall ranged from $1 \cdot 11$ to 8.80 inches. At the extreme north is desert plain. The Sind Hollow, a former bed of the Indus, traverses one-third of the district, and between it and the river the country is split up into numerous 'dhund' and 'dhoree.' On its north is a range of barren hills with fertile valleys, occupied by the Murree and the Bugti. Baluch tribes, Jumali, Dumki, Jakrani, Khosa, Mazari, form the population; Burdi, Sindi, Jumma, the nomade Jat, who rear canels, cattle, sheep, and goats, and Hindu cultivators. The Jat are a hardy, good-looking, industrious race, and their women are very comely, and drink largely of camels' milk. The Baluch use jowari (sorghum) flour, and bajra (Penicillaria spicata), and mill. The cultivation is by irrigating canals.

Jacobabad was founded by Major-General John Jacob as an entrenched camp, for the purpose of checking the inroads and forays of the Baluchi. The average annual rainfall is 4.39 inches; in $1869,12.05$ inches, and in 1867, 0.97.

JACOB'S IVELL, in the valley of Nablous, a few miles south of Shechem, is 75 feet deep.

JACQUEMONT, VICTOR, born at Paris 1801 , died at Bombay 7th December 1832. He was a travelling vaturalist to the Royal Museum of Natural History at Paris during the years 1828 29, 1830-31, and 1832. He travelled in India, the Himalaya, Ladakh, Tibet, Panjab, and Kashmir. His travels were published in the form of letters to his relatives.

JACYNTH, a gem owing its deep orange colour to the presence of zircon. It is the gul-maidah of India.

JADABILLAY. TAM. A woman's bead ornament in the Tamil country. See Jewellery.

JADDI. MAHR. Land left to grow fodder.

\section{JADE.}

Yuh, . . . . Chin. $\mid$ Yashm,Sang-i-yashm,Pers Khas, . . Mongol. Sootash, . . TURK.

This mineral, called also nephrite and axe-stone, is celebrated in China as the Yuh or gem of gems. It is found in Fung-tien-fu (Shing-king), Lienchau-fu (Canton), in Shan-tung, near Khoten, Karakash, Yarkand, and other places in Turkestan; in the rivers among the Siansk mountains, to the S.W. of Lake Baikal, in Eastern Siberia, at Mogoung north of Burma, and other places in Eastern Asia; also in N. Zealand, Egypt, Polynesia, and a few localities in the United States. It is of white, blue, yellow, and green colours; but the milk-white and the light-green varieties are most prized. Chemically, it consists of the silicates of magnesia and alumina coloured to the tint of the stone by varying proportions of chromium. Its hardness, weight, sonoriety, and peculiar sombre tint are the foundation of the Chinese taste for this stone. Their wearing of this stone is supposed to impart to the wearer, humane, just, intelligent, brave, and pure qualities, and philosophers and physicians have ascribed all sorts of properties to this substance, which for any mediciual purpose can be no better than soapstone or steatite. Jade mines in the Kouen Lun mountains have been deseribed by Dr. Cayley in Macmillau's Magazine, October 
1871. At a very early date nephrite was sent as a tribute to the imperial court. The emperor Chinnoung (B.C. 2737) delighted in ornaments of nephrite, and the emperor Chau-sin (B.C. 1154) had a pillow made of the same material. A chief source for nephrite is in Khotan. M. Blondin says-'La ville d'Yarkande envoie chaque année à Khotan pour être expédiés à la cour de Peking $6000 \mathrm{~kg}$. de jade. Nous ne comprenons pas dans ce chiffre les pièces taillées et sculptées, on ne peut plus habilement, par les lapidaires d'Aksou, la capitale actuelle de la Tartarie Chinoise, par ceux de Kachghar, et enfin par ceux d'Yarkande, l'ancienne capitale où le travail de jade occupe le plus de bras.'

Mr. John Anderson (Report on the Expedition to Western Yunnan, via Bhamo, Calcutta 1871) visited the bazar of Momien. He says the copper discs used in cutting jade are very thin, bend easily, and measure about one foot and a half in diameter. The centre is beaten out with a cup-shaped depression, which receives the end of the cylinder on which the disc revolves. In one establishment two men were at work, one using the cutting disc and the other a revolving cylinder tipped at the free end with a composition of quartz and little particles resembling ruby dust. Both were driven by the feet. The stone is held below the disc, under which there is a basin of water and fine silicious mud, in which the stone is dipped at intervals, the operator filling his hands with as much of the mud as possible. The stones are cut into discs oneeighth of an inch in thickness, when they are intended for ear-rings, and are then made over to the man at the silicious-tipped cylinder, who bores a round hole in the centre of each. The same course is followed in the case of the larger and thicker rings. Bangles made of jade come from Mogoung, in the north of Burma; the bright green tint seen in these specimens is the characteristic peculiarity of the Burmese jade. It occurs there in the form of rounded boulders, and is exported to China.

The Chinese have probably some sources of green jade unknown to us. Their jadeite, a different mineral from jade, is supplied, though probably not exclusively, by mines in the mountains to the north-west of Bhamo in the Lao State of Burma. Jahanghir and Shah Jahan seem to have taken pleasure in jade cups and ornaments; and the art of inlaid work that found such exquisite expression in the Taj Mahal was copied under their munificent auspices in the most precious materials, rubies and diamonds and other precious stones. being inlaid in jade of various colours, which was cut in delicate open-work and adorned with enamels, in the production of which India is still unrivalled. The collection of these beautiful productions of Indian art contained in the India Museum is the finest ever brought together.

Jade possesses the virtue of an extraordinary toughness. Easy to work when freshly extracted, it hardens just sufficiently to do the work of cutting, yet retain an edge. On that account New Zealanders used jade as well for tomahawks as for amulets, and the jade relics disinterred in Switzerland are often in the shape of hatchets.

The Mexicans worked a kind of jadeite. The Maoris work jade, which is a native mineral in their hornblendic rocks; and the inhabitants of
New Caledonia, and indeed of Polynesia gener. ally, have fashioned jade or some varieties of jadeite into implements useful, ornamental, and perbaps too, in one sense, sacred.

A cargo of this mineral was imported into Canton from New Holland, but the Chinese would not purchase it, owing to a fancy taken against its origin and colour. The Chinese use it for mandarins' buttons, pipemouth pieces, and various articles of personal ornament and luxury. They estimate it according to the purity of the white and brightness of the green tints.

JADU. HIND. Enchantment; hence Jadugar, a sorcerer.

JADUN, a race on the right bank of the Indus where that river issues from the Himalaya near Torbela. They are Pathans who speak Pushtu. They inhabit a tract below the Husanzai country, and on the right bank of the Indus opposite the British town of Torbela, and thence stretching westward. In this tract the most notable place is Mount Mahabun, of classical celebrity.

Beyond the Judun country on the north-west is Booneer or Bunoor. It is a rugged country, extending from the lower range of the Hindu Kush downwards to hills which command the Chumla valley and the central plain of the Yusufzai. On its western frontier, again, lies the Swat territory.

JAEDAD. Pers. Signifies a place or employment; also, in accounts, assets, funds, resources.

JAETI, gladiators; in the south of India Jetti. Colonel Tod mentions that in one of the courts in Cutch funds were set apart for Jaeti, at one time to fifty thousand rupees per annum. In the akhara (arena), with the prize-fighters Asman dikhlana is their phrase for victory, when the vanquished is thrown upon his back and kept in that attitude.-Tod's Rajasthan, ii. p. 589.

$\mathrm{JAF}$, a very large predatory tribe residing near Kanaki, on the Dialla, dependent on Turkey, and numbering about 25,000 families. They inhabit in winter the plains of Sulimania and Zohab, and in summer migrate to the mountain of Ardelan. They are the most warlike and unruly of all the Kurdish tribes; a fine-looking, brave people, but esteemed exceedingly uncivilised and barbarous even by the Kurds.-Ferrier, Journeys, p. 68 ; Rich's Kurdistan, i. p. 112.

JAFFA, or Yaffa as it is called by the natives, is the representative of the ancient Joppa, so often alluded to in holy writ. The timber hewn on Mount Lebanon for Solomon's temple was floated to this port (2 Chronicles ii. 16). Here Peter raised Tabitha from the dead (Acts ix. 42), and Simon the tanner resided. In this harbour, Judas Maccabæus burnt the Syrian fleet. The tract of country lying between Jaffa and Gaza westward of the mountains of Judea, was the ancient territory of the Philistines, and included the five cities of Gaza, Askelon, Ashdod, Gath, and Ekron. This district still bears the name of Palestine. It is the nearest seaport to Jerusalem, and is about 30 miles $\mathrm{S}$. of Cæsarea. It is built on a hill jutting into the sea. It has seen St. Paul, Pompey, Salah-ud-Din, and Napoleon. At four hours' journey is Edzoud, the ancient Azotus and the Ashdod of Scripture (2 Chronicles xxvi. 6).Robinson's Palestine, i. pp. 16, 21.

JAFFERABAD, on the Gujerat coast, in lat. $20^{\circ} 52^{\prime} \mathrm{N}$., has the best river on the coast. The 
chief of Jafferabad, who resides in Gujerat, the sidi of Janjira, who resides in the Konkan, and the nawab of Sucheen, are all of African origin.

JAFFERI - KASM, ARAB., is an oath considered by Muhammadans to be more solemn than that used in British Indian courts. Its words, Aksamto B'Illa hil Jabbar, il Kahar, il Mutakabbir, il Muntakim, mean, I swear in the name of the Omnipotent, Indiguant, High, and Avenging God.

JAFFNA, a district and town in the northern part of Ceylon. In the sandy parts of Jaffna a hollow palmyra is inserted to form a well.

JAG. Amongst the Mahrattas, if a Sudra die suddenly, his family hold a riotous vigil on the 10th night after the demise; it is called Jagar, and the object is to compel the spirit of the deceased to enter the body of the son or of some other person to reveal any secret matter desired to be known. Jagla, a night watchman. Jagni, a torch. The word is from Jagna, to wake.-Wils. Gloss.

JAGA or Jaga-Bhat, a division of the Bhat tribe, -Wils.

JAGADHRI, town in the Umballa (Ambala) district, Panjab, and has a considerable manufacture of metal work, vessels, and tools; also a refinery of the borax brought from the hills, and a manufacture of oxide of lead, for use by groldsmiths and in native medicines.-Imp. Gaz.

JAGANATH, Jaganatha, vernacularly Juggurnath, from Yoganatha, lord of the world, is a name now especially applied to Vishnu in the form in which he is worshipped at the temple of Jaganath at Puri in Orissa. All the land within 20 miles round this pagoda is considered holy, but the most sacred spot is an area of about 650 feet square, which contains fifty temples. The most conspicuous of these is a lofty tower about 184 feet in height and about 28 feet square inside, called the Bur Dewali, in which the idol and his brother and sister Subhadra are lodged. Adjoining are two pyramidical buildings. In one, about 40 feet square, the idol is worshipped, and in the other the food prepared for the pilgrims is distributed. The temple was restored in its present form in A.D 1198 by Raja Bhim Deo of Orissa, at an outlay of $£ 500,000$. It is in a square enclosed by a high stone wall, 250 yards each face, with the principal gateway on the eastern side. The walls are covered with statues, many of which are in highly indecent postures. The grand entrance is on the eastern side, and close to the outer wall stands an elegant stone column, 35 feet in height, the shaft of which is formed of a single block of basalt, presenting sixteen sides. The pedestal is richly ornamented. The column is surrounded by a finely-sculptured statue of Hanuman, the monkey chief of the Ramayana. The establishment of priests and others belonging to the temple has been stated to consist of 3900 families, for whom the daily provision is enormous. The holy food is presented to the idol three times a day. His meal lasts about an hour, during which time the dancing girls, the Deva-dasa, belonging to the temple, exhibit their professional skill in an adjoining building. Twelve festivals are celebrated during the year, the principal of which is the Rat'h Jatra. In the early years of the 19th century many statements were made as to the self-sacrifice of pilgrims by throwing themselves beneath the wheels. But self-immolation is entirely opposed to the worship of Jaganath, and the rare deaths at the car festival were almost always accidental, though there have doubtless been instances of pilgrims throwing themselves under the wheels in a frenzy of religious excitement. Any death within the temple of Jaganath renders the place unclean. The ritual suddenly stops, and the polluted offerings are hurried away from the sight of the offended god. According to Chaitanya, the Orissa apostle of Jaganath, the destruction of the least of God's creatures is a sin against the Creator. Self-slaughter he would have regarded with abhorrence. The image of the god is a rude block of wood, and has a frightful visage with a distended mouth. His arms, which, as he was formed without any, have been given to him by the priests, are of gold. He is gorgeously dressed, as are also the other two idols which accompany him. In a compartment in the temple of Rama, he is represented in company with Bala Rama and Subhadra, without arms or legs. The temple is built on a low sandy plain about $1 \frac{1}{2}$ miles from the shore. The car is painted with obscene figures. In the festivals at this Hindu temple the images brought forward are those of Krishna, his brother Bala Rama and sister Subhadra, and the populace reproach Krishna and his sister for having indulged in a criminal intimacy. In the Mahabharata, Subbadra is stated to have been married to Arjuna. Bala Rama and Subhadra are also similarly accused. Multitudes of pilgrims resort thither, especially at the two great festivals of the Snana Yatra and Ratha Yatra, in the months of Jyaishtha and Ashadha. In the Snana Yatra, the image is bathed; in the Ratha Yatra, or car festival, it is brought out upon a car, with the images of Bala Rama and Subhadra, and is drawn by devotees. Jaganath temple has three prominent classes of servants, - the Parcha or head priests, who superintend the collection and disbursement of the revenues, and see that the worship is conducted in an orderly manner; the Parharri, who dwell witbin the boly land of the temple, guard the seven inner doors of the pagoda, attend during the day and watch over it at night, and present pilgrims to the idol; and the Panda, who serve chiefly in the pagoda. The vile Pandas of Puri is a saying in every mouth.-Cole. Myth. Hind. p. 52 ; Carnegy; Douson; Imp. Gaz. iv.

JAGAT. Hind., SANsK. The world. JagatNarayana, a title of Vishnu. Jagatganj, a place near Benares. Jagat Point, a projecting land in Gujerat.

JAGATI. KARN. A gong. Jagati Dasari, in Mysore, religious mendicants who beat a gong as they move along the streets begging. $-W$.

JAGDALAK, a river, a valley, and defile in Afghanistan. The river rises in the kotal or pass, and after a course of ten miles falls into the Käbul river. The valley is occupied by the Jabr Khel, Ibrahim, and Ghilzai. The defile is steep, narrow, and winding, its width averaging 40 or 50 yards, but at one place is only 6 feet. It was in this defile that on the 12 th January 1842 , the remnant of the retreating division of the British Indian army were destroyed; only a few pressed on to Gandamak.-MacGregor, pp. 395-97.

\section{JAGGERY.}

Kund, . . . ARAB. Guda, Gura, . SANSK. Coompta sugar, BoM BAY. Kara vellam, . TAy. Jagari, Gur, Guj., Hind. Nalla bellum, . . TEL. Unrefined sugar, produced by evaporating the 
juices of palms, the cocoanut, the date, the Caryota urens, the Nipa fruticans, palmyra, and gomuti. In Bengal, it is from the Elate sylvestris or wild date that it is made. In Ceylon three palms yield palm sugar, the cocoanut palm (Cocos nucifera), the palmyra palm (Borassus flabelliformis), and the kittal or jaggery palm (Caryota urens). From each of these palms the juice of the flowering stalk is collected under the name of toddy, and from it jaggery is regularly prepared; but it is from the palmyra palm that nearly all the palm sugar is obtained, and it is from the saccharine matter of the cocoanut palm that arrack is made in Ceylon. This palm becomes productive there in about six or seven years. In collecting its toddy, the spathe is stripped off from the spadix before it has fully expanded; the spadices are afterwards beaten between pieces of hard wood, and slices are cut with a sharp knife so as to allow the juice to flow out. Each spadix continues to yield juice for about 40 days, at nearly the average rate of half a gallon in 24 hours. When it is intended to prepare jaggery from the toddy, great care is taken by burning pieces of wood in the small earthen vessels to be attached to the flowers, and rubbing their interior with charcoal, to remove any impurities likely to promote fermentation; and as an additional precaution chips of the bark of the Vateria Indica are placed in each, in order to retard fermentation.

JAGHIR, the state revenues of a tract of land assigned, with or without conditions, with the power to collect and appropriate the state revenue and carry on the general administration. This tenure was most common under the Muhammadan government. The jaghir given to the English Last India Company by the nawab Muhammad Ali, nawab of Arcot in the Carnatic, extended to the Pulicat lake northward, to Alampravé southwards, and westward beyond Conjeveram; that is, about 120 British miles along shore, and 47 inland in the widest part. This jaghir is now the Chingleput collectorate. Jaghirdar, holder of a jaghir.-Elliot; Rennell's Memoir, p. 264.

JAG JIVAN DAS, founder of the Sad'h Nami sect, was born at Sardaha in the Bara Banki district, 40 miles E. of Lucknow, in Samvat 1738 (A.D. 1682). His father, Ganga Ram, was a Chandal. IVilson says that he was a Kshatriya. He composed the Agh Binsh (Aghavinsa, sin remover), which is the sacred book of the sect. It is of various metres, and is a thick volume. He also wrote the tracts Inyan Prakas, Maha Pralaya, and Pratham Grantba; these are in Hindi couplets. The sect are found chiefly between Benares and Amritsar. The king of Oudh, about the middle of the 18th century, granted to the sect the village of Katwa, and Jag Jivan Das died there, A.D. 1761 (Samvat 1817). He left five sons. The sect prohibit the use of Masur, all intoxicating liquors, and also the egg plant fruit. He was a Grihastha or householder through life. The Sad'h Nami is a unitarian Hindu sect, who profess to adore the True Name alone, the One God, the Cause and Creator of all things, Nirgun or void of sensible qualities, without beginning or end. Although they profess to worship only the one God, they borrow their notions of creation from the Vedanta philosophy, and recognise accord- ingly the whole Hindu pantheon.-H.H. Wilson, i. p. 357.

JAGLAIN, a Jat clan, proprietors of a few villages in Paniput Bangur.-Elliot, Supp. Gloss.

JAH. Pers. Splendour; the second title amongst Muhammadans in India, as Asof Jah, Azim-Jah. See Titles.

JAHAD. ARAB. A religious war of the Muhammadans; generally used to designate a war against other religionists. It is described by the Arabs as Jahad-fi-Sabil Allah, a war on the path of the Lord. Unprovoked war is contrary to the letter and spirit of the Koran; but war against the enemies of El Islam, who have been the first aggressors, is enjoined as a sacred duty; and he who loses his life in fulfilling this duty (if unpaid) is promised the rewards of a martyr. Verses 40,41 , chapter 21 st of the Koran, are believed to be the first passage that was revealed respecting religious war. From Mahomed's time there were many small religious wars; but of memorable jahads, two by Harūn-ūr-Rashid in A.D. 902 against the emperor Nicephorus, all those of the Crusades led by Salah-ud-Din and others, and the great Wahabee movement at the close of the 18th century in Arabia, aimed at bringing Islam back to the actual state of things which existed in the prophet's time. This was a jabad pure and simple, and its promoters not only attacked Christians as unbelievers, but drove out their Turkish Muslim masters, and sacked the holy cities of Mecca and Medina, because they had been profaned with foreign rites. The movement was a purely Arab one, but it relied upon precisely the same principles as those of Mahomed himself ; and as these are the recognised foundations of Islam, it found an echo elsewhere. Yet when, later on, it was endeavoured to prove that India was a dal ul harb, or enemy's country, and that it was the duty of all Muhammadans, as such, to rise against their Christian rulers, the Ulema, with scarcely an exception, pronounced fatwás adverse to this opinion, and a meeting of doctors at Mecca taking the same view, the jahad was negatived once for all, and made impossible in the future. So far as Wahabeeism appealed to Arab peoples, it was eminently successful; elsewhere the summons was unheeded. Some of the Arab tribes, and with them some of their descendants, are exceedingly excitable, and there have been instances of this excitability among the Turk and Mongol converts; and the proclamation of a jahad would probably have met with response among the Arabs who migrated to Africa, and who set up the rival Muhammadan khalifat in Spain. But the jahad of the Crusades was brought about by the Christians themselves, who took the initiative. The Saracen rulers and inhabitants of the Holy Land, whether of Arab, Persian, or Moghul descent, found their very existence suddenly threatened, and banded together to avert the common danger. How high Muhammadan feeling ran at the time may be gathered from a contemporary Arabic ode, addressed to a grandson of Salah-ud-Din on the construction of extra fortifications at Damietta. The poet says:-
'Our holy faith exalteth still in thee, With victory's robes endued;
The miscreant bands of infidelity Are driven back subdued. 
Thee do we humbly now congratulate For what thy lord hath given,

For deeds that shall be looked upon as great, When deeds are weighed in heaven.

Egypt rejoiceth, but not she alone, Baghdad rejoiceth more ;

For had her king less pious ardour shown, She that was heretofore

The "Abode of Peace" had suffered war's alarm; Nay, but for Kamil's aid,

I swear that Muslims would have dreaded harm E'en in the Kaabah's shade.

Damietta wreaks her vengeance on the horde of foes who filled her strand,

Lo! he hath cleansed her city with the sword, And with his holy band.

Prayers, to Damietta's altars long unknown, Hath he restored again :

Ah, how long, yearning for the solemn tone, Had they in silence lain!

The Benu Asfar with the yellow hair, If e'er they sleep, meseems

Nought but thy yellow standard's flaunting there Will haunt them in their dreams.

Three years and months thou tarriedst to fight, And holy war didst wage

In thine own person, nor didst thou some wight As substitute engage.

Nor didst thou halt till God gave grace and aid Unto His chosen crew,

Until with joyous victory the face

Of earth all radiant grew.

Thou didst appease, with foeman's life-blood spilled, The thirsty sword and lance;

The hungry wolf and vulture, too, were filled Where'er thou didst advance.'

In India the influence of Muhammadanism has been scarcely more than superficial. Even at the present day an Indian Muslim, in his observances and tenets, is following several Hindu customs. The notion of ceremonial defilement if an Indian Muhammadan even eat out of a vessel which has been touched by Christian hands, is not anywhere sanctioned by Islam, the Koran itself expressly saying that 'the food of those who have received the Scriptures' - that is, Christians and Jews-is lawful for the true believer.

JAHAN. Hind., PERs. The world. Hence, Jahan-gir, world conqueror. Jahan-panah, world protector, meaning 'your majesty.'

JAHANABAD, in the district of Sekooba, governed by a chief of the tribe of Sharegi, the most powerful in Seistan. Sharegi is so called from Shabrek, the residence of this chief's family, and one of the principal places in Seistan.-Ferrier, Journ. p. 415.

JAHAN-ARA BEGUM, Roushan-ara Begum, and Surya Begum were three daughters of Shah Jahan. They were all three women of beauty, talents, and accomplishments. Jahan-ara was devoted to prince Dara ; Roushan-ara was devoted to Aurangzeb; Surya Begum, the third daughter, kept aloof from the family dissensions. Jahan-ara was in the prime of youth and beauty when her father was dethroned by Aurangzeb (June 1678) but she applied for leave to share his captivity, and continued to wait upon him till his death. Afterwards she was a bountiful benefactress to the poor and to religious men, and died with the reputation of a devout woman. On her tomb is the inscription, "The perishable fakir Jahan-ara Begum, the daughter of Shah Jahan, and the disciple of the holy men of Chishti, A.H. 1094 (A.D. 1682).' - Heber, ii. 293; Travels of a Hindu, ii. 223.

JAHANDAR SHAH, emperor of Dehli, A.D. 1712-13, was the eldest son of Bahadur Shah, who died in February 1712. He defeated his younger brother Azim-us-Shan. Farokhsir, son of Azimus-Shan, met and defeated him on the 1st January 1713, put him to death on the 4th February 1713, and ascended the throne.-Elphinstone, pp. $604-5$.

JAHANGIR. Selim, eldest son of the emperor Akbar, succeeded his father as emperor of Dehli, October 1605, and assumed the title of Jahangir, world's conqueror. He early remedied some vexatious laws which had escaped Akbar's notice, forbade his officers opening bales of merchandise without the merchants' consent, abolished the punishments of cutting off ears and noses, forbade the use of wine, regulated the sale of opium, and he restored the Muhammadan creed on his coin, together with most of the forms of that religion. In March 1606, A.H. Zi Haj 1014, his eldest son Khusru fled from court towards Lahore, and, being defeated there, attempted to reach Kābul, but was seized and brought in chains before his father, and made to witness the agonies of 700 of his followers, whom Jahangir impaled in a line leading from the gate of Lahore. Jahangir expatiates in his Memoirs on the long duration of their agonies. Khusru was kept under surveillance till his death, which occurred in the Dekhan about A.D. 1621, while under the control of Prince Kurrum, afterwards Shah Jahan. In A.D. 1607 (A.H. 1016) Jahangir sent an army under Muhabbat Khan against the rana of Udaipur, and another army under Khau Khanan to effect a settlement of the Dekhan, but Malik Ambar, an Abyssinian, the Nizam Shahi and Adal Shahi dynasties, and the Mahrattas kept the imperial troops in continuous employ till the close of his reign, which saw the commencement of the rise of the Hindu race that at length put an end to the Moghul dynasty. In the sixth year of his reign (A.D. 1611, A.H. 1020) Jahangir married Nur Jahan, widow of Sher Afghan Khan. She was a high-spirited but artful woman; her name was put upon the coins along with that of her husband, the emperor took no step without consulting her, and in every affair in which she took an interest her will was law. Her father Ghaias-udDin was made prime minister, and her brother Asof Khan was placed in a high station. To her influence was due the great improvement in the conduct of Jahangir after the first few years of his reign; he was still capricious and tyrannical, but his barbarous cruelties were discontinued, and he drank only at night and in his private apartments. She was his constant attendant until his death, aiding him with her counsel, but also embroiling him with her intrigues in behalf of her own and husband's relatives. Jahangir had bestowed on Prince Kurrum the title of Shah Jahan, and declared him heir-apparent; and in October 1616 (Zi Kaida 1025) the emperor moved to Mandu to support the prince in his efforts to reduce the sovereigns of the Dekhan, in which he was entirely successful. Sir Thomas Roe, ambassador from James I. of England, accompanied him on the march, and speaks highly of the courtesy and hospitality of the nobles and the magnificence of the 
court. But while Jahangir was in Kashmir in 1621 (A.H. 1030), the Dekhan again required Shah Jahan's presence, and while engaged there Nur Jahan used all her influence to secure the succession of her son-in-law Prince Shahriar, the youngest son of Jahangir, who had married her daughter by Sher Khan Afghan. Dissensions arose from this between Jahangirand Prince Shah Jahan, and the prince rebelled, A.D. 1623 (A.H. 1032), retreating at first to Mandu and afterwards by way of Telingana into Bengal (A.D. 1624), of which he obtained possession along with Behar, and then advanced towards Allahabad to oppose Prince Parviz and Muhabbat Khan. But he was overpowered, his army dispersed, and himself constrained once more to seek refuge in the Dekhan, where he united with Malik Ambar, but was deserted by his army, and, A.D. 1625 (A.H. 1034), he submitted to his father, and sent two of his sons, Dara Shekho and Aurangzeb, to court as hostages for his good behaviour. Nur Jahan induced Jabangir to order Muhabbat Khan to the court to answer charges of oppression and embezzlement during the time he had occupiod Bengal. When he approached the camp, then on the Hydaspes, he was not permitted to see the emperor, on which he seized on the emperor's person, March 1626 (Jamadi-ul-Akhir A.H. 1035). Nur Jahan at first was separated, but shortly rejoined and released her husband, who marched back from Kābul to Lahore and then on to Kashmir. Jahangir while in Kashmir was attacked with asthma, and for change of air he was moving towards Lahore, but before he had got over a third of the journey he sank under the complaint, on the 28th October 1627 (A.H. 28 Safar 1037), and he was buried at the Shah Darra, 3 miles W. of Lahore, on the opposite bank of the Ravi. Shahriar made an unsuccessful effort to seize the throne, but Shah Jahan arrived from the Dekhan, and was proclaimed emperor at Agra on the 26th January 1628 (A.H. 7 Jamadi-ul-Akhir 1037). Jahangir's tomb is constructed entirely of marble, of fine workmanship, beneath which rests the body of the monarch. The tomb of his wife Nur Jahan has been ruined; precious stones were daily carried away by the restless Sikhs. Jahangir also married the sister of Raja Man, but the Rajputni princess early put an end to her life by swallowing poison, disgusted with the quarrels of her husband and son. His drinking-cup was formed out of a large ruby. A few years ago it had been placed for sale in one of the English jewellery shops at Calcutta by the ex-king of Lucknow. The cup had been scooped hollow out of an uncommonly large-sized ruby more than three inches long, by as many broad, in the fashion of a goblet, with the name of Jahangir inscribed upon it in golden characters. Side by side was placed also a similar but smaller cup, with a leg to stand on, which had belonged to the great Timur. The cup having passed into private property, its whereabouts cannot be any more traced. In his reign, Persian was the court language, but the people spoke Hindustani, and the emperor and some of his ministers spoke Turki. Jahangir's memoirs were written by several authors, and have several titles, amongst others the Wakiat-i-Jahangiri and Doazdah Sala-iJahangiri; and Jahangir himself seems to have written the 18 years of his reign, but ceased to record on account of his age, and Muhammad Hdia continued it till the emperor's death. Jahangir wrote in Chaghtai Turki. The Imperial Gazetteer says that in his earlier years be had accepted the eclectic faith of his father. It is said that on his accession he had even permitted the divine honour paid to Akbar to be continued to himself. His first wife was a Hindu princess ; figures of Christ and the Virgin Mary adorned his rosary; and two of his nephews embraced Christianity with his full approval. - Elphinstone, pp. 483505 ; Imp. Gaz. iv.; Mohun Lal's Travels, p. 17; Tr. Hind. v. p. 460.

JAHANGIR, a title of Pir Muhammad, grandson of Timur. He entered India in A.D. 1398. by way of Ghazni, and took Multan, and then rejoined the main army under Timur. Timur gave him the government of all his Indian conquests, and named him his universal heir, but six months after the death of Timur, in 1404, he was assassinated.

Jahannam. Arab., Hind., Pers. Hell, the Gehenna of Scripture. The Muhammadans recognise seven hells, - Jahannam for Muhammadan, Lazwa for Christians, Hutama for Jews, Sair for Sabæans, Sagar for Magi, Jalum for idolators, and Hawia for hypocrites.

JAHEZ, ARAB., or Mayndhi, Hind, a Muhammadan bride's trousseau, which is carried in procession to the bridegroom's house, consisting of clothes, garlands, dressing-cases, trinkets, and a number of articles of furniture. This is the dowry, and is the lady's property, descends to her children, and in case of her dying without issue belongs to her nearest of kin. The settlement made by the bridegroom is called the mahr. The mahr is a religious obligation, without which no marriage is lawful; as, however, the bride is allowed to remit an indefinite portion of it, it is more generally owed than paid.-Burton's Scinde.

\section{JAHIL. Hind. A lake, a morass.}

JAHNAWI, the sacred thread of Hindus, and called Yadnupavita, also Zandiam. Second birth or twice-born are terms frequently met with in works on the Hindu people, and indicate that the person to whom it is applied has received the zonar or sacrificial cord. The artisan class of Sudras in Southern India, engaged in five avocations - viz. goldsmiths, Komsala ; carpenters, Wodla ; blacksmiths, Komala; coppersmiths, Konsagara ; and stone-cutters, Sungtrash-all wear it. They are Sudras, and are divisions of the same race, for they intermarry. It is also worn by Brahmans, Kshatriyas, Chetties. See Dwaita ; Poita ; Zandiam; Zonar.

JAHN-NUGGUR is about four miles west of Nuddea, and below which the Ganges formerly held its course. Brahmaditala, in Jahn-nuggur, is a spot where buman sacrifices were formerly offered to an image of Durga, and where a great mela is now annually held in July. One of the amusements in this mela is the Jhapan or the exhibition of the skill of snake-catchers and snakecharmers, and purchase of their antidotes.-Tr. of Hind.

JAHNU SAPTAMI, the seventh day of the month Vaisakh, when a festival is held in honour of Jahnu, father of Jahnavi.

JAHREJA, a Rajput clan who occupy parts of Cutch and Kattyawar, the different sections of 
them who inhabit Hallaur and Mucha-Kanta are as under:-

\begin{tabular}{|c|c|c|c|}
\hline $\begin{array}{l}\text { Jam-zadal, } \\
\text { descendants } \\
\text { of the Jam. } \\
\text { Hurdol. } \\
\text { Doongurani. } \\
\text { Sungeea. }\end{array}$ & $\begin{array}{l}\text { Kubliur. } \\
\text { Rewani. } \\
\text { Weebani. } \\
\text { Lakani. } \\
\text { Morani. } \\
\text { Kunderya. }\end{array}$ & $\begin{array}{l}\text { Ummur. } \\
\text { Bharani. } \\
\text { Bhanani. } \\
\text { Amrun. } \\
\text { Dil. } \\
\text { Halla. }\end{array}$ & $\begin{array}{l}\text { Hapa. } \\
\text { Khumani. } \\
\text { Kana. } \\
\text { Kao. } \\
\text { Batach, } \\
\text { etc. }\end{array}$ \\
\hline
\end{tabular}

The Jahreja were long notorious for killing their infant daughters. They obtained in marriage the daughters of any of the numerous races of Rajputs, and even found their facilities such as to allow of their being nice in selecting from the most respectable families. They were furnished with wives by the Jhalla, Wagela, Goil, Chura, Summa, Purmar, Surney, Soda, Jaitwa, Wala, and Wadal tribes; but there was a general preference in favour of the Jhalla. From the Jaitwa the Jahreja could not have obtained any wives for a long time, as it was more than a century since any grown - up daughters had been seen among them, female infanticide being prevalent among them. But in the early part of the 19th century, they, as well as the Jahreja among them, signed the instrument of abolition.-Hindu Infanticide, p. 38 ; Par. Report, pp. 161-169 ; Cormack's Female Infanticide, p. 108.

JAI or Jaya, also written Jye. SANSK. Victory; used as an exclamation, also preceding the name or title of a deity or person of rank, as Jai-Rama, Jai-Sita. $-W$.

JAI-CHAND, a Rahtor Rajput, the last Hindu sovereign of Kanouj. He was father of Sunjogata. When the Chauhan Rajput Prithi-raj, the last of the Dehli kings, assumed empire by the sacrifice of the Aswa Medha, Jai-chand, to sooth his mortified vanity, celebrated the Raj shui sacrifice. It was for the last time performed by a Hindu prince, and all the Hindu sovereigns of India attended it, except raja Prithi-raj of Dehli and Samarsi of Mewar, whom Jai-chand represented by effigies of gold, assigning the post of porter to Prithi-raj, and that of scullion to Samarsi. It was at this that Jai-chand brought forward his daughter Sunjogata to select her husband, but she threw the Burmala over the neck of Prithi-raj, and in A.D. 1175 Prithi-raj carried her off to Debli. In this successful rape he lost the flower of his followers, and his subsequent defeat by the Muhammadans has been partly attributed to this. Jai-chand, though thus bereaved of his daughter, sent her jahez or trousseau after her. Jai-chand closed his career by leaping into the Ganges at Ferozabad, the ancient Chandwar. The raja of Mandu in the Allahabad district is the direct descendant of Jaichand.-Report on the N.W. Provinces; Travels of a Hindu. See Jye; Prithivi.

JAIDAD. PERs. Assets.

JAIESTH. On the sixth day of this Hindu month, about May and June, Hindu women hold a ceremonial festival, called Aranya Shashth (Forest-sixth), in which they walk in a wood. The ceremony is in the hope of obtaining handsome children.-Wils.

JAIESTH-ESW ARA, a circular temple on the Takht-i-Sulaiman Hill in Kashmir.

\section{JAILS.}

\section{Gaol,}

Gefdngniss,

Kaid-khana,

voL. II.
. Fr. Carcere, Prigione, . IT. GER. Carcil, HIND, Zindan, . TURK.
The native governments of India had no jails Their punishments were immediate, and consisted of fine, branding, mutilation, or death. In the reign of Ranjit Singh there were not at any time 100 men in confinement in the Panjab, and the first sanction asked for, when it fell to British rule, was for jails to hold 10,000 prisoners. The general death ratio for the whole of India was nearly 74 per thousand in $1879-80$; nearly onetwentieth of the prison inmates are constantly under medical treatment. Death-rate per 1000-

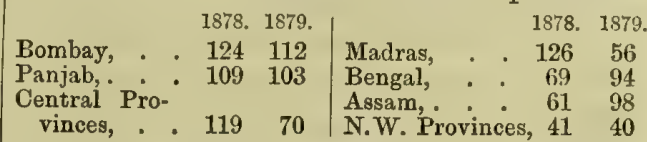

The death-rate per 1000 of all classes of prisoners in the jails of the Madras Presidency in the 23 years ending 1879 was-

$1857-58$, . $71 \cdot 7 \mid 1865$, . . $129 \cdot 4 \mid 1873$, . $28 \cdot 3$ $1858-59$, : $73 \cdot 8$ 1866-67, : $115 \cdot 6$ 1874, : : $26^{\circ} 8$ $1859-60,: 82.91867-68, \vdots 4241875, \vdots: 39 \cdot 0$ $1860-61$, : $67 \cdot 41868-69$, : $35 \cdot 11876$, : $42 \cdot 4$ $1861-62,: 93 \cdot 1869-70,: 39 \cdot 01877, \quad: 173 \cdot 7$ $1862-63,: 89 \cdot 41870,: 27 \cdot 41878,: 1256$ $1863-64$, . 109.9 1871, . . 18.4 1879, . . 56*3 $1864-65, \vdots 127 \cdot 0$ 1872, : : $22 \cdot 1$

In 1877 , the famine year, as many as 3593 deaths occurred among 20,678 prisoners. The following table contrasts the statistics of the year 1880 with the three preceding years in the Madras jails :-

$\begin{array}{lrrrr} & 1877 . & 1878 . & 1879 & 1880 . \\ \text { No. in jail, . } & 14,242 & 24,088 & 19,621 & 12,443 \\ \text { No. admitted,. } & 70,802 & 45,684 & 29,124 & \mathbf{1 9 , 6 0 6} \\ \text { No. discharged, } & 60,958 & 50,151 & 36,302 & 20,506 \\ \text { No. remaining, } & 24,088 & 19,621 & 12,443 & 11,543 \\ \text { Daily average,. } & 20,678 & 21,389 & 15,377 & 12,202\end{array}$

In British India, the average jail population in 1878 attained 127,914, and in 1882, 94,063. For the five years 1872-76 it had an average of 99,758 . According to the census of 1881, for every 10,000 of population, $4 \cdot 6$ persons were in jail. In 1882 there was much sickness throughout the jail population, -1213 admissions into hospital per 1000,-the death-rate standing at 39.96 ; the Bombay death-rate, 33.35 per 1000 , and 42.56 and 42.62 for Bengal and Madras. In Bengal, bowel complaints gave rise to by far the largest mortality. The jails in the Central Provinces had a death-rate of 89.66 per mille, and those in Lower Bengal and Assam show 59.25 per mille. In Berar the death-rate for 1882 was only 8.5 per 1000 . At Mymensing, in Lower Bengal, the ratio was 253.01 per 1000 ; at Raipur, in the Central Provinces, it was 205.56; and at Thayetmyo, in British Burma, 273.81.

JAIMINI was born at Dwaitavana. His father Shakatayana was author of a Sanskrit dictionary. Jaimini lived at Nilavata Mula, and while residing there he was described in the Skanda Purana as a short young man, of a light complexion, and wearing the dress of a mendicant. He founded the Mimansa scbool of philosophy. There are about 26 works extant illustrating the Mimansa system, but the Sutras of Jaimini are the best. Jaimini taught that the Vedas are uncreated, and are divine, and that God is to be worshipped only through the incantations of the Vedas, and through them emancipation and final absorption in Brahma. Jaimini's son Krita wrote verses in the Devi Bhagata. 
Jaimini is, however, believed to be a listorical literary name which must have been assumed by more than one Hindu author.

The Mimansa Sutras are attributed to a Jaimini, so is a Sakha of the Sama Veda; but the former refers to the latter, so they cannot possibly be of the same date. Again, there is a Grihya Sutra attributed to a Jaimini, which is relatively late, and an astrological treatise of a quite recent date is attributed to a Jaimini.

JAIMINI, a celebrated author in the south of India, who lived about the 13th century, wrote a free translation from the Sanskrit of the Aswa Medha Parva of the Mahabharata, detailing the sacrifice of the horse. This work is acknowledged by all to be the finest specimen of Canarese poetry extant. 'He has read Jaimini' is a proverbial saying, equivalent to, $\mathrm{He}$ is an accomplished man,-Garrett.

JAIN or Jaina, a sect in British India which numbers $1,221,896$. Their founder was a Hindu named Rishaba Deva. Their doctrines differ from Buddhism in this, that they recognise in the Jina Pati or Adi Buddha a divine personal ruler of all. They differ from Hindus in denying the divine origin and infallibility of the Vedas, and by their reverencing holy men whom they style Tirthankara, and also by their extreme, even ludicrous, tenderness of animal life.

The provinces of Mewar and Marwar became the cradle of their system, and there, as also in the Dekhan, they have many fine temples. They are to be found in most of the provinces of Upper India, in the cities along the Ganges, in Calcutta, Gujerat, in the northern part of the Malabar coast, and scattered throughout the Peninsula. The Jaina religion seems to have flourished for a time at Conjeveram and Mysore, and appears to have there succeeded Buddhism, after its expulsion in the 7 th century. But they have maintained their ground in Rajputana and in parts of Mysore, and followers of their creed hold in their hands a large part of the wealth and trade of India.

Sayana, in the Sarva darsanan graha, expounds the system of the Jaina sect. Their Angas constitute their true Veda. The Kalpa Sutra of Bhadra Bahu and Nawa Tatwa are two works illustrative of the Jaina religion and philosophy. The Yoga Sutra gives a summary of its morals. The Digambara sect regard the Kalpa Sutra as apocryphal. The Chatranjaya Mahatmya is a work of biography and legend.

Their leading religious tenets consist in a denial of the divine origin and infallibility of the Vedas; secondly, in the reverence of certain saints or holy mortals, who acquired by practices of self-denial and mortification a station superior to that of the gods; and thirdly, extreme and even ludicrous tenderness for animal life. The disregard of the Vedas and veneration of mortals are common to the Jain and Buddhist, and the former involves a neglect of the rites which they prescribe, but so far as the doctrines which they teach are conformable to Jain tenets, the Vedas are admitted and quoted as an authority. The Buddhists, although they admit that an endless number of earthly Buddhas have existed, confine their reverence to seven. But the Jain sect extend their number to twenty-four of their past age, twenty-four of their present, and twenty-four of the age to come. The statues of these, either all or in part, are collected in their temples, sometimes of colossal dimensions, and usually of black or white marble.

\begin{tabular}{|c|c|c|c|}
\hline Name. & Emblem. & Born. & Died. \\
\hline 1 AdinathaorVrish- & Bull. & Ayodhya. & Gujerat. \\
\hline 2 Ajitanatha, . . & Elephant. & " & $\begin{array}{l}\text { Mt. Sikhar, } \\
\text { Chodri Pa- } \\
\text { risnath. }\end{array}$ \\
\hline $\begin{array}{l}3 \text { Sambhunatha, } \\
4 \text { Abhainandanatha }\end{array}$ & $\begin{array}{l}\text { Horse. } \\
\text { Monkey. }\end{array}$ & $\begin{array}{l}\text { Sawanta. } \\
\text { Ayodhya. }\end{array}$ & Mt. Sikhar. \\
\hline 5 Sumatinatha, , & $\begin{array}{l}\text { Chakwa or } \\
\text { red goose. }\end{array}$ & , & $"$ \\
\hline 6 Supadmanatha, . & Lotus. & Kausambli. & \\
\hline 7 Suparswanatha,. & Swastika. & & $"$ \\
\hline 8 Uhan & mo & & $"$ \\
\hline 9 Pushpadanta, . & Crocodile. & Kakendrapur. & " \\
\hline $\begin{array}{l}10 \text { Sitalanatha, } \\
11 \text { Sri Ansanatha, }\end{array}$ & $\begin{array}{l}\text { Tree or flower } \\
\text { Rhinoceros. }\end{array}$ & & " \\
\hline 12 Vasupadya,. & Buffa & & Champapuri. \\
\hline 13 Vimalanatha, . & & Kump & Mt. Sikhar. \\
\hline 14 Anantanatha, & Porcupine. & Ayodhys. & $"$ \\
\hline 15 Dharmmanatha, & $\begin{array}{l}\text { Thunderbolt. } \\
\text { Antelope. }\end{array}$ & Ratanpuri. & g" \\
\hline I7 Kuntanatha,. & Goat. & $\begin{array}{c}\text { Hastinapu } \\
, "\end{array}$ & " \\
\hline 18 Aranatha, . - & Fish. & & " \\
\hline $\begin{array}{l}19 \text { Mallinatha, } \\
20 \text { Munisuvrata, }\end{array}$ & Pinnacle. & Mithila. & " \\
\hline 21 Naminatha, & $\begin{array}{l}\text { Lotus with } \\
\text { stalk. }\end{array}$ & Mithila. & " \\
\hline $\begin{array}{l}22 \text { Neminatha, } \\
23 \text { Parswanatha, } \\
24 \text { Vardhamana or } \\
\text { Mahavira, }\end{array}$ & $\begin{array}{l}\text { Shell. } \\
\text { Snake. } \\
\text { Lion. }\end{array}$ & $\begin{array}{l}\text { Dwaraka. } \\
\text { Benares. } \\
\text { Chitrakot. }\end{array}$ & $\begin{array}{l}\text { Mt. Girnara. } \\
\text { Mt. Sikhar. } \\
\text { Pawapuri. }\end{array}$ \\
\hline
\end{tabular}

Their Jinas or Tirthankaras have come to be regarded as veritable deities.

The saints held in highest esteem in Hindustan are Parswanatha and Mahavira, the twenty-third and twenty-fourth Jina of the present era. The generic names of a Jaina saint express the ideas entertained of his character by his votaries. $\mathrm{He}$ is Jagat prabhu, lord of the world; Kshina Karmma, free from bodily or ceremonial acts; Sarvajna, omniscient; Adhiswara, supreme lord; Devadi Deva, god of gods ; Tirthakara or Tirthankara, one who has crossed over Tiryati anena, that is, the world compared to the ocean; Kevali, the possessor of spiritual nature, free from its investing sources of error; Arhat, entitled to the homage of gods and men; Jina, the victor over all human passions and infirmities.

The last of the Jina was Mahavira, who was born of Trisala, wife of Siddhartha, of the family of Ikshwaku, and prince of Pavana, in Baratakshetra, and he married Yasodha, daughter of the prince of Samaravira. He afterwards became a Digambara or naked ascetic, and led in silence an erratic life for twelve years, and during his wanderings in this state he was repeatedly maltreated. He then commenced to lecture at Apapapuri in Behar. His first disciples were Brahmans of Magada, and Indrabhuti or Gautama of the Brahman tribe of Gautama rishi, who is not identical with the Gautama of the Brahmans. Mahavira died B.c. 600 , at the age of 72 , of which 38 had been spent in religious duties.

According to the Jains, the vital principle is a real existence animating in distinct portions, distinct bodies, and condemned to suffer the consequences of its actions by migration. The reality of elementary matter is also asserted, as well as of gods, demons, heaven, and hell. All existence is divisible into two heads, -Life (Jiva), or the living and sentient principle; and Inertia, or 
Ajiva, the various modifications of inanimate matter. Though the forms and conditions of these may change, as they are created they are imperishable. With them Dharma is virtue, and Adharma, vice. The Jain faith is supposed to be amongst the most recent of all the religious systems in India. Hema Chandra, one of their greatest writers, flourished in the end of the 12th century; and the compiler of the Jain Puranas of the Dekhan is said to have written at the end of the 9th century, and the Kalpa Sutra was not composed earlier than the 12th or 13th century. The Jain religion never extended itself into Bengal or Hindustan as a state religion, for two princes of Benares professed Buddhism up to the 11th century. In Western Marwar, and all the territory subject to the Chalukya princes of Gujerat, the Jain faith became that of the ruling dynasty about 1174, and Jain relics and followers are still abundant in Marwar, Gujerat, and the northern part of the Malabar coast. The Jain faith was introduced on the Coromandel coast in the 8th or 9th century, in the reign of Amoghversha, king of Tonda Mandalam. Thus the 8th or 9 th century seems to have been the earliest period of the existence of this religion there, and it was no doubt but an offshoot of the Buddhist faith, supposed by some to have been a branch of the Buddhists who escaped the fate of the orthodox followers of Gautama in the 8th and 9th centuries, by conforming somewhat to Brahmanism, and even helping to persecute the Buddhists. Hence many of the Jains acknowledge Siva, and in Mysore and other parts of Southern India they are even divided into castes.

In the reign of Himasitala, the Buddhist king of Conjeveram, about A.D. 800 , the Jains and Buddhists entered on a strife for supremacy, in which the Buddhists were defeated; some were sentenced to be crushed to death in oil-mills, others fled to Ceylon. In the reign of Kuna Pandiyan of Madura, about the 10th century A.D., the Jains were in their turn overcome by the Saivas, headed by Sampantar. The Triuviliadal Puranam states that 8000 learned Jainas, rather than recant, 'with obstinate prejudice put themaelves on the impaling stakes."

The Jain are at present divided into the Digambara or Skyclad, i.e. naked, and Swetambara, i.e. the white-robed. The Digambara are also called Nirgrantha, without a bound, also Nangnatha, naked mendicants. They seem to have the greater claim to antiquity. All of the sect in the Dekhan and in Western India appear to be Digambara Jain. Indeed, the term Jain seems a new appellation, for in the early philosophical writings of the Hindus they are styled Digambara or Nanga, but in the present day the Digambara do not go naked except at meal time, but wear coloured garments. The Digambara assert that the women do never attain Nirvan, but the Swetambara admit the gentler sex to final annihilation.

There are clerical as well as lay Jains, the Yati or Jati, and the Sravaka, the former of whom lead a religious life, and subsist on the alms which the latter supply. The Yati are sometimes collecter in mat'hs, called by them Pasala, and even when abroad in the world they acknowledge a sort of obedience to the head of the Pasala of which they wore once members. The Yati never officiate as priests in the temples, the ceremonies being conducted by a member of the orthodox priesthood, a Brahman duly trained for the purpose. They carry a brush to sweep the ground before they tread upon it, never eat nor drink in the dark, lest they should inadvertently swallow an insect, and sometimes wear a thin cloth over their mouths, lest their breath should inhale some of the atomic ephemera that frolic in the sunbeams. They wear their hair cut short, or plucked out from the roots. They profess continence and poverty, and pretend to observe frequent fasts, and exercise profound abstraction. Some of them are engaged in traffic, and others are proprietors of mat'hs and temples, and derive a comfortable support from the offerings presented by the secular votaries of Jina. The Jains of the south of India are divided into castes, but in Northern India they are of one caste, refuse to mix with Hindus, and recognise eighty-four orders amongst themselves, between whom no intermarriages have taken place. This classification is ealled the Gacheha or Got, the family or race, which has been substituted for the Varna, the Jati, or caste. Secular Jains follow the usual professions of Hindus, but collect chiefly in towns, where, as merchants and bankers, they usually form a very opulent portion of the community. There are many in Murshidabad, Benares, and the Doab, but they are most numerous in Mewar and Marwar; numerous in Gujerat, Mysore, and in the upper part of the Malabar coast, and scattered throughout the Peninsula. They form a large division of the population of India, and, from their wealth and influence, a most important one. More than half of the mercantile wealth of India passes through the hands of the Jain laity. The chief magistrate and assessors of justice in Udaipur, and most of the towns of Rajasthan, were of this sect; and as their duties were confined to civil cases, they are as competent in these as they are the reverse in criminal cases, from their tenets forbidding the shedding of blood. To this leading feature in their religion they owe their political debasement; for Komarpal, the last king of Anhilwara of the Jain faith, would not march his armies in the rains, from the unavoidable sacrifice of animal life that must have ensued. The strict Jain does not even maintain a lamp during that season, lest it should attract moths to their destruction.

Mewar afforded a refuge to the followers of the Jain faith, which was the religion of Balabhi, the first capital of the rana's ancestors, and many monuments attest the support this family has granted to its professors in the vicissitudes of their fortunes.

Rajasthan and Saurashtra are the cradles of the Jain faith, and three out of their five sacred mounts, namely, Abu, Palitana, and Girnar, are in these countries. One of the best preserved monumental remains in India is a column in Chitore, most elaborately sculptured, full 70 feet in height, dedicated to Parswanatha. The noblest remains of sacred architecture, not in Mewar only, but throughout Western India, are Buddhist or Jain; and the many ancient cities where this religion was fostered have inscriptions which evince their prosperity in these countries, with whose history their own is interwoven, and to their having occupied a distinguished place in Rajput society ; the libraries of Jeysulmir in the desert, of Anbil- 
wara, the cradle of their faith, of Cambay, and other places of minor importance, consist of thousands of volumes. These are under the control, not of the priests alone, but of communities of the most wealthy and respectable amongst the laity, and are preserved in the crypts of their temples, which precaution ensured their preservation, as well as that of the statues of their deified teachers, when the temples themselves were destroyed by the Muhammadan invaders, who paid more deference to the images of Buddha than to those of Siva or Vishnu.

The shrine in Hindu temples is always dark, and entered only by the single door in front; Jain temples, on the contrary, have very frequently several entrances. The patterns are very much alike, except in details, and consist chiefly of varieties and combinations of the figure called by the Jains Nandavarta, - a sort of complicated square fret,-the cognisance of the eighteenth Jaina.

The grouping together of their temples into what may be called 'cities of temples,' is a peculiarity which the Jains practise to a greater extent than the followers of any other religion in India. The Buddhists grouped their stupas and viharas near and round sacred spots, as at Sanchi, Manikyala, or in Peshawur and elsewhere; but they were scattered, and each was supposed to have a special meaning, or to mark some sacred spot. The Hindu also grouped their temples, as at Bhuvaneswar and Benares, in great numbers; but in all cases, so far as is known, because these were the centres of a population who believed in the gods to whom the temples were dedicated, and wanted them for the purposes of their worship. The Jains seem, almost more than any other sect, to have realized the idea that to build a temple, and to place an image in it, was in itself a highly meritorious act, wholly irrespective of its use to any of their co-religionists. This is a similar view to that held by their sister Buddhist creed.

Vasi, north of Dwaraka in Kattyawar, has a very ancient Jain temple. In S. Canara, at Karkala, there is a colossal Jaina statue; and Comateswara, a Jain figure of colossal size, is in front of a temple at Sravana Belgola.

The fragment of a little temple at Amwah, near Ajunta, shows it to have been a Jaina shrine of Sri Allat, the twelfth king mentioned in Tod's Rajasthan (i. p. 802).

Sonaghur, near Dutteah in Bundelkhand, and Muktagiri, near Gawilghur, in Berar, show the most modern styles of Jain architecture. Sonaghur is a granite hill covered with large loose masses of rock, among which stand 80 to 100 temples of various shapes and sizes. The sikra is rare, and the foliated pointed Muhammadan arch is the usual opening. Muktagiri is a deep romantic valley, and its largest group of temples are on a platform at the? foot of a waterfall that thunders down from a height of 60 feet above them. The temples are only remarkable from showing their adoption of the Muhammadan style. At Dehli is a Jaina temple of much beauty. The background of the strut of its porch has pierced foliated tracery of the most exquisite device. At Khandagiri, near Cuttack, are Jaina caves, and there is one at Badami without any inscription. But there are three Brahmanical caves, one of which has the date 500 Saka (A.D. 579). The
Indra Subha and Jaganath Subha groups at Ellora are supposed to be of the same age as the Badami cave temple. At Ajmir the Arhai-din-ka Jompra has been described as a Jaina temple. So also is a great part of the mosque at the Kutub, Dehli.

Mr. Fergusson, however, tells us that the principal Jain works are in Rajputana, Gwalior, and Bundelkhand. Their sculptures almost entirely are restricted to the representation of their twenty-four hierarchs, whom they call Tirthan$\mathrm{kara}$, to each of whom, as mentioned at page 402 , a symbol is attached, - generally some animal, fish, or flower; in one instance a crescent, in another a thunderbolt. Some of the Jaina temples are of great beauty. They have their shrines on the hills of Palitana, Girnar, Gwalior, Mount Abu, and Parasnath, but also in deep secluded valleys. That at Muktagiri, near Gawilghur, is in a deep, well - wooded valley, traversed by a stream with several waterfalls. At Sadri there is a group of temples, the principal one having been erected by Khumbo, rana of Udaipur, in a lonely silent glen, below his fort of Komulmer, dedicated to Adinatha or Reshabdeva, the first and greatest of the Jaina saints. It covers 48,000 square feet. The rock at Gwalior, in Central India, has one remarkable Jaina structure, dedicated to Padmanatha, their sixth Tirthankara, and the rock on all sides has a series of caves or rock-cut sculptures, most of them mere niches to contain statues, all of them excavated between 1441 and 1474. One of the figures is 57 feet high. In their temples the saint is very numerously represented by images in cells or niches. At Chandravati, a few miles southward from Mount $\mathrm{Abu}$, is a ruined city, with extensive remains of Jaina temples of the sarne age as those on the mount.

Jaina images are in Canara called Chindeo, a corruption of Jainadeva.

The Jain has been a builder of temples, has cut out cathedrals in the rock, and piled up towers and spires at his great places of pilgrimage for the last thousand years. Their temples are magnificent; the most ancient of them are at Girnar. the most exquisite on Mount $\mathrm{Abu}$, the most extensive and still flourishing at Satrunjaya near Palitana. The last mentioned were beautified and restored by Siladitya, and it is the most ancient and most sacred of the Jain shrines of Gujerat. Almost every Indian city has contributed to its adornment. Palitana, or the abode of the Pali, is the name of the town at the foot of the sacred mount Satrunjaya (signifying victorious over the foe), the Jain temples on which are sacred to Budheswara, or the lord of the Buddhist. Palitana seems derived from the pastoral (Pali) Scythic invaders bringing in their train the Buddhist faith, which appears indigenous to India. Palestine, which, with the whole of Syria and Egypt, was ruled by the Ykos, or Shepherd Kings, who for a season expelled the old Coptic race, may have had a similar import to the Palitana founded by the Indo-Scythic Pali.

The hill of Satrunjaya at Palitana, in the Gohelwar district at the mouth of the Gulf of Cambay, is dedicated to Adinath, the first of the 24 hierophants of the Jains. Each temple contains images in marble of Adinath or of some other of the Tirthankara, and perhaps no fabric of 
human workmanship in India is more calculated to arouse wonder, admiration, and lasting remembrance than Palitana in its unique and mysterious perfection.

Abu, in Jain estimation, is the holiest spot on earth. Dilwarra, according to tradition, has been famous from a remote antiquity. Hindu temples are said to have existed, to which, since A.D. 1034, pilgrims have resorted; but all traces of them have disappeared. On their traditional site, howèver, at Dilwarra, Bimul Sah, a rich Jain merchant, and others, erected the celebrated Jain temples which are now there. The Jain priests of $\mathrm{Abu}$ are chosen from amongst the youth of the Ossi tribe or Oswal of the Marwari people. They never marry, but live a sad'hu or pure ascetic life, and are scrupulously careful to avoid destruction of animal life. They move about with a cloth over their mouths to prevent insects entering; they use incessantly a small brush or broom to sweep aside all living creatures ; they eat seldom, generally once daily, and they never partake of stale food, lest in the interval since its cooking animalculæ may have formed in it.

The ancient Persian fire-worshippers, like the present Jain, placed a bandage over the mouth while worshipping.

The Jains have five great tirthas, or places of pilgrimage, to which the large bands of pilgrims called Sanghas may be seen slowly marching every cold season. These places are Parisnath, near Calcutta; Mount Abu, the sanatorium of Rajputana; Chandragiri in the Himalaya; Girnar in Gujerat; and Satrunjaya in Kattyawar.

Parasnath is the bighest point of the Bengal range of hills south of Rajmahal. It is one of the Jaina pilgrim shrines, and nineteen of their twenty-four Tirthankara are said to have died and been buried there; amongst others, Parswanatha, the last of them but one. The temples on it are numerous. But Jainism never seems to have taken a firm place in Bengal; and when the Pala dynasty of Bengal, about A.D. 1203, left Buddhism, and accepted the Vaishnava and Saiva superstitions, Jainism seems to have disappeared. There seems also to have been a pause, at least in the north of India; but a revival occurred in the 15 th century, especially under Rana Khumbo of Mewar, A.D. 1418-1468, who made his capital at Chitore. Though deficient in the extreme grace and elegance that characterized the earliest examples, those of the middle style are bold and vigorous expressions of the art.

The temples on Parasnath are contemptible. But the number of pilgrims, men and women well-to-do in the world, who journey from very distant spots to Parasnath, is considerable. Slowly and toilsomely they may be seen climbing the hill, and presenting their offerings to the figures within the temple, marching thrice round the building with low and not unmelodious chant.

Of the five great places of pilgrimage, Satrunjaya is now the most popular. Like Parasnath, it is a solitary peak. It rises to a height of about 2000 feet, a little to the south of Palitana in Kattyawar. Leaving that town, the visitor passes along a broad and clear road, shaded by the banyan tree, and supplied by wells of pure water, the work of derotees. The steep ascent begins with a wide flight of steps guarded by elephants, and is marked all the way up by miniature shrives covering marble slabs, on which the soles of two feet are carved, with Devanagiri inscriptions. There are frequent resting - places, considered especially holy, which are associated with events in the legends of Bharata and Krishna. The Hindus are represented by Hanuman, the monkey god, and the Muhammadans by the shrine of a saint, both marking the cessation of conflicts with the Jains. From the summit the view is magnificent. That a sect numbering less than half a million. of people all over India should send forth so many pilgrims every year to the five tirthas, is explained by the fact that pilgrimage is an essential part of their worship,-is, indeed, the only. means by which the devotee may attain to that complete annihilation, which, as distinguished from the Buddhist absorption, is the result of the breath, the only soul which they seem to believe in, leaving the body.

They have an extensive literature, Puranas of their own, works in grammar, astronomy, mathematics, and medicine. They were the first who reduced the Canarese language to writing, and cultivated it to a high degree of perfection. The best epic poem in the Tamil language, the Chintamani, was by a Jaina.-Barth, p. 140; Taylor's Catalogue, iii. pp. 424-436.

JAINTIA, a tract of country in the province of Assam, divided into the Jaintia hills and the Jaintia plains. Indra Singh, the last raja of Jaintia, was a petty chief whose family had risen to importance amid the ruins of the Kachari kingdom at the close of the 18th century. Previously to the conquest of Assam, in 1824, the inhabitants of Jaintia were in the frequent habit of capturing British subjects in Sylhet, to offer up as sacrifices at the shrine of Kali. In 1832, two British subjects were passing along the high-road in Assam, when they were suddenly seized and carried up into the hills in the neighbourhood of Goba, in the Nowgong district. After having been decked out with new clothes and jewels, they were led away to be sacrificed, together with two other persons, also subjects of the British Government. One of the individuals, however, succeeded in making his escape, and on his return to the plains he gave information of what had occurred; and as no tidings were ever afterwards heard of the three other individuals, little doubt remained but that they were sacrificed. The chief had been frequently required to surrender the guilty individuals, but all to no purpose; and there being strong reason for believing that the chief had wilfully screened the perpetrators of this horrible crime, the Governor-General, Lord William Bentinck, in February 1835, confiscated all his territory situated in the plains. Dantipar consequently became annexed to the district of Nowgong, and these horrible atrocities were put a stop to. The raja voluntarily resigned the hill tract, and of this the British also took possession.

The Jaintia Hills are divided into 25 fiscal divisions, of which 3 are inhabited by Kuki or Lushai inmigrants, and 1 by Mikirs. The remainder of the inhabitants are Syntengs, a race akin to the Khasiyas, but reported to have distinct ethnical characteristics and a language of their own.-Butler's Travels in Assam, pp. 246, 247.

JAIPALA was raja of I,ahore in the times of 
Sabaktagin and his son Mahmud. He was defeated by Sabaktagin; and subsequently, at Peshawur, by Mahmud (Ismail ?), who took him prisoner. On his release, he made over his kingdom to his son Anang Pal, and, mounting a pyre which he had ordered to be constructed, he set fire to it with his own hands, and perished in the flames.-Elph.

JAIPUR, Jayapuram, or Jeypore, a zamindari or tributary estate in Vizagapatam district, Madras, lying between lat. $17^{\circ} 30^{\prime}$ and $20^{\circ} \mathrm{N}$., and long. $81^{\circ} 20^{\prime}$ and $84^{\circ} 4^{\prime} \mathrm{E}$. The population is chiefly Kandhs and Sauras.

JAIPUR or Jeypore, the capital of a Rajput State of the same name. It is the most beautiful of the towns of India, situated in lat. $26^{\circ} 55^{\prime} \mathrm{N}$., and long. $75^{\circ} 52^{\prime} \mathrm{E}$., and the State lies between lat. $25^{\circ} 41^{\prime}$ and $28^{\circ} 27^{\prime} \mathrm{N}$., and between long. $74^{\circ} 55^{\prime}$ and $77^{\circ} 15^{\prime}$ E.; area, 14,465 square miles. The military consist of 452 artillery, 4600 infantry, 5142 cavalry, and 4096 Nagha. Its ruler is the chief of the Kachhwaha tribe of Rajputs, and claims descent from Rama, king of Ayodhya in Oudh. Between Rama and Dhola Rao, who founded the Jaipur State in A.D. 967, thirty-four generations are said to have intervened. At the time of the foundation of Jaipur, Rajputana was under petty Rajput and Mina chiefs, owing allegiance to the great Tuar dynasty of Rajputs, who then reigned at Dehli. Dhola Rao and his Kachhwaha clan are said to have absorbed or driven out the petty chiefs, and to have founded a substantial dominion, known as Dhundal. Half a century later, the Kachhwaha chief Hamaji wrested Amber from the Mina, and this place remained the capital until 1728, when Jai Singh II. abandoned it for Jaipur.

The emperor Akbar, in the sixth year of his reign, when on a pilgrimage to Ajmir, honourably received at Sanganir, Bihari Lal, then chief of Jaipur, and married his daughter. Bihari Lal, with three of his sons, entered the emperor's service. One of these sons, Bhagwan Das, attained distinction as a governor and commander; and his adopted son Man Singh was one of the most conspicuous of the imperial generals. $\mathrm{He}$ fought in Orissa, Bengal, and Assam; and at a critical period, under great difficulties, he maintained his authority as governor of Kābul.

Jai Singh II., commonly known as Siwai Jai Singh, was remarkable for his scientific knowledge. He began to rule in A.D. 1699. He constructed observatories at Jaipur, Dehli, Benares, Muttra, and Ujjain, by which he was able to correct the astronomical tables of $\mathrm{De} \mathrm{La}$ Hire, and to leave as a monument of his skill, lists of stars collected by himself, known as the 'Tij Muhammad Shahi,' or Tables of Muhammad Shah, the then emperor of Dehli, in whose favour Jai Singh stood bigh. He laid out and built the present Jaipur (Jeypore) in A.D. 1728. At a later period, the rajas of Jaipur united with Udaipur (Oodeypore) and Jodhpur to resist the Muhammadan power. And, to regain the honour of intermarriage with the Udaipur family, which his family had lost by giving a princess to the Moghul emperor, the raja of Jaipur consented that the issue of a Udaipur princess should succeed in preference to an elder son by other wives. This attempt to set aside the right of primogeniture brought great disasters both on Jaipur and
Jodhpur. Subsequently, at the beginning of the 19th century (1809), the Jaipur ruler was mixed up with a very horrible deed, to Krishna Kumari. The maharana of Udaipur had only one daughter, and the rajas of Jaipur and Jodhpur fought for her hand. The rana was helpless to decide between the two candidates, and the whole country was convulsed by the struggle, for nearly all the chiefs of Rajputana took a part in the war. The Mahrattas and Afghans saw their opportunity, and the progress of their armies through Rajputana was to be traced by blazing villages and ruined harvests. The rana implored the British Government for protection. Even the rival princes of Jaipur and Jodhpur joined in the solicitation. But public opinion in England was opposed to all such intervention. A word would have restored peace to Rajputana, but the British Government declined to interfere. Accordingly, the rana was obliged to purchase the protection of Amir Khan, the Afghan, by the cession of a large territory, and was then compelled by the Afghan to poison his own daughter to put an end to the war. The young Rajput princess accepted her doom, said, "This is the marriage foredoomed for me,' and drank the opium; but the tragedy filled Western India with shame and horror.

The political relations of the British Government with Jaipur commenced in 1803 , when Juggut Singh was then its maharaja ; in 1818 be ended a life which had been spent in the grossest debauchery, and regretted by no one. But on the 25 th April 1819, a posthumous son was born by one of the ranis, and he was recognised as heir, both by the Jaipur nobles and the British Government. Till the rani's death in 1833, Jaipur was a scene of corruption and misgovernment. The young maharaja, Jai Singh, died in 1835 , leaving a young son, Ram Singh, then under two years of age, and the agent to the GovernorGeneral then proceeded to Jaipur, reformed the administration, and assumed the guardianship of the infant heir. The agent's life was attempted, and his assistant was murdered. The larger portion of the Sambur lake belongs to Jaipur, and the salt manufactured from it yields 4 lakhs. Babra, three marches from Jaipur, on the road to Dehli, has one of the edicts of Asoka engraved on a block of stone or rock, on a hill, in old Pali, and of date B.C. 309. It is in the oldest Lat character. It differs somewhat in style and language from the pillar and rock edicts. The subject is the Buddhist commandment forbidding the sacrifice of four-footed animals. The Vedas are alluded to, but not named, and are condemned as mean and false in their doctrine, and not to be obeyed. The Jaipur artisans produce translucent enamels, that is, enamel colours painted on gold, or gold-leaf, which gives light and splendour to the colours. - Treaties, Engagements, and Sunnuds, iv. p. 29 ; Beng. As. Soc. Jo. ix. p. 617 ; Malcolm's Tr.; R. As. Soc. i. p. 69 . See Rajput. JAIS, a Rajput tribe of the Solar branch, residing principally about Muttra.

JAISALMIR or Jeysulmir is the capital of the Rajput State of the same name, situated in a broad belt of low rocky ridges, lat. $26^{\circ} 55^{\prime} \mathrm{N}$, and long. $70^{\circ} 57^{\prime} \mathrm{E}$. It was founded in the year 1156 by Rawal Jaisal; Elphinstone says A.D. 720.

The State lies between lat. $26^{\circ} 5^{\prime}$ and $28^{\circ} 23^{\prime} \mathrm{N}$., and between long. $62^{\circ} 29^{\prime}$ and $77^{\circ} 15^{\prime} \mathrm{E}$. It is 
almost entirely a sandy waste, forming part of what is called the 'Great Indian Desert.' A well, 32 miles south-east of the capital, is 490 feet deep. Rain-water is used for drinking purposes. The majority of the inhabitants are Yadu Bhatti Rajputs, who claim a very ancient lineage. The ruler of Jaisalmir is styled Maharawal, and holds his position as head of the Bhatti clan. The Maharawal has a force consisting of 651 infantry.

The castle of Jaisalmir is erected on an almost insulated peak, from 200 to 250 feet in height, a strong wall running round the crest of the hill. It has four gates, but very few cannon mounted.

Jaisalmir is separated on the north from Bahawulpur by the Great Desert, and is the modern name of the ancient Marusthali, the Desert of India. It is termed Mer in the traditional nomenclature of this region, from being a rocky (mer) oasis in the heart of the sandy desert. The greater part of Jaisalmir is thul or rue, both terms meaning a desert waste. From Lowar, on the Jodhpur frontier, to Kharra, the remote angle touching Sind, the country may be described as a continuous tract of arid sand, frequently rising into lofty tiba (sand-hills), in some parts covered with low jungle. This line, which nearly bisects Jaisalmir, is also the line of demarcation of positive sterility and comparative cultivation. To the north is one uniform and naked waste; to the south are ridges of rock termed muggro, rue, and light soil. There is not a running stream throughout Jaisalmir; but there are many temporary lakes or salt marshes, termed sirr, formed by the collection of waters from the sand-hills, which are easily dammed in to prevent escape. The sirr last but a few months, though after a very severe monsoon they have been known to remain throughout the year. The Kanoad sirr extends from Kanoad to Mohumgurh, covering a space of 18 miles, and in it some water remains throughout the year. When it overflows, a small stream issues from the sirr, and pursues an easterly direction for 30 miles before it is absorbed. The salt which it produces is the property of the crown, and adds something to the revenue. The country still dependent on the Rawal extends between lat. $26^{\circ} 20^{\prime}$ and $27^{\circ} 50^{\prime}$ N., and long. $70^{\circ} 30^{\prime}$ and $72^{\circ} 30^{\prime}$ E., though a small strip protrudes in the N.E. angle, as high as $28^{\circ} 30^{\prime}$. The Yadu of Jaisalmir, who ruled Zabulisthan, and founded Ghazni, claim the Chaghtai as of their own Indu stock, - a claim which Colonel Tod deems worthy of credit. The first chief with whom the British Government entered into political relations was Maha Rawal Mulraj, who succeeded to power in 1762. In 1818 , a treaty was concluded with Mulraj by which the State was guaranteed to his posterity, the chief was to be protected from serious invasions and dangers to his State, provided the cause of quarrel was not ascribable to him, and was to act in subordinate co-operation to the British Government. No tribute was demanded from him. During the lifetime of Mulraj, who died in 1820, the State was virtually governed by his minister, Salim Singh, who put to death nearly all the relatives of the chief. The town of Jaisalmir was depopulated by his cruelty, the trade of the country was interrupted, and the relatives of the Maha Rawal who escaped death fled from the country. In 1844 , after the con- quest of Sind, the forts of Shagur, Gurseea, and Guttura, which had been wrested from Jaisalmir, were restored to that State. 'The forts were given over by Mir Ali Morad, by order of the British Government. In 1846, the widow of Guj Singh adopted Ranjit Singh, who, in 1862, received a formal sunnud guaranteeing the right of adoption; he receives a salute of fifteen guns. The area of Jaisalmir is 12,252 square miles, the population about 73,700, and the revenues Rs. 5,00,000. The military force of the State does not exceed a thousand men.

Copper mines are in the neighbourhood of Khetri, but, owing to the want of proper appliances for keeping down the water, the richest veins, which are lowest, cannot be reached.-Tod's Rajasthan, ii. p. 284; Treaties, etc.

JAISHTHA. SANSK. The second month of the Hindu solar year, when the sun is in the sign Vrisha 8, answering to the Tamil month Viassei.

JAI SINGH II., the royal historian and astronomer of Amber, connects the line with Sumitra, the fifty - sixth descendant from the deified Rama, who appears to have been the contemporary of Vikramaditya, A.C. 56. From his love of science, he was one of the most remarkable persons of his nation. He was appointed by the emperor of Dehli to be viceroy of Malwa, but in public life he was not distinguished for firmness or decision, and in A.D. 1734 he surrendered Malwa to the Mabrattas with the tacit concurrence of the emperor, on whose behalf the territory was still to be held. But, in 1736, Baji Rao claimed as jaghir the province of Malwa and all the country south of the Chambal, together with the holy cities of Muttra, Allahabad, and Benares.Elph. p. 626. See Jaipur.

JAISWAR, a tribe of inferior Yaduvansi Rajputs of the Central Doab. Jaiswara, Jasawara, or Juswar, subdivisions of low-caste tribes, originally from Jais, in Oudh.

JAITW A, Jetwa, or Camari, an ancient tribe, and by all authorities styled Rajput, though, like the Jhala, little known out of Saurashtra, to one of the divisions of which it has given its name, Jaitwa. Its present possessions are on the western coast of the Peninsula. The residence of its prince, who is styled rana, is Porbandar. In remote times, their capital was Gumti, whose ruins attest considerable power, and afford singular scope for analogy, in architectural device, with the style termed Saxon of Europe. The bards of the Jaitwa run through a long list of 130 crowned heads, and in the 8th century have chronicled the marriage of their prince with the Tuar re-founder of Dehli.-Tod's Rajasthan, i. p. 113.

JAJMAN, in N. India, a person to whose services Brahmans, barbers, bari, and others have a prescriptive right. The village jajman must be fed, whether employed or not.

JAJU, near the ford of the river Bunganga, is generally called Jaju Sarai ; near it the battle was fought between Bahadur Shah, son and successor of Aurangzeb, and his brother the prince Muhammad A'zam.-Cal. Rev., Jan. 1871.

JA'K'HAN. HIND. The wooden foundation of the brickwork of a well. It is generally made of the green wood of the gulur tree (Ficus glomerata), which is less liable to rot than any other kind.-Elliot, Supp. Gloss.

JAKO, mountain peak in the Simla district 
of the Panjab, overhanging the station of Simla, lat. $31^{\circ} 5^{\prime} \mathrm{N}$., and long. $77^{\circ} 15^{\prime} \mathrm{E}$. The ridge, upon which stands the sanatorium and summer capital, culminates eastward in this noble height, 8000 feet above sea-level, and 1000 feet above the general elevation of the houses.-Imp. Gaz.

JAKUN. The wild tribes inhabiting the Malayan Peninsula, Sumatra, and a few of the neighbouring islands are divided into three principal classes, which are subdivided into many clans. The first of these divisions includes the Bhatta, who inhabit the interior of Sumatra and a few neighbouring islands. The second is that of the Semang, who are found in the forests of Kedah, Tringanu, Perak, and Salangor. The third division, the Jakun, comprise many tribes, who inhabit the south part of the Peninsula, from about Salangor on the west coast and Kemaman on the east coast, and extend nearly as far as Singapore. All these various wild tribes are ordinarily classed under the general and expressive appellation of Orang Binua, meaning people of the soil. The Malays, in the 13 th century, had but a short time inhabited the Peninsula, since we are informed by the Sejara Malaya that Singapore is celebrated in Malayan history as having been the first place of settlement of the early Malay emigrants from Sumatra. In course of time the early Arab trading vessels brought over priests from Arabia, who made a number of converts to Muhammadanism, and those of the Orang Binua who declined to abjure the customs of their forefathers, in consequence of the persecutions to which they were exposed, fled to the fastnesses of the interior, where they have since continued in a savage state. The principal localities of the Jakun are at the upper extremity of the rivers of Johore, Banut, Batu Pahat, and Muar. Those of Malacca are generally as tall as the common run of Europeans; they are darker than any other of the wild tribes; and in which respect there is not much difference between them and the darker of the Indo-Portuguese of Malacca. The Jakun of Johore are a fine race of men; many of them are taller than those of Malacca; the face also is expressive and well characterized, and the expression of the eyes in many of them is a little severe. Their nose does not recede at the upper part, neither is it so flat or so broad at its base as this organ is in the Chinese, Cochin-Chinese, and pure Malay. Several of them have aquiline noses. Some children and young men are beautiful. The women are plump, but not over stout. The Jakun of Menangkabau State are very short, their physiognomy is low, and seems to indicate great simplicity; many of them are ugly and badly made. A Jakun has always his spear, which is both a stick to walk with and an offensive or defensive weapon. The parang, an iron blade of about 1 foot long and 2 or 3 inches broad, with a haft like that of a large knife, they use to cut trees. Their marriages are ordinarily celebrated about the month of July and August, when fruits are plentiful. Amongst some tribes there is a dance, in the midst of which the bride elect darts off into the forest, followed by the bridegroom. A chase ensues, during which, should the youth fall down or return unsuccessful, he is met with the jeers and merriment of the whole party, and the match is declared off.
Adultery is punishable by death. It is not allowed to keep more than one wife. A man can divorce his wife and take another. In several tribes, children, so soon as born, are carried to the nearest rivulet, where they are washed, then brought back to the house, where a fire is kindled, incense of kamunian wood thrown upon it, and the child then passed over it several times. The practice of passing children over fire was in all times much practised among ancient heathen nations: and it is even now followed in China and other places. When death occurs, the sumpitan, quiver of arrows, knife, etc., of the deceased are buried with him, along with some rice, water, and tobacco. They are candid and honest, extremely proud, and will not submit for any length of time to servile offices, or to much control. Each tribe is under an elder, chief, or leader, termed the Batin, who directs its movements, and settles disputes. The Jakun hate the Malay, and the Malay despise the Jakun.

JAL. HIND. Water. Jăli dhan, a rice crop sown in marshy ground. Jalkar sair, revenue obtained from water. Jal, a Hindu water ordeal, in which the accused is dipped under water whilst an arrow is shot and a person runs and brings it. If, on his return, the accused be still alive, he is deemed innocent. Jala-Charaniya, any caste from whose hands a Hindu would drink water.

JALAGARA. KaRN. A caste who sweep the streets, sift or wash refuse in search of lost money or valuables. Jalagada-guwar, sifters of goldsmiths' furnaces.

JALAL. AraB., Hind., PErS. Splendour ; the dread attribute of the Almighty. See Sufi.

JALALABAD, a small town in Afghanistan on the bank of the Kabul river, in a rich country between Peshawur and Käbul. It is in lat. $34^{\circ}$ $24^{\prime} \mathrm{N}$., and long. $70^{\circ} 26^{\prime} \mathrm{E}$. It is 100 miles from Kābul, with about 300 houses of Hindus, Tajak, Alwwan, and Afghans. It is on the highroad from Peshawur to Käbul, and 1946 feet above the sea. Sir Robert Sale occupied it on the 13 th November 1841, and held it to the 7 th April 1842, when the garrison was relieved by General Pollock.

Jalalabad was long the residence of a chief of the Barakzai family, who had a revenue of about seven lakhs of rupees a year. The Safed Koh or Rajyal, on its south, attains a height of 15,000 feet; and about 30 miles on its north is the famous Nurgil; on the N.T. the lofty peaks of the Hindu Kush appear.

Earthquakes are repeatedly felt at Kābul. Vigne tells us (Pers. Narrat. p. 212) there are usually a dozen in the course of a year. While the British were besieged at Jalalabad, in 1841, its walls were thrown down by an earthquake. The prevailing rock is gneiss-MacGregor, p. 401 ; Burnes' T'r. i. 23 ; Mohun Lal's Tr. p. 343.

JALALABAD, a name given by Akbar to the town of Arail on the banks of the Jumna, after his own title of Jalal-ud-Din. By a public edict, he abolished the salutation of 'Salam Alaikum," substituting 'Allaho Akbar,' and the reply of 'Jal-i-Jalaliho;' in both of which are parts of his name, Jalal-ud-Din Muhammad Akbar. The Sipah Salar was ordered to see that the same exclamations were made at meals; and the aftabi, the rupee, and several other coins of his 
reign, as well as his seal, bore the inscription, Allaho Akbar, Jal-i-Jalaliho. There are several instances of Arail being mentioned prior to Akbar's time. In the Tarikh-i-Budaoni it is stated that the pargana of Arail was, in A.H. 977, before the composition of the Ayin-i-Akbari, given in jaghir to raja Ram Chund.-Elliot's Supp. Gloss. See Nagarabara.

JALALI, a sect of fakirs or darvesh, who look on Syed Jalal Bokhari as their founder. He married two daughters of Syed Badr-ud-Din.

JALALPUR, an agricultural village, in lat. $32^{\circ} 39^{\prime} 30^{\prime \prime} \mathrm{N}$., and long. $73^{\circ} 27^{\prime} \mathrm{E}$., close to the right bank of the Jhelum river. The village has been identified by General Cunningham with the site of the ancient Bucephala, built by Alexander the Great in memory of his charger, which was killed in the battle with Porus at the crossing of the Jhelum. Amusing Porus by marching and counter-marching bis troops along the banks of the river, as if searching for a ford, on the arrival of the boats, he passed the river at Jalalpur, 114 miles from Attock, where it is, in the rainy season, upwards of a mile broad and never fordable. In the battle which ensued, Porus was defeated and taken prisoner. It was at this part of the Hydaspes, on its right or western bank, that the conqueror, in commemoration of this event, built the cities of Nicrea and Bucephala. Remains of ancient walls still crown the summit of the hills, which rise to a height of 1000 feet above the village. Coins found among the ruins date back to the period of the Græco-Bactrian kings. Even in the time of Akbar the town covered a site four times as large as that which it now occupies; but since the foundation of Pind Dadan Khan, and the shifting of the river channel two miles eastward, it has undergone a constant decay.-Imp. Gaz.

JALAL-ud-DIN, son and successor of Sultan Muhammad, king of Kharasm. On the advance of the hosts of Chengiz Khan, he defended his country gallantly to the last. $\mathrm{He}$ gained a victory near Kandahar, and another still farther to the east, but these successes did not even retard his ruin. His last battle was near Bannu, in A.D. 1221, on the Indus, where, after displaying the most obstinate valour, and witnessing the total destruction of his army, he swam the river with seven followers amidst a shower of arrows from his enemies, whom he left in admiration of his intrepidity. In the course of the night and next day, he was joined by 120 of his soldiers, and before many days had passed he had assembled 4000 horse; but on the Moghuls threatening to cross the Indus, he fled towards Dehli, and applied to Altamsh for aid or an asylum. To this he received only a courteous answer; and, after a chequered career, finding the Moghuls withdrawn from Persia, he re-established his power in that country, opposed them with vigour in a new invasion, but was killed at last, in A.D. 1231, in Mesopotamia, ten years after his passage of the Indus._Elph. p. 321 .

JALAL-ud-DIN, one of the most celebrated of the Persian Sufi poets. He was a descendant of Abubakr, the khalif who succeeded Mahomed, and was born at Balkh about the beginning of the 13th century A.D. He finally settled at Koniah (Iconium), where he died A.D. 1273. He was a Sufi, a pupil of Shams-i-Tabriz, and instituted the
Maulani sect of darvesh. He is usually honoured with the appellation Maulāna, i.e. my lord. His poem, Masnavi, is in Persian, and consists of six books. He introduced the flute as a musical instrument in public worship. Ghulam Kādar Ghilani, 50 years before, had introduced the tambourine. Jalal defended the innovation by saying that the Romans might be converted by the aid of sweet sounds. The Maulani darvesh are excellent flute players. His Masnavi, or 'rhyming couplets,' as the name signifies, is a complete exposition of Sufi doctrines, illustrated with numberless tales, apologues, and scraps of history. It is more highly esteemed by the Shiah sect than perbaps any other work. The complete work consists of six books, containing 26,660 couplets, to which some authorities add a doubtful seventh book, to make up the number of the 'seven planets,' the 'seven zones,' and the 'seven heavens.' It is very unequal in merit, - grand and noble thoughts, exquisite language and imagery, and apposite illustrations lueing mixed up with much that is dull, commonplace, and stupid. The poem opens with some lines in praise of the reed-flute, Jalalud-Din having sanctioned the introduction of music and song as an accompaniment to the religious exercises of his followers. The reed is made to sigh for its separation from its home amid the rushes by the river-side, and the plaintive notes which it utters are said to be in unison with absent lovers' passionate moods because of this inherent sympathy. The Masnavi has been translated by Mr. J. W. Redhouse. It not only contains a full exposition of the tenets of that mystical creed which has preserved alive the ancient Aryan religious philosophy down to the present day under the guise of a Muslim esoteric doctrine, but it is a perfect mine of old-world stories, traditions, and striking sayings. The whole of the folk-lore of ancient Persia is, as it were, poured out into these pages, the tales and legends being used as pegs upon which to hang moral reflections, or brought in to illustrate some mystic dogma. He early adopted a life of literary and religious retirement, and founded a darvesh order and college at Iconium. His followers were called after him Mauliviyeh, and are the same as those known to European travellers as the Dancing Darveshes, from the symbolical dance, or rather waltz, with which they commence their services.

JALAL-ud - DIN MUHAMMAD AKBAR, grandson of Baber, and 7 th in descent from Timur, was the eldest son of the emperor Humayun and of his wife Hamida Banu Begum. He was born at Amerkot, in the valley of the Indus, on the 14th October 1542. See Akbar.

JALA-MURTTI, SANSK., whose form is water, a name of Siva.

JALANDHAR, a revenue division in the Panjab, comprising the three districts of Jalandhar, Hoshiarpur, and Kangra, in lat. $30^{\circ} 56^{\prime} 30^{\prime \prime}$ to $32^{\circ} 59^{\prime} \mathrm{N}$., and long. $75^{\circ} 6^{\prime} 30^{\prime \prime}$ to $77^{\circ} 49^{\prime} 15^{\prime \prime} \mathrm{E}$. The royal family of Jalandhar and Kangra is one of the oldest in India, and trace their genealogy from the time of the founder, Susarma Chandra. The scions of this house claim to be of Somavansi descent, and they assert that their ancestors held the district of Multan, and fought in the Great War on the side of Duryodhana against the five Pandu brothers: Since the occupation of the 
plains by the Muhanmadans, the ancient kingdom of Jalandhar has been confined almost entirely to its hill territories, which were generally known by the name of Kangra, after its most celebrated fortress. The district is also called Katoch, also Trigartta, which is its Sanskrit name in the Puranas and in the chronicle of Kashmir. It is mentioned by Ptolemy as Kulindrine or Ktulindrine. The British district is occupied by Jat, following Hinduism and the Sikh religion, with Rajputs, Brahmans, Banya, Gujar, Kamboh, Pathans, and Sayyid. The higher portion of he Jalandhar is a tract abounding in mineral wells, where the icy stream of the Parbati is close to the boiling fountain of Munnikarn, which rises in a jet at an elevation of 5587 feet. Some are reported to contain iodine or bromine. In this district, also, and on the banks of the Beas, is Bishiht, at an elevation of 6681 feet, with a thermal sulphuretted source. In the neighbourhood of Mundinuggur, in the Bul-Doon or valley of Sukeyt Mundi, in the Kohistan of Jalandhar, the women, gaily dressed, used to assemble in groups to greet the stranger with songs as he entered each village, for which honour he was expected to bestow a rupee on each knot. It was at Jalandhar where Hindus say the breasts of the corpse of Sita fell.-As. Res. vi. p. 477; Rennell; Cunningham.

JALANGI, one of the three great rivers of the Nadiya district, Bengal ; the other two being the Bhagirathi and the Matabhanga. All three streams are offshoots of the Padma.

JALARUPA, the makara or fish on the banner of Kama, the Hindu god of love.

JALAUN, a British district in the NorthWestern Provinces, lying between lat. $25^{\circ} 46^{\prime}$ and $26^{\circ} 26^{\prime} \mathrm{N}$., and between long. $78^{\circ} 59^{\prime}$ and $79^{\circ} 35^{\prime}$ E., with an area of 1553 square miles, and a population of Brahmans, who hold as many as 198 villages; Kurmi, with 107 ; Gujars, with 105 ; Kachlwaha, with 84 ; Sengar, 62 ; Kayasth, 50 ; and Muhammadans, 34.-Imp. Gaz.

JALIKAT. TAM. A sport in Madura in the south of India. It consists in loosing, either from a large pen or from a number of stakes to which they are tied, a lot of cattle with cloths or handkerchiefs tied to their horns, money being sometimes knotted in the cloths. When let go, the spectators shout and cheer, and a tremendous tom-toming is set up. This so far excites the animals that most of them go off at a gallop, and such of the spectators as wish to distinguish themselves in the eyes of their countrymen as swift runners and brave men, go after the cattle and strive to pull the cloths off the beasts' horns, the cloth and any valuable attached to it being the reward of the captor. This may be considered the national amusement of the people of Madura. It was practised at Trichinopoly, Puducottah, in parts of Tanjore, and was as much their passion as horse-racing is that of the people of England, or bull-baiting that of the people of Spain. The rich ryots, zamindars, and headmen are the great promoters of this kind of sport, by running their own cattle, etc. Directly they find that its practice is attended with danger of being tried for an accident, it is probable that they will voluntarily withdraw from actively continuing it, when it will greatly lose its interest and excitement among the people, and they will then pro- bably voluntarily give it up and take to or invent some more harmless amusement. Since the year 1855 , a prohibition has existed against the sport being indulged in, and in 1859 certain village servants were dismissed by the presiding magistrate for permitting it within the limits of their jurisdiction.-Orme.

JALKAR. HIND. Fowler, hunter; from Jal, a net. Jal-kar, from Jul, water, is a fisherman. Jal-kar and Ban-kar, products of the waters and woods; Jaliya is the right of fishing, from Jul, water. Jali, a net fabric.

JALLAD. ARAB. An executioner.

JALLALI, a masked or mumming derotee at the Maharram. The Jallali mummers adopt fancy dresses, sing Marsiah, satires, and songs. The great bulk of them are low-caste Hindus and Pariahs.

JALMOR, from Balti, a dark, hard, serpentinelike stone, takes a fine polish. It is used like zahrmohra for cutting into cups, etc. The value of a cup is from Rs. 3 to 4.

JALNA (Jaulnah), in lat. $19^{\circ} 51^{\prime} \mathrm{N}_{\text {., }}$, and long. $75^{\circ} 54^{\prime} \mathrm{E}$., in the Dekhan, a military station, 38 miles E. of Aurangabad, 1652 feet above the sea.

JALOTSARG. Hind, A Hindu ceremony where a pond or well is married to a neighbouring grove. The typical marriage of a newly-dug well or piece of water, the bridegroom being typified by a man holding a salagram fossil, and the bride by another person holding another of that fossil. Banotsarg and Jalotsarg are peculiar marriage ceremonies of Hindus in Northern India. The Jalotsarg is that of marrying a newly-planted orchard to a neighbouring well, without which it would be deemed improper to partake of the fruit. Brikhotsarg is the marriage ceremony performed in the name of the bull (saur-taurus), which the Hindus of N. India liberate on the 11th day of mourning for a near relative. In $\mathrm{N}$. India these are known as the saur (taurus) bijar, and the British call them Brahmany bulls.

JALPAIGURI, the north - eastern district of the Rajshahi Koch-Bahar division, lies between lat. $26^{\circ} 0^{\prime} 35^{\prime \prime}$ and $26^{\circ} 59^{\prime} 30^{\prime \prime} \mathrm{N}$, , and between long. $88^{\circ} 22^{\prime} 40^{\prime \prime}$ and $89^{\circ} 55^{\prime} 20^{\prime \prime}$ E., occupying the tract south of Bhutan and north of the state of Koch-Bahar and the Rangpur district. The Western Dwars became British territory as the result of the war with Bhutan in 1864-65. The newly-acquired territory was formed into the Eastern and Western Dwars. The great bulk of the population belongs to the Koch or Rajbansi. The headquarters of this race are in Koch-Bahar; but Koch, Rajbansi, or Pali are thickly scattered through all Northern Bengal, from Assam to the frontier of Purniah.-Imp. Gaz.

JALSA. Arab., Hind., Pers. An assembly, a meeting of men on business or pleasure; also the assembly or reception room. In an upperstorey house, the Jalsa is usually on the ground floor.

JALTARANG, a set of musical glasses or rather bowls.

JAL-TURPUN. HIND. Presenting water to the gods and manes; part of a Hindu's daily devotions.

JALUS. ARAB. Literally accession; the term applied to the ascent of a throne. In the Southern Konkan the Jalus San or San-i-Jalus has formed 
an era commencing with the year of Salivaliana 1578 (A.D. 1656), and running on henceforward in the ordinary solar manner. It corresponds exactly with the accession of Sultan Ali Adl Shah II. to the throne of Bijapur.-Thomas' Prinsep.

JALWA. HIND. The first meeting of the Muhammadan bride and bridegroom after marriage in the presence of relatives, when certain ceremonies are performed.

JAM, a Hindu title, supposed by Colonel Tod to be a corruption of Sambu, a titular appellation from the Sambu of Alexandria. It is, however, a Hindu title borne by the Jam of Bela, the Jam of Nowanagar in Saurashtra, the Jam of Kej, also the Jam of the nomade Muhammadan Jokya, a Samma tribe, west of Tatta, and has no connection with Jamshid, nor has it a Persian origin.Elliot; Burnes' Cabool.

JAMA, an article of Muhammadan dress, an outer coat.

JAMA. ARAB. A place where Muhammadan people assemble to pray, a house of public worship; also an amount, a total.

JAMA. ARAB., Hind. The revenue payable by a cultivator or a zamindar. Jamabandi, the village rent-roll, a statement of the rents fixed on every field in the township; the annual settlement of the rents between landlord and tenant, the collection of the revenue. The word has numerous combinations. Jama-Kharch, receipts and disbursements; account current.

JAMADAGNI, son of Bhrigu, was father of Parasa Rama by his wife Gandāra. He wrote a law treatise and a book on religious ceremonies. He taught that God is visible and assumes every variety of form. He is mentioned in the Sri Bhagavata, the Ramayana, the Ekamra, the Nandikeswara, and the Padma Purana.-Ward, iv. p. 43 .

JAMADAR, the chief or leader of any number of persons, also a native commissioned officer in the native armies of India.

JAMAI (Waziri), an embroidered white scarf worn by young women of the Waziri.

JAMAL-ud-DIN ABDUR RAZAQ, born at Samarcand A.D. 1413, was the son of Kazi Shah Ruh, who, in 1441, sent Jamal-ud-Din as ambassador to the king of Vijayanagar, afterwards as ambassador to Ghilan, and then to Egypt. See Shah Rukh.

JAMA MUSJID is the principal mosque in Indian towns in which Muhammadans meet for prayer and religious services. The Jama Musjid of Dehli cost ten lakhs of rupees, and took six years in its construction. It was begun and completed in the reign of Shah Jahan. Three of the highest, the broadest, and finest flights of steps in Dehli, made of stone, lead to the front and side entrance, whence the spectator comes to a square platform. In the centre of this is a large cistern, which is intended for the performance of the 'wazu,' or ablutions before prayer. While the three sides open inwardly with a corridor and cloisters, the west of the square platform is the cathedral itself, rising in three large domes and two of the most stately minarets within the town of Dehli. Its space admits of a vast congregation, and on the anniversary of a saint of any celebrity, or on any other particular occasion, it is crowded with Muhammadans, - Tour in India by French, p. 10.
JAMATAR. HiND, A shawl fabric with a pattern in stripes, intended, as its name implies, for a gown piece or jama.

JAMBEE, a cane with stiff stems and large knots, imported from China; a species of calamus. JAMBHA DATTA, author of the Vetala Panchavinsati.

JAMBHAJI, a Hindu who founded the religious sect known in the Dehli district as the Bishno. They regard Jambhaji as an incarnation of Vishnu; they bury their dead in a sitting position in the floors of their houses or cattle-sheds. They abstain from tobacco, and consider even its touch polluting. At their marriages, passages from the Koran and the Hindu Shastras are indiscriminately recited.

JAMBIA. Hind. A dagger.

JAMBOSA AQUEA. D.C.

Eugenia aquea, W. $I l l . \mid$ E. sylvestris, Moon.

Jambo,. . . . BENG. | Wal-jamboo, . . Singh.

Abundant in the Central Province of Ceylon up to an elevation of 5000 feet.-Thw. Zeyl.

JAMBOSA CYLINDRICA. Thwaites.

Eugenia cylindrica, W. I E. pauciflora, W. $I c$.

A moderate-sized tree of the Ambagamowa district in Ceylon, up to an elevation of 3000 feet. -Thw. Zeyl. ii. p. 115.

JAMBOSA SALICIFOLIA. Gibson. Pan jambool, MAHr. A crooked tree growing much on the rivers of the Bombay Dekhan country. The stem is generally useless for house purposes, on account of its crookedness, but the straight shoots are eagerly sought after as rafters.-Dr. Gibson.

JAMBU - DWIPA. SANSK. In the Hindu cosmogony, one of the seven grand divisions of the earth, including Asia, and so named from the tree called Jambu abounding in it. Modern commentators, however, allege that it refers only to certain parts of the interior of Asia. In this sense Jambu-D wipa is the central division of the world. India is so called in the Puranas. The golden mountain Meru is the centre of the mythical Jambu-Dwipa. Geographically, Jambu-Dwipa is the name given by the Indian Aryas to all the mountain region on the N.W. of India, including the ancient Indian province of Afghanistan. The basin of the Indus, which was earlier occupied by the Sudras (Cushites or Caucisas), they called Kouca-D wipa. It had nine varsha or subdivisions, -Bharata, Kim-purusha, Kin-nara, Hari-varsha, Ila-vrita, which contains Meru ; Ramyaka Hiranmaya, Uttaru-kuru, Bhadraswa, and Ketu-mala.

JAMBUKESWARAM, a famous temple, 400 years old, on Srirangam Island, Trichinopoly, Madras, lat. $10^{\circ} 51^{\prime} \mathrm{N}$., and long. $78^{\circ} 44^{\prime} \mathrm{E}$.

JAMBULGHATA, a town in the Chanda district, Central Provinces, lat. $20^{\circ} 33^{\prime} \mathrm{N}$., and long. $79^{\circ} 30^{\prime} \mathrm{E}$. Extensive quarries of soapstone are at a mile from the village, and have been worked over a hundred years; about 50 cart-loads are annually quarried and fashioned into bowls and platters. Near these quarries are others of a very fine black serpentine, where for three years Raghoji III. employed 250 workmen. I Imp. Gaz.

JAMDANI. HIND. Silk fabric with woven sprigs of flowers.

JAMES. Commodore James commanded the E.I. Company's Marine Force in India. In 1755, in alliance with the Mabrattas, he sailed from Bombay, to attack the strongholds of Angria, and on the 
2d April, unaided by the Mahrattas, he took Severndrug and Goa. Bancoote surrendered on the 8th April, and in February 1756 be attacked Gheriah.

Colonel Henry James, R.E., author of General Description of the Country of Abyssinia and of the different Routes leading into it.

JAMES AND MARY, a dangerous shoal in the Hoogly. It is an English corruption of the Hindustani words Jahaz marra, a ship struck ; also, it is said, of two Bengal words, Jumma marri, confused water. Shifting and dangerous alluvial deposits formed in the channel of the Hoogly by the meeting of the backwater of the Rupnarayan with the discharge of the Damodar, both of which last-named rivers enter the Hoogly at sharp angles from the west, nearly opposite Falta. Lat. $22^{\circ} 13^{\prime}$ to $22^{\circ} 17^{\prime} \mathrm{N}$., and long. $88^{\circ} 5^{\prime} 45^{\prime \prime}$ to $88^{\circ}$ 7' $30^{\prime \prime}$ E.-Imp. Gaz. v.

JAMESON. Deputy Surg.-Gen. W. Jameson, C.I.E., formerly Superintendent of Botanical Gardens in the North-West Provinces, died at Dehra Doon on March 13. Three years after his arrival in the country, in 1841 , he was sent to report on the geology of the Himalayas with a view to the discovery of the cause of the floods on the Indus. While on this expedition he was captured by the frontier tribes, and kept a prisoner until he was ransomed by the Government, who afterwards appointed him Superintendent of the Botanical Gardens in these provinces. Dr. Jameson devoted his energies to the introduction of tea cultivation into the North-West and Panjab. On his retirement in 1875, Government placed on record the opinion that but for Dr. Jameson's exertions this great and important industry would have had no existence in Northern India.

JAMI, the literary title of Maulana Nur-ud-Din Abdur Rahman, who was born at Jam, a small village near Herat, A.H. 817, A.D. 1401. He devoted his life to study and dissemination of the mystic doctrines of Sufi philosophy, for which, towards the end of his life, he abandoned all other occupations. He was unequalled as a grammarian, a theologian, and a poet. The Rubaiyat of Omar Khayyam, and the Salāmān and Absāl of Jami correspond in time with western mediævalism, ranging from the latter part of the 11th to about the middle of the 15th century. The earlier of the two poets represented, Omar of Naishapur, in Khorasan, is said to have been a tent-maker. At all events, his takhallus, or poetical name, Khayyam, taken literally, siguifies as much. Nur-ud-Din Abdur Rahman, who took the name of Jami from his birthplace, a little town of Khorasan, came into the world more than 300 years after Omar Khayyam; but there is no such apparent chronological difference between Jami's mystical poems and the Rubaiyat, or stanzas, of Omar, as we should expect to find. The philosophy, half-sad, half-merry, of both these poets is as forward an element of their verse as is the fertile imagination which they share by community of race.

JAMI - ut - TUARIKH. This comprehensive history was written by Fazl ullah Rashid, otherwise Rashid-ud-Din, son of Imad-ud-Daulah. Abul Khair was born at Hamadan about A.H. 645, A.D. 1247. Jami - ut - Tuarikh contains a detailed account of some important events and periods of history. It commences with the usual traditional Muhammadan account of the patriarchs and prophets, a history of the kings of Persia from Kayumars to Yezdejird, and a sketch of the life of Mahomed, of his immediate successors, and of the Ommaiyah and Abbassi khalifs of Baghdad. After this, those of the houses of Mahmud-ibn-Sabaktagin, the conqueror of Ghazni, the Seljukian and Khwarazmian Sultans, and of the Salghuri dynasty in Fars. This is followed by a history of the Ismaili. It is divided into two parts, the first treating of the Alawi khalifs of Egypt and Africa. The second deals with the Ismaili themselves, and especially that section of them who, under the rule of Hasan-us-Sabbah, were known as the Assassins, and gained such unenviable notoriety during the Crusades. The next section of the Jami-ut-Tuarikh deals with the history of Ughuz, the legendary head of the Turks, the founder of their world-wide empire, and the progenitor of the Sabaktagin, Seljuki, and Turkoman Sultans. The history of China is also here appropriately introduced, and ends with its final conquest by Uktai Khan in A.H. 631. The volume next contains a general review of the history of India, and a special account of the Moghul sovereigns, prefaced by an account of the origin of the Turkish races themselves. This part contains a minute account of Chengiz Khan, his ancestors, fainily, character, and history. The careers of Uktai Khan and of the other celebrated Tartar conquerors, including Kablai Khan, I'imur, and Hulaku, are also described, and tables given of the contemporary sovereigns in various parts of the east, from A.H. 549 to 693 . Rashid-ud-Din began this book A.H. 700 , by order of Ghazan, and completed it in ten years. In A.H. 718 he was put to death by Sultan Abu Sadi, having been accused of poisoning Oiljaitu.

JAMMA, in Coorg, feudal tenure of land, for which the tenant pays a small rent and gives military service. Such land cannot be mortgaged or alienated.

JAMMA ALLAH. ARAB. God's assembly.

JAMMADI-ul-AWAL, the fifth month of the Muhammadan year. Jammadi-ul-Akhir is the sixth month, also styled Jamadi-us-Sani.

JAMMALI, the amiable attributes of the deity. JAMMA MASJID, the great mosque in the towns of India, where the Friday assemblies take place. Those of Dehli, Agra, Madras, Hyderabad, are of great dimensions. See Jama Masjid.

JAMMU, a province and town in Kashmir State, Panjab. Estimated population, about 8000 . Situated in lat. $32^{\circ} 43^{\prime} 52^{\prime \prime} \mathrm{N}$., and long. $74^{\circ} 54^{\prime}$ $14^{\prime \prime}$ E., on the Jobi, a tributary of the Chenab. The town of Jammu is 1500 feet above the sea, and the bed of the Chenab is a little above 1000 feet. The boundary mountains of Jammu rise 12,000 to 14,000 feet. Jammu is the capital of a principality of which the rulers are Dogra Rajputs. The town contains 7000 or 8000 people. It is built on the summit of the first wooded sloping ridge that rises from the plains of the Panjab, and on the right bank, at the place where it is divided by a narrow ravine which allows an exit to the river Ravi? in its way to its junction with the Chenab.

General Cunningham (Ancient Geog. p. 133) gives the following as the States attached to the Jammu division of the Alpine Panjab, viz.:-

2 Hindu States, viz.-

Jammu, to east of Chenab. | Bhao. 


\section{JAMNOTRI.}

JAN.
9 Muhammadan States, viz.-

Rekasi, on Chenab.

\section{Aknur.}

Punach, on the Punach.

Rajaori, on the Tochi.

Kotali, on the Punach.

Bhimbar, at foot of hills.

8 Hindu States, viz. -

Khariali, near Bhimbar.

Kashtwar, on Upper Panjab.

Bhadrwar, to south of Kashtwar.

Chanem, to west of Bhad- Jasrota, to S of Bandralta.

rawar.
Bandralta, to S. of Chanem.

Samba, to S.W. of Band- Badwal or Vaddiwasa. ralta.

Ballawar or Bisohli.

General Cunningham also gives (p. 136) the names of 12 States attached to the Jalaudhar division of the Alpine Panjab, viz.:-

Kangra or Katoch. 5 Somaransi, viz.-

Guler.

Jaswal.

\section{Datarpur.}

Siba.

Chamba, on Ravi 2 Surajvansi, viz, Kullu, on Beas.

5 Pundir or Pandaya, viz. -

Mandi, on Mid Beas.

Sukhet, to S. of Mandi.

Nurpur, between Ravi and Beas.

Kotila, to E. of Nurpur. Kotlehar.

Also (p. 131) the 13 States attached to Kashmir or the western division of the Alpine Panjab, viz:-

\section{Kashmir.}

4 Khaha Bamba, viz. -

Gingal, on the Behat. |Khagan, on the Kumhar. Muzaffarabad. Garhi.

5 Muhammadan, viz. -

Rash, on Pakhli river.

Dhanteshwar, on Dor.

Gundgarh. Darband, on the Indus. Torbela.

\section{Gakkar, viz -}

Pharswala, near Behat. |Khanpur, on Haro.

Sultanpur, on Behat.

-Vigne; Schl.; Cunningham, Ancient India.

JAMNOTRI, a mountain in the Himalaya, in lat. $30^{\circ} 59^{\prime} \mathrm{N}$., and long. $78^{\circ} 35^{\prime} \mathrm{E}$., in Garhwal, on the left bank of the Jumna, about 8 miles $N$. of Kharsali. The hot spring Bassu Tarta and the level of the Jumna there is 9793 feet above the sea. The springs occur on the sides of a massive mountain block, known as Banderpunch, with an elevation of 20,758 feet above sea-level. In the centre stands a lake, in which the monkeygod Hanuman is said to have extinguished his flaming tail. The water rushes up through a granite rock, and deposits a chalybeate sediment. It has a temperature of $194.7^{\circ}$ Fahr. Elevation of the springs, 10,849 feet above the sea.-Rob.; Schl.; Imp. Gaz.

JAMRUD, ruined fort in Peshawur district, Panjab, situated in lat. $34^{\circ} \mathrm{N}$, , and long. $71^{\circ} 24^{\prime}$ E., at the mouth of the Khaibar (Khyber) pass.Imp. Gaz.

JAMRUH or Jamrat. ARAB. A rite at the Kaba, in Mecca, in which pilgrims throw stones, as if at the devil. It originated from Abraham throwing stones at the ram sent to take the place of his son.

JAMSAN. HIND. A kind of earth containing an alkali; useful in alum manufacture.

JAMSETJEE JEJEEBHOY, a benevolent Parsee of Bombay, who rose to great wealth by commerce. He founded schools and hospitals, and endowed charitable institutions. His private bounties were great, and he sought every opportunity for doing good. On the 3d March 1842, the Queen of Great Britain created him a baronet of the United Kingdom. He was born at Bombay 15th July 1783, and died there 14th April 1859.
His public benefactions amounted to upwards of $£ 200,000$.

JAMSHID. The fifth king of the Peshdadian dynasty of Persia, who, according to Bailey, flourished 3209 years before the Christian era. The Shah Namah describes him as the first to civilise mankind, and Persian writers consider the bas-reliefs at the ruins of Persepolis-still visible in all their pristine beauty after a lapse of 5000 years-to be representations of the court of Jamshid, more especially on the festival of the Nouroz. The celebrated Persian poet Fardusi wrote the Shah Namah about A.D. 1000, containing three heroes, Jamshid, Faridun, and Garshasp, as the three earliest representatives of the generations of mankind. A little way from the gate of the entrance of Toos, there stands a dome ornamented with lacquered tiles, so small as seemingly to form a part of some private house; this dome covers the dust of this celebrated poet, who, after the unworthy treatment he received from Shah Mahmud Ghaznavi, retired there to die, A.D. 1020.Fraser's Khorasan, p. 510.

JAMSHIDI or Djamshidi, a nomade tribe of Persian origin, who have inbabited the valley of the Murghab river from time immemorial. Their habits resemble those of the Turkoman, living in tents, and are equally predatory. Allah Kuli Khan conquered them and the Turkoman Sariks, their allies, and he removed the Jamshidi to Khiva. They remained on the banks of the Oxus for about 12 years, when, availing themselves of a general rising of the Turkomans, they marched across the desert by Hazarasp, Charjui, and Maimena to their hereditary lands on the Murghab. Jamshidi are the only tribe of Eastern Indians who are exclusively nomades. They derive their descent from Jamshid, and moved out of Segistan to the shores of the Murghab, which they have occupied from pre-historic times. They live in the neighbourhood of the Salor and Sarik Turkoman, and they use the round conical tent of the Tartars, surrounding it with felt and a reed matting, and their clothing and food are those of Turkoman, as also is their occupation, for they are as great man-stealers. They excel the other Aimak as horsemen, and for a chapao band themselves with men of Herat or with the tribes of Turkomans. It was this cause that led Allah Kuli Khan to transport them from Khiva to the banks of the Oxus, after he had conquered them with the allied Sariks. After a residence of 12 years, they fled and returned to the town of Murghab. The Jamshidi is polite in word and manner. They still retain parts of the Zoroastrian faith, reverence fire, pitch their tent-door to the east.-Central Asia, Collett. See Iranian.

JAMUNA, a river of Assam, rising in lat. $26^{\circ}$ $31^{\prime} \mathrm{N}$., and long. $93^{\circ} 31^{\prime} \mathrm{E}$., in the north of the Naga Hills. It falls into the Kapili river.

JAMUNA, Jamoona, or Janai is the name given to the lower section of the Brahmaputra in Northern Bengal, from its entrance into the plains to its confluence with the Ganges.

JAN. In India, the Jan, the Gin of the Arabian Nights, is only known amongst the Muhammadans. In Sind, the Jan resembles the Pwacca or Puck of Britain. The Jan of the Baluch Hills is wayward and often morose, but not necessarily malignant. He is described as dwarfish, with large eyes, and covered with long hairs, and often 
changes to the form of a camel, goat, or other animal. On meeting a Jan, it is essential not to be alarmed, and to use civil language. The Jan can become the servant of man and work hard. The evil ones are devils whose chief is Iblees (that is Satan, the devil); in general properties they are an intermediate class between angels and men. They eat and drink, and are subject to death, etc. Many of the superstitions respecting them form part of the religion of Muhammadans, being sanctioned by the Koran.-Burton.

JAN. HIND., PERS. Life, soul, spirit; hence Jandar, brave, spirited. Janwar, animal.

JANAB. HIND. A respectful form of address to Muhammadans, Hindus, and Europeans; it is the equivalent of 'highness.'

JANAKA, king of Vaideha and father of Sita, a wise, good, and devout man, who, with his priest Yajna-walkya, prepared the way for Sakya Sinha. He refused to acknowledge the hierarchical pretensions of the Brahmans, and claimed the right of performing sacrifices independent of priests. In the time of Buddha, and for many centuries afterwards, the people of Vaisali were called Lichhavi; and in the Trikandasesha, the names of Lichhavi, Vaideha, and Tirabhukti are given as synonymous. Vaideha is well known to the readers of the Ramayana as a common name of Mithila, the country of raja Janaka, whose daughter Sita is also named Vaideha. Tirabhukti is the present Tirahuti or Tirhut. Now the modern town of Janakpur, in the Mithari district, is acknowledged by the universal consent of the natives of the country to be the same place as the ancient Janakpur, the capital of Mithila. The correct rendering of the name is doubtful; but if the bearing and distance recorded by the Chinese pilgrims are correct, it is almost certain that the capital of Vriji in the seventh century must have been at Janakpur. Hiwen Thsang gives the name of the country in its Sanskrit form as Foli-shi, or Vriji; but it is also stated that the people of the north called the country San-fa-shiDowson: Cunningham.

JANAKHORI, the tribes in the small valley of Janakhwar in the Hasan Khel, Adam Khel, Afridi Hills, with two subdivisions, Tutkai and Barkai, and can turn out 1500 fighting men. They afforded shelter to men fleeing from justice. The Afridi of Janakhwar are the best of the Afridi, bold and intrepid in action.-H.A.N.W.F.P. i. pp. 35,36 .

JANAM. TEl. Birth. Purva Janam, a former birth. Janam Patri, a Hindu horoscope at birth, literally birth-tablet, it being indispensable to every Hindu child, being at once his horoscope and the guide throughout life-Burton's Scinde, p. 399.

JANAM ASHTAMI, the nativity of Krishna, held as a festival on the 8th day of the month Bhadra. It is also called Gokal Ashtami, and is a Hindu festival in commemoration of the birth of Krishna, an event which is said to have taken place at Muttra, at midnight, on the 8th of Shravan, about the 22d August. One Vaishnava sect keeps the holiday Janam on the 8th and another on the 9th of Shravan. Krishna is stated to have been born of Devaki, niece of Kans, king of Muttra. Kans having bad it predicted that one of his race would destroy him, he endeavoured to compass the death of Devaki's offspring, in which he failed, and on the 9th, Krishna was removed to the house of a cowherd named Nanda. The worshippers abstain during the day from certain articles of diet; at night they bathe and ornament the image, and offer the tulsi, or Ocimum sanctum. On the following day, a Brahman serves as pujari, and afterwards he himself is worshipped. The 8th day is held by the Gaoli or cowherd race as a great jubilee day; from the circumstance of Krishna having been reared by one of their people, they join hands and dance, and shout Govinda, Govinda. The shrines of Kanoba are much visited at night; the Bhagat of the shrine, by self-flagellation, becomes hysterical, which is deemed by the people to be a possession by the deity, on which they prostrate themselves, burn incense, and present sick people to the Bhagat. On the following day, the Bhagat's disciples work themselves into hysterics.-Bombay Gazetteer.

JANAMEJAYA, a great king, son of Parikshit, and great-grandson of Arjuna. Parikshi died from the bite of a serpent, supposed to indicate his death in war against the Naga people of Takshasila, and Janamejaya 'is said to have sacrificed many serpents (Nagas), hence his title Sarpa-sattrin.-Dowson.

JANAMI. MaLEal. A hereditary land proprietor.

JANAM SAKHI, a legendary biogxaphy of Nanak.-Cust.

JANEO. HIND.

Janwez, Jandum,. MAHr. / Yajno pavita, . SANaK.

This cord or string falls over the left shoulder to the right hip. It is worn by the Brahman, Kshatriya, and Vaisya castes, by the Ved or Bed of Bengal, and in the Dekhan by the five artificer castes. - Wilson's Gloss. See Yajana; Zonar.

JANGAMA, the priest of the Lingaet sect, who officiates at their religious rites. Where the population of a village consists in any large proportion of his disciples, he is a member of the establishment, and holds rent-free or inam lands, -thence known as Jangama Inam. He is sometimes domesticated in mat'hs or monasteries, and otherwise is a vagrant living on alms. The doctrines of this sect, as given forth in the 12th century by Basava, their founder, are based on the physiological philosophy of reproduction. They honour Siva under his symbol the lingam, and oppose the Tantrica doctrine of reverencing the Yoni, the symbol of Durga. See Lingaet.

JANGATA. Tel. The Satana, Jherra, and Dhasra are three mendicant sections of religious devotees of the Hindus. The Satana keep a god, Permaloo, the image of an incarnation of Vishnu, in their houses, and worship it daily. They perambulate the streets morning and evening, and accept alms from all but the lowest castes. They often demand alms, threatening otherwise to burn themselves with a lamp or torch. The Dhasra play on the Jangata, Tarti, and Sincu, and hold an iron worshipping lamp in their hands. They walk before the corpse when it is carried to the funeral pile.

JANGLI. HiND. A term applied to wild plants, grains, etc., as opposed to cultivated; also to any low forested country, and to any rude, unpolished person.

JANG TANG. BHоT. Uncultirated pasture lands; the uplands of Tibet. 
JANIPHA MANIHOT. Kunth.

Jatropha manihot, Linn. | Manihot utilissimus, Pohl. Pu-lau-pe-nang | Mara valli kelangu, TAM. myouk, . . Burm. Aal vulli kelangu, , Marachini, CAN., MALEAL. Manu valli gadda, . TEL. Tapioca, Mandioc, . ENG. Manu pendalam, . , Cassava, Bitter cassava, , Karra pendalam, . ",

The Janipha manihot plant grows about six or eight feet high, with a tuberous root weighing up to thirty pounds. The acrid milky juice, when fresh, is poisonous, but the roots are washed, scraped, ground, or grated into a pulp, and the juice pressed out and preserved. The pulp or meal that remains is called Couaque, and is made into cassava cakes or cassava bread. The expressed juice by standing deposits a white powder, which, when washed and dried, forms what the British call tapioca meal or Brazilian arrow - root, by the French Moussache, and in Guiana, Cypipa, and when this is dried on hot plates, the grains of fecula burst and adhere together and form tapioca. The expressed juice is sometimes fermented with treacle into an intoxicating fluid.

Cassareep, the concentrated juice of the bitter cassava, forms the basis of the West India dish pepper-pot. One of the remarkable properties of cassareep is that meat placed in it is preserved longer than by any process of cooking. Sweet cassava is prepared from the Manihot aipi, which is similar to J. manihot, but has no deleterious properties.

From the facility with which the bitter cassava can be rasped into flour, it is cultivated almost to the exclusion of the sweet variety, which contains in its centre a tough, fibrous, ligneous cord. The bitter variety, however, contains a highly acrid and poisonous juice, which is got rid of by heat or by fermentation, so that cassava bread is quite free from it.

The poorer classes of British India use the tapioca flour, but none is exported. The plant thrives in any soil, although a sandy loam is the best. It requires no cultivation whatever, and is occasionally met with in Arakan, growing wild in the jungle. At the Madras Exhibition of 1855 , excellent tapioca was exhibited by Mr. Rundall, of Razole, near Rajamundry.

Pearl tapioca is not from this plant, but from potato starch.-Tomlinson; J. Agri.-Hort. Socy. xii. p. 175 ; Hogg; Birdwood.

JANIZARI, said to be from Jeni-tcheri, meaning new soldiers, feudal troops of Turkey, but formed by Amurath out of his prisoners and the Christian youth. Down to the reign of Suliman the Wise, the Janizaries raised and retained the Othoman power to its highest pinnacle, but under his effeminate successors the Janizaries became a burden, and they frequently revolted. Usman II. was killed in one of their tumults. In 1807 Salim III. was deposed by them, and the regular troops, Nizam-Jadid, dispersed. And in 1808 they burned in his palace Mustaffa Bairactar, because he had revived, under the name of the Seimen, the Nizam-Jadid, whom they then massacred. The Janizaries were ultimately destroyed by Sultan Mahmud.

JANJH, Jhanjhi, also Jala, HIND., plants of the order Hydrocharidaceæ, growing in jhils, tanks, and other stagmant waters, as the Ceratophyllum verticillatum, Hydrilla vertioillata, Lemna,
Pistia stratiotis, Marsilea quadrifolia, Salvinia cucullata, Salvinia verticillati, Vallisneria.

JANJIRA, a Native State within the Political Agency of Kolaba (Colaba). It is in lat. $18^{\circ}$ to $18^{\circ} 31^{\prime} \mathrm{N}$, and long. $72^{\circ} 53^{\prime}$ to $73^{\circ} 17^{\prime} \mathrm{E}$., and is bounded on the north by the Rewadanda creek, in the British district of Kolaba; east by the Roha and Mahad subdivisions of the same district; south by the Bankot creek, in the district of Ratnagherry; and west by the Arabian Sea.Imp. Gaz.

JANNAT. ARAB, Paradise, literally a garden; in Persian Bahisht. Its eight regions or doors or stages of glory as named in the Koran are-

Jannat-ul-Khuld, the garden of eternity.

Dar-us-Salam, the dwelling of peace.

Dar-ul-Qarar, the dwelling which abideth.

Jannat-i-Adan, the garden of Eden.

Jannat-ul-Mawa, the garden of refuge.

Jannat-un-Nain, the garden of delight.

Jannat-i-Illiyun, the garden of Illiyun.

Jannat-ul-Firdus, the garden of Firdus.

In addition to these, Muhammadans believe in seven firmaments (asman), viz. of virgin silver, pure gold, pearls, white gold, silver, ruby, and garnet, and of crystal, in which respectively reside Adam, Enoch, and John the Baptist, Joseph, Jesus, Aaron, Moses, Abraham. Muhammadans assign three places for this terrestrial paradise, the garden of Eden,-one near Damascus in Syria; another towards Obollah in the Arabian Irak or Chaldea ; a third in a locality watered by the Nilab, and bordering upon the desert of Nanbandijan in Persia, called Shab Bouvan. It has also been fixed at Samarcand. Ancient traditions place it in Ceylon, where they say Adam was interred, and the Portuguese have named there a peak, a grotto, and an island chain after Adam.

JANNAT-ul-BAQIA, the name of the cemetery at Medina where Hasan was buried; literally the paradise of the eternals.

JANPAN. HrND. A sedan chair. In the Himalaya travelling is generally performed in the janpan by those who can afford it. The janpan is like a large tray with a pair of bamboo shafts behind as well as in front. Ladies have theirs covered over with scarlet cloth.

JANTREE or Jantu. HIND. An almanac or register. The word originally meant a perforated piece of metal through which wire is drawn, and may have subsequently been applied to an almanac on account of its having many open compartments or ruled divisions. See Almanac ; Josi.

JAPA. HIND, A repetition of the name of Rama, a religious rite of the Dadu Pant'hi Vaishnava. Japa-mala is a Hindu rosary, consisting of 27 beads, which are told over four times, the number of 108 being the most proper for the repetition of such forms as 'Ram, Ram, Ram!' Wab, Guru ji ki Fatah!' 'Shri Ganesaya Namaha!' etc. It is adapted for silent devotion. -Burton's Scinde, p. 419. See Dadu Pant'hi.

JAPAG. TiB. Chinese brick tea imported over the Chinese frontier.

JAPAN, in the east of Asia, is occupied by a Mongoloid race. The total area of the empire is 148,456 square miles, and population in 1883 , $36,700,118$, the number of heads of families being 7,684,986. The total foreign residents in the same year was 6187 . The population of the capital, Tokio, in 1883 was 823,557 , the next 
largest being Osaka, with 293,681 inhabitants. In 1884 the reigning monarch or Mikado was Mutsu Hito, born $22 \mathrm{~d}$ September 1852 , succeeded his father 1867. He is the $123 \mathrm{~d}$ emperor in unbroken descent, the founder of the dynasty B.c. 660 being Jimmu Tenno. It is an absolute monarchy, tempered by the Daijo-Kwan or Great Council, which is nearly as old as the monarchy itself, and whose members mainly form the heads of the executive departments which correspond in name and organization to the ministries of Europe. Then there is the Gen-roin or Senate, established in 1875 , to deliberate on legislative matters, its decisions being subject to confirmation by the Cabinet Council, and sanction by the sovereign. The number of senators is at present 37. Further, there is the Sanji-in or Council of State, created in 1881. Its functions are to initiate and frame bills, and discuss matters transmitted by the executive departments, and also to hear and decide cases relating to administrative questions. Each of the 47 districts (three Fus and 44 Kens) has its governor; while each district is subdivided into counties (Gun) and cities or boroughs (Ku), each with its chief (Cho), who manages local affairs.

Nipon, Kiu-siu, Jesso, and Sikoff, four large Japanese islands, together form a group not dissimilar in geographical configuration to Great Britain and Ireland. In the first island are situated Yedo and Miako.

The island of Nipon, popularly called Japan, is known to the Chinese as Yang-hu or Jih-punkwo, and its name signifies land of the rising sun. Kiu-siu or Ximo, the most southern of this group, in lat. $32^{\circ} 44^{\prime} \mathrm{N}$., and long. $129^{\circ} 52^{\prime} 7^{\prime \prime}$ E., has the harbour of Nangasaki on its western side, is 150 miles north to south by 270 east to west. Sikoff is about 100 miles in length by 60 in breadth.

Sagalin Island is a little smaller in extent than Nipon, and was formerly divided between the Chinese and Japanese, the former holding the northern and the latter the southern half. Its native population are the Kuriles, a very hairy, wild, and untutored race. The chief town in the island of Jesso is Matsmai ; the second is Hakodadi. Matsmai is an imperial city, built upon undulating ground, and the hills near are covered with oaks, firs, cedars, poplars, the yew, the ash, cypress, birch, aspen, and maple. Nipon or Nifon or Niphon constitutes the main body and strength of the Japanese empire. $\mathrm{Ha}-\mathrm{da}$, a port in Nipon, is about 40 miles from Simoda, and is built on a plain, 80 miles from the metropolis; it contains about 8000 people. The town is divided into wards separated by wooden gates. It contains nine Buddhist and one Sintu temple.

In 1882 the exports valued at $£ 7,447,155$, and imports $£ 5,833,608$. $£ 6,400,000$ were exported by foreigners, and of the imports $£ 5,600,000$ imported by foreigners. The staple articles of agricultural production were as follows in 1881:-Rice, 155,629,409 bushels ; wheat, $62,049,940$ bushels; beans, $10,795,717$ bushels. The paper money in circulation in 1883 was valued at $£ 19,658,070$ as compared with $£ 22,685,558$ in 1879 . The total debt in 1883 , according to official statement, was $£ 67,073,237$. The following is a statement of the revenue and expenditure for the years ending June 30,1881 -
1884, the first two actual, the last two the budget estimates :-

\begin{tabular}{|c|c|c|c|c|}
\hline & 1881. & 1882. & 1883. & 1884. \\
\hline are & $\frac{\mathfrak{E}}{12,673,450}$ & $\begin{array}{c}\mathcal{E} \\
14,288,343\end{array}$ & $\stackrel{\stackrel{\mathfrak{E}}{\mathfrak{n}}}{13,324}$ & 15,121 \\
\hline
\end{tabular}

Expended, 12,628,182 14,269,798 $|\mathbf{1 3 , 3 6 2 , 8 2 4}| \mathbf{1 5 , 1 2 1 , 2 2 0}$

The new army of Japan is modelled on the German system, compulsory service prevailing. In 1883 the active army was constituted as follows : - Iufantry, 44 regiments of 32,964 officers and men; cavalry, one regiment of 482 men; artillery, seven companies, 2687 men; engineers, three companies, 1167 men; commissariat, 520;-total, 37,820. In the first division of the reserve are 42,606 officers and men; in the second division, 16,080 ; the auxiliary forces, 6033 ; gendarmes, 1286 ; the total force in 1883 being 105,110. At the Military College and Military School are 1200 pupils. In the navy are 702 officers and 4511 seamen. The navy in 1883 consisted of eight large ships of war (five ironclads), with 122 guns, total tonnage about 15,000 , and horse-power about the same; leaving 18 miscellaneous vessels, with 103 guns, 10,340 tonnage, and 6730 horse-power.

From the 16th century the English have had intercourse with Japan, and from 1613 to 1623 the E. I. Company maintained a factory there. The Dutch from the earliest years had a factory, and St. Francis Xavier made many converts to Christianity. By treaties with the American and European Governments, the country has been thrown open to foreigners, and the extraordinary variety and beauty of Japanese scenery, the strange manners and customs of the people, the unparalieled rapidity of the changes which are transforming the social, political, and religious life of the nation, and the archæological remains which are to be found in the country, have been subjects of great and abiding interest; and the Japanese have eagerly cultivated western science. At first they employed learned men from Europe and America, but these have gradually been replaced by Japanese who had been sent to be educated in Europe.

The Japanese school of art has been eagerly examined by the nations of Europe. Dr. Christopher Dresser wrote on the Architecture, Art, and Art Manufactures; Mr. Quin, the British Consul at Hakodadi, reported on the Lacquer industry; the ceramic and ornamental arts of Japan have been illustrated in a work by Messrs. Audsley and Bowes; and M. Gonse issued a work on l'Art Japonais. The Japanese book, the Ko-gei Shiriyo, on their lacquer industry, has been noticed by Mr. Quin. In this, in drawing and painting, in embroidery, in crusted work and enamel, the Japanese have special schools. In their painting of the human figure there is invariably disregard both of drawing and anatomy, but in the place of these there is an exuberance of the most playful and grotesque action. Mr. Wilkinson (Sunny Lands) mentions a bronze image of Buddha at Kama Kura, 15 miles from Yokohama. It is in a sitting posture, and was cast in the year 1252 . Its height 50 feet. Sir J. E. Reid also mentions a bronze seated idol, cast A.D. 743 ; height from the base of the sacred lotus flower on which be sits to the top of the head, $63 \frac{1}{2}$ feet; $1,005,361 \mathrm{lbs}$, of material were used. 
The origin of the ceramic art in Japan is referred to the prehistoric era of Oanamuchi-nomikoto, and the inventor, Oosei-tsumi. But in B.C. 29, when an empress of Japan died, and, according to immemorial custom, a selection from among the slaves of her household were doomed to death, so that she might not descend unattended into the grave, then arose in the province of Idsoumi the worker in stone and pottery, whose name was Nomino-Soukoune. He made images of clay, and, taking them to the widowed emperor, persuaded him to bury them with the body of the august lady, and to spare the lives of her favourite servants. Thereafter the cruel custom was discontinued, and NominoSoukoune was allowed, as a title of honour, the designation Haji, - the artist in clay. It seems probable that for 1500 years or more, pottery only, and not porcelain, was made in Japan; but in the time of Henry VIII. of England, about 50 years before porcelain was first made in Europe, an artist who had travelled in China settled at Hizen, and instituted there a manufactory of the finer ware. But the earthenware of Japan is of such a quality that it has sometimes apparently been described as porcelain. 'Raku' ware, which figures in Japan at ceremonial tea-parties, closely resembles china, but is nothing more than a leadglazed earthenware, introduced by Ameya, a Corean, about the year 1500 . It is said that Ameya's descendants, in the 11th generation, still pursue the trade of their ancestor at Kioto, - such is the permanence of Japanese institutions.

In China it was not till the $3 \mathrm{~d}$ or 4 th centuries of the Christian era that fine materials were employed, and that some degree of perfection was attained. Still, taking the later date, the porcelain of China has a high antiquity, and must have been made at least 1250 years before English porcelain. When the Chinese had acquired a certain amount of skill and perfection, they appear to have rested entirely satisfied with the results, and to have continued producing them without variation for ages. So exclusively were the Chinese the manufacturers of porcelain, that it acquired the name of their land, and became universally known (on its introduction to Europe in 1518) as china. The Japanese have acted differently from the Chinese, and have produced porcelain ware of the finest fabric and in the bighest artistic forms.

The Japanese are a Mongoloid race of small stature. The women's hands and feet are small, and their necks and shoulders beautifully modelled. The race are gentle, kind to one another and to animals, but insincere, and personal gain overrides all other thoughts. In hot weather men and women go about the country unclothed. Their greatest failings are licentiousness and untruthfulness. The Aino have square and powerful frames; they have a profusion of coarse black hair, and the men wear long beards; they are peaceable, honest, and sociable.

A very large proportion of the Japanese population is engaged in fishing, mostly, however, as an adjunct to other occupations, and mainly for personal supplies, and not as a trade. In 1881 the number of fishermen was 848,288 , and women 753,118 , the number of boats being 190,045 .

The nobles, when sentenced to death, have the right to die by stabbing themselves, and being beheaded by a selected friend. The rite, known as the Hari Kiri, was instituted in the 14th century.

The mass of the Japanese people are Buddhists; and in 1882 there were 76,275 Buddbist priests, besides 21,011 student priests ; Shintooism had 17,851 priests and 1302 students.

Japan and China received with Buddhism many of the essential doctrines of Hinduism. On entering a Japanese temple, one is struck by the analogies to the Christian ritual on the one hand, and to Hinduism on the other. The chantings of the priests, their bowing as they pass the altar, their vestments, rosaries, bells, incense, and the responses of the worshippers, are similar to those in the churches of some Christian sects.

The Shin-shiu sect claims more than 10 millions of the 32 millions of Buddhists inhabiting Japan. It traces its origin back to a Chinese priest, Hwui-yuen, who in A.D. 381 founded a new monastery, in which the Buddha Amiattabha (Infinite Light) and his two great apostles were worshipped. This new school was then called the White Lotus school, and has since spread far and wide. Some of the friars belonging to it were sent to India to collect Sanskrit MSS., and several of these containing sacred texts of Buddhism, particularly descriptions of Sukhāvati, or the Land of Bliss, in which the believers in the Buddha Amiatabha hope to be born again, were translated from Sanskrit into Chinese. They form to the present day the sacred books of the White Lotus sect in China, Tibet, and Japan. After the doctrine of the White Lotus school reached Japan in the 7 th century, it branched off into different sects. The Shin-shiu sect dates from A.D. 1174.

The sacred books of the Buddhists in Japan are nearly all Chinese translations of Sanskrit originals. Many of these translations, however, are known to be very imperfect, and of one of the principal sacred texts used in Japan, the Sukbāvati-vyūha, the Description of the Land of Bliss, there are no less than 12 Chinese translations, which all differ from each other.

Of late the study of Sanskrit had become completely extinct in that country as well as in China, and two young priests, Bunyiu Nanjio and Keujiu Kasawara, were sent to Great Britain.

Bunyiu Nanjio, among other useful works which he did during his stay at Oxford, compiled a complete catalogue of the gigantic canon, called the Tripitaka or the Three Baskets. It contains 1662 separate works, - some small, some immeuse. In each case the original Sanskrit title has been restored; the dates of the translations, and indirectly the minimum dates of the originals also, have been fixed. This has led to a discovery which, according to Professor Muller, has revolutionized nearly the whole of the history of Sansk ritliterature, by showing that between the Vedic literature and the later renaissance literature there lies a period of Buddhist literature, both sacred and profane, extending from about the 1st century before to the 5th century after Christ. The catalogue prepared by Mr. Bunyiu Nanjio at the request of the Secretary of State for India, and printed at the Oxford University Press, is a work of permanent utility, a magnum opus, and has been welcomed in every country where Sauskrit is studied. 
Nowhere are the foundations of the earth more frequently and dangerously shaken than in Japan. Few months pass without the occurrence of shocks of greater or less intensity ; and so persistent are they, that it has been even found necessary to construct the lighthouses which have been recently erected on the coast on a special system, by which, whatever may be the oscillation of the buildings, the lights should always remain stationary. In the towns and villages also the people have been driven to practise a regular earthquake drill. At the first agitation they rush out of doors, if their houses are open, as in summer; but if it is the cold season, or the houses are closed for the night, each man, woman, or child of sufficient size to act independently, seizes one leaf of the shutters that slide in grooves on the edges of the verandah, lifts it tray-wise on to the head, as a protection from falling tiles or debris, and so, gaining the nearest open space, lays it down on the ground and sits on the middle of it, to minimize the liability to fall into cracks or rents in the earth's surface.

Japan is known to have 40 species of mammals, of which 26 are peculiar to the islands. Of its 165 land birds, 40 are common to Great Britain and Japan, 18 are peculiar to the Japan islands.

The Japanese flora is characterized by an unusually large proportion of woody plants, many of which belong to families which are rare elsewhere so far to the north, and by the abundance of maples, laurels, hollies, hydrangeas, figs, evergreen oaks, and remarkable forms of coniferæ. Taken altogether, it presents much affinity with the flora of the Southern United States of Eastern America. Sciadopitys verticillata, one of the most remarkable, and at the same time one of the rarest, conifers of Japan, is usually seen cultivated in gardens and around temples. Specimens met with in the vicinity of Kanagawa and Yedo were in many instances fully 100 feet in height. -Fortune, Japan and China; A. R. Wallace, p. 368 .

JAPAN-WAX. Jih-pen-lah, CHIN. Obtained by crushing the ripe seeds of Rhus succedanea? and separating the tallow-like covering by heat. It is employed in candle-making.

JAR. In the Durga puja festival of the Hindus, a sacred jar is an essential article in the celebration of the mysteries, and is marked with the combined triangles, denoting the union of the two deities, Siva and Durga. The worshippers of the sakti, or female principle, mark the jar with another triangle. The Vaishnava sect in their puja use also a mystical jar, which is also marked. These marks, Mr. Paterson says, are called Tantra, and are hieroglyphic characters, of which there are a vast number. He hence deduces the identity of this Hindu puja with some Egyptian rites of a corresponding nature. In the kalasi puja a kalasi or water jar is placed in a chamber as a type of Durga or other divinity, and is worshipped.-Asiatic Researches, viii. p. 401 .

JARA, the hunter who slew Krishna, mistaking his foot for part of a deer.

JARAB was the son of Sultan, the son of Eber, and brother of Peleg, and from him the ancient Arabians derive their ancestry. The Yaharabi, therefore, who claim the nearest approach to the parent stem, trace their genealogy further back than the other tribes in Arabia, and may, undoubtedly, be pronounced the oldest family in the world. Saba, the grandson of Sultan, founded Saba, and the Sabrans are supposed to be identified with the Cushites, who dwelt upon the shores of the Persian Gulf. This was the position which the seceders occupied at the period of the dispute for the khalifat between Ali and Mowaiyah, and it throws a ray of light upon the mist that envelopes the history of this remote period, when we find some direct evidence bearing on a point which has heretofore been a matter of mere conjecture. The name of Arabia, with some show of reason, has also been derived from the Jarab here alluded to.-Wellsted's Travels, i. p. 8.

JARAH. HIND. A surgeon. Jarāhat is surgery.

JARAK, a little town on an eminence overhanging the western bank of the Indus, about midway between Hyderabad and Thatha. It is the boundary between Vichalo or Middle Sind and Lar or Lower Sind. Three miles below Jarak is another low hill covered with ruins, which the people call Kafir Kot, and attribute to Raja Manjhira.-Cunningham's India, p. 287.

JARAN. JAV. A white wood of Java, taking the tool easily; the natives prefer it to all others for the construction of their saddles, which consist principally of wood.

JARAS, the hunter who accidentally killed Krishna-Dowson.

JARASANDHA, a warrior king of Magadha, of a Turanian dynasty, to whom various deeds and dates are assigned; perhaps several rulers bore this name. He twice waged war against Mathura, the Behar of the present day. Krishna repulsed the first invasion, but after the second invasion Krishna and the Yadava retired to Dwaraka. Jarasandha and Sabadeva, according to Professor Wilson, were contemporaries, B.C. 1400. Jarasandha is supposed by Sir William Jones to have been a contemporary of Krishna and Yudishthra, B.C. 3101. Jarasandha, king of Magadha, is the historical personage amongst the heroic kings of the Mahabharata. It was his wars and conquests which occasioned the great popular movement that took place immediately before the era of the five Pandava kings. He drove the Yadava from their settlements on the Jumna, and brought 86 kings prisoners to his capital. He held imperial sway. It was he who opposed Semiramis, B.c. 1230, defeated and drove her back to the Indus with immense loss. He was son of Bribadratha and grandson of Vasu. He was of the dynasty of the Barhadratha, which Bunsen estimates, B.C. 986 , was followed by the following dynasties:-Pradotya, B.C. 646 ; Bimbisara, B.c. 578 . In this dynasty Buddha appeared as a teacher, and died B.C. 543. Seshunaga, B.c. 446 ; Nand, 378; Maurya, whose first was Chandragupta, 312. After Jarasandba's death, his kingdom fell to pieces, and it was followed by the murderous war amongst the princes of the Kaurava and Pandava-Jarasandha ka Baithak, $\pi$ Buddhist tower near Sarnath, 28 feet in diameter and 21 feet high, with a basement 14 feet high. Its total height, when complete, was probably 56 feet. Fergusson says (p. 45) it is also described as a brick st'hupa at Giryek, 7 miles E. of Rajgir ; another at Rajgir, the ancient Rajagriha. - Wheeler's Hist. 
of India, i. pp. 164, 475; Bunsen, iii. pp. 547-591; Ferguson and Burgess, Cave Temples of India, p. 45 .

JARGAH and Nargah, the great circle of beaters in the Mongol hunting parties.

JARIB or Jureeb. HIND., PERS. A measuring chain or rope. Before Akbar's time it was a rope. He directed it should be made of bamboo with iron joints, as the rope was subject to the influence of the weather. In British survey measurements a chain is used. A jureeb contains $60 \mathrm{guz}$, or 20 gut'ha, and in the standard measurement of the Upper Provinces is equal to five chains of 11 yards, each chain being equal to 4 gut'ha. A square of one jureeb is a bigha. A jureeb in Hebrew and Arabic signified originally only a measure of capacity, equal to 4 qufeez, or 384 mud (Latin, modius), and in course of time came to signify the portion of land which required as much to show it as a jureeb would contain. The pat'ha and nalee of Garhwal and Kamaon have a similar origin. This use of the term must have altered before the reign of Timur, for in the Institutes we have an injunction, which is evidently the foundation of Akbar's division of soil into three classes. The words qufeez and mud are both retained in the Spanish cafiz and almud. Indeed, nearly all the Spanish weights and measures are, like very many administrative words, derived from the Arabic, as the quintal of one hundred pounds, from kintur, of which the fourth (rooba) is the arroba; arralde, a pound, from arrattle ; xeme, a span, from shamah ; and so on.Elliot, Sup. Gloss.; Al Makkari, i. p. 500 ; Asasul-Loghat.

JARID. ARAB. A reed, a javelin, thrown by the hand in the manner of the Roman pilum.

JARIDAH. ARAB. A book, a volume, a register, an account book, a branch of a palm tree stripped of the leaves; a number of horsemen or horses, part of a large body.

JARID-BAZEE. PERS. An athletic exercise, either played by two men on horseback, with a spear-shaft twelve or more feet long, or by a single horseman, with a stick two or three feet in length. In the former, the two opponents alternately gallop after each other, throwing the jarid or spear-shaft with full force; the aim of the thrower is to hit and unhorse his opponent, while he, by his dexterous agility, is not only to elude the blow, but to seize the weapon in the air, and attack in turn. The other game simply consists in putting the horse to its utmost speed, and dashing one end of the short stick on the ground, so that it may rebound upwards and be again caught. In Syria, horsemen armed with these ride at full speed, and throw their jarid against each other from a considerable distance. The assailant, so soon as he has thrown, turns his herse, and his antagonist pursues and throws in his turn. The sport is not unattended with danger. The Mamluks used to make these jarid staffs from the branches of the palm tree stripped of their leaves, about 4 feet long, and weighing 5 or $6 \mathrm{lbs}$. They are still so made in Persia.-Pottinger's Travels.

JARI-PATKA. MAHr. The pennon of the Peshwa's standard, or his flag. Qu. Zari-patka, golden pennon. $-W$.

JARRAH, a wood of Western Australia, Eucalyptus marginata, Smith, unsurpassed in soundness and durability ; for all works of magni- tude, such as dock-gates, wharves, etc., requiring strength, it is without equal. It is applicable for almost all purposes; is highly effective in all ornamental work, and most useful for all the requirements of the house-carpenter, such as window frames, doors, beams, and every description of furniture, and when cut at the proper time of the year, and allowed to season before being used, it has proved almost indestructible. It sets at defiance white ants on land, and the Teredo navalis in water. It is used for roofs, floors, window frames, mantelpieces, tables, and doors, resisting insects like so much marble, and is capable of receiving the highest polish.

JARTIKKA, one of the Arashtra races, the Adraistæ of Arrian, who places them on the Ravi. The Bahika was a tribe occupying the neighbourhood of the Indus near Attock, at the time of Alexander and Chandragupta. The Bahika also were one of the republican races known as the Arashtra (SANSK.), or the kingless, the republican defenders of Sangala or Sakala. The Arashtra were known by the several names of Bahika, Jartikka, and Takka, from which last is the name of their old capital of Taxila or Takka-sila, as known to the Greeks. The Takka people still exist in considerable numbers in the Panjab Hills; and their alphabetical characters, with the name of Takri or Takni, are now used by all the Hindus of Kashmir and the northern mountains, from Simla and Sabathu to Kābul and Bamian.-Sir H. Elliot.

JARYA, a tribe in Nepal, south of the Gurung, with whom they are intermixed and intermarry. They are Hindu in creed and manners. They may pertain to the Gurung, Nagar, or Newar tribes. See Newar.

JASHN. Arab., Hind. A royal ceremony, an entertainment.

Jashn-i-Wazan, the ceremony of weighing a person against money and ornaments, to be afterwards given away in presents or charity.

JASHPUR, a tributary state of Clutia Nagpur, in the Bengal Presidency ; area, 1947 square miles. Bounded on the north and west by the tributary state of Sirguja, on the south by Gangpur and Udaipur, and on the east by the Lohardaga district. The population consists of the Oraon, who are of the Dravidian race, with many of Kolarian descent.

JASMINUM. Many of the jasmine genus of plants are very pretty shrubs, with white and yellow flowers, in most cases scented. The Yuthika savala kesi, having golden or auburn hair, brown as the yellow jasmine, was deemed a mark of beauty in ancient India, and in the west of India such hair is even now sometimes seen, but the prejudice in favour of ebon locks is so strong that it is considered a morbid affection of the hair, and the women dye and conceal it. In the Hero and Nymph occur the words,'Her voice is music, her long tresses wear

Jasminum angustifolium, Roxb.

J. vimineum, Willd. $\quad$ N. triflora, Burm.

\begin{tabular}{l|l} 
J. triflorum, Pers. & Mogoriu \\
Nyctanthes angustifolia, $L$ & Lam.
\end{tabular}

Ban mallika, . . HIND. Kanana mullika, SANSK. Malati, Malur, MALAY. Asphota, . . ,

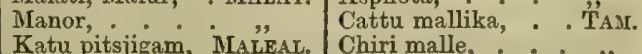
Grows in the forests of the Peninsula of India. Its root is used medicinally.-W. Ic. ; Roxb. 
Jasminum arborescens, $R o x b$. i. p. 95 . Nyctanthes grandiflora, Lour.

Buro-koondo, . BFing.| Munem-manus, . HiNd. Grows in all the south-east of Asia.

Jasminum auriculatum, $R o x b$.

J. trifoliatum, Pers. | Mogorium trifol., Lam. Juhi, . . . HINd. Tella adavi malla, . TEL Yerra adavi malla, TEL. Mallalu, Sannajajulu, ,"

This small, sweet-flowered species grows in the Mauritius, Bengal, Assam, Ajmir, and is much cultivated. - Roxb.

\section{Jasminum chrysanthemum, - ?}

J. revolutum, W. $I c$.

Pela chambeli, - Hind. Pachoha adavi malla, Tel. Hema pushpika, . SANSK.

This grows in Bengal and the mountains on the N.E. of India. It is a free flowerer, and highly ornamental.

Jasminum grandiflorum, Linn.

Myat-læ, . . Burm. | Chambeli, Jati, . Hind.

A native of the East Indies, and much cultivated for the flowers. This and another species yield the true essential oil of jasmine of the shops. It is the most exquisitely fragrant species of the genus, and is very generally cultivated, the oil being much prized as a perfume; and the large white flowers, haring a most powerful scent, and being in blossom throughout the year, are used in garlands on all festive occasions. In Hindu medicine, the flowers are considered a bitter and cool remedy, and are employed as an application to wounds, ulcers, boils, and eruptions of the skin. They act as an aromatic stimulant, and might be used as a substitute for the sambucus, elder flowers.-Roxb.

Jasminum heterophyllum, Roxb.

J. hirsutum, Linn. J. pubescens, Willd.

J. multiflorum, $A n d r$.

Nyctanthes hirsuta, Linn. N. pubescens, Retz.

N. multiflora, Burm.

Koondo, . . . . Beng. | Katu jeram mulla, Maleal

Grows in most parts of India.-Roxb.

Jasminum nudiflorum is of the north of China, where its yellow blossoms peep out from amongst the snow like the primroses and cowslips. Nearly as early is the pretty daisy - like Spiræa prunifolia; the yellow Forsythia viridissima, the lilac Daphne Fortunei, and the pink Judas tree become covered with blossoms, and make the northern Chinese gardens extremely gay. -Fortune's Res. p. 241.

Jasminum officinale, Linn., White jasmine.

J. revolutum, Sims. | J. pubigerum, var.

Suari,. . . Chenab. Jai, ... Panjab. Malto, Pitmalto, . Hind. Shing, . . Sutles. Chamba,

A native of the south of Europe, used generally by Europeans for covering trellis - work. Natives of India grow it in bushes, and use the flowers at most of their festivals. It is propagated by layers. The root is said to be useful in ringworm. A perfumed oil is prepared from this with the fixed oil of the Pterygosperma moringa.

Jasminum pubescens, Willd. Jasminum hirsutum, Linn. Its pretty white flower, the koondo of the Hindu, is sacred to Vishnu. It is cultivated as a flowering plant, and is very ornamental.

Jasminum sambac, Roxb.

J. undulatum, Willde. $\quad$ Nyctanthes sambac, Linn. Mogorium sambac, Lam
But mugra, Beng., DukH. | Pun mulla, . . Maleal. Sa bay, Ma lee, BurM. Zambak, . . Pers. Bela, Mutya, . HIND. Navamallica, . SANsK. Hazarea mugra, . " Mallai, . : : TAM.

There are two varieties of this beantiful and very fragrant twining plant, one is J. sambac, plenum, the great double Arabian jasmine, the rich-lobed branches of which are studded all over like the snowdrop tree with lovely white flowers, the size of small roses, and delightfully fragrant. This variety is probably more cultivated than any other flower, though the single-flowered, with a twining habit, is not unfrequently to be seen. The single variety is called Motiya; but beautiful varieties called Satha, with single and double flowers, which have the odour of fine green tea, are also cultivated. J. sambac is used to decorate the hair of the Chinese ladies, and to garnish the tables of the wealthy. All Chinese gardens, both in the north and south, are supplied with this favourite flower from the province of Tokein. This, J. paniculatum, and Olea fragrans, the orange tree, Murraya exotica, Aglaia odorata, and Chloranthus inconspicuus, are grown for their blossoms, which are used for mixing with the tea. The flowers of the sambac are supposed by the Hindus to form one of the darts of Kama Deva, the Hindu god of love.-Roxb.; Riddell; Fortune; Stewart; Irvine; Wight.

JASPER.

Jaspis, . DAN., Dut., Sw. | Diaspro, . . . . . IT. Jaspe, Fr., PokT., SP. Jaspis, . . . LAT. Jaspiss,. . . GER. Jaschma, . . . Rus.

Jasper, a quartzose mineral of a red and yellow colour. Jasper, onyx, common opal, and bloodstone are found in abundance in many parts of the Dekhan and amongst the Cambay stones. Yellow jasper occurs on the Tenasserim, but it is not of common occurrence. A soft green jasper, also precious green jasper, and striped jasper, are found in the Burmese provinces. - Mason.

JAT or Zat. Hind. Caste, clan, tribe, occupation. Jat-bhai, a fellow-countryman, one of the same sect or clan. When a Rajput has children by a Sudra woman, they are called Jat.

JAT, also written Jet, Jit, Jut, and Zjhut, a great race spread throughout all the N.W. of British India, in Afghanistan, the Panjab, all Baluchistan, the valley of the Indus, Sind, the Indian desert, Rajputana, and the N.W. Provinces. Mr. Growse says the Jat are supposed to be the Xanthii of Strabo, the Xuthii of Dionysius of Samos, the Jatii of Pliny and Ptolemy. They have been identified with the Getæ and their great subdivision the Dhe, with the Dahae, whom Strabo places on the shores of the Caspian. The existing division between the Jat and the Dhe has been traced back to the continuity of the Massa Getær, or Great Getæ (Massa, Pehlavi, great), and the Dahæ, who dwelt by the side of each otber in Asia Minor. The weight of authority is in favour of a Scythian origin for the Jat, and a similar descent has been claimed for some of the Rajput tribes.

The parent country of the Jat seems to have been the banks of the Oxus between Bactria, Hyrcamia, and Khorasmia. In this position there was a fertile district, irrigated from the Margus river, which Pliny calls Zotale or Zothale, and General Cunningham believes this to have been the original seat of the Jat, the Jatii of Pliny 
and Ptolemy, and the Xanthii of Strabo. The term Jat is only their tribal name; the general name of their horde is Abar. Taking these two names, their course from the Oxus to the Indus may be dimly traced in the Xanthii of Strabo, the Jatii of Pliny and Ptolemy, the Xuthii of Dionysius of Samos, who are coupled with the Arieni, and in the Zuthii of Ptolemy, who occupied the Karmanian desert on the frontier of Drongiana. Subsequently, the main body of the Jatii seem to have occupied the district of Abiria and the towns of Pardabathra and Bardaxema in Sind or Southern Indo-Scythia, while the Panjab or Northern Indo-Scythia was chiefly colonized by their brethren of the Medes.

In proceeding eastwards by the Bolan pass and other routes, they succeed the Tajak and Dehwar of the west of Afghanistan and the vicinity of Kandahar, and occupy the plains and the hilly country, descending into the plains, spread to the right and left along the Indus and its tributaries, occupying Upper Sind on one side, and the Panjab on the other. But in the Panjab they are not found in any numbers north of the Salt Range, and in the Himalaya they are wholly unknown, which would seem to show that the Jat did not enter India by that extreme northern route. Also, the Jat does not occupy Lower Sind, and they are not found in Gujerat. The Jat is, however, the prevailing population in all Upper Sind, and their tongue is the language of the country. They were once the aristocracy of the land, but latterly have been dominated over by other races, and thus have lost somewhat of their position as the higher classes of society. In the south and west of the Panjab, too, they have long been subject to Muhammadan rulers. But latterly, as the Sikh religionists, they became rulers of the whole Panjab and of the country beyoud as far as the Upper Jumna, in all which territories they are still, in every way, the prevailing population. Over greattracts of Hindustan, three villages out of four are Jat, and in each Jat village this race constitute perhaps twothirds of the entire community, the remainder being low-caste predial slaves, with a few traders and artisans. The Jat extend continuously from the Indus over Rajputana. The great seat of Rajput population and ancient power aud glory was on the Ganges; but since vanquished there by Muhammadans, the chief Rajput houses have retired into the comparatively unfruitful countries now known as Rajputana, where, however, the Jat is the most numerous part of the people. They share the lands with the Mina, the remains of the Brahman population, and the dominant Rajput, but they have the largest share of the cultivation. The northern part of Rajputana wrs partitioned into small Jat republics before the Rajput were driven back from Ajudiah and the Ganges. The southern and more hilly parts of Rajputana are not Jat, but are occupied by the Mhair, Mina, and Bhil ; but in Malwa, again, the Jat are numerous, and seem to share that province with Rajputs and Kunbi. Bhurtpur and Dholpur are Jat principalities. Those of Baluchistan are fine athletic men, with handsome features, but rather dark. Those in Upper Sind, up the course of the Indus, and in the SouthWestern Panjab, are for the most part of the Muhammadan religion. They have been long subject to foreign rule, and seem to be somewhat inferior to their unconverted brethren. In all the east of Baluchistan, the Baluch are but a later wave and upper stratum. There, about the lines of communication between India and Western Asia, in the provinces of Seistan and Cutch Gandava, the Jat form probably the largest portion of the agricultural population, and claim to be the original owners of the soil. In the west, advancing through Rajputana, we meet the Jat of Bhurtpur and Dholpur. Gwalior was a Jat fortress belonging, as is supposed by $\mathrm{Mr}$. Campbell, to the Dholpur chief. They do not go much farther south in this direction. From this point they may be said to occupy the banks of the Jumna, all the way to the hills. The Dehli territory is principally a Jat country, and from Agra upwards the flood of that race has passed the river in considerable numbers, and forms a large part of the population of the Upper Doab, in the districts of Alighur, Merut, and Muzaffarnagar. They are just known over the Ganges in the Moradabad district, but they cannot be said to have crossed that river in any numbers. To sum up, therefore, the Jat country extends on both sides of the Indus from lat. $26^{\circ}$ or $27^{\circ} \mathrm{N}$. up to the Salt Range. If from the ends of this line two lines be drawn nearly at right angles to the river, but inclining south, so as to reach lat. $23^{\circ}$ or $24^{\circ} \mathrm{N}$. in Malwa, and lat. $30^{\circ}$ on the Jumna, so as to include Upper Sind, Marwar, part of Malwa on one side, and Lahore, Arnritsar, and Ambala on the other, then connect the two eastern points by a line which shall include Dholpur, Agra, Alighur, and Merut, and within all that tract the Jat race etbnologically predominates, excepting only the hills of Mewar and the neighbourhood, still held by aboriginal tribes. Advancing eastwards into the Panjab and Rajputana, we find Hindu and Mubammadan Jat much mixed, and it often happens that onehalf of a village or one branch of a family are Muhanmadans and the other Hindus. Farther east, Muhammadan Jat become rarer and rarer, and both about Lahore and all that part of the Panjab along the line of the Upper Sutlej and Jumna, the great mass remain unconverted. In the Panjab, the Jat all take the designation of Singh, and dress somewhat differently from ordinary Hindu Jats; but for the most part they only become formally Sikhs where they take service, and that change makes little difference in their laws and social relations. The Jat of Dehli, Bhurtpur, etc., are a very fine race, bear the old Hindu names of Mull and such like, and are not all Singhs. In Rajputana, the Jat are quiet and submissive cultivators. They have now long been subject to an alien rule, and are probably a good deal intermixed by contact with the Mina and others.

Captain Postans tells us that the Jat in Sind, like all the tribes in the Sind countries, are divided into innumerable subdivisions, called Koum, and are a hard-working race, occupying themselves in rearing camels, feeding flocks, or cultivating the soil. They are invariably found in large communities, often living in temporary huts or wand, and migrate all over Sind and its confines, as shepherds, in search of pasture. Where this is not the case, they are farm servants either of the Baluchi chiefs or wealthy zamindars, 
who repay their labour with a modicum of the produce. The Jat in Sind are a quiet, inoffensive class. Their women are, throughout the country, noted for their beauty, and, to their credit be it also spoken, for their chastity. They work as hard as the men, and the labour of tending, driving home their flocks, milking the cattle, etc., is fairly divided. The Jat are very numerous, and form a large division of the population of Sind, though seldom found in its towns, being dispersed over the whole face of the country, particularly eastward to the desert tract which separates Sind from Cutch, known as the Runn, on which this tribe rear large flocks of camels.

In 416 of the Hijira (A.D. 1026), Mahmud marched an army against the Jat, who had harassed and insulted him when returning from his last expedition against Saurashtra. These Jat inhabited the country on the borders of Multan, along the river that runs by the mountains of Joud. When Mahmud reached Multan, finding the Jat country defended by great rivers, he built fifteen hundred boats, each armed with six iron spikes projecting from their prows, to prevent their being boarded by the enemy, expert in this kind of warfare. In each boat he placed twenty archers, and some with fire-balls of naphtha to burn the Jat fleet. The monarch having determined on their extirpation, awaited the result at Multan. The Jat sent their wives, children, and effects to Sind-Sagur, and launched four thousand, or, as others say, eight thousand boats well armed to meet the Ghaznians. A terrible conflict ensued, but the projecting spikes sunk the Jat boats, while others were set on fire. Few escaped from this scene of terror; and those who did met with the more severe fate of captivity. Many doubtless did escape ; and it is most probable that the Jat communities, on whose overthrow the state of Bikanir was founded, were remnants of this very warfare.

The Jat who remain of the Hindu religion are divided into clans, and they marry into their own, usually one wife, or, failing children, take another. Their widows can re-marry, and they can take the wife of a deceased brother if she has not had offspring. They are not strict as to the manner of cooking or eating their food. They are good agriculturists, honest carriers, and are a bold, independent, but not boorish race. In the Merut division, they are considered the most valuable subjects, the most industrious of all the castes, patient and long-suffering as taxpayers, quiet and peaceable generally, but, like the Rajputs, easily roused to avenge a fancied wrong, or in obedience to their chieftain's call. Many eat animal food; they are bardy, amenable to discipline, and make good soldiers. Though professing Hinduism, they are remarkable for their contempt of the Brahmans.

The Jat Singh of the Panjab and Upper Sutlej may probably be taken as the best representative type of the race. Compared to northern races, they are dark; they are tall, large, and wellfeatured, with plentiful and long beards, fine teeth, and a very pleasant, open expression of countenance. They are larger and taller than the Afghan Pathan, with the upper part of the body especially well developed, but not so stout limbed or quite so robust. They are a fine, remarkably handsome race of men, not excelled by any race in Asia. In courage, energy, and military qualities, they excel the more beautiful non-Pathan races of the northern bills, and they are as energetic in the peaceful arts as in that of war. They are good cultivators, hard-working, and thrifty ; they let little land lie waste, and pay their land tax punctually. Their women work as well as the men, and make themselves generally useful. They are not learned, though many men and some women can read and write. They have a great craving after fixed ownership in the soil. They are essentially agriculturists, seldom gardeners, and in Hindustan are never pastoral. They breed cattle largely, and sometimes rear camels when the country is suitable; and in Jat countries both ordinary carts and large mercantile waggons are usually plentiful, and as waggoners they not unfrequently carry their grain and other produce to distant markets on their own account. The Jat formerly dwelt in Rajputana in republics, such as, in the time of the Greeks, were alluded to as democratic institutions, and one recoguised republican state, that of Phul or Maraj, care down to the present day, and was the last recognised republican state in India. It was a Jat republic, and gave the chiefs who founded the states of Patiala, Nabah, Jheendea. The old territory of the Phulkian race was recognised by the British, and treated amongst the protected Sikh States, but has recently been brought under the general rule of British dominion. Every Jat village, however, is, on a small scale, a democratic republic, every man having his own separate and divided share of the cultivated land. The union in a joint village community is rather the political union of the commune, so well known in Europe, than a common enjoyment of property. $A$ father and son may cultivate in common, but commonality goes no further. The village site, the waste lands and grazing grounds, and, it may be, one or two other things, belong to the commune, and the members of the commune have, in these, rights in common. For all the purposes of cultivation, the remainder of the land is in every way separate individual property. The government is not patriarchal, but a representative communal council or panchayat. Re-marriage of widows is permitted. All the Jat are subdivided into many gentes and tribes, after the usual fashion of the peoples of the Aryau or Indo-Germanic stock, and the usual fashion is to marry into another gens. The Jat have little of the Hindu ceremonial strictness, and in Panjabi regiments they messed freely like Europeans, and had their two or three meals a day comfortably. The Jat, Rajput, and their congeners are branches of one great stock. Brahmans of Kashmir and the frontier hills are Hindus in an earlier stage of Brahmanical development. The Jat country is just such as would be occupied by a large stream of people issuing through the Bolan pass, in lat. $28^{\circ}$ or $30^{\circ} \mathrm{N}$, and the Rajput are ranged in a semicircular form around the eastern and northern and south edge of the Jat area, the mass of them occupying the richer valley of the Ganges. Mr. (Sir G.) Campbell's conjecture is that the Rajput are an earlier wave from the same source as the Jat, who came in by the same route, have farther advanced, and been completely Hinduized, while the Jat have come in behind them. Panjabi is the language spoken by the Jat, but which, in 
Upper Sind, is called Jati Gul or the Jat tongue ; and Mr. Masson calls it Jetki. It is an IndoGermanic tongue allied to the Sanskrit. In its main grammatical and essential features it is not widely different from the Hindi of the Rajput and other Hindustan people. It is one of the most Prakrit of Indian vernaculars. The Jat are partly Hindu, partly Sikh, and partly Muhammadan. They all refer to the west of the Indus and to Ghazni as their original seats; the Dhe or Pachhade reached India from the Panjab about the middle of the 18th century. The other section is the Hele or Deswale. Sind Jat seem to have entered by the Bolan pass, occupied the high pastoral lands about Quetta, and thence descended into the plains, which they still occupy. The Jat is the great agricultural tribe in the Panjab, and, in Panjab parlance, Jat and zamindar or cultivator are synonymous. There are no Jat in Kashmir or within the hills. The Aodi tribe of Jat dwell in Panipat and Soneput. The Aolania Jat in Panipat claim to be above other Jat, by having had the title of malik or king conferred on them. The race, however, spread throughout the Panjab, down the Indus into Cutch Gandhava, and eastwards to the Jumna and Ganges, is the same, and wherever spread they retain a dialect of their own. Mr. Masson seems to imply that they are descendants of the Getre who, he says, once possessed the whole of the countries immediately east and west of the Indus. The zamindars or cultivators of the soil at Jell, as throughout Cutchi, are Jat, who there seldom moved abroad but on bullocks, and never uuless armed. A Jat might generally be seen half-naked, seated on a lean bullock, and formidably armed with matchlock and sword. In the Panjab they are not found west of the Jhelum, but east of that river the Jat cultivators use waggons. The Jat has been so long settled in Cutch Gandhava as to appear the aborigines. Amongst their numerous subdivisions are the Kalora, Kokar, Hampi, Tunia, Abrah. The custom among the Jat of Curao, also written Karao, seemingly from Karana, to cause to do, is the term among the Jat, Gujar, Ahir, and other races and tribes in Western Hindustan for concubinage generally, but more especially for marriages of widows with the brother of a deceased husband.-Aitcheson's Treaties; Campbell, Ethn. of India; Beng. As. Soc. Journ.; Journ. Ethn. Soc.; Canningham's Sikhs; Elphinstone's Caubul; Elliot's Supp. Glossary; Government of India Records, No. 11; Institutes of Menu; Kennedy on the Origin of Languages; Masson's Journeys, ii. p. 125; Masson's Kalat, p. 352; Memoirs of Humayun, p. 45 ; Pennant's Hindustan; Postans' Sind; Selections from the MahaUharata; Elliot's Hist. of India; Thomas' Prinsep's Antiquities; Tod's Rajasthan; Vigne's Travels.

JATA. SANSK. A knot of hair on the heads of Hindu and Buddhist devotees. The Jata, or matted hair, was assumed by Rama and Lakshmana on dismissing the royal chariot at the village of Sringavera, to indicate their entering upon a forest or ascetic life. Jata therefore is a twisted braid of hair, worn by Hindu ascetics.

JATAIYU, a fabulous bird killed by Ravana.

JATAKA, the tenth division of the SutraPitaka, or second book of the sacred canon of the Buddhists, has legends relating to Sakya Muni, or Buddha's previous existences, which he is said to have related at various times to his hearers, and in which a good deal of his doctrine is embodied. These legends are still very popular all over the world of Buddhism, and have spread far beyond it, being the oldest source of \$isop's. Fables, and of the fairy tales, folk-lore, nursery songs and rhymes of every country in the world. Often they become changed, almost beyond recog. nition, till Gautama Buddha even figures as a Christian saint in the Romish calendar. The life of Barlaam and Josaf, attributed to St. John of Damascus, has been shown by Professor Max Muller to be the life of Gautama Buddha as told in the Jatakas. Its Latin title is S. Joannis Damasceni Barlaam Eremitæ et Josaphat Regis Indorum Gregorio Trapezuntio interprete, Prince Josaf being none other than Gautama Buddha, and St. Josaphat, who is worshipped by Catholics as a saint on every 27 th of November. Colonel Yule believes also (Marco Polo, ii. pp. 304-309) that the story of the Holy Grail (Sangreal) had its origin in the Buddhist legends of the begging bowl of Sakya Muni ; and he has been identified by Mr. Rhys Davids with the Man in the Moon, Gautama in a former state of existence having been a hare, and in the Kalmuk version of the Jataka legend the soul of that hare was translated to the moon, where he is still plainly visible to Kalmuk eyes.

The fables included in the Jataka book undoubtedly belong to the oldest Indian folk-lore; but they are universally ascribed by the commentators to Buddha himself. From all that is known of the life of Gautama, it was quite consonant with his method to make use of the household stories of the people in order to bring home to them the practical bearing of his moral teaching. A great deal of the Birth Stories, however, probably grew up after his death, and it is beyond doubt that in its present form the Jataka book represents a long process of accretion. Each story consists of several parts, and these are by no means of equal antiquity. The real Birth Story, or Story of the Past, is introduced by a Story of the Present, and is followed by a conclusion. The introductory story tells some episode of Buddha's life; how some disciple acted in such and such a way, and how Buddha accounted for it by the fact that the same person in a previous existence had behaved in a precisely analogous manner. The Birth Story itself is the account of this passage in the previous birth, put into the mouth of Buddha, who generally utters a stanza pointing the moral. The conclusion establishes the connection between the two episodes and identifies the characters. The introductory Story of the Present is clearly later than the Story of the Past, and is the work of the compiler or commentator; and the verses included in the latter (and sometimes in the former) are older in literary form than the stories, though the stories undoubtedly represent in substance popular fables which existed long before the verses were composed. There is a freshness and simplicity about the Stories of the Past that is sadly wanting in the Stories of the Present; so much so, that the latter (and this is also true of the whole long introduction containing the life of the Buddha) may be compared more accurately with mediæval legends of the saints, than with such simple 
stories as Asop's Fables, which still bear a likeness to their forefathers, the Stories of the Past. The Jatakas so constituted were carried to Ceylon in the Pali language, when Buddhism was first introduced into that island about B.C. 200 ; and the whole was there translated into and preserved in the Singhalese language (except the verses, which were left untranslated) until the compilation in the fifth century A.D., and by an unknown author, of the Pali Jataka Book.

As an example of the general character of the stories in their several parts, and also of their bearing upon European collections of popular tales, may be noticed the Baka Jataka (No. 38), or 'The Cruel Crane Outwitted, in which the case of two cheating tailors is told in the Story of the Present. The Teacher, i.e. Buddha, thereupon remarks that this was not the first time the one rogue of a tailor had taken in the other, and tells the Story of the Past, in which a crane who had treacherously devoured a pond full of fish, is himsclf outwitted and killed by a crab whom he had tried to deceive like the fish. Then comes the moral stanza, uttered by the Bodhi-satwa who had been looking on in the form of a tree spirit :-

'The villain, though exceeding clever,

Shall prosper not by his villany.

He may win, indeed, sharp-witted in deceit,

But only as the crane here from the crab.'

And, finally, by way of conclusion, the Teacher established the connection and summed up the Jataka by saying, "At that time he (the crane) was the Jetavana robe-maker, the crab was the country robe-maker, but the genius of the tree was I myself.' This fable can be traced through a numerous progeny; it is found in the Arabic Kalila-wa-Damna, the Persian Anwar-i-Suhaili, the Greek Stephanites kai Ichnelates, the French Livre des Lumières and Cabinet des Fées, in La Fontaine, the Arabian Nights, the Pancha Tantra, Hitopadesa, and many other collections of household stories; but it is not included in the socalled Esop's Fables. The moral it inculcates is of a well-worn type; but this is not observable with regard to all the series. - Saturday Revieu.

JATAKI, in Baluchistan, a language spoken by the Rind, Talpur, Murree, Chandia, Jemali, and Laghari; they speak either Jataki or the hill tongue of the Baluchi. The Jataki is also called Siraiki, from Siro or Upper Sind, where it is commonly spoken by the people; but also Baluchi from its being used by several of the Baluch clans settled in the low country. The word Jataki, spelt with the cerebral $t$, and the peculiar Sind $j$ or $d j$, is an adjective formed by the proper noun Jat, the name of a people. The author of the Dabistan applies the term 'Jat dialect' to the language in which Nanak Shah composed his works. The Journal of the Bombay Branch of the Asiatic Society, 1849, contains a short Grammar, which serves as a specinen of the Jataki tongue. It is extensively used throughout the province of Sind, and is spoken by probably one-fourth of the inhabitants. It abounds in varieties of dialects, and contains little or no original literature, except a few poetical pieces, and short tracts on religious subjects. The Langha or Sindi bards seem to prefer it to their own language, and many well-educated natives, especially Baluchi, have studied it critically, and composed works in it. The celebrated Arabic hymn, generally known by the name of Dua Suryani, the Syriac or Syrian prayer, from which language it was borrowed by Ali, or, as is more generally believed, by Ibn Abbas, has been translated into Jataki, and is learned by heart as a talisman agrinst accidents and misfortunes. The Jataki dialect is usually written in the Nastalik, and sometimes in the Nashki character. In the former, the system of denoting the cerebral and other letters which do not belong to the Arabic alphabet, is the same as in Urdu.

JATA-MALA. SANSk. Wearing matted locks ; a name of Siva.

JATAMANSI. HIND. The Cyperus stoloniferus of Hesne, Retz, and Wight, Contr., but the true Jatamansi is the Nardostachys jatamansi, D. C.; the Balch'haru or Balchur, HiND.; Sanbal-ul-trib, ARAB.; and Sanbal-i-Hindi, Pers. The true plant is only found at great elevations beyond the tropics, but in South India the term is applied to the sweet-smelling tubers of various species of Cyperus, and in Upper India to the lemon-grass, A. schœenanthus, and other species of Andropogon, which are also known under the names of Askhar and Sikhunas ( $\sigma \chi_{6}\left(\nu_{5}\right)$ ). Sir IV. Jones identified it as the spikenard of the ancients.

In the Makbzan-ul-Adwiah, four separate articles are described,-1st, Sumbul-Hindi; 2 d, Sumbul-Rumi, called also Sumbul-Ukleti and

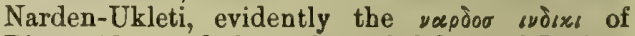
Dioscorides, said also to be called Sumbul-Italion, that is, the nard which grows in Italy; the $3 \mathrm{~d}$ kind is Sumbul-Jabali or Mountain Nard; and the 4th kind is Sumbul-Farsi, which is a bulbous plant, and is probably a kind of hyacinth. Polianthes tuberosa is described as being one of the kinds of Persian Sumbul. But the first alone, viz. S. Hindi, is that which is valued for its fragrance. The synonyms of it given by Persian authors are-in the Arabic, Sumbul-ul-Tib, or fragrant nard; in the Greek, Narden; in Latin, Nardum; in Hindi, Balchur and Jatamansi. The last is a Sanskrit name, and that which was given to Sir William Jones as the equivalent of Sumbul-Hindi, and which he informs us, like other Sanskrit names applied to the same article, has reference to its resemblance to locks of hair. -Royle's Ill. Him. Bot. p. 242; Elliot's Flor'a Andhrica.

JATA VARMA, ceremonies at the birth of a child, on which, before cutting the cord, some ghi is put into the child's mouth.

JATEORHIZA COLUMBA. Miers. Columba root, an excellent tonic, used by the Indian physicians in debility and diarrhoea, after fevers. It is often given combined with catechu.--Murray.

JATH. HIND. A post placed in a tank to denote that its water has been dedicated to a deity or has been married to a grove.

JAT-HARINI, a goddess worshipped by Bengal Hindus.

JATHI, a coil of dark-brown woollen thread, plaited with the hair by Kulu women.

JATI or Yati, a Jain teacher, an ascetic priest. The jati or yati are usually taken from the Banya tribe, and devoted, iu early life, to the purposes of religion. They pass their novitiate with a guru or teacher, and at a proper period are admitted as yati. On this occasion a novice is stripped of his apparel, and, with certain cere- 
monies, invested with the dress of his order. A blanket, a plate, and a cloth for his provisions, a water-pot and a broom, are then given to him. It is their duty to expound and read to the Sravaka (laity), the Scriptures, or Sastras, of the Jaina system. Sherring says (p. 265), but seemingly in mistake, that there are three sects of devotees bearing this designation. The first consists of those Gosains, Bairagis, and Udasis who practise celibacy. The second is akin to the jogi devotees. The third professes to be of Buddhist origin, and is also called Sewara. The two latter fi cits have their bands of disciples. The second at death are burnt; but the third are either buried or tlirown into a river.

JATRA. HrND. A religious assemblage at a Hindu temple or shrine. A Hindu pilgrimage to a place of reputed sauctity, a religious festival, a place of pilgrimage where a fair is held. In the S. of India, a festival in honour of a divinity, especially of the tutelary goddess of a village. $-W$.

JATROPHA CURCAS. Linn. Physic nut, Castiglionia lobata, Ruiz. | Curcas purgans, Adans.

Dundi birri, . . ARAB. Pahari-arand,. . HIND. Bag bherenda BENG Rotenjot, Them-bau-kyet-hsoo, $\quad$ Kat avanaku, . MaLeaL. BurM. Nepala,. . . SANsk. Mara narulle, . . CAN. Ratændaru, . Singh. Tung-shu, : CHIN. Katamanak, . TAM. Pignon d'Inde, : . Fr. Adivi amida, : . . TEL.

Grows in New Andalusia, Havannah, China, and is one of the most common small bushes throughout India, and largely used as a fence, taking root readily, and cattle do not ent it. It is in flower and fruit all the year. The seeds are purgative, but very uncertain in their operation; proving sometimes violent like those of the Croton tiglium, though they are naturally milder. Dr. O'Shaughnessy considers it a very dangerous article. Nearly all the Jatropha are powerful cathartics, and Fee cites J. gossypifolia, America; J. glandulosa, Arabia; and the J. multifida, or coral plant (Avellana purgatrix, grand ben purgatif), a native of America and India, a shrub 8 or 10 feet high. Dr. Wight gives also Jatropha peltata and J. villosa. A fixed oil (called in Canarese Mara haralu unnay) is prepared from the seeds by steaming and pressing, and is used in China for oiling boats and woodwork. It is reckoned a valuable external application in cases of itch and herpes; it is also used in chronic rheumatism and for burning in lamps. The milky juice boiled with oxide of iron makes a fine black varnish.

\section{JATROPHA GLANDULIFERA. Roxb.} Jatropha glauca, Vahl.

Addale, . . . Tам. | Dundigapu chettu, TEL。 Nila amida,. . . TEL. Kati amidapu chettu, ,

A native of the East Indies. The pale or whey-coloured thin juice which exudes from a fresh- wound is employed by the Hindus as an escharotic to remove flaws from the eyes. Its seeds also yield a stimulating oil, in appearance approaching castor-oil, fluid and light straw coloured. This is now chiefly used medicinally as a counter-irritant, but if procurable in sufficient quantity seems likely to prove a useful oil. Its leaves yield a green dye. $-R u x b$.

JATROPHA MULTIFIDA, the coral plant, a native of America, with its brilliant carmine corymbs, is common in Indian gardens; the seed is sometimes eaten by children, but is of a deleterious nature, and an emetic should be immediately administered. The inspissated juice forms a substance like caoutchouc.-Mason; Riddell.

JATTI, one of the titles given to the headman of a Hindu corporation.

JATUA. Hind. A tribe of the Chamar race in the Upper Doab.- $W$.

JATUKARNA, author of one of the Smriti and a compilation on military tactics, was born at Koch-Bahar, and resided at Chandra Shekhara. He taught that the deity is possessed of form, and that the world consists of matter partly eterual and partly created.-Ward, iv. p. 52 .

JAU. HIND. Hordeum hexastichum. JauDesi, common barley, a barley corn ; the primary unit of measure of length.

JAUGADA, in the Ganjam district, 18 miles W.N.W. of Ganjam, and 18 miles N.N.W. of Berhampur, has two separate edicts of Asoka addressed to the rulers of Samupa.

JAUHAR, I personal servant of the emperor Humayun, whose duty it was to carry a ewer for his master to wash his hands. He was in constant attendance on his master, and wrote the Memoirs of Humayun. Although unacquainted with his political relations and secret designs, he was a minute and careful observer of all that came within his reach, and describes what he saw with simplicity and distinctness. He was devoted to Humayun, and anxious to put all his actions in the most favourable light; but he seldom imagined that anything in his master's conduct needed either concealment or apology. Elphin. p. 384 ; Elliot.

JAUHAR. HIND. The practice of some Hindus, and especially of Rajputs, of putting their wives and children to death when unable to resist an enemy, and then sacrificing themselves. It is resorted to by the Tartars of China, and sometimes by Muhammadans. Dhai Bibu was living when the British forces captured Kalat in 1839. Her daughter, married to Shabghassi Nur Muhammad, was put by him to the sword, with his other wives and female relatives, when the town was entered. Mehrab Khan, the ruling chief, fell in the storm at Kalat.-W.; Masson's Journeys, ii. p. 94.

JAUHAR. HiND. A jewel, a gem. Jauhari, a pedlar, lapidary, jeweller. $-W$.

JAUHAR, water-mark on swords. Jauhar-dau', having a Jauhar watering or water-mark on steel, gun-barrels, etc.

JAULNAH, a large town and a military cantonment of the Hyderabad contingent, in lat. $19^{\circ}$ $50^{\prime} \mathrm{N}$., and long. $76^{\circ} \mathrm{E}$. The rocks of the country around are the basaltic formation of the Dekhan.

JAUN, ANGLo-Hind, also Office-Jaun or JaunPaun, a kind of conveyance, from Jana, to go; a conveyance like a chair, with a high back, and covered in on all sides, with doors, panels, curtains, and canopy. It is carried by four men at a time, on their shoulders, two to each pole. There are a great variety of shapes in the Simla, Mussoori, and Darjiling jaun-paun, the fastionable conveyance in those sanatoria, and the men (Jaunpauni) who officiate as the carriers of the jaunpaun are gaily attired in many-coloured garments, or different kinds of livery.-Mrs. Hervey's Adventures, i. p. 53 .

JAYA, an island in the Eastern Archipelago, 
the south point of which is in lat. $8^{\circ} 47^{\prime} \mathrm{S}$., and long. $114^{\circ} 29^{\prime} 10^{\prime \prime} \mathrm{E}$. It is the chief of the islands of Netherland India, the head ruler being styled the. Governor-General of Netherland India, Commander-in-Chief of all the forces of His Majesty the King of Holland to the east of the Cape of Good Hope. Java and Madura are separated by a narrow strait, and considered as one jurisdiction, with an area of 2380.7 square geographical Dutch miles, with a population in 1880 of $19,797,077$, viz. Europeans, 33,703; natives, 19,542,835 ; Chinese, 206,914; Arabs, 10,523 ; others, 3092 .

Java the less, of Polo and the Arab geographers, was Sumatra, the Iabadius or Yavadwipa of Ptolemy. Java, locally Jawa, is the name of the original occupants of the eastern part of the island, who in latter years have spread all over the island and have given it their name. The Chinese call it Chi-poo. Marco Polo, who described though he did not visit it, calls it Giaua. Java received a Hindu colony from Kalinga, B.c. 75 , and vestiges of Hindu mythology, superstitions, and language still remain. When the Chinese traveller visited Java in the 4th century, he found it peopled by Hindus. The Hindu Government continued in Java till it was overthrown in the 14th century by converts to Muhammadanism.

The Netherland India possessions in the Eastern Archipelago, for their civil government, are divided into provinces or prefectures, known under the names of Residencies. The mode adopted by the Dutch, in governing the people, has been to continue the semblance of authority in their own chiefs, while the real power rests with the Dutch officers, termed residents. During the convulsions in Europe in the early years of the 19 th century, Java was taken possession of by the British in 1811 , but restored in 1816. Near Samarang is the headquarters of the army of Netherland India, strongly fortified.

Java is traversed by two chains of mountains, from 10,000 to 12,000 feet in height, in which there are about 45 volcanoes, many of them in occasional activity; and it has explosive mud and brine springs, and a poison valley, in which accumulations of carbonic acid gas kill every form of life which penetrates into it. On the 26th and 27th of August 1883 there occurred the climax of the most tremendous volcanic eruption which, perhaps, the world has ever seen during historic times. In the course of it, Krakatoa Island, 3000 feet high or thereabouts, entirely disappeared. The usual volcanic products, including the finest particles both solid and vaporous, were ejected into the air to a height that no man will ever say, since for many miles round the scene of these devastating forces noon was as black as night, and darkness was over all the land for 36 or 40 hours. The scale on which the work was done was such that even the noise, the weakest part of it, was heard at a distance of 2000 miles. The shivering of the island produced a wave of water 100 feet high, which destroyed everything over which it swept, and left its mark on tidal registers nearly all over the world. The mere air pulse produced by the last fearful cataclysm was strong enough to pass with its gradually widening circle nearly three times round the globe.

Krakatoa Island was in eruption on the 26th, but it entirely disappeared on the 27 th, and a tidal wave 12 to 30 metres high swept the coast of Mirak as far as Tiyiringen, overwhelming the towns of Anjer, Mirak, and Tiyiringen, destroying about 20,000 people. Soengepen volcano split into five; between the site where Krakatoa had stood and Sibisie Island, sixteen new volcanic craters appeared. A lighthouse in Java and another in Sumatra disappeared. Where once Krakatoa stood, the sea now plays. Ships in the seas sailed through patches of pumice, and Sunda Straits were so much changed as to necessitate resurvey. The craters of the numerous volcanoes for which Java is noted were most of them in active eruption. Madura Island at its east, 500 miles away, also had a share of the terrible effects of this unprecedented convulsion. Sourabaya, in the Straits of Madura, suffered seriously. The steamship Gouverneur General, belonging to Batavia, was at sea at the height of the eruption, and steamed to Anjer to give the alarm, but found that place destroyed. The ship had a layer of ashes 18 inches thick on her deck. In some places masses of floating pumice-stone seven feet in depth were passed. The volcanic action must have been going on in lat. $5^{\circ} \mathrm{S}$. and long. $88^{\circ} \mathrm{E}$., at least three weeks prior to the terrible catastrophe in Java. S.S. Siam, from King George's Sound to Colombo, in lat. $5^{\circ} \mathrm{S}$, long. $88^{\circ} \mathrm{E}$., from 3.30 P.M. till dark was steaming through large quantities of lava floating in broad patches, and trending from north-west to south-east, some pieces larger than a cricket ball. $5^{\circ} \mathrm{S}$. and $80^{\circ} \mathrm{E}$. is in the middle of the Indian Ocean, about equidistant from the Keeling, Chagos, and Rodrigue Islands. The ancient Hindu temples, the Boro Buddor, the Chandi Siwa, and others, were greatly injured.

The volcanoes of Java are in two lines, - - one, commencing near Cape St. Nicholas, its N.W. extremity, passes diagonally across the island to its S.E. headland on the Strait of Bali. The other line runs parallel, and extends from Cheribon on the S. coast to the Strait of Sunda. The volcanoes are in two separate fissures in the earth's crust, and the volcanoes in it are cones of elevation, each distinct and separate; their number being 38 , and some of them of immense size. They throw out volcanic ashes, sand, and scorix, and sometimes trachytic lava. White clouds of sulphuric acid gas continually wreath their peaks, and is destructive to life. Large quantities of sulphur are dug out. A severe earthquake was experienced in Batavia, and over an extensive region in Java, on the 16th of November 1847. In the Courant of the 27 th October 1847 , it was mentioned that a shower of ashes had fallen at Buitenzorg on the night of the $17 \mathrm{th}$, which came from the Guntur mountain, in the district of Limbangan, Residency of Preangar. On Sunday the 17th October, at 11 o'clock P.M., the earthquake shocks, following each other in quick succession, were felt at Tijandjur, the first of which was very strong, and lasted for fully ten seconds. The shower of ashes began to fall the same night, and on the following morning had already clothed the earth, grass, trees, and buildings with a brown covering. The fall of ashes and sand lasted the whole day, and made it very inconvenient to be in the open air. The eyes of travellers suffered. The earthquakes had not wholly stopped at Tijandjur on the 29th October. The mountain had, however, fortunately begun to 
be at rest, and no damage had been caused by the eruption. The shower of ashes had reached as far as the frontiers of the Residency of Bantam, a distance of more than 80 miles to the west. Tengger mountains mean the wide or spacious mountains. There is here an old volcano with its trachyte crater 7500 feet above the sea, in diameter $3 \frac{1}{2}$ and $4 \frac{1}{2}$ miles. It is the largest crater in Java, and one of the largest in the world. Its bottom is a level floor of sand, which in some places is drifted by the wind like the sea, and is called by the Malays the Laut Pasar or Sandy Sea. Four cones of elevation rise from this sand floor, the smallest of which, called Bromo, in 1866, was active, throwing out ashes. It rises like Monte Somma in the crater of Vesuvius. But trachyte, obsidian, and pumice have been thrown out in succession.

Papandayang volcano, in 1772 , in the south of Java, in lat. $10^{\circ} 8^{\prime} \mathrm{S}$., in a single night threw out scoriæ and ashes which Dr. Jonghuhn thinks made a layer of 50 feet thick for seven miles around. In Dr. Horsfield's account of it, drawn up from the native testimony, it is stated that an extent of ground of the mountain and its environs, 15 miles long and full 6 broad, was by this commotion swallowed up within the bowels of the earth; but such sinking, according to Mr. Bikmore (p. 75), does not seem to have occurred.

Mount Galung-gong, a few miles N.E. of Papan. dayang, is also a Java volcano. On the 8 th July 1822, at noon, not a cloud was seen in the sky, when suddenly at half-past one a frightful thundering was heard in the earth, and from the top of this old volcano a dark, dense mass was seen rising higher and higher into the air, and spreading itself out over the clear sky with such an appalling rapidity, that in a few moments the whole landscape was shrouded in the darkness of night. Through this darkness flashes of lightning gleamed in a hundred lines, and many natives were struck down by falling stones. Then a deluge of hot water and flowing mud rose over the rim of the old crater and poured down the mountain sides, sweeping away trees and beasts and human beings. At the same moment, stones and ashes and sand were projected high into the air, and as they fell destroyed nearly everything within a radius of more than 20 miles. A few villages on the lower declivities of the mountains escaped, from being built on eminences, as they were above the streams of hot water and mud, and the stones thrown out fell beyond them, destroying villages at a greater distance. By 4 P.M. the extreme violence of the eruption had passed, by sunset the sky was again clear, and the sun shining on a scene of desolation. A second eruption occurred five days afterwards, and by that time more than 20,000 persons had perished.

The Javan group of languages embraces Sundan, Maduran (with its dialect Bawian), and Bali. According to Mr. Logan, Javan has a much broader, more forcible aspirate and primitive phonology than Malay. Up to the middle of the 15th century, the people of Java, from Cheribon, in long. $109^{\circ}$.to the west, spoke the Sundanese tongue. But in 1811 nine-tenths of all the population of Java spoke Javanese, and the Sundanese wasalready confined to the mountainous parts of the south and west, and to a small colony near Bantam. The Javanese alphabet, like all others in the Archi- pelago, is written from left to right, each letter is distinct and unconnected, and the writing is perpendicular and not slanting. It is the character used for the Javanese proper, the Sunda, the Bali, and it is believed the Lombok, and including Palembang in Sumatra, it is current among twelve millions of population. But in prior times other characters to the extent of twelve in number have prevailed in Java.

In the eastern and central parts there may be said to be three Javanese languages, - the popular, the polite (which is a kind of factitious dialect of it), and an ancient tongue, found only in old books and ancient inscriptions. The modern and popular language, as well as the polite dialect, is written in a peculiar character, of which the substantive letters amount to twenty. Sundanese is spoken over about one-third of the island, extending from Cheribon across the island down to its western extremity. This tract is more mountainous than that inhabited by the Javanese, and the people somewhat less advanced in civilisation, but possessing the same amiable and docile character as that nation.

The industrious, peaceful, and numerous people who speak the Madurese language, with its dialect the Sumanap, occupy the island of Madura, divided from Java by a strait, and form in some districts the bulk of the population on the opposite shores of Java, to which, depopulated by long wars for the past two hundred years, they have been emigrating.

In the adjacent island of Bali, which is small but fertile, well cultivated and populous, is the Balinese, with its ceremonial dialect and sacred language, and it is one of the most improved languages of the Archipelago.

The fourth language, which Mr. Crawfurd considers to have a strong affinity with the Javanese, is that of Lombok, a fertile and populous island, divided from Bali by a narrow strait. This is the termination in an easterly direction of the group of tongues which begins with Sumatra.

For nearly nine centuries (603-1479) foreign colonists continued to adorn this island with edifices almost unrivalled elsewhere. Boro Buddor is a great Buddhist temple there. It is a dhagoba with five processional paths and 72 small domical building's, each containing a statue of Buddha, but combining with it the idea of a nine-storeyed vihara. The bas-relief sculptures which line its galleries extend to nearly 10,000 lineal feet. On the inner face of the second gallery is portrayed, in 120 bas-reliefs, the entire life of Sakya Muni. In the galleries above this are groups of Buddhas, bodhi-satwas, and saints, and many crested snakes. The temple at Mendoet, two and a half miles from Boro Buddor, has three colossal figures, supposed to be Buddha, Siva, and Vishnu, with a figure of Lakshmi. The temple of Toempang also merits mention, and that of Pantaram (A.D. 1416) is called the serpent temple, because its basc is made up of eight great crested serpents. There are temples at Matjanpontik; and on the Djeing plateau there are five or six small temples, also temples at Suku. The ruins of Singha Sari include six principal structures of hewn stone, besides the base of a circular tower, with numerous figures.

The Javanese are of short stature, the men do not average more than 5 feet 3 inches, face lozenge 
shaped, cheek-bones high and prominent, mouth wide, and nose short. They all gamble greatly. They profess Muhammadanism, but still follow many Hindu customs ; a few are professing Christians. The dress of Javanese ladies differs but little from that of men of the upper class, except in the kabya being buttoned across the breast. No covering is worn for the head, their bright black hair being tastefully arranged in a knot, decorated with bunches of white flowers; the women of the lower class wear a blue sarong, and a wide shirt of the same colour. Both sexes, but more particularly the women, pay great regard to cleunliness, bathing at least once a day. Javans are an agricultural race, attached to the soil, of quiet babits and contented disposition, almost entirely unacquainted with navigation and foreign trade, and little inclined to engage in either. The people of the Tengger mountains may be a relict of an aboriginal race. This race, like a few others in India and the Archipelago, adopt the singular practice of building their villages in terraces, and the practice seems to have once prevailed in the Philippines. The inhabitants of the Serwatty islands select the summits of hills. They are a peculiar people, who speak a dialect of Javanese, and, despite the zealous efforts of the Muhammadans, they still follow the Hindu religion.

The Kalang people who reside among the inhabitants of the Tengger mountains are said to have been at one time numerous in various parts of Java, leading a wandering life, practising religious rites different from those of the people, and avoiding intercourse with them; but most of them are now stationary, and have embraced the Muhammadan faith. Thenever the Kalang move from one place to another, they are conveyed in carts, having two solid wheels with a revolving axle, and drawn by two or more pairs of buffaloes, according to the circumstances of the party.

The fishing canoes or flying canoes of Java are long, but very narrow, - just broad enough to enable a man to sit between the gunwales; the crew seldom exceeds four men. They are rendered steady by long semicircular outriggers, one end secured to the gunwale, the other to large bamboos, and of the same length as the canoe itself; and as they are daubed all over with some bright white substance, they have the appearance of huge spiders crawling over the dark blue sea; their speed, when propelled by paddles, is very great, but greater under their large triangular sails.

A mong the small groups of islands in the Java sea, the waterspouts are frequent, and not always accompanied by strong winds; more than one is seen at a time, whereupon the clouds whence they proceed disperse, and the ends of the waterspouts bending over finally cause them to break in the middle. They seldom last longer than five minutes. As they are going away, the bulbous tube, which is as palpable as that of a thermometer, becomes broader at the base, and little clouds, like stcam from the pipe of a locomotive, are continually thrown off from the circumference of the spout, and gradually the water is released, and the clouds whence the spout came again closes its mouth.

Ginding is the name given to a land wind in East Java, occasioned by the S.E. monsoon blowing right over the land through the gap at Kalakka, 1000 feet above the sea, between the Jyang and Tengger mountains, 8000 and 9000 feet high.
According to the traditions of the Javanese, Sumatra, Java, Bali, Lombok, and Sumbawa were all formerly united, and they give the dates of A.D. 1192, 1282, and 1350, but these are not to be received. The dividing line between Asiatic fauna and that of Australia must be drawn down the Straits of Macassar, and continued southward through the Strait of Lombok between Lombok and Bali.

The wild sand coast of Bantam in Java is annually frequented by large numbers of turtles, where they have often to creep over nearly a quarter of a mile of the beach, to the dry and loose soil at the foot of the sand dunes. In their progress to and fro, they are attacked by parties of wild dogs, birds of prey, and even tigers.

Zoology.-In Java are species of Pteruthius, Arrenga, Myiophonus, Zoothera, Sturnopastor, and Estrelda.

Java has seven pigeons peculiar to itself; a peacock; also the green jungle cock; two blue ground thrushes (Arrenga cyanea and Myiophonus Havirostris), the fine pink-headed dove (Ptilinopus porphyreus); three broad-tailed ground pigeons (Macropygia), and many other interesting birds found nowhere in the Archipelago out of Java.

The Gallus furcatus or green jungle fowl is common in Java; also G. bankiva, Buceros lunatus, and Loriculus pusillus, a pretty little lorikeet, about four inches long. In the western districts of Java are the calliper butterfiy, Charaxes Kadenii ; the elegant green and yellow Trogon, Harpactes Reinwardti; the gorgeous little minivet flycatcher, Peri Crocotus miniatus, which looks like a flame of fire among the bushes; and the rare black and crimson oriole, Analcipus sanguinolentus. Java has the Babirussa, the Bos sondaicus, Hylobates leuciscus, the Cercopithecus cynomolgus, Stenops Javanicus, Nycticebus tardigradus, Pteropus edulis, Pt. Javanicus.

The Papilio arjuna has its wings covered with grains of golden green, and P. coon also occurs.

The amphitrite or sea-worm of Java lives in holes of the great solid madrepores. The gills of these lovely creatures are in the form of spiral ribbons of brilliant orange-green and blue. These gaudy plumes are alternately extruded and retracted, and, seen through the pellucid water, present a very singular and beautiful appearance. -Crawfurd; Fergusson; Wallace; Bikmore; Logan.

JAVALI, a renowned logician of the time of Rama.

JAVAN, the ninth from Yayat, who was the third son of Ayu, the ancestor of the Hindu as well as of the Tatar Indovansi.

JAVAN. In ancient Sanskrit literature, a designation of the western world, generally supposed to be applied also to Ionia, the Isles of Greece, and Asia Minor. In the form of Yavana, it is also held applicable to the Greeks and their descendants who made inroads into India through the N.W. and from the Euphrates, and are said to have reached Orissa through Kashmir; and the term Yavana was applied also to Greeks left by Alexander to garrison the banks of the Indus. Javan or Yavan is, however, now applied by the Hindu both to Greeks and Muhammadans. Ezekiel xxvii. alludes to the Javan and Dan, but Yavana has been used by the Hindus to mean Iones, as it is used in Genesis $\mathbf{x}$, and in the Arabic, 
Persian, Coptic, and Armenian languages, to signify Greeks, Iones being once the appellation of all the Greeks.-Plato de Leg. iii. 684, in John's Archipelago, i. p. 284; Tod's Tr. p. 375.

JAVELINS are used in hunting by the $\mathrm{Yadu}$ race of Kerrowlee. They are about twice an arrow's length, are held by the feathered: end, and are three or four times twirled round the head before being thrown. The ancient German warriors had a custom of crowning their javelins with coronals of leaves from the sacred trees.-Postans' India, ii. p. 196.

JAW AI,AMUKHI, or Flame's Mouth, an ancient town in the Kangra district of the Panjab, in lat. $31^{\circ} 52^{\prime} 34^{\prime \prime} \mathrm{N}$., long. $76^{\circ} 21^{\prime} 59^{\prime \prime} \mathrm{E}$. It is situated on the road from Kangra to the Nadaun, at the foot of a precipitous range of hills, forming the northern limit of the Beas (Bias) valley. It has a temple built over jets of combustible gas, issuing from the ground, and kept constantly burning, as a manifestation of the Hindu goddess Devi. The devotion of centuries has enriched it with many costly offerings, amongst others a gilt roof, presented by Ranjit Singh in 1815. About 50,000 pilgrims attend the great festival in September or October. Six hot mineral springs occur in the neighbourhood, impregnated with common salt and iodide of potassium.-Imp. Gaz.

JAWARA, HiND., also Jaya, SANsk., small shoots of rice, which germinate when steeped in water, and shoots of barley forced in earthen pots at the Dashara festival, and presented to friends for good luck. $-W$.

JAXARTES, the Jihun of the Arabs, the Syr Darya or head-river, has its source in the very heart of the Tian Shan. In its upper course it is called the Narin, which has its chief head-stream at the foot of the Petroo glacier in the AkShiirak Hills. It passes 400 miles westward, then enters the khanate of Khokand, which it crosses for 300 miles in a S.T. direction. Reentering Russian territory again, it soon turns due north 400 miles, after which it meanders $\mathrm{N}$. W. to its outlets on the N.E. of Lake Aral. Its total length is 1500 miles. In the lower 400 miles of its course to Lake Aral there are many islets, and the country is disposed in long, low undulating surfaces of clay, interspersed with stretches of sand, and dotted with occasional sand hills. Amongst the princes from the Jaxartes are historians, poets, astronomers, founders of systems of government and religion, warriors, and great captains, who claim our respect and admiration. Chengiz Khan and his bands issued from the pastoral lands beyond this river. On the eastern side of Central Asia is a fertile tract, watered by the Jaxartes and the Oxus, and it is in this fertile tract that the conquests of Russia were made between 1864 and 1868. After long years spent in fortifying posts, Russia, in 1864 , made a sudden irruption into the upper valley of the Jaxartes, and in that year took three forts of Khokand,viz. Aoulietta, Turkestan, and Chemkend. In the spring of 1865 , the chief of Khokand fell in battle, and in June 1865 the city of Tashkend was stormed. On the 20 th May 1866 , they fought and won the battle of Irdjar, against the Bokhariotes, and later in the year captured the forts of Oratepe and Juzak, within 40 miles of Samarcand. On the 13th May 1868, a great battle was fought under the walls of Samarcand, and the city sur- rendered, and later in the year Bokhara yielded -Asia, by Keane and Temple, p. 406; Fortnightly Rev., July 1868.

JAY, an English name for species of the Garrulinæ, all noisy birds. Garrulus bispecularis, V'igors, is the Himalayan jay; G. lanceolatus, Vigors, is the black-throated jay. In wooded situations, on the western ranges of the N.W. Himalaya, the traveller is struck with the characteristic and elegant long-tailed jay, Calositta (Urocissa) Sinensis, Linn. This graceful creature attracts attention not only by the brilliancy of its plumage, but the loud, harsh screams it utters as the traveller approaches, now jerking up its long tail, after the manner of the magpie, now garrulously chattering, as though reproaching one for intruding on its haunts.-Adams. See Birds.

JAYADEVA is the literary name of the author of the pastoral poem the Gita Govinda, and also of the Prasanna Raghava, a drama of five acts. His real name is unknown, and the meaning of his pseudonym is God of Victory. He was a native of Kenduli in Tirhut, and is supposed to have lived about the 12 th century, and his tomb was still (1862) to be seen at Birbhum. Though now remembered as a poet, he was a great reformer. He spiritualized the worship of Krishna, denounced the caste system, and has left a lasting impress on Bengal. What Melanchthon was to the early Lutheran Church, that was Jayadeva to the reformation in Bengal. His Herdman's Song is now the devotional work of a great sect. It was translated in full by Sir William Jones, and printed in one of the early volumes of the Asiatic Society. He abandoned his ascetic life for a Brahman girl who had been devoted to Jaganath.

In the Gita Govinda, Jayadeva sings the praises of Krishna as an incarnation of Vishnu. At his time the worship of Krishna was taking a prominent position, and the history of his incarnations was the theme of the wondering praise of every rustic bard; and Jayadeva's poem describes Krishna as Vishuu the preserver, incarnate as man, man in his weakness, divine in his talents, aspirations, and final conquest of earthly desires. The Gita Govinda is the history of his carnal and finally of his spiritual passions.

The plot of the poem describes Krishna as coming to earth in a pleasant land of woods and streams, of fragrant flowers and warbling birds, with the spring fragrance of the jasmine and myrtle, and the prolonged note of the koel (Eudinamys orientalis) coming from among the yellow champa bushes. He is wandering in the forest alone, when his face and form attract the loveliest of the shepherdesses of the surrounding country, and he loves them all. "He eateth of the ripe fruit of desire till his soul abhorreth its lusciousness.' Then comes penitence, and his soul is sorely troubled. He meditates on the charms of intel. lectual delight (typified by the single and transcendently beautiful Radha) as contrasted with the charms of carnal pleasure (typified by the thousand fascinating shepherdesses). In time he relinquishes the latter and adheres to the former, and, after many trials, disappointments and hopes, rebukes and deferments, is at length indissolubly united to the incomparable Radha, the flower of the flowers of the garden.

In one respect the Gita Govinda may be likened to the Song of Solomon. Professor Lassen thinks 
it puts forth deep spiritual teaching under the guise of extremely plain and often coarsely voluptuous verse; but as no Hebrew youth was allowed to read the Song of Solomon until past the age of eighteen, so Jayadeva's poem should not be read by school-boys. It has been partially translated into English verse by Mr. Edwin Arnold, who, however, modifies much of it and omits a whole canto. The great charm of the Gita Govinda consists in its mellifluous style and exquisite woodland pieces. They exhibit in perfection the luxuriant imagery, the voluptuous softness, and the want of vigour and interest which form the beauties and defects of the Hindu school._Tr. of Hind. i. 56; Elph. 156 ; Ward, iv. 376 .

JAYADEVI, goddess of victory, worshipped in the Craunchadwipa under the emblem of a sword.

JAYADRATHA, raja of the Sindhu or Saindhava and of the Sauvira tribes, in the valley of the Indus. He married Duhsala, daughter of Dhritarashtra. While the Pandava were in exile, he carried off Draupadi, but the Pandava, on their return, pursued and made him prisoner, but spared his life. He subsequently took part with the Kaurava in their war with the Pandava, but was slain by Arjuna on the 14th day of the battle of the Mahabharata. -Douson.

JAYANTA, in Hindu mythology, a heavenly chorister, the son of Brahma, transformed into an ass by Indra. He married the daughter of king Tamratsena in that state.-Asiatic Researches, ix. p. 148.

JAYANTI. SANSK. The 8th day of the dark half of Sravana, the birthday of Krishna, celebrated as a festival by the Vaishnava sect.

JAYASINHA or Jai Singh II., raja of Amber, a distinguished astronomer of the 17th and 18th centuries. He constructed a large set of valuable tables; erected magnificent observatories at Benares, Dehli, Kotah, and Ujjain. His liberal patronage of science and art, and his attainments in mathematics and astronomy, made him known to European scholars.-As. Res. v. pp. 167, 177.

JAYA STAMBHA, the Kutub Minar at Dehli; also at Coel, Dowlatabad, and elsewhere; also at Gaur in Bengal.

JAZAIL. HIND. A long, heavy musket used in forts, etc. ; a ginjal.

JAZIA. ARAB. A capitation tax authorized by the Muhammadan law on all nonconformists. It was abolished by Akbar in the seventh year of his reign. In Persia, firmans have been issued that the Zoroastrians should henceforth be allowed certain privileges which they had not enjoyed hitherto, such as allowing them to ride, wearing new or white clothes, and building and repairing their dwellings. The Shah, however, has neither abolished nor reduced the Jazia tax, which is levied from the Zoroastrian residents, the Muhammadans being exempted from it. Jazia is from an Arabic word meaning subjugation, conquest, compensation,- - a capitation tax levied by the Muhammadans on their subjects of another faith. It appears from the Ayin-i-Akbari that the khalif Umar laid an annual tax upon every one who was not of the Muhammadan religion. A person of high condition paid 48 dirhems, one of moderate means 24 dirhems, and one in an inferior station 12 dirhems. It does not exactly appear when this tax was instituted in India. Tod thought it was imposed by Baber in lieu of the Tumgha, which he solemnly renounced on the field of battle, after the victory which gave him the crown of India ; but we read of it long before this, for as early as the time of Ala-ud-Din, only a century after the final subjugation of Hindustan, we find it spoken of as an established tax. The tax was abolished by Akbar in the 9th year of his reign, and was not imposed again till the $22 \mathrm{~d}$ of Aurangzeb, who, with his wonted intolerance, directed that its levy should be attended with every circumstance of contumely which his ingenuity could devise. From this period it appears to have been regularly levied, and with particular severity in the time of Ferokhsir (in consequence of the appointment of Inayat-Ullah as Financial Minister, who had been Secretary to Aurangzeb), until the time of Rafi-ud-Darjat, when the Barha Syud, or twelve Syuds, abolished it, and the Hindus again recovered their consequence, Ruttun Chund, a Hindu, being appointed Financial Minister, and being possessed even of such influence as to be empowered to nominate the Muhammadan Cazees of the provinces. After the death of Ruttun Chund, the capitation tax was once more levied, as it is stated to heve been again repealed by Muhammad Shah, at the intercession of Maharaja Jai Singh and Gerdhur Badahur. Since that period no emperor was possessed of sufficient authority to enforce the Javia, and this odious tax became extinct for ever; but not till it had operated as one of the most effectual causes of the decline of the Muhammadan power, by alienating the affections of the Hindu population, which the early Moghul emperors had courted, and in some measure obtained.-Tuwareekh-i-Mahomedshahee ; Elliot, Supp. Glossary; Rajasthan, j. p. 403.

JAZIRAH means an island, but is a term applied to the doab between the Euphrates and Tigris; the Mesopotamia of the ancients. The Sea of Oman or Persian Gulf, called also the Persian Sea and Erythrean Sea, also the Sea of Fars, has several islands, - the Jazira-i-Lafet, called also Jazira-i-Daraz or Long Island, known on maps as Kishm; also Khareg Island, on maps Karrack, a small island, but well watered, not very far from Bushir, and which once belonged to the Dutch, and was held from 1838 to 1846 by the British.

JEDDAH, a town in Arabia, on the borders of the Red Sea. It is the ancient Badio Regium. It is the port of Mecca. There are three gates, the east or Mecca gate being used solely by Muhammadans. The resident population number about 12,000 to 20,000 , but 120,000 pilgrims annually pass through it on their way to Mecca. Outside the town on the north, white-washed and conspicuous to the voyager and traveller from afar, is a diminutive dome, with an opening to the west, as is usual in El Hejaz. Haw-wa, Eve, the mother of mankind, is supposed to lie under this, and the outlines of the body is defined by two parallel dwarf walls, six paces apart. The trade of Jeddah is considerable.

JEDDO or Yedo, the capital of the empire of Japan, is situated at the northern extremity of the gulf of the same name in an extensive plain.

JEELUN. HIND. A mode of raising water from tanks; the pe-cottah of the Tamil people.

JEHOIAKIM, for three months king of Israel. 
While only 18 years old (in B.C. 598), Nebuchadnezzar burned and pillaged his palace and the temple of Jerusalem, and took the king and his mother and court to Babylon. He was succeeded by his uncle Zedekiah, whom Nebuchadnezzar placed on the throne. But in B.c. 589 Zedekiah rebelled, and in 588 Nebuchadnezzar laid siege to Jerusalem, and B.C. 586 took it by storm, burned the temple and palace, and put out Zedekiah's eyes.

JEHUR. HIND. A pile of water-pots placed me on the other. The word is pronounced also Jeghur, and also written Jehar. To take the water-pots off the head of a divorced woman is to inply consent to marry her. The custom prevails amongst the Jat, Ahir, and Gujar, but principally :inongst the former, and more commonly in liajputana than in the Oudh and Dehli provinces. -Elliot.

JEJURI, in the Mahratta country, is famed for its Hindu temple. Jejuri temple is very rich; it is said to expend 50,000 rupees yearly in the expenses and establishment for the deity, Kandeh Rao; horses and elephants are kept for him; he and his spouse are bathed in Ganges water, rosewater perfumed with otto, and are decorated with gems. The revenues, like those of most other temples, are derived from houses and lands given by pious people, and from presents and offerings constantly making by all descriptions of votaries and visitors, according to their means, or their faith, hope, or charity. The Murlidar women, however numerous, are not perhaps any expense, but rather a source of revenue to the temple. At the annual Jatra or fair, which commences on the last day of the dark half of Chaitra (in January), about 100,000 persons visit Jejuri. . It is customary for the worshippers to sacrifice a sheep, and the Brahmans assert that 20,000 , or, in particular years, 30,000 are slain on this occasion to the honour and glory of Kandeh Rao.-Moor, p. 422. See Kandoba.

JELL, a town in the S.W. quarter of Cutch Gandava, in a district replete with monuments, remnants of a former people, which bear a great analogy to the ponderous Cyclopian vestiges of ancient Europe. A hot spring, the Garm-ab, preserves its temperature throughout the year. The sulphurous spring of Lakha is some 20 miles south of Jell; there is another a little below Sehwan on the hills west of the Indus, and again other very hot springs near Kurachee. The several springs are found in the same line of hills, and those inferior ones at the base of the superior range dividing Sind and Cutchi from Baluchistan. Under the same hills, north of Jell and west of Suran and Sanni, are sulphur mines, indications of the same geological formation. Jell and Shadia are the chief towns of the Maghassi, one of the Baluch tribes, who have been located for a long time in Cutchi. The Maghassi and the Rind are alike addicted to the abuse of ardent spirits, bhang, and opium. Cultivation in the neighbourhood is extensive, principally of jowar and the cotton plant. The country occupied by the Maghassi is abundantly supplied with water.Masson's Journeys, ii. p. 124.

JELLY-FISH, one of the Rhizostoma. These are hardened in China by means of alum, and eaten. Some are three feet across. It is the only one of the Acalephr known to be used as food.
Cuttle-fish are exported from China, about 3000 pikul yearly, value about $25 \mathrm{Hk}$. taels per pikul. Their fishery lasts from March to September, and they are taken with nets and hooks, and are sold fresh or gutted and dried at 21 to 30 dollars the cwt.-Adams.

JELUDAR. Pers. Formerly called Rikab-dar or the 'stirrup holder,' a person who, on foot, accompanied a horseman.

JEMADAR, a commissioned native officer in the native army of British India.

JEM KOT has passed into Sanskrit under the form Yama Kota. According to Abul Fazl, it was considered as the eastern end of the habitable world.-Vambery.

JENKINSON, ANTHONY, envoy from Queen Elizabeth to Shah Tamasp of Persia, A.D. 15571560

JERABLUS, 90 miles from Aleppo, on the W. bank of the Euphrates, the aucient Carchemish, capital of the Hittites. The total circuit of the ruins is under 3000 yards. Out of its ruins was built the Roman city Hierapolis.

JERBOA RAT of India is the Gerbillus Indicus and G. erythrourus. These are eaten by the Wadara and other races.

JERDON, T. C., a medical officer of the Madras army, who devoted his life to the study of natural science in all its branches. $\mathrm{He}$ gave, in the Madras Literary Society's Journal, several contributions on the Fresh-water and Salt-water Fishes and Ants of the Peninsula. Also, in 1839, a Catalogue of the Birds of the Peninsula of India, arranged according to the modern system of classification, with brief notes on their habits and geographical distribution, and descriptions of new, doubtful, and imperfectly described species. The total number of this catalogue was nearly 390 , which, however, included 10 of Colonel Sykes', and nearly as many more observed by Mr. (now Sir) Walter Elliot, of the Madras Civil Service, who placed at Dr. Jerdon's disposal valuable notes on birds procured by him, by which, in addition to the new species added, this naturalist was enabled to elucidate several doubtful points, to add some interesting information on various birds, and to give the correct native names of most of the species. Subsequent to this, Dr. Jerdon published a series of supplements to his Catalogue of Birds, correcting some points and adding others. Jerdon's Birds of India in three volumes, printed in 1862 and 1864, has done much to complete our knowledge of this class of the animal kingdom, and his Mammals of India, published in 1867, has been of similar value for that branch.

JERICHO, an ancient city of the Hebrews, now a ruined hamlet. Near its site is Rihab, a Bedouin village. The channels of streams around Jericho are filled with the nebbuk trees, a species of Rhamnus, set down by botanists as the Spina Christi, of which the Saviour's mock crown of thorns was made. The twigs are long and pliant, and armed with small, though most cruel, thorns. The little apples which it bears are slightly acid, and excellent for alleviating thirst.

JERUSALEM, an ancient city of the Hebrews, frequently styled in the Scriptures the Holy City (Isaiah xlviii. 2; Daniel ix. 24; Nehemiah xi. 1; Matthew iv. 5; Revelation xi. 2); and the Jews to this day never call it by any other appellation than 
El Qadus, that is, the holy, sometimes adding the epithet As-Shereef or the noble. Muhammadans also style it Bait-ul-Maqaddas or the Holy City. Jerusalem was conquered and destroyed by the Babylonians, B.C. 588, and two tribes, Judah and Benjamin, were carried away captive for 70 years. They were then allowed by Cyrus, king of MedoPersia, to return to Judea to re-build Jerusalem. Its second temple was completed, B.c. 10th March 515 , under Darius, but they remained tributary to Persia until that country was conquered by Alexander, B.c. 330 . Jerusalem was built on the hills Zion, Millo, Acra, Bezetha, Moriah, and Ophel, the mountains which 'stand round about Jerusalem.' Its first name was the city of Malik Sadiq, then it was called Salem, and then Jebus, but the tribe of Benjamin called it Jerusalem. The Jews, as in all other eastern towns, are confined to a particular quarter, viz. the hollow space lying between the site of the ancient temple and that part of Mount Zion which is included within the walls. It is called Harat-el-Yahud. The tombs of the kings, situated in a small valley to the north of the city, are without ornaments, either sculptured or painted. There are fragments of sarcophagi in some of them. Jerusalem is the Sylia of the Greeks. Jaffa is the port through which Jerusalem deals with foreign countries. The vicissitudes it has witnessed from the glories of Solomon and Herod, through the violence of Roman conquerors, the neglect of early Christians, and the devotion of Khalifs and Crusaders, are now culminating in the revived interest which the whole civilised world may be said to take in this most sacred spot. Its destruction by Titus led to a very general migration of Jews from Palestine. It capitulated to the 3d Khalif Umar, A.D. 637. No property was destroyed except in the inevitable operations of the siege, and not a drop of blood was shed except on the field of battle. Umar entered the city conversing amicably with the Patriarch about its history. In 1099, under Godfrey of Bouillon, it fell before the arms of the Crusaders. It was taken by storm after a short siege, and for three days there was an indiscriminate slaughter of men, women, and children. 70,000 Muhammadans were put to the sword, 10,000 of them, it is Eaid, in the Mosque of Umar itself, but this must be a great exaggeration. The Muhammadans under Salahud-Din retook it in A.D. 1187. That general had vowed to revenge the slaughter of the year 1099 , but retracted his vow; no blood was shed, and captives were allowed to redeem themselves, the Frankish Christians leaving the city, the eastern Christians residing there in peace. - Taylor's Saracen, p. 68 ; Robinson's Tr.; Rich's Kurdistan, ii. p. 390; Mignan's Travels, p. 9; Tounsend's Outram and Havelock.

JERUSALEM ARTICHOKES.

Helianthus tuberosus.

Topinambours, . . FR. Tartufoli,

A species of sun- Ix. America. It goes to seed generally in October and November. This vegetable is ripe as soon as the stalk withers, and the best method of preserving them is to let the roots remain in the ground. The stems abound in fibres.

JERVIS. Major Thomas Best Jervis, of the Bombay Engineers, author of an Address on the Progress of Geographical Inquiry in India, in
Rep. Brit. Ass., 1839 ; also Bom. Geo. Trans. iv. ; on Surveys in India in Lond. Geo. Trans. vii. p. 129, and Bom. Geo. Trans. iv. p. 133; Geographical and Statistical Memoir of the Konkan, Bombay 1829, Calcutta 1814 ; Journey to the Falls of the Cauvery and Neilgherry Hills, Lond. 1834; Indian Metrology, or Account of Coins, Weights, Measures, etc., of India ; Observations on the Bore in Gulf of Cambay, in Lond. Geo. Trans. viii. p. 202; Topographical Description of Table-land on Cullery Mountain, Bom. Geo. Trans. iii. p. 198.-Dr. Buist's Catalogue.

JESSO, a large island, lying between those of Niphon and the Kuriles, subject to Japan. The shores swarm with seals and sea-otters, and the bays with fish. The natives are called Ainos, and life by fishing and hunting; they are strong, robust, and slovenly. Lat. $40^{\circ} 50^{\prime} \mathrm{N}$., and long. $142^{\circ} 30^{\prime} \mathrm{E}$.

JESSORE, a district in the presidency division of Bengal, lying between lat. $22^{\circ} 25^{\prime} 50^{\prime \prime}$ and $23^{\circ} 47^{\prime}$ N., and long. $88^{\circ} 57^{\prime} 33^{\prime \prime}$ and $90^{\circ} 0^{\prime} 13^{\prime \prime} \mathrm{E}$. Jessore forms the central portion of the delta between the Hoogly and the united Ganges and Brahmaputra. It is a vast alluvial plain, intersected by rivers and watercourses.

JESUIT or Society of Jesus, a Christian sect established in Spain by Ignatius Loyola, of whom it has been observed that 'he legislated at once in the spirit of his early and of bis later profession,--as a soldier and as a spiritual champion of the Church of Rome.' He designed his order in fact to be the embodiment of the idea subsequently formulated by De Maistre, that 'nothing accords so well with the religious as the military spirit.' And hence from the first its whole conception and aim was essentially Spanish and essentially despotic. The first three generals, who with the fifth-the fourth, Eberhard Mercurianus, was a nonentity-made it what it has been ever since, were Spaniards, and of the twenty-five members of the first General Congregation eighteen were Spaniards, so that the government of the company fell during the first ten years almost entirely into the hands of Spaniards. The three immediate successors of Ignatius, with the omission of Mercurianus, were Laynez, St. Francis Borgia, and Acquaviva. Laynez was an accomplished theologian, and had been specially selected with Salmeron, another Jesuit, to represent the papacy at the Council of Trent. To him the order owes that Molinist, as opposed to the Thomist or Predestinarian, system of theology which it has always consistently maintained. St. Francis Xavier, who came as a missionary to India, Malayana, and Japan, was of this order.

JESUS, an Alexandrian author, son of Sirach, who came into Egypt B.C. 132 , and translated into Greek the Hebrew work of his grandfather Jesus, which is named the Book of Wisdom or Ecclesiasticus. It is written in imitation of the Proverbs of Solomon, though its pithy sayings fall far short of the deep wisdom and lofty thoughts which crowd every line of that wonderful work. In this book we see the earliest example that we now possess of a Jewish writer borrowing from the Greek philosophers.-Sharpe's Egypt, i. p. 397.

JESUS, the Christ or Messiah, is styled by $\mathrm{Mu}$ hammadans the Ruh Allah or Spirit of God, born 
of the Virgin Mary. They reject his mission as a Redeemer and Saviour, but regard him as one of the prophets whose intercession is of value. According to Mahomed, Jesus was born of a virgin, was a prophet, and the Spirit of God or Ruh Allah. Mahomed in the Koran (p. 37) says, "The angels said, O Mary, verily God sendeth thee good tidings that thou shalt bear the Word proceeding from himself; his name shall be Christ Jesus, the son of Mary. Verily, the likeness of .Tesus, in the sight of God, is as the likeness of Adam; he created him out of the dust, and then said unto him, Be, and he was.' 'God said, O Jesus, verily I will cause thee to die, and I will take thee up unto me, and I will deliver thee from the unbelievers, and. I will place those who follow thee about the unbelievers until the day of resurrection.'-Koran, pp. 39,40 .

JESWUNT RAO HOLKAR. See Holkar; Mahratta Government in India.

JET.

Sortagat, . . . DAN. Gagata, Lustrino, . . IT. Git, $:$ : DUT, Gagus, Gagates, : LAT. Zwarte-barnsteen, ", Azeviche, . : PoRT. Jais, Jayet, . FR. Azabache, : : . SP. Gagat, . GRR., Sw.

Jet is imported into India from Europe, but is worn only by Europeans. Large quantities of lignite are found in the tertiary strata along the sea-coast of India, but none of it takes a good polish.-M'Cull. Dict. p. 656.

JETEE or Chittee, or 'Rajmahal bowstring creeper, Marsdenia tenacissima, grows in dry, barren places. Its dried milky juice serves as a caoutchouc. Its fibres are made into thread, twine, bowstring, and rope. It belongs to the family Asclepideæ.-Royle's Fib. Pl.

JETTI, in Southern India, a cæstus, which is worn over the first phalanges on the right hand of the boxers, also called Jeti. It is made of buffalo horn, with four sharp projections like knuckles, and the fifth near the little finger, with a greater prominence than the rest. The hitting is by a sharp perpendicular cut.

JETIV A, Gumli or Bhumli, in Kattyawar, is the Abpura Hill, the old seat of the Jetwa. Murvi is an old Jetwa capital. The rana of Porbandar, styled Puncheria, represents the Jetwa, one of the four ancient Rajput races still extant in the Kattyawar peninsula. In the days of Mahmud, all the west and north of Kattyawar belonged to the Jetwa Rajputs, but the forays of the Jhala and Jhareja have confined them to their present district, the shaggy range of hills called Burda. The Jhala of Kattyawar, who own the raj of Hulwud Drangdra as their chief, are supposed to have sprung from an offshoot of Anhilwara, on the extinction of which dynasty they obtained large territorial aggrandizement. The thakur of Murvi in Kattyawar is a Jhareja, and was the first in Colonel Walker's time to abandon infanticide. He has possessions in Cutch. See India; Kattyawar; Rajput.

JEU, according to the Gnostics, was Adam, 'the primal man.'

JEW, a broken nation dispersed throughout the world. In Muhammadan countries Jews are known as Ya-hud or Yahudi, but in India this term is regarded alike by themselves and those who apply it as derogatory. On the Bombay coast they style themselves Ban-i-Israel; but this name is used by the Afghan for themselves, as also for Muhammadans and Christians who, as possessors of revealed religions, are regarded as children of Israel. Though Jews were Israelites, yet the Israelites were not Jews. The word Jew (Judæus) is really Judæan, and dates only from the return from Babylon, when the tribe of Judah became the head representative of the nation. The Samaritans always call themselves the children of Joseph, and the Jews Yehudhim or Judathites. While in Egypt they fell into a servile condition. Moses led the Israelites out of Egypt, and the law was delivered on Sinai B.c. 1320. They reached Palestine, but from that time to A.D. 50 they were repeatedly conquered. During the government of the judges they were six times captives, viz. under the king of Meropotamia for eight years; under Eglon, king of Moab; under the Philistines; under Jabin, king of Hazor, when Deborah and Barak delivered them; fifthly, under the Midianites, from whom Gideon delivered them; then under the Ammonites and the Philistines.

In A. M. 3264 or B.C. 740 , Tiglath-Pileser, king of Assyria, took several of their cities, and marle many captives, chiefly from the tribes of Reuben, Gad, and the half tribe of Manasseh.

In A.M. 3282, B.C. 720, Shalmanezer, king of Assyria, transplanted the tribes which TiglathPileser had spared, to the provinces beyond the river Euphrates, and it is supposed that the ten tribes never returned from this dispersion.

As to the captivity of Judah, Shishak, king of Egypt, about B.c. 960, sacked Jerusalem. Also Jerusalem was thrice taken by Nebuchadnezzar, king of Babylon,- - first in the reign of Jehoiakim, about B.c. 606 ; again in the reign of his son Jeconias, about B.C. 598 ; thirdly, in the reign of Zedekiah, about B.c. 587, when Nebuchadnezzar carried them to Babylon, where they remained 70 years; when they returned and continued to be a people (though part of the time under the Roman Government), until the time of the Emperor Vespasian, whose son Titus entircly destroyed Jerusalem, about 50 years after the crucifixion of Christ, since which time they have never recovered from their dispersion.

Josephus, who is considered to have written his work on the ancient history of the Jews about the year 93 of the Christian era, says, in his eleventh book, with reference to the return from captivity of those who came back with Ezra, 'The entire body of the people of Israel remained in that country, wherefore there are but two tribes in Asia and Europe subject to the Romans, while the ten tribes are beyond the Euphrates till now, and are an immense multitude, not to be estimated by numbers.' To the same effect, St. Jerome, in the fifth century, in his notes upon Hosea, says, "Unto this day the ten tribes are subject to the king of the Parthians, nor has their captivity ever been loosed.'

Jews have a principality at Khaibar in the Hejaz, with a population of about 50,000 . They are said to be descendants of the Trans-Jordan tribes of Gad, Reuben, and Manasseh, and said to be brave. In manners and appearance they do not differ from other Arabs, but are held in great disesteem. Khaibar was captured by Mahomed A.D. 628 , A.H. 7. Throughout Persia, Bokbara, 
and Afghanistan they occupy themselves in petty traffic, and as bankers and spirit distillers; and in the Bombay Presidency they find employment in the subordinate offices of Government, and in the native army. Numbers of black Jews inhabit the interior of Cochin, principally in the towns of Trittur, Parur, Chenotta, and Maleb. The copper grant from the ruler, in their possession, bears a date equal to A.D. 388. They have their place of worship close to the Kotarum or palace of the maharaja at Muttuncherry, at the commencement of what is called Jews' town, the streets of which run south half a mile, the upper part occupied by the white Jews, the lower by the black Jews.

Forster, in a note to Bartolomeo (p. 109), says Erawi Wanmara, emperor of Malabar, in the year of the Kali Yoga 3481, corresponding to A.D. 426, in the 36th year of his reign, gave a charter to Isup Rabbaan (Rabbi Joseph), bestowing viceregal powers. But that all who went to India prior to 1371 have died out. The white Jews near Cochin went to India at later periods from different countries.

When Wolff reached Cochin, he found there black and white Jews celebrating the feast of Paschal. Those that are called black Jews are, he says, such as became Jews of their own accord at Cranganore, and in other parts of the country they are of black and half-black colour. For this reason the white Jews do not intermarry with them. They have neither priests, nor Levites, nor families, nor relations on foreign coasts. They observe the law as white Jews do. They are most numerous at Cochin. Many of the black Jews, however, assert that their ancestors became Jews when Haman fell, and affirm (though the white Jews deny it) that they were there when the white Jews came to India. They consider themselves as slaves to the white Jews, pay their yearly tribute and a small sum for the circumcision of their children, and for permission to wear frontlets in prayer time. They do not sit down with the white Jews, nor eat with them.

Kukel Kelu Nair is of opinion that at the time of the grant of three of the copperplate documents in the Jews' possession, and possessed by the Christian church there, two towns, viz. Mani-gramman, which Irani Korten of Mahadeva Patnam obtained by No. 1 in A.D. 230, and Achu Vanam, which Joseph Roben, a Jew, obtained by No. 3 in A.D. 186 , were chiefly inhabited by Jews and Syrian Christians; and he thinks that document No. 2 was granted in A.D. 316 by the last Perumal to the Tarisa Palli or church. It is obvious that Jews and Syrian Christians must have arrived in Malabar before the date of the documents 1 and 3 . The Jews there have not much increased. In the food, the clothing of the men, and language, the Syrian Christians are not to be distinguished from the Hindus, and few of them know the Syrian language. The Jews are in many of these respects similar, and some of them are black in colour. Many of them possess gardens and lands, and follow trades.

One legend of the Afghans is that they were Jews whom Nebuchadnezzar transplanted, after the overthrow of Jerusalem, to the town of Ghor, near Bamian, and that they continued in their faith till Kalid, in the first century of
Muhammadanism, summoned them to assist in the wars with the infidels. Another tradition is to the effect that they are descended from Afghan, son of Irmia or Berkia, son of Saul, king of Israel; but the Hebrews have no knowledge of such persons as Saul's descendants. Another tradition is that they are descended from Saul's father Kish. But Muhammad Hayat Khan, C.S.I., in his History of Afghanisan and its Inhabitants, states that the earliest mention of this legendary claim on the part of the Afghans occurs in a history of the Afghans, entitled Makhzan-iAfghani, drawn up by Khan Jahan Lodi, an Afghan noble of the court of the emperor Jahangir, with the assistance of his secretary, Niamat-Ulahi; that this history was avowedly based on the reports of four servants sent by the author to Afghanistan to make inquiry into the origin of the Afghan race; that this inquiry was made for the express purpose of furnishing the means of confuting the assertions of a Persian ambassador, who had made uncomplimentary statements regarding the descent of the Afghans; that the earlier histories referred to in the Makbzan - i - Afghani - namely, the Majma-i Insab, the Madan-i-Akbar-i-Ahmadi, and the Guzida - Jahan Kusha-trace the lineage of the Afghan no further than Kais Abd-ur-Rashid, who lived in the time of Mahomed.

All the Jews of Turkestan assert that the Turkoman are the descendants of Togarmah, one of the sons of Gomer, mentioned in Genesis $\mathbf{x} .3$.

The Jews in Bokhara are 10,000 in number. The chief rabbi assured Dr. Wolff that Bokhara is the Habor and Balkh, the Halah of 2 Kings xvii. 6 ; but that in the reign of Chengiz Khan they lost all their written accounts. At Balkh the Muhammadan mullahs assured him that it was built by a son of Adam, that its first name had been Hanakh, and afterwards Halah, though later writers called it Balakh or Balkh. T'he Jews both of Balkh and Samarcand asserted that Turkestan is the land of Nod, and Balkh, where Nod once stood. The Jews of Bokhara bear a mark, by order of the king, in order that no Muhammadan may give them salaam or peace. He thought the general physiognomy not Jewish, but he was wonderfully struck with the resemblance that the Yusufzai and the Khaibari, two of their tribes, bear to the Jews.

Of the Jews in the khanate of Bokhara the greater number live in Bokhara, others at Kattakurghan, Samarcand, and Karshi. In all these places separate quarters of the town are assigned to them, outside the precincts of which they are forbidden to settle, and therefore cannot intermix with the Muhammadans. They dare not wear a turband, but must cover their heads with small caps of a dark-coloured cloth, edged with a narrow strip of sheepskin not more than two fingers in breadth. Neither are they allowed to wear any other apparel than khalats of aledja, nor to gird their loins with a broad sash, still less with a shawl, but must twist a common rope round their waist. To prevent their hiding this distinctive mark, they are strictly forbidden to wear any flowing garment over the girded khalat.

Jews have existed in large colonies in Arabia ever since the captivity. In no country have they preserved their nationality more completely, 
though surrounded for centuries by hostile Muhammadan tribes. Their own tradition asserts that during the invasion of Palestine by Nebuchadnezzar they fled to Egypt, and subsequently wandered farther south till they came to the mountains of Arabia, where they permanently established their homes. The fertility of the soil, the salubrity of the climate, and its picturesque scenery, rapidly caused the little colony to increase by attracting fresh emigrants, who sought that peace which their own distracted country no longer afforded. Inured to hardships and nursed in war, these foreign colonists soon gained an ascendency over the wild Arab tribes by whom they were surrounded, and in a little time the exiles of Judea reigned where they had before only been tolerated. Two strong tribes of them settled at Medina; they had a fortified capital in Khaibar, and in the $3 \mathrm{~d}$ century of the Christian era they succeeded in converting one of the tobbas or kings of Yemen to the Jewish faith. A subsequent tobba, Dhou Nowas, became so ferocious a bigot in the cause of the Jewish religion, that he declared a holy war for the propagation of his creed, and took and destroyed the Christian city of Najran. On the complaint of the victims, and at the suggestion of Justin I., the nedjachi or king of Abyssinia undertook to avenge the cause of his co-religionists, and conquered Yemen, which thus became an Abyssinian dependency, until it was reconquered for the Yemenites by the Kesra or Chosroes of Persia, and governed by a Persian viceroy. During the reign of the Abysinian kings, however, one of them, Abrahael-Achram, built a magnificent church at Sanaa, and endeavoured to divert the reverence of the Arabs from the Kaba to worship and pilgrimage to his new cathedral. The Arabs flew to arms in honour of their national shrine, and in the course of hostilities Abraha laid siege to Mecca, but retired in great discomfiture, and died shortly afterwards. His assault of Mecca formed not only a crisis in the history of the Arab races, but the year, A.D. 570, of his expedition has become ever memorable as the year of Mahomed's birth, who was thus said to be born in the year of the Elephant, from the animal on which the king rode in his expedition.

The introduction of Muhammadanism materially altered their position, and severe enactments converted their once prosperous towns and villages into charnel-houses. Notwithstanding this persecution, however, every valley and mountain range still contains numbers of this race, who number in Arabia not less than 200,000 souls. At Aden the Jews are filthy in the extreme in their persons and habitations, and even the more wealthy of the community are nearly as uncleanly and parsimonious as their poorer brethren. The principal trades which they pursue in Aden are those of masons, builders of reed and mat houses, and workers in silver and ostrich feathers. In other parts of Arabia they are the most active, industrious, and hardworking people in the country. Rabbi Alkaree informed Dr. Wolff that the Jews of Yemen never returned to Jerusalem after the Babylonish captivity; and that when Ezra wrote a letter to the princes of the captivity at Tanaan, a day's journey from Sanaa, inviting them to return, they replied, "Daniel predicts the murder of the
Messiah and another destruction of Jerusalem and the temple.' Sanaa now contains 15,000 Jews. In Yemen they amount to 20,000. Wolff baptized there $16 \mathrm{Jews}$, and left them all New Testaments.

Jews are particular as to food. Animals are killed with a ceremony similar to that of the Muhammadan Halal, and a mark, כש (Kosher), meaning in Hebrew Lawful, is put on the carcase. The general prohibitions are based on the law laid down in the 11th chapter of Leviticus. No animals may be eaten except such as both part the hoof and chew the cud, as oxen, sheep, and goats. No rabbits, hares, or swine are touched. As to fish, none may come to table that are devoid of scales and fins; and birds of prey and reptiles are absolutely forbidden as food. One restriction forbids the Jews to eat of the sinew of the thigh, a custom introduced in memory of Jacob's wrestling with the angel at Peniel, when his thigh was put out so that the sinew shrank (Genesis xxxii. 25, 32). In many places in Italy and in Germany, formerly (and perhaps now), they did not eat the hind quarters at all because this sinew is in them, and few were able to cut it out with the exactness required. This, indeed, is believed to have been the first distinguishing characteristics of the Jews as a people. In the 17th chapter of Leviticus the eating of any manner of blood is forbidden, necessitating the employment of a separate class of butchers for the slaughtering of animals, who must be specially instructed, have to be provided with a licence from their priest, and have to use a sharp knife, for torn flesh is also forbidden as food, and the blood must fall upon the ground. After the meat has left the shop of the butcher, the custom is to lay it in salt an hour before dressing, and afterwards to wash it, so as quite to cleanse it from blood. A cow and her calf must not be killed on the same day, and the same rule is observed as to sheep and goats. More than ordinary care is taken that the animal presented for food has neither died a natural death nor been afflicted with disease. It involves the necessity of having special examiners, as well as special slaughterers, of animals for Jewish consumption; and the authorities of the synagogue appoint proper persons to the office.

The Jews of China call themselves Tiau-kin Kian, or the sect which plucks out the sinew. They are said to number one million of souls. They have synagogues, and keep themselves perfectly distinct from the other inhabitants of the villages. The earliest record of the Chinese Jews which can be relied upon is that of an Arabian merchant, who, in 877 , mentions the Jews that traded with him in China. In the 12th century the Rabbi Benjamin of Toleda visited the east to discover some of the scattered children of Israel, and he states that he found Jews in China, Tibet, and Persia. The Jesuit Ricci, whilst resident at Pekin in 1610 , states that there were ten families of Jews residing in Kiang-fu, and they had in their possession a copy of the Pentateuch, which had been handed down from generation to generation for six centuries. Therefore from the whole of these statements it may fairly be concluded that for many ages Jews have been inhabitants of China.

JEWAKI, a pass in Afghanistan, occupied by 
the Afridi. Their mountains are very strong. In the settlement of the N.W. Himalaya districts, the British Government was concerned chiefly with the Afridi of the two passes, i.e. the Kohat pass or Gullee and the Jewaki pass. For the guardianship of these passes the Afridi received consideration from successive dynasties, Ghiznivide, Moghul, Daurani, Barakzai, Sikh, and British, and broke faith with each and all. These mountaineers are great traders and carriers. They convey salt from mines in the Kohat district to the Peshawur market. They also cut and sell the firewood of their hills. By these means they procure a comfortable subsistence, which cultivation of their rugged hillsides would not alone suffice to afford. The British authorities can, by blockading the moutbs of the passes, stop the trade and reduce the Afridi to sore straits. The Gullee or Kohat pass is the direct and best route from Kohat to Peshawur.

JEWELLERY. Jauhar, Zewar, HiND. Working in gold was familiar to the Egyptians before the exodus of the Israelites; and Hindus have long been acquainted with its applications, as in the hymns of Rig Veda golden armour and golden chariots, and decorations of gold and jewels, are frequently mentioned.

The custom of wearing jewellery has doubtless been through all ages, and is alluded to in Isaiah iii. 16, 18. Some jewels of the Hindus are inconveniently massive; and heavy rings, usually of silver set with a fringe of small bells, are often worn by Hindu ladies. Hindu women wear loose ornaments one above another on their ankles, which at every motion of the feet produce a tinkling noise. Armlets and bracelets of gold and silver are worn alike by Hindus and Muhammadans, and by men and women. They are of gold or silver, some in the form of massive carved rings, some as lockets; the more expensive, worn by royalty, are the bazu-band, literally armlets. These are generally worn as ornaments, and since the most ancient times like ear-rings (Genesis xxxv. 4; Erodus xxxii. 3, 4; Hosea ii. 13; Judges viii. 24), the

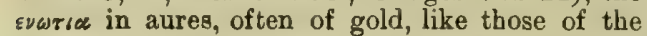
Ishmaelites. But they are often caskets containing, as with the Muhammadans, charms, their ta'viz, or, as with the Jangam sect of Hindus, the phallic lingam. Their ornaments are often worn round the neck like the golden bulla and leather torum of the Roman youth, or as in Proverbs vi. 21 , and most women have frontlet ornaments such as are alluded to in Deuteronomy vi. 8. Bracelets are also largely worn by all classes, of both ages and sexes, of every material, but those of the humbler women are principally of coloured glass and ornamented with lac and brass. In the East Indies and British India, personal ornaments and armour form the principal subjects for refined decorations. The silver work, filigree, gilt, chased, or engraved, - the koftgari work, iron or steel, inlaid or otherwise ornamented with gold, -bedri work, inlaid with silver, from the Dekhan and elsewhere, - are employed on bracelets, necklaces, shields, sword-hilts, and so on; while the hrass from Madras, Benares, and other places, are utensils, goblets, etc., used in worship. In all these, fineness and elaboration, both in design and workmanship, are held in the highest esteem, and secondary qualities of this kind produce good results in small articles of luxury.
Rings for the fingers and toes, rings for the nose and ears; bracelets, armlets, anklets, nose-jewels, neck-chains, a piece of gold for the forehead; ear, hair, and head jewels; chains and zones of gold and silver for the waist, are personal ornaments in daily use amongst the men and women of Muhammadans and Hindus in British India. Several of these are enumerated in Ezekiel xvi. 11, 12: 'I decked thee with ornaments, and I put bracelets upon thy hands, and a chain on thy neck; and I put a jewel on thy forehead, and ear-rings in thine ears,' etc. ; and xxiii. 40 says, 'Thou didst wash thyself, paintedst thine eyes, anil deckedst thyself with ornaments;' Proverbs xi. 22 speaks of a jewel of gold in a swine's snout; a ring in the septum of the nose being a very common ornament among the Hindu and Muhammadan women; another nose ornament, the nat'h, being placed in the left ala.

No specimen of the art of gold-working bas been met with which can with any certainty be attributed to the ancient period of Indian history. The oldest example now extant was found by Mr. Masson about the year 1836 in a Buddhist tope in the neighbourhood of Jalalabad. In the centre of the tope was a small apartment constructed of squares of slate. A steatite vase was found in it, containing, besides mould and the ashes of burnt pearls, a gold casket filled with similar remains. By its side were four copper coins, by which the monument is assigned to one of the dynasty of Greco-barbaric kings who ruled the N.IV. of India about half a century before the Christian ers.

In carrying on their artistic manufactures, the effect to be produced is the chief aim of the Indian jeweller. He thinks only of the dazzling variety of rich and brilliant colours. "He must have quantity, and cares nothing for commercial quality ; and the flawed "tallow drop" emeralds, and foul spinel rubies, large as walnuts, and mere splinters and scales of diamonds, which he so lavishly uses, are often valueless except as points, and sparkles and splashes of effulgent colouring." $\mathrm{By}$ their consummate skill and thorough knowledge and appreciation of the conventional decoration of surface, they contrive to give to the least possible weight of metal, and to precious stones absolutely valueless, the highest possible artistic value, never, even in their excessive elaboration of detail, violating the fundamental principles of ornamental design, nor failing to please, even though it be by an effect of barbaric richness and superfluity. Megasthenes was struck by the contrast of their love of sumptuous ornament to the general simplicity of their lives.

The rose chains of Trichinopoly, and the snake chains of the Northern Circars, all display great skill in the workmen, as also the silver filigree work for which Cuttack and Dacca are famous, the last named showing greater delicacy and beauty than either Genoa or Malta; the articles usually made in filigree work are bracelets, earrings, brooches, and chains, groups of flowers, attardans, and small boxes for native uses. Mr. Taylor tells us that the design best adapted for displaying the delicate work of filigree is that of a leaf. The apparatus used in the Indian jewellers' art consists merely of a few small crucibles, a piece of bamboo for a blow-pipe, small hammers for flattening the wire, and sets of forceps for intertwisting it. The art of making gold wire, 
that is, silver covered with gold, is practised in various parts of India. Several varieties of gold and silver thread (badla) are made at Dacca, as kalabatoon for the embroidery of muslins and silks; goshoo for caps and covering the handles of chauris; sulmah for turbands, slippers, and hookah-snakes; and boolun for gold lace and brocades. Much fringe of various patterns is made, and thin tinsel stamped into various forms of flowers, or impressed with excellent imitations of jewels, such as flat diamoads, emeralds, and rubiez. Many of the ornaments are made only for the poorer classes, for instance, imitations of precious stones, ornaments in pewter, in shell, and lac, and, still simpler, a bracelet with straw to represent the gold, and the red seeds of Abrus precatorius in the place of garnets. The names and uses of a few of the jewels of Southern India are-Vunkee, or armlet; Jampaloo, or ear jewel; Kutree paval, ear ornament; Vallel, or bangles; Nuthoo, nose jewel; Moothoo coopoo, or ear ornament; Patteel, or bangles ; Coopy, head ornament; Mayer Mootha, ear jewel; Jadabillay, head orvament; Adega, neck ornament; Curdapoo, head ornament; Thallysaman, head ornament; Giaya or Geddy gooloosoo, or leg ornament; Jaga undoo, head ornament; Cummul and Jameeka.

Bracelets, anklets, and armlets of gold, silver, brass, copper, deer horn, the metals being solidly massive and as chains, are in use in all eastern countries, and amongst Hindus and Muhammadans. Hindu men may be seen with gold or silver rings, ear-rings, and necklaces, but in general these are restricted to women and children. No Hindu will use gilded ornaments.

The Mabrattas wear the kitak, nag, khandani, phal, aud mohr head ornaments, also armlets and chain-like anklets. The silver filigree work of Cuttack is generally done by boys. It is identical in character with that of Arabia, Malta, Genoa, Norway, Sweden, and Denmark, and also with the filigree work of ancient Greece, Byzantium, and Etruria. It is also made at Murshidabad, Dacca, and Ceylon.

The manufacture of shell bracelets is one of the indigenous arts of Bengal, in which the caste of Sankhari at Dacca excel. The chanks of which they are made are large univalve shells of several species of turbinella, from six to seven inches long, and of a pure white colour. They are imported into Calcutta from Ramnad, and from the Maldive Islands. In making the large massive bracelets which are worn by Hindu women, they are sawn into semicircular pieces, and these are riveted and cemented to form the bracelets, some of which are elaborately carved and inlaid with a composition of lac and a red pigment. A pair of bracelets of this description frequently costs as high as 80 rupees. Of the thicker pieces of the shells, beads are made to form the necklaces which the Bengal sepoys wear. Some Marwari women and the Binjara women have the entire forearm from the wrist to the elbow covered with heavy massive bracelets, and the lower part of the legs equally covered with anklets. The armlets of the Binjara women are of deer horn, but it looks like ivory. Amongst the Rajputs, the women adopt a brother by the gift of a bracelet. The intrinsic value of such pledge is never looked to, nor is it requisite it should be costly, though it varies with the means and rank of the donor, and may be of flock silk and spangles, or gold chains and gems. The acceptance of the pledge and its return is by the katchli, or corset, of simple silk or satin, or gold brocade and pearls. Colonel Tod was the Răkhi-băndBhāi of the three queens of Udaipur, Bundi, and Kotah, besides Chund Bai, the maiden sister of the rana, as well as of many ladies of the chieftains of rank. Though the bracelet may be sent by maidens, it is only on occasions of urgent necessity or danger. The festival of the bracelet (Rakbi) is in spring. The adopted brother may hazard his life in his adopted sister's cause, and yet never receive a mite in reward; for be cannot even see the fair object who, as brother of her adoption, has constituted him her defender.

The mosaic work of Agra is chiefly applied at present to ornamental furniture and household objects of art, the inlay being of rock crystal, topaz, pearls, turquoise, carnelian, jade, coral, amethyst, bloodstone, garnet, sapphire, jasper, lapis-lazuli, agates, and chalcedony. It originated in the exquisite decorations of the Taj at Agra (A.I. 1627-1658) by Austin de Bordeaux. The art had almost died out, until about the middle of the 19 th century it was revived by Dr. (SurgeonGeneral) John Murray, of the Bengal Medical Service. It is Florentine in origin and style, but Indian in the forms of its ornamentation. The mirror mosaic work in the Shish Mahal in the palace of Akbar (A.D. 1556-1605), or of Shah Jahan (A.D. 1627-1658), and that of the Shish Mahal of Lahore, is the work both of Shah Jahan and Aurangzeb.

Two things are acting unfavourably on the hereditary skill of the Hindu craftsman in recent years. The authority of the trade guilds has been relaxed under the freedom of English rule, and the importation of British goods has forced many artisans into agriculture and even domestic service. It was under the Indian guild system that the sumptuary arts were carried to a state of perfection, 'until at length the whole bullion of the western nations of antiquity and mediæval times was poured into the east in exchange for them.'

Some of the best workmen of British India ae in Dacca, Chittagong, and Katch (Cutch). In Gujerat, at the towns of Dholka, Viragram, and Ahmadabad, working in gold and silver is largely carried on, and the Cutch, Gujerat, and Kattyawar goldsmiths are skilful in the decoration of arms, in silver and parcel-gilt and gold. At the present day, Dehli stands out prominently as the town of jewellers. The chief characteristics of its jewcllery are the purity of the gold and silver employed, the delicacy and minuteness of the workmanship, the taste and skill displayed in the combination of coloured stones, and the aptitude for the imitation of any kind of original art on the part of workmen. Panjabi artists have retained a high reputation for skill as goldsmiths. Their best known manufacture is in parcel-gilt water jars, graven through the gilding to the silver below.

Still more pleasing are the copper-bammered work, lotas, from Tanjore, of which Sir G. Birdwood has given several engravings. In its bold forms, the brass-work of the same place recalls the descriptions of Homer of the work of the artists of Sidon. Some are simply etched, others deeply cut in mythological designs, and others diapered all over with a leaf pattern similar to that seen in Assyrian 
sculpture. Those encrusted with silver are the most beautiful.

The beaten-gold jewellery of the purest Hindu style is made at Sawuntwari, Mysore, Vizianagram; and Damascus work, in gold, is chiefly carried on in Kashmir, at Gujerat and Sealkote in the Panjab, and is called koftgari or beaten work. Damascening in silver is also called bedri work, which is made at Beder, Purniah. In 1866 , only one Hindu family remained in Beder engaged in this tutanague work.

Enamelling, the master craft of the world, is practised in great perfection at Jaipur (Jeypore) in Rajputana. It is champlevé. A round plate presented to the Prince of Wales is the largest specimen ever produced, and took four years in the making. There is an engraving of a native writing-case in the shape of an Indian govdola, which is of admirable workmanship; the colours of the blue and green enamel being brighter even than the natural iridescence of the peacocks' tails. The canopy which covers the ink-bottle is coloured with green, blue, ruby, and coral-red enamels.

Throughout the Madras Presidency and in Mysore, the gold and silver metals are superbly wrought in swami work, the ornamentation consists of figures of the Puranic gods in high relief, either beaten out from the surface or affixed to it, and removeable at pleasure, like the emblemata of the Romans. The metal work for everyday use is in brass, copper, and tin, or their alloys, in the form of lotas, atr-dans, pandans, dishes, bowls, candlesticks, images, bells, sacrificial spoons, censers, and they are made all over India. Kashmir, Moradabad, and Benares are famed sites. Also Bandhua in Oudh, likewise in Nuddeah, Tendukhera, Nasik, Poona, Ahmadabad, Bombay, Madura, Travancore, and Tanjore.

Bracelets are made of chank-shells at Dacca. They are sawn into semicircular pieces, which are joined together and are carved and inlaid with a red composition. The manufacture of shell bracelets in Sylhet gives employment to a large number of people.

In Egypt, anklets (or khulkhal) of solid gold or silver are worn by some ladies. They are heavy, and, knocking together as the wearer walks, make a ringing noise. Isaiah alludes to this, or perhaps to the sound produced by another kind of anklet, viz. a string of bells on the feet, which (amongst the Arabs) is a common custom for young girls or young women to wear.

The Hindu jewellery often is imitations of the flowers of the Michelia champaca, Acacia Arabica, Chrysanthemum, Phyllanthus emblica, Elæagnus koluga, and Mangifera Indica. The bell-shaped ear-ring is from the flower of the sacred lotus, and the cone-shaped of Kashmir, in ruddy gold, represents the lotus flower-bed. The lotus is seen everywhere in Indian, Chinese, and Japanese decoration, and on Assyrian and Babylonian sculptures.

A chopped gold form of jewellery worn throughout India is made of pieces like jujubes, of the purest gold, flat or in tubes, and, by removal of the angles and octahedrons, strung on red silk. It is the finest archaic jewellery in India. Earrings of the nail-head pattern are like those represented on Assyrian sculptures.

Necklaces in Western India are often of gold, in form like clubs and knots of grass. Burmese necklaces are tubular beads of ruddy gold strung together, and pendent from a chain that goes round the neck, from which the strings of tubular beads of gold hang down the neck like a golden veil. The gold is sometimes wrought into flowers. The eastern jewellers' art is employed for children of the earliest ages, as rings, anklets, etc.

Hindu girls have as their sole covering a silver leaf, of the shape of the pipal leaf, sometimes suspended from the waist by a thread, but generally by a girdle of twisted silver with a serpent's head, wbere it fastens in front. In Algeria, girls wear a leaf-shaped silver ornament; and through the Barbary States (Berber) it is the emblem of virginity,

With the ancient Egyptians, the lotus and papyrus were types of ornament, and the Greeks adopted the date tree for their pillars.

Imitations of knotted grass and of leaves seem to be the origin of the simplest and most common form of gold ornament, the early specimens consisting of thick gold wire twisted into bracelets, etc. A second archaic type of decoration is to be found in the chopped gold jewellery of Gujerat. This is made of gold lumps, either solid or hollow, in the forms of cubes and octahedrons, strung together on red silk.

The finest gemmed and enamelled jewellery in India is that of Kashmir and the Panjab, and which extends across Rajputana to Dehli and Central India. It consists of tires, aigrettes, and other ornaments for the head ; also ear-rings, ear-chains, and studs of the chrysanthemum flower, noserings, nose studs, necklaces, some of chains of pearls and precious stones, others of tablets of gold set with gems, strung together by short strings of mixed pearls and turquoises; armlets, bracelets, rings, anklets, and rosaries, in neverending variations of form, and of the richest and loveliest effects in pearl, turquoise, enamel, ruby, diamond, sapphire, topaz, and emerald. Like the Assyriau sculpture, the bracelets often end with the head of some beast.

Goldsmiths of India generally stain their work of a deep yellow. In Sind, the goldsmiths and jewellers sometimes give it a highly artistic tinge of olive-brown. The Sind goldsmiths' work is very beautiful, and of purely indigenous design. In Kashmir and in Burma their work is in ruddy gold.

Throughout Southern India, a favourite design with the British consists of figures of Hindu deities in high relief, either beaten out from the surface, or fixed on to it by solder or screws. The Trichinopoly work proper includes also chains of rosegold, and bracelets of the flexible serpent pattern. The silver filigree work of Cuttack, identical in character with that of ancient Greece, and of Malta at the present day, is generally done by boys, whose sensitive fingers and keen sight enable them to put the fine silver threads together with the necessary rapidity and accuracy. The goldsmiths' work of Kashmir is of the kind known as parcel-gilt, and is further distinguished by the ruddy colour of the gold used. Its airy shapes and exquisite tracery, graven through the gilding to the dead-white silver below, softening the lustre of the gold to a pearly radiance, give a most charming effect to this refined and graceful work. The hammered repoussé silver. work of Cutch (Kachchh), although now entirely naturalized, is 
said to be of Dutch origin. Similar work is done at Lucknow and Dacca.

In many of the towns of India, the scarlet and black seeds of the Abrus precatorius (gunch), the flat black seeds of the Cassia auriculata (tarwar), the red seeds of the Adenanthera pavonina, the mottled seeds of the Areca catechu, the oval seeds of the Caryota urens, and the seeds of the Elæocarpus ganitrus, sct in gold and silver, are all used for personal ornaments.

'The goldsmiths' art contributes largely to embroidery. Gold and silver thread is made by being drawn out under the application of heat, and with such nicety, that one rupee's worth of silver will make a thread nearly 800 yards long. Before being used in the loom, this metallic thread is generally twisted with silk. For the manufacture of cloth of gold (sonari), or cloth of silver (rupéri), the wire is beaten flat, so as to form the warp to a woof of thin silk or cotton. A third kind of metallic ornamentation is practised at Jeypore in Rajputana and Hyderabad in the Dekhan, by printing muslins with patterns of gold and silver leaf.

Enamelling, as applied in India to jewellery, consists of an extremely fine pencilling of flowers and fancy designs in a variety of colours, the prevailing ones being white, red, and blue, and is invariably applied to the inner sides of bracelets, armlets, anklets, necklaces, ear-rings, sirpooch, tiara, and all that description of native jewellery, the value depending upon the fineness of the work, and often exceeding that of the precious stones themselves. The finest specimens are only made to order, and the best come from Benares, Dehli, and Jeypore. In the south of India, the manufacture of enamels on articles like the above is almost entirely restricted to Hyderabad. It presents no varieties, but in general consists of a blue coating interlined with white on a surface of silver, and is applied to rosewater sprinklers, spice-boxes, basins, and such like articles. The merit of the manufacture lies in the simplicity of the enamel itself, and in the lightness of the silver article to which it is applied. Though pleasing, it is the coarsest enamel produced in India. At Indore in Central India, it is applied to articles of personal decoration, such as necklaces, armlets, brooches, earrings, etc., which are set by native jewellers, according to the taste of the purchaser. The subjects generally consist in a representation of the avatars, or pictures of the metamorphoses of Indian deities; and the work is so perfect that it will stand, not only the influence of climate, but even rough handling. A set of the ornaments, consisting of a necklace, ear-rings, two armlets, and a brooch, in plain gold, contributed to the Exhibition of 1851 , was valued at Rs. 1700 , or $£ 170$. $\Lambda$ duplicate forwarded to the Paris Exhibition in 1855 , was purchased for Rs. 600 , or $£ 60$. - Toy Cart; Tod's Tr.; Rajasthan; Juries' Rep. Ex. 1851; Madras Ex. 1850̄; Ex. of 1862; Royle's Arts of India; Sir G. Birdwood; Imp. Gaz.

JHABAR. Hind. Low land on which water lies, and in which rice is grown.

JHALA, a race who own the ruler of HulwudDrangdra as their chief, and are supposed to have sprung from an offshoot of Anbilwara, on the extinction of which dynasty they obtained large territorial aggrandizement. The part of the Jhala Makwahana tribe who also inhabit the Saurashtra peninsula, is styled Rajput, though neither classed with the Solar, Lunar, nor Agnicula races; they seem, however, to be of northern origin. It is a tribe little known in Hindustan or even Rajasthan, into which latter country it was introduced entirely through the medium of the ancient lords of Saurashtra, the present family of Mewar. A splendid act of self-devotion of the Jhala chief, when rana Pertap was oppressed with the whole weight of Akbar's power, obtained, with the gratitude of this prince, the highest honour he could confer,his daughter in marriage, and a seat on his right hand. It was deemed a mark of great condescension of a recent rana sanctioning a remote branch of his own fanily, bestowing a daughter in marriage on the Jhala ruler of Kotah. This tribe has given its name to one of the largest divisions of Saurashtra, Jhalawar, which possesses several towns of importance. Of these, Bankaner, Hulwud, and Drangdra are the principal. Regarding the period of the settlement of the Jhala, tradition is silent, as also on their early history; but the aid of its quota was given to the rana against the first attacks of the Muhammadans.-Tod's Rajasthan, i. p. 113 .

JHALAWAN, Saharawan, and Las districts of Baluchistan, west of the Indus, are on a great mountain range or table-land that runs N. and S. Jhalawan, with less elevation than Saharawan, is held by Brahui tribes, amongst whom are the Minghal, Bizunji, and Samalari, in the bills. The fixed population in their little towns does not exceed 10,000, and are greatly exceeded by the pastoral tribes, - the great tribes of Minghal and Bizunji giving them the preponderance. Jhalawan and Saharawan are the two great central districts of Baluchistan, and these districts surround the districts of Kalat which depend on the capital. The plain of Dasht-i-Guran, south of Chappar, is inhabited by the Sunari, a branch of the Jehri tribe of Jhalawan. Many of the Jhalawan tribes are undoubtedly of Rajput origin, and, until lately, the practice of infanticide was prevalent amongst them. Near Bagwana is a cave in a rock, which was seen in the middle of the 19th century filled with the dried mummy-like bodies of infants, some of which had a comparatively recent appearance. See India; Kalat.

JHALAWAR is a Native State in Rajputana, under the political superintendence of the Rajputana Agency and the Government of India. Jhalawar has been a separate dependency from the 8th April 1838, when the Kotah principality was dismenbered, and maharaj rana Mudun Singh was established in Jhalawar under a treaty by which he acknowledged British supremacy, and he was vested with the titles of maharaj rana. During the mutinies of 1857-58, Pirthee Singh, his successor, rendered good service by conveying to places of safety several Europeans who had taken refuge in his districts. This state pays Rs. 8000 a year to the British Government as tribute. The area of the state is 2500 square miles, and the population 220,000 .

JHANSI, a British district in the N.T. Provinces, lying between lat. $25^{\circ} 3^{\prime} 43^{\prime \prime}$ and $25^{\circ} 48^{\prime}$ $45^{\prime \prime} \mathrm{N}$., and between long. $78^{\circ} 21^{\prime} 15^{\prime \prime}$ and $79^{\circ} 27^{\prime}$ $30^{\prime \prime} \mathrm{E}$., with an area of 1567 square miles, and a population in 1872 of 317,826 persons. The Purihar Rajputs are pointed out by tradition as the earliest Aryan immigrants into Jhansi, where 
thcy still possess 24 villages. Their last chief, Gungadhur Rao, died childless in March 1853, and as there existed no male heir of any of the chiefs who ruled Jhansi since the first relations of the British Government were formed with it in 1804 , the state was declared lapsed to the British. The rani then attempted to seize the supreme althority. On the 5th June 1857 the mutiny broke out at Jhansi, and on the 8th a massacre occurred. The country was held by the rani, whose bitterness against the British was intense. It was captured by Sir Hugh Rose on the 5th April 1858; the rani had previously fled with Tantia Topi, and finally foll in battle at the foot of the rock fortress at Gwalior.-Aitcheson's Treaties.

JHAPI, umbrella-shaped hats worn by the lower classes of Assamese, made from the coarse Jeaves of the toko-pant palm, the Livistonia Jenkinsiana, Griffith. The leaf of the talipot palm, Corypha taliera, is similarly used.-Simmonds' Dict.

JHAREJA, a Rajput race in Gujerat and Cutch, with a branch in Kattyawar, descendants of the Yadu, and claiming from Krishna. In carly ages they inhabited the tracts on the Indus and in Sewesthan. But at another place Colonel Tud relates that Samba obtained possession of the tracts on both sides the Indus, and founded the Sind Samma dynasty, from which the Jhareja are descended. There is every probability, he states, that Sambus, of Samba Nagari (Minagara), the opponent of Alexander, was a descendant of Simba, son of Krishna. The Jhareja chronicles, in ignorance of the origin of this titular appellation, say that their ancestors came from Sham or Syria. The Jhareja dominions extend over a tract of about 180 miles in length and 60 in breadth; the land is generally poor, indifferently cultivated, and thinly peopled, so much so, that although it contains an area of upwards of 10,000 square miles, the number of inhabitants is only half a million, one-twentieth part of which is confined within the capital, Bhooj, and another twentieth within the seaport of Mandavi. Except these two places, there is none which merits the name of city, though there are a few towns, as Anjar, Lukput, Moondia, etc., on the coast, which derive importince from their position. Of this population, the number of the dominant race, the Jhareja, fit to bear arms was estimated at only 12,000; the ''cmainder are Muhammadans and Hindus of all sects and classes. The thakur of Murvi is a Jhareja, and was the first in Colonel Walker's time to abandon infanticide. He had possessions in Cutch. In 1818, Captain M'Murdo estimated the number of Jhareja in Cutch at about 12,000 persons, of whom only about 30 were women. The Jhareja killed their daughters to avoid paying for them heavy marriage portions.

JHARIA, a name applied in the Central Provinces to the older settlers, supposed to be from Jhar, underwood, forest; they are much looser in their observances than later comers of the same caste, eating forbidden food, and worshipping strange gods.

JHARIA, a coal-field in Manbhum district, Bengal, situated in the pargana of the same name, a few miles S. and S.E. of Parasnath Hill, Bengal. -Imp. Gaz.

JHARIKARI, also Jharya, a caste who wash and sweep the ashes and dust of a melting-house n' goldsmith's shop. The Nyaria of Hindustan.
JHARWA, HrNd., also Sawan or Sawain, a grass yielding a grain which is sometimes eaten and made into bread. It ripens in the rains of the month Sawan, hence its other name Sawain.

JHEEL. HIND. A marsh or lake. The jhecls of Eastern Bengal owe their origin chiefly to the excessive rainfall of the Khassya and Sylhet Hills, and to the overflow of the Surma. They occupy an immense area, fully 200 miles in diameter from N.E. to S.W., which is almost entirely under water throughout the rainy season, and ouly partially dry in the winter months. They extend from the very base of the Khassya Hills and $\mathbf{E}$. extremity of the Cachar district southward to the Tiperah Hills and Sunderbans, and westward to the Megna river and considerably beyond it, thus forming \& fresh-water continuation of the Sunderbans, and affording a free water communication in every direction. The villages, and occasionally large towns, which are scattered over the surface of the jheels, generally occupy the banks of the principal rivers; these have defined courses in the dry season, their banks always being several feet higher than the mean level of the inundated country. Extensive sandbanks, covered in winter with a short sward of creeping grasses and annual weeds, run along the banks of the largest streams, and shift their position with every flood. The remainder of the surface is occupied by grassy marshes, covered in winter with rice crops, and in summer with water, upon which immense floating islands of matted grasses and sedges are seen in every direction, gradually carried towards the sea by an almost imperceptible current. Near Churra, the common water plants of the jheels are species of Vallisueria serrata, Damasonium, Myriophylla, Villarsix, Trapa ; blue, white, purple, and scarlet water-lilies; Hydrilla, Utricularia, Limnophila, Azolla, Salvinia, Ceratopteris, and floating grasses. The Pakhal Lake in the Nizam's dominions, to the east of Hyderabad, is said to be the work of a Hindu dynasty, and to be the largest piece of water in India. In the Bengal Presidency, swamps, expanded or contracted according to the seasons, take the place of lakes, except when the latter are formed by old beds of rivers of an oblong character. But the Bhandara district in the Central Provinces has an equal or greater storage of water, in jheels and tanks numbered by thousands, though no one of them singly may equal the dinensions of the Pakhal.-Hooker and Thomson; Hooker, Him. Jour: ii. p. 309.

JHELUM, a town in the Panjab, in lat. $32^{\circ}$ $55^{\prime} 26^{\prime \prime} \mathrm{N}$., long. $73^{\circ} 46^{\prime} 36^{\prime \prime} \mathrm{E}$., with upwards of 5000 inhabitants. It is the headquarters town of a district of the same name. The Kshatriva Hindus here are traders and money-lenders; the Arora are husbandmen. The industrious $J$ at are largely Muhammadans. They hold the whole central region to the north and south of the Salt Range, the bills themselves being the home of the Janjuahs. They remained loyal during the mutiny in 1857. The Awan are numerous, nearly a hundred thousand. An interest is thrown around them by the conjecture that they represent the descendants of Alexander's army; though they themselves put forward a more apocryphal genealogy from the son-in-law of the prophet. The Gujar, farther south, form a pastoral tribe with a bad reputation for cattle-lifting, but are here a 
body of thriving and honest agriculturists, with a fine manly physique, and considerable landed possessions around the town of Jhelum. Iarge numbers of Kashmiri arrive every winter in search of harvest work, and return home when the summer sets in. The Khokars, though numerically unimportant, possess great social distinction. One of their ancestors founded the town of Pind Dadan Khan, which he called after his own name, and has become the chief centre of the salt trade. The Jhelum river of the Panjab is the Hydaspes of the Greeks, and the Behut, Vehut, Vitasta, and Betusta of the Hindus. It rises in Kashmir, the whole valley of which it drains, and takes its course through the Baramula pass in the Pir Panjal range, entering the plain of the Panjab about 220 miles from its source. Below Jalalpur it runs nearly south, joining the Chenab a little above the Trimo ferry, in lat. $31^{\circ} 10^{\prime} \mathrm{N}$, and long. $72^{\circ} 9^{\prime} \mathrm{E}$., after a course of 450 miles. At this confluence the Jhelum is about 500 yards wide; after the union, the channel of the united streams is a mile broad and 12 feet deep.

The Jhelum district of the Panjab river yields gold, coal, marble, soapstone, gypsum, topaz, rocksalt, French chalk, sandstone, limestone. There is a thriving trade in horses and mules. The first thing a zamindar does with any small sum of money he has saved, is to buy a good mare, from which he breeds; and if any single individual is too poor to buy a whole mare himself, he and two or three others in the same condition as himself will club and purchase an animal amongst them. The colts or fillies produced there are largely bought up by officers of the cavalry service in search of remounts. Prices are given for them sometimes as high as Rs. 300 and Rs. 350 for threeyear-old colts and fillies. Brass vessels and leather and parchment jars are largely made at Pind Dadun Khan.

JHENGUR. HIND. Species of the cricket genus. See Acheta; Insects.

JHIND is one of the states situated to the east of the Sutlej (Satlaj) river. It consists of three or four isolated tracts. The town of Jhind is situated in lat. $29^{\circ} 19^{\prime} \mathrm{N}$., and long. $76^{\circ} 23^{\prime} \mathrm{E}$. In 1857 , Swarup Singh, then raja, was the first to march against the mutineers at Dehli. His troops acted as the vanguard of the army, and he remained in the British camp until the re-occupation of the city, and a portion of his troops took part in the assault. For these services he received a

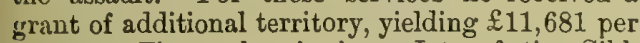
annum. The maharaja is a Jat, of the Sikh faith, and of the same descent as the maharaja of Patiala.

JHOJHA, an inferior class of Muhammadans who are scattered over different parts of the Doab and Rohilkhand, and are reported to be good cultivators. In pargana Burun of Bulundshuhur, they represent themselves as converted Rahtor, Chauban, and Tuar; but by others they are considered to be converted slaves of these tribes. In like manner, the Jhojha of Anupshahr are said to be slaves of the Moghul converted to Muhammadanism. Being Muhammadans, they are not restrained by Hindu observances of certain festivals, and thus, while Hindus are waiting for the Dit'hwun before they cut their sugar-cane, the Jhojha have already begun to press their cane and manufacture their sugar.-Ell. Supp. Gloss.
JHOOT'HA. HrND. Leavings of food; that which has touched food and is thereby defiled.

JHOW, in Baluchistan, has but one village, Nandara; its tribes are the Mirwari and Halada, the latter Brahui and pastoral. Numerous mounds, here called Daim, exist, where coins and trinkets are found, remnants of some former race. See Kalat.

JHUL. HIND. A saddle-cloth, also elephant's housing. Jhul-baili, a large pair of sacks for' grain, carried by a bullock.

JHULA. Hind. A suspension bridge. In the simplest form, a jhula has a single set of ropes, from which a wooden seat is suspended, which is pulled from side to side by means of a rope worked from the rocks on either side of the river. The rudest of the twig jhula are the usual communications across the Ravi; but good wooden bridges (sangla) are kept up for the sake of sheep at Oli, Ulasa, and elsewhere.-Cleghorn, Pan. Rep. p. 101; Dr. Thomson's $T r$.

JHULAN YATRA, a festival in honour of Krishna in the month Bhadra, when images of him and Radha are swung on decorated platforms.

JHUM, in Assatn, the cultivation known in the Peninsula as the kunari, where the forest is burned, and one or two crops raised.

JHUNT or Jhunti. BENG. The tuft of hair left on the top of the head of the Hindu, after the head being shaved. A crest, a top-knot.

JI, Hind., from Jiva, SANsk. Life, soul, pronounced in the various tongues of India, jio, $\mathrm{jib}$, and jiv. It means the vital principle, the mind or intellectual action, and enters into many composite words as an affix. Jivagar is a Buddhist teacher and ascetic. Jiva-hothi or Jeokothi, a. house for the reception of living animals, such as are at Bombay, and supported by the Jains at Surat. It is usually written jee, and it is applied to names of Hindus, as Krishna-ji, Sita-ji. It is also used alone as a respectful term of assent, or an interrogatory, as yes, your pleasure?

JIMACH, also called Wokhab. Dr. Francis Buchanan Hamilton, in Shahabad district, 'saw a jimach attack a very strong falcon as it was hovering over a bush into which it had driven a partridge. The moment the falcon spied the jimach, it gave a scream and flew off with the utmost velocity, while the jimach equally pursued. They were instantly followed by the whole party, foot, horse, and elephants, perhaps 200 persons, shouting and firing with all their might; and the falcon was saved, but not without severe wounds, the jimach having struck her to the ground; but a horseman came up in time to prevent her from being devoured.' 'The wokhab, or ukab, as it is also termed, is a small eagle, very abundant in the plains of Upper India, the Dekhan, etc., bearing many systematic names, the earliest of which is Aquila fulvescens; it is not quite so large or robust as the Aq. nævioides of Africa, with which it has been supposed identical. The wokhab is very troublesome in hawking after the sun becomes hot, mistaking the jesses for some kind of prey, and pouncing on the falcon to seize it. Mr. (Sir) W. Elliot once or twice nearly lost shahin (Falco peregrinator) in consequence, they flying to great distances for fear of the wokhab or jimach. The principal hawks employed in Indian falconry are identical with those of Europe, namely, the Bhyri of India, which is the peregrine falcon, or 
F. peregrinus, Gmel., of the west; and the Baz of India, Astur palumbarius, Linn., which is the goshawk or 'gentil' falcon of Britain. In a Persian treatise by the head falconer of the emperor Akbar, the various species used are enumerated, and may be recognised with precision; among them is the Shangar, which is clearly the gyr falcon of the north, represented as extremely rare and valuable, taken perhaps once or twice only in a century, and then generally in the Panjab.

JIN. ARAB. A demon, an evil spirit; one of the fabled genii. They are not restricted to any particular region, but the gigantic monsters, called dev, reside peculiarly among the rocks and forests of Masandaran or Hyrcania. In Muhammadan belief there are reckoned five distinct orders of such creatures, viz. jann, jinn, shaitan, ifrit, and marid, whose chief abode is in the Kaf mountains. They are good and evil creatures. Solomon is said to have had power over the Jin. In Arab mythology they are beings created out of smokeless fire, 2000 years before Adam; they are noticed in Suras i. xlvi. lvii. and lxxii. of the Koran.

To Muhammadan views, it is a material, intelligent being, with a body similar to the essence of fire or smoke.

Jin lived in the mountains of Kaf, near the mysterious sea of darkness, where Khidr drank of the fountain of life. And no one could tell when he might come across one of those terrible creatures, incarnate in the form of a jackal, a dog, or a serpent; or meet, perbaps, in his own hideous shape, the appalling Nesuās, who is a man split in two, with half a bead, half a body, one arm, and one leg, yet hops along with astonishing agility, and is said, when caught, to have been found very sweet eating by the people of Hadramaut.

JINA. SANSK. A victor over the desires. A teacher of the Jain doctrines, any one of the 24 deified teachers of the system, called also a Tirthankara. The last of the Jina was Mahavira, who was born of Trisala, wife of Siddhartha, of the family of Ikshwaku, and prince of Pavana in Baratakshetra, and he married Yasodha, daughter of the prince of Samaravira. He afterwards became a Digambara or naked ascetic, and led in silence an erratic life for 12 years; and during his wanderings in this state he was repeatedly maltreated. $\mathrm{He}$ then commenced to lecture at Apapapuri in Behar. His first disciples were Brahmans of Magada and Indrabhuti, or Gautama of the Brahman tribe of Gautama rishi, who is not identical with the Gautama of the Brahmans. Mahavira died at the age of 72 , thirty-eight of which had been spent in religious duties.

JINJIRA, a territory of a family of African origin, and known as the Sidi, also designated Habshi or Abyssinians.

Baji Rao, the first peshwa, waged an unsuccessful war with the Habshi ruler of Jinjira. They were as powerful at sea as Angria, and on the mainland were in the practice of ravaging the Mahratta territory, and had seized some forts. The utmost that the peshwa could obtain was a forbearance from these aggressions (A.D. 1736).

JIN-KIN, or classes of men, is a Chinese book of great authority. In it the sages occupy the first chapter, and in this Confucius is placed high above all others.-Bowring.

JIN-RIK-SHA. JAP. A kind of sedan chair.

JINTAWAN, an Urceola tree of Borneo, yield- ing caoutchouc. Its bark is soft and thick. In Borneo an Urceola grows to the size of a man's body, has a very rough appearance, on being cut emits its sap in the greatest abundance; and without destroying the tree, very large quantities might be obtained from a single trunk. There are three plants in Borneo called by the generic name of Jintawan; two are common in Sarawak, viz. the J. susuh, or milky jintawan, and the J. bulat, or round-fruited jintawan. They equally produce the caoutchouc, which differs in no respect from that produced by the Ficus elastica and other trees. The natives of Borneo use it to cover the sticks with which they beat their gongs and other musical instruments. The fruit, which is large and of a fine apricot colour, contains ten or twelve seeds enveloped in a rich reddish pulp, and though but a jungle plant, is one of the most grateful fruits of the country to the European palate.-Low's Sarawak, p. 52.

JIRGAH. Pushtu. A council of an Afghan tribe, composed of the elders. The government of the tribes is a democracy, their representation and self-government being by their Jirgah, but, like most rude people, no man's nationality extends beyond his own clan.

JIRJIS or Jurjos, the St. George of England, whom Mubammadans rank among the prophets, and confound with the prophet Elias. Mār Jurjos wat-tawnin, St. George and the Dragon, is the name of the place where St. George destroyed the dragon, near the bridge over the Beyrout river. A Christian chapel was erected here, but it has been made a mosque.

JITA or Jit. HIND, Conquered, victorious, as Run-jit, victorious in battle.

JIVA. SANSK. Life, the soul. Jivata means individual spirit. See Ji.

JIVAGAR. TAM. A Buddhist teacher and ascetic.

JIVA GOSWAMI, author of the Vidagdha Madhava, a Sanskrit writer on the loves of Krishna.

JIVA-PITRI, the father of life, a proper epithet for Mahadeva, the creative power, whose Olympus is Kailas.

JIYYARU. TEL. The head of the Vaishnava Brahmans in the south of India.

JNANI, or divine Buddhas, are five,-Vairochna, Akshobya, Ratna Sambhava, Amitabha, Amogha Siddha, the mental creations of Adi Buddha, each of whom produced, respectively, a Bodhi-satwa, viz. (1) Samanta Bhadra, (2) Vajrapani, (3) Ratnapani, (4) Padmapani, (5) Viswapani.-Fergusson and Burgess.

JO, a Burmese people speaking a rude dialect of the Burmese, lying east of Chittagong.

$\mathrm{JO}$, a beverage made from rice or millet, and used by the Bodo. The grain is boiled and flavoured by a root called agai-chito. It is left to ferment for two days in a nearly dry state. Water is then added, and it is fit for drinking in three or four days.

JOANNES DAMASCENUS, son of Sergius, a Christian who for many years was treasurer to the khalif Mansur. Sergius had a son, to whom he gave the best education, his chief tutor being Cosmas, an Italian monk who had been taken prisoner by the Saracens and sold as a slave at Baghdad. After the death of Sergius, his son succeeded as chief councillor (protosumbaulos) to the khalif Al Mansur. Such, however, had been 
the influence of the Italian monk on his pupil's mind, that he suddenly resolved to retire from the world and to devote himself to study, meditation, and pious works. From the monastery of St. Saba, near Jerusalem, he sent forth the most learned works on theology, particularly his Exposition of the Orthodox Faith. He soon became the highest authority on matters of dogma in the Eastern Church, and he still holds his place among the saints both of the eastern and western churches. His name is Joannes Damascenus, or St. John of Damascus. His knowledge of Greek earned him in after life the title of Chrysorrhoas or gold flowing. He boldly opposed the iconoclastic policy of the emperor Leo. Among the works ascribed to him was that of Barlaam and Josaphat. He wrote a separate work discussing the merits of Christianity and Muhammadanism. In his Barlaam and Josaphat he introduced a number of eastern fables, and took his principal hero Josaphat from the Lalita-vistara, the life of the Buddha or enlightened, a portion of the sacred canon of Buddhists. The story of Barlaam is, in its most striking points, a mere repetition of the story of the Buddha, but Josaplat, the hero of the story, has been raised to the rank of a saint, both in the eastern and western churches. And thus, though under a different name, the sage of Kapela-vastu, the founder of a religion, which in the purity of its morals is nearer to Christianity than any other religion, and counts even now, after an existence of 2400 years, $455,000,000$ of believers, has received the highest honours which the Christian church can bestow. If Buddha lived the life which is there described, few saints in the Greek or Roman churches are the equals of St. Josaphat, the prince, the hermit, and the saint.-Max Muller in Proc. Roy. Inst. Gr. Brit., June 1870. See Jataka; Josaphat.

JOASMI. Of the maritime chiefs of the Persian Gulf with whom the British Government have concluded treaties, are the Joasmi chief of Ras-ulKhyma, and Shargah, the chief of the Ban-i-As tribe of Abu-thabee or Bu Debaye, the chief of the $\mathrm{Bu}$ Filasa tribe of Debaye, a branch of the Bahija, and the chiefs of Amalgavine and Ejman. The possessions of these chiefs extend from Rasul-Khyma along the coast westward beyond the island of Bahrein. The Joasmi have occupied the province of Seer from the earliest times, and carried on a vigorous and profitable trade by sea, till, in 1805 , they succumbed to the influence of the Wahabee religionists, and were drawn into the piratical projects of that turbulent sect. Under their influence the Joasmi plundered two British vessels, aud treated the commanders with great cruelty. An expedition was sent to the Persian Gulf to punish them for this aggression, and to co-operate with the Imam of Muscat, who was then at war with them. 'The expedition resulted in the conclusion of a treaty on the 6th February 1806 , binding the Joasmi to respect the flag and property of the British, and to assist vessels touching on their coast. The spread of the Wahabee in Oman soon threatened the Imam of Muscat with destruction, and the British Government determined to support him and to destroy the piratical fleets as the only means of preserving the peace of the Gulf. A strong British force was despatched in 1809, which took Ras-ulKhyma, Linga, Luft, and Shinar, and destroyed the boats of the pirates. But piracy soon recommenced. In 1814, the Joasmi tribe wished to be at peace with the British provided they were allowed to war with Arabs. But they were quite unable to make good their professions. Even after the negotiation of preliminary articles of peace with the resident at Bushir, the Joasmi attacked and plundered British vessels. Other tribes were soon drawn under the Wahabee influence, and piracy increased beyond endurance. A second expedition was fitted out, and sailed from Bombay on the 1st November 1819. The naval part of it consisted of several British ships of war, the Company's cruisers under the command of Captain T. Collier ; and the land forces amounted to about 3000 European and Native troops, under the command of Major-General Sir William Grant Keir. This expedition reduced Ras-ul-Khyma, the principal stronghold of the pirates, which had been carefully fortified and was vigorously defended; and also the hill fort of Zyah, which was likewise well defended by a veteran Wahabee, deeply imbued with the boldness and character of that sect. Ras-ul-Khyma was taken on 9th December, and engagements were made with the Arab chiefs preliminary to the conclusion of a general treaty in 1820. By the 9th article, the carrying off of slaves from the coasts of Africa or elsewhere, and the transporting them in vessels, was declared to be plunder and piracy. Thereafter, it was renewed annually till 1840, when it was prolonged for ten years. On the expiry of the ten years' truce in 1853, a treaty of perpetual peace was concluded, which provided that there should be a complete cessation of hostilities at sea between the subjects of the subscribing parties.-Treaties, vii. p. 239; Fraser's Khorasan; Skinner's Jour. ii. 223 ; Wellsted, i. 257. JOB. Close to the village of Es Sadiyen are the tomb and fountain of Job, the former being a mukām or shrine, to which pilgrims from all parts repair. Africans come in great numbers from the Soudan, and the shrine is under the care of some 200 Negroes, who are exempt from taxation. The ruins of an ancient temple stand upon a mound near the tomb of Job, which Mr. Oliphant thinks has been successively a Phœnician temple of Baal, a Roman temple, a Christian church, and a Muslim house of prayer. A monolith, the top of which has been broken off, was formely the wellknown emblem of Baal. The name of Astaroth, the principal female divinity of the Phonicians, survives in the names of two adjacent villages, called Ashtereh and Tell Asherah. This was the country of the Amorites, "who served Baalim and Asherah.' Ashtereh, a village, was visited by Captain Newbold in 1846. The book of Job is a protest against the accepted Hebrew view which considered all afflictions as tokens of the divine displeasure. It thus runs directly counter to the most cherished Jewish prejudices, and could only obtain admission into the canon by being provided with a prologue and epilogue at variance with the true teudency of the work, and the interpolation of the speeches of Jehovah and Elihu.

JOB'S TEARS. I'-i-jin, I'-i-jin-mi, CHIN. The hard, bead-like seeds of the Coix lachryma and C. vernica. They make a good substitute for pearl barley, though larger and coarser, and make good gruel. The plant flourishes in the Philippines, where the Chinese settlers make from them 
a kind of meal, very nourishing for the sick, and in China it is sold for fivepence the Chinese pound. A wine is made in China by fermenting the seeds, and given in rheumatism. Sail matting and covers for boxes are made from the straw. The Chinese priests use the seeds as their rosaries.Smith, M. M. C.

JODAGIR, or Hill of Strife, called also the Bakur chiria or Bird's Nest, a hill in Rajputana with a castle on it.

JODEL of the mountaineers of Europe is used in India, and sounds Wāi-Wāōōo. In Fiji, Hēhāh-hŏ-hŏ-hŏ.

JODH BAI was the daughter of Raja Maldeo, and sister of Oody Singh of Jodhpur in Marwar. In 1569, Oody Singh gave her in marriage to $\Lambda \mathrm{kbar}$, whose favourite she soon became, and a few months after their union, she and Akbar made a pilgrimage on foot to the tomb of Moin-ud-Din at Ajmir. They travelled six miles a day. Arrived there, Moin-ud-Din appeared to Akbar in a dream and bid him seek the interposition of Shaikh Salem, a holy old man who dwelt on the top of Futtehpur Sikri. Shaikh Salem assured Akbar that Jodh Bai would bear a son who would live to an old age, and the Bai remained in a hut near the hermit till the promised boy was born. He was named Mirza Selim, and became the emperor Jahangir of Indian history. She died some time after A.D. 1600. Her tomb was to be seen on the artillery practice ground at Futtehpur Sikri, near Agra, till about the year 1840 , but the walls and gateways were first taken away and then the tomb destroyed in practising mining. No palliation can ever be urged to defend an outrage on the dead, far less can any plea extenuate the act of blowing up into the air the remains of a woman, no other than Akbar's favourite sultana, the empress Jodh Bai, to whom the people of India owed much of the good they enjoyed under his long reign, by inspiring not only her husband, but the most able Muhammadan minister that India has ever had, with feelings of universal benevolence. Oody 'le gros' was the first of his race who gave a daughter in marriage to a Tartar. Four provinces, yielding $£ 200,000$ of anuual revenue, viz. Godwar, Rs. 9,00,000; Ujjain, Rs. 2,49,914; Debalpore, Rs. $1,82,500$; Budnawar, Rs. 2,50,000, were given to lim in exchange for Jodh. Bai, at once doubling the fisc of Marwar. With such examples as Amber and Marwar, and with less power to resist the temptation, the minor chiefs of Rajasthan, with a brave and numerous vassalage, were transformed into satraps of Dehli, and the importance of most of them was increased by the change. Truly did the Moghul historian designate them 'at once the jrops and the ornaments of the throne.'-Tod's Rajasthan; Tr. Hind. ii. p. 2.

JODHPUR, the capital of the Rajput State of Marwar, in lat. $26^{\circ} 17^{\prime} \mathrm{N}$., and long. $73^{\circ} 4^{\prime} \mathrm{E}$. It was built by Rao Jodha in A.D. 1549. The river Luni is the most marked feature in the physical aspect of Marwar. The only important liske is the famous salt lake of Sambhar, on the Jorders of Jodhpur and Jeypore. Two other depressions of the same kind exist, one in the north of Jodhpur at Didwana, and the other in the south at Pachpadra. The annual out-turn of salt from these two latter lakes is estimated at about 1,200,000 maunds (say 43,000 tons). The population consists of Rajputs, Charans, Bhats,
Jats, Bishnawis, Minas, Bhils, and of the usual mixed Hindu population, with a scanty number of Muhammadans. The ruling chief of Jodhpur holds that position as chief of the Rahtor clan of Rajputs, to whom the territory belongs. The princes of Jodhpur and Udaipur (Oodeypore) term themselves Surjya Vansa or the Solar race. and claim descent from Rama. The founder of the dynasty migrated from Kanouj; and the Rahtor race, from its warlike and aggressive propensities, became the most powerful clan of the Rajputs. Several independent States were founded by offshoots from it, among which are the present States of Bikanir (Bikaneer) and Kishengarh in Rajputana, and Edar and Ahmadnaggur in Gujerat. On the 24th February 1873, Maharaja Jeswunt Singh succeeded to the throne. The installation ceremony was performed in the fort on the 1st March. His forehead was marked with a spot of blood which the thakur of Bugri, a dependency of Jodhpur, had supplied by cutting one of his fingers with a sword, according to custom. After all had taken their seats, it was announced that thenceforth Jeswunt Singh was the ruler of the territory. 'The brothers of the maharaja and other people then presented nuzzers, and the guns boomed forth salutes. At two in the afternoon the maharaja's sowari rode through the city. The populace turned out to render homage.-Rast Goftar.

JOG. SANSK. Union, junction. In Hinduism, amongst ascetics, the practice of religious abstraction, with the object of the individual being united to the universal soul and acquiring similar supernatural powers.-Wilson.

JOGADA NAUGAM, in the Ganjam district, is nearly four miles to the west of Purshottapur, a village on the banks of Rushukulia river. Rocks rise to about 150 feet from the plain. An inscription rock there was formerly enclosed by a fort, the remains of which are still traceable, and local tradition has it that the lofty walls were formed of impregnable materials, until a milkmaid revealed the secret, and allowed the besiegersamong whom was the girl's sweetheart-to effect an entrance into the fort. The inscription rock rises about 120 feet from the plain, and on the southern face are found three smoothed tablets filled with inscriptions of the Allahabad and other similar columns, which Mr. Harris believed to be a copy of Asoka's edicts.

JOGI or Yogi is a term properly applied to the followers of the Xoga or Patanjala school of philosophy, which, amongst other tenets, maintained the practicability of acquiring, even in life, entire command over elementary matter, by means of certain ascetic practices, consisting of long-continued suppression of respiration and other puerilities, such as fixing the eyes on the tip of the nose. Individuals are still met with who thus strive to effect a union between the portion of vital spirit residing in the body and that which pervades all nature, and the hysterical hallucinations which follow give airy nothings a local habitation and a name. It was practised in India so early as the 8th century. In the temples of Salsette, Elephanta, and Ellora, the principal figure is mostly Siva, decorated with ear-rings, such as are worn by the Kanp'hata Jogi sect. The walls are covered with ascetics in the various Asana or positions in which the Yogi is to sit. The cells attached to some of 
the temples are also indicative of Jogi residence, and one of the caves of Salsette is named that of Jogeswara, or Siva as the lord of Jogi. The Jogi sect of Gorakhnath are usually called Kanp'hata, from having their ears bored, and rings inserted into them at the time of their initiation. They may be of any of the Hindu castes, and live as ascetics in mat'bs. Siva is the object of their worship. They officiate, indeed, as his priests, especially at the celebrated Lat of Bhairava at Benares. They mark the forehead with a transverse line of ashes, and smear the body with the same; they travel in a cap of patch-work, and garments died with red ochre. Some simply wear a dhoti or cloth round the loins. The Saringhiha are a Jogi sect who use the saringhi or lute, and beg in the name of Bhairava. Another sect is the Duri-hara, from their peddling in thread to the housewives of the villages; the Matsyendri or Macchendri, from Matsyendri, whom they regard as their founder, are a third sect; and a fourth is the Bhartihari. They are all errants and mendicants, and many assume the character merely to lead a lazy life ; there are even Muhammadan Jogi. In the Dekhan they seem to be arranged into 12 orders-

Dubray Jogi or Bal santa ka Jogi.

Khani Bhai tie heavy stones to their body, beg, and sell medicines.

Launghoti Jogi or Juggai Jogi are merchants, selling beads.

Kanp'hata Jogi or Sonari Jogi live in temples, and are the priests.

Tingri ka Jogi, musicians, performing on the tingri. Sooe pat bechne-wala Jogi sell beads of coral, etc.

Mendiki Jogi beg by beating on the tambourine.

Shan ka Jogi.

Kulghari bechne-wala Jogi sell the drip-stones, which the Doombur caste make for Brahmans.

Thugganee Jogi sell wooden trays made by carpenters near Dharwar.

Chako or Katti Jogi sell knives and sissors,

Dubbray bajani-wala beat a kind of tambourine.

Their modes of obtaining alms are extremely varied. The Khani Bhai demands alms; if refused, ties his lengthened body to the latch of the door; and many Jogi use musical instruments to sing to and attract attention. The women make rings, beads, and toys for sale. They never devote their women to the gods. Their marriages take place in early youth, and cost about Rs. 50 or 60 . Two or three wives are sometimes in one household. The dead of the sect are buried by the Vaisya caste. In Persia, the term Jogi or Yogi is given to all Hindu religious mendicants, and to pilgrims who are occasionally seen there, on their way to Baku and other places of pilgrimage.

- Mewar could always muster many hundreds of the Kanfera or Kanp'hata Jogi, or split-ear ascetics, so called from the habit of piercing the ear and placing therein a ring of the conch-shell, which is their battle trumpet. The Bhartrihari Jogi mendicants profess to have been instituted by Bhartrihari, brother of Vikramaditya, in the century before Christ. In the early part of the 19th century was a remarkable Mahapurush at the Ghosaul's of Kidderpur, a man about 40 years of age, with a very fair complexion, and jet-black hair, who did not eat or drink anything, nor speak a word, but remained in a sitting posture, with his legs and thighs crossed, absorbed in meditation. In 1867 there was a Jogi thus sitting in one of the caves of Ellora, who had sat there for five years, and the people said they were unaware who brought him food. Garments coloured with geru, or red ochre, are worn by all classes of mendicants, and a little horn is often suspended around the neck. The Moodra, a round prickly seed, is worn by the ascetics as ear-rings. The Jogi's patera is a hollow gourd; that of the divinity Hari (the god of war) is the human cranium.Fraser's Journey into Khorasan, p. 394 ; Wilson; Tr. of Hind. i. p. 43 ; Tod's Rajasthan, ii. p. 236 ; Wils. Gloss.; Wilson's Hindu Sects.

JOGINI TANTRO, a work of high repute in Assam, as its contents are supposed to have been communicated by Siva to his consort Parvati. It states, regarding the king Norok, that though an Asur or infidel, he was in such favour with the gods, that they made him the guardian of the temple of Kamikhya.-Beng. As. Soc.'Journ.,1855.

JOHANNA, one of the Comoro islands in the Mozambique channel.

JOHAR or Jauhar, a general sacrifice in war, to which Rajputs resorted when pressed by overwhelming numbers. Colonel Tod relates that on one occasion when Jeysulmir was so pressed, Mulraj and Ruttun repaired to the palace of their queens, and told them to take the sohag, and prepare to meet in heaven, while they gave up their lives in defence of their honour and their faith. Smiling, the Soda rani replied, "This night we shall prepare, and by the morning's light we shall be inhabitants of swerga' (heaven); and thus it was with the chiefs and all their wives. The night was passed together for the last time in preparation for the awful morn. It came; ablutions and prayers were finished, and at the Rajdwara were convened bālā, prude, and bridu. They bade a last farewell to all their kin, the Johar commenced, and 24,000 women and girls, from infancy to old age, surrendered their lives, some by the sword, others in the volcano of fire. Blood flowed in torrents, while the smoke of the pyre ascended to the heavens. Not one feared to die, every valuable was consumed with them, not the worth of a straw.was preserved for the foe. This work done, the brothers looked upon the spectacle with horror. Life was now a burden, and they prcpared to quit it. They purified themselves with water, paid adoration to the divinity, made gifts to the poor, placed a branch of the tulsi in their casques, the saligram round their neck; and, baving cased themselves in armour and put on the saffron robe, they bound the mor (crown) around their heads, and embraced each other for the last time. Thus they awaited the hour of battle, and 3800 warriors, with faces red with wrath, prepared to die with their chiefs. Other instances of the awful rite of Johar, when a whole tribe may become extinct, have been recorded in the annals of Mewar, the object of it being undoubtedly to prevent the women falling into the hands of the enemy. To the women of Europe the fate of the Rajputni mustappear one of appalling hardship. In each stage of life, death was ready to claim her,-by the poppy at its dawn, by the flames in riper years; while the safety of the interval depends on the uncertainty of war. The loss of a battle, or the capture of a city, was a signal to avoid captivity and its horrors, which to the Rajputni are worse than death. It is singular that a nation so refined, so scrupulous in its ideas with regard to females, as the Rajput, should not 
have entered into some national compact to abandon such proof of success as the bondage of the women. When the foe was the Tatar the Johar might have been pardonable, but the practice was common in the international wars of the Rajputs ; and there are numerous inscriptions on stone and brass, which record as the first token of victory the captive wives of the foemen. When the mother of Sisera looked out of the window, and cried through the lattice, Why tarry the wheels of his chariots? have they not sped? have they not divided the prey; to every man a damsel or two ? gives a perfect picture of the Rajput mother expecting her son from the foray. The Jewish law with regard to female captives was perfectly analogous to that of Menu; both declare them 'lawful prize,' and both Moses and Menu establish rules sanctioning the marriage of such captives with the captors. When a girl is made captive by her lover, after a victory over her kinsmen, marriage is permitted by law. The forcible marriage in the Hindu law, termed Rac'chasa, viz. the seizure of a maiden by force from her house, while she weeps and calls for assistance, after her kinsmen and friends have been slain in battle, is the counterpart of the ordinance regarding the usage of a captive in the Pentateuch, excepting the shaving of the head, which is the sign of complete slavery with the Hindu. When Hector, anticipating his fall, prediets the fate which awaits Andromache, he draws a forcible picture of the misery of the Rajput; but, to prevent such degradation, the Rajput had recourse to the Johar, or inimolation of every female of the family. The very term widow (rand) is used in common parlance as one of reproach. The rule for the Jews is in Judges $v$. 2830 , Deuteronomy xxi. 10-13, 'When thou goest forth to war against thine enemies, and the Lord thy God hath delivered them into thine hands, and thou hast taken them captive, and seest among the captives a beautiful woman, and hast a desire unto her, that thou wouldst have her to thy wife; then thou shalt bring her home to thine house; and she shall shave her head, and pare her nails; and she shall put the raiment of her eaptivity from off her, and shall remain in thine house, and bewail her father and her mother a full month: and after that thou shalt go in unto her, and be her husband, and she shall be thy wife.'-Pennant's Hindustan, i. p. 56 ; Tod's Rajasthan, i. pp. 639, 640; Menu on Marriage, Art. 25, 33.

JOHN, DR., the founder of the missionary botanical garden at Tranquebar, into which were introduced many plants, chiefly of the Peninsula, but also from Ceylon.

JOHNIUS, a genus of fishes of the eastern seas, several species of which furnish isinglass.

Johnius diacanthus, Lacepede.

Lutjanus diacanthus, Lac. Johnius catalens, Cuv. Nalla katchelee, Russell. Katchelee, Russell.

\section{Corvina catulea,} Belanger and Bleeker. Corvina nalla katchelee, Richardson.

Sciæna maculata, $C$. and $V$. Ikan tambareh, . MALAY.

This fish grows to 2 feet 9 inches. It inhabits the Sea of Penang, Malayan Peninsula, Singapore, Malabar, Coromandel, Bay of Bengal, Gangetic estuaries, Tenasserim, Canton, China seas, Madura, and Java. The air-vessel, $\frac{1}{3} d$ of the length of the fish, is of a broad lanceolate shape, tapering behind into a very elongated point. This fish is valuable as food, but also on account of the quantity and quality of its isinglass.

Johnius Dussumieri, $C$. and $V$. Corvina Dussumieri, $C$. and $V$. The total length of this fish is $6 \frac{3}{4}$ inches. It inhabits the Sea of Penang, the Malayan Peninsula, Singapore, and Malabar. The length of the air-vessel is about one-fourth the total length. The isinglass is reputed good, but owing to the small size of the fish little is procurable.

Johnius maculatus, Bloch, Schneider, var.?

Sari kulla, TAM., Russell. I Corvina maculata, $C . \& V$. Inhabits Sea of Penang. The form of its airvessel resenables that of Johnius belengeri.

JOHNSON, FRANCIS, a professor of oriental languages at Haileybury, in England, who printed the complete Hitopadesa, and accompanied it with a copious vocabulary. He afterwards brought out a translation as close to the original text as the necessities of English composition would allow. The above work, and the Arabic and Persian Lexicon which bears his name, gave him a high place in the estimation of orientalists.

JOHORE, formerly the chief city of the empire of that name, and residence of the sultan, is situated about 20 miles up the river so called. The town was founded in A.D. 1511 or 1512 by Sultan Muhammad Shah II. of Malacca, who, after his expulsion from that place by the Portuguese, fled to the river of Johore. From that time the town of Johore has been the capital of the empire which took the name of the empire of Johore instead of that of Malacca, and up to 1810 there had succeeded 14 princes. Johore is the residence of a panghulu, who is appointed both by the sultan of Johore and by the tumungong of Singapore. It is the received opinion that Johore derived its population from Menangkabau. The Menangkabau race are a purely agricultural, mining, and inland trading people, and consequently when they began to emigrate to the Peninsula their proceedings were precisely the reverse of those of the Singapore colonist, and indeed of all other Malays. They passed through the maritime districts, and sought valleys amongst the mountains of the interior. This fallen empire is nominally bounded by the Cassang river on the W. coast, and by Kemaman on the E. coast, in lat. $4^{\circ} 15^{\prime} \mathrm{N}$. The sultan of Johore's present possessions on the Peninsula are subdivided into several petty states, -first, that of Muar, extending from the Malacca territory to Parrit Siput, including a large river of the same name, and an inland district called Segamet. This is under the immediate rule of the tumungong of Muar, a chief residing at Pancalang Kotah, on the river. Johore river is more than half a mile wide, with $8 \frac{1}{2}$ to 12 fathoms water. The Johore Archipelago is formed by the prolongation of the plutonic zone of elevation of the Malay Peninsula from Singapore to Billiton. The islands, with the exception of a few of the most southerly, formed the insular part of the kingdom of Johore from the 13th century till the occupation, in 1820, of Singapore. Several tribes in various stages of civilisation still possess the Johore islands.-J. I. A., August 1848, p. 518; Oliphant; Newbold, ii. p. 41.

JOHYA, a Rajput tribe in the tracts about Pakpattan, along the Sutlej. The Johya, Dahya, and Mangalya tribes are now Muhammadan, but are few either in the valley or desert, as also are the Bairowi, a class of Baluch, and the Khairowi, 
Jangria, Oondur, and Baggria, descended from the Pramar and Sankla Rajputs. By some authorities the Johya are included among the 36 royal races of India, by others they are considered a mere ramification of the Yadu Bhatti, and Colonel Tod calls them a Jat race. Some of the Joodi and Johya inhabit the range called in the native annals Juddoo-ka-dang, and by Baber the hill of Jud, skirting the Behut. Behera (Rennell calls it Bheera, in lat. $32^{\circ} \mathrm{N}$., and long. $72^{\circ} 10^{\prime} \mathrm{E}$., and Elphinstone, lat. $32^{\circ} 10^{\prime} \mathrm{N}$., and long. $73^{\circ} 15^{\prime} \mathrm{E}$.) is often mentioned in the Yadu Bhatti annals. It was one of their intermediate places of repose, on their expulsion from India and migration to Central Asia. Its position was minutely pointed out by the emperor Baber (p. 259), who in his attack on the hill tribes of Jat, Gujar, Guker, etc. , adjoining Kashmir, 'expelled Hati Guker from Behera, on the Behut river, near the cave temples of Garkotri at Bikrum,' of which the annotator remarks that they, as well as those of But Bamian, were probably Buddhist. Baber (p. 294) also found the Jat masters of Sealkote, most likely the Salpur conquered from a Jat prince in the 12 th century by the Patan prince, and presumed to be the Salbhanpura founded by the fugitive Yadu prince of Gujni. Among the Lahia and Johya Rajputs of the Indian desert, where they founded their first capital, Derrawul, many from compulsion embraced the Muhammadan faith, on which occasion they assumed the name of Jat, of which at least twenty different offsets are enumerated in the Yadu chronicles. Colonel Cunningham thinks that in the time of Alexander the Johya probably extended from Bhatner and Pakpattan to Sabzalkot, about half-way between Uch'h and Bhakar.-Cunningham's Ancient Geography of India, p. 245; Tod's Travels, xiv. p. 45; Tod's Rajasthan, i. p. 19, ii. pp. 233, 289; Erskine's Baber, p. 259.

JOKTAN. Arabians are divided by native historians into two distinct races, the posterity of Kahtan or Joktan, the son of Heber, who were termed al Arab al Araba, the pure Arabs, and the race of Adnan, the lineal descendants of Ishmael, who were called mixed Arabs, or Arab al Mostareba. The latter were intermixed with the descendants of Jorhan, one of the sons of Kahtan, and occupied the district of Hejaz, and from them were descended the tribe of Koresh. Kahtan was the first that wore a diadem in the land of Yemen, and his great-grandson Abid Shams or Saba was the first of the Arabian kings who undertook warlike expeditions and enriched his country with the spoil of his enemies, and is said to have received the name of Saba from the numerous captives whom he brought into Yemen. Kahtan was succeeded by his son Yarab, who was the first to speak the language and introduce the ceremonials of Arabia. Amongst the sons of Saba or Abid Shams were Hamyra, Amru, Kahtan, and Ashaar. Hamyar was the first of Kahtan's descendants who reigned over the whole of Yemen. He drove the remains of the tribe of Thamoud out of Yemen into Hejaz, and was one of the bravest, most skilful, and handsomest men of his time. Hamyar signifies red, and he is said to have received this name from the colour of his garment, and to have been the first king of Arabia who had a crown of gold.-Early Christianity.

JONAH, a prophet of the Hebrews. prophet suffered grievously from the eastern wind. This is the sherki so much dreaded in all these countries, which is hot, stormy, and singularly relaxing and dispiriting. The ruins opposite Mosul are called Nabi Yunus and Koyunjik, and a sketch showing the tomb of Jonah is given at p. 131, vol. i. of Layard's Ninéveh and its Remains. Ricold of Montecroce also mentions the traces and ramparts of Nineveh, and a spring which is called Fount of Jonah. He adds that as the inhabitants of the neighbourhood pointed out to him the tomb of Jonah upon the summit of one of the mounds, it was natural to conclude that it marked the site of the great Nineveh. But this tradition as to the site of the tomb of Jonah is not supported by Scripture. Mr. Layard tells us that the Jews, in the time of St. Jerome, pointed out the sepulchre of Jonah at Gathhepher, among the tribe of Zabulon. The building, which is supposed to cover the tomb, is very much venerated, and only Muhammadans are allowed to enter it.-Kinneir's Memoir, pp. 258, 259; Layard's Nineveh; Yule's Cathay, p. 351; Rich's Kurdistan, ii. p. 35.

JONAKAN, a titular designation of the Moplah race of Malabar in the S.W. of the Peninsula, supposed to be derived from the Grecian Yavana. Jonangi, also written Zonangi, Jonagar, and Jonakari, a Muhammadan tribe in the south of the Peninsula, where they are also called Cholia, also Labbi. They are considered to be descended from Arab fathers and native women. The term has been supposed to be from Yunani, Grecian, also from Shonahar, the name of some country.

JONES. Captain Felix Jones entered the Indian navy in 1828, and for the succeeding quarter of a century was uninterruptedly employed in almost every survey of importance on which the officers of his service were engaged. Though a mere boy of seventeen when he commenced work in the Red Sea survey, in the Palinurus, under Commander Moresby, his talents found ample recognition, and the draughting of the northern portion of the Red Sea was entrusted to him, the southern portion being by Capt. Dugald Campbell. On the completion of the survey of the Red Sea, which occupied between 1829-34, Felix Jones was engaged in the survey of the Maldive Islands, again under Capt. Moresby, and drew the original charts, the execution of which was so beautiful that they were submitted for the inspection of the Queen. In 1837 we find him engaged in the Gulf of Manaar and coast of Ceylon on the same laborious duty. Lieut. Jones commanded the steamer Nitocris in the Euphrates Expedition from May 6, 1840; performed the ascent of the Euphrates to Bales, a distance of 1130 miles, in twenty days, in conjunction with three other steamers, commanded by Lieuts. Campbell, Grounds, and M. Lynch ; and crossed the Syrian Desert to Beirout, where he communicated with the British fleet, then engaged in operations against Muhammad Ali, and connected the Euphrates and Mediterranean by chronometric measurements for longitude. $\mathrm{He}$ then brought the Nitocris down to the Gulf, but remained in Mesopotamia surveying the country under the late Lieut. Blosse Lynch, I.N., until 1846. In the following year, on his being appointed Surveyor-General of Mesopotamia, he returned The thither from Bombay, having completed a map of 
the countries between the Mediterranean, Kurdistan, Persia, and the Gulf. The journals of the Royal and Bombay Geographical Societies are enriched with many of his memoirs and maps, and others were published by Government. After twenty-five years' continuous service, he proceeded to England on sick leave, and returned by Asia Minor and Constantinople, bringing with him a nap, in three sheets, of Babylonia, which was lost in the India Office. The political relations with Persia assuming a threatening aspect, he returned hastily to Baghdad, and on March 1, 1855, was appointed Officiating Political Agent and Consul-General in Turkish-Arabia, and in the following October succeeded Capt. (now General Sir Arnold) Kemball as Political Resident at Bushir. In the capacity of Chief Political Officer to the Persian Expedition he received the repeated thanks of Sir James Outram, who recommended him for honours, which, however, he never received. Again, during the Indian mutiny, he rendered service to his country by keeping in check the disposition of Persia and the warlike Arab maritime tribes to intrigue against British supremacy, and he received the repeated thanks of the Indian and Home Governments. In February 1863, Capt. Felix Jones completed his magnificent map of Assyria, which occupied the declining years of his life, and then died. He wrote a Memoir on the Province of Baghdad.

Sir Harford Jones, Baronet, a civil servant of the East India Company, who was sent by Great Britain on an embassy to the court of Persia, in which he was eminently successful. He left Bombay on the 12th September 1808, and reached Bushir on the 14 th October. At Teheran, when the treaty was to be signed, the aged wazir, Mirza Shaffi, accused him of an attempt to cheat him, on which Jones pushed him against the wall, kicked over the candles on the floor, left the room in darkness, and rode home. The treaty was signed 12th March 1809. He wrote an account of the mission to Persia in 1807-11.

Sir William Jones, a judge of the High Court of Justice at Calcutta in the latter part of the 18th century, a learned orientalist, and voluminous writer. Many of his discourses and memoirs appeared in the first to the fourth volumes of the Asiatic Researches. The principal of these were,-A Preliminary Discourse; on Asiatic Orthography ; on the Gods of Greece, Italy, and India ; on the Sources of the Nile; Second Anniversary Discourse; Third ditto; on the Arabs; on the Tartars; on the Persians; Remarks on Johanna Island; on Hindu Chronology; on the Indian Game of Chess ; on the Second Classical Book of the Chinese, ii. p. 198; on the Antiquity of the Indian Zodiac; on the Cure of Snake-Bites; Design of a Treatise on Plants; on the Chinese; Supplement to Indian Chronology ; on the Spikenard; on the Borderers, Mountaineers, and Islanders of Asia ; Translation of Grant of Land in Carnata; on the Musical Modes of the Hindus; on the Mystical Poetry of the Persians and Hindus, As. Res. iii. p. 165; on the Lunar Year of the Hindus; on the Origin of Families of Nations; on Asiatic History; on the Loris or Lemur; on the Philosophy of the Asiatics, As. Res. iv. p. 164 ; a Catalogue of Indian Plants; Remarks on Dr. Hunter's Astronomical Observations made on Journey to Ujjain; Remarks on Playfair's Ques-

tions on Astronomy of Hindus. On his tomb was engraved the following:-

$$
\begin{gathered}
\text { 'Here was deposited } \\
\text { The mortal Part of a Man } \\
\text { who feared God but not Death, } \\
\text { and maintained independence } \\
\text { But sought no Riches; } \\
\text { who thought }
\end{gathered}
$$

None below him but the base and unjust,

None above him but the wise and virtuous.'

JONESIA ASOKA. Roxb. ii. p. 220.

J. pinnata, Willde.

J. Indica, Rheede.
Asok,

A-thau-ka-pho, Ashunkar, .

Wu-yu-wha,
Saraca pinnata, Willde. S. arborescens, Burm.

Beng. Jassoondi, . KONKan. Burm. Kankeli, . . Sansk. CAN. Diya rat mayl, . SINGH. Chin.

The Jonesia genus of plants, of the natural family Leguminosæ, was named by Dr. Roxburgh in honour of Sir William Jones. The species are few in number. They form trees, which are highly ornamental from their handsome, shining, abruptly - pinnate leaves, and from the showy nature of their crowded racemes of flowers.

Asoka is a Sanskrit word, from a, privitive, and Soka, sorrow. The asoka flowers appear in March and April, and the fruit in August and September, and when in full blossom the whole vegetable kingdom does not afford a more beautiful object. Its flowers are diversified with orange, scarlet, and bright yellow tints. In Hinduism, it is consecrated to Siva, and is often planted near temples, -as the lotus flower, called Kamala or Padma, is sacred to Vishnu and his wife Lakshmi. In Hindu poetry, despairing lovers very commonly address objects of nature, clouds, elephants, and birds, on the subject of their lost or absent mistresses, and the asoka tree is often invoked.

In the Toy Cart, translated by H. H. Wilson, Maitreya, describing a garden, says, 'And here the asoka tree, with its rich crimson blossom, shines like a young warrior bathed in the sanguine shower of the furious fight.' Differences in the colour of the flowers arise from their changing during development. When they first expand, they are of a beautiful orange colour, gradually changing to red, forming a variety of beautiful shades. They are fragrant during the night. Hindu men and women of all classes ought to bathe, on a particular day, in some holy stream, especially the Brahmaputra, and drink water with buds of the asoka floating in it. Sita is said to have been confined in a grove of the asoka tree, while in captivity by Ravana; other relaters say she was confined in a place or house, called Asokwan.-Mason's Tenasserim; Coleman's Mythology; Lady Faulkland's Chow-Chow; Pichardson's Flowers and Flower Gardens; Williams' Story of Nala, p. 117.

JOOGA. HIND. The yoke of a carriage or plough. The word is preserved in many IndoEuropean languages, thus - Sanskrit, Yug ; Persian, Yogh ; Greek, Zeugos; German, Joch; Latin, Jugum; Russian, Igum.-Elliot.

JORDAN rises a few miles N.E. of Paneas (Cæsarea Philippi), at the foot of Mount Hermon, a branch of the Anti-Libanus. Its apparent source flows from beneath a cave at the foot of a precipice, in the sides of which are several niches with Greek inscriptions. Crossing the bogs and fens of the lake Merom, subsequently called Lamochonitis, after a course of 15 miles, it passes under the city 
of Julias, the ancient Bethsaida, it then expands into a beautiful sheet of water, the lake Tiberius, anciently Gennesareth, and, after a winding course of about 60 miles through a hollow valley called El-Ghor, it empties itself into the lake Asphaltites, or Dead Sea, the Bahr-ul-Lut of the Arabs. Its whole course is about 130 miles; its breadth averaging about thirty yards, and in depth three. It is called by the Arabs Sheriat-ul-Kabir. The valley of the Jordan opens to the east, beyond which the eye loses itself in the desert of Hauran. - Robinson's Travels.

JOSAPHAT, a corruption of Bodhisatwa. Barlaam and Josaphat, a romance ascribed to St. John of Damascus, has been so completely received into the bosom of the Latin Church, that the names of 'the holy saints Barlaam and Josaphat of India, on the borders of Persia,' have been canonized, and have their proper day, November 27th, as may be read in the Martyrologium of Cardinal Baronius, authorized by Pope Sextus v. for general use in the Catholic world, at page 177 of the 1873 edition, endorsed by His Holiness Pius $\mathrm{Ix}$. The Greek Church assigns a different day to the holy Iosaph, son of Abener, king of India, and omits Barlaam. Josaphat or Iosaph is Bodhisat, or the condition of Sakya before he became a Buddha, and the religious romance of St. John of Damascus is simply a Greek version of the life of Gautama. Professor Max Muller pointed out the fact that Gautama, under the name of St. Josaphat, is now officially recognised and honoured and worshipped throughout the whole of Roman Catholic Christendom as a Christian saint! And just as Barlaam and Josaphat is an offshoot of Buddhist literature, so the wide series of tales represented by the Pancha Tantra, Kalila and Damna, Fables of Bidpai, Essop's Fables and La Fontaine's, are mainly traceable not only to an Indian, but to a Buddhist source. Sindbad the Sailor, and other tales of the Arabian Nights, have their birth in Buddhist Jātakas; Boccaccio, Chaucer, Gower, and Spencer have been indebted to this treasurehouse of Buddhist folk-lore; even the three caskets and the pound of flesh in the Merchant of Venice are ideas found in this wonderful old story-book. -Contemporary Review, 1870. See Barlaam; Jataka ; Lalita.

JOSEPHUS. Flavius Josephus, a Jewish historian. After a visit to Rome, he commanded the troops defending Jotapata against Vespasian, but subsequently joined Vespasian and aided in the siege of Jerusalem, and received great advancement from Vespasian and Titus. He wrote a History of the Wars of the Jews, first in Syriac and then in Greek; he also wrote the Antiquities of the Jews, also two books in defence of the Jews, and his own life. Born at Jerusalem A.D. 37, died at Rome about A.D. 93.-Catafago.

JOSHI, HIND., also called Joti, Jotisi, and Jotisaru, is an astronomer, an astrologer, in general ; professing astrology and fortune-telling, and employed in casting nativities. In Upper India, the name is applied to an inferior order of Brahmans following this occupation; in the Dekhan, to a caste of Sudras. The term, when restricted to a Brahman conversant with astronomical science, implies considerable respectability, as is the case with the Joshis of Kamaon. 'Their name is derived from Jotish, astrology, and they are known also by the names of Bhudurea

VOL. II.

and Dukout. The manner of the employment of the Joshi is described in Exodus xxxii. 5, where Aaron made proclamation, and said, 'To-morrow is a feast to the Lord.' Similarly, before a religious ceremony or festival, the officiating Brahman or an appointed person proclaims, "Tomorrow, or on such a day, such a ceremony will be performed;' and every morning, in Southern India, the joshi goes from house to house to inform the inmates as to the sacred rites of the day depending on the planetary movements.

The Hindu almanacs or panchanga are so complicated that ordinary persons cannot understand them, and every town has a number of men who earn a livelihood by going from house to house to explain the conditions which are to guide their religious rites. Jotidar, in Bengal, a village authority. Jotisastri-karia, SINGH., an astrologer. Jotish, correctly Jyautisham, in Sanskrit, includes mathematical, astronomical, and astrological science. The treatises on Jotish are all in Sanskrit, but some are written in other characters. The Sanskrit names for the zodiacal signs are-

Mesham, ram.

Vrisabham, bull.

Mithinam, twins.

Karkatacam, crab.

Simham, lion.

Kanya, virgin.

Jyotishia, in Sanskrit, is astronomy, astrology. Jyotishi, an astronomer; an astrologer who prepares the calendar, casts nativities, and tells fortunes.

The Jyotisha is a Sanskrit astronomical treatise, one of the Vedanga, detailing the most auspicious days and seasons for the Hindus to perform the Vedic sacrifices and ceremonies. One of its tracts, of 36 verses, is supposed to be of date B.C. 300 . -Elliot. See Almanac; Panchanga; Vedanga.

JOSHUA, a Hebrew chief who led the Israelites over Jordan, B.c. 1280 , and drove the Amorites from their territory near Hebron. Rameses II. was then reiguing in Egypt. Joshua divided Canaan into twelve parts, which the tribes drew by lot, according to their families.

JOSS-HOUSE, a Chinese temple. In every Chinese house, without exception, is found the shrine of the special joss or god of the family, with joss - sticks (aromatic pastilles) burning before it; and in some corner is the stove, and on it the tea equipage, ready for use at a moment's notice.-Frere, Antipodes, p. 209.

JOT. BENG. The land which a cultivator tills; also his tenure of it.

JOU-KHIAO. The first and most ancient of the faiths in China was that called Jou-khiao, the Doctrine of the Lettered, of which Confucius is regarded as the reformer and patriarch. It was based upon a philosophical pantheism, which has been variously interpreted at various epochs. It is believed that at a remote period, the existence of an omnipotent God, a requiter of human actions, was not excluded from it. - Huc's Christianity, i. p. 322.

JOVAKYER, a servile caste of toddydrawers in Malabar, inferior in social rank to the Jover or Tiyar, with whom, however, they intermarry.

JOWRAH. Ghaffur Khan, the first nawab of Jowrab, was brother - in-law of the Pindara leader Amir Khan, whom he represented at the 
court of Holkar when Amir Khan quitted Malwa on his expeditions into Rajputana. The lands which had been assigned to him by Holkar were guaranteed to him by the 12th article of the treaty of Mundisore, on condition of his maintaining a body of 600 horse, the quota to be increased in proportion to the increasing revenue of his districts. In 1842 the existing arrangement was commuted to a yearly contribution of Hali Rs. $1,85,810$, when the western Malwa contingent, consisting of the troops furnished by Jowrah, was amalgamated with the eastern Malwa contingent furnished by Holkar and Dewas. The contribution was reduced to Hali Rs. $1,61,810$ in 1859 , as a reward for the nawab's services during the mutinies. The area of Jowrah is 872 square miles; the population, 85,456 souls; the revenue, Rs. 6,55,240. Jowrah contains the best poppygrowing lands in Malwa, and yields yearly about 1000 chests of opium. The nawab keeps up a military force of 175 horse and 600 foot. The nawab received a sunnud guaranteeing the succession to his State according to Muhammadan law, in the event of the failure of natural heirs. $\mathrm{He}$ receives a salute of 13 guns,-Treaties, iv. p. 343 .

JUANGA, or Patuah, or Patra Saori, a forest race inhabiting the tributary mahals to the south of Singbhum in Cuttack, scattered in the mahals or killahs of Keonjur. Pal Lehra, 30 villages; Dhenkanal, 6 villages; and Hindole, 6 villages. The stature of the men does not exceed 5 feet 2 inches, and of the women 4 feet 3 inches or 4 feet 4 inches. Their forms are slight, with little muscular development, and physique weak. Their face is shorter and broader than that of the Uriya; the nose is flat, and nostril wide. Their colour is not darker than the Uriya peasant. The men are not handsome, but the women are repulsively ugly. The men dress like the peasantry of the neighbourhood, but, until 1871, all the covering of the women consisted of two bunches of twigs, with their leaves attached, one before and one behind, which were changed daily, and kept in their position by a strip of bark or a string of glazed earthenware beads, passed twenty or thirty times round the waist and over the stems of the twigs; hence the name of the tribe, Patuah,-literally people of the leaf; but they call themselves Juanga and Pudhan. The women also wear necklaces of the same kind of beads, and their hair is gathered together in a knot at the back of the head, fastened by a string with a silver or brass button at each end of it. The women wear no blanket or covering at night, but sleep between two fires. Their traditions are to the effect that they were formerly vain of fine dress, and were wont to lay aside their good clothes to prevent their being soiled, and wore such leaves when attending to the cleaning of the cow-houses or other duty, when one day a thakurani, or, according to some, Sita, appeared, and commanded them as a punishment for their vanity always to wear such leaves. They believed that if they violated these commands they would be devoured by tigers. Their villages are in the clearings or openings in the forest; are small, with about six or eight families in poor and mean thatched huts of wattle and daub, each family in its own dwelling. They have no lands, but sometimes assist in the cultivation of the neighbourhood. Their avocations are chiefly those of the chase, using the bow and arrow, and dogs; they kill deer, hogs, and not unfrequently snakes, of the flesh of which, especially that of the Python molurus, they are very fond. Except the cow, they are omnivorous. Their usual food is insipid and nauseous roots (tuga, kurba, and panialu), and the seeds of the jungle grasses. They have no system of caste. They deny that they worship any deity or have any image, but they pay homage to nameless spirits who inhabit the woods and mountains, and make offerings of a fowl, a goat, or rice, or spirits, to the genus loci. In the month Baisakh, they offer libations to the manes of their deceased ancestors. They bury their dead. Marriages are arranged by the parents, and are scenes of revelling and drunkenness. They adhere to one wife, unless she prove unfruitful. Like many of the Hindu races, they will not pronounce their wives' names. Their language is not similar to Uriya, and it shows that they are connected with the Munda of Chutia Nagpur, and that their nearest kinsmen are the Kheriah. But in their present position they are isolated from all other branches of the Kolarian family, and they have no suspicion that they are connected with them. The Juanga women are fond of ornaments, which they wear in the nose, ears, and hair. That for the nose is the ordinary nhut, or nose-ring of other Indian tribes. In the ears are worn two or three rings, and one larger ornament worn in the upper part of that organ; this latter ornament is bell-shaped, and not untasteful. The hair of the women is gathered into a knot at the back of the head, and fastened by a string, each end of which terminates in a brass or silver button. Sometimes, too, a bell-shaped ornament is worn in the hair, and has not a bad appearance. The effect of the Juanga costume on a person who beholds one of these women for the first time is ludicrous enough, but it is in the dance that such appears pre-eminently ridiculous. They dance in a circle to the noise of a large drum, beaten by the men, which marks the time, moving round and round in the same measured step, occasionally advancing towards the musicians, then receding from them, in the performance of which the Juanga ladies evince a strong disposition to attitudinize and make display. In the dance, they bend gracefully forward at an angle of about 45 degrees, the left hand slightly holding the extremity of the long strings of beads, the right hand hanging down towards the knee. In such an attitude, it must be evident that the stiff bundle of twigs in front will press inconveniently against the legs of the dancer as she bends forward; she therefore pushes it between them towards the rear, which necessarily forces up the rear bundle, and as the materials of the sylvan crinoline are about as flexible as a birch broom, the effect of a dozen such tails bobbing up and down together in the dance is ludicrous to European eyes, though the Juanga themselves do not seem to consider the sight at all promotive of laughter.

These people eat the flesh of all animals except the cow, from which they abstain out of deference to the Dhenkanal raja, whose lands they are permitted to live on rent-free, on condition of supplying him, when required, with ardent spirits, which they distil from mahwa flowers and wild honey, which is very plentiful in those jungles. The 
men, also, are bound to serve him as coolies for the conveyance of his baggage when he travels through the district, and to beat the jungle when he hunts, which latter duty they consider a pastime; as, next to killing game themselves, their greatest pleasure is to see it killed by others. Their quickness of sight, too, in tracking a wounded animal is quite wonderful; the Juanga will discover a deer's track, even some hours after the animal may have passed over fallen leaves and ground the least calculated for tracking an animal. They also hunt with dogs, of which they possess a very useful breed, but they have no firearms. Their expertness with the bow is quite astonishing, and at 80 yards they will hit a very small mark, and it is considered no feat to shoot a hare at full speed, or a bird upon the wing, - the latter being generally shot with blunt arrows. Their bows are generally of bamboo, and so powerful are they as to send an arrow through and through a wild hog or deer; but they do not care to meddle with the large animals, and have an especial dread of the bear and tiger. This tribe do not hold any land, and appear to have a strong aversion to agriculture, or any other laborious employment. They possess but few domestic animals, and these they rarely kill except for sacrificial purposes; thus they have to depend on the produce of the chase to supply them with flesh, but game of all kind is so plentiful in those jungles that the Juanga need never be in want of animal food. The flesh of snakes is, by them, considered a peculiar delicacy, but their ordinary diet consists of edible grass seeds, and roots, which must be an unpalatable and little nourishing kind of aliment; however, as before stated, the men show no symptoms of insufficiency of diet, for they appear plump and sufficiently fed, but the women have a meagre and halfstarved look, though, perhaps, this arises as much from want of clothing as the absence of sufficient nourishment; for a certain degree of warmth is quite as essential as food to maintain either man or beast in healthy condition. The Chenchu of the Guntur and Masulipatam jungles much resemble the Juanga in their habits, and the jungles of Malabar contain the Holier race, whose women, up till A.D. 1830, were in the practice of attending the market of Mangalore in similar vegetable costume.-Colburn's Journal, 1861.

JUBHA. HIND. A long outer garment, generally of cloth, worn by learned and respectable Muhammadans; it is a large wrapping gown, with sleeves, tight at the wrists, but wide above, open in front, and so wide as to admit of being. folded round the body, the one side lapping broadly over the other; it very much resembles the Persian 'barouni,' but in Persia is commonly made of coarser materials. The Khorasani jubha is most commonly made of brown or reddish-grey woollen, and frequently of camel's hair. It is a very good external covering, its close texture not readily admitting the wet, and in a great measure excluding the wind. In India, it is made of muslin, or cotton, or chintz.-Fraser's Khorasan, p. 266.

JUGAR, also Joojar'h. HrND. A monumental tablet raised by Rajputs to the memory of soldiers slain in battle. Colonel Tod, writing of one of these, says, His body was carried to Ranolli and burnt, and he had his cenotaph amongst the joojar'h of his fathers. At another place he says (p. 727), A humble altar of clay marks the spot where the brave Hara fell, having a tablet or joojar'h, representing a cavalier and his steed, armed at all points.-Tod's Rajasthan, ii. pp. $416,727$.

JUGGERNATH TURKOPUNCHANUM was Sanskrit tutor to Sir William Jones; compiled the digest of Hindu laws, under the patronage of Lord Cornwallis.

JUGGLERS. See Domba; Jatti ; Kollati (Khelati?); Modewar.

JUGGUT COONT, the point of land beyond Dwaraka in Kattyawar, the last stronghold of the Yadu race when their power was extinguished. It was at Juggut Coont, the Jigat Point of English maps, where the Badhail, a branch of the Rahtor, established themselves.-Tod's Rajasthan. JUGHI, Mezeng, and Luli are tribes classed as Musalmans in Bokhara, but they seem to be similar to gypsies; their women go unveiled, and the men are careless in their religious duties. Numbers of them are established at Bokhara and other towns as medical men, and telling fortunes, and horse dealing; such as lead a wandering life encamp in tents of a coarse cotton stuff called Bez. They have permission to halt near all the lakes and rivers of the khanate, whenever those places are not previously occupied by Uzbaks; in consequence of which a great number of them are dispersed along the banks of the Zar-afshan, near Samarcand, while others encamp in the neighbourhood of Karakul.

JUGLANDACE $\mathrm{E}$, the walnut tribe of plants, including many valuable timber trees. There are in the East Indies three species of the genus Juglans and three Engelhardtia, viz. E. Roxburghiana, Wallichiana, and Colebrookiana. J. arguta, Wallich, Theet-kya, BurM., grows in Burma; J. regia in Central Asia; Engelhardtia Roxburghiana in the mountains on the north-east of India, and E. Wallichii at Penang and Singapore. J. cordiformis, Maxim., a walnut tree of Japan. J. Sieboldiana, Maxim., a large walnut tree of Japan.

JUGLANS REGIA. Linn. Walnut tree.

Kas-shin, . . Внот.|Dun,. . . Kangra. Hu-t'au, Heh-t'au, CHIN. Ka botang, . . LADAKH.

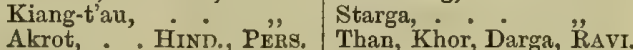
Charmaghz, ", " Ughz, Waghz, TR.-INDus.

J. regia extends from Greece and Asia Minor, over Lebanon and Persia, probably all along the Hindu Kush to the Himalaya, and is abundant in Kashmir, Sirmur, Kamaon, and Nepal; and J. arguta was found by Dr. Wallich as far south as Taong Dong.

It occurs wild in the Caucasus and N.W. Himalaya, and in Jalandhar is cultivated. The trunk of a very old tree is from 15 to 18 feet; wood hard, light, and strong, of a dark-brown colour, beautifully veined; receives a high polish, and is used principally for cabinet-making purposes, and for gun stocks; not subject to worms, nor liable to warp. The tree is found in the Sutlej valley, between Rampur and Sungnam, at an elevation of 7000 to 9000 feet. The fruit ripens well at Pangi, but not much higher; its pericarp contains tannic and gallic acid in abundance, and the nut is emulsive, and very rich in a valuable drying oil.

The husks and root of the walnut both yield a 
dye, which is much used by gypsies and theatrical performers for staining the skin brown. It is also used by cabinet-makers and joiners to stain white and yellow woods of a dark-brown or black colour, like that of the walnut. In the preparation of the dye from the husks, they should be allowed to rot, and then boiled in water, adding to the decoction fresh water, according to the colour required to be produced by the solution. The sap of the walnut tree contains a large quantity of saccharine matter; and in some countries the trees are tapped for the purpose of obtaining the sap, which by evaporation is converted into sugar. It is also, in many parts of Europe and Asia, fermented and made into wine, aud a spirit is also distilled from it. Cowley, in his Plants, sums up the virtues of the walnut in the following lines:-

' On barren scalps she makes fresh honours grow;

Her timber is for various uses good ;

The carver she supplies with useful wood;

She makes the painter's fading colours last.

A table she affords us, and repast;

E'en while we feast, her oil our lamp supplies.

The rankest poison by her virtues dies,

The mad dog's foam and taint of raging skies.

The Pontic king, who lived where poisons grew,

Skilful in antidotes, her virtues knew.'

Anglers employ an infusion of the leaves or husks for pouring upon the earth, in order to procure worms, which it speedily brings to the surface.-Royle's Ill. Him. Bot. 342 ; Voigt; Roxb. JUGLANS PTEROCOCCA. Roxb. Ta-sounglet-wah, BurM. This tree is found on the banks of the streams in the Pegu district, but is scarce; it is a hard, strong timber. Wood white coloured, adapted to every purpose of house-building.$M '$ Clelland.

JUGMUNDA, an island palace of Udaipur. During the mutiny, the Rao of Baidbah here gave shelter to 60 British women and children.

JUG-RAJ. Hind. Amongst the Hindus of India, the act of abdication confers the title of Jug-raj; or when they conjoin the authority of the son with the father, the heir is styled Jiva-raj. Four instances of this are on record in the annals of Bundi. Jug-rani, HiND., queen of the world. -Tod.

JUJUBE TREE, Zizyphus jujuba.

Unab (fruit), . . ARAB. | Liang-tsau,

Tsau, Ta-tsau, . CHIN. Kung-tsau,

Hung-tsau, . : ", Mih-tsau, Nan-tsait, ",

A tree of the south of Europe, Persia, China, India, and other countries, yields a wholesome fruit; preserved in syrup by the Chinese, after the surface has been scratched in numerous fine longitudinal lines.

JUKAN. PERS. A game of ball on horseback. The player, while riding at full gallop, has to catch up the ball from the ground with a bat, and send it in two strokes through two hoops affixed to poles, one behind the other. This game requires more activity than the Turkish game of jarid.-Vambery, Bokhara, p. 77.

JUL-JATRA. On the 14th (Sudi), or 29th, is a solemn festival in honour of Vishnu. It is called the Jul-jatra, from being performed on the water, Jul. The rana, chiefs, ministers, and citizens go in procession to the lake, and arlore the 'spirit of the waters,' on which floating lights are placed, and the whole surface is illuminated by a grand display of pyrotechny. On this day
'Vishnu rises from his slumber of four months,'a figurative expression to denote the sun's emerging from the cloudy months of the periodical floods.-Tod's Rajasthan, i. p. 598. See Jal.

JULO. BaluCH. The Bad-i-Simoom, or hot wind of the desert.

JULOSTYLIS ANGUSTIFOLIA. Thw. Kydia angustifolia, Arn. A middle-sized tree of the south of Ceylon, not uncommon.-Thu. p. 30 .

JULOTSURG, also written Jalotsarg, is a ceremony which is gone through when a pond, boali, or well is married. The only difference between this and the Bunotsarg is that the bride is personated by an image, instead of the tulsi.Elliot.

JUM, cultivation carried out on land cleared by buruing the forests. In Arakan, land cultivated with the hoe. The Kumari of S. India, and Cheena, is a mode of cultivation practised by the wild races in the forests of India. In the Cbittagong Hills, in the month of April, a patch of the forest is selected by the Jumahs, and cut down and cleared by burning it in May, after drying in the sun. The ground is sown, a house is erected, and the crops of grain, cotton, and tobacco carefully cleaned and watched. They usually move off to a new site next season.Mor. and Mat. Prog., 1868-69.

JUMA. ARAB. Friday, the principal day of religious worship among the Muhammadans, when they assemble at the mosque.

JUMMA MUSJID, in India, the common appellation of the principal mosque of a town. That of Debli, close to the Chandney Chowk, is built of great blocks of red sandstone, with three domes of white marble, and raised upon a terrace 50 feet high. It is a noble sample of Muhammadan architecture, and one of the grandest temples ever raised by man. It is the second most remarkable building in India, being next in rank to the Taj. Had it been wholly of white marble, the grandeur and effect would have been immeasurably greater; as it is, the red stone of the colonnades, and the pavilions, and the courtyard, and the gateways, seems to be a blemish in the design, though it may have been intended to set off more the beauty of the white marble of the mosque by contrast. It is the highest building in all Dehli, towering above every other object, and seen from every part of the city. The mosque itself rises on the west of the platform, indicating the direction of Mecca. In shape it is an oblong, 201 feet in lengtb, and 120 feet in breadth. The flags are about 3 feet long by $1 \frac{1}{2}$ broad, and their number is 900 , capable of holding 2000 persons. The Jumma Musjid was commenced in 1629 , and finished in 1648 . It is said to have cost ten lakbs of rupees.-Tr. of Hind. ii. p. 282.

JUMNA or Jamuna, a river of the North- Western Provinces and of the Panjab. It rises in the Himalayas, in the Native State of Garhwal, about 5 miles $N$. of Jumnotri, and about 8 miles N.W. of the lofty mountain Bandarpanch (20,731 feet), in lat. $31^{\circ} 3^{\prime} \mathrm{N}$, and long. $78^{\circ} 30^{\prime} \mathrm{E}$. The Jumna, at its source near Jumnotri, is 10,849 feet above the sea-level; at Kotnur, 16 miles lower, it is only 5036 feet; so that, between these two places, it falls at the rate of 314 feet in a mile. At its junction with the Tons it is 1686 feet above the sea; at its junction with the Asan, 
1470 feet; and at the point where it issues from the Siwalik Hills into the plains, it is 1276 feet. The catchment area of the Jumna is 118,000 square miles; its flood-discharge at Allahabad, 1,333,000 cubic feet per second; discharge per square mile of catchment area, 113 cubic feet per second. The Eastern Jumna (Jamuna) canal is an important irrigation work in Saharunpur, Muzaffarnagar, and Meerut (Mirath) districts, North-Western Provinces. The Western Jumna (Jamuna) canal is an important irrigation work in Umballa (Ambala), Karnal, Dehli, and Rohtak districts, Panjab. It takes its supply of water from the Jumna at Hathni Kund, on its western bank.

The spot where the Ganges and Jumna, sister nuddis (Greek Naiades), meet, makes a magnificent prospect. There is scarcely a lovelier spot than the prayag of Allahabad. The broad expanse of waters, the verdant banks, and the picturesque scenery, tell upon the mind, and fascinate the pilgrim. A special great mela is held here every year on the full moon in January,-Maghai Prayagai, as the common Hindu saying goes,and the holy fair lasts there about two months, and attracts people from far and near.

The Mesopotamia formed by the Ganges there, known as the Doab, is the Anterved of the ancient Hindus. From the narrow point in which it terminates, the valley broadens as it stretches away towards the west, embracing a greater and greater area between the Ganges and Jumna. The whole of its immense superficies forms a vast, populous, and busy hive, enriched by human industry, and embellished by human taste. It is thickly dotted with great townships and cities, and under the isun no country makes up such a highly interesting prospect of green fields, orchards, and gardens in a continuous succession. In this fair savannah were the cities of the preVedic Dasya races. Here rose the first cities of the Arya race. In the plains of the Doab, the rajas of Hastinapur, of Indraprasthra, and of Kanouj exhibited the highest power and splendour of Hindu sovereignty. The rich districts watered by the Ganges and Jumna have always tempted the avarice of the foreign conqueror. Here was the residence of the most famous Hindu sages. From this birthplace of arts and civilisation, wisdom travelled to the west. This Doab is the battle-ground of the Pandu against the Kuru, of the Ghaznivide and Ghorian against the Hindu, of the Mogbul against the Pathan, of the Mahratta against the Moghul, and of the British against the Mahratta, where many a spot is hallowed by tradition, and many a ruin is consecrated by history. In this Doab almost every inch of land is under the plough. From Allahabad to Sheeoabad, there are four large cities, and villages at frequent intervals. A similar distance in Bengal is no doubt dotted with the same number of villages, but has not one town equal to Futtehpur, Cawnpur, or Mynpori. Here the rural population is more intelligent and spirited than the same class in Bengal. The humblest Doabi lives upon better food, and covers his body with more abundant clothing, than the humblest Bengali. The cattle here are various. Camels, buffaloes, horses, donkeys, and oxen are all made to assist man in his labours. The fondness of the Doabi women for coloured millinery evinces a more cultivated female taste, and to them may remotely be traced the impetus which is given to the various dye manufactures of Northern India.

The Doab, like Bengal, is flat and alluvial. The vast plain is uninterrupted by a single eminence; the tall and robust figure, the firm step, the stern eye, and the erect bearing of the Hindustani are everywhere to be seen. In Bengal, the oxen alone form beasts of burden. A Hindustani coolie takes the load over the waist, and not upon the head. In Calcutta the Baboos do not know what it is to ride. In Hindustan rural women perform journeys on horseback, and princesses discuss the merits of horsemanship. The people of the Doab have for the most part wellformed features. The rude Jat, however, has a coarse, mean physiognomy. The Western and Eastern Jumna canals, of ancient construction, had fallen into disrepair, but were restored during the administration of Lord Dalhousie.-Imp. Gaz.

JUMNOTRI. Near this holy site of the Hindus is seen the junction of three streams. From the bed of the torrent the mountain rises at once to its height, apparently without any very extensive irregularities, and the steepness of the declivity at this point may in some degree be estimated, when it is understood that the avalanches from above fall into the channel of the river. The particular spot which obtains the name of Jumnotri is very little below the place where the various small streams, formed on the mountain brow by the melting of many masses of snow, unite in one, and fall into a basin below. The site is a place of pilgrimage to the Hindus, who perform ablutions at a small stream of warm water, of which there are several. One of them is too hot to allow of the hand being retained in it. The heights of several peaks are as under:Jumnotri, . 25,669 feet. Devadhunga, 29,002 feet. Nanda Devi, 25,598 " Kangchan,. 28,176" Dhonlagiri,. 27,600 " Chumalhari, 23,929 ", Gosain-thau, 24,700 "Fraser, Himalaya, p. 428.

JUMPING JOHNNY, the Boleophthalmus Boddærtii, is the leaping fish of the seas of the $\mathrm{E}$. Archipelago. These salamandrine-looking creatures are scarcely distinguishable from the mud on which they lie, but make a series of leaps on being alarmed. They are 3 or 4 inches long, wedgeshaped, with flat, pointed tails, head, and prominent eyes. They are called by sailors Jumping Johnnies. They leap by means of their ventral fins.-Collingwood.

JUMPTI, the state barge of the Amirs of Sind, an immensely long boat, some as much as 120 feet.-Postans' Pers. Observ. p. 128.

JUMRA. ARAB. Gravel or small stones thrown at pillars, representing the devil, in the valley of Mina.

JUMULMUDAGU, in lat. $14^{\circ} 50^{\prime} \mathrm{N}$., long. $78^{\circ} 30^{\prime} \mathrm{E}$.; here limestone occurs, with layers of muriate of soda.

JUN, a tribe in the waste tracts between the Sutlej and Indus. In the same locality are the Bhatti, Sial, Kurrul, and Kathi tribes. The Jun and the Kathi of Kattyawar are tall, comely, and long - haired races, who have vast herds of camels and black cattle, from which the towus are furnished with ghi or clarified butter, and the people themselves provided with libations of milk. The wild tribes of Chibh and Buhow in 
the hills of the Panjab, the Jun and Kathi, and the Dogher and Bhatti of the plains, have different characteristics, but the idle and predatory habits of some, and the quiet pastoral occupations of others, are equally the result of position as of character.-Cunningham's History of the Sikhs, p. 18. See Kathi.

JUNAGARH, Native State within the Political Agency of Kattyawar, in the province of Gujerat. Junagarb, lit. old fortress, a town with high land near, is on the coast of Gujerat, near Porbandar, and about 40 miles from Patan, and near Girnar. This ancient city is at the foot of and guards the sacred mount of Girnar. There is little doubt it is the Asildurga or Asilgurh of the Grahilote annals, where it is said that prince Asil, by the consent of his uncle the Dabi prince, raised a fortress called after him near to Girnar. It is now a large Muhammadan town with upwards of 20,000 inhabitants, and is the residence and capital of the nawab, a descendant of Sher Khan, Babi, a soldier of fortune, who seized it in the general anarchy which preceded the subversion of the Moghul rule. Twenty miles to the west are the ruins of Balabhipura. There is here an inscription on a rock with the Pali edicts of Asoka. It is in Sanskrit prose, but with grammatical errors and punning. It has the rock-cut palace of RahKhengar, with the caves of Khapara Kodia. When it was visited by Hiwen Thsang, there were some fifty convents (monasteries?), with about 3000 recluses, who followed the doctrines of the Sthaviru sect, which held by the (Mahayana) greater translation. Many of these convents have disappeared.

JUNCACE E. Agardh. The rush tribe of plants, found in moist places on the mountains of India. The common rush of Europe, Juncus effusus, is employed for making mats, baskets, and the bottoms of chairs, and its pith is employed for the wicks of rush-lights. According to Thunberg, it is cultivated in Japan for making floor mats. J. glaucus, a European species, is found in the Himalaya, and might be employed for all the purposes of the common rush. In China, Jerome observed a species of juncus, the stems of which are woven into beautiful mats, used by the natives for sleeping upon, for covering the floors of rooms, and for many other useful purposes. This is cultivated in water, somewhat like the rice plant, and is therefore always planted in the lowest part of the valleys. In the beginning of July, the harvest of this crop commences. -Illust. Himal. Bot. p. 401; Royle's Fib. Pl. p. 60.

JUNCAGINACE $\mathbb{2}$. Lind. The arrow grass order of plants. Potamogeton natans, $W$, the p'has of Sind, is the broad-leaved pond weed. P. pectinatum, $W$., also called in Sind p'has and jala, is common in ponds and tanks.-Murray.

JUND BADUSHTAR. ARAB. Castor, the dried Castoreum, obtained from the glands of the beaver, largely used in Hindu medicine, in hysteria and uterine ailments. In the living animal, the castor is nearly fluid, and in this state, as also when dry, it has a strong, penetrating odour.

JUNG. HIND., PERs. Battle, war; one of the titles of Muhammadan courts.

JUNGAM, the priest of the Lingaet sect, or Vira Saiva. In Southern India, one division of the Jungam worship one lingam, while the Panchabanjeka wanlu worship five lingams.
The Linga balja wanlu sect wear the lingam, the emblem of Siva, in a silver casket on their breasts, suspended from their necks.

The Jaloru balja wanlu wear the lingam on their right arm.

JUNG'HARA. HIND. A large and somewhat turbulent tribe of Rajputs of the Tuar clan, in the south-east of Rohilkhand, whence they appear to have expelled the Kut'herya. - Elliot's Supp. Gloss.

JUNGHIRA, a granite rock rising boldly from the river Ganges, between Rajmahal and Monghir. Since many ages it has been considered one of the most sacred places on the river, and Hindu devotees crowd to it on account of its reputed sanctity, and to worship at the shrine of Narayan in one of the pagodas.

JUNGIPORE is 21 miles from Sooty, where the Bhagirath branches off from the Ganges. The neighbourhood of Sooty is remarkable for the battle of Gheriah, fought between Ali Verdi and Sarfaraz Khan in 1740 . There was another battle fought here in 1763 between Mir Kasim and the British.

JUNGLE, Hind. ; A-yap, Burm, A forest, a scrubby forest, hence Jungli, wild, uncultivated, useless. The jungle in Africa is formed by dense and almost impenetrable gigantic grasses; in Australia by rich dense scrub of species of Eucalyptus, Melaleuca, etc., intertwined with scrub vine, a species of Cassytha; but the jungles of India are of bamboos, canes, and other palms, very difficult to penetrate.

\section{JUNIPER BERRIES.}

Hub-ul-huber, . . ARAB. Cocole-di-ginepro, . IT. Ab-hul, . . ..., Juniperus communis, LAT. Genever-bessen, : D’vт. Zimbro, . . . POR. Baies de genevere, .FB. Embro, : : . SP. Wacholder-biren, GER. Enbuske, : : Sw. Arkenthos, . . . GR. Ardich, . . . Turk.

The berries of the common juniper tree have stimulating and diuretic properties, and are used in the distilleries in England and Holland for flavouring gin or Geneva. The berries procurable in the Indian bazars are supposed to be brought from the Himalaya and Kābul. The berries contain sugar, mucilage, and a little essential oil. The oil is white or yellowish. It is prepared on a large scale in Holland, and is often adulterated with turpentine.-Faulkner, Ben. Ph.; Royle; O'Sh.

JUNIPERU'S CHINENSIS, Linn., grows in the Himalaya up to 15,000 feet, also in China and Japan. It grows rapidly, and attains a height of 75 to 100 feet, with a stem 13 feet in girth ; furnishes a reddish, soft, and fine-grained wood, and is perhaps the same as J. religiosa. - Royle; Mueller.

JUNIPERUS COMMUNIS, Linn., grows in Britain, Europe, and Asia. The two shrubby species, J. communis and J. squamata, are common in many parts of the Panjab Himalaya, from sometimes as low as 7000 to at times as high as 13,000 feet, and occur near the Safed Koh, TransIndus, often forming a belt, or more frequently patches, above the upper limit of trees, although seen at times very much below that. The common juniper was found by Captain Webb on Niti pass, called bilhara, pudma, pumaroa; and by $\mathrm{Mr}$. Inglis in Kanawar, 3 to 6 feet high, forming a dense, diffuse, irregular bush, occasionally tree- 
like, and attaining an elevation of 20 feet. Gin and Geneva are derived from the French name of this species, Genevère. The wood burns fairly well, and on the passes it is frequently the only decent fuel to be got within miles. Madden states that a spirit is distilled from the berries, with barley meal, the former being probably only added to impart a gin flavour. The berries are officinal in the plains, and are used in decoction, being considered stimulant.-Stewart, p. 223; O'Shaughnessy.

\section{JUNIPERUS EXCELSA. Bieb.}

Apurs, - Baluohistar. | Pencil cedar, . ENG. Shukpa, . . Chenab. Chalai, . . Jhelum Shur, : : ", Shukpa, . LADAKH, SPITI. Lewar (deodar), : ", Shurgu, . . . SutLeJ

The sacred juniper of the Kanawari and Tibetan is common in the upper and more arid parts of the basins of the Sutlej and Chenab, likewise in Ladakh, also in some numbers on the Kunhar, a tributary of the Jhelum, and near the Safed Koh (Bellew), and on Chahaltan (Masson, etc.). Cleghorn gives the crest of the Dhauladhar, above Kangra, as a habitat, which is perhaps doubtful, as the climate there is moist. The elevational range may be put at 8000 to nearly 15,000 feet. At the higher altitudes it is only seen as a shrub, but at 10,000 feet acquires a considerable girth. The timber, which has the same fragrance as that (also produced by a juniper) from which pencils are made, is light, and not strong, but is employed as supports for water channels, and the heart-wood when in moist earth is nearly imperishable. In Lahoul it is also used alternating with stones, for the walls of houses, as well as for beams. On the Sutlej some of the temples are built of it. In Kanawar, vessels made of it are much esteemed. The wood is used as incense by the Lamas. The twigs are used in several religious ceremonies, and the fruit is regularly burnt as incense. In Khagan, on the Kunhar, the small branches, under the name of Chalai ka dhup, are burned near the patient as a remedy for delirious fever. It is found in the Sutlej valley between Rampur and Sungnam, at an elevation of 9000 to 12,000 feet, and there yields an excellent, light, odoriferous wood.-Thomson; Stewart; Cleghorn; O'Shaugh.; Eng. Cyc.

JUNIPERUS RECURVA. Desv.

Khoubair, . . HIND. | Ubhul, . . HiND.

The weeping blue juniper and arboreous black one (called Tchokpo) yield beautiful wood, like that of the pencil cedar, but are comparatively scarce in Sikkim.-Hooker.

JUNIPERUS RELIGIOSA, Royle, grows at an extreme height on the Himalaya generally, and is held in reverence by the people.

JUNIPERUS SPHARICA. This curiouslyformed tree at first sight seems to confirm the old Virgilian tale of apples growing upon plane trees. It is one of those junipers which grow to a considerable size in the north of China, and which the Chinese are fond of planting round graves.-Fortune; Mueller.

JUNIPERUS SQUAMOSA, Creeping juniper. Beter, . . . HrND. Pama, Talu, . PANJ. Pethri, Bet'har, : ",

This is found at very high altitudes in the Sutlej valley, between Rampur and Sungnam, at an elevation of 12,000 to 13,000 feet, where forests disappear. It is used as firewood in crossing the high passes.-Cleghorn's Panjab Report, p. 63 .

JUNIPERUS WALLICHIANA, Hook. and Thom., grows in the Himalaya, from the Indus to Siklkim, at 9000 to 15,000 feet elevation. Mueller.

JUNIR is half-way between Nasik and Poona. It has a group of Buddhist caves, and one chaitya is like that at Nasik. They have no figures of Buddha, but one of Sri.

JUNK, a Malay word applied to the larger craft of the Archipelago, used both in war and for commercial purposes. The word is properly Ajong or Jong, corrupted by the Portuguese into Junco, which the English have improved into junk, and apply to the larger Chinese vessels. The Chinese word for the vessels called junk is Wang-kang. The word Ajong is used for boat by the Chinese and Malay. The ships known as cargo junk, called Ta hung t'ou yang ch'uan, are coasting craft of 1000 tons. They are built of soft wood, and have a flat bottom and a large rudder, which enables them to turn easily. The bow is very bluff, and the sterns are elaborately carved and painted. The hull is divided into water-tight compartments. They have four masts of hard wood. The two aftermasts on either side of the vessel are fastened together at the top by three spars placed horizontally. The low-dah or sailing master has a place beneath the poop. Junk are called Ch'ing t'ou chien ch'uan, Ch'ao-yang-pa-chiang-yuan-wei, Hsi ts'ao, and four others. - Crawfurd. See Boats.

JUNK SEYLON, or Salang Island, one of the islands of the Mergui Archipelago, and separated from the continent by Papra Strait. It is 8 leagues in length, and about 3 leagues broad. Its S. point lat. $7^{\circ} 46^{\prime} \mathrm{N}$., and long. $98^{\circ} 18^{\prime} \mathrm{E}$. It formerly belonged to the Malay raja of Queda, but it has since been forcibly occupied by the Siamese of Ligor. In the entrance of the Strait of Malacca, near the Nicobar and Acheen Islands, and betwixt them and Junk Seylon, there are often very strong ripplings, particularly in the S.W. monsoon. There is no perceptible current, yet the surface of the water is impelled forward by some cause. They are seen in calm weather approaching from a distance, and in the night their noise is heard from a considerable distance, alarming to persons unacquainted with them, for the broken water makes a great noise when the vessel is passing through it. They beat against a ship with great violence and pass on, the spray coming on deck, and a small boat could not always resist the turbulence of these remarkable ripplings. - Horsburgh

JUPITER AMMON, a temple, now in ruins, erected about B.C. 1800 by Bacchus, in memory of his father, in a fertile spot in Upper Egypt called the Oasis of Siwah, about 300 miles south of Cairo.-Catafago.

JURA or Joora. HIND. A rope of twisted grass or twine, made to support a round-bottomed jar. It is called also induri, endhua, chukwa, gururi, ginduri, and goduri.-Elliot.

JURDUK, a pass in Afghanistan, near which is Bahadur Khel. At Bahadur Khel, Lutumur, and Kharrah are the three Trans-Indus mines.See Khaibar.

JURI or Jooree, HIND., from Jorna, to join, 
a small bundle of sugar-cane. The tops of the Juri are brought home on the Ekadashee of Kartik, and are kept suspended from the roof of the house till the Holi, and burnt during that festival. Jora, a pair ; a pair of shoes, a married couple, a suit of clothes. Joru, a wife. See Dit'hwan.

JURZ or Juzr or Haraz, an ancient name given to Rajputana by the Arabs. The merchant Suliman, in A.D. 851, states that Haraz was bounded on one side by Tafek or Takin, which possessed silver mines, and could muster a larger force of cavalry than any other kingdom of India. Rajputana lies to the S.E. of the Panjab, possesses the only silver mine known in India, and has always been famous for its large bodies of cavalry.-Cunningham, Ancient Geog. of India, p. 312.

JUSSI. TAGAL. A delicate fibre of the Philippine Islands, of which dresses, etc., are made. Jussi fibre and striped jussi dresses from Manilla were exhibited in the Exhibition of 1851 ; the plant yielding the fibre was not known. -Royle, Fib. Pl.; Simmonds' Dict.

JUSSIEUA REPENS. Willde.

Kesara-dam, . BeNg. Bhuluvanga, . . SANsK. Nir-karambu, : C CAN. Langulae, : * : : T',
Kanchana, Kanchana, . Hind. Nir batsala, fo t in most parts of India floating on lakes and pools of fresh water; in flower during the rainy season. It floats by vesicles round the insertion of the alternate, obovate-cuneate leaves.

JUSSIEUA VILLOSA. Lam.

J. exaltata, Roxb., Rheede. J. suffruticosa, Linn. J. fruticosa, $D . C$.

Lal ban langa, . BeNG. Niru aghindra paku, TEL. Karambu,. . Maleal.

A perennial plant grows in Bengal, in both Peninsulas of India, and in Cochin-China. It is employed in medicine.-Voigt, p. $33 ; \boldsymbol{R} 0 x b$. i. p. 401.

JUSTICIA, a genus of plants belonging to the natural order Acanthaceæ; 32 species of Justicia were described by Dr. Roxburgh, a few only of which have any medicinal virtues attributed to them, and all but one of his, under the name Hwang-lien, Chis., are now referred to other genera. The roots of several species are used in China in medicine. A Canton species is stated by Fortune to yield indigo. Some of the species are planted as flowering shrubs.-Smith, M. M. C.

JUSTICIA COCCINEA bears a small pink flower. The leaves are of a reddish colour underneath. Natives say the root is an antidote to the bite of a snake, and it is sought after by them when bitten by the cobra.-Riddell.

JUSTICIA ECBOLIUM. Roxb.

$$
\text { J. dentata, Klein. }
$$

Oodoo jati, . . Beng. Jati, . . Hrnd. Tau-sa-lat, . BurM. Pachoha vadambaram, T. A shrubby plant common in most forests of India, and in flower nearly all the year. It is said to be diuretic. Flowers pale blue; tube very long and slender.-O'Sh.; Roxb.

\section{JUSTICIA NASUTA. Linn.}

Rhinacanthus communis, Nees.

Kabutar ki jar,

HiND.

A shrubby plant with white flowers in axillary and terminal panicles; grows spreading along the ground. The leaves are bruised and used by the natives for curing ringworm. The flowers are sold along with those of jasmine, and the roots are used in medicine as an excitant.-Riddell; Gen. Med. Top. p. 173.

JUTE, Corchorus capsularis; C. olitorius.

Ghi nalita pat, . BENG. Pat, Koshta, . HIND. Hei-ma, . . Chin. Bhungi, Isband, . ., Jews' mallow, . . ENG. Patta, . . . SANBr.

This fibre has long been known in India, as in use in the manufacture both of cordage and cloths, but only since 1855 largely used in England. It is the product of two distinct plants, Corchorus capsularia and Corchorus olitorius, both of them common all over India, Ceylon, and China, both cultivated for their leaves and under shoots as pot-herbs, and for their fibres; but the fibres of $\mathrm{C}$. fascicularis and $\mathrm{C}$. tridens are also used for making ropes. C. olitorius, the Jews' mallow, is supposed to be the plant alluded to in Job xxx. 4. From Guntur, in the Kistna district, to Ganjam, including Cocanada, Calingapatam, Chittavalsah or Bimlipatam and Gopalpore, the plant is cultivated to some extent, and manufactured by native weavers into ropes and gunny cloth for local use. The chief sites of its cultivation in the Bengal Presidency are Malda, Purniah, Natore, Rangpur, Dacca, Pabna, Dinajpur, Hoogly, Bogra, Julpigori, Serajgunj, Mymensing, and the Twenty-four Parganas.

Formerly indigo was largely grown in many of the Dacca districts, which still abound with ruins of deserted factories, but its place has been taken by jute, the cultivation of which has iucreased enormously, and now engages a large share of European capital. The great jute mart is Serajgunj, the trade of which place might well excite the envy of most Mediterranean ports. During the busiest season, the river, then swollen by the rains to a breadth of 7 miles, is simply covered with the vast lumbering country boats that are bringing the fibre from the local marts to the great commercial centre, and the sight of many steamers, and the ceaseless whir of machinery from the factories, might almost make a stranger think himself in some commercial city of the north. Besides jute, safflower and mustard are largely grown for exportation.

The first 100 tons of jute, and a small quantity carefully prepared by Dr. Roxburgh and sent home, appear to have drawn the attention of the mercantile community of London to this important fibre; but it was not until 1804 that any recognised trade sprang up, although it is certain that for some years previously it had been exported under the name of hemp and flax. From that date the shipments slowly increased. In 1829 a separate head was assigned to it in the Custom House records, when 496 maunds were exported, which increased to 2442 maunds in the following year. Since that time it has gone on increasing steadily year by year.

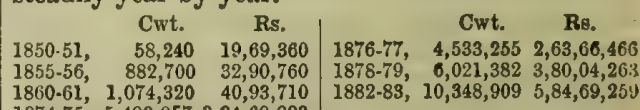
1874-75, 5,493,957 3,24,68,823

And in the last-named year the value of exported gunny bags, gunny cloths, gunny rope and twine, was Rs. $1,48,78,304$.

Eight jute spinning companies in Bengal were quoted in May 1884, of which the shares of two were above par.

The weaving of jute into gunny cloth is an 
indigenous handloom industry in Northern Bengal, chiefly in the districts of Purniah and Dinajpur. The gunny is made by the semi-aboriginal tribe of Koch, Rajbansi, or Pali, both for clothing and for bags ; and, as with other industries practised by non-Hindu races, the weavers are the women of the family, and not a distinct caste.

Jute is used for coarse bags, and such purposes where the strength and colour of the fibre is not important. It can be produced at a very cheap cost ; the cultivation of an acre of jute is estimated at Rs. 10 for the labour, and about half a ton of fibre is the usual crop; while by the retting process one man can prepare for market about two cwt. of fibre in the day. For the more valuable fibres this retting process is not available; a man can prepare only 5 to $12 \mathrm{lbs}$. of rhea or Manilla hemp fibre in a day by hand-scraping, while the waste is enormous. For the valuable fibres strength and brightness of colour are essential, and the ordinary process of retting or fermentation in stagnant water cannot be followed.

The mills of Dundee consume a larger proportion of this useful fibre than any other in Great Britain,-it is believed nearly one-half of the quantity imported; and yet its introduction in the trade of Dundee is, comparatively speaking, of recent date. About 1830, a well-known merchant brought a small quantity, and wished the spinners to make a trial of it, but he could not prevail upon them to do so. He then employed a person in the neighbourbood to tease it down, at the now fabulous cost of from $£ 4$ to $£ 5$ per ton, and then induced a spinner to mix it sparingly amongst tow; but it was not till the expiry of years that it was manufactured to any extent by itself. A process was subsequently invented by Mr. Clausen (a Dane), by which flax, hemp, jute, and other substances were converted into a substitute for cotton. The invention seemed to work well, but the Manchester people at that time would have nothing but American cotton on any terms, and the invention fell valueless. $\mathrm{He}$ cleaned the fibre from the straw by crushing and beating. The fibre was then steeped in a strong solution of bicarbonate of soda, and afterwards in water acidulated with sulphuric acid, which, combining with the soda, set free the carbonic acid with which the fibre was saturated. The liberated gas split the fibre into a material as fine as floss silk. It was then bleached by being steeped in a solution of chloride of magnesium, then dried and cut into lengths of the required staple, or rather longer, as the staple was ground down during the carding. It then passed to the carding machines, and was treated precisely as cotton, and it was said at the time that it worked perfectly in the ordinary cotton machinery. Jute is easily spun, and is much used to mix with codilla. It is made into gunny cloth (megili), cordage, and paper, and damask cloth made of jute is said to be more durable than that fabricated from cotton. The fibres are subdivisible into very fine fibrils, which are easily spun; they are long, soft, and silky, and, under the microscope, cannot be distinguished from those of flax to all the purposes of which the jute fibre is applicable.

At Dundee the yarn is spun very fine, and used for bags and handsomely-coloured carpets, and also interwoven with silk, linen, and woollen threads into cheap cloths, and it is largely made up into paper. An old papermaker writes in the American Paper Journal, that after several years' experience in using bagging and jute in all its various forms, he is satisfied that it is the cheapest, cleanest, and easiest wrought of any substitute for rags, and possesses the desirable qualities that give to the manufactured article all the qualities of rag-paper, at much less waste and cost. The cuttings and rejections can be reduced by boiling with lime into matter as easily operated on as ordinary rags, and more easily bleached than many of the imported rags.

In its culture the land is prepared as for rice, the plants are weeded when a foot and a half high, and it is cut close to the roots when it has flowered, and before the seeds are ripe, a few plants being left to allow the seeds to come to maturity.

After the Corchorus olitorius plants come to maturity, which is generally considered to be the time when they begin to ripen seed and the lower leaves in the stems begin to turn jellow, or about the second week in October, the whole are simultaneously cut down, - no matter if all have grown uniformly in size or not, or whether the plants be good, indifferent, or bad, the whole is reaped off. After the whole is cropped off, it is staked in bundles of about 200 to 250 sticks in each, and then put down in any convenient place to undergo the process of fermentation, which is generally done within three or ten days, according to the temperature of the weather. The stalks are then immersed in water, keeping the bundles down by any convenient means at disposal, but it is chiefly done with clods of earth, which are most conveniently obtained. The steeping process, if performed in a stagnant pool or pond, decomposes the vegetable matter within eight or ten days, but if it be done in clear water, or a running stream, or in a tank of ordinary depth, having clear water, then the period of time is about seventeen to twenty days. When decomposition approaches completion, a man generally goes down and examines the fibres once a day, and at its close both morning and evening, to see if all is perfected, and this is done by simply feeling the stalks with the thumb and forefinger, to which it readily yields. When the whole is known to be completed, he goes down about knee-deep in water, and takes a handful of the stalks, holding the same with his left hand over the surface of the water, and in his right hand holding a small palmata or a piece of flat wood or plank, with which he gently strikes towards the stem of the stalks, and whilst he does so he whirls the whole, repeating the strokes with the palmata as he does so, which at once separates the fibre from the stalk, or as much of the parts as is struck, which is generally from 15 to 18 inches in length from the lowest end ; the whole is then broken, the parts adhering with fibre are then held with the left hand, and with the right the part where the stalks are broken is held, and the whole immersed perpendicularly about 9 or 10 inches in water, and a few jerks are then given in rapid succession, which admits of complete separation of the fibre from the broken stalks; but if any still adhere, the same is gently taken off with the right hand. When this is done, the extracted fibre is then held with the right hand, wrapping a portion round the palm of the hand, 
and with his left the operator holds the stalk a little under water parallel to him; he again gives a few slight jerks from and towards him. He also uses his left band in pushing the stalks forward when drawing towards him. This manipulation can only be done with facility by those who are used to it. The whole of the fibre at once easily separates from the entire stalk and immediately floats up ; the fibre is then washed to take off its refuse, and the whole is then wrenched off, and taken up to be dried in the sun.

The quantity of jute and seed produced on an acre depends greatly on the richness of the soil on which it is planted. The plant will not thrive on a lateritic, or on a hungry, gravelly, or sandy soil. Seed planted under such conditions springs up and grows well at first, but for want of moisture and plant-food soon withers away. The plant stands excess of wet better than drought; on rich, loamy lands it thrives perfectly; clayey soils, mixed with a little sand, give a fair return, and even under the conditions of partial submersion the crop is not destroyed.

The same crop will not, of course, yield fibre and seed. It should be cultivated for one or the other. For the former, the plant should be cut just when it is in flower. It is then in its prime, and the fibre will be fine, silky, and glossy; but if left for the seed to ripen, the plant will have begun to decay, and the fibre to get stringy, barky, and coarse.

The seed would be better if sown in drills, as is done in America and in Mysore. It would enable manuring, weeding, planting, and thinning to be carried on better, and a longer and better fibre would probably be the result, and induce more attention to be paid to the growth and selection of seed, on both which points the ryots are said (as may be easily supposed) to be most careless. A commission suggested improvement in this matter, and in the better rotation of crops, and cutting and steeping the fibro, preparatory to its extraction; but the addition of suitable manure, all other conditions being favourable, would enable a farmer to grow the exhausting crop on the same soil annually without alternating it, or letting the land be fallow, as is now so uneconomically done.

It is now successfully grown in America, where a better mode prevails of clearing the bark, and paper is there made of the refuse, which is also a good manure. Jute water has a high value as a manure. Castor-oil cake and cow-dung are its best manures. It has been found that jute does not flourish in the cotton districts of the United States, nor does cotton where jute grows best.

No doubt the fibre can be greatly improved by attending to some essential points. Higher prices would be given for the best kinds that had been cut at the proper time, and carefully cleaned and dried, so as to produce the strength, fineness, silkiness, and gloss so much sought for.

To improve the jute fibre, two things are necessary to be looked after; the first is the process of fermentation, and the second is allowing the time for decomposition of the vegetable matter, and to avoid stagnant pools and ponds for the purpose, which, though it facilitates the object, injures the fibre very much. The process of fermentation is necessary to be carefully looked after, because if this be neglected, instead of obtaining the fibre with a fine, silky, glossy appearance, the whole of the produce becomes of a dark lead or black muddy colour, which is considered bad or inferior in quality.

The next point to be carefully attended to is the time allowed to steep the whole for the purpose of permitting the vegetable matter to decompose ; this part of the process, unless properly attended to, does not yield fibre of the usual size, but results as an inferior article, because it yields fibre of a coarse quality. The tender fibre, which otherwise is retained, rapidly decays, and is broken into threads and washed off when extracting the fibres from the stalk. When the bundles are steeped down after the fermenting process, they should be so arranged that the stems are first immersed in water with the top branches above its surface, and allowed to remain for a time, which is considered as sufficient for the stems to be partially decomposed, when the whole is properly steeped down, for the entire stalk to be decomposed at the same time. If this be not attended to, as stated above, the result is a short and coarse fibre, without any silky, glossy appearance.

The next point is to avoid pressing down the bundles with clods of earth, as at the time the decomposition is about to be perfected the mineral substances, being washed down, mix with the fibre, destroying the vegetable substance, and giving the fibre a red, muddy appearance. Stagnant tanks are likewise to be avoided for the impurities they contain, though the decomposition is much facilitated. Native cultivators can rarely avoid these two injuries for want of means and proper resources; but if they be avoided, no doubt the fibre extracted will yield a superior texture.

It was in 1870 that the United States Department of Agriculture began to show an interest in the question of growing Indian jute upon American soil. Experiments were conducted in Louisiana and other Southern States, with encouraging results. The climate and soil proved to be well adapted to the growth of jute; and it was found that, when planted around cottonfields, the jute was of great service in affording to the cotton plant protection from the ravages of insects; while a most luxuriant growth could be obtained on rice and pine lands.

Notwithstanding, however, the success which has attended the cultivation of jute in America, it has made no perceptible difference in the Indian trade, unless, perhaps, in the matter of gunny cloth. During the last eight years the export business with the United States in raw jute and gunny bags, more especially in the latter, has progressed most satisfactorily. Although the cultivation of jute has passed out of the experimental stage in America, the product has not been able to compete successfully with the Bengal article, owing to the high cost of manual labour employed in the separation of the fibre from the stalk, as compared with the cheap labour available in India. The great need is a cheap and effective mechanical process for this operation. The want of a really good machine for such a purpose is felt very much more in America than in British India, where the manual process of cleaning and preparing the fibre is simple and inexpensive. The plants are steeped in water until the bark 
begins to rot and the resinous substance in it is washed away. The bark is then stripped off by beating the stalks against the surface of the water, much in the same way as a dhobi washes clothes. Experiments have been tried, both in India and America, with machines for performing this operation, but the difficulty lies in the expense. From a report, dated Washington, 7th April 1881, which is to be found in the Calcutta Gazette of the 19th July, on the cultivation of jute and other fibrous plants in the State of Louisiana, it appears that a new machine for preparing jute and rami fibre has been invented in America, from which very profitable results are expected.-Imp. Gaz.; Dr. Hunter in Ed. New Phil. Journ. No. 2, x. October 1859; Dundee Advertiser; Annals Ind. Administration; Royle's Fibrous Plants, p. 244; J. Manuel in Indian Field, No. 25, 18th September 1858; Selec. Records Government of India Foreign Dept. No. 9, p. 25; $M^{6}$ Culloch's Commercial Dictionary, p. 401 ; Drs. Mason, Stewart, Royle ; M. E. J. Rep.

JUTIAL, a class of watchmen introduced into the hills near the Bhabar to watch the district under the Siwalik.

JUTTEEL, a pass in the Sind ranges, runs 60 to 75 miles south-west from Sehwan to Dooba, between lat. $25^{\circ} 32^{\prime}$ and $26^{\circ} 20^{\prime} \mathrm{N}$., and long. $67^{\circ}$ $48^{\prime}$ and $68^{\circ} 8^{\prime} \mathrm{E}$. Steep, in few places, less than 2000 feet. The road from Sehwan to Kurachee lies between them, and Keertar more to the west.

JYOTISH MATI, HIND., is the Anthistiria anathera or Cardiospermum halicacabum. Jyotish mati, literally light possessing, also Budha basara and Budha kakara, TeL., is Cardiospermum halicacabum, Linn. Popular superstition asserts that by eating its seeds the understanding is enlightened, and the memory rendered miraculously retentive.-Elliot's $\mathrm{Fl}$. Andh.

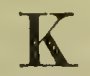

This letter of the English alphabet has a simple guttural sound, as in kalendar, keep, king, Koran, and has analogous letters in Arabic, Persian, Urdu, Sanskrit, Hindi, Mabrati, Gujerati, Bengali, Uriya, Telugu, Karnata, Tamil, Malealam, Chinese, Malay, and in all the languages of the Further Indies and Eastern Archipelago, and there ought not, therefore, to be any variations in representing the names and words of these tongues by means of this letter. Nevertheless, in writing them, owing to the English letter $\mathrm{c}$ as in candour, capture, and the letters ch as in character, chronic, churtish, having the same sound as k, many ordinary words of the East Indies are met with written in various ways, as in Cashmir, Kashmir, Kābul, Cabul, etc.

KA, a people inhabiting the mountainous country lying between Lao and Kambojia. Mr. Crawfurd mentions that the Siameso made no scruples in reducing them to slavery. He adds that the features of one whom he saw differed strikingly from those of a Siamese. They are described by other authors along with the Khong, the Gueo of the Portuguese, as rude tribes in Kambojia either actually pagan or imperfectly Buddhist.—Crawfurd's Embassy, p. 177.

KA, SANSK., the interrogative pronoun 'who,' 327 ; Lane. raised in the mythology of the Kanshitaki, the Satapatha, the Taittiriya, and the Tandya Brahmanas to the dignity of a prajapati. $\mathrm{Ka}$, the sign of the genitive in Hindi ; in Marwari it becomes ra.-Dowson.

KAAT, properly Kat'h. Can., Maleal., Tam. Wild, uncultivated. See Kat'h.

KA'B, a tribe of Arabs near the Persian Gulf, whose capital is Muhamerah. They extend north as far as Shuster and Ram Hormuz; to the east their territory is limited by Bebehan, and including Hindyan in their possessions, the Ka'b Arabs spread along the head of the gulf, touching Basra on the south. Their western territory touches on the wandering Arabs as far as Haniza. The greater part of this territory is watered by the Tab river with its numerous tributaries, and was known to Arab geographers by the name of Daurak. About the close of the 18th century they captured several English vessels. More lately, Muhamerah was taken by Ali Raza Pasha, and in 1857 by the Government of India in their war with Persia. See Fars.

KABA, a former piratical tribe in the Gulf of Cutch, to the north of the Mahratta provinces.

KA'BA. ARAB. A cube; also the square building in Mecca, held in reverence by Muhammadans, by whom it is frequented in pilgrimage. Tibban Asaad Abu Kariba or Abu Karib, commonly called Tobba, one of the most warlike of the Himyarite monarchs, was the first who, about A.D. 206, covered the Ka'ba with a tapestry of leather, and also supplied it with a lock of gold. The nawabs of the Carnatic, who claimed to be descendants from the khalif Omar, sent a ladder of gold for the pilgrims to ascend to the door of the Ka'ba. Immediately on arrival at Mecca, the pilgrims perform ablutions and proceed to the mosque, kiss the black stone, and encompass the Ka'ba seven times; commencing on the right, leaving the $\mathrm{Ka}$ 'ba on the left, they perform the circuit thrice with a quick step, and four times at a slow pace. They go then to the stone near the $\mathrm{Ka}$ 'ba, bearing the impression of the feet of Abrabam, repeat two prayers, and come and kiss the black stone again. In the Arab families, male children, when forty days old, are taken to the Ka'ba, prayed over, and carried home, where the barber draws with a razor three parallel gashes down the fleshy portion of each cheek, from the exterior angles of the eyes almost to the corners of the mouth. These Mashali, as they are called, may be of modern date. The Ka'ba is 24 cubits long from N.W. to S.E., its breadth 23 cubits, and its height 27 cubits; near its door in the east corner is the black stone, Hajr-us-Siah. This is set in silver, and is kissed by pilgrims. It seems to be the stone noticed by Maximus Tyrius, who says 'the ancient Arabians worship I know not whom, but the image I saw was a quadrangular stone.' Until Mahomed's reform, the Ka'ba contained 360 idols, amongst them Hobal, a statue of Abraham, and one of Mary; the white stone, which was supposed to be Ishmael's tomb, and the black stone, the Hajr-usSiah, which they say fell from heaven in Adam's time. Hobal had the figure of a man carved in red agate, and holding in his hands seven wingless arrows like those used in divinations. The Ka'ba was restored A.D. 1627.-Burton's Mecca, iii. p. 
KABAB? PHILIP. A measure of capacity.

KABAB. ARAB, Roast meat, or small pieces of meat roasted or stewed on little skewers. They are alluded to in Homer's Iliad in two places, xiv. 87 , and line 475-

\section{'Fixed on forks of wood,}

All hasty, on the hissing coals he threw ;

All smoking, back the tasteful viands drew, Broachers and all.

In rolls of fat involved without

The choicest morsels lay, from every part,

Some in the flames, he strewed with flour, then threw; Some cut in fragments, from the forks they drew.'

Kabāb curry is a favourite dish at the tables of Europeans in India, and consists of little pieces of meat with portions of onions, ginger, etc., on skewers. Kabab are generally, in India, spitted on little slips of bamboo, though silver is often used.

$\mathrm{KABAIZ}$, a tribe of the Bulbassi, a Kurd race, composed of the Kabaiz, the reigning family ; 2 . Manzur ; 3. Mamash; 4. Piran; 5. Rummuk; 6. Sinn and Taafah, who together make one tribe.

KABAL, HIND., of Muzaffargarh, the reticulum of the palm.

KABALA. Hind. A bill of sale.

KABAL KHEL, a wild, lawless section of the Utmanzai Waziri, with three subdivisions, Miami, Saefali, and Pipali, numbering 3500 fighting men. Between 1850 and 1854 they committed over twenty petty raids on British territory, and the British blockaded the whole tribe.

KABAN, a measure of capacity in the Molucca and Philippine islands.

KABANDHA, a disciple of Sumantu, the earliest teacher of the Atharva Veda.

KABAR. Hind, Black soil.

KABAR. ARAB. A tomb. Kabaristhan, a burial-place; also called Rozah, a garden; also Jai Khamush, the silent abode.

KABARAGOYA, a species of Monitor, a reptile of Ceylon, partial to marshy ground, and when disturbed upon land it takes refuge in the nearest water. From the somewhat eruptive appearance of the yellow blotches on its scales, a closelyallied species, similarly spotted, formerly obtained amongst naturalists the name of Monitor exanthematicus, and the Singhalese word Kabara has a similar meaning. The kabara-tel or cobra-tel is said to be prepared from the kabaragoya; and an individual suspected of having this poison in his possession is cautiously shunned by his neighbours. In the Mahawanso, chap. xxiv. p. 148, the hero Tissa is said to have been afflicted with a cutaneous complaint which made his skin scaly like that of the godho, the Pali name of the kabaragoya.-Tennent's Ceylon, p. 272.

KABIL. Arab. A name of Cain. KabilHabil, Cain and Abel. The Cain of the Bible is supposed to have been buried at Aden under the mountain Jabl Shamsham.

KABILA. ARAB, A term employed in Arabia and Northern Africa to designate the various tribal bodies. From Taifa to Medina there are ten such, with about 79,000 fighting men; those of Assir, 6 in number, with 44,500 fighting men; those of Taif, at Assir, 11 in number, with 66,000 . The term Kabylah, amongst the Mubammadans in India, is applied to the family or to the wife of an individual._Fontanier, India, etc. See Kabyle.

KABIR, the most celebrated of the twelve disciples of the Hindu reformer Ramanand. $\mathrm{He}$ lived at the beginning of the 15th century (13801449). He assailed the whole system of idolatrous worship, and, in a style peculiarly suited to the genius of his countrymen, he ridiculed the learning of the pandits, and doctrine of the Shastras. The Bhakta Mala gives an account of his birth and life. His doctrines are contained in the Sükh Nidan, and do not differ much from those of the modern Vaishnava sect. The moral code is short, but favourable to morality.

Kabir was equally revered by Hindus and Musalmans. He was the founder of the sect called Kabir Panthi, or Nanak Panthi, from which Nanak, founder of the Sikh, borrowed the religious notions which he propagated with success. Kabir is said to have been a weaver, or a foundling reared by a weaver, and subsequently admitted as a disciple by Ramanand. Another account makes Kabir \& Muhammadan by birth, and a weaver by profession. Kabir is also fabled to: have been the son of a virgin widow of a Brahman. Her father was a follower of, and was paying a visit to, Ramanand. Unaware of her condition, Ramanand wished her to the conception of a son, which occurred, but, ashamed of her condition, she bore the child in private and exposed it, but it was found and brought up by a weaver and his wife. His religious views are very obscurely laid down, but the latitude of usage which he sanctioned, and his employment of a spoken language, have rendered his writings extensively popular among the lower orders of Northern India. His disciples may be either Muhammadans or Hindus. On his death, the Muhammadans claimed a right to bury him, the Hindus to burn him, in consequence of which they quarrelled, and placed a sheet over the corpse, which when they withdrew, according to a legend, they found the upper part of his body to be metamorphosed into a tulsi plant, the favourite nymphr of Krishna, the lower part into rehan, an odoriferous herb of a green colour, the colour of the prophet Mahomed. Kabir is said to have been originally styled Inyani, the knowing or wise. He died at Magor, near Gorakhpur, which was endowed by Mansur Ali Khan with several villages. Kabir's doctrines and fame attracted the attention of Sikandar Lodi, emperor of Dehli.-Wilson's Hindu Sects.

KABIR PANTHI, a sect of Hindus whose founder was Kabir, the disciple of Ramanand. The Kabir Panthi are always included amongst the Vaishnava sects, and maintain friendly relations with these. It is no part of their faith, however, to worship any Hindu deity, or observe any of the rites or ceremonials of the Hindus. The Kabir Panthi are numerous in all the provinces of Upper and Central India. Their quakerlike spirit, their abhorrence of all violence, their regard for truth, and the unobtrusiveness of their opinions, render thein very inoffensive members of the state. Their mendicants never solicit alms, and in this capacity they are, in a social riew, in a very favourable position compared with many of the religious vagrants of India. The Kabir Panthi use no mantra or ritual, and those who have abandoned society abstain from all outward observances, and address their homage, by the chanting of hymns, exclusively to their invisible Kabir.

The chief guru of this sect liver in Kawarda, 
a town of the province of Ch'hatisgarh, where a third of the Hindus are followers of Kabir, but the principal mat'h is at Benares. Kabir Panthi have five commandments, - (1) Life must not be violated, - it is the gift of God; (2) The blood of man and beast must not be shed; (3) Man must not lie; (4) Must practise asceticism; and (5) Obey the spiritual guide.-Wilson's Hindu Sects.

KABLAI KHAN, emperor of the Chinese and eastern oriental Tartars, was the sovereign of the most enormous empire that the annals of the world have ever made known. It comprehended the whole of China, Corea, Tibet, Tonquin, Cochin-China, a great part of India beyond the Ganges, many islands of the Indian Ocean, the whole north of the continent of Asia, from the Pacific to the Dnieper; Persia also was a feudatory of his throne, its sovereigns, the successors of Hulaku, receiving their investiture from the omperor of China; and as the dominions of these great vassals extended to the Mediterranean and the frontiers of the Greek empire, it may be said that the whole of Asia was subject to the laws of the Great Khan, who had chosen Pekin as the central seat of his government. The empires of Alezander the Great, of the Romans, or even of Chengiz Khan, were as nothing compared with that of Kablai Khan. Kablai Khan had received a Chinese education; he appreciated the advantages of civilisation; he admired the institutions of China, and protected literature and the sciences. He had some of the best Chinese books translated into the Mongol language; he founded schools for the young people of his own country, and gave much encouragement to their studies. He received with favour learned and literary men of every country and religion, granting them many privileges, and exempting them from taxes and tributes. It was he who established the Han-lin college, the highest academical institution of China. He was assisted in improving the astronomical calculations of the Chinese by Arabian and Christian astronomers. Some Christian families were fixed by him in the city of Pekin, and many Greeks, who had followed the Mongol armies, were retained in his service as men whose attainments were much superior to those of his Tartar and Chinese subjects. Pekin was at the same time raised into an archbishopric by the Patriarch of Baghdad and the Roman pontiff; embassies and unissions passed into Tartary, and the Mongol sovereigns of China afforded their protection to every stranger whose talents might be useful to the state. Arghun Khan was Kablai Khan's great nephew. His wife was Zibellina, the Khatun Bulugan, a lady of great beauty and ability. She had been married to Abaka, but, on his demise, according to the marriage customs of the Mongols, she passed to the Urda of her stepson Arghun. On her death, Arghun sent Marco Polo for another wife, out of the Mongol tribe of Bayaut, but Arghun died before the lady, KukaChin, was brought, and she passed to Ghazan, the nephew of Arghun, for Arghun had been succeeded by Kai-Khatu, his brother.-Quart. Rev., July 1868 ; Huc's Christianity, i. p. 320 ; Chatfield's Hindustan, p. 298.

KABLI-GERU or Kabl-Giri, a race occupying the banks of rivers in the Dekbau, employed as ferrymen.

KABONG. Malay. Any palm, ns the cocoa- nut palm, the Cycas circinalis, the gomuti palm, or Arenga saccharifera. The last is cultivated for its sap to make jagari or coarse sugar, and for its strong fibre.

KABOOK. Singh. Lateritious deposit, in Ceylon said to be the product of decomposed gneiss.

$\mathrm{KABUL}$, the name of a city and a river on the N.W. borders of British India, under the rule of the Barakzai clan of Afghans. The origin of the name Kābul has not been traced. It is not mentioned by any of the Greek or Roman writers, who were familiar with the Aria territory of which Herat is the capital; with Ariana, the general name of the country east of Persia and Media, as far as the Indus; with Bactria, the country watered by the Oxus and its tributaries, and Sogdiana, the mountains which feed the Jaxartes and divide the two rivers. Mr. Masson derives its name from Kapila, a city ruled once by a prince Kanishka.

It is built directly under a rocky hill of gneiss that rises 1000 feet above it, and bends round it from the south-east to the south-west, where, with the dip of another hill opposite, is formed a pass which leads into Char Deh, 150 yards broad. At the eastern extrenity of the rocky hills which enclose it on the south is the Bala Hissar, on a neck of land about 150 feet high, which commands the city.

The Bala Hissar comprises two portions,-one is the Bala Hissar Bala, or upper citadel, and the Bala Hissar Pahin, or the lower fortress. The defences of the Bala Hissar are connected with and form part of those of the city, over which it dominates. There is a large open space in the centre, containing the Amir Mahal, with gardens and other places necessary for a chief's residence.

Witbin the Bala Hissar also are two wells lined with masonry, having been used as state prisons, and receptacles for the corpses of those executed or murdered for political purposes during the stormy periods of Kābul history. On one of the higher points of the Bala Hissar there are two blocks of hewn marble, called Takhts or thrones, as they have on each side a flight of three steps for ascending to sit upon them. The Bala Hissar Pahin contains about a thousand houses. It is also divided into its mahalas, or quarters. One is called the Mahala Araba, from an Arabic population; another is the Maliala Habashi, from its inhabitants being the descendants of Negroes; and another is the Mahala Armani, from its Armenian residents. These tell something of the very great variety among the dwellers in Kābul.

Both in a military and commercial point of view, Kābul possesses many advantages. The emperor Baber vaunts the commercial value of the city, and the consequent resort to it of the merchants of all countries, and the display in its markets of the fabrics and produce of all climes.

The secretary to Akbar the Great, writing in the Ayin-i-Akbari, says, 'Kābul is the gate of Hindustan towards Tartary, as Kandahar is towards Persia, and if both places be properly guarded, that extensive empire is safe from the irruption of foreigners. According to the Indians, no man can be called the ruler of Hindustan who has not taken possession of Kābul.'

The eminent advantage possessed by Kābul is 
that of locality, happily situate between India and Central Asia, lat. $34^{\circ} 30^{\prime} \mathrm{N}$., long. $69^{\circ} 5^{\prime} \mathrm{E}$.g at the gorge of the nearest and most practicable passes between the two countries. It is 88 miles from Ghazni, 318 miles from Kandahar, 103 miles from Jalalabad, and 190 from Peshawur. The southern parts of the city are supplied with water from a canal called Bala Jui, which is brought from the river at its entrance into the plain of Char Deh, and is carried on the western face of the hill Koh-i-Takht Shah.

The city is situated at the western extremity of a spacious and fertile plain. It lies in a triangular gorge, formed by the approach of two ranges of hills, which, running from the north and east, meet at the south-west corner of the city. A narrow gorge separates these hills, and through it dashes the Kābul river, bearing away to the north-east; while by its side runs the high road from Kandahar and Ghazni. The range which runs to the south of the city is only separated from the ruins of the old walls by a narrow path. These hills are steep, bare, and rugged, terminating in a commanding eminence, which dominates the south-eastern corner of the city, and on the slopes of which rise the walls of the Bala Hissar. 'The Kābul river is spanned by a bridge at the gorge which separates the two ranges, and on its left bank the hills trending away to the north-west join in with the lower spurs of the Hindu Kush. Along the crest of both ranges, starting from the Bala Hissar, and conforming to the configuration of the ground, runs a long line of loopholed wall, flanked at short intervals by round towers. This wall is carried up the steep side of the hills and across the narrow gorge which lies between them, and well round the western flank of the city. The town formerly was encircled by ramparts built partly of burnt bricks and partly of mud. It is said that the walls fell into disrepair in the reign of Timur Shah. About the year 1773 this monarch transferred the seat of the Daurani government from Kandahar to Kābul, and from that date the importance of the place largely increased. Prior to the visit of Nadir Shah, the population of Kābul in all probability did not exceed 20,000 souls; but on his death large numbers of foreign tribes domiciled themselves in the place, and their descendants now represent several thousands of people. The houses are slightly and indifferently built, generally of mud and sun-dried bricks; the few of burnt brick are those of old standing. Those occupied by the Shiahs in the Chandol quarter are particularly fine. The city is divided into quarters, called mahalas, and these again into sections, kuchas. The latter are enclosed and entered by small gates, and are invariably occupied by people of the same class or profession. On occasion of war or tumult the entrance-gates are built up, when the city contains as many different fortifications as there are sections in it. This means of defence is called kuchabandi. An insecure state of society has induced this precautionary mode of building the city. The Shor bazar and the Lahore bazar run parallel to each other, from east to west. The western portion of the latter street is occupied by the Charchata. Of this the inhabitants are exceedingly proud. It is ascribed to Ali Mardan Khan (A.D.1637), a man whose name is remembered in these countries from the many visible testimonies to his public spirit extant in various forms. It consisted of four covered arcades, of equal length and dimensions, handsomely constructed and highly embellished with paintings; these were separated from each other by square, open areas, provided with wells and fountains. The shops of the Charchata are tenanted by retail vendors of manufactured goods, who sit perched cross-legged on low counters in front of their shops, on which are displayed their wares. In Kābul, as in most eastern cities, the several descriptions of traders and artisans congregate. Thus the shops of drapers, saddlers, armourers, ironmongers, curriers, etc., are all found in their own quarter. Besides the shopkeepers or fixed tradesmen, a vast number of itinerant traders parade the bazar.

About a mile from the city of Kābul is the tomb of the emperor Baber (obiit 1530), in the sweetest spot in the neighbourhood; he had himself directed to be interred there. It is a brick building 50 feet high. From the hill which overlooks Baber's tomb is a noble prospect over a plain twenty miles in circumference, studded with gardens and intersected by three rivulets.

Its recent history requires to be noticed.

At the beginning of the 19th century the Daurani empire, extending from Herat to Kashmir, and from Balkh to Sind, had been built up by Ahmad Shah Abdallah, and remained undivided in the hands of his grandson Zaman Shah. Having incurred the enmity of the powerful Barakzai clan, Zaman Shah was deposed and blinded by his brother Mahmud, who was supported by Futteh Kban and the Barakzai. He eventually died a pensioner of the British Government at Ludhiana. In 1803, Shah Mahmud was driven out by Shuja-ul-Mulk, the younger brother of Zaman Shah, and Shah Shuja was in possession of the undivided empire of Ahmad Shah at the time of Mr. Elphinstone's mission in 1808. This mission was sent for the purpose of concerting with Shah Shuja the means of mutual defence against the threatened invasion of Afghanistan and India by the Persians in confederacy with the French. Mr. Elphinstone had scarcely left Kābul ere Shah Shuja was driven out by Shah Mahmud, with the aid of Futteh Khan. Wandering about for some years, the sport of fortune, now a captive in Kashmir, now the prisoner of Ranjit Singh at Lahore, in September 1816 Shah Shuja found an asylum in the British territories at Ludhiana. In the meantime, Futteh Khan Barakzai, who was the chief support of Shah Mahmud's power, having incurred the jealousy of that monarch, was blincled and slain. The death of Futteh Khan roused the vengeance of the Barakzai clan. Of the twenty brothers of Futteh Khan, one of the youngest, Dost Muhammad Khan, was foremost in avenging his murder. Shah Mahmud was driven from all his dominions, except Herat, the whole of Afghanistan was parcelled out among the Barakzai brothers, and in the confusion consequent on this revolution, Balkh was seized by the chief of Bokhara, the Dehrajat by Ranjit Singh,and the outlying province of Sind assumed independence. In the partition of Afghanistan, Ghazni fell to the share of Dost Mubammad, but he soon established his supremacy at Kābul also, and thus became the most powerful of the Barakzai sirdars. His kingdom con- 
sisted of four subdivisions, Kābul, the Hazara country, Kandahar, and Herat, but he was driven from it by the British in the war 1838 to 1843 .

Since the early years of the 19th century, Käbul has been three times occupied by the British. The first occasion was on the 7th August 1839, when Shah Shuja re-entered Kābul as Amir, escorted by a British army; but on the $2 d$ November 1841 the citizens and soldiery rose in rebellion against Shah Shuja, whom they killed. On the 21st December, the British Resident, Sir William MacNaghten, was shot by Akbar Khan, at an interview held to arrange terms for the British troops withdrawing from the city. On the 6th January 1841, the British forces marched out under solemn guarantee of protection, -4500 fighting men, with 12,000 followers, -but of all that number, one only, AssistantSurgeon Brydon, reached Jalalabad, and 95 prisoners were subsequently recovered from the Afghans. On the 15th September 1842, General Pollock returned to Kābul, took possession of the citadel (Bala Hissar), and remained till 12th October. Previous to the departure of the British Indian army, the great bazar, the Charchata, was destroyed by gumpowder. On the $3 \mathrm{~d}$ September 1879, the British Residency was attacked by a rabble of townspeople and troops, and the British Resident and his escort killed. In October 1879, a British Indian force marched under General (now Sir Frederick) Roberts up the Kuram, and for the third time occupied Kinbul, and shortly after again withdrew.

The Käbul river, a tributary to the Indus, rises in lat. $34^{\circ} 21^{\prime}$ N., long. $68^{\circ} 20^{\prime}$ E., near Sir-i-Chashma in Afghanistan, at an elevation of 8400 feet. Its course generally is east through the valley of Kābul and plains of Jalalabad and Peshawur, into the Indus. Its length, about 320 miles. It receives the Punchshir, 120 miles; Tazao, 80 miles; Alishang, 120 miles; SurkhRud, 70 miles; Kooner, 230 miles; Suwat, 150 miles; and about 42,000 square miles are drained. It is not navigable along the north base of Khaibar mountains, except on rafts and hides, but is navigable for boats of 40 or 50 tons to Dobundi.

At Kābul the river passes a gorge by two hill ranges, and flows through the centre of the town. At this gorge the walls and towers of defence come down on each side and join to a fortified bridge, with which is attached the name of Sirdar Jahan Khan, by whom the lines of walls over the hills were constructed. The principal bridge is abont the centre of the town; it is called the Pool Khisti, the Brick Bridge. It connects with all the busy parts of the town, such as the bazars, the corn market, and the custom house, etc. Not far from this, to the east, but within the town, is the Pool-i-Nao, the Boat Bridge. It is formed of hollowed trunks of trees fastened together. Outside the walls of the town, and still more to the east, is another bridge, near to which stood Mubammad Khan's fort, which played an important part towards the end of the British occupation of the Residency in the last days of $18+1$ and the few first days of 1842. Opposite the Residency there was another bridge, and it was at a spot on the left bank of the river, between these two last-named bridges, that Sir William MacNaghten met Akbar Khau by appointment, and was murdered. Immediately after the river passes out from the eastern wall of the city, the canal of Morad Khani begins. This runs parallel to the river, and passes along on the level ground between it and the site of the old British cantonments. Close to this, but slightly westward, are the Bemaru heights, and on the eastern side of the river are the Siah Sang heights.

A few miles below Jalalabad, the Käbul river is joined by a broad stream of considerable volume, which drains the Kuner valley, and is likewise practicable for rafts.

KABULIAT-NAMA. HIND. A deed of agreement.

KABYLE, south of Algiers, are the Berber race, the old Numidians, who differ in language, form, and habit from the Arabs of the plains. Their number is about 700,000 . They are a federal republic, the old Quinquegentes who gave so much trauble to the Romans, who tried the soldiership of Maximilian, and sixty years afterwards again revolted. See Kabila.

KACH or Sirsa. Hind. A kilt, a loin and hip cloth; a cloth round the waist, just covering the loins. In Kangra, breeches, the same as safa.

KACH'A, raw, unripe, crude, in contradistinction to Pak'ha, ripe, clever, skilled. Kach'a Ghara, or unbaked pot; as an ordeal, a pot is filled with water and carried to some distance without spilling. Kach'a Khana, with Hindus, consists of cooked food, such as rice and dal, and of a coarse, thick, flat cake, baked. Before partaking of this food, all Hindus, as a rule, wash hands and feet, and remove their garments from their persons, including the turband and skull-cap, leaving only a cloth round the loins. The castes are exceedingly particular in eating this kach'a khana apart. A Brahman and Rajput eating it together would both be expelled from their several castes. Pakkakhana comprises sweatmeats, most kinds of food cooked with ghi, and all dry food; is eaten by Hindus together indiscriminately, and if they choose, with all their clothes on, and also without a previous laving of feet as well as of hands. -Sherring's Hindu Tribes.

KACHAHRI. HiND. A court, an office, the cutcherry of the British in India.

KACHAR, a territory in the northern part of the valley of Assam, north-west of Bishnath and north-east of Gowhatty. The Kachari also dwell in the mountains south of the Assam valley, and to the east of Munipur, in lat. $24^{\circ} 40^{\prime} \mathrm{N}$., and long. $93^{\circ}$ E. Kachari, or Borro or Bodo as they call themselves, are numerous along the northern and southern borders of the Assam valley, but found in almost all parts of the valley. Chatghari, a frontier district situated between Desh Darrang and the Bhutan Hills, seems to be their chief locality, and here their numbers are said to amount to about 30,000 , which is about half the Kachari population in the valley. A large portion of their vocables are identical with those of the Garo, and almost all the rest may be traced to some dialect of the Tibetan.

The names of Mech and Kachari are indifferently applied to the same people, the latter name being especially used in the extreme east of the district. The tribe is widely scattered over al North-Eastern Bengal, being able to support life in the malarious tarai that continuously fringes the first slopes of the Himalayas.

The Kachari, the Naga, the Abor, and some 
other tribes bordering on Assam, are supposed to be of the same race as the Mechi.

Closely connected with the Kachari, among the inhabitants of the plains, are the Hojai Kachari, the Kochi, which include the Modai Kochi, the Phulguriya, and Hermia, the Mechi, the Dhimal, and the Rabha. Each of these speaks a separate dialect, between which and the Kachari, Mr. Robinson says, the differences are rather nominal than real. Their numbers are about $3,000,000$.

Until the middle of the 13 th century, the Chutia or Kachari dynasty continued to hold Southern Upper Assam and Saddiya, and part of Naugaon (Nawgong), but were then subjugated by Shans from the south, who, after establishing themselves in Upper Assam, forced the eastern portion of the Ko'cch-Hindu kingdom to submit, whilst the lower or S.W. part of Kamrup fell under the sway of the Muhammadan rulers of Bengal.

The Kachari are a fine atbletic race, fond of village merry-making and dancing. Their Mongolian features are strongly marked, no beards or whiskers to speak of, and with little hair on other parts of their bodies. They are found in small distinct settlements all over Upper Assam, and those who have become Hinduized call themselves Soromia. Others in the Eastern Douars call themselves Shargia; and near the Bot country, where they are adopting Lamaism, they style themselves Shargia Butia. They extend from lat. $25^{\circ}$ to $27^{\circ} \mathrm{N}$., and long. $73^{\circ} 30^{\prime}$ to $88^{\circ} \mathrm{E}$., and are supposed to be more than 200,000 souls. They worship the Sij (Euphorbia), as also do tribes in Central India and Orissa. The Ojha is priest and physician (Ojha, entrails). Their chief deity is Batho, and Lis wife Mainon; and chief priest, Deoshi. Eggs and hogs are offered in sacrifice. The Kachari and Mechi go through the ceremony of forcibly seizing the willing bride. The Dhimal of the sal forest do not exceed 15,000 souls. The Rabha and Hajong of Goalpara are branches of the Kachari.

Kachar has been largely occupied by tea planters. The soil of the plains of Kachar is a rich alluvial one, formed from the washings of the mountains which surround it on three sides. The country is drained by the river Barak, which runs in a most tortuous direction right through the whole of it from west to east. The banks of this river are the bighest parts of the plain country, and are about 200 feet above the level of the sea. The ground slopes inland from these banks for several miles, and then gradually ascends towards the foot of the mountains on eitber side, leaving a long line of jhils and swamps between the river and high lands. In the cold season the bed of the stream is about 30 feet below the top of the banks, but in the rains the waters overflow the banks and inundate the low tracts. Low ranges of hillocks intersect the country in many places, chiefly at right angles to the river. The soil of these ranges, on which cotton is chiefly cultivated, is a red sandy clay, and rests on a base of conglomerate rock, which in many places is seen to lie exposed. The red clay and the conglomerate also lie below the alluvium of the plains, and are met with in the bed and deep-cut bank of the river.

KACH GANDAVA, a district or section of Baluchistan, on the east of which the capital is Gandava. It is a great level tract, inhabited by three very distinctly-marked races, the Jet (Jat), the Rind (including the Maghazzi), and the Brahui. The Jat seem the prior race, and occupy the centre of the province. The Rind, with their lawless sub-tribes, the Jakrani, Dumki, Bugti, and Murree, are a more recent intrusive race, dwelling on the skirts. The Doda, a division of the widelydispersed great Murree tribe, have, for the last three centuries, occupied the hill ranges east of the plain of Kachi. The Murree are a brave race, and bave long been distinguished as daring depredators. Harand and Dajil, in Kach Gandava, but bordering on the Indus, are inbabited by the Gurchani tribe of Rind, and have the Muzari on their south. The great Rind tribes are subdivided into 44 branches. Their traditions affirm them to have immigrated ages ago from Damascus and Aleppo. Their language is the Jetki, in common with that of the other inhabitants of Kach Gandava, and Mard-i-Rind means a brave man. The Rind of Kach Gandava are of the Utanzai division.

Dumki, Jakrani, Bugti, and Doda Murree have always been distinguished by their rebellious and predatory habits. The Murree inhabit the eastern hills of Kach Gandava, and a peaceful and obedient portion of the tribe are in the hills west of the province below Jell. A large portion are at Adam Murree, on the S.E. frontier of Sind. The Murree and the Maghazai seem to have emigrated from Mekran to Kach Gandava at different periods, and to have become incorporated with the Jat cultivators. The Maghazi have only four families, the Butani at Jell being the chief. They are enemies of the Rind, but are probably of the same race. They boast of being able to muster 2000 fighting men, and between them and the Rind a blood-feud long existed. The Maghazzi and Rind are alike addicted to the use of ardent spirits, opium, and bhang.

$\mathrm{KACHH}$. HIND. Moist, low-lying country along the banks of the Ganges, as opposed to the bangar or dry upland tract away from the river. It gives a name to the Kach'handan pargana, in the Hardoi district of Oudh, originally in the possession of the T'batheras. In A.D. 1542, Sher Shah, on his proselytizing march from Jaunpur to Agra, compelled the inhabitants of several Chandel villages to apostatize. Their descendants now intermarry with the families of Abbans, Raikwars, and Gohelwars, who were converted to Islam at the same time.

KA-CH'HA, also Cholna. Hind. A cloth worn round the hips, passing between the legs, and tucked in behind, the Tamil dovati.

$\mathrm{KACHHI}$, a lowland tract on the left bank of the Indus, commences at Mari, opposite to Kalabagh, and extends in one form or other to the sea. In some parts of the lower portions, babul predominates. Tamarisk more or less exists everywhere, and jhand, karil, with other shrubs or trees adapted for firewood, are largely scattered over the entire area in greater or less density. In the upper portion, appertaining to the Miyanwalli tahsil, the shisham or Dalbergia sissoo greatly predominates, and appears to spring up spontaneously wherever the soil deposited by the river is left undisturbed, for a distance of at least 30 to 40 miles below Kalabagh. Almost the whole of the forest worthy of being taken into account is situated on part of the series of low islands, among which meander the numerous and varying channels into 
which the Indus is divided for many miles below Mari and Kalabagh. The Kachhi sissoo forest extends over 14 or 15 miles on low alluvial land, upon the left bank of the Indus, between the villages of Bukkri and Futteh Khan, and more sparingly for 15 miles lower down, or, altogether, 30 miles from Kalabagh. There are few trees in India which so much deserve attention as Dalbergia sissoo, the Fali of the Panjab, considering its rapid growth, the durability of the timber, and its usefulness for many purposes; the wood is universally employed when procurable, by Europeans and natives, where strength is required.C'leghorn's Panjab Report, p. 220.

$\mathrm{KACH}$ 'HI, a race spread throughout Hindustan, in Gujerat, and on the north-west borders of the Mahrattas. They are engaged in the finer branches of agriculture, are industrious market-gardeners, flower-growers, and in Behar are large poppygrowers. They recognise seven branches, - the Kanoujia, Hardiha, Singrauria, Jawanpuria, Bamhania or Magahya, Jaretha, aud the Kachhwaha, who do not eat together or intermarry. There are, however, other distinctions, and in the Mahratta territory others of them are named from the countries they have come from, as the Bundela and Marwari Kach'hi. Most of the Canarese, Tamil, Teling, and Mahratta nations of the Peninsula of India are engaged in agriculture. In the N.W. Provinces, the Abir, Kach'hi, and Koormi are similarly occupied. The Kach'hi, Koeri, Morow, Kumboh, and Kisan are gardening and cultivating tribes in Northern India. The Kach'hi of the Mahratta country state that they came as cavalry and infantry soldiers from Bundelkhand, in the times of former kings and of Alamgir, and that they were villagers and servants. In 1869 there were under 100 houses in Begumpur in Aurangabad city. There were many in Poona and a few in Bombay, but only one in Jaulnah. In Aurangabad, Poona, and Bombay they are fruit-sellers, unarket and flower gardeners, and agriculturists. They are of a bamboo colour, and speak Hindi. They worship Seetla in the form of a stone from the river, offering flowers and betel, and use red lead in sanctifying the stone. They also worship Hanuman and Balaji. After death they burn, but bury those who have died of small-pox, also the unmarried.-Elliot's Supp. Glossary.

KACH'HWAHA, a distinguished tribe of the Solar race of Rajputs, who claim descent from Kusa or Kusha, the son of Rama, and form the ruling race in the state of Jeypore, the raja of which is of the Kach'hwaha clan. There are three solar dynasties :-

The Grahilote or Gehlote, with 24 sakha or branches, of which the Sesodia is the most distinguished. The rana of Udaipur is a Grahilote.

The Rahtor, said to be descended from Rama by Kusa, his second son. It has $2 t$ branches, and the raja of Jodhpur or Marwar belongs to this tribe.

The Kach'hwaha also sprang from Kusa. The raja of Jeypore is of this tribe. It has 12 kotri or houses. - Tod.

KACHI, the language of Cutch, which has in it elements of the Gujerati. That of the hunters and tanners (dedh) is another dialect, but the language of Lar is purest.

KACHULA CHULA. Malay. Hard horns, or horn-like parts of animals, believed to possess magical or medicinal properties. Lang limu (ilmu) kahutan katungalam are lines to which the Malays cannot affix any definite meaning. The rendering would perhaps be (magical) science for protection when alone in the forest, or to make the offerer alone as when surrounded by a forest.-Jour. Ind. Arch. p. 309, December 1847.

KACSHA, in Hindu astronomy, the orbit of a planet, or the circle which ancient astronomers called the deferent; for the kacsha carries epicycles (paridhi) like the deferent.

KADAM. Arab., Hind., Pers. The foot, hence Kadam-bosi, feet-kissing ; in correspondence, a humble salutation. This word means sometimes a pace, a foot, also a yard measure of 30,33 , or 36 inches. Kadam-rasul, footprints of the prophet Mahomed. In Southern Asia, there is a great reverence shown to saints' shrines and footmarks, amongst these are the tombs of the Pir-i-Dastagir at Baghdad, of Kader Wali at Negapatam, and the footprints of the prophet at the Kadam Rasul Hill, near Secunderabad, to which multitudes annually resort. The footprints of Abraham are shown at Mecea, and those of Adam at the great Buddhist temple in Ceylon.

KADAMBARI, a prose novel written by Vana or Banabhatta in the 7th century, named after a daughter of Chitraratha and Madira.-Dowson.

KADAPHES or Kadphises, a dynasty of three rulers, who reigned in Kābul from the downfall of the kingdom of Vikramaditya.

Sir Walter Elliot says the Kadphises and Kanerki were Indo-Scythic invaders who established themselves for a time in the north of India, and even penetrated to the Dekhan. Coins belonging to the Kadphises group, though of a different form, have been found at Joghar in the Ganjam district, and nndoubted Kadphises coing have been obtained at Madras, Trichinopoly, and Masulipatam.

Kadphises' name is on the Aryan reverse of the Hermæus coins of Hercules type. The Hercules worship was readily borrowed from the Greeks by the wild Scythians, as a mere reverence of physical strength. The Kohistan is supposed to be the district of the first rise of Kadphises, while Kābul and its valley were subject to Indian rule; and, while there, the chief seems to have retained his Scythian title and rude worship of Hercules. Afterwards overpowering the Indian governor who had followed Vikramaditya into the Kābul valley and Panjab, he or his descendants seem to have adopted the Hindu religion, coining with Greek, and dropping their Scythian title. In a gold coinage by a Kadphises king, Siva occurs in the mixed male and female character, and very generally accompanied by the bull Nandi. Professor Lassen discovered in Chinese history, that Khi-out-chiuhi Kui-tsi-kio, a Yuchi or Yeutchi or White Hun, conquered the Szu or Azes Scythians in about B.C. 40 , and dying at the advanced age of 84 years, his son Yen-kao-Ching prosecuted his career of victory, and reduced the Indus valley and Panjab to subjection in about B.c. 20. The names are scarcely recognisable, but the facts and period correspond to the career and supposed era of the Kadphises kings.

Korosoko Kosoulo Kadphises, B.c. 50 ; in Aryan, Dhamarata Kujula kasa Sabashakha Kadaphasa. His coins are of the Hercules and Hermæus type. 
Zathos Kadaphes Khoranos, B.C. 20. On the reverse of the coins is a sitting figure, with the arm extended, and wearing a loose flowing Indian dress. They have monograms the same as the Azes coins. The Siva worship had not yet been established as the State religion.

Vohemo Kadphises, B.c. 5. His copper coins have the king standing in a Tartar dress, with coat, boots, and cap, his right hand pointing downwards to an altar or pile of loaves, and having a trident separate on one side and a club on the other. The reverse has the Siva Nandi bull.

The readings of the Aryan inscriptions on coins of the Kadphises kings, by Lassen, James Prinsep, and Wilson, are somewhat different, and it is suggested that the words Koroso, Kosoulo, Koranos, and Zathos were titles short of royalty. Professors Lassen and Wilson carry the dynasty of Kadphises through the whole of the first century of the present era, and consider it to have been then overpowered by a fresh swarm of Scythians under the Kanerki kings. Mr. H. T. Prinsep supposes that during the ascendency of the Kadphises kings, the Græco-Parthian party still held out in cities and communities, abiding their time to re-assert their independence, and rose again about the middle of the first century of our era; amongst these, coins show-

Undopherres, A.D. 40, calling himself king of kings in Greek, and in Aryan Maharajasa Raja Rajasa, Tradatasa, Mahatasa, Pharahitasa.

Gondopherres or Gondophares, B.C. 55, who took the same Aryan name of Pharahitasa.

Abagasus, king of kings, A.D. 70, in Aryan Abakhafasa. Professor Lassen supposes this name to be identical with Vologeses. Mr. H. T. Prinsep supposes these coins to be of Parthians who established for themselves a separate and independent sovereignty in Kābul and the Paropamisus

Abalgasius, A.D. 80. Captain Cunningham described the Aryan legend on the coins to be of the saviour king Abagasus, younger son of Undopherres.-Prinsep.

KADATAM. KARN. A leaf of cloth blackened with a preparation of charcoal and gum, and used as a slate for writing on with chalk or steatite. Leaves of such cloth, folded together, are commonly used as memorandum and account books. The writing may be effaced with a wet sponge or cloth.-W.

KADEE, HIND., is one of the stout cotton fabrics made over all India; as also are the fabrics distinguished as do-suti, tin-suti, and char-suti or chau-tari.

KADER, a race occupying the Animallay Hills in Coimbatore, but not higher than 4000 to 5000 feet. They are the lords of the hills, and exercise some influence over the Puliar and Malai Arasar races. They carry a gun, and even loads as a favour, but they do not perform menial labour, and are deeply offended if called coolies. They are expert at stalking game. They are a truthful, trustworthy, and obliging tribe. They are small in stature, and their features resemble the African. They have curly hair, tied in a knot behind, and file the four front teeth of the upper jaw to a point, as a marriage ceremony. The Kader, as also the Puliar, Malai Arasar, and Maravar, who also inhabit these hills, all gather the forest pro- ducts,-cardamoms, honey, wax, ginger, turmeric, resins, millets, soap-nuts, gall-nuts, - and exchange them in return for rice and tobacco. The Kader formerly located near Toomacadanu in the Animallay, entirely left the British portion of the forest, and went over to the Cochin territory, as the hill produce on the British side became exhausted; they paid the Cochin Government Rs. 100 per annum for the privilege of collecting cardamoms, ginger, etc. ; they paid no seigniorage for the hill produce collected in British forests. They were useful as guides, but otherwise they were of no use in the forest, refusing to undertake any labour whatever.

The Malai Arasar cultivate a little.

The Puliar, about 200, live among the lower plateaux. They worship demons, and are omnivorous.

The Maravar are timid and nomadic, have no fixed habitations, but wander over the mountains with their cattle, seldom staying above a year in a place. They worship the idols of the Puliar. They all are keen hunters.

KADER WALI and Khaja Muin-ud-Din, Chisti, Muhammadan saints. Chisti was a Sunni, was born in Sigestan A.H. 527, and came to Ajmir in the reign (A.H. 602-607) of Kutb-ud-Din Aibak, where he married a daughter of Syud Husain Meshedi, a Shiah. He died A.H. 628, and a magnificent mosque was built near his tomb, A.H. 1027, by the emperor Jahangir. He has also a shrine at Nagore, near Negapatam. Kader Wali is held in special reverence by the Moplah. His festival day is on the 11th Jamadi-ul-Akhir.

KADESIA, on the Tigris, the site of the battle fought by Rustam, the lieutenant of the youthful Yezdejird III., against the Arabs. Rustam was surprised and slain. The victory gave the conquerors the province of Assyria, since called Irak-Arabi; and this was followed by the sack of Ctesiphon.

The battle of Kadesia put an end to the Persian empire. It was fought in the fifteenth year of the Hijira (A.D. 632), under the khalifat of Omar, by the Arab general Saad, against Rustam, the commander-in-chief of the Persian army, in the reign of Yezdejird III., the last of the Sassanian race. The battle lasted three days, at the end of which the Arabs were victorious, and the Persian monarchy destroyed.-Decline and Fall of the Roman Empire; Rich's Residence in Kurdistan, ii. p. 155; Thomas' Prinsep. See Cadesia; Kai.

KADHO-AKHA or Ka-doh-ka. BurM. Ferry hire; a coin placed in the mouth of a corpse; Charon's fee.

KADHYA or Gudhia. HrND. A grasshopper which attacks field and garden produce.

KADI or Kari. Karn., Maleal. Boiled sour milk eaten with rice, supposed to be the source of the word curry. In Malabar majjige kadi is a curry of rice, sour milk, spices, chillies, etc. Kadipak, leaves of Bergera Konigii. Kadi, in Tamil, is the bazar and the bazar supplies, and is also supposed to be the origin of the word curry.

$\mathrm{KADRU}$, in Hindu mythology, daughter of Daksha, one of the thirteen married to Kasyapa. Her offspring have the metronymic Kadraveya ; among them are the mythologic serpents Sesha and Vasuki.

KADSURA CHINENSIS. Wu-wei-tsze, CHIN. A scrambling shrub of China, remarkable for 
the viscid mucus which abounds in the fruit and branches. Japanese women dress their hair with it, and the Pi-chi or mulberry bark paper is sized with it. In China the fruit and branches are employed in the form of mucilaginous decoction.-Smith.

$\mathrm{KADUR}$, a district of Mysore, forming the south-western portion of the Nuggur division. The centre of the district is occupied by the Baba Booden Hills, the Mulaingiri rising to a height of 6317 feet above the sea. Its forests contain inexhaustible supplies of the finest timber, and also furnish shelter for the coffee plantations. Sringeri or Rishya-sringa-giri is on the Tunga river. It was here that the sage Rishya-sringa was born without a natural mother, by whose intervention alone could the horse sacrifice be celebrated and Rama himself be brought into the world. Here also, in historical times, was the home of Sankaracharya, the great Sivaite reformer of the 8 th century; and here at the present day resides the Jagat-guru, or supreme high priest of the Smartta Brahmans.-Imp. Gaz.

KADURU, SINGH, means forbidden or poisonous trees, and from this word the idea of the forbidden fruits has been attached to the shaddocks and to some other trees. Strychnos nux vomica is the Goda-kaduru; Gon-kaduru, bullock's heart; Mudu-kaduru, sea fruit; Diwikaduru, tiger's fruit. Divi Ladner of Lindley's Vegetable Kingdom corresponds with the Diwikaduru. The Singhalese say that Paradise was in their island, and that the forbidden fruit of the garden of Eden was borne on the Divi Ladner of their country, probably the Tabernæmontana dichotoma. In support of this they point to the tempting beauty of the fruit, the fragrance of the flower, and show that it still bears the marks of the teeth of Eve. Till the offence was committed which brought misery on man, we are assured that the fruit was delicious; but from that time forward it became poisonous, as it now remains.-Fergusson's Timber Trees of Ceylon.

$\mathrm{KADYAN}$, an aboriginal tribe of Borneo, converts to Muhammadanism. They are peaceable and well disposed. They cultivate, fish, and collect forest products. Their women, when young, are very attractive. They are not concealed.

KAEMPFER, ENGELBERT, born 16th September 1651, at Lemgow, a small town in the circle of Westphalia, belonging to the Count de Lippe. His father, John Kaempfer, was minister of the church of St. Nicholas in that town. Kaempfer formed part of the embassy which proceeded through Russia from Sweden to the Persian court, where he resided; but on its return he separated from it, and proceeded to the Persian Gulf. He then entered the service of the Dutch, and was long employed in Japan, and his Amcenitates Exotice and History were the result. He seems to have died of phthisis, for bloodvessels burst in November 1715 and at the beginning of 1716 ; and on the 24th October, having been ever since the last attack troubled with a nausea and loss of appetite, his vomiting of blood returned upon him with great violence, followed by fever, which lasted till the $2 d$ of November, on which day he died, at five in the evening, 65 years and six weeks old. He was buried in the Cathedral Church of St. Nicholas at Lemgow.- History of Japan, i. p. 15.

KAEMPFERA, a genus of plants of the order Zingiberaceæ, of which several species are known to occur in the southern parts of the East Indies. The flowers of some species are ornamental, and the roots of several are used medicinally, or as condiments. One species, long supposed to produce the galangal root of commerce, is a native of China, and the Rev. Mr. Williams says that the root is sent from China to India, but that there are two sorts, the greater and the smaller, obtained from different plants. The best of these is the smaller galangal, and is procured from the Maranta galanga. This is of a reddish colour, about two inches long, of a firm texture, though light, and possessing an acrid, peppery taste, and a slight aromatic smell. The larger galangal is from Kaempferia galanga, and is inferior in every respect, but both are used as spicery in Europe as well as in India. Kaempfera candida, Pan-uphu of the Burmese, is often seen lifting its crocus-like flowers, without a single leaf, on the most arid spots in the jungles of Tenasserim. All the species of Kaempfera are furnished with tuberous roots, like the turmeric and ginger plants. The spikes of the flowers are short and rising from the root, in some species before, in others with, and nestled among, the leaves, and all are highly ornamental. K. parviflora, Wall., and K. Roscoeana, Wall., grow in Burma. K. ovalifolia is a plant of the peninsula of Malacca.Williams ; Mason; Voigt.

KAEMPFERA ANGUSTIFOLIA. Roxb.

Kanjon-bura, . BENG. | Mudun nirbisi. . HIND.

Has large, white, purple-lipped flowers. Its roots are used in Bengal as a cattle medicine.Roxb. i. p. 17 ; Voigt.

KAEMPFERA GALANGA. Linn.

Alpinia sessilis, Kan., AR. | Kats-julum, . Mareat. Chandro mula, . BENG. Kats-jolam, . . TAM. Kha-mung, . BuRM. Kachoram, . . TEL.

Common all over India; rhizoma fleshy, tuberous, with fleshy fibres; the roots are agreeably fragrant, and of a warm, bitterish, aromatic taste. Notwithstanding its specific name, it is not the source of the true galanga root of the druggists, a drug now known to be the produce of the Alpinia galanga. The roots of this plant may be often seen attached to the necklaces of Karen women, for the sake of their perfume. They also put them with their clothes, and use them to a small extent medicinally. It is cultivated by the Mug race of Arakan, by whom it is sold to the people of Bengal, who use it as an ingredient in their betel. The roots possess an agreeably fragrant smell, and a somewhat warm, bitterish, aromatic taste. The Hindus use them as a perfume and medicinally.-Roxb.; $O^{\prime} S h$.; Mason; Murray; Voigt.

KAEMPFERA PANDURATA. Roxb.

Curcuma rotunda, Linn. | Kaempfera ovata, Roscoe.

Grows in Gujerat, the Konkans, and the Moluccas; has large, whitish, rose-coloured flowers. -Roxb.

KAEMPFERA ROTUNDA. Linn.

Kaempfera longa, Redout. Melan kua, . . MaLEA Myæ-ban-touk, BURM. Kaha sau-kanda, Singr. Bhuim champa, - HIND. Konda kalava, . TEL.

This is cultivated all over India. It is the finest species of the genus, and is cultivated by 
amateurs for its beautiful sweet-scented blossoms. It was long considered to produce the zedoaries, but writers of authority state that zedoary is the root of the Curcuma zedoaria.-Roxb.; O'Sh.; Mason.

KAF. HIND. A mixture of emery and oil, used in cleaning metal.

KAF, the Koh-i-Kāf or Mount Kãf of the Persians, is the fabulous mountain which, according to oriental cosmographers, surrounded the world; but since the science of geograpby has made some progress in the east, the name has been confined to Mount Imaus to the east, and Mount Atlas to the west. The jan or genii, a race intermediate between angels and men, produced of fire, are supposed to have inhabited the earth for several ages before the birth of Adam, and to have been governed by kings, all of whom were called Suleiman (Solomon). They fell into a general state of depravity, and were driven into remote places by Eblis (the fallen angel), and such as remained in the time of Kaiumeras, the first of the Pesdadian dynasty of Persia, were by him driven to Mount Käf.

KAFAS. ARAB. A hamper artistically made of palm sticks, in which provisions are kept.

KAFFIYEH. ARAB. A square kerchief of cotton and silk mixed, generally of yellow and green colours, worn by the Bedouins. It is folded so that one corner falls backward, and a corner over each shoulder. See Kaifiet.

KAFI. Hind. Onoseris lanuginosa. In Kangra, it is the tomentum of the leaf of Onoseris aplotaxis.

KAFILAH. ARAB. A caravan-; a company of travellers. The Baluch and their neighbours consider a number of travellers, with their property, to be a karwan; but where all the goods belong to one merchant, they speak of a kafilah. Kafilah bashi, the conductor of a large caravan.

KAFIR. ARAB. One who denies, an infidel. A term generally applied in India to the thicklipped, curly-haired Negro races of mid-Africa, but also as an abusive epithet to Christians and all non-Mubammadans.

KAFIR, also called Siah Posh Kafir, are names applied by Muhammadans to a race who occupy the mountainous region on the southern slopes of the Hindu Kush, directly north of Käbul, bounded on the north by the Hindu Kush mountains, on the south by the Kunar range; for its western limit it has the Alishang river with its tributary the Alingar; its eastern boundary, taken roughly, would be the Kunar river from its junction with the Käbul to where the former receives the waters of the Kalashgum, thence, following up this affluent to its source, a line from that point to the Dura pass would be well within the march. It would also take in a small tract north-west of that pass, and subject to Munjan. There are three main tribes, Ramgal, Vaigal, and Bashgal, answering to the three chief valleys of the country. The Vaigal are the most powerful, holding the largest valley. Each has its distinctive dialect. The entire population is estimated at over 600,000 . Their country is picturesque, thickly wooded, and wild in the extreme; the men are of fine appearance, but, like all hill tribes, short of stature; they are daring to a fault, but lazy, leaving all agricultural work to their women, spending their days, when not at war, in hunting; passionately fond of dancing, in which both sexes join, indulging in it almost every evening round a blazing fire. It is purely owing to their having no blood-feuds among themselves that they hold their own against the Muhammadans, who hem them in on all sides, and with whom they are always fighting. Towards the British they are exceedingly well disposed. Slavery exists to a certain extent among them, but the trade in slaves would soon die out if human beings were not so saleable at Jalalabad, Kunar, Asmar, and Chitral. Polygamy is rare; mild corporal punishment is inflicted on a wife for adultery, while the male offender is fined so many heads of cattle. The dead are coffined, but never buried. One Supreıne Being, Imbra, is universally acknowledged. Priests preside at their temples, in which sacred stones are set up, but to neither priests nor idols is excessive reverence paid. In evil spirits, authors of ill-luck, the Kafirs firmly believe. Their drink is the pure juice of the grape, neither fermented nor distilled. Their arms are bows and arrows; a few matchlocks have found their way among them from Kābul, but no attempts have been made to imitate them. Wealth is reckoned by heads of cattle. There are 18 chiefs in all, chosen for bravery mainly, but with some regard to hereditary claims. Their staple food is wheat.

Judging from the nature of their idolatry and their language, there can be little doubt that they are an Indian people.

Fazl-i-Haqq, in 1864, said, "A breach of the seventh commandment in any form is not endured for a moment.' But both Syud Shah and Mian Gul assert that they are completely lost to all shame in this respect. Major Biddulph confirms this. He says, "The women are very immoral, and marital jealousy is satisfied with a short fine.' It has also been ascertained that the Kafirs sell their women as slaves. But it appears that a large slave trade is carried on directly with the Kafirs themselves. When one Kafir tribe defeats another, the women are seized and sold into slavery.

They are entirely independent. The country occupies a commanding position, dominating all mountain passes between the Oxus and Indus basin. It occupies the most western part of the independent highlands, where the chain of the Hindu Kush impinges on the extremity of the Himalaya, capping the mountainous region of Badakhshan, on the Oxus, and overlooking most of the passes at the head of the Kābul river. The people give no quarter to Muhammadans, but spare those who, like themselves, are technically Kafir, or non-believers in the creed of Mahomed, which is associated in their minds with barbarous cruelty from the earliest period of the Muhammadan invasion of Afghanistan.

They have numerous tribal names amongst themselves, that of Kafir, meaning unbeliever, being applied to them by their Muhammadan neighbours, with Siah Posh or Tor, meaning black clothes, from the colour of their apparel, both epithets being taken from their dress, like the Scythian Melanchlænæ of Herodotus (iv. p. 10), for the whole of the Kafir race are remarkable for their fairness and beauty of complexion; but those of the largest division wear 2 sort of vest of black goatskin, while the other dresses in 
white cotton. They are of fair complexion, regular features, shaded hair, with ruddy cheeks, and variously-coloured eye.

The Dara Nuri profess to be Tajak, and take great pride in the antiquity of their race. The language of the Dara Nuri is almost identical with that of their neighbours on the plain of Lughman. In appearance the Dara Nuri differ little from the Afghans.

The Chuguni is a numerous tribe dwelling beyond Shewa. They are of the same race as the Kafir, but have been converted to Muhammadanism. The true Kafir call them, in somewhat contemptuous language, Nimchah, which may be translated half-breed. They intermarry indifferently with Kafir and Afghan. They are principally employed as guides, and have access into Kafiristan. The Chuguni tribe live in the bighest habitable parts of the Kund range. Their appearance differs from that of the Afghans, their stature being shorter, and their features softer and more pleasing. The Chuguni are devout and attentive to their religious duties, and their women engage in prayer. They are the only Muhammadans who allow women unconstrained freedom, the women going about among the men as in Europe.

The view from Utchalic Eali pass, 7300 feet, overlooking the Arat valley, is extensive. On the summit of Kund there is a small lake, and it is stated that on its shores still rest the remains, petrified, of Noah's Ark, while in the plain below was the tomb of Lamech, Noah's father. $-C . M . S$. Intell., 1865, p. 203.

KAFIR KENNA is five hours and a balf from Tiberia; it is the Cana of Galilee, so called to distinguish it from another town of this name in the tribe of Asher (Joshua xix. 28). Antipatris of the Greeks is the Kafir Saba, the modern town.Robinson's Tr. p. 236.

KAFIR KOT, in lat. $32^{\circ} 30^{\prime} 55^{\prime \prime} \mathrm{N}$., and long. $71^{\circ} 21^{\prime} 28^{\prime \prime}$ E., 2194 feet above the sea, an ancient fort on the slopes of the Khusir range.H. A. i. p. 56 .

KAFIR KOT is a term used in the pretty valley of Khara Tucka, that overhangs Herar, in the hill districts to the S.W. of Mehur in Sind. This valley has regular artificial terraces, formed of buge boulders, which the people believe were lifted into position by a former giant race, whom they designate Kafir; hence these terraces and other ancient remains are called Kafir Kot. The huge boulders must have been arrested in their descent by some artificial contrivance. The practice of terracing is common now all over Afghanistan and the Himalaya, and was so throughout Baluchistan when it was more densely peopled than at present. They catch the rain-water running down the faces of the hills, and the detritus forms slight soil, in which the people sow wheat.

KAFIR KOT, in lat. $33^{\circ} 10^{\prime} 49^{\prime \prime} \mathrm{N}$., and long. $70^{\circ} 48^{\prime} 26^{\prime \prime} \mathrm{E}$., a series of peaks 4004 feet above the sea in the Waziri Hills.

KAFSHI. HIND. Slippers, or half shoes; they bave a raised iron piece on the heel underneatb.

KAFURI. HIND. A yellow colour, lemonyellow, the colour of amber. Seoti rang is a pale yellow.

KAGAR, or Dassendi, a people of Cutch, who receive their support from the charity of the
Jhareja. They are a tribe of Charon of the Tombel, or, as pronounced by the inhabitants of Cutch, Tümber, and emigrated with the Jhareja into that country.-Hindu Infanticide, p. 78.

$\mathrm{KAGAYAN}$, an island of the Archipelago, containing a curious circular lake, and at a height of about 90 feet is another beautiful lake, circular in form, and as nearly as possible similar to the lower one. The two lakes are separated by a sort of natural wall, and the spectator standing on its narrow edge can, by a mere turn of the head, observe them both. Opposite Kagayan are the Five Islands, known also as Babuyan.Keppel's Ind. Arch. i. p. 83.

KAGHAN is a barren dependency of Hazara. It is a long, narrow glen, stretching upwards till it nearly reaches Chelas, the latter outpost of the maharaja of Kashmir's kingdom. It is inhabited by pastoral and aboriginal races, and was given in fiefdom to a Syud family, who were confirmed by the British. These Syuds exercised internal jurisdiction, and kept certain members of the family in attendance on the Deputy Commissioner of Hazara, virtually as hostages for good behaviour. After the British conquest, the Syuds were summoned to answer numerous complaints preferred by the people of Kaghan; they came, but afterwards fled, and assumed an attitude of resistance, and intrigued with the Sitana fanatics and with the Hasanzai, then hostile to the British. See Hazara.

KAGHAZ. Pers. Paper; Akhbar Kaghaz, a newspaper. Kaghaz-tikli-dar, gold-ornamented paper. Kaghazi nimbu, the thin-skinned lemon, Citrus acida, Roxb.

KAGMAK, a fabric of camel's bair.

KAH. PERS. Grass, but in combination applied variously. Kah-i-Shutar, a juicy, bitter plant, growing near Jell in Baluchistan, eagerly eaten by camels.

KAHAN, $n$ town in Cutch Gandava, in the hill ranges east of the plain of Cutch. It belongs to the Doda Murree, a division of the great and widely-dispersed Murree tribe, who have been located in the neighbourhood for several centuries. The Murree are i brave race, and have long been distinguished as daring depredators.-Masson's Journeys.

KAHAR. HIND. A Sudra race of Hindustan, many of whom, in Behar, are considered impure. They numbered $1,840,856$ at the 1881 census. The Kahar are found following agriculture and as palanquin-bearers all through Hindustan and the east of the Panjab, and are strong, hard-working, rather good-looking men. They are watercarriers, fishermen, and cultivators. Hindus drink water from their hands. Near Gya, they are employed as palanquin-bearers, and carry burdens on a yoke over one shoulder. The name is one of the few real Indian words of which Ibu Batuta shows any knowledge.

KAH-GIL. PERs. Thick mud, mixed with chopped straw and other materials, used as plaster throughout Sind and Central Asia; literally straw-mud.-Burton's Scinde.

KAH-GYUR, a sacred book of the Buddhists of Tibet, consisting of one hundred rolumes, translations from the Sanskrit of stories and tales, many of them very childish, and common to all folk-lore. Tan-Gyur is another book, of which the philologist Csoma de Köros, a Hungarian, obtained 
a copy, and it has been translated into German by F. Anton von Schiefner, and part of it from that into English by W. R. S. Ralston. De Köros was born at the end of the 18th century; he studied at Göttingen, and became a Slavonic philologist. He conceived the desire to discover the origin of the Hungarian nation, and went to Tibet, where he studied the language of the country. His existence was that of an ascetic; his only food was boiled rice, his only stimulant tea. He died in Nepal in 1842, when he was on the point of starting for Lhassa, in the hope of finding there rich stores of Tibetan literature.

KAHI. HIND. Earth containing salts of iron in the form of an anhydrous sulphate; in the pure samples it takes the form of a whitish or cream-coloured radiated crystalline mass. Kahi-lal or Kahi surkh is bichromate of potash; Kahi-suja contains iron salts; Kahi-sabz, impure green vitriol ; Kahi-matti, sulphate of iron earth ; Kahisafed, white anhydrous sulphate of iron; Kahizard, yellowish variety of Kahi-safed.-Powell, Handbook.

KAHI-KATEA, or white pine timber tree of New Zealand, is Podocarpus dacrydioides, a tall, gregarious tree.

KAHIRA or Al-Kahira, the eity of Cairo, founded by Jauhar, the general of the first Fatimite khalif, who ordered the foundations to be laid, A.D. 968, when the planet Mars was in the ascendant, which Arab astronomers called Kahir or the conqueror. It was completed in five years. It was considerably enlarged by subsequent rulers, particularly by Salah-ud-Din, who enclosed the new and the old town, called Misr or Fasthath, with a wall 26,000 cubitsin circumference.

KAHK, ARAB., is a light and pleasant bread of ground wheat, kneaded with milk, leavened with sour bean flour, and finally baked in an oven, not, as usual in the east, upon an iron plate. The Kahk of Egypt is a kind of cake.-Burton's Mecca, i. p. 361 .

KAHKAR, Ghakkar, or Guker, a martial tribe in the time of Mahmud of Ghazni, inhabiting the Salt Range or Johd mountains between the Indus and the Behut or Hydaspes. The Moghul, and subsequently the Daurani, failed to master them; but the Sikh rulers, after having been frequently foiled, at length nominally accomplished their subjugation, by stirring up internal faction and by the perpetration of acts of cruelty and treachery. At an early period of history they were given to infanticide. It was a custom, says Ferishta, as soon as a female child was born, to carry her to the market-place, and there proclaim aloud, holding the child in one hand and a knife in the other, that any one wanting a wife might have her; otherwise she was immolated. By this means they had more men than women, which occasioned the custom of several husbands to one wife. When any one husband visited her, she set up a mark at the door, which, being observed by the others, they withdrew till the signal was removed. Baber writes the name Guker, but it is also written Ghuka and Khaka. The Guker are not distinguishable from the Awan in personal appearance, both being very large, fine men, but not exceedingly fair, inhabiting as they do a dry, bare, rather low country, hot in summer.-Rec. Govt. of India; Tod's Rajasthan, i. 636 ; C. 96.

KAHROR, an ancient town on the S. bank of the old Beas river, 50 miles S.E. of Multan, and 20 miles N.E. of Bahawulpur. It is one of the towns which submitted to Chach after the capture of Multan in the middle of the 7th century, and was the scene of the great battle between Vikramaditya and the Sakas in A.D. 79.-Cunnizgham.

KAHRUBA. ARAB. Amber; also copal, and the pure gum of Vateria Indica.

KAHTAH. BENG. A professional story-teller, who recites traditional poems.

KAHTAN, son of Ebor, is one of the ancestors of the present Arabs in Yemen. In Hebrew he is called Joktan. His descendants are styled Arab-ul-Araba, i.e. pure Arabs.-Sale; Lane; Palgrave.

KAI. TAM. Kar, TeL. The hand. Idan-kai, the left-hand caste; Valan-kai, the right-hand. Kai-kara, workers in basket work. Extensively combined to indicate handiwork and pecuniary and revenue transactions, as Kai-karan, an artificer; Kai-kilan, a weaver by caste and occupation. Kaikari or Kaikadi, any handicraftsman, in Berar are makers of baskets from stems of cotton plants and palm leaves. They are a migratory and predatory race, whose ostensible occupation is basket-making. They wander through Berar. -Berar Gazetteer.

KAI, an ancient Pehlavi title applied to a great king. It was part of the title of Cyrus, the Kai Khusru of Persia, and it has given the Kyanian dynasty its designation.

Kai Bahman, one of the kings of Persia who were known to the Persians by the name of Ardeshir, and to the Romans as Artaxerxes, which was their mode of pronouncing Ardeshir. He was the Ardeshir-daraz-dast, or Ardeshir of the long arm, the Artaxerxes Longimanus of the Romans of the Kyanian dynasty.

Ardeshir Babegan bin Sassan was an officer of the Parthian king Arsaces Artabanus V., who assumed the Persian throne in A.D. 226 as the first of the Sassanian dynasty.

Ardeshir II., the tenth king of the Sassanian dynasty, was the Shapur or Sapor who captured the emperor Valerian. He assumed power in A.D. 381 .

Artaxerxes Mnemon was a Persian king, B.C. 426 , at whose court Ctesias resided for some years. After Scylax, Ctesias was the next historian of India, and in his Indica (cap. iv. p. 190) he mentions that Artaxerxes Mnemon and his mother Parasatya presented him with two iron swords, which, when planted in the earth, averted clouds, hail, and strokes of lightning. This is the first notice of the lightning conductor.

Ardeshir III., in A.D. 629, was the 25th Sassanian. Under him anarchy prevailed, and the Sassanian dynasty ended in A.D. 641, when Yezdejird or Izdejerd III. was overthrown by the Muhammadans.

KAIF. Arab. Repose; the savouring of animal existence; the passive enjoyment of mere sense. In a coarser sense Kaif is applied to all manner of intoxication. Sonnini says, The Arabs give the name of Kaif to the voluptuous relaxation, the delicious stupor, produced by the smoking of hemp; and in Morocco the word is applied to the dried flowers of the Cannabis sativa.Burton's Mecca, i. p. 12.

KAIFIET, ARAB., worn in Oman by all classes, is a broad kerchief, striped green, red, 
and yellow, having the sides hanging down, with knotted strings appended to them, serving by their motion to keep off the flies, which are there excessively troublesome. See Kaffiyeh.

KAIKEYA, an ancient country mentioned as beyond the Saraswati and Beas, whose people took part in the war of the Mahabharata. A Kaikeyi princess married king Dasaratha, to whom she bore Bharata, his third son. She nursed her husband when wounded at the war, and as her reward sought and obtained the exile of Rama, in order that Bharata might succeed.-D.

KAI-KHUSRU, whose name was Ghaias-udDin, succeeded his father A.D. 1235. He married a daughter of the king of Georgia. During the first difficulties occasioned by the Mongols, with whom he was perpetually at war, he was on the point of concluding a defensive treaty with Baldwin II. of Constantinople, who sent to France for his niece, daughter of Eudes, Lord of Montaigu, to marry her to him. But this affair was not completed, and he formed an alliance with John Ducas Bataze, Baldwin's enemy. He died A.D. 1244. - Desguigne's Hist. des Huns, ii. part 2, p. 66 .

KAILA. ARAB. A weight of about 12 seers.

KAILASA, in Hindu mythology, the paradise of Siva, but now the name of a mountain near lake Manasarowara. Both Brahmanical and Buddhist cosmogony derive four great rivers of India - the Indus, the Sutlej, the Ganges, and the Sardha-from one holy lake at the foot of Kailas. The Sutlej rises near the sources of the Indus and the Brahnraputra; and the Kailas mountain is thus ascertained by modern investigations to have a real claim to the position which it holds in Sanskrit tradition as the meeting-place of waters. The Brahmaputra, or rather the Tsan-pu, as it is known in Tibet, flows to the east, the Indus to the west, and the Sutlej to the southwest. The Kailas or Gangri range of mountains extends in one unbroken chain from the source of the Indus to the junction of the Shayok, and forms the natural boundary between Ladakh, Balti, and Rongdo on the south, and Ruthog, Nubra, Shigar, and Hunzanager on the north. It has six passes, at heights from 15,000 to 18,105 feet. Gangri, in Tibetan, means ice mountain. Kailas means crystalline or icy, and is derived from Kelas, crystal, which is itself a compound of $\mathrm{Ke}$, water, and Las, to shine. The Kailas or ice mountain is N. of Lake Manasa. It is the Colus of the Latins; is the Indian Olympus, the abode of Siva and the celestials. The Tibetans look upon Ti-se or the Kailas peak as the highest mountain in the world. It is also called Ganaparvata ; also Rajatadri, silver mountain.

KAILAS TEMPLE at Ellora is a great monolithic temple isolated from the mass of rock, and carved outside as well as in. It stands in a great court averaging 154 feet wide by 276 long at the level of the base, entirely cut out of the solid rock, and with a scarp 107 feet high at the back. In front of this court a curtain has been left, carved on the outside with the monstrous forms of Siva and Vishnu.-Imp. Gaz. See Kal.

KAILWA, a small territory in Rajputana, famed in Rajput story. When Salumbra of Chitore fell at the gate of the sun, the command devolved on Putta of Kailwa. He was only sixteen. His father had fallen in the last shock, and his mother had survived but to rear this, the sole, heir of their house. Like the Spartan mother of old, she commanded him to put on the saffron robe, and to die for Chitore; but, surpassing the Grecian dame, she illustrated her precept by example, and, lest any soft compunctious visitings for one dearer than herself might dim the lustre of Kailwa, she armed the young bride with a lance, with her descended the rock, and the defenders of Chitore saw her fall fighting by the side of her Amazonian mother. The Rajputs had maintained a protracted defence, but had no thoughts of surrender, when a ball struck Jeimul, who took the lead on the fall of the king of Mewar. He saw there was no ultimate hope of salvation, the northern defences being entirely destroyed, and he resolved to signalize the end of his career. The fatal Johar was commanded, while 8000 Rajputs ate the last beera together, and put on their saffron robes; the gates were thrown open, the work of destruction commenced, and few survived to stain the yellow mantle by inglorious surrender. Akbar entered Chitore, and 30,000 of its inhabitants became victims to his thirst of conquest. All the heads of clans, both home and foreign, fell, and 1700 of the immediate kin of the prince sealed their duty to their country with their lives. The Tuar chief of Gwalior appears to have been the only one of note who was reserved for another day of glory. Nine queens, five princesses (their daughters), with two infant sons, and the families of all the chieftains not at their estates, perished in the flames or in the assault of this ever memorable day. Their divinity had indeed deserted them ; for it was on Aditwar, the day of the sun, he shed for the last time a ray of glory on Chitore. The rock of their strength was despoiled, the temples and palaces dilapidated; and, to complete her humiliation and his triumph, Akbar bereft her of all the symbols of regality.Tod, Rajasthan.

KAIMAL. MAL. Amongst the Nair a title of rank, and used by the inferior classes when addressing them.-Wils.

KAIM-MAKAM. ARAB. An occupant for the time being, a successor. At Mecca, equivalent to mehmandar of Persia.-Hamilton's Senai.

KAIM SALAMI. HIND. A fixed quit-rent in the Bombay Presidency.

KAIMUR, a sect of freethinkers of Persia who deny everything they cannot prove.-Chesney.

KAIMUR, the eastern but detached portions of the Vindhyan range, commencing near Katangi in the Jabalpur (Jubbulpur) district of the Central Provinces, and running through the state of Rewah and Shahabad district of Bengal. It contains a deposit of rich vegetable mould in the centre, producing the finest crops. The formation is primitive sandstone, intermixed with schistose limestone. The Kaimur ranges commence in lat. $24^{\circ} 31^{\prime} 30^{\prime \prime} \mathrm{N}$, and long. $83^{\circ} 24^{\prime} \mathrm{E}$, within the Central Provinces, and occupy more or less continuously the great hilly area which extends from that point to lat. $25^{\circ} \mathrm{N}$., and long. $84^{\circ} 3^{\prime} 30^{\prime \prime} \mathrm{E}$., within the Lieutenant-Governorship of Bengal.Imp. Gaz.

KAINCH. HIND. Ornamental cloth, worn by wrestlers.

KAIN KAPALA. JAV. A head-dress cloth, tied round the head like a turband. The Javanese never appear bare-headed. 
KAIOA ISLAND is subject to Ternate. Eclectus grandis, the great red parrot, occurs here. The Kaioa people are a mixed race, having Malay and Papuan affinities, and are allied to the peoples of Ternate and of Gilolo. Their language is quite distinct from, though somewhat resembling that of, the surrounding islands. They are now Muhammadans. - Wall. ii. p. 12.

KAI PADARU, in Canara, predial slaves, a subdivision of the Dher or Pariah race.-Wilson.

KAIRA, a town in Gujerat, in lat. $22^{\circ} 44^{\prime} 30^{\prime \prime}$ N., and long. $72^{\circ} 44^{\prime} 30^{\prime \prime} \mathbf{E}$. It gives its name to a revenue district, which has the Mahi and Sabarmati as parts of its boundary, with population, in $1872,782,733$. The Kumbi of certain villages are beld in honour, as descended from the leading men among the original settlers in Gujerat. Koli number 281,252. During the thirty years $1846-76$, they increased from 175,829 to 281,252 . Idle and turbulent under native rule, they are now quiet, hard-working, and prosperous. They formerly lived in comfort by weaving coarse cotton cloth, but the competition of the Bombay and local steam mills is now shutting them out of the market. At Lasundra, about 24 miles from the Nariad railway station, springs of hot water rise to the surface in ten or twelve cisterns, the hottest having a temperature of $115^{\circ} \mathrm{Fahr}$. The water, slightly sulphurous, is used in skin diseases.

KAIRIN, a quality latent in coal tar which resembles that of quinine; likely to prove a blessing to mankind should further experience confirm the result attained by careful experiments up to present time.

KAIRWAN, in the north of Africa, near Tunis, is a city rendered sacred to the Muhammadans from containing the tomb of Syud Abdullah, one of the companions of Mahomed. After the death of Mahomed, Syud Abdullah came to Kairwan, where he died. He was accustomed to wear a lock of Mahomed's bair over his breast. They style him Sidi us Sahib un Nabbi, the lord companion of the prophet. Kairwan rose on the ruins of the Roman Vicus Augusti. It is a place of pilgrimage, and the bodies of the dead are sent from a distance to be interred near.

KAIS or Kish, a legendary ancestor of the Afghan race. They say he was one of Mahomed's early disciples. Kais had the new name of Abd$\mathrm{u}$-Rashid given to him by Mahomed, with the title of Pathan, Guide, or Rudder. The race, however, claim to be Ban-i-Israel, who were carried into captivity from Palestine to Media by Nebuchadnezzar, subsequently emigrated to Ghor, and finally spread over their present lands. They are known as the Batan, Ghorghasht, Saraband, and Sarabar. Saraband or Sarabar is said to be a change from the term Surya-vansa.-Bellew.

KAISAR has been a title for emperor from ancient times, and seems to have been adopted by the rulers in Western Asia from the Cæsars of Rome. Amongst European nations, it is used at present for the German emperor, and Kaisar-iRum is a designation in Persia and India of the emperor of Turkey. When Queen Victoria assumed the title of Empress of India, it was rendered as Kaisar-i-Hind. The plural is Kaisarit. Freytag's Dictionary (iii. 453a) gives Cæsar Imperator Græcorum as the meaning.
Jones' Persian Grammar (p. 106, ed. of 1809) has a couplet--

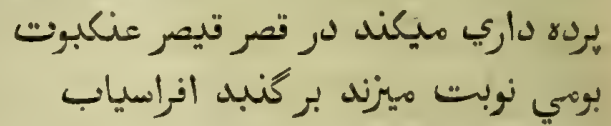

'Pardahdari mi-kūnad dar kasr i kaisar ankibūt ; Bumi naobat mi-zanad bar gumbaz i Afrasiab.'

'The spider weaves its web in the palace of Cæsar, The owl stands sentinel on the watch-tower of Afrasiab.'

The troops who embarked at Bombay for Malta shouted 'Victoria Maharani ki Jye,' and did not use the title ' Kaisar-i-Hind.' In Northern India, 'Victoria Maharani ki Jye,' Victory for the great Queen Victoria, is a familiar expression. The war-cry of the Madras soldiery, 'Deen! Deen! Deen! for the faith! for the faith! for the faith!' is suited to their less demonstrative character, and for the several nationalities to which they belong, -Muhammadan, Tamil, Teling, Mahratta, Canarese, Christian, and non-Aryan races.

KAISHAKU, amongst the Japanese, the friend who decapitates the victim in the Hara Kiri.

KAISHK. PERS. The Kurut or Koorut of the Afghans and Turkomans.

KAISI GHAT, a ghat where Krishna, while yet a mere boy, slew Kaisi, a devata of gigantic strength, sent by Kansa to take away his life. The anniversary of that exploit is still observed with great festivities.-Tr. of Hind. ii. p. 60 .

KAITANGATA. MAORI. Man-eater.

KAIVARTTA, a fisherman, also pronounced Kaivart or Kaibart or Kaibartha.

KAJAL. HIND. Lamp-black, used by women for their eyelids.

KAJANG. MaLAY. The leaf of the Nipa fruticans, written Cadjan by Europeans in India.

KAJAR, the tribe to which the reigning family of Persia belong. They are one of the seven Turkish tribes which supported Shah Ismail, one of the first kings of the Suffavi dynasty, about A.D. 1500, when he raised the sect of the Shiah to importance, and made their belief the national religion of Persia. Shiah means sect in Persian, and the name given them as a reproach he took as a title. The Kajar have been distinguished during several generations among the tribes of Masandaran, the ancient Hyrcania. But they have not been traced farther back than A.H. 906, A.D. 1500, when Piri Beg, Kajar, is mentioned in a MS. Mr. Foster says the Kajar are an extensive tribe, chiefly residing in Masandaran and Astrabad; and that the word in the provincial language signifies rebel or deserter. Like the Rajputs of India, they derote themselves principally to the profession of arms.

The greater number of the ancestors of Shal Ismail had been Sufis or philosophical deists, and Malcolm supposes that he raised the sect of Ali because he thought it necessary that the holy raptures in which the derotional men of his time and family indulged, should have some object more comprehensible to the mass of his countrymen than the abstract contemplation of the deity. The names of the other Turkish tribes who supported Shah Ismail were Oostajālu, Shamlu, Nikallu, Baharlu, Zulkudder, and Affshar. Aga Muhammad Khan, 1794, was the first monarch of the Kajar dynasty, and at that time the tribe were principally settled in the neighbourhood of Astra- 
bad; where they still remain. He was the son of a petty chieftain, who had been expelled from his state by Nadir Shah. In his youth he had fallen into the hands of a nephew of Nadir, who made him a eunuch. He was avaricious, revengeful, and loved power. In 1797 he was succeeded by his nephew Futteh Ali, in whose reign Persia had two disastrous wars with Russia, which gained the frontier of the Araxes and some territory beyond its mouth. But Persia reconquered Khorasan from the Uzbaks and Afghans. He died in 1834, and was succeeded by his grandson Muhammad Shah, and he again, in 1848, by Nasr-ud-Din.

Colonel MacGregor says the Kajar were brought from Syria by Timur, A.H. 803, and rapidly increased, that they are divided into the sections Yokaribash and Ashagabash, who have each six clans. The Ziadoglu Kajar division of the Kajar were settled at Granja in Russian Armenia, and remain there still. The Azdanlu section were removed to Merv in the reign of Shah Tamasp I., and beld it until conquered by and nearly annibilated by the Uzbak under the Khan of Bokhara. -MacGregor, iv. p. 609 ; Ferrier's Journeys; Malcolm's Persia; Tarikh Alam Arai; Ouseley's Travels; Foster's Travels; Chatfield's Hindustan. KAJARI. MAHR. A caste amongst the Mahrattas who make glass bracelets.

KAJAWAH. HIND. Boxes, panniers, cradles, formed of wooden frames, covered with cloth or leather, from $3 \frac{1}{2}$ to 4 feet long by 4 feet high, in which those who travel upon camels or mules are seated. They are partially open in front, and when fitted up with bedding make a conveyance by no means contemptible in a cold night, for those who can sit for many hours together in the Asiatic fashion, with their legs doubled or crossed under them. The traveller becomes soon accustomed to the measured motion of a camel's pace, and thus can enjoy both warmth and sleep, blessings most enviable during the long and wearisome nights of a winter's journey, and of which those who travel on horseback are totally deprived. Each camel carries two of these baskets or cradles, which are hung like panniers one on each side. They are largely used in Balkh by travellers and by Sindian ladies. Mr. Rich says that in a journey to Kurdistan the kajawah for Mrs. Rich's servants were slung on mules.

KAKAR, a tribe widely spread throughout Afghanistan, but their country is in the extreme S.E. corner of Afghanistan, west of the Sulaiman range, and bordering on the Kasrani and Bozdar Baluch, to near the head of the Bolan defile. They claim descent from Sharif-ud-Din, son of Sharaband, eldest son of Keysh, whom Mahomed himself converted. (See Kais.) The Gakkar, a branch of them, are located on the banks of the Jhelum in Kashmir. The whole of the asafœtida trade of Herat is in the hands of the Kakar, who annually send 5000 or 6000 people to collect it. Their subdivisions are - the Jalazai of Kaisar and Bori, 2000 fighting men; the Musa Khel of Sarai, 3000 men; the Kudizai of Darz-i-Karez, 2000; Abdulzai of Mayana, 2000; Kabezai of Tabezai, 1000; Hamzazai of Shahrang, 1100; the Utman Khel, the Khadarazai of Maskat, the Shabozai, Temzai, and Alizai, each 200 fighting men. Small numbers are at Ranizai, also near Kandahar, GLor, Shall valley.
There are some in the Azimgarh district, and Kakar were in small bodies in the Ceded Districts so late as the year 1845 , but by the year 1863 they had disappeared, probably merged into the general population. They were remnants of Pindara marauders, and had little ponies on which they brought grass for sale; they also were carriers, and traded in horses; they were a very dark-complexioned race; they professed Muhammadanism, spoke a Hindi language, which they called Lahaura-ha-Noche, and were under the leadership of a Rissaldar. - MacGregor; Elphinstone, p. 452 ; Sherring's Tribes, p. 239.

KAKHETIA, in lat. $40^{\circ} 50^{\prime}$ to $42^{\circ} 15^{\prime} \mathrm{N}$., and long. $44^{\circ} 55^{\prime}$ to $47^{\circ} \mathrm{E}$., a district of Georgia. The people are Georgians, Armenians, Tartars, Jalal, and Siknak, and are brave.-MacGregor.

KAKHYEN call themselves Ching - pa or Sheng-pa, men. They occupy both banks of the Irawadi, from Bhamo upwards. Each clan is ruled by a hereditary chief called Tsawbwa. The men are hunters. They capture men, women, and children, whom they keep as slaves. The men range from 5 to $5 \frac{1}{2}$ feet, and women 4 to $4 \frac{1}{2}$ feet in height, with short limbs. They never wash, and the clothes once put on are never changed. Combs are never used. The men smoke opium, but not to excess. The women do all the field and other work, weave and spin. They all drink a beer called Sheroo, from fermented rice. Chastity is not regarded in unmarried, but adultery in the married state is death. The brides are purchased by the bridegrooms. The dead are buried. The race is quarrelsome and revengeful, but not brave. They are a branch of the vast horde of Singpho, who inhabit the mountainous districts of Northern Assam, and stretch round the N. of Burma into Western China. Intermixed with $\mathrm{Ka}-\mathrm{Ku}$ and other kindred tribes, and the Shans, they extend not only all along the northern frontier of Burma, but occupy large portions of the hilly tracts of both sides of the Irawadi river as far south as Tagoung. Kakhyen are barbarians.Fytche, ii. p. 100; Mason's Burma, pp. 97, 641; Yule, p. 146.

KAKKOLA, also Kakkoloka. SANSK., TEL. A perfume obtained from a berry. It is oval, with a thick, green, sebaceous, fragrant integument, which dries and shrinks with age, becoming a thin, greyish epidermis. Within this is an aromatic kernel, abounding with a resin which is inflammable, slightly soluble in water, and more so in alcohol. The Kakkola is an esteemed drug, being described in the Raja Nightantu and Bhava Prakasa as pungent, bitter, and carminative.

The Kakkola drug is so called from its colour, which is black like that of the crow. The Hindus enumerate in their medical works a class of eight substances, which they denominate the Ashta varga, or class of eight; they are all roots, and appear to come chiefly from Nepal and the countries skirting the Himalaya. They may be employed either singly or collectively, and are described as cool, sweet, fattening, and aphrodisiac; promotive of digestion, sanative, lactiferous, and tonic. They are further said to possess great efficacy in urinary and phthisical affections, and in removing the sequelæ of fevers. Their names are Jivaka, Pisanabha, Meda, Mahameda, Kakkola, Kshira kakkola, Riddhi, and Vriddhi. The substance amongst these termed Kakkola is generally 
connected with the Kshira kakkola, and these two drugs are procured from Morung and the adjacent districts. Kshira kakkola resembles the root of the Pivari (Asparagus racemosus), and is of a white colour, a fragrant smell, and full of milky sap. The Kakkola is of similar form and character, but of a dark hue. They are both sweet and cooling, they remove fever, and correct a vitiated state of the blood and bile; the root of the Vidari (Batatas paniculatus) and the Aswagandah (Physalis flexuosa) are severally substitutes for the Kakkola and Kshira kakkola.-Wilson, As. Res. xiii. p. 411 ; Elliot, $F l$. Andh.

KAKO MATI. Gr. Evil eye.

KAKOOL, tufts of hair left on both sides of the head, the middle part being shaved from the forehead to the neck.

KAKORI, a town in Oudh, 9 miles west of Lucknow city. It contains the tombs of several Muhammadan saints, and is the birthplace of distinguished Musalmans, who have served under both the native and British Governments.-Imp. Gaz. v.

KAKSHIVAT, a Hindu poet, who was of the race of Pajra. He married ten daughters of raja Swanaya, on the banks of the river Indus. His hymns are found in the first and ninth mandala of the Rig Veda. He is said to have been a Kshatriya. Professor Lassen is of opinion that his father, Dirgha-Tamas, was one of the earliest Brahman missionaries in the southern parts of Bengal, among the Anga and Kalinga.

KAKU-BANS, the great hollow female bamboo.

KA-KUI and Ka-kua tribes are occupants of both sides of the Mei-kong. A tribe of wild Ka-kui dwell on the Man-lo-ho river, in lat. $22^{\circ} 20^{\prime}$ N., a tributary of, and flowing from the west to, the Mei-kong river. They have the Lilun and and Kak-bal on the east.

KAKUPUR, 10 miles N.W. of Bithur, and the intervening land is called the "five cos circuit of Utpalaranya.' The ruined mound of Kakupur is said to be the remains of a fort named Chhatrpur, which was founded by raja Chhatr Pal Chandel about the 10th century A.D. Kakupur possesses a temple dedicated to the Kshireswara Mahadeva, and one to Aswatthāma, son of Drona, near which a large annual fair is held.-Cunningham's Ancient Geog. of India, p. 386.

KAKUR. HnND. The rib-faced or barking deer, Styloceros muntjac, generally distributed over the lower and cultivated tracts of the Himalaya, being seldom met with at elevations exceeding from 8000 to 9000 feet above the level of the sea. The prevailing colour is a reddish-brown above, white underneath, inclining to ash on the inside of the legs of males, which have two short canine teeth in the upper jaw resembling those of the musk deer, but not so long.-Adams; Jerdon.

KAKUSANDA, the third Buddha previous to Gautama._Hardy's East. Monach. p. 437.

KAL. Sansk. Time, age.

15 nimsha $=1$ kashta. $\mid 12$ kshana $=1$ muhurtta.

30 kashta $=1$ kala. $\quad 30$ muhurtta $=1$ day and

$30 \mathrm{kala}=1$ kshana.

$\mathrm{Kal}$, as time, in the Kailasa temple at Ellora, is represented as a grinning skeleton, with cobra girdle and necklace, seated on two dying men, a wolf gnawing the leg of one, while behind him is Kali and another skeleton.

KALA, from Kal, SANSK., time in general, or any particular time or season; death, destiny. In the Atharva Veda, Kala, time, is addressed as the source and ruler of all things. Kala and Maha Kala are names of Siva. Kala-Bhairava, from Kala, time, and Bhairava, the terrific. Kala-Sutra, from Kala, time, and Sutra, a thread. Kala-Sa, gradation or manifestation of the Mula Prakriti.-D.

KALA, in Burma, is a term applied to a native of India, but more extensively to any western foreigner, such as an Arab or a European. Sir A. Phayre supposed it to have been derived from a name given to the aboriginal races of India, which is still traceable in the scattered tribes of $\mathrm{Kol}$, Koli, etc.

KALABAGH, in lat. $32^{\circ} 57^{\prime} \mathrm{N}$., and long. $71^{\circ} 35^{\prime} \mathrm{E}$, in the Panjab. The mean height of the town, 790 feet above the sea; Kalabagh peak, above 2357 feet. The Indus is here compressed by mountains into a deep channel 350 yards broad. The mountains on each side have an abrupt descent into the river, and a road is cut along their base for upwards of two miles. The first part of this pass is actually overhung by the town of Kalabagh, which is built in a singular manner upon the face of the hill, every street rising above its neighbour. The Hon. Mountstuart Elphinstone found the road cut out of solid salt, at the foot of cliffs of that mineral, in some places more than $\mathbf{1 0 0}$ feet high above the river. The town is picturesquely situated at the foot of the Salt Range, on the right bank of the Indus, at the point where the river debouches from the hills, 105 miles below Attock. The houses nestle against the side of a precipitous hill of solid rocksalt, piled one upon another in successive tiers, the roof of each tier forming the street which passes in front of the row immediately above. Overhead, a cliff, also of pure rock-salt, towers above the town. An Awan family, who reside in Kalabagh, have a certain supremacy over the whole of their fellow-tribesmen, the representative of the family being known as Sirdar or Khan. The salt is quarried at Mari, opposite the town, where it stands out in huge cliffs, practically inexhaustible. The similar outcrop at Kalabagh itself is not quarried. The quantity turned out in 1871-72 amounted to about 2717 tons, and the revenue to $£ 23,284$. Alum shale also occurs in the neighbouring bills.-Imp. Gaz.

KALABATUN. HIND. Gold wire and silver wire for making gold and silver thread and tinsel. The silver is called 'safaid' Kalabatun, and the gold 'surkh' Kalabatun. Also, gold and silver thread made by twisting the fine-drawn wire on to red and white silk, according to the metal.

KALADGI, lat. $16^{\circ} 12^{\prime} 9^{\prime \prime} \mathrm{N}$, , and long. $75^{\circ} 29^{\prime} 9^{\prime \prime} \mathrm{E}$., a town in the Dekhan. The Dak bungalow is 1744 feet above the sea, and the level of the Gatparba is 1653 feet. The rocks of the neighbourhood are stratified clayslate. Owing to its uncertain rainfall, Kaladgi district is very subject to failure of crops, and consequent scarcity of grain. In 1818-19 a failure of rain caused great distress. Other years of drought and scarcity were 1824-25, 1832-33, 1853-54, $1863-64,1866-67$, and in $1876-77$ the failure of rain was more complete and general in Kaladgi than in any other part of the Bombay Presidency. -Imp. Gaz.

KALAGOUK, or Curlew Island, an island 
pleasantly situated at the mouth of the Moulmein river.

KALAH or Killah. ARAB. A castle, a fortress. Kala-Jabar or Hasn-Jabar, near the Euphrates, the Ezion-geber of the Bible (1 Kings ix. 26, 27). Kalat-ar-Rum, on the Euphrates, south of Edessa. Kalat-ul-Mudik occupies the site of Apameia. Asshur or Assur was originally the name of a city on the banks of the Tigris, the ruins of which are now known as Kalah Shergbat. The name was of Accadian derivation, and signified 'waterbank.' Babylonia was an older kingdom than Assyria, which took its name from the city of Assur, now Kalah Sherghat, the original capital of the country. It was divided into two halves, Accad (Genesis x. 10) being Northern Babylonia, and Sumir, the Shinar of the Old Testament, Southern Babylonia. The primitive populations of both Sumir and Accad were related not to the Semitic race, but to the tribes which continued to maintain themselves in the mountains of Elam down to a late day. They spoke two cognate dialects, which were agglutinative in character, like the languages of the modern Turks and Fins ; that is to say, the relations of grammar were expressed by coupling words together, each of which retained an independent meaning of its own. At an early date the Sumirians and Accadians were overrun and conquered by the Semitic Babylonians of later history, Accad being apparently the first half of the country to fall. It is possible that Casdim, the Hebrew word translated Chaldees or Chaldrans, is the Babylonian casidi or conquerors, a title which continued to cling to them in consequence of their conquest. The Accadians had been the inventors of the pictorial hieroglyphics which afterwards developed into the cuneiform or wedge-shaped system of writing. Sayce, Fresh Light, p. 24.

KALAHASTI, Kalastri, or Calastri, a town in the North Arcot district, Madras, situated in lat. $13^{\circ} 45^{\prime} 2^{\prime \prime} \mathrm{N}$., and long. $79^{\circ} 44^{\prime} 49^{\prime \prime} \mathrm{E}$., on the right bank of the Suvarnamukki. It gives its name to a zamindari estate, situated partly in North Arcot and partly in Nellore district, one of the largest estates in the Karnatic. Population $(1871), 231,527$; number of villages, 784 ; number of houses, 41,551; area, 1127 square miles; peshkash (rent) to Government, $\$ 19,000$. The revenues of the zamindar are estimated at between $£ 40,000$ and $£ 50,000$ per annum. The country is in a great measure covered with scrub jungle, from which Madras city is supplied with firewood. -Imp. Gaz.

KALAHUNDI is bounded on the north by the Patna State, on the east by the Jeypore State and the Vizagapatam district, on the south by Jeypore, and on the west by Bindra, Nawagarh, and Khariar. The country is high, lying behind the Eastern Ghats, and the soil is fertile and easily worked, yielding heavy crops of almost every description. Villages are numerous but small, and the means of communication are limited; and though the people appear to be well off, the population is thinly distributed. According to the census of 1872 , the population numbered 133,483 , of whom 72,986 were Hindus, while the remainder mostly belonged to the Khond, who seldom remain long in one place, and the greater part of whom pay nothing to Government, and have but little intercourse with its officers. Both the Khond and the Kolita maintain themselves by agriculture, the former being an aboriginal and the latter a semi-aboriginal tribe. The Kolita, an industrious, hard-working race, have gradually spread themselves over almost every district in the eastern provinces of Central India, and have ousted the Khond out of many of their villages, and this quiet aggression has caused an ill-feeling that has at times broken out in a serious form.

KALAIGAR. Hrnd. A tinsmith; one who tins copper cooking utensils.

KALAKKAR. TAY. A low caste, the same as the Paleyar, hunters and fowlers.

KALAL or Kalar. HrND. A distiller, a vendor of spirituous liquors, a palm-wine drawer.

KALAM. ARab., Hind., Pers. A pen, a reed pen, the Roman calamus. Kalam-dan, a pen-andink stand. Kalam-band, reduced to writing. Kalam-kari, painting.

KALAM. Arabs divide their spoken and even written language into two orders, the Kalam Wati, or vulgar tongue, sometimes employed in epistolary correspondence; and the Nahwi, a grammatical and classical language. Every man of education uses the former, and can use the latter. And the Koran is no more a model of Arabic, as it is often assumed to be, than Paradise Lost is of English. Kalam is the Word. Animus, in Latin, is the breath of life breathed into man's nostrils, is the Ruah of the Hebrews, the Ruh of Arabia, and among the Greeks and Romans, Animus, Anima, and Spiritus. In their designation of the various prophets, Muhammadans style Moses, Kalām-Allah, the word of God; Abraham, the Kalil-Allah, friend of God; and Jesus Christ is the Ruh-Allah, the Spirit of God. Kalamm-Allah, the word of God, is the Koran.-Burton's Mecca.

KALAMAH. ARAB. The Muhammadan creed, consisting of five sections, - Taib, Shahadat, Tamhid, Tauhid, and Rad-i-Kufr. The Taib is their La - illaha - il - Ullaho - Mahomed ur - Rasul Ullah, There is no deity but God, and Mahomed is the prophet of God. The Shahadat is, I testify there is no deity but God alone, without companion; and I testify that Mahomed is his servant and prophet, etc. The Kalamah is not found in the Koran.

The words in Arabic are-

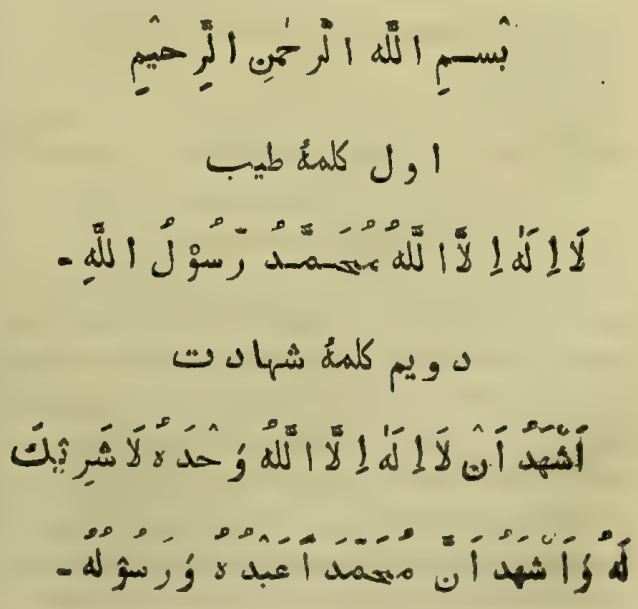




\section{سيو م كلمة تمسيديد}

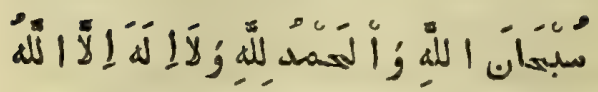

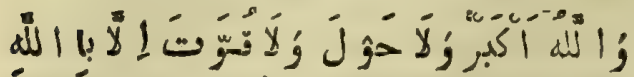

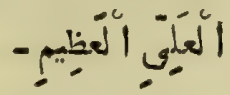

\section{حها}

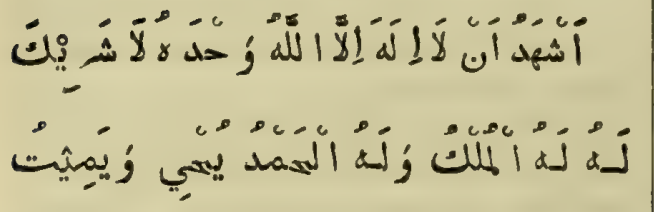

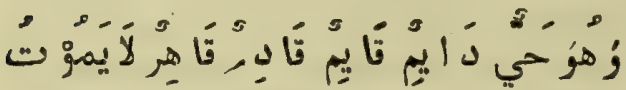

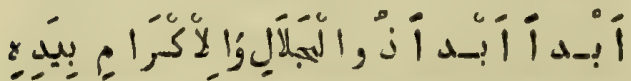

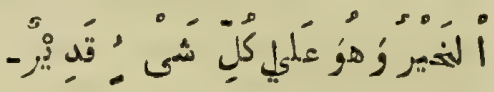

بْنمبم كلمهُ رد كفر

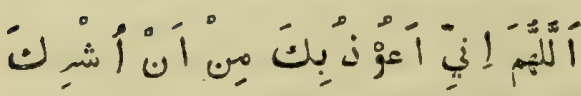

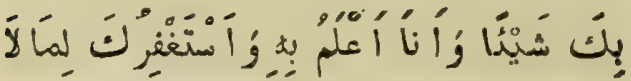

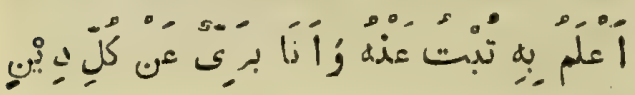

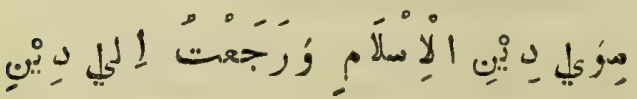

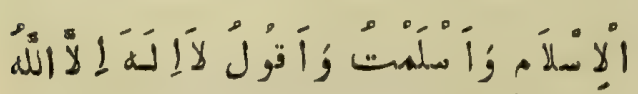

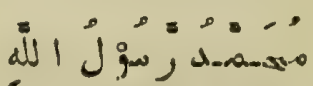

KALAMEKAM, a Tamil poet, supposed to have lived about the 15th century. His real to name is not known. He was called Kalamekam, 'the hail-pouring cloud,' from his severe satires upon those who did not, in his opinion, adequately reward his poetry. His conceit was excessive. $\mathrm{He}$ declared his ability to write an epic poem in a couple of days, and other compositions in proportionately less periods. His poetical remains consist of some short poems, the principal of which is a series of verses capable of twofold meaning.
KALANANAS or Kalyana, a Brahman who accompanied Alexander, but, repenting of having left home, he burned himself at Pasargada. $-D$.

KALANDAR, a sect of the Kadiri fakir or darvesh. A kalandar is defined to be a Sufi who has no murshid or religious teacher, but works out his salvation by himself. The orthodox Sufi sect blame the order, but cannot help owning that it has produced some very distinguished saints. The kalandar does not, however, refuse to take murid or followers.-Burton's Scinde.

KALA NEMI, uncle of Ravana, who undertook to kill Hanuman for half the kingdom of Ravana. But Hanuman discovered his worthlessness, took him up and whirled him through the air to Lanka, while he was meditating on the offered reward, which he imagined he had won.

KALANG, a people who resided among the inhabitants of the Tengger mountains, said to have been at one time numerous in rarious parts of Java, leading a wandering life, practising religious rites different from those of the great body of the people, and avoiding intercourse with them; but most of them embraced the Muhammadan faith.-Raffles' Java, i. p. 329.

KALANG or Coolen, HIND., is the common European crane, Grus cinerea, now a most rare bird in England, but still breeding somewhat plentifully in Scandinavia, and a winter visitant in large flocks in many parts of India. See Crane.

KALA-NIMAK. HIND. An artificial black salt, made by pounding together five seers of saji khar, two seers of dried anola fruit, and one maund of common salt, adding water, and boiling for some time. Is considered to promote digestion; is much eaten; used in many mesalib. Nimak manyari and Nimak nali are medicinal substances.-G€n. Med. Top. 144. See Bit-laban.

KALANJAR, a hill fort in Bundelkhand.

KALANJARA, a fabulous mountain north of Mount Meru.

KALANWAL. HIND, Musician who plays on the tambura.

KALA-PANI. Hind. The deep sea; also any perennial stream. It is the name of a river which falls into the Brahmaputra beyond Meyong, and of a river in the Pandua Hills.-As. Res. xvii. pp. 502-505.

KALAPASIKA and Dandapasika, in ancient Hindu times officers of justice; the bearers of the noose of death and of punishment.-Hind. Theat. ii. p. 167.

KALA-PATTA. HIND. The Jhareja princes, in making patta or grants, appear never to have had an idea of claiming any reversionary interest; there are no distinctions, as in Mewar, of Kalapatta or Chor-Utar estates, that is, those for life, or resumable at pleasure, of which there was in Mewar a large class. A great moral crime is the sole corrective of this political error; and it was to prevent the destruction of families by following the supreme law of sub-infeudation that the first law of nature and of God is violated, infanticide not being confined to female victims. Mr. Elphinstone, in his report on Cutch, confirmed this, adding that it accounts for the number of single beirs-male in families.-Tod's Travels, p. 488.

KALA-PRIYA-NATH is a Hindu deity not known to the pandits of the present day. 
Malanka takes no notice of the name. Jagaddhara is content to say it is that of a divinity worshipped in that country. In the Varaha Purana, Kala-Priya is said to be a form of the sun worshipped to the south of the Yamuna; and Kala-Priya-Nath, his lord or god, implies a linga, the construction of which is attributed to the sun. The more usual word in these compounds is Iswara, as Someswara, Rameswara, Visweswara, etc.; but Nath is the term more especially employed by a particular sect, that of the Yoyi or Pasupata, the oldest sect probably now existing amongst the Hindus, and with whose tenets and practices Bhava Bhuti appears to have been thoroughly acquainted.-Hind. Th. ii. p. 10.

KALAR. SingH, Saline soil.

KALASA. HIND, A water jar. On the first night of the Dasahara festival at Parvati, a kalasa or water jar is cleansed and consecrated by the officiating Brahmans-this vessel being considered as a symbol of the goddess-for the principal object of worship during the Dasahara, and bears three curious signs, according to the three principal castes of Brahmans; these are hieroglyphic tigures, denoting the character and attributes of Durga, and so truly are their forms Egyptian that many learned writers have engaged, from their coincidence, to prove the identity of the Hindu ceremonies of the Dasahara with those which celebrate the inundations of the Nile. Kalasi puja is the placing a water jar in a chamber as a type of, or receptacle for, Durga or otber Hindu divinity, and worshipping it. Kalasisthapana, setting up a water jar as an object of worship, a part of the Hindu marriage ceremony, in which offerings are made to the planets in different vessels.-Postans' Western India, ii. 165, 166; W.

KALA SANKALITA, memoirs on the eras of S. India, collected by Colonel John de Warren, Madras 1825. See Yojana.

KALASI, an ornamental top of a wall or building.

KALA-SUTRA. MAHR. A puppet showman, a rope dancer, juggler, musician, dancer, athlete.

KALAT or Khelat, chief town of the terri. tories of the khan of Khelat in Baluchistan; situated on the northern spur of a limestone hill, called the Shah Mirdan; lat. $28^{\circ} 53^{\prime}$ N., and long. $66^{\circ} 28^{\prime} \mathrm{E}$. It is about 6800 feet above sea-level. The suburbs of Khelat, one on the west and the other on the east side, are extensive, and the Babi portion of the community reside there. The town of Khelat is inhabited by Brahui, Hindus, Dehwar, and Babi. The Brahui form the great bulk of the inhabitants, but the cultivation is chiefly carried ou by the Dehwar communities. See Baluchistan.

KALAT-i-GHILZAI, a fort in Afghanistan, on the right bank of the Tarnak river, $1+4$ miles from Ghazni, 89 miles from Kandahar, and 229 miles from Kābul. It was occupied by a British detachment in November 1841, and on the 20th May 1842 they successfuly repulsed an attack of the Gbilzai, estimated at 5500 strong. Only two small villages are near it. The Tokhi clan of the Turan branch of the Ghilzai are the chief occupants of Kalat-i - Ghilzai. They number 12,000 families.-MacGregor, pp. 485, 486, 713.

KALAWANT. HIND. A professional musician and singer. Kalawantin, the female.

KALA YAVANA, a king from the far west who aided Jarasandha in his successful attack on Mathura. His soul is supposed to have animated Aurangzeb.-Growse, p. 621.

KALDANI. The Kaldani people, according to their own account, were converted to Christianity by St. Thomas and two of the seventy disciples. By means of a rigidly enforced system of exclusion, they have preserved their freedom as a republic; their religious tenets and simple liturgy have also remained nearly unchanged since the gospel was introduced into their secluded valleys. These Kaldi or Chaldæans are a Christian sect dwelling in the Hakkari district of Kurdistan. Every village has a priest and simple church, and both men and women assemble every Sunday to worship and take the sacrament. Fasts are frequent, and the priests do not take meat. Constantly prepared for or engaged in war, they are ferocious towards their enemies, and even towards peaceable strangers. They have been confounded with the Nestorians. The Kaldani country stretches eastward of the district of Amadiyah, between Lake Van and the Taurus. In the interior are terraces cultivated with rice or other grains, with a succession of deep, dark, wooded valleys, between the high and rugged alpine ranges of Julamerik, the Jawur Tagh, and other chains, which rise to the uplands, situated beyond the backbone of Kurdistan.-MacGregor.

KALESAR, the finest submontane forest tract in the Eastern Panjab Himalaya, is the remnant of a once far more extensive tract of sal at Kalesar, in the Ambala district. The forest is on the extreme north-erst corner of the district, in a fork of the Siwalik Hills, on the right bank of the Jumna, opposite the Khara head of the Eastern Jumna Canal, and about three miles above the head of the Western Jumna Canal at Haturkhund.

KALGHA. HiND. A crest, a plume, a crest of feathers, an aigrette. Khod, crest for a helmet. Kalghi plumes are made of the black feather of a kind of heron called onkar, peculiar to Kashmir, also of the monal. The royal plume of three feathers is of Moghul origin. The Moghul emperors of India, when they took the field, wore a plume of three black feathers as a symbol of command.

KALHANA, a pandit, who lived about A.D. 1148 , author of the Raja Tarangini, a history of Kashmir.-D.

KALHORA, a dynasty of Sind, whose rule first began about A.D. 1740. The aristocracy of Sind, as in most oriental lands, was purely one of rauk conferred by office, and in Sind consisted either of Sindi or of Jat.

The Kalhora and Talpur tribes furnished the last dynasties, and though the one deduced its origin from the Abbassides of Persia, and the other advanced pretensions to descent from the prophet, both were alike Baluch.

Yar Muhammad, Kalhora, assisted by the Rind Baluch, overthrew the Puar Rajputs, who held dominion in Sind. He directed that a number of clubs should be suspended in front of his tomb, as a memorial of the ease with which the conquest was effected. The clubs were still banging in 1847 in front of his tomb at Khodabad.

The Talpur have their name from the town (poora) of palms (tal or tar), and are said to amount to one-fourth of the population of Lohri 


\section{KALI.}

or Little Sind, which misnomer they affixed to the dominion of Hyderabad. There are none of the Talpur in the t'hul. They emigrated from Chot to Sind about A.D. 1760, and, after attaining power, ruled from A.D. 1799 to 1843 , when they were overthrown by the British. The family have four principal branches,--the Shahwani, the Shahadani, the Khanani, and the Munikhani. A minor branch is the Jumidani. The Talpur are of the Shiah sect, and claim to be Syuds.-Burton's Scinde, p. 235. See Kalora.

KALI. In Hindu cosmogony, the last and worst of the four ages of the world,-Krita or Satya, Dwapara, Treta, and Kali, which make a Maha Yoga, or great age. The Kali Yoga is the present age of the world, and is supposed to have begun on Friday the 18th February, B.C. 3102. It is to last 432,000 years, forming a period of progressive iniquity and deterioration, and ending in the general dissolution of existing forms. - W.

KALI. ARAB. Barilla; the common Kali salsola, Linn., grows in great plenty along the Arabic Gulf, and in the isles. The maritime plants from the ashes of which soda is obtained by lixiviation; and from the name of this plant, with the Arabic article al, is derived that of a class of substances possessing peculiar properties, which are called alkalies. Kali was also formerly employed to designate the alkali potash.-Eng. Cyc.; Niebuhr.

KALI, a branch of the Sardha or Gogra, separating Kamaon from Nepal.

KALI, a goddess of the Hindus, whom their mythology recognises as a form of Parvati, and called also Maha-Kali, Durga, Bhawani, and Devi. Kali is the consort of Siva, in his destroying character of Time. As such, she is painted of a black or dark-blue complexion. In pictures, she is shown (as the personification of Eternity) trampling on the body of Siva (Time). In one hand she holds the exterminating sword, in another a human head; a third points downward, indicating, according to some, the destruction which surrounds her, and the other is raised upwards, in allusion to the figure of regeneration of nature by a new creation. Whatever her gestures may import, the image of this goddess is truly horrid, as are the devotional rites performed in her honour. Her wild, dishevelled hair reaching to her feet, her necklace of human heads, the wildness of her countenance, the tongue protruded from her distorted mouth, her cincture of bloodstained hands, and her position on the body of Siva, altogether convey in blended colours so powerful a personification of the dark character which she is pretended to portray, that, whatever may be thought of their tastes, we cannot deny to the Hindus full credit for the possession of most extraordinary and fertile powers of imagination. Kali is the goddess of cemeteries, under which form she is described dancing with the infant Siva in her arms, surrounded by ghosts and goblins (likewise dancing) in a cemetery amongst the dead; her images, under this form, are worshipped by the Hindus as a propitiation against the destructive ravages of the cholera. To this ferocious goddess sanguinary sacrifices are made. The July (1859) No. of the Calcutta Review (p. 423) remarks that ' in Bengal, in the worship of the bloody Kali, all castes mingle together, and, after a libation of ardent spirits to
KALI.

the goddess, drink spirits and eat flesh, as their fathers did in the Vedic times, said to be practised to this day in the foul and secret rites of the Tantra, too abominable for Christian ears.' A festival held in honour of Kali is called also Kalipuja, as the Dasera in honour of the same deity, under the name of Durga, is called also Durgapuja and Durgotsava. Human sacrifices were chiefly offered to Bhawani in her character of Kali, and no religious rite can be more minutely ordered and detailed than this is in the Kalika Purana, the sanguinary chapter of which has been translated by Mr. Blaquiere, and given in the fifth volume of the Asiatic Researches, Art. xxiii., and the ceremonies, the implements, prayers, etc., used on these horrid occasions are minutely described and recited. In this article, premising that Siva is supposed to address his sons the Bhairava, initiating them in these terrible mysteries, occurs the passage, "The flesh of the antelope and the rhinoceros give my beloved (i.e. the goddess Kali) delight for 500 years. By a human sacrifice, attended by the forms laid down, Devi is pleased 1000 years; and by a sacrifice of three men, 100,000 years. By human flesh, Camachya, Chandica, and Bhairava, who assume my shape, are pleased 1000 years. An oblation of blood which has been rendered pure by holy tests, is equal to ambrosia; the head and flesh also afford much delight to the goddess Chandica. Blood drawn from the offerer's own body is looked upon as a proper oblation to the goddess Chandica. Let the sacrificer repeat the word Kali twice, then the words Devi-Bajreswari, then Lauha Dandayai, Namah! which words may be rendered -Hail, Kali! Kali! Hail, Devi! goddess of thunder! Hail, iron-sceptred goddess! Let him then take the axe in his hand and again make the same by the Calratriya text.' Different mantra are used, in reference to the description of the victim to be immolated; females are not to be immolated, except on very particular occasions; the human female never. Human sacrifices are nevertheless most pointedly prohibited in very ancient books. In the Brahma Purana, however, Nera Medha, or man-sacrifice, is expressly forbidden; and in the fifth book of the Bhagavat Sir William Jones pointed out the following emphatical words: "Whatever men in this world sacrifice human victims, and whatever women eat the flesh of male cattle, those men and those women shall the animals here slain torment in the mansions of Yama; and, like slaughtering giants, having cleaved their limbs with axes, shall quaff their blood.' Parvati, in the Mahratta countries pronounced Parbat or Parvat, is used as a name for a hill; one is near Poona, commonly called Parvati, on which is a temple of the goddess. In Durga we trace the origin of the names of hill forts in Mysore and other countries of the Dekhan, such as Chittuldroog, Rai Droog, Duri Droog, etc. The bright half of the month Aswini, the first of the Hindu lunar year, seems peculiarly devoted to Durga. The first nine nights, called Navaratri, are, with appropriate names, allotted to her decoration; the fifth is for the preparation of her dress; on the sixth she is awakened; on the seventh she is invited to a bower formed of the leaves of nine plants, of which the Bilwa is the chief. The seventh to the ninth are the great days; on the last of 
which the victims immolated to her honour must be slain, as particularly directed in the Kalika Purana. The sacrificed beasts must be killed by one blow, with a broadsword or sharp axe. The next day the goddess is reverently dismissed, and her image is cast into the river, which finishes the festival called Durgotsava and Dasera. On the fifteenth day, at the full moon, her devotees pass the night in sports and merriment, and games of various sorts; it is unlucky to sleep, for on this night the fiend Nicumbha led his army against Durga, and Lakshmi descended, promising wealth to those who were awake. On this night Kuvera and Indra are also worshipped. The goddess Bhawani is supposed to have inspired Sivaji to murder Afzal Khan, the general of the king of Bijapur. At a conference, Sivaji caught Afzal Khan with a wag-nak, and finally despatched him with the beautiful Genoese blade called Bhawani, which he always wore. That sword, down to the time of the British supremacy, had a little temple for itself in the palace of Sivaji's descendants, and it was annually worshipped by them and their household, not as a mere act of veneration for their ancestor's trusty sword, but because it was the chosen instrument of a great sacrifice; and the attendant who watched it used to say that no doubt some of the spirit of Bhawani must still remain in it. Many towns and rivers are named after Bhawani. Kali Koil, temples of Kali, are scattered over the Carnatic, and by tradition a human sacrifice was made at the foundation of each of them.-Taylor; Cole. Myth. Hind.; Ward.

KALIAN, a city of great commercial and political importance, mentioned by Arrian, author of the Periplus, in the 2d century, as Kalliana, which had been a famous emporium in the time of Saraganos the elder, and by Cosmas Indicopleustes in the 6th century as the seat of a Christian bishopric, under the name of Kalliana. The name of Kaliyana also occurs several times in the Kanheri cave inscriptions, which date from the 1 st and $2 \mathrm{~d}$ centuries of the Christian era.-Orme; Tod's Travels, p. 168; Cunningham, Ancient Geog. of India, p. 554 .

KALIANI, a fortress in the Dekhan, west of Beder, on the borders of the Canarese, Teling, and Mahratta nations. The Chalukya dynasty of Kaliani disputed the sovereignty of the Dekhan with the Chola dynasty, who held the Ceded Districts. The Chalukya rulers of Kaliani were overthrown by Basava, their minister, who established the Lingaet or Jangama religion. The Kalinga Chalukya capital was at Rajamundry, and they ruled throughout the Northern Circars. Sasanam or grants on copperplates and also sculptured monuments exist, showing several alternations of superiority between them and the Gajapti rulers of Orissa.

KALIAR, a caste of camel-owners and cattlebreeders in Shahpur.

KALI BAORI, a petty state in the Bhil Agency, under the Central India Agency and the Government of India. The chief or Bhumia receives $£ 137$ and $£ 12$ zamindari, on condition of guarding the pargana of Dharmpur, and being answerable for all robberies. He also receives $£ 15$ from Sindia, and is answerable for robberies in 17 villages in Bikanir.

KALI CHAKRAM, an ancient gold in the Tamil country, with an image of Kali on it. $-W$.

KALI-CHITRASWARI. Chitpur, in Bengal, on the Hoogly, is so called from the Kali-chitras. wari in that village, one of those old images to which many a human sacrifice has been offered under the regime of the Brahmans. It is said of her that a party of boatmen was rowing up the river to the sound of a melodious strain. Heightened by the stillness of the night, the plaintive carol came in a rich harmony to the ears of the goddess. She then sat facing the east, but, turning to hear the song of the boatmen as they passed by her ghat, she had her face ever since turned towards the river.-Tr. of Hind. i. p. 2 .

KALID, a celebrated general of the early years of the Hijira. See Jew.

KALIIASA, a great dramatist and epic poet of Northern India, and, according to Hindu tradition, the father of the erotic lyric. He lived about the beginning of the 6th century A.D. He is mentioned with Bharavi, another famous poet, in an inscription dated 507 Saka era, or A.D. 585-586. But his era has been supposed by Wilson to have been during the reign of a Vikramaditya. Dr. Bhau Daji supposed it to be that of Harsha Vikramaditya, in the middle of the 6 th century ; Monier Williams thinks he wrote in the middle of the $3 d$ century ; Lassen places him half a century later, and some believe that more than one person bore this name as a literary title.

His most celebrated dramas are Sakuntala, Vikramurvasi, and Megha-duta, but the Kumara Sambhava, the Raghu Vansa, the Malavi Kagnimitra, the Ritu Sanhara, Nalodaya, and Mudra Rakshasa are also attributed to him.

Sakuntala was made known to the west in 1789 by Sir William Jones. This drama relates how a Kshatriya prince, Dushyanta, prevailed on a Brahman's daughter to yield to him, under a promise of marriage, and he gave her his ring as a pledge of his troth. He then went to his own city, leaving the girl behind. She soon found that she was to become a mother, and she then set out to her husband, but lost the ring on the road, and he refused to recognise her until it was found. Vikramurvasi, or the Hero and the Nymph, celebrates Vikramsena, son of Indra and Urvasi, a celestial songstress. His Meghaduta, or Cloud Messenger, has 116 stanzas. In it an exile sends a message by a wind-borne cloud to his lore, and the countries beneath its long aerial route are made to pass like a panorama before the reader's eye. The Kumara Sambhava recounts the birth of the war god. It contains passages of much beauty of style and grace of thought. It has been translated into English verse by Mr. Ralph T. H. Griffitb.

The Raghu Vansa is an epic poem which celebrates the Solar line of Raghu, king of Ayodhya, but more particularly the ancestry and the life of his descendant Rama, who was the boast and ornament of the race. Rama's story occupies a considerable place in many of the Puranas, and is the sole object of the Ramayana by Valmiki; also in the Bhatti Kavya and the Raghava Pandaviya, all in Sanskrit, and in Hindi the Ramayana of Tulsi Das and the Rama Chandraka of Kesava Das. Portions of it also are in the Tamil and Telugu. 
Malavika and Agnimitra recounts the loves of those two. Mudra Rakshasa relates a contest between Rama and his sons Lava and Kusha. The Nalodaya is in four cantos, and tells the adventures of Nala and Damayanti. The long poetical descriptions of his dramatic works have led to the supposition that these plays were written for reading rather than representation; but such was not the case, as the MSS. which have come down to us contain full directions as to the proceedings on the stage. Wit is scarcely cared for by the Hindu, whose great delight is to portray the delicate loves of innocent and bashful youths. In this art none has excelled Kalidasa. No poet is so celebrated and highly esteemed in India ; to none have so many poems, epic, lyric, and dramatic, been ascribed. His play Sakuntala is considered the gem of oriental literature, and received the rapturous applause of Goethe. Professor Wilson's list of the Hindu Theatre contains the names of 60 pieces. Of these not more than six belong to the classical age, and two of these are the works of the famous Kalidasa. The most interesting, though it has not the beauties of the Sakuntala, is the Mrichikata or Toy Cart, and it is the only play from any part of India which has been acted on a European stage.

The Kumara Sambhava of Kalidasa, his Raghu Vansa, also the Neshadha of Sri Harsha, the Magha or Sisupala Badha and the Kiratarjuniya by Bharavi, are five of the six recognised excellent compositions in Sanskrit.-Imp. Gaz.; Taylor; Wheeler's Hist. of India, i. p. 50; Ward, iv. p. 1390.

KALIGHAT, a village situated on the bank of the old bed of the Ganges, a few miles south of Calcutta, lat. $22^{\circ} 31^{\prime} 30^{\prime \prime}$ N., long. $88^{\circ} 23^{\prime} \mathrm{E}$. It contains a temple in honour of Kali. Her dead body was carried over the world by her husband Siva, until the corpse was cut in pieces by Vishnu with his sacred dise (südarsan chakra), and the 52 places where the different parts of the body fell became sacred as places of pilgrimage. One of her fingers is said to have fallen at this spot. The temple was built about the 15th century by a member of the Sabarna Chaudhari family, who allotted 194 acres of land for its maintenance. A Brahman named Chandibar was the first priest appointed to manage the affairs of the shrine; and his descendants, who have taken the title of Haldai, are the present proprietors. They have amassed great wealth, not so much from the endowments as from the daily offerings made by pilgrims. The principal religious festival of the year is on the second day of the Durga-puja, when the temple is visited by crowds of pilgrims from all parts of the district.

A Kalighat is described by Ward as a landingplace on the left bank of the Hoogly at Calcutta, near a temple of Kali, and which gives its name to Calcutta. At Kalighat stands the temple of Kali, the energy of Siva in his destructive character of Kal, or Time. To this temple the collected crowds, from miles round the Indian metropolis, pour, like a living stream, and, till recently, exhibiting the most painful self-inflicted tortures, piercing their tongues and sides, and sticking in the wounds heavy pieces of iron, arrows, canes, living snakes, etc. etc., with which they danced with indecent gestures, to the obscene songs of the surrounding multitude. Mr. Ward says that in one year a man thrust his finger through the tongue of another, and they thus proceeded dancing with much indecency together through the streets; and that another had his breast, arms, and other parts stuck entirely full of pins, as thick as nails or packing-needles.-Ward's Hindoos; Imp. Gaz.

KALIKA PURANA, one of the 18 Upa Puranas, a Sanskrit work, in 98 chapters, containing 9000 stanzas, descriptive of the worship of Kali, bride of Siva, in one or other of her forms as Girija Devi, Bhadra Kali, Kali, Maha Maya._Garrett.

KALIKA - VARTTA. General Cunningham says the city of Klisoboras has not yet been identified, but he feels satisfied that it must be Vrindavana, six miles to the north of Mathura. Vrindavana means the grove of basil trees, which is famed over all India as the scene of Krishna's sports with the milkmaids. But the earlier name of the place was Kalika-vartta or Kalika's whirlpool, because the serpent Kalika was fabled to have taken up his abode just above the town, in a kadamba tree, overhanging the Jumna. Here he was attacked by Krishna, and the rapid convolutions of his tail in his dying struggles are said to bave caused the eddy which is now known by his name. The Latin name of Klisobora is also written Carisobora and Cyrisoborka in different MSS., from which he infers that the original spelling was Kalisoborka, or, by a slight change of two letters, Kalikoborta or Kalikabarta. In the Prem Sagar this whirlpool of the Jumna is attributed to the poison that was vomited forth by the serpent Kali against Krishna, when he was swimming in the river. In the 18 th century, raja Chet Singh of Benares is said to have poured all the milk of the two cities of Mathura and Vrindavana down the hollow kadamba tree, and as the waters of the Jumna were not even tinged, the serpent Kalika's miraculous powers of milk-drinking were established more firmly than ever.

KALIK-KA-TAWA. HrND. A girdle, an iron plate on which wheaten cakes are toasted or the kalik (soot) collected.

KALI-KUTKI. HIND. Picrorhiza kurrooa, in most books on Indian medicine kali-kutki, is termed Helleborus niger, but it is, in the druggists' shops, exactly similar to Kaur, the produce of the Picrorhiza, while the Asarun, which even in the native name attests its resemblance to the Asarum Europeum, is probably a species of valerian. -Pouell, i. p. 318.

KALILA-wa-DAMNA, an ethical work, which had its origin in the Sanskrit Hitopadesa, which was brought by Barzuyeh from India to the court of Nushirwan, king of Persia, was translated into Arabic during the khalifat of Mamun, afterwards into Persian by Abu-'l'-Maali with the title of Anwar-i-Subaili, and revised by Hasan Kashafi, who was also the author of the Persian Commentary on the Koran. Professor Max Muller says (chap. iv. p. 108), Abdallah-ibn-al-Mokaffah, a Persian, after the fall of the Omeyyades, became a convert to Muhammadanism, and rose to high office at the court of the khalifs. During the reign of al-Mansur, he wrote the Kalila-wa-Damna, a famous collection of fables, which he says were translations from the Pehlavi of Barzuyeh. Being in possession of important secrets of the state, he became dangerous in the eyes of al-Mansur, and was foully murdered A.D. 760 . The Arabic 
version was known as Kalila - wa-Damna, after the names of two jackals who play couspicuous parts in the first story of the collection, and the Arabian translator ascribed the work to the sage Bedpai. This version became a prime favourite with the story-loving Arabs, and thus came into contact with Europe. Greek, Hebrew, and Latin translations of it were made, from the 11 th to the end of the 13th century, and the Fables of Bedpai soon became famous over all Europe, and were done into Spanish, German, Italian, French, and English, whilst a Persian version, the Anwar-i-Subaili, is a standard book. The second Latin version bore the title Alter Assopus, or the New Essop. The collection of moral tales commonly known as Assop's Fables is the work of a Byzantine monk of the 14.th century, named Planudes; and thus the Latin version of Kalila and Damna had been done half a century before Asop's Fables came into the world. Many of Planudes' tales have been traced to Indian sources, and enable us to assert that Fsop's Fables, as we now have them, are not Greek at all, but are the descendants of Indian folk-stories of very great antiquity.

KALIN. HiND. Woollen pile carpet.

KALI NADI. Two rivers of this name in Hindustan, the East and the West. East Kali Nadi is a river in Muzaffarnagar and Meerut. The West Kali Nadi, of Saharunpur, the Muzaffarnagar districts, and N.W. Provinces, rises 16 miles south of the Siwalik Hills, at an elevation of about 1000 feet above sea-level.-Imp. Gaz.

KALINDI, a distributary of the Jamuna, a river in the Twenty - four Parganas district of Bengal. It branches off from the parent stream at Basantpur. The Kalindi is a fine deep river, averaging 300 feet in breadth.-Imp. Gaz.

KALINDI, in Hindu mythology, daughter of the king of the Asura. Another Kalindi was daughter of the Sun, one of the wives of Krishna. Another Kalindi, widow of king Asit, and mother of Sagara.

KALINGA is the Calingæ proximi mari of Pliny. The ancient kingdoms of the Peninsula of India were the Pandiya, Chola, and Kalinga, and, B.C. 75, an expedition left the ancient Kalinga kingdom, and formed a colony in Java.

The Kalinga Chalukya dynasty ruled at Rajamundry and in the Northern Circars. The town of Kalingapatam alone remains to indicate the rule of that dynasty; but the term Kling or Kalen is used in Burma to designate the people of the west of Burma, and the Hindu religion of the Javanese seems to have come from them.

The Gajapati was a sovereign race that ruled in Orissa. The name means Lord of the Elephant. In the Northern Circars, Chicacole and Rajamundry were the capitals of the Andhra sovereigns, who ruled anterior to the Christian err. A more exact knowledge of these and of the early Buddhist princes of Vegi or Vengi Desam, who reigned'at Dara Nagara on the Kistna, near Amaravati, and at Vengipuram, are important desiderata.

An early name for the capital of Kalinga was Sinhapura, so called after its founder Sinhabahu, the father of Vijaya, the first recorded sovereign of Ceylon. In the inscriptions of the Kalachuri or Haihaya dynasty of Chedi, the rajas assume the titles of lords of Kalanjjwrapura, and of Tri Kalinga. Kalinjar is the well-known hill fort in
Bundelkhand, and Tri Kalinga, or the Three Kalingas, must be the three kingdoms of Dhanaka or Amaravati (on the Kistna), Andhra or Warangal, and Kalinga or Rajamahendri (Rajamundry).

The Kalinga Chalukya dynasty ruled at Rajamundry and throughout the N. Circars. Extant sasanams and sculptured remains exhibit several alternations of superiority between them and the Gajapati of Orissa. The Ganapati or Kakateya dynasty ruled at Warangal, now in the Nizam's territory. It was once the capital of great part of the N. Circars. Of the Reddi rulers of Condavir little is known.

'The succession of the Buddhist rulers by the Chalukya of Rajamundry, the subsequent sway of the Ganapati, Vema Reddi, and Rayel of Bijanagar, together with their contests and the various relations between them, are little known.

The Kalinga of Pliny certainly included Orissa, but latterly it seems to have been confined to the Telugu-speaking country; and in the time of Hiwen 'Thsang (A.D. 630) it was distinguished on the south and west from Andhra, and on the north from Odra or Orissa. The language of the country is Telugu. The pandits derive this name from Tri-linga, 'the country of the three linga temples.' These were at Amaravati, Andhra, and Kalinga. Taranatha,"the Tibetan historian, speaks of Kalinga as one division of the country of Telinga.

The Kalinga are mentioned by Pliny as occupying the eastern coast of India, below the Mandei and Malli, and the famous Mount Maleus. This mountain may perhaps be identified with the high range at the head of the Kishikulya river in Ganjam, which is still called Mahendra Malé, or the Mahendra Mountain.

KALINGULA. TAM. A sluice, a weir, or waterway, constructed in the bunds or dams of tanks to permit the escape of surplus water, and thus guard against the accumulating waters overflowing the softer parts of the dam. Chadr (carpet) is the Hindi name for this.

KALINJAR, town and celebrated hill fort in Banda district, North-Western Provinces. The Mahabharata mentions it as a famous city, and states that whoever bathes in its Lake of the Gods is as meritorious as he who bestows one thousand cows in charity. Muhammadan bistorians mention the king of Kalinjar as an ally of Jaipal, raja of Lahore, in his unsuccessful invasion of Ghazni, A.D. 978. A raja of Kalinjar was also present at the battle of Peshawur, fought by Anand Pal in A.D. 1008, against Mahmud in his fourth expedition. In A.D. 120\%, Kutab-ud-Din, the viceroy of Muhammad Ghori, took Kalinjar. In 1554, when. besieged by Sher Shah, a live sbell rebounded from the walls into the battery where the sultan stood, set fire to a quantity of gunpowder, and Sher Shah died the following day. Before his: deatb, however, he ordered an assault, which took. place immediately, with success.-Imp. Gaz.

KALI PURUJ. MAHR. A dark race of aborigines: in the eastern and southern taluks of the Surat. district. They are quiet and inoffensive.

KALI SIND, a river of Central India, rises: in lat. $22^{\circ} 36^{\prime} \mathrm{N}$., and long. $76^{\circ} 19^{\prime} \mathrm{E}$, on the: south side of the Vindbya mountains. After a course of about 225 miles, it falls into the Chambal. There are four rivers called Sind in India,-first, the Sind or Indus, the Little Sind, the: 
Kali Sind or Black River, and the Sind rising at Latoti, on the plateau west and above Seronge.

KALIYA DAMANA. SANSK. Subduing a snake. Kaliya is from Kala, to move. Kaliya was a serpent king with five heads, who dwelt in a deep pool of the Yamuna. On Krishna stepping into it, Kaliya seized him, but he placed his foot on the middle of Kaliya's head and overcame him.

KALI YOGA or Kali Yug, the iron or fourth age of the Hindus, begins, according to some, 3101 years before Christ. It is estimated by Bunsen to have commenced B.C. 986 or 866 , by others is supposed to have begun on Friday, 18th February B.C. 3102 ; and the Hindus say it is to last altogether 432,000 years, when all existing forms having become delineated are to be dissolved; of 432,000 years, 3101 had expired on the 14th March A.D. 1. The Kali Yoga is the present age of the world. The actual period of the world's existence, according to the astronomical calculation of the Hindus, commenced 3102 years before Christ, on the 20th February, at 27 minutes 30 seconds past two o'clock.

KALI ZIRA. HIND.

Shauniz,. . Arab.|Zira-siah, . . Pers. Hab-sindi, : EGYPT. Siah-dana, : . "

These terms are applied to the seeds or fruits of several plants, Cuminum cyminum, Nigella Indica, Vernonia anthelmintica, or Serratula anthelmintica, also Aplotaxis candicans, and Carum carui.

KALKA. The country of the Kalka is ancient Mongolia. The Kalka live under tents along the banks of the rivers which water their country, that of Kalka-pira, though one of the smallest, and at present one of the least frequented, has given its name to the whole nation. The small and picturesque lake of Ikeougoun lies in the mountains to the north of Sanghindalai, and is held in great veneration by the Kalka. They erect a small wooden temple on the shore, and offer up milk, butter, and the fat of the animals, which they burn on the little altars. The large rock in the lake is with them a sacred stone, on which some rude figures are traced. The yourt of these people are constructed like those of the Kirghiz, and covered with felt. The Mongol are divided into several aimak or tribes. The largest is that of Kalka.

KALLAR, a race in the southern part of the Peninsula of India, in the Trichinopoly, Madura, and Tanjore districts. They are known in Orme and older writers as the Collery. They and the Maravar take Dever as a tribal name. Kallar in Tamil means thief. In very early times the Kallar had petty princes of their own,-and still have one at Puducottah, - and they were employed as soldiers by the more powerful kings of the south, and in predatory excursions against neighbouring sovereigns. For these services lands were assigned them. All ancient Tamil writers, when discoursing about land, divide it into five distinct different kinds, namely, Kuransee, Palei, Mullei, Maruthum, and Neythel : and the same writers distinctly state the castes and classes of people residing on each, but not one of these writers mentions the Kallar. The celebrated Jain, Mantala Puraden, in his Dictionary, mentions Kallar as a synonym for robber, not as the name of a caste. The tradition among the Kallar is that they and the Maravar are from the same stock: The legend is as follows :-When the gods churned the ocean, amongst other things brought to the surface was a most beautiful virgin, named Ahalya. After some discussion, it was agreed that the virgin should be given to him that performed the greatest austerity. The sage Gautama won the prize, but the god Indra was enamoured of the beauty, and, availing himself of an opportunity, he seduced her, and, she gave birth to three sons, the Maravar, the Kallar, and the Akumbadiar. In Hindu mythology Indra means the sum, and Abalya the night. Scholars will discover here the old fable of Acheron and Nox.

KALLAR. HIND. Saline soil, unculturable from reh, saline efflorescence, salt, or other reason detrimental to cultivation. It is also a saline earth yielding saltpetre; also earth impregnated with reh, but aiso means a soil which remedies the reh, used by dhobis for washing.

KALLAS. Hind, The ball at the top of any pyramidal structure.

KALLI-MEDU. TAM. Lit. Cactus eminence, is the Point Calimere of the English; the Kalligikon of Ptolemy, one of the names given by Ptolemy to the promontory of Koru, or Kallimedu, opposite Ceylon, Point Calimere.

KALLIYUN, a Persian pipe, in which the smoke is drawn through water. They are of two sorts, - the Kurnyee and Dastah, or snake and hand Kallyun; the one having a long pliant suake, similar to the hookah of India, made of leather, and the other being, as its name denotes, held in the hand, and smoked through a short tube, often made of gold or silver, and beautifully enamelled.

KALLU or Kalyamu, TeL.; Tari, Hind.; Kalla TAM. Palm wine, the fermented sap of different kinds of palm trees. Toddy, ANGLO-Hind, is Tari, from Tar, the palmyra palm. Sendi is from the date palm, tar-ka-jhar, and Nareli is from the cocoanut palm, narel-ka-jhar.

KALM. ARAB. A pen, a reed, a writing character. Kalm-trash, a penknife. In grafting trees, a shoot of a tree.

KALMUK, a branch of Eleuth, call themselves Olot, the peculiar people, or Durban Oirod, the four allies, meaning the Dzangar, Turgut, Choshod, and Turbet. A Kalmuk kingdom was founded in 1671 , but it lasted less than a century, and then fell under the Chinese rule. The name is sometimes derived from the Turkish word Kbalimak, those left behind, sometimes from the Mongol Ghol-aimak, fire horde, and again froun Kalmuk, fiery people. Some hordes have swarmed out across the southern border of the Gobi. After the fall of the Yuen dynasty, a swarm of Kalmuk, made up of Dzangar, Turgut, and Choshod, migrated to Koko Nor. 'They have continued their migratory habits up to the most recent times. They reached European Russia in 1616, and a portion of them waudered back to China in 1771 amid untold perils and hardships. Many of the inhabitants of T'urkestan described to Lieut. Burnes their mode of travel. The migrants, reported at 100,000 families, advanced with their herds and flocks, occupying in the breadth of the advancing column a journey of no less than three days, forced its way through all opposition to the Dasht-i-Kipchak, north of the Jaxartes or Syr Darya, and reached the primeval seat of their ancestors at Yarkand and Eela. The Muhammadans of Bokhara captured about 1500 , and 
made them slares. The Kalmuk and the Uzbak are said to have sprung from one tribe, and this change of habitations has now mixed it with the Kazak, a great tribe that once lay to the eastward of it; and Kalmuk, Kazak, and Kirghiz are now mingled together. See Kazak.

KALNEH, an ancient town on the Khaibar river. M. de Breses, President, Royal Academy, Paris, supposed that Kalneh stood on the side of Ctesiphon.-Mignan's Travels, p. 73.

KALOBIT, a climbing plant of Borneo, which the natives rend into long strips for rough cordage. 'I'he juice of this plant is intensely bitter, but the water which distilled itself slowly from the cut end was quite pure and tasteless.-Burbidge.

KALORA, a dynastic title of former rulers in Sind. The Kalora, a tribe of wandering religious mendicants, who for nearly three centuries had been settled in Sind; and about A.D. 1450, Adam Shah, a Baluch of this tribe, obtained fame as a devout man, and from him the dynasty arose. They received a jaghir from Aurangzeb in 1705 , and were made naibs of Tatta in 1735 . Their country was transferred to Persia by the treaty with Nadir Shab. The dynasty ended in 1788 by the succession of the Talpur. - Burnes; Postans, Pers. Narrative, pp. 164, 165.

KALPA. SANSK. The bright half of a day of Brahma. A creation or formation, a cycle of years. In Hindu theogony, at the end of every Kalpa (creation), all things are re-absorbed in the deity, who, in the interval of another creation, reposes himself on the serpent Sesha (duration), who is also termed Ananta (endless). In Hindu astronomy, a Kalpa is an age of time; a day of Brahma, 4320 millions of years. Amongst the Buddhists of Ceylon, a Kalpa is the period of a mundane revolution. - Wilson; Warren, Kala Sanhita; Hardy's East. Mon. p. 437.

KAL PASHI or Kalpasi. TAM. Identified by Ainslie with the Lichen rotundatus of Rottler? It is the Pathar-ka-phul, HiND., or rock flower, and Henna-ul-koresh, ARAB. Its value as a diuretic is especially when applied as a poultice over the kidneys.

KALPA STHANA. SANSK. Toxicology.

KALPA SUTRA. SANSK. Aphorisms of high authority regarding the performance of sacrifices enjoined by the Vedas. Written by human authors, and therefore not Sruti or revealed. It is from Kalpa, time, and Sutra, a thread. The Kalpa Sutra includes 45 Angama, 11 Anga, 12 Upanga, 10 Prakrinaka, 8 Cheda (sections or fragments), and 4 Mula Sutra. Their 14 ancient Purva were lost.

KALPA-VRIKSHA, the tuba or ash tree, in Hindu mythology, the 'Tree of the Gods which bestows everything desirable; it is the same with the Lakshmi-vriksha, and the same with the Parijata tree. Among the Buddhists, also, a magical tree, that gave whatever was desired; perhaps also same as the Kalpadrum or wisbing tree. The Shajrat-ul-Kudus or blessed tree, is a tree of Arabia.-Hardy's East. Mon. p. 437.

KALTAR. MAHR. An estimate of the produce of the fields, made while the grain is standing (ubha), or when cut but unthrashed (ogbla).

KALTHEE. MAHR. A grass which grows on salt wastes; its roots are ground and used as flour.

KALTIS, a gold coinage of Iudia mentioned by the author of the Periplus.
$\mathrm{KALU}$ and Ak-rohat, two passes in the Hindu Kush, 13,400 feet above the sea, near Bamian. Bamian is on the high road from India to Bactria lying at right angles to the path, and between the two passes.

KĀLU RAYA and Dakshin Raya are worshipped in S. Bengal as forest deities. They are represented as mitred trunkless heads set up along with earthen figures of tigers and crocodiles. Goats and ducks are offered in sacrifice.

KALYA-DAH, a famous ghat at Brindaban, where Kalya-nag, the black serpent, infested the waters of the Jumna. - Tr. of Hind. ii. p. 63.

KAL-YAMUN was the foe of Krishna, from whom he fled to Dwaraka, and thence acquired the name of Rinchor, or fieer from the battle-field. Modern Hindus have come to regard this as an honourable title.

KALYAN, chief town, port, and municipality of the Tanna district of Bombay, situated at the junction of the north-east and south-east lines of the Great Indian Peninsula Railway, 33 miles north-east of Bombay.-Imp. Gaz.

KAM, Hind, from the Sanskrit Karmma, work, business, affair; largely used in combination, as Kam-gar, Kam-kaj, Kam-dar, a servant, work in general, a man of business.

KAMA, amongst the Hindu deities, takes the place of Cupid. Ananga is a poetical epithet, literally incorporeal; from a, privative, and Anga, a body. Endeavouring to influence Siva with love for his wife Parvati, he discharged an arrow at him, but Siva, enraged, reduced him to ashes by a beam of fire darted from his central eye. Hence his name Ananga. According to the Tattiriya Brahmana, he is the son of Dharma, justice, by Sraddba, faith. Kama was scarcely created before he thought proper to make Brahma enamoured of his own daughter.

In the Tamil country this Hindu deity is usually called Manmatha, or heart agitator; Manasija, or heart-born; Ananga, or the bodyless. This Hindu deity appears to be the same with the Grecian Eros and the Roman Cupido; but the Indian description of his person and arms, his family, attendants, and attributes, has peculiar beauties. He is represented as a beautiful youtb, sometimes conversing with his mother and consort in the midst of his gardens and temples; sometimes riding by moonlight on a parrot or lory, and attended by dancing girls or nymphs, the foremost of whom bears his standard, which is a fish on a red ground. His favourite place of resort is a tract of country around Agra, and principally the plains of Muttra, where Krishna also and the nine Gopi, who are clearly the Apollo and Muses of the Greeks, usually spent the night in music and dancing. His bow of sugar-cane or flowers, with a string formed of bees, and his five arrows, each pointed with an Indian blossom of a heating quality, are equally new and beautiful. He has at least twenty-three names, most of which are introduced in a hymn by Sir IV. Jones; that of Kam or Kana siguifies desire, a sense which it also bears in ancient and modern Persian. And it is possible that the words Dipuc and Cupid, which have the same signification, may have the same origin, since we know that the old Etruscans, from whom great part of the Roman language and religion was derived, and whose system had a near affinity with that of the Persiaus and Indians, 
used to write their lines alternately forwards and backwards, as furrows are made by the plough.

The Rig Veda (x. 129) says that desire "first arose in It, which was the primal germ of mind.' Greek mythology connected Eros, the god of love, with the creation of the universe, something in the same way.

A curious hymn in the Atharava Veda exalts Kama into a supreme god and creator; another part makes Kama to be desire, then the power which gratifies desire, also identifies Kama with Agni.

The Indian Maya, or, as the word is explained by some Hindu scholars, the first inclination of the godhead to diversify himself by erecting worlds, is feigned to be the mother of universal nature and of all the inferior gods. But the word Maya, or delusion, in the Vedanta philosophy, signifies the system of perceptions, whether of secondary or primary qualities, which the deity was believed, by Epicharmus, Plato, and many truly pious people, to raise by his omnipresent spirit in the minds of his creatures, but which had not, in their opinion, any existence independent of mind. Maya or Ada Maya is a name of Lakshmi. She is thus the general attracting power; the mother of all, the sakti or energy of Vishnu, the personification of spirit; she, as attraction, unites all matter, producing love in animated nature, and in physics, the harmonization of atoms. Kama or Love is her offspring, and is united in marriage to Reti or Affection, the inseparable attendant on the tender passion; and in friendship to Vasant'ha (commonly pronounced Bassanth) or Spring, denoting Love's season, but literally in regard to the time when many animals are impregnated and vegetables burst into existence, and metaphorically touching the early portion of man's passage through life. There is an allegory of Kama being an avatara or son of Krishna, by Rukmeni, other names of Vishnu and Lakshmi, and this is a further instance of the correspondence of that goddess with the Roman Venus, the mother of Cupid. His riding or dancing by moonlight allude to the love-inspiring serenity of the time; such nights, about Agra and in the southern parts of India, affording, after the heat and tumult of the day, a delicious quiet feeling of happiness not easily communicated nor conceivable by the mere experience of the unsettled cloudy skies of northern latitudes. The banner of Kama, a fish on a red ground, and his vahan or vehicle, a parrot or lory, have doubtless their allusions, the former possibly to the stimulating nature of that species of food, stirring the blood to aid Kamdeo's ends; and perhaps the ensanguined colouring and extreme beauty of the lory, and, like the fish (and the dove of western mythology), its supposed aphrodisiac tendency as food may have had a share in guiding a selection of attributes for the ardent deity. The soft affection and fabled constancy of the dove may have weighed with the Greeks, although constancy may not, perhaps, be, in strictness, a striking characteristic of love.

This universal deity through all ages and all climes is the object of the hero's, the blockhead's, and the wise man's invocation; has been represented as Anteros with his leaden arrow, as the beauteous Eros with his golden dart, as the Egyptian Horus with the wings of the Etesian winds, as the Hindu-adored Kamdeo with bee- strung bow and flower-tipped arrow, as the son of Jupiter, of Mars and Venus ; of Porus, the god of counsel, and Penia, the goddess of poverty; of Cœlus and Terra, of Zephyrus and Flora; as the son of Brahma, of Vishnu or Krishna, and of Maya or illusion.

As with all Hindu deities, Kama's genealogy is traced upwards to the sun, who is Brahm. Lakshmi, in a divine and mortal view, both as Maya and Rukmeni, is his mother; she is Vishnu's wife and sakti or energy. Visbnu, or Krishna, Kama's father, is the sun, the source, literally and figuratively, of warmth and union, affection and love.

The Makara which Kama bears on his banner is an aquatic monster something like the sign of the zodiac Capricornus.

'What potent god, from Agra's orient bow'rs, Floats through the lueid aix, whilst living flowers With sunny twine the vocal arbours breathe? Hail power unknown!

Know'st thou not me?

Yes, son of Maya, yes, I know

Thy bloomy shafts und cany bow,

Cheeks with youthful glory beaming,

Locks in braids ethereal streaming,

Thy scaly standard, thy mysterious arms,

And all thy pains and all thy charms.

God of each lovely sight, each lovely sound,

Soul-kindling, world-inflaming, starry crown'd,

Eternal Kama! Or doth Smara bright,

Or proud Ananga give thee more delight?

What'er thy seat, what'er thy name,

Seas, earth, and air thy reign proclaim;

Wreathy smiles and roseate plensures,

Are thy richest, sweetest treasures.

All animals to thee their tribute bring,

And hail thee universal king.

Thy consort mild, Affection ever true,

Graces thy side, her vest of glowing hue,

And in her train twelve blooming girls advance,

Through golden strings, and knit the mirthful dance;

Thy dreaded implements they bear,

And wave them in the scented air,

Each with pearls her neck adorning,

Brighter than the tears of morning;

Thy crimson ensign, which before them flies,

Decks with new stars the sapphire skies.

God of the flow'ry shafts and flow'ry bow,

Delight of all above and all below!

Thy lov'd companion, constant from his birth,

I'hev'n clep'd Bessent, and gay Spring on earth,

Weaves thy green robe and flaunting bow'rs,

And from thy clouds draws balmy show'rs,

$\mathrm{He}$ with fresh arrows fills thy quiver

(Sweet the gift and sweet the giver !),

And bids the many-plumed warbling throng

Burst the pent blossoms with their song.

He bends the luscious cane, and twists the string

With bees, how sweet! but ah, how keen their sting!

He with five flow'rets tips thy ruthless darts,

Which thro' five senses pierce enraptur'd hearts :

Strong Champa, rich in od'rous gold,

Warm Amer, nurs'd in heav'nly mould,

Dry Nagkeser, in silver smiling,

Hot Kiticum our sense beguiling;

And last, to kindle fierce the scorching flame,

Loveshaft, which gods bright Bela name.'

The Champa, Michelia champaca, is of two sorts, white and yellow, small, and in its foliage like an expanded rosebud. Gardeners make and expose in the shops chaplets and long strings of the blossoms, with which the Hindu women decorate their hair and wear round their necks ; its potency is, however, so great, that nerves unaccustomed to it can scarcely bear its odour within doors. Another flower, commonly called mogri, is of the same description, and may, perhaps, be one of these named in the classic hymn. 'The fragrance 
of the Champa is so very strong that bees refuse to extract honey from it, a circumstance that could not escape the keen eye of the Hindu poets, and they accordingly feign the Champa to be sadly mortified at this neglect. They have, however, afforded it consolation, dedicating it to Krishna, the black deity, as they, contrary to some European poetical naturalists, consider the union of yellow and black peculiarly beautiful. The Champa is further consoled by the preference it has obtained in bedecking the glossy locks of black-haired damsels, also in the followiug stanza, literally translated from the Sanskrit:- 'That thou art not honoured by the ill-disposed bee, why, O Champa! dost thou so heavily lament? The locks of lotus-eyed damsels, resembling the fresh dark clouds adorning the sky, let these embellish thee.'

The Amer, mentioned in the extract from the hymn, is also called Amra and Amla, and is said by some to be the mango flower. Dry Nagkeser is also called Kesara; it is a handsome flower, with yellow and white petals. The Bela is a beautiful species of jasmine. The last days of spring are dedicated to Kamdeva, the Hindu god of love. There is no city in the east where the adorations of the sex to Kamdeva are more fervent than in Udaipur, 'the city of the rising sun.' On the 13th and 14th of Cheyt they sing hymns handed down by the sacred bards: "Hail, god of the flowery bow! hail, warrior with a fish on thy banner! hail, powerful divinity, who causeth the firmness of the sage to forsake him! Glory to Madana, to Kama, the god of gods; to bim by whom Brahma, Visbnu, Siva, and Indra are filled with rapture.'-Tod's Rajasthan, i. p. 255 ; As. Miscel. ii. ; Sir W. Jones' IIymn to Camdeo, xiii. p. 237 ; As. Res. i. p. 221 ; Moor, p. 437 ; Hind. Theat. ii. p. 84.

KAMA, amongst the Singhalese Buddhists, evil desire, the cleaving to sensuous objects. Kamadeva, the Hiudu god Kama, from Sanskrit Kama, desire, and Div, to play.

KAMA-DHENU, a cow, called also Surabbi, Savala, Kama-dub, produced at the chmrning of the ocean; she belonged to the sage Vasishta; this name means the cow which grants desires.

KAMAKSHI or Lust Eye, the sakti of Ekambeswara; she is a form of Durga.

KAMA-KUMBHA, SANSr., or vase of desire, the Hindu cornucopia, a common emblem on Buddhist coins and sculptures. There is amongst the Hindus a festival sacred to the sage Agastya, who presides over the star Canopus, when the sun enters Virgo (Kaniya). The Kamacumpa is then personified under the epitbet Kumbhayoni, and the votary is instructed to pour water into a sea-shell, in which, having placed white flowers and unground rice, turning his face to the south, he offers it with this invocation: 'Hail, Kumbhayoni, born in the sight of Mitra and Taruna (the sun and water divinities), bright as the blossom of the kusa (grass), who sprang from Agni (fire) and Maruta.?

KAMALAKARA, author of the Nirnaya Sindhu, a work on Hindu religious ceremonies and law.Douson.

KAMALAPURAM or Camlapoor, town in Bellary district, Madras, lat. $15^{\circ} 17^{\prime}$ N., long. $76^{\circ}$ $30^{\prime} 30^{\prime \prime}$ E. ; population (1871), 5145.-Imp. Gaz

KAMALAR, TAM.; Kansala, TeL. ; and Pan- chala, the artisan castes. They are mostly of the Saiva sect; they comprise the goldsmith, coppersmith, blacksmith, carpenter, and stone-mason.

KAMAI - ud - DIN ABDUR RAZZAK - bin JALAL - ud - DIN ISHAK - as - SAMARKANDI. He was born at Herat on the 12th Shaban A.H. 816 (6th November 1413 A.D.). His father Ishak was Kazi and Imam at the court of Shalı Rukh. On his father's death, A.H. 841 (A.D. 1437), he wrote a comment on Azd-ud-Din Yahya's treatise upon Arabic propositions. He was sent by Shah Rukh to the king of Bijanagar, and after, various adventures returned to Khorasan. He was also sent on an embassy to Ghilau. After the death of Shah Rukh, he served Mirza Abdul Latif, Mirza Abdullah, and Mirza Abul Kasim. He died in the month Jamadi-ul-Akhir 887 (August 1482). The full title of his book is Matla-as-Sadain wa Majma-ul-Bahrain; the rising of the two fortunate planets (Jupiter and Venus) and the junction of the two seas.-Elliot, Hist. of Ind.

KAMANCHAH. HIND. A violin with three strings, two of silk and one of wire. The iustrument is rested on the ground.

KAMAND of the ancient Persians appears to be the lasso of the modern South Americans, and was employed to snare persons as well as wild cattle.

KAMANDALA. SANSK, The drinking vessel of the Hindu and Jaina ascetics; often a gourd. -Burgess.

KAMANGAR, wrestlers and bow-makers, from Kamān, a bow. Manufacturers of bows and arrows. Some of them practise the surgical art in the setting of fractured and dislocated limbs. They are found in several districts, but are a small community.-Rev. M. A. Sherring, p. 319.

KAMARAN, an island in the Red Sea, midway between the ports of Lohaia and Hodaida. It is about 11 miles long, and from 2 to 4 miles broad, and 1 mile distant from the mainland. Its occupants are engaged in the pearl and turtle fisheries, and it has on it a Turkish stroughold. There is a small harbour, into which a spring runs. It was once intended to occupy the island before Aden was taken, when Mocha, which bas no harbour, was the only available point for supplies, there being none on Perim, which would have been otherwise preferred.

KAMAR KHEL, a small Afridi clan, with about 1470 fighting men, mostly scattered about the bills south of the Dwatawi pass to Tira Maidan. - N.W.F. i. p. 95.

KAIIATHI, HIND. A person who carries the water of the Ganges to distant places in vessels cased in basket-work.

KAMARUPA, the north - eastern part of Bharatavarsha (Bengal), also in W. Assam, a place of pilgrimage, celebrated for its temples to Kamakshi, the modern Kamrup.

KAMAT. MAHR. A distinction among the Senaw, usually added as a surname, as RamKamat.

KAMATHI, generally written and pronounced Kompti or Compti, a caste of Sudra. Those in the Mahratta districts are distinguished as Telinga and Karnata-Kamathi, from their country. At Poona they are employed as rice-cleaners, grinders of corn, and cutters of sticks, tent-pitchers, and artillerymen; in Telingana they are petty retail dealers or chandlers. The Kamathi of Canara is 
a pioneer, a labourer, one who works with a pickaxe or spade. In Mysore they are chiefly employed in road-making and in repairing public works. In general, they seem to be common labourers, and are probably the same as the Ganges water-carriers of Hindustan.-Wilson. See Kamarthi.

KAMAVISDAR. Under the Mahratta government, the chief revenue officer of a district.

KAMAWARU or Gumpe Cumlu. TeL. A caste of Teling husbandmen who permit no strangers to enter their houses.

KAMBACHEN, a pass in Nepal, in lat. $27^{\circ} 38^{\prime}$ N., and long. $88^{\circ}$ E. Its crest is 15,770 feet above the sea. It has a broad shelf of snow between rocky eminences. It was ascended by Dr. Hooker, December 1848. The distance to which the voice was carried was very remarkable; he could hear distinctly every word spoken at from 300 to 400 yards off.

KAMBALI. A tribe of this name was met with on the north of the Lopsha mountain, and was supposed to belong to the Gobi race. The young girls of the village of Lombi associated with the party. Young people have unrestrained intercourse, but when married the couple are faithful. - Vemukof in Journ. Royal Geog. Soc. xxxvi. p. 272, for 1866 .

KAMBALLU, a product of an umbelliferous plant used by Burmese ladies as a cosmetic for the face-Cat. M. Ex., 1857.

KAMBAR, author of the Tamil Ramāyanam, a popular epic poem written in a metre called the Viruttam. It is sung in every Tamil village, in bazars and houses, on festive occasions, by wandering Kavirayar, native minstrels. It is the folksong of S. India, but it is not intelligible to ordinary people, and a running comment is kept up by the singer or an assistant. Kambar is the most fertile and brilliant of Tamil versitiers. The author of the Chintamani alone can dispute with him for the palm of supremacy. Dr. Caldwell reckons that he lived in the 11th century A.D. He was brought up by a wealthy farmer at Vennai Nellur. His fame as a poet having reached the ears of Rajendra Chola, he was invited to his court, and honoured with the title of the king of poets. Several poets undertook to prepare a Tamil version of the Ramayana. When recited in the presence of Kulotunga Chola, who had succeeded to the throne, Kambar's translation was preferred. Among other works written by Kambar are the Sarasvati Antati, Erelapatu, and Kangsi Puranam. Some others are attributed to him, but their authorship is doubtful. It is said that Kambar's son was put to death for carrying on an intrigue with the king's daughter, and that Kambar himself was obliged to flee. In his old age he lost his poetical powers, and was obliged to support himself by manual labour. He is said to have listened with rapture to the recital of his own compositions.

KAMBARANI, a Baluch tribe. Kambar in the Baluch language means Abyssinian. The tribe emigrated under a leader called Kambar, herice it is that the chief clan is called Kambarani. They own, however, two distinct families, namely, the aborigines of Mekran, whom some call the Cutch Baluchi, and those Arabs who emigrated from Arabia with Hajjaj, the son of Yusuf, and settled in the conquered provinces of
Mekran and Baluchistan, while the rest of the invading army marched into Sind. - Burton's Scinde, p. 410 ; Masson's Journeys, ii. p. 45.

KAMBAR KHEL, a section of the Afridi in the maidan of Tira. They have two great divisions, with ten subdivisions. $-H . A ., N . W . F$.

KAMBATTAM. TAM. The old Tamil name for a mint.

$\mathrm{KAMBO}$ is a long cloth thrown over the right shoulder, and so fastened round the waist as to leave a place for the lambs and kids that are too young to walk.-Burton's Scinde, p. 410.

$\mathrm{KAMBOH}$, a tribe of Mubammadans in the Panjab in disesteem. A proverb goes, 'If there occur a scarcity of men, take few of the Afghan, the Kamboh, and the low Kashmiri. From the Afghan comes treachery, the Kamboh practises fraud, and from the Kashmiri comes only grief and sorrow.'

KAMBOJA, a people of ancient Arachosia, or north-eastern province of Persia.

KAMBOJIA, a small territory lying between Siam and Cochin-China, containing about 500,000 people, of whom four-tifths are the native Kbo. It contains the four provinces, Potisat, Kampong Suai, Kampong, and Kampot Son. Kambodia, Kamboja, or Cambodia was anciently called Kam-phu-cha ; its modern name is Khmer. Its commerce is in rice, ivory, silk, and cardamoms. The whole of the coast, from Kamas in Cambodia quite up to what is called by the Siamese Lem Sam-me-san, the Cape Liant of Europeans, is an uninterrupted archipelago of beautiful islands. The only part of the continent of Asia, the Malay Peninsula excepted, in which the Malays have settled and to which their language has extended, is Cambodia. In that country they seem to have established a little independent principality called Champa, well known both in Malay and Javanese story.

The river Mei-kong of Cambodia is one of the largest in Asia, navigable for boats even before it enters the kingdom of Laos. It falls into the sea by three mouths; the largest is said to have from 14 to 18 feet water on the bar at its mouth at high-water spring-tides. Besides the Annam race, the inhabitants of the present dominions of Cochin-China consist of several other races. The principal of these are the Kambojans, whose name in their own language is Kammer or Khmer, but who are called by the Siamese, Kammen; by the Cochin-Chinese, Kornen; by the Chinese, Tang. po-cha; and by the Malays, Kamboja. The Kambojans speak a language distinct from those of all their neighbours; but in physical form, manners, laws, religion, and state of civilisation, they bear a closer resemblance to the Siamese than to any other people.

In Cambodia is the great temple of Na-khonvat. It seems to have been built in the 10 th century. It is 600 feet at the base, and in the centre 180 feet high. Every angle of the roof, every entablature, and every cornice, bears the seven-headed serpent. Ujong is the capital of Cambodia. - Crawfurd's Embassy; Bovring's Siam; Lubbock's Origin of Civil. p. 243.

KAMBYSES, one of the ancient kings of Persia, of the Kayanian dynasty, and father of Cyrus. He conquered Egypt B.c. 525 to B.c. 522. He took Memphis by storm, and he visited the tomb of Menes.-Bunsen, Egypt. 
KAMERI. This appellation of the Indian cuckoo is derived from Kama, the god of love. The bird of Kama, says Colonel Tod, from an umbrageous pipal, poured forth his monotonous but pleasing notes amidst the stillness of a lovely scene, where the last tints of sunset illuminated the dark hues of the surrounding woods. At another place he says, the cuckoo accompanied us as far south as Chirasani. The Kol race call this bird Suk'bi, or ease-giving, - perhaps as expressive as Kameri, the bird of love.

KAMESWARI, styled Kamikhya, situated within the town of Gohatty, originally a Buddhist temple, is now a Hindu temple dedicated to the Yoni. The Yoni is here represented by a trikonakar jantra, or triangular stone, known in Buddhist mythology as Prajna Devi, the universal mother. Kamikhya temple is situated on a hill rising about 700 feet from the river Brahmaputra, just below Pragjyotisha or Gohatty. It is said that the number of young girls attached to this temple was in early times 5000 . There are still some hundreds.-Dalton, Ethnol. p. 80.

KA-MI, Ku-mi, Ki-mi, Ku-mwi, or Khu-mi, all sionifying man, is a tribe in Arakan on the Koladyn river, who assert that they once dwelt on the hills now held by the Kbyen. Their name seems the same as that of the Khu-mi of Chittagong. The Ka-mi probably arrived in the hills bordering the Koladyn river, in the middle of the 18th century, expelling the Mru or Myu. See Khami.

KAMI, JAP., seems to be a generic appendage to the names of the men of a certain rank in Japan, just as in Britain all noblemen between the ranks of marquis and baron are styled lord. Kami means noble, - not princely. The governor of Nagasaki and Hakodate style themselves Kami, but it is doubted if they have the right to do so. It is like a Frenchman using a 'de,' or a German a 'von,' to ennoble himself. In former days a Kami was one of the Japanese pantheon, but as a title it was at least either hereditary or only given to very great worthies; but now all the ministers, governors, and princes have usurped the title.-Hodgsun's Nagasaki, p. 156; Oliphant. KAMIA, an agricultural labourer of some low caste; in South Behar he is sometimes considered as a predial slave, either for a term or for ever; in the S.W. Provinces he is usually a bondsman or bond-slave who has sold his services for life, and may be transferred or sold himself; his children are free. One kind, the Bandhak-Kamia, is a slave only until he can repay the money advanced to him for his services.-Wilson's Glos.

KA-MI-DA-NA. JAP. A Sintu shrine, altar. KAMI-DANDA. SANSK.? Vigne gives this as literally almsgiving, applied in Kashmir to a Hindu woman, who, having lost her husband and being unable to re-marry, is devoted to the service of the gods, - Vigne.

KAMIN, in the N.W. Provinces, is the term applied to the artificers and servants of a village. In the Panjab, they are persons who are kept employed in cultivation without being actual hired labourers like the Mulazim.-Elliot; Powell; Wilson.

KA - MI - NO - MI - TSI. The original national religion of Japan is called Sinsyn, from the words Sin, the gods, and Syn, faith; and its votaries are denominated Sintu. Dr. von Siebold, however, says that the proper native name of this religion is $\mathrm{Ka}$-mi-no-mi-tsi, signifying 'the way of the Kami,' or gods; that the Chinese translated this compound word into Shin-tao, and that the Japanese adopted the Chinese term, and, according to the genius of their language, softened it into Sin-tu. According to Siebold, the Sintu have some vague notion of the immortality of the soul, of a future state of existence, of rewards and punishments, of a paradise, and of a bell.MacFarlane's Japan, p. 207.

KAMJANG, a Shan race in Saddiya.

KAMKAR, a caste employed chiefly by Hindus as servants in Benares, Allahabad, Azimgarh, and Gorakhpur. In the last-named district they numbered, at the census of 1865 , upwards of 14,000 persons.-Sherving's Hindus.

KAMLA KARRI. MAHR. Amongst the Mahratta, the handbook for the marriage ceremonial of the Sudra Hindus.

KAMLI. HIND. Small blanket, used as a wrapper, in one piece. Coats are made of the finer sorts, and look very well; much resembling camlet in appearance. The stuff is made of sheep and goat hair ; in warm climates the covering of sheep can scarcely be called wool.-E. $M$, Hindu Infanticide, p. 176.

KAMMALAR. TAM. In the singular, Kammalan, artificers, divided into five classes, - stonecutters, carpenters, blacksmiths, goldsmiths, and tinsmiths; all wear the sacred cord. They take the titles of Acharya, teacher, priest; also, of Puthen or Puther. See Kamsalar; Kansalar.

KAMMYA - BAN, near Govardban, is the famous scene of the incidents of the Vana purva of the Mahabharata, is really a classic spot for the reminiscences of the Pandava brothers. Here they were visited by their great friend Krishna, and beguiled by holy sages with the consolations of their philosophy. None of its ancient features is retained by the place, but while its name lives in the verse of the poet, the pilgrim will bend his steps to Kammya-ban.-Tr. of Hind. ii. p. 115.

KA-MOI or Moi, on the opposite side of the Mei-kong; occupy the broad expansion of the Annam chain towards Kamboja, and appear to extend northwards along these mountains, marching with the Lau on the westward. They are said to be black savages, with Negro features. The Kambojan style them Kha-men. They are the Kho-men of Leyden and the Kha-men of Gutzlaff.

KAMOTSAVA, a festival in honour of Kama on the 13th and 14th of the month Chaitra. It has merged, in some places, into the Holi, and so lost sight of, $-W$.

KAMPA, that portion of Tibet lying between the southern bank of the Tsan-pu river and the snowy ridges which separate Tibet from Bhutan.

KAMPILYA, one of the five sons of Haryasha, called the Panchala. The Panchala country was north-west of Dehli, between the Himalaya and the Chambal.

KAMPILY A, the city of king Drupada, in the country of the Panchala, where the swayamvara of Draupadi was held. It is in the doab of the old Ganges, in the modern Kampila.

KAMPONG. MALAY. A house enclosure or grounds; the Anglo-Indian compound.

KAMPOT, the principal harbour of Kamboja.

KAMRAN. Timur's titles, in the height of 
his power, were Sultan, Kamran, Amir, Kutb-udDin, Timur, Kur-khan, Sahib-i-Karan. Sultan means 'lord;' Kamran. 'successful;' Amir, 'commander;' Kutb-ud-Din, 'polar star of the faith;' Timur, 'it shall shake;' Kur-khan, 'of the lineage of sovereign princes;' and Sahib-iKaran, 'master or lord of the grand conjunctions.' The easterns believe that in all the great conjunctions of the planets, there is a great revolution in the world. Thus Abraham, Moses, Zoroaster, Christ, and Mahomed each came into the world in a grand conjunction. Kayomurs, Solomon, Alexander, Chengiz, and Timur were each in their turn Sahib-i-Karan, or 'masters of the conjunctions,' and of all the great events during their respective reigns. - D'Herbelot; Markham's Embassy, p. 47.

KAMRBAND. HiND. A girdle, sash, or scarf, etc., tied round the waist.

KAMR-BASTAH. PERs. Literally, with the loins girt; it signifies on duty, with the body and the mind ready; from Kamr, the waist, and Bastan, to fasten.

KAMR-KHASA (of Peshawur), a hunter's or soldier's belt, holding knife, flint and steel, powder-horn, shot-flask, etc.

KAMRUP, a British district in the central portion of Assam. It lies between lat. $25^{\circ} 50^{\prime}$ and $26^{\circ} 53^{\prime} \mathrm{N}$., and between long. $90^{\circ} 40^{\prime}$ and $92^{\circ} 2^{\prime} \mathrm{E}$. Its great river is the Brahmaputra, which is navigable by steamers all the year through. Its aboriginal tribes are the Ahom, Cachari, Chandal, Dom, Mikir, Rabha, Saranya. The Cachari, Rabha, Saranya, and Mikir are all wild tribes of Indo-Chinese origin, whose common affinities it would be difficult to trace ; they unite in repudiating the caste regulations and the ceremonial purity of living enjoined by Hinduism. In 1872, the Chandals numbered 10,222 ; the Doms, 9566; the Ahoms, who constituted the dominant race as late as the beginning of the 19 th century, at the 1881 census numbered 179,314 .

On the northern frontier of Kamrup there are five Doars, and on the north of Durrung, two. Their names are-Ghurkolah, Baksha or Banska, Chappaguri, Chapakhamar, Bijni, Buri Guma, Kulling.

Under the Assam Government, the Kamrup Doars had entirely fallen under the Bhutan authorities, and the Bhutan supremacy continued after the acquisition of Assam by the British Government. But the Durrung Doars were held alternately four months by the British Government and eight months by the Buteahs each year. In 1841, in consequence of aggressions, the whole of these Doars were annexed to British territory, and Rs. 10,000 a year paid as compensation to the chiefs of Kamrup, similarly with the Buteahs of Durrung, and Rs. 5000 a year paid for the Koreapara Doar.

To the east of the Jowang country are the independent clans of the Ruprye and Shirgaih Buteahs, whose custom it was to enter the Char Doar and Now Doar, which have been held by the British Government since the occupation of Assam, and to levy black-mail. But the blackmail was eventually commuted to an annual payment of money.

KAMSALAR, or goldsmith caste, perform marriage of their daughters both before and after the age of puberty. See Kammalar.
KAMSIN. Arab. A dust storm of N. Africa. KAMTHI or Kamptee, a large town and cantonment in Nagpur district, Central Provinces, in lat. $21^{\circ} 13^{\prime} 30^{\prime \prime} \mathrm{N}$., and long. $79^{\circ} 14^{\prime} 30^{\prime \prime} \mathrm{E}$., on the right bank of the Kanhan river, immediately below the junction of that river with the Pench and the Kolar. The open place near the church is 996 feet above the sea. It is 9 miles from Nagpur.-Imp. Gaz. v.

KAMTSCHATKA, on the extreme north-east of Asia, contiguous to Siberia, is inhabited by different nations. Some who live about the middle pay a contribution to the Russians.-Hist. of Japan, i. p. 21.

KAMUL, Komul, or Kamil, the Hami of the Chinese, is the station at which the routes eastward from the north and the south sides of the Tian Shan converge, and from which travellers generally start to cross the desert before entering China. The people of Kamil were all Buddhists in Marco Polo's time. In 1419, Shah Rukh's envoys found there the mosque and Buddhist temple side by side.-Polo, ii. p. 36 ; Benedict Goes in Yule, Cathay, ii. p. 394.

KAMUNING, MAL. (Camunium, Roxb., Chalcas paniculata, Lour.), is a light-coloured wood, close and finely grained, takes an exquisite polish, and is used for the sheaths of krisses. There is also a red-grained sort, in less estimation. The tree is very beautiful, resembling in its leaves the larger myrtle, with a white flower.

KAMUS. ARAB. The ocean; mid-sea; the name of an Arabic dictionary compiled by Firozbadi in the 14th century, contemporary with Timur, who presented him with 5000 ducats as a reward for his learning and industry. It was trauslated into Latin by Giggens, and published at Milan A.D. 1632.

KAN or Kanam. TAMr. A forest, a thicket.

KAN. The sun-god, according to Diodorus, is the Minos of the Egyptians. The hieroglyphics at Turin represent him with the head of an ibis or eagle, with an altar before him, on which a shade places his offerings, viz. a goose, cakes of bread, and flowers of the lotus, and awaits in humble attitude his doom.

KANA. According to Hindu law, a person blind of one eye is incompetent to succeed. Kana is the nickname given to a person labouring under this personal defect, which term is merely an anagram of Anka, the eye. The loss of one eye does not deprive an occupant of his rights, of which there was a curious example in the siege of the imperial city of Dehli, which gave rise to the remark, that the three greatest men therein had only the complement of one man amongst them. The emperor had been deprived of both eyes by the brutality of Gholam Kadir; the besieging chief Holkar was kana, and so was the defender, Sir D. Ochterlony. That Holkar's name has become synonymous with kana, and many a horse, dog, and man, blind of an eye, was called after this celebrated Mahratta leader. The Hindus attach a degree of moral obliquity to every individual kana, and appear to make no distinction between the natural and the acquired defect; though to all kana they apply another and more dignified appellation. Sukracharya, the Jupiter of the Hindu astro-mythology, came by his misfortune in no creditable way,-for, although the guru or spiritual head of the Hindu 
gods, he set as bad a moral example to them as did the classical Jupiter to the tenants of the Greek and Roman pantheon.-Tod's Rajasthan, ii. p. 269.

KANADA is spoken of in the Padma Purana as a devout ascetic. He was the founder of the Vaisheshika school of philosophy.-Ward, iv. 10.

KANAIT, an agricultural local tribe, holding most of the land on the Simla Hills. They are inferior in position to Rajputs, more perhaps of the level of the Kurmi and Lodhi, but they are often educated, and are generally ministers to the Rajput chiefs. Their women are very nice looking, and all the tribe who are not (in the upper hills) in contact with Tartars are quite Aryan, though not very large. In certain places is a partial and local practice of polyandry among them, but it is not the general custom of the tribe,-Campbell, pp. 88, 97, 123.

KANAKA - DANDAM. SANSK. A golden sceptre, one of the insignia of royalty of the Chalukya dynasty when ruling at Kalyan.

KANAKAN. MAL. Predial slaves in Malabar, also designated Kanaka charma. According to one account, they are a subdivision of the Palayar.

KANAKKAN. MAL., TAM. An accountant.

KANAM. TAMr. A titular equivalent of Iyer, but added after that title.

KANARAK, in the Puri district of Orissa, on the sea-shore of the Bay of Bengal, 19 miles northwest of Puri town, in lat. $19^{\circ} 53^{\prime} 25^{\prime \prime} \mathrm{N}$., and long. $86^{\circ} 8^{\prime} 16^{\prime \prime} \mathrm{E}$. Its temple, now in ruins, forms one of the most exquisite memorials of sun-worship in India; it was built between A.D. 1237 and 1282. Sculptures in high relief, but of an indecent character, cover the exterior walls. The nymphs are beautifully-shaped women; the elephants move along at the true elephant trot, and kneel down in the stone exactly as they do in life. Club-men, grifins, warriors on prancing horses, colossal figures of grotesque and varied shape, stand about in silent groups. Each of the four doorways, on the north, south, east, and west, has two lintels of bluish cblorite slate, very hard, and exquisitely polished. On these lintels rest massive beams of iron, supporting the wall above. The eastern entrance was, till some years ago, surmounted, as in other Orissa temples, by a chlorite slab, on which the emblems of the seven days of the week, with the ascending and descending nodes, are carved. The beauty of this elaborate piece proved a more fatal enemy than time, and tempted English antiquaries to try to remove it by sea to the museum at Calcutta. - Imp. Gaz.

KANARI caves in the island of Salsette. See Caves; Karli.

KANARY ISLANDS, in the Pitt passage, are an extensive chain of flat, woody, uninhabited islands, stretching along the $\mathrm{N}$. coast of Mysole.

KANASI or Kans. HiND. A sort of bell-metal, of which plate and utensils are made.

KANAT and Karez are subterraneous conduits and trenches or artificial water-courses above ground. The best of these in Shiraz is the Karez which Rukn-ud-Dowla Hasan-ibn-Buiah, a prince of the Dilemite race, first caused to be made; this Karez is denominated the water or stream of Ruknabad. - Ouseley's Travels, ii. p. 7.

KANAUJ, a district or province in Hindustan, known also as Kanya Kubja. It takes its name from Kanauj, an ancient city in Farrakhabad district,
North-Western Provinces, in lat. $27^{\circ} 2^{\prime} 30^{\prime \prime} \mathrm{N}$., and long. $79^{\circ} 58^{\prime} \mathrm{E}$. Kanouj for many hundred years was the Hindu capital of Northern India, but the existing remains are few and unimportant. In A.D. 1016, when Mahmud of Ghazni approached Kanouj, the historian relates that 'he there saw a city which raised its head to the skies, and which in strength and structure might justly boast to have no equal.' Just one century earlier, or in A.D. 915, Kanouj is mentioned by Masudi as the capital of one of the kings of India; and about A.D. 900, Abu Zaid, on the authority of Ibn Wahab, calls 'Kaduje a great city in the kingdom of Gozar.' At a still earlier date, in A.D. 634 , we have the account of the Chinese pilgrim Hiwen Thsang, who describes Kanouj as being $20 \mathrm{li}$, or $3 \frac{1}{2}$ miles in length, and 4 or $5 \mathrm{li}$, or $\frac{3}{4}$ of a mile in breadth. The city was surrounded by strong walls and deep ditches, and was washed by the Ganges along its eastern face.

At the time of Hiwen Thsang's visit, Kanouj was the capital of Raja Harsha Vardhana, the most powerful sovereign in Nortbern India. The Bais Rajputs claim descent from the famous Salivahan, whose capital is said to have been Dawndia Khera, on the north bank of the Ganges. Their close proximity to Kanouj is in favour of the sovereignty which they claim for their ancestors over the whole of the Gangetic Doab from Dehli to Allahabad. The more important architectural retnains are the shrine of raja Ajaipāl, supposed to have lived in the 9 th or 10 th century; the Jama Masjid; the tombs of Bala Pir and of his son Shaikh Mehndi.

The modern town of Kanouj occupies only the north end of the site of the old city, including the whole of what is now called the Kilah or citadel. The stream which flows under Kanouj, from Sangrampur to Mhendi Ghat, although now chiefly filled with the waters of the Kali Nadi, was originally the main channel of the Ganges.Cunningham's Ancient Geog. of India, pp. 376, 379 ; Imp. Gaz.

KANAUJIA or Canoujia. Hrnd. A designation of various tribes in Hindustan, implying a notion of their having come originally from Kanouj or Kanya Kubja. It is especially applied to a large and influential tribe of Brahmans. Five chief subdivisions of them are reckoned, all numerous and well known, - Kanaujia proper, Sarwaria, Sanaudha, Jijhotia, Bhunhar, - who are again divided into 16 classes, named either from their reputed founders, who were celebrated sages, as Garga, Gautama, and others, or from their former acquirements, as Dobe, Tewari or Trivedi, Chaube, or as learned in two, three, or four Vedas, or from their having been teachers, as Bhattachari and Upadhyaya, or from other circumstances, as Pande, Dikshit, Bajpeyi, etc.

The Kanaujia proper are found principally in the Central Doab, extending into Bundelkhand on the one hand, and on the other into Oudh, and are divided into 6 or $6 \frac{1}{2}$ families, thence termed Khat (for that six) Kol, or, severally Gotes (from the Sanskrit Gotra, a race), as the Sandel gote, Upaman gote, Bharadwaj gote, Katyayana or Viswamitra gote, Kasyapa gote, and Sakrint gote.

They correspond in rank to the Kulin Brahmans of Bengal, and although taking wives from the other tribes, allow their daughters to marry only into one of the Khat-Kul. 
The Sarwaria class is also called Saryu or Sarju-paria, living beyond the Saryu or Gagra river, or chiefly in Gorakhpur. The Sanandhas are met with principally in Rohilkhand and the Upper and Central Doab, extending westwards to Gwalior. The Jijhotias are settled to the southwest. The Bunhars are found with the Sarwarias in Oudh, and spread to the hills of Bundelkhand. The term Kanaujia is applied, however, to other than Brahmanical tribes, and we have Kanaujia Kurmis, or agricultural castes, and even Kanaujia Thugs. - Wilson's Glossary.

KANAWAR, between lat. $31^{\circ}$ and $32^{\circ} \mathrm{N}$., and long. $78^{\circ} \mathrm{E}$., a province in the Himalaya. The western as well as the eastern chain separate the great Hindu family of India from the Bhot of Tibet. Some mixed races are found to the south of each chain, as the Lahuli and Kanawari in the west, and the Ghurka and Bhutani in the east. In the upper valleys of the Sutlej, in Spiti and Kanawar, are mixed races exhibiting much Tibetan blood, and in religion apparently more Buddhist than Hindu. The Tibetan colony at Mohasu, just above Simla, are powerful, ruddylooking people, entirely unlike Indians; their women are industrious, but very unattractive. Kanawar produces great quantities of fruit, and from many other places men may be met travelling downwards with kilta or long baskets full of apples of very pleasing appearance, large and well coloured, but though sweet, their flavour is deficient.-Powell; Campbell, p. 146. See Kunawar; Polyandry.

KANAWEZ. HIND. A fabric of plain shot silk, that is, with a thread say of green one way and of red the other, the same as the daryai dhupchand of the Panjab, only better. It is made in Bokhara and Persia.

KANCHANI. HIND. A dancing girl by caste and profession, a common woman. Kanchani, a sect among the Gosains who gain their livelihood by dancing and singing. They wear the red cloth as devotees, and observe most of the ceremonies of the Gosains. They marry. At death, their bodies are either buried or thrown into a river. -Sherring's Hindu Tribes.

KANCHAR. TURK. A dagger; the Khanjar of Persia and Hindustan.

KANCHARAVITA KARU, a mendicant belonging to the five classes of artificers.

KANCHARI, MAHR. ; Kanchkar, HiND., a caste working in glass and crystal, a coppersmith, a tinsmith.

KANCHI or Conjeveram, a holy city, 45 miles west of Madras. It is one of the seven holy cities of India. It has two great Hindu temples, one of the Saiva and one of the Vaishnava sect. The former is poor and neglected, having in recent years been plundered by dacoits. Conjeveram pagoda was taken by Clive on the 29th August 1751, and again in December, and again in 1752. Conjeveram was at one time the capital of the Chola kingdom, one of the most ancient and prolonged of all the Indian dynasties, which held sway in parts of the south of India from the 8 th to the 17 th centuries, when Shah-ji, the father of Sivaji, totally annihilated every vestige of their once great power. During the pilgrim Hiwen Thsang's stay at Kanchipura, about 300 Buddhist monks arrived from Ceylon, which they had quitted on account of political disturbances consequent on the death of the king. Hiwen Thsang must have arrived in Kanchipura abont the 30th of July A.D. 639, and, according to Turnour's list of the kings of Ceylon, raja Buna Mugalan was put to death in A.D. 639. From the information furnished by these monks, the pilgrim drew up his account of Seng Kia-lo or Ceylon, which he was prevented from visiting by the disturbed state of the country. From Malayakuta he returned to Dravida (Conjeveram), and then proceeded to the north-west for $2000 \mathrm{li}$ or 333 miles, to Kong-kien-na-pu-lo or Konkanapura.-Cunningham's Ancient India, p. 548.

KANCHINJINGA, a mountain in the Sikkim Himalaya, in lat. $27^{\circ} 42^{\prime} 5^{\prime \prime} \mathrm{N}$., and long. $88^{\circ} 11^{\prime}$ $26^{\prime \prime}$ E., and 28,176 feet above the sea. It is the second loftiest mountain in the world. Its west peak is in lat. $27^{\circ} 42^{\prime} 1^{\prime \prime} \mathrm{N}$., and long. $88^{\circ} 8^{\prime} \mathrm{E}$., and the top of the peak is 28,156 feet above the sea. This peak is exceeded in height, as yet, by the Gaurisankar in Nepal, and the Dapsang peak in the Kara-korum chain. The latter, marked by the G. T. S., K. 2 , in lat. $35^{\circ}$ $41^{\prime} \mathrm{N}$., and long. $76^{\circ} 48^{\prime} \mathrm{E}$. Gr., attains a height of 28,287 feet. Kanchinjinga forms a central and predominant object in the Sikkim panorama of the Snowy Range. Kanchinjinga presents itself from Falut under a vertical angle of $4^{\circ} 51^{\prime} 10^{\prime \prime}$, and even the lowest point of the junction between Kabru and Kanchinjinga (the curve seen just below the eastern peak) has still in the panorama an angular height of $3^{\circ} 36^{\prime}$. Kanchinjinga is an immense mountain peak,-Jo. As. So. Beng., 1860 ; Hermann; Schlagentweit.

KANCHUKI. HIND. A eunuch. Kanchukini, a female attendant.

KANCHULI. HIND, A corset or bodice worn by Rajput women.

KANCHULIYA, a sect of Saiva Hindus, worshippers of the sakti, who are said in their rites to have a community of women without regard to consanguinity, and take measures to prevent individual selections.

KANDAHAR, a town in Afghanistan, situated in lat. $31^{\circ} 37^{\prime} \mathrm{N}$., and long. $65^{\circ} 30^{\prime} \mathrm{E}$, , between the Arghandab and Tarnak river, 89 miles southwest of Khilat-i-Ghilzai, 233 miles south-west of Ghazni, 318 south-west of Kābul, and 380 southeast of Herat. It is said to have been founded by Lohrasp, a Persian king who flourished in times of very remote antiquity, and to whom also the founding of Herat is attributed. It is asserted by others to have been built by Secunder $\mathrm{Zn}$ ul-Kurnin, Alexander the Great; and the traditions of the Persians here agree with the conjectures of European geographers, who fix on this site for one of the cities called Alexandria. The people of Kandahar are supposed to be the ancient warlike Gandhara, a cognate race with the Kshatriya, who fought in the army of Xerxes, B.c. 480 , armed with bows of bamboo and short spears.

Kandahar is said to have been called so from the Gandbara (Greek, Gandaridæ) who migrated to the westward from the Gandhara of the Indus in the fourth century. The early campaigns of the Arabs against Kandahar are given at length in the work of Biladeri, in M. Renaud's Fragments of Arab History, published at Paris about 1843. It was taken by Yakūb-bin-Leis A.D. 865, founder of the Sofarides dynasty, who were driven out by the Sassanides, thereafter fell to Mahmud, then to 
the Ghori, the Seljuk, the Turkoman A.D. 1153, and in succession to the Ghori again, to the Kharasmians, to Jahangir Khan (A.D. 1222), to 'limur (1389), and to Bāber, the Persians, and the Uzbak.

From the remotest times Kandahar must have been a town of much importance in Asia, as its geographical position sufficiently indicates, it being the central point on which the roads from Herat, Seistan, Gour, India, and Kābul unite, and is the commercial mart of these localities. Kandahar was retaken from the Moghuls by the Persians in 1642 , during the reign of Shah Abbas the Second.

The ancient city stood till the reign of the Ghilji, when Shah Husain founded a new one under the name of Husainabad. Nadir Shah attempted again to alter the site of the town, and built Nadirabad; at last Ahmad Shah, Saddozai, founded the present city, to which he gave the name of Ahmad Shah and the title of Ashraf-ulBalad, or the noble of cities; by that name and title it is yet mentioned in public papers, and in the language of the court; but the old name of Kandahar still prevails among the people, though it has lost its rhyming addition of Dar-ul-Karar, or the abode of quiet, or the city of stabilities. Ahmad Shah himself marked out the limits of the present city, and laid down the regular plan which is still so remarkable in its execution. He surrounded it with a wall, and proposed to have added a ditch; but the Daurani are said to have objected to his fortifications, and to have declared that their ditch was the Chaman of Bistan, a meadow near Bistan, in the most western part of Persian Khorasan. Kandahar was the capital of the Daurani empire in Abmad Shah's time, but his son Timur changed the seat of government to Kābul. The new town is surrounded by a ditch, flanked with a citadel, but the place is commanded on several points by rocky hills, the last slopes of which come up to the ditch of the fortification to be buried amongst gardens, orchards, and plantations of beautiful shrubs, through which flow streams of the clearest water. The citadel is situated on the north of the town, and contains a very good residence.

It has been thrice occupied by the British, in 1839-42, and again in 1878-79, and again in 1880 , and on the first occasion the fortifications were put into a good state by them. They also built large barracks on a great space, situated outside the Herat gate. The town is divided into many mahalla or divisions, which belong to the numerous tribes and nations that form the inhabitants of the city.

Some Persian authors considered Kandahar as an Indian, others as a Persian town; the Afghan: themselves include it in Khorasan, to which province they assign the Indus (called also the Attock and the Sind) as the limit. According to them, India commences only on the eastern side, and to the south of this river, from the point in which it receives the Sutlej. The Panjab, comprehending Kashmir and the country of the Sikh, and Zablestan, comprehending Ghazni and Käbul, form another country. The inhabitants of India they call Hindi, and those of Hindustan, Hindustani.

The population of Kandahar is one-fourth of the tribe of Barakzai, one-eighth of the tribe of Ghilji, one-eighth of various other tribes, Afghan, Daurani, half Parsivan, and Hindu. One large quarter of the town, however, the N.E., is entirely inhabited by the Berdurani tribe.

The province of Kandahar is everywhere subject to intense heat. In the fortress of Girishk, on the banks of the Helmand, in the month of August, the centigrade thermometer stood at $48^{\circ}$ or $49^{\circ}$ in the shade. This principality is bounded on the south by the deserts of moving sand of the Seistan, and is on this side open to violent winds, surcharged with exceedingly fine sand, which is very injurious to animal life.

At the foot of the old town of Kandahar is one of the most celebrated relics of antiquity belonging to the eastern world, the water-pot of Fo or Buddha. It was carried to Kandahar by the tribes who fled in the 4th century from Gandhara on the Indus to escape an invasion of the $\mathrm{Yu}$-chi, who made the irruption from Chinese Tartary with the express purpose of obtaining the pot. It is the holiest relic of the Buddhist world, and still retains among the $\mathrm{Mu}$ hammadans of Kandahar a sacred and miraculous character. It is called the Kashgul-i-Ali, or Ali's pot. It is formed of stone, and may contain about twenty gallons. A celebrated grotto, known by the name of Ghar-i-Jamshid, is situated 16 miles S.W. of the city, in the range of the Panj Bai Hills, which overlook the left bank of the Arghandab river. The whole of its roof is beautifully marked as if it were artificially carved.Elphinstone's Caubul; Ferrier's Journ.; Hist. of Afghanistan; Masson's Journey; Mohun Lal's Tr.; MacGregor.

KANDARI. KARN. A large kuri or fish creel, with the addition of an upper lip extended forwards and upwards at the angle of $45^{\circ}$. It is put in a natural run in a river, between boulders of rock, and made big enough to fill the whole passage, all minor ways being blocked with huge stones. The long protruding lip comes well out into the air, and prevents fishes from leaping over or being carried over the whole contrivance when coming down the rapids.

KANDELAI or Gan Talana, a tank near Trincomalee, constructed by Maha Seu, between A.D. 275-301.

KANDELIA RHEEDII. $W$, and $A$.

Rhizophora candel, Lin., Rox. | Jeru-kandel, Maleal.

A shrub growing in Malabar, in the Suuderbans, in the deltas of the Ganges, Godavery, and Irawadi, and in Tenasserim. Its bark is employed in medicine-Voigt.

KANDESH, a province in the Bombay Presidency, traversed by the Tapti river in its mid course. Adjunta, in Kandesh, is celebrated for its numerous caves, excavated out of the mountain. The period of this gigantic labour seems to have been towards the decline of Buddbism in the Peninsula of India, before or about the 8 th century. See Khandesh.

KANDH, written also Kond, Khond, and $\mathrm{Ku}$, a race in the N.E. part of the Peninsula, in the Tributary Mahals lying between the eastern borders of Gondwana and the sea, up to lat. $22^{\circ}$ $\mathrm{N}$, and south to Bastar. In 1835, when engaged in suppressing a rebellion in Gumsur, the British officers became aware that this race practised human sacrifice and female infanticide on a scale and with a cruelty which had never been sur- 
passed by the most savage of nations, and from that period strenuous efforts of very able officers have been directed to the repression of these most appalling crimes. Major Macpherson reported, in April 1842, that in many villages he did not find a single female child. They lilled their own girls, and purchased wives from other parts of the country. The custom was not mniversal. It was practised in what was called the middle Kandh region, but even there some tracts were honourably excepted, as Digi and Bodo Ghoro.

The Kandhs are strictly an agricultural people. They are divided into two sects. One worship Bura, and hold human sacrifice in abhorrence. The other devote themselves to Tari, the earthgoddess, and periodical human sacrifices were made in her honour. The procurers employed were usually the Pan or Panwa, a low tribe diffused amongst the population of all the Tributary Mahals, under different denominations, as Pan or Panwa, Chik, Ganda, Panka.

Colonel Dalton, the most recent writer, tells us that the Kandh call the victims Toki or Keddi, another term, Meriah, is Uriya. Persons of any race or age and of either sex were acceptable, if purchased, or the children of purchased Meriahs. Numbers were bought and held in readiness, and were well treated and fed. Male and female Meriahs were encouraged to cohabit, and other persons might have intercourse with female Meriahs, and iu this manner numbers of children were produced, who were all treated as dedicated to destruction. If a Meriah had intercourse with the daughter of a Kandh, it was considered a distinction.

Ten or twelve days before the sacrifice, the hair of the vlctim selected, till then unshaved, was cut off, and the villagers, having bathed, went to the sacred grove with the priest, who there invoked the goddess and implored her favour. 'The rites varied among the tribes. The ceremonies lasted three days, and it was a time of unbridled licence, drunken feasting, and mad dances. The forms of the sacrifice differed slightly in the villages. On the second morning, the victim, who had been kept fasting from the preceding evening, was carefully washed and dressed, and led forth from the village in procession, with music and dancing, to the Meriah grove. The victim was bound to a post in the middle of the grove, in a sitting posture, by the priest. He was then anointed with oil, ghi, and turmeric, adorned with flowers, and worshipped, and there was great contention amongst the bystanders to obtain some relic, even a portion of the unguent with which he had been anointed. He was then left all night, during which the licentious feasting of the previous night was resumed. As the victim must not die in bonds, the arms and legs were broken, or stupefaction by opium was produced.

The priest now offered up prayers to the earthgoddess. At noon of the third day, the priest took the branch of a green tree, cleft several feet down the centre. They forced the victim within the rift, fitting it in some districts to his throat, and forcibly closed by cords twisted round the open extremity of the stake. He then wounded the victim slightly with his axe, and on this the crowd threw itself on the sacrifice, and, leaving untouched the head and intestines, stripped the flesh from the bones, and fled with them to their fields. The remains were next day burned on a funeral pile, with a further sacrifice of a sheep, and the ashes scattered over the fields, or made into a paste, with which the floors of the houses and granaries were smeared. Subsequently a bullock was given to the father or procurer of the victim, and another was sacrificed and eaten at the feast, which terminated the rite; but one year after the human sacrifice, the goddess Tari Penna was reminded of it by an offering of a pig. Major Macpherson mentions that the Meriah in some districts was put to death slowly by fire, the great object being to draw from the victim as many tears as possible, in the belief that Tari would proportionately increase the supply of rain.

In July 1838, Lieutenant Hill, of the Survey Department, described the practice of human sacrifice as existing in the Kandh Mahal of Gumsur, in Daspala, Boad, and Sohnpur, just south of the Mahanadi, and in Chinna Kimedy, Pedda Kimedy, Jeypore, and Bastar. The Bastar raja had the credit of having himself organized the most extensive sacrifice that had ever been heard of, on which occasion 27 adult males harl been immolated; in fact, it was not supposed that any Kandh Mahal was free from the stain.

The number, however, it was said, had diminished from hundreds to ten or a dozen yearly; but this improvement was not general, and the Kandhs of Boad had promised acquiescence in the wishes of Government, but as a fiual sacrifice they offered Tari, before they gave it up, a sacrifice comprising 125 victims. On the 1st April 1848, Colonel Campbell reported that, with one or two exceptions, all the influential men of Boad had pledged themselves by the most solemn oaths (sworn on a tiger skin and ou some earth) thenceforth to abandon human sacrifices, and in earnest of their sincerity 235 Meriahs were given up.

Chinna Kimedy was found to be divided into seven districts, each under a Hindu chief or Pater, subdivided into Müttahs (groups of villages or parganas) and villages, each under a Kandh headman called Maji. The country is described as in steppes. Throughout this hilly region human sacrifice and female iufanticide generally prevailed, the only exceptions being in the districts of Sarangad, Chandraghari, and Degi of Kosadah. The annual season for the sacrifice was about to commence when the agent marched into this country, but 206 Meriahs were given up.

In Jeypore, human sacrifices had been annually offered to Maniksoro, the god of war, as well as to the earth-goddess. The victim was tied to a post by his long hair, assistants to the officiating priest holding out his arms and legs so that the body was supported over a narrow grave, with the face downwards. The priest, standing on the right side, prayed for success in battle and preservation, and as he prayed he at intervals hacked at the neck of the victim, whom he addressed in consolatory words, assuring him that he would soon have the honour of being devoured by the great god Maniksoro for their benefit, and that his obsequies would be performed decorously, and reminding bim that they had bought him for this special purpose from his parents. He was then decapitated, the body falling into the 
grave, and the bleeding head remained suspended from the post till the birds devoured it.

Colonel Campbell, in Jeypore, succeeded in rescuing 77 Meriah males and 117 females. After the suppression of human sacrifices in the Mahals of Jeypore, it was found that the practice existed in the low country amongst relatively civilised and educated men. The victims were generally of the Tura class, purchased from their parents. At the town of Mulcagherry, 100 of these children reserved for sacrifice were found and were surrendered.

Of the numerous Meriahs recovered from the Kandhs, a large proportion were young girls, who, becoming wards of Government, were brought up with care, and were more or less educated. It was deemed good policy to give some of these damsels in marriage to Kandh bachelors of respectability; but Colonel Campbell ascertained that these married wards had no female children, and, on being closely questioned, they admitted that at their husbands' bidding they had destroyed them. Captain M'Neill found that in the districts of Putiadeso, Sorabisi, Korkapatah, Jhumka, and Ryaghada, infanticide, both male and female, prevailed to an appalling extent. Colonel Dalton says that many of the Bura worshippers practised female infanticide.

The Kandh have serfs, and follow the practice of blood revenge. Over each village an elder presides called an Abbaye, and a number of adjacent villages form a district under a district Abbaye. In each village there is a house assigned to the bachelors as their dormitory and club, and another for the maidens. In Boad, the girls' dormitories are under charge of an elderly matron, who sleeps inside and locks the door. At one of the Kandh festivals, held in November, all the lads and lasses assemble for a spree, and a bachelor has then the privilege of making off with any unmarried girl whom he can induce to go with him, subject to a subsequent arrangement with the parents of the maiden.

Kandhs are as fond of dancing as the Oraons, and, like them, have a dancing-place in every village, surrounded by stones or wooden seats, and shaded by venerable trees. The dancers pay particular attention to their dress and to the arrangement of their hair. The hair, which is worn very long, is drawn forward and rolled up till it looks like a horn projecting from between the eyes. Around this is wrapped a piece of red cloth, and feathers inserted of favourite birds. The clothing of the women is nearly as limited as that of the males. The bosom is invariably exposed, and a kilt-like cloth round the loins, scarcely reaching to the middle of the thigh, is the sole garment.-Colonel Dalton, Ethnology of Bengal, p. 290 ; Imp. Gaz.

KANDHAR, an isolated rock in the plain between the Kandhar confluence of the Parbati and Chambal, and the famous Rin - t'humbor. Sagarji held the fortress and the lands of Kandhar. His descendants formed an extensive clan called Sagarawut, who continued to hold Kandhar till the time of Sawai Jai Singh of Amber, whose situation as one of the great satraps of the Moghul court enabled him to wrest it from Sagarji's issue, upon their refusal to intermarry with the house of Amber. Mahabat Khan, the most intrepid of Jahangir's generals, was an apostate
Sagarnwut. They established many chieftainships in Central India, as Omri Bhadora, Gumesgange, Digdolli.-Tod's Rajasthan, i. pp. 331, 355.

KANDH - MALS, a tract of country in Boad Tributary State, Orissa, now under a loose form of British administration. The country consists of a broken plateau, intersected by ridges of low hills, the last refuge of the aboriginal Kandh (Khond) race. The tract containg 826 villages, 10,811 houses, and a total population in 1872 of 51,810 persons, the aboriginal tribes being 35,798 , almost all of them Khands, others being Pan (6204), Goala, Sud, and Suri.

KANDI, a measure of weight; its value ranges in various places from 8 to 20 maunds, viz. :-

\begin{tabular}{|c|c|c|c|c|}
\hline 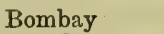 & Maur & & & Maun \\
\hline & & & istoms & 8, \\
\hline $\mathrm{Ma}$ & 28 & 500 & Mad & \\
\hline & & 500 & Bor & 20 \\
\hline , sea & & & Surat & 20 \\
\hline & & & & \\
\hline
\end{tabular}

KANDLA. Hind. The cylindrical silver ingot, the basis of works in wire drawing, also a square thin rod of iron, used in gun barrel making; the drawer of silver ingots in their first stage of being made into wire.

KANDOBA, a male deity of Jejuri in the Bombay Dekhan between Sassoor and Satara, also called Kandeh Rao. He is represented as an armed horseman, and is regarded as an incarnation of Siva. About the beginning of December, on the 6th of Margashirsh, a great festival and fair are held, to which pilgrims come from a great distance. Bhandar and champa flowers are sacred to Kandoba, and exorcists shout Elkot and give bhandar. Kandobr, next to Wittoba, is the most popular object of worship among the Mahrattas. The god Byroba, the local deity of herdsmen, is as largely worshipped in the Dekhan as is Kandoba, the deified hero of shepherds. The chief objects of Mahratta worship are certain incarnations or imaages of deified mortals, known as Etoba or Wittoba and Kandoba, at Panderpur, Jejuri, and Malligaon, but the village deities receive a large part of their attention in times of sickness or peril. Brabmans state that Siva became incarnate in Kandeh Rao for the purpose of destroying an oppressive giant named Manimal, at a place in the Karnatic called Pehmer. The giant Manimal made a most desperate defence against Kandeh Rao, but was at length slain, whereupon all the oppressed subjects of this giant paid adoration to Kandeh Rao, to the number, as the story goes, of seven kror of people, whence this avatara is called Yehl-khut; Yula in Tamil meaning seven, and Khut or Koot being a Mabratta pronunciation of $(1,00,00,000)$ a hundred lakh, or ten millions. A handsome temple, dedicated to the worship of Kandoba, is at Jejuri, a town of some extent about thirty miles to the south-east of Poona. It is situated in a beautiful country, on a high hill, and has a very commanding and majestic appearance; the temple, walls around, and steps up to it, are well built of fine stone. The murlidar, or musical girls attached to it, are said to exceed two hundred in number. A great many Brahmans reside in and about the temple, and many beggars. Kandoba is not an uncommon name with Brahmans and other Hindus, for instance, Lakpat Kandhi Rao.-Chow-Chow, p. 262; Moor, p. 424. $\mathrm{KANDY}$, in lat. $7^{\circ} 17^{\prime} \mathrm{N}$., long. $80^{\circ} 49^{\prime} \mathrm{E}$., one 
of the principal towns in the interior of Ceylon. Bellungallee village, S.W. of Kandy, is 2259 feet; Matina patin, S. of Kandy, is 3201 feet; Peredenia is $\mathbf{1 6 5 0}$ feet. Kandy is a table-land with a chief town of [same name, and was conquered by the British after the battle of Meyda Maha Nowera, 18th February 1815, where the sovereign Vikrama Raja Singa was taken prisoner and removed to Vellore, where he died. The British entered the Kandyan country, 11th January 1815 .

The Kandyan race are mountaineers, and, until the middle of the 19th century, followed polyandry. They are inhabitants of the bill country, and are a hardy, robust race, never till recently intermingling with the low countrymen. Their language is made up of three component parts, Elu (or Singhalese pure), the Pali, and the Sanskrit. They possess an extensive literature, and their religion is Buddhism. The low country Singhalese are either Buddhists, Roman Catholics, or Protestants. Among the Kandyans, polyandry was prevalent till declared illegal in 1856 , and the wife had the possession of all the brothers. The children call the eldest brother father. A man could bring in another, not a relation, to have joint marital rights with himself; indeed, the first husband can so introduce as many as the wife will consent to receive as husbands. In the Beena marriage, the husband went to reside in the wife's house, and the woman shared the family inheritance with her brothers. The husband, in this marriage, could be dismissed summarily by the family of the wife. In the Deega, a more respectable marriage, the wife leaves her own house for that of her husband, forfeiting all claim on the property of her parents, but acquiring some clain on that of her husband; and the wife cannot obtain divorce, unless with the full consent of the husband. Divorces were constantly sought for by women on trivial pretences. A child born within nine months of the divorce must be maintained by the husband. The Kandyans are a larger race of men than the Singhalese of the coast provinces, but are exceedingly indolent and thriftless.

KANERKI. At the close of the first century of the Christian era, when the supposed ArioParthian dynasty ceased to reign in Kābul and the Panjab, a new race of Scythian kings appeared, who issued gold and copper money of quite a different device and style from anything before eurrent. These bear a title of Kanerkes, at first with the title of Basileus Basileon, but afterwards with the Indian title of Rao Nano Rao. The number and variety of the Kanerki coins indicate a long dominion of kings of the race. 'The only characters on their coins are Greek, but these became at last so corrupt as to be quite illegible. On their obverse is the king standing, or in bust to the waist, in a Tartar or Indian dress, with the name and titles in a Greek legend round; while on the reverse are Mithraic representations of the sun or moon with HAIOS, NANAIA, OKPO, MIOPO, MAO, A $\Theta P O$, or some other mystical name of these luminaries, also in Greek letters. And on all the Kauerki coins is the same monogram as the Kadphises dynasty used, and which was borrowed apparently from the nameless Soter Megas. This would seem to indicate that the Kanerki dynasty, though interrupted, as Mr. Prinsep supposes, by the intervention of Ario-Parthians, was yet a continuation of the same tribe and nation as its predecessors of the name of Kadphises. The state religion seems to have been Mithraic, whence derived, not known; but on their coins the Siva bull device is also found on the reverse, the bull's head being to the left, - in the coins of the Kadphises being to the right. Their power seems to have lasted for more than two centuries. The style and device of the Greek, of the gold coins especially, of the coins both of Kadphises and the Kanerki, was carried on till it grew more and more corrupt, and was at last entirely lost through the deterioration of art, under the princes of Hindu race, who succeeded to the more energetic Greeks and Scythians.On the Historical Resulls deducible from recent Discoveries in Afghanistan, by H. T. Prinsep; Prinsep's Antiquities, i. p. 134.

KANG, Chinese bed-places, built of brick to admit of fires being made inside during the cold weather; ranged round the walls, leaving the middle of the room vacant.-Frere's Antipodes, p. 312.

KANGANA. HIND. A bracelet, or a string or ribbon, tied round the wrist at marriage. The Kangani is a ceremonial part of a Muhammadan marriage.

KANGANI. TAM. A ganger who brings native labourers from the Madras districts to the coffee estates of Ceylon.

KANGAROO, pouched quadrupeds of Australia, species of the genera Halmaturus, Macropus, and Petrogale. Bennett's kangaroo is Halmaturus Bennettii; H. ruficollis is the red-necked kangaroo; H. Derbianus is the Derbyan kangaroo; the great kangaroo is Macropus gigas; the blackfaced kangaroo, M. melanops, and the red kaugaroo, M. rufus. Petrogale xanthopus is one of six species of the rock kangaroo. The kangaroo rat of Australia is a species of Hypsiprimnus.

KANG-HI, an emperor of China of the 17th century, who instituted the custom of having read, on the mornings of new and full moon, a homily on the practical duties of life. He published an illustrated cyclopædia of 10,000 books in 300 volumes.

KANG-JAI, in Munipur, hockey on horseback.

KANGKEYAR wrote a Tamil lexicon in Venba metre, called Urissol Nikandu, much used in schools.

KANGO. JAP. A seat for one person slung on a bamboo or pole, and carried by coolies.

KANGRA, a town in the Panjab, in lat. $32^{\circ} 5^{\prime}$ $14^{\prime \prime} \mathrm{N}$, and long. $76^{\circ} 17^{\prime} 46^{\prime \prime} \mathrm{E}$. It is the chief town of a district of the same name, lying between lat. $31^{\circ} 20^{\prime}$ and $33^{\circ} \mathrm{N}$., and between long. $75^{\circ} 39^{\prime}$ and $78^{\circ} 35^{\prime} \mathrm{E}$. ; area $(1878), 8988$ square miles. It consists almost entirely of immense mountain ranges, whose three parallel lines, with a transverse ridge, form the four main basins, in each of which a great river takes its rise, - the Beas, the Spiti, the Chenab, and the Ravi. The Beas has its origin in the Rotang mountains, north of Kullu, and, after flowing southward for about 50 miles, traverses the state of Mandi, and then drains the whole valley of Kangra proper. The Spiti, rising in the Tibetan valley of the same name, runs due south to join the Sutlej in the native state of Bashahir. The Chenab springs 
from the slopes of Lahoul, and runs north of the Central Himalayas into the state of Chamba; while the Ravi, draining the Banganal valley, keeps to the south of the same chain, and flows north - westward also into Chamba. The principal castes in it are Brahmans, Rajputs, Girath, and Kanets, almost entirely confined to Kullu. In Spiti and Lahoul, the majority of the population consists of Tibetans, ruled over by Rajput landlords. Their religion is Buddhist, with a Hinduizing tendency. 'Throughout the rest of the hills, the substratum consists of aborigines.

The fort is in lat. $32^{\circ} 5^{\prime} \mathrm{N}$., long. $76^{\circ} 18^{\prime} \mathrm{E}$., situated on the top of a rock, 150 feet above the Bunganga, near its confluence with the Beas, and 2424 feet above the sea. This eminence is nearly 3 miles in circumference, and is bounded for the most part by precipices nearly perpendicular. The Gaddi are a hill sbepherd race about Kangra and elsewhere. The Kangra people are sturdy, honest, and independent. Most of the traders of the snow valleys have some members of their families residing at Daba or Gyani on the Nunakbar lake. The great body of the hillmen are Rajputs; there are a few villages of Brahmans, their residences are respectable, and occupy the more elevated portion of the village site, the huts of the Dom or Hali being on a low range. The Dom are hereditary bondsmen to the Rajputs. Basgi also dwell there, and are, both men and wormen, singers at the temples. The men of all castes in the hills are short and of poor physique; they look worn and get deep lined on the face at a comparatively early age. The young women are often extremely pretty, those living in the higher and colder villages having, at fifteen or sixteen, a complexion as fair as many Spaniards or Italians, and with very regular features. But they grow darker as they advance in years, and become very plain.

Kangra has been famed for centuries for the skill of its people in restoring noses by the rhino-plastic operation, instituted by Budyn, a physician of the emperor Akbar, to whom Akbar granted a jaghir at Kangra.

Dharmsala is divided into two stations, the lower and the upper, the one the residence of the civilians and visitors from all parts of the Panjab, and the other occupied by the officers' houses and lines of a regiment.

Dharmsala stands in the bosom of those mighty hills, circular in its outline, and commanding a view, unequalled in the world perhaps, of the placid and beautiful valleys of Kangra and the noble hills behind. The liouses are built progressing up the hill, so that they are at very different elevations, the lowest being at an elevation of 4000 feet, the highest 7000 feet. Iord Eigin died here. The sauatorium is on one of the spurs running south from the great range of Dhaoli Dhar. This range runs east and west, at a height of from 13,000 feet to 19,000 feet, and forms a great wall on the north; it is due to this range that the climate of Dharmsala is so mild and has such a heary rainfall. Kangra is the most beautiful district in India, excepting Kashmir. It is a most lovely fertile valiey, surrounded by lofty mountains, interspersed with undulating hilis, and situated between the rivers Ravi and Sutlej. On one side it has the territories of Kashmir and Chamba, on the other the wild but romantic hunting fields of Kullu, Spiti, and Ladakh.

The district produces iron ore in the Mundi Futtehpur mines; antimony in Lahoul, galena at Rupi Kullu, copper pyrites at Pelang, gold from the Beas river, rock-salt, talc, iron pyrites, silver ore? sandstone, and kaolin; also mineral waters of Beshisht, Kullu, Munikurn, Jowallee, Amte, Bassa, Bohun, and Kohalla. Sulphur, borax, from Lahoul. Spiti produces sulphuret of antimony, gold, gypsum, alabaster, marble, garnet, oxide of copper, belemnites, fossil molluses and fishes.

The Kangra district yields wheat, barley, gram, lentil, rape-seed, safflower, mustard, and flax among the spring crops; and rice, maize, millets, buckwheat, cotton, sugar - cane, opium, and tobacco are in the produce of the autumn harvest: Wool, tea, sugar, salt, ghi, honey, beeswax, soap, timber, iron, and slates for roofing are among the staples of the district. The Kangra district has a great export trade in rice, of which the most esteemed kind is the basmati. $-S c h l$. $H$. f. et Thom.; Journal, Asiatic Society of Bengal, 1840 ; Ann. Ind. Adm. xii., 1870 ; Dr. W. P. Dickson, 1870 ; Imp. Gaz.

KANGRI, of Kashmir, is a small earthen pot used as a warming-pan; it is about six inches in diameter, enclosed in basket-work. Live charcoal is placed within, and the people place it beneath their clothes for warmth.-Drew, The Northern Barrier.

KANG-SI, a lexicographer of the Chinese language. The Chinese lexicographers hitherto have not done much more than translate the meanings given in Kang-si's Chinese dictionary. - Meadow's Desultory Notes, p. 26.

KANGTISI, a range of mountains in High Asia. The general direction of this range is north and south, and it is said to connect the Himalaya and Mongolia as by a cross-bar. It runs to the east of the Manasarowar and Rawan Rud lakes; its highest point is said to exceed in elevation any portion of the Himalaya, and four large rivers have their sources in different parts of the range, viz. the Singh Khawab or Indus; the Langehu Khawab, which runs through Ladakh; the Marchaæ Khawab, which is known as the Gogra; and the Tamchu Khawab or Yaru, the great river of Eastern 'Tibet.

KANGUE. Punishment xviii. of the Tcha is that usually called by Europeans the Kangue, and is a common punishment in China for petty offeuces. It consists of an enormous tablet of wood, with a hole in the middle to receive the neck, and two smaller ones for the hands of the offender, who is sometimes sentenced to wear it for weeks or months together. He is suffered, provided his strength will enable him, to walk about, but the burden is so great, that he is generally glad to seek for a support of it against a wall or a tree. If a servant, or runner of the civil magistrate, take it into his head that he has rested too long, he beats him with a whip made of leathern thongs till he rise.-Macartney's Embassy.

KANHAR, a caste about Benares who supply water both to Hindu and Muhammadan families. Some of its members also act as servants in respectable Hindu families. Qu. Kahar, of whom in India 1,840,856. - Sherring, Hindu Tribes.

KANHEE, a valley to the west of, and which 
runs parallel to, that of Quetta, but extends farther south. Its length is about 30 miles, and breadth 5 or 6 . It is bounded on the east by the great Chahal tan range, which separates it from the valley of the Quetta, and on the west by a parallel range of much less height, which towards the north separates it from the valley of Peshin.

KANHELI. Near Tulsi Sashti, and a few miles from Thanna, are the Kanheri rock temples, about 100 in number, mostly small. The Kanheri cave on the island of Salsette, in the Bombay harbour, is $88 \frac{1}{2}$ feet by 39 feet 10 inches, and was excavated about the 4th century, when $\mathrm{Fa}$ Hian was travelling in India. It is a coarse copy of the Karli cave.

KANHERI, a barren hill, 18 miles from Bhandara in the Central Provinces. It yields good hone stones, building stone, and white stone for pottery.

KANI. TAM. Property, possession, hereditary right.

KANI. Tel. The Cawnee of the Madras Presidency, a land measure in the Karnatic and S.F. parts of the Peninsula. The Madras standard is 24 Manai or grounds, each of 2400 square feet, therefore equal to 57,600 square feet, something more $(1.322)$ than an English acre. There is another computation which makes it not quite an English acre, equal to the same number of square adi, or 57,000 native feet, each $=10.47$ inches. $-W$.

KANI-ACHI. TAM. The term given by Vellalars to communal rights of villagers, lands, offices, fees, held in free and hereditary property. When the land fell into the hands of Brahmans, it was called Swastium; when the same property was possessed by Muhammadans or Christians, it was called Mirasi, which is the term now usually employed. Pasang-karei in Tamil and Sarwadayan means the same thing. See Mandalam; Mirasi ; T'ondai.

KANI-AMMA, a goddess of the non-Aryan races in the Peninsula of India. See Hindu.

KANISHKA, a king who ruled in Kashmir and N.W. India in the 1 st century, about A.D. 40 ; but his sway extended to both sides of the Himalaya, from Yarkand and Khok and to Agra and Sind. He was the most famous of the Saka conquerors. Under him was held the fourth and last Buddhist council. Its 500 members drew up their commentaries on the Buddhist faith. These commentaries supplied in part materials for the Tibetan or Northern Canon, completed at subsequent periods. The Northern Canon is called by the Chinese Buddhists, the Greater Vehicle of the Law. It includes many later corruptions or developments of the Indian faith, as originally embodied by Asoka in the Lesser Vehicle or Canon of the Southern Buddhists, B.c. 244.

The Buddhist Canon of China, a branch of the Greater Vehicle, was arranged between A.D. 67 and 1285 ; it includes 1440 distinct works, comprising 5586 books.

The ultinate divergence between the canons is great, both as to the historical aspects of Buddha's life and as to his teaching. The original northern commentaries were written in the Sanskrit language. Kanishka and his Kashmir council became in some degree to the Northern Tibeto-Chinese Buddhists what Asoka and his Patna council (B.c. 244) had been to the Buddhists of Ceylon and the south. Kanishka, Hushka, and Jushka are three Turushka (Turk) kings, of the Buddhist religion, mentioned in the Raja Tarangini. The names of the first two are also on inscriptions and on coins in Northern India, that of Kanishka at Mathura,Manikyala,Bahawulpur, and Zeda; that of Hushka at Mathura, and on a metal vase found at Wardak in Afghanistan. The Manikyala tope was built by Kanishka, and a Roman coin. B.C. 33, was found in it. Kanishka founded the Suka era A.D. 79. Kanishka established Buddhism in the province between Kābul and the Indus. He erected a great st'hupa or tope at Peshawur, which $\mathrm{Fa}$ Hian (A.D. 400 ) describes as 470 feet high, but it was in ruins when Hiwen Thsang passed it in A.D. 629-645.

Kanishka's coins have two figures of Buddha, one as the teacher seated, and the other as the teacher standing, in each case with the right hand raised as if in the act of speaking. The word Saka can be read on all the coins.-Fergusson; Imp. Gaz.

KANIYA, a name of Krishna, who is also known as Nonita. The infantine appellation of Kaniya, when he pastured the kine of Cesana in the woods of Vindra, whence the ceremony of the sons of Hindu princes assuming the crook, and on particular days tending the flocks. As Muralidhara, or the 'flute-holder,' Kaniya is the god of music. When Aurangzeb proscribed Kaniya, and rendered his shrines impure throughout Vrij, rana Raj Singh offered the heads of 100,000 Rajputs for his service, and the god was conducted by the route of Kotah and Rampura to Mewar. An omen decided the spot of his future residence. As he journeyed to gain the capital of the Sesodia, the chariot-wheel sank deep into the earth, and defied extrication; upon which the Sookuni (Augur) interpreted the pleasure of the god, that he desired to dwell there. This circumstance occurred at an inconsiderable village called Siarh, in the fief of Dailwara, one of the sixteen nobles of Mewar. Rejoiced at this decided manifestation of favour, the chief hastened to make a perpetual gift of the village and its lands, which was speedily confirmed by the patent of the rana. Nat'h-ji (the god) was removed from his car, and in due time a temple was erected for his reception, when the hamlet of Siarh became the town of Nat'hdwara, which now coutains many thousand inhabitants of all denominations, who, reposing under the especial protection of the god, are exempt from every mortal tribunal. The site to the east is shut in by a cluster of hills, and to the westward flows the Banas, which nearly bathes the extreme points of the hills. There are seven celebrated images in Rajputana, viz. Nonita or Nouanda, the juvenile Kaniya, his altar separate, though close to Nat'hji. He is also styled Bala-mokund, 'the blessed child,' and is depicted as an infant with a péra, or comfit-ball in his hand. This image, which was one of the penates of a former age, and whicb, since the destruction of a shrine of Krishna by the Muhammadans, had lain in the Yamuna, attached itself to the sacerdotal zone (zunu) of the high priest Balba, while he was performing his ablutions, who, carrying it home, placed it in a niche of the temple, and worshipped it; and Nonanda yet receives the peculiar homage of the high priest and his family as their household divinity.

Of the second image, Mathura Nath, there is no particular mention; it was at one time at Kamnorh in Mewar, but is now at Kotah. The péra of 
Mathura can only be made from the waters of the Yamuna, from whence it is still conveyed to Nonanda at Nat'hdwara, and with curds forms his evening repast. The fourth statue, that of GokulNath or Gokul Chandrama (i.e. the moon of Gokul), had an equally mysterious origin, having been discovered in a deep ravine on the banks of the river; Balba assigned it to his brother-in-law. Gokul is an island on the Jumna, a few miles below Mathura, and celebrated in the early history of the pastoral divinity. The residence of this inage of Jeypore does not deprive the little island of its honours as a place of pilgrimage; for 'the god of Gokul' has an altar on the original site. 'The fifth Yadu-Nath, is the deified ancestor of the whole Yadu race. : This image, now at Surat, formerly adorned the shrine of Mahavan near Mathura, which was destroyed by Mahmud. The sixth, Vitul-Nath or Pandurang, was found in the Ganges at Benares, Samvat 1572. The seventh, Madhan Mohana, 'he who intoxicates with desire,' the seductive lover of Radha and the Gopi, has his rites performed by a woman.

The precise period of Balba Acharya, who collected the seven images of Krishna now in Rajasthan, is not known; but he must have lived about the time of the last of the Lodi kings, at the period of the conquest of India by the Moghuls. Damodra, the pontiff, at the beginning of the 19th century, was his lineal descendant; and whether in addressing him verbally, or by letter, was styled maharaja or great prince. As the supreme head of the Vishnu sect, his person was held to be Ansa, or a portion of the divinity; and it was maintained that so late as the father of the then incumbent, the god manifested himself and conversed with the high priest. What effect the milder rites of the shepherd god has produced on the adorers of Siva cannot be ascertained, but assuredly Eklinga, the tutelary divinity of Mewar, has to complain of being defrauded of half his dues since Kaniya transferred his abode from the Yamuna to the Banas; for the revenues assigned to Kaniya, who, under the epithet of yellow mantle, has a distinguished niche in the domestic chapel of the rana, far exceed those of Siva. Tod says that the priests of Kaniya are called Chobi, from the chob or club with which, on the annual festival, they assanlt the castle of Kansa, the tyrant usurper of Krishna's birthright, who, like Herod, ordered the slaughter of all the youth of Vrij, that Krishna might not escape.-Tod's Rajasthan.

KANJAR, a race amongst the Mahrattas who make baskets and sell strings of cotton and hemp. They are the Yerkal vadu of Telingana.

KANJKI, a running footman attached to the court of the Bahawulpur Daudputra.

KANJUR is the Tibetan translation of the Tripitaka.

KANKA. SANSK. A carrion kite? it is reverenced at Kanka kala or Tirukkazhuk-kunram, a shrine 30 miles S. of Madras, also called Paxitirtha.

KAN-KA-CHUHA. HiND. The large-eared rat of Kaghan, the marmot or arctomys.

KANKAR. Hind. One sort called Rewasa, another Chappar harsaru, consists of irregular and fantastically-shaped pieces of calcareous concrete. In some parts of India it forms the principal material for road-making. From Cal- cutta northwards, the road was made from kankar; this mineral yields, when burnt, an excellent lime for mortar. Professor Ansted's analysis of it is 72 per cent. carbonate of lime, 15 per cent. silica, 18 per cent. alumina.

KANKROWLEE LAKE, also called Raj Samund, was formed by Rai Singh, rana of Mewar, at a cost of $£ 1,150,000$. It was commenced in A.D. 1661, during a period of famine, and was finished in 1668. This great national work is 25 miles $\mathrm{N}$. of Udaipur, the capital, and is situated on the declivity of the plain, about two miles from the base of the Aravalli. The Gumti, a small perennial stream flowing from these mountains, was arrested in its course, and confined by an immense embankment, made to form the lake called after the ruler, Raj Samund, or royal sea. The bund or dam forms an irregular segment of a circle, embracing an extent of nearly three miles, and encircling the waters on every side except the space between the north-west and north-east points. This barrier, which confines a sheet of water of great depth, about 12 miles in circumference, is entirely of white marble, with a flight of steps of the same material, throughout this extent, from the summit to the water's edge ; the whole buttressed by an enormous rampart of earth, which, had the projector lived, would have been planted with trees to form a promenade. On the south side are the town and fortress built by the rana, and bearing his name, Rajnuggur; and upon the embankment stands the temple of Kankraoli, the shrine of one of the seven forms (sa-roop) of Krishna. The whole is ornamented with sculpture of tolerable execution for the age; and a genealogical sketch of the founder's family is inscribed in conspicuous characters. The $£ 1,150,000$ was contributed by the rana, bis chiefs, and opulent subjects, to be expended on this work; the material was brought from the adjacent quarries. But, magnificent, costly, and useful as it is, it derives its chief beauty from the benevolent motive to which it owes its birth, during one of those awful visitations of famine which from time to time recur in different parts of India.-Tod's Rajasthan, i. p. 389.

KANNAKKA. Maleal., TaM. Ciphering, arithmetic, accounts. $-W$.

KANNAKKAPILLAI. TAM. An accountant, the conicopoly of the British.

KANNIMAR. HIND. Virgin spirits. See Bhut.

KANOCHAR or Kanochan, HIND. of Kangra, supposed to be a species of barrera; used as an aromatic expectorant.

KANOJ. HIND. Seed of a small tree brought from Pali and Dehli ; considered heating and constipating; taken as a condiment, and also given as a medicine in diarrhœa.

KANON, Kot kasun, Rewapee, Patody, and part of the Baroaeh jaghir, form a tract of country called Beeghoto, occupied by the Ahir and the Chauhan Rajput.

KANPHATTA JOGI, a class of Hindu mendicants, so called because of their custom of slitting their ears and wearing a small cylindrical object in the incision. The Kanphatta worship Gorakhnat'h. They eat flesh, drink spirits, and partake of food in houses of all castes. They are found only in the temples of Bhairava, but they use the sacred texts both of Siva and Bhairava. 
The splitting of the ears is part of the ceremony of initiation. The novitiate is kept closely confined in a house for forty days, when he is brought out and is made a perfect disciple. They wear gerua-vastra, or reddish ochre-coloured cloth, and a head-dress of black ribbons, like the Sutharasain, a sect of Nanak Shahi. They carry a fan made of peacocks' feathers, with which they make passes over the credulous, for the purpose of exorcising evil spirits and of keeping imps and goblins at a distance.-Sherring's Hindu T'ribes.

KANS, Hind., Sansk.; Kansya, Beng.; Kansamu, Tez. Mixed metal, bell metal.-W.

KANSA, the king of Mathura, was the son of Ugra Sena, and cousin of Devaki, the mother of Krishna. He had been foretold that Krishna, a son of Devaki, would kill him, for which reason he caused all her children to be destroyed; but Krishna was preserved, and he ultimately killed Kansa.-Dowson.

KANSALA. In the south of India the five artisan classes are called Kammalan, Kamalar, Komsalar, or Kansalar; and Professor Wilson thinks the last word may be derived from the Sanskrit and Hindi Kans, Bengali Kansya, a mixed metal. They form the five left-hand castes of Madras, where the Kansala is the goldsmith, the other four being the Kanchari or brazier, Kasnmari or blacksmith, Kadlangai or carpenter, Kasi or stone-mason. These intermarry and eat together, and all wear the zonar. The distinction of right and left hand castes is peculiar to the south of India. It is supposed by Professor Wilson to be of modern origin, and to have been introduced at Conjeveram as a part of civil policy to divide the people and modify their power. But Sir Walter Elliot is of opinion that the separation into right and left hand castes had its origin in the violent conversion of the ancient races from Buddhism to Hinduism, and he had been shown a figure of Buddha which the artisan caste worship. At present many worship Viswakarma, but the bulk seem to worship Siva; they bury their dead in a sitting posture, with the head of the dead close to the surface; and their dislike to the Brahmans is intense. They claim, indeed, to be superior to the Brahmans, and Dr. Hunter regards them as Brahmans who have been overlain by more recent arrivals. It is amongst the Tamilian people that the right and left hand sections appear.

KAN-SU, a province of N.W. China, with Tibet and Mongolia on its west and north, and skirted on its north by the Hoang-ho, Chief town, LanChau.

KANTA BHAJA, a Hindu sect, founded about the beginning of the 19 th century by Rama Saran Pala, a Goala, and inhabitant of Ghospara, a village near Sukh Sagor in Bengal. They believe in the divinity of the guru as an incarnation of Krishna, and worship him as the creator.

KANTARI. MAHR. A turner, a cabinet-maker, workers with a lathe in wood or ivory.

KANTIRAI VARAHA. KARN, A coin of account in Mysore, value Rs. 2.14.8, equal to 10 gold fanams, each of 6 grains.-W.

KANUM, a town in Bashahir State, Panjab, the principal place in the subdivision of Kunawar, lat. $31^{\circ} 40^{\prime} \mathrm{N}$., long. $78^{\circ} 30^{\prime} \mathrm{E}$; ; situated in a mountain glen, near the valley of the Sutlej (Satlaj), about 9300 feet? above sea-level. Thorn- ton states that the houses rise above one another in tiers, the roof of each tier forming the roadway for the next. Contains a celebrated Buddhist temple with an extensive Tibetan library.-Imp. Gaz.

KANUN, ARAB. A kind of harp, the xaywy of the Greeks. Its strings, 50 or 60 in number, rest upon two bridges, and are touched by both hands, without using any plectrum or bow. It is laid on the knees of the player, who has two plectra attached to the forefingers, each plectrum being placed between the finger and a ring or thimble. There are three chords, of lamb's gut, to each note, and generally 24 treble chords altogether.

KANUN. ARAB, A rule; a law; a psaltery. Kanun-go, ARAB. - PERs., in India, recorders and registrars of land revenues in their respective districts. Literally a rule-teller, a name under Mahratta sovereigns applied to a revenue officer of their governments ; but his office was hereditary. Act xiii. of 1882 amended the laws relating to the Kanun-go and Patwari of the N.W. Provinces and Oudh.

KANVA, the earliest writer on Telugu grammar, lived at the court of Andhra raya, in whose reign Sanskrit was introduced into the Telugu country.

KANWA, an ancient teacher of the White Yajush Veda, and founder of several schools for the purpose.

KANWA, a dynasty of Indo-Scythian Turushka, mentioned in the Puranas. The dynasty reigned 45 years. The first was B.c. 66 . Kanwa, named Vasu-deva, usurped his master's kingdom, Fergusson says B.C. 76 to 31.-Wilson; Thomas' Prinsep's Antiquities; Fergus. 19. See Magadha.

KANYA, the Venetian sequin, from having a figure of the Virgin on one face. Kanya was a name of the mother of Krishna. She was a daughter of Yasuda Kanya, a maiden, a virgin, a girl. Kanyadana, the marriage cerenonial of the giving away of a Hindu bride to the bridegroom by her parents or guardian. Kanya, the astronomical sign Virgo.

KANYA-KUBYA. SANSK. The town of Kanouj. The word means a hunchback maiden, and the name is given in a Hindu legend.

KANYA KUMARI, a name of Durga. In the days of Pliny, her worship extended to Cape Comorin. $-D$.

KAN-YING-PEEN. CHIN. The book of retribution; a moral work often distributed gratuitously by good men.

KAOFU, an ancient name for the region now called Afghanistan. For several centuries, both before and after the Christian era, the Indian language and religion were predominant throughout all Afghanistan, from the Bolan pass in the south, to Bamian and Kaudahar on the west. This large tract was then known by the general name of Kaofu, but was divided into ten different states, of which Kapisa was the chief. The Tributary States were Kābul and Ghazni on the west, Lamghan and Jalalabad in the north, Swat and Peshawur in the east, Bolor in the north-east, and Bannu and Opokien in the south.

That Kandahar then belonged to Persia, is proved by the fact that the begging - pot of Buddba, which Hiwen Thsang (ii. p. 106) mentions as having been removed from Gandhara to Persia, 
still lies at Kandahar. The removal must have taken place during the 6th century, after the conquest of Gandhara by the king of Kissin or Kipin. It is called the Kashgul-i-Ali. The Kaofu of the Chinese would therefore have embraced the whole of modern Afghanistan. Kaof $u$ was the appellation of one of the five tribes of the Yuchi or Tochari, who are said to have given their own name to the town which they occupied towards the end of the $2 d$ century before Christ. This statement of the Chinese writers is confirmed by the historians of Alexander, who notice the city of Ortospana, without making any mention of Kābul. The latter name is first given by Ptolemy, who describes Kabura or Ortospana as the capital of the Paropamisadæ. General A. Cunningham concludes, therefore, that Ortospana was most probably the original metropolis of the country, which was supplanted by Alexandria during the Greek domination, and restored by the earlier Indo-Scytbian princes.-Cunningham, Ancient Geog. of India, p. 18.

KAOLIN. Chin. Porcelain clay.

Kau-ling-t'u, . . Chis. / Kiri-matti, . . SINGH, ? Peh-ngool, . . . ",

This is the aluminous ingredient of Chinese porcelain, named after a hill near Kin-teh-chin, in the Kiang-si pottery district. It is a silicate of alumina. Petun-tsze is the silicious element in Chinese ware.

For a long period it was erroneously supposed that the fine clay necessary for the production of good porcelain, consisting of silica and alumina in variable proportions, and called by the Chinese kaolin, was peculiar to their land, and that consequently no country in Europe could hope to attain eminence in this manufacture. But kaolin abounds in Ceylon, and in the 15th century was exported to China. Porcelain clay is very abundant in $\mathrm{S}$. and E. Asia, produced by the decomposition of felspar. As it occurs in Ceylon, an analysis in 1867 showed pure kaolin 70, silica 26, molybdena and iron oxide $4=100$. Kaolin is procurable in great abundance in Southern India.

In a report on the geology of the North Arcot district, Mr. Bruce "Foote writes: "The highly felspathic varieties of the granite gneiss are occasionally so greatly decomposed as to appear to offer sources for the collection of kaolin or China clay. But none of the North Arcot localities show rocks sufficiently rich in decomposed felspar to be of much importance. A very serious disadvantage is the difficulty of a suitable water supply. 'To insure the preparation of kaolin of good colour, which alone commands a high price, a very large supply of perfectly limpid water is a sine qua non. And in a dry climate like that of the Carnatic, this want could only be met by the construction of special reservoirs of large size, in which the water could be allowed to stand for many months after the rainy season, till all the suspended particles of ferruginous clay had settled, and the water itself had become perfectly limpid. If the great cost of providing such supplies of limpid water free from saline matter in an eminently dry country be taken into consideration, together with the fact that the kaoliniferous decomposed rock occurs in greatly smaller quantity, and is generally much less free from ferruginous staining, due to the filtration through the almost universaliy overlying red soil, the conclusion seems inevitable that the prospects of establishing profitable China clay works in North Arcot are not very promising.'

KAOORWA. This singular tribe of Rajputs is entirely nomadic, and is to be found chiefly in the t'hul of Dhat, though in no great numbers. They move about with their flocks, encamp wherever they find a spring or pasture for their cattle; and there construct temporary huts of the widespreading peeloo, by interlacing its living branches, covering the top with leaves, and coating the inside with clay. In so skilful a manner do they thus shelter themselves, that no sign of human habitation is observable from without. The roaming Sahrai was always on the look-out for these sylvan retreats, in which the shepherds deposit their little hoards of grain, raised from the scanty patches around them. The restless disposition of the Kaoorwa, who even among their ever-roaming brethren enjoy a species of fame in this respect, is attributed to a curse entailed upon them from remote ages. They rear the camel, cow, buffalo, and goats, which they sell to the charuns and other merchants. They are altogether a singularly peaceable race ; and, like all their Rajput brethren, indulge in uml-pani or opium water, which, in Rajputana, is the universal panacea for ills, both moral and physical.-M. C. B.; Tod's Rajasthan.

KAOTSCHE. A characteristic feature in Central Asiatic traditions is the derivation of their origin from some animal. According to the testimony of Chinese history, the Goa Gui (Kaotsche), otherwise known as the Telé or Chili people, sprang from a wolf and a beautiful Hun princess. One of the Hun princes had two daughters of such uncommon beauty that he determined not to marry them to any ordinary mortals. Building a high tower in an uninhabited wilderness, he left them in it, exclaiming, 'I pray heaven to take them!' The youngest princess falling a prey to ennui, encouraged the attentions of an old wolf, who for a whole year, night and day, prowled around the tower, and at last made his lair at the foot of it, till the princess, notwithstanding the entreaties of her eldest sister, married the wolf.

The Tugus (called Dulgasses by Père Hyacinthe) professed to derive their origin from a she-wolf, and the Tufans (Tibetans) from a dog. The Chinese assert that Batachi, hereditary chief of the Mongol Khans, was the son of a blue wolf and white hind (Memoires Relatifs à l'Asie, par Klaproth, p. 201). In like manner some of the redskimned tribes of North America pretend to be descended from beavers, tortoises, etc. It is evident, from these instances, that this kind of tradition in Central Asia, and even in America, is extremely ancient, and even seems to be regarded as a descent to be proud of. The tradition of the origin of the ninety-nine Kipchak branches has been preserved among the Uzbaks and Kazaks in such an indelicate shape, that it is doubtful whether it will ever be possible to present it to the general reader.-Russians in Central Asia; Captain Valikhanof and M. Vemukof, p. 96; Smith, M. M. Ch.

KAOULI. PERS. The dancing and singing girls of Persia are termed Kaouli, Malcolm says, a corruption of Kabuli or of Kābul, which denotes the quarter from whence they came.-Persia, i. p. 117.

KAP, a subdivision of the Varendra Brahmans of Bengal, inferior to the Kulin tribe of the same name. 
KAPADI. GuJ. A Hindu who has performed pilgrimages to Hinglaj; also a religious mendicant carrying a red flag, and selling rosaries, the sacred thread, and holy water.

KAPALA-MALA. SANSK. Wearing a garland of skulls; a name of Siva. Kapala-bhrit, wearing the garland of skulls; a form of Rudra or Siva. Kapalika, in the fifth century of the Christian era, a Hindu sect who wore necklaces of bone and skulls.-Dowson. See Chinna Mastaka; Kerari.

KAPALE, Tel.; Kumpli, Karn., a well from which the water is drawn in a bucket by oxen. $-W$.

KAPALI. HiND. Devotees who adopt the mantra or sacred text of Kali. They are somewhat similar in their babits to the Aghori, but not so shameless and abominable. They eat flesh and drink spirits, but refrain from eating dead carcases.-Sherring's Hindu Castes, p. 270.

KAPAS. MalaY. Gossypium Indicum, Lam. Cotton plant, raw cotton, cotton wool, cotton raw, cotton as a crop. Kapas is cleaned of seed, and prepared for the market by the ryots themselves. But not unfrequently traders buy up the raw material in large quantities, and pay for its cleaning by hired workmen. In this case the workmen are paid in proportion to the amount of clean cotton produced. For producing a maund of clean cotton the rate is sometimes as low as 6 or 8 annas, and sometimes rises as high as one rupee. The cotton seed or benowur obtained by passing the kapas through the charkhee may be valued at about one rupee per maund. Kapasi is the tomentum of the leaf of Onoseris lanuginosus and other plants.

KAPI of 1 Kings $x$. 22, in the form of the Greek $x \eta \pi 0_{5}$, an ape, in the Egyptian texts is kafu. Tukhiim is the Hebrew name for peacocks, 2 Chronicles ix. 21,-Weber.

KAPILA is said to be the writer of the preface to the Sankhya philosophy called the Sankhya Pravachana. His father's name was Vitatha. The Sankhya Karika of Eshwara Krishua is an exposition of the system of Kapila. The Sankhya Pravachana comprises 526 aphorisms in six books ; 72 distichs make up the Sankhya Karika. The system of Kapila given in the Sankhya Karika is the only contribution of India to pure philosophy. The exposition is the oldest in existence, and the most authoritative ; but it is doubtful how closely it represents the original teaching of Kapila, who lived before the time of Gautama the Buddha, in the 6th century before Christ. The Sankhya Karika has been several times edited and translated. Kapila is purely a philosopher, and the rites of Vedantic religion are an object of scorn to him; yet he allows gods, but only as emanations from nature, eventually to be reabsorbed like all other forms of matter. The object of philosophy with him is to escape from pain and sorrow, which he regards as inherent in the world of matter. Our present physical life is a mere bondage; it is full of pain, it can never be the isonrce of anything but sorrow and degradation. -Thite aim of philosophy is simply to free the soul 'from'this and every other connection with matter - for éver. We must seek to cast it away, as men crst of - a vile and loathsome garment; and this emancipation must be gained by the soul itself, without the aid, if such can be obtained, of any external power or influence. The Kapila system generally is a form of materialism, in which, however, the soul exists apart from consciousness and the outer world; but it is uncreative, and exists only as light does. In his system there is no place for virtue or vice, duty or sin. The soul has no purpose outside itself ; it is passive, unsympathetic. Virtue and vice are little distinguished except as matters of sensation; and, as pleasure and pain, they are to be avoided, because they imply action, and action is imperfection. Virtue and vice do not belong to the soul or in anywise affect it. The sense of guilt, implying a moral law, which in turn implies a higher power to ordain it, does not exist in Kapila's system. Even acquiring knowledge and thus delivering the soul from bondage is not a duty, nor the neglect of it a sin; it is a matter of individual advantage. The system of Kapila, though it could never have been very widely accepted or understood, presents points of interest to the student of comparative philosophy. Little is known of his life. One account calls his father Vitatha. Ward says (iv. p. 2) that he was author of the Kapila Sanghita, that his father's name was Karmada, and his mother's Deva-huti, and that he was born at Puskara, and lived at Ganga Sagara.-Ward, iv. p. 2.

KAPILAR is said to have been a brother of Tiruvalluvar, and one of the 49 Madura professors. A small work, Kapila Akaval, is attributed to him, but it is probably spurious.

KAPILAVASTU, the birthplace of the Sakya Buddha, which is known to the Burmese as Kappi-la-wot, was a small principality situated on the banks of the river Rohini, the modern liohäna, about 100 miles N.E. of Benares. It was ruled over by Suddhodana, chief of the Sakya tribe, and father of Sakya Muni. His mother was Maya, daughter of Supra Buddha, chief of the neighbouring tribe of Kolyan. Both tribes were of pure Aryan descent, and branches of the Suryavansi or line of the Sun. The Rohini flowed between Kapila and Koli, the latter being the native town of Maya Devi, mother of Buddha. The present village of Nagara has been surmised by General Cunningham to be the ancient Kapilavastu, and Gautama is still the title of the Rajput chief. Gautama is the name by which Buddlia is known to the Burmese. Pawa, between Kapilavastu and Kasinagara, is the place where Buddha died underneath a sal tree (Shorea robusta).Cunningham, Ancient Geog. of India, i. p. 417.

KAPPAR, in Baluchistan, near to Baghwana. Its lead mines are in a hill that seems entirely composed of the metal. About 200 workmen are constantly employed, the Merdui, a peculiar race, not Brahui, nor esteemed people of the country. Lead is a most abundant metal in the hills of Central Baluchistan, but it is said to be extracted only on a singular system at these mines.-Masson's Narrative, pp. 56, 57.

KAPU. TEL. A cultivator, a husbandman; in Telingana, the principal husbandman in a village. In 1881 census returns, the Kapu were 107,341.-W.

KAPURDIGIRI, a town with Buddhist remains near Peshawur. The Buddhist remains now existing in India are of four distinct classes, 1st, Cave temples, containing topes, sculptures, paintings, and numerous inscriptions; 2d, Vihara 
or monasteries; $3 d$, Inscriptions on rocks and pillars ; 4th, Topes or religious edifices. The Vihara or monasteries are of two kinds,-1st, Cave Vihara, of which several magnificent specimens have been published by Mr. Fergusson; and $2 \mathrm{~d}$, Structural Vihara, of which some specimens still remain at Sanchi, but in a very ruinous condition. The inscriptions on the pillars at Dehli and Allahabad, and on the Tirhut pillars at Mathiya and Radhiya, were deciphered and translated in the early part of the 19th century by the remarkable ingenuity of the late James Prinsep. The inscriptions on the rocks at Junagiri in Gujerat, and at Dhauli in Cuttack, were also interpreted by him. A third version of the rock inscriptions (but in the Ariano-Pali character), which was found at Kapurdigiri, near Peshawur, has been carefully collated with the others by Professor Wilson. Many short inscriptions from Gaya, Sanchi, and Birat, as well as from the cave temples of Southern India, have also been published at different times. The rock inscriptions contain the names of Antiochus, Ptolemy, Antigonus, and Magas. The inscriptions in the able work of Major Cunningham are of greater interest, and of much higher importance than all that had before been published. The Kapurdigiri inscription is on a rock, on the side of a rocky and abrupt hill, near a village of that name in the district inhabited by the Yusuizai. The mode of reading it was discovered by Mr. E. Norris. It reads from right to left, is in the Aryan or Bactrian character, and is nearly a transliteration of that of Girnar; and the language, he says, was in use for several centuries throughout that extensive line of country over which the Seleucidæ and their successors held dominion, that is to say, from the Paropamisus or Caucasus to the upper part of the Panjab, including all Bactria, Hindu Kusb, and Afghanistan.

At least two classes of people seem to have employed the language expressed in this character, the one using the Aryan or Bactrian of Bamian, Kapurdigiri, etc., the other using the Budh or Lat character found on the Girnar rock and on the pillar and in the cave temple inscriptions; and that these two classes of people seem to be the Getæ and Sakæ, the socalled Aryan character being that used by the Getæ, while the so-called Lat character was that of the Sakæ. The Lat character occurs rarely in the southern part of the Peuinsula; still it is the only one used on the sculptures at Amaravati, which have been described by the Rev. W. Taylor; and while in charge of the Government Central Museum at Madras, the Editor despatched to England a large collection of its sculptures, which have since been described by Mr. James Fergusson in his Tree and Serpent Torship, and are now arranged into the wall of the great stair of the British Museum.

KAPURTHALA, a Native State in the Panjab, lying between lat. $31^{\circ} 9^{\prime}$ and $31^{\circ} 39^{\prime} 30^{\prime \prime} \mathrm{N}$., and long. $75^{\circ} 3^{\prime} 15^{\prime \prime}$ and $75^{\circ} 38^{\prime} 30^{\prime \prime} \mathrm{E}$. Area, 800 square miles. The chiefs are Sikhs of the Jat tribe. The chief of Kapurthala at one time held possessions both in Cis and Trans Sutlej, and also in the Bari Doab. The scattered possessions in the Bari Doab were gained by the sword, and were the first acquisitions made by sirdar Jussa Singh, the founder of the family. In them lies the village of Aloo, whence the family spring, and from which the designation Aloowalia is derived. The Trans-Sutlej estates were also acquired by conquest, and from the chief city therein, Kapurthala, the family derives its general designation. Of the Cis-Sutlej possessions, some were conquered, and some were granted by maharaja Ranjit Singh, prior to September 1808. The total value of the Cis-Sutlej possessions was estimated at Rs. 5,65,000. By a treaty of the 25th April 1809 , the sirdar of Kapurthala was pledged to furnish supplies to British troops moving through or cantoned in his Cis-Sutlej territory; and by article 5 of the Declaration of the 6th May 1809, he was bound to the British standard with his followers during war. In 1826, the sirdar Futteh Singh fled to the Cis-Sutlej states for the protection of the British Government against the aggressions of Ranjit Singh, and protection was accorded. It was declared that the Aloowalia chief was under British protection in respect to his ancestral possessions east of the Sutlej, but dependent on Lahore for places conferred by the Lahore Government prior to September 1808 , viz. Bussi, Narraingarh, and Jugraon. The protection of the British Government, however, extended over both. In the first Sikh war, the troops of Kapurthala fought against the British at Aliwal, and, in consequence of these hostilities and of the failure of the sirdar to furnish supplies from his Cis-Sutlej estates to the British army, the Cis-Sutlej estates were confiscated.

In 1849, sirdar Nihal Singh was created a raja. He died in September 1852, and was succeeded by his son Rundhir Singh. During the mutiny of 1857, and subsequently in Oudh in 1858, the raja Rundhir Singh rendered service to the British. The Government, among other rewards, remitted a year's tribute, and permanently reduced the tribute to its former amount, viz. Rs. 1,31,000. For his services in Oudh the raja received the estates of Baundi and Bithowli in perpetuity, with remission of half the revenue, and he has been guaranteed the right of adoption.

In 1878 its ruler had as titles His Highness, Farzand Dil - bund, Rasukh - ul - Itikad Daulat Englishia, Rajai Rajgan, Jagat Jit Singh Bahadur, Aloowalia, Wali Kapurthala, Baundi, Bathowli, and Acowria. - Aitcheson's Treaties, etc., p. 373.

KAP-TI, a small rude tribe near the source of the Irawadi. See India.

KAPYANG. The Minak kapayang is an oil held in esteem amongst the natives of Borneo for cooking. It is produced by Pangium edule, which grows to about 40 feet high, and is planted by the Dyak race.-Low's Sarawak, p. 47.

KAR, HIND., from SAYSK. Karya, act, affair, work of any kind, business; largely combined with other words.

Kar-i-chakand, embroidery.

Kar-i-kalamdani, painted ware of Kashmir.

Kar-i-kharat, turned and lacquered ware.

Kar-i-manakkash, painted ware.

KARA, in many of the languages of the south and east of Asia, means black; in Mahratta, a prison. Kara, in Carnatica, a blacksmith. Kara-papak or black-caps, a warlike Turkoman race. The Kara-koiounli or black shepherd clan, with the Ak-koiounli or white shepherd clan, 
under the Seljuk dynasty, long ruled over Western Asia. They reside near Alajah Dagh.

KARA or Kura. MAHR, A form of oath with Hindus, in which a leaf of tulsi and a cup of Ganges water, placed upon some sacred book, are held by a person on his head whilst he is giving evidence. If no domestic affliction befall him within a few days, his testimony is considered conclusive. $-W$.

KARA. Maleal. A division of a revenue district in Travancore.

KARA BELA, also Arma-Bel of Arab authors, the modern town of Bela, the chief town of Las, in Baluchistan, which is built on a strong and rocky site on the northern bank of the Purali river. Coins, trinkets, and funereal jars are found near ; and in the neighbouring hills are numerous caves and rock-cut temples, now ascribed to Farbad and fairies, but are the earthly resting abodes of former chiefs and governors. There are also old Mubammadan tombs near. One-third of the houses are occupied by Hindus.-Elliot's India; Masson's Journeys, ii. p. 28.

KARA-CHI or Kara-tchi, a people in Northern Persia who resemble gypsies in many respects, besides the use of a particular dialect or jargon among themselves. They prefer tents to houses, pilfer eggs, poultry, linen, and other things; tell fortunes by inspecting the palm of the hand, and are nearly, or perhaps altogether, without any religion. A man, with whom Sir W. Ouseley conversed, acknowledged that most of his taifah or tribe had not any certain form of worship or system of faith ; but, some Muhammadans being present, he loudly thanked God that he was himself a true believer, a very orthodox disciple of their prophet. The Turkish couriers from Constantinople recognised this man and his companions to be a Chingani or Jingani ; and Mustafa, who had been in England, whispered to him that they were the same as the gypsies. Porter tells us that the words mean black race. The men, finely limbed, with countenances sufficiently bold and watchful of what was going forward. The complexions of both sexes appear much darker than the native Persians. Their physiognomy generally seemed to agree with that of most of their brethren and sisters he had met wandering about in various parts of Europe. The men steal, make sieves, hair ropes, etc., from the produce of which they pay an annual tribute to the Government of two tomauns per family or tent. The women, when not occupied in the little domestic affairs of their canvas household, beg and tell fortunes, the latter being generally muttered over a few torn leaves from a Faringi book, or the blade-bone of a sheep, and accompanied with the thread of your life. The general expression of their faces, both in men and women, is that of deep thought, interrupted with rapid turns of observation flashing from their bright and powerful eyes. In some parts they are called Kauli and Susman. Their women, in one respect, differ widely from gypsy females in Europe. Mr. Barrow, in his account of this extraordinary race, has commended the strict chastity of the gypsy women; but the Kara-chi women of Persia are quite independent of any such rigid virtue, and one and all earn money in other ways than by telling fortunes.Ouseley's Travels, iii. 40; Porter's Travels, ii. 528.

KARACHI or Kurachee, a seaport town of
Sind, in lat. $24^{\circ} 51^{\prime} 9^{\prime \prime} \mathrm{N}$., and long. $67^{\circ} 4^{\prime} 15^{\prime \prime}$ $\mathrm{E}$., at the extreme northern end of the Indus delta, near the southern base of the Pabb mountains in Baluchistan. It is the chief town in the province of Sind. It was a mere fishing hanlet until occupied by the British about 1840 , but in 1881 its population was 8922 , extensive commerce, splendid harbour works, and numerous flourishing institutions having sprung up since the introduction of settled administration. The supply of water is mainly derived from wells, tapping a subterranean bed of the Layari. Karachi district stretches from the mouth of the Indus to the Baluchi boundary. It possesses a hilly western region, lying in the subdivisions of Kohistan and Karachi. Large forests of babul and other trees fringe the river banks, the $\mathrm{Habb}$ forming the western boundary between Sind and Baluchistan. The Manchhar lake, in the Sehwan subdivision, forms the only considerable sheet of water in any part of Sind. The hot springs of Pir Mangho, situated about six miles north of Karachi town, among some very barren and rocky hills, gush up from a clump of date trees, which covers the extremity of a craggy limestone knoll in a pretty valley enclosed by considerable heights. A swamp close by is famous for its immense number of crocodiles. Hundreds of them bask lazily in the sun by the side of a green, slimy, stagnant pool, or move sluggishly about in search of food. The greater pond is about 300 yards in circumference, and contains many little grassy islands on which the majority of the crocodiles (Crocodilus palustris) bask. Some are to be seen asleep on its slimy sides, others half-submerged in the muddy water, while now and then a huge monster raises himself upon his diminutive legs, and, waddling for a few paces, falls flat on its belly. The water in the pool feels cold, although fed from two hot springs, one of which is of so high a temperature that a visitor cannot retain the hand in it; yet animal life exists in it, for where the water bubbled up from its sandy bottom, and in the little lade running to the tank, there is abundance of a species of small black spiral shell, wbich Mr. Woodward reported to be very like Melania pyramis, an allied species of which frequents the river Jordan. The crocodiles dig deep in the sand under the neighbouring date trees, and there deposit their eggs. Quantities of deciduous teeth of various sizes are strewn along the slimy sides of the pond. They seized their food with the side of the mouth, and tossed the head backward, in order that it might fall into the throat. Extensive salt deposits occur in Shahbandar subdivision, on the Sirganda creek, a branch of the Indus accessible for small craft of from 50 to 60 tons burden. Karachi harbour is the most westerly port of India, and it is the only landlocked harbour between Bombay and the Persian Gulf. Though it is a bar-harbour, it has 17 to 18 feet at high water of ordinary tides, and from 20 to $22 \frac{1}{2}$ feet at springs. It is easy of access to large ships, by night or day, even during the monsoons.-Adams.

KARACHIL, a corruption of the Sanskrit Kuvera-chal, a name of Mount Kailas, where, according to Hindu mythology, lies the city of Kuvera, the Indian Plutus. - Yule, Cathay, ii. 411.

KARADAGH MOUNTAIN runs up to Derbendi-Bazian, and thence, after running a little way 
straight like a wall, it runs a little west, and forms the hill of Tchermala, thence it turns more west, and forms that of Khalkhalan. The Karadagh diminishes in height all the way from the Seghirmeh, which is very high, and towers above all the other mountains in the distance.-Rich's Kurdistan, ii. p. 6.

KARADIYE. KARN. A silver box in which is held the linga of the Lingawant sect.

KARA-GHUZLU, in Persia, the eastern Punch. Kara-ghuz is Turkish, meaning black eye. Karagluz and Haji Aivat are the two chief characters in Turkish farces. These two characters resemble in appearance, character, and habits the clown and pantaloon of a Christmas pantomime, with this difference, that they talk as well as act. The character and interest of the piece depend, of course, on the latent wit and drollery of the improvising operator, and to a lesser extent on the nature of the audience. The spectacle is made up of a series of trivial incidents loosely strung together without any underlying plot. There are, however, in the dialogue many obscene jokes, and in the pranks of the two worthies much corrse unveiled indecency.

KARAGOLA, a village in Purniah district, Bengal, on the left bank of the Ganges, in lat. $25^{\circ} 23^{\prime} 30^{\prime \prime} \mathrm{N}$, and long. $87^{\circ} 30^{\prime} 51^{\prime \prime} \mathrm{E}$, , on the route from Calcutta to Darjiling. The south of Purniah supplies blankets and rugs.

KARAHI. Hind. An open, large, shallow iron caldron, vessel, or bowl.

Karahi-lena, HIND., is the ordeal of taking a piece of gold out of a pot of hot oil. If the accused do so without being scalded, he is deemed innocent. Karahi-lena is common in India. Burton, Scinde, pp. 390, 404; Tod's Rajasthan, i. p. 71 ; Wilson.

KARAK, Kharg, or Karrack, in lat. $29^{\circ} 15^{\prime} 2^{\prime \prime}$ $\mathrm{N}$., and long. $50^{\circ} 18^{\prime} 50^{\prime \prime} \mathrm{E}$., an island off the coast of Fars, in the Persian Gulf, 30 miles N.W. from Bushire. It is about $4 \frac{1}{2}$ miles long. Its northern extremity is rocky, and about 100 feet high. The people are Arabs, and are fishermen and pilots. The Dutch occupied and fortified it in A.D. 1748, but were driven from it in A.D. 1765 by the pirate Mir Mohanna. The British occupied it in June 1838, but withdrew on the Persians raising the siege of Herat.-MacGregor, p. 219.

KARAKAL, meaning Black Stone, is a town in the South Canara district, Madras, in lat. $13^{\circ} 12^{\prime} 40^{\prime \prime} \mathrm{N}$., and long. $75^{\circ} 1^{\prime} 50^{\prime \prime} \mathrm{E}$., on one of the main lines leading from Mysore to Mangalore. Karakal was formerly a Jain town of some size and importance, and the antiquarian remains are very interesting. Chief among them is a colossal monolithic figure of Buddha or Gautana, locally known as Gumpta, after Gumta Raya, once ruler of this country. The figure is placed on a huge black rock, and is within a fraction of 50 feet high. - Imp. Gaz.

KARAKALPAK, a subdivision of the Turk race, of which the Uzbak, Kazak, and Turkoman are branches. They are settled in the Bokhara and Khiva districts. In the latter they have from 10,000 to 15,000 tents, which are large and strong, and guarded by a breed of large dogs. Their women are famed for their beauty. They are agricultural, but very poor, being heavily taxed. They do not trade, have but few borses, and hardly any sheep. They have several times rebelled against the Khiva government, and are a wild, uuruly race. They have been estimated at from 40,000 to 100,000 families. This race moved from the mouth of the Jaxartes into the khanate of Khiva in the beginning of the 19th century. In appearance and dress they are intermediate between the Kirghiz, Kazak, and Kalmuk. They are tall, vigorous men, with more powerful frames than any of the Central Asian tribes, but clumsy, and with coarse features. They have large head, flat full face, large eyes, flat nose, slightly-projecting cheek-bones, a coarse and slightly-pointed chin. The Karakalpak are considered dull and foolish. They are even less warlike than the Kirghiz; they have seldom appeared as conquerors, and are even less employed as mercenaries. They are largely occupied as cattlebreeders, and they are active, benevolent, and faithful.-Trotter's Cent. Asia; Collett's Central Asia.

KARAKASH, a river which flows from Pumgal to Suget in a westerly direction, then takes a sharp turn to the north, and then flows for the most part in an E.N.E. direction. In its valley are very large quarries and mines, from which is dug the yashm or jade-stone, and which are resorted to by people living at great distances.-Proceedings of the Magnetic Survey of India, p. 3.

KARA-KORUM PASS, the name applied to the point where the principal route between India and Eastern Turkestan traverses the water-parting between the river basins of those two regions. Dr. T. Thomson, of the Bengal Army (19th August 1848), describes it as a rounded ridge connecting two hills, which rise somewhat abruptly to the height of perhaps 1000 feet above the summit of the pass. The name Karakorum has been extended by some geographers to a fancied range occupying the exact line of waterparting between those streams which discharge into the Tarim basin and those which join the Indus; while others have applied the name to the closely-contiguous range usually called Mustagh. Mr. R. B. Shaw has shown the fallacy of the former view; while the appropriateness of the name Mustagh (ice mountain), and the fact that the Kara-korum pass lies some distance northward of this undoubted range, have since induced most geographers to restrict the name Kara-korum to the above pass. Its height above mean sea-level is 18,550 feet; lat. $35^{\circ} 33^{\prime} \mathrm{N}$. Colonel Yule says Kara-korum was the chief place successively of the Khan of Kerait and of the Mongol Khan till Kablai established his residence in China. Bishbalik, i.e. Pentapolis, lay between Kara-korum and Almalik, and had anciently been the chief seat of the Uigur nation. It is now, according to Klaproth, represented by Urumtsi. - Yule, Cathay, ii. p. 506 ; Imp. Gaz.

KARA-KUL, a small district in the valley of the Samarcand river, N.W. of Bokhara, of which it is a division, occupied by Turkoman and Uzbak shepherds. Large supplies of lamb-skins, called Kara-kuli, are sent from it to Tartary, China, Persia, and Turkey. They are highly valued in Persia, and are used for caps, which have a beautiful shape, and are much better than those of the Tartars. The rich men of Persia, who are fond of showy dress, generally kill a pregnant sheep, the skin of the young of which is afterwards taken 
off, and covered with cloth and cotton, to prevent the effects of the sun and air. The skin of such a young lamb is delicate, soft, and light. The finest lamb-skin cap is valued in Teheran, and other places in Persia, at thirty rupees. The caravan of Bokhara which frequents Mashed during the course of the year, brings considerable quantities of the skins. The shawls of Kirman and the sugar of Yazd are most important articles of sale in Mashed.-Burnes; Mohan Lal's Travels, p. 193.

KARA KUM, a sandy desert about 360 miles long, traversed on the route from Merv to Khiva. Its surface is very irregular, with ravines and deep pits and high mounds and ridges, with a few bushes of camel's thorn and wormwood. The cold in winter is very severe, with snow and bitter cold winds.

KARA-LINGI, Saiva mendicants, who go naked, and, to mark their triumph over desire, affix an iron ring and chain on the male organ. It was these ascetics who attracted the notice of Bernier and Tavernier and other of the earlier travellers. Since the beginning of the nineteenth century, they have rarely, if ever, been seen by Europeans.-Wilson. See Hindu.

KARAMAN, the town of Caramania, at the foot of the lofty range of Bedlerindagh, a branch of Mount Taurus.-Catafago.

KARAMNASA RIVER rises on the eastern ridge of the Kaimur Hills, in the Shahabad district of Bengal, in lat. $24^{\circ} 34^{\prime} 30^{\prime \prime} \mathrm{N}$, long. $83^{\circ} 41^{\prime} 30^{\prime \prime} \mathrm{E}$. It is held in the utmost abhorrence by Hindus, and no person of any caste will drink or even touch its waters. The reason of its impurity is said to be that a Brahman having been murdered by Raja Trisanku, of the Solar line, a saint purified him of his sin by collecting water from all the streams in the world, and washing him in their waters, which were collected in the spring from which the Karamnasa now issues. This spot is near the village of Sarodag, and the river soon becomes a rapid streamlet of beautifully clear water, with deep holes, and abounding in fish. At Chhanpathar, in its course through Mirzapur district, the river forms a waterfall 100 feet high, which, after heavy rains, affords a magnificent sight. - Imp. Gaz.

KARA-MUREN. MoNGOL. The Black River, called by the Chinese Hoang-ho, or the Yellow River. The embankment of the river is said to date from the twenty-second century B.C. Its regulation has ever been a source of anxiety to the Chinese Government, and there used to be a tax on the Hong merchants at Canton expressly on account of this object. The will of the emperor Kea King, who died in 1820 , has the following passage:- 'The Yellow River has from the remotest ages been China's sorrow. Whenever the mouth of the stream has been impeded by sandbanks, it has, higher up its banks, created alarm by flooding the country.' This seems to have been eminently the case in 1855 or 1856 , when the stream of the Hoang-ho, near the debouchment of the Great Canal, was reduced to a few yards in width, the northern banks having given way far up, and the inundations poured over Shan-tung. On this occasion much of the water was reported to have escaped into the gulf of Peh-chi-li, which the Chinese believe to have been the original exit. During the reign of the last Mongol emperor, a project was adopted for restoring this channel. The discontent created by this scheme assisted in exciting the movement for the expulsion of the dynasty.-Davis, i. pp. 137, 190;. De Guignes, iv. p. 216 ; J. R. G. S. xxviii. p. 294 ; Biot in Jour. As. Ser. iv., i. and ii. in Yule, Cathay, i. p. 125.

KARANA. HIND. A doer of anything, hence the kurnum or village accountent, and the terminal syllable of such words as kudrikara, a horse-keeper. The Karana is also a mixed caste, following writing and accounts as an occupation. Hence the AngloBengal word Kerani, a clerk, an accountant. It is from the Sanskrit Kri, to do.-Wilson. See Kar.

KARANAM or Curnum. KARN, TAM., TEI, A village accountant, one of the chief officers of a village community in the Tamil country. The Karanam is usually a Sudra, and trkes the title of Pillai ; in Telingana, a Brahman.

KARANG, a tree worshipped in Chutia Nagpur.

KARANG. MALAY. A reef, a shoal; several of them off the Sumatra coast.

KARANG BOLONG, a district in the Residency of Baglan, division Ambal, on the southerly sea-coast, between the rivers Chinching Golong and Djetis. 4000 able-bodied men of this district find a livelihood by gathering edible birds' nests, as fishers, and in cultivating sawa. Their birdnesting is accompanied by various local usages, amongst others are a feast, always on a Thursday, and cleaning the cliff ; the next morning (Friday) buffaloes are killed. Two hours afterwards they take some pieces of flesh, tongue, entrails, etc., from the slaughtered animals, and place them on small bowls woven of bamboo, called Sadjen. They are then offered to Bolong Natu Tumpang, and near the watch-houses of the cliffs a he-goat is offered with incense. In the afternoon a wayang is performed in the Bolong, generally a piece of seven acts, while the necessary flowers, fruits, ointments, siri, pinang, etc., required for the offerings, are prepared by the Tukang Kembong, and placed on the bamboo bowls, and in the evening are brought by a servant into the Bolong near the seroot tree. A Javanese named Kaki is buried there, and the natives declare that the tree has sprung from his navel. They likew ise make offerings on the burial-place, at the waringin tree, and in the overseer's house. After the wayang players have returned from the Bolong, the devil's bed (Nyai Ratu Kidul, which has existed from time immemorial) is put in order by the Tukang Gedong woman, and ornamented with silk and other cloths. Every Thursday this bed is cleaned, and offerings are made to it. Small lamps are lighted, and small bamboo bowls, with flowers, fruits, etc., are placed with particular marks of honour by the Tukang Gedong before the bed on a small couch made for the purpose. At the same time she says in high Javanese, as if addressing some distinguished person, 'By order of Mijinheer, I bere bring wherewithal for you alone to eat.' After this speech the Tukang Gedong herself answers, 'Yes, mother Tukang Gedong, say to father Mijinheer that I return my thanks for the food which he has sent me.'. At this ceremony the Tukang Gedong further asks Nyai Ratu Kidul if it be agreeable to her that the birds' nests should be collected, and if it shall take place without mischance, to which Yes is the usual answer.-Journal of the Indian Archipelago, No. iii." p. 103. 
KARANI. Beng. A copyist. See Karana.

KARANIKA. TAM. In the Tamil provinces a Sudra of the Pillai caste, and in the Telugu a Brahman.-Wilson.

KARANPURA is the side of a coal-field in the Hazaribagh district, Bengal, between lat. $23^{\circ} 37^{\prime}$ and $23^{\circ} 57^{\prime} \mathrm{N}$., and between long. $84^{\circ} 51^{\prime}$ and $85^{\circ} 30^{\prime} \mathrm{E}$. Area, 472 square miles; greatest length, 42 miles; breadth, 19 miles. It is divided into two tracts by the Damodar river; and iron ores of good quality occur in abundance in the ficld, and the manufacture of iron forms one of the chief industrial features of Hazaribagh district. - Imp. Gaz.

KARAO, seemingly from Karana, to cause to do, the term given among the Jat, Gujar, Abir, and other races and tribes in N.W. Hindustan to concubinage generally, but more especially to - marriages of widows with the brother of a deceased husband. This practice is known to the eastward of the Panjab by the name of Oorhai, in the Dekhan of But'hee, and in other provinces by the term Dhureecha; it is followed among several races, but is not very openly confessed even among them, as some degree of discredit is supposed to attach to it. Amongst the Jat, it is only younger brothers who form such convections, elder brothers being prohibited from marrying their younger brothers' widows, but among the Jat of Dehli even this is not prohibited. This practice has been common among several nations of the east. The Jews followed it, and in Egypt it was admitted for a childless widow to cohabit with a brother of the deceased husband. At the time that the laws of Menu were compiled, Karao appears to have been a recognised institution; but, as is not unusual with the Institutes, there is much contradiction between the enactments relating to it. From a consideration of all the passages on the subject, it appears that failure of issue was the point on which the legality turned. He who was begotten, according to law, on the wife of a man deceased, or impotent, or disordered, after the due authority given to her, is called the lawful son of the wife (Menu, ix. 176). Amongst the Jat, Gujar, and Abir, children born to Karao are considered legitimate, and are entitled to inheritance accordingly. Children borne by the women previous to Karao, except in the case of fraternal Karao, are known by the name of Kudhelura, and do not inherit the property of the father-in-law. When a Manji Singh dies leaving no male offspring, his brothers, or his nephews of the full blood, assume the right of succession, to which the widow or widows become competitors. According to the Shastra (if they may be considered applicable to public property and chiefships), the prior title of the widows is held; but, as the Sikhs follow the custom termed karao or chad'r - dala or chad'r-andazi, which obtains in every family with the exception of those of the Bhai, the eldest surviving brother of the deceased places a white robe over, and the nuth or ring in the nose of, the widow, which ceremony constitutes her his wife. This practice accords with the Hindu and Mosaic laws (Deuteronomy xxv. 5-10), and acts as a counter-agent to the many evils attendant on female rule. If the free will of the widow were consulted, it is scarcely to be doubted she would prefer the possession of power, and the charms of liberty, to the alternative of sacrificing her clains to her brother-in-law, and taking her station amongst his rival wives. Judging from the masculine disposition, want of modesty and of delicate feeling, which form the characteristic features of Sikh females, necessity and not choice must have led them to yield to the adoption of a usage which must often be repugnant to their natures, and disgusting to their thoughts. Yajnyawolkya says, "If a brother die without male issue, let another approach the widow in the proper season.' And Menu ordains, 'Having espoused her in due form, she being clad in a white robe.' The Bhai tribes of Khytul and other places, although they reject the union by Karawa, yet set aside the claims of a widow in favour of the brothers and nephews of one dying without male issue. The widows of the Bhai tribes receive small jaghirs for their support during life.

KARA OGHLAN, ruins about half a mile S.E. of Kifri in Kurdistan, from which Rich excavated a quantity of earthen jars varnished black in the inside, and perfectly resembling those found at Seleucia and Babylon. He obtained also a small earthen lamp like that now used by the villagers. Gold and silver coins are also frequently found here, which the villagers immediately melt down. The jars, or sepulchral urns, refer to the Sassanians. Farther up the torrent, on the N.N.IV., are some excavations in the block, called Gabr houses, and others of the same kind are in the hills, ten minutes' ride from the S. extremity of the ruins, consisting of excavated sepulchral chambers, with very low doors, and, in the inside, three places to lay out bodies, but of small dimensions, about five feet long. The plan of these excavations resembled the Achæmenian sepulchres at Naksh-i-Rustam. Farther on, about three miles from the ruins, on the top of a hill, are some vestiges of building, which the people call Kiz. Kalasi, or the Girls' Castle. Here urns and bones are found; the place is nearly opposite Oniki Inaum. S.W. of Kifri is an immense mound like the Majallibah of Babylon. Mr. Rich dug about it, and found immense quantities of small pieces of human bones, and fragments of urns, all of which had a black varnish on the inside; but the pottery was of different quality, some coarse and unornamented. The soil, as deep as he could discover by means of a ravine, was impregnated with black unctuous mould, fragments of urns, and small bits of bones. On the centre of the mound is a burial-place of Arabs, and the Muhammadan now confounds his dust with that of the fire-worshipping Persian ; for that this was a Sassanian place of exposing the dead, Rich had no doubt from its appearance and character, and the style of the fragments found.-Rich's Kurdistan, i. pp. 18-21.

KARA-SU. There are several rivers of this name, - that of Diarbakr; one in Armenia ; one in Trebizond (Tarabizun). One of the Kara-su is the main branch of the Euphrates that flows near Erzerum. Another Kara-su is one of the numerous streams that fall into the Murad or Euphrates.-Markham's Embassy, p. 72.

KARATAGIN, a semi-independent Galcha State in the upper part of the valleys of the Surkhab and its tributaries; its chief town is Garm or Karatagin. Its chieftain, like all the Galcha chieftains, claims descent from Alexander the Great. Population, 100,000, chiefly Tajak. It has 22 small Begships or villages, each averaging 30 
houses. There is a hot spring at $\mathrm{Ab}-\mathrm{i}-\mathrm{garm}$ Kishlak. Gold is washed at Sarim Sali, and salt is found in the Langar Sha mountains. The people trap martens and otters, make firearms, weave woollens and cottons. $-T r . C . A s$.

KARATEEVO ISLAND, a name of Cardiva Island, about $1 \frac{1}{2}$ to 4 miles off the Ceylon coast. The N. point is in lat. $8^{\circ} 31^{\prime} \mathrm{N}$., and long. $79^{\circ}$ $46^{\prime} 40^{\prime \prime} \mathrm{E}$. It is a mere sandy ridge thrown up by the sea.

KARAULI or Kerrowlee is the capital of a state of the same name. It is situated about 70 miles equidistant from Muttra, Gwalior, Agra, Ulwar (Alwar), Jaipur (Jeypore), and Tonk, in lat. $26^{\circ} 30^{\prime} \mathrm{N}$., long. $77^{\circ} 4^{\prime} \mathrm{E}$. It is said to derive its name from Kalianji, a temple built by Arjan Deo. The maharaja of Karauli is the head of the Jadu clan of Rajputs, who claim descent from Krishna, and are regarded as Yaduvansi, descendants of the Iunar race. The clan has always remained in or near the country of Brij round Muttra (Mathura), and once held Biana, which was taken from them by the Muhammadans in A.D. 1053.-Imp. Gaz.

KARAVAN-SARAI or Caravansary or Sarai is a square, enclosed by walls, under which are many rooms or cells for accommodation. The merchandise and cattle are collected in the area. There is a chamber for each person, with strict privacy.

KARAWA, a fisher caste near Bentotte in the N. and N.W. of Ceylon. They originally came from Tuticorin. The Parawa are a section of the Karawa.

KARAWAN or Keerewan, the stone plover, species of œdicnemus? Linn., has a shrill voice, somewhat resembling that of the black woodpecker. The Turks and Egyptians keep it in a cage. It is a very voracious bird, catching and devouring rats and mice. It is often mentioned in the Arabian Nights. - Lane.

KARBAJ, or Phancha. HrND. Sacks in which borax is conveyed across the mountains on the backs of sheep and goats.

KARBALA, or Mash'had Husain, a town of Asiatic Turkey, in Irak-Arabi, 50 miles S.W. from Baghdad; population, 20,000. The town is built on a plain about 6 miles west of the Euphrates, with which it is connected by a canal said to be more ancient even than the era of Alexander. Husain, son of Ali and Fatima, was killed near, and is buried here. His tomb is adorned with a gilded cupola and a noble mosque. Muhammadans of the Shiah sect resort in pilgrimage. It is 24 miles from Hillah, is at the extremity of a very noble canal drawn from the Euphrates. Its cnvirons are shaded by extensive plantations, and the walls are upwards of two miles in circumference. Fatima. Mahomed's daughter, was slain near it.-MacGregor.

KARBAR, business, etc. Kardar, an agent. Kargah, a workshop. Karkun, a clerk. Karkhana, an office, a manufactory, an arsenal. Karani, a manager, writer. Karigar, a workman. See Kar.

KAR-CHEMISH, the Hittite capital on the Euphrates.

KARCHI, HIND. An iron plate for parching grain.

KAR-CHOB. HIND. Heavy gold embroidery for saddle-cloths, cushions, etc.

KARDAR, a race occupying the Animallay Hills in the collectorate of Coimbatore. They are open,

independent, straightforward men, simple, and obeying their Mopen or chiefs. They are strong. built and active, with woolly hair and something of the African features, and they file their front teeth to a point. The women wear enormous circles of pith in the lobes of their ears, which they distend down to their shoulders. A black monkey is the Kardar's greatest dainty.-Lieut. Col. Hamilton in literis. See Kader.

KAREJ. PERS. Three kinds of calcareous earth are found in most situations in the western desert between Babylon, Hit, and Ana. The first, called Nura, is a white powder particularly abundant at Hit and Ana. Mixed with ashes, it is used as a coating for the lower parts of walls, in baths and other places liable to damp. The second is also found in powder, mixed with indurated pieces of the same substance and round pebbles; it is called by the Turks Karej, and by the Arabs Jus. It is very plentiful between Hilla and Felujia, is the common cement of the country, and composes the mortar which is found in the ruins of Babylon. The third species, called Borak, is a substance resembling gypsum.-Rich's Ruins of Babylon, pp. 64,65 .

KAREKATTAREARU. KARN. Persons whose occupation is working ornamental borders to blankets.-Wilson.

KAREN is a Burmese word applied to many of the mountaineers in Pegu and Southern Burma. Some of them are known as the White, Red, and Black Karen, from the colours of their clothes; also Burmese Karen and Talaing Karen, as dwelling amongst these nations. The Shan call them Yang, pronounced in the different parts of Burma as Yen, Yein, Yen-ban, and Yen-seik. The redclothed Karen call themselves Ka-ya, and somo of the Bghai clans, Kay-ay. They describe themselves as having come from the north, and crossed the great sand desert that separates China from Tibet, and believe that formerly they had books. All the Karen family between the mouths of the Tenasserim and sources of the Sitang arrange themselves into the Sgau tribes, the Pwo tribes, and the Bghai tribes. The Karen people are found within the British, Burmese, and Siamese territories, and extend from about lat. $28^{\circ}$ to $10^{\circ}$ N. The Karen between Burma and China are independent, with a patriarchal constitution, and reckon themselves by families, not by villages or tribes. They are agricultural. Some of the tribes are Buddhist, but two of them, the Sgau and Pgho, are pagan. Sgau tribes, the Pwo tribes, and the Bghai tribes may be thus arranged:-

Sgau proper.

Maune Pgho. Paku.

We wa.
Bghai-ka-ten. Bghai-mu-htai Bghai ko hta.

Lay may. Manu manau.
Pwo proper.

Shoung khie. Kaya or Ka. Taru or Kho thu. Mopgha. Hashu. Toung thu. Kyen.

The Eastern Bghai, Bghai-mu-htai, or Red Karen, call themselves Ka-ya, their term for man, and are called by the Burmese Kayennee; by the Shan, Yen-laing, or Red Karen, from the colour of their dress, which was originally all red, but a mixture of black garments is now commonly seen. Every man carries a short knife in his belt, many have swords, and those who have not muskets or matchlocks carry from one to three light spears, which are used in war like javelins, and thrown 
from the hand. Every man has a pony, so that in time of war they form a body of light cavalry, when all turn out to service, and the cultivation is then carried on by the women exclusively.

The country inhabited by the Red Karen is the finest in the interior of Burma. They are governed by a Saubwa, and have occupied their present locality for forty generations, having been driven down from the north by the Burmese, and separated at Upper Pagan from the Chinese, with whom they were then associated. Here, on the high table-land, they have lived, a terror to both Burmese and Shan, plundering, kidnapping, and killing, as opportunity offered, and selling the slaves they did not need to the opposite nation, Shan to Burmese, and Burmese to Shan. Dr. Mason found the people, with all the savageness which is imputed to them, by far the most civilised Karen known. They are better clad, provide themselves with better food, are better skilled in the arts, are more vigorous, active, and laborious, than any jungle tribe he met. They make their own knives, axes, swords, spears, hoes, bangles, silver ornaments, and earthenware, bits and bridles, saddles and stirrups. Every foot of land they cultivate is hoed with a heavy hoe of the western form, such as is never seen among either Burmese or Karen, but is used by the Chinese. They have cattle in great abundance, which are trained to carry panniers as donkeys are in Europe, and which bring their produce from the fields to the villages. A considerable portion of the population are slaves; but slavery here exists in its mildest form. There seems to be very little difference between master and slave,

The Karen burn their dead, but rescue from the ashes a portion of the skull, which they suspend from a tree, with the clothes, ornaments, and arms of the deceased. They dance, singing beautiful songs, around these relics, which the elders afterwards convey to the foot of distant mountains, and there inter them. Dr. MacGown includes amongst them, the Ka-Khyien, Khyien, Kemmi, Karen-ni or Red Karen, the Pwo and Sgau Karen, who possess characteristics so much in common as to justify them in being regarded as divisions or fragments of one nation.

The Karen dialects of the Lower Irawadi and Tenasserim are more closely assimilated with the Yuma languages than with the Burman. Karen has been more assimilated to the Burman phonology, but it has remarkable affinities with the Mon Anam or Mon Lau alliance. Glossarially, it is mainly Tibeto-Ultra-Indian of the earlier form, or that which characterizes the Yuma and Naga Manipuri languages. A few have become Buddhists, and atheists are met with. They have no priesthood. They are, however, addicted to a considerable extent to Nat worship, demonolatry or pneumatolatry. To propitiate the spirits of the rivers, hills, plains, and trees, they sacrifice buffaloes, swine, and fowls. A portion of them worship their ancestors and make offerings to their manes. They commonly burn their dead.

Karen who dwell in the Sban country north of Mobya, wear a black dress. In Monai, Leg-ya, and Theen-nee, and in the southern part of the last district, their villages are quite numerous. They are much darker than the Shans. The men dress like the Shans, but the women wear a dark-blue skirt gathered at the waist and reaching to the knees, with a shorter over-skirt, and a close-fitting jacket tastefully ornamented with seeds trimming. They are Buddhists, and have Kayoungs, in which the youths are educated to read Shan books. They eat beef and buffalo meat, never pork. The Karen believe that every object of nature has its god, as the god of the sun, or the moon, or the earth, or the ocean. They propitiate evil spirits. They say that formerly they sacrificed oxen. They employ wizards to curse their enemies.

KAREZ, a Persian well or a series of wells, connected to each other by an underground aqueduct, and leading the water to the place required, with shafts at intervals to admit of repairs. There are several very valuable karez at Ahmadnaggur in the Dekhan. Pottinger mentions that, but for the karez or aqueducts, the natives of many parts of Baluchistan could not possibly exist. They are met with in great numbers in all the plain country of Persia and Afghanistan. Those of Hezekiah, 2 Kings xviii. 17, seem to be of this kind.

KARG or Kharg. Hind. A sword. Kargashapna, the Scythian adoration of the sword, is continued amongst the Rajput races as the Khanda-worship, part of the ceremonies of the Nou-ratri, or nine days dedicated to the god of war. The Scythians worshipped their god of war under the form of an iron scimitar. The Fresian Frank adhered to this practice. Charlemagne styled his sword Joyeuse. The Khanda is a double-edged scimitar- - Tod.

KARHADEE, a clan of Brahmans spread in Bombay Island, in Poona, in the Ceded Districts, Gujerat, and Sind; in 1881, about 23,040 in number. They are agricultural, but take Government service. Many are bhikhshu or mendicants, and serve in Hindu temples; are Purana readers. They were accused of a tendency to sacrifice human beings.

KARHARBARI, a coal-field in the Hazaribagh district of Bengal, lies between lat. $24^{\circ} 10^{\prime}$ and $24^{\circ} 14^{\prime} \mathrm{N}$., and between long. $86^{\circ} 16^{\prime}$ and $86^{\circ} 23^{\prime}$ E. Area, 11 square miles, of which $8 \frac{1}{2}$ miles are coal-bearing. The miners are chiefly Bhuiya, Bauri, and Santal.

KARI. TAM. A bazar, a market-place; the supposed source of the word curry, as, like bazar in Bengal, it means the market supplies. Kariapaak, Karia beken, curry leaf; leaf of Bergera Konigii.

KARIALAN. TAM. Meaning landlord; a tribal title of the Idaar or shepherd race, in the southern districts of the Tamil country.

KARIANG, Sawa, Ka, and Chong, are wild, migratory races of Further India, the first and second being the same people who inhabit various portions of the Burman dominions. The $\mathrm{Ka}$, a term which in the Siamese language means slave, but who are called by the Kambojans Pa-nong, inbabit the mountains of Lao, bordering upon Kamboja. The Chong, a more industrious and settled people, inhabit the hilly country on the eastern side of the Gulf of Siam, between the 11th and 12th degrees of north latitude.

KARIKA, the metrical aphorisms of Grammar of Bhartrihari.

KARIKAL is the name of a French settlement in the delta of the Cauvery, within the limits of Tanjore district, south of Madras, in lat. $10^{\circ}$ $55^{\prime} 10^{\prime \prime} \mathrm{N}$., and long. $79^{\circ} 52^{\prime} 20^{\prime \prime} \mathrm{E}$.; population, 
92,516 ; area, 52 square miles. Six miles south of Tranquebar, and about $1 \frac{1}{2}$ mile from the Arselar mouth of the Cauvery, the soil is fertile and watered by six small channels from the Cauvery.

KAR-i-KALMDANI. Hind. Papier-maché work, also painted wooden articles; the painted ware of Kashmir ; also called Kar-i-manakkash or painted ware, pen-case work; a papier-maché work inade at Srinuggur, in the form of paper cases, glove-boxes, tea-caddies.

KARLI, in the Poona district of Bombay, is situated on the road between Bombay and Poona, in lat. $18^{\circ} 45^{\prime} 20^{\prime \prime} \mathrm{N}$., and long. $73^{\circ} 31^{\prime} 16^{\prime \prime} \mathrm{E}$. The rock-cut chaitya at Karli is the finest, largest, and most complete of all the chaitya caves. The eight figures that originally adorned the porch are chiefs with their wives, and all the figures of Buddha that appear there now are long subsequent additions. The caves are close to the high road from Poona to Bombay, about half-way down, on the right-hand side of the valley as you proceed towards the sea. They are not so extensive as those of Ajunta, but they are purely Buddhist. The largest and most splendid chaitya cave-temple in India, which could be selected for reproduction by art, is the principal excavation at Karli, and it is also interesting as the oldest Indian work of the kind known to exist.

Kondane, Jambrug, and Amhivle are in the lower scarps of the Sahyadri range, near the Karjas station at the foot of the ghat; Bhaja, Bedsa, and Karli are in the spurs that strike out from the hills, Karli being near the Lanowli station.-Ferqusson; Burgess.

KARM. HIND. A sort of cabbage eaten by the Kashmiri and at Lahore.

KARMA. .SANSK. In Hinduism, act, work; an act of piety or religion, as sacrifice, marriage ceremony, funeral obsequies: duty or acts obligatory on a tribe or caste. In Buddhism, actions that control the universe. See Vaishnava.

KARMA - KANDA. SANSK. The exoteric doctrines of the Vedas.

KARMAN'TARA, the end of a Hindu funeral ceremony which continues for sixteen days.

KARMATI sect is an offshoot of the Ismaili heresy, and is often confounded with it. There were some points of doctrinal difference, but the uninitiated were ignorant of them, and unable to distinguish thein; so the two names came to be often used indifferently. Orthodox writers, hating and despising the heretics, were prone to speak of them by some general name; or if they attempted to be more specific, their ignorance frequently led to a confusion and misappropriation of terms. Thus the term Ismailian includes Karmatians, Assassins, and others, and for the Ismailians the wider term Mulahida, heretics, is often used.

The Ismailians do not admit the rightful succession of the Imams recognised by the orthodox. They acknowledge Ali, Hasan, and Husain, but maintain that the line closed with Ismail, son of Jafar Sadik, who was the seventh and last Inam. From him they take the name Ismailian, and from him also they are called 'Seveners.' The teaching of the Ismailians put a metaphorical interpretation on the Koran, which tended to explain away and supersede its doctrines, leaving only a negative religion, and substituting licence for morality. The doctrines of the Ismail- ians were embraced by a man named Abdullah, son of Maimun, a native of Persia, who devoted his powers not only to the overthrow of Arab ascendency, but to the subversion of Islam, and, indeed, of all religion. His mode of action was by secret influence and missionary exertion. The culminating doctrine of his teaching was the vanity of all religions, and the indifference of men's actions, the good receiving no recompense, and the bad no chastisement, either in this world or in the next. Among the followers of Abdullab was one named Ahmad, or, as he was afterwards called, Karmat. He rose about the year $\mathrm{H.} 278$ (A.D. 891), and was the founder of the Karmatians. The term Karmata or Karmat belongs to a kind of Arabic writing in which the letters are very small and the lines very close. This style beiug well suited for secret communications, was adopted by Ahmad, and hence he was called Karmat, and his followers Karmati or Karamata, Anglicé Karmatians. Teaching the doctrine that everything desirable was allowable, he differed from his predecessors by endeavouring to carry out his views by violence, and began an open unrelenting war upon the ruling powers. In H. 290 (A.D. 903) the Karmatians made a fearful inroad into Syria, and in H. 311 (A.D. 923) they plundered Basra and Kufa. In H. 319 (A.D. 931) under a famous leader, Abu Tahir, they took the city of Mecca with terrible slaughter, plundered the temple, and carried away the holy hajr-ul-aswad, or black stone, which they retained for twenty years. Ar Razi, the twentieth khalif, actually agreed to pay them an annual subsidy to secure the safe passage of the pilgrims to Mecea.

The Fatimite throne of Egypt, founded by an Ismailian in H. 297 (A.D. 909-910), in rivalry of the Arabian khalifat, grew rapidly in power, and became a source of great jealousy and trouble to the occupants of the throne of Baghdad. Political rivalry thus combined with religious hatred to make the war between the faithful and the heretics most savage and unrelenting.

From the Ismailians sprang another sect, which forced itself upon the notice of the Crusaders, and introduced a new word, Assassin, into the languages of Europe. This sect was founded by a native of $\mathrm{Re}$, narned Hasan Sabah, who was schoolfellow and companion of Nizam-ul-Mulk, the well-known wazir of the Seljuki government, and author of the Majma-ul-Wasaya. The forcible removal of all foes and rivals by the dagger of the assassin, was the profession and the distinctive practice of this abominable sect. Amongst others, Nizam-ul-Mulk, above referred to, fell under their daggers, and the author of the Jahan-kusha had nearly become a victim to Ismailian assassins. In H. 483, Hasan Sabah obtained possession of the strong fortress of Alah-amut or Alamut (the Eagle's Nest), in the province of Rudbar, about eleveu parasangs north of Kazwin, and here he and his descendants maintained themselves for nearly two centuries, when the fortress and many others fell under the iron tread of the Mongols. The excesses of the Assassins had impelled Mangu Khan to determine upon the extermination of the whole sect of Ismailians, and under him and his successor Hulaku, their fortresses were taken, and many thousands of their men, women, and children, and babes at the breast, were put to the sword. 
The Karmatians appear to have pushed themselves eastwards into the valley of the Indus, and to have sought a country in Sind about H. 375 (A.D. 985), and seem to have been ruling there at the time of Mahmud's return from the fall of Somnath. From Biruni we learn that the Karmatians destroyed the great idol at Multan, and the heretical chief, whom Mahmud of Ghazni drove away from that town, was no doubt a member of this sect, for the name of Karmatian is applied to him by one or two writers, although the more general name of Mulahida is more frequently used.

Mahmud's wazir, Hasnak, was brought to the stake by Masūd upon the charge of being a Karmatian. The personal enmity of Masūd no doubt precipitated this act; but there is ample proof that the khalif was greatly incensed against the wazir for having received a khilat from the Egyptian khalif, and that he had urged Mahmud so strongly to execute him that the incensed monarch broke out in the indignant words recorded by Baihaki, "Tell the doting old khalif that out of regard to the Abbassides I have meddled with all the world. I am hunting for the Karmatians, and wherever one is found he is impaled. If it were proved that Hasnak is a Karmatian, the Commander of the Faithful should soon see what had happened to them. But I have brought him up, and he is to me as my sons and my brothers. If he is a Karmatian, so am I.' When Mahmud departed, and Hasnak's enemy succeeded, the khalif's animosity was soon appersed.

Though Mahmud expelled the Karmatian chief from Multan, the heresy was not suppressed; for in H. 571 (A.D. 1175), Muhammad Gbori once more delivered Multan from the hands of the Karmatians. In II. 634 (A.D. 1237) we find them in some force at Dehli, where they made a concerted assanlt upon the faithful in the Great Mosque, and slew a considerable number; but they were finally overpowered, 'and every heretic and Karmatian was sent to hell.'

The Druse sect adored Hakim, the Fatimite khalif of Eigypt, as a god. In the year A.D. 1032, Muktana Baha-ud-Din, the chief apostle of Hamza, and the principal compiler of the Druse writings, was in correspondence with the Karmatian schismatics in Sind, his letter being addressed to Shaikh-ibn-Sumar, Raja Bal, in particular. The Karmatians, after successive defeats and subsequent persecution in Arabia, as refugees from Bahrein and Al Hasan, sought protection in Sind, where their progress amongst the Hindus was rapid. The Karmati, one of the Baluch clans, preserves the memory of its heresy. Independent of the general dissemination of Shiah sentiments in the valley of the Indus, which favoured notions of the incorporation of the godhead in mas, the old occupants of the soil must, from other causes, have been ready to acquiesce in the wild doctrines of the heretics, who now offered themselves for spiritual teachers, as well as political leaders. Their cursing of Mahomed; their incarnations of the deity; their types and allegories; their philosophy divided in to exoteric and esoteric; their religious reticence; their regard for particular numbers, particularly seven and twelve; the various stages of initiation; their abstruse allusions; their mystical interpretations, and their pantheistic theosophy, - were so much in conformity with sentiments already prevalent amongst these willing disciples, that little persuasion could have been required to induce them to embrace so congenial a systern of metaphysical divinity, of which the final degree of initiation, however cautiously and gradually the development was concealed, undoubtedly introduced the disciple into the regions of the most unalloyed atheism. So susceptible, indeed, must the native mind have been of these insidious doctrines, that Hammer-Purgstall and others, who have devoted much attention to these topics, have very reasonably concluded that the doctrines of these secret societies, such as the Karmatian, Ismailian, or Assassin, Druses, Batini, and sundry others, which at various periods have devastated the Muhammadan world, and frequently threatened the extinction of that faith, though originally based upon the errors of the Guostics, were yet largely indebted to the mystical philosophy aud theology of eastern nations, and especially of India, where the tenets of transmigration and of absorption into the deity were even more familiar both to Buddhists and Brahmans than they were to these miserable schismatics.-Elliot's History of Indir, ii. p. 497 ; Tr. of Hind. i. p. 431 ; Calcutta Revieu: KARNA, in Hindu mythology, son of Prithi or Kunti. Kunti had received from Dur-vasas a charm by virtue of which she could have a child by any god whom she preferred to invoke. She chose the sun, and the offspring was Karna, who was born equipped with arms and armour. He was thus older than his half-brothers, the Pandava. He became king of Anga, but in the great fight of the Mahabharata he was killed by Arjuna, and the Pandu brothers only then became aware of his relationship to then.-Dowson.

KARNA-CHAPARA. The Haft Khaneh, or Satgurh group of caves, is one of the Behar caves in the neighbourhood of Rajagriha, amongst the most ancient caves in India, being about B.C. 200. The others are the Milkmaid's Cave, the Brahman Girl's Cave, the Nagarjun Cave, and in the neighhood are the Karna-chapara and Lomas Rishi Caves.

KARNAK and Luxor are famed for their ancient temples. The sacred enclosure of the Karnak temple comprises a square of 2000 feet each way, with 26 temples within the enclosure. On the walls of these stupendous structures we have the history of Egypt from Sesortesen I., who reigned 5000 years ago, down to the Roman Augustus, - these being the earliest and latest names inscribed on the lithotomes of Karnak. The famous hypostyle court is 170 feet long; its width is 329 feet. It is supported by 134 columns. The centre twelve are 62 feet high in the shaft, and 36 feet in circumference. The remaining 122 columns are 42 feet in height and 28 feet in circumference. The lintel stone of the great doorway is within two inches of 41 feet in length. Every part of the walls, the pillars, and the roof, is covered with coloured sculpture.

KARNAL, a town in the Panjab, in lat. $29^{\circ}$ $42^{\prime} 17^{\prime \prime}$ N., long. $77^{\circ} 1^{\prime} 45^{\prime \prime}$ E., and 966 feet above the sea. The district is occupied by the agricultural Jat, who are careful and thrifty cultivators. Here, as in most other districts, they are confined to the once sterile uplands, while the Rajputs and Gujars occupy the fruitful Khadar; the Brah- 
nuans, most of whom are engaged in tillage, being found most thickly in the Jumna valley.

KARNATIC or Carnatic, a term applied by modern geographers to the low country below the ghats on the Coromandel or eastern coast of the Peninsula of India, also known as the Dravida or Tamil country. But the Karnatika, Kannadi, or Canarese language is spoken in the centre of the Peninsula. It is bordered by the Tamil and the Telugu ou the east, is spoken throughout the plateau of Mysore and in the S.W. districts of Hyderabad, in the Dekhan as far north as the village of Murkunda, lying 30 miles west of Beder. Also, it is largely spoken in the ancient Telugu country on the Malabar coast, now long designated as Canara, a name which it acquired from having been subjected for centuries to the rule of Canarese princes. But in Canara, the Malealam, the Konkani, and the Telugu are also spoken, though less extensively than the Canarese. The Canarese character differs slightly from the Telugu, from which it has been borrowed, but the characters used for Tamil, Malealam, and Telugu are quite distinct from each other. The ancient Canarese character, however, entirely differs from that of the modern Telugu, and the Canarese language differs even more widely from the Telugu than it does from the Tamil. There is an ancient dialect of the Canarese language current, as well as modern, the latter differing from the former by the use of different inflexional terminations. The ancient Canarese dialect, however, has no connection with the Sanskrit character to which that name has been given, in which, viz. the Hala Kannada, many very ancient inscriptions in the Mahratta country as well as in Mysore are found. The people who speak the Canarese language may number seven millions. This includes the Coorg people and the Hyderabad country, where Canarese, Mahrati, Gondi, and Telugu are spoken, the Urdu or Hindustani language being merely known to the Muhammadans there, and to the Hindus and Kayasths from Northern India, the resident population using it as a lingua franca. Of the books in the Karnatika language, mention may be made of the Kavya Sarya, KarN., Gems from the Works of ancient Canarese Poets, by Aggalah, a poet of the 12th century; Rudra Bhatta wrote the Jagannatha-Vijaya; the Bharata Sara is by Chandra Sekhara Kavi; the Abhinava Bharata Sara Sangraha was composed by Bijjalanka Raya of Kalyana pura in the 12th century.

KARNA-VEDHA, a Hindu ceremony of boring a child's ears.

KARNAVEN, in the Malealam, the head of a family community or tarwaad living in the form of Marumakatayam, or descensus ab matrice. See Polyandry.

KARNFULI, the river on the banks of which Chittagong is built.

KARNPHUL. HIND. Bunches of silk and tinsel ornaments worn in the ear.

KARNUL, a town on the right bank of the Tumbudra, near the junction with the Hindri, lat. $15^{\circ} 49^{\prime} 58^{\prime \prime} \mathrm{N}$., long. $78^{\circ} 5^{\prime} 29^{\prime \prime} \mathrm{E}$. ; population (1871), 25,a79. It gives its name to a revenue district, which was ruled by a Pathan family until 1839, in which year, in consequence of the nawab Alif Khan making preparations for war, he was taken prisoner at the battle of Zorapur, dethroned, and removed to Trichinopoly, where he was assassinated by one of his own people. The district has limestones, shales, and quartzite as the prevailing rocks. The limestone makes very good building material, and is used for lithographic purposes. Lead ore is also found. The Catholics of this place originally belonged to the Kapu caste, and their conversion to Christianity has not made any material change in their manners and customs. They eat and drink with Hindus, and in several cases intermarry with them. They have founded a village named Kothala. The wild tribes or Cheuchus live on the Nullamallays in small communities called gudems. Each gudem includes several tribes.Imp. Gaz.

KAROH. PERs. A cos, an Indian itinerary measure of India.

KAROND or Kala Handi, a feudatory chiefship attached to the Sumbulpur district, and lying between lat. $19^{\circ} 5^{\prime}$ and $20^{\circ} 30^{\prime} \mathrm{N}$, and long. $83^{\circ}$ $50^{\prime}$ and $84^{\circ} 40^{\prime} \mathrm{E}$.

KARRA. Hind. A bracelet, a metal ring for the wrist, assumed by a Bengali woman on marriage.

KARRACK ISLAND or Khareg, the Icarus of Arrian, was surveyed by Captain Goodfellow, of the Bombay Engineers. It is composed of coralline sandstone and limestone plentifully mixed with fossil tubipora. In the limestone are numerous oysters, cockles, limpets, and other molluscs. It is four miles long and three broad, and has a range of table-topped hills ending in bluffs.-Kinneir's Geographical Memoir, p. 18. See Karak.

KARS, a province in Asiatic Russia, lat. $40^{\circ} 8^{\prime}$ to $41^{\circ} 18^{\prime} \mathrm{N}$., and long. $42^{\circ} 45^{\prime}$ to $43^{\circ} 34^{\prime} \mathrm{E}$. The capital is in lat. $40^{\circ} 37^{\prime} 1^{\prime \prime} \mathrm{N}$., and long. $43^{\circ} 9^{\prime} 2^{\prime \prime}$ $\mathrm{E}$, and is 6000 feet above the sea. It is of great antiquity. It was taken by Russia in 1828,1855 , and 1877. Kars is the Charsa of Ptolemy, is one of the strongest places in that region, and is the very key of Armenia towards the north. Amurath III. restored the principal fortifications, and a pentagon redoubt was added about the close of the 18th century.-Porter's Travels, ii. p. 648.

KARSHA. SANSK. A weight of gold or silver of 180 troy grains. $-W$.

KARSHA, the mountain temple of Karsha of Shekavati, has an inscription in grammatical Sanskrit. It was erected A.D. 961, finished A.D. 973. It mentions the mythology of the Purana. Siva, the Pramahtes, Muni, and Yati are called immortal; Indra, Kama, Nandi, the Naga, Rama, Balarama, Vishnu, Krishna, Sambhu, and Visvakarma. The portico of the temple is graced with the presence of Gaya, the holy Asura. The inscription is at a temple of the Linga (Siva), and Dr. Mill says the character furnishes a definite standard from which the ages of other monuments, of similar or more remotely resembling characters, may be inferred with tolerable accuracy. The temple was built to commemorate the destruction of the Asura, or demon Tripura, who had expelled Indra and the god from heaven; and, on the mountain, Siva was felicitated by the gods, whence the name Karsha (joy). The princes are but donors and benefactors; the Brahmans are represented as the real builders; their spiritual genealogy is traced; one of them is made an incarnation of Nandi, similar in splendour to the great deity himself, and they are called Lords of the Earth. Indra is called Bharata in the inscriptions. Siva is identified with his phallic emblem, and be is 
also called the eight formed one. Nudity, clotted hair, and ashes characterize the Brahman teachers. Ganapati, the son of Siva, is not mentioned; seeming to indicate that his worship was not yet established.-Beng. As. Soc. iv. p. 367.

KARSHAGNI is a Hindu expiatory ceremony obtained from the use of the cow-dung for the cremation of the living. On one occasion of its performance, it happened, according to a legend, that a crow, named, from her friendly disposition, Mitra Kaka, was present, and immediately flew and imparted the welcome news that a Hindu who performas the Karshagni goes to heaven. This expiation consists in the victim covering his whole body with a thick coat of cow-dung, which, when dry, is set on fire, and consumes both sin and sinner. Until revealed by the crow, this potent expiation was unknown; and it has since occasionally been resorted to, particularly by the famous Sankaracharya. The friendly crow was punished for her indiscretion; was with all her tribe forbidden to ascend to heaven, and was doomed on earth to live on carrion.-Wilford.

KARTA, a title added to the names of petty princes and zamindars of Travancore; also the member of a joint Hindu family who manages the estate.

KARTABHAJA, a class of Bairagi who believe in the unity of God.-Sherring.

KARTIKA. SANSK. The eighth lunar month of the Hindu year, October and November, when the sun is in Kartika or Pleiades. During the months Asharh, Kartik, and Phalguna, Hindus perform four kinds of sacrifices to the Viswadeva and to Varuna. The sacrifices are called Viswadeva, Varuna praghasa, Sakamedha, and Sunasariya. The materials of sacrifice consist of roasted cakes of rice-flour to Viswadeva, with two figures of sheep made of flour, to Varuna, with vegetables to Agni, and the fourth to Indra.

Kartik Ekadasi is the eleventh, in some years the twelfth, day of the light half of the month Kartik, or about the 8th November. On this day Vishnu is supposed to rise from his four months' sleep, and this has reference to the sun being at the winter solstice.

Kartik Purnama occurs about the 11 th November, in the full moon of the month Kartik, when Siva is said to have gained a victory over a monster called Tripurasura, seemingly three cities of the Assyrians; presents of money (dakshina), or of lamps (dip-dan), are made to Brahmans.

Bhrathi-dwitaya is the Hindu festival on the second of the Hindu month Kartik, when Hindu sisters entertain brothers, in memory of Yamuaa entertaining her brotber Yama.-Wilson's Gloss.

KARTIKEYA, or Skanda, the Hindu Mars, the second son of Siva, occupies a prominent place among the Saiva sect of the Tamil country. It is said that the gods, persecuted by giants, implored the help of Siva. The lord of Kailasa then assumed six faces, and caused six sparks of tire to dart out of his six central eyes. The sparks were cast into a pond, which the southern Saiva assert is at Tritani, about 50 miles north-west of Madras. The six sparks became six infants, which were nursed by the six mothers, who form the constellation Kartika (the Pleiades). When Parvati took them in her arms, they assumed one united body, having six heads. The warlike son of Siva afterwards slew the giants. In North India, Kartikeya, he who was fostered by the Kartikas, is his common title. In the Tamil country, Subramaniyan, he who is like the diamond, is the usual epithet. He is also called Murugan, he who has perpetual youth, and Arumugan, the six-faced. Skanda is used in the Skanda Purana, and other of bis names are Agni-bhu and Ganga-bhu. Skanda is said to have had two wives, Devayanai, daughter of Indra, and Vallinachi, who was brought up by hunters. The month Kartika (part of November and December) is regarded by the Saivites as sacred to the Pleiades and Kartikeya. When the moon enters the third star of the constellation a great feast is held, and lawps are placed in every doorway. There are otber legends.

Kartikeya dipa is the name of the Hindu festival celebrated in the month Kartika, in honour of Subbramanya, when lights are placed at the door and other parts of the house, and fires kindled on hills.

KARTTA. SANSK. Maker, Lord, a name given to the Supreme Being.

KARTTAVIRYA, a king who stole the cow of the gods, and was killed by Parasurama.

KARUMNASSA, a tributary to the Ganges. It rises in the Kymore range, in lat. $24^{\circ} 38^{\prime} \mathrm{N}$., and long. $83^{\circ} 11^{\prime} \mathbf{E}$., and runs N.N.W. into the Ganges, near Ghazipur, after a length of 140 miles.

KARUNAIPPIRAKASA TESIKAR, a zealous Vira-Saiva of Kanjipuram. He wrote a poem on the lingam, Ishdalinga Akaval, and commenced a work called Kalatti Puranam, but he died before it was completed.

KARUND, a town in the south of Persia; the inhabitants are Ali Illahi, worshippers of Ali, whom they consider as God; they eat pork, drink fermented liquors, never pray, never fast in Ramzan, and are cruel and savage in their habits. Although almost always in revolt against Persia, it is scarcely possible to subdue them; therefore feuds are compromised and never thoroughly repressed by force. Col.Rawlinson says the religion of the Ali Illahi sect bears evident marks of Judaism, singularly amalgamated with Sabæan, Christian, and Muhammadan legends. The tomb of Baba Yadgar, in the pass of Zardah, is their holy place; and this, at the time of the Arab invasion of Persia, was regarded as the abode of Elias. The Ali Illahi believe in a succession of incarnations of the godhead, amounting to 1001; Benjamin, Moses, Elias, David, Jesus Christ, Ali and his tutor Salman, a joint development, the Imam Husain, and the Haft Tan (the seven bodies) are considered the chief of these incarnations. The Haft Tan were seven pir, or spiritual guides, who lived in the early ages of Mubammadanism, and each, worshipped as the deity, is an object of adoration in some particular part of Kurdistan. Baba Yadgar was one of these. The whole of the incarnations are thus regarded as of one and the same person, the bodily form of the divine manifestation having alone changed; but the most perfect development is supposed to have taken place in the persons of Benjamin, David, and Ali. The Spanish Jew, Benjamin of Tudela, seems to have considered the whole of these Ali Illahi as Jews; and it is possible that in his time their faith may have been less corrupted. Amaria also, where the false Messiab, David Elias, appeared, was certainly in the district of Holwan.-Journal of Royal Geographical Society, ix. p. $36 ; E d$. Ferrier, Caravan Journeys, p. 19. 
KARUN RIVER rises by many springs in the Zardah Koh (mountains) near Korreng; it is a large river from its source. It receives the $\mathrm{Ab}-\mathrm{i}-$ Bors river a little above Susan. After leaving the mountains, it is a tranquil river, and would be suitable for navigation but for a dam at Shuster, where numerous irrigation channels are drawn from it. It is joined at Band-i-Kir by the river of Dizfal, a large stream, exceeding in size the Tigris or the Euphrates. It discharges into the sea by the khor or channel of Bahmeh Shir, which is 40 miles long, and part of its waters enter the Shat-ul-Arab by an artificial channel. The town of Mohamrah is built on this channel.Chesney, p. 205; MacGregor, iv. p. 225.

KARUR (Caroor or Karuru), meaning black

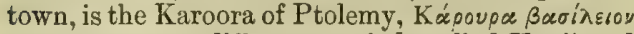
Kn,o ßódpov; at different periods called Vanji and Garbhapuri. The town is in Coimbatore district of Madras, situated on the left bank of the Amravati river, near its confluence with the Cauvery. Lat. $10^{\circ} 57^{\prime} 42^{\prime \prime} \mathrm{N}$, and long. $78^{\circ} 7^{\prime} 16^{\prime \prime}$ E. During the struggles between the rival dynasties of Chera, Chola, and Pandiya, the town changed hands more than once.-Imp. Gaz.

KARWAR or Carwar, a seaport town in the North Canara district of Bombay, lat. $14^{\circ} 50^{\prime}$ N., and long. $74^{\circ} 14^{\prime} \mathrm{E}$., 50 miles south-east of Goa.

KARIVI, a town in the Banda district, N.W. Provinces, lat. $25^{\circ} 12^{\prime} 10^{\prime \prime} \mathrm{N}$., and long. $80^{\circ} 56^{\prime}$ $50^{\prime \prime}$ E., situated on the river Paisuni.

KAS, a term applied to several regions in the $\mathrm{N}$.W. Himalaya. Kas-Mer is not the country of the Kas, but the Kasia Montes (mer) of Ptolemy, the Kha (mer) Kas or Caucasus. Mer is mountain in Sanskrit, as is Koh in Persian. Kas was the race inhabiting these; and Kas-gar is the Kasia Regio of Ptolemy. Gar is a Sanskrit word still in use for a region, as Cutchwaha-gar, Gujurgar, the region of the tortoise race, the country of the Gujar race.

But Kash, Khas, or Kas, a frequently recurring prefix in India, is supposed by Mr. Campbell to have its origin from the rishi Kasyapa, who gave his name to Kashmir, Kashgar, and to the people originally called Kasha or Kassia._Camplell, p. 58: Tod's Rajasthan, i. p. 303.

KAS, TAM.; Kasu, TEL., Karn. ; corruptly Cash. A small copper coin current at Madras up to 1832 ; the $\frac{1}{64}$ th part of a rupee, formerly rated at 80 to a fanam. In Tamil, Kas means money, coin.

KASAI or Cossye, a river of Bengal which rises in the N.W of the Manbhum district, in lat. $23^{\circ} 28^{\prime}$ $30^{\prime \prime} \mathrm{N}$., and long. $85^{\circ} 58^{\prime} 15^{\prime \prime} \mathrm{E}$. It flows a very winding S.E. and E. course, through Manbhum and Midnapur, till it falls into the Haldi in the latter district, about 20 miles above the confluence of that river with the Hoogly.--Imp. Gaz.

KASAULI or Kussowlee, cantonment and convalescent depôt in Simla district, Panjab, situated on the crest of a hill overlooking the Kalka valley; distant from Ambala 45 miles north, from Simla 32 miles south-west. Lat. $30^{\circ} 53^{\prime} 13^{\prime \prime} \mathrm{N}$., and long. $77^{\circ} 0^{\prime} 52^{\prime \prime} \mathrm{E}$. The land was acquired in $18+4$ from the Native State of Bija.

KASBI, also Kasbin. HIND. A daneing girl, a prostitute; literally a professional person.

KASERA. HrND. Workers in mixed metals, braziers, also melters and casters in moulds. There are in Hindustan various divisions of these people, and they have a conventional or tribal dialect peculiar to themselves.-Wilson's Glossary. KASHAN, a city of Persia, still tolerably flourishing, standing in one of the plains, southward of Isfahan, about half-way between Isfahan and Teheran, and also about half-way between Sultaniah and Yezd, long noted for its brocades and velvets, and also for its scorpions. It was founded by Zobeid. It contains a palace by Abbas the Great, a fine college, and upwards of 30,000 inhabitants, who are chiefly employed in the manufacture of copper utensils, or silk and cotton stuffs.-Yule, Cathay, i. p. 51 ; Colonel Chesney, Euphrates and Tiyris, p. 213.

KASHGAR. The city of Kashgar was founded A.D. 1513 by Mirza Abubakr. Kashgar State, in 1877, was estimated by Sir D. Forsyth to have 145,000 houses, with $1,015,000$ inhabitants.

Khotan,. . . 129,500|Kara Shahr, . 56,000 Yarkand, : : 224,000 T'urfan, : 126,000 Yangi Hissar, . : 56,000 Lob, : : : 70,000 Kashgar, : : 112,000 Maralbashi, : : 35,000 Ush Turfan, . 14,000 Sarighkol, . . 17,500 Aksu, . . . 84,000 Kirghiz, . . 21,000 Kucha, : : : 42,000 Pakhpuluk, : 14,000 Kurla, 14,000

Kashgar, also called Eastern Turkestan, is known to the Russians as the Yatti-Shahr or seven cities. Its northern boundary is the Tian Shan mountains, its southern is formed by the Kouen Lun and Karakorum mountains; to the east its limit is the shifting sand of the Gobi desert, and the eastern slopes of the Pamir plateau bound it on the west, the enclosed area being about 1000 miles from north to south and 500 from east to west, covering 243,750 square miles, the greater part of which is uninhabited waste. In 1876 it was under a ruler styled Atalik Ghazi. The Chinese have held it, and called the country north of the Tian Shan mountains Tian-shan-peh-lu, or the way north of the Celestial Mountains, and known to the Mongols as Zanghar, whence the Zangaria of European writers. The country to the south was called Tian-shan-nan-lu, or the way south of the Celestial Mountains, or Kashgar, whence the term Kashgaria. The rivers of the valleys converge to form four main streams, the Khotan, the Yarkand, the Kashgar, and the Aksu rivers, used for purposes of irrigation. They unite and form the Tarim river, to the south of Aksu. The desert is a vast undulating plain of sand, sloping gradually to the eastward, through which the rivers flow. The banks are fringed by thickets, in which lurk the tiger, wolf, leopard, and lynx. Eastward the Tarim river spreads over the surface, forming lagoons and marshes, and again flows in a clear channel until it reaches Lake Lob, on the edge of the Gobi desert. The desert sand has already buried the ancient cities of Lob and Katak. Each little state of Kashgar, Khotan, Yarkand, Yangi Hissar, Kashgar, Ush Turfan, Aksu, Kucha, Kurla, Karashahr, and Turfan has its own peculiarities of dialect and social customs. Chinese Kashgar is one of the district towns in the province of Nan-lu (southern country), and may be said to have enjoyed, ever since the days of the Ptolemies, great repute for caravans, particularly through its extensive tea trade. Kashgar stands in the same relation to Central Asia that Kiakhta does to Siberia, and Shanghai and Canton to other European nations. This town, moreover, is famed in the east for the glowing charms of its 
'chaukens,' young women, with whom the traveller may readily form an alliance for a certain number of years, or for the period of his stay, be it longer or shorter. Owing to these attractions, Kashgar is the resort of Asiatic merchants from all parts of the continent. Here can be met the Tibetan with the Persian, the Hindu with the Volga Tartar, Afghans, Armenians, Jews, gypsies, and runaway Siberian Cossacks.

Kashgar is one of the largest towns of Eastern Turkestan; it contains 16,000 houses, is situated between the rivers Kizyl and Tumen, surrounded by a clay wall six fathoms high, about ten arshines thick at its foundation, and five at the top, and about eight miles (twelve versts) in circumference. It is defended by six towers. The town has two gates, on the eastern and south-western sides; the first is called Suv-Davsa, the second Kum-Davsa (sandy).

Appak-Hodja was much esteemed by the people; the high reputation of the teacher and saint attracted to Kashgar the Musalman youth of the east, who were eager to follow his footsteps in the path of sanctity; and many rulers of Manero-Innahar even were numbered among his scholars. His tomb at Kashgar to this day attracts many pilgrims from various Musalman countries ; and the Eastern Turkestani, who regard him as their own peculiar patron, call upon his name in moments of peril.

Galdan conquered Little Bokhara in 1678, and appointed Appak his viceroy, with Yarkand for his capital. The family of the Kashgar Khan was carried by Galdan into captivity in the Ili region, and settled in the Musalman town of Kuldja.Russians in Central Asia, Capt. Valikhanof and M. Vemukof, pp. 51, 149, 168; Bellew.

KASHGOI, a Turki nomade tribe of about 12,000 families, whose chief is the Il-Khani of Fars, one of the most influential personages in that province. They arrive in spring on the grazing of Isfahan, where they are met by the wandering Bakhtiari, from their warm pastures of Arabistan, near the head of the Persian Gulf. At the approach of winter both the tribes return to their respective garm-sair or wintering lands.

KASHGUL-i-ALI, or Ali's Pot, a sacred Buddhist relic, the water-pot of Fo or Buddha. It was carried to Kandahar by the tribes who fled in the 4th century from Gandhara on the Indus, to escape an invasion of the $\mathrm{Y} u$-chi, who made an irruption from Chinese Tartary for the express purpose of obtaining it. It is now at the foot of the old town of Kandahar, and is one of the most celebrated relics of antiquity belonging to the eastern world, and still retains amongst the Muhammadans of Kandahar a sacred and miraculous character. It is formed of stone, and may contain about twenty gallons. It is under a tree at the tomb of Mir Wais. The capacity of the bowl is 15 cubic feet, or about 93 gallons, and its weight $(10$ c.f. $\times 170$ lbs.) about 15 cwt. Its lip has 24 facets, each about 7 inches wide. In 1879 Major le Messurier (p. 241) moved the bowl out from the tree, and raised it on stones. See Kandahar.

KASHIFI, Husain-bin-Ali-ul-Vaiz, surnamed Kashifi. He translated the fables of Bedpai into Persian prose from the Arabic of Ibn Makaffa, and named them Anwar-i-Sohaili, or Lights of Canopus. Kashifi lived about the middle of the 12th century (1150), in the time of Bahram Shah.

KASHMIR, a Native State in political connection with the Government of India. It extends from lat. $32^{\circ} 17^{\prime}$ to $36^{\circ} 58^{\prime} \mathrm{N}$., and long. $73^{\circ} 26^{\prime}$ to $80^{\circ} 30^{\prime}$ E. Area, 79,784 square miles; population in 1881, about 1,500,000. The State comprises, in addition to the districts of Kashmir proper, Jamu and Punch, the governorships of Ladakh and Gilgit, including the districts of Dardistan, Baltistan, Jeh, Talail, Sura, Zanskar, Rupshu, and others; but the provinces of Kashmir and Jamu form the more important part of the State. The valley of Kashmir is traversed in its whole length by the river Jhelum, which rises at the east end of the valley, and winds from one side of the plain to the other, at one time washing the base of the northern hills, at another receding to a considerable distance from them. The Jhelum flows with a tranquil stream, and being, for boats of considerable burden, navigable thronghout the whole of the level country as far up as Islamabad, is the great highway for the traffic of the country. From all times the valley has been the retreat from the heats of India for the conquering races. Its oldest record is contained in the Raja Taringini, composed in A.D. 1125, giving a historical account from B.C. 1182, and describing the draining of the valley through an opening in the Baramoola mountain. A Kaurava or Naga dynasty seems to have ruled there for about 1266 years, with one of whom, Gonerda, authentic history commences. It was annexed to the Moghul empire under Akbar in A.D. 1586. It has since been ruled over by chiefs of the Daurani and Barakzai tribes of Afghans, but was taken in 1819 by Ranjit Singh of Lahore; and on the 15th March 1846, Gulab Singh, ruler of Jamu, a Dogra Rajput, was invested at Amritsar with the title of maharaja of Kashmir.

The ancient rulers have been the Kashmir Kaurava dynasty, 1266 years, B.C. 3714 to B.C. 1217 ; Gonerdiya dynasty, 1013 years, B.C. 318 to B.C. 28; Aditya dynasty, 192 years, B.C. 10 to A.D. 135 ; Gonerdiya dynasty, 592 or 433 years ; Naga, 260 years 5 months, A.D. 594 to 1296 .

The principal ancient cities of Kashmir are the old capital of Srinagari, the new capital called Pravarasenapura; Khagendrapura and Khunamusha, built before the time of Asoka; Vijipara and Pantasok, which are referred to Asoka himself; Surapura, a restoration of the ancient Kambuva; Kanishkapura, Husbkapura, and Jushkapura, named after the three Indo-Scythian princes by whom they were founded; Paribasapura, built by Lalitaditya; Padmapura, named after Padma, the minister of Raja Vrihaspati; and Avantipura, named after Raja Avantiverma.

The Kashmir temples are Marttand, Avantipore, Payech, Bhaniyar, and Waniyat. Marttand, 60 feet by 38 feet, is now in ruins. It is 5 miles east of Islamabad, and is built on an elevated plateau that overlooks the valley. Its exact date cannot be determined, but it is somewhere between the years 370 and $500 \mathrm{A.D}$. It overlooks the finest view in Kashmir. Its enclosing courtyard is 220 feet by 142 feet. The enclosure was erected by Lalitaditya, who reigned A.D. 725 to 761 . General Cunningham, however, thinks that the temple was erected by Ranaditya, who reigned A.D. 578 to 594 . The courtyard of this, and of 
all the Kashmir temples, was constructed to admit of it being filled with water. The principal Naga figures in the niches have three or five headed snake-hoods at the back of their heads. The Avantipore temples were erected by Avantiverma, who was the first king of the Utpala dynasty, and reigned from A.D. 875 to 904 . He was a zealous Saiva. The style is rich in detail.

The Kashmirian sacred buildings are distinguished by great elegance of outline, massive boldness in the parts, and good taste in decoration. Lofty pyramidal roofs, trefoiled doorways covered by pyramidal pediments, and great width of intercolumniation, are among the principal features of the Kashmirian temple. The material generally found to have been used is a blue limestone, capabie of taking the highest nolish, to which circumstance Captain Cunningham refers the beautiful state of preservation in which some of the buildings exist.

The body of Srinuggur, the former capital, is intersected with a labyrinth of canals. To avoid the necessity of crossing the dangerous Wular lake, through which flows the main stream of the Jhelum, a navigable canal was constructed in early times to connect Sopur with Srinuggur.

The Dal or city lake is situated north-east of Srinuggur, and is connected with the Jhelum by a canal called the Tsont-i-kul, or Apple-tree Canal, which enters it opposite the palace. The Anchar is situated to the north of Srinuggur. It is connected with the Dal by means of the Nalli Mar, which flows into the Sind river near Shadipur. The Manasbal, said to be the most beautiful lake in Kashmir, is situated near the right bank of the Jhelum, and is $1 \frac{1}{2}$ miles long, $\frac{3}{4}$ of a mile wide, and very deep. But the Wular is the largest of all the Kashmir lakes. Its extreme breadth from north to south is $1 \frac{1}{2}$ miles, exclusive of the marches on the south side; extreme breadth, 10 miles ; circumference, nearly 30 miles; average depth, 12 feet ; deepest part, about 16 feet. The Jhelum flows into the Wular on its east side, near the middle of the lake, leaving it at its south-west corner in a fine open stream about 200 yards wide.

The valley is singularly free from any modern intermixture of foreign races, and, though now professing Muhammadanism, the features of the Kashmir people proclaim them to be one of the highest and purest races in the world. They are of quite high Aryan type, very fair, handsome, with chiselled features, and is strong, athletic figure, but none of them are of martial proclivities.

The Kashmir people, though long since converted to Muhammadanism, have been of the Brahmanical race. The educated class, who maintained their own tenets, and are still very numerous, are known as pandits. They are exceedingly clever, and are a somewhat oppressive bureaucracy, which has ruled Kashmir under every successive Government, and has sent out colonies to seek their livelihood in Northern India.

The industry and mechanical skill of the stoutlimbed prolific Kashmiri are as well known as their poverty, their tameness of spirit, and their loose morality. The few unmixed Rajputs possess the personal courage and the pride of race which distinguish them elsewhere.

The languages of Kashmir are divided into 13 separate dialects. Of these, Dogri and Chibhali, which do not differ much from Hindustani and Panjabi, are spoken in the hills and country of the Punch and Jamu districts. Kashmiri is mostly used in Kashmir proper, and is rather curiously and closely related to the Sanskrit. It is not, however, the court language, and for the purposes of a traveller through Kashmir either Hindustani or Panjabi will serve. Five dialects are included under the term 'Pahari,' a language spoken by the mountaineers in the east of Kashmir. Besides these, there are two dialects of Tibetan, which are spoken in Baltistan, Ladakh, and Champas; and in the north-west three or four varieties of the Dard dialects of Aryan origin.

The Kashmir Brahmans eat meat, and are excluded by the Indian Brahmans, alike from the five Gaur and from the five Dravid, and form a separate Brahmanical class, being more secular than the priestly Brahmans of Hindustan and the Dekhan, than whom they are altogether loose in their observances. The Kashmiri pandits are known all over Northern India as a very clever and energetic race of office-seekers: as a body they excel in acuteness the same number of any other race with whom they come in contact. Almost all the secular pandits use the Persian character freely; they are perfectly versatile, and, serving abroad, will mount a horse, gird on a sword, and assume at a push a semi-military air. The lower classes of Kashmir have long since been converted to Muhammadanism, but they seem to be ethnologically identical with the Brahmans, and tradition asserts that they are of the same race. The Brahmans of Kashmir are regarded by those of Bengal as of an inferior order, and the agricultural Brahmans on the Saraswati banks are similarly looked down upon.

Probably owing to the circumstance that the valley has so often been the resort of pleasureseekers, the morals of the people are not at a high standard. A satirical Persian couplet runs-

'Dar jahan ast do taifah be pir Sunni-i-Balkh, Shiah-i-Kashmir.'

which may be rendered that there is not an honest man among the Sunni of Balkh or the Shiah of Kashmir.

From Kashmir eastwards, all the easily accessible portions of the Himalaya are occupied by Aryan Hindus, as far as the eastern border of Kamaon and the Kali river separating Kamaon from Nepal,- the Tibetans being here confined to the valleys about and beyond the snow. People of Tibetan blood have migrated into Nepal, throughout its whole length, and have formed mixed tribes whose appearance and language is more Tibetan than Indian, but whose religion and manners are Hindu. East of Nepal, in Sikkim and Bhutan, the Hindu element almost disappears, and the Tibetans are altogether domiuant.

The hills westward from Kashmir to the Indus are inhabited by Kukka and Bumba, but towards the river itself the Yusufzai and other Afghan tribes prevail; while there are many secluded valleys peopled by the widely-spread Gujar, whose history has yet to be ascertained, and who are the vassals of Arabian syuds, or of Afghan and Turkoman lords.

In the hills south of Kashmir, and west of the Jhelum to Attock and Kalabagh on the Indus, are found Gakkar, Gujar, Khatir, Awan, Janjuh, 
and others, all of whom may be considered to have, from time to time, merged into the Hindu stock in language and feelings. Of these, some, as the Jaujub, and especially the Gakkar, have a local reputation.

Eastward of Kashmir are the Bhot race in Balti and Ladakh. Balti includes Hasora, Rongdo, Rong-yul, Shagar, Iskardo, Bulti, Paykuta, Tolti, Khartaksho, Kiris, Khaybalu, and Chorbat. Ladakh, inhabited by the Bhot-pa, includes Spiti, Zanskar, Purik, Suru, Hembako (Dras), Ladakh proper or Leh, Nubra, Rong, Rupshu, and Hanle. Garhwal is to a large extent Bhot. The language of the Bhutiahs of Tibet is also that of Bhutan, and is a connecting link between the polysyllabic and monosyllabic tongues.

In the valley of the Upper Indus, that is in Ladakh and Little Tibet, the prevailing race is the Bhot subdivision of the great Tartar variety of the human race. Lower down that classical stream, in Gilgit and Chulas, the remains of the old and secluded Dardu and Dungher races are still to be found; but both in Iskardo and in Gilgit itself there is some mixture of Turkoman tribes from the wilds of Pamir and Kashgar. Generally it may be observed that on the north, the Afghan on one side, and the Turkoman on the other, are gradually pressing upon the old but less energetic Dardu. The best and most recent notice of the tribes is the following, given by Mr. Drew in his Northern Barrier.

Dogra.-The maharaja of Kashmir is a Dogra. The Dogra or Dugar race dwell chiefly among the hills surrounding Jamu, 1200 feet above the sea. They are not met with in approaching Kashmir from the Panjab, and extend for about 150 miles, from the river Ravi on the east to the Jhelum on the west, and about 14 miles in depth, from the Daman-i-Koh or skirt of the mountain. The other inhabitants are the Hindu Pahari, the Mubammadan Chibhali, Kashmiri, and Dard, and the Buddhist of Balti, Ladakh, and Champa. The Dogra castes are Brahman, Mian Rajput, Working Rajput, Khatri, Thakur, Jat, Banya, and Karar, small shopkeepers, Nai or barber, Juir or carriers, the Dhiyar, the Megh, and the Dom.

The Rajputs are the ruling race, average about 5) feet 4 inches or 5 feet 5 inches, of slim make, with high shoulders, curionsly bow-legged, with turn-in toes; they are not muscular, but are active and untiring. They are of a light-brown colour, small features, nose generally hooked. Their character is simple and childlike, tractable, but very particular in caste observances, avaricious, and close-fisted. The Mian Rajput in particular is overbearing, proud, and conceited, and become spoiled by advancement. They do not learn any trade, and to put their hand to the plough would be deened a disgrace, so they employ others to cultivate their bits of land. They take to military service, and are expert swordsmen. Many of the Working Rajputs also follow arms as a profession, but they have a low social status. The Rajput clans are Chib, Jaral, Pal, etc.

The Bralmans are numerous as cultivators; they are in all employments.

The Kashmiri are false-tongued, ready with a lie, and given to deceit; they are noisy and quarrelsome, ready to wrangle, but not to fight; on the least exercise or threat of force they cry like children. They are talkative, cheerful, and humorous.

The Muhammadan Manij or boatmen are numerous; they are greedy and cowardly, but have good spirits, an active imagination, are energetic and versatile.

The Wattal of Kashmir are a gypsy tribe which supplies dancing girls and prostitutes; the women are among the handsomest of the valley.

The Guluwan of Kashmir are horse-grazers.

The Bamba dwell along with the Kukka in the rugged hill frontier beyond the Jhelum. They are of Brahmanical origin, but profess Muhammadanism. And, on the eastern side of the Jhelum, the hills are shared by other races, and by a numerous body of Sikhs, converts from Brahmans prior to the Sikh religion becoming a political power. They are useful soldiers and servants.

The Khatri are the higher class of traders.

The Thakur of Jamu are the chief cultivating class. They correspond in their avocations to the Jat of the Panjab, though not related; they are a well-made race, of larger frame than the Rajputs.

The Banya, Karar, and Nai or barber pursue their usual avocations; the Juir are water-carriers, like the Kahar race of the N.W. Provinces.

The Dom and $M e g h$ are numerous in Jamu, and are employed as sweepers, brickmakers, and charcoal burners. They are small limbed, short in stature, and of a dark colour.

The Chibhali, people of Chibhal, the region lying between the Chenab and Jhelum rivers, are converted Dogra, The Chibh tribe lying south of Kashmir have been but little reclaimed from barbarism.

The Jat is numerous in Chibhal, and is Muhammadanized.

The Sudan take a ligh place among the Muhammadans, and with others have the title of Sahu.

The Gakkir are numerous on the right bank of the Jhelum. Those of Rawal Pindi compose the gentry of the hill country in that neighbourhood.

The Pahari are a strong, hardy, and active race, of good, powerful frame; they have a straight forehead, good brow, with a nose markedly hooked. Their dress consists of a long or short coat, fastened by a kamrband or waistband; trousers (paijama) loose to the knee. fitting close to the leg below. The Dom and Megh are mixed among them. Many different dialects are current in the region occupied by the Pahari.

The Gaddi race in Jamu resemble the Pahari in physical form. Their head-dress is a hat of peculiar form.

The Bätal. of Kashmir do all the dirtiest work, remove and skin dead cattle, and make leather. The better circumstanced follow Muhammadans in their rules as to food; the poorer eat carrion, are musicians, and the dancing girls of Srinuggur are of the Bätal race.

The Dard are mostly Muhammadan, but some of them between Iskardo and Leh are Buddhist, and are very dirty people. At Rondu, the Dard and Balti are nearly equal, but at Dras the Dard preponderate. The Bhot designate the Dard Brokpa. Dard are a bold and independent race; they resist oppression; though not caring much for 
human life, they are not bloodthirsty. They dress in woollen garments. They have several races or tribes, the Ronu, Shin, Yashkun, Kremin, and Dom. The Dom are musicians, like the Dom of the N.W. Provinces, the Mirasi of the Panjab, the Bem of Ladakb, and Batal of Kashmir. The Kremin are carriers, potters, millers. The Yashkun are agricultural. The Shin occur mixed with the Yashkun along the Indus valley; they hold the cow in abhorrence, they do not use cow's milk, nor make or eat butter from it. They will not use cow-dung for fuel; they keep cattle for ploughing, but have as little as possible to do with them.

Ladakh is occupied by the Ladakhi or Bbot-pa and the Cham-pa. The Ladakhi has the features of the Mongoloid races; the outer corners of their eyes are drawn out, and the upper eyelids are hung by a fold of the skin above, the nose seems pressed into the face; the mouth large and inexpressive. The men average 5 feet 2 inches, and the women 4 feet $9 \frac{1}{4}$ inches. They are an ugly race ; they are cheerful, willing, and good tempered, but simple and clumsy, slow, inapt, and truthful. The choga and a cap and boots and gaiters are the sole articles of men's apparel; the women wear a gown. They are Buddhists.

$B e m$ is the name of the servile races of Ladakh.

Champa are nomades, and inhabit the higher country. They are found in the valley of the Indus above the villages, and in the plains or flatbottomed valleys of Rupsbu, and a few outlying places. In personal appearance and dress they do not differ from the Ladakhi. They are a cheerful, hardy race. They live in tents, occupying a spot for a month or two, and move to fresh pastures.

The Chanpan Pal or Pahal of Kashmir are shepherds who tend the flocks of other people.

The Ladakhi are all engaged in agriculture. A loose-grained barley is their most common cereal; it is cultivated up to 15,000 feet, and at 13,700 and 14,000 are villages depending on its cultivation. Wheat is grown up to 12,800 feet. Barley-meal is the common food, and chang, a light beer, is their national drink. Their women share in the work of agriculture. Polyandry, except among the few richer people, is quite general. The elder brother's wife is common to all the brothers, and the children recognise all as father. The woman may also choose another husband from a different family.

The Kham-ba of the Kham country, far to the east of Lbassa, are found in the districts of Zanskar and Rupshu. They are professional beggars; along with their wives and children they wander about some parts of India in the cold months, and to the higher parts of Ladakh in summer; live in small tents, which they carry ou goats.

Earthquakes are of not uncommon occurrence. In June 1828, the city of Srinuggur was shaken by an earthquake, which destroyed about 1200 houses and 1000 persons. For more than two months afterwards, lesser shocks were daily experienced.

The deodar is abundant, and is extensively employed in the construction of houses, temples, and bridges. The forests also contain Pinus longifolia and P. excelsa, Abies Webbiana, walnut (the quality of the wood for gun-stocks and furniture being little inferior to that of Britain), maple, poplar, willow, yew, and a species of juniper.
The oriental plane or Chunar (Platanus orientalis) is probably found nowhere more abundant or luxuriant than in Kashmir, though it is not indigenous. The absence of oaks, rhododendron, Andromeda, and Pinus Gerardina is remarkable. By order of the Moghul emperors, a grove of chunar and poplar was planted near every Kashmirian village; these were protected by a heavy fine on every tree felled, but the Sikhs destroyed many of them. Fruit of all kinds abounds in Kashmir. There are four varieties of walnut, one of which grows wild in the forest, and the others are cultivated. The former is very tiny, and the scanty keruel is encased in a thick shell. One of the horticultural species is very much superior to the others; it is called Kaghuzee (from Kaghuz, paper), because the shell is as thin as paper, and can easily be broken by the hand. The superiority of this species is attributed to its having been originally engrafted, but though now raised from seed, it does not become deteriorated. The Kashmirian use the walnut as a dye for black and green colours; the former, from the ripe fruit, is a fast or permanent dye, and the latter is furnished from the walnuts which fall to the ground while they are still green. The latter colour is not permanent. From the kernel an oil is extracted, which is used, not only for burning in lamps, but also for culinary purposes. It is said also to be made the medium for extracting the perfume of the jasmine, the yellow rose, and the narcissus.

In Kashmir are two eminences which bear the name of Takht-i-Suliman; one near Kashmir is called Sir-i-Sheo, or Siva's head, by the Hindus, but also Sankarachar; and the hill on the opposite side of the city is called Hari Purbat, or the hill of Vishnu or Hari. On the latter hill is the fort of Kashmir.

Kashmir has been famed for its woven shawls, also for its painted ware (manakkash), and its embroidery (chikand).

Kashmir yields gold, iron, coal, storax, antimony, borax, sal-ammoniac, sulphur, talc, marble, manganese, rock crystal.-Cunningham's Ancient Geography of India; Captain Knight's Diary of a Pedestrian in Kashmir and Tibet: Drev's Northern Barrier; Raja Taringini; Calcutta Revieu, 1871; Prinsep's Antiquities; Mr. (Sir George) Campbell; Sir R. Montgomery's Report; Kennell's Memoir; Dr. Thomson's Trs.; Asiatic Researches; Vigne's Trs.; Wilson's Glossary; Baron Hugel's Trs.; Imp. Gaz.

KASHMIR GHAR, a cave situated in the territory of the Baboozai, on a mountain which cannot be ascended but by a steep passage, hewn in a great measure out of the rock. This place is also called Pelley, and is $16 \mathrm{cos}$ from the town of Soukhor.

KASI. HIND. An encaustic tiling-work seen on old buildings.

KASI, the earliest name of Benares, and still in common use, either alone or joined with the later name, as Kasi-Banaras. It is, perbaps, the Kassida or Kassidia of Ptolemy. The name is referred to Kasi-raja, who was one of the early progenitors of the Lunar race. He was succeeded by twenty descendants, all rajas of Kasi, amongst whom was the celebrated Divodäsa.-Cunningham, Ancient Geog. of India, p. 438.

KASIA or Khasiya, a race occupying the hills $\mathrm{S}$ of the valley of the Brahmaputra, in lat. $25^{\circ} 20^{\prime}$ to 28 
$7^{\prime} \mathrm{N}$., long. $90^{\circ} 52^{\prime}$ to $92^{\circ} 11^{\prime} \mathrm{E}$, between Cherrapunji and the Shillong mountain. The Kasia are the ablest bodied of the borderers of Assam, and differ very little from the Garo. They are arranged in petty rajaships. Nat-worship seems the cult of the Kasia. They dread suakes. They 'build their houses on piles. They trap fish. They distil and drink intoxicating liquors, and between Ringhot and Cherra, and in other places, they have bridges of the fibres of the india-rubber tree. The Kasia is distinguished from all the surrounding languages-Indian, Ultra-Indian, and Tibetan -by its direct and prepositional ideology. It is a fragment of the Mon Kambojan formation of languages, and is a remnant of an older formation which preceded the Burma-Tibetan in Northern Ultra-India.

They have the Mongolian type of features in the lighest development. Colonel Yule mentions that porters of the Kasia nation used often to carry down from the coal mines of Cherrapunji to the plains, a distance of 11 miles, loads of two maunds or $165 \mathrm{lbs}$. of coals. Their strength and bulk of leg were such as he had never seen elsewhere. In the upper parts of the Kasia country, monumental stones are scattered on every wayside. These are of several kinds, but the most common is composed of erect oblong pillars, sometimes almost quite unhewn, in other instances carefully squared and planted a few feet apart. The number composing one monument is never under three, and runs as high as thirteen; generally it is odd, but not always so. The highest pillar is in the middle (sometimes crowned with a circular dish), and to right and left they gradually diminish. In front of these is what English antiquaries call a cromlech, a large flat stone resting on short rough pillars. These form the ordinary roadside restingplace of the weary traveller. The blocks are sometimes of great size. The tallest of a thick cluster of pillars in the market-place of Murteng in the Jaintia country, rising through the branches of a huge old tree, measured 27 feet in height above the ground. A flat table-stone or cromlech, near the village of Sailankot, elevated 5 feet from the earth, measured 32 feet by 15 , and 2 feet in thickness. In other instances the monument is a square sarcophagus, composed of four large slabs, resting on their edges and well fitted together, and roofed in by a fifth placed horizontally. In Bell's Circassia may be seen a drawing of an ancient monument existing in that country, which is an exact representation of a thousand such in the Khassya Hills, and nearly as exactly a description of them, though referring to relics on the eastern bank of Jordan, may be read in Irby and Mangles' Syrian Travels. The sarcophagus is often found in the form of a large slab accurately circular, resting on the heads of many little rough pillars close planted together, through whose chinks you may descry certain earthen pots, containing the ashes of the family. Belonging to the village of Ringhot, in the valley of Mausmai, deep in the forest, is a great collection of such circular cineraries, so close that one may step from slab to slab for many yards. Rarely may be seen a simple cairn or a pyramid some 20 feet in height, and sometimes one formed in diminishing stories, like the common notion of the tower of Babel, or like the pyramid of Saccara in Egypt. But the last is probably rather a burning place than a monument, or at least a combination of the two. The upright pillars are merely cenotaphs, and if the Kasia be asked why their fathers went to such expense in erecting them, the invariable answer is, 'To preserve their name.' Yet to few indeed among the thousands can they attach any name. Many of the villages, however, seem to derive their appellations from such erections, as may be seen from the number commencing with mau, which siguifies a stone; e.g. mausmai, the stone of the oath ; mau-mlu, the stone of salt ; mau-flong, the grassy stone; and others. Mausmai, the oath stone, suggests that these pillars were also erected in memory of notable compacts. On asking Umauz the origin of the names, his answer was a striking illustration of many passages in the Old Testament: 'There was war,' said he, 'between Cherra and Mausmai, and when they made peace and swore to it, they erected a stone as a witness (Sakhi ke wasté was his expression). Genesis xxxi. 45 : 'And Jacob took a stone, and set it up for a pillar.' Genesis xxxi. 47 : 'And Laban called it Jegarsahadutha: but Jacob called it Galeed' (both signifying the heap of witness). Genesis xxxi. 51,52 : 'And Laban said to Jacob, Behold this heap, and behold this pillar, which I have cast betwixt me and thee; this heap is a witness, and this pillar is a witness, that I will not pass over this heap to thee, and that thou shalt not pass over this heap and this pillar to me, to do me harm,' etc. See also Joshua xxiv. 26. The name of maumlu, the salt stone, is probably of kindred meaning, as the act of eating salt from a sword-point is said to be the Kasia form of adjuration. These large stones are also frequently formed into picturesque bridges for the passage of brooks. There is at Murteng a bridge of this kind, consisting of one stone, 30 feet in length. It is stated by Pemberton that Kai is the real name of the people, and Kasia the title bestowed on them by the Bengali. But Kasi is the only name which they acknowledge as that of their country and race. - Latham; Journal of the Indian Archipelago, 1853; Yule, Cathay, do. Embassy; Journ. of Beng. As. Soc.; Postans' Personal Observations, p. 15.

KASIBEK. The natives in this neighbourhood are of the Ossi tribe, a people of mixed persuasions, Christian, Muhammadan, and pagan. The village of Kasibek, as well as a few others in its immediate vicinity, are inhabited by Christians professing the same faith and observances as the Georgians.Porter's Travels, i. p. 77.

KASIM, an Arab general who invaded Sind during the reign of Dahir, raja of Sind. He was nephew of Walid, the sixth khalif of the house of Ommaya. He conquered Sind about A.D. 711, and sent two of the princesses to Walid. But, on being presented to $\mathrm{W}$ alid, the elder burst into tears, and declared she was now unworthy of his notice, having been dishonoured by his nephew before being sent from Sind. The khalif in his anger ordered Kasim to be sewn up in a raw hide, and sent to Damasous; but when he produced the body to the princess, she was so overjoyed at the sight that she exultingly declared Kasin to have been innocent, but that she had now avenged her father's death and the ruin of her family. The two princesses met with a cruel death.-Brigg's Ferishta; Pottinger's Travels.

KASIMBAZAR or Cossimbazar, a decayed town in Murshidabad district, Bengal. Lat. $24^{\circ} 7^{\prime} 40^{\prime \prime}$ 
N., long. $88^{\circ} 19^{\prime} \mathrm{E}$. Formerly the great silk mart of Bengal, is now three miles from the river, and a wilderness. The Dutch, the French, and the English all had factories here in the 18th century. -Tr. of Hind. i. p. 69.

KASINA. Amongst the Buddhists of Ceylon, an ascetic rite, practised to free the mind from all agitation. Kasina mandala is the circle used in the performance of kasina. By its performance it is supposed a miraculous energy may be received. There are ten descriptions of this rite, viz. :-

Prithavi, earth.

Apo, water.

Tejo, fire.

Vayu, wind.

For each of these forms there are various ceremonies.-Hardy's Eastern Monachism, p. 437.

KASINAGARA, the town near which Buddha died under a great sal tree.

KASI RAI wrote an account of the battle of Paniput, between the Daurani Afghans, confederate Muhammadans, and the Mahrattas under Sedasheo Rao Bhao. It was published in the Asiatic Researches, iii. p. 97. He was in the employ of Shuja-ud-Dowla, viceroy of Oudh, and was the agent in the attempts made before the battle to compromise the affairs.

KASIS and Kahi. HiND. Earths containing anhydrous protosulphate of iron in white satin-like crystals, and in the form of a sesqui-sulphate. They are obtained from bituminous shales, and are found extensively mixed with the alum shales at Kalabagh and at Pind Dadan Khan; they form a considerable article of internal trade, being much used for dyeing purposes, and in medicine as a styptic and astringent.-Pouell's Handbook.

KASKAS. HIND, Andropogon muricatum. The fibrous roots are made into tatties, which yield an agreeable perfume.

KASR. Arab, A palace. Pl. Kasūr. Madinatul-Kasur, the town of Luxor, the ancient Thebes. It is now a small village.

KASR or Al-Kasar, a mound of ruins in the vicinity of Baghdad. This mound of ancient. Babylon is supposed to belong to the hanging gardens which were on its western side. There are still to be seen beautiful tiers and buttresses. In one of the corners is a rough stone lion standing over the figure of a man. The mound is irregular in shape, about 700 yarrs in length and breadth, and in some places about 70 feet above the plain. The ruin, called by the Arabs Al-Kasr, is much smaller than the Majallibah, but is nearly similar in character. The tower of Nimrud is visible from the spot. Here is supposed to have been the site of Ctesiphon, and on the opposite shore are similar heaps where Seleucia stood. Tak-ul-Kesta, or the Arch of Chosroes, possesses no remains of extraordinary taste or ornament, but, in the name it bears, speaks of splendour and of power, now eclipsed by a simple tomb standing close to it, to which thousands flock in honour of the memory of a barber. A mile to the north of the Kasr, or full five miles distant from Hilla, and 950 yards from the river bank, is the ruin, which was described by Pietro della Valle, who determined it to have been the tower of Belus, an opinion adopted by Remell. The natives call it Majallibah or Mujalibe, meaning overturned.-Jackson, Journey from India towards England; Ouseley's Travels; Skinner's Overland
Journey; Mignon's Travels; Rich's Ruins of Babylon; Ptolemy.

KASRA-i-SHIRIN, a small village of twentyeight houses, with a caravansarai-shahi in good condition. It is situated on the side of a mountain, at the foot of which flows the Dialla. General Ferrier hazards the opinion that the ruins of Kasra-i-Shirin might be those of the city of Oppidam, which is placed by ancient authors in the Zagros mountains, between Opis and Ecbatana, and was founded by a colony of Bceotians, who followed Xerxes into Persia.

KASRANI are the most northern of the Baluch tribes on the British frontier. Their hills extend from the Korah pass downwards for a distance of about 50 miles; about half the tribe own lands and villages in the plain, a portion lead a wandering life in the front range of hills nearest the plain and the balf desert tract at its base, and the remainder live in the hills. They have 22 sections in Dehra Ghazi Khan district, of which 12 are in the hills. They are about 3000 strong.

The hill Kasrani can muster some 1200 fighting men, of whom 50 are horsemen. They are very thievish, and were in the habit of proceedin: through the lands of their brethren in the plain to plunder in the villages near Dehra Ismail Khan. The country round Dehra Futteh Khain was also harassed by them.

KASSAR, a Muhammadan tribe in the Rawal Pindi division, N. of the Salt Range. They are good cultivators.

KASSID. Hind, Pers. A mounted messenger ; written Cossid.

KASTHANE. SINGH. A. sword worn on state occasions.

KASTIRA. SANSK. Tiu. It is this word that gave to the British Isles their earliest name, the Kassiterides.

KASUMBO. MAHR. An infusion of opium and water, much drunk in Kattyawar.

KASVIN, an ancient Persian town, the capital of the country previous to Abbas the Great. It has many schools. It is also written Kazvin.

KASVINI, the literary name of Kakaria-binMubammad - bin - Mahmud - ul - Kousi - ul -Kazvini. He wrote in Arabic the Ajaib-ul-Makhluqat, or The Wonders of Creation; it treats of natural history, of the qualities of animals, vegetables, and minerals, as also of waters, aerial spirits, fairies, genii, and talismans, but all with a view to confute the Jewish rabbis. His book is much esteemed by Muhammadans, and has been translated into Turkish and Persian. He wrote also the Ghrāib-ul-Maujudat, the Asar-ul-Balad, and Akbbar-ul-Balad.-Hist. of Genghiz Can, p. 418.

KASVINI, author of the Labbu-t-Tawarikh, is the name given to Yabya-bin-Abdul Latif, surnamed Kazvini, because born in Kazvin. He was eminent as a theologian and philosopher. In his early career, he was patronized by Shah Tahmasp Saffavi, but his enemies subsequently. induced the king to give orders to imprison bius and his son Mir Abdul Latif at Isfahan. Kazvini was imprisoned, but died after a year and nime months, A.H. 962 (A.D. 1554-55), at the age of 77. His second son, Ala-ud-Dowla, known by the title of Kami, and the author of the Nafaisul-Maasir, had given information to his father and to the son Mir Abdul Latif, and the latter 
fled to Gilan and on to India, where Akbar had ascended the throne, and became Akbar's teacher. He died at Sikri A.H. 971. The eldest son of Mir Abdul Latif was Mir Ghiyas-ud-Din Ali, who continued in the service of Akbar and Jahangir, and (A.H. 1023) died at Ajmir, and was buried in a marble tomb within the area of Muin-ud-Din Chishti's mausoleum.-Elliot, iv.

KASYAPA, a Hindu philosopher moticed in the Mahabharata, the Sri Bhagavata, and the Padma Puraua. He was born at Kedara at the foot of the Himalaya. He taught that God is everlasting. He wrote a law treatise.-Ward, iv. p. 34.

KASYAPA, according to the Mahabharata, the Ramayana, and the Puranas, son of Marichi, son of Brahma, was one of the prajapati or progenitors of created things. He married thirteen of the daughters of Daksha, from whom descended the twelve Aditya or sun-gods by Aditi; the Daitya or Titans by Diti and the Dhanava; many classes of animals, etc. His son Vivasvat was father of Menu. Hence this family of men became known as the race of Menu, from whom Brahmans, Kshatriyas, and other men sprang. His eldest son, the Daitya named Hiranya - Kasipu, is famous throughout India for his denial of the omnipresence of Vishnu, which led to the manifestation of the Narasingha or 'man-lion' avatar. He was followed by his still more famous son Prahlada, the ardent worshipper of Vishnu, after whom Multan city was named Prahladapura. His great-grandson Bana, commonly called Bana the Asur, was the unsuccessful antagonist of Krishna, who took possession of the kingdom of Multan. Here Samba, the son of Krishna, established himself in the grove of Mitra-vana, and by assiduous devotion to Mitra or the sun, was cured of his leprosy. He then erected a golden statue of Mitra in a temple named Adyasthana, or the first shrine; and the worship of the sun thus begun by Samba has continued at Multan down to the present day.-Cunningham, Ancient Geog. of India, p. 232.

KASYAPURA, the modern Multan. According to the traditions of the people, Kasyapa-pura, the Kasperira of Ptolemy, was founded by Kasyapa, who was the father of the twelve Adityas or sun-gods by Aditi, and of the Daityas or Titans by Diti.

KAT. ARAB, A reef; pronounced Gad.

KATAI. Hind. A steel punch, used in perforating a wire-drawer's plate.

KATAI. MAHR. A caste or individual of it, worlkers in leather.

KATAIA. HIND. Four plants have this as a terminal name,-the Bhat-kataia is used in veterinary practice; the Bang-kataia is not used; but the Gol-kataia is used in native medicine.

KATAM. MALEAL. A league of four nariga, equal to 5 to 6 miles English.

KATAPANG. MALAX. A black dye is produced from the rinds of the mangostin fruit, and of the Katapang or Terminalia catappa, with sulphate of iron.

KATAR. HIND, A triangular, heavy-bladed dagger, with a peculiar steel handle.

KATAR. PERs., Turk. A string, a train of beasts of burden; from six to ten camels tied one behind the other. The English cxpression, ' $n$ string of camels,' best expresses the sense of the word.
KATAS, a holy fountain in the Jhelum district of the Panjab, and, after Kuru-kshetra and Jawala Mukhi, it is the most frequented place of Hindu pilgrimage in the province. Lat. $32^{\circ} 43^{\prime} 30^{\prime \prime}$ N., and long. $72^{\circ} 59^{\prime} 30^{\prime \prime}$ E. Siva, being inconsolably grieved for the loss of his wife Sati, the daughter of Daksha, rained tears from his eyes, and so produced the two sacred pools of Pushkara, near Ajmir, and Kataksha or Katas in the Sind Sagar Doab. The pool is partly artificial, being formed by the enlargement of a natural basin in the bed of the Ganiya Nala. Below these remains, an enclosure contains the ruined Sat Ghara or seven temples, with another group of twelve in number. The latter resemble in their general style the Kashmir order of architecture, characterized by dentils, trefoil arches, fluted pillars, and pointed roofs.-Imp. Gaz.

KATERH, the ancient Rajput name of Rohilkhand, given as a jaghir to Rohillas.-Campbell, p. 88.

KATHA or Kahta, Hind, from Kahna, to speak, to relate; a story, a tale, a fable, a recitation or narrative, interspersed with music and singing, of the actions of the gods or of individuals, with allusions to passing events or persons; a public recitation about the gods.Wilson.

KATH无I of Sangala are stigmatized in the Mahabharata as 'thieving Bahika,' as well as 'wine-bibbers and beef-eaters.' They are also called by a variety of names, as Madra, Bahika, Aratta, and Jartikka, and not even once by their own proper name, which, as known from Alexauder's historians, was Kathæi, and is preserved in the Kathi of the present day. General Cunningham therefore looks upon many of the ethnic appellations which the Greeks have handed down to us as mere nicknames, or abusive epithets applied by the Brahmanical Aryans to their Turanian neighbours. Pliny places the limit of Alexander's career in the territory of the Sudrakas, 'in Sudracis expeditio Alexandri termino,' and the altars on the opposite bank of the Hyphasis or Beas river. On a general review of all the data, General Cunningham thinks that the site of Alexander's altars must be looked for' along the line of the present course of the Sutlej. To this point, therefore, the territory of the Sudrakæ or Sudrakas must have extended in the time of Alexander.

KATHAK are professional musicians about Benares. They claim to be of high caste, and wear the janeo or sacred cord. Farther west, the Kathaks do not make a salam in saluting any one, as natives of India commonly do, but give their blessing like the Brahmans.-Sherring's Hindu Tribes, p. 273.

KATHARNAVA. SANSז. The Sea of Stories, a compilation in four books; the first two are the originals of the Hindi Baital Pachisi and Singhasin Battisi.-D. See Baital Pachisi.

KATHA SARIT SAGARA, the Ocean of the Streams of Narrative, or the Watery Ocean of Stories, reconstructed by Somadeva Bhatta of Kashmir, about the beginuing of the 12th century. The lost Vrihat-Katha, "the large or extendeil narrative,' was the great collection of Indian tales supposed to have been written in prose by Gumadhya as early as the 6th century. A Sanskrit poem based upon that work, and bearing the same 
name, was written by Kshemendra in Kashmir towards the end of the 11th century; but the original has disappeared. Its contents, however, have been to a certain extent made known by the compendium of the Tribat-Katha, made in Sanskrit verse by Sri Somadeva Bhatta of Kashmir in the 12 th century. This extensive poem is divided into eighteen books. It is a work abounding with pictures of national manners and feeling; and as offering the oldest extant form of many of the tales which were once popular in Europe, many of them throw a light on some of the obscurest portions of popular literature. Of such a nature is the account of how king Chandamahasena followed underground an enormous and terrible wild boar, which was a demon, vulnerable only in one spot; and how the king, aided by the demon's daughter, slew the demon and made the daughter his wife. The tale of how Saktideva, after an imprisonment in the belly of a fish, and an escape from a whirlpool into the branches of an overhanging banyan tree, discovered the Golden City, and found three apparently dead maidens in a part of its palace, which he, like Bluebeard's wife, was forbidden to enter. How Sringabhuja wounded a demon-king under the form of a crane, and carried off his charming daughter, and by her aid escaped from his demoniacal father-in-law's pursuit. The tragic story of Sakatala, an Indian Ugolino, who was confined in a dungeon with his sons, food for one only being supplied to the whole party. The Trojan horse stratagem, adopted by a king, who made a large artificial elephaut, filled it with warriors, and by its aid overcame a rival. monarch. How Jimutavahana gave himself up to be devoured by the bird Garuda, the enemy of Nagas, or gigantic semi-divine snakes, who interrupted his meal to remark, 'Although I am eating him, he is not at all miserable; on the contrary, the resolute one rejoices.' And, above all, it contains some of the most horrible stories about corpse-eating Rakshasas, Vitalas, and other ghoul-like monsters that the most morbid appetite could possibly demand. Namuchi was as devoted to almsgiving as the hero of the Wessantara Jataka, the generous prince who gave away not only all bis property, but also his wife and two small children. Having practised asceticism as a drinker of smoke for ten thousand years, and having been rendered by Brahma proof against all ordinary weapons, this charitable Titan made himself extremely annoying to the gods, especially after he had acquired a horse which had the power of restoring to life by a single suiff any of the Titanic brood whom a god had killed. At last Indra appealed to his generosity, and asked for the horse as a gift. Namuchi surrendered it, and Indra killed him with the foam of the Ganges, in which he had placed a thunderbolt. Being born again as a Titan composed all of jewels, he gave the gods more trouble than before. Then the gods took counsel together, and came to him and said to him, "By all means give us your body for a human sacrifice.' When he heard that, he gave them his own body, although they were his enemies. Also, the account of the loyal sentinel who was ready to sacrifice everything in order to save his lord from death. Viravara, with that aim, cut off the head of his youthful son, who had cheerfully consented. The daughter of Viravara, who was a mere girl, came up to the head of her slain brother and embraced it and kissed it, and crying out, 'Alas! my brother!' died of a broken heart. Whereupon their mother asked for permission to be burnt along with the bodies of her two children, and when her husband had given his consent, and constructed a pyre, she leapt into that burning pyre, with its hair of flame, as gladly as into a cool lake. After which Viravara resolved to cut off his own head, and would have done so if the goddess Durga had not interfered. The widely-spread tale of the ungrateful wife, who attempted to kill the selfsacrificing husband, who had kept her alive when she was suffering from hunger and thirst in a wilderness, by giving her his own flesh and blood. Somadeva's version of the story is very like that which is contained in the Tibetan Kah-gyur. The tenth book contains a number of the fables of Pilpai or Bidpai. The stories and the order in which they succeed agree better with the tales and arrangement of the Kalila-wa-Damna than even the Pancha Tantra; and it would appear, therefore, that we have in the Katha Sarit Sagara an earlier representative of the original collection than even the Paucha Tantra, at least as it is now met with. The Twenty-five Tales of a Vitala have been made well known by the numerous translations of the Baital Pachisi and other eastern recensions of the same story-book. The ninth book contains the legend of Rama and Sita, in which the suspected wife proves her purity by going down with some friendly hermits to a certain lake, and exclaiming, "Mother Earth, if my mind was never fixed, even in a dream, on any one besides my husband, may I reach the other side of the lake!' Having thus spoken, she entered the lake, and the goddess Earth appeared, and, taking her in her lap, carried her to the other side.

KATHAY. China is called by the western Mongol, Kathay; by the Manchu Tartar it is called Nikan Kourn; and by the Chinese, Tchoungkoue; the last name meaning the Central Kingdom. See China.

KA-THE, the Burmese name for the state and people of Munipur, called by themselves Moi-te.

KATHI or Cutty. MAHR. A land measure varying from 8 to 10 cubits.

KATHIATVAR, or Saurashtra, is the peninsular portion of Gujerat between the parallels of lat. $20^{\circ} 41^{\prime}$ and $23^{\circ} 8^{\prime} \mathrm{N}$., and the meridians of lony. $68^{\circ} 56^{\prime}$ and $72^{\circ} 20^{\prime} \mathrm{E}$. It was known to the Greeks and Romans under the name of Exuporrрnun. The extreme length of the peninsula is about 220 miles, its greatest breadth about 165 miles, its area about 22,000 square wiles, and its estimated population 2,500,000. The Kathiawar peninsula lies between the Gulf of Cambay on the south and the Gulf of Cutch and the Little Runn on the north, and a low isthmus between the Little Runn and the Gulf of Cambay unites Kathiawar to the mainland. In the isthusus is a noted depression, called the Nall. A highland occupies the interior of the peninsula. The highlands are remarkable for isolated mountains, amongst which is Girnar, rising to 3500 feet almost perpendicularly. It occupies the middle of a circular basin, into which admission is gained by four passes at the cardinal points of the compass. The Palitana mountain is another of the detaclied hills, 
1500 feet in height, on which the Jain race have erected numerous temples and images of their tirthankara. Kathiawar is ruled over by 188 separate states, large and small, of which 13 pay no tribute, 96 are tributary to the British Govermment, 70 to that of the Gaekwar as the representative of the Mahrattas, while, of the latter three classes, 132 pay a tax called Zor-Talabi to the nawab of Junagarh. The old territorial prants or districts are ten, viz. Jhalawar in the north, containing about 50 states; Mucha-Kanta, west of Jhalawar; Hallar, in the north-west, embracing 26 states; Okhamandal, in the extreme west, belonging to Baroda; Barada or Jaitwar, along the south-west coast, also known as Porbandar; Sorath, in the south ; Babriawar, a hilly tract in the south-east; Kathiawar, a large district near the middle; Und-Sarviya, lying along the Satrunji river; and Gohilwar, in the east, along the shore of the Gulf of Cambay, so named from the Gohil Rajputs, who are the ruling race in it. It comprises the Gogha district, belonging to the Ahmadabad collectorate; Bhownaggar, probably the foremost state in Kathiawar; and many others.

The later senapatis became kings of Saurashtra, who placed their lieutenants at Valabhinagar (identitied with the buried city of IVala, 18 miles north-west of Bbaunagar). When the Guptas were dethroned by foreign invaders, the Valabhi lings extended their sway over Cutch, Lar-desa (Surat, Broach, Kheda, and parts of Baroda territory), and Malwa (A.D. 480). It was in the reign of Dhruvasema II. $(632-640)$ that the Chinese pilgrim Hiwen Thsang visited Falapi (Valabhi ?). In A.D. 770, Wallabhipur fell before an inroad from the north of a race whom Mountstuart Elphinstone supposes to have been Persians under Nushirwan the Great; supposed by Colonel Tod to Lave been Scythians, and by another authority to have been Indo-Bactrians.

Kathiawar contains some of the oldest inscriptions in India, as those of Rudra Dama near Junagarb, and the inscriptions of Asoka near Girnar; a number of rock-cut Buddhist caves and temples at Junagarh, mentioned by Hiwen Thsang in the seventh century, and some fine Jain temples on Mount Girnar and Palitana. At Ghumli, a former capital of the Jaitwas, there are extensive ruins.

The principal chiefs are their highnesses the nawab of Junagarh, the jain of Navanaggar, and the rawal of Bhownaggar; also the rana of Porbaudar, the raj of Drangdra, and the thakur of Mlurvi. Junagarh, the most important, is held by a descendant of Sher Khan Babi, a soldier of fortune, who seized it in the general anarchy which preceded the subversion of the Moghuls. The jam is the head of the Kathiawar branch of the great class of Jharija Rajputs which surged into the country from Sind about the middle of the 15th century, and another stem of which is represented by the rao of Cutch. The rawal is at the head of the Gohil Rajputs, a race driven in from Marwar lyy the Rahtors in A.D. $1200 . \quad H e$ is descended from Mokheraju, a sea rover, who in the 14th century occupied Perim Island at the mouth of the Gulf of Cambay, and whose shade is to the present day propitiated by the passing mariner. The rana of Porbandar, styled Puncheria, repre. sents the Jetwa, one of the four ancient races still extant in the peninsula. In the days of Mabmud, all the west and north of Kathiawar belonged to the Jetwa Rajputs, but the forays of the Jhala and Jharija have confined them to their present district, the shaggy range of hills called Burda. The Jhala, who own the raj of Hulwud Drangdra as their chief, are supposed to have sprung from an offshoot of Anhilwara, on the extinction of which dynasty they obtained large territorial aggrandizement. The chief of Murvi is a Jharija, and was the first in Colonel Walker's time to abandon infanticide. He has possessions in Cutch.

The fortified post of Jafferabad or Muzaffarabad is held by the descendant of an African rover, the Siddi of Janjira.

The Kathi of Katbiawar proper immigrated into their present site in the eighth century, and are supposed to be of Scythian origin. Their religion is a Hinduism, mixed with a sun-worship. While the Rajputs have a modified primogeniture, the Kathi inherits by equal divisions. They are innately turbulent, and of all the tribes have ever given the greatest trouble. Although it is divided into such numerous chieftainships, and although the Kathi hold but a small portion, yet this IndoGetic tribe has given its name to the entire peninsula, completely superseding the ancient title of Saurashtra. There was, however, an intermediate term used to designate it before the irruption of the Kathi, a term familiar to the author of Almagestum, as well as to the Hindu geographers, and this was Lar-des, from the tribe of Lar, whence the Larica or Larice of the Greeks. The Kathi or Katti tribe are supposed to be the nation which so manfully opposed Alexander, and were then located about Multan. Against these Alexander marched in person, when he nearly lost his life, and left a signal memorial of his vengeance. The genealogists of Rajasthan and Saurashtra concur in assigning to this people a place amongst the thirty-six royal races of India. The Kathi claim descent from the Bala, an additional proof of northern origin, and strengthening their right to the epithet of the bards, 'Lords of Multan and Tatta.' The Kathi can be traced from those scenes to his present haunts. In the earlier portion of the annals of Jeysulmir, mention is made of their conflicts with the Kathi, and the Kathi traditions fix their settlement in the peninsula, from the south-eastern part of the valley of the Indus, about the eighth century. In the twelfth century, the Kathi were conspicuous in the wars with Prithivi raja, there being several leaders of the tribe attached to his army, as well as to that of his rival, the monarch of Kanouj. The name of their first settlement in Kathiawar was Kath-kote, from which they were dislodged by the first Jharija colony from Sind. They repeat couplets describing their migration from Multan, and temporary settlement in the tracts called Pawin, north of the Rumn, and of Megum Roa, their leader, conducting the first Kathi colony across the gulf into Saurashtra eight hundred years ago.

Captain M'Murdo says the Kathi differs in some respects from the Rajput. $\mathrm{He}$ is more cruel in his disposition, but far exceeds him in the virtue of bravery; and a character possessed of more energy than a Kathi does not exist. His size often exceeds six feet; sometimes with light 
hair and blue-coloured eyes. His frame is athletic and bony, and particularly well adapted to his mode of life. His countenance is expressive, but of the worst kind, being harsh and often destitute of a single mild feature. The Kathi are herdsmen in the districts of Pawur, Puchur, and Parkur. The Kathi women are large and masculine in their figures, often dressed in long dark garments like the Charan women, but have the character of being always well looking, and often remarkably handsome. They are more domesticated than the Rajput, and confine themselves solely to the duties of their families. They are often not brides till sixteen and seventeen years of age. To become a husband, the Kathi must be a ravisher. He must at tack with his friends and followers the village where his betrothed resides, and carry her off by force. In ancient times this was no less a trial of strength than of courage; stones and clubs were used without reserve both to assault and repel, and the disappointed lover was not unfrequently compelled to retire, covered with bruises, and wait for a more favourable occasion. The bride had the liberty of assisting her lover by all the means in her power, and the opposition ceased when her dwelling was once gained by the assailants, and the lady, then bravely won, submitted willingly to be carried off by her champion. The Kathi do not intermarry with any other caste. A Rajput will, however, eat food dressed by a Kathi. Kathi will do notbing of any consequence without consulting his wife and a Charan, and be in general guided by their advice. They are divided into three principal families, named Wala or Wara, Khachar, and Khuman, of each of which there are other subdivisions. The most celebrated is the Khuman Kathi, whose pallia, or funeral montumental pillars, are seen in groups at every town and village. He worships the cow, leaves a lock of hair on his head, and adores Mabadeo aud other Hindu deities, although he is more attached to the worship of the Sooraj (Surya or the sun), and to Ambha and other terrible goddesses.

The Jharija are the most powerful and numerous of the Rajput tribes of Gujerat, and possess all the western part of the peninsula. They are a branch of the family of the rao of Cutch, who, in consequence of intestine feuds, left their country about A.D. 800, and, having crossed the Runn at the head of the Gulf of Cutch, established themselves upon the ruins of the Jetwa Rajputs and a few petty Mubammadan authorities which at that time existed in Halar. The Jharija are also said to trace their origin from Jhara, a chief of the Muhammadan tribe of the Samma of Sind. The lands appear to have been divided in common among the whole tritue, the teelat, or eldest branch of the family, reserving to itself the largest portion, whilst the bh'yaud or brotherhood held their respective villages by a pure feudal tenure. The outlaws amongst them, the Bahrwuttia, acted with great violence. If he failed in getting flocks, he seized the persons of such villagers as he could find, and carried them off. These were styled bhan or captives, for whose release sums of money were demanded. The life of a Bahrwuttia was one of blood and rapine, until he was killed, or by the fury of his feud he compelled his chief to grant him redress; and the security of Charan (religious persons) and Bhat (Bards) races having been given on both sides, the outlaw and his family returned to their homes and occupations in perfect security.

Okhamandal is a sterile jungly tract in the extreme west of the peninsula, and contains about 13,000 inhabitants. These are the Wagher. Their only important places are the holy Hindu site of Dwaraka on the west coast, and Beyt, a small island a few miles to the north, with shrines boasting of scarcely inferior holiness. Okhamandal, as also Umreyli in Kathiawar proper, and Korinar in South Kathiawar, are under the direct rule of the Gaekwar. Thrice, in 1803, 1858, and in Oetober 1859, they repulsed British troops, but seemed in 1860 entirely dispersed or surrendererl. Kathiawar is rich in jungle fastnesses. Its population is habitually armed to the teeth, and largely intermixed with mercenaries from Mekran, Arabia, Sind, and Baluchistan.

The Miana of Mallia in Mucha-Kanta, on the banks of Muchu river, have a thakur, but own allegiance only to their own chowhattias or heads of tribes. They are turbulent, take service as soldiers in the neighbourhood, and, formerly, in every boundary fight a Miana or two was killed.

The district of Geer is full of almost inaccessible fastnesses, which for ages gave shelter to outlaws and robbers.

In the Jhalawar district, the property stolen, or the thief, had to be produced, and the paggi, who trace the pag or footprints, were there the most famous.

The Bhomea of Kathiawar still preserve a great portion of that spirit of hospitality for which their ancestors were celebrated.

Outlawry, political and predatory, has been recently suppressed, and life and property are as safe as in British districts.

KATHMANDU, capital of Nepal, is situated in the valley at the junction of the Bhagmutty and Bishmutty, and contains a population of 50,000 inhabitauts. A tradition is current in Nepal that the valley was at some former period a lake, and it is difficult to say in which character it would have appeared the most beautiful. The valley is almost unrivalled in its fertility, sup porting in comfort and plenty a population of 400,000 inhabitants, being 300 persons to the square mile. Throughout its whole length and breadth not a stone is to be found; it is well watered; its temperature is delightful, the thermometer in the hottest month seldom reaches $75^{\circ}$, in the coldest never falls below $30^{\circ}$, and has a mean annual rainfall of 60 inches. A great vernal festival is held at the capital annually. It is called the Pasupati Kshetra. Numerous visitors attend it from Oudh, Behar, and N.E. Bengal.-Oliphant's Jonrney, pp. 85-87.

KATHOLIKOS, a bishop of the Armenian Church, resides in the convent of Echmiadzin, at the foot of Ala-Goz in Russian Armenia.

KATHURIA. HiND. Makers of catechu from the wood of Acacia catechu.

KATI. MaLAY. A weight in the Archipelago and China. A kati weighs 1 lb. $5 \frac{1}{3}$ oz. It contains 16 tel; and 100 kati make 1 pikul $=133 \frac{1}{3}$ lbs. avoirdupois.

KATIB, ARAB., from Arabic Kut'b, he did write, a copyist or scribe. In all Southern Asia this profession is followed, and written books are preferred to those that are printed. They write by the juz or portion, and are paid at the rate of Rs. 5 to 15 per juz. 
KATIBA, a governor of Khorasan, who conquered Transoxiana A.D. 706-712, A.H. 87-93. He first occupied Hissar opposite Balkh. In the course of the next six years he took Samarcand and Bolkhara, overran the country north of the Oxus, and subdued the kingdom of Kharāsm on the Lake Aral. By the eighth year he was able to reduce the kingdom of Farghana, and extend his acquisitions to Mount Imaus and the Jaxartes (Syr Darya). The conquest of Spain took place in the same year, and the Arab empire then reached the greatest extent to which it ever attained. In A.D. 750 the rebellion of the great province of Khäräsm gave the last blow to the power of the Ommayad khalifs, and placed in power the descendants of Abbas, the uncle of Mahomed. Spain held out for the old dynasty, and the integrity of the empire was never restored. -Elph.pp. 269, 270.

KATIF or Al-Katif, an important town on the S. coast of the Persian Gulf.

KATINA, cloth used in Ceylon for making a Buddhist priest's robe.

KATIOW, a Borneo tree. The seeds are oblong, pointed, and of a shining rich brown colour; the oil which they yield on compression is of a yellow colour, burning with a bright and clear flame. It is produced chiefly on the Satong Lingah and Kallekka rivers, and exported to Sarawak and other places, under the name of Miniak Katiow. It is good for cooking.-Low's Sarawak, p. 47.

KATIRA. Hind. Gum of several plants, viz. of Cochlospermum gossy pium, Eriodendron anfractuosum, and Sterculia urens. It is often substituted for tragacanth. The gum of C. gossypium is semitransparent, white, in striated pieces, very much twisted and contorted, and is known as false tragacanth. It is much used as a demulcent in Upper India.--Birdwood; Powell's Handbook.

KATS or Kach. Puкhто, Cultivation on the bank of a stream.

KATTADIA, the devil-priest of Ceylon. There is a class of demi-gods, who are supposed to inhabit the waters and dwell on the sides of Mount Meru, and who are distinguished not only for' gentleness and benevolence, but even by a veneration for Buddha, who, in one of his earlier transmigrations, was himself born under the form of a Yakshyo. The malignant spirits of Ceylon are Yakka, who are the authors of indefinite evil; and the Singhalese have a demon or Sanne for each form of disease, who is supposed to be its direct agent and inflicter, and who is accordingly invoked for its removal; and others, who delight in the miseries of mankind, are to be propitiated before the arrival of any event over which their pernicious influence might otherwise prevail. Hence, on every domestic occurrence, as well as in every domestic calamity, the services of the Kattadia or devil-priest are to be sought, and their ceremonies performed, generally with observances so barbarous as to be the most revolting evidence still extant of the uncivilised habits of the Singhalese. Especially in cases of sickness and danger, the assistance of the devil-dancer is implicitly relied on; an altar, decorated with garlands, is crected within sight of the patient, and on this an animal, frequently a cock, is to be sacrificed for his recovery. Another kind of demonworship in Ceylon is a debased form of Hinduism, where the kapua priest is the performer.Tennent's Christianity in Ceylon, p. 232.

KATTI. TEL. A land measure of about 14 acres. $-W$.

KAfTikaran. Maleal. A tari or toddydrawer.

KaTtUBADI. Karn., Tam., Tel. Holding lands on military tenure, a favourably rated quitrent.

KATTUN, a mighty demon of the Hindus, feared and worshipped.

KATVANGA. HIND. A staff with a skull, carried by a Saiva sect.

RATYAYANA, a Hindu writer of great celebrity. He came after Panini, whose grammar he is said to have completed and corrected in what he called Varttikas, supplementary rules and annotations. $\mathrm{He}$ is generally identified with Vararuchi, the author of the Prakrita Prakasa. He was also the author of the Sranta Sutras which bear his name, and of the Yajur Veda Pratisakhya; as likewise of a Dharma Sastra. $\mathrm{He}$ has been supposed to have lived B.C. 25 (Weber); in the first balf of the $2 d$ century (Goldstucker). Max Muller places him in the second half of the 4 th century B.C. The missionary Ward says, iv. p. 37, he was born near Sumeru, married Sadbarmini, and dwelt on Mount Mandara. He taught that in the union of spirit and matter, God existed in unity; also the eternity of matter and a future state. As a boy, he was remarkable for his great talent and extraordinary powers of memory. He wrote a law treatise which bears his name; also the Gauri-shikhara-mahatma, an illustration of Panini's grammar; criticisms on the Sutra of the great grammarian; and he completed and corrected Panivi's yrammar as we now possess it. He has been identified with Vararuchi, the compiler of the doctrines of Saunaka.-Ward, iv. 37.

KAUFMANN, GENLRAL CONSTANTINE, i great commander of the Russian forces in Central Asia; obiit 188:. In the successive campaigns which he conducted against Bokhara, against Kliva. and against Khokand, General Kaufmann greatly increased the Asiatic dominions and influence of Russia, while narrowing the zone of debateable. ground which separated her from the countries under the government or control of Britain. $\Lambda$ the result of his success, he exercised for many years almost unlimited authority in Central Asia. He found no resistance to his advance in any quarter but the British empire; and consecquently his whole policy assumed an anti-English contplexion, and his court at Tashkend was more thin suspected of being the source whence sprang all the difficulties which had beset British policy in the east during the preceding 15 years. General Kaufmann was born at Maidaui in 1818, and was therefore only 64 when he died. He served first in the army of the Caucasus, where he rapidly distinguished himself. In 1855 he was selected to settle with General Williams the terms of the capitulation of Kars. In 1867 was transferrecl to Turkestan, the governor-generalship of which province be held till his deatb. Shortly aftrr his arrival war was declared by Russia against Jokhara; Samarcand was occupied in June $186 \mathrm{~s}$ and the whole country was subjected to Russja. This was the first step in General Kaufmaun's plan of bringing the whole of Central Asia under 
the influence, if not the actual government, of Russia. The expedition to Kbiva was the next act of General Kaufmann's government. In the spring of 1873 , General Kaufmann, advanced into the country in two main divisions, one starting from Turkestan on the east, and the other from Orenburg on the west. The former was led by the governor himself, who, after several victorious engagements, reached Khiva at 8 o'clock in the morning of June 10, only to find that the town had been already occupied three hours previously by the Orenburg column, under Generals Verovkine and Lomakine. The Khan fled as the Russians approached, but afterwards returned, and signed treaties by which he undertook to pay an indemnity of two million roubles, to cede frontier territories on the Amu Darya and Syr Darya rivers to Russia and to the Khan of Bokhara, who had assisted the Russian troops, and practically to commit to Russia the direction of his foreign relations. A campaign against Khokand was undertaken by General Kaufmann in 1875 , at the close of which all Khokand north of the Syr Darya was formally annexed to Russia, while the independence left to Khokand south of the Syr Darya was merely nominal. The absorption by Russia in succession of Bokbara, Khiva, and Khokand brought her into the close proximity of Afghanistan, and General Kaufmann seems to have next directed his ambitious designs to that quarter. His emissaries were despatched into Afghanistau. The Russian embassy, the reception of which by the Amir precipitated the Afghan war, may be attributed to his instigation.

KAUKARO, oritch plant, is a strange and dangerous growth. Instances have occurred when a man, having iguorantly selected this wood, either as timber from which to fashion his canoe, or a spar suitable for his mast, and incautiously sitting on the wood while carpentering, has discovered, when too late, that the subtle poison had entered by every pore, and that his whole body was rapidly breaking out into angry spots, causing an irritation utterly unbearable, and lasting for months, sometimes years. This needs verification.

KAULA DEVI, wife of a fugitive Hindu prince, ruler of Gujerat. Kaula Devi had been taken prisoner during her husband's flight to Baglana, and been placed in the haram of Ala-udDin Khilji; and when Alp Khan, governor of Gujerat, was ordered to proceed to Deogiri to co-operate with Malik Kafur, he was ordered to try to obtain Dewala Devi, a daughter of Kaula Devi, for the raja. Her escort was fallen in with near the caves of Ellora. He and Alp Khan took her to Dehli, where she was married to Khizr Khan, eldest son of Ala-ud-Din. The poet Khusru, in a Persian poem, celebrated their loves.

KAUR. The Kaur form a cousiderable proportion of the population of Jashpur, Udaipur, Sirguja, Korea, Chand Bhakar, and Korba of Ch'huttisoarh. They all claim to be the descendants of the survivors of the Kaurava, who, when defeated by the Pandava at the great battle of Kuru-kshetra, and driven from Hastinapur, took refuge in the hill country of Central India. The Kaur of Sirguja at one time encouraged widows to become satis, and greatly venerated those who did so. Sati shrines are not uncommon in the Tributary Mahals. Between Partabpur jilmilli in Sirguja, Colonel Dalton saw a grove sacred to a
Kaur sati (suttee), now the principal object of the village worship. Annually a fowl, and every three years a black goat, are sacrificed to her. Next to the Jashpur Oraon, the Kaur are the ugliest race Colonel Dalton had seen, being dark, coarse-featured, with wide mouths and thick lips. They are a very industrious, thriving people, about Korea and Udaipur, in the extreme west of the Chutia Nagpur Agency of Nagpur proper. They speak Hindi. They are considerably advanced in civilisation. They eat fowls, and do not reverence Brahmans, but worship Siva. They bury their dead. They claim to be descendants of the Kuru who fought the Pandu.-Campbell, pp. 22, 40; Col. Dalton, Ethn. p. 138

KAURAVA, descendants of Kuru, but commonly applied to the sons of king Dhritarashtra by his wife Gandhari; the Kaurava and Pandava therefore were cousins-german.

The poem of the Mahabharata contains 100,000 verses; the groundwork of the poem, the Kaurava aud Pandava war, contains 24,000 verses. This leading story commences with Atri, a flash of light from whose eye produced the moon (which in Sanskrit is male), and that being was the ancestor of the Lunar dynasty of king8. One of these kings was Pururavas, whose love for the heavenly nymph Urvasi is detailed in Kalidasa's drama Vikramorvasi. His descendants in a direct line were Ayas, Nabusha, and Yagati, the last becoming the father of Puru and Yadu. The line of $\mathrm{Yadu}$ acquired celebrity through Vasudeva and his sister Kunti or Pritha, and also through his sons Krishna aud Bala Rama, who have beconse reputed as incarnations of the god Vishnu. Puru is son was Dushyanta, who married Sakuntala, and their son was Bharata. From Bharata descended successively Hastin, Kuru, and Santanu. Santanu married Satyavati, already the mother of Vyasa, but their children died without offspring, and Satyavati then asked her son Vyasa to marry her widowed daughters-in-law ; by one of them he had Dhritarashtra, born blind, and by another, Pandu, born a leper or an albino. Dhritarashtra married Gandhari, aud amongst their many children was Duryōdhana, also called Suyodhaua, and Duhsasana, - these were the Kaurava. Pandu married two wives, viz. Pritha, sister of Vasudeva and aunt of Krishna, and Madri. By Pritha he had three sons, Yudishthra, Bhima, and Arjuna ; by the latter, twins, Vakula and Sahadeva, and these were the Pandava. Both the Kaurava and the Pandava were related to Krishna, but the Pandava more nearly so, owing to their mother Pritha being aunt of Krishna. Vyasa, the compiler of the Mahabharata, is the reputed grandfather of both the Kaurava and the Pandava. It is the series of events which happened in the lives of the Kaurava and Pandava that forms the groundwork of the great epos of the Mahabharata, and they may thus be briefly related.

Santanu had resided in Hastinapur, the ancient Delili, and after his demise, Dhritarashtra was by seniority entitled to succeed. But as he was blind, he resigned the throne in favour of his brother Pandu. The latter became a powerful monarch, but, after a while, having become tired of his regal duties, he abdicated, and retired to the forests of the Himalaya, to indulge in his favourite sport, the chase. His brother Dhrita- 
rashtra then resumed the reins of government, but, being blind, his uncle Bhishma governed for him, and conducted the education of his sons. After a while Pandu died, and his widow Pritha and her five sons returned to Dhritarashtra's court to be educated along with his own children, their cousins. But the Pandava brothers were superior lads, and their cousin Duryōdhana, out of jealousy, tried to destroy them, first by poison, then at trials of arms; subsequently, Drona, a Brahman, who had taught the Kaurava, brought about a reconciliation, and the relatives unitedly attacked Drupada, king of Panchala, who, principally by the Pandava's aid, was defeated. On this the blind king Dhritarashtra resolved to pass over his son Duryōdhana, and named his nephew Yudishthra, the eldest of the Pandava, to the throne, and their cousin Duryodhana made another effort to destroy them, by burning them alive. This, also, they escaped, but they considered it advisable to withdraw in disguise, which they did by assuming the character of mendicant Brahmans, and retired to the forests. After some time, they were informed by Vyasa, that Drupada king of the Panchala would make his daughter Draupadi queen of a tournament, to be won by the most successful competitor, and she was won by Arjuna. On this occurred a civil commotion, in which Drupada nearly lost his life; but Draupadi went with the Pandava brothers, and became their joint polyandric wife.

After the tournament, the Kaurava and Pandava made peace, the former to reign at Hastinapur, the ancient Dehli, and the Pandava at Khandavaprastha, the modern Dehli. Yudishthra, the eldest of the Pandava, reigned so successfully that he resolved to declare himself emperor, by the performance of the Rajasuya sacrifice. This was accomplished with much splendour, but Yudishthra was afterwards involved by his cousin Duryōdhana in a game at dice, and Yudishthra lost everything,- - kingdom, wealth, and his joint wife Draupadi. Duryodhana offered to restore their kingdom if they would exile themselves for 13 years. In these 13 years they all took service with king Virata of Matsya, and ultimately defended him against an attack of Duryōhana. On this account, Virata gave his daugher Uttara in marriage to Abhimanya, son of Arjuna by Subahdra. In claining restoration to their lingdom at the close of the 13 years, the Pandava first tried negotiations, offering to be content with five small towns, but they ultimately resolved to fight it out on the plain of Kuru-kshetra, the rules of battle being duly laid down. In the battle that ensued, and which lasted 18 days, the Kaurava lost successively all their chiefs, Bhishma on the tenth day, Drona on the fifth day, Karna on the second day, and their last commander, Salya, was killed on the first day of their commands. In these battles there was foul play on both sides. After the close of the battle, Yudishthra was elected heir-apparent of the old blind king Dhritarashtra. But the latter subsequently abdicated and led the life of a recluse, along with his wife Gandbari, Pritha, the mother of the Pandava, and their uncle Vidura. Vidura soon died, and all the rest of the royal exiles perished in a forest conflagration. The grief of the Pandava for this was great, and they too, after hearing also of Krishna's death and of the destruction of
Dwaraka, resolved to abdicate, and they all set out for Mount Meru, but all save Yudishthra perished before reaching it. According to the story, Yudishthra ultimately entered Indra's heaven, and there found all the Kaurava relatives and his brothers.

Both Professor Lassen and Mr. Wheeler consider that the Pandava story in the Mahabharata conveys a history of India.

Kritavarmam, Aswatthama, and Kripa were the three surviving Kaurava warriors after the battle of Kuru-kshetra.-Westminster Review, 1868; Wheeler's India; Bunsen's Egypt, iii. p. 558.

KAURIE TREE of New Zealand, the Norfolk Island pine, the Araucaria excelsa, attains the height of 200 feet, and yields an invaluable, light, compact wood, free from knots, from which the finest masts in the navy are now prepared.St. John's Forest Trees of Britain.

KAUSALA or Kosala is the modern Oudh (Ayodhya) or Benares.

KAUSALYA, the favourite wife of Dasaratha, and the mother of Rama and Lakshmana.

KAUSAMBI, the capital of Vatsa, the scene of the drama Ratnavali, supposed by Gen. Cunningham to be the modern Kosam or Kosambinagar on the Jumna, 30 miles above Allababad. According to the Ramayana, it was built by Kasamba, the son of Kusa, a descendant of Brahma. Buchanan, upon the authority of the Bhagavat, ascribes its foundation to Chakra, a descendant of Arjuna. Neither the Bhagavat nor Vishnu Purana state that Nimi Chakra built Kausambi. They only say that when Hastinapura shall be washed away by the Ganges, Nimi Chakra will reside at Kausambi. From which it is to be inferred that Kausambi existed at the time that Hastinapura was destroyed. The site of Kausambi, Buchanan supposed to have been that of the ruins ascribed to Hastinapura, but it was more probably lower down in the Doab, bordering upon Magadha on one side, and Kosala on the other. It is elsewhere intimated that it was possibly about Kurrah, which, according to the inscription found there, was comprised within Kausamba-mandal, or district of Kausambi. The city so termed was probably not far from Allahabad. - Hind. Theat. ii. p. 69 ; Orientul Magazine, Calcutta, No. 1, p. 67; Asiatic Researches, ix. p. 433.

KAUSIK or Kausika, a tribe of Rajputs, in considerable numbers in Ghazipur, Azimgarh, and Gorakhpur, claiming descent from Kausika, the father of Gadhi, the founder of Gadhi or Ghazipur. - Wilson's Glossary.

KAUSTUBHA, an epithet of Vishnu; also a sparkling gem, worn by that deity, elicited by the churning of the ocean; it is in some places taken as an emblem of the sun, but the pandits of the Carnatic do not admit of that allegory.

KAVA or Ava of Polynesia, an intoxicating drink made from the Piper methisticum, now almost ceased to be used. Formerly, in its preparation, the root was chewed by boys, and the fluid spat into bowls, but it is now grated.

KAVADI. TAm. Yoke or pole. The shoulderstick (cowrie) in use for carrying weights over the shoulder, with a sling at each end. It is the Bhangi of $N$. India.- $W$.

KAVA-KARAN, pl. Kava-karar, a branch of the Kallar race, occupying the Trichinopoly dis- 
trict. They are predatory, but are largely employed as watchmen.

The Kava-karar hold themselves responsible for the safety of everything in their employers' houses, and if a single article is lost or stolen, they invariably contrive, in some unaccountable manner, to detect the theft, and recover the stolen or missing property. The only duty of a Kava-karan is to watch the house of his emplover, and protect his property from the professional propensities of those of his own caste or kindred. In its moral aspect, every house is a sort of reformatory where one soul at least is in a sense reclaimed. Trichinopoly is the headquarters of the Kallar caste; and the only way of keeping away thieves is by employing a thief on the premises.

KAVAL, TAM,, corrupt Cawel, guarding, protecting. It is variously combined. Kavalali, a village watch, a guard. In Tinnevelly, a prisoner in custody.

KAVASHA, also called Ailusha, son of Ilusba, a slave girl, author of several hymns in the 10th book of the Rig Veda.-Dowson.

KAVELLI VENKATA BORIA, a learned Brahman who aided Colonel Mackenzie in collecting Hindu manuscripts relating to the history of India. In 1817, the Madras Government bestowed on Kavelli Ventaka Latchmiah the grant of a village near Madras, to be held by him and his two next heirs, in recognition of his public services.

KAVERI or Cauvery, a river of the southern part of the Peninsula of India, which rises in the mountains of Coorg. It has been noticed under the spelling 'Cauvery,' q.v. In the Mysore portion of its course it forms the two islands of Seringapatam and Sivasamūdram, which vie in sanctity with the island of Srirangam lower down. The istand of Sivasamudram is about nine miles long and one mile broad, with a cataract upon each branch of the river, both which are very magnificent during the floods. 'They are usually known as the Falis of the Kaveri. It is a spot combining many of the wild beauties of nature. The fall on the north side of the island is called Birra Chuki, 460 feet, that on the south, Gaugana Chuki, 370 feet. The rock over which the Birra Chuki falls has a curve nearly a quadrant of a circle, from the centre of which the fall is viewed. Over this spaco ten cascades are distributed, all nearly of the sime height, and dashing into the caldron below. The Gangana Chuki is even wilder than this. A little above the fall, this portion of the river is divided into two portions. 'The larger portion is nearest to the island, and plunges in one cascade, about 130 feet, into the chasm below, while three or four portions leap from lerlge to ledge, till at last they reach tho stream about sixty yards from the base of the great fall.

KAVERIPAK, town in Wallajah taluk, North Arcot district, Madras, 10 miles east of Arcot, lat. $12^{\circ} 54^{\prime} \mathrm{N}$., long. $79^{\circ} 30^{\prime}$ E. ; population (1871), 5711. Its irrigation tank is one of the finest in Southern India, which supplies water to about 6000 acres of rice land. It is fed by a channel from the Palar.-Imp. Gaz.

KAVI. From Baron Humboldt's researches into the Kavi language, the resemblances between the nations of the Polymesian Islands and the tribes of the Indian Archipelago, Malacca, and Madagascar, aro essential aftiuities, deeply rooted in the construction of these languages. Old Javanese belongs to the Polynesian family and the Nalayan branch. It is the parent of modern Javanese, and represents the language as we have it from A.D. 800 to 1400 . It has largely borrowed from Sanskrit, just as modern Javanese, Malay, and the Dravidian languages have. When the Muhammadans occupied Java, the Hindu religion found shelter in Bali, which still remains Hindu. The whole of the literature is thoroughly Brahmanical and Buddhist, and original versions of the great Sanskrit epics are found in the Kavi. It has a peculiar character.-Prichard in liep. Brit. Ass., 1847, p. 241. See Writing.

KAVI, the yellow colour of the dress worn by Hindu religious teachers. - Ablé Dubois, p. 5 .

KAVI. Sansk. A poet. Kavya, song, poetry, epic poetry, as the Ramayana and the Mahabharata; also the Raghuvansa and Kumarasambhava, said to be by Kalidasa. There are six Maha-Kavya.

KAVILE. TEL. A book made of palm leaves, an account book of slips of paim leaves, such as used by the village accountants in the Teling and Tamil country.

KAVIR, also Kafeh, the salt desert of Central Persia. See Desert.

KAVIRAJA, author of the Raghava-Pandaviya, a poem remarkable for its studied ambiguity, as it may be read as relating the history of Rama and the other descendants of Dasaratha, or that of Yudishthra and the other sons of Pandu.

KAVIRASA PANDITAR was a native of Virai. He wrote a licentious poem, Sauntariya-lakari, in praise of Parvati. It is said to be translated from the Sanskrit of Sankaracharya.

KAVIYARAJ, in Bengal, a physician. Many of them are learned men, actively engaged in their profession, according to the Hindu theory of medicine.

KA IVAITNAGAR, zamindari estate in North Arcot district, Madras, situated between lat. $13^{\circ}$ $4^{\prime}$ and $13^{\circ} 36^{\prime} 30^{\prime \prime} \mathrm{N}$., and between long. $79^{\circ} 17^{\prime}$ and $79^{\circ} 53^{\prime} \mathrm{E}$.

KA-WA-KA of New Zealand, Thuja Doniana. Hooker, attains a height of 60 to 70 feet, and a girth of 8 to 10 feet. Its wood is elegantly grained, close and heavy, and is used for ornainental purposes. $-G$. Bennett, p. 414.

KATVAN of the Assyrian texts, the Chiun of Amos V. 26, according to Professor H. H. Sayce, was the planet Saturn.

KAIVAN. MALAY. A solid oil of Singapore, of a pale-greenish colour, a good deal resembling the oils of the Bassia in character, though rather harder, and approaching more in properties to the myrtle wax of the Cape.

KATV-WAS or Cavass. Turki. A police officer, literally an archer, reminding us of les archers de la sainte Hemmandade; some spell the word Kawas.-Burton's Mecca, i. p. 29.

KAY or Ka, a tribe who dwell east and north of the Shoung, calling themselves Ka, but Kay by the Bghai, the Red Karen calling them Pahtoung, and the Burmese Gay-kho. They are a puguacious race. They rear the silk-worm and weave and wear silk. When a chief or owner of slaves dies, one slave is said to be buried with him, to be his attendant in the next world. They dwell 
on both sides of the boundary at Tounghoo separating British Burma from the Ava territory. They speak a dialect of Pwo-Mason, Burmah, pp. 92,642 .

KAYA. Hind. A compound metal of zinc, tin, and copper.

KAYAMAL, a title added to the names of petty princes and zamindars of Travancore.

$\mathrm{KAYAN}$, according to Mr. Dalton, amount to 270,000 souls; they were greatly addicted to head-hunting. This people inhabit the northwest of Borneo, in the interior of the country comprised between the rivers Baram and Rajang, which, with the small rivers intervening, allow the Kayan access to the ocean. The mongrel Malays occupy the coast, and the country between them and the Kayan is occupied by eleven other tribes, in number each about 500 , the majority of whom are subject to the Kayan. The Kanawit tribe closely assimilate to the Dyak of Saribas, whose neighbours they are. The tribes Punan, Sakapan, and Kajaman are the chief collectors of camphor and birds' nests. The Kayan women are immoral. Kayans are not so passionately fond of skulls as to bequeath them as fortumes to their children, as was said of the Dyak. They continue human sacrifices, but to a less extent. The Kayan name for God is Tanangan, whom they hold to be invisible and supreme. From the river Baram, coal is traced to the upper parts of the Bintulu, and thence southward to the Rajang river, on the left bank of which, at Tujol Nang, there is a seam exposed upwards of 13 feet in thickness. The coal and iron fields of the Balawi or Rajang are more extensive than any yet discovered on the island.-Mr. Burns in Jo. Ind. Arch., 1849.

KAYASTH, Kayastha, Kait or Kaest, numbered in India $2,159,813$ in 1881 . The tribe has twelve divisions, of which the Gaur Kayasth is one. Their habitual language of correspondence is the Persian; they are largely employed as clerks and accountants about native courts. They say that they spring from Chatrgoputr, the secretary of Dharmaraja. They are Hindus, generally worshippers of Siva. They allow their daughters to grow up before wedlock. Many of them drink to excess and gamble. Their features, physical form, and colour are more varied than those of any other section of Hindus. They are acute in business, active, and painstaking. In Northern India, they have adapted themseives to the British forms of administration, and are useful servints. They have become in places considerable landed proprietors. In Bengal, they are more numerous, and form an aristocratic class, have proprietary rights in the soil, and cultivate a great deal. The Chandraseua Kayasth of Bombay and Poona claim to be descendants of raja Chandrasena, a Kshatriya raja of Malabar, but the Brabmans declare thern to be of menial origin. 'They have, however, the honorific name of Puroob (Purvoe, Prabahu, or master), and are distinguished as Patavi and Dawani Prabahu. The race were employed by the Indian princes in the collection and records of their revenues, and their character for a spirit of extortion became proverbial. They appear to have been particularly obnoxious to the Brahmans. Kayastha is the Sanskrit name, from Kaya, the body, and Stba, to be situated.

Mathura Kaits are allowed by all to be a chief class. The Unai is a half-caste, according to Elliot, but is not admitted by the Kayasthas as a Kayastha class at all. The Brahmans allege that the Unai are Brahmans who by trade lost their caste. Kayasthas are perhaps the most clearly demarked of existing castes, both as a whole and in their subdivisions.-Toy Cart; Witson's Glossary; Tr. of a Hindu; Sherving's Tribes; Dalton's Ethn.

KAYE. Charles Turton Kaye, a civil servant of the Government of India, in the Madras Presidency, who distinguished himself along with Mr. Brooke Cunliffe in the examination of the fossiliferous beds in the neighbourhood of Pondicherry. Born in London 1812, died 1846.

John William Kaye, K.C.S.I., F.R.S., went to India as a sub-lieutenant of the Bengal Artillery in 1833. Within a comparatively short time he wrote and published two novels. He became then a regular contributor to a weekly literary journal issuing from the Hurkaru press. Not long after he was installed as editor-in-chief of the Bengal Hurkaru, he retired from the army, and, during the remainder of his sojourn in India, continued its editor. He projected the Calcutta Review, of which he was proprietor and editor. He was the editor of the Overland Mail from its commencement in Cornhill in the year 1855 until the year 1868, and for many years he was also editor of the Homeward Mail newspaper. He was the biographer of Sir John Malcolm, and of Sir Charles Metcalfe, author of the War in Afghanistan, and the Sepoy War. He was employed in the Indian Office from 1855? till October 1874 , and died on the 24 th July 1875 ?

KAYEA STYLOSA. Thu: Soovanda, SiNGH. An elegant tree in the south of the island of Ceylon, at no great elevation. The timber is valued for building purposes. - Beddume, Fl. Syll: p. 102.

KAYLULAH. ARAB. The half-hour's siesta about noon is habitual, and Mahomed said of it, 'Kilu, fa inna sh' Shayatina la Takil,' 'Take the mid-day siesta, for verily the devils sleep not at this hour.' Aylulah is the sleeping after morning prayers, which causes heaviness and inability to work. Ghaylulah is the sleeping about 9 A.M., the effect of which is poverty and wretchedness. Kaylulah (with the guttural kaf) is sleeping before evening prayers, a practice reprobated in every part of the east. And, finally, Taylulah is sleeping immediately after sunset, also considered highly detrimental._Burtor's Mecca, ii. p. 49.

KAYN, adjoining Herat, is the first Persian province to the west of Furra, and lies on the frontiers of the kingrlom. It is entirely inhabited by Muhammadans of the Shiah sect, which has led the Turkoman tribes to seek for slaves in it during their chapao or forays. The inhabitants are a timid race, and live in small forts, the number of which is very great. The Kayn country is badly watered, and the ber tree, as in all arid countries, is common. Birjind and Kayn are the principal places.-Papers, East India, Kübul and Afghanistar, p. 135.

KAYU. MALAY. Wood, timber, a tree. It is always prefixed to the names of timber trees; hence-

Kayu amballo, a timber tree of Bawean.

Kayu-api-api, Rhizophora gymnorhiza, maugrove.

Kayu-arang, charcoal. 
Kayu balean wood is the most esteemed amongst the natives of Borneo, on account of its hardness and durability. The tree is of the largest size, of quick and vigorous growth, and abundant in the low damp forests in the neighbourhood of the sea and of large rivers. It is much used by the natives for posts of their houses, which amongst the Dyak are handed down from father to son for many generations. Posts, in the river for ages, are as bard when cut as those fresh taken from the forest. The water worm (teredo) attacks it. but does not cause it to rot. Under the earth it equally resists the effects of the atmosphere and white ants. This is sought after by the Chinese, and is a source of considerable trade.

Kayu bidarru, a beautiful yellow wood of Borneo, of a very agreeable odour. It is plentiful, and, being very hard and durable, is much esteemed for posts of houses and other underground purposes.

Kayu-bin, Terminalia chebula, Retz.

Kayu bintangur. Several kinds of the poon of India grow in Borneo. They are called by the natives bintangur, and are valued in shipbuilding. One seems to be Calophyllum inophyllum.

Kayu boka, or Amboyna wood, and the Lingoa wood of commerce, are the produce of the same trce, the Pterospermum Indicum. The tree throws out knotty excrescences or burrs, which are sawn off in slabs 2 to 4 feet long, and 2 to 8 inches thick, which are much esteemed for small boxes, writing-desks, and other ornamental fancy work. Of late years its estimation seems to have decreased in Europe, but it is still much valued by the Chinese. It is brought from Ceram, New Guinea, Aru, and other islands of the Moluccas. It resembles the hue of the yew, is very hard and full of curls, the colour being reddish-brown, varying to orange. In Singapore it is sold by weight. Large slabs are obtainable from the lower part of the tree by taking advantage of the spurs or lateral growths. They can sometimes be had as large as nine feet in diameter. It is very durable, takes a considerable polish, is very abundant, and may be had in any quantity.

Kayu bung ngat of Cochin-China, Emblic myrobalan.

Kayu dungun grows on the banks of rivers, and though the timber is soft, the large buttresslike supports at the base of the tree are very hard, and are valuable for gun-carriages and other purposes.

Kayu gadis wood possesses the flavour and qualities of the sassafras, and is used for the same purposes in medicine. It is very common in the plains near Bencoolen.

Kayu galiru is the eagle-wood, aloes-wood, Aquilaria agallocha, Roxb., agallocha wood, lignum aloes, agala wood, and calambak of commerce. If of good quality it should melt in the fire like wax, yielding an agreeable odour. A very high artificial value is placed on the better qualities of this product by the natives of the east; the first quality selling at $£ 40,16$ s. 8 d. per $133 \frac{1}{3}$ lbs. avoird. at Malacca, the second quality at $\mathfrak{L}_{25}, 10$ s. per $133 \frac{1}{3} \mathrm{lbs}$., and the third quality at $£ 3,2$ s. per $133 \frac{1}{3}$ lbs.

Kayu-jelutong is a large growing tree of Borneo, with verticillate leaves, and a bark which, on being wounded, emits plentifully a white milk, which is inspissated by boiling, but has not yet been discovered to be of any use. The timber it prodnces, though large, is not esteemed by the natives, on account of its early decay when exposed to the rain and sun. It is white, and, being very soft and easily worked, it is much used by the poorer Malays for the sides of their houses, which are protected from the rain by the overhanging roofs.

Kayu kapur, a close-grained and durable timber of Borneo, much valued for boat-building purposes.

Kayu kapur barus. The timber of the Kapur barus, or true camphor tree, known to botanists as the Dryobalanops camphora, Cole., is also esteemed, but, excepting when charged with the valuable drug, it does not emit the camphor smell, as does the timber of the Laurus camphora, of which the Chinese manufacture trunks and boxes, which preserve whatever is put into them from the attacks of insects of all kinds, particularly of the small ants, which are so troublesome in hot countries.

Kayu kudrang, a wood of Malacca, furnishes a yellow dye, sells at $12 \mathrm{~s}$. $6 \mathrm{~d}$. per $133 \frac{1}{3} \mathrm{lbs}$.

Kayu kutoh, or wooden gong, on which the Malay 'mata mata,' literally ' man with eyes,' or watchman, beats the hour. This instrument closely resembles the 'teponaztli,' an instrument still in use by the Indians in the Cordilleras of Mexico, the deep thudding sound of which may be heard a distance of several miles.

Kayu lakka or Kayu lakah, of Singapore, a red dye-wood, applicable to the same purpose as red sanders wood.

Kayu lakkar and Kerta ambuk are woods of Malacca, burned as incense.

Kayu-legi, Kayu-manis, Cassia lignea, bark of Cassia lignea.

Kayu maranti, MALAY, a quick-growing timber tree of Borneo. In grain it resembles cedar, and, like it, is of a reddish colour. It is much valued for making packing-cases, planks for the sides of houses, etc., and when protected from the weather it is a good and useful timber.

Kayu mencabang, or Mencabang pinang, is one of the trees which produce the vegetable tallow. It is plentiful in the forests, but would be more profitable for its fruit (which is small and produces good oil) than its timber, though for this it is also held in high esteem. The wood is closegrained, hard, of a reddish colour, ensily worked, and very durable. This tree differs from the others which produce the vegetable oil, in growing to a much greater height.

Kayu merbau is a fine durable timber, very useful in ship and house building, being easily worked and very durable.

Kayu middang bunga, a fawn-coloured wood of Singapore, not durable if exposed.

Kayu mungris, a fine large tree; is, while fresh, nearly as hard as the iron-wood, and more difficult to work, though it is very durable, but not so much so as the balean or iron-wood.

Kayu nan in Tavoy, Kaiyah in Moulmein, Tavoy red-wood, Syndesmus Tavoyana, is very abundant on the sea-coast from Amherst to Mergui ; also on banks of rivers in the province of Martaban near the sea. It is one of the best woods in the country for helves; tough, light, very durable, plentiful; long in the fibre, neither liable to split nor to warp nor to break readily. Used by Burmese for planes, spears, boats, stocks 
of guns, and all kinds of purposes. This wood is of a most beautiful colour, a combination of pink, cream colour, and red, and takes a very high polish.

Kayu neri is a very hard wood, growing with the mangrove in salt swamps. Its timber, which has a reddish appearance, is not large, but very abundant.

Kayu pindis or Kapini of Sumatra, a species of Metrosideros, is named also Kayu besi or ironwood, on account of its extraordinary hardness, as it turns the edge of cornmon tools.

Kayu-puteh, white wood, Arbor alba of Van Rumph, the Cajaput oil tree or Kayuputi tree, Melaleuca cajaputi.

Kayu rasak, a wood of Borneo, resembles the bintangur, is close-grained, strong, and tough, and is used for rudders, masts, and oars for the trading boats.

Kayu rungas, a red wood, handsomely veined, which takes a fine polish, and is much used at Singapore for the purposes of furniture-making. Like the ebony, it is only the old wood in the centre of the tree which is of a useful colour.

Kayu sappan, Cæsalpinia sappan.

Kayu sona, a timber tree, much used at Bawean in prahu and house-building.

Kayu umur panjaong, literally tree of long life, grows on Dempo Hill in Sumatra; it is about 6 feet high.

Kay-vang-dee, Cocr.-Chis., sassafras wood.

Kayu wali kukun, a wood of Java, is equal to the kusambi in weight, and exceeds it in hardness. It is employed for anchors, naves of wheels, machinery, etc.

Kayu wrang or bayur, a light and tolerably durable wood, is employed for masts and spars of small vessels; but the surface must be well covered with resinous substances to prevent it splitting.

Kayu-yndhan, CocH.-Chin., Santalum album.

Kay yoob, Buru., a tree of Moulmein. Its wood is used as an ordinary building material. -Cameron; Dance; Low's Sarawak; Calcutta Revieu:

KAZA. ArAB. Fate, death. Al-kaza wa-lkadar, fate and destiny. Many Muhammadans hold that fate is in some respects absolute and unchangeable ; in others, admitting of alteration. The former they call Al-kaza al-mahkam, and the latter Al-kaza al-mabram.

KAZA GADDA. TEL. Urginea Coromandelica, R. ; Scilla Indica, R. ii. p. 147. The same name, however, is applied to $\mathrm{U}$. Indica and to Ledebouria hyacurthoides, which all grow abundantly together on the sands near Masulipatam.

$\mathrm{KAZAK}$, a nomade race, known in Europe as the Cossack, and erroneously the Kirghiz, for the people only style themselves Kazak. They are extended through the northern desert lands of Central Asia. Like all the Turkoman, they have many subdivisions, with branches, families, and lines, but the European classification into Great, little, and Middle Hordes is unknown to them. Love of travel and war have often brought together the most distant branches, and whether on the shores of the Emba, or of the sea of Aral, whether in the environs of the Balkash and Alatau, there is little difference to be found in the dialects spoken by them. The Kazak first appeared in Transoxiana as an independent tribe, under the leadership of Tokel Sultan. Lewchine, in his Description des Hordes et des Steppes Kirghiz. Kazaks, p. 141, calls him Teokel Sultan. The Kazak seem to have assumed a threatening attitude in the steppes north of the Jaxartes some time before this, for as early as A.H. 941 (A.D. 1534) Ivan the Terrible received the following report from his envoy, Danila Gubine :- 'Et les Kazaks, sire, sont tres-forts, dit-on, et l'on dit, sire, qu'ils ont fait la guerre a Techkene (Tachkend), et les fils du roi de Techkene, dit-on, se sont battus avec ceux deux fois, et les Kazaks les ont battus' (Lewchine, p. 140). Tokel sent several embassies to Czar Fedor at Moscow, and appears to have been one of the most powerful of the Sultans of the Kazaks.

These rough warriors, who believed in the powers of their Yada tashi (magic stone) to control the elements, cure diseases, and ensure victory in battle, were sincerely devoted to their religion and to its priests.

Kazan, up to the middle of the 16 th century, was the advanced guard of the Tartar hordes. These wandering tribes which, profiting by division among the Russian princes, overcame and ravaged all Russia, weakened in their turn by division, fell back from the invaded territory, and only held their own on the Volga, from Kazan to Astracan, till they were utterly routed and brought under Russian sway by Ivan the Terrible. Even then, however, though their strength was broken, their spirit was untamed. The inen of high warrior caste who survived their defeat sought a refuge among their kindred tribes farther east, at Samarcand, Bokhara, and Khiva, where the Russians have now overtaken them; but the mere multitude, accustomed to their pastoral life on the steppes, laid aside without giving up their arms, passively accepted without formally acknowledging the Czar's sway, and abided in their tents. Kazan has a population of 90,000 to 100,000 inhabitants, one-fourth of whom are Tartars. They have distinct, if not separate, quarters, and mosques, and a burialground of their own. Some of the Kazan Tartars are men of great wealth, enterprising merchants, carrying on important trading operations with Central Asia, Persia, and China. Some of them are also great landowners, and they indifferently employ Tartars or Russians in their field work. The Kazan Tartars of the upper classes are among: the best educated and polished of Muhammadans. The Russian civil law does not in any manner interfere with their domestic arrangements.

Shades of differences are perceptible amongst them, scattered as they are so extensively through the northern desert lands of Central Asia. In manner of life and language, the Kazak is hardly to be distinguished from the Burut. In colour the Kazak women and young men have a white, almost a European, complexion, which darkens by exposure. The Kazak have the short neck of the Turanian race, so different from the longnecked Iranian, and they have thick-set, powerful frames, with large bones; head not very large; crown round, and more pointed than flat; eyes less almond-shaped, but awry and sparkling; prominent cheek-bones, pug noses, a broad flat forehead, and a larger chin than the Burut. Beard on chin thin, only hairs on both ends of the upper lip. They deem the Kalun Kazak women more beautiful than their own. The men in 
summer wear the Kalpak head-dress, and in winter the Tumak cap of fur covered with cloth and flaps. They are almost all Muhammadans, but, like all nomade tribes, are lax in their observances, for they retain much of the Shamanist belief which they held prior to their conversion some centuries before. Chiromancy, astrology, casting out devils, are common to all Muhammadans; but the Kazak draw omens from the burnt sacrifices, of the shoulder-blade and the twisting of the entrails.

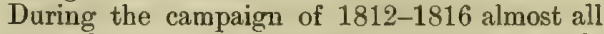
the population of the Kazaks of the Don capable of bearing arms were called forth; and about 50,000 may be computed to have fallen in that space of time. The quota of force which this branch of the Cossack nation furnished to Russia, for European and Asiatic service, amounted then to 80 regiments, each regiment numbering from 500 to 600 men.

The men of the Don are robust, fair, and handsome; hospitable, brave, honourable, and scrupulously religious. The female is short in stature, face of strong Tartar feature, with eye almost invariably large and dark. The dress of the women consists of a sort of chemisette (or small shift) of coloured linen buttoned round the neck, and with sleeves to the wrist. A pair of trousers of a similar stuff are covered by a silk caftan, reaching as low as the ankles. The waist is bound with a girdle. The heads of married women are adorned with a silken night-cap, which is wrapped about with a gaily-coloured handkerchief in the form of a fillet. The unmarried wear the hair in a long plait down their backs.-Vambery, Bokhara, p. 299 ; Porter's Travels.

KAZAMEEN, a town 3 miles $\mathrm{N}$. of Baghdad, and on the W. bank of the Tigris. It was inhabited at the beginning of the 19th century by about 8000 Persians, who had been induced to settle there on account of its being the buryingplace of Imam Musa Kassim (the father of Imam Raza) and Imam Muhammad Touky. MacGregor says it is a place of pilgrimage for Shiah Muhammadans from all parts, because of Imam Musa-ulKathem, son of the 8th Imam, Ali Raza, and Muhammad Taki, the grandson, being buried there. The town is inhabited by Arabs and Persians, and a few Shiahs from India.-Kinneir's Geog. Mem. p. 252 ; MacGregor.

KAZAN, an aucient capital of the Tartar monarchs, now a Russian province. It is inhabited by fragments of nations, Russian, Tartar, Chouvash, Chermes, Mordoa, Votiak, Kalmuk, Kirghiz, Bashkir, Noga, and Kazak.-Turnerelli's Kazan; Staunton's Narrative. See Kazak.

KAZEROON, once a considerable place, now in decay, lies in a valley on the road from Bushire to Shiraz. The entire southern region of Fars, bordering on the Persian Gulf, is called the Garm-sair. This region extends from the sea to the latitude of Kazeroon, and runs parallel with the Persian Gulf; from the banks of the Tab to the confines of Luristan, and from Bushire eastward as far as Cangoon, the tract is named the Dushtistan or 'land of plains.' The Tungistan, commonly pronounced T'ungistoon, or 'narrow land,' is a small tract of land east of Bushire. The greater portion of the people of the whole Garm-sair consists of an independent and lawless set, many of the tribes being robbers by profession. A huge wall of mountain separates the Garm-sair, or low region, from the Sard-sair, or high table-land of Persia. One of the most conspicuous of these is an abrupt lofty hill, named Hormooj, where coal is said to have been found. - Yule, Cathay, ii. p. 487.

KAZI or Kadi. ARAB. The chief judicial officer of Muhammadans. In British India he performs marriages. In a Muhammarlan country he decides in all cases of law, religious, moral, civil, and criminal. Kazi-ul-Kazaat, lit. Kazi of Kazis, chief-justice. 'The first who bore this title was Abu Yusuf under Harun-ur-Rashid. The Kazi or Kadi still retains great power in Turkey, though under the mufti, and among the Muhammadan states in India also he is the chief judge; but in Persia the kazi is considered as under the Shaikh-ul-Islam in all cities where that high office exists. In all patriarchal governments, particularly amongst the Arabs, the kazi has great power. The Imam of Muscat, a powerful prince, is compelled, by the usage of his country, to appear before the kazi, or judge, of his capital, if summoned by any one of his own subjects who deems himself aggrieved.-Malcolm's Persia, ii. pp. 248,$445 ; W$.

KAZI AHMAD - bin - NUHAMMAD - alGHAFFARI-al-KAZWINI. He went from Persia on a pilgrimage to $\mathrm{Mecca}$, and returned to Daibal in Sind, where he died A.H. 975 (A.D. 1567). He wrote the Nusakh-i-Jahan Ara, a useful compendium of history down to A.H. 972.-Elliot, Hist. of India.

KAZZAKI. HrND. A daka or burglary or highway robbery.-History of the Panjab, i. 143.

KAZZILBASH, a nartial tribe, numbers of whom have settled in Kābul. Their native country is the neighbourhood of ,Tabreez, Meshid, Kerman, and Shiraz, where they are horse-breeders, shepherds, and cultivators. A body of them werc serving in Nadir Shah's army at the time of his assassination, and on this event they retreated successfully to Kābul, under the command of Ahmad Shah, as he fought his way from Nadir's army. They are about 150,000 in number, a strength sufficient to hold their own in the many revolutions since Ahmad Shah's death. Lying to the west of the old city, between it and the river, lies the Chandol, once a village, now a suburb of the capital, and embraced within the limits of its defensive system. It is peopled by Kazzilbash. They are violent Shiahs, and bitterly opposed to their Daurani rulers, who are Sunnis ; but for all this they exercise great influence over the Afghan Sirdars. They constitute the bulk of the cavalry and artillery forces of the Amir, and a large number are found in British service. They possess some political power likewise, and as they are more or less educated, they are largely employed in secretarial duties by the various Sirdars. In the war of $1838-42$, the Kazzilbash were uniformly friendly to the British. A body of horse raised exclusively from this tribe accompanied Sir Richmond Shakespeare on his errand of mercy to the relief of Akbar Khan's captives.

KEANE. Lord John Keane, an officer of the British army, born 1781, was Commander-in-Chief, Bombay army, from $2 d$ July 1834 to 14 th February 1840. In 1839, commanded the army sent by the British against Afghanistan, then ruled by Dost 
Muhammad Khan. He led the army through the territories of Bahawulpur, skirted the Sikh possessions, crossed, near Sabzalkot, the frontier of Sind, and passed the Indus at Bukkur. The army was then led north-westerly though Shikarpur, Baug, Dadur, to the north of the Bolan pass, entering which it was harassed by Mehrab Khan, the chief of Kalat. The army with Shah Shuja-ul-Mulk was favourably received at Kandahar, and, after a halt there of two months, it recommenced its march on the 27 th June 1839 . On the $23 \mathrm{~d}$ of July it captured the fortress of Ghazni between 3 and 5 A.M., and on the 6th August it appeared before Kābul. Shah Shuja was declared ruler, and Dost Muhammad Khan fled. After this Sir John Keane returned to India, leaving an army of 8000 British sepoy soldiers at Kābul, and garrisons at Ghazni and Kandabar. In December 1839 he was raised to the peerage of Great Britain as Baron Keane. Died 24th August 1844.

A. H. Keane, in the latter part of the 19th century, a voluminous learned writer on educational, geographical, philological, and ethnological subjects, mostly relating to the countries of Eastern and Southern Asia, and to the races inhabiting them. Amongst others, on India and Further India, Afghanistan, Baluchistan, Persia, Turkey, Arabia; in 1882, an encyclopædic work on Asia, containing the results of the most recent researches; on the Indo-Chinese and InterOceanic Races and Languages, Types and Affinities; Philology and Ethnology of the Inter-Oceanic Races, with papers on Khorasan, Kbuzistan, and Baluchistan; Korean, Aino, and Afghan Ethnology; Malayo-Polynesian Linguistics; Hindustani Notes; on the Georgians, Kazak, Laos, and Turkoman; the Samoan Language,-as Sir Richard Temple says, all evincing a remarkably comprehensive knowledge of the ethnology and geography of Asia.

J. F. Keane travelled to Mecea in $1877-78$ as Haji Muhammad Amin; subsequently to Medina.

KEANG-SE is the eastern portion of the ancient province of Keang-nan, or Naukin, as known to Europeans. This ancient province was estimated to embrace a surface of 81,000 square miles, and its population was seventy millions. But now, in extent it is about three-fifths of the ancient province. The imperial canal traverses the whole extent from north to south, and the Yang-tzekiang from east to west.

KEAOU. The Chinese begin the day an hour before midnight, and divide the twenty-four hours into twelve parts of two hours each. Instead of numbering their hours, they give a different name to each period of two hours. The names and corresponding time, according to the English mode, are as follows :-

Tsze, . 11 to 1 Morning. / Woo, 11 to 1 Afternoon.

\begin{tabular}{ll|l} 
Chow, 1 to 3 & WVe, 1 to 3 \\
Yiu, 3 to $5 \quad$, & Shin, 3 to 5
\end{tabular}

Maou, : 5 to 7 " " $\quad$ Yew, 5 to 7 "

$\begin{array}{llll}\text { Shin, } 7 \text { to } 9 \quad " & \text { Seo, } 7 \text { to } 9 \\ \text { Sze, } 9 \text { to } 11 & \text { Hae, } 9 \text { to } 11\end{array}$

The word Keaou is added when the first hour of each period is intended, and Ching for the second. Thus, Keaou tsze is 11 at night, and Ching tsze 12 at night; Keaou chow, 1 in the morning, Ching chow, 2, etc. The word K'hih, 'quarter,' is used after the hour with the numerals yih 1 , urh 2 , or sau 3 , to subdivide the hours into quarters, which is the smallest division commonly employed: example, Ching maou yih k'hih, a quarter-past 6 ; Keaou woo urh $\mathrm{k}^{\prime} \mathrm{hih}$, half-past 11.

KEDAH or Quedah is called in Siamese Muang Sai, or the Sai kingdom. It extends from Trang river, in lat. $7^{\circ} 20^{\prime} \mathrm{N}$., to the Krian, in lat. $5^{\circ}$ $10^{\prime} \mathrm{N}$. The Trang formerly divided it from Siam. Several tribes are within its limits. The Semang and Udai reside in the forests of the north; the Rayat Utan, the Jakun, the Sakkye, Hala, Belanda, Besisik, and other's to the south; while the Akkye or Rayat Laut dwell upon the shores and islets of the Peninsula. Wherever scattered, they live totally apart from the Malays, and differ from them widely in person, habits, and religion. The Malays sometimes class them all as Orang Binua, men of the soil. The Panghulu of Rumbowe is chosen alternately from the Bodoanda Jakun and a Malay tribe.

The complexion of the Semang and Bila is black or sooty, the hair woolly, the features approaching to the African, and the stature dwarfish. An adult Semang male was found to be only 4 feet 9 inches high. Some of the Semang or Bila have fixed habitations, and practise a rude agriculture, but the majority lead an erratic life, gathering the rude products of the forest to exchange with the Malays for the necessaries of life, or subsisting by the chase The hair of the Semang is spiral, not woolly, and grows thickly on the head in tufts. They have thick moustaches, the growth being much stronger than in the Malay race. The expression of the face is mild, simple, and stupid. The voice is soft, low, nasal, and hollow, or cerebral. A line of tattooing extends from the forehead to the cheek-bones.

Semang Paya reside on the plains or edges of morasses; the Semang Bukit are the occupants of hills; the Semang Bakow are near the sea, in the creeks, and where the mangroves grow; the Semang Bila are partly civilised.

The Sakai and Allas tribes of Perak have curly but not woolly hair.

The Semang use the sumpitan, are skilful fowlers and hunters, and subsist on their game and on forest roots. They capture and eat the elephant, rhinoceros, monkeys, and rats.

Newbold (i. p. 421) remarked that the Semang and Udai are said to resemble the Papuan in colour, features, and hair, but adds that among all the tribes of these aborigines that had fallen under his notice, he had never met with the peculiar features that distinguish the Negro of Papua. In this remark he is not in accord with other observers.

According to Sir S. Raffles and Mr. Anderson, the Semang of Kedah has the woolly hair, protuberant belly, thick lips, black skin, flat nose, and receding forehead of the Papuan.

The people of Kedah more often approximate to the eastern Negro type than in southern Malaya, and Mr. Logan was particularly struck with the repeated occurrence of the deep nasal depression of the Semang, the Australians, and Papuans. Small heads, with all the features as it were contracted or compressed, were common.

KEDARIVATA, a fast for Hindu women in honour of Eswara.

KEDAR-KANTA, a mountain peak in Garhwal, elevation 12,541 feet, in lat. $31^{\circ} 1^{\prime} \mathrm{N}$., long. $78^{\circ}$ 
$14^{\prime} \mathrm{E}$. It separates the headwaters of the Jumna and the Tons.

KEDARNATH, in Garhwal, in lat. $30^{\circ} 44^{\prime} 10^{\prime \prime}$ N., long. $79^{\circ} 5^{\prime} 50^{\prime \prime} \mathrm{E}$., has a Hindu shrine devoted to Sadasheo, an incarnation of Siva, and situated within the Himalaya. Its rawal, like him of Bardarinath, is a Namburi Brahman. Pilgrims were wont to devote themselves to destruction here, by precipitating themselves from the summit of a snall rock, called by the people the BhairahJap, or by penetrating within the Himalaya until overwhelmed with snow. It is at the source of the Kali-Ganga, a stream far smaller than either the Bhagiruttee or Alacnunda, which joins the latter at Rooder-Prague. It is from Ke, SANSIs, water, and Dar, abounding with. It has one of the twelve great lingas of the Hindus, a shapeless mass of stone. With Kedarnath are included the four temples of Kalpeswar, Madmaheswar, Tungnāth, and Rudranath, forming the Panch Kedar containing the scattered portions of Siva's body.-Fraser's Himalaya Mountains, p. $381 ; D r . H . H$. Wilson's Hindu sects.

KEDARNATH, a temple at Porbandar. has a linga which was carried off from the temple of Naolakkha at Gumli.

KEDDAH. Hind, Corruption of Kheda, an enclosure into which wild elephants are driven; an elephant trap.

KEDGEREE, a hamlet on the left bank of the Hoogly river, in lat. $21^{\circ} 50^{\prime} 8^{\prime \prime} \mathrm{N}$.

KEDISH of Galilee was a băst or refuge city; sanctuary. See Bast.

KEDRON, a brook in Palestine, crossed by a bridge leading to the garden of Gethsemane. Kedron is a Hebrew word, signifying 'darkness' or 'sorrow ;' Gethsemane signifying 'wine-press.' On passing over the brook Kedron, and leaving the valley of Jehoshaphat on the right hand, the visitor ascends the Mount of Olives.-Robinson's 'Tr. i. p. 121 ; Skimer's Journey, i. p. 210.

KEEAR, in Cachar a land measure. 28 jeyt 1 keear; 12 keear 1 hull or koolba.

KEELING, CaPTAIN, commanded in the third voyage of the English East India Company's fleet in 1607. He tirst went to Surat, where he landed Mr. Finclı to form a factory, and sent Captain Hawkins, his second in command, on an embassy to the Great Moghul at Agra.

KEELING ISLANDS, also called Cocos, in the Indian Ocean, south of Sumatra, were discovered in 1608-9 by Captain W. Keeling, E.I.C. Service. Till 1823 they were little known, but then Alexander Hare established himself on the S.E. island with a party of Malays and Malay women. He was afterwards joined by Captain J. C. Ross. The South Keeling is a cluster of skeleton islets, rising about 20 feet above the sea, encircling a shallow lagoon of an oval form, about 9 miles long and 6 wide. The other islands are North Keeling, Selema or Fairlie Island, Burial, Ross, Water, Direction, and Horsburgh Islands. North Keeling is in lat. $11^{\circ} 50^{\prime} \mathrm{S}$., and long. $96^{\circ} 51^{\prime} 3^{\prime \prime}$ E. Fresh water is not scarce on the larger islands, and cocoanuts, pigs, poultry, pumpkins, turtle, maize, and sugar-cane may be procured. Captain, afterwards Admiral, Fitzroy observes that in these singular islands crabs eat cocoanuts, fish eat coral, dogs eatch fish, men ride on turtle; shells are dangerous man-traps, the greater part of the sea-fowl roost on branches, and many rats make their nests at the tops of high palm trees. Mr. Darwin found here evidence of subsidence ; earthquakes have been repeatedly felt; on every side of the lagoon, in which the water is as tranquil as in the most sheltered lake, old cocoanut trees were undermined and falling. The foundation posts of a stone house on the beach, which the inhabitants said had stood, seven years before, just above high-water mark, were then daily washed by the tide. The cocoanut crab, Birgus latro, hermit or robber crab of the Keeling Islands, is a kind of intermediate link between the short and long tailed crabs, and bears a great resemblance to the Paguri; they live on the cocoanuts that fall from the trees. The story of their climbing these palms and detaching the heavy nuts is merely a story. Its front pair of legs are terminated by very strong, heavy pincers, the last pair by others narrow and weak. To extract the nourishment, it tears off the fibrous husk, fibre by fibre, from that end in which the three eyes are situated, and then hammers upon one of them with its heavy claws until an opening is effected. It then, by its posterior pincers, extracts the white albuminous substance. It dwells in deep burrows, where it accumulates surprising quantities of picked fibre of cocoanut husks, on which it rests as on a bed. Its habits are diurnal, but every night it is said to pay a visit to the sea, perhaps to moisten its brauchiæ. It is very good to eat, and the great mass of fat accumulated under the tail of the larger ones sometimes yields, when melted, as much as a quart of limpid oil. They are esteemed great delicacies, and are fattened for the table.-Figuier; Bikmore, p. 149 ; Darwin, Voyage; Findlay.

KEENE, HENRY GEORGE, C.I.E., author of the Fall of the Moghul Empire; also the Administration of Indian Districts during the Revolt of the Bengal Army.

KEENGGREE, a musical instrument having three or four pumpkins, aud only two steel strings ; generally used by Hindus.

KEFFI, a green and yellow striped kerchief worn on the head by the Jehen tribe of Bedouin Arabs at Yambavi.-Mrs. Elluood's Letters.

KEFFING ISLANDS, a group of 17 islands in the Molucca sea, encircled by very extensive reefs projecting into deep water, rendering approach difficult. The cachalot or spermaceti whale abounds in the ocean, and might support an extensive fishery. Some of the islets are low, sandy, girdled by reefs, and, as in Ghissa, with a lagoon in the centre absolutely swarming with fish, while the shores are peopled by ducks and snipes. Keffing is also called Pulo Manok or Bird Island, and lies midway between Ceram and the Serwatty group. It is a high solitary mountain, resting on the bosom of the sea, with a truncated cone, desert, and the refuge only of myriads of birds, which deposit such vast quantities of eggs that many of the natives of the neighbouring isles visit the place and subsist for whole days on this wholesome food. Sulphur is also found on the rocks. The inhabitants resemble those of the S. coast of Ceram, and are not of the Papuan or Negro race; they are great traders, and constantly visit New Guinea and purchase birds of paradise, lory, crows, pigeons, megapodiidæ, and scented woods. The inhabitants of Motir are a gentle, 
potters, and supplying the neighbouring islands with vessels and utensils of various kinds made of red clay, elegantly moulded and of good quality. These compete in the markets of the Molucca sea with the plates and pans brought by the traders of Keffiug from the Ki Islands.-Kolff's Voyage; Darwin's Coral Reefs; Craufurd's "Ind. Arch. Temminck; As. Journ.; St. John's Ind. Arch. i. 142.

KEHAMA, a Hindu raja whose name is inmortalized in Southey's Curse of Kehama. By penance, he acquired supernatural power. His son Arvalau attempted to force Kaliyal, daughter of Jadurlad, and her father slew him with a stake, on which Kehama cursed him, but father and daughter escaped to Mount Meru, where Yedillian, wife of Ladurlad, rejoined him.

KEI. This group of ten islands adjoining the Aru Islands, is inhabited by the Arafura race, and the word Key, Kei, or Ki is prefixed to the names of all their villages. The Great Kei is about the size of T'anakeka, an island near Macassar. The men profess Muhammadanisu, but eat hog's flesh. In the island of Dori, the Papuans are called Myfore. They are about 5 feet 3 inches high, few attain 5 feet 6 inches. They wear their crisped bair its full length, and generally uncared for, which gives them a wild, scared appearance. The men, not the women, wear a comb. Amongst the Arafura or Papuan of $\mathrm{Ke}$, the women are not secluded, the children are merry, noisy, and have the nigger grin, and amongst the men is a noisy confusion of tongues and excitement on every occasion. The Ki form the northern of the southeasterly islands. The islands are covered with luxuriant forests, and produce maratigo and banyaro woods, well adapted for masts. They are occupied by two races, and it is the Papuan who make cocoanut oil, build boats, and make wooden bowls. Their boats are from small planked canoes to prahus of 20 to 30 tons burden. They build the skin first, and afterwards fit in the knees and bends and ribs. Money is not used, but every transaction is in kind. The Papuan wears a waistcloth of cotton or bark. The other race are $\mathrm{Mu}$ hammadans who were driven out of Banda, and wear cotton clothing. They are probably a brown race, more allied to Malays, but their mixed descendants have great varieties of hair, colour, and features, graduating between the Malay and Papuan tribes. The Cyphogastra calepyga, a beautiful species of the Buprestidæ, occurs here. The Carpophaga concinna occurs here, and in Banda, where it is called the nutmeg pigeon; also the butterfly orchis, here Phalænopsis grandiflora, and two large beetles, Therates labiata and Tricondyla aptera. T. labiata is ever on the watch, and from time to time emits an odour like otto of roses. T. aptera of the Malay Islands resembles a large ant more than an inch long, and is of a purple-black colour. It is wingless.-Bikmore; Wrillace.

KEIFIAT. ARAB. A kerchief used by the Arabs as a head covering. The aba or cameline, as it is styled in the Persian Gulf, and the Keifiat, are worn in Oman by all classes. It is a broad kerchief, striped green, red, and yellow, having the sides hanging down, with knotted strings appended to them, serving by their motion to keep off the flies, which are here excessively troublesome.-Wellsted's Tr. ii. p. 210.

KEILAMUHURTA, a Coorg festival held in
July and August, when all their arms are worshipped.

KEISH ISLAND, in the Persian Gulf, is 21 miles in circumference, well wooded, and from the sea the prettiest in the Gulf. There is plenty of good water, and some cultivation of barley and vegretables. The island is subject to the Shaikh of Canack on the mainland. The goats on this island were consecrated to Venus and Mercury in the time of Alexander, when Nearchus, with the Grecian fleet, cast anchor here; for the Catæa of his journal (preserved by Arrian) is Keis or Keish in the nomenclature of oriental geography: It is, however, said to have been named Keish since the 10th century, when one Keis, the son of a poor widow in Siras, embarked for India, with his sole property, a cat. There he fortunately arrived at a time when the palace was so infested by mice or rats that they invaded the king's food, and persons were employed to drive them from the royal banquet. Keis produced his cat, the noxious animals soon disappeared, and magnificent rewards were bestowed on the adventurer of Siras, who returned to that city, and afterwards, with his mother and brothers, settled in the island, which, from him, has been denominated Keis, or, according to the Persians, Keish. In countries widely separated, and in various languages, the same story has been related of different persons.-Ouseley's Travels, i. p. 170.

KEJ, the most western of the Kalat territories. Kej is called Mekran, sometimes also Kej Mekran, and is supposed to be the Gedrosia of the Greeks. It is inhabited by many tribes, of whom the Gitchki is the most numerous, but about half the population is a Muhammadan tribe called Ziggar. The maritime and fishing population of the little ports on the coast of Mekran from Sanmiani to Charbai, are denominated Med, and comprise four divisions, - the Guzbur, Hormari, Jellar-zai, and Chelmar-zai. Although often overrun by armies from Kalat, its subjection has been more nominal than real. A treaty was made with the naib of Kej, fakir Noor Muhammad, of the Bezunjo tribe, in 1862, by which he agreed, for an annual subsidy, to protect the Mekran telegraph which passes through his territories. The subsidy granted was Rs. 6000 , of which Rs. 1000 are paid to the chief of Pusnee. If the term $\mathrm{Kej}$ was in use anciently, it is likely to have given rise to the name Gedrosia.-Rennell's Memoir, 183; Treaties.

KEKIK, in lat. $1^{\circ} 83^{\prime} \mathrm{S}$, and long. $128^{\circ} 37 \prime^{\prime}$ E., is a high island in the Gilolo passage.

KEK-KIEO, of Ramree, is a lichen, doubtless Alectoria jubata, the Cornicularia jubata, Achard. It is gelatinous, and is eaten by the natives with rice.

KELA, a migratory people amongst the Uriya, who live by catching snakes, basket-making, etc.

KELAART, DR., a British medical officer of Ceylon, who paid much attention. to the natural history of the island.

KELINGU, Singh. ; Tamil, Kurung. In planting the seeds of the palmyra fruit, the germinating plant, in the first stage of its growth, is of the shape and dimensions of a parsnip, but of a more firm and waxy consistence. These are dried in the sun, and when dressed in slices form a palatable vegetable; esteemed a delicacy in the Tamil country, in Southern India, and in the south of 
Ceylon. The kelingu is reducible to a farina. It is an article of food in Ceylon, and is cultivated for that purpose; the seeds being sown in six to eight layers, under loose sandy soil. When fresh they are roasted, boiled, or sliced and fired like the bread-fruit. When it is to be kept, the parchment-like covering is removed, and they are dried in the sun, and kept under the name of Odial, and this when boiled is called Poolooc odial. When the odial is reduced to flour or meal, it is used to form the preparation of Cool of the Singhalese. The Singhalese also prepare from kelingu meal a dish called Putoo, which is occasionally eaten with rice, and also with jagari. It is made of prawns or fish, scrapings of cocoanut kernels, and unripe jack-fruit. It is the first shoot from the palmyra fruit, and is known locally as Ponnam kelingu. It is about the size of a common carrot, though nearly white. It forms an article of food among the natives for several months in the year; but Europeans dislike it from its being very bitter. Recent experiments have proved that a farina superior to arrowroot can be obtained from it, prepared in the same way; and 100 roots, costing $2 \frac{1}{2} \mathrm{~d}$., yield one and a half to two pounds of the flour.-Tennent; Simmonds; Seeman.

KELI-SHIN, a pass over the Kurdistan mountains leading from the plains of Azerbijan to the Rowandiz district of Kurdistan, and is the only line of intercommunication. The culminating point at Shaikhiwn is 10,568 feet. Great snow drifts occur in winter. Rowandiz is 75 miles N.E. of Mosul.-MacGregor.

KELLEK, ARAB., is a raft in use on the Tigris and Euphrates, nearly as long as it is broad. It is composed of goat-skins blown up, and fastened close together by reeds; this is strengthened by cross pieces of wood, and over these again are laid others to keep the bales of merchandise out of the water. The only fastenings of this raft are twigs. The skins are repaired and inflated afresh every evening, and duriug the day care is taken to keep them continually wet, which prevents their bursting. Those used by the Yezdi ferrymen on the Zab rivers, as described by Niebuhr, are composed of 32 bladder-shaped sheepskins, inflated with air; four of these are placed lengthways and eight in breadth, and on the oblong square thus formed a covering of planks is formed. The Kellek rafts are conducted by two long oars, the blades of which are made of pieces of split cane fastened together. The passengers arrange themselves as they can on the bales of goods; and if a person wish to be very much at bis ease, he procures a wooden bedstead covered over with a felt awning, which stands in the middle of the kellek, and serves him for a bed by night and a sitting-room by day. The historians of Alexander mention that the rafts on which that hero crossed the rivers of Central Asia were buoyed up with skins stuffed with straw; they were then, no doubt, as now, inflated with air; and it is thus that the Euphrates, the Tigris, the Karun, the Indus, the Oxus, and other rivers in $\Lambda$ sia are crossed. Besides the Kellek or raft, the Kufa or Gufa, a round-ribbed boat or coracle, is used on the Tigris and Euphrates, covered, not with skin, but bitumen. But of this the only valuable article is the bitumen; the ribs are of thin willow rods or the midrib of the frond of the date tree, and are useless if the boat be broken up. The rivers of the Peninsula of India, the Kistna, and Tumbudra are usually crossed in basket boats or coracles, with a framework of rattan covered on the outside with skins. But a single inflated skin, such as are used as buoys for nets on the east coast of Scotland, or a dried pumpkin, or a bundle of dry rushes, is used by individual travellers. On the Godavery, near the delta, a small double canoe is in use, the passenger sitting astride the connecting beam. The strata of rushes are evidently of the same kind as the vessels of bulrushes upon the water, alluded to in Isaiah xviii. 2. This peculiar mode of navigating that river is the same as was known to the ancients as the Navigia Conacia.-Rich's Kurdistan, ii. p. 128 ; Ferrier's Journ. p. 429 ; Mignan's Tr. pp. 23,423 .

KELON, of Kullu and Kangra, is the Cedrus deodara. The Kelon turpentine of commerce, or Kelon ka tel, is the oily product. The deodar or Himalayan cedar grows on the north slope of Dhaola Dhar, is a native of Kulu, and is also found in the Bunghalla forests. It is a tree of fast growth, and grows to a great height. Its wood is fragrant, of a reddish-yellow colour, highly resinous and inflammable; very durable, yields valuable timber; it is also not subject to warp. A thin oil exudes from the roots of the tree, which is held in much esteem as a cure for sores; it is also rubbed over inflated skins and on wood to preserve them. The wood is also used for flambeaux. In Kanawar it is the most valuable timber tree. It grows to 20 or 30 feet in circumference, and Gerard measured two trees of 33 and 34 feet, and had seen trees 150 feet high, and they may be 200. He supposed it to be the cedar of Lebanon. It is almost indestructible, and is used for beams of houses, temples, and especially granaries, as no insect touches it. This wood has an agreeable smell.

KELP or Barilla.

Wudasch, Kelp, . . Dut. | Sal de soda,. . . Pont. Soude, . . Fr. Sosa, . . SP. Aschensalz, : GER. Skottlandok soda : SW. Soda, IT.

Kelp, the ash of the common sea-wrack (Fucus vesiculosus, L.), with other species, burnt in the open air. It contains from 5 to 8.5 per cent. of carbonate of soda. The best kelp has an acrid, caustic taste, a sulphurous odour, is compact, and of a dark-blue greenish colour. It is used in the composition of soap, glass, etc.

KELT. Ernest Curtius is of opinion that the ancestors of the people of India, and of the Persian, Greek, Italian, German, Slave, and Kelt races, were originally one people dwelling in the uplands of Asia; and that the first to separate themselves from this united Aryan or Indo-European family, and to push their way into Europe, was the Kelt, who were followed by the German, and these by the Slave and Lett. The next great swarm that deserted the hive and left behind them the progenitors of the Medo-Persian and the Indian, was composed of the common ancestors of the Greek and Roman.

KELUMPIT. MaLAY. A very large tree of Singapore; sections are employed by the natives for cart-wheels.

KEM, a Turkoman clan in the valley of the Ettrek; formerly of the Yomut tribe, but now 
independent. They are greatly predatory. Collett, Khiva.

KEMANCHAH, the sitar of India and Persia. Those made at Shiraz are of tut or mulberry tree wood; the body (about eight inches in diameter) is globular, except at the mouth, over which is stretched and fixed by glue, a covering of parchment. But they are of various materials; often the body is merely a hollow gourd, or every part is richly inlaid and ornamented. They are sometimes made of the girdu or walnut tree wood.

KEMMENDINE, a village near Rangoon, taken 9th December 1824 by the British Indian army. It is now a part of the Rangoon cantonment.

KEMP, also Kempty, the coarse rough hairs of wool, which are avoided by the manufacturer in his purchases of wool, deteriorating as it does the appearance of even common fabrics by their inferiority and harshness, and not taking dye readily. The kemp of the Kashmir goats' wool is, however, made in to coarse cloth.-Simmonds' Dict.

KEN, an Egyptian goddess of Assyrian origin, the Astarte, Astaroth, and Mylitta of the Assyrians, Syrians, and Arabs. This divinity appears to have been introduced into the Egyptian pantheon in the time of the 18th dynasty, or at the commencement of the close connection between Assyria and Egypt. On comparing a representation of the goddess in the rock sculptures of Malthaigah with an Egyptian bas - relief in the British Museum, the mode of treating the subject is seen to be pearly the same. In both we have a female standing on a lion. The Egyptian figure holds two snakes and a flower, the stalks of which are twisted into the form of a ring; the Assyrian carries a ring alone. The flower resembles that borne by the winged figures in the place of Khorsabad, and is not found in the edifices of the first Assyrian period, where the flowers in the hands of a similar figure are of a different shape. For instance, the goddess Athor or Athy, Dr. Hinks reads the same name as that of the presiding divinity on the monuments of Assyria. Dr. Birch admits, in his observations on the cartouches, that the introduction of the Assyrian gods Baal and Astarte, of Renpu or Reseph, of Ken and Anata or Anaitis, can be traced to the 18 th and 19th dynasties, and is coeval with the epoch of the great conquests of Egypt in Central Asia. On a tablet at Turin she is called Atsh or Adesh, the name of the chief city of the Khitae, a Mesopotamian people attacked by the Ramessids (Prisse. Mon. PI. xxxvii.). She usually appears in a triad with Renpu and Khem or Chamno, also deities of Semitic extraction. The worship of the Sakti seems to have been introduced into India from the Egyptians and Assyrians, and the image of the Hindu Durga is unquestionably a modified type of Ken and Astarte. The image of Kali is an original of the Hindus, the worship of which is inculcated in the Upa Puranas, written at a considerably later period than the Puranas which first originated the present form of the idolatry of the Hindus.-Layard, Nineveh, ii. p. 213 ; Tr. of Hind. i. p. 37.

KENDULI, a village in the Birbhum district of Bengal, situated on the north bank of the Ajai, in lat. $23^{\circ} 38^{\prime} 30^{\prime \prime} \mathrm{N}$., long. $87^{\circ} 28^{\prime} 15^{\prime \prime} \mathrm{E}$. It is the native village of Jayadeva, a Vaishnavite reformer and Sanskrit poet, the author of the celebrated Gita Govinda, a Sanskrit poem in praise of Krishna.
An annual fair in honour of Jayadeva is held in the village on the last day of Magh (the commencement of February), and is attended by upwards of 50,000 persons. - Imp. Gaz.

KENERI (Kundari) is in the large island of Salsette, to the north of Bombay. Amongst the Buddhist caves in India, those of Keneri in Salsette are remarkable. T'hey are purely Buddhist, but inferior to those of Ajunta or Karli. They are excavated in a hill in the midst of an immense tract of forest country, and Mr. Fergusson supposes their date to be about the 9 th or 10 th century of the Christian era. The great chaitya at Keneri is regarded by him as a bad copy of that at Karli. A copper plate found in the relic chamber of one of the Keneri caves contains inscriptions in Old Pali. It is of the $2 d$ century B.C., about 100 years of the reign of the Trukudaka dynasty.

KENISAT-UI-KIAMAT, the Church of the Resurrection, commonly called the Holy Sepulchre. By the Arabs it is called Kenisat-al Komamat. This last word means a lay stall, in allusion to the place where the Holy Cross was found.-Robinson's Travels, i. p. 40.

KENJIU KASAWARA and Bunyiu Nanjio, two Buddhist priests of Japan, of the Shin-Shiu sect, of the monastery at Kioto, who about the year 1879 came to Oxford University in England to study Sanskrit. Kenjiu Kasawara returned to Japan in 1883, and died there, and Bunyiu Nanjio also returned in 1884. He had distinguished himself as a student in his monastery at Kioto by his knowledge of Chinese, which he speaks and writes like his native language. Some of his poems in Chinese are highly spoken of. He was selected, therefore, with one of his fellow-students, Kenjiu Kasawara, to proceed to England in order to learn English, and afterwards to devote himself to the study of Sanskrit, which took a great deal of time. While at Oxford he compiled a complete catalogue of the gigantic Canon of the Tripitaka or Three Baskets. It contains 1662 separate works. Besides this work, Bunyiu Nanjio and his friend Kenjiu Kasawara had prepared several Sanskrit texts for publication. Kenjiu Kasawara died soon after his return. Some of the shorter and more popular sacred texts have been published already by Mr. Bunyiu Nanjio and Professor Max Muller in the Anecdota Oxoniensia, such as the Vagrakkhedika, the Diamond-cutter, the Sulkavati-vyuha, the Description of the Land of Bliss.

KENKRA. HiND. The carapace or shell of the crab, used as a drug.

KENNEDY, GENERAL VANS, an officer of the Bombay army, born in Edinburgh in 1784, and died in Bombay 29th December 1846. In 1825 he published his Researches into the Origin and Affinities of the Principal Languages of Europe and Asia. Three years afterwards he put forth his Researches into the Nature and Affinity of Ancient and Hindu Mythology. Most of his other writings appeared in the Journals and Transactions of Societies.

KENSHI. JAPAN. A sheriff or witness to an execution.

KENTIA EXHORIZA, the Niu Sawa palm tree of Fiji. There are several other species of Kentia in New Guinea and Australasia.

KEONTHAL, one of the Panjab hill states. 
It lies around Simla station, between lat. $30^{\circ} 35^{\prime}$ $30^{\prime \prime}$ and $31^{\circ} 6^{\prime} \mathrm{N}$., and between long. $77^{\circ} 10^{\prime}$ and $77^{\circ} 25^{\prime}$ E. ; area, 116 square miles; estimated population in $1875,50,000$; the revenue in 1876 was estimated at $£ 6000$. Principal products, opium and grain. After the Gurkha war of 1818 , a portion of the Keonthal territory was sold to the maharaja of Patiala. The chief claims a Rajput origin. $\mathrm{He}$ is bound to render feudal service. In 1858 the chief was created a raja, and received a dress of honour worth 1000 rupees for his services during the nutinies. -Treaties, etc.; Imp. Gaz.

KEORI, in the N.W. Provinces, a caste of gardeners, cultivating the poppy, sugar-cane.

KEPPEL'S ISLE is from 10 to 12 miles in circumference, and distant from the mainland 6 miles. There are numbers of a singular fish, of the genus Chironectes, which leap with great activity over the mud, among the arched roots of the mangroves, among which are small crabs, Ocypoda, and Macrophthalmus. -Macgillivray's Voyage, i. p. 65 .

KERAIT, the royal dynastic tribe of Tartars to which Prester John belonged. Aung Khan of the Kerait Mongols, celebrated in Europe under the name of Prester John, was a contemporary of Chengiz Khan, whom, at the instigation of jealous enemies, he attempted, but failed, to destroy. Marco Polo states that Tenduc was the chief seat of Prester John when he ruled over the Tartars, and also the residence of his descendants in their reduced and subordinate position. Marco Polo says the Great Khans often gave their female relations in marriage to the kings of the Kerait or Prester John's line. And other intermarriages were frequent, e.q. the Christian mother of Gayuk Khan, and Dokuz-khatun, the Christian queen of Hulaku, were both princesses of the Kerait royal family, i.e. apparently of Prester John's. The mother of Hulaku was of the same family, and Chengiz, as well as several of his sons, took wives from it. On the destruction of the kingdom of the Kerait, a Kouriltai, or general assembly of the chiefs of all the hordes, was convoked. Vambery (p. 120) is inclined to regard Kerait as a Persian corruption of Kirit, meaning grey dog. Abul Ghazi says the word means whirlwind, but the names of most Turk tribes are taken from animals.-Elliot, p. 498; Marco Polo, ii. p. 50; Yule, Cathay, i. pp. 146, 147 ; Vambery.

KERALA, the land of cocoanuts. Keram, MALEAL., a cocoanut tree, a cocoanut; an ancient kingdom which extended from the Kangarote river in Canara in the north, to Cape Comorin in the south, with the Western Ghats as its boundary on the east. It thus included Malabar and Canara. This country, according to tradition, was miraculously reclaimed from the sea by Parasurama. In the 3d century B.C. (Asoka's edict), its king is called Keralamputra (Celobotras, Pliny; Kerabothrus, Ptolemy; Ceprobothrus, the Periplus). About the first or second century of the Christian era, a prince of the nortbern division of Kerala introduced into it a colony of Brahmaus from Hindustan, who divided it into sixty-four districts, and governed it by means of a general assembly of their caste, renting the lands to men of the inferior classes. The executive government was held by a Brahman, elected every three years, and assisted by a council of four of the same tribe. After a time, they appointed, as a chicf, one of the military class, and seem afterwards to have been under the protection of the Pandiyan kings. The language of the Kerala district is of the same stock as the Tamil, but the country does not appear ever to have been subject to the Chola kingdom. In the course of the 9th century. the southern part, that known as Malabar, revolted from its prince, who had become a Muhammadan, and broke up into many petty principalities; among the chief of which was that of the Zamorin, whom Vasco da Gama found in possession of Calicut in the end of the 15th century. Canara northern division seems to have established a dynasty of its own soon after the commencement of the Christian era, which lasted till the 12th century, when it was overthrown by the Bellal dynasty, and subsequently became subject to the rajas of Vijayanagar.-Eiplin. pp. 219, 220.

KERAN or Kran, a Persian silver coin worth about ninepence.-Simmonds' Dict.

KERANOH. HiND. Charity lands.

KERARI, Hindu worshippers of Devi in her terrific forms, and the representatives of the Aghora-Ghanta and Kapalika, who, so late as the 10th century, sacrificed human victims to Kali, Chamunda, Chinna Mastaka, and other hideous personifications of the Sakti of Siva. They are said, also, to have lacerated their own bodies, piercing their flesh with hooks, etc. -Wilsom, Hindu Sects.

KERBA. PushTU. A coarse cotton fabric manufactured in Afghanistan.

KERGUELEN LAND, a sterile island in the Southern Ocean.

KERKHAH is the ancient Choaspes. One of the most important of the water-courses of Khuzistan is the Kerkhah or Kerah, which begins to flow in three branches, all springing considerably eastward of Kermanshah. The first, and most inconsiderable, has its commencement about 25 miles west of Hamadan. A little south of the spot where the Kerkhah is joined by the Ab-iZal, are the remains of a bridge, and at one mile and a half from the celebrated ruins of ancient Shus or Sus, the Kerkhah bends a little west of south, and continues in this direction through the rich plain of Khuzistan, passing through the extensive marches which surround Hawiza, a commercial town of about 12,000 inhabitants; from thence it winds S.W., and falls into the Shat - ul - Arab, below Kurua, after a course of upwards of 500 miles.

KERKOOK, the Korkura of Ptolemy, is two miles to the vorth of Baghdad. Baba Goorgoor is the name given to a spot three miles from Kerkook, where, in a little circular plain, white with naphtha, flames of fire issue from many places. There appears to be little doubt, as D'Anville conjectures, that this is the Korkura of Ptolemy. The people of Kifri say that on the eve of Friday a little lamp is seen to burn of itself on the summit of the hills overlooking the plain: it is most probably a similar phenomenon to that of Baba Goorgoor. A celebrated doctor of Muhammadan law, surnamed Azam, or the honoured, is buried at this place.-Rich's Kurdistan, i. 44.

KERMANSHA $\mathrm{H}$, in lat. $34^{\circ} 26^{\prime} \mathrm{N}$., is a bandsome town, exhibiting the glittering domes of mosques within, and the battlements and towers of lofty walls without. Being erected on a south- 
western slope of the mountains, it commands a wide view of the vale; it is famous for an excellent manufactory of firearms; and the villages in its vicinity, for carpets of the most beautiful colours and fabric. Luxurious gardens surround the town, abundant in fruits of all kinds, but particularly in grapes of an exquisitely delicious muscatel flavour. The population amounts to about 15,000 families, some few of which are Christians and Jews. The mountain of Takht-iBostan forms a part of the chain of Be-Situn; and, like it, is craggy, barren, and terrific.Porter's Tr: ii. pp. 167-201; Ferrier's Jommey, 26.

KERMES, Coccus ilicis, Latr, is found in many parts of Asia. It lives on the Quercus coccifera, a small evergreen oak. With a solution of tin, its scarlet colour is equal to that of cochineal, but one part of the latter is equal to 10 or 12 parts of kermes.-Dr. T. L. Phipson, 40.

KEROSINE OIL is pre-eminently useful in the skin diseases of India, in itch, scald-head, lice in the head, ringworm, plant fly, and insects.

KERREH SAIDEH, known in Arabian geography as Khandak Sabur, Shahpur's ditch, is a bifurcation of the Euphrates, from near Hit, and after a course of several hundred miles enters the Persian Gulf by a separate mouth, rendering culturable a vast tract of ancient Chaldæa. Shahpur Dholactuf, in the 4 th century, either cut or re-opened this channel. He is said to have intended it as a defence against the Arabs.Rawlinson, i. p. 17.

KERROWLEE. This petty state, which paid a tribute of Rs. 25,000 to the peshwa, was cederl to the British Government by the 14th Article of the treaty of Poona in 1817. The maharaja had made over the village of Machulpore and its dependencies to the management of the peshwa in lieu of the tribute. In 1825, when Bulwant Singh, the legitimate heir to the state of Bhurtpur, was rebelled against by his cousin Durjun Sal, the rebel was supported by the maharaja of Kerrowlee. After several disputed successions, maharaja Mudden Pal succeeded in 1854. He rendered good service in the mutinies, in consideration of which the sum of Rs. $1,17,000$ due by bim to the British Government was remitted, and the maharaja received the right of adoption. The area of his state is 1878 square miles, and the population about 188,000 . The revenue from all sources is ouly about Rs. 3,00,000. The whole military force of the state is about 2000 men.-Treaties, iv. p. 99.

KESAR. HiND. Crocus sativus, saffrow. Kesara, a saffron-coloured robe worn by a Rajput when resolved to conquer or dic. Kesari rang, a saffron colour.-Wilson.

KESARI. BENG. A coarse grain of Hindustan, said to cause paralysis.

KESARI. The first glimmering of authentic history of Orissa occurred A.D. 473, when the Yavana are said to have been expelled by Yayati Kesari, and in the following 650 years, until A.D. 1131 , thirty-five rajas of the Kesari family follow. Their capital was then taken by a Ganga Vansa prince, whose dynasty occupied the throne until near the Muhammadan conquest. The Ganga Vansa seem to have been a dynasty from near the Ganges about Tamluk and Midnapur. They seem to have attained their highest prosperity towards the end of the 12 th century. They were succeeded by a Rajput family, and in the middle of the 15th century the Grovernment of Orissa sent armies as far south as Conjeveram, near Madras, and about the same time their raja advanced to the neighbourhood of Beder to aid the Hindu princes against the Mubammadans. The Orissa Goverument was invaded by Muhammadan armies from Bengal and from the Dekhan; it fell into confusion, was seized on in 1550 by a Teling chief, and ultimately was anmexed to the Moghul empire by Akbar in 1578.-Elphin. p. 223 ; Stirling: As. Pies. xv. p. 254.

KESARIYA. To the N. and N. W., distant 30 miles from Besarh, and somewhat less than two wiles to the south of the large village of Kesariya, stands a lofty brick wound capped by a solid brick tower of considerable size, supposed to be remains of ruins, occurring after the commencement of the Christian era. The Kesariya mound is 20 miles $\mathrm{N}$. of Bakhra, in sight of the Gandak river. It has an inscription in Sanskrit, of about the date of the Bakbra image inscription. The character used in the inscription is the same as the Sarmath and Bakhra character. The avatars and the sakta hymu of the Rig Veda are mentioned, but no invocation of Hindu gods named. Chandradatta, sun of Suryadatta, is mentioned. The inscription is imperfect, but the everliving Chandradatta was born on the Sunday appropriated to the readiug of the sakta by his fatuer Suryadatta. The sakta has for one of its verses the holy Gayatri. At Lauriya Aria-Raj, between Kesariya and Bettiah, at the distance of 20 miles to the N.W. of the Kesariya stupa, and one mile to the S.W. of the Hindu temple of Ara-Raj Mahadeo, there stands a lofty stone columm which bears in well-preserved and well-cut letters several of the edicts of king Asoka.-Beng. As. Soc. $J$. iv. pp. 128, 286.

KESAVA, a name of Vishnu or Krishna, means having fine hair or much hair. The word recurs in the Persian as Kesu, ringlet or forelock.

KESAVA or Kesi-raja, a Jaina; author of the S'abda-mani-darpanam, CAN., lit. the jewelled mirror of words, the most ancient and esteemed grammar of classical Canarese.

KESH, a town 36 miles south of Samarcand, 120 miles E. of Bokhara. It is the birthplace of Timur. Timur's fumous descendant Baber, the first Great Moghul, tells us that in spring the walls and terraces of the houses at Kesh are always green and cheerful. Timur and Baber both mention Kesh as Shahr Sabz, or the verdant city. Up to the time of the Samanides it was chiefly inhabited by Arabs of the tribe of Bekr-bin-Vail.-Markham's Embassy, p. $120 ;$ P. Arminius Vambery, Bokhara.

KESHAB CHANURA SEN, born A.D. 1838 , a theistic reformer of Hinduism. He joived the Adi Brahma Samāj in his 2uth year. He worked at first, for about five years, along with Debrendrahnath. He objected to caste and to caste restrictions, also to child marriages and polygamy. He acknowledged God as the first cause, and the immortality of the soul, and future rewards or punishments. He visited England in 1870. In 1879 he alleged having had a vision of Jesus, John the Baptist, and St. Paul. He died 8th January 1884. During his life, his eloquence, earnestuess, and mysticism led to the formation of many sects amongst the youth of India who 
bad been educated in Government schools. They were known as the Adi Samāj, the Sidhāran Samāj, the Bidhan Samāj, and in 1884 were 173 in number, sects diverging from the Brahma Samaij which Ram Mohun Roy founded. This may be only one of the many monotheistic movements which have occurred in India.

KESHKUL, the half of a cocoanut shell, in which alms are gathered. This and the Asi, or pilgrim's staff, are part of the insignia of a darvesh.-Vambery, Bokhara, p. 267. See Jhula.

KESRA or Kesri, a title which seems to have been indiscriminately applied to the later princes of the house of Sassan, and was probably derived from the Cæsars of the Romans; or the Khusru or Chosroes of the Persians. The title was certainly given to two dynasties of Persia.

KESTREL, Tinnunculus alaudarius, and the sparrow-hawk (Accipiter virgatus), are common iu India. The former may be observed hovering over the plains, and at dusk, not unfrequently in numbers, perched on stones and tufts of grass. Both prey extensively on mice, lizards, and beetles. The latter hawk is trained for quailhunting. $\Lambda$ bout Dugshai, the lesser kestrel, Tinnunculus cenchris, may be seen in numbers hovering over the sides of the mountains and the little terraced fields in quest of beetles and large insects.-Adams.

KETAS. Singhapura, mentioned by the Chinese pilgrim Hiwen Thsang, is supposed by General Cunningham to be the modern Ketas. Ketas is situated on the north side of the Salt Range, at 16 miles from Pind Dadan Khan, and 18 miles from Chakowal, but not more than 85 miles from Shahdheri or Taxila. And as there are no clear pools swarming with fish in the Balnath Range, he had little hesitation in identifying the place described by Hiwen Thsang with the beautiful limpid pool of Ketas, which has been esteemed holy from time immemorial.Cunningham, Ancient Geog. of India, p. 126.

KETU, in astronomy, the descending node, represented by a dragon's tail. Ketu, in Hindu popular belief, an imaginary planet, said to cause the eclipses of the sun and the moon. See Graha; Rahu.

KEU JIN. Chin. A literary degree, equal to M.A., meaning elevated man.

KEUNJHAR, a tributary State of Orissa, lying between lat. $21^{\circ} 1^{\prime}$ and $22^{\circ} 9^{\prime} 30^{\prime \prime} \mathrm{N}$, , and long. $85^{\circ} 14^{\prime}$ and $86^{\circ} 24^{\prime} 35^{\prime \prime} \mathrm{E}$. Bounded on the north by Singbhum district, on the east by Morbhanj State and Balasor district, on the south by Cuttack district and Dhenkanal State. Its river, the Baitarani, takes its rise in the hilly northwestern division. There are peaks rising from 1818 to 3479 feet. The Hindus numbered 113,207. The aboriginal tribes in the year 1872 numbered 44,438 , about a fourth part of the population; and the semi-Hinduized, 49,294 . $37 \cdot 5$ per cent. of the population are aborigines, who retain their primitive forms of faith.

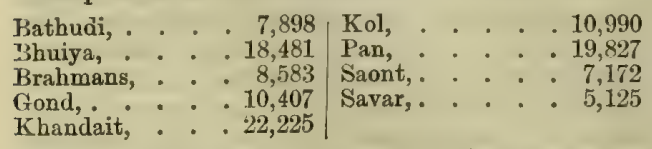

It is one of the chief seats of the Bhuiya or Bhumiya, who are still dominant there. The Bhuiya of the plains, including the Saont, a thoroughly Hinduized portion of the tribe, hold their lands on conditions of service. They maintained themselves in a state of preparation for taking the field at a moment's notice.

In Keunjhar, the Bhuiya are divided into four clans, viz. the dominant Raj-Kula Bhuiya, the Mal or Desh Bhuiya or Desh-log or Desh-lok, the Dandsena, and the Khatti. The Pawri claim to be the prior settlers in Keunjhar, and the prerogative of installing every new raja on his accession belongs to them. As a part of the form of installation, a sword is placed in the raja's hands, and one of the Bhuiya comes before him, and, kneeling sideways, the raja touches him on the neck with the weapon. The family of the Kopat hold their lands on the condition that the victim, when required, shall be produced. The victim hurriedly arises after the accolade, disappears, and must not be seen for three days; then he presents himself again to the raja as miraculously restored to life.

The sixty cbiefs of the Pawri Desh, the Bhuiya highlands, have from time to time assumed the government, and the country may be sair to be then ruled by an oligarchy. In their name, a knotted string is passed through the country, and the verbal message communicated in connection with it is implicitly obeyed.

A Government elephant (Kheda) establishment is maintained at Keunjhar (1875) under the superintendence of an English officer, and a large number of valuable animals are captured.-Imp. Gaz.; Dalton's Ethnology.

KEWOT, in Bengal, a fowler, a fisherman. A Hindu may fish for sport without loss of dignity, and people of caste may catch fish for their meals in baskets, traps, etc., but the man who makes it his profession is a degraded creature.

KHA-CHAN-YUL, Trz., Snow-land, or Ladakb, is the A-Khassa regio of Ptolemy. It is supposed by Major Cunningharn to be the Kie-Chba of the Chinese pilgrim Fa Hian. Ladakh is also known as Kha-pa-Chan, abounding in snow, or Kha-Chan or snow-land, and the people as Kha-pa-Chan-pa or Kha-Chan-pa, men of the snowy land.Cunninglam's Ladaki.

KHACHEE. HiND. The flats of Sind.

KHAD. The Sherwani occupy exclusively Khad and Kishna, and reside with other tribes in Shal and Mastung. They take their name from their belief that they came from Sherwan on the Caspian. See Baluch.

KHAD. HrND. A precipitous hollow or ravine.

KHADAR. HIND. Lowlands with alluvial soil, lying along the banks of rivers, especially suitable for rice cultivation, easily irrigated, and more or less subject to overflowing.

KHADI. TAM. A kind of coarse cloth.

KHADIJAH, Ayasha, Maria, and Zainab, the wives of Mahomed.

KHADIM. ARAB. Servant; and in India applied to persons in charge of tombs, mosques, etc. In Arabia, it is a term applied to the servile races, and thereby denoting that they are politically and socially inferior to the native Arab. They are only to be found in Yemen, and do not extend farther than the country of the Aseer on the north, and Balad-ul-Jehaf on the east,-in fact, in that part of the country which included the dominions proper of the ancient Himyarite 
Tobba. Physically, they differ considerably from the Arabs, and bear a resemblance to the races which inhabit the African coast. They have smooth hair, with a very dark complexion; their nose is aquiline, their lips thick; their stature is greater than that of the Arab; the latter are thin and angular, the former rounded, with a predisposition to obesity. They are considered in Yemen in the same light as are the Pariah of India. They are not admitted to eat with Arabs, nor can a Khadim marry an Arab woman. They are musicians, blacksmiths, public criers, etc., and their women have usually a lower stamp of character than the men; considerable numbers flock to Aden. It has been suggested that they are the remnant of the ancient Himyarites, or the descendants of the Persian conquerors of Yemen, but the legend related to M. d'Arnaud is probably more near the truth. It is as follows: - When the Arabs succeeded in shaking off the Abyssinian yoke (which they did with the assistance of the Persians), a number of Ethiopian families were scattered over the country. The Arabs, in order to perpetuate the remembrance of their victory, condemned them to the condition of serfs. Their chief men were subjected to a more infamous degradation, - they became barbers from fatber to son.' Khadima, a woman-servant.

The wages of such male servants are in many eastern countries very small, but they receive many presents, and this habit of irregular remuneration in lieu of fixed wages has been held by some observers to lead to the preservation of those domestic relations that exist there between masters and servants. In some respects they are often familiar in their manners to their master, oven laughing and joking with him. In others, they are very submissive, paying him the utmost honour, and bearing corporal chastisement from his hand with childlike patience.-D'Arnaud's les Akhdam de l'Yemen in Playfair's Aden; Lane's Modern Egyptians ; Urquhart's Spirit of the East.

KHAF, a town in Khorasan, $\mathbf{1 1 2}$ miles west of Herat, and 88 miles south-east of Turbat-iHaidari. It is between Turskish and Herat, and south of the road which leads from Mashed to that city, is the district of Khaf. It is a miserable tract, with a climate very uncongenial from high winds. It has been nearly depopulated by the Turkoman. The east Iranians are $(a)$ the Segestani or Khafi; (b) Char Aimak; (c) Tajak and Sart, each of which counts many subdivisions. The principal number of the Segestan people occupy Khaf and its neighbourhood Ruy, Tebbes, and Birjan.

KHAFTAN. PERS. A short cloak worn in Käbul and on the frontier, with a hood.

KHAG. HIND. The horn of a rhinoceros; also a village boundary mark, of a pillar or mound. $W$.

KHAGAN, a village in lat. $34^{\circ} 46^{\prime} 45^{\prime \prime} \mathrm{N}$., and long. $75^{\circ} 14^{\prime} 15^{\prime \prime} \mathrm{E}$., in a mountain valley in the Hazara district of the Panjab, 60 miles long and 15 broad, stretching into the mountain region. It is the most northern part of British India.

KHAH. PANJ. A stout cloth made of asses? hair in Amritsar.

KHAIBAR or Khybar, a pass leading from the Peshawur district of the Panjab into Afghanistan : centre of pass being in lat. $34^{\circ} 6^{\prime} \mathrm{N}$., and long. $71^{\circ} 5^{\prime}$ E. The Khaibar pass commences near
Jamrud, to the west of Peshawur, and twines through the hills for about 33 miles in a northwesterly direction, till it debouches at Dhaka. Jamrud is 1670 feet above the sea; Ali Masjid, 2433 ; Landi Khana, 2488; Landi Kotal, 3373 ; Dhaka, 1404. Mr. Scott, of the Survey, says the elevation of Jamrud is 2433 feet, and if so, all these figures would be increased by 763 feet.

The Khybar (Khaibar) pass is the most northerly of the passes leading between Afghanistan and British India; those to the south are the Kurum, the Gumal, and the Bolan. The Khaibar pass rises gradually from the east, but has a steep declivity westward. At Ali Masjid it is merely the bed of a rivulet, with precipices rising on each side at an angle of $70^{\circ}$. Near Landi Khana, it is a gallery 12 feet wide; on one side a perpendicular wall, and on the othex a deep precipice; and as it approaches the Kābul territory it becomes more formidable. Nadir Shah paid a sum of money to secure his passage through it. It was forced by General Pollock on the 5th April 1842, and has been repeatedly occupied by the Rritish since then.

Upon Ranjit Siugh's excursion to Peshawur, the Khaibari opened the bands or barriers of the Bara river, and inundated his camp by night, and, profiting by the consequent confusion, they carried off much spoil and many horses. The maharaja then precipitately left for Lahore, having made only a stay of three days. Of the Khaibar tribes proper there are three great divisions, - the Afridi, the Shinwari, and the Orakzai. Of these, the Afridi, in their present locality, are the more numerous; the Shinwari, more disposed to the arts and traffic; and the Orakzai, the more orderly. The Afridi occupy the eastern parts of the hills nearest Peshawur, and the Shinwari the western parts looking upon the valley of Jalalabad. The Orakzai reside in Tirah, intermingled with the Afridi, and some of them are found in the hills S.W. of Peshawur. It was a malik of this tribe who conducted Nadir Shah and a force of cavalry by the route of Chura and Tirah to Peshawur, when the principal road through the hills was defended against him. The Shinwari, besides their portion of the hills, have the lands immediately west of them, and some of the valleys of the Safed Koh range. More westerly still, under the same hill range, they are found south of Jalalabad, and are there neighbours of the Khogani. There are also some of them in Ghorband, and they dwell in great numbers bordering on Bajor to the northwest, where they are independent, and engaged in constant hostilities with the tribes of Bajor and of Katiristan. The Khaibari, like other rude Pathan tribes, have their malik or chiefs, but the authority of these is very limited, and every individual has a voice in public affairs, and it often hrppens that a nanawati, or deliberation on any business, terminates in strife amongst themselves. The portions of the Afridi and Shinwari tribes who inhabit the defiles of Khaibar, through which the road leads from Peshawur to the. Jalalabad valley, are but inconsiderable as to numbers. Under the Saddozai princes, they received an annual allowance of $\mathrm{Rs} .12,000$ on condition of keeping the road through their country open, and abstaining from plunder. They called themselves, therefore, the servants of the king. It is boasted that the Afridi tribe can muster 40,000 fighting 
men. On various occasions, when their strength has been exhibited, from 2000 to 5000 men assembled. The Khaibar mountains appear at first irregularly grouped, but the distinct arrangement of a chain is afterwards observable. The hills generally consist of slate and limestone, with overlying sandstowe. There are four passes through this range. Like all roads through ranges of mountains, the Khaibar pass is chiefly the bed of a torrent, liable to be filled by a sudden fall of rain, but at the other times dry, with the exception of a winding rill supplied by springs. The water is said to be unwholesome.

The Shinwari have eight clans. Of these, the Zakha are the more powerful in fighting strength, and the Kuki can bring into the field more than 3000 men. The combined force of these two clans would muster close on 10,000 men; but they are scattered over a very considerable tract of country. The Kuki dwell nearest the frontier, their permanent home is in the Bara valley, which would afford an admirable hill station for European troops. During the winter the Kuki move down from this exposed position and establish their quarters at and near the eastern entrance to the Khaibar, which they occupy as far as Ali Masjid and the caves of Kajurnai. The Kuki have earned during the last 20 years a reputation for friendliness. Their principal trade consists in supplying frontier stations with firewood. The Zakba have always been noted for their cunning and boldness as marauders. Holding the northern sides of the Khaibar to as far as Landi Kotal, they have ever taken the lead in all the hostile acts to travellers and trade which bave earned for the Khaibar such a sinister reputation. The treaty of Gandamak, in May 1879, left the Khaibar tribes for the future under British control. $-H$. and N.W. F. ii. p. 126-135; Imp. Gaz.; Vigne's Personal Narrative, p. 232 ; Masson's Journey, i. pp. 174181; Moorcroft's Travels, i. p. 358; Mohun Lal's Travels, p. 343.

KHAI-KHIEIV of Assam, a bright yellow root of a creeper.

KHAIRABAD, the principal town of the Sitapur district of Oudh, situated 5 miles south-east of Sitapur, the civil station and cantonment of the district, in lat. $27^{\circ} 31^{\prime} 30^{\prime \prime} \mathrm{N}$., and long. $80^{\circ}$ $47^{\prime} 35^{\prime \prime} \mathrm{E}$. The pargana was originally in the possession of the Pasi tribe, who were ousted by the Bais and Kayasths; but their descendants still hold many villages in the pargana. $-I m p$. Gaz.

KHAIRABAD, a large village, now in ruins. The river of Khairabad issues from the Snowy Range in an E.N.E. direction. It has a broad and pretty deep bed. It is the Ab-i-Shirin (sweet water) meutioned in Timur's route, perbaps the Arosis of the ancients, and the river of Hindian of the present day; the Hindian also, but erroneously, is called the Tab. From the Khairabad river to Behbehan is a distance of three farsang (eleven miles); the first in a north-west direction, across a very rugged country, abounding in selenite or foliated gypsum; the two last, westward, over a level, well-cultivated country.-De Bode's Luristan, pp. 260, 261.

KHAIRAGARH, a tributary State in the Raipur district of the Central Provinces; the ruling family is Raj Gond, related to the Garha Mandla family. Area, 940 square miles; population, in 1872, 122,264.-Hunter.

KHAIRAT. Arab, Hind, Pers. Charity, alms.

KHAIRPUR, chief town of the Khairpur State, Sind, situated on the Mirwah canal, about 15 miles east of the river Indus ; lat. $27^{\circ} 31^{\prime} 30^{\prime \prime}$ N., and long. $68^{\circ} 48^{\prime} 30^{\prime \prime} \mathrm{E}$. The State belonging to the Talpur family is 120 miles long and 70 broad. It consists of a great alluvial plain bordering on the Indus, and watered by canals. Population (1872), 130,350. With the exception of the fertile strip watered by the Indus and the Eastern Nara (a canal which follows an old bed of the Indus), the remainder of the area is a continuous series of sandhill ridges covered with a stunted brushwood, where cultivation is altogether impossible. The country generally is exceedingly arid, sterile, and desolate in aspect.

The Hindu inhabitants are principally Soda Thakurs or Rajputs, who inhabit the extreme eastern part of the State.-Imp. Gaz.

KHAISA GHAR, or the Takht-i-Suliman, is seen to the west of Dehra. It is a magnificent hill, famed in traditionary lore as the spot on which the ark rested, and for being the parent seat of the Afghan races. Its habitable parts are occupied by the Sherani, who also hold the inferior hills between it and the plains. They have for neighbours the Mikrani, their colleagues in marauding expeditions, and of equally infamous reputation.-Masson's Journeys, i. p. 47.

KH'AJA. PERS. Often written and pronounced Kh'waja and Khoja, a man of distinction, a rich merchant, a doctor, a teacher, a schoolmaster. Kh'aja - sara, a domestic servant, a eunuch. Kh'aja kardan, to castrate. It is sometimes prefixed to an individual's name, as the English word master, or is addressed to a person, as we should say, sir. It is the Cojia of the Arabian Nights, often now written Khoja. The term has not been much introduced into the Hindustani language of India, and is only used as a prefix to the names of certain Muhammadan saints, and under the pronunciation of Khoja to all eunuchs, who are also styled Aga.

KHAJA or Khoja is a titular appellation of a sect of Muhaminadans, who say that they emigrated from Persia. They are a sect of Ismaili Muhammadans, are therefore heterodox Shiahs; for, while the Ismaili believes only in seven Imam, the Khaja contiuues the line down to the present day. Aga Khan. who was a pensioner of the British Goverument at Bombay, was their Imam. He died April 1881, aged 81, and was succeeded by his son. They reject Abubakr, Umar, and Usinan, and reverence Ali, Hasan, Husain, Zainul-Abidin, Muhammad-i-Bakr, and Imam Jafari-Sadiq. They are in general illiterate, but have invented a written character for themselves, in which they have transcribed the Koran. Sir Erskine Perry, however, says the Khaja race, by their own traditions, were converted from Hinduism about 400 years ago by a Pir named Sudr Din (Qu. Sadr-ud-Din), and it is stated that the Bhattya is the Hindu clan from which they were converted. Aga Khan, who claimed to be head of the tribe, was a pretender to the throne of Persia, and afterwards headed a body of free lances, with whom he did good service along with 
the troops under Sir Charles Napier. When he claimed tribute as head of the Khajas, he had to show his pedigree and prove his descent. It was men of this sect who so kindly assisted Mr. Stanley when on his search for Livingstone.

'The Shial branch of the Muhammadan creed, whenever settled amongst anti-religionists, always hold as a tenet. and rigidly adhere to the practice called Takeyyah, i.e. the systematic concealment of everything that concerns their faith, history, customs, and, in a word, any peculiarities the disclosure of which might be attended with unpleasant consequences. In Bombay they are, generally speaking, wealthy traders, and their influence is not to be measured by their numbers, which are only estimated at 1400 families in and around the city of Bombay. In Kattyawar they have some 5000 families, in Sind 3000 . Cutch is another great Khaja centre. They have 800 or 900 families at Zanzibar, the trade of which thriving island is mainly in their hands; and all along the seaboard of Eastern Africa, Eastern Arabia, and on both sides of the Persian Gulf, the Khaja have established themselves in regular colonies. The book which from the beginning has been their accepted scripture, was given them by Pir Sudr Din, through whom they were converted, and contains in its ten chapters an account of ten incarnations. The first nine treat of the incarnation of Vishnu, the tenth of the incarnation of the Most Holy Ali. Their religion is consequently a strange jumble of creeds, and it is said that the majority of Khaja refuse to believe in the etticacy of prayer. The idea of the incarnation of Aga Khan had of late years been almost entirely confived to the women of the community, and had led, it is rumoured, to curious customs.

'The annual tribute Aga Khan received from his followers in Bombay alone amounted to a lakh of rupees. From time to time an effort to escape this heavy tax has been made by the more venturesome members of the community. About 1850, four Khojas, who disputed the supremacy of the Aga, were murdered in the streets of Mahin. But the murderers were hanged, and since then the Khoja people have fought for their rights only with such weapons as bills in the English Supreme Court of Bombay, replications and rejoinders drawn up by English counsel learned in the law, caste meetings and ont-castings after the orthodox Hindu fashion. In a famous trial of 1866 the rights of Aga Khan as spiritual head of the Khaja community were established, as well as his power to initiate senteuces of exconmmunication. But the question was revivel with reference to a Khaja murder case of 1878, and a Commission was then appointed by Government to examine the claims of the increasing body of dissentients, and to draw up fresh rules and regulations for the guidance alike of the ruler and the ruled. The Commission had no very practical result. Agin Ali Shah succeeded to the anomalous position occupied by his father. - Burton's Scinde; Bird's Eye licvieu.

KHAJA, a pedlar race of the Panjab, probably the Khoja sect of Sind and the Bombay Presidency, industrious and straightforward dealers. The first of them established a good business by selling cloth among the villages on the Simla road. Then, with introductions from Ambala native firms, they began a connection with wholesale merchants in Debli. The Khaja travel in small bands under a jemadar or headman, who is usually allowed credit to the extent of 25 per cent. on his cash purchases. They visit the villages in the winter months, and give credit to any villager to whose identity and respectability the patel testifies. In the harvest time they return to collect their accounts, and by May they are to be found at home, -in Gujerat and Sialkot. 'The Khaja are said to be scrupulously punctual in their payments to the Dehli firms, and their agents in Calcutta and Bombay, to whom they introduce themselves by letters from the imperial city. Should a jemadar fail to meet his obligations, his brother-traders subscribe the amount. No accusation of usurious practices is made against them, and their books are freely open for inspection. There are eight hundred pedlars in the trade.

KHAJA APPAK. The rulers of Eastern Turkestan have always been Muhammadan from the time of Taghalaq Timur, who was, we are told, the first Muhammadan sovereign of Kashgar of the lineage of Chengiz. Buddhism indeed was found still prevalent in the cities of Turfan and Kamil at the time of the embassy of Shah Rukh in 1419, and probably did not become extinct much before the end of the century. But, in the western states, Muhammadanisn seems to have been universal from an earlier date, and maintained with fanatical zeal. Saintly teachers and workers of miracles, claiming descent from Mahomed, and known as Khaja or Khoja, acquired great influence, and the secretaries attached to the chiefs of these divided the people into rival factions, whose mutual hostility eventually led to the subjugation of the whole country. For, late in the seventeenth century, Khaja Appik, the leader of one of those parties called the IVhite Mountain (having been expelled from Kashgar by Ismail Khan, the chief of that state, who was a zealous supporter of the opposite party or Black Mountain), sought the aid of Galdan Khan, sovereign of the Eleuth or Kalmuk of Zangaria. Taking the occasion so afforded, that chief in $1678 \mathrm{in-}$ vaded the states south of the Tian Shan, carried off the Khan of Kashgar and his family, and established the Kliaja of the White Mountain over the country in authority subordinate to his own. Great discords for many years succeeded, sometimes one, sometimes another, being uppermost, but some supremacy always continuing to be exercised by the khans of Zangaria. In 1757 the latter country was conquered by the Chinese, who, in the following year, making a tool of the White party, which was then in opposition, succeeded in bringing the states of Turkestan also under their rule.-Yule, Cathay, ii. p. 357.

KHAJA BAHA-ud-DIN, of Nakshband, instituted a class of Muhammadan mendicants or fakirs, who go about with a lighted lamp in one hand and sing verses in homour of their prophet. They are called Nakshbandi fakir. He took the appellation of Khaja Nakshband, and was tl.e founder of the order of Nakshbandi darveshes which still prevail in India, Turkey, and Tartary. His descendants to this day generally prefix the word Khaja to their names, and distinguish themselv $\in \mathbb{S}$ by the appellation of Nakshbandi. Khaja is a 
term of honour usually applied to persons who are eminent either for their sanctity or learning. The literal meaning of Nakshband is fixing an impression; and the term was figuratively adopted by Baha-ud-Din.-Wils.

KHAJA BANDA NATVAZ, the name of a Muhammadan saint.

KHAJA KHIZR. In Bengal, Muhammadan women, on the last Thursday of the month Bhadon, set afloat a small raft, bearing a paper or tinsel boat, in hovour of Khaja Khizr, in fulfilment of a vow. It is sometimes a small lamp filled with cocoanut oil, and placed in an earthen dish adorned with a wreath of flowers. The lamp is lighted and committed to the stream, while the fair devotee anxiously watches its progress down the current. On the banks of the Ganges and Hoogly, along the strand at Calcutta, great numbers thus make their offerings, -

"The maid or matron, as she throws
Champac or lotus, Bel or rose,
Or sends the quivering light afloat,
In shallow cup or paper boat,
Prays for a parent's peace or wealth,
Prays for a child's success or liealth,
For a fond husband breathes a prayer,
For progeny their loves to share,
For what of good on earth is given
To lowly life, or hope in heaven.'

-H. H. Wilson; Travels of a Hindoo, ii. p. 404. See Khizr.

KHAJA KUTUB-ud-DIN, of Ouse, in Persia, has a great name in the chronicles of Muhammadan sainthood. He was the guide and apostle of Altamsh.- Travels of a Hindoo, ji. p. 181.

KHAJA MU'IN-ud-DIN, the oldest Muhammadan saint in India. His dargah is in Ajmir. He was born in Segistan, and died in A.D. 1239 at Ajmir. He belonged to the Chishti sect of Muhammadans. The Moghul emperors often visited his tomb, especially Akbar and Jahangir. His tomb was visited by the emperor Akbar to implore male offspring. The shrine is of white marble, and is visited alike by Hindus and Muhammadans.-Calcuttı Reviev, January 1871 , p. 72 .

KHAJAN. HiND. Marshy or meadow land on the sea-coast.

KHAJUNAH, a dialect spoken on the N.W. frontier of British India, where three dialects are in use, called Shina, Khajunah, and Arniya. The Shina dialect is spoken by the peoples of Astor, Gilgit, and, lower down, in Chelas, Darel, Kohli, and Palas, on both banks of the Indus; the Kbajunah, by the people of Hunza and Nager; and the Arniya in Yasan and Chitral. Astor has an area of 1600 square miles on the left bank of the Indus. Gilgit, in Tibetan Gyilgyid, has an area of 2500 square miles on the right bank of the Indus. The Dard or Durd are supposed by Vigne to be the Dadicæ $\left(\Delta \alpha \delta_{6} \times \alpha \iota\right)$ of Herodotus, and the people who now occupy the county called Dardu. See Dard.

KHAJUR, ARAB, Hind., Pers, A date; also the date tree, Phoenix dactylifera, and the wild date, Elate sylvestris or P. sylvestris. Khajuri, HIND., is the Phoenix humilis, and Pindi-khajur is $P$. acaulis. Khajur munj is the fibre of the palm leaf. Khajuran, Hind, a sweetmeat. lime.

KHAJURA. Hind. A concrete or tuffa of town in Ch'hatarpur State, Bundelkhand, N.W. Provinces, famous for its magnificent architectural remains. Population about 900 . It is situated at the south-east corner of the Khajur Sagrar or Ninora Tal lake. It was the ancient capital of the Chandel dynasty, is about 125 miles W.S.W. of Allahabad, and 150 miles S.E. from Gwalior. It has in and around it about thirty temples, the most beautiful in form as well as the most elegant in detail of any of the temples now standing in India. They were erected simultaneously in the 11 th century, and are nearly equally divided among three religions, - Jaina, Saiva, and Vaishnava. Each group has one shrine greater than the rest, round which the smaller ones are clustered. In the Saiva groups it is the Kandarya Mahadeva; in the Vaishnava it is the Rama Chandra; and in the Jaina group it is the Jinanatha. The Parswanatha Jaina temple has a rich base, the Ganthai is the Bell temple, and the Chaonsat Jogini has sixty-four cells. Numerous inscriptions of the Chandel kings have been discovered at various places in the neighbourhood. Upwards of twenty temples still stand in the town, and the ruins of at least as many more bear witness to its former greatness. On one side General Cunningham counted over eight hundred statues of half lifesize, and eight sculptured elephants of like proportions. The inner shrine of this edifice constituted in itself a splendid temple, and was crowded with figures. Captain Burt noticed seven large temples of exquisite carving, whose mechanical construction adapted them to last for almost indefinite periods. Nost or all of these noble buildings must be referred to the great Chandel dynasty, who ruled at Khajurahu, apparently from A.D. 841 to A.D. 1157. The modern village contains only about 160 houses. The first part of one inscription is of date Samvat 1010 , A.D. 962 ; the last part, Samvat 1173 or 1060 . The character used in the inscription is called the Kakuda, and in the 11 th and 12 th centuries appears to have prevailed from Cuttack to Shekawati. It contains an invocation to Siva and other of the Hindu deities. The inscription is chiefly in honour of Banga. (by his son). The kings of Oudh and Ceylon attend to do him homage, and his captives are the wives of the kings of Andhra, Radha, and Anga! (Banga, of course), eulogized by the Brabmans, because he built dwellings for them, and gave them lands, and piously ended his days, aged 109, by drowning himself at the junction of the Jumna and Ganges, as did also the Brabman mivister of his father and grandfather. The inscription had twice before been engraved in irregular characters, and it was only in A.D. 1016 that it was put into proper Deva Nagari. The story of creation from Brahma and the egg is told. The influence of the moon on the tides is alluded to. The inscription alludes to a passage in the Mahabharata, in which Siva is represented to have given his own flesh to a hawk, instead of a bird which had sought refuge with him. This story is told of Buddha more than 1500 years before this time. - Imp. Gaz.; As. Soc. viii. p. 176 .

KHAK. PErs, Earth, dust. Khaki and Khaki-dud'hia, of the colour of earth, grey colour. Khak-i-Balkh, two mounds near to the Bala Hissar in Käbul. Kuakrob, a sweeper, a menial servant of the lowest class, also the 
sweeper of a village, acting at times as a watchman, a guide, a police spy, one of the village establishment.

KHAKAN. TURK. A khan, a chief, identical with the Greek Xaganos.

KHAKI, a sect of Vaishnava Hindus founded by Kil, a disciple of Krishna Das. They apply ashes of cow-dung to their dress and persons. They are not numerous, and seem to be confined to the vicinity of Farrakhabad, at Hanuman-Ghur in Oudh; but the Samadh or spiritual throne of the founder is at Jaipore. The residents in towns dress like other Vaishnava, but those who lead a wandering life go either naked or nearly so, smearing their bodies with the pale grey mixture of ashes and earth. They wear the Jata or braided hair, after the fashion of the votaries of Siva. They are derived from Ramanand, but not immediately.-Wilson.

KHAKI. HIND. A kind of hemp resin or charras.

KHAKSI, of Nepal, a shrub the leaf of which answers the purpose of emery or sandpaper, giving a fine polish to the harder woods.-Smith's Nepal, p. 68.

KHAL, a Ladakh land measure, being land for which one Khal of seed is sufficient. The word seems to mean only a load of any kind, and is apparently the same as the Indian Khara or Khari, a measure of 20 bhara.

K'HAL, also K'hala. HIND. A water-course, natural or artificial, a lagoon. Khalari, a saltpan.

KHAL. HrND. A skin or hide. Khal-po, a tanner.

KHAL. Hind. Oil-cake, the refuse of the mill after expression of the oil.

KHALA. HIND. A threshing-floor.- $W$.

KHALAJ. TuRK. Properly Khalij, a sword.

KHALASI. HrND. A sailor, tent pitcher, Muhammadan labourer.-W.

KHALASSAT-ul-AKHBAR, or Epitome of History, a book written by Khondamir, the literary name of Ghaias-ud-Din-bin-Humam-ud-Div. One of his books is entitled Habib-us-sayar-fi Afrad-ul-Bashar, that is to say, "the curious part of the lives of illustrious men.' It is a history which he extracted from that which his father Mirkhoud had composed, and entitled Rauzat-us-Safa, but to which be made augmentations. He dedicated this book to the secretary of state of the king of Persia, Shah Ismail Safavi, who gave him the name of Habib-Allah; and for that reason the book had the name Habib given to it in the year A.D. 1508, Hijira 927, in the reign of Lewis XII.-History of Genghiz Can, p. 422 .

KHALATA-TCHOLI, a sandy desert on the route from Khiva to Bokhara, and about 100 miles from Khiva. It is also styled Jan-Batirdigan, or life-destroyer. It is only traversed in the winter when the Karakol route is infested by Turkomans, who, when the Oxus is frozen, traverse the country in all directions.-Collett, Khiva.

KHALAUTI. HiND. A low-lying rice country.

KHALFAH. Hajji Khalfah, a learned Muhammadan, author of a great bibliographical lexicon, containing an account of every work of importance in Arabic, Persian, and Turkish, with brief notices of the authors. It was edited by Flugel.

KHALGI or Khulgi. PErs. The ornament of the bridle of a man of rank, is usually of silver with a feather, and stands on the head-stall between the horse's ears.-Malcolm's Central India, i. p. 229.

KHALI, under the jinswar system of revenue, a large rick-yard, where the produce of all the village fields is collected and threshed.

KHALID, a Bedouin tribe. The Beni Kbalid in Niebuhr's time were one of the most powerful tribes of Arabia. They conquered the country of Lachsa, and advanced to the sea.

KHALID-ibn-ul-WALID was the conqueror of Syria. He joined Muhammad in the 8th year of the Hijira. See Masailma.

KHALIFAH. ARAB. A ruler, king, deputy, a title assumed by the successors of Mahomed, who possessed absolute authority in civil and religious matters. Abubakr, who succeeded Mahomed, was the first to adopt it, styling himself Khalifah Rasul Allah, Vicegerent of the Apostle of God; and this, together with Amir-ulMomanin, Commander of the Faithful, which the khalif Omar assumed, was the principal title of all the reigning princes from the Hijira in A.D. 622 till the taking of Baghdad A.D. 1258. Khalifat is the dominion.

A. The four first khalifs.

Abubakr, . . A.D. 632 Osman, . . . A.D. 644

Omar, . : . 634 Ali, : : . . 625

B. House of Ommaya.

Muawia,

A.D, 661

Yezid, son of do., : : : : $\quad$ t

Muawia Ir, son of Yezid, : $\quad$ : $\quad$ : $\quad 683$

Merwan I.,. . . . . . 683

Abd-ul-Malik, son of Merwan, : : : $\quad 685$

Walid, son of Abd-ul-Malik, . . . . 705

Suliman, do do., . . . . 715

Omar-ibn-Abdul Aziz, . : : : : 717

Yezid II., son of Abd-ul-Malik, : : : 720

Hisham, do. do., . • • . 724

\begin{tabular}{l} 
Walid II., son of Yezid II., $\quad: \quad \cdot \quad \cdot \quad \cdot \quad \cdot \quad 743$ \\
Yezid III., son of Walid I., \\
\hline
\end{tabular}

Merwan II., - • . : : $\quad \cdot \quad \cdot \quad \cdot \quad 744$

C. House of Abbas, the period of Persian ascendency.

Abdallah-us-Saffa, . . . . . . 750

Abu Jafar-ul-Mansur, brother of us-Saffa, : 754

Muhammad-ul-Mahdi, son of ul-Mansur, : : 775

Musa-ul-Hadi, son of ul-Mahdi, . . . 785

Harun-ur-Rashid, . • : : 786

Muhammad-ul-Amin, son of Harun-ur-Rashid, 809

Abdullah-ul-Mamun, . . . . 813

Kasim-ul-Mutasim, 。 : : 833

Harun-ul-Wathik, son of Kasim-ul-Mutasim, : 842

Jafar-ul-Mutawnkkil, . . . . : 847

D. Decline of the khalifat during the tyranny of the Turkish Bodyguard.

Muhammari-ul-Muntasir, son of ul-Mutawakkil, 861

Ahmad-ul-Mustain, . $\quad 862$

Muhammad-ul-Nitaz, son of ul-Mutawnkkil, : 866

Muhammad-ul-Muhtadi, son of ul-Wathik, : $\quad 869$

Alumad-ul-Mutamid, son of ul-Mitawakkil, : $\quad 870$

Ahmad-ul-Mutadin, nephew of Ahmad-ulMutamid,

Ali-ul-Muktafi, son of Mutadhin,

Jafr-ul-Muktadir, do. do.,

Mubammad-ul-Kabir, do. do.,

Ahmad-ul-Rhadi, son of Míuktadir,

892

902

907

432

934

Ibrahim-ul-Muttaki, do. do.,

940

E. During the ascendency of the Bouide princes,

A.D. 945 (A.H. 334), A.D. 1050 (A.H. 447).

Ul-Mufadhl-ul-Moti, son of Muktadir, . 944

Abd-ul-Karim, son of ul-Moti, . : : : 974

Ahmad-ul-Kadar, son of predecessor, . . $\quad 992$

Abdallah-ul-Kaim, do. do., : 1031

F. From rise of the Seljuk dynasty to the destruction of Baghdad.

Muhammad-ul-Muktadi, son of predecessor, . 1071 
Fadhl-ul-Mustarshed, son of predecessor, Mansur-ur-Rashid, do. do., Muhammad-ul-Muktafi, son of ul-Mustazhir, Yusuf-ul-Mustaujid, son of predecessor, Ul-Hasan-ul-Mustadhi, do. do., Ahmad-ul-Nasar, do. do. Muhammad-uz-Zahir, do. do., Abu Jafar-ul-Mustanzir, do. do., Abdallah-ul-Mutasim, do. do.,

Destruction of Baghdad by Hulaku, grandison of Chengiz Khan,

A.D. 1118

1119

1119

1160

1170

1180

1225

1226

1242

1258

'The Shiah sect of Muhammadans hold as a teret that on Mahomed's demise Ali ought to have been elected the first khalifah. Many of this sect regard $\Lambda$ li as having so succeeded, and smaller sub-sects of the Shiah religionists believe in the incarnations of Ali up to the present day.

The Muhammadans of the Sunni sect have largely adopted the belief that in A.D. 1263 a descendant of Abu Jafur (ob. 1226) appeared in Egypt, and was recognised by Bibars, the Mamluk sovereign, as khalifah. And that in A.D. 1517 , when Selim r. of Constantinople overthrew the Cairen khalifah, Matawakkal b' Allah, Selim obtained the transfer to himself of the khalifat, and with it the sword and mantle of Mahomed, from whioh time the mantle has been a standard. This point has been discussed as regards British India, because the Muhammadans there have never introduced into their Friday service at the mosque, nor yearly at the Idgah, the name of any British sovereign, but sometimes have prayed for the emperor of Dehli, the Sultan of Rum (Constantinople), the Sharif of Mecca, or, indefinitely, the ruler of the age. On these points it may be remarked that it is held to be an essential principle in the establishment of the office that there shall be only one khalifah at the same time, and the office is acknowledged by all parties to be elective and not hereditary. Also the Sunni sect and the Wahabee consider that the khalifah should be of the Quraish tribe, and the Shiah sect even hold that he should be a descendant of Mahomed.

The Wahabee sect, when Sana took Mecca and Medina in 1804, regarded the Sultan of Turkey as a usurper. This question has divided Muhammadans up to the present day.

On the death of Mahomed, the people of Medina sugrested that they should elect one leader, and Mecea another; but this was not adopted; and under the three khalifs, who were successively acknowlidgred by the whole Muhammadan world, Arab armies poured across the northern sandy waste into Syria and Palestine. A few sieges, a fuw fierce battles, and these rich provinces were lost to the empire of Byzantium, the ancient Sassanian dynasty was crushed on the field of Kadesia, and Persia was added to the khalifat. In less than three years the Arabs were masters of Egypt.

The elected successor of Mahomed was Abubakr. Omar was the second khalif. His time was a period of great extension of Muhammadanism. The battle of Kadesia was fought and won by his general Saad, and put an end to the Persian empire of the Parsee. He imposed the khiraj on Syria, and dicd and was buried at Jerusalem, where his tomb still is.

When Omar had achieved the triumphs which consolidated the power of El Islam, an ambassador from the Byzantine emperor came to Arabia to pay homage to the great conqueror on the part of his master. Arrived at Medina, he was directed to the presence of the khalif, who, dressed in simple Arab garb, was reclining fast asleep and unattended beneath a palm tree. The simple life of one whose fame had filled the whole world, and still more the discourse which Omar addressed to him on waking up, made so profound an impression upon the Greek ambassador, that he there embraced the Muhammadan faith. The contrast between the unassuming manners of the early khalifs and the arrogance and luxury of the later commanders of the faithful in their palaces at Damascus or Baghdad, was striking. Arabic annals are full of examples of this, and the incident of the entry of Umar into Jerusalem clad in a rough mantle, and leading his own camel, like the poorest desert Arab, is familiar to all readers of the history of the Holy City.

The third khalif was Osman or Othman, on whose murder Ali succeeded. Ali was surnamed 'the ever-victorious lion of God,' but his succession marked the beginning of troubles. He was accused of having instigated Uthman's assassination. Othman's bloody shirt was conveyed to Syria, and displayed on the principal mosque of Damascus, to incite the Syrian army to revenge. 50,000 men, said the messenger who conveyed these tidings to Ali at Medina, are assembled about the robes of Othman, whose cheeks and beards have never been dry from tears, and whose eyes have never ceased from weeping blood since the hour of that prince's atrocious murder. They have drawn their swords with a solemn pledge never to return them to the scabbard, nor cease from mourning, until they have extirpated all concerned in that detested transaction. Simultaneously with this movement in Syria, Telha and Zobeir, two of the most renowned warriors among the Arabs, and Ayasha, the favourite wife of Mahomed, repaired to Bussora, and raised the standard of rebellion agninst the authority of Ali. But Ali, though deficient in political ability, and wanting in the tact requisite to conciliate rival and turbulent factions, was an unrivalled soldier on the field of battle. He placed himself at the head of 30,000 men, and advanced in the direction of Bussora. In the battle of the Camel, 17,000 Arabs are said to have fallen. Telha and Zobeir were both killed, and Avasha became a prisoner in the power of Ali. He treated her with the utmost courtesy and forbearance, and caused her to be escorted to Mecca. This signal victory made Ali the undisputed sovereign of Irak, Egypt, Arabia, Persia, and Khorasan; but the Syrian army remained implacable; and $\mathbf{A} \mathbf{m r u}$, the conqueror of Egypt, in the presence of the whole army, acknowledged Moawyah, son of Abu Sussian, as the lawful khalif and prince of the maslmin. Ali attacked the Syrian host on the plain of Suffein. Victorious again and again in the battlefield, he allowed himself to be outwitted in diplomacy, and in the month of Ramzan A.H. 40 , the career of Ali was brought to a close by the dagger of an assassin, and Moawyah became the undisputed khalif. In all the mosques wherever the Muhammadan doctrines prevailed, the names of Ali and of all his family were regularly cursed upon all occasions of public worship. His death was followed nine years after by that of his eldest son Hasan, poisoned by his own wife, at the instigation, it is said, of Moawyah; and 


\section{KHALIFAH-UL-AKBAR.}

after a lapse of two years, his second son Husain crowned the misfortunes of his family by his bloody death on the plains of Karbala, on the tenth day of the month Maharram A.H. 61. Yezid, son of Moawyah, was the reigning khalif at the time of the murder of Husain. That event was the signal for rebellious outbreaks in all parts of his dominions. The martyred Husain became a watchword which again and again deluged with blood the empire of the khalifs, and ultimately brought it to ruin, and has ever since separated the Muhammadans into two sects, embued with a bitter hatred, which up to the present moment, even under the strong power of the British, is ever liable to evince itself in outbreaks, needing armed intervention to be ready at hand. At present the only ruling house of the descendants of Ali is the Asof Jahi in Hyderabad in the Dekhan, which has been in existence for nearly 200 years.-Gibbon; Lane; Osborn's Islam; Osborn's Khalifs; Sir G. Birdwood; Dr. Badger; Bjornstjerna's British Empire in the East, p. 97 ; Bunsen, ii. p. 150. See Ali Ilahi; Ismaili; Khaja; Khutbah; Nahomed.

KHALIFAH-ul-AKBAR, God's vicegerent, a title given to Adam.

KHALIJ. Hind. The pheasants, Gallophasis albocristatus, Horsfieldii, and Melanotus.

KHALIL, a grandson of Timur, on whose demise Khalil, at Samarcand, declared himself emperor.

KHALIL, an Afghan tribe near the mouth of the Khaibar pass. Peshawur and the hills which surround it are peopled by various Afghan races, as Yusufzai and Mohmund in the north and west, Khalil and others in the centre, and Afridi, Khattak, and others in the south and east. Arbab, plural Arabic of Rab, lord, is the title assumed by the chiefs of the Khalil, Mohmand, and other tribes on the Peshawur frontier.

KHALIL-ALLAH. ARAB. Friend of God, the reverend designation of Abraham. The Messiah is the Ruh-Allah or Spirit of God, and Moses the Kalan Allah or Word of God.

KHALI MAHAINA, a term for the tenth month of the Muhammadan year, without festival.

KHALIS, a district and a canal which is cut from the Diala to the Tigris. The district of Thalis is situated to the north of Baghdad, and takes its name from the canal, which supplies sixty-two villages, most of which are now become mere nominal ones, with water for agriculture, the Tigris itself being unfit for that purpose. The principal of these villages are Yenghijeh, 20 miles fron Baghdad, on the banks of the Tigris, in Rich's time almost abandoned on account of the great oppression under which the peasantry laboured. Howeish was a village of a hundred bouses, famous for its fruit gardens.-Rich's Kurdistan, ii. p. 156.

KHAJPA or Kalpo, a low caste in Gujerat, who dress skins and prepare leather; they are sometimes village servants. - Wilson.

KHALSA. Hind. The Sikh people; the Sikh theocracy established by the Guru Govind; the old prominent division into Khalasa, meaning of Nanak, and Khalsa, meaning of Govind, which is noticed by Forster, is no longer in force; the former term Khalasa is almost, indeed, unknown in the present day. The word Khalsa, meaning select, is a term equivalent to a state or common-

vOL. II. wealth, but was supposed by the Sikh to have a mystical meaning, and to imply that theocracy or superior government under the protection of which they lived, and to the established rules and the basis of which, as fixed by Guru Govind, it is their civil and religious duty to conform. The Khalsa sect of Sikhs believe in the AdiGranth of Nanak, but do not conform to the institutions of Guru Govind. The word Khalsa is from Khalis, pure or select, and taken to mean the purest or the most select; by others it is derived from Khalas, free, and meaning the freed or exempt, alluding to the sect being exempt from the usages imposed on the other Sikhs.

The principal of the religious institutions of Guru Govind is that of Pahal, the ceremony by which a convert is initiated and made a member of the Sikh Khalsa or commonwealth. The forms which Govind employed are still observed. The neophyte is told by the officiating Granthi or priest that he must allow his hair to grow. When it las grown a month or two, he dresses himself in blue from head to foot, and is then presented with five weapons, a sword, a firelock, a bow, an arrow, and a pike. The candidate and the initiator wash their feet with water in which sugar is put, and this nectar (called pahal) is stirred with a steel knife or dagger, five quatrains from their scriptures being read. Between each quatrain the breath is exhaled with a puff, and the beveragre stirred as before. The hands of the convert are then joined, and the Granthi or initiator pours some of the nectar into them, of which he drinks five times, rubbing a little on his head and beard, exclaiming, "Wah! Guru ji ka Khalsa! Wah! Guru ji ki Fatah!'or 'TVah! Govind Singh, ap hi Guru chela!' Govind, who instituted the Pahal, it is said, went through this form with five of his followers, drinking of the water which had washed each other's feet. Women are made Sikhs in the same manner as men, except that the nectar is stirred with the back instead of the edge of the knife. The children of Sikhs go through this ceremony at an early age.-Cunningham's Sikhs, p. 96 ; Malcolm's Sikits; Hist. of the Panjab, i. pp. 101, 126; Forster's Tr. i. p. 309.

KHALSA, properly Khalisa. HrND. Land under the direct administration of Government. Under Muhammadan domination in India, the revenue office, containing the records of the Government lands revenue.

KHALSI, on the west bank of the Jumna, is famed as possessing one of the rock inscriptions of Asoka. Khalsi is just where the Jumna leaves the higher range of mountains to pass between the Duns or valleys of Kyarda and Dehra.

KHALIVAT. ARAB. Retirement, privacy. Khalwat-gah, women's apartments, private apartments.

KHAM. HiNd. Raw, crude, unfinished. Revenue is said to be collected kham, or land held kham, when done so direct by Government, and not through the medium of a farmer or other under-holder. It is the equivalent of Kach'ha.

KHAMAN, a word, meaning well done, shouted by the Rajput race. The Persian and Hindustani exclamations are Shahbash; fabahah, jio raja jio, jye.

KHAMAR. BENG., URIYA. A threshing foor. KHAMGAON, a town in Akola district, Berar, 
lat. $20^{\circ} 42^{\prime} 30^{\prime \prime} \mathrm{N}$., and long. $76^{\circ} 37^{\prime} 30^{\prime \prime} \mathrm{E}$. ; pop. (1867), 9432. Khamgaon is the largest cotton mart in Berar, perhaps in all India.-Imp. Gaz. v.

KHA-MI, the most important tribe in the Arakan Hill tracts. The population of the district is estimated at 12,000 , viz. :-

Rakhaing called Khyoung-tha,

Sons of the River, 1219 Khyaw or Kuki,

Kha-mior Khwe-myi, 7172 Mro, . . . 2126

The Rakhaing or Khyoung-tha (Sons of the River) are of the Burmese stock, and speak a dialect akin to Arakanese. They have seven clans, all of whom live on the Kuladan. Some of the clans are said to be descended from the Mon of Pegu. They have rough paper books of palmleaf shape, and are Buddhists.

The Shandu language is monosyllabic; they dwell north and north-east of the Blue Mountain, are polygamic. Their clans are always at war.

The Kha-mi or Khwe-myi are the chief tribe of the district. Their clans have each a toung meng or hill chief. Kha-mi means man. Their Burmese name, Kwe-myi, means dogtail, because their dress bangs down behind like a tail. They are wary and deceitful, but are inclined to trade.

The Mro live on the Mi. Formerly they used to construct a nest in a high tree, to which they ascended by a bamboo ladder.

The $A m u$ or Khoung-tso dress like the Kha-mi, but speak a distinct dialect.

The Khyeng inhabit the Yoma Hills east of the Le Mro river. Their language varies, but all acknowleage themselves of one tribe. They are shy, and averse to improvement. They tattoo their women.

The Khyaw or Kuli inbabit a small village on the Tsala river, and are of the Kuki family.

The religion of the tribes is spirit (ka-nie) worship, with bloody sacrifices to the spirits of the hills and the rivers, at seed-time and harvest. Also, with the Kha-mi and Khyoung-tha, annually the hpalaw or spirits of the dead, when the dead-house is opened, and food and rice spirit $(a-m u)$ are placed near the askes of the departed. Raiding murderers, when caught red-handed, are beheaded, and their heads stuck up in the village. All other crimes are punished by fine. The intercourse before marriage is unrestricted: after marriage divorce is easy.

The jum or toung-ya kind of cultivation is practised. They weave cotton blankets, etc.

An armed police force guards the frontier.

KHAMIR. HiND, PERS. Yeast, leaven. Khamira, a smoking mixture, of tobacco compounded with fragrant spices.

KHAMITIC or Turanian race was the earliest ruling power in Asia, and Nimrud was of that race.

KHAM MITTI. HiND. In Karnal, a product obtained in the process of making sal-amnıniac or naushadar.

KHA-MOUNG-NEE. BurM. In Tavoy, a heavy wood, not attacked by insects.

KHAMPA, wandering Tartars in Kanawar, who are in some respects similar to the Jogi of Hindustan. They visit the sacred places, and many of them subsist wholly by begging. Some are mummers, very humorous fellows; they put on a mask, perform a dance, singing and accompanying it with a drum, or they play, sing, and dance all at once, holding the fiddle above the head, behind the back, and in a variety of other strange positions. After the British Government got possession of the hills, the Khampa came down in crowds to visit the holy places to the westward.-Gerard's Kunawar, p. 117.

KHAMPTI, a Shan clan who occupy a tract of country on the extreme eastern frontior of Assam, bordering on Lakhimpur district. The Khampti are a hill tribe of Shan origin, akin to the Ahams. About the middle of the 18th century, owing to internal dissensions, a colony of Khampti migrated into Assam, and established themselves in the division of Saddiya. They came from the country known to the British as that of the Bor-Khampti, near the sources of the Irawadi. According to their own annals, they had occupied that country for many centuries; but Captain Wilcox found them a divided people. Two great clans had been at feud for 50 years. Captain Wilcox found amongst the Bor-Khampti, the Muluk, the Khalong, the Kumong, cognates of the Singpho, and the Khapok, whose language is allied to the Singpho, were the labourers.

The Siamese are now the most important branch of the Shan, Tai, or Thai race, and the Khampti belong to the same stock as the Siamese. Their language contains nearly all the Siamese words, and their creed and alphabet are Siamesc. There was once a great nation of this people, occupying a tract known by the Manipuri as the kingdom of Pong, which touched Tiperah, Yunnan, and Siam, and of which the city, called Mogong by the Burmese, and Mongmarong by the Shan, was the capital. This kingdom was finally broken up by the Burmese king Alompra, about the middle of the 1 th century; and on its dismemberment, brauches of the Shan race migrated to and settled in Assam. The Phaki or Phakial, on the Dihang river, the Kanijang of Saddiya, and the numerous settlements of Khampti, are all colonies of this race, retaining the costume, customs, and religion they brought with them into the valley.

The Khampti are very far in advance of all the north-eastern frontier tribes in knowledge, arts, and civilisation. They are Buddhists, and have regular establishments of priests, well verscrl in their religion, and a large proportion of the laity can read and write in their own language. Their houses are built of strong timber, witl raised floors and thatched roofs contiguous to each other, a trough of wood being fixed under the junction of the two roofs to carry off the water. The interior is divided into chambers, and the whole terminates in a railed open balcony. The roof of the houses comes down so low, that externally there is no appearance of wall. The temple and priests' quarters are also of timber, and thatched, but the temples are elaborately carved, and fitted with great taste and neatuess.

The priests have shaven heads, and ambercoloured garments, and rosaries. The office is not hereditary; any person may enter upon it after the necessary novitiate and instruction in the bapuchang, as the priests' quarters are called; but so long as they wear the sacerdotal habit they must renounce the world, and live a life of celibacy. Every morning the priests move 
quickly through the villages, preceded by a boy with a little bell, holding a lacquered box, in which he receives the offerings of the people, generally presented by the women, who stand waiting at the door with a portion of their ready cooked food. In their hours of relaxation the priests amuse themselves by carving in wood, bone, and ivory. In making ivory handles of weapons they evince great skill, taste, and fecundity of invention, carving in high relief twisted snakes, dragons, and other monsters, with a creditable unity and gracefulness of design. It is customary also for the chiefs to employ themselves in useful and ornamental arts. The Khampti work in gold, silver, and iron, forge their own weapons, make their wives' jewellery, and manufacture embossed shields of buffalo or rhinoceros hide, cilding and lacquering them with skill and taste. The women, although very clever in elaborate embroidery, and making embroidered bands for the hair and other pretty things, are not the less capable of bearing a very severe share of the outdoor farm work.

The Khampti are not a handsome race; they are darker of complexion and coarser of feature than other Shans, the Mongolian peculiarities being more strongly developed in them than in their reputed brethren. After settling in Assam, however, the Khampti chiefs frequently took to themselves Assamese wives, and the effect of this mingling is very marked in softening and improving the features of the later generations.

The Khampti have two great religious festivals in the year, -one to celebrate the birth, and the other the death, of Gautama. At these ceremonies, boys dressed up as girls go through posture dances. They are not restricted to one wife; and the Khampti women are allowed every freedom and independence of action, paying and receiving visits, going to market, etc.

The dress of the Khampti consists of nether garments of coloured cotton of a chequered pattern, or of silk, more or less ample, according to the rank of the wearer; tight-fitting jackets of cotton cloth, dyed blue, with a white muslin turband, so twisted as to leave exposed the topknot into which their long hair is twisted. The costume of the women is like that of the men,plain, but neat. They wear the hair drawn up from the back and sides in one massive roll, which rises four or five inches so much in front as to form a continuation of the frontal bone. The roll is encircled by an embroidered band with fringed and tasselled ends; the lower garment is folded over the breasts and under the arms, reaching to the feet; sometimes, in addition, the Khampti women wear a coloured silk scarf round the waist, and a long-sleeved jacket. Their ehief ornaments are necklaces of coral and other beads, and cylindrically-shaped pieces of bright amber inserted in the ears.

The most common weapon among the Khamptis is the dhao, a heavy short sword, plain or ornamented, according to the condition of the wearer, hanging in its sheath by a sling made of split rattan. It is worn somewhat in front, so that the hilt is readily grasped in the right hand; this, and the defensive round shield of buffalo hide, are sufficient for a Khampti to take the field with, but many of them now carry muskets or fowling. pieces. They are very useful auxiliaries in moun- tain warfare, capable of endurance and full of resources.

The burial-ground of the Khampti is generally a tidily-kept spot apart from the village. The graves are surmounted by conically - shaped tumuli, which, when first constructed, diminish from the base to the apex in a series of steps, the earth being kept in position by bamboo matting round each step. Some of these graves when opened have been found to contain coffins of massive timber, with gold and silver ornaments, and outside the coffins various utensils, arms, and implements of agriculture.

The Phakial tribe, with the exception of a few particulars, answer to the description given of the Khampti. They also are Thai emigrants, their original habitat being the valley of Hukong.

The Muluk, who dwell in the Hankhati Mouza; south of Saddiya, are a tribe subordinate to the Khampti. Their dress is similar to that worn by the Khampti, except that it is of ruder fashion and of inferior texture. There is another tribe about Saddiya known as the Khanijang, but in manners and customs they do not differ from the Muluk.

The Singpho have settled in Assam within the memory of man. Their first settlements were on the Tengapani river east of Saddiya, and on the Buri Dihang in the tract called Namrup. They are of a race called by the Burmese Ka-khyen or Kaku, whose original settlements were on the eastern branches of the Irawadi river; they are there in contact with the Kunung, with whom they are closely allied in language and origin. They assumed the name of Singpho, which in their own language means ' man,' only after emigration into the Assam valley. They occupy large villages on the frontiers, often in somewhat unassailable positions, and their villages usually consist of sixty or more large houses, each from 80 to 100 feet long and about 20 feet in breadth, with raised floor throughout, and an open balcony at one end, where the ladies of the family sit, and spin, weave, and embroider. The house is divided into different apartments on both sides of a long passage, open from end to end. Over the hearths are large bamboo racks hanging from the roof, on which are placed meat or fish requiring to be smoked.

They are generally a fine athletic race, above the ordinary standard in height, and capable of enduring great fatigue; but their energies are greatly impaired by their free indulgence in opium and spirits. Their features are of the Mongolian type, and their complexion varies from a tawny yellow or olive to a dark brown. Hard labour tells on the appearance of the famales, rendering them coarse in feature and awkward in gait; but in the families of the chiefs fair skins and pleasing features sometimes are seen.

The men tie their hair in a large knot on the crown of the head, and wear a jacket of coloured cotton, and a chequered under-garment of the same material or of silk. The chiefs assume the Shan or Burmese style of dress, and occasionally short smart jackets of China velvet, with gilt or amber buttons. The dress of the women consists of one piece of cotton clotl, often in large, broad, horizontal bands of red and blue, fastened round the waist, a jacket, and a scarf. The married women wear their hair in a large broad knot on 
the crown of the head, fastened with silver bodkins, chains, and tassels. Maidens wear their hair gathered in a roll resting on the back of the neck, and similarly secured. They are especially fond of enamelled beads and bits of amber. The men tattoo their limbs slightly, and all married women are tattooed on both legs from the ankle to the knee.

The national weapons of this tribe are the dhao or dha, the spear with a short staff, and a strong crossbow with bamboo arrows. They affect the use of the musket whenever they can get one, and are sometimes seen with Chinese matchlocks. They use shields of buffalo hide four feet long, and helmets of the same material, and sometimes of thick plaited rattan work varnished black, decorated with boars' tusks, etc. In warfare their attacks are confined to night surprises, which are speedily abandoned if they meet with steady opposition. They are skilled in fortifying naturally difficult positions, using freely the panji, a bamboo stake of different lengths, sharpened at both ends, and stuck in the ground, by which the sides of the hills and all approaches to their position are rendered difficult and daugerous. Sometimes they use muskets on these occasious; the weapons are generally fixed in loopholes of breastworks, ready loaded, and fired when the enemy reaches the point of the road covered by them. If they fail by such means to beat off the attacks at once, they abandon the position for another behind it. In travelling they carry a haversack of very neat appearance, cleverly adapted to the head and shoulders, and made of very fine plaited fibre, on a frame of wood, covered with the skin of the large grey monkey. They are also provided with handsome bags, woven and embroidered by the women, in which they carry their pipes and tobacco, opium, etc.

For several generations the Singpho were the terror of the inhabitants of the Assam valley, and were in the habit of making constant irruptions into the plains in conjunction with the Moamaria, and these repeated raids have won for them the lowlands they now occupy. These inroads were put a stop to when the British took possession of Assam, but for some time afterwards this wild people made attempts to revert to their old habits. One ofticer of the British force had 5000 Assamese captured slaves returned to him, and it was then estimated that there were 100,000 Assamese and Manipuri still held in slavery among these people in Burma.

The Singpho understand the smelting of iron; and their blacksmiths, with no implements but a lump of stone for an auvil, and a rude hammer, forge weapons, especially dhaos, which are highly prized all over the frontier for their temper and durability. The Singpho manufacture their own wearing apparel; the thread is dyed previous to being woven, and thus are produced the checks and coloured garments of which they are so fond.

The Singpho repudiate all affinity with the Shan. Their language is entirely different, approximating more to the Karen, Manipuri, Naga, and Abor dialects, and their religion is a rude paganism. The Singpho propitiate three spirits called Nats, by sacrificing fowls, pigs, and dogs to them, and when about to proceed on important expeditions a buffalo is offered. They have no regular priesthood, but they pay great deference to the Pugyees or priests of the Buddhist Shans. Some among them are supposed to possess powers of divination, and Col. Hannay mentions having witnessed the process. The diriner sat himself down at some distance from the crowd, and had beside him a small fire and a bundle of nal grass. Taking a piece of nal containing several joints, he held it over the flame until one of the joints burst with a sharp report; the fracture on each side threw out a number of minute, hair-like fibres, which were carefully examined and put aside. Another piece was then put into the fire and similarly treated. This continued for at least an hour, when the result was disclosed, namely, that a certain chief, whose arrival was awaited, would make his appearance in three or four days; and so it happened.

Polygamy prevails amongst the Singpho. The girl is bought with a price, and a feast completes the ceremony. They bury their dead, but the body of a man of note is kept for two or more years, in order that all the friends and relations of the deceased may Lave time to attend his funeral; the body being removed to some distance during the process of decomposition, after which it is placed in a coffin, and brought back to the house, where it remains in state, decked out with all the insiguia of rank used during life. When finally committed to the earth, a mound, sometimes of considerable dimensions, is raised to mark the spot. This custom they appear to have taken from their neighbours the Khampti. In succession to patrimonial property, the eldest son takes the landed estate with the titles, the youngest the personalities; the intermediate brethren, if any exist, are excluded from all participation, and remain in attendance on the chief or head of the family, as during the lifetime of their father.

The Doanniya. From the intercourse of the Singpho with their Assamese female slaves, a mongrel race has sprung up, well known in Upper Assam under the denomination of Doanniyas. They have been found very useful auxiliaries in frontier wars, from their knowledge of the Singpho language and tactics, and from their fidelity to the Government that relieved them from the Singpho yoke-Homeuard Mail, Sept. 1881; Mr. (Sir. G.) Campbell, p. 149; Colonel E. T. Dalton, Ethn. of Bengal.

KHAMSIN. ARAB. The climate of Egypt is characterized by extreme dryness, rain is almost unknown in the upper country, but falls occasionally in the Delta. The cold season extends from October to March; north winds then prevail, and the climate is favourable to the tourist; boats ascend the river with facility. The hot season commences in April, and lasts till September. In May and June, the Khamsin, called in Arabic the Simoom, a pestilential south wind of 50 days' duration, blows with violence. The natives of El-Hijaz assured Captain Burton that in their district the Simoom never kills a man, but he saw the dead body of an Arnaut, which was swollen and decomposing rapidly, the true signs of death by a poison wind. Injurious winds, exactly resembling the Kbamsin of Egypt, are common throughout the east of Persia, Afghanistan, and the regions lying to the south and east of the Indus as far as Cutch; but they do not 
extend southwards of the latter province.Burton's Scinde, p. 376 ; Pilgrimage, ii. p. 2; Bellew.

KHAN, a large tray. Khancha, a small tray. Khan-posh, or Toraposh, a tray lid.

KHAN, a title in use in Turkey and in Asia. It was seemingly first used by Tartar races in High Asia. It was adopted by, or granted to, Chengiz, and his successors were known as the Kablai Khan. It was in use prior to their conversion from paganism. In Turkey it belongs to the emperor alone; in China it is a title of the emperor; in Persia it is borne by nobles. It is the title of the Baluch and Afghan rulers, but every Afghan assumes it as his birthright. It has been granted by rulers to many of the Muhammadans of India, and it is as often conceded to others as Esquire is to the people of Britain. Afghans, called Pathans in India, when at Muhammadan courts, are prohibited the adoption of this title, lest doing so might interfere with its grant by the ruler. Khanam is a lady's title, and Kban Khanan, lord of lords, was a title of Mirza Khan, son of Bahram Khan, and was a Muhammadan title at the Dehli court. Khan Khel amongst the Afghans is the tribe furnishing the chief.

KHANA. HIND. A house. Khana Shumari, a census. The Khan of Asiatic cities is a caravansari or place for travellers to put up. In general they are substantial, handsome buildings, with arcades opening into an interior court.

Khana-zad, Pers., house-born, is the name usually given to the sons of slaves born in the family; and, among the Muhammadans, persons of this description are almost deemed relatives. The term is derived from Khana, a house, and Zaidan, to be born. In Baluchistan they are always kept near the persons of their chiefs, and employed on all affairs of great trust. Their character and station is considered highly respectable, and even after they are enfranchized, and rewarded with a portion of soil, they retain the designation. The ordinary term for a slave is ghulam, but for those born in the house Khanazad is a respectful appellation. There are various kinds of emancipation,-complete and immediate, gratuitously, or for a future pecuniary compensation; or future emancipation on the fulfilment of certain conditions, more frequently when the owner dies, in which case his heir cannot sell the slave to whom the promise was made.-Malcolm's Persia, i. p. 456 ; Pottinger's T'ravels.

KHANAM, an ordinary Muhammadan suffix for a Pathan lady, as Khadijah Khanam. Khanam. Khatun, Bi, Begum, Beebee, Nissa are honorific suffix appellations for Muhammadan women. Malik Kbanam was the daughter of Kazan, sultan of Samarcand, and mother of Shah Rukh. Harm women usually have the names of flowers, as Nirgis, Zaffran, Susan. The ordinary women have the designation of $\mathrm{Bi}$, as Khadijah $\mathrm{Bi}$. The higher classes are styled Begum, Khanam, Khatun, Nissa, as Fakkr-un-Nissa Begum, Jamilah Khanam. In countries where Arabic is spoken, the equivalent of Khanam is Site, the mistress or the lady. -Markham's Embassy, p. 118. See Harm.

KHANATE, a dominion, of which are several in Central Asia. The khanates of the Uzbak populations are Maemana, Sar-i-Pal, Shibbargham,
Andkhui, and Akcheh. Khiva and Bokhara also are khanates.

KHAN BABA, literally lord - father, a title bestowed on Bahram Khan, the counsellor of Humayun and his son Akbar. It is equivalent of the Turki Atabek. See Beg.

KHANBALIG. This city, now called Pekin, was founded or at least rebuilt by Kablai Khan after his conquest of Northern China, about A.D. 1280. Marco Polo calls it Cambalu, and says that in magnificence it surpassed every other city he had visited. Khanbalig are two Mongol words signifying the Khan's city. The Chinese capital was still so called by the Turks in the time of $P$. Ricci. The city on this site was originally (multum est vetus et antiqua, as Odoric says) the capital of the kingdom of Yan, B.C. 222. This was conquered by the Thsin sovereigns of China, and the city lost its importance A.D. 936. It was taken by the Tartar Khitan, and became their Nan-king or Southern Capital. In 1125 it fell to the Kin, ancestors of the Manchu, who gave it the name of Si-king or Western Capital. In 1153 it received from the fourth Kin sovereign the name of Chung-tu or Central Court. It seems also to have been known as Yen-king under this dynasty. It was captured by Chengiz in 1215, and in 1264 his grandson Kablai made it his chief residence. In 1267 he built a new city, three li to the north-east of the old one, to which was given the name of Ta-tu or Great Court, called by the Mongols Daidu, the Taydo of Odoric and Taidu of Polo, who gives a description of its dimensions and the number of its gates. The Chinese accounts give only eleven gates. The circumference of the present Tartar city appears from the plans to be about 15 miles. Martini speaks of it as having still twelve gates in his time, but he was almost certainly wrong. It has three on the south side, and two on each of the others. The circuit of the two cities together is about 22 miles, according to the scale on the plan given by Panthier, though Timkowski states it at 40 versts, or $26 \frac{2}{3}$ miles. The route followed on the second journey of the Polo relatives into China was up the Oxus, to its sources, through Badakhshan, whence, crossing the Pamir tableland to Khotun, they went across the Hamil or Shamil desert to Cambalu (Khanbalig) or Pekin. The return was by sea to Singapore, and round Ceylon to the Persian Gulf.-Yule, Cathay, i. p. 127; Prinsep's Tibet.

KHAND, Khund, written Kund, Cund. HIND. A piece, a portion, a district, a province, as Bundelkhand. Also the divisions or portions of the Skanda and Padma Puranas, and of the Bharata Varsha.

KHAND, a race in the Cuttack (Khatak) Tributary Mahals, until after the middle of the 19th century addicted to female infanticide and human sacrifices. See Kandh.

K'HAND. HIND. Saccharum officinarum, sugar-cane; Khandchi, one of the men at a sugar press.

KHANDA. HIND. A double - edged sword. The devotion of the Rajput is still paid to his arms, as to his horse. He swears by the steel, and prostrates himself before his defensive buckler, his lance, his sword, or his dagger. The worship of the sword (asi) may divide with that of the horse (aswa) the honour of giving a name to the 
continent of Asia. It prevailed amongst the Scythic Gete, and is described exactly by Herodotus. To Dacia and Thrace it was carried by Getic colonies from the Jaxartes, and fostered by these lovers of liberty when their hordes overran Europe. The worship of the sword in the Acropolis of Athens by the Getic Atila, with all the accompaniments of pomp and place, forms an admirable episode in the history of the decline and fall of Rome; and had Gibbon witnessed the worship of the double-edged sword (khanda) by the prince of Mewar and all his chivalry, he might even have embellished his animated account of the adoration of the scimitar, the symbol of Mars._Tod's Rajasthan, i. ; Royle's Arts, etc., of India, p. 460. See Kharg.

KHANDA. SANSK. In Buddhism, the elements of sentient existence, of which there are five constituti, viz. the organized body or the whole of being, apart from mental processes; sensation, perception, discrimination, consciousness.

KHANDAGA, also Khandi, in Coorg, a land measure of varying dimensions.

KHANDAGIRI, a hill in the Puri district of Urissa, situated about 12 miles west of the road from Cuttack to Puri, and 5 miles east of Bhuvaneswar. It is in lat. $20^{\circ} 16^{\prime} \mathrm{N}$., long. $85^{\circ} 50^{\prime}$ E. Two sandstone hills, Khandagiri and Udayagiri, stand abruptly out of the jungle, separated by a narrow gorge, each of which is honeycombed by caves and temples cut out of the rock, and which are believed to form the earliest memorials of Buddhism in India. The oldest of them consist of a single cell, little larger than a dogkennel, cut in the face of scarcely accessible precipices, and with no sigus of even the primitive carpentry architecture. Others of a somewhat later date are shaped into strangely distorted resemblances of animals. One has from time immemorial been known as the Snake Cave, another as the Elephant Cave, a third as the Tiger Cave. These sandstone caves, as a whole, represent ten centuries of humau existence, or from B.C. 500 to A.D. 500. The oldest are on Udayagiri Hill, the nore modern ones being on Khandagiri, whose summit is crowned by a Jain temple erected by the Mahrattas at the end of the 18th century.-Imp. Ga *; Beng. Ls. Soc. Journ. vi. 1085.

KHANDAIT, from KLanda, a sword, military retainers in Orissa, Cuttack, and Northern Circars, holding lands for service. In the Balasor district in Orissa, in 1881, the population was 770,232, the aborigines and semi-Hinduized being-

Bhumij,. . . 1,675 | Chamar, . . .4,383 Santal, . . 1,176 Brahmans, . 101,509 Pan, . . . 36,546 Khandait, . . 135,671 Kandara, 18,485

The Khandait are descendants of the soldiers of the ancient rajas of Orissa, who kept up large armies and allotted the land on strictly military tenures. The officers were men of birth, but the rauks were filled from all classes. They all came to be ranked with the military classes, but are now not distinguishable from ordinary agriculturists.

KHANDALA, in lat. $18^{\circ} 46^{\prime} \mathrm{N}$., long. $73^{\circ} 23^{\prime}$ E., a large village on the north-eastern foot of the Bhor Ghat. The Dak bungalow is 1768 or 1744 feet above the sea; a spring, three miles east of Khandala, is 1928 feet; Magfanni Hill, two miles S.W. of Khandala, 2601 feet.

KHANDAN. HIND., PERS. A term in use in India to designate the relatives of princes.

KHANDAR, a termed used in the Peepree, Rambaj, and Garvee Dang by the Bhil and Kunbi cultivators, signifying lopping the trees of their tops and branches for cultivation. By this destructive system acres of young trees were mowed down.

KHANDAVA, a forest district occupied by the Naga at the time of the Vedic Aryan. It was set on fire by Arjuna, and all the Naga were destroyed, except their raja Takshaka, who escaped.

KHANDESH, a district in the northern part of the Bombay Presidency, lying between lat. $20^{\circ}$ $15^{\prime}$ and $22^{\circ} \mathrm{N}$, and long. $73^{\circ} 37^{\prime}$ and $76^{\circ} 24^{\prime} \mathrm{E}$., with an area of 10,162 square miles, and a population in 1872 of $1,028,642$ souls. It is divided. into two parts by the river Tapti, the southern portion being drained by the Girna. Khandesh is an extensive and well-watered plain, interspersed with ranges of low barren hills, at the base of which run numerous rivers and rivulets, flowing from the table-land into the river Tapti. It is surrounded by lofty mountains clothed with trees, and very unhealthy. On the north are the Satpura mountains, clothed with forest; on the west is the steep and stony Sukhein range, with tangled masses of bamboo; and on the south are the ranges of Chandore Saatinulla and Ajunta, with babul jungle in the dells; and on the east low sterile hillocks separate it from Berar. Under Muhammadan rulers, Khandesh attained to much prosperity, but it was ravished by Holkar's army in A.D. 1802, followed in 1803 by a famine. Up to this, the Bhil race had mixed with the other inhabitants, and been watchmen and policemen of the district, but they then withdrew to the surrounding mountains. The Kunbi are the main body of the cultivating population of Gujerat, Khandesh, Maharashtra, and the Central Provinces. The settled agricultural people are chiefly Kunbi, with large numbers of Rajputs and Hindus from Northern India.

Besides the Mahratta cultivators, who are Kunbi by caste, large numbers of Pardeshi and Rajputs have long been settled in the district. Gujars are the most industrious and well-to-do of the agricultural population, - Banya from Marwar and Gujerat, and Bhatia, late comers from Bombay. Wandering and aboriginal tribes form a large section of the population, and Bhils, 11.87 per cent. of the whole, are the most important, with Banjara or Lamani, the pack-bullock carriers of former times.-Imp. $G(a \approx$.

KHANDOBA, an incarnation of Siva, largely worshipped in the Mahratta country.

KHANDPARA, a Native State in Orissa, lying between lat. $20^{\circ} 11^{\prime} 15^{\prime \prime}$ and $20^{\circ} 25^{\prime} \mathrm{N}$., and long. $85^{\circ} 1^{\prime}$ and $85^{\circ} 24^{\prime} 40^{\prime \prime} \mathrm{E}$. Its people, mainly composed of Kandhs and Savars, with semiHinduized aborigines, consist principally of Pans, Mihtar, and Kandara.

KHANDURI of Garhwal is a principal Brahman tribe.

KHANDWA or Khundwa, the chief civil station of the district of Nimar. The G. I. P. Railway has a station there, and here the whole 
traffic of Central India towards Bombay meets the line. The area of the district is 1553 square miles, and population in 1872 was 109,622 .

KHANDY, a measure of weight, and according to locality and the articles sold varying from 500 to 821 lbs. See Candy. Aziz.

KHAN-i-AZIM, a title of the poet Aziz. See

KHANJAR. Hind, Pers. A dagger, a short curved sword.

KHANJRI. HxND. A tambourine with bells.

KHAN-KHANAN, Lord of lords, a Muhammarlan title at the Dehli court. It was the title of Mirza Khan, son of Bahram Khan. In Persia, the title of Khan is also borne by noblemen. In 'l'urkey and in China it belongs to the sovereigns alone.

KHANWAH, an inundation channel in the Lahore and Montgomery districts of the Panjab. It supplies 173 estates.

KHANZADA, in Oudh, a Muhammadan convert from Hinduism. The Bachgoti of Faizabad and Sultanpur have three Khanzada chiefs, Hasanpur being at the head of all. The BhaleSultans have also three, and the Bhartawan clan one. Kheri has two Abhan Khanzada chiefs, Sitapur or Gaur and Barabanki or Bisen. Convorsions in Oudh were common under the Jounpur dynasty, A.D. 1394-1457, to which period most of the Oudh Khanzadas trace back. Qu. Khanazad.-Carnegy.

KHAR. HIND. Prosopis spicigera. The soda plant, Caroxylon Griffithii; also soda, potash, barilla, dry alkali; hence Khara, saline. Parkhar, from Par, beyond, and Kar or K'har, saline, is synonymous with Looni, the salt river. There are several Khari Nadi, or salt rivulets, in Rajputana, though only one Looni. The sea is frequently called the Looni-pani, the salt water, or Khara-pani, metamorphosed into Kala-pani, or the black water. Khara-pani also means saltish or brackish water. Khari-matti, saline soil. Khari-namak, medicinal sulphate of soda, glauber salts. Khara-matchi, salt tish. Khara-sajji, an inferior kind of carbonate of soda.-Tod's Rajesthean, ii. p. 304.

KHAR. Pers, A donkey, Gor-khăr, the wild ass, the Equus onager. Khatr-gosh, the hare, literally the ass-eared.

KHARACH. HIND. Expenditure, outgoings. The word is variedly combined: war-kharach, waste, extravagance.

IKHARADI. Hind. A wood turner; also the colours and colour-sticks for lacquer ware, used in the Panjab by the wood turner to colour his ware when the turning process is complete. The ;stick consists of shellac, melted down with a certain proportion of wax and sulphur, and coloured by various simple or compound colours. They are applied by the hand. The operator holds the colour-stick against the turned wood object while revolving rapidly; the heat produced by the friction melts the lac, and the colour is dicposited on the surface of the wood. The skill and fancy of the operator direct him either in lizying on a uniform layer of colour, or else putting it on in little spots or touches, by allowing the colour-stick only very lightly to touch the revolving wood, thus producing cither a smooth uniform colour, or the pretty mottled appearance so often observed in lacquered ware.
Two or three different colour-sticks are often applied, giving the whole a marbled appearance of great beauty. The colour thus applied is spread, fined, and polished, by pressing the edge against the turned object while revolving. The final polish is given by a rag with a little oil. The principal colours are of lac, crimson, orpiment, red lead, green made of orpiment and Prussian blue, dark blue, indigo or Prussian blue, black, white, brown or gold colour, light blue or ultramarine. They also bear the names of Kanair, Kundera, and Kundaira. - Powell's Handbook; Sherring's Hindu Castes, p. 316.

KHARAGORA, a small village on the outskirts of the lesser Runn of Cutch, where salt has been manufactured since 1872. The Kharagora salt is in beautiful crystals, about the size of an almond, and so hard that the wastage caused by removal is insignificant. Ordinary sea salt is made by solar evaporation of the sea water all round the coasts of India, in pans laid out near the sea, all along the western side of the Bay of Bengal from the Sunderbans to the southernmost point of Ceylon, all through the islands of the Archipelago, and on the west side of India, north and south of Bombay. At Kharagora, the cost of production is only a few anmas per maund of $82 \mathrm{lbs}$, but is a Government monopoly, and is sold at about 2 rupees 13 annas per maund.

The Runn of Cutch for miles and miles prescnts nothing to the eye but brown, barren waste. The Runn is supposed at one time to have been an arm of the sea, and if wells are sunk in almost any part of it, there filters through the sand a salt brine. But there are three or four kinds of soil in the Runn, all lying in different layers, and it is only through one of them that brine percolates. This laver is found at a very great depth, and sometimes not at all. The salt manufacture there only lasts from the beginning of October to the end of April; and the Agria transform them. selves into cultivators during the rains.

The salt works consist of between three and four hundred pans in ten rows, with a railway siding running between each two rows, and the whole is surrounded by a cordon of police stations. Each pan is 250 feet in length and 60 in breadth, and has at one end a well; and where the brine in the well is not of sufficient strength, a shallow reservoir is built by the side of the pan, and in it the water from the well is allowed to stand for two or three days, that it may settle and concentrate before it is poured into the pan. The pan is a work of art. There must be no soft mud left in it. The Agria work up the mud with their feet into a stiff paste, and then beat it down with heavy wooden mallets until it presents a smooth, tough surface; and this process takes two or three months. The sides of the pans are lined with grass, so as to prevent loose earth from falling in, and the sides of the wells are protected by matted basket-work. The mode of raising water consists of two long levers resting on fulcrums fixed by the side of the well, and the short arm of each is heavily weighted with hardened clay so as to bear it down and send the other end towering up over the well. Earthen pots are suspended from the higher ends by ropes, and two men standing on planks above the well draw down the pots until they have gone down into the depths and been filled; then, letting go. 
the ropes, the beams fly upwards, the pots come up with a rapid swing to the top of the well, and are emptied into an earthen channel which communicates with the pans. When the pans have been filled with water and allowed to stand, the formation of minute crystals begins to take place, and from then until the crystals are fully formed, or, technically speaking, until the 'salt is ripe," the pans must be raked from end to end, and fresh brine passed through them every day. If this is not done, all sorts of salt get mixed with the table salt, and the result is an unsaleable mixture. The raking is done by a man with a rough wooden rake made of twigs, too pliable to injure the bottom of the pan. During the earlier hours of the day, before the heat is great, each Agria trudges up and down his pan with this instrument behind him until no crystal has been left unshaken. By the end of March the salt is ripe, and is piled up by the side of the pans; from these it is removed along the sidings in railway waggons to the great godown which has been built for its storage during the wet months, and from thence it is distributed over the length and breadth of the land.

KHARAJ. Arab., Pers. Tax, tribute, land revenue, the tribute levied by Muhammadans on non-Muhammadans. La-Kharāj, untaxed.

KHARAK, an island 100 miles from the Persian Gulf, in sight of the Persian coast, and 100 miles from the Arabian coast. It is a small island $4 \frac{1}{2}$ miles long, where the pilots for the Euphrates river are obtained. Its population, which amounted to 100 poor fishermen and pilots when Baron Kniphausen first established himself in 1748 , increased within the eleven years that the Dutch held it, to upwards of 12,000 souls. It was neglected and lost in 1765 , because it was not worth preserving to the nation by whom it had been acquired. It is situated within 30 leagues of the Shat-ul-Arab, and half-way between the coast of Arabia and Persia. Ships proceeding to Bussora generally call here for a pilot; it is 5 miles in length, and between 2 and 3 miles in breadth. The fort is in lat. $29^{\circ} 14^{\prime} \mathrm{N}$, and long. $50^{\circ} 14^{\prime} \mathrm{E}$. The British occupied it for a few years about 1838-41.-Taylor's 'Tr. i. p. 353 ; Niebuhr's Tr. ii. p. 154 ; Malcolm's Persia.

KHARAL, a quarrelsome Jat tribe in the Googariah district of the Panjab, between the Ravi and the Sutlej; also, a tribe of Sunni Muhammadans in the Multan district.

KHARAN, a western province of Baluchistan, in which lie two small towns. It is occupied by a tribe of Persian origin called the Nushirwani, of whom the Alifzai are one branch. They cultivate a little wheat and barley. They claim a descent from Nushirwan, similar to the Udaipur Rajputs.

KHARASM, the ancient Chorasma and modern Khiva, is the country on the east of the Caspian Sea, the capital of which was Gurganj. The Arabs converted the name of the country into Jurjan, and that of the capital to Jurjaniya. The Mongol form of the name was Organj. Noshtigin, a Turki slave of Malik-Shah Seljuk, was made governor of this province, and contrived to secure his independence. His son Kutub-ud-Din extended his dominions, and acquired the title of Kharasm-Shah, a name which had been borne by the rulers of the country before the Muhammadan rule. This empire of the Kharasm kings rose upon the ruins of the Seljuk dynasty, and their territories extended from Azerbijan and the Caspian Sea to the Indus, and from the Persian Gulf to above the Jaxartes or Syr Darya. A succession of nine princes reigned for 138 years, from Hijira 491 to 628 (A.D. 1097 to 1230); but in H. 618 , the last of them, Jalal-ud-Din, was driven by Chengiz Khan beyond the Indus.

Bodies of the Kharasmian troops had approached the Indus, but Chengiz Khan fell on the sultan of Kharasm, defeated his armies, demolished his cities, laid waste his country, and massacred or reduced to slavery a great part of his subjects. He himself died of a broken heart in an inaccessible retreat on an island in the Caspian, and his son and successor, Jalal-ud-Din, was driven into the eastern extremity of his dominions. $\mathrm{He}$ gained a victory at Kandahar, and another farther to the east. His last battle was on the Indus, where his army was destroyed, and he swam the river with seven followers, amidst a shower of arrows from his enemies. After various changes, he was, ten years afterwards, killed in Mesopotamia.-Collett. See Khiva.

KHARA-TUCKA, in the hill districts to the S.W. of Mehar, in Sind, is a pretty valley that overhangs Herar. This valley must have been early inhabited, and curious remains of a bygone age are seen in the Kafir Kot, regular and evidently artificial ranges like river terraces. The popular belief is, that their huge boulders were lifted into position by the giant race then inhabiting the earth, but they must have been arrested in their descent from the higher ridges by accident or by some artificial contrivance. They are strange and imperishable memorials of an age and race long since passed away. These terraces were for purposes of cultivation; they caught the rainwater running down the face of the hill, also detritus, thus forming slight soil, in which the people sowed jowari or wheat, according to season. The practice is common now all over Afghanistan and the Himalaya, and was so throughout Baluchistan when it was more densely populated than at present. The extinct inhabitants of these days are always styled Kafir, hence these terraces and other remaius are called Kafir Kot.-Major Merewether in Bombay Med. Tr., 1860, p. 273.

KHARDA, 56 miles $\mathrm{E}$. of Ahmadnaggur, in lat. $18^{\circ} 38^{\prime} \mathrm{N}$., and long. $75^{\circ} 31^{\prime} \mathrm{E}$. In 1795 , the Nizam's army defeated here the Mahratta general.

KHARDAR, HIND., also Kar-i-Khardar, the work of points, the gold work of Käbul and Dehli.

KHARDOUR. In the villages of Upper India, the Khardour or Hardoul are mounds studded with flags to avert disease.

KHARG. Hind. A sword. Kharg band'hai, or binding of the sword, is a ceremony performed when a Rajput is fit to bear arms, as amongst the ancient German tribes, when they put into the hands of the aspirant for fame a lance. Such are the substitutes for the toga virilis of the young Roman. The rana of Mewar himself is thus ordained a knight by the first of his vassals in dignity, the chief of Salumbra. If we couple this martial rite with the demand of jüddan. there is an additional reason for calling the Yadu Indo-Scythic. Their worship of the sword is Kharg-thapna. Kharga, a Hindu sacrificial sword. 
-T'od's Rajasthan, i. pp. 159, 583, ii. p. 259. See Khanda.

KHARI, a rude pagan tribe on the hills of Assam, on the eastern frontier of the Mikir and Cachar. Near them are the Angami, another rude pagan tribe. These are associated with the Namsang, Joboka, Mulung, Tablung, Tengsa, Kbari, and Mozome Angami.

KHARI, a slate-stone of Cuttack, used for the manufacture of pencils and balls for writing on the ground or floor in all rural schools, and by native accountants.

KHARIF, crops sown at the commencement of the rains, ripening in autumn. In India there are two principal harvests, the spring and autumn, with, at some places, an intermediate crop. For the spring harvest, the Rabi or Fasl-i-Rabi, the seed is sown in September or October, at the close of the periodical rains. The grains sown consist of wheat, barley, and other cereals, different kinds of pulse which do not require irrigation or much water, and these crops are cut in February or March. The autumn or Kharif crops consist of rice and other grains requiring irrigation. For these the seed is sown at the commencement of the rainy season, and reaped about October or November. Other millets and pulses of quick growth are sown at the beginning of the rainy season, and form the Bhadoni or intermediate crop.

The Bhadoni includes sawan, urdi, kakun, makra, bagri-dhan, and sathi-dhan; the Kuari crop includes dhan, kodo, til, patua sanai, maize, and cotton; and the Agahni crop includes jarhan, sorghum, urd, mothi, mung, patua ; for seed, ramdana, lobiah, and bhatwans.-Carnegy; Burton's Scinde, p. 381; Wilson's Gloss.

KHARIK, also Khar-khanda. HiNd, MAHR, A tribe employed in cultivating salt marshes or saline soils.

KHARI MATTI. Hind. Fire-clay, pipe-clay, white earth. That of the Lahore bazar is a palecoloured clay, almost the same as chikni mitti, and used to make crucibles of. The term khari mitti is also applied to chalk.-Powell's Handbook.

KHAR-i-SHUTR. Pers. Camel's thorn, Alhaji maurorum ; in Arabic it is called Agul, and all the deserts of the east are covered with it. It is the Jouz of Afghanistan. It is a prickly bush on which the camels browse, and is called jowassa in the Upper Provinces of India, and Shinz in Baluchistan, and is often used to make tatties, or screens placed at the windows, and wetted, for cooling the apartments by evaporation in the hot winds. Pottinger says the Shinz, though to be seen in Baluchistan, is not in such plenty as in the lower countries.-Pottinger's Tr.p. 102 ; Ferrier's Journ. p. 378 ; Fraser's Khorasan, p. 91.

KHARITA. PERS. The ornamented or embroidered bag of embroidery or kbimkhab in which eastern letters are despatched. Khariti, a sort of chatelaine.

KHARJ, the key-note of musical scale.

KHARJI. Pers. Schismatics; the Sunni Muhammadans are so called by the Shiah sect. A Kharji is a person who separates himself from a community or religious faith; a seceder. The Shiah sect regard Ali as the immediate successor of Mahomed; the Sunni accept Ali as the fourth khalif. Sunnis designate all other Muslims by the term Shiyaees, signifying separatists or sectarians.
KHARMA, properly Khurma. ARAB. In Persia, certain trees are reckoned mubarak or blessed, such as the zeitun or olive, and the nakhl or khurma, the date-palm tree. Some Mubammadan tradition respecting the angel Gabriel seems to have consecrated the olive; and the date is said to flourish only in the regions of Islam, the land of true believers. - Ouseley's Travels, ii. p. 330.

KHARRAH, or Indian mackerel, a species of Thynnus, is found in abundance off the Burmese coast, and from thence great numbers, in a dried state, are annually imported into Bengal.

KHARRIA, a tribe in Singbhum in a very wild state, living much in backwoods and on the tops of hills apart from the Ho and Bhumij, who are somewhat in dread of them, as these isolated Kharria have the reputation of being great wizards. They are found also, under the same name, in the Manbhum Hills. The Kharria are also seen in villages with other tribes as farm labourers, but in the Chutia Nagpur estate they are far more civilised, living near the southern Koel river, one of the streams that rise on the Chutia Nagpur plateau, the principal source of the Brahmani. This river the Kharria venerate as the Santal the Damūdar, and into it they throw the ashes of their dead. Their ancestors, they say, were formerly settled between Rohtas and Patna. They quarrelled with their relations, and wandered away to the Koel. Part of them seem, however, to have reached the Koel from the soutb. They worship the sum under the name of Bero, and whom in prayer they address as Parmeswar. Every head of a family should, in his lifetime, make not less than five sacrifices to this divinity ; the first of fowls, the second of a pig, third of a white goat, fourth of a ram, and fifth of a buffalo. Their sacrificial altar is an ant-hill, which was also formerly used by the $\mathrm{Ho}$ and Mundah. They are said to have no word for marriage, but after certain festivities the bride and bridegroom are left to themselves, and the following morning are carried to the river to bathe, and the bride conveyed to her husband's home by her own friends. A dance is then got up, and the bride and her groom are carried through it seated on the haunches of two of their companions. Like all Kolarian races, they are fond of dancing. The women have three parallel lines tattooed on their foreheads, with marks on their temples. Those of Manbhum are said not to eat sheep. They burn their dead, and place the asbes in a pot, which they throw into the river. It is said that they do not allow their women to cook. -Dalton, Ethn. Beng. p. 161.

KHARRI BOLI, the Hindi taught in Government schools.-Cust.

KHARTRA signifies true, an epithet of distinction which was bestowed by Sidraj, king of Anhilwara Patan, on one of the branches (gatcha) of the Buddhist and Jain faith in a grand religious disputation (badha) at that capital in the 11th century. The celebrated Hemachandra Acharya was head of the Khartra-gatcha; and his spiritual descendant honoured Udaipur with his presence in his visit to his dioceses in the desert, in 1821. Colonel Tod's Yati tutor was a disciple of Hemachandra, and his patravali, or pedigree, registered his descent by spiritual successions from him. This pontiff was a man of 
extensive learning and of estimable character. $\mathrm{He}$ was versed in all the ancient inscriptions. His travelling library was in the charge of two of his disciples remarkable for talent. The letters of invitation written by his flocks in the desert were rolls, some of them several feet in lengtb, containing pictured delineations of their wishes. One from Bikanir represented that city, in one division of which was the school or college of the Jain, where the Yati were all portrayed at their various studies. In another part, a procession of them was quitting the southern gate of the city, the head of which was in the act of delivering a scroll to a messenger, while the pontiff was seen with his cortege advancing in the distance. To show the respect in which these high priests of the Jain are held, the princes of Rajputana invariably advance outside the walls of their capital to receive and conduct them to it,-a mark of respect paid only to princes. On the occasion of the high priest of the Khartra passing through Udaipur, as above alluded to, the rana received him with every distinction.-Tod's Rajasthan, i. p. 518.

KHARVAR, a measure of 100 Tabreez maunds, which is equal to 6 maunds and 10 seers of India, or about 520 lbs. avoirdupois. - Mohun Lal's Travels, p. 262.

KHARWA. HIND. A red-dyed cotton cloth of Mirzapore, used for lining dresses. It is also made at Bhaonagar, Surat, and other places.

KHARWAR, a race in Chutia Nagpur whose four clans are the Bhogta, Manjhi, Raut, and Mahato. The Bhogta are in the hills of Palamau skirting Sirguja, in Tori and Bhanwar Pahar of Chutia Nagpur, and in other places. In the middle of the 18th century, the head of the Bhogta clan was a freebooter, but he surrendered and kept to his engagement. His two sons, however, joined in the mutiny of 1857-58; one was hanged, the other transported, and the estate confiscated. The low Kharwar in feature resemble the Santal. They are very dark, with pyramidal-shaped low noses, thick protuberant lips, and the cheek-bones project so as to make the temples hollow. They claim to be Kshatriya, and wear the poita or sacerdotal cord. They have been for ages mixed up with the Cheru, and subject to them. They elaim affinity with each other, and have some customs in common. The rajas of Ramgarh and Jashpur are members of this family, who have nearly succeeded in obliterating their Turanian traits by successive intermarriages with Aryan families. The Jashpur raja wedded a lady of pure Rajput blood, and, by liberal dowries, obtained a similar union for three of his daugliters. The Kharwar worship Kali, also the goddess Chandi, to whom they sacrifice human victims, and some prisoners who fell into their hands during the rebellion of 1857-58 were so dealt with. They sacrifice every second year to Chindol, a male spirit, to Chanda, a female spirit, and to Parvin. Buffalo, sheep, and goats are offered to all these promiscuously. - Dalton, Ethn. of Bengal.

KHAR ZAHRA. PEIS. Lit. Ass-poison, very common over all India, probably oleauder?

KHAS. ARAB. Own, particular, select, private. Khowas, plural, are kept women, slaves. It is largely combined.

KHAS, a dialect of Hindi, spoken between Kamaon and Nepal. In Nepal it is called Parbatiya or Parbati.
KHAS, Khus, or Kus, the ruling tribe in Nepal, are also called Parbattiah or bighlander, from the circumstance of their residence in the hills. Until the year 1816, they ruled the entire tract from the Sutlej to the Tista river. They are of Turanian origin, and had a distinct language, but the Brahmans converted them to Hinduisin, gave them the rank of Kshatriya, and imparted to then the Hindi tongue, with which their own language became mixed. They possess masculine energy of character and love of enterprise, are excellent soldiers, and form a considerable part of the Nepalese army. They will carry several days' provisions on their backs, can despatch their meals in half-an-hour, and laugh at the pharisaical rigour of the Bengal sepoys, who must bathe from head to foot and worship their god before they begin to dress their dinner, must eat nearly naked even in the coldest weather, and cannot be in marching order in less than three hours, and would deem the carrying of a load intensely degrading.

KHASA, HIND. Soft calico, a fine clotb.

KHASA, a people who inhabited Persia and Northern India before the Aryan immigration. There is still a race in the Indian desert, now Mubammadan, and called Khosa. Elphinstone mentions the Khasa Khel. Kashgar is in the region of the Khasa, the Casia regio of Ptolemy. Menu says that the Saca, Yavana, the Pahlavi, and the Khasa of Central Asia, were all Kshatriya or Rajputs.-Birr.

KHAS-AAL, a powerful tribe of husbandmen on the east of the Euphrates.

KHAS-BARDAR, a matchlock-man in a great man's retinue.

KHAS-CHELA. Hind. Literally chief discip?e. The chief disciple and destined successor of the mabaut or head of a religious establishment of ascetic or mendicant Hindus. - Wilson's Glossa'y.

KHAS-DES, a term formerly applied to all the hill country in the N.W. Himalaya, of which the inhabitants were of mixed caste and impure to the Hindus of Lower India. The Khasiya people do not acknowledge the name as applicable to themselves, but apply it to the Bhotia.

KHASHI. HIND. The framo which supports the fine screen or strainer used in making paper.

KHASHKHA, Pens.; Tika, Hind. The sectarian mark on the foreheads of Hindus. Qu. Khushka.

KHASH KHASH. GuJ., HIND. Poppy secds of Papaver somuiferum. Khash-khash ka-tel, poppy seed oil.

KHASH RUD. The geographers describe this river as taking its rise in the mountains of Siahband, and trace its course from north to south until it falls into the Helmand at Kernasheen, whereas it flows in this direction only as far as Koh-i-Duzdan, a villacre situated between Washir and Ibrahimi; there it forms an elbow, turning suddenly south-west, and ruus from that point straight to the Seistan lake. At the cold senson of the year its bed is generally dry and full of reeds, in which are numbers of wild fowl.Ferrier's Journ. p. 401.

KHASIYA, a great tribe in Kamaon and Garhwal, who claim to be Rajputs, but this is doubtful, and Rajputs do not acknowledge the connection. The people of Kamaon consist of the Bhotia on the borders of Tibet, the Khasiya 


\section{KHAS-KHAS.}

or original hill population, and settlers from the plains. The mass of the population south of the snows consist of the Khasiya, whose country is called Khas-des, in distinction from Hundes, the country of the Hun, and Bhot, the country of the Bhotia. The Khasiya are now Hindu in religion, in language, and customs. They are identical with the Khasa Hindus inhabiting the bills, who were mentioned by Menu' 2500 years ago. Until British occupation, the Doms were the predial slaves of the Khasiya proprietors. In Kamaon the hill dialect is in the main Hindi, but has some curious grammatical affinities to the Bengali. Campbell, p. 67.

KHAS-KHAS. BENG. Andropogon muricatus, the cuscus of Europeans, remarkable for its agreeable odour. It is the Anatherum muricatum of Beauvois, a fragrant grass, the roots of which are made into door and window screens. Is much used as a packing material. The grass of the plant is called khavi and panni, and the flower izkhar.-Powell's Handbook, i. p. 518.

KHAS-KHELI. HiND. A slave race at the Bahawulpur court, whose daughters associated first with the nawabs before being married to other persons. The Gola were another class of slaves, and were principally from Africa, and of the Sidi Habshi, Khas-kheli, Sindi, and Zemghur races.

KHASRA, a written record of the particulars of a rough map or plan of a village. A tield book, day book, or journal.

KHASSYA HILLS with the Jaintia Hills form a British district in Assam, between lat. $25^{\circ} 1^{\prime}$ and $26^{\circ} 14^{\prime} \mathrm{N}$., and between long. $90^{\circ} 47^{\prime}$ and $92^{\circ} 52^{\prime} \mathrm{E}$, of an area of 6157 square miles, and with a population, according to the census of 1881 , of 169,113 souls. These hills form the central section of the watershed between the valleys of the Brahmaputra and the Surma. The Khassya Hills are occupied by a collection of States, each governed by an elective ruler on democratic principles. The Khassya States are 25 in number, of which five, viz. Cherrapunji, Khyrim, Nustung, Sungree, and Nuspoong are commonly called the semi-independent States. The chiefs exercise civil and criminal jurisdiction over their own people in all matters pertainiug exclusively to them. The minor States, known as the dependent States, are 20 in number, the chief of which are-

Nungklow.

Moleem.

Murriow.

Ramrye.

Mowlie.

Cheyla.

Dowarrah

Notoormen.

\begin{tabular}{|l|l|} 
Mowseuram. & Mowyang. \\
Mowdun Punji. & Nobo Sopho. \\
Mahram. & Jeerung. \\
Mullui Chummet. & Syung. \\
Bhawul. & Moflong Punji. \\
Seenai Punji. & Mowlong Punji. \\
Lengkhan Punji. & Lyksom Punji.
\end{tabular}

Moleem was conquered in 1829, and the raja of Khyrim ceded, to the British, the territory to the S.E. of the Oomean or Booga Pane river. In 1861, the raja was deposed, and Malay Singh, a new chief, installed. No engagements have ever been made with Nobo Sopho, Syung, Moflong Punji, and Lyksom Punji, but agreements were entered into with Mowyang in 1829, Dowarrah Notoormen in 1837, Soopar Punji in 1829 , and in 1860 with Bhawul. The whole tract of the hill country occupied by these confederates embraces an area of about 3800 square miles between Khassya, Sylhet, Assam, and the country

\section{KHASSYA HILLS.}

of the Garo. Some of the hills attain a height of 6000 feet, but the country includes belts of arable soil about 2000 feet above the plains, on which grow, in great luxuriance, oranges, limes, pine-apples, the jack-fruit, and mangoes, betelnut, and plantains, with the raspberry and strawberry.

The census of the Khassya and Jaintia Hills of 1872 showed 73,245 females to 68,593 males, and that of 1881 gives 88,710 of the former to 80,403 of the latter: that is, the district contains $110 \cdot 3$ women to every 100 men. In the Garo and Northern Cachar Hills the excess of females is trifling. In the Neilgherry Hills the excess of males is so great that polyandry is practised, and female Todas have a plurality of husbands.

Khasiya women are at the head of the family, bold property in their own right, and property descends in the female line. The sister's son inherits property and rank.

Marriages are made without ceremony. If the proposal of a youth is accepted by the young lady and her parents, he enters the household of the latter, or sometimes only visits his wife there occasionally; the union thus loosely made is easily broken. Separations are frequent; and when they mutually agree to part, they publicly intimate their wish by throwing away a few shells taken from each other; the children remain with the mother.

The Khasiya race deem a twin-birth unlucky, and, when twins were born, used to kill one of the infants. They deemed the twin-birth degrading, as assimilating them with the lower animals. The Aino of Japan, also, if a twin-birth occur, always destroyed one of the infants ; and this idea likewise prevails amongst the Bali population, and the Australian indigenes.

The Khasiya tribe habitually erect dolmens, menlirs, cists, and cromlechs, almost as gigantic in their proportions, and very similar in appearance and construction, to the so-called Druidical remains of Western Europe.

The undulatory eminences of the country, some 4000 to 6000 feet above the level of the sea, are dotted with groups of huge unpolished squared pillars and tabular slabs, supported on three or four rude piers. In one spot, buried in a grove, were found a nearly complete circle of menhir, the tallest of which was 30 feet out of the ground, 6 feet broad, and 2 feet 8 inches thick; and in front of each was a dolmen or cromlech of proportionately gigantic pieces of rock; while the largest slab measured was 32 feet high, 15 feet broad, and 2 feet thick. The method of removing the blocks is by cutting grooves, along which fires are lighted, and into which, when heated, cold water is run, which causes the rock to fissure along the groove; the lever and rope are the only mechanical aids used in transporting and erecting the blocks. The objects of their erection are various,--sepulture, marking spots where public events had occurred, etc. The Khassian word for a stone, 'man,' occurs as commonly in the names of their villages and places as that of man, maen, and men does in those of Brittany, Wales, Cornwall, etc. Thus Mansmai signifies in Khassya the stone of oath; Mamloo, the stone of salt; Manflong, the grassy stone, etc.; just as in Wales Penmaen mawr signifies the hill of the big stome, and in Brittany, a menhir is a standing and a dolmen a table stone, etc. 
The Khasiya are commonly classed with the neighbouring Synting, Garo, Naga, Kachari, etc., as a subdivision of the Indo-Chinese branch of the human family. The British stations, Shillong, Cherrapunji, and Jowai are the only large places in the Khassya and Jaintia Hills.

The ashes of a tribe are deposited under one vault or in one burial-ground. The remains of man and wife are never mingled, because they belong to different tribes. A husband is therefore in death separated from his wife and children, as the latter belong to the tribe of the mother, and their ashes are deposited with hers.

The climate of Khassya is remarkable for the excessive rainfall. Major Yule stated that in the month of August 1841, 264 inches fell, or 22 feet, and that during five successive days, 30 inches fell in every 24 hours! Dr. Thomson and Dr. Hooker also recorded 30 inches in one day and uight, and during seven months of Dr. Hooker's stay at Cherrapunji, upwards of 500 inches fell, so that the total annual fall perhaps greatly exceeded 600 inches, or 50 feet. From A pril 1849 to April 1850,502 inches, or 42 feet, fell. It is reported that in 1861 the total fall at Cherrapunji was 805 inches, 366 of them in July. This unparalleled amount is attributable to the abruptness of the mountains which face the Bay of Bengal, from which they are separated by 200 miles of jhils and sunderbans.

At 4000 to 5000 feet elevation in the Khassya, Dr. Hooker collected upwards of 50 species of Gramineæ alone, in an eight miles' walk, and 20 to 30 Orchideæ. There is only one pine in the Khassya mountains, Pinus Sinensis, which is not known as a native of the Himalaya. As in all very humid climates, orchids occur in very great abundance in the Khassya mountains, constituting at least a twelfth part of the vegetation, and being by far the largest natural order of flowering plants. They are equally abundant at all elevations. There are upwards of twenty kinds of palm in the Khassya district, including Chamærops, three species of Areca, two of Wallichia, Arenga, Caryota, three of Phœenix, Plectocomia, Licuala, and many species of Calamus. Besides these there are several kinds of Pandanus, and the Cycas pectinata.

Cherrapunji is a sanatorium in the Khassya Hills, in lat. $25^{\circ} 15^{\prime} 58^{\prime \prime} \mathrm{N}$, and long. $91^{\circ} 46^{\prime} 42^{\prime \prime}$ E., 4588 feet above the level of the sea. It is 40 miles north of Sylhet, and 60 miles south from Gowhatty.

The Jaintia Hills, on the other hand, are purely British territory, being a portion of the dominious of the raja of Jaintia annexed in 1835 . The first treaty with Jaintia was concluded in 1824 . The raja Ram Singh rendered no assistance during the Burmese war, but he agreed to acknowledge allegiance to the British, and his country was taken under protection. The population of the Jaintia and Khassya Hills is about 150,000.

The inhabitants of the Jaintia Hills, who call themselves Synting, have a less interesting history than the Khasiya. They first became British subjects in 1835 . In that year, the last raja of Jaintia, Indra Singh, was deposed, on the charge of complicity with certain of his tribesmen who had carried off three Bengalis, and barbarously immolated them at a shrine of Kali.-Campbell, p. 149; Col. Yule in Bengal Asiatic Journal for 1844;
Schlagentweit's General Hypsometry of India, ii. pp. 95-98; Hooker's Him. Jour. ii. p. 282 ; Lubbock, Origin of Civilisation, p. 21 ; Treatics and Sunnuds; Dalton's Ethnology.

KHAT. Arab., Hind., Pers. A letter. Khati-sharif, a royal letter.

KHATA-BANDI. Hind, MAHr. A system of assessment by Khatas or distinct estates ; in this, the tax or rent is paid, whether cultivated or left fallow.

KHATAK HILLS, a range or series of ranges in the Kohat and Peshawur districts, Panjab, so called from an Afghan tribe who inhabit them. They bound Peshawur district to the south, and extend from the Safed Koh system to the Indus. Between the plain of Peshawur and the Salt Range at Kalabagh lies the country of the Khatak and Sagree Afghans. The Khatak are divided into the chiefships of Akora and Teri. Akora lies east of the plain of Peshawur, on the river of Kabul. The Khatak of Akora live in the hills. The southern division is under the chief of Teri, who is able to assert his independence. Part of the Kohat district consists of the Khatak country, and in the Kohat valley they are the predominating tribe. They hold the Khushalgurh pass, leading from the Indus into Kohat, and offering the easiest entrance to the valley. On the whole, the Khatak have been loyal subjects. They are good soldiers, and can muster 12,000 fighting men. Many of them are in the British service. They are considered the best conducted and most respectable tribe on this frontier. The Teri Toi river divides the Khatak Hills into two main groups, the southern of which contains the famous salt mines of Narri, Babadur Khel, and Kharrak, while the mines of Malgin and Jatta lie among the spurs of the northern range. The peaks of the south-eastern group seldom attain a height exceeding 3000 feet; but Swanai Sir, in the opposite range, has an elevation of 4785 feet above sea-level. The salt, which gives these mountains their chief importance, occurs as a solid rock, uncovered and exposed in many places, so as to be quarried rather than mined. The deposit may probably rank as one of the largest in the world. The total quantity of salt extracted from the five mines in 1870-71 amounted to 407,098 maunds, and the duty realized to $£ 8556$. The Sikhs never managed these mines at all. They farmed them out to some local chief, and left him to collect what he could. Under British rule, the control and working of the mines is in the hands of Government officers. The salt is excavated and sold at the mine at a fixed duty of two, three, and four annas per maund of $80 \mathrm{lbs}$., covering all expenses. The first Khatak of note and influence regarding whom there is any information, is Akore, the founder of Akora, lying one march on the Peshawur side of Attock. The Khatak tribe is said to trace its descent from the Kurtani, from whom also the Orakzai of Thyruh, the Afridi, Bungush, Mohmund, Khuleel, and Daudzai claim descent. The Kurtani were called also Burdurani, in contradistinction to the Daurani, now divided into Popalzai, Bamizai, Saddozai, Nurzai, Alikuzai, Yusufzai, Alizai, and Barakzai (divided into Muhammadzai and Hassanzai). Akore came from Shuwal, near the Waziri country, to a place called at that time Hassan Tungi, and now known as 
Kurbagha, near to Dursummund, an independent village of Upper Miranzai, which lies between Hingu and Khurum. He is said to have been accompanied by 3000 of his relations and friends, and 8000 other men of Shuwal. At that time Kohat and Teri were occupied by the Orakzai. Akore with his adventurers drove the Orakzai from Teri, and held that country, their opponents retiring on Kollat, at which place the Bungush, rising on them and joining the Khatak, they were driven fairly out of the country to Thyrub. Tuppee, a village lying three miles S.E. of Kohat, and on the Kalabagh road, is pointed out as the spot where the engagement took place between the Kloatak and Bungush on one side, and the Orakzai on the other; after the battle, the conquerors divided the country, making a range of bills which divides Guddukheil and Luchee the boundary between the Khatak and Bungush. This range still forms the boundary between the two tribes. The Khatak country extended to Resee, a village near to and above Mukhud, on the Trans-Indus side. There were then two divisions of the tribe, Turi and Buluk. On the country being divided, Chountra, Dullin, and Durrah fell to the former, and from Buluk sprung two branches, Khurrum and Senee. Joullaee, Ghurzundai, and Unjukhulu lie in one valley, and belong to Khurrum, and the Senee branch passes from Teri to Purshai. Akore and his followers having entered the country as adventurers, left their wives and families at Kurbagha, and had difficulty afterwards in bringing them to rejoin them in their new country.-Selections from the Public Correspondence, p. 62 ; Papers, East Indies, Käbul and Afghanistan, 1859, p. 21; Burnes' Cabonl, p. 105; Records, Government of India, No. 11 ; Imp. Gaz.

KHATAM. AR. Seal or conclusion, the end of a book; a term in the science of exorcism. Klatami-Koran, the reading through of the entire Koran.

KHATAMBAND. HiND. Maker of stringed musical instruments.

KHATIB. ARAB. One who reads the Khutba, a preacher, a public speaker. Qanoon-i-Islam, by Jafir Sharif, translated by G. A. Herklots, M.D., 1832, says : "The Khatib (priest), after repeating two rukat prayers, also shukreea, ascends to the second or middle step of the mambur, and, the congregation being seated, he reads the Khutba ; that is, offers glory to God, praises the prophets, and passes eulogiums on his companions. He then descends to the lowermost step, recounts the many virtues of the $\mathrm{king}$, and offers up supplications on behalf of him. The king is he whose coin is current in the realm, and in whose name prayers are offered up after the Khutba is read at the mosques and at feasts.' At present (1832) it is in the name of the king of Dehli, but in the author's opinion erroneously, as it should be in the name of the Honourable East India Company.

KHATIK, in Bengal, a race who are poulterers.

KHATIRI, HiND, from Arabic Khatrah, danger; a crop raised in the sand on the banks of a river by manuring and hand-watering. A nominal rent is paid for such, as it may be swept away by a rise.

KHATMANDU. At the foot of the northern range, situated upon the easter'n bank of a small river, the Vishenmuttee, in lat. $27^{\circ} 36^{\prime} \mathrm{N}$., and long. $85^{\circ} 24^{\prime} \mathrm{E}$., stands the city of Khatmandu.
It is not the largest of the towas in Nepal, but it is the residence of the maharaja. It is said to have been founded by Raja Gunakamadeva about A.D. 723. In the square in front of the palace are numerous handsome temples. Many of these are like pagodas, of several storeys in height, and profusely ornamented with carvings, painting, and gilding. In front of several of the temples are tall monoliths, some surmounted by figures of old rajas, who founded the temples, others by the winged figure of Garur. They vary in size, from the gigantic pagoda of Taleju to a diminutive shrine cut out of a single stone, with an image a few inches high in the centre. Many of them present a most repulsive appearance, being dabbled over with the blood of cocks, ducks, goats, and buffaloes, which are sacrificed before them. In leugth Khatmandu may measure about a mile, its breadth nowhere exceeding half a mile. The name of the town in ancient books is Gorgoolputten; the Newar race call it Yindes; whilst among the Parbuttia, or mountaineers, it is styled Kultipur, an appellation wbich seems to proceed from the same source with Khatmandu, and derived, it is believed, from its numerous wooden temples, which are among the most striking objects in the city. These edifices are not confined to the body of the town, but are scattered over its environs, particularly along the sides of a quadrangular tank or reservoir of water. The houses are of brick and tile, with pitched or pointed roofs. On the street side, they have frequently enclosed wooden balconies of open carved work, and of a singular fashion; the front piece, instead of rising perpendicularly, projecting in a sloping direction towards the eaves of the roof. They are of two, three, and four storeys, and, almost without a single exception, are of a mean and poor appearance. The streets are exceedingly narrow, and very filthy. See India; Nepal.

KHATMI, or Barrä gul Khaira. Hind. Althæa rosea, hollyhock. The seed is considered cooling; in medicine one tola is given; the corollæ and pericarps, when fresh, are exceedingly mucilaginous and used in sherbets. Khatmi Kochak, PERS., is the small mallows. It grows in moist ground, and is useful when applied as a cataplasm to parts of the body stung by wasps or hornets. Khatmi Safaid, Hind., is Malva mauritiana.-Gen. Med. Top. p. 143 ; Ouseley's Travels, i. p. 216.

KHATNAH. Arab,, Hind,, Pers. Circumcision. It was enjoined in the law of Moses on all males of the Hebrews, on the eighth day after birth. It is practised by the Muhammadans on all males, at any age, but it is not enjoined in the Koran. It is practised on girls in Egypt by removing the prepuce of the glans clitoris. $-Z u-u l$ Mukhtar ; Tahlavi.

KHATRAN, an independent tribe adjoining the Dehra Ghazi Khan district, and behind the Bozdar Hills, in the midst of the Baluch tribes, with whom they are frequently at feud. They are special enemies of the Bozdars and the Murrees. Their hills scarcely touch the British frontier. Once they sought British alliance against the Murrees, and also offered their support, if an expedition were undertaken against that tribe; but the Government refused to have any relations of this nature with them, in order to avoid being implicated in the feuds of the hill tribes. They number 3000 fighting men, of whom 200 are mounted. 


\section{KHATRI.}

\section{KHATRI.}

KHATRI are a scattered Hindu race; a Khatri village is unknown. They, however, monopolize the trade of the Panjab, of the greater part of Afghanistan, and farther to the west in Central Asia, and even to St. Petersburg. They are the only Hindus in Central Asia. In the Panjab they are almost the sole people who perform the scriptory work, and there they are the chief civil employés of Government, and in the villages they keep the village accounts, act as bankers, and buy and sell the grain. They are also the gurus of the Sikh sects; both Nanak and Govind were Khatri, and the Sodi and Bidi of the present day are so. They do not usually engage in military pursuits, but the dewan Sawan Mull, governor of Multan, and his successor Mulraj, and very many of Ranjit Singh's chief functionaries, were Khatri. It is said that a Khatri was dewan of Badakhshan or Kunduz, as was the Peshkar Chandoo Lal of Hyderabad. Under the Afghans, a Khatri was governor of Peshawur, and Akbar's famous minister, Tudar Mull, was a Khatri; Joti Persad, a well-known Agra contractor, was a Khatri. The Khatri claim to be descendants of the old Khetrya, written also Chetriya and Kshatriya. They are Hindus; none, or very few, have ever become Muhammadans, and few have become Sikhs. The Khatri of Northern India are a very fine, fair, handsome race. Those of the western part of Peninsular India, about Bombay, are equally fair.

In Benares they arrange themselves into the two sections, Purbiya or eastern, and Pachhainya or western Khatri, both of whom point to the Panjab as the country from which they came. Some of the Kapur clan of the Pachhainya are, however, said to have adopted Muhammadanism.

In Gujerat and in Kattyawar, the Khatri are so largely engaged in dyeing that the name is applied to all dyers, Hindu and Muhammadan. The Hindu Khatri engaged in dyeing on this side of India, speak the Gujerat language; they were originally natives of Sind, but they have adopted the manners and customs of the places in which they reside. The old Khatri of Diu and several other places have all the look and manners of the Sindi. It is said that to avoid persecution an emigration from Sind took place in various directions. Those of them who settled at Lowaragad became the well-known caste of Iohana, and those that proceeded to Hingalaj became turners and dyers. From thence they emigrated to different places in Kattyawar and Gujerat.

In Benares they are closer observers of the ancient customs of Rajputs than that which is practised by modern Rajput tribes.

In Ludhiana there is a large number of thriving merchants of the Khatri race. They wear the sacred cord, which is put on their boys at the age of eight years, are taught the gayatri, and read the Vedas.

In Bombay and the adjoining districts, they are part of the writer class, whom Europeans style Purbho, and the Ror or Rora of Northern India are said to be Khatri. The Kukka, a handsome race on the east of the Jhelum, are said to have been Khatri originally; and of the Gaddi, an interesting race of fine patriarchal-looking shepherds in the interior of the Kangra Hills, the most are Khatri. In Behar is an agricultural class called Kshatri, Khatri, or Chatri, who some- times serve as soldiers or as the darwans or doorkeepers in Calcutta. In Ludhiana there is a large number of thriving merchants of the Khatri race, with a numerous colony of Kashmir shawl-weavers. Multani is a term applied to several trading classes in the north-west of India, wandering Pathan merchants and others.

Therenot, speaking of the people of Multan, says: "There is a tribe of Gentiles here, called Catry or Rajput; and this is properly their country, from whence they spread over all the Indies.' Diodorus Siculus marks them by the custom of their women burning themselves alive on the funeral piles of their husbands ; which continued a practice among them, as well as some other Hindu tribes, down to the middle of the 19th century. We find by Arrian, that the Cathei were confederated with the Malli and Oxydraceæ, that is, the people of Multan and Cutch, and which lay to the south-west of the place where Alexander might be supposed to cross the Hydraotes (or Ravi) on his way to India. After Alexander had crossed the Acesines (Chenab) and Hydraotes (Ravi), he appears to have been drawn out of the direct route towards the Ganges, to attack the city of Sangala. Sangala occurs only in Arrian, and is said to have been a city of great strength and importance in the country of the Cathei. Diolorus Siculus calls the same people Cathei or Kathei; and these may posssibly be recognised under the name of Catry of Thevenot, that is to say, the Khatri or Kshatriya tribe.

In A.D. 1000, Mahmud entered Hindustan, but in the course of eight years he made no farther progress than Multan. The people of Multan, who were the Malli and Catheri (that is the Khetry or Rajput tribe) of Alexander, must have preserved their ancient spirit, to be able to oppose, for so long a time, such formidable armies, headed by so furious an enthusiast. In 1008 we find the confederate Hindus defeated; and Mahmud's first essay towards effecting the downfall of their religion was the destruction of the famous temple of Nagarkot, in the mountains bordering on the Panjab country. His next expedition, being the sixth, was in 1009, when Tannasar, a more celebrated place of Hindu worship on the west of Dehli, experienced a like fate with Nagarkot; and the city of Dehli itself was taken at the same time. In 1018 he took Kanouj, and also destroyed the temples of Matra or Matura (the Methora of Pliny). His twelfth expedition, in 1024, was fatal to the celebrated temple of Somnat, in the peninsula of Gujerat, adjoining to the town of Puttan, on the sea-coast, and not far from the island of Diu, now in the hands of the Portuguese. The Khatri of the Panjab is, however, said by some authorities to be dissimilar to the Kshatriya of the Rajput. In the Panjab their avocations are looked upon as effeminate; but these writers and traders are not much inferior in courage and firmness to the ruder tribes, while they are superior in civilisation, refinement, and capacity for affairs. The Khatri and Urora of their cities and towns are enterprising as merchants and frugal as tradesmen. They are the principal financiers and accountants of the country. And even yet the ancient military spirit frequently reappears amongst the once royal Kshatri, and they become able governors of provinces and skilful leaders of arnies. The Kathri of Berar claim to be Rajput, 
and to be of the ancient Kshatriya, though many of them are weavers of nakki, kor, and kinara. In reality the Khatri of India are a fragmentary people, from some ancient stock now untraceable, but spread all through India, and actively engaged in peaceful avocations. In the Panjab they are designated Kirar.-Rennell's Memoir, pp. 123133; Records of Government of India, No. 2: Gita; Cunningham's Siliks, p. 22; Wilson's Hindu Drama.

KHATTA. HIND. Sour; the acid lime or citron, Citrus medica. Khatta-mitha is Oxalis comiculata.

KHAWA. Hind. A pass in the Salt Range, scarcely frequented, yet may be considered the most practicable. Timur crossed it on his march into Hindustan.

KHAWAK, a pass in the Hindu Kush, in lat. $35^{\circ} 38^{\prime} \mathrm{N}$., long. $70^{\circ} \mathrm{E}$. About 15 miles long. The crest is 13,200 feet. The ascent on the north side is a uniformly inclined plane.

KHAWAS. Arab. Plural of Khas. Nobles, grandees, personal servants. In Puranya, slaves in general. In the west of India, the children of a fomale slave belonging to a Charan or Rajput, the property of the owner of the slave, but treated as members of the family.

KHAYYAM, the takhallus or literary title of Omar, a native of Naishapur in Khorasan, a celebrated poet and astronomer.

In the days when Alp Arslan ruled in the stead of his father Toghrul Beg, three lads, each of whom was destined to rise to eminence or notoriety, might have been seen day by day meeting to learn wisdom from the instructions of the famous Imam Mowaffak of Naishapur. Every lad who studied under a master so renowned amongst the doctors of Islam, was deemed most fortunate, for his success in life was no longer a matter of doubt. One of the three was Nizam-ul-Mulk, afterwards vizir to Alp Arslan. Another was Hasan-bin-Sabbah, the founder of the sect of the Assassins, whose leader was known to the Crusaders as the Old Man of the Mountains. The third was Omar Khayyam, afterwards astronomer and poet. Nizam-ul-Mulk, in the Wasiyah, tells the story how Hasan one day, alluding to their good prospects, said, 'Let us make a vow, that to whomsoever good fortune falls, he shall share it oqually with the rest, and reserve no pre-eminence for himself.' 'Be it so,' the others replied. Nizamul-Mulk was the first to rise to eminence, and when he became vizir, Hasan received a good appointment, but, entering on a course of intrigue, he was degraded and disgraced, became the head of the Ismaili sect, which for a while was the terror of the eastern world, and Nizam-ul-Mulk fell a victim to their cruelty. Omar Khayyam received a pension from the royal treasury, and busied himself in 'winning knowledge of every kind, and especially in astronomy.' In the reign of Malik Shah he settled at Merv. He was one of eight scientific men employed in reforming the calendar. The result was the Jalali era, of which Gibbon says, "It surpasses the Julian, and approaches the accuracy of the Gregorian style.' He also wrote a treatise on algebra. But he is better known as a poet, and his Rubaiyat or quatrains have been translated into several European languages.

He wrote very little, but what he has written will live when the lengthy poems of inferior men are forgotten. By some he is thought to have been a Sufi; but though he uses Sufi forms of expression, his language is more in keeping with his position as a leading scientific man.

Those who place Omar among the Sufi quote the following verse :-

'In synagogue and cloister, mosque, and school,

Hell's terrors and heaven's lures men's bosoms rule;

But they who pierce the secrets of "the truth,"

Sow not such empty chaff their hearts to fool.

In one verse is a grave and serious rebuke, in a second is sarcastic ridicule :-

"Some feed false hope on that vain fantasy Of houris feigned in Paradise to be ;

But when the veil is lifted, they will see

How far they are from Thee, how far from Thee.

In Paradise are houris, as you know,

And fountains that with wine and honey flow;

If these be lawful in the world above,

What harm to love the like down here below?"

Another verse says :-

'Pagodas, just as mosques, are homes of prayer;

'Tis prayer that church bells chime unto the air;

Yea, Church and Ka'aba, Rosary and Cross,

Are all but divers tongues of world-wide prayer.'

Omar Khayyam loves to balance antitheses of belief. $\mathrm{He}$ formulated no system, but only scattered forth in elegant verse his doubts and difficulties. He lived and died a sceptic. He cannot understand the nature of things. He regrets that he has appeared on the scene at all :-

'I never would have come, had I been asked;

I would as lief not go, if I were asked;

And, to be short, I would annihilate

All coming, being, going, were I asked.'

He appears as lost in unbelief. Fatalism settled on his mind :-

"The "tablet" all our fortune doth contain,

Writ by the "pen" that needs not bliss nor blame;

'Twas writ at first whatever was to be,

'To grieve or strive is labour all in vain.

Moral responsibility is utterly denied :-

The potter did himself these vessels frame:

What makes him cast them out to scorn and shame?

If he has made them well, why should he break them?

And though he marred them, they are not to blame.'

The figure of a game at chess is introduced to show how helpless a creature man is under the inexorable rule of a pitiless fate:-

'We are but chessmen, who to move are fain

Just as the great Chessplayer doth ordain,

He moves us on life's chessboard to and fro

And then in death's box shuts us up again.

Omar had not always been thus resigned. He says-

'I put my lips to the cup, for I did yearn

The secret of the future life to learn;

And from His lip I heard a whisper diop,

Drink! for once gone you never will returu.

-Madras Mail, 23d March 1882; Saturday Review, 5th January 1884.

KHAZERIJ (Khezerj), a very ancient Arab tribe, in possession of Medina when Mahomed fled there. Abu Osaibi was of this tribe. The Rubina, once the most celebrated tribe in Arabia, is now a small broken clan. The Anizeh Arab come of this race.-Rich's Kurdistan, ii. p. 258.

KHEDA, HIND., written Kheddah and Khadah, an enclosure into which wild elephants are driven and caught, from Khedna, to chase. 
KHEDA, a village in the Cutch State, situated 13 miles south of Bhooj. To the S.E. of Kheda is a small village on a rising ground, above which stands the mausoleum of Pir Ghulam Ali. Inside the dargah is the tomb, under a canopy, supported by 12 small columns. Against the pall lies a representation of a Moghul pir, a water-colour portrait of Ali, with a nimbus round his head, and below him, Hasan and Husain, also with aureoles; and in a third frame, Mahomed in a blue choga, but the face left blank, - a curious compromise between the prohibition in the Koran and the desire for a palpable representation of the objects of reverence. - Imp. Gaz.

KHEDIVE, a Turkish word signifying prince, ruler. It was conferred on the hereditary ruler of Egypt by an imperial firman dated 26th May 1866 , from the emperor of the Turkish dominions. The previous title was Wali or Vali, viceroy, and had been conferred on Muhammad Ali, the first hereditary ruler.

KHEE. Hind. Kotaha land broken upon the steep slopes of hills.

KHEEL, the iron pillar of the Pandu race, mentioned in the poems of Chand. A legend relates that an iufidel Tuar prince wished to prove the truth of the tradition of ite depth of foundation; blood gushed up from the earth's centre, the pillar became loose (dhili), as did the fortune of the house from such impiety, and this is given as the origin of the name of Dehli.-T'od's Rerjasthan, ii. p. 31.

KHEESAH. Hind, PERs. A flesh glove. The importance of the condition of the skin to the maintenance of health and the comfort of the individual has been demonstrated by physicians. To preserve its surface free from all extraneous substances, to dislodge all concreted matter, collected dust, the deposit of the fatty secretions, etc., a glove made of burruk or Persian glove cloth, and called kheesah, has been in use from time immemorial throughout the east. It is applicable alike to the bath and the dressing-room. The hair-glove in India is used only for rubbing down horses.

KHEL. Pushev. A subdivision of a tribe; also a collection of tents, a village community, a portion of or even an entire tribe. It is a usual term with all Afghans and Baluch. Some Baluch live in mud huts, others in fortresses, but the usual lodging is a black felt or camlet tent, called gedaun, which is stretched over a tamarisk framework. An assemblage of gedaun constitutes a tumiun or village, common to the Khel, and a number of Khel form a tribe.

KHEL, a boat in use in Assam. Its roof is covered with the leaves of the Livistona Jenkinsiana palm. - Simmonds' Dict.

KHELAT, properly Kalat, in lat. $28^{\circ} 53^{\prime} \mathrm{N}$., and long. $66^{\circ} 28^{\prime} \mathrm{S}$, is 6800 feet above the sea. It is the capital of Baluchistan, and the seat of government of the Khan, among whose subjects are many tribes of Brahui and Baluch, some $\Lambda$ fghans, with sects from Persia, Arabs on the const line, and Hindus engaged in commerce. The Khan is of the Brahui. The better known tribes are all situated along the Dehra Ghazi frontier, and along Sind. From thence the country extends inwards to the Indian Ocean from above Kurachee to the border of Persia.

The Baluch believe that they came from Aleppo, and are descended from Mir Hamera, son of Abdul Mahtab, who died in the reign of Hazrat Imam Husain about A.D. 646 . Leaving Arabia, they first came to Kerman in Persia, and thence to Makran, where they remained 500 years. One of their chiefs, Yakub Khan, had four sons and a daughter, named respectively Rind, Hot, Lashari, Korai, and Massamat Yatoi. From these sprang the tribes called by these names. After some time the Rind and Lashari quarrelled, and the latter took refuge in Sind. The Brahui were supposed by Pottinger to be a nation of Tartar origin. The above are the great divisions, but there are many subdivisions. The aggregate number of men that could be brought into the field by all the tribes is calculated at $38,000 \mathrm{men}$; but not more than 8000 or 10,000 could be induced to go out of the country, even when their most popular rulers were in power. With the certainty of pay, the British should be able to get 8000 at least, and they would form a splendid body of troops. There are two great sirdars, hereditary heads of the districts of Saharawan and Jhalawan; to these sirdars the khan is supposed to submit ail his intentions before he can carry out anything lawfully. Besides these, there is a wazir chosen by the Tajak, or merchant community, who has a voice in the government. The language spoken in Kalat is Brahui, and is quite different from the Baluchi, though neither is written; nearly all the official documents being in Persian.

The Baluchi women are treated better than other Musalman women. The more independent tribes, such as the Murree, have women slaves amongst them, though not miany.

Raids are latterly confined to their Pathan neighbours, for Sir W. Merewether (then Captain Merewether) at Shagur in 1847, and Captain Raitt when he took Bugti Dehra (vide General T. Jacob's book on the Bugti campaign), gave them very sharp lessons. Sir W. Merewether killed 700 of them, and the Bugti have not recovered that punishment yet. Amongst themselves they are great sticklers to custom. For instance, in a fight between two tribes, one of them brought up a gun that had before been taken from the Khan of Khelat, and fired three or four stone shot at their opponents' village. Hardly had they done so when out rushed a whole crowd of women from the village, and, going up to the assailants, asked them how they could do so low a thing as fight with weapons that had never been used by their fathers. Curious to say, even in the heat of their passions, this argument prevailed, and the canuon being sent off to a place of security, the fight was continued with sword, shield, and matchlock. Since then, when a son of the Katrau chief, Imam Bux, used rifle skirmishing with the Murree, the same argument induced him to lay aside his rifie and take to his sword. One thing specially noticeable is how on both these occasions the women took the office of intermediaries, and in both cases no idea seemed to be entertained of interfering with them, while it is equally certain that if they had been caught after the fight was decided they would have become the prize of the victors.

A very large portion consists of barren hills and sandy plains, while only a snall portion is culturable. About Khelat, Mustang, and Quetta the maximum and minimum temperature in summer is about $105^{\circ}$ and $48^{\circ}$; in winter, $70^{\circ}$ and $4^{\circ}$. In the sandy 
deserts of Makran, the cold is not nearly so great, but the heat is so intense that during the Khurma păz, or date ripening, as it is called, a period of about three weeks, even the inbabitants keep close and do not go out.

The Baluch mare is a raw-boned animal of about 13 to 14 hands. These horses have considerable endurance, and can go 50 to 60 miles a day for several consecutive days. One man rode in and out with a letter just 80 miles in 24 hours, and his mare had the same wretched broken-down appearance as when it started, neither more nor less. Sometimes an extra good one appears on the scene, but such cases are rare. The Baluchi have the same habit as the Kurd of Central Asia, namely, they do not often take the saddles off their horses. The saddles are made of wood, and are very narrow; the stirrups are short, so that the knee goes well forward, and the foot back in a line with the hip. See Baluchistan.

KHENGAR, the most celebrated man of the Yadu line in Saurashtra, was the personal opponent and rival of the celebrated Sidraj for the hand of the Deora princess. Mandalica, though a proper name, is also titular, viz. Lord of the Region; this and Khengar are the two names best preserved by tradition, and to one or other many things at Junagarh - Girnar are attributed. Khengar is the name of the prince who erected the palace there.-Tod's Travels, p. 511.

KHER, also known as Ganga-Khair and Khair, in lat. $18^{\circ} 59^{\prime} \mathrm{N}$., long. $76^{\circ} 46^{\prime} \mathrm{E}$., in the Dekhan, on the high bank of the Godavery. The mean leight of the village is 1293 feet; level of the Godavery is 1245 feet. It is enclosed by a strong wall, and was a place of importance until the middle of the 19 th century, when it was plundered by Rohillas.-Cullen.

KHERA. HIND. A village; often compounded, unabbreviated and abbreviated. and variously spelled, as in Holal Kaira, Umar Kher, Hewerkeir, Ganua-Kher.

KHERD'HUR, the land of Kher, also called Kheralu, but more properly Kherala, the abode of Kher, the Kher being a shrub of great utility in these regions. It is a remote part of Rajputana, in which the Rahtor Rajputs first established themselves, expelling the Gohil tribe. Kherd'hur is named, in all probability, from the superabundant tree of the desert termed kher, and d'hur, land. Its astringent pods, similar in appearance to those of the laburnum, are used in food. Its gum is collected as an article of trade; the camels browse upon its twigs, and the wood makes their huts.-Tod's Rajasthan, ii. p. 303.

KHERI, a district in Oudh, between lat. $27^{\circ}$ $41^{\prime}$ and $28^{\circ} 42^{\prime} \mathrm{N}$., and long. $80^{\circ} 4^{\prime} 30^{\prime \prime}$ and $81^{\circ}$ '23' S. Area, 2963 square miles, and population (1869), 746,350 persons. In Paila and Kheri parganas are some large lakes. Population chiefly Chamar, Ahir, Kurmi, Murao, Kisan, with small numbers of the Brahman, Kshatriya, Kayasth, and Vaisya.

KHERIAH, an aboriginal tribe settled on the plateau of Chutia Nagpur. The Kheriah build substantial, comfortable houses. They say that their first settlement was Pora, a village on the Koel river. Their language, customs, and appearance is sufficiently approximate to those of the Mundah to evidence a consauguinity, and they are regarded as an offishoot of thie Santal or Ho race. They

VOL, II, worship their river, the Koel, with rites similar to those with which the Sautal or Ho adore the Damuda. The Kheriah, Bendkur, Birhor, and Bhuibar are described as regularly wild inhabitants of the bills and jungles, who have no fixed villages, but move about from place to place, burning down the jungles, sowing in the ashes, and after the harvest moving elsewhere. - Dalton, p. 155 ; Campbell, p. 36; W. W. Hunter.

KHES. HIND. A wrapper. Of these there are several kinds, - Khes-bafi, Khes-chandana, Khes-gadra. Khes-dabba is one with a large check; Khes-do-rukha has two right sides; Khes-tukridar is made of pieces of different colours joined together. At Hyderabad in Sind, the Khes is a chintz scarf. See Clothing.

KHEZAIL, a powerful and warlike tribe inhabiting the banks as far as the large village of Semavah, on the Euphrates, where the women are proverbial throughout the country for beauty of feature and perfect symmetry of form.-Mignan's Travels, p. 194.

KHIDMAT. Hind, PERs. Service. Peshkhidmat, also Khidmatgar, a servant, a lackey, a personal attendant. Khidmati, a sweeper, an attendant of a mosque.

KHILA HARIVANSA PARVA, a modern supplement to the Mahabharata, containing legends about Krishna.

KHILAT. Pers. A robe or dress bestowed by rulers in Southern Asia on persons whom they desire to honour. It usually consists of a set of shawls, pieces of silk, kimkhab, etc., but it may be any article-arms, horse, elephant-presented by the ruling or superior power as a mark of distinction.

KHILJI or Khalji, according to Elphinstone, p. 274, a Turki tribe, part of which, in the 10th century, was still near the source of the Jaxartes (Syr Darya), but of which a portion had even then been long settled between Seistan and India (i.e. in the Afghan country). In the 10th century they still spoke Turki. They seem very early to have been closely connected with the Afghan, with whom their name is almost invariably associated. Lieutenant Leech, in his valuable vocabulary of the languages west of the Indus, adrances the opinion that the Afghans were origiually a Turki or Moghul nation, but that at present they are a mixed race, consisting of the inhabitants of Gaur, the Turki tribe of Khilji, and the Perso-Indian tribes dwelling between the eastern branches of the Hindu Kush and the upper parts of the Indus.

KHILTA. HIND. A basket covered with leather, used for travellers' baggage in the N.W. of India.

KHILTVAT. Arab., Hind., Pers. Privacy, retirement. Khilwat-khanah or Khilwat-gah, a private apartment, the women's apartments.

K'HINDRAY SHAH, a Maharram fakir.

KHI-NIE, a Chinese traveller in India. There was much intercourse between the Buddhists of India and China for some centuries after the introduction of Buddhism into China, but in the 10th century, after A.D. 975 , the religious visitors from China became greatly more numerous. Chinese pilgrims had passed years in India in studying their religion, and wrote narratives of their travels. Of these there have been published the travels of Fa Hian, A.D. 399-414; of Hiwen 
Thsang, A.D. 628-645; of Hoei Singh, who set out A.D. 518. The later traveller, Khi-Nie, who journeyed A.D. 964-976, was sent by the emperor of China at the head of 300 monks to seek relics of Buddha, and to collect palm-leaf books. These pilgrimages continue; and Colonel Yule had met pilgrims at Hardwar, who had crossed the Himalaya from Maha-chin to visit the holy places at Jawala Mukhi in the Panjab.-Yule, Cathay, i. p. 22 , ii. p. 411.

KHIOU-PING. In China, the first civil and military mandarins who distinguish themselves in the administration or in war, receive the titles of koung, heon, phy, tze, and nan. All the officers, civil and military, of the Chinese empire, are divided into nine orders, the Khiou-ping, distinguished one from the other by certain buttons, or rather balls, of the size of a pigeon's egg, which are worn above the official cap. This distinctive ball is of plain red coral for the first order, of carved coral for the second, of a transparent deep blue stone for the third, of pale blue for the fourth, crystal for the fifth, of some opaque white stone for the sixth, and for the seventh, eighth, and ninth, of gilt and wrought copper. Every order is subdivided into two classes, the one active and official, the other supernumerary; but this makes no difference in the balls. All the official personages comprised in these nine orders, are desiguated by the generic term Kouang-fou, The tern mandarin is unknown to the Chinese; it was invented by the first Europeans who visited the country, and is probably derived from the Portuguese word Mandar, to command, which they made Mandarin. See China.

KHIR. HIND, Rice boiled to a porridge with milk.

KHIRAJ. ARAB. Tax, tribute, land tax, generally the largest item of revenue. In Timur's Institutes, the land tax was fixed at a third of the produce on all irrigated land, besides a certain due for using water from the public reservoirs; the land tax has, from the most remote ages, been the chief source of revenue in all Asiatic countries. The Sassanian kings of Persia established the tax at a third of the value of the prodnce; but when calamity overtook the crops, the cultivators received advances from the treasury. These are still continued in Southern India, and are called Takkavi, or support. By Muhammadan law the produce of the land is liable to two imposts, namely, the Ashr or tithe, a poor-rate due ouly on the actual produce of the soil; and the Khiraj or tribute, generally imposed on land within reach of irrigation or running water. No land can be subject to both Ashr and Khiraj at the same tine. The Khiraj was imposed on Syria by Umar, and on Egypt by Amru; but Arabia is Ashr, a very small part of it being under the influence of running water. The Khiraj is of two kinds, Mukassiamah and Wazeefa. The former is due on the actual produce only, and resembles the Ashr; the latter is due whether there be any produce or not. The khalif Umar levied the Khiraj in Syria and Persia, the rate varying according to the value of the produce. Kings of India exacted one-sixth of the produce, besides a poll-tax, which was Mukassiamah; but the Muhammadans converted it into Wazeefa in the time of Sher Shah; and the emperor Akbar, while adopting the same system, carried it into effect with greater precision and exactness.
In Persia, in the days of Timur, the land tax amounted to one-tenth of the produce of the soil; but the husbandman was loaded with a number of other taxes, which altogether exceeded half the produce. In India, Timur's descendant, the emperor Akbar, abolished all arbitrary taxes, and fixed the revenue according to the value of the different lands, which were divided into four classes-

\section{Poolej, which never lies fallow.}

2. Perowty, kept out of cultivation a short time, for the soil to recover its strength. The Poolej and Perowty were each of three kinds, - best, middling, and bad. The produce of a bigha of each sort was added together, and a third of the sum was considered as the average produce of Poolej or Perowty land; one-third of it being the revenue. Sher Shah exacted rather more.

3. Checher was land which had suffered from inundations or excessive rains, and received grants of remissions for five years.

4. Bunjer was land which had suffered from great inundations, and enjoyed still larger remissions.

Rewards were granted by Akbar for high cultivation, and the land settlement was made for periods of ten years.-Ayin-i-Akbari; Neil Baillie on the Land Tax, quoted in Markham's Embassy, p. 31.

KHIRD AFROZ, the Urdu version of the Pancba-tantra.

KHIRGAH, amongst the Hazara, a hunting match in which all the tribe take part; they surround a mountain, and, by firing matchlocks, drive the deer and other game to a place where some good shots are posted.

KHIRGAH, a circular tent. Moorcroft relates that after his first interview with the pirzada of Talikban, he was lodged in a khirgah near Kunduz, the only furniture of which was a few mats and a clay stand for a lamp. The wants of a Turkoman are few in number: a tent, called a khirgah, shelters the whole family, and this is of a superior manufacture to anything of the kind made by the nomadic tribes of Persia. They can make these khirgah warmer than the best built houses, - a matter of some consequence to them, seeing how severe the winters are in the country they inhabit. The khirgah is conical in form, the framework being made of laths of hard wood interlaced one with the other, which can be opened or folded up at pleasure, according as they wish to camp or decamp; a camel, or at most two, is able to carry this tent. Thick felts are stretched either entirely or partially across this framework, according as the Turkoman may wish to avoid the burning rays of the sun or protect himself from the rain or cold; they are very commodious, are of all sizes, and a ligh price is given for them by some of the Persian nobles.Moorcroft's $T r$, ii. p. 480 .

KHITAI, the Cathay of the nations of Europe, is the name by which China is styled to this day by all or nearly all the nations who know it from an inland point of view, including the Russians, the Persians, and the nations of Turkestan; and yet it originally belonged to a people who were not Chinese at all. The people of Khitai were a Manchu race who inhabited for centuries a country to the north-east of China, lying east of the Khingan mountains and north of the river Sira, and whose allegiance was rendered alternately to the khakans of the Turk and the emperors of China. In the beginning of the 10th century, the chief of one of their tribes made 
himself supreme, first over his own entire race, and then successively over the adjoining nations of Asia from the sea of Korea to the Altai. The son of this conqueror having assisted to place on the throne Kao-tsu, of the brief dynasty of the later Tcin, this prince in return not only transferred to the Tartar a large tract of Northern China, but agreed to pay him yearly tribute, and to acknowledge his supremacy. The next Chinese sovereign protesting against these degradations, the Khitai ruler overran all the provinces north of the Yellow River, and established his own empire within them, under the name of Leao or the Iron Dynasty. This Khitai empire subsisted for two centuries in Northern China and the adjoining regions of Tartary.-Yule, Cathay, $\mathrm{i}$. p. 116.

KHIVA is the ancient Kharasm, the Corasmia of European writers, which was famous between the 10th and 13th centuries, but was overthrown by Chengiz Khan, and its last sovereign, Jalal-udDin, fell in Mesopotamia (Kharasm), since which events the area of the territories have remained as at present, comprising a region along the Caspian from Persia north to the Kirghiz country and east to the Oxus and Lake Aral.

Khiva city lies about 40 miles west of the Oxus, distant from Merv 432 miles, from Herat and Orenburg 600 . It is situated on a fertile plain near the Oxus, in lat. $41^{\circ} 22^{\prime} 40^{\prime \prime} \mathrm{N}$., and long. $60^{\circ} 2^{\prime}$ $57^{\prime \prime} \mathrm{E}$, and is about balf a mile square, containing about 1500 houses, clay built and arranged in narrow streets, with a population of about 12,000 permanent inhabitants. It is surrounded by a wall and bastions and a broad belt of gardens. It has a few schools. The oasis is well watered by canals from the Oxus (Amu Darya), lying in a bend of both sides of that river at the southern shore of Lake Aral at the Kizil Kum steppe, Bokhara on the S.E., and on the W. the Ust Urt and desert of the Tchaudor Turkoman. It is 120 miles from N. to S., and 115 from E. to W.= 13,800 square miles.

The dominion subject to the Khan of Khiva is more extensive, viz. from the Caspian to the Aral, i.e. from the Russian fort of Alexandrovski to a little south of lat. $44^{\circ} \mathrm{N}$.

The area of these boundaries is about 410,000 square miles, but, except the oasis of Merv ana banks of the Oxus, the entire country is an unbroken expanse. The climate in winter is cold for five months, frost intense, $4^{\circ}$ to $8^{\circ} \mathrm{F}$. below zero. In summer the heat is intolerable, rain seldom falls; and in the autumn violent gales blow off the steppes and fill the air with impalpable dust, darkening the face of the land; in a few hours new sandhills are heaped up and former ones disappear; whole caravans are sometimes engulfed or suffocated in such sand storms, called Tebbad. The camels refuse to move, and lie stretched along the ground, and the travellers shelter themselves behind their beasts.

The population of the khanate consists of tribes of Uzbak, Turkoman, Karakalpak, Kazak or Kirghiz, Sart or Tajak, Persian, and Kurd slares, mostly Persian and Kurd, with a few Russians, Jews, and Hindus. The settled population of the khanate resided in 60,000 houses, and amounted to 300,000 individuals. The nomade population dwelt in 12,000 Karakalpak huts, and were 160,000 in number.
The Ilayat families tributary to Khiva were 195,000, viz. :

Yamut, Goklan, $15,000 \mid$ Kazak, $\therefore 40,000$ O 2,000 Sarokh, . . 15,000 Kalpak, . . . 30,000 Uzbak, . . . 40,000

Khiva, in 1874, had 5000 population. The Chosdar are said to have been brought from the further borders of the Oxus by Muhammad Rahim Khan. The silver tenga is 5:375 pence. The tila, a gold coin, is worth 12s. 6d.-Markham's Embassy; Fraser; Ferrier; Wolf's Bokhara; Vigne's Narrative; Moravief; Vambery's Bokhara; Collett's Khiva; Captain Valikhanof's Russians in Central Asia; Invalide Russe.

KHIZDE. Pushtu. The tent of the nomade Afghans near Herat and amongst the Hazara.

KHIZR, also written Khidjer and Khidr, is the Khaja Khizr of Muhammadans of Persia and India. The Hebrew notions about the identity of Phinheas and Elias have been adopted and expanded by the Muhammadans, who also identify in some way with them their mysterious prophet Khidr or Khizr. Hermitages or chapels dedicated to Khidr and Elias appear to have been very numerous in Muhammadan countries, especially on hill-tops, and the oriental Christians and semi-Christians also always associate Elias with mountain tops. There seems to be scarcely a prominent peak in the Greek Archipelago with which the name of Elias is not connected. Throughout India, Khizr is a popular Muhammadan saint. He is supposed to be immortal; having on one occasion drank of the waters of immortality, said to be situated in regions of darkness in a remote corner of the world, and some identify him with Enoch, some with Elijah. He is supposed to perambulate the world, like the wandering Jew, and to have occasionally appeared to different people. He is always clad in green, as his name in Arabic indicates. The government of Kassan terminates, and that of Sulmania in Kurdistan commences, at the river Leilan; near this is a small building, a ziyarat or place of pilgrimage, called the Makan of Kidder Elias, or restingplace of the prophet Elias. The Muhammadans believe that Elijah never died, and that he is still on earth, where he is to remain until the coming of Jesus Christ. They call him Khizr or evergreen, on account of the everlasting life which he enjoys, and by which he is kept ever in a flourishing condition, in a paradise which, say they, might be taken for heaven itself. In reference to this, a Turkish poet observes, "Keep yourselves from believing that this world is your home, your home is in heaven alone; strive therefore by the means of virtue to reach that home where Elias dwells, and where a place is prepared for you.' These notions of the Muhammadans are derived from the Jews. Jesus himself was taken for Elias, re-appearing after nine centuries of concealment. The prophecy that Elijah should come before the great and terrible day of the Lord, has probably given rise to the notion that he had not yet completed his part on earth. In Northern India, on the Fridays of the month Shaban, along the banks of the Jumna and Ganges, Muhammadan women launch tiny boats on the rivers in his name. Heber (i. p. 166) mentions that the legends in Lower Bengal regarding Khizr are made up of different Rabbin- 
icai fables concerning Eliezer, the servant of Abraham, and the propbet Elijah. He is by some supposed to be St. George of England, whom they call Khizr Elias. A legend is to the effect that he was vizir and general to Kai Kobad of Persia, and discovered and drank of the fountain of life, and will never die, but will await the last trump. -Ibn Batuta ; Burton's Scinde, ii. p. 249 ; Rich's Kurdistan, i. p. 52 ; Yule's Cathay.

KHO is a population of about 400,000 people occupying the delta of the Mei-kong, in Kambojia, between Siam and Cochin-China, the remaining 100,000 of the population being Chinese, CochinChinese, Siamese, Malays, Portuguese, and mired races. See Kambojia.

KHOGILU. According to the Jahan Numa, one of the earlier divisions of the province of Fars was into the five Kureh, circles or departments,-Istakhr, Darabjird, Shahpur, Ardashir, and Kobad. At present it consists of three principal parts, viz, - 1. Fars proper (Persis proper); 2. Luristan, near the Persian Gulf; and 3. Behbehan, or the country of the Khogilu, which represents the Kureh of Kobad. Behbehan is bounded on the north by the great belt of mountains which separate Irak Ajam from the southern provinces of Persia; the northern and northeastern shores of the Persian Gulf form its boundary to the south, Ram Hormuz and the Ka'b country lie to the west, while Shulistan separates Behbehan on the east from the direct dependencies of Fars. On the E. and S.E., Behbehan is surrounded by the Mamaseni tribe, on the N. and N.W. by the Bakhtiyari, and on the W. and S. by the Ka'b Arab. Besides the Khogilu, several other tribes inhabit these mountains, such as the Jarumi, the Yusufi, and upwards of a thousand families occupy the plain of Bebbehan, settled in villages or dispersed in tents. These are the JumaBuzurg, the Afshar, and some Arab settlers. The names of the Turkish tribes are-the Karabaghi, Agbaghi, Begdeli, Golebi, and Sheiri, speaking the Turkish language; while the Afshar, although of the same origin, have forgotten their mothertongue. The Doveti, Ghesti, Mayaz-kuli, Barash, Milosi, and Juleki are of the Lur race, and speak the Lurish dialect.-De Bode's Tr. p. 275.

KHOGIR. HIND. A native saddle, a packsaddle. Khogir Shah, a Maharram fakir.

KHOJ. HIND. Information, search. Khoji, a tracker. In the Panjab, professional trackers are employed to trace stolen cattle, by their footprints (kori or pyra). They do this even for a hundred miles, and their success, even through unpromising places, as sandy plains and gravel and kankar beds, and over rivers and swamps, is very extraordinary. The Paujab Khoji is similar to the Paggi of Gujerat. The system of tracking criminals to their homes and haunts rests in India solely on the responsibility of village headmen for the good behaviour of their charge.-Calcutta Reriew, No. lxxiii., Sept. 1861, p. 11 .

KHOJA, corrupt. of Khaja, a respectable man, a respectable term for a eunuch. Also the Khaja, name of an Ismaili sect of Sind and the western parts of India. See Ismaili ; Karmati ; Khaja.

KHOJA AHMAD YESEVI is to this day the patron saint of the wandering nomades in the steppes of Central Asia. His moral and religious poems, of which some examples are given in Vamkery's Tchaghataian Studies of Language, are as highly venerated by the Kirghiz and Uzbaks as the Koran itself.-P. Arminius Vambery, Bokhara, p. 246.

KHOJAK, a tribe of Pathans, an offshoot of the Kakar of Mekhtar.

KHOJEND has a turquoise mine, but the stones are of a greenish hue, and far less esteemed than those of Naishapur, in Khorasan. There is another of very insignificant note somewhere in Kerman. -Fraser's Khorasan, p. 105.

KHOKAND, the ancient Farghana. The khanate of Khokand is an almond-shaped valley about 160 miles long, from Makhram to Uzgend. It is surrounded on all sides by mountains and mountain plateaux. Khokand town is modern, with 75,000 inhabitants. Paper is largely made. Goitre is very prevalent.

KHOLA. BENG. The drier parts of the islands in the delta of the Ganges and Brahmaputra.

KHOMAN RASA, a Hindi work, descriptive of the last sack of Chitore.

KHOMASEE, a particular kind of magic square.

KHONBEE. HIND. A cotton and silk cloth bordered with gold and silver thread.

KHONDAMIR was born at Herat about A.H. 880 (A.D. 1475). He was the son of Mir Khond. His name was Ghaias - ud - Din Muhammad-binHumam-ud-Din, and he wrote the Khalasat-ulAkhbar, which is an abridgment of the Rauzatus-Safa, written by his father. From his early youth he devoted his life to the study of history, and had the benefit of the large library collected by Ali Shir. He accompanied an embassy to Khusru Shah, the chief of Kunduz, and was afterwards appointed to the ecclesiastical court. In the year 913 (A.D. 1507-8) Khorasan was overrun by the Uzbaks, and Khondamir went to Georgia, where he wrote the Maasir-ul-Muluk, the Akhbar - ul - Akhyar, the Dastur-ul-Wazra, the Makarram-ul-Akhlak. He left Persia about A.H. 935 (A.D. 1528-29), he was introduced to the emperor Baber at Agra, and accompanied him to Bengal. On Baber's death he attached himself to Humayun, in whose name he wrote the Kanuni-Humayuni, Elliot says the Humayūn Nama. He accompanied Humayun to Gujerat, and died in his camp A.H. 941 (A.D. 1534-35), aged 61 or 62. At his own request, his body was conveyed to Agra, and buried at the side of Nizam-ud-Din Auliyand the saint, and Amir Khusru the poet. The Khalasat-ul-Akhbar brings Asiatic history down to A.D. 1528. Khondamir's larger chronicle was the Habib-us-Siyar, or Friend of Travels.Elliot's Hist. of India; Ouseley's Travels, ii. p. 400.

KHONE, Kone, or Konar. 'TAM. Meaning king, a title of the Idayar or great shepherd race of the south of India.

KHONE. ARAB. Brotherhoor, the tribute claimed from time immemorial by the Bedouins in return for their protection. Each village pays Khone to one shaikh in every tribe, who then acknowledges the tribe as his ukhta or sister, and is bound to protect it against all the members of his own tribe.

KHONG-BONG, a musical instrument of the Siamese, composed of a semicircle of suspended tongues.

K'HOPRA. HiNd. Dried kernel of the cocoanut. K'hopra ch'hilni ki chouki, an instrument for rasping the kernel of the cocoanut. K'hopra, also small leather caps (shaped like the end 
or point of the cocoanut shell), used to blind cattle turning the Persian well-wheel.

KHOR, a territory south-east of Ladakh and eastward of the Byltæ of Balti or Little Tibet. Its people are supposed to be the Chauranœi Scythæ of Ptolemy.-A. Cunningham.

KHORAN, a tribe who, a little before the birth of Christ, ruled over Afgbanistan, the Panjab, and Khorasan.

KHORASAN may be regarded as comprising the whole of Persian territory lying between the Caspian and the Afghan border near Herat. On the north it is bounded by the Aral Caspian desert, from which it is now separated by the long narrow strip of Akhal Tekke Turkoman territory occupied by Russia; on the south it is severed from the rest of Persia by the Great Salt Desert; on the east a strip of savage, though fertile country, overrun by Turkomans, separates it from Afghanistan; and on the west the decrepit province of Astrabad, already half-Russianized, connects it with the Caspian portion of the Iranic empire. Its length is about 500 miles, its breadth 400 , and its superficial area about 200,000 square niles. MacGregor's calculation that the population of Khorasan is about a million and a quarter may be right. Perhaps it would not be a very erroneous calculation to fix the entire population of the region lying between the Caspian and Herat at two millions, consisting of scraps of various races, and all as much inflamed against the Persian as they are farourably disposed to Russian rule. The tribes are numerous, Arab, Baluch, Beyat, Chulai, Karai, Khurshahi, Jek, Jalayer, Mardi, Muzdurani, Nekhi, and Timuri. The country is essentially mountainous; and of the rivers, the Atrek is the only one that does not waste its waters upon the desert. The fertility of the province has long passed into a proverb, and no travellers exalt it more strongly than the Russians. Previous to the fall of Geok Tepe, General Skobeleff made a reconnaissance into the country to the south of the Kopet Dagh, which used to belong to Khorasan, but of late years fell under the sway of the Tekke Turkomans. This district is by no means the most favoured portion of Khorasan, according to Petroosevitch and Baron Bode. General Annenkoff, however, who was on Skobeleff's staff at the time, writes in the most enthusiastic strains of the district, praising it for its forests, its vines, and its magnificent pastures.

Khorasan contains many fruitful plains, some lofty ridges of mountains, and several wide tracts of desert. It is, except in its most fertile districts, but partially supplied with water; and from local position has, perhaps, been more exposed to preilatory invasions than any country in the universe. Its boundaries have greatly varied with the altering power of its rulers, and even at present surrounding nations use the name differently. The emperor Baber tells us, in his Commentaries, that in his time the people of India applied the term Khorasan to all the regions west of the Indus.

Whenever Persia was distracted by internal factions, or had to sustain foreign attack, the tribes of Tartary crossed the Oxus and spread themselves over Khorasan. It was this province which the valour of Rustum had to defend against the continual inroads of Afrasaib. The Seljuk chiefs invaded it long before their rule was extended over the other parts of the empire to which it belongs. It suffered greatly from the ravages of Chengiz and of Timur; and during the reigns of the first Suffavean kings, the Uzbaks, who had conquered the country of Bokhara, made annual attacks upon its fields and cities. The genius of Abbas the Great checked these ruinous inroads, and Nadir made this race of plundering Tartars tremble for their own possessions. But the death of that conqueror left his native province more exposed than ever to hostile invasion; for while his descendants, spite of the vast inheritance which he had bequeathed them, exercised a mock sovereignty over the city of Mashed, several military chiefs, taking advantage of the distracted state of the empire, seized upon the different forts of Khorasan, and, aided by the confusion of the times, succeeded in establishing a number of small principalities, over which they exercised an almost regal sway, making war or concluding peace with their petty neighbours as it suited their interest, and sometimes defying, and at others paying homage and tribute to, the powerful monarchs by whom they were surrounded. Mashed, the capital of the Persian division of Khorasan, is situated about two farsang from the ruins of the ancient city of Tous, and is celebrated for a very superb sepulchre, in which repose the relics of Imam Raza, and those of the khalif Harun-ur-Rashid. Khorasan is peopled by many races; its warlike inhabitants boast their descent from Arabian, Kurd, Turkish, and Afghan tribes, who came into the province at different periods to subdue or to defend it; but neither their having so long inhabited the same soil, nor a sense of common danger, has softened those inveterate prejudices, or abated that rooted hatred, with which these races regard each other; and it had been the policy of the monarchs of Persia to increase divisions, which enable them to keep in subjection a country whose inhabitants, if united by any feeling that resembled patriotism, would have been dangerous; for the men of Khorasan, from the robustness of their frame, and from their being continually inured to war, are proverbially brave; and Nadir Shah used to term this fine province ' the sword of Persia.' The Kayn Arabs have long enjoyed the reputation of being the hardiest and the bravest of the infantry of Khorasan. A part of the district of Kayn borders on the desert of Seistan, while it is bounded in another quarter by the territories of the Afghans.

Khorasan is the name by which the Afghans, Baluch, and Brahui designate the region known to Europeans as Afghanistan and Baluchistan. It is a softened pronunciation of Khoresthan, or country of the sun or the place of light, in other words and thus corresponding to the German Morgenland, the east, the orient, as being the easternmost province of the ancient empire of Cyrus and Darius. The Afghans, however, now distinguish their own land as Pukhtun Khwa or Pathan country, and Watan Khwa or native country. The ancient Khorasan stretched far into Chinese T'artary, and was occupied by several colonies. It had the Indus on the east, the desert of Yeza on the west, the river Amu Darya (Oxus) on the north, and the Arabian Sea on the south.-Markham's Embassy; Kinneir's Memoir; Malcolm's Persia; Khanikoff sur l'Ethnograplie de la Perse; MacGregor; Bellew. 
KHOREWAH, also written Kharawa, a considerable tribe dwelling near the Oraon and to the north of the Larka Kol, in the highest hills to the north of Jushpur, and in those between Sarguja and Palemow. They speak much the same language as the Ho, Santal, Bhumi, and Mundah, and they appear to be of the same stock, though much less civilised. They are a considerable, ugly, and ill-favoured tribe, in the district of Palemow, in Singrowlee, the hilly country of Mirzapur and Rewah, and on the borders of Benares and Behar, and westwards in parts of Sarguja and Jushpur, and they are numerous to the N.E. in those parts of the plains adjoining the hills. They are also found on the outskirts of the Patna and Arrah districts. A division of the Kharawa tribe is the Bhogtah. The Kharawa are the dominant tribe of Palemow and Singrowlee. They are labourers, palanquin-bearers, and porters. The rajas of Singrowlee and Jushpur are Kharawa, though claiming to be Rajput. They have no caste distinctions, and eat anything. The Kharawa of Sarguja do not use the plough. The race are mostly short of stature, but with well-knit muscular frames, complexion brown, not black, sharp, bright, deep-set eyes, noses not deficient in prominency, somewhat high cheek-bones, but without marked maxillary protuberances. The Kharawa of the hills are wild savages, armed with battle-axes, bows and arrows. They are nomadic, and migrate every second or third year. Their villages are therefore mere standing camps, consist of about forty houses built round a large square, in the centre of which is the dancing area.-Dalton, p. 176 ; Campbell, pp. 36, 40, 378; Captain Blunt in Bengal As. Soc. Res. vii.

KHORFAKEN. The date trees on the coast of Oman form a continuous grove to Khorfaken, a distance of 150 miles, and the Arabs have a saying that a traveller may proceed the whole distance without ever losing their shade. Dates form a principal export from Oman, large quantities being taken to India. The middle classes of the Muhammadan and Hindu population of India are very partial to them. The best are brought from Basrah and Bahrein, those from Oman being classed next in excellence. Some are simply dried and then strung on lines; others, which is the usual plan, are packed in baskets.-Wellsted's Travels, i. p. 188.

KHOSA. Pushru. A piece of fine pashmina cloth, very soft, worn as a shawl, at either end there is a slight border woven; also mufflers for feet of cattle, used by thieves.

KHOSA. There are in the delta of the Indus other pastoral and peaceable classes besides the Jat of Muhammadan persuasion, such as the Khosa in Upper Sind, the Sikh Lohana, and immigrants from the Panjab, who have in many instances become amalgamated with the people of the country. The Khosa occupy the sandy tract called the Thal between Hindustan and Sind, and become a predatory tribe on the eastern confines of Sind, verging towards the Cutch territories, where they are very troublesome. There are, also, on the eastern boundaries, Rajputs located as wandering herdsmen. The Daoudputra, who inhabit generally the country of that name in the north, are to be met with in various parts of Sind. The Sumah are Jat, though they are generally known by the former title; stich also are the Machi and numerous other subdivisions of the Jat tribes. Up till the early part of the 19th century, the Mair in the south, the Larkhani in the nortb, and the desert Sahrai and Khosa in the west, carried on a system of pillage in the Rajput countries. Tod's Rajasthan, ii. p. 155.

KHOTEN, Iltsa, Ilchi, or Ili, lies to the southeast of Yarkand, in lat. $37^{\circ} 15^{\prime} \mathrm{N}$., and long. $79^{\circ}$ $25^{\prime} \mathrm{E}$., and is situated between, or rather above, the junction of the Khoten and Karakash rivers. It is surrounded by a low wall, and has 18,000 houses, with eight serais for the use of foreign merchants and traders from Ilchi, Karakash, and Yurunkash. Khoten is nearer than Yarkand is to Kashmir, but the routes from and to the latter place are more generally adopted by traders. From Yarkand to Leh in Ladakh the distance is reckoned at very nearly 500 miles, while from Khoten to Leh it is about 350, and from Leh to Sultanpur in Kulu it is close on 250 miles more.

Khoten district has a population of 129,500 souls. It is at the northern base of the Kouen Lun mountains, and includes the deep valleys which drain its slopes into the river on which Ilchi or Iltsa, the capital, with its 6000 houses, stands. The district is famous for its musk, silk, gold, and jade.

Khoten may be considered the most central and inaccessible state of all Asia, but it was a seat of very ancient civilisation, and was already in friendly relations with China in B.C. 140 . In the 4th century of our era, Buddhism was in high development here. Though much of the surface appears to be rugged mountain, it is interspersed with level tracts, which are both fruitful and populous. At one time, like the other states of Eastern Turkestan, it was under a Muhammadan chief of Turkish or Mongol descent. -Bunsen; Yule's Cathay, ii. p. 567 ; Moorcroft's Travels, i. p. 367 ; Klaproth, J. Asiatique, No. xvii.; Histoire de la Ville de Khoten, Remusat; Quarterly Oriental Magazine, Calcutta, Sept. 1834; Russians in Central Asia; Capt. Valikhanof and M. Vemukof, p. $158 ;$ P. Arminius Vambery's Bokhara, p. 9.

KHOUNG. BUrm. A kind of rice beer made by the hill tribes of Burma.

KHOZDAR, a valley and small town in Baluchistan. The valley is extensive, in shape somewhat like a Maltese cross, and through it, from north to south, passes the caravan road to Wudd and Beyla. In the hills near Khozdar, lead is found. To the west by a little north of Khozdar, and distant about 10 miles, is the small town of Khappar, capital of the district, inhabited by the Kaidrani tribe. Khozdar figures in Persian romances, and was formerly beyond doubt a place of note. A considerable tappa or mound jies north of the town. From Khozdar along the bank of the Rudkhana, the soil is strewed with fragments of burnt brick and pottery, and farther on, a rude obelisk of mud, 20 to 25 feet in height, the base of cemented stones.-Dr. Cooke in Bombay Med. Trans., 1860; Masson's Journeys, ii. 44.

KHUBBES, a district of Persia, with a small town of that name, 50 miles $\mathbf{E}$. of Kerman. It is famed for its henna and its dates, the latter of the black and red kinds. The summer heat is so intense that the people go to the higher ground. The poisonous wind, the Bad-i-Simum, blows for forty days in summer, generally an 
hour before and an hour after noon. About 12 miles to the N.E. is a plain 9 to 12 miles long, with salt several inches deep. Eastward of Tekkah lies the great desert extending towards Seistan. It is uninhabited.-MacGr. p. 249.

KHUD. PerS. Self. Khud-rai, self-opinionated. Khud-pasand, vain, conceited. It has many combinations. Khud-ba-daolat, our royal selves.

Khud-baft, soft silk fabric made for shawls. Khud-kasht, a person cultivating his own (khud) soil (kasht); land so cultivated. Khud-rang, natural coloured or undyed, applied to woollen fabrics.

KHUDA. HiND. God. Khudawand, master: Nao-khuda, a shipmaster, the English nakoda. Khuda Hafiz, may God protect you, a cornmon Muhammadan salutation when parting with a friend; adieu. The Arabs say Allah Yesellemak, God preserve thee, or Allah Yebarik, God bless thee.

KHULK. PERS. The down which grows under the hair of the mountain goat. It is of this that the Kashmir shawls are fabricated.

KHULLA-MINAR, a pyramid of heads. In 1732 , Rustum Khan was appointed to the office of foujdar of the Northern Circars. He exterminated the petty chiefs whom he found there. He offered a reward, and a sufficient number of the heads of the zamindars and their followers were brought in to form two head pyramids or Khulla-minar.

KHULLEE. GUJ. In Gujerat an open spot contiguous to the village in which the whole harvest produce of the village is stored, over which a guard is placed. Attached to the Khullee are a number of pits into which the seed is thrown when brought from the field.

KHULM or Tashkurgan town is 307 miles N.N.W. of Käbul, 310 miles S.E. of Bokhara, 50 miles from Balkh, 70 miles from Kunduz, 420 miles N.E. of Herat, and 497 miles N.T. of Peshawur by Käbul. It is situated on a plain immediately north of the gorge by which the Khulm river escapes the hills. It consists of four or five villages, with a population, in 1845 , of 15,000 souls. Since the 9 th May 1855 it has been in the liands of the Afghans. Silk is largely produced, and passes through Kabul in the route to Multan. The caravans of Bokhara and Kābul in summer pass successively to Khulm, and render it populous and rich. A great majority of the inhabitants are Tajak. Khulm appears to have been at one time in the possession of a family called Khallach or Killich; and on the north side of the Oxus in this longitude, occupying part of the hill country east of Bokhara, is a poor but independent people of Persian race called Ghalcha. Meyendorff calls them very swarthy, but Valikbanof says expressly, "The Tajak have dark complexion and lair, whilst fair people are found among the Ghalcha.' This might explain the yellow-haired people mentioned by Goes, and his use of the expression Calciensium populos.-Mohun Lal's Travels; Ferrier's Journeys; Elphinstone's Caubul; Burnes' Travels; Yule's Cathay.

KHUMBO, a rana of Mewar capital, Chitore, A.D. 1418-1468, a zealous Jaina religionist, who built the Jaya Stambha towers on the brow of Chitore, also the principal temple at Sadri, near Komulmir. During his long reign he filled his country with beautiful buildings both civil and religious.
KHUMDAN was the name given by the Turkish and Western Asiatic nations to the city of Chhanggan, now represented by Sin-gan-fu in Shen-si, which was the capital of several Chinese dynasties between the 12 th century B.C. and the 9th century A.D.-Yule's Cathay, i. p. 51.

KHUMI and Kuki, two tribes who occupy the hills of Sylhet, Tiperah, and Chittagong; the Khumi on the skirts, and the Kuki on the tops of the hills. The Kuki are the ruder or more pagan, though also tinctured with Hinduism. They term their supreme being Khojein Putiang, to whom they sacrifice a gyal, and an inferior one is named Shem Saq, to whom they offer a goat. Shem Saq is put up in every quarter of a village, in the form of a rude block of wood. Before this they place the heads of the slain, whether of men in war or of animals of the chase.-Latham.

KHUMS or Khams. Ar. A fifth part, described in the Koran as the property of God, his prophet, and his relations, or men of his tribe, the Bini Hashim, who are poor and destitute. The right of the Bini Hashim to a share in the khams is grounded upon their being excluded from any portion of the zukat.-Malcolm's Persia.

KHUN, choli pieces of Dharwar, used by women working in the fields. 3 annas for each choli.

KHUN. Pers. Blood. Khuni, a murderer. Khunrez, bloodshed. Khun-i-Shavam or Khun Siawashan, dragon's blood; the Dam-ul-akhwain, also the balsam or resin of Pterocarpus draco.Powell.

KHUND or Khand. HIND. A pool, a spring, a bath.

KHUNDOOA. HIND. A silk fabric made in Khurdha estate, in the Puri district, and worn principally by the Puri people.

KHUNGROO. HIND. An article of female jewellery, anklets with bells.

KHUNNIARA, in Kangra, contains inscriptions in old Pali, of date 1st century A.C. The character used in the inscriptions is Aryan Pali. These are of paleographic importance, as showing the transition state of the Ariano-Pali character. -Bengal As. Soc. Journ. xxiii. p. 57.

KHUNOONG, a race or tribe occupying the mountains at the sources of the Irawadi river, in lat. $27^{\circ} 40^{\prime} \mathrm{N}$., and long. $98^{\circ} \mathrm{E}$. They dwell to the N.E. of the Khamti race.

KHUNUKIANA. ARAB. In Arabic medicine, cold remedies.

KHURAK. Pers. A dose of medicine; food. Khuraki, HiND., PEks., an allowance, a dose, a mouthful.

KHURD. PERs. Small. Khurdah, leavings, fragments, small money, change cash.

KHURDADBA or ibn Khurdadba, the surname of Abu'l Kasim Abdullah-bin-Abdullah-binKhurdadba, an officer of high rank under the khalifs, who died A.D. 912, A.H. 300. He employed his leisure in topographical and geographical researches, and wrote the Kitab-ul-Masalik wa ulMamālik. Elliot.

KHURDHA, in Bengal, is a place noted as the residence of Nityananda, the fellow-reformer of Chaitunya. The latter retired to Nilachull, leaving his colleague at the head of the diocese in Bengal. Nityananda at last took up his abode at Khurdha, and married a Brahman's daughter. Travels of a Hindu, i. p. 5 . 
KHURDHA, a subdivision of the Puri district in Orissa. It was a Native State until 1804, when, on the raja rebelling, it was resumed by the British; but the raja continued to be the hereditary guardian of the Jaganath temple until convicted of wilful murder in 1878 , and transported to the Andaman Islands. - W. $W$. Hunter.

KHURD KABUL, a formidable defile or pass about six miles long, shut in by lofty hills, between whose precipitous sides the sun, in winter, only looks in for a little. When General Sale's brigade passed through this defile in 1841 , they were opposed by 200 Ghilzai, and lost 67 men in killed and wounded. It was through this, after the evacuation of Kābul, that 4500 fighting men, including 700 European soldiers, and 12,000 native camp followers, with their women and children, endeavoured to retreat, but the Afghans fired on them, and 3000 souls perished in the attempt, 8th Jan. 1842. When Sir George Pollock twice passed through this defile, he crowned the heights and suffered no opposition, - MacGr.p. $5 \pm 0$.

KHURI, a clumsy sailing vessel peculiar to the Maldive Islands, which visits India during the fine weather of the north-east monsoon.

KHURM. The inhabitants of Khurm call themselves Tajak, but have no tradition of their origin. They are evidently a mixed race, some of them with remarkable large heads and features, some with small heads and sharp lineaments. The complexion of the men is dark, but that of the girls and young women fair, although they had all black hair and eyebrows, the latter as regularly arched as if they had been pencilled. They are generally pretty, almost handsome.Moorcroft's Travels, ii. p. 398.

KHURMA. Pers. Phœnix dactylifera. Dates, the dried drupes; also sugar of dates. The name is also given to the dried drupes of P. sylvestris.

KHURNK'H, the tribal name of the Oraon race of Chutia Nagpur, known in many parts of India as Dhangars, from Dang or Dhang, a hill.

The Oraons in the Lohardagga district, which includes the whole of Chutia Nagpur proper, number 362,480 ; in Sirguja, about 20,000 ; Jashpur, 25,000. They drink spirits when they have the opportunity, but indulge in no narcotics except tobacco, which the males chew and smoke; of ganja, bhang, and opium they have a wholesome dread.

The name of the day of the week is often given to their children, as Etwar to a boy, Etwari to a girl born on Sunday, Sumar and Sumari for Monday; but these are Hindi terms. They have no such names for the days of the week in their own language. Most of the common names are, by a change of termination, adapted to male or female, as Birsa, Birsi ; Dulka, Dulki ; Chamra, Chamri.

At their marriages most of the males have warlike weapons, real or sham, and as they approach the village of the bride's family the young men from thence emerge, also armed, as if to repel the invasion, and a mimic fight ensues, which, like a dissolving view, blends pleasantly into a dance. In this the bride and bridegroom join, each riding on the haunch of one of their friends.

KHURPA or Karpa. Hind. A weeder.

KHURUM, afterwards Shah Alam, was son of Aurangzeb by a Rajput princess of Amber, of the Cutchwaha tribe, and hence probably his name Kurm, synonymous to Cutchwa, a tortoise. - Tod's Rajasthan, i. p. 367.

KHUSH. Hind., Pers. Pleasant, agreeable: hence Khush bash, a well-to-do person; Khush khared, an open market; Khush-hal, in good condition; Khushi, pleasure; Khush hali, a voluntary contribution, a benevolence.

KHUSHAB, a battle was fought here on the 8th February 1857.

KHUSHHAL CHAND, author of the Tarikhi-Mahomed Shahi, also called Tarikh-i-Nadir uzzamani. It is a history of India from the time of Ibrahim Lodi to Muhammad Shah, A.H. 1152 (A.D. 1739-40), and gives also notices of other governments. He was a clerk in the Diwani office of Dehli in the time of Muhammad Shah.

KHUSH-HAL-KHAN, the khan of the Khatak tribe, a voluminous author, who wrote several poems for the purpose of exciting the national enthusiasm of his countrymen when Aurangzeb was engaged in a war with the north-eastern Afghans. The poems are remarkable for their high and ardent tone, and for their spirit of patriotism and indeyendence. He was the best governor the Khataks ever had,; being liberal, brave, and pleasing in manners. His poems are much prized by the Khataks. He was confined at Dehli by Aurangzeb for 12 years, owing to his eldest son, Byram Khan, having killed one of the sons of Shaikh Rahmkar, a famous Khatak saint. The whole of this time he employed in lis favourite pastime of writing poetry. He had 56 sons, of whom 32 lived to manhood. He was a descendant of Malik Akor. Malik Akor agreed with the emperor Akbar to protect the country south of the Kābul river from depredations, anıl he thus became the chief of the tribe, and handed his authority down.-Elphin. p. 561 .

KHUSHKA. HiND. Plain boiled rice, also the mark of sovereignty placed on the forehead of a Hindu prince. The Maasar-ul-Umra states that at the time when it was written the rajas of Udaipur were exalted over all the princes of Hind, and that other Hindu princes, before they could succeed to the throne of their fathers, had to receive the khushka or tilak of regality and investiture from them. The tilak of the Udaipur princes is made with human blood.-Tod's Rajas" than, i. p. 235.

KHUSH-ROZ. The No-roza, or New Year's Day, when the sun enters Aries, is one of great festivity among the Muhammadan princes of Persia; that alluded to by Prithi-raj and by the historian Abul Fazl was not New Year's Day, but a festival especially instituted by Akbar, held on the ninth day (No-roza), following the chief festival of each month. Abul Fazl says the court assembled, and was attended by all ranks. The queen also had her court, when the wires of the nobles and of the Rajput vassal princes were congregated, and a fair was held within the precincts of the court, attended only by females. The merchants' wives exposed the manufactures of every class, and the ladies of the court were the purchasers. Akbar was also there in disguise. by which means he learned the value of merchandise, and heard what is said of the state of the empire and the character of the officers of government. Abul Fazl thus softens down the unhallowed purpose of this day; but posterity cannot admit 
that the great Akbar was to obtain these results amidst the Pushtu jargon of the dames of Islam, or the mixed Bhaka of the fair of Rajasthan. At these royal fairs were sold the productions of princely artisans, men and women, and which out of compliment to majesty made a bounteous return for their industry.

The great Akbar hazarded his popularity and his power by the introduction of a custom appertaining to the Celtic races of Europe and the Goths of Asia, and degraded those whom the chances of war had made his vassals, by conduct loathsome to the keenly-cherished feelings of the Rajput. There is no doubt that many of the noblest of the race were present on the No-roza; and the chivalrous Prithi-raj was only preserved from being disgraced by the high courage and virtue of his wife, a princess of Mewar, and daughter of the founder of the Suktawut. On one of these celebrations of the Khush-roz, the monarch of the Mloghuls was struck with the beauty of the daughter of Mewar, and he singled her out from amidst the united faix. On retiring from the fair, she found herself entangled amidst the labyrinth of apartments by which egress was purposely ordained, when Akbar stood before her; but instead of acquiescence, she drew a poniard from her corset, and held it to his breast, dictating, and making him repeat, the vath of renunciation of the infamy to all her race. The anecdote is accompanied in the original description with many dramatic circumstances. The guardian goddess of Mewar, the terrific Mata, appears on her tiger in the subterranean passage of this palace of pollution, to strengthen her mind by a solemn denunciation, and her hand with a weapon to protect her honour. Rae Singh, the elder brother of the princely bard, had not been so fortunate; his wife wanted either courage or virtue to withstand the regal tempter, and although she returned to their dwelling in the desert loaded with jewels, as Prithi-raj expresses it, 'she returned to her abode, tramping to the tinkling sound of the ornaments of gold and gems on her person; but where, my brother, is the moustache on thy lip!'-The l'arsees; T'od's Rajasthan, i. pp. 72, 345 .

KHUSRU or Amir Khusru, of the 13th and 14th centuries, a famous poet of Hindustan, near whose tomb are those of Khaja Kutub-ud-Din, of Muazzam, son and successor of Aurangzeb, of Bahadur Shah, and the tomb of Altamsh, whose daughter, the sultana Raziah, occupied the throne. The tomb of Iman Mushudi, the spiritual guide of Akbar, is west of the mosque of the Kutub-i-Islam. The massive tomb of 'Tughalaq Shah is outside the southern wall of Taghalaqabad, and was built by his son Mubammad. The Leela Burj, a blue tomb near the Humayun, covers the remains of a holy Syud. The poet Khusru's tornb is side by side in the same courtyard with the saint, his friend and contemporary. No imaginary being, but a living Hindu princess, Dewala Devi, inspired the songs of Khusru. His honey-tongued muse got him the surname of the Parrot of India. The date of his tomb is 1350 . He lived and died in India, but was a native of Samarcand, and wrote in Persian. He was the contemporary and friend of Nizam-ud-Din Aolia, near whose tomb, in the vicinity of Dehli, is the Chôwnsăth Khumbé erected over Khusru's remains. He lived at the court of Ala-ud-Din Khilji. In a Persian poem he celebrated the loves of Khizr Khan and Dewala Devi.

KHUSRU, the Chosroes of the Romans, who applied it as a surname to almost every king of the Sassanian dynasty, and it was applied by the Arabs, like Cæsar among the Romans, to many ancient kings of Persia. Khusru, a polytheist, who was king of Elam (not of Persia), conquered Babylon.

The Tak-i-Khesra formed part of the royal palace of Ctesiphon. The palace was commencel by Sapor II., the ninth king of the Sassanian dynasty, at the beginning of the 5th century. It was added to about a century later by another king of the saine line, Nushirwan, usually called Kushru I., and was finished by his grandson, Kushru Parwez or Khusru Ir. The part remaining is merely a portion of the façade and one of the halls of audience,--not a tenth part probably of the original building. It was covered with brilliant white stucco, and the halls were decorated with historical paintings and figures of the heavenly bodies. It was taken from the Persians by the Arabs in the time of the khalif Umar in the sixteenth year of the Hijira, and was called by them the White Palace. Its splendour and magnificence, as related by the Arabian historians, are scarcely credible. The dimensions of the hall were-105 feet in height, 95 feet in width, and 180) feet in length. The building remained entire till the time of the khalif Al-Mansur, who endeavoured to destroy it in order to make use of the materials in the construction of his palace at Baghdad. At the close of the 9th century the khalif Muktassi-b-illah regularly unbuilt the White Palace, in order to erect his famous edifice called the Taj at Baghdad, and merely left this hall as a specimen of the Sassanian architecture.-Tr. of Hind. ii. p. 222 ; Catafago.

KHUSRU PARVEZ, king of Persia A.D. $590-628$, of the Sassanian dynasty, grandson of Chosroes Nushirwan, A.D. 531-579, married a daughter of the emperor Maurice, generally supposed to be the same person as the heroine of the eastern romances Khusru and Shirin, and of Farhad and Shirin. Khusru Parvez waged war with the Roman powers, at first with the greatest success. He invaded the dominions of the emperor, wasted a vast extent of territory, overran the Holy Land, took Jerusalem, and burned the Christian churches, carrying off immense booty. He next reduced Egypt, and great part of Northern Africa.

KHUtbah. Arab., Hind., Pers. A public prayer or discourse pronounced in the Muhammadan mosques during divine service. It is also pronounced once yearly at the Eed-gah, on the festival at the close of the Ramzan. But from the early days of Muhammadanism the reading of the Khutbah has been a point regarding which the rulers and the people have entertained dissimilar views. It is pronounced from the mimbur or pulpit, which has three steps, and Umar fixed on the second step from which to speak it, praising: Mahomed. This rite has ever been a cause of trouble. Scarcely had Mahomed left the scene when Ayzeed consented to three requests of Zainul-Abidin, but privately desired his own Syrian Khatib (priest) to read the Khutbah, and to offer up praises and eulogiums in the names of the 
descendants of Abu Soofean and Oomea. Accordingly on Friday the Syrian Khatib read the Khutbah, and praised the race of Abu Soofean and Oomea, and spoke with contempt of the descendants of the prophet. Usman fixed on the second or middle step of the mimbur from which the Khutbah was to be read. Since then Mubammadan rulers have claimed as royal prerogatives the right to coin, and to have the Khutbah read in their name. In British India, until the deposition of the emperor of Dehli, the Khutbah was read in his name. And, now, the congregation believe it to be in the name of the Sultan of Turkey. Jafar Sherif, author of the Qanun-i-Islam, says (p. 263), 'The Khatib (priest), after repeating two rukat prayers, alias shukrea, ascends to the second or middle step of the mimbur, and, the congregation being seated, he reads the Khutbah, i.e. offers glory to God, praises the prophet, and passes eulogiums on his companions. He then descends to the lowermost step, recounts the many virtues of the king, and offers up supplications on behalf of him. The king is be whose coin is current in the realm, and in whose name prayers are offered up after the Khutbah is read at mosques and feasts.' And here is the following note :- At present (1832) it is in the name of the king of Dehli, but in the author's opinion erroneously, as it should be in the name of the Honourable East India Company.'

Lane says it is first a prayer for Mahomed, Ibrahim, the four khalifs, and the companions of the prophet, and for El Hasan and El Husain, Fatima, etc., followed by a prayer for El Islam, and for the Sultan, son of the Sultan, etc.

All Muhammadans admit that the Friday Khutbah cannot be recited without the permission of the ruler.

There should, therefore, be in the Khutbah a prayer on behalf of the Empress Victoria, but it may be mentioned that although since the year 1834 the mints of British India have only issued coins bearing the names of the successive rulers of Great Britain, the Muhammadans of that country have never introduced the British ruler's name into the Khutbah, and Dr. Birdwood mentions, correctly, that until a very recent date the emperor of Dehli was the subject of the prayer.

Every Friday of the month of Ramzin the Khatib reads the Khutbah (sermon), which contains praises and eulogiums, and admonition and advice.-Herklots' Qanoon-i-Islam; Lane.

KHUZISTAN, a province in the extreme S.W. corner of Persia, between lat. $30^{\circ}$ and $32^{\circ} 30^{\prime} \mathrm{N}$., and long. $48^{\circ} 51^{\prime} \mathrm{E}$., bounded in the N. by Luristan and the Bakhtiari mountains, on the $\mathrm{S}$. by the province of Fars and the Persian Gulf, and on the W. by the Shat-ul-Arab and the pashalik of Baghdad. For administrative purposes it is divided under the rule of the Shaikh of the Chab Arabs, and of that of Shuster. Shuster is the capital. It has several khor or inlets. Its principal rivers are the Karun, Dizful, Jurahi, and Kerkhah. The population consists chiefly of nomade tribes dwelling in tents. In the north are Feili, Bakhtiari, Kohgelu, and Mamaseni, and in the south are the Arab tribes, Anafijiah, Ali Kathir, Chab, and Beni Lam, pastoral and agricultural, and weavers of cotton and woollen fabrics. Its chief towns are Shuster, Dizful, Ram Hormuz, and Fellahiah.
The Shuster people are not wealthy, live in stone-built houses, in which there are sard-ab or underground rooms for retreat in summer, and some houses have the areesh or open room on the roof. Several of the khor have been at times supposed to have been mouths of the Euphrates. Khor Muso is deep, that of Lusbah is close to the Jurahi, and there is one near Sarema, on the banks of the Indian, rather westward of the borders. The inland khor are those near the towns of Dorak and Mohammerah; one still more extensive is formed by the overflowing of the river Kerah at the town of Hawiza; and lastly, the Samidah marshes above Kurna, which appear to be part of the ancient Chaldean lake.

Khuzistan is also called Arabistan, and represents the Susiana of Strabo, as well as the Cissia of Herodotus. The celebrated ruins of ancient Sus are near a bend of the Kerkhah. In the bed of the Ab-i-balad, a torrent of ancient Susiana, which falls into the Dizful, a small fossil shell occurs which is in request for the mouthpiece of the nargil pipe, under the name of Sang-i-Birinj or rice stone.-Markham's Embassy, p. 2; Ouseley's Travels, i. p. 148; Chesney's Euphrates and Tigris, p. 205; Mignan's Travels, p. 294; MacGregor; Layard.

KHWA. Pukнтu. Side, quarter, tract, coast. Pukhtun khwa is Pathan country, Afghanistan. Watan khwa is native country.

KHWA-MI, a tribe of the Arakan Hill tracts. Their name means monkey tail, because the end of their waist-cloth hangs behind.

KHYEN is the name given to several populations of Burma and Arakan. One tribe who tattoo their skins, dwell on the Koladyn river in Arakan; another dwell on the Yoma mountains south of the Koladyn river; the Mru are sometimes called Khyen. Khyen, indeed, as also Kha, are probably names given to most of the rude tribes of the Arakan and Burmese mountains. The name seems to be the soft Burman pronunciation of Karen.

The Khyen or Kayn or Chin are a considerable tribe on the Yoma mountains that stretch from Arakan to the Naga Hills, and are scattered in small settlements on the north of Pegu as far as Tounghoo. Dr. Mason regards them as Karen, but Yule thought them Kuki, and Phayre regarded them as Burmese. They tattoo the faces of their women, to mar their beauty. They call themselves Shyou or Shyu or Sho, and the Burmese style them Pwo-meet Khyen, meaning river Khyen. They are interspersed among the Burmese and Karen, from lat. $23^{\circ} \mathrm{N}$., along both sides of the Arakan range, and southwards to the mouths of the Irawadi, and a few are found eastward. They are most numerous about lat. $20^{\circ} \mathrm{N}$.

The eastern portion of the district from the Yomadoung to the Lemroo river is mountainous and hilly. The hill tribes living on the eastern frontier are Khyen, Mru-khyen, and Koo. The Khyen, who occupy both banks of the Lemroo river, from the Wah Kheong to the Khee Kheong, and the low hills west of the Jegaendong range visible from the plains, to the valley of the Tarooe Kheong, and the low hills and plains within the Tandan, Ganacharain, Prwanrhay, and Dainboong circles, are a quiet, inoffensive people. The most northern village occupied by the Mru-khyen, paying revenue, is Sikcharoa, situated 14 miles 
north of the junction of the Sreng Kheong with the Lemroo river. The Mru-khyen occupy the valleys of the Wah Kheong, Saeng Kheong, Mau Kheong, and that part of the valley of the Lemroo between Peng Kheong and Saeng Kheong.-Latham; Mason, Burma; Yule; Dalton, Ethn. p. 114.

KHYENDWEN, a tributary to the Irawadi, in lat. $26^{\circ} 28^{\prime}$ N., long. $96^{\circ} 54^{\prime}$ E., runs generally south into the Irawadi, near the town of Amyenmya; length, 470 miles. It receives Myitia Khyoung, 170 miles.

KHYOUK PHYOO, the chief town in the island of Ramree, 55 miles from Akyab, in lat. $19^{\circ} 25^{\prime} \mathrm{N}$., long. $93^{\circ} 34^{\prime} \mathrm{E}$., forming a district in the Arakan division of British Burma. It is so called from the white pebbles on its beach.Findlay.

KHÝ-OUNG-THA. The seaboard of Arakan and the lower portions of the valleys opening into it, form the country of the Rakhoung-tha or Arakan tribe, of whom the Burmans are a branch. Some are found residing on the banks of the mountain streams, and are distinguished by the name of Khy-oung-tha. Their language proves that they do not belong to the Yuma group, but are intruders from the north; and their own traditions recognise the $\mathrm{Ku}-\mathrm{mi}$ as the tribe in possession of the seaboard when they entered Arakan. Khy-oung-tha means children of the river, are a race of Arakanese origin, who speak the old Arakan dialect, and conform to Buddhist customs. Khy-oung-tha of Eastern Bengal are Buddhists, but still offer rice and flowers to the spirits of the hills and streams. - Imp. Gaz.

KHYRIM or Nong Krem, a petty state in the Khassya Hills in Assam, presided over by a siem or chief. Its iron ore is the purest found in the Khassya Hills. Its wild products include caoutchouc, cinnamon, lac, black pepper, and honey.Imp. Gaz.

KHYRODA is a tuppa or subdivision of one of the greater khalisa or fiscal districts of Mewar, and consists of fourteen townships, besides their hamlets. Its land is of three classes, viz. peewul, or watered from wells; gorma, also irrigated land, extending three or four khet or fields around the village; and mar or mal, depending on the heavens alone for moisture. There are two harvests, viz. the oonaloo (from Oon, heat), or summer harvest; and the sealoo (from See, cold), the winter or autumnal. The sealoo crop consists of mukki or Indian corn, sorghum or jowar, and bajra, with the different pulses. The share of the Crown, as in all the ancient Hindu governments, was taken in kind, and divided as follows: -Of the first, or oonaloo crop, which consists of wheat, barley, and gram, the produce is formed into kulla (piles or heaps) of 100 maunds each; these are subdivided into four parts, of 25 maunds each. The first operation is to provide from one of these the seerana, or one seer on each maund, to each individual of the village establishment, viz. the patel or headman; the patwari, registrar or accountant; the shanah or watchman; the bullai or messenger and general herdsman; the kat'hi (alias sootar) or carpenter; the lohar or blacksmith; the khomar or potter; the dhobi or washerman; the chamar, who is shocmaker, carrier, and scavenger; the nae or barber-surgeon. This rough sketch of the agri- cultural economy of Khyroda, may be taken as a fair specimen of the old system throughout Mewar. -Tod's Rajasthan, ii. pp. 595, 598.

KI. Chrn. Several species of Cirsium, Cnicus, Centaurea, and Carduus.-Smith.

$\mathrm{KI}$, also written $\mathrm{Ke}$ and Kei or Key, a group of three large and many smaller islands, about 60 miles west of the Aru Islands, and the same distance S.W. from New Guinea, thinly peopled. The $\mathrm{Ki}$ appear like so many isolated mountains; one of them is famous for its potteries. At another are built the prahu celebrated among the mariners of Banda and Ceram for their sailing qualities and strength. -St. John's Archipelago, ii. p. 90 ; Horsburgh.

KIAHTU, near the Baikal lake, is 2400 feet above the sea.

KIAMAT, properly Qiamat. ARAB. The day of resurrection, literally standing. Muhammadans believe that the approach of the resurrection will be known by twenty-five signs.

KIANG, a famous general of the Chin dynasty of China, who was expert in detecting crine, and was canonized.

KIANG, the Dzightai or Jaghtai, is in all probability the true Equus hemionus of Pallas. It bas been often confounded with the Gor-khar or wild ass, though they differ considerably in appearance, and inhabit countries with very dissimilar climates. The kiang exists in the high cold regions and mountains of Tibet, the Gor-khar in the heated sandy plains of Sind and Baluchistan. The kiang is found in numbers nearly in the same localities as the yak ; it does not, however, go up the mountains so high as the yak, but the range of its distribution is greater than that of the yak. The kiang are abundant near the Pangong Tso, and between Chusal and Hanle. They roam on plains 14,000 to 15,000 feet above the sea. They are shy. The greatest elevation where the Messrs. Schlagentweit found the kiang, was 18,600 English feet, whilst they traced yaks as high up as 19,300 feet.

The natives of Ladakh deny the possibility of any approach at domestication of the kiang, and state that young always die in confinement. Major Hay sent a kiang to the Zoological Society of London. He mentioned that the mares are highly esteemed by the Tibetans for breeding with the thoroughbred Chinese stallion, the produce being a horse with great powers of endurance, and which, on this account, are much in request by the Zhakpa, a predatory race who inhabit the mountains. The chief food of this species appears to consist of the stunted fescue grasses common on the plains and mountains, together with a redflowered vetch, possibly Oxytropis chiliophylla of Hooker. The speed of the kiang is great; its action seems to consist of a long step or trot, which is never varied.

The regions where the yak and the kiang are found are, in a zoological point of view, among the most remarkable and interesting of our globe. The highest absolute elevation coincides here, it is true, with the greatest height of the snow-line, or rather it causes the snow-line to be higher. But those large, high plateaux and regions, though free from snow and ice in summer, remain a desert throughout the year. The amount of vegetation on them is less than it is in the desert between Suez and Cairo in Egypt. Nevertheless 
these bigh sterile regions are inhabited by numerous herds of large quadrupeds. Species of wild sheep, antelopes, and a few canine animals, chiefly wolves, as well as hares, are abundant. The herbivorous animals find here their food only by travelling daily over vast tracts of land, as there are only a few fertile spots, the greater part being completely barren. The great scarcity of vegetation, particularly the entire absence of mosses and lichens, has a very different effect, though an indirect one, on the occurrence of birds. Those small plants are the chief abodes of insects: the want of mosses and lichens, coinciding with a total absence of humus, limits, therefore, to its minimum the occurrence of insects, the exclusive food of small birds in all extremely elevated parts of the globe, where grains are no more found. The Schlagentweits, indeed, travelling twenty consecutive days between heights of 14,000 to 18,200 feet, met only with three individuals belonging to a species of Fringilla, but occasionally vultures were met with.

KIANG-SU, a province of China on the east coast, washed on the E. by the Yellow Sea. It has the large towns of Chin-kiang, Nankin, Suchan, and Shanghai, and the great river the Yang-tse-kiang runs through it to disembogue in the Yellow Sea.

KIAN-KU, the largest river of Asia, which rises on the north borders of Tibet, and, after a course of about 2200 miles, enters the Eastern Ocean opposite the island of Tsong-ming.

KIAONG or Kyoung. BURM. The monastery house of the Phoungye or Buddhist monks.

KIAO-YOU. Chinese Christians call themselves by this name.-Huc.

KIA-YU, a pass in China. The great highway between Pekin and Europe has from time immemorial been the caravan tract from the western end of the great wall across the desert of Gobi. The route issues from the western end of the great wall, and, moving through the Kia-yu pass, has to traverse N.W. 500 miles of a desolate sand tract to reach the city of Khamil. At this town the road bifurcates, the upper branch leading through Baykul, Urumchi, and Kurkur-usu into Zangaria; the lower through Pijan, Turfan, Karashar, and Kuchu to Aksa in Eastern Turkestan.

KIBITKA, a tent made of felt, called in Russia Jourta or Kibitka, is in Mongol called Gher; several tents together, forming a kind of village or station, are called Ourto. Oulous or Olos signifies in Mongol empire, people; Ordo, a chateau or imperial palace.-Timkouski's Journey to Pekin, i. p. 12.

KIBLAH, ARAB., signifies a point of adoration, and is usually applied to the kaba or holy edifice of the Muhammadans, situated in the Bait-ullah or temple of Mecca. But all eastern sects appear to have had some Kiblah or holy point, to which the face was to be turned during prayer. The Jew looked towards Jerusalem; the Sabæan, according to some, to the north star, or, according to others, towards that part of the heavens in which the sun rises, or towards the meridian; and the Magian to the rising sun. According to the Veda, Brahmans should direct their prayers to the east. The early Christians chose the east. Mahomed, who recognised the general custom, and found it necessary to adhere to it, in the early part of his career appointed Jerusalem, but afterwards directed the holy kaba of Mecca to be the Kiblah of his disciples. Kiblah is also a respectful term in common use in India by Muhammadan children towards their parents, or inferiors towards superiors, and in this case means the source of honour and esteem. One of the titles of the king of Persia is Kiblah-i-Alam, point of the world's adoration. Kiblah-i-Alam, asylum of the world, in letter-writing, is an expression of respect in Muhammadan countries from dependents to their masters, children to parents, or servants to a prince, implying towards whom all the world turns with veneration. It is a phrase of daily life, but the rulers of Bokhara were styled Kiblah-i-Alamian, the turning point for both worlds. - Ouseley's Travels, iii. p. 133; Tavernier; Layard's Nineveh, quoting Hyde's Relig. Vet. Persar. p. 8; Prideaux Connect.; Vambery, Bokhara, p. 316.

KIBT or Kibti, of Egypt, the Copts, an abbreviation of the Greek word Aiguptios, an Egyptian. They are descendants of the ancient Egyptians. They are agriculturists, and in the subordinate offices of the country.-Catafago.

KICH'HRI. HIND. Generally a mixture of lentils and rice, with clarified butter poured over it. This has become common in El Hejaz as well as at Suez, under the name of El Kajari, a corruption which denotes its foreign origin, and renders its name pronounceable to Arabs.-Burtoris Mecca, i. p. 269 .

KIDARKANTA, in lat. $31^{\circ} 1^{\prime} 4^{\prime \prime} \mathrm{N}$., long. $78^{\circ}$ $14^{\prime} \mathrm{E}$., in Garhwal, a peak commanding a fine view, in the ridge between the Tons and the Jumna. The base of the stone pillar there is 12,430 feet above the sea. The top of the highest peak is 12,518 feet according to the Grand Trig. Survey, and is 12,689 feet according to Herbert and Hodgson. The upper limit of conifers is 10,700 feet. The upper limit of oaks on the southern slopes of Kidarkanta towards Aur is 11,442 feet.-Ad. Schl. Gr. Tr. Sur. See Kedarkanta.

KIDARNATH, in lat. $30^{\circ} 44^{\prime} 10^{\prime \prime} \mathrm{N}$., long. $79^{\circ}$ $51^{\prime} 50^{\prime \prime} \mathrm{E}$, in Garhwal, on the right bank of the Mandagni, near its origin. The entrance to the Hindu temple is 11,794 feet, Rob. Schl, or 11,753 feet, J. A. S.

It is a great place of Hindu pilgrimage, being next to Badrinath in holy estimation. It marks the spot where an incarnation of Siva attempted to dive into the earth to escape the Pandava. Close to the temple is a precipice, the Bhairab Jap, from which formerly devotees threw themselves, but the British prohibited it. The rawal is a Jangam from Mysore.

The upper limit of trees in the Mandagni valley. below Kidarnath, is 11,020 feet. The lower end of the Kidarnath glacier, and origin of the Mandagni, is 12,372 feet. The confluence of the first glacier on the right side within the main Kidarnath glacier is 13,658 feet. The junction of the three principal branches of the Kidarnath glacier is 15,449 feet. The small glacier lake, right side of the Kidarnath glacier, is 13,349 feet.-Kob. Schl.

KIDD, CAPTAIN, a piratical leader, a native of England, whose stronghold is still shown in the neighbourhood of Johanna. He was employed by the goveruor of New York to suppress piracy in the Eastern Seas, but took to piracy, and on his return was convicted and hanged. 
KIEF. ARAB. In Morocco, died flowers of Cannabis sativa ; repose; Dolce far niente. It is a rest that does not presuppose labour, a relief that scarcely implięs previous care, a mental exaltation by mental effort only, and a dream that fulfils itself. It does not exist in the west, for things move too fast there; but it is a treasured possession of the oriental, which neither armies, treaties, nor fleets can take from him.

KIERNANDER, JOHN ZECHARIAH, a Protestant missionary to Cuddalore 1740 , and Calcutta 1758. He built the old church.

KIFRI. Near this town, in the pass through which the Ak-Su penetrates to the plains, is a naphtha pit. The hills are about a mile S.E. of the town of Tuzkurmatti, close to the gypseous bills of Kifri, and the pit, being in the bed of the torrent, is sometimes overflowed by it, and, for a time, spoilt. The pit is about 15 feet deep, and to the height of 10 feet filler with water, on the surface of which black oil of napbtha floats, small air-bubbles continually rising to the surface. They skim off the naphtha, and ladle out the water into a channel, which distributes it into a set of oblong, shallow compartments, made in the gravel, where they allow it to crystallize, when it becomes very good salt, of a fine, white, brilliant grain, without any intermixture of bitterness. Great quantities of this are exported into Kurdistan ; and it is worth annually about 20,000 piastres. The oil of naphtha is the property of the village. Part of it is consumed by the manzil khanah, or sold for its support, and part for religious establishments, etc. About two jars, each containing six oka, or one Baghdad batman, of naphtha, may be skimmed from this well in twenty-four hours. The spring is at the bottom of the pit or well, and once a year they cleanse the well, on which occasion the whole village turns out, victuals are distributed to all the poor, and sacrifices of sheep are made to the round of drums and oboe, in order to insure the good flowing of the spring again,-a ceremony in all probability derived from remote antiquity. The principal naphtha springs are, however, in the bills, a considerable distance south of this, towards Kifri. They are five or six in number, and are much more productive than this pit, but so salt is found there. Indeed, it is probable that naphtba may be found in almost any part of this chain. Near the naphtha pit in the hills are alum (zak or sheb) and chalk (tabashir), of a very fine, close, white grain; but the natives make no use of these products. An earth, also, is found, which they employ to give an acid flavour to some of their dishes; no doubt it is vitriolic. Sulphur is also found, and is used by the peasants to cure the itch in their cattle and themselves.-Rich's Kurdistan, i. pp. 27-29.

KI-GEN-SET-SU. JAP. The anniversary of the birthday of the first emperor of the reigning dynasty.

KIKATA, an ancient name of the people of Magadha.

KILAID-us-SHAM. ARAB. Stones of the yellow date, strung on twine, and worn as necklaces by the Hodeilah Arabs.--Hamilton's Senai.

KILI-KATR, Muddikpor, or Kotabu, a migratory people in the Southern Mahratta country. Kublgira or Ferryman, Koli, and Barkur are the terms most usually applied, but Muddikpor is their own designation. They are generally tall and powerful men, with an olive-yellow complexion, and they say that their original locality was the village of Talicot, near the town of Sorapur, and that all speak the Mahrati tongue, though a knowledge is requisite of the language of the countries in which they wander, to enable them to gain a livelihood. They are wandering minstrels.

KILOGRAMME, a French measure of weight, equal to $2 \cdot 2053 \mathrm{lbs}$, a bout $2 \mathrm{lbs} .3 \frac{1}{4} \mathrm{oz}$. avoirdupois ; it is about the same as the Pakha seer of India.

KILOMETRE, a French measure of length, about $1093 \frac{1}{2}$ English yards.

KILPATRICK, MAJOR, an officer of the E. I. Company in the time of Lord Clive. In May 1751 he served in the fight of Volconda. In November he marched with a detachment to relieve Clive at Arcot. On the 7th August 1753 he led the attack at Sugar-loaf Hill at Trichinopoly, and was desperately wounded. He died in October 1757, in command of the Bengal troops, and Member of Council at that Presidency.

KIMA. The shells of the taclabo, or gigantic Philippine oyster, are used as fonts in the churches of that group. The fish of the Kima cockle frequently weighs 30 or $40 \mathrm{lbs}$. Some of the shells measure three feet across, are several inches thick, take a fine polish, and form valuable articles of the trade to China. One was found weighing $278 \mathrm{lbs}$.

KIMEDI, a large zamindari hill tract, on the western border of Ganjam district, Madras. It contains the three estates of Parla Kimedi, Pedda or Boda Kimedi, also called Vizianagram, and Chinna Kimedi or Pratapgiri. Kimedi had been long subject to the family of Narrain Das, descended from the raja of Jaganath, who was formerly ruler over these countries, and whose sons are said to have separated on their father's nominating a natural son to the succession. Moving southward with a numerous train, one son conquered and established himself in Kimedi, as another son did at the same time at Vizianagar in the Itchapur country. The succession was hereditary, and the people regarded them as the offspring or even the incarnation of a deity. Kimedi is surrounded by mountains, the valleys, extensive and very fertile, having every advantage of tanks, rivers, and abundant dews, but the climate is extremely unhealthy.

KIMIA. Arab., Hind, Pers. Chemistry ; but among eastern nations this has always been considered as closely connected with, or indeed as forming a part of, the search for the philosopher's stone. It is the art of magic, supposed to be the constant and favourite study of Indian sages and enchanters, who are much dreaded in Persia. With the Arabic prefix al, we have th European word alchemy.

KIMIS or Koumis, a fermented beverage in use amongst the nomade Tartars.

KIMKHAB, HIND., corruptly Kincob, a fabric of silk with gold or silver in woven pattern; silk brocade, worked in gold and silver flowers. The costly and superb fabrics of cloths of gold and silver or the kimkhab, and the classes of washing satins or mushru and hemru, even if European skill could imitate them by the hand-loom, it would be impossible to obtain the gold and silver thread unless it were imported from India. The 
native mode of making this thread is known, but the result achieved by the Indian workman is simply the effect of skilful, delicate manipulation. The kimkhabs are used for state dresses and trousers, the latter by men and women; and ladies of rank usually possess petticoats or skirts of these gorgeous fabrics. Kimkhab, although only employed in India as articles for personal wear, might be used in Britain for covering chairs, couches, etc. The origin of the word kimkhab is said to be from Kum (Kam), little, and Khab, sleep. Kimkhab, hemru, luppa, tas, are all of the same order of manufacture, gold, or gold and silver, and silk. In the kimkhab, metal predominates, whereas in hemru the silk predominates, and in hemru the design is generally a diaper or buta-dar. Aftixes of single and double are also made use of to designate one colour or several, such as ekowdu hemru, and bewdu hemru. In Surat it is known as kumjurno aleeacha, which means that there is only a small quantity of gold thread used in it. Luppa has so much gold or silver that the metal only is visible. Tas is much thinner, but is manufactured in the same manner. Mushru and hemru are not used for tunics, but for men's and women's trousers, and women's skirts, as also for covering bedding and pillows ; they are very strong and durable fabrics, wash well, and preserve their colour however long worn or roughly used; but they can hardly be compared with English satins, which, however, if more delicate in colour and texture, are unfitted for the purposes to which the Indian fabrics are applied. For example, a labada or dressinggown made in 1842 , of scarlet mushru, was washed over and over again, and subjected to all kinds of rough usage, yet the satin in 1862 was still unfrayed, and the colour and gloss as bright as ever. See Clothing; Embroidery; Gold Embroidery.

KI-MO-NO. JAP. A long-sleeved robe, worn by men and women, and fastened with a girdle.

KIMUKHT, turquoise green leather made at Yarkand and at Bareilly, much used in Kābul and Peshawur. It looks like shagreen, is used for native shoes, and for sword scabbards. About Rs. 2000 worth is annually exported from Bareilly to Dehli and other places. It is made from asses hide.

KINA BALOW, a mountain near Bawang, in Borneo, estimated between 13,000 and 14,000 feet in elevation; properly Kini-ballu, the Chinese widow. It lies E.S.E. from the harbour of Ambong; it is the highest mountain in Borneo. $-J$. In. Ar.

KINARA or Kinaree. Hind. Edging either of silk, or gold or silver thread; also of wide gold and silver ribbon, which often has a pattern printed or pressed on it. Kinara-baf is the maker of silk edging and fringe.

KINAT. Hind, PERS. A tent wall.

KINCHINJUNGA, a mountain peak 45 miles distant from Darjiling, rising 21,000 feet above the level of the observer, out of a sea of intervening wooded hills; whilst, on a line with its snows, the eye descends below the horizon, to a narrow gulf 7000 feet deep in the mountains, where the Great Ranjit river, white with foam, threads a tropical forest with a silver line.Honker, Him. Jour. i. p. 122 . See Kanchinjinga.

KINDERSLEY, J. R., a member of the Madras
Civil Service, author of a Manual of the Law of Evidence of the Madras Provinces.

KING.

Sultan, . Arab, Turk. Nawab,. . . Hind.

Padishah, Malik, AraB, Padshah, Hind, Pers. Roi,

Konig,

KING. CHIN. An imperial capital, as in Pekin, Nanking: Tu, CHIN., is a court or imperial residence, as Tai-tu, Shang-tu. Fu, CHIN., is a city of the first class, or rather the department of which it is the head; Cheu, a city of the second class, or the district of which it is the head.-Yule's Cathay, ii. p. 262.

KING. Chrn. The five canonical books written and compiled by Confucius, the Yih-King, Shu-King, She-King, Le-Ke, and Ch'un Ts'ew.

KING CRABS of Acheen. Ikan-mimi, JAV.; Moi-moi, Acheen. Two of these crabs join themselves together by their under surfaces, and thus united burrow in the sand. They are eaten by the Chinese and Javanese.-Bennett's Wanderings, i. p. 401.

KING-CROW, Dicrurus macrocercus, is often seen on the backs of cattle; it is also called the Kotwal.

KING-FISHER, birds of the family Halcyonida, of which there are several species in the East Indies. The Tanysiptera nais of Amboyna, the racquet-tailed king-fisher, is one of the most singular and beautiful of that beautiful family. King-fishers are of the genera Halcyon, Todiramphus, Ceyx, Alcedo, and Ceryle. They are numerous in India, most of them diving in the water for small fishes; others eating crabs, insects, and reptiles. An instance is mentioned of a king-fisher darting into the Coum river at Madras, and being captured by the valves of the molluse closing on it. One or two of them hover over the water, questing on the wing till they sec their prey; others sit motionless, watching on a fixed perch. Their bright plumage is their ruin, for it is saleable, and a class of men make their living by capturing them. In solitary places, where no sound breaks the silence except the gurgle of the river as it sweeps round the rocks, the lonely king-fisher, an emblem of vigilance and patience, sits upon an overhanging branch, his turquoise plumage hardly less intense in its lustre than the deep blue of the sky above him and so intent is his watch upon the passing fish, that intrusion fails to scare him from bis jost. The common king-fisher (Alcedo Bengalensis, Gmel.), the black and white species (Ceryle rudis), and the Indian king-fisher (Halcyon fuscus, Bodd.), are often to be seen. The first is common in rice-fields, streams, and river banks; the two latter are not so plentiful; the Indian king-fisher is a tenant of grardens and pools; the large black and white king-fisher is the Ceryle guttata. Birds' feathers, from the cranes and king-fishers, form a considerable article of trade in South-Eastern Asia; the feathers of a large green king-fisher are exported from Madras, one lakh at a time, to Singapore, to be used by the Malays, Javanese, and Chinese. They sell there at 200 r er cent. profit.

The nest of a large red king-fisher of Borneo is said to be pendulous, and invariably to be accompanied in the same mass by a bee which is 
peculiarly vicious, so that the nest can only be robbed after destroying the bees.-Burbidge's Gardens of the Sun; Tennent's Sket. Nat. Hist. p. 249 ; Wallace's Eastern Archipelago; Adams.

KINNARA, in Hinduism, heaveuly choristers, beings with human shape, but with heads of horses ; from Sanskrit King, what, Nara, a man. They are also called Aswa-Mykha, also Taranga Vaktra. They dwell with Kuvera on Kailasa. Buddhists represent them with human heads and busts, and tail and legs of a fowl.

KINNARAYA, a small race in the Kandyan province of Ceylon. They are a well-formed race, and resemble the Rodiya in appearance and customs. They are mat-weavers. They shave their heads. They are illiterate.

KINNEIR, J. MACDONALD, author of a Geographical Memoir of the Persian Empire, London 1813 ; also of a Journey through Asia Minor, Armenia, and Kurdistan in 1813 and 1814. with Remarks on the Marches of Alexander and Retreat of the Ten Thousand, London 1818.

KINO.

Dam-ul-akwain, . ARAB. I Kino-harz, . . GER. Pulas-gond, - : BEnG. Kumr kusala, Kini, Hind, Padouk, : BurM. Chino, . . IT Gomme de kino, . Fr. Tamble-hoan, . TAM

The kino of commerce is a product of the Pterocarpus marsupium of India, Limn.; Pt. erinaceus Poiret, of Senegambia; the Pt. Wallichii and P. Indica or Padouk of Tenasserim, the Butea frondosa of India, and the Eucalyptus resinifera of Australia. The juice of the $\mathrm{Pt}$. erinaceus and that of the Eucalyptus resinifera have much the same properties as the catechu, and have been proposed to be used in dyeing green. Although the colour of kino is a deep-red, it has the power of communicating a green colour to the salts of iron. The true medicinal gum-kino is obtained from the Pt. marsupium; but the juice of Pt. Indicus, Pt. Wallichii, and of Pt. Dalbergioides are said to be also dried and exported under the name of kino ; and it is probable that the properties on which their value depends are of a general nature. Pt. Dalbergioides is found in the northern parts of the Pegu province in the Prome district, chiefly in the vicinity of towns and inhabited places, rarely in the forests. The kino of Botany Bay and Van Diemen's Land is the produce of the Eucalyptus resinifera, which sometimes yields, on incision, 60 gallons of juice. The East Indian kino, imported from Bombay and Tellicherri, is the produce of Pt. marsupium, a lofty, broadspreading forest tree, which blossoms in October and November. The bark is of a greyish colour, and is upwards of balf an inch in thickness on the trunk. When cut, a blood-red juice speedily exudes and trickles down; it soon thickens, and becomes hard in the course of 15 or 16 hours. The gum is extracted in the seasons when the tree is in blossom, by making longitudinal incisions in the bark round the trunk, so as to let the gum ooze down a broad leaf, placed as a spout, into a receiver. The gum is dried in the sun until it crumbles, and then filled in wooden boxes for exportation. Pt. erinaceus, a tree 40 to 50 feet in height, a native of the woods of the Gambia and Senegal, furnishes a kino. Butea frondosa, or the dhak tree of the East Indies, furnishes a similar product in the shape of a milky-coloured, brittle, and very astringent gum.
Some specimens of Butea kino, analysed by Prof. Solly, after the impurities had been separated, yielded $73 \frac{1}{4}$ per cent. of tannin. Kino generally occurs in shining grains, of a rich ruby-red colour, nearly all soluble in alcohol, and readily pulverizable between the fingers. It also occurs in small and shining, brittle, angular fragments of a deep-brown colour, which appears to be a natural exudation of some one plant, from the uniformity of its appearance. The gum of Butei frondosa was at one time acknowledged by the Dublin College, and Botany Bay kino, produced by Eucalyptus resinifera, or brown gum tree, by the Edinburgh College. The best is now inported into Great Britain from Bombay. The name is derived from the Indian term kini, applied to a similar exudation from the bark of Butea frondosa, of which the Sanskrit name is Kin-suka. Gum-kino is used medicinally as an astringent, and in India to dye cotton cloth of a nankeen yellow.-Waterstone; Faulkner; Royle, Him. Bot. p. 195 ; Proc. Royal Asiatic Soc., 1838; M'Clelland; Cullen, MSS.

KIO or Miaco, the residence of the emperor or Dairi of Japan, about twenty miles from Osacca, and contained, in the time of Kaempfer, according to a census, more than 500,000 inhabitants, besides the numerous court of the Dairi.MacFarlane, Japan, p. 149.

KIPCHAK, a race who have settled down in and around Khokand, and supposed by Vambery to be a division of the Burut. Their social relations are with Muhammadans and the people of Turkestan. He says they are the bravest and most warlike of the Turkish tribes, and are held to be the descendants of those Mongols who, under the name of Djete-moghul, waged such obstinate war against Timur, and afterwards, under the leadership of the sons of Yunis Khan, made themselves masters of the eastern part of Turkestan.-P. Arminius Vambery, p. 75.

KIRATA or Kiranti. This martial aboriginal race is spoken of by ancient Sanskrit writers, and classed by Menu and by the Mahabharata as one of the non-Hindu military peoples, along with the Khasa, China, Dravida, and other recognised non-Aryan races. They occupy at this day the exact position assigned to them by the Vishnu Purana, viz. the eastern border of Bharata Varsha. The Kirata are known in classical geography as the Cirrhadæ or the Cirrodes. They occupied the country to the east of the Bharata, and are still numerous in Dinajpur, which was part of the ancient Matsyades, all the inhabitants of which were considered as foreigners and borderers. They are part of the races styled as Limbu, an important segment of the population of Sikkim, and are the Kiranti of Nepal; but the people prefer the names Khwombo or Khombo, and Kirawa. Dr. Campbell says that the correct denomination of the people is Ekthumba; but that the term Limbu is generally used to indicate the whole population of the country between the Dud Kusi and the Mechi, thus including the Kirata, the Eaka (Hodgson's Yakha), and Rais, and that in appearance and habits they are all very much alike, and they intermarry, which is the great test of national connection.

The Kiranti are divided into Wallo Kirant or Hither Kirant, Manjh or Middle Kirant, and 575 
Pallo or Further Kirant. The Wallo include the Limbu and Yakha.

The Limbu and Kiranti have to buy their wives; those who are too poor to pay in cash, serve like Jacob in the father's house till they have given an equivalent in labour.

Those bordering between Sikkim and Nepal are partly Buddhists, partly Brahmanical.

The Kiranti, like the Munda and Kasia, burn their dead, selecting the summits of mountains for the purpose, and afterwards collect and bury the ashes, over which they raise a square tomb of stone about four feet bigh, placing an upright stone on it.-Dr. W. W. Hunter; Dalton, Ethnol. of Bengal.

KIRAT SAGAR, and Madan Sagar, ancient artificial lakes near the town of Mahoba.

KIRBAH. Arab. An inflated skin used by fishermen as a float on which to rest when fishing.

KIRGHIZ were originally a small tribe settled in a remote corner of Southern Siberia, on the banks of the Yenisei river, but migrated or were removed in the 17 th century to the shores of the Balkash and Issyk-kul lakes. In their new abode they amalgamated with the Kazak and Burut, and absorbed a host of smaller tribes, the debris of the old Ghuz, Koman, and Kipchak, and have gone on increasing until their number is now nearly three millions of souls, and constitute almost the exclusive population of the steppe from the Aral river in the west to the Mongolian frontier on the east, and north and south from the Siberian line to the plateau of Pamir.

Kirghiz are in the neighbourhood of Issyk-kul and in the valleys of the Tian Shan, also in those of the Alai mountains and the Pamir east of Badakbshan, to the south of Khokand. Their name for themselves is Kirghiz, but they are called Burut by the Chinese and Kalmuks; the Russians call them Kara-Kirghiz, meaning Black Kirghiz, also Dikokamenni, meaning Wild Mountain Kirghiz, to distinguish them from the Kazak. They are partly (about 200,000) under Russian sway, partly $(150,000)$ under Kashgar, and in Eastern Turkestan and Khokand. They are supposed to be 350,000 . Those at Pamir whom Lieutenant Burnes saw had flat countenances, and strongly resembled the Turkoman.

They profess Muhammadanism, but retain Shaman practices. Their Shamans wear long hair.

Kirghiz derive their origin from a red $\operatorname{dog}$ and forty maidens (Kyrk-kyz). Some tribes say the maidens were impregnated by the form of the lake Issyk-kul in the Kirghiz steppe. The fable of Cyclops is current, but there called Alp, a giant ogre, and a Kirghiz giant, Batur Khan, enacts the part of Ulysses.-Schuyler; Muller's Lectures; Malcolm's Persia; Staunton's Narrative; Markham's Embassy; Vigne's Narrative; Captain V. M. Vemukof.

KIRIAGHUNA, also Kiri Anguna. Singh. The cow-tree plant of Ceylon, Gymnema lactiferum, is harmless, notwithstanding it belongs to the asclepiadaceous order, which is usually acrid and dangerous.-Eng. Cyc. p. 178.

KIRI - ELEEMA. SINGH. The overflow of milk; a ceremony in Ceylon, when the liquid of the cocoanut is boiled till it runs over, as an emblem of plenty and a land flowing with milk. -Tennent's Christianity in Ceylon, p. 234.
KIRK, R. A., medical officer of the Bombay army, who wrote a Journal of a Journey from Tadjourra to Ankobar, in Lond. Geo. Trans., 1842, x. ; Measurements of Elevation and Astronomical Observations in Abyssinia, in Bom. Geo. Trans., 1844, vi. p. 355; Visit to Volcano of Gibbel Teer, Red Sea, ibid., 1842, vi. p. 366 ; Rise and Fall of River Indus and Range of Thermometer at Bukkur, 1841, ibid. p. 436. $-D r$. Buist's Index.

KIRKEE, near Poona. A battle was fought here on the 13th November 1817, which decided the fate of the Dekhan, and led to the downfall of the peshwa Baji Rao, and the extinction of Mahratta rule.

KIRKOOK. Naphtha is obtained near here. It is scooped out with ladles into bags made of skins, which are carried on the backs of asses, for sale. It is principally consumed in the southwest of Kurdistan, while the pits not far from Kifri supply Baghdad and its environs. The Kirkook naphtha is black. On the summit of a hill is a flat circular spot measuring fifty feet in diameter, with a hundred at least of small holes, whence issue as many clear flames. The natives call the place Baba Gurgur, Gur being an Arabic name for naphtha or bitumen. The bitumen pit at Kit must have furnished the builders of BabyIon; to qualify the bitumen for use as a cement, it must be boiled with a certain proportion of oil. Its chief use appears to have been in the lower parts as a preservative against damp; at present it is used for coating cisterns, baths, caulking boats, etc. The black naphtha springs at Baku, on the Caspian, are similar. Jonas Hanwav mentioned that when the weather is thick and hazy, the springs boil up higher, and that the naphtha, sometimes taking fire on the surface of the earth, runs like burning lava into the sea. In boiling, the oily substance gradually becomes a thick pitchy mass all round the mouth of the pit. The poorer people use it in lamps and to cook their food. It burns best with a sinall mixture of ashes; but, for fear of accidents, they preserve it in earthen vessels under ground, and at some distance from their dwellings. There is also $\mathrm{n}$ white naphtha, a thinner fluid than the black, and not found in such great quantities. This is sometimes recommended, inwardly for chest complaints, and outwardly for cramps and rheumatism. Both it and the black are used for varnish. Strabo calls it liquid bitumen, and asserts that its flame cannot be extinguished by water. The experiment tried by Alexander was horrible in its effects. The flaming soil, or everlasting fire, as it is called, of Baku, is not less famous than its naphtha springs.--Porter's Travels.

KIRMAN is situated in lat. $29^{\circ} 56^{\prime} \mathrm{N}$, and long. $56^{\circ} 6^{\prime} \mathrm{E}_{\text {., }}$ on the western side of a capacious plain, so close to the mountains, that two of them, on which there are ancient decayed forts, completely command it.

It is the chief town of a large province of Persia, the northern part of which is a salt and barren desert, but in the south the land is fertile. Many sheep are bred here, and their fine wool is an article of great trade. The capital of this province is a city of the same name, and it is celebrated for its beautiful shawls, carpets, and stuffs. The climate of this province is as varied as the face of the country, and it is accounted the least 
salubrious of any part of Persia. They have seldom any heary falls of rain, but snow lies to a great depth on the mountains in winter, and from their loftiness it does not melt for the greater part of the year.

The province is the ancient Carmania, and is bounded on the east by a part of Seistan and Baluchistan ; west by the province of Fars; south by parts of Luristan, Mekran, and the Persian Gulf; and north by Irak and Khorasan. Kirman fills up the space between Khorasan, Fars, Afghanistan, and Mekran. The surface of Kixman (including Luristan) contains about 72,741 square miles. The southern portion of Kirman, viz. Luristan and Moghostan, formed the chief part of the Himyaritic kingdom of Hormuz, through which rum an important commercial line from the capital, Harmozonte. These districts, together with the different islands, formed part of the territory of Mithrophrastes at the time of the visit of Nearchus, who learned from this monarch that the tomb on the island of Tyrina (Kishm) was that of Erythras, son of Ariarius, satrap of Phrygia, who was banished to this place by Darius (Strabo, lib. xvi. p. 776), whose name was given to the adjoining part of the sea. Artemidorus, however, thought the name was derived from the reflection of mountains glowing with the heat of a vertical sun (Strabo, lib. xvi. p. 779), which certainly cause a deep tint on the waters in this part of the world.

The khalifs, Chengiz Khan, Timur, and the Afghans, successively took, plundered, and destroyed Kirman, the last occasion being in 1794 , when it was betrayed into the hands of Aga Mubammad Klian, the founder of the Kajar dynasty ; but even yet its manufactures of shawls, matchlocks, and namad or felts are celebrated all over Asia, and are said to afford employment to upwards of onethird of the inhabitants, whether male or female. The wool of its goats approaches nearer than any other in fineness to that of Kashmir, and, under the commercial name Wahab-Shabi, it is used in adulterating shawl-wool.

A third of the inhabitants of the city are employed in their shawl manufacture. In texture and delicacy of fabric they rival those of Kashmir, but they are inferior in downy softness and warmth. The sheep are small and short-legged. After shearing, the wool is repeatedly and carefully picked and washed, and for some weeks is steeped in a wash. It is then spun by the women, and worked up by the men. In making carpets, the thrends (all of one colour) are of the length of an upright loom, which consists of two holizontal rollers. The cross coloured threads that form the pattern are worked in by as many small boys as the breadth of the web will permit to squat in front of the loom. As the work progresses, the web is gradually rolled up on the lower roller. After every two or three rows have been worked in, wide-teethed combs are inserted over the threads of wool, and hammered down close and firm with a mallet. The master weaver draws and colours the designs on paper ruled to represent the different threads, after which he teaches the pattern to the pupils, who commit it to memory. The shawls are woven in a similar manner, only on a horizontal loom. The workmen work with the reverse side of the web uppermost. The fabrics are exported to all parts of
Persia and Central Asia, and to Sind, India, and Arabia.

A lead mine is worked near the summit of a hill 32 miles N.TV. of Kirman.

Kirman and Mekran are peopled by Persians principally, but contain also Turk, Baluchi, Brahui, and Afghan. Kirman has the shrine of Fahm-i-Alam, the father of Nadir Sbah. Pottinger's Tr.; Kinneir's Memoir; Malcolm's Persia; Chesney's Expedition; E. A. Floyer's Baluchistan; MacGregor's Gazelteer.

KIRMANI, a Kurd clan in Kurdistan, who were originally from Pizhdar, near Sikoneh, on the frontier of Persia. The Babbeh is the chief family of the Kirmani, and its members are the hereditary chiefs; hence their whole territory and the people are now called the government of the Bebbeh or Baban.-Rich's Kurdistan, i. p. 80.

KIRMANSHAH, a district of Persia, lying between lat. $34^{\circ}$ and $35^{\circ} \mathrm{N}$, and long. $44^{\circ} 5^{\prime}$ and $48^{\circ} \mathrm{E}$, at present greatly depressed, though a peculiarly productive region of manna (Gazanjabin), sheep, and horses, and manufacture of carpets. It is inhabited by the Leh, Turk, and Kurds, of the following tribes,-Ahmadāwand, Bahtui, Balawand, Guran, Hersini, Jalalawand, Jalilawand, Kakawand, Kalhor, Nanakili, Panjanawand, Pyrawand, Surakji, Zanganah, Zuleh, Zobonawand. The town, in lat. $34^{\circ} 18^{\prime} 45^{\prime \prime} \mathrm{N}$, and long. $46^{\circ} 37^{\prime} \mathrm{E}$, is 25 miles S.W. of Teherau. -Mac Tregor.

KIRTAN. HiND. The relation of the deeds of Rama, during the nine days of the Rama Naomi; any hymn or poetical relation or ballad in praise of the Hindu gods, and sung to music. The kirtans are arranged for part singing, in constantly changing measures, and bave been composed to be sung by itinerant choirs of boys or young men, under a precentor, at country fairs, and in the village bazars of Gujerat and the Mahratta country. Each kirtan is headed by the auspicious word Sri, and begins with an invocation to Ganesha, the god of wisdum, and Saraswati, the goddess of learning and music, the Minerva Musica of the Hindus, and the other greater gods of their pantheon, and each ends with ascriptions of praise and loyalty to the Qucen, and supplication for the blessing of God, and the citation of the names of some of the idol gods invoked at the head of the kirtans. The different metres used are:-1. The Abhanga, unbroken, employed in religious songs; 2. Arati, exclusively sung before idols in the evening or at the end of a religious lecture or song; 3 . Ayra, employed in composing narrative; 4. Dhanakshari (?) ; 5. Dindi, a new metre, used chiefly in modern dramatic performances; 6. Katava or Katao, a fanciful measure, displaying the writer's command of alliteration, etc., and used chiefly in martial songs; 7. Kekawall, imitative of a series of cries of the peacock; 8. Laoni or Lawani, a metre generally used only in obscene songs, but latterly for religious also; 9 . Naman, the lines in praise of a deity at the commencement of a Puran; 10. Pad, used chiefly in praising a deity, and sung in Kathas aud singing parties; 11. Saki, a light metre used like the Dindi; 12. Sloka or Shlok, stanzas of two lines, the length of which varies, and used in ordinary poetical compositions.

KIRTHIPUR occupies the summit of a low 
hill, about three miles west of Patan. It was at one time the seat of an independent prince, and its reduction cost the Gurkhali prince so much trouble, that in resentment of the resistance mado by the inhabitants, he barbarously caused all the males whom he captured in it to be deprived of their noses. Chobar is also situated on an eminence, which, with that of Kirthipur, forms a kind of saddle hill.

KIRWAH. KASH. A weight equal to $384 \mathrm{lbs}$. English.

KISAN, in Bengal, as also Chasa, are terms by which the cultivators of the soil are there designated, like the Kunbi of the Mahratta districts, the Zamindar of the Panjab, the Kapu (Kapulu, pl.) of the Teling races, the Wakkaliga of the Canarese, and the ryot of the Muhammadans generally.

KISAN or Nagesar, a broken tribe in Sirguja, Jashpur, Palemow, and Lohardagga, who devote themselves to agriculture, from which probably they obtain their name. They dwell in the forests and cultivate on the skirts. At Moheri, Colonel Dalton found a great variety of nonAryan tribes, - the Mar, a mixed race, wild Korwa, Bhuiya, Bhuiher, and Kisan. The Kisan's chief object of worship is the tiger, the ban raja, lord of the jungles. They adore the spirits of their ancestors, and a spirit called the Shikaria deota, offering goats to the latter.

They also worship the sun, and offer a white cock to that luminary. All this is Kolarian, especially Santal, shamanism. Each village has two or more groves or sa, one is sacred to Moihidhunia, the other to a local deity, whom they designate Mahadeo, a guardian of their harvests. The Khunt, or tutelar god of the villages, is Darha, as with the Kol, and there are various pat or sacred high places dedicated to divinities, as the Bamonipat and the Andaripat. They keep the ceremony of the sarhul, as the Kol, and have the Kol dances, jadur, jumhir, and karm, but not the kharria, which they say is peculiar to the Oraon. They are singularly ill-favoured.

Kol and Oraon women are all marked distinctively with Godna, but if a Kisan female have herself tattooed, she is at once turned adrift as having degraded herself, - Dalton, Ethnol. of Bengal, p. 132.

KISAS. PERS. Blood revenge.

KISH, the birthplace of Timur, who beautified it, and erected many splendid edifices before he made Samarcand his capital. It is now the chief town of the Begship of Shahr-i-Sabz, by which name Timur and Baber noticed it.

KISHENGARH and Bikanir, according to Col. Tod, arose out of Marwar, and Macheri from Amber, to which we might add Shekhawati, which, though not separate, is tributary to Amber, now Jeypore. The Kishengarh family, according to Aitcheson, also is an offshoot from Jodhpur. A treaty was formed with maharaja Kullian Singh in 1818. Prithi Singh succeeded in 1840 ; he was granted the right of adoption, and he receives a salute of fifteen guns. His territories cover an area of 720 square miles, and contain a population of 70,000 souls. The revenues are about 600,000 rupees. The State pays no tribute, and contributes nothing to any local corps or contingents. The army consists of 250 cavalry, 300 infantry, and 30 guns.-Tod's Rajasthan, i. p. 420; Treaties, iv. p. 103.
KISHEN KOMARI BAI was born in 1792 . Her father, the rana of Udaipur, was the highest prince of Rajputana. Her mother was of the Chawara race of Anhilwara. She was very beautiful, and had an engaging manner. Both the Jeypore and Jodhpur chiefs asked her in marriage, and to obtain her overran the kingdom; but to settle the matter, in 1810 , Kishen Komari Bai, when only 17 , took poison, and in a few days her mother followed her to the funeral pile. When the Roman father slew the dishonoured Virginia, appeased virtue applauded the deed; when Iphigenia was sacrificed, the salvation of the country was the consolation, and Jephtha's daughter sustained her resignation in her father's fame; but Kishen fell a victim to a false sense of honour, and the sacrifice brought no peace to Rajputana.-Tod's Rajasthan.

KISHKINDHYA, the legendary monkey city of Bali.

KISHLAK and Yailak, amongst the Turkoman and Afghan races, are their winter and summer quarters respectively, from the Turki words Kish, meaning winter, and $Y$ ai, for summer. In the mountains south of Khokand, these are called 'Kstau and Yailau. These are the Sard-sair and Garm-sair of the nomade Persians.

KISHM ISLAND, called Jazirah-ut-Tul by the Arabs, and Jazirah-i-Daraz by the Persians, both meaning Long Island, is the Oaracta or Veroklutha of the ancients, where Arrian states that Nearchus saw the tomb of king Erythras, after whom the Persian Gulf was named the Erythræan Sea. In the 13th century it was called Jazirah-i-Laset, and one of its towns is still called Laset. The whole island and a large portion of the opposite coast, in both of which are mines of sulphur, was farmed by the Imam of Muscat. Kishm town is in lat. $26^{\circ} 57^{\prime} 30^{\prime \prime} \mathrm{N}$., and long. $56^{\circ} 19^{\prime} \mathrm{E}$., at the N.E. end of the island. Kishm Island is the largest by far in the Persian Gulf, being about 54 miles long, but narrow, averaging 8 miles, and greatest breadth 20 miles. Its eastern extremity is within 10 miles of Hormuz, nearly opposite Gambroon; it runs parallel with the Persian shore, and is in no place more than 12 miles in breadth, and is surrounded with coral reefs. Nearchus says its length is upwards of 800 stadia, which, at $1111 \frac{1}{2}$ to a degree, would give 43 geographical miles.

MacGregor says, on the authority of Colonel Pelly, that salt is quarried in the island, and that there are caves from which it has been excavated. It produces dates, wheat, vegetables, mangoes, and other fruits, including grapes without stones, and the usual abundance of water-melons. Bassadore is on a barren spot at the western extremity. The people are chiefly Arabs, subject to the Imam of Muscat, and their number may amount to 16,000 .

At one time it had 100 villages, only a few of which remain,-Kishm, Luft, Basidu, and Bruklı or Urukth, the Oaracta of Nearchus and Arrian.

At the N.E. point there was at one time a flourishing Portuguese settlement; the ruins of the town still exist. In 1821 a British force was stationed at this place. On its withdrawal in 1823, the headquarters of the Indian Naval Squadron were established here, the place being the healthiest in the island. Its silk weavers supply the Gulf with loongees and striped cloths of silks and cotton,-Ousetey's Tr. i. p. 162 ; Ches- 
ney's Ex.; Kinneir's Memoir; lieut. Kempthorne in Royal Geo. Soc. Journ. v.; MacGregor.

KISHR. ARAB. A decoction of the husks of the coffee berry, greatly used in Yemen. The decoction of the berry itself is not much used there. The natives prefer the husks, and the beverage is called Kishr; it is sometimes flavoured with ginger and other spices.

KISHTAH. HIND. Dried unripe apricots, brought from the hills and from Kābul, etc. They are used to clean gold and silver, also in dyeing and in making chatni.-Powell's Handbook, i. p. 453.

KISHTI or Kuchkole. HiND. A boat, ship, vessel; cup, or bowl, generally of beggars; a fakir's wallet; also a kind of tray, a flat shield.

KISHTWAR or Kistawar occupies the middle part of the Chenab valley between Lahoul and Jamu. The elevation of the Chenab about the middle of the province is from 6000 to 7000 feet. Kishtwar is separated on the north from the Tibetan valleys of Zanskar and Dras by the axis of the Himalaya, which is crossed by the Umasi pass into Zanskar, elevated 18,000 feet, and by other passes from Wardwan into Dras. The Wardwan district is to the west and to the south. Kishtwar is separated from Chamba by a range of 10,000 to 14,000 feet of elevation.-Hooker $f$. et T. p. 209.

KISMA'T. Arar., Hind., PErs. Fate, fortune. KISMIS, a small, pale-coloured, stoneless grape, when dried, and from which Shiraz wine is obtained. It is produced in Persia, whence considerable quantities are brought to Bombay. It is chiefly used in puddings as a substitute for currants, and is also served up with stoned almonds, as an article of dessert. They are called sultana raisins by European grocers. Kismis Surkh, red raisins, sun dried. Kismis Sabz, shade dried. Munakka are common dried grapes or pudding raisins.-Powell's Handbook, p. 16 ; Faulkner.

KISN-BAKHT, a name of the ascetic ManBhao sect.

KISRA, an Arabic title; Kesra, from the Persian (Chosroes, Cyrus) Khusrow, which signifies a great king. 'The Romans changed it into Chosroes, and applied it as a surname to every king of the Sassanian dynasty, like Casar among the Romans.

KISSA-i-SANJAN, a work compiled in the year 1599 by one Bahram, a Zoroastrian, resident at Nowsari, a town about twenty miles south of Surat. It details the various emigrations of the Parsees.-The Parsees, p. 7.

KISSILKORUM PASS, in lat. $35^{\circ} 57^{\prime} \mathrm{N}$, and long: $77^{\circ} 50^{\prime} \mathrm{E}$, in Turkestan, in the ridge between Yarkand and Yarakash. The top of the pass is 17,762 feet above the sea. From Kissilkorum, following the direction of the principal chain of the Kouen Lun, now turning to the south-south-east, Kiuk-kiul lake is reached. It is slightly salt, and is situated at the northern foot of the Chang-chenmo. Close to the Kiukliul lake is a group of more than fifty hot springs, chiefly containing muricite of soda (common salt), and a great quantity of carbonic acid. Their temperature varies from $25^{\circ} \mathrm{C}$. to $49^{\circ} \mathrm{C}$. $\left(77^{\circ}\right.$ to $120^{\circ} \mathrm{Fahr}$.). In the valley of the Nubra are two other groups, the one near Panamick (hottest spring, $78 \cdot 1^{\circ} \mathrm{C}_{0}=172 \cdot 6^{\circ}$ Fahr.), the other near Changtung $\left(74^{\circ} 1^{\circ} \mathrm{C} .=165.4^{\circ}\right.$ Fahr.) A march of seventy miles brings the traveller to (S. ?) Pumgal, where a route branches off to the valley of Bushia, and to Elchi, the capital of Khotan.-Robert Schlagentweit, Magnetic Survey of India, pp. 1, 2.

KISSING is a token of love and affection with many of the nations of the East Indies, as of Western Asia and Europe. Kissing of the cheeks and shoulders is noticed in Genesis xxxiii. 4, xlv. 14, 15 ; and in Luke xv. 20. Smelling the head is a mode of expressing intense affection, parental yearning, still common in India, and a very ancient oriental practice. It was perhaps rather the result of this practice than chance that Isaac noticed the smell of Jacob's person. 'And he came near, and kissed him: and smelled the smell of his raiment, and blessed him, and said, See, the smell of my son is as the smell of a field which the Lord hath blessed.' 'The Kadam-bosi, or footkissing of the Muhammadans of India, is a constant expression in their letters, though figurative with Muhammadans, but Hindus often touch a Brahman's foot with their fingers and then apply them to their lips. Kissing is unknown to the Burman, the Karen, and the Shan races, and the wild tribes of Arakan. They smell or sniff their relatives, applying the lips and nose to the cheek, and making a strong inhalation, which they call Nan-shok-thee, to sniff up a scent.-Hind. Th. ii. p. $45 ;$ Forbes.

KISSING COMFITS of Falstaff. Batatas edulis, Choisy. Sweet potato.

KIST. ARAB., Hind., PERs. Tribute, landrent, instalment. Aksat, plural.

KISTAWAR, in Kashmir, in lat. $33^{\circ} 18^{\prime} 30^{\prime \prime} \mathrm{N}$, and long. $75^{\circ} 48^{\prime} \mathrm{E}$., near the left bank of the Chenab, 5000 feet above the sea. Shawls and coarse woollens are made.

KISTNA, a river of Southern India, which runs almost across the Peninsula. Its source is in lat. $18^{\circ} 1^{\prime} \mathrm{N}$., and long. $73^{\circ} 41^{\prime} \mathrm{E}$., near Mahabaleshwar, at the ancient temple of Mahadeo, at the foot of a steep hill, at an elevation of about 4500 feet above the sea. Inside the temple is a small tank, into which a stream of pure water flows frow a spout fashioned into the image of a cow's mouth. This is the traditional fountain-head of the river. On reaching the frontier chain of the Eastern Ghats, the Kistna turns southwards to reach the sea. Its delta, for about 80 miles from the mountains to the Bay of Bengal, lies entirely within British territory, and is now known as the Kistna district, embracing the lands on each side of the eastern third of Kistna river, and part of it in the great alluvial flat formed by the deltas of the Godavery and Kistna. The district suffered from famines in 1686 and 1832-34, the latter especially in Guntur; and in 1763, 1843, and 1864 Masulipatam and other parts were inundated by storm-waves, destroying many people. The famine in 1832-31 caused a decrease of 200,000 in the population. It was most severe in the Guntur portion, and was due to the failure of both the monsoons. Since 1852 , to provide for irrigation, the British Indian Goverument has dammed up the river and its tributaries. The head-waters of the Bhima are dammed up at Kharakwasla to furnish Poona with a water supply. The Madras Irrigation 
Company have drawn water for the Kurnool district from the Tumbudra, On the Kistna itself a small work has been constructed high up in the Satara district, where a dam has been thrown across the bed of the river, from which a canal is taken parallel to the left bank, capable of irrigating an area of 1825 acres. But the greatest Kistna work is the Baizwara anicut, first commenced in 1852 , at a point where the river is confined by rocky hills on either bank. The length of the crest of this weir is 1280 yards. In 1874 the river rose 19.42 feet above the weir crest. This anicut is 1280 yards long, has a breadth of 305 feet, and a height of 21 feet. The river here is 1300 yards wide, has a rise of from 6 to 36 feet, and its maximum flood discharge is $1,188,000$ cubic feet per second. The principal canals are navigable, and the length in 1878 available was 254 miles. The irrigated area is 226,226 acres, and the revenue Rs. 8,90,753. The Baizwara anicut is a great tranverse dam thrown across the river from hill to hill. The total cost of constructing this dam, which consisted of a wall backed with stone, was less than $£ 75,000$. More than 340 miles of canals have also been opened, and on these a large number of cargo and passenger boats and rafts are constantly plying for hire.

The Kolar Lake, which covers an area of 21 by 14 miles, and the Romparu swamp, are natural receptacles for the drainage on the north and south sides of the Kistna respectively. Kolar Lake is navigable from June or July, according to the setting in of the heavy rains, till February.

The Kistna is one of the sacred rivers of the Hindus. The temple at Pandarpur, on the left bank, is visited by large bodies of pilgrims, and at other spots on its banks fairs are annually held. The chief of these are at Baizwara and at Cullapilly, where at high tide the salt water of the sea meets the fresh water of the river. There are Saiva shrines, and a Vaishnava shrine at Sricacolam, midway between Cullapilly and Baizwara. At Baizwara a considerable trade is carried on in dressed hides. Kistna district is, speaking generally, a flat country; but the interior is broken by a few low hills, the chief of which are Bellamkonda, Kondavir, and Condapilly.

In the hilly tracts of the more western and northern portion, minerals of value occur,-corundum and garnets in the Narsaraopet Taluk and other places; galena from the neighbourhood of Karuppudi; chrysoberyl, amethystine quartz, quartzose minerals used as inferior gems, agates at Condapilly, Madgol in the Palnad and other places, and diamonds in the mines at Partiyal. Diamond mines are still worked to a very slight extent in five villages belonging to the Nizam; and at other places in the district there are traces of mines which were abandoned long ago.

KISTNA PAKSHAM. SANSK. The dark half of the month, metaphorically a Hindu bastard.

KISTVAEN. Single dolmens or kistvaens, consisting of upright, side, and back slabs supporting a covering stone, the front side remaining open, are not unfrequent on the Neilgherry Hills ; and Mr. M. J. Walhouse mentions having seen in 1849 , beyond the Nidi-mand, a succession of opensided connected dolmens orkistvaens, - three large ones of equal height in the centre, and a smaller and a lower ome at each end. They stood in a line, the three central compartments being covered with three huge cap-stones, the edge of one overlapping the edge of the next; the supporting stones, four in number, being great slabs set up endwise, with slabs enclosing the back or north side; the front or south side of all was open ; the smaller structure at each end was similarly formed.-M. J. Walhouse in Indian Antiquary, October 1873, p. 275.

KITAB. APAB. A book. Ah'l-i-Kitab, people of the book, meauing believers in the old Bible, Testament, or in the Koran. This has the same meaning as Kitabi, a follower of the book, a term applied to Jews, Christians, and Muhammadans, as possessing books of revealed religion. In few Muhammadan countries, however, will Muhammadan religionists eat with a Christian; to salute him, even in error, with their ordinary salutation, Salam alaikum, Peace be unto you, is deemed unfortunate. $\mathrm{He}$ is looked upon as unclean, and a Muhammadan of India will rarely return the salutation of Alaik-us-salam, And unto you be peace. Nevertheless, amongst the Afghans the Christian is respectfully called a Kitabi, or one of the book. An invidious distinction of dress was, however, enforced generally on Christians at Bokhara, according to au edict of no remote date. It is possible that previously the same liberality of deportment towards Christians distinguished Turkestan. Katib is a scribe, a copyist, a writer; and Katibat, the act or cost of copying a book.-Masson's Joumeys, ii. p. 245.

KITAB-al-MAGHAZI, a history of the warlike expeditions of Mahomed, by al-Wakidi ; that rare and valuable work, dated A.H. 564, contains as much again as the printed text.

KITABAT. Alzaв. The inscription on a Muhammadan tomb; writing.

KITAB-i-KUSLUM NAMAH, a book put forth by a conclave of seven learned ladies of Persia on the rights of women. According to these ladies, there are three classes of husbands in the world, viz. a proper man, a half a man, and a Hupul pupla. If the wife of the last man absent herself from his house, even for ten days anil nights, he must not, on her return, ask where she has been; and if he see a stranger in the house, he must not ask who it is or what he wants.Tr. Hind. i. p. 399.

KITAI, the name of the wall near Darband in Daghistan.

KITAMA KURA. JAP. A fish, Tetrodon hispidus, so poisonous that when eaten it proves frequently fatal, or, according to the signification of the Japanese name, makes the north one's pillow, it being a custom with these people to turn the heads of those that are dying towards the north. -Thunberg's Tr. iii. p. 68 .

KITCHELLY CAPUR, a scented root of China, chiefly used in the perfumery powders called sicsa, rautha, and also used for medicine. This is also called Kitchelly Kelangu in Tamil; sold at from 40 to 60 rupees a candy; that from Malabar, from 28 to 40 rupees a candy.

KITE. Pattanga or Ialayang, MALAY. Lalayang are flown by inen and boys of the Muhammadans, by all classes, high and low. Kiteflying is a pastime universally practised amongst the Chinese, Japanese, and Burmese, who excel all other people both in the varied forms of their kites and the heights to which they can make 
them rise. They are constructed of paper made of refuse silk and bamboo. They assume every possible shape, and sometimes it is impossible, when they have reached the culminating point, to distinguish them from birds. By means of round holes, supplied with vibrating cords, on which the current of the air acts, the kites when ascending issue a humming noise, similar to the hum of a swarm of bees.-Burton's Scinde; Morrison's Compendious Summary.

KITES are birds belonging to the sub-family Milvina, and they are arranged in the genera Milvus, Haliastur, Pernis, Baza, and Elanus. In Bengal, the kites and Brahmany kites breed chiefly in January and February, and disappear during the rains. The Dung kite or Dung bird, Neophron percnopterus, Limn., called Pharaoh's chicken or the Egyptian vulture, is abundant southwards from Bengal, also in N. Africa, W. Asia, S. Europe, and even in England. The male has a dirty blackish-brown colour, but the hen bird is white, with yellow about the cheeks. It walks with ease and with a stately gait, and frequents localities where flesh or sweepings are thrown. It builds on cliffs, houses, and trees.

The Brahmany kite of India, the Haliastur Indus, Bodd., one of the Milvinæ, is known to all by its clear maroon-coloured black and white breast and abdomen, and frequenting the river valleys, lakes, and sea-coasts, wherever wet cultivation is in progress, swarming where fishers throw their nets, and about shipping in the harbours, picking up small fishes, prawns, or offal, the frogs from rice-fields, water insects, mice, and shrews, and young or sickly birds and wounded snipe. Near towns it is very tame and fearless, and every Sunday pious Hindus may be seen calling Hari! Hari! to attract the bird's attention, and then feeding it by throwing to it bits of flesh. The audacity of the Bralumany kite is admirable. Major Moor mentions as one instance, of which he was a witness, viz. stooping and taking a chop off a gridiron standing over the fire that cooked it. It receives its name from Europeans, because Brahmans and religious Hindus worship it, and regard it as Garuda, the type or vahan of Vishnu. The birds are expert fishers. Hindus of $\mathrm{N}$. India call it the Brahmany chil, and by the Muhammadans it is known as the Ru-mubārak or Blessed Appearance.

The Milvus goviuda, Sykes, the common pariah kite, extends through all India, Burma, and Malayana, and is one of the most abundant and common birds in India. Every town, cantonment, camp, and village has its colony of this kite, which ply their vocation from morning till night, picking up fragments of food and garbage. In Calcutta, 200 or 300 may be seen at a time. They are bold and fearless. Of all rapacious birds, the govind-kite is the most useful; wherever offal exists, this bird is to be found, hovering over the butcher's shop, the kitchen, or the barrack, - now leisurely sailing in circles, now darting like an arrow upon its prey, which it devours while on the wing, uttering a clear shrill cry whenever a companion disputes its possession. Its ordinary name is the chil, from its peculiarly shrill call. The govind-kite, Egyptian vulture, crow, Indian jackdaw, and mina may justly be termed the great scavengers of India.
The crested black kite of all India is the Baza lophotes, Cuv. ; it is not abundant. Its very handsome white and black plumage at once attracts attention.

The Lophastur Jerdoni, Blyth, is a kite of Malayana and the isles.

The black-winged kite of India, Elanus melanopterus, Daud., lives near the skirts of jungles, and is not much on the wing.

The kite eagles of India belong to the genus Neopus of the Aquilinæ. Neopus Malaiensis, Reinuardt, the black eagle, is found in most of the hilly and jungly districts of India, in Burma, and Malayana. It is generally seen circling or questing for prey at no great height. It is a bird of easy and graceful flight. Its chief food is obtained by robbing birds' nests of the eggs and the young.-Moor, p. 344; Adams; Jerdon's Birds of India.

KITTESOL or Kittysol, parasol, umbrella, paper summer-heads. They are an extensive article of export from China to Bombay, Calcutta, etc. They are a cheap sort of umbrella, made of bamboo frames, covered with oiled paper or cheap silk. They are sent to the Archipelago and India in boxes containing 100 umbrellas each, which is estimated to be a pikul. Considering the material they are made of, these umbrellas or parasols wear a long time, for their use is for the most part as a protection against the sun.Faulkner; Morrison; Willians' Middle Kingdom.

KITTUR, a town of peninsular India, 26 miles S.E. of Belgaum, in lat. $15^{\circ} 35^{\prime} 30^{\prime \prime} \mathrm{N}$., and long. $74^{\circ} 50^{\prime} \mathrm{E}$. In 1832 Kittur was the scene of a formidable insurrection, which, however, was suppressed by the zeal and intrepidity of two patels or village headmen.-Imp. Gaz.

KITU is a form of salutation in Japan, where the inferior, laying the palms of his hands on the floor, bends his body so that the forehead nearly touches the ground, and remains in this position for some seconds. The superior responds by laying the palms of his hands upon his knees, and nods or bows more or less low according to the rank of the other party.

KIUH-HIVA, Chrs., also Ku-Kiuh and HwangKiuh, CHIN., are the heads of several composite flowers of the genera Chrysanthemum and Anthemis. They are arranged into $k^{\prime} u$, bitter, and kan, sweet.

KIUN, in the Tartar language, the sun; or, according to Abul Ghazi, the sun and moon.

KIWI, a bird of New Zealand, of the genus Apteryx, some of which have been taken to Britain. Its egg, when fresh, weighs $14 \frac{1}{2} \mathrm{oz}$., the contents weighing $13 \frac{1}{2} \mathrm{oz}$. The weight of the living bird is nearly $60 \mathrm{oz}$. The kiwi is purely nocturnal in its habits, and in the nighttime will run about lively enough, probing into the ground and round every corner of the place where it is confined, with its long and sensitive bill.

KIZIL KIZL, the red sand deserts, have an area of about 35,000 square miles.-Wood's Lake Aral.

KIZIL OZAN, a river of Persia, which rises in the mountains of Abbas Beg in Ardelan, in about lat. $35^{\circ} 50^{\prime} \mathrm{N}$, and long. $46^{\circ} 45^{\prime} \mathrm{E}$., after a long course, and traversing Ghilan under the name of Safed Rud (IVhite River), it disembogues into the Caspian Sea. The annual take of sturgeon at the 
mouth of the river is abont 125,000 , principally in February, March, and April. The gross value of fish, caviare, and isinglass is about $£ 23,000$. The Kizil Ozan river is supposed by Major Rennell to be the Gozan of the Scriptures, 2 Kings xvii. 6.-MacGregor, iv. p. 267.

KIZLA SAFED. To the west of the province of Fars are the ruins of Kizla Safed, and, nearly in the centre, are those of the ancient capital, Persepolis. The territory of Fars represents ancient Persis, which was watered by the Araxes, Gyndes, Oroatis, Arasis, Pelevar, and Bagrad. Its cities were Corna, Axima, Arbrea, and Artacana, besides many others whose sites are unknown. Persepolis was the capital in the time of Alexander. More anciently the seat of the government was at Pasargada (Strabo, lib. xv. p. 729), the Persagadis of Quintus Curtius (lib. $r$. cap. vi.), but as this historian speaks of the fortress of Persepolis and the city of Persagadis (qu. Farsa-Gerd?), it is possible that the extensive ruins in the plain, near the former, may be the Pasargada of Pliny (lib. vi. cap. xxvi.).Col. Chesney, p. 210.

KIZZILBASH, a term applied in Kābul and Herat to a Turk race, principally of the tribe of Jawanshir, who were placed in the country by Nadir Shah. Under the rulers of Kābul, they have served as bodyguards, cavalry, and artillery, and still retain their own language. Their history has been often written. In the beginning of the 18th century, the feebleness of the Persian monarchy excited the cupidity of the Afghan race, who overran the fairer portion of that kingdom, and possessed themselves of Isfahan. Their successes called forth the energies of Nadir, who not only drove the Afghans from Persia, but annexed the whole of their own territories to his empire, and, turning their swords against India, with a mixed army of Persian and Afghan, sacked several of its cities.

When Nadir Shah marched towards Dehli, he had 12,000 fighting Kizzilbash with him. When he quitted that city, on his return, he left behind him 300 of these, who, with other troops, were directed to bring away his treasure, and follow him. They passed through Kābul, but when within two days' march of Kandahar they heard of his death; and a few days afterwards, Ahmad Shah, Nadir's lieutenant, came up with them, attended by 500 or 600 Daurani. He seized the treasure, and took the Kizzilbash into his service; and his kind treatment of them induced others to come from the neighbourhood of Tabreez, Mashed, Kirman, and Shiraz in Persia, where the true Kizzilbash exercise the profession of horsebreeders, shepherds, and cultivators. There are now perhaps about 10,000 Kizzilbash in the city of Kābul, who are ever ready to draw their swords as mercenaries. Their leaders are by far the most wealthy, the most intelligent, and the most influential men at Kābul. See Kazzilbash.

KLABAT, a mountain in Celebes. The town of Menado is built on a plain surrounded by mountains, the highest of which, Klabat, 6500 feet above the level of the sea, is a conical volcanic mountain in the northern peninsula of this island.-Marryat's Archipelago, p. 44.

KLAPROTH, JULIUS, a learned orientalist, author of Asia Polyglotta et Atlas, Paris 1823; Beleuchtung und Widerlegung der forschungen über die Geschichte der Mittel-Asiatischen Volker des herrn J. J. Schmidt, Paris 1824 ; and many other works.

KLEIN, a Protestant missionary in the south of India, who collected a large herbarium, which was principally described by Willdenow, and that of Heyne by Roth in his Novæ Plantarum Species. Heyne's collections were either obtained from, and were named by, Roxburgh, or were made in Mysore and the southern provinces, and the names attached by Rottler. Klein, Heyne, and Rottler were the scientific men who formed the Herbarium Madraspatense. Drs. Wallich, $M^{\prime}$ Clelland, Irvine, Lindsay, Stewart, and Thomson, medical officers of the Bengal army, also Dr. (Sir Joseph Dalton) Hooker, of the British navy, have done much for the botany of Bengal and India generally; Drs. Wight, Griffith, and Roxburgh, of the Madras army, for that of all India. Major Beddome, of the Madras army, has done much for the Madras Presidency. The names of Alexander Gibson, Dalzell, and James A. Murray are familiar in Bombay and Sind; and Messrs. Moon and Thwaites in Ceylon.

KLESA or Klesha, in Buddhism, evil desire, the love of pleasure, the cleaving to existence.Hardy's Eastern Monachism, p. 438.

KLEWANG. JAV. A sword, any weapon of war. KLING, the Burmese and Malay term for a native of India, evidently derived from the ancient kingdom of Kalinga. Newbold, however, supposes that Kling is a corruption from Teling or Telinga. But the Chulia and Kling of the Malays comprehend the traders and settlers, both Muhammadans and Hindus, from the Coromandel coast. These names have been given to them by the Malays from the earliest times of the ancient commercial intercourse subsisting between this part of Asia and India. They are in considerable numbers in Rangoon and Moulmein, also in the islands of Penang and Singapore, and are coachmen, and in similar employments. - Neubold's British Settlements, i. p. 8.

KLOI, a snow-white root of Siam, used as food, but requires to be steeped, in slices, in water and exposed to the sun's rays, as, in an unprepared state, it is poisonous.

KNIFE-GRINDER, a term applied to a species of Cicada or grasshopper of Ceylon, from the noise which it makes.

KNIGHTIA EXCELSA, $R$. Brown, the Rewarewa or honeysuckle tree of New Zealand, valuable for ornamental work and furniture.-Von Mueller.

KNIVES.

Messen, - . Dut. Pisau, Piso, . Malay. Couteaux, : : Fr. Noshi, : : Rus. Messer, : : GER. Cuchillos, : : SP. Churi chaku, Guj., Hind. Bichak, . : ' Turk. Coltelli, . . . IT.

KNOX. Captain Knox, an officer of the East India Company, who marched from Murshidabad to Patna in thirteen days; attacked and defented the troops of Shah Alam, 1760, dispersing his entire force. Captain Knox then, with a battalion of sepoys, 200 Europeans, a squadron of cavalry, and five field-pieces, in five hours utterly routed the nawab of Purniah, who had 12,000 men and 30 pieces of cannon.-Markman, p. 159.

Robert Knox, author of An Historical Relation of the Island of Ceylon, published in London 
in 1681. His father's ship, the Ann frigate, in the service of the E. I. Company, sailed from the Downs, 21st January 1657, but on 19th November 1659 was dismasted in a storm off the Coromandel coast, and, to refit, was taken to Cotiar Bay, opposite to Trincomalee. But the captain and two boats' crews were seized, and amongst them the captain's son. The captain died of fever, but the son for 20 years remained captive, and then escaped, 18 th October 1679 , to the Dutch fort at Aripo, and returned to England, where he was made commander of the E. I. Company's ship Tarquin.

KOAN or Koang. Singh. The Ceylon oak of the English in Ceylon. Grows in the southern parts of Ceylon; a cubic foot weighs $42 \mathrm{lbs}$. It is used for native oil-presses and wooden anchors ; its berries are eaten by the natives. $-M r$. Mendis.

KOBAD or Kaodes, a Sassanian king, A.D. 488 or 481. See Fars ; Sassanian.

KOBAD or Kei Kobad, A.D. 1286, an emperor of Dehli, who made his aged father, Bakarra Khan, undergo the abject oriental obeisance of kissing the ground before the royal throne. $\mathrm{He}$ fitted up a palace at Kilokeree, upon the banks of the Jumna, to enjoy there soft society, but nobody in that village now recollects the site of his palace. Kei. Kobad was assassinated A.D. 1288. - Tr. of Hind. ii. p. 199.

KOBANG, a gold coin of Japan, value about 22 shillings.

KOBI or Chamo, a vast desert of Chinese Tartary, which occupies almost all the south extremity of the country of the Kalkas.

KOBRA TEL. SINGH. A substance supposed in Ceylon to be a virulent poison. The ingredients are extracted from venomous snakes, and from the lizard called Kabaragoya. The receipt far outdoes, in dramatic arrangement, the witch's cauldron of Macbeth.-Tennent's Ceylon, p. 274.

KOCH'H, a dark-skinned people in the northern parts of Rangpur, Purniah, Dinajpur, and Maimansing, who have hitherto, erroneously Dalton thinks, been classed as belonging to the Lohitic or Indo-Chinese race. He believes them to be a branch of the great Bhuiya or Bhuniya family, whom he classes as Dravidian. They came from the W. and S., and overthrew the Kachari or Chutia dynasty.

The Koch'h are one of the most ancient of the peoples in India. Those in Koch-Bahar must be regarded as the present nucleus of the race, but they are still numerous in the old Kamarupa and the ancient Matsiya-desh, that is, in Rangpur and Lower Assam and Purniah, extending west as far as long. $87^{\circ} 45^{\prime} \mathrm{E}$., or to the boundary of ancient Mithila, and east to long. $93^{\circ} \mathrm{E}$.

In the north, the Koch'h established their dominion upon the ruins of the Aryan kingdom of Kamrup, which the Afghan king of Bengal had overthrown in 1489. The Koch'h gave their name to the native state of Koch-Bahar. The grandson of Haju, Vishu Singb, with all the people of condition, adopted Hinduism, and took the name of Rajbansi; but the mass of the Koch'h people became Muhammadans, and the higher grades, as Hindus, now reject and contemn the very name of Koch'h, and it is bad manners at the court of the descendant of Haju to speak of the country as Koch-Bahar; and the chiefs accept the myth which, by a reflection on the chastity of the daughters of Haju, give them for ancestor the god Siva. The Rajbansi Koch'h are the dominant tribe. They are all very dark; and as their cognates, the Kachari, Mech, Garo, are yellow or light-brown, and their northern, eastern, and western neighbours are as fair or fairer, it must be from contact with the people of the south that they got their black skins. Koch-Bahar was delivered from the Bhutia tyranny by the treaty of 1772 , in accordance with which the raja placed himself under British protection, and paid tribute to the East India Company.

The villages of the Pani-Koch'h lie along the skirts of the Garo Hills. They are much mixed up with that people, and with the Rabha, and in their religion, language, and customs appear to lean sometimes to the one, sometimes to the other.

They greatly respect the Garo for having retained their freedom in regard to food, which they, the Pani-Koch'h, resigned, and now they must not eat beef, and they reject dogs, cats, frogs, and snakes, which the Garos eat. They use tobacco and strong liquors, but refuse opium and hemp. They eat no tame animal without having first given one of their gods the refusal of it. Like the Rabha, they call their supreme deity Rishi, and his wife is named Jago, and they sacrifice to these deities, to the sun and moon, also to rivers and hills. The women do all work which is not above their strength, such as felling trees and the like. When a woman dies, the family property is divided amongst her daughters; and when a man marries, he goes to live with his wife's mother, and obeys her orders and those of his wife. Widows left with property generally manage to select young men as second husbands. -Turner's Embassy, p. 11; Treaties, Engagements, and Sunnuds, vii. p. 367; Hodgson; E. T. Dalton, Ethnol. of Bengal, p. 91.

$\mathrm{KOCH}$, the Mufflon or wild sheep. Its horns were found by Vigne intermixed with those of the ibex or chup, and the markhor or rawacheh of Little Tibet. - Vigne's Personal Narrative, 85.

KOCHIA-VILLOSA, Lindley, the cotton bush of Australia, resists the extremes of heat and drought. A species of Kochia is the Ti-fu-tsze, CHIN. The small roundish green seeds of this chenopod resemble the eggs of the silk-worm. -Von Mueller; Smith.

KODAGA, called Coorg by the British. The language is spoken in the small principality of this name, lying on the Western Ghats. Kodaga means west. It differs from Tamil, from Cauarese, and from Malealam. It was long regarded as Canarese, modified by the Tulu, but Mr. Mögling states that it is more nearly allied to the Tamil and Malealam than to the Canarese. The Coorgs still follow the primitive Dravidian custom of polyandry; they are far from being Brahmanized, and they have no literature, in the proper sense of the term. See Coorg.

KODAIKANAL, meaning The Forest of Creepers, a village on the Palni Hills, in the Madura district of the Madras Presidency, in lat. $10^{\circ} 13^{\prime} 21^{\prime \prime} \mathrm{N}$, and long. $77^{\circ} 31^{\prime} 38^{\prime \prime} \mathrm{E}$. It is a hill sanatorium, 7209 feet above sea-level, and is a summer resort of growing popularity.-Imp. Gaz.

KODAL of Cuttack is the inner bark of a forest tree. It makes a strong and most durable 
rope, which is said not to be liable to deteriorate from wet, and hence it is made into boat cables. At Autgurh, the fibre is collected for sale, on requisition, by the Saura race.

KODALI. HiND. A hoe. Kodali marna, to to dig with the hoe, a ceremony.

KO-DAIV-BA, literally Beg pardon, is one of the Burmese New Year customs. On this festival day, presents are made from vassals and dependents, as deprecatory offerings, to avert deserved punishment for offences against their liege lord. It is called by the British, Beg Pardon Day. It is the Chinese or Mongol Kow-tow (Kheu-theu). -Forbes, p. 76.

KODO or KODU. BENG. Kora millet or punctured millet, Paspalum stoloniferum, small grain eaten by the natives. In one form, called mataona, which does not in appearance differ from the ordinary grain, it has the property of intoxicating when made into bread.

KODU and Kondru, TEL., whence the ordinary name of Kond, a barbarous race of mountaineers inhabiting the hills west and north-west of Ganjam to the borders of Nagpur. The plural of Kodu is Kollu.

KODUNGALUR, the Cranganore of Europeans, a small seaport town in the Cochin territory, in lat. $10^{\circ} 13^{\prime} 50^{\prime \prime} \mathrm{N}$., and long. $76^{\circ} 14^{\prime} 50^{\prime \prime} \mathbf{E}$., and 18 miles N.N.W. from Cochin town. It was the first place in India at which St. Thomas laboured (A.D. 52). It was the seat of government of Cheruman Perumal, A.D. 341. Jew's now there claim to have been residents since A.D. 378 , and Christians have certainly been there since the 9 th century. The Portuguese built a fort there A.D. 1523 , but it fell to the Dutch (1661), who sold it to a native prince at the end of the 18th century, lost it to Tipu (1776), recaptured it, but in 1784 again ceded to 'lipu, and in $178 \pm$ they sold it to the mabaraja of Travaucore, and again in 1789 to Tipu.-Day; Hunter.

KOEL. HIND. Indian cuckoo.

Kokil, . . BENG. | Cowde-choa,

Chule, MaIAY Kokila pika,

This Indis a TEL

The male is of a deep black, and the female of a dusky green mottled white. Iike the cuckoo, the koel lays its eggs in the nests of some other birds. It inhabits Ceylon, India, the Malay countries, and China; all of its names are obtained from its ordinary call. Like the cuckoo of Europe, the bird is, in India, the harbinger of spring, and its call, koel, though shrill and disagreeable, is associated with all the joys and labours of hushandry of that season, and is quoted in the rhymes and proverbs of the people; and because the call of the koel is especially heard at the season of spring, it is called the friend of love-

' Sweet bird, whom lovers deem love's messenger, Skilled to direct the god's envenomed shafts,

And tame the proudest heart; oh, hither guide

My lovely fugitive, or lead my steps to

Where she strays.

Thus 'Koel boli, Sebundi doli,' the cry of the koel, is the grief of the Sebundi soldier, meaning that the disbanding of the armed men gathered together for collection of revenue depend on the koel's note; Sebundi being a corruption of Sipah Hindi, in distinction to Moghul or foreign troops, who were always kept up. The European names are all derived from the Sanskrit name Cuculus.
Pliny says that the vinedressers deferred cutting their vines till the cuckoo began to sing. They have the cuckoo ale of England, to partake of which the labourers leave their work when the first cuckoo's note is heard. There is also the vulgar superstition that it is unlucky to have no money in your pocket when the first cuckoo of the season is heard; and the amorous Hobnelia tells us, that in love omens its note is equally efficacious. The female lays its eggs in the nest of the common crow or of the carrion crow, Corvus splendens and C. culminatus; the birds called seven brothers have been seen assiduously feeding a young koel.-Elliot; The Hero and the Nymph, p. 267. See Kameri.

KOEL, South, a stream from the watershed of Chutia Nagpur which unites with the Sunkh in Gangpur, and takes the name of the Brahmany, and enters the Bay of Bengal at Point Palmyras. North Koel, river of Chota (Chutia) Nagpur, rises in the west of the Lohardagga district, and falls into the Sone-Dalton, p. 155.

KOENIG, JOHN GERARD, a native of Courland and pupil of Linnæus. He travelled in Iceland in the year 1765 , and arrived at Tranquebar, in India, in the end of 1768 or beginning of 1769 . He was physician to the Tranquebar mission in the Karnatic; but his enthusiasm, defiance of bodily fatigue, spare meals, the scorching climate, and his simplicity of manners and benevolence, soon made him known to and beloved by the Dutch, French, and British with whom he met. He became naturalist to the nawab Muhammad $\mathrm{Ali}$, and while at Madras made the acquaintance of Dr. James Anderson. In 1778, the Government of Madras granted him a salary to enable him to carry on his researches, and with this aid he visited the Straits of Malacca and Siam towards the end of 1779 , and made known the occurrence there of tin ore. His salary was again increased in 1780 , and he then visited Ceylon. He travelled along the coast to Calcutta, from which he was returning in 1785 , when he was attacked with diarrhoea or dysentery, and died on 26th June. He bequeathed all his plants to Sir Joseph Banks. His example and instructions diffused a similar taste among his companions, and hence originated the botanical labours of the society of 'United Brothers.' But although it may be said that scientific botany took its rise in India from Koenig, the flora of the East Indies had not been entirely neglected by European botanists prior to that period, as the works of Rheede, Rumphius, PJukenet, the two Burmanns, and finaily a large and well-preserved yet almost unknown collection of Indian plants in the Oxford herbarium, formed in the early part of the eighteenth century, amply testify.

KOERI, an agricultural and gardener race in Hindustan. The Kunbi are distinguished from the Koeri, as the latter are frequently gardeners as well as husbandmen. Socially, they are on an equality. The Koeri are also called Murao. In Behar they grow the poppy; they are in general very respectable, and the main distinction between the Kunbi and the Koeri is that many of the latter are exclusively kitchen gardeners and have immense gardens; these castes are both laborious. At Hindu marriages a custom prevails of placing a high crown, called maur, made partly of leaves and flowers, on the head of the bridegroom, and 
a smaller one, called maurt, on the head of the bride. It is said that no wedding can take place without these crowns. They are made by the gardeners, who receive a considerable price for them, according to the circumstances of the parties.-Sherring's Hindu Tribes.

KOFTGARI or Kofttila, HIND, is steel inlaid with gold in patterns. In former days it was carried on to a considerable extent in various parts of India, and was chiefly used for decorating armour, - guns, coats of mail, helmets, swords, and sword-handles. Since the mutiny and rebellion in India of 1857, the manufacture of arms has been generally discouraged, and koftgari work is consequently now chiefly applied to ornamenting a variety of fancy articles, such as jewel caskets, pen and card trays, paper-weights, paper knives, inkstands, etc. The process is exactly the same as that pursued in the inlaid work of Europe, and the workman can copy any particular pattern required. The work is of high finish, and remarkable for its cheapness. Admirable specimens of inlaid metal work by the native artisans of Bhooj were to be found in the collection of arms contributed to the 1862 Exhibition by H.H. the Rao of Cutch. Some of the cutlers still remain at lahore, but many of them went to Nizamabad in the Gujranwalla district, olbers to Gujerat, and the koftgari artisans also have mostly left Lahore to reside in the Kotli Loharan in the Sealkote district. At Baroda, iron vases and other vessels are ornamented with gold, hammered in, not in the brauching, coral-like designs of the koft work, but in discs or masses. The whole is afterwards polished in the lathe. Though less effective than the damascened koft work, it is a method capable of varied and artistic application.-Cat. Universal Exhibition, 1862; Porcell.

KOGHANI, an Afghan tribe occupying Gandamak. They formerly held the country in the west, but were expelled by the Jabbar Khel Ghilji. They claim to be Ghilji.

KOH. PERS. In Pukhtu, Roh. A mountain, a prefix to many solitary mountains and hill ranges from west of the Himalaya and the Indus even to the Caspian Sea. The Koh-i-Kush or Caucasus, one of these, is the great stony belt that separates Northern from Southern Asia. In traversing the kingdoms of Hindustan and Kābul, from the east of Bengal to Herat, we find them everywhere bounded on the north by a chain of mountains which is covered with perpetual snow for almost the whole of that extent, and from which all the great rivers of both countries appear to issue. This chain commences near the Brahmaputra, and runs nearly north-west as far as Kashmir ; during this part of its course it is called the Himalaya (Hima, snow, Alaya, abode). From Kashmir, its general direction is a little to the south-west as far as the high snowy peak of Hindu Kush, nearly north of Käbul. From this peak its height diminishes, it no longer bears perpetual snow, and is soon after lost in a group of mountains, which stretch in length from Kābul almost to Herat, and occupy more than two degrees of latitude in their breadth. Some ranges issue from this mass on the west, and extend so far into Persia as to justify, if not completely to establish, the opinion of the ancients, which connected this range with Mount Caucasus on the west of the Caspian Sea. From Kashmir to Hindu Kush, the whole range is known by the name of that peak. From thence to the meridian of Herat, the mountains have no general name among the natives, but that of Paropamisus was long applied to them by European geographers. As seen from the plains of Peshawur, the fourth is the principal range of the Indian Caucasus, and is always covered with snow. It is conspicuous from Bactria and the borders of India, and is seen from places far off in Tartary. Elphinstone says that the ridge of Imaus or Him. alaya is seen for a distance of 150 and even 250 miles. The Paropamisan chain, which bounds the Kohistan on the west, extends 350 miles from E. to W., and 200 miles from N. to S. The whole of this space is a maze of mountains. The eastern half of this elevated region is inhabited by the Hazara, and is cold, rugged, and barren; the level spots are little cultivated, and the hills are naked and abrupt. The western part, which belongs to the Aimak, though it has wider valleys and is better cultivated, is still a wild and poor country. The northern face of these mountains has a sudden descent into the province of Balkh; their acclivity is less on their other extremities, except perhaps on the west or south-west. On the north-west they seem to sink gradually into the plain which borders on the desert. The slope of the whole tract is toward the west.-Elphin. Caubul; Rennell, Memoir; Vigne's Narrative; Markham's Embassy; Masson's. Journeys.

KOHANU. MAHR. A tumbler, a rope-dancer, an acrobat, an athlete.

KOHAT, a British district in the Panjab, lying between lat. $32^{\circ} 47^{\prime}$ and $33^{\circ} 53^{\prime} \mathrm{N}$., and between long. $70^{\circ} 34^{\prime}$ and $72^{\circ} 17^{\prime}$ E. Kohat lies to the south and south-west of Peshawur. Its valley is 35 miles long, and, on an average, four niles broad. From Peshawur, through the Afridi Hills, it is reached by two passes, the Jowaki and the Gulli or Kohat; and from the Indus it is also approached by two passes, the Koshalgurh and the Kalabagh, through the Khatak Hills. Again, it is connected with Bannu to the south by two passes, the Surduk, seven miles long, and the Khoon-i-gao, from Nurri to Khurruk, a less direct but safer route. Up to 1848 , Kohat was held as a fief from the Kābul Government. It was then taken possession of by the British on account of hostility to them during the second Sikh war. The khan of Hungu in the Bangash country was in the British service as revenue collector, but he was murdered by one of his own relatives, and the khanship descended to his son. The Bangash suffered much from the raids of their hill neighbours, Orakzai, Turi, Kābul Khel, Waziri. The inhabitants of the Miranzai valley are also Bangash. This valley belonged to the fief of Sultan Muhammad, but, being an outlying locality, was overlooked when Kohat taken possession of. The Kābul Government then lost no time in arranging for the occupation of Miranzai, which appeared to have been vacated, so Sirdar Azim Khan, the governor of the Khurrum province, in 1851, summoned the Miranzai to surrender; but they petitioned the British to include them in Kohat. Under the circumstances, this request was acceded to.

Along the north-west boundary of Kohat, from the lands of the Sipah tribe as far as those occupied by the Zaimusht Afghans, lies the country of the Orakzai. These are one of the largest frontier 
tribes, and, if necessary, are able to muster upwards of twenty thousand fighting men. Some of the principal clans are the Samilzai, the Hungu, the Miranzai, the Shekhan, the Mishti, and the Raabeah Khel. The first three of these clans reside in the hills adjoining the Kohat district. The remaining three are those which have come more especially in contact with the British Government. There are a few Orakzai living at Peshawur, Amritsar, and in some other parts of the Panjab. The cool table-land of Terah is situated in the midst of the Orakzai Hills. This is the resort of the people with their cattle in the summer season. In the winter they return to the lower hills on the Kohat frontier. The Hungu valley is twenty miles long, by two or three broad; and the plains of Miranzai, into which it opens, are about nine miles square, and are held by seven fortified villages, which have been taken in charge by the British Government. Formerly each village was a commonwealth, and all were at feud with one another.

The Khatak and Bangash Pathans constitute together more than 60 per cent. of the population. The latter occupy the Miranzai valley, with the western portion of Kohat proper, while the Khatak hold the remainder of the eastern territory up to the bank of the Indus. The Khatak, who occupy the eastern half of the district, are an important tribe, holding the west bank of the Indus for a distance of 120 miles from Hund, north of the Kabul river in Peshawur, to Kalabagh in Bannu. The Khatak are tall and good-looking mountaineers, and have settled, honest habits. The Bangash are not brave. The other inhabitants are Sikhs, Arora, Brahman, Ahir, Jat, and Kshatriya. Hungu is a dependency of the province of Kohat. The inhabitants of the villages in the valley leading from Hungu to Kohat are principally Shiah, as are all the tribes of the Turi, their neighbours, although not so bigoted as these. The plain of Kohat and the valley of Hungu are well cultivated and populous. Wheat is grown, but the stony soil in many parts seems more adapted to the culture of maize, here called jowari, the "quality of which is excellent, and the returns large; while itsflour makes admirablebread, and is the general food of the inhabitants. The great command of water, in many situations, is made available for the irrigation of rice lands. Near Kohat indifferent coal is found, generally on the surface. Asbestos occurs in veins parallel with the coal strata at Kanigoram. Sulphur abounds in the northern range, and petroleum exudes from a rock at Panoba, 23 miles E. of Kohat. The valley is famous for its salt mines, the chief of which, at Bahadur Khel, is guarded by a fort. The salt rocks are in the line of low hills crossing the valley of the Teri Toi, and extending for 40 miles, and a quarter of a mile wide along either bank of that river. It occurs as a solid rock of bluish-grey colour, 1000 feet thick, and with hills rising 200 feet high. A bituminous substance called Momyai, deemed in India a useful and valuable medicine, is dug out of the hills of Kohat; it is black, and resembles gum.-Mohun Lal's Travels, p. 358; Ad. Schl.; Rec. of $G$. of I., No. ii.; Masson's Journeys, i. pp. 114-117; Cunningham's Sikhs, p. 6; Imp. Gaz.

KOH-DINAR, a mountain chain in the pro. vince of $\mathrm{Fars}$, visible from the sea near Bu-shahr.
It has a large extent of snow-covered surface, the snow-line is not below 14,000 feet, and the average height of the peaks is from 17,000 to 18,000 feet.

KOHI, female, Koheela, male ; also called Shahin, Falco peregrinator, black - eyed hawks, found in Sind.

$\mathrm{KOH}-\mathrm{i}-\mathrm{BABA}$, a remarkable snow-clad ridge, with peaks about 18,000 feet in height. It is the great contimuation of the Hindu Kush, is about 60 miles long, in lat. $34^{\circ} 30^{\prime} \mathrm{N}$, and between long. $67^{\circ} 30^{\prime}$ and $68^{\circ} 30^{\prime} \mathrm{E}$. It is at the S.W. extremity of Hindu Kush, with which it is connected by the transverse ridges of Kalu and Hajeguk. According to Burnes and Lady Sale, it is about 18,000 feet in height ; Outram, 20,000 feet ; Humboldt, 2800 toises, or 17,640 feet; the most probable is 16,000 feet. The highest accessible point is in lat. $34^{\circ} 40^{\prime} \mathrm{N}$., long. $67^{\circ} 30^{\prime} \mathrm{E}$., and is 13,200 feet; Hajikak or Hajeguk pass is 11,700 feet. It is a vast rounded mass, the culminating ridge ascending in lofty peaks, covered with perpetual snow, stretching as far as the eye can reach; farther to the west it sinks into the mazy mountains forming the Hazara highlands. The Helmand, Hari-Rud, Murghab, Balkhab, and Kunduz rivers all rise in the Koh-i-Baba. In 1840 Griffiths ascended it to 13,500 feet. Its general character is that of great barrenness. The Siah Koh is the south branch of the Koh-i-Baba.Moorcroft, ii. p. 384 ; MacGregor, p. 545 .

KOH-i-DAMAN, a district north of Käbul, a favourite resort of the wealthier inhabitants. Charekar, at the head of the Koh-i-Daman valley, north of Kābul, is famous for the gallant defence made there by Eldred Pottinger and Haughton, during the Kabul outbreak. It is mentioned by Ibn Batuta as Charkh. Leech, in his report on the passes, calls it Charka.

KOH-i-KAS, or Koh-i-Kush, or Caucasus, is the great stony belt that separates Northern from Southern Asia. Koh-i-Kush offers a plausible etymology for the Caucasus of the classical writers. It is supposed by Ritter and Wilford to be the mount mentioned by Pliny under the name of Graucasas, but slightly deviating from the Sanskrit Gravakasas, meaning shining rock. See Koh.

KOH-i-MEERIAH, a hill which produces coal of good quality. It is near Baljawar, one day's journey north of the Oxus river.-Wood's Journey to the Oxus.

KOH-i-MUBARAK or Ras Mubarak, a rock which British sailors call Bombareck. Koh-iMubarak means blessed mountain, but it is also called Ras Mubarak, the fortunate or auspicious headland. It is about 30 miles nearer the entrance to the Persian Gulf than Ras Jask. It is a remarkable isolated rock, situated on a sandy flat. It is a landmark for navigation.

$\mathrm{KOH}-\mathrm{i}-\mathrm{NAMAK}$, a salt mountain in Irak-iAjam, 12 miles N.W. of Kum. It is an insulated rocky mountain, from which saline springs issue and deposit salt, and slabs of the salt are quarried for use.-Abbott; MacGregor, p. 270.

$\mathrm{KOH}$-i-NOKREH, or Silver Mountain. Mines were formerly worked near the villages of Sabr Rud, Hassa, and Mubammadabad, but abandoned, like many others in Persia, when the produce was found inadequate.-Ouseley's Travels, ii. p. 106.

KOH-i-NUR, or Mountain of Light, a celebrated diamond, said to be the immemorial heirloom of Indian sovereignty from the days of the Pandu. 
It is said to have been found at Purteal or Purtyall, a village in the Masulipatam district of the northern division, and that it weighed originally 793 carats. The portion at the Great Exhibition weighed 186 carats. The great Russian diamond has been supposed to be another portion. Colonel Sleeman says that the Koh-i-Nur was first found in Golconda by Mir Jumla, and presented by him to Shah Jahan, as a nuzzer for a passport to his aggrandizement. But Baber states that on his capture of the palace of Ibrahim Lodi at Agra, he found one famous diamond, which had been acquired by Sultan Ala-ud-Din. It was so valuable that judges of diamonds valued it at half the daily expense of the world. Being carried off by Nadir Shah, it was afterwards obtained in that monarch's tents, by Ahmad Shah, from whom it descended to Shah Shuja, who, in his misfortunes, sought refuge in the dominions of Ranjit Singh. The Lion of the Panjab-once the owner of the diamond was in his power-at last got it into his possession. Zaman Shah, brother of Shah Shuja, when defeated near Sar-i-Asp, had fled to the Jalalabad valley, and stopped at Mula Askah's fort, about 14 miles from Jalalabad. Zaman Shah during his confinement there had secreted the Koh-i-Nur with some other jewels in the walls of his apartment. While on his way to Kābul Zaman Shah was blinded by a lancet, but on Shah Shuja ascending the throne, his first act was to release his blind brother. Ranjit Singh bequeathed the Koh-i-Nur diamond, now the property of the Queen-Empress Victoria of Great Britain and India, to Jaganath pagoda.-MacGregor, p. 414. See Diamond.

KOH-i-SAFED, or White Mountain, forms a most majestic boundary to the southern side of a plain. Its height is about 17,000 feet, and along the whole southern side of the Himalaya, from the Hindu Kush to Nepal, the Safed Koh is visible. Its snowy top is also visible from Peshawur, but it cannot be seen from Kābul, even from the top of the Takht-i-Shah, which rises behind it. Vigne's Personal Nar. p. 234.

KOH-i-SAFI. East of the Siah Koh is a billy tract, not mountainous, although waste and desolate, named Koh-i-Safi, from the tribe that pasture their flocks in it, and this tract intervenes between the Siah Koh and the valley of Tagow; moreover, through it meanders the river of the Kohistan.-Masson's Journeys, iii. p. 151.

KOHISTAN, literally hill country or highlands, and so applied to mountain tracts on the N.W. frontier of British India.

Kohistan of $\mathrm{Aba}$ Sin is a glen which drains into the Indus, between Gilgit and the Pathan valleys of Ghorband and Chakesar, supposed to be occupied by a race similar to those of Gilgit, named Rauza, Yashun, Karmin, and Duman.

Kohistan, a taluk in Sind, a British tract in the Karachee district, is a barren hilly tract, composed of outlying hills of the Kirthar range. Its chief streams are the Hab, Baran, and Malir. The people are nomades, Baluch, Numria, Jokia, who had long been at feud, and adhere to the vendetta. The Baluch inhabit chiefly the northern portion; the Numria and Jokia, who are Sindi tribes, range over the central hills and the southern plains. None of the people erect any buildings more substantial than a mat hut, which can be put up in a couple of hours. All the tribes are great adepts at cattle-lifting.

In the Kohistan of Kābul, the people occupy partially the valleys of Ghorband, Punjir, Nijrou, Tagow, Alishang, Alighur, and the Lower Kuner. To the south-east, the Kohistan extends to the hills of Tagow, and farther away, to Lughman, the Lamghan of Baber, and so called because the tomb of Lamech, the father of Nuh or Noah, is fabled to be seen there. On a detached and comparatively low hill, a whitish streak is observed, extending from the summit to the foot of it. This is the Reg-rawan or running sand mentioned by Baber. The natives say that it runs up again, and that it is never diminished; and that there is a cave at its foot where noises are heard. It is the scene of some romantic tales, which have been alluded to by Abul Fazl. It has been described by Burnes, Vigne, and other travellers.

In the Kohistan of the Jalandhar, the natives of Sukeyt, Mundi, and Kulu have sallow complexions, but appear to be of the same race as the inhabitants of Bashahir. The men are generally tall and strong, but few of them are handsome. Many of the young women are pretty, but at the age of 20 or 25 become coarse and stout. The dress of both sexes is nearly the same. It consists of a drab-coloured woollen frock, trousers of the same or of leather, and a flat skull-cap, generally black, with sandals made of coarse grass. The women, instead of the cap, sometimes have a coloured piece of cloth tied round the head, and occasionally twist their hair into one long plait, the end of which is then ornamented with slips of coloured cloth or shreds of worsted. The plait is by no means unbecoming to the young. The dress of the women on the western side of the Seukandir range consists of a tightly-fitting body and sleeves, with a full petticoat having a broad border at the bottom.

The women of Kulu and the adjoining states are inordinately fond of ornaments. These are of the usual description, with the exception of motherof-pearl amulets, which both men and women use, consisting of small thin plates of mother-of-pearl of various sizes, and engraved with mystical figures. Several of these are hung around the neck, and hang conspicuously on the chest. Polyandry is said to be unknown amougst them, nor are they guilty of infanticide, but polygany is general.

The Guddi inhabitants of the Chumba range are shorter and appear much stronger, and are certainly cleaner about their persons. They call themselves Rajputs, and say they belong to the Guddijat. They are sharp, and able to impose upon their less knowing neighbours. Most of the witch-finders are of the Chumba Guddi. When Europeans made their first appearance in the Kangra valley, these men had very slight notions of caste, and would eat or drink anything the former gave them, whereas, since their contact with the natives of the plains, they have become as bigoted as any Hindu. The Chumba Guddi may always be known by their peculiar conical caps, with lappets to turn down over the ears, like an English travelling cap. Witch-finders feign the power of discovering evil spirits, which wander over the mountains in the tangible form of witches. If a cow or any other living creature die, its death is immediately attributed to some evil eye, and a witch-finder is employed to discover it. This 
impostor having selected some old woman who had no means of propitiating him by gifts, places his victim in the centre of a group, whilst all interested in the case sit around her in a circle. He then dances round the poor creature, and nltimately nods his head towards her, whereupon all the lookers-on do the same, which coincidence is deemed a sufficient proof of guilt. Formerly she was condemned to be burnt to death. But since that district became a British province, and these inhuman proceedings have not been allowed to take place, they declare the victim of their superstitious credulity an out-caste, and refuse her the commonest necessaries of life; thus she is abandoned to her fate, and would probably starve to death, but for the timely gift of a goat or a sheep by some one of her relatives to the witch-finder, who forthwith fastens the guilt on some other person, in the hope of extorting a present in a similar manner from the relatives of the person last accused.

The Lahouli are a totally distinct race from the people of Kulu or the Chumba Guddi range. The Jahouli are a short, sturdy set of men, very ugly, and filthily dirty. The women are decidedly plain. The costume of both sexes consists of a pair of loose woollen drawers, with a frock of the same material, whilst a wrupper is also often wound around the body by being thrown over the shoulders and fastened by a brass clasp in front. Their dress, generally of a black colour, is of a kind of plaid, and their caps are of the same. The women wear their hair either in long plaits fastened at the back of the head with $\mathrm{a}$ profusion of red wool and coloured threads, or comb it back off the forehead, tying it in a lump behind, and adorning it in a similar manner. Around the flat circular caps are strung large white shells like cowries, glass beads, and pieces of amber. Around their neck, both men and women wear amulets of mother-of-pearl, pieces of amber, turquoises, and other precious stones. Each man has, hanging to his belt, a tinder pouch and a brass instrument for striking fire, with many other nondescript implements. They spend six months of each year in Kulu on account of the severity of the winter season in Laboul. The greater part of that time they pass in dancing and drinking. On their jubilees they set off fireworks and make a tremendous noise, whilst the women dance. These exhibitions do not terminate until they are all too drunk to continue them. In their orgies the women are ridiculously decked out, especially the aged dames. Many of the young damsels have beautiful eyes, of which they make the utmost use.

Kangra is situated in lat. $31^{\circ} 57^{\prime} \mathrm{N}$., long. $76^{\circ}$ $4^{\prime}$ E. Near Jalandhar, just after leaving Buttail, is a heap of stones in the centre of the road. This is a cairn formed by Tartar tribes, who invariably pass them on their right hand, as well as throw a fresh stone on the pile. These piles of stones are noticed in Lloyd and Gerard's Travels in the Himalaya, also in the Travels of the Russian Mission through Mongolia to China, by George Timkowski, and in the Journal of the Bengal Asiatic Society, April 1859, p. 385. - Elphin. Caubul, pp. 309-314; Imp. Gaz.

KOH-i-TAK. The Sulimani range is finished by the Pahar, or hills of Koh-i-Tak, and to the northwest is the Koh-i-Kondi, with a little snow upon its summit. The Kaysar mountain arises in front in a southern direction.

KOH KIRANA, a hill just within the boundaries of the Jhang district, yielding iron ore of good quality.

KOHL or Kohol. ArAB. Lamp-black used by women for staining their eyelashes, is collected by holding a knife over the flame of a lamp, and is applied with a glass, leaden, or wooden needle, called a mil, to the edges of the eyelids. This is the fuligo of the Roman ladies. The Arab and Indian women all use it. Women do not use surma or antimony, which men only apply to their eyes.

Smoke-black is also produced by burning 'luban' resin, a species of frankincense, also by burning almond shells. These kinds are used merely for ornament; but there are several kinds used for their medicinal properties, particularly the powders of several kinds of lead ore (Kohlel-pagar), to which is often added sarcocolla (Anzaroot), long pepper.-Burton's Scinde, i. 276.

$\mathrm{KOH}-\mathrm{PU}$, CHIN., also Kung Koh, a fibre made into cloth resembling linen. It is obtained in China from the climbing branches. It is of a yellow colour, very fine and durable, and much prized in Hankow. The best of this cloth comes from Wu-chang-hien, and from Kwang-sin-fu in Kiang-si._-Smith, Chin. Mat. Med.

KOHTUL is the Persian and Pushtu word for a pass or defile; Iukh is the Baluch term. It may be a contraction of Koh, mountain, and Tel, a rising ground, a hill, a tumulus, etc. But Tel is by some regarded as Arabic, and the Burhan-iKatia dictionary spells it Kutel. Yet, in a Persian translation of Sultan Baber's Commentaries, composed by himself in the Mogbul language, the spelling is two or three times Kotal. The Kohtul of the Shutar Gardan over a northern spur of the Koh-i-Baba, leading from the Kurram valley to Käbul, was stormed by the British Indian forces under Br.-Gen. Roberts on the 2d December 1878. There are many Kohtul in Afghanstan,-
K. -i-Agram.
K. -bed.
K.-i-chapar.
K.-i-Dara.
K.-i-haft pailan.
K.-ishtarak.
K.-kerskbana.
K.-i-khak safed.
K.-i-karteza.
K.-i-Lahori.
K. -i-mama-
khatun
K.-i-mircha.
K. -i-murdi.
K. -i-nal farash.
K. -i-nuksan.
K. -i-pah minar.
K.-i-pah minar.
K.-i-sang surakhi.
K. -i-sarghaz.
K. -i-siah Reg.
K. -i-Shinkae.
K. -Shutar.
K. , Gardan.
K. -spin gawe.

-Ouseley's Travels, i. 268; Pottinger's Travels, 151.

KOI-KOPAL, i.e. Gond Gopal, a settled race of Gond who are cow-keepers.

KOIL. TAM. A temple; thus Kali koil, a temple of Kali.

KOILA-BHUTAL, a wandering Gond tribe, whose women are dancing girls.

KOILASHA, SANSK., from Kelas, to shine in water. This is the Kailas of the Himalaya.

KOITOR, a section of the Gond, including the Raj Gond, the Raghuwal, the Daduvi, and Katulya. The Koitor is the chief clan of the Gond.

KOJAGARA, a Hindu festival in honour of Lakshmi. On the day of the full moon, in the month Aswin, Lakshmi is believed to have promised riches to all who observe a vigil on the right (from Ko, who, and Jagara, wakeful). The night is passed in festivity and in games of chance.

KO-JI-KI, a sacred book of Japan, taken down, 
A.D. 711 , to the dictation of Hi-ye-ta-no-Are.Sir J. E. Reed.

KOKAND, a small territory west of Kashgar, with capital of same name, the paternal kingdom of Baber. It was ruled by an Uzbak khan or chief of the tribe of $\mathrm{Yuz}$, who claimed a lineage from Baber. It is famed for its si]k. The khanate of Kokand comprises almost the entire valley of the Syr-i-Darya, the river Jaxartes, and its various confluents: partly in consequence of the nomade half-savage hordes which form its northern population, partly from its geographical position, it was among the very earliest to come into direct collision with Russia. It possesses considerable celebrity in being looked on as the capital of Afrasiab, and is historically connected with the campaigns of Chengiz and Timur; but it is better known as the birthplace of Baber, from which he raised himself, first to the throne of Kābul, and ultimately to that of Hindustan.

Kokand is the key of Turkestan; it is on the high road to the Chinese settlements of Kashgar, Yarkand, and Khotan, with which it carries on a considerable traffic. Also there is an open and regular communication from Yarkand to Kashmir and Ladakh.

Since 1865 , Kokand has been confined to lat. $39^{\circ} 40^{\prime}$ to $42^{\circ} \mathrm{N}$., long. $70^{\circ}$ to $74^{\circ} 30^{\prime} \mathrm{E}$. This is an area of 30,000 square miles, and it occuptes a hollow in the Tian Shan mountains, known as the valley of Ferghana. It is surrounded, except on the N.W. corner, on all sides by terraced mountains, occupied by a peaceful Uzbak population, ever at the mercy of the mountain tribes. The Russians subjugated it, and it was designated the Russian Ferghana province of Turkestan. Papers, East India, Cabool, and Afghanistan, pp. $120,130$.

KOKANI, a race who appeared in British India in 1871-72, and were escorted out of it by the police, via Lahore and Multan. In appearance they were true gypsies. The men had long hair like women, and, as a rule, had little beard or moustache. The women were all well featured, sorne being very pretty, noisy, and forward, with a marvellous amount of slang, and a perfect want of anything like shyness.

KOKA PANDIT, author of a work in Sanskrit verse, de rebus veneris. Translations are to be found in the vernacular dialects of India, as the Mahrati, Telugu, etc. There is no other book in eastern literature, except the Hitopadesa, which is to be found in such variety of languages. In Persian, Hindustani, and Panjabi it is called Lazzat-un-Nissa; in Arabic, the Marifat-un-Nayk; in Sindi, the Farhat-ul-Ashikin.

KOKCHA, one of the three principal affluents of the Oxus.

KOKO KHOTON has five great Lama serai, in each of which are more than 2000 Lama, besides 15 smaller serai; 20,000 is thus a low estimate for the number of Lama in this famous city. l'rinsep's Tibet, p. 51.

KOKO-NOR. MONGoL. 'The Blue Lake or Blue Sea is an immense reservoir of water, more than 400 miles in circumference. According to popular tradition in Tibet, this vast body of water once occupied what is now the site of the city of Lhassa, and found its way by a subterranean course to its present bed.

Central Aeia politically is largely under the dominion of China. Physically, it consists of three plateaux, viz. that of Tibet, which is the highest; the plateau of Koko-Nor, which is lower; and the Mongolian plateau, still lower. West of Koko-Nor, between Mongolia and Tibet, there is a depression, which is deepest at Lake Lob, and is the lowest part of Central Asia.

The Tibetan plateau has the Himalaya on the south, and the Kouen Lun mountains on the north, with the Pamir on the west, and Bayan Koro mountains on the east. At its western extremity, its plains are elevated 17,000 feet above the sea; its peaks are amongst the highest in the world, and its valleys are from 10,000 to 14,000 feet. Its greatest breadth in long. $90^{\circ} \mathrm{E}$. is 600 miles, and its extreme length, 1500 miles. It is largely drained into inland lakes, but it gives rise to the rivers Brahmaputra, the Indus, and the Yang-tze.

The Koko-Nor plateau is between Mongolia and Tibet. Koko-Nor is 10,500 feet above the sea.

The Mongolian plateau, including the Cbinese governments of Inner and Outer Mongolia and Ili, has the Tian Shan and Koko-Nor mountains on the south. It is elevated from 3000 to 12,000 feet.-Tr. Saunders in Geog. Mag., July 1877; Huc's Journey, p. 224.

KOKOONA ZEYLANICA. Thw. Kokoongass, SINGH. This is a large tree not uncommon on the banks of streams in the Saffragam and Ambagamowa districts, at an elevation of 2000 to 4000 feet. The inner yellow bark is employed by the natives medicinally as a sternutatory, and an oil is expressed from the seeds, which is used for burning in lamps. Wood unknown. A species of Kokoona occurs in Borneo.-Bedd. p. 146; T'hw. En. Pl. Zeyl. p. 52.

KOK-SINGHA, a pirate chief who, in A.D. 1661 , with a fleet and force of 25,000 men, attacked and destroyed the Dutch settlements in Formosa.-Collingwood.

KOK-TASH, a coronation stone in Samarcand, on which Timur and each succeeding amir has sat. $\mathrm{KOI}$, as popularly used, is a term which includes not only $\mathrm{Ho}$ and Mundah tribes, but also the Dravidian Oraon, while its scientific use embraces the three cognate Kolarian tribes of Mundah, Ho or Larka Kol, and Bhumij.

Kol is a term applied to the aborigines of the hill country of Chutia Nagpur, Mirzapur, and Rewah. Europeans apply the term to the Dravidian Oraon, as well as to the others, but perhaps erroneously, and most of the tribes have other distinctive names. In the south of the Chutia Nagpur country, about Singbhum, it is applied to the Larka Kol. The aborigines of Chutia Nagpur are in two tribes, Mundah and Oraon. These are generally separate, but are sometimes found occupying the same villages, cultivating the same fields, but their festivals and amusements are different, and they are of entirely distinct origin, and cannot intermarry without loss of caste. The Mundah were the prior occupants. The Kol, Larka Kol, and the wilder Larka Kol of the hills to the west of the Singblum district, speak nearly the same language as the Ho, Santal, Bhumi, and Mundab. The Kol, the Kur of Ellichpur, the Korewa of Sirguja and Jushpur, the Mundah and Kheria of Chutia Nagpur, the Ho of Singbhum, the Bhumij of Manbhum and Dhulbhum, and the Santal of Manbhum, Singbhum, Cuttack tributary mahals, Hazaribagh, and the Santal parganas, are kindred 
peoples numbering several million. Amongst the Kol, man and wife eat together, as is the custom with some Christian and Muhammadan races. The Kol and the Mundah tribes, and all those cognate to the Mundah, are passionately fond of dancing, which they commence in very early life, and regard as an accomplishment. They also sing well, and have musical voices and a great variety of simple melodies. Their dancing assumes a national character at their great periodical seasonal festivals and fairs, called Jatra, at which the young men treat their partners with fairings. The Kol have a belief in, and greatly dread, witches, and have killed many persons whoin they believed to be so. Chota Nagpur, properly Chutia Nagpur, is the country on the eastern part of the extensive plateau of Central India, on which the Koel, the Sabunreka, the Damuda, and other rivers have their sources. It extends into Sirguja, and forms what is called the Upar-ghat or highland of Jushpur, and it is connected by a continuous chain of hills with the Vindhya and Kymor ranges, from which flow affluents of the Ganges, and with the highlands of Amarkantak, on which are the sources of the Nerbadda. The plateau is, on the average, about 3000 feet above the level of the sea, with an area of about 7000 square miles. It is on all sides difficult of access, is a well-wooded, undulating country, diversified by ranges of hills, and it has a genial climate. The population in 1866 was estimated at about a million, and is formed of a number of non-Aryan tribes who had fallen back to that refuge from the plains, more than half of them, however, being the race known to Europeans as Kol. The other races in Chutia Nagpur and its adjoining tracts are, the Larka Kol, Ho, Bhumi, Mundah, and Sautal.

Ghasi are numerous wherever there are Kol. They are musicians, and amongst the Kol take the place of the Chandal.

The Larka $\mathrm{Kol}$, as they are termed, inhabit those extensive tracts which go under the name of the Kolehan. Part of these wilds is situated in the Singbhum district, and the inhabitants pay a nominal obedience to the mabaraja of that province; but the greater proportion of this population is more under the influence of the raja of Mokurbunj, than of any of the other powerful chiefs in that part of the country. But even his orders are obeyed only where they are supposed to tend to the advantage of the Kol themselves. Upon the whole, it may be said of this singular people, that, living in a primeval and patriarchal manner under their Mundah and Manki, they have managed to preserve a sort of savage independence, making themselves dreaded and feared by their more powerful and civilised neighbours. The Kolehan with its wilds and jungles is divided into different pir, as they are termed, or parganas. These pir are, generally speaking, not of any great extent, two or three moderate marches carry a traveller through each of them. There can be little doubt, and such is the tradition among the people themselves, that the Iarka Kol came originally from Chutia Nagpur, and are descendants of the old Mundah or Mundari of that district. They emigrated, finding the romantic hills and valleys of Chutia Nagpur too confined for their increasing numbers. The same cast of countenance prevails in the two races, though, perhaps, tinged with a wiliter and more fierce expression in the Larka Kol. The Oraon, who inhabit a great part of Chutia Nagpur, regard the Kol as a tribe inferior to themselves, and do not intermarry with them. The villages in the Kolehan are ruled by Mundah and Manki, as in Chutia Nagpur. The former, the Mundah, is the proprietor of one village; while the latter holds six, eight, or twelve. These village potentates used frequently to wage fierce war with one another, and bitter and long-existing feuds have often prevailed amongst them. There is this peculiarity in the $\mathrm{Kol}$ character, however, that serious and bloody as may be the domestic quarrels, no sooner are they threatened with hostilities from without, than all their animosities are laid aside and forgotten for a time. The villages are generally built on some elevated spot surrounded by trees, and, at some little distance from the principal entrance to the villages, the Kol standard or ensign, a pair of buffalo horns, is suspended in a conspicuous situation. The dress of both sexes is alike, a strip of cloth brought round the loins and passed between the thighs forming their only covering; the women wear a profusion of coloured beads suspended from their necks, and have their ears pierced with a number of small brass rings. Their diet is of a very promiscu ous nature, everything almost that can be considered eatable being relished by them, and much of what we consider carrion is eagerly sought for. In this respect they do not differ from the $\mathrm{Kol}$ of Chutia Nagpur. They are greatly addicted to drunkenness. The religion of the Larka $\mathrm{Kol}$ is nothing but a superstition of the grossest kind. The great divinity is the sun (suruj), next to the sun ranks the moon (chandu), and then the stars, which they believe to be the children of the latter. They uniformly, upon solemn and great occasions, invoke the sun, and by him many of these lawless men at times swore allegiance to the late E.I. Company. Another form of oath used by them is that of swearing upon a small quantity of rice, a tiger's skin and claws, and the earth of the white ants' nests; besides the sun and moon, other inferior divinities are supposed to exist, to whom the Kol offer up sacrifices of various kinds. These spirits are supposed to inhabit the trees and topes in and around the village. The belief the Kol entertain of the power and influence of the Bhonga must be considerable, as they will on no account allow those trees to be denuded of their branches, and still less cut down. It is the universal custom in the various $\mathrm{Kol}$ villages, that when a woman is seized with the pains of labour, she is immediately removed to a lonely hut, the door is shut upon her, offerings of various kinds are suspended near it to propitiate the Bhonga, and no one ventures near till all is over. The women, it may be observed, are not secluded or shut up. Then a Kol youth has fixed his affection on a lass, generally the inhabitant of some neighbouring village, she is waylaid and carried off to his house by himself and his friends. So soon as information of this reaches the parents of the girl, they proceed to the village of the ravisher, not, however, in general, with any hostile purpose. Interviews take place between the friends on either side, and at length matters are brought to a final settlement; the new husband paying to the father of his spouse a certain number of cows, goats, or buffaloes, according to his means, or the beauty and comeliness of his bride. After this a scene of feasting and 
intoxication generally follows, in which women and children, as well as men, participate. The Kol burn their dead, carefully collecting the bones and ashes, and bury them with offerings of rice, in or near their villages, placing perpendicular or horizontal slabs of stone over each particular grave. Those grave-stones form a remarkable object, and strike the eye of every stranger on approaching a Kol village. The only weapons used by the Kol, whether in war or hunting, are the bow and arrow, and the tulwar or axe.

The Mundah Kol or Ho comprise about twothirds of the population of the five parganas of Silli, Tamar, Baranda, Rabey, and Bundu, all others being recent settlers. But many of the Mundah Kol have been dispossessed of their ancestors' lands by middlemen, Brahmans, and Rajputs. Mundah settlements are chiefly in the eastern and southern parts of Chutia Nagpur. The Mundah and Santal are amongst the ugliest of mankind, the Santal being remarkable for good nature and ugliness. They are more like Hottentots than Negroes. The extreme featured of the Mundah race have high cheek-bones, small orbits, often with an oblique setting, flat faces, without much beard or whisker, and in colour from brown to tawny yellow. Mundah features are flat and broad. The richer people of the Mundah, who aspire to be zamindars, wear the poita, reverence Brabmans, and worship Kali; but the mass coutinue in their original faitb. The great propitiatory sacrifices to the local deities are carousals, at which they eat, drink, sing, dance, and make love, and the Hindus settled in the province propitiate the local deities. The Mundah country is arranged into Purha or divisions, each consisting of twelve or more villages under a chief, and the chiefs meet at times for consultation. Many of the Oraon, and some of the Mundah clans or Kili, are called after animals, the eel, hawk, crow, heron, and the clans do not eat the animal whose name they bear. The Mundah and Ho dead are placed in a coffin along with all the clothes and ornaments used, and all the money the deceased had, and all burned. The larger bones are preserved till a large monumental stone can be obtained, and the bones are interred below it, the Ho near the houses, the Oraon separate from the village. They are taken to the tomb in a procession, with young girls with empty and partly broken pitchers, which they reverse from them to him to show that they are empty. The collection of these massive grave-stones under the fine old tamarind trees is a remarkable feature in Kol villages. The stones are sometimes so large that the men of several villages are required to move one. The bones are put with some rice into a new earthen vessel, deposited into the hole prepared for them, and covered with the big stone. The Mundah and Oraon races are fond of ficld sports, and all game, large and small, disappear from near them. They form great hunting parties. Fishing and cock-fighting are also resorted to. The Mundah and Ho have a shamanite religion. They have no worship of material idols, but Singbhongu, the sun, is the supreme being, the creator and preserver, a beneficent deity, and they have secondary gods all invisible, and generally malevolent. Sacrifices to Singbhongu are made of fowls, pigs, a white goat, the ram and buffalo.

The Kol and Sura dwell towards the north of the
Gond and Kond in Central India ; their languages contain Dravidian words, but they belong to a totally different family of languages. The Kol also inhabit the forest and mountain tracts of Benares, South Behar, and Chutia Nagpur on the north of the Kond in Gondwana, and border on the people in the Rajinahal Hills, dwelling in the east at Sumbulpur, Sirguja, Gangpur, Chutia Nagpur, Ramgarh, and Mongir. The Kol were described by Lieutenant Tickell in 1840 in the Bengal Asiatic Society's Journal. One tribe, called Oraon, was driven at an early period from the neighbourhood of the Gavges, and found the Mundah Kol tribe in possession of Chutia Nagpur. The Mundah call thernselves Ho, though more generally known as Kol. The Kol are physically Ultra-Indian more than Dravidian, and the occupation of the Eastern Vindhya and hills on the opposite side of the Gangetic valley by UltraIndians implies that the valley itself was at one time possessed by the same race; the simplest conclusion is that the Kol were an extension of the ancient Ultra-Indo Dravidian population of the Lower Ganges and of the highlands on its easteru margin. The Kol and Larka Kol and Sura, in Singbhum, north of the Gond, are regarded by all writers as of the prior Scythic stock.

The Isarka Kol were subdued in 1821, and an agreement was made with them by which they bound themselves to be subject to the British Government, and to pay a fixed tribute to their chiefs. In 1857, a large number of the Larka Kol espoused the cause of the raja of Porahat, a Rajput chieftain near the Kolehan, but on the restoration of order they reverted to peaceful pursuits. The estate of the raja of Singbhum, afterwards styled the raja of Porahat, was then confiscated for rebellion. The total revenue from the district is about Rs. 45,000. The expenditure, including a police battalion, amounts to about Rs. 30,000. Kol arms are the bow, a piece of bamboo with bamboo string, the arrow barbed, and battle-axe. The Kol intermixed with the Gond on the Sumbulpur borders are said to be called Kirki.

In British India and on its borders are four distinct branches of the family of languages spoken by members of the Turanian race. In the north are the Hinalayan tribes, with their dialects, occupying from the Kanawars on the Sutlej to the Bhoti of Bhutan in the extreme east. Then there are the Lohitic class of languages, comprising with the Burmese and others of the Malay Peninsula the dialects of the Naga tribes and of the Mikir in Assam, and of the Bodo, Kachari, Kuki, and Garo in Eastern Bengal. Another class is the Kol or Mundah family of languages, including the Kol, Santal, and Bhumi of Singbhum and Western Bengal, and the Mundah of Chutia Nagpur, the Kur, or Korku, or Muasi in Hoshang:abad, Ellichpur, and westward in the forests of the Tapti and Nerbadda until they come in contact with the Bhil of the Vindhya Hills. Mr. Hislop held that the word Kur or Kor is identical with Kol.

The fourth branch is Tamilic or Dravidian, to which belong the language of the Oraons and of the Rajmahal hillmen, the Gondi, the Tuluva of Kanada, the Karnata of the Southern Mahratta country, the Todava of the Neilgherries, the Malealam of Travancore, the Tamil, the Telugu, 
and the Canarese. The Brahui of Baluchistan is also said to be allied to this family.

The Kur and the Santal are closely related, and are separated from the Dravidian. The Kur or Muasi and the Korku or Kurku, to the northwest and west of the Mahadeva Hills, are, in language at least, quite distinct from the Gond tribes.

Mr. Hodgson is of opinion that the Tamilian, Tibetan, Indo-Chinese, T'ungus, Chinese, Mongol, and Turk are so many branches of the Turanian family, and he regards the aborigines of British India as northmen of the Scythic stem, but he remains undecided whether they owe their Scythic physiognomy to the Tungus, the Mongol, or the 'Turk branch of the Tartars or Scytbians, and whether they emigrated from beyond the Himalaya at one period and at one point, or at several periods and at as many points. Professor Huxley, on the other hand, considers these people to be allied to the aborigines of Australia. All writers are of opinion that when the Aryans entered India, they found the country occupied by prior races, to whom their writers apply such contemptuous expressions as Dasya, M'hlecha, etc. These prior races seem to have been driven largely out of Northern India into and through the Vindhyan mountains into the Peninsula of India and Ceylon, where their idiom, the Tamil, Telugu, Malealam, and Karuatica are sister dialects of one speech; and Dr. Pritchard concurs in opinion with Professor Rask, who regards the languages of the mountain tribes of India, the Bhil, the Gond, the Toda, and others, as also of the Tartar stock, and mentions that some curious analogies have been observed between the Tamilian and other dialects of the Peninsula and the languages of Australia. Mr. Logan, however, who has had great opportunities of contrasting and comparing the Dravidians from various parts of India, inclines to call them South Indian. He remarks that, physically, the population of Southern India is one of the most variable and mixed which any ethnic province displays. A glance at a considerable number of Kling (Teling) and Tamilar of different castes and occupations, shows that the varieties, when compared with those of similar assemblages of men of other races, such as Europeans, UltraIndians, or Indonesians (including Negroes in the last two cases), are too great to allow of their being referred to $\pi$ single race of pure blood. Some are exceedingly Iranian, some are Semitic, others Australian, some remind us of Egyptians, while others again have Malaya, Polynesian, and even Semang and Papuan features. This varied character of the races of the south of the Peninsula may be seen daily in Madras, to which all the races from the south of India resort.

The language of the Mundah, Kur, and other Kol races differs from the northern languages not only in its greater fluency and agglutinative and inchoate flexional tendency, but in its dissyllabic character, its profusion of dual and relative forms of the pronouns, and in the position of the qualitive before the substantive.

Three lists of words were obtained by Captain Houghton from Chyebassa in Central India, and two by Colonel Ouseley from Chutia Nagpur, all of which Mr. Hodgson regarded as dialects of the great Kol language. The Oraon speech he traced without difficulty to that of the hillmen of the Rajmahal and Bhagulpur ranges. He considers that between those several Kol tongues and that of the Gond of the Vindhya there are obvious links. But Professor Max Muller says they have no affinity whatever. Mr. Elliot showed that much resemblance both in vocables and structure exists between that Gond language and the cultivated tongues of the Dekhan.

From the geographical distribution of the $\mathrm{Kol}$ aud Dravidian languages, Mr. Hislop concludes that while the stream of Dravidian population, as evidenced by the Brahui in Baluchistan, entered India by the north-west, that of the Kol family seems to have found admission by the north-east, and as the one flowed south towards Cape Kumari, and the other in the same direction towards Cape Romania, a part of each appears to have met and crossed in Central India. This hypothesis rests on the presence of the Brahui where they are, a fact which is not inconsistent, however, with the supposition that the Dravidian tribes may also have entered India from the north-east or even across the Himalaya, as the Kanawar, Newar, Chepang, and other tribes have done; while the Kol tribes were an offshoot from a later horde, the main body of which entered the Eastern Peninsula. The Brahui may have been driven westward by the invading Arya from the Upper Indus. To the early Arya the prior tribes were known as Dasi, who, Dr. J. Wilson tells us, were not altogetber barbarians, for they had distinctive cities and other establishments of at least a partial civilisation. Then, as now, they were darker than the Arya; and, according to Dr. Wilson, the more marked Turanians in Gujerat and other provinces are still denominated the Kuli Praja (corrupted into Parej) or black population. In former times the Kol tribes possessed the whole of Chutia Nagpur, which may now be said to be divided between them and the Dhangar or Oraon, who came from Rotasghur. The chief men in most of the villages are still, however, of the Mundah or Kol tribe, and they do not intermarry with the Dhangar. The greater part of Singbhum is inhabited by $\mathrm{Kol}$, and we find them numerous in Bananghotty, and dispersed to the vicinities of Cuttack and Midnapur. The Lurka $\mathrm{Kol}$, as they are termed, inhabit those extensive tracts, as yet but little known, which go under the name of the Kolehan.-E. Balfour in Jamesun's Edinburgh Journal, 1843 ; Ib. in Journal of Beng. As. Soc., 18t4; Dr. Voysey's Journal; Campbell; Dalton, pp. 150-185; Sir Walter Elliot in Journ. R. A. S., 1861; Mason, Burma; Aitcheson, Treaties, etc. p. 170 ; Mr. Hislop in Journ. Ant. Soc. Nagpur; Logan, Journ. Ind. Arch., 1853 ; Trans. R. As. Soc.; Lieutenant Tickell in Beng. As. Soc. Journ., 1840; Cunningham's Ancient India; Dalton's Ethnology.
KOLA. BENG. A class of Hindus whose principal avocations are basket and mat making.

KOLA, or in Shen Tamil Kozha, the Tamil name of the Tanjore province.

KOLABA district is in the Konkan division of the Bombay Presidency, lying between lat. $17^{3}$ $52^{\prime}$ and $18^{\circ} 50^{\prime} \mathrm{N}$, and long. $73^{\circ} 7^{\prime}$ and $73^{\circ} 42^{\prime} \mathrm{E}$. Area, 1482 square miles. The Sahyadri range forms its eastern boundary, and has two remarkable peaks, - Raigarh in the Mahad subdivision, where Siraji built his capital; and Miradongar, a station of the Trigonometrical Survey. Kolaba district lies immediately south 
of Bombry, and the north-west part touches the sea. The administrative centre, Alibag, situated in this portion of the territory, was the stronghold of the pirate Angria, who long held the coast in terror, and who founded a piratical dynasty. Kolaba Island formed a shelter for the pirate fleets. It is situated just outside Alibag harbour, and was fortified by Sivaji in 1662 . In 1772 it was still an important place, where the chief lived in much splendour, and a combined expedition of British ships aud Portuguese troops made an unsuccessful attack upon it. The rise of the Indian navy during the second half of the 18th century put an end to piracy on an organized and successful scale in Bombay waters. Under the Angrias, slavery was in force, and included terrible penaities on women, who, for certain offences, became the property of the chief. In $18 \pm 0$ the male line of the Angrias died out, and the application for leave to adopt an heir being refused, the state of Kolaba lapsed. Janjira is a native state. Janjira is, properly speaking, only an island at the entrance of a bay half-way between the rivers Savitri and Roha; but the name has been applied to the whole of the little principality on the coast west of that part of Kolaba which does not touch the sea. In the time of the Arab and early African traders, Janjira was a place of importance, and the descendants of these races, such as Abyssinians and the Beni-Israel, are still to be found there.Imp. Gaz.

KOLABA POINT is a spur of land protecting the entrance to Bombay harbour on the north. It was origiually a chain of small islands, wbich are now connected with each other and with the island of Bombay by causeways and reclaimed tracts.-Imp. Gaz.

KOLADYN or Kuladan is the chief river in Arakan. It rises near the Blue Mountain, in the Yoma doung range, in lat. $22^{\circ} 27^{\prime} \mathrm{N}$., long. $92^{\circ}$ $51^{\prime}$ E., and, after a course of 160 miles, during which it receives the $\mathrm{Myu}$ and Lemyo, it enters the Bay of Bengal in Combermere Bay. It is navigable to within a few miles of Arakan town for ships of 250 tons burden; above Akyab the stream is narrow, and navigable ouly for canoes. It is 10 miles broad at its mouth. The name is derived from Kula, western foreigner, and Tan, to stop, or its derivative Atan, a barrier, a boundary, and signifies the barrier of the western foreigner. The races dwelling in the valley of the Koladyn and its affluents are the Kuki, the Mru, the Sak, the Niru Sak, the Ka-mi, the Ku-mi, the RaKhyen, the Kin-ni, Shendu, and the Prou-ka-nij, all of them professing a creed partially Buddhist. Colonel Dalton, however ( $p$. 113), names the tribes Kheong-tha, Mron, Kumi, and Shendoo.

KOLAM or Kolamb, a Gond tribe, along the Kandi Konda or Pindi Hills, on the south of the IVardha, aud along the table-land stretching east and north of Manikgarh, and thence south to Dantanpilly, running parallel to the right bank of the Pranhita. The Kolam and Kurku hill tribes bring in wood and forest fruits for sale. The Kolam race are found also in the Ainraoti, IVun, and Maiker districts as a wild race. They were formerly predatory, occupying the Mailghat and southern skirts of the Vindbya Hills, along with the Andh, Gond, and Kurku. These four resemble each other in appearance, but each

speaks a different language, and in their features they are distinct from the villagers.

KOLA NUT is the seed of Kola acuminata, belonging to the natural order Sterculiaceæ. From 6 to 12 are contained in woody pods, from 3 to 6 inches in length, of which 5 or less are produced by each flower. Like olives, they enhance the flavour of whatever is eaten after them, and are said to have the power of staying, even for a prolonged period, the cravings of hunger, and of enabling those who eat them to endure prolonged labour without fativue. They are the product of the Sierra Leone district. They are largely consumed by the natives of the Gambia, are of bitter taste, and produce no exhilarating effect, but are said to satisfy for a considerable time the cravings of hunger. For this purpose, however, the nut is much less used than it is as a luxury. In the year 1860 the import was about $150,000 \mathrm{lbs}$; in 1870 , about $416,000 \mathrm{lbs}$. ; while in 1879 it had increased to over $743,000 \mathrm{lbs}$. The Kola acumiuata, in fact, plays the same part in tropical Africa that Erythroxylon coca does in South America. The plant has been introduced into the West Indies, and has been distributed to Calcutta, Cambridge (U. S. A.), Ceylon, Demerara, Dominica, Mauritius, Sydney, and Zanzibar. There are said to be useful seeds of two African trees, one Kola acuminata, $R$. $B r$., the other bitter Kola, an undetermined Guttifer, both highly valued, especially those of the bitter Kola. The seed of common Kola is said to possess the virtue of rendering water, becoming putrid, agreeable to the taste.

KO-LAOU. CHIN. The civil government of China is conducted by the Nuy-ko, or Interior Council Chamber, in which there are four clief councillors, two of them Tartar and two Chinese, who bear the titles of Choung-thang and Ko-laou. The Tartar minister presides. The Lu-pu are six boards for the conducting of goverument business, and the provinces of the country are each under a governor, or, where two provinces are united, a governor-general. Every province is divided into a certain number of districts, cailed a $\mathrm{Fu}$, Ting, Chow, and Heen. A Fu is a large portion or department of a province under the general control of a civil officer, immediately subordinate to the head of the provincial government. A Ting, a smaller division than, and sometimes a portion of, a Fu; when separate, it is governed as a Fu, and called a Chuh-le. A Chow is similar to a Ting, as also a Heen, but each is a smaller division; each $\mathrm{Fu}$, Ting, Chow, or Heen has one or more towns or walled cities under its guidance, one of which takes its name and rank as K wangChow-Fu and Shang-Hae-Heen, which latter, although of that subordinate rank, is the largest maritime city in the empire, and the greatest resort of the native ships or junks. - Forlses" China; Sirr's China; Huc.

KOLAR, a town in Mysore, in lat. $\left.13^{\circ} 8^{\prime}\right)^{\prime \prime} \mathrm{N}$. and long. $78^{\circ} 10^{\prime} 18^{\prime \prime}$ E., 43 miles E.N.E. of Bangalore. The Kolar district is known to yield gold, but as yet it is not found to be remunerative to work. Its people are Brahmans, Mahrattas, Kshatriya, Komati, Wakaliga, Beder, Kurubar, Bunijiga, with some wandering tribes. The Jain and Lingaet sects are not numerous. Nundidrug hill fort was taken by storm by the British, A.D. 19 th October 1791. 
KOLAR, a fresh-water shallow lake in the Kistna and Godavery districts of Madras, lat. $16^{\circ}$ $30^{\prime}$ to $16^{\circ} 45^{\prime} \mathrm{N}$., and long. $81^{\circ} 5^{\prime}$ to $81^{\circ} 27^{\prime} \mathrm{E}$. It is much reduced in the hot weather, and it has many islets or lankas. Fish and water-fowl are abundant.

KOLAR or Kolaria, an ancient name of India or part of India, supposed to be from the Kol of Central India, and Koli of Kattyawar. See Kol; Languages.

KULAVANT, a tribe of performers about Benares, professing Muhammadanism. They are persons of reputation and respectability, of much higher rank than the Dharshi.--Sherring's Tribes, p. 275 .

KOLFF, D. H., author of Voyages through the Moluccan Archipelago and along the Southern Coast of New Guinea, in 1825-26.

KOLHAN, a tract of country forming a British estate in the Singbhum district of Bengal; area, 1905 square miles, with 883 villages. It is occupied by the Ho, and is known also as Ho-desham. A group of from 5 to 20 villages forms a pirhi or pir, each of which has its own mundah or village head. Every mundah or village head is responsible for the payment of the revenue, and for the detection and arrest of criminals in his own village, to the manki or divisional head of the pir, and this latter official is in his turn responsible to Government. For acting as revenue collectors, the manki receive a commission of one-tenth, and the mundah one-sixth, of the rent which passes through their hands. Besides these duties, the manki and mundah, each in his degree, have certain informal powers to decide village disputes and questions of tribal usage.-Imp. Gaz.

KOLHAPUR, a Native State in the Bombay Presidency, between lat. $15^{\circ} 58^{\prime}$ and $17^{\circ} 11^{\prime} \mathrm{N}$., and between long. $73^{\circ} 45^{\prime}$ and $74^{\circ} 24^{\prime} \mathrm{E}$. Kolhapur city is in lat. $16^{\circ} 42^{\prime} \mathrm{N}$., long. $74^{\circ} 16^{\prime} \mathrm{E}$., opposite a gap on the Sahyadri Hills, 128 miles south by east of Poona, and 64 miles of Satara.

The rajas of Kolhapur trace their inheritance from Raja Ram, a younger son of Sivaji, founder of the Mahratta power. Kolhapur became separated from the Satara territory in 1731 ; and in 1760 , Sambaji, grandson of Sivaji I., died without issue, and with him the direct line of the great Sivaji became extinct. Successors were adopted in 1866, 1870, and 1884. The last was entitled Shahu Chhatrapati; he was adopted by the widowed rani.

During the captivity of Sahoji, the Mahratta power was exereised by his uncle Raja Ram, younger son of Sivaji. In 1731, Sahoji recognised Kolhapur as an independent principality. When the direct descendants of Sivaji became extinct on the death of Sambaji in 1760 , one of the Bhonsla was adopted, under the name of Sivaji, but the State was ruled by the widow of Sambaji amidst the greatest irregularities on land and piracy by sea; and in 1765 and 1792 , the British sent expeditions against this State. Sivaji, after a rule of 53 years, died in 1812 . His son Sambhu, or Apa Sahib, in 1817 sided with the British in their war with the Peshwa, and was granted the districts of Chikori and Munoli, but he was murdered in 1821. His son died after a year. His brother Bawa Sahib was an aggressive ruler, and three times between 1822 and 1829 the British sent forces against him. He died 29th
November 1838 , and was succeeded by his son Sivija, then a minor. The regency so mismanaged affairs, that the British appointed a regent, on which a general rebellion followed, which was suppressed by a large British force. During the mutiny of 1857 , the raja remained faithful to the British, but his younger brother joined the rebels, and was afterwards imprisoned. Since then there have been three adoptions.

KOLI, a race in the N.W. of the Peninsula of India, supposed to be an offshoot from Kol tribes farther east. Dionysius (Pereig. 1148) mentions the $\mathrm{K}\left(\lambda_{6} / 5\right.$, and Ibn Khurdad (ob. A.D. 912) alludes to the Kol as north of Malabar, in their present locality. The numbers returned in 1881 are 2,345,489, viz. Konkani Koli, 125,949; Mahratta Koli, 881,014 ; Baroda Koli, 676,661 ; and Talabda Koli, 661,865 .

Koli constitute a large part of the agricultural population in several parts of Gujerat. They are numerous in Attaveesy, and there are many in the Northern Konkan. In the hilly tract of country lying between Moosa, S.W. of Poona, and the hill fort of Trimbak, the inhabitants are chiefly Koli, and a few are scattered over the districts of Kandesh, Ahmadnaggur, Poona, and Sholapur, and along the Balaghat on the western frontier of the Hyderabad territory. They seem to have early occupied Gujerat and the Attaveesy, and part of the latter country is still called Kolwan. They are arranged into many separate tribes, but all of them retain the appellation of Koli. The Raj, Salesi, Tonkri, Dhour, and Dunggari Koli reside in the Attaveesy, Wun, Dandory, and Nasik districts, and worship the Hindu deities Kandoba, Bhairu, and Bhawani A few Raj Koli are settled in the Konkan and Jowair. They are an offshoot of the Mahadeo Koli, and said to have been expelled for some offence. They are farmers and labourers.

The Mahadeo Koli reside in the valleys of the Sahyadri range, extending from Moosa, S.W. of Poona, northwards to Trimbak, the source of the Godavery river, between lat. $18^{\circ} 15^{\prime}$ and $20^{\circ} \mathrm{N}$., and long. $73^{\circ} 30^{\prime}$ and $74^{\circ} \mathrm{E}$. These small valleys are known as Mawil, Khorab, Nahir, and Dang, i.e. valleys, glens, stratbs, and wilds. They are classed into 24 kula or clans, each of which has many subdivisions. The nembers of the same kulu do not intermarry. With the exception of the cow and village hog, the Koli eat all other animals. The women are generally slender and well formed, with a pleasing expression of features, and some are very pretty. They are chaste, and have large families. The Koli are fond of charms and amulets. The fishermen settled along the coast from Gheriah to the north, near Surat, and at Colaba, in Bombay, are Koli of the Sone tribe ; a few of them enter on board of vessels as mariners, but the vessels must be manned by natives, the Sone fearing to lose caste, which they say would take place did they sail with Europeans. The chief patel of this tribe residss at Angria. $\mathrm{He}$ is endowed with power to adjust their affairs, settle their disputes, etc. The women of the Sone Koli wear choli or jackets, and have a number of glass bangles on their left wrist; they are frequently seen in Bombay assisting their husbands in fishing and importing fish into the fort and outside market. When they marry, the omaments which were intended to 
adorn their right wrists are consecrated, and thrown into the sea, as an offering to the deity who presides over that element, and an invocation to defend her husband from the dangers of the ocean. Not a caste meeting of the Sone Koli can take place without large potations of mahwa flower arrack being imbibed.

The Dhour are the greatest drunkards, and eat the flesh of animals which have died a natural death. Koli have, in some instances, attached themselves to the Bhil, and taken the name of that race. The Mullar or Panburri or Choomli Koli is respectable. The Koli is employed in every Dekhan and Kandesh village as a member of the third division of the Balotta, and supplies water to travellers, wearing on his head the choomli or twisted cloth, hence the name, on which to rest the water-pot. This Koli is also found in the Hyderabad Balaghat, extending eastward to Khanbar, Indore, and Bodin, between the Godavery and Hyderabad, also near Naldrug, and down the banks of the Bhima and Kistna even to Alpur, near Kurnool.

The chief Koli location lies between lat. $18^{\circ}$ and $20^{\circ} \mathrm{N}$., in the Western Ghats, also on the seaboard. Some of the Koli are excellent farmers, those on the coast are fishermen, boatmen, and sailors, watchmen, water-carriers, and messengers. The Ambigar Koli are boatmen. The Patanwaria Koli of Gujerat are cultivators and labourers. The Dharala of Gujerat, mostly Koli, bear arms. The Machi Koli of Surat are fishers. The Wagri Koli of Gujerat are hunters. Dr. Carter says the Koli of the ghats refuse to bury the dead who die of cholera, small-pox, or the bite of the Phursa snake, a species of Lycodon. They make forks of sapling, with which they pick up the deceased and throw him over the precipice.

The A7ir Koli of Kandesh reside along the banks of the Girna and Tapti rivers, and are employed as watchmen.

The Murvy Koli is one of the Balotta in every village in the Northern Konkan, and in Bombay families they were employed as palanquinbearers. Sone Koli, settled as soldiery in Angria Colaba, and at Bombay and Colaba, in 1837 were 1000 families, and 500 to 600 families at Bassim, employing themselves as fishermen and seamen. At their meetings, whether for congratulation or condolence, they consume large quantities of spirits. Many are wealthy.

Mettah Koli, who reside in Bombay, are fishermen and seamen, and many have wealth.

In Bombay, Thana, Bhewndi, Kallian, Bassim, Daman, etc., are a great number of Christian Koli, said to have been of the Sone section, and to have been forcibly converted by the Portuguese, but, terrified by the cholera in 1820-21, a portion reverted to paganism.

Chanchy Koli are farmers and labourers, settled in Bombay, who came from Junagarh, in Katty«war.

In Gujerat, the most numerous are the Tullabdah Koli, then the Patanwaria, the Kahrez, the Dhandur, and Bhabria. They are in the Baroda district, north to Khyrallu and Massana in the Mahikanta, and form a large portion of the population. In 1837 , in the Khauir district alone, they were 70,000. They are labourers and watchmen, and a few, under the name of Selotta, form escorts of treasure.
The Bombay Island Koli are cultivators, toddydrawers, etc., and a great many of them sell game, which they suare and bring into Bombay. They are generally habited in a coarse jacket. which extends down to their back, and a small skull-cap, cut in front in the shape of a cone, with a lungoti to hide their persons.

Talapadi Koli are peaceful cultivators. Jugria Koli, also called Chunval Koli, of the Chunval district, are turbulent.

The Tonkri Koli are so termed from the occupation they follow of cutting down bamboos, - a large bamboo being called tonkri. The Dongri Koli are so called owing to their residing on hills,--the term for a hill being Dungur, etc.

The Koli are not so numerous now as they were in the early part of the 19th century, and this is attributed to the internal commotions which disturbed them since that period. They are now spread over various parts of Hindustan, and, owing to the opening of the Emigration Trade a few years back between India and the Mauritius, a great number of them repaired thither to better their circumstances.

Their numbers in British and foreign territory are considerable. The census of 1871 showed 68,302 in the Nasik district. 'The ferrymen on the rivers in the Peninsula are of the Koli race, stalwart men. The Kili-Katr or Maddakpur race are Koli, also Kabl-gira or ferrymen. The Koli are the labourers and lower cultivators in Gujerat.

In some districts the Mang Koli devote their young women to the gods.

Koli of the Konkan are partly Hindu, and in part Christians. They are a hardy race, of short stature, somewhat inclined to corpulency, but with muscular arms. The younger women are fair, but exposure to the out-door work soon darkens, them. The men wear a woollen waistcoat and loin-cloth, and a cap of red broadcloth. The women wear a loose-sleeved bodice and a cotton cloth around their waist, falling more than half-way to the knee, and the end of the cloth is drawn over the right shoulder, and tucked in front into the waistband. On the left wrist they wear glass bangles, those of the right wrist being taken off on their wedding day, and thrown into the sea to win its favour.

The Koli are somewhat ill-tempered, quarrelsome, jealous of strangers, and addicted to drink ; but they are manly, brave, honest, and faithful. Many are in debt, and some have taken to cultivation. The Alibag Koli were formerly predatory and piratical.

Koli occupy the sea-coast from the fort of Arnala, near Bassim, to Jaygad in the Ratnagherry district. For caste matters they have a Patel and Sir Patel; the latter is the chief of all the Koli from Kalian and Bhewndi in the Thana district to Harnal in Ratnagherry, and is said to have formerly had the power of life and death.

They are married from ten years of age upwards, and the husband may be younger than the bride. The women worship Gauri, and the men at the Narali Paurnima holiday offer a cocoanut to the sea, and all ships then put to sea. They speak a dialect of Mahrati. When a new boat is completed, the women break cocoanuts on its bows.

They make pilgximages to Nasik, Panderpur, Jejuri, Dehu, and other Hindu shrines, and at Thana there are deified Sadhu saints, with a temple 
to Dattaträya. The Christian Koli of the Thana district are under the Archbishop of Goa.-Exhibition of 1883 ; Elliot's Supplemental Glnss.; Sir G. Campbell, p. 125 ; Captain Mackintosh in Madras Lit. Soc. Journ.; Tod's Travels, p. 137 ; Dr. Carter; Census of 1881.

KOLI, the name given to the lower class of cultivators in the Simla Hills.

KOLI, the birthplace of Guatama Buddha's wife.-Hardy.

KOLI ROGA, or black-rot, in the Mulnad and Kadur district of Mysore, attacks coffee leaves and betel leaves.

KOLI'TA, a good-looking race in the S.IV. and E. of Bengal. The Bibor, Jubar, and Kulta or Kolita are populations to the north and east of the Abor and Mishmi localities, on the drainage of the Brahmaputra. But the Kolita are to be found in every district of Assam. Buchanan Hamilton says that the Kolita once had great sway in Rangpur, and many of those remaining there have assumed the title of Kayasths. A Hindu tribe in every way resembling them, and bearing the same name, Kolita, is to be found in the S.W. frontier of Bengal, in the Sumbulpur districts, and some of the Cuttack and Chutia Nagpur Tributary Mahals. These southern Kolita are noted for their industry as an agricultural class like the Kurmi, and are a cleanly, well-clothed, and good-looking race. The Assamese Kolita are not only themselves a good-looking race, but they are the people to whom the Assamese population generally owe the softening of feature which has so improved those of Mongolian descent. In the 1881 Census Report the Kolita are returned at 253,860.-Dalton's Ethnology of Bengal.

KOLKOI, in the Tinnevelly district of the Madras Presidency, at the beginning of the Christian era, was at the mouth of the Tamrapurni river, the silt from which has spread seawards, and Kolkoi is now 3 miles inland. The Kolkoi Emporion is mentioned by Ptolemy; also in the Periplus as the seat of king Pandya's pearl fishery, and in the Peutinger tables as Colcis Inderum; and it gave its name to the Colchic Gulf, now the Gulf of Manaar. It was the earliest seat of Southern Indian civilisation.-Imp. Gaz.

KOLI.AM, an era in use in Malabar.

KOLLA-MALIAA, a mountain range in the Salem district, Madras, lying in the Ahtur and Namkal taluks, lat. $11^{\circ} 10^{\prime} 30^{\prime \prime}$ to $11^{\circ} 28^{\prime} \mathrm{N}$., and long. $78^{\circ} 20^{\prime} 30^{\prime \prime}$ to $78^{\circ} 31^{\prime} 30^{\prime \prime} \mathrm{E}$. Its general elevation is from 2500 to 3500 feet, the highest point on the range being 4663 feet above sealevel. The population includes a number of Malayali, hillmen of the same race as those on the Shevaroy Hills.-Imp. Gaz.

KOLLAN. MALEAL., TAM. A blacksmith; also in Malayala, a tanner, a worker in leather, a turner in wood.

KOLLAR is the plural of Kullan. The prominent Kollar or Colleri tribe are in the Tondiman country, in the Vasanga district, in the eighteen palliams or districts, and throughout the Madura district. Until the 19th century they were so predatory that in the south of the Peninsula of India, Colleri became the ordinary designation of a thief, and their name is really derived from Kallara, thieves, plunderers. In ancient times they seem to have inhabited the woods from Trichinopoly to Cape Comorin.
Orme, writing of them, describes them in the middle of the 18 th century as expert thieves and plunderers, and the Jesuit Father Martin says they were very cruel. Pennant, writing of them in the 18 th century, says the adjacent countries are covered with thick forests and little cultivated by reason of the savage inhabitants, the Polygir and Collerie, who may be truly styled sylvestres homines ; they are predatory, and in their government, as also that of the Polygars, feudal. They are 30,000 or 40,000 in number. Their country is hilly. In the British wars against the French in the times of Clive and Dupleix, both the Kollar and Maravar became well known by their adhesion to the British or French standards, and for the fidelity and devotion to the cause of the party which they espoused. The chief Kollar districts were the Tondaman country, Nattam, and Mylore; the last two are in the Madura district. They have a first and second marriage, like the Maravar of Ramnad. The titular surname of all Kollar is Ambalakaren. Calicoil was the stronghold of the lord paramount, the raja of Tondamandalam, the country of the Tondaman, which was an ancient division of the Peninsula of India, of the part now occupied by the Arcot and Chingleput collectorates. H.H. the raja Tondaman of Puducottah is now a petty chief, and his country is a small tract near Trichinopoly. It was an ancient custom in Tinnevelly when a stranger wanted a guide, to appoint a Kullan girl as his guardian, and if any of her caste did her charge violence, she tore her ears, and when the criminals were caught, the same was done to their ears. Pennant's Hindustan, ii. p. 11; Orme's Hindustan; Wilson.

KOLLATI. The Dumur or Kollati, called by themselves Bhatu, are wandering acrobats, and their young women are common.

KOLLE-KALLU. TAM.? A term applied to ancient tombs in the Peninsula of India. See Cairus ; Dolmen.

KOL-NARU. TAM. Helicteres isora, one of the Sterculiacer, a genus included in the natural family of Byttneriaceæ (silk cotton tree and others). It is common in the lower parts of all the ghats, and in great abundance in the plains below Gudalur.

KOLU, in Coorg, a measuring pole. The Virajendra pole is $18 \frac{2}{3}$ feet. The Lingraj pole is 16 feet.

KOLWAH, in Baluchistan, four or five days journey from the coast, has several villages and castles, and is occupied by the Mirwari, Rodahi, Homerari, and Nushirwani tribes, who interchange their commodities with the coast, sending wool, ghi, hides, and bdellium.

KOMAN or Kipchak are a Turk race, generally styled Kirghiz-Kazaks, the Ghozz Turk of Arab writers.

KOMAR, a chief, a prince, a first-born; hence also Komari, a virgin, from which, according to a legend, is derived the name of Cape Comorin. Komari is also a term given to all forts until they stand an assault. It is usually written Kumar and Kumari. The law of primogeniture prevails in all Rajput sovereignties, and has rarely been set aside. The inconclusive dicta of Menu on this as on many other points, are never appealed to by the Rajputs of modern days. Custoin and precedent fix the right of succession, whether to 
the gadi of the state or to a fief, in the eldest son, who is styled Raj-komar or Pat-komar, or simply Komar-ji, the prince; while his brothers have their proper names affixed, as Komar Jowan Singh, prince Jowan. Seniority is, in fact, a distinction pervading all ranks of Rajput life, whether in royal families or those of chieftains : all have their Pat-komar and Pat-rani, or head child and head queen. The privileges of the Pat-rani are very considerable. In minorities, she is the guardian, by custom as well as nature, of her child; and in Mewar (the oldest sovereignty in India), she is publicly enthroned with the rana. Seniority in marriage bestows the title of Pat-rani, but so soon as an heir is given to the state, the queen-mother assumes this title, or that of Mah-ji, simply the mother. In the duties of guardian she is assisted by the chiefs of certain families, who with certain officers of the household enjoy this as an established hereditary distinction. On the demise of a prince without lawful issue of his body, or that of near kindred, brothers or cousins, there are certain families in every principality (raj) of Rajwarra in whom is vested the right of presumptive heirship to the gadi. In order to restrict the circle of claimants, laws have been established in every state limiting this right to the issue of a certain family in each principality. And in Jeypore, in the branch Rajawut (according to seniority), of the stock of Raja Man, there is a distinction between those prior, and those posterior, to Raja Madhu Singh ; the former are styled simply Rajawut, or occasionally conjoined, Mansingote ; the other Madhani. The Rajawut constitute a numerous frèrage, of which the Jhulaye house takes the lead, and in which, provided there are no mental or physical disabilities, the right of furnishing heirs to the gadi of Jeypore is a long-established, incontrovertible, and inalienable privilege.-Tod's Rajasthan, ii. p. 381.

KOMARAM. Maleat. A tribe of barbers who shave the lower classes.

KOMARASAMY, a hill south of Ramanmallai Hill, 30 miles west of Bellary, overlooking the valley of Sundur.

KOMARPAL, a sovereign of Gujerat, of the Chauhan race. According to a legend, astrologers having foretold that he would have a son born in Mula Nacshitra who would cause his father's death, the lad was sent as an offering to the shrine of Bageswara Mata, by whom he was not only preserved from destruction, but she herself, in the form of a tigress (bag), suckled the young Solankhi, whence his issue, which spread over the country, obtained the distinctive name of Bagela. The princes of Baghelcund are of this race, and there are many petty chieftainships of this tribe in Gujerat, as Lunawara, Mandvie, Mahera, Godra, Dubboye, etc. Komarpal was born in S. 1145; and, in the words of the Charitra, ' in S. 1222 (A.D. 1166), Komarpal became a ghost. He left this world, poisoned by his successor, Ajipal.' It was during the reign of Komarpal that the celebrated Arabian geographer El-Edrisi visited the kingdom of the Balhara, and from his work Bayer and D'Anville gleaned much information.-Tod's Travels, pp. 184-191.

KOMARPAL-CHARITRA, a history of the kings of Anhilwara.

KOMARSAMY, lat. $15^{\circ} 1^{\prime} \mathrm{N}$, and long. $76^{\circ}$ $35^{\prime}$ E., in Mysore, a pagoda west of Hirahall; a peak near the pagoda is 3400 feet above the level of the sea.-Cullen.

KOMATI, a Hindu race in the south of India, speaking Telugu, who claim to be pure Vaisya, are occupied as traders and in other peaceful avocations. The term is applied in the west of India to shopkeepers, and petty dealers, and clerks, who also claim to be the pure Vaisya. In Madras they are called Chettyar or Chetty; in Western India, Seth; the latter a term also applied to Parsee and Muhammadan tradesmen. The Komati of Mysore invite the Madaga to their weddings, but the Madaga consider the invitation an insult.

KOMERKOLLI or Comer-colli, a creek in the Gangetic delta. Herdsmen at the mouth of the Comer-colli wrap great turbands round the head and neck, and use longer and warmer mantles than are usual in Bengal. They are a caste by themselves, tall, robust men, many with long beards, and all wilder looking than the majority of their countrymen.-Heber's Journ. i. p. 174.

KOMSALA, also Komsallar. TAM. An artificer, from Kansa, a metal. In British India there are, amongst the Hindus, five artificer races-1. the gold and silver smith; 2 . the brazier or tinsmith ; 3. blacksmith; 4. carpenter; and 5. stone-mason or stone-cutter. These worship the Hindu gods, but they do not reverence Brahmans, and their marriage and funeral customs differ from those of the Brahmans. The goldsmiths regard it as a disgrace to have any of their daughters growing up without being married.

KONAJI ANGRIA, a person of low origin who long carried on a piratical warfare on the western coast of India, and rose to princely power. Gheriah was his headquarters, but Severndrug and every creek were fortified. Gheriah was captured by Clive and Admiral Watson in 1755. See Angria : Kolaba.

KONAKAN. MaL. A class of predial slaves in Malabar, a subdivision of the Vetuvar or forest and hunter tribe. They are employed in agriculture, also as boatmen and salt-makers.Wilson's Glossary.

KONDA. TAM., TEL. A hill.

KONDAI, TAM., also Kondek, TAM., a chignon ; a knot of hair at the back of the head, in which form the Tarnil and Teling women, and the men and women in the Southern and Central Provinces of Ceylon, bind up their hair.

KONDAMIR, the takhallus or literary title of Ghaias-ud-Din-bin-Humam-ud-Din. His book is entitled Habib-us-Sayar-fi-Afrad-ul-Bashar, that is to say, the curious part of the lives of illustrious men. It is a history which he had extracted from that which his father Mirkhond had composed, and entitled Rauzat-us-Safa, but to which he made augmentations. He dedicated this book to the secretary of state belonging to the king of Persia, Shah Ismail Safari, who gave him the name of Habib-Allah; and for that reason the book had the name of Habib given it in the year 1508 , Hijira 927, in the reign of Louis XI. He was also author of another history, which is entitled Khalasat-ul-Akhbar, or the Cream of Histories. Kondamir came to Baber's court soon after his invasion of India, and died in the camp of Humayun during his expedition to Gujerat (A.D. 1535), - History of Genghiz Can, p. 422. 
KONG-WHA. CHIN. A variety of safflower or Carthamus tinctorius which grows in China. It is held in high esteem by the Chinese, and is used in dyeing the red and scarlet silks and crapes which are so common in that country, and so much and justly admired by foreigners of every nation. Iarge quantities are annually produced in the Che-kiang province.

KONKAN or Konkana is an ancient name of the country between Devagarh and Sadasegarh; hence, perhaps, the modern Konkan. It is comprised between the ocean and the Western Ghats, and consists of a narrow belt near the sea, with saltwater inlets and a succession of mountain spurs. In the northern parts of the Bombay Presidency, the chain separating the Konkan from the Dekhan is called the Northern Ghats, or Sahyadri mountains, a term which may conveniently be extended to their whole length. Througbout the Konkan, the Sahyadri form a continuous chain of hills, interrupted, however, by deep depressions. Their summits rise to the height of 4000 to 5000 feet, but the mean elevation is very much less. The station of Mahabaleshwar is 4700 feet. In the latitude of Daman, $20 \frac{1}{2}^{\circ} \mathrm{N}$., the chain begins to sink abruptly into the Tapti valley, and changes its course, or sends off a spur of considerable elevation in an easterly direction, as the Chandor Hills.

The Konkan comprises the districts of Bombay, Kanara, Colaba, Ratnagherry, and Thana, and has an area of 13,580 square miles, and a population of $3,259,776$. South of Bombay it is divided into the districts of Ratnagiri and Colaba, and is much broken up by spurs from the ghat range and by outlying hills. There are in this district about 150 Buddhist caves, two in a ravine N.E. of Chaul; others at Kuda and at Mhar, at Dabhol, Chapalun, and Sangameswar. Gujerati is spoken in the north part, Mahrati at various central parts, and Canarese in the south. But the Konkani language by some is regarded as a sister language to Mahrati. It has claims to be considered a distinct Neo-Aryan tongue, but much influenced by the so-called Dravidian language. It has also a large literature, mostly dating from the times of the early Portuguese rule in Goa, and due to the zeal and ability of the former Jesuits; and for these reasons to a philologist is of great interest. There are three principal dialects of Konkani, but the Southern or Canara dialect is of greater interest to the philologist than either of the others, as it displays better the action of the Dravidian languages of the coast (Tulu and Malealam), which form a marked subdivision in the Dravidian family, not only phonetically, but in the vocabulary.

To others, the mixed Konkani tongue appears to be only Mahrati with a large infusion of Tulu and Canarese words, the former derived from the indigenous inhabitants of Tuluva of Canara; the latter, from the long subjection of this part of the Konkan to Canarese dynasties above the ghats. Mr. H. Moegling, however, mentions that the Konkani-speaking Brahmans of Mangalore consider it quite distinct from, though cognate with, Mahrati. Its limits extend from Goa, below the ghats, to a village north of Upi. From this part of the coast, in Northern Canara, a diagonal line running in a north-eastern direction towards Beder, marks the boundary between Mahrati and Canarese, of the latter at least above the ghats.
Konkaniga, of Coorg, are immigrants from the Konkan; many of them are Roman Catholics. The populations returned in 1881 as speaking Konkani was only 29,585 -

Coorg, . . . . 1,689| Mysore, . . . . 4,370 Cochin, : : :12,823 Travancorc, : : 10,703 -Burgess, p. 204 ; Elphin. p. 220 ; Cunmingham, Ancient Geog. of India, p. 552.

KOO. To avoid repetitions, for all the words frequently written with the double ' $\mathrm{o}$ ' see $\mathrm{Ku}$.

KOPHENE, according to General Cunningham, is Kābul. This district is first mentioned bv Ptolemy, who calls the people Kabolitz, and their capital Kabura, which was also named Ortospana. In some copies of ;Pliny the name is written Orthospanum, which with a slight alteration to Orthostana, as suggested by H. H. Wilson, is most probably the Sanskrit Urddhasthana, that is the high place, or lofty city. The same name is also given to the Kābul district by the Chinese pilgrim Hiwen Thsang. But General Cunningham suspects that there has been some accidental interchange of names between the province and its capital.

The Kophen river is mentioned in the Vendidad under the name of Kubha, and the Kophenes river, named in Alexander's marches, is supposed to be the river of Kābul. Kophes is a name as old as the time of the Vedas, in which the Kubha river is mentioned as an affluent of the Indus; and as it is not an Aryan word, General Cunningham infers that the name must have been applied to the Kanbul river before the Aryan occupation, or at least as early as B.c. 2500. In the classical writers we find the Khoes, Kophes, and Khoaspes rivers to the west of the Indus, and at the present day we have the Kunar, the Kurah, and the Gomal rivers to the west, and the Kunihar river to the east of the Indus, all of which are derived from the Scythian $\mathrm{ku}$, water. $\mathrm{Ku}$ is the guttural form of the Assyrian hu in Euphrates and Eulæus, and of the Turki su and the Tibetan chu, all of which mean water or river. The district of Kophene must therefore have receired its name from the river which flowed through it, like as Siud from the Sindhu or Indus, Margiana from the Margus, Aria from the Arius, Arachosia from the Arachotus, and others. It is not mentioned by Alexander's historians, although the river Kophes is noticed by all of them.-Cunningham's Ancient Geog. of India, p. 39. See Afghanistan; Bactria.

KOPIA, or Song-Ko, a skull-cap of Celebes, made of Pandan leaf, and worn by the Musalman inhabitants.

KOPPA CHOR. Leaving the Bhotea tribe, and proceeding eastwards, the following are the races on the north of the Brahmaputra river:Kachari, Akha, Koppa Chor, Mechu, Dofla, Miri, Abor, Bor-Abor, Khamti, and Mishmi.

The races south of the Brahmaputra areGaro, Mikir, Khasiya, Jaintia, Kuki of N. Cachar, Kutcha, Angami and Arung Naga, Munnipuri, Singpho, Muttuk, Bor Khamti, Khunung, and Shan.

Of those on the north, the Akba and Koppa Chor occupy the slopes of the Himalaya to the north of the Durrung and Luckimpur districts, and more to the eastward in the same range are the Dofla.

Farther eastwards from the Dofla are the Miri, 
who live on. lower land all along the north bank of the Brahmaputra river, eastwards from the Dofla up to the banks of the Subansiri river.

KORA. Hind. New, fresh, plain, unclyed silk; unbleached or undressed cotton cloth.

KORACHARU, a tribe in the Carnatic, who make bamboo baskets and bamboo mats. Professor Wilson writes their name also Korcharu, Karvaru, Korsam, etc., and adds that they carry betel nuts from market to market; but this, as an avocation of the Korawa race, is unknown. They live in the hills and forests, and are usually designated Korcha.

KORAGAR, a servile race occupying the hills and jungles of S. Canara and about Mangalore. They have three divisions, - the Ande Koragar, the Tastra Koragar, and Sappu Koragar. There are said to have been other two tribes, now extinct, the Kumaranna and Mungaranna. They clothe themselves like the poorest of the labouring class. The Ande Koragar, now rarely seen, are described as having a pot suspended from their necks. The Sappu Koragar wear leaves for clothes. The tribes intermarry. Their marriage ceremony consists of bathing; the couple, after sitting together on a mat, have a little rice sprinkled on their heads. Their dead are buried in a consecrated place, and four balls of rice are placed on the grave. They are called after the days of the week, Aita, Toma, Angara, Gurva, Tanya, and Tukra. Their elder present is their priest, and they worship beneath a Kasarkaua tree, spreading plantain leaves at the shrine, or Kata, on which they place rice mixed with turmeric. The women cover the lower part of their body with leaves interwoven together. Their träditions are that an Abyssiniau brought an army from Anantapore, of which they formed a part. The army was at first victorious, but afterwards, being defeated, the Koragar were driven into the forests.-The Lioragars, by Ullal Raghavendra Rao.

KORAH, a short but heavy Nepal sword of a half-moon shape, the edge of which is on the inuer side, like that of a scythe. Oliphant, in his Journey, mentions that the brother of Jung Bahadur with one blow of a korah decapitated a bullock. Down came the korah with crushing force, and passed right through the animal's neck. The headless trunk tottered for a second, and then fell heavily over.

KORA-KORA, a boat of the Malay Archipelago, near Batchian, some of them of 4 to 5 tons burden. They are open, have bamboo outriggers 5 feet on each side, which support a bamboo platform; they are low in the water. $-W a l$ luce, ii. p. 35.

KORAN, properly Quran, is the religious book of the Muhammadans, and is designated by them Quran-i-Sharif, the noble Quran; Quran Majid, the glorious Quran; Furqan, the distinguisher; Kalam Allah, the Word of God. Al-Furqan, the distinguisher, is the same as the Jewish use of Perek or Pirka, denoting a section of scripture. It is also called Al-Mushaf, the rolume; also Kitab, the book, answering to the Biblia of the Greeks; and also Us-Zikr, the admonition, which name is also given to the Pentateuch and to the Christian Gospel.

Koran or Quran is a term derived from the Arabic Qara, which occurs at the commencement of Sura xcv. It is said to have been the first chapter revealed to Mahomed, and has the same meaning as the Hebrew Kara, to read or to recite, frequently used in Jeremiah xxxvi. and other places in the Old Testament. It is therefore the equivalent of the Hebrew Mikra in Nehemiah viii. 18.

The origin of the book is variously given. Zaid-ibn-Thabit, secretary to Mahomed, is said to have been selected by the first khalif, Abubakr, to collect the scattered portions. The second khalif, Othman, on the representation of a devout man called Hudhaifa, that the books in existerce differed, is said to have made a recension of it, and sent a copy to all the countries of Islam, ordering all others to be burned. But a general opinion amongst the learned of Europe is that the oral deliveries of Mahomed were collected and committed to writing by the third khalif, Umar.

According to Sale (Prelim. Disc. pp. 77, 86, 87), Mahomed delivered it to his followers through the space of 23 years, and they are believed either to have committed it to memory or to have written it on palm leaves, stones, or, as Gibbon states (ch. i. p. 264, Milman edition), on shoulderblades of sheep. The original copies were thrown into a chest, and in this disorder they were left when Mahomed died. Two years later, Abubakr ordered the whole to be collected, both from what was written and what had been committed to memory. About 17 years afterwards, observing discrepancies in the existing copies, he ordered a large number of new ones to be transscribed. The Shiah Muhammadans assert that ten sections, one-fourth of the whole, were struck out by Othman, and the Dabistan is said to contain one of these.

Lane further says (p. 92), it is generally believed that few of the chapters as they now stand were delivered entire. The first five verses of the $96 \mathrm{th}$ chapter are supposed to have been the first delivered. Abubakr seems to have arranged the chapters in the manner they now present, and delivered the transcript to Hafza, a daughter of Umar, one of the widows of Mahomed.

The Koran is the highest authority for Muhammadan doctrine; but in addition thereto the believers in Islam must receive the sayings and practices of Mahomed as of divine obligation. In this faith the teachings of the traditions must be received by all its sects side by side with those of the Koran itself, and the opinions in the numerous commentaries of the learned expounders who wrote in the early days of Muhammadanism.

Muhammadans believe the Koran to be the inspired word of God, sent down to the lowest heaven complete, and then revealed from time to time by the angel Gabriel to Mahomed. It is generally diffused amongst the people of this religion in Arabic, but it has also been translated into English, Latin, German, Italian, French, Spanish, Turkish, Persian, Hindustani, Tamil, Burmese, and Malay, though the more strict Muhammadans reject translations. It has had numerous commentators, amongst whom are AlBaidawi, Maliki, Hanifi, Shafi, and Hanballi. The Koran inculcates the existence of one true God and obedience to his laws, and to this religion they give the name of Islam, and its followers Muslimin, the plural oblique form of Muslim, a Musalman. It contains doctrines and positive precepts as to faith and religious duties and 
institutions in civil affairs. It commands certain months to be kept sacred, aud sets apart Fridays for the especial service of God. It is arranged into 144 chapters, distinguished by their subjects, the first of which is called the preface, or Al-Fatihah, which is a prayer, and is much venerated by all Muhammadans, who often repeat it in their private and public devotions, as Christians do the Lord's Prayer. It words are'Praise be to God, the Lord of all creatures, the most merciful, the king of the day of judgment. Thee we do worship, and of thee do we beg assistance. Direct us in the right way, in the way of those to whom thou hast been gracious; not of those against whom thou are incensed, nor of those who go astray.' The Koran recognises men, genii, and angels, heaven and hell, and an intermediate spot, and two gardens where beauteous damsels shall await the good. The Arabic Koran is generally in use, but so little are Indian Muhammadans acquainted with its language, that in Madras in 1872, with 70,000 of this religion, it was supposed that only 4000 or 5000 could read to understand the Arabic Koran. There is probably no other book in the world which has remained 13 centuries with so pure a text.

The idea of a heavenly place enunciated in the Koran is, however, the grossest that any race has ever promulgated or given credence to. The wild hunting tribes of America have sublime uotions of a future life ; Hebrews were in conflict as to the immortality of the soul; most Buddhists helieve in absorption or annibilation as a release from all the troubles and trials of a mundane existence; Christians believe that the future will he a spiritual life; but the doctrines taught in the Koran as to the occupations in heaven are wholly confined to that book and its believers. For the Koran says (ch. lv. pp. 393, 394), 'They shall repose on couches, the linings whereof shall be of thick silk, interwoven with gold; and the fruit of the two gardens shall be near at hand to gather. Which, therefore, of your Lord's benefits will ye ungratefully deny? Therein shall receive them beautifuldamsels, refraining their eyes from beholding any besides their spouses, whom no man shall have deflowered before them, neither any genius (which, therefore, of your Lord's benefits will ye be ungrateful?), having complexions like rubies and pearls.... And besides these, there shall be two other gardens .... of a dark-green. In each of them shall be two fountains pouring forth plenty of water. ... In each of them shall be fruits and palm trees and pomegranates.

Therein shall be agreeable and beauteous damsels, ... having fine black eyes, and kept in pavilions from public view, ... whom no man shall have cleflowered before their destined spouses, nor any genius. . . Therein shall they delight themselves, lying on green cushions and beautiful carpets.'

Nevertheless Mahomed was a monotheist and an iconoclast, and when about to die, before the final struggle, lifting up his voice he exclaimed, - May God be far from those who make the tombs of his servants places of prayers!' The very last words he was heard to utter as he expired, as if in answer to an unseen visitor, were, 'In the company of the blessed on high.' Muhammadans do not speak of a person as dead. They say he has passed away, has taken his departure; and, as in the Koran, the living all believe in and hope for resurrection in a future state ; and the Koran says, "They who believe, and do that which is right, shall enjoy blessedness, and partake of a happy resurrection. ... Paradise ... is watered by rivers: its food is perpetual, and its shade also. This shall be the reward of those who fear God' (Koran, ch. xiii.). "Therein are rivers of uncorruptible water; the rivers of milk, the taste whereof changeth not; and rivers of wine pleasant unto those who drink; and rivers of clarified honey, and therein shall they have plenty of all kinds of fruits, and pardon from their Lord' (ch. xlvii.). 'There shall be gardens with shady trees, with fountains flowing, couches of silk interwoven with gold; beauteous damsels with black eyes, lying on green cushions and beautiful carpets, fruits, palm trees, and pomegranates' (ch. lv.). The words of the Kalaina or Mubammadan creed do not occur in the Koran, nor in it is circumcision enjoined. The Christian doctrine that man, in all that he can do of good, is still without merit, is not shared in by the Mulrammadan, the Buddhist, or the Hindu sectarians, who all consider that a personal merit is gained by their good-doing; and a Mubammadan passing the funeral of a Muhammadan turns with it a short way, and lends his shoulder to convey the body to the grave, to bring a merit on himself. The histories and legeuds, precepts and ceremonial of the Old Testament, and traditions of the Rabbi, are largely adopted in the Koran. The commentaries on it are called Maltika. The commentator Hanifi was born at Kufa A.H. 80 , died at Baghdad, in prison, A.H. 150 , nearly 70 years old. Shafi, born at Ghaza in Palestine A.H. 150, died in Egypt A.H. 204, nearly 50 years old. Hanballi, born A.H. 164 at Baghdad, died there A.H. 241 , nearly 70 years old. Maliki, born at Medina A.H. 95, died there A.H. 179 , nearly 84 years of age. Muhammadan schoolboys arc instructed, almost while in their infancy, to intone the Koran. The Koran is inadequate to provide for the legislative wants of the remote lands and times which it accidentally reached; and throughout Islam the Rasm or ancient practice of the country is held sacred by the people, always when not in direct opposition to revelation, sometimes even when it is so. The law of the Koran does not necessarily settle a disputed point between Muhammadans, and it is by no means an easy operation to adjust the balance between the good sense of the ancient practice and the discrepant decrees of the inspired volume. The Koran says that a man of the name of Dujjul will appear at Isfahan, who will arrogate to himself the attributes of the Supreme Being, and establish a sect of his own. The Koran is also understood to say that Mahdi is the 12 th Imam or regular successor of Mahomed, who is yet to come, and for whose coming the Mubammadans are still looking out with anxious expectation.

On a night near the 27th of Ramzan, the Koran is believed by Muhammadans to have come down from heaven. It is called the Lailat-ul-Kadr, the night of power ; and the Muhammadans of India pass the night with much solemnity.

The honour which the Muslims show to the Koran is very striking. They generally take care never to hold it or suspend it below the girdle, and they deposit it upon a high and clean place, 
and never put another book or anything else on the top of it. On quoting from it, they usually say, "He whose name be exalted (or God, whose name be exalted) hath said in the excellent book.' They consider it extremely improper that the sacred volume should be touched by a Jew or Christian, or any other person not a believer in its doctrines. It is even forbidden to the Muslim to touch it unless he be in a state of legal purity and hence these words of the book itself- 'None shall touch it but those who are purified' - are often stainped upon the cover.-Osborn's Islam, p. 11; Dr.J. Murray Mitchell; Wilson's Glossary Lane's Koran, pp. 84, 92; Rodwell's Koran ; E. H. Palmer's Koran; Hamilton's Senai, Hedjaz, Sourlan, p. 99 ; R. F. Burton's Scinde, pp. 398 413; Duff's Indian Rebellion, p. 179 ; Sale's Koran.

KORA VARA, Koravar, Koraman, a low caste tribe of Mysore. The Kalla Koramar are professed thieves; Walaga Koramar are musicians; Hakki Koramar, migratory basket-makers, fowlers.

KORAWA, a broken nation scattered throughout the south of India. In the Peninsula their subdivisions are-1. The Bajantri, called Gaon Korawa or Sonai Kolawuru; 2. Tiling Korawa or Kasbi Korawa or Kunchi Korawar ; 3. Kolla Korawa; and 4. Soli Korawa, a race of the Southern Mahratta country. The Yerkal Korawa or Kunchi Kuri are wanderers, of whose original country they themselves retain no knowledge in their traditions. They style themselves Yerkal, and they give the same appellation to the language in which they hold communication with each cther. Their ostensible occupation is birdsuaring. With the exception of the cow, almost all animals are used by them as food. Their dead are burned. A wild Korawar tribe dwell Hear the Pakhal Lake and the Godavery. The race are in Canarese called Kora-varana, Korama-ravanu, or Koravanu, and are there in three branches, - Kalla Koramar, who are professed thieves; Walaga Koranar, who are musicians; aud Hakki Koramar, who are a migratory race, and subsist by basket-making, catching birds, etc. In Mysore the Korawar are hill and forest tribes, and have a dialect of their own.

In the south the Yerkala are recognised as Koravar. They eat game and flesh meat of all linds, in which they are by no means nice. The jungle herbs, roots, and fruits also furnish them witli food. The majority of them pretend to fortune-telling. They also take to basket, mat, and wooden comb-making,-for the former two they use the midribs and leaves of the date jalm,-and occasionally work as coolies. Sometimes wealthy men of the tribe settle down in places, engage in cultivation, and hold land in juttah like other cultivators. As a rule, they wear only as clothing a small piece of cloth. Their habits are decidedly predatory. They form bands of dacoits and thieves. Their huts comprise mats set upon three sticks, and, when on the move, these they roll up, and place on the backs of their doukeys, and are thus easily transported from place to place. They rear pigs, and are partial to their flesh. They also keep poultry and dogs. Their pack animals consist chiefly of donkeys; occasionally some of them have a few horned cattle, and perhaps a few goats also. A similar tribe, under the name of Upu Koravar, was described by Dr. Bilderbeck as found in South
Arcot. Their language seems to be a medley of Tamil and Telugu. Most of them have some household god, which they carry about with them in their constant travels. Polygamy prevails. Marriages are only contracted between adults. The ceremony is usually conducted on a Sunday, preceded by a puja on the Saturday. Rice mixed with turmeric is bound on the heads of the married couple, and when the marriage string is tied round the wife's neck the ceremony is complete. Marriages within certain degrees of relationship are not allowed, and widow remarriages not permitted; they may occasionally live in concubinage. A custom prevails among them by which the first two daughters of a family may be claimed by the maternal uncle as wives for his sons. The value of a wife is fixed at 20 pagodas. The maternal uncle's right to the two first daughters is valued at 8 out of 20 pagodas, and is carried out thus: If he urge his preferential claim, and marry his own sons to his nieces, he pays for each only 12 pagodas, and, similarly, if he, from not having sons, or any other cause, furego his claim, he receives 8 pagodas of the 20 paid to the girl's parents by anybody else who may marry them. The value of a wife differs in different places. In some places they are very much less, and in others again only nominal. In Nellore the Yerkala or Telugu Koravar pledge their daughters to creditors, who may either marry them or give them away. When the Yerkala goes to jail, his wife lives with another man of her tribe. On release he reclaims his wife and children, if any are born in the interval. In North Arcot, Koravars mortgage unmarried daughters, who become the absolute property of the mortgagee till the debt is discharged. In Chingleput, the practice of mortgaging their wives exists among the Upu Koravars. In South Arcot it is said not to exist. In Tanjore it is common. Male children become the property of the mortgagee, females that of the husband of the woman pledged. In Madura they sell the wife for 50 rupees outright, and the husband can never reclaim her. Wives and daughters are both pretty freely pledged; disputes are settled by panchayets or arbitrations. Each gang or community comprises many distinct families, each having their own family names, and, like the Hindus, they form undivided families. Brown and Campbell define the word Yerkalavandlu. Wilson defines Kulaver, Yeraver, and Kuraver, etc.-Dr. Shortt, Madras Journ. Literat. and Science, 1851, p. 4; Asst.surg.-Gen. Edward Balfour; Wilson's Glossary; Madras Times, 8th Jan. 1873.

KORDAD-SAL, a Parsee festival day, the anniversary of the birth of the prophet Zoroaster. - Parsees, p. 61.

KOREA, a tributary State in Chutia Nagpur ; area, 1631 square miles; ruled by a family who claim to be Chauhan Rajputs. The people. 21,127 in number, are largely of Gond and Cheru races. It yields coal and iron, the latter worked by the Agariah race.

KOREA, known to the natives as Chō-sen, written by the French Tsio-sen or Tsyo Syeun, in some respects to be regarded as an independent section of the Asiatic mainland. It is a peninsula with the Sea of Japan and the Yellow Sea on the E. and W., and Manchuria and Russia on the $N$. Its area is 80,000 or 90,000 square miles, and its 
coast-line 1740 miles. Of all modern states, Korea has maintained the most exclusive isolation, not only from Western influences, but also from those of the surrounding lands. Politically, it consists of an autonomous hereditary monarchy, divided into eight tao or provinces, with a ruler who styles himself Hap-mun. People are chiefly agricultural ; but gold, silver, copper, iron, and argentiferous galena are abundant, and to some extent have long been worked. Coal has not been found. Some of the lead mines are 800 feet deep, with sidings.

The Koreans resemble the Japanese and Chinese in dress, habits, and religion. The Manchu call the Korean race Solgo, Sol-bo, or Sol-ho. The people follow Confucianism and Buddhism, but have many shamanist customs, with spirit and ancestor worship, sylvan, river, and mountain deities.

The Koreans were driven out of East Tartary into the peninsula which they now occupy. They have since been conquered by the Japanese. Their country was subsequently invaded by the Mongol, on which occasion the Siogour Yoritomo defeated Kablai Khan. From this province of Japan sailed, by way of Iki and Tsusima Island, the two expeditions of Japanese Catholics who, between 1590 and 1610, were banished upon a crusade against Korea, and through Korea, China. The then emperor, Taikosama, took this means, thinking, if his 150,000 Catholies perished, he would be rid of a faction dangerous to his supremacy; should they succeed, he would push them forward to conquer China. The Japanese expedition in three months fought their way to the Ping-Yang river; in other words, gained twothirds the length of the kingdom. But then, abandoned by Taikosama to their fate, they were driven by winter, cold, and snow, and by the Chinese troops who came to the aid of Korea with matchlocks, of which the latter then knew not the use, to relinquish step by step the ground they had so rapidly won.

The Koreans have flat faces, oblique eyes, broad cheek-bones, strong black hair, and scanty beard; they are strongly made; their skin varies from tawny or yellow to brown, wheat or straw colour, and reddish-yellow. They have a mixture of the Chinese and Japanese physical features. Their religion is Buddhist.

Korean Buddhists and Buddhism were made known to Mexico by Chinese priests in the 5 th century A.D., and had followers in that country until the 13th century, when the conquering Aztecs put an end to it.

Their mode of writing is alphabetic, and they are said to possess an extensive literature. The Korean or Corean language strongly resembles the Japanese, and it approximates phonetically to the Burma-Chinese group. Its Scythic character has been considerably modified by the Chinese. Dr. Gutzlaff says the present spoken language consists in great part of composite words, in which the words of both languages are united to express one idea.-Mr. Logan in J. 1 . Archipelago; Adams; Nagasaki, 12th May 1871; Latham; Encyclopædia Britannica; Huc's Christianity; Griff. Corea.

KORESH, an Arab tribe in the Hejaz. They were the descendants of the mixed Arabs, al-Arab - ul-Mostareba, lineal descendants of
Ishmael. Mahomed belonged to this Arab tribe. The Koreshi have in Sind many tribal names. They are cultivators, kazees, and scribes, and originally came from Syria, Iran, and Irak, and claim descent from Ali, Abbas, Abubakr, Umar, and Usman, styling themselves Alvi, from Ali; Abbasi, from Abbas; Sidiki, from Abubakx; Faruki, from Umar; Usmani, from Usmau. See Adnan; Iran; Joktan.

KOREYALA. HIND, The hen bird of Eudynamis orientalis, Linn., the koel.

KORGO, an island $1 \frac{1}{2}$ to 2 miles $N$. of Kharak; it was the stronghold of the pirate Mir Mohanua.

KORI, the name given to the eastern branch of the Indus. It is also known as Sunkra (narrow), and farther up as the Phran. Kori, also, is any inlet of the sea. The Kori or Lukput river (which separates Sind from Cutch), up to the earthquake in 1819 , was the eastern mouth of the Indus river, but that earthquake laid most of the towns of Cutch in ruins, and a ridge called Allah Band having been raised to the northwards of the Kori, entirely cut off the flow of the Indus river into it. Its mouth was greatly enlarged in area, and was shifted, as it formerly entered the sea to the northward of Jucku.-Findlay.

KORINCHI. The people of this name in Sumatra border on Menangkabau. Their alphabet has 29 characters, and consists of horizontal or slightly raised scratchings. See India.

KORING, the Persian wheel, for watering land from a tank or ditch.

KORKU, a hill tribe dwelling to the northwest and west of the Mahadeva Hills, speaking a language quite distinct from the Gond. They belong to the Kol or Mundah family. See Kol.

KORLA or Kora. Hind. A lash of one tail. Kora-kora-marna, to flog.

KORNA, a walled town of 800 houses, 47 miles from Basra, and 137 miles above the mouth of the Shat-ul-Arab. A fort here would command the navigation of the Tigris and Euphrates. - MacGregor.

KORNEGALLE or Kurunai-galla was the capital of the sovereigns of Ceylon from about 1319 till some year after 1347. During this period the dynasty was in extreme depression, and little is recorded except the names of the kings, Bhuwaneka Bahu II., Pandita Prakrama Bahu IV., Wanny Bhuwaneka Bahu IIr., Wijaya Bahu v.-Yule, Cathay, ii. p. 423.

KOROS. Alexander Csoma de Koros, also written Csoma Korosi. This extraordinary man set out on his travels in 1826 from Paris, and went via Constantinople to Persia in the disguise of a darvesh. On his arrival at Teheran he lodged with Sir Henry Willock. Thence he went to Bokhara, Lahore, and Calcutta. He resided for several years at Kanum in Tibet, where he translated from the Tibetan language a cyclopadia of Tibetan knowledge. He afterwards proceeded to Calcutta, and continued to reside there, engaged in communicating to the public, under the patronage of the Bengal Government and the Asiatic Society of Calcutta, the result of bis acquaintance with the language and literature of Tibet, of which he was the first European who had attained a critical knowledge. In the beginning of 1834 he published at Calcutta a Tibetan and English dictionary, and at the end of the same year a grammar of the Tibetan language. Before the 
appearance of these useful publications, he had communicated to the Asiatic Society of Bengal notices of the contents of the two great collections in which the principal works of the literature and religion of Tibet are comprehended, - the Kahgyur, a collection of one hundred large volumes, and the Stan-gyur, of two hundred and twentyfive. Of the former, he also prepared a detailed analysis, part of which is printed in the twentieth volume of the Asiatic Researches. A summary account of both these works, compiled from his information, was printed in the Calcutta Gleanings of Science, iii., and an abridgment of his analytical view of the whole of the Kah-gyur, in the first volume of the Journal of the Asiatic Society of Bengal. He also furnished to the same periodical several interesting papers on subjects connected with Tibetan literature and the religion of Buddha in that country. He illustrated extensively the Buddhism of Tibet.

KORPHA-PRAJA. BENG. A tenant-at-will; a tenant holding under a Khud-kasht cultivator.

KORSOSSA MAIL. SINGH. A creeper, the rough leaves of which are used at Galle as sandpaper.

KORUM-DEVI, a princess of Patan, and one of the wives of Samarsi, king of Mewar, who fell in the battle of the Caggar. During the minority of her son, she nobly maintained the raj of Mewar, and gave battle in person to Kutub-ud-Din near Amber, where that Muhammadan viceroy was wounded and defeated.

KORUR. A battle was fought here, according to Mr. Fergusson, A.D. 544, in which Harsha of Ujjain, styled Vikramaditya, finally defeated the M'hlecha. Its site is near Multan. At another place Mr. Fergusson places the great battles of Korur and Manshari, which freed India from the Saka and the Hun, between A.D. 526 and 544 .

KORWA, a savage tribe in Chutia Nagpur. They may be a portion of the Korava aborigines of Cutch, and of the Korawa of the Tamil, Telugu, and Ceded Districts.

KORWA. TAM. A fish of the Madras coast, the air-bladder of which furnishes isinglass.

KORYGAUM, a hamlet on the left bank of the Bhima river, midway between Seroor and Poona. It is famous for a successful stand made by a small body of the E.I. Company's troops against the peshwa's forces, which were estimated at 20,000 horse and 8000 foot. Captain Stanton left Seroor on the 31st December 1818 at six in the evening, and the following morniug, as be approached the Bhima, observing the peshwa's army in the plain on the right bank, he threw himself into Korygaum, which he reached as a body of the peshwa's infantry, chiefly Arabs, entered and took possession of its other side. At noon the British force began attempts to dislodge the enemy, but was soon compelled to restrict its efforts to defending itself against the assaults of the Arab infantry. They were met by repeated discharges of British artillery, but before evening Lieutenant Chisholm of the Artillery had been killed, many artillerymen killed or disabled, Lieutenants Pattinson, Conellan, and Swanston, and Assistant-Surgeon Wingate wounded; and Captain Stanton, Lieutenant Innes, and Assistant-Surgeon Wyllie, of the officers, alone remained effective. On the following day, 2d January 1819, the peshwa moved off along the Poona road, and in the evening Captain Stanton marched to Seroor, which he entered on the following morning, with drums beating and colours flying.-H. $H$. Wilson.

KOS or Coss, a measure of length. The kos of India varies greatly in length. One kos is about 13,000 feet, or 2 miles 5 furlongs 153 yards. In Mysore, the Sultani kos is about 4 miles. In $\mathrm{N}$. India, the kos-minar pillars are apart 2 miles 4 furlongs and 158 yards. In N. India, the Muhammadans having introduced the itinerary measures of their various native countries, there are a great variety of such measures to which the Hindu term kos is indiscriminately applied. The Muhammadan kos may be taken at 35 to. a degree. Kos-minar, milestones of India, in form are solid circular stone obelisks, little larger than the usual milestones of Britain. The kosminar were put up to mark the ancient Moghul royal road in India, at the distance of every two miles.-Baron Hugel's Travels in Kashmir, p. 93; Tr. Hind. ii. p. 9 . See Coss.

KOS. MAHR. A leather bag with which water is drawn from a well. The Ramia-kos has an iron hoop to keep the mouth open; and the Sundi-kos has a long tail, which is doubled up in the lift. Kosio is a water-carrier.

KOSAH, an Afghan tribe who extend from the Bozdar southern border to a point somewhat below the latitude of Dehra Ghazi Khan, a distance of 300 miles. The tribe dwells partly in the hills and partly in the plains, and can muster about 1200 fighting men. They are at enmity with the Bozdar above them and the Lughari below them: but are on good terms with the Khutrani, who are situated behind them. In 1848 the Lughari sided with the officials of the rebel Mulraj; but the Kosah rose on the side of the Government, under their chief, Korah Khan, and his son Gholam Hyder. Korah Khan and his son then joined Major Edwardes' irregular force in the Multan province with a contingent of 400 horse. Korah Khan was confirmed in the possession of a jaghir of Rs. 1000 per annum for his own life and for that of his son; he himself was granted a life-pension of Rs. 1000, and a garden at the native place of the family was confirmed rent-free in perpetuity. The chief always remained loyal. His tribe, however, occasionally joined in forays made by other tribes; cause for dissatisfaction has, however, arisen from plunder having been conveyed through the Kosah passes into the hills by other tribes.

KOSALA or Maba Kosala, written also Koshula and Koshulya, seems to have been an Aryan dominion in ancient India which varied greatly in extent, or may have been a name applied to several distinct kingdoms. One of these, ruled by the Solar dynasty, was on the banks of the Sarayu river, of which Ayodhya was the capital. This may at one time have extended into Vidarba, which has been identified with Berar. Dr. Hunter is of opinion that the Kosala mentioned by Hiwen Thsang had Ujjain on the north, Andhra and Kalinga on the south, and was 1000 miles long from Maharashtra to Orissa. In the Imperial Gazetteer, he says the limits of the kingdom may be roughly described as extending from near Berhampore on the Tapti and Nanda on the Godavery, to Ratanpur in Ch'hattisgarh and Nawagadha near the source of the Mahanadi.

In the ancient story of the Ramayana we are 
made acquainted with the distant maritime wars which the princes of India carried on. But even supposing Ravana's abode to be the insular Ceylon, he must have been a very powerful prince to have equipped an armament sufficiently nunierous to carry off from the remote kingdom of Koshula, the wife of the great king of the Surya race. It is most improbable that a petty king of Ceylon conld wage equal war with a potentate who held the chief dominion of India, whose father, Desaratha, drove the victorious car (ratha) over every region (desa), and whose intercourse with the countries beyond the Brahmaputra is distinctly to be traced in the Ramayana.-Tod's Rajasthan, i. p. 586; Hardy's Eastern Monachism, p. 438 ; Garret; Hunter.

KOSAMBI or Kosam, on the Jumna, was one of the most celebrated cities in ancient India, and its name was famous among Brahmans as well as Buddhists. The city is said to have been founded by Kusamba, the tenth in descent from Pururavas; but its fame begins only with the reign of Chakra, the eighth in descent from Arjun Pandu, who made Kosambi his capital after Hastinapura had been swept away by the Ganges. The ruins are on the Jumna, about 30 miles above Allahabad; there is an immense fortress of earthen ramparts and bastions, with a circuit of 23,100 feet, or exactly 4 miles and 3 furlongs, and the ramparts 30 to 50 feet high. It is largely visited by the Jains.-Cunningham's Ancient Geography, pp. 391-396.

KOSHA, SANsK., from Kush, to issue, to identify. In the trial by Kosha or image water ordeal, the accused person drinks some of the water with which an idol has been washed, and if the accused survive free from calamity through the next fortnight he is innocent. See Divination.

KOSSÆI. In the gradual diffusion of mankind, the western provinces of Iran appear to have fallen to the share of the Arameaus and Elamites, while the mass of the Kossæi, Ariani, Mardi, and other tribes composing the earliest inhabitants, moved more eastward, leaving some of their numbers in the mountainous districts to mix with or become subject to the new comers. The Semitic people and language having thus become dominant instead of the Cushite, the ethnography of the former rather than that of the latter becomes an important consideration. From this primitive language, or rather from one of its cognates (as the Himyaritic may possibly prove to have been), two distinct branches were derived, the original Arabic, with the Musnad, Koresb, and other dialects of that tongue, being one of these, and the Aramaic the other. The latter had two grand subdivisions, from one of which, known as the Western Aramaic, were derived the Ambaric, Syriac, Hebrew, etc.: and from the other, or Eastern Aramaic, came the Assyrian, Babylonian, and Chaldæan tongues. From its monosyllabic construction, the Eastern Eeems to be more ancient than the Western Aramaic, and it appears likewise to be the root of the Zend, Pehlavi, Sanskrit, and other dialects in use throughout a portion of the territory along which it had spread eastward. Whether the first of these languages was once in general use, or was merely the sacred language of Iran, the affinity of all of them is such as to imply a common origin. Peblavi was the court language in the time of the Sassanian monarchs, and, according to some authorities, as far back as that of Cyrus; it contains many words which belong to the Chaldaic and Syriac tongues, and Sir William Jones was of opinion that one of these must have been its root; but it is now generally presumed that the root of the Pehlavi is the Aramaic itself. The cognates of the latter spread westward and eastward, and one of them, the Chaldee, can scarcely be distinguished from the parent root. Another, the Parsi, being a softer language than the Pehlavi, became general in Farsistan, and gave rise to the Deri, or modern Persian. The Pehlavi, however, is still partially used in their sacred writings, in Shirwan, and also by some of the Gabr sect of the eastern provinces, as well as by a numerous section of the natives of India ; but among the Parsees it is largely intermixed with the Hindustani and other native dialects, which are more or less connected with the Sanskrit. The affinity of the latter to the Parsi is so great that a learned philologist has pronounced it to be one of its derivatives. The number of words which are identical anong the different dialects of Iran and Turan, and some portion of the territory more eastward, goes far to show that at a period anterior to anything like connected history there must have been some common language, and this was probably the Aramaic.

KOSSAH, Sehrai, Chandea, and Sudani are tribes of the Rajputana desert. The Sehrai was the most numerous of the Muhammadan tribes of the desert, but said to be Hindu in origin, and descendants of the ancient dynasty of Arore; but whether his descent is derived from the dynasty of Sehris (written Sahir by Pottinger), or from the Arabic word Sahra, a desert, of which he was the terror, is doubtful. The Kossah or Khossa, etc., are branches of the Sehrai, and their habits were the same. They reduced their mode of rapine to a system, and established koori or black-mail, consisting of one rupee and five durri of grain for every plough, exacted even from the hamlets of the shepherds throughout the t'hul. Their bands were chiefly mounted on camels, though some were on horseback. Their arms were the shail or sang (lances of bamboo or iron), the sword and shield, and but few firearms. Their depredations used to be extended a hundred coss around, even into Jodhpur and Daoudputra, but they eschewed coming in contact with the Rajput, who says of a Sehrai, 'he is sure to be asleep when the battle nakarra beats.' Their chief abode is in the southern portion of the desert, and about Noakote, Mittie, as far as Buliarie. Many of them used to find service at Udaipur, Jodhpur, and Sue-Bah, but they are cowardly and faitbless.-Tod's Rajasthan.

KOSSEIR or Cosseir, a seaport of the Red Sea, in lat. $26^{\circ} 6^{\prime} 50^{\prime \prime} \mathrm{N}$., and long. $34^{\circ} 26^{\prime} 30^{\prime \prime} \mathbf{E}$., on the African side of the Red Sea, has a population of 1500 or 2000 inhabitants.

KOSSI, an ancient tribe who occupied the mountainous country east of the Tigris. That country was the abode of the Scytbians under Nimrud, and Nimrud sprang from them.-Bunsen. See Kossæi.

KOSTI, Kusti, Custee, or Kushi, the sacred thread or cord of the Parsees. It is to this which Moore, in bis Lalla Rookh, alludes 
when he makes Hafiz declare himself a fireworshipper :-

" "Hold! hold! thy words are death!" The stranger cried, as wide he flung

His mantle back, and show'd, beneath,

The Gebr belt that round him hung.'

The Kosti is terminated by two small tails at each end, denoting the four seasons, three knots on each tail represent in the aggregate the twelve months of the year. The cord is twisted, of 72 threads, such being the number, according to Parsee interpretation, of the known kingdoms of the world at the time of Hushang. Every Parsee lad arriving at a certain age must assume it.

KOT, written Cote, Kota, Koth, Kotta, and Kottai, the Hindi, Bengali, Mahrati, and Tamil term for a fort or stronghold, and also applied to the wall of a fort, is alike an affix and suffix to many towns' names, over most parts of British India, or itself a name, as Kot Kangra, Kotah. The bulk of the towns with the affix are in Northern India. Goodicotta, however, is in lat. $14^{\circ} 50^{\prime}$ N., long. $76^{\circ} 40^{\prime}$ E. Sabzal Kot in Bahawulpur. Farid Kot, consisting of Farid Kot proper and Kod-kupoorah, is S.W. of Ferozpur, and borders to the S.E. on Patiala. It has an area of 643 square miles, and a population of 51,000 souls, with a revenue of Rs. 75,000.

KOTA, of Coorg, a site beneath a tree, where the Pariah gods are kept.

KOTAGIRI, on the Neilgherry Hills, in lat. $11^{\circ}$ $20^{\prime}$ to $11^{\circ} 20^{\prime} 10^{\prime \prime} \mathrm{N}$., long. $76^{\circ} 51^{\prime}$ to $76^{\circ} 56^{\prime} \mathrm{E}$., situated 12 miles east of Coonoor, and 6500 feet above sea-level, or rather from the Bowani river. This station is much drier than either Coonoor or Ooty, and although not so cold as the latter, during the summer months the thermometer never rises above $74^{\circ}$, and is then like an English summer, and far more pleasant than Switzerland. In a sanitary point of view, it is the healthiest of all three. Invalids who cannot stand the cold of Ooty and the damp of Coonoor, fly here for comfort and restoration to health. The Kotagiri Ghat begins about $1 \frac{1}{2}$ miles north from Metapolliam, and is about 12 miles in length. Tea is largely cultivated. Rainfall about 50 inches.

KOTAH, a Native State in Rajputana, between lat. $24^{\circ} 30^{\prime}$ and $25^{\circ} 51^{\prime} \mathrm{N}$., and long. $74^{\circ} 40^{\prime}$ and $76^{\circ} 59^{\prime}$ E. Kotah is an offishoot from Bundi (Boondee), forming with that state the tract named Harati, after the dominant tribe of Rajputs. Kotah, the principal town, is in lat. $25^{\circ} 10^{\prime} \mathrm{N}$., and long. $75^{\circ} 52^{\prime} \mathrm{E}$, , on the right bank of the river Chambal. East of the town extends an extensive artificial lake, the Kishar Sagar, which affords facilities for irrigation. The principality of Kotah was formed about the beginning of the 17 th century by the chief of Bundi, who was forced by the maharana of Oudeypore to cede half his territory to his younger brother. Subsequently, like all the other Rajput states, Kotah had been despoiled by the Mahrattas, and was under obligations to pay tribute to each of the three great Mahratta families of Malwa, the Puar, Sindia, and Holkar, as well as to the peshwa. Kotah was then saved from absolute ruin by the talents of its minister, raj rana Zalim Singh, into whose hand maharao Omeid Singh surrendered all power, and in the course of forty-five years he raised the Kotah state to be one of the most powerful and flourishing in Rajputana. He was one of the first of the Rajput chiefs to co-operate with the British Government for the suppression of the Pindaras in 1817. Zalim Singh died in 1824, and his son Madho Singh succeeded him. In 1828, the maharao Kishore Singh was succeeded by his nephew, Ram Singh. In 1834 disputes broke out between Ram Singh and his minister, Mudden Singh, the son and successor of Madho Singh. There was danger of a popular rising for the expulsion of the minister, and it was therefore resolved, with the consent of the chief of Kotah, to dismember the state, and to create the new principality of Jhallaw ur as a separate provision for the descendants of Zalim Singh. Seven teen parganas, yielding a revenue of 12 lakhs of rupees, were then made over to Mudden Singh.

In the mutiny and rebellion of 1857 , the Kotah contingent mutinied and murdered the political agent and his two sons, and the maharao made no effort to aid them. It was captured by General Roberts 30th March 1858, and Faiz Ali Khan, Bahadur, K.C.S.I., was for a time sent to administer the affairs of the state. The troops which the maharao is allowed to entertain are limited to 15,000 men of all descriptions. The state revenue from all sources is about $25,00,000$ rupees. The tribute payable to the British Government is $1,84,720$ rupees, in addition to the two lakhs of rupees for the Deolee Irregular Force. The maharao has been guaranteed the right of adoption.-Imp. Gaz. v.; Treaties, etc.

KOTAH, a village on a plain, on the left bank of the Pranbita river, 12 miles above its junction with the Godavery, in lat. $18^{\circ} 51^{\prime} \mathrm{N}$., and long. $80^{\circ}$ $2^{\prime} \mathrm{E}$. Ferruginous sandstone is well developed at the Mahadeva Hills, in the north of the province of Nagpur, in the vicinity of the city itself, and at Kotah on the Pranhita.-Carter's Geological Papers, p. 303.

KOTAL. Puкhtu. A pass. There are many in the mountains of Afghanistan. The Kotal-iAgram and the Kotal-i-Dara lead over the Hindu Kush, between Chitral and Zebak in Badakhshal. See Kohtul.

KOTAR, a tribe of the Neilgherries which ranks next to the Toda in priority of occupation of the hills. They are industrious, employ themselves as carpenters, smiths, basket-makers, curriers, barbers, washermen, etc. They acknowledge the Toda as lords of the soil, and pay to them the tribute by Gudu. At the same time they exact from each Badaga hamlet annual fees for services reudered as handicraftsmen, etc.

The station of Kotagiri takes its name from the Kotar villages in its vicinity. The Kotar as a body are dirty. All the dead cattle and carrion in the vicinity, of every kind, find acceptance among them as food. Some rude image of woor or stone, a rock or tree in a secluded locality, form their objects of worship, and to these saclificial offerings are made; but the recognised place of worship at each village consists of a large square piece of ground, walled round with loose stones three feet high, and containing in its centre two pent-shaped sheds of thatch open before and behind, and on the posts that support them some rude circles and other figures are drawn. They hold an annual feast in honour of their gods, which comprises a continuous course of debauchery and licentiousness, extending over two or three days. 
The Kotar language is a very old and rude dialect of Canarese, having the same Tamil roots, but differently pronounced, without the guttural or pectoral expression of the Toda. They are believed to be descended from some of the tribes of the plains, who sought refuge on the hills, and were the first among the other tribes who followed the Toda.

KOTEGARH, Kot Guru, or Guru Kot derives its name from a local saint, whose burial-place in the midst of the village is decorated with coloured flags. Kotegarh is $\check{5} 4$ miles N.E. of Simla, on the left bank of the Sutlej, and is on the high road leading from the plains of India to Tibet. It is 6700 feet above the level of the sea, and is built on the spur of a mountain about 11,000 feet high, which may be considered as the beginning of the Snowy Range towards the north-east. 'The district contains 41 villages, with a populatiou of nearly 2400 souls. The fields are laid out in terraces above one another. From nearly the crest of the mountain chain, they reach down to the bed of the Sutlej. Wheat, barley, and various sorts of graii grow freely. The Kulus form a considerable branch of the population, and are supposed to be the aborigines of the country. The chieftains are Rajputs, who emigrated from the plains of India during the first Muhammadan invasion. Besides these there are the Kunait or Khumah, also Brahmans, who employ themselves mostly in husbandry.

In former times human sacrifices were offered up in the temples, but since the establishment of British rule these have ceased. In most villages large flocks of goats are kept for sacrificial purposes. The sale of females for the worst purposes of slavery is still continued in various parts of the hill territory. For ages past the rich natives of the plains had been supplied with females from the hill regions, which, together with the custom of female infanticide, caused a great numerical disproportion between the two sexes, and gave rise to no less than four cases, in which the fathers had buried their children alive, being brought to light in 1840. No man can obtain a wife without paying a sum of money to her father. The price of one to a peasant is from seven to twenty rupees. Half a century ago, three or four or more brothers married one woman. Unable to raise the required amount individually, they clubbed together and bought one common spouse. Polyandry has now disappeared. But British territory once passed, especially towards the east, polyandry will be still found in Upper Kanawar. The cause assigned is, however, not poverty, but a desire to keep the common patrimony from being distributed among a number of brothers. A little beyond Kotegarh caste distinctions cease, and the physiognomy of the people points to Tartar extraction. The most important class which falls under missionary influence are the Pahari. With them every remarkable peak, cave, forest, fountain, and rock has its presiding demon or spirit, to which frequent sacrifices are offered, and religious ceremonies are continually performed in small temples crected on the spot. One deota is called Shaitan; wooden chairs dressed up with rows of masks fixed to them, and carried on shoulders when a procession takes place. A peculiar dance is kept up before these, people waving branches of trees or punkahs or swords in their hands. The deotas, which have no temples of their own, rest in the houses of zamindars.

KO-TEOU, or adoration, as the Chinese word expresses it, consists in nine solemn prostrations of the body, the forehead striking the floor each time. It is difficult to imagine an exterior mark of more profound humility and submission, or which implies a more intimate consciousness of the omnipotence of that being towards whom it is made. The person rests on his hands and knees, and nine times touches the ground with his forehead. It is literally knocking the head. It is almost the same as the Sajada of the Muhammadans of Southern Asia. -Macartney's Embassy, ii. p. 129

KOT KAMALIA, in the Panjab, identified with the first city of the Malli, captured by Alexander.

KOT KANGRA, a fortress in the east of the Panjab, surrounded by the river Beas on three sides. See Kangra.

KOTMAALE, in Ceylon, near Rambodde, on the road to Newera Elia, a lovely valley, through which meanders a flowing stream. The natives believe that whatever woman bathes in this river within three months after she becomes a wife, will be blessed with a numerous, beautiful, and fortunate family.

KOTRI, a small town in the Karachi (Kurachee) district, Sind, and headquarters of the taluk. Its population in 1872 , including the neighbouring hamlets of Khanpur and Miani Multani, was 7949. It is situated in lat. $25^{\circ} 21^{\prime}$ $41^{\prime \prime} \mathrm{N}$., long. $68^{\circ} 21^{\prime} 37^{\prime \prime} \mathrm{E}$, on the right bank of the Indus, here confined by a tolerably permanent bank. After the conquest of Sind, it became the headquarters of the Indus flotilla, and a fort was erected to protect the site.--Inp. Gaz.

KOTTAGAR. KARN. A division of the Hollayar or servile tribe.

KOTTAI. TAM. A grain measure, varying from 21 to 24 markals in different places.

KOTWAL. HrND. A military superintendent of police, one of the titles given to the headman of a Hindu corporation; head of town or village, a superintendent of markets, a police officer; under Muhammadan and Hindu sovereigns, a criminal magistrate.

KOTYA. MAHR. A coasting ship on the W. coast of India.

KOUCADWIPA was the name given by the Indian Aryans to the basin of the Indus, which was earlier occupied by the Sudras (Cusbites or Caucisas). These Aryans gave the name of Jambudwipa to all the mountain region on the N.W. of India, including the ancient Indian province of Afghanistan.

KOU-CHU. CHIN. The Chinese obtain from a tree of this name a fluid resembling milk, which they use in gilding with leaf-gold. This liquid is smeared over the surface of the article to be gilded, in the several forms which the device is intended to represent; the leaf-gold is then applied, which immediately becomes firmly cemented.

KOUK. Burm. Paddy. Kouk-hline, paddy sheaves; Kouk-kye, Kouk-lat, and Kouk-ying, glutinous paddy. See Rice.

KOUK-KO. BURM. A Tavoy wood, employed for bottoms of boats.

KOU-KOU? also K'u-shih-pa-tau, CHIN., is 
the St. Ignatius bean, the seeds of Strychnos sancti Ignatii, the Ignatia amara of some authors. It en joys a high reputation in the Chinese Materia Medica. It is bitter, and believed to be a good vermifuge, but is dangerous from the quantity of strychnine it contains.-Smith's Mat. Med.p. 116; Simmonds' Dict.

KOU-KOUO. CHIN. A plant originally from the Philippine Islands. Its fruits are of an ashy brown colour, extremely hard and bitter; by steeping in cold water, it forms an excellent application for wounds and contusions, and the water, taken inwardly, cools the blood and allays inflammation. This fruit plays an important part in Chinese medicine, and is sold by all druggists; it is also used to treat the internal maladies of oxen and horses. This is perhaps the seed Lusung-kwo, from a species of pine.-Smith's Chin. Mat. Med.; Huc's Journey, p. 97.

KOUMISS, the Ma-ju-tsiu of the Chinese, is a spirituous liquor of various kinds prepared from mare's milk by Mongolians. Tartar drinks of various kinds, made from whey and buttermilk, were called Ti-hu, a name applied to ghi or the oleine of butter. The milk of the mare has 17 per cent. of solid matter, and 8 per cent. of sugar of milk, which render it very liable to undergo alcoholic fermentation. Koumiss is quite distinct from the Russian drink quass. English koumiss is nade from the milk of the cow. Russian koumiss can be procured at several places in London.

KOUNG. KAREN. A beer brewed from rice.

KOUNG-KOUAN. CHIN. Communal palaces are, in China, found from stage to stage all along the road, and reserved for the use of the great mandarins when travelling on public service. Ordinary travellers are rigidly excluded from them. A Chinese family has the office of maintaining each of them in good order, and of making the necessary arrangements when a mandarin is about to occupy it. The expenses are paid by the governor of the town, and he appoints the domestics for the service of the palace. The Koung-Kouan of the province of Sze-chuen are particularly renowned for their magnificence, and they were completely renewed under the administration of $\mathrm{Ki}$-chan, who was goveruor of the province for several years.-Huc, Chinese Empire, i. p. 23.

KOUPOOEE, a tribe near the source of the Irawadi, comprises two clans, the Songpoo and Pooeer-on. The Koupooee occupy the hills between Cachar and Munipur in their whole breadth, a direct distance of about 40 miles; and from lat. $25^{\circ} \mathrm{N}$. they formerly extended over nearly an equal distance to the south. The whole of the tract was formerly thickly studded with villages, and Songpoo tradition gives, as the place of their origin, the mountain towards the south of the valley named Thung-ching. They and all the other races of hill people congregate in communities, composed usually of families connected with one another by blood ties. Before the subjugation of the Songpoo tribe to Munipur, almost every village was at war with its neighbour, and they would break out afresh were the restraining hand of Munipur withdrawn. A state of active feud appears to be the one natural to all the tribes from Cape Negrais to as far north as we have any knowledge. The Koupooee are much attached to their villages, and when they have been obliged to desert their village, they express their wish to return to it as being the grave of their ancestors. The spot cultivated this year is not again cultivated for ten years. Every village has three hereditary officers, namely, Kool-lak-pa, Loop-lak-pa, and Lum-poo, and officers besides these are elected. The Koupooee are also subdivided into families, Koomul, Looang, Angom, and Ning-than-ja. A member of any of these families may marry a member of any other, but intermarriage of members of the same family is strictly prohibited. Though not attended to with the same strictness, this prohibition in regard to marriage, and this distinction of families under the same designation, exists among the Munipuri race.-Dalton's Ethnology, p. 51.

KOUREN. The principal Lama Serai of all Mongolia is that of the Great Kouren (Oorga Kooren of Timkowski). It is situated in the country of the Kalkas, on the banks of the Toula river, and stands on the edge of the great forest that stretches northwards into Siberia. To the south lies the desert of a month's journey. It stands, however, in a pleasant valley, amid mountains, near the source of the Toula, which river falls into the great Baikal lake. There are 30,000 Lama, under several heads, at Oorga ; their chief is the Geesoo- Tamba, a regenerated Buddh of great sanctity. There has arisen a large city and mart of commerce in the immediate vicinity of the convent, and it is the headquarters of Mongolia, having been the capital of the princes of the family of Chengiz Khan before their conquest of China. Tea bricks are here the measures of value, an ounce of silver representing five tea bricks.

KOUSHAN, a pass in the Hindu Kush. It is the most frequented east of Bamian, in lat. $35^{\circ}$ $37^{\prime} \mathrm{N}$., long. $68^{\circ} 55^{\prime} \mathrm{E}$. It has three entrances, leads over the principal shoulder of the Hindu Kush peak, is impassable for wheeled carriages, about 40 miles long, narrow, and its crest is 15,000 feet above the sea. The road rocky, uneven, descent is 200 feet per mile.

KOUSSO, the flowers of Brayera anthelmintica, $K t h$, an Abyssinian tree; a celebrated vermifuge.

KOUTAN, a titular appellation of the Moplah Mubammadans of the S.W. coast of the Peninsula of India.

KOUTCHE town contains between 5000 and 6000 inhabitants, besides the Chinese garrison. To the north of the place is the Moussoor-Daban (or pass) on the route to Kulja, and the great volcano Pe-shan is on the east. Iron and copper are abundant in this region, and the latter mineral is worked. Sulphur and saltpetre are also foumd, and chloride of ammonium. To the south of Koutche a considerable quantity of rhubarb is produced; it is taken by the caravans to Mai-matchin on the Siberian frontier.-The Upper and Lower Amoor, p. 355.

KOU-TOUK-TON in Mongol, and Goussee (Geesoo) in Tibetan, M. Timkowski says is the name of the highest class of the priests of Buddha ; the one resident at Oorga is called by the Mongols Gheghen Kou-touk-ton. The Oorga high priest seems also to be called Geesoo-Tamba, a regenerated Bodhi-satwa of great sanctity. - Prinsep's Tibet, p. 51. See Kouren; Lama. 
KOUYUNJIK, so called by the Turks, but Armushiah by the Arabs, are mounds, opposite Mosul, long believed to be the remains of Nineveh. The ruins include the great mounds of Kouyunjik and Nabbi Yunus on the easteru bank of the river Tigris, and were examined by Sir A. H. Layard in 1849 and 1850. He sent to Great Britain, to the British Museum, many Assyrian and Babylonian sculptures, which were described in 1883 by Dr. Birch. They consist of slabs of gypsum or alabaster from the walls of Sennacherib's palace, of date between B.C. 705 and 681 ; also slabs of the time of Sennacherib's grandson, Assurbanipal, of date between B.c. 668 and 626 ; these are split and shattered by fire, which consumed the palace.

Three expeditions conducted by George Smith, and later ones of Hormuz Rassam, have added largely to the stock of tablets from Kouyunjik, originally acquired for the British Museum by Sir A. H. Layard, and have also brought to light a few other tablets from the libraries of Babylonia.

George Smith, the Assyriologist, deciphered the terra-cotta tablets inscribed with cuneiform characters belonging to the great fictile library of Kouyunjik.

Nimrud is stated to have migrated from Cappadocia to the land of Sumer or Shinar, and, meeting there with the Semitic population, he settled with his followers, and built Babylon and Birs Nimrud or supposed Tower of Babel. The language of these settlers, known as Akkadian, is yet preserved in several tablets, but it seems to have been entirely supplanted by the Babylonian about the 12th or 10th century B.C., the Babylonian incorporating many Akkadian words. From the fusion of the intellectual race of Nimrud with the martial Babylonians sprang the two great nations to whom history and tradition ascribe the foremost place of sovereignty among the empires of the ancient world, in science and arts as in war. Mr. Theo. G. Pinches considers that art reached a high degree of excellence during the reign of Assur Nazir - pal, declined for a time, and then again rose to very high excellevce about B.C. 700 , at the beginning of the reign of Sennacherib.

Assur was the national god of the Assyrians. Bel was the Babylonian god. Istar of Nineveh was the goddess of love. Um-napistim was the Assyrian Noah. - Sayce, Fresh Light from the Ancient Monuments, p. 17.

KOVIL, also Koyil. TAM. A Hindu temple, a Christian church ; written Koil or Coil.

KOWA DOL. The Barabur Hills are isolated rocks of syenitic granite, rising abruptly from the plain about 15 miles north of Gyah, by the left lank of the Phulgo or Mahanadi; the cluster is remarkable for the masses of rock, piled one above mother, with hardly any soil, and rising to various heights, from 100 to 400 feet. Each hill has a name of its own. The highest is called Barabur, also Sidheswur, from a temple to Mahadeva that once crowned its heights. The next in beight is the Kowa Dol, which is detached from the rest by near a mile to the south-west. A third is called Nag-arjuni, and is the easternmost of the great cluster. $\Lambda$ fourth, and the smallest, called Durhawut, is at the northern extremity; but others also have names. The Kowa Dol is an almost entirely bare rock, having nearly a perpendicular scarp on its northern face, and sloping at an angle of $45^{\circ}$ on the southern side; east and west, it is disjointed and inaccessible; huge stratified masses are piled one over the other, decreasing in length at each end, the whole is surmounted by single blocks like pillars, the centre one of which towers above the rest, and is conical. It is said that formerly there was a huge block balanced on the top of this cone, which, from its being moved by birds alighting on it, obtained the name of Kowa Dol, or crow-moved, or the crow-swing. A bout the middle of the 18th century, this rocking-stone fell down to where it may still be seen. This hill seems to have been -surrounded by a large town. There is an artificial mound continuous round the north and east faces, filled with broken pottery, bricks, and blocks of hewn stone; there are two names given, Sarain and Summunpur; on the portion called by the latter name there is an extensive Muhammadan cemetery. The caves of Barabur, with one exception, are entirely devoid of sculpture or ornament of any kind. They are seven in number; four in one bill, three in another; but the name Satgarba, commonly understood to mean seven chambers, is applied only to two.

KOWEIT, also called Quade or Grave, a town on the Arabian side of the Persian Gulf, on the south side of a bay 20 miles long; it is the native Al Quaat. The country round it is perfectly barren. The present town did not exist prior to the middle of the 18th century. It rose to some importance as a place of trade during a turbulent period in the latter part of that century, and retained its prosperity from baving enjoyed peace while all other parts of the Persian Gulf were embroiled. Its trade consists in supplying the inland tribes with grain, coffee, and Indian produce. The exports are ghi and horses. It has a considerable carrying trade between various parts of the Gulf.

KOWL, ARAB.; also Kowl-namah, HiND., deed of protection and assurance.

KOYYA, to cut, is found with variations in all the languages of the south of India, giving the terms for harvest, a reaping-hook, a reaper.

KOYYUNI,U, from the Turki word Koyın, a sheep. The Ak Koyyunlu and Kara Koyyunlu are mentioned in history. They were two tribes of Turk race, each of which founded a dynasty, and adopted, respectively, a white and a black sheep as the device of their standards, and hence their names.-Redhouse; Elliot, $H$. of $I$. iv.

KRAAL is the term used in Ceylon for the enclosure into which, when fresh elephants are required in Ceylon, a herd of wild ones is driven. In the continent of India, the enclosure is called a Kheda. The kraal is made in some spot convenient to the districts in which the elephants are supposed to be. The mudliar or headmen of these districts are required to find a certain number of coolies as beaters. These are formed into a cordon, surrounding the elephant district. The circle is gradually contracted, the coolies advancing slowly by day, beating the jungle as they go, and ligbting watchfires by night. The elephants are thus driven towards the kraal, into which they are eventually enticed by decoying elephants placed there for the purpose. Once within the enclosure, strong ropes are skilfully passed round their legs, and then fastened to the largest trees. There the elephant remains until he is subdued 
and partially tamed by hunger and fatigue, after which he is gradually liberated, and his education commences. Cordiner gives graphic descriptions of the grand kraals he witnessed at the beginning of the 19th century near Tangalle and Negombo, where scores of elephants were enclosed in parks of labyrinthine passages, many of them being drowned in the water snare. The parallelogram on one occasion was about 240 feet on cach side, so that the area was 6400 square yards. The wings were not more than 200 feet in length. The engraving in Tennent's Work (5th edition, ii. p. 340 ) gives an excellent idea of a Kandian kraal, its form and the principles on which it is constructed. Vacant spaces are left for two elephants to stand at each corner, which it is !nderstood will rush forward towards the entrance the moment the elepbants enter the enclosure, and cover with their protection the men employed in putting up the barricades. Cross rear lines are drawn through the jungle, when the beaters are satisfied that the elephants are in front; and is the drive nears the kraal, the cordon of beaters is drawn closer and closer until at last it closes in on the elephants and they have no choice but to break through the line or enter the kraal. Many of them do break through the line. On one occasion an elephant broke through the kraal, fairly raising up a portion of the palisades, cross beams, jungle vines, and all, with his tusks, and, scattering the watchers to right and left, rushed up to the palisade, seized a peeled wand pointed at him by a Koralle, and broke it over the man's arm and head, inflicting severe bruises. But this animal was manfully resisted and turned back.-Frere's Intipoles, p. 185. See Elephant; Kheda.

KRAKATOA ISLAND. Java is traversed by two chains of mountains, from 10,000 to 12,000 feet in height, in which there are about 45 volcanoes, many of them in occasional activity; and it has explosive mud and brine springs, and a poison valley, in which accumulations of carbonic acid gas kill every form of life which penetrates into it. On the 26th and 27th of August 1883, there occurred the climax of the most tremendous volcanic eruption which, perhaps, the world has ever seen during historic times. In the course of it, Krakatoa Island, 3000 feet high or thereabouts, entirely disappeared. The usual volcanic products, including the finest particles both solid and vapours, were ejected into the air to a height that no man will ever say, since for many miles round the scene of these devastating forces noon was as black as night, and darkness was over all the land for 36 or 40 hours. The scale on which the work was done was such that the noise was heard at a distance of 2000 miles. The shivering of the island produced a wave of water 100 feet high, which destroyed everything over which it swept, and left its mark on tidal registers nearly all over the world. The mere air-pulse produced by the last fearful cataclysm was strong enough to pass with its gradually widening circle nearly three times round the globe.

Krakatoa Islaud was in eruption on the 26th, but it entirely disappeared on the 27 th, and a tidal wave 12 to 30 metres high swept the coast of Mirak as far as Tiyiringen, overwhelming the towns of Aujer, Mirak, and Tiyiringen, destroying about 20,000 people. Soengepen volcano split into five; between the site where Krakatoa had stood and Sibisie Island, sixteen new volcanic craters appeared. A lighthouse in Java and another in Sumatra disappeared. Where once Krakatoa stood, the sea now plays. Ships in the seas sailed through patches of pumice, and Sunda Straits were so much changed as to necessitate resurvey. The craters of the numerous volcanoes for which Java is noted were most of them in active eruption. Madura Island at its east, 500 miles away, also had a share of the terrible effects of this unprecedented convulsion. Sourabaya, in the Straits of Madura, suffered seriously. The steamship Gouverneur-General, belonging to Batavia, was at sea at the height of the eruption, and steamed to Anjer to give the alarm, but found that place destroyed. The ship had a layer of ashes 18 inches thick on her deck. In some places masses of floating pumice-stone seven feet in depth were passed. 'The volcanic action must have been going on in lat. $5^{\circ} \mathrm{S}$. and long. $88^{\circ} \mathrm{E}$, at least three weeks prior to the terrible catastrophe in Java. S.S. Siam, from King George's Sound to Colombo, in lat. $5^{\circ}$ S., long. $88^{\circ}$ E., from 3.30 P.M. till dark was steaming through large quantities of lava floating in broad patches, and trending from north-west to south-east; some pieces larger than a cricket ball. $5^{\circ} \mathrm{S}$. and $80^{\circ} \mathrm{E}$. is in the middle of the Indian Ocean, about equidistant from the Keeling, Chagos; and Rodrigue Islands. The ancient Hindu temples, the Boro Buddor, the Chandi Siwa, and others, were greatly injured.

KRANI, Karani, or Crani, an English copyist or clerk in a Calcutta office, mostly of mixed European and native descent. The origin of the name has been disputed; it may be a mispronunciation of Carana, by which the Kayasth (Kayastha), or writing tribe, is designated in Bengal; and as most native clerks in public offices are of the Carana caste, it is not unlikely that by merely extending its signification, the same word has been used to designate English writers. The word, from being utterly harmless in its application, has begun of late years to be considered decidedly dyslogistic. In India, Kayasths are never styled Khaja. In Muhammadan countries west of India, however, the term is still applied to clerks and teachers. Dr. Shaw says of the Moors in Barbary, 'The Hojas suspend their inkhorns in their girdles' (p. 227); and Lady Montagu says, "The monastery is now belonging to a Hojia or schoolmaster.'-Letters, p. 176 ; Elliot's S'upplement.

KRANTA. BENG. A necklace from the species of chank shell.

KRAPF. John Ludwig Krapf, African explorer, and missionary of the Church Missionary Society, was born in Würtemburg in 1809. In 1837 he went to Abyssinia, but, failing to make way there, he went to the kingdom of Shoa, where he remained three years. In 1844, Dr. Krapf settled on the Zanzibar coast, fixing on Mombas as his base of operations, and in company with Dr. Rebmann made several exploring journeys in the interior, discovering the highest mountains in Africa, Kilimanjaro and Kenia. Krapf returned home in 1856 .

KRAW or Kraa, an isthmus at the head of the Malay Peninsula, between the Kaman branch of Pak-chan river in Tenasserim and the Champong river in Siam. Between the two rivers is about 
40 miles, and it has been proposed to form either a canal or a railway for the 22 miles that intervene. The Pak-chan river is said to be navigable for steamers drawing 6 fathoms of water for 15 miles from the sea, and the highest ground on the isthmus is not more than 75 feet above the sea-level. The distance saved would be nearly 500 miles; and the saving in a steamer's time, including stoppages for coaling, etc., would be four days, while the saving in cost would be enormous.

KRIS or Karis. Malay. A dagger or poniard, the ordinary weapon of all the civilised inhabitants of the Archipelago. It is of a hundred different forms, short or long, with a straight or serpentine blade, and with every variety in the shape and ornament of the hilt and scabbard. Men of all ranks, from the peasant to the prince, wear this weapon, and those of rank, when full dressed, two or even four. In Java, even women of rank sometimes wear a small one. The word is probably Malay, but is now of general adoption through the Archipelago. The Javanese have three native names for it besides the Malay one. It is represented on several of the ancient temples of Java. This dagger is in use in all the Indian islands, though ill suited as a weapon of war. The Javanese ascribe its invention to Inakarto Pati, king of Janggolo, in the beginning of the 14th century of our era. Constant use of it gives a facility in handling it. Those of the Eastern Archipelago get their names according to their form or uses; thus, Kris panjang (long), Kris sepucal (straight), Kris chinankas, Kris tumbu Ladah, Kris bladohe, Kris badeh. The kris is used for all purposes, in Bali even to kill the wife who wishes to be burned with her husband. It is always a near relation who gives the first wound with the kris, but never father or son. Sometimes dreadful spectacles occur. In one instance a woman had received eight kris stabs, and was yet quite sensible. At last she screamed out, driven by the dreadful pain, 'Cruel wretches, are you not able to give me a stab that will kill me!' A gusti who stood behind her, on this pierced her through and through with his kris.Crawfurd's Dict. p. 202; Ind. Arch. i.

KRISHI. SANSK. In the south pronounced Krūshi, ploughing, tillage, agriculture.

KRISHNA, written Krishn, Kistna, and Kisn, is familiarly known to the Hindus as Kaniya, and also called Heri. He was a prince of the Yadu tribe, and lived towards the closing centuries of the Brazen Age, calculated to have ended about B.C. 1200 to 1100 , and he has since been deified by the Hindu people of India. Who his parents were, is doubtful. Vasudeva, a chief of the Yadava, and brother of Kunti, the wife of Pandu, and Devaki, a damsel of the royal family of the Bhoja reigning at Mathura, are claimed; and Nanda and Yasoda, cowherds dwelling at Gokula, are indicated as his ostensible parents. Krishna is the greatest favourite with the Hindus of all their divinities. Of the sectaries who revere Vishnu to the exclusion of the other gods, one sect almost confine their worship to Rama; but though composed of an important class, as including many of the ascetics, and some of the boldest speculators in religious inquiry, its numbers and popularity bear no proportion to a division of the Vaishnava sect which is attached to the worship of Krishna, and the legends toli of him are innumerable. When Aurangzeb proscribed the idol of Kaniya, and rendered his shrines impure throughout Vrij, Rana Raj Singh offered the heads of one hundred thousand Rajputs for his service, and the god was conducted by the route of Kotah and Rampura to Mewar. One sect worships Krishna as Paramatma or supreme spirit, prior to all worlds, and both the cause and substance of creation. With them, in his capacity of creator, preserver, and destroyer, he is Brahma, Vishnu, and Siva; and in the endless divisions of his substance or energy, he is all that ever was and will be. Besides these manifestations of himself, he has for various purposes assumed specific shapes, as avatars or incarnations, Ansa or portions, Ansama or portions of portions, and so on ad infinitum. Professor Lassen regards him as identical with Horakles of Megasthenes.

Since the middle of the 19th century, several learned men have formed the opinion that some of the legends relating to Krishna have been taken from the life of Jesus Christ. Major Cunningham believes that the worship of Krishua is only a corrupt mixture of Buddhism and Christianity, and was a sort of compromise intended for the subversion of both religions in India. Several of the legends in the Mahabharata seem to have been written after the birth of Christ, whose miracles have been copied; and Krishna is made to straighten the crooked woman Kubja, which resembles the miracle of raising the bowed down woman. Weber (Krishna Geburts fest, p. 316, English ed. p. 71) thinks that Krishna's sectarian worship as the one God probably attained its perfection through the influence of Ohristianity.

The name of Krishna occurs in the Rig: Veda, but without any relation to the great deity of later and modern times. He appears prominently in the Mahabharata; and as a divine being he delivered to Arjuna the Bhagavat Gita, which is recognised as part of the great epic, in it distinctly declaring himself to be the Supreme.

The divine character was still further developed in the Harivansa, a later addition to the Mahabharata. In the Atmaprabodha and Narayana and Chandogyopanishads, Krishna is mentioned as a pious sage. It is in the Gopalatipaniyopanishad that he is declared divine; and in the Puranas, especially in the Bhagavat Purana, this attained its full expansion, Krishna being there described in his complete apotheosis, and in that he is represented as the eighth avatar of Vishnu.

All the stories told in the Bhagavat Purana, of his childhood and boyhood, and the love scenes of his youth, have been made popular in the Hindi translation called Prem Sagar, or Ocean of Love, and other versions. Much of the story of the early days of Krishna is of comparatively modern invention. The incidents of his relations with the Pandava princes are the most ancient.

Krishna lived during a period of religious changes, and he was able to induce the Yadava to discontinue the worship of Indra, and worship the cows that supported them. The disturbance resulting from this is denoted by the legend that Indra opened the heavens to deluge the race, but Krishna protected them by elevating the Govar. dhana mountain as an umbrella, which implies that he took shelter on that mountain. He migrated from Mathura to Gujerat, and built or 
fortified Dwaraka. But the religious contest continued, as shown by Krishna, while a guest or on a visit to Indra's heaven, stealing the Pari-jata tree from Indra's garden; and when Usha, daughter of Bana, carried off Aniruddha, Krishna's grandson, Krishna defeated Bana, though aided by Siva and his son Skanda.

Wherever the $\mathrm{Y}$ adava settled, great violence and disorder prevailed. Krishna seems to bave occupied the town of Mathura with his Yadava brethren, and to have been twice attacked by the Turanian king Jarasandha of Magadlaa, supposed to be Behar. The first attack was repulsed, but after the second Krishna retired with the Yadava to Dwaraka. There is, however, no account extant of the migration or flight from Mathura to Dwaraka, though it must have occupied at least a year. Krishna fought with and defeated Paundraka, though supported by the king of Benares. At some subsequent period of his career he entered the region of the Saura in Gujerat as a conqueror, is he had before been compelled to seek shelter there in defeat, on his flight from the king of Chedi, which obtained him the unenviable epithet of Rinchor, or fleer from the battle-field, though Hindus now appear to consider Rinchor a complimentary title, as under this designation they worship him in crowds. But he last visited this land in company with a few of his kinsmer, the remnant of that tremendous civil conflict which desolated India, to pass the remainder of their days in this insulated nook, in sorrow and repentance for the blood their ambition had shed, though in defence of their rights. Thus, wandering from one tirat or place of pilgrimage to another, he, with his friends Arjuna, Yudishthra, the abdicated paramount sovereign of India, and Baldeo, approached the sacred soil around the shrine of Somnath. Having performed his ablution in the holy Triveni, Kaniya took shelter from the noontide heat under an umbrageous pipal, and while he slept, a forester Bhil, says the legend, mistaking the padma or lotus-like mark on the sole of his feet for the eyes of a deer, sped an arrow to the mark. When his kinsmen returned, they found that life was extinct. For a long time Baldeo would not part from the corpse, but at length they gave it sepulture at the point of junction of three streams. A pipal sapling, averred to be a scion of the original tree, marks the spot where the Hindu Apollo expired, and a flight of steps now conducts to the bed of the golden Hiranya, for the pilgrim to lustrate himself. This place of puritication bears the name of Swargadwara, or door of bliss, and contends with that of Devaputtun for superior efficacy in absolving from sin.

The Mahabharata gives two summaries of his numerous exploits, overthrowing, while a youth, kings, cities, and demons. He was present at the Swayamvara of Draupadi, helped Agni to defeat Indra, connived with Arjuna to carry off his sister Subhadra, killed Sisupala, took part in the council which was held prior to the great war; was Arjuna's charioteer in the battle. On the eve of the battle, while acting as charioteer, he related to Arjuna the Bhagarat Gita, or divine song. In the battle he aided Arjuna, but in two instances he suggested unfair dealing. He afterwards went to Hastinapura with the conquerors, and attended their Aswa Medha sacrifice.
On his return to Dwaraka, he gave permission for wine to be drank for the day. A drunken brawl ensued, in which his son Pradyumna was killed in his presence, and nearly all the chiefs of the Yadava were slain. Bala Rama left the fray, and died peacefully under a tree, and Krishna was killed unintentionally by a hunter named Jaras, who shot him with an arrow, mistaking him for a deer. Arjuna proceeded to Dwaraka and performed the funeral obsequies of Krishna. A few days afterwards the city was overwhelmed by a storm - wave. Five of Krishna's widows were subsequently burned upon a funeral pile, in the plain of Kuru-kshetra.

During the discussions prior to the battle described in the Mahabharata, Krishna, who was related both to the Kuru and the Pandu, tried to bring about a reconciliation, and he seems to have continued his efforts to restore peace throughout the eighteen days of the conflict, but he did not personally engage in the fight, and the only part of his career in which he is shown as personally brave, is related in the legend describing his forcing an entry into Mathura. At the gate of the town, the bow of Siva was kept under the care of warders. Krishna entered by that gate to take part in the festival which king Kansa held on the occasion of a great sacrifice to Siva. As he entered the gate of the bow, he took and broke it, slaying the warders. A popular commotion followed, during which the troops of king Kansa were defeated, and Kansa himself was slain.

The popular history of Krishna is contained in the Puranas, which mix up fable with historical details; and the Bhagavat Purana is the great authority about raja Kansa and his cousin Devaki, her seventh conception of Krishna, his change to Rohini's womb, and his birth and preservation and rearing by Nanda, the herdsman in Gokala, where he was brought up. In his childhood killing demons and serpents, doing marvellous feats, playing tricks on the Gopi milkmaids; persuading Nanda to cease the worship of Indra and to worship the mountain Govardhana; his amours with the Gopi, seven or eight of whom he uarried, his favourite wife being Radha, with whom he danced in the Rasa Mundala. He afterwards killed Kansa, killed the demon Panchajana, defeated Jarasandha, father of his two wives, but retreated before Kala Yavana to Gujerat, where he built and fortified Dwaraka.

Here he carried off Rukmini, daughter of the raja of Vidarbha; he recovered the Syamantaka gem, and married Jambavati and Satyabhama. But he is fabled to have had 16,000 wives and 180,000 sons. Rukmini bore his son Pradyumna and daughter Charumati. Jambavati bore Samba, and by Satyabhama he had ten sons.

He killed the demon Muru and the king Naraka. With Satyabbama he visited Indra at Swarga, and she persuaded him to carry away the Parijata tree which belonged to Sachi, Indra's wife. Indra with an army tried to recover it, but was defeated by Krishna.

Pradyumna bore a son named Aniruddha, with whom a female Daitya, Usha, daughter of Bana, fell in love and carried off, but he was rescued by Krishna. Bala Rama and Pradyumna, and Bana and his allies Siva and Skanda, were wounded.

Krishna's names are numerous. He being Vishnu, they enjoy several in common,-Murari, 
Hari, Madhava (Vishnu destroyed the giant Madhu), Baghavan, are among them; Govinda, Gopala, Grokala are derived from his occupation of herdsman; Gopinatha, the Gopi's god; Murlidar, the tuneful; Kessu, Kesava, or Kesavi refer to the fineness of his hair; Vanimali, to his pendent garland; Yadva, Varshneya, and Vasudeva, to his tribe and family. Gokal is a small town on the banks of the Jumna, below Mathura; and Radha, the mistress of Krishna, was wife of a cowherd of Gokal; hence one of Krishna's titles is Gokal Nath, lord of Gokal. Gokal is almost an island, and is one of the prettiest spots in the holy land of the Hindus. The scene there is still as pastoral as it had been 3500 years ago. Large herds of heavy - uddered kine remind us of the days of Nanda, though their number is far short of nine lakhs, possessed by that shepherd-chief of old.

In the civil wars of his kinsmen, the Kuru and Pandu, when he sided with the latter and sbared their exile, he had thrown aside his Apollonic character of Murlidar, where, by the sounds of his pipe (Murali), he captivated the shepherdesses as he attended the kine in the pastoral Surasen, and had assumed that of Chacradhari, or wielder of the discus, the most ancient weapon of this Indo-Getic race.

Krishna is worshipped under his infant form as Gopala and Balagopala, and again as Gopi-natha, the god of the milkmaids. In the picture of Krishna, observes Sir William Jones, it is impossible not to discover, at the first glance, the features of Apollo, surnamed Nomios, or the pastoral, in Greece, and Opifir in Italy, who fed the herds of Admetus, and slew the serpent Python.

Krishna's favourite place of resort was a tract of country around Agra, and principally the plains of Mathura, where Krishna and the nine Gopia, evidently the nine muses, usually spent the night in dancing.

Krishna deified is the shepherd Apollo of the Hindus, and his deeds, like those of Rama Chandra, have been sung by the noblest poets of the east.

The legend generally believed by the Hindus is partly historical and in part fable. It is to the effect that Krishua was born in Mathura, and was the son of Vasudeva (giver of wealth) and Devaki, sister to Kansa, the king of that country. At the time of the nuptials of his father and mother, it was predicted to Kansa that the eighth child of Devaki would deprive him of his life and crown, and become sovereign of Mathura in his stead. The king, in consequence, commanded that Devaki should be closely watched, and that whenever she was delivered of a child, it should be brought to him immediately to be put to death. The princess gave birth to five sons and one daughter, who were thus, by the directions of her brother, destroyed as soon as they were born. When she became pregnant the seventh time, a voice from heaven commanded that the fruit of her womb should be conveyed into that of another female named Rohini, who gave birth to the third Rama, called Bala Rama, Krishna's elder brother; and when the period of her delivery the eighth time arrived, the tyrant gave orders for a stricter watch to be placed over her than had been before observed. The guards placed by Kansa over his pregnant sister having failed in their vigilance, Kansa, enraged, ordered all new-born infants to be slain. But Krishna escaped his various snares, one of which was sending a woman named Patnia, with a poisoned nipple, to nurse him. In a miraculous escape of the infant over the Yamuna (Jumna), he is represented as conveyed by his father, and protected by Sesha or immortality. He was fostered by a herdsman named Ananda, or happy, and his wife Yasoda, or the giver of honour, and passed the gay hours of youth dancing, sporting, and piping among a multitude of young Gopa or cowherds, and Gopi or milkmaids, from whom he selected nine as favourites. This is the period which has made most impression on the Hindus, who are never tired of celebrating Krishna's frolics and exploits as a child,--his stealing milk, and his destroying serpents; and annong them is an extensive sect which worship him under his infant form, as the supreme creator and ruler of the universe. Krishna excites enthusiasm, especially among his female worshippers. $\mathrm{He}$ spent his youth among the Gopi, or milkmaids, dancing, sporting, and playing on the pipe; and captivated the hearts, not only of his rural companions, but of the princesses of Hindustan, who had witnessed his beauty. In Brindaban, where he tended cattle, stole milk, played upon the pipe, and danced and sported with milkmaids, the scenes of his gay amours are now reckoned as objects of the holiest veneration. 'The cradle of Krishna is preserved among the treasures of Nandagaon, and the dairy is shown from which he used to steal milk and butter in his infancy. His subsequent life was chequered; he recovered his inheritance, but, being pressed by foreign enemies, he removed his residence to Dwaraka in Gujerat. He afterwards appeared as an ally of the family of the Pandu in their war with their relations the Kuru, for the sovereignty of Hastinapur. This war forms the subject of the great Hindu heroic: poem, the Mababharat, of which Krishna is in fact the hero. It ended in the dearly-bought success of the Pandu, and in the return of Krishna to Gujerat. His end was unfortunate, for he was soon involved in civil discord, and at last was slain by the arrow of a hunter, who shot at him by mistake in a thicket.

Other legends told of him are innumerable. At the age of seven, the legends relate that he uplifted on the tip of his little finger the mountain Govardban, the Hindu Parnassus, to shelter the Gopa and Gopi from the wrath of Indra, the Jupiter Pluvius of the Hindu pantheon, who, enraged with jealousy at the diminution of his votaries and sacrifices, consequent to the adoration of Krishna, attempted to destroy them by a partial deluge. This story is represented in the Matsya Purana, whence Sir W. Jones has thus poetically introduced it in his hymn to Indra. The bard

$$
\text { 'Warbling in a softer mode, }
$$

Sang the red lightning, hail, and whelming rain O'er Gokal green, and Vraja's nymph-lov'd plain, By Indra hurl'd, whose altars ne'er had glow'd Since infant Krishna rul'd the rustic train

Now thrill'd with terror. Them, the heavenly clild Call'd, and with looks ambrosial smil'd:

Then, with one finger rear'd the vast Govardhan, Beneath whose rocky burden,

On pastures dry, maids and herdsmen trod:

The lord of thunder felt a mightier god.'

In pictures of this miracle, Krishna is always represented as a man, attended by his favourite mistress Radha, and sometimes by a multitude of 
shepherds and shepherdesses; the former with poles, steadying the uplifted sheltering mountain, a shower of rain and fire falling vainly on its summit. Krishna and his Gopi are also represented as well in their characters of Apollo and the Muses, as in those of the sun and the planets in harmonious movements round him; and this picture was formerly adduced in support of the idea that the Hindus had a knowledge of the true solar system, a point tbat no longer requires proof. The colour of this deity is azure, and several animals and vegetables of a black or blue colour are sacred. The metamorphosis of his fleet nymph into the lovely shrub, the tulsi or black ocimum, is related in a style perfectly Ovidian in the Puranas. Tulsi forms a pretty feminine appellation to this day; and, among the wotnen of Hindustan, the beautiful, warlike, and amorous Krishna is a most popular deity. Nareda, the mythological offspring of Saraswati, patroness of music, was famed for his talents in that science; so great were they, that he became presumptuous, and, emulating the divine strains of Krishna, he was punished by having his vina placed in the paws of a bear, whence it emitted suunds far sweeter than the minstrelsy of the mortified musician. In a picture of this joke, Krishna is forcing his reluctant friend to attend to his rough-visaged rival, who is ridiculously touching the chords of poor Nareda's vina, accompanied by a brother bruin on the cymbals. The loves of Krishna and Radha, which, in the writings and conversation of the Hindus, are as constantly adverted to as those of Laila and Majnun by Muhammadans, are said to mean, in their emblematical theology, the reciprocal attraction between the divine goodness and the human soul. They are told at large in the tenth book of the Bbagavat, and are the subject of the beautiful pastoral drama, entitled Gita Govinda, by Jayadeva. This poet, in describing one of the events of Krishna's life in his amours with Radha, exclaims, 'Let him, then, if his soul be sensible to the raptures of love, listen to the voice of Jayadeva, whose notes are both sweet and brilliant.' Bring home the wanderer (Krishna) to my rustic mansion, spoke the fortunate herdsman Nanda to the lovely Radha. The firmament is obscured by clouds, the woodlands are black with tamala trees; that youth who roves in the forest will be fearful in the gloom of night. Go, my daughter, bring the wanderer home. Radha sought him long in vain. She roved among the twining vasanti covered with soft blossoms, when a daunsel, to whom his wanderings were known, pointing out the infidelity of her lover, thus addressed her : -The gale that has wantoned round that beautiful clove plant, breathes now from the hills of Malaya. The full-blown cesara gleams like the sceptre of the world's monarch, love, and the pointed thyrse of the cetaca resembles the darts by which lovers are wounded. See the bunches of patali flowers filled with bees, like the quiver of Smara full of shafts, while the amrita tree, with blooming tresses, is embraced by the gay creeper atimucta, and the blue streams of the Yamuna wind round the groves of Vrindhavan. A breeze, like the breath of love from the fragrant flowers of the cetaca, kindles every heart, while it perfumes the woods with the dust which it shakes from the mallica with half-open buds; and the coeila bursts into song, when he sees the blossoms glistening on the lorely rasala. In this charming seasou of youth, Hari (Krishna) dances with a company of damsels.' The jealous Radha, however, gave no answer; when her amiable friend pointed out Krishna, with a garland of wild flowers descending even to the yellow mantle that girds his azure limbs, distinguished by smiling cheeks, enjoyiug the rapturous embraces of his fair companions. One presses him to her swelling bosom; another meditates on the lotus of his face ; a third points to a vanjula bower. He caresses oue, kisses another, and smiles on a third; while a fourth, under the pretext of hymning his divine perfections, whispers in his ear, 'Thy lips, my beloved, are nectar.' Radha remained in the forest lamenting to a confidant the wanderings of her faithless swain. 'I saw him,' she exclaimed, 'in the grove with happier damsels, yet the sight of him delighted me. Soft is the gale that breathes over yon clear pool and expands the clustering blossoms of the voluble asoca, soft, yet grievous to me, in the absence of the foe of Madhu. Delightful are the flowers of the amru trees on the mountain top, while the murmuring bees pursue their voluptuous toil ; delightful, yet afflicting to me, $O$ friend! in the absence of the youthful Kesava.

The festival of Huli, more classically called Hulica, otherwise Phalgutsava, meaning the festival of Phalguna, as occurring in the month of that name, commences about the full moon, at the approach of the vernal equinox. It is one of the greatest festivals amoug the Hindus, and almost all sects seem to partake in its festivities, and all ranks, from kings downward, appear animated by the season, which is peculiarly dedicated to Krishna. Images of this deity are then carried about in palanquins, and on elephants, horses, etc. attended by music and singing, and various antics People of condition receive numerous visitors, who are entertained with dancing girls, music, singing, betel, and rose-water. An annual festival to celebrate the birth of this god is held in the month Bhadra. On this day his worshippers fast; but, on the conclusion of the worship, indulge themselves in music, dancing, singing, and various other festivities. In the month Shravunu, another festival is held in honour of him, which lasts from three to five days, during which the same festivities prevail, to which is added the ceremony of swinging the image of the god in a chair suspended from the ceiling. In the month Kartika, a third festival takes place, to celebrate his revels among the Gopi; and in the month Phalguna is also beld the celebrated festival of the dolu, the ceremonies of which last fifteen days, and are accompanied with great splendour and festivity. During these holidays the Hindus spend the night in singing and dancing, and wandering about the streets, besmeared with the dolu (a red) powder, in the daytime carrying a quantity of the same powder about with them, which, with much noise and rejoicing, they throw over the different passengers they may meet in their rambles. Music, dancing, fireworks, singing, and many obscenities, take place on this occasion.

The stories relating to Radha are familiar to every Hindu, being incorporated into their popular songs, and the image of Radba is placed near that of Krishna in many of the temples. Kaniya is the Saint Nicholas of the Hindu navigator, as 
was Apollo to the Grecian and Celtic sailors, who purchased the charmed arrows of the god to calm the troubled sea. As the destroyer of Kalinag, 'the black serpent,' which infested the waters of the Yamuna, Kaniya has the character of the Pythic Apollo. He is represented dragging the monster from the 'black stream,' and bruising him with his foot. He had, however, many battles with his hydra foe ere he vanquished him, and he was once driven by Kal-yamun from Vrij to Dwaraka, whence his title of Rinchor. In this myth we have the old allegory of the schismatic wars of the Buddhists and Vaishnava. Diodorus informs us that Kan was one of the titles of the Egyptian Apollo as the sun; and this is the common contraction for Kaniya, whose colour is a dark cerulean blue (nila); and hence his name Nila-nath, who, like the Apollo of the Nile, is depicted with the human form and eagle head, with a lotus in his hand.-Wh. Hist. of India, p. 68 ; Tr. of a Hindu; Elphinstone's Hist. of India; Tod's Travels; Tod's Rajasthan; Moor's Pantheon; Cole. Myth.Hind.; Ward's Hindoos ; Barth ; Cunningham; Dowson; Garrett; Weber.

KRISHNA, a river in the Peninsula of India, rises in the Mahabaleshwar Hills, among the Western Ghats. In Hindu mythology, this river issued from the sweat of Vishnu when he transformed himself into the shape of the Mount Salagram or Gandacisilla. - As. Res. xiv. p. 414. See Kistna.

KRISHNA. SAnsk., Srngh., Tel. Black; hence the distinguishing name of many plants, etc.

KRISHNA DAS, author of the Chaitanya Charitamrita.

KRISHNA MISRA, author of Prabodha Chandrodaya, meaning Rising of the Moon of Awakened Intellect, a theological and philosophical drama, supposed to have been written about the 5th century with the object of establishing the Vedanta doctrine. What others have asserted by reason and argument, Krishna Misra combats by ridicule. - Garrett.

KRISS, HiND, the root of Dioscorea deltoidea, is used in Kashmir to wash the celebrated shawls; soap is used only for white shawls. The root is bruised and mixed with pigeons' dung, and when mixed with water the shawls of Kashmir are steeped in it.-Simmonds' Comml. Products, p. 574; Honigberger, p. 265 ; Dr. J. L. Stewart.

KRITA. SANSK. Done, finished, made. This word has been adopted into all the Hindu languages under various combinations. Krita, purchased; Krita dasa, a purchased slave; Krita putra, an adopted son.

KRITA YUGA, an age, in Hindu theogony the first age of the world. There are four of these, according to Bentley, the

$\begin{array}{lrrr}\text { Krita or first, } & \text { B.C., 19th April } 2352 . \\ \text { Treta or second, } & \text { 28th Oct. } & 1528 . \\ \text { Dwapur or third, } & \text { " } & \text { 15th Sept. } & 901 . \\ \text { Kali or fourth, } & \text { ", } & \text { 8th Feb. } & 540 .\end{array}$

The Krita Yuga is the first or golden age.

KRODHAGARA, SANSK., from Krodha, anger, and Agaru, a house. The room of anger; a room in a house in which when angry a member of a house shuts himself up.

KROR, in India, is a hundred lakhs, or ten millions, a lakh being in India 100,000; but in Persia, the kror is only five lakhs, or 500,000 .
KSHAPANAKA, an ancient author, one of the nine gems of the court of Vikramaditya. - Dowson. KSHATRAPA, or Satrap and Mahakshatrapa, are titles which seem to have originated with Nahapana, and were continued by every member of the Sah dynasty.

KSHEMAKA, the last who ruled of the race of Pura.

KSHEMAVATI or Khemavati, the birthplace of the Buddha Krakuchanda. It has been identified with Kakua.

KSHETRA, SANSK., written Khetra and Khet, a field.

KSHETRAJA, a son born of a wife duly appointed to raise issue for a husband in failure of any begotten by him.

KSHETRAPALA, or the guardian of the soil, in Hindu mythology is a personage of various identification. At Benares he is one with Bindumadhava, among the Vaishnava; and, with the Saiva sect, the same as Bhairava. The latter view has the support of the Batukabhairavastotra. In many places the name of this agrestic protector is bestowed on figures of Hanuman.Moor, p. 7.

KSHETRIYA. Amongst the Aryan Hindus, a warrior branch of their race, taking social rank after the Brahmans. The word is an adjective from the ancient noun Kshatra, which, as meaning rule, dominion, occurs in all the three languages of the Veda, the Avesta, and the Persian inscriptions. Originally it simply denoted possessed of authority, and is so sometimes applied in the Veda even to the gods. A not unusual spelling of the word is Kshatriya, but Chetriya, Ch'hatrya, and Chettrya are not uncommon, and it is also written and pronounced Khatri, K'hetri, and Khutri. The third Upa Veda was composed by Viswamitra, and treats on the fabrication and use of arms and implements handled in war by the Kshatriya tribe. The insignia of a student of this caste, according to Menu, are thus alluded to in the Uttra Rama Cheritra (Hind. Th. i. p. 347) on the approach of Lava, twin son of Rama:-

'Janaka. Who is this youth that thus delights our sight?

Arundhati. Some Kshatriya lad who here awhile pursues his sacred studies.

Jan. You have rightly judged

His birth; for see, on either shoulder hangs

The martial quiver, and the feathery shafts

Blend with his curling locks; below the breast,

Slight tinctured with the sacrificial ashes,

The deer-skin wraps his body; with the zone

Of Murva bound, the madder-tinted garb,

Descending, vests his limbs : the sacred rosary

Begirts his wrists, and in one hand he bears

The pipal staff, the other grasps the bow.

Arun. Whence comes he?'

These insignia of the military student are according to Menu, with the addition of the ashes of the fuel used in sacrifice, and the bracelet or rosary of the seeds of the elcocarpus, which are not indispensable accompaniments, and indicate a bias to the Saiva faith. The pipal staff is a staff made of the wood of the Ficus religiosa. The zone of Murva is a girdle fastened over one hip and hanging loosely over the other, made of the fibres of the Sanseviera Zeylanica.

Barbarous Gond chieftains, in modern times, have learned not only to style themselves rajas, but even to assume the sacred thread of the twiceborn Kshatriyas; but the kings of the Kerala 
dynasty on the Malabar coast, from whom the rajas of Cochin claim to be descended, are believed to have been the only Dravidian rulers who were really of the Kshatriya caste.

Brahmachari means a Hindu student in theology. All twice-born Hindus, i.e. the Brahman, the Kshatriya, and the Vaisya, are enjoined to spend the first quarter of their life in this state.

Hindu writers give this branch of the Aryan immigrants the second place, the Brahmans being first, and the Vaisya and Sudra the third and fourth. In the rules of conduct for this branch of the Aryan race, the natural duties of the Kshatriya are declared to be bravery, glory, fortitude, rectitude, not to flee from the field, generosity, and princely conduct. Menu says, 'To defend the people, to give alms, to sacrifice, to read the Vedas, to shun the allurements of sexual gratification; such are, in a few words, the duties of a Kshatriya.' How this soldier branch broke up is extremely obscure, but though most of the Rajput families are usually believed to belong to them, it is now generally thonght that none of the present races in India can trace their descent from the ancient race, whose constant wars amongst themselves and for others exhausted them. If there be a doubt on this point, the present Rajput races undoubtedly take the Kshatriya place as soldiers, princes, and rajas. There seem to have been two branches of that part of the Aryan family that entered India: the Solar, who traced up to İkshwaku, and the Lunar, who traced up to Budha, and Budha married Ella, daughter of Ikshwaku. These soldier Aryans do not appear to have adopted Brahmanism readily; and the Brahmans, to overawe them, consecrated by fire on Mount Abu, a warrior body who still remain, and are known as the four Agnicula Rajput tribes, whose descendants still dwell in Rajputana. The third Upa Veda, which was composed by Viswamitra, treats on the fabrication and use of arms and of the implements handled in war by the Kshatriya tribe. The four Agnicula Rajput tribes are the Chauhan, Solunki, Puar (or Prumar), and the Puribar. The unnamed progenitors of these races seem to have been invaders who sided with the Brahmans in their warfare, partly with the old Kshatriya, partly with increasing schismatics, and partly with invading GræcoBactrians, and whose warlike merit as well as timely aid and subsequent conformity, got them enrolled as the Agnicula, or fireborn, in contradistinction to the Solar and Lunar families. The Agnicula are now mainly found in the tract of country extending from Ujjain to Rewah near Benares, and Mount Abu is asserted to be the place of their miraculous birth or appearance. Vikramaditya, the champion of Brahmanism, according to common accounts was a Puar. A Hindu race calling themselves Khatri, is numerous in the Upper Panjab and about Dehli and Hardwar, and they are found along the Ganges as far as Benares and Patna. These Khatri divide themselves into three principal classes-1. the Char-jati or four clans,viz. Seth,Marhota, Khunna, and Kuppur; 2, Bara-jati, viz. Chopra, Talwar, Tunnuhu, Seigul, Kukker, Meihta, etc. ; 3. Bawanjat or fifty-two clans, amongst whom are Bundari, Meindrao, Sehti, Suri, Sani, Unnud, Buhseen, Sohdi, Bedhi, Teehun, Bhulleh, etc. Inferior Rajput tribes are settled in Bundelkhand and in
Gurha Mandalla. Others, according to Thevenot, were settled in Multan, as the original country of the Khatri, from whom he says the Rajputs are believed to spring.-Hind. Th. p. 347 .

$\mathrm{KU}$ is the guttural form of the Assyrian hu in Euphrates and Eulæus, and of the Turki su and of the Tibetan chu, all of which mean river or water. It is the Scythic ku, as in the Kophes or Kābul river.

$\mathrm{KU}$ or $\mathrm{Cu}$ in Sanskrit is a prefix, meaning evil, bad; Ku-mar, the evil-striker. Hence, probably, the Mars of Rome. The birth of Ku-mar, the general of the army of the gods, with the Hindus, is exactly that of the Grecians, born of the goddess Jahnavi (Juno), without sexual intercourse. Kumara is always accompanied by the peacock, the bird of Juno.-Tod's Rajasthan.

$\mathrm{KU}$, a race who occupy the mountainous country near the sources of the Semru river, and its principal feeder the Peng Kheong, in lat. $22^{\circ} \mathrm{N}$., westward of the Yomadoung range, and estimated at about 14,485 souls. Those living on the Peng Kheong have intercourse with the neighbouring $\mathrm{Ku}$-mi of the Koladyn circle, from whom they differ but little in their habits. On occasions of rejoicing, they tie a bull or gayal (Gavæus frontalis) to a stake, and, as they dance round it, the animal is slowly despatched by numberless spear wounds aimed at every part of its body. The blood is caught in bamboo cups, and men, women, and children drink it. The Ku have the reputation of torturing human victims in a similar manner. They appear to be the most savage of these eastern tribes. No carriers or interpreters could be found amongst the adjacent tribes who would proceed to their villages. Their chief food is Indian corn, and they are unacquainted with the use of salt. $-J$. $H$. O'Donel, Esq., in xxxii. of 1864 of B. A.S. Jour.; Dalton, Ethnol. of Bengal, p. 115.

KUAN-TI-YEH-HSIEH. CHIN. The god of war crab, from the fancied resemblance on the shell to that deity. The Hai Kuan-ti-tao, the god of war's sword, is a fish, so called from its resemblance to that deity's weapon.

KUAN-YU, the Chinese god of war, was the greatest military hero of all Chinese history. He lived during the rule of the Han dynasty. He was canonized as a saint, and afterwards promoted to the rank of a god. $\mathrm{He}$ is now the guardian deity of every Chinese city.

KUBAT. Arab. A cupola, a vault. Kubatul-Haj, a mosque with a kiosk near Damascus, where the pasha who conducts the pilgrims passes the first night of the journey. Kubat-un-Nasr, the Arch of Victory, a tomb of a Muhammadan saint, not far from where the Barada or river of Damascus (the Chrysorrhoea or Golden Stream) breaks out from the mountains, on the crest of a hill overhanging the plain. It is a favourite place of resort. Kubat-al-Idris, the dome of Enoch, is a small octagonal building in the plain towards the Bekaa or Coole-Syria, about a mile from Balbec. It is surrounded by eight beautiful granite columns. This neighbourhood is supposed to be the site of the city built by Enoch (Genesis iv. 17). A mile from Zahle, on the south side of the village of Kerak, the inhabitants show the tomb of Noah, with a tombstone 10 feet long, 3 feet broad, and 2 feet high, over which is a structure 60 feet high. A mile from this is a 
ruined temple, called Hermes Nieha, the god Mercury.-Catafago.

KUBEIS, one of the holy mountains at Mecca, of which wonderful things are related. $-Y$ Yule, Cathay, ii. p. 391.

KUBJA. SANSK. Crooked, hunch-backed, a deformed female servant of Kansa, whom Krishna made straight, and relieved of her deformity; she became a beautiful woman.

KUBLGIRA or Kili-katr, a migratory tribe in the Southern Mahratta country, who act as ferrymen, and exhibit pictures of the Pandava heroes.

KUBO is the name applied to the Shan race in the Munipur language.

KUBO, a title of the former secular emperors of Japan.

KUBU, a wild race of Sumatra. Dragon's blood, from the Calamus draco, is a granular matter adherent to the ripe fruits, and obtained by beating or threshing the fruit in little baskets. The chief place of production is Jambi, on the N.E. side of Sumatra. The principal collectors are the Kubu, a wild race, who sell it to the Malays at a shilling a lb. About 48 tons are said to be collected in Jambi, but this seems an excessive estimate. The stems of the male plant form walking-sticks, and are supposed to be the Jambi so fashionable in the reign of Queen Anne.Crawfurd's Dictionary.

KUCHA or Kat'cha. Hind. A term in general use to designate anything improper or incomplete or of small value, in opposition to the word Puk'ha, meaning ripe, mature, complete. Kat'cha Bundi, herbalists.

KUCH-BEHAR, a Native State, situated between lat. $25^{\circ} 57^{\prime} 40^{\prime \prime}$ and $26^{\circ} 32^{\prime} 20^{\prime \prime}$ N., and long. $88^{\circ} 47^{\prime} 40^{\prime \prime}$ and $89^{\circ} 54^{\prime} 35^{\prime \prime}$ E., with an area of 1291.83 square miles, and a population of 532,565 souls. It is entirely surrounded by British territory, being bordered by the Western Dwars of Jalpaiguri on the north, and by Rangpur district on the south. It contained the ancient Kamrup, and is now ruled by the Koch tribe. The rajas claim descent from Siva with Hira, who bore a son, from which the ruling family take the title of Narayan, and all the Hinduized Koch call themselves Rajbansi. The official designation of the State is Nij-Behar, nij $=$ own, peculiar. In 1878, the raja married the daughter of Babu Keshab Chandra Sen, and visited Britain. The semi-Hinduized aborigines numbered 117,095, and the aborigines are Morang, Garo, and Mech. The Praja of KuchBehar are cultivators almost in a state of serfdom. Hajo, of the Koch tribe, is the earliest known founder of the dynasty; but, according to a second legend, more popular at court, the family trace back to a Mech called Heriya. There are a number of persons of Hindu origin not recognising caste; 48,086 Muhammadans. The great bulk of the population is undoubtedly of mixed origin, in which the aboriginal strongly predominates.

Kuch-Behar city, the residence of the raja, is situated on the Torsha river, lat. $26^{\circ} 19^{\prime} 36^{\prime \prime} \mathrm{N}$., and long. $89^{\circ} 28^{\prime} 53^{\prime \prime} \mathrm{E}$. The town contains a population variously estimated at 7132 and 10,000.-Imp. Gaz. See Koch'h ; Mech.

KUDAMI or Kudumi. TAM. A tuft of hair on the crown of the Hindu's head. It is called in Sanskrit Sik'ha, and seems to be the Sisoen of
Leviticus xix. 27. It is cut off the head of a deceased Hindu by his son, as a preliminary to the further funeral ceremonies. The Greeks, Romans, and Egyptians of old wore, and the Tartars, Chinese, and Hindus now wear, this. Christian missionaries have discussed the questions as to its retention or removal on becoming a convert. The Vellalan or Vellan of Tinnevelly, who become converts to Christianity, retain their kudami or top-knots of hair. They continus vegetarians, and seldom or never marry among lower-caste converts; a Christian Vellalan hesitates to marry a Shanar Christian girl. This is not because they are Hindus at heart, but on account of the great dissimilarity of the social habits of each. The Shanar wife could never live on vegetables alone, and the Vellalan husband has never been accustomed to flesh meat. Even their language, though the same, differs very much in accent. Under these circumstances, such marriages are very injudicious.

KUDDUS. ARAB. Holy, blessed, hence on of the names of God. The Shajrat-ul-Khudush, mentioned by Forskal as a tree of Arabia, is perhaps Kuddūs, blessed, the sacred tree, the olive. Many trees are deemed Kuddūs. Bait-ulMakaddas is the holy city of Jerusalem.

KUDI. TAM. A village, a town, a house, a tribe, an inhabitant, a tenant. It forms many compound terms. Pagoda is pai kudi, devil house.

KUDMI, a Parsee sect. A Parsee when he prays has to repeat the year, month, and day on which he offers his petition; therefore the mention of the date is the only distinction between the prayer of a Kudmi and that of a Shenshoy, and the same difference exists in the keeping of the festivals, which are common to both sects.-Census of Bombay, 1881.

KUDRAT HALVASSI. TURK.

Musi, . . . ARab. | Guzanjabir, Ghezo, Pers.

A manna found on the dwarf oak, though several other plants are said to produce it, but not so abundantly, or of such good quality. It is collected by gathering the leaves of the tree, Pearled lie,'

'The manna on each leaf did

letting them dry, and then gently threshing them over a cloth. It is thus brought to market in lumps, nixed with an immense quantity of frag. ments of leaves, from which it is afterwards cleared by boiling. Another kind of manna is found on rocks and stones, which is quite pure, of a white colour, and is much more esteemed than the tree manna. The manna season begins in the latter end of June, at which period, when a night is more than usually cool, the Kurds say it rains manna, and maintain that the greatest quantity is always found in the morning after such a night. It is called in Turkish, Kudrat halvassi, or the divine sweetmeat; in Arabic, Musi; in Persian, Guzanjabin; in Kurdish, Ghezo.-Rich's Kurdistan, i. p. 142.

KUDRAY MALAY POINT, in the Gulf of Manaar, is in lat. $8^{\circ} 32^{\prime} \mathrm{N}$. It is the Hippuros of Pliny, and may have been the Tarshish of Scripture.

KUDRAY-MUKHA, a peak on the Western Ghats, between the Mysore State and British districts, in lat. $13^{\circ} 8^{\prime} \mathrm{N}$., and long. $75^{\circ} 20^{\prime} \mathrm{E}$. It is a good landmark for sailors. It means the horse-face. 
KUDUL, PUshTu. Large-arched huts made of wattled tamarisk bushes, covered with hurdles and coated with clay; used by the Barechi in Shorawak.

KUDUMPAN means a headman or chief. It is the tribal title of the Pallan race of the Peninsula.

KUEN LUN, also written Kouen Lun, as seen from Sumgal in Turkestan, is in lat. $36^{\circ} 8^{\prime} \mathrm{N}$., and loug. $78^{\circ} 5^{\prime} \mathrm{E}$, and 13,215 feet above the sea. It is part of the great mountain range in Central Asia which bounds the high table-land of Tibet. The range is known to the nations who see it near and from afar by various names. It is their Belur-tagh, meaning Ice Mountain; it is the Bulut-tagh of Captain Strachey, meaning Cloud Mountain; Mus-tagh or Muz-tagh is another name; Kara-korum is a Turki word, meaning Black Mountains; the Tsun Lun, or Onion Mountain, is given to it because of the abundance there of a species of Allium; Tian Shan of the Chinese, or Celestial Mountain, is applied to it because of its great height; and Haro-berezaiti (Albordsh) of the Zendavesta is an ancient name. The range stretches over a space of 27 degrees of longitude, or more than 1500 miles, forming in its whole length the north frontier of Tibet, as the Himalaya does that of the south.

The Kouen Lun is the true watershed between India and Central Asia, the Indus absorbing all the streams which flow from the southern slopes of the range, while the northern rivers which form the Karakash force their way through or round the outer barrier of the Kouen Lun, and wend northward to the Gobi or Sandy Desert. In the Kouen Lun all passes above 15.000 feet are closed in winter by the heavy snowfall. Two systems of cleavage are particularly regular in the central parts of the Kouen Lun; the steeper one dips north $30^{\circ}$ to $50^{\circ}$ east, the other south $20^{\circ}$ to $40^{\circ}$ west. A hard crystalline rock occurs, not unlike pudding-stone, which contains enclosures of spherical and angular forms. The quarries where the Yashm stone is dug are at Gulbagashen, in the valley of Karakash. See Kara-korum.

KUFA was a town on the west bank of the Euphrates, about 40 miles from Baghdad, but it has entirely disappeared. It was founded during the khalifat of Umar, opposite Modain. Safah, the first khalif of the Abbassi, made it his capital, but when Mansur built Baghdad, he took there from Kufa a considerable part of the Kufa population. It was much famed for its literary men. The two sects of Arab grammarians were named the Kufiyan and Basriyan, from the towns of Kufa and Basra ; and the more ancient writing characters of the Arabs are called Kufic, from this town. The most ancient copies of the Koran are written in them. They are square and heavy, a good deal resembling the Syriac, and are more suited for inseriptions than for writing. The iuscriptions on Mahmud's pillar at Ghazni are in the Kufic. Ali was buried at Kufa after his fall here.

Shortly before the institution of El Islam, a character differing little from that now generally used by the Arabs was introduced at Mecca from Irak. The Kufi or Kufic character, which for many years superseded the former, was a later invention, for Kufa was not founded until the 17 th year of the Hijira.

The city of Kufa, founded by the khalif Umar, was constructed from the ruius of Babylon. It is 88 miles south of Baghdad, built on an affluent of the Euphrates. It was the residence of the khalifs, and a great town till Mansur removed to Baghdad, A.D. 760. Four miles to the westward, Mashed Ali stands conspicuous. Kufa gives its name to an old form in which Arabic was written.

Kufic coins have been largely found in Gothland. In the Stockholm Museum alone, 20,000 have been preserved minted in about seventy different towns within the former dominions of the Abbassi kbalifs.-Mignan's Travels, p. 325; Prideaux's Life of Mahoned, pp. 29, 30; MacGregor

KUFA, ARAB., is a round wicker basket, towed astern of each boat for the purpose of communicating with the shore. These are in use on the Tigris, Euphrates, and the Diala. The Kufa basket boat (so named from the Arabic word which means basket) is also used as the common ferry boat. Its fabric is of close willow-work, well coated, and made waterproof with the bituminous substance of the country. It holds about three or four persons with room enough, though not in the most agreeable positions. It is moved by paddles.-Mignan's Travels, p. 55.

KUFALZAI, more generally known as the Popalzai, a Daurani tribe, numbering 12,000 families, an offshoot of the Abdali, one of the branches of which, the Saddozai, gave sovereigns to the Afghans in the 17th and 18th centuries.

KUFF, also Kuffee. PANJ. Chaptalia gossypina is a mere weed, from Simla to Lolon, and covers the whole of the unwooded hills in the very greatest profusion. Kuff, pealed off the leaves of the plant, is called by the paharries Sokhta, and they use it instead of tinder for their matchlocks, etc. When the leaves are damp and green, the kuff is taken off the back of the leaf with great facility and quickness. Kuff would not make the stronger and larger kinds of paper, but it would be available for that of the finest and most delicate kind. One ton of leaves would produce 1 cwt. of the film. - General Cox, from Lieut. Ross, 25th July 1858.

KUFR. ARAB. Infidelity. Muhammadan sins against God are infidelity, despairing of God's mercy, considering oneself saved, false witness, falsely accusing a Musalman of adultery, falsely swearing, magic, wine drinking, appropriating orphans' property, usury, adultery, unnatural crimes, theft, murder, fleeing in battle before the face of an infidel, disobedience to parents. The punishments for adultery, fornication, slander of a married person, apostasy, are designated Hadd ; Tazir, punishments inflicted by the judge according to the law. Qisas, literally retaliation, the lex talionis of Exodus xxi. 24; but Mahomed allowed a money compensation, at the discretion of the next of kin, to the murdered person.

KUFRA, a town, six hours from Sert, on the Bitlis road, in the district of Shirwan. The castle of Shirwan is only an hour from Kufra. In Rich's time, the Bey was powerful and independent, and a younger branch of the Hasan Keif family, and consequently an Ayubi or descendant of Salah-udDin. There is a gold mine in Shirwan.-Rich's Kurdistan, i. p. 377. 
KUI KHEL, a section of the Afridi Khel dwelling in Bazar, residing in summer in Bar B3ara and Tordara, and in winter move to the mouth of the Khaibar, and to their caves in Kajurai.-H.A. N.W.F. pp. 243-245.

KUKA. The founder of this Puritan sect of Sikhs was Ram Singh, a carpenter, native of the small village of Bhaini, about 7 miles S.E. of Ludhiana. In 1845 he served as a soldier in the Sikh army, which he left after the overturn of the Sikh rule, and endeavoured to restore the Sikh faith in its purity. By the year 1867 he had gathered round him a numerous following, and he had about 100,000 disciples, and their objects seemed to assume a political form.

The Sikhs have ten commandments, so have the Kuka,-five affirmative, and five negative. The former are known as the five K's, and are Kard, Kachh, Kerpal, Kanghi, Kes, iron ornaments, short drawers, iron quoits or weapons, the comb, and hair. The negative commandments are Narimar, Kuri-mar, Sri Katta, Sunnat-katta, Dhir Malia ; no smoking, no murder; daughters not to marry the shaven crowns, the circumcised, nor the disciples of the guru of Kartarpur.

Sherring says they are like the Nanak Shahi, only more rigid. They wear a peculiar uniform. The term is derived from the loud tone in which they utter their mantra, or sacred text, compared to the kuk or loud note of the kaku or kokila. The Kukapanthis intensely detest all other sects. They care little about the body after death. They hold that after the soul has left the body, the remains require no more attention, and may be put out of sight in any way convenient. They feast, give sweetmeats, and read the Granth incessantly when one of their sect is about to die, and after he is dead they read the Granth day and night, relieving each other at the task, for thirteen days, after which they give a feast. Bishn Singh, a fanatic leader, was executed in 1872 , but his Granth, which was to be sent to the guru, was left in the Kuka temple in Lahore, and read by the men of his sect, who performed his obsequies. His ashes were given up on condition that there should be no demonstration by the relatives, and they were committed to the Ravi by his son, who took the remainiting bones to Hardwar, according to the Hindu and not Kuka custom.-Indian Public Opinion.

KUK'HA, a race in the north-western Panjab, who occupy the rugged mountains along with the Bimba, inhabiting the hills westward from Kashmir to the Indus.

KUKHNAR. TURKi. Poppy heads bruised in water; a narcotic drink.

KUKI occupy the country to the south of the Garo, Khassya, and Mikir areas, or the hill ranges of Garo, Jaintia, and Kachar, in Sylhet, Tiperah, and Chittagong, among the mountains to the north-east of the Chittagong province. They are found as neighbours of the Naga in Assam, and in contiguity with the Mugh of Arakan, and thus the hill country occupied by them extends from the valley of the Koladyn, where they touch on the Kumi, to Northern Kachar and Munipur, a distance of about 300 miles.

The Kachar old Kuki are arranged into three divisions, - the Rhangkul, the Khelma, and the Betch. The Kuki are also called Lungkta.

Now Kuki came from the ruder parts of
Tiperah and Chittagong, and their form of speech is not always intelligible to an old Kuki. The Munipur dialects and that of the new Kuki are mutually intelligible. In 1848-49, four Kuki tribes-the Thadan, the Shingson, the Changsen, and the Lhungam - were driven into North and South Kachar and into Munipur, from their locations, by the Lushai people, who speak a Kuki dialect, but dwell farther south. They were driven back by Colonel Lister and his Sylbet light infantry. He entertained the new Kuki as soldiers, and they formed good outpost soldiers on the frontiers of both the Lushai and the Angami countries. The Kuki on the eastern frontier are commonly known by Tiperah. In physiognomy some of them are like the Munipuri, but the greater part bear more resemblance to the Khasiya tribes, having strongly marked Kalmuk or Mongolian features, with flat faces and thick lips, not in general shorter in stature than Bengali, but far more muscular and strongly made; many of them with complexions scarcely darker than a swarthy European. The villages contain perhaps from 100 to 200 inhabitants eacl, and each house is raised on bamboo piles 4 or 5 feet from the ground. The sites of the Kuli villages are well chosen on the broadest parts of the highest ridges, with water near at hand, generally a small hill stream. Some of the chief villages contain as many as 200 houses, commodiously built on platforms raised between 3 and 4 feet from the ground. Every part of the house is formed of bamboo, there being but few trees of any kind.

Kuki of the Tiperah Hills are divided into the Umroi, Chutlang, Halam, Barpai, and Kochauk Kuki. Their only deity is Lachi, to whom they offer the head and neck of a cock. The Chittagong Kuki are divided into Chukma, Tiperal, Reang, and Susai Kuki.

The Kuki who came into Assam from the Chittagong Hills about the beginning of the 19 th century, were in a state of nudity, but were soon induced to wear clothing. Since then, four large tribes of Kuki - the Thadan, Shingson, Changsen, and Lhungam-were defeated in a war with the Lushai, and fled into Kachar, where the British Indian Government allowed them to settle.

The Khong-jai Kuki, until lately, occupied the hills to the south of the Koupooee. Whilst in this position, little or nothing of them was known, but they caused fear from their vicinity. South of them lay the Poi, Soote, Taute, Lushai, and other tribes, better armed than they were, and of the same gens as themselves, but at feud with them. By these they were driven from their native hills, the task being rendered easier by the internal animosities of the Khong-jai themselves, and the Khong-jai are now scattered around the valley of Munipur, and thence through the hills to North and South Kachar. Thus they broke into distinct tribes; although occupants of the hills to the south of the valley of Munipur, their traditions do not give the southern hills as the place of their origin, but rather lead them to the belief that it was in the north.

The new Kuki clans are presided over by rajas and muntris. One, among all the rajas of each class, is chosen to be the Prudham or chief raja of that clan. The tradition of the Kuki respect- 
offspring of the same progenitor, who had two sons by different mothers. The Mugh, they say, are the descendants of the elder, and the Kuki of the younger son. The mother of the younger having died during his infancy, he was neglected by his stepmother, who, while she clothed her own son, allowed him to go naked. Each man lives with his family in a separate house. The widows live in houses of their own (in this respect like the Naga and Kachari), built for them by the villagers. The men wear a large cloth, sometimes two, wrapped loosely round the body, and hanging from the shoulder to the knee. The women wear a short striped petticoat, reaching from the upper part of the body half-way down to the knee. Married women have their breasts bare, but all virgins are covered, wearing a cloth wound round the bosom underneath the armpits. They wear their hair prettily plaited at the back, the two ends being brought round in front, and tied just above the forehead in the form of a coronet. Like all hill people, the Kuki are dirty in their habits, very seldom washing their bodies. At 12 or 13 , a boy is excluded from the family mansion at night, and compelled to take rest or share of the vigil with the young men in the watch-houses.

When a married man dies, all his friends assemble and bewail their loss. Vegetables and rice are cooked, and placed on the left side of the corpse, with a gourd or bottle. The object of the Kuki inroads on the plains was not plunder, for which they have never been known to show any desire; but they kill and carry away the heads of as many human beings as they can seize, and have been known, in one night, to carry off fifty. These are used in certain ceremonies performed at the funerals of their chiefs, and it is always after the death of one of their rajas that their incursions occur. The Kuki smoke dry the dead bodies of the rajas. His body is kept in this state for two months before burial, in order that his family and clan may still have the satisfaction of having him before them. Should a raja fall in battle by auy chance, they immediately proceed on a war expedition, kill and bring in the head of some individual, hold feasting and dancings, and then, after cutting the head into pieces, send a portion to each village of the clan. This was done on the murder of the Kuki raja by the Nimzai Naga race. This is considered in the light of sacrifice to appease the manes of the deceased chief. The Kuki have been accused of cannibalism, and in one instance the charge seemed substantiated, but they disclaim the imputation with much vehemence.

In the spring of 1871 , they made several inroads into Assam, for the purpose, as was alleged, of obtaining heads for the manes of a chief's daughter.

Puthen is their chief deity, he is benevolent; and Ghumvishve is a malignant deity. The Kuki likewise worship the moon. They have no professed minister of religion. The Thempu, their priest and diviner, is not hereditary, and his office is not coveted from fear of the initiatory rites.Cole.; J. H. Reynold's Embassy of $1864, B . A$. S. J.; Buttler's Travels in Assam; Aitcheson's Treaties; Dalton's Ethnol.

KUKI. The Zakha and Kuki clans of the Afridi tribe hold the entire Khaibar pass from
Jamrud to Lundi Kotal, and are able to defy all the other sections combined. These turbulent hillmen break the most solemn engagement.

KUKRI. This Gurkha sword has a short handle and an incurvated blade, widening at the middle, and drawing to a point at the end.

KUL, HrND., of Lower Himalaya, a watercourse; a lake. Kulahu and Kuli, land watered from a kul or canal.

KUL. KARN. One who pays revenue to

Govermment.

KULA. SANSK. A family, a race, a tribe. Properly the got of a Hindu is his tribe, and Kula is the race. But Kula among the Rajputs means a tribe, and corresponds to the Afghan Khel. Gotra or Kula mean a family, and existed amongst Kshatriya, Vaisya as well as Brahmans. Gotra depends on a real or imaginary community of blood, and then corresponds to what we call families. Kula forms various compound words, as Kula-deva, household deity; Kulacharya, a family priest ; Kulina, of a good family.

No Hindu house is supposed to be without its Kula-deva or tutelary divinity, but the notion attached to this character is now very far from precise. The deity who is the object of hereditary or family worship, the Kula-deva, is always Siva, or Vishnu, or Durga, or other principal personage of the Hindu mythology; but the Griha-deva or household god rarely bears any distinct appellation. In Bengal, the domestic god is sometimes the saligram, sometimes the tulsi plant, sometimes a basket with a little rice in it, and sometimes a water jar, to any of which a brief adoration is daily addressed, most usually by the females of the family. Occasionally small images of Lakshmi or Chandi fulfil the office, or, should a snake appear, it is worshipped as the guardian of the dwelling. In general, in former times, the household deities were regarded as the unseen spirits of ill, the ghosts and goblins who hovered about every spot, and claimed some particular sites as their own. At the close of all ceremonies, offering's were made to them in the open air, to keep them in good humour, by scattering a little rice with a short formula. Thus, at the end of the daily ceremony, the householder is enjoined by Menu-3,90 ' to throw up his oblation (bali) in the open air to all the gods, to those who walk by day and those who walk by night.' In this light the household god corresponds better with the genii locorum than with the lares or penates of antiquity.-Wilson's Hind. Th.

KULAB, a hill state north of Badakhshan; its chief claims a Grecian origin.

KU-LA-DAN, a river of Arakan, in British Burma. Supposed to rise in the neighbourhood of the Blue Mountain, a peak in the Yoma range. After a course generally north and south, it falls into the Bay of Bengal at Akyab town, where it is called by Europeans the Arakan river. It is also written Koladyn.-Imp. Gaz.

KULAH. Burs. A native of India. Any foreigner. Qu. Kala. See Kling.

KULAM, also Cullam. TAM. A tank, a reservoir. $-W$.

KULA-PARVATA, in the geography of the ancient Hindus, are seven mountain chains of $\mathrm{S}$. India. Of these are the Mahendra of Orissa; Malaya of Malabar, in the southern part of the 
Western Ghats; Salyya in the northern part; the Suktimat-? doubtful; the Riksha in Gondwana; the Vindhya in the eastern part of that range; and the Paripatru or Pariyatra in the northern part of the range.

KULASAIKERA. Arya Chakravarti is found in Ceylonese history as the name of a warrior who commanded an army sent by the Kulasaikera, who is called king of the Pandiyans, or people of the Madura country, which invaded Ceylon in 1314. The same title re-appears as if belonging to the same individual in or about 1371 , when he is stated to have erected forts at Colombo, Negombo, and Chilaw, and, after reducing the northern division of Ceylon, to have fixed the seat of government at Jaffnapatam. He is mentioned as the first Pandiyan king, the patron of Agastya.-Yule, Cathay, ii. p. $42 \%$.

KULBURGA, a town in the Hyderabad territories, which was the capital of the first Muhammadan dynasty in the Dekhan, founded in the begiuning of the 14th century by Ala-udDin Husn Gangawi Bahmani. The seat of government was subsequently transferred to Beder. Both of these places have magnificent domed tombs. Syud Muhammad Gessu Daraz, a holy man, known as Banda Nawaz, is interred here.

Kulburga was centrical to the great body of the empire. The state fell to pieces with its own weight, and out of it were formed the kingdoms of Bijapur, Golconda, Berar, and Ahmadnaggur; each of these subsisted with a considerable degree of power, until the Moghul conquest; and the two first preserved their independency until the time of Aurangzeb. The five monarchs of these kingdoms, like the Cresars and Ptolemies, had each of them a name or title common to the dynasty to which he belonged, and which was derived from the respective founders. Thus the kings of Kulburga were styled Bahmani; those of Bijapur were styled Adal-Shahi; those of Golconda, Kutub-Shahi; and those of Ahmadnaggur and Berar, Nizam Shah Bhairi and Imad Shahi. Their histories are to be found in Ferishta, Khafi Khan, and the Tarikh-i-Shahābud-Din, Kazi of Ahmadnaggur.-Rennell's Memoir, p. 79 ; Orme's Historical Fragments, p. 36 ; Elphin.

KULDJA, a town in Central Asia, at which was signed a treaty between the Russians and Chinese, 12th-24th February 1881. According to the 16th article, the Chinese Government agreed to 'diminish proportionately to the value the export duty on some kinds of tea of inferior quality' exported to Russia by land.

KULEAH. Pers. A robe exactly similar to, but worn over, an al-khaliq.

KULI, Tam.; Kuri, Maleal. 4 measure one foot square. $-W$.

KULI. Turis. A slave. Nadir means wonderful, and is used as an epithet to describe the Almighty. The name of Nadir Kuli therefore signified the slave of the wonderful, or of God. When he was promoted by the favour of Shah Tamasp to the dignity of a khan, he took the name of that monarch, and was called Tamasp Kuli Khan; but on reaching the throne he styled himself Nadir Shah, resuming his original name of Nadir.-Malcolm's Persia, ii. p. 46.

KULIN, a race of Brahmans in Bengal who are deemed by other Brahmans to be of very pure descent, and in consequence many are anxious to wed their daughters to them. As a result, the Kulin men are great polygamists, and in the middle of the 19th century a pamplet gave the following amongst others:-

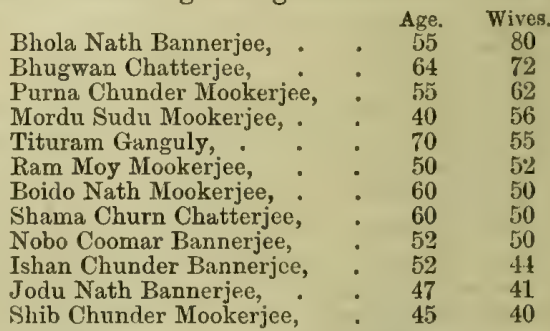

Pandit Iswara Chandra Vidyasagar wrote a pamphlet in Bengali, entitled 'Polygamy-Should it be abolished or not?' Most of these marriages are sought after by the relations of the girls, to kcep up the honour of their families; and the children of these marriages invariably remain with their mothers, and are maintained by the wives' relations: in many cases a Kulina father does not know his own children. Kulina women in Mr. Ward's time furnished a large number of the common women of Calcutta. The children of Kulina women, born while in their own father's house, are never owned by these husbands. In the year 1815, some Hindus proposed to petition the British Government to prohibit Kulin Brahmans marrying so many wives. The Kulin tribe take the suffix honorific names of Mookerjee, Chatterjee, Bannerjee, Ganguly. The Hindus of Calcutta, styled Ghose, Bose, Dutt, and Mitra, are Sudra tribes who accompanied the Kulin Brahmans into Bengal.

Shib Chunder Bose tells us (p. 232) that Oodhoy Chunder, a Brahman of Bagnapara, had 65 wives, of whom he had 41 sons and 25 daughters; Ramkinkur, a Brahman of Kushda, had 72 wives, 32 sons, and 27 daughters; Vishnu Ram, a Brahman of Gundalpara, had 60 wives, 25 sons, and 15 daughters; Gouri Churn, a Brahman of Tribani, had 45 wives, 32 sons, and 16 daughters; Rama Kant'h, a Brahinan of Bhusdarani, had 82 wives, 18 sons, and 26 daughters. He died in 1810 at the age of 85 , but married his last wife only three months before his death.-Ward, iii. pp. 181, 268.

KULK, in Khorasan, a fine goat's wool. Goat's hair enters extensively into the coarser woollen manufactures of Khorasan; beneath the coarser external hair of these animals, a wool called kulk is obtained, little inferior to the fine wool of 'Iibet, and from which various articles of clothing are made.-Fraser's Khorasan, p. 390.

KULKARNI. Mahr. A village accountant. The Kulkarni and Karnam of the Dekhan and south of India is the Patwari of Hindustan and the Tallati of Gujerat.

KULLA. HiND. Heaps of grain threshed in the open field, preparatory to being divided and housed.-Rajasthan, ii. p. 63.

KULLAH. PERS. Literally a hat; applied by the Afghans to crowned heads, also to hatwearing natives of Europe. The use of the kullah of black lambskin is universal among the Persians. Kullah-zarra, a chain-armour cap or head-piece. Zarra-baktar is armour. Kullahark, CHIN., is an embroidered cap.-Ouscley's 'Tr. i. p. 208. 
KULLEN; a predatory race in Puducottah, Madura, etc. Their name is also written Kallan, and plural Kallar. See Kollar.

KULLORA and T'alpur are Sind tribes which furnished its last two dynasties. The Kullora trace their descent from the Abbasside khalifs, and the Talpuri from Mahomed, but both seem to be Baluch. The Talpuri (Tal or Tar, Borassus flabelliformis or palmyra, and Pura, a town) amount to one-fourth the population of Hyderabad, which they call Lohri or Little Sind. 'There are none in the t'hul. The Kullora dynasty ruled in Sind in the 18th century, and their descendants are still residing at Hajipur in the Dehra Ghazi Khan district.

KULLU, a valley and revenue subdivision of the Kangra district of the Panjab, lying between lat. $31^{\circ} 20^{\prime}$ and $32^{\circ} 26^{\prime} \mathrm{N}$., and between long. $76^{\circ} 58^{\prime} 30^{\prime \prime}$ and $77^{\circ} 49^{\prime} 45^{\prime \prime} \mathrm{E}$.

Kullu or Kulu, in the N.W. Himalaya, consists of the mountain basin of the Beas and the west bank of the Sutlej. Sultanpur, its capital, is elevated 4584 feet. The chain hounding the Sutlej on the west is considerably higher than that on its east bank, and is crossed into Suket by the Jalauri pass, elevated 12,000 feet. The province of Chamba bounds it on the west, and the physical fentures of Kulu and Chamba are similar. The poorer Kulu people wear only a blanket wound around the waist, and one end flung across the shoulders and pinned across the chest; men and women often dress alike, but the long hair of the women is plaited in one tress. The natives of Bashahir, Sukeit-Mundi, and Kulu in the Kohistan of Jalandhar, have all sallow complexions, and secm all of the same race. In the hills of Kulu and Kangra are the Gujari and Guddi races, who cultivate little, and keep herds of buffaloes, and flocks of sheep and goats. They clain certain beats of the forests as their warisi, or ancestral property, subject to the payment of pasturage tolls. The forests of the lower hills are apportioned out among the Guddi or shepherds of the Snowy Range, who in the winter season bring down their tlocks to graze. In the same manner the Gujar with their buffaloes take up divisions on a hill-side, and carefully respect their mutual boundaries. A kingdom of Kulu, too, is placed by Hiwen Thsang at $700 \mathrm{li}$, or 117 miles, to the N.E. of Jalandhar. Gold is found in Kulu. Native gold-washers earn two or three annas a day by extracting from the river sand a very fine dust. The chief castes are Kanet and Dagi. Polyandry still prevails in Seoraj, but has almost died out elsewhere. It consists of a community amongst brothers of wives and all their goods, and they regard their women as farm labourers.

About Subathu one sometimes sees infants wrapped up like little mummies, and laid in such a position that a small rill of water falls on their heads. These infants are usually watched by some elderly female whilst their mothers are employed in the fields. The natives believe that this ordeal strengthens the children and renders them hardy, and that it cures dysentery and various other diseases. But the common object is to keep them asleep, and this is found to be a most effectual means of so doing. The Kulu people dread the evil eye, and have recourse to witch-finders, who feign the power of discovering evil spirits, which wander over the mountains in the tangible form of witches. If a cow or other living creature die, its death is attributed to some evil eye, and a witch-finder is employed to discover it. This impostor having selected some old woman who had no means of propitiating him by gifts, placed his victim in the centre of a group, whilst all interested in the case sat around her in a circle. He then danced round the poor creature, and ultimately nodded his head towards her, whereupon all the lookers-on did the same, which coincidence was deemed a sufficient proof of guilt. Formerly she was subsequently condemned to be burnt to deatb. But since that district became a British province, and these inhuman proceedings have not been allowed to take place, they declare the victim of their superstitious credulity an outcaste, and refuse her the commonest necessaries of life; thus she is abandoned to her fate, and would probably starve to death, but for the timely gift of a goat or a sheep by some one of her relatives to the witch-finder, who forthwith fastens the guilt on some other person, in the hope of extorting in a similar manner from the relatives of the last accused. - Cleghorn's Panjab Report, p. 89; H. f. et T. p. 203. See Ladakh.

KULLUKA, an ancient commentator on the Institutes of Menu.

KULLUR or Belaspore. Its Rajput rulers had estates on both sides of the Sutlej, but the sunnud given to raja Muher Chund in 1815 confirmed to him the eastern portion only. In acknowledgment of services during the mutinies in 1857 , the raja received a dress of honour of Rs. 5000 value, and a salute of seven guns. The revenue of this State is not less than Rs. 70,000. The population amounts to 66,848 .

KUL TEAK, a scarce variety of the teak tree in the Wynad, about Sultan's Battery. It is considered superior to the common teak.M'Tuor, M.E.

KUITI or Kullu. TAM. Gram or horse gram, Dolichos biflorus or D. uniflorus. D. bifforus, the two-flowered bean, is grown in fields after the rains, and chiefly used for cattle; when given to horses, it must first be boiled; they soon become very fond of it, and keep in as good condition as upon any other grain. The Bengal gram or chenna is the Cicer arietinum.

KULUMB, the name of several towns in the south of India. One of these is Colombo, the seat of government in Ceylon, which has a population of 40,000 people. It seems to have been selected by the Dutch from the proximity of the cinnamon gardens, for it has no other recommendation. It was visited by the Portuguese in 1505. It capitulated on the 16th February 1796. It is on the west coast of the island, in lat. $6^{\circ} 56^{\prime}$ $\mathrm{N}$., and long. $79^{\circ} 53^{\prime} \mathrm{E}$., and exports largely to Europe. Colombo is mentioned in Singhalese historical annals so early as A.D. 496; the name is said to signify a seaport. This and Covelong, south of Madras, and Quilon of the western coast, are all the same name, Kulumb. - Horsburgh; Sirr.

KULUNG. HiND. The kulm fowl of the Bombay side of India is the Grus cinerea, the European crane. It visits India in great flocks in winter, but wholly disappears in the breeding season. It is also called the karranch.

KULZUM represents the ancient $x \lambda \nu \sigma \mu \alpha$, 
situate at the northern extremity of a bay, in lat. $28^{\circ} 50^{\prime} \mathrm{N}$., and long. $63^{\circ} 20^{\prime} \mathrm{E}$., according to Ptolemy. But, says Hamd Allah Cazvini, the Sea of Kulzum is likewise called Bahr Ahmar or the Red Sea. Hameir or Hamyar is bestowed by the Persian geographer on another gulf. Natives of India regard the Bahr-i-Kulzum as the Caspian Sea._Ouseley's Travels, i. p. 28.

KUM, in lat. $34^{\circ} 45^{\prime} \mathrm{N}$., and long. $50^{\circ} 29^{\prime} \mathbf{E}$., a town in Irak-i-Ajam or Persia, 80 miles on the road from Teheran to Isfahan. The tomb of Fatima, the sister of the Imam Raza, is there; and it is the most celebrated of the sanctuaries of Persia. With Muhammadans it is a favourite place of burial. See Asylums; Bast.

KUMALA, the son of Asoka. A legend regarding him proves the antiquity of the practice of placing eyes on the outside of Buddhist temples. In a former birth, Kumala is said to have plucked the eyes from a chaitya, for which he was punished by the loss of his own in the next birth; and because he then presented a pair of golden eyes to a chaitya, he was afterwards born as the son of Asoka, with eyes beautiful as those of the Kumala bird, from which circumstance he obtained his name.

KUMAON, a district in the N.W. Provinces of British India, including Kumaon proper, Kali Kumaon, and the Bhabar; it lies between lat. $28^{\circ} 55^{\prime}$ and $30^{\circ} 50^{\prime} 30^{\prime \prime} \mathrm{N}$., and between long. $78^{\circ} 52^{\prime}$ and $80^{\circ} 56^{\prime} 15^{\prime \prime} \mathrm{E}$.; its area is 6000 square miles, and population, in $1872,433,314$ persons. Kumaon district consists, first, of the sub-Himalayan ranges, and, secondly, of the Bhabar or waterless forest, averaging from 10 to 15 miles in breadth, which stretches between the mountains and the Terai. The original Khasiya, or inhabitants of Khasdes, mentioned by the Hindu lawgiver Menu some 2500 years ago, were Hindus, and identical with the modern tribe of Khasiya. The Dom rank as the lowest of the Khasiya, and until the British occupation they were the predial slaves of the landholders. Every crag and summit has its local deity and shrine, at which kids are offered in sacrifice; at the larger temples at river junctions, buffaloes are similarly slaughtered. The obnoxious custom of polyandry is here unknown, but polygamy is frequent. The Bhabar or southern portion is about 10 to 15 miles broad. It consists of the loose alluvial detritus of the lower hills. It is of considerable elevation, with a total absence of running water, but is bounded on the south by a line of springs which mark the northern boundary of the Terai district. Up to 1850, the Bhabar was an almost impenetrable forest, given up to wild animals, and is still mostly unreclaimed jungle. Elephants are found in the Bbabar and in the forests bordering on the Siwalik Hills. The mura fly is very troublesome in the months of April and May. Limestone, sandstone, slate, gneiss, and granite constitute the principal geological formations of the district. The majority of the Hindus belong to the tribe of Khasiyas, identified by some with the inhabitants of the Khassya Hills in Assam. The crests of the watershed range which separates the Indus and Sutlej systems, is in general very great; the Niti pass is 16,570 feet above the sea, the Mana pass is 18,760 feet, the Juhar or Milam pass, 17,270 , and that of the Lanpya Dhura pass in Byans, 18,000. The elevation of the Terai varies from
600 to 1000 feet. The first mountain range rises 4300 fect, and the second 7700 feet. Srinuggur, in a valley on the banks of the Alaknanda, is 1500 feet. The mountains of the outer ranges rise to 7000 feet in many places, and in the interior attain to 10,000 feet; while still farther north many rise to 20,000 , and a few above 24,000 feet, and Nandadevi 25,750 feet. The highest mountain west of Nepal is in this province. The loftiest, as elsewhere in the Himalaya, are never on the axis of the chain, but are still farther north, and its great elevation may be judged of from the heights of the passes over it. Of these, proceeding from the eastward, may be mentioned the \begin{tabular}{c|c|c|} 
Feet. & \multicolumn{1}{c}{ Feet. } & Fect. \\
Lanpya, . 18,000 & Niti, . $16,570 \mid$ Naini Tal, 6,500
\end{tabular} Lakhur, . 18,400 Mana, : 18,760 Bhim Tal, 4,000 Balch, . 17,700|Almora, . 5,500

The vegetation of Kumaon includes fully 2000 flowering plants.

Kumaon and Garhwal furnish gold, copper, iron, lead, sulphur, borax, soapstone, silijit or native sulphate of alumina, gypsum, graphite, lignite, asbestos. The Pakhri copper mine is in Pargana Nagpur in Garhwal, also at Rai in Gangoli, at Siri in Barabisi, and at Sor.

Kumaon porters carry their loads on their heads; those of Garhwal on their backs.-Imp. Getz.

KUMARA is the Hindu god of war, and is supposed to be the analogue of Mars, the Roman god of war. Kumara was the son of Janavi (Juno), as Mars was the son of Juno, and like as the Roman Mars was produced by the agency of Vulcan, so was Kumara by the Hindu regent of fire. Kumara has the peacock as his companion, and this bird was likewise sacred to Juno; and as the Grecian goddess is fabled to have had her car drawn by peacocks, so Kumara (the evil-striker) has a peacock for his steed.-Tod's Rajasthan, i. p. 596 . See Ku.

KUMARA. SANSK. A youth, a young boy, a prince, vernacularly Kunwar, or Kuar, or Coour. Kumari, vernacularly Kunwar, a maiden, a young girl, a princess; a name of the goddess Durga, to whom, as a maiden, a temple has been erected at the extreme south of the Peninsula, at the cape known to Europe as Comorin. The author of the Periplus states that at the town of Komar, where there is a fort and a harbour, people came to bathe and purify themselves, for it is related that a goddess was once accustomed to bathe there monthly. Cape Comorin formerly ranked as one of the five sacred bathing places, and the monthly bathing in honour of the goddess Durga or Parvati is still continued, but the number of visitors to it is now very amall.

KUMARA, four or five mind-born sons of Brahma. They declined to create progeny, and remained pure and innocent. $-D$.

KUMARAKURU TESIKAR, author of several poems, of which Nitineri Vila-Kham is the best. T'wo juvenile compositions, Tirumutur Kalivenpa and Minaksi Pillai, TAM., are also well known. He was born at Strivy-guntam, in Tinnevelly, in the 17th century, and is said to have died in Benares.

KUMARA SAMBHAVA, a poem by Kalidasa in 16 cantos, parts of which have been translated by Stenzler into Latin, and by Griffithe into English. $-D$.

KUMARI, of Mysore and Canara, is the Punam 


\section{KUMARILA BHATTA.}

of Malabar, the Punakad of Salem, the Chena of Ceylon, Dhya in Central India, Jhum in Bengal, Kil in the Himalaya, and the Tungya of Burma. It is a rude system of culture, followed in all the countries wherein secluded tribes and others clear parts of the forest. The Kumari cultivators earn a cheap but wretched subsistence, and live in miserable huts. The Irular and Kurumbar races on the Neilgherries, the Malai also on the Shevaroys, the Punam cultivators in Malabar, the Kumari cultivators of Canara, and the Karen in Burma, all endeavour to obtain a precarious subsistence by scattering grain after burning the jungle, and thus avoid, to them, the irksome restraints of civilised life. A hill side is always selected, and at the close of the year a space is cleared. The wood is left to dry till the following March or April, and then burned. The ground is then sown with Italian millet, Panicum Italicum, as also with rice, Oryza sativa. In Canara, the seed is generally sown in the ashes on the fall of the first rain, without the soil being touched by a plough. It is fenced and weeded, and the crop gathered towards the end of the year. A small crop is taken off the ground in the second year, and sometimes in the third, after which the spot is deserted for 7,10 , or 12 years, until the jungle grows sufficiently high to tempt the tribe to renew the process. In Ceylon, the Chena lasts two years, and includes the culture of chillies, yams, sweet potatoes, cotton, hemp, etc. About the middle of the 19th century, in Bekal, the most southern taluk of Canara, 25,746 , or one-sixth of the rural population, were engaged in it, but north of that taluk it was carried on by the jungle tribes of Malai Kader and Mahratai to the number of 59,500. Kumari was then prohibited in Mysore, and under great restriction in the Bombay Presidency; and the Madras Government, in 1860 , prohibited it in Government forests, without special permission, which they commanded to be given sparingly, and never in timber spots. Mr. Camnan, a coffee planter of Wynad, says that in a spot thus treated, only wood re-grows unfit for any building purposes, and he had never been able to get coffee to grow on it.-Dr. Cleghorn in Reports to the Madras Government, 1858, etc.; Cleghorn, Forests and Gardens of India, p. 126.

KUMARILA BHATTA, a controversial Brahman of eminence, who is supposed to have lived at the end of the 7th century of the Christian era. Dowson says he was styled also Bhattacharya, also Kumarila Swami, a celebrated teacher of the Mimansa philosophy, and opponent of the Buddhists, whom he is said to have extirpated by argument and force. He was prior to Sankaracharya, in whose presence be is said to have burned himself.

KUMBHA, also Kumbi and Kumbhi, Careya arborea, Roxb. Its fibre is employed in the Himalaya as slow match for matchlocks.

KUMBHAKA. Sansk. Part of the Brahmanical ritual for obtaining control of the external senses. It consists of a suspension of breathing by closing both nostrils.

KUMBHAKARNA, a brother of Ravana, king of Ceylon, of gigantic stature. He fell in battle, killed by Rama.

KUMBHUPATIA, a sect of Hindu dissenters, lately founded in the Sumbulpur district, and known as Kumbhupatia, from the fact that its
KUM FA.

followers wear ropes of bark round their waists. They allege that their religion was revealed to 64 persons in 1864 by a god incarnate, whom they style Alekhswamy, - that is, the Lord, - whose attributes cannot be described in writing. They believe in Hindu deities, but do not respect images, saying that it is impossible to represent a Supreme Being whom no one has ever seen. They are subdivided into three classes, two of which renounce the world and make no distinction of caste; while the third lead a family life. Their habits are said to be very filthy, and they take no medicine in illness, but rely solely on divine help. In 1883, a party of 12 men and 15 women forced their way into the sacred temple of Jaganath at Puri. They were naked, but for the bark ropes worn round the waists. They had come from the Central Provinces, and boldly avowed their intention of burning the Jaganath idol, in order to show the unregenerate Hindus the futility of their religion. As there were a thousand other pilgrims about the temple, the attack on the idol never got beyond a scrimmage, in wlich one of the fanatics was killed. The rest were seized, and punished with three months' rigorousimprisonment. Kumbhupatia are spread throughout 30 villages in the Central Provinces. They were converted by a mendicant who appeared amongst them in the year 1864, and revealed himself as the incarnate god Alekhswamy from the Himalayan heights. He died a short time afterwards, leaving 64 chief disciples, who with their followers now worship him as a god. They do not believe in images, or in medicine, the only physic they take being a little earth and water. Their habits are filthy but ascetic, and they are pledged to a rigil celibacy, which has led to a split in the seet. One of the chief disciples was too intimate with one of his female devotees, but he told his scandalized followers that she was going to give birth to Arjun, 'who would root out all unbelievers.' The child was a girl, and many of his followers left him on her birth. He convinced the rest that it would be this girl's duty to destroy all uubelievers by means of her charms; but as soon as they were easier in mind the girl died, and many more of his followers departed; the residue being able to believe everything regarding him with greater fervency than ever. He erected an altar, over which he and bis wife sat in the morning. His followers worshipped them, and moved round the altar until the time for their morning meal arrived, when their feet were washed with milk, which was afterwards drunk by their adherents. The rest of the sect have taken another master, and if they break any of the sect rules, tell a lie, or commit a crime, they are forthwith excommunicated. A criminal class called Pan have been converted to the Kumbhupatian religion, and crime has been considerably reduced.

KUMB-KA-MELA. HiND. A sacred fair at Hardwar, held every twelfth year. See Mela.

KUMBOH, a Sudra caste of the Panjab, numerous at Lahore.

KUM FA, the Chinese tutelary goddess of women and children, the Venus genetrix of the Chinese. She was a native of Canton, and lived during the reign of Ching Hwa, who ascended the throne A.D. 1465. She was, as a young girl, a constant attendant on all the neighbouring temples, and is said to have had the power of 
communing with departed spirits. Becoming tired of the world, she committed suicide by drowning. When her body rose to the surface, and was placed in a coffin, a sandal-wood statue of her was burned, but was replaced by one of clay. Her principal temple is in the Ho-nan suburb of Canton. Her votaries are principally wives who wish to become mothers. She has 20 attendants. grain.

Shay-Tseih is the Chinese god of the land and

Fung-Fo-Shan are the wind and fire gods of the Chinese,-Gray. p. 163.

KUM FEROZ RIVER, across which Amir Azan Delemi built the Band-i-Amir or Bendamir. Aras is a modern name of the ancient Araxes, the Awerma of the Puranas, now called Kum Feroz. It laves the foot of the rock Istakhr. The snowy Ardegan mountains are the same with those which presented so formidable a barrier to Alexander's progress, and by whose slopes he descended into Persia in his advance on Persepolis. Towards the north of Armenia runs the Araxes, with its numerous tributaries. This river, which at its commencement, owing to its many affluents, bears the Persian appellation of Hazara, springs from the side of Bin Gol, or mountain of a Thousand Lakes, about 30 miles south of Erzerum, and nearly in the centre of the space between the eastern and western branches of the Euphrates. Its course, from its first spring near Jabal Seihan, is almost N.E. for 145 miles through Armenia, when it turns eastward, being then near the frontier of Kars; this proximity continues for 110 miles. The sources of the Aras and those of the north branch of the Euphrates are about 10 miles from one another. According to Pliny, those sources are in the same mountain, and 600 paces asunder. In modern times, the north-eastern districts, along the banks of the Araxes, intervening between Azerbijan and Georgia, have been in general subject to the sovereigns of Persia.

KUMHAR is a potter. It is a name derived from the Sanskrit Kumbhakara,-Kumbha meaning a water jar. The potter caste manufacture all kinds of earthen vessels, whether for domestic or general use. These are made by the hand, and often display considerable ingenuity.

KU-MI, also Ka-mi, a race in Arakan, in lat. $21^{\circ}$ $\mathrm{N}$., and long. $93^{\circ} \mathrm{E}$., in the valley of the Koladyn river, which disembogues at Akyab. They assert that they once dwelt on the hills now held by the Khyen. The Ku-mi of Arakan chiefly inhabit the Koladyn and its feeders. The Khy-oung-tha and Khu-mi or Kum-wi (properly Ku-mi) of the middle basin of the Koladyn belong to the Burman family. Their language has been partially examined by Captain Latter, who says it is evidently cognate to the Rakhaing form of the Burman. The majority of its words, however, are non-Burman. The Ku-mi are fair, with small features, are divided into 27 clans, and the estimated number of the people is about 12,000 . Of this tribe there are two divisions, called by themselves Ka-mi and $\mathrm{Ku}-\mathrm{mi}$, and by the Arakanese Awa Ku-mi and Aphya Ku-mi.

KUMIRAH, a variety of the elephant in Kachar.

KUMIS. Tartar. Ma-ju-tsiu, Chin. The ordinary drink of the Tartars, a spirit made of mares' milk. Mares' milk has 17 per cent. of solid matter and 8 per cent. of sugar of milk, which renders it very liable to undergo alcoholic fermentation. They pour the milk into a large leathern vessel, and when they have got a considerable quantity, beat it till it begins to ferment like new wine. When it becomes quite sour, they beat it again violently, and then draw off the buttery part. The fermented whey makes a brisk sort of liquor, with an agreeable acid flavour, very intoxicating to those not much accustomed to it. The Tartars also make, from goats' milk, a kind of butter, which they boil and keep for winter use in goats' skins, and though they put no salt in it, it never spoils. After they have taken off the butter, they boil the curd again to make cheese, which they dry in the sun, and which is as hard as iron; these cheeses they put into sacks for the winter store, and when the supply of milk becomes scanty, they put this hard, sour curd into a leathern vessel, pour hot water unon it, and beat it till it liquefies ; and with this acinl drink they have to content themselves during the time of year so severely felt by the pastoral nations. The Tartars live chiefly on their flocks and the produce of the chase.-Huc's C'hristiarity, i. p. 209 ; Smith's Chin. Mat. Mfed.

KUMMALAR, in the Malealam country, an artificer. The Ainkudi Kummalar of Malabar are the five artisan castes, - the Ashari or carpenter, the Mushari or brazier, the Tattan or goldsmith. the Perning-Kollen or blacksmith, and the Tol Kollen or tanner. These five castes follow the custom of marrying one girl among three or four brothers, and this custom is followed in some parts of Malabar by the Iduver, Juver, or Teer, toddy-drawers. Kookel Keloo, a Nair, a district munsiff in Malabar (No. 48 of the Madras Literary Society's Journal of $1859 ;$ pp. 52), says thi? Iyuver or Teeyer (toddy-drawers) are a section of the servile class of people who, during the time of the Brahmans and Perumals, came to Malabar from Ceylon to earn their livelihood. It cannot, however, be accounted for, how they in many parts, though not throughout the whole of Malabar, came to adopt the beastly custom of the Kummalar of the country, of a single girl being married to three and four brothers; and likewise, in some parts of the country, where this sacl custom is not so generally prevalent among them, the practice of taking their deceased brothers' widows for wives, as the Musalman Moplah do. It is only in the taluks of Nidunganad, Kuttanad, Chowghat, and some parts of Vettutnad, and a few adjoining spots in South Malabar alone, that a woman among the Nair is kept at the same time by two or three different men, who are, though, never brothers. It is, however, very possible that the Teeyer may have taken the idea from this latter error, and themselves fallen into the other and more shameful one; or perhaps they observe the custom, as they in general are, as a document in its beginning shows, sprung from Kummalar or the Kummalar from them, through their then frequent intermarriages. The document calls them also Iyuvahaiyer, a word equally low and contemptuous in Malabar, and of the same meaning as the word Kummalar. "Moreover, amongst the Nair of the whole of North Malabar (that is to say, from part of Cooroombranad as far as Mangalore), though sometimes unchaste practices occur in their families, yet I can most confidently 
assert that the above abominable custom of one woman being kept by two or three men at the same time, never in ancient or modern time was once known. A Nair there will, though, occasionally marry two or three women in succession, if the first or second prove barren, or all the children born die, or from any other like cause or domestic difference. Many of the Teeyer also of that part of the country do, in some measure, follow the custom of the Nair; but the Teyette (Teeyer women) of the remaining Teeyer there are notorious harlots, and become the concubines of strangers of any caste or religion, and this without the least prejudice to their own caste, or any loss of esteem in society; on the other hand, any such act proved against any females of the other castes, subjects the person to excommunication from caste, banishment from society, and all religious advantages. The Teeyer females of South Malabar do not, though, so readily as those of the north, yield themselves to this disgraceful practice. Owing to the very great number of castes, and the peculiar and different manners and customs in various parts of the country, the superficial inquiries of most foreigners have led them into error, and in their works they generally ascribe the same pernicious practices to all castes and parts of the country indiscriminately.'

'However, the Nair, Teeyer, and, indeed, all the other numerous castes of Malabar (including the Cochin and Travancore countries, these being indeed the most striking in this respect), are in some way or other in a greater or less degree of error; and reformation therefore is indeed much needed among them all. It is, though, very lamentable to find them dormant in their original state of depression, and not seeking for reformation, rather growing blindly proud of their vain and different castes and privileges, and ready to run any risk, even that of hazarding their lives, only to preserve their castes.'-Madras Lit. Soc. Journal, pp. 52-54 of 1859 .

KUMMERBAND. HIND. A sash, a waistbelt, a girder of the loins.

KUMMUNGAR, in Bengal, a bone-setter.

KUMPIL is a place of sacred resort amougst the Jains, where they annually bury an image of one of their Tirthankara, and has been immemorially established among them as a holy city.

KUM-QUAT. ChIN. Citrus Japonica; fruit about the size of an oval gooseberry, with a sweet rind and sharp acid pulp. Preserved in sugar, according to the Chinese method, it is excellent. Groves of the Kum-quat are common on all the hill sides of Chusan. The bush grows from three to six feet high, and when covered with its orangecoloured fruit is a very pretty object.

KUM-RUDI, men who have adopted the Chinese system of secluding themselves from the rest of the world. -De Bode's Travels, p. 22.

KUMULULU, a place 35 miles S.W. from Shivelliputtun, and 70 miles from Cape Comorin, has an unfinished Hindu rock temple of great elegance. It is supposed to have been erected to mark the triumph of Siva over Mahavira.Fergusson.

KUMUT, or bark cloth from the river Baram, supposed to be from a species of Artocarpus, is worn by the Kyan race when mourning their dead.-Royle, Fib. Pl. p. 341 .

VOL. II.
KUN or Khon, a tribe of the headwaters of the Koladyn river, beyond the Arakan boundary. The dialects of the Lung-Khe and Shendu have special affinities with the Kyan, Khy-eng, and $\mathrm{Ku}-\mathrm{mi}$. The Kun language also pertains to this group.

KUNA, a Pandiya king of the 9 th century, who was a follower of Samanal doctrines, which are supposed to mean those of the Jaina or Buddhist sect.

KUNAVIRA PANDITAR was born near Chingleput. He wrote two treatises in poetry, one called Neminatam, and the other entitled Venpapattiyal.

KUNAWAR is a subdivision of Bashahir State in the Panjab. It is a rugged, mountainous country, and lies between lat. $31^{\circ} 16^{\prime}$ and $32^{\circ} 3^{\prime}$ N., and long. $77^{\circ} 33^{\prime}$ to $79^{\circ} 2^{\prime}$ E. ; area, 21,000 sq. m. ; pop. 10,000 . It is bounded on the $\mathrm{N}$. by Spiti, on the E. by Chinese territory, on the S. by Bashahir and Garhwal, and on the W. by Kullu.

Kunawar is usually divided into Upper and Lower Kunawar, and includes the upper part of the Sutlej basin. In Lower Kunawar the population consists of mixed Tibetan and Hindu races, the Turanian element preponderating in the north, while the southern region is inhabited by people of Aryan type. In physique, the Kunawari are tall, athletic, well made, and dark skinned; while their character stands high for hospitality, truthfulness, and honesty. Alone among the neighbouring hill tribes, they successfully resisted the Gurkba invasion, and so completely baffled the enemy by breaking down bridges, that the Gurkhas entered into a convention by which, in returm for a tribute of $£ 750$ per annum, they agreed to leave the valley unmolested. The religion of the Kunawar people shows the same mixed origin as the ethnical peculiarities. The northern villages profess Buddhism of the Tibetan model; in the south, Hinduism prevails; while the middle region shades off gradually from one faith into the other, producing grotesque mixtures of ceremonial and belief. At Kanum, half-way across the tract, the Tibetan sacred books are in use, and the Lama priests are there, but the Hindu veneration for kine still exists, and the distinctions of caste survive; while at Hangrang, on the northern frontier, Buddhism assumes the pure Tibetan form.

The Tartar husbandmen have a custom similar to those of Scotch farmers, who plait the first corn cut three-fold, and fix it over the chimneypiece till next harvest, when it is renewed. The Tartars use three ears of barley, which they paste outside above the door. Polyandry is general in Kunawar from the bigher classes to the lowest Chamars, one family having one wife, the elder brother being the more special husband. It is called Kürpa. Polyandry prevails also in Chinese Tartary and in the hilly tracts towards the plains. Besides this drawback on the increase of the population, there is another peculiar to Chinese Tartary and the adjoining countries; that is, celibacy, which is professed by numbers of the inhabitants; and in some villages the monks or lamas and nuns form almost half the population.

At all the elevated passes there are a number of square piles of stones, called Shughar, upon which passengers usually place a piece of quartz, or attrch rags to poles, which are fixed in the 
middle. There are also several Shughar on the neighbouring beights, sacred to the deota or spirits of the mountains, who are supposed to inhabit the loftiest and most inaecessible points, especially where there is much snow. The Shughar at the passes are erected by travellers, but those on the higher peaks are commonly made at the expense of some wealthy pilgrim not much accustomed to the mountains, who has succeeded in crossing a pass, which is reckoned an arduous undertaking by an inhabitant of the plains.

The Tartars are called by the Kunawar inhabitants of the lower parts, Zhad, Bhoteah or Bhutani, and their country is often named Bhot and Bhutan; the Tartars are very different in appearance and manners from the inhabitants of Lower Kunawar; all those of Bashabir were formerly under the Chinese. The Tartars of Kunawar are not so stout as those farther to the eastward, and have less of the Chinese features, are muscular, well made, and tall. The people are fond of dancing and singing, and they have several annual festivals, which they celebrate with a degree of joy scarcely known amongst other Asiatic nations. The greatest festival is called Mentiko, which prevails throughout the whole of Kunawar; it is held in the beginning of September; its origin is not known. All the people who are able to move leave their villages, and ascend the nearest hill; they proceed slowly, making a circuit of several days, and this is a time of the greatest festivity. They adorn themselves with garlands and flowers, and sing and dance to the sound of music, which is much more melodious than the tunes of Hindustan. They have all sorts of amusements, run foot and horse races, when the ground will admit of it, perform feats of agility, feast, and drink.

The language shades off, like the religion, from the Tibetan in the north to Sanskritic dialects on the Indian side. In Lower Kunawar, the preponderating language is Hindi, and is called Milchan, but the Bhot preponderates in Upper Kunawar. The Lubrung or Kanum and the Lidung or Lippa are varieties of the Milchan. In Sungnam, the word Theburskud is used to designate all variations from the regular form of speech. The fleshy and stone fruits of Kunawar are the grape, apricot, peach, apple, walnut, and mulberry. Sungnam is famous for its apples, Akpa for grapes, and Pangi for walnuts. From Kanum to Miru ridge, in Upper Kunawar, are to be found the Cedrus deodara, Pinus Gerardiana, P. excelsa, Abies Smithiana, Abies Webbiana, Juniperus excelsa, Populus alba, Juglans regia, Corylus colurna, Armeniaca vulgaris, Pyrus malus, Cerasus puddum, Quercus ilex, and Salix alba.-Cleghorn, Panj. Report, p. 58 ; Imp. Gaz.

KUNAWEZ. Hind. A Bokhara and Persian fabric of plain shot silk, with a thread, say of green one way, and red the other; it is the same, but a finer fabric, than the Dariyai dhupchān.

KUNBI, a Mahratta race engaged in cultiration. They are also the main body of the cultivating population of Gujerat, where they are the chief owners of the soil ; and, though quiet and unpretending, are a robust, sturdy, independent agricultural people. Throughout the Mahratta country, Berar, Nagpur, and Kandesh, they are the principal agriculturists. Mr. Campbell considers them (pp. 93, 94, 95) to be quite Aryan in their features, institutions, and manners, though their institutions are less democratic than those of the Jat and Rajput, and, in the Mahratta villages, they have at their head a potail. Few of the Kunbi ever enlist as soldiers. Sivaji and his descendants and some of his chiefs were, however, of this race, but their followers were drawn from the mawals of the Western Ghats, and latterly their armies were composed of the soldiers of fortune of every race. The Mahratta chiefs sprang from the people of Satara and Poona, but Holkar was of the shepherd, and the Gaekwar was of the cowherd caste; while the Peshwa fauily, who put the descendants of Sivaji aside, were Konkani Brahmans. Sivaji is also said to have been of Rajput descent.

The Kunbi of the Hyderabad dominions are wholly illiterate. Indeed, till 1870 , no attempt had been made to educate the people of the Hyderabad territories. Though education is making enormous strides in Berar and in British Maharashtra, there was no proper school met with in all the Editor's journeys from 1866 to 1869 , amounting to about 9000 miles, and only occasionally a few lads were to be seen, children of foreigners, learning, in a verandah, the elements of the Hindi or Mahrati. In that eastern part of the Mahratta country, the knowledge of reading or writing of any tongue was almost unknown. The Arjawna Kunbi reside in Western India. They are subdivided into a number of classes, many of whom do not eat together, or intermarry. The Kunbi, in Berar, allot themselves into eleven classes-

\begin{tabular}{|c|c|}
\hline $\begin{array}{l}\text { Mali, } \\
\text { Full Mali, }\end{array}$ & $\begin{array}{l}\text { Haldi Mali. } \\
\text { Wanjeri. }\end{array}$ \\
\hline
\end{tabular}

The 1881 Census Report gave different appellations for these, and stated $5,388,487$ as the number of Kunbi in India.

With the exception of the Haldi Mali and Pazni, they have Roti vya whar amongst each other, but not Beti vya whar, i.e. they eat with each other, but do not intermarry. The Berar Kunbi and Mali eat flesh, drink liquor in moderation, and their widows may all re-marry if they choose, except those of the deshmukh, who follow the high-caste custom. The Kunbi form the stock of the people of the N.W. parts of the Hyderabad territory and in the Hyderabad assigned districts. Kunbi women are stout, coarse, and robust. This term, throughout the Mahratta country and Central India, is applied exclusively to the cultivating class of Hindu Sudra. It is derived from the Mahratta word Kunbawa, which means agricultural tillage.

Koeri, Kurmi, and Kunbi are great agricultural classes. Many other castes, Kamma, Kapu, Vallala, Wakkali, are employed in the cultivation of the soil. Indeed, every Hindu, however humble his station, likes to have his plot of ground, which himself or his wife and children, or other relations, or in default of them, some of his friends, may cultivate. Property in land is considered by the people generally, of every rank and caste, to be the safest and most satisfactory mode of investing money, little or much, notwithstanding the heavy tax upon the soil. Koeri, Kurmi, and Kunbi are agriculturists by profession, and perhaps, least of all the castes, have suffered themselves to be diverted from their own proper occupation.

Koeri, Kurmi, and Kunbi are very laborious in 
their habits; on which account, and also for their general peaceableness, they have secured the respect of all the other castes. While they are engaged in the cultivation of the land, the main distinction between them - for they are quite separate as tribes-is, that a considerable number of the Koeri are vegetable gardeners. They have immense gardens in the vicinity of cities and towns, which are supplied by them with various kinds of vegetables. The Koeri are the principal growers of poppy, and producers of opium, both in Benares and Behar. The 1881 census returned 1,207,95̄1 Koeri.-Sherring's Tribes.

KUNCHI, also Muthi. HIND. A handful ; the first is applied to grain in the stalk at harvest time; the other to such edibles in merchandise as sugar, raisins, etc., collectively termed Keranoh. Kunchi means also any small quantity; it is the Saxon, a puckle, the right of taking a handful at harvest, granted to holy men.

KUNCHI-TAGAR. KARN. A tribe of agriculturists in Mysore claining to be pure Sudra.

KUNCHNI. HIND. A dancing girl, properly Kănchni. Kunchni ka Taifah, a band of dancing girls.

KUND or Ghoont is a hill breed of horses of the Himalaya mountains, generally small, strongly made, hard-mouthed, and sometimes almost unmanageable. In ascending hill faces, or passing along the declivities of mountains, it is best to let them have their own way, for in an intricate passage they often show more sagacity than the rider. Their common pace is a kind of amble, and they stop every now and then to breathe, when no application of the whip will move them. They are sure-footed, and sometimes halt at the edge of a precipice, to the terror of the rider. They are not so quick in ascending hills as the lowcountry horses, but they descend with double the speed, and endure great fatigue. The ghoont animal seldom carries any burden but a man; they are bred chiefly for sale. They have two breeds, one a small ghoont, never above 12 hands high, peculiar to the country; and the other a large breed, from 13 to $13 \frac{1}{2}$ hands high, is bought from the Chinese, and usually comes from Chumutri. For a Chinese ghoont two years old, they give a Spiti ghoont four years old. All are equally hardy, and are kept out the whole winter, except the yearlings, which are housed. During winter the ghoont live on the roots of the stunted bushes, and are very expert at scraping the snow from off them with their fore feet. The breed of ghoont might be improved with a little care. Many are killed during winter by wolves and leopards.Powell's Handbook; Captain Gerard's Kunawar.

KUNDA, Kund, or Khand. Hind. A pit, a hollow, a lake, a natural reservoir. Sita Kund is a sacred pool near Monghyr; Brahma-Kund is at the source of the Brahmaputra. Also a large earthenware pot.

KUNDA-GOLAK is a term applied to the adulterous offspring of a Brahman man and woman, but it is applied to Brahmans of a low order. Kunda and Golaka are distinct words, the first being a bastard, the second the child of a widow.-Wilson.

KUNDALU. Hind. A nettle of the Himalaya ; its fibres are made into rope, also snow sandals.

KUNDA MOUNTAINS, in the Neilgherry district, in lat. $11^{\circ} 9^{\prime}$ to $11^{\circ} 21^{\prime} 40^{\prime \prime} \mathrm{N}$., and long. $76^{\circ}$ $27^{\prime} 50^{\prime \prime}$ to $76^{\circ} 46^{\prime} \mathrm{E}_{\text {., }}$ are the western wall of the Neilgherry plateau rising abruptly from Malabar. Avalanche peak, 8502 feet, and Makurti, 8402 feet. The Bhawani river rises in this range.

KUNDO - DHARA. S.ANSK. The umbrellabearer of the Hindu god Iswara.

KUNDUZ, when visited by Dr. Lord about 1836 , was a territory on the east of Balkh, ruled by a Mir. Colonel MacGregor names as districts Kunduz, Khulm, Baglan, Ghori, Doshi, Kalagae, Khosht, Khinjan, Indarab, Chal, Tashkurgan, and others, as parts of Afghan-Turkestan. It is a region of incessant change. Its river rises in about lat. $34^{\circ} 52^{\prime} \mathrm{N}$., long. $67^{\circ} 10^{\prime} \mathrm{E}$., is about 300 miles long, runs into the Amu or Jihun river. It receives the Indarab, 65; and Kanah-i-bad, 90 miles. Kunduz has varied greatly. It is surrounded on all sides by hills, and is so very insalubrious that the proverb runs, If you wish to die, go to Kunduz. The chief, Murad Beg, illtreated Moorcroft, and robbed him of money and effects to the extent of 23,000 rupees. In 1830 , be had occupied all the valley of the Oxus, and ruled all the countries immediately north of the Hindu Kush. It lies in a valley among the hills running from $\mathrm{E}$. to W. about 30 miles, and from $\mathrm{N}$. to S. about 40 miles, and the great mountain, the Hindu Kush, is visible.

KUNET, a race who form nearly two-thirds of the population of the hill tracts between the rivers Beas and Tons. The name of Kunawar is derived from them. They are the ancient Kuninda or Kulinda of the Kulindrine district of Ptolemy, which that writer places between the Vepasis and Ganges. The Kunet form 58 per cent. in Kullu, 67 per cent. in the states round about Simla, and 62 per cent. in Kunawar. They are very numerous in Sirmore and Bashahir, and considerable numbers in Ambala, Karnal, and Ludhiana, with. a few in the Dehli and Hoshiarpur districts.Cunningham, p. 17.

KUNG, a Chinese family, lineal descendants of Confucius, whose surname was Kung; the oldest and highest European families sink into insignificance before it. The great ancestor of the Kung, Kung Fu Tze or Confucius, was born 551 B.o., and died in the year 479 B.C., at the age of 72 or 73. During his lifetime the country now known as China was parcelled out into a number of independent states and commonwealths. He was the son of the chief minister at the court of the king of Loo, and was himself of royal descent. He rose to the dignity of minister of that kingdom, and by lectures on ethics gained many disciples, but later he resigned civil employ, and devoted himself to those works on philosophy which up to the present day regulate both the government and the religion of the State. He collected also the earliest documents relating to the history of his people and country, the popular songs and sacred hymns, the chronological emblems, and their explanations (Bunsen's God in History, i. p. 259). Confucius must have been almost contemporary with Pythagoras, Thales. Socrates, Solon, Buddha, and Herodotus, but the principles inculcated by the Chinese philosopher far outvie those promulgated by the sages of ancient Greece. See Confucius.

KUNGGUN. HrND. A bracelet. Kunggun kholna, a Mubammadan ceremonv.

KUNGI. HIND. Wheat blight or red rust. 
KUNG-QUA. Chin. A resting-place for travellers, or rather for officers of government in Loo - Choo. The Kung-qua corresponds very nearly to the Turkish khan, except that, being used only by persons of some consideration, it is far more neat and elegant in every respect. The house resembles a private dwelling of the better class. Kung means a palace; Kung Tsoi Chong, temporary resting-places for the dead.

KUNGU. HIND. A kind of rouge in great request among the ladies of Sind, who keep it in a little ornamented box.-Burton's Scinde, p. 392.

KUNGUR, Kunjur, or Chungur, a wandering, houseless race in the Panjab, probably the same as the Chinganeh of Turkey, the Italian Zingaro, the Spanish Gitano, and the English gypsy. About Dehli, the race is called Kunjur, a word which in the Panjab implies a courtesan dancing girl.

KUNIGAL, in the Tumkur district of Mysore, in lat. $13^{\circ} 1^{\prime} 40^{\prime \prime} \mathrm{N}$., and long. $77^{\circ} 4^{\prime} 10^{\prime \prime} \mathrm{E}$., has a horse-breeding establishment.

KUNJANA is the name given by Muhammadans in the Southern Mahratta country to a migratory tribe, who style themselves Raj-yogni. They are of ordinary stature, dark-featured, and not well-favoured, and state that they came originally from Bhopal about A.D. 1700. They encamp without the walls of cities, and have no definite period of residence. The men play on musical instruments, and the women combine the art of dancing to fascinate the spectators. They call themselves Hindus, and say they worship the Brahmanical deities; but they wear clothes like the Muhammadans, and never have Brahmans to preside at their festivals. They also eat the cow, but never eat the hog. They bury their dead, and they place offerings of rice to the manes of the dead, and draw the most favourable omen of the state of the deceased by the offerings being eaten by a crow.

KUNJI, Ganji, or Conji. HrND. A porridge or caudle made by boiling wheat, rice, etc. In the south of India, a usual term for food; also starch.

KUNJU. Hind. Red powder made by steeping turmeric root in an alkali, used in India for the forehead marks of the Hindus.

KUNKAR. HrND. Nodular, tufaceous, travertine-like deposits of carbonate of lime. It is formed in all soils by the action of springs, like the travertines of Italy. In some places it is a pure carbonate of lime; in others it is a concreted limestone or pisolite; these.kinds are used for road-making.

It is a Hindustani word, meaning nodule. There are two varieties, the red and the white; the red differs from the white solely in containing a large proportion of peroxide of iron; the white consists of carbonate of lime, silica, alumina, and sometimes magnesia and protoxide of iron. Kunkar is also deposited by calcareous waters abounding in infusorial animalculas; the waters of the annual inundations are rich in lime, and all the facts that have come under observation appear to indicate that this is the source of the kunkar deposit, which is seen in a different form in the Italian travertine, and the crescentic nodules of the Isle of Sheppey and of Boulogne. Kunkar is mostly nodular, - always fresh water and recent, in most cases in the act of being formed under our eyes. It is sometimes found in thick stratified beds like the travertine near Rome, and seems in this case to have been formed by calcareous springs. More generally it is met with in clay or alluvial soil, in the shape of small pieces from the size of peas or filberts to that of the hand. In the blue clay which stretches along the Indian shores, it is found in vast abundance, generally assuming the most fantastic forms; indeed, it abounds in every rice field and open soil all over the country. The more recent varieties seem to be formed by the agency of the rains. When the earth abounds with vegetation, the tepid waters are charged with fixed air, and dissolve the lime prevailing in the soil everywhere around, the mineral being again thrown down as the advancing season dispels the excess of gas. It in this state absorbs the clayey matter around, and cements it into kunkar. This is collected by the lime-burner, placed with firewood in small-sized conical kilns, and burnt in the usual way. It contains 72 of carbonate of lime, 15 of sand, and 11 of clay and oxide of iron ; but usually about 70 per cent. of carbonate of lime, about $2 \frac{1}{2}$ per cent. of carbonate of magnesia, a trace of oxide of iron, and 10 to 20 per cent. of sand and clay. Mixed with half its weight of river sand, it makes an excellent mortar; burnt in pieces of a cubic inch or so in size, and then powdered without slaking, it forms a first-rate water cement, setting in a few minutes, and becoming as hard as stone. The finer varieties of kunkar are burnt with charcoal all throughout the country, in neat pigmy-looking kilns, $2 \frac{1}{2}$ feet high and about as much in diameter at the base. These hold about a cubic foot of material, or about $36 \mathrm{lbs}$. of charcoal and kunkar in equal parts. When burnt and slaked, it is then made up into bricks, which are sold in the bazar for the purpose of whitewashing. The ordinary Indian cement is chunam in its various forms. The only Indian building materials which differ materially from those of the rest of the world are laterite, concrete, and kunkar. - Col. Sykes, Lond. Geol. Trans., $18: 36$; Dr. Buist; O'Shaughnessy.

KUNR-BOJI, also Kund-mandla, HIND, in Benares and the Doab, the day on which the seed-sowing is completed,-held as a holiday; the remnant of the seed-corn is made into a cake, which is partaken of in the field, and in part distributed to Brahmans and beggars.

KUNTA. HiNd. A mace or spear, which formed one of the insignia of royalty of the Chalukya dynasty when ruling at Kalian.

KUNTA in Coorg, Gunta in the Dekhan, a pond, a small tank.

KUNTAN. MaHr. A pander, a pimp. A caste said to be sprung from a Vaisya father and a Brahman mother, whose office is attendance on the women's apartments, and providing dancing girls and courtesans.-Wilson's Glossary.

KUNTHA. Hind. A necklace or rosary of large beads made of silver, crystal, or the earth of Karbala.

KUNTI, also called Pritha, also Parshni, was the daughter of the Yadava prince Sura, king of the Surasenas, whose capital was Mathura, on the Yamuna. She was sister of Vasudeva, but was given by her father to his childless cousin, Kuntibhoja, by whom she was brought up. Hindu mythology says that in her maidenhood she showed such attention to the sage Durvasas; that he gave her a charm by which she could bave a child by any god she wished. Sho in- 
voked the sun, and Karna was born, without any detriment to her virginity, but Karna was nevertheless exposed on the banks of the Yamuna. Subsequently she married Pandu, to whom she bore three sons, Yudishtbra, Bhima, and Arjuna, who were called Pandavas. After the end of the great war, she retired into the forest with Dhritarashtra and his wife Gandhari, and they all perished in a forest fire.- $D$.

KUN-YAM, the Chinese goddess of mercy, is worshipped with great pomp on her natal day, the 19th day of the second month. She was a Buddhist nun who was canonized, and women and children frequent her temples and burn incence pastilles; she is also much worshipped during the Tsing-Hing or worshipping of Graves. Her temples are very numerous.

KUP. Sind. Mud wells, mud volcanoes. See Ram Chandar; Volcano.

KUPASI or Kapasi, a plant remarkable for the under surface in its leaves being covered with a cotton-like tomentum. The people in the Himalaya use it as tinder. It is also spun into thread, and woven into cloth, of which bags are made. The string, until examined, looks as if formed of fibre. A coarse kind of blanket, called kurki, is said to be made of this substance by the hill people north of Dehra.-Royle, Fib. Pl.p. 301.

KUPPAM, Coopa, Cupa, TAM., as in Manjacupam, the name by which Cuddalore is known to the natives. It is a Tamil word, signifying a small village, one occupied by humble people or by fishermen.

KUPPA - MANI. TAM. Acalypha Indica, with which cats are so enchanted, that they play with it as they would with a captured mouse, throwing it into the air, watching to see if it will move.-Tennent, p. 33; Voigt.

KUPPARTHALA, a Panjab cliefship with a raja of the Sikh sect. The raja who died about A.D. 1876 ? was burned on the banks of the Godavery, near Nasik. The coffin was taken along a private road to the usual place of cremation on the banks of the Godavery, conveyed over the river ford to a special site, where the funeral pile was erected. A number of gold coins were scattered on the way; and the young raja and his brother, lads of twenty and eighteen, followed the corpse barefooted; and, after going through necessary religious ablutions, the former himself lighted the pyre. The deceased, prior to cremation, was wrapped in most gorgeous and expensive shawls and kinkobs, his jewels were left on him, and all consumed with the body in the flames. The ashes and bones were afterwards collected, the former deposited in the Government treasury, to be sbortly and finally deposited under a fountain about to be erected on the banks of the river; and the bones were deposited in a basin in the river set apart for the reception of such.

KUPPHUL. HiND. A salt of soda obtained from the waters of the lake of Lunar, used in fixing the red dyes of clotb.

KUR, the Persian form of Cyrus.

KUR. A Hindu practice for extorting a debt was called erecting a kur, meaning a circular pile of wood, which was prepared ready for conflagration. Upon this, sometimes a cow, and sometimes an old woman, was placed by the constructors of the pile, and the whole was consumed together. The object of this practice was to extort payment of a debt, or to intimidate the officers :of Government or others from importunate demands, as the effect of the sacrifice was supposed to involve in great sin the person whose conduct forced the constructor of the kur to this expedient.

In January 1880, the thakur of Sandwar had sent his vakeel to the village of Upni, near Bikanir, to collect the village revenues. The Siddhs of Upni refused to pay the usual malba, a small tax levied to defray village expenses. They got together other Siddbs from the neighbouring villages to the number of 150 ; and the whole body began to 'sit dharna,' and threatened to bury themaselves alive unless they were exempted from paying the tax. The thakur consulted with the tahsildar of Gujangarh, who tried to persuade the men to go to Bikanir and prefer any complaint there which they had to make. The Siddhs refused, and as the thakur still declined to give in to their demand, they actually buried alive two of their number, - an old man of 75 . and an old woman of 65 . The raj officials and the lumberdars of the village tried to prevent the murder; but the Siddhs drew their swords, and carried out their purpose.-Mrs. Ellwood; Cole. Myth. Hind. p. 148.

KUR. HIND, A remission in rent in favour of bigh-caste cultivators, to enable them to employ a ploughman.

KUR or Kar, a term in use amongst the Mahratta and Nair races. Many of the principal Mahratta families derive their name from a compound formed from that of the village where they were born, and the substantive Kur, which signifies an inhabitant, as Nimbal-Kur, PattumKur, etc. Kur, in Maleali, means a class, a party. The people of Malabar, from the rajas and Brahmans to the lowest races, are divided into classes, - the Chevara-Kur, the fighting or ruling class ; and the Panniyur-Kur, the civil and labouring class. Their usages differ materially, and the distinctions are carefully preserved.-Malcolm's Central India, i. p. 142; Wilson's Glossary.

KUR, Kurku, or Muasi, are a tribe of Kolarian race, who occupy Nimar, the Gawilgarh Hills of Berar, Kalibhit, the western Satpura, northwards towards Indore, and to the N.W. and W. of the Mahadeva Hills. They are not Gond, but a branch of the Kol family. The Kurku and Gond keep themselves separate, and they each have a separate language. There are 28,709 of Kurku in Berar. There are about 4000 of them in Woon and Amraoti. Along with the Andh, Gond, and Kolamb, they occupy the Mailghat and the southern skirts of its hills. They resemble each other in appearance, though they each speak a different tongue, and in their features they differ from the villagers. The Kurku have their headquarters on and around the Nerbadda hills, and extend westward through Baitul and Hoshangabad as far as Berhampur and Asirgarl. The Gond eat cow's flesh at most of their festivals, whilst the Kurku hold such a practice an abomination. Some of the Kurku hold parwanahs from the Moghul emperors, in which they are styled Rajputs. Their common word for man is Kurako, which is simply the plural of Kur or Kura (in Munda, a boy), and we have thus a term equally near the Koraku and Korwa of Sirguja, and the Kur of Gawilgarh. The close relationship of the 
Kur and Santal, and their separation from the Dravidian, may be illustrated by a few examples :

\begin{tabular}{|c|c|c|c|c|c|}
\hline $\begin{array}{l}\text { Eng- } \\
\text { lish. }\end{array}$ & Kuri, & $\begin{array}{c}\text { San- } \\
\text { tali or } \\
\text { Kol. }\end{array}$ & $\begin{array}{c}\text { Gond } \\
\text { dialects. }\end{array}$ & Tamil. & Telugu. \\
\hline $\begin{array}{l}\text { og } \\
\text { ar } \\
\text { Lair } \\
\text { ose } \\
\text { elly } \\
\text { ire } \\
\text { Jater } \\
\text { Louse } \\
\text { tar } \\
\text { lan } \\
\text { wo } \\
\text { bree }\end{array}$ & $\begin{array}{l}\text { Sita, Chit } \\
\text { Lutur } \\
\text { Op, Up } \\
\text { Mu } \\
\text { Lai } \\
\text { Singal } \\
\text { Da } \\
\text { Ura } \\
\text { Epal } \\
\text { Koro } \\
\text { Barku } \\
\text { Apkor }\end{array}$ & $\begin{array}{l}\text { Seta } \\
\text { Lutur } \\
\text { Up } \\
\text { Mu } \\
\text { Lai } \\
\text { Singel } \\
\text { Da } \\
\text { Ora } \\
\text { Ipil }\end{array}$ & $\begin{array}{l}\text { Nei } \\
\text { Kavi } \\
\text { Meir } \\
\text { Muku } \\
\text { Pir } \\
\text { Narpu } \\
\text { Tanni } \\
\text { Ron } \\
\text { Sukum } \\
\text { Nanwai } \\
\text { Mand }\end{array}$ & $\begin{array}{l}\text { Nay } \\
\text { Kadu } \\
\text { Mayir } \\
\text { Mukku } \\
\text { Wairu } \\
\text { Nerappu } \\
\text { Tannir } \\
\text { Vidu } \\
\text { Tarakei } \\
\text { Manidan } \\
\text { Trandu } \\
\text { Mundru }\end{array}$ & $\begin{array}{l}\text { Kukka } \\
\text { Chaoo } \\
\text { Yenteka } \\
\text { Mukku } \\
\text { Karpu } \\
\text { Neppu } \\
\text { Niru } \\
\text { Illu } \\
\end{array}$ \\
\hline
\end{tabular}

KURAB. PERs. This is seen when looking on a plain covered with haze or mist, but not reflected as the mirage. It constitutes, however, that deceptive appearance for which the Persians have various names, such as Kurab, Kavir, Namayash-i-Ab, Serab, etc--Ouseley's Travels, i. p. 270 .

KURACHEE LIGHTHOUSE, on Manora point, in lat. $24^{\circ} 47^{\prime} 20^{\prime \prime} \mathrm{N}$., and long. $66^{\circ} 58^{\prime}$ E. From Kurachee, iron steamboats ran on the Indus to Multan, calling at Beacon, Tatta, Hyderabad. Prior to the conquest of Sind, it was an insignificant fishing town, but is now of importance as the terminus of the Sind railway and the seaport of Sind, in 1881 with 73,560 inhabitants. See Karachi.

KURAL, a celebrated poetical production in Tamil, treating of morals, by Tiruvalluvar, regarded by all Tamilians as the finest composition of which the Tamil can boast. It appears to be not only the best but the oldest Tamil work of any extent which is now in existence. Its date seems not later than the 9 th century A.D. There is no trace in the. Kural of the mysticism of the modern Puranic system; of Bhakti, or exclusive enthusiastic faith in any one deity of the Hindu pantheon; of exclusive attachment to any of the sects into which Hinduism has been divided since the era of Sankara; or even of acquaintance with the existence of any such sects. From the indistinctness and undeveloped character of the Jaina element which is contained in it, it seems probable that in Tiruvalluvar's age and country Jainism was rather an esoteric ethical school, than an independent objective system of religion, and was only in the process of development out of the older Hinduism. Certain poetical compositions are attributed to Auvaiyar, the matron, a reputed sister of Tiruvaliuvar, of which some at least do not belong to so early a period. It teaches a monotheism, and the later Buddhists or Jainas acknowledged an Adibuddba or Adivara, called sometimes Adidevan or primordial god. Its form is exquisitely poetic.

Tiruvalluvar means divine soothsayer. Kural signifies short or condensed. It is divided into three parts, treating of virtue, wealth, and pleasure. It contains 133 chapters of ten distichs each, resembling the Sanskrit Sutras, the first line containing four feet, and the second line three. Ten commentaries have been written by native scholars upon the Kural, of which that by the Brahman Parimelalaga is considered the best. The Rev. H. Bower says, "The work is superior to the Institutes of $\mathrm{Menu}$, and is worthy of the divine Plato himself.' Beschi translated it into Latin, and Dr. Graul into German; $T$. W. Ellis, Esq., translated portions of it into English. The Rev. W. H. Drew translated 63 chapters, with occasional notes and an index verborum. The following is the first chapter as translated by $\mathrm{Mr}$. Ellis :-

'As ranked in every alphabet, the first,
The self-same vowel, stands, so in all worlds
Th' eternal God is chief.

What is the fruit that human knowledge gives, If at the feet of him who is pure knowledge Due reverence be not paid?

They who adore his sacred feet, whose grace Gladdens with sudden thrill the fervent heart, High o'er the earth shall soar to endless joy.

To him whom no affection moves nor hate, Those constant in obedience, from all ill, In this world and the next, are free.

Those who delight with fervent mind to praise The true and only Lord of heaven and earth, No false ideas of right and wrong can cloud.

Those who pursue the path of his true law, Who is of sensual organs void, in heaven Shall dwell in never-ending bliss.

The anxious mind against corroding thought

No refuge hath, save at the sacred feet

Of him to whom no likeness is.

Hard is the transit of this sea of vice, Save by that Being's gracious aid, who is Himself a sea of virtue.

Of virtue void, as is the palsied sense,

The head must be, that bows not at his feet

Whose eight-fold attributes pervade the world.

Of those who swim the wide extended sea

Of mortal birth, none ever can escape,

But they who to the feet of God adhere.'

-Murdoch's Catalogue. See Tiruvallavar.

KURALEA. KARN. A shepherd race, who manufacture coarse woollens.

KURAM district is the valley of the river Kuram, about 60 miles long, and breadth from 3 to 10 miles. The scenery is fine, and in some places grand, the Safed Koh forming a magnificent background to a picture of quiet beauty. The Kuram river runs through green fields and sunny orchards, and numerous villages dot the plain. The principal spur from the Safed Koh range is the Peiwar ridge, which runs south and divides into two branches, one of which is parallel to the Kuram. The number of fighting men of the Kuram tribes have been thus estimated-Mingal, 8000 ; Jaji, 800 ; Bangash, 5620; Turi, 5000.

Thall is about 2500 feet, Kuram is nearly 4800 , and the pass of the Peiwar is 8500 over sea-level. Of the peaks about Peiwar that of Karaia is 15,400 feet, while that of Sikuram is $15,600 \mathrm{in}$ height. The Kuram plains are in summer totally devoid of water, and in winter are covered with snow. Along the base of the Safed Koh range numerous valleys debouch upon the plain; these are extremely fertile. The oriental plane, the walnut, and the amlok grow to a great size; and orchards contain the apple, apricot, plum, quince, and grape. The soil yields two crops during the year, the first being barley, wheat, and clover; the second rice, maize, and one of the millets. On the slopes of the mountains the limit of forest is usually reached at 11,000 feet; in some favoured spots single trees of Pinus excelsa and Abies Webbiana not unfrequently exist up to 12,000 . A dense forest occupies the ridges of the Peiwar- 
kotal, consisting chiefly of deodar, with Abies Smithiana and Pinus excelsa. On its spurs this forest growth completely disappenrs at 11,000 feet, and is replaced with flat masses of the common juniper. This disappears at 12,000 feet, leaving the summits of the peak perfectly bare, unless where a boulder affords shelter to some alpine plant. Some of the exceptionally large trees measured as follows:-Plane, circumference, 33 feet; walnut, 17 feet; deodar, 21 feet; celtis, 16 feet; oak, 13 feet; a variety of the black poplar, 10 feet 6 inches. For light, pine splinters are used; and in lieu of vegetable oils for food, the melted fat of the tail of the largetailed sheep is consumed. A very handsome new clematis, with flowers of a pale lemon colour, and from 3 inches to 5 inches in diameter, called after General Roberts, and a new yellow rose, are among the many new species found.

KURAO. The practice, which is also known to the eastward by the name of Uorhuree, in the Dekhan by Butt'bhee, and in other provinces by the name of Dhureecha, is followed among the Jat races, but is not very openly confessed even among them, as some degree of discredit is supposed to attach to it. It is only younger brothers who form these connections, elder brothers being prohibited from marrying their younger brothers' widows; but among the Jat of Dehli even this is not prohibited. Ranjit Singh went some steps further. He took by Kurao a lady betrothed to his father, Maha Singh; he also took Dya Koonwur and Rutun Koonwur, the widows of Sahel Singh, the chief of Gujerat, his own uncle-in-law.

It is optional with the Jat widow to take either the eldest (Jeth) or the youngest, who is generally preferred and deemed most suitable. Should she determine to relinquish worldly ideas, and to reside chaste in her father-in-law's house, she may adopt this course, but such instances are very rare, particularly in the case of young females, and are not to be looked for in a society and amongst tribes notorious for the laxity of their morals and for the degeneracy of their conceptions.

In default of surviving brothers, and in accordance with acknowledged usage, the widow is at the disposal of her father-in-law's family. From the moment she has quitted the paternal roof, she is considered to have been assigned as the property of another, and ceases to have a free will.

The Jews followed this custom, and in Egypt it was permitted for a childless widow to cohabit with a brother of the deceased husband. When the laws of Menu were enacted, Kurao appears to have been a recognised institution. But, as is not unusual with the Institutes, there is much contradiction between the enactments relating to it. From a consideration of all the passages on the subject, it appears that failure of issue was the point on which the legality turned. He who was begotten according to law on the wife of a man deceased, or impotent, or disordered, after due autbority given to her, is called the lawful son of the wife (ix. 176).-Elliot; History of the Panjab.

KURBA. The coal-bearing or Damuda beds of Kurba extend for about 40 miles to the eastward, as far as Rabkub in Udaipur (Oodeypore). They also extend far to the south-east towards Gangpur, and to the northwards towards Sirguja. Main
Pat and the neighbouring hills, and all the country on the road from Main Pat through Chandargarh and Jashpur to Ranchi, consist of metamorphic rocks, with the exception of a cap of trap and laterite on Main Pat.

KURBAJ. ARAB. A switch of dried and twisted hippopotamus hide, the ferule, horsewhip, and cat-o'-nine-tails of Egypt.-Burton's Mecca, i. p. 30

KURBAN. ARAB. A sacrifice. Mark vii. 11 has, 'But ye say, If a man shall say to his father or mother, It is Corban, (that is to say, a gift,) by whatsoever thou mightest be profited by me; be shall be free.' This word is often used by men or women addressing a superior, in which case it means merely, I am your sacrifice. The word has allusion to an approaching to God, and means a șacrifice, a victim, an offering, an oblation, for which also we have the Greek Kaomo,s. The other words in the Arabic, Sadqa, Fida, and Tassaduq, mark the continuance of the sacrificial rite. Sadqa, properly Sadaqa, means alms, propitiatory offerings, and sacrifice. The words are continued into Hindustani, in Sadqejana or Sadqe-hona, to become a sacrifice for the welfare of another; and Sadqe-karna, to sacrifice for the welfare of another. Muhammadans of India have two great Kurban or religious festivals, - the Bakr-Eed, called also Eed-us-Zoha, also Eed-i-Kurban, which is held on the 10 th $\mathrm{Zu}-\mathrm{ul}-\mathrm{Haj}$, in commemoration of the offering up of Ishmael by Abraham. The other is the Eedul-Fitr or Ramzan-ki-Eed, held on the 1st of Shawal, at the close of the Ramzan fast. Three lesser Eed are the Akhiri Char Shambah, on the last Wednesday of Safar, when Mahomed in his last illness felt a little better, and bathed for the last time; the Shab-i-Barat, or night of recording, is another, and it is held on the 16th Shaban. Other Musalman religious festivals are Maharram, Bariwafat, Miraj-i-Muhammad, Charaghan-i-Zandah Shah Madar, Charaghan-iBanda Nawaz, Pir-i-Dastagair, and Urus-i-Kadarwali.

KURBANA WANLU, or Buljera wanlu, TEL., amongst the Teling races are migratory grain and salt merchants, like the Binjara race.

KURCHI-WANLU. TEL. People in Southern India who are engaged in mat-making, basketweavers, also makers of house mats of palm leaves.

KURDISTAN, the country of the Kurd, is a district in the east of Persia, though the Kurd are also found in the west of Persia, in Asia Minor and Syria. Its limits comprise the greatest part of the territory of the Kurd or Carduchi. This extensive tract is divided into four districts, two of which are Kermanshah and Ardelan. Lower Kurdistan is the name given to that part of the pashalik of Baghdad which lies to the N.E. of the Tigris, and which comprised the chief part of Assyria, and seems to be the land of $\mathrm{Kir}$ spoken of in the Second Book of Kings and in the prophet Amos. The people consist of two distinct races, the one consisting of the Kurd tribes, who are Sunni Muhammadans, pastoral and shepherd nomades; the other, termed Grooran, who are villagers, and among whom are the Kuldi and Nestorian Christians and Jews. There are some within the Persian, others within the Turkish boundary. The Sekkir, Nur-ud-Din, Shinki, Bulbassi, Mikri, Bahdinian, and other 
tribes are under the prince of Amadiyah and Rowanduz. The Lak Feili and Bakhtiari tribes divell south of Kermanshah. Kurdistan is a high table-land, surmounted by rugged and lofty mountains. Lake Van, situated on the northern edge of the region which contains the larger proportion of the Kurdish race, is 5200 feet above the level of the Mediterranean. Sir Henry Layard, in passing from Mosul to Van in the month of August, found snow on several of the passes which he crossed, 10,000 feet in height above the sea. The Toura Jelu he estimated to be not under, if not above, 15,000 feet high. Near Lake Van and to the south of that lake several peaks rise much above the line of perpetual snow. Kurdistan air is pure and bracing; the winters are severe, as snow falls to a great depth, and in some districts remains on the ground undisturbed for from four to five months of the year. The mountains of Kurdistan lie along the eastern edge and across the northern end of Mesopotamia. To have full and firm possession of these mountains is to command that immense plain from the sources of the Tigris and Euphrates to the Persian Gulf; nor could the conquest of the interior of Asiatic Turkey be accomplished so long as an enemy held possession of those mountains. While the military expeditions of the Medes and Persians, the Greeks and Romans, the Saracens, Russians, and Turks, have swept around or over those mountains, the Kurds have still clung to them as the Swiss have clung to their native Alps.

Mr. George Rawlinson, M.A., after mentioning the different tribes that have occupied the high table-land mentioned above, says: 'Of these various tribes, the one of greatest name and note -which may be traced uninterruptedly from the time of Xenophon to the present day, and which has apparently absorbed almost all the othersis that which ancient writers designate under the slightly-varied appellations of Carduchi, Gordiari, and Cyrtii, and which still holds the greater portion of the region between Armenia and Luristan, under the well-known name of Kurds. The country assigned to this race in ancient times is usually the rugged tract east of the Tigris, extending from the neighbourhood of Sert and Bittis (in long. $42^{\circ}$ ) to the vicinity of Rowanduz (in long. $42^{\circ} 50^{\prime}$ ).' At the present time, however, the Kurds extend over and are scattered through a far wider region than that assigned to them by the ancient writers; tens of thousands of them are now found even west of the Euphrates, and as far south as the southern slopes of the Taurus mountains in the region of Adiaman; the streets of Erzerum; far to the north, are often crowded by these semi-savage freebooters. Millingen (p. 152) estimated the number of the whole Kurdish nation at five millions. The Persian Kurds are estimated at 600,000 souls. The Shadilu, Kara Cherchulu, and Yezidi clans in Khorasan are descendants of 4000 families whom Shah Ismail brought from Kurdistan to check the inroads of the Turkomans. They have increased to over 50,000, and are formidable alike for their numbers and for their bravery. They are predatory. Kurds have spread into the khanate of Bokhara, and eastwards into Afghanistan and Cutch Gandava. The Kurd are distributed over the western part of Asia much after the manner of the Armenians; and there are whole tracts of country where the Kurd and Armenian villages alternate. The nucleus, however, of the Kurd family lies south of Armenia, along the mountain ridge which separates Asiatic Turkey from Persia. There are also a few of the Kurd within the Russian froutier. Some pay allegiance to both Persia and Turkey, but there are more which are independent of both. Some are well within the Turkish, others as well within the Persian, frontier. They all speak the Persian language, but their feelings of nationality are local and tribal rather than general. Their habits are rude and predatory. They are bardy, brave, rapacious.

History has recorded their presence for 2000 years on the lofty plateau on the eastern border of Asiatic Turkey, between Armenia on the north and the fertile province of Mosul on the west: Doubtless, however, they had held their savage highlands for innumerable generations before the Retreat of the Ten Thousand. As now under the Turk, so through the periods of Assyrian and Median as well as of Persian supremacy, they had seen spread out at their feet the accumulations of peace and wealth, tempting their love of plunder. Well acquainted with the mountains among which they dwell, they can readily retreat where cavalry and artillery cannot reach them, and where, behind rocks and on lofty peaks, they are a full match for any trained soldiers who dare follow them. Before Kurdistan was subdued by the Turkish and Persian Governments, Beys or chiefs were the feudal rulers of the country; their authority was based partly on hereditary descent, and partly on personal influence and character. Obedience to their commands, though voluntary, was nearly absolute. Since the subjugation of the provinces of Kurdistan, many of these Beys and their descendants have retained great influence with their followers. During the war between Turkey and Russia, as well as during the Crimean war, the Turkish Government negotiated directly with the Beys for their services, including a stipulated number of irregular cavalry. It was found, however, that such troops, indifferent as to the main results of the contest, and eager only for the spoils of battle, were easily panic-stricken, yet ever ready to violate the rules of civilised warfare by shooting defenceless prisoners who had laid down their arms. Kurds have to-day very much the same characteristics that they had 2500 years ago ; their manner of life is much the same now as then. They are now taking more to agriculture, but they are chiefly engaged in sheep farming and cattle-breeding. With their sheep, the proportion of male and female births is three-fifths and twofifths respectively. They dislike manual labour; they are treacherous; like the Indians, they are fond of roving about from one part of the country to another; like them, also, they are slow to adapt themselves to the restraints and discipline of a regularly-organized government. Several hundred determined men would be enough to hold many of the passes of the Kurdish mountains, and put a stop to commercial intercourse. Past experience has proved that the military expeditions of the Turks against the Kurds have generally been very barren of results. The difficulties of transport are very great; the summers are short, the winters long and terribly severe, and the physical 
features of the country such that an enemy can readily avoid an invading army.

Nomade Kurd tribes occasionally occupy the elevated valley of Dasht-i-be-Daulat, N.W. of Mustung, at the head of the Bolan pass. On the west of Saharawan, the country is held by pastoral tribes, the Sirpherra, and their branch the Rodani Kurd of the Dasht-i-be-Daulat; Sherwani of Ktad, and the Raisani of Dolai and Khanak. The Dasht-i-be-Daulat, in the northern part of Saharawan and west of the Bolan Hills, is about 15 miles in length and breadth. In spring it is covered with lovely fiowers and grasses, and is then dotted with the toman of the Kurd, who retire to Merv after the harvest of autumn, and then predatory bands of Kaka roam over the ground and attack travellers. The Kurd possess the Dasht-i-be-Daulat and Merv, also Tikari in Cutch Gandava. The Kurd of the Dasht-i-beDaulat are surmised to have come from the west in the train of some conqueror, and settled where they now are.

Mikri Kurd occupy the S. part of Azerbijan. They are brave horsemen, and on one occasion they drove the whole Russian cavalry off the field. The Kurds who inhabit the district of Khorasan from Nishabur up towards Astrabad along the northern frontier of Iran, had long been established in this locality, and always constituted a principal portion of the forces of Khorasan.

In their wide distribution, the Kurd speak the Kurmanji between Mosul and Asia Minor and the Zoza; the Baluchi, the Lur dialects, viz. Bashiari and Feili; those of the Tats in the S.E. of the Caucasus, and of the Iron or Assetes in the same neighbourhood,-Rawlinson; MacGregor, iv. p. 381; Arminius Vambery of Bokhara, p. 77; Sayce, ii. p. 83.

KURDLAH, a small fort in the Dekhan, near which a battle was fought between the Mahrattas, 11,000 strong with guns, and the Nizam, 82,350 strong and 192 guns, in which the army of the latter was utterly defeated.

KUREH, PERs., plural of Kurrah, means circles or districts of a country.

KURHURBARI, in the valley of the Barakar, a tributary of the Damuda, famed for its coalfields. See Coal.

KURI. CAN. A sheep. Kuraba, a shepherd.

KURI. CAN. A fish-trap basket made on the same principle as the mouse-trap, with narrowing entrance and springy bamboo spikes projecting inwards so as to prevent return; on the same principle as the mouth of the purse in a trawl-net. On this plan they are made of all sizes and of many shapes. The small ones used to catch the fry in the rice-fields are about a foot long, aud are made of finely-split and closely-twined bamboo; while those used in the rivers are sometimes the same, and sometimes as much as 10 or 12 feet in length, and more elaborately constructed. These traps are called cruives.

KURIA MURIA, a group of barren islands in lat. $17^{\circ} 27^{\prime} \mathrm{N}$., and long. $55^{\circ} 36^{\prime} \mathrm{E}$., on S. coast of Arabia, in Kuriyan Muriyan Bay, five in number,-Hasiki, Sodah, Kirzaut or Rodondo, Hullaniyah, and Kibliyah. They were ceded to the British by the Imam of Muscat, for the purpose of laying the Red Sea and Indian telegraph cable, and for the guano. Hasiki is in lat. $17^{\circ} 27^{\prime} 15^{\prime \prime} \mathrm{N}$, and long. $55^{\circ} 36^{\prime}$ E.-Findlay.
KURILE ARCHIPELAGO is on the east of Asia. It is a chain of small islands, 900 miles long, extending from Cape Lopataka, the southern promontory of Kamtschatka, in a south-west direction, to the Isle of Jesso or Yezo. They are 22 in number, and were first visited by the Russians in 1713. These islands are all mountainous, and in several of them are volcanoes and hot springs. They are partly under Russia, partly under Japan.

The Kurilian or Aino race occupy the mouth of the Saghalin and the southern extremity of Kamtschatka, on the mainland, and all the islands between Kamtschatka and Japan. The peninsula of Tarakai is Kurilian. In the island of Karafto, Kamoi is their chief deity. The Aino are the aboriginal race of Yezo, whose severe treatment by the Japanese has led them to other countries. They also occupy the southern part of the island of Saghalin, which is in possession of the Japanese: The Aino are of short stature, with broad faces of the Mongol type. They are a timid race, their limbs are hairy, they have bushy beards and long tangled hair, large heads, and clumsy figures; the expression of their faces is that of good nature cumbered with stupidity.

The Kurilians are courteous and hospitable to each other, though averse to strangers ; and are chiefly employed in hunting, catching birds, and taking sea animals and whales. They carry on a traffic with the Japanese, who bring utensils of metal and wood, sabres, stuffs, tobacco, trinkets, and small wares,' for which they receive whale blubber, skins, fur, and eagles' feathers for arrows. According to M. Rosney, their language is dissimilar to Japanese, and that spoken in the Kuriles and in the island of Yezo are also different from Japanese-Rev. Mr. Adams, p. 240. See Japan.

KURJA of the Panjab, camel bags of woollen or goats' hair stuff, often prettily ornamented.

KURKIHAR, about three miles to the northeast of Punawa, is the largest place between the cities of Gaya and Bihar. The remains at Kurkihar consist of several ruined mounds, in which numerous statues and small votive topes of darkblue stone have been found. $-B$. A. S. J. p. 32 , 1864.

KURKUTCHA, a range of mountains which separates the valley of Kăbul from the plain of Jalalabad, and connects the Hindu Kush with the Safed Koh. The altitude of the range varies from 1000 to 2000 feet above Kābul, and the highest part, in lat. $34^{\circ} 25^{\prime} \mathrm{N}$., and long. $69^{\circ} 30^{\prime} \mathrm{E}$., is 8000 feet above the sea. There are four routes over this range, practicable only for man and horse. At Lataband pass 4000 British troops were destroyed in their retreat in 1842 . Cold is intense during winter, the frost splitting the rocks into huge fragments.

KURMA, in Hindu mythology, was the second grand avatara of Vishnu, in the form of a tortoise, and evidently refers, like the first, the matsya or fish avatar, to the flood. For the purpose of restoring to man some of the comforts and conveniences that were lost in the flood, Vishnu is fabled to have become incarnate again in the form of a tortoise, in which shape be sustained the mountain Mandara, placed on his back to serve as an axis, wherewith the gods and asura-the vast serpent Vasuki serving as a rope-churned the ocean for the recovery of the amrita, or 
beverage of inmortality. And the result of the operation, and that which chiefly distinguished this avatara, was the obtainment of fourteen articles, usually called fourteen gems or chaturdesa ratna, in common language chauda ratni, viz. 1. The Moon, Chandra;2. Sri or Lakshmi, the goddess of fortune and beauty ; 3. Sura, wine, or Suradevi, the goddess of wine; 4. Uchisrava, an eight-headed horse; 5 . Kustubha, a jewel of inestimable value; 6 . Parijata, a tree that spontaneously yielded every thing desired; 7. Surabhi, a cow similarly bountiful; 8. Dhanwantara, a physician; 9. Iravati, elephant of Indra, with three probosci; 10. Shank, a shell conferring victory on whoever should sound it; 11 . Danusha, an unerring bow; 12. Bikh, poison or drugs; 13. Rhemba, the Apsara, a beautiful and amiable woman ; 14. Amrita, the beverage of immortality. In the churning, the gods stood at the tail of the serpent Vasuki, and the asura at the head. After obtaining these fourteen gifts, there broke out a violent contest between the gods and the asura.

Avatara means in the Hindi tongue descent or incarnation, and is usually employed by the Hindus to designate the ten incarnations of Vishnu, usually thus arranged and named: 1. Matsya or fish ; 2. Kurma or tortoise ; 3. Varaha or boar ; 4. Narasingha or man-lion; 5 . Vamana or dwarf; 6. Parasu Rama, the name of a favoured person in whom the deity became incarnate; 7 . Rama, the same; 8. Krishna, the same ; 9. Budha, the same; 10 . Kalki or horse. Of these, nine are past ; the tenth is yet to come.

KURMA PURANA, a poem of 17,000 stanzas. It gives the relation of an avatara of Vishnu, the great portion inculcating the worship of Siva and Durga.-D.

KURMI, cultivators dwelling north of the Kunbi, but to the south of the Rajput and Jat. They form the bulk of the population in the part of Manbhum near the Damuda river; in considerable numbers in all the central and eastern parts of the North-West Provinces or in Hindustan generally, who there attend to the finer garden style of cultivation much more than the Jat and Rajput; but, like the Jat race, Kunbi and Kurmi are assisted by their industrious women, who have passed into a proverb for industry :

'Bhale jat Kunbin ki K'hurpi hat'h

K'het nirawen apne pi ke sat'h.'

They have villages of their own, and are also spread in detached families or groups. Mr. Camplell considers Kurmi to be identical with the Kunbi, and to occupy from lat. $16^{\circ}$ to $23^{\circ}$ or $24^{\circ} \mathrm{N}$, and from the western frontiers of Gujerat, countries watered by the Wainganga, the Midole Ganga, and upper streams of the Nerbadda. But in the valley of the Ganges they are looked down upon as mere humble tillers of the soil. They are more numerous towards the Jubbulpur and Saugor territories, where they mingle with the Lodhi. Thence westwards, as on both sides of the Nerbadda, in Malwa, where they meet the Jat, and throughout the southern borders of Hindustan, there are numerous Kurmi who speak Hindi. Those in Hindustan are darker and less good-looking than Brahmans and Rajputs; but Mr. Campbell states (pp. 93,94) that they are quite Aryan in their features, institutions, and manners.
Sir H. Elliot says seven subdivisions are usually enumerated, as Khariband, Patanya, Ghorcharba, Jaiswar, Kanoujia, Kewat, and Jbunia. These do not eat together or intermarry. The Khariband and Patanya abound in the Central Doab and Oudh; the Ghorcharha are more to the west; the Jaiswar in Saugor and Bundelkhand; the Kanoujia in the lower tracts of the Doab; the Kewat to the $\mathrm{E}$. of Benares; and the Jhunia west of the Upper Jumna,

The best agriculturists of the Central Provinces are decidedly the Kurmi, found mostly in rich black soil tracts. It is a common saying that no Kurmi can exist where he is unable to raise rabi crops. They are a most peaceable set of men, and have always been remarkable for their loyalty to the ruling power. They are very tenacious of their ancestral holdings, and seldom alienate rights in land unless under the greatest pressure of circumstances. The real secret of their unfailing success in agricultural pursuits generally does not appear to lie so much in their reputed superior skill, as in the fact of women as well as men engaging equally in field work; while the women of several other agricultural classes are precluded, by prejudice or custom, from assisting the male population in their labours. Scarcely inferior to the Kurmi as agriculturists, are the Lodhi, who, however, are the opposite of the former in natural temperament, being turbulent, revengeful, and ever ready to join in any disturbance. They make good soldiers, and are generally excellent sportsmen. Others engaged in husbandry are Jat, Koeri, Kach'hi, and Lodhi.

Both among Kurmi and Lodhi there is no distinction between a mistress and wife, provided always that the former is of the same caste as the husband, or, better still, the widow of an elder brother or cousin, however far removed. The children born from such connections are on an equal footing as regards inheritance of property, whether personal, real, or ancestral, with those born from regular married wives. A Kurmi who sells himself into slavery (not an uncommon thing even now) is said to become a Dhanuk. The Kurmi, Kunbi, Jat, and Rajput are the chief territorial tribes of Northern India. Kurmi, Kach'hi, and Murao are the best agriculturists in the N.W. Provinces. The agricultural and gardening tribes of the Panjab, Hindustan, Central India, and Maharashtra number about 20,000,000, viz. Jat, 2,630,994; Kach'hi, 2,258,769; Koeri, 1,207,951; Lodhi, $1,305,391$; Kunbi, 5,388,487; Kurmi, 4,065,475; and in the south of India are the Kamma, Kapu, Reddi, Naek, Vellalar, and IVakkaliga.

KURMSAQ. PERS. As an expression of contempt, the word Sag, signifying a rog, is generally applied to Christians by the Persians; and among themselves, as equally contemptuous, Kurmsaq is in very frequent use. Ouseley suspects that Sag and Kurmsaq are the Sacæ and Khor-Sa-kæ mentioned by Solinus, those barbarous words being probably Latinized from an imperfect apprehension of their sounds. The Persians in their language, according to this author, call the Scythians Saca, and in return the Scythians call them Chor-saci. Scythas, Persæ lingua sua Sacas dicunt, et invicem Scytbæ Persas Chorsacos nominant.-Solin Polyhist. xlix. in Ouseley's Travels, ii. p. 542 . 
KURNAH. Apamea, daughter of Artabazus, the Persian, was married to Seleucus, who gave her name to three towns. Kurnah, one of these three Apamea, is situated at the confluence of the rivers Euphrates and Tigris, and although now dwindled into a petty town, it was formerly a place of consequence. It is on a low flat, with apparently a rich soil, and along the river are low banks to prevent the country being flooded. At this spot some oriental traditions have fixed the Garden of Eden. It commands the mouths of both the Tigris and Euphrates, and looks directly down the Shat-ul-Arab river. Suaib, a station with a fort of the same name, is opposite to Kurnah, on the eastern bank of the Euphrates, and near Sahal. After the junction of the two streams, which for some distance are clearly discernible from each other (the waters of the Euphrates being much the clearer), a striking change takes place in the character of the scenery. On entering the Tigris from the south, the belt of date trees almost immediately terminates, patches of cultivation show themselves more frequently, and the country (though still a dead level) has a fertile and less desert look. About 100 miles above Kurnah, on the right bank of the river, stands the tomb of the prophet-scribe Ezra, a pretty mosque of tesselated brickwork, surmounted by a green cupola.-Townsend's Outram and Havelock, p. 308; Malcolm's Persia,ii. p. 141; Skinner's Overland Journey, ii. p. 266; Mignan's Travels, p. 290. tion.

KURNISH. ARAB. A humble form of saluta-

KURNOOL, a walled town on a tongue of land between the right bank of the Tumbudra river and left bank of the Hindri, in lat. $15^{\circ} 48^{\prime} \mathrm{N}$., and long. $78^{\circ}$ E., 900 feet above the sea, the junction of the Hindri and Tumbudra occurring to its south-east. Kurnool was held by a Pathan chief. Lying between the Ceded Districts and the Hyderabad territory, it was surrendered to the East Indian Company on ]5th December 1815 , but on the 18th October 1839 was again taken possession of, and on the same day a battle was fought at Zorapore, three miles off, the nawab of Kurnool captured, and the territory annexed. The chiefs were a violent and illiterate race. Khizr Khan, to whom, in 1651, Aurangzeb granted the jaghir, was assassinated by his son Daoud Khan. Himmut Bahadur Khan, in December 1750 , during the battle of Ginji, treacherously slew his leader, Nasir Jang. In 1823, while Muzaffar Khan was being conveyed to Kurnool by Mr. A. D. Campbell, and while yet in British territory, he murdered his young wife with shocking cruelty. In 1839, his brother, Alif Khan, bought and made large quantities of warlike stores, and, refusing to obey the British authorities, an army advanced on Kurnool, in the battle at Zorapore took prisoner the nawab, who was afterwards assassinated at Trichinopoly by a follower. Kurnool province is now a small collectorate of the Madras Presidency to the north of Cuddapah.

KURRAH. HiND. A circular enclosure in which Brahmans were accustomed to place a woman, whom they threatened to burn if the servants of Government preferred a charge. See Kur.

KURRAL, a Muhammadan tribe of the Hazara, who claim descent from Alexander. Kurral, Dhund, Tanaoli, Alpial, Awan, and Gukkar, tribes north of the Salt Range, are described by Mr. (Sir George) Campbell as the finest and handsomest men in India, perhaps in the world. They profess Muhammadanism, and have fanciful Mubammadan genealogies, but are wholly Indian in their language, manners, babits, and constitutions. Their language is Panjabi. They have no connection with the Pathan races, and they claim none with the Jat and Rajput, the Dilzak alone claiming to be of Hindustan origin. Their features would seem to show that they have kindred with the Kashmiri, or with the preHindu congeners of the earlier Indians found in the hills far west; but their language and character, their dress and the architecture of their houses, would indicate that they are nearly allied to the Panjabi. The Dhund are a very handsome race; and the Tanaoli dwell to the north in the outer range of the Himalaya, and about the Indus near Torbela, but they are not considered to be brave or trustworthy. The Awan of the lower lands, and the Dhund, etc., of the higher lands, have democratic village institutions.-Campbell, p. 97.

KURREA of the Southern Mahratta country, armed retainers who convoy treasure, like the Angria of Bombay.

KURRIMIA ZEYLANICA. Arn.

Palang,. . . Singh. Alareya-gass, . SingH.

Hura-kandu, . . ,

A large tree of Ceylon; one variety grows in the warm, moister parts of the island, another variety in the central province, up to an elevation of 5000 feet.-Thw. i. p. 72 .

KURSAN. In Central India, cultivators are termed Kursan, a name which distinguishes them as a specific class from ryots, which is a more general term, including all ranks. - Malcolm's Central India, ii. p. 25.

KURSEONG, not far from Darjiling, of which it is a subdivision. Its climate is equable, and the mists which are of such frequent occurrence at Darjiling and the higher altitudes are rare. It is 4500 feet above the sea, and is within two hours' march of the plains by the old road, and the new cart-road from Silliguri to Darjiling passes through the heart of the station. Kurseong is in many respects a more suitable locality for troops than Senchal. Senchal is 9100 feet high, and the change from such an elevation to the plains has been found in more than one instance hurtful to the health of the men.

KURU, father of Santanu, great-grandfather of the heroes who are famed in the Mahabharata. He became an ascetic on the banks of the holy lake S. of Thaneswar. He was the ancestor both of the blind Dhritarashtra and Pandu, who were thus both designated Kaurava as their patronymic, though this term is usually applied to the sons of Dhritarashtra.

KURUBA. KARN. A shepherd race in the south of the Peninsula of India, who also weave woollen kamli or blankets. The shepherds of the Canarese-speaking districts arrange themselves into three classes, viz.-

Hala Kuruba, who do not weave blankets.

Hande Kuruba, a shepherd of a bigher rank.

Mesa Kuruba, one of an inferior condition.

In the $\mathrm{S}$. of Mysore their towns take the appellation of Hande. $-W$. 
KURU BISTAN, a custom amongst the Jaguri Hazara of lending their wives to strangers for a night or a week.

KURUK or Kourk, a coarse brown cloth, half woven and half felted, forming the ordinary winter dress of the Afghan. The best are made at Denzi, but those of Karabagh are very good. During the British occupation it was a favourite article of dress both with officers and men. The manufacture of the barik is from an exceedingly fine and silky wool which grows on the belly of the camel. Nothing can be softer or warmer than the barik, and, if better made, they would be preferable to every other kind of cloth. As the nomades never dye the raw material, the barik is of the same colour as the camel. The price varies from 10 s. to $£ 4$ a piece.-Ferrier's Journ. pp. 192 240. See Kulk.

KURUK. HIND. The practice of secluding and guarding the Muhammadan women.

KURU-KSHETRA, a holy tract and place of Hindu pilgrimage in the Amballa district of the Panjab, embracing the country lying around the town of Thaneswar as a centre. The name derives its origin from Kuru, father of Santanu, greatgrandfather of the heroes who figure in the Mahablarata. Kuru became an ascetic upon the banks of the holy lake south of Thaneswar. The Imperial Gazetteer says that in popular belief the Kuru-kshetra embraces 360 places of pilgrimage, and extends as far as the town of Jind, 64 miles from Thaneswar. Whaterer be the precise extent of the sacred tract, it is certain that the strip of country between the Saraswati (Sarsuti) and the Ghaggar (the Saraswati and Drishadvati of the Sanskrit epies) formed the earliest settlement of the Aryan colonists in India, and the Kurukshetra and the river Saraswati still attract numerous worshippers. The towns of Thaneswar and Pihoia are the chief centres of pilgrimage, but minor shrines line the bank of the river for many miles. At Thaneswar, as many as 100,000 persons still assemble on the occasion of an eclipse, and treble that number bathe annually in a tank filled from the Saraswati. The great conflict between the Pandava and the Kaurava is described in the Mahabharata as having been fought out in the surrounding country; and the Mahabharata keeps alive the memory of all the most famous scenes in the minds of Hindu votaries, who regard the Kuru-kshetra as the Holy Land of their religion.

The great lake of Kuru-kshetra is an oblong sheet of water 3546 feet in length from east to west, and 1900 feet in breadth. It is mentioned by Abu Rihan, who records, on the authority of Varaha Mihira, that during eclipses of the moon the waters of all other tanks visit the tank at Thaneswar, so that the bather in this tank at the moment of eclipse obtains the additional merit of bathing in all the other tanks at the same time.

The battle of Kuru-kshetra was a memorable event in the history of the Lunar race. It was fought about B.c. 1367, between the Pandu and the Kuru of Hastinapura, two branches of the race; and, after a series of single combats through a space of eighteen days, the Kuru were completely defeated, their leader Duryodhana had been slain, and Yudishthra then retired to Dwaraka with Krishna, his principal adviser. Buncen estimates B.C. 1606 or 1486 as the first year of the Kaurava, and B.c. 1107 or 987 as the last year, as the close of the great war, after the battle of Kuru-kshetra. They were all blood relations, some of them nearly allied to each other, and connected by intermarriages.

The commanders-in-chief whom the Kuru lost were Bhishma, slain on the 10th day, Drona on the 5th, Karna on the 2d, and Salya on the first, respective days of their commands. It is this war of succession which is described in the great Sinskrit poem the Mahabharata. One of the last incidents of this battle occurred on the night of the 18th day, when Aswatthaman entered the Pandava camp, and killed the sons of the Pandava, whose heads he brought to Duryodhana. A series of single combats had chiefly marked this war; each chief or warrior had challenged opponents, in the daytime, in the presence of the armies, and the act of Aswatthaman was so contrary to the usage of the war, that Kripa remonstrated with Aswatthaman against his doing it, but, along with Kritavarmam, accompanied Aswatthaman to the gate of the Pandava camp, and held the gate during the midnight butchery. The ultimate fate of Aswatthaman is uncertain, but he seems to have been pursued and killed by Bhima. This battlefield of the Kuru is near Thaneswar, between Kurnal and Sirhind, is generally identified with the field of Paniput to the north-west of Dehli, and the locality is deemed holy. It was a war to the knife between near kinsmen to gain possession of lands of which the Kuru had long held possession to the exclusion of the Pandu.

Yudishthra, Baldeva, and Krishna afterwards retired with the wreck of this ill-fated struggle to Dwaraka, but the two former had soon to lament the death of Krishna, who was slain by one of the aboriginal tribes of Bbils, against whom, from their shattered condition, they were unable to contend. After this event, Yudishthra, with Baldeva and a few followers, entirely withdrew from India, and, emigrating northwards by Sind to the Himalayan mountains, are there abandoned by Hindu traditional history, and are supposed to have perished in the snows. Herodotus describes the ruinous passion for play amongst the Scythic hordes, and which may have been carried west by Odin into Scandinavia and Germany. Tacitus tells us that the Germans, like the Pandu, staked even personal liberty, and were sold as slaves by the winner.

The life of Krishna forms a second memorable part of the history of the Lunar race, as he bas been deified throughout Hindu India, and is regarded as an incarnation of Vishnu.-Tod's Rajasthan, i. p. 50 ; Bunsen, iii.; Wheeler's Mahabharata, p. 567 ; Hardy's Eastern Monachism, p. 438 ; Imp. Gaz. v. ; Cunningham, Ancient Geog. of India, p. 334.

KURUMBAR or Kurubar. CAN. A shepherd, from Kuru, a sheep; a shepherd race who occupy the elevated plateau in the centre of the Peninsula of India. They are an ancient people, the earliest known occupants of Dravida Desam, the modern Carnatic, and Coromandel. They seem to have established numerous petty principalities over the whole Peninsula, which were ultimately absorbed in the Chola empire. Numerous sites attributed to this race, and still called Kurumbar Kot, are to be met with. Small communities of the Kurumbar tribe to this day wander with their flocks, and 
occupy the less accessible hills and forests of many parts of the Peninsula.

Arcot town, about 65 miles W. from Madras, takes its name from two Tamil words, Arakada, the jungle on the river Palar. It is the Arkatou Basileon of the Greeks, and the capital of the nomade Sorai ( $\Xi \omega p \alpha_{6}$ ), and once formed the centre of the Chola kingdom, the whole of the neighbouring territory for several centuries after the Christian era having been occupied by wandering Kurumbar.

On the Neilgherry Hills, above the Irular, at heights varying from 1000 to 2000 feet, in the clefts of the mountains and little openings in the woods, with which at this elevation they are girt, live a race calling themselves Kurumbar. I'hey occupy the highest range bordering on the Neilgherries. The Toda do not consider the Irular as forming a part of the inhabitants of the hills, but they allow this designation to the Kurumbar, whom they call Curb, and from them they receive certain services.

The Kurumbar of the Wynad forests have two sections, - the Jani and the Mulli; and Gurchea, Panniar, and Puliar races live along with them. The Jani Kurumbar live entirely in the forest; they are the ouly axe-men, and without them it would be difficult to work a forest, and the woodcontractor and planter alike employ them. They are very docile, quick of imitation, and slavishly submissive to their Mudali or headman. This individual, like a patriarch of old, exercises undisputed power over his own family, numerically containing about twenty or thirty beings. Those employed by the coffee planters are a little civilised, appreciating the comforts of life in a slight degree higher than their more savage brethren. They erect rude huts for the habitation of themselves and family.

Mr. Campbell (p. 31) described the Kurumbar, Irular, Puliar, and Veder as in the lowest stage of life, mere men of the woods, of very diminutive stature, with thickly-matted locks and supple limbs, living under trees, in caverns, or in the rudest wigwams, keeping sheep or collecting forest produce, very stupid, but also very mild and inoffensive, though reputed as sorcerers and believers in demons. But such a character is only applicable to the secluded families who have been forced into the forests and mountains. The Kurumbar who herd their vast flocks from the Godavery to Cape Comorin, are tall, slender, gxaceful men, with skins blackened by their food and the great heat; and, travelling over all the swelling lands of the interior, these self-reliant men are to be seen engaged in their lonely avocation. They wear only a coarse blanket or kamli. They appear to be a wholly different race from the Idayan or pastoral branch of the Tamilspeaking people, who take the honorific appellation of Pillay or son, to distinguish them from the Vallalar, who are styled Mudali or first man. The nomade shepherd is called Kurumbar-Idaan.Wilson's Gloss. ; Capt. Harkness, Neilgherry Hills; Mr. G. Campbell; Rennell's Memoir, part xxi. pp. 265-328.

KURUMBAR, a forest race on the skirts of the Neilgherry Hills, on their western flanks. They are very much dreaded by all the tribes of the Neilgherries, excepting the Todas, and are supposed to be necromancers, and each Badaga village has its own Kurumbar to keep off the evil eye of other Kurumbars. It is further believed that deaths are only caused by Kurumbar influence, and under this superstitious belief Kurumbars have several times been sacrificed. At the close of the year 1874, Kurumbars were massacred at Kotagiri, and on the 30 th April 1882 there was another massacre, about 15 miles east of Kotagiri. The son of the Badaga headman of Elmnaad village (northern boundary of Todanaad) had fallen sick and died. The village priest being consulted, the cause of the death was attributed to the evil eye and magic of the unfortunate Kurumbar, who was straightway seized and put to death, and his body burnt on the same funeral pyre, and with the ashes of the headman's son, as a sacrifice. One life not being considered sufficient to appease the wrath of the gods, a party was sent to fetch his wife and three children, who were hunted down to a village at the foot of the hills near Segur, there secured, and brought to the burning place, where they also were brutally murdered and cast into the flames.

The chief of the Irular stated that on the evening of the 30th April 1882, two Todas and a Badaga were seen going towards the missing Kurumbar's house, which was about twenty-five yards from his, and that on the same night he was roused from sleep by cries of murder proceeding from the Kurumbar's hut, which caused such a panic among the villagers, that they all deserted their homes, and sought refuge in a neighbouring jungle, where they hid themselves for two days. Returning to the village on the third day, they found the Kurumbar's house empty, and all his cattle missing.

KURUMINGA. Singh. The Butocera rubus, a beetle of the south of India, which penetrates the trunk of the cocoanut tree near the ground, and there deposits its eggs. Its grubs, when hatched, eat their way upwards through the centre of the tree to the top, where they pierce the young leaf-buds, and do incredible damage.Tennent's Ceylon.

KURUMNASSA, a river of Bengal. An ancient raja baving bad the misfortune to slay a Brahman, the mourderer was purified by a saint, who collected water from countless streams, and united them in the spring from which the river now issues. The river, so polluted, has to be crossed or forded in the dry season by every Hindu from Bengal, Behar, or Cuttack on his pilgrimage to Benares, and a stone bridge, to prevent pilgrims from dipping their feet in the accursed stream, was built by the liberality of a pious Hindu in the early days of the grand trunk road to Benares. The significance of the name is that the river absolutely blotted out all good deeds acquired by a pilgrimage to the holy city. Karma is deed in Sanskrit, and Nāsha is annibilation or destruction.

KURUN. MAHR. Land reserved for hay or grass.

KURUT. When well made this is excellent, though unknown in Europe. In Persia it is called Kesht or Kaishk, and is thus prepared. Some butter milk is boiled in a very large saucepan, by which means the watery particles escape in the form of steam, and the solid ones are deposited at the bottoin of the vessel. When sutticiently thickened, the mass is divided and 
made into little balls about the size of a pigeon's egg, which are dried in the sun, and will keep for years. When required, these balls of concentrated butter are continnously stirred in hot water, and in a metal dish, till completely dissolved; the epicures add a quarter of a pound of fresh butter, which gives the sauce an exquisite flavour. It is poured over the bread, maize, or meat which it is intended to season. Elphinstone says it is made of dried curds pressed into hard lumps. It is scraped down and mixed with milk, and in this state Afghans of all ranks are very fond of it, but it is sour, and to Europeans very unpalatable. - Ferrier's Journeys, p. 279; Elphinstone, Caubul, p. 261.

KURU VARNAKA, people of the forests in the upper part of the Panjab.

KUS, the ancient Cos or Apollinopolis Parva, between Keneh and Luxor, described by Ibn Batuta (i. p. 106) as in his day a large and flourishing town, with fine bazars, mosques, and colleges, the residence of the viceroys of the Thebaid.-Yule, Cathay, ii. p. 400.

KUSA, one of the twin sons of Rama and Sita, the other twin being Lava. After the death of Rama, his sons ruled over the Southern and Northern Kosala, and Kusa built Kusa-sthali or Kusa-vati in the Vindhya, $-D$.

KUSA. SANSK.

Kush, Kusha, . BENG. | Darbha,

SANSK

Kusa grass is the Poa cynosuroides, deemed sacred by the Hindus. It is used in their religious ceremonies, being strewed upon the altar, or held by the Brahmans in their hands whilst repeating the ritual; it is placed on the ground with its tips to the east, as a seat for the idols when offerings are made to them. In the Avenejana ceremony in the Srad'ha, the funeral cake is placed on kusa grass, and before offering it, water in which white flowers and sandal paste are immersed, is poured on the cake. Care must be taken not to confound Darbha with Durbha, which is Cynodon dactylon. A dying Hindu, when no hopes of his surviving remain, should be laid on a bed of kusa grass (Poa cynosuroides) in the open air, his head sprinkled with water drawn from the Ganges, and smeared with clay brought from the same river. A salagrama stone should be placed near him, holy strains from the Veda should be chanted aloud, and leaves of holy basil scattered over his head.-Wils. Gloss.

KUSAGARAPURA, the old capital of Magadha, also called Girivraja and Rajagriha, now Purana Rajgir.

KUSAILOO, also Kusaili. Hind. The bark of a small tree, wild about Ajmir; is tasteless: given to lying-in women to clear the blood and increase milk.

KUSBUL. HrNo. Aplotaxis fastuosa, the shepherd's tinder, is found in the Sutlej valley between Rampur and Sungnam at an elevation of 7000 to 9000 feet. The tomentum on the under surface of the leaves is employed by the hill people as tinder.-Cleghorn's Report, p. 67.

KUSH or Cush, a term familiar to readers of Scripture (Genesis ii. 13, also x. 6-8, and 1 Chronicles i. 10) as the name of the eldest son of Ham (Charma); and before the flood, of a country encompassed by the Gihon, the second river of Paradise. The name seems to have descended to Noah's progeny, who took it for themselves, and gave it to countries. There was an African Kush, and the Cushan of Habakkuk iii. 7 is another. The Hamitic Kushites appear to have spread along tracts from the Upper Nile to the Euphrates and Tigris. In the history of India, Kush or Cush, the second son of Rama, gave his name to the Kushwaha or Cutchwaha princes of Nirwar and Amber, though the tortoise is supposed to be a source of this name. The country of which Ayodhya (now Oudh) was the capital, and Rama monarch, is termed Koshula in the geographical writings of the Hindus, supposed by Colonel Tod to be from Koshulya, the mother of Rama; and in the archives of the rana of Mewar, the first emigrant from the north, is styled Koshulaputra, son of Koshula.

KUSH, or Koh-i-Kush, or Hindu Kush is the term applied to a lofty peak in the range of mountains continuous with the Himalaya, west of the Indus, and also to the range itself. The only part of the range covered with perpetual snow is the Koh-i-Baba between Kăbul and Bamian. The Hindu Kush peak is visible from Käbul, and is entirely covered with snow, and also from Kunduz, distant 150 miles. In its perpetual snow is a creature called the snowworm, which perishes if removed below the snow line. The highest pass does not exceed 12,400 feet. Many parts are devoid of wood and even of verdure. There grows merely a stunted furze, used as firewood, called Kullah-i-Hazara or Hazara cap.

The countries north of the Hindu Kush, which lie in the valley of the Oxus and its tributary rivers, from Balkh upwards, have no geueral designation. Eastwards of that city lies Kunduz, and it has Badakhshan farther eastward. To the north of this territory are the hill states of Wakkan, Shughnan, Darwaz, Kulab, and Hissar, whose people claim a descent from Alexander the Great. To the eastwards of Badakhshan lies the plain of Pamir, inhabited by the Kirghiz; and beyond the Belut Tagh mountains are Chitral, Gilgit, and Iskardo, that extend towards Kashmir. South of Badakhshan is the country of the Siah-Posh Kafir, who occupy a great part of the range of Hindu Kush and a portion of Belut Tagh. On the west it has Indarab and Khost, also in Balkh, and the Kohistan of Kābul, and on the east it extends for a great distance towards the north of Kashmir.

KUSHIDA. HIND. Embroidered muslin.

KUSHKAH. HiND. Boiled rice, properly Khushkah. Grains of ground rice in curds is the material for the primitive tika, which is applied on the foreheads of Hindus.

KUSHTA. Pers. Metallic compounds used as medicines, the principal being Kushta sikka, Kushta jast, Kushta tamba or mis, and Kushti loha. These preparations are made by native hakims; they are compound bodies (murakkabat), though called by the name of a simple constituent, taking their name from the metal which forms their basis. To prepare the Kushta sikka, or carbonate of lead, one tola of lead is placed in an iron pan, with the juice of the Euphorbia, or the kesu or dhak flowers (Butea frondosa). The Kushta jast is oxide of zinc; the Kushta tamba is arsenite of copper. The Kushta loha, an oxide of iron, is also called Khubs-ul-hadid, or Zafran-ulhadid.-Pnvell's Hanilbook. See Medicine.

KUSHTIGAR, or Phailwan. Pers. Wrestlers, 
athletes, throughout Southern Asia, who whirl overhead ponderous wooden clubs called mil, also magdar, instruments of a favourite but very laborious exercise, regularly taught by an ustad or teacher, who instructs in 360 band or forms. Ouseley's Travels, i. pp. 234, 236.

KUSI or Koosy, a river of Northern Bengal, rising among the Nepal Himalayas, in lat. $28^{\circ} 25^{\circ}$ N., and long. $86^{\circ} 11^{\prime} \mathrm{E}$. It first takes a course south-west for about 60 miles, then south and south-east for 160 more, during which it receives on its left bank its two great tributaries, the Aran and Tambar. It joins the Ganges after a course of 325 miles. The Kusi is remarkable for the rapidity of its stream, the dangerous and uncertain nature of its bed, but chiefly for its constant westerly attrition. According to a Hindu legend, Kausiki is the daughter of Kusik, raja of Gadhi, a Kshatriya, but was married to a Brahman. She bore a son, who became a soldier, and Kausika was changed to a river.

KUSIMA and Usima, small volcanic islands in the Archipelago of Japan, situated in the neighbourhood of Cape Sangir.

KUSINAGARA or Kusinara. Near this town was the scene of Buddha's death, at the age of 80 , in a grove of sal trees. It is the modern Khassya. At the time of Hiwen Thsang's visit, the walls were in ruins, and the place was almost deserted, but the brick foundations of the old capital occupied a circuit of about 12 li, or 2 miles. The only name now associated with the ruins near Khassya is that of Matha Kuar, or the Dead Prince. - Cunningham.

KUS KUSA. ARAB. One of the numerous kinds of what the Italians generally call Pasta. The material is wheaten or barley flour rolled into small round grains. In Barbary it is cooked by steaming, and served up with hard-boiled eggs and mutton, sprinkled with red pepper. The Bedouin Maghrabi Arabs merely boil it.

KUSSOIVLEE is in lat. $30^{\circ} 53^{\prime} 13^{\prime \prime} \mathrm{N}$., long. $77^{\circ}$ E., 45 miles distant from Amballa, and 32 from Simla; its height is 6322 feet; there is no table-land, and the peaks are rather steep. It is on the crest of a ridge which overlooks the Kalka valley; the inner slope is covered from the summit to perhaps 1000 feet below it, with an open forest of the Pinus longifolia. The climate temperate and agreeable, unless during the rainy season, when dense fogs make it gloomy and depressing.

KUSSUB. Arab. Penance; a term used in the science of exorcism.

KUSSUR-KA-GHAR. HIND. Literally fractional house, a term used in forming magic squares. KUSTI, the zouar worn by the Parsees.

KUSUMBA, a term used by the Rajputs to designate opium. Kusumba, in Sind, is the name given in good society to a solution of opium, which the natives extensively use. In Cutch it means a Rajput practice of drinking a solution of opium from each other's hands, to stanch feuds. In times of peace and ease, the Rajput leads an indolent and monotonous life. After a midday siesta, the chief rises, washes his hands and face, and prepares for the great business of the day, the distribution of the red cup, Kusumba or opium. He calls together his friends into the public hall, or perhaps retires with them to a garden-house. Opium is produced, which is pounded in a brass vessel and mixed with water.
It is then strained into a dish with a spout, from which it is poured into the chief's hand. One after the other the guests now come up, each protesting that kusumba is wholly repugnant to his taste, and very injurious to his health, but, after a little pressing, first one and then another touches the chief's hand in two or three places, muttering the names of Dev, friends, or others, and drains the draught. Each, after drinking, washes the chief's hand in a dish of water which a servant offers, and wipes it dry with his own scarf; he then makes way for his neighbour.-Rasamala, Hindu Annals, ii. p. 261; Burton's Scinde, ii. 143.

KUSUNDA, Chepang, Chetang, and Haiyu are four small uncivilised Bhot tribes who reside amid the dense forests of the central region of Nepal, to the westward of the great valley. They have no apparent affinity with the civilised races of the country, but live in huts made of the branches of trees, on wild fruits and the produce of the chase. The Chepang are slight, with large bellies. Mr. Hodgson says they are of Moghul descent. Their language is akin to the Lhopa. The Chepang, Haiyu, and Kusunda seem to belong to the Rawut group of frontier populations. They are named by Mr. Hodgson the Durre, Denwar, and Brahmo, which Mr. Latham believes to be the same as Tharu, Dhungur, and possibly Rawi. They occupy the districts where the soil is moist, the air hot, and the effluvia miasmatic.-Latham. See India.

KUSUST"HULLI DWARAKA, the capital of Krishna. The Bhagavat Gita states its founder was Anirt, brother of Ikshwaku.

KUSWUR. HiND. The flower from which is made the yellow kuswur dye used in Hindu marriages. To use it on the day of battle, is arnong the Hindus deemed a sacred pledge to conquer or die. Volunteers are often invited to assume the yellow dress, which implies desperation in any undertaking. Amongst Rajputs, it was a not unfrequent usage to imitate the Hindu saints and warriors, and dye their garments with yellow, the hymeneal colour, which indicated that they went to battle as to a bridal feast, and were determined to die or to live exulting conquerors.Malcolm's Central India, i. p. 358.

KUT, also Uplate and Putchuck. Hrind. The root of the Aucklandia costus. A bitter aromatic tonic, used in fever; the roots have a pleasant smell, and are used as perfumes. It is chiefly exported to China, where it is used as an incense. In India it is used medicinally.-Powell's Handbook, i. p. 356.

KUTAIBA, conqueror of Bokhara in the first century of the Hijira. The descendants of the Arab conquerors now number about 60,000 souls, chiefly in Samarcand, Vafkend, and Vardanzai. They are shepherds, and sell postins.-C. As.

KUTCH, the breeches of the Sikhs, the adoption of which is of as much importance to a Sikh boy as was the investiture with the toga virilis to a Roman youth.

KUTCHERRY. HIND. An office, a court or place of public business.

KUTCH GANDAVA, a champaign district of Baluchistan, a depressed level plain. See Kach Gandava ; Kalat.

KUTCHURA. HiND. Large quantities of arrowroot are prepared from different species of Curcuma, -C. angustifolia, C. leucorrhiza, and C. montana, from Travancore. It is a regular article of export. 
KUTH-LAH. HIND. A great black chubby fish of Northern India, with large scales, and a very big mouth without teeth. It has been known to attain a size weighing two Bengal maunds, which are equal to $164 \mathrm{lbs}$. This fish does not take a hook. The Ro-hoo and the Mir-gah resemble each other in size and habits; they are very much like the salmon, but have tiny little mouths with no teeth. The Ro-hoo in season has very pretty red fins, and both have ash-coloured backs, with silvery bellies; they attain to the weight of $20 \mathrm{lbs}$., and afford the angler excellent sport at bottom-fishing, sometimes engaging him for an hour before he can attempt to land his fisb. The Kheel-bause is a pretty little dark ash-coloured fish, with a small toothless mouth, and has a whisker on either side of it. This fish also affords the angler good sport, and is found of 5 or $6 \mathrm{lbs}$. in weight. These are all plentiful in Calcutta and Lower Bengal, and, while young, could be easily exported.

KUTHUMI, a Hindu sage, born at Badarikashrama, and who lived at Gandhara. His father, Narayana, was a philosopher, and his son Kütsana wrote a tract on the Rules of Poetry. Kuthumi taught the immortality of the soul, and that happiness and misery are the inseparable companions of works of merit and demerit.-Ward, iv. p. 41.

KUTIRA or Katira, a gum greatly resembling gum-tragacanth, yielded by the trunk of the Cochlospermum gossypium. It is used by native practitioners as a demulcent and emollieut; but, under the same name and of very similar properties, is often sold the gum of several species of Sterculia, Butea, and of Bombax pentandrum, Huttian ka gond, etc.-O'Sh.

KUTPUR, a town on the southern coast of Kattyawar, the ancient Kunu-kavati, said to have been built by Kunuk Sen, the great progenitor of the Choura race. Kunu-kavati was overwhelmed by an encroachment of the sea or storm-wave, the same occurrence, doubtless, that separated Perim, Shial Bate, etc., from the mainland. At Shial Bate the ruins are remarkably good. Wulleh seems to have been destroyed in the same manner.

KUTTINI. Hind. A silk fabric used by the Muhammadans of S. India, both men and women, for trousers.

KUTTIRIPPA. Maleal. Living with a Nair princess or queen as her husband.

KUTUA, HiND., also called Bungka Kutua. An aquatic beetle which eats rice plants. It is said to make a leaf-boat, which it paddles from plant to plant. - Ell.

KUTUB MINAR at old Dehli was erected from the pillars and other parts of Jaina temples, and many of them retain the sculptured figures. In 1794 , though its capital was then ruined, it was 250 feet 11 inches in height. Its present height is 238 feet 1 inch, deducting the modern pavilion. It has four ornamental balconies, respectively at $97,148,188$, and 214 feet from the ground, between which are richly-sculptured raised belts containing inscriptions. It is lower by 30 feet than the Campanile at Florence. It is a tower of victory, a Jaya Sthamba. The dates of the ruins in old Dehli are from 1196 to 1235 . The inner court was enclosed by Shahab-ud-Din. The central range of arches was built by Kutub-udDin; the wings by Altamsh, whose tomb is beyond the northern range. The base of this minar is a polygon of twenty-four sides, altogether measuring 417 feet. The shaft is of a circular form, and tapers regularly from the base to the summit. It is divided into five storeys, round each of which runs a bold projecting balcony, supported upon large and richly-carved stone brackets, having balustrades that give to the pillar a most ornamental effect. The exterior of the basement storey is fluted alternately into twenty-seven angular and semicircular faces. Up to the third storey the minar is built of fine red sandstone. From the third balcony to the fifth, the building is composed chiefly of white Jeypore marble. The Hindu architect has not failed to record his undertaking without the usual Hindu invocation, Sri Viswakarma prasade rachita, 'built under the auspices of Viswakarma,' the celestial architect of the Hindus. The object is at once apparent to the spectator, that of a Mazinah for the Muazzan to call the faithful to prayers. About A.D. 1830 , it suffered a little from an earthquake, but under the directions of the British Government it was repaired. Ibn Batuta was certainly misinformed as to the date and builder of the Kutub. He ascribes it to Sultan Muiz-ud-Din, otherwise called Kaikobad, grandson of Balban (A.D. 1286-1290). But the real date is nearly a century older. It was begun by Kutub-ud-Din Aibek, when governing for Shahab-ud-Din of Ghazni (otherwise Muhamuad bin Sam, A.D. 11931206), and completed by Altamsh (1207-1236). Ibn Batuta ascribes the rival structure to Kutuliud-Din Khilji (Mubarik Shal, 1316-1320), and in this also Colonel Yule thinks he is wrong. The iron pillar at the Kutub, in the centre of its courryard, stands 22 feet above ground, and extends 20 inches under ground; total, 23 feet 8 inches. Its diameter at the base is 16 feet 4 inches, and at the capital it is 12.05 inches. There is no date on it, but Mr. Fergusson says (p. 506) that Mr. Prinsep supposed an inscription on it to be of the $3 \mathrm{~d}$ or 4 th century; Dr. Bhau Daji supposed the 6th century. It is forged iron. An inscription on it says it was dedicated to Vishnu ; but its real purpose was a pillar of victory to record the defeat of the Balhikas near the seven mouths of the Sindhu or Indus. Behind the N.W. corner of the mosque is the tomb of Altamsh.-Tod's Travels, pp. 108-327; Col. R. Maclagan, R.E., in Yule, Cathay, ii. p. 434 ; French Tour; Elphinstone. See Architecture; Dehli.

KUTUB SHAHI, a dynasty of kings of the 16 th and 17th centuries, ruling in Golconda and Hyderabad in the Dekhan.

Sultan Kuli, . A.D. 1512 Muhammad, . A.D. 1580 Jamshid, : ", 1543 Muhammad, " " 1611 Subhan Kuli, ", 1550 Abdullah, . . " "1626 Ibrahim, ." ", 1550 Abdul Husain, ", 1673

Sultan Kuli was descended from the chiefs of the Karakonilu tribe of Kurds, and appears to have been born near Diarbikr. The tribe to which he belonged having been subdued by Mir Husain, and subjected to the Akunelu tribe of which that chief was head, Sultan Kuli, to save his life, fled from Diarbikr in company with his uncle, and, after many difficulties and dangers, found his way to Beder, at which place Sultan Muhammad Lashkari Bahmani of Beder and Gulburga then held his court. Ferishta, in his history of the Bahmani dynasty, states that Sultan Kuli in the first instance obtained employment at the 
Bahmani court as one of the Turki ghulam in personal attendance upon the king; but this appears to be denied by the author of the Towarikh-i-Kutub Shahi, who asserts that Sultan Kuli was from the first employed in a situation befitting his rank and family, and from his talents and courage early rose to the command of the Beder armies and the government of the province of Telingana. On the decadence of the Bahmani dynasty, during the latter part of the reign of Muhammad II., when the government had been virtually usurped by the minister Kasim Burid, Sultan Kuli seized the province of Telingana, and some years afterwards took the title of Kutub Shah; this latter event occurred in A.D. 1520 or thereabouts, and the Kutub Shahi dynasty existed in Telingana under this name for a period of nearly 200 years. The last ruler is commonly known by the name of Thannah Shah. Another account describes the founder of this dynasty, Sultan Kuli, as the son of Amir Kuli, a Turkoman chief, who claimed to be a lineal descendant of the prophet Noah, through his son Japheth. He was born in the town of Hamadan, and when a youth accompanied his paternal uncle to Beder, then the seat of government of the Bahmani kings, about the close of the reign of Sultan Muhammad Shah Lashkari Babmani, and there got the title of Kutub-ul-Mulk, i.e. the Polar Star of the State; to it was attached as a jaghir the town of Golconda and the surrounding villages. $\mathrm{He}$ was afterwards promoted to the command of all the troops in that vicinity. On the decadence of the Bahmani power, Kutub-ul-Mulk threw off its control in 1512, though, according to some historiaus, he did not assume the title of an independent sovereign for some years subsequently, probably about 1520 . The limits of the territory contained within his dominions are described by the author of the Hadikat-ul-Alam, as extending from Chanda in the north to the Carnatic, and from the seashore of Orissa, Vizagapatam, and Masulipatam, to Beder and the Bijapur territories on the west. After a reign of 31 years, Sultan Kuli was murdered by a Turki slave at Golconda, at the instigation of his son Jamshid, A.D. 1543, A.H. 950 . He was murdered in the mosque situated inside the town, and was in the act of directing the masons to break open a door to escape assassination, when the man employed by his son stabbed him. He died at the age of 90 years, and was succeeded by his son Yar Kuli Jamshid Khan, who had murdered his elder brother Malik Kutub-ud-Din during their father's lifetime. Jamshid died of cancer, having been guilty of the assassination of his father and brother and the death of many individuals, ordered for cxecution in moments of passion and pain. He is said to have lost the tip of his nose and a great part of his cheek by a sabre cut in battle. He was succeeded by his son Subhan Kuli, a boy of ten years of age, who reigned for a period of seven months. The weakness of the government, and the contentions existing between the reigning sovereign and his uncle, Daulat Kuli, whose cause had been espoused by Jagdeo Rao, raja of Warangal, induced Ibrahim to leave the Bijanagar court for Golconda, which he reached and succeeded in establishing himself in 1557 , and, after a reign of 23 years, he died in the year A.D 1580, A.H. 988, and lies buried in one of the tombs of Golconda. The two last figures of the above date only are visible. He was succeeded by his son, Sultan Muhammad Kuli Kutub Shah.

KUTUB-ud-DIN AIBEK, a slave of Shahabud-Din, who gave him the government of Dehli. In A.D. 1206, on the death of his master, Muhammad Gori, Kutub-ud-Din, retained possession of Hindustan till his death, A.D. 1210. He was the first of the Turki slaves who attained sovereignty, and furnished a succession of rulers to Hindustan. Kutub-ud-Din in 1210, after a reign of four years, was succeeded by his son Aram, who was within a year displaced, in 1211, by Altamsh, a slave and son-in-law of Kutub-ud-Din. Bakhtiar, general of Kutub-ud-Din Aibek, in A.D. 1201, had conquered Behar, and in 1203 conquered Bengal, but was defeated and driven back from Bhutan and Assam. Altamsh ruled Hindustan 25 years, and in that time subdued the fortress of Rintambore in Rajputana, captured Gwalior and Mandu, and conquered Ujjain. It was in his reign that Chengiz Khan ruled in Western Asia. He destroyed the temple of Mohakal, which a Vikramaditya had erected at the beginning of the Christian era. Altamsh died in 1236. His son Rukn-ud-Din reigned six months and was deposed, and then his daughter Sultana Razia, who ruled ably for three and a half years, and in 1239 was defeated and put to death. She was followed by Moiz-ud-Din Bahram, 1239 ; Ala-ud-Din Masaud, 1241 ; Nasirud-Din, 1246 ; Ghaias-ud-Din, 1266 ; Kai Kobad, 1286 , and the slave dynasty ended with his murder, A.D. 1288.

Kutub-ud-Din's name is preserved at his capital by the Kutub mosque, with its graceful colonnade of richly-sculptured Hindu pillars, and by the Kutub Minar, which raises its tapering shaft, encrusted with chapters from the Koran, high above the ruins of old Dehli. Kutub-ud-Din had started life as a Turki slave, and several of his successors rose by valour or intrigue from the same low condition to the throne. His dynasty is accordingly known as that of the Slave Kings. Under them India became for the first time the seat of resident Muhammadan sovereigns.

The Moghuls are said to have burst through Tibet into N.E. Bengal in 1245; and during the next 44 years repeatedly swept down the Afghan passes into the Panjab (1244-88).-Imp. Gaz.

KUTUNG. HIND. A seeding of the bamboo. A man who has seen two kutung is a very old man.

KUTWAR, a class of cultivators found in small numbers in various districts, especially to the north of the Jumna. They are also employed as watchmen.- Sherring's Hindu Tribes, p. 327.

KUVERA, the Hiudu god of wealth, and the regent of the nortb. This deity was a son of Viswasrava, and a brother of Ravan, who was overcome by Rama. He is also called Paulastya. He is represented as a magnificent personage residing in the splendid palace of Alaca, or borne through the sky on the heads of four figures, in a radiant car, called pushpaca, which was given to him by Brahma. In each of two of his hands he holds a closed flower of the lotus, and has on his head a richly-ornamented crown. His sakti is Kuveri. The Guhyaca are servants of Kuvera, and into such beings the dark souls of men, addicted in this world to selfish gratification, transmigrate. According to Hindu mythology, Indra is the regent of showers and of the east wind; Varuna, 
regent of the west; Vahni, of the south-east; Kuvera, of the north; Yama, of the south; Isa or Isani, of the north-east; Nairit, of the southwest. Vayu, in Hindu poetry, is the north-west wind.-Cole. Myth. Hind. p. 111 ; Moor, p. 108.

KUVERA or Kabir, in the middle of the 19th century, a Koli? of Sarsa or Sarasa, near the Anaud station of the Bombay and Baroda Railway, who elaimed to have received a portion of the Supreme Being. His followers called themselves Hari Jana, but were known as the Kabir Bhakta.

KUVIR or Kabir is the salt desert lands which predominate in Khorasan; and salt abounds in many districts, to which the desert does not reach. This salt desert penetrates through the inhabited isthmus extending between Herat and Mashed, into the mountainous districts of Kohistan and Hazara, where we are informed there is much salt and brackish water. There is a great deal of kuvir or salt desert all through the steppes of Kharezm and the desert lying between the Oxus and Caspian Sea-Fraser's Khorasan, p. 253.

KUVIRAJU. SANSK. From Kuvi, a poet, and Raja, a king. The kuviraj of Bengal are physicians.

KWANG-TUNG, the Chinese province known in Europe as Canton. It has an area of 97,000 square miles, and a population of about 19,000,000. It is traversed by the river Lung. Its chief towns are Canton and Hong-Kong.

Kwang-Tung-Chi, a general account of Kwangtung, is a Chinese work usually stitched in 140 Chinese volumes. Its officers are :-Tsung-tu, the governor-general; Fu-tal, the governor; Fantal, the superintendent of finance; Nie-tal, the provincial judge; Chi-fu, Chi-le-chou, and Chile-tung-chi, prefects; Tung-chi, sub, and Tungpan, deputy sub-prefects; Chi-chou and Chihsien, district magistrates; Ching-le and Chaumo, secretaries. Ghai-kwan, superintendent of customs in China, is the superintendent of the maritime customs of Yue. There is also a superintendent of customs for K wang-tung. The prefect of Kwang-chou is the chief local authority of a territory equalling in extent the kingdom of Holland, and containing a much larger population. His Yaman is the first court of appeal from fourteen others, each resembling in their power British courts of assize.-Meadou's Desultory Notes, p. 8.

KWAN-SE, a province of China, bounded on the north by Ho-nan and an irregular chain of lofty mountains, on the south and east by Kwantung, on the west by Yunnan. Its surface is estimated at 87,000 square miles, and its population is between 7 and 8 millions. Kwy-ling-fu is its capital. This province contains 11 cities of the first class, 25 of the second class, and 170 of the third class.

KWAN-TE, a distinguished Chinese general who lived in the third year of the Christian era. He was canonized 800 years after his death, and has now a state temple in every considerable city, and in almost every house morning and evening adoration is paid to him. He is regarded as the protector of the peace of the empire and its multitudinous families. He is represented with a red horse, and the horse is at the state temple of Kwan-tang.-Gray, p. 143.

KWAN-WA-SHIH. CHIN. A fabulous stone, described as large enough to be made into a knife, very brilliant, and able to cut precious stones with ease.
KWAN-YIN. ChIn. The Quan-won of the Japanese, is the Chinese goddess of mercy. The principal seat of her worship is at the island of Pooto: There are in the island many small caves dedicated to the use of hermits ; several of them have figures of Buddha.

Dr. Edkins relates that he paid a visit to a mandarin, who showed him, 'in the innermost of his apartments up-stairs, what seems to have been the most sacred thing to him that the house contained. It was the shrine and image of Kwanyin, (the Buddhist) goddess of mercy. On the table beside it was a copy of the book of prayers used in the worship of this divinity. . . . . Before the image sticks of incense were burning, which had been fresh lighted that morning.' On one occasion also, Yeh, the celebrated governor of Canton, and a stern Confucianist, in a report to the emperor describing a victory gained by his troops over a body of rebels, stated that, at a critical juncture of the battle, a large figure of Kwan-yin had been seen beckoning to the soldiers from the sky, - a sight which so inspirited them that they gained an easy victory over their enemies. It is the Hindu Avalokiteswara.

KWEI. CHIN. Rubruquis, speaking of certain envoys of a Corean nation whom he saw at the court of Kara-korum, says, "The principal envoy had in his hand a tablet of polished ivory, about a cubit long by a palm broad, and whenever he addressed the Khan or any other great personage, he kept his eyes fixed on this tablet, looking neither right nor left, as if he read there what he had to say.' The use of this tablet, called Kwei, was a very ancient Chinese etiquette. It is mentioned in Demailla's version of the Chinese annals in connection with $\mathrm{Yu}$, one of the most notable worthies of ancient China, who is said to have flourished B.C. 2286.-Rubruquis, p. 290, quoted in Yule's Cathay, i. p. 142.

KWOH-TSZE-KIEN, the Chinese Imperial Academy of Learning. Like the Han Lin, it is composed of titled literary dignitaries. It is in the N.E. angle of Pekin, near the temple of Confucius. The Pi-yung, or Imperial College of Antiquity, is in the centre of the quadrangle.-Mayer, Chinese Govt.

KWONG-FUN, or cosmetic powder of China, used by ladies to whiten their faces. It is fincly powdered marble, levigated, and is also used to give a whitish gloss to rice.

KYABOCA IFOOD, or Amboyna wood, appears to be the excresence or burr of some large tree, sawn off in slabs from 2 to 4 feet long, 4 to 24 inches wide, and 2 to 8 inches thick. It resembles the burr of the yew tree, is tolerably hard, and full of small curls and knots; the colour is from orange to chestnut-brown, and sometimes red-brown. It is a very ornamental wood, and is made into small boxes and writingdesks, and other ornamental works. Prof. Reinwardt, of Leyden, says it is the burr of the Pterospermum Indicum; but others, that of Pterocarpus draco. It is from the Moluccas, the island of Borneo, Amboyna, etc. The wood itself is of the same colour as the burr, or rather lighter, and in grain resembles plain mahogany. The root of the cocoanut tree, says Colonel Lloyd, is so similar when dry and seasoned to the 'bird's-eye' part of the wood here termed kyaboca, that no difference can be perceived; the cocoa has a 
tortuous and silky fracture, almost like indurated asbestos. The kyaboca and lingor wood of commerce are supposed to be the produce of the same tree. Of late years its estimation seems to have decreased in Europe, but it is still much valued by the Chinese. It is brought from Ceram, New Guiuea, and the Aru Islands of the Moluccas. In Singapore it is sold by weight. Very large slabs are obtainable from the lower part of the tree by taking advantage of the burrs or lateral growths. They are thus sometimes as large as 9 feet in diameter. It is very durable, takes a considerable polish, is very abundant, and may be had in any quantity.-M. E. Juries' Reports of 1851 ; Col. G. A. Lloyd; Holtz.

KYAIK-HTI-YO, in British Burma, a peak 3650 feet high, on the crest of the main dividing range between the rivers Tsit-toung and Salwin. On a huge egg-shaped boulder a pagoda has been built, actually overhanging by nearly one-half. A hair of Buddha or Gautama is enshrined in it. See Monastery.

KYAN, a tribe in Borneo of about 100,000 souls, who occupy the country from the south of the kingdom of Brunai, away into the interior. They strongly resemble the Dyak. Mr. Dalton states that the $\mathrm{K}$ yan amongst whom he lived amounted to 270,000 souls, and that they were greatly addicted to head-hunting. This people, differing, however, in various customs, are found on the great rivers Banjar, Pasir, and Coti, and probably on all the rivers of the eastern coast. On the north and northern parts of the island, they are found in the interior on the Bintulu, Barram, Rejang, and other great rivers, as far west as the country of the Sarebas Dyak, but they only occupy the inland parts at a great distance from the coast, always having between it and them other tribes, and frequently Malayan states. The Kyan of the rivers Banjar, Coti, and Pasir appear to have been always subject to the European or Malayan power, which held the mouths of their respective streams. But the Kyan of the north-west have been feared by the inhabitants of the Malayan towns of the coast; and the chiefs of Hoya, Mocha, Egan, and Serekei eagerly sought alliances with their barbarous neighbours. Their country is divided into little states, each of which coutains many villages. In some parts of it, gold and dianonds are found. On the Banjar river the people wash for these commodities, as do the Dyak of Suntang, in the interior of the western branch of the Batang Lupar river.

T'he houses of the Kyans are built, like those of the Sea Dyaks, in one long terrace, with the verandah frouting its whole length, the posts being always of the very hardest wood, and the roof of planks of the same material. They are allowed by all their enemies, aud others who have known them, to possess personal courage in a much higher degree than any of the other tribes inhabiting the island. Their bodies are tattooed of a blue colour in various patterns; but images of the sun, moon, and stars are amongst the most frequent.

It is reported that some of the tribes on the Barram and Bintulu rivers do not tattoo the persons of the males, and that the practice is there confined to the women, who thus discolour their arms and legs only. The Kenawit Dyaks, whose country borders that of the Kyans, also practise tattooing, as do the Orang Tatow, who live near the Bintulu river, and more towards the coast than the Kyans. In dress and person the Kyans much resemble the Dyaks, the women wearing the small bedang, and the men the chawat. The dress of the Kyan women of the Bintulu river is reported to consist of two cloths, a little longer than the bedang, which are tied on opposite sides of the person, the one covering lapping over the other; but their dresses from the Rejang are made like the bedang. The jacket of the Kyan women is not loose, like that of the Dyaks, but fits closely to the person, and is longer than the cotton ones of the hill tribes; it is also frequently made of the pine-apple fibre. In war, the dress of the men differs much from the Dyaks of other denominations. The jackets they wear on these occasions are made of the skins of beasts; those of the panther and the bear are the most esteemed, but those of goats and dogs are sometimes substituted in a scarcity of the others. The broad part of the skin forms the back part of the jacket, the edges of which are bound with wide strips of red cloth. Bunches of feathers of the rhinoceros hornbill, which seems to be the war bird of all their tribes, depend from little strings of beads fastened to the skin, and dangle in the breeze as they move about. Their head-dresses in war are also peculiar to these people, and unknown to the other inhabitants of the island. They are of various descriptions, but the favourite ones are caps made in the fashion of a man's face caricatured in those which represent the faces of animals. The weapons of the men are the sumpitan or blow-pipe. Mr. Dalton informs us that head-hunting was practised to a frightful extent, and that desolating wars were constantly carried on for the purpose of obtaining these ghastly trophies. On the death of a person, it is said that a head had to be procured previous to his burial. The manners of the young females resemble those of the Sea Dyak; but adultery after marriage is punished by death to the man, who, under whatever circumstances the criminal action takes place, is always considered the guilty and responsible party concerned.-Journ. Intian Archip.

KYANAN. BuRM. On the low lands near the sea-coast of Tenasserim there grows this large tree, of which canoes are occasionally made, and is much used for sandals, house-posts, musketstocks, and spear-handles. The wood is red, but turns black on being prepared with petroleum. The tree has pinnate leaves, with two pairs of oval leathery leaflets, and is a leguminous tree. Dr. Mason; Captain Dance; Cal. Cat. Ex., 1862.

KYANG, the Equus hemionus, Pallas. Mr. Drew mentions (p. 310) having seen in the Rukshu district of Ladakh, 100 kyang at one view, and 300 during one day's journey.-Dreu, The Northern Barrier.

KYAN-PHO. BURM. A tree of Moulmein. a strong wood, good for building purposes.-Cal. Cat. Ex., 1862.

KYBARTHA. Amongst the Hindus of Bengal, the Groli are the most numerous; after them, the Brahman and Kaist races, are the Bagdi, an aboriginal people, and the cultivators called $\mathrm{K} y$ bartha. The last named at the census of 1881 numbered 2,137,540.

KYD, Generax, au officer of the Bengal 
Engineers, esteemed by the subahdar of Bengal, to whom the subahdar presented a garden on the right bank of the Hoogly river, about four miles down the river from the city of Calcutta. $\mathrm{He}$ was a man of refined taste and scientific acquirements, and especially delighted in horticultural and agricultural amusements. He laid out the ground, and in $\mathbf{1 7 9 3}$ he recommended the Bengal Government to occupy it as a public Botanical Garden, which he tendered as a free gift. It was accepted, and Dr. Roxburgh of Madras was appointed its first superintendent. He died soon after, and a monument of marble, by Bacon, was erected to his memory opposite the principal river entrance to the garden.

KYDIA, a genus of plants occurring in Southern Asia. Several of the family it belongs to abound in mucilage; and as a Guazuma is employed in South America in clarifying sugar, so a Kydia is in India. Dr. Wight, in Icones, gives $\mathrm{K}$. calycina, fraterna, pulverulenta, and Roxburghiana. The genus occurs especially in the Pegu and Tounghoo districts. K. axillaris, $T h w$, a middlesized tree near Badulla, in Ceylon, growing at an elevation of about 2000 feet.-Roxb.; M'Clelland : Voigt.

KYDIA CALYCINA. Roxb. K. fraterna, $R$. Bo-ke-mai-za, . BurM. | Pola, Puli, . . PANJ. Putta-pulow, . KaMaON. Pandiki, . . . TEL. Pula, Pulli, . . PanJ. / Potari, . . . . ",

This is a middle-sized tree, about 20 feet high and 2 feet in girth, pretty common along the Western Ghats, in the valleys of the Circar mountains, in Mysore, and on the slopes of the Neilgherries, and plentiful throughout the Pegu torests, more especially in the F'egu and Tounghoo districts, in Kamaon and Garhwal, and in many parts of the Siwalik tract up to 3000 feet. The bark is mucilaginous, and is employed in Northern India to clarify sugar. The small saplings are nsed, from their great strength and elasticity, by the natives for making bhangi sticks, but it is large enough to afford timber of 3 or 4 feet girth. Its wood is white-coloured, and adapted for housebuilding, charcoal, and fuel, and, being light and elastic, is made into oars, and used on the rafts floated down the Ganges. This tree grows rapidly in the onter valleys, but is not common west of the Sutlej.-Roxb. iii. p. 188; Useful Plants.

KYEE-ZEE. BurM. A large one-headed metal drum. It is the standard of wealth among the Karen.-Forbes.

KYLAS, also written Kailas and Kailasa, a rock-cut Brahmanical temple at Ellora, in the province of Dowlatabad. The finest Brahmanical caves, properly so called, are at Ellora and Elephanta, though some good ones exist also on the island of Salsette and at Mahabalipur. In form, many of them are copies of, and a good deal resemble, the Buddhist vihara. But the arrangement of the pillars and position of the sanctuary are different from the Buddhist. They are never surrounded by cells as all vihara are, and their walls are invariably covered or meant to be covered with sculpture, while the vihara are almost as invariably decorated by paintings, except the sanctuary. The subjects of the sculpture of course always set the question at rest. Another class of caves consists of rock-cut models of structural Brahmanical temples. To this class belong the far-famed Kylas at Ellora, the Saivite temple at Doomnar, and the Ruth at Mahabalipur. This last is cut out of isolated blocks of granite.

The Kylas temple is surmised by Mr. Fergusson to have been excavated by the sonthern Dravidians, either the Chera or Chola, during the eclipse of the Chalukya dynasty. The Indra Subha group at Ellora should perhaps form another class, but whether they are Brahmanical or Jaina is undecided.-Fergusson. See Architecture; Kailas.

KYLASA, a mountain in the Himalaya, north of the Manasa lake, called also Gana-parvata and Raja-tadri. It is the heaven of Siva. He is usually represented with his bride, the mysterious Durga, by his side. It is also Kuvera's abode. See Kailas.

KYLASA, a hill in the Vizagapatam district in Madras, in lat. $17^{\circ} 47^{\prime} \mathrm{N}$., and long. $83^{\circ} 22^{\prime} \mathrm{E}$., rising to 1758 feet above the sea. It was resorted to as a sanatorium.

KYILINGIA MONOCEPHALA, Linn., of Sind, Dekhan, the Konkans, and common at A jmir in low grounds. The root is sweet-scented, used and named as zedoary, nirbishee.-Gen. Med. Top. p. 174.

KYMORE, a mountain range in Shahabad, of limestone which always shows itself in the valley of the river Sone, as far at least as Mungeysur peak in Mirzapur, and it crops up at Rhotas, forming a sloping base to the precipitous sandstone rock. Below the mountain limestone is one of a bluish-grey colour mixed with occasional crystals of calc-spar ; this is admirably suited for lithography. Below the latter, in Kymore, is a limestone of a hard, tenacious composition, admirably suited for building. The sandstones of the Kymore range at Chunar and Mirzapur are used as flagstones, and for ornamental purposes.

KYOUK-PHYU contains numerous mud volcanoes, from which gas is frequently discharged. The largest is in Cheduba Island. Earth-oil wells exist in several places; the deepest well is 48 feet. The oil is sold at 5 rupees the bottle. Population about 150,000 souls, Arakanese, Burmese, and Khyeng. The district, 4309 square miles, is in lat. $18^{\circ} 55^{\prime}$ and $19^{\circ} 22^{\prime} \mathrm{N}$., and between long. $93^{\circ}$ $25^{\prime}$ and $94^{\circ} \mathrm{E}$.

KYOUNG. Buru. A Buddhist monastery. All Burmese boys enter the monasteries as novices for the purpose of learning to read and write; they must at least be eight years of age. See Monastery.

\section{L}

$\mathrm{L}$ is the twelfth letter in the English alphabet, and by grammarians is usually denominated a semi-vowel or a liquid. In the English language it has only one sound, as in like, canal, but in other languages is found interchangeable with $r$, $\mathrm{n}, \mathrm{m}, \mathrm{d}, \mathrm{i}, \mathrm{u}$, and $\mathrm{z}$. Letters with the sound of 1 are in use in all the written tongues of the East Indies; but in the Vedas and in the Mahrati and other languages of the south of British India, 1 has a rather harsher sound, and in some parts of the Tamil country, medial $l$ has the sound of cerebral $r$, and that of a cerebal 1 when final. In other parts of the Tamil region, 1 has the sound of $\mathrm{lr}$, and in others again of $\mathrm{zh}$. $\mathrm{L}$ and $\mathrm{zh}$ are 
therefore froquently confounded. The languages of Southern India have a sound correctly expressed by $\mathrm{zh}$, but taken by the untutored ear to be l, and written 1 even by scholars; thus Tamil is properly Tamizh, Tuluva is Tuz-huva; Păllăm, fruit, is also pronounced Păzhăm. In non-Aryan speech 1 sometimes takes the place of $\mathrm{zh}, \mathrm{sy}, \mathrm{s}$, and $j$ or other sibilant. $L$ is used in China in the place of the letter r. L does not exist in Zend. In Japan d, and in New Zealand $r$, are substituted for 1 . Of all letters, $l$ and $r$ are the most subject to metasthesis, and after them the nasals.Farrar's Families of Speech; Dr. W. W. Hunter; Wilson's Glossary.

LA, also Ka-La, of the Karens, a soul or spirit; in Karen belief, every animal, plant, everything; spears, knives, arrows, stones, have their individual spirits. When the Ka-La departs, the thing dies or is destroyed. Besides his $\mathrm{Ka}$-La, every man has a 'tso' spirit attendant on him.

LAB. HIND. Nursery beds for raising poppy, tobacco, or rice.

LABADA. HiND. A dressing gown.

LABAN, of Java, a yellowish, hard wood, employed for the handles of axes and various utensils.

LABANAKHYA, a salt spring of great sanctity in Chittagong district, Bengal, situated three miles north of the sacred site of Sitakund. Visited by large numbers of pilgrims.-Imp. Gaz.

LABANNA, a not very numerous Hindu tribe in the central division of the Panjab, are farmers, traders, and carriers; never soldiers. They wear beards.

LABBAT-TUARIKH, a history of Asia by Kazvini.

LABBAY, a Muhammadan race in large numbers on the eastern coast, chiefly between Pulicat on the north and Negapatam on the south, their headquarters being at Nagor, near Negapatam, the burial-place of their patron saint, Nagor Miran Sahib, to whose shrine numerous pilgrimages are made by the tribe. The prevailing belief is that, like the Moplah of the western coast, they are descendants of Arab merchants and the women of the south of India. They are Muhammadans, and practise circumcision. Physically, they are goodlooking, tall, well made, and robust, are sometimes inclined to obesity, of light complexion and welldeveloped limbs, not unlike the Moplah of the western coast in their general configuration. The cranium is singularly and strikingly small; the eyes are slightly oblique, and not wanting in expression; cheek-bones prominent; lower jaw large and heary; beard in some instances full and long, but in most cases decidedly sparse. They generally wear the loongi, a cloth loosely wrapped round the waist and extending below the knees; they also wear bright-coloured jackets, occasionally turbands; the most frequent head-gear being a skull-cap, fitting closely to a shaved head. They live freely on animals and vegetables, making use of all kinds of flesh meats, saving pork, for which Muhammadans have a religious abhorrence. Their language is Tamil, though some talk a little Hindustani. They are exceedingly industrious and enterprising in their habits and pursuits, there being hardly a trade or calling in which they do not try to succeed. They make persevering fishermen and good boatmen. They are lapidaries, weavers, dyers, mat-makers, jewellers, gardeners, bazarmen, grocers, boat-makers, boat and ship owners, and merchants, and as regards the leather and horn trade, they excel as merchants. There are few classes of natives in Southern India who, in energy, industry, and perseverance, can compete with the Labbay. The Labbay of Tinnevelly are said to be descendants of Arab traders, who settled in the sea-coast towns some three or four centuries ago, and formed connections with the lower caste Tamil women.

The Labbay have obtained this tribal designation from their use, in conversation, of the Arabic word Labek, meaning I beg your pardon, or the plait-il of the French. They speak Tamil, into which they have translated the Koran. In Travancore they are called Methan and Jonagar. The former word means a convert, and the latter seems to mean a foreigner, but is also said to be Jonakan, a dialectal variation of the Grecian Yavana. The title is prefixed to their names. In Madras, in 1870 , only four or five of their women could read the Koran, but they are all good sempstresses and mat-weavers.-Drs. Bilderbeck and Wilson in Mad. Govt. Pro. See Labek.

LABDANUM or Ladanum.

Ciste ladenifere, . . Fr. | Ladanum, . . LAT.

This gum-resin was considered by old writers cephalic, pectoral, and nervine, but is now only used in the preparation of certain plasters. It is known to the Muhammadan medical practitioners of India, and has a place in the Materia Medica of the Arabs amongst their Munzigat (Suppurantia).

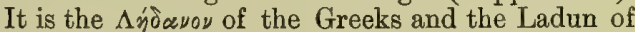
the Arabs. It is first mentioned by Herodotus (iii. p. 112) as procured in Arabia, and used by the Arabs for fumigation. The word is Arabic with a greek termiuation, and the Greeks used $\Lambda$ ñòs to indicate the shrub which produced the ladanum. Labdanum resin is exuded by the leaves and branches of Cistus creticus, $L$., and other species of the Levant. During the prevalence of plague, it is largely collected as a medicine, etc., by whipping the plants with long thongs attached to a rakelike frame, the resin adhering to the leathern straps. - Ains. Mat. Med.

LA BEHMEN, in Bombay, the dried roots of two varieties of a composite plant, chiefly obtained from Kābul. Used by the natives of India as a tonic in debility, in doses of 4 drachms; also in impotence as a deobstruent. Price 8 annas per lb. Not at present used in European medicine, but was formerly employed as an aromatic stimulant.-Cat. Ex., 1862.

LABEK or Lebek. ARAB. A conversational expression equivalent to I beg your pardon, or the French plait-il? In Arabia and with the Labbay Muhammadans of Southern India, when any one is called, he replies Lebek! or Allah ! which answers to the English sir! Originally it was the name of the deity worshipped at Baal Lebek (Balbec). There is a prayer attributed to Ali, son of Abu Taleb, -O Lebek! O Lebek! thou art his lord; be merciful, therefore, unto the most humble servant, whose refuge thou art!

LABEO, a genus of fishes in the south of Asia, largely used as food. Amongst them L. calbasu, L. gonius ; L. angra, Morala, HIND., of the Ganges, Irawadi, Sitang; L. calbasu, kalbans, rivers of India; L. rohita or rohi of Burma. They furnish sport to the angler. Fish-baits used in Bengal are cinnamon bark, fenugreek seed, oil 
cake, cotton, gingelly, mustard, Nigella satira, and Melilotus parviflora seeds, the stems of Kaempfera galanga and of Acorus calamus, boiled rice, chaff, pupæ of large silk-worm moth, earth-worms, prawns, cockroaches. See Mahsir.

LABIAT $E$, a name given by Jussieu to an order of plants, called by Lindley Lamiaceæ.

LABILLARDIERE. Naturalist on board the French ship which, with her companion ship L'Esperance, went in search of La Perouse in 1791.

LABLAB CULTRATUM. D.C.

I. lignosus, Grah., Wall.

Dolichos cultratus, Thun.

Shim, . BENG.

Bara mareca, HoRT. MaL. Tammakaia,. TEL Kosopulla, . SANSK. Tella chikur-kaia, ",

Six varieties of this very useful plant are cultivated in the cold season all over India, in gardens and about native houses, forming cool arbours, and furnishing an excellent pulse for curries; the pods of the plant used as vegetable, entire when young; when full-grown, only the seeds are used. The varieties are,-Falcatum majus, F. minus, Gladiatum flore albo, G. flore purpureo, macrocarpum, and rectum. L. vulgaris and L. cultratus are cultivated in the rainy season in gardens, and may be considered the analogues of the French and kidney beans of European gardens. The legumes are large, scimitar-shaped, flat, and compressed, tubercularly muricated along the sutures, and having the seeds separated from one another by transverse partitions. - Roxb.

LABLAB VULGARE. Savi., D.C.

Lablab nankinicus, Savi.

$\mathrm{L}$, lignosus, Wall.

L. leucocarpus, Savi.

Dolichos lablab, Linn.

D. spicatus, $\boldsymbol{K}$ on.

D. albus, Lour.

Bun-shim,

BENG. Lobi,

D. Bengalensis, Jacq.

D. purpureus, Jacq.

D. tetraspermum, Willde.

D. cuspidatus, Graham, Wall.

Wal pari.

Pai,

Pien-tau,

Sem ke phallé,

Liblab, , ВоM. Wall, Segapu muche, : TAM

Wild variety EGrPT. Anapa chikkudu kayr

BurM. Tatta pyre,

CHin. Segapu averai kai,

DUKH. Anumuln,

- TEL.

This is sown in the fields in rows, and is eaten both boiled or put into curries; when young, the legume is eaten pod and all; when full-grown, the seeds only are boiled and used. It is about five inches long; prefers a rich black soil that cannot be flooded by rains. It is a coarse but wholesome pulse, much eaten by the poorer classes in India. It is grown along with ragi, and is used in food along with ragi. It does not keep well, unless great care is taken in packing it in parcels, or in fact, as some of the ryots do in placing averay in the heart of the ragi in caves, when it will keep good for some years. Cattle are generally fed on the grain when dry. It has seven varieties, albiflorum, annapa, dumetorum, purpurascens, purpureum, rubriflorum, and sepiarium; all but dumetorum cultivated for food. When the testa are removed, the cotyledons are preserved for curvies. Its composition in 100 parts is as under : Moisture, . . . 10.81| Moisture, . . . 12.02 Nitrogenous matter, 24.55 Nitrogenous matter, 22.45 Starchy matter, . . 60.81 Starchy matter, . . 60.52 Fatty or oily matter, 0.81 Fatty or oily matter, 0.15 Mineral constituents,

ash, . 3.02 ash, . . . 286

-Roxb.; Voigt; Riddell; Ains.; Mason; Jaffrey.
LABOURDONNAIS, in the middle of the 18th century, governor of the French possessions in the Indian Ocean. He conducted an expedition to the shores of India, and took Madras.

LABUAN, an island about 10 miles long and from 2 to 5 broad, ceded to the British in 1846 . It has the harbour of Victoria on its south. The island is 6 miles off the N.W. coast of Borneo. The dependent islets all lie to the south. The measures of which the whole island is composed are alternating clays and sandstones. Coal occurs in several places, and is of very good quality, and has dispersed through its substance masses of imperfect amber, sometimes light-yellow and very transparent, sometimes approaching to black, and in a semi-carbonized state, but always extremely friable and brittle; when burnt, it diffuses the fragrant smell of recent resin, and is in a sufficiently perfect state to be collected by the workmen and used with fresh dammer in making torches. In some seams of coal on the river Bintulu, to the south of Brune, Mr. Burns mentioned that almost half the seam consists of this substance, which is there commonly dug and used by the inhabitants as dammer. Specimens of coal from Riteh, on the east coast of Sumatra, near the Indrageri, contain much of this substance. Hard nodular masses of brown iron ore occur in Labuan. The whole surface soil of the island and the beds of most of the streams are more or less covered with scattered masses of this substance. It is also found on the mainland, and is the ore from which the Kadyan and Murat, native tribes in the neighbourhood of Brune, manufacture their iron. Labuan is one of the smallest of all British colonies.

LAC, Gum-lac. Laak,

Khejijk,

Arab. $\mid$ Balo, . . . JAv.

Tsze-kang, . . Chin. Malau, Malu,

Tsze-kwang, . . Laksha, . : SANSK

Tsze-ts'au-jung, . ", Lakada, . . . SINGH

Chih-kiau, . . ", Lack, . . . . Sw.

Lak, DA., GUJ., HD., MÁ. Komburruki, . . TAM.

Lak'h,. . . HIND. Commulakka, . TEL.

Lac is obtained from incrustations made by an insect (Coccus lacca), similar to the cochineal (Coccus cacti), on the branclies and twigs of the Acacia Arabica, A. concinna, Aleurites laccifera, Anona squamosa, Butea frondosa, Carissa spinarum, Celtis, sp., Croton draco, C. lacciferum, C. sanguiferum, Dicrostachys cinerea, Erythrina Indica, E. monosperma, Feronia elephantum, Ficus Indica, F. infectoria, Gyrocarpus Asiaticus, Inga dulcis, Mimosa cinerea, Rhamnus jujuba, Schleichera trijuga, Terminalia tomentosa, Urostigma religiosum, U. elastica, Vatica laccifera, Vismia laccifera? V. micrantha? Zizyphus jujuba.

The Coccus genus of insects belongs to the order Hemiptera. The species known in the south and east of Asia are the C. cacti or cochineal insect; the C. lacca that yields the lac of commerce; C. maniparus of Arabia, which punctures the Tamarix gallica, and causes the exudation of the Arabian manna; and C. Sinensis of China, that secretes a wax from which candles are made. When the females of the C. lacca have fixed themselves to a part of the branch of the trees on which they feed, a pellucid and glutinous substance begins to exude from the margins of the body, and in the end covers the whole insect as with a cell of this substance, which, when hardened by exposure to 
the air, becomes lac. So numerous are these insects, and so closely crowded together, that they often entirely cover a branch; and the groups take different shapes, as squares, hexagons, etc., according to the space left round the insect which first began to form its cell. Under these cells the females deposit their eggs, which after a certain period are batched, and the young ones eat their way out. The accumulation of insects is so great that the trees on which they live are exhausted and injured by them. The parent lac insect, after laying her eggs, becomes a mere lifeless bag, of an oval shape, containing a small quantity of a beautiful red liquid. The young insects feed on this liquid, and their bodies assume the same hue, so that the branch which bears them appears to be covered with red powder. The cells of gum-lac which shelter them are more or less deeply tinged with the same colour.

The best time for gathering stick-lac so as to secure the colouring matter, is before the insects have made their escape. In some places the insect is sedulously cultivated, the modus operandi being the very simple one of cutting off old branches inhabited by it, and tying them to fresh branches; in other places nature is left to accomplish the work unaided. That a great deal may be done to extend the industry, is evident from the success which has attended its introduction into the territory of Kapurthala, where three maunds of seed were transported safely from so distant a locality as Oudh. The forests of Burma alone are capable of producing an almost unlimited quantity, if plantations are only formed.

The cells made by the insect for its eggs adhere to the branches in grains, completely encrusting them, and, in commerce, are either imported in that form, and called 'stick-lac,' or the grains are gathered from the branches, their colouring matter extracted, and formed into flat cakes, still preserving the granular appearance, and called 'seed-lac,' or the seed-lac is melted up into masses, and called 'lump-lac.' 'Shell-lac' is seed-lac further purified by being put in bags of fine linen, and melted over a charcoal fire mitil it passes through them. The bags are squeezed, and passed over a smooth surface of wood, on which the lac is deposited in thin layers. If pure, this kind of lac will take fire on a hot iron, and burn with a powerful smell. The heat of a ship's hold will sometimes run it into a solid mass, and thus diminish its value. By pouring warm water on stick-lac, a crimson colouring matter is obtained, which is made into square cales for sale, and called lac dye, lac lake, or cake lake. These cakes, when broken, are darkcoloured, shining, and compact, but when scraped they yield a bright red powder approaching carmine.

The best quality of stick-lac is obtained from Siam, the twigs being frequently encrusted all round to the depth of a quarter of an inch, while sometimes a great accumulation takes place on one spot; that of Assam ranks next; the sticklac of Bengal is inferior to these, being scanty and irregular in its coating of resinous matter.

The largest export is from the Central Provinces, but it is also produced in considerable quantity in Assam, and in the Gaya and Hazaribagh districts, in Oudh, the North-Western Provinces, the Panjab, and a limited portion of Sind, in Maisur, and in British Burma. The lac which is so largely exported from Burma is obtained chiefly in the Shan districts, and is perhaps the finest in the world, preferable even to that of Bengal. The jungle at Taldungah consists chiefly of thorny bushes, jujube of two species, an Acacia and Butea frondosa, the twigs of the latter often covered with lurid red tears of lac, which is there collected in abundance.

The supply of lac from among the mountains of India could support a consumption ten times greater than at present. In Cuttack, Travancore, Mysore, and most of the Madras districts; it is found in considerable abundance.

Previous to the discovery of the true cochineal, the colouring matter of the lac insect was universally employed for dyeing red. The crimsons of Greece and Rome, and the imperishable reds of the Brussels and Flemish schools, were obtained from this source.

A mixture of lac, alum, and tamarind-water is the native dye for silk or cotton cloth of a crimson colour.

After the dye is extracted, the gum-lac still requires much purification before it can be used for the more delicate varnishes. A premium of 30 guineas and a gold medal were offered by the Society of Arts for a varnish made from shell or seed lac, equally hard, and as fit for use in the arts, as that prepared from any other substance. These were claimed by two persons, Mr. Field and Mr. Luning, and as both their processes were found to answer the desired end, a premium of 20 guineas was awarded to each.

The chief consumption of lac in Europe is for the manufacture of sealing-wax and varnishes. In India the inferior kind is made into bangles or armlets for women of the lower classes, the superior is fashioned into rings, beads, and other trinkets. To fit it for such purposes, the natives purify it by melting in bags. When the lac begins to exude, it is scraped off, and the bags are twisted or wrung by means of cross sticks at their ends, to force out the melted contents.

The natives of India make a good varnish of lac, coloured with cinnabar or some other pigment, with which they varnish boxes, cabinets, and other articles. Coloured varnishes of this description are much used in theadornment of their religious houses.

Lac and sandarach form the basis of spirit varnishes; these resins are more soluble than amber, anime, and copal. They are dissolved in spirits of wine, or pyroligneous spirit, which is cheaper. Lac is harder than sandarach, and is the basis of most lacquers, and also of French polish. Sandarach is used for making a pale varnish for light-coloured woods. It may be hardened by the addition of shell-lac or of mastic if required to be kept pale; and when required to be polished, Venice turpentine is added to give it body.

The Indian lapidaries make use of lac as a vehicle for retaining the hard corundum powders used in cutting and polishing gems, and as laps.

Lac enters into the composition of the best Chinese lacquer,--gamboge or dragon's blood, with copal, being added to increase the colour.

The exports of lac, of kinds, from India have been as under :-

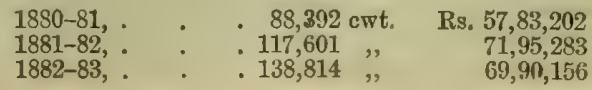


The name lac or laksha is derived from the word signifying a hundred thousand, from the great number of the insects which swarm over the tree.

It is the female insect of the Coccus lacea that produces the resin and the dye. This is a small, round, red-coloured, flat insect, having 12 abdominal rings, and a bifurcated tail. The male is much larger than the female, and is furnished with wings. It is stated that no more than about one male to 5000 females is to be met with. The female insect is said to be destroyed in the process of producing her young ones, for the eggs become hatched beneath the mother insect within the concrete resin globule, and escape by boring through the mother's back. At first, the young brood, having made its escape, clusters on the twigs of the trees, and very shortly afterwards the incrustation of lac begins to be formed over and round them, covering the twigs. The bubblelike exudations are all close together, and hollow and cellular inside. About the end of March the lac-resin exudation is complete, and the female insects within are glued down by it to the tree. The oval body of the insect becomes of a deep-red colour. If at this stage a little piece of the lac incrustation on a twig be broken off, the insect is perceived as a little bag of red liquid (which yields the dye), and the place where the wood of the twig has been punctured bears a snow-white mark, as if the place had been touched with a point of chalk. On removing an entire piece of lac incrustation from the twig, the bark underneath is observed to be covered with these little white dots, one in every cell and one under every insect ; under the microscope they clearly appear to be specks of a semi-crystalline saline efflorescence at the place punctured by the insect.

The proper stage to collect the lac (if intended to produce dye) is when the insect is in the stage of being like a soft red sac. At a later stage it lays its eggs under its body, which is glued down by the resin; when, therefore, the eggs are hatched, they have no means of egress save by eating through the body of the mother, which they do, feeding the while on the red colouring matter contained in her body, which is thus consumed.

When the lac is first gathered, it is picked off the twigs with the insects and all on it. In this state it is called 'kacha' or ' kham lakh.' This lac is treated with water, and thus the colouring matter is extracted. The clarified kind of lac is called ' chapra-lakh,' or shell-lac, chapra, a shell.

LACCADIVA or Laccadives, an archipelago off the coast of Malabar, extending from lat. $8^{\circ}$ $30^{\prime} \mathrm{N}$. to the parallel of lat. $13^{\circ} 52^{\prime} \mathrm{N}$., and from long. $71^{\circ}$ to $73^{\circ} 40^{\prime} \mathrm{E}$. Most of the islands are low, and surrounded by steep coral reefs. The inhabitants call them the Lakhera-deevh. Ptolemy mentions them as the Dimurce Insulæ, but Ammianus Marcellus, in the 4 th century, styles them merely Divi; the Arabs and Persians call them Debajat. They were re-discovered in 1499 by Vasco da Gama, and afterwards plundered by the Portuguese. They were then sulject to the Muhammadan chiefs of Cannanore, some of them afterwards were under the Beder queens of Bednore, and latterly under the Beebee of Cannanore and the British, and between the last two they are now apportioned. They were visited in
1844-45 by Mr. (Sir) W. Robinson, and in 1867 by Mr. Sewell ; 8 or 10 islands are more or less inhabited, and each with 2 to 3 miles of superficial area. They are all about 15 to 20 miles apart, separated by great channels, but none of the islands are more than 10 to 15 feet above the sealevel. The people in 1871 were 13,495 in number. They are of Maleala origin, but are Muhammadans, and adhere to the Alya Santana, or decensus ab utero, though some of the islands are adopting the filial law of inheritance. They are poor, quiet, and inoffensive, make good pilots. They produce the cocoanut palm and coir, jagari and a few pulses; a few cattle, sweet potato, and betel-nut. The castor-oil and arnotto plants are grown; tortoise-shell, holothuria or sea-slug, shells, and shark fins are collected.

The islanders subsist mostly on cocoanuts and fish, and their chief trade is in cocoanuts, coir, cocoanut oil, jagari, mats, and coral. Their boats vary from 1 to 15 tons burden, and they visit the western coast of India from Goa to Cochin. They are taught Arabic and Baltite (a dialect of the Maleali) in the mosques by the priests. The largest island is about 7 miles long and $2 \frac{1}{2}$ broad, and there are many navigable channels between the islands, the largest of which is the Mamaie or the Nine-degree channel. They pay tribute to the British Government. The islands are very difficult to find in thick, squally weather, as scarcely any of them rise more than 6 feet from the surface of the water. When first coming in sight, the cocoanut trees, with which they are thickly covered, have the appearance of growing out of the sea, and, as a rule, no bottom is found at 100 fathoms close up to the beach.

The language of the Laccadive group is Malealam, which is, however, written in the Arabic character; that of Minikoi is Mahl, with a mixture of corrupt Malealam. The headmen and pilots of most of the islands know a little Arabic; and the male inhabitants can generally both read and write. The inhabitants are bold seamen and expert boatbuilders.

Each of the islands is situated on an extensive coral shoal, with an area of from 2 to 3 square miles. Beneath this crust is loose wet sand; and by breaking the crust and removing a few spadefuls of sand, to allow the water to accumulate, a pool of fresh water may be obtained in any part. The water in these wells is quite fresh, and always abundant; but it is affected by the tide,-rises and falls several inches, - and is said to be not very wholesome.

The islands under S. Canara are Amin-Divi, Chetlat, Kadamat, Kiltan, and Bitra (uninbabited); and the Cannanore islands under the Beebee of Cannanore are Agathi, Kavarathi, Antrot, Kalpini, Minikoi, and Sukeli (uninhabited).

More than one-sixth of the adult male populalation of Minikoi perished in a cyclone in 1867.Jolnston, Gazetteer; Imp. Gaz.; Mr. William Robertson's Report; Mr. Sewell's Report.

LAC DYE or Lac Lake consists of the colouring matter extracted from the stick-lac, by treating the crushed lac with water to dissolve the colouring matter, evaporating the coloured fluid to dryness, when the residue is formed into little cakes, two inches square and half an inch thick; these are of various qualities, and are marked with different letters, by which the quality is recognised. 
They are used as red dyes for some purposes, instead of cochineal. Lac dye was formerly largely manufactured in Bengal, and exported to England, but the aniline dyes have nearly superseded the lac dye. Dr. Flynn prepared it by boiling coarsely powdered Rangoon stick-lac in several portions of water, until it ceased to yield any colouring matter; a small quantity of alum was then added to the filtered solution; after a few minutes, a small quantity of Liqr. potassæ was used to throw down the alumina with the colouring matter, the fluid at the same time being constantly agitated. The precipitate was allowed to settle for a day, the fluid then drawn off, and the sediment pressed into cakes, and dried in the shade. Dr. M'Leod, of Madras, prepared a superior lac dye by digesting stick-lac in a slightly alkaline cold decoction of the leaves of Memecylon tinctorium, and the solution being applied to woollen cloth, after preparation with a mordant formed of a saturated solution of tin in muriatic acid, produced a brilliant scarlet dy e.-M, E. J. R.; Powell.

LACE.

Kanten, . . . Dur. Renda (gold or silver),

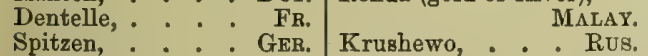

Merletti, Pizzi, . . Ir. Encajes, . . . Sp.

Lace is a term applied to two very distinct products, one consisting of gold and silver wire, or even silk thread, woven into ribands for embroidering hats and uniforms; the other is a transparent network, in which the threads of the weft are twisted round those of the warp. It may be made of silk, flax, or cotton, or even of gold and silver thread, and has usually a pattern worked upon it, either during the process of making the lace, or with a needle, after this has been completed. Much lace is made by machinery, but the highly esteemed genuine articles are made by hand. Lace-knitting is considered to be a German invention; but lace worked by the needle is of far older date, and was probably an eastern invention, though it does not appear to have been known or practised in India. Lace is, however, made in the territories of the raja of Travancore; and the Madras Central Committee, in their final report, stated that the lace of Nagercoil, though knit by matives of the country, was equal to the best French lace. This lace, when seen at the Great Exhibition, was much admired, and some said that it must have been made in France. Samples of six different kinds were sent. The broad black lace on wire ground, and the broad white and fine lace on Brussels ground, and of the nature of Bedfordshire lace, were highly approved of ; the broad being thought worth 4s. and the narrow worth 2s, a yard.-M'Culloch's Dictionary; M. E. J. R.; Royle's Arts, etc., of India, p. 503.

LACE BARK TREE, the Lagetta lintearia of the West Indies, so called from the lace-like layer of the inner bark, which may be readily separated from considerable lengths of the stem by beating and macerating. The lace is worked up into fancy articles. This might be introduced into India. See Daphne.

LACERTID $\mathrm{E}$, a family of reptiles known as land lizards. The following genera and species occur in India :-

Tachydromus sex-lineatus, Daud, Rangoon, Archipelago.

T. meridionalis, Gunth., Cochin-China, China.
T. septentrionalis, Gunth., Ningpo.

Cabrita Leschenaultii, Milne-Edwards, Coromandel, Panjab.

Ophiops Jerdoni, Blyth, Mhow.

Acanthodactylus cantoris, Gunth., Ramnuggur.

Under the family name Lacertians, Cuvier arranged -1 st. The monitors and their subdivisions, namely, the monitors properly so called, including the Ouarans of the Arabs (Varanus), etc., the dragons (Crocodilurus of Spix, Ada of Gray), and the Sauvegardes (monitor of Fitzinger and Ameiva); 2d. The lizards properly so called. The second group comprises, according to Cuvier, the genera Lacerta, Algyra, and Tachydromus; but these are now arranged under other families.

Lacerta scincus, Linn., is still used by the eastern doctors in leprosy.-Dr. Honig. p. 342.

LACQUER, a varnish either for wood or for brass, made with shell-lac and spirits of wine. Hard wood lacquer may be in the proportion of 2 lbs. of lac to the gallon. Another recipe is $1 \mathrm{lb}$. of seed-lac and $1 \mathrm{lb}$. of white rosin to a gallon of spirits of wine. For brass, the proportions are $\frac{1}{2} 1 \mathrm{lb}$. of pale shell-lac to 1 gallon of spirit. It should be made without heat, but simply by agitation for five or six hours. It should then be left until the thicker portions have subsided, when the clear lacquer must be poured off, or if not sufficiently clear it must be filtered through paper. It darkens by exposure to light, so that paper should be pasted round the bottle to exclude it. A pale-yellow lacquer may be prepared from $1 \mathrm{oz}$. of gamboge and 2 oz. of Cape aloes, powdered and mixed with $1 \mathrm{lb}$. of shell-lac. For a full yellow, $\frac{1}{2} \mathrm{lb}$. of turmeric and 2 oz. of gamboge; for a red lacquer, $\frac{1}{2} \mathrm{lb}$. of dragon's blood and $1 \mathrm{lb}$. of annotto. The colour, however, is modified by that of the lac employed. Lacquers may also be coloured by dissolving the colouring matters in spirits of wine, and adding the proper proportions of these to the pale lacquer, according to the tint required. Mr. A. Ross prepared lacquer with 4 oz. of shelllac and $\frac{1}{4}$ oz. of gamboge, dissolved by agitation in $2 \pm$ ounces of pyro-acetic ether. The clear liquor is decanted, and when required for use is mixed with eight times its volume of spirits of wine. Hard wood lacquer is applied nearly in the same manner as French polish. In lacquering brass, the work must be cleansed from grease and oil, and, if convenient, heated to the temperature of boiling water, when the spirit evaporates, and the varnish attaches itself more firmly to the metal, producing a brilliant effect. If heat cannot be applied, the air should be dry and warm. The lacquering should follow immediately after the work is polished, otherwise it will become tarnished, and prevent the lacquer from adhering.

LACQUER WARE. Three different processes are usually confounded under this term. The one prevailing in Burma is with the balsamic juices of trees, and was well known to Dampier in 1638, as he says, "The lac of Tonquin is a sort of gummy juice which drains out of the bodies or limbs of trees, and the articles laequered are cabinets, desks, etc.' Some chemical change no doubt takes place on exposure of these juices to the air. This kind of lacquered ware was much appreciated in the 18th century. Another kind of lacquer work is rather of the nature of papiermache, covered with one or more layers of lac 
varnish. This is the case with the lacquered boxes from Kashmir and Lahore, so remarkable for the beauty and elegance of their patterns.

The lacquered ware of China owes its lustrous colouring to a composition of lamp-black and the clarified juice obtained from a species of sumach, called Rhus vernix or $R$. vernicia. Wood oils are obtained from other plants of the same family, and the different qualities of lacquered ware are owing to the use of these various ingredients. The body of the ware is wood partially smoothed, or pasteboard, upon which two or three coats of a composition of lime, paper, and gum are first laid, and thoroughly dried and rubbed. The surface of the wood is also hardened by rubbing coarse clay upon it, and afterwards scraping it off when dry. Two coatings of lamp-black and wood oil, or, in the finer articles, of lamp-black and varnish, are laid upon the prepared wood, and, after drying, the clear varnish is brushed on, one coating after another, with the utmost care, in close and darkened rooms, allowing it to dry well between the several coats. The articles are then laid by to be painted and gilded according to the fancy of customers; after which a last coating is given them. The varnish is brought to market in brownish cakes, and reduced to its proper fluidity by boiling; it is applied to many purposes of both a varnish and paint, when it is commonly mixed with a red or brown colour. A beautiful fabric of lacquered ware is made by inlaying the nacre of fresh and salt water shells in a rough mosaic of flowers, animals, etc., into the composition, and then varnishing it. Another kind, highly prized by the Chinese, is made by covering the wood with a coating of red varnish three or four lines in thickness, and then carving figures upon it in relief. The great labour necessary to produce this ware renders it expensive. A common substitute for the Rhus varnish is the oils of the Dryandra, Jatropha, Croton, and otber members of the Euphorbiaceous family, expressed from their seeds by cylinders and pestles. The oil, after pressing, according to De Guignes, is boiled with Spanish white in the proportion of one ounce to lialf a pound of oil; as it begins to thicken, it is taken off and poured into close vessels. It dissolves in turpentine, and is used as a varnish, either clear or mixed with different colours; it defends wood-work from injury for a long time, and forms a good painter's oil. Boiled with iron rust, it forms a reddish-brown varnish. In order to prevent its penetrating into the wood when used clear, and to increase the lustre, a priming of lime and hog's blood simmered together into a paste is previously laid on.

The beautiful lacquer ware made near Nankin is considered far superior to that which is made in Kwang-tung and the other provinces. The process of the manufacture of a table, which has a landscape with figures delineated on the top in gold, may be thus described. The timber being first put together, and rendered perfectly smooth, is covered with transparent paper, besmeared with pork fat. As soon as this paper is quite dry, it is covered with a paste made from a peculiar clay. When this substance has become completely dry and hard, it is rubbed down with a whetstone, to remove all inequalities of surface; as soon as this process is complete, the lacquer is laid on, then allowed to dry and harden, when the process is again repeated three or four times, the lacquer being allowed to become completely dry and hard between each several coating. The intended landscape is traced on the top of the table by throwing a fine white powder over paper on which the landscape has been traced by means of small perforations, thus forming the outline of the picture; a minute instrument, somewhat resembling a style, is drawn carefully over the perforations, by this means tracing the landscape on the surface of the table. The picture is then besmeared with a compound of size and red paint; the gold, first reduced to a powder, is then applied; the raised appearance of the figures being produced by means of a preparation of gum combined with other ingredients. The picture is allowed to become perfectly dry, when, if requisite, another coat of the lacquer or varnish is then added. To prepare this lacquer ware in perfection requires a lengthened period; and a Chinese manufacturer mentioned that to produce a fine specimen, elaborately painted, six months ought to elapse between the commencement and the termination of the work, thus affording time for each coat of lacquer to become thoroughly hardened before another is applied.

Of all the works of art in which the Japanese excel the Chinese, the lacquer is the most striking. Some of that now made is very fine, but not to be compared with the real old lacquer, which is very rare, and is hardly ever brought into the market, except when some old family is in much distress for want of money ; they then bring pieces of antique lacquer (which is as highly esteemed by them as fanily plate with Europeans) to be sold at Yedo or Yokohama. There are on some of the noblemen's estates, manufactories of lacquer, celebrated for their excellence, and from which their owners derive great wealth. Articles made there are always marked with the crest or crests of the owner of the estate, so that ware which is much sought after, such as Prince Satsuma's lacquer, may at once be recognised by seeing his crest upon each piece. Old Japanese lacquer is. like good lace, inimitable; but an experienced connoisseur can at a glance pronounce upon its merits and reality. It is very difficult now to meet with a good old specimen; the market is stocked full of modern work, made expressly for Europe; now and then, however, a Daimio very hard up, or a courtesan in temporary embarrassment, sends secretly from $Y$ edo a choice piece for sale, and it is astonishing to find the enormons price it will realize. Twenty, forty, sixty sovereigns or more are given for an old box not a foot square; but the sale is tacitly interdicted; indeed, it is almost as disgraceful for a Japanese to part with old lacquer ware, as it is for an English gentleman to dispose of his family plate. Very great prices were marked on several small articles in the Health Exhibition of 1884. Sir Rutherford Alcock mentions $£ 100$ as a sum asked of him in Japan for a box 6 inches square; and Lady Parkes told him that in Tokio fine specimens were bringing their weight in gold. The lacquer ware of the period A.D. 910 to 1650 , known as Jiddi mono, are very highly esteemed (pp. 32, 33).

There are many kinds of varnish known to the Japanese. The best lac is supposed to be the sap or juice of the Rhus vernicifera. The bark of this tree, on being cut, yields a white milk, 
which becomes black on exposure to the air; the leaves, petals, and nearly every part of the tree yield also the same liquid. As one of the ingredients in its preparation, the oil of the Bignonia tomentosa is employed. If secret there was, it seems lost to us and themselves, for the modern lac is such a wretched imitation of the ancient, that it is very difficult to admit that the same composition could have produced the two qualities. Ordinary lac has the consistency of treacle, and much the same colour; the first coating is thin and yellowish, the second of a brownish tinge, and the last a bright mahogany.

In Japan, the woods on which lacquer is applied, are Abies tsuga, Buna, Chamæcyparis obtusa, Ch. pisifera, Cyptomeria Japonica, Cercidiphyllum Japonicum, Hi-me-ko-ma-tsu, Ginko biloba, I'go, Ka-rin, Magnolia hypolema, Morus, sp., Pinus densiflora, Planeria Japonica, Powlownia imperialis, Prunus pseudo-cerasus, Shi-tan, Shoji, Ta-ga-ya-san, 1'hujopsis dolubrata.

The lacquer ware of Benares is good. Two kinds of resin are used; one called ral or rala is sold at eight annas the seer, and is said to be brought from Mirzapur to Benares. The fine lacquer is made of a resin called gaharba, for a seer of which one rupee and two annas are paid.

Colour-sticks for lacquer ware are used in the Panjab by the Kharati, or wood-turner, to colour his ware when the turning process is complete. The stick consists of shell-lac, melted down with a certain proportion of wax and sulphur, and coloured by various simple or compound colours. They are applied by the hand. The operator holds the colour-stick against the turned wood object while revolving rapidly; the heat produced by the friction melts the lac and the colour is deposited on the surface of the wood. The skill and fancy of the operator directs him either in laying on a uniform layer of colour, or else putting it on in little spots or touches, by allowing the colour-stick only very lightly to touch the revolving wood, thus producing either a smooth uniform colour, or the pretty mottled appearance so often observed in lacquered ware. T'wo or three different colour-sticks are often applied, giving the whole a marbled appearance of great beauty. The colour thus applied is spread, fined, and polished, by pressing the edge against the turned object while revolving. The final polish is given by a rag with a little oil. The principal colours are of lac, crimson, orpiment, red lead, green, made of orpiment and Prussian blue, dark blue, indigo or Prussian black, white, brown, or gold colour, light blue or ultramarine.-Hodgson's Nagasaki; Sirr's China: Powell's Handbook; Sir R. Alcock; Tomlinson; Rovle's Arts of India; $M . E . J . R$. Williams' Middle Kingdom; Morrison's Comp. Descrip.; Consul John J. Quin in Par. Pap., 1882.

IACTUCA SATIVA. Linn. Garden lettuce. Choff, . . . Egrpt. / Kahu, . . . . Hund.

The lettuce is a garden vegetable, inodorous, of scarcely sensible taste, or slightly bitter. At the flowering time it contains a milky juice, which has acquired some celebrity under the name of Lactucarium or Thiridace. Its seed, called Khaska-bij, is in Hindu medicine regarded as a very cold remedy. It is used by natives of India as a demulcent only.

L. scariola, Linn., is the wild plant; L. virosa,
Linn., is a biennial. All yield lactucarium or lettuce opium. The Ku-chih-kau of the Chinese is obtained by cutting off the tips of the fullgrown lettuce, collecting the milky juice which exudes, and inspissating it by a moderate heat. It is said to produce sleep without determining narcotism, to prove seductive without any previous stimulation, and to afford an excellent substitute for opium in many cases in which the latter drug is inadmissible.-O'Sh.; Powell's Handbook; Dr. Stewart.

LADAKH is called La tag in the Tibetan, $\mathrm{Ka}$-chan-pa or Snowland, Mar-yul, Redland or Lowland. Ladakb anciently was called Kiechha by the Chinese, and is still called by them Kha-pa-chan or Kha-chan, Abounding in Snow or Snowland; the people as Kha-pa-chan-pa or Kha-chan-pa, men of the Snowy Land; and Khachan-yul is Snowland. Ladakh is part of one of. the three outlying governorships under the maharaja of Kashmir (Cashmere), the other two being Baltistan and Gilgit. It may be described as comprising the valley of the Indus, and also of most of its tributaries, from lat. $32^{\circ}$ to $35^{\circ} \mathrm{N}$., and from long. $75^{\circ} 29^{\prime}$ to $79^{\circ} 29^{\prime} \mathrm{E}$. The different districts of Central Ladakb, Rupshu, and Nubra, besides the bleak and almost uninhabited plateaux of the Kouen Lun and Linzhitbang plains, together make up the province. The area of Ladakh, including Zanskar and some other districts which do not belong to the maharaja of Kashmir, is about 30,000 square miles. Mr. F. Drew ascertained the maharaja's population at the census of 1873 as 20,621; the 168,000 given by Cunningham, the 165,000 of Moorcroft (1822), and the estimate of 200.000 furnished by Dr. Bellew in 1873 , apply to the more extended area. Ladakh lies at the back of the great central range of the Himalayas, and is one of the loftiest of the inhabited regions of the globe. The valleys and plateaux vary between 9000 and 17,000 feet, while many of the peaks attain altitudes of 25,000 feet. The chief rivers of Ladakh are the Indus, and its tributaries, the Shayok, Nubra, Chanchengmo, and Zanskar. There are several salt lakes, the more important of which are the Pang Kong and Cho-moriri. The climate is characterized by remarkable extremes, burning heat during the day being succeeded by piercing cold at night.

The earliest mention of Ladakh is probably to be found in the description of Kie-chha by the Chinese Pilgrim Fa Hian (A.D. 300). It appears to be referred to again in the Akhassa Regio of Pliny, and in the Mo-lo-pho or San-pho-lo of Hiwen Thsang (middle of the 7 th century).

In the valley of the Upper Indus, that is in Ladakh and Little Tibet, the prevailing race is the Bhot subdivision of the great Tartar variety of the human race. Lower down that classical stream, in Gilgit and Chulas, the remains of the old and secluded Darda and Dungher races are still to be found; but both in Iskardo and in Gilgit itself there is some mixture of Turkoman tribes from the wilds of Pamir and Kashgar. 'The Ladakh people are of a cheerful disposition, and often may be heard humming simple tunes. At Leh itself, and among the wandering Tartar tribes, the women dress with woollen or variegated petticoats, and tanned sheep or goat skins as mantles. Their principal ornament is a head-band hanging like a long 
tail, and studded all down with large turquoises; this is called berak, and often, even with common people, worth Rs. 20 or 30 . Nearly all Ladakh is of the Buddhist faith. The valley of Leh or Ladakh proper, Zanskar, Hembaks or Dras, Suru and Purik, Spiti, Nubra, Janski, Rong, Rupshu, and Hanle are all Buddhist, and is Bhot along the banks of the Chandra and Bhaga, but Hindu after their junction. In Ladakh, the nuns and monks bear a large proportion to the population. To the north of the Ladakh country, the people of Yarkand and Khotan speak Turki. To the west, beyond Balti, the people of Astor, Gilgit, and Hunza Nager speak different dialects of Dardu, while the Kashmiri have their own peculiar language. To the south, the people of Chamba, Kulu, and Bishahar speak a dialect of Hindi, and to the east and south-east, the people of Rudok, Chang Thang, and Gnari speak Tibetan only.

The Dard race, lying along the Indus to the westward of Ladakh, speak three distinct dialects. They use the Persian character in writing Dardu, the three dialects of which are called Shina, Khajuna, and Arniya. The Shina dialect is spoken by the peoples of Astor, Gilgit, and lower down in Chulas, Darel, Kohli, and Palas on both banks of the Indus; the Khajuna, by the people of Hunza and Nager, and the Arniya in Yasan and Chitral. Astor has an area of 1600 square miles, on the left bank of the Indus. Gilgit, in Tibetan Gyilgyid, has an area of 2500 square miles on the right bank of the Indus. Dard or Durd are supposed by Vigne to be the Dadicæ $\left(\Delta \alpha \delta / \chi_{\alpha}<\right)$ of Herodotus, and the people who now occupy the country called Dardu.

The richer people of Ladakh have more than one wife, but the prevailing custom is polyandry, and is usually in the form of a community of brothers with their one wife.

Ladakh is agricultural, but enjoys a transit trade, and much labour has been expended in constructing roads through Kashmir, Jummoo, Kulu, Lahoul,-leading to the Panjab, Kābul, Lhassa, Chinese Tartary, Khotan, Yarkand, Little Tibet, and Balti. All these follow the lines of rivers, cross passes 18,000 feet high, and over rivers by ferries, by inflated skins and suspension bridges. Three varieties of the sheep and three of the goat are domesticated in Ladakh, and sheep and the domesticated yak are used for carrying loads. The Dso, hybrid between the yak and cow, is a beast of burden. The great article of trade in Ladakh is the shawl-wool from the further provinces. The route to Amritsar via Ladakh is that which brings the trade of Yarkand and Eastern Turkestan. There is also a route from Amritsar, Jalandhar, or Ludhiana, via Nurpur, Mandi, and Kulu, to the same places. At stated times caravans from Yarkand arrive with brick-tea, shawl-wool, China silks, ponies, etc., which are exchanged for grain, English calicoes, and the like; so that Leh is but a market-place for Kashmir and Yarkand merchants. - Latham's Ethnology ; Cunningham's Ladakh; Adams; Cleghorn's Reports; Mrs. Hervey's Tartary; Powell; Hooker and Thomson; Imp. Gaz.

LADDU. HIND. A sweetmeat made of sugar, milk, and flour, rolled into the form of balls. Laddu is of two kinds, one called Bundi ka; the other is Sada, plain or Maida ka-laddu.
LADRONES. PORT. A term applied by the Portuguese to the Chinese pirates, who commenced to gain power by the close of the 18 th century. The Ladrones of the Archipelago consisted wholly of the inhabitants of the free Muhammadan states in Sumatra, Lingin, Borneo, Magindano, and Sulu, the natives who remained uncontaminated by the doctrines of the Arabs never being known to engage in the like pursuits. Europeans who were unfortunate enough to fall into their hands were generally murdered, while the natives who composed the crews of the captured vessels were sold for slaves. - Mr. G. W. Earl, p. 42 .

LADRONES, a group of islands in the Canton river, also islands in the eastern verge of the Archipelago. Of the former, the Grand Ladrone is the outermost island of the Canton river, in lat. $21^{\circ} 55^{\prime} \mathrm{N}$., and long. $113^{\circ} 43^{\prime} 45^{\prime \prime} \mathrm{E}$. It is called by the Chinese Ty-man-shan. It is a steep, bold island. The Little Ladrone, or Po-ching Han of the Chinese, is separated from the west side of the Grand Ladrone by a narrow passage.

Ladrones, in the Pacific Ocean, eleven in number. The bread-fruit tree is cultivated here in abundance; and the natives are of a pleasing aspect, and well made. Lat. $11^{\circ} 22^{\prime} \mathrm{N}$., long. $14^{\circ}$ $6^{\prime} \mathrm{E}$. The Ladrones were the first islands seen by Magellan. Entering the utmost eastern conines of the Archipelago, Magellan discovered the Ladrones, or Isles of Thieves. They have since been named the Mariannes, but still deserve their original appellation, as the people of the surrounding groups stand in dread of their predatory inhabitants. On one of the Meiaco-shimah isles walls have been raised and pierced with loopholes, as a defence against these roving banditti of the sea. From these Magellan sailed to the Philippines, where, in the island of Mactan near Zebu, he was killed, as also was Barbosa. Magellan's companions then visited Timor in 1522, and returned to Lisbon, making the first circumnavigation of the globe. The Ladrones lie about four hundred leagues east of the Philippines. - Bikmore; St. John's Ind. Arch.; Sir E. Belcher, i. p. 84 ; Horsburgh.

LADY-BIRD of N. India, a species of Coccinella, very injurious to plants. See Insects.

LAF, a"fish of the Seychelles; the spines on its back are said to be hollow, and to contain a poisonous fluid.

LAG, HIND, means to, or near to, connection, continuity. Lagān, a place where a boat is fastened. Lăgăn, MAHR., a marriage. Lagna, the rising of a sign in the zodiac. Lagga is the habet of the Roman populace, signifying that something, man or animal, has been struck.

LAGENARIA VULGARIS. Serr. Cucurbita lagenaria, Linn., Bottle gourd.

Charrah,... ARAB. White pumpkin, ENG. Kodu, Iau, . . Beng. Kaddu, . . HIND Quara tauvil, : EGYPT. Tomra kaddu, : MALAY, Quara m'davar, . ", Bella shora, - MALiaL Dubha dibhe, . ", Soriai-kai, . . TAM. Calabash, : ENG. Sorakaia, : : TEL

The bottle gourd, from Lagena, a bottle, is commonly cultivated by the natives, to whom it is of some importance as food; but is seldom eaten by Europeans, being very coarse. In Tenasserim, the bottle gourd grows luxuriantly, and several varieties may be seen. In China, its soft downy herbage is sometimes eaten. Its long fruit bulges 
at the further end, and into very odd shapes. It is there made into calabashes, floats, dishes, beggars' platters, musical instruments, and receptacles for drugs. The long white gourds are hollowed out, and made into buoys for rafts for crossing rivers. The large round kind are used for making a kind of stringed instrument like a sitar, called in Tamil Kinnayri, and are hence termed Kinnayri soriai-kai: A longer and narrow sort are employed in making the wind instruments, called in Tamil Maghadi, with which the snakemen (Pamu pudarer, TAM.) entice snakes from their holes. In China the dried bottle gourds are tied to the backs of children on board the boats to assist them in floating if they should unluckily fall overboard. The dried outer rind of the fruit is hard, and is used as a bottle, called the fakir's bottle. In its wild state, this plant, or a variety of it, produces a poisonous fruit; and Dr. Royle states that a very intelligent native doctor informed him that cases of poisoning have occurred from eating the bitter pulp. Some sailors also are said to have died from drinking beer that had been standing in a flask made from one of those gourds. Don says that the poor people among the Arabians eat the edible kind boiled with vinegar, or fill the shells with rice and meat, and so make a kind of pudding of it. The pulp of the fruit is often employed in poultices; it is bitter and purgative, and may be used instead of colocynth. The seeds, Doodee seed, yield a bland oil, and they are given in headaches.-Jaffrey; Mason; O'Sh.; Pou'ell; Eng. Cyc.; Dr. J. Stewart; Roxb.; Voigt, Useful Plants ; Smith, M.M.C.

LAGERSTRCEMIA, a genus of plants of the natural family of Lythracer, growing in the Peninsula of India, along the foot of the Himalaya, in the northern parts of India, and from the Malaya Archipelago into China and Japan. The species are highly ornamental, and in China by far the most beautiful plants met with on the low ground are different species of this genus. L. hypoleuca, Kurz, is a timber tree of the Andamans; $L$. villosa, Wall., a timber tree of Tounghoo. The whole of the species may be propagated by seed or cuttings in any garden soil. - Roxb. ; Eng. Cyc.; Fortune's Wanderings; Williams' Middle Kingdom; Riddell; Mason.

LAGERSTRGIMIA GRANDIFLORA. Poxb. Dua-banga, Hind. In the Terai, east of Siligori, Bombax, Erythrina, and the Lagerstroemia grandiflora were found by Dr. Hooker in full flower, and, with the profusion of Bauhinia, rendered the tree jungle gay; the two former are leafless when flowering. The Dua-banga is the pride of these forests. Its trunk, from 8 to 15 feet in girth, is generally forked from the base, and the long pendulous branches which clothe the trunk for 100 feet are thickly leafy, and terminated by racemes of immense white flowers, which, especially when in bud, smell most disagreeably of asafotida. -Roxb. ii. p. 503 ; Hooker, H. Jour. i. p. 401.

IAGERSTRCFMIA INDICA. Linn.

Velaga globosa, Gertn. | Lagerstromia alba.

Pyen-ma, . . BurM. | Telanga cheena, - TAM. China henna, : Hind.

There are three varieties-(a) rosea, (b) lilacina, and $(c)$ alba- of this small, pretty shrub, which is common in gardens in Moulmein, and of easy cultivation. It has one of the most beautiful flowers in Indian gardens, grows to the height of seven or eight feet; the flowers hang in bunches at the extremity of the branches, and are of a beautiful lilac colour. The white flowering variety grows easily from cuttings at the commencement and during the rains.-Drs. Roxb., Mason, Ains., Riddell, Voigt.

LAGERSTROEMIA LANCEOLATA. Wall.
Sokutia, . . MAHR.
Boda, Bondaga,: HIND.

An erect tree with oblong lanceolate leaves; flowers small, white, appearing in April and May; common in the Bombay Presidency, found in Mysore and at Courtallum, and cultivated in the Lal Bagh gardens at Bangalore.-Riddell; Beddome.

LAGERSTROEMIA MACROCARPA. Roxb. Pyen-ma, BurM. In Amherst, its timber used for house posts, carts, boats, paddles, oars, etc. It is a capital wood, and would answer for all the purposes of common sal; specific gravity, 0.920 . - Cat. Ex., 1851.

LAGERSTRCEMIA MICROCARPA. W. Ic. Bolandur, Billinandi, CAN. | Ventek, Veveyla, . TAM.

This has often been confounded with L. parviflora, Roxb. It is a very handsome tree, abundant in all the western forests of the Madras Presidency. It flowers in the hot weather, and its seed ripens in the rains. The wood is light-coloured, straight fibred, and elastic; it is very much used for building purposes, flooring, rafters, etc., and also in dockyards. If left in the forests exposed it very soon rots, and is rapidly attacked by white ants. It makes capital coffee cases.-Beddome, Fl. Sylv.

\section{LAGERSTRCEMIA PARVIFLORA. Roxb.}

Ben-teak, ANglo-Hind. Wundi-mana, . MAHR. Bakli, Dhan, Dhaura, ," Belli-nundi, Nanab, , Tsam-be-lay, . . BuRM. Bellinger, . MAL"', Ven-taku, : : CAN. Cutcha-catta maram, TAM. Bondara, : : MAHR. Chinna nagi, . TEL.

A handsome tree, very common in the Northern Circars and on the Nullamallays of the Kurnool district, but also, though rarely, in the Seegoor forests; found in Bombay, Bengal, and Burma. The wood is whitish or light-brown, close-grained, straight fibred, and elastic; it is much used for building purposes, beams, and rafters, and for boat timber, ploughs, axe-handles, etc. In Meerut it is in great request for buggy shafts. It grows to 90 and 100 feet long, and from 12 inches to 3 feet in diameter; it is perfectly straight and without branches, excepting at its top; the leaves are small and very thick. The wood is not so durable as the poon; it is very much lighter in colour, and in this respect much resembles the American red oak. It is tough, and valued for its qualities in withstanding water. In the Nullamallay it has a light-brown, compact, hard, serviceable wood, and used generally. As a wood of British Burma, it is not much used. A cubic foot weighs 40 lbs. It sells there at 8 annas per cubic foot, is yellowish, elastic, and tough, and is valued for agricultural implements, etc. In the N.IV. Provinces it is reckoned one of the best woods for buggy shafts, etc.-Roxb.; Voigt; M'Ivor; Drs. Gibson, Wight, Brandis, Mason, and J. L. Stewart; Captain Beddome, Fl. Sylv.; Mr. Latham.

LAGERSTRGEMA PUBESCENS. Wall. Laizah, BurM. A very large tree of British Burma, stem not always perfectly round, and inclined to form buttresses; timber valued for bows and spear- 
handles, also used for canoes and cart-wheels. A cubic foot weighs 53 lbs. In a full-grown tree on good soil the average length of the trunk to the first branch is 100 feet, and average girth measured at 6 feet from the ground is 12 feet. It sells at 8 annas per cubic foot.-Dr. Brandis; Cal. Cat. Ex., 1862.

\section{LAGERSTRGEMIA REGIN止. Roxb.}

L. flos reginæ, Retz.

Arjuno, Adambea glabra, Lam.

Pyimma, : BurM. Adamboe,

Challa, Hali dasul, CAN. Maoroota MALAY.

Jarool, . . . HrND. Kadali,. . . TAM.

This is a large tree of Ceylon, the Peninsula of India, Coimbatore, Canara, Sunda, in the mountains north-east of Bengal, in the Jaintia Hills, in Pegu and Tenasserim, Amherst, Tavoy, and the Mergui Archipelago, and when in flower is most conspicuous. In full blossom in the morning, a tree looks as if mantled with roses, but the flowers change through the day to a beautiful purple, making it appear at evening, if seen from a short distance, like a bower of English lilacs. It is not uncommon in the warm, moister parts of the western and southern parts of Ceylon, up to an elevation of 1500 feet. In Canara and Sunda, it grows near the banks of rivers, and reaches a large size. It is common in the jungles below the ghats, south of the Savitree river, but is hardly found north of that, and never in the inland Bombay jungles. In Ceylon its wood is used for water casks and buildings; in Coimbatore and in Hyderabad this tree is more celebrated for its large handsome flowers than for its timber, which last, however, is used for common purposes. Its timber from the Bombay forests is reckoned rather good, and is used, being generally crooked, for the knees, etc., of native boats. In the Madras Gun Carriage Manufaotory it is used for light field cheeks, felloes, cart naves, framing and boards of waggons, limbers, platform carts, ammunition box boards, and heary field cheeks. - Roxb. ii p. 505; Voigt; Thw.; $M^{\prime} \mathrm{Cl}$.; Rildell; Wight; Brandis; Masm; Gibson; Mendis; Captain Dance; Major Benson; Col. Maitland; Hooker's Him. Jour.

LAGHAR, or Hobby, and her mate the Jaghar, Falco jugger, Gray, is the only long-winged hawk generally used in Sind. She is large and blackeyed, with yellow legs, black claws, and a tail of a cinereous white colour: She is a native of Sind, moults during the hot months from April to October, and builds in ruined walls and old mimosa trees. The laghar is flown at quail, partridge, curlew, bastard-bustard, and hares; the best sport is undoubtedly afforded by crows, only she is addicted to carrying the quarry, and is very likely to be killed by her angry enemies. Carrying is the technical word for walking off with the wounded bird.-Burton's Falconry, p. 13.

LAGHARI, ఇ subordinate branch of the Talpur family. The Laghari of the Dehra Ghazi Khan plain dwell south of the Khosa, extending from Viddore to Gungehur, between Choti Bala and Harrand. They joined Lieutenant Edwardes' camp in his advance against the dewan Mulraj. The Laghari claim to be able to trace their pedigree up to their departure from Arabia. They have 55 sub-sections, of whom a large number reside in the hills.

LAGHU KAUMUDI, an edition of Panini's
Grammar, edited by Varada Raja. It was also edited and translated by Dr. Ballantyne in 1849 , as a Sanskrit and English Grammar.

LAGOMYS BADIUS. On entering Tibet, Dr. Hooker found the ground burrowed by innumerable marmots, foxes, and the Goomchen, or tailless rat, Lagomys badius. Other tailless rats, as L. Hodgsonii, are plentiful, and L. Roylei, common on the Kashmir ranges. One or both may be the Pharaoh's mouse mentioned by Marco Polo. The lagomys is said to be eaten by certain tribes in Tartary. L. Curzoniæe, Hodgson, is of Sikkim, Tibet, Ladakh, and countries beyond the Snowy Range.-Hooker, Him. Jour. ii. p. 156 ; Adams.

LAGOMYS ROYLEI. Ogilby.

L. Nepalensis, Hodgson. | L. Hodgsonii, Blyth.

It is the Rang-duni and Rang-runt of Kanawar. The Himalayan mouse hare occurs in the Himalaya up to 14,000 feet. They are said to hibernate.

LAGOMYS RUFESCENS. Gray. A little quadruped found on the mountains of Afghanistan, and perbaps onward to the Hindu Kush, but which is very unlikely to inhabit the Indian side of the passes.-Cal. Rev.

LAGOON. Shallow salt-water lagoons, known as backwaters, run around the shores of the Bay of Bengal and of the Arabian Sea, some of them from twenty to fifty miles loug; they afford great facilities for a safe inland traffic along the coastline, the violence of the monsoons, and the few sheltered harbours on the eastern coast of the Peninsula, rendering navigation perilous at all times and often impossible. On the E. coast of the Peninsula the Ennore or Pulicat and Kolar lakes are the largest, and a large lagoon runs along the coast-line of the Travancore state. The lagoons of the coast of India are quite dissimilar from those of the coral islands. In the latter, the surf beating loud and heavy along the margin of the reef, presents a strange contrast to the prospect beyond, - the white coral beach, the massy foliage, and the embosomed lake, with its tiny islets. The colour of the coral lagoon water is often as blue as the ocean; although about fifteen or twenty fathoms deep, yet shades of green and yellow are intermingled where patches of sand or coral knolls are near the surface, and the green is a delicate apple shade, quite unlike the usual muddy tiut of shallow waters. "These garlands of verdure seem to stand on the brims of cups, Seven miles east of Clermont Tonnere, the lead ran out to eleven hundred and forty-five fathoms (six thousand eight hundred and seventy feet) without reaching bottom. Within three-quarters of a mile of the southern point of this island, the lead had another throw, and, after running out for a while, brought up for an instant at three hundred and fifty fathoms, and then dropped off again, and descended to six hundred fathoms without reaching bottom. The atoll lagoons are generally shallow, though in the larger islands sounding gave twenty to thirty-five, and even fifty and sixty fathoms."

The lake of Kolar, in the Kistna and Godavery districts of Madras, is a marine lagoon. In the rains it is a fine lake; in the dry season a large part of the area is half mud. In the intervals of the dry and wet seasons it is a swamp. Naturally it abounds in fish and water-fowl, and in a very dry year the remains of old villages are to be seen, with large quantities of charcoal and charred beams. A succession of lagoons or backwaters, 


\section{LAGUNARIA PATERSONII,}

connected by navigable canals, extends along the Malabar coast. The extreme length is nearly 200 miles from Changhat to Trivandrum; but between the latter place and Quilon there rises a high promontory of land about 6 miles in breadth, which is being cut through to make the line of water communication complete. The total area of these lakes is $227 \frac{1}{2}$ square miles in Travancore, Cochin, and British territory. A strip of land from seven to about half a mile wide separates these backwaters from the sea ; but at Chetwai, Kodangalur, Cochin, Kagankulam, Iveka, and Paravur are outlets by which the rivers enter the - sea. The whole commerce of the country is carried on these waters. Most of the boats are formed of a single teak, angely, or cotton tree, the trunk of which is hollowed out. The ordinary size is about 20 feet by $2 \frac{1}{2}$ feet. The boats for carrying rice to a distance are larger, and have a deck or roof.-Gosse's Nat. Hist. p. 94 ; Cheever's Sandwich Islands. See Coral; Polype.

LAGUNARIA. PATERSONII, B.M. (Hibiscus Patersonii, D.C.), grows in Norfolk Island. It is the white oak or white wood tree, and grows to 16 or 20 feet high. It has a pretty appearance in a garden or shrubbery. Its wood is spongy, but is used for knees of boats.-G. Bennett, p. 343.

LAHAD. ARAB. In Muhammadan sepulture the grave is dug as usual, and at the bottom, at one side, a niche called Lahad is made, into which the body is placed. Lahad-churna, lit. filling the grave, is a Muhammadan ceremony.-Wils.

LAHANGA. HiND. A Muhammadan woman's petticoat of silk or cotton.

LAHANZA, HiND. A green and blue dyed cloth of Lucknow.

LAHARI, also known as Lahori or Larry Bandar, stands on the Pitti branch of the Indus river. The delta of the Indus has varied in breadth from 60 to 90 miles from east to west, and the Pitti is only one of twenty or more channels leading to the ocean; the old or recent mouths of the river appear and disappear with the continuous changes of the main channel.

LAHARIYA, agricultural Brahmans in the North-Western Provinces of India.

LAHAURA-HA-NOCHE, a dialect spoken by the Kakar.

LAHEJ, a sovereignty on a large sandy plain north of Aden. It is watered by a hill torrent, $\mathrm{Al}$-Howta is the only place meriting the name of a town. The population is chiefly agricultural, and consists of true Arabs, - Khadami, Hijri, and Muwalladi. The Khadami and Hijri are of African descent. The Muwalladi are a mixed race, the offspring of an Arab and a Sowahilee slave. Sorghum vulgare is the principal food plant, and of it they obtain two or three crops a year.Captrin Prideaux, The Arab Tribes.

LAHERA, about Benares, a tribe of earthenware varnishers. They also bave donkeys, with which they carry house-building materials.

LAHM. ARAB. The dried flesh of sharks, used by all the races in the S.E. coast of Arabia.

LAHN, HIND. Lees of wine added to the molasses to promote fermentation in distilling.

LAHNA. Hinn. Species of Sueda used for camel fodder, also for soda burning.

LAHORE, a large city in the Panjab, in lat. $31^{\circ} 34^{\prime} 5^{\prime \prime}$ N., and long. $74^{\circ} 21^{\prime}$ E., gives its name to a revenue district of that province. Its popula-
LAHORE.

tion in 1881 numbered 149,369, chiefly Muhamrnadans and Hindus, with a small number of Sikhs. Situated on the high road from Afghanistan, Lahore has been visited by every invader of India, from Alexander downwards. It long formed the centre of a democratic confederation, which successfully opposed the Muhammadan invasions. It next became the capital of the Ghazni rulers; later, it was the capital of the Moghuls, followed by Ranjit Singh, until the Panjab territory was annexed to the British Government on the 16th December 1845. Lahore was occupied by the British 22d February 1846, and the treaty of Lahore was dated 9th March 1846.

Lahore has been the capital of the Panjab for nearly 900 years. It is said to have been founded by Lava or Lo, son of Rama, after whom it was named Lohawar. Both Jai Pal and his son Anand Pal, the successive antagonists of Mahmud, are called rajas of Lahore by Ferishta. This Hindu dynasty was subverted in A.D. 1031, when Lahore became the residence of a Muhammadan governor under the king of Ghazni. Upwards of a century later, in A.D. 1152, when Bahram was driven from Ghazni by the Afghans of Ghor, bis son Khusru established himself at Lahore. But this new kingdom lasted for only two generations, until A.D. 1186, when the sovereignty of the Ghaznavi was finally extinguished by the capture and imprisonment of Khusru Malik, the last of his race. Milton notices Lahore as one of the towns in the far east, when indicating the various nationalities, thus-

'From Samarchand by Oxus, Temir's throne, To Agra and Lahore of Great Mogul,

Down to the Golden Chersonese,

And utmost Indian Isle Taprobane.'

Lahore is surrounded by a wall which was 25 feet high, but it has been lowered to 16 feet. It has several gates.

The Jat form the leading agricultural community. Half of them follow Hinduism, and the other half are Muhammadans. Besides the usual numbers of bakers, barbers, blacksmiths, goldsmiths, carpenters, and washermen, etc., are to be seen the Akali, Arain, Aroro, Bhabra, Bhat, Brahman, Changar, Dogur, Gil, Gilgo or Kumhar, Hujra or Bava, Jat, Kahar, Kalal, Kakazai, Kharol, Khatu, Kumbo, Labana, Mullab, Phailwan, Rajput, Sansi, Sikh, Mazhabi Sikh, and Sudh. The manufacture of armour-swords, guns, and the like-once had its grand centre at Lahore, but when the Sikh rule passed away, the demand ceased. The artisans went into the Gujerat and Gujranwalla districts, where they now, instead of Sikh armour, inlay caskets and studs, vases, paper-cutters, letter weights, and other fancy articles.

In the neighbourhood of Lahore are many large and delightful gardens; the fruit trees, flowering shrubs and plants, are, however, those common in Hindustan. About three miles north-east of Lahore is the once delightful garden of Shalimar. The marble tanks and fountains are still there. Jahangir erected the Khābgāh or sleeping palace, the Moti Masjid or pearl mosque, and the tomb of Anarkalli. The tomb of Anarkalli is a huge mausoleum. He was a favourite of Jahangir, but was seen to smile to one of the zanana, and was bricked up in a cell. Aurangzeb built the Jama Masjid. It bas white marble domes and simple 
minarets. During Jahangir's reign, the Sikh guru, Arjun Mall, compiler of the Adi Granth, died in prison at Lahore, and his humble shrine stands between the Moghul palace and the mausoleum of Ranjit Singh. Jahangir's mausoleum at Shahdarra is one of the chief architectural structures in Lahore. It is of red sandstone and marble, is very extensive and beautiful, with mosaics of a quadrangular form, and with a minaret 70 feet high at each corner. The tombs of Jahaugir's wife, Nur Jahan, and of her brother, Asof Khan, have been stripped of their marble facings and coloured enamels by the Sikhs. The Saman Burj contains an exquisite pavilion, inlaid with flowers wrought in precious stones, which derives its name of the Naulakha from its original cost of 9 lakhs, together with the Shesh Mahal. Ranjit Singh's mausoleum is a mixed work of Hindu and Muhammadan architecture. The mosque of Aurangzeb, with its plain white marble domes and simple minarets, the mausoleum of Ranjit Singh, with its rounded roof and projecting balconies, and the desecrated façade of the Moghul palace, stand side by side in front of an open grassy plain, exhibiting one of the grandest coups-d'œil to be seen in India.Cunningham's India; Masson's Journeys; Cunningham's Panjab; Powell's Handbook; Adams; Inıp. Gaz.

LAHOUL or Lahul is a subdivision of Kangra district, Panjab, lying between lat. $32^{\circ} 8^{\prime}$ and $32^{\circ} 59^{\prime}$ N., and long. $76^{\circ} 49^{\prime}$ and $77^{\circ} 46^{\prime} 30^{\prime \prime} \mathrm{E}$., and comprising the valley between the Chamba mountains on the north-west and the Kanzam range on the south-east. Area, 2199 sq. miles. It is bounded on the north-west by Chamba, on the north-east by the Rupshu subdivision of Ladakh, on the south-west by Kangra and Kulu, and on the south - east by Spiti. At Tandi the sister streams Chandra and Bhaga unite to form the great river Chenab, which flows immediately into Chamba on its way to the Panjab plain. The Kanet, who form the mass of the population, have a mixed Indian and Mongolian origin. The thakurs form the gentry of the valley, which ruled until a recent period. They are pure Bhotiyas or Tibetans by blood, but affect a Rajput ancestry. The people are Buddhist, but have castes, and abstain from beef. Numerous monasteries stud the hills, the largest being that of Guru Gantal, at the point of confluence of the Chandra and Bhasra. Polyandry is customary. The Lahuli bear a good character as peaceable and honest mountaineers, but are much addicted to drunkenness and unchastity.

The Lahouli are a totally distinct race from the people of Kulu or the Chamba Guddi range. The I ahouli are a short, sturdy set of men, very ugly, and filthily dirty. The women are decidedly plain. The costume of both sexes consists of a pair of loose woollen drawers, with a frock of the same material, whilst a wrapper is also often wound around the body, being thrown over the shoulder, and fastened by a brass clasp in front Their dress, generally of a black colour, is of a kind of plaid, and their caps are of the same. The women wear their hair either in long plaits fastened at the back of the head with a profusion of red wool and coloured threads, or comb it back off the forehead, tying it in a lump behind, and adorning it in a similar manner.
Around the flat circular caps are strung large white shells like cowries, glass beads, and pieces of amber. Around their neck both men and women wear amulets of mother-of-pearl, pieces of amber, turquoises, and otber precious stones. Each man has hanging to his belt a tinder pouch and a brass instrument for striking fire, with many other nondescript implements. They spend six montbs of each year in Kulv on account of the severity of the winter season in Lahoul. The greater part of that time they pass in dancing and drinking. On their jubilees they set off fireworks, and make a tremendous noise, whilst the women dance. These exhibitions do not terminate until they are all too drunk to continue them. The tree which gives character to the district is Juniperus excelsa or pencil cedar, the Shukpa of Lahoul, and Lewar of Kanawar. It forms small forests, especially on the southern slope of the hills, at an elevation of 9000 to 12,000 feet.-Mrs. Hervey's Tartary; Powell's Handbook; Hooker and Thomson's Fl. Ind.; Cleghorn, Panj. Rep.; Thomson's Travels ; Jacquemont's Tr. ; Imp. Gaz.

LAHOUL i o la kouti illa ba illah il ali o il azeem, No repentance, virtue, or power except by God the high and the great, - a Muhammadan invocation.

LAHW-ul-MAHFUZ, in Muhammadan belief, is that tablet on which the Koran was written. Imam-ul-Mubin, the clear prototype, is the tablet on which the actions of men are written.

LAILAH. ARAB. A night.

Alif-Lailah-o-Lailah, the Thousand and One Nights, the Arabian Nights.

Lailat-ul-Juhni, the 23d night of the month Ramazan, esteemed fortunate for those who pray.

Lailat-ul-Kadr, the night of power or of the divine decrees. On this night the Koran is said to have been sent down to Mahomed. Moreover, the gate of heaven being then opened, prayer is held to be certain of success. The Lailat-ul-Kadr occurs on one of the last ten nights of Ramadan, generally supposed to be the 27th of the month, not, as supposed by Sale, between the $23 \mathrm{~d}$ and $24 \mathrm{th}$.

Ramazan, in Egypt, Arabia, and Turkey, pronounced Ramadan, is the 9th month of the Muhammadan year, during which Mahomed enjoined a rigid fast from sunrise till the appearance of the stars, and abstaining from all conjugal duty, the sick, the traveller, the soldier in the field, and others, being obliged to fast a complete month when their health and circumstances allow. Most Muhammadans regard the night of the 27 th of this month as the Lailat-ul-Kadr or night of power; they believe that the Koran began to descend from heaven. They continue through the night fervently in prayer, believing that the petitions then made to the Omnipotent will be favourably received.

Lailat-ul-Miaraj, ARAB., the night of Mahomed's ascent to heaven, observed as an annual festival by devout Muhammadans on the 15th, 16th, or 27 th of the month Rajab.

Lailat-ul-Mubarak, the blessed night.

Lail-wa-Nahār, night and day.

LAILAN-SHAH, supposed to be the same with Pururava or Aila, and with Ninus and Nilan.

LA ILLAHA IL LULLAHO Muhammadur-Rasul Ullahay, There is no deity except God, and Mulammad is the prophet (or messenger) 
of God. This is the first part of the Muhammadan creed; but the same words occur in the Muhammadan azan or call to prayers, viz. Allah-hoAkbar! Allah-ho-Akbar! Ush-ud-do-un, la-il-laha, il-ul-la-ho ; Ush-ud-do-un, la-il-la-ha, il-ul-laho. O Ush-ud-do-un, Muhammad-ur-Rasul Ullahay, Hy-ul-us-salwat! Hy-ul-us-salwat. Hy-ulul-fullah! Hy-ul-ul-fallah. Us-sul-la-to Khairun-min-nun-nowm. Allah-ho-Akbar! Allah-hoAkbar! La-illa-ha illul-la-ho! The translation of this azan by which the Muhammadan muazzan, five times daily, calls Muhammadans to prayers, is, God is great! God is great! I bear witness there is no other deity but God; I bear witness there is no other deity but God, and I bear witness that Muhammad is the prophet of God. Come, enliven your prayers; Come, enliven your prayers. Come for refuge to the asylum; Come for refuge to the asylum. Prayer is preferable to sleep; Prayer is preferable to sleep. God is great; God is great. There is no deity but God.

Prayer is better than sleep is only added to the morning call, and not repeated in the other four summons.

LAING, SAMUEL, a member of Parliament, succeeded, in 1861, on Mr. Wilson's death, to the office of Finance Minister in India, and Indian history should not utter his name without praise. Possessed of vast abilities, a home-bred fundamental knowledge of finance, cautious in manner, and ready in argument and writing, he gave great satisfaction in India, but Sir Charles Wood's letters induced him to resign. By submission, Mr. Laing might have served India longer; but by independence he really served it most.Thurlow, p. 19.

LAIRI. Hind. An inferior ruby or garnet, or even pink topaz or amethyst.

LAJAR BASTRO. BENG. Literally a garment of modesty, a silk cloth spread over the heads of a betrothed couple.

LAKA, a dye of Sumatra, said to be from Tanarius major, Rumph.

LAKADONG, a village in the Jaintia Hills, on a small plateau, 2350 feet above the sea, around which coal was discovered in 1843 , and has been profitably worked since then.

LAKALO, a silver ingot used in large payments by the Bhot.

LAKE, EDWARD, author of Journals of the Sieges of the Madras Army in the years 1817, 1818 , and 1819 , with a volume of plates.

LAKE. Lord Lake, a British officer, born 1772. He was commanding-in-chief in India. He commanded the grand army, 10,500 strong, in the Mahratta war of 1803. On the 20th August 1803 he defeated the troops of Sindia under General Perron, at Alighur, and on the 4th September he stormed and carried the fort. On the 11th September he fought the battle of Dehli, and released the emperor Shah Alam, whose eyes had been put out by Ghulam Kadar, and who had been, since 1771, a prisoner of the Mahrattas. He took Agra on the 18 th October 1803 ; on the 31 st October he fought the battle of Laswari, and he took Deeg on the morniug of the 24 th December 1804 . He defeated Holkar at Farrakhabad, 17th November 1804. He failed before Bhurtpur in 1805 . He was created a viscount 4 th November 1807 . His

British and native troops put down the Mahratta armies, showing themselves more perfect than the enemy in Parthian forms of warfare.

LAKES.

Tal, Cho, T'so, . Внот. Jhil, . . . Hind. Ing, . . . BurM. Danau, Tasek, Malay.

Throughout British India there are few natural lakes, most of them only fit for purposes of irrigation; the largest natural waters in the country are equalled, and in many cases surpassed, by the magnificent tanks which have been formed in several places by throwing embankments across great valleys. Valuable marine lagoons or backwaters, however, occur along all the eastern and western coasts of the Peninsula of India, and there are large jhils near the river banks of the Ganges and Brahmaputra. For the most part they are not very deep, and their surface is very variable. Artificial lakes or tanks are numerous throughout the country, and testify the importance attached to them by the natives. In the Himalaya, also, there are but very few lakes. The Vullar lake in Kashmir (5126 feet), and the Chinar lake, near Srinuggur, at about the same height, suffice to exhaust the category of those deserving mention. Of those in Kamaon, Naini Tal is 6409 feet (6520?) above the sea, and has a circumference of $2 \frac{1}{4}$ miles. Bhim Tal is 4500 feet; Nankuchiya is 4000 feet; and Malwa Tal, 3400 . In September 1880 , a landslip at Naini Tal destroyed many Europeans and natives.

Glacier lakes, which are accumulations of water formed by one glacier obstructing the outlet of a higher one, are of frequent formation. At times the wall of ice breaks away before the pressure of the swollen waters, when the lower lands become suddenly inundated, and the torrent rushes on with uninterrupted violence for miles, exercising a marked influence even down to the lower parts of the rivers. Two of the most elevated glacier lakes known are the Deo Tal, in Garhwal (17,745 feet), and the Namtso or Yunam, in Lahul (15,570 feet). The following are lakes of Western Tibet and Turkestan :-

Aksae Chin, . . 16,620 ft. | Tso Moriri, . . 15,130 ft. Tso Gyagar, . . 15,693 ," Nima Kar, : . 15,100," Tso Kar, or Hanle, . . 14,600, Khauri Talau, 15,684 ", Tso Gam, . . 14,580 ", Mure Tso, . . 15,517 ", Tso Rul, : . 14,400", Kiuk Kiol, . . 15,460 " Tso Mitbal, . . 14,167 ", Mansaraur, or Upper Tsomog-

Tso Mapan, . 15,250 ," nalari, . . . 14,050,

Rakus Tal, or Lower Tsomog-

Tso Lanag, . 15,250 , $\quad$ nalari, . . 14,010,"

Nearly all the trans-Himalaya lakes seem to contain salts of various description.

$A b$-Istada, literally standing water, between Hamoon and the Kābul river, is a receptacle for the waters of Afghanistan. It varies greatly in size at different seasons.

Aral Lake is in the western part of Central Asia. Its surface is 117 feet higher than the Caspian.

$A l a-K u l$ and Balkhash Lakes probably at no distant period formed one common water basin, and during spring inundations, Ala-Kul, according to the testimony of the Kirghiz, communicates indirectly with that of Balkhash by a marshy, saline belt of land. This belt forms, in Mr. Semenof's opinion, the natural boundary of the Kirghiz steppe, beyond which Central Asia commences, together with a new soil and new flora and fauna. 
Baikal Lake, in Mongolia, is an expansion of the Angura river. Its length is nearly 400 miles (according to Bell, 300 miles), with 45 miles of average breadth from north to south. It has steamboats plying on it. Its seal and sturgeon fisheries are valuable, and also the oil of the fish called the golomynka, the Callionymus Baicalensis. Mountains encompass the lake entirely. The river Selingue falls into it from the S.W., and here the lake is about 50 miles broad; the Paeurku-simo from the S.E., and the Gong-ko-la (Upper Angura) from the N.E. Towards the N.E. end of the lake is an island called Oleao-han (Olchon), about $50 \mathrm{li}$ in breadth, and 200 or more in length. This island is frequented by families of the wandering tribes of the Mongols and the Pu-la-te (Buraty of Bell), and they bring hither with them their horses. Baikal lake is 1715 feet above the level of the sea; Selinghinsk, 1779 feet; and Kiakhta, 2400 feet. A fish called omully, in shape and taste resembling a herring, but broader and larger, comes in vast shoals from the Baikal, in autumn, up the river Selingue to spawn. These fish advance up the river about 10 miles a day, and the people catch as many as they need either for present use or winter provisions.

Dobsoon-noor, or the Salt Lake, is celebrated over all the west of Mongolia. It furnishes salt, not only to the neighbouring Tartars, but to several provinces of the Chinese empire. The Dobsoon-noor is less a lake than a vast reservoir of mineral salt mixed with nitrous efflorescence. The latter is of a faint white, and friable between the fingers; it is easily distinguishable from the salt, which is of a greyish tint, and with a shining and crystalline fracture. The lake is nearly 10 miles in circumference, and here and there are yourtes inhabited by the Mongols, who are occupied with the salt trade; they have also Chinese partners, for Chinese take part in every kind of trade or industry. The manipulation to which the salt is subjected requires little labour or science. It consists of nothing more than picking up the pieces, laying them in heaps, and covering them with potter's clay, and the salt sufficiently purifies itself.

Lake Fife, an artificial lake formed by throwing a dam across the Mutha river, 10 miles from Poona.

Mareotis Lake, to the westward and southward of Alexandria, in N.E. Africa, is about 150 miles in circumference. According to Strabo, in B.C. 223, when Alexandria was founded, it was a lake filled by several canals from the Nile, and kept full for the purposes of navigation. In the time of Pliny it was a marsh; but at the close of the 18 th century it was dry land with 300 villages, and was said to have been the most fertile portion of the Delta. From the necessities of war, the barrier was then cut through, and the sea admitted, since which time it has formed a lagoon, diluted by the Nile at the periods of flood.

Munchur Lake, in Sind, extends from the foot of the hills in the north, and is lost on the low lands to the eastward. When swollen by the inundation of the Indus, it is an enormous expanse of water, about 20 miles long and 10 miles broad, and covering an area probably of about 180 square miles. It has been described by Orlebar, Postans, and Knight.
Pulicat Lake is a marine lagoon, skirting th Bay of Bengal, north of Madras, in the Nellor collectorate.

Kunkeraoli Lake, also called the Rajsamund, i a great national work, 25 iniles north of Udaipur the capital of Mewar, and is situated on th declivity of the plain about 2 miles from the base 0 the Aravalli. A small perennial stream, called the Gumti or "serpentine," flowing from these moun tains, was arrested in its course, and confined by an immense embankment, made to form the lak called after himself, Rajsamund, or 'royal sea. The bund or dam formas an irregular segment of circle, embracing an extent of nearly 3 miles and encircling the waters on every side excep the space between the north-west and north-eas points. This barrier, which confines a sheet 0 water of great depth, about 12 miles in circum ference, is entirely of white marble, with a fligh of steps of the same material throughout thi extent, from the summit to the water's edge; the whole buttressed by an enormous rampart o earth, which, had the projector lived, would bav been planted with trees to form a promenade On the south side are the town and fortress buil by the rana, and bearing his name, Rajnuggur and upon the embankment stands the temple 0 Kunkeraoli, the shrine of one of the seven form (sarüp) of Krishna. The whole is ornamented with sculpture of tolerable execution for the age and a genealogical sketch of the founder's famil is inscribed in conspicuous characters. $£ 1,150,00$ sterling, contributed by the rana, his chiefs anc opulent subjects, was expended on this work, o which the material was from the adjacent quarries But, magnificent, costly, and useful as it is, i derives its chief beauty from the benevolen motive to which it owes its birth, - to alleviate th miseries of a starving population, and make thei employment conducive to national benefit durin one of those awful visitations of providence. Kiri Sagar and Madan Sagar are ancient artificia lakes, near the town of Mahoba.

Sambhar Salt Lake, in lat. $26^{\circ} 53^{\prime} \mathrm{N}$., and long $73^{\circ} 57^{\prime} \mathrm{E}$., is 20 miles long and $1 \frac{1}{2}$ broad.

Taruba, a lake of the Central Provinces, 1 miles E. of Segaon.

Colair Lake is a marine lagoon in the Norther Circars of Madras Presidency.

Lake Debur is in Udaipur.

Lonar Lake, about 2 miles in circumference, i a body of water low down in the crater of ar extinct volcano. It is among the Shiel Hills in the Dekhan, in lat. $20^{\circ} \mathrm{N}$., and long. $76^{\circ} 30^{\prime} \mathrm{E}$ It yields carbonate and muriate of soda.

Oodi-Sagur Lake. The Bairis river issues fron the Oodi-Sagur lake of Rajputana, and passe within a mile of Chitore. Here are two gran reservoirs within 6 miles of each other, viz. th Peshola, or internal lake, having an elevation o 80 feet above the external one; and the Oodi Sagur, whose outlet forms the Bairis. Th Peshola may be called the parent of the other although it is partly fed by the minor lake at th villa of Suhailea-ki-bari. Both are from 12 to 1 miles in circumference, in some places 35 fee deep, and, being fed by the perennial stream from the Aravalli, they contain a constant supply of water. From the external lake to Chitore the fall is so slight that few locks would be required; and the soil being a yielding on 
throughout, the expense of the undertaking would be moderate.

Oornomiah Lake is 100 miles long by 30 broad. Several large towns are in the immediate vicinity of the lake, as Tabreez, with a population of 100,000 , and Ooroomiah, with 40,000 .

Pangong Lakes in Tibet are a series east of Noh. Lake Tengrinor or Namchu is 15,000 or 16,000 feet above the sea. Dangra-Yum-Cho is 45 miles long and 25 miles broad; and Kyaring-cho, 40 miles by 8 to 12 broad.

Tso Gam, in Eastern Ladakh, in Tibet, is a salt lake, 14,580 feet above the sea, and in lat. $33^{\circ} 10^{\prime}$ N., and long. $78^{\circ} 34^{\prime} \mathrm{E}$.

Manasarourara, or Tso Mapan, is a salt lake, lat. $30^{\circ} 8^{\prime}$ N., long. $81^{\circ} 53^{\prime}$ E., in Guari Khorsum, about 15,250 feet above the sea.

Tso Mitbal, in Pangkong, in Tibet, is a salt lake, in lat. $33^{\circ} 25^{\prime} \mathrm{N}$., and long. $78^{\circ} 40^{\prime} \mathrm{E}$., and is 14,167 feet above the sea.

Tso Mognalari, in Pangkong, in Western Tibet, is a salt lake, in lat. $33^{\circ} 39^{\prime} 48^{\prime \prime} \mathrm{N}$., and long. $78^{\circ}$ $38^{\prime} 30^{\prime \prime}$ E., and 14,010 feet above the sea. It is about 120 miles long from $\mathrm{E}$. to $\mathrm{W}$.

Tso Moriri, in Rupchu, in Western Tibet, is in lat. $32^{\circ} 45^{\prime} 24^{\prime \prime} \mathrm{N}$., and long. $78^{\circ} 16^{\prime} 36^{\prime \prime} \mathrm{E}$, and 15,130 feet above the sea.

Lake Van is 4000 feet above the sea-level, and has an area of 1200 square miles.

Chonto Dong Lake, in Tibet, is 20 miles long and 16 broad, and is 14,700 feet above the sea.

lssyk-Kul Lake is amongst the mountains bordering between Central Asia and China.

Kashmir Lake is near the capital. Its shores have an unrivalled loveliness. The gardens on the northern aspect have been there from the time of Jahangir, and to the south is the Takhti-Suliman, with the fort of Srinuggur on its summit. The lake is everywhere shallow, its water of a brilliant blue colour and great purity, with numerous long water plants and grasses waving beneath the surface, and on its surface are numerous rahd or floating gardens, consisting of wood rafts fixed by poles and covered with earth, and cultivated with flowers.

Yamdok-cho is the famous ring lake of Palti, shown on D'Anville's map. Pandit Nain Singh, C.I.E., who visited it in 1866, reported the water to be perfectly fresh. He was told by a man who had made the circuit of the lake for 'neko' (that is, the making a journey for cleansing from sin and sloth), that the circuit of the lake took 15 days. The lake may be put down as having a circumference of 100 miles. The great iron chain bridge over the Sanpo river, between the Yamdok-cho and Lhassa, is called Chazumtuka, the small monastery at the south entrance to the bridge is called Chazumchori. The bridge is formed of four iron chains, two on each side. From the chains are suspenders of rope carrying the footway, which only allows of one passenger crossing at a time. During the rains the bridge is not in use on account of its northern end being separated from the shore by a wide stretch of water; then the river is crossed in boats. The neighbouring villages support the monastery and maintain the bridge as payment of their revenue. The chains are stretched very tight, and are fastened off by wrapping round huge bollards of wood built into the masonry of the piers. The width between the piers is 300 paces. The chains are formed of loops of iron a foot long; the diameter of the iron rod forming the loops is only one inch.

Yunnan-fu Lake, in China, is 6380 feet above the sea.-Buist's Catalogue; Col. Dixon; Lond. As. Trans. iii. 181 ; As. Journ. xvii. 372; Tod's Rajasthan, i. 389, ii. 627; Russians in Central Asia; Capt. Valikhanof and $M$. Vemukof; Strachey.

LAKH. HIND. A hundred thousand, a vaguely great number; a multitude, as expressed by our word millions, is expressed by the Hindi term lakh-kror. The Tibetans, to express a multitude, use 84,000 ; khrag-khrig, a hundred thousand millions; the Chinese, wan, or 10,000 .

LAKH. HIND. Lac, adopted from the word lakh, a hundred thousand, from the multitude of insects that congregate together. It is sold in the form of chapra-lakh, shell-lac, fused-lac, dana or seed-lac, and kham-lac or lac gathered in a crude state. Lakhi, HrND, a leather dyed red with lakh at Nurpur, etc.

LAKHA, by assassination, mounted the throne of Chitore in S. 1439 (A.D. 1373). His first success was the entire subjugation of the mountainous region of Mairwara, and the destruction of its chief stronghold, Beratgarh, where he erected Bednore. Lakha rana has the merit of having first worked the tin and silver mines of Jawura, in the tract wrested by Khaitsi from the Bhils of Chuppun. It is said the 'seven metals (haft-dhat)' were formerly abundant; but this appears figurative. There is no evidence for the gold, though silver, tin, copper, lead, and antimony were yielded in abundance (the first two from the same matrix), but the tin that has been extracted for many years past yields but a small portion of silver. Lakha rana defeated the Sankla Rajputs of Nagarchal, at Amber.-Rajasthan, i. p. 274.

LAKHIMPUR, a British district of 11,500 square miles, occupying the extreme eastern portion of the province of Assam; situated on both banks of the Brahmaputra, and lying between lat. $26^{\circ} 51^{\prime}$ and $27^{\circ} 54^{\prime} \mathrm{N}$, and between long. $93^{\circ} 49^{\prime}$ and $96^{\circ} 4^{\prime} \mathrm{E}$. The district is bounded north by the Daphla, Miri, Abor, and Mishmi Hills; east by the Mishmi and Singpho Hills; south by the watershed of the Patkai range and the Lohit branch of the Brahmaputra; west by the districts of Darrang and Sibsagar, the latter district being separated by the Maramornai river. The Brahmaputra flows through the district for a distance of 400 miles. As far as Dibrugarh it is navigable.

The most numerous tribe is the Ahom, the former rulers of the country. Next come the kindred Chutias, the Doms, a tribe of peculiar exclusiveness in Assam, and the Koc'chs. There are tribes of Shan descent, who have forced their way across the hills from the south, represented by the Khamti and Singpho; a group of Indo-Chinese origin, comprising the Mishmi, Abor, Miri, Daphla, and Aka, who occupy the slopes and spurs of the Himalayas along the north of the district. The cultivation and manufacture of tea is conducted by European capital and under European supervision.-Imp. Gaz.

LA-KHIRAJ. ARAB. Rent-free land, free from rent or public taxes.

LAKHNOUTI is the city of Gaur, called by Humayun, Jannatabad, and supposed by some to be the Gangia Regia of Ptolemy. It stood on the left bank of the Ganges, about 25 miles below Rajmahal.-Cal. Rev., 1871 ; Rennell, p. 55. 
LAKSHMANA, son of king Dasaratha by his wife Su-Mita. He was twin-brother of Satrughua, and the half-brother and especial friend of Rama Chandra.

LAKSHMI, the Hindu goddess of prosperity, is called also Sri, Padma, Hira, Indira, Jaladhi-ja (ocean born), Chanchala or Lola (the fickle, as goddess of fortune), Loka-mata, mother of the world, and other names, which are mentioned below. There are several legends as to her origin. The Taittiriya Sanbita describes Lakshmi and Sri as two wives of Aditya. The Satapatha Brahmana describes Sri as issuing forth from Prajapati. The Ramayana legend makes her spring from the froth of the ocean, like Aphrodite, in full beauty, with a lotus in her hand, when it was churned by the Asuras and the gods, hence called Kshirabdhitanaya, daughter of the sea of milk. According to the Puranas, she was the daughter of Bhrigu and Khyate, and she was the wife of Rama in all his incarnations. These legends are all comparatively modern, for though in the Rig Veda the word Lakshmi occurs, it is not as a goddess personifying good fortune, though in a kindred significatiou.

As the consort or sakti of Vishnu, she is painted yellow, sitting on the lotus or water-lily, and holding in her hand sometimes the kamala or lotus, at others the shell, or the club of Vishnu. At her birth she was so beautiful that all the gods became enamoured of her, but Vishnu at length obtained her. She is the Hindu Ceres, or goddess of abundance; Sri or Sris, goddess of prosperity. She is called Padma or Kamala, from the lotus or nymphæa being sacred to her; also Varahi (as the energy of Vishnu in the Varaha avatar); Ada Maya, the mother of the world; Narayani, Vidgnani, etc. She is described as the daughter of Bhrigu: but in consequence of the curse of Durvasa upon Indra, she abandoned the three worlds, and concealed herself in the sea of milk, so that the earth no longer enjoyed the blessing of abundance and prosperity. She is said to have been born from the churning of the ocean, rising from the waters radiant with beauty.

\footnotetext{
- Queen of the gods, she leapt to land, A lotus in her perfect hand;

And fondly, of the lotus sprung,

To lotus-bearing Vishnu clung.

Her, gods above and men below,

As beauty's queen and fortune know.'
}

One of her names by Amara Sinha is Kshirabdhitanaya, daughter of the milky sea. When as Rumbha, the sea-born goddess of beauty, she sprang as one of the fourteen gems from the ocean, she then assumes the character of the Venus Aphrodites of the Greeks, who, as Hesiod and Homer sing, arose from the sea, ascended to Olympus, and captivated all the gods.

The followers of Vishnu esteem Lakshmi as the mother of the world, and then call her Ada Maya; and such Vaishnavas as are saktas, that is, adorers of the female energy or nature active, worship her exclusively as the symbol of the Eternal Being.

The name of this goddess is given to the last stalks of grain which the Hindus, as the Scotch, carry home from the field and preserve until next harvest; and with all who desire that prosperity attend their Laksbmi, of whom the Roman prototype is Ceres, it receives their arloration.
In the Belgaum province, until the early part of the 19th century, Maha Lakshmi was regarded as the goddess on whom the productiveness of the land depended, and every twelfth year a great Jatra was held in her honour, at which buffaloes, goats, and fowls were sacrificed, and their blood mixed with boiled rice, a portion of which was sprinkled over every field to secure its fertility. The Dher killed the buffalo, but the Patels sacrificed the smaller animals.

The Mahratta cultivators are still attentive to her worship, and when the rabi crops are well above the ground, they proceed to their fields, where they place five stones around a tree, on which they set spots of vermilion and some wheaten flour; they worship these as the PanchPandu. In the evening they take a few stalks of sorghum, with a lamp surrounded by a cloth, to their homes, which they regard as their Lakshmi. It is an interesting sight to see the wives of the cultivators each returning to her home with her lit-up basket of sorghum. The ceremonial is performed on the 28th day of the moon, Amas, which in 1867 fell on Christmas day. The Hindus have other things which they adopt as their Lakshmi, or luck-token. One that is greatly valued is rarely obtained. Snakes when in congress rise upright almost on the tips of their tails, and a Hindu will touch them with a handkerchief, which he carefully preserves at home.

In Rajputana, in one festival, Lakshmi is depicted by the type of riches, evidently the beneficent Ana Purna in another garb, and the agricultural community place a corn - measure, filled with grain and adorned with flowers, as her representative; or if they adorn her effigies, they are those of Padma, the water-nymph, with a lotus in one hand and the pashu (or fillet for the head) in the other. As Lakshmi was produced at 'the churning of the ocean,' and hence called one of the fourteen gems, she is confounded with Rembha, chief of the Apsara, the Venus of the Hindus. Though both were created from the froth (sara) of the waters (ap or up), they are as distinct as the representations of riches and beauty can be. Lakshmi became the wife of Vishnu or Kaniya, and is represented at the feet of his marine couch when he is floating on the chaotic waters.

In some parts of Northern India, Lakshmi is a personification of the luni-solar year, in the same manner as Durga is that of the solar one; but this allegory is rejected by the pandits of the Karnatic, who likewise deny that she lends occasionally her name to the moon, and even to Jupiter. Amongst the Rajputs, Gouri seems to be the analogue of Ceres, and the festival of the Ahairea or Muhurat ka Shikar-the slaying of the wild boar-is in honour of Gouri or Ceres.

'Lakshmi has no temples, but, being goddess of abundance and good fortune, she is assiduously courted, and is not likely to fall into neglect. She is worshipped on the full moon of Aswin (September-October), by bankers and merchants especially. A ceremony in her honour is performed by a bride and bridegroom when the bride has been brought to her husband's house.

Gaja-Lakshmi, in the Kailasa temple at Ellora, is represented with a lotus in her hand, and four attendant elephants, who are pouring water over her. Like Aphrodite, she sprang from the froth of the ocean (when it was churned), in full 
beauty, with a lotus in her band.-Fergusson and Burgess, p. 458 ; $W$.

LAKSHMI DEVI, a learned woman, who wrote the Vivada Chandra, a law book of the Benares school.

LAKSHMI-VRICSHA, in Hindu mythology, a tree of gold, produced from the churning of the ocean.

LA LA or Lalla. Pers. A clerk, a writer, a copyist; also used as an address, equal to Mr., Sir, as Lala-ji. It is added to the names of the Kayasth race of clerks and accountants, and is allowed to the race generally as an honorary designation. It is also the form of address to Hindu schoolmasters. $-W$.

LALA-KHU, literally tulip disposition; in Baluchistan, an expression of endearment, synonymous with darling, pet, etc. Lala-Rukh, tulip cheeked, frequently used in Persian poetry. Khakani prettily says-

' Lala rūkhä, saman barā, sarv-i-ræwān ki-esti ?

Sang dilā, sitam-garā, afat-i-jān ki-esti ?'

LALAM or Lalmi. Pukнto. Land dependent on rain for its cultivation.

LAL BAGH. Hind., Pers. Ruby garden, a country house or pleasure garden. Many of the Muhammadan rulers of India had such gardens; there is one at Ahmadnaggur and another at Bangalore.

LAL-BEG, a designation of the Muhammadan sweepers.

LAL DAS, a Meo of Ulwar, who lived S. 1597, A.D. 1540. He fornded the Lal Dasi sect of monotheists. He lived for many years at Dhaoli Dhub, and at Bandoli, and at Todi in Gurgaon. He had a son and a daughter; one infant son was buried at Bandoli. He died A.D. 1648 ?

LAL-GURU, the familiar name of the rakshasha Aronakarat, worshipped by the Bhangi race of Northern India.

LALI or Leli, a tribe who inhabit the high glens on the north side of the Safed Koh range.

LALITADITYA, a celebrated king of Kashmir, who took the city of Kanouj, carried his conquests to the far south, and returned by Dwaraka or Gujerat and the IVestern Sea.

LALITA - VISTARA, a legendary life of Buddha, compiled 1400 years after he died. It is one of the most popular books of the Buddhists, and is part of the Buddhist canon. It describes the four drives of Buddha. His coachman was Chandaka (Sanan, BurM.). It was translated by Foucaud, and printed in the Bibliotheca Indica. See Joannes Damascenus.

LALITPUR, a British district in the LieutenantGovernorship of the North-Western Provinces, lying between lat. $24^{\circ} 9^{\prime} 30^{\prime \prime}$ and $25^{\circ} 14^{\prime} \mathrm{N}$., and between long. $78^{\circ} 12^{\prime} 20^{\prime \prime}$ and $79^{\circ} 2^{\prime} 15^{\prime \prime} \mathrm{E}$. Area, 1947 square miles; pop. in 1872, 212,661 persons. Lalitpur is the southern district of the Jhansi division. The earliest inhabitants of Lalitpur whom tradition commemorates were the aboriginal tribe of Gonds. At present the more numerous tribes are Chamar, Lodha, Kach'hi, Ahir, and Gond; about 10,000 Sahariyas, scattered all over the district in the thickly-wooded tracts. The latter are a very degraded type of humanity, subsisting till lately on the produce of the jungle, and popularly described as more like monkeys than men.-Imp. Gaz.

LALLEMANTIA IBERICA is the Gundschit
Sivah of Kerman. It is grown from Suria to N. Persia, and attains a height of $1 \frac{1}{2}$ to $2 \frac{1}{4}$ feet. A plant will give 2500 seeds, from which a pure - oil is obtained, suitable for culinary purposes.

LALLY. Count Lally Tollendal, a French officer, arrived in India in 1758 as commander-inchief in the French possessions. His father was Sir Gerard O'Lally, an Irishman, who, having defended Limerick, took service with the French. He formed the Irish Brigade, and his son Thomas Arthur, at the age of one (1702) was a private in the French army, and at the age of forty-three (1745), at Fontenoy, his charge and that of his brigade, the command of which he had inherited from a grand-uncle, Count Dillon, decided the day, which had been won by the stolid, immoveable English advance. Lally served in Russia with credit, and under Marshal Saxe, who regarded him as a future Marechal de France, and on the 31st December 1756, when 54, he was appointed commander-in-chief of the French possessions in the east; he was in the vigour of his powers, and a perfect disciplinarian; but he at once reversed the policy of Dupleix, whose whole policy had been a policy of conciliation. But with Lally, Brahmans were compelled to carry the loads their caste forbade them to touch, and were yoked with the Pariah and Sudra to draw carts. When de Leyrit and the Council remonstrated, they were treated as accomplices who had been bribed. When before Madras his officers shrank from an assault out of hate for him, and at last, deserted by his fleet, with a mutiny in his army, and an object of active hatred to every officer under his command, he was compelled to raise Bussy to the active command. After the battle of Wandiwash, in which Colonel, afterwards Sir, Eyre Coote, totally defeated him, he was compelled, with mutinous troops and hostile population, to defend Pondicherry. But all resources having been exhausted, and having but four ounces of rice left for distribution to each soldier, he was compelled to surrender at discretion (16th January 1761). The inhabitants had subsisted for a long time upon their elephants, horses, camels, etc.; a dog sold for 24 rupees. He returned to France, and, on an investigation, was condemned on two charges, -insolence to his majesty's other officers, which was true, treason to his majesty, which was false,-was taken in a dungcart to his execution, and died exclaiming, "Tell my judges that God has given me grace to pardon them; if I were to see them again, I might no longer have the forbearance to do it.' - The Career of Count Lally, a Lecture by Major G. B. Malleson, Calcutta.

LAL MITTEE, HIND., red earth, is a term applied to ordinary soil and to, murum; murum being a term indiscriminately applied to decomposing trap, soft, sedimentary rock, or anything which is too hard for agricultural, and too soft for building purposes. Red earth is found lying immediately over greenstone, or some similar variety of friable trap.-Carter's Geolog. Papers, p. 185.

LAL SHAHBAZ, a Muhammadan saint, whose shrine at Sehwan is a place of pilgrimage. His tomb is enclosed in a quadrangular edifice, covered with a dome and lantern, said to have been built A.D. 1356. It has beautiful encaustic tiles, with Arabic inscriptions. Mirza Jani of the 
Tarkhan dynasty, A.D. 1639, built a still larger tomb to this saint. A gate and balustrade of hammered silver was added to it by Mir Karam Ali Khan Talpur, who also crowned the domes with silver spires.

LAMA, correctly b'lama, is the Tibetan word for a superior, and applied to monks. The Dalai Lama, literally ocean superior, is the highest in rank of the Tibetan Lamas. He resides at Yulsung or Lhassa. He is viewed as an incarnation of the Dlyano Bodhi-satwa Chenresi, who is supposed to effect his re-embodiment by a beam of light which issues from his body and enters the individual whom he selects for his re-descent. The honorific title of Lama (b'lama) strictly belongs only to the superiors of convents, but is applied also to ordained priests. The Tibetan priests are ordained to celibacy; but as they live under the same roof with nuns, this prohibition is probably not followed out. The Khanpo is a head Lama, and these are the superiors of the larger monasteries. The Dalai Lamas are selected by the clergy, but, since 1792 , the Chinese Government influences the election, to obtain the sons of families known for their loyalty. In Bhutan the Khanpo have made themselves almost independent of the Dalai Lamas, and the ruler of Bhutan, the Dharma Rinpoche or Dharma raja, yields but a loose obedience. Lamas are very numerous at Lhassa and its vicinity; Dr. Campbell gives a list of 12 principal monasteries, inhabited by a total of 18,500 Lamas. In Ladakh there are about 12,000 Lamas in a population of 158,000 . There has been some misapprehension regarding the Buddha and Bodhi-satwa, the regeneration of the Grand Lama being considered by some as an exceptional case of a Buddha returning amongst mankind. Mr. Hodgson (pp. 137, 138) truly calls the divine Lamas of Tibet, Arhanta, but he believes that a very gross superstition has wrested the just notion of the character to its own use, and so created the immortal mortals, or present palpable divinities of Tibet. Fra Orazio says that 'Lama sempre sara coll' istessa anima del medesime (iany-c' iub) oppure in altri corpi.' Remusat was not aware of this fact when he stated, 'Les Lamas du Tibet se considerent eux-mêmes comme autant de divinités (Bouddhas) incarnées pour le salut des hommes.' But the explanation which Major Cunningham received in Ladakb, which is the same as that obtained by Fra Orazio in Lhassa, is simple and convincing. The Grand Lama is only a regenerated Bod'hi-satwa, who refrains from accepting Buddhahood that he may continue to be born again and again for the benefit of mankind; for a Buaddha cannot possibly be regenerated, and hence the famous epithets of Sathagata, thus gone, and Sugata, well gone, or gone for ever. The ordinary monk or priest in Tibet is the Gylong, above whom are the Lama or presidents, and below whom are the Tohba and Tuppa. The Tuppa is a probationer who is admitted into the establisbment to which he would attach himself at the age of 8 or 10 , and receives instruction accordingly. At 15 , he becomes a Tohba, and at 24 a Gylong, provided his acquirements be satisfactory.

There are two sects, the Gyllupka, who dress in yellow, and the Shammar in red, the Shammar Gylong being allowed to marry.
Tepa is the Lama Yeungjing, the private guru or high priest of the Grand Lama. He is also appointed by order of the emperor, and is sometimes an avatari Lama, but not always. His office is to teach and train the Grand Lama in childhood and youth, and lead him, if he can, afterwards. He is indeed an important personage in the Buddhist world, being no less than the keeper of the Grand Lama's conscience. The nomination to this post being in the hands of the emperor, furnishes an interesting clue to the extent of the imperial power over the church of Tibet.

The Che Kap Kemu Lama is a churchman of great influence in the government. He appears to represent the Grand Lama in the council of state and in the deliberations of the Shapi. He may be called secretary or minister for the church ; and the Shapi may, correctly enough, be called the financial, judicial, revenue, and home secretaries or ministers.

The Tibetan treasury is managed by two officers named Jhassa; both are Lamas, and act conjointly, although one of them is treasurer on behalf of the Grand Lama, and the other on behalf of the Noume-hen, or temporal estate. They are assisterl by two sub-treasurers, styled Shangjotes. Four officers, designated Da-pun, are the commanders of the Tibetan troops, and act as civil and political commissioners on occasions of frontier or other disturbances; they are Tibetans, and not Lamas. The ordinary course of official promotion is from a Da-pun to a Shapi; of equal rank to the Da-pun is the Che-pun, who is, however, a civil officer, and acts in all departments as leputy to the Shapi. Shate Shapi was the energetic commander-in-chief of the Tibetan army which opposed the Nepalese under Jung Bahadur. The Shapi is often employed as commissioner on deputations in civil affairs, either judicial or fiscal, and all the cases sent up by the police for trial before the Shapi are forwarded through this officer. All appointments to the offices above noted require the confirmation of the emperor.

A religious exercise or penance, much practised by the Buddhist, is that of going round the convent, prostrating himself at every step. Sometimes an immense number of devotees will be going through their act of devotion at the same time, one after the other, and they will include all the neighbouring buildings in their prostrations. The feat must be performed all at once, without any interruption, even that of stopping for a few moments to take nourishment; and the prostrations must be perfect, that is to say, the body must be extended its whole length, and the forehead must touch the earth, while the arms are stretched out in front, and the hands joined. Before rising, also, the pilgrim must describe a circle with two rams' horns, which he holds in his hands. Some content themselves with taking a walk round the convent, rolling all the while between their fingers the beads of their long chaplet, or giving a rotatory movement to a kind of praying mill, which turns with incredible rapidity. This instrument is called a Chu-kor, that is, turning prayer ; and it is common enough to see these fixed in the bed of a running stream, as they are then set in motion by the water, and go on praying night and dny, to the special 
benefit of the person who has placed them there. The Tartars also suspend these convenient implements over their domestic hearths, that they may be put in motion by the current of cool air from the opening of the tent, and so twirl for the peace and prosperity of the family. Another machine which the Buddhists make use of to simplify their devotional activity is that of a large barrel turning on an axis. It is made of thick pasteboard, fabricated of innumerable sheets of paper pasted one on another, and upon which are written in Tibetan character the prayers most in fashion. Those who have not sufficient zeal or sufficient strength to place on their backs an immense load of books, and prostrate themselves at every step in the mud, adopt this easier method, and the devout can then eat, drink, and sleep at their ease, while the complaisant machine does all their praying for them.

Kablai Khan was the first of the Mongol Khakans to adopt Buddhism as the state religion. The Mongols called the Buddhist priests Lama, and in January 1261 Kablai Khan promoted a young man called Mati Dhwadsha to the title Pakba Lama, or supreme holy Lama. He was born at Sazghia in Tibet, and belonged to one of its best families, that of the Tsukoan, who had for more than six centuries furnished ministers to the kings of Tibet and other western princes. By his wisdom, etc., he won the confidence of Kablai Khan, who not only made him Grand Lama, but also temporal sovereign of Tibet, with the title of ' King of the Great and Precious Law and Institutor' of the Empire.? Such was the origin of the Grand Lama. Lamaism in China is a state religion.

The inanes of the dead Lamas are revered in several ways, but only of the soverign Lamas are the mortal remains preserved entire. So soon as life leaves the body, it is seated upright, with the legs folded in front, the instep resting on each thigh, and the sides of the feet turned upwards. the right hand is rested with its back on the thigh, with the thumb bent across the palm. The left arm is bent and held close to the body, the hand being open and the thumb touching the point of the shoulder; this is the attiturle of alostracted meditation. They are deposited entire in shrines prepared for their remains, which are deposited in monuments, ever af terwards regarded as sacred, and visited with religious awe. The bodies of the inferior Lama are usually burnt, and their ashes preserved in little netallic idols, to which places are assigned in their sacred cabinets. Ordinary persons are treated with less ceremony, - some are carried to lofty eminences, where they are left to be devoured by ravens, kites, and other carnivorous amimals. But they also have places surrounded by walls, where the dead are placed. The Mongols sometimes bury their dead; often they leave them exposed in their cofins, or cover them with stomes, paying regard to the sign under which the deceased was born, his age, the day and hour of his death, which determine the mode in which he is to be interred. For this purpose they consult some books, which are explained to them by the Lama. Sometimes they burn the corpse, or leave it exposed to the birds and wild beasts. Children who die suddenly are left by their parents on the road. In Spiti, in the North-IVest Himalaya, when a person dies, the body is sometimes buried, or burnt, or thrown into the river, or cut into small pieces and burnt; admonitions are made over the body to the departed spirit, such as, "Do not trouble yourself, you camnot enter it (meaning the dead body); in summer it quickly becomes corrupt, in winter it freezes and is too cold for you.' Howorth's Hist. of the Mongols, p. 220 ; Fytche, i. p. 328 ; Fra Orazio in Nouv. Jour. Asiat. xiv. p. 408; Jour. des Savantes, May 1831, p. 263 ; Turner; Cunningham's Blilsa Topes; Lubbock's Orig. of Civil.; Huc's Journey; Timkowski's Journey; Moorcroft's Travels.

L.AMAU or Lummun, a trading race who formerly brought slaves to Bombay. Lamu was long a centre of the African slave trade, and the former importers of slaves into British India were called the Lamau.

LAMB. A vegetable curiosity known as the Tartarian Lamb was thus apostrophized by Dr.

Darwin :-

' Cradled in snow, and fanned by Arctic air,

Shines, gentle Barometz! thy golden hair;

Rooted in earth each cloven hoof descends,

And round and round her flexile neck she bends;

Crops the grey coral-moss and hoary thyme,

Or laps with rosy tongue the melting rime;

Eyes with mute tenderness her distant dam,

Or seems to bleat, a Vegetable Lamb.

The plant about which these fables had gathered is referred to the fern genus Cibotium, formerly to Aspidium. The rhizoma of Aspidiun barometz presents a rude resemblance to an animal. It is covered with a silky down, and when cut into has a soft inside, with a reddish, flesh-coloured appearance, sufficient to account for the origin of the fables with regard to its animal nature.Yule, Cathay, i. p. 145.

LAMBADI, Lambani, Lambari, or Binjara, are chiefly migratory grain merchants, spread all over India, from the Panjab to Cape Comorin. The Binjara style themselves Gohur. The Lambari are carriers. In some districts they are addicted to thieving and robbery, and are believed to practise infanticide, human sacrifices, secret murders, witchcraft, sorcery. Their religion is a mixture of Hinduism and Muhammadanism, and their priests control the bands. Their dress, language, habits, and customs are peculiar. They are sworn to secrecy as to their habits, manners, doings, and ceremonies, and do not let straugers in to their secrets. The Lambari grain carriers pursue all the avocations of the Binjara, with whom, however, they do not eat or intermarry. The Binjara of Berar is a notorious plunderer. In the rainy season they make gumny cloths, and engage in ficld labour. Their language is said to be intermediate between the Hindi of Marwar and the Mahrati. The Lambadi speak a dialect of the Hindi..

LAMBAR or Lambardar, in Northern India, the village headman, who collects the revenue from the proprietors of his village, and pays it into the tahsil; he is a sort of middleman between the officials of Government and the body of proprietors and rent-payers; he is called in Hazara, etc., Mustajir ; and in other parts, as also generally before British rule in the Panjab, Mukaddam. It is an Anglo-Indian word from number and dar, and in Bengal is a farmer who settles with the Govermment. In the Malratta country this task is taken by the potail. 
LAMB - DOR. HIND. Cord from fibre of Calotropis gigantea.

LAMBODURA, a name of the Hindu god Ganesa, from SANSK, Lumba, long, and Udara, the belly.

LAMB-SKINS.

Peaux de agneaux, Pilli agnelline, .

GER. Pielles de corderos, . SP.

Lamb-skins are very extensively used with the hair on in Afghanistan, Hazara, Kafiristan, N.W. Himalaya, Tartary, in Tibet, China, Persia, as articles of dress for the head and for mantles. Lamb-skins are used in Persia and Tibet dressed with the wool and made into caps. Lamb-skins sell at Leh for one rupee each; lambs are much cheaper if bought alive. Lamb-skins are imported into Britain from the north of Italy, Sicily, and Spain, and are dressed white or coloured for gloves. The skins of goats and kids form the best kinds of light leather. The chief supply of the best kid-skins is from Switzerland and Tuscany, whence they are shipped, chiefly at Leghorn.

LAMBTON, COLONEL, a British officer who commenced the Trigonometrical Survey of India, continued by Sir George Everest, Sir Andrew Waugh, and others. Colonel Lambton was Surveyor-General of India, and is buried near Hinganghat. He wrote on the Measurement of an Arc on the Meridian in As. Res. xiii. p. 1, ibid., 1816, xii. p. 285; Method for extending a Geographical Survey across the Peninsula of India, ibid., 1801, vii. p. 312; Measurement of an Arc on the Meridian on the Coromandel Coast, ibid., 1805, viii. p. 137, ibid., 1816, xii. p. 1; Account of Trigonometrical Operations across India, connecting Fort St. George and Mangalore, ibid., 1808, x. p. 290.-Dr. Buist's Cat.

LAMECH, Laghman, Lamghan, or Lanpo district is noted by Hiwen Thsang as being 600 li, or just 100 miles, to the east of Kapisene. The modern name is only an abbreviation of Lampaka, formed by the elision of the labial. It is also called Laghman by the simple transposition of the middle consonants, which is a common practice in the east, and is a rule in the Celtic grammar. The credulous Muhammadans derive the name from the patriarch Lamech, whose tomb they affirm still exists in Lamghan. It is noticed by Baber and by Abul Fazl.-Cunningham, Ancient India, p. 42.

LAMELLICORNIA, the chafer group of beetles; antennæ short, terminating in a club formed of a number of moveable layers. They feed on plants or dung. See Insects.

LAMINARIA, or Tangles, a genus of the Fucacex. L. bulbosa, Ag., and L. digitata, Lam., are deep-sea plants, but their fronds are thrown up on the sind beach. Laminaria saccharina, Lam., is the sweet tangle. the Gillur ka patta, HIND., and Hai-tai of the Chinese. It is used in scrofula and in syphilitic eruptions, is officinal at Lahore and in Kashmir. The fronds are procured from Tibet, where they are reported to grow in a salt lake, but some maintain that they are brought from the Caspian Sea. This plant, the edible sugar sea-beet, is one of the algæ, and probably grows in all the salt lakes of High Asia, also it is probably brought from the sea through China. It is imported from Yarkand and viâ Kashmir. It contains much iodine, and acts as an alterative in scrofulous affections and enlargement of the thryroid gland or goitre (gillar or gal), a common disease in many parts of the Himalaya. If washed and hung up, a saccharine substance exudes. It consists of long ribbon-like pieces. Dr. Cayley states that 16 seers of this were imported from Yarkand to Leh in 1867. This and $\mathrm{L}$. digitata furnish to the Chinese size, jelly, and many excellent dishes of food. Laminarian horn is prepared from $\mathrm{L}$. buccinaris, Ag., of the Cape of Good Hope. L. saccharina is highly esteemed in Japan, where it is extensively used as an article of diet, being first washed in cold water and then boiled in milk or broth.

Several species of Laminaria, Rhodomenia, Iridæa, etc., are included under the Chinese names Hai-tai, Hai-wan, and Kwan-pu, the last being the tangle.-Honigberger; Powell's Handbook, i. p. $384 ; D r . J$. L. Steurart; Simmonds' Comml. Product, p. $379 ;$ Smith, M. M. Ch. See Seaweed.

LAMMAY. BURM. In Amherst, a timber used for house posts ; it is a red, light, but useful timber, like sandal-wood, and is free from attacks of insects.-Captain Dance.

LAMMERGEYER, or Bearded Vulture, the Gypaetus barbatus, is without doubt the Roc of Arabian Nights and the Nisser mentioned by Bruce in his Travels in Abyssinia. - Adams. See Birds.

LAMP.

Dipa, . . . . Beng. Lampadu, . . . Rus. Lampe, : : FR., GER. Dwipa, . SANsK., TEL. Charagh, : . HIND. Lampara, : . SP. Lucerna, . . IT. Vallak, ... TAM.

Lamps are formed of various materials and shapes, arranged for burning materials readily fluid at ordinary temperatures, in order to produce light. Muhammadans, like the Jews, light a lamp in honour of persons, and Hindus follow this custom.

A feast of lamps was held by the Egyptians in honour of the goddess of war. They held these solemn festivals in honour of Minerva at Sais. We may deduce the origin of this grand oriental festival from that common mother-country in Central Asia, whence the Dewali, or festival of lamps, radiated to remote China, the Nile, the Ganges, and the shores of the Tigris; and the lamps and fireworks of the Shab-i-Barat of the Muhammadans of Islam is but the feast of lamps of the Hindus. In all these there is a mixture of the attributes of Ceres and Proserpine, of Plutus and Pluto. Lakshmi partakes of the attributes of both the first, while Kuvera, who is conjoined with her, is Plutus, as Yama is Pluto, the infernal judge. The consecrated lamps and the libations of oil are all dedicated to him; and, in Rajputana, 'torches and flaming brands are likewise kindled and consecrated, to burn the bodies of kinsmen who may be dead in battle in a foreign land, and light them through the shades of death to the mausion of Yama.'

The Hindus have a feast of lamps, Dipawali, at the same period of the year as that of the Jews, in honour of Kartikeya or Skanda, the god of war; and the Rajputs, in honour of Lakshmi. The Parsee religionists have a feast of lamps. The Chinese have a feast of lanterns, on which occasion are many inscriptions on the lanterns; 
a usual invocation is Tien-ti, San-sbiai, Vaulin Chin-tsai; Oh! heaven, earth, the three limits, and thousand intelligences, hail!

The Dipdan is a lamp suspended from a tree for ten days after the death of a relative, to light the spirit on its way to Yamapuri, the city of Yama, the judge of the dead.

Every Hindu temple of any pretensions has a st'hamba, or pillar of stone or wood for lamps.Roberts, p. 17; Faulkner; Wilson's Gloss. LAMP-BLACK.

\section{Kohl,}

Kohl, . ARAB. Arang-para, . MALAY. Noir de fumée, . . Fr. Kajal, Siahi, . . Pkrs. Kienruss, .. . . Ger. Negro de humo, . . SP. Kajal, . . HIND. Mai, . . . . TAM. Nero di fumo,: : IT. Katike, : : : TEL.

In Europe, lamp-black is obtained by burning the impurities left in the precipitation of tar and pitch, and collecting the deposit in the form of soot. The finest kind is procured by collecting the smoke from an oil-lamp. It is used in the arts, particularly in the manufacture of printer's ink. The Muhammadan women of Arabia, Egypt, Persia, and India stain their eyelashes with it. Muhammadan men use antimony for this purpose.-M'Culloch; Herklots.

LAMPEAN or Laban, a wood of Java, light but durable, and affords materials for the handles of the spears or pikes borne by the natives.

LAMP-OIL.

Charagh ka tel, . HiND. | Vallak yennai, . TAu,

The kind of oil used in different parts of the world for burning in lamps varies with the sources of supply, and these are numerous. In India, cocoanut, castor, poppy, sesamum, and ground-nut oils are in use; on the eastern and southern coasts of the Mediterranean and in China, oil of sesamum seed; and in tropical countries, cocoanut oil (which at the temperature of Britain is a white solid, like tallow) is burnt, often in lamps made of the shell of the cocoanut and of bamboo. Much of the lamp-oil used in China is expressed from the seeds of Camellia oleifera, cultivated for the purpose, as is also a shrub, Croton sebiferum, from the fruit of which a solid oil is obtained by expression. The cocoanut and poppy oils have double the illuminating power of castor, gingelly, and earth-nut. Petroleum and naphtha are used in localities which produce them.

LAMPONG, a district of Sumatra, of about 12,926 square English miles, bounded on the south by the Indian Sea and the Straits of Sunda, and on the east by Java; the rivers Masuji and Pisang bound it on the north and west. In the year 1882 the population comprised 77 Europeans, 125,401 natives, 246 Chinese, 18 Arabs, and 14 others.

LAMPYRIDES, a tribe of the Malacodermous Coleoptera, including the glow-worm and firefly. Fire-fly is the name given to species of Elater and Lampyris, of the order Coleoptera, and to the Fulgora of the tropics. F. laternaria is of S. America, F. candelaria of S.E. Asia. The latter resort to moist places. The Lampyris fire-fly is the Mouche lumineuse of the French. The Romans styled the luminous insects by the common names Noctiluca and Luciola. Glowworms are common in all parts of India. The glow-worm of Ceylon is the female of a Lampyris, and attaius a size of nearly 3 inches. Mr. Morren reported that he found phosphorous in glowworms, as well as a system of prisms in transparent lenses above the luminous matter. The fire-fly is a little luminous beetle, a species of Lampyris. The lower part of its body has some apparatus for emitting a bright phosphorescent light. Usually it is emitted in flashes at intervals of a second, and it is interesting to guess where the creature in its flight will next show itself. But occasionally the light is continuous. A splendid species of Lampyris was observed by Mr. Adams at Sarawak ; when placed around the finger, it resembled a superb diamond ring. See Insects.

LAM-YIP, CHIN. (blue leaf), with alum and sulphate of copper, are used for dyeing green.Von Mueller.

LANA, Hind., of the Panjab, salsolaceous plants used for camel feeding and burning for sajji, barilla. The chief of these are-

Baggi lana, also Chhoti lane, Suæd̀a fruticosa.

Kuti lana, Withania coagulans.

Shori lana, Anabasis multiflora.

Gora lana, Anabasis multiflora, also Caroxylon foetidum. Metra lana, Anabasis multiflora.

Moti lana, Caroxylon fotidum.

Peshak lana, Suæda fruticosa.

Lanebar is Orthanthera viminea.

LANAULI, in lat. $18^{\circ} 45^{\prime} \mathrm{N}$., and long. $73^{\circ} 26^{\prime}$ E., in the Dekhan, east of the Bhor ghat. The mean height of the village is 2307 feet.

LANCA, in Hindu cosmogony, one of the four imaginary cities which are supposed to lie under the equator at $90^{\circ}$ distance from each other, viz. 1st, Yavacoti ; 2d, Lanca ; 3d, Romaca ; and 4th, Siddhapuri. Bornacoti is stated to be the third, but the pandits have rejected that spelling. Lanca is considered by all manner of Indian astronomers to lie under the first meridian, to which all computations should be referred; though several, and particularly the Telugu people, refer to that of Rameswara. Towards the north, and under the same meridian as Lanca, the Sastra states that there are two other cities and a great mountain, viz. Avanti (supposed to be the same as Ujani or Oogein), Rohitaca, the mountain; and Sannihita sarah, which in former, or rather fabulous times, were the seats of colleges and observatories. The meridian of Lanca lies in $75^{\circ} 53^{\prime} 15^{\prime \prime}(5 \mathrm{~h}$. $3 \mathrm{~m} .33 \mathrm{~s}$.) east of Greenwich; and $73^{\circ} 33^{\prime}$ ( $4 \mathrm{~h}$. 54m. 12s.) east of Paris.-Warren. Kala Sanhita. LANCASTER, CAPTAIN SIR JAMES, sailed from Torbay on the $2 d$ May 1601, with a fleet of four ships and a victualler, for India. He was general of the fleet in the first voyage made on account of the East India Company. The pilot was Captain John Davis. The commander of the next fleet was Captain (Sir Henry) Middleton, to Bantam and the Moluccas. They only visited the eastern islands, and brought home ladings of pepper. Captain Keeling commanded in the third voyage in 1606-1607. He went first to Surat, where he landed Mr. Finch to form a factory, and sent Captain Hawkins, his second in command, on an embassy to the Great Moghul. Then followed Sharpey's unlucky voyage and shipwreck on the shoals of Cambay, and Sares' remarkable voyage to Japan. Mr. John Davis of Limehouse, who made five royages, condensed the observations of these navigators into Rules for the East India Navigations.

Captain Sir James Lancaster advocated the N.W. passage to India, which led to Hudson's 
famous voyage. His name is preserved in Lancaster Sound, in Baffin's Bay. The voyage of Sir Henry Middleton to Bantam and the Molucca Islands was printed for Walter Burre in 1606.Harris' Voyages.

LANCAVA. This group of islands, off the Malay coast, consists of three large and many smaller, extending nearly N.W. and S.E., from lat. $6^{\circ} 8^{\prime} \mathrm{N}$. They are high, bold islands, particularly Lancava, the centre one, which has on it a high peaked hill. The Laddas, which form the easi and south parts of the group, are high barren islands.

LANCE-WOOD, a commercial name, in use in most countries to indicate a light elastic wood. The lance-wood of Tenasserim is from a tree which produces a timber possessing the properties of lance-wood. It is not uncommon in the Tenasserim provinces, but it belongs to the dogbane tribe, and is not at all related to Guatteria virgata, the lance-wood of commerce. The Meenaban or Pavètta Indica? one of the Cinchonacere, is called Moulmein lance-wood, but it is not equal to lance-wood in elasticity, and beyond beingr useful for handles of tools, and such purposes, Major Benson thinks its qualities have been generally overrated; besides, it is susceptible to the attacks of insects. The Guatteria virgata of Jamaica is much valued as a lance-wood on account of its exceeding even ash in lightness, strength, and elasticity. It is chiefly used for shafts of carriages. Lance-wood of Australia is the Backhousia Australis, a myrtaceous tree. Lance-wood of Moulmein is from a tree found all over the province, which yields a wood that the residents at Moulmein sometimes call lance-wood tree. The Karen make bows of it, but prefer Cassia fistula. Dr. Mason never met with the tree in flower, but thinks it a species of Dalbergia, one of the Apocynaceæ, though it may possibly be a Cassia._Dr. Mason; Faulkner.

LAND. According to Menu, cultivated land is the property of him who cut away the wood, or who cleared and tilled it, and this ordinance is binding on all the Hindu race, which no international wars or conquests bas overturned. At present, in British India, -

Oulh has great zamindars, almost complete owners, with few subordinate rights; tenantright was found non-existent, but has since been conceded to old proprietors, a limited class.

The N.W. Provinces has moderate proprietors; the old ryots have fixity of tenure at a fair rent.

The Panjab, very small and very numerous proprictors; old ryots have a measure of fixity of tenure at fair rates.

In Bengal are great zamindars, whose rights are limited. Numerous sub-proprietors of several grades under them, with ancient ryots who have fixed tenure and fixed rents, and other old ryots who have fixity of tenure at a fair reut, variable from time to time.

The Central Provinces has moderate proprietors with ancient ryots, who are sub-proprietors of their holdings at rents fixed for the term of each settlement. Other old ryots have fixity of tenure at a fair rent. Ryots are complete proprietors of the soil, subject only to payment of revenue.

Sir William Muir says that the British found the lands of India owned or managed in three different ways, viz, $a$. ryot occupancy or pro- prietorship; $b$. official zamindarship; and $c$. village proprietorsbip.

The first of these signifies that the ryot is the hereditary occupant or holder of his own individual holding. The last, village proprietorship, signifies that one or more persons, or a body of co-parceners, possess proprietary right over all the land (including waste) contained within the boundary of their village or estate; village proprietors may be either talukdars, zamindars, or pattidars, or merabers of a proprietary or cultivating brotherhood. In a general sense, il may be stated that on the British obtaining possession of the empire of India, they found ryot proprietorship prevailing in the south of India, official zamindarship in Bengal, and village proprietorship in the N.W. Provinces. The zamindar of Bengal was nothing more than a manager; or, if he laid clairn to the ownership, the title was shared between him and the ryot. It is far otherwise in the N.W. Provinces and in Oudh. In both of these the village landlord, whether talukdar or zamindar, is owner of the soil. The cultivating ryot was distinctly regarded as cultivating the lands of another. $\mathrm{He}$ appears nowhere to have claimed the right of occupying the fields he cultivated longer than he cultivated them.

Among the Mahratta communities, the whole land of a village is designated Sewar, being contained within the village sew or boundary Wawur, cultivated or arable land; Tika, a parcel, a field; Shet, a field; and Purtim, a field of convenient length; Mullai, garden or meadow land; Kurun, preserved grass land; Gairan, pasture land; Gutkoli or 'I'hul, or field of an extinct family.

Menu, on the principle that the state is the sole owner of the entire land of the country, says there is to be a lord of a single village, a lord of ten, a lord of one hundred, and a lord of a thousand towns, all to be appointed by the king. Each is to report all offences, etc., to his immediate superior. The compensation for a lord of one town is the provisions and other articles to which the king is entitled from that town; that of a lord of ten villages, two ploughs of land; the lord of a hundred villages is to have the land of a small village; and of a thousand, that of a small town.

All ancient legislators, especially Moses, grounded the success of their ordinances concerning virtue, justice, and morality upon securing hereditary estates, or at least landed property, to the greatest possible number of citizens.

The most prominent feature of the tenure of land throughout the Peninsula is that the soil is everywhere held by small farmers not ranking above labourers. When the British became masters of the country, they retained this system, but gradually moderated the revenue demand. Later on they attempted to establish landlords in some parts of India, in the hope that they would perform the functions of English and Scotch landlords, but this hope has not been realized, and the people have been worse rack-rented under this plan than under the native governments. In other parts of the country they made the peasantry proprietors, who, not understanding the boon, sold themselves to usurers, so that their last state has become worse than the first. According to the ancient Indian practice, an area of land is often 
named after the quantity of seed required to sow it, or the quantity it will produce, and of course the actual area differs according to the opinion of the person who makes the estimate. Where linear definition is given, mention is made of rods or ropes, of so many cubits, but the cubit is undefined, and areas of the same denomination are derived from different multiples of the rod or rope. Of the more definite terms, the bigha prevails in Bengal and the N.W. Provinces. In Bengal it is 1600 square yards, and in the N.W. Provinces it is 3025 square yards. In the Bombay Presidency it is not authoritatively defined, but averages about $\frac{3}{5}$ of an acre. The term is quite unknown in the Madras Presidency, where the authorized measure is the cawnie of 57,600 square feet, or 1.3223 acre: there are also other local land measures defined, but presenting great differences one from the other, as the chain of 3.64 acres, the seed-cottah of 1.62 acre, the vaylie of 6.6 acres, and the bullah of 3.82 acres.-Elphinstone, Hist. of India, ii. p. 39 ; Niebuhr. See Weights and Measures.

LANDA. HiND. A style of writing used by village shopkeepers, etc.

LANDH. PUsfTu. Mutton dried like pemmican by the people of Shall. The Baluch call it Khaddit. LANDOLPHIA FLORIDA, Benth., the African rubber tree, also L. Oweniensis, are the best known, but there are other species. The stems attain a diameter of six or eight inches a few feet from the ground. The sweet acidulous pulp of the fruit is eaten by the people.

LANDOUR, a sanitary station in the Dehra Doon district, in lat. $30^{\circ} 27^{\prime} 30^{\prime \prime} \mathrm{N}$., long. $78^{\circ} 8^{\prime}$ $30^{\prime \prime} \mathrm{E}$. It is on a ridge, bounding Dehra Doon on the north; it is 3 miles distant from Mussoori, is 7459 feet above the sea, and 1041 miles from Calcutta. In the ascent from Rajpur, at the foot of the hills, to Landour, the traveller passes through a vegetation which graduates insensibly from the tropical into that of temperate regions. The Doon contains numerous forms which are strictly tropical, such as, among forest trees, the Acacia elata, which extends up along the Terai from the banks of the Irawadi; the sal or Shorea robusta, and species of Pterospermum, etc.; while the slopes of Mussoori and Landour are covered with forests of oak and rhododendron, together with the other temperate forms generally associated with them. Dr. Nurray attempted in 1843-44 to employ the sulphuretted and chalybeate springs in the valley below Landour for the benefit of the invalids at that sanatorium, but the situation of the springs, at the bottom of a hot and confined though picturesque valley, was an obstacle to success.

LANDSE, the term applied by the Singhalese to anything European. It is a corruption of Hollandishche, Dutch.-Teunent's Christianity in Ceylon, p. 103.

LANE, EDWARD WILIIAM, an Arabic scholar, was the third son of Theophilus Lane, a prebendary of Hereford, and of Sophia Gardiner, a niece of the artist Gainsborough. He was born in 1801, and died in 1876. He visited Egypt first in 1825 , and stayed there for a time, spent partly in Cairo, and partly among the tombs at Thebes, with a view to the writing of his Description of Eigypt, which was never published. The publishers shrank from the expense which its illustrations would entail, and Lane would not consent to the appearance of the work in an incomplete form. His second visit to Egypt was in 1833. Its chief object was the perfecting of his Manners and Customs of the Modern Egyptians, his first published work, which appeared in 1836. About a year after his arrival in Cairo, the plague destroyed about 75,000 of the inhabitants, and he went to Thebes, and took up his abode in a tomb from January till the end of June 1835. On his return to England, he published his Modern Egyptians, and in 1838 his translation of the Thousand and One Nights. From 1842 the Arabic-English Dictionary began to claim his exclusive devotion. In that year he made his last voyage to Egypt, where he remained for seven years, preparing the groundwork of his labours and collecting manuscripts. The pecuniary part of the work of publishing the Arabic Lexicon was undertaken by Lord Prudhoe, afterwards fourth Duke of Northumberland. With the exception of his short volume of Selections from the Koran, issued in 1843, and of one or two monographs upon points of Arabic scholarship, for the remaining thirty-four years of his life he worked at nothing else but his Lexicon, of which the first part appeared in 1863, the fifth in 1874, ani the sixth part, almost completed at the time of his death, has since been published by Mr. Poole.

LANGA, Loongi, or Lahanga, a piece of cloth used by the men of several Indian races as a lower garment, applied like an unsewed petticoat. Where the loongi is not worn, paijama or trousers take their place. These are sometimes worn loose, as in Oudh and Bengal; and elsewhere as tight as they can be made. The cutting out of women's tight trousers is no easy matter, for they have several gores on the inside of the thigh, and are contrived so that they are flexible, however tight, and do not hinder the wearer from sitting crosslegged. With the trousers, which are tied at the waist, are worn the angia or choli bodice, the kurtni or shirt, and the do-patta or scarf.

LANGAHA, a tribe following Mubammadanism, proselytes from the Solanki Rajputs, one of the four Agnicula races. The Solanki gotra acharya, or genealogical creed, claims Lokote as their settlement. Their use of the word Pathān by no means preclndes their being Hindus.

LANGAN TREE, Nephelium longanum. Its fruit is imported into England from China.

LANGAR, HiND.; Langaru, TEL. Anchor. Langar ki rassi, HiNd., cable. Langar Nikalna, Hind., literally to take out an amchor, is a cercmonial performance of a vow by Muhammadan men and women, usually given effect to on the fifth k'hun, i.e. the fourth day of the Maharram. Wealthy Muhammadans take out an anchor annually, whether for a vow or not. It is quite a sight to see that of the nawab of Hyderabad.

IANGAR KHANA. HiNd. An almsbouse.

LANGAR KHEL, a section of the Manzai branch of the Alizai Mahsud Waziri. They have 1000 to 1500 fighting men. They reside chiefly on the Badr Algad or Uch Kivara. The nawabs of Tank are allied with them.

LANGEH, a bee of Borneo, and one of smaller size called Nuang, produce valuable honey. They generally place their nests underneath the larger branches, and the Dyaks, to remove the honey and honeycomb, ascend the trees by neans of a rail of bamboos. 
LANGHA, musicians in Sind. These are of two kinds: 1 . the Kalwat or respectable singers; 2. the Langha or Mirasi, the bards of the country.

The Langhan or Mirasi are of Jat or Sindi extraction, and are considered a vile race. The Kalwat are respectable singers. There are some charming Sindi poems, amongst them is that of Sasani and Punha, the history of whose love and death much resembles that of Romeo and Juliet.

Luri, bards or troubadours, who attach themselves to high Baluch families in Baluchistan and Sind. They are musicians, tinkers, vagabonds, and fortune-tellers. They are in troops, with a chief in each. They profess Muhamıadanism, but are really pagans.-Burton's Scinde, p. 302.

LANGOTA or Langoti. HiND. A cloth passed between the thighs, and fastened to a string before and behind. Langoti-dost, a friend from infancy, from the days when they wore the langoti.

LANGUAGES in Eastern and Southern Asia are numerous. Along the low level tract bordering the ocean, from the Red Sea to the southernmost point of the Malay Peninsula, we find vernacular, the Arabic, Turkish, Kurdish, Syriac, Persian, Jataki, Sindi, Gujerati, Mahrati, Hindustani, Konkani, Canarese, Tulu, Malealam, Tamil, Telugu, Uriya, Bengali, Rakhui, Burmese, Siamese, Chinese, Javanese, and Malay, a number truly perplexing to traders on the seaboard.

Two hundred years ago (A.D. 1634), a master mariner, Master Richard Kynge, said, 'And in this founde wee oftimes much trouble and vexation, with moreover losses, both of precious time and lucre. Fyrste, that wee could never aske in Indian tongues for such herbes, or fruites, wodes, barks, or gummes, as wee knew full well, by experience in sundrye other partes, to bee wholesomme (many of our crewe lying sicke at the tyme), or savorye, or usefulle to trafficke withall. Nexte, that when anye were shewne us, we coulde in noe-wise tell, from : names given to them by : Gentooes, whether or noe e like were already knowne in European countryes; and yett these parts doe myghtylie abound with herbes and woodes of sovraigne virtew.'

The diversity thus alluded to is continued into the Archipelago, but it is not peculiar to the littoral tract, nor to the islands of the East Indies, the races, tribes, and nations of ail the old world being kept apart from one another by the dissimilarities in their spoken and written tongues. This condition has received the attention of many learned men, and amongst the philosophers of the 19th century much of the fame of not a few rests on the results from their linguistic studies. One such result has been the discovery of certain affinities in the various known languages, which admits of their being arranged into families, branches, and groups, but the learned investigators have not decided on a common grouping.

Dr. Prichard has suggested four groups or dynasties, three of which are confined to Europe and Asia, a fourth being common to Africa and those parts of $A$ sia which are near that continent. The first of his four groups, the Indo-European, is sometimes termed Indo-Germanic, and by later writers Aryan or Iranian. He considers that the Indo-European languages and nations may be further subdivided, and he styles his first subdivision the Eastern group, which by many writers has been termed exclusively the Aryan family of tongues. It includes all the idioms of the ancient Medes and Persians, who named themselves A rii, and their country Eeriene or Iran, and likewise the Sanskrit, with all the Prakrits, properly so termed, and the Pali of India. Among the former was that ancient Persian language in which one particular set of the cuneiform inscriptions was written. This dialect was so near the Sanskrit that the inscriptions in it have been interpreted through the medium of that language.

Chevalier Bunsen's terms differ from those of Dr. Prichard. He classes one group as the great Asiatic-European stock of languages, which he subdivides into eight families, viz. Celt, Thracian or Illyrian, Armenian, Asiatic-Iranian, HellenicoItalic, Sclavonic, Lithuanian tribes, and Teutonic. His fourth or Asiatic-Iranian, or the Iranian stock as represented in Asia, he again subdivides into-

$a$. The nations of Iran Proper, or the Aryan stock, the languages of Media and Persia. It includes the Zend of the cuneiform inscriptions and the Zendaresta; the younger Pehlavi of the Sassanians and the Pazend, the mother of the present or modern Persian tongue. The Pushtu or language of the Afyhans, he says, belongs to the same branch.

$b$. The second subdivision embraces the Iranian languages of India, represented by the Sanskrit and her daughters.

His Semitic stock of languages he constructs from the following nations, who form another compact mass, and represent one physiologically and historically connected family: the Hebrews, with the other tribes of Canaan or Palestine, inclusive of the Phonicians, who spread their language, through their colonization, as that of the Carthaginians; the Aramaic tribes, or the historical nations of Aram, Syria, Mesopotamia, and Babylonia, speaking Syrian in the west, and the so-called Chaldaic in the east; finally, the Arabians, whose language is connected (through the Himyaritic) with the Ethiopic, the ancient (now the sacred) language of Abyssinia.

Dr. Haug divides the Iranian languages into East or Bactrian, and West or Median and Persian.

The Iranian family of language seems to be called Aryan by Mr. Farrar; it is the IndoEuropean and Indo-Germanic of some philologists; Pictet and Burnous called it Aryan, from the Sanskrit word Arya, meaning noble; Rask called it Japhetic. According to Mr. Farrar, it has eight divisions, viz. Hindu, Persian, Greek, Latin, Lithuanian, Sclavonic, Teutonic, Celtic. Of these it is uncertain whether Celtic or Sanskrit represents the older phase. But it is known that all of them are the daughters of a primeval form of language which has now ceased to exist, but which was spoken by a yet undivided race at a time when Sanskrit and Greek had as yet only implicit existence.

Professor Steinthal, in his Charakteristik der hauptsächlichsten Typen des Sprachbaues, has proposed to arrange all languages into two great classes, viz. cultivated languages and uncultivated languages, and each of these he would subdivide into two classes, viz. the isolating and the inflecting. Taking the uncultivated first, under the isolating class he proposed to place the TransGangetic, and under the inflecting he would place three divisions - (1) the Polynesian, which ex- 
presses all the minor modifications of the meaning, all distinctions of declension and conjugation, by reduplications and prefixes; (2) the Ural-Altaic (which Farrar calls the Alatyan), which expresses them by annexing separate words after the root; and (3) the American, which expresses them by amalgamation. The cultivated languages are similarly subdivided - (1) into the isolating, represented by Chinese; (2) into the inflectional, under which head he places (i.) the Egyptian, which achieves a sort of inflection by a loose addition of grammatical elements; (ii.) the Semitic, by internal modification of the root; and (iii.) the Aryan, throughout which the formal elements have been reduced to mere conventional suffixes, such, for instance, as the letter s, which is an all but universal sign for the plural number.

Professor Max Muller arranges all languages, exclusive of Chinese and the dialects of America and Africa, into three grammatical families, the Semitic, the Aryan, and the Turanian.

The whole of what is called the Turanian family of specch consists of terminational or agglutinative languages, and this Turanian family comprises in reality all languages spoken in Asia and Europe, and not included under the Aryan and Semitic families, with the exception of Chinese and its cognate dialects. The term Turanian is used in opposition to Aryan, and is applied to the nomadic races of Asia, as opposed to the agricultural or Aryan races. The 'l'uranian family of languages has two great divisions, the Northern and the Southern. The Northern is sometimes called the Ural-Altaic or Ugro-Tataric, and it is divided into five sectious.

It is, however, more than probable that the Mongol, the Manchu, and Tungusan belong to one great stock, that the Turkoman, as well as the Tshude, Fin, Laplander, and Magyar (Hungarians) present another stock closely united, and that both these families are originally connected with each other.

Turkish is a Turanian dialect. Its grammar is purely Tataric or Turanian, and the Turks possessed a small literature and narrow civilisation before they were converted to Mubammadanism; but as the language of Mahomed was Arabic, this, together with the Koran, and their law and religion, the Turks learned from the Arabs. Arabic became to the Turks what Latin was to the Germans during the middle ages; and there is hardly a word in the higher intellectual terminology of Arabic that might not be used, more or less naturally, by a writer in Turkish. But the Arabs, again, at the very outset of their career of conquest and conversion, had been, in science, art, literature, and polite manners, the pupils of the Persians, whom they had conquered; they stood to them in the same relation as the Romans stood to the Greeks. Now, the Persians speak a language which is a branch of the IndoEuropean or Aryan family of speech. A large infusion of Persian words thus found its way into Arabic, and through Arabic into Turkish, and the result is that the Turkish language, as spoken by the higher ranks at Constantinople, is so overgrown with Persian and Arabic words, that an uneducated Turk from the country understands but little of the so-culled Osmanli, though its grammar is exactly the same as the gramuar which he uses in his Tataric utterance.
The different Turkic dialects, of which the Osmanli is one, occupy one of the largest linguistic areas, extending from the Lena and the Polar Sea down to the Adriatic.

The languages of the South and East of Asia have been investigated by many distinguished philologists. Professor Sayce (ii. p. 33) arranges those of the east of Africa and of Eastern and Southern Asia under the headings Bushman, Hottentot, Kafir, Nubian, Nile, Hamitic, Semitic, Aryan, Turanian, Dravidian, Kolarian, TibetoBurman, Thai, Mon - Anam, Khasi, Chinese, Korean, Malayo - Polynesian, Malayo-Javanese, Papuan, and Aino.

Recently, also, Mr. R. N. Cust bas classified the languages of the East Indies into eight families, subdividing his Aryan family into two groups, his Tibeto-Burman family into eight, and his Malayan family into ten groups, as under:-

Family. Branch or Group. $\begin{gathered}\text { No. of } \\ \text { Languages. }\end{gathered} \begin{gathered}\text { No. of } \\ \text { Dialects. }\end{gathered}$

1. Aryan-

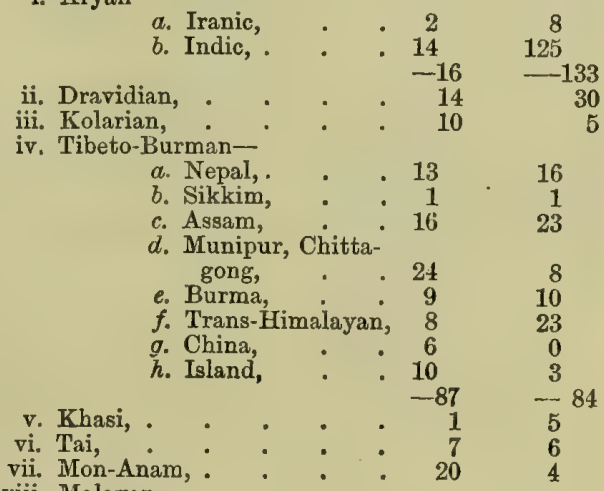

viii. Malayan-

$$
\begin{aligned}
& \text { a. Sumatra, Malacca, } 11 \\
& \text { b. Java, . . } 4 \\
& \text { c. Celebes, : : } 8 \\
& \text { d. Borneo, - : } 12 \\
& \text { e. Philippines, : } 12 \\
& \text { f. Molucca, : } 10 \\
& \text { g. Timor, : : } 18 \\
& \text { h. China, : : } 1 \\
& \text { i. Madagascar, : } 1 \\
& \text { j. Alfurese-Negrito, } 1 \\
& \frac{-88}{243} \quad \frac{-44}{296}
\end{aligned}
$$

Dr. W. W. Hunter, in his Dictionary of the non-Aryan Languages of India and High Asia, classes them as under:-

1. Reflecting types.-Arabic, Sanskrit.

2. Compounding types. - Bask, Finnic, Magyar, Turkish, Circassian, Georgian, Mongolian, Manchu, Javanese Ngoko, Javanese Krama, Malay.

3. Isolating types. - Chinese of Nankin, Amoy, Pekin, Shanghai, and Canton, Amoy colloquial,
Japanese.

? Brahui.

4. Chinese Frontier and Tibet. - Gyami, Gyarung, Takpq, Manyak, Thochu, Sokpa, Horpa, Tibetan written and spoken.

5. Nepal (West to East). - Serpa, Sunwar, Gurung, Murmi, Magar, Thaksya, Pakhya, Newar, Limbu.

6. Kiranti Group, East Nepal.-Kiranti, Rodong, Rungchenbung, Chingtangya, Nachhereng, Waling, Yakha, Chourasya, Kulungya, Thulungya, Bahingya, Lohorong, Limbichhong, Balali, Sang-pang, Dumi, Khaling, Dungmali.

7. Broken Tribes of Nepal.-Darhi, Denwar, Pahri,

Chepang, Bhramu, Vayu, Kuswar, Kusunda, Tharu.

Lepcha (Sikkim).

Bhutani or Lhopa. 
8. N.E. Bengal. - Bodo, Dhimal, Koch'h, Garo, Kachari.

9. Eastern Frontier of Bengal.-Munipuri, Mithan Naga, Tablung Naga, Khari Naga, Angami Naga, Namsang Naga, Nowgong Naga, Tengsa Naga, Abor Miri, Sibsagor Miri, Deoria Chutia, Singhpo.

10. Arakan and Burma. - Burman written and spoken, Khyeng or Shou, Kami, Kumi, Mru or Toung, Sak.

11. Siam and Tenasserim.-Talain or Mon, Sgau Karen, Pwo Karen, Toung-thu, Shan, Annamitic, Siamese, Ahom, Khamti, Laos.

12. Central India. - Ho (Kol), Kol (Singbhum), Santali, Bhumij, Uraon, Mundala, Rajmahali, Gondi, Gayeti, Rutluk, Naikude, Kolami, Madi, Madia, Kuri, Keikadi, Khond, Savara, Gadaba, Yerukala, Chentsu.

13. Southern India.-Tamil ancient and modern, Malealam ancient and modern, Telugu, Karnataka ancient and modern, Tuluva, Kurgi, Toduva or Toda, Kota, Badaga, Kurumba, Irular, Singhalese.

Mr. E. L. Brandreth, in volume $\mathbf{x}$. of the Royal Asiatic Society's Journal, has given the following classification of the non-Aryan languages of India, and Dr. Hunter has adopted it at page 183 of volume iv. of the Imperial Gazetteer.

Dravidian Group. - Tamil, Telugu, Canarese, Malealam, Tulu, Kodaga, Toda, Kota, the dialects of the Mahadeo, Raj, and Maria Gonds, Naikudi, Kolami, Kandh or $\mathbf{K u}$, Uraon or Dhangar, Malé or Rajmahali, Kaikudi, Yerkala.

Kolarian Group. - Santali, Mundari, Ho or Larka Kol, Bhumij, Korwa, Kharria, Juang, Kuri, Kurku, Mehto, Savara.

Tibeto-Burman Group-

i. Kachari or Bodo, Mech and Hojai, Garo, PaniKoch, Deori-Chutia, Tipura or Mrung.

ii. Tibetan or Bhutia, Sarpa, Lhopa or Bhutani, Changlo, Twang.

iii. Gurung, Murmi, Thaksya, Newar, Pahri, Magar. iv. Lepcha.

v. Dafla, Miri, Abor, Bhutia of Lo.

vi. Aka.

vii. Dialects of the Mishmi, Chulikata, Taying or Digaru, Mijhu.

viii. Dhimal

ix. Dialects of Kanawar, Milchan, Tibarskad, and Sumchu.

x. Kiranti, Limbu, Sunwar, Bramu, Chepang, Vayu, Kusunda.

xi. Dialects of the Naga clans, Namsang or Jaipuria, Bonpara or Joboka, Mi-than, Ta-blung, and Mulung, Khari, Naugong, Tengsa, Lhota, Angami, Rengma, Arung, Kucha, Liyang or Kareng, and Maram.

xii. Miri

xiii. Singpho, Jili.

xiv. Burmese.

xv. Kuki dialects, Thado, Lushai, Hallami, Khyeng, Manipuri, Maring, Khoibu, Ku-pui, Tangkhul, Luhupa, Khungui, Phadang, Champhung, Kupome, Takaimi, Andro and Sengmai, Chairel, Anal and Namfu.

xvi. Kumi, Kami, Mru, Banjogi or Lung-khe, Pankho, Shendu or Poi, Sak, Kyau.

xvii. Karen dialects, viz. Skau, Bghai, Karenni, Pwo, Taru, Mop-gha, Kay or Gaikho, Toung-thu, Lisan.

sviii. Gyarung, Takpa, Manyak, Thochu, and Horpa.

xix. Khasi.

xx. Tai, Thai or Siamese, Lao, Shan, Ahom, Khamti, Aiton, Tao-Mow or Chinese Shan

xxi. Mon-Anam, Mor, Kambojan, Anamese, and Paloung.

The classifications of Dr. Hunter and Mr. Brandreth were restricted to the non-Aryan tongues. Our present acquaintance with the languages and dialects of British India, west of the Bay of Bengal, permits their classification as follows :-
Gaura or Sanskritoid, viz.:-

Bengali-

a. Tírhuti or Mathala or Maithili.

b. Assamese proper.

Hindi-

a. Hindustani or Urdu.

b. Brij Bhasha.

c. Rangri Bhasha.

d. Bhojpuri

e. Panjabi.

f. Multani.

g. Jataki.

h. Kashmiri.

i. Nepal court language.

$j$. Sindi.

k. Tharreli.

l. Takkarani ji Boli.

m. Harnoti.

n. Mairwari.

Gujerati-

a. Kachi.

Mahrati-

a. Konkani

Uriya.

Dravida, viz. :-

a. Cultivated.

Tamil or Dravida proper. Malealam.

Telugu or Telinga. $\quad$ Tulu.

Karnata, Kannadi, or Kodaga of Coorg.

Canarese.

Singhalese.

b. Uncultivated.

Peninsula of India.

Toda.

Kotah.

Gond.

Kond, Kandh, or Ku.

Irular.

Yenadi.

Korava.

Kurumbar.

Veddah.

Central India.

Bhuiya.

Bhuiher.

Binjhia or Binjwar.

Kaur, or Kaurai, or Kaurava, or Raj Kaur.

Koch'h.

Mal.

Malé, Paharia, or Rajma hali.

Ora.on.

Rautia.

\section{Kolarian Tribes-}

Asur or Agariah.

Bhil.

Bhilalah.

Bhui.

Bhuiher.

Bhumia.

Bhumij of Manbhum.

Bhunjia.

Binjwar.

Birhor of Chutia Nagpur.

Boyar.

Bygah.

Cheru or Cherwa, a broken tribe.

Dhangar.

Gudba.

Ho of Singbhum.

Juang.

Kawar.

Kharriah or Delki

Kharwar or Khyrwar.

Kisan, or Nageswar, or Naksia.

Kol.

Kora.

Korwa of Sirguja.

Kur, Korku, or Muasi.

Mair.

Manji.

Mehtu or Mehto.

Mina.

Munda.

Nahux.

Santal.

Saont.

Savara.

The Cheru, Kharwar, Kisan, and Saont of Chutia Nagpur have lost their own language. The Cheru, Bhuiher, Boyar, Kaur, Kharwar, Kisan, Mair, Nagbansi, and Parbeya are broken tribes, and have become Hinduized.

Dravidian languages are spoken by abont 46 millions of people in India and Ceylon. Six of their languages are cultivated, and three writing characters are used. The numbers speaking them have been estimated as under :-

Telugu, . 15,500,000/Uriya and hill

Tamil, . . 16,000,000 languages, . 640,000

Canarese, . 6,000,000 Gond, . : 500,000

Kodaga of Coorg,

Malealam, . 4,226,533 Toda, . . . 300

Tulu, . . . 29,763 Kotah, . : : 1,000

Amongst the nations of Eastern and Southern Asia, their vernacular and sacred languages furnish examples of all the forms indicated by the philosophers of Europe.

Mr. F. Jagor (Travels, 1875, p. 69) quotes from a work of Barentes the names of 27 distinct languages officially recognised in the Philippines, besides which there are dialects innumerable spoken both by the Malayan and Negrito wild tribes. 
LANGUAGES.

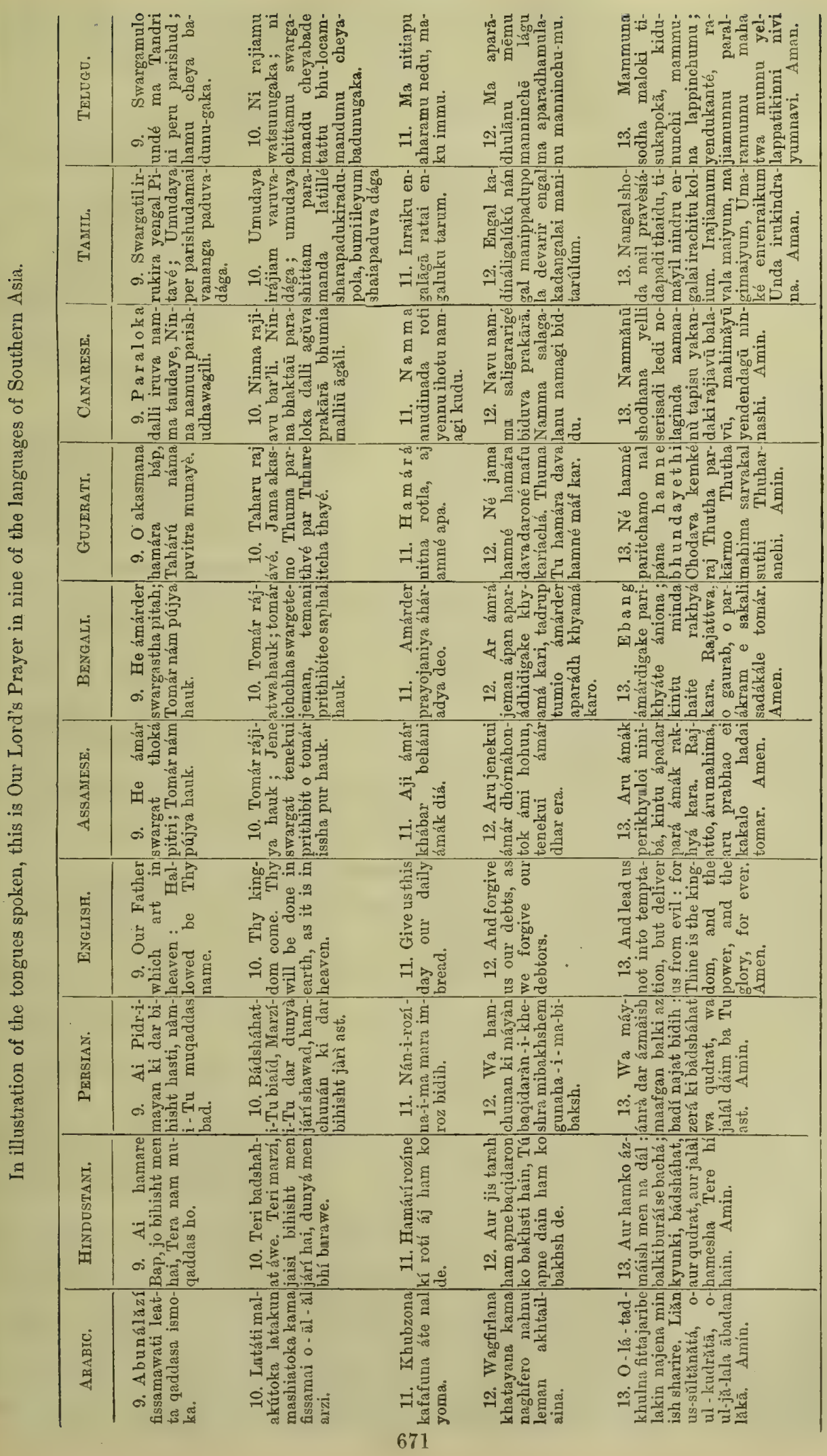


The 1881 Census Report of British India enumerates 115 Asiatic languages spoken in British India, not including the recognised dialects of several of the current tongues; and there were 28 non-Asiatic tongues recorded, but the languages of $22,626,486$ of the population were not distinguished.

\begin{tabular}{|c|c|c|c|c|c|}
\hline & & 821 & & & \\
\hline ic, : & & '21,188 & Ladakhi, & $\dot{0}$ & - \\
\hline canese, & & 362,988 & Lahali,. & & 10,303 \\
\hline nian, & & . . 1,308 & $n g$, & & 46,920 \\
\hline & & $1,361,759$ & adi, & & 072 \\
\hline & & - $\quad 1,019$ & Lambani, & & - 111 \\
\hline & & - $\quad 116,755$ & cha, & & . 4,611 \\
\hline chi, & & - 177,273 & bu,: & & \\
\hline ali, & & $38,965,428$ & rati, & & $16,968,013$ \\
\hline & & . . 19 & rani, & & \\
\hline in, . & & - · 34 & $\mathrm{y}$, . & & \\
\hline nese, & & - $\quad 1,340$ & lam, & & 4 \\
\hline & & - 24,510 & & & - \\
\hline ese, . & & $2,248,479$ & ari, & & \\
\hline se, & & $8,336,008$ & vari, & & 246 \\
\hline & & $\begin{array}{l}. \quad 587 \\
\end{array}$ & ech, . & & - \\
\hline & & & ikir, . & & • \\
\hline & & & , & & $\cdot$ \\
\hline g-tha, & & $\begin{array}{r}14,400 \\
2,341\end{array}$ & Mughi, . & & $: \quad 15,709$ \\
\hline & & - $\quad 28,618$ & Murmi, & & \\
\hline & & 12,434 & a, . & & 104 \\
\hline & & - 549 & am, & & \\
\hline & & - 1,995 & Iri, & $\cdot$ & \\
\hline & & - . 4,152 & lese, & . & - 10 \\
\hline & & - 108,019 & ar, . & & \\
\hline & & 12,041 & & & 1,3 \\
\hline & & - $\quad 540,094$ & bi, & - & 14,269 \\
\hline & & - 137,1 & ayy, & - & - \\
\hline & & 87 & & & \\
\hline se, & & $\begin{array}{r}47,038 \\
\end{array}$ & & & - 915 \\
\hline ti, & & $\begin{array}{l}1,079,565 \\
9,620688\end{array}$ & nool, & & - \\
\hline & & $\begin{array}{r}9,620,688 \\
12666\end{array}$ & ha, . & & 56 \\
\hline & & $\begin{array}{r}\text { - } 1,266 \\
901\end{array}$ & & - & . . \\
\hline & & 7,989 & Sanskrit, & : & : \\
\hline stani, & & $82,497,168$ & Savara, & & $\begin{array}{r}1,300 \\
\quad 31,933\end{array}$ \\
\hline & & & . & . & $\begin{array}{l}\cdot \quad 59,723 \\
\end{array}$ \\
\hline & & $1,604,760$ & doo, & - & . . 71 \\
\hline ri & & - $\quad 316$ & Siamese, & & \\
\hline & & - 263,187 & & & 2,101 \\
\hline & & $\begin{array}{r}6,976 \\
ن\end{array}$ & Singhalese & , & $\cdot 1$ \\
\hline & & $\begin{array}{r}459,622 \\
12,209\end{array}$ & o, & - & \\
\hline & & - & g, & - & \\
\hline & & $\begin{array}{l}90 \\
99\end{array}$ & $\begin{array}{l}\text { ng, } \\
\text { g, }\end{array}$ & $\dot{.}$ & $\begin{array}{r}4,013 \\
154,553\end{array}$ \\
\hline & & 49,8 & Tami & & $13,068,279$ \\
\hline & & 83 & il and & Telo & $\mathrm{gu}, \quad 1,05$ \\
\hline & & 110 & & & $17,000,358$ \\
\hline & & 1,893 & & - & . 2 \\
\hline . & & 109,876 & rah, & - $\cdot$ & · \\
\hline & & 24,794 & Toda, & $\cdot$ & $\cdot$ \\
\hline & & 81 & $\begin{array}{l}\text { Toung-thu } \\
\text { Tulu, }\end{array}$ & , & : \\
\hline & & $\begin{array}{r}1,140 \\
29\end{array}$ & $\begin{array}{l}\text { Tulu, } \\
\text { Turkish, }\end{array}$ & $\dot{.}$ & \\
\hline & & . . & & . . & - 3 \\
\hline & & 29,0 & & . & 6,81 \\
\hline & & 20 & en, & - & - \\
\hline & & - $\quad 10,852$ & & - & \\
\hline ba & & - . 3,886 & & & \\
\hline & & . $\cdot \dot{T}$ & & & $\mathrm{rg}, 1$ \\
\hline & & & & & \\
\hline & & & & & \\
\hline & & 89 & & & \\
\hline & & - 114 & & e, & 02 \\
\hline & & - $\quad 202,920$ & & n, & \\
\hline & & 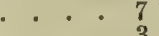 & & & . . \\
\hline & - & - i510 & & & $\cdot$ \\
\hline & & - 1,510 & & & \\
\hline & & - 14 & & - & - \\
\hline & & - 1,47 & & & - \\
\hline & & - 15 & , . & - & • \\
\hline & & 15 & & & \\
\hline & & - & & & \\
\hline & & 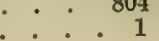 & & & \\
\hline & & & & & \\
\hline
\end{tabular}

Mr. Wallace (ii. p. 292), an accurate observer, who resided for many years in different islands, enumerates the languages spoken in the islands of the Eastern Archipelago, as under:-

1. Malay, at Singapore.

2. Javanese, at Java.

3. Sassak, at Lombok. Indigenes of Lombok, a pure Malay race, profess Muhammadanism.

4. Macassar, at S. Celebes, near Macassar ; Muhammadans.

5. Bugis, in large part of Celebes ; Muhammadans.

6. Bouton, at Boutony, a large island S. of Celebes.

7. Salayer, at Salaver, a smaller island $\mathrm{S}$. of Celebes.

8. Tomore, at E. Peninsuls of Celebes; pagans. The people speaking these five languages of Celebes are of pure Malayan type, and all but the Tomore race are equal in civilisation to the true Malays.

9, 10. Tomohon and Langowen, at plateau of Minahassa.

11, 12. Ratahan and Belang, at S.E. coast of Minahassa.

13. Tanawanko, at W. coast of Minahassa.

14. Kema, at E. coast of Minahassa.

15. Bantek, at a suburb of Menado.

16. Menado, at chief town.

17. Bolang hitam, on N.W. coast between Menado and Licoupang. These nine languages (9 to 17 ), with many others, are spoken in the $\mathrm{N}$.W. Peninsula of Celebes, by the people called Alfuro. These languages are falling into disuse, and Malay is becoming the general medium of communication. Most of the people are being converted to Christianity.

18. Sanguir islands and Siau; the inhabitants resemble the people of Menado.

19. Salibabo islands also called Talaut

20. Sulu islands, E. of Celebes, Malays of the Moluccas type; Muhammadans.

21, 22, 23. Cajeli, Wayapo, Massaratty, three villages on the E. side of Bouru. These people are allied to the natives of Ceram ; Cajeli people are Muhammadans.

24. Amblau island, S.E. of Bouru; Muhammadans.

25. Ternate, the most northern island of the Moluccas. Inhabitants somewhat mixed with indigenes of Gilolo.

26. Tidore, the next island of the Moluccas. Inhabitants undistinguishable from those of Ternate.

27. Kaioa islands, at N. of Batchian.

28. Batchian; Muhammadans; inhabitants like the preceding.

29. Gani, at a village on the S. Peninsula of Gilolo. Moluccan Malays, Muhammadans.

30,31 . Sahoe and Galela, at villages in N. Gilolo. Inhabitants called Alfuro. They are indigenes of Polynesian type, but brown skins and Papuan hair and features ; pagans.

32. Liang, at villages on the $\dot{N}$. coast of Amboyna. of mixed Malay and Polynesian type, they are Muhammadans or Christians.

33. Morella and Mamalla, at villages in N.W. coast of Amboyna.

84. Batumerah, at a suburb of Amboyna. Inhabitants of the Molucea Malay type; Muhammadans.

35. Lariki, Asilulu, Wakasiho, in W. Amboyna; Muhammadans from Ternate.

36. Saparua island, at $\mathbf{E}$. of Amboyna. Inhabitants of the brown Polynesinn type, and speaking the same language as those of Ceram, opposite.

37, 38. Awaiya and Crmarian, at villages on the S. of Ceram. Indigenes of Polynesian type, now Christians.

39, 40. Teluti and Hoya, Ahtiago and Tobo, at villages on the S. coast of Ceram. Mixed brown Papuan or Polynesian and Malay type; Muhammadans.

41. Ahtiago, indigenes, inland from Ahtiago. Alfuro of brown Papuan or Polynesian type; pagans.

42. Gah, at E. Ceram, Alfuro of Ceram

43. Wahai, at $N$. coast of Ceram. Inhabitants of mixed race, speak several dialects of this language; Muhammadans.

44. Goram, at small islands $\mathbf{E}$. of Ceram. Of mixed race; Muhammadans.

45. Matabello, at small islands S.E. of Ceram. Brown Papuan or Polynesian race; pagans. 
46. Teor, at small islands S.E. of Matabello. Brown Papuan or Polynesian race; pagans.

47. Ke islands, on the W. of the Aru islands, true black Papuans ; pagans.

48. Aru islands, W. of N. Guinea ; true Papuans.

49. Mysol coast, N. of Ceram, semi-civilised Papuans, with mixture of Moluccan Malays.

50. Mysol interior, true Papuans; pagans.

51. Dorey, at N. coast of N. Guinea, true Papunns; pagans.

$52,53,54$. Teto, Vaiqueno in E. Timor, Brissi in W. Timor. Intermediate between the true and the brown Papuans ; pagans.

55, 56. Savu and Rotti. Islands west of Timor, of mixed race, with apparently much of the Hindu type.

57, 58. Allor and Solor. Islands between Flores and Timor, inhabitants of dark Papuan type.

59. Baju, a roaming tribe of fishermen of Malayan type, all over the Archipelago.

Professor Keane enumerates 112 Australasian tribes and languages, when he gives the names of many islands and districts and races in Australasia:-

Adane, Luçon.

Agutaino, Plsilippines.

Alaguetes, Luçon.

Aloma, N. Guiner.

Ansmaropu, N. Guinea.

Apayao, Luçon.

Arfak, N. Guinea.

Asahan, Sumatra.

Baju Laut, Celebes.

Basisi, Malacca.

Battak, Sumatra.

Batu-mera, Amboyna.

Belon, E. Timor.

Betsi-misaraca, E. Madagascar.

Botsileo, Hova nation.

Bicol, Philippines.

Bila, Malacca Negrito.

Bilong, N. Celebes, Minahassa.

Bima, E.Sumbawa, Malays.

Bisaya, Dyak tribe, meaning tattooed.

Bola ango, N. Celebes, Papuans.

Boni, Coleber.

Botango, Minahassa, N. Celebes.

Brajerak, all the S.E. Australian tribes.

Bugis or Wuji, Celebes.

Burik, wild, Philippines.

Calinga, Luçon.

Chimarro, Luçon, Leyte, Samar.

Dadaya, uncivilised Tagala people.

Dedele, N. Guinea.

Dorey, N. coast of N. Guinea.

Doumajal, Mindoro.

Dyak, Borneo.

Ende, Floris.

Favor-long, Formosa.

Gaddan, the Tagala nation, Luçon.

Gah, Ceram, Papuans.

Galela, Tabellor, Galelor, N.W. Gilolo.

Galeteng Papuans, Floris, Sunda.

Gani, Gilolo.

Garontalo, Minahassa Malays.

Gilolo, Halmahera, and Kaha-lamo Papuans.

Guimanes, Luçon.

Hongotes, Philippine

wountains.

VOL. II.
Hotontalo, Minahassa.

Hova or Ibara, dominant in Madagasoar.

Ibalao, Luçon.

Ibanag, Philippines.

Idayan, Philippines.

Ifugan, Luçon.

Igorotte, Philippines.

Ikolu, N. Guines.

Illanos, a piratical raoe, now in Brunai, Borneo.

Ilocano, Luçon.

Ilongote, Luçon.

Isinayes, Luçon.

Itaneg or 'Tinguianes, Luçon.

Itanes, Luçon.

Jakun, Malay Peninsula.

Javenese, Java.

Juru, Malacca.

Kanalk, the South Sea islanders, from the Maor Tanata, meaning man.

Kapatsi, N. Guinea.

Karus, N. Guinea.

Kawi, ancient Javanese.

Kayan, Borneo.

Keao, a Dyak tribe.

Kedah, Malacca.

Kema, N. Celebes

Kio, Papuans, Floris.

Koiari, Koitapu, Papuans, N. Guiner.

Konga, Papuans, Floris, Sunda.

Korinchi, Malays, W. Sumatra.

Kubu, Malay tribes, centre of Sumatra.

Kulkalija, Papuans, N. Guinea on its east.

Kulo, N. Guinea tribe.

Kupan, Timor Papuans.

Lampung, Malay, S.W. Sumatra.

Letti, Papuans, Serwatti Islands.

Lubu, tribe of Central Sumatra.

Madang, Dyaks, E. Borneo Madurese, Malays, Madura.

Malaneg, a Tagala tribe, Philippines.

Malay, Archipelago.

Mallikolo, N. Hebrides.

Malo, Dyak, Borneo.

Mamamanua, Philippines, Negrito.
Maiva, N. Guinea.
Manatoto,Timor, Papuans. Mandar, Celebes.

Mandaya, Malays, Philippines.

Mangarai, Floris, Papuans. Mangkassa (Macassar), of S. Peninsula of Celebes and on Salayur Island; akin to the Wugi.

Manguianes, Malay tribes of Mindoro.

Manobo, Malay tribes, Mindanao.

Mara (indigenes) or $\mathrm{Nga-}$ pui, dominant in $\mathrm{N}$. Zealand.

Marhuna, Ceram Papuans.

Maros, Maruiva, natives of Hog and Banyak Islands, on W. coast of Sumatra.

Mentawi or Mantawi, calling themselves Tchagelalegat, Malays of Nassau, Pora, and Pagai Islands on W. coast of Sumatra.

Millanawi, Sarawak.

Mincopi, Andamans.

Mintira, Malacca.

Miriam, Papuans, Torres Straits.

Motu, N. Guinea Papuans.

Murong, Borneo, Dyak.

Murut-Idaan, Dyak of Borneo.

Myfor, Papuans of N. Guinea, Myfor, Mansonam Islands, Dorey, and Amberbaki; akin to the Arfak and Biak islanders

Naman, N. Guinea Papuans.

Nancowri, Nicobars.

Negrito; Aëta, Philippines; Simang, Malacca; Mincopi of Andamans.

Oelo, interior of Sumatra.

Orang Binua, of Malacca;

Orang Hindi, of Waigiou;

Orang Kling, natives of India; Orang Kubu, of

The Languages of India.--One of the most interesting chapters in Mr. Plowden's report on the census of British India is that relating to the statistics of language. From this we find that English is spoken as their native language by 202,920 persons, and Portuguese by 10,523 . Of the latter, however, only 147 were born in Portugal, and of the former Mr. Plowden says it is believed that not more than 150,000 are pure British. The remainder embraces a certain number of Eurasians, who may vary from individuals approaching so closely to Europeans as not to be distinguishable from them, or again may approach so closely to natives in appearance as otherwise to be undistinguishable from them. The other European tongues are the languages of a comparatively small number of people. For instance, French is the language of only 1510 persons; German, of 1471 ; Italian, of 804 ; Swedish, of 310 ; Spanish, of 126 ; Dutch, of 114; Norwegian, of 375 ; Danish, of 189 ; Russian, of 112 ; Greek, of 193 ; Hungarian, of 12 ; Finnish, of 7 ; Roumanian, of 6 ; Polish, of 4 ; Flemish, of 3 ; Swiss, of 2 ; and Sclavonic of 1. Welsh, which is, unaccountably, not included in Mr. Plowden's list of cultivated dialects, is spoken by 205 ; Scotch, by 124 ; Gaelic, by 149 ; Irish, by 158 ; and Celtic, by 2 persons. The French-speaking section of the community 
numbers 1510 , of whom the larger proportion (625) live in Madras. There are 145 Frenchmen in the Bombay Presidency. It will surprise many persons to learn that the German-speaking population in India is slightly less numerous than the French. The former, according to Mr. Plowden, number 1471. The British-born population of Bengal, notwithstanding its large planting community, was considerably below that of Bombay. This fact is referred to by $\mathrm{Mr}$. Plowden, who points out that the largest number of British-born persons is found in the NorthWestern Provinces $(20,184)$ and the Paujab $(17,590)$, owing to the heavy garrisons in those parts of India. Bombay (exclusive of the Feudatory States) follows with 13,772, and Bengal with only 10,583. The other provinces and states stand as follow:-Madras, 5883 ; Burma, 5346 ; Central India, 4978; the Nizam's Dominions, 2956 ; the Central Provinces, 2774; Mysore, 2686; Ajmir, 872; Assam, 795; Baroda, 267; Coorg, 134; the Feudatory States of Bombay, 98; and Berar, 97. Mr. Plowden thus classifies the English-speaking population:-Born in the United Kingdom, 89,015; Eurasians (persons of mixed parentage), 62,085 ; born of British parents outside the United Kingdom, 50,360; born in America, Australia, and at sea, 2098. Of the eighty-nine thousand odd born in the United Kingdom, nearly fifty-six thousand males are in the army, and about three thousand in the Civil Service. When to this is added the wives and families of British military and civil officers, it will be seen how insignificant, numerically, the non-official portion of the English community in India still is. In his list of the great cities of India, Mr. Plowden places Bombay, with its 772,196 inhabitants, first, and Calcutta $(766,298)$ second. $\mathrm{He}$ contends, however, that the population of Howrab, on the right bank of the river Hoogly, should be added, which would bring up the number of inhabitants of the Bengal capital to 871,504 . From the chapter on the religions of the people, we find that the Parsees of the various presidencies aggregate 85,397 , of whom 78,973 are to be found in Bombay and its Feudatory States, and 8118 in Baroda. There are 916 Parsees in Central India, 638 in Hyderabad, 462 in the Panjab, 399 in the Central Provinces, 242 in the Berars, 156 in Bengal, 143 in Madras, 114 in the North-West Provinces, 83 in Burma, 75 in Ajmir, 47 in Mysore, 21 in Coorg, 7 in Rajputana, and 3 in the Feudatory States of the Panjab.

Urdu. -In the past eight centuries, Muhammadan armies have been bringing into India the Arabic, Turki, Mongol, and Persian tongues. The first of these continues to be the language of the Muhammadan religion; and though the Koran has been translated into Persian, Urdu, and Tamil, also Burmese and Malay, their sacred book, in the original Arabic, is still preferred in British India, is studied by all youths, and read by all their educated religionists. Persian, on the other hand, has been the written language of the Muhammadan courts of Persia and India, and is used by all the educated classes in their correspondence. Under Mahmud, the civil administration must have been entirely conducted by Persians. The two celebrated vizirs, Abūl Abbas and Ahmad Maimendi, were of that nation. The former introduced the practice of writing all public papers in Persian. Ahmad restored Arabic in permanent documents. It is owing to this circumstance that, although India was never directly conquered by Persia, the language of business and of writing in general is all taken from the latter country. The Muhammadan conquerors, whom the Mahrattas first and then the British succeeded, thus left as a legacy the Persian language, as the tongue in which all the learned people, and many of the official people, wrote; but since the 14th century, from it and from the Turki, Arabic, and Hindi a vernacular language has been formed, to which the name of Urdn, or camp tongue, is given. The new tongue is based on the Hindi, with many words from the Arabic, Persian, and Turki, II sprinkling from the Sanskrit, and all the Hindi, Dravidian, Kolarian, and Portuguese tongues spoken in British India. In the south of India; Urdn is called Hindustani, because it had its origin in Northern India or Hindustan; but it was only in the early part of the 19th century that it was given regular forms by Dr. John Borthwick Gilchrist. It is used as a medium of intercommunication by the Hindus of the towns of Oudh and Dehli, by all Indian Mubammadans amongst themselves, and by Hindus and Europeans as a common tongue. It is, however, as a written language, only used by the less educated Muhammadans and by their women, the more highly educated employing Persian. In some districts of Northern India, Persian words predominate in the Urdu; in other parts of India, Hindi words are the more numerous; in the southern part of the Peninsula there is a very considerable admixture of Arabic, and on tlic west of the Peninsula the Mahrati is greatly infused into it.

Hindi is a term used over much of Northern India to denote the vernacular tongue of the district. Hindi and its dialects are spoken by about 80 millions of people. On the north and east it comes in contact with the Tibeto-Burman family in the Himalaya and in Further India on the south, in Gondwana, it has on its borders the Uriya, the Karnatica, the Telugu, and the Mahrati; and on the N.W. and W. the Pushtu, the Baluchki, and Brahuiki bound it. Its recognised dialects are reckoned fifty-eight, but there are others wild and uncultivated.

Speaking generally, the whole of Upper India, including the Paujab, from the Himalaya to the Vindhyan range, but exclusive of Bengal, may be said to be possessed by one language, the Hindi. According to Colebrooke and the Serampore translators of the Bible, Hindi owes nine-tenths of its vocables to Sanskrit roots; when it is spoken by Muhammadans, who add to it Arabic and Persian roots, it becomes converted into Urdu or Hindustani. When Hindi is spoken by Hindus, who draw on Sanskrit for enrichment or cubellishment, it appropriately retains the name of Hindi. Modified in these various ways, it is found not only on the plains of Hindustan, but also on the southern slope of the Himalaya, for Mr. Trail informs us that the language of Kamaon and Garhwal is Hindi. Indeed, generally, along the Sub-Himalayan range, as far as the Gogra river, an impure Hindi dialect introduced by the Gurkha from the plains appears to be extirpating the vernacular Tibetan tongues of the aboriginal 
mountaineers. Mr. Masson says that by means of Hindi he made himself understood throughout the whole of the Kohistan, and it will thus be seen that the term is used to bring under one common designation the various dialects of a language essentially one, but which has received no great cultivation in any of its forms. According to the Brahman pandits of Benares, there are hundreds of dialects equally entitled to the name. The Brij Basha (or Bhaka, as it is pronounced on the Ganges) and the Panjabi are the two most cultivated varieties of it, but the Panjabi passes into Multani, which a good philologist has shown to be a corrupted form of Panjabi; whilst Jataki, again, farther to the south, is a corrupted form of Multani; Sindi, according to Lieutenant Burton, is a perfectly distinct dialect, though directly derived from Sanskrit. When the Mahrattas extended their conquests into Hindustan, they found Hindi everywhere prevalent, from the limits of the desert to the frontiers of Bundelkhand; and finding it different from their own tongue, they called it contemptuously Rangri Basha, quasibarbarous jargon. Sir John Malcolm extends the Rangri Bhaka as far west as the Indus, and east as far as the frontier of Bundelkhand, where, as in all the country to the Indus, from the western frontier of Bengal, dialects of Hindi prevail. The Marwari and other dialects of Rajputana are varieties of Hindi introduced by the Rajput races.

The Bible has been translated into Hindi, the Nagari and Kaithi characters being used.

The Gujerati, a Sanskritoid language, is spoken throughout that peninsula, and has been adopted by the Parsee religionists.

Konkani has three dialects, a northern, a southern in Goa territory, and a third used by a particular class of the inhabitants of $\mathbf{S}$. Canara.

Malealam extends from Cape Comorin to the Chandragiri river, or, more strictly, perhaps, to Nileshwar (Nileswara), where a Nair raja, conquered by Hyder, formerly ruled. Mr. Cust (p. 70) tells us that it is peculiarly related to and gcographically intermixed with the Tanil. A dialect of it is spoken on the western slopes of the Animallay Hills by wild forest tribes, and a remarkable one by the Mappilla or Moplab race of the western coast, and the inhabitants of the Isaccadive Islands, with an adapted Arabic character, used by all educated Mappilla Muhammadans, except those who retain Vatteluttu or old Tamil-Malealam character. This dialect must have been formed a thousand years ago; it has a literature of its own, and sub-dialects.

The Tulu or Tulura, although of the same derivation as the Malealam, is a distinct tongue, but much intermixed with others, especially the Canarese. Tulu uses the Canarese character. It is destitute of a literature, but is the most highly developed of the Dravidian family of tongues.

Malealam and Tulu are considered by Dr. Caldwell to be in gradual course of extinction. The people speaking the Tulu shrink from contact with foreigners, even from people of their own race, retreating from the great roads, cities, and bazars as eagerly as the Tamil flocks to them; and the Maleala-speaking race are to be found isolated with their families in their high walled parambu, even in parts where the lines and centres of communication are entirely occupied by the

more enterprising Tamil people, whose language, too, seems gradually pushing the Maleala aside.

Xerxes, son of Darius, king of Persia, issued orders to the rulers of the 127 provinces of his empire, to each in the vernacular and peculiar character of his respective district. But of these characters there are remnants only of the Hebrew, Samaritan, Phonician, Greek of Ionia, the old Bactrian of the Avesta, the Demotic of Egypt, the three languages of the tablets of Behistun, the languages of Akkad and Susa, and possibly that of the Asoka inscription at Kapurdigiri. All the others have perished. Dr. W. W. Hunter says that from inscriptions on rocks, pillars, and copper plates the Indian alphabets can be traced back to the third century B.C. Mr. R. N. Cust says (p. 19) that all the characters used in writing the languages of the East Indies can be traced back to the Asoka inscriptions, and through them to the Phoenician alphabet, and thence backwards to the hieratic ideographs of the old kingdom of Egypt, and thence to the venerable hieroglyphics of the 4 th dynasty. The solitary exception is the Chinese character used in Annam.

The various characters used in the inscriptions found on ancient sculptures in Southern Asia and India may be briefly summarized as under :-

Allahabad Lat.

Allahabad Gupta.

Amraoti.

Aramæan.

Aryan or Bactrian.

Bengali.

Bhilsa.

Chaldæo-Pehlavi or Parthian.

Deva-Nagari.

Gujerat copper plate.

Gujerati modern alphabet Kistna.

Kufic.

Kutila.

Lat, or Indian Pali.

Nerbadda.

Pehlavi modern alphabet.

Pehlavi, Sassanian.

Mr. H. T. Prinsep gives the following list of transitions of the Indian alphabet from the time of Asoka, with some of the most marked local varieties at present in use, viz. those used in the sculptures of

Asoka's edicts of the $3 d$ century B.c.

Western Caves.

Sah inscription, Girnar.

Gupta inscription, Allahabad.

Valabli plates from Gujerat.

Kutila inscription of the 10th century A.D. at Bareilly.

And he gives the following ten modifications of the Sanskrit alphabet from B.C. 513 to A.D. 1200, viz.:-

Fifth century B.C., rise of Buddhism.

Uncertain, Western Caves.

Third century B.C., Sanskrit inscriptions of Asoka, Junagarh.

Second century A.D., Gujerat dated plates.

Fifth century A.D., Allahabad inscriptions of the Gapta dynasty.

Seventh century A.D., Tibetan alphabet formed from Sanskrit.

Ninth century A.D., Kutila inscriptions from Bareilly, A.D. 992 . 
Eleventh century A.D., Bengali alphabet as now modified Adisur, A.D. 1065

Modern Deva-Nagari alphabet.

Old Pali alphabet of the Burmese, compared with A.D. 200 .

The writing characters in use in the East Indies are undergoing absorption, but are numerous. Several learned men have proposed to substitute the Roman and italic forms for those in use in the native tongues. Professor H. H. Wilson in his Glossary expresses the opinion that the English alphabet bad enabled him to represent the letters of 9 alphabets of 13 different languages of British India. But by diacritic points and marks, and by compounding letters, he increased the English alphabet from 26 letters to 70 of his characters, 19 of the English letters having 2 to 6 forms, viz. $b, c, e, i, j, o, p$, and $u$ each $2 ; g, b$, and 1 each $3 ; \mathrm{d}$ and $\mathrm{k}$ each $4 ; \mathrm{a}, \mathrm{r}, \mathrm{s}, \mathrm{t}$, and $\mathrm{z}$ each 5 ; while $n$ has no less than 6 forms; and he has even recommended additions to these.

The Arabic, of all the ancient Semitic languages, is the only one that has retained its original abode, in Arabia proper, while it has also spread itself on all sides into the districts of other tongues. Others are wholly extinct, as the Phonician, or they exist in a degenerate form as the Aramæan among the Syrian Christiaus in Mesopotamia and Kurdistan; the Ethiopic in the newer Abyssinian dialects (Tigre and Amliaric), and the Hebrew amongst a portion of the Jews. Letters of the Arabic alphabet are arranged as solar and lunar,-huruf-shamsiyah and hurufkamariyah. The former are 13 in number. The Arab alphabet is ill suited for producing Aryan sounds; it is altogether without such useful letters as $p$, ch, zh, and $g$, so that $f$ and $b$ is used for the Aryan $p$ and for the Roman $f$, and the Arabic use of the letter $w$ is often doubtful. The living dialects of the Himyaritic, or Southern Arabic, are the Ekhili and Mahrah. The Arabic characters, and those known as the Niskh, are usually employed for the Arabic, Persian, and Urdu or Hindustani. These characters represent consonants and long vowels, with diacritic marks for short vowel sounds.

When Sind was annexed to British territory in 1842 , twelve or thirteen written characters were found to be in use, some of them differing widely from others. Gurmukhi is a written character in which the sacred books of the Sikh religionists was written, and is still used by the Sikhs for their private correspondence, their signet rings, and sacred books. It is a variety of the Indian character. Thakuri is in use in the Kangra district. It is a modification of the Nagari character. Lundi, a written character in use with mercantile firms in the Panjab; it is a modification of the Nagari character. Sanskrit, Hindi, and Mahrati are written in the Deva-Nagari character; Bengali, Gujerati, Uriya, Telugu, Karnata or Kannadi or Canarese, Malealam, and Tamil have each their own distinct character. The Canarese and Telugu characters, upwards of fifty in number, are almost identical, and they, as also the Malealam, consist almost exclusively of portions of circles; but in the Deva-Nagari, the Bengali, Uriya, and Tamil, straight lines prevail, modified in many by portions of circles.

The Chinese form of writing, as used in printed books, the Kiai-shu of the present day (allowing for certain improvements added under the Sung dynasty about the tenth century), dates from the fourth century of the Christian era. It is composed of 103 different elements or strokes, the position of which was an imitation of the more rounded and thicker writing, called $\mathrm{Li}-\mathrm{shu}$, modified by the rapidity of execution, which had become possible through improvements in the writing paper and hair-pencil. The Li-shu in the days of the Tsin dynasty had been devised through the necessity for a uniform system throughout the empire. This, again, had been preceded by the Siao-chuen character, composed of meagre and monotonous strokes such as were adapted to the materials then in use, viz. a bamboo written on with a stylus. This, again, was an official modification, originating in the same desire for uniformity which had been atternpted in the reign of the great Shi-Hoang of the Tsin. The Siaochuen had been modified from the ancient mode of writing called $\mathrm{Ta}$-chuen, in which great variations had developed themselves among the different states which had once been subject to the ancient dominion of the Choeu; but from these successive official changes came a great number of alterations in the elements of the characters, intended to make them answer more exactly to their signification, as shaped by the ideas then dominant, and by the systematic interpretation more or less in vogue; the addition in compound characters of a considerable number of determinative ideographic elements without affecting the sound, all leaving their stamp on the composition of the characters in use. In this undertaking the written character was reconstructed as one of hieroglyphics. This has aided the spread of the Chinese power, and facilitated its maintenance over a vast area, but it has at the same time been a clog, so far as its action could go, upon its development, in the sense in which this expression is understood among the higher races, to whose progress the possession of an alphabet has contributed so immensely.

Archipelaro.-Notwithstanding the numerous languages there, the written characters are only eight, or at most nine, in number. The Javanese alphabet, like all others in the Archipelago, is written from left to right, each letter is distinct and unconnected, and the writing is perpendicular and not slanting. It is the character used for the Javanese proper, the Sunda, the Bali, and it is believed the Lombok; and including Palembang in Sumatra, it is current among twelve millions of population. But in prior times, other characters to the extent of twelve in number have prevailed in Java.

In Sumntra, beginning from the west, the first evidence of a native written character is among the Bataks, and it is singular that a nation of cannibals should possess the knowledge of letters. There was assuredly nothing of the kind in Europe or continental Asia until long after men had ceased to eat each other. The form of the Batak letters is horizontal.

The Korinchi alphabet, among the people of this name in Sumatra, who border on Menangkabau, has twenty-nine characters, and consists of horizontal or slightly raised scratchings.Journal of the Indian Archipelago; Mr. Hodgson, $M r$. Robinson, Mr. Samwells in Journal of Asiatic Society of Bengal; Dr. Latham, Dr. 
Prichard, Dr. Max Muller, Chevalier Bunsen, General Briggs, Messi's. Schlagentweit, in Reports, British Association, 1815 to 1858 ; Journal Royal Asiatic Society; Astley's Voyages, iv. p. 194 ; Bikmore's Travels; E. I. Brandreth in vol. x. Jo. Ro. As. So.; Bunsen's Egypt; Burnell; Burton; Dr. Caldwell's Grammar and Shanars; Sir G. Campbell in Beny. As. Soc. Jo.; de la Couperie; Crawfurd's Malay Dictionary; Cunningham's Ancient India; Cust's Modern Languages; Dalton's Ethnoligy, and in Jo. As. Soc., 1866 ; Sir W. Elliot in Jo. R. As. Soc., 1861; Sir H. M. Elliot, Hist. of India and Supplemental Glossary; Elphinstone's Hist. of India; Farrar, Lectures on the Families of Speech; Huc, Chinese Empire; Hunboldt's Cosmos; Dr. Haug; Hunter, Non-Aryans and Imp. Gaz.; Hodlgson's Aborigines N.E. India; Hyslop in Journ. Antiq. Society of Nagpur; India Census 1881 ; Jagur on the Philippines; Professor A. H. Keane's Asia; Kennedy on the Origin of Languages; Lassen; Latham, Philology, Descriptive Ethnology; Logan in Journ. Ind. Archip.; Lubbock, Origin of Civilisation; Menander, Voyage of; Max Muller's Lectures and Ancient Sanskrit Literature: Newbold in Journs. R. As. Soc., Mailras Literary Soc., also Malacca; Peschel, Races of Man; Prinsep's Antiquities by Thomas; Rask; Raverty's Grammar; H. Rau'linson; Renan's Langues Semitiques; Sayce; Spreewenberg in .J. Ind. Arch., 1858; Dr. Isaac Taylor; William Taylor in Jo. Mad. Lit. Soc.; E. Thomas ; Thomson's Tr. ; A.R. Wallace, Malay Archipelago; Weber, Indian Literature; H. H. Wilson's Glossary; Y-Ben A in Times of June 6, 1880; Yule's Embassy.

LANGUR. Singh. Large monkeys of Ceylon and S. India. Presbytes entellus, the Bengal langur, the Hanuman of the Hindus; P. schistaceus, Himaliyan langur; $P$. priamus, the Madras langur; P. Johnii, the Malabar langur; P. jubatus, the Neilgherry langur. See Mammalia.

LANIAD $A$, a fanily of birds, including the shrikes or butcher-birds. It comprises the subfamilies Lanianæ, Malo-conotinæ, Dicrurinæ, Artaminæ, and Campephaginæ. The harsh chatterings of a very common kind of shrike, Lanius superciliosus, in Indian gardens, are the earliest intimations of coming change of season. The species of Lanius are L. arenarius, L. cristatus, L. erythronotus, L. Hardwickii, L. lahtora, L. nigriceps, and L. tephronotus.

LANKA. Hind. An island, a name of Ceylon, also of the islets of the Godavery. Lanka tobacco is grown on the islets, in the delta of the Godavery, in the alluvial silts deposited from the river floods and out of the influences of the sea freshes.

In the Hindu story of Rama, the residence of the giant Ravana, supposed to be the modern Ceylon. In Hindu cosmogony, Borna Coti is an imaginary city, supposed to lie under the equator at $90^{\circ}$ from Lanka. From a note in the English translation of Abul Fazl's Ayin Akbari (Calcutta edition, iii. p. 36), we learn that there are many reasons for concluding the Ceylon Lanka to bave been part of the Taprobane of the ancients.Ouseley's Travels, i. p. 33 .

LAN-KEET or Long-eet, literally dragon's cave or den, an uninhabited island in the Canton river, in lat. $22^{\circ} 41^{\prime} \mathrm{N}$.

LAN-PO or Lamghan. SANSK. Lampaka, Ptolemy's Lambatæ, and modern Lamghan.
LANSEH. MALAY. A small oval fruit, of a whitish-brown colour, which, being deprived of its thin outer coat, divides into five cloves, of which the kernels are covered with a fleshy pulp, subacid, and agreeable to the taste. The skin contains a clammy juice, extremely bitter, and, if not stripped with care, it is apt to communicate its quality to the pulp. M. Corréa de Serra, in les Annales du Mus. d'Hist. Nat. x. p. 157, pl. 7 , gave a description of the Lansium domesticum, from specimens of the fruit preserved in the collection of Sir Joseph Banks. The chupak, ayerayer, duku, and rambutan are other prized fruits of the Straits Settlements. The last named, rambe, Malay, is the Nephelium lappaceum.Marsden's Hist. of Sumatra, p. 101.

LANSIUM ANIMALLAYANUM. Bedd. A handsome, good-sized tree, common in the dense moist forests of the Animallays (particularly in the Anagoondy shola) at an elevation of about 2000 feet, also in Malabar at the foot of the Neilgherries; it flowers early in April, and fruit ripens in July; the succulent aril in the latter is greedily eaten by monkeys and birds. It is the only species of the genus found in the Peninsula; one species occurs in the Himalayas, and a third in Java.-Beddome, Fl. Syl. p. 131.

LANSIUM AQUEUM. Jack. The Ayer-Ayer, MALAY, is a fruit so nearly resembling the lanseb in most particulars, that Dr. Jack, hesitating to rank it as a species, mentions it as a permanent and well-marked variety under the name var. $\beta$ L. aqueum. The fruit of the ayer-ayer is rounder, and the pulp more watery, and dissolves more completely in the mouth than the lanseh. Both are highly esteemed by the Malays, aud are equally agreeable to the European palate. The juicy envelope of the seeds is the part eaten, and the taste is cooling and pleasant.-Linnæan Transactions, iv. p. 114 ; Eng. Cyc.

\section{LANSIUM DOMESTICUM. - ?}

Var. a. Langsat, MALAY, JAV., shape globular.

Var. b. Duku, MALAY, JAV, shape oblong.

Langsab, Langsat, Malat.

Europeans regard its fruit as next to the mangosteen. It is about the size of a pigeon's egg, having a tough white skin with a bitter taste, and the edible part is the pulpy semi-transparent envelope of the seed. To the same genus belong the duku, also the lanseh, langsat, or langsab, for in all these forms the word is written, the rambe and the ayer-ayer. The duku is the most esteemed of them, and to the European palate is the best of the native fruits of the Archipelago, after the mangosteen. The natives class it after the durian and mangosteen. Mr. Hogg states this plant to be a native of the Antilles? The species seems, however, to be indigenous in the western portion of the Archipelago, but to have been introduced into the Philippines, where the lanseh is cultivated.-Crawfurd's Dict. p. 125 ; Hogg's Veg. Kingdom, p. 171.

LANTANA, a genus of plants belonging to the natural order Verbenaceæ or vervains.

L. nivea, var. mutabilis, is a straggling shrub in the neighbourhood of Moulmein. The flowers are yellow when they first open out, but after. wards change to a rose colour.-Mason.

L. Indica, Roxb., a shrubby, erect plant of all India.-J. A. Murvay.

L. selloviana, a large shrub, producing pink, 
yellow, orange-coloured heads of flowers; they blossom at all seasons, and are found in most gardens in India. The leaves have the scent of black currants; the berries are eaten.-Riddell.

LANTERN FEAST. The feast of lanterns, amongst the Chinese, takes place on the first full moon of the new year, or the 15th day of the 8th month. It affords opportunity for a display of ingenuity and taste in the construction and mechanism of a variety of lanterns made of silk, varnish, horn, paper, and glass, some of which are supplied with moving figures of men galloping on horseback, fighting, or performing various feats, together with representations of birds, beasts, and other living creatures, all in full motion. The moving principle in these is formed by a horizontal wheel, turned by the draught of air created by the heat of the lamp, and the circular motion is communicated in various directions by means of fine threads attached to the moveable figures.-Davies. SeeDewali; Dipa mala; Lakshmi.

LANTOA or Ty-ho, in the Canton river, an island 14 miles long and 5 miles broad, is near Canton, and its S. or S.W. point is in lat. $22^{\circ} 12^{\prime}$ N., and long. $113^{\circ} 51^{\prime}$ E., the N.E. point being in lat. $22^{\circ} 21^{\prime} \mathrm{N}$., and long. $114^{\circ} 2^{\prime} 22^{\prime \prime} \mathrm{E}$. On its north point is the Cap-sing-moon or Throat passage.

LANTSAN, a river in the west of China. To its west is a country inhabited by the numerous tribes of Yatezu, Mooquor, Moso, and Leisu. These tribes live in small villages, each under its own headman, the whole tribe being ruled by one chief, who holds the Chinese rank of Bluebutton, and is a tributary of the Chinese Government, having authority in all cases except those involving life and death, which are referred to the nearest Chinese mandarin. The whole of these tribes inhabit a strip of country lying between the Kinchar Kiang and Lantsan river; they are peaceable and industrious, cultivating peas, tobacco, opium, and scanty crops of cotton; they also collect gold, both by washing the sands of the Lantsan Kiang, and by mining in the hillsides. Each tribe pays $\pi$ tithe to its chief, who in turn pays two-thirds of his share as tribute to the Chinese Government. The costume of the women is fantastic but graceful; it consists of a hear-dress of red cloth, closely braided with corvrie shells, for which the Moso women occasionally substitute a very becoming little cap or hood of red and black cloth, with pendent tassel, a short loose jacket with long wide sleeves, and buttoned up the front, and a kilt-like petticoat of home-made cotton stuff, reaching from the waist to the knee, and made in longitudinal plaits or gathers. The road from the Jeddo range of mountains near Ta-tsian-lu, up to the banks of the Lantsan river, crosses ravge after range of mountains, all running from the north-east to south-west, and the great snowy ranges lying on each bank of the Lantsan and Nou-Kiang rivers are a continuation of the great ranges, which, rising to the north of the Tibetan town of Tsiamdo, must form at their conjunction with the Himalaya what is believed to be the chief barrier to direct communication between Bathang and Lhassa.

LANTZA. TrB. Ranja in Nepal, a system of letters used in writing or engraving the Sanskrit language. It is used by the Buddhists of Nepal proper, who call it Ranja. It is the Nepalese form of the Deva-Nagari. It is the common extant vehicle of those original Sanskrit works of which the Tibetan books are translations.

LANUN or Illanun, a piratical race occupying stations in the Archipelago. They have been repeatedly displaced by the expeditions against the pirates.

LAO. Hind. A run, a fetch of water, from Lana, to bring. An ordinary mode of raising water from wells by leather buckets raised by bullocks. Lao-charsa, the rope and bucket apparatus for drawing water from wells in districts where the Persian wheel is not used.

LAOS are a people of the Thai or Siamese group, the most civilised of whom occupy the valley of the Menam and its feeders. They dwell in Zimumay, also on the Menam, between lat. $19^{\circ}$ and $22^{\circ} \mathrm{N}$., due north of Siam proper, and due west of the Burmese frontier, with Laphun and Lakhon, two small territories, attached.

The Laos races are divided into two very distinct sections, those who tattoo their bodies, the Thaung Dari or black bellies, and those who do not, the Thaung Khao or white bellies. The tattooed or black bellies occupy the districts of Xieng Mai, Laphun, Lakhon, Muang Phre, and Muang Nan. The non-tattooed (white-bellied) live in the districts of Muang Lom and Muang Luang and Phra-Bang.

Laos inhabit also the valley of the Mei-kong from lat. $13^{\circ}$ to $21^{\circ} \mathrm{N}$., and are thinly scattered over the muun :aiuous countries which extend between that valley and the confines of Tonkin and Kamboja.

The Laos country has undergone great changes. About the 12th century of the Christian era, the Laos were a powerful and conquering people in the upper portion of the basin of the Irawadi, where their capital was at Mo-gaung (Muanggaung or Mung Khong), and whence, in A.D. 1224, they sent an expedition which subjugated Assam, and established Ahom rule. Their native country, own territory, being a portion of the basins of the Mei-kong and the Menam, including Yunnan. A bout the same time they took possession of a higher portion of the upper basin of the Mili, where their chief seat was at Khamti, whence the name by which this branch is still known. At present the Laos people, under the names of Shan and Khamti, are found in Upper Assam, and scatterer? over a large portion of the northern half of the basin of the Irawadi, nearly to the confluence of the Khyen-dwen with the principal stream. Scattered villages are even found in Arakan; on the eastern side they are scattered along the Saluen as far as lat. $18^{\circ} \mathrm{N}$. The whole of the Menam basin is in their hands, with the exception of a small part of the right side near its head; and they also occupy a large portion of the basin of the Mei-kong. The eastern tribes are known as Lo-Lo, Lau, and Thai.

In the basin of the Irawadi, the Shan are intermixed with the Tibeto-Burman tribes amongst whom they have intruded, but in large portious of it they are the principal population, and, in the N.E. corner of the empire, the Khanti inay be considered as independent. It is probable that the Siamese, with the tribes of the Upper Menam and of the Mei-kong, are directly connected with those of Yunnan, and are not offshoots from the colony of Muang-gaung. The Siamese 
have advanced more than half-way down the Malay Peninsula, and but for the check given to them towards the close of the 18 th century by the establishment of Penang as a British settlement, their sway would now have embraced Perak, and probably have extended to the confines of Malacca. The northern clans almost every where retain their independence, although owning a nowinal allegiance, and in some instances paying tribute to Burma, to China, or to Siam, those on the frontiers of Yunnan propitiating both the Golden Foot and the Son of Heaven by an acknowledgment of fealty, and some sending a trienninl offering to the latter.

The Laos people on the borders of China differ little from the Chinese of Yunnan, and their stock was probably the same. Where they are in contact with the older races, they have considerably altered. In the valley of the Menam, their height is about $1 \frac{1}{2}$ inches less than the average Chinese; but as the average stature of the French is the same ( 5 feet 3 inches), the Siamese may still be considered as of the middle size.

The Laos people are partly under Burmese, partly under Siamese rule, and those of Burna are known as the Lu, or Thai, or Shan.

When the French mission moved up the valley of the Mei-liong in 1869, there were four tributary kingdoms or governors of the Laos. In the year 1828 Laos had been laid waste, Vien-chan, its capital, was utterly destroyed, and its people exterminated or deported by an army of Siamese. Its king was taken to Bankok, where he died, and all his relatives were in a degraded position (De Carne, p. 131). The manners, customs, and languages of Siam and Laos are similar.

Their language is the same as that of the Sirmese. The alphabet more resembles that of Kambogia than that of Siam; they use rice, and distil and use a liquor from it.

The arts of mining and smelting ore are understood by the northern Lao tribes and the Shan races of Yunnan. The Laos pugilists bave a metal cestus for their hands. M. de la Loubere says the Siamese nation was a colony from Laos. The Phi-phrai and the Phi-lok are their wood demons. The Thevada are their tutelary deities. Ifr. Logan in Journal of the Indian. Archipelago; Latham's Ethnology; De Carne's Travels in IndoChina; Moor's Indian Archipelago.

LAUU TSZE was born B.C. 604, and died B.C. 520 , at the age of 84 ; Confucius, Kung-fu-tze, was born B.C. 551 , and died in B.C. 479 , at the age of 72 ; thus they were contemporaries. Confucius visited Lrou Taze at the court of Chow. The parents of Laou Tsze were probably very poor, his father, according to one account, being a peasant who had remained unmarried up to his seveutieth year, and then married a pessant woman of forty. Laou Tsze, through his learning and abilities, obtained employment at the court of Chow, but eventually withdrew to retirement among the hills of his native country on the eastern borders of Ho-nan, where he devoted his whole time and energies to philosophical research, and there produced his celebrated book the Taou-TihKing. The ethical doctrines of this book exalt virtue as the chief good, and are based on metaphysical speculations. The Taon-Tih-King, the book of virtue and reason, contains his religious philosophy. It was translated into French by M. Stanislas Julien.
His followers are known as Taou-tsze or Taouists. The word Taou means, in the first place, a way, and then a principle, and is used to signify the supreme principle of the universe. The meaning which Laou Tsze gave to Taou is obscure; and as Taouism exists in China, his metaphysical explanations are disguised in gross superstitions, and bis ethical doctrines are indolent indifferentism.

Laou Tsze himself is now the third in a trinity of persons in whom Taou has assumed personality, called in the writings of the sect Shang-Te, and worshipped as the three pure ones; and they assert that he left heaven and became incarnate as the sage of Chow. They are alchemists. The priests of the sect of Taou are numerous, and constitute nearly all the followers. Some are celibates and hermits. They worship the sun, moon, and stars. There are Taouist nunneries; their nuns do not shave their heads. - Archleacon Gray's China, 96.

LA PEROUSE, a navigator and explorer of France, who was wrecked on Vanikoro Island, and he and all his people were destroyed by the natives.

LAPIDATION is an ancient practice still common in some eastern countries, and is a token of hate. Yet in some parts of Arabia, stones are thrown at tombs as a compliment to the tenant. And in the Somali country, the places where it is said holy men sat, receive the same doubtful homage-Burton's Mecca, iii. p. 341.

LAPIS-ARMENUS. P'ien-ts'ing, CHIN. Armenian stone; an azure mineral, brought in flattish pieces to China from Hainan Islan? When roasted and powdered, it becomes the powder blue (Liu, CHrN.) of Chinese commerce. It is supposed to be a smaltine or arsenuiret of cobalt. Lapis-armenus is, however, mentioned by Duhalde as a white translucent stone, found in Yunnan and Sze-chuen.-Smith.

\section{LAPIS-LAZULI, azure stone.}

Liu li, Ho-tsi, . CHIN. Lazwardi, . . MALAY. Lajaward, Lajburd, HIND.

Lapis-lazuli is a complex combination of silicate and sulphate of aluminum. It is found in Persia, Baluchistan, China, Siberia, Bucharia, and Chili, and varies in price from $10 \mathrm{~s}$. to $15 \mathrm{~s}$. the ounce. It is found in the ruby mines of Badakhshan, also in the mountains at the source of the Koultouk, a little river which flows into the Bailsal Lake, where it is detached from the rock by heating the rock with fire, and then dashing cold water on it. It is said to be found massive, with iron pyrites, amongst the Ajmir Hills, especially the Nag-pahar range; but this is probably a copper ore. This stone is sold by all the attars or druggists of India, both as a medicine and as a pigment. Firgamu, in Badakhshan, stauds at the head of the fertile portion of the Kolicha valley, which south of this takes the name of Koran. Beyoud Firgamu, the mountains rise directly from the bed of the river. Where tho deposits of lapis-lazuli occur, the valley of the Kokcha is about 200 yards wide. The formation is of black and white limestone, unstratified, though plentifully veined with wavy lines. Under the spot to be quarried a fire is kindled, and its flame, fed by dry furze, is made to flicker over the surface. When the rock has become sufficiently soft, flake after flake is knocked off by hammering, till the mineral is discovered. Decp grooves are then picked out round the lapis- 
lazuli, into which crowbars are inserted, and the stone and part of its inatrix are detached. The workmen enumerate three varieties, viz. the neeli or indigo-coloured, the asmani or light-blue, and the sabzi or green, and their relative value is in the order they are mentioned. The richest colours are found in the darkest rock, and the nearer the river the greater is said to be the purity of the stone. The mines have been known from a very early period. Its chief use is for affording ultramarine, a beautiful pigment, highly valued by painters. The colour of this stone is a fine azure blue, having little lustre, but susceptible of a fine polish. The Chinese are supposed to use it in painting upon copper and on their porcelain. The Chinese Buddhists regard this mineral as one of the seven precious things. By exposure to heat and moisture, it loses its beantiful azure, and assumes sometimes a black, sometimes a chalky appearance. It is used in native medicine for mixing with jalap powders, and in other compounds; it is not taken alone.-Emmanuel; Gen. Med. Top. p. 162 ; Morrison, Comp. Desc. ; T.W. Atkinson's Siberia, p. 596; Wood's Source of the Oxus, p. 264 ; Powell's Handbook, p. 65 ; Smith's Mat. Med. of China; MacGregor, p. 188.

LAPLAND. The Laplander or Lapp race is one of the most diminutive of the Mongolian group of the human family. The Lapp mode of divination is to put a shoulder-blade in the fire, and then foretell the future by the arrangement of the cracks. The same custom exists among the Mongol and Tungus of Siberia and the Bedouin. The lines vary of course greatly, still there are certain principal cracks which usually occur. The Chipeyan of North America also make their magic drawings on shoulder-blades, which they then throw into the fire.

LAPORTEA CRENULATA. Gaud, Roxb. Urtica crenulata, Roxb. | Dendrocnide crenulata, U. Javanensis, Gaud. $\quad$ Mig.

L. gigantea, Gaud.

Fever nettle, . . ENG. Maoosa-gass, . Singh. Devil nettle,

This dreadfully stinging tree or large shrub is only too common in most of the western coast moist forests of the Peninsula up to 5000 feet. It also grows in Ceylon, Bengal, and Java. Lescherault de la Tour, describing the effect of gathering Urtica crenulata in the Botanic Garden at Calcutta, says:--'One of the leaves slightly touched the first three fingers of my left hand; at the time I only perceived a slight pricking, to which I paid no attention. This was at seven in the morning. The pain continued to increase ; in an hour it had become intolerable; it seemed as if some one was rubbing my fingers with a hot iron. Nevertheless there was no remarkable appearance, neither swelling, nor pustule, nor inflammation. The pain rapidly spread along the arm as far as the armpit. I was then seized with frequent sneezing, and with a copious running at the nose, as if I had caught a violent cold in the head. About noon I experienced a painful contraction of the back of the jaws, which made me fear an attack of tetanus. I then went to bed, hoping that repose would alleviate my sufferings, but it did not abate; on the contrary, it continued nearly the whole of the following night, but I lost the contraction of the jaws about seven in the evening. The next morning the pain began to leave me, and I fell asleep. I continued to suffer for two days, and the pain returned in full force when I put my hand into water. I did not finally lose it for nine days.' A similar circumstance occurred with precisely the same symptoms to a workman in the Calcutta Garden. This man described the sensation when water was applied to the stung part, to be as if boiling oil was poured over him. In cutting boundary lines, exploring forests, botanizing, etc., Colonel Beddome bas been very often stung by this plant both on the hands and face, but never found the effects so violent as described by Leschenault; they are, however, bad enough, the pain being felt more or less for several days, and always being intensified by the application of water. With natives the sting often brings on fever, and the plant is known to coffee-planters as the fever nettle and the devil nettle.-Beddome, Fl. Sylu.; Thu. En. Pl. Zeyl. p. 259.

LAPORTEA TERMINALIS, $W$. Ic., grows in the Central Province of Ceylon at an elevation of 4000 to 6000 feet.-Thw. Zeyl. p. 259.

LAPWINGS are birds of the family Charadridæ, of the sub-family Vanellinæ, and of the genera Vanellus, Chetusia, Lobivanellus, Sarciophorus, and Hoplopterus. The crested lapwing, Vanellus cristatus, the English peewit, occurs throughout a great part of Europe and Asia. It breeds in the Panjab.

The little brown-coloured lapwing, Chetusia leucura, is rare in most parts of India, and most probably migratory in the Panjab. It is said to be common in Afrhanistan, where, according to $\mathrm{Mr}$. Blyth, it is known by the name of Chizi. The call of the spur-winged lapwing, Lobivanellus goensis, is peculiar. This unsettled water-sprite often flies about at night, startling the unwary with its cry of Did dee doo it, did did did dee doo it. Like the European lapwing, it assails all who intrude on its haunts. It has horny spurs on the wings. Dr. Jerdon names V. cristatus, Chetusia gregaria, Ch. leucura, Ch. inornata, Lobivanellus goensis, Sarciophorus bilobus, Hoplopterus ventralis.

Whoever has unhooded the falcon at a lapwing, or even scared one from her nest, need not be told of its peculiarly distressing scream, as if appealing to sympathy. Tradition relates that a lapwing was scared from her nest as the rival armies of the Kuru and Pandu joined in battle, when the compassionate Krishna, taking from an elephant's neck a war-bell (vira gunt'ha), covered the nest, in order to protect it. When the majority of the feudal nobles of Marwar became self-exiled, to avoid the almost demoniac fury of their sovereign after his alliance with the British Government, Anar Singh, the chief of Ahore, a fine specimen of the Rahtor Rajput, brave, intelligent, and amiable, was one day lamenting, that while all India was enjoying tranquillity under the shield of Britain, they alone were suffering from the caprice of a tyrant; concluding a powerful appeal to Colonel Tod's personal interposition with the foregoing allegory, and observing on the beauty of the office of mediator. 'You are all-powerful,' added he, ' and we may be of little account in the grand scale of affairs, but Krishna condescended to protect even the lapwing's egg in the midst of battle.' Colonel Tod replied in the same strain, "Would to God, Thakur 
Sahib, I had the vira gunt'ha to protect you.'Tod's Rajasthan, i. p. 524; Adams; Jerdon. See Birds.

LAQUIS of the Bisaya, a variety of the manilla hemp plant; the fibres of the original abaca are tcrmed Lamot by the Bisaya. Rumphius states that the Malay name is Pissang utan; that it is called in Amboyna, Kula abbaal ; in Ternate, Fana; and in Mindanao, Coffo, as also the cloth made from it. He distinguishes the Mindanao kind from that of Amboyna.-Royle, Fib. Pl.

LAR. Hind. A necklace of several threads or rows; Sat-lăr, 7 rows, etc. ; also a strand of untwisted rope.

LAR, the local name of the southern portion of the province of Sind, from Hyderabad to the sea, where the people speak the Lari dialect of Sindi.

LAR, a river, rises not far from the town of Barkhan, in the country of the Ketrani or Khuttiani in Baluchistan. It flows westward, and joins the Narra in the Murree Hills, south of Sibi.

LAR, the $\Lambda$ apixé of Ptolemy, the Lata of Sanskrit writers, a country comprising Kandesh and part of Gujerat about the Mhye river.

Ptolemy and the Periplus mention Gujerat under the term Larice, and Biruni and Abulfada place Somnath and even Tana in or on the borders of the province of Lar. The merchant Sulaiman calls the Gulf of Cambay and the seas which wash the Malabar coast, the seas of Lar; and Masudi says that at Saimur, Subara, Tana, and other towns, a language called Lariya is spoken. The Charita enumerates Lardes, or country of the Lar, amongst the eighteen regions dependent on Anhilwara, but, for some fault, Komar-pal chased the tribe of Lar from the country. Ibn-Said says that he had met with authorities which placed the famous temple of Somnath in the country of Lar. Lardes seems to have at one time included the modern collectorates of Surat, Broach, Kaira, and parts of Baroda territory; and the name probably embraced a wider or uarrower region according as the power of the Lar race varied. It is very doubtful whether the Indus ever did disembogue so far to the east as the Gulf of Cutch. The remains of this ancient tribe are now only to be discovered in Rajputana in the third or mercantile caste, forming one of the eighty-four great families resicling in Maru, and following the Jain faith. In Maiker of Berar is a race named Lar, who seem to be a broken portion of a considerable tribe, the Lar of NorthIVestern India. They are returned as a Hindu people of Maiker. They are named Lour in Amraoti, and are there 3485 in number. The Lar are weavers of cloths of silk in Berar. Lari are pieces of twisted metal, which Tavernier found to be current as coin on the Malabar coast, and Thunberg saw them in Ceylon. They had their name from the province of Lar.-Elliot's History of India, i. p. 378 ; Tod's Travels, p. 187.

LARCH TREES occur in Europe and Asia. In the latter continent, the Larix Griffithii, $H . f$. et $T h$, is of Nepal and Sikkim, and L. Sibirica, Led., is of Russia, Siberia, and the Ural Altai mountains. The bark contains a good deal of tannin, mucilage, and some resin, and is sometimes used as a substitute for oak bark, for tanning the inferior sheep skins, known as basils.

Larix Griffithii, $H$. $f$. et $T h_{\text {., }}$ is the sah or Himalayan larch. It splits well, and is the most durable of any of the genus; but the planks are small, soft, and white. It is a timber tree of Chumbi in Tibet, N. of Darjiling.-Hook. ii. p. 45. LARD.

Chu-yu, Hwa-yu, . Chin. Sur ki charbi, . . Hind. Chu-pan-yu, . , Dukkur-ki-charbi,

The fat of the omentum and mesentery of the pig, the melted fat of the domestic pig. Lard is employed in the formation of ointments, plasters, liniments, for other medicinal purposes, and also in cookery.-Waterston; Faulkner.

LARD-STONE, Kw'ai-hwoh-shih, CHIN., is a magnesian mineral resembling steatite.

LAREK or Larrak, 8 miles S.S.W. of Hormuz, at the entrance of the Persian Gulf. It is a small barren island $5 \frac{1}{2}$ miles long and 4 broad, about 15 miles in circumference. Larek is supposed by a learned writer to be the Organa of Arrian rather than Hormuz, which it nearly equals in size. Niebuhr has written its name Larej.Kinneir's Geographical Memoir, p. 13.

LARES of the ancient Romans were two deities of inferior power, who presided over households. They were the sons of Mercury by Lara. The offerings of the Romans to their lares and manes resembled the Hindu offerings to the pitri. In S. 750 (A.D. 694), when the Assurs blockaded Ajmir, Lot, the infant son of Manika Rae, was playing on the battlements, and was killed by an arrow. He has ever since been worshipped amongst the lares and penates of the Chauhans; and as he had on a silver chain anklet at the time, this ornament is forbid to the children of the race. In all these Rajput families there is a putra (adolescens) amongst the penates, always one who has come to an untimely end, and is chiefly worshipped by females; having a strong resemblance to the rites in honour of Adonis.-Rajasthan, i. p. 246.

LARI, a tribe who exclusively hold Nermuk, but reside also at Mustung and Shall, with other tribes. Kuhak is occupied by the Muhammad Shabi, Nermuk by the Lari Brahui, Lup by the Kalui Rind, Kishan by the Sherwani. See Kalat.

LARISTAN bounds part of the frontier of Fars to the south. Laristan is the ancient kingdom of Lar. Gilam and Siras are on the coast of Laristan. Gilam appears to be the $\mathrm{Ila}$ of Arrian, but we can scarcely suppose it the Ghilan which Hand Alla Kazvini enumerates among the islands of the gulf, subject to the Persian Government.-Ouseley's Travels, i. p. 174 ; Nearchus, p. 375.

LARKA-KOL. HIND. The name of a mountain tribe in Ch'hattisgarhi. See Ho; Kol.

LARKANA or Larkhana, 40 miles from Shikarpur, in Sind, is a large, populous, and commercial town, in lat. $27^{\circ} 33^{\prime} \mathrm{N}$., and long. $68^{\circ}$ $15^{\prime} \mathrm{E}$. It gives its name to a sub-district of the Shikarpur collectorate in Upper Sind. The people are chiefly Muhammadans, - the Chandia, Jamali, Abra, and Jat. It is from the first that this part of the country obtained the name of Chanduka or Chandko. The Jamali are a Baluch race living on the borders of the desert; the Abra inhabit the south-west of Larkana; the Jats are all over the sub-district, and are cultivators and cattle-breeders. It is subject to floods or lets, which at times cause great destruction to life and property. Dyeing forms an important industry. T'he exports comprise grain of sorts, wool, cotton, 
and other agricultural products.-Imp. Gaz.; Masson's Journeys, i. p. 460.

LARKHANI, in the early part of the 19th century, a community of robbers; their name in Rajputana, like Pindari and Kazak, was held to be synonymous with freebooter; they could then muster 500 horse, and their raids were rather formidable. Larkhan conquered an appanage, Dantah Ramgarh, on the frontiers of Marwar, then a dependency of Sambur. Besides this district, they had the tuppa of Nosul, and altogether about eighty townships, including some held of the rajas of Marwar and Bikanir, to secure their abstinence from plunder within their bounds.-Tod's Rajasthan, ii. p. 427.

LARKS are singing birds of Europe and Asia, of the sub-family Alaudinæ. They have been arranged by Jerdon into the bush larks, true larks, and long-billed or desert larks.

Mirafra Assamica, Bengal bush lark.

M. affinis, Madras bush lark.

M. erythroptero, red-winged lark.

M. cantilans, Jerdon.

M. Horsfieldii, of Australia.

M. Javanica, of Java.

Ammimanes phænicura, rufous-tailed finch lark.

A. Iusitanica, pale rufous finch lark.

Pyrrhulauda grisea, black-bellied finch lark.

Calandrella trachydactyla, short-toed social lark. Alauda raytal, Indian sand lark.

A. triborhyncha, Himalayan skylark.

A. gulgula, Indian skylark.

A. Malabarica, Malabar skylark.

Otocoris penicillata, horned lark.

O. Iongirostis, long-billed horned lark.

Spizalauda deva, small-crested hormed lark.

Galerida cristata, large-crested Iaxk.

Certhilauda desertorum, desert lark.

Alauda gulgula is the common lark of the plains of India and of Bengal. A. Malabarica may be somewhat inferior to the European skylark, so far as regards variety in the notes, but the difference is so very little, that the two birds could not be distinguished by the voice alone, nor by the mode of flight.

Alauda triborhyncha, Hodg., of the lower region, scarcely differs from the skylark of Europe, but it seldom mounts so high or remains so long on wing. It is a summer visitor only, possibly migrating to the lowland valleys in winter. A Kashmir boatman would consider his establishment incomplete without the Afghan lark, Melanocorypha torquata, said to frequent the valley of Kashmir in winter. The sweet notes of these songsters, issuing from the boats as they pass up and down the river, are very enchanting. In all the desert parts of Sind, the crested calandre lark, the Charndol, Galerida cristata, is plentiful. It is not unlike the skylark, is generally met with in flocks during the cold months, and is the most abundant lark on the plains of Upper India and table-land of the Peninsula. It is of rare occurrence in Britain. The song of this bird, also its mode of delivery of it in the air, are not very unlike that of the skylark, although it does not soar so high.

Larks are often domesticated in S.E. Asia. In China, the Acridotheres cristellatus, the Shantung lark, has great facility in learning sounds, and will bark, mew, crow, cough, and sneeze, sometimes talk, and a single bird will fetch $\mathfrak{L} 6$. The Acridotheres will imitate the human voice accurately. In China, a starling is often domesti- cated; it is lively, good-natured, and easily tamed. They also tame the fork-tailed parus, the Leiothrix luteus of Scopoli. It is in form and habit like the robin of Britain, is pretty, olive green, black forked tail, with wing primaries bright yellow and red. It turns summersaults on its perch. They have a short, loud song. Canaries are sold in many shops of Japan. The grackle, Gracula religiosa, called the Mina, is largely domesticated. The partridge, the shrike, are also largely domesticated. The hoopoe is to be seen occasionally.-Blyth; Adams.

LA ROQUE, author of a Voyage to Arabia the Happy, by the way of the Eastern Ocean and the Straits of the Red Sea, performed by the French for the first time in A.D. 1708, 1709, and 1710 ; also of a Journey in 1711, 1712, and 1713, from Mocha to the Court of the King of Yemen.

LARUS BRUNNICEPHALUS. Jerdon. Indian hooded gull. L. fuscus, lesser black-backed gull, of the Atlantic, Mediterranean, Red Sea, Indian Ocean, Cape of Good Hope, N. Zealand, Kābul (Burnes), Bay of Bengal. Xema ridibunda, or Larus ridibundus, is the black-headed gull of Europe, Asia, N. Africa; not rare in India, but less common than the nearly affined $\mathrm{X}$. brunnicephalus. X. brunnicephala, Jerdon, the brownheaded gull, and the Kroikocephalus ichthyretus, Pallas, the great black-headed gull of all Asia. $-J e r d o n$.

LARVA, a caterpillar. In China, the dried larvæ of flies, Wuh-kuh-ch'ung, Crin., are given to chilaren ill with marasmus. See Insects.

LAS. TIB. In Tibetan Buddhism, actions on which the destiny of human beings depend.

LAS, HrND., of Jhelum district, inferior land.

LAS, a section of Baluchistan bordering the Arabian Sea. Its ruler is styled the Jam. Las is separated from Lower Sind and the Indus delta by the Hala mountains.

It is a small maritime province, 100 mileg long and 80 miles broad, and bounded on the north by the hills of Jhalawan, and east and west by high mountains. On the north is the Wuil State, and on the south the Indian Ocean. Najor Preedy gives the names of nine tribes of this province, as the Bhoor'u, Goonga, Guddore: Hungaryah, Mandra, Roonja, Shaikh, Sabra, and Jamote ; but Colonel Goldsmid enumerates nineteen, viz.-

\begin{tabular}{l|l|l|l} 
Jamote. & Goonga. & Guddra. & Bodhur. \\
Sabra and Achra. & Boona. & Mussoor. & Manga. \\
Guddore. & Moondrance. & Baradia. & Waora. \\
Angaryo. & Sheikh. & Meree. & Zor. \\
Roonjha. & Mussona. & Dhira. &
\end{tabular}

The Guddra, Guddon, or Guddo, settled in Las, are an Arab tribe, there probably since the first occupation of Mekran and Sind by Muhammadans. They have characteristies sirnilar to those of the Jokya, Numria, and Jutt, etc. Beyla is its capital, and is north of Sonmeanee, its principal seaport. In winter the climate is cool and dry, but the summer heats are great. It produces grain, and is occupied by the Lassi division of the Lumri or Numri tribe. They have about twelve divisions or clans, one of which, the Jamhut, furnishes their chief or jam. They claim to trace their origin to Samar, who foundeil Samarcand, and acknowledge a consanguinity to the Bluatta of Jeysulmir. The Lumri are an active, 
hardy, pastoral people; their wealth consists in flocks of goats, with fewer buffaloes and camels. They despise agriculture; wild Lumri are found grazing on the rocky banks of the Hab river. Their language varies little from that current in Sind. They manufacture coarse fabrics from the wool of their goats and camels. The Lumri eats meat almost raw, and is greatly addicted to the use of opium. Las has only two or three places for receipt of custom. Near one of these, Bela, are found coins, trinkets, and funereal jars. Sonmeanee contains numerous of the Mehman sect, and part of the fixed population of Bela is called Jaghdal. Hormara, a sterile district, with a port of same name, is subject to Las. Near Jabl Malan is a tribe called Gujur; at Garuki, the Sangur tribe; and at Hormara, in Mekran, with four hundred houses, is a tribe of this name. The Hormara tribe say they came originally from Sind. Persani, west of Hormara, is a small port of two hundred houses.-Findlay. See Baluchistan; Kalat.

LASCAR. ANGLO-PERS. A seaman; a noncombatant in the army, from Lashkar, PERS., army; a public follower of the ordnance or camp equipage department.

LASH, a small province adjoining that of Herat, to the north of Seistan, and south of Furra, one of the governments under Herat. Lash itself is a place of considerable strength in those parts, being a fort on a scarped hill or rock, which resisted all Kamran's endeavours to talke it.-Burnes' Par. Pap. E. India, p. 134.
LASIANTHERA APICAULIS. Thw
Stenmorus, Blume. | Urandra, Thw.

Urukann, . . SINGH.

A very large tree of Ceylon, growing in damp forests at 1000 to 3000 feet elevation.-Beddome, Fl. Sylv.

LASSEN, a learned German philologist of the 19th century, author of Commentatio Geographica atque Historica de Pentapomia Indica, Bom 1827; Die Altpersischen, Keil 1836; Die Taprobane Insula, Bonnæ 1842; Indische Alterthum Skunde, Indian Antiquities, 4 vols., 1847 to 1861. Lassen drew up a fairly complete alphabet of 39 characters of the cuneiform inscriptions, and translated those with which at that time Europe was acquainted.

IASURA. HIND. Cordia latifolia and C. myxa fruits, the Sebesten of old writers, sweetish and highly mucilaginous fruit. Leaves used as fodder for cattle, and as plates or trenchers. Fruit edible and in great request.-Powell's Hundbook.

LASWARI, a village in the Ulwar (Alwar) State of Rajputana, in lat. $27^{\circ} 33^{\prime} 30^{\prime \prime} \mathrm{N}$., and long. $76^{\circ} 54^{\prime} 45^{\prime \prime} \mathrm{E}$. It is famous in Indian history as the scene of a great battle, won by Lord Lake, on the 1st November 1803, which destroyed the Maluratti power in India. The engagement was the severest in which the E. I. Company's troops had ever been engaged, not excepting that of Assaye. It was even reported that one-half their number was left on the field, killed or wounded. On the British side the casualties amounted to 824 , one-fourth of which belonged to the 76 th regiment, who bore the brunt of the action. An armed force of 9000 , trained by Europeans and well armed, but from whom the European officers had been withdrawn. were defeated by 7000 under Lake, only one regiment of which was English, the opposed forces, with this exception, being fellow-countrymen. Laswari is the best example of a battle fought by a purely Mahratta army against it force of combined European and native troops, the latter led by British officers. It proves, as the actions on the Sutlej and in the Panjab proved subsequently, that native soldiers will fight splendidly, even against Europeans; that they only require to be led. Side by side with British troops, and opposed to an enemy whom those British troops are eager to encounter, they would vie with their British comrades. At Laswari, fighting against the British without European officers to lead them, they displayed, writes the historian and eye-witness, Major Thorn, a firmness of resolution and contempt of death, which rould not fail to command the admiration of their opponents.-Imp). Gaz.

LAT. HIND., SANSK. An obelisk, a pillar, a staff, a column, a monolith. The Lat pillars of North-Western India have been made famous in the world from having engraved on them ancient characters, now known as the Lat character, first deciphered by Mr. James Prinsep. At Allahabad is one of the famed Lat obelisks or pillars, a monolith containing a Gupta inscription on its surface. The more ancient engraving on this stone, and for whose exhibition we may conclude the pillar to have been expressly fashioned, consists, however, of a counterpart of the edicts of Asoka, which appear severally on the Lat at Dehli, the rocks of Girnar on the western coast, and Dhauli in Cuttack, in addition to the transcript in the Semitic character on the rock at Kapurdigiri. The inscription contains 26 verses, which give a survey of the political divisions of India at the time, contain the names and titles of very many of the reigning families, and, extending beyond the boundaries of India, the regions of the great king of Persia, and the hordes of the Huns and Scythians. Though the capital of the Lunar princes had been removed to Hastinapur, and though Menu or the Mahabharat makes no allusion to the name of Allababad, still its importance in the third century before Christ is established beyond a doubt by this column of Asoka.

The Bhitari Lat is a pillar in the Ghazipur district, bearing the same royal names and genealogy as on that of Allahabad.

The Dehli Lat is known as the pillar of Feroz, also the Golden Lat, from the silt pinnacle or ball (Kalasa) placed over it by Feroz Taghalan, who reigned at Dehli from A.D. 1351 (A.H. 752) till 1388 (A.F. 790). 'This is the most remarkable of all the objects in the Kotila, as well as the monument of highest antiquity in all Dehli. Till modern European scholars read and expounded its inscriptions, much erroneous opinion had prevailed about this pillar. It was the club of Bhim Sena of the Hindus, the walking-stick of the old emperor Feroz of the Muhammadans, anil the pillar of Alexander the Great, in memory of his victory over Porus, with Greek inscriptions, of Tom Coryate and the other early Englisb travellers, until, after the lapse of centuries, it once more became appreciable to the last generation as one of the edict columns of Asoka. The pillar that is now just outside the Dehli gate of the city, was originally on the west bank of the Jumna, in the district of Salora, not far from 
Khizerabad, which is at the foot of the Siwalik mountains, 90 cos from Dehli. But the original site of the pillar is supposed by Cunningham to have been somewhere near the ancient capital of Shrughna, described by Hiwen Thsang as possessing a large vihar, and a grand stupa of Asoka's time containing relics of Buddha. The pillar is stated to have been conveyed by land on a truck to Khizerabad, from whence it was floated down to Ferozabad or New Delli. This removal took place about the year 1356 , by the orders of Feroz Shah, as is said, to confound the Hindus, who had boasted of its immoveable fixity in the eartb. Underneath the pillar had been found a large square stone, which also was transported and placed in the same position as before, when the pillar was put up in the courtyard of the palace of Feroz. In the face of this circumstantial account, which a contemporary writer has left of the removal of the pillar, it can by no meaus be taken for the same that the bard Chand speaks of 'as telling the fame of the Chauhan.' This must have been some other column that stood at Negumbode, and has disappeared from causes not known now to anybody. The head of the Feroz Lat is now bare; there is now no ornamentation of black and white stonework surrounded by a gilt pinnacle, from which, no doubt, it received its name of Minar Zarin, or golden pillar; but this gilt pinnacle was still in its place in A.D. 1611, when William Finch entered Dehli, as he describes the stone pillar of Bimsa, which, after passing through three several storeys, rises 24 feet above them all, having on the top a globe surmounted by a crescent.

The pillar is a single shaft of pale pinkish sandstone, being of the usual height of all Asoka's pillars, 42 feet 7 inches, of which the upper portion, 35 feet in length, has received a very high polish, while the remainder is left quite rough. It seems that all the pillars of that monarch were made to his particular order of a certain specified length. The weight is rather more than 27 tons. The numerous pillars of Asoka, all of one size, but of a variety of stones, arising from the respective rocks from which they were quarried, exhibit an unequal workmanship which may help to throw some light on the state of sculptural art amongst the ancient Hindus in different parts of India. There are two principal inscriptions on Feroz Shah's pillar, besides several minor records of pilgrims and travellers from the first centuries of the Christian era down to the present time. The oldest inscriptions for which the pillar was originally erected, comprise the well-known edicts of Asoka, which were promulgated in the middle of the third century B.C. in the ancient Pali. The alphabetical characters, which are of the oldest form that has yet been found in India, are most clearly and beautifully cut, and there are only a few letters of the whole record lost by the peeling off of the surface of the stone. The inscription ends with a short sentence, in which king Asoka directs the setting up these monoliths in different parts of India as follows: 'Let this religious edict be engraved on stone pillars (Sila sthamba) and stone tablets (Sila phalaka), that it may endure for ever.' The record consists of four distinct inscriptions on the four sides of the column facing the cardinal points, and of one long inscription immediately below, which goes completely round the pillar. The last ten lines of the eastern face, as well as the whole of the continuous inseription round the shaft, are peculiar to the Dehli pillar. The second inscription is that which records the victories of the Cbauhan prince, Visala Deva (Beesildeo), whose power extended 'from Himadri to Vyndhia.' 'This record of the fame of the Chauhan consists of two separate portions, the shorter one being placed imomediately above Asoka's edicts, and the longer one immediately below them. But, as both are dated in the same year, viz. S. 1220 , or A.D. 1163 , and refer to the same prince, they may be considered as forming only one iuscription.

The inscription is in a more recent character below, and is in Sanskrit, to the effect that raja Vigrah or Visala Deva had in A.D. 1169? caused this pillar to be inscribed afresh, to declare that the said raja, who reigned over the Sikambari, had subdued all the regions between the Himavat and Vindhya.

This monolith, like the kindred pillar at Allahabad, was in the first instance exclusively devoted to the exbibition of a counterpart text of the edicts of Asoka, but succeeding generations have taken advantage of the ready prepared monument to supplement a record of their own prowess. Of the tivo stone pillars at Dehli, one was moved down, as has been said, from near Khizerabad, at the foot of the Himalaya; the other was taken from Mirat.

Iron Pillar at Dehli.-In the centre of the mosque, says Colonel Yule, there is to be seen an enormous metal pillar. The height of the pillar above ground is 22 feet, and its greatest diameter a little more than 16 inches. The pillar was considered by James Prinsep to date from the third or fourth century. The inseription on it has no date, but is scarcely earlier than A.D. 800 . Many letters agree with the Kanouj Nagari, but the general aspect is more modern. It concludes with an invocation to Vishnu. It mentions also prince Dhava, a usurper, at Hastinapur. The inscription is punched upon the pillar, and the only thing remarkable in it is the mention of the Bactrians, called Vahlika, being still in Sind. From the compound letters used, the inscription must be long after the fifth century.

Nigumbode. - A column is alluded to by Chand, as telling the fame of the Chauhan, and he says it was placed at Nigumbode, a place of pilgrimage on the Jumna, a few miles below Dehli. It has disappeared.

Benares.-One of Asoka's edict columns is erected at Benares. It is of stone, with many carvings and inscriptions. All Asoka's columns appear to be of the same height, 42 feet 7 inches, inclusive of the part underground. The one at Benares and the other at Allahabad measure exactly the same altitude. The columns were erected only in large, populous, and opulent cities.

Ghazipur.-A Buddhist pillar at Ghazipur has an inscription on it in Sanskrit, not pure nor easily intelligible. This inscription, like one of Allahabad, is intruded on a Buddhist column, and is subsequent to it, as it carries on the Gupta family from Samudra to the boy Mahendra. Chandragupta 2d and Kumara Gupta followed the Vishnu worship, but Skanda Gupta attached himself to the 
opposite doctrines, now so prevalent, of the mysterious and sanguinary Tantra. Skanda Gupta was dispossessed of his kingdom, for a time, by a treacherous minister. This was the case when the Chinese traveller Hiwen Thsang reached Behar, in the seventh century, and he may refer to the event mentioned in the inscription; but he calls the king by a name construed to be Siladitya, and no king of this name reigned in Behar, nor nearer than in Gujerat. The Gupta, probably, succeeded the Buddhist kings of Bebar. The absence of the insertion of the Tantra in the Allahabad inscription, and their insertion here, would seem to indicate the period of the origin of this worship. The character used is the same as Allahabad No. 2, or Kanouj Nagari, with numerous mis-spellings. The date is subsequent to Allahabad No. 2; and, Dr. Mill says, not earlier than Charlemagne in Europe, A.D. 800, if the Gupta be those of the Purana. Moreover, the mention of the sectarial worship of the Bhagavata and Tantra makes the date comparatively modern; Indra, Varuna, Yama, Krishna, Siva, Sita, the Tantra, Devaki, the mother of Krishna, Rudra, are mentioned, and loads of forest timber are collected for the completion of sacrifices for Indra, Varuna, and Yama only, and not for Siva or Vishnu. The kings or princes mentioned are the great king, Gupta; his son, do., Ghatot Kacha ; do., King of kings, Chandragupta ; do., King of kings, Samudra Gupta; do., Chandragupta $2 d$; do., Kumara Gupta; do., Skanda Gupta, a minor ; Mahendra Gupta?

Mr. Carleylle found unfinished monoliths of sandstone on hills in Rupbas in the Bharatpur State; one of them $33 \frac{1}{2}$ feet, another $22 \frac{1}{2}$ feet.

Dhauli in Cutlack. - Inscriptions in the Iat character were discovered here by Lieut. Kittoe. 'The character used in the inscriptions in the Lat character are those of Allahabad and intermediate between these two; also a character at Balibhi, and the parallelogram-headed character of Seoni.

Asoka's pillars in Orissa are of sandstone.

At Junir there are two inscriptions, one on the Naneh ghat is in keeping with the inscriptious on the Dehli pillar and Giruar rock.

The Girnar inscription was supposed by Mr. J. Prinsep to be Pali.

Lat Character.-It was a remark of Colonel Tod, Let us master the characters on the columns of Indraprestha, Prayag, and Mewar, on the rocks of Junagarh, at Bijoli, and on the Aravalli, and in the Jain temples scattered over India, and then we shall be able to turn our regard to Indian history. This was effected by Mr. James Prinsep, who made the observation that the language of the Lat inscriptions differs from every existing written idiom, and is, as it were, intermediate between the Sanskrit and the Pali. The nouns and particles in general follow the Pali structure. The verbs are more frequently nearer to the Sanskrit forms; but in neither, any more than in grammatical Pali, is there any great dissimilarity from Sanskrit. That on the Bhilsa monument is in the Gupta class of inscriptions. Numerals were first supposed to be discovered by $\mathrm{Mr}$. James Prinsep on the Bhilsa monument. In the Buddhist pillar inscriptions, the dates were uniformly expressed at full length.

Lat, an early Pali alphabetical character, so called from the pillars whereon it is used, is the same as Aryan, but larger, inscribed on rocks at Kapurdigiri in Afghanistan, in the parallel Semitic writing, and at Cuttack, at Dehli on a pillar, also on pillars at Allahabad, Bettia, Multiah, and Radhia, in the true Pali, of Indian origin. One Dehli pillar, square, on each face is a framed inscription. Another pillar, facing cardinal points, near Dehli, is called Pillar of Feroz, the reading of which somewhat differs from that of the others. Though resembling the Girnar inscription in general purport, these inscriptions differ considerably in the structure of certain sentences. The Dehli inscription seems to have been directed to a more refined people.

Pillar of Feroz, so called because it stands on the summit of a large building supposed to have been erected by Feroz Shah, who reigned in Dehli between A.D. 1351 and 1388. Feroz pillar, 37 feet high, is a single stone, hard and round. Its circumference where it joins the building is $10 \frac{1}{2}$ feet. It has an ancient Lat inscription, and one with a more recent character below in Sanskrit, as noticed above.

Lat Inscriptions.-Asoka's first edict prohibits the sacrifice of animals for food or in sacrifice, and enjoins moral virtues.

The second edict provides medical aid throughout his dominions; orders planting of trees, and wells to be dug, along the sides of roads.

The third edict is in the twelfth year of Piyadasi's inauguration, and enjoins a quinquennial humiliation.

The fourth edict of the twelf th year of Piyadasi compares the past condition of his country with that then existing.

The fifth edict records the appointments of ministers of religion or missionaries.

The sixth edict appoints pativedaka, custodes morum, also criminal magistrates.

The seventh edict contains the king's desire to reconcile diversities of religious opinions.

The eighth edict contrasts the carnal enjoyments of former rajas with the harmless amusements of the king,-visits to holy people, almsgiving, respect to elders, etc.

The ninth edict continues the thread of a moral discourse, the Dharma Mangalam, happiness of virtue, benevolence, reverence, charity.

The tenth edict comments on $\mathrm{Y}$ aso va Kiti va, the glory of renown, founded on the vain and transitory deeds of this world, and the higher objects of life.

The eleventh edict, at Dhauli and Girnar, upholds that the imparting of Dharma is the chiefest of charitable donations.

The twelfth edict is addressed to all unbelievers with entreaty.

The fourtcenth is summary of the preceding, and is complete in itself.

LAT and Manat, mentioned in the Koran, tradition says, are the names of the idols of Bamian. Lat, Uzzah, and Minat were demigods of the Koresh tribe in the time of Mahomed.-Mohun Lal's Travels, p. 90 ; Palgrave.

LATA, or Larike, the ancient names of the country about the mouth of the Nerbadda on the Guif of Cambay. See Lar.

LATAKIAH, a seaport town of Syria, the ancient Laodicen, 70 miles from Tripoli. Iu 1822 it was destroyed by an earthquake. 
LATANIER, a plant of China, which has spread throughout the East Indies.

LATERITE. Cabook, Singh. A clay iron ore peculiar to India. It covers the western coast almost continuously, and for the most part up to the very foot of the ghats, from near Bombay to Ceylon. It is found in detached beds along the Coromandel coast, near Madras and Nellore, Rajamundry, and Samulcottah, extending into Cuttack. It caps the loftiest summits of the Eastern and Western Ghats, and some of the isolated peaks in the table-land in the interior. A small patch of it is to be seen in Berar on the left bauk of a river, eleven miles $\mathrm{N}$. of Amraoti, on the road to Ellichpur, and it covers all the country around Beder. It occurs in the Southern Mahratta country, Mysore, Salem, Coimbatore, South Arcot, the Carnatic, and Tanjore. It is found in Malwa, and in many parts of Bengal and Ceylon. It fringes the shores of Burma, Malacea, and Siam, and appears on the coast of Singapore and Sumatra. It is found in boulders and rolled masses all along the Malabar coast from Bombay north to Gogo in the Gulf of Cambay. Beyond the region of the formation itself, pieces of it have been met with three hundred feet under the surface, in the blue clay beds at Calcutta, as also in similar beds of lesser thickness in Bombay, and close by Cambay and Kurachee; so that the formation at one time was probably much more extensive than at present. Its colour is of a red irony or brick-dust hue, sometimes deepened into dark-red. It is marked with whitish stains, and is occasionally cellular or perforated with tubiform holes. It rarely if ever contains either crystals or organic remains, is never stratified or columnar, and generally spreads out in vast sheets over the surface of the plutonic or volcanic rocks. When the upper surface is cleared away, the rock below is found soft and easily cut into blocks of any form. It quickly hardens and darkens in hue by exposure to the air, and is then not at all liable to decomposition or injury from the weather. The Arcade Inquisition at Goa is built of it, also St. Mary's Church, Madras, and the old fortress of Malacca. It is called by the natives, from its worm-enten appearance, Kire-ka-patthar, or Silika-patthar. T'be T'amilar call it Chori kullu and Vettic kullu, and on the Malabar coast it is termer Stika kullu. There are two strong objections to supposing laterites to be the decomposed rock over which they lie; first, because were such the case, we ought to observe at the foot of a laterite bill a gradual blending of the laterite into the secondary greenstone, but such has never presented itself. - Carter's Geological Papers on Western India, p. 77 ; Cole on Laterite, in Madras Journal Lit. and Soc.; Newbold in Asiatic Society's Transactions.

LATES CALCARIFER, a fish of the southern seas, the Begti or Cockup of Europeans.

\section{LATES HEPTADACTYLUS. Lacepede.}

Perca maxima, Sonnerat. Pandoo menoo, Russell.

Holocentre heptadactyle, Coius vacti, Hom.

Lacepede.

Lates nobilis, Cuv, and Val.

This fish inhabits the sea and estuaries of Penang, Malayan Peninsula, Singapore, and Madras. It yields little isinglass, owing to the thinness of the air-vessel. That of a fish when dried weighs upwards of one ounce. At Penang this kind sells at the rate of 25 to 30 dollars per pikul. L. nobilis is a fish much esteemed in Calcutta. It is the Ikan siyakup of the Malays.

LATHE. Indian carpenters use a lathe, consisting of two rough upright supports mortised into two bars, one of which is fixed while the other may be adjusted by sliding along two slips of wood or bamboo, to which it is then fixed by moveable wedges; a boy having in his two bands the ends of a cord passed round the work to be turned, causes it to revolve as in the pole lathe. When the work cannot be so fitted, the lathe used by brass-smiths is had recourse to; in this a kind of rough wooden mandrel, with a broad face smeared with lac for fixing objects to be wrought, works between a back centre as in the carpenter's lathe and a collar shaped, the collar being formed of a plank sawn down the middle and embracing the mandrel, which is turned to fit.- Rohde, MSS.

LATHI. Hind. A staff, a club. Lathial or Lathiwal, a clubman armed with a bludgeon.

LATHS or Shingles.

Du latten, Lattes, . Fr. $\mid$ Correnti, . . . . IT. Latten, . . GER. Slegii, : : RUs.

These are largely used in Burma for the tiling of houses, in lieu of slates.

LATHYRUS, a genus of plants, many of them handsome when in flower, but requiring sticks or trellis-work to support them. L. cicera of Spain has poisonous seeds. L. inconspicuus, Linn., is a plant of Sind. L. pratensis, Linn., is the meadow pea of temperate climates; $\mathbf{L}$. silvestris and $\mathbf{L}$. tuberosus can be utilized for fodder plants. L. odoratus, sweet-pea. The seed should be sown after the rains, at the commencement of the cold season, in pots. It is very seldom that they blossom in India.-Riddell.

\section{LATHYRUS APHACA.}

Chuna, Bura chuna, Hind. | Jangli matar, . . Hind.

Its ripe seeds when largely eaten are narcotic; when ground are said to be harmless.

\section{LATHYRUS SATIVUS. $L$}

Teora, . . BENG. Kisari, . . Hind, Gilban, EGYYT. Mattar, Chural, . "' Lang, . GuJ. Masang, . . PERs.

Cultivated in many parts of India, but, being very rich in nitrogenous matter, requires to be largely diluted, and it is not considered a wholesome food either for man or beast. It is often cultivated in the plains of the Panjab as a coldweather field crop for its pulse, and is grown to 12,000 feet in Tibet. The grain is grey-coloured, with minute specks of black, also a thin line of black passes all round the seed as if to separate it into two halves. It is used as a pulse, being made into dal, but is hard and indigestible. Its composition in 100 is

Moisture, . . . . 10.10| Fatty or oily matter, 0.95. Nitrogenous matter, 31.50 Mineral constituents, Starchy matter, . 54.26 ash, . . . 319 Like L. cicera, its continuous use induces paralysis both in man and animals. Dr. Thomson observed at Saspola at least thirty people, of all ages, from a full-grown man to an infant, and of both sexes indifferently, who had been attacked with paralysis within the previous two years, and he attributed it to this plant. The palsy was confined to the lower extremities, and differed much in degree. The sufferers were in other respects the most healthy and good-looking portion of the inhabitants.-Ainslie; Stewart; T'homson's Tr. p. 391. 
LATRODECTES LAGUBRIS, a spider called Kara-Kurt by the Kirghiz. It is about the size of the finger-nail ; it is very poisonous, and it is said can kill a man and animals. It can jump several feet; it lives in the grass.-Schuyler, ii. p. 123. See Spider.

LATTICE IEAF, the Ouvirandra fenestralis of Madagascar, night beneficially be introduced into India. The interstices between the veins of the leaf are open, instead of being filled with cellular tissue as in ordinary leaves, hence its lace or lattice-like appearance. The fleshy root, when cooked, yields a farinaceous substance resembling the yam; hence its native name, Onvirandrano, litcrally yam of the water.-Mr. Ellis, Madagascar.

LAUGHING JACKASS or Feathered Jackass, a bird of Australia. It has a peculiar gurgling call like laughter.

LAUGHING KINGFISHER, Dacelo gigantea of Australia, seldom approaches the water, but lives in the dry scrub, and feeds like birds of prey upon insects, reptiles, and small mammals; is excessively adroit in catching mice, and will wait, as patiently as a cat, at a hole whence it expects one to emerge. His note strangely resembles a rude powerful laugh, and may be often heard far. The regularity with which this laughter rings through the Australian forest at certain hours of the day has given it the name of the Settlers' Clock.

LAURACE A. Lindl. The cinnamon tribe of plants, comprising about 17 genera and 86 species, viz. daphnidium, litsæa, tetranthera, cylicodaphne, actinodaphne, cryptocarya, beilschmiedia, machilus, alseodaphne, camphora, cinnamomum, haasia, apolonias, aperula, phœbe, hernandia, lindera, laurus. The inost important economically are the species of alseodaphne, beilschmiedia, cinnamomum, daphnidium, laurus, litsæa, machilus, and tetranthera.

LAUREL, a term applied to various plants. Laurus nobilis, Linn., the sweet bay of Italy, is the laurel of poets; Cerasus laurocerasus is the common laurel of English shrubberies; and the Portuguese laurel is C. Lusitania, and the name is given in India to the variegated croton.

Laurus nobilis, Linn.

Hub-ul-ghar (berry),ARAB. |Warrior's laurel, Sweet bay, . . ENG. Zafnee,

ENG.

Its berries are used in medicine in Indin, with the Greek name Daphne corrupter into Zaknee and Zafnee.-Royle; O'Sh.

LAVA and Kusa, twin sons of Rama and Sita, born after Rama had repudiated Sita, and brought up in the hermitage of Valmiki. Kusa built Kusa-sthali on the brow of the Vindhya, the capital of Kosala. Kusa and Lava were the first rhapsodists, and to this day Kusilava, their combined naue, means a reciter of poems. Kusa's eldest son, Kusamba, founded Kusambi, the modern Kanouj. According to a legend relating to them, Rama, previous to sacrificing a horse, had sent it off, but Kusa and Lava seized and held it till Rama came and recognised his two sons. Lava was famed for his strength and his skill as an archer.

LAVA, a volcanic product, is very abundant at Aden. In the Rajmahal Hills are several outpourings of lava which have taken place at different epochs, and numerous thermal springs close to these hills still proclaim the existence of subterranean fires. The lake of Loonar, about two miles in circumference, is a body of water low down in the crater of an extinct volcano, and farther west the site of the Aden cantonment is also the crater of an extinct volcano. On the east, twenty miles north of Chittagong, is Sita Kund, a hot spring, the gaseous exhalations on the surface of which may be inflamed by the application of fire. Volcanic fire has frequently broken out from the bosom of the ocean opposite Cheduba Island, in lat. $19^{\circ} \mathrm{N}$.; and a few miles south of Pondicherry, in A.D. 1757, a sub-marine cruption also took place. The volcauic fire near Cheduba, as was described by an eye-witness, in 1846 rose into the air as a brilliant column of fire, illuminating the sea for miles. From the south-eastern point of Java, in lat. $9^{\circ} \mathrm{S}$, and long. $114^{\circ} \mathrm{E}$, , to Chittagong, a distance of 3000 miles, are twentyseven known active volcanoes and twenty-nine extinct ones.

LAVAJAH, timber, short round logs of timber in the Madras market, from 12 to 16 feet in length, 2 to $3 \frac{1}{2}$ feet square.

LAVAL. Francis Pyrard de Laval went to India in 1601. He was detained in the Maldives for several years, and about 1609-11 he was in Goa, where he found Italians, Germans, Flemings, and Frenchmen, and men from all parts of Asia. He found there also three Englishmen, prisoners of the Portuguese, whom he describes as a proudlooking set, who, though in chains, took every opportunity of showing their contempt for the French and other foreigners around them.

LAVENDER.

Lavendel, DA.,Du.,G.,Sw. | Lavandula, . . LAT., SP. Lavande, . . FR. Alfazema, . PORT. Ustakhudas, : HIND. Unyetshnayatrava, RUs. Lavendola, Spigo, . IT. Espliego, . . . SP.

Twelve species of lavender have been described, only two of which are of much interest, viz. the common lavender, Lavandula vera, and French lavender, L. spica. The former yields the fragrant oil of lavender usea in perfumery, its solution in spirits of wine forming what is called lnvender water, and the latter oil of spike, used by painters on porcelaiv, and in the preparation of varnishes for artists. English oil of lavender is prepared chiefly at Mitcham in Surrey, where the plant is extensively cultivated for the purpose. It is in highest perfection when about a year old. At first it is nearly colourless, but gradually acquires a pale amber tint. Lavender water is the distilled water of lavender flowers.

Lavandula spica, D.C. Sita-ki-pungeri, Dukн. This native of Europe grows to great perfection ou the Neilgherry Hills. The bush there bas a strong aromatic scent, but seldom survives morc than two years. The volatile oil is limpid, very transparent, yellowish-white; four parts contain nearly two of camphor. Often adulterated with the oil of turpentine, and of a species of lavender of superior aromatic power, though more acrid. Oil much used by porcelain painters, and called 'oil of spike.'

Lavandula stœehas, $W$.

Esta-kudus, . ARAB. | Osta-kudus, . ARAB Oostakhudus, . ", French lavender, . ENG.

This is much prized by the Arabs, as an expectorant and antispasmodic. It is imported into Bombay from the Persian Gulf, and is used medicinally by the natives of India.-O'Sh. $\mathrm{p}$. 489 ; Faulhner.

I.AW, Monsieur, a descendant of John Iaw, 
of Lauriston, who started the South Sea Company. Monsieur Law, in 1748, defended Ariacopang, and subsequently commanded the French troops with Chanda Sahib at Trichinopoly. His command was not advantageous to the French interests. He delivered up Chanda Sahib to Monaji Rao, and on the 3d June capitulated, and surrendered himself and all his troops and stores to Major I,awrence.-Or'me.

LAW.

Adalat, Sharra, . ARAB. $\mid$ Dharma, Dhamma, SANgr. Dad, Smriti, . Hind.

The laws by which British India is now ruled are the successive development of legislative action by circular orders, by regulations, by Acts, and by legislative councils. In the earliest practice of the English East India Company, its civil servants were ruled by letter writing. Warren Hastings, the first Governor-General, promulgated rules and published laws in the shape of regulations, but Lord Coruwallis was the father of Indian legislation. He put the perpetual settlement regulation into regular sections and clauses; he established civil and criminal tribunals in their several grades, police superintendence, rules for the salt and customs departments, and all the various agencies indicating that the East India Company was assuming its imperial position. This mode of creating laws continued through the administrations of Lord Minto, the Marquess of Hastings, Lord Amherst, and Lord William Bentinck, largely aided by the Boards of Revenue, the Boards of Customs, Salt, and Opium, the Judges of Sessions, and the Sadr Adālat Court, whose suggestions, in letters and minutes, were submitted to the Secretary to Government in the Home Department, who, with the aid of a member of the Council, laid the matter before the GovernorGeneral. A draft was then published in the official Gazette, and finally passed, with such alterations and additions as the press and public bodies may have suggested. Many of these regulations were lengthy and cumbrous, but they were framed by men thoroughly conversant with the habits and languages of the native community, fearless of responsibility, and early taught to rule the varied races of India with the equity and vigour which orientals value. There had been a local legislature at Madras and one at Bombay; but at the renewal of the charter in 1833, these were abolished, and the regulations became 'Acts of the Governor-General in Council.' Also, the India cabinet had consisted of the GovernorGeneral, a military and two civilian nembers; but in 1833 a legal member was added, the most prominent of whom have been Macaulay, Amos, Charles Cameron, and Bethune.

At the last renewal of the E. I. Co.'s charter in 1853, a Legislative Council was formed distinet from the Executive Council, its members being the cabinet, with the addition of members for Bengal, Bombay, Madras, the N.W. Provinces, and two judges of the old Supreme Court. This form lasted through seven years, during which a Penal Code, a Code of Civil and Criminal Procedure, a Rent Act, and other inoportant measures were passed; but during Viscount Canning's administration, and the period of otfice of Lord Halifax as Secretary of State for India, the legislatures of Bombay and Madras were re-established, and eminent officials and merchants, and Hindus and
Muhammadan rajas and nawabs, were selected for seats in Council, to represent all classes of the empire. The judges ceased to be members of the Legislative Councils, and these then assumed the representative character which they still retain. The members when speaking do not rise from their seats. The Anglo-Indian Legislature, before acting, has ever been careful to ascertain the opinions of all local functionaries conversant with the questions under consideration. In the High Courts at Calcutta, Bombay, and Madras, European as well as native judges sit, and there may be mentioned Rama Prasad Roy, the first native judge of the High Court; Shambunath Pandit, Dwarkanath Mitra, and Anukul Chandra Mukarji, three native judges of the Calcutta High Court, and Mutusami Iyer at Marras.

The great lawgiver of the Hindus is supposer to have lived at some time subsequent to B.C. 1400 . The book of Institutes that bears his name, called the Manava Dharmasastra, seems to have been a compilation from the various laws in force throughout a part of Northern India and of existing lawbooks or Dharmasastras. Since his time there have been numerous glossaries, digests of textbooks, and commentaries, forming the authorities for the five schools of Bengal, Mithila, Benares, Mahratta, and Dravira. Menu's Institutes were translated by Sir IVilliam Jones.

After the Institutes of Menu come the Codes of Yajnavalkya and Parasara. Raghunandana, who is the author of a complete digest for Bengal, lived in the 16 th century. The Vivada Bbangarnava, a code of Hindu law, according to the Bengal school, by Jagan-natha Tarkalankara, written at the end of the 18 th century.

The Mithala school has the Vivada Chintamani by Vachaspati Misra, who also wrote the Vyavahara Chintamani.

The Benares school has three law-books, the Vivada Chandra, by Lakhima Devi; the Vivada Ratnakara, by Chandeswara; and the Vivada Tandava, by Ratnakara.

Smarta Bhattacharya wrote the Vyavahara Tatwa, a modern work on law, according to the Bengal school of Raghunandana.

The Vyavahara Mayukha is a Mahratta lawbook, by Nilakantha Bhatta. It was translated by Major Borrodale.

In the Telingana portion of the south of India, the work that is deemed authoritative in the Hindu law of inheritance is the Saraswati Vilasa, a code of laws which raja Pratapa Rudra Deva, a ruler in Orissa, caused to be written in the early years of the $16 \mathrm{th}$. century. The title means the recreations of the goddess of learning. It is in Sanskrit, and it purports to embrace the whole range of the religious, moral, and civil laws of the Hindus. It continues to be of some authority to the northward of the Pennar river, but even there it is in a great measure supplanted by the commentary of Vijianeswara, the prevailing authority in Southern India. The Saraswati Vilasa seems to have most in common with the Mitakshara. Yimuta Vahana's Digest, the authority generally followed in Bengal, does not seem to to be anywhere referred to.

The trial scene in the Mrichchbakati is regarded as a true scene in an ancient Hindu eourt of justice in Northern India.

In the south of India the Mitakshara is the 
received authority with the British courts, and Mr. Justice Innes is of opinion that the rules of Hindu law are fairly represented in the Mitakshara and other such works.

Learned British lawyers have had their thoughts directed to a possible codification of the Hindu civil law, and with that object Mr. Justice Cunningham, in 1877, framed a digest to help forward what seemed to him a great desideratum for the country. The difficulty, however, that is encountered arises from the fact that the Hindu population consists of numerous races, who through thousands of years have each been following their own social customs. Dr. W. W. Hunter plainly says that the codes of Menu and Yajnavalkya, on which all the later law-books and commentaries profess to depend, only recorded the usages of certain Brahmanical centres in the north, and perhaps did not fairly record even them.

All Muhammadan law is founded on the Koran, and is inseparably bound up with the religion of Islam. But the commentaries upon their religion and law which have been produced by their two grcat sects, the Sunni and the Shiah, are almost innumerable. The Sunni have four distinct schools of jurisprudence, the Shafai, Maliki, Hanbali, and Hanifi, each named after its founder, the most important being that founded by Abu Hanifa, born A.D. 699. This learned doctor had a true judicial mind, and gave great scope to reason in his interpretation of the maxims of the Koran. His teachings prevail in India. In the early years of British rule in India their Muhammadan law was administered both in civil and criminal cases. But there has been framed for all India a criminal code, famed for its justice, humanity, and comprehensiveness; and their civil law is still in force, and under an Act passed in 1864 the judges decide cases upon their own knowledge and judgment.

T'wo great disciples were Abu Hanifa and $\mathrm{Abu}$ Yusuf. The latter was the friend of Harun-urRashid, and is stated to have earned in one night fees of $£ 18,000$ to $£ 25,000$.

India has the best code of penal law in the world, and many chapters of the civil law have been similarly consolidated, with excellent general results, by Macaulay and the eminent jurists by whom he has been succeeded. The courts of first instance are entirely manned by native judges, who sit without juries, and have unlimited jurisdiction, without distinction of creed or colour. A native judge has a seat on the bench of every one of the four High Courts constituted in the varions provinces, which hear causes criminal and civil with scarcely any appellate control at all.

The British lawyers who have been most distinquished in India are Colebrooke, Ellis, Sir William Jones, Sir Francis Macnaghten, Sir Edward Ryan, Sir Thomas Strange, Sir Lawrence Peel, Sir James Colville, Sir Barnes Peacock. - Rumesey's Law of Inheritance; Foulkes, Hindu Law of InTheritance; Nelson's Prospectus of Hindu Law; Maine's Early Law and Custom; Cunningham's Digest of Hindu Law; Dowson.

LAWA, a tribe, in lat. $21^{\circ} 20^{\prime} \mathrm{N}$., west of the Mei-kong river, and dwelling along with the Karen, in the mountainous tract due east of Kalagouk Island at the source of the Sesa Wat river, in lat. $15^{\circ} 30^{\prime} \mathrm{N}$., and long. $99^{\circ} \mathrm{E}$., and others in lat. $18^{\circ}$ $20^{\prime} \mathrm{N}$, and long. $28^{\circ} 40^{\prime} \mathrm{E}$., at the sources of the

voL. II.
Meping river which unites with the Menam river. A body of savage Lawa dwell east of the Salwin river, in lat. $22^{\circ} \mathrm{N}$., and long. $98^{\circ} 40^{\prime} \mathrm{E}$., with the wild Kakui, Shan, and Nutsa on the east. A Lawa population also dwell on the watershed between the Irawadi and Menam, on the frontier of Siam and Ava. Dr. Latham considers the word to be the same as Lao, Lau, or Laos.Latham's Eth. See India.

LAWANG or Kulit Lawang. Malay. The clove bark of commerce. According to Crawfurd (p. 215), this is the bark of the Cinnamomum sinto, and takes its name from having a clove flavour. It is a product of Borneo, and an object of export to China.

I.AWRENCE. Sir Henry Lawrence, an officer of the Bengal army who was employed in 1842 as Political Agent, in 1853 as Resident at Ajmir, in 1857 as Resident at Oudh. He was besieged in Lucknow during the mutiny, was defeated at Chinhut 30th June 1857, and on the 4th July he died from a gunshot wound. The Lawrence Asylums, a series of educational institutions for European children, were endowed by him.

John Laird Mair Lawrence, Baron Lawrence, a Bengal civil servant who rose to be GovernorGeneral and Viceroy of India. He was Chief Commissioner in the Panjab during the revolt and rebellion of 1857 . By his energy he saved the Panjab, and contributed materially to uphold British supremacy in India. He had, in 1856 , been created a K.C.B. for his work in the Panjab, in 1857 he was promoted to the dignity of G.C.B. for his services on the outbreak of the mutiny. In 1858 he was further honoured by being created a baronet and a member of the Privy Council, and on the institution of the Order of the Star of India was created a K.C.S.I. The Court of Directors of the East India Company granted him a life pension of $£ 2000$ a year, which, under a special Act of Parliament, he continued to enjoy, together with his full salary, when he became Viceroy of India. He succeeded Lord Elgin in that post, 12th January 1864, and held it for the usual period of five years. In April 1869 he was created Baron Lawrence of the Panjab, and of Grately, in the county of Southampton. After bis final return from India, on the formation of the London School Board in 1870 he was chosen to be its chairman, and he held the post till November 1873 , when he resigned. He opposed the Afghan policy of the Government, which was a distinct departure from that which he had carried out in India, and which had been described by the phrase of 'masterly inactivity.' Born 4th March 1811, died in Londou 1880.

Lord Canning says, in a minute on the services of officers during the mutiny and rebellion, ' Of what is due to Sir John Lawrence himself no man is ignorant. Through him Dehli fell, and the Panjab, no longer a weakness, became a source of strength. But for him, the hold of England over Upper India would have had to be recovered at a cost of English blood and treasure which defies calculation. It is difficult to exaggerate the value of such ability, vigilance, and energy at such a time.'

Major Lawrence, an officer of the English East India Company, who from the year 1746 was engaged in the wars in support of the claims of Anwar-ud-Din Khan to the musnud of the Carnatic, against Dupleix, who supported Muzaffar 
Jang. He was in Fort St. David in June 1748, when he successfully opposed an attempt by Dupleix to take Cuddalore; but in August he was taken prisoner. The following year, however, he commanded the division sent against Tanjore, and took Devicottah, and returned to Britain in October 1750. In 1752 he fought along with Clive against the French at Trichinopoly, took Elmiserum, and sent Clive to Samiaveram, and received the surrender of Monsieur Law. In 1752, after the death of Chanda Sahib, the garrison of Ginji surrendered to Major Lawrence without resistance. In September 1752 he marched on Wandiwash, which was ransomed. On the 9th May 1753, the united forces of the French and Mahrattas, who had entrenched themselves on the banks of the Pennar, within sight of Trivady, attacked Lawrence, but were repulsed. They continued to harass the British force until the 1st April, when I,awrence, while marching from Fort St. David to Trivady, was furiously attacked by the Mahrattas, who were with difficulty overcome. A few hours later, when near Trivady, he fell in with the French army, and entirely defeated them. For several months in 1754 he bravely defended Trichinopoly against the French, and received the commission of Lieut.Col. of the British army, with a sword from the East India Company, but he felt aggrieved at being superseded by Lieut.-Col. Adlercron to the general command of the British troops in India.-Orme.

LAWRIE, W. F. B., an officer of the Madras Artillery from 1842, author of Notes on Pondicherry, or the French in India; the Moghul Empire in India; Orissa and the Temple of Jaganath; Narrative of the War in Burma, 1853-54.

\section{LAWSONIA INERMIS. Linn.}

Lawsonia alba, Lam., W. | Lawsonia spinosa, Linn.

Urkan, . . . ARAB. Henna, Mhendi, GuJ, His.

Shudu, . . . Beng. Ponta letshi, . Maleat..

Dan, : . : BurM. Mailanshi, Daunlacea, ,

Chi-kiah-hwa,. . CHIN. Sakachara, . . SANSK.

Hai-nah, . . ", Marudani, : : TAM

Yen-chi-kiah, : . ", Goranta, Iveni, : TEL.

Egyptian privet, . ENG. Na-kriz,. TRANs-Indus.

The henna shrub is the camphire of the English Bible, and the cypress shrub of the Greeks and Romans. . It is held in esteem by the Arabs, the Turks, and Indian and Persian Muhammadans. The colouring of the flowers is soft, and fragrance delightful; hedges formed of it are common in all India. The distilled water of the flowers is used as a perfume. The extract of the flowers, leaves, and shoots is used by the hakims in lepra, and in obstinate cutaneous diseases, balf a teaspoonful being given twice in 24 hours. Muhammadan women in India, Persia, Arabia, and Barbary use the shoots, triturated with rice gruel or water, in staining the nails, palms of the hands, and soles of the feet of a red colour. In all these countries the manes and tails of the horses are stained red in the same manner. The essential oil of the petals is priced at Rs. 2 per tola. Ispund, the seeds of this plant, are burnt as a charm with benjamin, or with mustard seed and patchouli, Pogostemon patchouli. Its wood is strong, and suited for tool handles, tent pegs, etc. Moore alludes to it when he says-

'Some bring leaves of henna to imbue

The fingers' ends of a bright roseate hue,

So bright, that in the mirror's depth they seem

Like tips of coral branches in the stream.'
This use of the leaves is as old as the Egyptian mummies.

LAYARD, Sir HENRY AUSTEN, author of Description of Khuzistan. He made the discovery of the ruins of Nineveh, and sent to the British Museum many sculptures and clay books. He was afterwards employed as Ambassador at Constantinople.

LAZ, a fine, bold race, born warriors, exercised to the use of weapons, more especially firearms, from an early age, and are thus unerring marksmen. They are not so handsome in feature as their Georgian neighbours, and are of darker complexion; but their physique is much finer, and they are far more industrious. They excel as fishermen, and the boldest and most skilful mariners of the Black Sea coast are of this race. In agriculture they are not very successful, but as mechanics their work is good, and they are more to be relied upon than the Georgians, who have greater skill. Before the 1878 war, large numbers of them were in the habit of crossing over to work in the Russian towns of Trans-Caucasia after they had sown their fields, invariably returning in time for the harvest.

LE. Chin. A long measure, equal nearly to $\frac{1}{3} \mathrm{~d}$ of a mile.

LE. TIB. A low stone wall, put up in the grazing grounds of the N.W. Himalayas, to shelter from the wind. The word is supposed to give its aid to the formation of names and places, as Han-le.

LEAD.

Rassās, . . Arab. | Surb, . . . Pers.

Khai-pok, . . Burm. Olow, . . . PoL.

Chai-ma-pok, : " Chumbo, : : PORT.

Heh-yuen, Heh-sil, CHIN. Swinctz, : : Ros

Lood, Loot, . . Dut. Sisaka, . . . SANsK.

Plomb, . : Fr. Plomo, : : . SP.

Bley, Blei, . Gre. Bly, . . . Sw.

Shish, . . HIND. Eium, : : TAM.

Piombo, : : . IT. Sheshumu, : . TEL

Plumbum, . . LAT, Kurshun, . . TURK. Timah-itam, . Malay.

Lead, the saturn of the ancients, is one of the most anciently known of the metals. It is found chiefly as sulphuret or galena, but a little in a metallic state also, as an oxide, and combined with several acids. It is a soft and flexible metal, of a pale livid grey colour, easily malleable, but slightly tenacious, and not sonorous. It is of common and extensive use in the arts. Alloyed with tin in different proportions, it forms solder and pewter, and with antimony it constitutes type metal. Combined with oxygen, it forms massicot, a protoxide of a pale-yellow colour. Litharge, also a semi-crystalline protoxide, obtained in separating silver from lead ores, enters largely into the composition of flint glass. Minium or red lead, deutoxide, extensively used as a paint, and also in the manufacture of flint glass. The carbonate of lead, or white lead, is a dense white powder, commonly employed as a pigment. The chromate of lead, of a beautiful yellow colour, is also much used as a pigment; and the acetate, or sugar of lead, is employed for various purposes.

Galena is the richest ore of lead, and from which that metal is chiefly obtained. As met with in commerce, it is in heavy, shining, black or bluish lead-coloured cubical masses, having a great resemblance to the sulphuret of antimony.

The old lead mines of Kohel lie near the Red Sea, a day's journey N. by E. from Jabal Zubara, 
in about lat. $24^{\circ} 40^{\prime} \mathrm{N}$. Not far distant are the lead mines of Jabal Rassas, lit. mountain of lead. The mines are situated about $1 \frac{1}{2}$ miles from the W. shore of the Red Sea, and the ores,-galena and carbonate of lead, occur in an argillo-siliceous schist, associated with small quantities of sulphur and iron,-a poor carbonate.

Lead ore is also found in Oman and at Ras-ulHad in Arabia, also in the mountains of Baluchistan, where the nomade Brahui pick it up from the surface soil. Lead mines exist at Kappar in the hills contiguous to Baghwan and Khozdar. Lead occurs at Raie, Chendak, Kerrage, Patal, Dhunpore, and Jak. At Dessouly, about 55 cos east of Srinuggur, is a lead mine of considerable value.

Lead is worked at Jamu, and large quantities of galena are imported from Kābul and Kandahar, under the name of Surma (antimony), from which natives of India do not distinguish it, and, being reserved for medicinal purposes, finds its way only to the druggists.

A mine near Sabāthu, in the Simla district, worked by a mining company, yielded 40 tons of ore monthly, and gave 16 to 72 per cent. of lead.

There is a lead mine at Baljawar, a day's journey north of the Oxus, so rich in the ore that the people who work at it for two months, earn sufficient for a year's subsistence.

In a defile close to Bamian there are 10 or 12 lead mines.

There are also lead mines at Lara, Leedang, Pokso, and some other places; they are very productive, but the lead is reckoned inferior to that of Sirmur and Jounsar. It sells at two or two and a half pounds per rupee.

In the Panjab lead is found in the districts of Kangra.

Lead and copper ores occur in the Ceded Districts; galena lead ore at Coilguntla in the Dhone taluk, 30 miles S. of Kurnool; also at Sidhout and Badwail, and near Jungumrazpilly, in the Nullamallay Hills, 29 miles north-east of Cuddapah; the last-named substances occur in the sandstone formation.

In Dhone, galena in very large blocks was obtained; one piece measured about 18 inches in diameter, and weighed upwards of $3 \mathrm{cwt}$. This ore was tried at the mint, and at the Madras School of Arts for glazing pottery; it was found to succeed better when reduced to the form of minium, and then ground with felspar and an alkali. Examination of the Kurnool ore proved it to contain upwards of 1 per cent. of silver, or 374 ounces in the ton, the quantity of lead and silver together being only 45 per cent., which was occasioned by there being a considerable quantity of gangue disseminated through the portion examined. A further specimen of this unwashed ore was analyzed by Dr. Scott in 1859, and when fused with carbonate of soda and nitrate of potash, produced about 60 per cent. of metallic lead. The resulting lead, on being cupelled, furnished a bead of silver weighing 1.18 grs., which is equivalent to $96.64 \mathrm{oz}$. in the ton of ore, or $165.76 \mathrm{oz}$. in the ton of metal. Malagah and Dorochet had found that when sulphide of silver is associated with the sulphides of other metals, it is always unequally distributed.

Mr. Blanford examined a promising lead vein at Chicholi, near Raipur.

Lead is found in several places in the Burmese territories, but is chiefly brought from the Shan States. It is used all over Burma for musket bullets, in refining silver, and as small change in the bazars. Its price varies from 5 to 8 tikals the viss. Lead is found in abundance in the Shan States, and is extracted from galena. It is also imported from Yunnan.

Lead ore of the richest kind, and containing a large quantity of silver, is obtained in the province of Mergui.

In the valley of the Salwin there is a rich vein of argentiferous galena. A specimen that Dr. Morton sent to England for analysis contained lead, sulphur, silver, gold (traces), lime, magnesia, iron, silica, carbonic acid.

In a small hand-specimen of ore from Martaban, the amount of silver was found to vary in different portions of it, the percentage of lead being about 75. In the first trial the silver was found to amount to about 70 ounces to the ton of ore; but in the second to not less than 300 ounces in the ton, or a little less than 1 per cent.

Lead ore is found in Amherst, at Tounghoo, in Maingay Island, and in the Pahpoon district; the latter yielding 50 per cent. of lead and 31 ounces of silver to the ton.

The primary ranges in S.E. Asia and the Indian Archipelago are all more or less metalliferous.

Lead mines are worked in that part of the Malaya range which traverses the kingdom of Ava; and copper mines have been opened in the Annam or Cochin-Chinese range, the produce of which is equal in quality to South American copper, but inferior to that of Japan.

Iron is smelted from the native ores on the western side of the Annam range.

The tin of the Malay Peninsula, Banca, and Billiton, and the gold of the Peninsula, Borneo, and Celebes, are all collected from the detritus in which the projected metal has been deposited. Lead and antimony ores are found in the Cambodian range to the north of Kampot.

In China a mine of the zinkenite lead ore occurs 15 miles from Chefoo; the ore contains 38 per cent. of antimony.

Galena occurs in China, in Che-kiang, Fohkien, and Sze-chuen.

Acetate of lead, Yuen-shwang, Burmese, is made by the Chinese by mixing up an amalgarn of 14 parts of lead and 1 part of mercury, and exposing sheets of it to the fumes of vinegar in covered jars for some time.

Black lead or plumbago is an iron ore found in Ceylon, in Travancore, also in the Northern Circars at Vizianagram. It is sold for antimony in the bazars.

Carbonate of lead, called also sub-carbonate of lead, white lead, or cerussa, is used as a white paint.

Chromate of lead, Valayati peori, is a precipitate produced by the addition of bichromate of potash to a solution of acetate of lead. It is the chrome yellow of artists' colourmen, and called peori from its resemblance to the Hardwari peori or Indian yellow.

Red lead.

Isrenj,. . . . ARAB. Sada langgam, . MALAx. H'sang, : Bury.
Yuen-tan, Tan-fen, CHIN.
Chu-fen, Hung-tan,

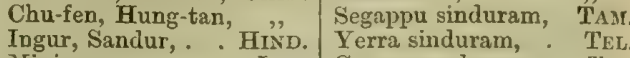
Minium, . . : LAT. Trunga sanduram, : T'B. This is largely used in India and China for 
painting, glass-making, and decoration. It is manufactured in Kiang-si in China. In the Madras Presidency it is used both as a pigment and a drier by moochees. Hindus use it for religious purposes, smearing it on their idols, etc., putting it on their rupees at certain seasons for good luck; and in numerous places in the Peninsula it is to be seen smeared on stones to convert them into 'dev' or objects of worship.

Semivitrified oxide of lead.

Mih-to-sang, . CHIN. Murdar singh, . . Hind.

Litharge, " ENG., Fr. Lithargyrum, . LAT.

Blei-oxyd, : . GER. Murdara-singy, . TEL

When lead continues to be exposed to a current of heated air, the surface of the metal becomes rapidly covered with a scaly powder of a sulphuryellow colour. This is the protoxide of lead, and, being skimmed off, is known in commerce by the name of massicot. When the heat is continued to a bright red, some metallic lead is separated, the oxide is fused, though imperfectly, and on cooling becomes an aggregated mass, which readily separates into crystalline scales of a greyish-red colour. These form the litharge of commerce, which varies in colour, and is called gold litharge when of a red colour, owing to the presence of a little red lead, but silver litharge when lighter coloured. These are frequently obtained in the process of refining gold and silver by means of lead, and in separating the silver from argentiferous lead. The litharge of commerce is liable to contain a little iron, also copper, carbonate of lead, silica and other earths. Litharge is employed for making diacetate of lead, and by combining with oil to form the lead plaster. It is used as a drier in painting, but only seldom, the red lead being preferred by moochees; it is, however, suitable for rendering drying oil for varnishes.

White carbonate of lead.

Isfidaj, . . ARAB. Blei-weiss, . . . Grer. Peh-fen, Fen-sih, CHIN. Kohlen saures blei-oxyd,,, Kwang-fen, Fen-yuen, , Safida, . HIND., TEL, Hu-fen, Kwan-fen, ", Tima-putih, . MALAY. Shwui-fen, Yuen-fen, ", Valle, . . . TAM. Carbonate de plomb, . Fr.

This is a manufacture used as a white paint. When exposed it rapidly decomposes the oil with which it is mixed, or it changes from the presence of hydrate of lead or adulterating additions. Oxides of lead are avoided in all outside work in India.

Yellow oxide of lead is the Hwang-tan of the Chinese, and massicot of the English.-Newbold; Powell; Turner's Embassy; M.E.J. R.; Ains.; Oldham in Yule's Embassy; Gerard's Kooncwar; Cat. Exhib., 1862; Masmis Tenasserim; Smith's Mat. Med.; Rolide, MSS.; Birdwood, Bombay Products; Royle, Mat. Med.

LEAF INSECT. One of those of Ceylon, the true leaf insect, is the Phyllium siccifolium. It eats leaves, and those of the janibo in particular. The Phyllium psyche, common in the East Indies, is called the walking leaf. It seems, indeed, to be a bunch of leaves endowed with life. A writer of the 17th century gravely related that 'these little animals change into a green and tender plant which is about two hands'-breadth. The feet are fixed into the ground first; from those, when necessary, humidity is attracted, roots grow out, and strike into the ground; thus they change by degrees, and in a short time become a perfect plant, while the upper part remains as before, living and moveable. After some time the animal is gradually converted into a plant.' The edges of the wings seem torn and ragged, and, moreover, stained with dirty brown, as if from incipient decay. Upon close inspection, the jagged margin and the stained spots that imitate decay, are observed to be as carefully executed as the ocelli that ormament the gayest butterfly. The leaf insect moults its skin three times, each time making a gradual advance towards its perfect form. The third time the full-grown wings and antennæ are produced. After each moulting the body of the animal is soft and tender, and in a few minutes expands to a larger size. In the course of half an hour its body and wings acquire their proper firmness, and the insect is prepared to enter upon its appointed course of life. Looking at this curious insect, it is impossible not to feel what must be the goodness and superintending love of a Being who with such minute care protects and provides for a creature apparently so humble and so insignificant. The twig-like leaf insect is a species of Phasma. The Mantis religiosa, or the soothsayer, le precheur and le prie Dieu of the French, is a predacious insectdevourer, catching butterflies and other insects with its formidably armed fore legs, and then devouring its captives. Hooker, in his Himalayan Journal, mentions that the predacious mantis was erroneously supposed by the natives to feed on leaves.

From the Phasma type have been produced the narrow, green or yellow, wingless Bacilli : when clinging to a plant they stretch out rigidly their elongated limbs, so as to assume the appearance of a slender plant.

The flattened and rugged lobed, mossy-looking Prisopi and Creonyli, when the wings are folded, cannot be distinguished from a piece of lichencovered bark. - Churchman's Family Magazine. See Insects ; Mantis ; Phasma ; Phyllium.

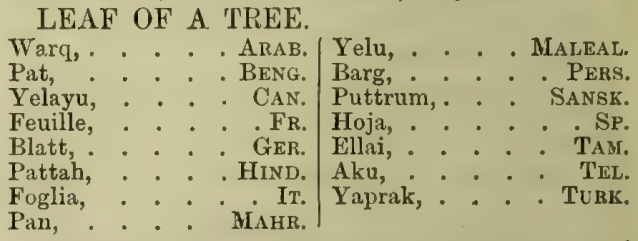

The first invented drinking cup or eating ressel seems to have been made from the leaf (pat) of particular trees, such as the palasa (Butea frondosa) and barr (Ficus Indica). The word pat seerns to occur in the Roman patera and the Greek or Saxon pot. The leaves of the palm trees are used for writing on in all the south of India, in Ceylon, in Burma, and in Malayana and the Archipelago ; and pattah, a leaf, means a lease.Tod's Rajasthan, i. p. 333.

LEAF ROT. Koleroga, CAN. The name giren to a diseased condition of the leaves of the coffee plant, caused by an epiphyte growing and developing upon the leaf, to which it is superficially attached. The most serious of the diseases under which the coffee plantations in Ceylon have so long been suffering, is the red rust or leaf disease, Hemileia vastatrix. It is a true endophyte, developing in the tissues of the leaf, and expanding outwards, as is the case with the red rust of corn and grasses. Mr. Graham Anderson 
says (Treatise, p. 2) the leaf disease is a fungoid disease originating in, or at least affecting the cellular tissue, and causing a fungoid efflorescence or eruption on the leaf. Whereas the leaf rot is a fungoid deposit from without, assisted by the impaired condition of the system of the plant. Under the microscope, leaf disease is found to consist of innumerable minute fungi, which are forced out of the pores of the leaf; whereas the tenacious fungoid web, which in 'rot' completely creeps over the lower surface of the leaves, is evidently a mildew deposit caused by atmospheric action, coupled with a passive submission of the leaf to the insidious attack, owing to the vital energy of the plant being impaired. The leaves of the coffee plants have been covered with spots of apparent dust, which, spreading from leaf to leaf, from branch to branch, and from tree to tree, has ravaged large areas of country, until the plantations, instead of presenting a bright deep green colour, have assumed a dark orange hue; the health of the trees has suffered, and the production of berries deteriorated both in quality and quantity. Picking. off the diseased leaves, sponging with a solution of Condy's fluid, and an emulsion of kerosene oil. After many remedies, such as paraffin, dilute sulphuric acid, etc., had been used in vain, the experiment of dusting the leaves with finely-powdered sulphur was tried, with extraordinary success. The fumigation of the trees, by placing a large umbrella or tent-like structure over and round them, and burning sulphur within the closed space, has been almost equally efficacious, though naturally more cumbersome and difficult of application. Trees so treated are reported to have quickly assumed a healthy appearance, and if these effects are permanent there is every probability of the disease being stamped out. Whether the same remedy will at the same time kill the spider, the white grub, and other insect pests which have combined in their attacks on the coffee plantations, remains to be seen. See Coffee ; Insects.

LEAF-VOWS. At Bangalore, when any female, barren or not, fulfils a vow to the Annumomia goodi, she covers herself with margosa leaves over her dress, but not over her naked person. There are other temples where a similar practice prevails, in Baitmangalam, Malwyal, Atikappa, Yelcharka, Sorab, and Manjarabad.

\section{LEATHER.}

Lader, . . DAN. Charm, . . Pers. Leder, Leer, Dut, Ger. Coiro, : : : PORT. Cuir, . . . FR. Kosha, . . . Rus. Charmo, Chamra, . Hind. Cuero, . . . SP. Cuojo, . . . . IT. Lader, . . . . Sw. Corium, : LaT. Tol, : TAM. Irulit, Balulang, MaLAY. Meshin, Sakhtiyan, ToRK.

The skins of animals removed from the body are in their fresh state tough, flexible, and elastic, and seem, at first view, to be well adapted for clothing; but in drying they shrink, become horny, pervious to water, and, on exposure to moisture, putrid and offensive. But if the skin be separated from fleshy and fatty matters, and then be put into a solution of certain vegetables containing tannin, the skin separates the whole of the tannin from the liquid, and becomes hard, insoluble in water, almost impenetrable by it, and incapable of putrefaction. The subsequent operation of currying renders it pliable and more waterproof.
Similar but less decided changes are produced upon a skin by impregnating it with alum, and also with oil or grease. The object of these processes being to render soft and flexible that which would otherwise be hard and unyielding, the skin thus transformed was called by the Saxon races lith, lithe, or lither, that is, soft or yielding, whence the English term leather. The word tan, and the French tanner, are from the low Latin, Tanare. There is a large and constant demand for leather as an article of clothing. It enters into the construction of various engines and machines, supplies harness for horses, linings for carriages, and covers for books. Leather is a chemical combination of skin with the astringent vegetable principle called tannin or tannic acid. The Hindus have long been acquainted with, though it is doubtful whether they have ever made leather of very superior quality. Leather of very excellent quality used to be made at the British farm at Hunsur in Mysore, likewise in Calcutta, and native shields are not to be surpassed. Nevertheless the manufacture of leather generally is by no means so thriving as it might be, considering the great abundance of tanning materials at command in the East Indies. This is perhaps owing to the very low position of the artisans, Madiga, Chakili, or Chamar.

Goat skins, sheep skins, buffalo and bullock hides, are much used, and are generally procurable; but currying being the province of the shoemaker's wife, while manufacturing it for the market belongs to the husband, inferiority of Indian leather may be ascribed to want of skill on the part of the currier, and to the use of quicklime. There is no better tanning material than oak bark, but Indian divi divi, catechu, Cassia auriculata bark, gambier, etc., produce their effects more rapidly, and the leather so manufactured is said to be nearly as durable. The native tanner does not leave his hides to soak in the pits containing his bark infusion, but, having sewed up a quantity of bark in the skin (made into a kind of bag), he exposes it to a constant stream of water, which forces the astringent matter into the pores of the hide very rapidly; but to make the process still more rapid, the hide is taken out, wrung, and re-filled every four or five days. A hide can be ready in this way in about a month, but the leather is less strong, durable, and pliable than English leather. The currying process also is often entirely omitted, and when performed it is generally on a minute scale, and very inefficiently.

Great Britain annually imports hides and skins to the value of about five millions sterling, and leather and leather gloves of value five or six millions. The value of the imports into India and exports from India of leather and manufactures of leather have been as under :-

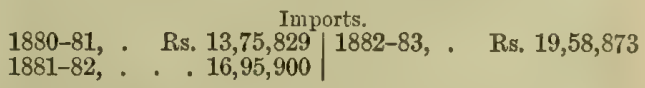

The value of the hides and skins-

$\begin{aligned} & \text { Imports. } \\ & 1880-81, \text {. . Rs. 7,27,314 }\end{aligned} \mid \begin{aligned} & \text { 1880-81, Exports. } \\ & \text { Ks. 3,73,35,653 }\end{aligned}$

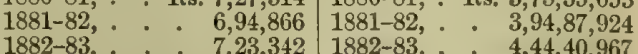

The Government possesses a large leather factory at Cawnpur, which turns out saddlery, etc., of excellent quality.

Russia leather, Balghar, occasionally comes to 
Peshawur. A kind of leather having a metallic lustre, called Kimsana, is imported also from the north-west; also a beautiful leather, used in the manufacture of the bright blue-green shoes of Kashmir and Peshawur, which is called Kimmookht. This is not made in the Panjab. Peshawur sword scabbards are often covered with a black leather, looking like morocco; it is probably an imitation. Russia leather is said to be made of horse's skin; it is thick but pliant, and of most grateful fragrance. Skins are very much valued for the preservation of merchandise, as insects will not attack them.-Imp. Gaz.; Royle, Arts and Manufactures of India; Heyne's Tracts; Madras Exhibition Juries' Reports; Powell's Handbook.

LEATHER WORKERS.

Sanigar, . . CAN. Chakili, . . TAMr. Chamar, Dhor,. . Hrnd. Madiga, . . Té. Mhang, MARR.

Leather workers throughout British India, Japan, and China are regarded as unclean races. In Berar the workers in leather assert that they consist of $12 \frac{1}{2}$ castes, amongst whom are the Dhor, who are tanners, make water-bottles, buckets, and water-sacks, the budla, pakhal, and mashak. The Bandela and Kullar Chamar are both tanners and shoemakers. The Mahratta Chamar is a shoemaker; the Pardesi Chamar, a cobbler; the Mang Chamar make sandals. The Muhammadan Chamar is a bookbinder. The Katai Chamar make shoes and sandals, and labour in the fields at seed and harrest times. They are identical in personal appearance with the Chuckler (Chakili) of the very south of India. The Chamar of Aurangabad worship Mariamma and Sitla. They marry when under age amangst themselves, proceeding on foot to the goddess Sitla, whose shrine they circumambulate five times. The expense is about 100 rupees. They burn their dead. The 1881 census gave 2,333,121 as the number of Chamar, Sakkili, Madiga, and Mhang in India.

LEAVEN.

Khamir,AR., Hind, PERs. $\mid$ Tsiu-miu,

Shin-kiuh, Kiuh, . CHIN. Tsiu-kian,

Chin.

Tsiu-kian of the Chinese is the residuum left after distilling spirits of wine. Tsiu-miu are cakes of barley meal, or mixed with bean meal, hung up by the Chinese till they become mouldy; and Shin-kiuh or sacred leaven is a coarsely-ground grain, mixed with the juice of Artemisia and other plants, and kept till it becomes mouldy. The leaven used in the southeast of Asia generally is fermented juice of the palms. Yeast is rarely obtainable.

LEBANON or Jabl Libnan, an extensive mountain system chiefly belonging to central Syria, but thrown off towards the south from the great chain of Mount Taurus and the lofty tableland of Anatolia, and, under various names and aspects, extending along and beyond the $\mathbf{E}$. coast of the Mediterranean to the $\mathrm{N}$. shore of the Red Sea. The Alma-Tagh or Amanus is a spur of the Southern Taurus. On the banks of the Nahr-ulKabir (Great River), the chain takes the name of Jabl-Nosairi or Ansari. The Anti-Libanus is a prolongation of the chain which skirts the valley of the Orontes on the east side. Under the name of Jabl-us-Sharkh, it runs parallel to the Lebanon along the east side of the valley of Balbec, with a breadth in some parts of 20 miles. Lebanon is inhabited by a variety of tribes, who from time immemorial have found a refuge in its fastnesses.

The Ansari occupy a lower branch of the Libanus, and their clans are the Shamsi, who worship the sun, the Kalbi, and Mokladi. An nasr-ut-tair, meaning a soaring eagle, is a mystical term of the Ansariyeh, signifying the sun. The Ansariyeh celebrate with great solemnity the two festivals of the vernal and autumnal equinox.

The Maronites, founded in the 6th century by St. Maronius, in religious matters acknowledge the supremacy of Rome, though its clergy maintain the right of electing their own bishops or patriarchs, and of entering into the married state.

The Mutawali are found in the plain of the Boccah (between the Libanus and the AntiLibanus), the sides of the Anti-Libanus, and the lower part of the Southern Libanus, extending to the N.E. of Sour or Tyre, but they form only an inconsiderable portion of the population of this part of Syria.

Druse. - From the neighbourhood of Beirout to the heights above Sidon, we come to the country of the Druse. They are idolators. One of their objects of worship is said to be the image of a calf. The Druse occupy the whole of the southern range of the Lebanon chain, the western slope of Anti-Lebanon, and Jabl-usSharkh, where they hold exclusive possession of 40 towns and villages, and with the Maronites share 200 more. 80 villages in other parts of Jubanon are also peopled by them. They owe their origin to a Persian, Muhammad-bin-Ismailud-Daräzi, who settled in Egypt A.D. 1017, but was driven out of the country, and took refuge in the Wadi-ut-Taim, where he propagated his doctrine; but this was afterwards modified by Hamza, whom the Druse venerate as their real founder. The Druse are tolerant in religious matters, and some of them cenform outwardly to the religious observances of those with whom they may be associated. They are a brave and honest race, practising the virtues of hospitality, but never forgetting an injury.

Politically and in its administration the Lebanon is as distinct from the rest of Syria as if it were a European province. The change was brought about by the Great Powers after the massacres of 1860 , when they jointly framed a constitution and named a governor, who holds his post for ten years under their guarantee, and not subject to dismissal by the Porte. Before that date the Lebanon had continually been a source of anxiety, alike to the Imperial Government and to friendly interested powers, from the almost ceaseless conflicts between the various sects.-Catafago.

LEBIAD Ft, a family of the Coleoptera, of rare occurrence in the east. L. unicolor is from the Himalaya ; Aploa is found at Poona ; Orthogonius is common to Africa and Asia, the gigantic species, however, predominate in the latter country. See Insects.

LEBIDIEROPSIS ORBICULARIS. Mull. A timber tree of Chanda.

LECANIUM COFFE无, Walker, of the order Hemiptera, the coffee bug of Ceylon, for some years devastated some of the plantations of Ceylon. They are greedily devoured by the 
attempt was made to eradicate the bug by the introduction of the ant, but their attacks on the coolies' bare skins prevented the full success of the experiment. Lecanium coffeæ establishes itself on the young shoots and buds, which it covers with a noisome incrustation of scales, enclosing its larvæ, from the pernicious influence of which the fruit shrivels and drops off. It is a Coccus, and a number of brownish wart-like bodies may be seon studding the young shoots and occasionally the margins on the under side of the leaves. Each of these warts is a transformed female, containing a large number of eggs (700), which are hatched within it. When the young ones come out of their nest, they may be observed running about on the plant, looking like woodlice; but shortly after being hatched the males seek the under side of the leaves, while the females prefer the young shoots as their place of abode. The larvæ of the males undergo transformation into pupæ beneath their own skins, and their wings are horizontal, and their possession of wings may possibly explain the comparatively rare presence of the male on the bushes. The female retains her powers of locomotion until nearly her full size, and it is about this time that her impregnation takes place. The pest does not produce great injury until it has been two or three years on an estate; but at length the scales on the plants become numerous, the clusters of berries assume a black, sooty look, and a great number of them fall off before they are mature. The young shoots have a disgusting look, from the number of yellow pustular bodies forming on them, the leaves get shrivelled, and on many trees not a single berry forms. The coffee bug first appeared in 1843 on the Lupallu Galla estate, and it or a closely allied species has been observed on the Citrus acida, Psidium pomiferum, Myrtus Zeylanica, Rosa Indica, Careya arborea, Vitex negundo, and other plants, and most abundantly on the coffee bushes in moist places. It reappears though eradicated, and is easily conveyed on clothes, and from one place to another. Dr. Gardner, whom Sir J. E. Tennent quotes, is of opinion that all remedies have failed, and that it must wear itself out as other blights do. The male of the brown or scaly bug, Lecanium coffeæ, is of a clear, light pinkishbrown colour, slightly hairy and very pretty. It is more delicate than the male Pseudococcus. The females when young are yellowish, marked with grey or light brown, and old individuals are light brown with a dark margin. It affects cold, damp, and close localities 3000 feet in height, and the propagation, as in the white bug, is continuous. The brown bug is much infected with parasites, amongst which the most common are eight minute Hymenoptera (wasps), with brilliant colours; but a mite, the Acarus translncens, and the larvæ of the Chilocorus circumdatus, a kind of lady-bird, also feed on the bug. In the larva state, the male and female brown bug are not distinguishable. The number of eggs produced by a female brown bug is about 700 . Those of the white bug are not so numerous, but their propagation in Ceylon is continuous throughout the year, and this explains their great abundance compared with cold countries, where the produce is one generation of young annually. The brown bug, particularly the full-grown female, is largely infested with parasites, which thus greatly help the planter. Indeed, it is a question whether coffee-planting could be carried on without their aid in the destruction of the bug. The black bug is Lecanium nigrum, but the female only is known. In colour it is from yellowish-grey to deep-brown, and almost black in age, and of a shield-like shape. It occurs alone, but also intermixed with the brown bug, but it is much less abundant, and therefore not demanding the planter's attention. Its occupation of a coffee or any other tree gives rise to the appearance of a glutinous saccharine substance, which has received the name of honeydew. This is either a secretion of the bug or the extravasated sap which flows from the wounded tree, or probably a combination of both. A fungus, or two fungi, the Syncladium Nietneri and Triposporium Gardneri, seem to depend on this for vegetation, as the honey-dew and the fungus disappear with the bug.-Sir J. E. Tennent's Ceylon, i. p. 261, ii. p. 248; Hooker, Him. Jour.; O'Shaughnessy, p. 680 ; Rohde's MSS.; Royle's Hindu Med.; Wise's Hindu Med.; Eng. Cyc.; Mad. Lit. Jour. See Bug; Coffee.

\section{LECANORA TARTARICA.}

Shih jui, . . . CHIN. / Litmus,

See Dyes; Lichen.

LEDEBOURIA HYACINTHINA, syn. Erythronium Indicum, a native of Bundelkhand and Hyderabad. Martius and Ainslie describe the bulbs as a substitute for squill. From trials this article holds out but little prospect of its ever being usefully employed in medicine.-O'Sh. 663 .

LEEA CRISPA. Linn. Ban-chalita, BENG. Grows wild among bushes near Calcutta. The flowers are not conspicuous, but the uncommonly elegant curled wings give to the whole plant a great degree of beauty.

Leea hirta. - Roxb.

Kaka-jangha, . . BENG. Veluma sandhi chettu, TeL. Sura padi, . . TEL. Chiviki velama, . .,

Grows in Bengal and throughout the Peninsula of India.

Leea macrophylla, Roxb.

Tolsu-mudriya, . BENG. Sumudruka, . SAN8k.

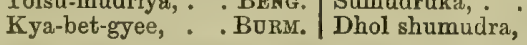

This curious-looking herbaceous plant, with large leaves and small white flowers, grows in the south of India, and is used in medicine in ringworm. It is sometimes cultivated for the astringent properties of its roots. The Burnaans use it to stop the effusion of blood in wounds; in Hindustan it is said to be a remedy for the guinea-worm.

Leea staphylea, Wight

Gilibertia nalugu, D.C. I S. Indica, Burmann.

Kukur-jhiva, . BENG. | Ka-let, . . . BuRr.

Grows throughout British India and Burma.Roxb.; W. Ic.; Voigt.

LEECH, MAJOR R., an officer of the Bombay army, author of A Description of Seistan; Account of the Hazara ; Accounts of Panj Kora Valley, of the Taemuni, of the Early Ghilzai, of the Khaibar Pass, of the Passes over the Hindu Kush and Koh-i-Damān; On the Affairs at Kandahar in 1838; On the Trade between Shikarpur to Herat; Memorandum on the Chief Towns of Afghanistan ; List of Tribes on the N.W. Frontier; Routes from Dehra Ghazi Khan to Kandahar, and from 
Kandahar to Kābul : author of Vocabularies of Seven Languages spoken on the West of the Indus, in Bom. Geo. Trans., 1836, 1838: Bom. Reprint, i. 8vo; Notes on a Tour through Baluchistan, in Bl. As. Trans. viii. p. 667; and Grammar of the Kashmir Language, ibid. xiii. p. 553. -Dr. Buist's Cat.

\section{LEECHES.}

Aluk, Khirahin, . Arab. $\mid$ Sanguisuga, . IT., Port. Hm-yau, . . BURM. Patchet, Lintah, Malsy. Shwui-chih,

Ma-hwang,

Blodigel,

Bloedzuiger,

Sangsue,

CHIN.

Alintah,

DAN., S'w. Jaluka,

Dut. Kudalla,

Blutigel . Fr. Sanguijuela,

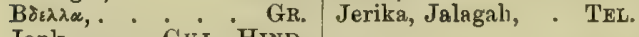

Jonk, . GuJ., Hind.

The leech genera, Bdella, Hæmadipsa, Sanguisuga, belong to the family Hirudinidx of the class Annelidæ, and contrain the true medicinal leeches, which are procurable in all the stagnant waters of India. Sanguisuga Egyptiaca is the leech of Proverbs Xxx. 15. S. medicinalis, Savigny, the speckled leech, occurs also in China. Leeches are of both aquatic and terrestrial habits. Hirudo tagalla, also called H. Ceylonica, lives in the thickets and woods of the Philippine Islands, and also up to 11,000 feet above the sea in the Himalayas. Hæmadipsa Ceylonica occurs in Ceylon, H. Boscii in the Archipelago. Hirudo sanguisorba is the paddy-field leech of Ceylon, and Hæmopsis paludum is the cattle leech of that island. There are said to be leeches one foot long in the province of Shan-tung in China. The leech zone of Malabar is from 1000 to 5000 feet above the sea. In the wet season travelling in the forests is very unpleasant. There are no leeches, mosquitoes, or peepsas in Tibet, and maggots or flies are never seen there. There are no bees or wasps in Dingcham or Tibet. The Planaria occurs near Madras. Leeches and their effects must have been known from the earliest times; they were early employed by the Hindus and Arabs, and six kinds of useful and six of venomous leeches are mentioned by Susruta and Avicenna.

Dr. Carter, in a menorandum on the Leeches of Western India, mentions as the difference between the Matheran and common leech, that the common leech is about one inch in length, of an olive-green colour, has seven lines down its back, but no black spots; twelve eyes, arranged quadrilaterally, an uneven lip, with its centre notched, and is aquatic. The Matheran leech is about three-quarters of an inch long, of a light reddish-brown colour; has a black line down its back, and is covered over with black spots; ten eyes arranged in a semicircle, a smooth lip, with centre projecting, and is terrestrial. He has remarked that a species of Matheran leech appear to be common throughout the jungles in the western part of India, as well as in the islands of Ceylon and Madagascar, and is so abundant, active, and voracious, that it becomes a considerable obstacle to those who have to pass through localities infested by them, not only extracting a large quantity of blood, but often producing irritable and festering ulcers.

The numbers of these annelids in moist warm parts of the world are immense. Dr. Hooker mentions that, when travelling in Sikkim, between Singhtam and Chakung, wading through deep mud or climbing over rocks, leeches swarmed in incredible numbers in the streams and damp grass, and in the bushes. They got into his hair, hung on his eyelids, and crawled up his legs and down his back. He repertedly took upwards of 100 from his legs, where the small ones used to collect in clusters on the instep, and the sores they produced were not healed for five months. He thinks snuff or tobacco applied to the feet the best means of preventing their attacks. He thinks that the extraordinary abundance of these annelids in Sikkim may cause the death of many animals. Some marked murrains have followed very wet seasons, when the leeches appear in incredible numbers; and the disease in the cattle, described to him by the Lepcha as in the stomach, in no way differs from what leeches would produce. It is a well-known fact that these creatures have lived for days in the fauces, nares, and stomachs of the human subject, causing dreadful sufferings and death. He has seen the cattle feeding in places where the leeches so abounded that 50 or 60 were frequently together on his ankles; and ponies are almost maddened by their biting the fetlocks. It is said that cattle are frequently affected by their adhering to their throats when drinking. Mr. Rohde recommended salt to the ryots as a remedy, and thinks an addition of salt to the bran mash usually given, an effectual remedy. In the dry climate of the IV. Dekhan a caste of Hindus rear leeches for hospital use. The full-grown leech of Madras and Bengal will draw six drachms, but those employed in Bombay scarcely a drachm.

The leeches used in the Calcutta hospitals are caught in tanks and jhils in the direction of Baraset, by persons who allow them to fasten on the naked skin. In the Upper Provinces a superior kind of leech is used, called the Shak uabadi jonk, caught in the tanks about Shakuabad in the Agra district. The Panjab leeches are the next best, and are procured in abundance about Patiala in the Sirhind district. The Shakuabad leech will generally bear three applications, and it is the only description of leech that will do so. The animal is of a light olive-green colour, and marked with two bright yellow stripes on the sides. The common wild leech of the Upper Provinces is called Dabri ; but for hospital purposes it is very inferior to those mentioned. In Europe, leeches are kept in pans with a little soft water, the vessels being covered with canvas to admit the air. In India they are placed in common earthen vessels with moist clay. In Southern India they are found in almost all pools which are not dry in summer, and in which the water is good, and is not impregnated with salts.

LEEDES, Newberry, Storey, and Fitch, four adventurous merchants, who, twenty years after the E.I. Company obtained its first royal charter, were commissioned by the Turkey Company to visit India and ascertain what openings for British enterprise existed there. They traversed Syria, descended the Tigris to Bussora, and thence took shipping to Ormuz and Hindustan. One entered the service of the emperor Akbar, another died in the Panjab, a third became a monk at Goa, and the fourth, Ralph Fitch, after wandering to Siam and Malacca, halted at Ceylon and Colombo on the 5th March 1589, and was probably the first 
Englishman who ever beheld the island.-Sir J. E. Tennent's Ceylon. See Fitch.

LEEKS, the Allium porrum of Linnæus. The native inhabitants of Tenasserim are as much attached to leeks as the Israelites were to the leeks and onions of Egypt, and they abound in their gardens. The seed may be sown at the commencement of the rains, or after, in beds, broadcast. When about six inches high, they require transplanting into large beds or rows, at least one foot apart ; they go to seed in the course of six months, and grow very well in all parts of the Dekhan. Menu, however, says garlic, onions, leeks, and mushrooms, no twice-born man must eat, and all vegetables raised in dung.-Mason; Riddell; Menu, ch. v. par. 5.

LEEZAN, a village of scattered houses on the side of a hill which slopes down to the river Zab. A mountain stream empties itself into the river at the foot of the village, which it separates from the church. During the massacre of the Nestorians by the Kurds, the inhabitants of Leezan took refuge upon a platform on the rock above the church, where they defied all the attempts of Beda Khan Bey to dislodge them. But, being at last starved out, they capitulated, on the understanding that they were to surrender their arms and property, and their lives to be spared. The Kurds, on being admitted to the platform, and having taken the arms, commenced an indiscriminate slaughter. Few persons throughout the entire valley escaped this terrible massacre.

\section{LEFT-HAND CASTE.}

Edagai, Eddayai, . KARN. Idangai, Idam, - TAM. Edagai kula, . . ", Idakai, . . . . ,

The Vaishnava Hindus in the south of India speak of themselves as of the right or left hand. The Karnatic enumeration of the left-hand castes furnishes nine, viz. :-

1. Panchala or artisans.

a. Kammaranu, black smith.

b. Badage, carpenter.

c. Kansagar, brazier.

d. Kallurtiga, stonecutter.

e. Akasale, goldsmith. 2. Beri-sethi, traders.

Much animosity and many quarrels occurred between the right and left band sects, the cause of which, or the points of difference, the disputants themselves are generally unable to state. Professor H. H. Wilson, in his Hindu Sects, implies that there exists in N. India a sectarian Hindu division into right and left hand sects, and that the left-hand sect are worshippers of the sakti or female powers of the Hindu deities. He says that when the worship of any goddegs is performed in a public manner, and agreeably to the Vedic or Puranic ritual, it does not comprehend the impure practices which are attributed to a different division of the adorers of Sakti, and which are particularly prescribed to the followers of that system. In this form it is termed the Dakshina or right-hand form of worship, to distinguish it from the Vami or Vamachari, the left-hand worshippers, or those who adopt a ritual contrary to that which is usual, and to what, indeed, they dare publicly avow. They worship, he says, Devi, Lakshmi, Saraswati, the Matri, the Nayika, the Yogini; and even the fiend-like Dakini and Sakini are admitted to a share of homage. Siva with the two hands is an object of veneration, especially in the form of Bhairava, with which modification of the deity it is the object of the worshipper to identify himself. The worship of the Vamachari is derived from a portion of the Tantras. It resolves itself into various subjects, apparently into different sects, of which that of the Kaula or Kulina is declared to be pre-eminent. The object of the worship is, by the reverence of Devi or Sakti, who is one with Siva, to obtain supernatural powers in this life, and to be identified after death with Siva and Sakti. All the forms of worship require the use of some or all of the five Mukara,-flesh, fish, wine, women, and mystical gesticulations are the five-fold Mukara which takes away all sin. But such a sect of Sakti worshippers are wholly unknown in the south of the Peninsula of India, in which the enmity between the right and left hand castes is bitter, and which in Madras was only restrained by the energy of Mr. Edward Elliot, the chief magistrate, between 1820 and 1860.-Wilson's Hindu Sects.

LEGASPI, in 1564, in the reign of Philip II. of Spain, with five ships and 400 seamen, went from Spain as governor of the Philippines, and ultimately fixed himself on Zebu, which for some time was the central seat of Spanish power.

LEGGADA, a genus of mammals of the family Muridæ.

Leggada Jerdoni, Blyth, lives at 12,000 feet in the Himalaya.

Leggada lepida, Jerdon.

Leggada booduga, Gray. | Mus lepida, Elliot.

Chitta burkani,. TeL. Chitta ganda, . ThL. Chitta yelka,. . . ,

A pretty little mouse which lives in pairs in the red soil of S. India. It is preyed on by the jay or Indian rollers, and is used as a bait to catch that bird, with bird-lime.

Leggada platythrix, Jerd.

Kal-illi, . . . CAN. / Kal jelu, Gljeli gadu, TeL.

The brown mouse of S. India, lives in burrows of moderate depth. The burrow leads to a chamber containing a number of small pebbles or sticks, on which the mouse sits, the thick, close hair of its belly protecting it against the cold and roughness of the stones. It is monogamous, nocturnal, and a vegetable eater.

Leggada spinulosa, Blyth, occurs throughout India.-Jerdon.

LEGISLATIVE COUNCILS, for making laws for British India, sit at each of the presidency towns. On the 16th January 1862, the GovernorGeneral in Council, under the authority vested in him by the Act 24 and 25 Vict. cap. 67, sec. 16, appointed Saturday the 18th of January 1862, and the Council Chamber in the Government House at Calcutta, for the first meeting of the Council of the Governal-General, for the purpose of making laws and regulations under the provisions of the Act. On the 17th January 1862, there was issued the proclamation that the provisions of the Act touching the making of laws and regulations for the peace and good government of the presidencies of Fort St. George and Bombay were extended to the Bengal division of the presidency of Fort William, from the 18th of January 1862 .

LEGUMINOSE is a name of the Fabaceæ or bean tribe, q.v. Leguminous and cruciferous 
plants occupy the largest part of the Chinese kitchen garden; many sorts of peas and beans are cultivated, and the pods and seeds of two species of dolichos are eaten, and the beans of another species made into soy by boiling and powdering the kernels and then fermenting them with yeast, and mixing other ingredients, according to the $t$ aste of the maker or purchaser. Peas and beans form important objects of culture, and the condiment called soy (a word derived from the Japanese Soya) is prepared chiefly from a species of dolichos. One of the commonest modes of making this condiment is to skin the beans and grind them to flour, which is mixed with water and powdered gypsum or turmeric. The common Chinese eat few meals without the addition of one form or other of the bean-curd or bean-jelly. The soy was at one time largely used as a condiment in the several countries of Europe, but has been displaced for others. See Fabacex.

$\mathrm{LEH}$, a chief town in Ladakh, is situated about three miles from the northern bank of the Indus, at an elevation of 11,538 feet above sea-level. Lai. $34^{\circ} 10^{\prime} \mathrm{N}$., long. $77^{\circ} 40^{\prime} \mathrm{E}$. ; estimated population, 4000. Leh stands in a small plain, between the river and a chain of mountains; $\mathrm{a}$ wall with conical and square towers surrounds the town, and runs up to the crest of the range. It is the entrepot for the trade between the Panjab and Chinese Tartary, being the principal mart for the shawl - wool imported from the latter country. In summer, caravans from distant regions meet at Leh. It is the rendezvous for merchants travelling to and from Yarkand; and the variety of tribes then to be found in it is particularly great. The level of the Indus at Leh is 10,723 feet. The town occupies the slope, and surrounds the base of a low spur, on the left or east side of the valley, while the centre and right side are occupied by extensive tracts of cultivation, the fields rising in terraces one above another, and watered by little rills drawn from a stream which descends in the centre of the valley. Along the road by which the town is approached, there is a mani, extending for more than half a mile. It consists of two parallel walls, 12 or 15 feet apart, and nearly 6 feet high, the intervals between which are filled up with stones and rubbish, and the whole covered with a sloping roof, which rises at a gentle angle to the central ridge, midway between the two walls.

A considerable number of Kashmirians are domesticated at Leh, and a mixed race has originated from them and the women of the country, termed Argand. The Kashmiri and their descendants are engaged in commerce, and the lower orders are butchers, cooks, and petty retailers. There are also some Turani merehants; and in the lands of Chushut, a colony of Balti Muhammadans is established, addicted to intoxicants. The Kashmirians here, as well as everywhere else, are notorious for every kind of profligacy; and where they abound the people of the country are tainted by similar vices. The women of Ladakh, in consequence of their great proportionate number, find it difficult to obtain subsistence, and besides domestic occupations and wool-picking, in which they are very expert, they are the principal labourers in the fields. They are a very lively, good-humoured race, and scolding and railing are almost unknown amongst them.Magnetic Survey of India; Rob. Schl.; MIrs. Her- vey's Tartary; Thomson's Tr.; Imp. Gaz.; Latham; Cunningham; Moorfoot's Tr. p. 321.

LE'HPET. BURM. Pickled tea.

LEIP-BYA, BURM., literally a butterfly, is a term applied to the soul. It is the psyche of the Greeks, the life, the perceptive principle. The Burmans regard the Leip-bya in man as that principle of his nature which perceives, but not that of which moral actions are predicated. They believe that the Leip-bya may be temporarily separated from the body, as when startled the body becomes unconscious. In deep sleep it leaves the body and roams far and wide. A sleeping wife dreams of her absent husband; their two butterfly souls have met.

LEITNER, GOTTLIEB WILLIAM, M.A., Ph.D., LL.D., born at Pesth, October 14, 1840. He was First-class Interpreter to the British commissariat department during the war with Russia in 1855 ; was Lecturer at King ${ }^{3}$ C College, London, in 1859, in Arabic, Turkish, and Modern Greek; in 1861 was Professor of Arabic with Muhammadan Law, and founded the oriental section. He was appointed to the Panjab University College in 1864; he founded the association styled the Anjuman-i-Panjab, for social, political, and educational reforms; and he originated journals in English, Arabic, Urdu, etc. At the Imperial Assemblage at Dehli on the 1st January 1877, the Viceroy, Lord Lytton, referred to his ' succeseful services in the cause of education as an honour to India and to all of us.'

His published writings comprise works on the Theory and Practice of Education; Philosophical Grammar of Arabic; Sinin-ul-Islam; The Races of Turkey; Vocabulary and Grammar of the Dardu Languages, with Dialogues ; Results of a Tour in Dardistan, Kashmir, Little Tibet, Ladakh, Zanskar; History of Dardistan, Songs, Legends, etc.; Græco-Buddhistic Discoveries; on a National University for the Panjab; and Adventures of a SiahPosh Kafir.-Panjab Gazette, Men of the Time.

LELAH. Malay. A small brass canister swivel gun, carrying $\frac{1}{2} \mathrm{lb}$. shot, manufactured by the Achinese at Palembang.-Lowe's Sarawak, p. 220.

LEMA, a pass in the Western Himalaya. A tract in which the bottoms of the valleys are from 15,000 to 15,500 feet, and the mountain summits from 16,000 to 17,000 feet above the level of the sea.-Thomson's Trs. p. 151.

LEMNACE 庇. Schleiden. The duck-weed tribe of plants, of which $\mathrm{L}$. cruciata, L. obcordata, $\mathrm{L}$. orbiculata occur in India. Lemna gibba, Tatarinov. Shwui - p'ing, Crins. The duck - weed of China, used medicinally, is deemed cooling, diuretic, antiscorbutic, astringent, and alterative. It is used in skin affections and to wash sore eyes, carbuncles, syphilitic sores. The dried plant is burnt to destroy mosquitoes. Lemna minor, the common duck-weed, grows in the Sikkim Himalaya.-Smith, Mat. Med. Chin.; Hooker, i. p. 306. LEMON.

Citrus limonum, Risso and Poit.; C. medica, Roxb. Lemu, AR., Hrnd., Pers. | Limoni, . . . . . IT. Korna-nebu, . . BENG. Limbo, : : : P PRrs. Ning-mung, : CHIN. Limoes, : : PORT. Limoenen, . : DUT. Limonu, : : : RUs. Limons, . : . FR. Limones, : : . SP. Limonen, : : GER.

This is the fruit of a largely-cultivated tree, which grows wild in the Garo Hills and at the 


\section{LEMON GRASS.}

foot of the Himalaya. Its fragrant white flowers are tinged with red. Its rind and juice are used medicinally and dietetically. - Roxb.

Lemonade, a refreshing drink made with water and the expressed juice of the acid lime.

Lemon juice.

Ning-mung-chih, . CHIN. | Limbu-ka-ras, HIND. Jus de limon, - FR. Agro o sugo de limone, IT. Zitronen saft, . GER. Jugo de limon, . SP.

The expressed juice of limes or lemons. It is an approved specific in the prevention and cure of scurvy; a powerful and agreeable antiseptic, as well as an ingredient in many pleasant refrigerant drinks.-Faulkner.

Lemon peel.

Lames d'ecorce de citron, Limbu-ka-chal, . . HIND. $\begin{aligned} \text { Zitron enshalen, . FR. } & \text { Gimbu-ka-chilta, : . " } \\ \text { GER. } & \text { Scorze de limone, . . }\end{aligned}$ Limonschellen,. . " Courtezas de citra, . SP.

The rind of the lemon is a bitter aromatic, and is frequently employed in stomachic tinctures, and for making preserves and liqueurs; it also yields an essential oil, which is much used in perfumery. $-M^{\prime}$ Culloch.

LEMON GRASS, Camel's hay; Sweet rush.

Ask'hur, . . ARAB. Malatrinakam, . SANSK,

Gundho-bena, BENG., GUJ. Kamachi-pillu, . . TAM. Gund-bel, Olacha, . HIND. Wassina-pillu,

Siri, . . . JAV. Cavatum-pillu, .

Growr-gah, : : PERs. Kamaohi kasuvu,

The English name is given to Andropogon citratum, A. schœuanthus, and other allied species, sweet-smelling, bitterish, aromatic grasses, having long, striated, scabrous leaves. They furnish by distillation the fragrant essential oils called lemon-grass oil and citronelle oil. The grasses are frequently substituted for tea, and the white succulent centre of the leaf-bearing culms is often put into curries to give them an agreeable flavour. The plants are cultivated in gardens, but grow wild, and large tracts of waste land in India and Ceylon are covered with them. They flourish in any good soil, are propagated by slips from the root, and only require watering. A. schoenanthus is cultivated all over the Tenasserim provinces, and a decoction made from the leaves is deemed of much efficacy in colic and similar complaints.

Lemon-grass oil.

Camachie pilla tylum, TAM. | Camachi kasavu yennai, TeL.

This oil is obtained by distillation from the Andropogon schœenanthus grass. It is much used as a rubefacient for rheumatic affections, as well as in perfumery, for which purposes it is said to be largely exported from Travancore and Ceylon. When newly made it is of a light straw colour, but age changes it to a deep red. Another oil, also called lemon-grass oil, or citronelle, is the produce of Andropogon citratum, and is made in Travancore and Ceylon. In Madura are three grasses, named Poathapil, Seegompil, and Comatchipil. To make the oil, the grass is cut in pieces a span long (the little roots excepted), and the pieces are put into earthen pans. Their subsequent exposure to the warmth of fire extracts the oil--Riddell; Mason.

LEMURIA. Naturalists suppose that a continent formerly extended from Madagascar to Ceylon, India, and the Malay Islands. Others suppose only the former existence of several large islands, all the areas around which have subsided.

In 1874 (R. G. Soc.), Mr. H. F. Blanford, from

\section{LENCHA.}

the similarity of fossil plants and reptiles, formed the opinion that India and S. Africa had been connected by a continent, and remained so connected, with some short intervals, from the Permian to the end of the Miocene period; and Mr. Woodward expressed his satisfaction with this further evidence, derived from the fossil flora of the Mezozoic series of India, in corroboration of the view taken as to the former existence of a now submerged continent.-Forbes; A. R. Wallace, p. 398.

LEMURID $\mathbb{E}$, a family of mammals, the lemurs, mostly of Madagascar, one genus of Africa and two or three in India and Malayana. The lenurs constitute a distinct group of quadrumanous animals. They live almost entirely in trees, and are most active at night. The fur of the lemurs is soft, dense, and woolly. Their nostrils, unlike those of either group of monkeys, have a curved opening, and the tail is never prehensile. The extremities of the lemurs differ remarkably from those of the monkeys, in having a long, sharp, curved claw on the first finger of the hinder pair, and generally in the broad, flat character of the nails of the other fingers. The form of the face is somewhat fox-like in the prolongation of the muzzle, and affords a physiognomical character which will be readily recognised.

Nycticebus tardigradus, Jerdon.

Stenops Javanicus, Auctor. I N. Bengalensis, Geoff.

Lajja banar, . BENG. Slow-paced lemur, ENG. Lajjawoti banar, . ", Sharmindah billi, . HiND.

Found in Bengal, Rangpur, and Dacca.

N. Javanicus, Blyth, of Java.

Loris gracilis, Jerd., Lemur Ceylonicus, Fischer. The slender lemur, ENG. Tevangar, ... TAM. Sloth of Madras, . ,, Dewantsi pilli,. . TEL.

Found in Ceylon and Southern India.

Tarsium, a genus of Java.

Galeopithecus volans, Shaw.

Lemur volans, Linn. |Cato-simius volans, Vespertilio admirabilis, Camelli. Bont.

ENG. Flying cat, ... Flying fox, : : " | Kubung, : : MALAY.

This is the only species of the genus. It inhabits India, Burma, Penang, the Malay Peninsula, Siam, Sumatra, Java, and Borneo.

G. marmoratus, Philippensis, Ternatensis, rufus, undatus, and Temminckii are considered by Shaw and others to be varieties. It is nocturnal, lives on young fruits and leaves, and does very great injury to gardens and plantations. As evening approaches they quit their shady retreat, and are to be seen in considerable numbers making oblique leaps from one tree to another. The membrane or expansile skin by which it is enabled to leap, like the flying squirrel, is continued on each side from the neck to the fore feet, thence to the hind feet, again to the tip of the tail, and to the roots of the claws.-Horsfield's Mammalia; Jerdon.

LENCHA. TrB, Common salt. Three sorts of salt are known in the commerce of the Himalaya and Tibet, - Sercha, white and best; Chama, reddish and good; Pencha, yellowish and bad, contains soda or magnesia and earthy matter. All the salt consumed in Eastern Tibet is the produce of lakes or mines situated to the north of the Yaru river, or comes from Lache, a district lying between Digarchi and Ladakh, which is traversed 
by the Yaru. But there are people who assert that it is also dug out of the ground. The saltproducing districts are rugged and inaccessible. Men and sheep only can reach the deposits, and the elevation prevents their being worked, except for the warmer half of the year, April to November. Thousands of sheep are employed in carrying the salt from the deposits to places accessible to yaks. These latter animals carry it all over Tibet in loads up to $160 \mathrm{lbs}$. Sheep in open places will carry 20 to $24 \mathrm{lbs}$.

LEN-DEN, also Lewa Dewi. HiNd. Buying and selling, trading, traffic.

LENE. MArrr. The cave temples of Ellora and Ajunta, from Lena, a picture; also called Yerola.

LENGA. HIND. A thick plaited skirt of a woman's dress.

LENT is a periodical abstaining rite in the religions of Christians, Muhammadans, and Burmese. With the first of these, the abstinence is only from certain diet articles, for a period of forty days. Muhammadans, for a lunar month, called Ramadan or Ramzan, between sunrise and sundown, fast and are continent, and Burmese have a lenten period of nearly three months' duration. See Monastery; Myenmo.

\section{LENTIL.}

\begin{tabular}{l|l} 
Buro-musoor, : BENG. & Linsen, \\
P'ien-tau, : . CHIN. & Masur, Masur dhai, Hind.
\end{tabular}

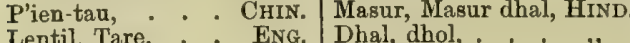
Lentilles, . . . FR. Linti, . . . . ."IT,

The lentils of Genesis xxv. 34 are from the Ervum lens of botanists, a leguminous plant, one of the oldest food plants of which there is any record. Ever since the time of Esau they have been eaten in the east. In Egypt and Syria they are parched in a frying-pan and sold in the shops, and considered by the natives as the best food for those who are on long journeys. Its composition in 100 parts has been found to be in samples from

Moisture, . . . $12.70 \quad 11.40$

Nitrogenous matter, . $24.57 \quad 26 \cdot 18$

Starchy matter, . $59 \cdot 43 \quad 59 \cdot 43$

Fatty or oily matter, $1.01 \quad 1.00$

Mineral constituents (ash), $2.29 \quad 1.99$

Bombay bazar. $10.72 \quad 12.50$ $25 \cdot 20 \quad 24 \cdot 65$ $59.96 \quad 59.34$ $1 \cdot 92 \quad 1 \cdot 14$ $2 \cdot 20 \quad 2 \cdot 37$

Lentils, like all the other leguminous fruits, contain a large quantity of nitrogenized matters. Einhoff found that 3840 parts of lentils contained 1260 parts of starch and 1433 parts of a matter analogous to animal matter. Dr. Playfair found that 100 parts of lentils contained 33 parts of albumen or gluten, and 48 parts of starch, etc.; whilst the same quantity of peas contained 29 parts of albumen, and of beans 31 parts. Lentils constitute one of the most highly nutritious foods in nature. There are three varieties known in France and Germany, - the small brown, which is the lightest flavoured and the best for soups; the yellowish, which is a little larger and the next best; and the lentil of Provence, which is almost as large as a pea, with luxuriant straw, and might be cultivated as food for cattle. In its cultivation the lentil requires a dry, warm soil; it should be sown later than the pea, at the rate of a bushel or a bushel and a half to the acre. It ripens earlier than the pea, and requires the same treatment and harvesting. The produce of the lentil in grain is about a fourth less than that of the tare, and the straw is not more than a third as much. The straw is, however, considered very nourishing, and is used for feeding calves and Iambs. The Ervum lens was largely advertised in London about the year 1840, under the term Ervalenta, afterwards as Revalenta. On analysis, Warton's Ervalenta was found to consist of a mixture of the French or German lentil, ground and reduced to powder, including portions of the shells or husk, and of a substance very closely resembling in its microscopic characters, maize or Indian corn meal. The French lentil, either whole or ground, is of a yellowish colour, and has the taste of peas. It has been stated that the farina of Durra, etc., has been discovered in either Ervalenta or Revalenta. Durra is the Sorghum vulgare of some other writers. Its meal resembles that of Indian corn. The two following are receipts for lentil flour :\begin{tabular}{c|l} 
Red Arabian lentil \\
flour, . . 2 lbs. & Malt, Mix into a uniform 3 oz.
\end{tabular}

Barley flour, : $1 \mathrm{lb}$. powder.

or

Pea flour, . . 2 lbs. Salt, . . . . 3 oz. Indian corn flour, $1 \mathrm{lb}$. Mix as before.

-Eng. Cyc.; Powell, i. p. 340 ; Roxb.; Voigt; Ainslie; Hassal.

LEO, the lion, the Felis leo of Iinnæus, the Asiatic lion, occurs in India. It was called by Smee the Felis Gujerattensis, and the people call it the Sher, the Babbar-sher, the Untia-bag or camel-coloured tiger, also Singha and Shingal. Its length is from $8 \frac{1}{2}$ to $9 \frac{1}{2}$ feet, and its height $3 \frac{1}{2}$ feet. The Asiatic and African lion is identical, and is found in the N.W. of India from Gujerat and Cutch to Hurriana, Gwalior, and Saugor.

LEO AFRICANUS, a Moor of Granada. He was named after Leo, baving abjured the Muhammadan religion during the pontificate. He wrote a description of Africa in Arabic and Latin, and died in 1556.

LEONOTIS LEONURUS, the scarlet dandelion, a beautiful small scarlet flower, native of the Cape, and now common in all Indian gardens; blossoms throughout the year.-Riddell.

LEONTODON TARAXACUM, the dandelion ; found in the Sutlej valley between Rampur and Sungnam at an elevation of 6000 to 10,000 feet. - Cleghorn's Panjab Report, p. 68.

LEONURUS SINENSIS.

Ch'un-gwei, . . . ChIN. | Yih-mu-ts'au, . ChIs. It grows all over China, especially in Hankow. It is dried, and used medicinally, as a tonic, alterative, vulnerary, and general remedy in puerperal and menstrual ailments. Leonurus tataricus, the Tartarian mother-wort, is a shrubby plant, grown from seed, and cultivated in some gardens. -Riddell; Smith, Chin. Mat. Med.

LEOPARD.

Pau, Ching,. . . Chrs. | Shi-tsze sim, . Tungus. Several distinct species of leopard are known.

Felis leopardus, Schreb., the leopard or cheeta of India. F. pardus, the pard or panther or gorbacha of the Dekhan.

F. diardi, Desm., clouded leopard of India and Malayana.

F. jubata, maned leopard or hunting leopard of India.

F. melas, Peron, black cheeta of India and Malayana.

F. pardochrous, Hodgs., of Nepal and Tibet.

F. Horsfieldii, Gray, of Darjiling.

F. Javanensis, Desm., of Sumatra, Borneo, Java.

F. Sumatranus, Horsf., of Sumatra.

Latterly, naturalists have regarded the $F$. 
leopardus and F. pardus as varieties of the same animal; and Horsfield and Jerdon say the black leopard, F. melas, Peron et Lesueur, is now uniformly admitted to be a black variety of $\mathrm{F}$. pardus. Most Indian sportsmen, however, regard them as distinct, though black and yellow cubs are said to have been seen following a female yellow leopard, and the black leopard is of a more vicious temper.

Panther. - There is undoubtedly in British India a large and a small leopard, the larger variety being commonly called the panther.

F. pardus, Hodgs. $\quad$ F. leopardus, Temm.

Tendwa of . . Bowrr. Adnara, . . Hind.

Honiga, : : CAN. Asnea, : : MAHR. Barkal, Gond. Leopard of : STKES. Bay-hira of . Hrmalara. Chinna puli, . Tel. Tahir-hay, '. ". . . . TIв.

It is found throughout India, in the more open country, near low hills and ravines. It is from 4 to 5 feet long, tail $2 \frac{3}{4}$ to $3 \frac{1}{6}$, total about $6 \frac{3}{4}$ to $8 \frac{1}{6}$ feet. They destroy deer, occasionally kill and carry off cattle and ponies, not unfrequently carry off children, also old women. Sir Walter Elliot says an instance occurred of four men being killed by one before it could be destroyed.

Leopard, or smaller variety.

Felis leopardus, Hodgs.

F. longicaudata, Valen.

F. pardus, Temm.

Bibla of . . BowrI. Bibla-bagh, . . . MAHR. Gorbacha, : . DukH. Ghur-hay, : SIנLA. Borbacha, : : ", Dhir-hay, : : . "

This is smaller than the other, with a round bulldog head. It seizes on dogs, sheep, goats, deer, monkeys, peafowl. It is more abundant in forest countries, in Malabar, Wynad, Gumsur, in the woody parts of the Himalaya and Malay Peninsula. It is stealthy, not unfrequently attacks man, and has been known to carry off men who were watching grain at night.

Black leopard.

F. melas, Peron.

F. perniger, Hodgson.

It is found throughout British India, but sparingly in a forest country. It is of a uniform dull-black colour. On one occasion, when shifting the tigers and leopards of the Government Central Museum from one cage to another, a black leopard leaped violently against the doorway, which it forced open, and escaped into the garden, creeping close to the low hedge. It was followed up for about fifty yards, but it turned on the Editor, who backed and leaped to the top of a wall five feet high, followed by the black leopard, which sprang from the ground, but was caught in the leap by a blow on the head, from which it fell at the foot of the wall stunned. It was restored to its den, and recovered from its insensibility on the following day, but on the twelfth day it was killed by a panther in the same den. It had a vile temper.

Felis jubata, Linn., hunting leopard.

$$
\text { F. guttata. }
$$

F. venatica.

Chircha, Chirtsa, . CaN. Yuz, Hindustani of the

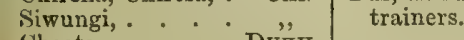

Cheeta, : . . Dukr.

They are caught in the Southern Mahratta district, and are trained to kill the Antelope cervicapra. They are taught always to single out the buck, which is generally the last in the herd. The huntsmen are unwilling to slip until they get the herd to run across them, when they drive on the cart and unhood the cheeta.

The leopards and panthers have been variously named by naturalists. L. Chinensis, Gray, L. Ellioti, Gray, L. Reevesii, Gray, and L. inconspicuus, Gray, are synonyms of Felis Bengalensis, Desmoulins. And F. pardochrous, Hodgs., L. dosul, Hodgs., is Felis marmorata, Martin, Blyth. L. Sumatranus, Gray, is F. leopardus Sumatranus, Horsf.; L. varius, Gray, is F. pardus, Linn.; L. viverrinus, Gray, is F. leopardus viverrinus, Bennett. The panther and the leopard are used in Chinese heraldry.-Smith; Jerdon's Mammals; Adams; Horsfield's Catalogue, E.I.C. Museum; Tennent's Ceylon, pp. 25-29.

LEPCHA, a Mongolian tribe forming a large part of the population of Sikkim. The country of Sikkim and Darjiling is the land of the Lepcha, a Bhot race who are hemmed in between the Newar and other Nepal tribes, and the Lhopa of Bhutan, the Lepcha area being barely 60 miles in breadth. His physiognomy is markedly Mongolian, stature short, from 4 feet 5 inches to 5 feet; face broad and flat, nose depressed, eye oblique, chin beardless, skin sallow and olive, with a little moustache on the lips; broad chest and strong armed, but small-boned legs, with small wrists, hands, and feet. The Lepcha is honest, timid, and peaceful, with mild and frank features. The Lepcha throws over him loosely a cotton cloak striped with blue, white, and red, and uses an upper garment with sleeves in the cold weather; a broad umbrella-shaped hat of leaves, and a pent-house of leaves in the rains. The women dress in silk skirt and petticoat, with a sleeveless woollen cloak. The Lepcha man carries a long, heavy, and straight knife, serving for all purposes to which a knife can be applied. They drink the Murwa, the fermented juice of the Eleusine coracana, which gives a drink, acidulous, refreshing, and slightly intoxicating, and not unlike hock or sauterne in its flavour. Their songs and the music of their bamboo flute is monotonous. They marry before maturity, the brides being purchased by money or service. The Lepcha, like many other races, kindle a fire by the friction of sticks. Mountain spinach, fern tops, fungi, and nettles are used as food. Their ailments, small-pox, goitre, remittent fevers, and rheumatism. Their language assimilates to the Tibetan. Some of the Lepcha tribes call their country Dijong. Amongst themselves they divide into two tribes, the Rong, also Arrat, and Kham-ba. The Rong has no tradition of immigration; but the Kham-ba appear to have come about 200 years ago from Kham, a province of Tibet on the borders of China. The present Sikkim raja is a Kham-ba. The Lepcha have no caste distinctions, but they speak of themselves as belonging to one or other of the following sections:-

\begin{tabular}{l|l|l} 
Burphoong phoocho. & $\begin{array}{l}\text { Sundyang. } \\
\text { Udding } \\
\text { Thurjokh }\end{array}$ & $\begin{array}{l}\text { Lucksom. } \\
\text { Therim. }\end{array}$ \\
Tung yeld. & Songme.
\end{tabular}

Captain J. D. Herbert, when writing of the Lepcha race, says that they are the sime people whom he had seen at Nialang, at Jabnabbi, at Sbipcbi on the Sutlej, in Hangarang, and at Lari in Ladakb.

Chastity in adult girls previous to marriage is not very rigidly insisted on. The Lepcha bury their dead, as is the custom generally of the Buddhists. 
The house of the Lepcha is generally square, roomy, and comfortable, built on posts, with a stage in front of the door, and low-eaved thatch of bamboo stems, split and laid flat. The walls are of bamboo wattle-work. In all respects it resembles the Bhoteah house. The Limbu and Murmi build smaller houses, often on the ground, but more frequently raised; the roof is of grass thatch, or occasionally of a species of bamboowork matting.-Dalton, Ethnol. of Bengal, p. 102; Hooker, Him. Journal; Dr. Thomson in Eth. Soc. Journ.; Beng. As. Soc. Jour. No. xxix. p. 20; Capt. Hertert; Latham's Ethnology.

LEPER LEPER, a canoe of Amboyna, dug out of a single tree, with raised sides.-Biknore.

LEPIDIUM LATIFOLIUM. L. Gon-yuch, LADAKH. Grows in Ladakh, 10,000 to 14,000 feet; is browsed by sheep and goats, little by the yak.

LEPIDIUM SATIVUM. Linn. Garden cress. Half, . . ARAB. | Nasturtium, . PLiNY. Aliveri, . . BENG. Detander,

Sa-mung-ni, . BURM. Ahreo,

Halim, Tara-tezak, Hind. Adala vitala,

SIND.

TEL.

This is grown in many parts of India. Its small ovoid, reddish mucilaginous seeds are used medicinally by the natives of India as a laxative and antiscorbutic, and by the native physicians as a gentle stimulant. An oil has been extracted in India, as well as in Europe. The seed is of an agreeable warm taste. Bruised and mixed with lime-juice, it is deemed useful for checking local inflammation. Taken whole in half-drachm doses, it answers as a gentle and warm aperient.-Roxb.; Voigt; Ainslie; O'Sh.; Birdu'ood; Exhib., 1862.

LEPIDOSIREN, a curious reptile of Africa and South America, placed midway between the reptiles and fishes, and has gills and true lungs. It has the habit on the approach of drought of burying itself several feet deep into the mud of the ponds in which it usually dwells. It does not appear to possess the power of travelling. The Hydrargyræ of Carolina leave the drying pools and seek the nearest water, in a straight line, though at a considerable distance; and $\mathrm{Sir} R$. Schomburgh tells us that certain species of Dora (called by the people the Hassar) in Guiana have the same habit, and are occasionally met with in such numbers in their travels that the negroes fill baskets with them. If they fail in finding water, they are said to burrow in the soft mud, and pass the dry season in torpidity like the Lepidosiren. Gosse, p. 122.

LEPIRONIA MUCRONATA. Cl. Richard. A rush of all the $\mathrm{S}$. and $\mathrm{E}$. of Asia, cultivated in China, like rice, for mat-making. It rises to 7 feet, and propagates by sprouts from its perennial roots. The stems are beaten flat, to fit them to be woven as mats, bags, mat sails, or floor matting.- Von Mueller.

LEPISMA. This tiny silver insect has six legs, filiform antennæ, and abdomen terminated by three elongated setæ, two of which are placed nearly at right angles to the central ones. This is one of two genera of insects which infest books in India, and which are usually regarded as accomplices in the work of destruction, but which, on the contrary, pursue and greedily feed on the larvæ of the death-watch, and the numerous acari and softbodied insects, which are believed to be the chief depredators that prey upon books. Another of these maligned genera is a tiny tailless scorpion (Chelifer), of which three species have been noticed in Ceylon, the $\mathrm{Ch}$. librorum, Temp.; Ch. oblongum, Temp.; and Ch. acaroides, Hermann, the last of which it is believed had been introduced from Europe in Dutch and Portuguese books. Of the Lepisma, the fish-insect genus, so called by Fabricius from its fish-like silvery scales, only two species have been described, viz. the L. niveofasciatus and L. niger, Temp. One of larger size is remarkable for the whiteness of the pearly scales, from which its name is derived; these, contrasted with the dark hue of the other parts and its tripartite tail, attract the eye as the insect darts rapidly along. Like the Chelifer, it shuns the light, hiding in chinks till sunset, but is actively engaged during the night, feasting on the acari and soft-bodied insects which assail books and papers. Linnæus states that the European species was brought in sugar ships from America. The Chelifer found in Ceylon has been brought thither from Europe.-Tennent's Ceylon, p. 476 .

LEPROSY, a disease which attacks the human race in Europe, Asia, and Africa. It appears on the skin of the body in various forms, but European medical men regard it as a constitutional ailment. Their number in all India in 1881 was 131,968 , of whom 98,982 were males, 785 were under five years of age, 100,991 Hindus, and 24,376 Muhammadans :-

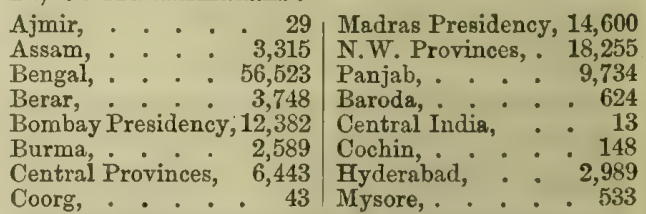

The disease is not ordinarily deemed contagious, and the welfare of the community does not demand the complete segregation of those aftlicted with it. But leprosy causes much suffering, and it fosters mendicancy; also from the most ancient times, in all countries, their presence amongst their respective communities has been objected to, and they have been placed in outlying localities. According to Manetho, as quoted by Josephus, the Egyptian king Menephthab, son of the great Rameses, collected together all the lepers, and located them in the quarries in Lower Egypt, on the edge of the Arabian desert, but subsequently mitigated their lot, and placed them in the deserted town of Avaris. These outcasts, however, sided with the people of Palestine who rose in a religious war against animal-worship, and Menephthah fled to Ethiopia.

Lepers are numerous in China, and are only allowed rope-selling as a trade. Numbers of those not actually suffering from the disease, but subject to it, stand at the corner of every street in Canton, with coils of rope and hanks of cord for sale. The term Lizard, atill applied to that part of old towns in which a rope-walk is situated, is supposed to be a corruption of Lazare, the lepers' quarter. The Lizard Point in Cornwall, and Lezardieux, a village in Brittany, are supposed to take their names from the lepers.

Dr. Bhau Daji of Bombay, who died about the year 1873 , was very successful in treating tubercular leprosy, it was supposed with the Chaulmoogra oil from the Gynocardia odorata.

The Puranas relate that Janamejaya was sorely 
afflicted with leprosy as a punishment for having killed some serpents. Hindus believe that a man who may have killed a serpent in his former life is sure to be attacked with leprosy. The leper is regarded by Hindus as a loathsome, unclean being: After his death, his remains must be buried, and cannot be burnt without certain peculiar rites. Also, now, at the close of the 19th century, a man who has not been blessed with offspring, and whose doom is sealed if he do not beget a son, considers that the serpent has denied him children, and thus barred his entrance to the gates of heaven. The disease of sore eyes is also attributed to the serpent's wrath. The worship of the serpent is therefore essential to lepers, the sore-eyed, and the childless, who, to appease the wrath of the serpent, perform many costly ceremonies of Sarpa Sampaskara and Nagamandal. For the former of these ceremonies, a day is selected, either the 5th, 6 th, 15th, or 30 th of the month. The family priest is summoned as the director of the ceremony. The childless sinner has first to take a bath, and next to dress himself in silk or linen garments. A spot in the house is chosen, and the family priest, sprinkling grains of rice, drives away any devil that may have been lurking there. He takes his seat with the performer on two wooden stools. He gets some rice or wheat finely pulverized, and, kneading the dough, makes a figure of the serpent. The holy Mantra are then said to give the figure animation, and transform it, to all intents and purposes, into a live serpent. It is then offered milk and sugar. The image receives the worship common to other gods. After the worship, the Mantra snatch away from the figure the life just imparted, for they are said to have the power of giving life and of taking it away again. After the serpent is dead, the sinner assumes the signs of mourning, which consist in shaving off his beard and moustaches. Then he carries the figure on his head, and, having reached the bank of a river, he reverentially places it upon a pile. The figure is carefully fenced in with chips of sandal or jack wood, and camphor and melted butter are poured over it. The pile is then kindled with the fire which the performer brings with him from his house. He previously enters into a vow with the fire that it shall be solely used for the cremation of the serpent-god. The fire reduces the mass to ashes, which are carried to the river, and put into the water. The performer is considered unboly, and cannot be touched for three days. On the fourth day, the funeral of the serpent-god or Sampaskara ends with an entertainment to eight unmarried youths, below the age of twenty. They are considered to represent eight serpents, and are treated with the utmost respect. The performer rests satisfied for a time that the ceremony will produce the desired effect. But if such be not his good fortune, he then resorts to the other ceremony, Nagamandal. On one of the days named the leper gives a grand feast to a number of his caste-men and unmarried youths. The evening comes, and one of the Deckayavara or musicians, duly summoned for the purpose, scatters on the spot already selected some bruised rice, and inscribes the figure of a huge serpent in a large circle. The figure is worshipped, and then the musicians perform their part. They are the children of the Deva-dasa or temple women. Their band generally consists of two pipes and several drums. They dress themselves for the occasion in women's clothes, and put on various jewels. The chief man among them pretends that he can represent the deity, and, going to and fro, reels about expressing the approbation of the deity by uttering some words, which are attended to as if they proceeded from the mouth of the deity itself. The musicians produce a variety of discordant sounds. While the drummers tap with their fingers on each side of the drum, their head, shoulders, and every muscle of their body are in motion. The musicians, the drummers, the observers of the ceremony, and the representative of the deity keep going round the circle throughout the night, singing songs at one time in praise, at another in depreciation of the deity. To keep up their strength, the drummers have frequent recourse to the toddy bottle, and soon become intoxicated. As the night passes away, the ceremony is over.

One of the severe remedies to which the leper and the childless expose themselves is as follows:On the 6th day of every month, he entertains a number of unmarried youths at dinner. Though fasting the previous day, he does not himself partake of food in their company. After dinner, and before the leaves whereon the guests had taken it have been removed, he enthusiastically rolls himself over them. The next part of the ceremony is to cleanse himself in a bath, and for the remainder of the day he cannot take any food that contains salt. A rich Sudra of low birth is not allowed to observe any of these rites. But the compassionate priest comes to his aid, and offers him his services by observing them on his behalf. After they are over, the priest takes some water in his hand and pours it into that of the Sudra. This process is said to transfer every merit of the ceremony to the Sudra, while the priest holds himself liable for all the defects in the observance.

Mr. Apothecary Phillips has published pamphlets on the Gurjun oil treatment, and professes to have a radical cure of anæsthetic and tubercular leprosy. A medical officer with large experience in the disease, writing of Gurjun oil, says: 'I have no faith in any specific, nor indeed is it in the nature of things to find a specific for this fell disease.' Combined with other remedies, such as iron, arsenic, etc., which generally help to form the so-called specifics, the treatment is only palliative but never curative.-Bunsen, Eyypt's Place in Universal History, ii. pp. 500, 563, iii. pp. 188, 195.

LEPTADENIA JACQUEMONTIANA. D. C. Kip, Sind. This is employed in Sind along with Periploca aphyllum, for making into ropes and bands used for wells, as water does not rot them. Leptadenia reticulata, $W$. and $A$., Pala-tige, TEL., is used as a vegetable. Leptadenia spartea, another species of the genus yielding a fibre.Royle, Fib. Pl. p. 306.

LEPTOCEPHALID $\mathbb{E}$, a family of fishes of the Asiatic seas, from the Leptocephalus or Glass Eel genus. There have been 18 species described.

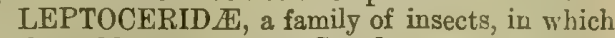
is the caddis-worm genus Setodes.

LEPTONYCHIA MOACURROIDES. Bedd. An elegant small tree inhabiting the western coast forests of the Madras Presidency, 1000 to 
3000 feet elevation, met with on the Carcur ghats in the Wynad, on the Coimbatore Hills, and on the Tinnevelly ghats.-Beddome, Fl. Sylv. p. 114.

LEPTOPTILOS ARGALA. Linn.

Ciconia nudifrons, Jerd. | Argala migratoria, Hodg. C. marabou, Temm.

\begin{tabular}{l|l} 
Chaniari-dhauk, BENG. & Hargeyla, - . HIND. \\
Adjutant,
\end{tabular} Adjutant, . ENG. Dusta, - ' $\begin{array}{lll}\text { Gigantic stork, . Hargela, Hurgela, HIND. } & \text { Grarur of . Pini-gala-konga, PURNIAH. } \\ \text { Har. TEI. }\end{array}$

The adjutant bird is migratory. It is rare in the south of India, though it occurs in Hyderabad and Mysore, but it is common in Bengal, $\mathrm{N}$. and N.E. India, Burma, and the Malay Peninsula. The adult birds make their appearance as soon as the rains set in, and becoming in fine plumage towards the close of the rains, depart at that time to breed in the eastern portion of the Sunderbans, in Moulmein, in the Tenasserim provinces upon lofty trees, and along the eastern coast of the Bay of Bengal upon trees and rocks. It is a bold, familiar bird, eats all sorts of animal refuse, frogs, fish, and dead bodies. Though called a gigantic crane, it is not a crane. The three ordinary Indian cranes are Grus antigone, Gr. cinerea, and Gr. virgo. Grus leucogeranus occurs rarely in the N.W. Provinces. The words Crane and Grus, and the Hindustani names of the three common Indian species, Saras, Karranch, and Kakarra, all have reference to the loud trumpeting of these birds, which have a curious internal conformation resembling that of the trumpeter swans; whereas the storks are voiceless birds, having actually no vocal muscles, and can make no sound, but by clattering their maudibles together, which they do pretty loudly.-Jerdon's Birds; $Z$. in Indian Field.

LEPTOPTILOS CRUMENIFERUS. Cur. A bird of tropical Africa, furnishes the marabout feathers of that continent; the L. argila and L. Javanicus, those of India.-Jerdon; Z. in Indian Field; Simmonds' Dictionary.

LEPTOPTILOS JAVANICA. Horsf.

Ciconia calva, Jerdon.

C. capillata, Temm.

C. nudifrons, $M^{*}$ Clell.

Chandana, . . BENG.

Chandiari,

Madanchur, * "

Moduntili,

Moduntiki, . · "' Dodal-konga, : TEL.

Hair-crested stork,

C. cristata, $M^{\prime} C^{\prime} l e l l$.

Argila crinita, B. Ham.

A. immigratoria, Hodg.

Chinjara, . . Hind. Bang-gor of . PuRNIAH.

The Tamil name of the small grey and black stork, Leptoptilos Javanica, is Nutha-cootee-narai, literally shell-fish (Ampullaria) picking crane. They have nests two feet in diameter, and contain three eggs or young. The eggs are of a dirty white colour, of the same shape, but not quite so large, as those of the turkey. The joung when fully feathered are in prime condition. Their flesh is eaten by Muhammadans and Pariahs. The bird keeps entirely to marshy fields, edges of tanks, etc.; it never approaches towns. Some half a dozen or more of these birds may often be seen in the morning sunning themselves with outstretched wings in the dry fields. They only differ from the adjutant, or Leptoptilos argala, in size and colour. These nest early, and the young are firm on the wing in the month of February. They are found throughout Asia, feed on fish, frogs, crabs, and locusts. A pair of these birds were purchased by a detachment of the 74th Highlanders, who in June 1877 were stationed at Penang. The birds stood about three feet in height. They were never kept in confinement, and from the very first were allowed to roam over a large open expanse of ground. They never seemed inclined to stray far, and very seldom ever attempted to fly. They would spend more than half the day standing motionless opposite each other, bill to bill, and with both their wings outspread. 'They were coarse feeders, and neither quality nor quantity seemed to trouble them much; one of them on an occasion gulped down one by one as fast as they could be thrown to it, 32 small fishes, each about six inches in length, and evidently was ready for more. After they had been with the regiment about a month, one of them began to look downcast. One morning it remained basking in the sun for several hours, with outspread wings. I ater in the day it lay down on the grass, with its eyed closed, and evidently very sick, and by it stood its brother, apparently quite unconcerned. Like this they remained until late in the afternoon, when the healthy bird was seen to put his head on one side, and, looking curiously at his sick comrade, proceeded to stir him up with his beak, without making him move; and on going to look, he was found to be dead. A post-mortem examination was immediately held, and in the poor bird's stornach were found the legs and claws of a large fowl, quite undigested, which were the apparent cause of the intense inflammation. While the investigation was going on, the surviving bird evidently regarded it with much interest, and as great lumps of muscle were stripped off his comrade's bones he gobbled them up. Having thus got a good meal, he at length stalked demurely away, satisfied with his afternoon's performance.

LEPTOSPERMUM SCOPARIUM, the Kaetatowa or Manu Ra of New Zealand, a tree of the myrtle family, grows on the mountains to a height of 25 or 30 feet. Its hard, heavy wood is used for war-clubs, paddles, and articles requiring strength and durability.-G. Bennett, p. 416 .

LEPURANDA SACCIDORA. Nimmo.

Antiaris saccidora, Dalz. | Araya anjely, . Maleal. Chundul,. . Hind. Navil maram, . TAM.

This stately forest tree is indigenous on the west side of Iudia, in the ravines at Kandalla, and in the jungles near Coorg, where people manufacture sacks from the bark by a very simple process. A branch is cut, corresponding to the length and diameter of the sack wanted. It is soaked a little, and then beaten with clubs until the inner bark separates from the wood. This done, the sack formed of the bark is turned inside out and pulled down, until the wood is sawed off, with the exception of a small piece left to form the bottom of the sack, and which is carefully left untouched. These sacks, called Kurumbur bags or sacks, are in general use among the villagers for carrying rice, and are sold for about six annas each. This is very common, and the most gigantic of all the trees in the Wynad jungles; wood not much used.-Royle, Fib. Pl.; M'Ivor.

I.EPUS, the hare, is of the family Leporidx. There are five species known to inhabit the East Indies,-L. ruficaudatus, the common Indian hare ; L. nigricollis, the black-naped hare; L. hispidus, the hispid hare; L. Peguensis of Burma, and L. pallipes of Tibet. Hares are unknown in Arakan and in the Tenasserim provinces, also throughout 
the Malayan Peninsula and Archipelago, with the exception of Lepus nigricollis, $F$. Cuv., in Java, which has most probably been introduced from South India or Ceylon, as it doubtless likewise has in the Mauritius; but several notices occur of hares in the Indo-Chinese countries, even in Cochin-China the species being as yet undetermined.

Lepus Egypticus, Egyptian hare, is found in Egypt.

Lepus cuniculus, Linn., rabbit, coney.

Konyn, Konin, . . BELG. Coelho, . . . . PoRT.

Kanine, : DAN. Conejo, . : ISP.

Konyn, Konin, . . Dur. Kanin, . . . ' Sw.

Kaninchen, . . GER. Cwningen, . W WeLsH.

Coniglio, . : IT.

The rabbit begins to breed at the age of six months, and produces several broods in a year, generally from five to seven or eight at a time. The young are blind at their birth, and nearly naked. The fur of the rabbit is in considerable demand, particularly for the hat trade; and at one time the silver-haired varieties, or silversprigs, fetched three shillings a piece, for ornamental linings to cloaks.

Lepus hispidus, Pearson.

Caprolagus hispidus, $B l$. | Hispid hare, . . EvG.

The great sal forest at the base of the subHimalaya and of their offsets, from Gorakhpur to Tiperah, also at Siligori in the Terai, is the peculiar and exclusive habitat of the hispid hare, which never ventures into the open plains on the one haud, or into the mountains on the other; and hence it is but little known, deep cover and deadly malaria contributing alike to its obscurity. As the black-necked bare or L. nigricollis is the s ngle species of the Dekhan, and the redtail, I. ruficaudata, of Hindustan and Bengal, so is the lispid of the vast sub-Himalayan forest; and it is rwnarkable that the mountains beyond the forest, cve'n up to the perpetual snows, have no peculiar species. The sal forest hare feeds chiefly on rools and the bark of trees, a circumstance as reluarkably in harmony with the extraordinary rolent power of its structure as are its small eyes and ears, weighty body, and short, strong legs, with what has been just stated relative to the rest of its babits. The whole forms a beautiful instance of adaptation without the slightest change of orcranism. If anything, the male is rather the lirger and darker. The male measures $19 \frac{1}{2}$ inches from snout to vent. The female is 19 inches long and $5 \frac{1}{4}$ lbs. Both have a girth behind the shoulder of 12 inches. Compared with the common species, these animals are conspicuously of darker hue and heavier make, but not larger. They have heavier beads, much shorter ears, smaller eyes, shorter tails, limbs shorter, stronger and less unequal, -in that respect like a rabbit ;and, lastly, their mystaccal tufts are much less, and their fur much harsher. The profile of the head is less curved in the hispid than in the common species, the nails somewhat larger, and the digits slightly different in gradation, the thumb in particular being less withdrawn, and the little tinger more so, from the front, in hispidus. The ears both in male and female considerably exceed one-half of the length of the head, and are broader as well as shorter than in L. ruficaudatus or L. timidus; and it is remarkable that the tail in the male is shorter than in the female, -in both more so than in L. timidus. The teats are six, two pectoral and four ventral.

Lepus macrotus inhabits the Himalaya and Nepal. It is larger than the black-necked hare, L. nigricollis, of the Indian plains.

Lepus nigricollis, F. Cuv,, Bly., Ell.

L. melanauchen, Temm.

Malla, . . . CAN. Sassa, . . MAHr. Black-naped hare, ENG. Musal, : : TAM. Khar-gosh, . . HInD. Kundeli, . . Tel.

This is the hare of Ceylon, of the Peninsula of India, of Sind, the Panjab, and of Java.

Lepus oiostolus, Hodgs. L. Tibetanus, Waterh. The blue, woolly, or alpine hare of Tibet and Nepal is considered by Major Cunningham to be the I. pallipes of Hodgson. There was, says Dr. Hooker (ii. p. 157), much short grass about the land, on which large antelopes, Chiru (Antilope Hodgsonii), and deer, Goa (Procapra picticaudata, Hodgson), were feeding. There were also many slate-coloured hares with white rumps (L. oiostolus), with marmots and tailless rats. He found the horns of the Chiru on the south side of the Donkia pass, but he never saw a live one except in Tibet. The Procapra is as described by Mr. Hodgson. Dr. Adams says of the alpine hare, L. oiostolus, that it was common among the fallen boulders, and along the long bottoms and sides of the valleys leading towards the Pugha lake. This species very much resembles the alpine hare of Europe.

Lepus pallipes, Hodgson; L. tollai, Pallas, Gray. White-foot hare, Ri-bong, TIB., occurs in Ladakh and Tibet.

Lepus Peguensis, Blyth, is very similar to the L. ruficaudatus, Is. Geoffroy, of Bengal. It occurs in all Upper India, Assam, and Upper Burma. Tail black above, as in the generality of the genus. Upper parts same colour as Bengal hare, but the belly abruptly white.

Lepus ruficaudatus, Geoff., Blyth.

L. Indicus, Hodgs. | L. macrotus, Hodgs. Sasru, . Beng. Khargosh, . . Hind. Common Indian hare, ENG. Kharra, . : : ", Molol, . . Gondr. Lamma, . . . "

This hare is found from the Himalaya and the Panjab to the Godavery, Malabar, and Assam.

Lepus Sinensis, Gray, of Hardwicke's Illustrations of Indian Zoology, is known only by that figure. The skull closely resembles that of $\mathrm{L}$. ruficaudatus, Is. Geoff. (the common Bengal hare); the general structure of $\mathrm{L}$. Sinensis and L. ruficaudatus would appear to be quite similar, but the colouring is remarkably different, being a mixture of deep tawny or rufo-fulvous with much black on the upper parts, and the under parts whitish. The paws are black underneath, mingled with some tawny along the lower surface of the tarsus; the latter being almost pure white externally, and thus forming a remarkable and striking contrast with the hue of the lower surface. Tail black above and at the tip, whitish below towards its base. On the sides towards the belly the fur much resembles both in colour and texture that of the entire upper parts of L. ruficaudatus; but on the back the fulvous hue is very much deeper, and the admixture of black is much greater, the short soft under-fur is deep buff or fulvous, whereas in $L$. ruficaudatus the same is whitish or rather almost pure white.-Adams; Mr.?Blyth in Beng. As. Soc. Journ., 1846, 1847, 1852 ; 
British Museum Catalogue; Eng. Cyc.; Jerdon's Mammals.

LERA. HrNd. A coarse brown gum, imperfectly soluble, used in calico printing.

LESCHENAULT DE LA TOUR, a French botanist, who accompanied Baudin's voyage to the Moluccas, Java, and Sumatra. He appears to have been appointed director of the botanic garden at Pondicherry, and to have investigated some of the southern provinces of the Peninsula; the plants he collected seem, however, to be chiefly from the Neilgherries, and are principally published by $\mathrm{De}$ Candolle in his Prodromus Systematis Naturalis Vegetabilium.

LESGHI, an agricultural race of about 18,000 families who occupy Daghestan in Caucasia. They speaka peculiar dialect; one of the seven Caucasian nations, between the Black Sea and the Caspian. They are supposed to be descended from the tribe of mountaineers known to ancient geographers under the name of Lesgre or Ligyes. They are alike remarkable for their valour and turbulence. They are now subject to Russia. The Lesghi kamri is a broad two-edged knife-MacGregor; Malcolm, ii. p. 125.

LESPIDEZA STRIATA, Hooker and Arnott, the Japan clover of China and Japan, grows readily on dry soil, and the cattle like it. It is much valued + in N. America as a grass for cattle.-Von Mueller.

LESSEPS. Ferdinand de Lesseps, a native of France, who planned the formation of the Suez Canal, between Port Said on the Mediterranean and Suez on the Red Sea. A great engineer.

LET-HTA, a small tribe in the Karen-ne country, who so call themselves, but are designated Goung-dho by the Burmese. They occupy the country to the N.W. of Mobyay, called the twelve hills of Levay Loung. They have a bachelor hall and a spinster hall at opposite ends of their villages. They have an intense sensitiveness; and if one of them be accused of any evil act by several of the community, he will retire to some secluded spot, dig his grave, and strangle himself.

LET-PHET. Burm. Pickled tea. It is prepared from the Elæodendron Persicum. The leaves are brought from native Burma, and are kept constantly moist. When to be used they are mixed with a little salt, oil, fried garlic, green ginger, and parched sesamum seeds. Let-phetdhok are small packets of the pickled tea which form part of every Burman ceremonial, and are sent as invitations instead of notes or letters.

\section{LETSOMIA NERVOSA. Roxb.} Argyreia speciosa, Choisy.

Bich-tarik, . BENG. Elephant creeper, ENG. Googuli, . DEKHAN. | Sumandar soh, HiND.

A woody twining perennial plant of Arabia, Sind, and all India. Its leaves are useful as a maturant and discutient, and are rubbed on the skin in cutaneous affections.-Murray.

I,ETSOMIA SETOSA, a large red-flowered creeper of the convolvulus tribe, is seen in Tenasserim during the rainy season on almost every hedge.-Mason.

LETTI, a high island of considerable extent, in lat. $8^{\circ} 11^{\prime} \mathrm{S}$., and long. $127^{\circ} 45^{\prime} \mathrm{E}$., 18 miles E. by N. from Pulo Jackee, in the Arafura Sea. The S.W. islands of the E. Archipelago are the Baba, Sermatta, Letti, Roma, Wetta, and Lamma groups. The Baba people are known to have destroyed an English trading vessel. Each family preserves on a scaffold of their dwelling the head of one of their ancestors.

LETTUCE, Lactuca sativa.

Peh-ku, Sang-tsai, CHIN. | Kaboo, . GuJ., HrNo. Lattuo, Salat, . DAN. Lattuga, . . . IT. Laktuk, . DAN., Sw. Alface, . . . PokT. Laitue,. . . FR. Latuk, . . . Rus. Lattich, . . . GER. Lechuga, . . . SP.

The most esteemed sorts of lettuce are the cabbage, red and brown cos-lettuce. For early salading, the seed may be sown at the commencement of the rains, although neither are in perfection until the cold season. They are mostly raised in small beds, and then transplanted into others at about one foot apart, or on ridges around other vegetables; they do not require any particular care. The ground should be light and rich, and when the plants are of a sufficient size they should be tied up, and this may be done with shreds of plantain-leaf or twine--Riddell.

\section{LEUCAS ASPERA. Spreng.}

Phlomis esculentum. |Kulkusa, . . Beng. Choto,. . . BenG. Thumbay keera, TAM.

A small annual weed with white flowers; appears during the rains; the leaves are used as greens mixed with others.-Jaffrey.

\section{IEUCAS CEPHALOTES. Spreng. Phlomis cephalotes, Roxb.}

Chatra, . . HrND. / Tummi, . . TEL.

The leaves are eaten; the flowers are sacred to Siva, and are offered in his temple. But there are many species to which the term Tummi is indiscriminately applied.

LEUCAS ZEYLANICA. $R . B r$. The plant is used as a stimulant, sialogogue.

LEUCISCUS RASBORA, Buch. Ham., of Penang, numerous in rivulets and in rice fields when they are flooded.

LEUCORYX, Oryx leucoryx, of N.E. and W. Africa, from the Gambia to Abyssinia. In S. Africa it is replaced by the Gemsbok (Oryx gazella). In Dongola and on the coasts of the Red Rea a third beautiful species of this form occurs, the Beisa; and in Arabia a fourth species, described and figured under the name of Oryx beatrix.

LEUCOSPERMUM, an interesting genus of plants, with entire downy or hairy leaves, and terminal heads of yellow flowers. - Riddell.

LEVISTICUM.

Tang-kwei, - ChIN. Ta-kung, . . ChIN. Ch'uen-kung, . . " | Fuh-kung, . . . ,

Species of Levisticum are used in China, like sumbul root and valerian plants. - Smith.

LEWES UERTOMENES, a learned gentleman of Rome, who in A.D. 1503 gave an account of Cambay, and of its quartzose minerals.

LEYDEN, DR. JOHN, a celebrated linguist, antiquary, and poet; born 1775; entered the Madras Medical Service in 1802 ; became Professor of Hindustani, College, Fort William, 1806 ; accompanied Lord Minto to Java in 1809, where he died. Author of Translation of the Memoirs of the Emperor Baber, Lond. 1826, 4to; On the Indo-Chinese Languages, in As. Res. x. p. 158; On the Rosheniah Sect, ibid. xi. p. 363.-Dr. Buist's Cat.

LEZAM. HIND. An iron bow with chain, used for gymnastic exercises in the Talimkhana or gymnasium of India. 
LHA. Trв. God. Lhamo, goddess.

LHASSA. To the Lhassan kingdom of Great Tibet is applied the name of Kha-chan-pa or Snow-land. Lhassa is the seat of the great priest of the eastern Buddhists. Its houses are large, and are fresh whitewashed and painted every year, so as to present a gay appearance. In the city of Lhassa, and over the whole of Tibet, Geawa Remboochi or the Grand Lama is nominally the supreme anthority in temporal and spiritual affairs. His residence is in Patala Goompa, which is on the north side of Lhassa. M. Huc says that Lhassa in the Tibetan language means Land of Spirits. The Mongolians, on the same authority, call this city Monche-dhot, i.e. Eternal Sanctuary. The Chebu Lama gives the following interpretation:-L'ha means God; Sa, abode or resting place; hence it is the city of God, or the Eternal City. There are two resident envoys from China, called Ampas, stationed at Lhassa; subordinate to them are two great Chinese officers, designated Daloo-he. Their rank and occupation are those of general officers. Next to these are two Phopun, who act as paymasters of the troops, and perform the duties of British Adjutant and Quartermaster-Generals. They also are Chinese. One of the Daloo-he and one of the Phopun are generally stationed at Digarchi. These officers constitute the general staff of the army in Tibet. Next in rank are three Chonghar. They are Chinese, and military commanders; one is generally stationed at Digarchi and another at Tingri, near the Nepal frontier of Tibet. Below these are three Tingpun, noncommissioned officers, - also Chinese. There are no other Chinese military officers in Tibet. The usual number of Chinese troops, all Manchu Tartars, in Tibet, did not exceed 4000 men. Stationed at Lhassa, 2000; Digarchi, 1000; Giangtechi, 500; Tingri, 500. The Chinese functionaries in Tibet are political and military officers only. All the civil appointments are held by Tibetans. The local temporal government of Tibet is headed by the Grand Lama, who is entirely guided in all political and military affairs. Prinsep's Tibet.

LHOPA, a quarrelsome and cruel but not brave race of Eastern Tibet and Nepal. They have invariably black hair, which is cut close to the head. The eye is small, black, with long pointed corners, as though stretched and extended by artificial means. Their eyelashes are so thin as to be scarcely preceptible; and the eyebrow is but slightly shaded. Below the eyes is the broadest part of the face, which is rather flat and narrow from the cheek-bones to the chin. Many are more than six feet high, and, taken altogether, they have a complexion not so dark by several shades as that of the European Portuguese. They make paper from the bark of a tree called deah, steeped in a ley of wood-ashes, drained, beaten to a pulp, cleansed, and formed into sheets. This is done by spreading it over a frame of reeds. These the manufacturer dips into the water which contains the pulp, until he has covered the surfaces. Then he raises them perpendicularly, and has nothing further to do beyond the drying and pressing. They are industrious agriculturists, and skilful in artificial irrigation. Lho-pa-to or Bhutan people are Buddhists of the sect called in Tibet Bruk-pa (vulgarly Duk-pa), which they adopted in the 17th century. The four valleys of
Bhutan are called Thet-yul, Thim-yul, Patro or Pato, and the middle district.

LI. The ancient Chinese philosopher $\mathrm{Li}$ or Licius flourished in the latter half of the 5th century B.C., or about 100 years after Confucius. His writings seem to indicate a protest against the purely secular wisdom of the latter sage, and to represent those more religious and imaginative elements of the national thought which afterwards led to the diffusion of Buddhism. His theory of the universe appears substantially pantheistic, and offers considerable affinity to the Indian in its practical conclusions, though resting rather on an empirical than a metaphysical basis. Licius would also seem to have been considerably influenced by Lao-tsze; the existence and efficacy of magic, at all events, appear to be taken for granted by him. On the whole, his writings may probably be taken as a fair example of the Chinese mind alike in its strength and weakness. Childish absurdity, as at least it appears to us, alternates with shrewd homely sagacity; and in their independence of foreign influence they afford an interesting proof of the tendency of the awakened intellect in all ages and countries to occupy itself with the same problems, with a remarkable correspondence in the results ultimately attained. His aphorisms are for the most part cast into the form of apologues or anecdotes, some quaint and ingenious, others at the first aspect puerile or extravagant. Licius is full of interesting incidental illustrations of Chinese manners and customs, indicating the progress which civilisation had made in his time. Medicine, architecture, and music seem to have attained a considerable degree of development, - the latter especially was almost as highly regarded as in contemporary Greece. True intellectual progress has been arrested in China since Licius' time, and the nation has even retrograded in several respects.

LI, a Chinese copper coin ; ten to a candareen. 10 li, 1 candareen; 100 li, 1 mas; 1000 li, 1 tael; 1 tael about $5 \mathrm{~s}$.

LI, a Chinese measure of length, about onesixth of a British mile, or 293 yards.

LI, a Chinese word of very extensive meaning, sometimes rendered reason, courtesy, propriety, good breeding. The saying is, $\mathrm{Li}$ and Wen (learning) make up the whole sum of human excellencies.-Bowring.

LI. Many non-Aryan peoples of India take their tribal designations from the word for 'man' in their respective dialects, and the term mi (man), with some prefixed or supposed syllable, supplies the basis of the race name to not less than forty ascertained tribes. Thus Du-mi, Ka-mi, Ku-mi, Anga-mi Naga, Mi-than Naga. And if we recognise the non-Aryan phonetic displacements of $m$ and $l$ and of $l$ and $r$, the list can be greatly increased. Thus, in the Sak, lu; Toung, mru; Murmi, mi ; Thaksya, mli ; and the root li affords the generic term Homo, man, to a whole series of tribal names. Thus Ma-li, the people of Rajmahal ; Bala-li, Dhima-li, Santa-li, Banga-li, meaning the people of Bala, Banga, and so forth. $\mathrm{Li}$ is thus often added to specific names for man to form names for aboriginal tribes. In Santali, li furnishes the nomenclature connected with the propagation of our species, such as lai, laih, etc., and appears in li dih, a child; le-daka or lad ko, children; Khi li, a generation of men (ho-li), and 
the hitherto unexplained terms, Che-la, Che-li (= Khi-li $=$ holi), for son and daughter, used by all the semi-aboriginal castes of Lower Bengal. The root ko, with the generic aftix li, is met with in all periods of history, and in all India. The Mahabharata and Vishnu Purana speak of Ko-li tribes in connection with Mikala, Dravida, Kirata, and others, and the Aitareya Brahmana speaks of the Koli as Dasya. Among a section of the nonAryan races of India, or aborigines, as Dr. Hunter styles them, the root ho, shortening in some to hu and ha, or interchanging into $\mathrm{ko}, \mathrm{ku}$, and $\mathrm{ka}$, furnishes the specific word for man amongst the $\mathrm{Kol}$ tribes of Central India, and is one of the oldest and most widely spread roots for man. In the Sanskrit play the Mrichha kati, go-ho is man; among the Kur, near Ellichpur, it is ho ko; amongst the Siamese it is khon or kun, which is the same form as it takes amongst Khond.-Dr. W. W. Hunter on the Non-Aryan Languages of India, p. 24

LIANG. A tchokli, in Chinese thsian, pronounced tchin in the Mongol, is a small round brass coin with a square hole in the centre; the reign during which it was struck is marked on the reverse. Five hundred tchokhi are strung together upon a ribbon. All the way to Pekin, Timkowski received 1150 tchokhi for a liang or lan.-Timkouski's Pekin, i. p. 274.

LIBADA, properly Labadr. AraB., Hind. A caftan of chintz quilted with cotton, the winter dress of the people about Almorah.

LIBATION. Amongst the Hindus, the Argha offering to an idol, a Brahman, a bridegroom at the marriage ceremony, or to any venerable person, and in farming operations. It consists chiefly of fruit and flowers, or water, or milk and honey; and when the first bundle of corn is brought home from the threshing-floor and deposited, cultivators of the N.W. Proviuces make a libation of water, offered between the threshold and the spot where it is so deposited.

Libations of the Hindus are offererl to the gods, the rishi or sages, and progenitors, with the parts of the hand severally sacred to each. The offerer bathes, puts on clean clothes, and scatters water thrice to gratify the gods: as many times to please the rishi, and once to Prajāpati; he inust also make three libations to satisfy the progenitors. -Wilson; Carnegy. See Argha.

LIBER. The inner bark of a plant is a layer consisting of woody tissue, cellular substance, and vessels of the latex, forming a compact zone immediately applied to the wood. The woody tissue of which it is composed quickly becomes thick-sided, by the addition of internal ligneous strata, the consequence of which is that such tissue in this part is more tough than elsewhere. Hence it is usually from the liber that are extracted the fibres employed in making cordage or linen thread; this at least is its source in hemp, flax, the lime tree, the lace bark, and the many other exogens which furnish fibres; but in endogens, which have no liber, as the cocoanut, it is the ordinary woody bundles of the leaves, stem, and husks of the fruit from which the fibres used for ropes is procured. It is said that certain exogens, such as Menispermacer, have no liber. In many plants a new layer of liber is formed annually, contemporaneously with a new layer of wood, but this is by no means universal; on the contrary, the oak and the elm increase their liber slowly and irregularly. - Eng. Cyc., quoting Comptes Rendus, v. p. 393.

LIBOCEDRUS DECURRENS, a tree of N.IV. America, which grows associated with the Sequoia (Wellingtonia) gigantea. It attains a height of over 200 feet. Its timber is much sought after by farmers for rails and fencing timbers. It might be introduced into N.IV. India.

LICHEN ODORIFERUS. Royle. Borreri ashneh is a product of the Himalaya, and otticinal at Lahore. The hakims administer it in disorders of the stomach, dyspepsia, vomiting, pain in the liver or womb, induration in the uterus, amenorrhæa, calculi, and nocturnal spermatic discbarges. L. stapelioides mentioned by Griftith, and the lichen of Masson, is the Boucerosia aucheri.-Dr. Honigberger, p. 299.

LICHEN ROTUNDATUS. Rottl.

Hinna-i-koreish, . ARAB. Kull pashi, . . TAM. Pathar-ka-phul, . Duкн. Ratipanchi, . . TEL.

This is a dried rock moss which the Tamil practitioners suppose to possess a cooling quality, and prepare a liniment with it accordingly. - Ains. Mat. Med. p. 86.

LICHEN's possess two distinct characters; several are nutritious, some bitter, and some yield to ammoniacal solutions a variety of brilliant colours, and are much used as dye-stuffs.

Lichen bread is used in Finland in times of scarcity. They are perennials, spreading in the form of a crust over rocks, trees, or the surface of the earth. Or the Kunda Hills of the Neilgherry Hills, all the rocks are covered by lichens. Of lichens, the Stricta orygonosse aud several other species give a beautiful pink dye; Parmelia periolata and $P$. Nepalense yield a yellow dye; P. borreri, a deep brown dye.

Ramalina farinacea is used for food. R. vulpina yields a fine deep yellow dye; and the following are plentiful on the Kundas, viz. Cetraria glauca, Cetraria, sp., Parmelia periolata, Lecanora tartarea, Gyrophora deusta, Cladonia rangiferina.

Rocella fusiformis, a dye lichen of Ceylon, was sent to the 1851 Exhibition, and there valued at $£ 380$ the ton. Parmelia periolata, a dye lichen of Ceylon and the Neilgherry Hills, was sent to the Fxhibition of 1851 , and was valued then at $£ 195$ to $£ 225$ per ton. Other dye plants are Lecanora atra, L. hæmatomma, L. parella, Ach., and L. tartarea, Ach.

Alectoria jubata, the Keh-Kieo of Ramree, is a gelatinous lichen, and is eaten witl rice by the natives.

Several lichens grow on the top of the Donkia pass, as Cladonia vermicularis, the yellow I.ecidea geographica, and the orange $I_{\text {s. miniata, also some }}$ barren mosses. At 18,300 feet, Dr. Hooker found on one stone only, a tine Scotch lichen, a species of Gyrophora, the 'tripe de roche' of arctic voyagers, and the food of the Canadian hunters; it is also abundant on the Scotch alps. Parmelia Kamtschadalis, Esch., occurs in the Panjab bazars. It is used as a dye and as a stimulant to digestion in disorders of the stomach and womb, and in cases of calculus. Its vernacular name is chalchalira, also ashneh. The chief lichens employed in the manufacture of orchil and cudbear are the Angola weed, Ramalina furfuracea, and Mauritius weed, Rocella fusiformis, which, however, comes also from Madagascar, Lima, and Valparaiso, and 
then bears the distinctive commercial name of the port of shipment.

Rocella tinctoria, from Tenasserim and other parts of India, had been introduced by the E.I. Company. R. tinctoria and R. fusiformis furnish the orchil or orchilla weed of commerce, which is sometimes sold as a moist pulp, but usually in the form of dry cakes, known under the nawe of Jitmus; it produces a fine purple colour. The English imports are derived chiefly from the Canary, Azores, and Cape de Verd Islands. Rock orchilla was shown at the Exhibition of 1851 ; from the Berlingen Isles, from Angola, Madeira, and the Cape de Verds. Orchilla weed is very plentiful about the shores of the islands of New Zealand, some was sent from thence to that Exhibition; but from a want of knowledge as to the time at which it should be gathered, and the mode of preparing it for the ruarket, it had not yet become a saleable commodity. The rich varieties of lichens on the rocks and plains of Australia have not been tested as they ought to be. Iceland moss (Cetraria Islandica, Hoff.) is chemically allied to starch; it swells in water, and when boiled gelatinizes on cooling. It is used by invalids.

The Cladonia rangiferina, Hoff., is the reindeer moss, that animal using it as its winter food.Hooker, Him. Jour. ii. p. $130 ; O^{\prime} S h$. p. $671 ;$ Dr. J. L. Stewart, p. 269.

LICH'H. HIND. The payment in kind for the laud in the Panjab.

LICHHAVI, a tribe of the Vriji. There were ancient kings of Nepal, Tibet, and Ladakh of this race.

LICHI or Leechee or Li-tchi, the Nephelium litchi, is a shady and large tree, some 40 feet high, orsamental, and bears the fruit of that name; it is a delicious fruit, as large as a good-sized plum. It produces a very large quantity of fruit, and there is not the least injury to be feared from a free use of it. In that respect it is like the mango. The fruit is dried in India. Fu-chufu, in Foh-kien in China, is noted for this fruit, and the trade in them in a dried state is extensive.-Bonynge, America; Vegetable Kingdom.

LICTORS of the king of Burma are generally, if not always, convicts whose sentence has been commuted. Often the pain of death is changed to perpetual infamy; the criminal is then branded on the face, his offence is written in indelible characters on his breast, and he is doomed to act as a satellite or executioner.-Yule, p. 93.

LICUALA, a genus of palms of the tribe Coryphinæ of Martius, Corypheæ of Lindley, and so named by Rumphius, from the Macassar name of the species, L. spinosa, figured by him in Herb. Amboin. i. t. 9, and which is found in the islands of Macassar and Celebes. L. peltata is described by Dr. Roxburgh as a native of the mountainous and woody parts near Chittagoug, which separates that province from the Burma territories. Both species are small, with palmate, somewhat fanshaped leaves, but of little use. Rumphius describes the narrow leaves of this tree as being formed into pipes for smoking tobacco, while the broader are employed for wrapping up fruit, and for other domestic uses. This genus of palins is confined to the tropical parts of Asia, and composed of about a dozen species.

The species of Licuala are shrubby, sometimes stemless, palms of the East Iudies as well as the islands of the Eastern Archipelago. The stem in many is marked with rings, and sometimes rough with the persistent indurated petioles of fallen leaves. The leaves are piunately funshaped, with the petioles armed towards the margins with horny conical or often hooked prickles.

Licuala acutifida, Griffith., are the Plass tikoos, MaLAY; the walking-sticks called Penang lawyers are the stems of this small palm. It is a miniature palm, inhabiting Penang, and attaining generally only 3 or 5 feet, and in exceptional cases from 15 to 20 feet in height.

Licuala dentifida, Martius, grows in Penang; its Malay name also is Plass tikoos. Its stems also afford the Penang lawyer walking-stick. These are prepared by scraping with glass and polishing; each stem is well scraped, by which the epidermis is altogether removed; care must be taken not to take away much more, as the inside is like the substance of a rattan. It is on this account that the smaller thinner sticks are so much sought for, and are so rare. The sticks are then straightened by fire. No other process is used. The plant seems to be confined within narrow geographical limits; it is not known, as Griffiths believed, about Malacca, where its place seems to be supplied by several other closely-allied species. Martius, however, states it is to be found throughout the Malayan Peninsula. Griffiths had an impression that under this species, as given by Martius, two distinct palms will be found; for though the description by Martius agrees well with Griftiths' Penang specimens, yet the drawing of the spadix represents the parts nearly of the same size as in L. spinosa. L. pumila, Blume, appears only distinguished from this by the broader equal teeth of the pinnules (the intermediate ones of which are the broadest), being described as 16 to 21 lines broad, and 6 to 8 toothed, while the two innermost ones are said to be only an inch broad.

Licuala glabra, Griffiths, is a miniature palm, the trunk being from 3 to 5 feet high, and rather more slender than that of the preceding. The petiole, the rete, and the ligula are much the same as those of the preceding. It grows solitary on Gunong Miring, an offset of Mount Ophir. Flowers in February. Its Malayan name is Plass gunong. Griffiths first met with this species on Nlount Ophir; he subsequently received specimens from the same locality. It is closely allied to the preceding Penang lawyer, from which, indeed, the leaves are scarcely distinguishable, except by the broad sinuses of the lobes, and their more obtuse points. The smooth inflorescence and flowers, however, at once distinguish it both from that species and L. pumila of Blume. Griftiths was not aware of its stem being used for walkingsticks.

Licuala peltata, Roxb. Chitta-pat or Chattahpat, ASSAMr, is one of the finest of the genus. It inhabits all the woody mountains to the eastward of Bengal in Sikkim, as well as the base of the Himalaya, below Darjiling, Rangpur, Assam, aud the Andamans; and its large peltate orbicular leaves, though coarser than Toka-pat of Assam, are used for making chattas or umbrellas, punkahs or hats. Nevertheless the demand for them is very great, scarcely a single ploughman, cow- 
keeper, or coolie being without his jhapi or chatta, umbrella-hat, made of chatta-pat. Other species are L. longipes, Griff., L. paludosa, $G r$., L. spinosa, $G r$, and L. triphylla, Gr., but are of no economic importance.-Roxb. ii. p. 179 ; Seeman; Hooker; Griffith.

LIE-TEA, a commercial term for inferior adulterated tea.

LIEUN. BUri. In Amherst, a most valuable compact wood, homogeneous and very heavy, of deep-brown colour and fine grain, and exempt from attacks of inscts; used for house posts and rafters._Dance.

LIEU PEI, in A.D. 221, by the aid of Chu-koliang and $\mathrm{Kwan}$-yun-chang, made himself emperor of Western China. Chu-ko-liang was the wisest of counsellors, and Kwan-yun-chang the most loyal of heroes. These men have been honoured by subsequent dynasties. $-D r$. Edkins.

\section{LIGHTHOUSES.}

In the Red Sea, the lights-

At Ashrafi, on the N.E. part of the reef at Jubal Strait, in lat. $27^{\circ} 47^{\prime} 21^{\prime \prime}$ N., and long. $33^{\circ} 42^{\prime} 27^{\prime \prime} \mathrm{E}$.

The Brothers on N. Island, in lat. $26^{\circ} 18^{\prime} 50^{\prime \prime} \mathrm{N}$., and long. $34^{\circ} 50^{\prime} 12^{\prime \prime} \mathrm{E}$.

On the Dedalus Shoal, in lat. $24^{\circ} 55^{\prime} 30^{\prime} \mathrm{N}$., and long. $35^{\circ} 51^{\prime} 30^{\prime \prime} \mathrm{E}$.

El Weg (Sherm Wej'h), in lat. $26^{\circ} 13^{\prime} \mathrm{N}$., and long. $36^{\circ} 27^{\prime} \mathrm{E}$.

Ras Gharib Cape, lat. $28^{\circ} 20^{\prime} 52^{\prime \prime} \mathrm{N}$., and long. $33^{\circ} 6^{\prime}$ $30^{\prime \prime} \mathrm{E}$.

Suez Light Vessel off Newport Rock, lat. $29^{\circ} 53^{\prime}$ N., and long. $32^{\circ} 32^{\prime} 45^{\prime \prime} \mathbf{E}$.

Perim Island Obstruction Point, lat. $12^{\circ} 38^{\prime} 59^{\prime \prime}$ N., and long. $43^{\circ} 25^{\prime} 6^{\prime \prime} \mathrm{E}$.

Zafarana Point, lat. $29^{\circ} 6^{\prime} 29^{\prime \prime} \mathrm{N}$., and long. $32^{\circ} 39^{\prime}$ $40^{\prime \prime} \mathrm{E}$.

South Coast of Arabia, Gulf of Aden, and West

Aden, Ras Marshigh Cape, lat. $12^{\circ} 44^{\prime} 50^{\prime \prime}$ N., and long. $45^{\circ} 2^{\prime} 35^{\prime \prime} \mathrm{E}$, and a light vessel $\mathrm{S}$. side of channel, in lat. $12^{\circ} 46^{\prime} 50^{\prime \prime} \mathrm{N}$., and long. $44^{\circ} 57^{\prime} 45^{\prime \prime} \mathrm{E}$.

Berbereh, south shore, Kurachee, near bastion of Manora Fort.

Gulf of Cutch at Mandavi, Toona, Roji, Beyt or Bate, Dwaraka, Porbandar, Mangarol, and Verawal.

Gulf of Cambay at Bhaunuggur, Bulsar, Goapnath, Gogo, Bhagwadandi, Tankari, Jafarabad, Khunbandar, Perim, Tapti.

Bombay, Outer and Inner Light Vessels, Dolphin Rock, Pringreep, Kenery, and Tourbah.

West Coast. - Ratnagherry, Rajapur, Malwan, Vingorla, Goa, Karwar, Oyster Rock, Karwar Bay, Coompta, Mangalore, Cannanore, Tellicherri, Calicut, Cochin, Alleppy, Muttum, Cape Comorin.

Ceylon, Colombo, Point de Galle, Great Basses, Little Basses, Batticalao, Trincomalee.

\section{East Coast of Peninsula.}

Tuticorin, Paumben Pass, Calimere, Negapatam, Karikal, lat. $10^{\circ} 55^{\prime} \mathrm{N}$, , and long. $79^{\circ} 50^{\prime} 35^{\prime \prime} \mathrm{E}$. Colerun, Pondicherry, Madras, Pulicat, Armegon, Divi, Masulipatam, Coringa, Cocanada, Vizagapatam, Santapilly, Calingapatam, Gopalpur, Pooree, False Point

Mouth of Hoogly, Ganges, Brahmaputra (Megna), E. Channel Ship, Intermediate Ship, Lower and Upper Gaspar, Saugor, Cowcolly, Mutlah.

Further India. - Chittagong, Kutubdea, Oyster Reef, Savage Island, Terribles, lat. $19^{\circ} 23^{\prime} 10^{\prime \prime} \mathrm{N}$., and long. $93^{\circ} 16^{\prime} 15^{\prime \prime} \mathrm{E}$.

Mouth of Irawadi and Alguada Reef, lat. $15^{\circ} 42^{\prime} 5^{\prime \prime} \mathrm{N}$., long. $94^{\circ} 11^{\prime} 10^{\prime}$ E. Krishna Ship, Great Coco Group, China ba-keer, Eastern Grive, Rangoon River, Double Island.

Sumatra.-Pulo Brasse, Acheen Head.

Malacea Strait. - Kalang Strait, Cape Rachada, Malacca, Pulo Penang, Raffles, Singapore, Pedra Branca or Horsburgh.

\section{LIGHTNING.}

Barq, . . . ARAB. | Skimshek, . . TuRK. Bijli,

HIND.

Sheet-lightning is an electric phenomenon very common in India; it is unaccompanied by thunder, or is too distant to be heard. When it appears, the whole sky, but particularly the horizon, is suddenly illuminated with a flickering flash. The zigzag appearance is often observed. Philosophers differ much as to its cause. Matteucci supposes it to be produced either during evaporation, or evolved (according to Pouillat's theory) in the process of vegetation; or generated by chemical action in the great laboratory of nature, the earth, and accumulated in the lower strata of the air in consequence of the ground being an imperfect conductor. Arago and Kamtz, however, consider sheet-lightning as reflections of distant thunder-storms. Saussure observed sheetlightning in the direction of Geneva, from the Hospice du Grimsel, on the 10th and 11th of July 1783 ; while at the same time a terrific thunder-storm raged at Geneva. Howard, from Tottenham, near London, on July 31,1813 , saw sheet-lightning towards the south-east, while the sky was bespangled with stars, not a cloud floating in the air ; at the same time a thunder-storm raged at Hastings, and in France from Calais to Dunkirk. Arago supports his opinion, that the phenomenon is reflected lightning, by the follow ing illustration. In 1803, when observations were being made for determining the longitude, M. de Zach, on the Brocken, used a few ounces of gunpowder as a signal, the flash of which was visible from the Klenlenberg, sixty leagues off, although these mountains are invisible from each other.Cosmos; Curiosities of Science; Collingwood.

LIGHTNING CONDUCTORS. The most important ancient notice of the relations between lightning and conducting metals is that of Ctesias, in his Indica, cap. iv. p. 190. He possessed two iron swords, presents from the king Artaxerxes Mnemon and from his mother Parasytis, which, when planted in the earth, averted clouds, hail, and strokes of lightning. He states that he had himself seen the operation, for the king had twice made the experiment before his eyes. The H'tee or Tee placed on the summit of each Buddhist pagoda seems to be a lightning conductor.Humboldt.

LIGN-ALOES, Eagle-wood, Aloes-wood. Ahel, masc, . . ARAB. Calumbac, . . ENG. Ahelat, fem., : : " " Agila-wood, : : . ", Ahelun, $p l .$, : : " " Ahilim, Ahiloti, : 'H" Chin-hiang, : : CHIN. Agar, . . . HrND, A-kia-lu-hiang, : ", Agallochum, : LAT. Ya-hiang, Mih-hiang," Kayu gahru, MALAY. Agalocha-wood, . ENG. Agaru, Agur, SANSK., HD. Lign-aloes is mentioned in Numbers xxiv. 6, Psalms xlv. 8, Proverbs vii. 17, Canticles iv. 14 It is obtained from the Aquilaria agallocha, Roxb., the Opbiospermum of Loureiro, a large evergreen tree. The wood of the sound tree is light, pale, and very slightly odorous, and is used to scent clothes. A very high artificial value is placed on the better qualities of its resinous product by the natives of the east, the best quality being worth about $£ 14$ to $£ 30$ the pikul of $133 \frac{1}{3} \mathrm{lbs}$. The wood of the tree contains a quantity of an odoriferous oleo-resin, which, when heated, undergoes a sort of imperfect fusion, and exhales a fragrant and very agreeable odour. There are several kinds in 
Borneo, called generally by the natives Kayu garu, but produced apparently by diseases in the tree, the scented and resinous parts not being procurable until the tree has been cut down and decayed. The garu has long been an article of considerable export from Borneo and the other islands to Arabia and China, where it is burned as incense. The Aquilaria agallocha, Roxb, is something like the cedrela tree. It grows in Persia, Sylhet, Assam, the Laos country, CochinChina, Cambodia, in China, in Kiung-Chan (Hainan Island), in Shanking-fu and Lien Chan-fu in the Canton province. The wood, when boiled, produces several substances, to which the Chinese apply separate names. If part of the tree rot while growing or at any time after being felled, a dark resinous aromatic substance exudes in the heart-wood, which is the eagle-wood perfume under notice--Simmonds, p. 439 ; Low's Sarawak; Smith's Chin. Mat. Merl. See Aloes - wood; Aquilaria ; Eagle wood.

LIGNIN. When fine sawdust is boiled, first in alcohol, then in water, next in a weak solution of potash, afterwards in dilute muriatic acid, and lastly, several times in distilled water, so as completely to remove all the soluble portions, the substance which remains when dried at $212^{\circ}$ is called lignin; it forms the skeleton of plants and the basis of their structure. It varies in texture from delicate pith to the hard shells of seeds; it forms the bulk of such manufactured products as linen, cotton, and paper, and the washed and bleached fibre of hemp or flax is a good example of it. Pure lignin has a specific gravity of 1.5 ; it is white, tasteless, and is not soluble in water, alcohol, ether, or oils.-Tomlinson.

LIGNITE is a fossil wood, somewhat carbonized, but displaying its wooden texture. In structure it is intermediate between peat and coal, and comprises jet, moor coal, bovey coal, brown coal, and basaltic coal. It occurs in Sumbulpur, Talchere, Rajmahal, Chittrgong, amongst the hills up the Kurnfuli river in Assam, and, underlying the clay, in the recent strata all along the seacoast from Cutch to Singapore. On the banks of a small tributary of the Tenasserim, in about 10 degrees of latitude north of Tavoy, trunks of trees changed to lignite may be seen in the stiff clay, and near them the trunks of other trees completely silicified, and turned to stone. There is a great variety in this wood coal, both in its appearance and chemical analysis. Dr. Morton described specimens of lignite collected by the commander of the surveying vessel on the coast below Amherst. Mr. O'Riley, near the headwaters of the Ataran river, found two separate lines of lignite in a coarse sandstone conglomerate, with shale and a semi-indurated blue clay containing limestone pebbles. This lignite is highly pyritous, its decomposition affording a copious deposit of sulphate of iron which covers the exposed surface with a dirty-coloured efflorescence. Some of the specimens taken from the deposit retain their original characteristics, do not fracture, and may be sawn through in sections across the grain, the same as wood imperfectly carbonized. Other deposits of wood less charged than the foregoing are found in the banks of the rivers Dahgyaine and Gyaine, some 20 to 30 miles to the N.E. of Moulmein, covered with the same blue clay, but none possess any useful quality as a combustible material.-Dr. Mason.

LIGNUM COLUBRINUM, the wood of Strychnos colubrinum, supposed to be an antidote against the poison of venomous snakes, as well as a cure for intermittent fevers. It is also produced by Strychnos ligustrina. S. tieute yields the Upas tieute and Tiettek of the Javanese, which is an aqueous extract of the bark. S. toxifera yields the Woorali or Ourari poison of Guiana. $\mathrm{S}$. pseudoquina is employed in Brazil as a substitute for chinchona bark, and the seeds of S. potatorum, Roxb., the airmulee of the Hindus, are employed by them to clear muddy water.Faulliner; Hogg's Vegetable Kingdom.

LIGNUM VIT 2 of Pegu is the Melanorrhæa usitatissima, Wall.

Lignum vitæ (Guaiacum officinale, $L$.), of the West Indies, grows slowly, but attains a great size. The wood is remarkable for the singular brownish-green of the heart-wood, and its extreme hardness and toughness, which adapt it for pestles, mortars, rulers, etc. It yields a green resin used in medicine, which is obtained either from incisions in the trunk, or by heating the wood broken up into fragments.

LIGOR, in Siamese, Muang Lakhon, is also called Na-khon-si Thamarat. It was founded four centuries ago by the king of Ayodhya. Ligor is in lat. $8^{\circ} 20^{\prime} \mathrm{N}$., and long. $99^{\circ} 25^{\prime} \mathrm{E}$., and is a seaport of the Malay Peninsula. Its chief trade is in tin, rice, and pepper. It has 150,000 souls, of whom three-fourths are Siamese.

LIGORA. Assam. A female servant granted to officers of state.

LIGUSTICUM AJOWAN. Roxt.

Ajwan, . . Hind. Brahmadurbha, SANSK. Yavanika,. : SANSK.

Cultivated all over India. The seeds and those of L. diffusum are highly carminative, promote the secretions, good in dyspepsia; much used in all mesalihs; 8 seers for 1 rupee. This is one of the most useful and at the same time grateful of the umbelliferous tribe. It is much cultivated in Bengal during the cold season. Ligusticum diffusum, Roxb., Junglee-ajowan, Hind., is found wild in the vicinity of Calcutta during the cold, and the begimning of the hot, season; it delights in shady, moist places.-Roxb.

LIGÚSTRUM, a genus of plants belonging to the natural order Oleaceæ. The species are shrubs or low trees, natives of Europe and Asia, have a fleshy fruit, the berry containing two membranous one-seeded nuts. The genus has bitter and astringent leaves, and coloured berries, used in dyeing wines. A bluish colour which they yield is very much admired. Dr. Wight gives Ligustrum intermedia, macrophylla, and ramiflora. I. bracteolatum, Don., and L. Nepalense, Wall., occur in Nepal, and L. lucidum, Ait., in China, $\mathrm{L}$. glabrum is the tung-ts'ing of the Chinese. L. Sinense has lanceolate tomentose leaves, white flowers, and very small brown berries. It is a native of China, near Canton. I. spicatum has elliptic acute leaves, Lairy beneath, as well as the branchlets. It is an evergreen shrub, native of Nepal, on mountains, growing from 6 to 8 feet in height.

LIGUSTRUM JAPONICUM. Tourne.

L. lanceolatum, $\boldsymbol{H} b$., Lam. $\quad$ Lo spicatum, D. Don.

L. Nepalense, Wall., Ro:xb. 
A plant of Nepal, China, and Japan, with oblong ovate grooved leaves and white flowers, growing to the height of 6 or 8 feet. Japan privet is a valuable hedge plant, which grows well under trees.-Voigt; Von Mueller; Eng. Cyc.

LIGUSTRUM LUCIDUM. Ait.

Lah-shu, . . CHIN, | Tung-ts'ing,

A handsome evergreen tree of Chine, wit ovate pointed leaves, profuse white flowers with panicled cymes, and bearing a black capsular fruit. The Chinese term tung-ts'ing is applied to several plants on which the vegetable wax insect congregates, as $\mathrm{L}$. Japonicum and L. obtusifolium, both of which, with Rhus succedaneum, are also in China called $\mathrm{Nu}$-ching. Another wax insect tree is the Ligustrum ibota of the province of Sze-chuen, But L. lucidum principally harbours the insect. Its fruit and bark are used by the Chinese in the form of tincture, and its leaves are applied to swellings and sores. In the Keenchang district, the Ligustrum lucidum thrives in abundance, and on its twigs in the spring of the year countless flies swarm like a brown film. The branches soon become covered with a white, soapy incrustation, that increases in volume until the commencement of the fall of the year, when the sprays are cut off and immersed in boiling water. The viscid substance rises to the surface, and is skimmed off, melted, and allowed to cool in deep pans. It was accidentally discovered that, by transporting the insects from their native district to Keating Fu, in the north of the province, their capability of discharging wax was largely augmented, which was availed of by the Sze-chuen traders. The period between morning and evening is chosen for conveyance, because many hours of sunlight would precipitate the hatching. This should take place only after the females have been attached to the trees. Arrived at their destiuation, six or more of the mothers are tied, wrapped in a palm leaf, to a ligustrum. A few days later the young flies are swarming on the twigs, where they fulfil their mission by the month of August. Then they perish in the caldrons, where the results of their brief existence are collected. It is said that this peculiar industry requires the exercise of great care, forethought, and experience.-Voigt; Smith, p. 229.

LIKHAWAT, HiND., from Likhna, HiND, to write ; a written document, a handwriting.

LILAC. In India several plants are known as lilacs. The Syringa Persica is the true Persian lilac: the Melia azederach is the Persian lilac of the English in India; Melia sempervirens, $W_{\text {. }}$, is the West Indian lilac of English writers.

LILAM or Nilam, in the sea-coast towns of India, means an auction sale. They are both from the Portuguese Leilao, auction sale.-Wilson.

LILASTHAN, in Hindu mythology, a place near the Hradancita where Samirama resided with Lileswara.-As. Res. iv. p. 370.

LILAVATI, the title of that chapter of Bhaskara Charya's Siddhanta Siromani which treats of arithmetic and geometry. It has been printed and been translated by Colebrooke and Dr. Taylor. Lilavati and Bija Ganita, by Bhaskara Charya, are the best Hindu books on algebra and arithmetic.

LILESA, also Lileswara, sprung from Baleswara, is identical with Ninus.-As. Res. iv. p. 376.

LILIACE $\approx$. D.C. The lily tribe of plants, comprising, in the East Indies, about 20 gen. and
$66 \mathrm{sp}$. Liliaceous plants grow all over the world. Many of the tulip section are ornamental, but the roots of Methonica superba are considered to be a virulent poison. The Aloeæ yield valuable fibres from species of Sanseviera and Aloes; also the medicinal aloes, the flowering hyacinth and other ornamental plants, are found in the Asphodeleæ, as also the useful squill, leek, onion, garlic, rocambole, shallot, and chires.

\section{A. TULIPEe.}

Gesneria stellata, Hooker, Kamaon.

Notholirion roseum, Wall., Gosainthan.

Lilium Nepalense, $D$. Don, Nepal.

L. giganteum, Wall., Nepal.

L. Wallichianum, Schult, Kamaon.

L. Neilgherrense, Wight.

Methonica superba, Lam., all British India.

\section{B. Agapanthex.}

Funkea albo-marginata, Hooker, Japan.

F. corulea, Spreng., China, Japan.

F. cordata, J. Grah., China, Japan.

Polianthes tuberosa, Linn., East Indies.

\section{AlOR.E.}

Sanseviera Zeylanica, Willde., Ceylon.

S. Roxburghiana, Schult, all British India.

A. Barbadensis, Mill., Barbadoes aloes.

A. Indica, Royle, North-West India.

L. Socotrina, Lam., Socotra, East Indies.

Lomatophyllum Borbonicum, Willde., Bourbon.

Yucca aloifolin, Linn., West and East Indies.

Y. gloriosa, Linn., West and East Indies.

$Y$. draconis, $L$. ; filamentosa, $L$. ; and glaucens, Ham. About 104 introduced species.

\section{AsPHODELEE \\ a. Hyacinthine.}

Muscari moschatum, Tourne., Asia.

Hyacinthus orientalis, Linn., S. Asia. Scilla Indica, Roxb., Konkans.

S. Coromandeliana, Roxb., Coromandel. Ormithogalum thyrsoides, Jacqu., Arabia.

O. Arabicum, Linn., Africa.

Allium sativa, Linn., garlic, all East Indies.

A. controversum, Schrad., all East Indies.

A. scorodoprasum, Linn., rocambole, all East Indies.

A. proliferum, Roxb., China, all East Indies.

A. porrum, Iinn., leek.

A. ascalonicum, Linn., shallot, all East Indies.

A. ascalonicum, var. Chinese, China.

A. cepa, Linn., onion, all East Indies.

A. schoenoprasum, Linn., chives, all East Indies.

A. fragrans, Vent., var. Nepalense, Nepal.

A. tuberosum, Roxb., Bengal.

Asphodelus fistulosus, Linn.

\section{b. Anthericince.}

Anthericum Nimmonii, J. Grah., S. Konkan.

Chloopsis acaulis, $B l$., Java.

$$
\text { c. Asparagince. }
$$

Dianella ensifolia, Red., South-East Asia.

Asparagus officinalis, Linn., all British India.

A. volubilis, Buch, all British India.

A. curillus, Buch., Nepal, Assam.

A. sarmentosus, Rheede, Ceylon, Peninsula of India

A. racemosus, Willde, Ceylon, Bengal.

A. acerosus, Roxb., Burma.

A. adscendens, Roxb., Hindustan.

A. maritimus, Rall., Caspian shores.

Dracæna reflexa, Lam., Mauritius.

D. draco, Linn., Canaries, Socotra.

D. cernua, Jucqu., Mauritius.

D. umbraculifera, Jacqu., Java.

D. terminalis, Willde, China, Moluccas.

D. ferrea, Linn., China, Moluccus.

D. angustifolia, Roxb., Amboyna.

D. spicata, Roxb., Chittagong.

D. maculata, Roxb., Sumatra.

D. terniflora, Roxb., Sylhet.

D. atropurpurea, Roxb., Sylhet.

D. ensifomis, Wall., Sylhet.

-Voigt; MLrray. 
LILIES OF THE FIELD, alluded to by Jesus, Messiah, are supposed to be the Amaryllis lutea, also supposed to be the Chalcedonian or scarlet Martagon lily, formerly known as the lily of Byzantium. The plains westward of the lake of Gennesareth which surround the Mount of Beatitudes, are covered at different seasons of the year with liliaceous flowers of many kinds, nearly all of which are brightly coloured. The Chalcedonian lily was in blossom at the season that the sermon on the mount was spoken.

LILIUM CANDIDUM. Peh-hoh, Chis. In China the bulbs, the unopened flower-buds, and the flowers of this and of L. tigrinum are used medicinally. L. Wallichianum, Roem. et Sch., is a plant of Naini Tal.-Smith's Chin. M. $M$.

LILLAH. ARAB. For the sake of God; out of charity, gratuitously. Lillahi, for God; Lillahi l'Azim, for the love of the great God. Lillahi'lhamd-wa-al-manat, to God be praise and glory.

LILY-FLOWERS.

Kin-chin-tsai, . . CHIN. i Hwang-hwa-tsai, . CHIN.

Hæmerocallis graminet and Lilium bulbiferum, and a reddish variety of the orange lily, are largely raised in the Chinese province of Shan-tung, for their flowers, which are collected and dried for use in China, and for export, as all Chinese use them medicinally, and as a relish with meat dishes. -Smith, M. M. C.

IILY OF THE VALLEY, a common name for the Convallaria majalis.

LIMBU, called by the Lepcha, Chung, a partly Buddhist, partly Brahmanical border race between Nepal and Sikkim, a branch of the Kiranti or Kirati; and a hardy, hard-working people. They engage in the cultivation of grain, and feed cows, pigs, and poultry; their huts are made of split bamboo, and the roofs of leaves of the wild ginger and cardamom, guyed down with rattans. They drink to excess. The Limbu near Darjiling eat their sacrifices, dedicating, as they forcibly express it, 'the life-breath' to the gods, the flesh to ourselves. According to Dr. Campbell, the Limbu tongue is more pleasing to the ear than the Lepcha, being labial and palatal. The Limbu, Sunwar, and Chepancr possess a small Mongolian type, strongest in the Limbu, and their language is referable to either the Tibetan or Indian standard. The Rong, the Khampa or Kamba, and the Limbu, are people from different parts of 'Tibet. All these people have powerful frames, but are idle.-Latham; Lublock, Orig. of Civ.: Dr. Canipbell, p. 148 ; Dalton's Ethn. p. 102.

LIME, Quicklime, Caustic lime.

1
5
5
5 'H' Lime is an English term applied alike to quicklime or freshly-burned limestone, to the same when the form of mortar. Lime, in its pure form, is a greyish-white, earthy-looking inass, moderately hard, brittle, sp. gr. 2.3 to 3.03 , having an acrid alkaline taste, corroding animal substances. It is made by burning limestones of various kinds, also by burning shells of the mussel, cockle, oyster, Unio ampullaria. When fresh burnt, it absorbs both moisture and carbonic acid from the air. It will abstract water from most bodies, and is hence often employed as a drying substance. White Carrara marble, calcareous spar, chalk, shells, nodular limestone, or kankar, all yield good lime. With heat sufficiently great, the carbonic acid is expelled, and about 56 per cent. of lime left in a caustic state, and tolerably pure; but if shells have been employed, mixed with a little phosphate of lime and oxide of iron. Water being added, lime cracks and falls to powder; the rest is a hydrate of lime.

The farmers of the south of India manure the fields on which Sea Island cotton is grown with a compost of shells and mud saturated with seawater.-Royle.

Lime, slaked.

Hydrate of lime, . ENG. Kapur mati, . . MLLLAY. Calcis hydras, : LAT.

The slaked lime is obtained by pouring water over quicklime. It is used for making inortar, by mixing it with sand, also after watery dilution as a whitewash; in this form it is deemed to possess great purificatory power; and in British India it is applied annually to buildings, but of tener when necessary.

Lime, carbonate of.

Kwang-fen, . . CHus. Valaiti chuna, - HIND. Craie, . Fr. Chuna, . : '" Carbonate de chaux, G,
Kohlensaures kalk, GER.

Carbonate of lime assumes, in nature, several forms, - chalk, marble, limestone, calc-spar, kan$\mathrm{kar}$, and in most of its varieties is useful in the arts and manufactures.

Lime fruit, Bergamotte lime, acid lime.

\begin{tabular}{l|l} 
Citrus bergamia, Risso. & C. acida, Roxb.
\end{tabular}

C. limetta, var, $D . C$.

Korna nebu, Nebu, BENG. Jarak tipis, . . Malar. Tan-pu-lo, : : CHIN Jaruk nipis, : : SA" Jambira, . Cay tanh-yen, Соск.-CHIN. Dehi, . : SINGH. Khatta nimbu, . . HIND. Elimitcham pallam, TAM. Limbu, Nimbu, : " Nemma-pandu,. TEL.

This fruit grows on a shrub or small tree. The rind of the fruit is of a pale-yellow colour; the pulp within is very acid. It is largely used in cookery, and the expressed juice kuown as limejuice is preserved and used on board ship as an antiscorbutic; also used to make lemonade. Dried limes are used by dyers in some parts of India to fasten and improve colours. There are eight varieties of this nimbu fruit,-the pati, kaghazi, gora, China-gora, Kamurali, Rungpur, and taba nimbu of Bengal, and the Arabian lime of Muscat. It is grown throughout India, in Assam, the Sunda Islands, and Moluccas. - M'Culloch; Faulkner.

Lime, sweet lime, Citrus limetta, Risso and Poit. C. hystrix, D.C.

Shouk-cho, . Burs.| Mitha nimbu, . Hind.

The sweet lime grows to the size of a large orange. The juice of the fruit is very grateful to persons with fever, although rather tasteless. It is easily propagated by seed. It will grow also from cuttings. The young shoots make a very good stock for orange grafts.

LIMESTONE occurs abundantly in many parts of the $\mathrm{E}$. Indies, in the form of nodular masses, also as a compact stone and granular as marble, rarely as chalk. There is much granular marble in the Tinnevelly district in the south of the 
Peninsula of India, both pure white and veined. The marble rocks of the Nerbadda river, below Jubbulpur, are also famed, and marble is found and largely worked in Burma. Chalk is rare in India, but a nodular limestone called kankar occurs in the black soil throughout British India. Compact limestone occupies great districts,much of the valleys of the Godavery, Kistna, Tumbudra, Gutparba, Malparba, and Bhima rivers. The great Buddhist st'hupa of Amraoti is of this marble. Between one and two hundred pieces of its sculptures were sent to England by the Editor, and are arranged against the wall of the great stair of the British Museum. The carvings are minute. Mr. Fergusson noticed them in his Tree and Serpent Worship. A limestone underlies the whole of the Kymore range in Shahabad, and it also shows itself along the valley of the Sone as far at least as Mungeysur peak in Mirzapore. In some parts, as in Rohtas, it crops up boldly to 200 or 300 feet, forming a sloping base to the precipitous sandstone rock. There appear to be three well-defined strata, viz. an upper one of a yellowish-blue mixed with disintegrated sandstone, iron pyrites, and chalk, all in thin plates. Below that again, a more bluishgrey limestone, with occasional calc-spar crystals, is found, but generally of the same nature as the German lithographic stone. Under the aforesaid strata lies a very dense bluish-grey limestone mixed with veins of calc-spar. It is not used by native lime-burners, as being intractable. This is the lowest stratum, and would be an almost indestructible building or flooring stone, from its great hardness. Much harder than granite, and approaching to porphyry, it may be had in large blocks, and, if sawn into slabs, would be a very handsome building stone, bluish-grey with white streaks, and, moreover, it would probably make a superior kind of lime. Immense quantities of lime are made from the quarries of the western bank of the Sone, and exported down the Sone and the Ganges as far as Monghyr. Perhaps 300,000 to 400,000 tons are made annually, and the material is inexhaustible. The same limestone rock crops out on the northern face of the range, with intervals, between the Sone river and Mirzapore, and again, especially in the singular and interesting limestone caverns of Gupteswar, in the valley of the Durgowtee river, at Beetree Band, in Khawah Koh, at Mussai, on the Sooreh river, and near Mirzapore. The cost of the lime at these quarries varies from 6 to 16 rupees per 100 inaunds, or, say, $5 \mathrm{~s}$. to $14 \mathrm{~s}$. per ton.

Close to Jubbulpur is a range of low bills within a circumference of about 10 miles, interspersed with masses of limestone both above and below the surface. In burning it for lime, the stone is broken into fragments of 6 to 12 inches in size, then piled like a dome over a hole of about 9 feet diameter dug in the ground, and a passage left for introducing the fuel. This kiln is kept burning continually for the whole of the day, and the lime removed on the following morning. The fuel is used in the proportion of 40 maunds to every 75 maunds of limestone, and the yield is about 50 maunds of well-burnt lime.

White saccharine marble occurs on the banks of the Nerbadda, at Bhera Ghat, near Jubbulpur, on the line of the railway to Bombay. It has been used in a limited degree at Jubbulpur, sometimes to make lime, and other times for metalling roads. It is made up into images by natives, but does not take a good polish. But a block was sent to the Paris Exhibition of 1855, and pronounced to be equal to Italian marble for statuary purposes.

The marble of which the images of Gautama are formed is a granular limestone, but are usually called alabaster images. It is a primitive limestone abundant near Ava. All the limestone of the Tenasserim provinces belongs to the older secondary formation. The limestone of Tavoy has a sp. gr. of $2 \cdot 7$, and is a perfectly pure, semi-crystalline carbonate of lime, akin to statuary marble. It is well adapted to act as a flux in the smelting of iron. The limestone of Mergui has a sp. gr. of 2.7 ; it is a pure calcareous carbonate.-Cal. Cat. Ex., 1862 ; Mason's Tenasserim; Edward Balfour in Goternment Central Museum Records.

LIMONIA, a genus of plants of the order Citraceæ.

L. acidissima, Linn., all the $\mathbf{E}$. Indies.

L. alata, $\boldsymbol{B b}$. Madr, Wight, Ill., Ceylon, Neilgherries.

L. alternans, Wall., Pegu.

L. angulata, $W$. and $A$., Moluccas.

L. caudata, Wall., Khassya Hills.

L. grata, Wall., - ?

L. laureola, D. C. Wall., Nepal.

L. missionis, Wall., W. Ic., T'anjore.

The leaves of some of the Limonia are fragrant, the small fruits of $\mathrm{L}$. acidissima are very acid. L. laureola is the only plant of this family found on the tops of cold mountains. The people of the Himalaya, remarking its highly fragrant leaves, fancy that it is by feeding on them that the muskdeer acquires its strong and peculiar flavour.Roxb.; Wallich, Pl. As. Rar.t. 245 ; Voigt.

\section{LIMONIA ACIDISSIMA. $L, D, C$.}

L. crenulata, Roxb.

Jeru kat narigam, MALEAL. | Torelaga, . . . . TEL.

Grows at the falls of Gokak; common on sandstone hills at Padshapur, in the forests of the Godavery, at Hardwar, Monghyr, and Assam. It is a shrub with pinnate leaves and winged petioles; its flowers are small, white, and fragrant ; its fruit small, size of a pea, is an article of commerce with the Arabs, used as a tonic. Wood very hard, and worthy of attention,-Riddell; Graham; Voigt.

LIMONIA ALATA. Wight, $I l l$.

Kat yellu mitcha, . TAM. | Adivi nimma, . . TEL.

Tree small, but its wood is remarkably closegrained, hard, and heavy. It is pale-yellow or straw-coloured, and if procurable of adequate size would be very valuable. Is found in the Southern Ghat forests of the Bombay Presidency, above and below, but it is not a common tree.Drs. Wight, Gibson.

LIMONIA ANGULATA. $W$. and $\Lambda$. Citrus angulata, Willde., of the Moluccas and Sunderbans, with small white fragrant flowers.

LIMONIA CARNOSA. M'Clelland. Taushouk, Burm. The small fruit of this tree, not larger than a nut, is a favourite spice, known in the bazars of Bengal under the name of Keklani. It is only found in the Pegu district. $-M^{6}$ Clelland.

LIMONITE, Wu-meng-i, ChIN., was formerly used medicinally by the Chinese; it is a perhydrous oxide of iron.

LIMOSA, a genus of birds known as godwits, of the order of Grallatores or Waders, family 
Scolopacidæ. L. melanura, the black-tailed godwit of Europe, Asia, N. Africa, Australia, is very common in India. L. rufa, bar-tailed godwit, of Europe, Asia, N. Africa, W. Asia, Nepal (Hodgson, Gray), Java and Timor (Temminck).

LIMRI or Limbadi, a Native State of Kattyawar, lying between lat. $22^{\circ} 30^{\prime} 15^{\prime \prime}$ and $22^{\circ} 37^{\prime}$ $15^{\prime \prime} . \mathrm{N}$., and between long. $71^{\circ} 44^{\prime} 30^{\prime \prime}$ and $71^{\circ}$ $52^{\prime} 15^{\prime \prime} \mathrm{E}$. The chief has power to try his own subjects for capital öffences without the express permission of the Political Agent.-Imp. Gaz.

LIMULUS, a genus of crustaceans belonging to the family Xyphosuræ. The species are found in all the seas of Southern Asia and the Eastern Archipelago, as also in the Atlantic and near the coast of $\mathrm{N}$. America, and sometimes come upon the sandy beaches. They do not appear to have a bigher range than lat. $44^{\circ}$, and seem confined to the northern hemisphere. Their food consists of animal substances, and when stranded they often bury themselves in the sand as a protection against the heat of the sun, which is soon fatal to them. The Limuli undergo in their youth considerable changes of form. At first there is no sword-like or styliform tail, which in the adult Limulus equals, at least, the rest of the body in length; their abdominal buckler is rounded posteriorly, and the last pairs of false feet are not developed. Two species are common at the mouth of the river Ganges; one is distinguished (among other characters) by having a cylindrical tail.

LIMULUS LONGISPINA. Milne-Edws. Un-kiie, . . . . Chin. Kabuto-gani or Umi-do-ganie, . : " $\mid$ helmet crab, . . JAP.

It is found on the coasts of Japan, and probably of China.

LIMULUS MOLUCCANUS. Latreille.

L. polyphemus, Fabr.

L. gigas, Muller.

L. tridentatus, Leach. Cancer Moluccanus, Clus. C. perversus, Rumph.

The Molucca crab or king crab is found in the Molucca seas. L. Moluccanus is apparently the Cancer figured by Bontinus in the fifth book of his Natural and Medical History of the East Indies, p. 83; he notices its sword-lilke appendages, and states that if any incautious fisherman is wounded by it, the pain is like that caused by a scorpion, adding that its flesh is not so delicate as that of the other crabs. The chapter is headed by the following verse, which refers to the painful wound inflicted by the tail :-

Quisquis caudati sensisti tela Paguri,

Disce meo exemplo morsus vitare dolosos,

Dente leonino quos aula volubilis infert,

A tergo, et pejus retinet fors cauda venenum.'

LIMULUS ROTUNDICAUDATA. Edwards. Cancer marinus perversus, Seba., a native of the Molucca seas.

LIMULUS VIRESCENS. Milne-Edwards. Polyphemus heterodactylus, Lam., a native of the Molucca seas. See Crustacea.

LINARIA, the toad-flax, a genus of unimportant plants, of the natural order Scrophulariacex, section Antirrbineæ.

L. bipartita, Willde., N. Africa, cultivated in India.

L. incana, Wall., Nepal.

L. juncea, Ait., Europe, cultivated in India.

L. purpurea, Mill, Europe, cultivated in India.

L. ramosissima, Wall., Bengal, Hindustan, Burma,

L. spartea, Hoffin., Europe, cultivated in India.

L. triphylla, Mill, Europe, cultivated in India.

L. vulgaris, Mill, Europe, cultivated in India.
As flowering plants, they are easily raised from seed; colours mostly purple, blue, and yellow.

LINARIA CYMBALARIA. Mill. Karamba, SANSK., ivy-leaved snap-dragon. Given in India with sugar for the cure of diabetes.-O'Sh. p. 477.

LINARIA RAMOSISSIMA. Wall. This little yellow-flowered plant may be seen in the Sikkim valleys, crawling over every ruined wall, as the walls of old English castles are clothed with its congener, L, cymbalaria.-Hooker, Him. Jour. i. p. 42.

LINDEN TRIBE, the Tiliaceæ of botanists, comprise about 91 species of the East Indies, mostly with valuable economic properties, the following being the more important of them :--

Corchorus acutangulus, Lam., all India, Malayana.

C. fascicularis, Lam., all British India.

C. olitorius, Linn., all British India, Egypt, Malayana.

C. capsularis, Linn, all British India, China.

C. trilocularis, Linn., all British India, Burma.

Triumfetta angulata, Lam., all British India.

T. annua, Linn., Bengal.

T. rotundifolia, Lam., Bengal, Circars.

T. trilocularis, Roxb., Bengal, Senegambia.

Grewia abutilifolia, Juss., Peninsula of India.

G. Asiatica, Linn., Bengal, Peninsula of India.

G. columnaris, Sm., Peninsula of India, Khassya,

G. denticulata, Wall., Nepal.

G. elastica, Royle, Himalaya.

G. floribunda, Wall., Burma.

G. humilis, Wall., banks of Irawadi.

G. lævigata, Vahl., all British India, Malayana.

G. microcus, Wight, Peninsula of India.

G. microstemma, Wall, banks of Irawadi.

G. occidentalis, Linn., introduced.

G. oppositifolia, Buch., Dehra, Kheree Pass.

G. orientalis, Linn., Peninsula of India, Bengal.

G. paniculata, Roxb., Penang, Malacca.

G. pilora, Lam., both Peninsulas of India.

G. polygama, Roxb., Bengal.

G. populifolia, Vahl, Peninsula of India.

G. sapida, Roxb., Bengal.

G. sclerophylla, Roxb., Dehra, Kheree Pass.

G. sepiaria, Roxb., Bengal.

G. tiliæfolia, Vahl., Neilgherries.

G. trochodes, - ? Bengal.

G. ulmifolia, Roxb., Assam, China.

G. umbellata, Roxb., Penang, Sumatra.

G. villosa, Hb. Missionis, Trichinopoly.

G. viminea, Wall., Prome.

Berrya ammonilla, Roxb., Ceylon, Peninsula of India.

Brownlowia elata, Roxb., Chittagong.

The Tiliaceæ abound in a mucilaginous wholesome juice. The fibres of the inner bark are very tough, and are used for a variety of economical purposes. The wood is generally white, light, and tough; that of Grewia elastica is used for making bows in India. The Trincomaleewood, used at Madras for making the Masula boats, is the produce of Berrya ammonilla. Corchorus olitorius is cultivated in Egypt for use as a pot-herb, and species of Corchorus and Triumfetta furnish valuable fibres. The wood of Brownlowia is also valuable.-Roxb.; Royle; Voigt.

LINDLEY, DR., an eminent English botanist, who rendered essential service to Indian botany by numerous descriptions and figures of Indian plants that had appeared in various illustrated periodicals. He laboured indefatigably in the distribution of the great Wallichian herbarium. His elementary books of botany, and his great work the Vegetable Kingdom, are indispensable both to botanical students and to proficients; whilst by the scientific direction he gave to the study and practice of horticulture, as an author and as secretary to the Horticultural Society of 
London, he was the means of rendering European botanists familiar with the plants of India in a living state, to an extent that would have been thought visionary a few years before his time.H. et T.

LINDSAY-BETHUNE. Sir Henry LindsayBethune, an officer of the Madras Horse Artillery, who was sent to Persia with Sir John Malcolm, along with Captain Christie, of the Bombay army, and employed in training the Persian soldiery. After many years' service, he resigned his Persian appointment, and settled on his estate of Kilconqubar, in Scotland, adding Bethune to his previous surnane of Lindsay. In 1834 he was again sent to Persia, where he led the advanced division from Tabreez to Teheran, and quelled a rebellion against Mubammad Shah, for which he was created a baronet. In 1836 he was a third time sent to Persia, with the rank of MajorGeneral.

LINEAR MEASURE. In India, the distance from the elbow to the tip of the middle finger of a tall man is known as the Hat'h, Hind., or Moolum, TAM., Mora, TEL, and averages $19 \frac{1}{2}$ inches. It is always translated cubit, though invariably exceeding the English cubit of 18 inches by $1 \frac{1}{2}$ or 2 inches. In the Southern Karnatic, the adi, or length of a tall man's foot, is in use, and averages $10 \frac{1}{4}$ inches. The gaz or guz of India (translated yard) is partially in use all over India, but varies in different localities from 26 to 36 inches. In the N.W. Provinces of India it had been defined by Government, for the purpose of survey, at 33 inches. The British yard and foot are, however, very extensively adopted by native artisans; and in all the public works of India, which give employment to thousands of natives, the British linear measure is invariably employed. See Measures; Weights. LINEN.

Lynwaat, - . Dur. Panno de linho, . PORT Toile, : : Fr. Lenu, Polotno, KUs. Linnen, Lienwand, GER. Lienza, Tela de lino, SP. Lein, . . . GoThIC. Keten-bezi, . . TukK. Linon,

Tela, Punno lino, : IT. L'lin, . . . . WeLSH.

Nost of the names for linen in use in Europe are derived from Lin, the Saxon for flax, the word flax being derived from the Greek word Pleko, to weave. Linen is also a term applied to linen cloth, to body clothing, and bed linen.- $M^{\circ} \mathrm{Cul}$ loch's Dictionary, p. 761 .

LINGA or Lingam is the symbol or form under which the Hindu deity Siva is principally worshipped. There are various kinds of linga to all of which worship is offered. As usually seen in British India, the lingam is a round conical stone, rising perpendicularly from an ovalshaped rim cut on a stone platform. The salunkha is the top of the lingam altar, and the pranalika is a gutter or spout for drawing off the water poured on the lingam. The lingam is the Priapus of the Romans, and the phallic emblem of the Greeks; and the oval rim-like lines sculptured or drawn around it is the yoni or bhaga, symbolical of the female form, as the lingam represents that of the male. The effigies worshipped in Tibet are known to the Chinese as Hwan-hi-Fuh, i.e. Buddhas of Delight.

In British India, for at least 1500 years, the lingam has been the object under which Siva is worshipped by his followers, in this instance as a regenerator, whilst the yoni or bhaga is regarded as emblematic of his sakti or consort Parvati. These two emblems represent the physiological form of worship followed by the great Saiva sect; and the worship of Siva, under the type of the lingam, is almost the only form in which that deity is now reverenced. About two-thirds of all the Hindu people, perhaps $80,000,000$ of souls, worship these emblem idols. They are conspicuous everywhere, in all parts of British India from the Himalaya to Ceylon. Throughout the whole tract of the Ganges, as far as Benares, in Bengal, the temples are commonly erected in a range of six, eight, or twelve on each side of a ghat leading to the river. At Kalna is a circular group of 108 temples, erected by a raja of Bardwan. Each of the temples in Bengal consists of a single chamber, of a square form, surmounted by a pyramidal centre. The area of each is very small, the linga of black or white marble occupies the centre; the offerings are presented at the threshold. This worship is unattended by any indecent or indelicate ceremonies, and it would require a very unusual imagination to trace any resemblance in its symbols to the objects they are supposed to represent. The Vedas do not seem to inculcate this form of worship; their ritual was chiefly, if not wholly, addressed to the elements, and particularly to fire; but the lingam is undoubtedly one of the most ancient idol objects of homage adopted in India, subsequently to the ritual of the Vedas. The worship of the linga is the main purport of the Skanda, Saiva, Bramadandi, and Linga Puranas.

In the Saiva Purana and in the Nandi Upa Purana, Siva is made to say, 'I am omnipresent, but $I$ am especially in twelve forms and places.' These are the twelve great lingas, viz. at Somnath, Pattan, Mallikarjuna, near the Krishna, MahaKala Omkara, all three at Ujjain; Amareswara, Vaidhya, at Deo-garh in Bengal, Ramisseram, at Dra Charam in Rajamundry, at Benares, on the banks of the Gumti, at Kedarnath in the Himalaya. That at Benares is called Viveswara, Lord of All.

The idol destroyed in A.H. 415 by Mahmud of Ghazni, is said to have been a linga. It was a block of stone of four or five cubits long, and of proportionate thickness. Sonnerat says the lingaun may be looked upon as the phallus or the figure representing the virile member of Atys, the wellbeloved of Cybele, and the Bacchus which they worshipped at Hieropolis. The Egyptians, Greeks, and Romans had temples dedicated to Priapus, under the same form as that of the lingam. The Israelites worshipped the same figure, and erected statues to it.

Scripture (1 Kings xv. 13) informs us that Asa, son of Rehoboam, prevented his mother Maachah from sacrificing to Priapus, whose image he broke. The Jews cansed themselves to be initiated into the mysteries of Belphegor, a divinity like the lingam, whom the Moabites and Midianites worshipped on Mount Phegor; and which worship, in all appearance, they received from the Egyptiane. When Judah did evil in the sight of the Lord, and built them high places, and images, and groves on every high hill and 
under every tree, the object was Baal, and the pillar, the lingam, was his symbol. It was on his altar they burned incense, and sacrificed unto the calf on the fifteenth day of the month, the sacred monthly period, the amavas of the Hindus. The calf of Israel seems the bull Nandi of Bal Iswara or Iswara, the Apis of the Egyptian Osiris, and throughout all British India a sculptured stone bull, called Nandi, the vahan or conveyance of Siva, is seated with its face looking towards the lingam. According to Colonel Tod, the lingam is identical with the Arabic idol Lat or Alhat. The worship reached France, doubtless with the Romans, and the figure of the lingam is still to be seen on the lintel which surrounds the Circus at Nismes, as well as on the front of some of their ancient churches, particularly on that of the cathedral of Toulouse, and on some churches at Bourdeaux. Plutarch says that the Egyptian god Osiris was found everywhere with the Priapus exposed. Ptah-Sokari is also so represented, and images of that kind were called Ptah-Sokari Osiri.

There can be no doubt but that the god Baal, whose votaries the Hebrews frequently became, is identical with the lingam, and the god styled Chiun in Amos v. is Siva, whose name the races dwelling in Hindustan and along the valley of the Indus pronounce Seb, Seo, Sivin, and Chivin. Yet there is nothing to fix the date at which the worship of Siva was brought to India, nor by whom brought; but the wars between the Buddhists and the linga worshippers of the Dekhan extended up to the 11th century of the Christian era, and formed a series of important events in Hindu history.

The worship of Vishnu seems to have come from Tartary, and that of Siva about the beginning of the Christian era, from the basin of the Lower Indus through Rajputana, and to have displaced the nature-worship of the Vedas. But which race brought the lingam-worship is not known. At Ujjain it was particularly celebrated about the period of the Muhammadan invasion, but probably long before, and one particular linga was named Vinda-swerna, from Vindu, drop, Swerna, gold. At present there is a four-faced lingam, sometimes three-faced or tri-murti ; and tri-lingam is said to be the source of the name Telinga and Telingana, the country extending from north of Madras to Ganjam, and west to Bellary and Beder. The four-faced lingam is called the Choumurti Mahadeva, such as may be seen in the caves of Ellora, and of common occurrence in other districts; and a famous shrine of ek-linga or the one lingam is situated in a defile about six miles north of Udaipur, and has hills towering around it on all sides.

This ek-lingam, or one phallus, is a single cylindrical or conical stone ; but there are others, termed Seheslinga and Kot-Iswara, with a thousand or a million of phallic representatives, all minutely carved on the monolithic emblem, having then much resemblance to the symbol of Bacchus, whose orgies both in Egypt and Greece are the counterpart of those of the Hindu Bagh-es, so called from being clad in a tiger or leopard's hide, as Bacchus had that of the panther for his covering. There is a very ancient temple to Kot-Iswara at the embouchure of the eastern arm of the Indus; and there are many to Seheslinga in the peninsula of Saurashtra. At the ancient Dholpur, now called Barolli, the shrine is dedicated to Gut-Iswara Mahadeva, with a lingam revolving in the yoni, the wonder of those who venture amongst its almost impervious and unfrequented woods to worship. Very few Saiva followers of the south of India ever realize the lingam and the yoni as representations of the organs of the body, and when made to apprehend the fact they feel overpowered with shame that they should be worshipping such symbols.

LINGA-BALJA-VADU, members of the Lingaet sect who follow the Jangam religion, natives of Telingana. They seem to be identical with the Linga-banjigya, or Linga-banjaga, or Lingabanijaga. Linga-banajiga, a merchant or trader of the Lingret sect. Lingadhari, sectarian Hindus who wear the linga.

LINGAET, Jangam, Lingadhari.

Banjigya, : : CAN.
Banijaga, Wani,
Winga-balja-vadoo, MAHR. TE.

The Lingaet, a Hindu sect in Southern India, also called Lingadhara, Linghawant, Lingamat, and Jangama. They are Vira Saiva, whose sole object of worship is the lingam, a model of which in atone or gold (Ezekiel xvi. 17) they carry on their arms, or suspend from their necks in caskets of silver or gold, the workmanship of some of them being of great beauty. They are sectarian Saivavi, for their creed does not recognise castes nor acknowledge Brahmans. Their customs and belief were described about the year 1833 by Mr. C. P. Brown, of the Madras Civil Service, in the Madras Literary Journal. They are very numerous amongst the Canarese people from Bangalore, northwards to Panderpur on the Kistna, and towards Kalliani fort, where the sect was originated in the 12th century by a Brahman named Basava, and north to Berar. They are largely engaged in agriculture, and as shopkeepers. They are rigid in external ceremonial, but they have loose ideas in morals, probably resulting from what Wilson styles their belief in the equality of women. The sect are sometimes styled Jangam, from jangam, the title of their priesthood. They do not reverence Brahmans nor acknowledge the Vedas, their principles do not recognise caste (though they have established one of avocation), and they deny polytheism and the inferiority of women. Besides the trade divisions, there are also race, sectarian, or social distinctions amongst them. The Aradhya, for instance, are of Brahman birth, and though some Aradhya are well versed in Sanskrit, they are not held in esteem by the other Lingaet, who are of Sudra birth. The Samanya or ordinary, the Visesha or extraordinary, and the Samanya Bhakta and Visesha Bhakta, are other sects. The Samanya Bhakta differ from the ordinary Samanya Lingaet only in retaining caste distinctions; the Visesha Bhakta are puritans, have no caste distinctions, and are bound by a vow to honour their guru. Their religious book is the Basava Purana, written in the Canarese tongue, in which language, as also in the Telugu, they have other writings. Lingaet women, in widowhood, re-marry by inferior ceremonies. In such case the widow returns to her parents' home, and is there remarried. The ceremonies are few, and the bridegroom gives small sums, of Rs. 5 or 10 , with two cloths. A village head, who will expend 
about Rs. 200 for his spinster marriage, will expend about Rs. 5 to 100 for his marriage with a widow. The lingam casket of the Lingaet is called Ayigalu. Although authorized by their principles, without castes, they are undoubtedly the most bigoted of all the Hindu sects. They are all engaged in civil avocations. Perhaps in the Madras native army, 20,000 strong, there are not one hundred soldiers of this sect. They are vegetarians, and will not sell, and will not even buy or bring, a creature that is to be killed and used as food. Their dislike to Brahmans takes many shapes; at a village near Kaladgi, three miles distant from the Gutparba river, they would not dig a well in their village, lest a Brahman should be attracted to reside, and their wives had to bring all the drinking water from the river bed.

The three words, Om! Guru, Linga, Jangam, comprise the creed of the sect, and evidently were intended to disavow every part of the Brahmanical priestly tyranny. This mystic phrase is thus expounded. The image (lingam) is the deity; the jangam is the wearer or fellow-worshippers; and he who breathes the sacred spell in the ear is the guru.

The men of the Lingaet sect have a small casket of gold or silver enclosing a lingam of stone or metal, and suspended from their necks, or fastened to the left arm; this form is known as the Jangama lingam, meaning the moveable or locomotive. That in the temples is called the Sthavara lingam, meaning the standing or stable lingam.

Lingam-worship was conducted in Phœnicia (the Canaan of Scripture) in its worst aspect. According to Lucian (De Syria Dea), after the return of Bacchus, he placed the two colossal phalli, each 300 fathoms high? in the vestibule of the great Syrian temple. In the great Bacchic pomp, celebrated by Ptolemy of Alexandria, we read (Athenæus, lib. v.) of a golden phallus 120 cubits high.

The Bana-lingam or Ban-lingam, and the Chakram-lingam of India, are stones formed by attrition in a river bed into a lingam-like form; the saligram is a fossil shell, the interior parts of which resemble a lingam. The lingam of the temples of India is almost invariably of stone of some kind, and is imbedded in the yoni, and varies from a little projecting knob to a considerable cylinder of two feet high and a foot in diameter. The figure inside the temple is often of copper or silver. The Ada-sarpa, or old serpent, in the form of a single cobra, or three, five, or nine headed cobra, is often figured bending over the lingam, with the figure of a bull Nandi, or Basava, the vahan of Siva, sitting before it.

At the Hogena Kallu, or smoke rock, where the Cauvery turns southwards on its way to the rice-fields of Tanjore, 10 or 12 huge lingam stones are arranged in a line, each in a separate cell. At Munoli, Parasgad, in the Belgaum collectorate, are a group of temples of Pancha-linga Deva. At the present day, in the south of India, the principal Siva temples are at Conjeveram (Kanchi), at Jambuk Eswar, near Trichinopoly, Tirunamalle, Callestry (Kalahistri), and at Chadambaram. The Saiva Hindu, however, is essentially polytheist, worships at every temple, and reverences all Brahmans.-Cole. Myth. Hind. p. 175; Wilson's Gloss.; Latham; Lubbock's Origin of Civil. p. 236 ; Burton's Mecca, i. p. 134; Sonnerat's Voyage, p. 52 ; Tod's Rajasthan, i. pp. 219-514, ii. p. 658 ; Hind. Theat. ii. p. 97 ; Cat. Ex., 1862; C. P. Brown in Madras Lit. Soc. Journal. See Jangam.

LINGA PURANA, a mystical and spiritual work of 11,000 stanzas, written about the 8 th or 9 th century.

LING CHEE. CHIN. The name for the punishment inflicted on great criminals in China. The criminal is bound to a cross, and is cut into 120 , or 72 , or 36 , or 24 pieces.-Gray, p. 59 .

LINGI. SANSK. One who wears the outward emblems of the Lingaet order or sect to which he belongs; but it is more usually applied to signify a pretender, a hypocrite, or one who assumes the external emblems of a caste or order to which he does not belong, or of which he does not perform the duties; the bearer of a linga. -Wilson.

LINGOA WOOD, or Amboyna wood, is said to be from the Pterospermum Indicum; it is very durable, and takes a high polish. It was imported into Britain from the Moluccas in considerable quantities at the time when the latter were British possessions; it may be had in any quantity. Very large circular slabs are obtained from the lower part of the tree, by taking advantage of the spurs or lateral growths; they are sometimes as large as nine feet in diameter. A circular disc of wood thus obtained, nearly seven feet in diameter, as well as some other specimens, were exbibited in 1851 by Messrs. Almeida of Singapore, and received a prize medal from the jury. The importa tion ceased with the cessation of British intercourse with those islands. The wood is abundant at Ceram, New Guinea, and throughout the Molucca seas. It is prepared in large circular slabs by the natives of these islands, and can be obtained in almost any quantity if the precaution be taken of ordering it during the previous trading season. The Kayu-boka or Kyaboca wood of commerce is the knarled excrescence of this tree; slabs can be had six or seven feet in diameter, by taking advantage of the spurs which project from the base of the trunk, as the tree itself has not sufficient diameter to furnish such wide slabs. They are occasionally met with as large as nine feet in diameter, but the usual size is from four to six feet. This wood is brought to Singapore by the eastern traders from Ceram, Aru, and New Guinea, and is sold at Singapore by weight. It is much esteemed as a fancy wood, both in Europe and China, but the demand in Europe seems to have decreased of late years. See Amboyna Wood; Kyaboca Wood; Pterospermum Indicum.

LINSCHOTEN. Jan Hugo van Linschoten travelled in India from 1583 to 1589 . His travels were described in a book entitled Voyages into the East and West Indies. It gives information of the early struggles of the Dutch with the Portuguese.

\section{LINSEED, flax seed of Linum usitatissimum.}

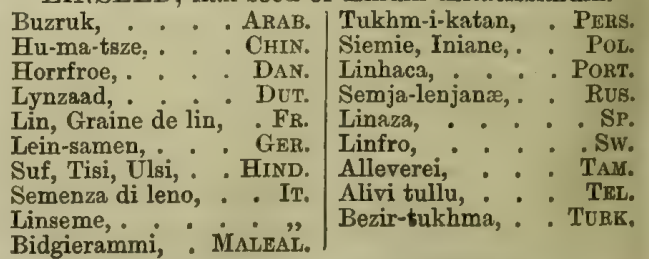

In India the seed is the chief product of the 
flax plant, and is principally used in the manufacture of linseed oil. The first export from Calcutta was made by Mr. Hodgkinson in 1832, and amounted to only ten bushels, but the increase has been rapidly progressive. In 1860-61 the exports from India were 550,700 cwt., value Rs. $1,25,57,790$; and in 1882-83 there were $6,724,514$ cwt., value Rs. $3,52,84,813$; in $1883-84$, $8,543,766$ cwt, value Rs. $4,58,40,234$.

This crop in India is sown thickly in the linseedproducing provinces. In the poorer western districts it is often sown as an edging crop to wheat and other grain, because it is not eaten by cattle in the green state. The reason for its being sown in both long and cross drills, is that the plant, being weakly, requires much sowing to guard it against the action of the weather. It does not seem improbable that the spurious white 'atees' roots of the bazar are occasionally obtained from this or from the Gula-shupre, or Linum trigynum, indigenous in the Lower Provinces. The oilcake which remains after the oil is expressed from linseed, contains the albuminous part of the seed, and is used for fattening cattle. The oil is contained in the kernel of the seeds, and may be either cold drawn, or, as is usual, obtained after the seeds have been subjected to a heat of $200^{\circ}$. The oil obtained by the former process is paler, with less colour and taste, than where heat has been employed. The seeds of different countries yield different proportions of oil. It is one of the cheapest fixed oils; is a drying oil, and is used in the manufacture of paints, varnishes, and printing inks. Where the linseed oil of India is not possessed of the full drying properties of the oil prepared in Europe, there is no doubt this is owing to the Indian linseed being expressed before the mustard seed has been separated, with which it is commonly mixed, in consequence of the two plants being often grown together. Byboiling with litharge, its drying properties are much improved. When used as the vehicle for the harder resins, it should be pure, pale, well clarified, and combined with the resin at as low a temperature as possible. Unless these conditions be attended to, a dark varnish is produced, which becomes darker by age. This oil gives softness and toughness to the resin, but produces a slowly drying varnish. It is clarified for the best varnishes by being gradually raised to near the boiling point in a copper pan. It is used also in printers' ink.- $-M^{\prime}$ Culloch; Smith.

LINUM USITATISSIMUM. Linn. Flax was cultivated in Egypt in very early periods. It is extensively grown in many parts of British India, and produces abundance of seed for oil, but its fibre is inferior. European linseed, on the other liand, is better for fibre than for oil. By proper treatment, however, good fibre can be got from plants raised in India. In N. India it is cultivated as a mixed crop, with'grain; it is sown in October, and never irrigated. Every 5 seers of seed yield $1 \frac{1}{4}$ seers of oil by the native process of pressing. Flax fibre is prepared by steeping, stripping off the bark, and then beating, so as to separate the fibres. Linen cloth and cambric are prepared from it, the latter differing from the former in its fineness, and in being obtained from. plants which are more thickly sown. Linen clothing is cool, being a better conductor of heat than cotton; but when the skin is covered with perspiration, or exposed to cold, it feels cold and chilly. The fibre of flax is a straight tube-like cylinder, and is therefore less irritating than the twisted fibre of cotton. Hence lint, which is prepared by scraping linen, is preferable to cotton for surgical dressings. Tow consists of the short fibres of the flax which have been removed in the process of hackling. In India the seeds are officinal with natives, being given in infusion? for asthma. The seeds, after having had the oil pressed from them, are in the form of a flat mass, commonly called oilcake.-M.E.J.R.; Poucll; Roxb.

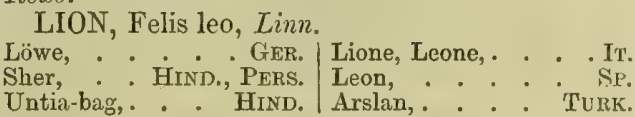

The lion is generally recognised to be of only one species, with the lion of Senegal, the lion of Barbary, the lion of Persia, the lion of Gujerat, Rumn of Cutch, and Kattyawar, and the lion of Gwalior and Hurriana as varieties. The lion is the desert king, as the tiger is the monarch of the jungles. It was, till early in the 19 th century, tolerably plentiful at Gwalior, and also about Goonah, and lions have been killed 20 miles from Saugor, but wretched, mangy-looking things, the male generally nearly maneless, and usually inferior in size and appearance to its African brothers. Tigers are said to avoid the lions, and to desert those jungles in which any roving lion may make its appearance. In the Kattyawar district, which the lions most affected, tigers were said to be unknown, though panthers are common. It has been also supposed that the lion avoids the tiger; and in the Central Provinces, since tigers have been shot off, lions began to appear in the northernmost parts. The lion is very rare in Afghanistan, but has been heard of in the hilly country about Kābul, and there they are small and weak compared with the African lion. The lion is found as far as Tashkend, in a northerly and easterly direction. In 1837, Major Brown ('Gunga' of the Bengal Sporting Magazine) remarked that ' only 23 years elapsed from the occupation of the Hurriana country, when the lions, which were at one time in the dry and sandy deserts of the Hurriana, became extinct south of the Cuggar. Having no inaccessible dens to retire to during the hot weather, the lions, from necessity, took up their abode where water could be found; and as places of this description were rare, and generally near villages, their retreat was easily beaten up, and their entire destruction speedily effected. We have the evidence of Jahangir and the Rev. Edward Terry, that in their days the province of Malwa abounded with lions. Jahangir records that he had killed several, and Mr. Terry mentions his having been frequently terrified by them in his travels through the vast woods and wilderness of the country. Bernier had frequent opportunities of witnessing the chase of this animal, an amusement which was reserved for the emperor Aurangzeb alone. Captain Postans observed that while Kattyawar abounded with the tiger and lion species, Cutch, the neighbouring province, was free from them. The Times of India related how Lieut. Heyland, 56 th Regiment, succeeded in killing 11 tigers, 2 lions, several cheetas, bears, and wild jungle boars; and while stationed at Dessa, he shot three lions in one year. One of them, which measured some nine feet in 
length, had severely wounded Lieutenant Clarke of the R.A. some time in August. When the $3 \mathrm{~d}$ Bombay Cavalry was stationed at Rajkote in Kattyawar (in 1832-33), Captains Reeves, Berry, and others of that regiment used to shoot lions on horseback. Major Fulljames turned out a lion from the Bhet (a sort of island in the Runn of Cutch), opposite the town of Junjuwara, in 1835, and followed it up to a place called Khura Suttapur, on the southern border of the Runn, where he shot it; and Colonel Le Grand Jacob, when First Assistant to the Political Agent in Kattyawar, killed a lion and lioness in one day in the Geer jungle valley, in the southern part of Kattyawar.

In the year 1862, a correspondent in the Times of India, writing of Kattyawar, says lions existed then in certain portions of this province, and in Gujerat also, on the range of hills near Deesa. The figure of a lion is on the top of each of the three tall pillars or columns at Bettia in North Berar. A lion was shot by Mr. Arratoon, a little before the appearance of the Asiatic lion in the Barah jungles. Colonel Clifton Benbow, of the Bombay Army, in his youth a great hunter of large game, with his companions hunted the lion in the Runn, by galloping at them and firing, but continuing to gallop on without pausing to see the effect of the shot, - each of the party acting similarly until the lion fell.

One of the largest lions seen in England was caught, when very young, in Hurriana, by Gen. Tatson, and was presented to George IV. The Sporting Review, in 1845 , mentions the lion as an inhabitant of the territories south of Gwalior. About 1848 there was in Calcutta a lioness, more than two-thirds grown, which had been captured as a small cub in Sind. There were also then in the London Zoological Gardens a young lion and lioness from Gujerat.

Heber mentions (ii. p. 149) having been informed in the year 1825 , that lions were in considerable numbers in the Saharunpur and Ludhiana districts, and that they had been killed in the northern parts of Rohilkhand, and in the neighbourhood of Moradabad and Rampur. One was killed in the Sagar district in 1851; and some years later, another only a few miles from the Jubbulpur and Allahabad railway.

In the Pro. Beng. As. Soc, Dr. King adduces several instances of the lion (not the maneless variety of Gujerat) having been recently shot by sportsmen in Goonah in Central India.

In the report of the great Trigonometrical Survey for 1871-7\%, Captain Trotter, R.E., gives an account of the lion of Gujerat. It is not maneless, although the mane is considerably shorter and of lighter colour than that of the African species. It is called the Untia-bag, camel-coloured tiger, by the natives. The male is rather darker than the female, and is a little heavier about the head and shoulders, the female being very much the same shape as the tiger. There are no difficulties to the lion crossing to the Runn from the south of Persia. And it is supposed to be the lion that visits India, from which the figure was taken that is used in the royal arms of England.

The lion is frequently met with on the banks of the Tigris below Baghdad, rarely above. On the Euphrates it has been seen, almost as high as Bir. In the Sinjar, and on the banks of the Khabour, they are frequently caught by the Arabs. They abound in Khuzistan, the ancient Susiana, three or four together, and are hunted by the chiefs of the tribes inhabiting that province. In 1861, Captain Balfour, of the Indian Navy, in one day, at daybreak, saw a group of four lions. About noon, from a 'tell ' close to the river, on the plain below, ten were counted; and in the evening, some twenty miles up the Tigris, three were seen.

Mr. Layard was given a tame lion by Osman Pasha, commandant of Hillah; and Sir Henry Rawlinson had a tame lion for some years at Baghdad, which was much attached to him, and ultimately died at his feet, not suffering the attendants to remove it.

The maneless lions, by the people of Babylonia, are called mōmin, or true believers; the maned lions they call gabar; the former they say will spare a Musalman if he pray, the latter never. Sir Gardner Wilkinson says the same of the green and the black crocodile of Egypt.

The Hindus, in their fifth avatar of Vishnu, recognise that deity as Nara Sinha (Nara, a man, and Sinha, a lion), a man-lion.-Madras Mail, May 12, 1873 ; G. Rawlinson, i. p. 40.

LIP-LAP, in Netherlands India, a half-caste, a child of a European and a native.

LI PU, the six bureaux of administration in China.

LIQUEURS are alcoholic fluids variously flavoured and sweetened. They are called Shrab, and are largely made in all parts of India, from arrack, and spirit of aniseed, roses, saffron, musk, citron, or simply sugar.

\section{LIQUIDAMBAR.}

Mia-sailah, . ARAB. | Liquid storax, . ENG. Nan-tu-yok, Tu-yok,BURy. Rasamalay,. . MALAY.

The name is derived from Liquidum, fluid, and Ambar, the Arabic name of amber. Theliquidambar of commerce is a product of three plants. I. styraciflua, a large, fine tree, is the species found in Mexico and the United States, in the latter of which it is called sweet gum, and the fragrant liquid exudes, though not copiously, from incisions in the stem. This is called liquidambar, oil of amber, and copalm balsam, and in this form has a pleasant balsamic odour, and an aromatic bitter taste. This becoming dry, forms what is called soft or white liquidambar, which resembles very thick turpentine, has a feebler odour than the liquid balsam, and contains less volatile oil, but more benzoic acid. L. orientale is a native of Cyprus, where it is called Xylon Effendi (the wood of our Lord); it produces an excellent white turpentine, especially by incisions in the bark. It is also said to be produced on the island of Cabross, at the upper end of the Red Sea, near Cadess, which is three days' journey from Suez. The product of the $\mathrm{I}$. altingia is said to be mixed with the substance obtained by boiling the branches of Styrax officinale, or acting upon them with oil, spirit, or naphtha. The subject is interesting as connected with ancient commerce, inasmuch as old writers mention a liquid with the solid storax, the mia-sailah and mia-yabseh of the Arabs. L. cerasifolia of Wallich (Sedgwickia cerasifolia of Griffiths) grows in Assam, but it is not known if it yields any balsam.

All these balsams are obtained either by spontancous exudation, by incision into the bark, or decoction of the bark, leaves, and branches.- 
Eng. Cyc.; O'Sh.; Dr. Mason in Beng. As. Soc. Jour., 1848; Hogg, Veg. King.

LIQUIDAMBAR ALTINGIA. Blume.

Nan-tar-ok, . . . BURM. Rose maloes. . . ENG. Nan-tu-yok, $:$ "
Liquid amber tree, Eiquid storax tree,
Rasamala, JAV., MALAY

A superb tree, native of the forests of Java, at elevations of 2000 and 3000 feet above the level of the sea, and indigenous on the Tenasserim coast, in some parts of which it is quite abundant, and a considerable stream in Mergui derives its name from this tree, in consequence of its growing so thickly on its banks. It grows also in N. Guinea, rising to 200 feet. The bark of L. altingia of Tenasserim and Java is bitter, hot, and aromatic, and when wounded affords a resinous substance, which is employed to mix with balsam of Peru ; and a similar substance is obtained from L. orientale of the Levant islands, L. cerasifolia, and L. styraciflua of Mexico. The balsam of L. altingia, with that of $\mathrm{L}$. orientalis of Rhodes, furnish the rasamala or rose maloes of commerce. This is shipped from Rhodes to Alexandria. The latter is said to follow down the Red Sea to Aden, and to the Persian Gulf and Bombay, whence it is sent to China, Asia Minor, Arabia, Surat, Annam, and Sumatra, and seems to have been shipped to places from which it was formerly sent. The balsam called liquid storax, rasamala or rose maloes, is a stimulating expectorant, influencing the mucous membranes, especially that which lines the air passages. -Dr. Mason in Ben. As. Soc. Jour., 1848; O'Sh.; Hogg, Veg. King; Smith.

\section{LIQUIDAMBAR CERASIFOLIA. Griff.} Sedgwickia cerasifolia, Griff., Wall.

Grows in Assam, but it is not known if it yields any balsam.-O'Sh.; Hogg, Veg. King.

LIQUIDAMBAR FORMOSANA. Hance. $\mathrm{L}$. Formosana, L. altingia (Altingia Sinensis, Oliv.), and the maple-leaved L. Maximowiczii, all grow in China, where they are called Fung-shu. They are large timber trees, with gnarled branches and rustling leaves, and the Chinese believe that ghosts hide in their branches. The chi-ling or pigs' tubers are the corky excrescences on these trees. A silk-producing insect is reared on the L. Formosana.-Hance; Smith, Mat. Med.

LIQUIDAMBAR ORIENTALE. Von Mueller. L. imberbe, Aiton, a tree of Asia Minor, yields liquid storax, which is vanilla scented, containing much styrol and styracin. It keeps moths from woollen clothing, and is used in perfumery. Liquidambar orientalis is a small tree, a native of Cyprus and other parts of the east. It was introduced into the Jardin des Plantes, Paris, from Smyrna, and is said to occur along the Red Sea. Dr. Pococke, as quoted by Dr. Lindley, states that it is called Xylon Effendi (the wood of our Lord) in Cyprus, where it produces an excellent white turpentine, especially by incisions made in the bark. Liquid storax is said to be obtained by boiling the bark.-Von Mueller.

LIQUIDAMBAR STYRACIFLUA. $L$.

Usteruck, . . . ARAB。 Liquidambar, . . ENG. Meati-lubani,": " Rasamala, : iracay. Salajit, Meah, : " " Cotter mija,. : . Turk. Sillarus, ${ }_{\text {Copalm balsam, : " ENG. }}$ Kara-ghyunluk-yaghy, ,

vor. II. The Lishari is a more degraded creature even
than the Gurchani. In 1850 , one raid was

from the bark of this tree, is at first liquid, transparent, yellow, rather consistent; its odour is strong, and resembles that of liquid storax; taste very aromatic and acrid. By long keeping it dries into a deep brown resin. It contains benzoic acid, and has a benzoin odour.

LIQUORICE JUICE, Spanish juice.

Arak sus,. . . ARAB. Regaliz, . . . . SP. Jetimad-ka-ras, . HIND. Ati madhuramu, . TEL. Sugo di regolizia, . . IT. Yashti madhukamu, ", Succus liquoritiæ, . LAT.

This is the inspissated juice of the root of the plant Glycirrhiza glabra. The juice is boiled to a consistency for rolling into paste, when it is wrapped in bay leaves. It costs about $£ 5$ the cwt. Liquorice lozenges are made with extract of liquorice, or of Gunch, gum-arabic, each six ounces, pure sugar one pound. Dissolve in boiling water, and concentrate to a proper consistence. Use, - demulcent in irritating coughs. - Beng. Phar. p. 435 ; Poole; $M^{*}$ Culloch.

\section{LIQUORICE ROOT.}

Ussul-u-suz, . ARAB.|Pao doci, . . PORT. Kan-ts'au, . . Chis. Regoliz, Alcaçuz, . , Lakris, : DAN. Solod kovyi koren, Rus. Mit'ha lakri, . . DuKH. Madhuka, . . SANSK. Zoethout, : DUt. Yastimadhuka,. " Reglisse, : . Fr. Wellmi, Olinde, SINGH. Racine donce, . . " Regaliza, Orozuz, . SP. Sussholz, Lakritze, GER. Lakrits, . . . . Sw. Jetimad, . . Hind. Lakritze, . : : " Regolizia, Logorizia,. IT. Adimodrum, : TAM. Liquirizia, . . . ", Athimadhuramu, . ", Bekh-mehak, : PERS.

In Europe, the liquorice roots are obtained solely from the Glycirrhiza glabra, a perennial plant, a native of the south of Europe and Persia, but cultivated in some parts of England. It is grown in large quantities about Peshawur, dug up, dried, and cut into pieces, and used by the natives as a tonic in fever, in doses of sixty grains, also as a demulcent in coughs, and in all diseases consequent upon an undue accumulation of phlegm or bile. The roots are very long, about an inch thick, flexible, fibrous, of a brown colour, and, when fresh, juicy; taste sweet. They are apt to spoil, and it is necessary to pack them in sand, when not required for immediate use. They are an article of the Materia Medica, particularly in coughs, colds, etc., and are also in demand by brewers and druggists. Throughout Southern India it is the roots of Abrus precatorius that are sold for liquorice. They are a perfect substitute, and are sold in the bazar as a medicine. In China, the roots of Glycirrhiza echinata and Gl. glabra are used.-Cat. Ex.; Faulkner; Mason; O'Sh.

LIRIODENDRON, the tulip tree, one of the large size, and well adapted for a plantation or lining an avenue; the flowers are large and of a yellow and red colour, they appear in the rains; it is easily raised from seed. The bark is a strong tonic, and is said to be equal to the Peruvian. The wood is fine-grained and smooth, used by coachmakers and carpenters. Roxburgh describes L. grandiflorum and L. tulipiferum. - Riddell; Gamble.

LISHARI, a section of the Gurchani tribe. Magnoliacex, is highly ornamental, growing to a 
reported against them; in 1852 , one; in 1853 , four; and in 1854, four. These raids were not, however, successful. In front of the Gurchani and Lishari Hills, and between Harrand and Mithunkote, are plains inhabited by the Dreshuk, British subjects.

LI SHE CHAN, sometimes called Li Poon Woo, a Chinese author of botanical and medical works.

LITCH. BALUCH. Proprietors' dues, corresponding to jaghir. Hăq Litch paid to the proprietors generally $\frac{1}{16}$ th share of produce. Pani Litch pay Abiana for the water of wells on another estate.

LITCHI. ChIs. Fruit of Nephelium litchi, Euphorium litchi, $C a m b$., common in China, but the tree is also grown in Tenasserim, Bengal, Travancore, and the island of Mauritius, a tree belonging to the natural order Sapindaceæ. The eatable part is a pulpy flesh, which covers a stone enclosed in a hard, dry, tesselated, prickly pericarp. The Rambutan, Nephelium lappaceum, and the Long-yen or Longan, Nephelium longanum, are yielded by species of the same genus. The Chinese cultivate many varieties of each. The litchi fruit, called by the Chinese Tanli, is imported from China into England in chests, and can be had in Liverpool at about $6 \mathrm{~d}$. per dozen. The litchi looks like a strawberry in size and shape; the tough, rough, red skin encloses a sweet watery pulp of a whitish colour surrounding a hard seed. The whampe, lichi, longan or dragon's eyes, and loquat, Eriobotrya Japonica, are four indigenous fruits at Canton. The whampe resembles a grape in size and a gooseberry in taste.-Hogg, Veg. Kingd.; Williams' Middle Kingdom; Mason, Tenasserim; Smith.

LITERATURE. From the most ancient times there have been races and nations in the south and east of Asia who have been famed for their literary attainments. The Akkadians were preeminently a literary people; their conception of chaos was that of a time when as yet no books were written, and in their legend of creation the art of writing was seemingly to be traced back to the very beginning of mankind. They were the inventors of the cuneiform system of writing. They left behind them a considerable amount of literature, which was highly prized by their Semitic successors, the Babylonians and Assyrians. Accordingly, a large portion of the tablets which have been found at Nineveh consist of interlinear or parallel translations from Akkadian into Assyrian, as well as of reading books, dictionaries, and grammars, in which the Akkadian original is placed by the side of its Assyrian equivalent. In the Akkadian mythology, there was a tree of life, of Irmin, the personified Euphrates, and of Hea, the snake-god of the tree of life.

The Hittite, another powerful race, carried their arms, their arts, and their religion to the shores of the Egean. At one time their empire stretched from the Euphrates to the Dardanelles, and they held mastery in Syria in the era of the Judges and earlier kings of Israel. To the Phœnicians and the Hittites the Greeks owed their alphabet and their early civilisation, and the alphabet as used in Europe came through the Greeks and Romans. The Hittites were defeated by the Egyptian king Rameses II., about. B.C. 1340 ; their last king, Pirsiris, was defeated and slain by the Assyrians B.C. 717 , and their writing character was displaced by the Assyrian cuneiform.

From another race of that south Asian region there has been handed down a sacred book, the Zendavesta. It is a compilation, for liturgical purposes, from various older books which have been lost. It is composed of eight pieces or books, entitled Yaçna, Visporatu or Yisparad, Vendidad, Yashts, Nyayish, Afrigans, Gahs, Sirozah. It is written in the old form of Aryan speech called the Zend, a language closely cognate to the Sanskrit of the Vedas, and to Achrmenian Persian, or the Persian of the cuneiform inscriptions. The original texts of the Zendavesta are supposed to have been written in Media by the priests of Ragha and Atropatene, and to exhibit the ideas of the sacerdotal class under the Acbæmenian dynasty.

The taste for literary pursuits continues to be. evinced by the Iranian, Turanian, and Semitic races of Central Asia and Arabia. In Central Asia most of the celebrities in the field of religious knowledge and belles-lettres have been Tajaks. At the present day the most conspicuous of the Mawla and Ishan are Tajaks, and the chief men of the Bokhara and Khiva courts are Tajak, or, as the Turks style the race, Sart. In Central Asia, the warrior, the shepherd, the priest, and the laymen, youth and old age, equally affect poetry and reciting of tales. The literature of the Muhammadans or settled nations brought from the $\mathrm{S}$. is filled with exotic mataphor and illustration. In the three khanates, the Mawlas and Ishans have written much on religious subjects, but its mystical allusions are beyond the reach of the people. The Uzbak, the Turkoman, and Kirghiz esteem music as their highest pleasure, and often break out in song, singing soft minor airs. The Uzbak poetry on religious subjects is exotic, derived from Persian or Arabic sources. The Tartar compositions are tales, and relate to heroic deeds, similar to the romances of Europe. The Arab writings up to the time of Mahomed consisted of poetry and romances, and their learned men were accustomed to compete with one another, and invite criticism by suspending their poems in the temple of Mecca. These were known as the Muallakat or suspended, and Mahomed with some chapters of the Koran followed this popular course.

The Muhammadans of Arab, Turk, and Iranian descent have followed this predilection, and to the present day throughout British India every educated Muhammadan occupies his leisure in writing poetry, works on grammar or history.

In the middle of the 19th century Sir Henry Niers Elliot availed himself of this trait, and undertook to gather the writings of all the Muhammadan authors on India, with the object of compiling a history of India, as told by its own historians. He collected from all sources, and the Editor sent him catalogues of the books available in the libraries of the Nawab of the Carnatic and the Dewan Mudar-ul-Umra. He did not live to complete his project, but the task was entrusted to Professor John Dowson, who edited eight volumes of extracts from 17 early Arab geographers and historians of Sind and India, and 154 historians of India. Many of these authors are known to the people of Europe and 722 
Asia,-A Abul Fazl, Abu Talib, Biladuri, Biruni, Ibn Haukal, Idrisi, Istakhri, Kazwini, Khafi Khan, Khondamir, Khurdadba, Masudi, Mir Khond, with the royal authors Timur, Baber, Firoz Shah, Aurangzeb, and Jahangir.

Another large class of the literature of Southern Asia relates exclusively to India proper, and emanated from the Brahmanical branch of the Aryans which penetrated into India from the north-west. They have had in use a spoken language or Prakrita bhasha, and a Sanskrita bhasha or perfected speech. Their Sanskrit literature was almost entirely in sloka or verse. Astronomy, mathematics, medicine, surgery, music, the drama, architecture, and painting engaged their attention, as also law as in the Gribya Sutras and the code of Menu. To the Brahmanical race India is indebted for the four Vedas,-Rig, Sama, Yajur, and Atharva Veda; also the Brabmanas supplementary to the Vedas; likewise the Sutras or sacred traditions, and two great epics, the Māhabhārata and Ramāyana. India is also indebted to the Brahman race for a system of theology, for six darsana or schools of philosophy, known as the Sankhya, the Yoga, two Vedanta schools, the Nyaya and the Vaiseshika; and the science of language in grammars and dictionaries has received the attention of their ablest grammarians.

The reverence of the Brahmanic race for learning is evinced by their recognising in Saraswati a goddess of learning, and in Ganesh or Ganapati a god of wisdom. In all their letters and all their books they commence with an invocation to Ganesh, and he is propitiated at the beginning of every undertaking.

The early Sanskrit literature comprises the Vedas and the works collected in the Buddhist Tripitaka. The Vedas are religious books of the Hindus, of which the Rig Veda, Yajur Veda, Sama Veda, and Atharva Veda are deemed inspired, and regarded as canonical. But the term is also applied to scientific works, as Ayur Veda, the art of medicine, science of life; Dhanur Veda, the art of war (the bow); Gandharba Veda, the science of music. Besides these are several series of ancient books, the Upa Veda, the Upanishad, etc. The latter writings of this race are to be seen in the Bhagavat Gita, the dramas of Kalidasa, such as Sakuntala and Urvasi, a few episodes from the Mahabharata and Ramayana, such as those of Nala and Yajnadatta badha, the Hitopadesa, and the sentences of Bhartrihari.

The Mahabharata and the Ramayana books are the national treasuries of the traditions and legends of the Hindus, and contain all that has been preserved of Vedic ideas and institutions, as well as the expression of that later Brahmanical system, which forms the basis of the existing religion and civilisation of the masses, ramifying more or less throughout the entire body of Hindu literature. The Mahabharata is the source of all the Puranas. It is the Purana properly so called. The Bharata war relates to the period of Aryan invasion, when the invaders had reached the upper courses of the Jumna and Ganges. The Ramayana refers to a period when an Aryan empire had been established in Oudh, and when Vedic rites and institutions had been established in the very heart of Hindustan. There are three works bearing this name, the first edition in Sanskrit, by Valmiki ; a later edition in Hindi, by Tulsi Das; and a third in Tamil, by Peruntevanar.

The Pancha Tantra (five chapters) is one of the oldest collections of Indian fables. It can be traced back to the 6th century A.D. The Hitopadesa, founded upon it, is still more celebrated. Among the well-known books may be mentioned twenty-five stories of a demon, thirty-two tales of the animated images supporting the throne of Vikramaditya, the tales of a parrot, etc. Each fable is designed to illustrate and exemplify some reflection on worldly vicissitudes, or some precept for human conduct; and the illustration is as frequently drawn from the intercourse of human beings, as from an imaginary adventure of animal existence; and this mixture is in some degree a peculiarity of the Hindu plan of fabling or story-telling. Again, these stories are not aggregated promiscuously, and without method, but they are strung together upon some one connected thread, and arranged in the framework of some continuous narrative, out of which they successively spring, - a sort of machinery to which there is no parallel in the fable literature of Greece or Rome. As far, therefore, as regards the objects for which the apologues or stories are designed, and the mode in which they are brought together, this branch of literary composition may be considered as original with the Hindus; and it was the form of their fabling that served as a model, whilst at the same time the subjects of their tales afforded materials, to the story-tellers of Europe in the Middle Ages. That the fables of Pilpay were of Indian extraction was known to the orientalists of Europe in the latter part of the 18 th century.

The Vrihat-Katha contains the Sanskrit form of the Beast Stories, and the Hitopadesa and Pancha Tantra have been arranged for translation into many of the languages of Asia and Europe.

Kalidasa, a great dramatic and epic poet, the father of the Sanskrit drama, wrote the Raghuvansa, the Knmara-sambhava, and Sakuntala. There also appeared Mrich'chha-kati or Toy Cart, a drama in ten acts; the poem of Nala and Damayanti; the Megha-duta or Cloud Messenger; the Gita Govind of Jayadeva, about the 12th century; and between the 8 th and 16 th centuries there appeared the eighteen Puranas, meaning old writings, which form the sacred texts of the modern Hindus.

Hindus reckon six great poems, or Maha-Kavya, three of them, the Raghuvansa, the Kumarasambhava, and Megha-duta, by Kalidasa; the Kiratar-juniya, anthor unknown; the Sisupalabadha by Magha; and the Naishadha-charitra by Sri Harsha.

The great defect in all the Sanskrit writings is in the absence of historical literature. On the other hand, the Muhammadan histories always present a connected narrative of the progress of events, show a knowledge of geography, a minute attention to dates, and a readiness to quote authorities. None of the Hindu nations have books from which a history of their own, country could be drawn up, similar to what Sir Henry Elliot contemplated, the sole work of a historical character by any of the Brahman race being the Raja Tarangini, a history of Kashmir by Kalhana. Their writings have been largely speculative,- 
works of imagination, poetry, and the drama; and religion, astronomy, mathematics, ethics, grammar, etymology, and philosophy, with books on medicine, have formed a large part of their writings. Hindu literature is largely interwoven with the Hindu religions.

Buddhism has had two great revivals in India. Asoka (B.C. 257) collected the body of Buddhist doctrine into an authoritative version, in the Magadhi language, or dialect of his central kingdom in Behar, and this version for 2000 years has formed the canon of the southern Buddhists. He issued and engraved on rocks fourteen edicts enjoining the principles of that faith. Later on, Kanishka, a great Saka conqueror who ruled (A.D. 40) over the N.W. of India, from Yarkand and ? Khokand to Agra and Sind, drew up three commentaries on the Buddhist faith. These commentaries supplied in part materials for the Tibetan or Northern Canon, completed at subsequent periods. The Chinese designate this Northern Canon as the Greater Vehicle of the Law, and it includes many later developments or corruptions of the faith as originally embodied by Asoka in the Lesser Vehicle or Canon of the Southern Buddhists (B.C. 244). The Buddhist Canon of China, a branch of the Greater Vehicle, was arranged between A.D. 67 and 1285. It includes 1440 distinct works, comprising 5586 books.

In A.D. 410-432, the holy books of Asoka were rendered into Pali, which is now the sacred language of the Buddhists of Ceylon, Burma, and Siam.

The literature of the Singhalese Buddhists is in Pali, and the Dipavansa contains a history of Buddhism in that island which breaks off with the death of Mahasena, A.D. 302. The Mahawansa was compiled by Mahawana, who lived about A.D. 500, was brought down by successive writers to the 18th century, and was translated by the Honourable G. Turnour, of the Ceylon Civil Service. The Singhalese language, according to Rask, belongs to the Turanian family of speech; but in Ceylon, where the Aryan and Dravidian element is intermixed, a remnant of Buddhists is still to be found who use the Pali scriptures.

Pittakayan, or the Three Baskets, embodies the doctrines, discourses, and discipline of the Buddhists. Its contents extend to 592,000 stanzas, and the Atthakatha or commentaries, which are as old as the 5th century, contain 361,550 more. They were translated into Pali from Singhalese by Buddhaghoso, A.D. 420 (Mahawanso, cxxxvii. p. 252). The legendary tales profess to have been related by Gautama Buddha, and were collected under the title of Pansiya panas jatakapota, or the 550 births.

India has been repeatedly overrun by races from the west, - Turanians, Iranians, and Semites, -and this has led to the formation of a new language, known as Urdu or Hindustani. It is a lingua franca, and largely in use throughout British India. It is a mixed tongue, formed on the Indian dialect of Kanouj, to which have been added numerous words from all the languages of the native Indian races and of the invading armies. This new tongue has been almost solely used for poetry; and Wali, the earliest of the celebrated poets who have used modern Hindustani, wrote in the middle of the 17 th century;
Sauda in the 18th century. They have been followed by a multitude; but their compositions are in general mere imitations of the Persians.

Of all the Turanian languages, Tamil is probably the most highly cultivated, and possesses the richest stores of indigenous literature. Its name signifies sweetness, and though it has not the softness of the Telugu it is a harmonious tongue, and much cherished. The Tamils have a kind of elegy which they denominate Ula or Malai, consisting of couplets. The Parani also consists of a succession of couplets, but has its lines of equal length. The Kalampakam is a sort of poetry in which the author mixes at pleasure all kinds of verse. The Ammanai consists of couplets, composed of lines of four feet. The diction ought to be perfectly familiar. This kind of poetry is used in recounting the lives of princes, etc.

The Burmese Buddhists' sacred book is the Beetaghat; the Wee Nee contains the whole duty of the Burmese monk. Young Buddhists learn the Payeht Gyee and the Payah Shekho, Pali sermons and forms of worship, also the Mingula Thoht, Buddhist Beatitudes. Later on they pore over the Abidhamma Konit-gyan, the seven books of the most difficult parts of the Beetaghat, with the Thing-yoh and Thaddah. Their lay literature consists of beast tales, fables of animals, with the Nataka or drama, from Nata, a dancer, or the Pooay or Pwe, a dramatic performance; amusement winds up with the Pwe or Pooay.

The dramas are all founded on the tales which Gautama told of his 510 previous existences, all of them taken from the Sanskrit or Pali. These, called Zaht or Woottoo (i.e. a real story), are religious plays, the 510 Jatakas. The work of fiction is called Paya Zaht, an acting play.

China.-Letters are held in higher esteem in China than in any other country in the world. Natural inclination, personal interest, and popular feeling are thus all on the side of literature. It is the key which opens the door to official life, and is the passport for admittance into cultivated society. Nine-tenths of the educated youths of China devote themselves to imitate the established literary models. The four highest collegiate degrees are the Chwang-yuen, Pangyen, T'an-hwa, and Ch'uen-lu.

In the classical literature of the Chinese, at the head of the Wu-king, or five classics, is placed the Yih-king, or Book of Changes, which is held by the Chinese in great veneration for its antiquity, and the occult wisdom, which only sages can understand, supposed to be contained in its mystic lines. It was composed in prison by Wan-Wang, the literary prince, about B.c. 1150 , and is doubtless one of the most ancient books in any language.

The Yih-king treats of general philosophy, and the first cause is supposed to have beell taught by Fuh-hi, whose Institutes were founded on the Pa-Kwa, or eight diagrams, which he invented, and by subsequent combinations increased to 64 . These diagrams are merely trinities of straight lines, upon which has been founded a system of ethics, deduced by giving names to each diagram, and then associating the meaning of these names according to the changes which could be rung upon the 64 combinations. Adding to the diagrams, the points of the compass and elemental appellations, bumid, light, hot, rigid, flexible, 
cold, heavy, and dry, they have formed the material for a cabalistic logomancy, peculiarly pleasing to Chinese habits of thought. They have supplied also the basis for many forms of divination by shells, lines, letters, etc. The leading idea of this curious relic of antiquity seems to have been founded upon the physiological notion of the creation of the world, according to which all material things proceeding from two great, male and female, vivifying elements, the yin and yang, were made in harmony. There are about 1450 treatises on the Yih-king alone, consisting of memoirs, digests, expositions, etc.

Japan and China received from India their Buddhism, with many of the essential doctrines of Hinduism. The Shen Shiu sect of Japan, founded in China A.D. 381, under the title of the White Lotus School, sent friars to India to collect Sanskrit MSS., and several of these contain descriptions of Sukbāvat. In Japan the Shen Shiu sect dates from A.D. 1174.

India. - The latest arrivals from the west have been from nations of Europe,-Portuguese, Dutch, Danes, French, and British, and their authors are so numerous, and have contributed so largely to the literature of Southern Asia, that even for the bare mention of their names space cannot be given. The learned men of each of the civilised nations of Europe and America have formed an Asiatic Society to attend to Asiatic subjects, and individuals are competing with them.

The sacred books of the east, edited by Professor Max Muller, have been transiated by several oriental scholars. They comprise-(1) twelve Upanishads; (2) the laws of the Aryas, as taught in the schools of Apastamba, Gautama, Vasishta, and Baudhayana; (3) the Confucian Shuking, parts of the Shih-king, Yih-king, and Hsiaoking ; (4) the Zendavesta, comprising the Vendidad, the Sirozahs, Yasts, and Nyayis; (5) Pehlavi texts, comprising the Bundahis, Bahman Yasts, Shayast la-shāyast, the Dadistan-i-Dinik, the epistles of Manuskibar, the Dina-i-Mainog-iKhirad, Shikand-gu-mani, and Suddar; (6) the Koran; (7) Institutes of Vishnu; (8) the Bhagavat Gita, with the Sanatsugatiya and the Anugita; (9) the Dhammapada and Sutta Nipata, canonical books of the Buddhists; (10) seven Buddhist Suttas ; (11) the Satapatha Brahmana; (12) the Patimokha, Mahavagga, and Kulavagya, Vinaya texts; (13) the Fo-sho-hing-tsanking, life of Buddha; (14) the Saddharma or the Lotus of the True Law; and (15) the Akaranga Sutra.

The following are the names of the more famed Muhammadan and Hindu authors of works relating to India. The mere names of the European writers would fill a voluminous catalogue:-

$$
\begin{gathered}
\text { a. Muhammadan authors, chiefly in Arabic, Persian, } \\
\text { and Turki. }
\end{gathered}
$$

Abbas Khan, son of Shaikh Ali Sarwani, author of the Tarikh-i-Sher Shahi, written by order of the emperor Akbar.

Abdullah, author of the Tarikh-i-Daudi, A.D. 1575.

Abdullah, styled Wassaf, son of Fazl Ullah, author of Tazjiyat-ul-Amsar-wa-Tajriyat-ul-Asar, A.D. 1312.

Abu Abdullah Muhammad, styled Al Idrisi, author of the Nuzhat-ul-Mushtak-fi-Ikhtirak-ul-Afak.

Abu Is'haq, Al Istakhri, author of Kitab-ul-Akalim, A.D. 951 .

Abu-1-Fazl, Allami, author of the Akbar-Namah, was one of the sons of Shaikh Mubarak, the most learned man of his time. Abu-l-Fazl and bis elder brother, Shaikh Abu-1-Faiz, surnamed Faizi, were the intimate friends of their sovereign Akbar. Abu-l-Fazl's escort was treacherously waylaid and its leader slain.

Abu-l-Fazl-bin-al-Hasan al Baihaka, author of Tarikhus-Sabaktagin, died A.D. 1077. It is also known as Tarikh-i-Baihaki.

Abu-l-Hasan Abi, styled Al Masudi, died A.D. 956. He was a native of Baghdad, a great traveller, acute observer, and able writer. He wandered to Morocco and Spain on the west, and eastwards to China, through all the Muhammadan and many other countries, and he wrote his travels, which he styled Muruj-u-Zahab, or meadows of gold.

Abu-l-Kasim Ubaid-ullah-bin Abdullah-bin Khurdadba, died A.D. 912.

Abu Nasr Muhammad ibn Muhammal-al-Jabbar-ul Utbi, author of the Tarikh Yamini, about A.D. 1030 .

Abu Rihan Muhammad-bin-Ahmad al Biruni al Khwarizmi, author of Tarikb-ul-Hind, born about A.D. 970-71. He was an astronomer, geometrician, historian, and logician, died A.D. 1039.

Abu Umar Minhaj-ud-Din, Usman-ibn-Siraj-ud-Din al Juzjani, about A.D. 1227-1247, author of the Tabakat-i-Nasiri.

Abu Zaid-ul-Hasan, of Siraf, A.D. 916.

Ahmad Yadgar, author of the Tarikh-i-Salatin-iAfaghana, about A.H. 1020.

Abmad-ibn-Yahya-ibn-Jabir, al Biladuri, author of Fatah-ul-Baldan, died A.D. 892. He was also surnamed Abu Jafar and Abu-l-Hasan.

Ala-ud-Din Malik, son of Baha-ud-Din Muhammad Juwaini, author of the Tarikh-i-Jahan Kusha, died A.D. 1253.

Ali Sher Kani, A.D. 1767-78, author of Tuhfat-ulKiram.

Bakhtawar Khan, author of the Mirat-i-Alam and Mirat-i-Jahan Numa.

Beg-lar Nama, written about A.D. 1625 by a dependent of Shah Kasim Khan, son of Amir Saiyid Kasim Beg-lar.

Fakhr-ud-Din, Binakiti, A.D. 1317, author of the Tarikh-i-Binakiti, an abridgment of the Jami-utTawarikh of Rashid-ud-Din.

Fazl Ullah Rashid, styled Rashid-ud-Din, author of Jami-ut-Tawarikh, A.D. 1310.

Ghiyas-ud-Din Muhammad-bin-Humam-ud-Din, styled Khondamir, was a son of Mir Khond, of whose book he wrote an abridgment which he called the Khulasat-ul-Akhbar. He was born at Herat about A.D. 1475. He also wrote the Dastur-ulWazra and the Habib-us-Siyar.

Haidar Mirza Doghlat, cousin of Baber, was the author of the Tarikh-i-Rashidi.

Hamd Ulla-bin-Abu Bakr-bin-Hamd-bin-Nasr, Mustaufi, Kazwini, A.D. 1329, author of the Tarikh-i-Guzida.

Hasan Nizami, author of Taj-ul-Maasir, about A.D. 1205.

Ibn Batuta, a native of Tangiers, travelled over the greater part of Asia, visited India in the reign of Muhammad Taghalaq.

Ibrahim-bin-Hariri, author of the Tarikh-i-Humayuni, which was dedicated to Sultan Baber, A.D. 1528. It is an abridged history of India.

Jahangir. His autobiography has several titles, amongst them Jahangir Nama, Tarikh-i-Salim Shahi, Tuzakhi-Jahangiri, and Wakiat-i-Jahangiri. A continuation of it was written by Muhammad Hadi, called the Tatimma-i-Wakiat-i-Jahangiri. Mutamad Khan, called also Muhammad Sharif, wrote the Ikbal Nama-i-Jahangiri, and Kamgar Khan wrote the Maasir-i-Jahangiri.

Jauhar, Aftabchi, or Ewer-bearer of Humayun, author of the Tazkirat-ul-Wakiat, private Memoirs of Humayun.

Kamal-ud-Din Abd-ur-Razzak-bin Jalal-ud-Din Ishakus-Samarkandi, the author of the Matta-us-Sadainwa-Majma-ul-Bahrain. He was born at Herat, 6th November 1413.

Kazi Ahmad-bin-Muhammad-al-Ghaffari al-Kazwini, author of the Nusakh-i-Jahan Ara, a useful compendium. He was a Persian who went to Mecca and died at Dewal, in Sind, A.D. 1567.

Khushbal Chand, author of the Tarikh-i-Nadir-uz. 
Zamani. He was in the service of the emperors Aurangzeb, Bahadur Shah, and Muhammad Shah.

Majmal-ut-Tawarikh, an Arabic work by an anthor who wrote it between A.D. 1126 (A.H. 520) and A.D. 1193 (A.H. 589). His name is not known, but he was the grandson of Muhalib-bin-Muhammad-binShadi. It is a chronological abridgment of universal h 2 tory to the 6 th century of the Hijira. The Majmal-ut-Tawarikh, about the tenth century was translated from Sanskrit into Arabic by Abu Salihbin-Shu-aib-bin-Jami, and into Persian, A.D. 1026, by $\mathrm{Abul}$ Hasan Ali.

Mir Ali Sher, or Ali Sher Amir, minister of Sultan Husain of Persia, was born A.H. 844 (A.D. 1440). He was of an illustrious family of the Chaghtai tribe. He passed his later days in the com position of Turki and Persian works, of which Sam Mirza names twenty-one. Daulat Shah, the biographer, Mir Khond, and Khondamir dedicated their works to him, and he supported the poet Jami. He patronized sculpture and architecture and music. His Chaghtai Odes are called Nuai, and those in Persian Fanai. He died A.H. 906 (A.D. 1500).

Mir Khusru, died A.D. 1325, author of the Tarikh-iAlai or Khazain-ul-Fatuh. He also wrote the Bakiya Nakiya and the Ijaz-i-Khusruvi.

Mir Muhammad Masum of Bhakkar, author of Tarikhus-Sind, about A.D. 1602, also called Tarikh-iMasumi.

Mir Tahir Muhammad Nasayani, son of Sayyd Hasan of Thatta, author of the Tarikh-i-Tahiri, A.D. 1606.

Misar-bin-Muhalhil, author of the Ajaib-ul-Baldan, frequently quoted by Zakariya-al-Kazwini.

Muhammad Abd-ul-Baki, author of the Masir-iRahimi, a history of the Muhammadans in the Dekhan.

Muhammad Abu-I-Kasim, styled Ibn Haukal, author of the Ashkal-ul-Bilad or Kitab-ul-Masalik-wa-IMamālik.

Muhammad Ali-bin-Hamid, bin Abu Bakr Kufi, about A.D. 1216 translated the Chach-nama or Tarikh-iHind-wa-Sind from the Arabic. The name of the author is not known.

Muhammad-bin-Khawand Shah-bin-Mahmud, styled Mir Khond, author of the Rauzat-us-Safa-fi-Sirat-ulAmbia-wa-ul-Muluk-wa-ul-Khulafa, was born A.D. 1433, lived in Balkh and Herat, and died in Balkh. His father, Syud Burhan-ud-Din Khawand Shah, a native of Mawar-un-Nahr, claimed descent from Hasan, son of Ali. The name of his son, also an author, known as Khondamir, was Ghaias-ud-Din Muhammad-bin-Hamam-ud-Din.

Nuhammad Hadi Kamwar Khan, author of the Haft Gulshan-i-Muhammad Shahi and the Tazkira-iChaghatai.

Muhammad Hashim, styled Khafi Khan, author of the Muntakhab-ul-Lubab Muhammad Shahi, frequently entitled Tarikh-i-Khafi Khan. It is a highly esteemed work, commencing with the invasion of Baber, A.D. 1519, and concluding at the 14th year of the reign of Muhammad Shah. It is full of details of Aurangzeb's reign.

Muhammad-ibn-Isa of Moquinay in Morocco.

Muhammad Kasim Hindu Shah, Ferishta, author of the Tarikh-i-Ferishta, born about A.D. 1570 at Astar. abad, died about 37 years of age, at Bijapur, during a great pestilence. His work is a history of the Muhammadan dynasties of India.

Muhammad Saki Mustaid Khan, author of the Maasiri-Alamgiri, finished A.D. 1710.

Muhammad Uf, author of Jami-ul-Hikayat, about A.D. 1211.

Mulla Abd-ul-Kadir, Badauni, author of the Muntakhabut-Tawarikh, a history of India from the time of the Ghaznavi to the fourth year of the reign of Akbar.

Niamat Ullah, historiographer at the court of Jahangir, author of the Makhzan-i-Afghani and of the Tarikh Khan Jahan Lodi. The former book was written at the request of Khan Jahan Lodi.

Nizam-ud-Din Ahmad, Bakhshi, author of the Tabakati-Akbari. It is one of the most celebrated histories of India down to A.D. 1593.

Nur-ud-Din Lutf Ullah, styled Hafiz Abru, author of the Zabtat-ut-Tawarikh Baisangari, which contains a complete history of the world down to A.D. 1425 . He died A.D. 1430.

Rai Bhara Mal, author of Lubb-ut-Tawarikh-i-Hind. He was the Dewan of Dara Shekoh.

Rashid-ud-Din, A.D. 1310, author of the Jami-ut-Tawarikh, a chapter of Al Biruni's work.

Rustam Ali, author of the Tarikh-i-Hindi, compiled A.D. $1741-42$.

Saiyid Jamal, son of Mir Jalal-ud-Din, Husaini, Shirazi, A.D. 1654-55, author of the Tarkhan Nama or Arghun Nama.

Shah Jahan had several biographers, viz. Muhammad Amin, Kazwini, author of the Badshah Nama, during the reign of Shah Jahan. It was completed by Muhammad Waris; also Inayat Khan, author of the Shah Jahan Nama; also Muhammad Salih, Kambu, author of the Amal-i-Salih, a valuable history of Shah Jahan from his birth to his death, A.D. 1665; also Muhammad Sadik Khan, author of Shah Jahan Nama.

Shaikh Abd-ul-Hakk, author of the Tarikh-i-Hakki, a general history of Muhammadan India.

Shaikh Nur-ul-Hasik, author of Zubdat-ut-Tawarikh, a general history; it is an enlarged edition of the book by his father, Shaikh Abd-ul-Hakk, entitled the Tarikh-i-Hakki.

Shaikh Zain-ul-Abidin, author of the Tabakat-i-Baberi, A.D. 1589-90, an account of Baber's fifth invasion of Hindustan.

Shanıs-i-Siraj-i-Afif Tarikh-i-Firoz Shahi.

Sharaf-ud-Din, Ali, Yazdi, Zafarnama. He died A.D. 1466. A partial biography of Timur.

Subhan Rai, author of the Khulasat-ut-Tawarikh, a general history of India, written A. D. 1695-96.

Sulaiman, the merchant, A.D. 851, author of Salsilatut-Tawarikh.

Sultan Firoz Shah, author of Fatuhat-i-Firoz Shah, an autobiography. Firoz Shah born A.D. 1309.

Sur-ul-Baldan, a compilation from Istakhri and Ibn Haukal.

Timur. Malfuzat-i-Timuri, the autobiography of Timur. This is in Persian. It is supposed to have been written originally in Chaghtai Turki, but in that language it has never been found. In the reign of Shah Jahan it was translated into Persian.

Yahya-bin-Abd-ul-Latif, author of the Lubb-ut-Tawa. rikh, a general Asiatic chronicle, A.D. 1541. He is also named Ismail-bin-Abdul Latif, also Mir Yahya Husaini Saifi.

Yahya-bin-Ahmad-bin-Abdullah Sirhindi, author of the Tarikh-i-Mubarak Shahi. He seems to have died about A.D. 1448.

Yamin-ud-Din Muhammad Husain, styled Amir Khusru, born A.D. 1253, died A.D. 1325. He is said to have left behind half a million of verses.

Zahir-ud-Din Muhammad Baber wrote his autobiography, called Tuzak-i-Babari or Wakayat-i. Babari, in Turki, and they were translated into Persian in the middle of Akbar's reign.

Zakariya, al-Kazwini, about A.D. 1263 or 1275 , author of Asar-ul-Bilad-wa-Akhbar-ul-Ibad, also Ajaib-ulMakhlukat-wa-Gharaib-ul-Maujudat, wonders of things created and marvels of things existing.

Zia-ud-Din, Barni, author of Tarikh-i-Firoz Shahi. This is the foundation of Ferishts's history of the period.

\section{b. Buddhist and Hindu authors, chiefly in Sanskrit,} Hindi, and Tamil.

Agasti or Agastya, the earliest teacher of the Tamils.

Amara Sinha, author of the Amara Kosha Vocabulary.

Anandagiri, author of a Sankara Vijaya.

Angirasa, author of hymns in the Rig Veda.

Apastamba, author of Sutras connected with the Black Yajur Veda, and of a Dharmasastra, and two recensions of the Taittiriya Sanhita.

Aryabhata, the earliest Hindu writer on algebra.

Asoka, king of Magadha, Buddhist Edicts.

Aswalayana, author of Srana Sutras, Grihya Sutras, and other ritualistic works. Founder of a Sakha of the Rig Veda.

Auvaiyar, the most famed Tamil poetess.

Barthrihari, a celebrated poet and grammarian, who wrote the Sringara-sataka, Nita-sataka, Vairagya- 
sataka, also the Vakya-padya and the BhattiKavya.

Bharata, a muni, author of the Gandharva Veda, the science of music and song.

Bharavi, author of the poem Kiratar Juniya.

Bhaskaracharya, an astronomer and mathematician, about A.D. 1100, author of the Siddhanta Siromani, a chapter on arithmetic, known as the Lilavati.

Bhatta Narayana.

Bhatti, author of the Bhatti-Kavya.

Bhava Bhuti, author of the Maha Vira Charita, Uttara Rama Charita, and Malati Madhava, about A.D. 800.

Brahmagupta, an astronomer, author of the Brahma Gupta Siddhanta.

Casi Chetty, author of the Tamil Plutarch.

Chaitanya, a Vaishnava reformer, A.D. 1485-1527.

Chand, a celebrated poet of Hindustan.

Daksha, one of the writers of the Dharmasastras.

Dandi, or Sri Dandi, author of the Kavya Darsa or Mirror of Poetry.

Devi Mahatmiya, author of the Chandipatha, an episode of the Markandeya Purana.

Dhanwantari, a physician.

Dya Diviveda, author of the Niti Manjari, a work on ethics.

Gautama, or Akshapada, founder of the Nyaya school of philosophy.

Gopi-natha, author of the Kantuka Sarvaswa, a modern farce.

Gritsa Mada, reputed author of many hymns in the second Mandala of the Rig Veda.

Halayudha Bhatta, A.D. 700, author of Abhidana Ratnamala.

Hari Charan Das.

Hema Chandra, A.D. 1300, author of Abhidana Chintamani.

Jaimini, author? of the Sama Vedas and its teacher, founder of the Purva Mimansa philosophy.

Jayadeva, author of the erotic lyric Gita Govinda, about A.D. 1200.

Jimuta Vahana, author of the Daya Bhaga, law of inheritance.

Kabir, A.D. 1380-1400, a disciple of Ramanand. He was a celebrated Hindu Unitarian, equally revered by Hindus and Muhammadans, founder of the sect called Kabir Panthi or Nanak Panthi, from which Nanak, founder of the Sikhs, borrowed the religious notions which he propagated with the greatest success. Kabir and other Hindu sectarians used the Hindi language in opposition to the Brahmans, with whom Sanskrit was the language employed.

Kalhana, a pandit of Kashmir, author of the Raja Tarangini.

Kalidasa, author of the dramas Sakuntala, Vikramorvasi, Malavikagni - mitra, Raghu-vansa, Meghadhuta, Kumara Sumbhawa, Nalodaya,Ritu-sanhara, and the Sruta-boatha, a work on prosody.

Irampar, a celebrated Tamil writer, author of the Sarasvati Antati, Erelapatu, and Kangsi Puranam.

Katyayana, author of the Varttika, a continuation of Panini's grammar. He is generally identified with Vararuchi, the author of the Prakita Prakasa, about A.D. 200. He also wrote Srauta Sutras, also the Yajur Veda Pratisakya, and the Katha-saritsagara.

Kautsa, author of the Nirukta, a rationalistic philosopher.

Kavi-karna-pura, author of the Chaitanya Chandrodaya.

Kavi Raja, author of the Raghava Panda Viyam, a poem of studied ambiguity.

Khushal Chand.

Krishna Dwaipayana, styled Vyasa, the reputed compiler or arranger of the Vedas and of the Mahabharata epic poem.

Krishna Misra, author of the Prabodha Chandrodaya, rise of the moon of knowledge.

Kulluku Bhatta, a commentator of the Vedas.

Madhavacharya, a celebrated scholar and religious teacher. He and his brother Sayana have attributed to them many important works, scholia on the Sanhitas and Brahmanas. Madhavacharya was a warm supporter of the views of Sankaracharya, and among his works are the Sarva-darsana Sangraha and the Sankshepa Sankara Vijaya.
Magha, author of an artificial poem, the Sisupala-badha or Magha Kavya,

Mallinatha, a poet and commentator on the Raghuvansa, Meghaduta, and Sisupala-badha.

Mamatta Bhatta, of Kashmir, author of the Kavya Prakasa.

Manu, author of Manu-Sanhita, the code of Manu, also called the Manava Dharmasastra. It is attributed to Swayambhuva, the first Ment. 2685 verses are extant.

Markandeya, author of the Markandeya Purana.

Murari Misra, A.D. 1300? author of Anargha Raghava. Nalo Daya, ascribed to Kalidasa.

Nanak, founder of the Sikh religion, author of their religious book the Adi Granth.

Nannaya Bhatta.

Panini, about B.C. 400, a great grammarian. His writings are in the form of aphorisms.

Parãsara, a rishi, author of some of the Rig Veda hymns. Patanjali, B.C. 150, founder of the Yoga philosophy, author of the Mahabhashya, supposed to be Patanjali, author of a commentary on the grammar of Panini.

Pavananti wrote the Nannul Tamil grammar.

Raghunandana Bhatticharya, author of the Daya Tatwa, law of inheritance.

Raja-sekhara, author of the Bala Ramayana.

Ramanand, A.D. 1250, a Vaishnava reformer.

Ramanuja, A.D. 1150, the first Vaishnava reformer.

Sama Raja Dikshita, author of the modern drama Sridama Charitra.

Sankaracharya, A.D. 800, a great Saiva reformer, author of several Bhashyas or commentaries on the Sutras or aphorisms of Vyasa, on the Bhagavat Gita, and Upanishads, and the Ananda-lahari, a hymn in praise of Parvati.

Sayana, author of the great commentary on the Veda. He was brother of Madhavacharya.

Sayani Chandra Sekhara, author of the Madhu-raniruddha, a modern work.

Somadeva Bhatta, author or compiler of the stories in the Katha-sarit-sagara, drawn from the Brihat Katha.

Sri Harsha, author of the poem Naishadha Charita, a life of Niala.

Sri Harsha Deva, the royal author of the work Ratnavali.

Sri Krishna Tarkalankara, author of Daya KramaSangraha, the law of inheritance.

Sundara Misra, A.D. 1599, author of Abhirama Mani.

Sudraka, a king, author of the Mrich'chba-kati or Toy Cart.

Tiruvallavar, author of the Tamil Kural.

Tolkappiyanar, author of the Tamil grammar Tolkappiyam.

Tulsi Das, wrote the Hindi Ramãyana.

Vachispati Misra, author of a gloss, called the Bhamati, on Sankara's commentary.

Vaidya Natha Vachispati, author of the drama Chitrayajna.

Vallabhacharya Vallabha Swami, A.D. 1520?

Valmiki, author of the Ramrayana.

Vana Bhatta.

Varaha Mihira, author of the astronomical works Brihat Sanhita and Brihaj Jataka.

Vararuchi, a grammarian supposed to be the same with Katyayana.

Vasishta, author of many Vedic hymns.

Vatsiyayana wrote the Kamasutras.

Vepa-deva, author of the grammar Mugdha-bodha.

Vikramaditya, B.c. 57, and the nine eminent literary men of his court, called the nine gems, viz. GhataKarpara, al poet; Dhanwantari, Kalidasa, a dramatist ; Kshapanaka, Amara Sinha, Sanku, Vetala Bhatta, Varaha-Mihira, and Vararuchi.

Visakha-datta, author of the Mudrarakshasa, the signet of the minister.

Vishnu-sarman, compiler of the Pancha Tantra tales.

Visvanatha Kavi Raja, author of the Sahitya Darpana.

Yajna Walkya, reputediauthor of the White Yajur Veda, Sathapata Brahmana, the Brihad Aranyaka, and the Yajnawalkya Smriti.

LITHANG. From Hokow it is four days' journey to Lithang, a Chinese and Tibetan mili- 
tary station, famous for its gold-roofed Lama monastery, containing about 3500 Lamas. Lithang is situated on a high grassy plateau surrounded by mountains of perpetual snow, and indeed the whole country from Ta-tsian-Iu, gradually increasing in elevation, seems at this point to reach a climax. Not a sign of regetation beyond grass is to be seen, and the town, built on the plains at the foot of the mountains, and surrounded by a wall, stands out, making the nakedness of the country still more marked, reminding one of the cities seen along the shore of the Gulf of Cutch. Numbers of Lama priests are to be seen dressed in flowing garments of green cloth, each devoutly twirling his prayer-wheel, and muttering the great Tibetan prayer of 'Om Mani Padmi Om!' but not only amongst the Lamas is this solemnity of demeanour noticeable; even the rough tea-traders and town's-people, dressed in their sheepskin coats, carry prayer-wheels, which they constantly twirl, and join in the universal cry, pronounced 'Omani peminee, Omani peminee !' The people are mostly tall in stature, with a profusion of black hair hanging over their shoulders, while their complexion is a very dark brown; but many of the Lithang people are thick, sturdy fellows, with short woolly hair and lighter complexion, forming a great contrast with the general appearance of the Eastern Tibetans.

LITHARGE. ENG., Fr.

Mih-to-sang, . . CHrN. | Budar, . . . . PERs. Solvskum, Blyskum, DaN. Glet, : . : : Rus. Gelit, . . . DUT. Almartaga, . . SP. Glotte, Glatte, : GER. Litarjirio, : . : ' Murdar-sang, HrND., PERs. Glitt, . . . . Sw. Litargirio, : . IT. Marudar-singhi, . TAM. Lithargyrium, . LAT.

Litharge is a semi-vitrified oxide of lead, in the form of small shining heavy scales, or more or less agglutinated masses. It is usually produced in the purification of silver from lead, and the refining of gold and silver by means of this metal. According to the degree of fire and state of oxidation, it has a pale or a deep colour. The one is called litharge of silver, and the other litharge of gold. Litharge is used for various purposes in the arts, by potters, glassmakers, painters, etc.; it is also employed in medicine. Crude litharge is procurable in most Indian bazars; it sells at \&18 the ton.-M'Culloch; Smith; Poole.

LITHOGRAPHIC STONES are obtained from a magnesian limestone in the valley of the Tumbudra near Kurnool. They were tried in Madras, and answered well. Mr. Bingham made stones for lithographic purposes from a grey limestone, and used them in the office of the SurveyorGeneral. They answered admirably for the purpose, but the stone must be freshly quarried or it chips, as after exposure to the atmosphere it grows intensely hard, and can then only be sawn into shape.-M. E. J. R., 1850 ; Cal. Cat. Ex., 1862.

LITHOMARGE. Wa-sih-shih-chi, CHIN. That obtainable in China is a fine siliceous earth or clay, a sort of fulling earth, containing silicate of alumina with some magnesia. It is often streaked or mottled. Blue and dark varieties occur. Lithomargic earth occurs below the granite detritus of the Neilgherry Hills. Lithomargic hills and lateritic rocks are associated all along the western coast.

LITHOSPERMUM SEEDS are long, very white, and like small stones or pearls, on which account they have been popularly used as a remedy for stone. They are known in India by the name of Lubisfirmun. The roots of some species of Lithospermum afford a lac for dyeing and painting. I. villosum, Wallich, occurs at Hardwar.-Royle; $O^{\prime} S h$.

LITMUS.

Lakmus,

. . DAN. Lackmus, . GRR., Sw. Tournesol, : : : FR. Tornasol en pasta, - $\begin{aligned} & \text { TT. } \\ & \text { SP. }\end{aligned}$

A violet-blue dye, prepared chiefly in Holland from Lecanora tartarea, a lichen which grows in the Canary and Cape de Verde Islands. It is met with in small cubical cakes, of a dusky-blue colour, light, and easily pulverized. It is employed to stain marble; also as a chemical test of acidity, being reddened by acids, while the blue is restored by alkalis; for this purpose it is employed either in the form of a tincture, or of unsized paper coloured with it.-Waterston; Faulkner. LITSÆA CONSIMILIS. Nees.

Charka, . . BEAs. Chindi, . . RAvi. Chirndi, . Chenab. Chilotu, . : . ", Kalban, : : PANJ. Rauli, : : : " "

A small tree which grows in parts of the Panjab Himalaya at 2500 to 6820 feet, up to the Chenab. In some places in Chumba, an oil, expressed from the fruit, is burned. According to Madden, a species of Litsæa, which may be this, yields a coarse oil in Kamaon. L. lanuginosa, Nees, is also of the Outer Himalaya.

Litsæa fuscata, Thw., a tree growing to 20 feet in height in the Central Province of Ceylon, at an elevation of 6000 to 8000 feet. L. glauca is a plant of Japan.-Dr. J. L. Stewart; Thw. En. Pl. Zeyl. p. 258.

Litsrea Zeylanica, Nees.

L. foliosa, D.C. $\quad$ L. umbrosa, D.C.

L. scrobiculata, $D . C$. $\quad \mathrm{L}$. consimilis, $D . C$.

This large tree (Belori of the Burghers) grows at Simla; is very abundant on the Neilgherries at 6000 to 7000 feet elevation; is found throughout the IVestern Ghats above 2000 feet; and equally common in Ceylon, where it is called DawalKurundu. Its wood is in use for house-building purposes, planks, rafters, etc.; it is yellowish in colour, straight-grained and tough, and when fresh emits an odour of sweet briar.-Beddome, Fl. Sylv.; F. Von Mueller; Gamble; Voigt.

LITTERS for travelling, in Arabia are commonly borne by mules. The litter is generally one resembling the palanquin; it is borne by four mules, two before and two behind, or by two only, but more commonly by two camels, and sometimes by two horses. When borne by camels, the head of the hindermost is painfully bent down under the vehicle. Nevertheless it is the most comfortable kind of litter, and two light persons may travel in it. The Persian name generally given to it is Tukht-rawan. The Arabic Mihaffeh is often used as a general name for a camel litter, and particularly applied to one with a flat top. A very common kind of camel litter, called Musatteh or Heml-mu-sattah, resembles a small square tent. Another kind of litter, called Shibreeyeb, is composed of a small square platform with an arched covering. The Musatteh and Shibreeyeh (but particularly the latter) are also called Hodaj. LITTLE BASSES. See Basses.

LITTLE BOKHARA, also known as Chinese 
Tartary and Eastern Turkestan, is a depressed valley shut in by mountains of great height on three sides, and on the east are barren sands which merge imperceptibly into the great desert of Gobi. The Tian Shan range separates it from Zungaria; the Bolor range from Trausoxiana, and the Kara-korum and Kouen Lun from India and 'Tibet on the south. The land is clayey near the base of the mountains, but sandy in the central tracts. Rain is rare and the air is of exceeding dryness, but the climate is temperate and healthy. It is well watered from the mountains, the waters converging towards the Ergol or Tarym. The country has grold, copper, salt, sulphur, and the jade-stone. The southern line of the caravan route passes through it from Khamil to Aksu and Kashgar. From Aiksu to Khokand is 800 miles. It was subject to China from the beginning of the Christian era, to the time of Chengiz Khan. After the middle of the 18th century, the Chinese regained possession of it. Alti-Shahr, or the six cities, forms the western district, comprising Yarkand, Kashgar, Khotan, Aksu, Yanghisar, and Ush-Turfan, with territories subordinate to each. Eastern Turkestan is eminently Muhammadan. Yarkand is the entrepot of trade between China and Bokhara. Khotan, from the time of C'tesias, has been celebrated for its rnineral products, its jade and emeralds, its shawl-wool and flax. It was at one time the entrepot of a vast trade with Hindustan, and now imports largely furs, broadcloth, leather, and sugar.

LITTLE MAN'S BREAD, of the Neilgherry Hills, is an underground fungus of the genus Mylita. It seems very closely allied to, if really distinct from, the so-called native bread of Tasmania, M. Australis. 'Fresh specimens of this fungus,' says Berkeley, 'have a subacid smell and little taste; but we have seen others of an extremely compact horny texture, resembling a mass of sage forcibly compressed into a solid ball.' The specimens of the little man's bread submitted by Mr. Whynton are here very clearly indicated.Pioneer.

LITTLE TIBET, the modern Balti, is a good deal to the north-east of Kashmir, and northwest of Ladakh. Gilgit is a country, conquered by Gulab Singh, to the west-north - west of Iskardo. The Chorbat district is a dependency of the Government of Iskardo, which, like that of Leh, is subject to Kashmir. The desert country by which Nubra and Chorbat are separated, has acted as a barrier to the further extension eastward of the Muhammadan religion, which is now universally that of the people of the whole of Iskardo (or Balti) district, as well as of Dras. On the Indus, and in the valley south of it, there is no uninhabited tract between the two, so that the Muhammadan and Buddhist population are in direct contact. The result is, that Muhammadanism is in that part gradually, though very slowly, extending to the eastward. The name Iskardo, capital of Balti, is a Muhammadan corruption of the Tibetan name Skardo, or Kardo, as it is very commonly pronounced. The mountains which surround the Iskardo plain rise at once with great abruptness, and are very steep and bare. The houses of Iskardo are very much scattered over a large extent of surface, so that there is no appearance of a town.
Bhot comprises the Little Tibetans, the natives of Ladakh, the Tibetans of Tibet proper, and the closely-allied Bhoteah tribes of Bhutan. Balti or Baltiyul is called Palolo or Balor by the Dard, and Nang-Kod by the Tibetans. It is preserved in Ptolemy in Byltre.

Little Tibet contains about 12,000 square miles, is about 170 miles long, and lies between long. $74^{\circ}$ and $76^{\circ} 35^{\prime} \mathrm{E}$. Little Tibet or Baltistan is called by the Kashmiri Sri Bhutan. Tibetan districts are Khapolor, Chorbad, and Keris, on the Shayok river; Khartakshe, Totte, and Parguta on the Sing-gechu; Shigar on the Shigar river, and Balti and Rongdo on the Indus.

Balti proper is a small table-land, and, with that of Deotsu, is about 60 miles long and 36 broad; the mean height of its villages above the sea is about 7000 feet. Cultivation in Little Tibet is carried on entirely by irrigation. The Balti people of Little Tibet, though Tibetan in language and appearance, are all Muhammadans, and differ from the more eastern Tibetans of Leh (who call themselves Bhoteah or inhabitants of Bhot) by being taller and less stoutly made. Their language differs considerably from that of Leh, but only as one dialect differs from another. Little Tibet has several times tendered its allegiance to British India.-Dr. Thomson's Travels; Cunningham's Ladakh; Latham; Mason; Campbell.

LITTORAL CONCRETE is a rock found close by the sea-shore of the Bombay coast and western coast of the Peninsula of India, resembling the artificial stone formed by the cementation of sand, gravel, or other coarse material, by lime-water or mortar. It is composed of shells, sand, gravel, and pebbles, and varies in its character with the rocks in the neighbourhood, being micaceous towards Cochin and Tellicherri from the quantity of sand and other nodules from the granite and gneiss; gravelly to the north of Bombay and around it, composed almost entirely of fragments of shells. It is met with only in the regions where rains abound. Along the shores of Sind, Arabia, and the Red Sea, though the material composing it is abundant in a position similiar to that in which it exists on the Malabar coast, it is nowhere cemented into stone. Even on Bombay Island, indeed, the cementation is far from invariable. In one part of the esplanade there is loose sand on the surface, and concrete beneath. At another, sand or concrete, as the case may be, from the surface throughout to the rock. And in a recent excavation, concrete was found for the first 20 feet, resting on a bed of fine sand, perfectly loose. It is frequently found to rest-as, for example, at Sewree and Mahim - on a bed of blue clay filled with kankar and mangrove roots, offering evidence of a depression from the time the mangroves grew at high-water mark, so as to permit the gravel deposit to accumulate. The whole must then have been raised by a second upheaval to its present level. The principal quarries of these are at Versova, about 20 miles to the north of Bombay, where the shore is sheltered by a vast dyke of basalt formerly submerged. In quarrying it, the sand, which seldom extends more than a few inches down, is first removed, and the rock is smooth on the surface. A space about 12 feet each way is next divided into slabs one foot square, the grooves between them being cut with a light, flat-pointed, siugle-bladed pick. These are 
raised successively by a tool something between an adze and a mattock, a single stroke of which is in general sufficient for the detachment of each from its bed. The blocks thus cut out and raised being thrown aside, the bed is once more smoothed, and the operation resumed till the pit reaches the depth of six or eight feet, when, it being no longer convenient to remove the stones by hand or basket, a new pit is cut. This variety of building material is brought in vast quantities to Bombay, where a large portion of the native houses are built of it. It is not very strong, but with admirable cement, employed with lavish hand, it makes a good and economical wall.-Dr. Buist, LL.D., in Bombay Times.

LIU-KIU, a dominion of a group of 36 islands, lying between those of Kiu-siu and Formosa, feudatory to China. The island of Liu-Kiu is the largest of the group. It is about 60 miles in length from north to south, with a varying breadth of from 5 to 10 miles, and its scenery, especially at its northern and eastern side, is wild and mountainous. In Liu-Kiu, the salutation consists of clasping the hands together, and in that position elevating the knuckles to the forehead, and bowing sufficiently low for the hands so placed to touch the ground. The Liu-Kiu people wear a cloak, which is gathered in at the waist with a girdle of brocaded silk or velvet; in this is stuck an embroidered pouch, containing a small pipeand some powdered tobacco. In Liu-Kiu the hair is shaven off the forehead for about three inches in front, and carried from the back and sides into a tuft on the top of the head, where it is held by one or more pins, gold being in most esteem with the men, and polished tortoiseshell among the women.

LIVISTONIA, a genus of palms, natives of Eastern Asia and Australia, of noble aspect and elegant foliage. The L. Jenkinsiana, Griff., furnishes the Toko-pat of the Assamese, an indispensable article in every native gentleman's house. The leaves are in universal use throughout Assam for covering the tops of the peculiar umbrella hats (Jhapis) of the Assamese.

In some sections of the country the Karen thatch their houses with large palmated leaves of a tall wild palm, probably a species of Livistonia. Sometimes the leaves of a species of rattan are used; but the Burmese and Europeans almost universally thatch their houses with the leaves of the Nipa.

Livistonia spectabilis, Griff., is a lofty palm, 50 or 60 feet high. Trunk smooth. It inhabits Malacca, is solitary in the low littoral tracts, adapted to rice cultivation. The Penang Malay name is Sardang.

Livistonia Sinensis, Griff., is 20 or 25 feet high, with a stout obscurely-annulated trunk. Crown round. It grows in Southern China.

Livistonia inermis is of Australia. L. rotundifolia is supposed by Mr. Wallace to be the fanpalm, of the leaf of which the people of Celebes make water-buckets and baskets. - Seeman; Mason.

LIZARDS form, in natural history, the reptile order of Sauria, which comprise the Crocodilidæ or crocodiles of the Old World, the alligators of the New World, the Varanidæ or water lizards, the Lacertidæ or land lizards, the Zonuridæ or cordyles, the Scincidæ or skinks, the Acontiadæ or acontiads, the Sepsidæ or sand lizards, the
Geckotidæ or geckos, the Agamidæ or agames, and the Chameleonidæ or chameleons. Most of these will be found noticed under their respective names. About 1300 are known. Oaths are taken on a lizard's skin by the Kandh race.

The lyre-headed lizard is not uncommon in the woods about Kandy. It is more bulky than any of the species of Calotes, and not nearly so active in its movements.

The ghoor is a lizard of Gujerat, which the natives believe to be poisonous. There are two kinds of ghoor, according to native report, Putlah ghoor and Chundun ghoor.

The Tuatera or Navara is a lizard of New Zealand; is also called the Hatteria punctata, and is upwards of two feet long.

Stories about venomous lizards of different species are abundant in India and other tropical countries, but on investigation have always been found to be destitute of foundation. There is, however, one lizard of which the bite is certainly highly dangerous, though probably not fatal, to man. This is the Heloderm (Heloderma horridum) of Mexico and Lower California, commonly known to the natives of those countries as the Scorpione or scorpion. Mr. J. Stein, a traveller in Mexico, who was bitten in the finger by one, suffered from symptoms similar to those produced by a snake-bite. See Reptiles.

\section{LOADSTONE.}

Magneet, . . Dut. Basi-barani, . MAL Aimant,. . . . Fr. Ahan-suban, : PErs. Magnet, : : Ger. Magnit,. : .RuS Chumuk-puttur, :GסJ. Kauntum, : SAN\$E., TEL. Calamita, . . : IT. Iman, . . . SP. Batu-barani, . . MaL. Kaundum, . . TAM.

Magnetic iron ore, a peroxide of iron, is found in considerable quantities in most countries. Ayaskanta mani Salakeva, 'Like a rod of the ironstone gem,' is a phrase used in the Sanskrit poem Malate and Mad'hava, and makes it seem possible that artificial magnets, as well as the properties of the loadstone, were known to the ancient Hindus. The loadstone, as sung by Orpheus, was supposed to detect adultery.-M $M^{6}$ Culloch; Malate and Mad'hava in Hindu Theatre, ii. p. 22.

LOANS are raised by the Indian Government, both in British India and in Great Britain. On the 31st March 1883 the amount of outstanding debt of all loans raised in India was $£ 90,519,566$. Of that amount $£ 87,051$ bore no interest; $£ 57,470$ of $1853-54$ carried interest of $3 \frac{1}{2}$ per cent.; $£ 170,867$ was from railway loans, bearing 4 and $4 \frac{1}{2}$ per cent.; $\mathfrak{E} 66,759,421$ was at 4 per cent. ; £23,420,757 bore $4 \frac{1}{2}$ per cent.; and $£ 24,000$ was at 7s. per Rs. 100.

LOBELIA, an interesting genus of plants, easily cultivated by seed. The blossoms are extremely beautiful from their variety of colours; they require a light, rich soil, with a moderate quantity of water. Dr. Wight, in Icones, gives L. aromatica, excelsa, nicotianæfolia, trichandra, and trigona. L. cardinalis is an annual, creeping, glabrous plant, a native of China, with flowers of a pink colour. In gardens it spreads over the soil, rooting at every branch, and is well adapted for borders to parterres. One China species is called Tan-pa-ku or Tom-ke-ki, and seems to have been used as a kind of tobacco. L. nicotianæfolia, a stout, tall species, occurs in the vicinity of Bangalore. L, radicans was accidentally intro - 
duced from China into the Calcutta garden. L. inflata, Indian tobacco, a native of the United States, an acrid narcotic and violent emetic; in small doses diaphoretic and expectorant; a popular remedy in the United States, where from incautious use it has often proved fatal. Its chief employment is in asthma, and in the form of enema in strangulated hernia. L. succulenta, Blume, Neilgherry grass. A small procumbent plant, well adapted for hiding the earth in flower-pots, as is also I. erinus. L. trigona, $R o x b$, is a small annual ramous plant which delights in wet pasture ground, and appears during the wet and cold seasons.-O'Sh. p. 426; Roxb. i. p. 506 ; Riddell; W. Ic.; Jaffrey.

LOBIA. Hind. Dolichos Sinensis, also D. cajang. Kala lobia is D. lablab. Large red and white beans, haricot bean, Phaseolus vulgaris or P. lunatus. Lobian, a white bean with a black eye, D. Sinensis.

LOBIPES HYPERBOREUS, Phalaropus hyperboreus, the red-necked phalarope, has the circuit of northern regions. One specimen obtained in Nicaragua, and a pair in the Bermudas. It is a little arctic bird, of rare occurrence even in the north of Scotland, Orkney, and Shetland; but a specimen was, about A.D. 1845, procured near Madras, which was sent to the Calcutta Museum.

LOCHANA, a favourite sakti of the Mahayana sect of Buddhists.

LOCK.

Dabbeh,

Sloten,

Serrures,

Tala, Kufl, Kulf

ARAB, Serrature,

Dumo

FR. Samki, PoRt.

GER. Cerraduras, Cerrajos, SP.

An implement applied to doors, boxes, etc., for securely fastening them. The Egyptian Dabbeh is a wooden lock from 14 inches to 8 or 9 inches, for doors of houses, cupboards, etc., and for gates of quarters, public buildings, etc., two feet and even more in length. In Cairo the key plays a considerable part in the daily life. The handing it over ratifies a bargain for the sale or letting of a house. A fee is payable to the Shaikh of the quarter on the transfer of the key. And the inhabitants of a quarter pay an annual fee to its Shaikh,--the 'Fee of the Key,' that is the gates of the quarter being thereby made free to them without challenge, as in the case of strangers. $-M^{\prime}$ Culloch.

LOCUST.

Jarad-ul-bahr, . ARAB, Locusta,. . . . IT. Faridi, . EGYPT. Maig, Malakl, : PERs. Sauterelle, : Fr. Malakh-i-halal, : ,

Heushrecke, : : GER. Malakh-i-haram, : ,

Ophiomachez, : : GR. Malakh-i-daryai, :",

\begin{tabular}{c|l} 
Chargol, Arbeh, : HEB. & Logosta, : : PORT. \\
Tiri, Tiddi, . : HIND. & Langosta, : . SP.
\end{tabular}

One of the principal genera contained in the family Locustidæ is the Locusta of Leach, in which the hinder legs are about equal to the whole body in length, and the antennæ filiform or terminated in a club. Upwards of 20 species of this genus are known, and it is to this group to which the Gryllus migratorius of Linnæus belongs, a large species, which sometimes multiplies to such a degree as to devastate large districts. Africa at all times appears to have been peculiarly subject to the ravages of locusts. Mr. Barrow states that, on one occasion, in the southern parts of Africa, an area of nearly 2000 square miles might be said literally to have been covered with them. When driven into the sea by a north-west wind, they formed upon the shore, for 50 miles, a bank 3 or 4 feet high; and when the wind was south-east the stench was smelt at the distance of 150 miles. The locusts migrate in masses. 'They often cross from Africa to Madagascar, from Africa to Syria and Arabia, and sometimes to Italy. They often appear in Sind, in Baluchistan, and British India, particularly in Central India, but less frequently in the Peninsula; yet even there Dr. Buchanan, on his way to Seringapatam, observed a flight of locusts, in length about 3 miles, its width about 100 yards, and its height 50 feet. At a distance they appeared like a long, narrow, red cloud near the horizon, which was continually varying its shape; and in the famine years of 1876-77 they reappeared in several parts. In 1883, at Satary (Goa), the orange trees had been so damaged by locusts that it was difficult to find even a dozen oranges that season. Thousands had always been exported in former years.

Kirby and Spence (i. p. 218), on the authority of Major Moor, relate that a flight of red locusts (evidently identical with the Indian species), forming a column 500 miles long, ravaged the Mahratta country. Pottinger states that these destructive insects never penetrate to the districts of Saharawan unless in years of drought and famine; they then come as though it were to complete the devastation; they invariably appear from the south-east, and return to the same quarter. Locusts visit the Panjab and N.W. Provinces, and do much mischief while pursuing their devastating course.

In 1861, in rent-free lands in Khurda, belonging to the temple of Jaganath, the rice crop was nearly destroyed by a small green Acrydium about an inch in length, called Jhintiki by the Uriya. But history is full of accounts of the destruction caused by this plague, and one feature appears in nearly all the descriptions, the simultaneous death of whole flights, and pestilence ensuing on the putrefaction of their bodies. So Joel, 'But I will remove far off from you the northern army, and his stink shall come up, and his ill-savour shall come up, because he hath done great things' (Joel ii. 20). Joel i. 3, 4, and ii. 3, writes of the locusts' ravages, 'Let your children tell their children, and their children another generation. That which the palmer-worm hath left hath the locust eaten.'

The Phymatea punctata is a large, beautiful locust, with scarlet abdomen, and yellow and bronze above, which occasionally causes great injury. Mr. Nietner says they do not touch the Illuk grass of Ceylon, Saccharum Konigii, Retz, and seem only to attack cultivated plants. At Tangalle they destroyed tobacco plantations, and the larvæ and pupæ are as destructive as the perfect insects.

It is the Acrydium migratorium which, at intervals, devastates Africa and the south of Asia, and Gryllus gregarius is that of Sinai. Acrydium (Edipoda) migratorium, which occurs in Africa and the south of Asia, is greenisb, with transparent elytra, of a dirty grey, whitish wings, and pink legs. They have the power of inflating thernselves with air, and of travelling about 18 miles a day. The genus Acrydium 
of Latreille may be distinguished from CEdipoda by the presence of a large and prominent tubercle on the præsternum, or between the two fore legs, by the one central ocellus instead of three disposed triangularly, and by the deep transverse striæ of the prothorax. A. peregrinum, Olivier, has been described by that author in his Voyage dans l'empire Othoman, and by M. Audinet Serveille in his treatise on the Orthoptera, forming part of the Nouvelles Suites à Buffon. This author described a yellow variety from specimens taken in Senegal, and the red one from Mount Sinai, - a wide distribution. Both varieties occur in India; some from Raniganj show no trace of red, while in those ordinarily described, red is the predominant colour. Serveille figured the red variety in his 12th plate, fig. 3. He quotes from the work of Olivier, previously named, a description of the habits of this species. Accompanying the burning south winds in Syria, he says, clouds of locusts (A. peregrinum) arrive from the interior of Arabia and the south of Persia, causing a devastation as complete and almost as rapid as that produced on Europe by the most violent hailstorms. It is difficult to express the effect of the sight of the whole atmosphere filled on every side, and to an immense height, with an innumerable quantity of these insects, moving in slow and uniform flight, with a noise like that of rain, the sky darkened, and the light of the sun diminished. In one instant the flat roofs of the houses, the streets, and the fields were covered with locusts, and in two days they had destroyed nearly all the foliage; but fortunately their life was but short, and they seemed to have emigrated only to reproduce themselves and die. For some days afterwards the fields were covered with their bodies.

The Acrydium lineole, which is sold for food in the markets of Baghdad, and the CEdipoda migratoria, extending its ravages from Tartary to Central Africa, and from Paris to Isfahan, are the only well-known migratory species; but local species sometimes multiply to such an extent as to cause infinite damage.

Maig and Malakh are Persian names for a locust, which the Arabs most commonly call Jarad. The kind, blown over, from the opposite coast of Arabia to Bushahr, the Persians styled Malakh daryai or the sea-locust, and the Arabs, Jarad-ul-babr, in the same sense. Bochart has enumerated various Hebrew and Arabic names for the locust in his elaborate Heirozoicon (lib. vi. cap. i. et seq.), but does not mention the above Persian names, neither does he remark that in the dialect of Misr or Egypt, those Jarad-ulbahr or sea-locusts, above noticed, are called Faridi, according to the MS. Burban-i-Katiah. Zakaria Kazvini divides the locusts into two classes, like horsemen and footmen, mounted and pedestrian, which will call to the recollection of the Biblical reader some passages from Joel and the Apocalypse. Forskal calls the locust which infests Arabia, Gryllus gregorius, and thinks it to be different from that which is called by Iinnæus, migratorius.

Locusts of Australia are species of Tettigoniæ or tree-hoppers, all of a green, orange, brown, or black colour, with membranous wings remarkable for their iridescence. Their names are the Cicada morens and $\mathrm{C}$. curvirostra; the orangespotted Tettigonia, Fidicina angularis; the Cylo- chila Australasiæ; the Thopa saccata. Some of them are partly covered with a whitish secretion, and get the names of millers and bakers; and the Cylochila Australasiæ are called lamplighters by the boys, from three ruby-coloured spots on the front of the head.

In 1813 Marseilles expended 20,000, and Arles 25,000 francs for the destruction of injurious insects. The hunt commenced in May, and almost the whole population of certain villages were employed in it. A cloth of coarse web is carried by four men, one holding each corner. The two who walk first make the foremost edge of the cloth sweep the ground, and the insects leap into the cloth, where they are caught as in a bag. A small bag at the end of a stick, like an entomologist's bag-net, is also used. The females lay from August to October, the eggs being placed in holes in the earth in a cylindrical tube of glutinous matter covered with a thin envelope of earth (exactly as stated by Aristotle). The tube is about an inch and a half long by 3 or 4 lines wide, and placed horizontally. Each tube contains from 50 to 60 eggs, and a child trained to the work can collect 10 to 14 pounds per diem, each pound containing about 800 eggs. In other places carts are driven up and down over the breeding grounds with the object of destroying the egg-pouches by crushing them into the earth.

Mr. Taylor says the Turdus roseus, called by the Mesopotamian Arabs Sammir-med, destroy great quantities of locusts by cutting them in two. They seem to be the Seleucidæ of Pliny, which, consequent on the prayers offered up to him by the people of Mount Casius, were sent by Jupiter to destroy the locusts ravaging their corn crops (Pliny, book x. ch. 39). In Central India locusts are destroyed by digging trenches for them to fall into. As they spring from eggs deposited by previous flights of locusts, when hatched they hop along in dense masses while yet unfit for flight, and in their progress lay waste all vegetation. In Bikanir they dig trenches to leeward of where these young broods appear, and take measures to drive the locusts into them, and the sides being perpendicular, the creatures hop in, but cannot hop out, and earth is thrown in upon them. A resident at Ajmir on one occasion adopted this plan. He says : 'In about two hours we succeeded in getting several trenches dug, varying from 25 feet to 60 feet long, 1 foot wide, and about 2 feet deep. Then we sent native soldiers in a horse-shoe direction from the trench about 1000 feet away to wave hands and drive the locusts on. They came, and thickened as they approached, one dense mass, hopping along till they hopped into the trench. It was a curious sight to stand at the end and look at it all,-a seething, hopping mass inside the trench, while a regular short cataract came pouring down on to them until they were about two inches deep, then the hopping ceased in the trench. They had nothing hard to kick against, but the influx continued till they were half up the ditch, when we quickly threw in earth and buried them, and then off to another trench and repeat the whole operation. We continued this for two hours. While at one of the trenches, I sent for a finger-glass, and immersed it in the mass of locusts, as one might dip it into water, then struck it off with a piece of cardboard, so I had it as full as it would hold. When I got 
home I weighed the glass full, then emptied it and weighed the glass, so I got the weight of the locusts; then I counted them out (566), then measured very accurately the solid contents of the glass, by weighing the amount of water it held, and computing from that; thus I had space, number, and weight for data. Knowing we had dug and filled 300 feet of trench one foot wide, filled to one foot deep, I calculated, and $\mathrm{J}-, \mathrm{S}-$, and $\mathrm{C}-$ checked the calculations with me: result, killed and buried, $7 \frac{1}{2}$ millions of locusts, weighing $10 \frac{1}{2}$ tons, in two hours from the time the trenches were ready, about four hours altogether! After such results ought any district to be thus infested?'

Mr. Portchinsky, secretary of the Russian Society of Entomology, was sent to the southern provinces of the empire to ascertain in what places grain locusts (Anisoplia Austriaca) preferred to lay their eggs, and he came to the following conclusions :-The grain locust generally deposits its eggs in wheat-fields, and so soon as they are hatched the attacks of the insect on the grain commence. There are generally from 20 to 50 locusts per square archine (an archine is 27 inches) of wheat. Rye and barley fields contain comparatively much fewer larvæ (from 2 to 5) a square archine, but if these fields be near wheatfields, the larvæ are then just as numerous. The fields which have been sown with wheat the preceding autumn are the receptacles of an immense quantity of larvæ, which it is impossible to destroy before they have become chrysalides. The state of the fields whence the owners have driven the locusts is very different. The pursued insects fly in masses to the neighbouring fields, and while the wheat-field where the owners have fought them does not retain more than 3 to 16 larvæ a square archine, adjoining fields of flax, buckwheat, oats, etc., which are not generally attacked by the locusts, become infested, and contain from 16 to 26 larva an archine. It follows that the use of ropes or machines to drive away the locusts is very dangerous, because, instead of laying their eggs in wheat-fields, where they may be destroyed in the spring while in the state of chrysalides, they light upon the surrounding fields, no matter what they are sown with. Experiments made on the spot by Mr. Portchinsky prove that the larvæ turned up by the plough re-enter the earth quickly, but if they can be kept exposed ten minutes to the sun, they infallibly perish under its heat. He concludes that in the spring, when the larvæ (become chrysalides) are in a state of complete immobility, ploughing the fields will be of great use, because the chrysalides, exposed to the action of the sun, will certainly perish. As to fighting the locust by destroying its eggs, Mr. Portchinsky considers this as impossible, inasmuch as the period during which the eggs remain in the ground before they become larvæ is precisely that during which the grain is standing.

According to Wellsted, they are sold in the markets of Yemboh and also at Jeddah, and are considered wholesome and nutritious. The Mukin or red species, being the fattest, is preserved, and, when fried and sprinkled with salt, they are considered wholesome and nutritious food. This part of the sea-coast of Arabia is occasionally visited by an incredible number of these insects, which do much damage to the date palms. Swarms are drowned in their passage to and from the Egyptian coast, and the beach is strewed with their carcases. How insects apparently so ill qualified for flight are enabled thus to cross the sea, affords matter for curious inquiry ; but passing swarms are seen in its centre. The Acridophagi of Ethiopia, who are fabled to have subsisted entirely on this aliment, are said to have been thin and weak, and to have suffered an early and agonizing death. This was doubtless merely from semi-starvation. These people lighted large fires of dry leaves under the flight, and so brought the insects down in considerable numbers. A character in Aristophanes (Acharn. 1116) raises the question whether locusts or fieldfares are the daintiest eating, and answers in favour of the locust, from which one might infer that it was a recognised, though not a frequent, article of food among the Greeks. The Hottentots, unlike the Acridophagi above mentioned, are said to grow fat upon this diet. But this also is merely exaggeration, though Burton says of the Arabs that where they have no crops to lose, the people are thankful for a fall of locusts. In Hejaz the flights are uncertain; during the last five years preceding Captain Burton's visit, Medina had seen but few. They are prepared for eating, by boiling in salt water and drying four or five days in the sun. A wet locust to an Arab is as a snail to a Briton. The head is plucked off, the stomach drawn, the wings and the prickly part of the legs are plucked, and the insect is ready for the table. Locusts are never eaten with sweet things, which would be nauseous. The dish is always hot, with salt and pepper, or onions fried in clarified butter, when it tastes nearly as well as a plate of stale shrimps. At Bushire these insects are generally called Maig, and sometimes Malakh. One kind is distinguished by the epithet halall, the eating of it being lawful; the other is harām or forbidden; this is smaller and more destructive than the Malakh halāl, from which it differs also in colour. The Arabs prepare a dish of locusts by boiling them with salt, and mixing a little oil, butter, or fat; they sometimes toast them before a fire, or soak them in warm water, and, without any further culinary process, devour almost every part except the wings. Ouseley ate several locusts variously cooked, and thought them by no means unpalatable. In flavour they seemed like a lobster or rather a shrimp, - one neither offensively stale nor absolutely fresh. The natives of Senegal are said to dry them, and, having reduced them to powder, use them as flour. Captain Yule (p. 114), in his account of an interview with the king of Burma, and the repast which followed, mentions that the most notable viand produced consisted of fried locusts. These were brought in hot and hot, in successive saucers. They were very much like what one would suppose fried shrimps would taste. The inside, he believed, was removed, and the cavity stuffed with a little spiced meat. Locusts of Inner Arabia, the jarad or jerad, a reddish-brown insect, and about the size of the little finger, are used as food. The hind legs are called keraa. They are boiled and fried. The locust of Northern Arabia, a small green grasshopper, is not used as food.-Winslow; Dr. Buist; Central India Times; Kirby and Spence; Friend of India; Pottinger's Travels Burton's Mecca; Ouseley's Travels; Niebuhr's Travels; Wellsted's Travels; Palgrave; G. Bennett, pp. $270,271$. 
LOCUSTELLA RAYI, the Salicaria locustella, or British grasshopper warbler of Europe, Asia, and North Africa, is migratory. Has been obtained in Central India and in Lower Bengal, where an affined species, L. rubescens, is not uncommon. It would appear to be not uncommon at Mhow. A specimen has also been seen from the North-west Himalaya.

LOCUST TREE, Hymenæa courbaril, $L$. Wood tough and close-grained, valuable for trenails and timber of steam-engines. Some of the Brazilian locust trees, according to Von Martius, attain a size so great that 15 Indians with outstretched arms could just embrace one of them.

LODHA, a class of Muhammadan thugs, descended from or graft upon the Oudh stock, and found chiefly on the borders of that kingdom, or in the Terai bordering on Nepal.

LODHI, an agricultural race in Central India and the N.W. Provinces, and about Bhurtpur, supposed by Mr. (Sir George) Campbell to be cognate to the Kurmi, and to have at one time occupied a very considerable position in the Jubbulpur and Saugor districts. The Lodhi came from Bundelkhand about the 16th century ; the Kurmi from the Doab about A.D. 1620. The Lodhi are scarcely inferior to the Kurmi as agriculturists, are hardy and active, but are the opposite of the Kurmi in natural temperament, being turbulent, revengeful, and ever ready to join in any disturbance. They make good soldiers, and are generally excellent sportsmen. Both among Kurmi and Lodhi there is no distinction between a mistress and wife, provided always that the former is of the same caste as the husband, or, better still, the widow of an eider brother or cousin, however far removed. The children born from such connections are on an equal footing as regards inheritance of property, whether personal, real, or ancestral, with those born from regularly married wives. The Lodhi agriculturists of Upper India attained to some distinction as swashbucklers and marauders in the Nerbadda country, and some of their chiefs still retain all the popular respect due to families which have forgotten to live on their own industry. Amongst the Mahrattas, the foreign Lodhi or Lodhi paradesi, from being a native of Hindustan, is employed as a thatcher and keeper of bullocks, etc.-Mr. Campbell, p. 193; Central Province Gazetteer: People of India.

LODHI KHERA, a rich trading town in the Ch'hindwara district, 38 miles from Ch'hindwara, on the Nagpur road. The river Jam flows by the town.

LODOICEA SEYCHELLARUM. Labillard. Nux medica, Cocos Maldivica.

Darya ka narel, . Dekн. | Cocos de Maldives, Port. Sea cocoanut, : ENG. Ubdie narikaylam, SANSK. Double cocoanut, . ", Kaddel taynga, TAM. Cocos de mer, . . Fr. Samudra-pu-tenkaia, Tex.

The double cocoanut tree of the Seychelles is a palm which attains a height of 80 or 90 feet. When preserved whole, and perforated in one or two places, the nut serves to carry water, and some of them hold six or eight pints; and by slicing them in different directions they are formed into plates, dishes, drinking cups, etc., known in the islands as Vaisselle de l'isle Prasten. The Muhammadan fakirs of India use it as a scallop. The crown of the trunk is eaten like the American cabbage palm. The down attached to the young leaves serves for filling mattresses and pillows; the ribs of the canes and fibres of the petiole are fabricated into baskets and brooms, and the young canes are plaited to form hats. Germinatiug nuts were sold in London in 1854 for $\mathfrak{E} 10$ a-piece.

Many fabulous accounts were formerly related respecting the Lodoicea Seychellarum, such as, that it was produced at the bottom of the sea, the nuts being only found thrown up on the coasts of the Maldive Islands. They were called Coco de Maldivia, or Coco de Salomon, by the early Portuguese navigators. Many marvellous medical virtues were ascribed to these nuts by the physicians of the age, both Asiatic and European, and they were consequently sold at a high price. The tree yielding them was first noticed by Barre, a French officer of engineers, in 1697, then described by Sonnerat, but for the first time accurately described by Labillardiere in Ann. Mus., Paris, ix. p. 140, t. 13 . To the inhabitants, the tree is useful for its timber, which is hard externally, and employed in building their huts and for posts; the leaves and their footstalks are used for the roof, walls, and partitions, and for many other domestic purposes. The nuts weigh from 23 to $25 \mathrm{lbs}$. each, and when fresh contain a white, transparent, and jelly-like substance, which is edible. The shells are employed in making vessels and dishes of various kinds; and the entire nuts form articles of commerce, as they are esteemed in other countries both for their fabled virtues and as curiosities.

LOGAN, a legal practitioner in the island of Penang, who started and long conducted the Journal of the Indian Archipelago, and contributed to it a great number of important editorial articles, principally relating to the ethnology of Eastern and Southern Asia. He arranges the races of S.E. Asia into types, as the Aryan, Gangetic, S. Indian, Gondwani for Vindhyan tribes, East African, Turanian, Tibetan, and Asianesian. He had great opportunities of contrasting and comparing the Dravidians from various parts of India, and called them South Indian.

\section{LOGWOOD.}

Ch'ik-su-muh, . . CHIN. Campeggio, . . . IT. Campechetrae, : DAN. Pao de Campeche, Pon'. Kampecheh hout, . DUT. Kampeshskoe derevo, Rưs. Bois de Campeche, Fr. Palo de Campeche, SP. Blauholz, . GER. Kampecheträd, . SW. Campesche-holz, . ,

Logwood is the heart-wood or duramen of Hæmatoxylon Campechianum, $L$., a large tree of Central America, Honduras, Campeachy, etc. and the West Indies. It is imported into Britain in logs, which are cut up into chips and ground for the use of dyers and painters, being esteemed as one of the best deep-red and black dyes. The dyewood is hard, heavy, of a deep orange colour, a sweetish astringent taste, and peculiar odour. It is extensively employed for compound colours, but its chief use is for blacks and certain shades of grey. It is also now common in the woods of Jamaica and St. Domingo, and has been intro duced into India. In Tenasserim, the logwood tree is cultivated in a few gardens, and appears to flourish there as well as an indigenous plant. It is sometimes used in medicine as an astringent. 
The introduction of logwood was prohibited by a statute of Elizabeth, under heavy penalties, and all that was found in the country was ordered to be destroyed. It was not until the reign of Charles II. thatits use was re-permitted.-Faulkner; Simmonds; Mason; Tredgold.

LOHA. GUJ., HiND. Iron. Lohar, a blacksmith. The Lohar is one of the five artisan castes of the Hindus, the others being the carpenter, goldsmith, brazier, and stone-cutter. Loha chur. iron filings. On the ninth of the light half of Aswin, Hindus worship their weapons or arms. The lustration is called Loha bhisara, and at native courts was of great splendour. The blacksmith wears the zonar. The Taremuk of the Central Dekhan, known as Bail Kambar in Canarese, Ghissari in the Dekhani, Lohar in the Mahrati, is a wandering blacksmith. -Wilson's Glossary.

LOHAGHAT or Rikheswar is a cantonment in the Kamaon district, N.W. Provinces, in lat. $29^{\circ} 24^{\prime} 15^{\prime \prime} \mathrm{N}$., long. $80^{\circ} \overline{7}^{\prime} 10^{\prime \prime} \mathrm{E}$, , situated on the left bank of the little river Loha, at an elevation of 5562 feet above sea-level, and enclosed on almost every side by precipitous mountains. It is said to be unsuited for invalids. - Imp. Gaz.

LOHAIA, a town in Yemen, in lat. $15^{\circ} 42^{\prime} \mathrm{N}$., long. $42^{\circ} 39^{\prime} \mathrm{E}$. Lohaia has stood only since the 16th century. Its founder and patron was a Muhammadan saint, called Shaikh Saleh, who built a hut on the shore where Lohaia now stands, and spent there the rest of his days as a hermit. The territory of Lohaia is arid and barren. Population, 5000. The harbour is so indifferent that even the smallest vessels are obliged to anchor at a great distance from the town.-Niebuhr's Tr. i. pp. $252,253$.

LOHANA, a powerful tribe who have been known as residents in Sind since the earliest times, and have undergone great vicissitudes, but still retain their credit as well as their religion, and, whether regarded as merchants or officials, are the most influential tribe in Sind. They have spread into Afghanistan, Baluchistan, and Arabia, where they expose themselves to inconveniences, insults, and dangers, in pursuit of their darling objects, wealth and final return to their native soil, to enjoy the fruits of their industry. Their name is derived from Lohanpur in Multan, from which they migrated in very remote times. They have about fifty subdivisions, of whom the Khudabadi and Sihwani are the chief. They all wear the poita, janeo, or zonar. Most of them are Hindus, but a few have become Sikhs. They eat meat, are addicted to spirituous liquors, do not object to fish or onions, drink water from their inferiors as well as superiors in caste, and are neither frequent nor regular in their devotions. The town of Agham and Agham Lohana seems to have got its name from a Lohana chief named Agham, who was governor of Brahmanabad in the time of Chach. It lies about 30 miles S.E. from Hyderabad in Sind, and though now almost forgotten, it was formerly a place of some consequence. This tribe is numerous both in Dhat and Talpura. Formerly they were Rajputs, but betaking themselves to commerce have fallen into the third class. They are now scribes and shopkeepers, and object to no occupation that will bring a subsistence; and as to food, to use the expressive idiom of this region, where hunger spurns at law, 'excepting their cats and their cows, they will eat anything.' Three or four caravans annually travel between Deraband and Kābul, and into Calcutta to Bokhara and St. Malaire in Russia, carrying coarse piece-goods, salt, indigo, kimkhab, and fruit. Baber mentions them.

The Lohana of Sind are Vaishnava and Saiva Hindus. Some of them worship the river Indus deity and his wazir under the names Jenda Pir and Udhero Lall. The suffixed titles of their subdivisions are-Mul, Chund, Rae, Ram Das, Lal. They are the principal number of Hindus in the country, but, like the Saraswati Brahmans, they eat meat, fish, and onions, and drink spirits, buying the flesh from the Muhammadans, it being unlawful for them to kill. They are not highly educated, but in the time of the Talpur Amirs they were largely employed as revenue collectors; and were described as scheming and crafty. Under British rule they have shown an earnest application and devotion to duty, able and energetic, honest and upright. They are financiers, bankers, merchants, and shopkeepers.

The Lohani section of the great trading tribe of Povindah, according to Vigne, claim to be descended from Lohani or Luhur, the son of Miani, a Muhammadan shepherd or goatherd of Ghor or Mushkon, a district east of Herat. There were Lohani with Mahmud of Ghazni, who returned with him after his victories in Hindustan. Mahmud's son was Sultan Muhammad. Sultan Masud, who succeeded, had no sons, and about this time the Lohani were placed at Deraband, which was given to them. From that time to this, they have traded between Hindustan and Kābul. Such is their own account. They have subdivided into three branches, - the Daulat Khel, Pani Khel, and Mian Khel. The two first and portions of the last have settled as farmers in the lands of Tank and at Deraband in the Dehrajat, and about Thal and Choti Ali. The other part of the Mian Khel are traders in the countries between Calcutta, Bombay, Benares, Lahore, Samarcand, and Bokhara using camels. Their horses are fine, usually 15 hands high. In their marches parties of the younger men protect their flanks. They traverse the Gulair and Cheri passes, which unite in the Deraband. The Lohani from Calcutta, Dehli, Jeypore, all take the route to their rendezvous at Deraband. The merchants assemble in Dehrajat in April, and, being joined by their families, who have waited on the banks of the Indus, they pass into Khorasan, where they remain during the summer. -Vigne's A Personal Narrative, pp. 32, $53,54,118$; Elliot's History of India; Tod's Rajasthan.

LOHA'RA, a chiefship attached to Raipur, lying to the south-west between the Balod and Sanjari parganas. The zamindar is a Gond by caste, and the estate was originally granted in A.D. 1538, in return for military service, by one of the Ratnapur rajas.

LOHARDAGA or Lohardugga is a revenue district in the Chutia Nagpur division of the Bengal Presidency. Its principal rivers are the Subarnarekha, and the North and South Koel. The Karu, the Deo, and many minor streams fall into the South Koel. The highest hills in Chutia Nagpur are Saru (3615 feet) and Baragai 
or Marang Buru (3445 feet); and in Palamau, Bulbul on the south-eastern boundary (3329 feet), Buri on the south-western boundary (3078 feet), and Kotam (2791 feet). The most numerous tribes are the Mundah, the Kol, and the Uraon; but the word Kol, as popularly employed, includes not only the Mundah of Chutia Nagpur proper and the Larka or Ho of Singbhum, but all Kolarian aborigines wherever found. The Uraon or Oraon are, excluding the semi-Hinduized aborigines, the strongest Dravidian tribe in Bengal. They are the people known in the plains as Dhangar (hillmen), and are found in great numbers throughout the Chutia Nagpur division. The most numerous of the semi-Hinduized aboriginal tribes in Lohardaga are the Bhuiya, the Kharwar, the Bhogta, and the Dosadh. Of lower classes of Hindus, the most numerous are the Ahir, a pastoral caste; the Kurmi, the great agricultural caste; the Kamar, and after them the Teli, oilmen. It yields iron ore, gold, coal, lime, soapstone, lac, resin, catechu, tasar silk, oil-seeds, cotton, hides, foodgrains, blankets, ropes.

LOHIT, a branch of the Brahmaputra river which, after a winding course of about 70 miles, rejoins the parent river, thus forming the large alluvial island of Majuh Char or Kamlabar of 280,000 acres.

LOHRASB or Lohrasp, a king of the Medes, according to Mr. Masson, the patron of Zoroaster and of the Magian religion, who he supposed occupied Bamian. It is surmised that the foundation of the city of Herat or Hari was laid by Lohrasp, who was succeeded by Gushtasp. Gushtasp erected many buildings thereon; Behman, after him, added greatly to the town, and Alexander put the finishing stroke to it. Vigne remarks that if the traditions of the Persians may be credited, we should look to Bamian as the residence of king Lohrasp, the patron of Zertusht and the Magian religion, but as these traditions have been banded down to us only through the romance of Firdusi, it is not possible to say what credence they deserve.-Mohun Lal's Travels, p. 263.

I.OI or Lui. HiND. Blanket, a woollen wrapper; these are of single, double, or triple breadths, ek-arz, do-arz, and tin-arz. Loi-kinardar has a coloured border, Loi-Kashgiri is a striped kind, and Loi-Lahori is made of Kābul wool at Lahore.

IOI KAT"HONG, a Siamese festival on the Menam river, held on the 15th day of the 12th month, when offerings of little rafts of plantain leaves, bearing lighted tapers, are launched into the river.

LOIKOB, aborigines of the east coast of Central Africa, divided into two tribes, the Wakuapi and the Masai, who are often at feud. They are pastoral, nomade, and predatory. They are handsome, tall, light complexioned, and their women are prized in Arab harams. They wear leather dresses. They kill all prisoners. Their sacred place is the mountain Kilimanjaro, which overlooks their land and fertilizes the soil by its streams. There dwells the Engai, their god. They practise circurncision.

LOKA, SANSk., Locum, LAT., a place, a sphere, and used to designate a region, as tri-loka, the three worlds, heaven, earth, and hell. In Hindu mythology, there are fourteen spheres, exclusive of Naraka or Tartarus. Of these, seven are upper spheres, viz. :-

Bhur-loka or earth.

Bhuvar-loka, atmosphere or firmament.

Swar-loka or Swarga, heaven, the sphere of the inferior deities.

Mahar-loka, the region above the pole-star, tenanted by saints.

Jana-loka, the sphere of the sons of Brahma.

Tapa-loka, the region of devotion, abode of Rishi.

Satya-loka or Brahma-loka, the region of truth and of Brahma, to which the pure are elevated.

The seven regions below the earth are habitations of the snake-gods, and are as under, in the order of their tala or descent, viz. Atala, Vitala, Sutala, Rasatala, Talatala, Mahatala, and Patala.

The Vaishnava sectaries have instituted loka of their own, as Vaikuntha, the sphere of Vishnu, and Golaka, the region of Krishna. - Wilson's Glossary.

LOKA, also Lok or Log. SANsk. Man, mankind. Sahib-log, gentry, Europeans.

LOKAKSHI was the son of Chitrakitu, who lived at Kanchi, but Lokakshi dwelt at Sri Saila. He inculcated the dictum, often quoted by Hindus, 'The way of the Great One, that is to be followed.' One of the Smriti, also Lobayataka, one of the Tantra, and an astrological work, are ascribed to his pen.-Ward, iv. p. 50 .

LOKA-MATA, lit. mother of the world, a name of Lakshmi.

LOKA-PALA, in Hinduism, the guardians of the world, are sometimes confounded with the deities presiding over the different cardinal points ; but this is not quite correct, and they are more properly the divinities who were appointed by Brahma upon the creation of the world, to act as rulers over the different kinds of created things. Lists occur in several Puranas, and in the Harivansa portion of the Mahabharat.-Hindu Theatre, ii. p. 218.

LOKE, a mixed race near Mount Abu. The name is probably a corruption of the Hindi word $\mathrm{Log}$, people. It is supposed that the Bhil race were the aborigines of Mount $\mathrm{Abu}$ and the neighbouring bills, but at some remote time became mixed with marauding Rajputs from the plains, and with the workmen who were so long engaged in building the Dilwarra temples. This mixed race called themselves Loke, and are now in possession of almost all the land under cultivation. See Abu.

LOKMAN, according to some authors, took up his residence at Saba, in Yemen, about B.c. 1750, and, finding that the country was continually ravaged by impetuous mountain torrents, while at other times parched from drought, he built a dam across it. It was provided with thirty sluices, and, according to Pliny, the town became the mistress of eities and the diadem on the brow of the universe. See Mareb; Saba.

LOLIGO, the squid, one of the mollusca. The calamary, a species of Loligo, is luminous at night. Many species of squid can leap from the water and float through the air to some distance, like the flying fish. Loligo sagittatus is the flying squid. In China, the naked cephalopods are not only eaten fresh, but one species, a Loligo, forms in its dried state a considerable article of traffic. The preparation consists in removing the ink-bag without laying open the mantle. After all impurities have been removed 
by water, the molluse is submitted to a slight pressure, and ultimately exposed to the sun. Small bundles of one catty weight are tied up with slips of rattan, and enclosed in cases holding ten catties and upwards. The pikul sells at the rate of 14 to 16 Spanish dollars.-Collingwood, Journal Ind. Arch. iv. p. 480 ; Morrison's Compendious History, p. 141 ; Crawfurd's Dict. p. 440 ; Bennett, ii. p. 280.

LOLIUM ITALICUM, Italian rye-grass, affords fine fodder for cattle. Is a useful cold-weather green crop, and is well worthy of extensive cultivation. The best fodder grasses of Europe are usually dwarf species, or at least such as do not rise above four or five feet from the ground. The most esteemed are Lolium perenne, Phleum, Festuca pratensis, Cynosurus cristatus, and various species of Poa and dwarf Festuca.

LOMARIA SCANDENS, the scandent Lomaria fern. The low lands near the mouths of rivers and nullabs, in Tenasserim, are often fantastically dressed with this species of Lomaria, which creeps up to the tops of the tallest trees.-Mason.

LOMASHA, author of a treatise on Hindu law, and of other three works. He was born at Saurashtra, but his hermitage was at Chandra Shekara.-Ward, iv. p. 29.

LOMBARD. Long beards gave a name to the Lombard nation. A Sikh is never so much offended as when you touch him by the beard; the great facial characteristic of manhood is never allowed by him to be profaned by the razor. $-T r$. of Hind. i. p. 303.

LOMBOK, a fertile and populous island, divided from Bali by a narrow strait. The population consists chiefly of Sassak, Balinese, and Bugi. The Bugi reside upon the coasts. The raja of Lombok has the title of Anak Agong, which means son of heaven. The indigenes are called Sassak. The people of Lombok believe that some men can turn themselves into crocodiles, which transformation they adopt in order to devour their enemies. The Sassak are a Malay race, hardly differing from those of Malacca or Borneo, and have been converted to Muhammadanism. But the ruling race are Brahmanical, and from Bali. The men are jealous and strict with their wives; infidelity is punished by the couple being tied back to back and thrown into the sea, where crocodiles devour the bodies. Even a married woman accepting a flower or betel from a stranger has been punished by death with the kris, and any one found without leave within the grounds of a house is krised, and his body thrown out to the street. The people frequently do amok, but it seems to be deliberately done. On one occasion a person doing amok killed seventeen people before he could be killed. In war, a whole regiment will agree to amok, and then run on with such desperate resolution as to be very formidable to men less excited than themselves.

Mr. Crawfurd considers the Lombok language to have a strong affinity with the Javanese. This is the termination in an easterly direction of the group of tongues which begins with Sumatra. According to Mr. Logan, Javan has a much broader, more forcible aspirate and primitive phonology than Malay, and the Javan group embraces Sundan, Maduran (with its dialect Bawian), and Bali. In Lombok are beautiful grass-green doves, little crimson and black flowerpickers, large black cuckoos, metallic king-crows, golden orioles, the jungle-fowl, the Pitta concurna, the Megapodus Gouldii, small white cockatoos, the Ptilotis honey-sucker, and the little yellow zosterops. In a pond at Gumong Sari, in Lombok, the fish swam round after Mr. Wallace, expecting food.

The Balinese may not eat beef, but substitute for it pork. Both races eat buffalo flesh, goat's flesh, fish, and poultry.

The raja of Mataram is, by right of conquest, absolute sovereign of the island. The rajas of Mataram are, like their ancestors of Kawang, Assem, and Beliling, members of the Vaisya caste of Hindus. Although absolute monarchs, they nevertheless, of their own accord, in all important matters consult the principal gusti and ida of the country, some of whom are entrusted with the execution of what is resolved upon.

In Lombok, wives may suffer themselves to be burned after the death of their husbands; they are not compelled to it. They have the choice of allowing themselves to be burned or krised. The first is the more rare.

The straits of Lombok are about 15 miles wide, but on the opposite sides of the straits the animals of various classes differ as greatly as the animals of the old and new world, not only in species, but in genera.

LON, Hind., also Lun, GuJ., from Sanskrit Lavan, salt. Lona matti, salt land; Lonar, a salt pit ; Lonari, salt maker; Loni, the saline inflorescence on damp walls.

Lona, in Urdu, is a vinegar or acidulous salt which forms on the leaves of the Chana or Cicer arietinum.

LONAR, a small town in the Buldana district of Berar, in lat. $19^{\circ} 58^{\prime} 50^{\prime \prime}$ N. ., long. $76^{\circ} 33^{\prime} \mathrm{E}$. ; population in 1867,1865 . It is a place of great antiquity, at the side of a lake, which in Hindu fable is the dwelling of Lonasur, a giant who was overcome in single combat by an incarnation of Vishnu, and around the edge of the lake basin are several old temples. The lake is at the bottom of a crater-like depression, about 510 feet below the level of the surrounding country, and its bottom is 3 miles in circumference, with a depth varying from 5 to 14 feet, according to the season of the year. Dr. Bradley in 1851 is said to have found scoria and lava. The Sichel Hills terminate in the neighbourhood of Lonar. The crater is a nearly circular depression, in a country composed of tabular and nodular basalt. From Lonar the basaltic district extends to the S.E. as far as Beder; to the west, 200 miles to Bombay; and northward, to the banks of the Nerbadda, near the ancient cities of Indoor and Mhysir, reported to have been buried at a remote period under volcanic eruptions. It is a great basaltic region, and the Sichel range passes in a south-east by east direction to the confluence of the Wardha and Godavery, and towards the Eastern Ghats. Hot springs and streams, loaded with carbonate of lime, occur along the line of elevation of these mountains, at Mahoor, Urjunah, Kair, Byorah, and at Badrachellum, a short distance above the pass through which the Godavery reaches the alluvial plains of the east coast. Springs of clear soft water occur close to the lake. A stench of sulphuretted hydrogen is emitted by the lake 
during the heat of the day, but flocks of duck and teal dot its surface. There are two saline springs near the centre of the lake, and about half a mile apart. These never become dry. It is supposed that the muriate of soda from this source, coming in contact with the carbonate of lime which abounds in the vicinity, causes the deposition of carbonate of soda or natron salt in a greater or less state of purity. The salt is raised by divers, who bring it up in their hands. It is much prized, and finds a ready sale in both Berars, Nagpur, Kandesh, and Poona. The lake was regularly worked up to 1836 , in which year 2136 candies of the different salts were raised, valued at Rs. 60,081. In 1853, Major Johnston raised 35 candies, valued at Rs. 1461.4. The sulphuretted hydrogen, especially during the heat of the day, rises in millions of bubbles to the surface. The purest carbonate of soda or natron salt deposit is found close to the springs. The following are the names of the principal varieties:-1. Dulla, carbonate of soda, containing 83.8 per cent. of soda; 2. Nimmak Dulla, nearly pure salt, containing $92 \cdot 8$ per cent. of chloride of sodium. Dulla and Nimmak Dulla are used for dyeing silks, fixing colours, as medicine, and in the manufacture of bangles, of which there are two manufactories near the lake, where 600 or 700 are made by each man daily. 3. Khappul contains 72 per cent. of carbonate of soda, is used in fixing the red dyes of cloths; 4. Pappree contains 72 per cent. of carbonate of soda, is used in making bangles, in baking the cake called papar, and in medicine as an antacid; 5 and 6. Bhuski are neutral earbonates of soda, containing 29 and 27 per cent. left as a deposit on the margin of the lake, and used in the manufacture of soap. The average quantity is 213 candies per annum, valued at Rs. 608 .

The water is clear and free from odours, but the mud at the bottom is highly charged with sulphuretted hydrogen. Natron slowly forms under the mud. The water of the lake contains, besides a little potash, muriate of soda, 29 grains; sesquicarbonate of soda, $4 \cdot 2$; sulphate of soda, 0.1 , in 1000 grains of water. No lime or magnesia detected in it.

Dulla, a carbonate of soda with a faint trace of muriate of soda, about 2 per cent, of impurities.

Nimmak Dulla, nearly pure muriate of soda.

Khappul, carbonate of soda, with water and about 2 per cent. of impurities.

Pappree, nearly pure carbonate of soda.

Madkhar, an impure salt containing carbonate of soda,

Clay and sand,

Water, about

Common salt,

Bhuski, a crude impure substance containing neutral carbonate of soda,

Insoluble matter, chiefly sand and clay,

Water,

Conomon salt,

Travertin, contains carbonate of lime,

Carbonate of magnesia,

Insoluble matter with oxide of iron, etc.,

Chloride of sodium,

Water, .

-Carter's Geological Papers on Western India, p. 33 ; Drs. G. Smith and J. E. Mayer in M. $E$. J. R. of 1857 ; $A$ Paper by Dr. Buist in Trans. Bombay Geog. Snciety.

LONARI. MAHR. A caste whose occupation is hewing wood, making charcoal, etc.
LONDON, the chief town of England, where the minister who rules India has his office. His title is H.M. Secretary of State for India.

LONGAN (Nephelium longanum, $H k$.). Fruits of China and the East Indian Islands, imported in small quantities, dried for dessert.

LONGEVITY. In most eastern countries, the aged amongst their fellow - citizens are much respected, and the Chinese have in their cities temples of longevity. The races occupying British India are short-lived compared with those of Britain, and advance more rapidly to old age, both physiologically and pathologically, yet Anwar - ud - Din is said to have fallen at Ambur, when upwards of ninety years old, probably lunar years.

Rabbits live 7 years; squirrels and hares, 8 years; a fox, 14 to 16 years; cats, about 16 years; a bear lives rarely more than 20 years; a wolf likewise 20 years; hogs the same; the rhinoceros lives but 25 years; cows live to about 25 years. A horse has been known to live 62 years, but the average duration is about 25 years. Of the longevity of snakes nothing is known. Lions live from 30 to 40 years; though a lion of the Zoological Gardens of London reached the age of 70 years. Tortoises live often up to 100 years; elephants live to a great age, for centuries even. When Alexander the Great had vanquished the Indian king Porus, he consecrated to the sun an elephant, which had fought courageously for this monarch, and named him Ajax. He set him at liberty after having attached to him an inscription. The animal was found 350 years after. Amongst birds, a pelican lives for 62 years; an eagle died at 103 ; and ravens and parrots have been known to attain to ages beyond 100 years. At Vienna, there is the skeleton of a swan which lived for 307 years. Dolphins and sword-fish reached the age of 30 years. Cuvier supposed that whales live 1000 years. The greatest age of man or animals is, however, far out-distanced by that of some trees; for instance, in the vast forests of North America veterans have fallen to the woodman's axe whose age was to be reckoned not by hundreds, but by thousands of years. Amongst European trees the oak is the most celebrated for its longevity, and remarkable also for the slowness of its growth. In the forest of Hagenau is the oldest oak in Alsace, and, in all probability, the most aged tree in the entire world. According to tradition, Saint Arbogast had, in the 8th century, built his hermitage beneath the shade of its branches. The bucherons of the forest assign to it an existence of 1300 years. It stands in a very favourable situation, sheltered from the north wind; it has been planted in a piece of ground watered by a rivulet. Not only the trunk, but also the principal branches, are completely hollow, which does not, however, prevent the oak from reassuming its livery of green with the advent of each new season. Throughout all the neighbourhood this antique tree is regarded as the emblem of strength and immutability.

LONGICORNIA, the long-horned and long and narrow bodied group of beetles. They feed on plants; their larvæ often burrow in the wood of trees. In the $\mathbf{E}$. Indies are the genera of the families Trictenotomidæ, Cerambycidæ. See Insects. 
LONG PEPPER, Chavica Roxburghii, Mig. Dar-filfil, - ARAB. Lada-panjang, MALAY. Pih-poh, Pih-po-li, CHIN. Tabi, . . MALEAL. Poivre long, . . Fr. Filfil-daraz, . PERs, Lange pfeffer, : GER. Pippali Krishna, SANSK. Pepili, . . . GUJ. Pimenta larga, . . SP. Pepe lungo, : . IT. Tipili, . . . TAM. Chabai-jawa, : Malay Pippallu, : : TEL.

This kind of pepper is the produce of a perennial plant, a native of Bengal, Siam, and the Archipelago. The fruit is hottest in its immature state, and is therefore gathered whilst green, and dried in the sun. It is met with in entire spikes about an inch long, possessing a darkish-brown or grey colour. It has a weak aromatic odour, an intensely fiery and pungent taste, and its properties correspond closely with those of black pepper. Long-pepper root, Pih-poh-mu, CHIN., Piplimul, HuND., in China is deemed to be stimulant, tonic, and peptic.-Smith.

LONI or Loonee is a term applied to several salt-water rivers in British India. One of them rises in the Aravalli mountains, near Pokur, in lat. $26^{\circ} 37^{\prime} \mathrm{N}$., and long. $74^{\circ} 46^{\prime} \mathrm{E}$. It runs west, nearly parallel with the Aravalli range, and enters the Runn of Cutch by two mouths, the principal of which is in lat. $24^{\circ} 42^{\prime} \mathrm{N}$., and long. $71^{\circ} 11^{\prime} \mathrm{E}$., after a course of 320 miles. It receives the Rairee, 88 miles; Sokree, 130 miles; and about 19,000 square miles are drained. The river, notwithstanding the great width of its bed, in some parts of its upper course appears to be scarcely anywhere continuously navigable, being full of micaceous quartz-rock, banks low, and little above the surrounding level. Perhaps the most remarkable feature in the desert is the Loni or Salt River of Marwar. It is the barrier between the fertile lands and the desert; and as it leaves this country for the t'hul of the Chauhan race, it divides that community, and forms a geographical demarcation; the eastern portion being called the Raj of Sooe-Bab, and the western part, Parkur, or beyond the Khar, or Loni.-Report, Royal Commission.

LONICERACE无. Lindley. The honeysuckle tribe of plants, comprising the genera abelia, aidia, diacicarpium, leycesteria, lonicera, mastixia, polyosina, triosteum, sambucus, and viburnum.

Lonicera hypoleuca, Dne., is the Kharmo, Kodi, of Chenab, and Zhiko, Rapesho, of Sutlej.

Lonicera Leschenaultii, Wall. Moulli-quedi, TAM. A twining villous shrub, native of the Neilgherries; found in many gardens of the Dekhan, where it grows in great luxuriance; it is easily propagated by cuttings or layers.

Lonicera xylosteum is the Jin-tung and Kinyin-hwa of the Chinese. Its flowers, stalks, and leaves are valued by the Chinese as a discutient application to carbuncles, abscesses, swellings, sores. Its dried flowers smell like tobacco.Smith; Jaffrey; Riddell.

LONKA, a sect of deist Hindus who worship the 'One' alone, and 'not in temples made by hands,' which they never enter. The mountain top and sylvan solitude are deemed by them more fitting places to pour forth their homage. They credit the missions of the twenty-four tirthankara of the Jains, considering them as superior mortals, whose sanctity and purity of life gained them the divine favour and the reward of 'mookht,' or beatitude.-Tod's Travels, p. 357.

LOO-CHOO, called Kiu-Kiu in Japanese, and
Lu-Kiu in Chinese, islands to the N.E. of the Patchu group, consist of one large island surrounded by many smaller ones. The large island is well peopled, and extends from lat. $26^{\circ} 3^{\prime}$ to $26^{\circ} 53^{\prime} \mathrm{N}$., and long. $127^{\circ} 34^{\prime}$ to $128^{\circ} 25^{\prime} \mathrm{E}$., being 58 miles long and about 10 or 12 miles broad. In language and physical form, the Loo-Choo islanders resemble the Japanese, their Buddhism being more imperfect, and their manners more simple. The people in the small islands between the Loo-Choo group and Formosa are Japanese rather than Malay. The largest of the islands in loveliness of landscape, as in the careful attention paid to agriculture, looks like one vast enchanting garden. The principal products of the group are rice, millet, sugar, cotton, tobacco, indigo, and tea; of less importance, bananas, pine-apples, oranges, peaches, and plums. Domestic animals are ducks, geese, swine, goats, cattle, and horses. The chief minerals are iron, coal, and sulphur. The inhabitants make paper, cloths, coarse linens, earthen and lacquered wares, bricks, tobacco pipes, and baskets. Their written character is Chinese. For several centuries back, each successive king has had to seek formal recognition from Japan, but the Chinese emperors since the 15 th century have claimed and exercised the prerogatives of investiture. Moreover, in virtue of the tribute paid by the islanders, they have always enjoyed certain privileges granted by the Chinese Government, and held by the latter to establish the virtual sovereignty of China.

LOOM. Nawl, Muhāka, ArAB.; Tānt, Rāch, Rās, Hind.; Aba Aba Kudu, MalaY; Mansaj, PERs. The hand-loom is to be seen in most parts of S.E. Asia and the Archipelago, but the fly-shuttle is rarely used. Both cotton and silk fabrics are woven. During the period anterior to the great advance made by Jacquard, the contrivances at the disposal of the weaver may be divided into three classes. The simplest of these consisted first of the use of healds for figureweaving in any practicable number and order without machines, as in weaving satins, twills, spots, or small figures. In the second, or diaper weaving (from the Latin Diasper), invented, it is thought, by the silk-weavers of Asia, and known in England in the 11th century, two or more divisions or sets of healds in harness were used, each division containing eight healds connected with treadles. By this system, tablecloths, shawls, and other fabrics of widely various design might be woven. In the third system, the warp was passed through two sets of harness, the first of which formed the pattern, as it were, upon a large scale, the second breaking it up into detail, and completing the necessary minute intersectious. This was known technically as the draw-loom. The merit of introducing perforated cards, generally claimed for Jacquard (1801), has been traced back to Bonchon who in 1725 employed a band of pierced paper, pressed by a hand-bar against a row of horizontal wires, arranged like a comb, so as to carry loops through the corresponding blank spaces. Improvements were made in 1728 by $\mathrm{M}$. Falcon, and in 1745 by Vaucanson. But from the Jacquard machine may be said to have been developed the entire series of complex ingenious machinery which has given its marvellous expansion to the European weaver's craft. Among the more marked stages of development stands the 
introduction, by Dr. Cartwright, in 1785 , of the power-loom, to supersede manual labour, preceded, yet perhaps without his knowing it, by the models of De Gennes, Roberts, and Barber. There are not less than 700,000 power-looms at work in Great Britain, producing daily about 15,000 miles of cloth, and giving employment to 300,000 weavers.

Lace manufacture is the highest and most complicated of the processes of weaving. The first attempt of Mr. Heathcoat in his bobbin-net machine, patented in 1808 , was followed up by the more consummate effort of his mechanical genius. The Levers machine, provided with a double-action of Jacquard apparatus, is chiefly employed in weaving guipure or narrow lace, though it can be arranged to produce lace of any width, and even shawls. The Levers lace frame fairly represents the present state of the lace manufacture of Nottingham, and in it is reached as yet the highest or culminating point in that important and attractive industry.--Barlow on Weaving.

LOOT. HIND. Plunder. Lootee bazar literally signifies plundering the bazars or shops, but it implies no more than a general rising of the inhabitants. This ancient usage is still preserved in Persia.-Malcolm's Persia, ii. p. 6.

LOPEZ SOAREZ formed the first settlement in Ceylon in 1517.

LOPHANTUS RUGOSUS. Smith. Ho-hiang and Ho-ken, Chin. Its rough leaves are used by the Chinese to scour metallic vessels, and are given in infusion in disorders of the stomach and bowels.-Smith.

LOPHIAD $\approx$, a family of fishes which includes the anglers, fishing-frog, or sea-devil, and the frog-fishes.

LOPHOBRANCHII, an order of fishes comprising the families Solenostomidæ, Syngnathidæ, and Hippocampenæ, and these include the East Indian genera solenostoma, synguathus, ichthyocampus, nannocampus, urocampus, doryichthus, cælonotus, stigmatophora, nerophis, protocampus, gastrotokeus, solenognathus, phyllopteryx, acentronura, and hippocampus.

LOPHOPETALUM WIGHTIANUM. Arnt. Balpale, CAN. A large handsome tree of the Western Ghats, from Cape Comorin to the Bombay ghats. It grows in the moist forests in the plains of South Canara (at Parapa), but it also ascends the ghats to an elevation of 3000 feet; its timber is much esteemed by the natives. Beddome, Fl. Sylv.

LOPHOPHORUS IMPEYANUS. Lath. The monal pheasant of the Himalaya. It is double the size of the pheasant of Great Britain. The male has a crest of great beauty, head and throat has metallic green, wings and plumage steelblue, and tail reddish-brown. The hen bird is smaller, of a dull brown, and white throat.

LOPHOSPERMUM SCANDENS. Don. A beautiful climbing plant with large purple or rose-coloured bell-shaped flowers. It is of fast growth, and well adapted for covering trelliswork.-Piddell; Jaffrey.

LOPHOTID E, a family of fishes of the one genus, lophotus. See Fishes.

LOPISIP BARK, a dye-wood of Celebes and other islands of the Eastern Archipelago. Lopisip bark, bunchong bulu wood, and the gaju gum (from undescribed plants), have been introduced into England. They are said to furnish excellent dyes in the Asiatic Islands. Native dyes from Arakan have also been imported, viz. thittel and thedan, yielding red dyes; ting-nget and reros, affording dark-purple dyes; and thit-nan-weng, a chocolate dye.

LOQUAT.

Eriobotrya Japonica, Lind. I Mespilus Japonicus, Thun. Lu-kuh, Yung-mai, Chin. Yang-ma, . . CHIN.

This small tree of Japan and China has been introduced all over the Dekhan, the Panjab, and New South Wales. It bears fruit twice in the year, and is highly esteemed both for desserts and preserves. The finest is the second crop, at the end of the cold season, and requires protection day and night from birds and flying foxes. The fruit is of a yellow colour, with thin skin, a sweet acid pulp, one or two seeds in the centre, - sometimes more. The seeds grow easily. It is very common in China, and Fortune found it growing along with peaches, plums, oranges, the Chinese gooseberry Averrhoa carambola, the waughee Cookia punctata, and the longan and leechee. In China, the fruits of Citrus olivæformis and C. Madurensis are also called Lu-kuh. - Fortune, Tea Districts, pp. 7, 30; Drs. Riddell, Irvine.

LORANTHACE A, the mistletoe group of shrubs, almost invariably parasitical upon other plants, with leaves usually opposite, thick, and fleshy. In tropical countries species abound, some with large, brilliantly-coloured flowers. In India they are found in the mountains of Nepal, the two Peninsulas, and the Archipelago, and have above 400 species, in the genera loranthus, schopfia, and viscum. Roxburgh described eight species, and Wight eleven.

Loranthus globosus, Roxb.

Chota mauda,. . Beng. | Kenneli itti kanni, . CAN.

A ramous, shrubby parasite which grows on trees in Bengal.

Loranthus longiflorus, Desi.

Pand, . Beas, Kangra, Banda,. . . Panjab. Parand, . BEAs, Ravi. Amut,. . . SurteEJ.

A handsome parasite, with branches sometimes 6 or 7 feet long, large broad leaves, and orangecoloured flowers. It is found in the Panjab Himalaya, chiefly on the eastern rivers, from 1500 to 3000 feet, and occasionally higher, $-D r . J . L$. Stewart.

LORCHA, a vessel in use in the Chinese seas, sometimes employed in war.

LORD, P. B., an Assistant-Surgeon of the Bombay army, author of Memoir on Kunduz; on the Trade with Turkestan; on the Sheep and Goats of Kābul; on the Tribes of the Khaibar; and a Visit to the Plain of Koh-i-Daman, Ghorband, and Hindu Kush. Also author of Medical Memoirs on the Plain of the Indus, in Bom. Geo. Trans., 1836,1838, i. p. 293 ; on the Medicines found in the Bazars of Sind, in Bom. Med. and Phys. 'Irans. iv. p. 127. He was killed in battle at Parwandara, in 1841.

LORD OF THE OXEN, or Shora-pati, a title of the king who drove Semiramis back across the Indus.

LORD OF THE WHITE ELEPHANT, a title of the king of Burma. See Titles.

LORDS OF CREATED BEINGS. Menu describes these as being produced by one of the 
Hindu triad, but in a legend they are ascribed to the joint powers of the three great personified attributes of Brahma, Vishnu, and Siva. They are in places called Muni, in other passages they are considered as Brahmadica, or Prajapati, and as Rishi.-Moor, p. 91.

LORD'S PRAYER, a form of prayer recommended by the Messiah to his disciples. It is of ten repeated by Christians in their supplications to the Almighty. It was published in 1548 in 14 languages, by Bibliandro; in 1591 in 26 languages, by Roceca (Bibliotheca Apostolica Vaticana, a fratre Angelo Roccha, Romæ 1591, 4to); in 1592 in 40 languages, by Megiserus (Specimen XL. Linguarum et Dialectorum ab Hieronymo Megisero à diversis auctoribus collectacum quibus Oratio Dominica est expressa, Francofurti 1592); in 1593 in 50 languages, by the same author (Oratio Dominica L. diversis linguis, cura H. Megiseri, Francofurti 1593, 8vo). The Bible has been printed and distributed in India in 25 different languages, in ten of which between 100,000 and 600,000 copies have been printed, and in Tamil 1,560,950 have been issued since 1706, when the Bible was printed in that language. The Bible was printed and issued in Bengali in 1796, and in Malealam in 1816. The whole of the copies printed in the 25 Indian languages is $4,772,621$.

LORI, in the Jummoo territory, a religious festival, in which a kid is beheaded and offered to the fire.-Drew, The Northern Barrier.

LORIES or Lorikeets are birds of the tribe Scansores, family Psittacidæ, sub-family Loriinæ, and genus Loriculus.

L. vernalis, Sparrm., the Indian lorikeet, is of a grass-green colour, is known as the latkan or pendent, because in captivity they commonly rest and sleep pendent from the wire roof of their cage. This one occurs in Malabar, Travancore, Dharwar, the Sub-Himalaya, Assam, Sylhet, and Burma; and they are commonly known as love birds, a name also applied to the Agapornis of Africa, Psittacula of S. America, and Trichoglossus pumilus of Australia. L. Asiaticus is a Ceylon lori; L. galgulus of the Malay Peninsula, and others in China and the Archipelago. Some of them have bright colours,

\section{'Gay, sparkling lories, such as gleam between The crimson flowers of the coral tree \\ In the warm isles of India's sunny sea.'}

A lori of Fiji, Domicella solitaria, is one of the most beautiful parrots. A very bandsome scarlet lori was obtained by Macgillivray, closely allied to Lorius domicellus, a bird widely spread over the Indian Archipelago._Jerdon; Macgillivray's Voyage, i. p. 211.

\section{LORIS GRACILIS. Geoff.}

Stenops gracilis, $V$. Hocv. Theivanga, . . TAM. Nama-theivanga, Singh. Dewantsi-pilli, : TEL.

The Loris gracilis inhabits S. India and Ceylon. It is a species of a genus of mammals, belonging to the family Lemuridæ. Its Tamil name, theivanga, means thin-bodied; and hence a deformed child or an emaciated person has the same epithet applied. The light-coloured variety of the loris in Ceylon has a spot on its forehead, somewhat resembling the namam, or mark worn by the worshippers of Vishnu, and from this peculiarity it is distinguished as the Nama-tha. Its eyes are extracted by the Singhalese as charms, and for love potions.-Jerdon; Tennent; Horsfield.

LO-SA, or Lo-za, or Lok-zah, CHin., is the term applied to the branches of the Chinese green dye plant, when tied up in faggots for sale to the dyer. But there are two kinds of such faggots, one termed pa-hi-lo-sa, or white-skinned green vine branch, and the other hom-hi-lo-sa, red skinned green vine branch. Father Helot states that the people of Canton, on whose mountains the plant grows, call it lieu-lo-chou, willow green tree. Fortune states that a farmer near Hong-tcheou-fu, who had some plantations of the cultivated Rhamnus, named it loh-sah and sob-loh-shu. Mr. Sinclair gives hwuy-chiang-chi, or lee-chi, as the name of a bark used in Foh-kien for dyeing cotton green. The Hong-pi-lo-chou has all the characteristics of a wild shrub. The magnificent lustre is only obtained after immersion in the infusion of the pe-pi-lo-chou. At Ayè, Father Helot was assured that the lo-kao was prepared from the bark of the pe-pi, and the dyers of Khiu-tcheou-fu described a process for dyeing silks and cottons with the pe-pi only. It would seem that the pe-pi alone yields violet, blue, and green, according to circumstances, and a peculiar kind of the lo-kao or green dye on cloth of a watery green tending to azure, with lime or alum; that the hong-pi yields a yellow to impart a green to the colour, and that the lo-kao is impure if the admixture of this yellow be in too great a proportion. The shrubs from which the green dye is obtained are thorny. The Rhamni indigenous to China are-

R. crenatus, Sieb. and Zuccarini, Japan.

R. globosus, Bunge, North China.

R. lineatus, Lour., Berchemia Loureiriana, De Cand., China, Cochin-China.

Rhamnus tinctorius of China differs from $R$. chlorophorus only in the shape of the calyx.

M. De Caisne told M. Rondot that an English horticulturist had reared a scrophularaceous plant, which had been sent to him as the Lo-za.

$\mathrm{Ma-ly}$ is the name of a tree growing wild in the province of Hit-cheou, the bark of which is used to dye common cloths.

Toxocarpus Wightianus, Hooker, is the Asclepias curossavica of Lour. It is called in Chinese Mali-kiu.

The Chinese have two modes of dyeing green, first, with the flowers of the hoai-hoa and indigo; second, by indigo alone.

LO-SHU. It is known that, in transacting business before the commencement of the Chinese monarchy, little cords were used, with sliding knots, each of which had its particular signification. These are represented in two tables by the Chinese, called Ho-tu and Lo-shu. The first colonies who inhabited Sze-chuen had no other literature besides some arithmetical sets of counters made with little knotted cords, in imitation of a string of round beads, with which they calculated and made up all their accounts in commerce.-Astley's Voyages, iv. p. 194 ; Lubbock, Orig. of Civil. pp. 29-31.

LOTA. Hind. A small metal pot, made of brass or copper or iron tinned, used for drinking and ablution by Hindus and Muhammadans.

LOTOPHAGI, an ancient people represented as living on the coast of Africa, near the Syrtes (Herod. iv. 177), and so named from their eating 
the lotus. Homer says that whoever ate of the lotus lost all desire of returning to their own country. It has been supposed to be the fruit of Zizyphus (Z. napeca). Mungo Park found a species of Zizyphus in the interior of Africa, which forms a large tree with yellow farinaceous berries of a delicious taste. The natives convert them into a sort of bread, by exposing them some days to the sun, and afterwards pounding them gently in a mortar until the farinaceous part is separated from the stone. This meal is then mixed with a little water, and formed into cakes, which when dried in the sun resemble the sweetest gingerbread. The fruit of several species of Zizyphus is eaten in India. One kind, commonly known by the name Ber, forms a moderate-sized tree in a cultivated state, with oval fruit of a yellowish or reddish colour, and about the size or somewhat smaller than a common plum, which is much esteemed. The taste is mild and sweet, with a slight degree of acidity, probably coming nearer to the taste of dates than any other fruit.

In Persian works, Berri and Jharri are given as its Hindustani, Kinar and Khial as its Persian, and Sidr as its Arabic name, with Nebbe for the fruit. The fruit of the wild kind is dried and powdered, as was done with the lotus of the Lotophagi. This powder, in Arabic, is called Savik-un-Nebbek; in Persian, Arud-i-Kinar; and in Hindi, Ber-Chuni. The Egyptian lote tree is the handakuk misri.-Eng. Cyc.

\section{LOTUS.}

Nufar, - ARAB. Nilofar,

Padma podoo, Beng. Kamala, Padma, SANsk. Komol, Ponghuj, " Tamare, . . TAM. Lien-ngau, . . CHIN. Yerra tamare, . TEL. Ambuj, Kangwel, HiND. Tellani padmam, . ",

Lotus is a name given to three plants; the Nelumbium speciosum, or Egyptian lotus, figured on the ancient monuments of Egypt and India, is now extinct in Egypt, but grows in the south of Asia and in the islands of the Archipelago; one lotus of the ancients was the Melilotus officinalis, and the lotus of the Lotophagi is by some thought to be the fruit of the Zizyphus lotus, Desfontaines, but by Munby supposed to be that of Nitraria tridentata, called Damouch by the Arabs of the desert of Soussa, near Tunis. Its berries have intoxicating qualities.

With the ancient Egyptians, and after them with the Buddhists and Hindus up to the present day, in India, Ceylon, Burma, Siam, China, and Japan, the lotus flower of the Nyrnphra pubescens, Willde., has been an emblem of peculiar sanctity. It is the Indian or Egyptian lotus. Its large white flowers have a vinous smell. $N$. rubra, Roxb., and N. versicolor, Roxb. are also of India; as also N. edulis, $D . C$., the roots of which are eaten and medicinal.

The Nile was a sacred river; many of its plants, as the Faba Egyptiaca, a species of bean, and the Nymphæa, were sacred also; and the former on account of its resemblance to a boat, and the latter from its well-known quality of always floating above the surface of the water, were adopted very generally as symbols of the ark. The Egyptian priests were accustomed to crown themselves with the lotus. The lily of 1 Kings vii. 26 , the emblem of the Israelites, is supposed to be the lotus.

The lotus flower among the Hindus enters into all the ornaments of brass vessels used in the temples; it is alluded to in the most popular poems, and their poets say that the lotus was dyed by the blood of Siva that flowed from the wound made by the arrow of Kama, the Indian Cupid, as in Midsummer Night's Dream, Act ii.

'Yet marked I where the bolt of Cupid fell ;

It fell upon a little western flower-

Before, milk-white, now purple with Love's wound, And maidens call it love-in-idleness.

Moore sang of the water lilies-

- These virgin lilies, all the night

Bathing their beauties in the lake

That they may rise more fresh and bright When their beloved sun 's awake.'

In the Ratnavali, or the Necklace, - a Sanskrit play written in the 12th century,-Vasantaka says to his lady-love: 'My beloved Sagarika, thy countenance is as radiant as the moon; thy eyes are two lotus-buds; thy hand is the full-blown flower, and thy arms its graceful filaments.' In Hindu theogony, the lotus floating on the water is an emblem of the world; the whole plant signifies both the earth and its two principles of fecundation.

In Japanese mythology we find the goddess Quan-won represented sitting upon the same aquatic plant. In China, the deity upon the lotus in the midst of waters has been long a favourite emblem; and the god Vishnu, in Hindu mytho$\operatorname{logy}$, is still represented in the same manuer. In connection with this diluvian emblem, Diana is mentioned by Strabo, Artemidorus, and Pausanias, by the title of Limnatis, or the maritime deity. In an ancient inscription in Gruter, she is also called Regina undarum, queen of the waves and Orpheus invokes her under the appellation of preserver of ships. It is possible that an eastern legend may have given origin to the transformation of the nymph Lotis flying from Priapus into the Aquatica lotus.-Ovid, Metamorph. ix. p. 341. See Nelumbium; Nymphæa; Padma.

LOUISIADE ARCHIPELAGO is S.E. of New Guinea. It extends about 400 miles in length, by about 160 miles in breadth, where broadest. The centre of the Archipelago is under lat. $10^{\circ} \mathrm{S}$, and long. $152^{\circ} 25^{\prime} \mathrm{E}$. The islands are inhabited by a black Papuan race with woolly hair, and Macgillivray described the natives as dark copper coloured, the hair nearly all frizzled out into a mop, in some instances of prodigious size. The physiognomy varied much; the nose was narrower and more prominent, the mouth smaller, the lips thinner, the eyes more distant, the eyebrows less overhanging, the forehead higher, but not broader than in the Australian; one man, whose head was shaven, had his forehead narrow and receding, appearing as if artificially flattened, thereby giving great prominence and width to the hinder part of the skull; and he often observed the same configuration of head combined with dark-coloured skin and diminutive stature. None had the artificial prominent scars on the body peculiar to the Australians, or wanted any of the front teeth, but the septum of the nose was perforated to admit an ornament of polished shell, pointed and slightly turned up at each end. The lobe of the ear was slit, the hole being either kept distended by a large plug of rolled-up leaf, apparently of the banana, or hung with thin circular ear-rings made of the ground- 
down end of a cone-shell (Conus millepunctatus) one and a half inches in diameter, with a central hole and a slit leading to the edge. A piece of cloth-like substance, the dried leaf of the pandanus or some palm, was used by all, passed between the legs, and secured in front and behind to a narrow waistband. Several of the Megapodius duperreyi were seen by Mr. Macgillivray in the Louisiade Archipelago.-Macgillivray's Voyage, i. p. 189.

LOUK-KA. The green dye of China, louk-ka, lo-kao, or king-lok, was first made known to Europe in 1845 . Its price in China has continued steady at 24 dollars the catty. In China, the green cloths dyed by this material are called liou-sai, but are known to the trade as so-lo-pou, green colour. cloth, when dyed by the bark; nghiou-lo-se (green nymphæa colour) and nghioulo-pou (green nymphæa cloth), that is, cloth dyed with the lo-kao of the colour of the leaves of the nymphra. Each piece of liou-sai is one foot or one foot one inch broad, and in 1848 cost from 50 to 53 cents. In addition to the lokao, the French consul, M. Montigny, sent one green dye-stuff called pih-chou-elle, ten catties of which cost 4920 sapeques; and another called tong-loh, green paint, said to be prepared from no-me, fifty catties of which cost 20,800 sapeques. Lo-kao or lou-kao, in Chinese signifies green glue or green lac, and all who sent samples of the green dye itself, call it lo-koa or lo-kiao. In Canton it is louk-ko; in Foh-kien, liok-kor and lek-ko. The first considerable consignment of the green dye was received in Paris in 1853, since which date it has become an article of trade. At the Universal Exhibition held at Paris in 1855 , samples of green dye were exposed, and Dr. Royle subsequently stated that there were three kinds of the green dye of China, or green indigo from China, from Burma, and from Assam. That from the valley of the Brahmaputra, in Assam, is called roum, and is extracted from a species of Ruellia. This plant, or a nearly allied species, is cultivated with the same object in Pegu and Burma. It is altogether different from the bila-roum, the product of the Wrightia tinctoria, $R$. Brown. Others point to the R. comosa, Roxb., and the Buteræa ulmifolia, De C. MM. Edan and Remi in 1854 reported that they had procured a very fine green from the fruit of the lo-za, but were unsuccessful in regard to the bark. Mr. Fortune informed M. Edan that without doubt the bark of the lo-za was employed to furnish the stuff with which to dye cloth green, and that the fruit was used in the preparation of green paint for paper. These points were repeated by M. Remi in 1855 . All the experiments hitherto made with the bark and the leaves of the Rhamnus chlorophorus and $R$. utilis have not been decisive. M. Persoz had succeeded in extracting a yellow dye from the bark of $R$. chlorophorus and the berries of the $R$. utilis, but he could not discover a trace of the green dye in the extracts prepared from the berries of both kinds, which were sent to him by the Agri-Horticultural Society of India. Nevertheless the united testimony of Fathers Helot and Aymeri, MM. Arnaudtizon, Edkins, Fortune, and Remi, is to the effect that it is the bark of the branches, and perhaps also of the roots of the $R$. chlorophorus and $R$. utilis, but especially of the former, that gives to the green dye that brilliant colour which it assumes under the influence of artificial light. The fruit, at least that of the $R$. chlorophorus, probably yields a green colouring matter analogous to the bladder green, and differing from the true green dye both in colour and properties. The Chinese declare that other species of the same genus have dyeing properties. The pe-piu-lo-chou is the $R$. chlorophorus, De Caisne, and the hong - pi - to-chou the R. utilis, but until some European chemist shall have discovered traces of the green dye in some of the parts of the plants, the flowers, the berries, the seeds, the leaves, the bark, or the root, it cannot be asserted that the plants are really those the Chinese use to dye their cottons with or from which they prepare the lo-kao. Some European plants dye a green colour; the blue-flowered Scabiosa is used for that purpose in Sweden; the Melissa officinalis yields, under the action of spirits of wine, a permanent green dye, and the Mercurialis perennis yields a permanent blue-green. The green dyes from the Ruellia, Justicia tinctoria, Lour.; Adenostemma tinctorium, Cass.; Sanseviera læte-virens, Ham.; Asclepias tingens, Roxb.; Melissa officinalis, Linn., have not yet been examined. Various plants stated to yield a green dye colouring matter have been examined, but in vain, for the green dye of China. These are the Arundo phragmitis, Linn.; the artichoke, deadly nightshade, wild chervil, ash tree, lucerne, Lycopersicum esculentum, Mill.; Mercurialis perennis, Linn.; Ronabea arborea, Blanco; the groundsel, and the common field clover. M. Michel obtained tolerable greens from the berries of $R$. catharticus, Linn., and R. alaternus, Linn., but not improving by artificial light. He found that cloth taken out of the bath with a light nankeen dye, and placed at night on the grass, had assumed towards morning, and long before it was exposed to the rays of the sun, a deep green colour. A damp atmosphere and dew were found to increase the intensity of the tint. The lower side near the grass was scarcely at all coloured, and a cloth left all night in a dark room was found in the morning to be unchanged. M. Persoz found the fruit of a buckthorn to yield a pretty lilac on silk. The green fruit of the R. infectorius, Linn. (Avignon berries; R. saxatilis, Linn.), Persian berries of R. alaternus, Linn., and R. amygdalinus, Desf., afford a yellow colour. The fruit of the R. frangula, Linn., gathered in July and August before they are ripe, yield, according to Damboumey and Leuchs, a fast and brilliant yellow; according to Buchoz, a green; and when they are ripe, in September and October, they dye a purplish-blue without any mordant, and green, violet and blue violet or blue, according to the nature of the mordant employed. Dambourney obtained on wool, from the juice of the ripe berries fermented, very fine and fast greens, varying from an apple to a dark green. The colouring matter of the berries of the $R$. infectorius is yellow before they are ripe, and dark purple-red so soon as they have attained maturity. Buchoz notices similar peculiarity in the fruit of the $R$. catharticus; before ripening it yields a saffron red; after maturity, a green, known as a bladder green, and still later a scarlet. According to Waldstein and Kitaible, the green berries of R. tinctorius have dyeing properties similar to 
those of the fruit of $R$. catharticus, but more esteemed by the dyers. The inner bark of $R$. infectorius dyes yellow, when fresh; brown-red, when dry. The dry bark of the $R$. frangula yields a brown or dark red, and the fresh a yellow dye; and the root as well as the bark and seeds of $R$. catharticus, a yellow and volatile colour, named Rbamno-xanthine, which is dissolved by the alkalies, and converted into a magnificent purple. The bark of $R$. catharticus and $R$. alaternus dye yellow; the wood of the latter species dyes dark-blue, and the root of $R$. infectorius a brown. The leaves of $R$. alaternus yield a yellow colour, and those of $R$. frangula a greenish-yellow. A mixture of the cuttings of $R$. alaternus, which yield a dark-blue, with the fresh bark of the same buckthorn and of $R$. catharticus, $R$. frangula, and $R$. infectorius, which contain a yellow colouring matter, ought to produce a green. The European Rhamni contain a volatile principle, and nearly the same changes take place in the colouring matter of the several species, from red to violet, to blue, to green, and to yellow. The lo-kao possesses similar qualities ; and it is possible that the green dye, so remarkable when exposed to light, is a compound of blue and yellow having separately the same property, and united in the bark of $R$. ehlorophorus. But M. Rondot suspects that the supplementary yellow requisite to produce the green of lo-kao is not obtained from one of the Rhamni, but from the hoang-chi, the fruit of Gardenia, or the hoai-hoa, the flower-bud of the Styphnolobium Japonicum. In 1855, when Mr. Robert Fortune was sent to China by the E. I. Company to procure tea plants for the nurseries in the Himalaya, he was particularly directed to give his attention to plants of that country stated to produce a green dye. Accordingly he sent seeds and samples to the Agri-Horticultural Society of Bengal, from which numerous plants were forwarded to all parts of India. It seems established that the trees from which the green dye is prepared are two species of Rhamni, one wild, called by the Chinese white skin, and which grows in abundance in the vicinity of Kiabing and Ningpo. The other is called yellow skin by the Chinese, is cultivated at Tsoh-kaou-pang, where some thirty men are employed in the preparation of the dye-stuff. The flowers, leaves, roots, bark, and fruit have all been indicated as the part of the plant from which the lo-kao was prepared. Mr. Fortune sent to India and to England plants of both the cultivated and wild species. The wild species is a shrub, and is called hom-bi-lo-za, from the circumstance that when its bark is boiled in water a white scum is formed, which subsequently passes to rose-hom-bi, meaning red scum bark. The pe-pi-lo-chou, or $R$. chlorophorus, is cultivated between lat. $25^{\circ}$ and $36^{\circ} \mathrm{N}$., but more especially about lat. $30^{\circ}$ and $31^{\circ} \mathrm{N}$. The hongpi-lo-chou, or $R$. chlorophorus, is mentioned as high as lat. $39^{\circ} \mathrm{N}$., and down to lat. $30^{\circ} \mathrm{N}$. This seems the hardier buckthorn, and capable of withstanding the severe frosts of Che-li, but it is evident that both species exist in abundance in the northern parts of the province of Che-kiang, over a space of 45 square miles,-Report on the Green Dye of China.

LOUNG-KIO, a bird of Chinese Tartary, described by $M$. Huc. It is about the size of a quail, of an ash colour, with black spots, its eyes of a brilliant black, and surrounded with a bright sky-blue rim. Its legs are covered with long rough hair, and its feet resemble those of the green lizard, and are covered with a shell so hard as to resist the sharpest knife. 'This singular creature is called by the Chinese Loung-kio, that is, dragon's foot. They generally arrive in great flocks from the north, especially when much snow has fallen, flying with astonishing rapidity, so that the movement of their wings is like a shower of hail. When caught, they are extremely fierce. -Huc's Journey, p. 92.

LOUREIRO, J. DE. Father Loureiro, a native of Portugal, author of the Flora Cochin-Chinensis, 1 vol., 1790, resided for 36 years in the kingdom of Cochin-China, whither he proceeded as a missionary; but finding that Europeans were not permitted to reside there without good cause, he entered the service of the king as chief mathematician and naturalist. The Flora CochinChinensis was published at Lisbon, in 2 volumes quarto, in 1790; and a second edition, edited by IVilldenow, with a few notes, appeared iu octavo, at Berlin, in 1793. In the herbarium of the British Museum there are several small collections, which are of great importance to the Indian botanist, especially one containing many of Loureiro's plants, which are not readily recognisable, at all events as to species, by the descriptions in the Flora Cochin-Chinensis. There are also considerable numbers of specimens forwarded to Sir Joseph Banks by Roxburgh, Hamilton, and Russell, which are occasionally of use in determining the species described by Roxburgh. The British Museum also contains Konig's collections and manuscripts, Kaempfer's Japan and other plants, and Hermann's herbarium.-Hooker and Thomson's Flora Indica.

LOUSE. Jeo, HIND. Of these there are four kinds, - head louse, Pediculus capitis ; body louse, $\mathrm{P}$. corporis; louse of sick persons, $\mathrm{P}$. tabescentium; and pubic louse, P. pubis.

Lice are parasites of the mammalia, with climbing feet, terminated by pincers, by which they seize the hair of the animals on which they live. Their eggs are known as nits. They are hatched at the end of five or six days, and reproduce at the end of eighteen days. Phthirius pubis has been found only on white races. In the Salt Range, the Ajuga bracteata is used to kill lice.

Wood lice are of the order Isopode crustaceans, of the family Cloportidæ.

The flea is the Pulex irritans of man; P. canis, $P$. musculus, and $P$, vespertilionis are of the dog, mouse, and bat. In the sandy, rocky parts of India, $P$. irritans is the flea; they are very numerous. The Hematopinus tenuirostris flea attacks horses. There is a species of Pediciuus peculiar to monkeys.-Van Beneden.

LOVE-APPLE, or tomato, the Lycopersicum esculentum, is a native of South America, and of $₫$ genus of the same family as potatoes. There are two sorts, single and double; they may be sown immediately the rains commence, in beds; afterwards transplanted in rows, two feet apart, and trailed upon sticks of a strong description. If the soil is good, they will grow to seven or eight feet in height. The double are the finest, and if sown in June, ripen in October. The lower branches should be pruned, and a succession of 
crops may be kept up until A pril. The small single tomato, with a slight protection from the dry winds, will continue until the rains. - Jaffrey.

LOTV, COLONEL JAMES, an officer of the Madras army, long employed in the civil administration of the Straits Settlements. He wrote Treatises on Siamese Grammar, Literature, and Government, on Buddha, on the Phrabat, on the I aws of Siam, and on the Soil and Agiculture of Penang.

IOWER BENGAL, a term applied to the districts in the proximity of Calcutta. The Lower Provinces, another term in use, cornprise Bengal, Behar, and Orissa. Their area is 193,198 square miles, and, in 1881, population 69,536,861. The Bengal part is intersected by numerous branches of the Ganges and Brahmaputra, the chief of which are the Hoogly, formed by the junction of the Bhagirathi and Jellinghi; the Matabanga, a branch of the Ganges; the Mutlah, a mouth of the Ganges; the Kosi, a tributary of the Ganges; and the Damuda, a tributary of the Hoogly.

L'R PUKHTUN, also L'r Pushtun, a term applied by the Afghan race to their language.

LU. CHIN. A gong.

LUANG PHRA BANG, a Laos district on the Mei-kong, which has largely extended its powers towards the north, and carries on trade with Siam, Cochin-China, and a Chinese race called Lo-Lo.

LUBAN, from Greek Libanos, benjamin ; Olibanum; resin of Boswellia thurifera, frankincense; Styrax benzoin. Boswellia serrata, also Styrax benzoin, yield gum benjamin, used as a stimulant, and eaten in betel leaves. The attar or perfumers of India sublime the benzoin acid very purely, and administer it as an aphrodisiac; one seer costs from two rupees to two and a half. The gum-resin of the Boswellia thurifera is also considered as luban by the community.-Genl. Med. Top. p. 144.

LUBANAH. HIND. A caste of agriculturists, also grain carriers, settled in Bagur and Kantul; they live in villages, sometimes mingling with other cultivators, and sometimes having a village exclusively to themselves. They are Sudra Hindus, originally from Gujerat, and are a quiet and inoffensive race, differing widely from the Brinjara, though engaged in the same trade. Brinjara have settled down as agriculturists on waste tracts. They are very careful and thrifty cultivators. There are numerous colonies of them along the right bank of the Ravi.-Malcolm's Central India, ii. p. 152.

LUBB-US-SIYAR, a book of travels, by Abu Talib. See Literature.

LUBU, a people apart from the Malays of Menangkabau. They build houses like the Malays. One of their towns is Lubu Sipeking. The Lubu eat fruit, maize, dogs, monkeys, and snakes, but never rice. They are slaves to the raja of Acheen. Lubu Raja peak rises 6200 feet above the sea. It is the highest in the Batta land.

LU-BYO-LAI-THEE-KALA. BurM. Courting time. Burmese girls receive their bachelor acquaintances at 8 P.M. A lamp placed in their casement intimates that they are at home. An old bachelor (Loo-byo-hoing) or old maid (Apyohoing) is unknown.

LUCANIDAE, the group of stag beetles; the mandibles of the males are very large. The larvæ feed on wood, the beetles on sap. Of all the beetles, Lucanus cervus is the most destructive to living trees. Their larvæ live for three and fouryears in that state in the interior of the trunks of oaks, and about Naini 'l'al, barely one in ten trees escape from their attaclss. They bore circular chambers, penetrating to the heart of the stem, winding into various passages, both up and down the trunk. If felled logs be immersed in water, the larvæ are destroyed. These and the larvæ of Prionus beetles seem exclusively to attach themselves to the oak as their habitation. See Insects.

LUCERNE, Medicago sativa. Rishka, Shasta, PERS. In Afghanistan, lucerne and a trefoil called shaftal are grown for fodder. Panicum Italicum (arzun) and P. miliacum are also grown for fodder. Lucerne is sown in spring and autumn; grows to perfection in three months, after which it can be cut once a fortnight. The plant is often ten or fifteen years old. Shaftal can be cut in three months, and never lasts longer than three years.-MacGregor.

LUCHA. Hind. A necklace worn tight round the neck; a skein or bunch of gold wire or silk, etc.

LUCK is the past tense and past participle of the Anglo-Saxon Lreccan, to catch, and means anything caught; thus the haul of the fisherman would be his luck. The word used by the Hindu for luck is the name of the goddess Luchmi or Lakshmi, or from the Sanskrit word Luchmee. The Hindu phrase, she is the Lutchmee to her man, signifies that she is the source of good luck to her husband.--Tr. Hind. ii. p. 344.

LUCKNOW or Lakhnau, the capital city of the province of Oudh, situated on both banks of the river Gumti, in lat. $26^{\circ} 51^{\prime} t 0^{\prime \prime} \mathrm{N}$, and long. $80^{\circ} 58^{\prime} 10^{\prime \prime} \mathrm{E}$. Area, 13 square miles; population in 1881, 261,303 persons. Lucknow was not, by the most probable accounts, founded before the time of raja Jye-chand of Kanouj, the downfall of whose kingdom, at the hands of Shahab-ud-Din in A.D. 1194, saw the last of the Hindu dynasties of Northern India. Owners of the Oudh country, before the early Rajput and Muhammadan settlers, were tribes of Bhai, Arakh, and Pasi. At present the non-Hindu Pasi, Chamar, are numerous ; other tribes being Ahir, Brahman, Kshatriya, Kach'hi, Kurmi, and Lodha, with Muhammadans. The Hindus form by far the greatest portion of the agricultural classes. Saadat Khan, founder of the last Oudh kingdom, began life as a Persian merchant of Naishapur, and ended it as the greatest warrior of his age, except perhaps Ahmad Shah. He became subabdar of Oudh in A.D. 1732. Before his death he had made Oudh practically an independent principality. Even in his old age he retained his personal strength and his military skill; and his Hindu foes recorded with awe how he slew in single combat Bhagwant Singh Khichi, and how his troops, when almost beaten, rushed again to the conflict where the long white beard of their chief led the van of the battle.

Ghazi-ud-Din Hyder, son of Saadat Ali Khan (1814), was the first of his line who bore the name of padshah or king. For a hundred years, until the middle of the 19 th century, it was the capital of a great Muhammadan kingdom. It was then assumed by the British; but it is still the centre of modern Indian life, the leading city 
of native fashion, and the chief school of Indian music, grammar, and Musalman theology. It was taken by the Indian rebels in 1857 . It was entered on the 25th August 1857 by Generals Havelock and Outram, and was relieved by General Havelock on the 25th September 1857. The second relief of Lucknow was effected by Sir Colin Campbell on the 17th November 1857 ; its final capture occurred on the 19th March 1858. Lucknow was so named by Rama, in compliment to his brother Lakshman. The most remarkable objects are the Inambara in the eastern Gothic style, erected to the memory of Asof-ud-Dowla. It consists of buildings of great extent, in two courts; in the inner is the tomb of the founder, on which are placed his turband and sword; the Rumi Darwazah or Constantinople gate; the tomb of Nawab Saadat Ali; the tomb of general Claude Martine; the palace called Dil Kusha.

LUCKPUT, a fort $2 \frac{1}{4}$ miles in circumference, on the bank of the Koree river, at the western extremity of Cutch. The stones from which it was built had been taken from Wagam-chaora-kaGhar, a ruined city of the Chaora Rajputs.

LUCULIA GRATISSIMA. Sweet. Grows in profusion on the dry micaceous rocks at the Tambur river in East Nepal ; in great abundance on Nag-Arjun and some of the other smaller hills in the valley of Nepal; also at Bechiaco and Kulakan. It delights in exposed, rather naked situations, blossoming, according to the situations where it is found, nearly the whole year round. It is also found on the Pandua Hills in Sylhet, flowering in the month of September. Wallich says it is impossible to conceive anything more beautiful than this tree when covered with its numerous rounded panicles of pink-coloured very fragrant large blossoms. Its locality and affinity are interesting, particularly when coupled with the prevalence in the same mountains of two other genera, Hymenodictyon and Hymenopogon, belonging to the same sub-tribe Eucinchoneæ, and therefore equally allied to the true cinchonas; all indicating the part of the Indian territory where these valuable plants might most certainly be grown, and yield a profitable article of commerce. L. pinceana makes a gorgeous show in the Khassya Hills in October.-Hooker, Him. Jour. ii. p. 286 ; Wallich, Tent. Fl. Nepal, t. 21.

LUD or Ludi, a Semitic race, the original inhabitants of Asia Minor, Pontus, and Cappadocia as far as the Halys, where the historical Lydians were seated. The race which settled west of Arphaxad is the representative of the Semitics who went into Asia Minor and settled there, but afterwards passed the Halys, when they founded the Lydian empire.

LUDHIANA, a town in the Panjab, in lat. $30^{\circ}$ $55^{\prime} 25^{\prime \prime} \mathrm{N}$., and long. $53^{\circ} 36^{\prime} \mathrm{E}$., with a population of 44,163 , the greater number being Mubammadans. The Jat rank first both in number and in agricultural importance; they form one-third of the whole population, and nearly two-thirds of the cultivating class. As a race, the Jat are patient, laborious, and enterprising. The Rajputs cluster thickly in the fertile strip by the bank of the Sutlej. Though they hold the richest portion of the district, they are here, as elsewhere, careless and improvident cultivators, and ill fitted for any but a predatory regime.
The mercantile classes are represented by Kshatriya and Banya, also Kashmiri, employed in weaving shawls and woollen goods. The town was founded in 1480 by two of the Lodhi race (then ruling at Dehli), from whom it derives its name. It gives its name to a revenue district. The shrine of a Muhammadan saint, Shaikh Abdul Kadir-i-Jalani, yearly attracts an important religious gathering, frequented by Hindus and Musalmans alike.-Imp. Giaz.

LUDWIGIA PARVIFLORA. Roxb. i. p. 419.

L. jussiroides, Wall.

L. diffusa, Ham.

L. perennis, Linn.

This plant grows in Bengal, the Peninsula of India, and is common in stagnant water, in Tenasserim. It is used in medicine-Mason.

LUDZU country extends westward beyond the Noukiang, and is inhabited by a tribe of that name. Their village consists of a dozen $\log$-houses. The Ludzu are barbarous in their habits and mode of life. Except the Christian converts, who have adopted the ordinary Chinese costume, and who are industrious and peaceable cultivators, the rest of the tribe are a terror to their neighbours, against whom they carry on a continual warfare. In religion they sacrifice fowls to propitiate the evil spirit. In appearance they are darker than any others of the neighbouring tribes, and wear their hair long. Their costume consists of a girdle of cotton cloth or skins; at least the warriors of the tribe, on their way to fight in Yunnan, had no other garments, except a few of the leaders, who wore cloaks of leopard, goat, or fox skins hanging from their shoulders. Their arms, like those of the other tribes, consisted of knives brought from the Khamti country, on the borders of Assam, spears and crossbows. They owe no allegiance and pay no tribute to the Chinese authorities, but occasionally serve as voluntary allies for the sake of plunder, and could muster about 1200 fighting men.

LUFFA AMARA. Roxb.

L. plukenetiana, Ser, in D. C. Prodromus,

Tito-dhundhul, . BENG. Adavi bira, . . TEL. Luffe amere, . . . FR. Chedu bira, : . . " Luffa bittere, - GEr. Sendu birakai, . . " Kurella, . . Hind.

The Luffa genus of plants, belonging to the natural order Cucurbitaceæ, owes its name to the Arabic word for L. Egyptiaca, viz. louff, loof.

Every part of L. amara is remarkably bitter, the fruit is violently cathartic and emetic. The juice of the roasted young fruit is applied to the temples by the natives to cure headache. The ripe seeds, either in infusion or substance, are used as emetics and purgatives.-Roxb. iii. p. 715 .

LUFFA FOETIDA. Cav.

L. acutangula, Roxb. | Cucumis acutangulus, $L$. Jhingo, . . Bherg. Pichingah, . Malaal. Tha-bwat-nha-wai, BoRM. Pikunkai, . . TAM. Turai, Chaul-turai, HIND. Birakaia, . . . TrL. Kalitori, Jhinga, ", ",

This gourd may be easily recognised by its ten sharp ridges; with a little butter, pepper, and salt, it is little inferior to green peas. The leaves are a favourite pot-herb, and are esteemed very wholesome.-Mason; Roxb. Voigt. 
LUFFA PENTANDRA. $R ., W . I c$.

L. Egyptiaca, - ?

L. catupicinna, Ser. Dhundhul-ghoosa, BEN

Tha-bwat, . BuRM.

Gusali-turai, : : DUKस

(Thiaturai,

HIND.

L. petola, Ser.

Purula, Porol, . Khyar, . . PERs. Turi, - Sind. Ghia-tori, . . . " Neti bira, Nune bira, TrL. Five-stamened, much cultivated in the rains. It is a long gourd with a striped skin, considered by the natives a delicious vegetable. When quite ripe within, it has no pulp, but is dry and filled with netted fibres, very much interwoven. It is used in Turkish baths as a scrubber. It is a useful product, is of easy culture, and should be trained on a raised mundwa or platform, similar to the snake-gourd, etc.

L. pentandra, L. acutangula, L. clavata, and L. racemosa are cultivated or found wild in all parts of India.-Genl. Med. Top.; O'Sh. ; Roxb.

LUGGUN. HIND. A large flat hollow basin.

LUGGUR or Laghar, female hawk; Juggur or Jaghar, male; native of Sind, with dark eyes. They are trained for the season, and then let loose ; the Falco juggur.-Gray.

LUGHAR, a well-affected tribe of Afghans who live near the Kosah tribe, partly in the hills and partly in the plains. Their country extends from Fidore southwards about 30 miles. In these hills is situated the town of Lukkee Surwar, a place venerated by both Hindus and Muhammadans. An annual fair is held here. The pass which runs by this point is one of the chief thoroughfares to Kandahar, and the route traverses the Khutran country to the westward. The Khutran and the Kosah were greatly favoured by the government of Sawun Mull, who desired to use them as a counterpoise against other tribes.

LUGMAN is supposed to have been Esop.

LUI-SHIN, according to the Chinese, is the spirit that presides over thunder. This figure has the wings, beak, and talons of an eagle. In his right hand he holds a mallet, to strike the kettledrums with which he is surrounded, whose noise is intended to convey the idea of thunder, whilst his left is filled with a volume of undulating lines, very much resembling those in the hands of some of the Grecian Jupiters, and evidently meant to convey the same idea, namely, that of the thunderbolt or lightning.-Baron Macartney's Embassy, i. p. 33.

LUK is the Baluch word for a pass or defile, called Kohtul in Persian.--Pottinger, Trav. 151.

LUKH. HIND. A reed or flag, which is much used to make floor-mats, resembling the matting made out of Typha elephantina in the plains.Powell's Handbook.

LUKKEE, a range of hills in Sind, length about 50 miles, runs S.E. from Jutteel towards Hyderabad. The centre of the range is in lat. $26^{\circ} \mathrm{N}$., and long. $67^{\circ} 50^{\prime} \mathrm{E}$. Highest part, 1500 to 2000 feet. Between Lukkee and Sehwan the mountains have a nearly perpendicular face, towards the Indus above 600 feet high. They are of recent formation, and contain a profusion of marine exuviæ. Huge fissures traverse this range, and hot springs and sulphureous exhalations are of frequent occurrence. See Hot Springs; Khaibar.

LUKUT is the chief tin-producing basin in the south of the Malay Peninsula. It has a large population of Chinese, Malays, and Binua, and its importance induced the king of Salangor for some time to reside there. From Lukut, good Malay paths lead to the Langat on the one side, and Simujong on the other.-J. Ind. Arch., 1850.

LULI. PErS. A dancing girl, a kept woman, a common woman. See Gypsies.

LULLETPUR, in Bundelkhand, noted for the ferruginous spherules which occur in the sandstone strata there.

LUMINOSITY. Sea water, in the deep, is of a deep violet-blue, but often in the ocean are seen luminous sparks or points of light; also a soft, liquid, general, and wide-spread effulgence. Occasionally are moon-shaped patches of steady light and instantaneous recurrent flashes, and a milky sea is often seen. There are many minute ocean creatures, Entomostraca andothers, which are luminous at night. Often the globular Noctilucæ are to be seen; they are $\frac{1}{275}$ to $\frac{1}{325}$ of an inch in diameter, and Pyrosoma are also supposed to be causes. The cause of a milky sea is not known, but a bucket of water brought up from one had a small Entomostraca, Megalopas, minute Medusæ, small Porpitæ, Pteropods, Annelids, Globigerinæ, etc., and all night the Crustaceæ gave forth bright spots of luminous light. It is the small Crustaceæ (Entomostraca) and small Medusæ (Medusidæ) which seem to exhibit the more prominent luminous properties; not the larger Medusæ (Lucernaridæ), as Aurelia, Pelagia, Rhizostoma, etc. ; the Physophoridæ, the Porpita or Velella, nor the Physalia, or Portuguese man-of-war. The Protozoæ, Noctilucæ, however, retain their luminosity so long as they retain organic contractility. In the majority of cases of luminous annelids, the light manifests itself in scintillations along the course of the muscles alone, and only during their contraction. The Squalus fulgens of the South Seas gives forth a bright phosphorescent light, resembling that of the Pyrosoma. The tunicated mollusc Pyrosoma gives forth a livid greenish phosphorescent glow. The Salpæ, Cleodora, and other points or dots are luminous. On the night of October 30, 1772, Dr. Foster saw a very beautiful exhibition of this sort of sea-light off the Cape of Good Hope, at a few miles' distance from the shore, and while a fresh gale blew. Upon examining the water on which it was displayed, he was convinced that it proceeded from living animalcules. Dr. Sparmann, in the years 1772 and 1775, observed Mollusca and Medusæ in such masses near the surface of the ocean, and moving with such a rising and falling motion, as seemed perfectly adequate to the production of the phenomenon. The Noctilucæ of the ocean are so minute, that seventy of them ranged in a line would only make an inch, and millions could be contained in a wine-glass.

Luminous appearances at sea, observed by Dr. Bennett in the South Pacific, were caused by Medusæ, species of Salpa. Pyrosoma, Cancer, and Scopelus. The molluscs, Nereis noctiluca, Medusa pelagica, var. B, and the Monophora noctiluca, when alive, during pleasure emit a weak phosphoric light, generally of a bluish colour. In July 1853 , between lat. $12^{\circ}$ and $13^{\circ} \mathrm{N}$., and long. $50^{\circ}$ and $65^{\circ} \mathrm{E}$, when the Peninsular and Oriental Steamer Madras was on her voyage to Aden, with the sea very high during a gale, at midnight the horizon was visible all round. The sea was of the faintest green colour, almost like milk. The 
luminous Scopelus stellatus, Bennett, occurs in the Pacific.

Luminous shark is Squalus fulgens, Bennett. In a dark apartment at night the entire surface emitted a vivid and greenish phosphorescent gleam, which faded away after the shark died.

Luminosity of land animals is exlibited in the fire-fly, the glow-worm, among the Myriapoda, and the luminous centipede, Geophilus fulgens. In Australia it occurs in a species of Agarieus, which gives out a pale livid light. With the glow-worm (Lampyris) there is neither combustion nor phosphorus, but the light is the product of a nervous apparatus, and dependent on the will of the animal. A species of Agaricus of Australia emits light sufficient to show the time on a watch.-Huniboldt in Jam. Ed. Jour. v. p. 328 ; $M$. de Quatrefages, Kolliker, quoted by Collingwood; Bennett's Gatherings; Niebuhr's Travels, i. p. 441 ; Harturig.

\section{LUMNITZZERA RACEMOSA. Willd.}

Jussiæa racemosa, Rottl.

Petaloma alternifolia, Roxb.

Combretum alternifolium, Herb., $\mathbf{M a d r}$.

Pyrrhanthus albus, Wall.

Bruguiera Madagascarensis, Rheede, D.C.

Hmaing, Yen-yai, BurM. | Kara kundal, Maleat.

This tree grows in Madagascar, in the delta of the Ganges, on the banks of salt-water creeks, on the western coast of India, and Malay Peninsula. Its strong and durable wood is used for posts and other purposes in house-building, but, in Calcutta, chiefly for fuel. $-R o x b . F l$. Ind.

LUMRI or Numri or Luka is a grand subdivision of the Baluch race, and is mentioned by Abul Fazl as ranking next to the Kulmani, and being able to bring into the field 300 cavalry and 7000 infantry. The Lumri are also styled Luka, a familiar term for fox, and are affirmed to be of Jit origin.

The country of the Bulfut tribe of Lumri extends in the direction of Kurachee until, parallel to Tatta, they are met by the Jukia, another Baluch tribe. The Bulfut boast of comprising 12,000 khana or families, and as many fighting men. The Bulfut tribe are denominated Lumri Barani, in contradistinction to the Lumri tribes of Las, called Lassi. In the public records of Sind they are called Namadi, by which designation they are mentioned in the treaty between Nadir Shah and Muhammad Shah of Dehli. There are two important divisions, the Bappakbani and the Amalani. The Lumri are addicted to the use of opium.-Masson's Journeys, ii. p. 152.

LUNAR RACES. The Rajput races of India, who trace their descent or origin from the moon, Soma, or Chandra, through Yadu or Jadu, are called Yadava. It has eight branches, of which the Jhareja and Bhatti in Cutch and Jeysulmir are the most powerful. The dynasties which succeeded the great beacons of the Solar and Lunar races, are three in number, -1st, The Suryavansa, descendants of Rama; 2d, The Induvansa, descendants of Pandu through Yudishthra; $3 \mathrm{~d}$, The Induvansa, descendants of Jarasandha, monarch of Rajgraha. The Bhagavat and Agui Purana are the authorities for the lines from Rama and Jarasandha; while that of Pandu is from the Raj-Taringini and Rajao. The descendants of Krishna and Arjuna carried down the Lunar line of Indian chieftains, as the Cushites and Lavites from Cush and Lava, sons of Rama, carried down that of the Sun.
The earliest settlement of the Aryan race in India lay probably in that portion of the Panjab which surrounds the upper waters of the Sarsuti or Saraswati river. In the Doab they founded the famous city of Hastinapur, the capital of the Lunar race, who also ruled at Muttra, Kasi or Benares, Magadha, and Behar. The Solar race, on the other hand, gave princes to Ayodhya in Southern Oudh, and founded colonies in many parts of the North-Western Provinces. The Vedas show us the Aryan settlements as almost confined to the upper basin of the Ganges and the Jumna, with a few outlying branches in Tirhut, Western Bengal, the Vindbyan Hills, and the Nerbadda valley; while the south of the Peninsula still remained almost entirely in the hands of the Dravidians. Throughout the whole historical period, the Upper Gangetic valley retained its position as the chief seat of the Aryan supremacy in India, and afterwards the centre of the Moghul empire at Dehli or Agra.

The earliest traditions of the North-Western Provinces cluster round the city of Hastinapur, on the Ganges, in Meerut district, the ancient metropolis of the Pandavas. Only a few shapeless mounds now mark the site where lived the children of the moon, the descendants of Bharata, whose great war is chronicled in the Hindu epic of the Mahabharata. The poem deals chiefly with the conflict between the five Pandavas, sons of Pandu, and founders of Indraprastha (see Dehli City), and the Kauravas, who held the older capital of Hastinapur. These events, if not absolutely mythical, may be assigned to the 15 th century B.C. But the earliest empire in this portion of Upper India of which any certain monuments remain, was that of the Buddhist dynasty of Magadha. The founder of the Buddh. ist creed, Sakya Muni, was born at Kapila in B.c. 598 , and died at Kassia in Gorakhpur district in 543. After his death, the creed which he had preached spread rapidly over Hindustan, and became for many centuries the dominant religion of the Aryan race. See Rajput; Solar Race.

LUNAR ZODIAC. As well as a solar, the Hindus have a lunar zodiac, divided into twentyeight mansions, called Nakshatra, and believed to have been so divided or invented by Daksha, a mythological son of Brahma; hence their poetical astronomy feign these Nakshatra to be the offspring of daughters of Daksha, and, as diurnally receiving the moon in his ethereal journey, to be the wives of Chandra. Of these wives, Chandra is fabled to have the greatest affection for Rohini, the fourth daughter of Daksha, who, on the complaint of the majority of this pointed partiality, cursed Chandra with a consumption that continued 15 days; but on his due repentance his strength and power were eventually restored. The meaning of this story, which is detailed in the Siva Purana, is an allusion to the waning and waxing moon. Chandra, like the western Lunus, is somewhat proverbial for inconstancy, and tales are related of his adulterous communication of his influences to the radiant spouses of others of the heavenly host.

\section{I.UNATIC.}

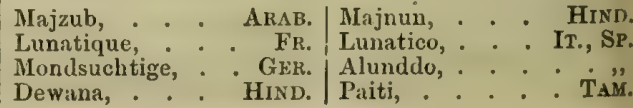


In Asiatic countries lunatics are numerous. St. Luke, viii. 27 , mentions that "there met him out of the city a certain man, which had devils long time, and ware no clothes, neither abode in any house, but in the tombs.' A deranged person at liberty in the streets is almost a singular object in Britain, but it is a very common sight in India, where such unfortunate beings wander about in all manner of dresses, frequently without any dress at all; some perish while wandering from place to place. The numbers returned in the 1881 census were 50,328 males and 30,776 females. They are not held in any reverence by Hindus, and in but little by Indian Muhammadans. In Arabia and in Egypt they are more objects of awe, and Lane devotes several pages to noticing that there the idiot or fool is vulgarly considered an especial favourite of heaven.

LUNAWARA, capital of Lunawara State, Rewa Kanta, Bombay; a fortified town, situated in lat. $23^{\circ} 8^{\prime} 30^{\prime \prime} \mathrm{N}$., and long. $73^{\circ} 39^{\prime} 30^{\prime \prime} \mathrm{E}$., about 4 miles east of the confluence of the Mabi and Panam rivers.-Imp. Gaz.

LUNGA. HIND. In Kangra, a method of rice cultivation by sowing seeds broadcast.

LUNGAR. HrND. Literally anchor. A string of flowers or leaves. Lungar-nikalua, a Muhammadan ceremony. See Langar.

LUNGI or Loongee or La hunga. HiND. Long pieces of cloth made of silk, or silk and cotton, used as sashes or turbands, or as a scarf thrown over the shoulders and upper parts of the body, or wrapped around the lower part of the body. Some of them, the manufacture of Sind, are very beautiful and rich, where the loom-made goods consist of turband, dhoti, lungi, kamrband, and saree.

Many of the borders of the lungis, dhotis, and sarees are like plain silk ribbons; in some instances corded or ribbed, in others flat. The saree, boonee, bafta, jore, ekpatta, gomcha, etc., of Dacca are now entirely made of imported British yarn.Pottinger's Travels; Burton.

LUNG-KUH, dragon's bones, also an herb.

LUNG NAOU HEANG, dragon's brain perfume. Borneo camphor, product of Dryabalanops camphora of Borneo and Sumatra.

LUNG-NGAU, the dragon's-eye fruit of China.

LUNGOTI. Hind, A narrow strip of cloth worn in India by Hindus and Muhamadans, which is passed between the thighs, and tucked in before and behind to a waist string. It is worn by the men and boys of all the races in British India, whose habits of life necessitate their appearing uncovered in public. The women and girls of British India, however poor, never wear the lungoti; but girls wear, suspended from a string, a silver or gold ornament, shaped like a leaf of Ficus religiosa.

LUNG-TAN, literally dragon's tail, gentian or other bitter root; the root of a species of Erythræa.-Smith.

LUNG WONG, the dragon king, is the rain god of the Chinese. He is worshipped on the 1st and 15th of each lunar month, with sacrifices of a sheep, a pig, and fowls; but the great ceremonials are at the spring and autumnal equinoxes. In seasons of drought, intercessory service extends over three days.-Gray, p. 146.

LUP or Luff, HiND., is as much as two hands joined can hold, the Scotch gow pan; but in Benares, Dehli, and the Doab, it means only one handful; in Scotch, luff or loof signifies the hollow of the hand, and hence is derived the term love, used in the scale of the game of whist, when the adversaries score none. It originally meant that they have so many love (luff), i.e. so many in hand.Jamieson's Scottish Dict.; Elliot, Supp. Gloss.

LUPINUS ALBUS. Zurmish, Turmuz, HIND., said to be brought from Egypt, and used as a carminative, and said to be useful in leprosy and internal heat. The small blue-white lupin, rose lupin, and Egyptian, flower freely. Some of the species are very common in Egypt, and grown for food, the seed being ground into flour.-Porcell; Riddell.

LU.PU. Chin. The civil and criminal courts of justice in China. The government of China is conducted by the Nuy $\mathrm{Ko}$, or interior council chamber, in which there are four chief councillors, two of them Tartars and two Chinese, who bear the titles of Choung-thang and Ko-laou. The Tartar minister presides. The lu-pu are six boards for the conduct of government business, and the provinces of the country are each under a governor, or, where two provinces are united, a governor-general.

LURI, a houseless migratory race in Persia, in many respects with a marked affinity to the gypsies of Europe. They speak a dialect peculiar to themselves, having a king to each troop, and are notorious for kidnapping and pilfering. Their favourite pastimes are drinking, dancing, and music. Both men and women dress in the most fantastic way they can devise, adorning themselves with feathers, skins, berries, shells, and other baubles. They are impudent and immodest in demeanour, and addicted to every species of vice. They pretend to be Mubammadans, but they are avowedly indifferent about it.-Pottinger's T'ravels, Beluchistan and Sinde, p. 153.

LURISTAN, a province of Persia which extends westward for about 270 miles, from the borders of Fars, in lat. $31^{\circ} 51^{\prime} \mathrm{N}$., to those of Kermanshah, about lat. $34^{\circ} 5^{\prime} \mathrm{N}$., with an ordinary width of about 70 miles. Luristan is divided into two provinces, Luri-buzurg and Luri-kuchuk, or the Greater and Lesser Luristan. The former is the mountainous country of the Bakhtiari, stretching from the frontiers of Fars to the river Dizful; the latter is situated between the river and the plains of Assyria, being bounded to the north and south by Kermanshah and Susiana. The province of Lurikuchuk is again subdivided into two districts, Pesh-koh and Pusht-i-koh, Cis and Trans-Alpine Luristan, referring to the great chain of Zagros. The Luristan mountains west of Irak, between Shuster and Isfahan, and from Shuster to near Kermanshah, are occupied by the Bakhtiari tribe, who often wander to other parts. The Mehmasani have branches in Seistan and the hills of Luristan. Luristan-kuchuk is bounded on the north by Burujird and Kermanshah ; the river Dizful separates it on the east from the Bakhtiari of Luristan-buzurg, but the boundary line on the south and west is much more uncertain, as the Lur tribes, in their winter migrations, disperse with their flocks over the plains of Dizful, lying to the southward of their mountains, and meet with the wandering Arabs on the Turkish frontier on the west, in the vast Assyrian plains. Luristan-peshkoh lies east, and Luristan-pusht-i-koh west of 
family, their principal divisions being the tribes of Koghilu, the Lek, and the Kurd. They are not of Arab or Turkish descent, but seem to have always occupied the hilly country which runs from the south-east to north-west of Persia. The Lur do not receive Mahomed and the Koran. They worship Baba Buzurg, and have amongst them seven holy men, whom they regard with little short of adoration. Many of their observances are traceable to a time long prior to Mahomed. They have had attributed to them the custom of formerly meeting at night, supposed to be a remnant of the physiological worship of Anaitis and Mithra.

The four principal tribes who occupy the Peshkoh are the

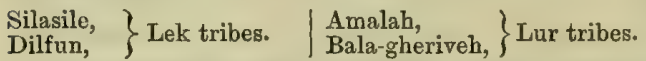

The Silasile and Dilfun amount to about 30,000 families; the former are the more powerful, also the more unmanageable. The Amalah were formerly very numerous, but have been much reduced since Aga Muhammad Khan, the founder of the present Kajar dynasty, transplanted them into Fars. After his death, it is true, the greater part returned, but their force was broken. A portion of the Amalah Iliyat was found by De Bode encamped at the foot of Mount Istakhr, in the plains of Persepolis. They are styled worshippers of violence, who always submit tamely to any sort of authority, good or bad; whereas the other Lur tribes cannot easily brook oppression. Their number is held to be between 2000 and 3000 families, but it appears to be rather underrated. The Bala-gheriveh do not exceed 4000 families, but are a very troublesome tribe. The Pusht-i-koh tribes, who bear the name of Feili, are less numerous than those of Pesh-koh; Major Rawlinson estimated them at 12,000 families. They consist of the Kurd, Dinarved, Shuhon, Kalhur, Badrai, Maki. The Feili clan inhabit a portion of the province of Khuzistan. They have two sections, the Pesh-koh and Pusht-ikoh. The Pesh-koh are notoriously predatory, and single travellers or caravans cannot travel with safety. Luristan could raise 4000 or 5000 horsemen, and 20,000 matchlockmen.

The Feili pretend to have more respect for an oath, and to be less bloodthirsty, than their neighbours the Bakhtiari; but there is little difference between them.

Independently of the tribes mentioned in Pesh and Pusht-i-koh, there live in the plains of Huru, between Burujird and Khorremabad, the Bajilan and the Beiranevened, who belong to the Lek family.-Layard; MacGregor, iv. pp. 287-297; De Bode's Luristan; Ferrier's Jour.; Rawlinson, Royal Geog. Jour. ix.; Strabo, xi.; Euphrates and Tigris, by Col. Chesney; Kinneir.

LUSCINIA, a genus of birds, the species of which, L. philomela and others, are known as nightingales. In Southern Asia, the birds familiarly known as bulbuls must not be confounded with the Persian bulbul, which is a species of true nightingale (Luscinia), a genus very closely related to some of the small thrushes of America. There are no true nightingales wild in India; but the Shama, Cercotrichas macrourus, undoubtedly the finest song-bird of that part of the world, is not unfrequently designated the Indian nightingale. It is common to India and the Malay countries; there is a second species (C. luzoniensis) in the Philippines, and a third (C. erythropterus) in Africa. The Orocetes cinclorhynchus is also termed shama in the Madras Presidency.-Blyth.

LUSHAI, a race dwelling south of the Kookee, and south-west of the Kom Naga in the Tiperah territory, in lat. $23^{\circ} 30^{\prime} \mathrm{N}$., and long. $92^{\circ} 30^{\prime} \mathrm{E}$. They dwell at the sources of the Kurnafula or Chittagong river. On the southern frontier of Cachar, they inhabit the hilly tract lying between Cachar and Chittagong, and claim and hold all the tract of country to the south of the parallel of the latitude of Chatter Choora Hill, and east of Hill Tiperah to the Tepai river is Burmese frontier. In 1848-49 they drove the Kuki from the south into Cachar. In their turn they are being pressed up into Cachar by the $\mathrm{Poi}$, a tribe who are advancing from the south-east.

At the close of 1868 and beginning of 1869 , they descended on the territory of the Tiperah raja. and advanced on Sylhet, burning, plundering, and killing; and an expedition was sent against them, with only partial success.

In the beginning of 1871, the Lushai made a prolonged raid on the N.E. Provinces of British India; and in that year an expedition was sent against them, in two columns; one moved south from Cachar, and the other north from Chittagong; all captives were recovered, and they promised to live amicably. They are an Indo-Chinese people, speaking a language different from that of the Siamese or Burmese, though related thereto.

LUSIAD, a book written by Camoens, an exile from Portugal; the grotto in which he resided is only a brick and mortar enclosure between two rocks ; there is no view from it to the sea, nor of anything else, except the tops of some straggling trees growing in the shrubbery below.-Frere's Antipodes, p. 244.

LUSTRAL CEREMONIES are deemed very important by Brahmans, and are attended to, as prescribed in their books, with a degree of minute particularity that appears ridiculous to those not interested or informed on the points to which such lustrations are supposed to have reference; indeed, there is no end to the Hindu lustral ceremonies, to which the Romans also gave the greatest attention. Images are frequently bathed with water, oil, etc. Lingas are constantly washed. Nandina of the Romans presided over the lustral purification of infants on the ninth day of their age. Nandina was, from her office, a form of Diana. In a great many Hindu ceremonies, lustrations make a part; spoons and the argha are therefore in extensive use. The argha in a circular form is called Patra, and is an attribute to Devi. It is sometimes called pana patra, and is seen in many drawings borne by her and others of her family, apparently both as a drinking and ceremonial utensil. The lustral spoons are called Sruva and Druva in Sanskrit; by the Mahrattas and other Hindus, Pulaphi and Achwan; and have different forms, according to the rites or objects of adoration. One such spoon represents Naga, the holy serpent, overspreading Ganesha; in another, the Naga overspreads the image of a deity; and in another, the spread hood of the snake appears to cover Hanuman. The argha is a vessel shaped like a boat, used by the Hindus in lustrations; it is of spout-like form, so that liquids may be poured from it. The Hindu Sth'nanam, after childbirth, is performed 
on the 16th day. In this purificatory rite the Mubammadans adhere to the Hebrew forty days. Amongst Hindus, the Sth'nanam is the religious rite of purification, and ordinarily performed once daily, in the early morning; their evening ablution not involving the head, but from the neck. The Abhiangana Sth'nanam is that, generally twice a week, in which the head is anointed with oil, and corresponds to the anointing of the Jewish ceremonial, and to the Indian Mubammadan's Sir-Nabana or head-washing, of which perhaps the initiatory head-washing rite of certain craftsmen in Britain is a remnant; as possibly similarly may be the feet-washing of the British marriage ceremony. In Britain, the bride's feet used to be washed, and in the south of India the engaged son-in-law performs the ceremony palal-kal-kazhu-viradu (TAM.) of washing his intended father-in-law's feet. Mark vii. 2-4 mentions that when the Pharisees saw some of the "disciples eat bread with defiled (that is to say, with unwashen) hands, they found fault; for the Pharisees, and all the Jews, except they wash their hands oft, eat not, holding the tradition of the elders. And when they come from the market, except they wash, they eat not. And many other things there be which they have received to hold, as the washing of cups and pots, brazen vessels, and of tables.' And, up to the present hour, the Hiudu ritual is almost identical Along the banks of the Ganges, at every large place, crowds of men and women are to be seen at certain hours of the day bathing. In Japan there are bathing houses, in which, at Hakodadi, both men and women of the lower ranks assemble. Mr. Hodgson tells us that on one occasion, at Yedo, the bathers of both sexes indiscriminately sallied out to see them pass, from some twenty of their common cells, in all the natural simplicity of our first parents' costume before their expulsion. On another occasion, when Mr. Alcock went, preceded by a band of music, to the Governor's Yamun, all the bathers of both sexes came out, unabashed and without the slightest idea or reflection that they were naked, to gratify their curiosity by a good long gaze on the novel spectacle. - Moor, p. 394; Wanderings of a Pilgrim, p. 265.

LUTRINA, the Otters, a sub-family of the carnivora, several species of which occur in S.E. Asia.

Lutra auro-brunnea, Hodgson, of the Himalaya, Neilgherries? and Ceylon mountains?

Lutra barang, Raffles, the Barangia varang of Gray, of the Malay Peninsula.

Lutra kutab, Gray, Hugel, Kashmir.

Lutra leptonyx, Horsf., Blyth, clawless otter. Aonyx Horsfieldii, Gray. |'Lutra indigitata, Hodg. A. Sikkimensis, Hodg. $\mid$ Chusam, Suriam, . LePCH.

This otter is found throughout all the Himalaya, south and east to Calcutta, Arakan, and the E. Archipelago. Length of head and body 24 inches, tail 13 inches.

Lutra nair, F. Cuv., common Indian otter.

L. Chinensis, Gray. | L. Tarayensis, Hodg., L. Indica, Gray.

Nir-nai, . CAN. Jal-manjer, . MAHR. Ud, Hud, Ud-nai, HIND. Anjing-ayer, : MALAY. Ud-billai, . . ", Pani kutta, : : ", Sag-i-abi, : : : PANs. Udur,. . . KAsHMir. Neeru-kuka, : : TEL. Jal-marjar, : MAHR.
Found from the Indus to the E. Archipelago. Length 46 inches, of which tail is 17 . It frequents marine lagoons and rivers. It is very easily domesticated, and in Bengal it is trained to drive fish into the nets. In the Panjab and N.W. Himalaya the skins of the Lutra nair are used for fur caps and postins. It is extensively tamed and trained along the course of the Brahmaputra, as cormorants are trained in China. Fishermen of the Jessore Sunderbans train otters to drive fish into their nets, the otter being rewarded with some fish each time it is successful. These tamed otters have a collar round their necks, and they are secured by it to the prow of the boat, and when required they are slipped like hounds.

\section{Lutra simung, Raffles.}

L. barang, Fischer. | Mustela lutra, Marsden. Anjing-ayer, : MaLAY. | Simung, . . MaLAY.

\section{An otter of Sumatra.}

Lutra vulgaris, Erxleben, Blyth, hill otter. L. monticola, Hodgson, is the common otter of Europe, and is found in the interior of the Himalaya. Length, head and body 20 to 22 inches, tail 12 to 13 inches.-Jerdon's Mammals, pp. 8689; Horsfield's Cat. pp. 115-120; Powell's Handbook; Blyth.

LUXOR or Lugsor, the ancient Thebes. Luxor temple was begun by Amenhotep III., carried on by Seti I., Rameses II., Horus Sabaco, and Alexander CEgus; and the great pylons erected by Rameses II. are sculptured with battlescenes similar to those at $\mathrm{Abu}$-Simbel, and inscribed with a version of the heroic poem of Pentaur.

LYCIUM, a genus of plants of the natural order Solanaceæ, the nightshade tribe, of which L. barbarum, Linn., of Asia, Africa, and Europe; L. Chinense, Mill., of China; L. Europeum, Linn., of the Himalaya, are known to occur in the Himalaya and China.

\section{LYCIUM EUROPEUM. Linn.}

Kangu, Kungu, . Beas. Mral, Chirchitta, . PANs. Ganger, Gangru, . HIND.

A small thorny plant of Asia Minor, Sind, and the Panjab, browsed by camels and goats, and used for fuel and wattling. Its fruits are deemed aphrodisiac. - Dr. J. L. Stewart.

LYCOPERDON, a genus of fungi. L. pratense occurs in the Panjab and S. India. Other fungi of that province are Polyporus oblectans, Geaster limbatus, G. mammosus, Erysiphe taurica, a boletus infested with Sepedonium mycophilum, Scleroderma verrucosum, an Ecidium, and a Uromyces, both on Mulgedium tataricum, about half-a-dozen agarics, one at an altitude of 16,000 feet above the Nubra river, a Lycoperdon, and Morchella semilibera, which is eaten in Kashmir, and exported when dry to the plains of India. L. giganticum, the Ma-peh of the Chinese, and L. squalmatum, are used medicinally by the Chinese internally and externally.

LYCOPERSICUM, the tomato or love-apple, the produce of South America, a genus of the same family as potatoes, a delicious vegetable, cultivated in many gardens. There are two sorts, single and double; may be sown immediately the rains commence, in beds; afterwards transplanted in rows, two feet apart, and trailed upon sticks of 
a strong description. If the soil is good, they will grow to seven or eight feet in height. The double, which are the finest, if sown in June ripen in October. The lower branches should be pruned, and a succession of crops may be kept up until April. The small single tomato, with a slight protection from the dry winds, will continue until the rains.

Lycopersicum esculentum, Mill.

Solanum lycopersicum, L. | Pomum amoris, Blackw. Wal-mangi,. . BомваY. Thah kali, . . . HrND.? Kha yan mya phung, BurM. Thak kali, . . . ", \begin{tabular}{l|l} 
Fan-kia, \\
Love-apple, Tomato, ENG.
\end{tabular} Wolf peach, . . ", Simi takali pallam, TAM.

This fruit is a valuable ingredient in soups and stews, also as a preserve and for sauces, chatnies, garnishing, soups, etc. It produces the best fruit when trained on a trellis; more a luxury than valuable as a vegetable. The large-lobed red and very succulent berries contain much malic acid. The plant is a native of South America, but it is much cultivated in England, in Southern Asia, United States of North America, and in France, Germany, and Italy. Near Rome and Naples, whole fields are covered with it, and scarcely a dish is served up into which it does not enter as an ingredient. There are several varieties cultivated; the best are called the large and sinall cherry and pear shaped red, and the large and small or cherry-shaped yellow.-Roxb. i. p. 570; Jaffrey's Hints; Riddell's Gardening.

LYCOPODIACE无. D.C. The club moss tribe of plants, comprising the genera Lycopodium and Isoetes. The green woods of Tenasserim are often carpeted with the club moss. Mr. Fortune met with a dwarf Lycopodium on the hills of Hong-Kong, which he carried to Messrs. Dent's garden. The old compradore was quite in raptures of delight, and coolies and servants gathered round the basket to admire this curious little plant. I had not, says Fortune, seen them evince so much gratification since I showed them the 'old man cactus,' Cereus senilis, which I took out from England, and presented to a Chinese nurseryman at Canton. On asking them why they prized the Lycopodium so much, they replied, in Canton Encrlish, " $\mathrm{Ob}$, he too much a handsome; he grow only a leete and a leete every year; and suppose he be one hundred year ould, he only so high,' holding up their hands an inch or two higher than the plant. This little plant is really very pretty, and of ten naturally takes the very form of a dwarf tree in miniature, which is doubtless the reason of its being such a favourite with the Chinese. L. aristatum, cernumm, Hookeri, imbricatum, phlegmaria, and Wildenowii occur in India. L. clavatum, of the British moors, grows at Chakoong in the Lachen Lachoong valley, Sikkim, and amongst mosses, the superb Himalayan Lyellia crispa, with the English Fumaria hygrometrica. Lyellia crispa also grows at Chakoong in Sikkim, in the Lachen Lachoong valley. It is one of the most remarkable mosses in the Himalaya mountains, named after Charles Lyell of Kinnordy, the father of the eminent geologist. The Lycopodium is an inflammable powder used in fireworks, obtained from a common moss-like plant.-Mason; Fortune's Wanderings; Hook. Him. Jour.; Waterston.
LYCOSA SINGORIENSIS, a black tarantula on the Kirghiz plateau. It is about the size of a pigeon's egg, covered with dark brown or black hair. It is not deadly.-Schuyler, ii. p. 123.

LYCURGUS, a lawgiver of ancient Greece, is said to have penetrated as far as India.

LYDIA or Lydda, in the plain of Ramla in Palestine, the birthplace of St. George, the patron saint of England. Lydian and other languages of Lesser Asia were altered to the Hellenic or Pelasgic Greek. See Mar Jurjyus.

LYGODIUM FLEXUOSUM. Swz. Bhoot Raj. The powder of the leaves are used as a powerful errhine in obstinate headache. Lygodium scandens, one of the most elegant climbers on the Tenasserim coast, is a species of fern, easily recognised by its habit of running over other plants, and by the fringed margin of its leaflets, from which it is sometimes called fringed fern. An allied species is found in the United States. Mason, Tavoy.

LYMN EA HOOKERII. Reeve. The waters of the Lachen in Tibet contain many shells of this species of Lymnxa. This is the most alpine living shell in the world, many specimens being from nearly 17,000 feet elevation.-Pro. Zool. Soc. No. 204 ; Hook. Him. Juur. ii. p. 156.

LYMO. Chin, Printing in China is by a system of stereotype, the types being made from the pear-tree wood, called by them ly-mo. Their paper is made from refuse paper, rags of silk and cotton, rice-straw, the liber of a species of morus, but principally of bamboo.

LYNCH, LIEUTENANT, an officer of the Indian navy who ascended the Tigris nearly to Nimrud in 1838, in the Euphrates steamer. - Layard, Ninereh, i. p. 139.

LYNX. The caracal, or Indian lynx or lynx cat, called the siah-gosh or black-ear, has immense speed, runs into a hare as a dog into a rat. It often catches crows as they rise from the ground, by springing five or six feet into the air after them. It is an eastern custom of great antiquity of training certain feline animals, as the cheeta and the caracal or siah-gosh; the lion, too, as it would appear, was trained in ancient times; and in Britain and India the otter is employed in fishing, as cormorants are in China.

LYRE BIRD, Menura Australis, also called mountain pheasant, also native wood pheasant. It is a good mocking bird, and imitates the notes of the more pleasing songsters. Its elegant tailfeathers are sought after for commercial purposes. Its principal habitat is New South Wales, and its range does not seem to extend so far to the eastward as Moreton Bay, nor to the westward of Port Philip. It appears to inhabit alike the bushes on the coast, and those that clothe the sides of the mountains in the interior. The Menura is most shy and difficult to procure.G. Bennett, Gatherings.

LYTHRACE $\mathbb{E}$, the Loosestrife tribe, furnishes several useful products. The leaves of Ammannia vesicatoria are applied as a blister in rheumatism; the soft yellow wood of the lofty Duabanga Sonneratioides readily seasons; several Lagerstrœmia furnish valuable timbers; the excellent pomegranate fruit is from the Punica granatum. Grislea tomentosa flowers are given medicinally, and are a dye, and Sonneratia acida wood is good for modelling, and its fruit is edible. 


\section{M}

This letter of the English alphabet has representative letters in Arabic, Persian, Urdu, Sanskrit, Hindi, Mahrati, Gujerati, Bengali, Uriya, Telugu, Tamil, Karnatica, and Malealam. Some nations, however, are unable to sound the letter $\mathrm{m}$, and in its place have used $\mathrm{a} b$. On a mummy from Memphis, and on the sarcophagus of Amyrtæus, we find the name of the god Ammun Ra written Oben-Ra, and this is the spelling used on a plate of ivory found among the ruins of Nineveh, to which distant city the Egyptian style of art had made its way two centuries earlier. Sharpe's Egypt, i. p. 200.

MA. Hind. Mother; a respectful address to a woman in Asia, Turkey, and Egypt.

MA. Chin. Fibres of Ayave Americana, Boehmeria, Corchorus pyriformis, Dolichos trilobus, jute, Hibiscus cannabinus, linum, sesamum, Sida urtica, tuberosa, Triumfetta, etc.

MAA. ARAB. Water.

MAADITE ARABS for the most part trace their origin from Abraham, although, according to Genesis, some must be descended from Abraham's brother Nahor, and his nephew Lot. The nations mentioned in Genesis under the name Ishinaelite, 'the rams of Nebaioth,' 'the tents of Kedar,' the Kedarenes, the Edomites or Idumæans, the Amalekites, the descendants of $\mathrm{Uz}_{\mathrm{z}}$ and Buz, sons of Nahor, the Moabites, and the Ammonites (descended from Lot), the Midianites, were all of this Arab branch of the Semitic family.

MAASH. ARAB., HIND. Food, livelihood. Bad-maash, an evil liver; Be-maash, without employ; Madad-i-maash, aid to subsistence, a pension.

MAASIR - i - RAHIMA, a valuable historical work by Muhammad Abd-ul-Baki-ur-Rahim-unNahavandi. It relates chiefly to the Dekhan history, and notices the poets of the era. - Elliot.

MAAZAM, son of Aurangzeb, on ascending the throne assumed the title of Bahadur Shah. $\mathrm{He}$ defeated and slew his brother Azam in a battle near Agra. He died in 1712 at Lahore, aged 72 , after a reign of 5 years. $\mathrm{He}$ was succeeded by his son Ferokhsir.

MABA BUXIFOLIA. Pers.

Ferreola buxifolia, $R o x b$.

Irumbeli, . TAM. | Utti chettu,

A small tree of the Circar mountains and of the forests of the Godavery, furnishing a darkcoloured wood, small but remarkably hard and durable. M. geminata, $R$. $B r$., also M. fasciculosa, ebouy trees of Queensland. There are several other species. - Von Mueller; Voigt; Beddome, $F l$. Andh.

MAB'AR, mentioned in Briggs' Ferishta (i. p. 373), means the place of crossing over, a place of passage or ferry, and has very generally been supposed to be Malabar, as well from the resemblance of the names as from the position of the latter country in reference to Arabia; but there is no doubt that the appellation really applies to the tract on the eastern coast of the Peninsula, the coast of Madura extending north from Rameswara.

It is possible that this Arabic name was originally a corruption of Marawa, the name of the Hindu state which adjoins Adam's Bridge, and the chief of which state was called Setu Pati, the lord of the bridge. Ritter puts Mab'ar on the west coast, and I aassen (iv. p. 888) says that the name with Ibn Batuta signifies the southernmost part of the Malabar coast; but both learned authors are certainly wrong. Kunstmann, again, says 'it has been recently pointed out that the name applies neither specially to the S.W. nor to the S.E. coast, but to the whole southern apex of the Peninsula.' It is, however, clearly used for the S.E. coast, as Abulfeda precisely says it commences from Cape Comorin.-Elphinstone's India, ii. p. 47 ; Gildemeister, pp. 56, 185 ; Yule's Cathay, i. p. 80 ; Marsden's Marco Polo, p. 626.

MA'BUD. ARAB. The adored one, a title applied by orthodox Muhammadans to God alone. In the Bagh and Bahar the darveshes who narrate the stories which make up the work, commence their discourses with the ejaculation, Ya ma'bud Allah! (O adored God!) as a sort of apology for withdrawing their attention one moment from contemplation of him, and as a suggestion that though addressing their fellow-creatures they have God only in view. This is a mere commonplace with the Sufistic darveshes, and is as natural to them as Amen is to a Church of England parish clerk. The assumption of such a title is by no means rare among the self-styled saints of the Shiah rite. Their doctrine starts with the assertion that God is the only real existence, and that everything else is but hypothetical, or at best a reflection of his; and that man, the most perfect expression as well as the ultimate object of creation, is but an emanation from him, and has no higher aim than to return to the divine source whence he sprang. The nearer, therefore, the fanatic feels that contemplation brings him to bewilderment, the nearer he thinks he has drawn to God, and when the slight barrier between religious exaltation and madness is overleapt, the enthusiastic mystic may and does believe his union with the Deity to be complete, and he proclaims himself one with him, as did the Ma'bud Syud Ma'sum Ali Shah, and as did Mansur of Hellaj, who constantly exclaimed, Ana 'l Hakk, I am the Truth! and was hanged for his temerity in the year 309 A.H. This is the reason why Sufi poets are always talking about their giddiness, their eestasy, and their fainting with passion. It is the explanation, too, of half the vagaries of the darveshes. See Sufi.

MACACUS, a genus of mammals, of the family Simiadæ, of which there are several species in India, the Malay Peninsula, and Eastern Archipelago. Their tails vary greatly in length.

Macacus Assamensis, M'Clelland.

M. pelops, Hodgson. I Inuus pelops, Jerdon.

A native of Assam, of a bluish-grey colour, dark brownish on the shoulder.

Macacus cynomolgus, Linn., common macac.

Simia cynomolgus, Linn., the male.

S. aygulah, Linn., female.

Cercopithecus cynomolgus, Muller.

Hare-lipped monkey, ENG. Jakko of sailors, . ENG. Egret monkey,. . ", Kra, . . . MaLAY.

This monkey occurs in the Nicobar Islands, Tenasserim, and all over the Eastern Archipelago. It is intelligent, good-natured, docile, and easily trained to the performance of amusing tricks. In 
advancing age it becomes sullen, morose, and mischievous. Dr. S. Muller regards M. auratus of Belanger and M. carbonarius of F. Cuvier as varieties.

Macacus nemestrinus, Linn.

Simia nemestrina, Linn. I Inuus nemestrinus, Erxl. S. platypygos, Schreb. $\quad$ Papio nemestrinus, Erxl. S. carpolegus, Raffles.

Pig-tailed monkey, ENG. | Bruh sepotong, SuMatra. Broh, . . Penang. Bruh selapi, . ",

Bruh, . . Sumatra. Bruh putih,. . ",

This macac occurs in Penang, the Malay Peninsula, Sumatra, and Borneo. There are three varieties of it. It is good-natured and intelligent. The natives of Sumatra have taught it to climb the cocoanut palms and throw down the fruit, to select the ripe from the unripe fruit, and pluck no more than its master desires.

Macacus pileatus, Shaw and Desmarest. Rilawah, SingH. This appears peculiar to Ceylon.

Macacus radiatus, Geoffroy.

Cercopethecus radiatus, Cercocebe toque, Geoffin. Kuhl.

Simia sinica, Linn.

Munga, . . . CAN.| Waanur of the . MAHR.

Madras monkey, ENG. Makadu, . . :

Bonneted monkey, ." Vella munthi, . MALEAL.

Kerda of . . GHATS. Koti, . . : . TEL.

Bandar, . . HIND.

When young this monkey is inoffensive, and soon acquires a knowledge of various feats of agility and tricks. It is the most inquisitive and mischievous of its tribe, and its powers of mimicry are not surpassed by any other. With age it becomes more sullen and less amenable to discipline.

MACADAMA TERNIFOLIA. Von Mueller. Helicia ternifolia, Von Mueller.

The nut tree of sub-tropical East Australia. The nuts have the taste of hazels. It might be introduced into India.- Von Mueller.

MACAO, in lat. $22^{\circ} 11^{\prime} 30^{\prime \prime} \mathrm{N}$., long. $113^{\circ} 32^{\prime}$ $30^{\prime \prime} \mathrm{E}$., is built on a rocky peninsula. The Portuguese settled there in 1557 . They paid a rent of 500 taels, till Governor Ferreira refused it in 1848. The town is regularly built on a high peninsula, which terminates the beautiful island of Macao to the southward. The island is also called Heang-Shan, or the Fragrant Hills. In the 16th century Macao was given up to the Portuguese as a reward for services against some daring pirates, who then infested the neighbouring islands. The most interesting object now to be seen is the cave of Camoens, the author of the Lusiad. Camoens wrote this exquisite poem at Màcao. The cave is at the summit of a rock, over which is erected a very elegantly tasteful temple, in which is placed a fine bust of Camoens; on the walls are inscribed some of his choicest lines in the original, to which is also added a Chinese translation. Some of these lines are descriptive of the boundless sea lying beneath.-Horsburgh; Davies' China; Sirr's China, i. p. 127.

MACARANGA INDICA. $R$. $W$.

Putta thamara, . MaLeal. | Vutta thamar, . TAM.

This tree grows on the Neilgherries, and is common in Travancore." A simple pure gum of a crimson colour is obtained from the tree. It has been used for taking impressions of leaves, coins, medallions, etc. When the gum is pure and carefully prepared, the impressions are as sharp as those of sulphur, without its brittleness; the exudation so far as known is an entirely unknown production. Is used in medicine.-M. $E$. of 1857 ; Drury's Useful Plants.

MACARANGA ROXBURGHII. Wall.

Osyris peltata, $R_{.}, W . I c$. | Boddi chettu, . . TEL. A shrub of the Circars and Tavoy. All the young parts are covered more or less with soft, resinous, adhesive matter, smelling strongly of turpentine.-Voigt.

MACARANGA TOMENTOSA. W. Ic.

Upligi, Upalkar, . CAN. Kanda, . SINGH. Chenthakanni, . ", Vatte kanni, . TAM. Chanda, . : MAHR.

A small or middling-sized tree, is of very rapid growth. It is very common in all the western forests of Madras, Bombay, and Ceylon, up to 3000 feet, generally affecting old clearings of forest, and often planted for shade by coffeeplanters. A gum exudes from the tree, which is used medicinally by the natives, and for taking impressions. The timber is soft and useless.Thwaites, p. 274; Useful Plants; Beddome, Fl. Sylv. MACARONI.

Men-kin, . . . CHIN. Simian, . . HIND. Save, : : GuJ. Bughra, : : Pers. Suin, Siwin, : HrND.

A wheaten paste, formed into long, slender, hollow tubes, and used in soups, etc. Macaroni is similar to vermicelli, the only difference consisting in the latter being made into thinner and smaller tubes. The macaroni in use by the people of Persia and India is prepared by themselves. The Indian variety is not in the tubular form. It is properly served up in a boiled state, mixed with milk and sugar. 'I'hat used by most European households in India is imported, though cooks also make it for ordinary use. In China it is made from wheat flour by kneading and washing with water to get rid of the starch, then squeezed into short lengths. It is reckoned very nutritious, and forms part of the diet of priests and those abstaining from animal food. A macaroni, called Taukiu, is made from bean curd.-Smith, M. M. China.

MACASSAR, the Mangkasara of the Celebes, is the chief settlement of the Dutch on the Celebes, and is in lat. $5^{\circ} 8^{\prime} 15^{\prime \prime} \mathrm{S}$., and long. $119^{\circ} 23^{\prime} 30^{\prime \prime}$ E. The N. coast of Celebes is in general high, bold land. Macassar town has a good harbour, defended by Fort 'Rotterdam. It was occupied in 1810 by the British without any resistance. The Macassar race differ from the Bugi or Wugi in having larger and more open features, as well as in the peculiar ruddiness that is mixed with the brown tincture of their skin. The hair is suffered to fall down and float loosely upon the shoulders, and its ends have a deep red hue. The little boys and girls of the Macassar race are often very handsome, while the lineaments of the latter are sometimes not only faultless in design, but they have withal a shade of thoughtfulness and melancholy, which is rightly esteemed to be the last touch and finishing stroke of personal beauty. These promises of future loveliness vanish before maturity. In the manufacture of gloves and baskets, the workmanship for delicacy and fineness cannot be surpassed. Their writing character is the same as the Bugi, with a deficiency of three or four letters. Many can read. They value themselves as being of a more ancient and noble stock than the Bugi, but 
they esteem it creditable to understand that language. It is said that Dr. Leyden translated a Gospel into the Bugi. The Damasonium Indicum and the gomuti are common.

Macassar Men is a common name of the Bugi race. Macassar is the most notorious place in the Eastern Archipelago for the Bugi people to run amok. It is, in fact, amongst the natives of Celebes the national mode of committing suicide, and is therefore the fashionable mode of escaping difficulties. Ten or twenty persons are sometimes killed and wounded at one of the amok. Stabbing and killing all he meets, the amok runner is at last overpowered, and dies in all the excitement of battle. It is a delirious intoxication, a temporary madness, absorbing every thought and action.

There are five Bugi states, the system of government being that of a limited monarchy, with feudal nobles styled Arong and Pangwa or freeholders. Their vessels take from Singapore, as return cargo, British calicoes, iron, hardware, muskets, gunpowder, of value from 10,000 to 20,000 dollars.

The Bugi tribes inhabiting Celebes are celebrated for the temper they give to steel, and for their arms in general. In addition to those of the Malays on the Peninsula, they use defensively the baju ranti (chain jacket), and both a long and a round sort of shield. They swear by their krisses, for which they bave a great veneration, and on going into battle drink the water in which they have been dipped, uttering imprecations on the foe. The inhabitants of Pulo Nias, an island off the western coast of Sumatra, wear for armour a baju made of thick leather, and a cap to match, covered with the eju, the vegetable substance resembling black horse-hair obtained from the Arenga saccharifera.-Journ. Ind. Arch., 1852; G. Tradescant Lay, Voyage of the Himmaleh in 1857 ; Singapore Free Press, 1837.

MACASSAR OIL. This is supposed to be the oil of the Carthamus tinctorius seed. Macassar poison is from Hernandia sonora.

MACAULAY, THOMAS BABINGTON, LORD MaCAULAY, the first legal member of the Council of the Governor-General of India, born 1800, died 1859. Since his time, legislative councils, for making laws for British India, sit at each of the presidency towns. On the 16th January 1862 , the Governor-General in Council, under the authority vested in him by the Act 24 and 25 Victoria, cap. 67, sec. 16, appointed Saturday the 18th of January 1862 and the Council Chamber in the Government House at Calcutta, for the first meeting of the Council of the Governor-General, for the purpose of making laws and regulations under the provisions of the Act. On the 17th January 1862 there was issued the proclamation that the provisions of the Act, touching the making of laws and regulations for the peace and good government of the presidencies of Fort St. George and Bombay, were extended to the Bengal division of Fort-William presidency. See Law.

MACAIT TREE, the Acrocomia sclerocarpa, Mart., of the West Indies and Brazil, is chiefly valuable owing to its fruit, which yields an oil. The fruit is slightly roasted and ground to a paste, first in a mill and then on a levigating stone. This paste, having been beated and mixed with $3-10$ ths of its weight of boiling water, is put in a bag, and pressed between two heated plates of iron; it yields about 7-10ths or 8-10ths of oil. The oil can be purified, when melted, by filtration. It is then of the consistence of butter, of a golden yellow hue, bas an odour like violets, and a sweetish taste. If well preserved, it will keep several years; if spoiled, it loses its golden hue and delightful aroma. It is frequently sold in the shops as palm oil, and enters largely into the composition of toilet soaps. It might be usefully introduced into the East Indies.-Seeman.

MACCAW, birds of the tribe Scansores. The true maccaws are large birds, with long tails and gorgeous plumage; some of them blue and yellow, others red and blue. Another group, Conurus, is smaller, usually green, with various markings.

M'CLELLAND, Dr. J., a Bengal medical officer, distinguished by his researches into the natural history of India. In 1842, in the Calcutta Journal of Natural History, he described the freshwater fishes which Dr. Griffith had collected; and in 1843 he described a collection made at Chusan and Ningpo. He wrote on the Indian Cyprinidæ in the As. Res. xix. p. 217; he added birds from Assam and Burma. He also wrote on the timber and other vegetable products of Burma, and edited Griffith's Writings. He rose to be the principal Inspector-General of the Bengal Medical Department. He wrote on the Geology and other Branches of Natural Science in the Province of Kamaon, Calcutta 1835; a Report on the Physical Condition of the Assam Tea Plant, 1837. His personal exertions were mainly instrumental in adding isinglass to the articles of exportation from India to the European markets.

MACDONALD, GENERAL, an officer of the E. I. Company's Service, who raised in India the Deolee Irregulars, known as Macdonald's Meenas. $\mathrm{He}$ exerted an extraordinary influence over the men, became the chief of the clan, and introduced to them the bagpipes and the glengarry. It is told of the Meenas that, when once exhorted by an enthusiastic missionary to adopt Christianity, they professed their readiness to be converted on the spot if Macdonald Sahib would pass the order. MACE.

Talzuffar, . . ARAB. Bunga-pala, . MALAY̌.

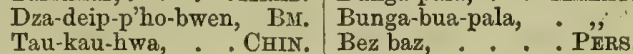
Tau-kau-hwa, : : CHIN. Bez baz, ${ }_{\text {Mushkatngi tsoget, RUS. }}$ Foely, Foelie, : : D"̈r. Jatipatri, . . SANSK. Muscaat-bloom, : " Wassawassie, : SINGH Fleur de muscade, "Fr. Macio,. . . . . SP Macis, FR., GER., IT., LAT. Flor de noz moscado, ", Muskaten-bluthe, GER. Jadiputri,. . . TAM Jaiwantry, Jaiputri,HrND. Japatri, . . . . TEL. Kambangpala, . JAV.

Nace is the aril or arillus of the nutmeg, and forms around the shell of the nutmeg. It has a pleasant aromatic smell, and a warm, bitterish, pungent taste; it is a favourite medicine of the Hindu physicians, who prescribe it in the slow stages of fever, etc. It is imported into India from Singapore, Batavia, and the Banda Islands. Mace is fleshy, branching, and, when recent, of a bright scarlet colour; but in the process of drying it changes to yellow, orange-yellow, or, what is considered best, golden-yellow, and becomes transparent and horny. It is prepared by drying in the sun for some days. The aril is sometimes flattened out, and dried in a single laver, but 
frequently also is pressed together in two layers. The Dutch sprinkle mace with salt water prior to packing it in sacks. London dealers distinguish three sorts of true mace.

Penang Mace is flaky and spread, and fetches the bighest price.

Dutch or Batavian Mace, a fleshy sort, scarcely so high priced as the Penang mace.

Singapore Mace, a somewhat inferior kind.

The mace of the male or false nutmeg is distinguished from the true mace by being formed of three or four regular bands united at the sumnit. The chemical properties of this article are analogous to that of the true mace, but the oil is so inferior that the male mace is but of little commercial value, and is used in India only among the poorer natives. It is procurable in most bazars under the name of Ramputri, is of a dark-red colour, and deficient in flavour and aroma.

Mace oil.

Jaiwantry, - HIND. Wassa wasitali, SINGH. Jaiputri-ka-tel, . ", Jaiputri tailum, . TAM.

A brown-coloured, highly-fragrant, almost solid soil. It is obtained by expression, and is of a butyraceous consistence. It is very stimulant, and is much employed as a liniment and embrocation in rheumatism.-Faulkner; M. E. J.R.; Food Adulteration; $M^{\prime}$ Culloch; Mason; Powell; Poole.

MACEDONIANS. There were Grecian military colonies established at Alexandria ad Caucasum, Arigæum, and Bazira, and garrisons at Nysa, Ora, Massaga, Peucelaotis, and at Aornis, a mountain range, supposed to be the mountains of Mahaban in the Pir Panjal or Mid-Himalayan range. See Greeks ; India.

MACGREGOR, GENERAL, C.M., a distinguished officer of the Bengal army, in which he rose to be Quartermaster-General. He travelled over much of Persia, Baluchistan, Afghanistan. He wrote accounts of the Khugiani, Mohmand, Safi, Shinware, of the Valleys of Jalalabad and Kunar; Gazetteers of Afghanistan, Persia, N.W. India.

MACHAN. HIND. A raised platform or scaffold in a field, from which crops are watched.

MACHARAS or Muchiras. HIND. A reddish brittle gum-resin, stated to be obtained from the Moringa pterygosperma. It is considered by the natives a temperate remedy, is used as an astringent in diarrhoea and special diseases, also for pain in the loins and colic. Usually given moist._Powell, i. p. 333.

MACHA REWA, a river in Garrawara, the principal affluent of the Sher. It rises in the Seoni district, but its course is chiefly through the Bachai subdivision of the Narsingpur district. Coal is exposed in the river-bed two miles above its junction with the Sher.

MACH'HA. HiND. A fish. Mach'hi-mar, a fisherman. Mach'hua, a fisherman, a vender of fish. Mach'hwa, a small boat, a fishing boat.

MACH'H-GIDHI, BENG., is the Hypsirhina enhydras. It is one of the Homalopsidæ, a freshwater serpent, common in Bengal, Assam, Burma, and Tenasserim. It is a timid reptile.

MACHI. HIND. An insect which injures paddy.

MACHILUS MACRANTHA. Nees.

M. macrantha, Wight. $\mid$ M. glaucescens, Wight.

Iruli,. . ANIMALLAY. Koorma, . . S. CAN.

Kroma, - NeIlgherRef. Ullalu, . . SINGH.

This is a very handsome tree when in full blossom. It is most abundant in all the western moist forests of the Peninsula, from Canara down to Travancore and Tinnevelly, and in Mysore and Coorg very abundant from elevations of about 1000 feet up to nearly 6000 . It is also found in the Bombay ghats, and in the Central and South-IVestern Provinces of Ceylon at an elevation of 1500 to 4000 feet. The timber is often used for building purposes ; it is light and even grained, and would answer as a substitute for deal. The tree flowers in March and April. Other fine species occur in N. India_-Thwaites, En. Pl. Zeyl. p. 254; Beddome, Fl. Sylv.

MACHILUS ODORATISSIMUS. Nees?

Badror, Muskru, . BEAs. Chau, Chandna of RAvt.

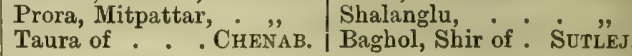

A tree of the Panjab Himalaya up to 4050 and 7000 feet, and of Simla and Darjiling. The cocoons of the Mugah silk-worm feed on its leaves in Lakhimpur and Sibsagar--Brand. Ex., 1878.

MACHIN or Maha-China, Great China, the name by which Hindus style the empire of China. But it is often used pleonastically coupled with Chin to denote the same thing; Chin and Machin, a phrase having some analogy to the term Sind wa Hind, used to express all India, also similarly to Yajuj and Majuj, applied to the northern nations of Asia. The use of a double assonant name, sometimes to express a dual idea, but of ten a single one, is a favourite oriental practice. As far back as Herodotus we have Crophi and Mophi, Thyni and Bithyni. The Arabs bave converted Cain and Abel into Kabil and Habil, Saul and Goliath into Talut and Jalut, Pharaoh's magicians into Risam and Rejam, of whom the Jewish traditions had made Jannes and Jambres; whilst Christian legends gave the names of Dismas and Jesmas to the penitent and impenitent thieves in the gospel. Jarga and Nargali was the name given to the great circle of beaters in the Ifongol hunting matches. In geography we have numerous instances of the same thing, e.g. Zabulistan and Kābulistan, Koli Akoli, Longa Solanga, Ibir Sibir, Kessair and Owair, Kuria Muria, Ghuz and Maghuz, Mastra and Castra (Edrisi), Artag and Kartag (Abulghazi), Khanzi and Manzi (Rashid), Iran and Turan, Crit and Mecrit (Rubruquis), Sandor and Candor (Marco Polo), etc.

The name of Achin in Sumatra appears to have been twisted in this spirit by the Mubammadan mariners as a rhyme to Machin; the real name is Atcheh. In India such rhyming doublets are not confined to proper names; to a certain extent they may be made colloquially, at will, upon a variety of substantives. Thus chauki-auki means chairs simply (chauki), or, at most, chairs and tables; lakri-akri, sticks and stakes.-Quatremere's Rashid, p. 243 ; D'Avezac, p. 534 ; Prairies d'Or, i. p. 399, in Yule, Cathay, pp. 119, 120.

MACHULAK, a plant with yellow flowers and succulent root, found in the neighbourhood of Liya and Bakkar, west of the Indus. The root is employed as a horse medicine.

MACKENZIE. Colonel Colin Mackenzie, C.B. a native of the island of Lewis, was appointed to the Madras Engineers in 1782, and in 1783 visited Madura, where he began to collect Hindu manuscripts relating to the history of India. He was employed throughout the war with Mysore from 1790 to 1792 . He was afterwards employed in 
geographical researches in the Dekhan, and after the fall of Seringapatam, he was specially appointed to examine the districts obtained. $\mathrm{He}$ was appointed Surveyor-General of India, and in 1821 his manuscripts were purchased by Government from his widow for $£ 10,000$, but they had cost him $£ 15,000$. A catalogue (Raisonné) was published by Professor Wilson jn Calcutta in 1828, and a second catalogue in Madras in 1857 by the Rev. William Taylor. He was celebrated as a geographer, antiquary, linguist, and naturalist. A biographical sketch and literary career of him, by Sir Alexander Johnstone, was given in the London As. Trans. i. p. 333. From 1783 to 1796 , he was variously employed south of the Kistna, in Dindigul, Coimbatore, and accompanied the expedition to Ceylon. He died in 1821 in Bengal. Wilson's Mackenzie Catalogue, in 2 vols., reported on 1568 MSS., 2070 local tracts, 8076 inscriptions in Sanskrit, Tamil, Telugu, Karnatica, Hala Kanara, Kanara of the Gainas, Malealam, Uriya, Mahrati, Hindi, Hindustani, Arabic, Persian, Javanese, Burmese, mostly palm leaves. The Rev. William Taylor's Report is in three volumes. -Dr. Buist's Catalogue.

MACKENZIE, GENERAL COLIN, an officer of the Madras army, who distinguished himself in the British wars against the Afghans in 1838 to 1843 . He was the means of releasing the British prisoners taken before and after Kābul.

MACKINTOSH, CAPTAIN A., 27th M. N. I., author of an Account of the Origin and Present Condition of the Tribe of Ramoossies, including the Life of Umiah Naik, Bombay 1833 ; Account of the Tribe of Mhadeo Kolies, and of the Maun Bhows, or Black-clothed Mendicant Devotees, 1836.

MACLEOD, SIR DONALD FRIELL, C.B., K.C.S.I., was the son of General Duncan MacLeod, and was born at Calcutta in 1810. He was employed for 42 years, the last five of which he was Lieutenant-Governor of the Panjab. During the mutiny he did good work, helping Sir Jobn Lawrence to send troops to put down the mutiny in the North-Test Provinces. As Lieutenant-Governor of the Panjab, he succeeded Sir Robert Montgomery in 1865 . He was made C.B. in 1858 , and in 1866 he was created a K.C.S.I. He was crushed to death on the London and Metropolitan Railway.

MACLURA TINCTORIA. D. Don.

Broussonetia tinctoria, Kth.; Morus tinctoria, Linn.

This tree, one of the Urticaceæ, grows to the height of 30 or 40 feet; a yellow dye is obtained from the wood, known as fustic wood in commerce. It has been introduced into the AgriHorticultural Gardens, Calcutta_-Jaffrey; Voigt.

M'MURDO, Captain J., wrote on the Canals of Scinde; Observations on the Indus, in Bom. Geo. Trans., 1836, 1838; Bombay reprint, i. p. 9 ; Account of a Supposed Volcano in Cutch, ibid. ii. p. 110 ; Notes on the Mahra Tribe of South Arabia, Bom. As. Trans., 1847, p. 339 ; Earthquake in Cutch, 1819, Bom. Lit. Trans. iii.; Former State of Runn of Cutch (in Appendix to Burnes' Bokhara Travels). - Dr. Buist; Lond. As. Trans. i. p. 123.

MACNAGHTEN, Sir WILLIAM, a Bengal civil servant, who entered the E. I. Company's service at Madras in 1809 as a cavalry cadet, and in 1814 was transferred to Bengal. In 1830 he accompanied Lord Bentinck in a tour through Upper India, and afterwards held the office of Political Secretary. In 1838 he was sent on a mission to Ranjit Singh, who was then at Adinanagar, and marched with him to Lahore, where a treaty was signed on the 26th June, to the terms of which Shah Shuja agreed. Subsequently armies were formed by Ranjit Singh, Shah Shuja, and the British, and Mr. Macnaghten was sent with the Shah as envoy and minister, and a declaration of war issued on the 1st October 1838. He was killed on the 24th December 1841 by Akbar Khan, son of Dost Muhammad Khan, at a conference.

MACPHERSON. Duncan Macpherson, M.D., a medical officer of the Madras army who served in the first war with Chiua, 1841-42; also in the war of the Crimea against Russia. He wrote on the War with China, also the Antiquities of Kertch, and Researches in the Cimmerian Bosphorus.

MACPHERSON, SIR JOHN, came to Madras at the age of 22 , and served the nawab of the Karnatic in various capacities. He revisited England, and secured a seat in Parliament, but returned to Calcutta as second member of Council. His economy of the public monies obtained for him a baronetcy, and on the resignation of Warren Hastings he held the government for 22 months, 8th February 1785 to 12 th September 1786.

MACPHERSON, MAJOR SAMUEL, a Madras officer, eldest son of Dr. Macpherson, professor of Greek in King's College, Aberdeen, was born in 1806. While engaged in the Trigonometrical Survey of Orissa, he became acquainted with the fact that the Khand race till then offered up periodical human sacrifices to the deity who presided over the fields, and he did much to suppress it. Lord Dalhousie afterwards named him Political Agent at the court of Sindia, where he gained the entire confidence of the maharaja and of his enlightened minister, Dinkur Rao. Died 15th April 1860.

MACREIGHTIA BUXIFOLIA. Pers.

Kaloo-habaraleya-gass, . • SINGH.

Of this there are four varieties, $\alpha, \beta$, in the hot drier parts of Ceylon, in the Ambagamowa district, and near Ratnapura. M. oblongifolia, Thw., is a small tree of Ceylon, near Ratnapura, and in the Singheraja and other forests between that place and Galle.-Thw. Zeyl. p. 183.

MACROCLADUS SYLVICOIA is a handsome palm, about 40 feet in height, with somewhat the habit of Cocos nucifera. Crown subhemispherical, dense. Leaves pinnate, ample, 12 to 15 feet long, spreading in every direction. Grows in Malacca, in forests at Ching. Malayan name, Ebool.

MACROCYSTIS PYRIFERA. Agh. An enormous seaweed, abounding in the Antarctic Ocean, between the parallels of $40^{\circ}$ and $64^{\circ}$. Sometimes from 500 to perhaps 1000 feet.

MACROPANAX UNDULATUM. Seem. A timber tree of the Darjiling Hills, one of the Araliaceæ. Another species, M. oreophilum, $M i q$. , is an evergreen tree, growing above 5000 feet, on the Martaban Hills.-Brandis, Paris Ex, 1878.

MACROPHTHALMUS, a genus of the crustacea. M. transversus, Edws., is a species of Pondicherry; M. parvimanus, Edus., Mauritius ; M. depressus, Edws., Red Sea.

MACROPIPER METHYSTICUM. Its root, or 
rhizome, is used in the South Seas in the preparation of the ava drink. It is chewed, spat in a bowl, and allowed to ferment, and drank. In the Samoan Islands, the large ava bowl is made from the tamanu, Calophyllum inophyllum, and occupies a conspicuous place.-Elph.; Erskine, Western Pacific, p. 46.

MACROPODIDE, the sea spider tribe of brachyurus decapodous crustacea, of the order Decapodes of Milne-Edwards, Legion Podopthalmiens, as under :-

Egeria arachnoides, Edw., Coromandel coast.

E. Herbstii, Edw., Asiatic seas.

E. Indioa, $\boldsymbol{E} d w$., Indian Ocean.

Doclea ovis, $E d w$. , Indian Ocean.

D. hybrida, $E d w$., Coromandel coast.

D. muxicata, $E d w_{\text {. }}$ E. Indies.

Composcia retusa, E. Indies.

MACROPODUS PUGNAX, Cantor, of Siam, occurs numerously at the foot of hills at Penang. Like the rest of the family, it is capable of living for some time out of water. The Siamese denominate them Pla kat, Pla, fish, Kat, a fighter. The real fighting fish appears to be a variety produced by artificial means, like the varieties of the golden carp of China, and Dr. Cantor named it Macropodus pugnax. When the fish is in a state of quiet, with the fins at rest, its dull colours present nothing remarkable. But if two are brought within the sight of each other, or if one sees its own image in a looking-glass, the little creature becomes suddenly excited, the raised fins and the whole body shine with metallic colours of dazzling beauty, while the projected gill membrane, waving like a black frill round the throat, adds something grotesque to the general appearance. In this state it makes repeated darts at its real or reflected antagonist. But when taken out of each other's sight, both instantly become quiet. A gentleman at Singapore was presented with several by the king of Siam. They were kept singly in glasses with water, fed with larvæ of mosquitos, and lived for many months. The Siamese are as infatuated with the combats of these fishes as the Malays are with their cock-fights, and stake on them considerable sums, and sometimes their own persons? and their families. The licence of exhibiting fish fights is farmed, and affords a considerable annual revenue to the king of Siam.Cantor. See Fishes.

MACROTOMIA EUCHROMA, $H$. $f$. et $T$., occurs in the N.W. Himalaya. It is the Lithospermum euromon of Royle, and the Onosma echioides of Linnæus, the Rattanjot or Gao zaban. The bruised root is applied to eruptions, and is sent to the plains as the officinal rattanjot, Potentilla Nepalensis, which is also used in dyeing wool. Royle assigned rattanjot to $L$. vestitum (See Geranium nodosum). In Lahul, Spiti, and Kanawar, it is used by the Lamas to stain images, and as a red dye for cloth, being applied with ghi or the acid of apricots.-Dr. J. L. Stewart, M.D.

MACTRA, a species of the sand clam, is fished up near Macao.

MACULLA is a commercial town on the south coast of Arabia. It is in lat. $14^{\circ} 30^{\prime} 40^{\prime \prime} \mathrm{N}$., and long. $49^{\circ} 6^{\prime}$ E. Maculla and Shuhur were the two principal ports on the southern coast of Arabia. On the 14th May 1863, Brigadier Coghlan concluded an engagement with nakib
Silah-bin-Muhammad of Maculla and nakib Ali Naji of Shuhur, in which they agreed to abolish and prohibit the export and import of slaves.Horsburgh ; Treaties, vii. p. 308.

MAD. ARaB. Rise, extension. Mad-o-Jazr, flood and ebb. Mad is often used in the complimentary phrases of letters as Mad-o-zillaho, May your shadow increase.

MADA, an ancient gold coinage of the Peninsula of India, known as the Kamala-mada. Mada is the Telugu term for a half pagoda $=48$ grains.

MADAD. HIND. An intoxicating mixture of betel-leaf and opium, swallowed or smoked in a pipe. $-W$.

MADAGASCAR ISLAND, 250 miles from the east coast of Africa, extends from lat. $12^{\circ}$ to $25^{\circ} 30^{\prime} \mathrm{S}$., almost 1000 miles long, and 260 miles of average breadth. A lofty granitic plateau, 80 to 160 miles wide and 3000 to 5000 feet high, occupies its central region, bare undulating moors, on which rise peaks and domes of bazalt and granite to a height of nearly 9000 feet. Many islands are on its north and north-east, - the Comora, Bourbon, Mauritius, Roderiques, Amirantes, and Seychelles, with the Chagos and Maldive coral atolls fartber east, which are supposed to mark larger subsided islands. The queen is nominally sovereign of the whole island, though practically several of the western tribes are independent. So long ago as 1828, king Ravama, with the aid of England, not only threw off the Sakalava yoke, but, invading their country again and again, compelled them, as well as other tribes, to submit. Madagascar has 66 species of mammals. Near, comparatively speaking, as it is to Africa, and broad as is the belt of forest which surrounds the island in an almost unbroken line, it has no lions, leopards, elephants, monkeys, zebras, or giraffes, and no hoofed animals, except a species of river hog. The special occupants of its tropical woods are the lemurs, which in Africa are unknown. The original relationship between Madagascar and Malaysia is indicated in some measure by the flora, and still more by the fauna; and a hypothesis has been constructed by several naturalists, of the existence of a lost continent, named by Mr. Sclater Lemuria, to which Madagascar and Malaysia are supposed to have both belonged. The coral reefs of the region are a sign that the surviving islands belong to the class called by Mr. Darwin sinking lands. Several mines of excellent coal were being energetically worked in 1881, and the iron and copper manufactures evinced much skill.

One language only is spoken throughout, with trifling varieties of dialect. The inhabitants are of two classes, the Hova, the ruling nation at present, and the Malagasy. Both are of African lineaments, but the Hova fairer than the Malagasy, with hair less woolly, and said in features to bear some remote resemblance to the Malays. The eyes of the Malagasy are large, brilliant, and restless; ears large; nose short and flat, though not so much so as in the Negro; lips moderately thick; height middling, and limbs well proportioned; lower jaws large, and mouth well garnished with teeth; colour dark; hair jet black, thin, and curly, occasionally inclining to woolly; beard very slight. The women are generally small and well proportioned, usually 
plain, but some of them very handsome. They are about the size of the native women of India. Christian missionaries abated infanticide and some of the worst horrors of war. They have shamed into secrecy the cruel superstitions connected with divination and charms. They have promoted external modesty and sobriety.

MADAKPOR, a migratory race of the Central Dekhan, known also as Kelikatr.

MADAN, a village with turquois or firozah mines, on the declivity of a mountain, two miles from the village. The firozah stratum in some places is in very narrow seams. There are many different minerals intermixed with the firozah, and most part of the rock contained iron ore. A small wheel is turned by one hand, while the stone is applied by the other, till sufficiently polished. It is then fixed to the end of a small piece of stick with sealing-wax, and exposed for sale.-Mohun Lal's Travels, pp. 174, 175.

MADANA, a name of Kama, the Hindu god of love. Festivals are held on the 13 th and 14th of the month Chaitra, in honour of Kama. Madana is he who intoxicates with desire. The festivals of the 13th and 14th are called Madana triodasi (thirteenth), and chaturdasi (fourteenth). On these days the Rajputs of Udaipur sing hymns handed down by the bards, "Hail! god of the flowery bow ; hail! warrior with a fish on thy banner; hail! powerful divinity, who causeth the firmness of the sage to forsake him. Glory to Madana, to Kama, the god of gods ; to him by whom Brahma, Vishnu, Siva, and Indra are filled with enotions of rapture.' There is no city in the east where the adorations of the sex to Kama-deva are more fervent than in Udaipur, the city of the rising sun. Madanotsava, a festival held in Kama's honour on the 13th and 14th of the month Chaitra.-Tod's Rajasthan.

MADAPOLLAM, a cotton fabric, manufactured in the Madras Presidency at Madapollam. The trade in madapollams and long cloths was annihilated by the goods laid down by the British manufacturer in all the bazars of India.

MADAR. HIND. Calotropis gigantea, also $\mathrm{C}$. procera: The stalks of both of these plants yield a strong fibre, used in making fishing-lines; the silky floss of the seeds in the seed-pod has been woven into a fine silk-cotton like fabric, and has been employed to mix with silk, and the juice furnishes a substance very like gutta percha in many of its qualities. It comes to maturity in a year, is perennial, and requires no care. Mr. Strettel estimated the cost of bringing an acre into cultivation, planting four feet apart, at $\mathfrak{\&}$, 9 s. $8 d$., after which the only recurring expense would be for harvesting and treatment. He estimates that it will yield a crop of from 5 to 7 cwt. per acre yearly, and the fibre is pronounced equal to good flax, and therefore worth $£ 40$ to $£ 50$ per ton.

MADARI, a race who pretend to cure snakebites by charms.

MADARIA, a sect or school of fakirs, founded by Badi-ud-Din Shah Madar, a converted Jew, born at Aleppo A.D. 1050. See Dam-i-Madar.

MADARU, a servile race in Coorg who make baskets. The Madagaru, predial slaves of Coorg, are seemingly identical. - Wils. See Madega.

MADD. ARAB. A line drawn across the top of a letter, when addressed to a superior, meaning that the writer of all below the line is a person wholly inferior to the recipient. See Măd.

MADDAL. TAM. An enclosure of a Hindu temple.

MADDANG KAMENHJIR, a Penang wood, used by the Chinese for making boxes.

MADDER.

Fuh, . . . Arab.|Ru-nas, . . Pers. Ti-hiveh, - : CHIN. Granca, Ruiva, - PorT. Krap, . . . DAN. Mariona, Krap, . Rus. Mee, Meekrap, : Dut. Manjishtha, - SANsK. Alizari, Garance, : Fr. Well-mudutta, : SINGH. Farberothe, Krapp, GER. Granza, Rubia, . SP. Manjith, GUJ., HiND. Krapp, : . . Sw. Robbia, : . IT. Man-jisti, : TAM., TEL. Puntvyar, . Maleal

The dyers of France seem to use madder as a generic term for all plants yielding a red dye. Of these may be enumerated, Ventilago acalyculata, V. maderaspatana, Oldenlandia umbellata, Morinda bracteata, M. citrifolia, M. tinctoria, Rubia cordifolia, and $R$. tinctorum. In Great Britain, the product known as madder is the long slender roots of the $R$. tinctorum. The principal supplies of it are obtained from Holland, Belgium, France, Turkey, Spain, and the Balearic Isles, the Italian States, India, and Ceylon. The best soil for it is dry, fertile, and deep sandy loams. It is propagated by dividing and transplanting the long and fibrous roots, but it grows from seed, and between the years 1881 and 1883 the imports into Britain of madder, madder root, garancine, and manjith were-

$1881,19,585$ cwts. $£ 28,633 \mid 1883,21,574$ cwts. $£ 28,197$ $1882,23,162,, \quad 23,050$

And the imports of madder or manjith into India were as under-

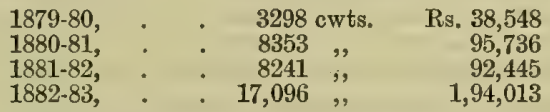

Garancine is prepared from madder by the action of sulphuric acid. Madder requires three years to come to maturity. It is, however, often pulled in eighteen months without injury to the quality ; the quantity only is smaller. When the soil is impreguated with alkaline matter, the root acquires a red colour; in other cases it is yellow. The latter is preferred in England, from the long habit of using Dutch madder, which is of this colour; but in France the red sells higher, being used for the Turkey-red dye. Madder does not deteriorate by keeping, provided it be kept dry. It contains three volatile colouring matters, madder purple, orange, and red. The latter is in the form of erystals, having a fine orange-red colour, and called alizaine. This is the substance which yields the Turkey-red dye. A field may be planted with madder, and fed off by cattle for three or four years, without any detriment to the roots, which are afterwards as good for dyers' uses as those cultivated in the ordinary way. The flesh, milk, and bones of animals fed upon madder become tinged.

The dyers of India use the chay root (Hedyotis umbellata) and the aal root (Morinda citrifolia), and the manjith (Rubia cordifolia) as substitutes. R. cordifolia, the manjith of India, has white flowers, is a native of Siberia, but is cultivated largely about Assam, Nepal, Bombay, Sind, Quetta, China; etc. It thrives best at elevations of 4000 or 5000 feet in Nepal and Sikkim. The long 
tendrils are cut into pieces of a foot long, and laid on the ground. The plant grows over the stumps of trees and trails along the ground. The process of dyeing with madder as practised by native dyers is simple; the dye colour is deepened afterwards when required by alum. The fabrics to be dyed are first steeped in a decoction of main, the galls of the tamarisk, and then submitted to the madder solution hot. It is fixed by alum as a mordant; the galls seem to impart to the cloth a facility for taking the colour.-Simmonds ; M'Culloch; Home Neus; Poole's Statistics of Commerce; Powell, Handbook.

MADEGA. KARN., TEL. In the Peninsula of India, the Chakili or Chaklar of the Tamil people, and the Mhang of the Mabratta nation. They are leather manufacturers, shoemakers, executioners. They are a very humble people, dwell in the outskirts of villages, and in many places are almost slaves. They are, in general, black, with slender lower limbs. They are largely addicted to robbery. They eat creatures which die of disease. They have certain territorial rights in the soil, and are bēgār or forced coolies. Their right to dead carcases is often disputed by the Dher or Pariah, and continued litigation results. In the years 1866 to 1868 , the Dher or Pariah and the Madega or Mhang of the village of Dongopura, 25 miles west of Beder, were litigating on this point, and none of the men would come as bēgär till it was settled. Colonel Tod tells us that the bhangi or scavengers of Ramkhaira mortgaged their rights in the dead carcases of their town to a professional brother of Laisrawun. - Tod's Rajasthan, i. p. 624.

MADEIRA WINE, once on every table, has ceased to be used in India. The character of this wine, famous for centuries, was first damaged during the wars with France at the close of the $18 \mathrm{th}$ and opening of the $19 \mathrm{th}$ centuries, when the high prices tempted many merchants of Funchal to throw inferior wines into the market. The island never produced more than 70 pipes of first-class wine, but in $1825,14,432$ pipes left the island. In the autumn of 1852 , the vine fungus, the Oidium tuckeri, appeared. It settles on the leaves in the form of fine white powder, drying up the leaves, preventing them inhaling carbon and exhaling oxygen; the leaves are thin, and the plant falls and dies. In 1864 only 2085 pipes were exported, and in 1865 probably not one pipe of wine left the island.

MADH or Madha. Hind. Honey; sweet; any intoxicating substance; the Saxon mead. Madhaki, a hookah to smoke opium in. Madhava-rapiala, or intoxicating cup, to which the Rajputs have always been accustomed, is a solution of opium, or a cold infusion of the poppy capsules. The atrs or essences, whether of grain, of roots, or of flowers, still welcome the guest, but is secondary to the opiate. See Hookah.

MADHAM, the fourth note in the musical scale, Fa. Madham-sitar, a kind of sitar, q.v.; one of the strings in the guitar (Tambura).

MADHAVA, a name of Krishna, from Ma, the goddess Lakshmi, and Dhava, husband.

MADHAVA, a celebrated Brahman, native of Tuluva, who became prime minister to Vira Bukka Raya, king of Vijayanagar in the 14th century. Madhava was brother of Sayana, author of the great commentary on the Veda, in which work Madhava is believed to have shared. Both brothers are celebrated as scholars, and many important works are attributed to them, not only scholia on the Sanhitas and Brahmanas of the Vedas, but original works on grammar and law. Among those of Madhava are the Sarva-DarsanaSangraha and the Sankshepa Sankara-vijaya. Madhava was a worshipper of Vishnu, and as a religious philosopher be held the doctrine of Dwaita or dualism, according to which the supreme soul of the universe and the human soul are distinct. Sankaracharya, who lived in the 8 th or 9 th century, was a follower of Siva, and upheld the Vedanta doctrine of Adwaita or non-duality. according to which God and soul, spirit and matter, are all one.

Madhava wrote the Jaiminiya Nyaya Mala Vistara, a work on philosophy. The various styles and subjects in the writings attributed to them point to a variety of authorship. But Dr. Burnell says the 29 writings of Madhava were composed by him between A.D. 1331 and 1386, whilst he was abbot of the monastery of Sringeri.

$\mathrm{He}$ is the founder of the Dwaita philosophy, and was known by the name Ananda Tirtlı. $\mathrm{He}$ established temples at Udipi, Madyatala, Subrahmaniya, and other places; also eight mat'hs or monasteries in Tuluva, below the ghats. The superior gurus of this sect are Brahmans or Sunyasis, who profess cænobitic observances; the disciples who are attached to the several mat'bs profess also perpetual celibacy, lay aside the Brahmanical cord, carry a staff and a waterpot, go bareheaded, and wear a single wrapper stained of an orange colour with an ochrey clay. They are usually adopted into the order from their boyhood, and acknowledge no social affinities nor interests. They regard Vishnu as the Supreme Spirit, as the pre-eminent cause of the universe, from whose substance the world was made. In Karnata, the sect is presided over by eight Swami or spiritual heads.

Madhava's Sarva-Darsana-Sangraha is a critical review of the principal systems of philosophy which have exercised the greatest minds of India throughout its middle age. From the Vedanta point of view (for Madhava was in 1331 elected Prior of the Smarta Order, founded by Sankaracharya in 8th century), these systems are arranged in a progressive series, beginning with the Charvāka and Bauddha, as being the furthest removed from the Vedanta, and gradually ascending to the Sankhya and Yoga, the systems nearest approaching to Madhava's, and therefore the highest. He successively passes in review the sixteen philosophical systems current in the 14th century in the south of India, and gives what appeared to him to be their most important tenets, and the principal arguments by which their followers endeavoured to maintain them. In the course of his sketches he frequently explains at some length obscure details in the different systems. As a rule, he draws his observations directly from the works of their founders or their chief exponents. One author says he was born A.D. 1199 in Tuluva. Professor Wilson says he lived in the 13th century.-Wilson; Burnell's Vansa Brahmana; Weber.

MADHAVACHARYA or Brahma Sampradayi, a small sect of Vaishnava Hindus in Southern India, founded by Madhavacharya. Madhava Brahmans hold the niuth day of the 11th lunar 
month as a festival,-Wils. Gloss. See Brahmacharya; Brahma Sampradayi.

MADHU. SANSK. Honey; anything sweet; anything intoxicating. Madhu is one of the poetical names of Krishna, viz. the intoxicator (from Madhua, strong drink, and Madhu, the bee, perhaps originating the English mead). Amongst the Hindus, a new-born infant has a little honey put into its mouth as a ceremonial rite, called Madhu prasana. Several of the drinking races of India and Asia still use the cup or piala to welcome the coming guest. Colonel Tod tells us, regarding the love of strong drink and indulgence in it to excess, so deep rooted in the Scandinavian Asi and German tribes, and in which they showed their Getic origin, that the Rajput is not behind his brethren either of Scythia or Europe. Though prohibited by ordinances which govern the ordinary Hindu, the Rajput welcomes his guest with the munwar peala, or cup of request, in which they drown ancient cumities. The heroes of Odin never relished a cup of mead more than the Rajput his madhua; and the bards of Scandinavia and Rajwara are alike eloquent in the praise of the bowl, on which the Bardai exhausts every metaphor, and calls it ambrosial, immortal: "The bard, as he sipped the ambrosia, in which sparkled the ruby seed of the pomegranate, rehearsed the glory of the Rajput race.' Even in the heaven of Indra, the Hindu warrior's paradise, akin to Valhalla, the Rajput has his cup, which is served by the Apsara, the twin-sister of the celestial Hebe of Scania. 'I shall quaff full goblets amongst the gods,' says the dying Getic warrior; 'I die laughing,' are sentiments which would be appreciated by a Rajput.-Tod's Rajasthan, i. 377; Wilson's Gloss. MADHU PAYKA. SANSK. An offering of honey, butter, and curds, presented to a person to whom it is intended to show particular respect, as to a guest, a bridegroom, or Brahman. - W.

MADHU RAO I., Peshwa from A.D. 1761 till bis death in 1774 , at the early age of 28 . Madhu Rao II., from 1774, died 1797.

MADHYA-DES, the middle country; according to one authority, the country comprising the provinces of Allahabad, Gorakhpur, Oudh, Dehli, Agra, and part of Bundelkhand, bounded N. by the Siwalik Hills, $S$. by the confluence of the Ganges and Jumna, E. by the S. branch of the Himalaya, and T. by the Vindhya mountains. Also the Doab; but the Madhya-des of the Mahratta is the country between the Konkan and Kandesh. Central Hindustan or Central India was the Madhya-desa of the ancient Aryans, the middle region of Aryavarta, the Arya country. In a slokam in the Sanskrit work, the Amarakosha, the ancient boundaries of it are thus defined:-

'Ariavartaha punia bhumi hi

Mad'hiam Vindhya Himava yoho;'

i.c. the Aryan country, the sacred land (lies) between the Vindhya and Himalaya, in this way indicating both the ruling race and the boundaries of the country held by them at the time that Amara Sinha wrote the Amarakosha. The first known dynasty was the Bharata, so called from the first king Bharata, and the last of the dynasty was Samvarama, who was driven westward by the Panchala of Kanouj, B.C. 589. The Bharata kingdom seems to have been established between B.c. 2600 to B.c. 2200 .-Wilson; Dowson.
MADIVALA, a bard or berald, one of the mixed castes, born of a Vaisya father and Kshatriya mother; also a native of Magadha or South Bahar.

MADKI. A battle was fought here on the 18th December 1845.

MADOORKATI. Papyrus pangorei. A sedge, extremely common about Calcutta, and very extensively employed in Bengal for making the elegant, shining, useful mats for which the capital of India is famous, and which are frequently imported into Europe. Strips of this sedge are suited for platting.- Royle.

MADOOWA. Amongst the superstitious ceremonies of the races in Ceylon are a variety of forms for the recovery of the sick, -1 , daana, or 2 , the food-offering, the harvest-home of the Singhalese, and horn-ptlling, a rite in honour of Pattine, performed to drive away pestilence. But the principal ceremony is the Dewal madonwa, which is celebrated on a larger scale, and frequently performed on behalf of a whole village or district which has been afflicted by cholera or fever. It takes place in a madoowa, or temporary building constructed of branches, and decorated with white cloths and garlands; and it generally lasts throughout seven days, on each of which ofterings are made of wild flowers and fruit, together with rice and money.-Tennent's Christianity in Ceylon.

MADRA, the ancient name for a country and people to the N.W. of Hindustan. Its capital was Sakala, and the territory extended from the Beas to the Chenab.

MADRASSA, any Muhammadan college. One of these was established in Calcutta in the year 1780 by Warren Hastings. Another was established in Madras by Nawab Gholam Muhammad Ghouse, which after his death was taken over by the British, but abolished in 1884 .

MADRAS CITY, on the Coromandel coast, is situated in lat. $13^{\circ} 4^{\prime} 6^{\prime \prime}$ N., long. $80^{\circ} 17^{\prime} 22^{\prime \prime} \mathrm{E}$. It is the principal town of the presidency which bears its name, and in 1881 had a population of 405,848 souls. It is the third largest town of British India, the population of Bombay being 773,196 , and Calcutta town and suburbs, 736,316 ; that of the Calcutta municipality being 433,219 , its north suburbs 51,658 , and its south suburbs 251,439. Madras, Bombay, Calcutta, Rangoon, Kurachee, Singapore, all of them now busy mercantile towns, are alike creations of the British since the 17th century. Madras city is an aggregate of 16 hamlets, viz. Mootial Pettah and Peddoo Naik Pettah, which are commonly called Black Town; Chintadrepettah, St. Thomé, Triplicane, Comaleswaram Coil, Nungumbaukum, Egmore, Vepery, Pursawakum, Nadoombary, Chetput, Peramboor, Veysurpady, Eroongoondum, and Tondiarpet. St. Thomé, 3 miles south of the fort, is famed as having been a Christian hamlet since an early part of the Christian era. This part of the coast has no sheltered harbour, and the waves of the Bay of Bengal break continuously on the shore, with which communication can only be held by means of catamaran rafts, and masula boats of planks sewed together.

The history of the Madras Presidency forms an integral part of the history of India, and occupies many hundred pages of Mill and Wilson, Elphinson, Grant Duff, and other standard works. Alaud-Din, the second monarch of the Khilji dynasty 
at Dehli, and his general, Malik Kafur, conquered the Dekhan, and overthrew the kingdoms of Karnatica and Telingana, which were then the most powerful in Southern India. But after the withdrawal of the Musalman armies, the native monarchy of Vijayanagar arose out of the ruins, with its capital on the Tumbudra river. This dynasty gradually extended its dominions from sea to sea, and reached a pitch of prosperity such as had been before unknown. At last, in 1565, after a glorious history of two centuries, Vijayanagar was overwhelmed by a combination of the four Muhammadan principalities of the Dekhan.

Mr. Francis Day, the representative of the English E. I. Company A.D. 1639, obtained permission from the local chieftain, Damerlu Venkatadri Naidu, to settle at the fishing village which is now the site of Madras, and on the 1st March 1640 , the Rayel of Chandragiri, a descendant of the Vijayanagar kings, issued a sunnud granting permission to erect a fortress. The city gets its name from Mundir-Raj, but the Rayel wished it to be called Sri-Ranga Patnam, and the Naik wished its name to be Chinnapa Patnam, by which last it is known to the natives to this day. In A.D. 1653 the Agent and Council of Madras were raised to the rank of a presidency.

In 1702, Daoud Khan, Aurangzeb's general, blockaded the town for a few weeks; and in 1741 the Mahrattas attacked the place, also unsuccessfully. In 1746, Madras was besieged by M. de la Bourdonnais, and on the 10th September the city capitulated, but it was agreed to be ransomed by a payment of $11,00,000$ of pagodas. On Bourdonnais departing, however, M. Dupleix declared the treaty void, and the British were taken prisoners to Pondicherry, or escaped to Fort St. David, which, till 1752, became their chief town, though in 1749, Madras, after the treaty of Aix la Chapelle in 1748, had been restored to the British. War again broke out between the British and French, and M. Lally a second time besieged Madras, from the 15th December 1758 till the 17th February 1759, when the French withdrew to Pondicherry.

The progress of Madras through the two centuries of its existence has been continuous, though its government has sustained some severe strains. In 1774, the governor, Mr. Wynch, was deposed by orders from the Court of Directors. In 1775, Lord Pigot was appointed, but in 1776 he was deposed by his Council, and confined; he was restored, but in April 1777 he died. In 1770, Sir Thomas Rumbold was appointed Governor of Madras, but dismissed in January 1781. In the beginning of the 19th century much agitation occurred whilst Sir George Hilaro Barlow was governor, and in 1860 Sir Charles Edward Trevelyan was removed from the Governor's office. Its annals contain some of the most romantic episodes of Anglo-Indian history, such as a struggle with the French for supremacy, the exploits of Clive, Wellesley, and Cornwallis,-Assaye and Seringapatam, the mutiny of Vellore. As soldiers, Sir Barry Close, Major Laurence, Generals Harris and Meadows, acquired fame and honours. As soldiers and administrators, it produced the great Lord Clive, Sir Thomas Munro, Governor of Madras, and Sir John Malcolm, Governor of Bombay. As botanists, the missionaries John, Rottler, and Koenig, and Drs. Roxburgh and
Wight, laboured in the Madras Présidency; Dr. Jerdon, author of the Birds of India and of the Mammals of India, was a Madras medical officer; and Dr. Russell and Dr. Day described the fishes of the coasts. Xavier, Ziegenbald, Dubois, and Caldwell have been eminent as Christian missionaries; and the first Government Museum in India was established there in 1851 by AssistantSurgeon Balfour.

The first essay at forest conservancy in the Madras Presidency was the introduction of a State royalty over teak and other valuable timber in Malabar and Canara in 1807. The existing Forest Department for Madras Presidency was first organized by Dr. Cleghorn in 1856, and placed on a new footing in 1875 . The tea plant was introduced on the Neilgherry Hills about 1838 .

Madras, as a presidency, has a dissimilar military and a civil jurisdiction. The former extends from Cape Comorin northwards to the Nerbadda, and includes the foreign territories of the mabarajas of Travancore, Cochin, Mysore, Hyderabad, and part of the British Central Provinces and British Burma; while its civil sway may be described as of four parts, - the Telugu country of the north, extending northwards from, and including Nellore; the Tamil country of the south, and the Canarese, Tulu, and Malealam districts of the western or Malabar parts of the Peninsula; and these surround a central table-land, elevated about 1000 to 2000 feet above the sea, comprising the inland districts of Salem, Coimbatore, Bellary, Kurnool, and Cuddapah, in which Canarese is the prevailing language.

The several languages have somewhat sharp boundaries,-Telugu. Tamil, Canarese, Malealam, Tulu, Uriya, and hill languages, Hindustani or Urdu being used by the bulk of the Muhammadans, their Labbai section of the Tamil country speaking Tamil, and the Moplah of Malabar speak Malealam.

The area thus indicated is partly British, and in part the territories of the following sovereigns in alliance with the British, - Travancore, Cochin, Banaganapilly, Sundur, Hyderabad, Puducottah, with a population of about 14 millions. The British territory is 141,001 square miles, with a population in 1881 of $31,170,631,-221$ to the square mile. In 1871 it was $31,597,872$, being a decrease of 427,241 . This was the consequence of a famine in 1876-1877, which prevailed in several of the plateau districts, and affected chiefly the males, of whom there was a decrease of 453,192 ; while of the females the increase was 25,951 .

1881. Males, . 15,421,043 1871. Males, 15,874,235 "Females, $\frac{15,749,588}{31,170,631} \mid \begin{aligned} & \text { "Females, } \\ & \text { Total, . . . } \frac{15,723,637}{31,597,872}\end{aligned}$

The famine was the consequence of failure in the rains of 1876. The water supply of the several districts is somewhat varied. The average annual rainfall during a period of years ranged from 17.57 inches in Bellary to 146.31 inches in $\mathrm{S}$. Canara. The N.E. monsoon prevails with heavy weather from the middle of October till the beginning of December, and violent gales sometimes occur in May. Cyclones also occur, and do immense damage. Those of $1807,1828,1836$, and 1847 were very violent.

The three principal rivers of Madras are the 
Godavery, Kistna or Krishna, and Cauvery, each with a large tributary system of its own.

Dodabetta ( 8640 feet) is the loftiest peak in Southern India. There are, besides, many outlying spurs and tangled masses of hills, of which the Shevaroys in Salem, the Animallay in Coimbatore, and the Palni (Pulney) Hills in Madura are the most important. The Laccadive Islands form, for administrative purposes, a part of Madras Presidency, being attached to the districts of Malabar and South Canara.

The Madras Presidency is eminently agricultural. Its males so engaged numbered $6,779,971$, and its females $4,024,032$; but there are several important towns.

Madras, . . 405,848| Tanjore, . . 54,745 Bangalore, . . 155,857 Negapatam,. . 53,855 Trichinopoly, . . 84,449 Bellary, . . . 53,460 Madura, $\therefore 73,807$ Salem, Calicut,. . . 57,085 Coombaconum, . 50,098

The presidency for revenue purposes is arranged into 21 districts, ranging from 4000 to 19,000 square miles in extent. The districts of Ganjam, Vizagapatam, Godavery, and Kistna are on the N.E. coast, to the E. of the Central Provinces and Hyderabad; and other E. coast districts are Nellore, Madras, Chingleput, South Arcot, Tanjore, Madura, and Tinnevelly, the last named being situated in the extreme south of the Peninsula. To the west of Madura and Tinnevelly, and on the W. coast of the Peninsula, are the Travancore and Cochin territories governed by feudatory rajas. North of these states, on the same coast, are the Madras districts of Malabar and South Canara. The central districts of the presidency are those of Coimbatore, Trichinopoly, and Salem, between Malabar and Madras, and those of Bellary, Kurnool, Cuddapah, and North Arcot, between Hyderabad and the Mysore country, which intervenes between Canara and Bellary and Nellore.

There are several large zamindaries, - Venkatagiri, Kalastri, Karvetnuggur, Punganur, Ramnad, Shevagunga, and Palicondah, with permanent settlements similar to those in Bengal.

The Madras revenue system is largely that known as the ryotwari, which had its strongest advocate in Sir Thomas Munro in the latter years of the 18th and beginning of the 19th centuries, and means a settlement direct with the occupying cultivator. About the year 1870 there were $3,227,726$ farmers and sub-tenants, holding $2,297,158$ single or joint farms. Under the ryotwari system, the peasantry pay an average of Rs. $2 \frac{1}{2}$ per acre. Of the ryots on the rent-roll only 420 were paying upwards of $£ 100$ a year of rent to Government, only 1627 from $£ 50$ to $£ 100$, only 5641 from $£ 25$ to $£ 50$, and only 77,408 from $£ 10$ to $£ 25$. Of all the rest, forming about 90 per cent. of the whole, 118,672 were paying less than $£ 5$ a year, 431,569 less than $£ 3$, and $1,197,157$ -the great majority-less than $£ 1$ a year. Only one country of Bengal-Chittagong-presents a parallel to it, and there Government has long tried to induce the peasantry to accept a fee-simple tenure. Mr. Maltby, Acting Governor, in a minute on Sir W. Denison's proposal to remove the poverty and agricultural ignorance of the Madras ryots by model farms and imported machinery, observed that the surest way of promoting improvement is to render land valuable and attract capital to it by such methods as fixing a light and permanent assessment, giving security of title, enlarging the means of irrigation, and facilitating the conveyance of produce. Mr. Pycroft, with similar wisdom, said, 'The main remedies are the lowering of the land assessment where unduly high, and placing it on a permanent footing, security of tenure, devlopment of internal communication, extension of irrigation, reduction of the interference of subordinate revenue officials, cheaper and more prompt administration of justice, and diffusion of education.

Mr. Dalyell, secretary to the Madras Government, estimated that there was produced an annual supply of 129 million ewt. of grain for the support of the population, or more than 5 cwt. for each person, being more than $1 \frac{1}{2}$ lbs. per diem, whereas a family of five can subsist upon 7 lbs. per day, without difficulty ; and 3 acres of superior land, supposing 1 acre to be irrigated, or 4 acres of unirrigated land, would support such a family for a year. The produce of an acre of the best rice land varies from 1080 Madras measures (= about $30 \mathrm{cwt}$.) in the southern districts to 1200 measures (= about 33 cwt.) in Godavery and Kurnool ; and the worst rice lands yield 8 to $14 \mathrm{cwt}$. Mr. Dalyell's estimate of $7 \mathrm{lbs}$. for five of a family is, however, a scant allowance.

The following inams or revenue-free tenures are found in the Madras Presidency:-(1) Lands held by religious institutions, with an estimated area of $1,458,081$ acres, on which the Government assessment would be $£ 242,247$; the larger portion of these are held by the pagodas in the southern districts, at Tripati, Conjeveram, Srirangam, Rameswaram, and Madura. (2) Grants for purposes of public utility, chiefly for providing water and shade.

The Chetty and Komati are the chief trading classes; the Kama, Kapu, Naik, Reddi, Wakkaliga, Vellala, and Velama are the agriculturists, with Bant and Nadavar in Canara, and Nair in Malabar. These belong to the well-to-do ranks of the community. They do not usually cultivate with their own hands, and many of them formerly held their lands on a military tenure. The pastoral castes are called Idaiyar in Tamil, and Golla in Telugu. Of the artisan castes, called Kamalar in Tamil and Kamsala in Telugu, nearly one-half are employed with metals. They have succeeded generally in maintaining a higher position in the social scale than is awarded to them in Northern India. The agricultural labourers belong to castes that were predial sqrfs up to the close of the last century. Even at the present time the conditions of service are not favourable to the labourer.

In the south, the Vannian supply the bulk of agricultural labour. The Maravar and the Kallar, whose acknowledged head is the raja of Puducottah, bear a bad reputation for thieving and general lawlessness. The Upparavar are chiefly engaged in the manufacture of salt and saltpetre; the Wadavar in tank-digging and road-making. The fishing and hunting castes are called Sembadavan in Tamil and Besta in Telugu. Many of them have now betaken themselves to agriculture. The non-Aryans proper, whose Tamil name of Parayen has been adopted into European languages, are called Mala in Telugu, Holia in Canarese, Poliygar in Malealam, and Dher in Mahrati. In the country round 
Madras they amount to about one-quarter of the total population. In 1871 the Pariahs returned themselves under more than 200 subdivisions in the census report. The principal wandering tribes are the Brinjara and Lambadi, carriers of grain and salt. The Koravar races wander over a wide area in Nellore and the adjacent districts, and constitute one of the chief criminal classes.

In 1881 there were 519,823 children under instruction ; $1,535,790$ adults could read and write, and $12,843,296$ could neither read nor write. Over 28 millions of the population (28,497.678) follow forms of Hinduism ; 711,080 are Christians, and 1,933,561 Muhammadans. The great bulk of the population is of Turanian origin, the Brahmans and Rajputs who claim Aryan origin being only $1,136,111$ out of the $31,497,678$ of total inhabitants. Christians are more numerous in this presidency than in any other part of the country, the total of British India being 1,862,525. 473,352 of the Madras Christians are of the Romish persuasion. The Muhammadans, 1,933,56 61 in number, are chiefly of the Sunni sect.

The following are the more numerous of the castes in Madras, Mysore, and Travancore :-

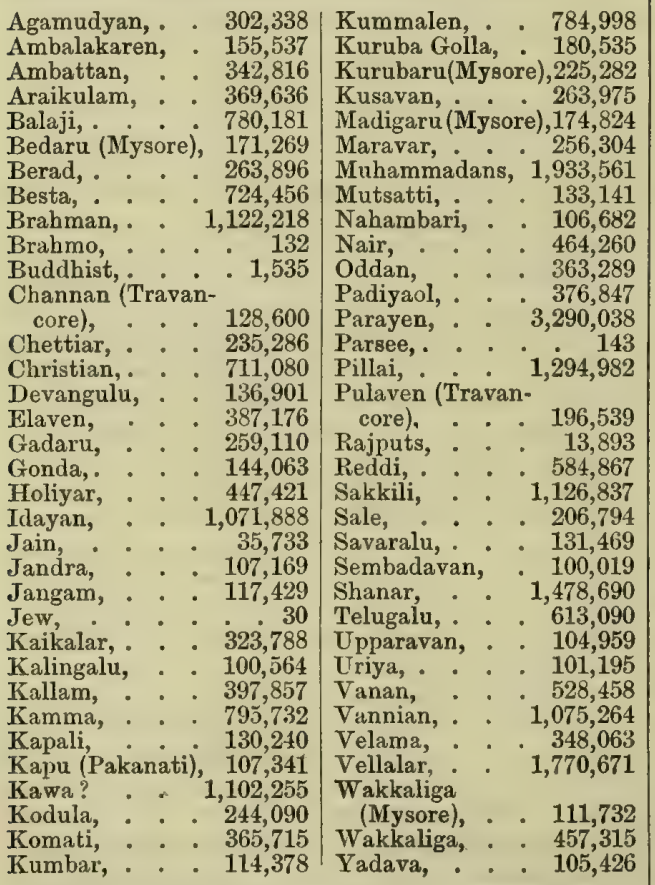

MADREPORIDA, a family of zoophytes in which the polypes have ten short tentacles and a stony polypidom, sometimes branched and arborescent, sometimes developed in a leaf-like or fan-like form. They exist in all the warm seas. Large, strongly-branched corals of the genus Madrepora fringe the island of the Mauritius. The corals or coralliaria have already been briefly noticed under that heading. But it may be here mentioned that under the general name of coral animals are included all those members of the Actinozoa which have the power of secreting hard structures of the nature of a skeleton. This skeleton is what is known as the coral or corallum, and the animals which produce it are the so-called coralligenous zoophytes, Actinozoa coralligena. The forms of the class Actinozoa which secrete a corallum, belong to the orders Alcyonaria, Rugosa, and Zoantharia. No corallum is ever produced in the order Ctenophora; even many members of the Zoantharia are destitute of a skeleton, or have but an imperfect one ; aud that of the Alcyonaria is also often rudimentary.

The class of the Actinozoa is divided into four orders, viz. the Zoantharia, represented by the sea anemones, madreporaria, etc.; the Rugosa, in which occur the genera cyathophyllum, zaphrentis, etc.; the Alcyunaria, which comprise the red coral sea-pens, sea-shrubs, organpipe corals, etc.; and the Ctenophora, comprising the Beroë, Pleurobrachia, Venus' girdle, etc.

ORDER I. Zoantharia (Hexacoralla).

Section. Zoantharia malacodermata, sea anemones.

Fam. i. Actinidæ, no corallum. Genera, actinia, adamsia, antheus, bunodes, bolo cera, cancrisocia, corynactis, phymactis, sagartia, tealia, etc.

Fam. ii. Ilyanthidæ, no corallum. Gener'a, ilyanthus, peachia, Edwardsia, cerianthus, halcampa.

Fam. iii. Zoanthidx, generally a pseudo-skeleton.

Section. Zoantharia sclerobasica, the black corals or Antipathidæ. They form colonies which are attached by the base to some foreign object, and are generally more or less branched and plant-like. It comprises the genera gerardia, cirrhipathes, antipathes, arachnopathes, rhipidopathes, leiopathes, etc.

Section. Zoantharia sclerodermata (Madreporaria) includes most of the coralligenous zoophytes of eastern seas. They always possess a corallum. They propagate by gemmation and fission. The genera are madrepora, dendrophyllia, cladocora, oculina, lophohelia, astroconia, astrangia, rhizangia, caulastroea, moeandrina, diploria, latimaandra, rhipidogyra, phytogyra.

The Zoantharia sclerodermata were arranged by Milne-Edwards and Jules Hoime into the four great sections Aporosa, Perforata, Tabulata, and Tubulosa

Aporosa, with six families, - Turbinolidxe, Pseudo-turbinolidæ, Oculinidæ, Astroeidæ, Pseudofungidæ, and Fungidæ.

The two Perforata families are the Eupsammidæ and Madreporidæ.

The genera of the Tabulata are not yet agreed upon, but the Millepora, the Heliopora, the Favositidæ, the Chœtetidæ may be named.

The corallum of the Tubulosa is both simple and compound.

ORDER II. Rugosa possess a well-developed sclerodermic corallum, all fossil.

ORDER III. Alcyonarir (Octocoralla) comprise the families Alcyonidæ, Tubiporidæ, Pennatulidæ, Gorgonidæ, and Helioporidæ.

The Tubiporidæ are known as the organ-pipe corals; the sea-pens and sea-rods form the Pennatulidæ; and the Gorgonidæ are known as sea-shrubs.

The simplest corallum is most commonly cylindrical, conical, or turbinate (Caryophyllia, Turbinolia, Balanophyllia, etc.), but it may be more or less compressed (Flabellum); also arborescent or dendroid (Madrepora, Dendrophyllia, Lophohelia, etc.), or in clusters of branches springing from a common base (Mussa, Caulastræa, many species of Porites, Madrepora, etc.); others are foliaceous, as species of Madrepora, Pocillopora, Manopora, etc.

Amongst the more important reef-building corals may be mentioned the Astrœidæ generally (Astrœa, Astrangia, Cladocora, Diploria, Mœandrina, etc.); also the Madreporidre (Madrepora, etc.); the Poritidæ (Porites, Goniopora, Monti- 
pora, etc). : many of the Oculinidæ (Orbicella, Stylaster, Pocillopora, etc.); the majority of the Fungidæ and the Millepores. Various alcyonoid corals (Heliopora, Tubipora) also help with many of the Gorgonidæ and the calcareous algæ (Nullipores and corallines).

The structures raised by them are known as barrier reefs, fringing reefs, and atolls. Fringing reefs are in the immediate neighbourhood of land, in shallow water, either surrounding islands or skirting the shores of continents. Barrier reefs also may either encircle islands or skirt continents, but far from land. The barrier reefs occasionally surround islands. An atoll is a ring-shaped reef enclosing an open lagoon.-Darwin, Encyc. Britan. See Corals.

MADURA, a town in the southern part of the Peninsula of India, in the Madras Presidency, in lat. $9^{\circ} 55^{\prime} 16^{\prime \prime} \mathrm{N}$., and long. $78^{\circ} 9^{\prime} 44^{\prime \prime} \mathrm{E}$. It gives its name to a revenue district, lying between lat. $9^{\circ} 4^{\prime}$ and $10^{\circ} 44^{\prime} \mathrm{N}$., and long. $77^{\circ} 14^{\prime}$ and $79^{\circ} 20^{\prime} \mathrm{E}$., and bounded on the S. by Tinnevelly, Palk's Strait, and the Gulf of Manaar. Madura is on the banks of the Vaiga river. It was the capital of the ancient Pandiyan monarchy, which was overthrown by Muhammadan invaders in the 11th century. Another Hindu dynasty, that of the Naiks of Madura, began about A.D. 1420. Tirumala reigned from A.D. 1623 to 1660 or 1662 , and the public edifices erected by him furnish evidence of his wealth and magnificence. The Naik dynasty ceased to rule in the middle of the 18th century, but so late as 1820 a great-grandson of Bhangaru, the last Naik, visited Madras from Vellikurchi, seeking pecuniary assistance from the Goverument. After the dynasty was set aside, the Madura district witnessed for years the contests for dominion, in which Clianda Sabib, Muhammad Ali, Muzaffar Jung, Muhammad Yusuf, Polygars, and the British were engaged; but it was finally, in 1801, placed under British rule.

In the legends of the south of India, Kula Sakara is said to have founded Madura city, and the story is abundantly illustrated in the sculptures of Tirumala Nayak's choultry, and in other buildings there. Seventy-three kings are said to have reigned prior to the accession of the Naik dynasty. Extant legends connect the city with fables about Agastiya, for it was the great seat of Tamil learning, and was fumed for its Sangattar or College Council, with which the names of Agastiya and his 12 pupils are associated. Their names are Tholcāpyar or Tiranathumagini, Athankotas̄ān, Thuralingam, Kākipādini, Nattathan, Vāminau, Vyapican, Vaypyan, Panambaran, Kalaramban, Sembootsay, and Avinayan. The three works published by them were the Paragathyam, Sittagathyam, and Tholcappyam. Madura has been both the political and religious capital of the extreme south. The Madura College exercised as great an authority over Tamil literature as the Academy of Paris in its palmy days in France. At the first institution of the Madura Sangattar, it would appear that some dispute arose immediately between the professors and the Saiva priests, connected not impossibly with that contention for pre-eminence of knowledge which has ever prevailed in the Tamil countries.

Madura had formed the southern part of the Regnum Pandionis of Ptolemy, the Pandi Man- dalam of the Indians, and its capital, the Madura of Ptolemy, was the royal residence of the ancient monarchs about the beginning of the Christian era.

Pandiya, the Pandion or Oi Pandiones of the Greeks, was the titular name of the dynasty of Madura, and the race were styled Pandyi, Pandiya; the king, the Pandyan or Pandiya Deva. T'wo embassies were sent by the Pandiyan king to Augustus, the first of which he received at Tar. ragona; the second is mentioned by Strabo. The friendship of the Romans was sought by only one other Hindu prince, $\mathrm{O}$ Kerobothros, the $\mathrm{king}$ of Chera or Kerala, who was also a Dravidian.

At the beginning of the Christian era, Pandiya territory appears to have embraced all the Peninsula south of the Cauvery. It was about the $2 d$ century that the ruler, Vamsa Sekhara, founded a college at Madura, with a council or sangattar of 48 professors. The college was broken up between the 6 th and 9 th centuries. About the 11 th century the town of Madura was destroyed by fire, the king and all his family perished, and the Pandiva dynasty was ended. This was followed by a long period of anarchy, till the Naiks became dominant in the 15 th century. Their power culminated during the reign of Tirumala, and the dynasty allowed Christian missionaries, Robert de Nobilibus, De Britto, and others, to labour among the people. The great Hindu temple forms a parallelogram 847 feet long from north to south, by 744 feet broad, with 9 gopuras, one of which is 152 feet high. The principal structure is the Sahasra-stambha-mantapam or Hall of One Thousand Pillars (the actual number being 997), which was built by Arya Nayaga Mudali, the general and minister of Viswanath, the founder of the Naik dynasty. The whole is profusely ornamented both with sculptures and paintings. Several of the great buildings of Madura city are associated with the name of Tirumala. The palace is the most perfect relic of secular architecture in the Madras Presidency.

The Vellalar are the most numerous and the most respected class of agriculturists. They speak a pure Tamil dialect. The Maravar chiefly inhabit the two zamindari estates bordering the sea-coast. Their hereditary chiefs are the rajas of Ramnad and Siva-ganga. T'hey were a martial race, and more than once rose against British authority. They bury their dead, and allow the re-marriage of widows. The Kallar are predatory, with headquarters in the Tributary State of Puducottah.

The Pulney Hills, called Varaha or Pig mountains, project across the district for about 54 miles. Their highest peaks attain an elevation of more than 8000 feet above sea-level. On this plateau a sanatorium for Europeans has been established at Kodaikanal, and coffee-planting is rapidly extending. The precipitous fortress of Dindigul, and the Elephant Rock, the Cow Hill, and the sacred Skandamalia, are in the neighbourhood of Madura town.

In Tinnevelly and Madura are valuable marbles. In Madura was a dangerous sport called jalicut. It consisted in making a bull infuriated, and then letting him loose, with cloths or money tied to his horns, which became the property of any person who could succeed in removing them. Since the year 1855 a prohibition existed against the sport being indulged in, and in 1859 certain village 
servants were dismissed for permitting it within the limits of their jurisdiction.-Orme, Friend of India; Tennent's Hindustan, ii. p. 7 ; Caldwell's Grammar.

MADURA or Madoera Island, in the Eastern Archipelago, forms part of Netherlands India. Its N.W. point is in lat. $6^{\circ} 55^{3^{\prime}} \mathrm{S}$., long. $112^{\circ} 51 \frac{3^{\prime}}{4} \mathrm{E}_{\text {. }}$, and its E. point in lat. $6^{\circ} 59^{\prime} \mathrm{S}$., long. $114^{0^{4}} 11 \frac{1}{4}^{\prime}$ E. It is the most important of a line of 75 islands which runs along the northern and eastern coasts of Java, and is separated from the great island by a strait not more than two miles wide, which serves to form the capacious barbour of Sourabaya, the strait widening at its eastern extremity to fifty miles. Its soil is poor compared with that of Java, but its inhabitants are peaceful and industrious. Since the early part of the 18th century, the Madurese have been migrating to and settling on the opposite shores of Java, depopulated by long wars, and in some districts they form the bulk of the present population, so that the Madurese language is not confined to Madura. In 1880 , its population, 810,135 in number, comprised-Europeans, 509; Natives, 804,015 ; Chinese, 3932 ; Arabs, 1516 ; others, 163. The sultan resides at Bangkallan. Few mammals are found, and none peculiar to Madura. The island is famous, however, for its breed of cattle, and supplies from its rich pastures provisions to many of the agricultural and seafaring communities of the neighbouring regions. The meat when cured resembles, but is far superior to, the jerked beef of South America. The people are similar to the hillmen of Java, and from them the Dutch recruit the line of their native army with the best troops in their service. Raffles' History of Java; Earl, Eastern Seas; Horsburgh; Temminck, Coup d'Eil sur les Possessions Neerlandaises, i. p. 335 ; St. John's Indian Archipelago, i. p. 337.

MADUWAR, a tribe occupying the higher slopes of the Animallay Hills in Coimbatore. They hunt the ibex and sambur, using powerful bows and arrows and large dogs. See Kader.

MADYAL, a savage Gond tribe, called in Bastar Jhodia, dwelling on the Beila Dila Hills, and in the remotest parts of Chanda. The women wear a bunch of leafy twigs to cover them before and behind. In this they resemble the Juanga to the south of the Kol country, the Chenchi near the Pulicat lake, and to the north of Ellore; and till about the year 1830 a similar leaf dress existed amongst the Holier of the forests near Mangalore.

MAEMANA is situated on a plain in the midst of hills. It is 172 miles N.E. of Herat, 105 miles S.W. of Balkh, 380 miles E. of Mashed, 280 miles S. of Bokhara, 350 miles W.N.W. of Kabal, 665 miles N.N.W. of Kandahar by Kabal, 572 miles from Kandahar by Herat, and 230 miles S.E. of Merv. The inhabitants are Uzbaks, with some Tajaks, Herati, about 50 families of Jews, a few Hindus and Afghans, in all about 15,000 or 18,000 souls. The district is 20 miles long by 18 broad. In 1857, the Mir of Maemana tendered submission to Persia. Early in 1858, being threatened by Persia, he applied to Muhammad Afzal for assistance; in 1859 he headed a rebellion against the Afghans, but was defeated. In 1861 he tendered his submission to Herat, and in the end of the year transferred it to Kabül.
In the beginning of 1868 , Maemana stood a siege by Abdur Rahman, and the inhabitants gallantly repelled three assaults, but at last submitted to terms. It is at the present time (1884) regarded as forming part of Afghan Turkestan, but it is a region of change. - MacGregor.

MASA INDICA. A.D.C. Matabimheya-gass, Srngr, A Ceylon tree, very abundant up to an elevation of 5000 feet. $-T h w$.

\section{0.}

MAFI. HIND. A rent-free tenure. Mafidar, holder of a rent-free tenure. Properly Mũāif.

MAFINE, in Polynesia, an imaginary being who is supposed to bear the world on his shoulder, and earthquakes are caused by his shifting the earth from shoulder to shoulder.

MAGADHA. The territory of which this is the ancient name corresponds with that part of the present Behar which extends along the south of the river Ganges. The capital was Rajagriha. Magadha is mentioned so early as in the Atharvan Veda, and is met with so late as the 7th century A.D., when Chinese pilgrims speak of it under the scarcely intelligible name of Moki-a-to. The present appellation Behar is from Vihara or a monastery of the Buddhists, whose most reputed convent was at Behar, the place where Buddha obtained the law. As Magadha was the scene of Buddha's early career as a religious performer; it possesses a greater number of holy places connected with Buddhism than any other province of India. The chief places are Buddha, Gya, Kukkutapada, Rajagriha, Kusagarapura, Nalanda, Indrasilaguha, and the Kapotika monastery.

The kings of Magadba were of six dynasties, viz. that of

Barhadratha, of the line of Pandu, the first of which was Jarasandha, a co-temporary of $\mathrm{Yu}$. dishthra and Krishna. According to Sir William Jones, B.C. 3101, according to Professor Wilson in the reign of Sahadeva, B.c. 1400, Parakshita was born, and the great war ends, and in the reign of Ripunjaya, B.C. 915 , a Buddha was born. The accepted era of the Pandu dynasty is B.C. 1400 to 915 .

The Sunaka dynasty, kings of Bharatkanda, of Magadha kings, reigned 128 years.

The Saisunaga or Sesnag reigned 360 years, and we find amongst them, B.c. 415, Nanda Mahapadma (B.C. 1602 Jones, 360 Wilson), regarding whom it was said he will bring the whole earth under one umbrella; he will have eight sons, Sumalya and others, who will reign after Mahapadma. He and his sons will govern for 100 years. The Brahman Kaulilya will not root out the nine Nanda.

The Maurya dynasty governed 137 years, the first of whom, according to Wilson, B.C. 315 , and 1502 Jones, was Chandragupta, the Sandracottus of the Greeks, contemporary with Seleucus.

The Sunga dynasty reigned 110 years, the first of whom, Pushpamitra (B.C. 178), put his master, the last of the Maurya, to death.

The Kanwa dynasty reigned 45 years. The first was, B.c. 66 Wilson, Kanwa, named Vasudeva, who usurped his master's kingdom.

Sahadeva was king of Magadha at the end of the war of the Mahabharata. The 35th king in succession from him was Ajata Satru, in whose reign Sakya or Gautama, the founder of the Buddh- 
ist religion, was born, and Sakya died ahout B.C. 550 . The 6th in succession from Ajata Satru, inclusive, was Nanda; the 9th from Nanda was Chandragupta, and the $3 \mathrm{~d}$ from him was Asoka. Pali was the spoken tongue.

Magadha was first mentioned by the Greeks B.c. 300 . The last mention of it was about the 5th century A.D. It is mentioned in a note in the Vishnu Purana.

The Magadha kingdom occupied the tract called Prachi by Hindu authors, the Prasii of the Greeks. Megasthenes was ambassador at the court of Chandragupta when king of Magadha, who had Pataliputra as his capital, known to the Greeks as Palibothra.-Cunningham's Ancient Geography, p. 452 ; Elphinstone, pp. 138, 143 ; Dowson.

MAGAHI, a tribe of agriculturists in Behar, probably a vernacular form of Magadhi, or native of Magadha.

MAGALHAES, FERDINANDO DE, more generally known by his Spanish designation Magellanes, in the year 1520 set out on a voyage of eastern discovery, passed through the straits which bear his name, discovered Mindanao, and died in Mactan on 26th April 1521, from wounds received in action. Only one of his fleet, the Vitoria, commanded by Elcano, a Biscayan, returned to Spain. Magellan had become disgusted with the Portuguese service, and he offered to Charles V. to discover a passage to India by the west, in order to divide the rich traffic of the Spice Islands. He passed the straits in S. America which have since gone by his name, in 1520, and, entering the South Pacific Ocean, arrived in a few months at the Philippine Islands, of which he took possession in the name of the Spanish monarch. Barbosa fell three days after Magellan, and in twelve days more the people waylaid and murdered twenty-four of his companions._Bikmore, p. 308; Chatfield's Hindustan, p. 37.

MAGAR or Mugger, a small martial tribe in Nepal, originally from Sikkim, from which they were first driven west by the Lepcha, across the Mechi and Kook rivers, and thence farther west by the Limbu, beyond the Arun and Dud Kushi. The Magar race now occupy the lower levels on the banks of the Kali in Nepal. They use a monosyllabic language, like the Tibetans, Chinese, Burmese, and Siamese, with an alphabet of Indian origin. They abstain from beef, drink to excess, and have an Indian priesthood. They are divided into twelve thum, supposed to be descendants of twelve different male ancestors. They do not marry in their own thum. This exogamic practice occurs in Australia, North and South America, Africa, and Europe. They reside in the valleys. -Dr. Latham's Ethnology.

MAGAR-BANS. HIND. Bambusa arundinacea, a solid bamboo, called a male bamboo.

MAGAR TALAO, or Crocodile Tank, also called the Magar Pir, or more correctly Pir Mangho tank, has hot springs and a temple in the Kurachee district of Sind. It is about 7 or 8 miles north of Kurachee. The swamp is not more than 150 yards long, by about 80 yards broad; and in this confined space a visitor counted above 200 large crocodiles. The natives say they never touch a buffalo, but will instantly attack any other animal, however large, and a goat was therefore killed for them. The animal was slaughtered on the edge of the swamp, and the instant the blood began to flow, the water became perfectly alive with the brutes, all hastening from different places towards the spot. In the course of a few minutes, and long before the goat was cut up, upwards of 150 had collected in a mass on the dry bank. When the meat was thrown among them, it proved the signal for a general battle; several seized hold of a piece at the same time, and bit and struggled and rolled over each other until almost exhausted with the desperate efforts they made to carry it off. At last all was devoured, and they retired slowly to the water. The mosque is a neat white building. It is dedicated to Pir Haji Mangho, who is esteemed a saint by both Hindus and Muhammadans, and is held in such high veneration throughout Sind, that numbers of corpses are yearly brought from a great distance to be interred near his shrine. The valley is in consequence covered with buryinggrounds, which are full of tombs elaborately carved and ornamented.-Imp. Gaz.

MAGDAR. HIND. Indian clubs, used for exercise in developing the muscles of the arms and chest.

MAGH, commonly applied to the natives of Arakan, particularly those bordering on Bengal or residing near the sea, and to the people of Chittagong. The Arakanese, however, disclaim the appellation, and restrict it to a class whom they hold in utter contempt, the descendants of the Arakanese who were settled at Chittagong and Dacca, by Bengali mothers. The word is also written Magh, Mug, or Mugh, and is an ancient name for the Magi, also, in Central Asia, called Gabr, applied to a fire-worshipper, also a wine-drinker or tavern-keeper.

The Magh of Bakarganj came from Arakan in the beginning of the 19th century, when that country was overrun and conquered by the Pegurs. They profess Buddhism, but nearly all traces of that religion have been obliterated, and many have accepted Hinduism. They intermarry among themselves, adhere to their own mode of living, build their houses like those of Burma, and are fond of revisiting their old homes.

MAGH or Magha. SANsis. The tenth month of the Hindu year, when the sun enters Capricorn, and when the full moon is near the asterism Magha (January-February). On the 1st of Magha, according to solar calculation, or the first lunation of the moon, that is, the day of new moon, a great festival is observed in Upper India, when bathing in the sea at Ganga Sagara, or the mouth of the Bhagirathi, is considered of peculiar efficacy. At the full moon a great festival is held at Combaconum. Magh Bihu and Baisakh Bihu are the two national festivals of the Assamese. The two great festivals, Pocham and Pochi, of the Buddhist Shan and Burmese, are held about the same period of the year. The Baisakh Bihu is as gay as a carnival, and the women, especially the maidens, enjoy unusual liberty. The prettiest girls dance with their hair hanging loose on their shoulders.

MAGHA or Sisupala-Badha, a collection of Hindu heroic epic poems of 20 cantos, written by different authors, under the patronage of king Magha. The subject is the death of Sisupala, slain in war by an arrow from Krishna. - Ward, iv. MAGHAZZI, one of three great tribes in 
Baluchistan, the other two being the Nahrui and Rind. Jell and Shadia are the chief towns of the Maghazzi, who have been located for a long time in Kacbi. They are divided into four principal clans, of which the Bhutani is the more illustrious, and furnishes the Sirdar of the whole. They boast of being able to muster 2000 fighting men, and when visited by Mr. Masson, had been engaged in endless hostility with their neighbours the Rind, an inextinguishable blood-feud existing between the two tribes. The Maghazi and the Rind are alike addicted to the abuse of ardent spirits, bhang, and opium. Their clans are the Abra, Birdi, Isobani, Jakra, Jakrani, Jatki, Kakrani, Kalandarani, Lashari, Maghzi, Mataiki, Musani, Nari, Turbandzai, and Unar.

MAGH-MELA. Hind. A sacred fair held at Allahabad. Every twelfth year an unusually great gathering takes place at the Magh-Mela of Allahabad, which is then called the Koombh Mela. See Mela.

MAGHRAB. ARAB. The west; sunset. Maghrab-ka-namaz, the eventide prayers. Maghrabi, a western person. Maghrab, the west, is applied to Western Africa and its people; the common plural is Maghrabin, generally written Mogrebyn. 'The form of this word in the singular seems to have given rise to the Latin Maurus, by elision of the letter Ghain, to Italians an unpronounceable consonant. From Maurus comes the Portuguese Moro, and the English Moor. When Vasco da Gama reached Calicut, he found there a tribe of Arab colonists, who in religion and in language were the same as the people of Northern Africa, - for this reason he called them Moors. This was explained long ago by Dr. Vincent (Periplus, lib. $3)$, and lately by Prichard. Maghrabin or Westerns then would be opposed to Sharkiyin, Easterns, the supposed origin of Saracen. The word Saracens came through the Greeks (Ptolemy uses it), who have no such sound as sh in their language, and the Italian, which, hostile to the harsh sibilants of oriental dialects, generally melts sh down into $\mathrm{s}$. So the historical word Hash-sha-shiyun, hemp-drinker, was civilised by the Italians into assassino. The Maghrabi dialect is the harshest and most guttural form of Arabic. It owes this severity to its frequent use of the Sukun, or the quiescence of one or more vowels, Klab, for instance, for Kilab, and Msik for Amsik. Thus vowels, the soft and liquid part of language, disappear, leaving in their place a barbarous sounding mass of consonants.-Burton's Mecca, i. pp. 274, 293; Natural History of Man; Niebuhr Tr. p. 101.

MAGHRABI, a small gold coin current on the Malabar coast. Maghrabin, a western Arab of Northern Africa.

MAGHWAY. A pagoda called the Emerald Couch, standing in the town of Maghway on the Irawadi, is reputed to contain a relic of the bed of the last Buddha, Gaudama.

MAGHZ. Hind. The brain, the kernel of a nut, fruit, etc: : hence Maghzak, the mango; Maghz-khubani, apricot kernels ; Maghz-pipal, or Filfil-i-daraz, Piper longum, or Chavica Roxburghii ; Char-Maghz, Juglans regia.

MAGI were the priests of the Persians, Bactrians, Charismians, Aryans, and Sakæ. Diogenes Iarertius (in Proem, p. 2, Lond. 1664) notices their reverence for fire, earth, and water, $-\mathrm{O} v_{5} x_{x}$

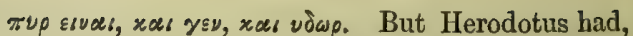
before him, mentioned sacrifices offered on mountains to Jupiter by the ancient Persians, and their worship of the sun and moon, of the earth, of fire, water, and of the winds; he adds, also, that they learned from the Assyrians and Arabians to adore Venus, Urania, or celestial, which the Persians called Mirpa. Strabo, like Herodotus, declares that the Persians neither erected statues nor altars; 'they regard,' says he, 'the heavens as Jupiter, and reverence the sun, which they call Mithra. The moon also, and Venus, fire, the wind, and water.' Yet in a previous passage of the same book, if the text be correct, he had affirmed that Mars alone was worshipped by the Persians. What they called Jupiter, says Herodotus, was the whole compass or circuit of heaven, which Strabo, as above quoted, confirms. From both authors it appears that the Persians did not attempt to embody, under the human form, an object of such materiality as the celestial expanse. But Clemens Alexandrianus gives us reason to believe that some of their idols resembled human beings, and the statue of Venus Tanais, Tns

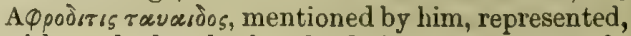
without doubt, the female divinity more correctly named Anaitis, that Venus, we may suppose, whom the Persians learned to worship from neighbouring nations, as Herodotus had already declared.

The Magism of the Chaldees, as it prevailed about B.C. 2234, when a Median dynasty sat on the throne of Babylon, was a modification of the doctrines of Zoroaster.

Their cult seems to have been essentially a worship of the elements, and of these fire was deemed the most worthy of representing the deity.

The Magian religion was of a highly sacerdotal type. No worshipper could perform any religious act except by the intervention of a priest or Magus, who prepared the victim and slew it, chanted the mystic strain which gave the sacrifice all its force, poured on the ground the propitiatory libation of oil, milk, and honey, and beld the bundle of thin tamarisk twigs, the Zendu Barsom (Baresma), the employment of which was essential to every sacrificial ceremony. In the time of Darius, the Magi were not the priests of Ormazd, and Darius treated them most unmercifully. After the time of Ardesbir Daraz-dast (Artaxerxes Longomanus), the Magi seem to have converted the rulers to their creed. Professors Westergaard and George Rawlinson regard Magism as in its origin completely distinct from Zoroastrianism.-Geo. Raul. ii. pp. 347-354.

MAGIC. The Tamil people enumerate 64 arts and sciences, 20 being counected with magic, spells, charms, some of a malignant character. One of these, an invocation to Kali, for the destruction of an enemy, runs :-

\section{'Om!}

Adoration to thee, Supreme Power, Kali ratri, black night,

To whom the bloody flesh of man is dear,

Whose very form is fate and death.

Seize, seize on the life of such $a$ one.

Drink blood ! drink blood !

Devour flesh! devour flesh !

Make lifeless! make lifeless !

$$
\text { Hum Phut !' }
$$

MAGINDANAO, an island of the Eastern Archipelago. The people use the Tagala alpha- 
bet of the Tagala nation, of the great island of Luçon.

MAGIZADI SERVAI, a Hindu festival celebrated at Tiruvattiyur village, six miles north of Madras. According to the Sthalapuranum, Sundara Swami, a disciple of Siva, fell in love with one of the two maid-servants of the goddess Parvati, and Siva ordained him to marry her at some future period in the nether world. The girl was accordingly re-born in the house of Nayirkila, and brought up under the name of Sangilnachiar. During one of her daily visits to the Tiruvattiyur temple, she met with Sundara Swami, who was spending bis days in the service of the deity, and who, being fascinated by her charms, begged Siva's permission to marry her in the temple. Sangilnachiar prevailed upon Suntharur to celebrate the marriage under a Magizada tree, in the presence of Siva, whence the festival takes its name. At the conclusion of the wedding, the leaves of the tree are torn off, and showered down. On this occasion, the two celebrated birds of Tirukkazikundrum, which were once rishis, said to be thousands of years old, are said to visit the temple. Thousands of people attend this festival from distant villages.

MAGNESIA is the Fi-kan-shih, Lu-kan-shih of the Chinese. A soft white powder, used in medicine. It is prepared by burning the carbonate of magnesia, but latterly also from the bittern of sea water after the crystallization of common salt.

Magnesia carbonas.

Magnesia alba.

Magnesia sub-carbonas.

Carbonate of magnesia.

Kohlensaures bittererde,

Kohlensaures talkerde, ,"

This forms a constituent of the dolomitic, or magnesian, limestone which is found largely in Southern India, near Trichinopoly. Very fine silicious and magnesian earths, such as rottenstone, alkaline loam, and Armenian bole, occur near Sundur, Bangalore, and Cuddapah.

Magnesia sulphas.

Sulphate of magnesia.

Epsom salts.

Sulphate de magnesie, $\mathrm{FR}$.

Schwefelsaure bittererde,

A medicinal salt, valuable as a cathartic. It is usually made from the bittern of sea water, but could be prepared from the magnesite of Southern India.

MAGNESITE, carbonate of magnesia, is found in Styria, Moravia, Spain, Silesia, at Hoboken, in New Jersey, N. America. A few miles N.W. of Moosery is a small mountain composed of beautifully pure magnesite and brucite, and some other magnesian compounds. Near it, in the direction of Cannanore, is an extensive bed of pure chlorite potstone, which is wrought to a considerable extent, and the vessels made of it find a ready sale in Trichinopoly, Madura, and other large towns. Magnesite formations occur at Yedichicolum and other places in the valley of the Cauvery. It is a nearly pure carbonate of magnesia. About three miles from Salem, on the Woomaloor road, there is a remarkable deposit of magnesite, containing 48 per cent. of magnesia, 52 per cent. of carbonic acid, and a trace of silica. It occurs in seams in the gneiss rock. Local traditions make it the bones of Jataya, king of birds, who was killed by Ravana. A water cement was proposed to be formed from it by Dr. $M \cdot$ Leod, and again by M. Sorel, by mixing powdered calcined magnesia, in the form of thick paste, with a solution of chloride of magnesia.

MAGNET.

Zeilsteen, . . DUT. / Calamita, . . . IT. Aimant, : . FR. Ahan-subah, : PkRs. Chamak pat'har, : HIND. Iman, .' SP., PorT.

Of native loadstone, magnetic iron ore, there is an abundance in the Peninsula of India, and it is largely used in the manufacture of iron or wootz steel. The Chinese names for magnetic iron ore are Yen-sang, also Ts-ze-shih. More than a thousand years before the Christian era, a people living in the extremest eastern portions of Asia had magnetic carriages, on which the moveable arm of the figure of a man continually pointed to the south, as a guide by which to find the way across the boundless grass plains of Tartary ; and at least 700 years before the use of the mariner's compass in European seas, Chinese vessels navigated the Indian Ocean under the direction of magnetic needles pointing to the south.-Humboldt's Cosmos, i.; Curiosities of Science, p. 194.

MAGNOLIACEA, the Magnoliad tribe of plants, occur in America, Hindustan, China, Japan, N. Holland, and N. Zealand,-fine trees or shrubs, with large, beautiful, often strongly odoriferous flowers. The Indian species are variously ranged, under the genera Michelia, Manglietia, Magnolia, Euptelea, Illicium, Schizandra, Kadsura, and Talauma.

MAGNOLIA CAMPBELLII, Hooker, the purple-flowered magnolia, hardly occurs in Sikkim below 8000 feet, and forms an immense, but very ugly, black-barked, sparingly-branched tree, leafless in winter, and also during the flowering season, when it puts forth from the ends of its branches great rose-purple, cup-shaped flowers, whose fleshy petals strew the ground. On its branches, and on those of oaks and laurels, Rhododendron Dalhousiæ grows epiphytically, a slender shrub, bearing from three to six. white lemonscented bells, $4 \frac{1}{2}$ inches long and as many broad, at the end of each branch. M. globosa, Hk., M. Griffithii, Hk., and M. sphenocarpa, Roxb., occur in India.

MAGNOLIA CONSPICUA. Smith.

Sin-i, Yu-lan,. . CHIN. | Ying-chun-hwa, . CHIN.

A splendid flowering tree of Shen-si and Chekiang in China. Its large white flowers appear before the leaves, welcoming the spring, as Yingchun-hwa implies. Its cones are used medicinally. It has been cultivated by the Chinese since A.D. 627. It attains a height of 30 or 40 feet. It is a very showy tree, having white flowers sometimes suffused with purple, which give out a most delicious perfume.

MAGNOLIA DISCOLOR. D.C., Vent.

M. purpurea, Curt. | M. obovata, Roxb.

Grows in Japan and China. A shrub with large, dark purple, rose-coloured iuodorus flowers. -Roxb.; Voigt.

MAGNOLIA EXCELSA. Wall. The whiteflowered magnolia of Nepal and Sikkim, near Darjiling, forms a predominant tree at 7000 to 8000 feet. The wood, called Champ, is highly prized in the neighbourhood of Patna for joinery work, it being at first of a fine greenish colour, but changing to a fine yellow, and the grain very close-Royle; Hog., p. 25; Hooker, Him. Jour.

MAGNOLIA HYPOLEUCA. Siebold. Hau- 
p'oh, Chrn., is a stately tree of Cochin-China and Japan, and introduced into S. China; trunk one foot in diameter, with very large whorled leaves. The rough thick bark is rolled into large tight cylinders, very thick, and from 7 to 9 inches long; taste aromatic and bitter, but mostly inert; wood flexile, used for utensils.-Smith, M. M. C. ; Von Mueller.

MAGNOLIA RUBRA. Smith. Chih-p'oh, Chis. Grows in Sze-chuen and Ngau-hwui, in China. The bark is rolled into short, thick quills of a reddish-brown colour; taste bitter.-Smith, M.M.C.

MAGOG and Gog, applied in the Scriptures to the nations of Northern Asia, known to Muhammadans as Yajuj and Majuj. See Machin.

MAGOUNG, an old kingdom of the IndoChinese nations, also called Pong. See Maha Radza Weng.

MAGURA, a fish in the Colombo lake, said to grunt under water when disturbed. Bishop Pallegoix, in his Account of Siam, speaks of a fish resenbling a sole, but of brilliant colours with black spots, called by the natives dog's tongue, which attaches itself to boats, and gives out a very sonorous and even harmonious sound.Jenn. ii. p. 470.

MAGUS, a native of Persia, of considerable celebrity as a physician. His name was Ali Abbas. He lived in the 10th century. He was author of a book styled the Royal Work.Catafago.

MAH. Pers. A month. Mahwar, montbly.

MAHA. SANsk. Great, applied literally and figuratively to gods, individuals, books, countries, and towns. Maha is thus largely used as an honorific affix to men, but it is also prefixed to the Hindu gods and goddesses, as Mahabali of Mahabalipura, the seven pagodas near Sadras; Mahabharata, a great epic poem; Mahabhashya, Patanjali's commentary on the grammar of Panini; Mahadeva, Mahadevi, the great god and great goddess; also Maheswara and Maheswari, titles of Siva and his consort; Maha Kala, great time, the destroying power; Maha Kavya, great poems, a title of six poems in Sanskrit, famous amongst the Hindus, viz. Raghavansa, Kumara sambhava, Megha duta, Kiratarjuniya, Sisupala badha, and the Naishadhacharitra; Maha Purana, the two great Vaishnava Puranas, the Vishnu and Bhagavata; Maha-Purusha, the great male, a name of the god Vishnu; Mahanaga, the serpent Sesha; Maharashtra, the Mahratta country; Maha-Sena, great captain, name of Kartikeya, god of war; Mahishasura, a great Asura.

M. R. S. are letters prefixed to all addresses on letters to Hindus. They are the abbreviation of Maharaja Sri. Maharaja is the highest title of a Hindu prince or ruling sovereign, under that of Chakravarta, which means an emperor.

Maha-Muni means a great saint; Maha Prabhahu, great lord; Maha-Lakshmi, Maha-Vishnu, and Maha-Kali; Maha-Bal-Eswar is the great god Bal.

MAHABALESWAR HILL, in lat. $17^{\circ} 58^{\prime}$ $5^{\prime \prime} \mathrm{N}$., and long. $73^{\circ} 42^{\prime} 35^{\prime \prime} \mathrm{E}$., is an elevated plateau of the Sahyadri range of hills. It takes its name from a Brahman village at the north end of the table-land, near the source of the river Krishna, the name meaning the god of great power. The western side rises abruptly from the
Konkan. It varies from 8 to 15 miles in breadth, is 17 miles from N.E. to S.W., and its greatest height is 4700 feet above the sea.

Mean elevation of plateau, $.4500 \mathrm{ft} . S y k$.

A rock E. of Beckwith's monument, 4712 , Bomb. Cal. Source of the Krishna, . . 4110 ", Schl. Ad. Yenna lake,

Southern border of plateau,

Eastern border of plateau,

$.4070 ", "$,

. 3510 ," ,, ,"

The mean temperature is $66^{\circ} \cdot 2$; maximum, $71^{\circ} \cdot 2$; minimum, $61^{\circ} \cdot 3$; and daily variation, $9^{\circ} .8$. The rainfall averages $229 \cdot 19$ inches, and there are 127 rainy days. It is a sanatorium, and the founder's name still survives in the village of Malcolmpet. The monsoon strikes this outlying range of the ghats with its full force, and deposits on their slopes the main portion of its aqueous burden. The average discharge is about 240 inches, and the residents leave the station en masse on the first burst of the summer rains, and retire to Poona.-Bombay Almanac; Bombay Times; Schlagentweit; Imp. Gaz. vi.

MAHABALIPURAM, called by the people Mavelpuram or Mavalivaram, and by the British the Seven Pagodas. In the Sthala Purana, written in Sanskrit, the name is simply Mallapuri. But in the inscription near the Varashvami temple it is enlarged into Mahamallapuram, by prefixing the Sanskrit adjective Maha. It is a village on the coast, 35 miles south of Madras, in lat. $12^{\circ} 36^{\prime}$ $55^{\prime \prime} \mathrm{N}$., and long. $80^{\circ} 13^{\prime} 55^{\prime \prime} \mathrm{E}$. Legends describe it as the city of a great king, which was submerged by the sea, and six temples are said to have been thus overwhelmed. According to the legend, Mahabali was a raja living in the tretayuga, who by penance and austerity had obtained possession of the whole universe, including heaven, earth, and hell, so that he was a universal monarch. $\mathrm{He}$ became so elated by his greatness, that he omitted to perform the customary religious ceremonies to the gods. Vishnu, in order to check the influence of so bad an example, became incarnate in the person of a wretched-looking Brahman dwarf, and in this form appearing before Mahabali, asked as a boon as much of his wide possessions as he could pace in three steps. This the king readily granted, upon which the dwarf grew larger, and continued to expand till he filled the whole universe, thus depriving the insolent monarch of all his possessions except hell, which he was allowed to keep. This legend probably represents the victory of Hindus of the Vaishnava sect over some powerful non-Aryan king.

It is a moot point whether to the Malla family of the Chalukyas, or to Bali of legendary greatness, belongs the antiquities of the place. These may be divided into three groups, - (1) the 5 raths to the south of the village, belonging probably to the latest Buddhist period; (2) the cave temples, monolithic figures, carvings, and sculptures, west of the village, probably of the 6 th or 7 th century A.D. (these contain some marvellous relievos, ranking with those of Ellora and Elephanta); (3) the more modern temples of Vishnu and Siva, the latter being washed by the sea. To these two and five others, buried (according to tradition) by the sea, the place owes its English name.

The shore temple is so close to the sea that the surf in the calmest weather dashes against the doorway. This and the usual stone pillar in front of such temples lying in the sea, as well 
as fragments of images, large quantities of stone and broken bricks lying about, some partially buried in the sea, plainly show that at one time buildings existed to the eastward, but have been overwhelmed by the sea. Besides tradition, it is stated in the catalogue of the Mackenzie MSS. - that the whole coast from Mailapur, or St. Thomé, down to Mahamallapuram was overflowed by the sea, and that many towns were destroyed. The monolith temples consist of chambers cut out of the solid rock, and with figures and inscriptions in an ancient character; only one of them is now on the land. A temple on the shore has a statue of Vishnu entwined by the cobra; also a lingam and other Saiva remains are observable near. Rocks partly covered at high water are carved with the figures of tigers. Inland 400 yards are sculptured rocks running parallel with the sea. A small but elegant fane contains a statue of Ganesh. A temple of Vishnu has the giant figure assumed by that deity after throwing off the dwarf form; in another compartment is a figure of Durga surrounded by adorers, and one of Vishnu as Varaha or the Boar Avatar, with his sakti Lakshmi. Near this is a small Saiva temple with bas-reliefs of Siva and his son Subramanya. Underneath a small monolithic pagoda is a colossal statue of Vishnu reclining amid the coils of an enormous five-hooded cobra. Opposite this group, Durga mounted on a lion is seen rescuing a figure from Yem-raja, a buffalo-headed monster. There is also a rock 20 feet high and 70 to 80 feet long, facing the sea, literally covered with the sculptured figures in bassorelievo of gods, men, and animals, many of them of great artistic beauty.-Chalmers, 1772-76; Goldingham, 1806 ; Bishop Heber, 1826.

MAHABAN, meaning Great Forest, is a hill on the Panjab frontier, 40 miles up from Attock, at the east end of a spur of the Ilam range. It is situated on the right bank of the Indus, and rises to a height of 7400 feet above the sea, and 50 miles in circuit. The sonthern side of the hill is thickly wooded, and is inhabited by the Jadun tribe, the north side being peopled by the Amazai. The hill would be suitable for a sanatorium, but as a strategical point it is said to be worse than useless. The country of the Jadun is below that of the Husanzai, and on the right bank of the Indus, opposite the British town of Torbeila, and thence stretching westward. The most notable place in this tract is Mount Mahaban. Near its base and on the bank of the Indus was the Sitana colony. The Syuds of Sitana are the remnant of the followers of Syud Ahmad, who gathered a handful of Muhammadan devotees from various parts of India, and raised a formidable rebellion in Peshawur. After winning and losing Peshawur and Yusufzai, the Syud was eventually slain at the mouth of the Kaghan glen by Sher Singh, son of Ranjit Singh. Most of his adberents, chiefly foreigners to the Panjab, dispersed, and the remainder settled at Sitana. One of the rulers of Swat was elected to his position. They intrigued with the Wahabees in various parts of India, and more than once correspondence relating to them was intercepted. The Bezoti and other Afghan tribes gatbered and fought against the British from 1860 to 1868 . Theories as to the locality of Aornos have been held by General Court, the missionary Loewen- thal, General James Abbott, and General Cunningham. The Mahaban most nearly corresponds in height and in its position on the Indus with the ancient description. The height was from 11 to 16 stadia, or from 7000 to 10,000 feet; Strabo represents its base as washed by the Indus near the spot whence that river issues from the Himalayas. The Mahaban, too, supplies best the very object-shelter with wood and water-sought by a comparatively large population, such as Ranigat would have failed to accommodate, fleeing from a resistless invader. The Chinese pilgrim Hiwen Thsang, who visited it, describes the Mahaban as a great mountain which derived its name from the Mahavana monastery in which Buddha, under the name of Sarvrada raja, had dwelt in a former life. Thence the pilgrim descended to the Masura monastery, now the large village of Sura in the Chamba valley, 10 miles to the north-west of the Muchaie peak.MacGregor's N.W. Fr. p. 296.

MAHABAN, or Gokula, in the N.W. Provinces, in lat. $27^{\circ} 25^{\prime} 35^{\prime \prime} \mathrm{N}$., and long. $77^{\circ} 47^{\prime} 30^{\prime \prime} \mathrm{E}$, situated on the left bank of the Jumna (Jamuna), is six miles S.E. of Muttra, on the Etawa road. It is the reputed birthplace of Krishna, who is supposed to have been reared at Gokul, one mile to the west. Mahmud of Ghazni conquered the raja in 1017, and the town was sacked, after the native prince had slain his wife and children and then committed suicide. A bill, extending over 30 acres, occupies a large part of the town. On its summit stands a ruined fort of great antiquity, containing a shrine of Syam Lala. The Gosain are descendants of Tallabhacharya, through his only son Bitthal-nath. It is an insignificant village. There is a high hill in the town. The Assi Khamba, or 80 pillars, are the covered court of Nanda's palace.

MAHABHARATA, an epic poem, or a collection of ancient lays, of different dates. The groundwork of the poem, the Kaurava and Pandava war, contains 24,000 verses. The leading story commences with Atri, a flash of light from whose eye produced the moon (which in Sanskrit is male), and that being was the ancestor of the Lunar dynasty of kings. One of these kings was Pururavas, whose love for the heavenly nymph Urvasi is detailed in Kalidasa's drama Vikramorvasi. His descendants in a direct line were Ayas, Nahusha, and Yagati, the last becoming the father of Puru and Yadu. The line of Yadu acquired celebrity through Vasudeva and his sister Kunti or Pritha, and also through his sons Krishna and Bala Rama, who have become deified as incarnations of the god Vishnu. Puru's son was Dushyanta, who married Sakuntala, and their son was Bharata. From Bharata descended successively Hastiu, Kuru, and Santanu. Santanu married Satyavati, already the mother of Vyasa, but their children died without offspring, and Satyavati then asked her son Vyasa to marry her widowed daughters-in-law: by one of them he had Dhritarashtra, born blind, and by another, Pandu, born a leper or an albino. Dhritarashtra married Gandhari, and amongst their many children were Duryōdhana, also called Suyodhana, and Duhsasana, - these were the Kaurava. Pandu married two wives, viz. Pritha, sister of Vasudeva and aunt of Krishna, and Madri. By Pritha he had three sons, Yudishthra, Bhima, and 
Arjuna; by Madri, twins, Vakula and Sahadeva ; and these were the Pandava. Both the Kaurava and the Pandava were related to Krishna, but the Pandava more nearly so, owing to their mother Pritha being aunt of Krishna. Vyasa, the compiler of the Mahabharata, is the reputed grandfather of both the Kaurava and the Pandava. It is the series of events which happened in the time of the Kaurava and Pandava that forms the groundwork of the great epos of the Mahabharata, and they may thus be briefly related. Santanu had resided in Hastinapur, the ancient Dehli, and after his demise Dhritarashtra was by seniority entitled to succeed. But, as he was blind, he resigned the throne in favour of his brother Pandu. The latter became a powerful monarch, but after a while, having become tired of his regal duties, he abdicated and retired to the forests of the Himalaya, to indulge in his favourite sport, the chase. His brother Dhritarashtra then resumed the reins of government, but, being blind, his uncle Bhishma governed for him, and conducted the education of his sons. After a while Pandu died, and his widow Pritha and her five sons returned to Dhritarashtra's court to be educated along with his own children, their cousins. But the Pandava brothers were superior lads, and their cousin Duryōdhana, out of jealousy, tried to destroy them, first by poison, then at trials of arms. Subsequently, Drona, a Brahman, who had taught the Kaurava, brought about a reconciliation, and the relatives unitedly attacked Drupada, king of Panchala (Kanouj), who, principally by the Pandava's aid, was defeated. On this the blind king Dhritarashtra resolved to pass over his son Duryōdhana, and named his nephew Yudishthra, the eldest of the Pandava, to the throne; and their cousin Duryôdhana made another effort to destroy them, by burning them alive. This also they escaped, but they considered it advisable to conceal themselves, which they did by assuming the form of mendicant Brahmans, and retiring to the forests. After some time, they were informed by Vyasa that Drupada, king of the Panchala, would make his daughter Draupadi queen of a tournament, to be won by the most successful competitor, and she was won by Arjuna. On this occurred a civil commotion, in which Drupada nearly lost his life; but Draupadi went with the Pandava brothers, and became their joint polyandric wife.

After the tournament the Kaurava and Pandava made peace, the former to reign at Hastinapur, the ancient Dehli, and the Pandava at Khandavaprastha, the modern Dehli. Yudishthra, the eldest of the Pandava, reigned so successfully, that be resolved to declare himself emperor by the performance of the Rajasaya sacrifice. This was accomplished with much splendour; but Yudishthra was afterwards involved by his cousin Duryōdhana in a game at dice, and Yudishthra lost everything,-kingdom, wealth, and his joint wife Draupadi. Duryōdhana offered to restore their kingdom if they would exile themselves for 13 years. In these 13 years they all took service with king Virata of Matsya, and ultimately defended him against an attack of Duryōdhana. On this account Virata gave his daughter Uttara in marriage to Abhimanya, son of Arjuna by Subahdra. In claiming restoration to their kingdom at the close of the 13 years, the Pandava first tried negotiations, offering to be content with five small towns, but they ultimately resolved to fight it out on the plain of Kuru-kshetra, the rules of battle being duly laid down. In the battle that ensued, and which lasted 18 days, the Kaurava lost successively all their chiefs, Bhishma on the tenth day, Drona on the fifth day, Karna on the second day, and their last commander, Salya, was killed ou the first day of his command. In these battles much foul play was practised on both sides. After the close of the battle, Yudishthra was elected heir-apparent of the old blind king Dhritarashtra. But the latter subsequently abdicated and led the life of a recluse, along with his wife Gandhari, Pritha, the mother of the Pandava, and their uncle Vidura. Vidura soon died, and all the rest of the royal exiles perished in a forest conflagration. The grief of the Pandava for this was great, and they too, after hearing also of Krishua's death and of the destruction of Dwaraka, resolved to abdicate; they all set out for Mount Meru, but all save Yudishthra perished before reaching it.

The legends connected with it relate that Yudishthra ultimately entered Indra's heaven, and there found all the Kaurava relatives and his brothers. It is also related in the Mahabharata that after the battle of Kuru-kshetra, when the widows of the slain were talking over their losses, Vyasa bid them repair to the banks of the Ganges. Vyasa also was present, and called out the names of the slain. All appeared in great glory and splendour, and more beautiful than when they were alive; widows went to their husbands, daughters to their fathers, mothers to their sons, sisters to their brothers, and all the fifteen years of sorrow which had passed since that war were forgotten in the ecstasy of seeing each other again. The night passed away in the fulness of joy, and when the morning dawned, all the dead mounted their horses and chariots and disappeared. But Vyasa said that the widows who wanted to rejoin their dead husbands might do so, and all the widows went and bathed in the Ganges, and came out of the water again, kissed, one by one, the feet of Dhritarashtra and Gandhari, and then went and drowned themselves in the river; and, through the prayers of Vyasa, they all went to the place they wished, and obtained their several desires.

The complete text of the Mababharata has been twice printed in India. It has been partially translated into French by M. Fauche. It is the longest poem in the world, consisting of 220,000 lines, divided into 18 parva or books, viz. the Adiparva, Introductory Book, the Sabha, Vana, Virata, Udyoga, Bhishma, Drona, Karna, Salya, Sanptika, Stri, Sauti, Anusasana, Aswa-medhika, Asrama, Mansala, Maha-prasthanika, and the Swarga-rohana. Within the poem is an acknowledgment that it was put into its present form by Sauti, who received it through another person from Vyasa, who was contemporary of the events which it relates. 24,000 verses out of 100,000 are alleged in the same place to be the work of the original author. But in some parts it mentions the Yavanas, showing that such portions at least were subsequent to the 4 th century B.C.

Professor Williams believes that the earliest or pre-Brahmanical composition of the Rama- 
yana and Mahabharata was not later than the 5 th century B.C., but that the first orderly completion in their Brahmanized form may have taken place in the case of the Ramayana about the beginning of the $3 \mathrm{~d}$ century B.C., and in the case of the Mababharata still later.

Lassen was of opinion that three different arrangements of the Mahabharata are distinctly traceable.

Weber shows that the Mahabharata was known to Dion Chrysostom in the $2 \mathrm{~d}$ half of the 1st century A.D. ; and as Megasthenes does not mention this epic, and he was in India about B.C. 315, Weber supposes its date to be between the two.

It is in the Sanskrit language. The Puranic legends tend to show that the language of the Mahabharata is not in its older form, but, as it has come down to us, has been the subject of various recensions, the latest of which can scarcely be fixed later than the $3 \mathrm{~d}$ century B.C. (between B.C. 500 and 250). Of the two great Epopæia, the Mahabharata and Ramayana, it is doubtful whether either of them was composed as a whole, and the Mahabharata was undoubtedly a compilation of popular lays on national events. The main story in each belongs to a post-Vedic age, when the Aryans had pressed far into the Peninsula. That of the Mahabharata describes the internecine war of two closely-allied tribes, the Kuru and Pandu, for the supremacy of the land of the Doab, with Hastinapura, the modern Dehli, as its capital. The war fought by the Kaurava and Pandava kinsmen to gain possession of the lands near Hastinapura lasted 18 consecutive days, and terminated in the complete destruction of the Kaurava. The war is described as conducted by a series of challenges and personal combats, which would seem to bave been related in ballads, and then subsequently gathered together and embellished by a Vaishnava Hindu. The Pandava family were supported by the advice of their Yadava kinsman Krishna, who was brought up as a worshipper of Vishnu, and seems to have actively opposed the worship of Siva and of Indra; and the Vaishnava compilers of the Mahabharata have interwoven the story of the battle with innumerable legends regarding Krishna, whom they deify as an incarnation of Vishnu. In addition to falsifications, exaggerations, and embellishments, geographical, religious, moral, inythical, legendary, scientific, and physiological dissertations are interpolated, interwoven, and forcibly intermixed. It bas never been entirely translated, but extracts from it were discovered by Mr. Wheeler in the library of the Bengal Asiatic Society, and these formed the foundation of his History of India, which is an interwoven commentary on the war. Portions of the interwoven materials seem to relate to the life of Christ, portions are taken from the Koran, and it is said Buddhist elements also are found in it. Hastinapura is probably the place on the Ganges, north-east of Dehli, which still bears the ancient name. The family itself was of the Lunar race, but the different parties were supported by numerous allies, and from some very remote quarters. Krishna, who was an ally of the Pandu section, though born on the Jumna, had founded a principality in Gujerat. Among the allies on each side are chiefs from the Indus, and from Kalinga in the Dekhan; some, the translators are satisfied, belonged even to nations beyond the
Indus, and orientalists consider the Yavana to apply in all early works to the Greeks. The Pandava were victorious, but paid so dear for their success, that the survivors, broken-hearted with the loss of their friends and the destruction of their armies, abandoned the world, and perished among the snows of the Himalaya; and Krishna, their great ally, is known to have been killed in the midst of civil wars in his own country. Some Hindu legends relate that his sons were obliged to retire beyond the Indus; and as those Rajputs who came from that quarter in modern times to Sind and Cutch are of his tribe of Yadu, the narrative seems more deserving of credit than at first sight might appear. The more authentic account, however (that of the Mahabharata itself), describes them as finally returning to the neighbourhood of the Jumna. The story of the Mahabharata is much more probable than that of the Ramayana. The date of the war was probably in the 14th century B.C.

This poem is interesting to astronomy, because it records the first eclipse of the sun mentioned in any of the Sastra. Modern European commentators suppose that the date of the eclipse which it records is the 25th October in the year 945 before Christ, and therefore anterior to that transmitted to us from the Chaldrans, which was observed on the 19th March 720 before Christ. Professor Lassen and Mr. Wheeler both consider that the Pandava history in the Mahabharata conveys a history of India in successive periods.-Dowson: Elphinstone, pp. 154, 173, 390; Wheeler, Hist. of Iridia; Muller, p. 47 ; Darwinism in Morals, p. 296; Westminster Review, April 1868.

MAHABHASHYA, a commentary by Patanjali on the grammar of Panini.-Dowson.

MAHA-BRAHMANA. SANSK. A great Brahman, but applied contemptuously in Bengal to a low class of Brahmans, who officiate at funeral rites, and are the first feasted after the period of mourning; also a Brabman who performs religious ceremonies for Sudras and mixed castes.

MAHADEO or Mahadeva hills, in the Hoshangabad district, the finest in the whole Satpura range, at one point rising to a height of 4500 feet above the sea. It is in this cluster that the very remarkable group of rocks, known by geologists under the name of the Mahadeo sandstones, attains its greatest development. Here the sandstone mass presents a thickness of 2000 feet, and the finest of all those striking vertical escarpments which characterize this formation is seen on the south face of the Mahadeo block, where it rises from the flat ground of the Denwa valley. See Geology.

MAHADEO KOLI reside in the valleys of the Syhadri range, extending from Musa S.W. to Poona, northwards to Trimbuk, the source of the Godavery river, between lat. $18^{\circ} 15^{\prime}$ and $20^{\circ} \mathrm{N}$., and long. $73^{\circ} 30^{\prime}$ and $74^{\circ} \mathrm{E}$. These small valleys are known as Mawils, Khorahs, Nahirs, and Dangs, i.e. valleys, glens, straths, and wilds. These are classed into 24 Koli or clans, each of which has many subdivisions. Their numbers in 1837 were estimated at about 50,000 souls. The members of the same Kol do not intermarry. With the exception of the cow and village hog, Koli eat all other animals. The women are generally slender and well formed, with a pleasing expression of features, and some are very pretty. They are chaste, and have large families. Koli are fond of 
charms and amulets.-Captain Mackintosh in Madras Lit. Soc. Journ.

MAHADEVA, Great God, a title given to Siva by his followers of the Saiva sect, who acknowledge Siva as their great or supreme god. Similarly they style his consort Parvati or Bhawani, Mahadevi, or great goddess. Siva's emblem is the lingam, the priapus or phallus, rising from the yoni, usually in stone, with the bull Nandi kneeling in front. Mahadeva has Parvati, the mountain nymph, as his sakti or female energy; and in the figures of Mahadeva and Parvati, commonly called Gouri Sunkur, Parvati is seated on Mahadeva's knee, with the bull Nandi at his feet, and the Sinha or lion at her feet. The Lingaet are a Vira-Saiva sect, whose sole object of worship is the lingam. Benares is a great site of the Saiva worship, and there is a celebrated temple of Mahadeva at Karikal, four miles south of Hardwar.

MAHADEVI. Devi, the goddess, is a title given to Laksbmi, to Saraswati, and to Parvati, but the last is most commonly called Mahadevi and Devi. The mythological origin of these three goddesses is thus described in the Varaha Purana, translated in Colonel Vans Kennedy's Researches on the Mythology of the Hindus, etc. In consequence of the distressed situation of the gods from the oppression of the Asura, Brahma hastened to Kailasa and Siva. Siva in thought summoned Vishnu, who instantly stood between them, and from their three refulgent glances sprang into being a virgin of celestial loveliness, who bashfully bowed before them. They said, 'Who art thou, lovely one? and why art thou thus distinguished by the three several colours of black, white, and red?' She replied, 'From your glances was I produced,' Brahma then bestowed on her this blessing: "Thou shalt be named the goddess of the three times, Morning, Noon, and Evening, the Preserver of the Universe; and under various other appellations shalt thou be worshipped, as thou shalt be the cause of accomplishing the desires of thy votaries. But, 0 goddess ! divide thyself into three forms, according to the colours by which thou art distinguished.' On hearing these words she divided herself into three forms of a white, a red, and a black colour. The white was Saraswati, the sakti of Brahma; the red was Lakshmi, the beloved of Vishnu; and the black, Parvati. This account differs widely from other accounts of the origin of these goddesses, but consistency is not to be found in Hindu mythology.-Cole. Myth. Hind. p. 95; Moor's Hindu Pantheon, p. 65.

MAHAGANDI and Sulagandi are Buddhist sects of Burma. The Paramat is another sect. The Sulagandi are puritans; the Mahagandi are less strict.

MAHAIL and the Dhuttola tree of Nepal are varieties of plums; the former bears abundance of beautiful flowers.

MAHA-INDRA, the Vedic god of the elements, the personification of the sky, the god of thunder; the king of immortals and the lord of the firmament, the chief of the Devata or Sura.

MÁHAJAN, literally a great man, but applied to a banker, a money-lender, also the hereditary officer or the headman of a village. In the villages of $\mathrm{N}$. India, the mahajan are generally Brahmans. Their advances or loans are entered in their books as-(1) Takawi for the purchase of cattle or implements; (2) Khawi for food, given in cash or grain; (3) Besari for seed, given in money or kind; (4) Biahi, loans for marriages; and (5) Karza, loans of money at 24 per cent. Mahajani, a written character used in their mercantile bookkeeping. $-W$.

MAḦAJLU. URIYA. Lygodium scandens, used as a twine for tying beams.

MAHA-KALA. SANSK. In Hindu mythology, eternity. This deity is a representation of Siva, and in the Elephanta caves he is represented with eight arms. In one he holds a human figure. At Ujjain, worshipped in the form of a lingam. The name is from Maha, great, Kala, time. Mahakala, in Hindu astronomy, the conjunction or opposition of the sun and moon. Maha-kala Sanbita is a book translated by Captain John Warren. See Cala.

MAHA KAVYA. SANSK. A classical Sanskrit work. Of these six are recognised. One by Sri Harsha is the Naishadha Charitra. See Maha.

MAHAL. Arab. A house, a section of a town. Mahallat, fem. pl., women's apartments; figuratively women. Mahal, a ward of an Indian town, which is regulated, with a view to its police, in a manner very similar to what it is in Europe. Mahal is also applied to a district or section of country, as the Bara-mahal of the Salem district of the Madras Presidency. It is also equivalent to a fort or killa, and to ghar or country. Also an estate made up of a parcel or parcels of land. In Oudh the mahals are small estates, which are held by independent zamindars, and are called Mufrid mahal or independent mabal, in contradistinction to the large properties held under sunnud, called taluka.-Malcolm's Persia, ii. p. 177; Malcolm's Central India, i. p. 216.

MAHA-MAGHA (commonly Maman-gam), i.e. the occurrence of the full moon in or about the asterism Magha with other astronomical incidents, which recur once in 12 years. Peculiar rites in honour of Siva are then performed. The time is auspicious for bathing. At Combaconum is a large tank, the water of which is supposed to rise once in 12 years, on the above occasion, and then people in great numbers assemble from distant places to bathe and obtain remission of sins.

MÄHA-MARRI. HIND. Lit. great death, from Maha, great, and Mri, to kill; a plague which appeared in the Kamaon and Garhwal Hills, and on one occasion extended to the Rohilkhand plains. It was believed by the people to be contagious. It broke out about the year 1837.

MAHA-MERU, a fabulous mountain of extraordinary height, in the extreme north of India, supposed to be upheld by elephants. See Meru.

MAHA MOHA. SANSK. In Hinduism, extreme illusion, causing addiction to the enjoyments of sense; one of the five kinds of obstruction to the soul's liberation, or, as they are called in the Patanjala philosophy, one of the five afflictions,the five-fold ignorance of the Vishnu Purana.Garrett.

MAHAMRA, a town in Khuzistan in Persia, situated on the N. bank of the Hafan Canal, 26 miles below Basra. The climate from June to October is said to be unhealthy to Europeans. The Shat-ul-Arab is here about a half mile wide, and of sufficient depth to float the largest ships alongside the perpendicular clay bank. A great channel connects the Karūn with the Shat-ul- 
Arab. In November 1856 the Government of India declared war against Persia ; in December Kharag was occupied; on the 8th February 1857 , Sir James Outram defeated the Persian forces at Khushab; on the 26th March Mabamra was captured, and a treaty of peace was entered into at Paris.-MacGregor, iv. p. 300.

MAHA-MUNI, a pagoda in the Akyab district of the Arakan division of British Burma, situated in lat. $20^{\circ} 52^{\prime} 40^{\prime \prime} \mathrm{N}$., and long. $93^{\circ} 5^{\prime} 30^{\prime \prime} \mathrm{E}$., to the north-east of Mro-houng, or Old Arakan. This edifice is visited by numerous pilgrims. It enshrined formerly an image of Gautama Buddha.

MAHANADI rises in lat. $20^{\circ} 10^{\prime} \mathrm{N}$., and long. $82^{\circ} \mathrm{E}$., in the Raipur district, and, after a course of 520 miles through the Central Provinces and Tributary States of Orissa, it falls into the Bay of Bengal. Its catchment basin is estimated at 43,800 square miles, and its rapid flow renders its maximum discharge in time of flood second to that of no other river in India. During high floods, $1,800,000$ enbic feet of water pour every second through the Naraj gorge, 7 miles above Cuttack city. About 250,000 cubic feet per second strikes into Puri district by means of the Koyakhai. The remaining six-sevenths pour every second, through the Katjuri, Birupa, and Mahanadi proper, into Cuttack district. An elaborate system of canals starts from the Mahanadi, with the design, in the first place, to regulate the water supply for irrigation ; and, secondly, to utilize it for navigation and commerce. In this end a massive masonry weir 3000 feet long has been erected across the mouth of the Katjuri, the southern bifurcation of the Mahanadi; another enormous weir, 6400 feet long, across the Birupa at Chandwar. The first two of these weirs are $12 \frac{1}{2}$ feet, and the third 9 feet high. Orissa canals, when completed, are designed to irrigate a total of 1,600,000 acres. In 1868-69 a drought at the end of the rains awoke the fears of the husbandmen, and water was taken for 9378 acres at an aggregate charge of £2288.-Imp. Gaz.

MAHANANDA, a tributary to the Ganges, rises near Darjiling, in the Sikkim Hills, lat. $26^{\circ} 57^{\prime} \mathrm{N}$., and long. $88^{\circ} 20^{\prime}$ E. ; S., 40 miles; S.W., 60 miles; S.E., 50 miles; S., 20 miles; S.E., 40 miles; S., 30 miles. Length, 240 miles. It is navigable during the dry season for craft of 8 tons as far as Kishengunge; for those of much larger burden during the rains.

MAHANT, the head of a religious establishment of the mendicant orders of the Hindus; the prior or superior of a monastry or mat'h.

MAHANTI. URIYA. A man of the writer or accountant class? The caste itself is Mahayajna. Mahanti, amongst the Munda, a deputy headman.

MAHA-PATA. SANsk. A heinous crime. Of these the Hindus reckon five, - the murder of a Brahman, intercourse with the wife of a guru, stealing gold from a priest, drinking spirits, and associating with persons guilty of such offences.

MAHA-PRAHU or Maha-prabahu, a respectful term of address amongst the Mahratta nations.

MAHA-PRALAYA. SANSK. According to the Hindu cosmogony, the universal collapse of all creation at the close of the Kali Yoga. See Yoga

MAHA-PRASADA. SANSK. The great food, i.e. the distribution, amongst the persons present, of food offered to an idol, such as sweetmeats and the like. It is especially applied to the distributions at Jaganath.

MAHA-PURUSHA, great or supreme spirit, a title applied to Vishnu ; also any great man, but also to religious ascetics, especially to such as pretend and are believed to have overcome physical infirmities, to be able to live without food, and to be impassive to external or elemental influences.

MAHA-PURUSHYA, a Hindu sect in Assam, who follow the doctrines of Damudhar, Gopal, and Hari-Deb, and regard Vishnu as the sole god. They are arranged into Grihi or laymen, who worship images of Vishnu and Krishna and the saligramma, and the Udasin, who are interdicted all image-worship. Its founder was the remarkable Maha-purush at the Ghosauls of Kidderpur. He was apparently a man about 40 years of age, with a very fair complexion, and jet-black hair. He did not seem to eat or drink anything, nor speak a word, but remained in a sitting posture.

MAHA RADZA WENG or Radza Weng, Burmese chronicles of kings. These are found in the kingdoms of Burma, Pegu, Arakan, Manipur, the old state of Pong or Magoung, and indeed in all the Indo-Chinese nations, even in such small states as Tavoy and the Shan principalities of Zimme and Laboung.

MAHARAG, Arad, and Famahoy are three islands surrounded by the Jiha or Arad coral reefs, and only separated from each other at high tides. They form one side of the entrance to the port of Bahrein in the Persian Gulf. The town of Maharag stands on the island of that name, and, with the adjacent town of Manama, contains the trading population of the main island of Bahrein.

MAHARAJA. SANSK. This title was originally applied in the Puranas and Hindu books to the sovereign of a vast monarchy, which in the second century comprised a great part of India, the Malay Peninsula, Sumatra, and the neighbouring islands. But there are now in India several Hindu rulers by whom the title of maharaja has been assumed, or been given by the British, - the maharajas of Gwalior, of Indore, of Travancore, of Vizianagram. It is occasionally bestowed on Hindu civil officers of rank; as an honorific title, is also assumed by religious teachers of the Hindus, particularly by the leaders of the Rudra Sampradayi sect, followers of Vallabhacharya; and it is a term of respect used by inferiors when addressing any person in authority. The Malay ruler of Johore also bears this title. With the reigning princes it is always associated with other titular designations; those of the sovereign of Travancore, for instance, are His Highness Sri Patmanabha Dasa Vanchi Bala Rama Varma, Kulasikhara, Kiritapati, Manny Sultan, Maharaja, Raja Ramaraja Bahadur, Shamshir Jung, G.C.S.I. -India in 15th Cent.

MAHARAJA, an honorific appellation of the head of a sect of Hindus styled the Rudra Sampradayi, also Vallabhacharya, also Gokalastha. The sect arose about the 15th century, from the teachings of $\nabla$ allabhacharya, a Telinga Brahman, and his doctrines are best known as those of the Gokalastha gosai, the title of its teachers, who are usually in Bombay styled Maharaja. The doctrine of Vallabha was that privation was not sanctity, and that the duty of teachers and disciples was to worship the deity, 
not in nudity and in hunger, but in costly apparel and choice food. The followers of this sect are very numerous and opuleut; the merchants and bankers, especially those from Gujerat and Malwa, belong to it. Their temples and establishments are numerous all over India, but particularly at Mathura and at Bindraban; but at Sri Nat'h Dwar, at Ajmir, is the most celebrated and most richly-endowed of all the Gcsain establishments. The disciples who are devout make the threefold Samarpana, tan, man, d'han, of body, mind, wealth, to the guru, whom many of the Bhattia race regard as an incarnation of Krishna, the worship of whom, as Bala Gopala, they follow. There are about 60 or 70 maharajas in India. Of these, the maharaja at Sriji is said to be the chief, and he has a great temple near Udaipur. When the people wish to worship a maharaja, they fetch him to their houses, offer him flowers, wave a light round him, present him with money, and prostrate themselves at his feet. The maharajas worship the gods much in the same way, and in addition they bathe and dress the images. On certain occasions it is customary to worship the idol by swinging it; and at these swinging festivals, swinging the maharaja is a religious ceremony which is performed by the female members of the different families of the disciples. Whilst the maharaja is swinging he throws the red powder called gulal amongst his devotees, and some of it falls upon the necks and breasts of the women. If any one else threw gulal upon women, it would, excepting on the Holi festival, be regarded as an insult. Nautch dances are occasionally given by the maharaja, but in a different part of the temple to that which the idols are placed, and female devotees occasionally visit the maharaja's family in a separate part of the temple. The maharajas have temples in Bombay, and sometimes there are several residing in the island. When Gokalnath maharaja originally visited Bombay, in 1811, all the Vaishnava sect requested his holiness to settle permanently with his family, for the purification of their souls, offering at the same time to build a temple for him, and to make arrangements to meet his expenses in connection with the temple. Accordingly a tax upon articles of trade was determined upon; and all the Vaishnava merchants, who in Bombay possess a monopoly in almost every important article of trade, solemnly bound themselves to add it to the price of every article they might buy or sell. The result is that about Rs. 1,62,000 are raised every year for six different maharajas, of whom the maharaja of Bombay receives about half a lakh per annum.

According to the doctrines of the Vallabhacharya sect, every maharaja is considered as the husband of his female devotees; but in 1855 the followers beld a meeting, at which it was resolved that none of their daughters or wives should be allowed to resort to the mabarajas for worship except at certain stated hours, when the mabarajas would be necessarily occupied in ceremonies at the temple. Many amougst them no doubt were as ignorant as the public in general were, before the trial took place in 1862 , of the babits of the maharajas; or, if they knew what was done, they considered such practices to be sanctioned by their religion. Bold and earnest words fitly concluded Sir Joseph Arnould's judgment-'It is not a question of theology that has been before us; it is a question of morality. The principles for which the defendant and his witnesses have been contending is simply this,--that what is morally wrong cannot be theologically right; that when practices which sap the very foundations of morality, which involve a violation of the eternal and immutable laws of right, are established in the name and under the sanction of religion, they ought for the common welfare of society, and in the interest of humanity itself, to be publicly denounced and exposed. The defendants have denounced and have exposed them. At a risk and at a cost which we cannot adequately measure, these men have done determined battle against a foul and powerful delusion. They have dared to look custom and error boldly in the face, and proclaim before the world of their votaries that their evil is not good, that their lie is not the truth. In thus doing they have done bravely and well. It may be allowable to express a hope that what they have done will not have been in vain, that the seed they have sown will bear its fruit, that their courage and constancy will be rewarded by a steady increase in the number of those whom their words and their example have quickened with thought and animated to resistance, whose homes they have helped to cleanse from loathsome lewdness, and whose souls they have set free from a debasing bondage.' Their persons are deemed very sacred. At the trial in 1862, Jadunathji Brijruttonji Maharaj, the plaintiff in the case, when under cross-examination in the witnessbox by the late Mr. Anstey, was shown a document for identification. Mr. Anstey, who stood near the witness-box, stretched forth his hand holding the paper, in order to deliver it to the maharaj. The latter shot back into the furthermost corner of the box. Mr. Anstey felt indignant, and his indignation increased when the interpreter of the court explained to him the Wallabhacharyan doctrine of touch. He told the witness through the interpreter, 'I would not touch you with a pair of tongs.'

MAHARAJPUR, a village in the Gwalior State in Central India, in lat. $26^{\circ} 29^{\prime} \mathrm{N}$., and long. $78^{\circ}$ $5^{\prime} \mathrm{E}$., 15 miles N.W. of Gwalior fort. The British, under Sir Hugh Gough, on the 29th December 1843 , here gained a victory over the Mahratta forces, and captured 56 guns and all their ammunition waggons.

MAHARANA means Great Prince, the title by which the Rajput rulers of Udaipur are always distinguished. Maharani, the queen.

MAHARASHTRA, the Mahratta country. The race now occupying Maharashtra is known as the Mahratta. The men are robust, and generally employed as cultivators. The women are not well featured nor well shaped. In the Sareda Tilaka, a monologue of later date than the play of Mrich'chba-kati, which was of the 1st century of the Christian era? but still of comparative antiquity, there is a description of some of the various women of India, distinguishing each by her nationality :

'There goes the maid of Gurjara (Gujerat), blooming as with perpetual youth, having eyes like the chakora, of the complexion of the yellow rochana, and a voice musical as that of the parrot. She wears anklets of silver, large ear-rings set with pearls, and her bodice is buttoned below the hips with gems. 
'The matron of Maharashtra proceeds youder, her forchead stained with saffron, and with silver chains upon her feet; she wears a coloured veil, and a girdle round her loins.

'A Chola feroale (south of India) approaches, whose cheeks are tinted with saffron, and whose dress is embroidered with the buds of the lotus.'

A bodice which buttons below the hips is certainly unknown at the present day, either in Gujerat or elsewhere in India; and as no single clotb, as a scarf or the present saree, could be buttoned, it can only be presumed that the garment was cut out and sewn in the fashion of a long tight-fitting robe, as in use among Persian women of the present time.

MAHA-RAWUL, a royal title of the rulers of Jeysulmir and Doongurpur.

MAHARI. In the Uriya, a dancing-girl attached to a temple is called a Mahari.

MAHARI. ARAB. A ridiug camel. It is more slender than the camel used for burden. In the desert it is of great value.

MAHARNAVAMI, a festival in Coorg, held on the 9th day of the seventh month. Arms are worshipped.

MAHARRAM, the first month of the Mubammadan year; the first ten days of the month are held as a festival, which is celebrated as Christmas is, sometimes by strict religious rites or by great festivity, according to the opinions or ignorance of the sects. The Shiah Muhammadans and learned Muhammadans are generally most strict in the observance of their religious duties for the first thirteen days of this month. The twelve months in succession are-
Maharram.

Suffer.

Rubbi-ul-Awul.

Rubbi-us-Sani.

Jemadi-ul-Awul. Jemadi-us-Sani. Rujjub. Shaban.

Shawal.

Zu-ul-Kaida. Zu-ul-Hajja.
Ashrah, an Arabic word, from Ashr, a tenth, are the first ten days of the Maharram, or the ceremonies observed during that part of the month. Houses are appropriated, in which they set up the Allum, Taboot, Shah-nasheen, Booraq, etc., and sometimes screens made of mica. These places are called the Ashoor Khanah (ten day house); Tazeea Khanah (the house of mourning); and Astana (a threshold or fakir's residence). In Northern Hindustan, opulent Mubammadans erect an Imambara, and the Shiah sect generally follow a similar practice.-Herklots.

MAHA SAKSHI, Maisaksbi, or Meshakshikusuma, a gum - resin found in druggists' shops, which is said by Ainslie to come from Arabia, and is said by Wight to be a kind of bdellium. In the bazars at Madras, the Pansari or druggists, if asked for maisakhshi, will produce gugul, which is the same as the Arabic muql. The word means buffalo's eye.-O'Sh.

MAHASAL. ARAB. A government servant sent to obtain payment of village dues. It is rarely resorted to in the British administration, though legal under Regulation xvii. of 1827 , section 12. The villagers had to feed the peon; and in the event of their not complying, a second, a third, even up to 10 or 20 peons, would be sent, and horsemen also often sent. The Mahasal were often quartered on a village in case of a robbery.

MAHA - SANKRANTI. SANSK. The great Sankranti, the sun's entrance into Capricorn; the winter solstice. The Pongol festival in the south of India.

MAHASHTAMI. SANSK. The 8th day of the festival in Aswin in honour of Durga; the Durgapuja.

MAHA SIVA RATRI, one of the greatest festivals in the Hindu calendar, occurs about the middle of February. Various legends are given in connection with this festival, but public opinion among the Hindus is in favour of the following:Ravana, king of Lanka, undertook a pilgrimage to Mount Meru, the residence of Siva, and there put himself through a course of the most rigid penauce, and supplicated the god by fasting and prayer. Siva appearenl to him and asked him his desire. The king replied that he had only one request to make, and that was that none of the gods should be permitted to invade his country, and that they should not have power either to conquer or slay him. Siva, in reply, gave him a lingam of stone, and commanded him to take it to his country, and there build a temple over it to his honour. He further enjoined him not to place it on any carriage, but to carry it himself. $\mathrm{He}$ was also not to set it down anywhere on the road, for if he did he would never, the god said, be able to lift it off the ground again. An implicit obedience to these injunctions would obtain for him a favourable answer to his prayers. When Ravana had started from Mount Meru with the lingam, the other gods supplicated Pillyar after this wise: "This Ravana has been a constant source of annoyance and trouble to us; and now that he has obtained from Siva this lingam as a protection from our power, he will become yet more arrogant and troublesome. You must therefore devise some means of depriving him of the lingam before he reaches the country.' Pillyar acceded to this request, and, summoning Varuna, he desired him to enter into the stomach of the king of I anka and become water, so as to fill lim. This Varuna accordingly did. Ravana, when the watery element filled him, began to feel exceedingly uncomfortable and clropsical, and looked out for some shady retreat where he might rest a while till the waters had subsided! Pillyar at this moment assumed the form of a Braliman child, and appeared to him, and Ravana asked him to carry the lingam for a few minutes.

MAHAVINYAKA, sacred peak of the Barunibunta Hills, Cuttack district, Bengal ; visible from Cuttack city.

MAHAVIRA, the title of Vardhamana, the 24th and last Jaina tirthankara, began his austerities at the age of 30 , continued them for twelve and a half years as a digambara or naked ascetic, without even a bhikhshu's begging dish, and at the age of 72 he died at the court of king Hastipala, about B.c. 526. His disciple Gautama Swami or Gautami Indra Bhuti is supposed by some to have been Gautama Buddha, the founder of the Buddhist religion. The Buddhists designate Gautama as Mahavira, and mention Maha Kasyapa as his chief and eminent disciple. The Jains style him Kasyapa Mahavira, and mention Gautama as his chief disciple (Ganadhara). Both Buddhists and Jains concur in making Mahavira the friend and spiritual teacher of a king of Rajagriha, the capital of Magadha, whose name was Srenika or Bhambhasara according to the Jains, and Bimbisaro according to the Buddhists. 
Mr. Garrett gives a legend which relates that Mahavira was repeatedly born again. His first birth was as Nayasara, headman of a village in the country of Vijaya, from which he was transferred for oceans of years to the Sandharma heaven. He was then re-born as Marichi, the grandson of Rishaba, the first tirthankara, and thence transferred to Brahma-loka, whence he returned as a worldly-minded and sensual Brahman, the consequence of which was repeated births in the same caste, each birth separated by an interval passed in one of the Jaina heavens. He then became Visvabhuta, prince of Rajagriha, and next a Vasudeva named Triprishta; then a Choravartti Priyamitra, then a Nandana, leading a life of devotion. On the return of the spirit of Nandana to earth, it first animated the womb of the wife of a Brahman, but was transferred to the womb of Tresala, wife of Siddharta, of the family of Ikshvaku, a prince of Ravana in Bharaksbetra. He was born on the 13th of the light fortnight of Chaitra. His father named him Varddhamana, but it was changed to Mahavira. He married Yasoda, daughter of prince Samara Vira, by whom he had one daughter, named Priya Darsana, who married Jamali, a prince, one of the saint's pupils, and founder of a schism. Siddhartha and his wife died when Mahavira was 28 years of age, on which Mahavira adopted an ascetic life, the government devolving on his elder brother Nandivarddhana. After ten years of abstinence and self-denial, he commenced an erratic life, often fasting and in silence. In twelve and $a$ half years he attained the Kevala or only knowledge, under a sal tree on the north bank of the Rijupalika, and commenced to instruct from a stage. He enjoined to avoid injury to life or giving pain, to speak truth, not to steal, to be continent. On his death his body was burnt, but unconsumed portions were kept as relies.Dr. Bhau Daji in Bo. R. As. Voc.; Garrett.

MAHA-VIRA CHARITA, a stirring and martial drama by Bhava-Bhuti, which has been translated into text by Pickford; it relates the exploits of the great hero Rama. There are several editions of the text.

MAHAWANSO, a metrical chronicle in Pali of the dynastic history of the island of Ceylon, from B.c. 543 to A.D. 1750 , discovered and translated by the Honourable George Turnour. Mahawanso and other Ceylonese scriptures were reduced to the present form by Buddhaghosa in the beginning of the 5th century A.D. The 17th chapter of the Mahawanso is entitled the Arrival of the Relies, and details the acquisition to Ceylon by Dewanan-piyatipo, of the collar-bone and otber relics of Buddha. The right canine tooth was transferred in A.D. 310 from Dantapura to Ceylon, and is now enshrined in the Dalada Maligawe temple in Kandy. In the Mahawanso, p. 249 , it is mentioned that Upatisso, son of Buddha Das, built bospitals for cripples, for pregnant women, and for the blind and diseased. Dhatusena ( $p .256)$ built hospitals for cripples and sick. Buddha Das himself (p. 245) ordained a physician for every ten villages on the high road, and built asylums for the crippled, deformed, and destitute.

MAHA - WELLI - GANGA, the Ganges of Ptolemy, rises near Adam's Peak in Ceylon. traverses more than one-third of the mountain zone, and drains upwards of 4000 square miles. Mahawellaganga is the largest river in Ceylon. Its principal branch has its source in Pedro tallagulla, on the plain of Nuwera Elia; when near the east coast, it divides into two branches, one of which falls into the great bay of Trincomalee, the other, called the Virgel, into the sea 25 miles south of Trincomalee-Sir. J. $E$. Tennent's Ceylon.

MAHAYAJNA. SANSK. A great sacrifice. Of these, in Hinduism five are recognised:-1. Brahma-y, the study of Brahma or the Veda; 2. Pitri-y, offering to the manes; 3 . Deva-y, offerings to the gods; 4. Bali or Bhuta-y, worship of all things, of evil spirits; 5 . Nri-y, worship of man, hospitality.

MAHAYANA, a form of Buddhism, which was introduced by Nagarjuna, and those who assisted at the fourth convocation under Kanishka. It means the Greater Translation, and was said to have been preserved by the Nagas, from whom Nagarjuna received it. It spread from Peshawur over all Northern and Eastern Asia. From that time the Tibetans, Burmese, and Chinese date the introduction of Buddhism into their countries. It was considerably in advance of the Hinayana school of Central India in all complications of ritual observances. - Fergusson, p. 180.

MAHA YAZA WVIN, also written Maha Radza Weng, a royal chronicle of Burma, which gives dates from B.c. 1000 . There is no doubt that Tagoung and Prome and Pagan were each in their turn for many centuries the seat of an empire, but there is no certainty until the middle of the 16 th century. According to this chronicle, however, the first ruler was Maha Thammada, the object being to connect the royal line with prince Siddhartha, the Buddha of the present cycle of religion. To give this theory the greater verisimilitude, the chronicle represents the whole Burmese race as descended from a tribe of the Indian Solar race, who, with Abhi Raja, their king, were driven from their home in Kapilavastu, and, marching eastward, finally settled in the valley of the Irawadi, where they built Tagoung for their capital. This ancient capital is said to have been founded by Anawrata Saw. He was a very devout Buddhist, and marched with a large army into China to obtain a tooth of the Buddha. In this he was not successful, but he came back with a golden replica obtained from the Hwang-ti. This was about the time of the Danish kings in England. Five hundred years later, Buyin Noung, a monarch a monster of cruelty, succeeded to the throne. The country was then divided into four separate and independent kingdoms, - Pegu, Arakan, Burma, and Ava. When he died he had exalted Burma at the expense of the neighbouring kings, and, besides subduing Zimme, had ravaged Siam up to the gates of the capital. Cæas Fredericke says about him, 'The king (Branginoco he calls him) bath not any army or power by sea, but in the land, for people, dominions, gold and silver, he far exceeds the power of the Great Turk in treasure and strength.' Buyin Noung employed Portuguese soldiers of fortune in his various expeditions, and prominent among them were Philip de Brito and Nicote and Gonsalves. The former, originally a cabin-boy, established himself for thirteen years as an independent monarch at Syriam, below Rangoon, and the ruins of the 
fort he built may yet be seen. Gonsalves was a common soldier, who became a pirate on a large scale, and, after a brilliant eight years of murder and plundering, lapsed into the common soldier again. Philip de Brito and Nicote was impaled on a spike. Many of the Portuguese captured during these expeditions were sent as prisoners into the interior, and their descendants form a distinctly recognisable class to the present day at Mandalay, though they dress as natives of the country, and have Burmese names.

During the period between Buyin Noung and Aloung-payah, the founder of the present dynasty, at one time the Burmans were masters, at another the Peguans, while the kings of Arakan or of Tounghoo made raids on the lowlauds. About the middle of the 18 th century, the Talaings of Pegu rose against the Burmese, and not only drove them out of Pegu, but, under their king, the prince of Dala, a village opposite Rangoon, overran the Burmese dominions, and finally sacked and burnt Ava, the capital of the country. But Oung Zaya, a hunter, finally overthrew the Talaing near Prome, and proclaimed himself king, with the title of Aloung-payah. He was the founder of the town of Rangoon, and in the eight years of his reign not only possessed himself of Pegu, but annexed Arakan, Tavoy, and Tenasserim, and was on the march against Siam when he was seized with the illness which ended in his death. His son Sin-byoo-shin, however, inherited his military genius; and, besides conquering Siam, came off victorious in four severe struggles with the Chinese, who invaded the country with large armies. Under him and the next few kings the power of the country was consolidated, the Shan states and Manipur were overrun, and finally the Burmese came into collision with the British. Under Bodaw-payah, the last of the sons of Aloung-payah, the empire reached its largest extent, and had become one of the most formidable powers in Asia. It bad nearly 1000 miles of sea-coast, and extended from the borders of Chittagong to the centre of Siam. The Burmese soldiery were feared all over Indo-China as the most ruthless and invincible of foes. But the braggart spirit which led Bodaw-payah to proclaim himself an embryo Buddha, and lord it over British envoys, prompted his successor to demand from the Indian Government the surrender of Chittagong, Dacca, and Murshidabad. Actual aggressive movements on Chittagong led to a declaration of war in 1824, and in 1826 Sir Archibald Campbell dictated peace close to the walls of Ava.

MAHA-YOGA, in Hindu cosmogony, a period of four Yoga. It comprises 12,000 years of the gods, which, according to the Vishnu Purana, are $4,320,000$ years of mortals. See Yoga.

MAHAZAR. ARAB. A representation. Mabazarnama, a written statement.

MAHBUB-i-SUBHANI, or Dastagir, a Muhammadan saint.

MAHDI. ARAB., HIND. A guide; according to the Shiah sect of Muhammadans, the twelfth and last of the Imams or successors of Ali. The Mahdavi part of the Shiah sect believe him to be still alive. The Gbair Mahdavi believe that he has been on, but has disappeared from, earth. The Sunni sect believe that Mahdi is yet to come. From time to time, amongst the Muhammadans, persons lave been appearing claiming to be the Mahdi. One of these appeared in Hindustan at Jonepur early in the 16 th century; his followers are the Ghair Mahdi. In the early part of 1884 one such rose in the Soudan in Northern Africa, and gained many adherents. There are continual prophetic announcements made. There is an old widespread prophecy that the Mahdi is to appear in the 14th century of the Hijira, which begins about 1886. The adberents of a numerous sect, which has ramifications throughout all Northern Africa, believe that the Mahdi is to bear the name of Abdullah, his father's name to be Mahmud, his mother's Aminat, while his vicegerent is to be called" Abdul Muttalib. The Mahdi's troops attacked Jazireh, which, as its name signifies, is an isle near Berber. The explanation is that there is an old tradition that the future ruler of the Soudan will come from that isle. The people of the Soudan are very superstitious; and the fall of the flag by a gust of wind on the occasion of Tewfik's proclamation at Khartoum was looked on as an omen of the end of Muhammad Ali's dynasty. There is an old tree opposite Cook's office at Jerusalem in Tophet, belonging to an old family, and protected by the Sultan's firman, and the Arabs believe that it will fall when the Sultan's rule ends. It lost a large limb during the Turco-Russian war, and is now in a very decayed state. All Muhammadans believe that Mahdi will reappear before the second coming of Christ, and the most of them indicate Damascus as the site. See Imam.

MAHE, a town in Malabar district, Madras, is in lat. $11^{\circ} 41^{\prime} 50^{\prime \prime} \mathrm{N}$., and long. $75^{\circ} 34^{\prime} 25^{\prime \prime} \mathrm{E}$. This little French settlement is about 4 miles to the south of Tellicherri. Between 1761 and 1793 it repeatedly changed hands, during the strife between the British and the French. Mahé has an area of 1445 acres, with a patch of ground in the town of Calicut further south.

MAHENDRA, son of Asoka, king of Magadha, in B.C. 236 converted Ceylon to Buddhism. The earliest recorded voyage down the Bhagirathi was made in the age of Asoka, who sent this son Mahendra, with a branch of Buddha's sacred pipal tree, on a mission to the king of Ceylon.Tr. of Hind. i. p. 20.

MAHENDRAGIRI or Mahendra Mallai, a mountain peak in the Eastern Ghats, Ganjam district, Madras, in lat. $18^{\circ} 58^{\prime} 10^{\prime \prime} \mathrm{N}$., and long. $84^{\circ} 26^{\prime}$ $4^{\prime \prime}$ E., and 4923 feet above sea-level. Mahendragiri mountain is in the Parla Kimedi district, distant about 20 miles from the sea-coast. The view to the south-west rauges over the greater part of Parla Kimedi; on its western side runs a deep valley, on the opposite side of which rise the numerous and extensive hills occupied by the independent Saurah tribes, some of them but little inferior in height to the Mahendragiri. To the north and north-east are the Jarada, Jalantra, Bodarsingi, Surungi, and Chikati hill zamindaris, and the taluks of Itchapur, Moherry, and part of Pubaconda. The Mundasa zamindari extends from the east face of the range to the sea-shore. The valley which divides the Mahendragiri range from the hill tracts of the independent Sourah to the west extends from the Jarada zamindari completely into the Parla Kimedi country. It was tried as a sanatorium, but proved very unhealthy. 
MAHENDRAGIRI, near Cape Comorin, about 5000 feet high, is the mountain with which the ghats terminate. Indragiri means the great mountain of Indra. It is allurled to in the Ramayana as that from which the monkey god Hanuman leapt to Ceylon, alighting on the summit of Adam's Peak. The Tinnevelly Gap separates it from the mountains to the immediate north. To the south are a few rocky hills, the Arambully pass, and then the open sea. Upou the Tinnevelly side, immediately under the shadow of this mountain, lies the town of Trichenagoody, with its fine gopuram, or temple tower; and on the Travancore side is the town of Nagercoil, famons as a station of the London Missiouary Society since the days of Ziegenbalg. Several large and highly-cultivated coffee estates spread over its sides. The forests, consequently, which once rolled around it, and enfolded it as it were with a grand mantle of green, are fast disappearing.

MAHESH, a village, a suburb of Serampur, in the Hoogly district of Bengal, lat. $22^{\circ} 44^{\prime} \mathrm{N}$., and long. $88^{\circ} 23^{\prime} 45^{\prime \prime} \mathrm{E}$. Famous for the two great festivals of Jaganath, the S'thnam-Jatra or bathing of the god in May, and the Rath-Jatra or car procession, six days later. At the latter, the god is dragged to the village of Ballabhpur, a mile distant, and brought back after eight days' visit to the temple of Radhaballabha. An important fair is held at Mahesh during the eight days, with an attendance of about 8000 persons daily, and 100,000 people on the first and eighth day, when the procession and return journey take place. At Mahesh, Jaganath and his brother Balaram, having fasted the whole day, on one occasion are said to have pawned a bracelet with a shopkeeper to procure some food. The ornament was missed by the Pandas (priests) on their return to Puri, and they released it from the shopkeeper.-Imp. Gaz. vi.; Tr. of Hind. i. p. 5.

MAHESHA, a demon of the Hindus of great power, who, having been troubled by the army of Durga, assumed the form of a buffalo to destroy them, but was speared by Durga. In the sculptures at the Burabur caves, Durga slaying 'MaheshAsur' is the principal and most often repeated. Maheshasura Mardini is the form of Durga as the destroyer of the buffalo-born giant Mahesha. Maheswara (the great lord), one of the five great lords or faces of Siva. It is this nane which Europeans have changed to Mysore.

MAHESHWAR. SANSK. The Binlang stones, worshipped as emblems of Siva, are formed at Maheshwar, on the Nerbadda, where a whirlpool occurs, and rounds and polishes fallen stones into the form of a lingam.

MAHI. PERs. A fish. From Basrah to Hormuz, the sea-coast people still principally live on fish. The Mahi-abah and Mahi-ashnah, literally fish bread and fish soup, used among the people of Lar, is prepared from fish (more particularly a small kind found near Hormuz) by exposing it to the sun. Strabo and Arrian relate that the ancient Ichthyophagi made into bread in a similar manner the fishes which they had dried and roasted. The region of the Ichthyophagi commenced at Malana near Cape Arabah, and ended between the ancient Dagasira and the place now called Cape Jashk. Churchill's Collection of Voyages mentions that " the coastes of Persia, as they sailed in this sea, seemed as a parched wildernesse, without tree or grass; those few people that dwell there, and in the islands of Lar and Callon, live on fish, being in manner themselves transformed into the nature of fishes. So excellent swinmers are they, that seeing a vessel in the seas, though stormie and tempestuous, they will swimme to it five or six miles to begge almes. They eate their fish with rice, having no bread; their cats, hennes, dogges, and other creatures, which they keepe, have no other dyet.' Nieuhoff, who travelled in 1662, says that about 'Gambraon the common people make use of dates instead of bread or rice; for it is observable that the ordinary food of the Indians all along the coast from Basora to Sinde is dates and fish dried in the air; the heads and guts of the fishes they mix with date stomes, and boil it all together with a little salt water, which they give at night to the cows after they come out of the field, where they meet with very little herbage.'

MAHI, river of Bombay, with a course of from 300 to 350 miles in length, and a drainage area estimated at from 15,000 to 17,000 square miles. After the Nerbadda and the Tapti, it is the largest river of Gujerat. The main branch of the Mahi rises about 1850 feet above sea-level in the Amjhera State, Malwa, in lat. $22^{\circ} 52^{\prime} \mathrm{N}$., and long. $75^{\circ} 5^{\prime} \mathrm{E}$., about 160 miles east of Cambay. The source of the river is in the Mehad lake.

MAHIDPUR, in lat. $23^{\circ} 30^{\prime} \mathrm{N}$, and long. $75^{\circ}$ $38^{\prime}$ E., in Malwa, 23 miles N. of Ujjain. The mean height of the village above the sea is 1600 feet. The battle of Mahidpur, on the 21st December 1817, fought and won by the British in war against the Mahrattas. - Scout.

MAHIJAH. HIND, In the Bari Doab, high lands above river inundation.

MAHIKANTA, a group of Native States under the Government of Bombay; situated between lat. $23^{\circ} 14^{\prime}$ and $24^{\circ} 28^{\prime} \mathrm{N}$, and between long. $72^{\circ}$ $40^{\prime}$ and $74^{\circ} 5^{\prime} \mathrm{E}$., with an area of about 4000 square miles. In 1838, Captain (Sir James) Outram instituted border panchayats for the settlement of the numerous blood-feuds and disputes between the wild Bhils on the Mahikanta and Rajputana frontier.

MAHI MURATIB. Pers. The fish-banner, a Muhammadan regal distinction, granted also by sovereign princes, entitling the receirer to have carried before him the gilt metal figure of a fish, borne upon a pole, with two gilt balls similarly elevated. Shah Alam conferred the honour on Lord Lake. - $W$.

MAHI-RUBIAN. HIND. Dried shrimps, from the coast of Sind; also an undetermined drug, in appearance consisting of dried-up pieces, having a grey colour.

MAHMAN. In Gujerat is a numerous ruce, called Mahman, or in conversation, Mehman. Many families of this sect live in Bombay, and are a very useful, hard-working, trusty people.

MAHMUD, son of Sabaktagin, commouly called of Ghazni, was a brave, experienced, prudent sovereign, distinguished in war and as a civil administrator. He ruled from A.D. 997 to A.D. 1030, in which period he extended his dominions from the Persian Gulf to the Sea of Aral, and from the mountains of Kurdistan to the banks of the Sutlej. He was the greatest sovereign of his time, and is considered by $\mathrm{Mu}$ hammadans among the greatest of any age. He 
was athletic and well-proportioned, but scarred with smallpox ; prudent, active, and enterprising, zealous in the encouragement of literature and art to a degree which has not yet been surpassed. The poets Dakiki, Ansari, and Fardusi were attracted to his court. He founded at Ghazni the mosque called the Celestial Bride, which was the wouder of the east, and the nobility imitated his taste for architectural display. Such were the multitudes of slaves he brought from India, a purchaser could not be found for them at $4 \mathrm{~s}$. $7 \mathrm{~d}$. a head. At that time the northern part of India seems to have been under the sway of four rulers, one at Dehli under the Chauhan, one at Kanouj under the Rahtor; Mewar was under the Gehlot, and Anhilwara under the Chaura and Solanki. The Dehli rule extended to the Indus in the west, and the Himalaya to the north; Kanouj eastwards to Benares, with part of Bundelkhand; and Mewar and Anbilwara consisted probably of the present Mewar and Malwa, and thence to the Lower Indus and the sea.

Mahmud put aside his elder brother Ismail in A.D. 997. In A.D. 1001 (A.H. 391) be made his first campaign against the Hindus of India. He left Ghazni with 10,000 chosen horse, and on the 27th November, near Peshawur, defeated and took prisoner raja Jaipal I. of I,ahore, afterwards stormed Batinda, and returned to Ghazni rich with plunder. Jaipal, on his return from captivity, immolated himself on a pyre which he had ordered to be constructed.

Mahmud's second expedition was against the raja of Bhattia, south of Multan, who, being driven from a well-defended entrenchment, and then from his own fortress, at last destroyed himself in the thickets of the Indus, where he had fled for concealment, and where many of his followers fell in endeavouring to revenge his death.

His third expedition was to reduce his dependent, the Afghan chief of Multan, Abul Fattah Lodi, who had formed a close alliance with Anang Pal. Anang Pal interposed his army between those of Mahmud and Abul Fattah, but was routed near Peshawur, and Mahmud invested Multan, but after seven days' siege he accepted the submission of the chief. Taking advantage of Mahmud's occupation near the Indus, Elik Khan sent an army to iuvade the Ghaznavi dominions of Herat and Balkh, but Mahmud left his capital under Suk Pal, a converted Hindu, met Elik Khan near Balkh, drove the Tartars with prodigious slaughter from the field of battle, and Elik Khan escaped across the Oxus with a few attendants. In the meantime Suk Pal had renounced Muhammadanism, and revolted, but Mahmud came unexpectedly on him, took him prisoner, and confined him for life.

His fourth expedition (A.D. 1008, A.H. 399) was formed to punish Anang Pal's combining with Abul Fattah Lodi. Anang Pal had induced the rajas of Gwalior, Ujjain, Kalinjar, Kanouj, Dehli, and Ajmir to enter into a confederacy, and their united forces advanced into the Panjab. Hindu women sold their jewels, melted down their gold ornaments, and sent their contributions from a distance to furnish resources for this boly war. Mahmud formed an entrenched camp, but the Ghakkar overthrew his guards, and cut down 3000 or 4000 of his army. The elephant of Anang Pal, however, unable to withstand the archers, fled from the field, his army gave way, and Mahmud sent in pursuit 10,000 chosen men, who killed great numbers of the enemy before they reached a place of safety. Mahmud then advanced on Nagarkot, a fortified temple on a mountain connected with the lower range of the Himalaya, and he carried off from it to Ghazni 700,000 gold dinar, 700 man of gold and silver plate, 200 man of pure gold in ingots, $2000 \mathrm{man}$ of unwrought silver, and 20 man of various jewels, pearls, corals, diamonds, and rubies.

In A.D. 1010 (A.H. 401) Mahmud went in person against, and defeated, Mubammad Sur of Ghor, in the mountains east of Herat; the chief swallowed poison.

His fifth expedition was in the same year; he returned to India, took Multan, and carried Abul Fattah Lodi prisoner to Ghazni.

His sixth expedition was to Tanesar, not far from the Jumna, where he plundered the temple, sacked the town, and returned with an incredible number of captives to Ghazni, before the Indian princes could assemble to oppose him.

His seventh and eighth expeditions were to Kashmir. In returning from the last, at an adranced period of the year, many lives were lost.

After the expedition against Kashmir, Samarcand, Bokhara, and Kharasm were occupied without opposition.

His ninth expedition against India, A.D. 1017, A.H. 408, was on a great scale. Ferishta says 100,000 horse and 20,000 foot were assembled from all parts of his dominions. He set out from Peshawur, and kept close to the mountains until he passed the Jumna, when he turned towards the south, and presented himself before Kanouj. The raja was so entirely unprepared, that be came out with his family and gave himself up to Mahmud, who left Kanouj uninjured. $\mathrm{He}$ halted for twenty days at the holy city of Muttra, during which the city was plundered, the idols broken, the temples profaned, and the city fired. The raja of Mahawan, near Muttra, submitted, and was received with favour; but a quarrel broke out between the two armies, when the Hindus were massacred and driven into the river, and the raja, imagining himself betrayed, destroyed his wife and children, and then made away with himself. At Munj, after a desperate resistance, part of the Rajput garrison rushed out through the breaches on the enemy, while the rest dashed themselves to pieces from the works, or burned themselves with their wives and children in their houses; not one survived. Various other towns were reduced, much country laid waste, and Mahmud returned to Ghazni with the spoil and prisoners.

His tenth and eleventh expeditions into India were made A.D. 1022, A.H. 413 , and A.D. 1023, A.H. 414. The first was to the relief of the raja of Kanouj; but before Mahmud arrived, the Kanouj raja had been cut off by the raja of Kalinjar in Bundelkhand, against whom Mahmud turned his arms, but made no permanent impression in this or a subsequent campaign. During the first of these expeditions, Jaipal II. was on friendly terms, but on the second he opposed Mahmud's march on Kanouj, and Mal-mud annexed Lahore and its territory to Ghazni. In A.D. 1024, A.H. 415, Mabmud marched to 
Transoxiana, in person, to crush a revolt, and then returned to Ghazni.

In his twelfth and last expedition to India, he directed his forces against Somnath. His army moved from Ghazni in September, A.D. 1024 (A.H. 415), crossed the desert without any disaster, and made good his hold near Ajmir. The raja fled, Ajmir town was given up to plunder, and the country ravaged. Advancing on Anbilwara, the capital of Gujerat, its raja also fled, and Mahmud reached Somnath. Its temple was erected on a peninsula, and the isthmus connecting it with the mainland was fortified. The Ghazni troops on the first day occupied the ramparts, only to be driven from them. Next day brought a still more signal repulse. On the third day the rajas of the neighbourhood, with the Anhilwara raja, presented themselves in order of battle, and Mahmud had to move against them. His troops wavered, but Mahmud charged, and 5000 Hindus fell. The garrison, 4000 strong, then abandoned the place, and fought their way to the boats. Mahmud entered the temple, and it is said refused all offers to abstain from destroying the idol. Two pieces were sent to Mecca and Medina, and two to Ghazni, where one piece was to be seen at the palace, and one at the public mosque, as late as when Ferishta wrote his history. The treasure taken on this occasion exceeded all former plunder. After a year's stay in Gujerat, he returned to Multan and Ghazni by the sands of Sind, in which many of his troops perished miserably. This expedition lasted from October-November 1024 to A pril-May 1026.

After his return he chastised a tribe of Jats in the Jund mountains, who had molested his army on its march from Somnath. He afterwards moved in person against the Turki tribe of Seljuk, and defeated them, A.D. 1027, A.H. 418 , in a great battle. His next success was against the Buya or Delmi. He invaded Irak, took possession of the whole territory, took Isfahan and Kaswin, putting to death thousands in each city. These were the last acts of his reigu. Soon after his return to Ghazui he was taken ill, and died on the 29th April 1030. Muhammad, son and successor of Mahmud, was put aside and blinded by his brother Masaud; but ten years after, Masaud, unsuccessful in war, was dethroned and put to death, and Muhammad reinstated. Modud, son of Masaud, was at Balkh when his father was murdered; he hastened eastwards with his army, defeated and put to death his rivals (A.D. 1040, A.H. 433), and afterwards crushed a rebellion excited by one of his own brothers. - Elph. p. 302.

MAHOBA, an ancient city, in lat. $25^{\circ} 17^{\prime} 40^{\prime \prime}$ N., and long. $79^{\circ} 54^{\prime} 40^{\prime \prime} \mathrm{E}$., in the N.W. Provinces of India, at the foot of a low granite hill 54 miles to the south of Hamirpur, at the junction of the Betwa and Jumna, 34 miles to the north of Khajuraho. Its name is a contraction of Mahotsava-nagara, or "the city of the great festival,' which was celebrated there by Chandra Varmma, the founder of the Chandel dynasty. To the west of the city lies the great lake of Kirat Sagar, about $1 \frac{1}{2}$ mile in circumference, which was constructed by Kirtti Varmma, who reigned from A.D. 1065 to 1085 . To the S. is the Madan Sagar, about three miles in circuit, which was construeted by Madana Varmma, who reigned from A.D. 1130 to 1165 . To the $\mathrm{E}$. is the small lake of Kalyan
Em Sagar, and beyond it lies the large deep lake of Vijay Sagar, which was constructed by Vijaya Pala, who ruled from A.D. 1045 to 1065. The last is the largest of the Mahoba lakes, being not less than four miles in circuit, but the most picturesque of all the sheets of water in the beautiful lake district of Bundelkhand is the Madan Sagar.

According to the legend, as related by the poet Chand, the Chandels are sprung from Hemavati, daughter of Hem-raj, the Brahman Purohit of Indrajit, Gahirwara of Banaras.

Hemavati was very beautiful; and one day, when she went to bathe in the Rati Talab, she was seen and embraced by Chandrama, the god of the moon, as he was preparing to return to the skies. Hemavati cursed him. 'Why do you curse me?' said Chandrama. 'Your son will be lord of the earth, and from him will spring a thousand branches.' Hemavati inquired, 'How shall my dishonour be effaced, when I am without a husband?' 'Fear not,' replied Chandrama. 'Your son will be born on the bank of the Karnavati river; then take him to Khajuraya, and offer him as a gift, and perform a sacrifice. In Mahoba he will reign, and will become a great king. He will possess the philosopher's stone, and will turn iron into gold. On the hill of Kalinjar he will build a fort. When your son is 16 years of age you must perform a Bhanda jag to wipe away your disgrace, and then leave Banaras to live at Kalinjar.'

According to the prophecy, Hemavati's child, like another Chandrama, was born on Monday, the 11 th of the waxing moon of Vaisakh, on the bank of the Karnavati, the modern Kayan or Kane river of the maps. Then Chandrama, attended by all the gods, performed a great festival (Mahotsava), when Vrihaspati wrote his horoscope, and the child was named Chandra Varmma. At 16 years of age he killed a tiger, when Chandrama appeared to him and presented him with the philosopher's stone, and taught him polity (rajnit). Then he built the fort of Kalinjar, after which he went to Kharjurpur, where he performed a sacrifice (Jag or Yajnya) to do away with his mother's shame, and built 85 temples. Then Chandrama Rani and all the other queens sat at the feet of Hemavati, and her disgrace was wiped away. Lastly, he went to Mahotsava or Mahoba, the place of Chandrama's great festival, which he made his capital. -Cunningham, Ancient Geog. of India, p. 486.

MAHOGANY, Swietenia mahogani.

Mahonitræ, . . DAN. | Maogani, . . . IT. Mahonichout, : : DUT. Pao-magno, : : PorT.

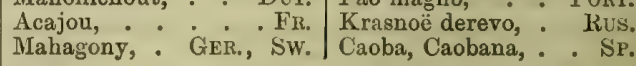

This name is given in Europe and America only to the wood of the Swietenia mahogani of botanists, but in India the timber of the Cedrelir toona, Roxburgh, is so called, and in Australia it is applied to that of a species of Eucalyptus. S. mahogani was named after Gerard van Swieten, a physician of Leyden, is indigenous in the West Indies and Central America, and naturalized in some parts of India. It is a lofty tree, with a large spreading head, and glossy pinnate leaves. The trunk frequently exceeds 40 feet in length, with a diameter of 6 feet; the timber of a rich red-brown, of different shades and markings, capable of a brilliant polish. 
MAHOMED, the founder of the Muhammadan religion, was born on the 10th November 570, and died on the 8 th June 632 , in his $63 \mathrm{~d}$ year. Arabian Prophet and Apostle are terms sometimes applied to him in European literature, but his followers in India only recognise the appellations of Rasul Allah, the messenger of God, and Paighambar, the bearer of a message. He was of the tribe of Koresh; his great-grandfather's name was Hashim; that of his grandfather was Abd-ul-Mattalib, whose son Abdullah was Mahomed's father. Mahomed is generally supposed to have been of Ishmaelitic origin, of the tribe of Kenanah. In Genesis, Ishmael is made to marry an Egyptian woman, but Arab traditions make him marry into the family of Jorhem, a descendant of Kahtan. Probably he had two wives. The Kenanah tribe was near akin to that of Kais, and both were descended from Nezar, whose name was the war-cry of the northern Arabs, in their combats with the armies of Yemen. The descendants of Kahtan, Arab-ul-Arāb, were held to be the noblest of all Arabia, and it has been surmised that this alliance was introduced to raise Mahomed into the noble families of Arabia.

The melancholy incidents associated with almost every step of Mahomed's birth and parentage, deepened the seriousness and heightened the sensibility of his character. He was a posthumous child, orphan of both father and mother at five years of age, among a people with whom to be an orphan was a disgrace. How deeply he felt his unprotected state, is evident from the earnestness and frequency with which in the Koran he recommends orphans to the care of the Faithful. The life and destiny of his father Abdallah was also peculiar, for he had narrowly escaped being offered in sacrifice to an idol, in consequence of a rash row of Abd-ul-Mattalib, and was only rescued at the price of a hundred camels. Mahomed was born during the period of tears and desolation of his mother Amina, after the death of her young husband, at the age of twenty-five, on a caravan journey. When born, he was carried by his grandfather before an idol, and received his name. Unable to nurse her own infant, his mother, after Arab fashion, wished to send him to the desert to be reared; but the Bedouin nurse who ultimately took him, at first refused to have charge of a fatherless boy. At six years of age Mahomed lost his mother also, and was taken care of by his grandfather; and on the death of the latter, three years later, by Abu Talib, his uncle, who, as long as he lived, gave him his protection. The events known of his youth are few. He appears to have accompanied his paternal uncle to Syria, and on that journey Muhammadans place the absurd legend of Sergius, Djerzi, or Bahzra, recognising the boy as the future prophet by a mark between his shoulders. During the wars of the tribes, known as the wars of the Fidjar, he is reported to have been present at one battle when he was fourteen, and to have picked up arrows for his uncle; at twenty he was keeping sheep for something like a farthing a day, an occupation considered disgraceful by the Arabs, and abandoned to slaves and women. But Mahomed always loved to dwell on the fact that Jacob, Moses, and David had been shepherds before him. Not long afterwards he cntered the service of Khadijah, a wealthy trading widow with three children, as camel-driver of the caravans which she despatched to the different markets of Arabia and Syria, and rose by his good conduct to be master of the caravan, a position of confidence. He was found a good man of business, and to have an acute perception of the market value of the striped stuffs and incense of Yemen, and the leather of Arabia, which he exchanged in the markets of Syria for corn and oil, and the silk goods of Damascus. His good qualities gained him the title of $\mathrm{El}$ Amin, the honest fellow. He was of comely appearance, and Khadijah, in spite of being fifteen years older than Mahomed, -an immense difference in a country like Arabia,-conceived the project of marrying him, and carried it into execution. For such a marriage, Mahomed seems to have been an exemplary husband. He married other wives, it is true, one of them in two months after Khadijah's death; but he never ceased to speak of his deceased wife in such terms of praise, that Ayasha declared she was the only one of the prophet's wives of whom she had ever felt jealous. Seven children were the result of this marriage; and throughout the east many claim to be descended from some one of the three daughters who survived. There were three sons, who all died young; one was called Abd Manaf, after the idol, which proves that Mahomed was at that time still an idolater. The last daughter, Fatima, was born eleven years after the marriage, when Khadijah was beyond fifty. Four years after the birth of Fatima, he had his first vision, and in connection with that event some considerations are necessary respecting his mental and bodily constitution. Whatever may have been the superiority of his moral character, it is certain that be was as unlike the most esteemed type of Arab manliness as it is possible to conceive. Nowhere in the world does man reach such a degree of dauntless independence as the Arab, educated in the freedom of the desert, and exposed to its hourly and daily vicissitudes of destiny. The ideal of the Arab was a fierysouled, irresistible warrior, always in sight of his tribe, bold in speech, rapid with song and repartee, indulging in wine, feasting, gambling, and love of women; holding tears to be disgraceful, with limbs as iron as his armour, supporting without suffering the heat of the desert under an Arabian sun; delighting in the beauty and swiftness of his steed or of his camel, impassioned for the chase, a match unarmed for the lion, indefatigable in combat, and routing like Antar whole armies with his single spear and shield. Recent travellers have confirmed the experience of ages, that the Bedorin have the least religious sensibility of any known race; at the present time they are mere Muhammadans in name, and never utter a prayer, or, if they perform any religious rites at all, these may possibly be some lingering relic of the old Sabæan adoration of the rising sun. In the days of Mahomed, the people of Mecca upheld the worship of their idols from motives of gain, but Arabs in general had little respect for them, and treated them worse than Neapolitans have ever treated a refractory saint. If the prophecies of their kalim, seers, or boly men, did not concur with their wishes, they often put them to deatl. 
When Amr-ul-Kais commenced an expedition to avenge the death of his father, he entered, according to custom, the temple of the idol Dhul-Kholosa, to obtain his approbation by means of the divining arrow. Drawing the wrong arrows three times in succession, he broke them all, and threw them at the head of the idol, saying, - Wretch, if your father had been killed, you would not forbid revenge for his death!' Mahomed was directly the opposite of this Arab ideal. He had inherited from his mother a delicate, nervous, and extremely impressionable constitution. He was gifted with an exaggerated and sickly sensibility; he had a woman's love for fine scents and perfumes; he was melaucholy, silent, fond of desert places, solitary walks, and lonely meditations at set of sun in the valleys; full of vague restlessness, weeping and sobbing like a child when he was in pain; subject to attacks of epilepsy, and without courage in the field of battle. In addition to all which, he had religious excitubility of the most acute character. He was of middle height, but of a strongly-built frame; his head was large, and across his ample forehead, and above finely-arching eyebrows, ran a stronglymarked vein, which, when he was angry, would turn black and throb visibly. His eyes were coalblack, and piercing in their brightness. His hair curled slightly; his beard was long, his step quick and firm, and between his shoulders was a mark the size of a pigeon's egg, which his disciples persisted in believing to be the sign of his prophetic office. He was naturally shy and retiring; as bashful, said Ayasha, as a veiled virgin. He lived soberly, in humble houses, and the fare of the desert seemed most congenial to him.

His principal biographers have been-

Ibn Ishaq, A.D. 768, A.H. 151.

Ibn Hisham, A.D. 833, А.H. 218.

Waqidi, A.H. 130-207, A.D. 747-822.

Ibn Saad, A.H. 230, А.D. 844.

Tabari, A.D. 922, А. H. 310.

Mir Khond, 15th century.

Ali Jannabi, 16th century.

Ismail Abul Fazl, prince of Hamah in Syria, A.D. 1332, A.H. 733. His book was translated by John Gagnier, professor of Arabic at Oxford, A.D. 1723, and into English by the Rev. W. Murray, Episcopal clergyman at Duffus in Scotland.

Dr. A. Sprenger, in 1851, published part of Mahomed's life at Allahabad in English, and in 1869 a completed life in German was published at Berlin.

Sir William Muir, of the Bengal Ciril Service, in 18581861 published a life in London.

He is lauded by Muslim authors for his religious and moral virtues, his piety, veracity, justice, liberality, clemency, humility, and abstinence. He expended his all in charity. His judgment was excellent, and he had a happy memory. He was of few words, of an equal and cheerful temper, pleasant and familiar in conversation, courteous to his friends, and condescending towards inferiors. His person was comely and agreeable, and his address polite.

He began to teach at the age of 40 . He had only nine followers in his first military expedition after his flight from Mecca to Medina; but before his death, which happened in the 23d year of his mission and the 10th after bis flight, he had brought all Arabia under his obedience, and had commenced an attack on the dominions of the Roman emperor in the direction of Syria. Abul Fazl mentions (pp. 195-267) 27 military expedi- tions undertaken by Mahomed; and of smaller actions and skirmishes some enumerate as many as 48 .

The reformation commenced by Mahomed was continued by his successors. Within six years after his death, Syria and Egypt had been subdued by his successors. Persia was invaded in A.D. 632 , her force broken A.D. 636 , in the great battle of Kadesia, and after the battle of Jallalia (A.D. 637) and Nehawand (A.D. 642), her government was entirely destroyed, and her king driven into exile beyond the Oxus. At the death of the second khalif Omar (A.D. 644, A.H. 23), the whole of Persia as far east as Herat, nearly coextensive with the present kingdom, was annexed to the Arab empire. In A.D. 650, an insurrection in Persia induced the exiled monarch to try his fortune once more, but he was cut off near the Oxus, and the northern frontier of the Arabs was advanced to that river, including Balkh and all the country north of the range of Hindu Kush. The boundary on the east was formed by the rugged tract which extends (north and south) from those mountains to the sea, and (east and west) from the Persian desert to the Indus. The northern portion of the tract was then known by the name of the mountains of Ghor, whose inhabitants may have been Afghans, and is now inhabited by the Aimak and Hazara. On the west, after Syria, Roman Africa (from A.D. 647 to 749), and Spain (A.D. 713), followed in succession; and within 100 years from the death of Mahomed, his followers had pushed their conquests into the heart of France, but were defeated by Charles Martel, A.D. 732, between Poictiers and T'ours.

In A.D. 644 , A.H. 44, an Arab force from Merv penetrated to Kābul, and made converts of 12,000 persons.

Abdur Rahman, governor of Khorasan, A.H. 80 , led a large army in person against Kābul, and subdued the greater part of the country. His proceedings displeased Hujaj, governor of Basrah, and Abdur Rabmam rebelled, took Basrah, occupied Kufa, and threatened Damascus, but, after a struggle of six years, he was defeated, and chose a voluntary death.

While they conquered they proselytized, and at the present day their creed is professed by nearly all the people of Arabia, N. Africa, Asiatic Turkey, Persia, Central Asia, Baluchistan, Sind, and Afghanistan, and by about a third part of those of European 'lurkey and of British India, with many in China and the Archipelago. Their religion is called by them Islam, but it had no sooner become a power, than divisions, feuds, wars, and schisms broke out among its professors. In their lust for personal distinction and temporal power, immediately on Mahomed's death, disputes arose as to the rightful succession to the office of leader of the Faitbful. The first to succeed was Abubakr, the father of Ayasha; following him came Omar, and then Osman, who died A.D. 655 , and Ali then succeeded. In A.D. 660, Ali was assassinated by a Muhammadan in a mosque at Kufa, on which Hasan, his eldest son by Fatima, sold his birthright of empire for an annual stipend, to Moawiyah, of the family of the Ommeiades. He took up his residence at Medina, occupying himself in acts of charity and benevolence, but in A.D. 669 he was poisoned by his wife 
at the instigation of Yezid, the second Ummiah khalif, and son of Moawiyah. Eleven years thereafter, viz in A.D. 680 , Husain, the younger son of Ali and Fatima, left Medina for Kufa, to contend for the khalifat against the Ommeiades; but on reaching Karbila, a day's journey from the west bank of the Euphrates, he was attacked, and slain with thirty -three strokes of lances and swords. The story of Husain is one of the most touching pages of Muhammadan history. His head, by order of Yezid, was carried about on the point of a javelin.

MAHOMED ALI, a nawab of the Karnatic, from the middle to the close of the 18th century. He was supported by the British in S. India, whilst the cause of Chanda Sahib was upheld by the French in India. His father, Anwar-ud-Din, in 1749 , when about seventy years old, fell at the battle of Amboor, on which Mahomed Ali fled to Trichinopoly. After the defeat of the French in the Karnatic, Mahomed Ali was recognised as nawab by the treaty of Paris in 1763; and till his death in 1795 , the Karnatic was occasionally under his rule, and at times under the civil and military administration of the British. In 1795 he was succeeded by his eldest son, Umdat-ulUmra, who died in 1801, when the British put aside Umdat-ul - Umra's son, Ali Husain, and placed his nephew, Azim - ud - Dowla, on the throne. The British in 1856 , on the demise of Mahomed Ghous, grandson of Azim-ud-Dowla, finally abolished the titular nawab.-Malleson's French in India.

MAHOMED ALI HAZIN, a Persian poet, who was in Isfahan during the siege by Mahmud the Ghilji chief, in 1722, when Shah Husain, the last of the Saffavi dynasty, ruled.

MAHOMEDANISM. At present the followers of Mahomed are styled Muhammadan, Moslem, and also Musalman, by the Europeans, the lastnamed being from the singular Muslim, and plural Musalmin, of the Arabs. 'I'he Burmese call them $\mathrm{Pa}$-thi, and the Chinese in Yunnan, Panthay, also Quay. The Chinese know them also as the Hoai-Hoai ; the Tamil race designate them Turka-kara and Chulia; and the Teling style them Turka-vadu and Jonangi. Moor, until the middle of the 19th century, was the softened pronunciation of Maghrabi, the designation of the western Arab race in the north of Africa; and Saracen, another name for them, is the changed form of Sharkia, the eastern race.

In the time of the emperor Jahangir, in India, the Hindus were estimated as 5 to 1 Muhammadan. Nr. Elphinstone's estimate about 1840 was 8 to 1 . Another estimate made the relative numbers as $6 \frac{1}{2}$ to 1 , or about 17 per cent. of the population as Muhammadans.

In the Feudatory States of India in alliance with the British, the predominant numbers follow Hinduism, or worship local deities; but in the territories under British rule, the census of 1881 showed the Muhammadans to be 50,121,585, viz.

N.W. Provinces, 6,162,900

Bengal, - . 21,704,724

Madras, : : $1,933,561$

Panjab, * : $11,662,434$
Bombay, $\quad 3,774,360$

Central Provinces, 285,687

Mysore, . . : 200,484

Assam, : : : i, 317,022

Herar, . . . 187,555

VOL. II.
In India, the people of this religion are of the most varied descent, the offspring of Arabs of every tribe, from the Iranian races of Persia, from the Scythic, Tartar, Mongol, Turk, Baluch, and A.fghans, with bodies of converts from the Agnierala Rajput, from the Jat, and from the prior Mongoloid tribes who preceded the Aryan immigrants. In the northern parts of India, the bulk of the Mubammadans are of Mongol or Afghan descent, and recognise themselves by the titles of Moghul and Pathan converts, Arab Muhammadans being styled Shaikh.

The descendants of the various Muhammadaus who from time to time, as conquerors and campfollowers, entered India with Mahmud, Chengiz Khan, Timur, Nadir Shah, A hmad Shah, and others, have found employment in the armies of Dehli, Hyderabad, Arcot, Lucknow, and Rohilkhand, and in the native Indian armies of Great Britain.

On the western frontier of India, in the Paujab, and in the territories lying on each side of the Indus, the Muhammadans are chiefly of Mongol, Turk, Afghan, and Baluch descent, with other smaller bodies, converts from Hinduism, of Rajput and Jat races. There are the Multani, Bhatti, and Khurul of the Rechnab Doab in the Panjab, the Awan of the Sind Sagor Doab, who are supposed to be of Grecian descent, the Daoudputra of Bahawulpur, the Tuwana of the Shahpur district, the Mewatti of Gurgaon, and many of the Gajar race scattered through different parts of Northern India. In the N.W. Provinces are the Afghan Rohilla of Rohilkhand, and the Kourboh of Meerut, likewise Muhammadan. There are also Muhammadans in Bhopal, Mundisor, and Joura; the late rulers of Oudh were Syuds, the late rulers of Hyderabad in Sind were Balucb, and the rulers of Hyderabad in the Dekhan are Syuds. The Daoudputra Mahummadans trace their descent to the khalif Abbas, but take their name from Daoud, the first of the family who acquired a name. They are, however, supposed to be Baluch, changed by a long residence in Sind. They moved from Bahawulpur, and seized land on the Sutlej, reducing the remains of the ancient Lungga and Johia, and introducing the Sind system of canal irrigation. Their claim to be descendants of the race of Al Abbas, who reigned at Baghdad from A.D. 749 to 1258 , may, however, be correct. The surnames met with -Gori, Kirmani, Koreshi, Sherazi-show their possessors' views as to their old homes, and the tenacity with which the families look to their original starting-places. All Afghans, while in India, carefully retain their tribal names, the Yusufzai, Mehmun, Barakzai, etc. The Wallajah family, who for a few years had a troubled rule in the Karnatic, trace their descent from the khalif Omar, A.D. 644 , and in their conversations would notice the course of their fortunes as having had amongst them a khalif, a kazi at Samarcand, and nawabs of the Karnatic. Races who, as in this instance, can take a retrospective view of their history for 1280 years, who can disregard many hundreds of years of obscurity, and can see in that long time only the dignities possessed by three ancestors, a khalif, a kazi, and a nawab, will readily accept a reverse of fortune as God's hand laid upon them, will regard it as but of temporary duration, and will watchfully await a change. 
In Peninsular India, the only important rulin power of these religionists is that of the Syud of Hyderabad, the Nizam Subahdar of the Dekhan, whose sway has existed above a century, them:selves strangers, ruling with a mixed foreig $n$ soldiery of Arabs, Negroes, Abyssinians, an d northern Hindus, over parts of the Canaress, Teling, Mahratta, Gond, and Kol races, and thei $r$ capital is now the principal resort of adventurers.

In the extreme south of India there are three: Muhammadan races, - the Moplah, the Labbai, and the Nao-Aiti,-_differing, by very marked characters, from all around them. The Labbai are a tall and large-made race, of a deep bronze colour. Their usual dress consists of a wrapper round the loins. They are extensively engaged in mercantile business, and as pedlars. They use the Tamil alphabet, have a Tamil Koran, and speak and read the Tamil language only. Their name is derived from the Arabic word Labek,-May it please you, - and the people are usually supposed to be descendants of trading or sailor Arabs with mothers of India. The Nao-Aiti are a small nonmilitary race, who, but for a slightly xanthous tinge, would have an almost English fairness. They are called Nao-Ait, new-comers, emigrated from Arabia about 300 years ago, and are to be found in considerable numbers in Southern India. They are slender, fair men, with very handsome women, and are engaged in civil avocations, never becoming soldiers. They say that they came from Arabia to the Konkan. Indian Muhammadans assert that they are the descendants of women and children from Arabia, whose men were killed on being detected in an attempt to rob the tomb of Mahomed, and with their wives and children were sent off in a ship, which landed on the western coast ; but this is doubtless a story got up to vilify the race.

The Moplah on the south-western coast of India and in Ceylon are said to have had a similar origin to the Labbai, viz. from Arab fathers and Indian mothers, and the name is supposed to be derived from the Tamil $\mathrm{Ma}$, mother, and Pillai, son. On several occasions since that part of India came into the possession of Great Britain, they have required to be coerced, and are believed to possess a restless spirit, with much fanatical zeal; but it is generally recognised that agrarian disputes have been a prominent cause of their outbursts. The Moplah of North Malabar, although Muhammadans, follow the rule as to property of descensus a matrice, the Marumakliatayam, having in this respect conformed to Hindu usage, in the times of Hindu ascendency. The Moplab also take the wife of a deceased brother.

The Moplah and Labbai are called by the Teling, Jonangi, Zonangi, Jonagar, Jonakara. The intercourse of Muhammadan merchants and seamen with the women of Western India seems to have been from the most ancient times. Abu Zaid, writing A.D. 916, mentions that the more devout merchants of Siraf, when young men were on board, avoided sending their ships to Ceylon, as the women were very licentious, and merchants would, when newly arrived, make advances to the daughter of a king, and she, with the knowledge of ber father, would go to meet him in some woody place.

The Abyssinian and Negro races in India are usually known as the Habshi, Habush, or Sidi. fo
Many of them are slaves, but both as slaves and freemen they are often employed about the households of native sovereigns. The Sidi of Janjera or Zanjera was long powerful and independent, occupying the coast a few miles south of Bombay.

The Bohra are found on the north-western coast of Peninsular India, and in the Rajput states, and represent themselves to be the descendants of the followers of the Shaikh-ul-Jabl, or the celebrated Old Man of the Mountain. They call themselves Ismaili, acknowledge an Archamandrite or religious chief. They principally follow mercantile pursuits, and are a robust, active, intelligent mercantile race. They are scattered all over the country, but are found principally in Gujerat and the adjoining provinces of Cutch, Sind, and other parts of the Bombay Presidency, and are a peaceable, inoffensive body of men.

The Maiman or Mehman are said to be the descendants of a couple, of Sind, long childless, who about six hundred years ago became converts to Muhammadanism, in consequence of the prayers in their behalf by Mahbub Sub'hani at Baghdad being rewarded by seven children. Their original language is Sindi. They greatly revere Mahbub Sub'hani. Many families are met with in Gujerat and Bombay, and they are a useful, hard-working, trusty mercantile people.

In Sumatra and the more western islands of the Archipelago, there has been a large conversion to the creed of Islam. In Sumbawa the Muhammadans take a high place, and they are largely proselytizing the mountaineers, who, however, secretly trust in their idols.

There are many Muhammadans in China who are neither zealous in the propagation of their doctrines nor over-strict in the observances of their religion. But their religion is one of the authorized state creeds of that country.

Muhammadan religionists are of two great sects, the Sunni and Shiab, the former being the more numerous in India, Turkestan, Turkey, and Arabia, while the Shiah are most numerous in Persia. The Sunni hold, amongst other points, the succession to the khalifat to have followed in the line of Mahomed, Abubakr, Omar, Osman, and Ali; the Shiah sect, on the other hand, maintaining Ali to have, and by right, succeeded his cousin and father-in-law Mahomed. There are other points on which their sectarian differences turn; but small numbers of the Shiah religionists, in several parts of Asia, as in the west of India, believe in incarnations of Ali, and of these the Ismaili may be instanced. The Muhammadans of India, of these two great religious sects, worship apart; but amongst both sects are to be found men of Syud, Shaikh, Moghul, and Pathan descent, and sons will be found as Sunni and the daughters Shiah. The Syuds, the Saadat, or lords, are chiefly descendants of Mahomed through his daughter Fatima and her husband Ali, and as a rule are quiet, humble-minded men, not distinguished by other qualities from the Shaikhs. They are of the Sunni and also of Shiah persuaion, and are met with in India serving as soldiers, $\mathbf{r}$ in civil avocations, or following some religious uties. The term Shaikh is given to other escendants of Arabian origin, and is applied znerally to all of the Sunni sect other than ruds, Pathans, or Moghuls. The Shaikh, therere, is of the most varied origin, and is engaged 
in all arocations, military and civil, as soldiers in regular and irregular armies, as police, shopkeepers, and a sprinkling of them in learned professions or occupations requiring prior education. The Pathan is the descendant of the Afghan soldiers who came iuto India with the armies of Mahmud, Timur, Chengiz Khan, Baber, Nadir Shah, and Ahmad Shah, and carved out principalities or obtained lands for themselves and their descendants; but there are numerous individuals of the Afghan and Baluch tribes, large, powerful, fair men, scattered throughout India, who are seeking a livelihood in it as soldiers, traffickers, and chapmen. The Pathan claims for himself the designation of Khan, but this is never permitted at courts, Khan being one of the honorific appellations bestowed by Indian sovereigns.

Moghuls assume the suffix of Beg. They are comparatively few in number, are generally fair people, of a larger physical frame than the Arab Muhammadaus, and are of unassuming manners. Of all these religionists of foreign descent, few have taken to agriculture; a very small number have fitted themselves for the civil situations available under the British Government; except in entering the disciplined armies of Britain as private soldiers, and forming perhaps one-fourth of its Indian forces, very few of them have accommodated themselves to the changes which the British supremacy has introduced. In India, the bulk of them are essentially a people not belonging to the present time, but dwell on the past and look forward to the future, the religious among them meditating on the transgressions which have brought upon them great reverses, and all, perhaps without exception, looking forward to the time when it shall be God's will again to give them dominion. As a whole, they are earnest, ardent men, who can be easily excited. As soldiers they are patient, and have an elan in warfare which the steady, calmer Hindus of Southern India do not possess. Their religious feelings, for many years past, have been personal, and though dwelling and ruling in parts of India since nine hundred years, and though holding an essentially proselytizing faith, they have not made many voluntary conversions from Hinduism, either from the Aryan family or from the nonAryan servile classes. Perhaps nothing has ever taken place from the efforts of Muhammadans like the upheaving which has for some years past been agitating non-Aryans in the extreme south of the Peninsula. In India, as a body they are illiterate, and even as regards their religion they have acquaintance only with a few formulas in the Arabic language. Their book, the Koran, has been translated into Persian, Hindustani, English, Tamil, Burmese, and Malay; but in India the Arabic is deemed the more sacred language, although a very small number of them know that tongue.

The spoken language of Muhammadans in India is the Urdu, or camp tongue, called in the Peninsula Hindustani, which, since the beginning of the 19th century, under British influence has become a written tongue, and a few books have been printed in it; but the educated of the higher classes all use Persian as their sole means of communication. Living as they have been amongst races so highly educated as Hindus are, it is perhaps this want of learning that has blunted their proselytizing efforts, the only great changes which their religion has effected having been amongst the Jat, the Rajput, and the people of Bengal.

Social Customs:-Distributed as these religionists are, from the Atlantic to the islands of the Pacific, the acknowledgment of the Koran and of their creed by all of them, gives a certain similarity to their religious observances, bu the customs of social life in all the varied nations are as varied as are the nations themselves. In India there are ceremonials before and after childbirth, such as congratulations to the young wife on the seventh month of her pregnancy. As in the Hebrew law, after the birth of a child, the chahlam or fortieth-day ceremonial is performed, and each stage of development in childhood is attended with certain forms. There is no time rigidly adhered to for circumcision, which is not in the Koran, and grown-up lads have not unfrequently remained unattended to in India up to the seventh or the fourteenth year. The coming of age of a girl amongst the Hindus is made known by noisy music, a practice which is imitated by the humbler Muhammadans, though the educated and noble families abstain from all such rude rejoicings. Very few of the Muhammadan women of India can read, and still fewer can write. But in the towns of India, amongst the better classes, all boys are sent to school, and their education is conducted in such a manner as permanently to fix their faith. At the age of four years, four months, and four days, each child is taught to pronounce the name of God with much ceremonial, - with more even than is shown when children of the Episeopal persuasion in England are confirmed, for the ceremony is made to last for days. The boy is then taught the first words that were revealed to Mahomed. They are recorded in the $96 \mathrm{th}$ chapter of the Koran, which says, "Read in the name of thy God, for he it is who hath created all mankind out of a lump of coagulated blood. And he is likewise that almighty Being who has blessed us with the voice of utterance and taught us the use of the pen ;' and until the lad has read the Koran (many of them learning it all by heart, and then receiving the literary title of Hafiz), and until they have been carefully instructed in all the books of their faith, the lad is not allowed to read any other tongue. In their marriages the Indian Muhammadans are united by the civil and religious rite, the Nikkah, similarly with all other of their co-religionists, but to this has been added several days of costly ceremonial rejoicings (Shadi), which they have gathered from the Hindus. Divorce, in India, is almost unknown, for in the Nikkah the dower which the bridegroom promises is a fabulous sum, which no one can pay, and as, until paid, divorce (tallaq) cannot be concluded, no one in India is ever divorced. The Indian Muhammadan lives faithfully to his one wife, polygamy being almost unknown, except amongst the loose livers of great towns. The Ramazan month of fast is very strictly attended to; but amongst the Sumni in the south of India the Maharram is a period of extravagant amusement, in which many nonHindu and many Hindu races join. The illiterate Sunni, by far the majority, at this period grossiy outrage the grief of the Shiah sect, and scandalize the learned and devout. In Southern $\Lambda$ sia 
there is a great reverence shown to saints' shrines and foot-marks. Amongst these are the tombs of the Pir-i-Dastagir at Baghdad, of Kadar Wali at Negapatam, and the footprints of the prophet at the Kadam Rasul hill near Secunderabad, to which multitudes annually resort. The great religious festivals are the Ramazan month of fasting and prayer; the thirteen days of the Maharram, a period of festivity amongst the Sunni and grief amongst the Shiah; the Shaban feast of Shab-i-Barat on the 14th day of that month; and the sacrificial festival of the Bakrid or Zibaj, also known as the Eed-us-Zoha, which is held in commemoration of Abraham's sacrificial offering up of his son,-of Ishmael according to Muhammadans, and of Isaac according to Hebrews and Christians.

The Akhiri Char-shambab is the last Wednesday of the month Suffur, on which Mahomed in his last illness felt a little better, and bathed for the last time.

The Bari Wafat, or great death, is commemorative of the demise of Mahomed, on the 12th-13th of Rabi-ul-Awal, A.H. 11.

Muhammadans speak reverentially of the dead. They will say, Rahlat farmaia, he has taken departure; Intikal kia, has made a change; Guzr gaia, has passed away; and they believe in the consciousness of the departed while awaiting resurrection in the tomb.

Amongst those who crave for other aids to salvation, some seek the spiritual advice of a holy man, who is reckoned a pir, or religious teacher, and by certain secret words and signs are initiated as his murid or disciples. Others, even men of rank, adopt the darvesh or fakir life of the religious mendicant devotee, often attended with solemn rites of investiture, and followed by the severest of ascetic lives; but the bulk of these mendicants are, in India, idle, dissipated men, and a few are of very degraded habits. They arrange themselves into the followers of certain pir or spiritual guides, and those generally met with in India are the Kadria or Ba-nawa, Chastia, Shutaria, Tabqatia or Madaria, Mallang, Rafai or Gurz-mar, Jalalia, Sohagia, Naksh-bandia, and Bawa Piray. All these have their own rules and customs. Some of them are ascetic devotees, eating if given to eat, but never begging; some largely use intoxicating fluids and vegetable narcotics; some, as the Salik, have wives; the Majzub and Azad have no wives; and some Calandar marry, and some do not. There are, among Mubammadans in India, good, devout men, leading pure and holy lives, earnestly seeking for the truth, cultivating literature assiduously; but they are coin. pelled by the multiturle of ordinary people to retire into the peaceful slrade, as the purity of their lives begets for them the objectionable name of Wahabee. The Muhammadans in India, when their limited education is considered, are but little superstitious. They believe in Mahomed as an intercessor, and in the second coming of Christ. 'I'hey believe that at death the soul will be judged, and that the angels Nakir and Mankir will visit it in the tomb to question as to the life on earth. They believe that all must cross the Pul-i-Sirat, a bridge for the good, but a sharp sword to the wicked; they believe in a purgatory called Iraf, and in places of future rewards and punishments, and they picture the latter as fearful. But the idea of a heavenly place as enunciated in the Koran, is the grossest that any race has ever promulgated or given credence to. The wild hunter tribes of America have sublime notions of a future life : Hebrews were in conflict as to the immortality of the soul; the Buddhists believe in absorption or annihilation, as a release from all the troubles and trials of a mundane existence; and Christians believe the future to be a spiritual life; but the doctrines taught in the Koran as to the occupations in heaven are wholly confined to that book and its believers. For there, the Koran says (lv. 393-394), 'they shall repose on couches, the linings whereof shall be of thick silk interwoven with gold; and the fruit of the two gardens shall be near at hand to gather. Which, therefore, of your Lord's benefits will ye ungratefully deny? Therein shall receive them beautiful damsels, refraining their eyes from beholding any besides their spouses, whom no man shall have deflowered before them, neither any genius (which, therefore, of your Lord's benefits will be ungratefully deny?); having complexions like rubies and pearls. ... And besides these, there shall be two other gardens, . . . of a dark green. In each of them shall be two fountains, pouring forth plenty of water; ... in each of them shall be fruits and palm trees and pomegranates. . . Therein shall be agreeable and beauteous damsels, ... having fine black eyes, and kept in pavilions from public view; ... whom no man shall have deflowered before their destined spouses, or any genius. . . . Therein shall they delight themselves, lying on green cushions and beautiful carpets.'

Such is the heaven of the Koran. Yet Mahomed was a monotheist and an iconoclast. And before the final struggle, lifting up his voice, he exclaimed, 'May God be far from those who make the tombs of his servants places of prayers.' The very last words he was heard to utter as he expired, as if in answer to an unseen visitor, were, 'In the company of the blest on high.'

The tombs of Muhammadans have usually been of earth, or unbaked brick, but every material is employed, and names are even engraved on the tombs. The tombstone of a man is distinguished by a raised part in the centre, and that of a woman by a depression. The prevalent form in India for the toubs of the rich is a dark or black tombstone, with verses of the Koran engraved on it, aud covered by a cupola. Some of these are very magnificent. Those of the Adal Shahi dynasty at Bijapur and Gogi have attracted much attention, as also have those of the Bahmani dynasty at Kulburga and Beder, and Kutub Shabi dynasty at Golconda. The cupolas at Roza, where Aurangzeb also is buried, have not any display, and that of Aurangzeb himself is the least ostentatious. His daughter's tomb at Aurangabad is magnificent; and many of the tombs at Dehli and Agra are great structures. That of Mumtaz Begum, known as the Taj Mahal, is particularly remarkable. Reformers amongst the Muhammadans consider that unbaked brick or earth should alone be used.

Muhammadans are bound to recognise professors of Muhammadanism, being enjoined to do so in the Koran: "Do not say to one who meets you and salutes you, You are not a true believer,' and, ' $O$ ye true believers, avoid suspicions, for suspicion is often a crime, 'are two texts known to all, 
and generally obeyed. Hence the pronouncing of the first part of the creed, La illaha il Allaho, There is no deity but God, entitles the speaker to a favourable reception.

Mahomed in the Koran asserts that his religion is that of Abraham. The religion he established is termed Islam, signifying safety or salvation, and comprises the two essentials, Iman, implicit faith, and Din, practical religion. Five points are insisted on, namely, belief in God and Mahomed his a postle; prayer; almsgiving; fasting during the month of Ramazan; pilgrimage to Mecca. The first of these belongs to Iman; the latter four to Din.

Muhammadanism, as it now exists, stands upon other foundations than the Koran. This book not furnishing a guide or precept to meet every emergency, a great body of tradition, denominated the Hadis, has been added; and this law, oral as it originally was, is generally considered equally binding with the written law of the Koran. These traditionary precepts were derived from Mahomed himself, his companions, and immediate successors. Some of them are, however, of doubtful authenticity, and not a few are evidently of more modern fabrication. The Persians reckon four kinds of Hadis.

The principal places for minor pilgrimages are the tomb of Ali, called Mash'hid-i-Ali, at Naj'f near Kufa; the shrine of Imam Husain at Kerbela ; and that of Imam Raza at Mash'hid in Khorasan; but all the numerous Imam-zadah and tombs of holy characters throughout the country are visited. The minor pilgrimage is termed a Ziyarat, as distinguished from the Haj or great pilgrimage to Mecca.

Of the Muhammadan saints of Asia are AbdulKadar, surnamed Ghous-ul-Azam, the great contemplative, born at Jal, near Baghdad, A.H. 471 (A.D. 1078-79). He was endowed with great virtue, and, with the gift of miracles, had many disciples, and is still much revered. He is called Shaikh, but was a Syud, i.e. of the race of Husain,and died in A.H. 571 (A.D. 1175), aged ninetyseven years. Where he died or was buried does not appear.

Sultan Sarwur, at Baluch, four cos from Multan, was distinguished for piety and purity of manners, and died as a martyr, with his brother, fighting against a troop of idolaters, and was buried with his wife (who died of grief) and his son in the same tomb. Several miracles are related as having happened at his tomb. A camel's leg, when broken, was forthwith made whole; the blind, the leprous, the impotent were cured.

Shah Shams-ud-Din, Dariai, at Depaldal in Lahore, is stated to have bad even a pious Hindu among his disciples. The latter having expressed a wish to go and bathe in the Ganges, the saint directed him to shut his eyes, when lo! the Hindu found himself among his relations and friends on that sacred stream, in which (as he supposed) be bathed with them. On opening bis eyes again, be straightway found himself beside his spiritual guide in Lahore. His tomb is guarded by Hindus, who will not resign their posts to the Muhammadans. It is also related that some carpenters, having proceeded to cut down a tree which grew near his tomb, split it into many pieces for use. Suddenly a dreadful voice was heard; the earth shook, and the trunk of the tree arose of itself; the workmen fled terrified, and the tree did not fail to resume its flourishing condition.
Kutub Sahib, or Kutub-ud-Din, lies buried at Kutub, a town near Dehli, named after him, in which the late Shah Alam and many members of the royal family of Dehli are buried. His tomb is much frequented by pilgrims, he being one of the most renowed and venerated of the Muhammadan saints.

Shaikh Baha-ud-Din, Zakaria, born at Cotcaror in Multan. He was a great traveller, having, it is said, overrun Persia and Turkey, and a disciple for some time of Shahab-ud-Din, Sohurmurdi, at Baghdad. He died on the 7th Sufur, A.H. 665 (A.D. 7th September 1266), and was buried at Multan.

Furrid-ud-Din, born at Ghan-awal, near Multan. He was so holy, that by his look clods of earth were converted into lumps of sugar. He was therefore surnamed Shakargunj, the treasury of sugar.

Shaikh Sharif bu Ali Qalandar, born at Paniput, a town 30 cos north-west of Dehli, to which capital he came at forty years of age, and became a disciple of Kutub-ud-Din. He devoted himself for twenty years to external sciences; after which he threw all his books in the Jumna, and began to travel for religious instruction. In Asia Minor he profited greatly by the society of Shams Tabriz and Mulvi Rumi. He then returned home, lived retired and worked miracles, and is said to have died A.H. 724 (A.D. 1323-24?).

Shah Nizam-ud-Din Aulia, by some supposed to have been born at Gazna, A.H. 630 (A.D. 1222-23), and by others in A.H. 634 (A.D. 1236), at Badaun, a town in the province of Dehli, where he lived. He died A.H. 725 (A.D. 1325), and was buried near Dehli, hard by the tomb of Kutub-ud-Din. Through his great piety he was considered one of the most eminent saints of Hindustan.

Kabir, a celebrated Hindu unitarian, equally revered by Hindus and Muhammadans, founder of the sect called Kabir Panthi or Nanak Panthi, from which Nanak, founder of the Sikhs, borrowed the religious notions which he propagated with the greatest success.

Baba Lal, a darvesh (and likewise a Hindu), who dwelt at Dhianpur, in the province of Lahore, the founder of a sect called Baba Lali. He held frequent conversations on the subject of religion with Dara Shikoh, eldest son of Shah Jahan, and brother of Aurangzeb, which have been published in a Persian work by Chandarbhan Shah Jahani.

Shah Dola died in the seventeenth year of the reign of Alamgir, was at first a slave of Humayandar Sialkoti, in Lahore. But he seems afterwards to have attained great affluence, as well as fame; for, having settled at Ch'hotee Goojrat (Little Gujerat), he built tanks, dug wells, founded mosques and bridges, and wondrously embellished the city, for though his contemporaries came to visit him from far and near, and made him presents of gold, money, and other objects, he returned to each three or four fold more than he received. His generosity was such, that had he been contemporary with Hatim Tai, no one would have mentioned the name of that hero.

Syed Sbah Zuhur, distinguished by his wisdom, piety, and austerity of life. $\mathrm{He}$ built a small monastery of earth at Allahabad, which still remains. He was celebrated for his miracles; and by his prayers the most frightful chronic complaints were immediately removed, of which an instance is given in respect to the case of the governor of Allababad, Nawab Umdat-ul-Mulk 
Amir Khan. Zuhur boasted of having lived 300 years.

Shaikh Muhammad Ali Hasin Jilani. His tomb is at Buxar, where he died in A.H. 1180 (A.D. 176667), distinguished for his science, learuing, and literary talents. He wrote in both prose and verse with equal skill.

There may be mentioned also Abdul - Kadar, Gilani, styled Pir-i-Piran and Pir-i-Dastagir, and Badi-ud-Din, a Syrian saint.

They recognise about 156 sects. As a broad distinction, they are generally classed as Shiah and as Sunni, but the six bodies of sectarians who oppose the Sunni are classed by them as Rafziah, Kharjiah, Jabriah, Kadriah, Jahmiah, and Marjiah, each of whom are broken up into smaller bodies. Before the end of the 1st century, from the ascetic turn and the theosophy inseparable therefrom, a combination, styled among the Arabs Sufi, had arisen. This made rapid strides, and in the end of the 3d century of the Hijira was already itself the subject of learned works, and the Muhammadan world has carried the system to the utmost extreme. Their Sufi outstrip in every point of view both the Hindu Jogi and the Christian monks. The asceticism of the Sufi is more systematic, their pantheistic teaching deeper and more consistent, and their vices more enormous, than those of any other people. Spinoza and Schelling are left far behind by Ibn Arabi.

Great portions of the earth have been brought under the sway of the races professing Islam, and this has moulded the heroic character of the Muhammadan world. The pride of belonging to the dominant creed makes every man a hero, and, even in the domain of mind, produces under such circumstances the elements of greatness.

Muhammadan law comprises things lawful and things unlawful. The lawful are arranged into five classes, viz.:-

Farz, enjoined in the Koran.

Wajib, there are some doubts as to its divine injunction.

Sunnat, the example of Mahomed.

Mustahab, that which he sometimes did, and sometimes omitted.

Mubah, that which may be left unperformed, without any fear of divine punishment.

The unlawful things are-

Haram, distinetly forbidden in the Koran and Hadis.

Makruh, that which is by common consent considered to be unclean or unlawful.

Mufsid, that which is corrupting and pernicious. -Sale's Koran; Malcolm's Persia; Malcolm's Central India; Huc, Chinese Empire; P. Arminius Vambery of Bokhara; Richard F. Burton, Scinde; Bunsen, God in History; Ferrier's Journey; Araishi-Mahfil; Price's Muhammadan History; The Bhilsa Topes; Cunningham; Dr. Sprenger ; Herklots, Qanoon-i-Islam.

MAHOMED - bin-KASIM, a general of the Khalif Walid; about A.D. 718, overran Gujerat, and was advaneing on Chitore when he was met by Bappa and entirely defeated.

MAHOMED GORI, in Hindustan, overthrew and slew Prithi, raja of Dehli and Ajmir, took Kanouj and Benares, plundering all their Hindu temples. In A.D. 1206 he was assassinated in his tent on the banks of the Indus. He was succeeded by Kutub, one of his slaves.
MAHOMED HAIDAR, commonly called Mirza Haidar, author of the Tarikh-i-Rashidi. He was a cousin of Baber. He was killed in a night attack, A.H. 958.

MAHOMED HUSAIN KHAN, author of the Makhzan-ul-Adwiah, or Storehouse of Medicine. It was written A.D. 1769, and printed at Hoogly 1824. Another work, Qarabidin, is also by this author.

MAHOMED KASIM was nephew of Hejaj, governor of Basra. During the khalifat of Walid, Hejaj sent his nephew from Shiraz with an army 6000 strong, to attack Dewal (A.D. 711, A.H. 92), a seaport connected with Sind, belonging to Raja Dahir. It had numerous Brahman inhabitants, but was garrisoned by Rajputs. A shot from a catapult carried away the flagstaff displayed on the tower of the temple; the garrison, dispirited by the event, yielded, and the town was occupied. At first he contented himself with circumcising the Brahmans, but they still refused Muhammadanism, on which he ordered all above seventeen years of age to be put to death, and all under it, with the women, to be reduced to slavery. The rich booty obtained was equally divided, after reserving one-fifth for Hejaj. A son of Dahir was in the garrison, and retreated to Brahmanabad, where he was followed by Kasim, and surrendered on terms. Kasim then advanced on Neirun (Hyderabad), and thence to Sehwan, which the garrison evacuated after a seven days' siege. Kasim then waited till reinforced by 2000 horse from Persia, and, after several indecisive combats, reached the neighbourhood of Alor, where he was opposed by Dahir, who fell fighting in the midst of the Arabian cavalry. His son fled to Brahmanabad, but Dahir's widow defended the city against the attacks of the enemy until the failure of provisions rendered it impossible to hold out longer. Then the whole garrison resolved to die. The women and children were first sacrificed in flames of their own kindling; the men bathed, and, with other ceremonies, took leave of each other and the world, threw open the gates, rushed out sword in hand, and, throwing themselves on the weapons of their enemies, perished to a man.

One more stand was made at Ashcandra, after which Multan and the other parts of the dominions of Dahir seem to have been occupied without resistance, and tribute enforced from the Hindus who refused to be converted.

Kasim sent to the court of Walid two daughters of Dahir, but when the eldest was brought into his presence she burst into tears, and said she had been dishonoured by Kasim, on which Walid gave orders to sew Kasim into a raw hide, and send him to Damascus. This was done, and the khalif showed the body to the princess, who now exultingly declared that Kasim had been innocent, and that she had thus revenged the death of her father and the ruin of her family. About 36 years after the death of Kasim, the Muhammadans were expelled by the Rajput tribe of Sumera, A.D. 750 , A.H. 132 . -Elphin. pp. 264-65; Ayin-iAkbari, ii. p. 119 ; Tod's Rajasthan, i. p. 243; Tarikh-i-Hind-wa-Sind.

MAHOMED MUMIN-ibn-MUHAMMAD DILIMI, a celebrated physician, author of the Persian book on medicine, Tuhfat-ul-Muminin. He was an inhabitant of Tinkaboon, in the pro- 
vince of Mazanderan, on the S.W. coast of the Caspian Sea.

MAHOMED SHAH, emperor of India, was the son of Shah Jahan. He ascended the throne in September A.D. 1719 (A.H. Zi Kaidah 1131), and died April A.D. 1748 (26 Rabi-us-Sani 1161). His name was Roushan Akhtar, and he was selected for the throne by Abdallah and Husain Ali, two brothers, Syuds of Barrh, after the deaths of Rafi-ud-Darjat and Rafi-ud-Dowla. In October 1720 he accompanied Husain Ali in his march against Asof Jah, but the Syud was assassinated, and Abdullah Khan, his brother, revolted, and put another king on the throne; but in November Mahomed Shah's army defeated and made him prisoner. Mahomed Shah was indolent, irresolute, and ruled timorously. During his long reign he witnessed the breaking up of the Moghul empire by the Mahrattas, chiefly while Nizam-ul-Mulk, one of his officers, founded the sovereignty of Hyderabad in the Dekhan. The Mahratta Peshwa, Baji Rao, obtained Malwa as a jaghir, with a large portion of country south of the river Chambal. In $1739 \mathrm{Nadir}$ Shah defeated Mahomed Shah in battle, and plundered Dehli, massacring its inhabitants, of whom about 50,000 perished, and carrying off treasure valued at 10 or 12 millions sterling. Nadir Shah reinstated him on his throne, receiving the cession of all the provinces west of the Indus river. Mahomed Shah, in 1748 , sent his son Ahmad Shah and his minister Kamr-ud-Din against the Abdali; but his minister was slain, and Mahomed Shah, on hearing of the death, died in convulsions.--Orme.

MAHOMED TAGHALAQ, emperor of India, reigned from (A.H. 725) A.D. 1325 to (A.H. 752) A.D. 20th March 1351. His name was Juna Khan, but he took the title of Mahomed Taghalaq. He succeeded to the throne as a parricide. $\mathrm{He}$ erected a wooden structure, and after his father the king, Ghaias-ud-Din, had alighted and was resting in the pavilion with his favourite son Mahmud, Mahomed proposed that the whole of the elephants should pass in review before the building. When they came over the fatal spot, the structure came down on the heads of Ghaiasud-Din, Taghalaq Shah, and his young son. After intentional delay, the ruins were removed, and the king's body was found bending over that of his boy as if to shield him. It was carried to Taghalaqabad, and laid in the tomb which the king had built for himself. This still stands one of the simplest and grandest monuments of Muhammadan antiquity, rising from the middle of what is now a swamp, but was then a lake. Mahomed Taghalaq was the most eloquent and accomplished prince of his age, with an extraordinary memory, devout, abstinent, and moral, of distinguished gallantry and personal activity; but his whole life was oceupied with visionary schemes, pursued in an irrational manner, with a total disregard of the sufferings of his subjects. He completed the reduction of the Dekhan. He sent an army 100,000 strong across the Himalaya to conquer China, but they had to retreat, and scarcely a man returned. It is difficult to guess by what point this host entered the Himalaya, nor has the town of Jidiah, at the base of the mountains, mentioned by Ibn Batuta, been identified, which would indicate the position. He maintained an enormous royal establishment analogous to the
Gobelins, or weavers in silk and gold brocade, to provide stuffs for his presents, and for the ladies of the palace. He repeatedly massacred his subjects, whom he drove into revolt in Malwa and Bengal, and Karnata and Telingana threw off their allegiance. He twice made Deogiri, the modern Dowlatabad, his capital, removing the inhabitants of Dehli to it. His court was visited by Ibn Batuta about A.D. 1341.-Yule, Cathay, ii. p. 405; Elphinstone's Hist. of India.

MAHOMED YAKUB-bin-YUSUF, physician to the emperor Shah Jahan. He compiled the Alfaz-ul-Adwiah, a catalogue work on medicine, which was translated into English in A.D. 1793 by Mr. Gladwin.

MAHOMEDZAI or Mamanzai, a mixed population of 25,000 souls in the Hashtnagar division of the Peshawur district. They have about 5000 matchlock men.-H. A. N. W. F. p. 302.

MAHR. Arab. A Muhammadan bride's dower, settled on her before marriage, and due to her or her heirs. Dirorce cannot be completed until the dower is paid, and in India the dower is fixed so high that divorce is almost unknown.

MAHR or Mohur, from Muhr, HIND., a seal, is a gold coin of value 15 or 16 rupees.

MAHRATTA, a country, called Maharashtra, first mentioned in Indian history in the Mahawanso. Maharashtra was one of the nine kingdoms of Southern India in the time of Hiwen Thsang, the Chinese Pilgrim (640 A.D.). The Mahratta race inhabit the country lying between the range of mountains which stretches along the south of the Nerbadda, parallel to the Vindhya chain, and a line drawn from Goa, on the sea-coast through Beder to Chanda, on the Wardha river. That river is its boundary on the east, as the sea is on the west. At the census of 1881 the number speaking the Mahratta language was returned as $16,966,663$.

The district of Poona, and the adjacent tracts of Satara and Sholapur, the home of the Mahrattas, stretch for about 150 miles along the Sahyadri ghats, between the 17th and 19th degrees of latitude, and extend at one point as far as 160 miles inland. To the west the Mahrattas possessed the narrow but strong tract of country wbich borders on the Konkan, and stretches parallel with the sea from near Surat to Canara. This country is well calculated for the maintenance of defensive warfare, but that the people were not of the Kshatriya military caste is proved by the names of their particular tribes, the Kunbi, the Dhangar, and the Goala, or the farmer, shepherd, and cowherd, all of them rural occupations.

It is not known under what form of government the Mahrattas anciently dwelt. Early in the Christian era, Maharashtra is said to have been ruled by the great Salivahana, whose capital was at Paitan, on the Godavery. At a later period a powerful dynasty of Chalukya Rajputs reigned over a large part of Maharashtra and the Karnatic, with their capital at Kalliani, not far from Sholapur. The founder of the line, Jai Sinh, had overthrown another Rajput tribe, the Pallava. The Chalukyas rose to their greatest power under Talapa Deva, in the 10th century, and became extinct about the end of the 12th century, when the Yadhava rajas of Deogiri became supreme, and were ruling at the time of the Muhammadan invasion in 1294. There was also a raja at 
Punalla, near Kolhapur, at the end of the 12th century, whose power extended as far north as the Nira river. He was conquered by Singhan, the Rajput ruler of Deogiri, whose camp is shown at Mhasurna, near Pusesauli, in the Satara district.

The first Muhammadan invasion took place in 1294 , but the Yadhava dyuasty was not finally extinguished until 1312 .

The Dekhan remained subject to the emperor of Dehli till A.D. 1345, when the Muhammadan nobles revolted from Muhammad Taghalaq.

The Mahrattas are mentioned by Ferishta in the transactions of the year A.D. 1485, but it was under the Bijapur kings that the Mahrattas first began to make themselves conspicuous. In the middle of the 16th century, the Adal Shahi king of Bijapur adopted the Mabratta language for his financial papers, and he enlisted a considerable number of Mahrattas in his army, and others of them were employed by Kutub Shah, king of Golconda. Later on, among the officers of Malik Amber (A.D. 1610, 1612) was Malaji Bhonsla, a Mabratta of respectable family, an active partisan, who at one time had been in the service of the Ahmadnaggur dynasty. His son Shah Ji married a daughter of Lukji Jadu Rao, one of Malik Amber's officers. One of the fruits of this union was Sivaji, the founder of the Mahratta empire.

It is certainly extraordinary that a nation so numerous as the Mahrattas should have remained almost wholly unnoticed in Indian history for so long a period as from the first Muhammadan conquest until the reign of Aurangzeb; but it appears probable that prior to the time of Sivaji, the Mahratta country, like the other parts of the Dekhan, was divided into little principalities and chiefships, many of which were dependent on the neighbouring Muhammadan princes, but never completely brought under subjection. Towards the close of the 17th century they suddenly started on a career of conquest, during which they obtained the control over a great portion of India, and established governments of shorter or longer duration at Poona, Satara, Kolhapur, Gwalior, Nagpur, Indore, Gujerat, and Tanjore.

Shah Ji had taken an active part in the last events of the kingdom of Ahmadnaggur, but was subsequently employed in the southern districts of the Adal Shahi of Bijapur, who gave him Sira and Bangalore in jaghir. His son Sivaji, however, born A.D. 1626, was brought up at Poona; while still a youth he engaged in predatory expeditions, in 1648 openly plundered a convoy of royal treasure, and before his death, on the 5th April 1680, by alternately aiding and attacking the Moghul and Bijapur armies, or allying himself with the Kutub Shahi kings of Golconda, while taking every opportunity of securing for himself the fortresses and their adjoining territories, he had created a nationality which, in spite of numerous internal disorders, was kept together until it had established its supremacy over the greater part of India. In A.D. October 1659, Sivaji was guilty of the treacherous assassination of Afzal Khan at a conference near the hill fort of Partabgarh; but he was a skilful general and able statesman, and though he latterly became superstitious and austere, he left a character which has never since been equalled by any of his countrymen. His eldest son Sambaji succeeded, but he was cruel and wilful ; he put to death the wife of Sivaji in a cruel manner, and he left his army in arrears. His country was overrun by Aurangzeb and Prince Azim, and he himself was captured at Sangameswar in the Konkan, and carried to Aurangzeb in the Moghul camp, where (A.D. August 1689) his eyes were destroyed with a hot iron, his tongue was torn out, and he was then beheaded along with the Brahman Calusha. This cruelty raised the indignation and religious hatred of the nation, and his infant son Saho was acknowledged by them as raja, with his uncle Raja Ram as regent, but in 1690 Saho also was captured at Raighar, and remained a prisoner till Aurangzeb's deatb.

On the capture of Saho, Raja Ram assumed the government, and took the field against the Moghuls with the largest army that the Mahrattas had ever raised, but with little success; and he died in the early part of 1690 , to be succeeded by his son Sivaji II., under the regency of Tara Bai. Aurangzeb's efforts to conquer the Dekhan in his advanced years all failed, and he retreated to Ahmadnaggur, where he died on 21st February 1707, in the 89th year of his life and 50th of his reign. His successor, Bahadur Shab, released Saho. But during his captivity other claimants had been striving for power, and it was not until A.D. 1720, through the aid of Balaji Wiswanath, that Saho became the recognised ruler of all the territories conquered by Sivaji and his successors. Balaji Wiswanath, a Brahman, was the founder of the dynasty of the Peshwas, who from this time ruled the Mahratta counsels, and on his death he was succeeded by his son Baji Rao.

Baji Rao had been brought up in camp, and he combined the habits of a Mahratta horseman with enlarged judgment and extensive knowledge, never flinching from fatigue or danger. $\mathrm{He}$ established the Gaekwar families in Gujerat, April A.D. 1731, and Udaji Puar, Mulhar Rao Holkar, Ranaji Sindia, and Parsoji Bhonsla were officers of high rank in his army. They invaded the Karnatic, defeated Dost Ali, took and evacuated Trichinopoly, and plundered Porto Novo and Cuddalore. In 1731, Baji Rao compelled the Azof Jahi dynasty to permit him to plunder the northern parts of the Moghul territory. He crossed the Nerbadda in 1732, plundered Malwa, obtained a third of the Jhansi territory ; in 1736, obtained the cession of Malwa; in 1737, he exacted from Azof Jah an assignment of all the countries south of the Chambal, the surrender of Benares, Gya, Mattra, and Allahabad. For 20 years Baji Rao headed the Mahratta Confederacy, and elevated it to a bigh pitch of glory. He died 28th April 1740, on the banks of the Nerbadda, and was succeeded by his son Balaji Rao.

Raja Saho died without issue, December 1749 , and Balaji Rao took possession of the government. Balaji Rao's brother Ragonath Rao, surnamed Ragoba, took Dehli in 1758 , and then withdrew to the Dekhan, leaving one division of his army under Dataji Sindia, and another under Mulhar Rao Holkar. The Mahratta power was at this time at its zenith, and Sedasheo Rao Bhao, the cousin of the Peshwa, with an army which has been stated at 300,000 of all arms, advanced and took Dehli. Ahmad Shah, Abdali, also advanced, and passed the Jumna, 25th October 1760 , on which the Mahrattas retreated to Paniput. Detachments 
and foraging parties of the two armies harassed their respective opponents, till the Mahrattas opened the action on the 6 th January 1761 . The battle was well contested, but the whole Mahratta army gave way, and on the field and in the pursuit 200,000 were slain. Sedasheo Rao Bhao, also Wiswas Rao, the Peshwa's son, and most of the great Mahratta chiefs, fell. The government of the Peshwa never regained its vigour; and though most of the Mahratta conquests were subsequently recovered, this was effected by independent Mahratta chiefs, several of whom were aided by European officers, with soldiers disciplined in the European manner. From 1768 to 1799 , these chiefs were operating south of the Kistna river, sometimes in alliance, sometimes at war, with Hyder Ali, Tipu Sultan, and the British.

The first war between the British and the Mahrattas lasted from 1779 to 1781 . The British in the beginning of the 19th century interfered in their internal dissensions, and war again broke out in 1803. The campaign commenced on the 7th August. It was directed against Sindia and Perron and the Bhonsla raja of Berar; these two Mahratta powers had 72 regular battalions officered by Frenchmen, and 200,000 troops untrained, but from the sources whence they were drawn, such took a higher social standing than their soldiers of the line. Before the end of December there were gained by the British four battles, amongst which were Assaye, and Argaum, and Laswari. The British completed eight sieges and storms, and effected the almost total destruction of the 72 trained battalions, the dispersion of the rest of their armies, the capture of 738 pieces of cannon, the British force being about 55,000 regular troops, amongst which were 10,000 British soldiers. To effect these results, Sir Arthur Wellesley had been moving northwards, taking Ahmadnaggur, the key of the Dekhan; taking Gawilgarh in the Vindhya, also Asirgarh; and Lord Lake moved southwards, fighting the battle of Laswari. Subsequently, in 1817, war again broke out between the British and the Peshwa Baji Rao and the Bhonsla raja of Nagpur, but the Mahrattas were politically annihilated in $1817-18$, under the administration of the Marquis of Hastings, by the actions at Kirki, Mahidpur, and Nagpur.

On 19th February 1818, the Peshwa's power was destroyed at the battle of Ashta, where Gokla, his general, was defeated and slain, and the Peshwas disappeared; and on the 11th April 1818 , a descendant of Sivaji was replaced on the throne at Satara, from which he was again removed in $\mathbf{1 8 3 9}$ for alleged intrigues, and his brother, who was put in his place, died without an heir. The Bhonsla of Nagpur died in 1855 without an heir, also the Tanjore raja without a son, and in the 19th century the Kolhapur rajas have been continued by repeated adoptions. In 1878, the States of Holkar at Indore, of Sindia at Gwalior, of the Gaekwar at Baroda, of the Kolhapur at Sawuntwari, have continued in alliance with the British Government. There are also several chieftains of this race with almost regal powers, amongst whom may be mentioned the branches at Sundur, Gunjundurghur, and Akulkote, a few miles from Kaladgi, all of the once powerful Ghorphara family.

The British Indian Government, after the fall of the Peshwa, provided for those who had been high officers under the rajas of Satara and the Peshwas. Some, as the Vinchurkar in Ahmadnaggur zillah, and the nawab of Sadernur near Dharwar, had held offices under Aurangzeb and other Moghul emperors. They were, as a rule, guaranteed the enjoyment of their ancient rights and privileges, by treaties binding them to provide a contingent of troops, to make adequate police and judicial arrangements, in consultation with the political agents, for the extradition of criminals. By Regulation 29 of 1827 , three classes of Sirdars were established, and an agent to the Governor, for Sirdars in the Dekhan, was appointed to try such suits against them as would ordinarily be cognisable by the judges of Poona or Ahmadnaggur. No decree of the agent against is Sirdar is executed without the order of the Governor in Council, to whom also plaintiff may appeal, a further appeal to the Queen in Council being open to either party. The personal privileges of Sirdars consist in formal courtesies, varied with each class. Their precedence in durbar is exactly settled.

The Mahratta race has family names like the people of Europe. Bhonsla, Holkar, Sindia, and Gaekwar are patronymics. Mahrattas, even of the highest rank, have not a dignified appearance. They are under the European standard, but well-proportioned, with dark skins and irregular features, and the women, as a rule, are not well favoured. They are sturdy men, rude, rough, boorish, and illiterate, but patient under labour. Their fields and gardens are kept in excellent order, and they have formed good, hardy, and active soldiers, capable of endurance, much of their tactics having resernbled that of the Parthians, though even in this Lord Lake's energy overcame them. Speaking generally, the race is shorter, more robust and darker in contplexion, than the races of Northern India, or even than the Teling people, and their appearance is so dissimilar to that of the Aryan families as to preclude the belief that they have come of that stock. The Mahrattas bordering on the Teling and Canarese countries in the south-east are taller and better formed men than those around Ahmadnaggur.

During their military operations, if the Mahrattas showed none of the pride and dignity of the Rajputs, they had none of the Rajput indolence or want of worldly wisdom. A Rajput warrior, so long as he did not dishonour his race, seemed almost indifferent as to the result of any contest in which he was engaged. The Mahratta thought of nothing but the result, and cared little for the means if he could attain his object. For this he would strain his wits, renounce his pleasures, and hazard his person, but had not a conception of sacrificing his life, or even his interest, for a point of honour. This difference of sentiment affects the outward appearance of the two nations : there is something noble in the carriage of an ordinary Rajput, and sometbing vulgar in that of the most distinguished Mahratta. The Rajput proved the most worthy antagonist, the Mahratta the most formidable enemy, as they did not fail in boldness and enterprise when these were indispensable, and always supported them or supplied their place by stratagem, activity, and perseverance.

The efforts of the Mahrattas in emancipating 
themselves from a foreign yoke were neither guided nor strengthened by any distinct hope or desire. They became free, but knew not how to remain independent, and they allowed a Brahusan to turn their aimless aspiration to his own profit, and to found a dynasty of Peshwas on the achievements of unlettered Sudras. Ambitious soldiers took a further advantage of the spirit called up by Sivaji, but as it was not sustained by any pervading principle of action, a few generations saw the race yield to the expiring efforts of Muhammadanism, and the Mahratta owe their present position, as rulers, to the intervention of European strangers. The genuine Mahratta can scarcely be said to exist, and the 200,000 spearmen of the 18th century are once more shepherds and tillers of the ground. The attention of the Mahratta Sudra, for nearly 200 years, from the middle of the 17 th up to the 19 th centuries, was directed solely to foreign conquest, and nearly all India, from Cape Comorin to Dehli, yielded the fourth part of the revenues as tribute to their kingdoms. During that period of war, agriculture cannot but have been neglected, and even in the early part of the present century they were characterized as mountaineers, herdsmen, and soldiers, but essentially bad farmers. Since 1820 , however, they have been settling down to their fields, and are now extremely well-to-do agriculturists, for the great bulk of them follow this pursuit, and are usually designated the Kunbi.

The races and tribes and sects and fragmentary nations dwelling in the Mahratta country are numerous, with many immigrants. The most prominent are the Kunbi cultivator, the village authorities, amongst whom are the Mhar and Mhang as predial slaves, Muhammadans, Brahmans, and Parsees. The chief races and castes daily seen are-

Brahman, Deshasth or Jain, shop-keepers,

Mahratta, and Konkani. Muhammadans, in every Kunbi, cultivators.

Kulkargi, cultivators.

Wani, Lingaet, cultivators.

Manwar, cultivators.

Baghwan or Mali, gardeners.

Goliwar keep sheep and goats.

Komti, banya merchants, generally grain merchants; they wear the sacred thread, and are in several sections.

Teli, oilmen, oil-makers, and oil-sellers; are many of the Lingaet sect ; some of their sections are deemed impure, and must not enter sacred places. avocation

Sempi or tailor.

Julai or weaver.

Wattan or bangle-maker.

Kumhar or potter.

Sutar or carpenter.

Sonar or goldsmith.

Lohar or blacksmith.

Dhobi or washerman.

Kallal, palm-wine drawers.

Hajam or barber, unclean.

Burud, bamboo basketmakers.

Kaikari, palm-leaf basketmakers.

Chamar, leather-workers. Dher or Mhar or Pariah.

Mhang or tanner.

Thakur.

Gosai.

Bairagi.

The Mahratta people have amongst them, outside every village, the Pariah or Dher, whom they designate as Mbar; the tanner, who is called Mhang; and inside the hamlets dwell the Dhor or currier.

Though professing Brahmanism, amongst them is a more general amount of demon, spirit, fetish, totem, shaman, and hero worship than is observed amongst the other races of the Peninsula. The Mahratta Kunbi race chiefly worship the deified heroes Kandoba, Etoba, and Hanuman. The idols of Kandoba and Hanuman are to be seen in every village south to the Tumbudra, and blood sacrifices of sheep and fowls are largely made. Hanuman is the chief of the village gods, and is invariably smeared over with red lead, which is also applied to every bit of stone or wood that has been erected into a fetish god.

The temple of Kandoba near Poona is famous. Panderpur, on the left bank of the Kistna river, is a celebrated place of pilgrimage, and there is a famous temple and image of Ganesh at Morgaum; and a tree, said to be 300 years old, is an object of great veneration, in the belief that, in the 18th century, the leaves had the virtue of turning into gold on being taken to Benares. The superstitions of the low Mahrattas are said to have a strong resemblance to those of the Bbils. Yet they have all outwardly assimilated to the Brahmanical teachings, and have amongst them a Brahmanical body, who are considered to apply Brahmanical tenets as to caste more stringently than any other Brahmans of India; the bulk of the Mahratta nation, however, are only of the Sudra caste. Their chief objects of worship are certain incarnations or images of deified mortals, known as Etoba and Kandoba at Panderpur, Jejuri, and Malligaon, but the village deities receive a large part of their attention in times of sickness or peril.

There has seemed amongst them, also, a more extensive polytheism than prevails in any other part of India, and an introduction even of the Semitic and Christian names. Between Ellichpur and Amraoti, the Pariah converts are ordinarily called Krishn, $\rightarrow$ not Krishna, but a variation of the word Christian; all along the tract soutbwards to Udghir, the Bawa Adam near Panderpur is largely worshipped, and the Jabral Abral, worshipped in East Berar, is evidently the Gabriel or Jibrail of the Semitic races. Even amongst the Kunbi race, who profess Brahmanism, the Hindu deities Siva and Vishnu are little heard of, and the Editor put up for two days in the temple of the village of Assaye, to which the villagers came at the usual periods to worship Hanuman and the serpent, and the officiating priest to wash and ornament its lingam. An officer of Sindia's artillery, who had fallen in the battle of Assaye, had been buried beneath a neighbouring tree, and there the villagers continue to worship his spirit. Sickness is usually attributed by them to the influence of a malignant spirit, and all through the Mahratta-speaking districts the practice of the Bolwan prevails, viz. the ceremony of propitiating the Bhuta or spirits who bave entered a village, inducing them to leave the village, and conducting them across the borders with music and a procession. The conductors often move to the next village, and thereby cause intense fear and anger, as the morbific influence is supposed to be conveyed to it. Ai, mother, equivalent to the southern Ammun, is largely worshipped in the form of a rude stone smeared with red lead, and her temples are to be seen in lone places, passes, and defiles. The Mahrattas have public recitations of histories or stories of the gods, called Katha. The Gondana or Gondala or Gondhal of the Mahrattas is a tumultuous festival held in honous of Devi.

They have the Pat, the Murat, or the Mohatar forms of marriage of widows, a custom of which it is hard to judge between the advantage of the women, who get a husband or part share in one, 
and the misery of the men, who often get more wives than they can manage. Women are, in truth, often deliberately sold by their parents. Mahratta men are faithful, kind husbands, kind to their children and dependents. Mahratta women have the full control of the households, and are the friends as well as the helpmates of their busbands. Mahratta Sudras, being widely spread, differ greatly in appearance, in language, and in caste observances, but all intermarry and eat together. It is the custom with all the Mahratta and Canarese Brahmans to take their wives to their homes a few months before they grow up.

Owing to the powerful position so long occupied by them in India, they imposed their language and some of their customs on about twice their own number of menial and helot races, such as the Dher and Mhang, who speak Mahrati in Nagpur, but Hindi in the Nerbadda valley. Mahratta linguistic influence did not penetrate to the north much beyond the Nagpur plain, consisting of the lower valleys of the Wardha and Wainganga. The northern line of demarcation may be drawn along the southern crest of the Satpura range, for though a few Mahrattas are found on the table-land, there are probably more Hindi speakers below the ghats in the Nagpur plain, and the almost universal language of the three Satpura districts, Seoni, Chindwara, and Betul, is Hindi. The establishment of a Mahratta government at Nagpur drew many of the nation into that part of Gondwana, and made their language general for a considerable distance round the capital.

In Hindustan and Bengal the republic or village system has been greatly disturbed by the repeated inroads and conquests of foreign races and the long period of Muhammadan rule, and the village officers and servants are less complete. But even there the headman and the accountant are almost invariably retained, and some of the other officers and servants are also to be found, and in most instances the offices are hereditary, are capable of being mortgaged or sold, are paid by recognised fees and perquisites, by allotments of grain at the time of harvest, or sometimes by portions of land held rent-free or at a low quit-rent.

In the Canarese and Mahratta countries the village authorities are still ruling. They greatly vary in number and in duties, but there are office-holders who claim to be descendants of the persons who first settled, and at dates long before the oldest of the European dynasties were established. Potails are in the Mahratta country who trace their descent from persons who settled a thousand years ago and more in the villages they now hold, and the same is to be found amongst the Reddi and Gauda of the south and east. It is this that preserves the Indian villages from the changes which would otherwise have occurred from the irruptions of the Aryan, Brahui, Jat, Persian, Tartar, Rajput, Arab, Moghul, Afghan, Portuguese, French, and British. Amongst the Maliratta, office-bearers are known as Balute or Alute; amongst the Canarese, as Ayakarru, Ayagarru, or Ayangandlu. The following municipal officers may be enumerated:-

Head office, styled Potail, | Chaudari or convener of Reddi, Gauda, and assistant do. or Changala. Accountant or Kalkarni, district do. or Despandi.
Barber, Nhawi or Nai. Washerman, Parit, Dhobi. Temple servant or Gurao. Carpenter or Sutar.

Potter or Kumhar.

Gate-keeper or watchman, usually a Pariah or Mhar, Mhang, Ramusi, or Bhil, called Eskar Veskar, Tallari.

Waterman, do.

Astrologer or Josi.

The Mahratta village head, the potail, rents the lands to cultivators, collects the Government land tax, and forwards it to the tahsildar. $\mathrm{He}$ is also the civil magistrate, and settles petty civil matters to the extent of two maunds of grain, or four or six rupees, and sends higher claims to the tahsildar. In criminal matters he is only the police, and sends all to the Amin. In lieu of pay for the above services, the potail is allowed from 25 to 50 bighas of land rent free, the laud tax being about Rs. 3 or 4 the bigha. For the cultivation of his rent free lands two to four bullocks would be needed, because from 10 to 16 bighas, according as the rains are heavy or light, are all that a pair of bullocks can get over. There are, generally, two to four potails in a village, not always of the same caste; for instance, the village of Khanpur, zillah of Nandair, has four potails, two Mahratta, a Canarese-speaking Lingaet, and a Kulkargah, and there are a few Brahman and Muhammadan and Pariah potails, but a Christian potail is unknown.

Their prominent leaders were-

Shah Ji Bhonsla, 1634.

Sivaji, son of Shah Ji Bhonsla, born 1627, died 1680 .

Sambaji, son of Sivaji, reigned 1680-1689.

Their successors, the Peshwas, were-

Balaji Viswanath

Balaji, 1st Peshwa, 1718.

Baji Rao, 2d Peshwa, 1721-1740.

Balaji Baji Rao, 3d Peshwa, 1740.

Madhu Rao, 4th Peshwa, 1761-1772.

Narayan Rao, 5th Peshwa, 1772, assassinated.

Madhu Rao Narayan, 6th Peshwa, 1774-1795.

Baji Rao II., the 7th and last Peshwa, 1795, defeated and deposed 1818, died at Bithur near Cawnpur.

-Prinsep's Antiquities, p. 286; Moor, pp. 241, 424 ; Cole. Myth. pp. 189, 285 ; Wilson's Glossary; Central Provinces Gazetteer; Elphinstone's India.

MAHSIR or Maha-sir, literally great-head, the native name of species of Barbus (carp); B. macrocephalus, $\mathrm{M}^{\circ} \mathrm{Cl}$; B. mosal, Buch. Ham.; B. tor, Buch. Ham.; and B. Neilli, Day. They afford good sport to amateur fishermen, and they are good eating. Voracious as an English pike, many a one is taken with his own species while spinning in the heavy rapids of the Upper Brahmaputra, the Ganges, and the Tohee river in Jummoo territory. They will eat every fish they can swallow, but love change of food, rising greedily at all large and gaudy flies, natural and artificial, and will also take wild fruits and sweet pastes, when the angler is trying for other fish. The mahsir pulls and rushes very violently at first, and then moves down sulkily to the bottom, where he will remain for hours together if not opposed; it swarms in all the mountain streams of India, when they retain water in the hot season; the Ganges, Jumna, and Brahmaputra hold the largest; next, the great rivers of the Panjab; but this fish is often met with running to a huge size in small streams with deep pools. 
The Indian mahsir are only to be caught from dawn to eleven, or from late in the afternoon till dusk. Its favourite haunts are in the rocky fastnesses of rapid rivers flowing from the hills. Mahsir run not unfrequently to $40 \mathrm{lbs}$, and even 50 lbs., and show more sport than a salmon. When the rod is stiff, the first pull on the tackle is great. Unlike the salmon and the trout, the mahsir, except under peculiar circumstances, is only to be taken in clear water; and in clear water, under cloudless skies, the angler must make himself and his tackle as little conspicuous as possible. Like all fish that inhabit rough water, it is, of course, extremely vigorous; and, as it runs out the line over a rocky bottom, the angler is very likely to be 'broken.' The mabsir does not hold out so long as the salmon, but the fight while it lasts is more exciting, the first struggles being more violent, and the rush more impetuous. The difficulty of playing it may be conceived from the fact that the length of line which Mr. Thomas recommends is 120 yards, -- some authorities, indeed, prescribe 250 yards, - and he admits that with the lesser quantity it is at least possible that an active fish may get to the end of the tackle. The strain upon the reel may be tremendous. As a specimen of the sport the mahsir give, we may refer to an article extracted from the Madras Times; it was where the Darrung, in its lower course, flows through a plain, and the presence of mahsir bad not been even suspected. But, chancing to camp for the night on a sandbank, the sportsmen heard heavy fish jumping in the darkness. Next morning they tried their luck, and caught or lost monster after monster. When one of the party had his hands full, another would go by in a boat, fast to a fish that was towing him along as if he had been whaling in the Arctic Seas. There is the excitement of danger, too, when fishing from what does duty for a boat in some of the mountain rivers. The frail craft is a wickerwork basket, slighter than the Welsh coracle, although at least as buoyant.

The teeth in the throat of the mahsir seem unusually powerful. They are required to be so to crush fresh-water molluscs and large crabs, Ampullaria glauca, Paludina Bengalensis, one of Unio species, Limnea stagnalis, Planorbis Indicus, P. Coromandelina.

Fish also form a large portion of their food. The gall-bag is large, and is much prized by the country people as a remedy in cases of stomachache, cholera, and puerperal fever. When the south-west monsoon commences, the rivers are at once in flood, and continue so for four months, subsequently diminishing by slow degrees. While in flood, the malssir abounds most at the heads of the rivers; the higher up they are, the more advanced their roe and milt generally was, and lower down there was scarcely a mahsir to be found at the same time, though they are well known to abound there later in the year.

Mabsir fishing, for which the Dun is so celebrated, is always most successful after rain. The Ganges at Hardwar is the beau-ideal of an Indian mahsir stream. This river, before it enters the plains, stands in the first rank as regards this species, five or six brace of which, weighing 60 or $70 \mathrm{lbs}$. each, may be killed by a good hand in a good day.
The most sport is had and the finest specimens are taken with a paste made of coarse flour and coarse sugar, kneaded with ghi and a little chopped cotton, also with the ripe fruit of Ficus Indica. It frequents sacred ghats and steps of temples, the Pind Puja, with its balls of rice, flour offerings, and Ficus fruits being greatly attractive. Large specimens (up to 20 lbs.) are taken about the temples at Hardwar, in Upper Assam, at Bagesur in the Sundab, and in other parts approacbing the mountains. This fish, after a short time, with all the cunning of the carp species, evades the hook, flattening the paste gradually with his nose, and it is then sucked off in fragments.

MAHSUD, a section of the Waziri inhabiting the hills on the Tank and the south Banu borders. Their clans are the Alizai, Shahman Khel, and Batozai. They number about 15,000 . They have always been highly predatory, especially the Alizai, and are at enmity with all around them. After British occupation they continued their habits, and in 1860 the tribe was coerced by a force under General Chamberlain, but they have continued to give trouble. $-H . N . W . F . I$. ii.

MAHSUL. Arab. Revenue, a tax or toll.

MAHTABI. HIND. Cloth on which is pasted devices of the heavenly bodies in gold or silver.

MAHTAR. HIND. Scavengers, and, like the Dher or Mhar, and Mhang and Totti, generally village servants.

MAHTO, the title of the headman amongst the Kurmi, Koeri, and Goalla in Behar, Gorakhpur, Hurrpur, and the neighbouring parts.

MAH-ul-LAHM. HIND. Essence of meat, used in medicine. The flesh of a young, lamb being cleared of bones, fat, sinews, etc., is boiled in a moderate quantity of water, until only onethird of the water remains. This is strained and condiments added, and portions dissolved when needed.-Powell.

MAHWA. Marr. Bassia latifolia. A fatty substance, obtained from the kernels of the fruit, is of common consumption in India, and may often be met with under the names of Mowha or Yallah oil in the London market. The tree grows wild, but is also planted in groves in most parts of Oudh, near villages, etc. Its cultivation can be extended almost indefinitely, and it thrives without any trouble. Its flowers have a thickened and enlarged tube, in which is contained a considerable amount of sugar. They are dried and eaten by the natives, and also fermented for the manufacture of mahwa spirit. The cost of the oil extracted is 3 rupees per maund. The proportion of oil yielded by native process is about half the weight of the seed. It is used only for burning. In Oudh, four gallons of a mahwa spirit, between $25^{\circ}$ and $30^{\circ}$, can be made for Rs. 1.13 , and from gur for Rs. $5 \frac{1}{2}$, the different prices of the raw material causing the difference.

MAH YUH GAH. BURM. A tree of maximum length, 18 feet. Abundant all over the Tenasserim and Martaban provinces. It is used for elephant bells, but is not a durable wood.Captain Dance.

MAI-BEE, lit. lady mother, the priestesses of the Munipore people, deemed oracles. The Baiga tribe worship most of the Gond deities, but have a special reverence for Mai Dharitri, mother earth. 
MAIDAH. BENG. A conical hillock raised on a salt field to serve as a filter of the saline soil.

MAIDAN. HIND. In India, an open plain, or the esplanade outside a city or fort. In Western Asia it seems to be used specially for the public square or piazza, in the Italian sense, of a city.

\section{MAIDEN-HAIR.}

Adiantum capillus Veneris. | Shih-chang-sang, . CHIN.

A fern found wild in many parts of Eurnpe, on damp shaded rocks, and a favourite garden plant with the British in India. It is the 'Adíavion of the Greeks, and probably gained its name from its having formed a part of the preparations used by the ladies for stiffening their hair. Adiantum capillus Veneris, Limn., is used medicinally in India as a febrifuge, and in catarrhal affections. Gingko, the maiden-hair tree of Japan (Salisburia adiantifolia), is planted about all the temples, and attains a great size. The Chinese are fond of dwarfing it. Its fruit is sold in the markets in all Chinese towns by the name of Pa-kwo. and is not unlike dried almonds, only white, fuller, and more round.-Fortune, Tea Countries.

MAIKAL, a range of hills running S.W. from Amarkantak, for a distance of some 70 miles, whence they are continued by a similar range, locally known as the Saletekri Hills. The Maikal Hills form the eastern scarp or outer range of the great hill system which traverses India almost from east to west, south of the Nerbadda. They do not ordinarily exceed 2000 feet in height, but the Lopha Hill, which is a detached peak belonging to this range, has an elevation of 3500 feet.

MAIKAY. BURs. A species of Murraya? a timber tree of Amherst, Tavoy, and Mergui, maximum girth 1 cubit, and maximum length 15 feet. It is used by Burmese for handles of knives and other weapons, and is a strong, tough wood, in grain like boxwood.-Captain Dance; Major Simpson's Report.

MAIL GHAT, a strip of wild country along the Wardha river, where dwell Gond, Raj Gond, Agarmunde Gond, Bhoya Gond, the Pardhan or Bard of the Gond, the Ballai or Gond Pariah, the Nihal or out-caste of the Kurku, the Muge fishers and quail-catchers, numbering in all about 34,650 souls of the aborigines, along with whom are 5196 Hindus. - Campbell, pp. 41, 42 .

MAIMANSINH or Mymensing, a British district of Bengal, lying between lat. $23^{\circ} 56^{\prime}$ and $25^{\circ} 25^{\prime} \mathrm{N}$., and between long. $89^{\circ} 43^{\prime}$ and $91^{\circ} 18^{\prime}$ E. Its rivers are the Jamuna, the Brahmaputra, and the Megna. Its chief aboriginal tribes are the Hajang, the Garo, the Chandal. The proper home of the Garo is the Garo Hills, but the Garos of Maimansinh dwell in villages of their own at the foot of the hills. They are hard-working - people, of unusually robust constitution. They eat all kinds of flesh, and are very fond of liquor, manufacturing for themselves a kind of rice-beer, of which they consume large quantities.

The Chandal are cultivators, fishermen, daylabourers, etc., and some of them are also employed as menial servants in the housebolds of the upper classes; but they are greatly despised, and are not allowed to touch any vessel containing drinking water, or any article of food.

Aus rice is sown from February to April and even May, and reaped from the middle of May till about the middle of September. Aman or winter rice, which forms the main harvest of the year, is sown in April, May, and June, and reaped in October, November, and December. Boro rice is sown in November and December, and reaped in March, April, and May.

Jute is largely cultivated throughout the district, but particularly in the rich alluvial tracts formed by the Brahmaputra between Ghafargaon in the south-east, and Bhairab Bazar in the north of Dacca District. The river has here silted up a great deal of late years, and jute is grown on the alluvial accretions (chars) thus formed. The seed is generally sown in A pril or May, after the cold-weather crops have been reaped and the fields repeatedly ploughed. The ordinary quantity of seed used is about 8 lbs. per acre. Seed is raised from the plant by the cultivator.

Tigers infest the char lands in the river beds in the north-west of the district, and bears and other wild animals are found in the Madhupur jungle.-Imp. Gaz.

MAIMONIDES, the Latin name of Musa bin Maimun, a learned philosopher and physician, born A.D. 1135 at Cordova in Spain, and died at Fostat, at the age of 70 , in 1204 . He wrote a work on the Jewish Calendar, but left Spain for Acre in 1165 , to escape persecution, and finally settled at Fostat, near the modern Cairo, where he practised medicine, and was physician to Salahud-Din. He composed a religious guide (his Mishneh thorah), based on revelation and tradition, and then, 'to prove that the principles there set forth were confirmed by philosophy, ' he wrote his Dalalat al-hairin, the Guide of the Perplexed, called in Hebrew Moreh nebhuchim. A charge of apostasy from the Jewish faith under Muhammadan persecution, was brought against Maimonides, which was either suggested or corroborated by a letter on Involuntary Apostasy, purporting to be written by Maimonides, and containing such sentiments as that death must be preferred to the worship of idols, but Islam is not idolatry; that the profession of a belief in Mahomed is not a breach of any divine commandment; and that Jews should in such a case seek an opportunity to leave the country, but need not suffer martyrdom. MAIMUNA. Across the Murghab, and towards Balkh, lie the small states of Audkho, Maimuna, Shibbargham, Siripool, and Akchee. Maimuna is the most important. Maimuna itself is an open village of about 500 houses, but the strength of the chief consists in his il, or moving nomade population, who frequent Umur, Tankira, Sorbagh, Kafir Killa, Khyrabad, Kusar, Chuckaktoo, Takht-i-Khatun, and other sites, which can scarcely be called villages, and Arabs have been long settled here.

At Andkho or Andkhoee, Shah Wale Khan, an Afghan Turk, settled, with others of his tribe, in the time of Nadir. They were then Shiahs, but are now Sunnis. The il of the Andkho chief, besides the chief's race, were Arabs. Andkho has a larger fixed population than Mirinuma, being in one of the high roads to Bokhara, but there is a scarcity of water in this canton; here wheat is a triennial plant. Andkho is the place where Moorcro!t died.-Papers, East India, Cabool and Afghanistan.

MAINPURI, a British district in the N.W. Provinces, lying between lat. $26^{\circ} 52^{\prime} 30^{\prime \prime}$ and $27^{\circ}$ $30^{\prime} \mathrm{N}$., and between long. $78^{\circ} 27^{\prime} 45^{\prime \prime}$ and $79^{\circ} 28^{\prime}$ $30^{\prime \prime} \mathrm{E}$; area, 1696 square miles. The earlicst 
historical inhabitants were Meos, Bhars, and Chirars, most of whom were entirely supplanted by the Chauban Rajputs in the 15th century. At a still earlier date, the warlike Ahirs had swarmed over the wild ravines of the western regions, where they remain by far the most numerous and powerful tribe to the present day. Many great Thakur families still retain their hereditary estates in Mainpuri, where they have long formed the aristocratic class. The Ahirs are the most important among them, both in numbers and influence. The Chamar are numerous, and are the labourers of the community. In 1865, Mr. Colvin took a census of the Chauhan and Phatak villages, and found six of the former without a single female infant.-Imp. Gaz. vi.

MAIRWARA is inhabited by predatory tribes, and belongs partly to Udaipur, Jodhpur, and the British Government, in virtue of its possession of Ajmir. Mairwara was entirely subdued by a British force in 1821. It was taken under British administration, and a local corps was raised, to which Udaipur and Jodhpur were to contribute annually 15,000 rupees each. Under the British Government, the Mairs greatly benefited. In 1847, the British wished to take over all Mairwara, but this was not done. The Mair is also called Mairote and Mairawut. Mera is a mountain in Sanskrit; Mairawut and Mariote, of or belonging to the mountain; the name of the Albanian mountaineer, Mainote, has the same signification. Mairwara is that portion of the Aravalli chain between Komulmer and Ajnir, a space of about 90 miles in length, and varying in breadth from 6 to 20 . The Mair are a branch of the Cheeta, an important division of the Meena, a race which consists of as many branches as their conquerors the Rajputs. All these wild races mingle their pedigree with that of their conquerors. The Cheeta-Meena accordingly claim descent from a grandson of the last Chauhan emperor of Dehli. Unail and Anoop, they say, were the sons of Lakha, the nephew of the Chauhan king. The cocoanut was sent from Jeysulmir, offering princesses of that house in marriage, but an investigation into their maternal ancestry disclosed that they were the issue of a Meena kept woman, and their birth being thus revealed, they became exiles from Ajmir, and associates with their maternal relatives. Unail espoused the daughter of a Meena chieftain, by whom he had Cheeta, whose descendants enjoy almost a monopoly of power in Mairwara. The sons of Cheeta, who occupied the northern frontier near Ajmir, became Muhammadans about fifteen generations ago, when Doodha, the sixteenth from the founder of the race, was created Dawad Khan by the hākim of Ajmir; and as Athoon was his residence, the Khan of Athoon signified the chief of the Mairote. Athoon is still the chief town of the Mair race. Chang, Jhak, and Rajosi are the principal towns adjoining Athoon. Anoop also took a Meena wife, by whom he had Burrar, whose descendants have continued true to their original tenets. Their chief places are Burrar, Bairawara, Mundilla, etc. The Meena were always notorious for their lawless habits, and importance was attached to them so far back as the period of Beesildeo, the celebrated prince of Ajmir, whom the bard Chand states to have reduced them to submission, making them carry water in the streets of Ajmir. Like all mountaineers, they broke out whenever the hands of power were feeble. The Mair country is situated but a very few miles west of Ajmir, and is composed of successive ranges of huge rocky hills, the only level country being the valleys running between them. From the sturdy valour of this race, the rulers of India never made any impression on them, notwithstanding their vicinity to the occasional residence, for a long period, of the emperors of Hindustan. In later times the Mair were the terror of their lowland neighbours; and even the Rajputs, perhaps with the sole exception of the Rohilla, the bravest men in India, dreaded their approach. The Koli assert their relationship to them, and they admit having intermarried with the Bhil and Meena, and, as Colonel Dixon says, for hundreds of years they have been recruited by refugees and all sorts of rascals from Hindustan, and they are probably a very mixed race. They are described as rather good looking. No native corps did more substantial service at the time of the mutiny than the Mairwara Battalion. The mere fact of its having held Ajmir with an immense arsenal, when the troops in Naseerabad mutinied, was a boon to the British which it would be difficult to overestimate. Had the mutineers got possession of the arsenal, with its vast stores, it would have given them a prestige which would have made it impossible for the Rajput princes to resist the pressure of the people to rise against the British Government. In subsequent actions they were always loyal, often very gallant. A single company on one occasion turned the whole of Tantia Topi's force when trying to pass the Aravalli. They were some years afterwards formed into a police corps. This has been felt keenly by the Mairs, who are proud of their old prowess. Ajmir is remarkable for a monument to Colonel Dixon, of the Bengal Artillery, who was superintendent there for many years. His efforts in reducing the Mairs to order, in clearing a jungly country of bands of robbers, in forming an irregular corps out of those very banditti, and in persuading the inhabitants to do away with witch-finding, female infanticide, and slavery, were repeatedly acknow ledged. He died in June 1857. He had, with others, to leave Ajmir when the Bengal sepoys broke into mutiny at Naseerabad, the military cantonment, and the Bombay cavalry, till then believed to be stanch, refused to charge their comrades.

MAI-SHUTR-ARABI, blood which has congealed in the belly of a young camel, after being overfed; the young camel is driven about violently, and then killed, and the blood extracted; is brought from Bombay and Dehli; supposed to benefit in impotency. One tola costs 3 rupees.-Gen. Med. Top. p. 147.

MAIZE, Indian corn.

Durrah shameh, ARАB. | Turkischer weizen, GrR. Yu-kan-liang, : CHIN. Mokka juari, HuvD. Yuh-mi, Suh-mi, . " Nan-ban ki bi, . JAP. Yuh-shuh-shu, : ", Jagung, . . MaLAY. Pan-ku, Pan-su, : ", Maiss, Kukuruza, . Rus. Tyrkisk hvedi,. : DAN. Trigo de Indias, . . SP. Turksche tarwe, : Dur. Trigo de Turquia, : ",

The Zea mays of botanists is much cultivated in India, and in all the islands of the Asiatic Archipelago; is, however, more reared in the 
western than. in the old continent. The stem and leaves, when dry, are chopped up and given to cattle. The seed is ground for bread, and eaten under the name of Chabena.

In China, large portions of the population depend on this grain. It is parched, or ground into meal for cakes. In Japan it is honoured with a place in the armorial bearings of the State.

The growers of Nepal reckon three kinds of maize: a white-grained species, which is generally grown in the low and hot valleys; and a smaller one, called Bhoteah or Murilli Moki, which is considered the sweetest of the three, but, from being less productive, is not generally grown on good lands. Maize thrives best on a siliceous, well-drained, rich soil. The finest Indian corn of the Sikkim range is grown where the soil consists of a substratum of decomposed mica from the under or rocky stratum, with a superstratum of from 3 to 6 inches of decayed vegetable matter from leaves, etc., of the ancient forests. Throughout Hindustan, June is the usual time for sowing. In Behar, about two seers are usually sown upon a bigba; in Nepal, twenty-four seers upon an English acre; in the vicinity of Poona, one and a half seer per bigha. In Nepal, the seed is sown, after one delving and pulverization of the soil, in the latter end of May and early part of June, the seeds being laid at intervals of 7 or 8 inches in the drills, and the drills an equal space apart. The drills are not raised as for turnip sowing, but consist merely of rows of the plant on a level surface. The seed is distributed in this manner with the view of facilitating the weeding of the crop, not for the purpose of earthing up the roots, which seems unnecessary. Indian corn sowing resembles that of the gohya or upland rice in the careful manner in which it is performed, the sower depositing each grain in its place, having first dibbled a hole for it, 5 or 6 inches deep, with a small hand hoe, with which he also covers up the grain.

Cattle are voraciously fond of the leaves and stems, which are very sweet, and even of the dry straw. It is said that near Kaliyachak, though the people give all other straw to their cattle, yet they burn that of maize as unfit for fodder. In Nepal, the stalks, with the leaves attached, often 12 feet long, cut by the sickle, are used as fodder for elephants, bedding for cattle, and as fuel. The maize crop within the hills of Nepal suffers much from the inroads of bears, which are extremely partial to this grain. In the Peninsula of India it is roasted as a luxury. Maize is increasing in cultivation in Java and some of the eastern islands. It is found to have the advantage there over mountain rice, of being more fruitful and hardy.-Simmonds, Commercial Products; Schouw in Jumeson's Philosophical Jour'nal; Simmonds, Colonial Magazine, ii. p. 309.

MAJAWAR. ARAB., Hind., PERs. An attendant at a shrine.

MAJLAS, ARAB., is an assembly; Ijlas, ArAB., a sederunt.

MAJMA - ut-TUARIKH, an Arabic work, descriptive of the early Arab inroads on Sind. It is an abridgment of universal history up to the 6 th century of the Hijira. It was commenced in the reign of Sanjar of the Saljuki (A.D. 1126, A.H. 520 ), but the unknown author must have died an old man, as he notices an event of A.D. 1193.
MAJNUN. HIND. Salix Babylonica, weeping willow ; also, PERS., a lunatic.

MAJUM. Hind, SANSK. An electuary or compound, generally; an intoxicating electuary, formed of ganja leaves (Canabis sativa), milk, ghi, poppy seed, flowers of the thorn-apple or Datura, the powder of the Nux vomica, and sugar, sometimes also cloves, nutmegs, mace, saffron, and sugar-candy. It is used by the Muhammadans and Hindus, particularly the more dissolute, who take it to intoxicate, to ease pain, as Kaif (intoxication), Kuwat (aphrodisiac, tonic), and Imsaq (impotence). There are many recipes, in some of which charras, opium, mastic, cinnamon, aniseed, cummin, cardamoms, are mixed with other ingredients. One kind is prepared from the larger leaves and capsules of the hemp plant, boiled in water along with ghi, sugar, and milk. When of sufficient consistence, it is poured on a slab, when it hardens into a cake, which is divided into small lozenge-shaped pieces.- $W$.

MAJUSI, or Gaor Yezdi, a religious sect in Persia who are said to worship the cow.-Ogilvy; MacGregor, iv. p. 303.

MAKADAM. ARAB, HIND. The leader of a gang, also the headman of a village; also called Jeth-rayat, Mahto, etc.; and in Bengal, Mandal, Makadam, Karbhari, Karbhari patel, Sirkari patel, and Patwari are used synonymously. The Patwari is likewise called the Pandya or Kulkarni; but Kulkarni is solely applied to the person who transacts the business. In some parts of the Mahratta country, the terms Grammadhi-kari and Gramlekhak are used for Patel and Patwari.

MAKALLAH, the principal commercial town on the south coast of Arabia, trading in gums; hides, senna, and coffee, with India, the Red Sea, and Muscat, and importing cottons, lead, iron, crockery, rice, slaves from Berbera, Cosseir, and other ports near the town. Ras Makallah projects into the sea.

MAKAN. HIND. A house, a burial-place. Makandar, the proprietor of a burial-place.

MAKARA, a fabulous sea animal of the Hindus, representing their Capricornus sign of the zodiac, and is depicted with the head and fore legs of an antelope, and the body and tail of a fish. It is also called Asita danshtra, 'black teeth,' and Jala rupa, water-form. It is the vahan or vehicle of Varuna, the god of the ocean, and is on the banner of Kama-deva, god of love.

MAKARA - TORANAM. SANSK, The royal arch ; one of the insignia of royalty of the Chalukya dynasty, when ruling at Kalian.

MAKAR SANKRANTI, a Hindu festival day, held on the occasion of the sun entering the sign Makar, corresponding to Capricorn. It occurs on the 1st of the solar month Magh. From this day, when the sun reaches the most southern, till the time of his arriving at the most northern, point of the zodiac, is called Uttarayana, and the time from his leaving the northern sign Karka or Cancer, till he again returns to Makar, is called Dakshinayana. The days of Uttarayana are reckoned lucky, and those of Dakshinayana unlucky. During the days of Dakshinayana, it is said the gates of heaven are shut, and in the Uttarayana they are open. For the good to die in the Uttarayana is considered more blessed, because they are said to get immediate entrance into heaven; but if they die in the Dakshinayana, 
they have to wait outside the gates till the Uttarayana sets in. In Uttarayana, Munj - the ceremony of investing youths with the sacred triple thread-and marriages are celebrated. On the day of Makar Sankranti, just at the time of the sun's entrance into the sign, the Hindus go to the sea, accompanied by a Brahman priest, to bathe; there they rub their bodies with tila or sesamum seed, the favourite grain of the sun, and wash themselves in the manner prescribed in the Shastras. The Brahman then repeats certain prayers suited to the occasion, and closes the ceremony by receiving adoration and a present of money for himself. On their return home they invite Brahmans, present them with cups of bellmetal filled with tila seed and with money, according to the ability of the Yajaman or worshipper; some present copper pots, new dhotis, umbrellas, etc., and the whole family receives benediction from them, which is done by the Brahmans repeating certain words, and throwing on their heads a few grains of red-coloured rice. After the performance of this ceremony, they go to take their meals, which consist of sweetmeats. They invite their friends and relations to dinner; and towards evening they wear new clothes, gold and other ornaments, and frequent the houses of their friends and relations, distributing tila seed mixed with sugar. At the time of putting the tila seed into the parties' hands, they repeat these words: 'Receive these tila seeds mixed with sugar, and be friendly 'with me throughout the year.' All the praise and prayers offered this day are to the sun, and to no other god. The second day of Sankranti is named Kar, and is generally celebrated by the women making small presents among their own sex.

MAKHDUM SAHIB, a Muhammadan pir or saint, whose tomb in Mahim is a place of pilgrimage. His full name is Fakih Ali Makkdum Sahib.

MAKHSAN - ul - ADWIAH, a medical book, written in A.D. 1769 by Muhammad Husain Khan.

MAKKA PARIJE, a kind of marriage amongst the Coorgs. In the event of there being no male in the house, a daughter is retained to represent the family, and a husband is procured for her from another family. The husband does not become alienated from his own family, but can take a wife from bis own family also, thus raising up seed for both houses. A Makka parije marriage must be made expressly for the purpose at the time; the arrangement cannot be made after the marriage.

MAKKATAYAM. See Marumakkatayam.

MAKKRUH, anything which Mahomed himself abstained from without enjoining others to do so.

MAKLEUA, the berry of a large forest tree at Bankok, said to be the Diospyros mollis, which is used most extensively by the Siamese as a vegetable black dye. It is merely bruised in water, when a fermentation takes place, and the article to be dyed is steeped in the liquid and then spread out in the sun to dry. The berry, when fresh, is of a fine green colour, but, after being gathered for two or three days, it becomes quite black and shrivelled like pepper. It must be used fresh and whilst its mixture with water produces fermentation.

MAKOK, a Siamese plant, producing a sharp acid fruit, after eating which, if water be drunk, a sweet taste is left in the mouth and palate, which remains for a whole day.

MAKRAN, a province to the east of the Persian empire, and on the borders of Sind, by the Greeks called Gedrosia or Gadrosia. Cape Monz terminates a range of mountains that form the boundary between Persia and India.-Ouseley's Travels.

MAKSE. AMB. The hair-like fibre of Arenga saccharifera. Gomuto.

MAKTA, ARAB., from Kata, ARAB. In Maharashtra, quit-rental, land held at a fixed low rate. Maktadar, the holder of an estate which pays a quit-rent. $-W$.

MAKTAB. ARAB. A Muhammadan domestic festival in India, held on the first occasion of a child's going to school.

MAKWA, a fisherman race on the Malabar coast. Makati, females of the Makwa.

MAL or Mar, a tribe scattered over Sirguja, Palamau, Belounja, etc., who are now a thoroughly Hinduized people, and resemble Hindus in appearance. They declare they came originally from Malwa. They are said to have at one time formed the bulk of the population in Palamau, but there are very few there now.

MALA, also Malavadu. TeL. The Pariah or Dher race of Telingana.

MALA. HIND. A necklace, a garland, a rosary. The tulasi or rudraca has the same estimation amongst the Hindus that the misletoe had amongst the ancient Britons, and was always worn in battle as a charm.-Tod's Rajasthan, i. p. 619.

MALA - ARAYAN. Various tribes of wild mountaineers occupy the higher hills and the mountains of Travancore. The hillmen proper number close upon 12,000, and Ulladars, a hunter race, 2829. The Vedar hunters are at the foot of the hills, and in a social condition very similar to that of the Pulayars. The tribes living towards the south of Travancore are usually designated Kanikar, those in the north being commonly called Mala-Arayar in Malealam, from Arachan, chief, or from Raja, a king; in Tamil they are called Malei Arasar. Kanikaran means hereditary proprietor of land, thus recognising their ancient rights over the forest lands.

The Kanikar are very short in stature and meagre in appearance. They live together in little clans, each hamlet under the patriarchal rule of a headman (Muttukani, the 'stem' or principal Kanikaran). They are wandering husbandmen; cut down a patch of forest, burn and clear it, and sow a crop, with little or no tillage. They can never tell their own ages. They are unable to count a hundred; over ten they lay down a pebble for each ten. They knot fibres of various climbing plants to express their wants. In the south they speak Tamil, and Malealam further north.

The Mala-Arayans have fixed villages, generally on the western slopes of the higher range of mountains or their spurs. They will not often work for hire, and are very averse to carry loads. Some of them are well to do. They are great hunters of the wild beasts and game which abound in their hills, and relate a tradition giving them special permission to eat the black monkey. From this they are called by the low country people Kurangu tinni, 'monkey eaters.' The Hindus regard them as beings in alliance with some powerful demonolatry, and presents are 
abundantly bestowed in order to prevent their curses producing ill effects. Each village has its priest, who, when required, calls on the Hill (mala), which means the demon resident there, or the Pretham, ghost. If he get the afflatus, he acts in the usual way, yelling and screaming out the answers sought. They have some sacred groves in which they will not fire a gun or speak above a breath.

Jlladar are a jungle tribe of timid savages. They are without settled villages or civilised clothing, wandering within certain boundaries prescribed to each division. They subsist chiefly on wild yams, arrowroot, and wild beasts. They are adepts in the use of the bow and arrow. The arrow they use has an iron spear-head, and an Ulladar has been known to cut a wriggling cobra in two at the first shot.

A small number of Urali wander over the Todupuley Hills, building their huts on trees like the Arayans.

The Pulayar are a hunter race.

The Mannan are strange-looking mountain men, hardy, and very black, speaking bad Tamil, much employed by the Travancore Sirkar to collect cardamoms, as watchmen, etc. They rarely cultivate anything but ragi.

The hill Pandaram are without clothing, implements, or huts of any kind, live in holes, rocks, or trees. They bring wax, ivory, and other produce to the Arayan, and get salt from them. They dig roots, suare the ibex of the hills and jungle-fowls, eat rats and snakes, and even crocodiles. Some seen by Mr. Baker were perfectly naked, filthy, and very timid. They spoke Malealam in a curious accent, and said that twentytwo of their party had been devoured by tigers within two monsoons.-Mateer's Travancore.

MALABAR, a region on the western part of the Peninsula of India, between the mountains and the sea. Its name is obtained directly from the Portuguese Malavares, but the people call themselves Maléallar, from Malé, a mountain, and Alam, a district or country. The term Malabar, as usually applied by geographers, designates the whole of the narrow belt of country, rarely above fifty miles broad, west of the great peninsular chain, from Gea to Cape Comorin; it thus includes the British district of Malabar, and the kingdoms of Cochin and Travancore to the south. This tract is in general hilly and mountainous; a narrow strip of lowland borders the sea, frequently intersected by long sinuous salt-water creeks, and covered with cocoanut trees; the hills, which are thrown off as spurs from the main axis, often reach the sea and dip suddenly into it; they enclose well-cultivated valleys, and though generally low to the west, they rapidly rise to the east, where they join the chain. The climate of Malabar is characterized by extreme humidity, and an abundant rainfall during the south-west monsoon, when the temperature seldom rises above $75^{\circ}$, the mean of the year being $81^{\circ}$.

The area of the Madras portion is 6002 square miles, lying between long. $75^{\circ} 14^{\prime}$ and $76^{\circ} 52^{\prime} \mathrm{E}$., and lat. $10^{\circ} 15^{\prime}$ and $12^{\circ} 18^{\prime} \mathrm{N}$., and bounded on the north by South Kanara, east by Coorg, the Neilgherries, and Coimbatore; south, by the Native States of Cochin and Travancore; and west by the Arabian Sea.

Malabar is the garden of peninsular India.
Here nature is clad in her brightest and most inviting robes; the scenery is magnificent, the fields and gardens speak of plenty, and the dwellings of the people are substantial and comfortable.

Hindu legend ascribes its creation to Parusu Rama, who caused the sea to retire from the Western Ghats, and introduced Brahmans into the country, which he divided into sixty-four gramam or districts, and these were subsequently separated into two divisions, Tulu and Kerala, the Kangarote or Chandragiri river being the boundary. According to the Kerala Ulpati (a Hindu historical book), the Malabar coast was formerly divided into four provinces. The most northerly was called Tulu Rajyam, the Tulu kingdom. It commenced at Gokuru in N. Canara, and extended southward to Perumbura, near Mangalore. From Perumbura to Pudapatuam, near Nelishwaram in S. Canara, was called Capa Rajyam; thence to Canneti, near Quilon, was the Kerala Rajyam; and thence to Cangakumari, or Cape Cormorin, the Muchica Rajyam.

Chera was a small ancient state between the territory of the Pandiya and the western sea. It comprehended Travancore, part of Malabar, and Coimbatore. It is mentioned in Ptolemy, and may have existed at the commencement of the Christian era. It ruled at one time over the greater part of Carnata, but was subverted in the 10 th century, and its lands partitioned among the surrounding states.

Vasco da Gama visited Malabar in 1498, and his successors speedily established themselves at Cochin, Calicut, and Cannanore. In 1656 the Dutch appeared in the Indian seas, to compete with the Portuguese for the trade of the country. They conquered Cannanore, and in 1663 captured the town and fort of Cochin, as well as Tangacheri, from their rivals. In 1717 they secured the cession of the island of Chetwa from the Zamorin. But in the next half century their power began to wane: Cannanore was sold to the Cannanore family (Bibi), represented at that time by Bamali Raja, in 1771; Chetwai was conquered by Hyder in 1776 ; and Cochin captured by the British in 1795.

Malabar, when overrun by Hyder Ali, was made tributary to Mysore, but after the war of 1791-92, the treaty of 1792 transferred part of it to the British.

The French first settled in 1720 at Mahé, in 1752 obtained a footing at Calicut, and in 1754 acquired Mount Dilli, and a few outposts in the north, all of which fell into the hands of the British in 1761. Their frequent wars with the British ended in the destruction of their commerce in the east, Mahé having been thrice taken and restored. The British bad established themselves in 1664 at Calicut, in 1683 at Tellicherri, and by 1714 at Anjingo, Chetwai, and other commercial factories. Tellicherri became their chief entrepôt for the pepper trade.

The rainfall is on the average 120 inches. The rainfall in June, July, and August averages 80 inches, or two-thirds of the total fall for the year. Cattle suffer from murrain and foot-and-mouth disease, but no epidemic rinderpest has been recorded. Gold is washed for in all the rivers of Malabar; but in 1877 to 1881 it was not found in sufficient quantity to repay the expenditure for European machinery and labour. 
A great Brahman colony, known as the Namburi, are large landed proprietors; there are small tribes of Jews, and Tamil-speaking Hindus have come in considerable numbers into this region. Other languages spoken are Malealam and Tulu, with some Canarese ; and in the nortbern part of the coast, the Konkani.

Juan Ribeyro mentions that in his time, 1656 , there were fifteen kings ruling in the low tract of country between the sea and the ghats, in the short space between the Salt River and Cape Comorin; and that to this minute division of the country was due the facility with which the invaders overran it.

After the pacification of the country in the early years of the 19th century, the sub-collector, Mr. H. Baber, turned his attention to coffee-planting in Wynad; and by 1840 this important industry was fairly established. Since 1850 it increased greatly.

Malabar has many Muhammadan Moplahs, active, intelligent men, engaged in commerce. They have several times in the 19th century risen in rebellion, feeling aggrieved by the laws which regulate Hindu property, and they have displayed on these occasions much fanatical bravery.

The Charumar race are predial slaves, whose name Wilson derives from Chera, Malealam for the soil; they follow the rule of Alya Santana. They are very diminutive, with a very black complexion, and not unfrequently woolly hair. The Makkavan is a fisherman caste, also called Makwa, and their women Makate. The toddy-drawer is called Katti Karan. The Ashary is the carpenter caste. In common with the brassfounder, gold and iron smiths, they continue the practice of polyandry, but in civil inheritance follow from father to son, and not the practice of maternal descent, descensus ab utero. The elder brother marries, and the wife is common to all the brothers. If a junior wish to marry, he must live apart and set up business apart; but if any of his younger brothers reside with him, his wife is common to them. The Panni Malayan are a servile caste. The Adiyan is a slave, serf, or vassal, who lives under the protection of a raja or religious establishment. The Malealam Sudras, of whom the better class are called Nairs (or lords), are the bulk of the respectable population,- the landholders, farmers, soldiers, officials, and rulers of the country. The Nair are the ruling race of Malabar. They were formerly accustomed to duelling. The practice was called Ankam, and hired champions were often substituted. The Pulichi is a forest tribe, who are deemed so unclean that they are not allowed to approach other castes. The Uradi or Urali are a servile race. The Tiyar race are toddy-drawers and agriculturists. The Pulayan or Pulian is a servile caste, often slaves; this is doubtless the Puller.

In South Malabar, descent to sons is the law, but in North Malabar, the Nair, the artisans, carpenter, brass-smith, blacksmith, goldsmith, the Tiyar, who are toddy-drawers, and the Makwa, who are fishermen, are all polyandrists, and descent of property goes in the female line. In North Malabar this law of descent is called Marumakkatayam, and the Muhammadan Moplah has conformed to this usage. In Canara, a similar law, called Alya Santana, or nephew inheritance, prevails, and is in practice more strictly carried out than in North Malabar. In North Malabar, the adherents to Marumakkatayam form united family communities, termed Tarwaad, the senior member of whatsoever branch is the head of the family, and is termed Karnaven; the other members are styled Anandraven. The remotest member is acknowledged as one of the family, and entitled to maintenance if living under subordination to the head of the family, and taking part in their religious observances; for the women there is nothing analogous to the state of widowhood as existing elsewhere, -whether in alliance with men or not, they reside in their own families. The Nair marries before he is ten years of age, but though he supports, he never associates with his wife, who receives at her pleasure any men, provided they be not of lower birth. Consequent on this form of descent, a Nair does not know who his father is. In law, property is held to vest in the females only; practically the males are co-sharers with the females. In default of males, females succeed to the management of the family property. In some families, the management devolves on them preferably to the males, and the senior female takes it. There is, however, a growing tendency to convey property from father to son, arising from the gradual abandonment of polyandrism. The connubial connection in question is called in Malabar 'Goona-dosham' (Goona, good, Dosham, evil-for better for worse). In Travancore it is styled Mundu-vanga, viz. Mundu, cloth, Vanga, receiving, where the girl taken is of ripe age, and her consent must be obtained. Personal acquaintance thus precedes the union. The hour selected is 8 P.M. ; there is an assemblage of friends; the man presents the woman with a Mundu, or white muslin cloth, in a corner of which, in North Malabar, a small sum of money is tied. The girl either goes to the man's house, or remains in her own and is visited by him there. Each party is unrestricted as to the number of such connections that may be formed, but these ordinarily do not exceed two or three, The descent being in the female line, the parentage of the father is immaterial. The Marumakkatayam law is not followed in North Malabar by the AkaPodwal, a class of pagoda servants, nor by the Brahmans of North Malabar or of Canara; but in Travancore law, only the eldest brother of a Brahman's family is allowed to marry with his equal, and the other brothers form other connections. In the Tuluva country, the Brahman widow can devote herself to the temple, and reside outside or inside its walls. If within the walls, she is a servant of the idol, and receives the visits of men of her own caste only; the offspring of such, if boys, are called Moylar, and the girls are married to them. But if she elect to reside outside the walls, she must pay a monthly sum to the pagoda, and may cohabit with any man of pure descent. This, however, is disputed.

Malabar is a term applied erroneously to the Tamil language. Malabar black-wood is Dalbergia latifolia. Malabar civet cat, Viverra cirettina, Blyth; Malabar creeper, Ipomoea tuberosa; Malabar hemp, Crotalaria juncea; Malabar nightshade, Basella rubra; Malabar nut, fruit of Adhatoda vasica; and Malabar sago palm is Caryota urens. MALABAR HILL. With the exception of Malabar and Worli Hills on the western, and Chinchpugly Hills on the eastern shore, the land 
in Bombay island is flat, and a very large area is still below the level of the sea at high water, and is annually flooded during the rainy season. Malabar Point, in Bombay, has the ruins of a very ancient black stone temple, and has many fragments strewn about with a variety of images sculptured on them. Below the Point, among the rocks, there is a cleft esteemed very sacred, where the believing Hindu obtains regeneration or a second birth. He comes to the spot and deposits all his clothing, then, passing through the aperture, he is supposed to be born again, and ablution in the tank and gifts to the priests complete the washing away of his sins.-Chow Chow, p. 60 .

MALABATHRUM, among the writings of the ancients, was applied to a leaf imported from India, and employed by them both as a medicine and as a perfume. From it there was prepared both an oil and a wine, by maceration of the leaves in these menstrua. Many fabulous statements accompany the earliest accounts, as that of Dioscorides, by whom it is stated that by some they are thought to be the leaves of the Indian Nard; that they are, moreover, found floating on Indian marshes, and that they grow without roots (lib. i. c. 11) ; and that (lib. ii. c. 10) it is by feeding on them that the animal affording the Onychia or Unguis odoratus of the ancients becomes aromatic. In the works of the Arabs, Saduj is given as the synonym of Malabathrum; and Saduj, both in Persian works and in India, is applied to Tej-pat or Tej-bal, or the leaf of the Tej, which is from Cinnamomum albiflorum, growing in the dense forests of the valleys of the Himalaya, from Rangpur to the Dehra Doon, in lat. $30^{\circ}$ N. Dr. Hamilton found the same name applied to the C. tamala, C. nitidum, as also C. aromaticum. They are analogous in all respects to bay leaves produced by the Laurus nobilis. The physician Garcias da Horto, in his work on the Aromatics of India (first published at Goa in 1563), pointed out that Malabathrum was the Tamalapatra, the leaf of a species of cassia. O'Sh.; Eng. Cyc.; Yule, Cathay; Powell.

MALACCA, a town on the sea-coast of the Malay Peninsula, which gives its name to a district, forming part of the Straits Settlements under the British Colonial Office. The lighthouse is in lat. $2^{\circ} 11^{\prime} \mathrm{N}$., and long. $102^{\circ} 16^{\prime} \mathrm{E}$. The mean length of the province is 40 miles, the average breadth being 25 , comprising an area of 1000 square miles, with a population of 77,756 . Malacca derives its name, according to Malay history, from the Malaka tree, Jambosa Malaccensis. The country a few miles inland is formed of undulating hills, moderately elevated, called Malacca Hills, and $7 \frac{1}{2}$ leagues E. by N. $\frac{1}{3}$ N. From it rises the high mountain Gunong Ledang, called also Queen Mount, also Mount Ophir, about 7000 feet high. Except Goa, Malacca was the earliest European settlement in the east, and was at one time the great emporium of trade from the innumerable islands of the Eastern Archipelago, but has seen many changes since it was wrested from Muhammad Shah by the Portuguese in 1511; and in 1547 the salvation of this city from the Achinese was ascribed to the sudden appearance of Saint Francis Xavier, the apostle of India, who was then on his pilgrimage through the east. After remaining in quiet possession of Portugal for 130 years, it fell into the hands of the Dutch, who held it for 74 years, when the British took possession, and their first act was to demolish the fort, erected at a vast cost by the Portuguese, and much improved by the Dutch. In 1818, Malacca was again ceded to the Dutch, who finally exchanged it with the British for Bencoolen and other settlements in Sumatra. In 1825, the British, by treaty with the Dutch, agreed to hold no possessions in the Archipelago south of the equator, and the Dutch, vice versa, north of the equator.

The great mineral product is tin. In the great tin mining district thousands of Chinese work, some by surface washings, others by following up veins deep into the bowels of the earth, and others by grinding the quartz so richly impregnated with the stanniferous ore that is almost metallic in its matrix. Water power, somewhat in principle of the Egyptian wheel, is the usual means resorted to to raise the accumulating water from the pits, the chain of buckets running down an inclined plain often exceeding a hundred feet. The ore is smelted in small furnaces, a rapid white heat being produced by the action of a double bellows made from the trunk of a tree hollowed out, and the ore, as in iron, runs out at an aperture below the furnace into moulds prepared for it. The tin is sold on the spot for 25 dollars a pikul; the price in England is double that. Near Malacca are thermal springs, $137^{\circ}$ being the average heat throughout the year. There are six of these springs in a square of about 100 feet, perpetually steaming and boiling over. A powerful odour of sulphurated hydrogen is evolved; the water is clear, strongly impregnated with iron and sulphur, and held in great repute both as a vapour and plunge bath, chiefly in cutaneous maladies.

At the census of 1881 the population was found to be-Malays, 57,474; Chinese, 13,450; Kling, 2874 ; Arabs, 303 ; Boyanese, 135; Bugis, 85; Javanese, 339 ; Siamese, 6 . The district produces many valuable timber trees.-Census.

MALACCA CANE. Dr. Griffith believed these canes to be produced from the Calamus scipionum of Loureiro, the Heo-tau of CochinChina. They do not occur about Malacca, but are imported from Siak, on the opposite coast of Sumatra. Some of them are simply mottled or clouded, others of a brown colour, in consequence, it is said, of their having been smoked. The most slender specimens, with the longest internodes, are the most valued.-Seeman.

MALACCA STRAITS, a seaway leading from the Bay of Bengal into the Archipelago. They are bounded on the north by the island of Singapore. There are three banks in it, - the One-Fathom Bank, on which is a light vessel; the Sumatra or Third Bank is to the N.W. of the Carimons. Towards the entrance of the Strait of Malacca, near the Nicobar and Acheen Islands, and betwixt them and Junk Seylon, there are often very strong ripplings, particularly in the S. W. monsoon. There is no perceptible current, yet the surface of the water is impelled forward by some cause. They are seen in calm weather approaching from a distance, and in the night their noise is heard from a considerable distance before they are near, alarming to persons unacquainted with them, for the broken water makes a great noise when the vessel is passing through it. They beat against a ship with great violence, and pass on, the spray 
coming on deck; and a small boat could not always resist the turbulence of these remarkable ripplings.-Horsburgh.

MALACHITE.

Luh-tsing, . . . CHIN. Shih-tsing, . . CHIN. Shih-luh,.

This carbonate of copper is found in many parts of China, where it is used as a pigment and for making ornaments. The mines of Siberia at Nichne Tagilsk have afforded great quantities of this ore. A mass partly disclosed measured at top 9 feet by 18 feet, weighing 40 tons, and the portion uncovered contained at least half a million pounds of pure malachite. Other noted localities are Chessy in France, Sandlodge in Shetland, Schwartz in the Tyrol, Cornwall, Australia, and the island of Cuba. This mineral receives a high polish, and is used for inlaid work, and also earrings, snuff-boxes, various ornamental articles, slabs for tables, mantelpieces, and vases, which are of exquisite beauty, owing to the delicate shadings and radiations of colour. At Versailles there is a room furnished entirely with tables, chairs, etc., wrought in malachite. Malachite is easily distinguished from turquoise by its shade of colour and much inferior hardness. It is a valuable copper ore when abundant, but it is seldom melted alone, because the metal is liable to escape with the liberated volatile ingredient, carbonic acid. In India it is rarely worn as a gem, and only by Europeans.-Eng. Cyc.; Smith.

MALACHRA CAPITATA. Linn. A plant of Bengal, Kutch, N.W. Provinces, Sind, and the Panjab. M. rotundifolia is a plant of S. America, belonging to the natural order of Malvaceæ. Marshy places within the tropics are considered favourable to its growth. The fibre is prepared in precisely the same way as jute, but requires to be steeped directly it is cut. The fibre is in length from eight to nine feet, has a silvery appearance, with a peculiar lustre, and is almost as soft as silk. In passing the fibre through the machinery, damped with oil and water, as is commonly done with Bengal and Konkan jute, yarn was produced strong enough and nearly equal to that made from the second quality of Bengal jute. If the plant is carefully grown and well looked after, the fibre would then no doubt rank fully equal to Bengal and Bombay jute. The fibre, if carefully prepared, would command a ready sale at 3.12 to 4 rupees per Indian maund.

MALAGASY, the people of Madagascar.

MALAGUETA, or Grains of Paradise, is also written Mellighetta, Malagueta, Manighetta, aud has been applied sometimes to two kindred species of Amomum exported from different parts of the West African coast (Am. Granum-Paradisi and Am. Melegueta), and sometimes to the seeds of the Unona Ethiopica or Ethiopic pepper. It appears to be one of the former which Gerarde and Mattioli describe as the greater cardamoms or melegette, for Gerarde states they were said to come from Ginny, and were called in England Graines of Paradise, the Grana-paradisi of authors. -Yule, Cathay, i. p. 88.

MALAI ARASAR. TAM. Lit. hill kings; a tribe inhabiting the foot of the Animallay Hills, very useful in the forest, preparing elephant ropes from the vaca nar, assisting in the clearing of brushwood, and the repair of roads, etc., for which they are paid. See Malé Arasar.
MALAMIUM, an order of darvesh, supposed to resemble speculative freemasons.

MALAM KOLLE? a kind of wax produced from the wild plantain.-Ind. Arch. 1853, p. 267.

MALANG, a Muhammadan mendicant who lets his hair grow loose and uncombed.

MALANGI. BENG. A salt maker.

MALARIA, a climatic influence unfavourable to health. It is more frequently observed in dense moist forest lands, valleys and gorges of mountains, but even dry arid tracts are not free from it. It has been remarked along the Mahavelliganga, a few miles from Kandy, that during the sickly season, after the subsidence of the rains, the jungle fever generally attacks one face of the hills through which it winds, leaving the opposite entirely exempted, as if the poisonous vapour, being carried by the current of air, affected only those aspects against which it directly impinged. A malarious part of India is the Terai, near the Himalaya, also the Wynad.

MALATI and Madhava is the title of a drama by Bhavabhuti, in which the social life of the Hindu race is largely represented. It was translated by Professor Wilson. Malati puts on her bridal dress in presence of the deity. It was customary also amongst the Greeks for the intended bride to pay her adoration to some deity before her marriage, usually to Diana; but at Athens no virgin was allowed to be married before worshipping Minerva, who was the tutelary deity of the city. Madhava's passion is described as

'Heard, felt, and seen, possesses every thought, Malati alone fills every sense, and pants in every vein.'

The passion of Malati is equally intense with that of Juliet; but her unconquerable reserve, even to the extent of denying her utterance to him she loves more than life, is a curious picture of the restraint to which the manners of Hindu women were subjected, even whilst they were in enjoyment, as appears from the drama, of considerable personal freedom. Megasthenes tells us that the Indians of his time did not communicate their metaphysical doctrines to women, thinking that, if their wives understood their doctrines, and learned to be indifferent to pleasure and pain, and to consider life and death as the same, they would no longer continue to be the slaves of others. We find from the later ceremonial sutras (Srauta and Grihya sutra) that women were not allowed to learn the sacred songs of the Vedas, the knowledge of which constituted one of the principal acquirements of a Brabman before he was admitted to the performance of the sacrifices. Menu ix. and 18 says, "Women have no business with the text of the Vedas, thus is the law fully settled; having therefore no evidence of law, and no knowledge of expiatory texts, sinful women must be as foul as falsehood itself, and this is a fixed rule.' The practice of the wife worshipping the husband is very ancient. In the drama styled Ratnavali, or the Necklace, Vasavadatta, after worshipping the image of the deity, her attendant says-

"The worship of the divinity concluded, be pleased, madam, to pay adoration to your lord.

'Vasava. Where are the flowers and unguent?

'Kanch. Here, madam.'

On which Vasavadatta worships the king. This is conformable to the Bhavishyottara Purana, 
which directs, 'Having offered adoration to the mind-born divinity, let the wife worship her husband with ornaments, flowers, and raiment. Thinking internally with entire complacency, This is the god of love.'-Hind. Theat. ii. pp. 67, 122, 275 ; Muller, Hindu Literature.

MALAUN, a hill fort in the Hindur State of the Panjab, situated in lat. $31^{\circ} 12^{\prime} \mathrm{N}$., and long. $76^{\circ} 52^{\prime}$ E., 4448 feet above the sea, on the crest of a ridge bearing the same name, and rising from the left bank of the Sutlej to the subHimalayan range. It was taken by the British; the engineers constructed a road practicable for heavy artillery up the difficult heights, and a battery being formed close to the fort, the Gurkhas surrendered, and evacuated, by the terms of capitulation, all the hill states west of the river Kali.-Imp. Gaz.

MALAVIKA and Agnimitra, a drama by Kalidasa. The text has been printed at Bombay and Calcutta; it has also been printed and translated by Tullberg; a German translation by Weber, an English one by Tawney, and a French one by Foucaux.-Dowson.

MALAY. The Malay race are found in the Malay Peninsula, and in the western islands of the Archipelago. In the Maldives the people speak the Malay language, and the Hova of Madagascar are said to bear in their features some resemblance to the Malays.

Peschel says ( $p$. 355) that when Roderigues, Mauritius, and Bourbon were discovered by
Europeans and still unpeopled, Madagascar was peopled by Malays; and Crawfurd says (Grammar and Dictionary, i. p. 148) very clear traces of a Malayan tongue are found in the languages of the island of Madagascar, an island some 3000 miles distant from the nearest part of the Malayan Archipelago, and only 240 miles from the eastern shore of Africa. Peschel adds that the similarity of words of the Malagasy or Madagascar language with Malay words had been observed by Sir Joseph Banks and by Hervas the philologist; and Wilhelm von Humbolt's researches into the Kawi language have shown that Madagascar was peopled by Malays.

In 1847, Mr. Spencer St. John estimated the population of the Malay Peninsula and Eastern Archipelago at 18,436,622, as under :-

Malay Peninsula, 562,482 | Sumbawa, . . 200,000 Sumatra and adjacent Floris, : $: 278,000$ islands, . 4,964,770 Solor, Adenatti,

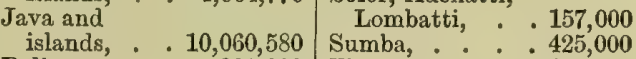
Bali, . : $: 900,000$ Timor, : : $: 639,000$ Lombok, : : 250,000

The latest estimate by Behm and Wagner gives the population at $63,969,000$ :-

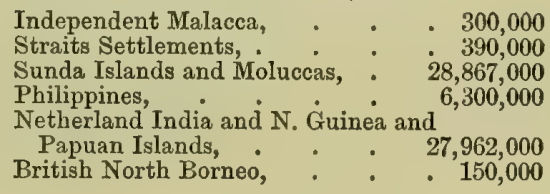

The Malay Races and Languages have been given (Asia, p. 620) by Professor A. H. Keane, as under :-

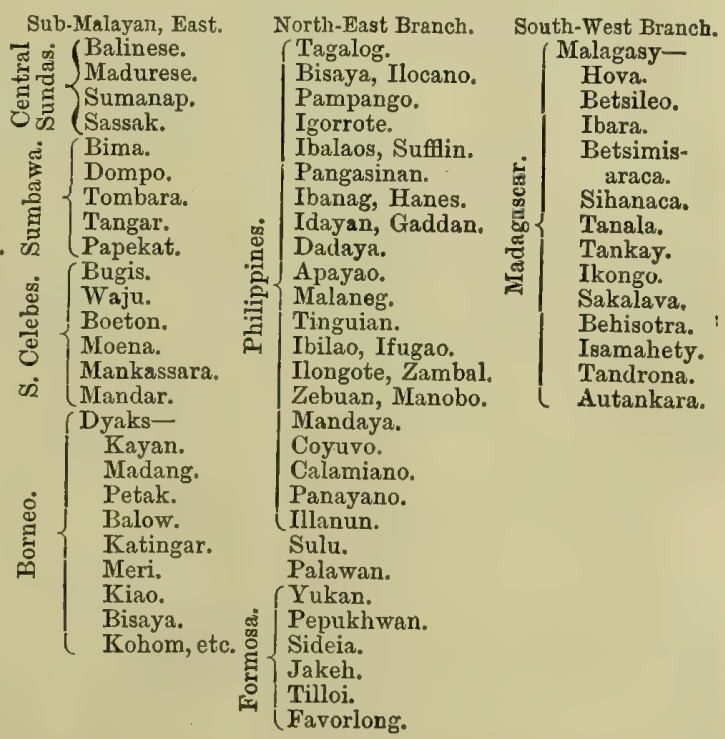

to designate the black-skinned races, of whom mention is now made. But from the Andaman Islands eastward to the races in the Pacific, of the people generally classed as Negroes there are at least 12 varieties, differing from each other in physical appearance, some being pigmies under five feet, and others large and powerful men of near six feet. Keeping this marked difference in remembrance, to the Malay type, and to the Papuan type respectively, all the people of the various islands can be grouped. The Asiatic races include the Indo-Malay, and all have a 
continental origin; while the Pacific races, including all to the east of the Malay (except perhaps some in the Northern Pacific), are derived not from any existing continent, but from lands that now exist or have recently existed in the Pacific Ocean. On drawing a line to separate the Malay and Papuan races, it almost coincides with that which divides the zoological regions, but juts somewhat eastward of it, as the maritime enterprise and higher civilisation of the Malays have enabled them to overrun from the west a portion of the adjacent region on the east, to supplant the original inhabitants, and to spread much of their language, their domestic animals, and their customs far over the Pacific into islands where they have but slightly or not at all modified the physical or moral characteristics of the people.

Peschel classes the Malay people amongst the Mongoloid races. He believes with Moritz Wagner that the shape of the skull, the form and colour of the face, as well as the whole physical constitution of the Malay race, is so nearly allied to the Mongolian that in similar apparel the two races are hardly distinguishable.

Mr. Wallace believes that the Malay and the Papuan races have no traceable affinity to each other; that the Asiatic races include the Malays, and all have a continental origin; while the people of the Celebes and Pacific races in the islands on its east are derived from lands which now exist or have recently existed in the Pacific Ocean. He allots the Eastern Archipelago amongst two races, and shows their islands thus :-

\begin{tabular}{|c|c|c|c|}
\hline $\begin{array}{c}\text { Indo-Malayan } \\
\text { Regions. } \\
\text { The Malay }\end{array}$ & $\begin{array}{l}\text { Austro- } \\
\text { Malayan } \\
\text { Regions. } \\
\text { yan Group. }\end{array}$ & \multicolumn{2}{|c|}{$\begin{array}{l}\text { Polynesian or Pacific } \\
\text { Regions. } \\
\text { The Papuan Group. }\end{array}$} \\
\hline $\begin{array}{l}\text { Sumatra. } \\
\text { Lingen. } \\
\text { Banca. } \\
\text { Billiton. } \\
\text { Java. } \\
\text { Madura. } \\
\text { Bali. } \\
\text { Baweean. } \\
\text { Borneo. } \\
\text { Sulu Archi- } \\
\text { pelago. } \\
\text { Palawan. } \\
\text { Philippines. } \\
\text { Samar. } \\
\text { Mindanao. }\end{array}$ & \begin{tabular}{|l|} 
Lombok. \\
Sumbawa. \\
Celebes. \\
Moena. \\
Bouton. \\
Sula-mangola \\
Sula-basi. \\
Part of \\
Bourou. \\
Part of \\
Ternate.
\end{tabular} & $\begin{array}{l}\text { Floris. } \\
\text { Sumba or } \\
\text { Handana. } \\
\text { Adenara. } \\
\text { Solor. } \\
\text { Lombata. } \\
\text { Rutar. } \\
\text { Ombay. } \\
\text { Wetter. } \\
\text { Rotte. } \\
\text { Seratty. } \\
\text { Babbar. } \\
\text { Timor Laut. } \\
\text { Larat. } \\
\text { Tenember. } \\
\text { Part of } \\
\text { Bourou. } \\
\text { Part of } \\
\text { Ternate. }\end{array}$ & $\begin{array}{l}\text { Ki Islands. } \\
\text { Ceram. } \\
\text { Banda. } \\
\text { Amboyna. } \\
\text { Batchian. } \\
\text { Oby. } \\
\text { Gilolo. } \\
\text { Morty. } \\
\text { Aru. } \\
\text { Vorkai. } \\
\text { New Guinea. } \\
\text { Australia, } \\
\text { Myfor. } \\
\text { Jobi. } \\
\text { Mysol. } \\
\text { Waigiou. } \\
\text { Salwatty. } \\
\text { Sook. } \\
\text { Biak. }\end{array}$ \\
\hline
\end{tabular}

The cradle of the Malay race was the plains of Menangkabau, in the interior of Sumatra, from whence they emigrated and pushed their conquests, or formed settlements to their present extensive limits. They formed colonies in the Malay Peninsula and in Borneo, the former probably, and the latter certainly, occupied before their arrival by rude tribes of the same race of men, who could offer no effectual resistance. In the remoter islands, or in those occupied by powerful and civilised nations, the Malays appear only as settlers and not colonists, as in Java and the principal islands of the Philippine Archipelago.

The Malay Peninsula, called Tannah Malayu, or Land of the Malays, with the exception of a few diminutive Negro mountaineers, is occupied by Malays or by men of the same race, for the several wild tribes in the interior speak the Malay language, and have the same physical form as the Malays, although not calling themselves by this name, and their language contains many words that are not Malay. Nearly the whole of the coast of Borneo is occupied by. Malays, who are supposed to have first emigrated to that island about the date of the reign of the Saxon king Athelstan.

The annals of several ancient Malay states point to Palembang as the original land of the Malays. They afford various indications of a close connection between it and Java, and mention Java invasions and settlements long anterior to the modern conquest of Palembang by Majaphit. From their concurrent tenor, it appears that the royal dynasties of Menangkabau, Malacca, and other states, traced their descent from Palembang. It may be inferred that it was in Palembang that the Malay race and language received their earliest and deepest impressions from Hindu and Java influences, and that the Indian monarchical form of government was first engrafted on the native Sumatran institutions, which are of a mixed patriarchal and oligarchical form.

Mr. Crawfurd has regarded the Malays as consisting of four great tribes and a few minor semicivilised tribes ; and a number of others who may be termed savages. The four great tribes are:--

The true Malay races, the Malay proper, who inhabit the Malay Peninsula, and almost all the coast regions of Sumatra and Borneo. They all speak the Malay language, or dialects of it; they use the Arabic characters in writing, and they are all Muhammadans in religion.

The Javanese, who inhabit Java, part of Sumatra, Madura, Bali, and part of Lombok. They speak the Javanese and Kawi languages, which they write in a native character. They are of the Muhammadan religion in Java, but Bali and Lombok is Brahmanical.

The Bugis are the inhabitants of the greater part of Celebes, and there seems to be an allied people in Sumbawa. They speak the Bugis and Macassar languages with dialects, and write these in two different native characters. They are all Muhammadans.

The Tagala of the Philippine Islands are the fourth great Malay race; many of them profess Christianity ; their native language is Tagala, but they speak Spanish.

Moluccan Malays, who inhabit chiefly Ternate, Tidore, Batchian, and Amboyna, may be held a fifth division. They are Muhammadans, but they speak a variety of curious languages, which seem compounded of Bugis and Javanese, with the languages of the savage tribes of the Moluccas.

The Savage Malays are the Battak and other wild tribes of Sumatra, the Dyak of Borneo, the Jakun of the Malay Peninsula, the aborigines of Northern Celebes, of the Sulu Island, and of part of Bouru.

Peschel and Friedrich Muller have proposed other classifications, but neither of them have resided among the races under notice.

The Malay tongue is now, and was, when Europeans first visited the Archipelago, the common language of intercourse between the native nations among themselves, and between these and foreigners. It is in the Archipelago what French is in Western Europe, Italian in 
Eastern, Arabic in Western Asia, and Hindi in Hindustan. All nations who hold intercourse of business with strangers must understand it, and all strangers must acquire it. This is the case in Sumatra, where other languages are also vernacular, in Java, in Celebes, in the Moluccas, in Timur, and in the Philippine group. Mr. Crawfurd attributes the spread of this language to the enterprising or roving character of the people, whose native tongue it is, as also its own softness of sound and simplicity of structure and consequent facility of acquirement.

The Malay family approximates closely to the ruder or more purely Mongolian type of UltraIndia, and the identity in person and character is accompanied by a close agreement in habits, customs, institutions, and arts, so as to place beyond doubt that the lank-haired populations of the islands have been received from the Gangetic and Ultra-Indian races. The influx of this population closed the long era of Papuan predominance, and gave rise to the new or modified forms of language which now prevail. The rude maritime tribes who frequent the coasts and islands of the Malay Peninsula, and amongst whom several distinct tribes are distinguishable by their physical characters, speak a language mainly Malay, but with differences in pronunciation. The Malay race, as a whole, very closely resembles the East Asian populations from Siam to Manchuria. The Malays are frequently quite Burmans in appearance, but the normal and least mixed Malays are more Binua and also more Siamese than the Western Burmans.

The colour of all the Malay tribes is a light reddish-brown, with more or less of an olive tinge, not varying in any important degree over a wide extent of country. The hair is equally constant, being invariably black and straight, and of a rather coarse texture, so that any lighter tint, or any wave or curl in it, is an almost certain proof of the admixture of some foreign blood. It is plentiful on the head, but other parts of the body are smooth. The moustaches alone are retained on the face, other hairs being removed by pincers. The stature is tolerably equal, and is always considerably below that of the average European,-five feet two or three inches being considered the average height of a man, and that of a woman is a few inches shorter. Their bones are large and clumsily put together, but strongly knit; arms and legs usually short compared with the length of the body; and the whole frame robust, and capable of much labour. The body is fleshy and muscular, legs remarkably so, thighs so large as to be unwieldy: Malays seldom become obese; the breast well developed, the feet small, thick, and short, the hands small and rather delicate. The head is round, and elongated at the summit, broad at the back, and set on a stout, thick neck. The facial angle seldom exceeds 50 degrees, while that of the European is seldom less, and sometimes is nearly ninety, or perpendicular. The face is a little broad, and inclined to be flat; the forehead is broad and rather rounded, the brows low; the eyes loug and narrow, rather deep set, black or dark hazel in colour, and seldom clear about the white. The nose is rather small, not prominent, but straight and well shaped, the apex a little rounded, the nostrils broad and slightly exposed; the cheek-bones are rather prominent; the mouth large; the lips broad and well cut, but not pro: truding; the chin well formed; ears large and ill-shaped; jaws wide and square; teeth regular, large, and white, unless discoloured by lime and gambier. The Malays, when mature, are certainly not handsome, but in youth up to 15 years of age both boys and girls have pleasing countenances, and in their way almost perfect. Women soon show signs of old age; they become wrinkled and haggard after bearing a few children, and in old age are hideous. With shades of difference, not to be fixed in words, this, with the exception of a few Negroes, is a description which applies to all the inhabitants of Sumatra, the Peninsula, Java, Borneo, Celebes, the Moluccas, Timor, and the whole Philippine group.

In character, the Malay is impassive. He exhibits a reserve, diffidence, and even bashfulness which is in some degree attractive, and leads the observer to think that the ferocious, bloodthirsty character imputed to the race must be grossly exaggerated. $\mathrm{He}$ is not demonstrative. His feelings of surprise, admiration, or fear are never openly manifested, and are probably not strongly felt. He is slow and deliberate in speech, and circuitous in introducing the subject he has come expressly to discuss. Children and women. in the company of men are silent, and are generally quiet and obedient. When alone, the Malay is taciturn, he neither talks nor sings to himself. When several are paddling in a canoe, they occasionally chant a monotonous and plaintive song. He is cautious of giving offence to his equals, he does not quarrel easily about money matters, and practical joking is utterly repugnant to his nature. The higher class of Malay are exceedingly polite, but this is compatible with reckless cruelty and contempt of human life, which is the dark side of their character. They are proud, and, if ill-treated, revengeful; but under generous treatment are gentle, kind, humane, grateful, docile, and faithful. Capable of the warmest attachments, and yet impelled to madness and the commission of the most revolting deeds by real or imaginary unkindness. They are dutiful children and kind parents. They treat their aged kinsmen with the greatest kindness, and feel it a duty to relieve the wants of an indigent relation. Old men and women are always regarded with respect.

Dr. Oxley described the character of the unsophisticated Malay as remarkable for its simplicity and honesty; having no artificial wants, they are satisfied and content with what would be considered positive destitution by a Chinese ; they are consequently apathetic and inactive, and will not for any amount offered to them labour beyond their usual habits or customary routine; they have little of any speculative turn; they have a regard for truth, and may generally be depended upon in their statements. What has so often been written of their revengeful spirit, he says, is much exaggerated; polite in the extreme, according to their own ideas, they never indulge in abuse one towards the other, the only reply to any deviation from this rule is the kris, for which they will watch their opportunity, and most certainly not afford their adversary any advantage it is in their power to deprive him of. This is their code of honour, and, being fully 
aware of it amongst themselves, provocation is seldom given, and satisfaction as seldom required. When goaded, however, to the necessity, they become perfectly reckless, and should discovery attend the deed, they attempt no refutation, but sell their lives at the utmost cost they can to the captors. "Too often have I known the officers of police compelled to shoot them on these occasions. Such is one species of amok, and how offenders of this description are to be dealt with can admit of but little doubt; but there is another variety of the Orang Beramok vastly different, and by no means the least frequent, which requires discrimination on the part of the medical jurist to prevent irresponsible persons suffering the penalty of the injured law. For instance, a man sitting quietly amongst his friends and relatives will, without provocation, suddenly start up, weapon in hand, and slay all within his reach. I have known so many as eight killed and wounded by a very feeble individual in this manner. Next day, when interrogated whether he was not sorry for the act he had committed, no one could be more contrite; when asked, "Why, then, did you da it?" the answer has invariably been, "The devil entered into me, my eyes were darkened, I did not know what I was about." I have received this same reply on at least twenty different occasions; on examination of these monomaniacs, I have generally found them labouring under some gastric disease or troublesome ulcer, and these fearful ebullitions break out upon some exacerbation of the disorder. Those about them have generally told me that they appeared moping and melancholy a few days before the outbreak.' The Bugis are by far the most addicted to the amok. They are a bold, self-reliant, maritime people of Celebes, of which they occupy the northern part, and they are known, in consequence, as the men of Macassar. The Bugis, originally from the same stock as the Malay, are superior to all other natives of the Archipelago in their spirit of adventure. They are a brave, active, haughty, fierce, and vigorous race. They love justice, and are faithful to their bonds, but seldom forgive injuries. Under the name of Macassars, they form the flower of the colonial troops in the Dutch service; they are bold hunters, and, mounted on their brisk little horses, drive the deer through the woods, and capture it with a lasso. The Bugis bave been the greatest colonists as well as the principal traders of the Archipelago. The ingenuity of the savage and the amenity of the civilised man, appear united in them. They have received the Koran, but not abjured the practices of their ancient faith, - the dark old idolatry once universal in the Archipelago. Stones and trees, painted red, still share their devotions with the invisible god of Islam. Women are treated honourably among them, - a distinction in their manners not yet effaced by the Muhammadan social law. They determine many disputes by single combat, but never avenge themselves by personal assassination. The Sulu race, on the contrary, have no idea of putting themselves on a footing with their antagonist, but always attack him in the dark or off guard. Both the Malayan and Bugis nations are maritime and commercial, devoted to speculations of gain, animated by a spirit of adventure, and accustomed to distant and hazardous enterprises; while the Javans, on the contrary, are an agricultural race, attached to the soil, of quiet habits, and contented dis. positions, almost entirely unacquainted with navigation and foreign trade, and little inclined to engage in either.

Religion.-Malays have largely become converts to Muhammadanism. The earliest conversion recorded was that of the Achinese, the nearest people of the Archipelago to the continent of Asia. This was in 1206 of our era. The Malays of Malacca were not converted until 1276; the inhabitants of the Moluccas not until 1478, and the people of Celebes not until 1495, only the year before Vasco da Gama passed the Cape of Good Hope. Thus the earliest conversion of these islanders took place 574 years after the death of Mahomed, and long after the first zeal of his followers had evaporated.

The Malays were not coerced into Muhammadanism, nor have instances of violent conversion been frequent in later times. The Arabs and other Muhammadan missionaries have conciliated the natives, acquired their language, followed their manners, intermarried with them, and their superiority of intelligence and civilisation was employed only for the instruction and conversion of a people, the current of whose religious opinions was ready to be directed into any channel into which it was skilfully diverted.

In the Malay Peninsula the race are in part Muhammadan, and in part pagan in the more impracticable parts. To this day there are a few mountaineers in Java still professing a kind of Hinduism, and the Javanese retain numerous of their old pagan superstitions, and have added those of their subsequent religion. They people the air, the woods and rivers, with various classes of spirits. They have the praying or fleeting ghosts; the barkas-a-han, kabuka-male, and wewe, evil spirits; and the damit and dadun-gawu or tutelary spirits. They now consider the Hindu gods of their former belief not as imaginary beings, but as real demons, and have added the jan of the Arabs. The Malay of Borneo firmly believe in ghosts. If a man die or be killed, they are afraid to pass the place.

Learning.-Malays can hardly be said to have an indigenous literature, for it is almost entirely derived from Persia, Siam, Arabia, and Java. Arabic is their sacred language. They have, however, a celebrated historic Malay romance, called the Hang Tuah, parts of which are frequently recited in their villages after sunset prayers by their village raconteurs, and some Arabic and Hindu romances stand high in popular favour. They have one Malay historical composition, dated A.H. 1021. The conversion of the Sumatra Malays to Muhammadanism arose mainly out of their cornmercial intercourse with Arabia.

Customs.-Malays rub noses, in lieu of the kissing of Europe. Most of the advanced nations of the Asiatic islands are gamblers, and the little fighting fish of Siam and cock-fighting are largely betted on. In the Archipelago, in Bali, Lombok, Celebes, and the Philippines, cock-fighting is quite a passion. The only material exceptions are the Javanese. The passion for cock-fighting is indeed impressed in the very language of the Malays, which has a specific name for cockfighting, one for the natural spur of the cock, and another for the artificial spur, two names for the comb, three for the crow of the cock, 
two for a cock-pit, and one for a professional cock-fighter. The passion is nowhere carried further than in the Spanish dominions of the Philippines. There it was licensed by the Government, which derived from it a yearly revenue of about 40,000 dollars, or about $£ 8000$.

Malay women of the Peninsula, when engaged to be married, have their teeth filed down about a fourth part.

War. -Sulu, Mindanao, and the crowd of islands extending from Mindanao to the N.E. coast of Borneo, and separating the Mindoro from the Sulu sea, were the great seat of piracy in the Archipelago.

The Ladrones, or pirates of the Eastern Archipelago, consisted wholly of the inhabitants of the free Muhammadan states in Sumatra, Lingin, Borneo, Magindanao, and Sulu.

The Malay pirate prahu or prow are stockaded, and armed with heary guns, generally the mariam and lelah, to which last the Malays are very partial; also matchlocks, long spears, pointed nibong stakes charred at the end, and others cut short for throwing when at close quarters, and large stones. The signal for attack is the sound of a sort of gong, called tawa tawa.

The Malay are the great manufacturers of weapons of war. They have the sword, the kris and spear, brass and iron cannon, of sizes called miriam, rantaka, jala rambang, ekor lotong, and lelah. They have also the blunderbuss and matchlock, satengar and pemura.

The Baju wear the baju ranti, or chain jacket, and a shield of a long or round form. They swear by their krisses, for which they have a great veneration, and on going into battle, drink the water in which they have been dipped, uttering imprecations on the foe.

In Pulo Nias, the war jacket and cap is of thick leather, covered with the black horsehairlike eju of the Arenga saccharifera palm. They have a spear and short sword. The Orang Laut have the limbing or lance, the tampuling, a large hook, the kujore, broad-headed fishing spear, and the Serampong prong.

The Sumatran races have also the rudus and pemandap swords and suvar dagger; the Batta race wear the kalassan and jono swords, also the tombak leda and terjing, the last a long curved knife, which is used to cut up human flesh, according to Mr. Anderson, and guns, matchlocks, the kris, and ranjow.

Games.-Sumatrans and Burmese have the sepa raga, or cane football game. It does not require strength or courage, but is an exhibition of skill, dexterity, and activity. The ball is hollow and elastic, about 4 in. in diameter. The players are unlimited in number, and stand in a circle about 6 feet apart from each other. The ball is thrown into the air, and as it descends, one of the players strikes it up again with hand or foot, shoulder, elbow, or knee, arm, forearm, thigh, or leg. Sometimes the ball descends beyond the circle, and is dexterously struck back again with the sole of the foot, without the player altering his position. Expert players will keep the ball from touching the ground for a considerable time.

The Malays are exceedingly fond of music, but the drum seems to be their sole native instrument, though they have the violin. They have a drama called Myong, in which young lads take the part of women. It is supposed to be of Siamese origin, as none but natives of Siam engage in it. Music from drums and brass instruments accom pany the performance. The actors move about to the sound of the instruments.

Dress.-Malays set the fashion of dress to the islanders, and the principal portions of the apparel are worn by the Malays, the Bugis, the Javanese, and most of the smaller races all over the Archipelago. The sarong is worn by both sexes; it is a cloth two yards long and four feet broad, and is wrapped round the lower part of the body from the waist, like an unsewed gown. It is often the sole dress worn in the house and courtyard.

The saluar or sluar is a pair of drawers or trousers, invariably worn when abroad; there are several kinds, the Achinese, the Chinese, the Singapore sluar, and that of the Bugis, the last reaching the middle of the thigh.

The baju or jacket. Its arms have several shapes, and have respective names, Baju sikat, Baju chari, and Baju pesa sabla or Baju tutop iman. The Baju tangan-kachang is a long gown reaching to the ankles, worn by old women; Baju bastrob is a vest or shirt; Baju ayit karang resembles a shift.

The saluar, sarong, and baju are the essential parts of their dress.

The bang-kong, or waist-cloth, or sash, is often worn. It is of cotton or silk.

The dustar or justar, a kerchief, is worn as a turband. The turband and flowing dress of the Arab are worn by all who have performed the Mecca pilgrimage.

The kris is never allowed to be visible in the presence of a superior or equal.-Bitkmore's Trav.; Crawfurd's Grammar; Journ. Indian Archip.; Latham's Ethnology ; Logan; Le Moniteur, 1847; M'Nair, p. 233 ; Newbold; Peschel; Wallace; St. John's Ind. Archipelago; Marryat's Ind. Archipelago; Earl's Ind. Archipelago ; Quarterly Review, No. 222 ; A. H. Keane's Asia.

MALAYANESIA. The name Indian Archipelago being too long to admit of being used in an adjective or in an ethnographical form, Mr. Earl suggested the term Indu-nesia, but rejected it also in favour of Malayanesia. The purely geographical term Indonesia was, however, suggested by Mr. Logan, as we thus get Indonesian and Indonesians for the Indian Archipelago or Indian islanders.

MALAY ARCHIPELAGO is a term sometimes applied to the multitudinous islands of the Archipelago to the east of the Straits of Malacca, though this is more usually called the Archipelago, also the Eastern Archipelago. It is sometimes applied to the Mergui Archipelago along the Tenasserim coast, in the Bay of Bengal.

MALAY PENINSULA, or Tanna-Malayu, extends for 500 miles from the southern extremity of Tenasserim almost to the equator, the island of Singapore being in lat. $1^{\circ} 41^{\prime} \mathrm{N}$. Its width varies from 50 to 150 miles, and the entire area will be about 83,000 square geographical miles. The possession of it is chiefly divided between the British and the Siamese. Engagements have been formed by the British with the Kedah State, which is tributary to Siam, and with the Independent States of Perak, Selangor, the Confederate States of Rambowe, Sungei Ujong, 
Johole, Sree-Menanti, and Johore. The districts of Tringanu and Kalantan are also protected by the British Government, under the treaty of Bankok. A forest-clad mountain chain, rising in Perak to ascertained heights of 8000 feet, runs down its whole length near the centre, with extensive outlying spurs and alluvial plains on both sides. In the early part of the 19 th century, Newbold thus estimated the population :-

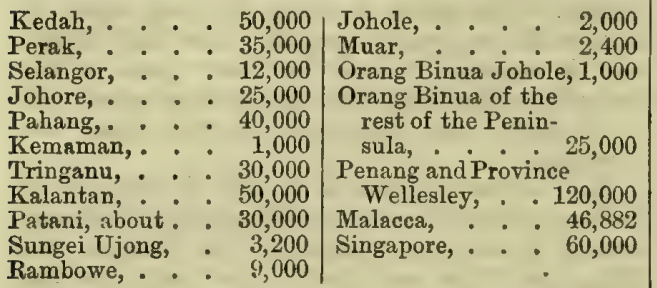

On the west side of the Peninsula are the Native States of Kedah, Perak, Selangor, and Sungei Ujong, the last three of which are under British protection; and on the east are Patani, Kalantan, Tringanu, and Pahang; the southern extremity being occupied by the state of Johore. The interior, which is scarcely at all known, contains towards its centre the Negri Sembilan, a confederation of eight (formerly nine) small states. The northern and eastern states of Kedah, Patani, Kalantan, Pahang, and Tringanu are more or less tributary to the Siamese empire, which at intervals has exacted a golden rose, the token of vassalage, from every state in the Peninsula.

The British possessions in the Peninsula are the detached provinces of Wellesley, with the island of Penang, also the Ding Dings, Malacca, and the island of Singapore, and in 1881 their respective population was as under :-

\begin{tabular}{l|r|c|c}
\hline & $\begin{array}{r}\text { Penang, } \\
\text { Prov. Well., } \\
\text { Ding Dings. }\end{array}$ & Malacca. & Singapore. \\
\cline { 2 - 3 } Arabs, . & 574 & $\ldots$ & $\ldots$ \\
Europeans, : & 674 & $\ldots 40$ & 2,768 \\
Eurasians, : & 1,597 & 2,213 & 3,094 \\
Chinese, : & 67,502 & 19,741 & 86,766 \\
Malay, : & 84,724 & 67,488 & 22,114 \\
Tamil, : & 25,094 \\
Armenians, : & 32 & $\ldots$ & $\ldots$ \\
Jews, & 32 & $\ldots$ & $\ldots$ \\
Eastern races, & $\ldots$ & 4,697 & $\ldots$ \\
\hline
\end{tabular}

The East India Company acquired Penang in 1775 , Province Wellesley in 1798 , Singapore in 1823 , and Malacca in 1824. These were under the rule of the E. I. Company until they were consolidated in 1867 into one government under the British dominion, and are known as the Straits Settlements.

The Ding Dings; a lively group of small islands, ceded to Britain by the Pangkor treaty.

The mainland of the Peninsula, with the exception of a few diminutive Negro mountaineers, is occupied by Malays, or by men of that race, for the several wild tribes in the interior speak the Malay language, and have the same physical form as the Malays, although not calling themselves by this name, and their language containing many words that are not Malay.

The wild tribes have been vaguely estimated at 8000 to 11,000 souls. The Semang race are found in the forests of Kedah, Tringanu, Perak, and Selangor. Jakuns inhabit the south part of the Peninsula, from about Selangor on the west coast, and Kemaman on the east, and extending nearly as far as Singapore. Orang Binua signifies men of the soil. All these various wild tribes are ordinarily classed under this general and expressive appellation, Orang Binua or Orang Utan, and in Perak the Sakei ; there are also the Udai, Hala, Belanda, Besisik, the seafaring Selong, and the seafaring Akkye or Rayat Laut or Orang Laut, men of the sea.

The Semany are about the same height as the Malays, but their hair, instead of being lank and straight like theirs, is short and curly, though not woolly like that of the African Negro, and their skins are of a dark brown, nearly black. Their noses incline to be flat, their foreheads recede, and their lips are thick. They are singularly shy, and shun intercourse with men of other races.

With the Sakei or Jalkun, Orang Binua or Orang Utan, the mouth is wide and the lips are large, the lower part of the face projects, the nose is small, the nostrils are divergent, and the cheekbones are prominent. The hair is very abundant and long, and usually matted and curly, but not woolly. They have broad chests, and very sturdy, muscular limbs. They are much shorter in stature than the Malays, the men in some of the tribes rarely exceeding 4 feet 8 inches in height, and the women 4 feet 4 inches.

The Rayat or Orang Laut, subjects, or men of the sea, live almost entirely upon fish. They are altogether restless and impatient of control. They are passionately fond of music, and are most ingenious in handicrafts, specially in boat-building.

Kedah or Quedah, called in Siamese Muang Sai or the Sai kingdom, extends from the Trang river, in lat. $7^{\circ} 20^{\prime} \mathrm{N}$., to the Krian, in lat. $5^{\circ} 10^{\prime} \mathrm{N}$., which separates it from Perak. The purest Malay is written and spoken in this state, being often in the Archipelago influenced by mixture with other tongues. The highest detached hill is Gunong Gerai or Kedah peak. Penang was sold by the raja of Kedah for $£ 2000$ a year, which is paid at the present day to his successor. When the Kedah prince ceded Penang to the British he represented himself as independent, and as such was treated by the British.

Several tribes are within its limits, the Semang and Udai in the forests of the north; the Rayat Utan, the Jakun, Sakei, Hala, Belanda, and Besisik in others to the south; while the Akkye or Rayat Laut (lit. people of the sea) dwell upon the shores and islets of the Peninsula. Wherever scattered, they live totally apart from the Malays; and differ from them widely in person, habits, and religion; in short, are of a much lower grade in the seale of civilisation. The Malays themselves sometimes class the various tribes under the general appellation of Orang Binua, men of the soil.

The names of inland places are chiefly Binus terms. There is a striking resemblance in feature between the Binua and the Malay, and scarcely less in their respective languages. Many Malay believe the Udai tribe are a class of Jakun. The Tuanku Puteh of Rambowe informed Newbold that the Udai are thinly scattered over the states 
of Jellabu, Pahang, Tringanu, and Quedah, and resemble in feature the darker variety of Jakun. Their size is represented as smaller, and their habits more savage. According to Sir S. Raffles and Mr. Anderson, the Semang of Quedah has the woolly hair, protuberant belly, thick lips, black skin, flat nose, and receding forehead of the Papuan. Mr. Anderson described the Semang of Perak as resembling those of Quedah in personal appearance, but speaking a different dialect. They possess, he says, the same curling black hair, are a little darker in colour, and have not the thick lips of an African; they subsist by hunting, and make huts of the branches, and cloths of the bark of trees, shunning the haunts of more refined beings. They are numerous in Quedah, and reside generally on or near mountains, such as those of Jerrei and Juru, and are found in Tringanu, Perak, and Selangor. They live in rude huts, easily removed from place to place, constructed of leaves and branches.

Perak lies between lat. $4^{\circ}$ and $6^{\circ} \mathrm{N}$. It is famed for its tin mines. Gold is net with in all its rivers. Perak (pronounced Payrah) is the richest and most important of the states of the Peninsula, as well as one of the largest. Its coast-line is about 125 miles in length. Perak river is a most serpentine stream. Its population, 971,940, is chiefly Chinese and Malays. Tin is the most abundant of the mineral products of Perak. Gold is found in tolerable quantities even by the Malay easy-going manner of searching for it, and diamonds and garnets occur.

Selangor is a small Malay state lying between lat. $2^{\circ} 34^{\prime}$ and $3^{\circ} 42^{\prime} \mathrm{N}$. Its coast-line is about 120 miles in length; population about 20,000 . Its rivers, up to 1871 , were shelters for pirates. In Selangor and Perak are isolated hills of limestone from 80 to 1000 feet in height. At Batu are magnificent limestone caves with stalactites and stalagmites. The roof of one cavern is 355 feet from the floor.

The Negri Sembilan or Nine States are inland, south of Selangor. These have been independent since the breaking up of the kingdom of Johore.

Sungei Ujong is mainly an inland state, access to its very limited seaboard being by the river Linggi, its area about 700 square miles. Its aboriginal tribes, the Besisik, Jakun, Orang Bukit, Rayat Laut, Rayat Utan, and Semang, have been largely pushed aside by Malays. Its population in 1883 was 12,000 , of whom the Chinese were 10,000 . It is rich in tin. It is the great mineral product of the Peninsula, and is largely washed by the Chinese. The tin districts which have been most worked of late years have been those at Klang in Selangor, at Laroot in Perak, and at Linghie near Malacca. Gold, garnets, and sapphires likewise occur, and it is said diamonds also. - Rev. P. Faver, Apostolic Missionary, Malacca; Oshorn's Quedah; Newbold's British Settlements; Sonnerat, ii. p. 177; St. John's Ind. Archip.; Journ. Ind. Archip.; J. L. Bird, Golden Chersonese.

MALBUK, Arab., confused, possessed, ecstatic, is a term applied to a Muhammadan permanently insane, or overcome by religious excitement. It is the ecstatic condition described in 1 Samuel $\mathrm{x} .5-11$, when Saul reached the hill of God, 'Behold, a company of prophets met him; and the
Spirit of God came upon him, and he prophesied among them.'

MALBUS. ARABO-Hindr. Clothing; clothed; $\mathrm{pl}$. Malbusat. Malbus-khas, an annual investment of fine muslins, formerly furnished from Dacca, for the royal wardrobe at Dehli.- $W$.

MALCOLM. Three brothers of this name are known in the history of the East Indies. Sir Pulteney Malcolm, who rose to the rank of Admiral in the British navy, and in 1798 was employed in cutting out of vessels at Manilla. Sir Charles Malcolm, born in 1782, also a British naval officer, served under his brother Sir Pulteney at Manilla in 1798. He saw much service during the war with France. He was knighted by Lord Wellesley at Dublin in 1826, became Rear-Adrniral in 1837. He was appointed as the first Commander-inChief of the Indian navy in 1827, where he served till 1838 , and instituted several extensive and important surveys along the shores of the Arabian Sea, Bay of Bengal, and Indian Ocean.

Sir John Malcolm, born 1769, entered the Madras army (1782) at the age of 13 . When the Nizam's army took the field in Mysore against Tipu Sultan, Captain Malcolm accompanied it as Political Agent, and after the fall of Tipu Sultan and the reduction of Seringapatam, he was associated with General Arthur Wellesley, Colonel Close, and Captain Munro in the commission appointed for the settlement of Mysore. He was on four occasions sent as ambassador to the court of Persia in 1799 ; again in 1808, but was not allowed to advance beyond Bushire; a third time whilst Sir Harford Jones was there; and he went a fourth time on a supplementary mission, but it was a mere pageant and very costly, though from it resulted his History of Persia and Pottinger's Baluchistan.

During the war against the Pindara and Mahrattas, which lasted from the 5th November 1817 to the 13 th May 1819 ; in all the operations of the war, as second in command at Mehidpur, 21 st December 1817, in the pursuit of Baji Rao and of Apa Sahib, and in the final reduction of the fortress of Asirgarh, he was the prominent authority. At the close of that war he was appointed to the civil and military command of Malwa, and in the year 1827 he became governor of Bombay. He was an active, able man, of large stature, with much energy and great bonhomie. He was a voluminous writer. Amongst his other books were-Sketch of the Political History of India from 1784 to the present time, London 1826; Observations on the Disturbances in the Madras Army in 1809, London 1812; History of Persia from the most early period to the present time, London 1815; Report on the Province of Malwa and adjoining Districts, Calcutta 1822; Instructions to Officers acting under his Orders in Central India, 1821, London 1824; Sketch of the Sikhs; History of Persia; Letter on the Persian Army; on the Present (1810) Condition of Persia; Memoir of the Kajar Family; on the Trade of the Persian Gulf; Sketches of Persia.

MALCOLMSON, JOHN GRANT, M.D., F.R.S., F.G.S., a Madras medical officer from 1823 to $1840 \mathrm{He}$ wrote on Beri-beri, on the Rheumatic and Neuralgic Affection, termed by the natives burning of the feet; on the Fossils of the Gawilgarh Range, and on the Basaltic District of India, in the Madras Journal of Literature and Science; 
also on the Effects of Solitary Confinement of European Soldiers in Warm Climates. While geologizing in Gujerat and Kandesh, he died of hepatitis at Dhoolia, 23d March 1844.

MALDAH, a British district in the LieutenantGovernorship of Bengal, occupying an eastern projection of the Bhagulpur division. It lies between lat. $24^{\circ} 29^{\prime} 50^{\prime \prime}$ and $25^{\circ} 32^{\prime} 30^{\prime \prime} \mathrm{N}$., and long. $87^{\circ} 48^{\prime}$ and $88^{\circ} 33^{\prime} 30^{\prime \prime} \mathrm{E}$. Three of its towns have been its capitals. Gaur is said to have been abandoned on the occurrence of a great pestilence. Its ruins, lying between the Mahananda and the Ganges, are scattered over an area of more than 20 square miles. The foundation of this city is referred back to the remotest antiquity. It was the Hindu metropolis of Bengal before the Musalman conquest, and continued to be the capital of the Afghan invaders for at least three centuries, and its name distinguishes a class of languages and a tribe of Brahmans. Pandua or Perua, which lies about 20 miles north-east from Gaur beyond the Mahananda, superseded the latter city as the seat of government during the reigns of five successive Afghan monarchs, towards the close of the 14th century. Tandan Tangra succeeded Pandua. As far back as 1686 the E. I. Company had a silk factory here. In 1770, English Bazar was fixed upon for a commercial residency; the buildings of which, strongly fortified after the fashion of those days, exist to the present day.

The two staple manufactures of the Maldah district are silk and indigo. The weaving of silk is said to date back to the Hindu kingdom of Gaur, and the peculiar cloth known as Maldahi has been for generations a speciality of external commerce. The English had a factory at Maldah at least as early as 1686 . The population comprise the aboriginal Kharwar, Dhangar, Koch, Pali, Rajbansi, Chain, and Bind; also the Hindu Kaibarta, Nagar, Teli, Goala, and Tiar, with a few Muhammadans.

MALDEO, died S. 1671 (A.D. 1615); he had twelve sons. His death formed an important epoch in the annals of the Rahtor race. The banner of the Moghul empire floated over the panchranga, the five-coloured flag, which had led the Rahtor from victory to victory, and had waved from the sandhills of Amerkot to the salt lake of Sambhar; from the desert bordering the Garah to the peaks of the Aravalli. Thenceforward the Rahtor princes were required to maintain a contingent of their proud vassals, headed by the heir, to serve at the Moghul's pleasure. Iod, ii. p. 30.

MALDIVE ISLANDS, Zabiyah-ul-Mohli, a vast group of islands, estimated at 1200 , extending southward from lat. $7^{\circ} 6^{\prime} 30^{\prime \prime} \mathrm{N}$. to $0^{\circ} 42^{\prime} \mathrm{S}$. A memoir of them, by Lieuts. J. A. Young and W. Christopher, I.N., is given in Bom. Geog. Trans., 1836-1838. These islands and rocks have about 60 miles of breadth, the islands being formed into large groups, which the natives call atoll or atollon.

The most northern is Heawandoo Pholo Atoll, 12 miles by 7 , contains 24 islands, of which 7 are inhabited, with a population of 760 .

Tilladoo Matte Atoll, 35 miles in extent, has 38 islands, all the northern of which are inhabited.

Malcolm Atoll contains 100 inhabitants; many ships have been wrecked on it.

Milladoo Madou Atoll contains 101 islands, of which 23 are inhabited, with a population of 1700 or 1800 .
Phaidee Pholo Atoll, 10 miles south of Milladoo Madou, has about 10 islands near it.

Mahlop Mahdoo Atoll extends from lat. $5^{\circ} 1^{\prime}$ to $5^{\circ}$ $59^{\prime} \mathrm{N}$., in long. $72^{\circ} 55^{\prime} \mathrm{E}$., has 4 small islands on its south.

Ari Atoll has a number of small islands on its eastern boundary.

Male Atoll has near it Male Island or King Island, with a population of 1500 or 2000 . It is unfavourable to the health of European strangers.

Cardiva or Cardoo, in lat, $4^{\circ} 58^{\prime} 30^{\circ} \mathrm{N}$., and long. $73^{\circ} 25^{\prime}$ E., has 200 inhabitants.

South Male Atoll contains 22 islands, of which only 3 are occupied with 200 people.

Pha-lee-doo Atoll is situated between lat. $3^{\circ} 19^{\prime} 30^{\prime \prime}$ and $3^{\circ} 41^{\prime} \mathrm{N}$

Moloque Atoll is 15 miles broad from east to west.

Nillandoo Atoll extends from lat. $2^{\circ} 40^{\prime}$ to $3^{\circ} 1^{\prime} 30^{\prime \prime} \mathrm{N}$. At its south extreme is a group of 20 islands, and there are detached small islands on the boundary.

Coollo Mandoo Atoll, Adou Matto Atoll, Suadiva or Hooahdoo Atoll may be named.

Phoowa Moloku Islands, the most south-easterly of the Maldive islands, is 2 miles long; it has 300 or 400 inhabitants, who are fishers and weavers.

Addoo Atoll is the south extreme of the Maldive chain of islands. Its south point is in lat, $0^{\circ} 41^{\prime} 30^{\prime \prime} \mathrm{S}$, and long. $73^{\circ} 5^{\prime} \mathrm{E}$.

The group extend 466 geographical miles in length, and 46 or 48 miles in breadth. Between the islands the water is of great depth, but on the surrounding reefs the waves beat with great violence. The reefs have openings which admit ships to enter, and though the water inside the atolls is generally shallow and calm, the depth is sufficient to allow vessels to pass from one side to another. The soil is sandy, all the islands are densely clothed with palms, fig trees, bread-fruit trees, and a thick jungle covers them all. Indian corn, sugar-cane, and millet are grown in a few.

Large numbers of vessels have been wrecked upon the islands, the steamers Sea Gull (in 1879) and Consett (in 1880). As a rule, shipwrecked people are well received by the Maldivians, and the Ceylon Government occasionally have an opportunity of reciprocating that kindness by providing for Maldivians wrecked on the Ceylon coasts. The islands are inhabited by 30,000 or 40,000 people. They trade with India, Ceylon, Chittagong, and Singapore, carrying in their peculiar ships cocoanuts, salt fish, cocoanut oil, coir, jagari, coral, ornamental mats, tortoise-shell, and cowries, and import grain, cotton, silk, and tobacco. The coir is noted for its light colour, fineness, and comparative strength. Maldive mats, for delicacy of pattern and permanence of dye, are perhaps unsurpassed in the world.

The Maldivians construct their own quadrants, and translate into their own language the nautical tables. The people are quiet and inoffensive. Their ruler is styled Sultan of the thirteen atolls and 12,000 isles. Upon the acquisition of Ceylon by the British in 1796, the inheritance of the suzerainty over the Maldives fell to them by the freewill of the Sultan. The present Sultan sends an ambassador to the Governor of Ceylon annually, and his arrival at Colombo, and formal journey from the wharf to the Government House, is one of the most curious sights to be had in the capital. Maldivian etiquette requires the ambassador to bear with both hands on his head the silver salver containing his sovereign's letter (in a double envelope of coloured silk and spangled muslin) and two tiny silk bags of ambergris and sea cocoanut. The management of all state and 
revenue matters is entrusted by the Sultan to vizirs, and he frequently consults with them. Justice is dispensed in the house of the Fadiyaru or Kazi, who is head of the church and chief magistrate, and sometimes, in important cases, in the king's palace. With the education imparted to the children is the reading and writing of the Koran. Three different writing characters are found on the tombstones, the Dewehi Hakura, the Arabic written from right to left, and the Gabali Tana similarly written, and the last is the common dialect of all the atolls. It is said to be Malay. Muhammadanism has been the accepted religion of the Maldivians for at least six centuries, but side by side with it there has continued to exist an older creed-not the less real because disowned -in demons and spirits, spells, charms, and the like. Every man in his lifetime provides for himself a burying-place.-Darwin; Lieuts. J. A. Young and W. Christopher, 1.N., in Bombay Geog. Trans., 1836-1838; Encyc. Brit.; Mr. Bell's Report.

MALE, in Coorg, a class of people whose mothers have forfeited their caste by reason of adultery, after widowhood.

MALÉ or Paharia are hillmen of Rajmahal, whence their other designation Rajmahali. The Rajmahal hill country extends from the banks of the Ganges at Segrigalli, in lat. $25^{\circ} 15^{\prime} \mathrm{N}$., and long. $87^{\circ} 3^{\prime} \mathrm{E}$, to the Brahmani river and the boundary of the Birbhum district, a distance of 70 miles. To the south of the Bralumani, the hills continue to the river Dwaraka as the Ramgarh Hills of the Birbhum district.

The Rajmahal Hills form a kind of knot at the extreme eastern point of the hill country of Central India, dividing Bengal from Behar, and the people are known as Malé. They are to the east of the Oraon, and are entirely different from their neighbours the Santal.

In the year 1832, the British Government, in order to protect the Malé race, marked off by pillars their territory. The cordon or ring-fence encloses a tract called the Daman-i-Koh, and within it the Malé dwell. It is 295 miles in circumference, containing 1366 square miles, of which 900 are said to be culturable. At the census of 1872 , there were returned 53,866 Paharia, 191,462 Santal, and 18,985 of other races. The rest of the hill country is called the Santal Parganas, and, including the Daman-iKoh, its area is 5456 square miles, the population aggregating $1,257,281$ souls, of whom 455,513 were Santal. The bulk of the Santals are in the Bhagulpur and Bardwan divisions $(569,643)$. The total in all India, 1,087,202, of whom 203,264 are semi-Hinduized.

The Rajmahali is less cheerful than the Santal, less industrious, and does not join in the dances to which the people of the Mundah stock are so devoted. The Malé are better looking than the Santal. It was the Malé race amongst whom Mr. Cleveland successfully laboured to impart to them settled habits. They are quiet cultivators, and formed the bulk of the corps formerly kuown as the Bhagulpur Hill Rangers. Ghatwal estates are particularly numerous in the Bhagulpur and Birbhum districts adjoining the Rajmahal Hills on either side. The estates pay no revenue, but are beld on the condition of guarding the passes against hill robbers, murderers, and cattle-lifters.

The Malé language abounds in terms common to the Tamil and Telugu, and contains so many Dravidian roots of primary importance, though it also contains a large admixture of roots and forms belonging to the $\mathrm{Kol}$ dialects, that Dr. Caldwell considers it had originally belonged to the Dravidian family of languages. Test words show an identity of language among the Rajmahali on the east, and the Maira in the remote jungles down to the Godavery, and the Gond, who live along the Satpura as far west as Nimar and Malwa.

The Paharia arrange themselves in three tribes, the Malér, the Mal, and the Kumhar; the first retain more of the habits of their ancestors than the others, and they eat the carcases of auimals which die of disease.

The houses are built of wattled bamboo. A long bamboo is fixed in the grownd in front of each house to ward off evil spirits.

The Malér call themselves the Asal Pabaria, pure Paharia. The people of the southern or Ramgarh Hills, called Mal, have another division called Kumbar, who abstain from cow's flesh, from flesh of animals which die a natural death, and will not partake of food that has not been cooked by themselves; repudiating all notions of consanguinity with the impure feeding Northerners.

The Malér is short of stature and slight of make, and wears his hair well oiled and combed in a knot on the top of his head. The features are of a mild Tamil type. The Oraon custom of excluding the unmarried adults of both sexes from the family residence is followed by the Pabaria, and the bachelors' hall and maidens' dormitories are institutions of the Rajmahal Hills, as well as of the Chutia Nagpur highlands. Colonel Dalton says the hill lads and lasses form very romantic attachments; they work together, go to market together, eat together, and sleep together. But if they overstep the prescribed limits, a sacrifice of animals is enforced at their expense in atonement. But this is fanciful.

In their marriages, the groom, with the little finger of his right hand, marks the girl on the forehead with red lead, and then, linking the same finger with the little finger of her right hand, he leads her away to his own house. Colonel Daiton says polygamy is practised, and if a man leave several widows they can become the wives of his brothers or cousins, but only one to each.

The Malér have a firm belief in the transmigration of souls; they call God Bedo, and the title affixed to the name of all their deities is Gosai. They have priests, Demonos, and priestesses, Khiendri, who, when officiating, become wildly excited. They make wooden images, which are honoured for a season as idols, and annually renewed, the old ones being thrown away as rubbish. In each village, as in nearly all Hindu villages, a shed is put up for the tutelary gosain, in which stones are placed to represent him and his attendants. There are two processes of divination. Lieutenant Shaw calls one Satani, the other Cherin. The former is a test by blood sprinkled on bel leaves. The Paharia bury their dead, but a priest's body is carried on a cot into the forest, and placed under the shade of a tree, where it is covered with leaves and branches, and left. The reason assigned by them for treating Demonos exceptionally, is that their ghosts 
are exceedingly troublesome if the bodies are laid in the village cemetery. The bodies of people who die of contagious diseases are similarly disposed of.-Logan ; Dalton's Bengal ; Tickell; Hodgson.

MALEALAM or Malayalam, also called Kerala, a region in the extreme S.W. portion of the Peninsula of India, extending from the Chandragiri river, in lat. $12^{\circ} 29^{\prime} \mathrm{N}$., to Cape Comorin, in lat. $8^{\circ} 4^{\prime} 20^{\prime \prime} \mathrm{N}$. It is fabled in Hindu legend to have been reclaimed from the ocean by the now deified warrior Parasu Rama, and within historic times it has had many dynastic changes. The Zamorin of Calicut, the Bibi of Cannanore, the raja of Travancore, the Portuguese, Dutch, French, and the Muhammadan Sultan Tipu, have held sway there, but the present paramount power is the British, and it is now partitioned into the British districts of South Canara and Malabar, the States of Cochin, Travancore, and the Bibi of Cannanore. The region is a series of hills and valleys, which explains the name Malealam, meaning literally hill and dale,-Malai, a mountain, Alam, a dale. Kerala, its other name, is of doubtful origin, one derivation being from Keram, a cocoanut, another being from a wise ruler of that name.

The prominent race are the Maleala Sudra or Nair. Of them, the 1881 census returned 664,260 , and the people speaking the Maleala language at $4,847,681$.

Malealam, Malearma, Malayarma, or Malayalam is the vernacular, but Tamil is spoken by 16.8 per cent. of the population, these two tongues being used by 99.2 per cent. of the inhabitants, Tamil chiefly south of Trevandrum, and Malealam to the north; but all along the southern portion of the west coast, a large part of the population is of foreign blood. There are settled here numerous smaller tribes or castes of Indian races, of Aryan and non-Aryan and Semitic descent, speaking Canarese, Gujerati, Hindustani, Konkani, Mahrati, Nagari, Tamil, Telugu, and Tulu, with foreign races speaking Arabic, Hebrew, English, Freuch, Portuguese. Malayarma is spoken along the Malabar coast on the western side of the ghats or Malealam range of mountains from the vicinity of Mangalore, where it supersedes the Canarese and the Tulu, to Trevandrum, where it begins to be superseded by the Tamil. Malealam was separated from the Tamil before the latter was cultivated and refined, and, from Brahmanical influence, has since had an infusion of Sanskrit words more than in any other Dravidian language, the fewest of such being in the Tamil. In all the southern languages, save the Malealam, the pronoun is postfixed in a contracted form to the verb. Some of the postfixes are also made honorific by slight euphonic changes.

In this tract the Nair race occupy large holdings; the maharaja of Travancore is a Nair, and there are many of the Moplah or Mappila Muhammadans. The Mappila in N. Malabar, known also as the Chulia, write Malealam with the Arabic character, but with additional vowel marks for e, $o$, and $i$, and some of the consonants have additional dots. In S. Malabar they use the old Tamil character called vattezhuttu.

The Moplah, written also Mapillai, possibly derived from the Tamil words $\mathrm{Ma}$, mother, Pilla, a son, are all Muhammadans, and are descendants of Arabs who visited or settled in Malabar; and
Wilson supposes that the Malabar women who bore children to them, from such casual or permanent intercourse, ignorant as to who of the race of foreigners were the fathers, styled the children sons of mothers; but the probability is that the law of descensus ab utero, marumakkatayam, followed by the mothers, was prevailing from prior ages. The Moplah are active, enterprising, and possess much landed property. Their origin is explained by the fact that till lately Tyatti, or women of the Tiyar race, did not lose caste by forming connections with rich and respectable foreigners, though, since two or three have risen in the Government service to position (one was a deputy collector) they have put a stop to this practice. The Mappila race have several times risen in insurrection, seemingly from agrarian grievances. Hindu landlords kept the land in their own hands or leased it out to the Mappila at high rents, and then took advantage of legal rights to turn them out.

MALEALI, a cultivator and shepherd race of mountaineers, about 3500 in number, occupying 79 villages in the rude valleys scattered over the Shevaroy Hills. They are said to have emigrated from Conjeveram in the 13 th century. The houses are circular in form. They speak the Tamil, and are Hindus. They cultivate the soil, but have herds of cattle.

MALE ARASAR, hill kings, are hill tribes inhabiting the Southern Ghats. They speak corrupt Malealam in the northern part of the range, where the Malealam is the prevailing language, and corrupt Tamil in the southern, in the vicinity of Tamil-speaking districts. The Malé Arasar tribes inhabit the range of ghats between Tinnevelly and Travancore, in small communities of five or six families, and probably do not exceed 500 in all. Their huts consist of a few sticks covered with bark and thatch. They live on wild forest products, but, since A.D. 1850 , they have been cultivating potatoes for their own family use. They have a fow fowls and dogs. As a race they are diminutive and pot-bellied, their crania small and pear-shaped, rising to a point about the junction of the occipital bone and the sagittal suture; a low retreating forehead, long, tangled, black hair, flat nose, and small eyes. They are averse to intercourse with strangers. They catch wild animals with pits and traps, and use bows and arrows. They are miserably low in the scale of civilisation. See Malai Arasar.

MALEGAON, in lat. $20^{\circ} 32^{\prime} 18^{\prime \prime} \mathrm{N}$., and long. $74^{\circ} 36^{\prime} 51^{\prime \prime} \mathrm{E}$., is a town and military cantonment in the Nasik district of the Bombay Presidency, built on an affluent of the Girna. The mean height of the village is 1587 feet. Wils.; Schlag. MALEGAWA, a Buddhist temple at Kandy, contains the Delada or reputed tooth of Buddha.

MALEKUDI, literally hill inhabitants, races dwelling on the skirts of the Malabar forests who gather the wild produce of the forests. They are known in some parts of the forests as Mahratta, also as Malemaylaru, Kudubi, Gowda, Koragar, Davalu, Nangaru, and Holyar. They sell the produce to the bazar men, but the sale proceeds are so trifling as barely to suffice for their food and their very limited clothing. In bad seasons they live on roots, fruits, and game. They were formerly largely engaged in the kumari cultivation, which was stopped in Fasli 1267. 
MALE MANGOSTEEN, fruit of Gareinia purpurea. $-R o x b$.

MALEO, the Megacephalon rubripes, deposits its eggs in the loose sand of the sea-beach, in holes just above high-water mark; the female lays one large egg, which she covers over and returns to the forest; but many birds lay in the same hole. A dozen eggs are often found together. One egg fills an ordinary teacup, from 4 to $4 \frac{1}{2}$ inches long, and $2 \frac{1}{4}$ to $2 \frac{1}{2}$ wide. They are very good to eat, and much sought after. The hen-bird takes no further care of the eggs, which the young bird breaks through about the 13th day, and runs at once to the forest. Each hen lays six or eight eggs in a season of two or three months.

MALER KOTLA, in lat. $30^{\circ} 31^{\prime} \mathrm{N}$., and long. $75^{\circ} 59^{\prime} \mathbf{E}$., is 30 miles south of Ludhiana. It is the chief town of a Native State in the Panjab, ruled by a Muhammadan nawab of Afghan descent. It is about 165 square miles in area, with a population 91,560 in 1876.

MALEVARA, a tribe of hillmen in the Nagar district of Mysore, said to be the aboriginal landholders. Malevelan is Malealam, and means a tribe of mountaineers.

MALGUZAR. HIND., PERS. In India, the person responsible to Government for the payment of the revenues assessed on a village. Malguzari, revenues.

MALI. HIND, A gardener. The gardener race of India are a very large body, engaged in the finer branches of their profession. Many of the Koer of Northern India, and of the Kunbi of the Mahratta districts, with the Tota Kara or Tota Vadu of the Teling and Tamil countries, follow gardening. The Mali at the 1881 census were returned at 1,209,019. They are particularly numerous in the Dowlatabad province, extending into Ahmadnaggur and Poona, southwards to Sholapur, and northwards to Berar. They are cultivators, and sell vegetables, fruits, and flowers. In the Mahratta country the Mali is distinguished by the article he chiefly cultivates, as Jiri-Mali, grower of cummin and other aromatic seeds; Phul-Mali, grower of flowers, etc.

Mali are supposed by Mr. Campbell to be a considerable and widespread people. Between Ambala and Dehli are a good many Mali villages, and they are scattered about the N.W. Provinces as gardeners. They are common about Ajmir, and on the southern frontier of Hindustan. South of Jubbulpur, they are many and mixed with the Kurmi; all through the Mahratta country they are mixed with the Kunbi, and most of the potails are either Kunbi or Mali, and extending with the Kurmi far to the east, the Mali into Orissa, and the Kurmi into Manbhum and other districts of Chutia Nagpur.-Campbell.

MALIA, a small Native State in the Kattyawar province of the Bombay Presidency. Its ruler is a Jarija Rajput, with a yearly income of $£ 6098$; pays tribute of $£ 136$ jointly to the Grekwar of Baroda and the nawab of Junagarh, and maintains a military force of 50 men.

MALIAH or Maliya, hill tracts in Ganjam and Viragapatam districts, a hilly or mountain tract in the western portion of the Ganjam district, covering an area of 3500 square miles, and inhabited by the Khond and Savara races. The country is covered with dense forests of sal. The Khond race are skilful and energetic, and well-to-do farmers. This hilly country nearly encompasses the more productive parts of Gumsur.

MALIDA. Hind., Pers. Soft food, used in India by toothless people. Also cloth of shawl-wool, fulled or rubbed so as to have the surface felted like cloth. It is a woollen fabric in use in Tibet.

MALIK, also called Dasht-i-Malik, also Chol Malik, is a flat desert plain on the road from Bokhara to Samarcand.-Tr. C. As.

MALIK. ARAB. A king. It is the title of every Afghan house or tribal subdivision. Malikah is a queen.

MALIK or Mullak, a race in Behar, who follow the Muhammadan religion of the Sunni sectarians.

MALIKANA. HIND. A sum paid in money or kind to the malik or owner of land by the kashtkar or pahi kasht cultivator, who is his tenant.

MALIK DIN, a khel or section of the Afridi. Their three sections are located close together in the central portion of the Tira Maidan.

MALIKI. In the first periods of Muhammadanism, four Arabian doctors made commentaries on the original text of the Koran, which were adopted by sects, now severally distinguished by the names of the commentators. But these explanations did not militate with much force against the first system, nor create any violent feuds among the different sectaries. The Muhammadans have now about 150 sects.

The names of the four great commentators were Malik as above; Hanbali, born at Baghdad A.H. 146, died 241; Hanif, born at Kufa A.T. 80, died in prison at Baghdad A.H. 150; and Shafi; and their followers are designated Maliki, Hanbali, Hanifi, and Shafai.

MALIK-ibn-ANAS was born at Medina A.D. 713-714, and died there 795. The years A.H. 95 and 179 are also given.

MALIK RYHAN SAHIB. Oblations are offered at his shrine.

MALIK-SHAH-JALAL-ud-DIN. There are two eras in Persia, viz. that of Yezdejird III., king of Persia, dating from his accession, 16th June A.D. 632, and that of Malik-Shah-Jalal-udDin, king of Khorasan, which dates from A.D. 1079, the date of his reforming the Yezdejird era. It is still in use in Persia. The Persian tropical year consists of $365 \mathrm{~d}$. 4 h. $49^{\prime} 15^{\prime \prime} 0^{\prime \prime \prime} 48^{\prime \prime \prime}$, which is more correct than the Gregorian year.

MALIK TAOUS. Mr. Rich, describing the Kurd tribe who worship this idol, says (ii. p. 70) their pir or shaikh reads prayers, every hearer at intervals crying out, Amen; and this is the whole of their worship. It is true that they pay adoration, or at least a sort of worship, to Malik Taous, the figure of a cock placed on a kind of candlestick, and produced once yearly for the purpose of worship.

MALIKZA, a section of the Razar division of the Yusufzai of the Peshawur district.

MALIMBI, a mountain in the Yelusavira range of hills, Coorg; 4488 feet above the sea. The summit is conspicuous from every part of Coorg. -Imp. Gaz.

MALIPUR or Maliyapuram, a group of hamlets in Malabar, Madras. Lat. $11^{\circ} 3^{\prime} 2^{\prime \prime} \mathrm{N}$., long. $75^{\circ}$ $51^{\prime} 21^{\prime \prime}$ E.-Imp. Gaz.

MALKA, a village in the Amazai country, on a plateau in the N.W. of the Mahaban mountain. 
Wahabee sectarians from Hindustan settled in it, and in 1863 led to an expedition being sent against them. Major James, C.B., Commissioner of Peshawur, induced the Boner tribes to send a contingent of 2000 men with the Corps of Guides to burn down Malka. Thus the elder branch of the Yusufzai repeated the vengeance which they once before took on the fanatics, when in May 1831 their fathers rose against Syud Ahmad, the founder of the sect, who was then slain at Balakot on the Indus, drove his family to take refuge with the nawab of Tonk, who long sheltered them, and expelled his Ghazi followers.

MALKAGIRI or Malkaugiri, in the Jeypore zamindari of the Vizagapatam district, Madras, a wild forest-clad tract, watered by the Taveri and Sitern, and sloping from the Tulasi Dangari Hills. Average elevation above the sea, about 1200 feet. There are some splendid sal and teak forests, and the whole tract is full of large game. -Imp. Gaz.

MALKANGANI. Mahr. Celastrus montana, C. paniculata. The oil is empyreumatic, obtained by the destructive distillation of the seeds of Celastrus paniculata, either alone or in combination with other ingredients. It was much used in the treatment of Beri-beri.-Malcolmson's Essay.

MALKAPUR, town in Buldana district, on the western frontier of Berar; situated in lat. $20^{\circ} 5^{\prime}$ $\mathrm{N}$., and long. $76^{\circ} 23^{\prime} 20^{\prime \prime} \mathrm{E}$., on the Nalganga river; elevation above the sea, 900 feet. Population (1867), 7988.

MALKAVI, a Baluch tribe in the Dehra Ghazi Khan district.

MALLA, the Telingana Pariah, or Dher people, of Turanian origin, worshippers of Ammuns, scarcely of Brahmanical faith; properly Mala.

MALLA. According to the Mackenzie MSS., the patronymic of a northern tribe of mountain chiefs, who sprang from the aboriginal inhabitants, and who were non-Aryan. The Khond call themselves Mallaru. Both Khond and Mallaru mean highlanders.

MALLA, a king of Mallapuram, to whom Brahmans apply the legends relating to Mababali and Mahabalipuram.

MALLAH. HIND, A sailor, a boatman, a maker of salt.

MALLAR. TAM. Agricultural labourers of the Pallar tribe; cultivators generally.

MALLESON, GEORGE BRUCE, Companion of the Star of India, an officer of the Bengal arnay, who rose to the rank of colonel. His literary labours have produced the Red Pamphlet on the Mutiny of the Bengal Army, 1857; Essays and Lectures on Indian Historical Subjects, 1866; History of the French in India, 1868; Studies from Genoese History, 1875; Historical Sketch of the Native States of India, 1875 ; Final French Struggles in India and on the Indian Seas, 1878; History of the Indian Mutiny, 3 vols., 1878-80; History of Afghanistan, 1878; Herat, the Granary and Garden of Central Asia, 1880; The Life of Lord Clive, 1882; The Decisive Battles of India, 1883; The Battle - Fields of Germany, 1884; The Life of Field-Marshal London, 1884.

MALLI, the ancient people of Multan.

MALLI. TAM., TeL. Properly Malai, a hill, as Raman-malli, Nalla-malli. Malavari, a pass through mountains; Malealam, the mountain country in the west of India, the province of Malabar.-Wits.

MALLIAL, a people who are very industrious cultivators and gardeners, on the N.W. frontier of British India, above the Salt Range, and extending up into Peshawur. They now profess Muhammadanism.-Campbell, p. 108.

MALLIMBI, a peak lying on the confines of Yelusavira and Yeddavanad; it is an exact cone.

MALLINATHA, a poet and author of commentaries of great repute on the Raghuvansa, Megha-duta, Sisupala-badha, and other great Sanskrit poems of the ancient Hindus.-Dowson.

MALLOTUS PHILIPPENSIS, Mull., is the Rottlera tinctoria, Roxb. The capsules are covered by a mealy powder, consisting of minute rubylike glands; and the tomentum on the under side of the leaves yielde a dye called Kameela. This imparts a fine yellow colour to silks. The mealy powder is of a rich purplish-red colour, and has a melon-like heavy odour. It mixes with difficulty in water; but when boiled with alkaline salts, it gives out a very deep blood-red colour. Kameela is used as a vermifuge, its action depending on the minute stellate hairs in the powder. $-J . A$. Murray.

MALMALIA. HIND. Slightly brackish water.

MAL-NADU. KaRN. Any hill country; the woody and hilly districts of Nagar in Mysore.

MAL OCCHIO. Iт. Evil eye.

MALOJI BHONSLA, a Mahratta officer of rank in the army of Malik Ambar. He was of a respectable, though not a considerable family, and served with a few men, mounted on his own horses. He was especially dependent on the protection of Lukji Jadu Rao, who attained to a command of 10,000. Lukji Jadu Rao is supposed to have been of the Jadu race of Rajputs; and when Maloji rose in the service of the Ahmadnaggur State to a command of 5000 horse, and to the possession of a large jaghir, of which the chief place was Poona, his son Shah-ji was married to the daughter of Lukji Jadu Rao, and one of the fruits of the union was Sivaji, the founder of the Mabratta empire.-Elphinstone, pp. 544, 545.

MALONI BAPCAI, seed of a small plant found about Ajmir; tasteless, has a fine scent, is of a warm nature; a drachm is given in medicine; used externally with other medicines to cure the itch.-Med. Top. p. 127.

MALOPE, a genus of very beautiful annual plants of the Malvaceæ; the colour of flowers purple and violet; the plant grows to the height of seven or eight feet. M: grandiflora, a plant of India which yields fibres.-Riddell.

MAL PAHARIA. In the Ramgarh Hills of the Birbhum district, and at the foot of the Rajmahal Hills, there are villages and detached houses occupied by this tribe, but who appear to be altogether unconnected with the Rajmahal hillmen. They resemble the Kharria and Paharia met with in Manbhum, who belong to the Kolarian group. They dance like the $\mathrm{Kol}$, and are fond of the amusement, and have one great festival in the year, in the month of January or Magh, corresponding with the great harvest joy of the Ho and Munda.-Dalton's Bengal, p. 274.

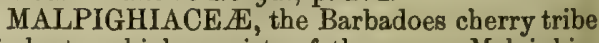
of plants, which consists of the genera Malpighia, Byrsonima, Gaudichaudia, Hiptage, Hiræa, Stigmatophyllum, Heteropteris, Banisteria, Ancistro. 
cladus. Malpighia coccifera is a small stunted shrub, with leaves resembling the box; common in gardens. M. heteranthera, a handsome shrub, with leaves like the holly, is occasionally cultivated in European gardens. M. punicifolia, the Barbadoes cherry, is an ornamental shrub introduced from the West Indies.-Hort. Garden, p. 25.

MALT.

Mout, . . . D Dт. |Maly, . . . Ger. Mal, Bledgerme, : FR. Malto, . . : Ir.

Malt is grain steeped in water, and made to germinate to a certain extent, after which the process is checked by the application of heat. This evolves the saccharine principle of the grain, which is the essence or malt. Rice, and almost every species of grain, has been used in malting; but in Europe, and especially in Great Britain, malt is almost entirely prepared from barley. It is the principal ingredient in the manufacture of beer, and is little used except in brewing and the distillation of spirits.

The consumption of malt liquor of local brew is steadily increasing in the army in India. During the ten years from 1872-73 to 1882-73, the cost of the malt liquor imported has decreased $\mathfrak{£} 98,000$; while the expenditure for locally-brewed beer and porter has risen to Rs. $18,13,000$, i.e. an increase of $\mathrm{Rs.} 15,74,000$.

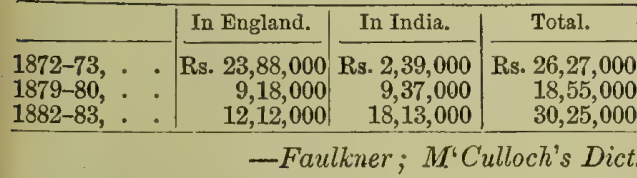

MALTA, an island in the Mediterranean Sea, in lat. $35^{\circ} 54^{\prime} \mathrm{N}$., long. $14^{\circ} 31^{\prime} \mathrm{E}$., about 200 miles from the African coast, and 60 from Cape Pessaro in Sicily. The population, exclusive of the garrison and sailors of the fleet, comprising a mixture of Maltese, Franks, Greeks, Africans, and natives of the Levant, is about 150,000 . Malta had been successively occupied by Phœnicians, Greeks, Carthaginians, and Romans. On the decline of the Roman power, it was seized by the Gotbs and Vandals, and then passed for a short period into the hands of the eastern emperors, who surrendered it to the Saracens. It then came into the possession of the Norman and German king's of Naples, with whom it remained until 1522 , when it was granted by Charles v. to the knights of St. John of Jerusalem, who on several occasions valiantly defended it against the Turks, but surrendered it to Napoleon on the 12th of June 1798, at the first summons. The island was soon after blockaded by the British fleet under Lord Nelson, and, after suffering severe privations, the French finally relinquished the island to Sir Alexanker Ball in August 1799. The climate is excellent in the winter.

MALTHA, or Sea Wax, is a solid, whitish, inflammable, vegetable substance, not unlike tallow, and may be impressed with the nail. It swells when heated, and on cooling assumes the consistence of white cerate. It affords a better light than petroleum, and emits a less disagreeable smell. It is found on the surface of the Baikal Lake in Siberia, at the foot of the Bakhtiari mountains in Persia, and other places.

MALVACE $\approx$, the mallow worts, a natural order of useful plants, comprising the East Indian

VOL. II, genera,-abutilon, althæa, hibiscus, gossypium, malachra, malva, pavonia, senra, sida, thespesia, and urena. The mallow worts are extremely numerous in species; these abound chiefly in tropical parts of the world in the form of trees and shrubs, though the mallow and marsh-mallow extend to temperate climates. They are remarkably destitute of all noxious properties, are mucilaginous, afford from the inner layers of the bark useful fibre, and many are employed in different countries as sources of commercial products, - the genera malva, hibiscus, sida, althæa, lavatera, and urena yielding tenacious fibres suited for cordage and other purposes, and the hairy covering of the seeds of the various species of gossypium forms the raw cotton so important to manufacturers. The seeds of Abelmoschus moschatus are warm and musky, and are employed in perfumery as a substitute for musk. Those of A. esculentus form the ochra, much used in hot countries as a mucilaginous ingredient in soups. A few species are acid, as Hibiscus sabdariffa. Tenacious fibres are procured from the inner bark of $\mathrm{H}$. elatus and H. tiliacea, and several kinds of sida. Urena lobata and $U$. sinuata, the one called bun-ochra and the other kunga, and common in most parts of India, also abound in strong fibre, and a tolerable fine substitute for flax. The common mallow (Malva sylvestris, etc.) of Europe, and the marsh-mallow (Althæa officinalis), abound in fibre. Malva crispa is said by Cavannilles to have its fibre separated in Syria, and Althæa cannabina is sometimes so employed in the south of Europe; so Lavatera arborea, or tree mallow, will be found to abound in fibre. As emollients they are well known in medical practice, the marsh-mallow (Althæa officinalis) being one of the most useful among this kind of remedial substances. Malva cuneifolia is an annual growing in single plants here and there all over the Burmese country, but chiefly in the jungle. It affords a strong yellowish-white fibre, but it would be difficult to collect it in any quantity. M. tiliæfolia, a straggling annual widely dispersed in Burma during the rains. Its fibre resembles jute. Some of the best materials for paper-making in India are the barks of trees allied to the hibiscus, mulberry, malvaceous and cotton plants; the bauhinias, grewia, and guazuma or bastard cedar. The principles of cleaning them are the same as for other fibres, viz. to get away the sap and juices of the plants as soon as possible, and if this is done within 20 or 30 hours after the plant is cut, a nearly pure white strong fibre can be obtained. Several trees contain tannin, which almost immediately begins to discolour the fibre of the bark, as soon as the branch is cut off from the parent tree. To remove this, a caustic ley made of fresh burnt lime and wood ashes should be prepared, and the bark, after having been stripped off, well beaten with sticks and washed with water, may be soaked for one night in this caustic ley; next morning the bark should be well beaten with sticks on a flat board, washed with clean water, and hung up in the shade to dry. In this way very strong and nearly white materials for paper can be prepared at a cheap rate. The beating or crushing allows the water to remove the sap, and the tannin is dissolved by the alkali before the fibres have time to get discoloured. $-M^{6}$ Clelland; Riddell; Royle; Murray.
$3 \mathrm{~F}$ 
MÁLVA MAURITIANA.

Kungi ki pat, . HrND. | Khatmi safed, . Hind,

It is cultivated in most parts of India.

MALVA PARVIFOLIA, Linn.

Sonchal of . . RAVI. Narr of ... SUTLEJ

Gogi, Sag, : : ", $\left.\right|_{\text {Panirak, Supra, Tr.-IND. }}$

In Kanawar, women clean their hair with an infusion of the root, and woollen cloth is washed by its aid. Bellew states that the root is used as resha khatmi? See Althæa rosea.

MALVA ROTUNDIFOLIA. Willd.

\begin{tabular}{l|l} 
Seed. Khabazi. & Leuves, Kangi-ka-sag. \\
Flowers, Gui-khaira,Kangi. &
\end{tabular}

Mucilaginous and emollient, used to form poultices, said to be inferior to Althæa, cultivated in India.-Roxb. ii. p. 184.

MALVA SYLVESTRIS. Linn.

\begin{tabular}{l|l} 
Anjil, . * * AraB. & $\begin{array}{l}\text { Marsh-mallow, } \\
\text { Khitmi, }\end{array}$ Eng. \\
Phabazi,
\end{tabular}

Common mallow, . ENG. The seed-Towdri, .,"

Grows in the Panjab, Kashmir, and the W. Himalaya, in waste places. It is used largely by native physicians, in decoction with rose leaves, as a demulcent.- $O$ 'Sh.

MALWA, in Central India, is a region bounded on the north by Hindustan proper, east by Bundelkhand, south by the Dekhan (Dakshin), and west by Rajputana. It is an upland region, with many fertile valleys, included within the main rivers of the Ganges, the Sone, the Chambal, and the Nerbadda. In pre-historic times, the capital was at the ancient city of Ujjain, associated in Hindu legend with Vikramaditya, a great king, the date of whose accession (B.C. 57) has given the Samvat era to all India.

The ancient rajas of Malwa are known from the writings of Abul Fazl, whose information is supposed to have been furnished from Jain authorities. It would appear that in an early age Mahahmah founded a fire temple, which was destroyed by Buddhists, but restored in B.c. 840 by Dhanji (Dhananjaya), a name of Arjun, about 785 before Vikramaditya. Between A.D. 866 and A.D. 1390 , the country repeatedly changed hands from Hindu to Muhammadan sovereigns from the time that, in 866, Maldeva was conquered by Shaikh Shah, father of Ala-ud-Din, to 1390 , when Dilawar Khan Ghori, viceroy of Malwa, assumed sovereignty. Malwa was added to the Dehli empire by Humayun, before his flight, but the Mahrattas have since been its dominant possessors.

At the close of the Pindari war (1817-1818), the districts in Central India and Malwa were left in a disorganized state, the Mahratta chiefs had parcelled out amongst themselves the possessions of the Rajput chiefs, and the smaller states were all subject to Sindia, Holkar, or the Puar, and sometimes to all three. Many of the smaller chiefs had been driven from their possessions, and had sought refuge in the jungles and mountains, where they robbed or levied tankhah or blackmail from the larger states.

Under an engagement mediated by Sir John Malcolm in 1819 between Purbut Singh, raja of Rutlam, and Dowlat Rao Sindia, the former agreed to pay an annual tribute of Salim Sahi rupees 84,000 , while Sindia undertook never to send any troops into the country, or to interfere in any way in the internal administration or succession. This tribute was assigned under the treaty of 1844 with Sindia, in part payment of the Gwalior Contingent. It is now paid to the British Government under the treaty of 1860 . The raja of Rutlam is considered the principal Rajput leader in Western Malwa, and in consequence receives a voluntary allegiance and assistance if called for from the neighbouring Rajput chiefs. Raja Bulwunt Singh rendered good service during the mutinies, in recognition of which his successor, Bhyru Singh, received a dress of honour value Rs. 3000, and the thanks of Government. The military establishment of the raja of Rutlam consists of 500 sepoys. The revenue from all sources is estimated at Rs. $3,64,064$, and the population at 94,839 . The town of Rutlam is the principal opium mart in Western Malwa. The area of Rutlam is about 500 square miles. Sillana pays an annual tribute of Rs. 42,000 , under the same conditions as Rutlam. The tribute is paid to the British Government under the treaty with Sindia of 12th December 1860, having been assigned in $\mathbf{1 8 4 4}$ in part payment of the Gwalior Contingent. The revenue of Sillana is estimated at Rs. $2,49,000$, the population at 88,978 , and the area at about 103 square miles. Seetamhow, like Sillana, was once a part of Rutlam, but separated from it in A.D. 1660, on the death of Ram Singh, raja of Rutlam. A tribute of Rs. 60,000 from this state was guaranteed to Sindia by an agreement mediated by Sir John Malcolm in 1820. The total revenue of Seetamhow is about Rs. $1,50,000$, and the population about 20,000 . In consequence of repeated representations from the raja, Rs. 5000 of the annual tribute were remitted in 1860 by Sindia of his own free will, on the occasion of the raja's son waiting on him at Gwalior. The raja of Seetamhow remained faithful to the British Government during the mutiny of 1857 , and received a dress of honour of Rs. 2000 . The raja keeps up a military force of 40 horse and 200 foot.

Malwa and Gwalior are great centres of trade. In Malwa, the towns of Indore, Bhopal, Ujjain, Mundipore, Rutlam, Dhar, Jowra, Augur, Nemuch, Shoojawulpur, and Bhilsa are the principal marts. The opium exported from Malwa is about 17,000 chests.-Thomas' Prinsep, p. 259; Orme; Malcolm's Central India, i. p. 67 ; Treaties, Engagements, and Sunnuds, iv. p. 364.

MALWA and Be-Malwa, terms by which the Assamese designate the Garo race.

MALWAN, chief town of the Malwan subdivision of Ratnagiri district, Bombay, situated on an island off the coast of the Konkan, 70 miles south of Ratnagiri, in lat. $16^{\circ} 3^{\prime} 20^{\prime \prime} \mathrm{N}$., and long. $73^{\circ} 30^{\prime} 10^{\prime \prime} \mathrm{E}$.; pop. (1872), 13,955.-Imp. Gaz.

MAMANGONI, a very ancient festival, celebrated every twelve years at Tirnavay by the Vellaterra raja, and afterwards by the Zamorin of Calicut. It lasts twenty-eight days, and is attended by immense numbers.-Bombay Lit. Suc. Tr. i. p. 2.

MAMASENI, a nomade tribe dwelling in Luristan, who belong to the Lur family, as do likewise their neighbours the Khogilu and the Bakhtyar, who, like themselves, occupy the valleys of the great chain of Zagros which separates Irak Ajam from the provinces bordering on the Persian Gulf. All these tribes are the 
descendants of the ancient Zend race, and the Mamaseni claim great antiquity. The country inhabited by the Mamaseni is called Shulistan, and has the direct dependencies of Fars to the east, Kazerun to the south, the Khogilu tribes and the hilly country descending towards the Persian Guif to the west, and the chain of the Ardekan mountains to the north.-De Bode's Tr. p. 262.

MAMIRA, also written Mamiran, are roots of two different kinds in the Lahore bazar, the one from Kashmir, the other from China, called Khatai (Scythea). The latter is officinal all over the east, being much used by the hakims, who deem this root to be a specific in ophthalmia; but the genuine drug is seldom to be met with, as it has many substitutes, Chelidonium majus and C. glaucum, and Dr. Royle affirms Ranunculus ficaia or ficaria to be the plant from which the Kashmirian mamira is produced. Both sorts are used, in general externally, and in composition with other drugs are applied to the eyes as a dry collyrium. Mamira or Mamiran is the Thalictrum foliolosum.-Honigberger, p. 304.

MAMLATDAR, the head native revenue and police officer of a district of India.

MAMLUK, ordinarily written Mameluk, a purchased slave or captive taken in war. Ghuz, an emancipated Mamluk. A body of them in Egypt for a long time governed that country, although a ruler with the title of pasha was sent from Constantinople; they were at last exterminated by Muhammad Ali. At one time these were of two races, the Baherite and the Borgite, the latter of Circassian origin. In the times of Selim the First, the Mameluks were all of pure Circassian blood, but their ancestors had all been originally slaves.

MAMMALIA. The animal kingdom was arranged by Cuvier into four great subdivisions, - Vertebrata, Mollusca, Articulata, and Radiata. The Articulata has since been greatly subdivided, and the limits of two of the other subdivisions have been slightly altered. Vertebrate animals comprise four distinct classes, some of which, viz. fishes and reptiles, have blood nearly the temperature of the water or air in which they live, whilst the others, viz. the birds and mammals, are warm blooded. The mammals, which are here to be noticed, are warm - blooded, vertebrate, viviparous animals, and are distinguished from birds, as well as from the other vertebrate animals, by the possession of mammary glands, secreting milk for the nourishment of their young, and terminating outwardly in all (except in one or two) by teats. They are also distinguished by a covering of hair, except whales, but even the foetus of whales has some tufts of hair. Most mammals bave four limbs, from which they were formerly termed quadrupeds, but that term has been discontinued, as it is not applicable to the Cetacer. In cold climates, several animals pass the winter in a state of torpidity; and even in India certain bats and hedgehogs, and perhaps some rats, are more or less torpid during the cold season. Two species of bears found in the Himalaya retire to their caves during winter, and are rarely or never seen from the month of December till the end of March.

The animals of the East Indies in this branch of natural history have been described by several eminent men. In 1830-34 Dr. J. E. Gray published

Illustrations of Indian Zoology, chiefly selected from a collection made by Major-General Hardwicke; Colonel Sykes published a list of the animals observed by him in the Dekhan; Sir Walter Elliot in 1839 gave a Catalogue of the Mammalia of the Southern Mahratta Country; Mr. Hodgson published several lists of the Mammalia of Nepal; Colonel Tickell gave a detailed History of a few Animals; Major Hutton recorded some facts on the Manamals of Afghanistan; Mr. E. L. Layard, Dr. Kelaart (in his Prodromus Floræ Zeylanicæ 1852), Dr. Templeton, and Sir J. E. Tennent, almost exhausted the subject of the Fauna of Ceylon; Dr. Horsfield $(1824,1851)$ and Sir T. S. Raffles were amongst the first to describe the animals of the Eastern Archipelago; and Professor Bikmore and Mr. A. Russell Wallace have recently extended their predecessors' researches. Mr. Wallace in 1869 and 1872 wrote on the Malay Archipelago, and in 1876 and 1880 on the Geographical Distribution of Animals. In 1846-47 Dr. Cantor furnished a valuable list of the Mammalia of the Malay Peninsula; Dr. T. C. Jerdon in 1864 published the Mammals of India; and the labour's of all these zoologists were reviewed by Mr. Blyth, curator of the Bengal Asiatic Society's Museum, in the scientific journals of the day. Colonel A. C. MacMaster, of the Madras army, in 1870 gave to the public his interesting Notes on Jerdon's Mammals, and since then, in 1874, Dr. Jerdon's book has been reprinted. In 1876, Captain J. H. Baldwin described the Large and Small Game of Bengal and the N.W. Provinces. In the same year (1876), W.T. Blanford, in the second volume of his book on Eastern Persia, described its Zoology and Geology; also those of Abyssinia, in 1879; and in the same year he gave the scientific results of the second $Y$ arkand mission. In 1881 the Calcutta Museum published a Catalogue of its Mammalia; in 1884 Mr. R. A. Sterndale's Natural History of the Manamalia of India and Ceylon was printed; and it may be added that Sir Joseph Fayrer has written on the Tiger. The Journal of the Bengal Asiatic Society contains numerous contributions from other able zoologists.

Classification.-The animal kingdom has been arranged by learned naturalists in varied modes. Mr. A. R. Wallace, one of the ablest of the present day, in his Geographical Distribution of Animals, i. p. 85, gives the following classification as according with the views of Professors Huxley (1869) and Flower (1870):-

i. Monodelphia, 11 orders, viz. :-

\section{Primates.}

Chiroptera.

Insectivora.

Carnivora

Cetacea.

Sirenia.

ii. Didelphia, 1 order, viz. Marsupialia.

iii. Ornithodelphia, 1 order, viz. Monotremata.

$$
\text { Mammalia. }
$$

Order I. Primates. Sub-Order. Anthropoidea.

Homidx, man.

Simiidz, anthropoid apes.

Semnopithecidæ, old

World monkeys.

Ungulata.

Proboscidea.

Hyrocoidea.

Rodentia.

Edentata.

\section{Lemuridæ, lemurs.

$$
\text { Sub }
$$

Cynopithecida, baboons and macaques.

Cebidæ, American monkeys.

Hapalidæ, marmosets.

Lemuroidea.

Chiromyidx, nye-ayes. 
Order II. Chiroptera.

Pteropids, fruit-eating Rhinolophidæ, horse-shoe bats.

Phyllostomidæ, leaf-nosed Vespertilionidæ, true bats. bats.

Noctilionidæ, dog-headed,

Galeopithecidæ, flying lemurs.

Macroscelididæ, elephant shrews.

Tupaiidæ, squirrel shrews.

Erinaceidæ, hedgehogs.

Centitidæ, tenrecs.

\section{Order iv. Carnitora.}

Felidæ, cats, lions, etc.

Cryptoproctidx, crypto. procta.

Viverridæ, civets.

Protelidæ, aard wolf.

\begin{tabular}{l|l} 
Hyænidæ, hyænas, & Trichechidæ, w \\
Canidæ, dogs, foxes, etc. & Phocidæ, seals.
\end{tabular}

Order v. Cetacea.

Sub-Order i. Mystacetæ.

Balænidæ.

Balænopteridæ.

Sub-Order ii. Odontoceti.

Catodontidæ.

Monodontidæ.

Hyperoodontidæ.

\section{ORDER VI. SIRENIA.}

Manatidæ.

ORDer vil. UNGUlata.

\$ub-Order i. Perissodactyla or odd-toed Ungulates.

Equidre, horses.

Tapiridæ, tapirs.

Sub-Order ii. Artiodactyla or even-toed Ungulates.

Hippopotamidæ, hippopo- Cervidæ, deer.

tamus.

Suidæe, swine.

Camelidæ, camels.

Tragulidæ, chevrotains. Camelopardidæ, giraffes Bovidx, cattle, sheep, antelopes, etc.

Order vili. Proboscidea.

Elephantidæ, elephants.

ORDER IX. HYRACOIDEA.

Hyracidæ, rock rabbits.

\section{ORDER $x$. RODENTIA.}

Muridæ, rats.

Spalacidæ, mole-rats.

Dipodidæ, jerboas.

Myoscidæ, dormice.

Saccomyidæ, pouched rats.

Castoridx, beavers.

Sciuridæ, squirrels.

Haploodontidæ, sewellels.

Chinchillidæ, chinchillas.

Octodontidæ, octodons.

Echymiidr, spiny rats.

Cercolabidx, tree porcupines.

Hystricidæ, porcupines.

Caviidæ, cavies.

Lagomyidæ, pikas.

Leporidæ, hares.

\section{Order xi Edentata.}

Bradypodidæ, sloths. Manididæ, ant-eaters.

Dasypodidæ, armadilloes.

Orycteropodidr, ant-bears Myrmecophagidx, anteaters.

Order xir. Marsupialia.

Didelphidæ, opossums.

Dasyuridæ, native cats.

Myrmecobidø, native anteaters.

Peramelidæ, bandicoots. Macropodidæ, kangaroos.

Phalangistidæ, phalangers.

Phascolomydx, wombats.

ORder xir. Monotremata.

Ornithorynchidæ, duckbill. | Echidnidæ, echidna,

Dr. Jerdon arranged mammals into Placental, or those in which the foetus is nourished in the maternal uterus by means of a placenta; and Implacental or Marsupial, or those in which the young foetus is expelled at a very early period, and maintained, in a pouch, firmly attached to a nipple. The implacental or marsupial animals occur in the Australian region, and a few in America.

\section{Mr. Blyth arranged the Placental mammals} into-

I. Typodontia, animals with the typical forms of teeth developed, and include man, monkeys, bats, carnivorous animals, and shrews. The majority live on animal food.

II. Diplodontia, rarely more than two kinds of teeth, and include rats, squirrels, deer, sheep, cattle, the elephant, pig, horse, and the almost toothless ant-eater. They chiefly live on vegetable matter.

III. Isodontia, teeth, when present, are all of one kind, and comprise the whales and porpoises.

The details of the above classification are thus shown-

a. Placental mammals, foetus nourished in the uterus, through a placenta.

I. Typodontia, teeth of all four kinds.

1st group, Primates, hair of one kind only.

ORDER, Quadrumana, with thumb on the feet.

ORDER, Cheiroptera, winged.

$2 d$ group, Secundates, hair of two kinds.

ORDER, Carnivora, molars trenchant, mixed with tubercular ones.

ORDER, Insectivoria, molars studded with cusps.

II. Diplodontia, teeth generally of two kinds only, abnormal.

ORDER, Rodentia, front teeth long and chisel-like.

ORDER, Pachydermata, teeth varied, skin thick, do not ruminate.

ORDER, Ruminantia, upper incisors generally absent, chew the cud.

ORDER, Sirenia, want posterior extremities.

ORDER, Edentata, incisors absent.

III. IsODONTIA, teeth, when present, of one kind, and often very numerous.

ORDER, Cetacea, posterior extremities wanting.

b. Implacental or Marsupial mammals.

I. UNGUICULATA, with nails.

Distribution.-Southern India, more particularly the richly-wooded Malabar coast, possesses more species peculiar to it than all Central and Northem India, except the Himalayan range. Of the animals found in the Himalayan range, several equally belong to the Indo-Chinese fauna, of which they appear to be the western extension, and $a$ few others to Central Asia, whilst a moderate number appear to be peculiar to the Himalayan mountains.

The Langur monkeys (Presbytis) form a wellmarked group in India, and are still further developed in the Indo-Chinese provinces and Malayana. Out of five continental species, one is spread through all the plains of Central and Northern India, one through the Himalayas, and there are three well-marked species in the extreme south of the Peninsula. Macacus radiatus of Southern India replaces Inuus rhesus of all Northern and Central India. A well-marked form of this group, Inuus silenus, is peculiar to the south-west corner of the Peninsula.

The lemurs are almost peculiar to Madagascar, but one species of the Lemuridæ is very abundant in the extreme south, and a Malayan species extends sparingly through Burma into the N.E. corner of Bengal.

Two species of frugivorous bats are spread all over India, and one species occurs only in the south. Of insectivorous bats, seven species of Rhinolophus have been found in the Himalayas, but only two species in Southern India. The 
Hipposideros section is represented equally in the north and south of India, and is more Malayan. The Cœlops of Blyth has as yet been found only in the Bengal Sunderbans. The yellow-bellied Nycticeji occur pretty generally throughout India, N. ornatus occurring in the Himalayas.

A few European forms are found in the Himalayas. Moles occur in the Indo-Chinese region, and in the S.E. portion of the Himalayas. Shrews occur in all parts of India, but are most abundant in the Himalaya. One species of Tupaia occurs in Southern India, and another extends from the S.E. Himalayas to Burma.

Of the carnivora, two species of bears are Himalayan, and a third species extends throughout all the plains of India. Ailurus fulgens, one of the Ursidæ, is peculiar to the Eastern Himalayas. Weasels occur only on the Himalayas ; one marten is found both on the Neilgherries and Himalayas. One species of otter is found in the south of India ; in Bengal are two species, and others occur in the Himalayas. Of fifteen feline mammals found in India, five are common to India and Africa, seven are found in India and the Indo-Chinese region, but three of these occur only in the S.E. Himalayas. One, the ounce of Central Asia, is Himalayan, and the srnallest of the feline animals are peculiar to the plains of India, two of them in the extreme south of the Peninsula, and the other on the N.W.

Of the strictly Asiatic Parodoxurus, more Malayan than Indian, one species is common in most parts of India, and two occur on the Himalavas and adjoining Terai. The genus Herpestes is common to India and Africa; out of seven Indian species, five occur only in the south of the Peninsula, and of these four only in the extreme south. One small civet-cat is found throughout India, and is common in the Himalaya, a large species on the Himalaya replaced by a different race in the extreme south. Arctonyx, Arctictis, Helictes, Urva, and Prionodon are found in the S.E. Himalayas and in the Indo-Chinese region. The wolf, the jackal, and wild dog are found throughout India; two small desert foxes are found throughout the plains, and a fox of the European type occurs in the Himalayas. Squirrels are found throughout India up to the foot of the Himalayas, in the Indo-Chinese region, Assam, Burma, and Malayana. One species of flying squirrel is limited to the extreme south of the Peninsula, one in the south of the Peninsula, but several species in the Himalaya. Marmots only occur in the Himalayan region, to which they have been extended from Central Asia. Of the Muridæ, Golunda, three species of Leggada, and the curious Platacanthomys are peculiar to the south of India. Arvicula occurs only on the Himalayas, and Rhizomys in the Himalayas and the Indo-Chinese district.

The ran-hun or wild dog, Cuon rutilans, is a mative of the Kashmir ranges, and although not to say common, is by no means rare; it is so stealthy in its habits that attempts to obtain specimens often prove abortive. They hunt in packs, and attack the largest deer. Even the Kashmir stag is said to be brought to bay and killed by packs of wild dogs. The wild dog seen by Dr. Hooker on the Khassya mountains, and known there by the names kulsam and kbas, may be a different species, though Colonel Sykes considers it identical with the kolsum of the Dekhan.

The domestic dog of the Jhelum district has a great resemblance to the pointer, and doubtless was introduced from India. Mr. Vigne makes a similar remark with reference to the dogs of the Rajawar district, south of the valley of Kashmir, where a formidable breed is also found, having the external appearances of the shepherd's dog, but much larger. A closely-allied form, not differing in any way from the Scotch collie, is common all over the cultivated regions of the Western Himalayas, and even westward to the sources of the Oxus, as observed by Lieutenant Wood. This uniformity is in favour of the view that the shepherd's dog forms almost a permanent race, which may have been one of the original varieties.

The Tibetan black bear, Helarctos Tibetanus, probably finds its way across from the Lower Himalaya. The black bear of the Southern Provinces (U. labiatus) is not found in the Panjab. Helarctos Tibetanus is common in the Panjab, and hunts among the ravines and around the villages at night. The isabella, or brown bear of the Himalaya, is an exceedingly stupid and unsuspicious animal in districts where it has not been disturbed. The contents of the gall-bladder are much prized as medicine by the hill people.

Malayana. -170 species of mammalia are known to inhabit Indo-Malaya. There are 24 of the quadrumana or monkey tribe, 10 of which occur in the Malay Peninsula, 11 of them in Sumatra, 9 in Java, and 13 in Borneo. The orang-utan are found only in Sumatra and Borneo; the siamang, next to them in size, in Malacca and Sumatra, and the long-nosed monkey only in Borneo. The gibbons or long-armed apes and monkeys, and the lemur-like animals, Nycticebus, Tarsius, and Galeopithecus, are found in all the islands. With the exception of the orang-utan, the siamang, the Tarsius spectrum, and the Galeopithecus, all the Malayan genera of quadrumana are represented in India by closely-allied species. In the Indo-Malay region are 33 carnivora, 5 of which-a tiger, leopard, civet, tiger-cat, and otter -are found in India and Malacca, and 20 in the Malayan region; 13 have representatives in India of closely-allied species.

The Malacca glutton, Helictis orientalis, has the H. Nepalensis in the Himalaya. There are 22 hoofed animals in Indo-Malaya, 7 of which are found in India and Burma. The Bos sondaicus is found in Burma, Siam, Java, and Borneo. There is a goat-like animal in Sumatra; the twohorned and the long-horned rhinoceros occur in Burma, Sumatra, and Java, and the elephant of India is found in Malacca, Sumatra, and Borneo. There are about 50 bats, of which under a fourth part occur in India; 34 rodents (squirrels, rats, etc., of which 6 or 8 are Indian; and 10 insectivora, 9 of which are peculiar to the Malay regions. The Tupaia, insect-eaters, closely resemble squirrels, are almost confined to the Malay islands, as also are Ptilocerus Lowii of Borneo and Gymnurus Rafflesii. In Timor there are 15 bats and 7 land mammals ; amongst them the Macacus cynomolgus, the coinmon monkey of all the IndoMalay islands. Paradoxurus fasciatus, a civet-cat, is found over much of the Archipelago.

Felis megalotis, a tiger-cat, is peculiar to, and rare even in Timor. Cervus 'Timoriensis, Sus 
Timoriensis, Sorex tenuis, and Cuscus orientalis are all found in Timor and the Moluccas. Paradoxurus fasciatus is a civet-cat of Timor.

The nammalia of Celebes consist of 7 bats and 14 terrestrial species, amongst them the Tarsius spectrum, Viverra tangalunga, and Rusa hippelapha. Cynopithecus nigrescens in Batchian is of a jet-black colour, and the size of a spaniel.

The Anoa depressicornis, called Sapi-utan or the wild cow of the Malays of Celebes, approaches the ox-like antelopes of Africa, and has been classed as an ox or a buffalo and antelope. It is found only in the mountains, and never occupies places where there are deer.

The wild boar of Celebes is peculiar, but the Babirussa or pig deer there has long and slender legs, and the male has curved upper tusks turned back so as to resemble horns. It feeds on fallen fruits; it is found in the Celebes, in the Sulu Islands, and in Bouru. There are also 5 species of squirrels and 2 species of Cuscus or eastern opossums. Cynopithecus nigrescens, the black baboon monkey, is also of Celebes.

Out of the very small number of mammals which inhabit Celebes, it possesses three genera of singular and isolated forms, viz. the Cynopithecus, tailless ape, allied to the baboons; the Anoa, a straight-horned quadruped, quite unlike anything else in the Archipelago or in India ; and Babirussa, an altogether abnormal wild pig. With a rather limited bird population, Celebes has an immense preponderance of species confined to it, and has also six remarkable genera (Meropogon, Ceycopsis, Streptocitta, Enodes, Seissirostrum, and Megacephalon) entirely restricted to its narrow limits, as well as two others (Prioiniturus and Basilornis), which only range to a single island beyond it.

The Moluccas consist of three large islands, Gilolo, Ceram, and Bouru, with many small isles and islets, Batchian, Morty, Obi, Ke, Timor Laut, Amboyna, Ternate, Tidore, Kaiva, and Banda. There are 25 bats, but only 10 land mammals are known in the group; amongst them Cynopithecus nigrescens, Viverra tangalunga, Rusa bippelaphus, the Babirussa, Sorex myosurus, common to Sumatra, Borneo, and Java, and four marsupials, viz. the small flying opossum, Belideus ariel, a beautiful little animal resembling the flying squirrel in appearance, and a species of Cuscus, peculiar to the Austro-Malayan region. They are opossum-like animals, with a long prehensile tail, of which the terminal half is generally bare; they have small heads, large eyes, and a dense covering of woolly fur, often pure white, with irregular black spots or blotches, but sometimes ashy brown. They live in trees, and feed on the leaves, of which they devour large quantities; they are very tenacious of life.

The islands eastward from Java and Borneo form a part of a previous Australian or Pacific continent.

Australia has no apes, monkeys, cats, tigers, wolves, bears, hyænas, no deer or antelopes, sheep or oxen, no elephant, horse, squirrel, or rabbit. In lieu, it has kangaroos, opossums, wombats, and the duck-billed palypus. It has no woodpecker or pheasants, but has in lieu the mound-making brush turkeys, honey-suckers, cockatoos, the brush-tongued lories, which are found nowhere else in the globe; and all these peculiarities are found in the islands which form the Austro-Malayan division of the Archipelago.
The Aru Islands, Mysol, Waigiou, and Jobic agree with New Guinea in their species of mammalia and birds, and they are all united to New Guinea by a narrow sea. The 100 fathom line around New Guinea marks the range of the paradise birds.

The Papuan Islands consist of New Guinea, 1400 miles long, and its adjacent islands. In them only 17 mammals as yet are known, viz. 2 bats, 1 Sus Papuensis, and the rest are marsupials, one of these a kangaroo of Mysol and the Aru Islands. An allied species occupies N. Guinea. Two species of the tree kangaroo with powerful claws. There are 4 species of Cuscus, and the small flying opossum; and there are 5 small marsupials, one of which is the size of a rat, and takes its place by entering houses and devouring provisions.

Uses.-The horse, the donkey, the camel, the $\mathrm{dog}$, the elephant, and the otter have been trained to be servants to man. The first four have been entirely domesticated, and there are now many varieties of them. The elephant has rarely bred in captivity, but they are captured in a wild state in Ceylon, in the Peninsula of India, in the east of Bengal, and in Assam. They were not in use by the Moghuls, as Polo tells, until Kablai's capture of a number in the war with Mien or Ava. A few continued to be kept at the Chinese court at Timkowski's visit in 1821. The huge creatures are docile, and soon accommodate themselves to the requirements of man. They are usually employed in India, both in peace and war, in carrying heavy articles, but are trained also to carry individuals. There are many elephants in Africa, but the people there have not learned to ensnare them, and they are destroyed for the ivory of their teeth and tusks.

In the south of Asia, the wild ass or gor-kbar of the desert, Equus onager, Pullas, also the Equus hemippus, Is. Geoffroy, and the kiang or dzightai of the Tibetan plains, Equus hemionus, Pallas, still roam untamed; and the E. asinus or Asinus tæniopus, Heuglin, is in South Arabia and N.E. Africa. No attempt within historic times has been made to domesticate any of these, but many of the Kattyawar breed of horses have the shoulder-stripe of the wild and common ass distinctly across the withers.

Naturalists arrange the whales, porpoises, and dolphins under the Cetacea, a title taken from the Greek word Kntos, a whale. The fat and whalebone of the whales, and the spermaceti of one of the species, are largely used. The natives of the Arctic Atlantic shores, and those of the Northern Pacific Islands, eat the whale blubber, and the whalebone is applied to many useful purposes. Ships from Europe and America visit the Northern and Southern Seas to catch these great mammals. Many thousands of seals are yearly brought from the Greenland shores to furnish warm winter robes. Few of the ladies of Europe and America are aware of the fact that many ornaments for their hats which look like feathers are of split whalebone.

The porpoises are distinguished from all their allies by their great strength and ferocity, being the only cetaceans which habitually prey on warmblooded animals; for, though fish form part of their food, they also attack and devour seals and various species of their own order, not only the 
smaller porpoises and dolphins, but even fullsized whales, which last they combine in packs to hunt down and destroy, as wolves do the larger ruminants. The Platanista. Gangetica of the rivers Ganges and Irawadi is quite blind. It feeds on small fish and crustacea; it ascends as high as there is water to swim in, but never passes out to sea.

The mammals which chew the cud are known to naturalists as the Ruminantia. They comprise most of the animals most useful to man, camels, deer, cattle, and sheep. They are the most truly and exclusively vegetable feeders, and grass forms their chief food. They have four stomachs. The first of these, the paunch, receives the food as it is plucked, and passes it on to the second, where it receives a good maceration. From this it is returned to the mouth in pellets or boluses, to undergo a complete trituration by the molar teeth; is then passed into the third stomach, where it undergoes an additional preparation; and is lastly received into the true digestive stomach. This provision of nature enables them to crop a large quantity of food quickly, to be masticated at leisure, and thereby obviate the many interruptions they are liable to from beasts of prey and other alarms, as they are all excessively timid and wary. All of them are eaten as food by man, and all but the deer have been domesticated from the most ancient times. The camel, the sheep, and goats, by the Arabs and other races, have been offered in sacrifice. The races who follow Hinduisin look with abhorrence on the slaughter of the cow. Their reverence for it almost amounts to worship, and they typify the earth as the ever-yielding cow. The camel, the ox, and the buffalo have all been trained for carriage, and they are utilized in agricultural operations. In Egypt, the camel and the ox, or the camel and the buffalo, may be seen yoked together at the plough. The cow is rarely thus employed. The hare and the rabbit, species of the rodentia or gnawing tribe, are eaten by most races, but as they do not chew the cud, they are abstained from by religionists who follow the Mosaic law. For the same reason, the hare, the rabbit, and the swine are aroided by Jews and Muhammadans, for though they divide the hoof they do not chew the cud. The swine and the rabbit have been domesticated. The Chinese and most Christian races eat the swine largely ; and in India, to hunt the wild boar with the spear is a favourite sport.

Many of the races professing Hinduism, and all the Jains and Buddhists, ought by the tenets of their religion to abstain from all animal food. No Hindu would eat the cow. The Buddhists of Ceylon, Further India, Tibet, China, and Japan ought to be similarly abstinent; but though many of them will not kill to eat, few have scruples to use what another has killed, or creatures that have died of disease. The Burmese on the banks of the great rivers partake largely of fish, and the pig is reared for food by all Chinese. One or other of the non-Aryan races of India eat most of the quadrupeds and fishes, and many reptiles, amongst which may be mentioned the field, bush, and bamboo rats, the jerboa rat, a species of Gerbillus, several of the frogs and snakes.

Some of the frugivorous bats are occasionally used medicinally, as also the secretions of the musk deer and civet, Viverra zibetha. Otters are trained in China to aid in fishing with the cast or bell net. The net is cast, and the otter, attached by a cord to the boat, is lowered to frighten fish out of holes in rocky or uneven bottoms into the net, which, as soon as lifted, is closed at the bottom by the leaden sinkers, and the fikh are thus caught.

Jerboa rats, in thousands, issue from their holes in the dusk of the evening, and stand erect on their long hind legs. The credulous and superstitious greatly value as a charm the projecting process on the frontal bone of the jackal, and imagine it to be a horn; the claws and teeth of the tiger are also prized. The striped and spotted skins of the tiger, the lion, the leopard, and the panther are prepared as rugs for the drawingrooms of the wealthy; the horns of the rhinoceros are valued by the Chinese carver; the ivory of the tusks and teeth of the elephant is used for many purposes in the arts; but the hides, skins, furs, hair, wool, horns, and bones of the horse, cattle, deer, sheep, and goats far outweigh in value to man the arts products of all other mammals.

Of the other mammals of the East Indies, many are even hurtful. The elephant, the lion, the tiger, the leopard, the hyæna, and the wolf, the jackal, the fox, the wild dog, and the bear cause many deaths of man and domestic animals. In British India, in the seven years 1875 to 1881 , the yearly numbers of human beings so killed $(144,260)$ ranged from 19,273 to 21,990 ; and the deaths of cattle $(362,027)$ from 43,669 to 58,386 . The Government of India pay annually ten or twelve thousand pounds as rewards for killing wild beasts. About 1600 elephants are destroyed annually, 7000 tigers and leopards, 2000 bears and hyænas, 5000 wolves, and 200,000 snakes.

The following were the numbers of human beings killed by

\begin{tabular}{|c|c|c|c|c|c|c|c|c|}
\hline & & 1875. & 1876. & 1877. & 1878. & 1879. & 1880. & 1881. \\
\hline Elephants, & & 61 & 52 & 46 & 33 & 38 & 46 & 58 \\
\hline Tigers, • & .. & 828 & 923 & 819 & 816 & 698 & 872 & 889 \\
\hline Leopards, & . . & 204 & 156 & 200 & 300 & 277 & 261 & 239 \\
\hline Bears, & . & 84 & 123 & 85 & 94 & 121 & 108 & 75 \\
\hline Wolves, . & - & 1,061 & 887 & 564 & 845 & 492 & 347 & 250 \\
\hline Hyænas, & . & 68 & 49 & 124 & 33 & 28 & 11 & \\
\hline Otber wild $b$ & oeast & 2,015 & 1,143 & 1,180 & 1,323 & 1,270 & 1,195 & 1,232 \\
\hline nakes, . & . . & & & & $16.81 \%$ & 17,388 & 19150 & 18,670 \\
\hline
\end{tabular}

Tigers, leopards, and wolves are the most destructive.

One species of hare is found in the south of the Peninsula, another in Northern and Central India; the hispid hare in N.E. Bengal, and lagomys on the Himalayas. One elephant is common to all India; two species of rhinoceros occur in N.E. Bengal, one of them extending to the extreme south of the Malay Peninsula; one wild pig occurs throughout all India, varying slightly in appearance ; and a peculiar dwarf species is found sparingly in the Terai adjoining the S.E. Himalayas. The wild ass of Western Asia and Persia is found in the north-western deserts. Two species of the true deer of the red deer type occur only within the Himalayas, beyond the outer range in Kashmir and Sikkim, and these two extend over a great part of Asia. The maral, a large stag, is found in all the higher regions of the Ala-tau and Mus-tau. He affords noble sport for the hunters, and his horns are highly valued by the Chinese. But it demands a fearless hunter 
to follow him into his haunts among the precipices, glaciers, and snowy peaks of this region. In winter and spring he is found in the valleys, but as the weather becomes warmer he ascends, to escape the flies and other insects. They are seldom found in herds, though groups of 10 or 12 are sometimes seen standing on the brink of a precipice 1500 to 2000 feet in height, quite inaccessible to man. Two Cossacks hunting the maral, followed the game far up into the Ala-tau, and found a magnificent animal, whose horns were worth 120 roubles.

Four rusine deer are found throughout India, one of them, the rucervus, occurring only in Central and Northern India, and extending into Assam. The musk deer is only in the Himalayas, and the memimna or moose deer throughout India and in Malayana. The nil-gai and fourhorned antelope, peculiar to India, are found throughout the Indian region. Gazelles occur both in India and Africa. The goat-like antelope, Nemorrhodus, is found on the Himalayas, and is peculiar to Eastern Asia from Burma to Japan. One type of the true goats, the type Hemitragus, has a representative on the Himalayas, and another on the Neilgherries. The Siberian ibex extends to the Himalayas; and the markbor, quite of the type of the domestic goat, is found on the N.W. Himalayas and adjoining hilly districts. Of two species of wild sheep, one occurs in the Panjab Salt Ranges, and the other in the Himalayas.

The bison of sportsmen, the magnificent gaur, Gavæus gaurus, abounds in the forests of S. India, and extends into Central India, Burma, and the Malay Peninsula.

Two species of the manis, the scaly ant-eater, occur, one common throughout all India, and one extending from Darjiling into China.

The dugong occurs sparingly on the southern coasts of India ; various species of Delphinus, one Globiocephalus, and one Balænoptera, and the fresh-water porpoise of the Ganges, Indus, and Irawadi, the Platanista, is a peculiar type.

Along the base of the Himalayas, in the dense jungles, an occasional tiger prowls ; the leopard is not uncommon; while many of the game birds about Dugshai are there also plentiful. Among the lesser ranges bordering the plains, and to an elevation of 8000 or 9000 feet, barking-deer are common; and on the more secluded and craggy mountains the goral or chamois (Nemorrhoedus goral) may be occasionally seen sporting among the pine-clad precipices. This little antelope is gregarious, feeding in seattered herds, so that when the loud hissing call of alarm is uttered by one individual, the others, one by one, take it up; and the hunter, from a prominent position, may see from 10 to 20 gorals in different parts of the hill bounding across the precipices. The goral is rather higher than the barking-deer, and more compact and agile in appearance.

The species of mammalia in the Southern Mahratta country were described by Mr. (now Sir) Walter Elliot, of the Madras Civil Service, in the Madras Literary Society's Journal, July 1839. The district of India in which the animals were procured is a part of the high table-land towards the south of the Dekhan, commonly called the Southern Mahratta country, and constitutes the British zillah of Dharwar. It ought likewise, geographically speaking, to include the small province of Sunda. The general boundaries are the rivers Kistna and Bhima on the north and northeast, the Tumbudra river on the south, the Nizan's territory on the east, and the Syhadri range of mountains on the west. The latter are generally called the ghats, a term which, however, properly applies only to the passes leading through them. The general face of this tract is much diversified, and affords a great variety of elevation and of geological structure, thereby materially affecting the distribution and the habitat of the different species of animals existing within its limits. The whole of the western portion is a thick forest, extending from the outskirts of the mountainous region of the ghats to their summits, and clothing the valleys that extend between their different ridges. It abounds with the teak and various other lofty forest trees, festooned by enormous perennial creepers. The bamboo forms a thick and luxuriant underwood in some places, while others are entirely open, and the banks of many clear and rapid streams flowing through it abound with the black pepper plant, the wild cinnamon, and other odoriferous shrubs. Portions of this forest are often left entirely untouched by the axe or knife, forming a thick impervious shade for the growth of the black pepper, cardamom, and Mari palm (Caryota urens). These are called kans, and are favourite resorts of wild animals. To the east of the regular forest lies a tract called the Mulnad or rain-country (though the natives of the plains often include the jhari or forest under the same denomination), in which the trees degenerate into large bushes, the bamboo alınost entirely ceases, and cultivation, chiefly of rice, becomes much more frequent. The bushes consist chiefly of the karunda, the pallas, etc. It abounds in tanks and artificial reservoirs for purposes of irrigation. East of the Mulnad is a great extent of alluvial plain, producing fine crops of wheat, cotton, maize, Holcus sorghum, Panicum Italicum, Cicer arietinum. And on the Nizam's frontier are found a succession of low dry hills with tabular summits, often rising in abrupt scarped precipices, and intersecting and traversing the plains in various directions. They are clothed with low thorny jungle of babul and other acacia; and their bases, and the valleys between, composed of a light sandy soil, are cultivated with millet, vetches, etc., Panicum spicatum, $\mathrm{P}$. miliare, Phaseolus max, $\mathrm{Ph}$. mungo, etc. The first or mountainous division consists chiefly of micaceous clay and other schists, which to the northward are succeeded by basaltic or trap formation. The Mulnad is composed of undulating clayslate hills, which become covered with basalt to the north. This trap formation extends in a slanting direction from S.W. to N.E., nearly coinciding with a line drawn from Sadasheghur on the coast to Bijapur and Sholapur, and, what is remarkable, is almost coincident with that marking the separation of the two great tribes of the population using totally distinct languages, the Mahrattas and Canarese. The hills to the N.E. and E. are all of primitive sandstone, sometimes resting on schists, sometimes immediately on granite, which latter is the rock nearest the surface in the central and eastern plains. But a well-defined range of hills to the S.W., called the Kupputgud, is entirely composed of micaceous 
and clay slates, resting on granite. The hills more to the N. and N.W. are basaltic. The extensive plains lying between these different lines of hills and eminences are composed of the rich black mould called regur or cotton ground, resulting from decomposed basaltic rocks. To the N.E. a considerable tract of limestone is found, resting on the sandstone, about Bagalcote, Badami, Hungund, Mudibihal, etc.

The strange-looking goat-antelope (Nemorrhoedus bubalina), known by the name ramoo in Kashmir, and serou in other districts of the Western Himalaya, is perhaps the rarest of the wild ruminants. Occasionally the sportsman comes across an individual in the depths of the alpine forests, but the animal is very solitary in its habits, and seldom more than a couple are seen together. Both in figure and movements the serou is perhaps one of the most ungainly of its tribe, and so stupid is it that when come on unawares it will stand and gaze at the intruder; even the report of a rifle seldom scares it. The serou has the legs of a goat, the horns of an antelope; its general appearance is bovine, whilst the long stiff bristles on its back, and general shape of the head, are decidedly porcine,-a sort of nondescript beast, which European sportsmen often call a very extraordinary looking animal, and so it is. The serou is said to fight desperately ; it has been known when wounded or brought to bay to have kept off a pack of wild dogs, and killed several by its sharp-pointed horns. A few are met with on the Kashmir ranges, and in favourable situations eastward to Nepal.

The houriar (Caprovis Vignei) extends along the eastern spurs of the Salt Mountains, but becomes less common as we proceed eastward, and is seldom met with on the ranges beyond the town of Jhelum, or southwards of the Beas river. It is confined to the north and western portions of the Panjab, including the Suliman chain, where it is known by the name of kuch. It is also a denizen of the mountains around Peshawur, including the Khaibar pass, Hindu Koh, and Kafiristan. The shapoo or shalmar of Ladakh, if not identical, is certainly very closely allied; its differences are slight, and such as might result in a great measure from the marked diversity of climate, food, etc., of the two regions. This species is no doubt the sha of Tibet described by Vigne, and possibly the wild sheep of Western Afghanistan, Persia, the Caucasus, Armenian and Corsican mountains, is the same species altered mayhap by climate and other external agencies. The eastern limits of the shapoo have not been fixed with certainty; but so far as inquiries have extended, it would seem that, commencing at Ladakh, it proceeds westward towards the Indus, into the regions where the houriar is found; and probably when these regions are explored we shall find out the relation between what has been supposed distinct, but which Dr. Adams was inclined to consider one and the same animal.

The ibex (Capra Himalayana) frequents many of the lofty ranges of the western chains, and is known to the natives by the names skeen and kail, which they apply indiscriminately in the districts of Aserung, Spiti, Kanawar, the Northern Kashmir mountains, Ladakh, Chinese Tartary, and the Altai. There appears to be a variety in Ladakh with shorter horns than the Himalayan, and specimens of the Siberian ibex possess the same peculiarity. The leopards, panthers, wild $\mathrm{dog}$, and bearded vulture are the common enemies of the ibex; the vulture preys on the kids only. The ibex is found on certain ranges in Ladakh, especially on the chains northward.

The Caucasian ibex (Capra Caucasia) frequents the mountains of Baluchistan, and it is likewise a native of the Murree and other ranges on the north-western frontier of Sind. The Caucasus, Asia Minor, Syria, and Arabia are also countries which it inhabits. It does not appear to travel any great distance eastward, and is probably replaced on the higher ranges of Afghanistan and Persia by its noble congener the Himalayan ibex. The Caucasian ibex has the hair short and darkbrown, with a black line down the back. The beard is also black. Like the European and Himalayan animals, the horns are also bent backwards, but they differ in being more slender and tapering. In the latter, moreover, the horns are three-sided, and the anterior and posterior surfaces sharp, and generally smooth, with the exception of a few irregular tuberosities on the frontal aspect. Like the other species, it frequents dangerous and inaccessible places, such as bleak and barren mountain tops.

Some quadrupeds are undoubtedly diminishing in British India, and markedly the elephant and the lion. The lion, until the middle of the 19th century of not unfrequent occurrence in the region between Sind, Kattyawar, and the Central Provinces, is now (1884) almost unheard of. We have the evidence of Jahangir and the Rev. Edward Terry that in their days the province of Malwa abounded with lions. Jahangir records that he had killed several, and Mr. Terry mentions his having been frequently terrified by them in his travels through the vast woods and wildernesses of the country. It is known to the people as the Untia-Bag, literally camel-coloured tiger. They do little injury. Tigers, however, have always been destructive to the domestic cattle, and as the opening up of British India by roads and railways has led to the destruction of the herds of deer, the tiger has been more and more making man his prey. They are supposed to breed largely in Bustar. In the extreme south of the peninsula of Malacca they are very numerous. The uncultivated forest tribes of India revere the tiger, style him brother, and the Burmese eat the tiger in the belief that they may improve their courage. They buy its flesh at a shilling a pound.

A mere mention of the hyæna, the jackal, the wild $d o g$, the porcupine, rbinoceros, and tapir will suffice. They cause little injury to man. From time to time, frequently following famine years, swarms of rats invade the already wasted lands, and their original habitats remain untraced. One of the leopards, the Felis jubata, has been trained to hunt the deer. The mungoose, species of the genus Herpestes, readily attacks and kills the venomous cobra, and thus aids to protect man.

The wolves, wild dogs, and jackals hunt in packs, and evince much intelligence and cunning. Notices of them will be found under their respective headings.

The following details exhibit the families, genera, and principal species of mammals in the south and east of Asia, with some of Africa :- 


\section{MAMMALIA.}

Order, Primates.

Fam. Simiadr, Monkeys, the Quadrumana, the Heopitheci, Van Hoven, and Catarrhinæ, Geoffrey. Sub-Fam. Simianæ, Apes.

Troglodytes niger, chimpanzee, Africa.

T. gorilla, gorilla, Africa.

Simia satyrus, orang-utan of Borneo.

S. morio, orang-utan of Sumatra.

Sub-Fam. Hylobatinæ, Gibbons of Indo-Chinese countries and Malayana.

Hylobates hoolook, hoolook of Assam, Cachar, Khassya, and Sylhet.

H. lar, gibbon of Tenasserim.

H. agilis, gibbon of Malay Peninsula.

There are several others in the Malay islands. Monkeys.

Presbytis illiger, syn. Semnopithecus, $F$. Cuvier, the hanuman or langur.

P. entellus, Jerd., Bengal langur.

Simia, Dufresn.

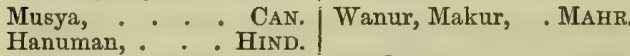

Common in Bengal and Central India.

P. schistaceus, Hodgs., Horsf., Himalaya langur.

Kubup, . . . BHот. | Kamba suhu, . LePCH. Occurs throughout the Himalayas.

P. priamus, Ell., Blyth, Horsf., Gandangi, Tex., the Madras langur, inhabits the eastern side of the Peninsula and the north of Ceylon.

P. Johnii, Jerdon.

Simia Johnii, Fisher. I Sem. Johnii, var. Martin. Semnopithecus Dus- Sem. cucullatus, Is. Geoff. sumierii, Schinz. $\quad$ Sem. hypoleucos, Bl.,Hors. The Malabar langur, of Travancore, Cochin, Malabar, and South Canara.

P. jubatus, Jerdon (Semnopithecus Johnii, Wagner, Blyth, Martin), the Neilgherry langur, of Neilgherries, Animallay, Pulney, and Wynad, not below 2500 and 3000 feet.

P. pileatus, Blyth, Sylhet, Cachar, Chittagong.

P. barbei, Blyth, interior of 'Tiperah Hills.

P. obscurus, Reid, Mergui.

P. Phayrei, Blyth, Arakan.

P. albo-cinereus, Malay Peninsula.

P. cephalopterus, Blyth, Ceylon.

P. ursinus, Blyth, Ceylon.

Several other species occur in the Malay islands.

Sub-Fam. Papioninæ, the true Baboons of Africa and monkey-like Baboons of India. Generic name Bandar.

Inuus silenus, Jerdon, lion-monkey.

Simia leonina, Linn. | Silenus veter, Gray, Bly.

Nil-bandar, . . BENG. | Nella-manthi, . MALEAL.

Siah-bandar, . HIND.

W. Ghats, Cochin, Travancore.

I. rhesus, Jerdon, Bengal monkey.

I. erythræus, Schreb. | Pithex oinops, Hodg., Hor.

Morkot, . . . BENG. Marcut-banux, . LEPCH.

Piyu, . . . Bнот. Banur, Suhu, . .",

Inhabits nearly all India.

I. pelops, Jerdon, hill monkey (Macacus Assamensis, $M^{\prime}$ Clelland, Horsf., Blyth), high up on the Mussoori Hills.

I. Assamensis, Jerdon? is Macacus Sikkimensis, Hodg. ?

I. nemestrinus, Jerdon, Tenasserim, Malayana.

I. leoninus, Blyth, Arakan.

I, arctoides, Is. Geoffroy? Arakan.

Macacus radiatus, Jerdon, Madras monkey.

Simia sinica, Linn., Ell., Blyth, Horsf.

Munga, . . . CAN. Wanur, MAHR. of SYkes. Makadu,. : MAHR. Vella munthi,. TAM.

Kerda, MaHR. of GHats. Koti, . . . . TEL. All over Southern India.

M. pileatus, Shaw, Ceylon.

M. carbonarius, $\boldsymbol{F}$. Cuvier, Burma.

M. cynomolgos, Linn., Burma.

Fam. Lemuridæ, the Lemurs, mostly of Madagascar, one genus of Africa, and two or three from India and Malayana. Cheiromys, indris, lemur, and lichanotus are Madagascar forms.

\section{MAMMALIA.}

Nycticebus tardigradus, Jerdon.

Stenops Javanicus, $A$ uct. | N. Bengalensis, $G ., H ., B l$.

Lajja banar, . . BENG. Slow-paced lemur, ENG. Lajjawoti banar, . " Sharmindah billi,. HIND. Found in Bengal, Rungpur, Dacca.

N. Javanicus, Blyth? of Java,

Loris gracilis, Jerdon, Lemur Ceylonicus, Fischer, Bly.

The slender lemur, . ENG. Tevangar, . . TAM.

Sloth of . MADRAS. Dewantsi pilli, : TEL. Found in Ceylon and Southern India.

Tarsium, a genus of Java.

Fam. Galeopithecidæ, Flying Lemurs.

Galeopithecus, sp., natives of Malayana, form a link to the frugivorous bats. They have pectoral mammæ. They have a membrane connecting their limbs, but have not the power of sustaining flight. They are nocturnal and insectivorous, and sleep with their heads down.

\section{Sub-Order, Cheiroptera, Bats.}

Fam. Pteropodidæ, Frugivorous Bats of Malayana, Ceylon, India, Burma, Malacca, Java.

Pteropus Edwardsi, Jerd., large fox bat, flying fox.

Pt. medius, Temm. Pt. leucocephalus, Hodg. Blyth.

Badul, . . BENG. War-baggul, . MAHR. Toggul bawali, : CAN. Sikat yelli, : . TEL.

Gadal, Bar-bagal, HiND. Siku rayi,

Found in Ceylon, India, and Burma.

Pt. Leschenaultii, Jerdon.

Pt. seminudus, Kelaart. | Fulvous fox bat, . ENG. Madras, Carnatic, and Trichinopoly.

Pt. edulis, Java and Malacca.

Pt. Dussumierii, Is. Geoff., continent of India?

Cynopterus marginatus, Jerdon, small fox bat.

C. aftinis, Gray. Pteropus pyrivorous, $\boldsymbol{H}$. Ell., Bly., Horsf.

Cham gadal, . BENG. | Gadal, . . . HIND. Throughout all India and Ceylon.

Macroglossus minimus (Jerdon, the Pteropus minimus, A uctorum), Tenasserim and Malayana.

$$
\text { Fam. Vampyridæ. }
$$

Sub-Fam. Megadermatinæ, Vampire Bats.

Megaderma lyra, Jerdon.

M. schistacea, Hodg8., | M. Carnatica, Ell. Bly., Horsf.

Large-eared vampire bat, over all India.

M. spectrum, Jerdon, Kashmir vampire bat.

M. Horsfieldii, Blyth, Tenasserim.

M. spasma, Linn., Ceylon, Malayana. Sub-Fam. Rhinolophinæ, Leafy-nosed Bats.

Rhinolophus perniger, Jerdon, Hodg., Blyth (R. Iuctus, Temm.), large leaf bat of Nepal? Malabar? Java? Darjiling.

R. mitratus, Blyth, mitred leaf bat, Chybassa, Mussoori, Central India.

R. tragatus, Hodg., Blyth, dark-brown leaf bat of Nepal, Mussoori.

R. Pearsoni, Horsf., Blyth, Darjiling, Mussoori.

R. affinis, Horsf., Blyth.

R. rubidus, Kelaart. Malabar? Ceylon, Burma, Malayana.

R. rouxi, Temm., Blyth (R. lepidus, Bly.), rufous leaf bat of Malabar, Calcutta, Colgong, Mussoori.

R. macrotis, Hodg., Bly., large-eared leaf bat, Himalaya, Nepal, Mussoori.

R. subbadius, Hodg., Bly., bay leaf bat, Nepal, Him. alaya.

R. brevitarsus, $B l y$. , Darjiling.

Other species of Rhinolophus occur in the Malayan islands, China, and Japan.

Hipposideros armiger, $B n . \boldsymbol{H} n$. (H. nobilis, var. Blyth), large horse-shoe bat, Nepal, Mussoori, Darjiling.

H. lankadeva, $K e l$., Ceylon.

H. nobilis, Cantor, Burma, Ceylon, and Malay Penin. sula.

H. speoris, $B l ., E l ., J e r d o n$.

\begin{tabular}{l|l} 
H. apiculatus, Aray. & H. Dukhunensis, Sykes. \\
H. penicillatus, Gray.
\end{tabular} Indis generally, Ceylon, Archipelago. 
H. cinerasceus, Bly., ashy horse-shoe bat, Panjab, Salt Range.

H. murinus, Jerdon (Rhinolophus fulgens, Ell., Blyth), little horse-shoe bat, S. India, Ceylon, Nicobars, Burma, Malayana.

H. larvatus, Horsf., Burma, Malayana, Sylhet.

H. insignis, nobilis, diadema, and galeritus, Cantor, are from the Malay Peninsula.

Cœlops Frithii, Bly., tailless bat, Sunderbans.

Rhinopoma Hardwickii, Gray, Blyth, long-tailed leaf bat, all India, Burma, Malayana.

Nycteris Javanica, Geoff., Java, Malacca.

Fam. Noctilionidæ.

Sub-Fam. Taphozoinæ.

Taphozous longimanus, Hard., Blyth.

\begin{tabular}{l|l} 
T. brevimanus, Blyth. & T. fulvidus, Blyth \\
T. Cantori, Blyth. & Long-armed bat.
\end{tabular}

All India.

T. melanopogon, Temm., Horsf., black-bearded bat of Canara and Malayana.

T. saccolaimus, Temm., Blyth.

T. crassus, Blyth.

White-bellied bat of Madras and Malayana.

T. bicolor, Temm, E. Indies?

Emballonura, sp., from Java.

\section{Sub-Fam. Noctilioninæ.}

Nyctinomus plicatus, Jerdon.

Vespertilio plicatus, Buch., Bly.

N. Bengalensis, Geoff.

N. dilatatus, Horsf.

N. tenuis, Horsf.

The wrinkled-lip bat of Madras, Calcutta.

Cheiromeles torquatus, of Java.

\section{Fam. Vespertilionidæ.}

Sub-Fam. Scotophilinæ.

Scotophilus serotinus, Jerdon, silky bat.

Vespertilio noctula, Geoff. I V. serotinus, Schr.

Europe, Himalaya, Tyne Range beyond Mussoori.

S. Leisleri, Jerdon :(Vespertilio dasycarpus, Leisleri, Blyth), hairy-armed bat, Tyne Range, Himalaya.

S. pachyomus, Jerdon, the thick muzzled bat of India?

S. Coromandelianus, Jerd. (Kerivoula Sykesii, Gray, Ell.), Coromandel bat of all India.

S. lobatus, Jerd. (Vespertilio abramus, Temm.), the lobe-eared bat of India.

S. fuliginosus, Jerd. (Nycticejus atratus, Blyth), the smoky bat of Nepal.

S. fulvidus, Ell., Tenasserim.

S. pumiloides, China.

S. Hodgsonii, Calcutta.

S. falcatus, India.

S. fulvus, Madras, Java.

Noctulinia noctula, Gran, Vespertilio lasiopterus, Sch. V. altivolans, White, V. labiata, Hodgs., Blyth. The noctule bat of England, Nepal. Flies high.

Nycticejus Heathii, Horsf., Bl., large yellow bat, Southern and Central India.

N. luteus, Blyth (N. flaveolus, Horsf.), Bengal yellow bat, all India, Assam, Burma.

N. Temminckii, Jerd.

Vespertilio belanger, Geoff. I V. noctulinus, Is. Geoff The common yellow bat of India, Burma, Malayana.

Nycticejus castaneus, $G r$., Bly., chestnut bat of Bengal, Burma, Malayana.

N. atratus, Blyth (Scotophilus fuliginosus, Bly.), sombre bat of Darjiling.

N. canus, Blyth (Scotophilus Maderas-patanus, Gray), hoary bat of all India.

N. ornatus, Blyth, harlequin bat, Darjiling.

N. nivicolus, Hod., Horgf., alpine bat, near the snows of Sikkim.

Sub-Fam. Vespertilioninæ.

Lasiurus Pearsoni, Horsf., Bl. (Noctulinia lasiura, Hodgson), the hairy-winged bat of Darjiling.

Murina suillus, Jerd.
N. lasiura, Hodg.

The pig bat of Darjiling, Malayana

Murina Formosa, Jerd., the beautiful bat.

Vespertilio Formosa, $\boldsymbol{H}$. | Nycticejus Tickelli, Blyth. Kerivoula Formosa, $G r$. N. isabellinus, Horsf. Central India, Nepal, Sikkim, Darjiling.
Kerivoula picta, Jerd. (Vespertilio kerivoula, Boddaert), painted bat of all India, Burma, Malayana.

K. pallida, Blyth, the pale-painted bat of Chybassa.

K. papillosa, Jerd., the papillose bat of Ceylon, Calcutta, Java, Sumatra.

K. tenuis? Tomes (Vespertilio tenuis), Java, Sumatra.

K. Hardwickii, Tomes (Vespertilio Hardwickii), Java, Sumatra.

Vespertilio caliginosus, Tomes, mustachoed bat of India.

V. Siligorensis, Hodg., Horsf., Terai bat, Siligori in the Sikkim Terai.

V. Darjilingensis, Hodg., Darjiling bat, like V. mystacinus of Europe.

V. Blythii, Tomes, Nasseerabad.

V. adversus, Blyth, Horsf., Malayan bat of Ceylon, Calcutta, Burma.

V. Horsfieldii, Temm. (V. tralatitius, Horsf.), Malayan Peninsula and Java.

Myotis murinus, Jerd. (Vespertilio murinus, Geoff.), mouse-like bat of Europe, Mussoori.

M. Theobaldi, Blyth (M. pallidiventris, Hodg., Blyth), mouse bat of Kashmir.

M. parvipes, Blyth (M. pipistrellus, Bly.), small-footed mouse bat of Mussoori

M. lepidus, Blyth, Kandahar.

M. Berdmorei, Blyth, Tenasserim.

Plecotus auritus, Jerd.

P. homochrous, Hodg. $\quad$ P. Darjilingensis, Hodg. Long-eared bat of Darjiling.

P. Timorensis, Geoff., Timor.

Barbastellus communis, $G r ., B l$.

Vespertilio barbastellus, Schr. | B. Daubentoni, Bell. Barbastelle bat of Himalaya, Mussoori, Nepal.

B. leucomelus, Jerd. (Vespertilio leucomelus, $\boldsymbol{R}$ uppell), Red Sea.

B. macrotis, Jerd. ( $\nabla$. macrotis, Tenzm.), Sumatra,

Nyctophilus Geoffroyi, $B l$., Leach, the large-eared leaf bat of Europe, Australia, Mussoori.

ORDER, INSECTIVORA, Insectivorous Mammals.

\section{Fam. Talpidæ, Moles.}

Talpa micrura, Hodg., Blyth (T. cryptura, Blyth).

Biyu kantyem, . Bнот. | Pariam, . . LEPCH. Nepal, Sikkim.

T. macrura, Hodg., long-tailed mole, Sikkim

T. leucura, Blyth, Sylhet, Tenasserim.

T. mogura, Temm., Japan.

Urotrichus talpoides, Japan.

Fam. Sorecidæ, Shrews.

Sorex cærulescens, Shaw, Blyth, musk rat, musk shrew.
S. Indicus.
S. giganteus.
S. Sonnerati, Geoff.
S. myosurus, Gray.

Sondeli, CAN. / Chachundi, HIND.

All India.

S. murinus, Lin., Blyth

S. myosurus, Pallas.

S. Swinhæi, Blyth,

S. viridescens, Blyth.

S. nemorivagus, Hodgson (S. murinus, Horsf.), Nepal wood shrew of Nepal and Sikkim.

S. Griffithii, Horsf., Khassya Hills.

S. serpentarius, Is. Geoff. (S. Kandianus, Kelacnt) rufescent shrew of Ceylon, S. India, Burma, Tenasserim.

S. heterodon, Blyth, Khassya Hills

S. saturatior, Hodg., Darjiling.

S. Tytleri, Blyth, Dehra Doon.

S. soccatus, Bly., Hodgson, hairy-footed shrew of Nepal, Sikkim, Mussoori.

S. niger, Ell., Horsf., Neilgherry wood shrew.

S. leucops, Hodgs., long-tailed shrew, Nepal.

S. Hodgsonii, Blyth, Nepal pigmy shrew.

S. Perroteti, Duvernoy, pigmy shrew of Mysore, Neilgherries, Dekhan.

S. micronyx, Blyth, small-clawed pigmy shrew of Western Himalaya

S. melanodon, Blyth, black-toothed pigmy shrew of Calcutta.

Hodgson described Sorex Sikkimensis, homourus, oligurus, macrurus, holo-sericeus, and tenuicauda of Darjiling.

Sorex ferragineus, montanus, Kelaarti, purpurascens, Temp., and Horsfieldii, Tones, of Ceylon. 
S. fuliginosus, Blyth, and S. nudipes, Blyth, Tenasserim.

S. atratus, Blyth, Khassya.

S. albinus, Blyth, China.

S. pulchellus, Licht., Central Asia.

Soriculus nigrescens, Jerd.

Corsira, Gray, Blyth. $\quad$ S. soccatus, Hodg.

S. Sikkimensis, Hodg. Ting-zhing, . . Внот.

S. aterrimus, Blyth. Tang-zhing, . . LEPCH.

Mouse-tailed shrew of Sikkim, Nepal.

Crossopus Himalaicus, Gray.

Choopitsi, . ВНот. / Oong-lagniyu, . LEPCH.

The Himalayan water shrew of Sikkim.

Corsira alpina, Jerdon (Sorex caudatus, Hodgson, Bly.), alpine shrew of Europe and Sikkim.

C. Newera-elia, Kel., of Ceylon.

Feroculus macropus, $\mathrm{Kel}$. (Sorex macropus, Blyth), Ceylon.

Myogalea (mygale) or musk rat of N. America. The scaly tails of this shrew are imported into India.

Fam, Erinaceidx, Hedgehogs.

Erinaceus collaris, Aray, Blyth (E. Grayii, Bennett), N.W. Provinces, Panjab, Sind.

E. micropus, Blyth.

E. nudiventris, Horsf. | E. collaris, Gray. South India, Neilgherries.

E. mentalis, Gray, India; E. spatangus, Benn., Himalaya; E. Grayii, Benn., Himalaya ; E. auritus, Pallas, Central Asia; E. megalotis, Blyth, Afghanistan.

Fam. Tupaidæ.

Tupaia Elliotti, Water., Bl., Madras tree shrew, Eastern Ghats.

Tupaia Peguana, Less.

T. Belangeri, Wagner. | Sikkim tree shrew, . ENG.

T. ferruginea, var. Blyth. $\mid$ Kalli-tang-zhing, LEPCH. Sikkim.

T. Javanica, Java; T. tana, Sumatra; T. murina, Borneo; T. ferruginea, Blyth, Malayana.

Order, Carnivora, or Beasts of Prey.

Feræ normales, Gray. I Secundates, Blyth.

Tribe, Plantigrada, walk on sole of foot.

Fam. Ursidæ, the Bears.

Ursus isabellinus, Hors., Blyth.

U. Syriacus, Hemp?

Barf ka reetch,. Hind. Harput,

Bhalu, . " " Drin-mor, ТАDAKH The snow bear, brown, yellow, grey, silver bear of Himalayas.

Ursus Tibetans, $\boldsymbol{F}$. Cuv., Blyth

U. torquatus, Schinz. U, ferox, Robin.

Bhalak, . . BENG. Bhalu, .

HIND.

Thom,. . BHOT. Sona, . . LEPCH

Himalayan black bear, Himalaya, Assam.

U. Malayanus, Burma, Arakan, the Malay Peninsula.

U. euryspilus of Borneo.

U. labiatus, Ell., Blain, Blyth.

Bradypus ursinus, Shaw. I Melursus lybicus, Meyer.

Karadi, Kaddi, . CAN. Aswail, . . MAHr.

Yerid,. . GERd. Riksha, . . SANSK

Banna, : Kol. Elugu, . . TEL.

Indian black beax or sloth bear, has a $\mathrm{V}$ mark on breast. All India.

Ailurus fulgens, $\boldsymbol{F}$. Cuv., Bly., Hard.

A. ochraceus, Hodgs.

Wahdonka, . Bнот. Wah, . . . NEPAL.

Sunnam, Suknam, LEPCH. Negalya-ponya, . " Red cat bear, S.E. Himalaya, Nepal, Sikkim.

Tribe, Semi-Plantigrada, Blyth (Mustelidæ of Blyth), Badgers, Weasels, and Otters.

Fam. Melididæ, Badger-like animals.

Arctonyx collaris, Cuv., Blyth.

Mydaus, Gray, Hardw. I A. isonyx, Hodg.

Bhalu-sur, . Hind, Bear pig, Hog badger.

Nepal, Sikkim, E. Bengal, Assam, Sylhet, Arakan.

Arctonyx taxoides, Blyth, of Sylhet, Assam.

Mellivora Indica, Jerdon.

Ursitaxus inauritus, $\boldsymbol{H}$.

Ratelus Indicus, Schin.
Bhajubhal, . BENG. Tavakaradi, . . T.ı. Biju, . . HIND. Biyu-khawar, . TEL. Indian badger. All India.

Meles albo-gularis, Blyth, Tibet.

Taxidea leucura, Blyth, Tum-pha of Tibet.

Helictis Nepalensis, Jerd. Gulo, Hodg., Blyth. Nepal wolverine, Nepal.

H, orientalis, Malayana.

Fam. Mustelidæ, Weasels and Martens.

Martes flavigula, Jerdon, Indian marten.

Mustela Hardwickii, $H$. Gatidictis chrysogaster,

M. Gwatkinsii, Jardine. Jardine.

Huniah, Aniar, . Внот, Sakku,. . . LEPCH.

'Tuturala, . KAMAON. Mal sampra,. . NePAL India, Malayana.

Martes toufoeus, Hodgson, Tibet, Ladakh, at 11,000 feet, Afghanistan, Peshawur, Qu.? M. abietum of Europe.

Mustela zibellina, Blyth, Tibet sable marten.

M. sub-hemachalana, Hodg., Blyth.

M. humeralis, Blyth. 'Kran, KAsH,

Zimiong, . Bнот. Sang-king, : : LеPCH, Himalaya, Nepal, Kashmir.

M, erminra, the stoat, the ermine, W. Himalaya, Nepal.

M. kathiah, Hodg., Blyth.

M. auriventer, Hodg. | Kathiah nyal, . NEPAL. Yellow-bellied weasel of Nepal, Himalaya, Bhutan.

M. strigidorsa, Horsf., Hodgs., striped weasel of Sikkim.

M. Horsfieldii, Gar'y, Bhutan.

M. temon, Hodg., Tibet.

M. nudipes, $\boldsymbol{F}$. Cuv., Java, Malayana.

M. Sarmatica, Pallas, North and Central Asia, Afghanistan.

M. Sibirica, Pallas, China, is M. Hodgsoni of Gray.

M. larvata (Putorius Tibetanus, Hodgs.), Tibet.

$$
\text { Sub-Fam. Lutrinæ, Otters. }
$$

Lutra nair, $F$. Cuv.

Lutra Chinensis, Gray. I. Tarayensis, Hodgson,

L. Indicus, Gray.

Indian ${ }^{\circ} \cdot$ CAN. Ud, Hud, - HIND.

Pani kuta, . ' HING. $\mid$ Jal-manjer, . ' MÄHR. Ceylon, India, Burma, Malayana.

L. vulgaris, Erxleben, Bl. (L. monticola, Hodgson ?), the hill otter of Inner Himalayas.

L. auro-brunnea, Hodgs., Himalayas, Neilgherries? Ceylon mountains?

L. monticola, Hodgs. (L. vulgaris apud Jerdon), of Himalaya.

L. barang, Raffles (Barangia varang, Gray), Malay Peninsula.

L. kutab, Gray, Hugel, Kashmir.

I. leptonyx, Horsf., Blyth, clawless otter.

Aonyx Horsfieldii, Gray. | Aonyx Sikkimensis, Hodg. Lutra indigitata, Hodg.

Chusam, . . BHOT. | Suriam, . . LEPCH Himalaya.

Tribe, Digitigrada, walk on the digits, typical carnivora, very quick and speedy.

Fam. Felidæ or Cat tribe, lions, tigers, leopards, cats, and lynxes.

Of these, the lion, pard, cheeta, chaus or wild cat and the caracal or lynx, are common to Africa and India. Seven, viz. the tiger, pard, clouded leopard, marbled tiger cat, large tiger cat, leopard cat, and bay cat, are common to India, Assam, Burma, and Malayana, and three of the seven, viz. the clouded cat, marbled cat, and bay cat, occur in the S.E. Himalaya. One, viz. the ounce, is an outlayer of Central Asia; and only three, the F. Jerdoni, F. rubiginosa, and F. torquata, appear peculiar to the Peninsula of India.

Felis leo, Linn., the Asiatic lion.

F. Asiaticus, F, Gujrattensis, Smee., Benn., Blyth.

Shingal, . . BENG. | Sher, Babbar sher, . Sind,

Untia-bag, HIND, in GuJ. Singha,

Allahabad, Jubbulpur, Cutch, Gujerat, Gwalior, 
Felis tigris, Linn., the tiger.

Tigris regalis, Gray, Blyth.

Go-vagh, . . BeNG. Bag, Bagni, . Hind. Tut, : Bhagulpur. Tukh, : : Bнот.

Huli, CAN.

Nahar, Central InDIA. Sela-vagh, . Suhtong, : : LEPCH. Wuhag, . . MAHR. Nongya-chor, GORAKHPUR. Tagh, : : TrB. All India, up to 6000 or 7000 of Himalayas, measures up to 10 feet 2 inches long.

F. pardus, Linn., the pard.

.F. leopardus, Schreber. | Leopardus varius, Gray.

Var. a. Larger, the panther.

F. pardus, Hodg. $\quad$ F. leopardus, Temm.

Honiga, . . CAN. Chita, Chita-bag, Hind, Burkal, GoNDI Adnara? Bay-hira, : Himalaya. Asnea, . : : MAHR. Tahir-hay, : " ", Chinna puli, : . TEL. Tendwa, : : HiND. Sik, . . : : TIB. India.

Var. b. Sinaller, the leopard.

F. leopardus, Hodg.

F. pardus, Temm.

Bibla, . . BAorI. | Bibia-bag, . . Hind. Kerkal, : . CAN. Ghur-hay, . SimLA. Gor-bacha, : HrND. Dheer-hay, : . "

Borbacha, India.

F. melas, Peron, black leopard (F. perniger, Hodg.), Ceylon, India, Himalaya, Assam, Malayana.

F, uncia, Schreber, Blyth, Hodg., ounce.

F. uncioides, $\boldsymbol{B}$ odg.

F. pardus, Pallas.

Sah, . . Bнот. Pah-le, . . Lepch. Snow leopard, . ENG. Burrel-hay, . SIMLA. Thur-wag, Kanawar. Iker, . . . TIB. Himalaya, at great elevations, and on Tibetan side. F. diardi, Desm., Blyth.

F. macrocelis, Temm., F. nebulosa, Griff. Horsf.

F. macrooeloides, $H o d g$.

Clouded leopard, . ENG. Lam-chittia of the KHAS. Zik, BHоT. Tungmar, . LEPCH. S.E. Himalaya, Nepal, Sikkim, Burma, Sumatra, Java, Borneo.

F. nebulosa, Jerdon (F. diardi, Blyth), Himalaya.

F. viverrina, Benn., Blyth, large tiger cat.

F. viverriceps, Hodg., $\mid$ F. Himalayana, Jardine. Hardw.

F. Celidogaster, Temm., Gray, Blyth. F. Bengalensis, Buch.

Bag-dasha, BENG., HIND. | Mach-bagrul, . . Hind. Bengal, Burma, Malayana, China.

F. marmorata, Martin, Blyth.

F. Charltoni, Gr., Blyth. | F. diardi, Jerd.

F. Ogilbii, Hodg.

F. Durancelli, Hode.

Marbled tiger cat of Sikkim, Assam, Burma, Malayana.

F. Bengalensis, Desmoulins.

F. Sumatrana, Horsf. I. pardichrous, Hodg.

F.Javanensis, Jerd., Hor. Leopardus Chinensis, $G r$.

F. minuta, Temm.

F. undulata, Schinz.

F. Nepalensis, Hodg.

L. Reevesii, Gr.

L. Elliotti, $G r$

Chaus servalinus, $G r$.

Leopard cat, . . ExG. | Wagati, . . MAHR Hilly regions of Ceylon, India, Himalaya, Tibet, Assam, Burma, Malayana, Sumatra, Java. Fierce and variable.

F. Nepalensis, Vigors, probably a hybrid.

F. Jerdoni, Blyth (F. rubiginosa, Geoff. ?), lesser leopard cat, Peninsuls of India.

F. aurata, Temminch, Moormi cat.

F. Moormensis, Hodg. $\quad$ F. nigrescens, Hodg.

F. Temminckii, Vigors.,

Hor'sf., Blyth.

Black cat or bay cat of Nepal, Sikkim.

F. rubiginosa, Is. Geoff., Belanger.

F. Jerdoni, Blyth. I Namalli pilli, . TAM. Rusty spotted cat of Ceylon, India Peninsula.

F. planiceps, Vigors, Malayana. b. LynXine Group.

F. torquata, F. Cuv., Blyth.

F.ornata, Aray,Hardw., | F. Huttoni, Blyth.

\begin{tabular}{l|l} 
Blyth. & Leopardus \\
Gray.
\end{tabular}

Spotted wild cat of Salt Range to Central India.

F. chaus, Guld, $F$. Cuv, Blyth, jungle cat.

F. affinis, Gray, Hardw. F. Jacquemontii, Is. Geoff

F. kutas, Pears.

Chaus lybicus, Gray. $\quad$ Hodg.

Ban-beral, . . Berg.| Mota-lahn manjur, MAHR.

Katas, . . " Cherru puli, . MAL

Birka, . BHAgulPUR. Jinka pilli, . . TEL.

Mant-bek, . . CAN. Kada-bek, - WADDAR,

Jangli billi, . . HIND, Bella-bek, . . , All India.

Felis caracal, Schveb., Blyth.

Caracal melanotis, Gray, Wolf. | Siah-gosh, . Pers, Red lynx of Arabia, Persia, Tibet, Vindhya, Africa, Central India, N.W. Provinces, Panjab.

F. isabellina, Blyth, Tibet.

F. manul, Blyth (F. nigripectus, Hodgson), Tibet.

F. megalotis, Temm., Timor.

F. jubata, Schreber, hunting leopard.

F. guttata, Hermann. I F. venatica, A. Smith.

Tendua bag, . BENG. / Yuz, Cheeta, - Hind

Chircha, : : : CAN.
Sivungi, Laggar,
Chita puli, : : : TEL.

Africa, S. W. Asia, India.

Leopardus Japanensis, Gray, Japan.

L. brachyurus, Swinhoe, Formosa.

Fam. Viverridæ.

Sub-Fam. Hyeninæ, Hyænas.

Hyena striata, Zimmerman, striped hyæna.

H. vulgaris, Desm., Ell., Hundar, . . . . HIND$$
B l \text {. }
$$

Har-vagh

Thirak,

BENG. Lokra-bag, Lakra-bag, ,"

Katkirba, •. CEYLON. Taras, . HIND, 'MA"

Kirba, . : " , Korna gandu, . TEL.

All India.

Sub-Fam. Viverrinæ, Civets.

Viverra zibetha, Lin., Blyth.

V. Bengalensis, Aray, V. melanurus, Hodgs.

Hardio.

V. undulata, Gray.

V. orientalis, Hodgs.

$\mathrm{V}$. civettoides, Hor'sf

Puda gaula, . BENG. Large civet cat, . ENG.

Mach-bandar,BENa.,Hind. Katas, . . . HIND.

Bag-dos, . ," ", Sa-phiong, . LEPCH

Kung, : " Bнот. Bhran, Nit-biralu, NEPAL,

All S.E. of Asia

V. civettina, Blyth.

V. zibetha, Waterh.

S.W. parts of Peninsula of India.

V. Malaccensis, Gmel., Blyth.

\begin{tabular}{l|l} 
V. rasse, Horsf. & V. pallida, Gray.
\end{tabular}

V. Indica, Ell., Geoff.

Jowadi manjux, . BENG. Gando-gaula, . . Hind.

Katas, . . . ", Kasturi, . : MAFR.

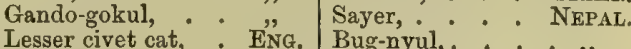

Lesser civet cat, . ENG. Bug-nyul, . . . ",

Mashk billi, . HIND. Punagu-pilli . TEu

All India.

V. tangalunga, Gray, Malayan islands east to the Philippines.

V. rasse, Sykes, Western Ghats.

Prionodon pardicolor, Hodgs., tiger civet.

Zik-chum, - Bнот. | Suliyu, . . LEPCH.

S.E. Himalaya, Nepal, Sikkim.

Parodoxurus musanga, Jerdon.

P. typus, $\boldsymbol{F}$. Cuv., $\boldsymbol{E} l l . \mid$ P. fasciatus, Gray.

P. Pallasii, Gray. $\quad$ P. prehensilis, Pallas.

P. musangoides, Gray. Viverra hermaphrodita,

P. Crossii, Gray.

P. dubius, Gray.

Bhondar, . . BENG. Khatas, . HiND.

Kera-bek, . . CAN. Jhar ka kutta, . ",

Toddy cat, Tree cat, ENG. Ud, . . : MA"Br.

Menuri, - HINs. Mara pilli, $\because$ MAL.

Lakati, , ' Ceylon, India, Malayana, Burma. 
MAMMALIA.

P. Ieuco-mystax, Gray, Malayan Peninsula and islands. P. quadriscriptus, Hodg., Qu. ? P. musanga, Var.

P. Derbyanus, Malayan Peninsula and islands.

P. Tytleri, Tytler, Qu.? P. musanga, Var., Andamans

P. trivirgatus, Temm, Malayan Peninsula and islands.

P. Grayi, Benn, Blyth.

P. Nepalensis, Hodgs.

P. auratus, Blain.

P. bondar, Temm.

P. Zeylanicus, Pallas, Ceylon.

P. bondar, Gray, Terai tree cat.

P. hirsutus, Hodgson. | P. Pennantii, Gray, Hardw

Bondar, Baum, . Beng. Malwa, . . NePAl.

Chinghar, . . Hind. Machabba, . . ",

Nepal Terai, Bengal, Behar.

Paguma laniger, Gray (Martes laniger, Hodgson), Tibet and Snowy Himalaya.

Arctictis binturong, Jerdon.

Ictides ater, $F$. Cuv. | Viverra binturong, Raflles.

Paradoxurus albifrons. Black bear cat, . ENG. Nepal, Assam.

Cynogale Bennettii, Gray (Potamphilus barbatus, $\bar{K} u h l)$, Malay Peninsula.

Herpestes grisens, Geoff., Blyth.

H. pallidus, Schinz. | Mangusta mungos, Ell.

Mungli, . . CAN. Newara, . . Hind.

Madras mungoose, ENG. Nyul, : Hond. Mangus; : Hind, MaHR

$\begin{array}{r}\text { Koral, : : : Gond. } \\ \text { Newal, Hangus, . Hind, MAHR. } \\ \hline\end{array}$ Peninsula of India.

H. Malaccensis, F. Cuv., Blyth.

H. nyula, Hodg. | Cynogale nyula, Gray.

Baji, Biji,. . BEng. Nyul, . . . HIND.

Newol, : Hind. Newara, . . , Bengal to Malayana.

H. monticolus, Ell. (H. Jerdoni, Gray).

Long-tailed mungoose, ENG. | Konda yentawa, . TEL.

Eastern Ghats.

H. fulvescens, $K e l$. (Onychogale Maccarthiæ, Gray), Ceylon.

H. Smithii, Gray, Blyth.

H. rubiginosus, Kelaart. Calictis Smithii, Gray.

H. Elliotti, Blyth. Ceylon and S.E. of Peninsula.

H. Nepalensis, Gr., Blyth.

H. auro-punctatus, Hodg. | H. pallipes, Blyth.

Gold - spotted mungoose of Afghanistan, Panjab, Lower Himalayas, Bengal, Assam, Burma, Malayana.

H. Javanicus, Java and Malayana.

H. thysanurus, Wagner, Kashmir.

H. fuscus, Waterh., Bl., brown mungoose.

H. vitticollis, Benn., Ell., Blyth (Tœeniogale vitticollis, Gray), striped-necked mungoose of Western Ghats, Neiloherries.

H. brachiurus, Malayana.

H. exilis, Eastern Archipelago.

Urva cancrivora, Hodg., Bly.

Gulo urva, Hodg.

Viverra fusca, Gran

Osmetictis fusca, Gray.

Crab mungoose, S.E. Himalaya, Assam, Arakan.

Fam. Canidre, the Dog tribe.

Canis pallipes, Sykes, Blyth (C. lupus, var. Ell.).

Bighana, BundelkHaNd. Bhera, Bheria, Hind.

Tola, . . . CAN. / Nekra, . . . ",

Indian wolf, : . ENG. Hundar, Hurar, . ",

Landgah, : Hind. Toralu,. . . TEL.

All India.

C. laniger, Hodgs., Tibet white wolf.

Chankodi, . Kamaon. / Changu,

Himalaya.

C. niger, Jerd., black wolf of Tibet, the hakpo-chanko.

C. chanco, $G r a y$, red wolf, gold wolf of Tibet.

C. aureus, Linn., Bly., Ell., the jackal.

Siar, Sial, Shialu, BENG. Kola, Kolia, . . Hind.

Amu, Внот. Ghidar, . .

Nari, : $\vdots \vdots \vdots$ CAN. Shigal, : $\vdots$ : PERS,

Nerka, : GoNDI. Nakka, : : TEL.

All India, Ceylon, Burma, Asia, S. Europe.

Cuon rutilans, Jerd., wild dog.

Canis Dukhumensis, Syk. | Cuon primrevus, Hodas.

C. familiaris, wild, var. $\boldsymbol{E}$.

MAMMALIA.

Pao-ho,

Sakki-sarai,

Sram-naiko,

GONDI.

Bhaosa, Bhoonsa, HiNd.

Buansu, W. Him-

alaya to Sikkim,

Ran hun,. . " KA'B.

Suhu-tum, . LEPCH.

Kolasa, Kolasra, MadAR.

All India, Burma, and Malay Peninsula.

Vulpes Bengalensis, Jerdon, Sh., Bly., Ell., Hardu.

Canis rufescens, Gray.

C. chrysurus, Gray.

C. kokree, Sykes.

C. corsac, A uct.

Khek-sial, BENG., HIND. Lokri, Lokeria, . HIND. Kong, . . CAN.

Kemp-nari,

Chandak-nari,

Indian fox,

Lumri, Lomri, All India.

V. leucopus, Blyth, desert fox of N.W. India, Cutch, Panjab.

V. ferrilatus, Hodgs. (Cynalopex ferrilatus, Blyth), a pretty, small fox of Tibet.

V. montanus, Pears., Blyth., hill fox.

V. Himalaicus, Ogilby. | $\quad$. Nepalensis, Gray.

Loh, . . Kash. | Wamu, . . NEPAL. Himalayas.

V. pusillus, Blyth (V. flavescens, Blyth), Panjab fox, Salt Range.

V. fuliginosus, Hodg., Thec-ke, Sikkim, Tibet.

V. flavescens, Gray (V. montanus, Hodgs., Horsf.), Tibet.

V. Griffithii, Blyth (V. flavescens, Blyth), Afghanistan. Order, Cetacea, the Whale tribe.

Cetæ, Auctorum. I Mutalata, Owen.

Sub-ORDER, MrstacoceTI, the Balænoidea or Whalebone Whales.

Balæna Japonica, North Pacific, Japan Seas.

B. Australis, S. Atlantic, S. Seas.

B. mysticetus, Arctic Seas, Greenland whale.

B. Biscayensis, N. Atlantic.

B. antipodarum, S. Pacific.

B. antarctica, S. Seas.

B. Novæ Zelandiæ, S. Seas.

Neobalæna marginata, Australian and N. Zealand Seas,

Rachianectes glaucus, N. Pacific.

Megaptera, $s p$. , humpbacks, all seas.

Balienoptera borealis, Indica, musculus, rostrata, Sibbaldii, called rorquals, finners, and razorbacks.

B. Indica is of the Bay of Bengal, near Ceylon.

SUB-ORDER, ODONTOCETI, the Delphinoidea or Toothed Whales.

Fam. Physeteridæ. Sub-Fam. Physeterinæ.

Physeter macrocephalus.

P. simus, Owen (Euphyseter simus), Bay of Bengal.

Kogia breviceps, Bay of Bengal, N. and S. Pacific. Sub-Fam. Ziphiinæ.

Berardius arnouxi, N. Zealand.

\section{Fam. Platanistidæ.}

Platanista Gangetica, Jerd.

Delphinus rostratus, Shaw., Hardw.

Sishuk, . . BENG. Susa, Sons, Susu, Hinn,

Gangetic porpoise, ENG. Sisumar, . . SANSK. Ganges, Jumna, Gogra, Brahmaputra.

P. Indi, Blyth, Indus porpoise of the river Indus.

Fam. Delphinidx.

Monodon monoceros, narwhal, Arctic Seas.

Delphinapterus leucas, Aretic Seas.

Phocæene communis, porpoise.

P. melas, Japan.

$P$. brevirostris, Bay of Bengal.

Orcella brevirostris, Bay of Bengal.

O. fluminalis, Irawadi.

Orca, sp., Grampuses, all seas; the number of species uncertain.

Orca gladiator?

Globiocephalus Indicus, Blyth, Indian ca'ing whale, Bay of Bengal.

Grampus griseus, N. Atlantic.

G. Richardsoni, Cape. 


\section{MAMMALIA.}

Fam. Delphinidæ, Porpoises.

Delphinus perniger, Ell., Blyth, Bay of Bengal.

D. plumbeus, Dussumier, Malabar coast.

D. eurynome, Gray, Bengal Bay.

D. godama, Bengal Bay.

D. sandama, Owen, Bengal Bay.

D. lentiginosus, Owen, Bengal Bay.

D. maculiventer, Owen, Bengal Bay.

D. fusiformis, Owen, Bengal Bay.

D. pomeegra, Owen, Bengal Bay.

D. delphis, Atlantic, Mediterranean dolphin.

D. Forsteri, Australian Seas,

D. Bairdii, N. Pacific.

D. Sinensis, Chinese Seas.

D. albirostris, N. Atlantic.

D. Peronii, S. Seas.

D. tursio, British Seas.

D. letcopleuris, N. Atlantic.

Steno frontatus, Cuvier, Bengal Bay.

S. attenatus, Gray, Bengal Bay.

Neomeris phocoenoides, Duss, Bengal Bay. Sub-Order, Sirenia, $\Pi l$, Horbivorous Cetacea.

Halicore dugong, Jerd.

Duyang trichechus, Erxl, Bly., F. Cuv,

H. cetacea, Illiger.

Dugong,. . ENG. | Talla maga, . . SINGH. Ceylon, Andamans, Malayana, Singapore, marine lagoons of Malabar.

H. tabernaculi, Ruppell, Red Sea.

H. Australis, Australia.

The dugongs feed on seawater algæ. They inhabit the shallow bays and creeks of the Red Sea, the east coast of Africa, Ceylon seas, and islands of the Bay of Bengal, the Eastern Archipelago, and north coast of Australia, and are never met with in the high seas far away from the shores.

ORDER, RODENTIA, the Gnawing tribe, Glires of authors.

Fam. Sciuridæ, or Squirrels.

Sciurus Malabaricus, Schintz.

S. maximus, Bly., Horsf. | Jangli gilhri, . . HIND. Malabar, Wynad, Neilgherries, Travancore.

S. maximus, Schr., Ell., Blyth.

Kat berral, . . Beng. Karrat, . . . HrND.

Rasu, Ratuphar, : ", Kondeng, . . . KoL.

Per-warsti, . Gond. Bet-udata, . TeL.

Red squirrel of Central India.

S. Elphinstonei, Sykes.

S. Bombayanus, Sch., $E$. | Red squirrel of Bombay.

Kes-annalu, . CAN. | Shekra, . . . MAHR. Western Ghats, Malabar, Mahabaleswar.

S. macruroides, Hodgson.

S. bicolor, var. Indica, S. giganteus, $M^{\prime}$ Clelland. Horsf., Blyth.

Shingsham, ... Bнот. |Le-hyuk, . . LEPCH. Black hill squirrel, ENG.

S.E. Himalaya, Nepal, Sikkim, Assam, Burma.

S. macrourus, Forst., Blyth, Horsf., Hardw.

S. Ceylonensis, Bodd. / Grizzled hill squirrel, ENG. Ceylon, S. India.

S. ephippium, Muller, Borneo.

S. lokriah, Hodgson, Blyth.

S. subflaviventris, $M^{\prime} \mathrm{Cl}$. | Orange-bellied grey squirrel.

Zhamo, . . . Веот. Killi, . . . LEPCH.

Lokria, . NepaL. Killi-tingdon,

S.E. Himalaya, Nepal, Sikkim, Bhutan.

S. lokrioides, Hodg., Blyth.

S. lokriah, Gray. I Hoary-bellied grey squirrel. S.E. Himalaya, Nepal, Sikkim, Bhutan.

S. Assamensis, $M^{6}$ Clell., Sylhet, Dacea.

S. ferrugineus, $F$. Cuv., N.E. India.

S. erythrœus, Pallas, N.E. India.

S. erythrogaster, Blyth, N.F. India.

S. hyperthrus, Blyth, N.E. India.

S. chrysonotus, Blyth, N.E. India

S. hyperythrus, Is. Geoff., N.E. India.

S. Phayrei, Blyth, N.E. India.

S. Blanfordi, Blyth, N.E. India.

S. atrodorsalis, Gray, N.F. India.

S. palmarum, Gm., Bl., Ell.

S. penicillatus, Leach. I Common striped squirrel.
MAMMALIA.

Beral, Lakki, . Benc. | Kharri, . . MAHR. Alalu, . . . CAN. Vodata, . . . TEL. Gil'hri, . . HIND. Urta, . . WADDAR. Peninsula of India.

S. tristriatus, Waterhouse.
S. palmarum, $E l l ., B l$.
S. Kelaarti, Layard.

S. Brodiei, Layard.

Striped jungle squirrel of Ceylon and Peninsula of India.

S. Layardi, Blyth, striped squirrel of Ceylon and Travancore.

S. sublineatus, Water., Blyth.

S. Delesserti, Gervais. Neilgherry striped squirrel.

Ceylon, forests of S. India, Travancore, Neilgherry.

S. insignis, Horsf., Java.

S. M'Clellandi, Horsf., Blyth, Hodg.

S. chikhura, Blyth. I. Pembertoni, Blyth.

Small Himalayan squirrel. I Kalli gangdin, . . LEPCH.

N.E. India, Himalaya, Sikkim, Bhutan, Khassya.

S. barbei, Blyth, Tenasserim.

S. plantani, Horsf., Java.

S. Berdmorei, Blyth, Mergui.

S. Europœus, Linn., North and Central Asia, Europe.

Pteromys petaurista, Pallas, Blyth.

P. Philippensis, Ell. | P. oral, Tick.

Brown flying squirrel, Eng. $\mid$ Pakya, . MaHr. of GHat. Oral of. . . Kou. Para-chaten, . MALAY.

Forests of Ceylon, Peninsula of India, and Central India.

P. inoratus, Is. Geoff., Jacq., Blyth.

P. albiventer, Gray. I Rusi-gugar, . KASH. White-bellied flying squirrel, N.W. Himalaya, at 6000 to 10,000 feet

P. magnificus, Hodg., Blyth.

P. chrysothrix, Hodg. |Biyom, . . . . LEPCH.

Sciuropterus nobilis, $\mathrm{Gr}$.

Red-bellied flying squirrel, S.E. Himalaya, Nepal to Bhutan, Khassya Hills, Assam Hills.

P. cinerasceus, Blyth, Burma.

P. nitidus, Geoff., Malay Peninsula.

P. elegans, S. Muller, Java.

P. Philippensis, Gray, Philippines.

Sciuropterus caniceps, F. Cuvier, Gray, Blyth.

P. senex, Hodgs. $\mid$ Grey - headed flying

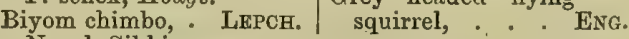
Nepal, Sikkim,

S. fimbriatus, $G r_{\text {, }}$ Blyth.

P. Leachii, Aray. Grey flying squirrel.

N.W. Himalaya, Simla to Kashmir.

S. baberi, Blyth, Afghanistan.

S. alboniger, Hodgson, Blyth.

S. Turnbulli, Aray.

Piam piyu, . . Внот. / Khim, . . . LEPCH

Black and white flying squirrel of Nepal to Bhutan.

S. villosus, Blyth.

S. sagitta, Walker. | Hairy-footed flying squirrel. Bhutan, Sikkim, Assam, at 3000 to 6000 feet.

S. fusco-capillus, Jerdon, Blyth, small Travancore flying squirrel.

S. Layardi, $\bar{K} e l ., B l y t h$, Ceylon.

S. spadiceus, Blyth, Arakan.

S. Phayrei, Blyth, Pegu, Tenasserim.

S. sagitta, Linn., Malayana.

S. Horsfieldii, Waterhouse, Malayana.

S. genibarbis, Horsf., Malayana.

Sub-Fam. Arctomydinæ, MIarmots.

Arctomys bobac, Sch., Blyth, Pal.

A. Tibetanus, Hody. I. caudatus, Jacq.

A. Himalayanus, Hodg.

Chibi,. . . . . Bнот. Lho, Pot sammiong, LEPH. Brin, : : KASH. Kadia-piu, . TrB.

Tibet marmot, white marmot of E. Europe, Central

Asia, Snowy Himalrya, Kashmir ${ }_{d}$ to Sikkim, at 12,000 to 16,000 feet.

Arctomys hemachalanus, Hodgson, red marmot.

A. Tibetanus, Hodgson. Drun, . . . KAsH.

Chipi, . BHOT. Sammiong, LEPCH. Kashmir, ‥W. Himalayas, at 8000 to 10,000 feet.

Fam. Muridæ, the Rat tribe, includes the Jerboas, the Dipodidie or Jerboidie of authors. 
Sut-Fam. Murinæ, Rats and Mice.

Gerbillus Indicus, Ell., Jerdon, Blyth.

\begin{tabular}{l|l} 
Dipus, Haraw. & G. Cuvieri, Waterhouse. \\
G. Hardwickii, Gray. &
\end{tabular}

Jhenku indur, BENG., SAN. I Hurna mus, .. . Hind.

Billa ilei, . . . CAN. Yeri-yelka, Yelka, . TeL.

Indian jerboa rat, . ENG.

All India.

G. erythrourus, Gray, Jerdon, desert jerboa rat of Panjab, Hurriana, Jumna.

Nesokia Indica, Jerdon.

Aricola Indica, Gray.

Mus kok, Hardw.

M. providens, Elliot.

M. pyctoris, Hodgson.

Kok,

CAN. I Galatta koku, . . Ter.

Indian mole rat, all India, Ceylon.

N. Hardwickei, Jerdon.

N. Huttoni, Blyth. | Short-tailed mole rat. Gardens of India, Afghanistan, Bahawulpur.

N. Griffithii, Horsf.? Afghanistan.

N. hydrophila, Gray?

Mus hydrophilus, Hodg. I Arvicola hydrophila, Hodg. Small Nepal water-rat.

N. macropus, Jerdon (Mus hydrophilus, Hodgson), large Nepal water-rat.

Mus bandicota, Bechstein, Blyth.

M. giganteus, Hard., L. M. perchal, Shaw.

M. Malabaricus, Shaw. MI, setifer, Horsf., Elliot.

M. nemorivagus, Hodg.

Ikria, Ikara, . . BENG. Ghus, Ghous, - HIND,

Heggin, . . CAN. Indur, . . SAnsk.

Bandicoot-rat, ENG. Pandi koku, : TeL

Pig-rat or bandicoot-rat of Ceylon, India, Malayana.

M. Andamensis, Blyth.

M. Nicobaricus, Scherzer. I M. setifer, Cantor.

Nicobar, Andaman, and Malay Peninsula.

M. rattus, Linn., Bly., Ell., black rat.

M. rattoides, Hodgson. | M. Andamensis, Blyth. All India.

M. decumanus, Pall., Blyth, Elliot.

M. norveyicus, Buffon. ! M. decumanoides, Hodg.

Demsa indur, . BeNg. Brown rat, . . ENG.

Manei ilei, : CAN. Ghur-ka-chuha, HIND. All India, Akyab.

M. plurimammis, Hodgson, Nepal rat.

M. Tarayensis? Hodfson? Qu. M. decumanus?

M. infralineatus, Elliot, Blyth.

M. Elliotii, Gray.

M. Asiaticus? Kel.

Striped-bellied field-rat, Bustar, Madras.

M. Morungensis? Hodgson? Nepal Terai.

M. brunneus, Hodgson.

M. nemoralis, Blyth. | M. æquicaudalis, Hodg.

Tree-rat of Ceylon, India.

M. rufescens, Gray.

M. flavescens, Ell., Bly. $\mid$ M. brunneusculus, Hodg.

M. arboreus, Buch.Ham., Gachua indur, . . BENG. Horsf.

Rufescent tree-rat, all India.

M. niviventer, Blyth, Hodgson, white-bellied house-rat of Nepal.

M. nitidus, Blyth, Hodgson, shining brown rat, Darjiling.

M. caudatior, Hodgson, Horsfield.

M. cinnamomeus, Blyth. | Chestnut rat, . . . ENG. Nepal, Burma.

M. oleraceus, Sykes, Elliot, Blyth.

M. dumeticola, Hodgson. | M. povensis, Hodgson.

Marad ilei, . CAN. | Meina-yelka, . TEL. Long-tailed tree-mouse, Ceylon, all India.

M. Nilagiricus, Jerdon, Neilgherry tree-mouse.

II. concolor, Blyth, thatch-rat of Pegu and Tenasserim.

M. badius, Blyth, Burma.

M. Peguensis, Blyth, Burma.

M. gliroides, Blyth, Khassya.

M. castaneus, Gray, Philippines.

II. palmarum, Sch., Nicobars.

M. urbanus, Hodgson, Blyth.

M. musculus, Ell., Kel. I M. Manei, Gray.

M. dubius, Hodgson. Common Indian mouse.

Ceylon, India.
M. homourus, Hodgson, Blyth.

M. Nipalensis, Hodgson. I Hill-mouse, . . ENG。 Himalaya, from Panjab to Darjiling.

M. crassipes, Blyth, large-footed mouse of Mussoori.

M. Darjilingensis, Hodg., Horsf., Darjiling mouse of Neilgherry, Darjiling.

M. Tytleri, Blyth, long-haired mouse, Dhera Doon.

M. Bactrianus, Blyth.

M. gerbillinus, Blyth. | M. Theobaldi, Blyth. Sandy mouse of Afghanistan, Kashmir.

M. cervicolor, Hodyson, Blyth.

M. albidiventris, Blyth. | Fawn field-mouse, . ENG. Bengal, Nepal, Malabar.

M. strophiatus, Hodgson, Nepal.

M. fulvidiventris, Blyth, Ceylon, is the M. cervicolor of Kelaart.

M. terricolor, Blyth, earthy field-mouse of South India, Bengal, the M. lepidus, Elliot.

Leggada platythrix, Jerdon.

Mus platythrix, Sykes, | Gijeli-gadu, . . . Tex. Bly., Elliot.

Kal ilei, . . . Car. Kol-yelka of: "

The brown spiny mouse of $\mathrm{S}$. India.

L. spinulosa, Blyth, the dusky spiny mouse of the Panjab and Malabar.

L. Jerdoni, Blyth, Himalayan spiny field-mouse of Kanawar, Sutlej.

L. lepida, Jerdon, small spiny mouse.

Mus lepida, Elliot. | Leggada booduga, Gray.

Chitta-burkani, . . TEL. Chitta-ganda, . . TrL.

Chit-yelka, . : : ", Chitta-yelka, : : ,

S. India.

Platacauthomys lasiurus, Blyth, pepper rat or longtailed spiny mouse of Western Ghats, Malabar, Cochin, and Travancore.

Golunda Elliotii, Gray, Blyth

Mus hirsutus, Elliot. । M. Coffæus, Kelaart.

Gulandi, . . CAN. Sora panji gadur, YaNADr.

Gulat-yelka of WADDAR.

Bush-rat, coffee-rat, of Ceylon, S. India.

G. meltada, Gray.

Mus lanuginosus, Elliot. | Metta-yelka, TEL. of Y AN.

Kera ilei, . . CAN. Mettade, . WADDAR.

Soft-furred field-rat of S. India.

G. newera, Kelaart, Newera-ellia.

Rhizomys badius, Hodgson, Blyth (R. minor, Gray), bay bamboo rat, Terai of Sikkim.

R. pruinosus, Blyth, Khassya Hills.

R. castaneus, Blyth, Burma.

R. Sumatrensis, Blyth, Malay Peninsula and islands.

R. sinicus, Gray, China. Sub-Fam. Arvicolinæ, Voles, etc.

Arvicola Roylei, Gray, Royle, Blyth, Himalayan vole, of Panjab, Kashmir.

A. thricotis, Jerdon, Darjiling.

Neodon Sikkimensis, Hodgson, Blyth, Sikkim vole.

Phaiomys leucurus, Blyth, Tibet. Fam. Hystricidæ.

Sub-Fam. Hystricine, Porcupines.

Hystrix leucura, Sykes, Blyth, Elliot.

H. hirsutirostris, Brandt. | H. cristata Indica, Gray,

H. Zeylanensis, Blyth. $\quad$ Has'dwicke.

Sajru, . . . . BENG. Sahi, Sayal, Sarsel, Hind,

Yed, . . . CAN. Salendra, . MAHR.

Ho-igu,. . . Gondr. Dumsi,. . . NEPAL

Saori, . . . GUJ. Yeddu pandi, . TEL

The Indian porcupine, all India.

H. Bengalensis, Blyth:(H. Malabarica, Sclater), Bengnl porcupine, Malabar, Assam, Bengal.

H. longicauda, Mar'sden, Blyth.

H. alophus, Hodgson. Acanthion Javanicum, $\boldsymbol{F}$.

H. Hodgsonii, Gray. Cuvier.

Sa-thung, . . LEPCH. Anchotia dumsi, . NePAL. $\mathrm{O}^{\prime}-\mathrm{e}$, . . Lrmbu.

Crestless porcupine, Nepal and Sikkim.

Atherura fasciculata, Jerdon, Tiperah Hills to Malay Peninsula.

Fam. Leporidæ, or Hares.

Lepus ruficaudatus, Geoffroy, Blyth, Indian hare.

L. Indicus, Hodgron. I L. macrotus, Hodgson. 
Sasru, . . Beng. L Lamma, . . Hind. Kharra, Bing., Hind. Khar-gosh, Hind, Pens. Molol, . . GONDI.

Panjab, Hindustan, Malabar?

L. nigricollis, F. Cuv., Bly., Ell.

L. melanauchen, Temm. | Sassa, . . . MAHR.

Malla, . . . CAN. Musal, . . . TAM.

Khargosh, . HIND. Kundeli, . . TEL,

Black-naped hare of Peninsula of India.

L. Peguensis, Blyth, Upper Burma.

L. Sinensis, China.

I. pallipes, Hodgson (L. tollai, Pallas, Gray), Tibet.

L. Tibetanus, Waterhouse (L. oistolus, Hodgson), the Ri-bong of the Bhot, Tibet.

L. hispidus, Pear'son, Blyth, hispid hare of Terai, from Gorakhpur to Assam.

Lagomys Roylei, Ogilby, Himalayan mouse hare. L. Nepalensis, Hodgson. $\quad$ L. Hodgsonii, Blyth.

Rang-runt, . KANAwAR. Rang-duni, . KANAwar. Himalaya.

L. curzonix, Hodgson, Sikkim, Tibet.

L. rufescens, Gray, N. and Central Asia, Afghanistan.

Order, Ungulata, Hoofed Mammals, the Pachydermata and Ruminantia of Cuvier.

Tribe, Proboscoidea, Cuvier.

Fam. Elephantidæ.

Elephas Indicus, Cuvier, Blyth, Elliot.

E. Asiaticus, Blumenbach. Yenu, . . . . Gond

Ani, CAN, ,MAL.,TAM.,Thi. Hathi, : : : Hind.

Indian elephant, forest parts of all India.

E. Sumatranus, Schl., Sumatra.

E. Africanus, Schl, Africa.

\section{Tribe, Perissonactyla, Owen.}

Fam. Rhinocerotidæ, Nasicornia, $I l l$.

Rhinoceros Indicus, Cuvier, Blyth.

R. unicornis, Linn.

R. Asiaticus, Blum.

R. inermis, Less.

Gonda, Genda, . . Hrnd. | Ganda, Genra, . HInd. Great Indian rhinoceros of the Terai, from Bhutan to Nepal, Assam, and Bhutan Doar.

R. Sondaicus, Mull., Blyth (R. Javanicus, $F$. Cuvier, Horstield), lesser Indian rhinoceros, of the Sunderbans, Mahanadi river, Rajmahal Hills to Burma, Malayana, Borneo, Java, Assam, Arakan, Sumatra, Chin-India

R. Sumatranus, Mull., Blyth, two-horned rhinoceros of Assam, Sumatra.

R. Crossii, Gray? Qu. R. Sumatranus? Mull.

\section{Fam. Hyracidæ.}

Tribe, Lamnunguia, Wagner.

Hyrax Syriacus, coney of Scripture, Palestine, Arabia. Fam. Tapiridæ, the Tapirs.

Tapirus Malayana, Malay Peninsula, S. Tenasserim.

Fam. Equidæ, Horses, Asses, and Zebras, the Solidungula and Solipedes of authors.

Asinus, the ass, domesticated.

Equus onager, Pall., Blyth, Cuvier.

E. hemionus of India. Asinus Indicus, Sclater.

Wild ass, . . . ENG. Koulan, . . KIRGHIZ.

Gor-khar, . HIND. Ghour, . . PERs.

Cutch, Gujerat, Bikanir, Jeysulmir, Sind, west of the Indus, Baluchistan, Persia, Turkestan.

E. hemippus, Is. Geoff.

Asinus treniopus, Heug. $\quad$ E. asinus of the ancients.

Wild ass of Scripture.

Syria, Mesopotamia, N. Arabia, west of the onager.

Wild horse of Col. Chesney.

E. hemionus, Pallas.

Kiang, Dzightai, . Trв. | Wild horse, Cunning.

Tibet and Central Asia.

\section{ArTiodactrla, Owen.}

Tribe, Chesrodia, Bly., the Pig and Hippopotami. Fam. Suidæ, Pig.

Sus Indicus, Schinz, Indian wild boar.
S. cristatus, Wagm
S. vittatus, Schl.
S. scropha, Linn, Bly.,

VOL. II.

Kis, . . Bhagulpur. | Sur,

HIND,

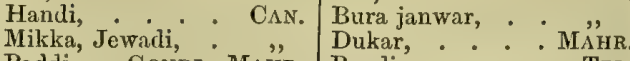

Paddi, GoNDI, MAHR. Pandi, : . : TEL.

Ceylon, all India, up to 12,000 feet.

S. Bengalensis, Bly., and S. Neilgherriensis, Gray, Qu. vars. of S. Indicus, Schinz.

S. Malayanus, Blyth, Tenasserim.

S. Zeylanensis, Blyth, Ceylon.

S. Andamanensis, Blyth, Andamans.

S. babirussa, Blyth, Babyroussa, Malayana.

S. Papuensis, Blyth, New Guinea.

S. larvatus, Africa, Madagascar.

Porculia salvania, Hodg., Horsf., pigmy hog. Chota sur, : HrND. | Sano-banel, .

Nepal and Sikkim Terai, Assam, Bhutan.

Tribe, Ruminantia, Ruminating Animals, camels, deer, horned cattle, sheep, in three groups.

1st Group, Camelidæ, Camels, Ancerata, Bly.

Camelus dromedarius, Linn., the dromedary or onehumped camel of N. Africa, Arabia, India.

C. Bactrianus, Linn., the Bactrian or two-humped camel of Central Ásia.

2d Group. Fam. Camelopardidæ, Camelopards.

Camelopardus giraffa, Linn., the camelopard or giraffe of Africa.

3d Group. Fam. Cervidæ, the Deer tribe.

Sub-Fam. Cervinæe, True Stags.

Cervus Wallichii, Cuv., Bly., F. Cuv.

C. pygargus, Hardw. $\quad$ C. claphus of Asia, Pallas.

C. Caspianus, Falconer. C. nareyanus, Hodgs.

C. Kashmiriensis, Fal.

Kashmix stag, . . ENG. Hangul, Honglu, . KAsH. Bara-singha, : Hrnn. Maral, . : . PERs.

Euxine Sea, Western and Central Asia, Persia, Caucasus, Altai mountains, Lake Baikal, Kashmir up to 9000 and 12,000 feet, Western and Central Asia, Black Sea. Approaches the red deer of Europe.

C. rusa, S, Muller (Rusa tunauc, Vigors), Sumatra

C. affinis, Hodg., Bly.

\begin{tabular}{l|l} 
Alain of Atkinson. & Irbisch, . . . Siberra.
\end{tabular}

Sikkim stag, - ENG. Shou, Sia, : . TIB.

Eastern Tibet, Chumbi valley in Sikkim. The great stag of N. China.

C. Moluccensis, S. Muller, Moluccas.

C. sika, Schlegel, Japan.

C. peronin, Grav, Timor.

C. Manchuricus, Swinh., Manchuria.

C. taiouanus, Swinh., Formosa.

Sub-Fam. Rusinæ, includes the swamp deer, the sambur, spotted deer, and kakur or muntjac, all peculiar to tropical Asia and its Archipelago.

Rucervus duvaucelli, Jerdon, swamp deer.

C. elaphoides, Hodgs. $\quad$ C. euryceros, Knovosley.

C. bahraiya, Hodgs.

Goen, goenjak, . C. INDIA, Jhin-kar, KYARDA DooN, Gaoni (female), ", Potiya-harn, MoNGHIR. Maha,. " Hrmalaya. Baraya, . Nepal T'reat. Bara-singha, HIND.

Bengal, Oudh, Central India, forests at foot of Himalaya, Assam, islands of Brahmaputra, or Eastern Sanderbans, Midnapur, Assam, Nerbadda, Nagpur, Gumsur.

Panolia eldi, Gunth., Blyth.

Cervus frontalis, $\boldsymbol{M}^{6}$ Clell. $\mid$ C. dimorphe, Hodg.

Burmese deer, or brow-antlered deer of Burma and Nepal.

Rusa dimorpha, Gray?

Tha-min, Te-min,. Burm. Ghos? Seving? . Hind, Ghour? Sing-nai, Hivp.

Nepal, Munnepur, Burma, Siam.

R. Aristotelis, Jerdon, sambur stag.

Cerrus hippelaphus, C. $\quad$ C. jarai, Hod $\Rightarrow$

C. equinus, Cuv.

C. Leschenaultii, Cuv.

C. heterocercus, Hodg.

C. niger, Blaim.

C. saumur, Ogilby. 
Ghous, Gaoj, . BENG. Sambar, HIND, MAHR.

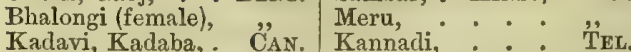
Ma-ao, : Gond, Maha, : . TERAI

Jarai, Jerrao, . HIM.

All India forests up to 10,000 feet. Ceylon, Assam, Burma, Malay Peninsula.

Axis maculatus, Gray, Bly., Cuv., spotted deer.

Cervus axis, Erxleben. $\quad$ Axis major, Hodgson.

C. nudipalpebra, Ogilby. A. medius, Hodgson.

Boro-khotiya, . BENG. Buriya, . GoraKHPUR,

Chatidah, BHagulpur. Chital, Chitra, Hind,

Saraga, . . . CAN. Chitri, Jhank (male), ,"

Lupi, : : GONDI. Dupi,. . TEL. Two kinds are known, the larger in $\mathrm{E}$. and $\mathrm{W}$. Ghats, Panjab, Central India ; smaller in Malabar, Ceylon? Neilgherries.

A. oryzeus, $K e l$. ? (C. medius, Hod.), Ceylon spotted deer.

A. porcinus, Jerdon, hog-deer.

Cervus oryzeus, $K_{e l}, B l_{*} \mid$ C. niger, Buch. Ham.

C. dodur, Royle.

Nuthrini harn,. - Beng. Khar laguna, - NePAL.

Para, . . : Hind. Sugoria, . . . ,

Bengal to Panjab, Assam, Sylhet, Burma, Central India rare, Malabar.

Cervulus aureus, Ham., Sm., rib-faced or barking deer.

C. vaginalis, Boddacrt, C. albipes, Wagler, Hodg. Blyth.

C. ratwa, Hodgs.

C. styloceros, Ogil., Roy. I Muntjacus vaginalis, Gray.

\begin{tabular}{l|l|l} 
Maya, . - : BENG. & Kakur, \\
Karsiar, : BHor. & Siku, Sikku, Suku, LEPCH.
\end{tabular}

Kan-kuri, : : CAN. Jungle sheep of MADras.

Red hog-deer, Cerlon. Bekra, Bekur, . Mahr.

Jangli bakra, : . DukH. Ratwa, . : NEPAL.

Gutra, Gutri, GONDI. Kuka-gori, . ' TEL.

All forests and jungles of India.

C. vaginalis, Sclater, Java, Sumatra?

C. Reevesii, Ogilly, China.

Fam. Moschidr, the Musk Deer.

Moschus moschiferus, Linn., Bly., musk deer.

M. saturatus, Hodgs.

II. chrysogaster, Hodgs.

Kastura, Kasture, HrND.

Bena, . . Kanawar. La, Lawa, . . Tib.

Rous or Roos, . . KASH.

Himalaya, at great elevations.

Fan. Tragulidx.

Tragulus kanchil, Malayana.

Memimna Indica, Jerd., moose-deer.

Moschus memimna, Erx- | Moschiola mimenoides, leben, Elliot.

Hodg.

Jitri haran, . . Beng. Mirgi, . . . MAhr.

Pisuri, Pisai, Hind, Ma Mr. Kuru-pandi, : Tel.

Pisora, "., Gandwa,. . Urira.

Yar, " " ǨL.

Central India.

Fum. Bovidx.

Sub-Fam. Antilopinæ, Antclopes.

Sub-Fam. Tragelaphinæ, Blyth, Bush Antelopes.

Portax pictus, Jerdon, Nil-gai.

Hippelaphus of Aristotle. Damalis risia, H. Smith,

Antilope tragocamelus,

Pallas, Blyth.

A. pictus, Pall.

Maravi,

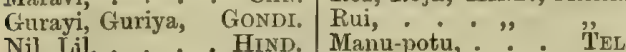

CAN. Roz, Rojh, Hind., MaHR.

All India, but rare in extreme north and south.

Tetraceros quadricornis, Jerdon, four-horned antelope.

Antilope chickaro, Hard. A. sub-quadricornutus,

T. striaticornis, Leach. Elliot.

T. iodes, Hodgs.

T. paccerois, Hodgs.

Kotri, BASTAR.

Hhirul, : : : BHIL.

Kondmuri,: CAN.

Jangli bakri, . DEKH. Bhirki, : SAUGOR

Kurus, . : GoNDI. Konda-gori,: : TEL.

Bhir-kuru, Bhir,

All India, not Ceylou, nor Burma, nor valley of the Granges.
Antilope bezoartica, Jerlon, Indian antelope.

A. cervicapra, Pall., Ell., Hardw., F. Cuv.

Alali (m.), . . BAORI. Kalwit(black buck), HIND.

Gandoli (f.), . . ", Mirga, HIND., SANsK.

Kalsar (m.), : BEHAR. Phandayat, . " MAHR

Baoti (f.), . . , Barout, Sasin, NePal.

Bureta, . BhagulPur. Irri (m.), Ledi (f.), Tel.

Chigri, . . . CAN. Jinka, . . . ",

Harm, Harna (m.), Hind. Guria, Goria, . Tiruut.

Harnin (f.), .

All India.

Gazella Bennettii, Jerdon, ravine deer.

Antilope Arabica, Ell. | A, hazenna, Is. Gcoff.,

A. dorcas, var., Sundev.

A. Bennettii, Sylies.

Jacque

A. Christii ? Gray.

Porsya (m.), Chari, BAORI. Kal-punch, . . Hrnd. Tiska, Budari, . CAN. Kal-sipi, . . MAнR. Mudari, . . . ", Burudu-jinka, . . TEL. Chikara, : : HIND.

The goat antelope or Indian gazelle of all India.

G. subgutturosa? Baluchistan, Sind, Panjab, Persia, Afghanistan.

G. dorcas, Blyth.

Antilope Arabica, Bly. $\mid$ G. corinna, $\boldsymbol{H}$. Sinith.

Gazella cora, $\boldsymbol{H}$. Smith. A. dorcas, vav. Persica,

G. kevella, H. Smith, Rrepoll. Arabia.

Kemas Hodgsonii, Chiru of Tibet, the Kemas of Elian.

Procapra picticaudata, Hodly., the gow and ra-roa of Tibet.

P. gutturosa, Auctornm (Antilope gutturosa, Pallas), Central Asia, China.

Saiga Tartarica, Saiga antelope, of Eastern Europe, Tartary, Central Asia.

Sub-Fum. Caprinæ, Goats and Sheep.

1st Capricorns or Antelope Goat or Mountain Antelope.

Nemorhoedus bubalina, Jerd., the serow forest goat.

Antilope thar, Hodg. $\quad$ N. proclivus, Hodg.

A. bubalina, Hodg.

Sarao, Serou, Himalaya. Thar, . . . NePal

Sarraowa, . . " "

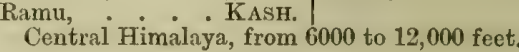

N. goral, $J e r d$., gural or Himalayan chamois.

A. Duvaucelei, $\boldsymbol{H}$. Smith.

Ra-giyu, . . BHOT. | Suh-ging, . LEPCH Gural, . Hinalaya. Sah, Sarr, . SuTleJ.

Pijur,. . . . Kash.

Gural. Himalayan chamois; all the Himalaya at 3000 to 8000 feet.

N. crispus, Japan.

Sub-Fam. True Goats.

Hemitragus jemlaicus, Hodgs., the tehr or Himalayan wild gont.

Capra jharal, Hodgs. $\quad$ Hemitragus quadrimammis, Hodys.

Tare, Tehr, Tahir, HIND. Kart, . . . . Kulu. Kras, Jagla, . KASH. Jharal, : : NEPAL.

Jhula, Thar, Kanawar. Jehr, . . . SImLA.

Tharni, Esbu, Esbi, . SutleJ. All the Himalayas".

H. hylocrius, Jerd., Neilgherry wild goat, ibex.

Capra warryato, Gray. I Kemas, Ogilby, Blyth.

Ibex of . Neilgherries. Warri-atu, . . TAM.

Warra-adu,. . TAM.

Neilgherry, Animallay, and neighbouring hills S. to Comorin.

Capra megaceros, Hutt., Bly., the markhor.

C. Falconeri, Hugel.

Mar-khor or snake-eater. | Ra-pho che, . . LAnAkir.

Ra-che,

Pir Panjal, Hazara Hills, Wurdwan Hills, Sulimai Hills, Kashmir, Jhelum.

C. agagrus, Gmelin, Persia, CentraI and Western Asia.

C. Sibirica, Meyer, Blyth, Himalayan ibex.

\begin{tabular}{l|l} 
C. sukeen, Blyth. & Ibex Himalayana, Blyth.
\end{tabular}

C. Pallasii, Schift: 
Skin, Skyin, . HIND., TIB. Tangrol, . . . KuLU,

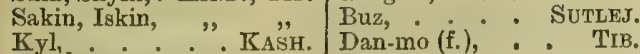
Throughout Himalaya.

Ovis cycloceros, Hutt., Sclater, Blyth.

O. Vignei, Blyth. | Panjab wild sheep.

Uria, Oorial, . Hind. | Koch, Kuch, . Sulimant. Salt Range, Hazara, Peshawur.

O. Vignei, Blyth (O. montana, Cunningham).

Sha, . . JadAkr. | Sha-pao, . . TIB. Hindu Kush, Pamir Range, Ladakh.

o. nahoora, Hodg., Blyth, burhel.

O. nahoor, Hodgs.

Burhel, blue wild sheep. Wa, War, H. of SotLEJ.

Bharal, . . HINd. Na, Sna, . LAdaKh, Tib. Menda (m.), : " Nervati, . . NePAL. Bharur, HiND. of HrMaL.

Sikkim, Bhutan to near Simla, Kamaon, Garhwal.

O. ammon, Linn., gnow of Tibet.

o. argali, Pallas.

O. ammonoides, Hodgs.

O. Hodgsonii, Blyth.

Hyan, Nuan, Nyan, . Trв. I Niar, Nyund, .. . TIв

The Tibet side of Central Asia above 15,000 feet.

o. Polii, Blyth, the rass or roosch of the steppe of Pamir, east of Bokhara, 16,000 feet.

O. nivicola, Eschsholtz, Kamtschatka.

O. Gmelini, Blyth, Armenia.

O. cylindricus, Blyth, Caucasus.

\section{Sub-Fam. Bovinæ.}

Gavaus gaurus, $J$ crd., gaur, bison.
Bibos
Bos gour, Traill. Ell.

B. assel, Hor'sf.

Vana-go, Ban-gau, BENG. Gaoiya, . . MAHR

Kar-kona, . CAN. Ban-parra of - MUNDLA.

Pert-mau, : Gond. Bod of . : SEONI.

Gour, Gauri-gai, . Hind. Katu yeni, . . TAM.

Jangli-khulga, .

Bison of Madras sportsmen. All the large forests of India.

G. frontalis, gayal or mithun of the hilly tracts E. of the Brahmaputra.

$\mathrm{G}$. sondaicus, the ban-teng, is the Burmese wild cow of Chittagong, Burma, Malayana.

Bubalus Arni, Jerd., wild buffalo.

Bos buffelus, Blyth. | B. bubalus, Auctor.

Mlung, - Bhagulpur. Ama (m.), Hind., MaHr.

Gera erumi, - GoNd. Arni (f.

Jungli bhains, . HIND.

Var. a. Macrocercus, Hodgs., Assam, Terai, Tirhut, Central India, south to the Godavery, Ceylon.

$V(c r$. b. Spirocercus, Hodgs.

Order, Edentata, the Tartigrada or Sloths, and the Effodientia or Burrowers.

Fam. Manididr, Pangolins.

Munis pentadactyla, Linn., Blytlı.

Pholodotus Indicus, $G r . \mid$ M. brachyura, Evrcleb.

Manis crassicaudata, Griff., Ell.

M. inaurita, Hodgson.

Shalma, . . BAORI. Bajra kapta,HIND, SANSK

Keyot-mach, . BENG. Armoi, . . KoL

Kat-pohu, : : , Kaulimah, . MAHR

Lan-rohu, . Dukн. Kowli-manjra,

Sillu, Sal, Salu, : Hind. Kassoli manjur, : "Ä̆.

Bajar-kit, Hind, SANSK. Alawa, . . TEL

Indian scaly ant-eater of all India.

Manis aurita, Hodg., Blyth.

Sikkim scaly ant-eater. | Mr. leucura, Hod!s.

Pholidotus Dalmanni, $G$. M. Dalmanni, Sunder.

M. Javanica, $B l y$.

Fimalaya, Burma, Java, Malayana.

-Royle, Ill. Him. Bot.; Elliot in Madras Journ. of Scicnee; Jerdon, Mammals, 1804; Wallace, Malay Archipelago; Geographical Distribution, i. p. 85 ; Blyth; Kelaart; Tennent; The Upper and Lower Amoor, p. 110.
MAMMATA BHATTA of Kashmir, author of the Kavya Prakasa, a work on poetry and rhetoric.

MAMMEA AFRICANA. Sab. From Sierra Leone and the Niger. Delicious tropical fruits. M. Americana, the Mammee apple or wild apricot of $\mathrm{S}$. America, might be introduced into India. The gum of the American Mammee is used to destroy the chiggers (Culex penetrans) in the feet of the Negroes.

MAMMET. This word, used by Shakespeare in Romeo and Juliet,-

'A whining mammet in her fortunes tender,

similarly to Spenser in his Faerie Queen, -

'And oftentimes by Termagaunt and Mahomed swore, was meant to apply to Mahomed, in an age when Muhammadans were supposed to be idolators.

MAMMOTH, Elephas primogenius, the mammoth. One was discovered in 1799 by a Tungus, near Lake Oncoul in Siberia. It is surmised that in the north the mammoth was covered with long hair. They are extinet.-Mangin.

MAMMOTH TREE, or Wellingtonia (Sequoia gigantea), of California. The Wellingtonia was first found in the Sierra Nevada, at a spot called Calaveros Grove, near the sources of the Stanislaus river, at nearly 4600 feet above the sea. It occur's in other localities in the same region. The Mariposa grove numbers about 400 trees, the Fresno grove about 600. In the Calaveros or Mammoth Tree Grove, most of the trees attain the average height of 300 feet. A tree has been described 450 feet in height, with a trunk 116 feet in circumference.

Dr. Bigelow describes a tree which had been felled, which required five men twenty-two days to perform the operation. After it was severed at the stump, the same five men were occupied two days in driving wedges with a battering-ram to throw it out of its equilibrium sufficiently to make it fall. It might be introduced into India.

MAMOOL. ArAB. Usage, custom. Immemorial custom is declared by $M$ enu (i. pp. 108-110) to be the root of all law. It is the vital spirit of the Hindu system, and the immediate cause of the permanence of their institutions.-Ji/ph. p. 48.

MAMUN, son of Harun-ur-Rashid, was the fourth khalif of the house of Abbas. He reigned A.D. 813 to 833 . He was the greatest of the khalifs of Baghdad. In A.D. 814 he caused a degree of the earth's surface to be measured on the sandy plains of Mesopotamia, between Palnyra and the Euphrates, by which 56.66 miles were fixed as the equivalent of a degree of the earth's circumference.-Catafago.

MAMUZAI, a branch of the Lashkarzai Orakzai. Also a subdivision of the Razar division of the Yusufzai plain. They rebelled during the mutiny of 1857 , and were subdued.

MAN. ARAB., HeB., Hind., TAM.

Maund, . . . Eng. Manugu, . . TeL Mannah, . . HEB. Mahana, . UnIIA

A measure of weight amongst the Ilebrews, and now in India, but varying in quantity according to locality and the article weighed.

Bengal bazar man $=40$ seers $=\$ 2 \mathrm{lbs}$

factory man $=74$ lbs. $100 \mathrm{z} .10^{\circ}(\mathrm{j} \mathrm{gr}$

Central India , $=20$

Gujerat $=40 "$ of hess valuc

Bombay " " $=28$ " avoirdupois.

Southern India , $=25$, 
Bengal man of $1833=87 \% \mathrm{lbs}$, avoirdupois. Akbar's , $=34 \frac{3}{4}$,

Mysore $=163$

Hebrew man or mannah $=13,125$ grains or $1-14 \mathrm{lbs}$.

The man or maund weight, therefore, varies according to the article weighed. In the Panjab, villagers use a kucha man, which is only 13 to 20 seers, and the Lahori man is = 3 kucha maunds.

The man of the British Government is $82.6 \mathrm{lbs}$. In the time of the emperor Akbar, it is defined as 40 seers, each seer being 30 dam in weight. This gives 388,275 grains, about $55 \frac{1}{2}$ lbs.-Wilson; Powell. See Weights and Measures.

MAN. ENG., Gothic.

Rajal, . . . Arab. Vir, Homo, Homines, LAt. Jin, Jan, Yan-nyang, Chin. Zeme,. . Lithuanian. Lang-fiu, .

7 'menes,

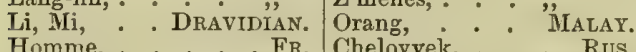
Mensch, Mann,. . Ger. Manu, Manava, SANSK, Mannisks, . . Gotr. Manusha, Manush, ,, xauas,. . . . GR, Manushya, . . ,"

Ish, : : HEB. Hombre, : : "SP Adam, Heb, Pers. Manushi, Amlam, TAM. Admi, Mard, . Hind. Manushi, Vadu, . Tel. Uomo, . . . . IT. Adam, . . . . TURK. Hito, . : JAP. Zem, : ZEND.

Man, a derivative root, means to think. From this we lave the Sanskrit manu, originally thinker, then man. In the later Sanskrit we find derivatives, such as mânava, mânusha, manushya, all expressing man. In Gothic we find both man and mannisks, and in the modern German mann and mensch.

The question whether mankind consists of one or of several species, has of late years been much agitated by anthropologists, but those naturalists who admit the principle of evolution, though they may, for the sake of expressing their amount of difference, designate them as distinct species, nevertheless feel no doubt that all the races of man are descended from a single primitive stock. Virey held that there were six species or races; Jacquinot, three; Kant, four; Blumenbach, five; Buffon, six; Hunter, seven; Adgassiz, eight; Pickering, eleven; Bory St. Vincent, fifteen; Desmoulins, sixteen; Morton, twenty-six; Crawfurd, sixty; and Burke, sixty-three.

Leibnitz and Lacepede classed the human race into Europeans,'Laplanders, Mongols, and Negroes; Linnæus into white, red, yellow, and black; Kant into white, copper-coloured, black, and olivecoloured races; Blumenbach into Caucasians, Ethiopians, Mongols, Americans, and Malays; Buffon into Northern (viz. Laplander), Tartarian, South Asiatic, black, European, and American races ; Prichard into Iranians (also Indo-Atlantics or Caucasians), Turanians (Mongolians), Americans, Hottentots and Bushmen, Negroes, Papuans (or woolly-haired tribes of Polynesia), and Alfourous (or Australians); and Pickering arranged them into whites, Mongolians, Malays, Indians, Negroes, Ethiopians, Abyssinians, Papuans, Negritos, Australians, and Hottentots.

Peschel, a recent writer, separates mankind into seven groups, races, sub-species, or species, viz. (1) the Australians and Tasmanians; (2) the Papuans of New Guinea and adjacent islands; (3) the Mongoloid nations, comprising the Asiatics of the continent, the Malayo-Polynesians, and the aborigines of America; (4) the Dravida of Western India of non-Aryan origin; (5) the Hottentots and Bushmen; (6) the Negroes; (7) the Mediterranean nations answering to the Caucasians of Blumenbach.

But although the existing races of man differ in many respects, as in colour, hair, shape of skull, proportions of the body, yet if their whole organizations be taken into consideration, they are found to resemble each other in a multitude of points. Europeans and the bulk of the Hindus belong to the same Aryan stock, and speak language fundamentally the same, but they differ widely in appearance, which is supposed by Broca to have arisen through the Aryan branches having, during their wide diffusion, been largely crossed by various indigenous tribes. In the East Indies, where, amongst Hindus, the system of caste prevails and keeps each sub-species distinct, the Scythic Jat, the Rajput, the Brahman, the Turanian, and Helot races are seen to vary, from the black squat tribes of the mountains to the tall olive-coloured Brahman, with his intellectual brow, calm eyes, high but narrow head; and in the Further Indies, the Burman, the Malay, the Negrito or Negro, and Papuan are all at once distinguishable. Amongst Indian Mubammadans, too, as obtained from Arabia, Persia, and Scythia, and converts from Hinduism, where they have not intermarried, the distinctions are very marked.

Man was long supposed to have existed in the earth since about 6000 years, but it is now believed that he has existed from an incomparably greater period. The world appears as if it had long been preparing for the advent of man. At the present day, even the most distant races of man, with the exception of some Negro tribes, are much more like each other than is generally supposed. In India, a newly-arrived European cannot at first distinguish the various native races, though they soon appear to him extremely dissimilar; and the natives of India cannot at first perceive any difference between the men of several European nations. There are, however, marked distinctions. The Mongolian, the Negro, the Australian, and the Hottentot differ in a multitude of characters, some of slight, some of considerable importance, and are undoubtedly distinct species of the family of man, the Negroes of the present day being of the same form as those of 4000 years ago. The Malays and Papuans who live under the same physical conditions, differ greatly. The different races of man are distributed over the world in the same zoological provinces as those inhabited by distinct species and genera of mammals. This is manifestly the case with the Australian, Mongolian, and Negro races of man ; in a less marked manner with the Hottentots, but plainly with the Papuans and Malays, who are separated by nearly the same line which divides the great Malayan and Australian provinces. The different species, however, mingle together and produce progeny with mixed characters. In Brazil is an immense mongrel population of Negroes and Portuguese. In Chili and other parts of South America, the whole population consists of Indians and Spaniards blended in various degrees, and with complex crosses of Negroes, Indians, and Europeans. Capt. Burton observes that the mixture of French with Indian blood produces a favourable progeny, but that the offspring of the Portuguese and of natives of the East Indies is coarse and darkcoloured. In S. America, on the contrary, the 
offspring of the Portuguese and Indians are often fairer and never darker than that of the Indian. In one island of the Pacific is a small population of mingled Polynesian and English blood; and in the Viti Archipelago is a population of Polynesians and Negritos crossed in all degrees.

There are great differences in the physical structure of the races. As to height, the smallest among the peoples measured by Dr. A. Weisbach are the Hottentots (1286 millimetres). This is far behind any other people, as the next, the Tagals, are 1562. Then follow the Japanese (1569), the Amboinese (1594), Jews (1589), Zingani (1609), Australians (1617), Siamese (1622), Madurese (1628), South Chinese (1630), Nicobars (1631), Roumanians (1643), Sundanese (1646), Javanese (1657), Magyars (1658), Bugis (1661), North Sclaves (1671), North Chinese (1675), and Congo Negroes (1676). The longest measurements, however, are found among the Sandwich Islanders and Kanaks (1700 millimetres), Kafirs (1753), and the Maoris of New Zealand (1757). To compare these with the stature of European peoples, we find that that of the English and Irish is 1690 millimetres; the Scotch, 1708; Swedes, 1700; Norwegians, 1728; Danes, 1685; Germans, 1680 ; French, 1667 ; Italians, 1668 ; and, lastly, Spaniards and Portuguese, 1658.

The mental characteristics of different races are markedly dissimilar. The old Aryans designated natural phenomena or the forces of nature according to the impressions made by these on their senses. They soon forgot the origin of these terms, which gave rise to endless myths. The Semites, on the contrary, gave to their gods names referring to abstract qualities, such as El, the Strong; Bel or Baal, the Lord; Bel-samin, the Lord of Heaven; Moloch, the King; Eliun, the Highest; Ram or Rimmon, the Exalted. These terms, at first adjectives, became nouns, and the Jews forgot the derivation, and worshipped El and Baal as separate deities. The Semites, however, had an inherent tendency to spiritualize all things.

With the Hindus as with the Romans, there are domestic ceremonies when their youths and girls grow up. The dhoti of the Hindu men is an unseamed cloth worn by men as a wrapper around the lower limbs. It is kept up to the waist by a waist-belt of cord or of gold or silver, and recalls the Roman cingulum. And, as in Rome, when the ceremony of changing the toga pretexta for the toga virilis was performed, the aurea bulla was taken from the boy's neck and consecrated to the domestic Lar, so in India, at the ceremony of investiture with the sacred thread, an identical ornament, a hollow hemisphere of gold, hung from a yellow cotton thread or chain of gold, is taken from the boy's neck, and the sacred cord, the symbol of his manhood, is put on him.Birdwood, Indian Arts; Report, Brit. Association; Darvin, Animals and Plants; Origin of Species; Bopp, Glossarium Sanskritum; Muller's Lectures; Peschel.

MANA, a pass in Garhwal district, North-West Provinces, over the crest of the main Himalayan range, dividing British territory from the Chinese empire. Elevation of Mana village above sealevel, 10,492 feet; of the pass, 18,000 feet. In the Mana pass is the temple of Badarinath. The people who occupy the Mana district are Bhots, dwelling in the passes and their neighbourhood at heights above 6000 feet. The pass-men state that ridges which within the memory of man were covered with forest and pasture lands, are now covered with snow, showing the extension of the snow zone. The Niti pass on the Duli, a feeder of the Ganges, is the best, and the Juwar on the Gauri (Douli) pass, a feeder of the Sarda or Gogra, is the worst. Mana is on the Saraswati, and the Byans pass on the Kali.

The Bhot here, as elsewhere, is an agriculturist, and is assisted by slaves, who live under the roofs of their masters. The people in the Mana, Niti, Juwar, and Byans passes are supposed to be immigrants from Tibet who drove out an earlier body of occupants, and many of the chief families trace their origin to a Tibetan locality. The inhabitants of the Dharma pass are said to be a body of Mongols left in Kamaon by Timur. The Dharma inter their dead for a time, and in the month Kartik exhume and burn them, but the other pass-men burn their dead on their demise. The Dharma practise divination, taking their omens from the warm livers of sheep sacrificed for the purpose. The women of the Dharma and Byans passes dress alike, and these two clans eat the yak, and would eat the cow, while those of Mana, Niti, and Juwar abstain from beef of all kinds, and look down, as on an inferior caste, on the Dharma and Byans. The Juwar nearest India have the largest trade, and resort to an annual fair in September at Gartokh, the residence of the Lhassa viceroy. These passes are the roads from India to Nari or Gnari, Tibetan provinces of the Chinese empire. Immediately below the village of Mana is the Hindu shrine of Badarinath, dedicated to an incarnation of Vishnu, and one of the most sacred Hindu temples. The temple is built on the bank of the Bishen Ganga, immediately over the site of a hot spring, the existence of which no donbt led to the original selection of this remote spot. The rawal, or chief priest, is invariably a Namburi Brahman from Malabar, no other class of Brahman being allowed to touch the idol.-Cunningliam's Ladahh; Latham's Ethn.

MANA. HiND. A platform erected in tall crops; on these people sit to frighten off birds, etc.

MANA or Manike. TEL. A measure of capacity in Telingana, 8 or 16 to a tum or t'hum.

MANAAR ISLAND, in the Gulf of Manaar, a dreary sandy waste, 14 miles long and $3 \frac{1}{4}$ broad. The town is in lat. $8^{\circ} 59^{\prime} \mathrm{N}$., and long. $79^{\circ} 53^{\prime}$ $20^{\prime \prime}$ E. Manaar, according to Sir J. E. Tennent (ii. p. 555), is the island of Epiodorus, which, according to the Periplus, was the seat of the pearl fishery. Manaar Gulf, separating Ceylon from the Peninsula of India, is so named from the island of Manaar near Ceylon, which, with that of Ramisseram near the continent, almost connect Ceylon to the Peninsula, the two islands receiving the name of Adam's Bridge. The gulf passage was deepened by a series of engineering operations.

MANAI. TAM. A ground, a land measure. At Madras, 24 mauai, each of 2100 square feet, is the standard cawnee.

MANAK or Manik. HIND. A ruby; also any gem or precious stone.

MANAKARI, families in the Mahratta country who claim to be of Rajput descent.

MANAKHYALA, a town in Afghanistan. A 
tope there was opened by General Ventura in April and May 1830.

MANAMADOO, in the district of Trichinoply, makes eloth very superior in quality, and used as clothing under the name of Manamadoo Sullah. That at Arnee, in the district of Chingleput, is known as Arnee Sullah.

MANANTODDY, Manantadi, or Manantawadi, a town in Malabar district, Madras, in lat. $11^{\circ} 48^{\prime}$ N., and long. $76^{\circ} 2^{\prime} 55^{\prime \prime}$ E. Population (1871), 10,959.-1mp. Gaz.

MANAS, a river of Assam, which takes its rise far up in the Bhutan Hills, and flows south into the Brahmaputra. It enters the Brabmaputra in lat. $26^{\circ} 15^{\prime} \mathrm{N}$., and long. $90^{\circ} 41^{\prime} \mathrm{E}$., just opposite Goalpara town.-Imp. Gaz.

MANAS, an encyclopædical collection of all the Kirghiz mythological tales and traditions, brought down to the present period, and grouped round one person,--the giant Manas. Another epos, the Samyatei, serves as a continuation of the Manas, and is the Burut Odyssey.

MANASA, in Hindu mythology, the snake goddess. She is worshipped as a preservative against the bite of these reptiles, and is represented sitting on a water-lily environed with snakes. If a Hindu be bitten by one, incantations are pronounced to propitiate the favour of Manasa.Cole. p. 338 .

MANASA BUL, one of the most beautiful tarns in Kashmir. On its banks are the remains of the once noble palace and gardens of the famous Nur Jahan. The clearness of the water and the grandeur of the mountain scenery northwards, render this a most perfect little picture of Kashmir beauty.-Adams.

MANASA-PUTRA, the seven (or ten) mindborn sons of Brahma, also known as the Prajapati. Manasi, SANSK., spiritual.

MANASAROWARA, properly Manasa-sarovara, a lake in Tibetan territory beyond the great southern wall of the Himalayas, in about lat. $30^{\circ}$ $8^{\prime} \mathrm{N}$., and long. $81^{\circ} 53^{\prime} \mathrm{E}$. The lake lies to the south of the Kailas mountain, and, like that celebrated peak, occupies an important place in Hindu mythology. No river flows from the Manasarowara lake. Close to it is another lake, Ravana-hrada, from which the Sutlej flows. The Kailas mountain forms a great water-parting to the north of the southern range of the Himalaya. The Indus starts eastward from its northern slope; the Sutlej takes off to the south-west from its southern side, and the Tsan-pu or Brahmaputra flows castwards from its eastern base. The Manasarowara formed a beautiful feature of the elysium of the Hindus, or Siva's paradise, on the Kailas mountain. It is one of the four lakes of which the gods drink.-Imp. Gaz.

MANATAPPAN, a caste of cultivators originally from Coimbatore, first settled in Palghat, and intermixed and often confounded with the Nairs.-Wilson.

MANAVA DHARMA SUTRA, the code of Menu; Menu's book on the Tedic rites; part of it has been published by Goldstucker.-Dou'son.

MANAVALA, the head of the Tengala Vaishnava sect of the south of India.

MANBHOW, dissenters from Hinduism in Berar and the Deklian. They wear a black dress, and are of quiet, inoffensive manners. These Hindu religious sectaries are worshippers of
Krishna, and about the year 1830 were described by Captain Mackintosh. They are under a vow of celibacy, and elect young people into their order; but there are errors, and if pregnancy occur, the parties are allowed to withdraw. The sect was formed by Krishna Bhat. Their chief locality is in the country between the Syhadri Hills and the east Gond country on the east of Berar, and between the Kistna river and Malwa. A few are to be found in the Panjab. They dwell in mat'hs, the chief mat'h being at Rudpur, near Ellichpur, Umarkher. They resemble in their relations some of the Christian monks. They are believers in Krishna, as his life is detailed in the Bhagavat Purana, and they reject all other Hindu Shastra, and do not worship other Hindu gods.-Capt. Mackintosh, M. J. L. and S., 1836.

MANBHUM, a British district of Chutia Nagpur, which has numerous remains of Aryan colonization close to its southern and eastern approaches, but none on the plateau itself. The most numerous aboriginal tribes are those of the Santals, the Bhumij Kols, the Bhars and Rajbhars. Amongst the semi-Hinduized aborigines are the Bauri and the Bhuiya. The Bhumij Kol are the characteristic aboriginal race of Manbhum, as the Ho are of Singbhum, and the Munda and Oraon of Lohardaga. Colonel Dalton, in his Ethnology of Bengal, describes them as being located in the country between the Kasai and Subarnarekha rivers. They had once large settlements to the north of the former river, but they were dislodged by Aryans, who, as Hindus of the Kurmi caste, now occupy their old village sites. The Bhumij Kol of Western Manbhum are pure Munda. Manbhum and Purulia have surface coal.-Dalton, p. 63 ; Imp. Gaz.

MAN-CHANG, a minor deity of the Chinese pantheon, who is worshipped by collegians and school-boys. He is supposed to record their names in a note-book. He was famous for his great literary attainments and love of virtue. His most important temple is at Chr-toong-yu-ne. - Gray, p. 144.

MANCHE. CAN. A boat or ship. The Calicut manche is a boat very similar to that of Mangalore, with the exception only of a raking stem, for the purpose of taking the beach, as the port of Calicut is open to the coast and there is no river. These boats are propelled by the paddle and sail, and generally carry eight men. They are much employed in watering and completing the seastock of ships homeward bound; also in loading ships with pepper, timber, etc., from Bombay; and in shipping the produce of the forests of Canara and Malabar, all of which is rafted off to vessels called dow, boatile, patamar, etc.

The Panyani manche is a coasting boat of about 50 feet long, 10 to 12 feet broad, and 5 to 7 feet deep. It is framed with timbers and planks, which are sewed together. The timbers are about 4 feet asunder, and on them, inside, some few planks are placed as bands and clamps, which are nailed to the frame. These are very rudely put together, and not of much importance either in form or construction. During the south-west monsoon, or from June to November, they are laid up at Baipur river for safety, and are only used in the fine-weather season. They carry the coir husk of the cocoanut, from which rope is made; copra, the inside albumen of the nut, 
from which oil is expressed; cajan, the leaf of the Corypha umbraculifera tree, which is used for thatching houses, also for books, and various other purposes; jagari sugar, made from the toddy or juice of the palm; oil and arrack, a strong spirit, distilled from the toddy taken from the palm. These vessels keep along shore, and take advantage of the sail in rowing. They have generally from eight to ten men, who are fishermen of the Moplah Muhammadans, descendants of Arabian settlers on the shores of the Peninsula, and who, marrying the daughters of the country, obtained the name of Mapillai, or sons-in-law, corrupted by Europeans into the above term.

The Boatila manche, of the island of Ceylon, navigates the Gulf of Manaar and the coasts of the southern part of the Peninsula of India. This boat is about 50 to 60 feet in length, 16 to 18 feet in breadth, and 8 to 10 feet in depth, has more of the European form than any of the Indian-built vessels that are met with. The after part shows the construction to be of Portuguese origin, as it is very simailar to that of many of the boats still in use by the people of that country, which are said to be of the same shape as the vessels in which Vasco da Grama sailed to India. They have a deck fore and aft, and are built with all sorts of jungle wood in a very rough manner, and fastened with nails and bolts. They are equipped with one mast, which inclines forward, and a square lug-sail; also a small bowsprit, at about the angle of $45^{\circ}$, with a sort of jib foresail, one pair of shrouds, and a backstay, which completes the rigging. These vessels carry on the trade of the island across the gulf.

Mangalore manche, of the western coast of the Peninsula, is a flat-bottomed boat of burden, about 25 to 35 feet long, 6 to 7 feet broad, and 4 to 5 feet deep. It is formed to meet the river, which is very shallow and flat; and to land the cargoes of the patamars, which are discharged and loaded at the mouth of the rivers. These boats are sewed together similar to the masula boat and other native vessels ; they are forced along by bamboo poles, as the water is not more than from 6 to 10 feet deep, except in the south-west monsoon, when the rapids swell, and the whole of the river is considered impassable; and at this period all the vessels are taken to the shore and laid up.-Edye.

MANCHHAR, a lake in the Sehwan subdivision, Kurachee district in Sind. A little north of Larkhana, on the right bank of the Indus, the Narrah or Suake River, a Sind Scrpentine, falls into Lake Manchhar, flows through it, and issues from the sonthern extremity under a fresh name, the Aral. The Narrah and the Aral form a scmicircle of about 60 miles from point to point. 'l'hey are probably artificial, as their tortuous course presents the appearance of man's rather than Nature's doings. The country is so level that, when the Indus rises, the water flows up the Aral, and vice versa when the main stream falls.

At certain periods, when the Indus is higher than the lake, the current runs into it through numerous openings in the belt of alluvium between its bed and the lake.

The fisheries of the lake yield an annual revenue of about $£ 170$, the rule being that one-third of the fish caught becomes the property of Government. The principal fish are the pala, which may be considered the finest in Sind, and the dambhro (or chelri), a reddish-coloured fish, often attaining an enormous size.-Burton's Scinde, ii. p. 231 ; $\operatorname{Imp}$. $G a \approx$.

MANCHIL. HIND. A litter slung on a pole, with a top like a tilt, used in the Himalaya.

MANCHU, a race who, in A.D. 1644, became rulers in China. The original seat of the reigning Manchu Tartar dynasty is the north-east of China. The dynasty has given every encouragement to the Chinese forms of education, and has admitted the learned men of the Chinese to a share in the administration, while retaining the higher offices for the Manchu. The emperor has numerous titles, all indicating some attribute of virtue or greatness, besides the most commonly used one of Hwang-ti. The family name of the dynasty is Gioro or Golden, so called from its original founder, Aisin Gioro. All members of the blood are registered in the Clan Court. Those who are descended from an emperor have the privilege of wearing a yellow girdle; those from the Manchu chiefs before they had become Chinese sovereigns may only wear a red girdle. They all enjoy an allowance, but this is gradualiy reduced the further they recede from the throne, until at last it barely suffices to procure the necessaries of life. There are four grand secretaries, but their power is very limited. They are called Ta-his-sze, and two of them are Manchus, and the others are Chinese. The senior post was always reserved for a Manchu, Li Hung Chang, about 1883 , being the first Chinese to possess the preeminence. There are two under-secretaries-one Manchu and the other Chinese-with ten subordinates. Upon these sixteen officials devolves the work of placing all public matters before the emperor, and of receiving the answers which are to be sent forth as the official decisions. The fact of being a grand secretary does not prevent the official from holding other offices. The formation of the Grand Secretariat goes back to the first half of the 17 th century, when the present dynasty was placed upon the throne, and the principal value of membership is that it gives social preeminence. The general council or Kiun-ki Chun was founded in 1730 by the emperor Yung-Ching. The members of this council rarely exceed four. They meet every morning in a chamber set apart for their deliberations in the interior of the palace.

Next to these come the six boards of administration, which have existed under slightly varying forms from a remote antiquity. The senior of these is that of Civil Officc or the $\mathrm{Li} \mathrm{Pu}$. The work of this board is very heavy, and it is divided into four departments. The next in order of rank is the Board of Revenue or Hu Pu.

All girls of Manchu race, on attaining the agc of twelve, ought to appear before the emperor for him to make selections for lis harem, and the families that have personal objects of ambition to attain consider it highly desirable to obtain admission in this way for one of their members into the palace. The Board of Revenue is charged with the task of keeping and revising a complete list of the Manchu maidens. The next board, that of Rites, supervises all the ritual performances and court ceremonies. Its members possess grcat power aud influence at a court where everything is decided in strict accordance with precedent as established by the Book of Rites. The Board of 
War comes fourth, and all matters appertaining to either the army or the navy come under its purview. The fifth board, that of Punishments, the Hing $\mathrm{Pu}$, has power in both civil and eriminal cases. The Court of Censors, in conjunction with the Board of Punishments, forms the highest judicial authority in the kingdom. The most onerous as well as the most dangerous duty which a censor has to perform is to remonstrate with the emperor for any acts that may seem unworthy of his rank and injurious to his reputation as a good and wise prince. The six'th and last of these boards is that of Works. It has the supreme direction of all public works throughout the realm. These include the state of the canals, the highroads, and the rivers, in addition to that of the fortifications of the towns and of the arsenals; it provides the stores of the army, and attends to the sewers and the cleansing of the gutters of the capital.

The Tsungli Yamen department only came into existence in January 1861, for the transaction of business with the foreign ministers resident in the capital, whose sovereigns possessed by treaty the then novel position of admitted equality with the Chinese emperor. But from an early period a department called the Li Fan Yuen has transacted all business with the tributaries and other external states which held intercourse with China on a footing of distinct inferiority. This department is now usually termed the Colonial Office, the privilege of membership being reserved for Manchus and Mongols. This office superintends the whole of the arrangements for the management of the four divisions of Mongolia, as well as those with regard to the dual government maintained in Tibet.

The Hanlin Yuen is the Chinese academy. To be a member of the Hanlin is in itself the highest distinction, and alone qualifies a man for the highest posts in the state. The Hanlin doctors are employed in drawing up all important state papers, in the most elegant language and according to the most approved form. They also collect daily the records of the reign, which are duly placed in the historiographer's department, but which never see the light until the dynasty has ceased to reign, and has been superseded by another. The Pekin Gazette is brought out by officials answerable for its accuracy to the police authorities of the capital. There are sixteen forwarding stations at Pekin for the purpose of sending copies of the Gazette immediately on publication into the provinces.

It is computed that in Pekin alone there are not fewer than 20,000 officials employed in the public offices and departments. For the provincial service in the higher grades there are not more than 2000 persons employed in it above the rank of assistant district magistrate. Of these there are eight viceroys, or Tsung-tuhs or Chetais, who govern fifteen out of the eighteen provinces of China proper. Peh-chi-li and Sze-chuen are the only single provinces having viceroys. The six others are $\mathrm{Kwang}$-tung and $\mathrm{K}$ wang-si (the Liang or Two Kwang); Kiang-si, Kiang-su, and Anhwui (the Liang or Two Kiang); Foh-kien and Chekiang (Min Cheh): Yun-nan and Kwei-chu; Kan-su and Shen-si; and, lastly, Hu-peh and Ho-nan (Hou-kwang). In each of these provinces, with three exceptions, there is also a governor or Futai, while the three provinces Shan-si, Honan, and Shan-tung are administered by officials of that grade. There were, therefore, fifteen governors serving either under viceroys or in independent command; but in 1877 Formosa was, after much deliberation, converted into a governorship, and placed under the 16th Futai. By usage the official entrusted with the control of the Yellow River is styled governor-general or viceroy, and although he has no territorial authority, it is clear that he holds an office of greater difficulty than even the administration of a province. A recent change in the form of government in Manchuria has also resulted in the addition of one to the ranks of the viceroys. When the Manchus established themselves in China they left the form of government in their own province practically undisturbed, and as it was formed on a military basis it was very much simpler than that in force among the Chinese. But at the same time, in order to sustain the national spirit, or gratify their own vanity, or possibly only to do honour to their ancestors, they declared Moukden or Sheng-king to be the twin capital of the empire, and that the great administrative boards of Pekin should have offices there as as well as in the capital. The chief military officer was of the rank of Tsiang-kun, but it naturally followed that he and the civilians of the boards soon came into collision, and gradually his authority was enfeebled, if not absolutely superseded. This state of things led to a formal investigation, and in 1875 it was proposed that for the Tsiang-kun a Tsung-tuh or viceroy, having supreme direction of all questions within the three divisions of Manchuria, should be substituted, and the president of the commission of inquiry became the first viceroy of Sheng-king.

The city of Pekin has a government of its own, and is in no way dependent upon the viceroy of Peh-chi-li, in which province it is situated. It has a mayor or Furgin, who is, however, subordinate to a minister from the Board of Works duly appointed for the purpose. There are two distinct magistrates to assist in the regulation of a city, which, with what is believed to be a declining population, still contains a million human beings. The military officials are divided not less strictly than the civilian. The Ti-tuh is the highest, and of this rank there are only sixteen; but the Tsiang-kun, who commands the Manchu garrison in each of the larger cities, is perhaps the most powerful of them all. He is quite independent of all the civil Chinese authorities, and only reports to the captain-general of his banner at Pekin. In the same way the general-in-chief of the Pekin field force, who is usually a Tartar of high birth and position, is only answerable to the throne itself.

The number of Manchu troops is estimated at 60,000 men. They are habitually under arms, and are assiduously exercised in their profession. The Government watches over them with great anxiety, for the emperor has a strong interest in not allowing these troops to stagnate in inaction. He takes care that they shall preserve something at least of the warlike character to which they owe their conquest of the empire. A Manchu is under obligation to enrol himself under some banner, and, failing to do so, loses his privileges. Many neglect to enrol themselves voluntarily in 
order to avoid the conscription. The Manchu, who are still (1884) ruling, obtained possession of the kingdom in 1643. Their founder was Shun-shi, and the dynasty is styled Tsing, or pure. They have placed Tartar garrisons in all the principal towns. His son Kang-hi, an able administrator, reigned from A.D. 1661 for 61 years. The people had previously made several important canals, but Kang - hi excavated the grand canal which connects the inland navigation of the great river with Pekin to the north, and with Ningpo to the south. Early in the 18th century, Kwei-chow broke out in rebellion, but it was suppressed; subsequently dominion over Tibet was acquired, and in the beginning of the 19th century Nepal was made tributary.

The Manchu dynasty has four times been at war with European powers, viz. with Great Britain 1840-42, Great Britain and France 1859-60, and France 1884. China proper is arranged into 18 provinces, 15 under viceroys and 3 under governors, and these deputies or the rulers long strove to prevent British ambassadors having personal interviews with the sovereign. The viceroys were all in practice autonomous. But about A.D. 1858 the Imperial Customs department was placed under Europeans, and has been a recognition of the supreme authority. Insisting upon the responsibility of the emperor, and refusing to treat with subordinate or provincial officers, though at first deemed most obnoxious to its pride, has nevertheless afforded the most efficient support to the administrative rights of the Imperial Government.

The Manchu is the most vocalic of the Tartar languages. It approaches to the Corean, but has other special vocalic affinities to the Japanese.$M r$. Rouland Hamilton.

MANCHURIA lies within lat. $39^{\circ}$ and $49^{\circ} \mathrm{N}$., and long. $120^{\circ}$ and $133^{\circ}$ E., and measures approximately 800 miles in length, and 500 miles in breadth. It is bounded on the south by the Gulf of Peh-chi-li and the highlands of Corea, on the east by the river Usuri, which divides it from Russian territory, on the north by the Amur, and on the west by the rivers Naun, Sungari, and the South-West Palisades. It is divided into three provinces, viz. Liau-tung or Southern, Kirin or Central, and Tsi-tsi-har, the Northern Provinces. The climate presents the extremes of heat and cold. The Liau-Ho and Ta-yang-Ho, Sungari, Harka, Usuri are the only important rivers. The population numbers about fourteen millions, Manchu, Tartars, and Chinese.

In 1859-60, Russia's representative at Pekin, General Ignatieff, obtained the surrender to Russia of the maritime province of Manchuria, the value of which had been discovered at the time of the Crimean war, and the Russian froutier was accordingly advanced to the close vicinity of Corea and the important city of Moukden.

Manchuria for ages past has swarmed off masses of humanity into other lands, and at present her millions are pressing on ber neighbours for room. Researches have made it more than probable that the Tartar, Manchu, and Tungus belong to one great stock; that the Turkoman, as well as the Tshude, Fin, Laplander, and Magyar (Hungarians), present another stock closely united, and that both these families are originally connected with each other. They sit upon the throne of
Byzantium, and upon that of China. Manchu Tartars of Manchuria are the bravest of the Mongol race. Much of Manchuria is now Chinese, and the Chinese language has been introduced. Manchu Tartars are strongly made and active; they are fond of the chase, and use the rifle and wolf-dogs. They dress like the Chinese, but wear long hair parted down the middle. The women have a loose jacket close round the neck, and reaching to the waist, where it is fastened with loops on the right side. A bright red petticoat reaches half-way below the knee. They have silver ear-rings, wear bracelets of brass and white metal, and they wear their hair with two long tails separated by a leathern band, edged with blue beads and a central line of cowries and brass beads below it.

The Manchu forbid marriage between those whose family names are different. In this respect they differ altogether from the Chinese and Brahmans, who abstain from marrying into families with their own race name. The Manchu and the Coreans have legends relating immaculate conceptions. Mr. Meadows and Mr. Griffis (p. 155) relate a Manchu legend of three heaven-born virgins who dwelt near the Great White Mountains. As they were bathing in a lake a magpie dropped a blood-red fruit on the clothes of the youngest. This the maiden naturally ate, and forthwith conceived, and she bore a son, whom they named Ai-sin-Gioro, or Golden Family Stem, which is the family name of the emperors of China.

The Fuyu are the aboriginal race of Corea. They trace their descent from a waiting-maid of the king of To-li or Korai. One day, while her master was absent on a hunting expedition, she saw floating in the atmosphere a glistening vapour, which entered her bosom. This tiny cloud seemed as big as an egg. Under its influence she conceived, and bore a son, who became the king of the tribe and kingdom of Fuyu.-Williamson; Griffis, Korea; Adams; Meadous.

MAND, probably another name for the Med. There are several tribes,-the Mandar, Mandhor, Mindhra, the Baluch tribe of Mondrani; and the ancient towns of Mandra, Mandropat in Chachgam, to the east of the Guni; Mandrasa, to the north of the Makali Hills; and Mundra and other similar names in Cutch.

MANDAKU or Manda chettu. Tel. A plant, the juice of which is said to prevent baldness.

MANDAL. ARAB. A form of divination in Egypt, which owed its celebrity in Europe to Mr. Lane. In the mandal, or palm-divination, a black slave was considered the best subject. When Lane wrote his account of this jugglery, he was unaware that Osman was a confederate of the supposed magician, and supplied him with the necessary hints. When Osman died, the Maghrabin magician said all bad gone wrong since Osman Effendi departed. Three travellers had a seance in 1836, resulting in blunder after blunder, until they got disgusted and left. On that occasion, amongst others, an absent person was named, and was described by the magician as a tall Frank, with black hair, a long black beard, and one eye gone, - he being fair-haired, with eyes still (1884) perfect.-Lane; Burton, Mecca. MANDAL. GUJ. A close-woven silk and gold fabric, used to form the rope-like turbands.

MANDALA. HIND. A circle, a district, a division 
of a country, a region, as Tonda Mandalam, Pandu Mandalam, Chola Mandalam, Mandlaisir, and Okamandal. Also an orb; also a section of a book. The Rig Veda has ten Mandala. In Bengal, the headman of a village. In Pturniah it is the title of any respectable Hindu Sudra. A township, in its simplest form, is under a headman, called in the Dekhan and in the west and centre of Hindustan Patel, Mandel in Bengal, Makaddum in many places. He is assisted by different officers, of whom the accountant and watchman are the most important. 1. The accountant, called Patwari in Hindustan, Kulkarni and Curnum in the Dekhan and south of India, and Tallali in Gujerat. 2. The watchman, called Pasban, Gorayet, Peik, Domaha, etc., in Hindustan, Mahar in the Dekhan, Tillari in the south of India, and Paggi in Gujerat; 3. Moneychanger or silversmith; 4. Priest; 5. Astwhju; 6. Smith; 7. Carpenter; 8. Barber ; 9. Potter; 10. Worker in leather; 11. Tailor; 12. Washerman; 13. Musician; 14. Minstrel; 15. Dancinggirl. The number is fixed by common opinion, and by the native name Bara-balotta, at twelve, but varies in different villages, and the officers included are not always the same, though up to No. 10 are seldom wanting. From 11 to 14 are not so general, and the dancing-girl seems only to be in the south of India. Each of these village officers has a fee, sometimes in money, but more frequently a portion of produce, as a handful or two out of each measure of grain.-D.; Wilson.

MANDALA PURUDAR was a Jaina ascetic, said to have lived in the time of Raja Krishna Rayar, who reigned at Vijayanagaram in the begimning of the 16th century. He wrote a poetic lexicon, Sudamani Nikanda, somewhat on the plan of the Sanskrit Amerakosha.

MANDALAY, the capital of Independent Burma, is situated in lat. $21^{\circ} 59^{\prime} 4^{\prime \prime} \mathrm{N}$., and long. $96^{\circ} 8^{\prime} \mathrm{E}_{\text {. }}$ about two miles from the left bank of the Irawadi, in a level plain at the foot of an isolated hill 600 feet in height, from which the city takes its name. The city proper is laid out in a square, each side of which is a little over a mile in length. It is enclosed in a brick wall, 26 feet high and 3 feet thick. An inner square, covering, an area of about 72 acres, is taken up by the royal buildings. The parts of the city outside the royal enclosure are inhabited by the officials, civil and military, the soldiers, and the general population. The central or royal square is surrounded by an outer stockade of timber and an inner wall. Entering, the stranger comes on a wide space, and then finds on the right the Government offices and the royal mint. There is also the high court, or hlot dau, where the four chief ministers sit to hear appeals. The Pakhan Menghee, or Foreign Minister, and the Yaw-Ahtwen-WVon, or Minister of the Interior, have likewise their offices here. The palace buildings lie behind a wall on the left. The reception-Lall with its rich decorations and golden throne, and some of the outer apartments, have been described by travellers; but into the inner apartments no European has ever been admitted. The repoussé gold and silver work is very beautiful and finished in execution; and the ivory and wood carvings, in clear and bold alto-relievo, are artistic in composition and design. -Imp. Guz.
MANDAPA or Mantapam, the portico of a Hindu temple; an open building, a pavilion for receiving and sheltering idols when carried in procession for the performance of marriage or other festive ceremonies.

MANDARA. Mount Mandara, celebrated in the Puranic legends for the churning of the ocean, lies southward of Bhagulpur. Vishnu is fabled to have become incarnate in the form of a tortoise ; in which shape he sustained the mountain Mandara, placed on his back to serve as an axis, whereon the gods and demons, Sura and Asura,- the vast serpent Vasuki serving as a rope,-churned the ocean for the recovery of the amrita, or beverage of immortality. And the result of the operation that chiefly distinguished this avatara, was the obtainment of fourteen articles, usually called fourteen gems, or chaturdesa ratna, in common language chowda ratni,-1. the moon, Chandra ; 2 . Sri or Lakshmi, the goddess of fortune and beauty; 3. Sura, wine, or Suradevi, the goddess of wine; 4. Uchisrava, an eight-headed horse; 5. Kustubha, a jewel of inestimable value; 6 . Parijata, a tree that spontaneously yielded everything desired; 7. Surabhi, a cow similarly bountiful; 8. Dhanwantara, a physician; 9. Iravati, elephant of Indra, with three probosci; 10. Chank, a shell conferring victory on whoever should sound it ; 11. Danusha, an unerring bow; 12 . Bikh, poison or drugs; 13 . Rhemba, the Apsara, a beautiful and amiable woman; 14 . Amrita, the beverage of immortality.

On the downfall of Buddhism, Mandara fell into the hands of the Saivites, and became a seat of their god so as to rival Benares, and form, as the Kasikhund states, a second Kailasa. The legend of the churning of the ocean is an interpolation in the Mahabharata, and evidently refers to the contest between the Brahmans (Sura) and the Buddhists (Asura), the great serpent Vasuki alluding to the Naga race.

MANDARIN, a magistrate of China, or a person having authority, from a Portuguese word Mandar, to command. Chinese mandarins use bamboo caps in summer as the official head-dress. -Wathen's Voyage, p. 180.

MANDARIN DUCK of China is the Aix galericolata, costly birds even in China, where they are called Een yeong. They are regarded by the Chinese as patterns of conjugal fidelity, and are usually carried about in their marriage processions. Sir John Bowring had great difficulty in obtaining a few. The Mandarin duck appears to be indigenous to the country north of Pekin. It has also been found in a wild state on the Southern Amur.-G. Bennett, Gatherings, p. 189.

MANDAVAR KOOLY. TAM. Graves of the dead, ancient burial-places in the Coimbatore district, circles of various sizes. They contrin earthen jars, with fragments of human bones in earth. The term is supposed by Dr. Shortt to be a dialectal change from Panda curzi, the usual name for the cairns of the south of India.

MANDAVI, a large seaport town, in lat. $22^{\circ}$ $51^{\prime} \mathrm{N}$, , and long. $69^{\circ} 34^{\prime} \mathrm{E}$., on the west side of a narrow creek, close on the Gulf of Cutch. Its vessels are from 25 to 200 tons burden, have 2 large lateen sail, with two masts, and are never decked. They trade with Zanzibar, Persian Gulf, Mekran, and Sind. Population about 50,000 . Its chief is of the Baghela race. It 
sends out some of the best seamen, pilots, and merchants, and exports cotton, wool, grain, ghi, and oil.

MANDELSLO, a traveller to India, accompanied the Duke of Holstein's mission to Russia and Persia, to which Olearius was secretary, in 1633-39. He had left Isfahan 16th January 1638, saw the ruins of Persepolis, passed through Shiraz, and on the 23d February 1639 reached Gomroon or Bandar Abbas. His surgeon, John Weinberg, died on the 22d March, and was buried in the English cemetery. On the 6th April, he embarked for Surat with Messrs. Mandley and Hall, two English merchants, and arrived on the 25th; and from Bandar Abbas be went on to Surat and Baroach, Brodera (Baroda), Ahmadabad, Cambay, 'Lahore, and Vezeapour, returning to Denmark, where he landed, May 1, 1640, from Surat. The narrative of his Voyages and Travels, translated by John Davies, was published in England, in one volume, with Olearius' account of the Duke of Holstein's mission in 1662 and 1669, and gives a most interesting account of the factory at Surat, and of the factors' manner of life. They were the inventors of punch (Puntz of Mandelslo, Paunch of Fryer), so called from the five (in Hindustani panch) ingredients, spirit, lemon or lime-juice, spice, sugar, and rose-water, used in its composition. The $\pi \varepsilon \nu \tau \alpha-$ $\pi \lambda c^{\infty} \propto$ of the Greeks was composed of wine, honey, cheese, meal, and oil.-Sir G. Birdwood.

MANDEVILLE, SIR JOHN, author of a book of alleged travels in India and China. He set out from St. Albans in 1332, and returned and died in Liege in 1366. His descriptions of Ceylon are borrowed from Marco Polo and Odoric of Portendu. He seems to have adopted, as regards Sumatra, the accounts of Odoric when he says, 'Beside the ysle of Lemery is another yclept Sumobor; and fast beside, a great ysle yelept Java.'-Marsden's Sumatra, p. 7.

MANDHATA, an island in the Nerbadda, belonging to the Nimar district, containing numerous temples, ancient and modern, including the great shrine of Omkar, a form of Siva. It is cleft in two by a deep ravine running nearly north and south, the eastern end containing about one-third of the whole arca. The southern bank of the Nerbadda opposite Mandhata (called Godarpura) is as precipitous as Mandhata, and between them the river forms an exceedingly deep and silent pool, full of crocodiles and large fish, many of which are so tame as to take grain off the lower steps of the sacred ghats. The worship of Siva was established here at an early age. On Mandhata the shrine of Omkar, and on the soutbern bank that of Amareswar (lord of the immortals), are two of the twelve great lingauns which existed in India when Mahmud of Ghazni demolished the tcmple of Somnath in A.D. 1024. The name Omkar is from the syllable Om, which, says Professor Wilson, is a combination of letters invested by Hindu mysticism with peculiar sanctity, employed in the begiuning of all prayers. It comprehends all the gods, the Vedas, the three spheres of the world, etc. The Brahmans who now officiate at the shrine wish to exclude Omkar from the twelve lingams, and it is usually called A' di, or first, as something above and before them all. The Narmada Khand supports them in this assertion, but as it contains a prophecy of the time when India shall be ruled by M'hlecha (non-Hindus) and other modern allusions, its antiquity is certainly a good deal open to doubt. The evidence of the Kasi Khand and other Saivite writings is against them, and the pilgrims who have vowed to visit the Bara jyoti lingam pay their adorations both to Omkar and Amareswar. The raja of Mandhata, who is hereditary custodian of all the modern temples, is a Bhilala, claiming descent from a Chauhan Rajput named Bharat Singh, who is stated in the family genealogy to have taken Mandhata from a Bhil chief in the year A.D. 1165 . $-A t$ :

MANDHATA, Gurla Mandhata, also called Nimo Namzil, lies ten miles south of Lake Manasarowar. According to the legend told by the Nilam Bhotia, the great mountain is the transformation of the body of a raja of Benares of the name of Mandhata, who is said to have died some thousands of years ago on the shores of the Manasarowar lake while on a pilgrimage to its waters. Another notable peak is Kailas; it lies to the north of Manasarowar, and being in the shape of a Hindu temple is greatly venerated by all the Hindus of Northern India. 'Owing to its immense bulk and height,' says Mr. Ryall, '3000 feet above any within a radius of 40 miles, it is perhaps the most impressive sight in the whole of the Himalayas ; the celebrated mountain of Nanga Parbat, N.W. of Kashmir, alone excepted.

MANDI, a Native State of the Panjab, lying between lat. $31^{\circ} 23^{\prime} 45^{\prime \prime}$ and $32^{\circ} 4^{\prime} \mathrm{N}$., and between long. $76^{\circ} 40^{\prime}$ and $77^{\circ} 22^{\prime} 30^{\prime \prime} \mathrm{E}$. The ruling family is Rajput, of the Chanda Bansi clan, and is known as Mandial. Sen is the title borne by the ruling chief, whilst the younger members of the family are called Sinh. The chiefships of Mandi and Sukhet were originally a single state, bounded by Kangra on the west and Kullu on the east, by the Dhaoladhar mountains on the north and the Sutlej on the south. Mandi means the market, and its favourable position on the Beas river, at the junction of the two roads from the west and south, must have ensured its early occupation, which was rendered prosperous and lasting by the existence of valuable mines of iron and rock-salt in its immediate vicinity.

Mandi town, in lat. $31^{\circ} 43^{\prime} \mathrm{N}$, , and long: $76^{\circ} 58^{\prime} \mathrm{E}$., is on the banks of the Beas. The river here is a swift torrent, and is spanned by the new 'Empress' bridge. The banks are bigh and rocky.-I Imp. Gaz.

MANDIOCA or Manioc, the cassava root, is the Janipha manihot of Kunth, and Jatropha manihot of Linnæus, and furnishes the tapioca of commerce. The pulp, after grating and washing, is thoroughly drained, and strained through long cylindrical and plaited baskets. In India cvery planter or landholder should have at hand the cassava or mandioca plant, the root of which is of the same nature as rice, as delicious as the potato, and keeps fresh under ground for years, indifferent to great changes of heat or cold.

It is a liniversal article of food in Brazil. Tirhut is in latitude morth what Santa Catharina is south, and conforms to a great diversity of climates, seasons, and soils. It is easily planted and cultivated, and gives a return six times greater than wheat. It is branchy, and the numerous knots or leaf-marks on the branches are each a new plant. In cutting the branches to 
plant, the slips are made about three inches long, and include two or three of these knots, and each plant will give from say twenty to sixty separate slips, and therefore as many new plants.

Manioca and arrowroot are both rather extensively grown in the maritime provinces of Ceylon, the former being inferior in quality to that grown in the West India Islands. From the manioca, the Singhalese prepare a fine flour resembling arrowroot, but much sweeter and far more nourishing. Boiled or baked with milk, it forms a most delicious meal, partaking of the nature of a rich custard. See Arrowroot; Manibot.

MANDIR. HIND. A dancing hall at a Hindu temple. The mantapam of the Dravidian temples.

MANDLA, a town and district in the Jubbulpur division of the Central Provinces, on the right bank of the Nerbadda. The district lies between lat. $22^{\circ} 14^{\prime}$ and $23^{\circ} 22^{\prime} \mathrm{N}$., and long. $80^{\circ}$ and $81^{\circ}$ $48^{\prime}$ E., with Rewah and part of the Balaspur district on the east, and Seoni, Balaghat, Raipur, and Balaspur on the south, with an area of 4719 square miles, and in 1877 a population of 223,883 . It is a wild highland region, and 1724 feet above the sea.

While the rani Durgavati, widow of Dalpat Sa, was regent, A.D. 1564, Asaf Khan, the Dehli viceroy, invaded Mandla. Durgavati opposed him, but she was defeated near Singaurghar in Jubbulpur district, and she fell back on Garha, and then on Mandla, where she took up a strong position in a narrow defile. Asaf Khan renewed the action, and suffered a check, but the next day he brought up his artillery and renewed the battle. The rani, though wounded, defended the pass in person, but the river in the rear of her army began to rise, and the Gond troops, alarmed at their retreat being cut off, broke and fled. Durgavati snatched a dagger from her elephant driver, and plunged it into her bosom and died.

The aboriginal tribes consist of Ahir, Baiga, Basor, Gauli, Gond, Dher, Mhar or Dhimar, Kach'hi, Kol, Kurmo, Yelo, Lodho, 'Teli, Panka, Marar, Mehra.

The original inhabitants of this district are undoubtedly the Gond and Baiga, who at the present time form the larger share of the population. Next to these are Brahman families, some of whom affect to trace back their arrival in Mandla to the time of Jadhava Raya in Samvat 415 (A.D. 358), though it is much more probable that the settled here in the reigns of Hirde Sah and Narendra Sah, from Samvat 1663 to 1788 (A.D. 1606 to 1731). The former of these two kings introduced a number of foreigners into the country, especially a large colony of Lodhia, who settled in the valleys of the Banjar, Motiari, and Nerbadda, gave the name of Hirdenagar to the taluka thus brought into cultivation, and did much by digging tanks and otherwise to colonize the best parts of the district. The Mahto are the best cultivators, are Hindus, originally of the Teli caste, and formerly resident at Maihir. The Mandla Gond is divided into two classes, which again are subdivided into forty-two different clans or got. The two classes are the Raj Gond and the Rawan Bansi. The former is the higher, and outdo the highest caste Hindus in the matter of purifying themselves and aping them in all their religious ceremonies. They wear the janeo or Brahmanical thread, and consider themselves deeply insulted if compared in status with a Gond. Mr. Hislop says that they carry their passion for purification so far that they have the faggots with which their food is cooked sprinkled with water before use. See Gond.

MANDLESAR, town in Indore State, Central India, situated on the right bank of the Nerbadrla, in lat. $22^{\circ} 11^{\prime} \mathrm{N}$., and long. $75^{\circ} 42^{\prime} \mathrm{E}$., on the route from Mhow (Mhau) to Asirgarh. - Imp. Gaz.

MANDOH, the ghost of a Muhammadan, in Hindu demonology deemed the most maliguant of all demons.

MANDONG or Mandrong. Malay. A rush much used by the natives in the manufacture of rice and sugar bags, mats, and for tying up articles, the fibre being strong. It grows spontaneously in the rice-fields of Province Wellesley, after the crop has been gathered, and overspreads them like a second crop. It may prove a suitable paper material.--Royle.

MANDOO, now in ruins, some time the capital of the independent Muhammadan kingdom of Malwa. It is on a spur of the Vindhya mountains, overlooking the valley of the Nerbadda and the plains of Nimar, having a site at an elevation of more than 2000 feet above the sea. The city of Mandoo was founded by Hoshang Shah, the founder of Hoshangabad; the second king, Muhammad Khilji, erected a mausoleum of white marble over the remains of Hoshang Shah, still in good preservation. On the Mandoo Hill is a terrace on which its Hindu queen would recline to gaze on the sacred Nerbadda winding through Nimar; close to this terrace was erected a palace, near a well-known spring, which to this day is called the queen's fountain. In general, Mubammadan ruins are situated on the plain, but the Mandoo ruins are in the midst of beautiful mountain scenery, so that the combination of works of art with the beauties of nature is most charming. Mandoo is built on coralline limestone, but that used for building is derived from near Baug or Bagh.

MANDRAKE, Atropa mandragora.

Usul-ul-lufah, . . ARAB.| Mandragen,. . GER. Astrung, . : . ", Mandragola, : : IT. Tuhfah-us-shaitan, " Lufahat, . MArar. Serag-ul-koshrob,. ", Mardam-i-giah, PErs. Yebruj, . . . ", Yabruz, Yabrukh, . ," Lakmuna, Lakmuni, HIND. Kaat-juti, . . . 'TAM. Mandragore, . . Fr.

The mandragora or mandrake, the fetid root of which was so celebrated in the magic rites and toxicology of the ancients, is known in the bazars of Central Asia and the north of India. It has various names, arising from its fancied resemblance to the human form. It was formerly an article of the materia medica of Europe, but is now exploded, though the leaves are still sometimes employed in preparing anodyne fomentations. The Arabians place the root, which they call Usulul-lufah, amongst their most powerful cathartics, and also suppose it to be of use as an antispasmodic. What of it is found in India is probably brought from Persia or Arabia. It is found in many parts of the south of Europe, is of poisonous qualities. Lufah is the plant. Tubfah-us-shaitan is the fruit. Its properties are identical in nature with those of Atropa belladonna, but weaker, in consequence of drying and decomposition of the atropia. The mandrakes of Genesis xxx. 14, are generally supposed to be the root of Mandragora officinalis. 
Calmet regards dudaim and plantains as citrons; but violets, lilies, jasmines have all been named. The Chinese physicians assert that this plant possesses the faculty of renovating exhausted constitutions. Some nations have believed that the root of the mandrake, if wholly dislodged from the ground, becomes the good genius of the possessor, not only curing a host of maladies, but discovering hidden treasures, doubling the amount of money locked up in a box, keeping off evil spirits, acting as a love-charm, and rendering several other notable services. - O'Sh. p. 466 ; Hog., p. 552 ; Faulkner; Ain. p. 26 ; Calmet.

MANEGAR or Maniyakaran. TAM. An agent, a native accountant, an overseer.

MANEL, a pink water-lily of delicious perfume, commonly offered before the figures of Buddha. Its flower closes at sunset.

MANELAVADU. TEL. An itinerant dealer in coral and gems, commonly termed a Manillaman, but probably from Mani, S.iNsk., a jewel.

MANERUNG, in the Himalaya, in lat. $31^{\circ} \overline{5} 6^{\prime}$ $\mathrm{N}$., long. $78^{\circ} 24^{\prime} \mathrm{E}$. Its crest is 18,612 feet, and the source of the Darbung there, 15,000 feet. A very difficult pass. See Kanawar.

MANES of Hindus are worshipped and have sacrifices offered to them on the third day, the twelfth day after demise, every month of the first year, and on every anniversary. The Bhumij, Bhuniya, and Kol tribes practise the ceremony by which the soul of a man just deceased is attracted back into the house soon after the funeral, apparently with the object of worshipping it as a honsehold spirit. All Hindus bring back into the honse the soul of their deceased relative, and then release it.

MANG or Mhang, a low caste tribe scattered through Kandesh, the Konkan, and Kolhapur, employed as village watchmen and in humble offices. The Mang reside outside villages. They are met with in most of the hamlets throughout the Hyderabad country and in Berar, and serve as scavenger, guide, watchman, and executioner. Their signature mark is a knife. They are part of the Baluth, and, like the Dher and Mahar, are predial slaves of the village. There were 556,771 in 1881 census returns of India.

MANGA of Zanzibar is Arabia. The Arabs are called Wa Manga by the people of Zanzibar.

MANGALA. SANSK. The planet Mars. In Hindu mythology, Mars was son of Siva and the earth, and had several names. Nangal-var is Tuesday. - D. See Graha; Va'ra.

MANGALA SUTRA. SANSK. Tali, HiNd. A thread with a gold coin or other valuable, which every Hindu married woman in the south of India wears during her husband's lifetime round her neck. It is tied on by the bridegroom at the time of marriage. In the north of India, it is a string or piece of silk tied round the wrist during the marriage ceremony. In other parts of India it is a string of glass beads set in gold, worn round the neck of the married woman. Its absence is a sign of widowhood. With the Teling people Mangala is applied to a married woman, a wife. The Hindu women of Bengal, on marriage, assume an iron bracelet. The Christian women of Europe wear a gold ring on the fourth finger of their left hand.

NANGALORE, on the coast of Canara, in lat. $12^{\circ} 51^{\prime} 40^{\prime \prime} \mathrm{N}$., and long. $74^{\circ} 52^{\prime} 36^{\prime \prime} \mathrm{E}$., is built near the mouth of a river navigable by small vessels, with about 10 or 11 feet on the bar. It is a civil and military station of British India. It has long been resorted to by vessels trading with Arabia. It was taken in 1708 , again in 1783 , by troops from Bombay; and on one occasion afterwards was successfully held for nine months against a besieging force from Mysore, 10,000 strong, with 100 guns. The garrison was commanded by Colonel Campbell, of the $42 \mathrm{~d}$ Highlanders, with 700 Europeans and 2000 sepoys; but when taken, the defenders were reduced to 850. In 1799, Mangalore became British territory, and since that time it has only once been disturbed by the appearance of an enemy, namely, during the Coorg insurrection in 1837.-Imp. Gaz.

MANGALORE or Mangala means fortunate. The native name is Kaudial; the Mangalur, Manjarur, and Mangaruth, according to the Greek writer Cosmas (6th century), of Arab travellers. -Yule, Cathay, ii. p. 451.

\section{MANGANESE.}

Mung-kin, . . . CHIN. I Braunstein, Glasseise, GER. Savon du verre, : . Fr. Iddali kalu, : : TEL.

The substance known in commerce under this name is the peroxide or black oxide of the metal. It is commonly of an earthy appearance, and mixed with other ingredients, but sometimes in erystals of a black colour and metallic lustre. The substance is well suited for glazing pottery, along with galena and felspar. In small quantities it gives a yellow colour; in large, brown; then a blood-red, purple, or black, as the proportion of manganese is increased. It has also the property of hardening the glaze, so as to resist vinegar and weak acids. Concentrated mineral acids, however, will corrode it. It is largely consumed in the manufacture of bleaching compounds; it is also used by potters; and it is considered the cheapest material from which to procure oxygen.

At the Madras Exhibitions of 1855 and 1857, the silicated sesquioxide was exhibited from Vizianagram in blocks, weighing from 2 to $3 \mathrm{cwt}$. each, with from 53 to 54 per cent. of metallic manganese. It has been discovered in a good many parts of the Madras Presidency under the form of earthy manganese ore, dendritic manganese ore, and combined with iron in a good many of the ochrey ironstones, laterites, claystones, and cotton soils of India. It was mined by Hyder Ali and Tipu Sultan in the Kupputgode range. It has been found also in the iron ore near the lake at Ootacamund, and in the Kaiti valley; also in Mergui, Burma, and the Himalaya.

Good ore occurs in Kurnool, at Tumkur in Mysore; in Sundur and Rudrar in the Coilcuntlah taluk. Brown wad and brown fibrous manganesc occur at the Red Hills, Bangalore, and Cuddapah.

In the bazars of the Panjab, manganese in the forms of a silicated sesquioxide and a peroxide is obtainable as a black powder, or in lumps of the pyrolusite.

Manganese is found in China in connection with the iron ores of Chin-Chan of Ho-nan.-Smith; M. E. J. R.; Waterstone; Faulkner; Pouell, Handbook; Mason's Tenasserim.

MANGCHAR has a few dispersed hamlets. It is well irrigated with canals, and the whole plain is intersected with bunds or dams to preserve the rain. The tomans are scattered over the plain. 
Many brood mares are kept. It is separated from Mustung by a lengthened valley termed Khad, in which the Shirwani tribe of Brahui dwell. The Brahui tribes on the east border with the Mandawari, Kuchik, and Puzh Rind tribes, and the Ghazgi Brahui adjacent to Cutch Gandava.

\section{MANGEL-WURZEL.}

Field beet, . . ENG. Mangold-wurzel, . GER. Betteraves, . . Fr. Biettola, . . : . IT,

A variety between the red and white beet has been a good deal cultivated in France, Germany, and Switzerland, partly as food for cattle, and partly to be used in distillation and in the extraction of sugar. Its culture in Great Britain dates only from the end of the 18 th century. It is employed almost entirely in the fattening of stock and the feeding of milch cows.

MANGIFERA, a genus of plants belonging to the natural order Auacardiaceæ. There are several species, but only M. Indica is of much value. M. coloneura, Kurz, of Burma; M. foetida, Loureiro, a native of Cochin-China, the Moluccas, Sumatra, and Penang; M. laxiflora, Desv., indigenous in Mauritius; M. sylvatica, Roxburgh, a native of the hilly districts bordering on Sylhet, called Lukshmi-Am, grows to a great size, and bears a fruit which ripens in February and March, and is eaten by the natives, though not so palatable as even a bad mango. It is also dried and kept by them for medicinal purposes. M. oppositifolia, Roxburgh, a native of Rangoon, was proposed by Messrs. Wight and Arnott to be formed into a distinct genus; $M$. glauca, Blainv., a tree of the Moluccas ; M. quadritida, Jack, M. cæsia, Jack, trees of Sumatra; M. gandaria of the Moluccas, and M. sylvatica of Tinnevelly.-Voigt; Roxb. p. 1641.

MANGIFERA FETIDA. Lour. Horse mango. La moot, . . Burr. | Bachang, . . MALAY

This large mango is cultivated at Mergui, and is quite a favourite with the natives. It has an odour resembling the dorian, and, like that, has been introduced from the Straits.-Dr. MLason.

\section{MANGIFERA INDICA. Linn. Mango.}

M. montana, Heyne. | M. domestica, Gertn.

Maghzak, . . ARAs, Mang'ga, . . Sunda, Am, . BENG., HIND. Ma maram, $\vdots$ TAM. That-yat, : Burm. Mavi, Mamidi chettu, Tei. Mavena,. : . CAN. Ela (fragrant) mavi, Mang-kwo, : : CHIN, Gujju (dwarf) mamidi, ", Palam, : . JAV, Etamba (wild) mamidi,", Kapalam, : LAMpung. Racha mamidi, : " Mampalam, Mava, MaLEA. Tiyya mamidi, . ", Makandamu, Amra, SANS. Ambo, Uria, . . ", Amba, Attamba,. SINGH.

The mango tree is generally diffused over all the warmer parts of S. Asia, as far worth as $30^{\circ}$ in the Panjab, in N. India up to $3 \overline{500}$ feet, and up to Nabu at an altitude of 4000 . It has been successfully introduced into the West Indies. It grows to a great size, with an erect trunk, and dark-coloured cracked bark. Its flowering time is January, February, and March; the fruit ripens in May, June, and July, and is one of the most grateful fruits of the tropical parts of Asia. The Archipelagic names of the cultivated mango are all, according to Crawfurd, derived from the Sanskrit, Maha-pahala, or great fruit. Through the agency of Europeans, however, the corrupted form of the Sunda name for the wild mango has become prevalent throughont the east, from Mada- gascar to the Philippines, and has extended to America. The mangoes of Mazagaon were once celebrated. The best mangoes come from Goa, Bombay, Multan, Hushyarpur, and Karnal. The best of all are the Paiwandi, or grafted mangoes, at once known by the utter absence of all stringiness of texture, and by their delicate flavour. Natives usually prefer mangoes when they are so ripe that they have lost their firmness, and are quite flabby and soft. The wood is of a dull grey colour, porous, yet pretty durable if kept dry, but soon decays if exposed to wet, of the effect of which it is very sensitive. In very large old trees it acquires a light chocolate colour towards the centre of the trunk and larger branches. This is hard, closer grained, and much more durable. It is generally used for constructing masula boats, and for packing-cases; the cabinet-makers at Madras prefer it to other wood for veneering on ; it is also generally used by coach-builders, cabinetmakers, and others, where common light wood is required, being the cheapest wood obtainable for packing-cases, boarding, and rough work, and for backs and linings of furniture. The wood holds a nail faster than any other wood. It is very serviceable for planks, when not exposed to wet, and is much used for house purposes. It seems to bear the action of salt water better than that of fresh; is hence used for camoes. It could be readily creosoted. It is used in Mysore for the solid wheels of country carts and rough furniture. The root bark is an aromatic bitter. The kernels are large, and seem to contain some nourishment; during times of scarcity and famine, they are boiled in the steam of water, and used as an article of diet. Propagating by layers, and grafting by approach, are the only modes of certainly continuing fine sorts, as well as of improving them. These have the advantage also of bearing when small in size, that is, only a few feet in height, and therefore well suited to culture in the hothouses of Europe.

The mango tree is said to have been brought into India by Ravana from Ceylon. Some of the most esteemed sorts of this fruit in India are the Alphonso, Raspberry, Doria, Maghrabah, and the Mazagong. The practice of engrafting the mango was first introduced at Madras by Dr. James Anderson, who improved it in a great degrue. Propagation may easily be effected by seed and cuttings, etc., but the process is slow, as a tree thus raised will not bear fruit before the fifth or sixth year, whereas those that are grafted produce in the second or third, although it is injurious to the tree to let it bear so early, and the blossoms should be removed. Young grafts will sometimes, indeed very often, blossom the first season they are removed, but if allowed to bear fruit, it checks them for a length of time after. A mango graft may be applied at any time of the year, but the stock must be kept continually moist by watering. When the graft and stock have become united, the former must be partially divided by a notch with a sharp knife; this may be done after six weeks have elapsed from the time of its first being united. A second cutting may be effected a fortnight later, and the complete removal from the parent tree at the expiration of nine or ten weeks. After this, remove the graft into the shade for a fortnight longer, when it may be put into the spot where it is to remain. A graft tree never attains the size 
of a seedling, neither will it continue to live or bear so long, and it is doubted if the seed of a graft mango would produce the same fruit, whereas a seedling often does so. The time that a seedling takes to produce fruit is the great objection to this mode of rearing trees; nevertheless a young tree of three years old might have one of its branches brought into blossom by ringing; this would enable the cultivator to judge if the tree was worth preserving' or not. The Maghrabah variety is of a greenish tinge inside when ripe, and by far the largest of the whole, being three times the size of an Alphonso, and it ripens the last. When the graft is planted out, it requires only a moderate proportion of care, clearing the ground of all weeds, and removing any buds that show themselves. Within the space from the ground to where the first branches are to rise from, all superfluous and weak shoots should be removed, more particularly those from the centre of the tree, as also all branches that trail on the ground, unless required for grafting from. The tree is better for being pruned, and whenever the interior of a tree may contain superfluous branches, or when there is not sufficient room for the growth of the young and fruit-bearing shoots, a clear space must be provided, and this can only be done by pruning. The best time for this operation is soon after the tree has done bearing fruit. No old and decayed wood should be allowed to remain, and great care must be taken to remove, on the first appearance, the 'borers,' should they indicate their presence by their appearance on the bark. When trees are old and have their bark injured, it must be all cleared away, and the parts covered with a composition. One mode of propagating by slips or cuttings is thus described: Take slips from the healthy branch of a mango tree, at least two feet long, taking care to cut it one inch above the joint at the top, and the same below the joint at the bottom. The cuttings will not all be equal, as in some branches the joints are short and in others long. The thickness of the slip is to be from $\frac{3}{4}$ to 3 inches in diameter. Half the length of the slip is to be slightly punctured with an awl, and then inserted into the ground to that depth (half of the slip), perfectly perpendicular, and then make a knob at the top of the slip with plain cow-dung. The cuttings must be well watered in such a manner as to keep up an uninterrupted moisture in the ground; and, moreover, the cutings are to be well shaded, and the coverings only to be removed by degrees as the plants attain leaves and strength, and not to be transplanted on any account until the next monsoon. The slips begin to bud within a month generally, but sometimes take a much longer period. In all cases the punctures are indispensably necessary, to admit of root-fibres being thrown out from them.

The tree and its fruit may both be improved, if, during the cold season, the ground is dug all round the roots, and by the addition of a suitable quantity of good old manure. The seed will only grow when fresh, and seldom after six weeks. IVhen green, it is used for making preserves, pickles, tarts, etc. The mango may be procured twice in the year in Bombay. Mango tree leaves are liable to be attacked with a blight caused by an aphis.Drs. Ainslic, Royle, Riddell, $\mathbf{M}^{+}$Clellaml, Gihson, Wight, Cleghorn, Voigt, Mason.
MANGIFERA OPPOSITIFOLIA. Roxb

Cambessedea oppositifolia, | Boueia oppositifolia, Meis. $W$. and $A$. Mayan,

A lofty spreading tree which grows wild in most parts of Burma. Fruit edible, yellow; the size of a plum. There are several varieties, of which some are sweet, and others sour. Wood used for building purposes.-Cal. Cat. Ex., 1862; Roxb. i. p. 640; Malcom's Travels, i. p. 179.

MANGLIETTA, a genus of plants belonging to the natural order Magnoliaceæ. M. glauca has a white solid wood, which is largely employed in Java, and is supposed to prevent the decay of corpses put into coffins made of it.-Eng. Cyc.; Horg, Veg. King.

MANG-MO, a name of Bamo, a frontier town in the Shan territory, between Yun-nan and Burma. It has the Pu-long tribes and the Kakhyen around it.

MANGO BIRD, the bright yellow oriole.

MANGO FISH, species of Polynemus, of the Irawadi and Ganges. P. longifilis, Cuv., P. paradisæus, Linn., and P. risua, the Tupsee-mutchee, 8 or 9 inches long and 2 deep, are splendid fish and favourites with many; they are nearly related to the mullets; the last is remarkable for the long filaments to the pectoral fins, and as being without a swimming-bladder, while the other species have it large and stout. Five species are described by Dr. Buchanan in his Gangetic Fishes, but only two are of considerable size, occurring in the estuary of the Hoogly. One of these, with another large species, is also described by Dr. Russell in his work on the Fishes of the Madras Coast. That figured in his tab. 184, and called maga-booshy, is Polynemus uronemus of Cuvier; while the magajellee, tab. 183, named P. tetradactylus by Shaw, is probably $\mathrm{P}$. Teria of Buchanan. Both, but especially the first, Russell says, are esteened for the table, and called roeball by the English.Mason. See Polynemus.

MANGOH. HiND. An edible Himalayan root. MANGO PEEL, dried mango, the Am chur or Am khusk or Ambusi, HiND., dried mangoes. Mango pickles are much in use amongst both Europeans and natives. Take about 300 green mangoes, divide into two, and dry in the sum for three days. Take of turmeric, $4 \frac{1}{2} \mathrm{oz}$; garlic, $3 \frac{1}{5}$ oz. ; salt, $6 \mathrm{lbs}$; mustard, $1 \frac{1}{2} \mathrm{oz}$; and coriander seed, toasted, $1 \frac{1}{2}$ oz.; - mix the spices together, and lay the mixture in alternate layers with the mangoes, and add 9 oz. of gingelly oil. The green fruit of the mango is used for making chatnies, pickles, and curries. Mangoes, when full grown, are cut into slices, dried in the sun and preserved, and they form an article of commerce; used in acidulating curries, mulligatawnies, etc. Mango spirit is prepared from the mango. The taste of the spirit is not unlike whisky, and far superior to anything of the sort sold in Indian bazars for every purpose to which the latter is applied. With the specific gravity about 9035 , temperature of $80^{\circ} \mathrm{F}$, gives about 60 per cent. of alcohol to the volume of spirit.

MANGOSTEEN, Garcinia mangostana. Manggis, BALI, JAV.,MIL. Shan-chuh-kwo, . CHIN, Manggusta, . . , 1 Monggos, . Liniunc. Manggisi, : : Bugr. Mlangu, : . SundA.

The mangosteen plant is about the size of a cherry tree, and very handsome. It grows in perfection as far as $14^{\circ}$ north of the equator and 
$7^{\circ}$ south of it. A congenial proportion of heat and moisture throughout the year seems much more requisite than soil or latitude for the successful growth of this fruit. Malaya's nectared mangosteen is truly a delicious fruit, and is by many esteemed as the most palatable of known fruits. It is cultivated to a considerable extent in Mergui and Tavoy, - in Mergui ripening in May, -and it has been successfully introduced into the Travancore province; and both the nutmeg and the mangosteen have been introduced with singular success at Ceylon, while their cultivation has entirely failed in Bengal.

Bontius thus describes this delicious fruit-

'Cedant Hesperii longe hinc, mala aurea fructus,

Ambrosia paseit Mangostam, et nectare Divos.'

Its characteristic quality is extreme delicacy of flavour, without being rich or luscious. It is a drupe of a brownish-red colour, and the size of a common apple, consisting of a thick rind, somewhat hard on the outside, but soft and succulent within, encompassing kernels which are covered with a juicy and perfectly white pulp, which is the part eaten, or more properly sucked, for it dissolves in the mouth. The thick fleshy rind is given internally in diarrhoea and dysentery, and is applied as an astringent externally.-Marsden's Sumatra; Crawfurd's Dict.; Mason's Tenasserim.

MANGROVES are plants, shrubs, and trees, of the natural order Rhizophoraceæ, Lindley. In the East Indies, the principal are-Bruiguiera caryophylloides, cylindrica, eriopetala, gymnorhiza, Malabarica, parviflora, and Rheedii; Carallia garcinifolia, lanceæfolia, lucida, Zeylanica, and Candollianus ; Rhizophora conjugata, mangle, and mucronata; Ceriops Roxburghianus, Candoleana, and Kandelia Rheedii.

Mangroves abound on the coasts of the Bay of Beugal, and of the Indian islands. The true mangroves are remarkable for the copious development of adventitious roots, which arch outwards from the base of the stem over the reeking mudflats in which they delight; and yet more so from the circumstance that the seed germinates in the ripe fruit while still attached to the parent tree, growing down into the mud, or attaining a footor more in length before falling. Rhizophora mangle is used in tanning, and its wood gives a red dye. The tree forms a striking feature in the physical geography of the Archipelago, as it does indeed of all tropical countries, for a belt of it as deep as the reach of the tide is always found wherever there is a shallow and muddy shore. The tree rises to the height of 40 or 50 feet, and is invariably found in such situations constituting a dense and almost impenetrable forest. Each tree stands on a cradle of its own roots from 5 to 6 feet high, bare at low water, but as the tide rises covered so as to give the appearance of trees growing in the sea. Mangrove jungle is the favourite resort of mosquitoes and crocodiles, and affords a convenient and almost inaccessible retreat to pirates. The bark of Rhizophora mangle is used in the East and West Indies to dye chocolate colour. This was one of the colours introduced by Dr. Bancroft, and for the exclusive use of which he obtained an Act of Parliament. It is procured in plenty at Arakan, in Malabar, and at Singapore, and as it is often imported for tanning, can be readily enough obtained if found valuable to the home dyer. The bark of a small tree from the mangrove swamps is used by the Tavoy women in dyeing red, but Mr. Mason thinks only as a mordant. Rhizophora gymnorhiza, the Kayu api-api of the Malays, is used for fuel in the Indian Archipelago, The cuttings of the black mangrove or Rhizophora (uppu ponna), as of the white mangrove, the Avicennia tomentosa (Mada chettu) and of the Sonneratia, are used for firewood at Masulipatam. Mangrove bark is imported from Singapore and Siam into China, where it is used to tan sails, cordage, and nets, and is called Kaup'i. Curriers in England have failed with it, although the bark, fruit, and roots all abound in tanniu.-Smith, M.M.C. ; Royle, Fib. Pl. p. 301 ; Mason; Crawfurd, p. 266 ; Cat. Ex., 1862.

MANGU. This wood, and the ati ati, the kraminan, the purwo-kuning, and several others, are employed as timber at Singapore.

MANGUIAN, aboriginal tribes occupying the interior of the island of Mindoro. The Manguianes are a mild people, but so little advanced in civilisation, that European visitors, who have not had opportunities of personal communication with the Manguian, often leave the island with the impression that they are only a more savage variety of the same race.-Jour. Ind. Arch.; Earl, p. 133.

MANI. SANSK. Literally precious stone. In Tibet, long dykes covered with slate slabs, engraved with the words, 'Om ! mani padma om,' or walls 4 to 5 feet in height and 4 to 8 in breadth, but their length varies much. One, 2200 feet long, is on the road leading from the banks of the Indus to Leh. They are generally of loose stones, and have flagstaffs at their ends. They are of ten of mingled heaps of broken things, which are raised up in notable places and hills as objects of peculiar veneration. $\mathrm{Om}$ is an often occurring word amongst Buddhist Tibetans in the prayer, Om! mani padma om. In passing the Mani, the Ladakhi keep them on the right hand. The same is done in passing monasteries. They are votive offerings from all classes of people for the attainment of some object.

MANI. HiND, A weight (agricultural) $=6 \frac{1}{2}$ maunds.

MANI or Manes, a Persian of the time of Shapor, A.D. 277. He pretended to be the Paraclete promised in the 14th chapter of John, and soon established a sect, but was persecuted by Shapor, on which he fled to Eastern Tartary. While there, he engaged in drawing, and produced a great many extraordinary figures, which his followers, on his return, believed were given to him in heaven, where he informed them he had spent the time during his retreat. His religion is known to Europeans as the Manichean, a mixture of magian, Christian, Buddhism, and Hinduism. Christian patriarchs and bishops followed him. He blended with his doctrine the metempsychosis and the two principles of Zertusht. He was put to death by Bahram I. about A.D. 277. Sir W. Jones, however, gives the date 242 as that of king Sbapor of Persia, and the date of the death of Mani as A.D. 272.-Chatfield's Hindustan; Sir W. Jones, v. p. 600 ; Mosheim, Eccl. Hist. i. c. v. Socrat. Schol, Lit. i. c. xxii.; H. G. Keene.

MANIAM or Maniyam. ARAB. In the south of India, lands held rent-free or under easy conditions. Professor Wilson traces it from Manya, SANSK., respectable. It is probably from Inam, ARABIC, gift. There are four kinds of tenure, 
viz. ardha, dumbala, sanad, and sarva-manyam. - Cal. Cat. Ex., 1862.

MANIAUK or Maneeoga. Burs. A wood much used for rice-pounders. Abundant all over the Tenasserim and Martaban provinces. When seasoned, it floats in water; when stored, it soon dies and rots. The roots are used for medicine; the fruit is eaten by Burmese.

MANI CHAKA, Chandra-kanta. SANSK. The moonstone.

MANIHAR, Maniar, or Mannair, a maker of glass bracelets worn by women, a jeweller.

MANIHOT AIPI. Pohl. The sweet cassava plant; the root reddish and harmless, and can be used as a vegetable after simple boiling, and tapioca can be prepared from it ; it grows several feet high. $-F$. V. Mueller.

MANIHOT UTILISSIMA. Pohl.

Janipha manihot, $K t h . \quad$ Cassava manioc.

Aipy, Kaviaraku, BraziL. Piwore, Ouycon, Guidana. Tapioca plant, . ENG. Masato, . . MEXICO.

Manibot utilissima, Pohl., the bitter cassava or tapioca plant. The yellowish tubers attain a length of three feet, and a weight of $30 \mathrm{lbs}$., in warm countries, and are available in eight months, though they continue to grow longer than that. The growth of the plant upwards is checked by breaking off the buds. The propagation is effected by cuttings from the ligneous part of the stem. It is a very exhausting crop, needs rich soil and manuring, and the soil must not be wet. The tubers do not become soft by boiling. They can be converted into bread or cakes, the volatile poison of the milky sap being destroyed through pressing of the grated root in the first instance, and the remaining acridity is expelled by the heating process. The starch, heated in a moist state, furnishes the tapioca.-Von Mueller. See Mandioca.

MANIKHYALA, a village and group of ruins in the Rawal Pindi district of Panjab, lying in lat. $33^{\circ} 27^{\prime} 30^{\prime \prime} \mathrm{N}$., and long. $73^{\circ} 17^{\prime} 15^{\prime \prime} \mathrm{E}$. The small village is 40 miles from the Jhelum on the high road. It is a little more than half-way between Attock and the town of Jhelum. It is built on the ruins of a very ancient city of unknown origin, but its position and the abundance of coins found in the ruins, admit of the assumption that it must have been the capital of all the country between the Indus and Hydaspes, a country which the ancients knew by the name of Taxila, and of which frequent mention is made in the history of Alexander. Near it are 15 or 20 Buddhist topes, most of which were opened by General Ventura and $M$. Court about the year 1830 , when relics of great value were found. In one was a gold cylinder enclosed in one of silver, and that again in one of copper. In the innermost one were four gold coins, ten precious stones, and four pearls, with some worn Roman coins, one of date 3.C. 30. General Cunningham opened one, in which he found a copper coin of the Satrap Zeionises, enclosed with other relics in a glass stopper bottle. The principal tope was figured by Mr. Elphinstone, and is 127 feet in diameter. General Ventura found in it three separate deposits of relics with coins, some Sassanian, one of Yasoverma (A.D. 720), one of Abdullah-bin-Hassim, struck at Merv A.H. 66 (A.D. 685). One tope is 80 feet high, and 320 feet in circumference.Fergusson, p. 79.

VOL. II.
MANIKI, amongst the Kol, the head of a number of Munda.

MANIK RAI, a Chauhan king who; in A.D. 685 (Hijira 63), met the first Muhammadan invaders of India, who were part of an army sent into Sind by the khalif Umar. Manik Kai and his son Lot were both killed, but the anniversary of Lot's death is still preserved by the Chauhan. The family then retired to Sambur in Rajputana, where they prospered, and great Rajput families descended from it are known as the Hara, Mohil, Bhadaurea, Dhanarea, with the Kheechee, Narbhana, Bhowreecha, etc. The first-named four established independent kingdoms. In A.D. 1170, the Chauhan wrested Dehli from the Tuar Rajputs, as recorded in inscriptions in a Jain temple at Morakuro, and on the column at Dehli. Through: out the subsequent period of the Muhammadan conquests of India, the Chauban retained their fame for heroic endurance of misfortune above all other warlike tribes of India.

MANIKYAVA-CHAKAR, a devotee of Siva, a poet.

MANILA, the capital of Luçon and the Spanish Indies, one of the largest in the Philippine Islands, and the seat of the Spanish Government in the east, situated in lat. $14^{\circ} 36^{\prime} \mathrm{N}$., and long. $120^{\circ} 57^{\prime} 20^{\prime \prime}$. E. Manila is on the right bank of the river. It was founded in 1581, and in 1851 contained a population of 150,000 . In 1762 , Roya surrendered, and transferred the island to the British. It is a large city and convenient for trade, the adjacent country producing excellent indigo, sugar, tobacco, and hemp for cordage. Manila Bay is a large inlet in the S.W. coast of Luçon, about 22 miles in extent each way; the city of Manila stands on its eastern shore, about 25 miles from the entrance. The Spanish Indians are passionately fond of dress and personal decoration, and are given to pleasure. To a certain point they will work, but they are improvident and devoid of ambition, taking no thought for the morrow. There is much sympathy between the Indians and the Spaniards, and inter. course between the two races by no means entails the social degradation of the children which it does in India. The Mestizos of the Philippines are a more fortunate product than the Indian half-castes, for they usually combine the best points, physically speaking, of both parents. The true aborigines of the Philippines, in the mountains and the less habitable parts of the islands, are several tribes of savages who have not been brought within the government of the priests. The Negritos are woolly-headed people of the true African type. They are harmless and docile. The Iggrotos, a straight-haired tribe, fierce and untameable, inhabiting still more remote parts of the jungle, are very little known to the Spaniards. In the Philippines earthquakes are not only frequent but severe. A very important one occurred in 1880 .

Cock-fighting is carried to a passion unknown elsewhere. Every Manila Indian has a game cock upon his shoulder, or tucked under his arm, or occasionally perched on his head; and when two men meet they will speak a few words, squat down, and allow their respective birds, who have meanwhile been bristling up with warlike ardour, to take a few quiet pecks at each other, and without further comment each will go on his way, and each cock resume a peaceful attitude. Yet, as 
there is a tax on cock-fighting, it is unlawful to allow the cocks to come to a regular pitched battle, excepting at the proper certified cock-pits; the same with gambling out of the licensed houses ; and half the convicts that are seen working on the roads in chains are doing sofor the grave offence of fighting their cocks or playing ' monte' in unlicensed places, by the roadside, or anywhere but at one of the Government establishments. The principal saints' days and Sunday afternoons are the favourite cock-fighting times. The cocks are spurred with bright pieces of steel, about 3 inches long, and as sharp as the best razor,-generally made out of old razors; and frequently both birds lie dead at the same moment. Sometimes an accidental blow from the inferior bird settles the question, for the spurs are deadly, and do not need much repetition to become effective. In general, the handsomer bird is the vanquished, and the lesser and meaner-looking the hero and victor. The Indians often pluck a beaten cock alive in revenge at his having lost, though the poor brute has been the petted and constant companion of his master for months before, and has learnt all the ways which domestic animals do learn when in hourly contact with man.-Literary Gazette.

MANILA DRAGON CANES. These white and brown canes of commerce are supposed to be the stem of the Calamus draco, the dragon's blood palm. See Calamus; Cane; Dragon Cane.

MANILA HEMP. La mot, BISAYA; Abaca, TAG. The Musa textilis plant, which yields this hemp, was introduced by Dr. Roxburgh into the Northern Circars, but it had been neglected and died out, and during the administration of Lord Harris, Colonel (now Sir George) Balfour obtained for Madras a fresh supply of its roots, and it is growing freely in the Wynad; but Great Britain is annually importing 18,000 tons of it from Manila, value nearly a million sterling, although India, in two years' care, could supply all the demand. It is a native of the Philippine Islands, where there are several varieties known under different names. The Abaca brava, the wild abaca, is called by the Bicoles, agotai, but the fibres of the mountain abaca, only, serve for making ropes, which are called by them Agotag, Amoquid. The Sagig and Laquis of the Bisaya are other varieties. Rumphius states that the Malay name of the Laquis is Pissang utan, which means wild plantain. It is called in Amboyna Kula abbal; in Ternate Fana; and in Mindanao Coffo; also the cloth made from it. The abaca is abundant in the volcanic region of the Philippine Islands from Luçon to Mindanao, as also in the neighbouring islands as far south as the Moluccas. It therefore extends from the equator to lat. $20^{\circ} \mathrm{N}$., and may probably be easily cultivated in Travancore, Arakan, Assam, and the Northern Circars.

Mr. G. A. K. Honey, British Consul, Manila, reports that the plant thrives best in soil largely impregnated with decayed vegetable matter, the districts in which it is planted being to a great extent reclaimed forest lands. Hilly land is the most suitable, the plant yielding more abundantly on such than on low-lying flat ground. The plants require a large anount of moisture, and the production is chiefly in the southern districts, where the rainfall is greater. The plants suffer severely during long periods of excessive heat and drought. The custom there, after cleaning the land thoroughly, is to plant small plants of about 3 feet high, leaving a space of from 2 to 3 yards between each, the young shoots which spring up later round the parent stem filling up the intervening spaces, the ground being thoroughly cleaned and freed from weeds at least twice a year. In a favourable soil, the first crop will be available in about two years after planting, but will only be about one-third of the full production. In the fourth year a full crop will be obtained. The plants must on no account be allowed to fruit, as they then become worthless. When matured, they are cut down about a foot from the ground; and the labourer strips off layers from the trunk, which are cut into strips of about 3 inches wide, or, say, three strips to each layer. The strips are each drawn through between a blunt knife and a board, to remove the pulpy vegetable matter from the fibre, which is then spread in the sun to dry. So soon as it has been thoroughly dried, it is ready for the market. The appearance of the fibre depends entirely on the care bestowed in drying it, as, should it be exposed to rain or not thoroughly dried, it becomes discoloured or assumes a brownish tinge, and loses strength to some extent. The outside layer produces a reddish-coloured fibre, which is, however, quite sound, and is easily distinguishable from spoiled hemp. The cost of preparing and planting a quinon (10,000 square fathoms), and keeping it clean up to the time of the first crop, is estimated at $\$ 200$ to $\$ 300$, not including the original cost of the land, and afterwards an annual outlay of about $\$ 60$ would be required to keep the soil free from weeds, etc. The above-mentioned extent of land would produce 30 to 40 pikuls (140 lbs. English each), after the plantation is three years old. The labourers receive one-half of the result of their work, the other half going to the owners of the trees. The quantity cleaned by one man working steadily day by day averages about $12 \mathrm{lbs}$. When once planted, the trees send up shoot after shoot from the old roots, and a plantation will continue to give a good production for from 15 to 20 years, after which the soil becomes exhausted, and new land has to be planted. The total production of the fibre in the islands in 1882 was 325,600 bales, or 40,700 tons, which is just about the estimated total consumption of the world.

The imports into Britain of hemp from Manila were-

$1877, \quad 332,304$ cwt. $£ 488,069 \mid 1581, \quad 353,770$ cwt. $£ 691,186$

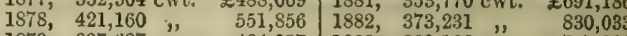
\begin{tabular}{llll|llll}
1879, & $337,687, "$ & 434,037 & 1883, & 330,132 & $\prime$ & 747,031
\end{tabular} In Britain it is used for the finer cordage, yachts' rigging, and clothes-lines.-Royle, Fib. Pl.

MANIPUR STATE is the Kasse or Kathe of the Burmese. It is situated between lat. $23^{\circ} 49^{\prime}$ and $25^{\circ} 41^{\prime} \mathrm{N}$., and long. $93^{\circ} 5^{\prime}$ and $94^{\circ} 32^{\prime} \mathrm{E}$. The population of the valley and surrounding hills is estimated to be about 74,000 hillmen and 65,000 Manipuris. It is bounded to the $W$. by Cachar and the Naga Hills, to the N. by the Naga Hills Agency and independent Naga tribes, to the $E$. by the Naga tribes and Burma, and to the S. by Kuki tribes. It has an area of 7600 square miles, of which 7000 square miles are mountainous lands, inhabited by various bill 
The valley part of Manipur is the centre of the chain of valleys which connect India and Burma, having to its east and west those of Kubbo and Cachar. The valley is 2570 feet above the sea. Much of the valley is at all seasons covered with water. It seems indeed at one time to have formed a large lake, and the piece of water in the south, called the Logtak, appears to be the rapidly filling remnant of it. The valley seems originally to have been occupied by several tribes, the principal of which were named Koomul, Looang, Moirang, and Mei-thei, all of whom came from different directions. For a time, the Koomul appear to have been the most powerful, and after its declension, the Moirang tribe. The principal is now the Mei-thei, next the Phoongnai, after whom the Teng-kul, the Ayok-pa, the Kei, the Loee, and Mubammadan. The Mei-thei population is divided into four parts, called Punnah, which are designated in the order of their seniority,-Ka-phum, Lai-phum, Ahull-oop, and Nihar-oop. The Loee pay tribute, and is considered so inferior that the name Mei-thei is not given to it.

The Manipuri native tribes on the south of the valley of Assam are the Manipuri, Songpu, Kapwi, Koreng, Maram, Chanphung, and Luhuppu. They are bounded on the east by the Shan of the Kynduayn, and on the N., S., and W. by the Naga and Heuma. Indeed, it may be doubted whether there is any marked transition from the Manipuri tribes and dialects to those of the Southern Naga on the one side, and those of the Yuma range and the Blue Mountain on the other. The Meiung speak a language of Sanskrit derivation. They are now in a servile condition, performing the duties of grass-cutters to their conquerors. The Maibee are priestesses of an order said to have been instituted many hundreds of years ago by one of the royal princesses. The oldest family of Brahmans in Manipur is called Huugoi-bun, from Hungoi, a frog, assigned as a nickname to the first Brahman, because he astonished the Manipuris by the frequency of his ablutions.

The Manipuris are distinguished for their enthusiastic love of horses, and skill in equitation over all the neighbouring tribes. Their breed of small horses is celebrated, but it is said they are fast dying out. The great national game of the Manipuri is hockey on horseback. The principal natioual festivals are the Hiyang, the Lumchail, and the Hanchong, at which the national game of hockey, with boat racing and foot racing, are the chief attractions.

The inhabitants of the hills around the valley of Manipur in the west are known under the general appellation of Naga and Kuki.

The marshes of the south, in the vicinity of the Logtak, afford a retreat to serpents of a formidable size, and the whole valley of Manipur is much infested by them. Some of then are exceedingly active and bold, as the Tanglei. It is fond of ascending bamboos, along the branches of which it moves with great velocity, and if enraged, throws itself from au extraordinary height upon the object of its anger. Its bite is said to be mortal. This, added to its great activity and fierceness, makes the Tanglei an object of dread.-Dalton's Ethnology; M'Culloch's Records.

\section{MANIS AURITA. Hodgsor.}

M. Javanica, Blyth. | M. pentadactyla, Hodgson.

The Ling-li of the Chinese is the scaly anteater. The genus Manis belongs to the order Edentata, in which also are classed the Tardigrada or Sloths and the Effodientia or Burrowers, the family Manididæ being the Pangolins. This manis occurs in Sikkim, and extends thence through the Indo-Chinese countries into China itself ; the Chinese name means the jungle carp. It is sold in the markets of Canton, where its flesh is considered excellent and its scales medicinal. Dr. Gray described this species as Pholidotus Dalmanni.-Jerdon.

\section{MANIS JAVANICA. Desmarest.}

M. leucura, Blyth. $\quad$ Chum or scaly hill borer. \begin{tabular}{l|l} 
Chun-shau-cap, CHIN. & Pangolin, . . . JAV. \\
Lingli or hill carp,
\end{tabular}

Inhabits Burma, the Malayan Peninsula, several parts of China, and islands of the Archipelago.

\section{MANIS PENTADACTYLA. Linn.}

M. crassicaudata, Griff. | M. inaurita, Hody.

M. macroura, Desm. $\quad$ Pangolinus typus, Less.

M. brachyura, Erxleb. Pholidotus Indicus, Gray.

M. laticaudata, Illeg.

Shalma, . . BAORI. Armoi, . . KoL. Kat pohu, : : BENG. Kauli mah, : : MAHr. Bajra kapta, . . ", Kowli manjra, . . ", Ban-rohu, sill : DEKH.
Sillu, Sal, Sallu, HIND. Keyot-mach, RUNGHIRE. Sukun-khor, : " Bajar-kit, HiND, SAN"sk. Thirya, . : : .,

This manis, or Indian scaly ant-eater, the common pangolin, is 26 inches long, tail 18 inches. It is nowhere abundant, but is found throughout the whole of India, and into the Lower Himalayas and Nepal. It walks with its fore feet bent over, and with its back conversely curved. It lives on insects, the white ant, but cannot be kept alive in captivity.

The manis burrows in the ground, in a slanting direction, to a depth of from 8 to 12 feet from the surface, at the end of which is a large chamber about 6 feet in circumference, in which they live in pairs, and where they may be found with one or two young ones about the months of January, February, and March. They close up the entrance of the burrow with earth when in it, so that it would be difficult to find them but for the peculiar track they leave. A female that Mr. Elliot kept alive for some time slept during the day, but was restless all night. It would not eat the termites or white ants put into its box, nor even the large black ant (Myrmica indefessa, Sykes), though its excrement at first was full of them. But it would lap the water that was offered to it, and also conjee or rice water, by rapidly darting out its long extensile tongue, which it repeated so quickly as to fill the water with froth. When it first came it made a sort of hissing noise if disturbed, and rolled itself up, with the head between the four legs, and the tail round the whole. The claws of the fore feet are very strong, and in walking are bent under, so that the upper surface is brought in contact with the ground; its gait is slow, and the back is curved upwards. After its death a single young one was found in it (September 15th), perfectly formed, and about 2 inches long. The marks of the future striated scales were distinctly visible, and its long tongue was hanging out. The tongue of the old one was 12 inches. in length, 
narrow, flat, fleshy to the tip, the muscle along the lower surface very strong. The length of the animal was 40 inches; the weight 21 lbs.Jerdon; Elliot.

MANISURUS GRANULARIS. Linn. Peltophorus granularis, Beauv. A plant of the south of India used in medicine. Roxburgh notices also M. myurus, Linn., the Nalla punuku of the Teling.

MANJARABAD, a taluk in the Hasan district of Mysore. The hills of Manjarabad afford some of the most beautiful scenery in India. Forests of magnificent timber are broken by green glades, and overhung by precipitous rocks. The soil is fertile, and rice is grown in abundance on the terraced slopes of the valleys. Coffee was introduced about the middle of the 19 th century. By the latter quarter there were 155 estates in the taluk owned by Europeans, occupying 21,000 acres, and 9500 native holdings, covering 9000 acres,-Imp. Gaz.

MANJERA, an affluent of the Godavery, rises in lat. $18^{\circ} 44^{\prime} \mathrm{N}$., long. $75^{\circ} 30^{\prime} \mathrm{E}$., runs S.E., S.W., into Godavery. Length, 330 miles. It receives the Thairnya, 95 miles; Narinja, 75 miles; Munnada, 100 miles. About 11,000 square miles are drained. While flowing through arid granitic plains, it obtains but a scanty addition of water, except during the rainy season.

MANJ'H or Manjha, the circle of village land beyond the bara or goind lands. Manjha also means alluvial laud.

MANJHA, or the middle land, is the country and people around Lahore. It is a term applied to the southern part of the Bari Doab, near Lahore and Amritsar, but vaguely includes all the Sikh district and people north of the Sutlej. Ganj-i-bar is a bald tract in the central dorsal plateau in the Manjha or middle part of the Bari Doab. The soil of the Ganj-i-bar is intensely arid, often saline, and produces only sal and some salsolaceous plants, with a few bushes of jhand. The men in the Manjha or Bari Doab, between the Ravi and Beas, are reputed to be the bravest and rnost warlike of the Panjabis. The Sikhs who inhabit the country between the Sutlej and Jumna are called Malawa Singh, a title conferred upon them for their extraordinary gallantry, under their leader Banda, the successor of Guru Govind, the founder of the Sikh nation. The Malawa Sikhs are almost all converts from the Hindu tribes of Jats and Gujars.-History of the Panjab.

MANJHI, a boatman, master of a traffic or cargo boat on the Ganges, the steersman of a boat. Also the title of the headmen of the Santal villages.

MANJOOSER, the patron deity of Wootai in China. At the monastery of Shoo-siang-si, S.W. from $\mathrm{Poo}$-sa-ting, he is represented by a large gilt figure seated on an immense lion.

MANKA. In the 8th century, a Hindu physician who went to Baghdad and practised at the hospitals. Manka and Saleb were the physicians of Harun-ur-Rashid.

MANKAH, pl. Manke. Hind. Beads or cut agates, pebbles for signet rings.

MANKARI, nobles, persons entitled to honour or distinction.

MANKIR, according to Muhammadanism, an angel who, with another named Nakir, questions the dead as to their past life. A Shiah about to die should say in the name of God, the Prophet, aud the Imams, 'I confess that God is my Lord, and Islam my religion, and Mahomed ny prophet, and the Koran my book, and the Kaba my kibla, and Ali my Imam, and also that the twelve Imams are my guides. O merciful God, this confession I deliver to thee, the Prophet, and the twelve Imams; release me in the grave when Mankir and Nakir come, O most merciful.'

MANKUHA. ARAB. A married woman; amongst Indian Muhammadans, a woman married by the simple marriage Nikkah ritual. They take a lower social place than the wives married by the Shadi ceremony; the one is called a Nikkah wife, the other a Shadi wife.

MANMATHA, a name of Kama, the Indian Cupid. He was burnt to ashes and revived by Iswara. He has various names. Manmatha bana chettu, TeL., Ixora bhanduca, $R$. ; also Jasminum sambac. Its literal meaning is Cupid's arrow tree.

MANNA.

Mun, Turanjabin, . Arab. Tsau-mih, . . ChIN. Kudrat-ul-halwassi, , Manne, : : Fr. Ching-ju, - . CHIN. Mannaesche, : GER. Kan-kau, Kan-lu, " , Gambing, : : JAV. Kan-lu-mih, . ", Kapur-rimba, MALAY. Tse-mih,. . . ", Shir-i-khist, . PEns.

The manna of the south of Europe is the concrete exudation from a species of ash, the Fraxinus ornus, Linn., but sweetish secretions are exuded by some other plants of those regions, and are usually considered to be kinds of manna. F. gargavica and F. rotundifolia, Lam., are also said to yield it. F. florifera, the Ornus florifera or Howering ash tree, grows in the mountains of the south of France, and F. rotundifolia, the Ornus rotundifolia or round-leaved manna ash tree, is a native of Calabria and Sicily. Of the manna obtainable in Central Asia, several kinds are used in native medicine. One of these, in the form of small dark grains, is the turanjabin, said to be derived from the Alhagi maurorum; another, somewhat whiter, is the shirkhist or shaklu, which is believed to be produced in Käbul by a species of Fraxinus, but Bellew says it is from the Siah chob or blackwood tree. The shirkhist is the best kind known in India.

The shakr-ul-ashar or shakar taghar is a round cell resembling in shape a small gall, and is said to be produced by the puncture of an insect on the Calotropis procera, the akh or mudar; it has a sweet taste. A fifth kind is mentioned as being obtained on an umbelliferous plant. Manna of the tamarisk, in China is called Ching-ju, CHIN. Turanjabin, in the Kābul bazars, is in small round tears, while shirkhist is in large grains, irregular masses, or flat cakes.

The manna of ancient Assyria (Exodus xvi. $15,31,33$, and 35 ; Numbers xi. 7 ), in Turkish called Kudrat-ul-halwassi, or the divine sweetmeat, is found on the leaves of the dwarf oak, and also, though less plentifully, and scarcely so good, on those of the tamarisk (the Tarfa of the Arabs), and on several other plants. It is collected in the early part of spring, and again towards the end of autumn; in either case the quantity depends upon the rain that may have fallen, or at least on the abundance of the dews, for in the seasons which happen to be quite dry, little or none is obtained. People go out before 
sunrise, and, having placed cloths under the oak, larch, tamarisk, and other shrubs, the manna is shaken down from the branches. The Kurds eat it in its natural state as they do bread or dates, and their women make it into a kind of paste, being in this state like honey, and it is added to other ingredients used in preparing sweetmeats, of which all oriental nations are fond. The manna is partially cleaned, and carried to the market at Mosul in goat-skins, and there sold in lumps, at the rate of $4 \frac{3}{4}$ lbs. for about $2 \frac{1}{2} \mathrm{~d}$. But, before using it, it is thoroughly cleaned from the fragments of leaves and other foreign matter by boiling. In the natural state, it is of a delicate white colour, or, as in the time of the Israelites, like coriander seed (Numbers xi. 7), and of a moderate but agreeable sweetness, and Calmet compares it to condensed honey. Burkhardt, however, says it is of a dirty yellow colour, slightly aromatic, of an agreeable taste, sweet as honey, and, when eaten in any quantity, it is purgative; he adds that the time of collecting it lasts six weeks. Under the Persian names gaz or gazu (Gaz, PERS., tamarisk), a glutinous substance like honey, deposited by a small green insect upon the leaves of the oak tree, is much used for making sweetmeats in Persia. It is a manna of the chemist. Gazanjabin is a manna produced on branches of the Tamarix Indicus by the punctures of the Coccus mannifera. This is often called Arabian manna, to distinguish it from turanjabin, Persian manna, and from the shirkhist or Khorasan manna, and from Sicilian manna.

Manna of Australia is obtained from the Eucalyptus viminalis, Labill., the Yarra yarra of the natives. It exudes from the places bored by the Australian Tettigonia. It differs from the European mannas, and is a kind of sugar. Another saccharine secretion occurs in Australia and Tasmania, principally on the leaves of the Eucalyptus dumosa or mallee tree. It is the Leup of the natives, and forms on the leaves small conical cups of gum covered with white sugary hairs. It is a secretion from an insect of the genus Psylla, and is very nutritive. It assumes a crystalline structure when dried. Dr. T. L. Phipson says (p. 89) a sort of mauna is produced in Australia and Tasmania on the Eucalyptus resinifera. A sweet substance exudes from the leaves, and dries in the sun's rays, and a strong wind shakes it down like a snowfall.

A manna from the Pinus cedrus of Lebanon sells for 20 to 30 shillings an ounce.

A manna sugar is obtained from Chamærops humilis, also from Pinus Lambertiana, and from the Quercus manuifera of Kurdistan. - O'Sh.; Powell; Wellsted; Royle, Ill.; Ferrier, Journal; MacGregor ; $G$. Bennett, Gatherings ; Dr. T. $L$. Phipson.

MANNA-NIR, in Malabar, from Manna, a seat, and Nir, a waterpot, alluding to the right of carrying the bridegroom through the street on the marriage day.

MANNARGUDI, a small town situated in lat. $10^{\circ} 40^{\prime} 10^{\prime \prime} \mathrm{N}$., and long. $79^{\circ} 29^{\prime} 30^{\prime \prime}$ E., 24 miles south-east of Tanjore. There is a fine pagoda with a popular car festival.

MANNO-DHARA. KARN. Labourers who execute heavy work, such as heaving blocks of stones, constructing earthen walls, etc.
MAN OF WAR BIRD, species of the genus Phæton, $\mathrm{Ph}$. rubicauda, $\mathrm{Ph}$. candidus.

MANOONGAN, Manoongan putih, and Manoongan manga are three plants of Borneo yielding caoutchouc. Their stems are 50 to 100 feet in length, and rarely more than 6 inches in diameter. The fruit is yellow, the size of an orange, and containing seeds as large as beans, each enclosed in a section of apricot-coloured pulp, highly valued by the natives. Other plants of Borneo yielding the gutta of commerce, besides the Isonandra, are species of Ficus and Willughbeia, that of the latter being the gutta soosoo.Burbidge.

MANOTIDAR, in the Bombay Presidency, a money-lender, a money-broker.

MANPAN. MAHR. Honorary and prescriptive rights claimed by the hereditary patel and other village office-bearers at weddings, and the right of precedence at processions; the rights and privileges enjoyed by the patels of Mahratta villages at the three Hindu festivals of the Pola, the Dasara, and the Holi. The Pola is held on the day of the new moon of the month Srawan or Bhadrapad. The bullocks of the whole village move in procession under the 'toran' or sacred arch dedicated to Maroti, which is made of twisted ' $m o l$ ' grass, and covered with mango leaves. The gurhi, or sacred pole of the patel, is borne aloft to the front; the patel gives the order to advance, and all the bullocks, his own leading the way, file under the toran, according to the respective rank of their owners. The villagers vie with each other in having the best painted and decorated bullocks, and large sums are often expended in this way.

At the Dasara, a male buffalo (hela) is provided at the village expense for a solemn sacrifice to the goddess Durga. The buffalo is taken up to the flagstaff (jhenda) in front of the village town hall (chouri), where it is slaughtered by the patel's own hand, and then carried away by the Mhars to be eaten.

At the Holi, the patel and astrologer (joshi) meet and invoke the demons (rakshas) in whose honour it is held. The patel then lights the sacred fire. He provides the red powder (gulal) and other accessaries of the festival.

MANSA, a Native State of Mahikanta, in the province of Gujerat, Bombay. It is situated in the Sabarkanta subdivision, and surrounded by the Gaekwar's territory. The chief is descended from the Chaura dynasty, one of whom founded Anhilwara Patan in 746.-Imp. Gaz.

MANSAB. ARABO-HINDI. An office or dignity, a military title of rank conferred by the Moghul government. Mansab-dar, the holder of a mansab; at Muhammadan courts, a military or civil officer. $-W$.

MANSAROVARA LAKE or Mansaraur or Manasa-Saras, a lake in Hundes, is in Tibetan called Tsho-ma-phan. It is the same with the Binda Sarovara of Hindu mythology, produced from the heart of Brahma. It is called Anandat. Four rivers are supposed to spring from it, and that it is near Su-meru, the abode of gods, the Vindhyasaras of the Puranas. It is a place of Hindu pilgrimage of peculiar sanctity. There are several Buddhist monasteries on its banks.As. Rs., 1816, xii.

MAN SINGH, a ruler of Jeypore, who ascended 
the throne A.D. 1592. He commenced a palace at Amber, which Siwai Jye Singh finished. He also erected an observatory at Benares, and a temple at Bindraban. He was one of Akbar's generals. His sister was married to Jahangir, and was the mother of prince Khusru.-Cal. Rev., January 1871.

MANSUR of Hallaj, a religious reformer of the Shiah sect, who constantly repeated the Arabic assertion Ana'l Hakk, - I am the Truth. He was executed for his temerity, A.H. 306, A.D. 919.

MANSUR, a khalif who built Baghdad, A.D. 763 , out of the ruins of Ctesiphon.

MANSURA. Brahmanabad was the capital of Lower Sind in the time of the dynasties that preceded the Arabs, and is supposed to be the modern Hyderabad; but it seems to have intermediately borne the name of Mansura after the Arab conquest. - Mansura, Alor, and Multan are places of note in the valley of the Indus, noticed by early travellers to India.-Elliot.

MANSURCOTTAH and Calingapatam, in Telingana or the Northern Circars, are increasing seaports. Aska is a large sugar manufacturing place.

MANTAKHAB-ut-TA W ARIKH, a book finished in the end of the fortieth year of Akbar's reign. It was written by Abdul Kadar of Badayun, and is a history of the Muhammadan kings of India.

MANTAPA, the porch in front of a Hindu temple, the part of the building known in architectural nomenclature as the 'pronaos.' The word is also written Munduf, also Mantapam. The mindra or cella, in Hindu temples, contains the statue of the god. The Mindra, dedicated to the linga, is a double-roofed Gothic building, the body square, but the upper part short and tapering to a point. It contains one, two, three, or more rooms, about three cubits by four, with a porch in front for spectators. The centre room contains the lingam. Mindra, says Ward, means any edifice of brick or stone; but custom has appropriated it almost exclusively to the temples of the lingam. Figures of the deities are placed there on being brought from the mindra on days of festivals for worship.-Ward's Hindoos, ii. p. 1 ; Cole. Myth. Hind. p. 390.

MANTIS. Several species of this genus of insects occur in India,-M, superstitiosa, M. aridifolia, and M. extensicollis. M. tricolor, Nietner, the mantis of the coffee tree, is green, lower wings reddish, with large blackish spot at the posterior margin. The female is 1 inch long, with $1 \frac{1}{2}$ inch of an expanse of wings. The male is considerably smaller. The eggs are deposited upon coffee leaves, in cocoon-like masses of $\frac{5}{8}$ of an inch in length, but drawn out further at each end. The Mantis religiosa, amongst the peasants of Languedoc, is held almost sacred; they call it the Prega Deori or Prie Dieu.

The Mantidæ are usually of the colour of the leaves or foliage amongst which they dwell. They are all predatory. See Insects.

MANTRA. SANSK. Counsel; hence Mantri, a counsellor. In Hinduism, a prayer, an invocation, a charm. Mantra is from Matr, to repeat in the mind, and is applied to a formula or litany in use in invocations of the Hindus. There are many of these. The great mantra of the Brahmans is styled the Gayatri, and is deemed the holiest verse of the Vedas; it is an invocation to the sun. Its words are in Sanskrit, and are O'm! Bhürbhuvă ssuvăhā, O'm! Tatsa vit'hru varênnyâm; B'hargo devâsayâ dhimahi dhiyo yonaha pracho dayath,the translation of this prayer being $0^{\prime} \mathrm{m}$ ! Air, Earth, Sky. O'm ! let us meditate on the supreme splendour of the divine Sun: may he illuminate our minds. That of the Srisampradaya or Ramanuja sect of Vaishuava is said to be 'O'm! Ramaya namah,' O'm! salutation to Rama. A mantra generally consists of the name of some deity or a short address to him; it differs with various sects, forms the chief ceremony of initiation of the Hindus of all sects, and is communicated by the teacher to the disciple in a whisper; and many . mantra, or formulæ of prayer, are supposed to have a magic power. Six descriptions of charms or mantras are known in Gujerat, which are described in a series of works forming the scriptures on the subject, or the Mantra Shastra. A charm called Marun Mantra has the power of taking away life; Mohun Mantra produces ocular or auricular illusions; Sthambhun Mantra stops what is in motion; Akurshun Mantra calls or makes present anything: Wusheekurun Mantra has the power of enthralling; and Oochatun Mantra of causing bodily injury short of death. Mantra drooma is from Manan, to meditate, and Drooma, a tree.Rasamala, Hindu Annals, ji. p. 403. See Gayatri ; Hindu.

MANU, from the Sanskrit root Manu, to think, in Hindu mythology is a titular name applied to fourteen progenitors of mankind, each of whom ruled the earth for a manwantara or period equal to $4,320,000$ years. The names of the fourteen were Swayam-bhuva, Swarochisha, Auttami, Tamasa, Raivata, Chakshusha, Vaivasvata or Satyavrata, Savarna, Daksha-Savarna, BrahmaSavarna, Savarna or Rudra-Savarna, Rauchya, and Bhautya. Manu Vaivasvata of the present period, the seventh Manu, is represented as conciliating the favour of the Supreme Being by his piety in an age of universal depravity. He is noticed in the Satapatha Brahmana, which contains an important legend of the deluge, of which he was warned by a fish, and told to build a ship, which the fish guided. Manu alone was saved, but Ida was produced from his side, and the two were the parents of a new race of men. He is the Noah of the Hebrews.-Warren, Kala Sanhita.

MANU is the name given to the author of the Manava Dharma Sastra, comprising the Hindu system of duties, religious and civil. It is ealled the Institutes. Mr. Hunter fixes the date of Manu's Code as B.C. 500 ; B.c. 900 used to be assigned to this ancient work, and some have recently brought it down to A.D. 1200 . It relates to Hinduism and the laws and customs of the various races following some form of Hinduism, and therefore seemed to Chevalier Bunsen to be a patchwork. It undoubtedly preceded, or was at least contemporary with, Buddhism. But it is posterior to Kapila, for the philosophy is that of the Sankhya to a certain extent, and it is probable that the 6th century B.C., the date given by Professor Wilson as that of parts of this compilation, is the correct one, and the book as it has come down to us seems merely an abbreviation of a far larger and more ancient one,-Elphinstone says B.c. 900 . It opens with an account of the creation, and goes through the category of every difficulty in which a man, a state, or a community can possibly be found. It embraces the whole duty 
of man and of men, religious, political, social, domestic, and private. The duties of monarchs are laid down with as little ceremony as those of the bumblest panchala. It was verbally translated from the original, with a preface by Sir William Jones, about A.D. 1770, and this, with the subsequent Sanskrit text by Professor Haughton, and the translations of Haughton and Loiseleur Deslongchamps, made this book known in Europe. Professor Wilson is of opinion that the Institutes of Manu, though disfigured by interpolations, and only cast into their present form in about B.C. 200, are still entitled to date many authentic portions of their text from B.C. 800, which was the estimate of Sir William Jones. In fact, the Institutes are a compilation of the laws of very different ages, races, and states of society. Many are word for word the same as the Sutra of some of the oldest rishi, and there are other unquestionable proofs of high antiquity. The people of Bengal, Orissa, and the Dravira race of the south were not Hindus when one passage was written, and Dr. Caldwell places Dravira civilisation through the Brahmans six or seven centuries after Christ. There is no mention of, or allusion to, Siva or Krishna, which places parts of the work before the Mahabharata; there is evident familiarity with the Vedas, persons and legends being alluded to not found anywhere else. All such passages we could consent to consider at least as old as B.c. 800 . On the other hand, there are many references to the merit of Ahinsa, 'noninjury of animal life,' and these are probably later than Buddhism; and there is mention of the China race, a name that sinologues say is not older than two centuries B.C. It is therefore believed that the work may have been put together about that time, though very much of it is a great deal older. The present estimation of the laws of Manu is somewhat different from that of Sir William Jones. Many of the laws are doubtless extremely ancient, in the same way that the laws "Thou shalt not steal" and "Thou shalt not kill' date back in all probability to the primeval period when man first became a living being. It thoroughly recognises caste. It inculcates the worship of inferior gods and goddesses, of the elements, and of the heavenly bodies, and the caste of Brahmans is to be held in great reverence.

It is not included amongst the Sutra or sacred revelations, but amongst the Smriti or traditions. Indeed, the term Smriti implies recollections, a name which seems to indicate pretty precisely the character of the code of Manu. There is a form and completeness about the work which indicates that it was compiled long after the age which produced the Pentateuch; and, judging from its intensely Brahmanical character, we should place it nearer to the Puranic age than to the period when the elemental worship, as exbibited in the Vedas, was the religion of the people of India. In a word, the laws of Menu are not to be illustrated by the Vedas; but by the Puranas; they belong not to the religion of the patriarchs, but to that of the priests and kings. The Vedas exhibit the oldest form of the Hindu religion with which we are familiar, and that was nothing more than the worship of the elements, of Agni or fire, of Indra or the rain-giving firmament, of Varuna or the waters, of Tayu or the wind, and of some mino deities. Amongst the

first items of information we receive on Hindu history is in a passage in Manu which gives us to infer that the residence of the Aryan race was at one time between the rivers Saraswati (Sersoty) and Drishadwati (Kaggar), a tract about 100 miles to the north-west of Dehli, and in extent about 65 miles long, and from 20 to 40 broad.Prin. Ind. Int. p. 223 ; Elphinstone, History of India, i. p. 388.

MANUEL FARIA DE SOUZA, author of Asia Portuguesa, etc., Lisbon 1666.

MANUFACTURES of the south and east of Asia are largely articles for personal or domestic use. Compared with the industries of Europe and America, there are no great shipbuilding establishments, or metal foundries, or glass-works. The people of India make excellent glass, but they turn out only prettily-tinted bangles for women's bracelets. Candles, clocks, watches, machinery, and mill-work are all imported from foreign countries, as also are much of their cotton and silk and woollen goods, porcelain, hardware, malt liquor, and paper.

In 1882-83, the British India total imports from and exports to foreign countries were respectively to the value of 65 and 84 kror, as under:-

Imports, Rs. $65,55,20,362$, viz.

Merchandise, Rs. 52,09,86,720 | Treasure, Rs.13,45,33,642 Exports, Rs. 84,52,67,860, viz.

Merchandise-

Foreign goods, . . . . Rs. 2,80,24,163

Indian produce and manufactures, $80,59,82,631$

Government stores, . $\quad 8,42,578$

Treasure, . . . . 1,04,18,488

The following are the details of the imports and exports of manufactures:-

\section{British India Imports, 1882-83-}

Apparel, . Rs. 76,97,371 Malt liquor, beer,

Cabinetware

furniture, . . 5,07,736

Caoutchouc manu-

factures, work, $1,34,23,985$
Matches, lucifers, 17,44,301

Candles, . . 8,89,749 Mats, . . 1,25,631

Carriages, carts, 5,12,134 Metals, brass, cop-

Clocks and per, iron, lead, watches, - 9,23,937 mercury, steel,

Corks, . . : 2,35,797 tin, zinc, 4 4,61,38,588

Cotton goods, twist and yarn, $24,81,00,625$ Oil-cloth, floor-

Earthenware, Paints, colours, porcelain, . 17,00,022 materials,.

Fireworks, . 5,64,183 Paper, paste-

Flax manufactures,

$14,00,923$

Gilass, .

Hardware, cutlery,

Instruments, apparatus,

Ivory manufac-

tures, '

precious stones, $30,69,858$

Jute manufac-

tures, . 3,97,938

Leather and mant-

factures of, 19,58,873

board,

$1,68,625$

$23,44,502$

Perfumery,

$33,42,989$

- 6,33,356

Printing materials, $3,46,063$

Railway plant, $1,11,64,342$

$79,17,912$ Silk and manu-

factures, . . 97,77,693

Soap, : $6,04,117$

Stationery, . 14,75,814

Sugar, : $1,08,69,610$

Tea, . . 19,30,515

Tobacco, : : 8,36,087

Toys, . . 10,68, 167

Umbrellas, . $23,28,292$

Wool manufac.

tures, . . 98,48,285

British India Exports, 1882-83-

Apparel, . . Rs. 5,79,148| Hemp manufac-

Books,. . . 2,12,343 tures, . . Rs. 3,176

Cabinetware, - 2,01,872 Ivory manufactures, 15 Coir manu-

factures, Jute manufac-

Cordage, : : 2,84,106 Oils, : : $42,52,768$

Cotton goods, $\quad$ Opium, . . 11,48,13,764

twist, yarn, 2,57,20,616 I Perfumery, . . . 67,729 


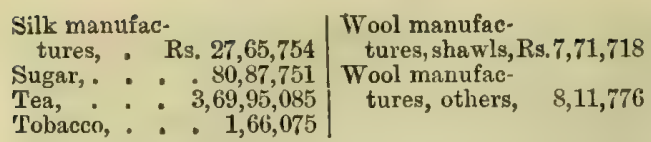

The people of several of the races in the south and east of Asia are skilled in many of the industrial arts, and they are diligent in their respective callings, but they are not producing the manufactures needed by foreign nations. In field and garden cultivation, in the economy of water, and the utilisation of manures, no nation excels the Chinese, and they are stimulated by the example of the imperial family, the head officials annually ploughing the first field, and the empress and her attendants taking an interest in the silk-worms and their produce. In spinning, in the weaving of shawls and carpets, and dyeing of cotton and silk stuffs, of such kinds as are suitable for the clothing that they wear and to their habits, the weavers and dyers in SouthEastern Asia are not approached by any European race. Nevertheless, as will be seen by the above lists, India has to import Rs. $24,81,00,625$ worth of cotton goods; but yet holds its own in the finer artistic work of its mushroo and kimkhab, its satins and brocades of Ahmadabad and Benares, and its delicate muslins of Dacca and North Arcot. The shawls of Kashmir and the Panjab have no rival; the carpets of Persia, Kirman, and Turkestan are readily bought by the wealthy of Europe, and the Rampur chadars from the Himalaya are to be purchased in the fashionable shops of London. It is the highlyfinished, machine-made articles of Europe and America that are imported into India. The manufactures of Europe have a mechanical perfection of finish, which is quite out of place in the bold free-hand composition of colour and form characteristic of the best native work. The barbaric splendour of Indian jewellers' work, in jewellery proper and as seen on arms and armour, is due to the lavish use they make in it of diamonds, rubies, emeralds, and other gems. Their work being manual, they need use only flat diamonds, mere scales so light that they will float on water, and rubies and emeralds full of flaws, - stones, in fact, which have no value as gems. But European jewellers' work necessitates the use of gems only of the purest water, and far too costly to be used as mere decoration, or except for their own effect solely.

Cotton-weaving is a very ancient industry of India. Cotton cloth has always been the single material of Indian clothing for both men and women, except in Assam, Burma, and China, where silk is preferred. The author of the Periplus enumerates a great variety of cotton fabrics among Indian exports. Marco Polo, the first Christian traveller, dwells upon the cotton and buckram of Cambay. But the productions of the handlooms of to-day are undersold by the machine-made fabrics of Europe; and without foundries and mill-works the cost of erecting even a spinning mill in India is treble what would be required for one in Great Britain, and the erection of weaving mills has been almost avoided. The people of India are importing twist and yarn, and are weaving these into the fabrics they require. These are chiefly the stout cloths used by the labouring classes. The cotton carpets of India, called shatranji and darri, are usually white, striped with blue, red, or chocolate, and sometimes ornamented with squares and diamonds. Their woollen or pile carpets, known as kalin and kalicha, have attained so much popularity in Great Britain by reason of the low price at which they can be placed on the market.

Europe and America recognise the artistic skill of the goldsmiths and silversmiths of India; also that of ivory carvers of Travancore and China, and that of the lacquer workers among the Shans of Burma, China, and Japan; the enamellers of Jeypore, the koftgari inlayers of the Panjab, and the tutanague inlayers of Beder. The pith models of Madura are much admired, as likewise have been the horn and woodwork armour, horse and elephant trappings of India. These and much of the loom-work hold their own among the people.

In the N.W. of India, in the vicinity of the Himalaya, blanketing, called loee, is made of red and white patterns at Bulrampore, Muzaffarnagar, Rampur, and Gujerat. The Rampur chadar is well known in Britain for the remarkable warmth, lightness, and softness of its texture. It is said to be made of pashm wool.

The namad or namda felts are largely made in all the western parts of India, also in Sind and Baluchistan. Throughout the greater part of India, every agricultural labourer has a cumbli or coarse blanket. The usual mode of wearing them is to bring the two corners together, one overlapping the other, and the eud being tucked under, thus forming a hood which is placed over the head, and protects the shoulders and the body in the day, and at night they are converted into bedding, one-half doing duty as a mattress, the other as a blanket or covering. The puttoo, a woollen fabric of Kābul, is made from the under hair of goats, and when old is re-made into malida, a mixed woollen fabric.

The refined art of India is to be seen in its silver work, filigree or gilt, chased or engraved. Its koftgari work of iron or steel, inlaid or otherwise ornamented with gold, is mostly produced in the Panjab; also the Dekhan, Beder, and other work inlaid with silver.

Mr. Pollen describes the goldsmiths' work as precisely similar, in many forms, to the old Eitruscan goldsmiths' work as it has been recovered for us from tombs in Italy and elsewhere. The methods of working gold, now lost in Europe, are still in full use in parts of India; particularly that of fretting gold by soldering fine spines or hairs of gold wire as delicate in fact as thistledown, yet done by unscientific workmen possessed of certain chemical secrets, which they put into practice by traditional usages. Koftgari work is iron chased with a tool, into which soft gold, very pure, is afterwards hammered, the rough iron taking, by this means, permanent hold on the softer metal, which gets beaten into the fine scratches and hollows. The most imposing use of this material is in the decoration of arms and armour. It is also used to decorate buckles, clasps, work-boxes, caskets, arms, headpieces, sword - blades, sword - hilts, and various small objects for European use.

Baroda artisans also ornament iron and steel by hammering in gold, not as in the koftgari, but in discs or masses, polishing afterwards in the lathe. 
Cutch and Ahmadabad is famed for its repoussé work.

The inlaid work of Beder is usually silver, sometimes gold, inlaid on a black amalgam in bold, flat patterns; sometimes seemingly it is of pure tin, which has all the display of silver. The bedri work of Beder is applied largely to the domestic utensils in use by the people, except where Europeans give special orders. It is of black metal (an amalgam), inlaid with silver and gold, in bold, flat patterns. It is made by casting the vases; the core is first formed, then a vase of wax is formed round it, and a mould over that. The wax is melted out through holes made on purpose, and this leaves a mould for the vase. When the vessel is cold, it is chased or roughed out in designs, and the soft silver or gold gently hammered into it.

The goldsmiths' and jewelled productions of India are minute in an extraordinary degree, of elaborate handiwork, obtainable only where labour is cheap. In the enamels of Jeypore, for example, gold itself is completely invested with enamel colours, some of them encrusted with precious stones. For translucent enamels, that is, enamel colours painted on gold (generally), or gold-leaf, which gives light and splendour to the colours, Jeypore is the finest school. A shield of rhinoceros hide, decorated with a border and bosses of this translucent enamel, was sent from Cutch to the Exhibition of 1851.

Brass and gilt basins are covered with a diaper of ornament. Brass work of Moradabad, Jeypore, and Nagpur has the body of the work in brass, and pure tin is hammered over it, leaving spaces of the ground as ornament. The polished surface of the tin is so white and bright as to have the appearance of silver of plain manufacture.

Silver filigree work, gilt, chased, and engraved, is produced in many parts of India and of Burma ; the koftgari work of iron and steel, inlaid or otherwise ornamented with gold, is chiefly an art of the Panjab, employed on shields, sword-hilts, necklaces, bracelets. In all these, fineness and elaboration, both in design and workmanship, are held in the highest esteem, and secondary qualities of this kind produce good results in small articles of luxury. It represents the earliest metallic traditions with which we are acquainted.

In the decorative manufactures of Kashmir, designs in outline and colours are prepared for their shawl manufacturers, and in several parts of India blocks are used for printing on calicoes and on the borders of silks.

The chidree is a form of printing in Bombay, which consists in tying up the design previous to dyeing the cloth.

Brass stencil plates are used for the decoration of floors during festivals. The workman produces these stamps without drawing any preliminary outline. In one hand he holds the punch and in the other the hammer, and punches the metal as it rests on a piece of flat board until the design is completed. In use, powdered marble is passed, by a gentle tap, through the perforated plate, and leaves a white dotted outline on the floor, the design being afterwards filled in with powders of various colours. The Dewali is the best time to see these kunna drawings, but they are also much used on other festivals and weddings.

The colours of the cotton and silk sarees in use amongst all the Hindu women of the south of India show great skill in dyeing. The loongis of Sind have also attracted much praise. Bedcovers, called palempores (palang-posh), were at one time very largely exported from the east coast of the Peninsula, and are again making their way in the fashionable shops of London.

In their ivory carvings, lacquer work, and dyeing, China and Japan are in advance of all other races. The Chinese and Japanese excel in ceramic manufacture, which the caste rules prevailing in India utterly debar the Hindus from attaining to anything beyond the cheapest unglazed earthenware, and Muhammadans of India have accepted this position. They are restricted to unglazed earthen pots for holding water, pots for cooking, pans for frying or baking.

The stone vessels of Carwar are made by turning on a lathe their indurated talc or talcose slates, sometimes light grey, sometimes darker; it is an object of great curiosity. Representations of mosques, yoblets, etc., are cut from it, but it is also much prized for its intrinsic merits. Pickles, milk, and other substances likely to suffer in contact with copper vessels, or to be absorbed in common pottery, are kept by careful housekeepers in these pots.

Metal workers in gold, silver, copper, brass, tin, zinc, iron, and steel, and for all articles of jewellery and articles used in Hindu work, are very numerous, and weapons of all kinds, daggers, swords, and matchlock barrels, are largely made. The larger articles being the abkhora or drinkingcup, attardan or perfume box, gulab pash, rosewater sprinkler, gulab dan or rose-water holder, the hookah, the kummul or pedestal, the pandan or betel-leaf holder, the pullye or lustral spoon, and the various kinds of lamps. The ruder wares are the gella and chumboo, water-pots, the hookah bowl, and the chillum for the fire; the handi, ghagar, or chatty for carrying water in; the mudka, topee, and towlee, cooking pots; the purrel, baking pot; the tawa, frying pan, and the thali dish.

The embroidery of Asia has been famed through ages, and still takes a high place. The chogha, made of the coarser wool of the goat and camel, is embroidered in Kashmir and the Panjab. The shawls of Kashmir and the Panjab are beautifully embroidered.

Muslin is embroidered with silk and gold thread at Dacca, Patna, Dehli, and Madras. Sind and Cutch (Kachchh) have special embroideries of coloured silk and gold. Ieather work is embroidered in Gujerat. At Gulbargah and Aurangabad, velvet (makhmal) is gorgeously embroidered with gold, to make canopies, umbrellas, and housings for elephants and horses, for use on state occasions. A chadar or shawl made by order of a late Gaekwar, was composed entirely of inwrought pearls and precious stones, disposed in an arabesque fashion, and was said to have cost a kror of rupees. Although the richest stones were worked in it, the effect was most harmonious. When spread out in the sun, it seemed suffused with an iridescent bloom, as grateful to the eye as were the exquisite forms of its arabesques. Sir George Birdwood.

MANÚK-DEVATA or Burung-devata. MAL., JAV. Lit. bird of the gods, or bird of paradise. The high value set upon them awakened the 
cupidity and the fraud of the Chinese, who made up from parrots, parrakeets, and others, artificial birds of paradise. Their various names are Manuk-devata, MaL., lit. God's birds; Burong mati, MaL., dead birds ; Passaros de Sol, Portuguese sun birds; and the English name is birds of paradise. They are unknown in Ternate, Banda, or Amboyna. The Paradiseidæ are a group of moderate-sized birds, allied in structure and habits to crows, starlings, and to the Australian honey-suckers, but they are characterized by extraordinary developments of plumage, which are unequalled in any other family of birds. Many naturalists arrange them into two families, Paradiseidæ and Fpimachidæ. Paradisea apoda, Linn., the great bird of paradise, has a dense tuft of long and delicate plumage, which comes out from each side of the body, from beneath the wivg, sometimes two feet long, very glossy, and of an intense golden-orange colour.-Wallace, ii. 267.

MANURE. Zibl, ARAB.

Khad, Khau, Eru, Paus,

HiND.

The productiveness of any soil depends principally on its natural or artificial capability of retaining or transmitting its moisture, the vehicle, at least, by which the nourishment is conveyed to plants. The soil whose constituent parts are best adapted for retaining a sufficient supply, and transmitting a proper portion in very dry weather to the plants growing in it, without holding it in injurious quantities in the time of very wet weather, is possessed of the principle of vegetation, and will be found to be of the most productive nature. The too tenacious clay soils must be made artificially friable, by drainage and the admixture of marls, sands, etc., and kept so, and be pulverized and mechanically altered, before they can become productive. Until this is done, such soils resist effectually the enriching influence of rains and dews, which merely fall on their surface, and either run off or lie there without penetrating into them. The sun and wind also may beat on them and blow over them, but they can never waken up the dormant energy that lies within; they only by their repeated attacks dry and barden the surface, crack it into irregular portions, and more firmly lock up any languid and dormant principles of vegetable life that may be within the mass. When clay is in excess, it is remedied by the application of sand, chalk, marl, or burned clay, light unfermented manures, and perfect pulverization, to make the soil friable. There are in soil eleven substances necessary for the growth of vegetables, viz. potash, soda, lime, magnesia, alumina, silica, iron, manganese, sulphur, phosphorus, and chlorine; and soil is composed of two classes of ingredients,-one, the inorganic or mineral; the other, the organic, or such as have at some time formed parts of individuals of the animal or vegetable kingdoms. Certain phosphates, though present in soil in the smallest quantity, are its most important mineral constituents, and are derived principally from the animal kingdom; and the following substances, procurable in considerable quantities in India, may be employed as manures:-Animal manure, stable manure, both fresh and old, dung of all animals ; guano, pouvre, night-soil, bones of all animals, fresh, calcined, or merely crushed, burnt earth, dead animals' blood, and animals' hair, hoofs, horns, parings of skins, offal, urine, feathers, fish; and the quickest way to utilize animal substances is to throw them into a stone-lined tank, with water, quicklime, and wood-ashes; the tank should be kept covered, and the liquid parts may be run off from below. Weeds, green, dry, and burnt, branches and leaves of trees both fresh and dry, the leaves of oil-producing plants and those that contain milky juices being the best, as they yield nitrogen, ammonia, and carbonic acid; rotten wood, tan-bark; straw, stubble, roots, etc. : lime, burnt shells, old mortar, gypsum, refuse of soda water, sulphuric and nitric acid, manufactures, broken bricks and tiles, silt and sand from tank and river beds, marls, soda, potash, and magnesian earth, road-dust, house-sweepings, wood-ashes, coal-ashes, burnt cow-dung, muriates, carbonates, sulphates, nitrates and acetates of potash and soda, soot, gas, liquor and sulphate of ammonia, phosphate and superphosphate of lime tartrates and acetates of iron, refuse from dyeworks, leaf-mould; leaves both green and dry, if steeped for a week in water, decay afterwards much more rapidly, and the brown liquor that comes from them is good liquid manure; the leaves should then be laid in alternate layers with earth and half-burnt weeds, and the heap should be covered with matting to prevent the escape of the moisture and gases. If watered and turned once in ten days, the leaf-mould will be fit for use in three months. Keep dung-heaps covered, and dilute liquid manure in them with one or two waters, by which the escape of ammonia will be in a great measure prevented. Liebig says a soil will reach its point of exhaustion sooner the less rich it is in the mineral ingredients necessary as food for plants. But we can restore soil to its original state of fertility by bringing it back to its former composition, i.e. by restoring to it the constituents removed by the various crops of plants. A fertile soil must contain in sufficient quantity, and in a form adapted for assimilation, all the inorganic materials indispensable for the growth of plants. It is obvious, he remarks, that we furnish the conditions essential to the formation of starch or of sugar, when we supply to the plants their necessary constituents, i.e. such as we find always present in them. The sap of such plants as are rich in sugar or in starch contains much potash and soda, or alkaline earth. As experience proves that a deficiency of alkalies causes a defieient formation of woody fibre, sugar, and starch, and that, on the contrary, a luxuriant growth is the consequence of their abundant supply, it is obvious that the object of culture, viz, a maximum of crops, cannot be obtained unless the alkalies (necessary for the transformation of the carbonic acid into starch or sugar) be supplied in abundant quantity, and in a form fit for assimilation by plants. In fact, the principal object of scientific agriculture is to restore to land, in whatever way the restoration may be most convenient, the substances removed from it, and which the atmosphere cannot yield. Professor Johnston says lime is indispensable to the land; every $1000 \mathrm{lbs}$. of fertile soil contains $56 \mathrm{lbs}$. of lime; every 1000 lbs. of less fertile, 18 lbs.; and of the barren soil, only $4 \mathrm{lbs}$. Vegetable matter, i.e. woody fibre, in the state technically called humus, according to Liebig, does not afford nourishment to plants in the form in which we see it in soils, being, in 
fact, very nearly insoluble, and therefore incapable of being taken up by the roots, which cannot take up any solid matter, but only as the carbon. A mixture of two or three earths, such as lime, silica, and alumina, is better fitted to absorb moisture and gaseous matter than either of the earths taken singly.

The Chinese are successful gardeners, and use the night-soil largely diluted without decomposing it. In India, cattle manure from the denudation of forests is too often made into fuel. The scanty manure heaps, with the exception of those rare instances where sheep can be hired to fold on the land, form the main resource of the country, and they consist almost entirely of the dung of lean cattle, and of the ashes of that which has been used as fuel; and the soil never can be kept in any other than in a very low and exharsted condition. It is robbed of its vegetable matter, because this is wanted to feed cattle, and, from the absence of trees, there is no means of procuring leaf manure. It is deprived of its phosphate of lime, which is very partially replaced, and of its potash, which can hardly be said to be replaced at all. A Madura native district officer, writing of the subject, says: 'I have not known a case in which, even with the greatest care, a ryot would have been able to secure, by collecting the dung of his own cattle, sweepings, etc., of his house, a quantity of manure sufficient for his field; nor can any be purchased at any reasonable price, since every one is careful to collect as much manure as he can.' In Kurnool, in dry cultivation, manure is never used, as it is all required for the irrigated lands. No village in the Panjab has enough manure for more than its best lands. But in many instances the cultivator has not, in consequence of the scarceness of pasture, even full command of his paltry manurial resources. In parts of the country the cattle are brought home every night to the sheds, but the bulk of the cattle have to be driven off to distant pastures, and do not return till the end of January, or early in February. In Bengal, even with such an exhausting crop as jute, no manure in many instances is used.

The native cultivators at Farrakhabad for ages liave used the night-soil for manure. As much as Rs. 15,000 to Rs. 20,000 are paid there by the cultivators to the sweepers, and their lands yield a triple crop of maize, potatoes, and tobacco. At Dinapur, a cultivator who used some poudrette for his field was, for so doing, fiued five rupees by his caste men. At Farrakhabad, careful inquiry showed that a household of five persons furnish enough manure to fertilize 12-20ths of a bigha; and a plough with its usual complement of seven head of cattle did the like for one bigha and 12-20ths of laud.

In no country in the world is the necessity for manuring the land more appreciated than in India, and in few is the supply more wasted. It is carelessly collected and stored, and for the eight dry months of the year the sweepings of the stable and cow-house are used as fuel. The bones of dead animals are lost.

The practice of sowing the sunn plant for the purpose of a green manure proves that the natives appreciate the effect of manures decomposing in the soil. The use of liquid manure, specially carted for the purpose of distribution, is common in some parts of the country. The high manurial value of indigo water is well known, and largely used wherever available. The sonai or jute water, in which jute has been steeped, is equally valuable. Many of the plants, Janjh, HrND., growing in jhils, tanks, and other standing water, are useful. Water impregnated with the decomposed plants of the genera Ceratophyllum verticillatum, Hydrilla verticillata, Vallisneria, Lemnia, Pistia, Marsillea quadrifolia, Azolla binnata, Salvinia verticillata, and Salvinia cucullata, may be applied with great advantage to the soil. The species of Chara (C. vulgaris) in Europe. $1000 \mathrm{lbs}$. of green chara were found to consist of $158 \mathrm{lbs}$. of carbonate of lime, mostly deposited on the plant itself, $8 \mathrm{lbs}$. of chlorine, $12 \mathrm{lbs}$. of soda, and $596 \mathrm{lbs}$. of water. Nitrate of soda and superphosphates (viz. dissolved bones, bone-ash, and rock phosphate), with potash, magnesia, etc., are the fertilizers of the day.

The Calotropis gigantea is valued as a manure, and is ploughed into the ground, as also are the leaves of the cassia. In Afghanistan the dung of camels is carefully avoided, from a belief that it impregnates the soil with saltpetre.

In Rangpur, refuse indigo weed, which is thrown out of the vats, is used either fresh or after rotting like dung. Water from indigo vats is also used on poor lands. Oil-cake from mustard seed is applied both before and after sowing or planting in the cultivation of sugar-cane, wheat, barley, oil-seeds, etc. Oil-cake soaked in water and applied to the sugar-cane tops previous to planting prevents white ants' attacks. Weeds, straw, husks are burnt and strewed on the field. But throughout India, the country is for the most part destitute of wood, and firewood, baving to be brought from great distances, is so scarce and dear that dried cattle dung is the usual fuel; the grass is short and scanty; the straw of the various crops is entirely consumed by cattle, which, with the exception of the finer kinds of draught breeds, are necessarily lean; the proportion of cattle, too, to the cultivated area is small, and as the food is extremely deficient, the manure is not only poor in quality, but small in quantity.-Ben. As. Soc. Journ., April 1848; Hull, p. 311.

MANIVAR PIALA, amongst the Rajput races a favourite expression, and a mode of indicating great friendship, "to eat off the same platter (thali), and drink of the same cup (piala).' Tod (Rajasthan, i. p. 183) relates how a Rajput pledged another's health and forgiveness in the manwar piala, on which they made merry, and in the cup agreed to extinguish the remembrance of their feud.

MANYAM, KARN., from the Sanskrit Manya, or from the Arabic Inam, respectable. In the south of India, land held free or at a low assessment in consideration of services done to the state or the community. The tenures are of many kinds, as Tarapadi Manyam, Dumbala or Sanad Manyam, Sarva Manyam, and Ardha Manyam. The Manyam, in the Tamil country, is an alienation of state demands. $-W$.

MANYARG, Birar, and Solon are three tribes of Tungus, dwelling on the Nonni, who occupy the vast prairies above the Bureya mountains, and keep large herds of horses. They number 20,000 souls. See Tungus.

MANZAL. ARAB. A balting-place, a stage of 
a journey, a dwelling-house, a storey of a dwellinghouse; a stage in the spiritual development of the Muhammadans in the tarihat or way of salvation. MAOUTIA PUYA. Weddell. A nettle of India, growing up to 4000 feet. It is taller than Boehmeria nivea, but furnishes a similar fibre.

MAPILLA, in the plural Mapillamar, a Malealam word, cominonly written Moplah or Moplay, a native of Malabar, a descendant of the Arabs who first settled in Malabar, lit. the son (pilla) of his mother (ma), or sprung from the intercourse of foreign colonists, who were persons unknown, with Malabar women. The term is also applied to the descendants of the Nestorian Christians, but is in that case usually distinguished by the prefix Nasrani, while Jovakan from Yavana is prefixed to Muhammadan Mapilla, whose usual title is Maraikan or Marakan. The Mapilla of both classes are numerous in Malabar.

MAPLE. Several of this family of trees, the Acer genus, occur in the Archipelago, Himalaya, Kashmir, and Japan. They are trees principally of temperate Europe, Asia, and America, having opposite and mostly lobed leaves, with the veins radiating from the leaf-stalk. The sycamore (Acer pseudoplatanus, L.) is extensively planted in Britain. Its white, soft wood was much used for making trenchers, bowls, platters, etc. There might be introduced into India from the United States and Canada the sugar maple (Acer saccharinum, $L$. $)$, the sweet sap of which is collected in spring by tapping the tree to the depth of about half an inch with an auger, and inserting a spout. The juice is boiled down to a syrup, clarified, drained, and crystallized. Good sugar maples yield each about an average of four pounds of sugar in the season. The wood of this species sometimes exhibits beautiful curled and spotted markings (bird's-eye maple); such is much valued for inlaying and cabinet-work. Acer campestre, Linn., is the common maple of Europe. T'here are about 14 Indian species in the N.W. Himalaya, Assam, Burma, Bhutan, viz. A. Campbelli, cæsia, caudatum, Hookeri, isolobum, lrevigatum, niveum, oblongum, pentapomicum, pictum, Sikkimense, stachyophyllum, Thomsoni, villosum.

MAPPIA FETIDA. W. Ic. Gandapaana, SingH. A good-sized and very common tree in the moist forests of the western side of the Madras Presidency, and in Ceylon, from no great elevation up to 7000 or 8000 feet. It is very abundant on the Neilgherries.-Beddome, Fl. Sylv.

MAR. Amongst the broken tribes in Palamau and Sirguja are a few Mar families, who say that they came from Malwa. They live in good houses, and are careful cultivators. Some in Sirguja are of a yellow or tawny complexion, with handsome features, eyes well protected by prominent brow and nose, with good teeth and well-formed mouths, and of average height. Some have the same light complexions, with very flat features, and some are very dark. Mar or Mala is a name applied to or assumed by several people in different parts of India, but it may be that there is some affinity between all the tribes who bear it. It is the name assumed by the Rajmabal hillmen, who, from their language, are one of the Southern Dravidian nations.-Dalton, Ethnol. of Bengal.

MAR or Maar. Hind. A stiff clay or loamy soil, with some sand and vegetable mould.
Bundelkliand the term designates a rich black loam, also called Moti. Maradi in Bombay is an inferior red soil.

MAR. ARAB. A saint; Mar Yuhanna, St. John; Mar Jurjios wa Tannin, St. George and the dragon, the name of a place about seren miles from Beirout, to the east, where St. George destroyed the dragon. A small chapel, now a mosque, was erected to mark the spot near the bridge of the river of Beirout. St. George, Mar Jurjios, is said to have been martyred at the town of Lydda, now a heap of ruins, the most remarkable of which are the remains of a very handsome church built by Richard Cour de Lion, in honour of St. George. He is held in great veneration by Syrian Christians. In every church is to be seen a representation of his combat with the dragon, with the inseription Mar Jurjios in Arabic, or Ayros $\Gamma$ espros in Greek. - Catafago.

MARA or Manh, an evil nat, who subjected Sakya to varied forms of allurements whilst at Buddha Gya. Mara, the tempter, was the name given by the ancient Buddhists to the essence of the evil spirits.

MARA, SANSk., from Mri, to die. From this, words have been derived in many tongues, - moribund, mortal, mortality in English ; mort, death, in French; morire, to die, in Italian; mout, marna, marana, in Hindi. Maru, SANSK. ; Marubhumi, dry, sterile land; Maru-des or Marusthala, the sandy deserts between Rajputana and the Indus.-Wilson.

MARABOUT is a name applied to feathers of certain birds, and also to the birds themselves. Leptoptilus crumeniferus belongs to a group of storks, distinguished by the head and neck being naked or only covered with small hair-like feathers, the strong cuneate bill, and the large external pouch in front of the throat. It is found dispersed over the tropical portions of Africa, and is said to frequent the negro villages, and to assist the vultures in clearing off garbage of all sorts. Under its wings grow the beautiful plumes known as marabout feathers. Nearly allied to the marabout is the adjutant (L. argala), so well known in British India from its extreme voracity. In Pegu the name is given to the under tailcoverts of a species smaller than the common adjutant, and without a pouch, found all over Pegu, but not so numerous as they were, owing to their being so constantly disturbed and fired at. The beautiful dorsal plumes of the white paddy birds during the breeding season, are objects of commerce, and pass by the name of egret feathers.

MARAE, in the Society Islands, the temples at which human beings were offered to idols.Montgomery, p. 113.

MARAH of Scripture, supposed to be the modern Howara, with its bitter pools. Marah (bitterness). This name, in the form of Amarah, is now borne by the bed of a winter torrent, a little beyond which is a well called Howara, the water of which is bitter. The well rises within an elevated mound, surrounded by sand-hills, and a few date trees grow near it. Camels when thirsty will drink sparingly of this water, but the Arabs never attempt it. - Wellsted, ii. p. 43.

MARAKAL, Marakkal, or Mercal, a Madras measure of capacity of 8 padi. A padi contains 100 cubic inches. A marakal of rice or salt 
weighs 960 rupees $=24$ lbs. 6 oz, avoir., or 12 seers. This standard was fixed, 20th October 1846, at 28 lbs. $12 \mathrm{oz} .13 \mathrm{dr} .22 \mathrm{gr}$, , or $2 \frac{9}{10}$ the imperial gallon. $-W$.

MARAKAR, a titular appellation of the Moplah Muhammadans on the S.W. coast of the Peninsula of Iudia.

MARAMMAT, ARAB., HIND., from Imarat, a dwelling; at Muhammadan courts, equivalent to the Public Works Department.

MARANTACE $\mathrm{E}$, the arrowroot tribe of plants, includes the genera Phrynium, Maranta, Calathea. In the IVest Indies, arrowroot is obtained from the Maranta arundinacea, M. allongia, and M. nobilis, but also from the Canna glauca and C. coccinea, to both of which the local name of tous les mois is applied. In the E. Indies, arrowroot is prepared from M. arundinacea, also from M. rarnosissima, a Sylhet species. Mahabaleswar arrowroot is obtained from Curcuma caulina, Graham. Travancore arrowroot is obtained mostly from the Maranta arundinacea, but the fecula of Curcuma angustifolia and of the cassava meal from the manihot is likewise sold under that name. Curcuma angustifolia is also the source of an arrowroot prepared at Benares, Bengal, and Chittagong. A wild arrowroot plant grows in Cuttack, and arrowroot made of it is not distin. guishable from that of Maranta arundinacea, except, perhaps, by a slightly earthy taste and smell observable in the wild arrowroot, which is easily accounted for by its imperfect manufacture. Genuine Maranta arrowroot, when pressed, crackles beneath the fingers. Maranta ramosissima, Wall., a plant of Sylhet; its roots yield arrowroot. Maranta virgata, Wall. (Phrynium virgatum, Roxb.), grows in the mountains between Travancore and Courtallum. The Curcuma or East India arrowroot, as exported to England, principally from Calcutta, has a white and a brown variety. -Voigt ; Roxb. ; O'Sh.; Cat. Ex., 1862.

MARANTA ARUNDINACEA. Linn. Penbwa, BURM. A native of the W. Indies, but now grown in many parts of the $\mathrm{E}$. Indies. This produces the best $W$. India arrowroot, which is prepared by maceration of the roots in water, and conducting the further processes similarly to the mode of manufacturing starch from wheat, potatoes, or other farinaceous substances. The Maranta arundinacea was introduced in 18401841 into Ratnagherry, where it throve extremely well, though it is not grown to any extent. It was also introduced into the Tenasserim Provinces, and the arrowroot made from it was not inferior in quality to any. Maranta arundinacea is largely grown in Travancore, at Chittur near Arcot, in the Tenasserim Provinces, and at the Andaman Islands.

MARANTA DICHOTOMA. Wall.

Phrynium dichotomum, | Donax arundastrum, Lour. Roxb.

Mukto-pati, . . BENG.

Pati-pati,

Thalia cannæformis, Hor'sf.

Madra ". Then, ... . BurM.

This straight-stemmed Maranta grows in Coromandel, Bengal, Sylhet, Assam, Tenasserim, Siam, Cochin-China, Moluceas, and New Hebrides; the stems are split and woven into smooth and particularly cool and refreshing mats. Tenasserim mats are also made from the split stems of a species of Maranta imported from Rangoon, although the plant from which they are made, or an allied species, is abundant in Tenasserim forests.-Drs. Roxb., Voigt, O'Sh., Mason.

MARASCHINO, a liqueur, chiefly manufactured in Venice, Trieste, and Zara in Dalmatia, from a variety of cherry, named the Griot marasquin. The fruit and seed are crushed together, one part to the hundred of honey added, and the whole mass subjected to fermentation; during this process it is distilled, and the product is rectified. To the rectified spirit, sugar and water are added, in proportions guided by the taste of the manufacturer, and the resulting liqueur is stored for some months before use, to free it of empyreumatic flavour. The fruit tree is the Cerasus caproniana.-O'Sh. p. 323.

MARASU-WAKALIGA, a cultivating race of Mysore. Up till the year 1873 , the women on marriage made a vow that on the birth of their first child they would offer as a sacrifice the joints of their fingers to the goddess Kali. In some instances where the family was well-to-do, gold or silver finger-joints were substituted for human ones. This barbarous rite, it appears, had existed for years in many parts of the Mysore province, and was not discovered till lately. It is performed on the third or fourth day after accouchement, and in many cases death has ensued. On discovery of the existence of the rite, the district magistrate immediately sent for the leading men of the class, and asked them whether they would like the rite abolished, and why they observed it. They are reported to have said that they simply observed it because all the class observed it, and that it was a very old custom amongst them. They said that if the order extended to the whole class, they would be very glad to give up so barbarous a rite, but that as long as some of them observed it, they could not fly in the face of their ancient traditionary customs. The Chief Commissioner of Mysore and Coorg, by public proclamation in the Mysore Gazette, prohibited the practice.

MARATHALI, the goddess of smallpox.

MARAVA, a race in the extreme south of India, in the Madura, Tinnevelly, Ramnad, and Sivaganga districts, who differ from other neighbouring races in personal appearance, and their language and customs also differ. They worship local deities, to whom they offer liquor, flesh, and fruits, and they practise divination. The men do not wear turbands. They possess lands. They are a robust, hardy, dark-skinned, stalwart race, athletic, with well-developed muscles, active, of moderate height, the cranium rounded, narrow in front, forehead low, eyes large and full. They are employed as village watchmen, and are honest to their employers, but have been largely given to thieving and gang robbery. They use as food the flesh of all animals except that of the cow. They wear their hair long, and arranged like the women of the Dekhan. In their marriages, disparity of age is not considered, nor is the presence or assent of the bridegroom necessary, - a blade of wood, in his absence, serving as proxy. They worship evil spirits, to whom they sacrifice, and, on the occurrence of a smallpox or cholera epidemic, the whole village is excited, and devil dances are common. The Maravar women of Ramnad and Sivaganga wear cloths of 25 or 30 cubits in length, folded in plaits, which they fasten behind. This is unlike other women of S. India, whose cloths do not 
exceed 20 cubits, and are fastened on the right side in front. They intermarry, some of the subdivisions not marrying into the father's family; but Hindus in general intermarry with the mother's relations. Maravar means a warrior. In Ramnad and -Tinnevelly, the titular surname of all the Maravar is Dever, also Thavan, which means God.

The Ramayana describes the forest or wilderness of Dandaca as covering the whole extremity of the Southern Peninsula, and the rude inhabitants are designated Rakshasa (monsters) or Vanara (monkeys), the former term meaning races or tribes hostile to the Aryan race. But Vanara is from Vana, a wilderness, and Nara, a man, that is a wild or uncivilised man, and to this sense, as to the wild races in the extreme south, the fable of Hanuman, the chief monkey, and that of his army, Mr. Taylor thinks may be reduced. He says that those who have seen the Colleri and Marava will readily consider them to differ from all family likeness of the Aryan Hindus, and as their visages often resemble baboons more than men, it would require even less than the ardent poetical imagination of a Valmiki to induce the employment of an equivalent word which would so aptly seem to convey the idea imparted by their appearance.

During the wars of the 18 th century, the Colleri and Maravar adhered to the British or to the French standards, and evinced fidelity and devotion to the cause of the party they espoused. Orme, the historian, relates that the Maravar chief of the Colleri race in 1752 sent $t 000$ peons and Colleri to aid Chanda Sabib. Like the Ramusi of Sholapur and Bombay, the Marava are subsidized by being employed as watchmen of houses. The zamindar of Ramnad is a Marava. Maravar marriages are sometimes of an incomplete character, and they have a second and more complete one.

Marawar or Marava is perhaps the Marullo of Cosmas Indicopleustes, which was on the continent adjoining Ceylon, and produced conch-shells. The history of the race is obscure. Two centuries before the Christian era, we find Kirata, its reigning sovereign, making war with Kula Bhushana Pandiyan, and reducing him to sad straits. The invader overran the whole country, but the Marava host and its commander were afterwards destroyed. The invasion of the country by the Muhammadans terminated the Paudiyan dynasty, and the Setupathi threw off his allegiance to the ruler of Madura, and during the administration of the Nayakkans, the Marava sovereigns continued practically independent. Professor Wilson says: 'A few years after the irruption of Mujapid Shah (? Muzaffar), or about 1380 , the governor of Ramnad threw off his dependence on Madura, and his successors extended their authority to the neighbouring provinces, since called the Great and Little Maravas.'

The title Setupathi was conferred upon Wodeya Deva, the ruler of Ramnad, by Mutu Krishnapa Nayakkar, as an acknowledgment of the former's services in escorting a holy guru to and from the shrine at Ramisseram.

In the reign of Tirumalei Nayakkar, the Setupathi distinguished himself by repelling a Mysorian invasion with an army of $6000 \mathrm{men}$, for which he was rewarded with a lion-headed palanquin and other insignia by the sovereign of Madura. From the year 1729 , the power of the Maravars began rapidly to decline. The Sivaganga zamindari was then formed out of two-fifths of the Ramnad territory, and made over to one Seshavarna Dever.

Ramnad, on its occupation in 1772 by the British under General Joseph Smitb, became an integral portion of the British Indian empire.

There are at present only two Marava zamindaris in Madura, viz. Ramnad and Sivaganga, but Tinnevelly contains more than a dozen, of which Nelliturgavale, Chokkampatty, Utumalei, Kadambur, and Tirukanangudi are the chief. Almost all the other polygars are of the Totia caste, and the descendants of the Telugu chieftaius that came with the Nayakkans from Vijayanagar. The Madura Chronicle tells us that Viswanatha, the first of the Nayakkan dynasty, distributed the country amongst his adherents, to the number of seventy-two, for the better defence of the kingdom. The Maravar's names occur in that list. Professor Wilson says: 'Upon the occupation of Madura by the first Nayak, five rajas are said to have combined to revenge the wrongs of the ancient dynasty of Madura. These petty chiefs were the ancestors of some of the polygars of the south, who gave so much trouble to the British forces in the middle of the 18th century.' This was not Cataboma Naick, zamindar of Panchalancuritchy, for he was a Totian, and consequently a Telugu; the chiefs spoken of being no other than Pulee Taleivar and his confederates, who withstood the British forces in 1755. Being all of the Maravar caste, they refused to pay tribute to the nawab. They were literally swept from off the face of the earth; for nothing remains of their old grandeur and state except the debris of their capitals. Pulee Taleivar was hanged, and his zamindari of Nellitungavale now consists of a few wretched villages in the possession of a branch of the Maniatchy family. Chokkampatty has been sold off to meet the claims of a Nattukotei Chetty. Kadambur, Utumalei, Nalanthila, and Sirukanangudi drag on a miserable existence compared with their wealth of former times; while Maniatchy is split up into three or four parts.-Yule, Cathoy; Rev. Mr. Taylor in Madras Government Records, 1867, p. 4; As. Soc. Journ; Orme's Hindustan.

MARBAU. Malay. The Metrosideros Amboinensis, $R$., of Sumatra, grows to a large size, and is used for beams both in ship and house building, as well as for other purposes to which oak is applied in Europe.

MARBLE.

Tau-wha-shih, . . ChIN. | Pualain, Marmar, MaLAy, Marmer, . : D Dut. Sung-i-marmar, PERs Marbre, - . . FR. Marmore, . : PORT, Marmo, : : : : Iт. Mramor, : : Pus. Marmor, . . . LAT. Marmol, . . . SP.

Marble is the granular limestone or carbonate of lime of mineralogists. It is hard, compact, of a fine texture, and readily takes a fine polish. In colour, some marbles are quite black, others again are of a snowy white; others are greenish, greyish, reddish, bluish, or yellowish, and some are variegated and spotted. In Europe, the finest solid marbles are those of Italy, Blackenburg, France, and Flanders.

The marbles of Tabreez and Khorasan are transported to the most remote quarters of the Persian empire, and marble is found in many 
parts of British India, in Burma, and in China. It is obtained in Ho-nan, Shen-si, Yun-nan, and Canton. The blue-clouded marble slabs of China are about a foot square, and are exported to India, Sydney, South Amcrica, etc., for pavement or floors. It is obtained to the north-west of Canton. There is also a red breccia marble brought to Canton, which is employed in tables, stone stools, etc., and is seldom sent abroad. The marbles of the Madras Presidency are of rare colour and fine quality. The specimens sent to the Great Exhibition of 1851 were favourably reported upon as indicative of a valuable material, well adapted to sculptural and ornamental purposes. At present the Indian manufacture of this article is comparatively insignificant, and chiefly confined to small miscellaneous articles for domestic use.

Marble is found in considerable quantities in the Coimbatore district, through a tract of 7 or 8 miles, extending to the Walior jungle. Its colours are white, grey, and pink, compact, dense in structure, with veins of other colours. A green marble is found in Tinnevelly.

The pure white marble of Tinnevelly is in large crystals like that of Burma. The marbles of the Cuddapah district are of greenish colours, from pale apple-green to deep leek-green, and beautifully shaded; they attracted attention in the Exhibition of 1851. At Bhera Ghat, on the Nerbadda, 10 miles from Jubbulpur, on the line of the railway to Bombay, a white saccharine marble is plentiful and easily accessible. It has been used in a limited degree at Jubbulpur, sometimes to make lime, and other times for metalling roads. It is made up into images by natives, who do not give it a good polish. A block which was sent to the Paris Exhibition of 1855 was pronounced to be equal to Italian marble for statuary purposes; very large slabs can be easily quarried. The marble rocks at the Bhera Ghat, on the Nerbadda, about 10 miles from Jubbulpur, narrow the stream there to 20 yards, and the shining cliffs of white marble, a dolomite or magnesian limestone, rise there to 80 or 120 feet. The granular white marble of Korhadi, 3 feet by 2 , and 9 inches thick, is sold at Rs. 2. This marble and the sandstone and coal of the same locality, with the alabaster, gypsum, and dolomite of Jubbulpur, will probably become articles of export. At Tinnevelly, also, there is an excellent white marble, but considered rather too hard for statuary purposes; and Guntur and the Ceded Districts abound with marbles of great variety of colours, being tints of grey, yellow, and red. Marble occurs at Attock. Both white and grey occur at Nooshky. The marbles and building stones, and the red sandstone so commonly seen in all ancient buildings from Benares up to Lahore, were formerly imported from these parts, and magnificent mosques, tombs, and shrines yet remain to tell us of that trade.

Marble in the Panjab is found in the Dehli district, at Sahi Bullubghur, Hissar, and Jhelum.

The marble used by the Burmese in the manufacture of their numerous figures of Gautama, for the pagodas, etc., is obtained from the quarries in the small steep ridge of the Tsagyen Hills, near the village of Mowe in the district of Madeya, a little N. of Mandalay. The great mass of the limestone forms the summit and eastern face of the hills, and here are situated all the quarries from which the marble has been extracted. The limestone rests upon hornblendic gneissose rocks, which form the lower portion of the hills, and is for the most part tolerably pure and massive, but occasionally has an imperfect lamination, given by flaky plates of mica arranged in lines of the mass. It is, in the mass, of nearly a pure white, and is largely and finely crystallized. Portions of it have a delicately blue tint, while others are stained by ferruginous spots. A block suitable for a figure 3 feet high can be had at Amarapura for about 50 tikals, or about $£ 6$, and a figure of these dimensions may cost about 150 tikals, or about 180 rupees $=£ 18$. Large blocks can now rarely be had, the largest obtainable do not now average more than 4 or 5 feet long by 2 or 3 feet thick, but even these are not frequently obtained, and are expensive. For smaller blocks there is a constant demand. The marble workers are settled at Amarapura and Tsagaing. With a hammer and chisel the workman rapidly gives a rough outline to the mass, and by occasionally, with a few lines of charcoal, marking out the drapery and limbs, he rapidly completes the figure. Partly owing to the delicate tinge of blue, and to the generally large crystallization of the mass, there is a peculiar semi-transparent look about the finished sculptures, which has most probably given rise to the general notion that these images are of alabaster. Pallagoix speaks of the beautiful marble he found in the island of Si-Hang, on the coast of Siam, polished as brightly by the waves of the sea as it could have been by the hand of man.-Balfour on the Marbles of Southern India; Central Provinces Gazetteer; Madras Ex. Jur. Reports; Poucll; Oldham in Yule's Embassy, p. 327; M'Culloch's Commercial Dictionary, p. 787; Bowring's Siam, i. p. 30.

MARCHANTIACE E. Lindl. The liverwort tribe of plants, including the genera marchantia, Grimaldia, plagiochasma, fimbriaria, dumortiera, riccia, jungermannia, and blandovia. Dr. Griffiths collected 48 species in Assam; they grow in the earth or on trees, and are unimportant.

MARCHES of soldiers in India, from their prolonged character, require to be performed in a manner as if permanently in the field. Sir John Malcolm mentions (ii. p. 158) that Aga Muhammad Khan reached Isfahan on the third day, travelling 250 miles. Captain Cunningham mentions (History of the Sikhs, p. 225) that Colonel Steinbach with his Sikh regiment marched 200 miles in twelve days, which was equal to $16^{\circ} 6$ miles daily. When General Sir Frederick Roberts marched from Kābul to Kandahar against Ayub Khan, the distance of 318 miles was accomplished in twentythree days, including two halts. Thus the average distance per marching day was 15 1-7th miles, or, including the days of halt, $1319-23 d$ s per day. Such a feat, considering the nature of the country, and that the force moved in a single column, has never been exceeded. The great difficulty, as usual, was the transport; but the Afghan war has initiated a reform of a most important nature, by largely cutting down the amount of baggage, without which it has been hitherto thought that an Anglo-Indian army could not take the field.

The march commenced on August 9. Ghazni, a distance of $97 \frac{1}{2}$ miles, in which the Zamburak pass (7000 feet) and the Sher-i-Daban pass (9000 feet) were crossed, was reached on August 
15. For this part of the march, an average distance of 13 13-14th miles was covered daily. The remaining distance of $134 \frac{1}{2}$ miles was covered in eight days, or 16 13-16th miles daily. 10,148 troops, 8143 native followers, and 11,224 animals, including cavalry horses, composed the column; the daily supplies for all these were drawn from the country after arrival in camp. Food was distributed and cooked with fuel (difficultly procurable, and brought in from a distance) during the eight days' march from Ghazni to Kalat-iGhilzai. The longest marches on any one day were 20 miles, from Ghazni to Zerghalta, and 21 miles, from Mukur to Panjak.

During the Indian Mutiny, the average number of camels, including those for the mess, was certainly not less than $2 \frac{1}{2}$ per officer; for the march from Kābul to Kandahar the allowance was one mule per officer, and one for mess purposes for every eight officers. To each European soldier was allowed 34 lbs. of kit, and to each sepoy $20 \mathrm{lbs}$, including camp equipage. The tent accommodation was also much restricted, yet to carry baggage and food there were required 1589 yaboos (large Käbul ponies), 1244 Indian ponies, 4510 mules, and 912 donkeys. Moreover, on the road there were purchased 35 yaboos, 1 mule, 208 donkeys, and 171 camels. Of these there perished before the arrival at Kandahar, 410 yaboos, 106 Indian ponies, and 217 mules.

In the Käbul and Kandahar march, in addition to the daily ration, a tin of pea-soup was issued to every two British soldiers daily, from August 18, which was commonly taken before the march commenced; lime-juice was regularly issued. Extra rum was issued three times during the march to all British and native spirit-drinkers, and an extra ration of meat to those who did not drink rum, with a meat ration for all followers whenever sheep could be obtained.

In the beginning of the 19 th century, General Doveton left Jauluah with a rissala of cavalry, a wing of a European regiment, 4 companies of rifles, an infantry corps, and in two days and one night reached Bassein, 60 cos distant, having allowed three halts for refreshments.

During the campaign against the Mahrattas in the year 1804, the army, under General Lake, made a tremendous forced march of $5 \pm$ miles in 30 hours, surprised Holkar and his cavalry at Farrakhabad, and routed them with great slaughter. The British had marched 250 miles in 13 days.

During the Sikh war in 1843 , when the Governor-General was pushing on by forced marches with the grand army, with the view of relieving Ferozpur, on the 16 th he advanced 30 miles, the train of camels exteuding in a line almost from the point of departure to that of arrival. On the following day 10 miles more were traversed, the troops suffering from want of water. Betwixt the 11th and 18th, in the course of six days, they had marched over a distance of 160 miles, along roads of heavy saud, the incessant toil scarce leaving them leisure to cook their food.

It may be interesting to refer here to other marches. General Crawford marched with the $43 \mathrm{~d}, 52 \mathrm{~d}$, and $95 \mathrm{th}$ Regiments of Foot to reinforce Sir A. Wellesley, at the battle of Talavera, in July 1809 ; the brigade marched 62 miles in 26 hours, carrying arms, ammunition, and pack, in all a weight of between 50 and $60 \mathrm{lbs}$. per man. In the Franco-German war, Dr. Roth, who served as chief medical officer with the Saxon army, mentions that the 18th division marched, from October 29th to November 17th, $55 \frac{1}{2}$ German miles, which is equal to 260 English miles, in nine days, nearly 18 miles a day; while on December 16th and 17th, in the various manouvres about Orleans, they marched 54 English miles. They were very heavily accoutred, and the roads were bad. A company of a regiment of Chasseurs of MacMahon's army, after being on grand guard, without shelter or fire, during the rainy night of August 5th-6th, started at three in the morning to rejoin its regiment in retreat on Neiderbronn, after the battle of Weissenburg. It arrived at this village at 3.30 in the afternoon, and started again for Phalsbourg at six o'clock. The road was across the hills and along forest tracks, which were very difficult for troops. It arrived at Phalsbourg at 8.30 in the evening of the next day. The men'had therefore marched part of the night of August 5th-6th, the day of the $6 \mathrm{th}$, the night of the $6 \mathrm{th}-7 \mathrm{th}$, and the day of the 7 th till 8.30 p.m. The halts were eight minutes every hour, from 3.30 to 6 , one hour in the night of the 6 th $-7 \mathrm{th}$, and $2 \frac{1}{2}$ hours on the $7 \mathrm{th}$; altogether, including the halts, the march lasted $41 \frac{1}{2}$ hours, and the men must have been actually on their feet about 30 hours, in addition to the guard duty on the night before the march. The exact distance is not known, but, considering the extreme difficulty of that rugged mountain country and the bad weather, this is perhaps the most toilsome march on record.-Bombay Times.

MARCO POLO was of a noble Venetian family. Nicolo and Matthew, two brothers, had mercantile establishments at Constantinople and in the Crimea. They quitted Venice for the east in 1254, left Constantinople in 1260 , and passed through Bokhara to the court of the Kablai Khan, who sent them back as ambassadors to the Pope, and they reached Acre in 1269, when Nicolo found his wife long dead, but his son Marco grown to 15 years of age. After two years' delay, the two Polo, Nicolo and Maffei, in 1271, taking with them Marco, the young son of the former, set out on their return along with a priest, who, however, soon left them, delivering the Pope's letters into their hands. Starting from Acre, on the coast of Syria, the Polo were three years and a half upon this journey. They moved by Mosul, Baghdad, Hormuz, they traversed Kerman and Khorasau, Balkh and Badakhshan, in which last country they seem to have been long detained by the illness of young Marco. From Badakbshan they ascended the Oxus to the lake of Sirikol, and the plateau of Pamir. They crossed the steppe of Pamir, and descended into Kashgar, whence they proceeded by Yarkand and Khoten, and across the great desert of Gobi to the Tangut province on the extreme N.W. of China, partly within, partly without, the wall. Here they were met by a deputation sent by the Kablai Khan, who was at the time residing at Shang-Tu, about 50 miles north of the wall. Their journey had occupied $3 \frac{1}{4}$ years. Upon their arrival at Pekin, which they call by the Tartar name Cambala or Khanbalig, young Marco, then 21 years of age, was taken immediately into favour; be learned the language, and for 26 years 
afterwards was a nobleman of the Great Khan's court, employed in several missions, and in other high offices of state. He came away at last, in A.D. 1294, in charge of a princess who was to be married to the Tartar sovereign of Persia. He was sent on a mission through Yun-nan to the frontiers of Ava, and successively to Kara-korum, to Champa or Southern Cochin-China, and to the Indian Seas, and afterwards by sea via Sumatra and India through Cambay to the Mongol tribe of Bayaut, to select a lady for the Kablai's great nephew, Arghun Khan of Persia, which he did, handing over the lady in 1294. He is the first European who speaks of Sumatra. He returned to Venice A.D. 1295. Marco was subsequently taken prisoner at the battle of Curzola (near Lissa), on the 8 th September 1298. On his return to his native country, he circulated his travels, in manuscript, amongst his friends. The narrative was in 1298 transcribed by a Genoese named Rustigielo, four years after the death of Kablai Khan. They were first published in Latin in 1320. 'A copy had been presented by the government of Venice to the Infante Don Henrique in 1428 , from which an edition was published at Lisbon in 1502. The earliest edition published in France bears date 1556. His book was entitled Viaggi di Messer Marco Polo Gentilhuomo Venetiano. There are two translations of it into Latin. He treats in his book De Regionibus Orientis. Kablai Khan was the conqueror of Southern China, which the Arabs call Machin, and which Chengiz Kban, his grandfather, had charged bis children to conquer, after he himself had gotten the Northern Cbina called Khatai.

Marco Polo sojourned in the hills of Badakhshan for the sake of his health, and he describes the countries of Wakan, Pamir, Bolor, and Kashmir. His book and life have been repeatedly published, and in most of the European languages. It was translated in 1818 by Sir William Marsden, and Colonel Yule has since largely contributed to make the travels known.-Marsden's Sumatra, p. 4 ; History of Genghiz Can, p. 443 ; Prinsep's Tibet, Tartary, Mongolia, p. 8; Yule's Cathay.

MARD KHOR. PErs. Man-eaters, the Aghora ascetics of the neighbourhood of Mount Abu, said to have resided there from the most ancient times, and formerly to have been cannibals; hence their name, meaning man-eater.

MARDUM SIAH. PERS. Atropa acuminata, also A. mandragora, mandrake; literally black manikin.

MAREB, a dam which formed a celebrated reservoir above the city of Saba in Yemen, between two hills of Balak. It burst about A.D. 120 , and deluged the country far and wide. The bursting of Mareb lake is mentioned in chapter 34 of the Koran as the Sail-ul-Arem, or rush of water from the reservoir, and its bursting is there attributed to a punishment sent from God for the impiety, pride, and insolence of the city of Saba. "The descendants of Saba had heretofore a sign in their dwellings, namely, two gardens, one on the right hand and one on the left; and it was said unto them, Eat ye of the provisions of your Lord, and give thanks unto him; ye have a good country and a gracious Lord. But they turned aside from what he had commanded them, wherefore he sent against them the inundation of El Arem, and he changed their two gardens for them into gardens producing bitter fruit, and tamarisks, and some little fruit of the lote tree.' Reservoirs in which to store rain-water in Arabia are generally found in localities devoid of springs, and dependent on the winter rains for a supply of water during the summer months. The most remarkable instance on record is this great dam of Mareb. All the travellers who have penetrated Yemen describe many tanks in the mountainous districts ; and others exist in the islands of Saaded-Din, near Zailah, in Kutto, in the Bay of Amphila, and in Dhalak, near Massowah.

MAR ELIAS, a monastery 64 miles $\mathbf{E}$. of Mosul. Near it is a sulphurous spring much resorted to. It is called by the Muhammadans Deir-el-Munkoosh, the ornamented or painted monastery, and is the remains of a Nestorian monastery. Assemanni does not give the date of its foundation, but it is mentioned incidentally by him thus: Joshua Bar-num of Bath Gabar, a village on the Tigris, between Nineveh and Mosul, lived thirty years in the monastery of St. Elias before he was elected primate of the east, which happened A.D. 824. Abu Saed was Archimandrite of Mar Elias in A.D. 1028. - Rich's Kurdistan, ii. p. 113 ; MacGregor.

MARGALI. TAM. The 9th month of the Hindu year (November-December), when the moon is in the asterism Mriga-sirsha.- $W$.

MARGARINE. Most fats and fixed oils, vegetable and animal, are mixtures, generally of three distinct compounds, each of which taken singly has all the properties of fat. The first of these substances, called stearine (from $\sigma \tau \varepsilon \dot{x} \propto p$, tallow or suet), is solid at common temperatures; it constitutes the solid fatty ingredient in muttontallow. The second is oleine (from s' $\lambda_{\alpha}$ oil), and is liquid at ordinary temperatures, and down to the temperature of freezing water. The third substance is named margarine (from uкprápov, a pearl), on account of its mother-ofpearl lustre; it is solid at ordinary temperatures. All fats may therefore bè regarded as mixtures of the fluid oleine with the solid stearine of margarine. If the solid be in larger proportion than the fluid, as in various kinds of tallow, it requires a greater degree of heat to melt it. If the fluid portion prevails, as in the oils, the melting point is lowered.

MARGARY, AUGUSTUS RAYMOND, born A.D. 1846. He left Shanghai on the 23d August 1873, ascended the Yang-tse to Hankow, and crossed to Bhamo, which he reached on the 17 th January 1874. He returned alone in advance of Colonel Brown, and was killed on the 21st or 22d February at Manwyne.

MARGGA KARAN. Maleal. In Malabar, a designation of Roman Catholics; qu. Marya Karan?

MAR-GHAT. HIND. A place of cremation. The place for the cremation of the Hindu dead.

MARGIANA. The second settlement of the Aryans was in Mouru, Merv, or Margiana. This is Margiana (from the river Margus), now Marghab (Margus-water), Margush in the cuneiform inscriptions; a fruitful province of Khorasan surrounded by deserts. In the Record (iii. verse 6 ) it is described as "the third best land, the mighty and pious Mouru (Marw). ... Ahriman created there wars and marauding expeditions.'

MARGOSA, the Portuguese name of the 
Azadirachta Indica, which grows to $3 \frac{1}{2}$ feet in diameter. In appearance the wood is much like mahogany, and is used by the natives for general purposes. Its bark,

Bewa, . . . CAN, Tel-kohumba, . Singh. Nim-ka-chal, : HIND. Vaypum puttay, TAN, Nimba, . . SANSK. Vaypa putta, . TEL. is bitter, is considered a valuable tonic, and has been tried by European physicians with a success nearly equivalent to what might have been expected from cinchona bark. Oil is obtained from the seeds by either expression or boiling, and is much used medicinally. The fruit is not unlike a small French olive in size and appearance. The oil is of a deep yellow colour, has a strong smell and an umpleasant bitter taste; is much esteemed by native doctors as a warm medicine, as an external application in foul ulcers, and as a liniment in rheumatic and spasmodic affections, etc. It is frequently burnt in lamps, and is sold in the bazar under the name of bitter oil, also black oil. Dr. Maxwell found this oil equally efficacious to cod-liver oil in cases of consumption and scrofula. He began with half-ounce doses, morning and evening, which were gradually reduced. Margosa, as well as illipoo oil, mixed with an equal quantity of cold drawn castor-oil, produces a hard vegetable wax of an agreeable roseate colour.

The leaves of the genera Melia and Azadirachta, dried and kept in books, are much used by the people of India to preserve furs, feathers, books, papers, and clothes that are lodged in trunks, book-cases, etc., from the attacks of insects. It is useful to place along with them small packets of camphor, or little cups of camphor dissolved in alcohol.-M. E.J. R.; Simmonds ; Edye; Faulkner.

MAR GREGORIUS ABU-1-FARAJ, also called Gregorius bar Hebræus, also Abul Farag, also Gregorius Abu-1-Faragius, was a Jacobite Christian of the city of Malatia, in Cappadocia, of the Armenian race, born A.D. 1226 at Malatia or Melite, a town near the western bank of the Euphrates in Lesser Asia. His father, the Hakin Harun-ulMalati, was a physician. Abul Farag studied theology, philosophy, and medicine, and passed the greater part of his life in Syria. He became a Christian, and rose successively to be bishop of Gaba, then of Aleppo, and in A.D. 1266 primate of all the Jacobite Christians in the east. $\mathrm{He}$ was the author of a great number of books written in Arabic and Syriac, but the best known is his History of the Dynasties from the Hebrew Patriarchs to the Moghuls, which Dr. Pococke published in 1663, with a Latin translation and a supplement. He died in A.D. 1286 at Meragba, in Azerbijan. He wrote the Book of Dymasties in Arabic, in the reign of Arghun Khan, the last of Chengiz Khan's grandsons. It was arranged in ten chapters, -1 . On the Saints siuce Adam; 2. The Judges of Israel ; 3 . The Kings of Israel ; 4. The Chaldæan Kings; 5. The Kings called the Magi; 6. The Ancient Greek Kings; 7. Latin Roman Kings; 8. Christian Greek Emperors; 9. Muhammadan Arabic Kings; 10. The Moghul Kings.

MARI-AMMUN. Ammun or Amma, literally mother, in the south of India is the honorific suffix of various local deities, as Mari Amma, Yagath Arma. Professor Wilson thinks that Mari Amma comes from the Virgin Mary, and that Yagath Amma is from St. Agatha. But
Mari Amma seems to be from Mari, death, and Ammun, mother, mother-death. Amongst the Tamil people, Mari-Ammun is a new goddess who sends smallpox. She is said to scatter pearls; to propitiate her, sacrifices are offered and hookswinging practised. She is a mixture of the village goddess and Kali, the sakti of Siva.

MARICHI, a Hindu author of a law treatise, and of one on religious services. The Kapila Purana describes him as an old man in the habit of a mendicant, and states that he lived as an anchorite at Bhadrashwa Varaha. - Ward, iv. 17.

MARIETTE BEY, a distinguished Egyptologist, died 1881. In 1848 he was attached to the Egyptian Museum at the Louvre; in 1850 he was sent to Egypt to search for Coptic manuscripts. He discovered the site of the Serapeum, the temple and enclosure dedicated in ancient times to the worship and custody of the sacred bull Apis, as well as the long range of tombs in which the bulls were buried. The tombs, dated and inscribed, furnish a check and a verifieation of Egyptian chronology derived from independent sources, while the actual remains discovered in situ are invaluable as illustrations of the ritual and worship of ancient Egypt. His explorations at Memphis were continued for four years. During his first visit to Egypt, Mariette had excavated the buried part of the Sphinx, and demonstrated anew the fact that that stupendous monument is hewn from the solid rock.

MARIGNOLLI, JOHN DE, a Minorite friar of the Franciscan monastery of Santa Croce at Florence, was sent by Pope Benedict on a mission to Cathay in 1338. $\mathrm{He}$ sailed from Avignon to Naples, and thence to Constantinople, and on to Caffa (Theodosia) in the Crimea, whence he proceeded to the court of the khan of Kipchak at Sarai, on the Volga, who forwarded him on to Armalec (Almalik), the capital of the Chaghtai khans of the Middle Tartar empire. He arrived at Cambalec (Pekin) in May or June 1342 , and, after remaining there three or four years, sailed from Zayton for India, the 26th December 1347, and arrived at Columbum (Quilon) the following Easter. In 1349 he made a pilgrimage to the shrine of St. Thomas on the Coromandel coast, and thence proceeded to Saba, which he piously identified with the Sheba of the Bible, but which was probably Java. Sailing back to Malabar, he was driven to Ceylon, whence he sailed to Ormuz, and afterwards travelled by the ruins of Babylon to Baghdad, Mosul, Edessa, Aleppo, and thence to Damascus, Galilee, and Jerusalem, making his way back to Italy by Cyprus. He recognised as the Tower of Babel the ruins called by Rich, Mujalibe, and by Layard, Babel. These are about half a mile from the present channel of the river. The excavations at the Mujalibe or Babel show that the structure was much as Marignolli describes, viz. an exterior of burnt bricks laid in bitumen enclosing the unburnt bricks which form the interior mass.Yule's Cathay, ii. p. 386 ; Sir George Birdwood.

MARIGOLD. Kin-tsien-kiueh, CHIN. The Chinese force it successfully in the early spring, when it is a common ornament. Tagetes patula and T. erecta grow well on the plains of India.Jaffrey.

MARIJ. ARAB. Lit. flame without smoke, i.e. But $\mid$ wind, the genii are formed of it. 
MARINO SANUTO, a Venetian nobleman who travelled in the east about A.D. 1300-1306. His book, entitled Liber Secretorum fidelium Crucis, super Terræ Sanctæ recuperatione, presented to Pope John XxII. at Avignon, initiates us into all the details of the course of the Venetian commerce with India at this period. Down to his own time, it used to take the route by the Persian Gulf. The merchandise of Malabar and Cambay was first conveyed to Ormuz and Kish in the Persian Gulf, and was thence transported to Bussora on the Euphrates, whence it passed up the Tigris to Baldae (Baghdad), and across the Syrian desert to Antioch and Cilicia, where it was embarked for Europe on board the ships of Genoa and Venice. Latterly, however, the merchants of Southern Arabia had gradually recovered their old commerce, and part of the merchandise of India and the east now came into Europe by way of Ahaden (Aden) and Chus (Coptos) on the Nile, and Alexandria. The rarer commodities, such as cloves, nutmegs, mace, gems, and pearls, were still conveyed up the Persian Gulf to Bussora, and thence to Baghdad, from which they were carried to. some port on the Syrian or Arabian coast of the Mediterranean; but all the more bulky goods, such as pepper, ginger, cinnamon, together with a portion of the more valuable articles, were now conveyed by the ancient route to the Red Sea, and thence across the Libyan desert and down the Nile to Alexandria_-Sir George Birdwood.

MARJORANA HORTENSIS. Mrnch.

\begin{tabular}{l|l} 
Origanum marjorana, $L$. O. onites, $L a m$.
\end{tabular}

O. marjoranoides, Willd. $\quad$ O. acinacifolium, Wall.

o. Wallichianum, Benth. Amaracus vulgatior, Lob.

Mir-zun-jush, . . Arab. Murwa, . . GuJ., Hind. Marjoram, E ENG., GER. Marru, : : . . TAM. Marjolaine, . . FR. Maruvamu, : . TEL.

Sweet marjoram is a culinary herb cultivated in most parts of Lower India. It is used for flavouring sauces and roast meats. The flowers are considered by Hindu doctors as possessing cephalic qualities, and the plant is known to possess tonic virtues. It is easily reared in beds or pots, either by slips from the roots or seed. Hindus offer it at the shrines of Vishnu and Siva. It is a shrub in its native country, but an annual in gardens of Europe. It is a native of the north of Africa near Mascar, on hills, and of Asia, on the mountains of Kamaon. When in blossom, the plant is cut and dried for winter use as a savoury ingredient in cookery.-Faulkner; Jaffrey; Voigt.

MARKAN. HiNd. A Panjab grass, eaten in famine; such a famine is recollected in the Panjab by the name Markanwalli sal.

MARKANDA, a valley in the Siwalik branch of the sub-Himalayan mountains, where a fossil ruminant was discovered by Dr. Faulkner, and named by him Sevatherium giganteum.

MARKANDEYA, one of the Purana religious books of the Hindus, an uninterrupted succession of legends. It is supposed of date the 8th to 10th century A.D. Markandeya, in Hindu mythology, a being who lived through several kalpas. $-D$.

MARKHAM, CLEMENTS R., C.B., F.R.S., in early life was a midshipman in the British navy, and served in the Arctic Expedition of 1850-51. He was for twenty years in the India Home Office, serving in the Geographical
Department from 1867 to 1877 , where he had opportunities for promoting the well-being of the people of the East Indies, devoting himself from 1859 to the introduction there of species of cinchona. He had previously travelled in $\mathrm{S}$. America, and had become acquainted with the people and their languages, the Spanish and Quichua; and in 1860 he proceeded to the cinchona regions, accompanied by Mrs. Markham, who, at Arequipa, directed the work of the other collectors whilst her husband was in the forests of the Andes; and he twice proceeded to India to secure the suitable treatment of the plants and seeds which he had collected. He was ably assisted by Mr. John Weir, Dr. Spruce, Mr. Robert Cross, Mr. Pritchett, and Mr. Ledger, and, in India, by Mr. M'Ivor.

By the year 1880 there were 12,667 acres under cinchona cultivation on the hills of S. India and Ceylon, and in Sikkim; and the bark from British India sold in London in $1879-80$ was 1,172,060 lbs., selling at from 9s. 1d. to $15 \mathrm{~s} .8 \mathrm{~d}$. per $\mathrm{lb}$.

The introduction of the cinchona had cost $£ 129,628$ up to 1876 , and $£ 173,046$ had been realized. Considering the value to the people of the febrifuge, and to the planters as an agricultural product, it is one of the largest boons bestowed on India.

In 1875 he selected Mr. Robert Cross to proceed to Central America to collect India rubber plants of the genus Castilloa; and in the following year a supply of those obtained was forwarded to India. Again, in 1876, Mr. Cross was sent to South America, this time to collect plants of the genera Manihot and Hevea, supplies of which also were sent to India, Ceylon, and Burma.

India is also indebted to Mr. Markham for the Cuzco variety of maize, for the quinua, and for the true Peruvian cotton, a perennial species which takes a bigh place as a cotton-yielding plant.

He published (1862) his Travels in Peru and India, while superintending the collection of chinchona plants and seeds; in 1880, Peruvian Bark, a Popular Account of the Introduction of Chinchona Cultivation into British India. He publișhed a Memoir on the Indian Surveys; a Memoir on the Irrigation Works of Eastern Spain ; the Narratives of Bogle's Mission to Tibet, and of Manning's Journey to Lhassa, with an Introduction and Biographical Notices; also a History of the Abyssinian Expedition; a History of Persia a Life of Lord Fairfax. And among other works, etc., of public importance he was secretary to the Royal Geographical Society and to the Hakluyt Society; he wrote, for 1871-72 and 1872-73, the Moral and Material Reports on India, and edited, for the Hakluyt Society, a translation of the Embassy of Clavijo to the Court of Timur.

MAR-KHOR. HIND.

Rawacheh of LitTLe Tib. | Rass of the . . . Oxus Tsura or water-goat, " Capra megaceros.

Capra megaceros of Hutton, the wild goat of Hazara and the N.W. Himalaya, etc., is called mar-khor, because fabled by the mountaineers to kill snakes by looking at them; and in Yaghistan and Chilas they say that when its foam falls on certain stones it turns them to zahr-mohra. The ibex and mar-khor often dispute each other's footing. It is found on the mountains of Persia 
and Afghanistan, and is plentiful on the ranges around the Khaibar pass. From Torbela and Little Tibet it wanders down the Suliman Range as far as Mitenkote on the Indus, at the junction of the latter and the Sutlej. It is common on the north-western ranges of Kashmir, including Dardu; from thence a few herds are to be met with all along the southern or Futi Pinjal as far as Kishtewar on the Chenab. The northern ranges of Kashmir and Ladakh are apparently without a single individual, perhaps on account of the ibex and wild sheep frequenting these mountains. Mr. Blyth and Dr. J. E. Gray consider this species as most likely a variety of the domestic goat; but from all Dr. Adams could learn of its habits and appearance, there is perhaps more cause to consider it the progenitor of the domestic animal than even the ibex. The mar-khor is usually found in small herds. Like the ibex, it delights to browse on steep and rocky mountains, ascending and descending with the seasons. In winter, in common with other alpine species, the fur becomes dense from the woolly pileage, which gives a lighter colour to the coat than during midsummer and autumn, when it disappears, and the fur is short and brown. Hunters have strange stories of the serpent-eating disposition of the mar-khor. Ajiz Khan assured Dr. Adams that an ammonite he picked up on the mountains had become petrified from having passed through the intestines of a mar-khor.-Adams; Jerdon.

MARKING NUT, or Malacca bean.

Beladur, - . ARAB. Shayrang cottay, TAM. Gheru, : CAN. Nelajidi, . ' ',

The Semecarpus anacardium tree is a native of all India. Its nuts are black, smooth, shining, and flattened on both sides. The nut rests upon a thickened stalk (peduncle). The pericarp or shell of the nut is composed of two laminæ; between them are cells which contain the black, corrosive, resinous juice, which is employed to mark cotton cloth. The colour is improved and prevented from running by a little mixture of quicklime and water, whence its name of marking nut. The tribe of plants to which it belongs abounds in plants yielding a blackish, acrid, and resinous juice, used for varnishing and other such purposes. The oil is acrid and vesicating; it is found, as related above, between the two laininæ of the pericarp, and is used as a preventive against the attacks of white ants, and by native practitioners as an escharotic in aches, pains, sprains, and in rheumatic and leprous affections. It is obtained by boiling the whole nut not divested of its pericarp. The preparation or collection either of the oil or acrid juice is liable to cause much irritation and inflammation of the hands and face, etc., of those engaged in the work. The oil obtained from the kernel of the nut is of a different character; seems to resemble the mild oil of cashewnut kernels.-M.E.J.R.; Roxb.

MARLBOROUGH. James Ley, Third Earl of Marlborough, an eminent mathematician and navigator, was slain in the great sea-fight with the Dutch, June 3, 1665. His body lies in Westminster Abbey. He had arrived in Bombay on the 18th of September 1661, with a fleet of five ships, to take possession of the island of Bombay as part of the Infanta Catherina's dower on her marriage with Charles II. The Portuguese in Bombay having refused to give up the island, Marlborough landed the 400 soldiers under Sir Abraham Shipman on the small island of Anjideva, 12 leagues to the south of Goa, where, having left them, he sailed away to England. The consequence was that Sir Abraham Shipman and 300 of his men miserably perished on this unliealthy spot, of exposure during the rains of 1662 . The survivors formed the cadre of the Hon. Company's 1st European regiment, or Bombay Fusiliers, since the $103 \mathrm{~d}$ Foot. The other regiment raised at the same time became known as Kirke's Lambs, since the 2d or Queen's Regiment. Under date the 15th May 1663, Pepys writes: 'The Portugalls have choused us, it seems, in the island of Bombay in the East Indys, for after a great charge of ourfleets being sent thither with full commission from the king of Portugall to receive it, the Governour by some pretence or other will not deliver it to Sir Abraham Shipman, sent from the king, nor to my Lord of Marlborough.' And under date of September 5 , he speaks of 'the disappointment of the king by the knavery of the Portugall Viceroy, and the inconsiderableness of the place of Bombaim even if we had had it.'-Sir George Birdurood.

MARLEA BEGONIFOLIA. Roxb. ii. p. 261.

Bodara, Mandra of Beas. Prot of . . KANGRA. Sialu of .. Chenab. Padlu of . . Ravi. Til-pattra of : JHeLuM. Marlea of : SYLHEr. Chit, Kurkni of ,"

A small but handsome timber tree, with maplelike leaves, occurring near the Indus from about 3200 to 6000 feet; wood used for house-building. Its leaves are eaten by sheep. $-D r . J$. L. Stewart, M.D.

MARMALA WATER, a fragrant perfume distilled in Ceylon from the flowers of the Egle marmelos, and used in the ceremonial sprinkling of visitors.

MAR-MATTEI, a monastery 30 miles N.E. of Mosul, founded A.D. 334 by Mar Mattei, companion of St. George.

MARMOT, a genus of mammalia of the subfamily Arctomydinæ; one species occurs in Europe, and two species in the region around the Paropamisus.

Arctomys hemachalanus, red marmot.

Chipi, . . . BHor. Sammiong, . . Lepch. Pheea, : ' Hunsia. Drun, .: Trier.

Occurs at 8000 to 10,000 feet in Kashmir and the N.W. Himalaya. The total length of an adult is from $2 \frac{3}{4}$ to 3 feet; the colour chestnut, with black splashes on the back and hip. It is seldom met with under 8000 feet above the level of the sea.

Arctomys bobac, Schreber, is the Tibet and Russian marmot or white marmot. Dr. Adams, when crossing the Tang Lang pass, came on a colony of white marmot, distinguished at once from the red species by its lighter colour, being a yellowish-white, but also by its call, which more resembles a whistle than a scream. One side of a spur was riddled by their burrows. The white seems to take the place of the red marmot on the more barren and higher ranges above 10,000 and 12,000 feet. The bearded vulture and larger eagles are among their chief enemies. He saw the former bear off a marmot with great ease. The marmots are generally supposed to be the animals alluded to by Herodotus as gigantic ants, which dug up gold. They form a small group of rodents allied to the squirrels, but strictly terres- 
trial in their habits. They are found in the northern portions of both hemispheres, and live generally in societies in mountainous districts. They excavate extensive galleries, in which they reside, passing the winter months in a state of torpidity. The alpine marmot is the commonest European species.

MARMUT, a lichen abundant in the crevices of the rocks of Baluchistan, used medicinally by Hindus in diseases of languor and oppression of the vis vitæ. The plant, replete with juice, and extremely bitter and nauseous, is dried, and a quantity of the powder swallowed, after which water is directed to be drunk. The same, or an analogous plant, abounds in the Khaibar Hills, and is carried to Peshawur, where it is largely used as an article of food by Hindus. - Masson's Journeys, ii. p. 116.

MARONITES are the most numerous of the Lebanon tribes, numbering about 200,000, of whom 35,000 were reckoned capable of bearing arms. Maronites, along with the Druse, occupy the most central valleys and the highest ridges, from the neighbourhood of Tripoli to the south of Beyrout. The Keshrouan, in the neighbourhood of D'Jounie Bay, is exclusively occupied by this Christian sect, said to have been founded in the 6 th century by a certain St. Maronius, and which, in religious matters, acknowledges the supremacy of Rome, though its clergy maintain the right of electing their own bishops or patriarchs, of dispensing with a state of celibacy, and of entering into the marriage state. Maronites live in dispersed hamlets and homesteads, engaged in cultivation. The head of their religion has the title of Batrak or Patriarch of Antioch. They do not allow re-marriage of widows. They are governed by a Kaim Makam; their monastery of Kizhaia is 20 miles E. of Tripoli ; they exorcise demons.Catafago.

MAROO. HIND: Two antelope horns joined in opposite directions at their bases, carried by fakirs.

MAROOST"HALI, the desert of Rajputana; the word means the abode of death, and is a very emphatic appellation of this sterile region. Though all these regions collectively bear the term Maroost'hali, or region of death (the emphatic and figurative phrase for the desert), the restrictive definition applies to a part only, that under the dominion of the Rahtor race.-Rajasthan, i. p. 18.

MARRI or Murree, a sanatorium town, in lat. $33^{\circ} 54^{\prime} 30^{\prime \prime} \mathrm{N}$., and long. $73^{\circ} 26^{\prime} 30^{\prime \prime} \mathrm{E}$., and 32 miles N. of Rawal Pindi. The southern side of the station of Marri is 6963 feet above the sea. Rawal Pindi, to the west of the Jhelum, is $\mathbf{1 7 3 7}$ feet above the sea. The range of hills on the right bank of the Jhelum overhang the platform of Rawal Pindi. It is a narrow ridge separating two deep river valleys, whose regetation is quite tropical. $-H$. f. et T. p. 213 ; Schl.

MARRI or Murree, a race or tribe occupying part of Baluchistan. Kahan town, in Kach Gandava, is in the hill ranges east of the plain of Kach. It belongs to the Doda Marri, a division of the great and widely-dispersed Marri tribe, who have been located in the neighbourhood for several centuries. The Marri are a brave race, and had long been distinguished as daring depredators.Masson's Journeys.

\section{MARRIAGE CUSTOMS.}

Zijah, . ARAB. Muta (temporary), Hind. Nikah, Shadi, "DekHan. Laggan, . ' MAHR. Byah, Akd, . Hind, Tazawaj, : : PERs. Katkhudai, : : ." " Kalyanam, : : . TAM. $^{-}$

In the E. Indies, amongst its various races, forms of marriage are to be seen from the simplest modes of mutual consent, through all the various known procedures of marriage by capture, community of right, polygamy, polyandry, temporary marriages, permanent lifelong marriages, endogamous marriage within the tribe or race, exogamous marriage out of the tribe or race; and there are sects of men and women who never marry, and men and women who marry only once.

Mr. M'Lennan and Sir John Lubbock have examined, at length, the subject of primitive marriage, and various writers on the tribes and races in the south and east of Asia have furnished notices of the prevailing marriage customs. A popular theory is that marriage sprang from the family, which developed into the clan; but according to Mr. M'Lennan, observation among the savage races still existing in the world always leads back to groups of naked savages living by the capture of wild beasts or upon the more easily caught shell-fish. These groups, he contends, only very slowly developed the idea of kinship, the primary one being that as they held their women in common they were never certain of relationship, except through the mother's side.

Sir John Lubbock points out that in some cases the exclusive common possession of a wife could only be legally acquired by a temporary recognition of the pre-existing communal rights. Thus, in Babylonia, according to Herodotus (Clio, p. 199), every woman was compelled to offer herself once in the temple of Venus, and only after doing so was she considered free to marry; the same, according to Strabo (lib. 2), was the law in Armenia. In some parts of Cyprus, also among the Nasamones (Melpomene, p. 172) and other Ethiopian tribes, he tells us there was a very similar custom ; and Dulaure asserts that it existed also at Carthage and in parts of Greece. The account which Herodotus gives of the Lydians, though not so clear, seems to indicate a similar law. The Rev. Joseph Roberts relates (p. 9) that in Madura, Balane, and other places, beautiful virgins used to go to the temple once in their lives to offer themselves in honour of the goddess, the story being that a god had converse with them. That the special marriage was an infringement of these communal rights, for which some compensation was due, seems to Sir John Lubbock the true explanation of the offerings which virgins were compelled to make before being permitted to marry. Among the Santal, one of the aboriginal Indian tribes, marringes take place once a year, mostly in January. For six days, all the candidates for matrimony live in promiscuous concubinage; after which only are the separate couples regarded as having established their right to. marry. In the patriarchal history of Scripture, and in the early accounts of the manners of ancient nations, the daughter was always considered the property of the parent, the wife as the purchase of the husband, and the marriagecontract as the deed of transfer. This is still the foundation of the Hindu marriage ceremony, and 
the Muhammadan bridegroom by the dower purchases his wife of herself.

Arrian mentions (Indica, cap. xvii.) an ancient Hindu practice of giving their daughters to the victor in prescribed trials of force and skill ; and a memorable instance of this is related in the Mahabharata, of Arjuna, one of the Pandu, by his skill in archery winning Draupadi at her Swayamvara tournament.

Capture.-Among the Khand, the boy's father pays a price for the girl, and usually chooses a strong one, several years older than his son, usually about 14 years old, the boy about 10. A feast is held, and the girl is forcibly carried off. The primeval custom of capture of wives continues to have symbolic representations. The old Norse for marriage is quan-fang or wife-catching; the German is brut loufti or bride-racing.

In Circassia, weddings are accompanied by a feast, in the midst of which the bridegroom has to rush in, and, with the help of a few daring young men, carry off the lady by force, and by this process she becomes his lawful wife. According to Spencer, another important part of the ceremony consists in the bridegroom drawing his dagger and cutting open the bride's corset. Mr. Lecky tells us (i. p. 338) that amongst the Greeks and the Romans, the bride was girt with a girdle, which the bridegroom unloosed in the nuptial bed, and hence zonam solvere became a proverbial expression for pudicitiam mulieris imminuere.

Among the Kalmuk, Dr. Hell tells us that, after the price of the girl has been duly agreed on, when the bridegroom comes with his friends to carry off his bride, a sham resistance is always made by the people of her camp, in spite of which she fails not to be borne away on a richly-caparisoned horse, with loud shouts and feu-de-joie.

Amongst some of the Mongol tribes, the girl mounts on horseback and flees, pursued by the lover, who only detains her as a wife if he overtake her. The girl is first mounted, and rides off at full speed. Her lover pursues; if he overtake her, she becomes his wife; after this she returns with him to his tent. But it sometimes happens that the woman does not wish to marry the person by whom she is pursued; in which case Dr. Clark was assured that no instance occurs of a Kalmuk girl being thus caught, unless she have a partiality to the pursuer. Among the Tungus and Kamtskadale, says Ernan, a matrimonial engagement is not definitely arranged and concluded until the suitor has got the better of his beloved by force, and has torn her clothes. Attacks on women are not allowed to be avenged by blood, unless they take place within the court or house. The man is not regarded as to blame, if the woman have ventured to leave her natural place, the sacred and protecting hearth. Pallas observes that in his time, marriage by capture prevailed also among the Samoyede.

Major Dalton mentions (p. 233) that among the $\mathrm{Kol}$ of Central India, when the price of a girl has been arranged, the bridegroom and a large party of his friends of both sexes enter with much singing and dancing, and seeming fighting, in the village of the bride, where they meet the bride's party, and are hospitably entertained. Occasionally, a few of the young man's friends assemble outside the fields where the women are at work, and rush on them to capture the girl he has fixed on, carrying her off from amongst the labourers, though a defeat and rescue are not uncommon. Kurku girls in Central India go through the form of preventing the removal of a bride. When they get near enough to the cavaliers, they pelt them with balls of boiled rice, then coyly retreat, followed, of course, by the young men; but the girls make a stand at the door of the bride's house, and suffer none to enter till they have paid toll in presents to the bridesmaids.

The Gond of Nimar serve for a wife, but practise forcible abduction of the bride, with a mock fight. They are polygamic. Mandla Gond have the Lamjana Shadi, in which the betrothed lad serves an apprenticeship for his future wife. A Gond girl, however, may exercise her own will and run off with a man, but it is quite allowable for her first cousin, or the man whom she has deserted, to abduct her from the man whom she has chosen. Their Shadi Bandhone is a compulsory marriage. In their Shadi Baitho, a woman goes to a man's house. Widows re-marry either to a younger brother of the deceased husband, or to some other man. The men and women of the Gond along the banks of the Wardha river are never associated in their labour, but work at a distance apart. A Gond having ascertained that an adjacent village has a girl whom he would like, goes with some friends to the place where she is working, and rushes to seize her. His companions will not aid him to carry her away by force, unless he, unaided, succeed in touching her hand before she reach the shelter of her village. The women often contest every inch of the ground with their pursuers, inflict very serious hurt, and often shameful defeats. The touching by the bridegroom once effected, the marriage contract is complete, and cannot be broken. But the contest continues even after the bridegroom has touched the bride's hand; and if the fight has drawn to the skirts of the village, the men join the women, and pursue the runners back to their own village.

Writing of the Khand race of Orissa, MajorGeneral (Sir John) Campbell says that on one occasion he heard loud cries proceeding from a village close at hand. Fearing some quarrel, he rode to the spot, and there he saw a man bearing away upon his back something enveloped in an ample covering of scarlet cloth; he was surrounded by 20 or 30 young fellows, and by them protected from the desperate attack made upon him by a party of young women. On seeking an explanation of this novel scene, he was told that the man had just been married, and his precious burden was his blooming bride, whom he was conveying to bis own village. Her youthful friends were seeking to regain possession of her, and hurled stones and bamboos at the head of the devoted bridegroom, until he reached the confines of his own village.

Dulha Deo is a favourite deity in Bundelkhand and amongst the Gond of Central India. It is the apotheosis of a bridegroom (dulha), who died in the marriage procession, and whose death so affected the people that they paid him divine honours. The worship of Adonis is similar, and also that of Thammuz, whose annual wound in Lebanon still allures the Syrian damsels to lament his fate.

The custom of capture is also to be traced in 
the rite of lifting the bride oyer the doorstep, which has prevailed in such different and distant races as the Romans, Redskins of Canada, the Chinese, and the Abyssinians. Hence, also, perhaps the honeymoon of England, during which the bridegroom keeps his bride away from her relatives and friends; hence even, perhaps, as Mr. M'Lennan supposes, the slipper is in mock anger thrown after the departing bride and bridegroom. Amongst the people of Tucupoia, the man has to gain the affections of his intended bride, but that step having been accomplished, he sends three or four of his friends to carry her off by force.

The marriages of the Jakun of the Malay Peninsula are ordinarily celebrated about the months of July and August, when fruits are plentiful. The bridegroom frequents for some time the house of his intended, and when he has obtained her consent, he makes a formal demand to the father. On the appointed day an entertainment is prepared, the bridegroom repairs to the house of the bride's father, where the whole tribe is assembled. The dowry given by the man to his intended is delivered, and must consist at least of a silver or copper ring, a few cubits of cloth; perhaps a pair of bracelets or other ornaments and furniture are added. Amongst some Jakun tribes there is a dance, in the midst of which the bride-elect darts off into the forest, followed by the bridegroom; a chase ensues, during which, should the youth fall down, or return unsuccessful, he is met with the jeers and merriment of the whole party, and the match is declared off. Or if the tribe be on the bank of a lake or stream, the damsel is given a canoe and a double-bladed paddle, and allowed a start of some distance; the suitor, similarly equipped, starts off in chase. If he succeed in overtaking her, she becomes his wife; if not, the marriage is broken off. But the chase is generally a short one, for though the maiden's arms are strong, her heart is soft and her nature warm, and she becomes a willing captive. Or if the marriage take place where no stream is near, a round circle of a certain size is formed. The damsel is stripped of all but a waist-band, given half the circle's start in advance, and if she succeed in running three times round before the suitor come up with her, she is entitled to remain a virgin; as in the other case, but few outstrip their lovers.

Among the Aheta of the Philippine Islands, when a man wishes to marry a girl, her parents send her before sunrise into the woods. She has an hour's start, after which the lover goes to seek her. If he find her and bring her back before sunset, the marriage is acknowledged; if not, he must abandon all claim to her.

Exogamy and Endogamy both prevail in the Indies. Some races through all ages have been carefully abstaining from marrying in their own tribe, while others take their wives from amongst their own people. The instance may be mentioned of Abraham sending his servant to obtain for his son Isaac a wife of his own people; and about the year 1860, a Kayasth Hindu family in Madras sent the son for a wife to Benares, 1000 miles away. At the present day, amongst the Brahmans and Rajputs of British India, throughout Western and Eastern Africa, in Circassia, Tartary, Siberia, China, and Australia, as well as in North and South
America, marriages take place between persons of different tribes. All Brahmans marry with women who have not the same pravara, i.e. who do not invoke the same Rishi as their ancestor (Asvalayana, xii. p. 15). Apastamba says, "Thou shalt not give thy daughter to a man belonging to the same gotra or family.' Yajnawalkya says, 'Let a man marry a woman who is free from disease, who has brothers, and who is not the daughter of a man having the same ancestors, and belonging to the same gotra as himself.'

Burton says that some clans of the Somali will not marry one of the same, or even of a consanguineous family; and the Bakalari have the same rule. In India, the Warali tribes are divided into sections, and no man may marry a woman belonging to his own section. In the Magar tribes the same rule prevails. Col. Daiton tells us that the Ho, Mundah, and Oraon are divided into clans or keeli, and may not take to wife a girl of the same keeli. The Garo are divided into mahari, and a man may not marry a girl of his own mahari. Mr. M'Culloch tells us that the Manipur and other tribes inhabiting the hills round Manipur, the Koupui, Mow, Maram, and Murring, are divided into four families, - Kumrul, Luang, Angom, and Ningthaja. A member of any of these families may marry a member of any other, but the intermarriage of members of the same family is strictly prohibited. General Campbell and Major Macpherson mention that the Khand regard it as degrading to bestow. their daughters in marriage on men of their own tribe; consider it more manly to seek their wives in a distant country; and regard marriage between people of the same tribe as wicked, and punishable with death. The Kalmuk, according to Dr. Hell, are divided into hordes, and no man can marry a woman of the same horde; the bride, says Bergman, is always chosen from another stock, among the Dubet, for instance, from the Torgot stock, and among the Torgot from the Dubet stock. The same custom prevails among the Circassian and the Samoyede. The Ostiak regard it as a crime to marry a woman of the same family, or even of the same name. Amongst the Chinese, exogamy is so severely adhered to, that a man must not marry into a family with the same family name.

It had long been known, from the researches of. Sir George Grey and Mr. Gideon Scott Lang, that marriage laws like those of the Red Indians, the people of Ashantee, and many other backward races, prevailed among most tribes of the Australian blacks. They were divided into stocks, each of which was named after some animal or plant. No man might marry a woman who bore the same stock name and the same cognisance. A man of the Kangaroo stock might not marry a woman of the Kangaroo stock, but he might marry an Emu woman, or a Wombat woman, and so forth. Children took the stock name and cognisance of the mother. These cognisances are now usually called totems, from their Red Indian name.

Among the ancient Jews, Abraham married his half - sister, Nahor married his brother's daughter, and Amram his father's sister; this was permitted because they were not regarded as relations. Tamar also evidently might have married Amnon, though they were both children: 
of David. 'Speak unto the king,' she said, 'for he will not withhold me from thee;' for as their mothers were not the same, they were no relations in the eye of the law.

Some of the Bedouin, also another Semite race, unmistakeably follow the rite of marriage by capture; and yet a man can claim to marry his cousin, if only he be willing to give the price demanded for her, and amongst the Muhammadans of Arab origin, in the Peninsula of India, to wed the maternal uncle's daughter is a recognised right.

The Koch' $h$ and the Ho are forbidden to marry excepting within the tribe. But the latter are not thoroughly endogamous, for they are divided into keeli or clans, and may not take to wife a girl of their own keeli. Thus they are in fact exogamous.

The Toda race, according to Metz, are divided into five distinct classes, known by the names Peiky, Pekkan, Kuttan, Kennae, and Tody ; of which the first is regarded as the most aristocratic. These classes do not intermarry with each other, and can therefore never lose their distinctive characteristics.

Among the Yerkala of Southern India, the first two daughters of a family may be claimed by the maternal uncle as wives for his sons. With them the value of a wife is fixed at twenty pagodas, The maternal uncle's right to the first two daughters is valued at eight, out of twenty pagodas, and is carried out thus: if he urge his preferential claim, and marry his own sons to his nieces, he pays for each only twelve pagodas; and similarly, if he, from not having sons or any other cause, forego his claim, he receives eight pagodas of the twenty paid to the girls' parents by anybody else who may marry them.

The Doingnak of the Arakan Hill tracts, a branch of the Chuk-ma, appear to have been endogamous. Captain Lewin mentions that during the chiefship of Janbux Khan, about 1782, the chief passed an order that the Doingnak should intermarry with the tribe in general. This was contrary to ancient custom, and caused discontent and eventually a break in the tribe.

The Kalang of Java, who have some claim to be regarded the aborigines of the island, are endogamous, and when a man asks a girl in marriage he must prove descent from their peculiar stock.

The Manchu Tartar race forbid marriages between those whose family names are different. In Guam, brothers and sisters used to intermarry, and it is even stated that such unions were preferred as being most natural and proper.

With the royal family of Burma, the custom is continued of half-brothers and half-sisters marrying. The king's eldest daughter remains unmarried. The Siamese rulers also marry their balf-sisters.

Endogamy would seem to have prevailed in the Sandwich Islands and in New Zealand, where, as Yate mentions, 'great opposition is made to any one taking, except for some political purpose, a wife from another tribe; so that such intermarriages seldom occur.'

Polygamy.-The Hebrew Bible shows a progressive change in Jewish views on women. The elevated conception of marriage presented in the record of the creation, testifies to a most profound sense of the sacredness of monogamy as the most intimate possible union of two persous; and the Canticle of later times is a song of wedded love and fidelity. Yet, at the outset, the right of woman to choose her lot seems to have been wholly disregarded, as Abraham twice permitted Pharaoh to have Sarah, Judah condemned his daughter-in-law to be burned; a thousand years afterwards, God threatened to give David's wives to his neighbours or to his son; Michal was transferred to Phalti from David by Saul, who had quarrelled with David; and at that era kings of David's tribe habitually succeeded to their predecessors' wives. Polygany was not prohibited amongst the Hebrews, but there is nothing to warrant the terrible seraglio customs depicted in Judges, and instituted by David and Solomon as regal.

In later Jewish history, the idea came to be that it was better for a woman to be a transferable concubine than to die an old maid, and virginity and childlessness were the only lots bewailed under the later Old Testament regime. A writer in the Westminster Review observes that wherever the regime has been theocratic, as in the Jewish and Papal theocracies, there woman has fared the worst; and her position has been most favourable wherever a strong, rough, moral sense of individual right, as in pagan Greece and Rome, has been dominant. In pagan Rome, seclusion was not known, but on its change to Christianity this became prevalent, divorce became impracticable; and while woman, theologically, was pronounced to be queen of heaven and mother of God, she became a mere chattel of her husband.

Polygamy has prevailed in Asia generally from the most ancient times, but as a rule it has been practised only amongst the rich and luxurious, or by those whose first wives gave no children, or amongst tribes whose traditions and customs compelled them to raise up seed to their deceased brethren. The Vedas, however, recognise monogamic marriages, the union of one man and one woman, as the natural state: husbands and wives are described in the Rig Veda (Mand. i. Hymn 131, v. 3; also Hymn 43) as presenting their oblations two and two together, and at another place (Mand. ii. Hymn 39) a husband and a wife are given amongst other illustrations of pairs. On the other hand (Mand. i. Hymn 126), a young rishi named Kakshivat celebrates the generosity of a raja who had given him his ten daughters in marriage. Amongst ancient mountain tribes on the western parts of the Himalaya, known as Gandharva, and supposed to be the modern Kandahar, the practice was at one time prevalent amongst the Kshatriya tribes of forming a union by mutual consent, and associating together without any preliminary ceremonies. The Brahmanical legislator Manu (ch. iii. v. 26-32-41) recognises the legality of such marriages, but declares none but the Kshatriya race may contract them; he denounces them as base unions, the offspring of which will act cruelly, speak untruthfully, and abhor the Vedas. Such pairings, in the present day, are not known to occur.

Manu says there are eight forms of the nuptial ceremony used by the four classes, some good and some bad in this world and in the next. They are termed-

Brahma, the gift of a daughter to a Brahman learned in the Vedas, voluntarily invited.

Deva, the gift of a daughter to the officiating priest at a sacrifice. 
Arsha, or that of the Rishis, in which the father receives from the bridegroom the gift of one or two pair of kine.

Prajapatya, the Oppu of the Tamils, that of the Praja pati or patriarchs, in which the father gives away his daughter with due reverence.

Asura, that of the Asura, the Arumponi Vinai of the Tamils, in which the bridegroom makes valuable presents to the father and relatives of the bride.

Gandharva, in which the parties are mutually agreed. This is considered to include the Swayamvara, in which a princess voluntarily chooses a husband.

Rakshasa, the violent abduction of a maiden after defeating or slaying her relations.

Paisacha, the violation of a girl when asleep, or in liquor, or of weak intellect.

Manu says, "The first six ceremonies in direct order are by some held as valid in the case of a priest,' etc. Manu utterly reprobates the idea of Gandharva marriage. In chap. iii. para. 32, he says that by the Brahma, Deva, Rishi, and Prajapati marriages only are born sons illumined by the Veda, learned men, beloved by the learned, adorned with beauty and with the quality of goodness, wealthy, etc., performing all duties, and living a hundred years; while from the other four marriages are produced sons acting cruelly, speaking falsely, abhorring the Veda and the duties prescribed in it. And further, he declares that the son of a Brahma marriage, or wife by the first ceremony, redeems from sin if he perform virtuous acts, ten ancestors, ten descendants, and himself the twenty-first person. A son born of a wife by the Deva nuptials, redeems seven and seven in higher and lower degrees ; of a wife by the Arsha, three and three; of a wife by the Prajapatya, six and six. 'From the blameless nuptial rites of men springs a blameless progeny; from the reprehensible, a reprehensible offspring. Let mankind, therefore, studiously avoid the culpable forms of marriage.' 'By culpable marriage, etc., great families are sunk to a low state.'

Adi Sur, the founder of the Sen dynasty, brought from Kanouj five Sagnic Brahmans of the tribes or gotra Sanhila, Kashyapa, Vatsa, Saverna, and Bharudwaja. Sudra families, Ghose, Bhose, Dutt, Mittra, and others, accompanied them, and these take the position of Kulin Kayasths. In the reign of Bullal Sen, about 284 years before the Muhammadan invasion, all these Kulin Brahmans and Kulin Sudras had greatly increased, and though degenerated in learning, they arrogated to themselves a position above all the Sapta-sali or aboriginal Brahmans. Bullal Sen enuobled the Brahmans by giving to them the title of Kulin. The Kulin Brahman subsequently consented to marry the daughters of the aboriginal Brahman; these eagerly seek alliances with the Kulin, who have established a scale of fees for condescending to accept a daughter of an inferior. They marry for gold. Of the Kayasths who came from Kanouj, Bhose, Ghose, and Mittra were ennobled by Bullal Sen with the title of Kulin Kayasths. Dass, Day, Dutt, Guha, Kar Paulit, Sen, and Singh hold a second rank.

Kulin Brahman women are married with difficulty, and generally to aged men. In 1868 , there were 11 Kulins in Hoogly and 1 in Bardwan, each of whom had contracted 50 to 80 marriages; 24 in Hoogly and 12 in Bardwan, who had contracted from 20 to 50 marriages; and 48 in Hoogly and 20 in Bardwan, who had contracted between 10 and 20 marriages. Kulinism is thus a great polygamic institution, and a few women have become prostitutes. In 1867 the abolition of this polygamy was contemplated, and will doubtless be carried out. Kulin marriages are sought after by the relations of the females, to keep up the honour of their families; and the children of these marriages invariably remain with their mothers, and are maintained by the relations of the females. In some cases a Kulin father does not know his own children.

Women unmarried.-It is not possible to learn from the legends of India all the marriage customs formerly prevailing in it. Several of its numerous races, from the most ancient times, have kept themselves distinct from each other, and the evidence of the Mahabharata, of the Ramayana, the Institutes of Manu, the Puranas, and the Vedas can only be accepted as relating to portions of the inhabitants. When we read that in the famous Indian city of Vesali, 'marriage was forbidden, and high rank attached to the lady who held office as chief of the courtesans," such must be regarded as an exceptional or local condition, of which, even yet, in British India, there is an instance in a town in North Canara, in the Peninsula.. It is stated that when Saky a Muni in his old age visited Vesali, he was lodged in a garden belonging to the chief of the courtesans, who drove out to visit him, attended by her suite in stately carriages. Having approached and bowed down, she took her seat on one side of him, and listened to a discourse on Dharma.... On re-entering the town she met the rulers of Vesali, gorgeously apparelled, but their equipages made way for her. They asked her to resign to them the honour of entertaining Sakya Muni, but she refused, and the great man himself, when solicited by the rulers in person, also refused to break his engagements with the lady. This custom, of the temple dancing-girls advancing to meet a great man, is still prevalent, and they show this honour alike to a governor or a bishop. Until recently, the Deva-dasa, or slaves of the idols, were the only educated Hindu women in India. All the great Hindu temples have bands of the Deva-dasa, who follow their trade without public shame; and a woman born of, or adopted by, one of the temple slave women is not held to pursue a shameless vocation, though other women who have fallen from good repute are esteemed disgraceful. The explanation of this is that every Hindu, according to the Institutes of Manu, is pure in 'bis or her own vocation, and the Deva-dasa continue the old custom of the country, under solemn religious sanction. Caste women, on the contrary, who have given way to lawless inclinations, bave outraged public feelings, have probably broken their marriage vows, and brought disgrace on their families. At the present day, the Hindu weaver races near Chingleput, 35 miles from Madras, devote the eldest daughter to the temple, and all classes of Hindus, in time of trouble or in hope of offspring, vow their girls to the temples.

Polyandry now prevails in Tibet, is common in the Himalayan and sub-Himalayan regions adjoining Tibet; in the valley of Kashmir, in Spiti, in Ladakh, in Kishtwar, in Sirmor, in the Siwalik range, in Khassya ; there are unmistakeable traces of its existence, till recently, in Garhwal, Sylhet, and Cachar; and it is still prevalent among the Toda of the Neilgherry Hills, the 
Coorg, the Maleala Sudra, and other castes of Malabar, Canara, and Travancore; also in Ceylon amongst the Kandyan race, and farther east, is an ancient though now almost superseded custom ; in New Zealand, in one or two of the Pacific Islauds, and in the Aleutian Islands; also to the west and north of the Aleutian, among the Koryak to the north of the Okotsk Sea; and, crossing the Russian empire to the west side, we find polyandry among the Saporogian Kazak. It is also found in several parts of Africa, and, according to Humboldt, it is prevalent in Anerica among the tribes on the Orinoco, and he vouched for its former prevalence in Lancerota, one of the Canary Islands. But the forms in which it has been followed have varied. Crsar found it in Britain; as it exists in Tibet and in the Western Himalaya, and Coorg and Kandy, it is limited to brothers. The restricted form known to the Jews and early Hindus, as noticed in Ruth and Manu, in which only the childless widow fell to the brother, is now not heard of.

In the Panjab, among Jat families too poor to bear the marriage expenses of all the males, the wife of the eldest son has sometimes to accept her brothers-in-law as joint husbands. The Ghakkar, the brave people of Rawal Pindi district, are now Mubammadans, but their polyandry was one of the characteristics which specially struck the advancing Muhammadans in 1008. The Karakat Vellalar of Madura, at the opposite extremity of the Peninsula, no longer practise polyandry; but they preserve a trace of it in their condonement of cobabitation with the husband's kindred, while adultery outside the husband's family entails expulsion from caste. The Reddi race of agriculturists in the southern Tamil provinces have a similar custom, in order to preserve their family lands; and the Namburi Brahmans of Travancore, to preserve their farnily property, allow only the eldest son to marry.

In Ceylon there were two kinds of polyandric marriage, the Diga marriage and the Dina. In the former the woman went to her husband's hut, in the latter the man transferred himself to that of the woman. Moreover, according to Davy ( $p$. 286), marriages in Ceylon were provisional for the first fortnight, at the expiration of which they were either annulled or confirmed.

In most countries, man has arrogated to himself a superiority over woman, and has regarded her duty to be to submit to man's decisions. But the ancient Britons, as also some of the Median Cantons, the Pict, and the Gete, were polyandrous, and the custom is traceable among the ancient Germans. The origin of polyandric customs has been referred to the communist practice still in force amongst Hindus with respect to all property and earnings, for where small parcels of land were to be subdivided amongst families, it was of consequence that the members should continue limited. The scarcity of women amongst a military class of foreign immigrants, and the absence of brothers on pasturing or commercial expeditions, whilst others stayed at home, have also been pointed to.

The Mahabharata relates that Pandu, with money and jewels, purchased Madri from her brother Salya, king of Madra. But in former times the princesses of some parts of India appear to have enjoyed the privilege of selecting a husband from amongst a number of suitors as- sembled for the purpose at a Swayamvara or tournament. In the Institutes of Manu (book iii. ver. 27), eight different forms of marriage are mentioned, but this right of selection is not one of them. In the 9 th book, ver. 9, there is an allusion to it, but it is doubtful whether this has reference to any but the commercial and servile classes: "Three years let a damsel wait though she be marriageable. After that time let her choose for herself a bridegroom of equal rank.' In Kalidasa's celebrated poem, the Raghuvansa, there is a beautiful description of the Swayamvara of Indumati, sister of the king of Vidarbha, in which she chooses Aja, the son of Raghu, out of a large assemblage of royal suitors. In the Mahabharata we have an account of the Swayamvara of Draupadi, the daughter of Drupada, king of Panchala, and afterwards the wife of the five Pandu princes.

From the fact of her marrying the five Pandu brothers, we learn that polyandry must have prevailed amongst some races of that period; and Curao was no doubt not uncommon; indeed, the compiler of the Mahabharata, Vyasa, was himself appointed to raise up offspring to his deceased brother. Herodotus tells us that polyandry prevailed among the nomadic Scythians, as it does at present among the Bhoteah. The practice is adopted also by races in Malabar, between whom and the people of the Himalaya Wilson traces the obscure vestiges of a connection.

It prevails in a household form amongst the people of Coorg, as also amongst the Toda of the Neilgherry, amongst the Kapilli tribe on the Dindigul valley, and amongst the Totti, a Pariah race in Mysore. The Coorg believe themselves to be descendants of the daughters of Chandra Varma, king of Matsa Desha, obtained by the intercession of Parvati. Chandra Varma is said to have come originally to Coorg. They marry at a ripe age, but the wives of brothers are in common. They are a compact body of mountaineers, who have been lords of the soil from time immemorial, and live in farm-houses far apart. The Amma Coorg take among the Coorgs a place similar to that of the Brahmans among Hindus.

The Kunawar people may be found as petty traders between Tibet and Hindustan, in almost every hill state between Nepal and Kashmir. The custom of several brothers having but one wife amongst them is universal. The women of the Himalaya really marry a plurality of husbands, usually brothers.

The Nair woman has only one married husband, with whom, however, she never associates, but at will receives any other men of her own race. The most recent writer on the Nair customs, the Rev. Mr. Mateer, tells us that the object in going through a marriage ceremony has never been surmised. These Maleala Sudra or Nair customs admit of no real nuptials.

The females of a wealthy Nair family, especially where there is but one sister, are visited at their own homes by Brahmans, or by persons of their own caste; and their children are reared up in the same house, and inherit from their mothers' brothers. Females of poorer families go to reside with partners of their own caste, so long as they agree together, and the average duration of such unions happily is increasing. There is, indeed, a marriage ceremony performed 
in the childhood of every Sudra girl; but it is never consummated as a marriage, conferring no connubial claims or obligations on the nominal bridegroom, who has thenceforth no further communication with the girl, and it rather serves to set the girl at liberty, as soon as she arrives at maturity, to form temporary associations, or to change them as she pleases. At any time subsequently, the girl may ' receive cloth' from any suitable man, and consort with him. The subsequent trivial bond, signified by giving and receiving a cloth, is dissolvable with a word at the will and pleasure of either partner. With the Nair there is no fixed rule that the person who married her must not give cloth.

The ceremony called giving a cloth, or agreement for concubinage, is performed in the presence of relatives and neighbours, usually at night. The girl is placed with the man on a mat on the ground, the emblems called lingam and yoni being marked in front. A valuable cloth being offered by the youth, the girl asks her uncle, 'Shall I receive it?' 'Yes.' The same question is put to the mother, who gives her consent. A cheaper cloth is given to the woman's father, mother, sister, brother, and other near relatives. As the succession to the Travancore throne is continued through sister's sons, the unions of the ruling family are those common to the Nairs, except that an Ammachi, or associate of a raja, if put away or widowed, is not allowed to marry any other man. The Ammachi has no communication with the reigning ranis. She is not a member of the royal household, has neither official nor social position at court, and cannot even be seen in public with the ruler whose associate she is. Her issue occupy the same position as herself, and the law of Malabar excludes them from all claims to public recognition.

Nairs either go to the woman chosen, give the cloth, and take her home, or reside with her at her brother's house. In the case of the royal family, a number of splendid cloths are sent, and she is brought to the palace of her consort. But, unlike other Sudra unions, the Ammachi, having once been taken by a raja, is required to remain apart from all other men all the remainder of her days, and is guarded in her own residence. It is not all parents that are willing to give their daughters on these terms. The Tangachis, or daughters of the raja, who, like sons, have no titles of rank, are first married in childhood by a Tirmulpād. When one attains to maturity, cloth is given by some one who takes her to wife. 'The nieces, however, the raja's sister's daughters, who, like nephews, have the titles of highness and rani, are married when young to Coil Tamburans, who afterwards live with them so long as both parties are mutually content. It is not necessary that the same person who nominally married the lady in childhood should actually consort with her in maturity. The princess can choose for herself, and if one consort dies, another is called in. The Coil Tamburans, or Lords of the Temple, are usually regarded as Kshatriyas, and from their rank are chosen the consorts of the princesses of the realm. Several families of this caste reside in the northern part of the Travancore dominions. The Coil Tamburan men give cloth to Sudra females, while the women aøsociate with Namburi Brahmans.
The reigning family has often died out from lack of direct heirs, and has been recruited by adoptions. There are several families of petty rajas in Travancore allied to the maharajas, the principal of whom is the Mavelikara family, from whom adoption of princesses is usually made, and with whom, therefore, close relations of friendship subsist. The present ranis were selected from this family in 1858. It is said that the Mavelikara line was itself perpetuated in ancient times from Travancore, mutual adoptions thus producing intimate union between the two houses.

The twelve Antarāla, intermediate castes between Brahmans and Sudras, generally called Ambalavasi, temple dwellers, officiate as temple servants. They mostly follow the nepotistic law. Sudras or Kshatriyas have sometimes to pay heavily for engagements with men of higher caste to consort with their families. The nieces of the Cochin rajas, whose male children succeed to the throne, form alliances with the Namburis, who, however, lose to some extent in caste, forfeit all ancestral privileges, and, becoming dependent on their new connections, receive in compensation large marriage portions and separate establishments at the palace. The nieces or sisters of the Travancore royal family intermarry with Kshatriyas only, and this seems to be the sole reason why the Cochin rajas are admitted to be of higher caste to those of Travancore: the former manage to procure Namburi Brahmans as consorts ; the latter only Kshatriyas of the Coil Tamburan class. Polyandry is not rare among Sudras, carpenters, Ilavars, and other Marumakkal castes.

Ilavar girls, Mr. Mateer further tells us, are all married in infancy as a mere form, at various ages, from one to nine. The person who marries a girl in infancy does not afterwards live with her. To save expense, several girls are usually married at one time. A pandal is erected. They are taken to the river to bathe, dress, and put on their ornaments. On returning, they are accompanied by the barber-women of their caste, who sing marriage songs, and by men, women, and children of their own people, shouting, blowing snake-horns, and the 'five kinds' of music. At the entrance of the pandal the noisy display is stopped, and the eldest of the brides is prepared for marriage; her face is veiled, and she is carried by one of her cousins and seated on a decorated platform, while the other brides are seated upon the boards, having their heads covered with white and red cloths. On the left side of each girl is laid a plantain leaf, and on this a nari measure, an edungaly measure made of the wood of Alstonia scholaris, and filled with paddy, a brass vessel containing an edungaly of rice, and a clean cloth folded, on which half a coeoanut containing a little oil and a wick is placed. A brass lamp is also lit, and laid close to each leaf, in addition to silver rings (worth one fanam each) tied with thread. After other of their customary marriage ceremonies, on the seventh day the ring tied up by the barber-woman is taken off, the wedding is over, and the bride's party give to the mock bridegroom 23 fanams and a bunch of plantain fruit, with five edungalies of rice and $a$ suit of cloth, and conduct him back to his home.

The Pariahs of Travancore are a strongly-built and bold race. They live in separate hamlets, and eat the flesh of dead cattle, tigers, etc. As 
with the Sudras, nephews are the heirs. Their girls are married when very young-as a mere form-by their cousins, but when grown up they are selected by others, who give cloth. Instances occur among them both of polygamy and polyandry.

A native writer, G. E. Varmman, says, "The Muttathu marry females of their own caste; but they only perform a ceremony, while Brahmans cohabit with them, and beget children. Should men of their own caste dare to approach them, it is like incest with a mother,-there is no atonement possible for them, - and such progeny are sacrilegious.'

Among these polyandric races, property is by the women. Colonel Yule says that this remarkable custom of inheritance exists, or has existed, among the aborigines of Hispaniola and tribes of New Granada and Bogota; among Negro tribes of the Niger; among certain sections of the Malays of Sumatra; in the royal family of Tiperah, and among the Kasias of the Sylhet mountains (both east of Bengal) ; in a district of Ceylon adjoining Bintenne; in Madagascar; in the Fiji Islands; and among the Hurons and Natchez of North America.

In ancient India, the position of the Hindu wife was far more honourable than it is in the India of the present day; and against this degradation of the sex, the Hindu marriage ceremonies, which have descended from bygone ages, make their constant protest, for in them the woman is recognised as the first and greatest blessing the gods granted to man. A Hindu poet has said-

'Woman is man's better half ;

Woman is man's bosom friend ;

Woman is redemption's source."

Hindus of Bengal say that the good fortune of a husband depends on that of the wife, hence a woman is an emblem of Lakshmi or Luckee. Girls are taught to offer prayers to all the gods for the gift of a good husband; but in Bengal, Siva and his wife Durga receive the chief invocations, because of Siva's fidelity to his spouse, Krishna being avoided because of his association with the Gopin milkmaids of Bindraban.

The whole spirit of the Hindu ritual is opposed to polygamy, but inculcates firm and undeviating allegiance to each other on the part of both husband and wife.

Age.-A Brahman girl who grows up without being married, loses her caste. The duty of choosing a husband belongs to the girl's father; but should he be dead, it devolves in succession upon the paternal grandfather, brother, paternal uncle, male paternal cousins, and lastly upon her mother. If these omit to perform their duty till after the girl has reached the age of eight, she may choose for herself. She can only marry with those of her own caste, and the preference should be given to the sons of her mother's brother or of her father's sister. It would be considered a dreadful sin to marry the sons of the father's brother or of the mother's sister.

It is a duty imperatively enjoined by the Shastras upon the parents or other relatives, and even friends, to see that a girl does not remain unmarried. In extreme cases people have to obey the letter of the law, by formally marrying to an Ashvattha tree (Ficus religiosa), a girl who, after all efforts, fails to secure a human husband. The artisan goldsmith race deem it so sacred a command to marry their daughters in infancy, that if permitted to grow up unmarried, the families say that it would be a duty to drown themselves. And all Brahman girls ought to be married and taken to their husbands' homes before they leave girlhood.

In all classes of the community there is a general predilection in favour of early marriages both of sons and daughters. Hindu mothers wish to see their sons married soon. If a son of a well-to-do Hindu grow up unmarried, the fact is considered as a stigma on the family, and rumours begin to be circulated against the health or constitution of the boy. A man of good family is showered with offers of a bride for bis son; but the age for lads has been increasing in the Presidency towns since the British introduced the education tests for employment, and fathers of girls strive to obtain educated husbands for their daughters. At the 1881 census of British India, out of a total of $123,949,970$ females, there were of married, $2,325,688$ under 9 , $5,616,460$ from 10 to 14 years old ; and of these respective periods of life, 78,976 and 207,388 were already widows. The widows between 15 and 24 years of age numbercd 1,134,705.

According to Dr. Buhler, Manu, Gautama, and Baudhayana, though they recommend early marriages, allow the fatber to keep his daughter at home up to the age of thirteen, after which age daughters were permitted to choose husbands for themselves. The Smartta Brahmans admit that this is the more ancient rule, and some of the Grihya Sutra show that marriages with women as well under as of more than full age were permitted by law, and, indeed, that infant marriages were not in force during the Vedic age of the Aryans. It is in the Smriti Shastras that infant marriages are enjoined, and one class of these works, to which the Samvarta, Angirasa, and Parasara belong, limit the marriage age much more than Manu. The Rig Veda seems opposed to infant marriage. Amongst the Riks which are recited at the marriage ceremony, there are some which express the belief that the bride belongs to the three gods of the Vedic times,Soma, the moon ; Gandharva ; and Agni, the firegod,-before she passes into the possession of mortal man. The bridegroom prays to Agni and Gandharva to cede the bride to him, and afterwards proclaims aloud that Agni has freed her, - Agni has given up his right of possession. A Hindu author, Gobhila-putra, asserts this to be an allegory, and that a girl falls into the power of Soma when inguen pube contegitur; into the power of Gandharva when mammæ ejus intumescunt; and into that of Agni on the occurrence

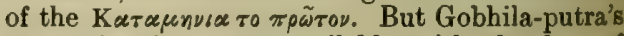
suggestion is not reconcilable with the fact of the existing ceremonial at marriage, also that, amongst the present Hindus, married women can always be pointed out, fair and comely, but childless, who are supposed never to have been released from the deity, and others whose offspring are supposed to have been begotten under celestial influence. These are current beliefs. In Vedic times, then, every bride must have been grown up. With the bridegroom, though they too, but not so invariably, are married while still boys, 
the existing laws, though now wholly neglected, plainly preclude marriage till maturity; for a Hindu can only enter on his student life when seven or eight years of age, and as this term lasts nine years at the shortest, a Hindu lad cannot by law marry till 17 years of age at least, which is absolute manhood. With the Dravida races, though the bride is almost invariably under age, often a mere child, and may reside from time to time with her husband's parents, there is no association till she have been a second time unwell.

Ritual.-The minute ceremonials of marriage considerably vary. The Brahman and the five artisan classes are not permitted by the social customs to ride on horseback when in procession, Sudra Hindus and the non-Aryans asserting their exclusive right to that honour. The artisan races do not acknowledge Brahmans, do not permit them to perform their marriage ceremonies, but they are not allowed to use the plantain for ornament.

When seated, the girl is formally given to the husband (Kania-danam), literally spinster-giving. A priest blesses some water in a small vessel, and the father of the girl, taking this and his daughter's right hand, places them together in the bridegroom's right hand, saying, I do this that my father, grandfathers, and great-grandfathers may attain Swarga. The bridegroom then rising, and standing before the bride, amidst the deafening din of tom-toms, ties round her neck the mangala sutram, a thread coloured with turmeric, to which a golden jewel, called bottu or talai, is attached. Sandal-wood paste, perfume, and flowers are presented to the guests; betel-nut is offered to all relatives and friends, and money presents are made. The married couple receive Asir-vadam, benedictions and congratulations from the assembly, and as they prostrate themselves at their parents' feet their parents bless them. In Northern India part of the marriage ceremony consists in tying a string or thread round the wrist of the bride; and with many of the races in India, whether of Aryan or Turanian descent, part of the marriage ceremonial consists in tying the corners of the bride and bridegroom's cloths together (Phylu bandhna), and causing them to circumambulate the village deity. There is also the ceremony of Sat-phéri, or seven turns round the sacrificial fire.

A marriage procession in the north-west of India has many elements different from those in Bengal. The Basanti, spring months of April aud May, being considered as the most auspicious season, hymeneal processions may then be daily witnessed in any of the great cities. In the northwest, the bridegroom, instead of being carried in a palanquin, and followed quietly by a crowd of guests, proceeds on horseback, with musicians playing right and left, and a band of female songstreases singing songs suited to the occasion.

The married Hinduani of Bengal during their husbands' lifetime wear an iron bracelet or a bit of iron twined round with a piece of gold wire. The wives of the agricultural Od-chasa race in Orissa wear bracelets so long as their husbands live; but the Mahinti and other Uriya tribes throw off their brass kharu or bracelets as soon as they can afford to purchase ornaments of the more precious metals. The pote or bead necklace is tied on the Hindu and Muhammadan bride of
Northern India. Wedding rings of stones are erected by Baluch nomades as a memorial. Sakhisungbad and Biraha are love songs sung by Brahman women on the first occasion of a bridegroom and bride being left together.

Marriage in Hindu law is indissoluble, and it is to be of one wife; except that if a wife be barren for eight years, or for eleven years have no male offspring, or be drunken, or immoral, or extravagant, or bear malice to their husbands, a second wife may be taken; but the first wife is always the head of the house. A wife who quits her husband's house, or neglects him for a twelvemonth, may be deserted altogether.

There are five things considered essential to the Hindu marriage ceremony, viz, the betrothal, the gift of the virgin, the acceptance, the seizure of the hand, and the seven steps or Sapta-padi. In giving a way the virgin, the girl's father or guardian must say, in the presence of the Bralimans, to the father of the bridegroom: 'I give you, for your son, my beautiful virgin daughter; accept her therefore.' The father of the youth replies: 'With my mind, with my voice, and with my body I joyfully accept thy daughter for my son, and religiously receive her among my own kindred.' The girl's father then declares his gotram (tribe), and gives grains of rice tinged with red and betel leaves to the bridegroom, declaring again that he gives him his daughter, and promises to defray all the expenses of the marriage. With the girl there should be given one or more cows, some land, and a salagram stone.

The girl's father next makes a solemn declaration in the presence of the assembled Brahmans, thus : 'O Brahmans! to this youth M., learned in the Vedas, the son of N., to him I give my daughter, dressed in gay apparel, and adorned with gems.' The Brahmans answer: 'Tatha astu,' So let it be. The father-in-law having taken the hand of his daughter, now puts it into the hand of the bridegroom, and pours over them water sacred to Vishnu. The pouring of water, according to eastern custom, makes a gift irrevocable, and the marriage should be now complete. The Sapta-padi, and the ceremony of tying on the Tali, have, however, been superadded. The wooden yoke of a bullock used to the plough is brought, and lightly laid upon the head of the bride. A veil is then held up between her and the bridegroom, and the mangala ashtaka or eight auspicious verses are recited. They form a canticle calling upon the gods, the saints, the trees, the hills, and the rivers to witness and to be auspicious to the union. The veil then falls, and the bridegroom binds a golden ornament, called the Tali, around the neck of the bride. This can never be removed except in the unhappy event of her becoming a widow. Then follow the homam or sacrifice to Agni, the god of fire, in which the bride and bridegroom take together the Sapta-padi, or seven steps, amidst the loud chanting of the Vedas. From this observance the term Sapta-padinam has become synonymous with friendship; and it is common for two persons to swear eternal friendship by taking seven steps together. Next comes the ceremony of eating, what is called Madhu parkam, literally mead mixture. Grains of parched rice are now substituted, but the name of the ceremony is still allowed to perpetuate the memory of the fact, that in times past the 
Brahmans did not scruple to drink fermented liquors, although they now strictly prohibit their use. On the third day after marriage, the attention of the bride is directed to a small star named Arundhati, near the constellation of the Great Bear, and she is exhorted to follow the chaste example of Arundhati, the wife of the rishi Vasishta, who, on account of her conjugal fidelity, was deified and placed among the stars. On the fourth night a torch-light procession sets out, and the bride and bridegroom are carried round and round the village in a palanquin, with music and dancing. This goes on till sunrise. They are then conducted home, and are received at the threshold by some married women, whose husbands are still living, for the sight of a widow at such a time is considered most inauspicious. They are then seated, and a lamp is waved round their heads to avert the ill effects of the evil eye; and for the same purpose the bride sometimes wears a coral bead with the jewel of her Tali. Somewhat in the same way as the English send round weddingcake and cards, the Hindus distribute betel leaves with the nut of the areca paln, and grains of rice coloured red. The friends of the bride now come to offer their congratulations, and a common wish at this time is: "May you live long and bear sixteen.

Expenses at the marriages of several of the races of India are very heavy. Among Shrimali Vania and Oswal Vania it is difficult to secure a bride unless the bridegroom spend between 2000 and 3000 rupees for her. The number of Shrimali and Oswal Vania among the Jains is no less than 32,280 , or more than two-thirds of the entire Jain population of Baroda. Besides this, their commercial and trading tendencies oblige many of them to leave their homes, and thus they are obliged to remain single. Moreover, the daughters of Shrimali Vania are returned as Hindus when they are married to Meshri or Vaishnava Vania. The Shrawaks often give their daughters to the Vaishnava, while the latter but rarely give their daughters to Shrawaks.

The ruling family of Rewah have been dominant in that state for many generations. They are much respected by the people and neighbouring chiefs, taking daughters in marriage from the very highest and proudest houses in Hindustan. About the year 1874 one bride was said to have taken with her a dower of five lakhs of rupees.

The dowry in Tamil marriages is regulated according to a fixed scale, the highest caste being rated lowest. That of a maiden of the Vellalar, the first in rank of the Tamilian agricultural castes, was formerly 11, and is now 21 pon, which in everyday usage are represented by $38 \frac{1}{2}$ and $73 \frac{1}{2}$ rupees, -a pon being equal to a pagoda. In addition to the dowry, the bridegroom's parents give another pon tied up in a piece of cloth, under the name of Mulei pal mudichi, or Mulei pal kuli, literally breast-milk packet, or breast-milk hire, typifying that the expenses of the bride's rearing are thereby discharged, and that she has become thenceforth the purchased property of her husband.

The passages in Manu as to the purchasing a bride by a dower are contradictory ; possibly the practice varied, as now, with the different races. With the agricultural classes of the N.W. Provinces, the bride's father purchases the bridegroom by gifts of money and household utensils. When
Prithi-raj carried off the daughter of Jye-chand, her father nevertheless sent to him the richest gems, the fruit of the victory of Biji Pal, inestimable wealth, pearls, elephants, and dyes. And when Prithi-raj married the daughter of Dabima of Biana, her father gave him 8 beauteous damsels, 63 female slaves, 100 Irak horses, 2 elephants, 10 shields, a pallet of silver for the bride, 100 wooden images, 100 chariots, and 1000 pieces of gold: This costly system has its origin in the desire to marry a daughter into a higher family. The dread of these marriage expenses and pride of race led to infanticide. They chiefly went in presents to Bards, Charans, and Brahmans. If the legend can be trusted, when Sita was married to Rama the palace of Janaka was full of Brahmans-

\section{'How many thousand Brahmans here, From every region far and near, \\ Well versed in holy lore appear.}

But Muhammadans of India also have a profuse expenditure. In the year 1850, when the fosterbrother of the nawab of the Carnatic was married, about $£ 10,000$ were expended in idle ceremonial. More recently, a Gaekwar of Baroda, on the demise of his first wife, married a second time. The procession passed on its way, winding through the city till it arrived at the bridal abode, which was very tastefully ornamented and fitted up. The bride was modestly and thickly veiled. The bands played, the guns thundered a royal salute, the soldiers fired a feu-de-joie-

\footnotetext{
"Twas not the air, "twas not the guns, 'Twas not the feu-de-joie that runs Fair up and down the double rank, But one glad shout that softly sank, At once a thousand voices said

"It is the veiled Marathi maid."
}

The bride, as is customary, sat on a basket, her royal lover sat in front of her, and fine cords were then wound round the two contracting parties to betoken the indissoluble nature of the bond between them.

Wealthy Hindu families often marry their daughters into poor families in order to keep their son-in-law under their own roofs. These are called Ghar-jamai, or home-bred son-in-law. A son-in-law of the Kulin race is particularly desired, but the position is deemed degrading. In some cases in Baroda the father of a Hindu girl retains a lad in his house, and the girl and the lad live as man and wife without being united in marriage. In such cases the lad is called Ahariyo or Asariyo. In other instances the bridegroom-elect has to serve his father-in-law for five years before he is entitled to take away his bride. He is then called Bandadiyo.

Widlows. - With the Koupoi tribe of the Nagas of the N.E. frontier, on the death of a man's wife, her father or next-of-kin demands the price of her bones (Mundoo) from the widower-husband. Their widows are taken by the deceased husband's brother. It was a custom amongst several Scythic races for widows to burn themselves, or be buried alive, or to be destroyed by the sword or dagger, and interred along with their husband's remains. This practice prevailed in the East Indies up to the middle of the 19th century, when it was prohibited by the British, but it is still followed in the island of Bali, in the Eastern Archipelago. In a Government notification in the Foreign 
Department, Simla, the 7th April 1847, the Governor-General expressed much satisfaction in republishing a proclamation by the Gwalior darbar, prohibiting the practice of sati within the territories of maharaja Sindia. The GovernorGeneral also, in 1847, republished documents prohibiting female infanticide in Jeypore, and limiting the demands of the religious Bhat, Charan, Dholi, and Merasi sects on occasions of marriages in Rajput families.

Re-marriage of Brahman and Rajput widows is never permitted; and though re-marriage is lawful by the Muhammadan law, the followers in India of that religion have largely adopted the Hindu practice. In some of the otber Hindu castes a woman may re-marry more than once.

Much attention is at the present time directed towards this portion of the Hindu code. An influential sect of theists, the Brahmo Somāj, followers of Ram Mohun Roy, use a revised ritual, in which, while idolatrous invocations of the Vedic and Puranic deities are suppressed, and the One without a Second is entreated to sanctify the union, the ceremonies which are not idolatrous, and which have been consecrated by the use of ages, are preserved with a view to the relief of the members of the Brahmo Somãj. Marriages between natives of India not professing Christianity must be solemnized in the presence of a registrar, and of at least three credible witnesses, in whose hearing each of the parties makes the following declaration:-'I, A. B., am a native of British India, I do not profess the Christian religion, and I object to be married in accordance with the rites of the Hindu, Muhammadan, Buddhist, Parsee, or Jewish religion.: The bride and bridegroom are then to repeat words to the following effect:-' $I$, A. B., declare, in the presence of the Almighty God, that I take thee, C.D., to be my lawful wedded wife (or husband).?

The husband must have completed the age of 18 , and the wife must not be under 14 . If she be under 14, the consent of her father or guardian is necessary.

The Hindu law does not recognise the second marriage of widows, though seven forms of cobabitation are observed with certain ceremonial rites. The mere act of being betrothed disqualifies from a second marriage. The affianced becomes a widow, though a komari or maid. Latterly, however, re-marriage of females left widows before attaining a really maxriageable age, is being less objected to amongst respectable Hindus. Nothing can be crueller or more unwise than to condemn girls to a life of celibacy. The seven forms of cohabitation are,--when the first marriage has not been consummated; when a girl has been unchaste, and is married to another than the gallant; when a widow is allotted to a kinsman to raise issue for her deceased husband. In these three the woman is $P \bar{u} n \bar{a} r-b h \bar{u}$, she who is wedded again. In the other four she is termed Swaireni, independent, uncontrolled.

Curao is the Urdu or Hindi term given among the Jat, Gujar, Ahir, and other races and tribes in North - Western Hindustan, to concubinage generally, but more especially to marriages of widows with the brother of a deceased husband. The practice is known to the eastward by the name of Urhuri, in the Dekhan as But'hee, and in other provinces by the name of Dhureecha. It is followed among these classes, but is not very openly confessed even among them, as some degree of discredit is supposed to attach to it. It is only younger brothers who form these connections, elder brothers being prohibited from marrying their younger brothers' widows, but among the Jat of Dehli even this is not prohibited. The practice has been common among several nations of the east. The Jews followed this custom, and in Egypt it was perinitted for a childless widow to cohabit with a brother of the deceased husband. When the laws in Manu were collected, Curao appears to have been a recognised institution; but, as is not unusual with the Institutes, there is much contradiction between the enactments relating to it. From a consideration of all the passages on the subject, it appears that failure of issue was the point on which the legality turned. He who was begotten according to law on the wife of a man deceased, or impotent, or disordered, after the due authority given to her, is called the lawful son of the wife (chap. ix. ver. 176). When the two younger sons of king Santanu Vichitru Virya died childless, the Mahabharata mentions that Vichitru Virya's widow first asked Bhishma, saying, 'Take the raja's widows, I pray you, and raise up sons that shall be to him as his own sons;' and being refused, in consequence of his row, How can I do this thing? have I not vowed a vow that I would never become the father of children by any woman? she sent for her own kinsman, Vyasa, to whom was born the blind Dhritarashtra, Pandu, and Vidura. This practice is identical with that of the Jews, as described in Ruth. There is perhaps no circumstance which so strongly shows the northern descent of the deified heroes as this marriage. Amongst the Jat, Gujur, and Ahir, children born in Curao are considered legitimate, and are entitled to inheritance accordingly. Children begotten by the woman previous to Curao, except in the case of fraternal Curao, are known by the name of Kudhelura, and do not inherit the property of the father-in-law.

In Berar, most Hindu women are allowed to make a second marriage, but a widow is married there by the 'pat' form, an inferior ceremony. The groom is not married to the woman, but to the swallow-wort plant, or to a ring, or a pitcher. The twigs of five plants are used,-the mango, the shami, jambul, apata, and swallow-wort. The trees are worshipped, a twig is cut from each; in the bride's house they are placed in an earthen pot, around the mouth of which is bound a strip of yellow cloth torn from a woman's bodice. They are subsequently worshipped at the Deokundi ceremony.

Plant Marriage.-In Chutia Nagpur amongst agriculturists, and in Singhbum amongst all classes of Kol, girls have a fixed price, sometines up to 40 head of cattle; and girls often long remain unmarried, even to be old maids. When such are married, the bride clasps a mahwa tree, the groom a mango tree, and at the close of the ceremonies the bridesmaids pour a jar of water over the heads of each of the couple, who then retire to change their wet clothes. The next morning the bridesmaids burst into the nuptial chamber and bring forth the bride and groom.

The marrying with plants is not restricted to human beings. Banotsarg is the Hindu ceremony 879 
of marrying a newly-planted orchard to its neighbouring well, without which it would be held improper to partake of the fruit. Brikhotsarg is the marriage ceremony performed by Hindus when liberating a bull. Hindus, in sickness, at marriages and other ceremonial occasions, loose a bull, which thenceforward rambles at will without an owner. These haunt the market-places and landing-places, and in large towns such as Benares, the Ranh, Sanrh, and Sirhi or widow's bulls are numerous. The bulls are generally in good condition, are often in the way, but rarely mischievous, though very cunning.

The Matsya Purana and other books denounce marriage to a third wife under the penalty of early death, but incurrence of the penalty is evaded by the man himself being married to a plant. On a day when the sun is in the lunar asterism called Hasta, the resolve to marry is expressed, the manes of the deceased ancestors worshipped, and then the priest has to worship the Rui plant, a kind of swallow-wort which is considered to represent the sun in union with his wife Chhaya (shadow), raw sugar and rice offered, and the sun is thus invoked: "O thou who dwellest in the three worlds, do thou, along with thy wife Chlaya, obviate the dangers that attend a third marriage, and confer on me felicity.' In the further ceremony, the man, placing his hand on the bush, says, 'Mercifully preserve me now that thou art come to be my wife ; ' and after other ceremonies, a veil is drawn between the parties, a benediction given, and the veil removed.

Seasonal. - With the Kadava Kunbi of Gujerat, an interval of twelve years elapses between one marriage season and another. After the lapse of nine years from one marriage season, the Kadava patels of Ahmadabad and Unjha, and the priests or Pujari of the goddess Umia Devi, the tutelary goddess of the Kadava Kunbi, whose temple is at Unjha in the Kadi division of Baroda, consult the goddess as to the marriage season. Two bits of paper, one containing the word yes, and another the word no, are thrown before the goddess, and a virgin is asked to take up one of them. If the bit selected by the virgin contains the word yes, it is construed into a permission on the part of the goddess for celebration of marriages that season. If, on the other hand, the bit containing the word no is taken up by the virgin, it is construed as a prohibition, in which case the bits of paper are again thrown before the goddess after a lapse of two years. If at that time also the bit taken up contains no, the experiment is tried again and again until the bit with yes is obtained.

The Kadava Kunbi are also very particular as to their intermarriages. But when a suitable match for a girl cannot be found, she is married to a bunch of flowers, which are afterwards thrown into a well. She is then a widow, and can be married with the natra rites. Or she is married to a married man, on the agreement that he divorce her on completion of the ceremony, and she can then, as a divorced woman, be remarried by the natra ceremony.

With non-Aryan aborigines, both parties are over 15 or 16 years old. The Kurumbar, for instance, marry after a girl is grown up, as also do the Betta Kurumba, the Teling Balja Vadu, the Devanga, Jadar, and Kaikalar weavers, also the Palli race of the Tamil-speaking people, also the Hala-Paik and the Bilwara of Canara; also the Kansa Wakkala, the Upara or builders, the Bedar, the Lala Gundara, and the Soligara. A literary race called Kayastha, or Kayat, or Kayasth, who claim origin from a deified mortal called Chatrgoputr, also many of the Pariah tribes, allow their girls to grow up and remain in their father's house without any feeling of impropriety being associated with the practice.

The Reddi of the south of India are divided into 24 clans, who marry in their own clans. They profess to be Vaishnava. As a law, the men marry their sister's daughter, but an aunt does not marry her nephew. Sometimes the bride is a mere child of five or six years old; sometimes the bridegroom's age is no more, while the wife to whom he is married is a fullgrown young woman, who, by the time her husband has grown up, has a young family of four or five children. Property descends through the issue of a son and granddaughter, uncle and niece. If a man refuse to marry his own sister's daughter, his father's property descends not to him, but to the man who marries the rejected woman. When a young Reddi woman of sixteen or twenty years of age is married to a boy of five or six years, she lives with some other adult male, perhaps a maternal uncle or cousin, but is not allowed to form a connection with the father's relations; occasionally it may be the boyhusband's father himself, that is, the woman's father-in-law! Should there be children, they are fathered on the boy-husband. When the boy grows up, the wife is either old or past childbearing, and he in his turn takes up with some other boy's wife in a manner precisely similar to his own case, and begets children for the boyhusband.

The Komati or Hindu shopkeepers of Madras, before contracting marriage, send an offering of betel to the Chakili or shoemakers, and in Vizagapatam, Brahmans go through the ceremony of asking the Mala's consent to their marriage.

With the Maravar of Ramnad and Sivaganga disparity of ages is not considered, nor is the presence or assent of the bridegroom necessary,a blade of wood in bis absence serving as proxy. Some of their subdivisions do not rnarry into the father's family ; but Hindus in general intermarry with the mother's relations.

The monkey-faced Kallar in the south of India are a brave and martial people, with much physical power and endurance. Their habits and customs are entirely aboriginal. Nominally of the Saiva sect, they are mostly devil-worshippers. They have a first and second marriage, like the Maravar of Ramnad. The titular surname of all Kallar is Ambalakaren, and they numbered 155,537 in 1881 . Divorce and re-marriage of widows are allowed. Marriage of near relatives is usual. The Western Kallar of Madura are polyandrists. It constantly happens that a woman is the wife of either ten, eight, six, or two husbands, who are held to be fathers jointly and severally of any children that may be born of her body. And when the children grow up they style themselves the children not of ten, eight, or six fathers, as the case may be, but of eight and two, or six and two, or four and two fathers.

The Palli race of the Cuddapah districts pledge 
their wives as security for loans of money, and if not repaid, the woman is re-married to another man. A case of this bigamy was tried in 1876 at the Session of Cuddapah, and all the parties were fined. The husband had borrowed some money from his mother-in-law, and left his wife with her till he could repay. Having failed to pay within the prescribed period, the wife was re-married to another man. The twice-married wife, her mother, and a third party who was present at the second marriage, were held to be equally punishable as principals, all having been present at the re-marriage.

The Karakatan Vellalar of the Madura Hills occupied their present locality before the Vellalar of the plains adopted the customs of the Aryan immigrants. And now, amongst them, when an estate is likely to descend to a female in default of male issue, she is forbidden to marry an adult, but goes through the ceremony of marriage with some male child, or, in some cases, with a portion of her father's dwelling-house, on the understanding that she may receive any man of the caste. Her children inherit the property, which is thus retained in the woman's family, the childhusband being the supposititious father.

The Khond are faithful and brave, boundlessly hospitable, and a guest's safety and care are paramount duties. Agriculture and war are deemed. the sole honourable arocations. A boy is married in his tenth year to a girl four or five years older than himself. In the middle of the marriage feast, at night, while the dancing goes on, the girl's uncle lifts her on his shoulder, while one of the boy's uncles does the same with the bridegroom. Suddenly the uncles exchange burdens, and the boy's uncle makes off with the bride. In a moment the festivities cease, the kinsmen range themselves into two hostile tribes, the girl's friends trying to recapture the bride, the boy's to cover her flight. The two parties carry the fight to great lengths, and the conflict exhibits an ancient custom of marrying by capture.

The Yerkal, Korawa, or Kunchi Kori are wanderers, of whose original country they themselves retain no knowledge. They are darker than the usual tinge of Hindus around them. In their own communities they style themselves Ycrkal, and they give the same appellation to the language in which they hold communication with each other. With the exception of the cow, almost all animals are used by them as food. They worship'a goddess called Poler Amma. Polygamy is common; and if a man owe money to his neighbour, he pledges his wife or daughter to his creditor, who may either live with them or transfer them to another person. On the release of the debtor, he reclaims his wife and any children that may have been born in the interval. In N. Arcot, Chingleput, and Tanjore, the Korawa mortgage their unmarried daughters, who become the absolute property of the mortgagee until the debt is discharged. In Madras, the Korawa, when in want of money, sell their wives outright for about 50 rupees. In Nellore, they all purchase their wives at from 30 to 70 rupees, making payment in asses or cattle. Their various clans do not intermarry. They bury their dead. In Travancore there are 56,274 Korawa; and there is a race of this name in Cutch of similar habits.

The Toda or Todawar (properly Tuda or Tuda- rara) live in hamlets or 'mund' on the Neilgherry plateau. They never could have exceeded a few thousand, but they have diminished through opiumeating and polyandria, and, at a former period, the prevalence among them of female infanticide. It is said that no girl has been destroyed since 1819 , but their present numbers do not support this. Before marriage, young people associate. After marriage, the Toda wife, or if there be more than one, all the wives, in a family of brothers are common to all the brothers.

According to Colonel Dalton (Tran. Ethn. Soc. vi. p. 25), the Khariah of Central India have no word for marriage in their own language, and the pairing appears to be little more than a sort of public recognition of the fact. The Badaga can scarcely be said to have any marriage ceremony. The Kurumbar tribe of the Neilgherry Hills have no marriage ceremonies; but occasionally, when two have been living together for some time, they will enter into an agreement, in the presenee of friends, to remain united for life ; and in a family where a succession of such unions has taken place, they will, once in two or three generations, perform a ceremony, and hold a festival in celebration of them. This is done by pouring pots of water over one another, the pairs seating themselves together for this purpose; the ablution commencing with the seniors. They then put on new clothes, and end the day in feasting and merriment.

The Dhor, leather-workers of the Dekhan, marry in their own tribe, making the marriage procession on a bullock; they are not entitled to proceed on a horse. The Chamar in Aurangabad worship Mariamma and Sitla. They marry when under age, proceeding on foot to the goddess Sitla, whose shrine they circumambulate five times. The expense is about 100 rupees. Kol girls, till they are married, occupy at night the same house as their fathers and mothers. Boys and young men sleep in the Morang or town hall, and when a man marries, he and his bride leave the paternal roof, and form a separate home. The Kharriah bride and bridegroom, as part of the ceremony, are carried through the dances seated on the hips of two of their companions.

Santal are shy and superstitious. To obviate disputes between them and the lowlanders, the Government, in 1832 , erected a boundary line of stone pillars; but they fell into debt, and in 1855 a body of 30,000 men, armed with their bows and arrows, started to walk to Calcutta to lay their grievances before the Governor-General. But they began to plunder, and, when checked, they went into open rebellion, and in putting it down many were slain. A simple form of government was then introduced among them; nevertheless, again, in 1881, a few of them took up arms to resist the census-taking. They dwell in villages of their own, apart from other inhabitants, and each hamlet is governed by a headman, assisted by a deputy and a watchman. The Santal bachelors are under a separate head. The young people select their own partners, and at the marriage ceremony the girl's relatives pound burning charcoal with the household pestle, and extinguish it with water, in token of the breaking up of her former family ties. The dead are burned, and they float three portions of the skull down the Damuda river, the sacred stream of their race. 
In Sumatra there were formerly three perfectly distinct kinds of marriage, - the Jugur, in which the man purchased the woman; the Ambelanak, in which the woman purchased the man; and the Temando, in which they joined on terms of equality. In marriage by Ambelanak, says Marsden, p. 262 , 'the father of a virgin makes choice of some young man for her husband, generally from an inferior family, which renounces all further right to, or interest in him, and he is taken into the house of his father-in-law, who kills a buffalo on the occasion, and receives twenty dollars from his son's relations. After this, the buruk baik'nia (the good and bad of him) is invested in the wife's family. If he murder or rob, they pay the bangun, or the fine. If he be murdered, they receive the bangun. They are liable for any debts he may contract in marriage, those prior to it remaining with his parents. He lives in the family in a state between that of a son and a debtor. He partakes as a son of what the house affords, but has no property in himself. His rice plantation, the produce of his pepper garden, with everything that he can gain or earn, belongs to the family. He is liable to be divorced at their pleasure, and though he has children, must leave all and return naked as he came. The Temando is a regular treaty between the parties on the footing of equality. The adat paid to the girl's friends has usually been twelve dollars.

In Bali Island girls are stolen away by their lovers, who sometimes surprise them alone, or overpower them by the way, and carry them off with dishevelled hair and tattered garments to the woods. When brought back from thence, reconciliation is effected with enraged friends by a certain compensation price being paid to her relatives.

In the Korea, when a man marries, he mounts on horseback, attended by his friends, and, having ridden about the town, stops at the bride's door, where he is received by her relations, who then carry her to his house, and the ceremony is complete.

Amongst the Australians, the bride is carried off by force.

Japanese, of all classes, look upon their wives as upon a faithful servant. A Japanese is never known to beat his wife. It is a custom amongst some Japanese to take a woman a few weeks on trial before deciding upon whether to marry her or not. The Japanese marriage ceremony is very simple. The bride and bridegroom drink wine with each other three times, exchanging cups with each other every time, in the presence of a few select friends, after which the young lady gets her teeth blackened, and she is married for better and for worse. Amongst the Muhammadan women of India, also, the custom is followed of blackening the bride's teeth with missee on marriage; women never use it before their wedding-day, and it is by the black mark in the crevices between the teeth, occasioned by the application of the missee, that a Muhammadan woman can be observed to be married or not. With the same object, Malay women have their front teeth filed down.

Amongst the Siah-Posh Kafir, the marriage ceremonies consist merely of procuring two twigs or rods of the respective height of the bride and bridegroom, and tying them together. These are presented to the couple, who preserve them so long as they live together. If desirous to separate, the twigs are broken, and the marriage is dissolved.

With the Buddhist races of Tibet and Burma, marriage is readily contracted, and the tie as easily broken. In Burma, marriage and concubinage are regarded as civil contracts, and all breaches are punished by fines; seduction is also punishable by a fine. Girl marriages, as in India, are unknown in Burma, and a Burmese girl is courted and won. The period of the day between eight in the evening and midnight is called courting-time, during which the girls receive five or six bachelor admirers, who act as a check to each other. This courting-time is called Loo-byo-lai-thee-kala in Burmese. A lamp placed in their casement intimates that they are at home. An old bachelor (loo-byo-hoing) or old maid (apyo-hoing) is unknown out of the ascetics of the monasteries. Burmese women wear as a lower garment a gay-coloured cloth, which just wraps the lower part of the body, and opens at every step, disclosing the left thigh.

In China marriage is universal, and such a being as an old maid or an old bachelor is unknown. With the Hindus, Muhammadans, and Chinese, parents choose wives for their sons, as was customary with the early Hebrews. (Genesis xxi. 21, xxxviii. 6 ; and Deuteronomy xxii. 16.) A Chinaman cannot take as a wife a woman who bears the same family or clan name as himself. If he do so, the marriage is null; neither can he marry his cousin on his mother's side, nor his step-daughter, nor his mother's sister. No lady can marry until she is fourteen years of age. Play-actors, policemen, boatmen, and slaves must marry into their own respective classes. The Chinese attach great importance to marriage. It is not considered respectable for a widow to marry again. Where a betrothed girl loses her affianced husband, public opinion regards it as meritorious for her to abstain from marriage. Testimonials are often voted by the people to commemorate such instances of fidelity; and where a widowed betrothed girl chooses to die voluntarily, her memory is held in the highest honour. Nevertheless, women, even as first wives, do not take a high place in families, although as mothers their condition is vastly improved. They are in theory monogamists, but polygamy is common amongst the well-to-do, though rather in the form of concubinage. Nunneries of Buddhists are formed in China, but the inmates are not respected; they are admitted after 16 years of age, and their heads are shaven.

In the marriage ceremony, the Chinese bride and bridegroom, after the worship of the tablets, rise to their feet, and remain standing in silence. One of the female attendants takes two goblets from the table, and, having partially filled them with a mixture of wine and honey, she pours part of the contents from one to the other several times; she then holds one to the mouth of the grnom, the other to the mouth of the bride, who sip a little of the wedding wine, and, continuing to face each other, she then changes the goblets, and the bride sips out of the one the groom had used, the groom out of that of the bride, and this completes the marriage.

With the Chinese, the closing act of the ceremony is for a female attendant to present to 
the bridegroom a small linen sheet, which he spreads on the nuptial couch, and on the following morning it is presented to his parents. This rite is adhered to in a modified form by the Jews throughout the world. It lingers among some races professing Christianity. About the year 1882 ; a trial took place before the Court of Assize at Naples, terminating with the condemnation of Vincenzo and Carolina Garguillo, son and mother, the former to hard labour for life, the latter to seclusion for three years. The daughter of Carolina, one of the beauties of Sorrento, was married to a sailor called Guiseppe Esposito. The usage of the lower classes of the country, which efforts have been made in vain to suppress, is for the bridegroom to visit his motherin-law on the morning following the marriage, and Esposito was reminded of it. The visit was not, however, paid, nor was it after waiting a fortnight. The mother-in-law then becoming furious, complained to her son, urging him to avenge the honour of his sister and of the family. Vincenzo Garguillo thereupon went to his sister's house and waited for the husband, who on his arrival welcomed him, and begged him to stay and dine. The answer was that Vincenzo, drawing a knife and throwing himself on his brother - in - law, stabbed him and laid him dead at his feet. In the Samoan group, the Jewish ceremony customary on such occasions is adhered to.

There are difficulties in the way of the Manchu emperor obtaining a bride. He acknowledges no other king or rank of his own kind, hence there is no prince's daughter who can be asked for his wife. There are princes in China, but they are of the imperial family, and cannot intermarry. He must take his wife from the people, and she must belong to one of the eight banners. In a recent case there were two empresses, the one was called the Eastern Empress and the other the Western. When the selection of a bride had to be made, these two ladies issued orders to all the chiefs who had daughters of the desired age to send them to the palace. But families do not like their daughters to become the wife of an emperor, not even to be his empress. A girl is in a sense lost to the family, for she is kept so secluded in the palace that the relatives seldom or never see her, and it brings the parents and family into $\pi$ position and prominence which is dangerous in a country like China. So parents allege that they are cripple, or deaf, or blind, and in some cases lameness is imitated, and deformities are artificially produced. To such an extent had this been carried, that orders, it is said, were issued that blind, lame, and deaf were all to be sent to the palace. Somewhere about 600 or 700 girls appeared on the day fixed, and about 50 or 60 young ladies were selected as a result of the first inspection. Their names were taken, and the character and position of their families were inquired into; their horoscopes also would be carefully calculated. After tbis had been done, another inspection was gone through, and 30 were separated from the batch; these were then kept in the palace, so that their merits and demerits could be more accurately ascertained. After a short stay, the number was reduced to 20 , then to 10 , and at last became a tie of two; and thus an empress was selected. At the same time four other wives were chosen, and these were to form the commencement of the imperial haram.

Silver and golden wedding days are almost as much observed by the Chinese as by the Germans. On these festivals children present parents with magnificently embroidered banners, which are hung up in the ancestral hall, a large room so appropriated in the house of every wealthy man. In this apartment, besides these tokens of filial affection, are kept boards, on which are painted, in gold on a scarlet ground, the names and titles of the families with which the family has intermarried. When a woman marries, all the boards from her father's ancestral hall are carried in procession before her.

Some peculiar customs in various races. may be noticed. There is occasionally practised amongst Hindus of the Komati caste, the marriage of the living and the dead, the principals being a living woman and a dead man. In one case the living woman and the dead man had lived to. gether for many long years as man and wife, when, after suffering from a febrile attack for only four short days, the man died. Agreeably to the peculiar custom of their caste, it was imperative, ere the corpse could be removed for interment, that the sacred rites of matrimony should be performed. The sad intelligence was soon communicated to the neighbouring residents, and to a host of friends and acquaintances, and a fluctuating stream of passers-by. A guru or priest being summoned, and the necessary preparations for the celebration of the nuptials being hurriedly completed, the ceremony commenced. The inanimate form was placed against the outer wall of the verandah of the house in a sitting posture, attired like a bridegroom, and the face and hands besmeared with turmeric. The woman also was clothed like a bride, and adorned with the usual tinsel ornament over the face, which, as well as the arms and the drapery, was daubed over with yellow. She sat opposite the dead, now addressing it with light and unmeaning words,-as is customarily done upon such occasions, - and then chewing bits of dry cocoanut, and squirting it on the face. And thus the ceremony continued for three or four hours. At length, as the sun was mearing the horizon, the nuptial ceremony was brought to a close, and the preparation for the interment commenced. The head was divested of its bridal attire, then bathed, and finally laid upon a bier, and covered with a cloth of silk. 'I'he face was next rubbed over with some red powder, and in the mouth were placed some betel leaves. The widowed bride then looked her last at the shrouded form of him whom never more she would behold, when, amid agonizing shrieks and deafening tom-tomming, the bier was lifted up, and the funeral cortege proceeded in the direction of Sion; one man preceded the corpse, throwing at intervals a handful of pie to the right and left, which were eagerly picked up.

A Hindu mother-in-law is not permitted to appear before her son-in-law; to do so would be deemed scandalous.

In China, Borneo, and the Fiji Islands, a fatherin-law after his sou's marriage never again visits his daughter-in-law, and if they chance to meet, he hides himself. In Australia, a man must not pronounce the name of his father-in-law, motherin-law, or son-in-law. The Muhammadans of 
Western Asia indicate their wives as the mothers of their sons. No Hindu or Malay woman can be induced to pronounce her husband's name.

The Aleutian islander, says Mr. Farrer, quoting Dall, knows nothing of what civilised nations call modesty, yet he blushes when he is obliged to speak to his wife, or to ask her for anything in the presence of others. Custom compels them to assume the attitude of perfect strangers. The Hottentot woman may never enter her husband's room in the hut, and the husband, as among the Spartans, must never be seen in the neighbourhood of the wife. Among the Yoruba, an African tribe, a woman is forbidden to speak to her husband, and may not even see him if it can possibly be avoided. Apparently a similar custom existed among the early Sanskrit-speaking peoples, for the wife, in the famous story of Urvasi and Pururavas, says to her lord, "Never let me see thee without thy royal garments, for such is the manner of women.' And when this rule is accidentally broken, Urvasi must softly and suddenly vanish away.

A Circassian bridegroom must not see his wife nor live with her without the greatest mystery ; and Fiji islanders display the utmost distress of mind when adventurous missionaries suggest that there is no real harm in a man's living under the same roof with his wife. The young Kaneka bolts with a wild scream into the bush if you even mention the name of his sister; while in Fiji not only brothers and sisters, but first cousins of opposite sexes, may neither eat together nor speak to each other.

Among Muhammadans there is only one legal ceremony, the Nikkah, by the kazi or his deputy, but there are several deviations from it. In Persia and India their Nikkah ceremony is with rejoicings or Shadi, if the bride be a spinster and of equal rank with the bridegroom; their Mutai marriage is for a limited time in consideration of a present, and the Nikkah-i-Muwakkat is a temporary marriage. According to the Sunni ruling, the offspring of the Mutai and the Nikkah-i-Muwakkat are illegitimate. The Sunni say a usufructuary marriage, i.e. where a man says to a woman, 'I will take the use of you for such a time for so much,' is void; so also is a temporary marriage (e.g. a marriage for ten days), whether for a short or for a long time; but it is one of the points on which the Shiabs differ from them. A verse of the Koran has been interpreted by the Shiahs as warranting such a temporary marriage; the Sumnis have come to a different and certainly a more moral interpretation. Kings and great men have occasionally availed themselves of the diverse views of the different schools to obtain legal sanction for irregular practices. A king of Beder in the 15th century is described as complaining to his Sunni lawyers of being limited to four wives, and desired to know how he might marry more. They pointed out that, although he could have only four at a time, he might divorce one wife and marry another as often as he pleased. This was not what he wanted; so he addressed himself to a learned Shiah, who was present at his court. From him he obtained the opinion that a Mutai or temporary marriage was legal, and had been practised in the time of the prophet. Marriage carries with it rights of inheritance, and the dower settled upon the wife may, and often does, interfere with the rights of the ordinary heirs. Dower is held to be the price promised or paid by the husband for possession of the wife's person. If unpaid, it is a debt on the husband's estate. It takes precedence of all claims by inheritance, and descends by inheritance to the wife's heirs. The amount of dower is entirely arbitrary, and varies according to the position in life, and the youth, beauty, and accomplishments of the bride. It is settled by the relatives of the contracting parties; but if a marriage has been agreed upon and the amount of dower is disputed, the magistrate has authority to determine the just amount. Divorce under the Muhammadan law may be effected at the mere will of the husband; but a man cannot repudiate his wife without paying her dower; so it frequently happens that a very ardent lover, or one willing to divest himself of the power of divorce, will agree to an amount of dower which it is quite impossible for him to discharge. From this there is no escape but payment, or remission on the part of the wife. A free man may not have more than four wives at the same time; a slave may not have more than two. There is a long and well-defined table of Prohibited Degrees, and this includes not only relations by blood, but, generally speaking, those also who stand in the same relation by fosterage. Free persons cannot marry their own slaves, because parents have by law an equal right in their offspring, and this right is incompatible with the position of owner and slave.

The marriage of Hindu women by Muhammadan emperors commenced with the father of Firoz Shah, whose mother Naila was the daughter of raja Malla Bhatti. Howell states that when the Hindu rajas submitted to Timur, it was stipulated that the emperor should marry a daughter of Jet Singh's house, and that the head of the house should be governor of Bengal.

About A.D. 1306, Kaula Devi, wife of the raja of Gujerat, had been captured in Baglana during her liusband's flight, and was carried to Ala-udDin's haram. She had great influence over him, and induced him to make efforts to capture her daughter Dewala Devi. This was accomplished, and her beauty made such an impression on the king's eldest son, Khizr Khan, that he soon after married her. Their loves are the subject of a celebrated Persian poem by Amir Khusru.

Jodh Bai, daughter of Bahāra Mal, raja of Amber (now Jeypore), was the emperor Akbar's wife, and she was the mother of Salim, who became the emperor Jahangir. The marriage of Salim with the daughter of raja Bhagwan Doss, son of Bahāra Mal, was performed according to Hindu form at the raja's house, and in the presence of Akbar. Other Muhammadan emperors had Hindu wives, but no Hindu was permitted to marry a Muhammadan girl. Jahangir said, 'Marrying a Hindwani is not so bad, but to give one's daughter to a Hindu! Lord protect us against the machinations of the evil one!' The practice of the Muhammadan emperors marrying Hindu women was a rnatter of policy, calculated to preserve a good understanding.

In Egypt, girls are prepared for marriage with a very great deal of ceremony. There are tirewomen who make the beautifying of brides their special profession. On the wedding morning the bride is dressed in her bridal robes; her hair is 
plaited with the Grecian plait, small pieces of gold-leaf are stuck on her forehead and on her breast; care is taken not to conceal any of the stars or spots tattooed on her face and chest in infancy; a line of blue dots encircling the lips is sometimes seen, and a spot on the chin is very common. A little rouge is added to heighten the colour of the cheeks where necessary.

In British India, the descendants of all the - Musalman races-Arab, Iranian, Turanian, Mongol, and Hindu converts-intermarry. Rarely a Christian man and a Muhammadan woman.

The Koran of the Muhammadans enjoins the strictest seclusion of women. They are prohibited from appearing unveiled before any but very near relations, children, or eunuchs. But elderly women of the poorer classes, married or widows, appear abroad, do all the marketing and other out-of-door domestic work, and without veils of any kind. This practice of seclusion is followed also by the Rajputs of rank and the Namburi Brahmans. But with the mass of the Hindu people, the women attend to all ordinary in-door and out-of-door duties, drawing water at the well, obtaining the daily bazar supplies, and the women of the agricultural and gardening and labouring races of the Aryans and non-Aryans share their husband's toils.

Erroneous physiological notions of the races in Central Asia and China lead some husbands to marry more than one wife, or to have haram or slave women in their homes, and it is this which keeps up slavery there. The Muhammadan haram custom is given in the rule for the Jews, Judges v. 2830; Deuteronomy xxi. 10-13: 'When thou goest forth to war against thine enemies, and the Lord thy God hath delivered them into thine hands, and thou hast taken them captive, and seest among the captives a beautiful woman, and hast a desire unto her, that thou wouldest have her to thy wife; then thou shalt bring her home to thine house; and she shall shave her head, and pare her nails: and she shall put the raimant of her captivity from off her, and shall remain in thine house, and bewail her father and her mother a full month: and after that thou shalt go in unto her, and be her husband, and she shall be thy wife.'

In British India, the rule which Europeans affects the European community is the resolution of the Governor-General in Council, dated the 8th October 1852, which prescribes that certificates of marriage should be transmitted to England in every case when either party to the marriage is what is commonly called a British subject, or the legitimate offspring of such a person; and in other cases, whenever either party to the marriage desires it to be so transmitted. Subjects of foreign European states were provided for in 1854, when returns of births, deaths, and marriages of European Christians, of all denominations, throughout British India, were prescribed by the Governor-General in Council. Every marriage between British people, or in which one of the contracting parties is of legitimate extraction from English parents, has become capable of proof by simply referring to the Registrar-General in London.

In the old Roman forms of marriage, confarreatio was the most sacred, and the bride and bridegroom were joined together by the Pontifex Naximus in a set form of words, in the presence of at least ten witnesses, the contracting parties having to partake of a cake made of salt, water, and flour, called far. Of that panis farreus, the wedding cake of the British is the relic, and their bridesmaids and groomsmen have their origin in the ten wituesses. Amongst the Romans, special honour was given to the children of such marriages, and from amongst them were chosen the flamens of Jupiter and the vestal virgins.

The bride's cake which so invariably accompanies an English wedding, and which should always be cut by the bride, may be traced back to the old Roman form of marriage by confarreatio or eating together. The Fiji islanders have a very similar custom. The act of eating together is, amongst the Burmese, the ceremony of union. Among the Tiperah race of the hill tribes of Chittagong, the bride prepares some drink, sits on her lover's knee, drinks half and gives him the other half; they afterwards crook together their fingers. But marriage amongst the Romans was of three kinds, - the confarreatio, which was accompanied with the most awful religious rites, was practically indissoluble, and was jealously restricted to patricians; the Coemptio, which was purely civil, and which derived its name from a symbolical sale, and which, like the confarreatio, gave the husband complete authority over the person and property of his wife; and the Usus, which was effected by a simple declaration of a determination to cohabit. The Usus became general in the Roman empire, and in it the married woman remained in her father's house and under his guardianship. Her dowry passed into the husband's hands, but, with that exception, she held her property in her own right; she inherited her share of her father's wealth, and she retained it altogether independent of her husband; - and thus a very considerable portion of Roman wealth passed into the uncontrolled possession of women. During the ascetic stage of morals in Europe, many Romans and Christians regarded a second marriage as improper.-American Expedition; Bowring's Ethnol. of India; Burton's Scinde, Mecca, and City of the Saints; Major Bushby in Berar Gazetteer; Balfour on Tribes, in Jameson's Ed. Journ.; Cameron's Eastern Possessions; $M r$. (Sir George) Campbell's Ethnol. of India; Dalton's Ettnol. of Bengal; Davy's Ceylon; Doolittle's China; Elliot's Glossary and India; Fraser's Himalaya Mountains; Frere's Antipodes ; Forbes' Rasamala; Graham's Khandesh Bhil Tribes; Gray's China; Hodgson's Aborigines of India; Histoire Abregee des Cultes; Journs. Beng. As. Soc., Ethnol. Soc., Indian Archipelago, Royal As. Soc.; Imperial Gazetteer; Kearns' Tribes of S. India; Layard's Nineveh; Lecky's European Morals ; Lubbock, Civilisation; Lewin's Chittagong Hill Tracts; Mahabharata Selections; Mateer's Travancore; M'Lennan's Primitive Marriage; Marsden's Sumatra; Metz, Neilgherry Tribes; Menu, Institutes; Perry's Bird's-eye View of India; Newbold's Malacca; Rafles, Java; Ramayana; Recherches Phil. sur les Chinois; Calcutta, Westminster Reviews; Robert's Oriental Illustrations; Rogers' Domestic Life in Palestine; Shortt's Hill Ranges, and in Ethnol. Soc. Journ.; Mrs. Spiers, Ancient India ; Tod's Rajasthan; Vishnu Purana; Ward's Hindoos; Watson and Kaye's People of India; Weber's Literature; Williams' Nala and Damayanti; $H$. 
H. Wilson's Hindu Theatre, Glossary, and Sects; Dr. Wilson's India 3000 Years Ago.

MARRI AI, literally the death-mother, the goddess worshipped by the Beldar race of Berar.

MARROW, Vegetable. Cucurbita ovifera, one of the most nourishing and wholesome of the gourds.

MARRUBIUM VULGARE. Linn.

M. hamatum, H.B. | M, Germanicum, Schr.

Horehound is a plant of Europe and Mid Asia, near Kashmir, on the Chenab, in the Salt Range and Trans - Indus, at elevations varying from 2000 to 7000 feet.-Dr. J. L. Stewart, M.D.

MARSDEN, SIR WILLIAM, a medical officer of the E. I. Company, author of History of Sumatra, its Government, Laws, Customs, and Manners; Numismata Orientalia Illustrata, Lond. 1823-25; Bibliotheca Philologica et Orientalis. A Catalogue was printed of the Books and Manuscripts collected by him on the Chronology of the Hindoos, Lond. 1790.

MARSDENIA ROYLII. Wight.

Pathor of . . Chenab. | Tar of . Ravi and Sutles. Veri of RAvi and SUTLEJ.

A climbing plant, growing up to 8000 feet in the Outer Himalaya bills and in the Salt Range. Its fibres are made into fishing-lines, and the powdered unripe fruit is given as a cooling medicine.-Dr. J. L. Stewart.

MARSDENIA TENACISSIMA. $W$. and $A$. Asclepias tenacissima, Roxb.

A. tomentosa, Herb. Gymnema tenac., Spr.

Tongus, . . Hind. | Chittee, Jeti, . TAM,

The Rajmahal bowstring creeper grows in the Peninsula of India, in the Rajmahal Hills, Palemau, Nepal, and Chittagong. It has small greenish-yellow flowers; from wounds in it a milk-like juice issues, which hardens into an elastic substance, with properties like caoutchouc, and from the bark, beautifully fine silky fibres are obtained, of which the Rajmahal mountaineers make their bowstrings. These are said to last for five years, though in constant use and exposed to all sorts of weather. In preparing the fibres of this plant, the hill people do not put the stems in water, but let them stand in the sun for a day till drier; from the ends, when cut, there exudes a milky juice, which thickens into an elastic substance, like, indeed forming one kind of, caoutchouc, acting in the same way in removing blacklead marks. The fibres are beautiful, durable, and strong; some twine made with it bearing 248 and $343 \mathrm{lbs}$. in the dry and wetted states, when hemp twine bore only 158 and $190 \mathrm{lbs}$. in the same state. The stems are cut into lengths, and then slit down the middle; then dried, and afterwards steeped in water for about an hour or more, when the fine silky filaments are separated. A $1 \frac{1}{2}$-inch rope in Calcutta was found to break with 903 lbs., when Europe rope broke with $1293 \mathrm{lbs}$, and others with greater weights. It stood ninth in strength, but second in elasticity. $\mathrm{Mr}$. Taylor states it might be easily cultivated. -Journ. Agri-Hortic. Soc., 1844, p. 22; Royle, Fib. Pl.; Roxb. ii. p. 51; Voigt, p. 537.

MARSDENIA TINCTORIA. R. Brown. Asclepias tinctoria, Roxb. Cynanchum tinjeris, Herb. Pergularia tinctoria, Sps: Ham.

This creeper grows in both the Peninsulas of India, in Assam, Sylhet, Pegu, Tenasserim, and
Sumatra; and Dr. Roxburgh recommended its extensive cultivation. The Burmese obtain from it quite a good indigo blue, though not equal to the dye from the Ruellia.

MARSHALL, THOMAS, a surgeon of the Bombay or Bengal Army, who was Statistical Reporter in the S. Mahratta country. His reports on the parganas of Padshapur, Belgaum, Kalaniddee, Chandgarh, Khanapur, Bagulcot, Badami, and Hoondgoond were printed in Bombay in 1822. He died between the 29th July and 6th September 1821.

MARSH DATE or Ground Rattan is the Calamus rotang or common cane plant. Its leaves are used at Cuddalore for making ropes and mats. Marsh date palm is the Phoenix paludosa.

MARSH MALLOW, Altbæa officinalis. A syrup of this is a mucilaginous demulcent; syrups for the same purposes may be prepared of Bombax Malabaricum root, of dried Abelmoschus esculentus capsules, of Asparagus sarmentosus, of Aigle marmalos.-Benq. Phar. p. 407.

MARSHMAN, JOSHUA, colleague of Carey and Ward, born in 1768 at Westbury Leigh, the son of a weaver and Baptist minister. He arrived in India in 1799. John Clark Marshman, his eldest son, was born August 1794 accompanied his father to Serampur in 1800 , and from 1812, for mearly 20 years, living like his colleagues on $£ 200$ a year, conducted an enormous correspondence, and betook himself to secular work, though never abandoning his projects for the evangelization of Bengal. $\mathrm{He}$ started a paper mill, founded the first newspaper in Bengali, the Sumachar Durpun; established the first English weekly, the Friend of India, which in his hands speedily became a power; published series of law books, one of which, the Guide to the Civil Law, was for years the civil code of India; and started a Christian colony on a large tract of land purchased in the Sunderbans. All his undertakings except the last succeeded, and the profits and influence acquired through all were devoted in great measure to his favourite idea, that education must in India precede Christianity. While still a struggling business man, he expended $£ 30,000$ on building and maintaining a college for the higher education of natives, a college still worked with the greatest success. Knowing Bengali as only skilled native pandits know it, and law like a trained lawyer, he was asked by Government to become Official Translator. The salary was $£ 1000$ a year, and for ten years he paid away the whole salary every month in furthering the cause of education, and this in silence so complete that his own family probably only after his death learned the fact for the first time. He wrote the first, and for years the only, History of Bengal, and published a History of India after his return to England in 1852 .

MARSIAH. ARAB. An elegy, a dirge, read during the Maharram on the deaths of Ali, Hasan, and Husain.

MARSILEA QUADRIFOLIA. Linn. Soosni-shak, . BENG. Ari kiray, . . . TAM. Chuppati ke baji, DUKH. Ara kura, . . : TEL. Godhi (the bulbs), HIND. Mudugu tamara, . " Chittur dulla, . SANsk. Munugu tamava, " ",

A plant of Europc, N. Africa, India, and Australia. Its bulbs are eaten either raw or 
boiled. M. Egyptiaca, Willd., is found in Egypt and in the Peninsula of India, and M. Coromandeliana, $N$. L. Burm., in the southern part of the Peninsula of India.-Voigt; Pou'ell; Ains.

MARSUPIALS, an order of mammals found only in Australia and America. They bring forth their young in an incomplete state. After their birth, the young become attached to the teats of their mother placed inside a pouch situated beneath the abdomen, and are there retained until sufficiently adult to be able to shift for themselves, as in the opossums and kangaroos.

MARTA, in Malabar, a Pariah aboriginal race who personate demons.

MARTABBAN, a province and small town in British Burma. The town is at the junction of the Gwyne and Salwin rivers opposite Moulmein, in lat. $16^{\circ} 32^{\prime} \mathrm{N}$., and long. $97^{\circ} 37^{\frac{1}{2}} \mathrm{E}$. The rise of the tide is 21 feet, the district is occupied by the Mon or Talaing race. The town was taken by the British 30th October 1824, and again on the 2d April 1851. The district is bounded on the west by the Bay of Bengal, and is traversed from south-east to north-east and then north by a range of hills culminating in the Zeng-gyaik peak, 3500 feet above sea-level. Towards the end of the 16th century, Martaban was taken by the king of Siam, who appointed a governor over it and the surrounding country. In Martaban the amount of silver was found to vary in different portions, from about 70 ounces to the ton of the ore; but in a second assay to 300 ounces in the ton, or a little less than 1 per cent. Martaban jars are jars of glazed earthenware. Dulaurier quotes from Father Azar, a Maronite, that Martaban means a casket or vase for keeping medicines and comfits, etc. But the word is used for the great vessels of glazed pottery, called Pegu or Martaban jars from the places where they were purchased, and which retained a wide renown up to the present century.-Yule, Cathay, ii. p. 476 ; Imp. Gaz.

MARTEN. The martens of the genus Martes chiefly belong to the northern parts of the world, but three species occur in the south and east of Asia. The Indian marten, Martes flavigula, is found up to 7000 and 8000 feet throughout the whole of the Himalaya, south and east to China and Malayana, and on the Neilgherry Hills and in Ceylon. M. tufoeus, Hodgson, is found in the villages of Tibet and Ladakh at 11,000 feet, also in Afghanistan, and its skin is sold in the Peshawur bazars. Dr. Adams seems to recoguise this as identical with the M. abietum or pine marten of Europe, and he says that the skins of the pine marten (M. abietum) are imported from Afghanistan and sold in the bazars of the city, where also those of the ermine are occasionally observed. M. zibellina, the sable marten, is obtained in Tibet.-Adams; Jerdon's Mammalia, pp. 81, 82.

MARTIN. Sir James Ranald Martin, a medical officer of the Bengal army, author of Brief Topographical and Historical Notice of Calcutta, London 1817; Memoir on the Advantages of the Re-occupation of Negrais Island, in Bl. As. Trans., 1834; Johnston and Martin on Tropical Climates.

MARTIN, MONTGOMERY, wrote on the History, Autiquities, Topography, and Statistics of Eastern India, London 1838, 3 vols.

MARTIN. This name is given to several genera of birds, the genus Cotyle or sand martins, of which C. riparia, C. subsoccata, C. Sinensis, aud C. concolor, also Chelidon urbica, C. Cashmiriensis, and C. Nepalensis, occur in India. Dr. Adams thinks that the common house martin of the Neilgherries and Southern India is identical with Chelidon urbica of Europe. On the Lower Himalayas and Kashmir ranges, a bird appears in spring, very closely allied to the above. Gould named it the Chelidon Cashmiriensis. This martin migrates to the Panjab during winter.

MARTINE, MAJOR-GENERAL CLAUDE, was a private soldier from France, who rose to the rank of General in Oudh. He founded the Martinière. The sum he set apart for endowing the noble charity called La Martinière, was $3 \frac{1}{2}$ lakhs of Sicca rupees; but by the interest up to October 1832 , this had increased to $9,62,825$ Sicca rupees, or nearly $£ 100,000$ sterling. Sir Edward Ryan, Chief Justice of Calcutta, drew up a decree on the $22 \mathrm{~d}$ October 1832 , regulating its internal economy, and the building was completed on the 31st December 1835, and opened for the reception of the wards on the 1st March 1836 . It provides for fifty Christian children, irrespective of sect, on the foundation, and educates boarders, day boarders or day scholars. His house and tomb are at Castalia, about three miles from Lucknow. He died A.D. 1800.

MARTYN, HENRY, a missionary clergyman of the Protestant sect, who laboured in India and then proceeded to Persia, where he died. His zeal was beyond the strength of a naturally delicate constitution, and he expired at Tokat on the 16th October 1812. He had been Senior Wrangler at Cambridge in 1801. From Shiraz to Isfahan, from Isfahan to Teheran, from Teheran to Tokat, he struggled onwards, hoping to reach his home.Porter's Travels, ii. p. 703 ; Kaye's Christianity.

MARTYR, in Arabic shahid; this term is applied by Muhammadans to the professors of Islam who fall in battle in a religious war. Twenty descriptions of persons become so.

MARU, SANSK. from Mri, to kill. Maru is also a contracted form of Marusthala, a dry, sandy, sterile tract, a desert. Maru-des or Marusthala, a desert country, is applied to the sandy tracts between Rajputana and the Indus. $-W$.

MARULA MATANGI, or Tal Noppi, or Marulu Jada Chettu; Xanthium orientale, $L$. The prickly involucre is applied to the ear to cure headache.

MARUMAKKAL. In Travancore the law by which property descends to heirs of the body is called Makkatayam, or 'children's inheritance.' That law by which the nephews of Nairs are their heirs is called Marumakkatayam; the term Marumakkal being used for nephews, or sometimes for sons-in-law, from Maru, to dwell, or fondle,-those who reside with one, and are affectionately treated as one's own children.

MARUMAKKATAYAM. MALEAL. The law of succession by sister's' sons, in the female line. observed in Malabar by the Nair race, by some of the Brahman and Mapilla families, and some of the servile tribes there. $-W$.

MARUT and Harut, according to the Koran, two angels who visited Babylon. When the angels in heaven expressed surprise at the wickedness of the sons of Adam, God let them select two of themselves to be sent down to earth. Marut and Harut were chosen, and they exercised their office with integrity, until Zohrah, the planet Venus, 
descended in the shape of a woman, who euticed them to love her, and then flew to heaven. She was followed by Marut and Harut, but Ridwan, the guardian of paradise, refused them admission. As a punishment, they were confined at Babylon until the day of judgment.

MARUT, in the mythology of the Hindus, a personification of the wind. The Marut deities are the forty-nine winds personified. In the Vishnu Purana they are described as the children of Diti by Kasyapa, or rather as the child divided by Indra into forty-nine portions, and afterwards addressed by him in the words 'ma rodih,' weed not, whence the name Marud. The Marut hold the first place amongst the inferior deities. Marut is one of the most prolifie roots in Aryan speech. This root is mar or mal, to crush or pound, aud hence either to destroy or to soften, and by softening sometimes to sweeten. The Maruts are therefore emphatically the crushing, grinding, or pounding storm-winds, who overturn everything in their path, and set forests on fire by the friction of boughs. The Greeks also had their grinders and pounders in the Moliones and the Aloadai, as they had both Aleuron and Maleuron as words for ground corn; while another crusher, Ares, reappears in the Latin Mars and in the Teutonic Thor Miolnir.-Williams' Story of Nala, p. 237 ; Vishnu Purana, p. 151.

MARUTHA, in Travancore, the spirit, shade, or ghost of a woman who has died of fever; they are buried inside the house, mantrams being said over them to hinder their attacking the survivors. The graves of virgins dying young are used as places for worship, some tree, such as pala (Alstonia scholaris), being planted over the grave, and a lamp kept burning. Pregnant women dying are supposed to become demons, and are therefore taken for burial to some distant and lonely jungle, and mantrams repeated over the grave to prevent their spirits from returning to injure people.-Matcer.

MARVES, a race in the Neilgherry Hills, known as the Badaga, corruptly Burgher.

MARIVAR ranks among the states of Rajputana next in importance to Mewar and Jeypore. Tradition ascribes its foundation to Jodha, a descendant of the Rahtor Rajput kings of Kanouj, who is said to have founded its capital, the city of Jodhpur, about A.D. 1459.

Marwar is bounded on the N.W, and N. by Jeysulmir, Bikanir, and Shekawati; on the E. by Jeypore, Kishengarh, Ajmir, and Mewar; on the S. by Udaipur and Sirohi; and on the W. by the Ruon of Cutch and Sind. It lies between lat. $24^{\circ} 36^{\prime}$ and $27^{\circ} 42^{\prime} \mathrm{N}$, and long. $70^{\circ} 6^{\prime}$ and $75^{\circ}$ $24^{\prime}$ E., and has an area of 35,672 square miles. Revenue, $17 \frac{1}{2}$ lakbs, with a population about $2,850,000$. Its capital is Jodhpur, in lat. $26^{\circ}$ $19^{\prime} \mathrm{N}$., long. $73^{\circ} 8^{\prime} \mathrm{E}$., and is a walled city; the buildings within are all of stone, with terraced roofs. The palace is built on an abrupt sandstone ridge, commanding the town.

Marwar is a corruption of Maroo-war, classically Maroost'hali or Mooroost'han, the region of death. It is also called Maroo-desa, whence the Mardes of the early Muhammadan writers. The bards frequently style it Mard'hur, which is synonymous with Maroo-desa, or, when it suits their rhyme, simply Maroo. Though now restricted to the country subject to the Rahtor race, its ancient application comprehended the entire desert, from the Sutlej to the ocean. The sac'-hæ or branches of the Rahtor early spread over the desert. The fabulous genealogy of the Rahtor deduces their origin from the raht or spine of Indra, their nominal father being Yavan-aswa, prince of Pailipur, which they say was somewhere in the north. This indicates their Scythic origin.

The river Looni, rising on the eastern frontier at Poshkur, and pursuing a westerly course, nearly bisects the country, and forms the boundary between the fertile and sterile lands of Maroo.

The districts of Deedwanoh, Nagore, Mairta, Jodhpur, Palli, Sojut, Godwar, Sewanoh, Jhalore, Beenmahal, and Sanchore, are the more fertile and populous, with a population of eighty souls to the square mile. The N.E. portion includes a portion of Nagore, the large towns of Filodi, Pokurn, etc., and may be calculated at thirty; the remaining space to the S.W., as Godadeo-ka-thul or desert of Goga, Sheo, Barmair, Kotra, and Chotun, can scarcely be allowed ten.

The Jat constitute five-eighths, the Rajputs twoeighths of the population, while the remaining classes, Bishnavi, Mena, Bhil, Bhat, Charan, with a few Muhammadans, sacerdotal, commercial, and servile, make up the integral number. The Jat are the industrious class. The Rahtor character stands deservedly high in the scale of the thirtysix royal Rajput tribes, but is debased by the abuse of opium. The Rahtor cavalry was formerly the best in India. At one time there were several horse-fairs, especially those of Bhalotra and Poshkur, where the horses of Cutch and Kattyawar, the jungle, and Multan were brought in great numbers. Valuable horses were also bred on the western frontier, on the Looni, those of Raydurro being in high estimation.

The family gave several daughters in marriage to the imperial family of Dehli, and furnished some distinguished generals to the imperial army. By the 8th Article of the Treaty of 1818 with Maun Singh, the Jodhpur State was bound to furnish a contingent of 1500 horse. Under this article a demand was made in 1832 for a force to co-operate against freebooters who occupied Nuggur Parkar. The contingent proved perfectly useless, and in 1835 the obligation to furnish the contingent was commuted to an annual payment of Rs. $1,15,000$ towards the Jodhpur Legion, which was then raised. This legion mutinied in 1857. Maharaja Takht Singh did good service during the mutinies, received the right of adoption, and is entitled to a salute of seventeen guns. The troops kept up by the state do not exceed 6000 men. The Political Agent is also President of the Marwar Interjurisdictional Court of Vakeels, which decides all border disputes arising between Bikanir, Jeysulmir, Kishengarh, Sirohi, Pahlunpore, and Jodhpur. The court is composed of vakeels from these states and from Udaipur, Jeypore, and Seekur. It meets once a year at Ajmir, Balmir, Nagore, and Mount Abu. At the commencement of 1869 the Political Superintendent of Sirohi discovered that both in that state and in Marwar the practice of Samadh, or burying alive, prevailed to a considerable extent, though confined almost entirely to persons in the last stage of leprosy, by whom it was practised to put an end to their sufferings. As it was thought probable that in some cases priestly influence, and in others the desire of the 
other members of the family to rid themselves of the presence of a nuisance, might have induced the self-sacrifice, the Political Agent considered it advisable to bring to the notice of the darbar of His Highness the Rao of Sirobi, that Government regarded the commission of a Samadh in the same light as a sati, and that they would expect His Highness to use his best endeavours to put a stop to it. It was also notified that in case of his not doing so, he would incur the displeasure of Government, and the number of guns with which he was saluted would be reduced. His Highness at once issued a proclamation declaring that Samadh was forbidden, and that any one assisting at any case in future would be liable to imprisonment extending to ten years; that the jaghirdar on whose estate it took place would be liable to the same punishment and the forfeiture of his estate; and any raj official, through whose culpable neglect a case might occur, would also incur the same liability. The maharaja of Marwar was also addressed on the same subject, although the Political Agent of that province could not hear of any cases having occurred.-Treaties, Engagements, and Sunnuds, iv. pp.41-45; Tod's Rajasthan, ii. pp. $9,162-64$.

MARWARI, from Marwar, a country in Rajputana. In India, generally applied to a Rajput engaged in banking or trade. There are, however, various financing tribes, Saukar, Sarraff or Shroff, as the Marwari, the Bhatya, the Vaisya Komati, the Modi grain-seller, and the Banya. T'he Marwari arrange themselves into twelve tribes. The Mestri, the Urwar, Bijabargi, Kandalwal, and Porwal are of the Vaishnava sect of Hindus; the Agarwala are partly Vaishnava and partly Jain; but the Sarogi and the Oswal are wholly Jain, and it is from amongst the Ossi tribes of Oswal that the Jain priests of Abu are chosen. These Jaina never use animal food, their offerings are fruits and sugar ; and the Oswal and Sarogi never eat the prasadh or meat offered to the idols. Marwari are less frequently of the Saiva sect. The Marwari mercantile men and bankers hold almost exclusively the entire banking business of India, and regulate the exchange operations of almost all the nations of India. The Oswal is the richest and most numerous of the eighty-four mercantile tribes of India, and is said to amount to 100,000 families. They are called Oswal from their first settlement, the town of Ossi. They are all of pure Rajput birth, of no single tribe, but chiefly Pura, Solanki, and Bhatti. Many profess the Jain tenets, and the pontiffs of that faith must be selected from the youth of Ossi. T'hese wealthy bankers and merchants, scattered throughout India, are all known under the denomination of Marwari, which means belonging to Maru or Marust'han, the desert. It is singular, Colonel Tod adds (Rajasthan, ii. p. 234), that the wealth of India should centre in this region of comparative sterility. The Marwari is essentially following similar mercantile pursuits to the Vaisya Komati of Peninsular India, and those of the Wani or Bani or Banya, viz. banker and merchant, to which, however, the Komati add that of retail shopkeeping. If a Marwari be asked as to his caste, he replies that he is a Mahajan, a Banya, a Bais or Vais, meaning that his profession is that of the commercial people. But, on further questioning, he explains that the Narwari is a Rajput, that there are twelve great tribes, of whom are the Oswa, Messar, Agarwala, Bijabargi, Sarogi, Neddatwar, Parwar, and five others. These all subdivide into numerous kap or clans; in the Messar tribe alone are seventy - two, amongst whom are the Rathi and Dhaga. All the Marwari of Rajputana adhere to the principle of reckoning their descent from a founder, and in their marriage ceremonies they abstain from blood relationship, never marrying into their own gotra. Their widows never re-marry. The mercantile tribes of Western India, of Rajput origin, sank the name and profession of arms when they became proselytes to Jainism, in the reign of Raja Bheem Pramar. The Chittur inscription of this prince (he was ancestor of Raja Maun, whose date, S. 770, A.D. 714) allows us to place this grand conversion prior to A.D. 650. The Banya or Komati merchants and bankers are generally of the Vaishnava sect of Hindus, though some of them worship Siva. They are most numerous in Telingana and in Madras. In the north and east of Dekhau proper there is not one of them in twenty villages, their places there being taken by the Marwari race. There are, however, many in Punderpur and Sholapur. Those of the Komati who die unmarried are buried, all others are burned, whether belonging to the Saiva or Vaishnava sects. Their language in their families is Telugu, and it is spoken by them as far as Bombay. But, as the west is approached, Mahrati becomes nixed with it. Komati Banya are essentially shopkeepers, sellers of dry grains, doing a little in mercantile business, and cultivate, but do not hold the plough. They are mostly dark men, of short stature. In their marriages the bridegroom may or may not be before or after puberty, but girls are under age, and the ceremonial is performed at the house by a Brahman. The death srad'ha rituals are conducted by Brahmans. Their Janawi or zonar is put on and the mantra taught when married. The Wani of the western coast will only marry with the Komati Banya. They are in cousiderable numbers in the northern part of Hyderabad, adjoining Berar.-Ted's Rajasthan, ii. pp. 134, 234.

MARWAT and Bannu are on the same plain. The people of Marwat are larger in stature than those of Bannu, and are usually clad in coarse white linen, like the Afghan on the banks of the river Indus.

MARIVAT. HIND. A pensionary provision in land for the heirs of one who has been killed in battle.

MARY, the mother of Jesus, the Messiah. The Koran says, ' $O$ thou mother of Jesus and sister of Aaron,' thus confusing the two. The Ansariah hold that the planet Venus or Zuhra, Isis of the Egyptians, Mary the sister of Moses, Mary the mother of Jesus, and Fatima-uz - Zuhra the daughter of Mahomed (their goddess), is the same person; the Minerva of Athens, Cybele of the Phrygians, the Ceres of Eleuses, the Proserpine of Sicily, the Diana of Crete, and Bellona of the Romans, the same and identical deity.-Catafago.

MARYUL, or Lowland, from Mar, TIB., low, and Yul, land, the non-Chinese portions of the Bhot territories. These are arranged by Colonel Strachey as-(1) that of Bulti, which is the Muhammadan name, and includes Hasora, Rongdo or Rongyul, Shigar, Skardo or Bulti proper, Parkuta, Tolti, Khartaksho, Kiris, Khaypalu, and Chorbat ; 
and (2) the Buddhist Ladakh, in which we have Spiti, Zangskar, Purik, Suru, Hembaks (Dras), Ladakh Proper or Leh, Nubra, Janksti, Rong, Rupshu, and Hanle. In this list of Colonel Strachey, Lahul, Hungrung, and Kanawar are omitted as Indian; whilst Hasora is treated as Bhot.-Latham, Ethnology.

MASAH. ARAB., HEB. Anointing, a form of installation practised in Europe, but which seems to have been of eastern origin. Masih of the Arabs forms the Hebrew Messiab, meaning the anointed one. In Rajputana, anointing appears to have been in all ages the mode of installation. The unguent on this occasion is of sandal-wood and atar of roses made into a paste or very thick ointment, of which a little is placed upon the forehead with the middle finger of the right hand, and then the jewels, the aigrette, and necklace are tied on. Amongst the earliest notices of this ceremonial is that in Genesis xxviii., when Jacob rose up early in the morning, and took the stone that he had put for his pillow, and set it up for a pillar, and poured oil upon the top of it. The Brahmans and Hindus anoint their stone images with oil before bathing, and some anoint them with sweet-scented oil. This practice probably arises out of the customs of the Hindus, and is not necessarily to be referred to their idolatry. Anointing persons as an act of homage has been transferred to their idols. There are resemblances betwixt the Jewish and Hindu methods of, and times for, anointing. Oil is applied to the crown of the head till it reaches all the limbs; it is called abhyanga, which is noticed in Psalm cxxxiii. 2 , 'It is like the precious ointment-upon the head, that went down to the skirts of his garment.' Again, we are told in Mark xiv. 3 that there came a woman, having an alabaster box of ointment of spikeuard, very precious ; and she brake the box, and poured it on his head; and pouring sweetscented oil on the head is common amongst the Hindus. At the close of the festival in honour of Durga, the Hindu races worship the unmarried daughters of Brahmans, and amongst other ceremonies pour sweet-scented oil on their heads. Amongst the Hindus the ceremonial is attended to after sickness, which in Psalm xlv. 7 is mentioned thus: 'Thy God hath anointed thee with the oil of gladness.' And Hindus, when fasting, or in sickness or sorrow, abstain from the daily anointing of the body with oil, and again anoint on recovery, as in 2 Samuel xii. 20, where 'David arose from the earth, and washed, and anointed himself, and changed his apparel, and came into the house of the Lord, and worshipped.' Bathing, anointing the body with oil, and changing the apparel, are, among the Hindus, the first outward signs of coming out of a state of mourning or sickness.-Ward, Hindoos; Tod's Rajasthan, ii. 568.

MASAILMA and El Aswad, in Mubammadan history called the liars, lived in A.D. 632 , in the time of Mahomed. The first was of the tribe of Hanifa, of the Yemama province, and a man of consideration. He at first embraced Mubammadanism, and then for a time set up as a prophet on his own account as a rival to Mahomed, and near the close of the latter's career. He afterwards was slain at Akraba, in a battle near Yemama with Khalid-ibn-Walid, whom Abubakr, Mahomed's successor, sent against him. He fell by the hands of a Negro slave named
Wahsha, and with the same weapon that had despatched Hamza, the uncle of Mahomed.

MASALA. Hind. Properly spices or compounds of spices, also used to mean any compound or substance used in any manufacture or operation. MASAN. Hind, A place of cremation, a cemętery. Sanskrit, Samasan; and Uriya, Masanihura.

MASCARENHAS. George Mascarenhas accompanied Fernao Peres de Andrade in 1517 to China ports, and paved the way to commercial intercourse with that nation.

MASHA. HIND. A weight in India varying from 14.687 to 18.5 grains troy, the average being $15 \frac{1}{2}$ grains. The rupee of Akbar, which was based upon that of Sher Shah, weighed $11 \frac{1}{2}$ mashas. The masha or masa is a goldsmith's weight. It is reckoned as 5, 8, or 10 rati or seeds of the Abrus precatorius, which usually weigh about 2 grains troy. As an elementary weight, it was the basis of the weight of the current silver coin of India. It is the 12th part of a tola.

MAS'HAB. ARAB. Also call Mahgin, a light, crooked stick about two feet and a half long, used in Arabia for guiding camels. The mas'bab is of almond, generally brought from Syria. At the thick end is a kind of crook, formed by cutting off a bit of larger branch from which the stick grows. This crook is afterwards cut into the shape useful to seize a camel's nose-ring, or a horse's bridle. Arabs of all degrees are fond of carrying these sticks.

MASHAD, the capital of Khorasan, is in lat. $36^{\circ} 17^{\prime} 40^{\prime \prime} \mathrm{N}$., and long. $52^{\circ} 35^{\prime} 29^{\prime \prime}$ E., 472 miles from Teheran. It is a place of pilgrimage from possessing the shrine of Imam Raza, from which it is a place of sanctuary (Bast) even for murderers, and some stay there for years. The mosque and its minarets are very fine. The population has been estimated at from 45,000 to 100,000. The Muhammadans bring their dead from great distances to be interred at this holy place. There are 100 families of Jews engaged in petty traffic. The manufactures are shawls, velvets, steel for weapons, silks. - MacGregor, iv. p. 311.

MASHAD ALI, a town of Turkish Arabia, 30 miles from the ruins of Babylon. Ali, son-in-law and cousin of Mahomed, is buried here. It was taken by the Saracens in the 7th century. This city, according to Kinneir, was founded by Alexander the Great, and was for a considerable time called Alexandria. It is 30 miles from Hillah, and 4 from Kufa, a town founded by the khalif Umar.

Mashad Husain or Kerbela is situated a short distance from the west bank of the Euphrates, and not very far from Hillah, the supposed site of Babylon. It is 16 farsang westward from Baghdad, is a place of pilgrimage to Shiah Muhammadans, and is surrounded by gardens and groves of palm trees, which are watered by a canal from the river. The chief object of interest is the mosque, built in the reign of Shah Abbas the Great, on the spot where Husain, son of Ali, was murdered. It is a sacred place of pilgrimage and burial to the Persians who are Shiah Muhammadans. Kerbela fell into the power of the Turks when Sultan Murad IV. took Baghdad, A.D. 1636. The Persians frequently send their dead to be buried at Kerbela from the interior of the country. On leaving Kerbela one 
traveller met nine mules laden with coffins, and while at Baghdad he often saw others passing to their last resting-place, near the honoured remains of the grandson of the prophet. The revenue arising to the hierarchy of Kerbela from the drains on the purses of its visitors, are enormous, and must more than sufficiently pay for all the expenses of the state. The city is large, and crowded with inbabitants, being respected as a bast or place of refuge. In India, Kerbela is the name given to a plain near a sea, river, or tauk, whither the Muhammadans at the close of the Maharram festival annually carry their tabut.Herklots; Porter's Travels, ii. p. 281 ; Mignan's Tr. p. 112 ; Catafago.

MASHAIKH, amongst Muhammadans, elders, holy persons, heads of religion.

MASHAJU, Hind., properly Mushajjar, flowered, applied to silk and satin, also to damask table-linen.

MASHAK. ARAB. A leather bucket; leathern bag for carrying water, used by travellers all over the east.

MASHAL. ARAB,, HIND. A lamp, a torch. Mashal-chi, a torch-bearer, a lamp-lighter.

MASHALI. ARAB. At Mecca, in most Arab families, male children, when 40 days old, are taken to the Kaba, prayed over, and taken back to their homes, where the barber draws with a razor three parallel gashes down the fleshy portion of each cheek, from the exterior angles of the eyes almost to the corners of the mouth. The cicatrices are called mashali.

MASHOBRA, near Simla. An annual fair is held here, at which women are sold.

MASHRABIYAH. ARAB. A projecting latticed window, made of wood richly carved. Cairo was once famous for these, but they are growing out of fashion with young Egypt, disappearing before glass and green blinds. Lane says Moshan, or more commonly Mashrabiyah, are windows of the upper apartments, generally projecting a foot and a half or more, and are mostly formed of turned wooden lattice-work, which shut out the light and sun, while they admit the air.-Burton's Mecca, i, p. 51.

MASHRU, a mixed fabric of silk and cotton; striped satin, partly made of silk and partly cotton. Mashru badshahi and Mashru solchi are kinds of satin.

MASJID. ARAB. A mosque, the sanctuary of the Muhammadans for public prayer. From masjid is derived the word mosque, chauged by the Egyptian Arabs, who pronounce the letter $\mathrm{j}$ as a hard $g$, so that jab'l, a mountain, jam'l, a camel, and masjid, a mosque, become gab'l, gam'l, masgid. Outside Egypt, as for instance at Aleppo, jam'l becomes softened into jimmael, and masjid into misjeide.-Burton's Mecca, i. p. 141.

MASKARAT or Masakkarat. AlaB. A collective name for intoxicating drugs on which excise is laid, -opium, bhang, charras.

MASKAT, the capital of Oman, in lat. $23^{\circ} 38^{\prime}$ $\mathrm{N}$., and long. $58^{\circ} 35^{\prime} 50^{\prime \prime} \mathrm{E}$. Including the adjacent villages, it has about 60,000 inhabitants. Until the demise of Syud Said, the Oman territories and African districts of Zanzibar were under one dominion. On that event one son took the Oman principality, the other son took Zanzibar. Maskat is built on a slope, rising with a gradual ascent from the sea, where the water nearly washes the bases of the houses. The inhabitants are descendants of Arabs, Persians, Indians, Syrians, by the way of Baghdad and Basarah, Kurds, Afghans, Baluchis, etc. The Persians at Maskat are mostly merchants, who deal in Indian piece-goods, coffee, hookahs or kaleans, and rose-water. Others, from BandarAbbas, Lar, and Menon, manufacture swords ano matchlocks, for which there is a great demand in the interior. Banyas constitute a body of the principal merchants. There are a few Jews, who mostly arrived there in 1828 , being driven from Baghdad by the cruelties and extortions of Daoud Pacha, when nearly the whole of this race were compelled to fly. Some took refuge in Persia, while others, in their passage towards India, remained here. The same toleration exercised towards all other persuasions is extended to the Beni Israel, no badge or mark, as in Egypt or Syria, being insisted on. When Wellsted wrote, early in the 19 th century, about 4000 slaves, of both sexes and all ages, were disposed of annually. The Towayli, from the Zanzibar coast, formed one class. They were known by having their teeth filed, sometimes to a point, and sometimes in notches like those of a saw, also with some perpendicular incisions on either oheek, made with a penknife when the children are five or six years of age, and the scars which remain denote the tribe to which they belong. The price of a Towayli was from 40 to 60 dollars. The Nabi, another race from the interior of Africa, were said to be vindictive and treacherous. The Bedowi here, as in the Hejaz, were the only purchasers. The Galla brought from Abyssinia were highly valued. They fetched from 100 to 150 dollars, the price of the women being about the same as that of the males; and strength, health, and good temper in the latter were considered as a set-off against the comeliness of the former. They brought eunuchs occasionally from Darfur, who fetched from 200 to 300 dollars, and were mostly purchased by the Persians.Findlay; Wellsted, i. pp. 13-388.

MASNAD. ARAB., PERS. The throme of Muhammadan rulers; the embroidered carpet on which dignitaries sit.

MASNAVI. ARAB. A form of poetry where the second line of every distich rhymes with the same letter.

MASNAVI-i-SHARIF, or sacred Masnavi, a book of moral doctrine by Maulana, Jalal-ud-Din Muhammad, Rumi, the founder of the sect to which Europeans give the name of dancing or whirling darveshes, the most important of all the orders of oriental illuminati, and known as the Maulaviah, from the founder. Jalal-ud-Din was descended from Abubakr, father-in-law of the reformer Mahomed, and was himself a grandson of the actual Kharezmian ruler of Balkh. He settled at Iconium, where he founded a college, and enjoyed a wide reputation as a saint, a worker of miracles, and an inspired poet. The peculiar philosophical and religious tenets which he professed are better known under the name of Sufiism, and consist chiefly in the assumption that God is the only actual and real existence, everything elsc being merely hypothetical ; and that man's highest and ultimate aim is reabsorption into the divine principle from which he has sprung. This Masnavi is a complete exposition of Sufi doctrines, illus- 
trated with numberless tales, apologues, and scraps of history, and is the work of Jalal-ud-Din himself. Next to the Koran, it is more highly esteemed by the Shiah sect than perbaps any other work. The complete work consists of six books, containing 26,660 couplets, to which some authorities add a seventh book, to make up the number of the seven planets, the seven zones, and the seven heavens. It has been partly translated by Mr. James W. Redhouse. Jalal-ud-Din speaks in the highest terms of his teacher and spiritual guide, Shams-i-Tabriz, whose arrogance and violence led to a tumult, his arrest, and disappearance. The anecdotes in the Masnavi are remarkable, and embody such legends as the following: Solomon, who was king, not only of men, but of the angels, genii, elements, beasts, and birds, was one day holding a court, when a poor fellow who was present suddenly exhibited signs of the most extreme terror, and declaring that it was the Angel of Death who had frightened him, begged Solomon to command the wind to convey him far away to Hindustan, which was accordingly done. Another day, when the Angel of Death attended the monarch's levee, the latter asked him how it was that he had driven the poor fellow forth from his home to wander like a waif throughout the world. The angel answered that God had commanded him to

'Go this very day

And take his soul in Hindustan, his debt to pay. In wonder then I said within myself : "Had he A hundred wings, in Hindustan he could not be." But going still to Hindustan, by God's command,

There I found him, and took his soul with my own hand.'

Jalal-ud-Din revived the use of music and dancing as aids to devotional ecstasy, and his great poem commences with a few stanzas in which the reed-flute is made to complain of its separation from its native reed-bed by the river side, and to declare the harmony of its own musical lament with the varying moods of man, whose soul is likewise ever sighing at its separation from the divine source from which it sprang. This is the key-note of the mystic philosophy, and forms an appropriate introduction both to the poem and the religious exercises of the sect, the members of which always preface their evolutions by chanting these very verses. The plaintive and traditional melody to which they are sung is given in Carl Engel's work on the music of all nations. Starting from this point, the poet presently leads on to the next great doctrine of Sufism, and, indeed, of every other form of mysticism, particularly the Christian, namely, that God is everywhere and everything is God; that God is the only legitimate object of man's love and aspiration, but that the veil of matter and of sense prevents the union of the two. As the Masnavi puts it-

'Nature's great secret let me now rehearse :

Long have I pondered o'er the wondrous tale

How Love immortal fills the universe,

Tarrying till mortals shall his presence hail ;

But man, alas! hath interposed a veil,

And Love behind the lover's self doth hide.

Shall Love's great kindness prove of none avail ?

When will ye cast the veil of sense aside,

Content in finding Love to lose all else beside?'

To arrive at this state of emancipation from the trammels of sense, and lose themselves in the con- templation of the Infinite, is the object of the darveshes' dance and of other ecstatic performances. The incidental stories scattered through the poem are all interesting. But it is the quaint wisdom, the cheerful, though transcendental, philosophy, and the really elevated thoughts, which form the chief charm of the Masnavi.

MASON, REv. S., wrote on the Fauna, Flora, and Minerals of Tenasserim, of British Burmah, and Pegu, Lond. 1852 ; also author of Burma.

MASON WASP, of Ceylon, is the Pelopcens spinola, St. Fargeau, one of the Sphegidæ. The Ampulex compressa, which drags about the larvæ of cockroaches into which it has implanted its eggs, belongs to the same family. The male of the mason wasp of India is about $1 \frac{1}{2}$ inch long, of a bright brown-yellow. The female is about $\frac{1}{4}$ of an inch long, of a bright bottle-green. The male makes a round house of mud, in compartments, into each of which the female drops a few eggs, and the male thrusts in large green caterpillur's for the subsistence of the young.-Tennent.

MASSAGET Æ. According to Strabo (lib. xi.), all the tribes east of the Caspian were called Scythic. The Dahæ were next the sea; the Massagetæ and Sacæ more eastward, but every tribe had a particular name. All were nomadic, but the best known are the Asi, the Pasiani, Tachari, Saccarandi, who took Bactria from the Greeks. The Sacæ made irruptions into Asia similar to those of the Cimmerians, and possessed themselves of Bactria and the best district of Armenia, called after them Saca-senæ. Of the first migrations into India of the Indo-Scythic Gete, Takshak, and Asi, that of Sehesnag from Sehesnagdes (Takshak from Tacharist'ban), six centuries before Christ, is the first noticed by the Puranas. About the same period a grand irruption of the same races conquered Asia Minor, and eventually Scandinavia, and not long after the Asi and Tachari overturned the Greek kingdom of Bactria. The Romans felt the power of the Asi, the Catti, and Cimbri from the Baltic shore. Colonel Tod (i. p. 49) supposes the Asi and Tachari to be the Aswa and Takshak or Turshka races of the Purans of Sakadwipa; the Dahæ to be the Dahya, now extinct, one of the 36 royal Rajput tribes, and he supposes them to be the descendants of Baldeva and Yudishthra, returued under different appellations. The country on the east is still occupied by the Turkoman race. Herodotus (Clio, i. c. 216) mentions that they were said to eat their aged relatives. When any one was far advanced in years, they called together their immediate friends and neighbours, and, having sacrificed him, made a common feast upon his dead body.-Chatfield, Hindustan, p. 181; Herod. lib. i. sect. 216. See Gete.

MASSEH ISLANDS, in the Bay of Tajurn, near Arabia, were purchased by the British in 1840 , but never occupied.-Horsburgh. MASSICOT.

Yuen-tan, . . Chin. / Yellow monoxide of Hwang-tan, : : "

It is an oxide of lead obtained by heating lead, or by adding sulphur, nitre, and vinegar to melted lead. It is often prepared from the dross of the melted metal. It is of a pale yellow colour, and is used as a pigment.-Waterstone, quoled by Faulknèr.

MASSOBA, a celebrated idol. In the Chauki 
jass, in the Lakenwara range, which forms the watershed between the Godavery and the Tapti, about 10 miles north of Aurangabad, there is a shrine of this deity to which, from a circle of a hundred miles, people of all castes resort,-Brahman, Sudra, and Dher, but chiefly the Mahratta Kunbi. The Jatra is held in the month Cheita, and lasts for four days, during which many sheep are offered in sacrifice. It is in the northern side of the pass, a mere block of stone, with smaller stones at its foot all smeared with red lead. The objects of their pilgrimage are wholly personal, beseeching the deity to give them, or preserve their children, their flocks, and their food.

MASSON, CHARLES, a traveller and numismatologist, author of Journeys in Baluchistan, Afghanistan, and the Panjab, Lond. 1842, 3 vols.; Notice of the Countries West of the Indus, in Bom. Geo. Trans., 1836-1838; Narrative of a Journey to Kalat, including an Account of the Insurrection in that Place in 1840, and a Memoir on Eastern Baluchistan, London 1843.

MASSOW AH ISLAND, in the Bay of Arkeeko, on the west const of the Red Sea, about half a mile long, is about 4 miles $N$. of Arkeeko, at the $\mathrm{N}$. extremity of Abyssinia. Half of the island is occupied by tanks and a burial-ground, and on the inner half is the town, which is crowded with habitations to the water's edge. Eight or ten large ships, with double the number of smaller ones, could be securely moored in the harbour. There is also a good harbour called Daha-leah, larger than Massowah, about a mile to the north. Fresh water is not abundant either here or in any other part of the Red Sea, but the supply at Massowah could probably be increased by digging wells on the mainland. The rainy season is from November to March. There is no other spot but Massowah and its immediate neighbourhood where ships could lie safely for any time, and where troops and munitions of war conld be disembarked with celerity and safety.-Findlay; Lieut.-Col. H. James, R.E., in Par. Paper.

MASSURI, a sanatorium on the Himalaya. The following heights of mountains and points in the environs of Massuri were determined by the great Trigonometrical Survey of India, under General Sir Andrew Waugh:-

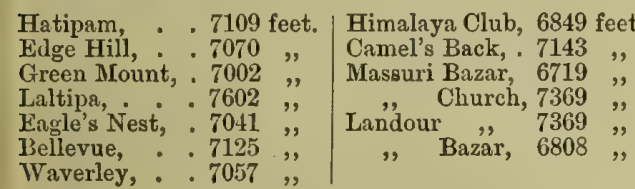

MAST. PERS. Coagulated milk or clotted cream, slightly sour, which, when diluted with water, forms ab-i-dugh, a beverage in warm weather equally grateful aud salubrious.-Ouseley's Tr. i. p. 268.

MASTAKA, also Chinna Mastaka, in Hindu idolatry, is a form of Parvati as Kali, and possibly is the sakti of Siva, in the form of Kapali. She is described as a naked woman, with a necklace of skulls. Her head is almost severed from her body, and her blood is spouting into her mouth. In two of her hands she holds a sword and a skull. In a note in Ward's work on the Hindus, it is stated that this goddess was so insatiate of blood that, not being able at one time to obtain enough of that of giants, she cut her own throat to supply herself therewith. Ward derives the name from Chinna, cut off, and Mastaka, a head.-Cole. Myth. Hind. p. 94; Ward's Hindoos. MASTAKANAGRAHA or Mastan. URIYA. A Brahman race of Orissa following agriculture.

MASTAKAVAGRAHNA. MAHR. A ceremony in the rite of adoption of smelling the head of the adopted child. $-W$.

MAS'IIC, Mastik.

Mastaka, . . Arab. Kinnoli, Kinneh, . Pers. Mastix, DAN., Ger., Sw. Mastique, - . Port. Rumi mustaki, : HIND. Sakes, . . : TorI. Mastico,

Mastic resin is produced in Scio, from an incision in the bark of the Pistacia lentiscus, the mastic or lentish tree. That which collects on the branches of the trees is called mastic in the tear, and fetches the highest price, while that which falls to the ground constitutes the common mastic. Mastic varnish is well known from its transparency and peculiar toughness and tenacity, even when spread in the thinnest coat on wood or on canvas. This is due to the presence of a peculiar resin, which does not possess any acid properties, and which has a composition C. 40 H. 310.2 . Dissolved in spirits of wine or oil of turpentine, it makes a very pale varuish; it is brilliant, works easily, and flows better on the surface than most other varnishes. It can also be removed by friction with the hand; hence its use as a picture varnish and for other delicate works. It is imported into India from the Persian Gulf, also from Kābul, and is used by the natives as an astringent in diarrhcea, which property it owes to the volatile oil contained in it; also in all diseases depending on an undue accumulation of phlegm. Price, one shilling per pound.-M'C. Dict. p. 796.

MASTISA, from the Portuguese Mestico, person of mixed Indian and European descent.

MASTIXIA ARBOREA. Wight. Bursinopetalum arboreum, | B. tetrandrum, Wight.
W. Ic.

A large tree of Ceylon, very abundant in the dense moist forests of the Western Ghats, from Canara southwards to Cape Comorin, at elevations from 2000 to 7000 feet. It is abundant in the Bolamputty forests at 2500 feet elevation, and is common on the Neilgherries at 6000 to 7000 feet. At the higher elevation it is not nearly such a large tree, but its leaves are much larger and more coriaceous, and its flowers are larger. Beddome, Fl. Sylv.

MASTODON, a genus of extinct manmals of great size, of several species, of which remains have been found in the Siwalik Hills, in Perim Island, in Burma, viz. M. angustidens, M. arvernensis, M. latidens, M. longirostris, M. Perimensis, M. Sivalensis. Mastodon latidens and M. Sivalense have been found fossil both in Ava and the Siwalik Hills. They are found in the upper miocene strata. Dr. Faulkner considered the Siwalik deposit to be synchronous with that from which Mr. Crawfurd obtained the remains near Prome, on the banks of the Irawadi. Captain Cautley found jaws in which the front teeth are not to be distinguished from the teeth of M. latidens, and those in the rear from the teeth of M. elephantoides; he conceived that the distinction which was established on detached teeth will be found to be erroneous,-Eng. Cyc. 
MASUDI, the literary title of Abu-1-Hasan, Abi, A.D. 890-956, author of Meadows of Gold and Mines of Gems. He met Abu Zaid at Basra, A.D. 916 (A.H. 303). Masudi mentions that, at the time of the Muhammadan conquest, the country about Basra was called Arzul-Hind, the Land of India. The Meadows of Gold, Kitab Mirooj-u-Dhhab, treats of all things in nature and history, and of China. He travelled far and wide, and from a very early age, visiting Sind in A.D. 912, and afterwards, according to his own account, Zanzibar and the island of Kanbalu, Champa, China, and the country of Zabaj, besides travelling a long way into Turkestan. He mentions that in his time, A.H. 332 , offices in India were hereditary. His is a historical and commercial cyclopædia. He mentions nutmegs, cloves, cubebs, camphor, areca nuts, sandal-wood, and aloes-wood as productions of the Indian Archipelago. It was translated by Dr. Aloys Sprenger.-Ind. in 15th Century; Prairies d'Or, iv. p. 225, in Yule, Cathay, i. pp. 110, 243. See Literature.

MASULA BOAT, a boat built without knees, used on the Madras coast for crossing the surf. The planks are sewed together over withes of straw, and the boat has no thwarts. They are used in landing and discharging cargoes, and carrying passengers to and from ships in the roads. They are sometimes broken to pieces from the heavy surf, which at times runs as bigh as from 6 to 10 feet. A catamaran can be kept in attendance as a life-preserver, in the event of any accident to the masula boat by upsetting, or in case of any of the occupants being washed out by the surf. The masula boats receive their cargoes and passengers from the ships outside the surf. They are rowed by twelve men, with bamboo or casuarina paddles, that is, a board about 10 inches broad and 14 inches long, fixed at the end of a bamboo or young casuarina tree. They are steered by one or two tindals (coxwains), and two men are constantly kept to bale out the water; from which employment they are promoted to the paddle or bow oar; after which they fall aft in rotation, to be a tindal or steersman. The steersman gives time by a song, which is sung by all the boatmen; and according as its modulations are slow or quick, the oars are plied. These modulations are regulated by the waves, as they may be slow or rapid, in succession. On one occasion, when a passenger of rank showed impatience at this noisy song, the boatmen were desired to cease, but the steersman refused compliance with the order, saying that without his song he would not be answerable for the safety of the passenger. The dimensions of the masula boat are from 30 to 35 feet in length, 10 to 11 feet in breadth, and 7 to 8 feet in depth.--Note by Sir J. Malcolm; Edye; Orme.

MASULIPATAM, in lat. $16^{\circ} 9^{\prime} \mathrm{N}$., and long. $81^{\circ} 13^{\prime} \mathrm{E}$., a large town on the Coromandel coast. Masulipatam is supposed to be the ancient Mesolia. Every village has a tutelary goddess, whom the aboriginal races worship. The Kistna, the chief river, is a sacred stream. The harbour of Masulipatam is an open roadstead, and large ships lie two or three miles off. It was the earliest British settlement on the continent of India, a factory having been opeued there in 1522. It was acquired by a treaty with the
Nizam, 6th April 1759. During the cyclone of 1864 , a storm-wave swept over the land. The whole country in the vicinity of Masulipatam was submerged, and 60,000 men and animals destroyed. There are two large mountains in the district, one at Bezoara, on the bank of the Kistna, and the other at Condapilly; the former is called Indrakaladry, and the latter Condapilly Durgum.

MASUM ALI SHAH, a Syud of the 12th century, who went about calling Ana'l-Haq, I am the true God! He was put to death.

MAT, BurM., in the weights of Burma, is the one-fourth part of a kyat or tikal.

MATA, or mother, is a term applied to the sakti of the god Siva. It is said that Mylitta of the Babylonians, a name of Succoth-Benoth, also meant -mother. The sakti of Siva is also called Vali or Bali, under which appellation she assumed the form of a girl twelve years of age. In Madura, at Balane, and other places, virgins used to go to the temple once in their lives to offer themselves in honour of the goddess. The story was that a god had intercourse with them. In all the temples of Siva and his consort, women are kept to dance and sing before the idols.

Mata is the Hindu goddess who presides over smallpox, also styled Sitla.

Mata Janavi, the mother of births, is the analogue of the Juno Lucina of the Rajputs. Mata-ji is the universal mother, worshipped in India from the most ancient times. In a temple to Mata-ji, the universal mother, in Rajputana, is an inscription to the purport that Komarpal Solanki and his son Sohunpal, in the month of Pos (the precise day illegible), (S. 1207, winter of A.D. 1151), came to worship the universal mother in her shrine at Palode.

About the beginning of August 1882, a terrible tragedy occurred in the village of Khera, close to Wudhwan. The corpses of five Kolifather, mother, and three grown-up sons-were discovered, in each case the head being nearly severed from the body by a sword-cut at the back of the neck. The fourth and eldest son was missing. On search being made, his dead body was found in a neighbouring well. The whole family was thus accounted for. The bodies of the parents and one son were found in their own house, those of two other sons laid out on either side of the entrance of the temple of Khodiar Mata close by. It is supposed that the whole family devoted themselves as willing victins in sacrifice to the Khodiar Mata, an incarnation of the bloodthirsty Kali, and that the eldest son, after slaying his parents and brothers with the sword, threw himself into the well where his corpse was found.-Tod's Rajasthan, i. p. 357, ii. p. 618; Roberts, Or. Ill. p. ix.

MATABHANGA, or Hauli, one of the three great rivers of Nadiya, the other two being the Bhagirathi and Jalangi. All three rivers are offishoots of the Padma, the main channel of the Ganges.-Imp. Gaz.

MATADAR, the headman of a village in the Kaira and Ahmadabad collectorates, from Matu, n signature.

MATA-GLAP. Malay. The diseased or distempered condition of a Malay, when he runs demented or amok.

MATA KOOUR, a colossal alto-relievo, situated 
near Kussia Tanna, in pargana Sidowa, eastern division of the Gorakhpur district.

MA TAMPI, Karta, and Kaymal are titles added to the names of remote descendants of zamindars and petty princes of Travancore.

MATAWLAH. ARAB. A Shiah sect of Muhammadans in Syria. Their principal possessions are in the Anti-Libanus, and in Bilad Bishara in Palestine, Balbec being their chief station.

MATCHLOCKS or toradar-banduq of a peculiar make were manufactured in the Shorapur district, as also jumbea, knives, daggers, etc., etc. The price of a good matchlock without ornament is from Rs. 10 to 12 . A superior matchlock is made at Koteli; the barrel is filed smooth on the outer surface, and, being carefully cleansed from grease by scouring with wood-ashes, is set upright in a hollow cylinder of brass, which is filled.with a solution of white vitriol in water. The cylinder is placed upon a slow fire, and in two days the veins of the damask are developed in high relief. Nothing can be imagined more elegant than the twisted damask of Koteli. It surpasses that of Herat. The straight damask being less tenacious than the twisted variety, should be made of greater solidity. Matchlocks are usually constructed with an oviform chamber, which is harmless enough with the weak gunpowder of the bazars, but dangerous when English gunpowder is employed. It no doubt economizes the charge. The barrel is made to swell abruptly at the breech, to accord with the shape of the chamber. The matchlock of Herat is generally rifled, a process unknown at Koteli, where, however, flint and detonator locks are made superior to those of most Indian fabrics. The rifling process is very rudely contrived at Herat. In a cylinder of hard wood corresponding in length with a gun-barrel, two parallel and spiral grooves are rudely chiselled; a collar of wood is formed in an upright post, opposite to another post, into which the barrel is to be jammed, and "within this collar are two short iron pegs, fitting into the grooves of the cylinder. A boring - rod is then firmly attached to the cylinder, the cylinder forming both haudle and guide. The boring-bit is a cylindric rod rather thicker towards the extremity than elsewhere. Its thickest portion exactly fits the muzzle of the piece. It has a groove at the extremity, into which fits a small sharp wedge of hardened steel. When first inserted into the barrel, this wedge scarcely projects above the surface of the boringrod. It is now introduced into the muzzle, and the wooden cylinder is pushed forward by the workman, who leans his weight against it. Of course, as it enters the barrel, the spiral grooves of the wooden cylinder, being guided by the fixed pegs in the collar, give the rod and bit a corresponding spiral motion, by which a spiral scratch is made in the interior of the barrel. The wedge is then slightly heightened and the scratch is thus deepened, until the workman cousiders it sufficient. This process is repeated until six or seven grooves have been formed. The Herat rifle, being carefully loaded with balls wrapped in leather or cloth, is tolerably true.

MAT'H, Ast'hol, or Akora, also Matham in the Tamil language, are the residences of the monastic communities of the Hindus, and are scattered over the whole of India. They generally comprehend a set of huts or chambers for the mahant or superior and his permanent pupils; a temple sacred to the deity whom they worship, or the samadh or shrine of the founder of the sect, or some eminent teacher; and a dharmsala, one or more sheds or buildings for the accommodation of the medicants or travellers, who are constantly visiting the mat'h. Most mat'hs have endowments of land, generally of small extent, but as the mat'hs are numerous, the quantity of land in a district pertaining to a mat'h is extensive. But besides lands, they receive presents from lay votaries, ask alms daily in their neighbourhoods, and sometimes traffic. The mat'h is under the entire control of a mahant or superior, with a certain number of resident chela or disciples, with a large number of vagrant or out-members. The mat'hs of the various districts look up to some of their own order as chief, and, under the presidence of this chief mahant, on the demise of any of their brethren, they elect a successor from amongst the chela or disciples, the new mahaut being regularly installed at the hands of the president of the assembly, by investment with the cap, the rosary, the frontal mark or tika or other monastic insignia. In these matters the British Government never interfere. Amongst the Hindus, there is a lay and a priesthood class, the latter being sometimes monastic and sometimes secular, and the Vaishnava sect leave this a matter of choice. The Vallabhacharya sect, indeed, give the preference to married teachers, and all their gosains are men of business and family; the preference, however, is usually assigned to teachers of an ascetic or cœnobitic life. The cœnobitic members of the different communities, at one period or other of their lives, have pursued an erratic mendicant life, travelling over India singly or in bodies, subsisting by alms or merchandise, or some of them, as must be the case amongst such large bodies of men, by less unexceptionable means, like the Sarabaites of the east, or the mendicant friars of the Latin Church. The doctrine that introduced similar unsocial institutions into the Christian church in the 4th century, is still most triumphantly prevalent amongst Hindus and Buddhists in the east, the land of its nativity. Monastic establishments and solitary mortification originated in the specious appearance and pompous sound of that maxim of the ancient philosophy, that in order to the attainment of true felicity and communion with God, it was necessary that the soul should be separated from the body here below, and that the body was to be macerated and mortified for that purpose.Wilson in As. Soc. Proceedings. See Monastery.

MAT'HA. HIND. The forehead, the brow of the head. Matha Din, a name applied by the Sikhs to the Hindus, because of the sectarial marks which the latter place on their forebeads.

MATHANI. ARAB. A term employed by Mahomed to designate certain reiterated passages in the Koran.

MATHERAN, a hill in the neighbourhood of Bombay, with lovely scenery, wooded lanes, and the air fragrant with wild flowers. The best views are from Garbut Point in the morning, and from Panorama Point in the evening, from the latter looking down on Bombay with its broken coast and harbour, on Malabar Hill, by Mazagon and Mahim, a scene rarely equalled. It is in lat. $18^{\circ} 58^{\prime} 50^{\prime \prime} \mathrm{N}$., and long. $73^{\circ} 18^{\prime} 20^{\prime \prime}$ E., 2460 
feet above sea-level, and is within four hours of Bombay by rail.

MATHURA, in lat. $27^{\circ} 30^{\prime} 2^{\prime \prime} \mathrm{N}$., and long. $77^{\circ}$ $40^{\prime} 3^{\prime \prime} \mathbf{E}$, in Hindustan, on the right side of the Jumna, 35 miles N.W. of Agra. Mean height of the cantonment, 655 feet. It was founded by Satrughna, the younger brother of Rama. It has been a place of note from remote antiquity, and in Buddhist times it was one of the centres of that religion. At Fa Hian's visit it had 20 Buddhist monasteries, and about 3000 monks. Its western half is now the home of Vaishnava Hinduism. The river Jumna runs through the district. On the right bank are the Kosi and Ch'hata parganas, and on the left those of Nob-jhi, Mat, and half of Mahaban as far east as the town of Baldeva. This extent is almost identical with Brijmandal of Hindu topography, the circuit of $84 \mathrm{cos}$ in the neighbourhood of Gokal and Brindaban, where the brothers Krishna and Bala Rama grazed their herds. On the Baibhar Hill are sacred temples and wells, the wells at the foot being clustered around the large Brahmakund. The Ganga-Jumna-kund has warm water. 'T'he tract of country around Agra, and principally the plains of Mathura, is that famed in Hindu legend where Krishna and the nine Gopia usually spent the night in dancing.

Mathura is one of the five districts,-Agra, Mathura, Eta, Aligarh, and Manipuri,-which together make up the Agra division of the N.IV. Provinces. Its area is 1435 square miles, with a population of nearly a million of Hindus, of Jat, Brahman, Thakur, and Banya races.-Growse.

MATHURA NATH, a librarian of the Hindu college, author of History of the various Hindu Sects.

MATI of Tahiti, Ficus prolixa. Mati fruit is used for dyeing cloth of a red colour. The bark of thestree is made into cordage.

MATICO (Artanthe elongata), the leaves used as a styptic in Peru, a powerful vegetable astringent, first made known to the medical profession by Dr. Jeffreys of Liverpool. The leaves are covered with a fine hair-Lancet, January 1839.

MATIYA cultivators of Jeypore say their ancestor sprang from the soil, and they point to an opening from which he came.

MATRI. SANSK. A mother; in Hinduism, a class of female divinities of a mystical character, the mothers of the gods, also their personified sakti or energies.-Wilson.

MATRICARIACE E, an order of plants spread all over the globe, including about 900 genera. About 132 genera and 700 species occur in the E. Indies. The medicinal, economic, or food plants are of the genera-

Vernonia.

Elephantopus.

Ageratum.

Adenostemma.

Eupatorium.

Tussilago.

Aster.

Sphæranthus.

Grangea.

Berthelotia.

Conyza.

Blumea.

Ephaltes.

Inula.

Vicoa.

Pulicaria
Eclipta. Blainvillea. Xanthium. Moonia. Wedelia. Wollastonia. Guizotia. Sclerocarpus.

Helianthus.

Verbesina. Spilanthes.

Matricaria.

Pyrethrum.

Chrysanthemum.

Artemisia.

Tanacetum.
Carthamus. Carduus.

Serratula.

Oreoseris.

Species of Aster, Calliopsis, Bellis, Zinnia, Helianthus, Tagetes, Chrysanthemum, Artemisia, Centaurea, are ornamental or fragrant flowering plants. Vernonia anthelmintica, the Som-raj of Bengal, is used medicinally. The leaves of Eupatorium triplinerve, Vahl, were formerly employed in India and America in snake-bites, and are still used in the Mauritius as a substitute for tea. Sphæranthus mollis and species of Blumea are fragrant plants. Guizotia Abyssinica is a valuable oil plant, Cynara scolymus is the edible artichoke, Cichorium intybus, the chicory or succery, etc. Endivia, the endive, and Taraxicum dens leonis is employed in old-standing ailments.

MATRICARIA CHAMOMILA. Linn.

I. sirsciformis, D.C. | M. prehox, D.C.

Ye-kiuh-hwa, - CHIN. | Babuna, Sutei-gul, HiNd.

This occurs wild in China and in the plains of the Eastern Panjab, but is also cultivated. Might be used as a substitute for Anthemis, chamomile flowers, in dyspepsia, flatulency, and intermittents, as an aromatic tonic and carminative. It was formerly used for chinchona. $-D v . J . L$. Stewart. MATRICARIA SUAVEOLENS. Linn. M. chamomila, Wall. This chamomile plant grows in Persia, Kashmir, and India.-Roxb. iii. p. 437 ; Voigt.

MATS.

Matten, . . Dut., Ger | Galeran, Klasa, Malay. Nattes, . . Fr. Burya, . Pers. Chattai, GUJ., HiND, Esteiras, : PoRT., SP. Stuoje, Stoje, . IT. Progoshki, . . Rus. Tikar, Bogor, - Malay. Hassir, : . TURK. Mats are formed of rushes, of the bark of trees, or of the leaves of different species of palm trees, interwoven, and are made in all countries. In Russia, bast mats are manufactured from the inner bark of the lime tree, and China mats are in general use in India for covering floors and lining staircases. In India, in places where bamboos or canes grow readily, mats are made of these materials, but also of-

Andropogon muricatus. Arundinaria falcata.

Arundo donax.

A. tibialis.

Borassus flabelliformis.

Calamus rotang.

Chamærops Ritchiana.

Cocos nucifera.

Cyperus inundatus.

Hedychium spicatum.

Malocochæte pectinata.

Maranta dichotoma.

Pandanus odoratissimus.

P. furcatus.

Papyrus pangorei

Phœenix dactylifera.

P. sylvestris.

Phrynium dichotomum.

Saccharum sara.

S. fuscum.

S. spontaneum.

Thalia dichotoma.

Typha angustifolia.

T. elephantina.

Saccharum fuscum, the Khari of Bengal, is made into the mat called Chanch. Cyperus inundatus, the Meliya of Bengal, is made into the Jhentala mat. Palghat mats, made of the split stems of a species of Cyperus, are very strong and durable, pleasant and cool to lie on, and remarkable for their quiet colours and peculiar patterns. The Darmas mat of Bengal, used to sleep on, is made from the Arundo tibialis. The Moula mat, the Kachkachya, the Valandiya, the Kati from the Pati grass, and the Hogala, are other mats. Table mats in use by the people of India are often goldembroidered.

The leaves of the Pandanus odoratissimus make a very fine matting, largely employed by cabinet- 
makers as a packing material. The leaves of the palmyra are largely used for the palm-leaf books in use by Hindu and Buddhist sects. The stalks of Andropogon muricatus are used as a thatch grass, and its roots are woven into screens, called tatti, which are wetted to cool the atmosphere.

In Arakan there are six kinds of bast, called Sha, which might be successfully fabricated into mats. The Sital Pati mats of Bengal are made from the Phrynium dichotomum. Several species of Typha, Juncus, and Saccharum, in the Madras Presidency, are applied to useful purposes. Many of the mats exported from Calcutta are made from the Papyrus pangorei. Some of the Burmese mats are made from the split stems of the Maranta dichotoma, called Then, which grows abundantly in the forests of Burma and the Tenasserim Provinces, but the large coarse mats in general use in Burma are made from the leaf of the Pandanus furcatus? Tha-ban, BurM., known as the lowland screw pine, in distinction to the highland species of Pandanus, which grows on the high lands above tide waters, from which the smaller and finer mats are fabricated. Chinese table mats are exported to all parts of the world. Floor mats of China are made of a rush cultivated for the purpose; the best are the Lien-tan mats, plain white or plain red and white. The manufacture of matting for sails of Chinese boats and junks, for floors, for bedding, and envelopes of boxes and cases, employs thousands of workmen. The exportation is to the United States, India, South America, Sydney, etc. Besides mats made of rattan for table-furniture, grass mats for floors are largely exported from China. The latter is manufactured of different widths and patterns, and though the amount annually sent abroad is large, it forms a very small proportion to the home consumption. A sail containing nearly 400 square feet can be obtained for ten dollars. The rolls are largely exported and still more extensively used in the country for covering packages for shipment. A stouter kind made of bamboo splints serves as a material for huts, and many other purposes that are elsewhere attained by boards or canvas.

The manufacture of mattings from coloured grass has long been carried on successfully in the Madras Presidency, and those from Cochin, Palghat, Tinnevelly, and Wandiwash are in considerable demand, on account of their brilliance of colours, fine quality, and extreme cheapness. Several grasses appear to be employed, some being broad, flat, and soft, while others are round, fine, and wiry; the mats of Cochin, Palghat, and the western coast are of the latter description, and are the more durable.

The plain coir mattings of Malabar, and the coloured red and black matting of Canara, are well known. The local names of the Palghat mats are - Manha Poo Paya, Cooroo Nare Virallee, Anjee Pooketty Mookeya Velle, Shooyakunden Virallee, Kella Mooka Virallee, and Ketta Mookya Virella. Excellent mats are made in the Laccadive Islands, from the cocoanut leaf cut out of the heart of the tree just before it unfolds. These are employed in the islands as ships' sails; they are of fine quality, and much esteemed when exported. In the Peninsula of India, however, the most common and most generally useful mats are formed of the bamboo, those made with the shining outside strips are used for matting of rooms where the rattan is not procurable. Common bamboo mats are used for lining vessels previous to receiving cargo, and for covering bullock carts. Rattan mats are generally preferred for rooms; Tonga mats, similar to those of Bengal, are prepared in many parts of Southern India; date-leat and palmyra-leaf mats are generally used by natives for sleeping on, and are very useful. Palghat mats and those from Cochin are considered the finest in Southern India. Mats of Travancore are made from the grass Cyperus textilis, and another grass called Cooray.

The mats of Sylhet are famed. Hindus sit on mats, and have large pillows at their backs, upon which they rest their arms. Europeans use only the better kind of mats, and almost exclusively for the covering of floors in their houses, but natives employ them to sit and sleep upon. Every Muhammadan, however poor, after having performed the prescribed ablutions, spreads a small mat before him while saying his prayers. The Hindu uses it as a sort of table-cloth; in many a poor hut it constitutes the only piece of furniture perceptible. The finest kinds of the Bengal matting are manufactured at Midnapur, near Calcutta. The price varies according to the size of the border, which is coloured either red or black; and one large mat, 25 feet square, cost at Midnapur $£ 30$. But besides these extremely fine mats, a cheaper description is manufactured, of which considerable numbers are exported to Madras, Bombay, Mauritius, and Australia. These are much cheaper; and a good strong mat, about 20 feet square, may be had for $£ 4$, if plain, and $£ 5,10$ s., with a black or red border. The mats next in point of fineness are those from Jessore, also in the vicinity of Calcutta, and called Sital Pati ; these, however, are never made, for India, of the size of an entire room floor, but only in the shape of rugs, and have invariably a red border, sometimes also a red-flowered centre. They are generally made about 4 to 5 feet long and 2 broad. At Hoogly, near Calcutta, an inferior kind of small mat is made, of which very large quantities are exported to Mauritius, Demerara, and New South Wales. The small mats made in the Madras Presidency, North Arcot, and the whole of the Malabar coast, are celebrated.-Williams' Middle Kingdom; Rohde, MSS.; $M^{*}$ Culloch, Cat. Ex. 1862. MA'I'SA KANDA. TEL. Pterospermum acerifolium, Willde. The petals bruised in honey are reckoned a cure for stomach-ache.

MA-TSO-BOO. BurM, A shout of the Burmese maidens at their water festival. On the first day of the New Year, this festival begins, and lasts for four days. At daybreak, they sprinkle the pagodas with water, and present jars of water to the priests, and ask forgiveness for any wicked thought, word, or deed of the bygone year. The carnival then begins. The fronts of the houses are decorated with green leaves and flowers; and all, but particularly the young men and maidens, send showers of water on all they meet, loudly shouting Ma-tso-boo! Ma-tso-boo! not wet. It is a joyous time, in which the young rush about, their light dresses all wet, clinging to their lithe figures.-Briggs.

MATSYA, the fish avatara of the Hindu god Vishnu, has been demonstrated to have immediate reference to the general deluge, and to be the 
same history, disguised in oriental fiction, of that event, as is related in the Hebrew Scriptures. Sir W. Jones assents to the opinion of Bochart, that the fable of Saturn was raised on the true history of Noah. He shows that the seventh Menu, Satyavrata, corresponds in station and character. In his reign, the Hindus believe the whole earth to have been destroyed by a flood, including all mankind, who had become corrupt, except the pious prince himself, the seven rishi, and their several wives, who, by command of Vishnu, entered a bahitra, or spacious vessel, accompanied by pairs of all animals. Vishnu, assuming the form of a fish, commanded the ark to be fastened by a cable, formed of a vast serpent, to his stupendous horn, secured thereby until the flood subsided; when he and Brahma slew a monster named Hyagriva, who, while Brahma was reposing at the end of a kalpa, stole the Vedas, and mankind had consequently fallen into the depths of ignorance and impiety. This mighty demon is called the prince of Danava, a name which means horsenecked. The Vedas having been recovered, the world was progressively repeopled with pious inhabitants, descendants of the devout Satyavrata and his favoured companions. The history of this avatara is the subject of the first Purana or sacred poem, consisting of 14,000 stanzas, and is concisely told in the eighth book of the Sri Bhagavata, or life of Krishna.-Sir W. Jones' Asiatic Researches.

MATSYA, a country which produced fish, sometimes said to be Bengal, sometimes Gujerat. The Hindu races who worship, in addition to the works of their own hands, so many varied products, and so large a number of mammals and reptiles, do not, seemingly, worship fish. A tank or pond with all its contents may, however, with the Hindus be devoted to a deity; and Colonel Tod mentions that, when one day he had thrown his net into a lake which abounded with a variety of fish, his pastime was interrupted by a message from the regent, Zalim Singh, to tell Captain Tod that Kotah and all around it were at his disposal, but these fish belong to Kaniya. On which Colonel Tod immediately desisted, and the fish were returned to the safeguard of the deity. In such a sacred tank, fish will feed from the haud; and in the Mahanadi, where it is three miles broad, he tells us fish will follow for miles for a little burnt rice.-Tod's Travels, p. 9.

MATSYA PURANA, a religious book of the Hindus, narrated to Menu by Vishnu in the form of a fish. Many of its chapters are the same as parts of the Vishnu Purana, Padma Purana. $-D$.

MATTAN. HIND. The ground, field, or plain-coloured centre of a shawl.

MATURA, on the east coast of Ceylon, in lat. $5^{\circ}$ $58^{\prime} \mathrm{N}$., and long. $80^{\circ} 37^{\prime} \mathrm{E}$., is a considerable town with a fort. Many gems have been from ancient times exported from Ceylon, where the ruby, amethyst, topaz, sapphire, spinel, chrysoberyl, corundum, and cinnamon stone are found in great abundance, but not emeralds. The sapphires, which are red, purple, yellow, blue, white, and star-stone, are met with at Matura and Saffragam, and rubies and sapphires at Badulla and Saffragam. The white tourmaline or Maturese diamond, called in Singhalese Suda Turemali, is a topaz of a pale-yellow colour. The zircon family is richer in Ceylon than in any other part of the world. It is found in the districts of Matura and Saffragam, and is most abundant in the former. Matura-diamond is the name applied to its finest varieties by the dealers in gems. Besides the two well-established species, common zircon and hyacinth, there is a third, massive, opaque, and uncrystallized, and of a dark-brown colour. Specimens of it from Saffragam weigh two or three ounces. The yellow varieties are sold by the natives as a peculiar kind of topaz, the green as tourmalines, the hyacinth red as inferior rubies, and the very light grey as imperfect diamonds. All the varieties are found in the beds of rivers, or in alluvial ground, which, both in Saffragam and Matura, is of the same kind.Horsburgh; Thunberg's Travels, iv. p. 219.

MAT-WAN-LIN, a Chinese editor of a Chinese cyclopædia. It gives an account of India, translated from the Wan-heen-t-hung-Kaow, or deep researches into ancient documents.

MATY, in the Madras Presidency, a house servant who cleans up, supposed to be from the English mate, or from the Malealam Metti, an inferior servant, an under-servant who cleans dishes, shoes, etc.

MAULA. ARab. A Muhammadan judge, a learned or venerable person. Maulana, a person of learning or respectability, a doctor, a teacher. In the Mahratta countries, a Muhammadan schoolmaster. Maulavi, Maulvi, or Mulla, pronounced Mulvi, is a learned man of the Muhammadans; a teacher of, or learned in, Arabic ; an expounder of Muhammadan law, a doctor of divinity, a teacher of the Muhammadan religion. Maulavi, Alim (pl. Ulama), and Mujtahid (pl. Mujtahidin) are the three grades of doctors of divinity.

MAULMAIN or Moulmein, town and headquarters of Amherst district, and of the Tenasserim division, British Burma, situated on the left bank of the Salwin, at its junction with the Gwyne and Attaran rivers, in lat. $16^{\circ} 30^{\prime} \mathrm{N}$., and long. $97^{\circ} 38^{\prime} \mathrm{E}$. The town is built around the base of a hill, and the houses of Europeans are on the slopes and summits of the hill. From the top of the hill, on which are several Buddhist pagodas, the eye ranges over a grand prospect,the Gwyne, the Salwin, and the Maulmain river lie below. The Maulmain river has a ridge of rock running across its mouth, endangering navigation.

MAULOOD. ARAB. Poetry chanted before the bier of a deceased person when carried out.

MAULUDI, ARAB., HIND., applied to a foreign race born in India.

MAUND or Măn, a measure of weight of India, which varies from 25 to $82 \frac{1}{8} \mathrm{lbs}$, according to the substance weighed. The Bengal bazar maund is $82 \mathrm{lbs} .2 \mathrm{oz}$. avoirdupois. Goods weighed or passed by viss are converted at the rate of 365 lbs. avoirdupois per 100 viss. Grain shippers declare their own weight. At Isfahan, the Shahi or royal man is always used, instead of the Tabreez man employed at Shiraz. One Shahi man is equal to two Tabreez man. A khurwar or ass's load is estimated at 100 Tabreez man, or about $725 \mathrm{lbs}$. English.

In the Persian Gulf at Muscat, the maund is 25

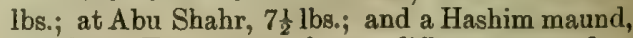
116 lbs. Every town has a different maund.Fraser's Khorasan, p. 369.

MAUNDRELL, HENRY, travelled in Syria 
and the country of the Euphrates. In A.D. 1699 he visited Kala Jerablus, the ancient Carchemish.

MAUNI, the last day of the month of Phalgun, when bathing in silence is to be practised by Hindus.

Mauni, a Hindu ascetic who has taken a vow of perpetual silence, like Paul the silentary. They are also called Mauni-dasi. They are devotees under a vow of silence, generally for a term of years, and there are said to be many in Benares. They are regarded as possessing extreme sanctity, and are even worshipped by other Hindus.Sherring's Tribes; Wilson.

MAURICE, THOMAS, author of Ancient History of Hindustan, its Arts and Sciences, London 1795-98; Modern History of Hindustan, London 1802 ; on the Ruins of Babylon, 1826 ; Ancient Egyptian Grandeur, 1818.

MAURI CONWAI, a great reservoir in Mysore. MAURITIA CARANA, the Carana palm. The leaves are used as house-thatch. Mauritia flexuosa is the most largely distributed palm throughout the basins of the Amazon and Orinoco, or from the Andes of Peru and New Grenada to the shores of the Atlantic. The earliest American voyagers and missionaries noted its abundance in the delta of the Orinoco, and how, in the season of inundations, the natives dwelt on stages supported by the growing trunks of the Mauritia. The edible part of the fruit is the rather thin orange pulp, which easily separates from the endocarp when ripe, but is clad with cartilaginous scales that it requires practice to get rid of. It might be introduced into India.-Dr. Spruce; Seeman.

MAURITIUS, or Isle of France, a mountainous island about 300 miles west of Rodrigues. Its S.W. point is in lat. $20^{\circ} 28^{\prime} \mathrm{S}$., and long. $57^{\circ}$ $17^{\prime} 30^{\prime \prime} \mathrm{E}$., and the N.E. point in lat. $19^{\circ} 53^{\prime} \mathrm{S}$., and long. $57^{\circ} 36^{\prime} \mathrm{E}$. It was discovered by the Portuguese Mascarrhenas in the early part of the 16 th century, and has been in their possession, in that of Spain, and of Belgium, France, 1721, and Britain in 1810 . Coral reefs nearly encircle the island. The lighthouse on Canonier Point is in lat. $20^{\circ} 0^{\prime} 35^{\prime \prime} \mathrm{S}$., and long. $57^{\circ} 35^{\prime} 24^{\prime \prime} \mathrm{E}$. Pouce, the highest mountain, is 2847 feet, and Pieter Botte, 2530 feet. - Findlay.

MAURYA, a dynasty of Magadha, founded by Chandragupta, the Sandracottus of the Greeks. Chandragupta was the illegitimate son of the last Nanda by the beautiful but low caste Mura, from whom he obtained the designation of Maurya. In the Mudra Rakshasa, a Sanskrit drama detailing his elevation, Chandragupta is frequently named Vrishala, a term said to be equivalent to Sudra; and as Nanda himself was the son of a Sudra woman, there can be little doubt that the celebrated Maurya family were of Sudra extraction. They ruled from Palibothra (Pataliputra), the modern Patna. Chandragupta's grandson, the great Asoka, raised this dynasty to the highest fame by his conversion to the Buddhist faith, and his eager promulgation of it. It was the first dynasty in historical times who seem to have united all India into one great kingdom.

The Mudra Rakshasa, a Hindu drama, gives the history of the causes of the revolution which placed the Maurya dynasty on the throne. The Maurya dynasty lasted 130 years.

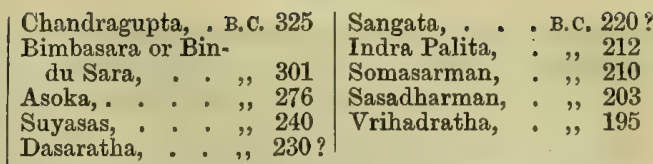

The names of the sovereigns vary in the several Puranas. In the Vishnu Purana they are given as Chandragupta, Bindu Sara, Asoka, Vardhana, Su-yasas, Dasaratha, Sangata, Salisuka, Somasarman, Sasadharman, and Brihadratha.

MAUSOLEUM. Most of the Muhammadan rulers of India bury their great men under a mausoleum. The mausoleum tomb of Humayun, with its white marble dome, is a conspicuous object for miles around. It cost 15 lakhs of rupees, and was erected by his widow Hamida Banu Begum, who is also interred near. There are magnificent structures over members of the Kutub Shahi dynasty at Golconda, and over the Adal Shahi at Gogi and Bijapur; and large tombs at Ahmadnaggur over the Nizam Shahi, and over the Bahmani at Beder and Kulburga. That over Ibrahim Adal Shah is very grand, and those at Gogi are in excellent preservation.

MAUZA. Arab., Hind., Pers. A village, a parcel or parcels of land, a cluster or clusters of habitations, a settlement, an estate.

MAWA. HIND. A glutinous preparation of wheat, used in glazing pottery.

MAWAL. MAHR. Fertile valleys of Maharashtra, the mountain valleys of the Syhadri range.-Wils. Gloss.

MAWALI, a Bedouin tribe between Aleppo and Damascus.

MAWAR-u-NAHR is the geographical term in use by Arab geographers to designate the vast plains exteuding westward from the Pamir steppe, watered by the Oxus and Jaxartes (the Amu Darya and Syr Darya). It is the Scythia intraImaum of ancient classical geography, and the Transoxiana of modern geographers. Beyond this region Asia (Scythia extra-Imaum) was occupied by the races known as Turks and Tartars. Mawar-u-Nahr is bounded on the north by the Jaxartes (Syr Darya), on the west by the Caspian Sea, and on the east by Mount Imaus. Large portions of it are desert, but others are susceptible of high cultivation. Most of the fixed inhabitants are Persians, and all the moving shepherds Uzbak.

MAYA, an ancient author on Hindu architecture. He was a Danava, and built the palace of Yudishthra.

MAYA. The Vedantist school of Hindu philosophy affirm that matter exists not independent of perception, and that substances are indebted for their seeming reality to the ideas of the mind. All that we see is Maya, deception and illusion. There are no two things in existence, there is but one in all. There is no second, no matter, there is spirit alone. The world is not God, but there is nothing but God in the world. In this view, Maya morally means nothing more than the nothingness of this world; poetically, the inability of man to appreciate the world in which he lives, and, philosophically, it is identical with the idealism of Bentley. Brahma says, in this life, man, as in a dream, finds delight in eating, drinking, and other enjoyments, but as soon as he awakes, they yield no longer pleasure, for the joys and pleasures of his life are as unreal 
as dreams. By devout abstraction (that is, by meditating on God) man awakes to a knowledge of divine truths, and finds his former enjoyments nothing but illusion. Thus, a supreme eternal Spirit, the Creator of all, pervades all, and will finally destroy all; in fine, all things are Maya which do not proceed from the light of divine knowledge. By the Vaishnava, Lakshmi is called Maya or Ada Maya, by the Saiva it is Durga.

MAYA AH. BURm. A tree said to grow in the celestial regions, and to be a favourite food of the nat.

May-byoung, a hard, tough, knotty wood, which the Tavoyers select for anchors to their large boats, wooden anchors loaded with stones constituting the greater part in use.

May-gyee, tamarind tree.

May-klin, a timber used for rudders and anchors. May-maka, a timber used in ship-building.

May-rang, a timber said to be very durable.

May-to-bek, in Tavoy, a wood used for the bottoms of ships; preferred to teak.

May-yam, a Tavoy timber; an indestructible, strong, heavy, dark-red wood.

Maza-neng, in Amherst, a close-grained wood, nearly allied to teak. It is used for house-posts, carts, boats, paddles, oars, etc.

MAYA SHUTR ARABI. ARAB.? Rennet from stomach of camels. The genuine article is brought from Arabia, and sells at about $4 \mathrm{oz}$. for 8 rupees.

MAYFLOWER, a ship sent from Gombroon to Masulipatam by the English East India Company about 6th May 1659. It has been supposed to be the same ship which landed with the Pilgrim Fathers from Plymouth, in America, 22d December 1620.

MAY-KUANG, a deep, broad river of Cambodia. It takes its rise in Tibet, and flows through Laos, Cambodia, and Cochin-China, forming a delta at its entering the China Sea by numerous channels.

MAYO, EARL OF, K.P., was Viceroy and Governor-General of India from the 12th January 1869 till his death at Port Blair, where he was assassinated, on the 8th February 1872 , by a Pathan convict. The two great administrative measures of his rule were the institution of a Department of Agriculture, Revenue, and Commerce, and a Statistical Survey of India. A Memorial Hall was erected to his memory at Allahabad,'Dedicated to the memory of Richard Southwell Bourke, Earl of Mayo, K.P., M.A., P.C., LL.D., some time Viceroy and Governor-General of British India, who, after three years of beneficent rule, during which he inaugurated many wise measures, and won the regard of all classes, fell beneath the hand of an assassin at Port Blair. Andaman Islands, on the 8th of February 1872. This tablet is set in the centre of a frame, of which the late Earl's coat of arms, with the motto, 'A cruce salus,' artistically done in marble, in relief, forms a conspicuous feature. He did much to develop the extensive salt mines in Jhelum district, Panjab ; lat. $32^{\circ} 39^{\prime} 30^{\prime \prime} \mathrm{N}$., long. $73^{\circ}$ $3^{\prime} \mathrm{E}$. The mineral occurs in the chain of hills known as the Salt Range, the beds cropping out from the red marls and sandstones of the Devonian group, on the southern escarpment of the hills. They run throughout the whole length of the system in layers of considerable thickness, some- times standing out in the form of solid salt cliffs, as at Kalabagh on the Indus.-Imp. Gaz.

MA YO. ChIN. Local anæsthetics. The flowers of a species of Cannabis, called Ho-ma, and those of the Datura (Man-tou-lo) were formerly in China infused in wine and drunk, as a stupefying medicine preparatory to acupuncture, the opening of abscesses, or the application of the actual cautery. A solanaceous plant called $\mathrm{Yah}$ puh-lu, probably identical with the Atropa mandragora, is said to be capable of causing a trance of three days' duration. Aconite root, the tubers of Pinellia tuberifera, long pepper, the root of Heterotropa asaroides, the flowers of Hyosciamus, Azalea, Andromeda, and Rhododendron, the tubers of Arisæma and of Arum pentaplyyllum, a gum-resin called Mwan-hiang, are all reputed anæsthetics. Robbers use the last substance to lult their victims to sleep.-Smith.

MAY-POLE. These are erected at the entrance of every Hindu village in the happy vassant or spring time, whose concluding festival is the Holi Saturnalia. Every pole has a bundle of hay or straw tied at the top, and some have a cross stick like arms and a flag flying; but in many parts of the Pathar, the more symbolic plough is substituted, dedicated to the goddess of fruition, and serving the double purpose of a spring-pole, and frightening the deer from nibbling the young corn.-Tod's Rajasthan, ii. p. 662.

MAYT. ARAB. Dead, a dead body. Bahrul-Mayt, the Dead Sea, or Lake Asphaltites.Catafago.

MAYURU-PINCH'HA. SANSK. The peacock fan, which formed one of the insignia of royalty of the Chalukya dynasty when ruling at Kalian.

MAYWAY-ka-TABAK. HIND. The fairy fruit tray.

MAZAFFAR JUNG, the title of the favourite grandson of Nizam-ul-Mulk, his name being Hadayat Mohi-ud-Din. After the death of Nizamul-Mulk, he strove to attain the sovereignty of the Dekhan against his uncle Nasir Jung, and entered into agreements with Chanda Sahib and the French. He was present with Chanda Sahib at the battle of Ambur, where Anwar-ud-Din fell. He gave Masulipatam to Dupleix, but was seized and imprisoned by Nasir Jung. His uncle Nasir Jung was assassinated by a conspiracy, and ultimately, after a varying contest, Mazaffar Jung fell at Cuddapah, during the revolt of the Pathan chiefs, by the arm of the nawab of Kurnool. Orme.

MAZAGON, northern suburb of Bombay city, noteworthy as containing the docks and workshops of the Peninsular and Oriental Steam Navigation Company. Lat. $18^{\circ} 56^{\prime} \mathrm{N}$., long. $72^{\circ}$ $53^{\prime}$ E.-Imp. Gaz. vi.

MAZANDERAN, a province of Persia, in lat. $35^{\circ} 45^{\prime}$ to $57^{\circ} \mathrm{N}$., and long. $50^{\circ} 15^{\prime}$ to $54^{\circ} \mathrm{E}$., lying between the $\mathrm{S}$. coast of the Caspian and the Elburz mountains. The inhabitants are partly Lek and partly Turk, in a number of separate tribes and clans. The khalif Harun-u-Rashid was interred here. It was for some years the residence of the court of Nadir Shah. It is very mountainous and rich, and the mountains are, with the exception of those in Georgia, the only ones in Persia covered with forests, principally composed of the Azad-darakht, admirably adapted for ship-building. This fact made Peter 
the Great and Catherine II. so anxious to obtain possession of Mazanderan and the neighbouring province of Ghilan; and indeed they were ceded to Peter by treaty at one moment, although he was afterwards obliged to relinquish them. Down to the middle of the 19th century, the Russians never ceased their efforts to gain even a small footing in this neighbourhood; and in 1881 Mazanderan was ceded to them, and they succeeded in obtaining and fortifying the small island of Ashounada, close to the shore, in the neighbourhood of Asterabad. Mazanderan is said to have been conquered in pre-historic times by Rustum, who is said to have killed there a number of elephants, an animal now unknown in Persia. Mazanderan and Ghilan may be divided into two distinct climates, the mountainous region, and the flat country along the shore of the Caspian Sea. The small province of Asterabad is sometimes included in Mazanderan, which it resembles in appearance, climate, and productions. This is the ancient Hyrcania, and the paternal estate of the king of Persia, as chief of the Kajar tribe, who have entire possession of the province. It extends to the east as far as long. $58^{\circ} \mathrm{E}$, and is divided from Dahestan by the river Ashor. Asterabad is situated near the mouth of the river Easter, on a bay of the Caspian Sea. From Asterabad it is eighteen days' journey to Herat, and from thence, passing through the hilly country of the Hazara people, you arrive at Kābul on the eleventh.-Malcolm's Persia, ii. p. 126; Mohun Lal's Travels, p. 320; Kinneir's Memoir, p. 166 ; Ferrier's Journey, p. 70 ; MacGregor, iv. pp. $318,327$.

MAZARI, a tribe still to a great extent predatory. They continually plundered the river boats, and made frequent incursions into the Babawulpur territory on the left bank of the Indus. They were often at war with the Bugti and Mari, and did not hesitate to attack the Dumbki and Jakrani at Pulaji, Chatar, etc., from whom they occasionally succeeded in driving off much cattle. The Mazari were the most expert cattle-stealers in the border country, and have the reputation of being brave warriors.

MAZAR-i-SHARIF, a town said to be the burial-place of Ali, and pilgrims visit the tomb. The legend the Uzbaks tell is that when Ali fell his body was placed upon a milk-white she-camel, which was then let loose to go wherever she liked. They had decided to bury the body wherever she first stopped. Far and wide she wandered, all over the world; at last, coming to Mazar-i-Sharif, she stopped and died, and on that same spot Ali was buried by his followers. The Persians dispute the legend, and firmly believe that Ali is buried at Kerbala.

MAZDAC, a religious enthusiast of Istakhr who flourished in the reign of the Sassanian king Kobad, in the 6th century of the Christian era. He set up the doctrine of the community of women.

MAZHAB. ARAB. Religion. See Din.

MAZHABI. The Rungret'ha Sikbs are sometimes styled Mazhabi, or of the religion. The name may also be applied from the circumstance that the converts from Islam are so called, and that many sweepers throughout India have become Muhammadans. Churas, a man of the sweeper caste, brought away the remains of Tegh
Bahadur from Dehli. Many of that despised, though not oppressed, race have adopted the Sikh faith in the Panjab, and they are commonly known as Rungret'ha Sikhs. Shiah Muhammadans are also called Mazhabi.

MAZINAH, a site on a minar of a mosque, from which the Muazzan gives forth the Azan or summons to prayers.

MAZRA or Majra. Hind. A tilled field ready for sowing; also a hamlet.

MEAD or Metheglin.

Meede, Meedrank, . Dut. |Idromele, . . . . IT. Hydromel, : : Fr. Lipez, . : : : Rus. Meht, Meth, . . GER.

An intoxicating drink made of honey. See Madhu.

MEADOW FOXTAIL GRASS, Alopecurus pratensis, $W$., grows in Sind. It is much relished by cattle. Meadow grass, in Tenasserim, has one or two representatives among the species of Poa. -J. A. Murray; Mason.

MEADOW SAFFRON, Colchicum autumnale. Sorinjan, Arab. A bulbous plant, the roots and seeds of which are employed in medicine.-Hogg, p. 737.

MEAL, Farina.

Mil, : : : : DUT.
Farine, Tapung, Pulur, . : MAL. Mehl, : : . GER. Muka, : : : Rus.

The edible parts of wheat, oats, rye, barley, and pulse of different kinds, ground into a coarse flour. - Faulkner; $M^{\circ}$ Culloch.

MEALY BUG or White Bug of Ceylon coffee planters is the Pseudococcus adonidum. The male insect is of a dirty brownish colour, and slightly hairy. It is very minute (very much smaller than the females; only about half a line long), and resembles certain small Ephemeridæ or May flies. The female is oval, brownish-purple, covered with a white mealy powder, which forms a stiff fringe at the margin and at the extremity of the abdomen two setæ. The larvæ and pupæ are active and move about. The insects in all stages of development are found in Ceylon all the year round, chiefly in dry and hot localities, on the branches of trees, and on the roots to one foot under ground. Mr. Nietner says it is identical with the species naturalized in the conservatories of Europe. It is preyed upon by the Scymnus rotundatus, a minute beetle of the lady-bird tribe, of the size of a pin's head, black and pubescent; also the yellow-coloured and common Encyrtus Nietneri and the black-coloured scarce Chartococcus musciformis, two minute Hymenoptera (wasps), only $\frac{1}{2}$ "long, and the minute whitish mite Acarus translucens. Of the members of this family of insects, the Coccidr, some, as the cocbineal and lac insects, are of great economical importance; but others, as the sugarcane blight of the Mauritius, the aspidiotus, and the coffee bug, are excessively baneful to the gardener and agriculturist. - Nietner.

MEANGIS or Menangus, a group of islands on the S. coast of Mindanao, in about lat. $5^{\circ} \mathrm{N}$., and long. $127^{\circ} 45^{\prime} \mathrm{E}$. There are three islands of moderate size, with some smaller ones adjoining; they lie about 36 or 42 miles N.E. of the Talour Islands. Sangir and the numerous islands of this group, in the Celebes, occupy a superficies of 13 square leagues; the Tolaut and the Meangis Islands united are 18 square leagues. These 
archipelagoes, formerly subject to the authority of the sultans of Ternate, now make part of the larger Dutch Residency of Menado. Several extinct volcanoes, and some still in full action, are found in the Sangir group; the devastations which they commit from time to time have often been fatal to the inhabitants. The eruption of Duwana, in 1808, completely annihilated the village of Tagalando, destroyed all the surrounding forests, and suddenly deprived the inbabitants of all means of livelihood by the destruction of their fields. The Gunong Api causes numerous ravages in the island of Siau; its peak, 6000 feet above the level of the sea, forms the culminating point of this group. Gunong Api covers with its base all the northern part of Sangir-besar. In 1812 torrents of lava from it destroyed the extensive forests of cocoanut trees with which this part of the island was covered, and caused the death of many of the inhabitants. These islands furnish more than 25 kinds of wood suited for building and furniture. Two harbours, sheltered from all winds, exist in the larger Sangir, one in the Bay of Taruna, the other, called Midelu, on the eastern side.-Joum. Ind. Arch., 1850, p. 764 ; Horsburgh.

\section{MEAOU. CHIN. A funereal temple.}

MEASLES, in pork, is a tainted form caused by the introduction of the eggs of the Trnia solium into the intestines. See Cysticercus.

MEASURES. See Weights and Measures.

MECCA, Medina, Aden, Sana the capital of Yemen, and Daraieh, are the chief towns of Arabia. Mecca is a holy city of the Muhammadans. It is situated in an arid and barren tract bf country, a full day's journey from the seaport town of Jedda. In the summer months the heat is excessive. There are several structures in it of historical interest, one of them, the Ka'ba, so called from its form being nearly a cube (kaab). It is a massive structure of grey Mecca stone, nearly 44 feet long by 35 feet wide, and from 35 to 40 feet high, with a flat roof, supported by two columns, between which are hundreds of lamps hung in festoons. The Ka'ba is encircled by an immense curtain (kessoua) of rich black stuff, on which appears in large Arabic characters the essence of the Muhammadan creed, "There is no other deity but God, and Mahomed is the prophet of God, also some prayers worked in gold thread. Beyond these are the mambar (pulpit), Al Bab-us-Salam, and the buildings enclosing the well of Zamzam. Serving as an upper chamber to this structure is the Makam-us-Shafiah, and opposite to the remaining three sides of the $\mathrm{Ka}$ 'ba are the makam of the other orthodox sects, viz. the Hanefi, the Hanbali, and Maleki. There are arcades around the square in which the Ka'ba stands. Built into the Ka'ba wall is the black stone, Hajar-us-Siah, said to have been brought by the angel Gabriel in order to the construction of that edifice. The stone, according to the legend, was at first of a bright white colour, but is absolutely black or deep reddish-brown. This stone every Muhammadan pilgrim must kiss, or at least touch, every time he goes round the Ka'ba. Neither the stone of Abraham nor that of Ishmael receives the same honours; pilgrims are not obliged either to visit or to kiss them. The Arabs venerate the Ka'ba as having been built by Abraham, and having been his house of prayer. Within the same enclosure is the well of Zamzam. Hagar, when banished by her master, set little Ishmael down here while she should find some water to quench his thirst. Another ornament of the $\mathrm{Ka}^{\prime} \mathrm{ba}$ is a row of metal pillars surrounding it. The black stone has suffered from the iconoclastic principle of Muhammadanism, having once narrowly escaped destruction by order of the ruler of Egypt. In these days the metal rim serves as a protection as well as an ornament. Its height from the ground is 4 feet 9 inches; Ali Bey places it 42 inches above the pavement.

Mecca territory is reputed sacred to a certain distance round, which is indicated by marks set for this purpose. Every person, it is assumed, should perform the pilgrimage to Mecca who has a beast to ride upon, and who can supply himself with provisions for the journey. Ul-Shaffei says, Those who have money, if they cannot go, should perform this journey by deputy. Malik thinks all who have strength sufficient should go to Mecca ; but Ul-Hanifa deems both money and health of body requisite before this duty can be deemed obligatory. During the pilgrimage, the city becomes an immense fair, in which products of Arabia are exchanged for the richest and most valuable commodities of Persia, India, and Europe, to the amount of several millions of dollars. There are few khans, baths, serais, or even mosques, and there are few cisterns for collecting rain; the well-water is brackish, and during the pilgrimage sweet water becomes an absolute scarcity. At other times the city is chiefly supplied by a conduit coming from the vicinity of Arafat, a distance of six hours' journey. This extensive work was constructed by Zobeida, wife of Harun-ur-Rashid. Year after year thousands of unfortunate and improvident pilgrims crowd these places, and are left to look after themselves as they please, without the slightest regard being had to sanitation. In 1881 cholera broke out with great severity at Mecca. On the day of pilgrimage the preacher sits on a camel, because the prophet, during his last pilgrimage, being sick, made the tour of the Ka'ba on his came], and remained on it while he preached. Mount Arafat (recognition) is so called because Abraham the patriarch, after the vision in which he was commanded to sacrifice his son Ishmael, waudered about for a day in perplexity as to whether the order came from God. On the second day, being at Arafat, he had a second vision, and he then recognised, i.e. arafa, its truth. In Mecca immorality is conspicuous, and the pilgrim may often apply to himself the words of Umr-ibn-Ali Rabiah on his return from Mecca- 'I set out in hope of lightening the burden of my sins, and returned bringing with me a fresh load of trans. gressions.'

The city is chiefly situated in the wadi of the same name, which is also called Mekka, a narrow sandy valley which runs north and south, but inclines towards the N.W. at the latter extremity of the town. The city, with the exception of three castellated buildings and a few watchtowers, is defenceless. Around are several sandy wadi, which are separated from the desert by a low barren chain of hills from 200 to 500 feet in height, the most elevated part of which is on the eastern side. Mecca houses are built of stone, usually three storeys high, with terraced roofs 
surrounded by open parapet walls, and having the unusual addition of numerous windows, shaded by lightly-formed reed blinds; the aspect is more European than oriental, especially as the streets are very wide, in order to afford the necessary space for an addition of about 50,000 to 100,000 to the permanent inhabitants, who are between 18,000 and 30,000 souls. Ali Bey (A.D. 1807) calculates 83,000 pilgrims; Burckhardt (1814), 70,000 . Burton reduced it, in 1853 , to 50,000 . In A.D. 1854, owing to political causes, it fell to about 25,000 . Of these at least 10,000 are Meccans, as every one that can leave the city does so at pilgrimage time. A visit to the Masjid-unNabawi, and the holy spots within it, is technically called Ziyarat or Tisitation. The visitor, who approaches the sanctuary as a matter of religious ceremony, is called Zair, his conductor Muzawwir, whereas the pilgrim at Mecca becomes a Haji. The Masjid-un-Nabawi, or the Prophet's Mosque, is one of the Haramain, or the Two Sanctuaries of El Islam, and is the second of their three most venerable places of worship in the world, the other two being the Masjid-ul-Haram in the centre of the town of Mecca (Mecca connected with Abraham) and the Masjid-ul-Aksa of Jerusalem (the peculiar place of Solomon). Muhammadans have the largest cathedral in the world, St. Sophia's at Constantimople. Next to this ranks St. Peter's at Rome ; thirdly the Jamma Masjid, or Cathedral of the old Muhammadan city of Bijapur in India; the fourth is St. Paul's, London. It is to Walid the First (A.H. 88) that the Saracenic mosque-architecture mainly owes its present form. He had every advantage of borrowing from Christian, Persian, and even Indian art. From the first he took the dome, from the second the cloister, -it may have been naturalized in Arabia before his time, - and possibly from the third the minaret and the prayer-niche. The last appears to be a peculiarly Hindu feature in sacred buildings, intended to contain the idol, and to support the lamps, flowers, and other offerings placed before it. Mecca has as many as 29 designations, such as Om-el-Kora (Mother of Towns), Balad-el-Amin (Region of the Faithful).

Six Christians of Europe are known to have visited Mecca. Lodovica Bartema, a gentleman of Rome, visited Mecca A.D. 1503; Joseph Pitts, of Exeter, A.D. 1678 ; John Lewis Burckhardt, A.D. 1814; Lieutenant Richard Burton, of the Bombay Army, A.D. 1853; Herman Bicknell, the translator of Hafiz; and T. F. Keane, who resided there six months, and afterwards went on to Medina, and published his pilgrimages. It reads like one of those stories which are to be found in the pages of juvenile magazines. During the pilgrim season $1877-1878$, the author, apparently a light-hearted young sailor, found himself at Jedda, and conceived the audacious idea of making a pilgrimage to the holy shrine. Unlike his great predecessors, Burckbardt and Richard Burton, he did not prepare himself for the task by long study and experience of eastern tongues and manners; still less did he take the preliminary precautions adopted by Herman Bicknell, who qualified as a Muslim at Cairo before setting out for Mecca. On the contrary, so slight was his acquaintance with oriental languages, that he seems at first to have adopted the name of Abdur Muhammad, a title that is not only impossible, grammatically and philologically, but offensive to Muslim ears. A kind bint from a travelling companion, a young Indian nobleman to whose suite he attached himself, induced him to exchange his preposterous appellation for the more reasonable one of Muhammad Amin.

MECH and Kachari, according to Colonel Dalton, are considered to be the same people, or at least of common origin. Buchanan calls them a tribe of Kamrup, who appeared to have undergone great changes. The large tract of country called Mechpara, in the Gowalpara district, no doubt took its name from them; and its proprietor, Colonel Dalton says, is a Mech; but he and most of his people repudiate this origin, and call themselves Rajbansi. The Mech are to be found in the Bhutan Dwars, and they extend from thence in a westerly direction into the Nepal Terai, as far as the Konki river, subject respectively to the $\mathrm{Ne}$ palese, Sikkim, Bhutan, and British Governments. Their habits and customs are found much modified by the people with whom they come in contact, viz. the Pani Kocchi, Rajbansi, Dhimal, Thawa, and Garo on one side, and the Limbu, Keranti, Lepcha, Murmi, and Bhutia on the other. They are fairer than the Kocchi, and have more markedly the Mongolian characteristics, but accompanied by a softness of outline which distinguishes them readily from the Mongoloid Lepcha, Limbu, and Bhutia. They are said also to resemble the Mug and Burmese, and to be, like them and like the Khasiya, greatly addicted to drinking spirits, smoking, and eating the betel leaf. It is said that when living beyond the pale of Hindu influence they are as omnivorous a race as any in the world, but they will not eat the flesh of the elephant. They are very migratory, continually shifting their cultivation and abodes that they may have the full benefit of the virgin forests to which they cling. It is their love for such forests that retains them under Nepalese or Bhutan rule. The Mechs are possessed of a physical constitution that enables them to live and flourish all the year through in a malarious tract which is absolutely fatal to strangers, and their rude methods of agriculture are gradually rendering the country habitable for successors of a superior race.

The Rajbansi tribe is identical with the Kocch of Assam and of Koch-Behar.

The Mech language is not written, and is apparently of Bengali origin. They never live at elevations higher than from 800 to 1000 feet above the sea, and prefer cultivation in the clearances of the Terai. The Bhutan Mech are a quiet, inoffensive, weak race; they are precisely the same class as the men inhabiting the British Terai ; like them they appear to enjoy perfect immunity from the ill effects of malaria. They are, however, a finer and less sickly and sallow-looking set than the Mech of the Darjiling Terai, probably because the Bhutan Terai is more healthy and drier than the British Terai. They worship the Sij (Euphorbia) as the emblem of the supreme deity, like the Kachari, and they call themselves Bodo or Boro, which means a great people, and Rangta, a heavenly, and other designations in which the Kachari rejoice.

In the census report of 1881 the Rajbansi are returned as 106,376; the Kachari, 281,611; and the Kocch, 1,878,804. The numbers of Bodo or Boro, Bhutia, Khasiya, Lepcha, Limbu, Mech, Mug, and Pani Kocch, and Rangta are not 
given.-Mr. (Sir) George Campbell, p. 58; Dalton, Ethnol. of Bengal; Imperial Gazetteer; Census Report.

MECONOPSIS ACULEATA, Prickly poppy. Guddikum, Gudia, Hind. | Kanta, . . PANJAB. Meconopsis is from unкwy, a poppy, and $o \psi(5$, a resemblance, a genus of plants belonging to the natural order Papaveraceæ, and formerly referred to Papaver. This species is found at Kaghan, in the Sutlej valley, between Rampur and Sungnam, at an elevation of 10,000 to 12,000 feet; also in Nepal, Chur, Kedarkanta, and Pir Panjal. Flowers blue-purple, showy. The roots are reputed to be exceedingly narcotic, but an alcoholic extract of one drachm of the root given to a small dog produced no perceptible effect. Meconopsis Nepalensis is a Nepal plant, and is described as being extremely poisonous, especially its roots. Meconopsis Wallichii, Hooker, is the blue poppy of Mount Tonglo, on the Sikkim Himalaya at 12,000 feet. - Eng. Cyc.; O'Sh.; Cleghorn; Royle's Him.

MED or Medi, a Scythic tribe that colonized the Panjab. General Cunningham says the Med or Mand are almost certainly the representatives of the Mandrieni, who lived near the Mandrus river, to the south of the Oxus; and as their name is found in the Panjab from the beginning of the Christian era downwards, he concludes that they must have accompanied their neighbours the Jatii or Jat on their forced migrations to Ariana and India. In the classical writings the name is found as Medi and Manduevi, and in the Muhammadan writers as Med and Mand. The tribe may have been transplanted to the banks of the Indus, when the Medo-Persian empire extended that far east; or they may have been pressed southeasterly by intruding Scythians, or have left during the persecution of the Magi, who constituted one of the six tribes of Medes. Admitting that the Jartaka of the Mahabharata and the Puranas represent the Jat, the Madra also mentioned there must be regarded as representing the Med, confirming thereby the antiquity and synchronisms of these two races on the banks of the Indus. The Med devoted themselves to a pastoral life, repeatedly invaded the territories of the Jat, putting them to great distress, and compelling them to cross the river; but subsequently the Jat, being accustomed to the use of boats, recrossed and defeated the Med, whose country they plundered. They made up their differences, and asked Daryōdhana, king of Hastinapur, to send them a king, and he sent his sister Dassal (Dahsalu), wife of Jayadratha, who made Askalandha her capital, perhaps the Uch of later times. After a reign of more than 20 years, Jayadratba was killed on the fatal field of Thanesar, and his widow burned herself on his funeral pile. On the same field the Bharata dynasty was extinguished. The earliest historical notice of the Med race is by Virgil, who calls the Jhelum, Medus Hydaspes. This epithet is explained by a statement of Vibius Sequester, which makes the Hydaspes flow past the city of Media. This is the same place as Ptolemy's Euthymedia, which was either on or near the same river, and above Bukephala. Also in the Peutingerian tables, which are not later than A.D. 250, the country on the Hydaspes is called Media. From this evidence, the Medi or Med were in the Panjab as early at least as the time of Virgil, or B.C. 40-30. Shortiy thereafter, about B.c. $30-20$, the Med seem to have been forced southwards into Sind, where the Jat long resented their intrusion. The Erythræan Periplus mentions that about A.D. 100 , the rulers of Minnegara were rival Parthiuns, who were mutually expelling each other. When the Muhammadans arrived in Sind, they found the. Med or Mand firmly established there along with their former rivals the Jat. Ibn Haukal describes the Mand of his time, about A.D. 977, as occupying the banks of the Indus from Multan to the sea, and to the desert between Makran and Fambal. Masudi, who visited India A.D. 915-16, calls them residing in Sind. During the period of the Arab occupation of Sind, Muhammad Kasim is represented as making peace with the Med of Saurashtra, seafarers and pirates, with whom the men of Basra were then at war. In the Muhammadan period, Amran, the Barmekide governor of Sind, directed an expedition agaiust the Med, advancing from several directions, and reduced them to great extremities. Nevertheless, in the time of Masudi, the inhabitants of Mansura were obliged continually to protect themselves against Med aggressions. They have remained in this locality ever since, for there can be no doubt but that they are now represented by the Mer of the Aravalli range to the east of the Indus, of Kattyawar to the south, and of Baluchistan to the west. The name of Mer or Mand is still found in many parts of the Panjab, as in Meror of the Bari and Rechna Doabs, in Mera, Mandra, and Mandanpur of the Sind-Sagar Doab, and in Mandali of Multan, offering strong evidence that the Med or Mer were the first Indo-Scythic conquerors of, and once the dominant race in, the Panjab. Meris or Moeris was the king of Pattala who, on the approach of Alexander, abandoned his capital and fled to the mountains ; he was possibly a Mer. The Mer of the Aravalli are but little advanced beyond the tract where the Med, a thousand years ago, were a numerous and thriving population. Their brethren the Mena can be traced in their original seats to the bank of the Indus, and Mer still reside in Kattyawar, the Saurashtrian peninsula, which was the nursery of the piratical expeditions; and the Mer, Mena, and Med seem identical. Med still exist both to the E. and W. of the Indus, and those on the coast, unable to practise piracy, after the manner of their ancestors, follow the occupation of fishermen. To the east they are found roving on the borders of Sind and Jodhpur, the seats of their occupation during the Arab period; and to the west they are found in the little ports of Mekran, from Sanmiani to Charbar, divided into the clans of Gazbur, Hormari, Jellarzai, and Chelmarzai. When the Mubammadans first appeared in Sind, towards the end of the 7 th century, Zath (Jat) and Med were the chief population of the country. But the original seat of the Med or Medi was in the Panjab proper, from which Mr. Thomas concludes that the original seat of the Jatii or Jat colony was in Sind.-Elliot's Histury of India.

MEDA. TEL. Tetranthera Roxburghii, T. monopetala, Nees, T. apetala, $R$. Meda lakri is one of the ashta varga or eight medicinal roots of the Hindus; Meda-chob is the wood, and Medasaq the bark. $-A s$. Res. xiii. p. 410. 
MEDA. KAnN. Medaravan, TAM. ; Medara, TEL. A helot race occupied in cutting and selling bamboos, or making and vending bamboo baskets. In Coorg they are umbrella and basket makers and drummers; they dress like Coorgs, but eat beef. Medara, a worker in bamboo.

MEDE. The ancient territory of Medea is now included in modern Persia. The rise of the Median nation is wrapped in profound obscurity. They first appear about B.C. 850. The word Madai occurs in Genesis x. 2, along with Gomer, Javan, Magog, Meshech, and Tubal. Berosus mentions the Medes as having conquered Babylon prior to B.C. 2000 , and held it for 224 years. History first notices the Medes in the latter half of the 9th century B.C. Shalmaneser II. led an expedition into Medea. Cyaxares, B.C. 632, led an invading bost of Medes against Nineveh, but was met and defeated by Assur-Bani-pal at Adiabene, and the father of Cyaxares was among the slain. Cyaxares again led an army, and this time was victorious, but was prevented following up his victory by a Scythian inroad on his own dominions.

The Mede were a dominant race dwelling in part of modern Persia, and were classed as Arii. The Mede had many colonies. Herodotus mentions the Sigynnæ, a colony settled beyond the Danube. Medians are also said by Sallust to have accompanied the expedition of Hercules when he crossed over from Spain into Africa. The Sauromatæ were Median colonists beyond the Tanais or Don, and the Matienoi, Matienes, Kharimatai, and possibly the Mares, were Caucasian colonists from Medea, preserving in their names the national appellation of Mada or Madia.

The Mede occupied the western part of the table-land of Iran and the bordering mountains of Kurdistan, from the frontier of Persis to the mountains of Armenia and the range of Elburz, which skirts the southern shores of the Caspian. The monarchy, as conquered by Cyrus and recovered by Darius, extended over the eastern part of the table-land as far as the Suliman mountains, which divide it from the Indus valley, and also the strip of coast between Mount Elburz and the Caspian and the other northern slopes which descend to the valley of the Oxus. These nay be called the natural limits of the MedoPersian empire, and they correspond to the extent of modern Persia, except that the eastern part of the table-land has been lost to Persia by the incursions of the Turkomans, and the Afghans, and the Baluch. But beyond Iran, the great Achæmid kings extended their power westward over the former dominions of Assyria, Babylon, and Syria, over Egypt and the region of Cyrene, and to the N.W. over Asia Minor and its adjacent islands, and beyond the Hellespont over Thrace. This wide empire was the Persia known to the Greeks from the reign of Darius to the conquest of Alexander, by whom the monarchy was overthrown in B.C. 330 . This was the empire ruled over by Ahasuerus or Xerxes, noticed in Esther i. 1, an bundred and seven and twenty provinces. In Africa the furthest western boundary was at the bottom of the Great Syrtis. Modern Persia has only eleven of those provinces. The nations of Iran proper, or the Aryan stock of languages, comprise those of Medea and Persia. It includes the Zend of the cuneiform inscriptions and the Zendavesta; the younger Pehlavi of the Sassanians and the Pazend, the mother of the present or modern Persian tongue. The Pushtu or language of the Afghans belongs to the same branch. The Irauian languages of British India are represented by the Sanskrit and her daughters. -Rawl. ii. 385; Elliot, p. 525; Bunsen; Cal. Rev.

MEDHA. SANSK. Apprehension or conception, from Medh, to be apt to learn.

MEDHI, in Assam, a member of a monastery ; Medhi raj is the chief Medhi.

MEDHURST, a British consul in China, author of the Chinese and their Rebellion; also of Ancient China, the Shu King, or the Historical Classic, and A Glance at the Interior of China, London 1850.

MEDIA-BHUMI. Most nations have indulged in the desire of fixing the source whence they issued, and few spots possess more interest than the elevated Media-Bhumi or central region of Asia, where the Amu, Oxus or Jihun, and other rivers have their rise, and in which both the Surya and Indu races (Saca) claim the hill of Sumeru as sacred to a great patriarchal ancestor, whence they migrated eastward. The Hindus do not make India within the Indus the cradle of their race ; but west, amidst the hills of Caucasus, whence the sons of Vaivaswata, or the sun-born, migrated eastward to the Indus and Ganges, and founded their first establishment in Kosulya, the capital of Ayodhya or Oudh.-Tod's Rajasthan, i. p. 24.

MEDICAGO ARBOREA, Linn., is the shrubby yellow lucerne of S. Europe.

Medicago lupulina, the black medich of Europe, Asia, and North America, useful as pasture grass. Medicago radiata, Smith.

Muh-suh,. . . . CHIN. | Herdsman's root, . ENG.

This leguminous forage plant was introduced from Ferghana into China by Chang-k'ien of the Han dynasty. Chinese farmers use the legumes as food and as forage for cattle, and get three mowings in a year.-Smith.

Medicago sativa, $L$., purple lucerne. Al-falfa, . . ARAB? Valaiti gawuth, . MAHR. Hol, Afeh, : : LADAKH. / Rishka, Dureshta, PUSHT. Lucerne grows wild in Kashmir, in Ladakh, in the Pir Panjal range, and in the N.W. Himalaya, from 5000 to 12,000 feet. It is cultivated extensively in Afghanistan, where it is used as fodder for horses, etc., and Moorcroft says also in Ladakb, and that fields of it continue to be regularly cut for 50 or 60 years. This is the Mnòsx'́n of Theophrastus (Plant. de Caus. lib. 2, cap. 20) and the Medica of Pliny (lib. 2, cap. 20; also 18 , cap. 20). It is cultivated in the Dekhan for feeding horses; also in Gujerat, where it is coming into use among the natives as green food for cattle. It is propagated by seed, and may be sown at any season, in bed or rows. It requires much water, and each plant should have five or six inches of space allowed to it. Cultivators generally cut it as it begins to blossom, when fresh shoots spring up, and by manuring it occasionally a succession of crops is continued in this way for several months. - Stewart; Riddell.

MEDICINE. The medical art, amongst the natives of the south and east of Asia, has had the knowledge of western Europe added to it during the 16 th and up to the 19 th centuries, and from Europe to the Pacific Ocean. In Egypt, in Africa, 905 
Portuguese, Dutch, and Spanish East Indies are many medical schools, and numerous European, American, and native medical men teaching and practising their profession according to the doctrines of the schools of Europe. Amongst the Hindus, the art of medicine has been carefully studied from the most ancient times, and books on the subject have a large circulation. Of these, the Ayur Veda, which is reckoned a portion of the fourth or Atharva Veda, is considered the oldest treatise and the highest standard. It is said to have consisted originally of 100 sections, each containing 1000 stanzas, but fragments only are now procurable. The works of Charaka and Susruta, who are said to have lived about the time of Rama, are also regarded as of great authority; and Agastya, a Tamil writer, is fabled to have written upwards of 50 treatises on medicine, alchemy, and magic, but some of those attributed to him have been composed after the arrival of Europeans in India; and there are upwards of 120 Tamil works on medicine, some of them of considerable size. Amongst the Hindus of the 19th century, medical science is, however, much in the same state as it was in Greece in the time of Hippocrates. The Greeks seem to have derived from India their systems of philosophy and medicine, and Hippocrates and Plato taught that fire, air, earth, and water were the elemental constituents of our bodies. The views which Pythagoras and Plato entertained of health and disease precisely accord with those of Plato and the Hindu Susruta, and the Hindu system of therapeutics is much the same as that of Galen, who taught that the properties of all medicines are derived from their elementary or cardinal qualities, -heat, cold, moisture, and dryness,--and taught that if a disease be hot or cold a medicine with the opposite qualities is to be prescribed. A general belief in the hot and cold inherent qualities of medicines at this day pervades the whole of India, and the most illiterate labourer, as well as the most learned pandit, explains the action of medicine on this Galenical principle only. Some Hindu medical men, are able and trustworthy, but the great mass of the native practitioners have not yet been taught anything of the science of Europe, and have not the slightest knowledge of their art, even according to their own authors. Nevertheless their materia medica is sufficiently voluminous, and their rules for diagnosis, as laid down by their ancient writers, define and distinguish symptoms with great accuracy. Their authors have also paid great attention to regimen and diet, and have a number of works on the food and general treatment suited to the complaint, with a variety of works on the medical treatment of diseases, containing much absurdity with much that is of value. Their value of experience and of a thorough education is also proved by many of their proverbs. The Muhammadans of Persia and India tell us, Nim hakim, khatra-i-jān, With a half-educated physician there is danger to your life; which is the English proverb, "A little knowledge is a dangerous thing.' A familiar Tamil proverb warns that he only can be a good doctor who has killed ten persons; and a Singhalese proverb is that he who has killed half a thousand is half a doctor. But both the Tamil and Singhalese proverbs simply mean that there is as yet no regular teaching for their physicians, who must acquire their knowledge by their own series of successes and failures. The kachabonda is a herbalist. T'he vidyan is a learned Hindu practising medicine, the hakim of the Muhammadans is a learned man, and the tabib is a physician. In Southern India the native medical practitioners claim to be either of the Yunani i.e. Grecian school of medicine, or of the Misri, i.e. Egyptian. The Misri is sometimes designated the Suryani or Syrian school. Most of the Muhammadan physicians are of the Yunani school, and the generality of the Hindu physicians follow the Misri school. The Yunani physicians use chiefly vegetable drugs in their treatment of the sick, and with them bleeding is deemed a suitable line of practice. The Misri physicians, on the other hand, chiefly use oxides of metals, sulphur, cinnabar, or sulphide of mercury, and orpiment or sulphate of arsenic ; but these drugs are first combined, by the action of fire, with some other mineral substance, otherwise they are regarded as noxious. Also, they consider bleeding as never admissible. Every Muhammadan gentleman necessarily knows something of the healing art. The medical profession, therefore, ranks next to the clerical in point of respectability; and so highly is the study thought of, that even royalty itself will occasionally condescend to dose its subjects. There were in 1872 in Madras several men of noble family who regularly gave medical advice gratis.

The British Indian Government has established medical colleges at Calcutta, Madras, Bombay, and Lahore, and at Bareilly is a medical school for native girls.

The nawab of Hyderabad in 1846 permitted Dr. Maclean, the Residency surgeon of Hyderabad, to open a medical school near the Residency. In 1876, the Madras Government, on the suggestion of Surgeon-General Balfour; arranged for the medical instruction of women, and the Governments of Bombay, Bengal, and the Panjab have since followed in this, and in the N.W. Provinces, Travancore, and the Panjab other schools have been formed. The Bengal Government and the Travancore Government have founded scholarships for them. The English E. I. Company from their first arrival in the country brought to it commissioned medical officers from Britain for their military and civil services; and since the middle of the 19 th century medical colleges have been established in connection with the Universities of Bombay, Madras, and Calcutta. At these Indian colleges the majority of the students had been educated for the public service in its military and civil branches, but there have been many private students who have graduated in medicine and surgery.

In the 1st century of the Christian era, Dioscorides made inquiry into the medicinal virtues of many Indian plants which were then brought to the markets of Europe. In the $2 d$ century, the great Cornelius Galen published his famous work, the leading opinions in which, as to hot and cold medicines, were borrowed from India, where they still prevail. In the 7 th and 8 th centuries, natives of India practised as physicians in the Arabian hospitals of Baghdad, employing many valuable Indian drugs in their practice. Under Mamun, the Arabian professors of that school obtained, and taught from translations of, the 
Sanskrit medical shastras of Charaka and Susruta. Thus, in teaching medicine to the Hindus and Muhammadans, Europeans are literally merely repaying what, for at least seventeen centuries, they owed to India. The first establishment which British enterprise obtained in India, was won by the science and the noble disinterested patriotism of two British surgeons,-Gabriel Broughton, who cured Shah Jahan's daughter of a frightful burn, and William Hamilton, who cured an ailment of Feroz Shah. Several of the medical officers of the E. I. Company's Service have been distinguished as authors, as botanists, as zoologists, as philologists, as statisticians, as historians, and as physicians. Amongst them may be named Sir Whitelaw Ainslie, James Anderson, Sir James Annesley, Sir George Birdwood, Buchanan Hamilton, Cantor, Crawfurd, Francis Day, Sir Joseph Fayrer, John Borthwick Gilchrist, William Griffiths, William Hamilton, Jerdon, Sir William Marsden, M'Clelland, Sir William O'Shaughnessy, Richardson, Roxburgh, John Forbes Royle, Thomson, Nathanael Wallich, Edward Waring, Robert Wight, Horace Hayman Wilson. On the 10th January 1836 , pandit Mudusudun Gupta, a medical teacher of the Baid or physician caste, began to teach the Hindus the study of practical anatomy by dissecting a human body with his own hand. And by 1872 , about 1200 native students in the medical colleges of India were following his example. Also Hindu gentlemen, who, having passed through a course of study as complete as any school in Europe can afford, have lately received in the Calcutta University that high degree of doctor, which iv Salamanca of old gave the humblest scholar right of place among the superb Hidalgos of Spain, which in England ranks the physician and bis brother doctor graduates only a few degrees below nobility. Doctor Chuckerbutty, a native of Bengal, and the first of his nation who achieved the honour of becoming a medical officer in Her Majesty's Indian army, first projected the Bengal Medical Association. About the year 1840 , the plan of a Medical Mission was first recommended for China, - that is, of a Christian mission, - one main object of which was the conversion of the natives, the missionaries being medical men, securing an introduction through the practice of their profession. The arrangement seemed to be, for China, one of the best that could be conceived. And a similar plan has been adopted in India, in which Christian missionaries practise medicine, whilst instructing in their own doctrines. The Rev. Drs. Scudder, Strachan, Carslaw, Elder, Elmslie, Valentine, Parker, Green, Williams, Chester, Palmer, and Paterson have taught a pure faith to, and cured the bodily ailments of, the people, and their names will long be remembered.

S.E. Asia.-The books in use in Asia amongst the Buddhist religionists, the Hindus, the Chinese, and the Muhammadans, are all of ancient date. The Burmese obtained from India their theory of medical science, and most of the medical writings in the hands of their practitioners are translations from the Sanskrit into the Pali, Burmese, or Shan languages. The principal of them are the Ayur Veda by king Dhanwantari of Benares, of which an epitome has been framed called after that sovereign, who seems to have lived upwards of a thousand years before the Christian era. They have also Sasruta's book, called after its author, whose era was seemingly between the 9 th and 5 th centuries before Christ. The Drebyaguna Pudartha, a translation from the Sanskrit, purports to give a philosophical account of the physical, natural, medicinal, and dietetic uses of the different objects in nature. Nidana, still in Sanskrit, is the title of their works on nosology; and the Psara Korimudi and Lekshyana (Deepa) are their standard works on the theory and practice of medicine.

Burma. - There are no medical schools in Native Burma. The majority of the students are trained as private pupils or disciples by the older and more experienced physicians, who teach, feed, and clothe them, receiving in return only respect and obedience. A few of the future physicians are taught the elements of their art in the ky-oung or monasteries of the H'poongyees. There are three classes of physicians, - the Bein-dau-Saya (Beindau, medicine, and Saya, teacher), the Dat-Saya (Dat, element), and the Payoga-Saya or Seh-Gzan (Seh, a form of medicine, and Gzan, harsh or rough). The Bein-dau are the most numerous class, and in their practice rely entirely on the exhibition of drugs obtained from the vegetable or mineral kiugdoms. They have adopted the theory of the five elements, - earth, water, fire, air, and ether. Amongst the Burmese, the surgeon, even in the oldest and lowest acceptation of the title, does not exist, and there is not the faintest knowledge of anatomy amongst those who in any way practise the healing art. They use no knife or instrument of any kind; all congenital and acquired deformities are left to nature, and even abscesses are never opened. They enforce a rigid abstention from all animal food during sickness and convalescence; and the foreign Chinese, Moghuls, and Armenians living amongst them have all adopted this injurious practice. The after-treatment of their parturient women is barbarous in the extreme. As if the hot, humid climate of that region is not more than enough to depress the woman, immediately after delivery, for the space of nine days, the room she occupies is fumigated with heated bricks placed in water, charcoal fires are kept constantly burning, she is made to sit on warm bricks, and her body is smeared with turmeric and saffron water. The Siamese also follow this exhausting practice.

The Dat-Saya are less numerous than the Beindau-Saya, and, like the latter, hold to the elemental theory; they are more frequently called in to prescribe in the advanced stages of disease, when the patients are too weak to bear the effects of drugs, or when the Bein-dau-Saya give up all hopes of the patient's recovery.

The Payoga-Saya are sorcerers or witch doctors, who resort to charms and incantations.

In Chinese philosophy, also, the five elements or factors enter into the composition of all things, and this theory guides their medical men. The old medical writers of China were the naturalists of their times, and that country had a long line of imperial, princely, and magisterial observers, who directed their attention to medical matters, - the ancient Shin-nung, Hwang-ti, Chi-peh, Lu-pien, Li-tang-chi, Hwa-to, Wang-shuh, and Li-shi-chin. The good sense of Li-shi-chin to a great extent purged the pages of his cyclopredia, the Pen- 
tsau, of nonsensical or disgusting things; but in the present day, as a rule, Chinese doctors employ few mineral or metallic substances in the treatment of internal diseases ; and to instruct all of them in the rational uses of mercurial and ferruginous preparations, would be to confer on their country a great boon. The first edition of the Pen-ts'-au-kang-muh was published by the emperor Wan-leh about A.D. 1597, and the last regular reprint appeared in A.D. 1826, the sixth year of the reign of the emperor Tau-fang. In 1884, Surgeon-General C. A. Gordon added largely to our knowledge of Chinese medicine.

Ceylon. - The medical books of the native practitioners of Ceylon are mostly in Sanskrit or in Pali, but written in the Singhalese character, and some of them have been translated into Singhalese. They are in verses and stanzas, and may be arranged in five classes, according to their subjects, viz. :-

On medicinal plants-

Wasudeva Negundo, 938v. | Namawali Negundo, $290 \mathrm{v}$. Saswati ", 336,, Sara , 112 st.

On the nature and symptoms of diseases, and on the anatomy of the human body-

Arishta Sataka, 100 st. | Sariru-shana, ? SutrasMadhaiva Nidana, 1375 v. thana,? Rupa Lakshana,?

On the qualities and properties of medicinal plants, drugs, etc.-

Guna-patha, 700 stanzas. $\begin{gathered}\text { Siddhanshudda Negundo, } \\ 331 \text { verses. }\end{gathered}$

On the nature and cure of diseases-

Manjusa, - 4770 stanzas. Sara sangsepa, ?

Yogar-nawa, ?

Wara-sura Sangraha, ? Vydia-lankara, 278 stanzas.

Commentaries on the Manjusa-

\section{Yogo-pitake.}

Bhaisajja-kalpa.

Lakshana Jaya-deva.

Kola-wid'hu, 400 sentences Wara-yoga-sara, 5000 ," Ratna-kana, 4000 ",
The Hindu physicians in British India are designated Baid or Vydian, and there are also many learned pandits practising medicine. The Muhammadan physician is styled Hakim or Tabib; and both of these religious sects have surgical practitioners, who occupy a bumble position, as also oculists, cuppers, bleeders, bone-setters. The elemental philosophy is adopted alike by Muhammadans and Hindus; but the former recognise only the four elements of Hippocrates, fire, air, earth, and water, whilst the Hindus have the fifth element in akasa or ether, as adopted by Pythagoras. In the central parts of British India, as in the Central Provinces and at Benares, the medical books in the possession of the Vydians are either in Sanskrit or in translations from that tongue. Their names are-

Koshmabati and Nidan Gudmogdur in Sanskrit. Sarangdhar-Amrit-Sagar in Sanskrit and Nagari.

Vydia Chintamani, by Dhanwantari? on fevers, nervous affections, and derangements of the urinary system.

Roga Nidhanam, by Dhanwantari? on constitutions, temperaments, and their peculiar diseases.

Vydia Sastram, by Dhanwantari? materia medica.

Dhanwantari Negundo, author unknown, a work on medicine, of great antiquity ; very scarce.

Benares, built on the bank of the sacred Ganges, is a holy city of the Hindus, to which many pilgrims resort, and with many wealthy residents. It is a great seat of Hindu learning; but neither there nor in any other part of what is now British India, has there been, for unknown centuries, any
Hindu or Muhammadan public school for teaching the theory and practice of medicine. The establishment of such institutions at Calcutta, Madras, Bombay, Nagpur, Lahore, Agra, Dacca, and other places, has been the act of the British, imitated at Hyderabad in the Dekhan by the Nizam, and at Trevandrum by the maharaja of Travancore.

At Benares, as elsewhere in India, those who wish to follow the healing art, whether according to the doctrines of the Hindus or Muhammadans, place themselves under some well-known Vydian or hakim, as pupils or disciples; and throughout that extensive country, the learned men willingly impart instruction gratuitously. The Vydian practitioners of Benares are well supplied with books, some of them in Sanskrit, some in Bengali, some in Hindi, translations from the Sanskrit, but a mention of the names here will suffice-

Anjan Nidhan.

Madho Nidhan.

Ajorna.

Ang-prakasham.

Bhava-prakash.

Bal-chikitsa.

Gaj-chikitsa

Bangsen.

Charaka.

Chikitsarjun.

Chakratta.

Chikitsa Kalika.

Dhatrimanjari.

Dhanwantari

Negundo.

In the Travancore country three schools of medicine are known, The most generally accepted theory, however, is that taught in the Ashtangahirudayam, and its disciples call themselves Ashtanga-hirudaya Vydians. Their therapeutic agents are chiefly vegetable substances, but with a few drugs of mineral origin, of a mild nature. This school prevails throughout North Travancore, Cochin, and Malabar, and seems peculiar to those districts. In South Travancore, where Tamil is largely spoken, the medical practitioners style themselves Chintamani Vydians. They follow the writings of Agastya. In the capital, Trevandrum, also, there was, in 1876, one Muhammadan hakim or physician practising according to the Yunani or Grecian school. He was resorted to by persons wishing aphrodisiac drugs; and the books in his possession are such as are known to other Yunani hakims. The bulk of the Muhammadans in that part of India, however, avail themselves of a physician of one or other of the Hindu schools, which explains why there are so few of the $\mathrm{Mu}$ hammadan religionists engaged in medical practice. In the capital, where there are many Tamil immigrants from British territory, both of the Hindu systems are in operation. The Ashtanga-hirudaya Vydians are of all classes of the community, from the highest Namburi Brahman to the humblest Chova and Thien. Among Chintamani Vydians, also, there are some high-caste people, but, generally speaking, the barber caste form the bulk of these practitioners. The Chintamani Vydians use chiefly the writings of Agastya. A large number of his books, printed in Madras in the Tamil language, are sold in Travancore; but his books are also obtainable in manuscript on palm leaves. There are also on palm leaves the books in Sanskrit of Charaka and Susruta, and one called Belam; but they are very scarce, and few practitioners are acquainted with them. 
The Ashtanga-hirudayam is said to have been written by Bagada-Chariar, a Brahman convert to Buddhism; and the Travancore people suppose that he obtained his knowledge of medicine from the Buddhists. The book is in Sanskrit, in the Malealam character, written on palm leaves; but few of the practitioners possess a full copy of it. Thirteen of its chapters, with a Malealam explanation, were printed at the Government Press, Calicut, by Mr. Oopoti Cunnen, deputy-collector, Malabar. The complete book, however, has 120 chapters, and treats on hygiene, gives the outlines of anatomy and physiology, practice of medicine, surgery, ophthalmic medicine and surgery, obstetric medicine and surgery, and the manufacture and use of various obstetric and surgical medicines.

Kairava-gramam is an epitome of the Ashtanga-hirudayam. It is on palm leaves, in the Malealam language and character.

Satha-yogam, or the Hundred Modes of Administration, and Sahasra-yogam, or the Thousand Modes of Administration, are partly Sanskrit and partly in Sanskrit mixed with Malealam, a dialect known as the Mani-prasalam. They are palm-leaf books, in the Malealam character, and treat on the preparation of medicines, such as electuaries, decoctions, etc. the modes of administering them, and their uses.

Prayoga saram describes diseases and their treatment. It is a palm-leaf book, in the Malealam language.

Yoga ratna-samchayam is a palm-leaf book, in the Malealam language. It is descriptive of diseases and their treatment; but also indicates needed incantations and 'danam,' or charitable gifts distributed for the relief of the patients' ailments.

Yoga Mirtham is in print, also on palm leaves, in the Malealam language. It describes the treatment of disease.

Manhali, a palm-leaf book, in the Malealam language, on the treatment of disease.

A few other medical books are still on palm leaves, but have also been printed in Malealam; they are said to be selections from larger works.

Karnatica. - The race who speak the Canarese tongue have been partitioned by several states, part of them under the Mysore kingdom, part of them under the British Presidencies of Madras and Bombay, and a part in the Hyderabad Government dominions. Their medical practitioners are usually known as Vyda and as Chekichika. The Vyda claim to be learned men who have derived their knowledge from the study of books. The latter believe that experience is the great teacher; but on the western side of the Canarese country, pandits also engage in the practice of medicine. Though acknowledging that surgery and midwifery were formerly regarded as branches of the medical art, and in the possession of books on those two subjects, they are all now-a-days physician purists. They possess printed and written and also palm-leaf books. Those of Charaka, Susruta, the Agni besa, Bhillu 'Tantra, Parasara Sanhita, Jatukerna Tantra, Atrya Sanhita, Vagbhata, Neghutra Naker, Chekechasurasungraha, Vidyamruta, Lolumburaja, Sahrungdhara, Madhava Nidana are in Sanskrit, printed in the Nagari character, with a Mahrati commentary. But they are costly, and the people are poor, and parts only of most of them are purchased by the physicians, relating chiefly to internal diseases, or what may be termed medical ailments. Others, Vidyarnava,* Bhasaja Culpa,* Rasaratnakerra,* Shadrasa Negundo,* Dhanwantari Negundo, Kasava Nidana,* Raja Negundo,* Sata-sloki, Bhoom-Amruta, Jagachoondari, Sarvangasoondari, are also in Sauskrit, in metre, but are all on palm leaves, and the seven marked with an asterisk are incomplete.
The last two of this series, the Jaga and Sarvangasoondari, are on the treatment of venereal complaints. Their remaining works are on surgery and midwifery, and are Salaya, Salakaya, Aupadhanaha, Aurbhara.

In the Madras Presidency, where the spoken cultivated Hindu languages are Tamil, Telugu, Canarese, Uriya, Malealam, and Tulu (the people numbering in all about $30,000,000$ ), we find amongst Hindu practitioners medical books in all the languages, but, with the exception of many of the Tamil works, the writers in which seem to have been original authors, most of the treatises appear to have been translations or compilations from the Sanskrit. The first of these to be mentioned are the medical books by unknown Authors in Sanskrit:-

Silpoy Sastrum, on the arts and manufactures of the Hindus, in Sanskrit, Tamil, and Telugu.

Bhashujah Sarwaswam, on the medicines applicable to a number of diseases.

Vydia Saravali, Sidayoga Ratnavali, Sarasungraham, Shatashuloki, on the medicines applicable to a number of diseases.

Bashajah Sungraham, sometimes called Shatasuloky, a medical work by an ancient doctor. The Bavardah Dauyekah and the Chendra Caleh are commentaries on it.

Chunnypatarn Avum, on thirteen kinds of delirium.

Dhanwantari Negundo, a very ancient work on medicine.

Abhidana Ratnamala, also called Shadrasa Negundo, on several medicines not in common use, also on various minerals and metals.

Siddayoga Ratnavali, a desultory work on various diseases, by an ancient author.

Kalpastamum, partly translated by Dr. Heyne.

Agni Purana, an epitome of Hindu learning, one treatise being on the healing art, applicable to man and beast.

\section{Sanskrit Books by known Authors.}

\section{Dhanwantari-}

Vydia Chintamani, on the pulse, fevers, spasmodic and nervous affections, derangements of the urinary organs, etc.

Vydia Shattasloki, on materia medica.

Gonda Padum, on natural history and the nature of different ailments.

Kurma Kandum, on the causes of disease.

Roga Nidanum, on peculiar constitutions and temperaments, and diseases arising therefrom.

Vydia Sastrum, on materia medica.

Susrutum, by Susruta, on terms and definitions, on the different parts of the body, the nature of diseases, remedies, diet, and general management.

Ashtanga Hirudayam, by Vagabutti Vydia, on general principles, or theory of medicine, on the human frame; the nature of fever and other diseases, remedies for them, pharmacy, diseases of children.

Hirudaya Dipika Negundo, by Bosha-deva, is a dictionary or book of reference to the last.

Rasaratna Samuchayam, by Vagabutti, on pharmaceutical preparations, in which mercury, arsenic, and nine other metals are combined, sulphur and gems, also formulæ for diseases.

Padardha Chandrakah, also called Ayur Veda Rasayanum, by Hamadri, is a part of the Ayur Veda.

Servangascendary Tika, by Aruna Datta, is a commentary on the Ashtanga Hirudayam and the Padardha Chandrakah.

Sekitcha Sara Sungraham, by Vungasha, on fever and other diseases, with their remedies.

Sekitcha Meruta Sagarum, by Devi-Dasi, on diseases resulting from vicious habits.

Rasa-Ratnacaram, by Nityananda Siddah, on pharmaceutical preparations, in which metals enter.

Rasa Saram, by Govind Achari, on metals, gems, pharmacy, and mysteries.

Vydia Chintamani, by Valla-bendra, on diseases and their remedies. 
Bhalum, by Bhalacharya Rishi, on nosology and the practice of medicine.

Sharanga Dariyam, by Sharanga, on nosology and the practice of medicine.

Kulliana Karaka Bhashujam, by Wugraditya Charya Rishi, a general work on medicine.

Shikritcha Kalika, by Tisat, on medicine.

Vydia Amrutam, by Siva? on medicine.

Dhanwanatri Saranedi, by Vesya Maha Rishi.

Aurogyah Chintamani, by Pandit Damudara, on medicine.

Rugvi Nachayam, by Madava Chya, on medicine.

Chandrakala, by Bopa Dawa, a commentary on Shatashuloky.

Bavardah Dauyekah, by Vanyduttah, do.

Vydia Jivanam, by Solomba Raja, a short treatise on medicine.

Yoga Shatakam, by Vararoochy, do.

Chunnipata Pada Chendreka, by Manikeyah, is a commentary on Yoga Shatakam.

Bojana Kutuhalum, by Ragunadah Suri, on the nature of alimentary substances, on the differences in the constitutions of men and women. It refers frequently to the Dharma Sastra.

Ayur Veda Prakasam, by Madvopaddeyæy, on the venereal disease.

Ayur Veda Mahodadi, by Stree Mukah, on diet and regimen.

Chamutcara Chintamani, by Govinda Raja, on the treatment of many diseases.

Vydia Vatumsum, by Solimba Raja, on diet and the general management of patients during the time they are taking medicine.

Bhashaja Kulpum, by Bharadwajah, the vulgarsynonyms of medicines,

Raja Negundo, also called Abhidana Chudamony, by Narasemma Pandit, a collection of medical tracts.

Patleyah Vebodaha Negundo, awork similar to Kaja Negundo.

Mahapadam, dictated by Pala Kavya to Roma padi Raja it treats of elephants, their breeding and diseases.

Amara Kosha, by Amara Sinha, a Sanskrit dictionary. It was translated by $\mathrm{H}$. T. Colebrooke.

Raja Balabha, by Narayan Dasa, on materia medica. It is in the Bengali character.

The Tamil-speaking people are about sixteen millions in India and Ceylon. Their craving for knowledge is great; their energy and self-reliance remarkable. They emigrate readily to the West Indies, South Africa, Mauritius, Burma, Straits Settlements, and the Malay Peninsula. A knowledge of the English language is largely diffused amongst them, and many medical books have been printed in Madras and Jaffna, in Tamil and in English.

The Telugu-speaking people occupy the eastern part of the Peninsula of India, from Ganjam to a few miles north of Madras, and from the Bay of Bengal to Dangapura and Murgunda on the west of Beder, and are therefore partly under British rule, and partly under the Nizam of Hyderabad.

Medical Books in Tanil.

Agastya, nineteen books by, viz.-

Vydia Vagadum Ayriti, 1500 verses.

Kanda Puranam, a work on ancient history, 1000 stanzas, written in Sanskrit, and translated by Kashyapa Brahmini into Tamil.

Tiruvaliadal Puranam, 3367 stanzas, on moral philosophy, written in Sanskrit, and translated into Tamil by Parinjati a Pandaram.

Pusavedi, 200 verses, on the religious rites and ceremonies of the Hindus.

Diksha avedi, 200 verses, on magic and enchantment, on the use and virtues of the rosary, and on the education of youth.

Pernul, 10,000 verses, in Shen Tamil, treats fully on all diseases, regimen, etc.

Purana Nul, 200 verses, on exorcising, and contains many forms of prayer,
Purana Sutram, 216 verses, on the initiation of religious disciples and their forms of devotion; also on materia medica and regimen.

Karma Kandam, 300 stanzas, on diseases result. ing from folly and vice, supposed to be a translation from the Sanskrit of Dhanwantari.

Aghastier Vydia, Nutiambedu, 150 stanzas, on purification, on sixty-four poisons, metallic, vegetable, and animal, and their manipulation to make them safe medicines.

Aghastier Vydia (Ernuti Anji), 205 stanzas, on medicine and chemistry.

Aghastier Vydia Vagadum, Narpottettu, 48 stanzas, on the cure of gonorrhcoa.

Aghastier Vydia, Padinaru, 16 verses, on diseases of the head and their remedies.

Kalig-ghianam, 200 stanzas, on theology.

Muppu, 50 stanzas, on 18 different kinds of leprosy and their cure.

Aghastier Vydia, Ayriti Eranuru, 1200 stanzas, on botany and materia medica.

Aghastier Vydia, Annuru, 500 stanzas, treating very fully on many diseases, and containing a great variety of useful formulæ.

Aghastier Vydia, Mun-nuru, 300 stanzas, on pharmacy.

Tanmundri Vagadum, by Tanmundri (Dhanwantari), translated by Agastya into Tamil verse. It has 2000 verses. Hindu practitioners hold it in high veneration for the particular account it gives of many diseases, and the valuable receipts it contains.

Tirumullar Vydia Vagadum, by Tirumullar, 2000 stanzas, on the symptoms of disease, and on the diet while under treatment.

Aghastier (Qu. Agastya) has also-

Karaser Punjadi, Munuru, 300 verses, teaching how to compound strong powders, pills, and other medicines

Dhanwantari Vagada Vydia Chintamani, teaches how to judge of the pulse, also treats of many diseases, and of the nature of animals, and contains some valuable recipes.

Kylasa Chintamani, Vadanul, on the art of converting nine metals into strong powders. It also treats on arsenic and other powerful drugs.

Bogar, a poetical description, in 700 verses, on the mode of compounding many powerful medicines.

Bogar Yoga Marga Mulika, in two sections-

Kayasiddi, or the art of strengthening the body.

Yogasiddi, or the art of making preparations for strengthening the body (Kulpum), and several other medicines.

Bogar Negundo, on corrosive and soluble drugs, also on gems and various animals. It, moreover, instructs how to mitigate the violence of powerful drugs, and how to make alcoholic tinctures.

Bogar Nainar Terumantram, on the art of preparing several medicines into which metals enter.

Nadi Sastrum, a treatise on the pulse.

Vydia Vagadum, enumerates the name and nature of many diseases and medicines.

Konkana-Ninar-Nul, teaches how to compound many powerful medicines.

Kumbali Chintamani Negundo, a dictionary of drugs and the art of compounding medicines.

Pannamaday Selladi, treats on several medicines pre. scribed for different diseases.

Yuga Muni, Ennuru, 800 verses, describing several medicines.

Ponnamuttay Palakulembum Attavanai, enumerates several medicines, and treats of a few diseases. This book is not much sought after.

Attavanai Vagadum, similar to the last.

Agaradi Negundo, a dictionary of medicine, in good repute.

Netra Vydiam, 300 verses, on diseases of the eye, and the best remedies for such complaints.

Kermapakum, 300 verses, on surgery?

Detchavadi, 200 verses, on medicine, said to be from divine inspiration.

Shesyam, 100 verses, and Wottiyam, 32 verses, are two works explanatory of six arts, viz. Vussyam, Stumbanam, Moganam, Aukershanam, Uchatanam, Maranam. 
Yuga Muni, Chintamani, 700 verses, on chemistry and the science of medicine.

Koraker Vypu, 100 verses, similar to last.

Chutta Muniar Ganam, 200 verses, partly theological, partly medical.

Chutta Muniar Kalpam, 100 verses, on the art of preparing strengthening medicines from various plants.

Ramadever, 500 verses, and Ramadaver, 200 verses, both books treat on corrosive and soluble drugs, also of chemistry and general medicine.

Kamalamuni Sutrum, 77 verses, on chemistry and physics.

Eda-kattu Sidder-pandel, 35 verses, similar to last.

Pali-kani, author of several medical works.

Muhammadan medical practitioners are known by the designations Hakim and Tabib. The former means a scientific or learned man; the latter a physician purist. The Jarāh is a surgeon. Muhammadanism, known to its followers as Islam or Din-i-Islam, has been adopted by many nations, but the Arabic and the Persian are the languages chiefly employed by learned men when writing on any scientific subject. Most of the medical books of the old physicians of Turkish Arabia, Syria, Spain, and Northern Persia were in Arabic, some of which have been translated, and a notice of the books in these two languages may now be given.

\section{Arabic Medical Books.}

Qanun-fi't-Tibb, the canons of Avicenna, Abu Ali Husain-bin-Abid Allah-bin-Sina, born at Bokhara A.D. 980, died at Hamadan in Persia A.D. 1036. It contains five books-

On the theory and practice of physic.

On simple or uncompounded medicines, with a description of their qualities and virtues.

On anatomy and complaints affecting particular parts of the body.

On diseases in general.

On compound medicines.

An Arabic edition was printed at Rome A.D. 1595, and a Latin edition at Venice A.D. 1608.

Hal-o-Mujiz-ul-Qanun, annotations by Nafiz-bin-Iwaz on the Mujiz-ul-Qanun-fi't-Tibb, an epitome or commentary, by Ala-ud-Din-Ali-ul-Koreshi-ibu-Nafiz, of the Qanun of Avicenna. Nafiz-bin-Iwaz resided at the oourt of Ulugh Beg about A.D. 1450.

Sharah-un-Nafisi, same author, a commentary on the above work.

Al-Mughani-fi-Sharh-il-Mujiz, by Sadid-ud-Din Gazaruni, a commentary on the Mujiz of Ala-ud-DinAli-bin-Abu-1-Hazim-ul-Koreshi, being a compendium of the science of physic, compiled from the works of Hippocrates, Galen, Avicenna, Honain-ur-Razi, and others. It is arranged into four chapters-

On the laws of nature, also on the human constitution, and the means of preserving health.

On the strength of different kinds of food, and of simple and compound medicines.

On complaints which affect particular parts of the body.

On diseases in general and their proper remedies.

Sharh-ul-Asbab-wa'l Ilamat, by Nafiz-bin-Iwaz, dedicated to Sultan Ulugh Beg Gurjani, a commentary on the Asbab-wu-Ilamat of Najab-ud-Din Muhammad Umar-us-Samarkandi, a very celebrated treatise on the causes, signs, and remedies of diseases.

Tazkarah Taswidi, by Muhammad Ishaq, a general treatise on medicine,

Hawi-us-Saghir, by Hafiz Muhammad, a general treatise on medicine.

Bahr-ul-Juahar, an ocean of gems, by Muhammad-binYusuf, a diffuse treatise on general medicine.

Salwa-ul-Mustaham, same author, and similar subject. Dur-ul-Mantakhab, the pearl of epitome, an abridg. ment of the Bahr and Salwa; anthor not known.

Rasalah-i-Tib, do. do.
Taqwim-ul-Adwiah, by Abul Fazal-bin-Ibrahim of Tabreez, the physician, and apothecaries' tables descriptive of the disorders to which each part of the human frame is particularly subject, and the proper medicines detailed.

Makhtasar-u-Jalinus, an abridgment of the work of Galen; same author.

Zabdat-ul-Hikm, by Ahmad-bin-Muhammad, dedicated to Sikander Pasha, rules for the preservation of health, by attention to food, dress, cleanliness, etc.; also a treatise on farriery.

Khoas-ul-Fuakah, same author, an essay on fruits, describing their good and bad properties, particularly those species which are wholesome to be eaten at meals for promoting digestion.

$$
\text { Persian Books. }
$$

Zakhirah-i-Kharazam Shahi, by Ismail-bin-Husainbin-Muhammad Jurjani, a topographical account of Kharazam, its climate, diseases, in ten chapters, A.D. 1110.

Khif-i-Alai, by same author, a treatise on the pre. servation of health.

Tibb-i-Yadgar, by same author, on medicine, an extensive pharmacopoia, in fourteen chapters.

Aghraz-ul-Tibb, by same author, the whole science of physic, uniting the theory of the ancients with the practice of the moderns.

Kafayat-i-Mujahidin, by Munsur Muhammad, dedicated to Sikandar Shah II. of Dehli, A.D. 1300 , on the diseases of women and children, and their treatment.

Dastur-ul-Ilaj, by Sultan Ali of Khorasan, A.D. 1334, dedicated to Abu Said Bahadur Khan, emperor of the Moghuls ; a diffuse work on the whole practice of physic.

Madan-i-Shifa, by Ali-bin-Husain of Bokhara, A.D. 1368, the Mine of Health, an alphabetical list of all diseases, with the proper method of cure

Rahat-ul-Insan, by Abd-ul-Qawi-bin-Shehād, A.D. 1376, a general treatise on medicine, with prayers and charms for averting sickness.

Tuhfa-i-Khani, by Mahmud-bin-Muhammad, a phy. sician of Shiraz, A.D. 1496; the whole science of medicine, in five chapters.

Madan-us-Shifa-i-Sikandar Shahi, the Mine of Remedies, by Beva-bin-Khas Khan, A.D. 1512, dedicated to Sikandar Shah II., king of Dehli.

Tuhfat-ul-Muminin, by Muhammad Momin, son of Muhammad Dilimi, a compilation from various Arabic and Sanskrit authorities, on the whole science of medicine; Persian; written A.D. ?

Mantakhab-i-Tuhfat-ul-Muminin, by Hasan Nasir Allah, A.D. 1587, an abridgment of the Tuhfat. ul-Muminin ; much esteemed.

Takwim-ul-Adwiah, author unknown, an extensive list of medicines, with a description of their various qualities and uses, arranged in regular tables.

Qarabidin Masumi, by Masum-bin-Ibrahim Shirazi, A.D. 1649 , a complete dispensatory, with the qualities of medicines and modes of compounding.

Ikhitiarat-i-Badi, by Ali-bin-Husain of Baghdad, a list of medicines, simple and compound, with their uses ; written A.D.?

Tashrih, by Mansur-bin-Muhammad,A.D.1396, dedicated to Pir Muhammad Jahangir, grandson of Timur, who commanded the advanced guard of the Tartar army when it invaded Hindustan. It is a general treatise on the anatomy of the human body, with plates of the veins, arteries, bones, intestines, etc. Considering its age, it is of considerable merit, and is in great estimation amongst Muhammadans.

Taqwim-ul-Abdan, by Yahia-bin-Tsa Ali Jazar, A.D. 1677 , a tabular analysis of the human frame, with a description of the various complaints to which each member is separately liable, and an explanation of the proper remedies for every disease.

Tibb-i-Akbari, by Muhammad Akbar Arzani, physician to the emperor Aurangzeb, A.D. 1678. It is a translation of the Arabic Sharh-ul-Asbab.

Tajribat-i-Akbari, by same author, is a general treatise on physic, explained on the author's own experiences.

Qarabidin-i-Kadari, by same author, an extensive pharmacopoeia of medicines used in Hindustan. 
Riaz-i-Alamgiri, by Muhammad Raza, a treatise on medicine, food, clothing, etc., dedicated to the emperor Aurangzeb.

Sih'at-ul-Amraz, by Pir Muhammad Gujerati, A.D. 1726 , prescriptions for the cure of all diseases.

Qarabidin-i-Shifai, by Mazaffar Shafa, a complete dispensatory, alphabetically arranged.

Qanun-i-Sikandari, by Sikandar-bin-Ismail of Constantinople, physician to Nawab Walaja Muhammad Ali Khan of Arcot, to whom this is dedicated, A.D. 1747 ; a very diffuse treatise on all the dis orders to which mankind is subject.

Moalijah-i-Sikandari, same author, an appendix to the Qanun.

Qarabidin-i-Sikandari, same author, A.D. 1751, a complete pharmacopoeia of the medicines used in the Carnatic.

Madan-i-Tajribat, a mine of experience, by Muhammad Mahdi, A.D. 1756, an esteemed treatise of medicine, alphabetically arranged, in which the virtues or qualities of each drug are particularly explained.

Farhangi Tabiban, European Physicians, a medical dictionary, an alphabetical list of medicines, with a description of their qualities. Author unknown.

Mizan-ut-Tibb, several well-written treatises on heat, cold, drought, moisture, and pregnancy. Author unknown.

Mizan-ut-Tibb, by Muhammad Akbar, styled Muhammad Arzani : MSS.

Mufarrih-ul-Kulub, do. do.

Nuskhah-i-Adwiah, a collection of medical prescriptions. Author unknown.

Tajriba-i-Hakim Ali Akbar, by Ali Akbar, a diffuse treatise on medicine, based on the author's practice.

Rasalah-i-Tibb, by Muhammad Masum, a treatise on medicine, and containing injunctions for care in compounding prescriptions.

Fan-i-duam-dar-Tibb, by Ali Yar Khan, is a general treatise on disorders to which mankind are liable.

Majmu-i-Rasail, by Abul Fazl Husain, an essay on medicine, one on astrology, and one on interpretation of dreams.

Jami-ul-Fuaid, by Yusuf-bin-Muhammad, a collection from the most esteemed books on physic.

Faidat-ul-Akbar, same author, similar subject.

Khulassat-ut-Tajribat, by Muhammad-bin-Musaud, a short treatise on medicine, one on the art of dyeing, and a third on making paper.

Rasalah-i-Chob-Chini, same author, on the virtues of China root.

Asrar-i-Atibba (Secrets of Physicians), by Shahab-ud. Din, essays on the virtues of amulets, medicines, and charms for averting and removing diseases.

Shifa-ur-Rajal, the cure of mankind, same author, a poetical treatise on medicine.

Tajriba-i-Jamasp Hakim, by Jamasp, a general treatise on medicine.

Bahr-ul-Manafia, an Ocean of Benefit, by Maulud Muhammad, A.D. 1794, dedicated to Tipu Sultan, a diffuse treatise on midwifery, diseases of children, enchantments, exorcising devils, etc.

Tuhfa-i-Muhammadi, by Muhammad Nasir Afshar Turk, a general treatise on medicine, dedicated to Tipu Sultan.

Qanun dar Ilm-i-Tibb, a translation, by order of Tipu Sultan, of the complete London pharmacopœia.

Tarjumah-i-Kitab-i-Angriz, a translation of an English treatise on electrical and medical experiments.

Tarjumah-i-Kitab-i-Farang, a translation of Dr. Cockburne's treatise on the twist of the intestines.

Tuhfa Kan-i-Ilaj, translated from the Hindi by Muhammad Kasim-bin-Sharif Khan, the whole system of farriery.

Rasalah-i-Tibb-i-Aspan, translated from the Sanskrit by Zain-ul-Amin, A.D. 1519, and dedicated to Shams-ud-Din Muzaffar Shah, on farriery.

Mufradat-i-Sikandri, originally written in Syrian by Yahia Kurb, and translated into Persian by Sikandar, a work on materia medica of the Arabian physicians, also of the later views of the medical men of Europe.

Mufradat-i-Mumina, on the materia medica, originally in Arabic, but translated by Mumina into Persian.

Kitab-ul-Adwiah-wa'l-i-Aghziat, by Abu Yakub Ishaq-
ibn-Suliman-ul-Israili, a work on medicine and regimen.

Kitab-ul-Adwiah, by Bin Baitar, an Arabic book on simple medicines.

Kitab-ul-Judri-wa-Hasbah, by Abu Jafar Ahmad-binMuhammad, an Arabic work on smallpox and measles.

Kitab-i-Sirsam-wa-Barsam, same author, in Arabic, on phrensy and madness.

Kitab-us-Sumum, originally written by Shanak (Qu. Sharaka) of India, translated into Persian by $\mathrm{Abu}$ Hatim, and afterwards into Arabic by Abbas Saedul-Jauhari.

Kitab-i-Shashard-ul-Hindi, originally written by Shashar of India, but translated into Arabic. It is a work on the materia medica, with rules for identifying the articles.

Kitab-ul-Ghiza-wa'l-Mughtazi, by Abu Jafar, the Tabib, in Arabic, on diets and on the sick who require them.

Kitab-un-Nabz-il-Aristu, $\llbracket$ work by Aristotle on the pulse, first rendered into the Syrian language, then into Arabic.

Mufradat-i-Ghani Muhammad, an Arabic work on the materia medica.

Alfaz-ul-Adwiah, the materia medica in Hindi, Persian, and Arabic, by Nur-ud-Din Muhammad Abdullah, Shirazi, physician to the emperor Shah Jahan.

Mufradat-dar-Ilm-i-Tibb, on botany and natural his tory, translated into Persian by order of Tipu Sultan, from French and English.

Riaz-i-Alamgiri, by Muhammad Raz, an esteemed treatise on medicines, food, and clothing, in Persian, dedicated to the emperor Aurangzeb.

Sharh-i-Hadaet-ul-Hikmat, an Arabic commentary on the Hadayet-ul-Hikmat. It is by Muhammadbin-Ibrahim, chief judge of Shiraz, and contains the whole course of the sciences read in schools. It is much esteemed amongst the Muhammadans of India.

Kitab-us-Shifa, by Abu Ali-bin-Sina (Avicenna), a celebrated system of natural philosophy, in Arabic (24 chapters), on theology, metaphysics, logic, rhetoric, arithmetic, mathematics, geometry, astro$\operatorname{logy}$, anatomy, poetry, and music.

Kifaya Mansuri, by Mansur-bin-Ahmad; Persian ; printed.

Khulasat-ul-Hikmat, by Hakim Muhammad Husain Khan; Persian; printed.

Nafisi, by Mulla Nafis, Kashafi ; Arabic ; written.

Risala-i-Nabz-o-Karora-o-Byhran, by Hakim Ahmadullah-Khan; Persian; written.

Makhzan-ul-Adwiah, by Hakim Muhammad Husain Khan; Persian; printed.

Alfaz-ul-Adwiah, by Muhammad Yakub; Persian.

Tazkirah-ul-Hind, by Raza Ali Khan, a hakim, is a materia merlica in Persian, written in the early part of the 19th century, and lithographed in 1866 at Hyderabad. It is an interesting volume.

MEDINA, a small city 245 miles from Mecca, where Mahomed died and was buried, A.D. 622, and the succeeding khalifs, Abubakr and Umar, are interred at his side. The building which encloses the tombs is hung with silk. It has 500 houses, with about 8000 population.

Medina is about a day's journey distant from the port of Jambo, in lat. $24^{\circ} \mathrm{N}$., and long. $40^{\circ} 10^{\prime} \mathrm{E}$., with indifferent walls, and situate in a sandy plain. Before the days of Mahomed it was called Yathreb, but it was re-named Medinatun-Nabi, the City of the Prophet. The tomb of Mahomed is in the corner of a large mosque, and is held in respect by the Muhammadans, but they are not obliged to visit it in order to the performance of any devotional exercises. Muhammadans attach much importance to, and consider sanctity derivable from, burial in particular spots, though the notion appears so entirely contrary to the spirit of their religion. Great numbers of dead are sent continually from all parts of Persia 
for interment, at the sepulchre of Ali on the frontier of the Arabian desert. The prevailing idea is that, by being buried near a holy saint, they will be raised along with him at the resurrection, and receive his protection and countenance; but the opinion is certainly heterodox. A similar idea seems to have been received in Israel of yore; the old prophet of Bethel desired to be buried beside the man of God that came from Judah, whom he had deceived into his destruction, and Acts vii. 15, 16 is to the same effect. One traveller relates that he met a caravan of dead. Each mule bore two dead bodies slung like portmanteaus on either side; and by the time they could reach their destination their burdens would be in a loathsome state. A few of the friends and relatives of some of the deceased were accompanying this mournful caravan, but by far the greater number of the corpses had been consigned to the muleteers, without any one else to look after them. Mr. John F. Keene, of whose visit to Meeca mention was made under that name, shortly afterwards visited Medina, and his account of his journey was supposed to be authentic.-Niebuhr's Travels, ii. pp. 39, 40.

MEDITERRANEAN SEA, an inland sea that extends between Asia, Africa, and Europe, communicating with the Atlantic by the Strait of Gibraltar, and with the Black Sea by the Strait of Galipoli, the Sea of Marmora, and the Strait of Constantinople. It is above 2200 miles in length, but has little or no tide, and a constant upper current sets in from the Atlantic, through the Strait of Gibraltar. By way of eminence, it is called the great sea in Numbers xxxiv. 6 and elsewhere. In Exodus xxiii. 31 it was called the Sea of the Philistines, because their country, Palestine, bordered on its shores.

MEDLAR. Mespilus Germanica, Linn.

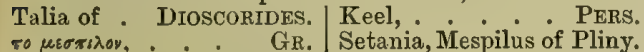

Common in many parts of Europe, and grows in the hedgerows of England.

MEDUSE, a group of the Acalephæ. Aurelia, Pelagra, Chrysaora, and Chrysopora are the more common genera. The Medusæ and the Actinix are known as sea-nettles, because of their stinging powers. Cyanea caliparea of Pondicherry (Medusa caliparea, Reyn.) secretes an extremely acrid and irritating fluid. The Portuguese manof-war, Physalia, also causes a considerable amount of irritation.-Figuier; Moquin Tandon.

MEDYA-WAR or Mewar, the central region, a territory of India, bounded to the north by the Aravalli, to the south by the country of the Pramara race of Dhar.-Rajasthan, ii. p. 8 .

MEEANEE, a Sind village, six miles on the north of the town of Hyderabad. Meeanee is the general name for the little villages in Sind, populated chiefly by fishermen.-Burton's Scincle.

MEEAN MEER or Mian Mir, a British military cantonment in the Lahore district of the Panjab. Lies in lat. $31^{\circ} 31^{\prime} 15^{\prime \prime} \mathrm{N}$, and long. $74^{\circ} 25^{\prime} 15^{\prime \prime} \mathrm{E}$.

MEENA, a term commonly used in the Panjab, expressive of contempt or opprobrium.-Cunningham's Sikhs, p. 57.

MEENA, an active, energetic race, whose history illustrates several points. They constitute a portion of the population of Rajputana, especially in the Jeypore country between Ajmir and Dehli. In Northern Rajputana the country to the east

voL. II. of Shekhawatti is the chief bome of the Meena, and it is a region politically as well as naturally favourable to the dacoit and the thief. IVild hills and ravines abound in parts of it. Within a radius of 25 miles is comprised a territory subject to no less than nine governments, namely, a part of Shekhawatti and Jourawatten in the dominions of the maharaja of Jeypore, Kol-Puti belonging to the raja of Khetri, but held direct from the British Government, Dadree to Jheed, Narnoul to Pattiala, Kante to Nabha, a portion of Ulwar, Loharoo, Bikanir, and Shahjahanpur, where lie the Meena settlements of the district of Gurgaon. These tracts are superintended by several officers.

The Purihar branch of the Meena occupy the Kherar, to the south of Deolee in Haraoti. They are said to be descended from the Puribar Rajput of 'Mundore, claiming from the celebrated Nahar Rao, king of Mundore, in Marwar; whose son Shoma married a Meena woman. The Meena were the prior occupants of Mewar and Jeypore, till driven out by the Rajputs. The most powerful clans of the Marwar Meena found shelter in the strip of country at the junction of Boonda, Mewar, Jeypore, and Ajmir, called the Kherar. They are a very brave, bold race. The Jeypore Meena in like manner have their stronghold at the junction of the Ulwar, Jeypore, and British districts. In Serohi, the Meena are still the aborigines.

The Cheeta Meena is a branch of the Meena race, from whom sprang the Mair or Mera race, whose country is styled Mairwara, or region of hills.

The Mair branch of the Cheeta Meena is also called Mairote and Mairawut. Mera is a mountain in Sanskrit; Mairawut and Mairote, of or belonging to the mountains; the name of the Albanian mountaineer Mairote has the same signification. Mairwara is that portion of the Aravalli chain between Komulmir and Ajmir, a space of about 90 miles in length, and varying in breadth from 6 to 20. The Cheeta Meena claim descent from a grandson of the last Chauhan emperor of Dehli. Unail and Anoop were the sons of Lakha, the nephew of the Chauhan king. The cocoanut was sent from Jeysulmir, offering princesses of that house in marriage, but an investigation into their maternal ancestry disclosed that they were the issue of a Meena kept woman, and their birth being thus revealed, they became exiles from A jmir, and associates with their maternal relatives. Unail espoused the daughter of a Meena chieftain, by whom he had Cheeta, whose descendants enjoy almost a monopoly of power in Mairwara. The sons of Cheeta, who occupied the northern frontier near Ajmir, became Muhammadans about fifteen generations ago, when Doodha, the sixteenth from the founder of the race, was created Dawad Khan by the hâkim of Ajmir; and as Athoon was his residence, the Khan of Athoon signified the chief of the Mairote. Athoon is still the chief town of the Mair race. Chang, Jhak, and Rajosi are the principal towns adjoining Athoon. Anoop also took a Meena wife, by whom he had Burrar, whose descendants have continued true to their original tenets. Their chief places are Burrar, Bairawara, Mundilla, etc. The Meena were always notorious for their lawless habits, and importance has been attached to them for back as the period of Beesildeo, the celebrated prince of Ajmir, whom the bard Chand states to 
have reduced them to submission, making them carry water in the streets of Ajmir. Like all mountaineers, they broke out whenever the hands of power were feeble. A thousand years ago, Meena chiefs ruled much of the territory now held by the maharaja of Jeypore. A clan of them are still the hereditary guards of the city gates, and of the fort which holds the treasures of the state. The Mair country is situated but a very few miles west of Ajmir, and is composed of successive ranges of huge rocky hills, the only level country being the valleys running between them. From the sturdy valour of this race, the rulers of India never made any impression on them, notwithstanding their vicinity to the occasional residence, for a long period, of the emperors of Hindustan. In later times the Mair were the terror of their lowland neighbours; and even the Rajputs, perhaps with the sole exception of the Rohilla, the bravest men in India, dreaded their approach. The Mair of the Mairwara Hills occupy the Aravalli range running towards Ajmir. The Koli assert their relationship to them, and they admit having intermarried with the Bhil and Meena; and Colonel Dixon says that for hundreds of years they have been recruited by refugees and all sorts of rascals from Hindustan, and they are probably a very mixed race.

Sir W. Sleeman pronounced the Meena irreclaimable; but Colonel Younghusband, about 1864 , took the Kherar police in band, and began operations which resulted in complete success. The Meena from the north were the most formidable class with whom he had to deal. The Thuggee and Dacoity Department had been bringing the Meena to justice ever since its operations began, but special efforts and systematic proceedings against them in their homes had never been pursued so persistently and vigorously as the matter required. An officer was then appointed to conduct, under Colonel Harvey's direction, operations for the suppression of dacoity throughout Northern Rajputana, amongst the Meena, who, in consequenc. of a famine, had been doubly active in robbing the Government mail, and committing other depredations. They made free use of the railway, and had, it is said, resolved in council assembled to continue their mode of life and resist all measures of repression and reform. The mode of proceeding in Native States, when the chiefs act at all against robber tribes, is to drive them away if possible, and this was formerly the system in Jeypore. But the true way of dealing with them is to control their movements at their homes, where they rarely commit depredations. The successful plan pursued against the Purihar, was to hold the headmen responsible for the presence of the Meena in their villages. None could absent themselves from their respective villages without a leavecertificate, or if any did so, they were liable to be seized and punished. The Meena are not of low caste, like the Sansee, the Bhowree, and other thieving tribes.

Colonel Tod, writing in the early part of the 19 th century, says the Meena afford an excellent practical illustration of Menu's axiom, that the right in the soil belongs to him who first cleared and tilled the land. The Rajput conqueror claims and receives the tribute of the soil, but were he to attempt to enforce more, he would be brought to his senses by one of their various modes of self- defence, incendiarism, self-immolation, or abandonment of the lands in a body. Throughout India, he adds, where traces of originality yet exist, it will invariably appear that the right in the soil is in the cultivator, who maintains, even in exile, the huk bapota-ca-bhom in as decided a manner as any freeholder in England.-Campbell, p. 45; Colonel Brooke in literis; Tod's Rajasthan, i. 681, ii. 612, 672; Cole. Myth. Hind.p. 299. MEERSCHAUM, a mineral belonging to the series of silicates of magnesia. The richest beds are near Eski-shahr, in Asia Minor, but it is also found in Moravia, Spain, Greece, and the Crimea. - It is dull-white, opaque, and earthy, nearly like clay. Its hardness is $2 \cdot 0$, and sp. gr. $2 \cdot 6$ to $3 \cdot 4$.

Silica, . . 42.0| Water, . 23.0 $\mid$ Alumina, . 2.0 Magnesia, . 30.5 Lime, . 2.3

When heated, it gives out water and a fetid smell, and becomes hard and perfectly white. When first dug up it has a greasy feel, like soap, and on this account is used by the Tartars in washing their linen. In Europe it is made into bowls of tobacco pipes, which are hence called meerschaum. The magnesite of the Peninsula of India might be utilized as meerschaum.-Dana.

MEERUT, a town and military cantonment, which gives its name to a revenue district of the N.W. Provinces of India, lying between lat. $28^{\circ}$

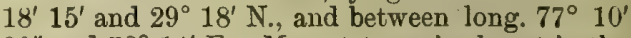
$30^{\prime \prime}$ and $78^{\circ} 14^{\prime} \mathrm{E}$. Meerut town is almost in the centre of Meerut district, nearly midway between the Ganges on the east and Jumna on the west, about 3 miles west of the Kali Nuddi. It is in lat. $29^{\circ} 0^{\prime} 41^{\prime \prime} \mathrm{N}$., and long. $77^{\circ} 45^{\prime} 3^{\prime \prime} \mathrm{E}$., 850 feet above the sea. The Suraj Kund, constructed in 1714, is surrounded by numerous small temples, sanctuaries, and sati pillars; the Dargah of Shah Pir, of red sandstone, was erected about 1620 by Nur Jahan, wife of the emperor Jahangir; the Jama Masjid, built in 1019 by Hasan Mahdi, wazir of Mahmud of Ghazni, was repaired by Humayun; near are the remains of a Buddhist temple. It has also mausoleums of Abu Muhammad Kamboh (1658), Salar Masaud Ghazi (1194), and Abu Yar Khan (1577).-Imp. Gaz.

MEGACEPHALON RUBRIPES, the Maleo bird. It deposits its eggs in the loose sand of the seabeach, in holes just above high-water mark; the female lays one large egg, which she covers over, and returns to the forest; but many birds lay in the same hole. A dozen eggs are often found together. One egg fills an ordinary tea-cup, from 4 to $4 \frac{1}{2}$ inches long, and $2 \frac{1}{4}$ to $2 \frac{1}{2}$ wide. They are very good to eat, and much sought after. The hen-bird takes no further care of the eggs, which the young bird breaks through about the 13th day, and runs at once to the forest. Each hen lays six or eight eggs in the season of two or three months.-Bikmore's Travels, pp. 101-378; Wallace's Archipelago, i. p. 175.

MEGACHILE, the leaf - cutter bee. Their nests are to be found in thousands in the cliffs of the hills of the Sone valley, with May-flies, caddisworms, spiders, and many predaceous beetles.Hooker, Him. Jour. i. p. 52.

MEGADERMOTINA, a sub-family of mammals of the family Vampyridæ. Its genera in India are the Megaderma Horsfieldii, of Tenasserim; M. lyra, of all India; M. spasma, of Ceylon and Malayana; and M. spectrum, of Kashmir. Megaderma lyra bat is the M. Carnatica of 
Mr. (Sir Walter) Elliot, and seems to be very generally diffused throughout India, being replaced in the Malay countries by M. spasma, and further east by M. Philippinensis, Waterhouse, P. Z. S., 1843 , p. 69, while in Africa it is represented by the M. frons.-Blyth.

MEGALAIMA INDICA. Latham. M. Philippensis, var., Latham. The incessant call of the greater red-headed barbet resembles the blows of a smith hammering a caldron, hence its name of coppersmith. There are several species of this genus, viz. M. flavifrons, M. rubricapilla, and M. Zeylanica. The Megalamidæ family of birds comprise the genera Megalaima and Megalorhynchus.

MEGAPODID E, a family of gallinaceous birds, found in Australia and its surrounding islands, as far west as the Nicobars, also the Philippines and the N.W. of Borneo. They bury their eggs in sand, earth, or rubbish, and leave them to be hatched by the sun or by fermentation. They have large feet and long curved claws, and most of them rake together rubbish, dead leaves, sticks and stones, earth and rotten wood, until they form a mound often 6 feet high and 12 feet across, in the middle of which they bury their eggs. The eggs are as large as those of a swan, and of a brick-red colour, and are considered a great delicacy. The natives are able to say whether eggs lie in the mounds, and they rob them eagerly. It is said that a number of these birds unite to make a mound, and lay their eggs in it, and 40 or 50 are found in one heap. The mounds are found in dense thickets. The species of the Megapodida in Lombok is as large as a hen, and entirely of a dark hue with brown tints. It eats fallen fruits, earth-worms, snails, and centipedes, but the flesh is white, and, when properly cooked, well flavoured. The young birds when they come out of the egg are sufficiently developed to do without a mother's care, and provide for their own wants. Talegalla is the Australian name. The Megapodius or Leipoa is called by the natives of Borneo Menambun (from Tambun, to pile, to heap up). One nest or heap was found close to the edge of the sea-sand, and was formed over a fallen Aru or Casuarina tree, and covered, but not densely, with shrubs. The pile was 60 feet in circumference. These birds lay most disproportionately large and thin-shelled eggs, and the young comes forth from them well plumed, and sufficiently advanced to make their way in the world. The Megapodius Nicobarensis has not hitherto been met with excepting in the Nicobars, but would appear to be common on all the islands of that group, according to the personal observation of the Rev. J. Barbe, p. 351 . M. Cumingii occurs in Labuan.-Keppel's Ind. Arch. ii. p. 120.

MEGAPTERA KUZIRA, a finner whale of the Japanese seas. Other finners are-

Physalis iwasi, the Japan finner. It is very rare. In 1760 , one 25 feet long was cast ashore at Kii.

P. antarcticus, Gray, inhabits the New Zealand seas.

P. Braziliensis, the Bahia finner.

P. Australis, the southern finner, inhabits the seas of the Falkland Islands. See Mammalia; Whales.

MEGASTHENES, B.c. 306-298, was sent by Seleucus Nicator on an embassy to Sandracottus or Chandragupta, ruler of the Prasii or Prachya, whose cupital was Palibothra, identified with the Sanskrit Pataliputra and the modern Patna. Megasthenes tells us that the Indians of his time did not communicate their metaphysical doctrines to women, thinking, as he says, that if their wives understood their doctrines and learned to be indifferent to pleasure and pain, and to consider life and death as the same, they would no longer continue to be the slaves of others. We find from the later ceremonial Sutras (Srauta and Grihya Sutra) that women were not allowed to learn the sacred songs of the Vedas, the knowledge of which constituted one of the principal acquirements of a Brahman before he was admitted to the performance of the sacrifices. Menu ix. 18 says, Women have no business with the text of the Vedas, thus is the law fully settled; having therefore no evidence of law, and no knowledge of expiatory texts, sinful women must be as foul as falsehood itself, and this is a fixed rule. Megasthenes was perhaps the first European who had ever beheld the Ganges. He dwelt for several years in Palibothra, and wrote an account of the country, which, though now lost, has probably been transmitted to us pretty closely in the narratives of Diodorus Siculus, Strabo, Alian, and Arrian. His Indika, written about B.c. 300, has been translated by Mr. M'Crindle in the Indian Antiquary. Describing the races, he says: "Next follow the Nareœ, enclosed by the loftiest of Indian mountains, Capitalia. The inhabitants on the other side of this mountain work extensive mines of gold and silver. Next are the Oraturo, whose king has only ten elephants, though he has a very strong force of infantry. Next again are the Varetatce, subject to a king who keeps no elephants, but trusts entirely to his horse and foot. Then the Odombœrœ, the Salabastrœ, the Horato, who have a fine city defended by marshes, which serve as a ditch, wherein crocodiles are kept, which, having a great avidity for human flesh, prevent all access to the city except by a bridge; and another city of theirs is much admired, Automela, which, being seated on the coast at the confluence of five rivers, is a noble emporium of trade. The king is master of 1600 elephants, 150,000 foot, and 500 cavalry. The poorer king of the Charmo has but 60 elephants, and his force is otherwise insignificant. Next comes the Pando, the only race in India ruled by women. They say that Hercules having but one daughter, who was on that account all the more beloved, endowed her with a noble kingdom. Her descendants rule over 300 cities, and command an army of 150,000 foot, and 500 elephants.?

It is to Onesicritus, one of the companions of Megasthenes, that we are indebted for the earliest account of Ceylon or Taprobane. From him we first hear of its trained elephants, its pearls, and its gold. Megasthenes maintained friendly relations at the court of Palibothra between Syria and India, and effected a matrimonial alliance. His journal names as rivers Cainos, the Cane; Cossoanus, Cosa or Coss; Sonus, the Sone; Condochates, Gunduk; Sambus, Sumbul or Chambal; Agoramis, Gogra ; Commenses, Caramnassa, etc.

Megasthenes went on his embassy at a very interesting period. The old line of the Nandas had been overthrowin, and Chaudragupta had won the crown. Brahmanism was the prevailing religion, 
but Megasthenes refers distinctly to Boira, or Buddha. The caste system was in full vogue, so Brabmanism must have been in the ascendant; but the fact that Chandragupta married a daughter of Seleucus Nicator, shows that the monarch favoured the rising faith of Buddha. Megasthenes makes the number of castes seven, and his divisions seem to be of a professional character. His description of the life and manners of the Hindus applies in many respects to the people of the present day; in their simple food they continue unchanged. Chandragupta is represented as living in a large palace, with a body-guard of women fully accoutred, who accompanied him in his hunting expeditions. His camp, when he took the field for war, contained 400,000 men. The capital, Palibothra, stretched 10 miles along the bank of the Ganges, and was 2 miles wide. Diamachus was the next Greek ambassador after Megasthenes." -Cal. Rev., 1868: Rennell's Memoir, p. 30 ; Straho's India, p. 39.

MEGHADUTA, an ancient Sanskrit drama, an excellent example of purely descriptive poetry. A yaksha or spirit banished from heaven charges a cloud with a message to his celestial mate, and describes the countries over which it will have to pass.

MEGNA, a river running through the eastern part of the province of Bengal. It is formed by the junction of the Surma and the Barak, which have their sources in the mountains running along the $\mathrm{N}$. and $\mathbf{E}$. frontiers of the Sylhet district. The united stream, after a course of about 30 miles, joins the Brahmaputra, in lat. $24^{\circ} 9^{\prime} \mathrm{N}$., and the Brahmaputra thence takes the name of the latter. Thus augmented, the Megna swells into an expanse resembling an inland sea, studded with islands. About 10 miles further down it receives another branch of the Ganges, and in the remainder of its course is separated from the latter river only by a narrow strip of land. In lat. $23^{\circ} \mathrm{N}$. it takes a S. direction, and, after a general southerly course of 120 miles, discharges itself by a wide embouchure into the Bay of Bengal, and closely adjacent to the delta of the Ganges, with which it forms numerous interlacements. The muddy waters of these great rivers form numerous banks and islands, the principal of which are Dekhan Shahbazpur, Hattia, and Sandwip, and between these the tides run with great rapidity.

The regular rise of the tide is from 10 to 18 feet, and at every full and new moon the sea rushes up in a single wave, known as the "bore.' The bore is heavier at the time of the biennial equinoxes, when navigation is sometimes impeded for days together, especially when the wind blows from the south. Before anything can be seen, a noise like thunder is heard in the far distance seawards. Then the tidal wave is suddenly beheld, advancing like a wall topped with foam, of the height of nearly 20 feet, and moving at the rate of 15 miles an hour. In a few minutes the wall rushes by, and the brimming river has at once changed from ebb to flood tide. A greater danger than the bore are the cyclone stormwaves, which occasionally sweep up the Megna. These are most liable to recur at the break of the monsoons in May and October. In the cyclone of May 1867, the island of Hattia was entirely submerged by a wave, which is estimated to have reached a height of 40 feet. Again, towardsevening of 31 st October 1876, the wind had gradually risen till it blew a gale. Suddenly at about midnight in some places, and nearer dawn in others, the roar of the wave was heard, drowning the noises of the storm. Two or three waves came on in succession, flooding in one moment the entire country, and sweeping before them every living thing. The destruction of human life on that night is estimated at 100,000 souls in the mainland portion of Noakhali district, and the two islands of Sandwip and Hattia, or about 19 per cent. of the total population. The mortality subsequently caused by cholera, and a train of dependent diseases, equalled that due directly to drowning.

Over all these islands, flat as a table, and without any shelter, the hurricane blew; while the wretched people cowered behind their crashing huts and falling groves; but the first blast was only the eastern periphery of the circular storm, which thus swept up the Megna, meeting the current, and partly conquered by it. The boatmen of the Sunderbans do not so much fear the cyclone upon the water when it thus fights the tide. But on this occasion the islands of the Megua and its broad channel seem to have been the very centre of the circular storm, which accordingly, after thus with its upward sweep sconrging the land and piling up the water, tumed almost like a wheel over Lakhipur, and, whirling downward again, drove with its western segment the heaped-up waters of the two great rivers in a wall of death thrice as high as the 'bore,' washing clean over the rich and populous islands. They stand some 20 feet above midtide, yet this wave of the cyclone ran at least another 20 feet high over the dry land, submerging every hamlet and cattle-shed, drowning men, women, and children in their sleep, bursting over tauk, garden, and teraple. From the moment when the first howl of the cyclone was heard tearing upward from the ocean, to the awful return-stroke of the tempest, herding before it the dark waves of water, hardly thirty minutes had elapsed. Tens of thousands of human beings were by that time caught up and washed like drift-wood into the boiling bay; tens of thousands more were choked in their beds by whelming waves and ruined buildings; and all the works of their hands, all their possessions, all their cattle, were similarly seized in the black flood and destroyed. A few escaped, for these poor natives are the most dexterous climbers. Thanks to this habitude, some, on being dashed against the trunks of the palms and areca trees, managed to climb out of the flood, and eling upon the bending stems until the waters subsided; others, clamberiog on the chupper-roofs of their liuts, were washed out to sea, and driven upon the opposite bank of the Megna. By noon next day these miserable survivors saw the diy land again, and were saved; but 100,000 had perished out of an island and shore population of about a million, and soine villages lost as many as 70 per cent. of their inhabitants. Sir Richard Temple visited the submerged district, and reported 3000 square miles desolated, and the whole area of islands and shores lying like the corpse of a province,drowned, bare, and ghastly. One of the certain effects of this cyclone-wave was that the animals of the jungle were all drowned; the carrion-eating 
creatures, the snakes, the insects, the rats, all had shared the common fate. Even the birds were surprised by the deluge, and died in vast numbers. There had been nothing so awful since the similar catastrophe in 1822 in the same district, when 100,000 people are said to have perished. On that occasion no fewer than 40 children were brought to birth by the frightened mothers while taking refuge in the tree-tops, a circumstance which sufficiently depicts the terror and helplessness of such a visitation. It may be possible in future to protect the Megna villages against such calamities, by the old Assyrian device of erecting nigh at hand a spacious and lofty mound of clay. Such artificial eminences would have saved 100,000 lives on that frightful last night of October, when the pent-up tide of two enormous rivers rolled over every home and every refuge.

The tract between the Megna and the Hoogly is often devastated. It is hardly accurate to call it land. Some name should be found for the marshes, chars, khals, dones, and islands of Bakarganj and the Sunderbans. Every acre in this vast watery wilderness has been brought down from countries hundreds of miles away, and piled up in the sea until the restless rivers have conquered league after league from the deep water, and built a district there. Two of the mightiest streams of earth, the Ganges and the Brabmaputra, are for ever at this silent work, and their discoloured waves roll perpetually down from the mountains of Tibet and the plains of the NorthWest that red and yellow mud which has formed a province. The larger part of their labours is still hidden under the Bengal Sea, and silt which the leadsman brings up off Saugor Island has come as likely as not some 2000 miles, from Gangotri or the Jumna. The two great rivers unite in the Megna estuary, sending out a labyrinth of arms and branches which interlace the alluvial soil with a thousand channels, and turu into an archipelago the province which the Brahmaputra and its Indian sister have created. The intervening islands and islets are like nothing in the world beside themselves. Flat as the Essex and Kentish marshes, monotonous in feature as I.ower Egypt, they are yet the most fertile and the greenest country to be seen. The soil, level and clean as a lawn, is richer than even the alluvium of the Nile; not a square inch of it is bare; if man does not plant it, the slimy mangroves fringe every bank, canes and reeds cover every shoal; and the drier parts, or kholas, are dressed in waving jungle full of kerua, goma, and gab trees. But the population of Bengal has pushed into this moist and steaming corner of the earth, and nowhere are there such vast rice gardens, such feathery palm groves, and such verdurous orchards of plantain and jack, mango and tamarind, betel, cocoa, and sugar-cane. The Mugh, Muhammadans, and Hindus who people this countless host of marshy islets, dispute possession with crocodiles, tigers, and snakes. The Sunderbans and the Megna flats team with these; and the wood-cutters never return from their yearly expeditions without having paid a tribute of life to the savage animals. Everything and everybody in this watery world know how to fish and to swim. Almost at every mile of travel you come upon a broad waterway, so that boats are the universal vehicle; and fish of a thousand kinds, some parti-coloured, some monstrous in size, some poisonous, some delicious, - the bilsa, the silon, the koral, and the pangas,-feed beast and man alike in the aquatic desert. The very leopards devour finny food, and even swim the khals, while huge crocodiles crawl forth into the orchards, and watch for the children fetching water and the herdsmen at the ferries. It is a land of strange swooning sounds, of sweeping tempests, and sudden dislocations of earth undermined and carried off by the rushing rivers. There is an occasional thundering noise heard here called the Barisal guns, and to this day nobody knows its origin. A well-to-do landowner will wake up to find his property wafted away by the Megna or the Madhumati to the other side of the creek; and others, who have painfully constructed valuable tanks for fresh water, see a single wave of the dreaded 'bore' sweep into the hollow and spoil it for ever. Such victims of nature in the Sunderbans are styled nădi-bhanga lōg, or ' riverbroken people;' but for the most part the enormous population of these Indian swamps fares prosperously, growing betel-nuts for half Asia, catching fish for Calcutta, weaving reed-mats and covers for the boatmen of the Ganges, and producing vast crops of paddy and sugar-cane. They are, on the whole, a gentle and simple people, largely Muhammadan in creed. At new and full moon the 'bore' comes up the Megna in a wall of white water 15 feet high, crushing every boat not drawn up, - a terrible rolling bank of foam, which on account of its speed the people call the shar or arrow.

In this great estuary of the Megna, Shahabazpur, Hattia, and Sandwip are the greatest and the most fertile islands, full of rice grounds and cocoa groves, with a population of nearly 500,000 souls. These are not unfamiliar with the dangers of their marshy home, for there have been at least seven cyclones since 1822 ; but the islands stand fairly high above the water, and hitherto it is the storm-wind which has wrought most damage, though it generally gives notice of its approach long beforehand by the unnatural hush in the air and the livid colour of the sky. But occasionally there is no warning.

MEHIDPUR, a town in one of the outlying portions of the territories of the Maharaja Holkar, in lat. $23^{\circ} 9^{\prime} 30^{\prime \prime} \mathrm{N}$., and long. $75^{\circ} 46^{\prime} 30^{\prime \prime} \mathrm{E}$., on the right bank of the Seepra river, in an angle formed by the confluence of a small feeder. The opposite bank of the river was the scene of a decisive victory. gained on 21st December 1817 by the British under Sir Thomas Hislop over the Mahrattas under Holkar. The British, crossing the river by a ford just above the town, routed the enemy at the point of the bayonet, taking their camp, with 63 guns and a large quantity of ammunition. The British loss was 174 killed and 604 wounded; that of the Mahrattas was estimated at 3000 men.-Imp. Gaz.

MEHINTELAl, 'the mountain without fear,' is a precipitous rock in Ceylon, about 7 or 8 miles to the north-east of Anarajapura, but connected with the ancient city in the time of the kings by one continuous street, along which were conducted the solemn processions of the Buddhist priests. The ascent to the summit is effected by a series of stone steps, about 2000 in number, winding 
past the ruins of former buildings, temples, dagobas, and shrines; and on the loftiest peak, which commands a view over the forest country beneath to the very verge of the horizon, there exists one of those prodigious structures of brickwork, under which is deposited a sainted relic of Buddha, - a hair which grew on a mole between his eyebrows. With such veneration have the Singhalese been accustomed to regard this sacred mountain, that every crag has some tradition, and every rock has been scarped into sites for religious buildings, amidst the ruins of which are to be traced the fragments of broken statues and inscriptions in the Nagari character, the most ancient in which the dialect of Pali has been written. The ruins of Anarajapura form one of the most conspicuous objects in the grand panorama which is beheld from Mehintelai. They cover an extent of ground equal to 16 square miles, once surrounded by a wall 64 miles in circumference. The city is to be found on the map of Ptolemy in its proper site and ancient name, Anurogrammum.-Tennent's Christianity in Ceylon, p. 336.

MEHKAR, a small town of the Buldana district of Berar, in lat. $20^{\circ} 9^{\prime} 30^{\prime \prime} \mathrm{N}$., and long. $76^{\circ} 37^{\prime}$ E. It gives its name to a revenue district. It is said to take its name from Meghan Kara, a demon who, after a combat, was put to death by Sharangdhar, an incarnation of Vishnu.-Imp. Gaz.

MEHMAN, a Muhammadan sect, numerous about Hyderabad, Sehwan, and Kurachee, in Sind. They are a quiet race, largely engaged in trade. Their name is a corruption of the Arabic word Momin, a true believer, and was given to the people when they were converted from Hinduism to be Muhammadans. The word, in its fullest signification, is applied to two distinct races of people, - to the Khwaja tribe, and to the Mehman Sayyat (i.e. green, from the Sindi sawo) or Achhra (white), who are followers of Abu Hanifeh. Numbers of them are found in Cutch. In Sind they are employed chiefly in agriculture and breeding camels. Their dress is that of the common Sindi, except that they frequently shave the head, especially when old, and wear the turband; sometimes, though rarely, they adopt the peculiar Sind hat. They have produced many very learned men, and have done much to introduce the religious sciences into Sind. The tribe merits some notice, as it has either abandoned or never adopted the practice common among their brethren in Bombay, viz. that of depriving the females of their pecuniary rights in wills and inheritances. Among the Mehman, the widow and daughter are provided for according to the Koran. Their Pir, or holy men, are the family called Rashid Shahi (descended from one Muhammad Rashid Shah), or the Rohri-wara Sayyids, remarkable for nothing but excessive polygamy. Rashid, the founder of the house, took unto himself thirty-two wives (instead of four), and justified the practice by the usual sophistical arguments of the Safi order to which he belonged. The Sindi divines pronounced his tenets to be heretical, and his conduct damnable. The Mehman, however, did not object to it, and still reverence his descendants. The Mebman in Sind bas his own handwriting character; in Cutch he uses the Gujerati. Altogether the Mehman are a respectable race, though they have acquired a bad name by their rapacity in dealing with strangers; and
Wadho Mehman (a great Mehman) in Sindi means a miserly usurer.

In the Kurachee district they take their tribal names as given below, principally from their original places of abode. The Khwaja are of the Shiah sect, and call themselves followers of Khwaja Suliman, Farisi. Their tribal names are
Akhoond.
Bandroo.
Hudokut.
Kussabi.
Loosi.
Mirzapori.

$$
\begin{aligned}
& \text { Katiyar. } \\
& \text { Patoli. } \\
& \text { Puggir. }
\end{aligned}
$$$$
\text { Qazi. }
$$
Khebrana. Khwaja Surha.

-Burton's Scinde, p. 247.

MEHMANDAR, from the Persian word Mehman, a guest, means a host, but is the term applied to a person appointed on the part of a government to attend upon, and supply the wants of strangers while travelling through the country. This custom is most particularly observed towards all ambassadors from foreign powers. The provision thus furnished is called Soorsat; and in Persia it forms one of the most grievous parts of the saderat, or irregular taxes; for it is claimed not only by strangers, but by all great men, or messengers travelling on the part of the king, and is levied with extreme severity. Usually on his arrival at a town or village, the mehmandar sends for the mayor, the Ket-Khuda, to whom he briefly gives his orders to furnish the articles required, and, by way of commencement, installs himself in the best house in the place.-Ferrier, Journ. p. 47 ; Fraser's Khorasan, p. 88.

MEHMASANI, a Baluch tribe who have branches in Seistan and the hills of Luristan.

MEHNDI. HrND. Lawsonia alba, the henna of the Persians, an important dye-stuff, and the distilled water of its flowers is used as a perfume. The Muhammadan women in Asia use the shoots for dyeing their nails red, and the manes and tails of horses are also stained red in the same manner. The soles of the feet also are stained with the red juice of the Mehndi. Mehndi is also a term applied to Elsholtzia polystachya. Jangli mehndi is Ammannia auriculata, Vilayati mehndi is Myrtus communis.

MEHNDI, or Jahez. HiND. A Muhammadan bride's trousseau.

MEHRA, a forest in Hazara which has as its timber trees juglans, cedrela, Pinus longifolia, fraxinus, quercus, yew, cerasus, olive, buroongi, umloke, mulberry. pyrus, Cedrus deodara.

MEHRAWAN, a brother of Ravan, who, in the war of Lanka, by a surprise, took Rama and his brother Lakshmana prisoners, and carried them to Patala (or hell), from whence they were released by Hanuman as they were about to be sacrificed.

MEHR GYA, a product imported from China into India through Tibet, and sold in Lucknow, Nagpur, and Hyderabad at from Rs. 130 to 150 per tola: It is supposed to be the Ginseng drug, called by the Chinese Jin-san, Jiau-san, Hwang-san, Shin-tsan, Kwan-tung-jin-san, and Kwan-si-jin-san.

MEHTAR. HIND. A hereditary village officer; a man who follows the lowestmenial offices, a sweeper, a scavenger. The term originally means a prince, and is used ironically. In Cuttack, the mehtar is sometimes a slave.

MEI-JIN. CHIN. A matchmaker, a go-between, a middleman.

MEI-KONG, a river, flows through the eastern 
side of Laos and Cambodia. It is called by the Chinese Lan-tsang or Lan-chiang. It rises about lat. $33^{\circ}$ or $34^{\circ} \mathrm{N}$., in the Kouen Lun range, near Koko Nor. Its two branches have their confluence about lat. $30^{\circ} \mathrm{N}$., north of Cha-mon-to or Kiam-do, and it then traverses the provinces of Chra-ya and Riang-ka before entering Yun-nan. It is the longest of all the Indo-Chinese rivers. Its course has been traced from its source in Eastern Tibet, where but a single narrow ridge separates it from that of the Kinsha-kiang or Yang-tzekiang, the two streams flowing for a long distance in parallel meridional valleys along the eastern range of the Tibetan plateau. In this peculiar feature of long parallel trenches and mountain ranges is to be sought the key to the little understood geography of the great Siamese Peninsula system: It is said to be more than 2200 miles long. The Lusiad says-

'See thro' Cambodia Meikon's river goes, Well named the Captain of the waters, while

So many a summer tributary flows

To spread its floods upon the sands, as Nile

Inundates its green banks.'

In the Irawadi and Mei-kong basins there are remnants of tribes strongly distinguished from the dominant races, and tending, with the evidence of language, to show that the ethnic history of Ultra-India is very ancient, and has undergone repeated revolutions. One of the most remarkable is the Ka-Kyen. They are described as being in their appearance not Mongolian, and totally different from the surrounding Shan, Burmese, and Chinese races. The Moi or Kamoi, on the opposite side of the Mei-kong, are said to be black savages, with Negro features; they occupy the broad expansion of the Annam chain towards Kamboja, and appear to extend northwards along these mountains, marching with the Lau on the westward. The Kambojans style them Kba-men. They are the Ko-men of Leyden and the Kha-men of Gutzlaff. On the same side of the Mei-kong basin, but towards the sea, between lat. $11^{\circ}$ and $12^{\circ} \mathrm{N}$, a hill tribe, called Chong, preserve more of the ancient AustraloTamilian character than the surrounding tribes. In the Chong, the hair, instead of being stiff or harsh as in the Mongolian, Tibetan, and prevalent Ultra-Indian and Malaya-Polynesian races, is comparatively soft, the features are much more proininent, and the beard is fuller.-Bowring's Siam, ii. p. 28; Loyan, Journ. Ind. Arch.

MEI-THEI-LEI, the valley of Munipur; Burmese call it Ka-the, the Bengalis Moglai, and Assamese Mei-thei-lei.

MEKHITAR, born at Sebaste in Cappadocia A.L. 1676, was the founder of the order of the Mechitarists, and reviver of Armenian literature. In 1691 he entered an Armenian convent at Sebaste, and subsequently became secretary to Archbishop Michael. He secretly became a prosely te to the Romish Church, and in 1700 openly preached submission to the Pope. To escape the anger of the people, he fled to Smyrna, and to the Morea, then under the dominion of Venice. On the conquest of the Morea by the Turks, he went to Venice, where he founded a convent, set up a printing press, and published numerous Armenian translations of the best European works, an Armenian grammar and dictionary, and in 1733 an Armenian Bible. He died 1749.
MEKRAN, sometimes called also Kej Mekran, a province of Baluchistan which extends from near Cape Jashk, in lat. $25^{\circ} 38^{\prime} 3^{\prime \prime} \mathrm{N}$., long. $57^{\circ}$ $46^{\prime} 13^{\prime \prime} \mathrm{E}$., to the Hingol river, and the river of Las, reaching to Cape Maize, in lat. $24^{\circ} 51^{\prime} \mathrm{N}$., and long. $66^{\circ} 35^{\prime} \mathrm{E}$., a distance of 480 miles.

Mekran has Persia on the west, the provinces of Las and Jhalawan on the east, Persia, Afghanistan, and the Kharan district on the north, and the Arabian Sea on its south. Its western portion is under Persian rule, and its eastern under the Khan of Kalat; the boundary being at long. $62^{\circ}$ $\mathrm{E}$. Its name is supposed to be the combination of two Persian words, Mahi-khoran, Ichthyophagi. It was also known to the ancients as Karmania altera. From Cape Jashk on the Purali river, a distance of 500 miles, the shores of the coast of Mekran are washed by the Arabian Sea. The country is one vast arid and sterile waste, with high mountains rising at the back wholly destitute of both trees and vegetation.

It is a district of hills and valleys, in parallel ranges running east and west, but almost rainless. On many of the hills are beds of clay, 50 to 100 feet thick, containing fossil shells of the miocene formation. Between Gwadur and Ras Kuch are many of the mud volcanoes called Chandr-kup, and near Ras Jashk is a hot spring with temperature of $128^{\circ}$. One group of the Chandr-kup, consisting of three cones, is a mile to the W. of Huki and about 60 miles from Saumiani. The other group, consisting of two cones, is about 10 miles $\mathrm{N}$ : of Ormara.

Alexauder the Great, after his conquests in N.W. India, returned through this province; and the sufferings of his army from want of water and prorisions were intense. There are, in Mekran, cyclopean structures raised by some unknown prior race. They are called Ghorbasta or Ghorband, and bear a resemblance to the cyclopean remains of Europe. They are built across ravines to form tanks, and on the declivities of mountains to distribute the water. They have been constructed by an agricultural race, who on entering it had foreseen that the country would not otherwise support them. The race is supposed by Dr. Cook to have been a people with kindred habits to the Pelasgi. Arrian says that the fishermen on the coast of Gedrosia lived in small huts, whose walls were composed of sea-shells piled upon each other, and their roofs of fish bones, the backbones serving instead of rafters. But the present population of Mekran is formed of many different tribes and independent chiefs, of whom the Baluch are the most numerous: a middle-sized race of men, spare, muscular, and active, and armed with a matchlock, sword, shield, and dagger. The common language of the country is a corrupt Persian, mixed with Sindi, and the generality of the Baluch are Muhammadans of the Sunni persuasion. Those of the centre countries reside mostly in towns; those of the lower countries are scattered over the plains, in hamlets of eight or ten huts, built of the branches of the palm, and covered with mats; but the Narhui race of Bunpur live in tents of black hair, and remove from place to place as their flocks or agriculture require their attention. The women of Mekran appear freely in public.

The Gitchki is the most numerous tribe. About half the population is of a sect of Muhammadans called Ziggar. The maritime and fishing 
populajion of the little ports on the coast of Mekran, from Sanmiani to Charbai, are denominated Med, and comprise four divisions, - the Guzbur, Hormari, Jellarzai, and Chelmarzai.

Its natives on the sea-coast are of larger proportions and blacker complexions than the northern ones, probably owing to their frequent intermarriages with the Negroes of Muscat and Arabia. The Mekrani are a puny and delicate race when compared to the Baluchi or Brahui, owing perhaps to the climate, and their sensual lives, for which both sexes are notorious; they likewise drink great quantities of an intoxicating beverage made from fermented dates. The women of Mekran are usually very ugly, and proverbially unfaithful; they set no bounds ta the gratification of their passions; at an early period of their lives they are tottering under decrepitude and premature old age.

The Biruvi tribe dwell near Bela; they sell their children when in want. They are better looking than the Sidi, and, as they speak Sindi, Hindus prefer them as domestic servants. - Kinneir's Geog. Memoir, p. 202 ; Pottinger's Travels.

MELA. HIND. A fair; gathering of the Hindus partly for business, partly for religious purposes. At some places the visitors number hundreds of thousands. A great religious gathering known as Magh Mela is held at the junction of the Ganges and the Jumna at Allahabad. It is particularly crowded in the Khumb or twelfth year. The number of visitors is estimated at from $1,000,000$ to $2,000,000$.

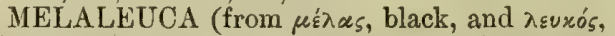
white), a genus of plants belonging to the natural order Myrtaceæ. M. ericifolia, Smith, is a tall shrub of S.E. Australia, yields a comparatively large quantity of cajaput oil, and is of importance for consolidating muddy shores. M. genistifolia and M. linarifolia can be grown in swamps; M. parviflora, Lindley, is valuable for fixing coast sands; M. styphelioides, Smith, yields a hard, close-grained timber; M. squarrosa and M. trichostachya, Lindley, are valued for growth in swamps. M. styphelioides, Simith, a tree 60 feet high, and $2 \frac{1}{2}$ feet in diameter, of E. Australia. Its timber hard, close-grained, and stands well in damp situations. It is adapted for swamps, and timber never known to decay. All these might be introduced into India. T'he tea tree of the Australian colonists is a species of Melaleuca; and M. leucadendron, Linn., is the paper bark tree of N. S. Wales. - Von Mueller.

\section{MELALEUCA CAJAUPUTI. Roxb.}

$$
\text { M. minor, Smith, D.C. }
$$

Thit-tha hpu tshi, BurM. | Kayu-puteh, . MaLAY. Cajaput tree, . ENG.

$$
\text { The oil. }
$$

Kayu-puteh-ka-tel, HrND. | Kayu-puteh-tailam, . TAM. Kayu-puteh-miniak, MaL.

The Malays give the name of Kayu-puteh both to M. cajaputi and M. leucadendrou. It is a small tree with an erect but crooked stem, covered with thick, rather soft, light-coloured bark; branches scattered, with slender twigs, which droop like those of the weeping willow. It is a native of the Molucca Islands, especially of Boeroe, Manipe, and of the S. of Borneo. According to Dr. Mason, is indigenous in the Karen forests of the southern provinces of Tenasserim, but Dr. Mason has not observed it north of the valley of the Palouk river, about lat. $13^{\circ} \mathrm{N}$. The leaves are collected on a warm, dry day in autumn, and placed in dry sacks, in which they become heated and moist. They are then cut in pieces, macerated in water for a night, and then distilled. Two sackfuls of the leaves yield only about 3 drachms of the oil. This is clear and limpid, of a light green colour, very volatile, diffusing a powerful odour, having a warm aromatic taste, something resembling that of camphor, followed by a sense of coolness. Sp. gr. 0.914 to 0.927 ; soluble in alcohol. When the leaves are distilled with water, a light aud colourless oil first comes over, and then a green-coloured and denser oil, which, with less odour, is more acrid. It is sometimes adulterated with the oils of rosemary and of camphor; it is diffusible, stimulant, antispasmodic ; and is used externally in rheumatism.-Royle; Crawfurd; Morrison; Com. Desc. p. 9; O'Sh.; Roxb.; Mason ; Voigt.

MELAJEU'CA LEUCADENDRON. Linn., D.C., Roxb. A tree of the Moluccas, of Malacca, and of the $\mathrm{N}$. and $\mathrm{E}$. of Australia, as far as lat. $34^{\circ}$ S., where it attains a height of 80 feet, with a stem up to 4 feet in diameter on tidal ground. It can be utilized for such areas with great advantage, for subduing malarian vapours in salt swamps where no Eucalyptus will live. Its bark protects it against conflagrations. The wood is fissile, hard, and close-grained; is well suited for posts, ship-building, various artisans' work, resists the attacks of termites, and is almost imperishable under ground.-Von Mueller.

MELANESIAN, a race with frizzled hair; the Malaysians have straight hair. The Melanesian languages resemble Hebrew, Arabic, etc., in their power to form a causal verb. In Maori, the prefix ' whaka' gives to any word this causative sense, viz. ako, learn, whaka ako, teach. In Nengove, ' $a$ ' is the prefix, as puja, rise; apujani, elevate or raise. In Bauro, ha, hai, hau are prefixes, as surutai, rise; hasurutai, raise. In the New Hebrides there are several languages, - the Mai, the Api with two dialects, the Ambrym, Pama, Vun-Marama. The Mota is spoken in Banks Islands; in the Solomon Islands are the Bauro, Ulana, Mara-masiki, Mahaga, and Anudha; and in New Caledonia, the Yehen. - Bikmore; Bishop Patteson.

MELANORRHAA USITATISSIMA. Wall. Theet-see, . . BurM. Kheu of . . MANIPUR Theet-see-yaing, . ", Lignum vitæ of . PEGU.

This black varnish tree or Burmese varnish tree grows from Maripur southward to Tavoy, thus extending from lat. $14^{\circ}$ to $25^{\circ} \mathrm{N}$. At Kubbu, an extensive valley elevated about 500) feet above the plains of Bengal, and 200 miles from the nearest seashore, it attains its greatest size, some of the trees having clear stems of 42 feet to the first branch, with a circumference near the ground of 13 feet. It forms extensive forests, and is associated with teak and sal, and also with the gigantic wood-oil tree, a species of Dipterocarpus. It is in full foliage during the rainy season, which lasts from the middle of May until the end of October. It is rare in the Irawadi valley, but common in the forests east of the Sitang river, particularly south-east of Sitang town. It is very common above the parallel of Tounghoo, and grows there to a girth of six feet, and it is plentiful in the Tounghoo and Prome forests. Its wood is the lignum vitæ of Pegu, 
and is of a dark red colour, or a dark brown, of dense structure, and of particularly fine close grain. It is very strong, durable, hard, and tough, and is used by the Burmese for toolhelves and the stocks of their wooden anchors, etc., for the anchors of the Burmese boats are always of wood to which stones are lashed, the flakes being of Pyeng Khado, and the stocks of Theet-see or of some other heavy wood. Its great hardness and weight prevent its being employed in house-building, but it would answer for sheaves or block-pulleys, for railway sleepers, gun-stocks, rammer heads, and helves. It exudes a black oil, which is used by the Burmese as a varnish. The collecting season lasts from January to April. The oil is obtained by cutting a hole in the tree, about 3 feet from the ground, the cut being about 4 or 5 inches deep into the trunk of the tree. The base is hollowed out to retain the oil. The whole of the hollow is cleared with fire, after which the oil exudes, and is collected in the hollow at the base, and removed at intervals. The oil is thus extracted year after year, and sometimes there are two or three holes in the same tree. The oil is allowed to settle, on which the clear part separates from a thick portion, which is called the 'gand.' If a growing tree is cut down, and cut to pieces, the oil exudes and concretes on the stem and end of the pieces, very much resembling camphor, with an aromatic smell also. It is said that a tree yields from 3 to 5 maunds yearly, i.e. 240 to 400 lbs., value $\mathrm{Rs}$. 10 per maund, and the same tree will yield oil for several years. It is a good balsamic medicine, and very generally used as a substitute for copaiba. As a varnish it is a preservative to wood, to which it gives, with little trouble of application, a fine surface polish; it becornes, however, white and milky if exposed to wet. In Manipur it is used for paying river craft and for varuishing vessels designed to contain liquids. In Burma, almost every article of household furniture intended to contain either solid or liquid food is lacquered by means of it. The process consists in first coating the article with a layer of pounded calcined bones, after which the varnish is laid on thinly, either in its pure state or variously coloured. The most difficult part consists in the drying. It is also much employed in the process of gilding ; the surface, being first besmeared with this varnish, has then the gold leaf immediately applied to it. Finally, the beautiful Pali writing of the Burmese on ivory, palm leaves, or metal, is entirely done with this varnish in its pure state. - Artillery Records; Voigt; Drs. Wallich, Pl. As. Rar., M'Clelland, Mason, Royle, Brandis; Cal. Cat. Ex., 1862.

MELANTHESA RHAMNOIDES. Retz.

Phyllanthus vitis Idæa, $R$. | Ph. rhamnoides, Retz.

Surasaruni, . HrNd. Pavala pula, . . TAM.

A shrub of the Coromandel coast. It has an attractive appearance from its bright red fruits, which are used medicinally.-Wight.

MELANTHESA TURBINATA. $R . W$.

Ph. turbinatus, Roxb. | Ph. simsianus, Wall.

A shrub of the Peninsula of India, where it is employed in medicine.-Wight.

MELANTHIUM COCHIN-CHINENSE. Smith. Tien-men-tung, CHIN. A trailing plant of CochinChina and China. The tubers have the properties of squills.-Smith, M.M.C.
MELASTOMA MALABATHRICUM. $L$. Buro-phutika, . BENG. Kadali, . . . MAL. Myeet-pyai, : BurM.

The Melastomads are an extensive natural order of polypetalous exogenous plants nearly related to Myrtacex. This shrub grows in the Moluccas, Sumatra, Cochin-China, Malay Islands, in both Peninsulas of India, in Orissa, Jellasore, Khassya mountains, and Nepal. Its flowers are large and red, and it fruits the whole year. Its fruit is edible, and is also einployed for a purple dye to cotton cloths. It is one of the black-dye plants of S.E. Asia. Its calyx opens like a lid, and bears a fruit which in taste and flavour strongly resembles the blackberry of temperate regions. The blossoms of the shoe-flower plant are used by the Chinese to dye leather black; the juice of the cashew tree gives a black to linen, and the fruit of this melastoma affords a black dye. In the Tenasserim Provinces, this species is a common weed. In Bengal the same plant is cultivated as a garden flower, but it does not compare with the wild plant of Tenasserim. Other species -amcenum, decemfidum, and glaucum-grow in Tenasserim, Penang, and Singapore. - Roxb. ; Mason ; Voigt ; W. III.

MELEAGRINA MARGARITIFERA. Lam. The pearl oyster, which furnishes the finest pearls and finest nacre. When secreted in the globular form, it is the pearl; when on the inner walls of the shell, the nacre. The pearl oyster is met with in the Persian Gulf, Arabian coast, in the Japanese and American seas, on the shores of California, and near the islands of the South Seas, Bay of Bengal, Gulf of Manaar, Ceylon, and near the mouth of the Indus. Pearls are artificially produced by the Chinese, introducing beneath the mantle a grain of sand, around which the nacrous substance is thrown. Pearl mussel spat or spawn is thrown out in some years in great quantities, perhaps similar to the edible oyster of Britain, wbich threw much spat in 1849 , and not again until 1860 . The spat floats in and on the water, and attaches itself to anything with which it comes in contact, attaining, it is said, the size of a shilling in six months. In its seventh year the pearl mollusc attains its maturity as a pearl producer, pearls obtained from a seven-year oyster being of double the value of those from one of six years of age. In oysters under four years the pearls are not of any mercantile value, and after seven years the pearls deteriorate. Those from mussels of about four years old have a yellow tinge, and the older kinds a pinky hue, but pearls of a red and even black, as also with other colours, are also met with. Baghdad dealers prefer the round white pearl; those of Bombay esteem pearls of a yellow hue and perfect sphericity; while other nations choose the gems with a rich pink colour. There seem reasons to believe that pearl mussel spat is migratory, forming colonies at places remote from the parent bed. Between the years 1732 and 1746, there was little pearl fishing at Ceylon, and there were long suspensions between 1768 and 1796 , between 1820 and 1828 , and between 1837 and 1854, and during the last period the expenses were covered. The late Dr. Kelaart is stated to have been of opinion that the molluscs are capable of leaving their shells. In the Persian Gulf the pearl banks extend 300 miles in a straight line, and the best beds are level and 
of white sand, overlying the coral in clear water, and any mixture of mud or earthy substance with the sand is considered to be detrimental to the pearl mollusc. In the Persian Gulf there is both a spring and a summer fishery, and as many as 5000 boats will assemble from Bahrein and the islands, and continue fishing from April to September. The net revenue from that of Ceylon, from 1828 to 1837 , was $£ 227,131$. Each boat is manned with a crew of twenty-three persons, ten of whom are divers, two divers to each stone, of which there are five in the boat. When fishing for Government or for a speculator, those receive three-fourths of all the produce. Pearls are obtained also from the Avicula margaritifera, the Unio margaritiferus, the common oyster, Anodonta cygnea, Pinna nobilis, Mytelus edulis, and Spondylus gæderopus. Pearls found in Arca noæ are violet, and in Anomia cepæ purple. -Cornhill Magazine, August 1866.

MELEAGRIS MEXICANA is the wild turkey of Mexico. It had been domesticated by the people of America before the discovery of that continent, and from it the domestic breeds have been derived. But the other wild species of America crosses with it. English turkeys are smaller than either wild species. The better known breeds are the Norfolks, Suffolks, white and copper-coloured, or Cambridge. In India the breed of turkeys has greatly degenerated in size, is wholly incapable of rising on the wing, is of a black colour, and its long pendulous appendages on the beak are enormously developed.Daruin, Species. See Pavo.

MELEGUETA PEPPER, Guinea grains, grains of paradise. This pepper is the seed of Amomum grana-paradisi, a native of the coast of Guinea, but cultivated in the West Indies.

MELETTA VENENOSA. Cuv. et Val. Some specimens of Clupeonia perforata, procured by W. T. Lewis, Esq., Assist. Resid. Councillor, Penang, were accompanied by the following account of a phenomenon witnessed by that gentleman during his official residence at Bencoolen :In 1822, great numbers of what was supposed to be an edible species presented the unusual appearance of having red eyes. Many natives, after having eaten these fishes, were suddenly attacked with violent vomiting, which, in cases where remedies were not immediately applied, was known within an hour to terminate fatally. At the same time, such of these fishes with the ordinary silvery eyes were, as formerly, eaten with impunity. This phenomenon recurred at Bencoolen during the seasons of 1823 and 1825, but not of 1824. It was surmised that the poisonous fishes had fed on a gelatinous substance which at that season exudes from the beautifullycoloured coral reefs on that part of the coast of Sumatra. It is, however, more probable that the poisonous fishes were shoals of Meletta venenosa, an inhabitant of the Seychelles and the neighbouring seas, which happened in those seasons to visit Sumatra. M. Valenciennes describes this fish as being poisonous, and producing effects as noted above. In the Straits of Malacca, Clupeonia perforata has never been known to produce bad effects.

MELGHAT, a hill tract in the Ellichpur district of Berar. It is a section of the Satpura range, extremely rugged, and broken into a succession of hills and valleys; the main ridge rising to 3987 feet above sea-level at Bairat. The tea plant thrives in Melghat. In this tract are situated the forts of Gawilgarh and Narnala, and the hill station of Chikalda, 3777 feet above the sea-level. MELIACE E. Juss. The bead tree tribe of plants, with the genera munronia, melia, azadirachta, mallea, amoora, milnea, walsura, monocyclis, sphærosacme, dysoxylum, epicharis, sandoricum, lansium, heynea, xylocarpus, and aglaia, in the E. Indies, Java, the Moluccas, Assam, the Khassya, Nepal, the two Peninsulas, Ceylon, Sumatra, and Bengal. Species of the order have bitter, tonic, and astringent qualities, and in some non-Indian species so strongly developed as to be dangerous. Azadirachta Indica bark is used in fever, and the bitter oil of its seeds extervally; the pulpy fruit of the Lanseh is esteemed in the Indian Archipelago, and that of Milnea edulis is eateu in Sylbet, where it seems to resemble the leechee and longan of China.-Voigt; Crawfurd.

MELIA AZADIRACHTA. Linn., Roxb.

Aria bepou, Rheede. | Azadirachta Indica, Juss.

Kohomba in . Ceryon. Margosa tree, . . Eng. Lien-tsze, . . CHIN. Nim,. . : Hind. Ku-lien-tsze, . . " Veypam, . . . TAM Kin-ling-tsze, : :" Y Yepa, . : : TEL.

An ornamental tree, very much planted in avenues and groves, common throughout India, Burma, in Hu-peh in China, and in Ceylon, generally in a planted state, though occasionally in the forests; it grows well in almost any soil in the plains, and occasionally attains very large girth. The wood is very like mahogany, beautifully mottled, hard, and heavy ; it is much used for cart-wheels and ordinary building purposes, and old trees yield a first-rate furniture wood, and which is much used in Bengal in the manufacture of idols, as it is so bitter that no insect will attack it. The bark is very bitter; the leaves beaten into a pulp are externally applied with great efficacy in cases of pustular eruptions, in rheumatism, and for bruises and sprains; and the leaves are useful in keeping away the boring-worm from books. The dried leaves are often added to common poultices by the natives, and are said to act in preventing glandular tumours from coming to maturity. The fruit yields an acrid bitter oil, which is exported from the Madras Presidency; it is said to have valuable antispasmodic properties, and is anthelmintic and stimulant. It is used by the natives as a remedy in leprosy, and as a liniment for rheumatic affections; it is obtained by boiling or expression, is of a deep yellow colour, and is used for burning in lamps. The bark yields a gum which is said to be a stimulant. A toddy called veypam khalloo is obtained from young trees.-Beddome, Fl. Sylv.

MELIA AZEDARACH. Linn., D.C., Roxb. Kachen? or Jek of BRAS. | Luna-midella, . SINGH. Bavena or Bayrena, CAN. Male vembu, : TAM. Zonzalacht, . EGYPT. Vepa manu, : . TEL. Lilac or bead tree, EiNG. Turka vepa, : :" Nim, . . . HIND. Seed-Hab-al-ban, :"

This species grows in Syria, the north of India, and in China. It is a handsome ornamental tree, attaining a height of about 40 feet, and a quick grower; it produces its sweet-scented, lilac-like flowers in the hot season. It is found sparingly as a planted tree throughout the Madras Presidency, Bengal, Mysore, Bombay, Africa, and has 
been naturalized in the south of Europe; the wood of older trees is handsomely marked, rather durable, and in use for furviture, but is apt to split. The seeds are often strung as beads, and a valuable oil is produced from them. The root is nauseous and bitter, and in use as an anthelmintic. -Beddome, Fl. Sylv.; Thunb. iii. p. 228; Roxb.

MELIA BUKAYUN. Royle.

\section{M. sempervirens, $\boldsymbol{R} 0 x \boldsymbol{b}$.}

Ban, - ARAB. Persian lilac, , ENG.

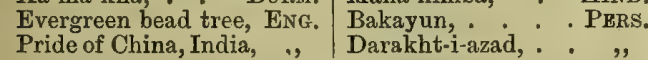

A tree of Nepal, Kamaon, and Persia, with small, fragrant, lilac-coloured flowers. It fruits all the year, being very ornamental when in blossom, and odoriferous. It is common in the Panjab and in the less elevated villages of Afghanistan, and up to 5000 and 6000 feet on the Himalaya. Below Chamba, up to 2800 feet, trees with 12 or 14 feet of girth may be obtained. The wood is yellowish, soft, brittle, and weak, but is bitter and not subject to the attacks of insects. It is a smaller tree than the M. azedarach.-Drs. Stewart, O'Sh., Roxb., Voigt; Gen. Med. Top.

\section{MELIA COMPOSITA. Willd., $W$. and $A$.}

M. robusta, $R o x b$.

M. superba, Roxb.

Nimbara, . . MAHR. Mallay vemboo, - TAM. Lunu midella, : . SrNGH.

A very large, quick-growing, ornamental tree, with smooth dark-brown bark. Common in Ceylon, in Malabar, Wynad, Coorg, Mysore, South Canara, and other parts of the Madras Presidency. Its timber is very light and cedar-like, and in Ceylon is in use for outriggers of boats and for ceilings; and it is said white ants will not attack it.Dr. Gibson; Beddome, Fl. Sylv.

MELIANTHUS MAJOR, frequent at the Cape of Good Hope. The genus derives its name from the copious secretion of nectar in the little depression at the base of the flower. To the natives this juice is a well-known dainty. It should be introduced into India.

MELICA. Roxburgh (i. p. 327) describes four species of this genus of plants, - diandra, digitata, latifolia, and refracta. M. nutans, $L$., is the pearl grass of North and Mid Asia.

MELICOCCA BIJUGA, Linn., has been introduced into India. It grows on the mountains of Central America, and in Jamaica; the pulp of the fruit is of grape taste; the seeds can be used like sweet chestnuts. - Voigt; Von Muller.

MELICYTUS RAMIFLORUS, the Myhoe tree of New Zealand. Grows to the elevation of 25 to 30 feet, but is of small circumference. Its wood is heavy, and is only used for obtaining fire by friction.-Bennett's Gatherings.

MELIDID A, a family of badger-like animals. The following occur in N.E. Asia, viz. :-

Arctonyx collaris, Cuv., Blyth.

Mydaus, Gray, Hardio. | A. isonyx, Hodgson.

Hog, Hog-badger, . ENG. | Bhalu-sur, . . HrNd. Nepal, Sikkim, E. Bengal, Assam, Sylhet, Arakan.

Arctonyx taxoides of Sylhet, Assam.

Mellivora Indica, Jerdon.

Ursitaxus inauritus, Hodg. | Mellivora ratel, Blyth.

Ratelus Indicus, Schin.

Bhajrubhal, . . BENG. Tarakaradi, . . TAM.

Biju, . : . Hind. Biyu-khawar, . TEL. Indian badger, all India.
Meles albo-gularis, Blyth, Taxidea leucura, Blyth, or. Tum-pha, and Meles albo-gularis, are three mammals of Tibet.

Helictis Nepalensis, Jerdon (Gulo, Hodg., Blyth). Oker, NePal. Nepal wolverine, Nepal. Helictis orientalis is of Malayana.

MELILOTUS, the Trifolium of Linnæus, a genus of the Fabacer, plants of Europe and Asia. M. Italica is cultivated in the north of India, M. leucantha in Bengal, Assam, and the Peninsula. Cows fed on it are said to yield an abundance of milk. M. officinalis of Europe is used for flavouring Gruyere cheese. It is the Pai of the Burmese, the Asperuck of Hindustan, and the Zireer of Persia. M. parviflora is of Europe and Asia, and M. sulcata of N. Africa.

Melilotus alba, Desrousseaux, Kābul clover or Bokhara clover. A fragrant biennial herb of S. Europe, N. Africn, and Central Asia. This plant attracted notice in Ireland. It is nearly allied to M. leucantha, and therefore not a true clover. It grows so freely as to yield in the season five or six cuttings of green herbage, from which, it is said, a considerable proportion of strong fibre may be obtained; but the committee of the Irish Flax Society stated that the trials made in the steeping this plant were unsuceessful with them. Griffith saw large fields of melilot in the neighbourhood of Ava. Several native and foreign species are grown in India,-M. arvensis, Italica, leucanthus, officinalis, parviflora, and sulcata.-Griffith; Mason; Royle, Fib. Pl. p. 298 ; Murray.

MELIOSMA ARNOTTIANA. Wight.

Milling tonia Arnottiana, $W$. | Sapindus microcarpus, $W$.

$A$ very common large tree in $\mathrm{S}$. India and Ceylon at 4000 feet and upwards; very abundant at Coonoor on the Neilgherries, where it is known as the Huli-makay (tiger-like); grows in the sholas of the Animallays, and is a most beautiful sight in June when in full blossom, its whitish panicles forming a perfect sheet of flowers over the top of the tree. The heart-wood of very old trees is striped reddish and white, tiger-like; the timber is spongy and light, but is occasionally used for rafters and as firewood. M. dilleniæfolia, Wallich, grows in Simla, and M. Wallichii, Planch, in the Darjiling Hills.-Beddome, Fl. Sylv.; Brandis; Par. Ex., 1878.

MELISSA OFFICINALIS. Linn.

M. graveolens, Host. I. M. poholusa, Opiz.

M. Corsica, Host. $\quad$ M. occidentalis, Rafin.

Buklut-ul-faristum, ARAB. | Mountain balm, . . ENG. Mek', utrujyeh, " Ram tulsi, . . HIND. Common balm, DEKH. Badrunjbuyeh, PERS.

The balm plant of Europe and Central Asia. ' It is sold in all the Indian bazars, and used medicinally.

MELITHREPTUS PACIFICUS, or honey seeker of the South Sea Islands and Sandwich

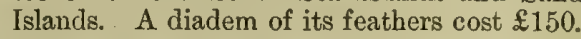

\section{MELLIVORA INDICA. Jerdon.}

Ursus Indicus, Shaw. | Ratelus Indicus, Schinc.

Ursitaxus inauritus, Hodg. Mellivora ratel, Blyth.

Bajru bhal, . . . BENG. Tava karadi,. . . TAM. Indian badger, - ENG. Biyu khawar, : ' TEL, Biju, . . . HIND,

The Indian badger is found throughout the whole of India, from the extreme south to the foot of the Himalaya.-Jerdon. 
MELLOON, Burmese defeated here by the British Indian army, 19th January 1826.

MELOCANNA BAMBUSOIDES. Trinius. The berry-bearing thornless bamboo of Chittagong and the E. Archipelago. It is the Beesha Travancorica, Berldome. It grows beautifully erect on dry slopes of hills, height up to 70 feet, circumference towards the base one foot. The fruit is very large, fleshy like an apple, and contains an edible seed. M. humilis, Roeper, is a more slender and smaller species; M. Travancorica, Von Mueller, is the Beesha Travancorica of Beddome. - Von Mueller.

MELOCHIA CORCHORIFOLIA. Linn. Poonnacoo keera, . TAM. |Tsjerou, . . . URIYA. Ganuka peindi koora, TrL.

The whole of this plant, with the exception of the root, boiled in oil, is supposed on the Malabar const to be an efficacious remedy for preventing bad consequences from the bite of a water-suake. - Hortus Malabaricus, in Ains. Mat. Med.

MELODINUS MONOGYNUS. Roxb. Shanch'ang, Chin. A plant of India and China, one of the Apocynaceæ, said to yield an edible fruit.Smith, M.M.C.; Roxb. ii. p. 56 .

MELOE, a genus of the order of Coleoptera, class Insecta. The species are beetles with large and swollen bodies, and short oval elytra, lapping over each other at the base of the suture. They are sluggish creatures, and feed on various plants, especially the species of ranunculus. When alarmed, they emit from the articulations of their legs an oily, yellow or reddish liquid. Latreille maintained that one insect was the Buprestis of the ancients, to which noxious qualities were attributed. The females lay their eggs near the ranunculus and other plants whose Howers are regularly visited by bees. After these are hatched, the larvæ ascend into the flowers, and, attaching themselves to the back of a bee, are carried into the hive. Dr. C. V. Riley mentions that the young of all vesicants belonging to the Meloidæ develop in the cells of honey-making bees, first devouring the egg of the bee, and then the honey and bec-bread. They are all remarkable for passing through several larval stages. The young Meloidæ are at first simple larvæ, called triungulins, running actively about, climbing to flowers visited by bees, to which they attach themselves. They bave stont thighs and claws, but feeble jaws. Only a few get attached to the proper bees, the others perish. Once in the cell, the creature eats the bees' egg, and then moults and assumes the second larval condition. In this state it is clumsy and little locomotive, and feeds on the honey store. It then becomes a pseudo-pupa, and later a third larva within the partially rent skin, the true pupa stage being still later.

MELOLONTHID $\mathbb{E}$, the chafer group of beetles; they are large; their larvæ feed on grass, the beetles on the leaves of trees, round which they fly in the evening. Under the name of white grub, one of the insects injurious to coffee plants, are included the larvæ of various Melolonthidæ, the cockchafers of Ceylon, which do much harm to coffee plantations, young and old, by eating the roots of the trees. Mr. J. L. Gordon of Rambodde considered the white grub to be by far the greatest enemy of the coffee trees which the planter has to contend with, as he never knew a single tree recover after their attack; and they destroyed at Rambodde, in two years, between 8000 and 10,000 trees of fine old coffee. Mr. Gordon used to dig up the soil at the foot of the trees, and take out such grubs as he could find.

The larvæ of the moth called Agrostis segetum is the very destructive black grub of the Ceylon coffee-planters. This pest is about an inch long, and is most abundant from August to October. The caterpillar lives in the ground, but comes out at night to feed, and is very common and injurious. They attack not only coffee trees, but all sorts of vegetables and flowers, and are very destructive to gardens and in the field, as they eat everything that is artificially raised, despisiug grass and weeds. They generally appear only on certain fields, and will not go over an estate. The insect is not confined to Ceylon; its ravages are well known in India, at the Cape of Good Hope, and Europe, where it injures the grain and beet-root crops. In Ceylon it attacks young coffee trees, gnawing off the bark round the stem just above the ground. Where the trees are very small, they are bitten right off, and the tops sometimes partially dragged under the ground, where the grubs may easily be discovered and dislodged. The damage which they inflict on plantations may be estimated, when it is mentioned that Mr. Nietner lost through them in one season, in certain fields, as many as 25 per cent. of the young trees he had put down.

MELON. Under this name several vegetables are known, viz. Citrullus cucurbita, Linn., watermelon; Si-kwa, Han-kwa, Chin., Turbuza, Hind. The water-melon is to be had at the same time as, and grown in a similar manner to, the Cucumis melo. The seed should always be preserved from the finest and richest-flavoured fruit, and is better for being three or four years old. The green melon is the finest flavoured, although many of the others are very good. The cause of melons growing finer in the sandy beds of rivers is attributed to the temperature being more equal about the roots than it is in beds in the garden, especially during the night. Cucumis dudaim, Queen Anne's pocket melon, is a native of Persia, and produces a fruit variegated with green and orange, and oblong, unequal green spots; when full ripe, it becomes yellow and then whitish. It has a very fragrant, vinous, musky smell, and a whitish, flaccid, insipid pulp. Cucumis melo, Linn., musk melon, melon; Kharbuj, Kharbuza, Hind, Sarda, Paliz, Hind. Native of Jamaica, Persia? and Kābul? but cultivated throughout India. The rock, green, and musk melons are all sown in the Dekhan at the same time,- - generally in beds of rivers, where the soil is light and sandy. They are very seldom sown in gardens. The seed is put down in November, three or four seeds together, with as rich manure as can be procured. The plants must not be close together,- a distance of from six to eight feet is generally allowed. They come in about March, and continue until the rains. In Bombay they are in season at the same time, and a second crop is grown during the rains; this is not the case in the Dekhan. In China, liquid night-soilis largely used in the cultivation of melons.

Melon seed oil, Pitcha pusjhum yennai, TAM., is obtained from the Cucumis melo.-Hogg; Voigt, O'Sh.; Roxb.; Riddell; Jaffrey. 
MEMBU, the capital of the Abor people, on the borders of Assam.

MEMECYLON, a genus of plants, shrubs, or small trees of the E. Indies. M. cuneatum is of the Central Province of Ceylon, at an elevation of 3000 feet; $M$. ellipticum, in the forest between Galle and Ratnapura, at no great elevation; M. Gardneri and M. leucanthum grow at a height of 2000 to 5000 feet in the Central Province; M. ovoideum, in Ambagamowa; M. obiculare at Hinidun Corle; M. parviforum, in the Central Province, at 7000 feet; M. rhinophyllum and M. rostratum at 3000 , and $M$. sylvaticum is common in forests at an elevation of 4000 feet. M. angustifolium, W. Ic., is common on the banks of Ceylon rivers, up to an elevation of 2000 feet; M. fuscescens, Thw., occurs in Ceylon at Kokool Corle, at no great elevation; M. macrocarpum, Thw., occurs in Ceylon at Ambagamowa, at an elevation of about 3000 feet; M. revolutum, Thw., foliis-coriaceis, has leathery leaves, and occupies Rambodde, 5000 feet; M. umbellatum, Burm., called Coracaha by the Singhalese, is very abundant, up to an elevation of 2000 feet. M. varians, Thw., of the Ceylon Central Province, at an elevation of 2000 to 5000 feet. There are two varieties,-M. Wightii, Thw., M. amplexicaule, also a small tree of the Central Provinoe, at an elevation of 3000 to 4000 feet.Thw.; Wight, Ic.

\section{MEMECYLON AMPLEXICAULE. $R$.}

M. cordatum, Wall. | M. depressum, Benth., Rheede.

A flowering shrub in the forests of the $W$. coast of India, used in medicine. It is the Nidam shetti of the Maleali, -Roxb. ii. p. 260.

\section{MEMECYLON CAPITELLATUM. Lim}

Welli-kaha, . S Singr. | Alli-chettu, . . TEL,

A plant of Ceylon and Coromandel, with small blue flowers. Its ripe berries, Aali pundu, TEL., are eaten by the natives. It is a small bush, common in most jungles on the Coromandel coast; it has much pulp of a bluish colour and of an astringent quality. It is M. edule; Roxb.-Ainslie; Thw.; Voigt.

MEMECYLON RAMIFLORUM. Lam.

M. tinctorium, Kcen., Iron-wood tree.

Myen-khæ-tanyet, BurM. | Dœdi-gaha, . . Singh, Anjuna, Kurpa,. MAHR. Kasha maram, . TAM. Surpa, . . . ", Kayam puvu cheddi, , Kana-yavu, : MALEAL. Alaika, Alli-chettu, TÉ.

This occurs in Sylhet, the Malay Peninsula, Tenasserim, Coromandel, Mahabaleswar, Kandalla, along the Western Ghats, in the woods about Cochin, common in jungles in the Carnatic. The flowers are small, blue; its leaves are used in dyeing yellow. The wood is brought into Madras for firewood, and a large quantity of the leaves are imported daily for dyeing purposes. Cold infusion of the leaves imparts a yellow dye. A crimson dye is also said to be obtained from them. It is a highly ornamental tree, with deep-green shining leaves; flowers in February and March, of a purple colour, with the calyx beautifully streaked on the inside. It bears its flowers in compound corymbs, which contrast favourably with its shining green leaves. Wood is very strong and tough. Does not yield readily to wet. Is much employed, when procurable of sufficient size, for agricultural implements, cart furnishing, etc.-M.C.C.; M.E.J.R.; Dis. Mason, Gibson.
MEMECYLON UMBELLATUM. Burm.

M. amplexicaule, $W . \& A$ : $\mid$ M. sessile, Benth., $W . \& A$. M. cordatum, Lam.

M. ramiflorum, Lam.

M. tinctorium, Wight, Ill. Kora-kaha, . SINGH.

Under these narnes Colonel Beddome unites several of the above species. He says the middlingsized tree occurs in all parts of the Madras Presidency and Ceylon, and on the mountains is often a tree of considerable size. Grows in the Kodin Karnal shola, on the Pulneys, at 7000 feet elevation, and the same form occurs on the Neilgherries. The wood is very hard and close grained, and might answer as a substitute for box. In Ceylon the leaves are used in conjunction with the wood of Morinda citrifolia and Crasalpinia sappan for producing a permanent red dye.Beddome, $F l$. Sylv.

MEMNON, according to Hesiod and Pindar, was king of Ethiopia. Eschylus said he was son of a Cissian woman, and Herodotus and others say he founded Susa, and led a combined army of Susanians and Ethiopians to the assistance of Priam, his father's brother, and perished in one of the battles before Troy. The Egyptians claim him to be their king Amunoph rII., whose statue became known as the vocal Memnon. Memnonia was the name of several towns in Egypt and at Susa, supposed to have been built by Memnon, and there was a tribe of Memnones near Meroe. Memnon has a statue of a highly crystallized sandstone or granular quartz. - Jameson, Ed. Journ., 1819.

MEMPHIS, a city of the Pharaohs. Misr, the town of old Cairo, near Cairo, was built out of the ruins of Memphis.

MEM-SAHIBA. ANGLo-Hind. An English woman, a mistress of a house.

MEN. BuRM. A Burmese title bearing an ambiguous meaning, applied equally to a king of England, the Governor-General of India, to the king of Burma, and to all the high dignitaries of his provinces.

MEN. CHIN. Literally gate, is often used in Chinese to designate a religion. Thus King-Men, the Luminous Gate, is the synonym of Luminous Religion, and in the monument of Si-ngan-fou is used for Christianity.-Huc's Christianity, i. p. 52.

MENADO. The tongue of land in the north of Celebes, known administratively under the name of the Dutch Residency of Menado, comprehends all the northern extent of the island, from the bay of Palos in the west to the Cape of Taliabo in the east, and comprises the great bay or arm of the sea of Gunong-tello, which stretches in a westerly direction between the two peninsulas. The Residency includes under its jurisdiction the whole federative states of Minahasa, the small kingdoms of the northern coast, the very extensive districts in the west part of the Peninsula, where Government exercises sway, besides the islands of Sangir and Talaut to the north, as well as the lesser islands of the west coast and the large gulf of Tomini. In 1882, Menado, Minahasa, and Gorontalo had an area of $1267 \cdot 2$ Dutch geographical square miles, with 776 Europeans, 231,357 Indigenes, 2356 Chinese, and 52 others. The Alfoura population are in the elevated and woody parts of Kayeli, Toradja, and Tomeiku. Near Menado is a race called Bintek, strong but intractable, who have hitherto resisted all efforts to improve them. Some of the less civilised tribes 
have semi-Papuan features and hair, while in some villages the true Celebes or Bugi physiognomy prevails. The plateau of Toudano is chiefly inhabited by people nearly as white as the Chinese, and with very pleasing semi-European features. The people of Siao and Sangir much reserable these, and Mr. Wallace believes them probably to be immigrants from some of the islands of North Polynesia. The Papuan type will represent the remnant of the aborigines. The languages con tain a Celebes - Malay element and a Papuan element, along with some radical peculiarities derived from the Siao and Sangir Islands farther north, and therefore probably derived from the Philippine Islands._J. I. Arch.; Wallace; Horsb.

ME-NAM, a river of Cochin-China, has its source in the mountains of Yun-nan in China. It receives many tributaries in its course, divides itself after receiving the waters of the Phitsalok branch, and again unites above Bankok, where, with a depth of from 6 to 8 fathoms, it rolls its magnificent tide into the Gulf of Siam. Me-nam in Siamese means mother of waters. The old name is Me-nam Chan Phya. It is only navigable to a distance of about 30 leagues. It rises and falls like the Nile, the Indus, the Ganges, the Brahmaputra, and the Irawadi. There are 20 waterfalls between Zimmay and Bankok. It has a course of 453 miles, or 800 miles including its windings. The town of Bankok is 27 miles from its mouth, on an islet, in lat. $13^{\circ} 58^{\prime} \mathrm{N}$, and long. $100^{\circ} 34^{\prime}$ E.-Bouring sian.

MENANDER. About the 1st century B.C., a Seythian race swept southwards from the frontier of China, and submerged Bactria. The Macedonians were driven from Kãbul into the Panjab. The Greek captain Menander, and afterwards Apollodotus, passing through the Khaibar, overran the valley of the Indus, and reduced Gujerat and Kashmir. The Greeks were afterwards crushed between the advancing Scythians and the great Indian empire of Magadha. Of all the kings who followed Eukratides, Menander and Apollodotus alone are mentioned by classical authorities.

MENANGKABAU, a state in Sumatra, the original country of the Malay race.

MENAVAN, Maleal, pronounced also Menon, corruptly Menewar. The village or district accountant in Malabar; according to some, the appropriate designation of a Maleala Sudra, Nair writer or accountant; same as the Karnam of the Tamil race.-Wilson's Glossary.

MENCIUS, known in Europe, is the Chinese philosopher Meng-tsze, who died about B.C. 317. See Meng-tsze.

MEND. HiND. A dam, a dyke, the boundary of the village lands or of the lands of a village.

MENDHI or Henna. HIND. Lawsonia inermis. Its leaves are used as a dye for the beard and hair, and for fingers and for horses' tails; they are also given to goats and sheep, etc., when attacked by itch.-Powell, i. p. 452.

MENDHI. HIND. A Muhammadan bride's paraphernalia.

MENDICANTS. Mendicancy in India, Burma, and Tibet, amongst Muhammadans and Hindus and Buddhists, is largely associated with their religious views, and begging is supposed in a great measure to be honourable, a badge of religion, and the honoured occupation of old age. Some of these religionists are professed ascetics; those of the
Hindu faith wander about in the scautiest of garbs, with profusion of ashes on their forehead, beads round their necks, and devotional phrases and verses in their mouths. They visit the most pious of their respective castes and sects, and extort money. The fact that so large a number are professed mendicants is an important one, both from a social and political point of view. Poverty is an evil in any land; but when a large portion of the populace of any country try to remedy the evil by systematic begging, then the evil to the whole land is rendered tenfold worse. Hand in hand with vagrancy go half the crimes that sully human nature.

Amongst Hindu inendicants are the Vaishnava Byragi, Saiva Sanyasi, Ramanaya or worshippers of Rama; Nanik Panthi, followers of Nanik; Kabir Panthi, Sukhee Bhava, Khelanta Jogi, Kanuphata Jogi, Shurevuri, Aghora Panthi, Brahmachari, etc. They have their various forms of austerities. Mr. Ward was informed that in his day scarcely less than an eighth part of the whole population abandoned their proper employments, and lived as religious mendicants by begging. Many of the more enlightened Hindus and Brahmans hold these mendicants in the utmost contempt, and would consider their being compelled to work as a great blessing conferred upon the country.

The Abdhut is a Hindu mendicant of the Vaishnava or Saiva sect. The term is from the Sanskrit Avadhuta, and this class are supposed to have shaken off the tranmels of humanity.

The Akas-mukhi, from Akas, the sky, and Mukha, the face, are religious ascetic mendicants among the Hindus, who hold up their faces to the sky till the muscles of the back of the neck become contracted and retain position.

The Atit religious mendicant is usually a Vaishnava.

Gosain mendicants worship Siva in the form of the lingam, Sanyasi worship Vishnu; Sanyasi mendicants and the ancient ascetic Viragi are followers of Ramanuj. Mendicants carry water from the Ganges to a great distance. The four orders of Hindu life are not now given effect to. The Bhikshuna, the mendicant of the fourth order, may now have a wife and family.

Jogi, ascetic religious mendicants, are followers of the Saiva doctrines taught by Gorakhnath. They have several sections. But, in popular acceptance, Jogi is a term of almost as general application as those of Sanyasi and Bairagi, and the vagrant mendicants who so style themselves usually follow the dictates of their own caprice as to worship and belief, often assuming the character as a mere cloak for obtaining a lazy livelibood. Indeed, the Jogi, more than other religious mendicants, add to their religious personification more of the mountebank character. Most of the religious mendicants deal in fortune-telling, interpretation of dreams, and palmistry; they are also often empirics, profess to cure diseases with specific drugs or with charms and spells; but besides these, the Jogi is usually musical, and plays and sings. He often travels with a small bullock, a goat, or a monkey, whom he has taught to exhibit tricks. The dress of the Jogi is generally a cap and coat or frock of many colours. They profess to worship Siva, and often carry the lingam, like the Jangama, in their cap. All classes and sects assume the character, and even 
Muhammadan Jogi are not uncommon. The Hindu Saringihar Jogi carry a Saringi or small fiddle, with which they accompany their songs ; these are usually Bhasha stanzas on religious or mythological topics, amongst which are stanzas ascribed to Bhartrihari, and a Puranic legend of the marriage of Siva and Parvati is peculiarly celebrated. The Saringihara beg in the name of Bhairava (Siva). The Doribar Jogi sect are small pedlars, selling thread and silk. The Matsyendri or Moch'ch-lendri J ogi take their name from Matsyendra, whom they regard as their founder; and the Bhartrihari Jogi, from a traditional reference to him as their founder. The varieties of the Jogi cannot be specified; they are all errants, fixed residences, or mat'hs, of any Jogi except the Khan Phata rarely occurring.

Besides the above, mention may be made of the Hindu devotees, - Abhyagat, Akali, Aghora, Bahikatha, Bhartrihari, Brahmachari, Bhat, Baitali bhat, Bhau-rupya byragi, Digambar, Gosain, Jati, Jogi, Kanphatta, Kapali, Karta bhoja, Khaki, Sanyasi, Sewara suthra, Uddasi.

In Buddhist countries, the Phoungyes pass rapidly through the streets, ringing a bell to attract attention, but otherwise accepting the unsolicited offerings of the people, for the daily food of their monasteries.

The Muhammadan religious mendicants are the darvesh (darvis) of Persia and fakir of India. Their sections in India and Persia are about ten in number, but some in India are not respectable. Mendicancy has undoubtedly greatly diminished since the middle of the 19th century; it is not deemed reputable, and people give less freely. But when a marriage is being celebrated, either in a Hindu or Muhammadan household, the professional beggars of the sect, bhat, ghatak, naga, raywo, and fakir, hang about the doors, and exact largesse.

The Buddhist mendicants of Tibet are not better than the Muhammadans, but those in Burma and Siam are more respected. The Jangama priests and Vaishnava rnendicants of Mysore wound themselves to extort alms. It is called Pavada.Wilson in Oudh Rept. p. 121.

MENES. The first who is said to have reigned in Egypt was Menes or Mena, the Eternal, from whom the later kings traced their lineage. According to Egyptian chronologists, he came to the throne about 1500 years before the Persian invasion, that is to say, 2000 years before the Christian era. The accepted date is B.C. 3623. He was probably the Minos of the Greeks, their earliest law-maker and their judge of the dead.Sharpe's Egypt, ii. p. 9.

MENG-BA or Ming-ba. BurM. In Amherst, a timber used for house-posts and rafters.

MENG-DONG, the sacred stone monuments of Tibet. On each of its ends are inscribed the words, Om Mani Padmi Hom,-Oh! the jewel of the lotus, or Oh! the jewel on the lotus, or Hail to him of the lotus and jewel.

MENG-GYI. BuRM. The commissioner of a province. Meng-tha, son of a prince. Menglong, a ruler. Meng-shim-byin, a king.

MENGLA THUT, or Mangala Thok in Sanskrit, Mangala sutra in Pali, Mangala sutta in Burmese, written Mangalasutt, pronounced Mangala Thok. It is the blessed instructions of Gautama; the beatitudes of the Buddhists of Burma, eleven in number. It is the Burmese first book of reading, after the pupil has mastered the Than Bon Gyee or spelling-book. The Mengala Thut are chanted occasionally to drive away the evil one. It was translated by Professor Childers.

MENG-TSZE, the Mencius of Europeans, a great philosopher of China, died B.C. 317. His system of philosophy was in favour for 1300 years.

MEN-GU. BURM. Elæagnus conferta, also the Garcinia mangostana, Linn.

MENGUN, a town near Mandalay, the capital of Burma, famed for its great pagoda, the Sen-byu. It was built A.D. 1816 (Burmese year 1178) by Bagyeedau Piyah, grandson of king Bodo Piyah.

MENHIR, a standing-stone used as a monument to the dead. See Cairn; Khassya.

MENISPERMACE E. D.C. The Cocculus tribe of plants, comprising the genera Anamirta, Clypea, Cyclea, Cocculns, Epibaterium, Pselium, Gynostemma, Cissampelos, Stephania, Phytocrene, Natsiatum, and Coscinium. The plants formerly arranged under the genus Menispermum are now placed to the genera Anamirta, Cocculus, Coscinium, Clypea, and Tinospora.

MEN-JOGI. MAHR. A class of Jogi mendicants in the Mahratta country, worshippers of Bhairava.-Wils. Gloss.

MENON is not a Travancore title, strictly speaking, but has been brought into that state from North Malabar, and indicates that the holders' ancestors immigrated from that district.

MENTAUS, also Jumberit, a tree of Java; the wood is white and fine-grained, and is used for inlaying, for furniture, and cabinet-work.

MENTHA, Mint.

Nana, •. A ArAB. | Podinah, HINd, PERs. Bu-di-na, : : BurM. Jia manis, . MALAY. Poh-ho, . . ChIN. Widda, . . TAM.

A genus of plants belonging to the natural order Lamiaceæ or Labiatæ. M. sylvestris, M. viridis, M. piperita, and M. arvensis, remarkable for their odour and taste, have long been used in medicine, and some as sweet herbs. M. arvensis, stems and leaves carminative, antispasmodic, stomachic, alexipharmic. Infusion, as a cooling drink, also as an eye lotion. M. hirsuta, M. crispa, and M. Canadense leaves are used for the extraction of peppermint oil. The oil is used as application to the head, and in the manufacture of peppermint pastilles. A kind of camphor, prepared from the oil at very low temperature, strongly polarizes light. It takes the form of transparent and colourless crystals. M. incana, Willde., is Persian mint. A species of Japan, the peppermint camphor, yields a crystalline substance called minthol.

MENTHA PIPERITA, the peppermint, grows wild in Europe, Asia, N. and S. America. Its aroma is almost destroyed by drying. It is an aromatic stimulant, and the most pleasant of all the mints. It is employed in medicine for several purposes. The essential oil is greenish-yellow, and very liquid; after long keeping, it deposits crystals of camphor; it is useful in flatulent diseases, and in the early stages of malignant cholera. Dissolved in spirit, it constitutes the tincture or essence; distilled with wator, it forms the peppermint water of the shops.- O'Sh.

MENTHA PULEGIUM, or Pennyroyal, is found 
in wet ditches in most parts of Europe, also in the Caucasus, Chili, and Teneriffe.

MENTHA ROYLEANA. Benth.

Kushma, . . BeAs. Koshu, . . SutleJ. Yura, Pudna, Chenab. Velanne, Trans-Indus. Vien,

Baburi,

KANGRA. Mushk tara, . ,

JHELUM.

Grows common in the plains, Trans-Indus, and either M. incana or M. Royleana grow in the Himalaya and Tibet to 11,000 or 12,000 feet. M. incana is also occasionally cultivated in gardens, and its leaves are officinal as an astringent. M. Royleana is much used by the hill people of the Himalaya.-Ainslie; Royle; O'Sh.; Stewart.

MENTHA SATIVA. Roxt.

M. arvensis, Linn. | Marsh whorled mint.

Nana, Hubbuk, . ARAB. Pudina, . . HIND. Bu-dina, . BurM. | Widda, . . TAM.

This is found wild in Kashmir at elevations of 5000 to 9000 feet, and it is grown in gardens throughout India. It is officinal at Lahore, and is prescribed by the Muhammadans in dyspeptic complaints, and to stop vomiting.-Drs. O'Sh., Honig., Stewart.

MENTHA VIRIDIS. Linn. Spear-mint.

Pahari podina, . Hind. | Podina kohi, Hind, Pers.

Found in the milder parts of Europe, the Canaries, Cape of Good Hope, and America, both North and South. It is a mative of Kashmir, and is cultivated throughout the $\mathbf{E}$. Indies for its essential oil and its distilled water; greatly resembles M. piperita. The colour, however, is of a deep green. It is given as a stimulant in cholera. $-D r$. Stewart. MENTIKO, a gay festival of the Kanawari.

MENU. The Menu of the Hindus are seven, Swayambhuva (who by some is termed an incarnation of Brahma), Swarochesa, Uttoma, Tamasa, Raivata, Chaishusha, and Satyavrata. Sir William Jones has considered Swayambluva to have been Adam, and Satyavrata, Noah.

Menu, the name of the author of a book called the Institutes of Menu, composed at least 800 but probably 1200 years before Christ. Menu's Iustitutes are later than the Vedas, and show the legal, social, and political rather than the poetical and religious aspects of Brahmanism. But it is a compilation of the customs current among the various races in India, and therefore contains many contradictory passages. Many of his dicta by no means tend to elevate the condition of women. In his lengthened catalogue of things pure and impure, he, however, says the mouth of a woman is constantly pure, and he ranks it with the running waters and the sunbeam; he suggests that their names should be agreeable, soft, clear, captivating the fancy, auspicious, ending in long vowels, resembling words of benediction. Where females are honoured, he says, there the deities are pleased; but where dishonoured, there all religious rites become useless; and he declares, that in whatever house a woman not duly honoured pronounces an imprecation, that house, with all that belongs to it, shall utterly perish. Strike not, even with a blossom, a wife guilty of a hundred faults, says another sage, - a sentiment so delicate, that Reginald de Born, the prince of troubadours, never uttered any more refined. Menu lays down some plain and wholesome rules for the domestic conduct of the wife; above all, he recommends her to preserve a cheerful temper, aud frugality in domestic expenses. Some of his texts savour, however, more of the anchorite than of a person conversant with mankind; and when he commands the husband to be reverenced as a god by the virtuous wife, even though enamoured of another woman, it may be justly doubted if ever he found obedience thereto; or the scarcely less difficult ordinance, for a whole year let a husband bear with his wife who treats him with aversion, after which probation he is permitted to separate.

Menu has imposed obligations towards the Brahman little short of adoration, but these are limited to the learned in the Vedas; and he classes the unlearned Brahman with an elephant made of wood, or an antelope of leather, nullities save in name. And he adds further, that as liberality to a fool is useless, so is a Brahman useless if he read not the holy texts, comparing the person who gives to such an one to a husbaudman who, sowing seed in a barren soil, reaps no gain; so the Brahman obtains no reward in beaven. These sentiments are repeated in numerous texts, holding out the most powerful inducements to the Brabmanical class to cultivate their minds, since their power consists solely in their wisdom. For such there are no privileges too extensive, no homage too great. A king, even though dying with want, must not receive any tax from a Brahman learned in the Vedas. His person is sacred. Never shall the king slay a Brahman, though convicted of all possible crimes. Banishment, with person and property untouched, is the declared punishment for even the most heinous crimes. A Brahman may seize without hesitation, if he be distressed for subsistence, the goods of his Sudra slave. What prince could gain wealth by oppressing these (Brahmans), who, if angry, could frame other worlds and regents of worlds, and could give birth to new gods and mortals ?

The code of Menu is still the basis of the Hindu civil jurisprudence, but is received according to the interpretations and modifications of approved commentators. Since his time the Sudra races of Hindus have ceased to be slaves, but until the early part of the 19 th century widows continued to immolate themselves on the funeral pyre of their husbands; intermarriages between castes have become prohibited; Bralımans have taken to soldiering; and to live apart in separate villages, or in a secluded part of the village; caste distinctions have become more rigid, except in the interested relaxation of the Brahmans; animal food has becorne prohibited to large classes of Hindus, the avowed imposts on the land doubled, and the laws less liberal towards women. -Tod's Rajasthan; Elph.; Cole. Myth. Hind.; Menu by Haughton. See Manu.

$\mathrm{MEO}$, a tribe of cultivators in the Dehli province, inhabiting the low hills about Gurgaon.

MER signifies a hill in Sanskrit, hence Komulmer, or properly Kumbhomer, is the hill or mountain of Kumbho; Ajmir is the hill of Ajya, the invincible hill. Mèr is pronounced with the long è like mère in French.-Tod's Rajasthan.

MER, a race of the Aravalli, possibly noticed in the code of Menu as the Meda who must live without the town, and maintain themselves by slaying the beasts of the forest; the Med or Mair 
race are possibly meant. General Cunuingham thinks the Mer of the Aravalli are the same race.

MERCAL, Marakal, or Markal ; Tamil Marakkal, a grain measure in use at Madras, containing 8 padi or measures, and being 1-12th of a kalam. It formerly contained 750 cubic inches, but is now fixed at 800 cubic inches; 400 markal $=$ 1 garce or garisa.

MERCANDEYA, one of the Puranas; a Hindu sacred book. See Lakshmi.

MERCHANT. A great part of the Hindus of British India follow mercantile pursuits. Many Muhammadans, of Arab and Hindu descent, as the Moplah, the Labbai, the Bora, the Mehman, are active merchants. The Parsee race are extensively engaged in commerce. The Baboo of Calcutta, chiefly of Sudra origin, are also great merchants. The Chettyar of Madras, all of them Vaisya Hindus, are also largely engaged; and there are 80 clans of Rajputs engaged in commercial transactions. These Rajput tribes are known as the Marwari. Many of the Hindus of Cutch and Gujerat are largely engaged in foreign trade with the west coast of Africa, and have been great slave-dealers, occupying the coast from Zanzibar to Mozambique. The Parsees have spread from Gujerat and Bombay into Madras, Calcutta, Rangoon, Singapore, China, and London, and the chief towns on the coasts of the south and east of Asia have traders from most parts of Western Asia, from Europe, and from America.

\section{MERCURY.}

Abuk, Zibakh, . . ARAB. Hydrargyrum, . LAT Shwuyyiu, Hung, . CHIN. Sim-ab, . . Pers, Mercure, Vif-argent, Fr. Parada, Rasa, . . SANsk. Quicksilber, . GER. Rasam, . TAM., TEL. Para, . : Hind.

Mercury or quicksilver was known to the ancients. The Romans and Arabs seem to have employed it as a medicine externally, and the Hindus prescribed it internally. It is found in China, at Almaden in Spain, at Idria in Carniola, and likewise in S. America. Mercury was found by Dr. J. P. Malcolmson in the lava of Aden and in the laterite on the western coast of the Peninsula of India. It occurs usually as the native bisulphuret or cinnabar, combined with silver, forming a native amalgam; or with chlorine, as in horn mercury. It is chiefly obtained from the sulphuret by distillation with lime or with iron, which, combining with the sulphur, the metal distils over and is condensed. Quicksilver is said to be brought to Ava from China.

Bichloride of Mercury, corrosive sublimate. Hydrargyri bichloridum. | Rus-capoor, GUJ., HIND.,
TAM.

This is white, with an acrid, metallic, and persistent taste, without smell. It is met with in small crystals, or in semi-transparent masses. It is made in many parts of British India, and seems to have been long known to and prepared by the natives of India. It is much used as a preservative of timber, canvas, etc., from the ravages of mildew, the dry rot, and of white ants. A solution is made in the proportion of one pound to four gallons of water, and in this the article to be protected is steeped a variable time, according to its nature.

Chloride of Mercury.

Hydrargyri chloridum. | Calomel, . . . ENG. Several preparations of mercury are described

VOL. II.

by the Sanskrit and Tamil writers. Dr. O'Shaughnessy examined the processes, and found that they generally led to the production of a mixture of calomel and corrosive sublimate. The ras-karpur is usually calomel. Once, however, he met a specimen which was corrosive sublimate of the finest kind.

Russapuspum, in great repute amongst the Tamil people, appears to be administered by them in larger doses than any other preparations of this metal. But it generally happens that through defective manipulation a mixture of calomel and bichloride is formed.

Shavirum is a strange compound, administered by the Tamils in very small quantities; is a harsh, uncertain, and dangerous preparation. In the mode of preparing it, the vapours of calomel simultaneously rising and meeting the chlorine are converted into the bichloride of mercury.

Nitrate of Mercury, Hwang shing-yoh, CHIN. Made in China by heating and subliming a mixture of red led, mercury, sulpbate of iron, and nitre.

Nitric Oxide of Mercury.

Hung-shing-yoh, . CHIN. | Hung-shing-tan, . CHus.

This is a mixture of peroxide of mercury and a little nitrate of mercury, made by fusing cinnabar, nitre, alum, realgar, and sulphate of iron.

Red Oxide of Mercury.

Hung-fen, . . Chin. | San-sien-tan, . CHIN.

It is prepared in Hankow: nitre is melted in a small boiler, alum is added, and mercury is put into the middle of the mass. T'he red oxide is obtained as sublimated scales of a brick-red colour.-Snith; O'Sh. Beng. Phar.; Mason; Royle.

MERDIN, a city in Diarbekir, Asiatic Turkey, lat. $37^{\circ} 26^{\prime} \mathrm{N}$., and long. $39^{\circ} 59^{\prime} \mathrm{E}$. It is situated on the slope of the Karajadagh or ancient Mount Masius; population about 11,000, of whom 1500 are Armenians and 200 Jews. Merdin Rocks are at the Baghdad frontier towards Constantinople. The pashalik of Baghdad extends from the Merdin Rocks to the mouth of the Shatt-ul-Arab.

MERDUI, a Brahui tribe of shepherds living near Khozdar, who obtain antimony and lead from the hills of Kapper. Writing of Jhalawan, Dr. Cook says the mountain range of Baluchistan is the great natural boundary of Western India, and may be described, figuratively, as composed of a vast under structure, surmounted by parallel rows of walls (represented by mountain ranges) cut through here and there by long and meandering passages. Amongst these mountains the Merdui tribe of the Brahui obtain lead ore, and reduce it. A place called Seman is situated amongst low sandstone hills, black externally, with fragments and boulders of dark blue limestone, and arenaceous nummulitic rock scattered around. Beneath the sandstone is a red sandy clay, and in this is found red-ore, carbonate of lead in thin, flat, tabular masses, looking like a broken-up vein, which are covered externally with a layer of calcareous earth that prevents them from being easily detected. The shepherds poke about with a stick, pick up any promising pieces, roughly estimate the specific gravity by the hand, and if they have not the proper weight, reject them. At Khozdar the implements for reducing the lead ore are very rude: a rough furnace, with four upright square stones and a hole below to insert the nozzle of a pair of bellows. 
MEREI. TAM. A cess paid by mirasidars for the communal expenses.

MERGELLUS ALBELLUS, also Mergus albellus, the smew, has the circuit of northern regions, W. Asia, Sind, Panjab, Oudh, and is not rare along the Panjab rivers.

MERGUI, Myo of the Burmese, is in lat. $12^{\circ} 27^{\prime} \mathrm{N}$., and long. $98^{\circ} 38^{\prime} \mathrm{E}$., on an island at the entrance of the principal branch of the Tenasserim river. High water at the springs occurs about $11 \frac{1}{2}$ or 12 hours, when the rise is from 18 to 22 feet. The harbour admits ships of 18 feet draught of water. Population about 12,000. Mergui possesses coal. The beds are extensive, from 9 to 18 feet thick, and about 16 feet from the surface. The principal mine is about 90 miles up the great Tenasserim river. Mergui was taken 15 th September 1824. The Tenasserim, the Legnya, the Pak-chan, and the Pa-look are the rivers, and the passes into Siam are the Tsa-raw, the Mawdoung, and the Khow Maun.

MERGUI ARCHIPELAGO is called by the people Myut Myo. The innumerable islands fronting the coast of the Malay Peninsula extend to the distance of 70 miles from it, and form the Mergui Archipelago. They exhibit a great variety of picturesque and wild scenery, the larger islands rising in successive ranges of hills thickly wooded at their tops with trees of a rich and varied foliage. The small rocky islands with their rugged sides rise in contrast. There are few settled inhabitants on the archipelago, but roving seafaring tribes pass from island to island, living partly in their boats and partly in temporary huts, collecting sbell-fish, turtle, trepang, bechede-mer, and edible birds' nests, which they barter for rice and cloth. Seyer Islands and King Island are the principal islands. Maingy (Maingay) Island, in lat. $12^{\circ} 32^{\prime} \mathrm{N}$., and long. $98^{\circ} 7^{\prime} \mathrm{E}$., can be seen for 11 miles, and the $\mathrm{S}$. peak of St. Matthew's, in lat. $10^{\circ} 52^{\prime} \mathrm{N}$., and long. $98^{\circ} \mathrm{E}$., for 13 miles.

An almost uninterrupted belt of islands extends along all the western side of the isthmus, and is continued as far as Penang; although an interval between it and the Lankawi group contains only a few. The rest of the western coast, and the greater part of the eastern, are more thinly sprinkled with islands. But there are several extensive groups of islands, some of them remarkably bold and imposing, along the latter coasts, such as the Eastern Johore Archipelago and the Redang Islands. The concave southern coast half embraces the island of Singapore, and an archipelago of several hundreds of islets stretching to the S.E. by S. from the termination of the continent to Banca and Billiton, marks that the peninsular zone has not yet wholly sunk beneath the sea, and, expanding as it does to the west, and blocking the extremity of the straits, attests how nearly a junction with Sumatra has been accomplished. The chain of high islands fronting the coast of Tenasserim extend from Tavoy Island, in lat. $13^{\circ} 13^{\prime} \mathrm{N}$., to the Seyer Islands, in lat. $8^{\circ} 30^{\prime} \mathrm{N}$. The number of the Selong or wandering fishermen of the Malay Archipelago amounts to about 1000 souls.-Journ. Ind. Arch.

MERGUS MERGANSER, the Goosander (M. orientalis of Gould), has the circuit of northern regions; not rare in the Himalaya; rare in Central India.
MERIAH, the name given to the rictims of sacrifice in the Khond tracts near Orissa, where young persons were sacrificed to propitiate the divinity supposed to preside over the soil. The Meriah sacrifices to the earth goddess were made amongst the Khond until the close of the Gumsur. war in 1836. In Boad and Gumsur, the form under which the goddess was worshipped is as a bird, but in Chinna Kimmedy that of an elephant. In one place there was a pit dug, over which a hog is killed, and the Meriah's face then forced into the bloody mire until suffocated. Pieces of the flesh were then cut off and buried beneath the village idol and in the fields of the villagers. In Boad, great value was attached to the saliva of the Meriah. A Meriah Agency was instituted for the purpose of suppressing the buman sacrifices, and it has nearly attained that object. The Meriah victims were natives of the low countries bordering on the Khond mountains. They were procured for the purpose by the Khond from the Pano by a regular system of crimping and kidnapping. All were acceptable, from the Brahman or Muhammadan to the Pariah, without distinction of age or sex. The greater number were very young children, who were purchased or stolen, carried to the hills, and allowed to live till some occasion called for a sacrifice. The rescued Meriah were placed in villages of their own, on land granted them by Government, and they made considerable progress in acquiring settled and industrious habits. The Khond inhabit an immense tract of mountainous country, covered with dense jungle. They are a hardy and independent race, who looked on human sacrifice as the only means of averting the anger of heaven. Meriah sacrifices in the hill tracts of Orissa have much decreased, and the Khond have been sacrificing buffaloes instead. The establishment has not succeeded in entirely preventing Meriah sacrifices even on shore, and on board the country ships plying in the neighbourhood of the districts where the practice prevails, they were rather the rule than the exception.

The Digalo is found in Khond communities occupying the position of servant and counsellor to the Khond headman or Moliko; he is of the Pano caste, a race possessing more cunning than the Khond, and exercising much indirect influence in consequence. They are thieves and kidnappers, and officiate as priests at Meriah rites. Their influence is exercised usually for evil.

MERIANDRA BENGALENSIS, Benth.

Kafur ka patta, . HIND. I Sima karpuram, . . TEL.

A plant of the family of Labiatæ, with a camphor-like smell and taste, in use amongst the people of India as a medicine. Its leaves are stomachic, equal to Salvia officinalis. M. strobilifera, Amurtoo, HrND., has a strong camphorlike fragrance.-O'Sh. p. 492.

MERISTA LEVIGATA, the Tipau tree of New Zealand, grows straight, 16 to 20 feet high. Its wood is hard, heavy, and durable, and is used for poles. $-G$. Bennett.

MERKARA or Madhukeri or Mahadevapet; the chief town of Coorg, is in lat. $12^{\circ} 26^{\prime} 50^{\prime \prime} \mathrm{N}$., and long. $75^{\circ} 46^{\prime} 55^{\prime \prime} \mathrm{E}$., on a table-land 3809 feet above the sea, 130 miles south-west from Bangalore. The fort is situated on an eminence 
of considerable natural strength, but commanded by neighbouring hills. Merkara is said to have been founded in 1681 by Muddu Raja; the original seat of the family had been at Habri.

Merkara was captured by the Madras army on the 6th April 1834. The raja's palace, a spacious building, is supposed to have been built by an Italian, who is said to have been bricked up in a wall as soon as the building was finished. Verajenderpet is 20 miles on the road leading to Cannanore from Merkara.

Fraserpet is 20 miles from Merkara. The river Cauvery runs past it, and forms the boundary between Coorg and Mysore. The S.W. monsoon, which always rages throughout Coorg from June to November, is scarcely felt at Fraserpet. Coorg became one vast coffee plantation, and estates were vigorously cleared wherever they abutted on the road, by which produce could alone be carried off.

MERODACH was a favourite Babylonian god. From the earliest times the Babylonian monarchs placed him in the highest rank of deities, worshipping him in conjunction with Anu, Bel, and Hea, the three gods of the first triad.-Rawlinson's Religions, p. 68 .

MEROE, in Ethiopia, a country mentioned in the Scriptures, corresponding to the present kingdoms of Nubia and Abyssinia. It was also called Seba, as also Meroe. It is named in Milton's Paradise Lost, when describing the inhabitants of the world, -

$$
\text { ... some from farthest south, }
$$

Syene, and where the shadow both way falls, Meroe, Nilotic isle.'

It was at one time occupied by Arabs under a settled form of government, who conquered Nubia and harassed the Thebans. During the earlier centuries, all these Arabs were easily conquered by the Egyptians. - Sharpe's Egypt, i. p. 104.

MEROO'T, also called Idaan, a race in Borneo who inhabit the more hilly districts towards the north, in the vicinity of Kina-Balou. They are said to sacrifice human victims like the Kyan. The Idaan, of different places, go under different denominations, and have different languages, but in their manners and customs they seem to be nearly alike. The name Idaan is, in some measure, peculiar to those of the north part of Borneo; the inland people of Passir are called Darat; those of Benjar, Biajoos; the Subano of Magindanao appear to be the same people. The Idaan are reckoned fairer than the inhabitants of the coast. The custom obtains of arranging human skulls about the houses of the Idaan as a mark of affluence.-J. Ind. Arch., 1849, p. 557.

MERU, a mythological mountain of the Hindu religionists, also called Sumeru and Hemadri. It is the Mien-mo of the Burmese, and the Simeru of the Siamese. It is termed by the Hindus in their theogony, the navel of the world, and is the fabled residence of their deities. Hindus, Siamese, and Burmese describe this mountain differently. On one of its three peaks is Kailasa, the heaven of Siva; and on another is Swarga, or paradise of Indra. In the Ramayana (book i. p. 236), Mera is the mountain nymph, the daughter of Meru and spouse of Himavat, from whom sprang two daughters, the river goddess Ganga, and the mountain nymph Parvati. She is, in the Mahabharata, also termed Syeela, the daughter of Syeel, another designation of the snowy chain, and hence mountain streams are called in Sanskrit silletee. Syeela bears the same attributes with the Phrygian Cybele, who was also the daughter of a mountain of the same name; the one is carried, the other drawn, by lions.

Meru mountain is famed in the traditions of the ancient Hindus. Pamir is the country about Meru (upa-meru). Meru seems to mean strictly the terrestrial orb. The Greeks also metamorphosed Parvat Pamir, or 'the mountain Pamir,' into Paropamisan, applied to the Hindu Koh west of Bamian; but the Parvat put Pamir, or 'Pamir chief of hills,' is mentioned by the bard Chand as being far east of that tract, and under it resided Kamira, one of the great feudatories of Prithivi raja of Dehli.

Until the middle of the 19th century, the Hindus at Bikanir, Rajputana, taught that the mountain Meru is in the centre, surrounded by concentric circles of land and sea. The Brahmans supposed that, as there is sea at the coasts, there must be alternate circles of land and sea. Some Hindus regard Mount Meru as the North Pole. The astronomical views in the Puranas make the heavenly bodies turn around it.-Cole. Myth. Hind. p. 253 ; Moor, p. 270; Hindu Theatre, i. p. 241; Bunsen, i. p. 431; Tod's Rajasthan, i. p. 24; Ramayana, lib. i. p. 236.

MERUTUNGA, a learned man of the Jaina sect, who flourished in the 15th century, and wrote several historical books.

MERV is situated in an oasis of the same name. It was the capital of the ancient Margiana, is said to have been founded by Alexander the Great, and became the residence of one of his successors, Antiochus Nicator, who called it Antiocha Margiana. In more modern days it was one of the four imperial cities of Khorasan, and was long a seat of many of the sultans of Persia, but in particular of those of the Seljuk dynasty. Alp Arslan, the most powerful prince of his time, reigned here for a number of years in all the pomp and splendour of oriental magnificence.

The Merv of to-day is a cluster of Turkoman encampments. The old city of Merv (the Margiana Antiocha of the ancients) is 12 miles away, and consists of merely a number of ruins imbedded in the sands. The river Murghab, which runs through Merv, is deep and rapid, and affords a plentiful supply of water for the numerous canals that branch off and irrigate the oasis. The number of Tekke Turkomans living in the oasis itself may be roughly reckoned at 100,000 . The country is famed throughout Central Asia for its fertility; and if peace and security prevailed in the region, the surplus of the crops would be sufficient for 50,000 troops. Caravans from Khiva, Bokhara, and other provinces of Central Asia pass through it on their way to Persia, Afghanistan, and India. Most of the people possess large flocks of sheep, and herds of camels and horses. Their bravery had passed into a proverb; and it was said that the clans, if united, could put forth a fighting strength of 100,000 sabres. But Russia overcame them in 1883 , after a few years of fighting.

In 1786 it was sacked by the Uzbak Amir of Bokhara, and it dwindled to an assemblage of about a bundred mud huts, surrounded by a small mud wall. It is on the right bank of the Murghab, 200 miles from Bokhara, 215 from Meshed, and 
432 miles S.E. of Khiva. The area of the plain of Merv is about 2400 square miles. Four cities of Merv have been in existence, and their ruins are still visible. One was built by Shah Abbas, another was destroyed by Murad Beg of Bokhara. The Russian Government have occupied the Merv oasis. The occupation is extremely important, not only from a strategical, but from a commercial point of view. The city of Herat is only some 200 miles to the south of it. Merv was regarded by the Persians as the spot where Adam received from the angel the first lesson in agriculture.Malcolm's Persia, ii. p. 232 ; M. Veniukof; Collett's Khiva; Kinneir's Geog. Memoir.

MESAKHEE, a shrubby plant of Assam, very abundant. Its young branches, which are tender and red-coloured, as well as its leaves, are edible. Its fibre is well adapted for cordage. Large quantities grow wild in Upper Muttuk, and elsewhere in the district.

MESEMBRYANTHEMACE $\nexists$ or Mesembryaceæ, Lindl., a natural order of plants, cornprising the genera Mesembryanthemum, Glinus. M. crystallinum is the ice plant. The principal species seem admirably adapted for fixing loose, shifting sand. Its thick bark enables it to bear without shrinking a long privation of moisture, at the same time that it gives shelter to the nascent shoots of other plants. The mucilaginous capsules of M. edule or Hottentot fig are the chief material of an agreeable preserve. Mesembryanthemum nodiflorum, at the Cape, is used in making morocco leather. They are mostly Cape plants.

MESHA'AB. ARAB. There are three kinds of sticks used for driving camels. The mesha'ab, which is a branch of almond wood cut out of the bough so as to leave an obliquely-inclined head. This is chiefly but not exclusively used by the sherif, and in the prince of Mecca's hand is the symbol of sovereignty; the bark is left on it entire. The 'matrak' is a longer and perfectly straight peeled wand; and the 'bakur," shorter and heavier than the last, is bent round at the end; both the bakur and mesha'ab are held by the straight part. The mesha'ab is of immemorial use in Arabia, and is historically interesting. A mesha'ab is mentioned as forming part of the scanty succession of Mahomed.-Hamilton, Sinai.

MESHED is in lat. $36^{\circ} 15^{\prime} 44^{\prime \prime} \mathrm{N}$., and long. $57^{\circ} \mathrm{E}$. It is the ancient Tus. It is in Khorasan, and is famed for the tomb or mausoleum of Imam Raza, in which the remains of Harun-ur-Rashid are placed.

Nadir Shah entered Dehli on the 9th March 1739 , and, in returning from India, retained all west of the Indus at Attock. He was assassinated in his tent at Meshed in Khorasan, by three of his officers, on 8th June A.D. 1747. The fate of Nadir Shah has been thus recorded, doubtless by some mullah: 'Nadir baduzakh raft,' Nadir is gone to the abyss of hell. These letters give 1161, the year of the Hijira which corresponds with A.D. 1747.-Fraser's Journey.

MESHED ALI, a town of Turkish Arabia, 30 miles from the ruins of Babylon. It contains the tomb and mosque of Ali. It was the capital of the Arab and Christian dynasties till taken by the Saracens in the 7 th century.

MESMERISM is largely practised by the Chinese, especially in the Toong Koon district of Kwang-tung.-Gray, i. p. 265 .
MESONA WALLICHIANA, a labiate plant that grows on the ascent of the Jaintia Hills, whose bruised leaves smell as strongly of patchouli, as do those of the plant producing that perfume, to which it is closely allied. Pogostemon patchouli has been said to occur in the Khassya Hills. It is a native of the Malay Peninsula, whence the leaves are imported into Bengal, and so to Europe. -Hooker, Him. Journ. ii. p. 314.

MESOPOTAMIA is the name by which Babylouia was desiguated after the Macedonian couquest. Strictly, it comprises all the country between the Euphrates and the Tigris, but the name is usually restricted to the part of it $\mathrm{S}$. and E. of Orfa and Mardin. The most of it is within the province of Baghdad. The upper part of it is called al-Jazirah, and the lower part Irak-Arabi.

Its limits were somewhat differently defined by ancient writers.

Strabo says that the Tigris washes the eastern side of Mesopotamia, and the river Euphrates its southern and western; whilst the 'laurus separates it from: Armenia on the north. Pliny, who is still more distinct, says that Mesopotamia has the Tigris to the east, the Euphrates west, the Persian Gulf south, and the Taurus north, with a length of 800 miles and a breadth of 360 miles, the city of Charax being at the extremity of the gulf (lib. vi. c. xxvii.). Mesopotamia extends above $10^{\circ}$ in longitude, from Balis, in long. $38^{\circ} 7^{\prime} 10^{\prime \prime} \mathrm{E}$., to the estuary of the old Karun, in lat. $7^{\circ} 31^{\prime} 5^{\prime \prime}$ N., and long. $48^{\circ} 45^{\prime} 16^{\prime \prime} \mathrm{E}$.; from the shores of the Persian Gulf, in lat. $30^{\circ}$, to Sumeisat, in lat. $37^{\circ} 31^{\prime} 5^{\prime \prime} \mathrm{N}$. ; its greatest width being about 170 miles, from Jaber Castle to Hisn Keifa on the Tigris, and its extreme length nearly 735 miles. The irregular triangle thus formed has a superficies of nearly 76,117 square miles, including the shores of the gulf from the Pallacopas to the old Karun. Truffles and wild capers, peas, spinach, and the carob, Ceratonia siliqua, are found in Mesopotamia. A pea called Arab addis is particularly good. The principal towns of Mesopotamia are Diyar Bekr, Hisn Keifa, Jezireh, Mosul, Tekrit, Sammara, and Kut-el-Amarah along the Tigris ; Erzingan, Kemakh, Egin, Kebban Maden, Malatiyah, Ram, Kal'ah, Bir, Rakkah, Deir, Rawd, Anah, Hadisah, El' Uzz, Jibbah, Diwaniyah, Lamlun, Sheikh-el-Shuyukh, and Kurnab along the Euphrates ; in addition to Suverek, O'fah, Haran, Seroug, Ras-el-ain, Mardin, Nisibis, Sinjar, El Hadhr, Kerbelah, Meshed Ali, Samawah, Zobeida, and many other villages, both in the mountains and along the streams, between the two great rivers. Grane or Quade, Mohammarah, and Basrah are the ports; and the last, being the principal, is next in importance to Baghdad, the capital. The inhabitants consist of Arabs, Osmauli Turks, Kurd, Turkoman, Syrians, Jews, and Christians. Arabic is the general language, Turkish, Kurdish, Chaldee, Syriac, and Syro-Chaldæan dialects being the exceptions. The Sunni Muhammadan religion is prevalent; but in Upper Mesopotamia there are many Christians of the creed of Nestorius (some of whom have become Roman Catholics), and Jacobite as well as Roman Catholic Syrians.

The races that have ruled here have been many, and from the most remote times, and remnants are still to be traced of former dominant peoples in the varied languages still spoken. The present rulers are the Turks of Constantinople. 
MESPILUS GERMANICA. $L$.

Ukuj, Shajarat-ul-dub, AR. | Laroos, Keel, . . Hrnd.

Common edible medlar; common in many parts of Europe, and occurring in English hedgerows.

MESSIAH, a title of Jesus, born of Mary. It is from the Masah of the Arabs, and is the Christos of the Greeks. Anointed is an epithet. St. Peter (Acts x. 38) tells us that God had anointed Jesus of Nazareth to be the Christ. This is held to mean specially set apart for God's service-whether persons or things, required anointing; and the anointing of Jesus was the work of the Holy Ghost (Acts x. 38), first, at his conception (Luke i. 35), second, at his baptism (Matthew iii. 13). Thus the term, as applied to Jesus, is not a name, but the expression of his office, a title, whether expressed by a Greek, Hebrew, or English word, Christ, Messiah, Anointed.

MESTRI or Mistri, a carpenter, mechanic, mason, artificer, a chief builder, a master mason.

MESUA, a genus of plants of the order Garciniaceæ or Clusiaceæ. All the species have a very hard, heavy, reddish-coloured timber, known as iron-wood, and perhaps the hardest and heaviest timber in India. Axemen dislike very much to fell them, as they turn the edge of their axes. Their wood is most valuable for engineering purposes, and is largely used in Ceylon.

Amongst the described species are M. Coromandelina, $W . I c$., M. ferrea, W. Ic., M. pedunculata, W. Ic., M. pulchella, Planch, of Ceylon, M. Roxburghii, W., and M. speciosa, Choisy. It is relating to one of them that the Burmese say that their next Buddha, Aree-ma-taya, will enter the divine life while musing beneath its hallowed shades, hence it is a favourite tree with the Buddhist priests of Burma, who plant it around their monasteries. In Sanskrit it is called nagakesara.

MESUA COROMANDELINA. W. M. ferrea, W. and A. Prod. I M. pulchella, Planch.? Nag'ha,Naga-champa, Hn. | Nangal, . . . . TAM. Mallay nangal,. TAM. Nir-nang, : : TA

This is a very handsome tree, common in most of the mountain forests on the western side of the Madras Presidency, growing with its congener M. speciosa, from which it is readily known by its much smaller leaves and flowers. On the T'innevelly ghats it is very abundant, and its timber much in use ; it is there called Nir-Nang, to distinguish it from Mesua speciosa, which is called Nang. This species is much in use with the natives in Tinnevelly, and is looked upon as one of the best timbers; but in the Wynad and other parts, where it is also abundant, it is not utilized, and seems hardly to be known.-Thw. En. Pl. Zeylan. ; Beddome, Fl. Sylv.

MESUA ROXBURGHII. W. $I l l$. Iron-wood. M. ferrea, $R$. ii. p. 605 .

Ken-gau, Gungau, BurM. Naga-kesara, . SANsk. Kagkesar, . . . HIND. Irul maram, : : . TAM. Nag-champa, : MAYR. Chikati manu, : TEL Beluta-champagam, MAL. Naga-kesara chettu, ", Kesaramu nagasara, SANS. Suvarnam, . . . ",

The blossoms are remarkable for their fragrance, and are sold in the bazars of India under the name of Nagkesar. Sir William Jones says that the delicious odour of its blossoms justly gives them a place in the quiver of Kama Deva, the Hindu god of love.
As. 'with foot as light

As the young musk roe's, out she flew,

To cull each shining leaf that grew

Beneath the moonlight's hallowing beams,

For this enchanted wreath of dreams ;

Anemones, and seas of gold,

And new-blown lilies of the river,

And those sweet flowerets that unfold

Their buds on Cama-deva's quiver.'

It flowers in the beginning of the warm season. The wood is very strong and tough. The seeds are contained in a strong brown skin, -one, two, or three in each. When ripe, the skin bursts, and the seeds drop out. The oil is an excellent remedy for cutaneous diseases; dried buds, considered a temperate remedy, used in coughs, especially while attended with much expectoration.-Roxb.

\section{MESUA SPECIOSA. Choisy.}

Mesua ferrea, Linn. | Deya-na-gass, . SingH.

A tree of Nepal, and growing on the banks of streams in the Ratnapura district of Ceylon.Thw.

MESUE. Two of this name, both of them Nestorian Christians, were in medical practice at Baghdad,-John, the elder, in the 8 th and 9 th, and the younger in the 10th century. John of Damascus was president of the college at Baghdad founded by the khalif Mamoon, A.D. 813. He wrote several works, which have disappeared, but he was the first who made correct translations into Arabic from the works of the Greek physicians, especially of Hippocrates and Galen.

The younger Mesue wrote a treatise on Materia Medica and Pharmacy, which for a long time was held in great estimation, and was republished and commented upon so late as the 16 th century. He mentioned several new remedies, and was doubtless in advance of the knowledge of the day.

MET. SIND. A clay quarried near Hyderabad and other places. The Persian name is Gil-i-sar shui, 'the head-washing clay.' When mixed up with rose leaves, it makes anything but a bad wash-ball-Burton's Scinde, i. p. 31.

METALS imported into India consist of wrought brass, copper unwrought and wrought, cast or pig iron and wrought iron, lead ore, pig lead, wrought lead in sheets, pipes, and tubes, quicksilver and steel, tin unwrought and wrought, zinc. These will be found noticed under their individual names, but the total quantities and value imported were as under :-

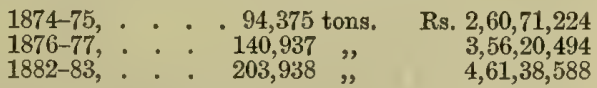

The metallic products of the East Indies comprise antimony, arsenic, cbromium, cobalt, copper, gold, iron, lead, manganese, mercury, nickel, platinum, silver, tin, titanium, and zinc.

Metal casting in India is very largely practised, and the processes are of great simplicity. The natives generally prepare a model in wax, and imbed it in moist clays, which, after being dried in the sun, is heated in the fire, the wax run out, and the metal run in. A better plan, where accuracy is required, is to cut the model in lead, and, having bedded it in clay, it may, when the mould is dry, be melted and run out, and the metal run in. In Nanbhum, a core is made of plastic clay, all carefully shaped to the internal form of the fish or other object to be imitated. This core is then baked and indurated. On this, 
the pattern designed to be represented is formed with clean beeswax. This done, and the wax having cooled, it becomes tolerably hard. Soft clay is moulded over all. The whole is then baked, the heat indurating the outer coating of clay, but softening the wax, which all runs out of the mould, leaving empty the space occupied by it. The mould being sufficiently dried, the molten brass is poured into the empty space, and, when cool, the clay is broken away, when the figured casting is seen. These are untouched after the casting, excepting on the smooth and flat surfaces, which are roughly filed. The Chinese excel in all working in metals, in ordinary blacksmith work, metal smelting, alloys, particularly their white metal of copper, zinc, iron, silver, and nickel, their sonorous gongs and bells, one at Pekin being $14 \frac{1}{2}$ feet by 13 feet, and their ingenious metallic mirrors, some with engravings. The Burmese, also, are skilled.

Indian metal ware is of several descriptions, some of it being much admired by Europeans. The black engraved work of Moradabad, N.W. Provinces, is well known, and so is the Tanjore brass ware. Madura men also manufacture brass vessels, to sell to the pilgrims.-Messrs. Morrison, Rohde, Cal. Cat. Ex. 1862.

METARI. TEL. A headman among the lower castes, as palanquin-bearers, washermen, cowherds, etc. Qu. Mehtari.

METAWALI, a Shiah Muhammadan sect in Palestine, supposed to be ancient Syrians.

METCALFE, CHARLES THEOPHILUS, a Baronet of Great Britain, afterwards created a Baron of the Empire, a civil servant of the E.I. Company in Bengal. Before he was twenty years of age, he served at the court of Sindia, under the Resident, Colonel Collins. When only twenty-three years old, he was sent by Lord Minto on a mission to Ranjit Singh at Lahore. He met the maharaja at Kussoor on the 11th September 1808. On the 25th April 1809 he concluded a treaty stipulating that the maharaja should retain possession of the territories to the north of the Sutlej, but refrain from all encroachments on the possessions of the chiefs on the left bank of the river, who were now taken under British protection. He rose to be Governor-General of India, was afterwards Governor of Jamaica, and subsequently Governor-General of Canada. He was Governor-General of India from the 20th March 1835 to the 4th March 1836, and during his administration a free press was given to that country.

METEMPSYCHOSIS, or transmigration of the soul, is believed in by the Hindus and Buddhists of Asia, and by all the pre-Aryan aboriginal races in British India. The metempsychosis doctrine seems to have been held coeval amongst the Brahmans and Egyptians. The Pythagorean sect of Magna Grecia seem to have derived it from Egypt. In the Institutes of Menu, at least thirty different creatures are named into whose bodies malefactors are imprisoned, according to their crimes, the scale descending down to such particulars as that he who stole perfumes should be changed into a musk-rat. Metempsychosis is the idea that a human being guilty of sensual sins should be changed into an animal that is only conscious of the senses. But metempsychosis, according to Bunsen, is the recognition that there is a solution of the enigma of existence, which is not to be found in the term of a single life on earth, and yet which we are impelled to seek after, in order to explain this life. All guilt must be expiated ; but the final issue, though reached only after the lapse of unnumbered ages, will be the triumph of the good, the general reconciliation, and a life in God will be the eternal heritage of the soul. Thousands of years before Christianity announced the certainty of immortality, the three civilisations of the Egyptians, the Brahmans, and the Druids believed that the human soul died not after death. Abu Zaid, the historian, writing in A.D. 916, mentions that in Balhara and other parts of India, men burned themselves on a pile, influenced by their belief in a metempsychosis; and he adds that when a man or woman became old, he or she begged that they might be thrown into the fire or into water. The Tibetan Buddhists count six classes of existence, viz. four bad, those in hell, the brute, asur, and yidag; and two good, those as man and God.-Fraser's Journ., 1868; Bunsen, Elliot's History, pp. 1-9; Haughton's Menu, p. 406.

METEORIC FIRES. The shahaba or wandering meteoric fires, on fields of battle and in the places of great sacrifice, produce a pleasing yet melancholy effect, and are the source of superstitious dread and reverence to the Hindu, having their origin in the same natural cause as the wandering fires of Odin, the phosphorescence produced from animal decomposition. - Tod's Pajasthan.

METEORIC IRON. A mass, 15 inches long and $12 \frac{5}{8}$ inches broad, was found imbedded in the soil on the top of the forest-clad Kurruckpur Hills, near Monghir. The hillmen exhumed it, and for many years worshipped it. It was sent to the museum of the Beng. As. Soc.

METEORITES. Till the beginning of the 19th century, the fall of stones from the sky, aerosiderites, aerosiderolites, and aerolites, seemed an event so strange, that neither scientific men nor the mass of the people could be brought to credit its possibility. Such falls are, indeed, recorded by the early writers of many nations, Hebrew, Chinese, Greek, and Roman; but the witnesses of these events had been in general laughed at for their delusions. The oldest undoubted sky-stone at present known is that which, though after the Revolution in France removed for a time to the library at Colmar, is once more suspended by a chain from the vault of the choir of the parish church of Ensisheim in Elsass.

The famous mass known as the Pallas-iron, weighing $1500 \mathrm{lbs}$., of which the greater part is now in the museum at St. Petersburg, was met with at Krasnojarsk by the traveller Pallas in the year 1772, and had been found on the surface of Mount Kemirs, between Krasnojarsk and Abekansk in Siberia, in the midst of schistose mountains : it was regarded by the Tartars as a holy thing fallen from heaven. The interior is composed of a ductile iron, which, though brittle at high temperature, can be forged either cold or at a moderate heat.

At 8 o'clock on the evening of December 19 , 1798 , many stones fell at Krakhut, 14 miles from Benares, in India (S. 150); the sky was perfectly serene, not a cloud having been seen since December 11, and none being seen for many days after. According to the observations of several Europeans, as well as natives, in different parts of the country, the fall of the stones was preceded by the appearance of a ball of fire, lasting for only a few instants, 
and accompanied by an explosion resembling thunder. After an explosion are generally heard sounds which have been variously likened to the flapping of the wings of wild geese, to the bellowing of oxen, to the roaring of a fire in a chimney, to the noise of a carriage on the pavement, and to the tearing of calico; these sounds are probably due to the rush of the fragments through the air in the neighbourhood of the observers. Sometimes the fragments reach the ground before the sound of explosion is heard, proving that the break-up has taken place while the velocity of the meteorite was considerably higher than that of the sound vibrations ( 1100 feet a second).

As to the nature of the matter of which these meteorites are composed, about 24, and those the most common, of the 64 elements at present recognised as constituents of the earth's crust, have been met with, while no new element has been discovered. The most frequent are iron, magnesium, silicon, oxygen, and sulphur; next follow aluminium, calcium, nickel, carbon, and phosphorus; while in smaller quantity occur hydrogen, nitrogen, lithium, sodium, potassium, titanium, chromium, manganese, cobalt, copper, arsenic, antimony, tin, and chlorine. All of these are met with in the combined state, but some, among which may be mentioned iron, carbon, and sulphur, are present also in the elementary condition.

There is no record as to where all that have fallen in India have been placed. The stones which fell at Parnallee in 1857 were lodged in the Government Central Museum, Madras, and the Muddoor stone of 1865 was placed in the Mysore Museum.

\begin{tabular}{|c|c|}
\hline Name of Fall and Locality. & $\begin{array}{l}\text { Date of Fall } \\
\text { or Find. }\end{array}$ \\
\hline sa & 1866 \\
\hline $\begin{array}{l}\text { Nedagolla, Mirangi, Vizagapa- } \\
\text { tam, }\end{array}$ & Jan. 23,1870 \\
\hline ut, Benares, . . . & Dec. 19,1798 \\
\hline Bengal, : : & \\
\hline $\begin{array}{l}\text { Near Gurramkonda, between } \\
\text { Punganur and Kadapa, }\end{array}$ & 1814 \\
\hline rict, Oudh, & Jan. 29,1838 \\
\hline ur, & April 18, 1838 \\
\hline Berar, & June 6,1838 \\
\hline , near Eidulabad, & June 29,1843 \\
\hline nah), if 'All & 7,1822 \\
\hline $\begin{array}{l}\text { Futtehpur, N.E. of } \\
\text { abad, }\end{array}$ & \\
\hline $\begin{array}{l}\text { Bithur and Shahpur, N.T } \\
\text { of Allahabad, }\end{array}$ & Nov. \\
\hline Ambala, : . & 1822-23 \\
\hline Mhow, Ghazipur, . . . & Feb. 16,1827 \\
\hline Durala, Patyala, . . . & Feb. 18,1815 \\
\hline Charwallas, near Hissar, & June 12, 1834 \\
\hline $\begin{array}{l}\text { Assam, } \\
\text { Shalka, Bancoora, Bengal, }\end{array}$ & $\begin{array}{l}\text { Found } 1846 \\
\text { Nov. } 30,1850\end{array}$ \\
\hline $\begin{array}{l}\text { Bustee, between Gorakhpur } \\
\text { and Fyzabad, }\end{array}$ & Dec. $\quad 2,1852$ \\
\hline e, Bengal, . . & 6,185 \\
\hline Parnallee, Madras, & Feb. \\
\hline $\begin{array}{l}\text { Pegu (Quenggouk), } \\
\text { Panpanga, Philippines; }\end{array}$ & Dec. 27,1857 \\
\hline $\begin{array}{l}\text { Panpanga, Phulppines, } \\
\text { Khirigurh, S.E. of Bhurtpur, }\end{array}$ & 28,1860 \\
\hline Kusiali, Kamaon, & June 16,1860 \\
\hline $\begin{array}{r}\text { Dharmsala, N.E. of Panjab, } \\
\text { (Qutahar bazar), }\end{array}$ & July 14,1860 \\
\hline Butsura $\left\{\begin{array}{l}\text { (Chireya), } \\
\text { (Piprassi), }\end{array}\right.$ & May 12,1861 \\
\hline Pulsora, N.E. of Rutlam, & Mar. \\
\hline
\end{tabular}

Shytal, 40 miles N. of Dacca, Aug, 11, 1863 Manbhum, Bengal, . . . Dec. 22, 1863 $8 \cdot 9$

$4,379 \cdot 7$

\begin{tabular}{|c|c|c|}
\hline Name of Fall and Locality. & $\begin{array}{l}\text { Date of Fall } \\
\text { or Find. }\end{array}$ & $\begin{array}{l}\text { Weight in } \\
\text { Grams. }\end{array}$ \\
\hline $\begin{array}{l}\text { Louza Khoorna, Sidowra, } \\
\text { Gorakhpur District, }\end{array}$ & & $4,050^{\circ} 6$ \\
\hline $\begin{array}{l}\text { ubuowly Indigo Factory, } \\
\text { Supuhee, Gorakhpur, }\end{array}$ & Jan. 19,186 & $200 \cdot 0$ \\
\hline (3) & May 23, 1865 & $147^{\circ} 0$ \\
\hline y, near Gya, Berar, & Aug. 25, 1865. & $126 \cdot 8$ \\
\hline , . & Sept. 21, 1865 & $407 \cdot 3$ \\
\hline near Bustee, Gorakh- & $\left|\begin{array}{lr}\text { April } & 1866 \\
\text { May } & 27, \mathbf{1 8 6 6}\end{array}\right|$ & $\begin{array}{r}3,306 \cdot 0 \\
45 \cdot 9\end{array}$ \\
\hline ir, Ahr & Oct. 5, & 18 \\
\hline o, Phulee, & Jan. 19,1867 & \\
\hline $\begin{array}{l}\text { oalpara, Assam, : : : } \\
\text { odran, Multan, : }\end{array}$ & $\begin{array}{l}\text { Foun } \\
\text { Oct. }\end{array}$ & $\begin{aligned} 1,187 \cdot 0 \\
66 \cdot 5\end{aligned}$ \\
\hline $\begin{array}{l}\text { Ioteeka Nugla hamlet, } \\
\text { Ghoordha, Bhurtpur, }\end{array}$ & Dec. 22,1868 & $407 \cdot 9$ \\
\hline Java, & Sept. 19 & 13 \\
\hline & Dec. 10,1871 & $14^{\circ} 0$ \\
\hline Sultanpur, Oudh, & May 8,1872 & $269^{\circ}$ \\
\hline SE. of Baha- & June & 1,9 \\
\hline Khairpur, $35 \mathrm{~m}$ & & \\
\hline $\begin{array}{l}\text { Rajputana, } \\
\text {, Agra, . }\end{array}$ & Mar. 4, & 600 \\
\hline $\begin{array}{l}\text { Judesegeri, Kadaba Taluk, } \\
\text { Mysore, }\end{array}$ & & $135^{\circ}$ \\
\hline Gorakhpur, . & Sept. & $2,245^{\circ} 0$ \\
\hline
\end{tabular}

METEOROLOGY, in its connection with the East Indies, the people and their industries, has to be noticed with reference to its rainfall and its winds. For the latter, the articles Cyclones, Famines, Monsoon, Storms and Winds may be seen. All the dearths and famines of India and the south of Asia have been the consequence of insufficient rainfall and droughts in particular districts, and in some of them millions have perished for want of food.

AVERAGE ANNUAL RAINFALL AND TEMPERATURE.

\begin{tabular}{|c|c|c|c|c|c|c|}
\hline \multicolumn{2}{|l|}{ Station. } & $\begin{array}{l}\text { Rainfall. } \\
\text { Inches. }\end{array}$ & $\begin{array}{l}\text { Mean } \\
\text { Heat. } \\
\text { Fahr. }\end{array}$ & $\begin{array}{l}\text { Max. } \\
\text { Temp. }\end{array}$ & $\begin{array}{l}\text { Min. } \\
\text { Temp. }\end{array}$ & $\begin{array}{l}\text { Altde } \\
\text { Fect. }\end{array}$ \\
\hline & & $62 \cdot 36$ & $68 \cdot 1$ & $97 \cdot 2$ & $32 \cdot 8$ & 4000 \\
\hline jmir, . & & & & $118 \cdot 0$ & & 1800 \\
\hline kola, . & . & $27 \cdot 05$ & & $113 \cdot 7$ & & 929 \\
\hline cyab, . & & $196 \cdot 63$ & & 1005 & $47 \cdot 3$ & 21 \\
\hline ahabad,. & . & $35 \cdot 92$ & & $119^{\circ} 0$ & $36^{\circ} 0$ & 298 \\
\hline Bangalore, & - & 38 & & $98: 3$ & & 3131 \\
\hline llary, . & . & & & $108 \cdot 3$ & & 1500 \\
\hline mbay, & . & $.74^{\circ}-x+3$ & & $94 \div 9$ & 0 & 14 \\
\hline Calcutta, . & . & $65^{\circ}$ & & $106^{\circ} 0$ & 4 & 18 \\
\hline Chakrata, & - & $59 \cdot 96$ & 56 & 91.0 & $18 \cdot 7$ & 7056 \\
\hline apunji, & & $359-615$ & & & & 4460 \\
\hline alda, . & . & & $71^{\circ} 1$ & $103^{\circ} 0$ & $44 \cdot 7$ & 3773 \\
\hline gong, & & 10 & & 99.0 & $45^{\circ} 4$ & 90 \\
\hline $\mathrm{ck}$, & • & $55^{\circ}$ & & $118^{\circ} 0$ & 48 & \\
\hline ling, . & . & $118^{\circ}$ & & $4 \cdot 2$ & 26 & 6885 \\
\hline . & - & & & $111: 2$ & $39 \cdot 2$ & 474 \\
\hline & & 0 & $77 \cdot 2$ & $121 \cdot 2$ & & 715 \\
\hline alpara, & 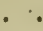 & $93 \cdot 34$ & 75 & $99 \cdot 7$ & 42 & 120 \\
\hline ibagh, & & $48 \cdot 52$ & $74 \cdot 4$ & $110^{\circ} 0$ & $37 \cdot 3$ & 2010 \\
\hline bad, & & & 5 & $119 \cdot 5$ & 6 & 213 \\
\hline bulpur, & - & & & $114 \cdot 5$ & $32 \cdot 3$ & 1306 \\
\hline & . & $81^{\circ}$ & & $8 \cdot 2$ & 14 & \\
\hline hee, . & & & & 11 & 1.5 & 35 \\
\hline & - & & & & & 1000 \\
\hline $\mathbf{w}$, . & & & & & & 364 \\
\hline & 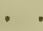 & & & & $\cdot 4$ & 53 \\
\hline alegaon,. & . & & & & & 1480 \\
\hline lmein, & & $189 \cdot 39$ & & 101 & 56 & 87 \\
\hline Multan, . & & & & & $26^{\circ} 0$ & 408 \\
\hline Murree, & & & & & & 7518 \\
\hline Nagpur, & & $43 \cdot 43$ & 78 & $117 \cdot 1$ & $43 \cdot 2$ & 1025 \\
\hline Newera Elia & & $99 \cdot 45$ & & & & \\
\hline Pachmarhi, & & & & $107^{\circ} 0$ & 30.0 & 3538 \\
\hline Patna, . & & & & & 50. & \\
\hline
\end{tabular}




\begin{tabular}{|c|c|c|c|c|c|c|}
\hline Station. & & $\begin{array}{l}\text { Rainfall. } \\
\text { Inches. }\end{array}$ & $\begin{array}{l}\text { Mean } \\
\text { Heat. } \\
\text { Fahr. }\end{array}$ & $\begin{array}{l}\text { Max. } \\
\text { Temp. }\end{array}$ & $\begin{array}{l}\text { Min. } \\
\text { Temp. }\end{array}$ & $\begin{array}{l}\text { Altde. } \\
\text { Feet. }\end{array}$ \\
\hline $\begin{array}{l}\text { Port Blair, } \\
\text { Rangoon, } \\
\text { Rawal Pindi, } \\
\text { Roorkee, } \\
\text { Sambalpur, } \\
\text { Saugor, } \\
\text { Seoni, : } \\
\text { Shillong, : } \\
\text { Sibsagor, : } \\
\text { Silchar,. } \\
\text { Simla, : } \\
\text { Sirsa, : } \\
\text { Trichinopoly, } \\
\text { Wellington, }\end{array}$ & : & $\begin{array}{r}117 \cdot 39 \\
99 \cdot 69 \\
33 \cdot 89 \\
40 \cdot 92 \\
54 \cdot 18 \\
47 \cdot 23 \\
49 \cdot 02 \\
86 \cdot 93 \\
93 \cdot 98 \\
147 \cdot 54 \\
70 \cdot 20 \\
15 \cdot 17 \\
38 \cdot 70 \\
40 \cdot 82\end{array}$ & $\begin{array}{l}80 \cdot 6 \\
79 \cdot 6 \\
69 \cdot 2 \\
74 \cdot 6 \\
79 \cdot 2 \\
75 \cdot 8 \\
74 \cdot 4 \\
62 \cdot 2 \\
73 \cdot 0 \\
75 \cdot 5 \\
54 \cdot 5 \\
75 \cdot 7 \\
82 \cdot 9 \\
61 \cdot 2\end{array}$ & $\begin{array}{r}99 \cdot 0 \\
106 \cdot 7 \\
124 \cdot 6 \\
116 \cdot 6 \\
114.5 \\
114.0 \\
112.0 \\
84.0 \\
99 \cdot 5 \\
99 \cdot 0 \\
90 \cdot 0 \\
116.8 \\
107 \cdot 9 \\
83.4\end{array}$ & $\begin{array}{l}67 \cdot 0 \\
57 \cdot 4 \\
20 \cdot 0 \\
29 \cdot 7 \\
36 \cdot 5 \\
40 \cdot 3 \\
37 \cdot 4 \\
32 \cdot 5 \\
39 \cdot 1 \\
42 \cdot 0 \\
20 \cdot 0 \\
29 \cdot 9 \\
59 \cdot 6 \\
37 \cdot 4\end{array}$ & $\begin{array}{r}\cdots 41 \\
1709 \\
905 \\
459 \\
1944 \\
2043 \\
4951 \\
460 \\
87 \\
7159 \\
702 \\
275 \\
6160\end{array}$ \\
\hline
\end{tabular}

METHIN, the wild cow of the hills near Cachar. It is the Gavreus frontalis, a large, unwieldy animal, growing to a size beyond that of the buffalo, and is reared by the Kuki and hill tribes for slaughter.

METHONICA SUPERBA. Linn. Gloriosa superba, $\operatorname{Linn}$.

Eesha-nungula, BENG. Kookora-neja, . BENG. Ulatchandul, Longool, ,, $\mid$ Cariari, . . . . HIND.

A pretty flowering plant of India.

METROSIDEROS (from $\mu y$ r $\rho \nu$, the heart of a tree, and sísnpos, iron), a genus of plants belonging to the natural order Myrtaceæ, so named because of the hardness of their inner woods. M. lucida, a beautiful tree, occurs as far south as Auckland Islands, in lat. $50 \frac{1}{2}^{\circ} \mathrm{S}$. M. polymorpha, a tree of the Sandwich Islands, is said to be the plant from which are made the clubs and other weapons employed in warfare by the South Sea Islanders. M. vera, of China? Java, and Amboyna, is said to furnish the iron-wood of China. It grows among rocks. M. diffusa is a tree of New Zealand. The Aki or lignum vitæ of New Zealand, the Rata and the Pohurucawa of the same country, all belong to this genus. M. buxifolia, Allan Cunningham, is the Aki, a rambling sbrub adhering to trees, and climbing by means of its lateral roots to the summits of the loftiest trees in the forests of Wangaroa and the Bay of Islands. Dr. Roxburgh described (ii. p. 477) M. comosa, M. linearis, M. sessile, and M. vera.

Metrosideros tomentosa, A. Cunningham, is the Pohurucawa of New Zealand, a timber tree of the rocky shores of New Zealand and North Island, growing to 80 feet in height, with a stout, short trunk; timber suitable for framework in ship-building, for jetties, docks, sills.

Metrosideros vera, Rumph., a tree of Amboyna and Java. Flower small, white. The Chinese and Japanese value the wood of this tree, which they apply to many purposes, as the making of rudders, anchors, etc., for their ships and boats. The bark is used in Japan as a remedy in mucous discharges, diarrhœa, and dysentery. It is usually mixed with some aromatic, as Penang cloves or nutmeg.-Roxb.; Voigt; Von Mueller; Hogg; Eng. Cyc.

MEWA. HIND. Fruit. Kala mewa is Solanum verbascifolium. Mewa farosh, a fruit-seller, usually of the Mali caste, but in the Mahratta country Brahmans and Kalawant or singers follow the business in towns. The fruit-sellers in the villages are sometimes Muhammadan gardeners.
MEWAR, an independent principality in Rajputana, often called by the name of its present capital, Udaipur. It is ruled by a maharana, in alliance with the British Government. The capital is in lat. $24^{\circ} 37^{\prime} \mathrm{N}$., and long. $37^{\circ} 49^{\prime} \mathrm{E}$., and is 2064 feet above the sca. The territory lies between lat. $23^{\circ} 46^{\prime}$ and $25^{\circ} 56^{\prime} \mathrm{N}$., and long. $72^{\circ} 50^{\prime}$ and $75^{\circ} 38^{\prime} \mathrm{E}$., with a population of $1,443,144$ souls. Mewar is the most ancient but not the most powerful state of Rajputana. The Mewar ruler is the elder branch of the Suryavansi, or children of the sun. Another patronymic is Raghuvansi, derived from a predecessor of Rama; but Rama is the focal point of each scion of the Solar race. To him, the conqueror of Lanka, the genealogists endearour to trace the Solar lines.

The ruling chief is considered by Hindus to be the direct representative of Rama, from whom was descended Kanak Sen, who was the founder of the Udaipur family about A.D. 144. The families of Dungarpur, Sirohi, and Partabgarh are offshoots from the same line. The titles of several Rajput claimants are disputed; but the Hindu races yield unanimous suffrage to the prince of Mewar as the legitimate heir to the throne of Rama, and style him Hindua Suraj, or Sun of the Hindus. Hindu-pati, chief of the Hindu race, is a title appertaining to the ranas of Mewar, but was assumed by Sivaji and many vassal Rajputs.

The Mewar ruler is universally allowed to be the first of the 36 royal tribes, nor has a doubt ever been raised respecting his purity of descent. Many of the royal tribes have been swept away by time, but the genealogist has filled up their place with others, mere scions of some ancient but forgotten stem. With the exception of Jeysulmir, Mewar is the only dynasty of these races which has outlived eight centuries of foreign domination in the same lands where conquest placed them. The ruler still possesses nearly the same extent of territory which his ancestors held when Mahmud of Ghazni first crossed the Indus to invade India; while the other families now ruling in the northwest of Rajasthan are the relics of ancient dynasties driven from the pristine seats of power, or their junior branches, who have erected their own fortunes. This circumstance adds to the dignity of the maharana of Mewar, and is the cause of the general bomage which the maharanas receive, notwithstanding diminution of their power. The capitals of Mewar have been Chitore and Udaipur. After the destruction of the Balhara monarchy of Saurashtra, and two centuries' sojourn of the family in the Bhander desert, Baph or Bappa conquered Chitore, and founded a dynasty in A.D. 727. The hereditary title was changed from Gehlot to Aditya. 'The title of the family has, however, undergone many cbanges. It was first Suryavansa, then Grahilot or Gehlot, then Aharya, and now Sesodia. These changes arise from revolutions and local circumstances.

It was by Bappa Rawal that Muhammad Kasim, the lieutenaut of the khalif Walid, is supposed to have been defeated upon his advance to Chitore after the conquest of Sind. Between Bappa and the accession of Samarsi to the throne of Udaipur a period somewhat exceeding four centuries intervened. In 1193, the sovereignty of Chitore was given to the younger branch; the 
elder having been expelled, fled to the wilds, founded the city of Dungarpur, and became the ancestor of the ruling family of that state. In 1201, Rahup was in possession of Chitore. He changed the title of his family and tribe from the clan name of Gehlot to the subdivisional name of Sesodia, and that of its prince from Rawal to. Rana. From Rahup to Lakumsi nine princes of Chitore were installed. In the rule of this last-named prince (A.D. 1275-1290), Ala-ud-Din besieged Chitore; and in A.D. 1303 the jmperial forces captured and sacked it. It was, however, almost immediately afterwards recovered by Hamir, who then ruled in Mewar. On the 15th of March 1527, Baber drew up his army in front of the entrenchments. A desperate conflict ensued for several hours, in which Baber ultimately obtained a decisive victory, and Rana Sanga retired with the wreck of his gallant army towards the hills, resolved never to enter his capital except in triumph.

Rana Udai Singh was the youngest son of Rana Sanga, During his rule in 1568, Chitore was taken by the emperor Akbar, with great slaughter. On the loss of his capital, the rana retired to the valley of the Girwa, in the Aravalli Hills, where he founded the city of Udaipur, henceforth the capital of Mewar. But Akbar's successor, Jahangir, while striving for the entire subjugation of Mewar, was twice defeated by Rana Umra.

A section of the Aravalli range of mountains extends over the south-western portion of the state, from the city of Udaipur to the frontier of Sirohi, whence it stretches northwards through Kumalmir towards Ajmir, separating Udaipur from Jodhpur. Northward of Kumalmir, this mountain tract is called Mhairwara; its breadth here varies from 6 to 15 miles, and its deep and rugged valleys and gorges have in all ages afforded haunts to the Bhils, Minas, and Mhairs, and other aboriginal or half-blood tribes. Southward of Kumalmir the-range is inhabited by communities of the aboriginal races acknowledging no paramount power, and paying no tribute. Aborigines occupy the several hill ranges, viz, the Mhairs on the north-west, the Bhils on the south, and the Minas on the north-east. The Mhairs and Minas live in villages; but Bhils generally occupy a pal, that is a number of houses, each built upon a hillock at some little distance from its neighbour. A pal, therefore, may cover several square miles of ground. The object of the Bhils in thus building their dwellings is to render it impossible to surprise a whole village at once. A single individual may be arrested, but the warning cry which he will utter gives the alarm to the whole community, and in a few minutes, the war-cry being taken up from hill to hill, the country seems suddenly to swarm with semi-naked savages, armed and prepared to attack the intruder. The Bhils are under the partial control of their own chiefs, but rarely acknowledge any other power. And it is generally difficult for the Udaipur darbar to coerce them, for the climate is unhealthy, supplies are scarce, and the country is extremely difficult. There are few wilder or more lawless tracts throughout the length and breadth of the Indian Peninsula.

The zinc mines of Mewar were once very pro- ductive, and yielded no inconsiderable portion of silver and gold; but the caste of miners is extinct, and political reasons during the Moghul domination led to the concealment of such sources of wealth. The most celebrated of these mines are undoubtedly those of Jawar, where the ore is found in veins 3 or 5 inches thick, and sometimes in bunches in quartz rock, and mixed with other stone. The pieces are broken with a hammer, and freed from the quartz rock with which it is mixed. The pure ore, being very friable, is then pounded and freed from quartz, and placed in crucibles some 8 or 9 inches high and 3 inches diameter, with necks 6 inches long and half an inch in diameter. The mouth being fastened up, the crucibles are inverted and placed in rows on a charcoal furnace, when the ore is fused in about three or four hours. If pieces of the quartz are allowed to remain with the ore, the crucibles break. From each crucible the quantity of metal collected does not vary much. Copper of a very fine description is likewise abundant, and supplies the currency. Surma, or the oxide of antimony, is found on the western frontier. The garnet, amethystine quartz, rock-crystal, the chrysolite, and inferior kinds of the emerald family, are all to be found within Mewar. Iron is abundant on the now alienated domain on the Chambal, but lead least of all. Marble quarries also added to the revenue. The rich mineral products enabled the Mewar family long to struggle against superior power, and to raise those magnificent structures which ornament their kingdom. In Mewar An was the oath of allegiance ; in Col. Tod's time three things in Mewar were royalties, -a subject could not meddle with the An or oath of allegiance, the Dan or transit dues on commerce, and the Kan or mines of the precious metals. The rana of Mewar is the dewan or vicegerent of Siva, and when he visits the temple of Eklinga he supersedes the high priest in his duties, and performs the ceremonies.

The shrine of Eklinga is endowed with 24 large villages from the fisc, besides parcels of land from the chieftains.-Tod; Captain Brooke; Aitcheson.

MEWASI, a predatory, turbulent, tribe in North Gujerat. They occupy several villages in the ravines in the Nariad pargana, north of the Mahi river. They are settling to agricultural pursuits.

MEWAT, a tract lying south of Dehli, and including parts of the British districts of Muttra and Gurgaon, a considerable portion of Ulwar, and some of Bhurtpur. For many centuries its people were predatory, and gave great trouble to the Dehli rulers. They are now mostly all Muhammadans, but are of ancient Hindu race; and in the time of Prithi-raj, the chief of Mewat was one of his vassals. Raja Mangal, of Mewat, a Jadun Rajput, married a sister of a wife of Prithi-raj. In 1265 , about 100,000 were put to the sword, and a line of forts was drawn along the foot of their hills. The whole of its towns were levelled to the ground by Jess-raj. The ruling race are called Mewati or Khanzada. They are famous in the history of the Dehli empire, under which they were distinguished soldiers. Since the close of the 18 th century the territory has merged into Ulwar and Bhurtpur. 
The mass of the population are the Meo. For many centuries they were highly predatory, and they are atill noted cattle-lifters. They are different from the dominant Mewati race, who, however, are also Muhammadans, but are of the Jadu race. The Meo of Mewat are in fifty-two clans, of which the twelve larger are called Pal, and the smaller Got. Others of them are in Muttra, Bhurtpur, and Gurgaon. They claim to be Rajputs, but many of them are supposed to be of Meena descent. Though Muhammadans, they keep several Hindu festivals, - the Holi, Jan'mashtmi, Dassera, and Diwali ; and on the Amavas, or monthly conjunction of the sun and moon, Meo, the Ahir, the Gujar, etc., cease from labour. They do not marry in their own clan or pal. They sometimes sell their daughters.-Malcolm's Central India; Rennell's Memoir; $T$. of $H$.; Campbell, p. 103 ; Tod's Rajasthan.

MEYA or Mya, a martial race of Kattyawar and about Junagarh. In the year 1872 , when the nawab of Junagarh was at Bombay, a Charun girl named Nagbai pretended to be an incarnation of a Charuni Nagbai who flourished some centuries ago. She soon got a gathering of many persons, chiefly Meyas, with also some remnants of the Churasoma dynasty that preceded the present Baba rulers of Junagarh. They strove for the ousting of the nawab, and restoration of the Hindu dynasty, which had been driven out about A.D. 1714. With the consent of the Agency, the Meyas were disarmed, and some arrests were made, among them the son of Omra Meya. He was released, and a general rising occurred of the Meyas, who proceeded to the Camera Hill in the Gheer in a body, under Omra's leadership. The Meya are almost as bold and resolute as the Waghir.

MEYKANDA TEVAR is said to have been born at Vennai-nullur, on the river Pennai. His teacher was Paranjoti Tambiran. The Sivagnana Potam, his principal work, translated into English by the Rev. H. R. Hoisington, is considered of grent authority.

MEYT AIS, or Burnt Island, called also Bird or White Island, lies in lat. $11^{\circ} 13^{\prime} \mathrm{N}$., and long. $47^{\circ} 16^{\prime} 30^{\prime \prime} \mathrm{E}$., is a barren rock 430 feet high, $5 \frac{1}{2}$ miles from Ras Hambais, the nearest point on the mainland. Many of the aged men, natives of the place, return to Meyt to die.

MEZEREON, the Mazreoon of Persian writers, is the Daphne mezereum. It is employed in medicine. D. gnidium, D. laureola, spurge laurel, and other species, are also employed in Europe. The bark of the latter forms much of what is used, even in England, for Mezereon.

MEZZALE. Burm. A tree of Amherst, Tavoy, and Mergui. Its wood is used for rulers, mallets, and walking-sticks; is of very haudsome streaked grain, like palmyra wood.-Captain Dance.

MHAIRWARA, a hill tract in the British district of Ajmir-Mhairwara, Rajputana, bounded on the north and west by Marwar and Ajmir, east and south by Mewar and Ajmir. It comprises a narrow strip of territory, 70 miles in length, varying in breadth from 1 to 15 miles, composed of successive ranges of huge rocky hills, the only level country being the valleys running between them, It was inhabited by the Mhair or Mer (see Mer), a predatory race of aborigines. Colonel Dixon's efforts were directed to civilising them, and gradually they became attached to industrial pursuits. He built a new town, strong and well planned, with two miles of wall as a defence, and encouraged strangers, particularly shopkeepers and banias, to settle in it. Civilisation dawned on the face of those long-troubled hills in some of its most benignant forms. The Mhairwara Battalion transformed the wild mountaineers into brave and disciplined soldiers, whose influence on the pacification of the country cannot be overvahed. Mhairwara rapidly underwent a great social change.-Cole.; Camplell, p. 45.

MHANG or Mang are scattered through all the northern parts of the Indian Peninsula, in the Bombay Presidency, Gujerat, Kandesh, the Konkan, and Kolbapur. They dwell outside the walls of the villages. They are tanners, workers in raw hides and leather, shoe and harness makers, messengers, scavengers, and executioners. They are never horse-keepers. Their avocations are the most abject, and only a very few have ever been known to have the ability to read or write. They claim the right to have for food all cattle and camels and horses that die of disease, but in some villages this is disputed by the Dher; and in the village of Dangopura, in 1866 and 1867, this point was for twenty months under litigation, the ultimate decision being in favour of the Dher.

In the Northern Dekhan are the sections Mhang Garoro, Hollar Mhang, Dekhan Mhang. The Mhang Garoro are also styled Pharasti or migrants, as they have no settled abode, but move from place to place begging. Their men and women assume other clothes, and smear their foreheads with the red kuku, a mixture of turmeric and safflower. They are also conjurors and sleight-of-hand adepts, from which they have their name Garori. The men also beat the dholak when practising their conjuring tricks.

The Hollar Nhang are village musicians; at marriages, play on the saunai, a wooden musical instrument, and beat the dafra; they are also labourers, and go messages.

The Dekhan Mhang make brooms and mats from the date palm; are also labourers, bring wood, marry girls under age, fall at the foot of the god Hauman, but worship at a distance, not being allowed to approach the idol. They, like the Dher and the humble native Christian, are also prohibited approaching the house of any Hindu, but stand some yards off and intimate their presence by calling out baba, or maharaj, or ayer, i.e. father, great chief, lord, and, as with the Dher, everything they have brought and everything they touch, as also the place they touch, is unclean. If it be a metal dish it is passed through fire, and if cloth or other material, it is washed, or sprinkled with water, or placed on the ground for earth purification. They mount on horseback in procession to their marriage, a privilege which they prohibit to the Dher, and to the Teli or oilman.

The Mhang worship the leather ropes which they make. They also make cakes, which they place in the ground, and over it five stones and a lamp, and worship these. They worship geuerally all the local deities or village gods, the Ammun, Ai, Mata, Musoba, Mari Ai, Devi, Kandoba, etc., and the Mangir or ghosts of deceased relatives. Their Mangir is the form of a human being engraved on silver or copper, intended to represent a deceased father or mother; sometimes it is 
a casket of copper, containing a silver figure of a man. The Mangir is worshipped at the dewali and dassara $\bar{a}$, and at $\bar{a}$ mas or moonless nights, and full moon and anniversaries. The figure is worshipped by washing and burning frankincense. They bury or buri their dead. They place the corpse in the ground, then bring a potful of water from the river, pour it on the body, and cover the dead with earth; after three days they take food and place it over the dead.

MHLECHCHA, a term applied by the Aryan immigrants to the peoples whom they found occupying India. This name long continued to be applied to all the unsubdued tribes in India. The aboriginal inhabitants of India seem to have been subdued and transformed from Mhlechchas into Sudras by slow degrees. In the age of Menu they retained their independence, under the appellation of Mhlechcha in Bengal, Orissa, and the Dekhan; but in the earlier period which is referred to in the historic legends of the Mahabharata, the Mhlechcha and Dasya are mentioned as disputing the possession of Upper India itself with the Arya, and, in conjunction with certain tribes connected with the Lunar line, they succeeded in overrunning the territories of Sagara, the thirtyfifth king of the Solar dynasty. The Mhlechcha are alluded to in the Mudra Rakshasa, a fact corroborative of that drama's being written in the 11 th or 12 th century A.D., when the Pathan princes were pressing upon the Hindu sovereignties. To the Hindu, every man not twice born is a Mhlechcha.-Hind. Theat. ii. p. 251.

MHOW, a town and British cantonment in Holkar's dominions, 14 miles S.W. of the Indore Residency. The town is built on the Gumber river, in lat. $22^{\circ} 35^{\prime} \mathrm{N}$., and long. $75^{\circ} 48^{\prime} \mathrm{E}$. The cantonment is $1 \frac{1}{2}$ miles to the S.E., 2019 feet above the sea.

MHUD, a beer made by the Abor. It is palatable when fresh brewed.

MHYE rises in a small plain five miles west of Amjherra, and shortly after passing Bhopawur pursues a northerly course till it reaches the upper confines of Bagur, where the boundary hills give it a sudden turn westward past Mongana. Soon, however, the high mountains of Mewar bend it south, and this course it pursues, with little deviation, till it falls into the sea in the Gulf of Cambay, near the town of that name. It is not navigable above 12 or 15 miles from its mouth, owing to its numerous shallows.

MIA. Hind. The temple of the Sintu creed of Japan.

MIAKO, a town in Japan. Fudsiyama is a high volcanic mountain of Japan, which tradition reports to bave risen in one night, and as it rose there occurred a depression in. the earth near Miako, which now forms the lake of Mit-su-noumi. In A.D. 864 the mountain burst asunder from its base upwards, and at its last eruption in 1707 it covered Yedo with ashes. It is a sacred mountain. It is crested with snow, and presents the appearance of a truncated cone; the gathering of a white cloud around its summit is a sign of bad weather. It is occasionally ascended by Japanese pilgrims for the worship of the god of the winds.

MIAN. Hind., Pers. Sir, master; an honorific title applied to holy men; a respectful term used by a Hindu to a Muhammadan, who himself generally applies it to a pedagogue or to a son. The village schoolmaster has always the honourable epithet of Mean-ji. This word for Sir is known to the Bedouins all over El-Hejaz; they always address Indian Muhammadans with this word, which has become contemptuous, on account of the low esteem in which the race is held.-Burton's Mecca; Tod's Rajasthan.

MIAN, a branch of the Kaka Khel Khatak, in the Hashtnagar division of the Peshawur district. They are carriers.

MIANA. HIND. A palanquin, a sword sheath. MIANA, n predatory race in Kattyawar. The Miana of Mallia in Mucha-Kanta, on the banks of Mucha river, have a thakur, but own allegiance only to their own chowhattia or heads of tribes.

MIANA, also called Mai, Miani, or Moana, a tribe in Sind, fishermen and boatmen. The Miana form a large tribe, apart from either the Jat cultivator or the Baluchi. They are the most active aud athletic race in Sind, with a buoyancy of spirits and general frank bearing unknown to the other classes. All have villages immediately on the bauks of the river, their boats and nets furnishing all that is required for their maintenance. In many parts of the stream, especially near lake Manchur, whole families live entirely after the Chinese fashion in their boats, having no other habitation. The women share the labour equally with the men, and a sturdy lass is generally seen steering or paddling the boat whilst the man works at the nets, a child being often suspended in a network cot between the mast and rigging of the craft, which is always very small and light for the advantage of easier navigation amongst the shoals and creeks. The Miana is the only pilot to be trusted in its intricate channels. The pulla fishery, for which the Indus is so celebrated, is conducted by this people. Placing on the water a large earthen vessel, and commending it to the care of Allah, the fisherman casts himself on it in such a manner that the mouth of the vessel is completely closed by the pressure of his stomach ; he then paddles himself by means of the action of his hands and feet into the centre of the stream, holding deep in the water a forked pole about 15 feet in length, to which is attached a large net; in his girdle he carries a small spear, and a check string attached to the net indicates the moment when a fish is entangled. The spear is used to kill the fish when drawn up after capture, and the jar receives the spoil. The Miana are dissipated, and a large proportion of the courtesans and dancing women of the country are from this tribe: they are of very dark complexion, but possess regular features, and some of the women would be considered remarkably handsome. The Miana are also noted for the manufacture of mats and baskets, which are beautifully woren from the high reeds and strong grasses growing on the edge of the river. The Miana, when found near towns and villages, occupy a distinct quarter, generally outside or apart from the other inhabitants. Here they sell spirits, the men beat drums and sing, and the women dance and perform all the usual acts of courtesans calculated to allure the passing stranger._-Postans' Personal Observations, pp. 58-60.

MIANEE, a small village in Sind, 6 miles north of Hyderabad city. Here Sir Charles Napier, on the 17 th of February 1843 , with a force of 2800 men 
and 12 pieces of artillery, encountered a Baluch arny numbering 22,000 , strongly posted on the banks of the Fulali. The enemy were totally routed, 5000 men being killed and wounded.

MIAS. JAV. The orang-utan of the Malay, species of Pithecus. One kind, called Mias chappan or Mias pappan, has the skin of the face broadened out to a ridge or fold at each side. One killed by Mr. Wallace was 7 feet 3 inches across the arms, and 4 feet 2 inches from head to heel. The small mias is called by the Dyak race Mias kassir. They live in the low swamp in forests. Their food consists of fruit, with leaves, buds, and young shoots. They rarely descend to the ground. The Dyaks say that only the crocodile and python will attack the orang-utan; that when fruit is scarce it goes for food to the banks of rivers and to the sea, and the crocodile tries to seize it, but it gets on the crocodile, beats him with its hands and feet, tears him and kills him by main strength, tearing open his jaws and throat. The python it seizes and bites and kills. The orang-utan is confined to Borneo and Java. A full-grown mias is quite a match for a naked man, and generally before he can be killed contrives to bite off two or three fingers, or otherwise maim the individual. Many Dyaks are to be seen thus mutilated by them.

Mias chapin is Pithecus curtus. Mias pappan, a species of orang-utan of Borneo. Mias rambi, Pithecus Brookei of Borneo.-Wallace, i. 54, 60.

MIAU-TSZE or Miao-tzu and Mau-tzu, are aboriginal tribes in the various highlands in the $\mathrm{S}$. and W. Provinces of China proper. They are regarded by the Chinese as barbarians, and are designated by derogatory and contemptuous appellations. Recent travellers, and particularly Mr. Colquhoun, in his Travels across Chryse, have given notices of them : the more important are as follows :-

Yuh-lun follow agriculture, and weave cloths. They are skilled archers, and excel in the use of spears and javelins.

Yang-tung-lo-han are farmers, traders; their women rear silk-worms.

Kih-mang-ku-yang live in excavations in high cliffs, some reached by ladders. Their district is in Kwang-shun-chau.

Tung-miau cultivate cotton, and enter China as labourers. They dwell in Tien-chu, near Kin-ping.

Shwui-kia-miau, i.e. the water-family Miau of the Li-po district. The men are fishers and hunters, and the women spin and weave.

King-kia of Li-po-hien have a festival on the last day of the 10 th month, and sacrifice to demons. In the 11th month, the unmarried folk dance and sing in the fields, and choose life partners for themselves. This is called marrying at sight. Both men and women wear blue-flowered handkerchiefs on their heads.

Tsing-miau dwell in the Ping-yuen-chau. They are farmers, but not skilful; they weave clothes for themselves.

Luh-ngeh-tsze of the Wei-ning district in Ta-ting-fu, are both black and white; the women wear long petticoats. They bury their dead in coffins ; and, after a year, they sacrifice, and reopen the graves, brush and wash the bones clean, wrap them in cloths, and reinter them, and thus clean them annually for seven successive years. The men wear $\pi$ slender head-dress.

Peh-ngeh-tsze, or the White Foreheads, dress in white men with short, and women in long petticoats.

Yen-kia-man dwell in Sz-nan-fu, and are fishermen.

Tung-kia-miau inhabit Li-po-hien. They wear blue dyed cloths which reach to the knees. They grow cotton and weave; they are illiterate, and put notches on sticks as memoranda. On New Year's day they make offerings of fish, flesh, rice, and spirits.

Kiu-ming and $\mathrm{Ku}$-sing, cultivators in Fuh-shan-chou, are violent, quarrelsome, treacherous, and given to drink, readily seizing weapons in their drunken bouts.

Mau-tau-miau, farmers in the Hia-yu and $\mathrm{Ku}$-chau districts. The women dress and ornament their hair with fan-shaped garlands of silver thread, fastening it with a long skewer; they wear two ear-rings in each ear, and n necklace. The cuffs and edgings are worked with figured silk. Paternal aunts' daughters must marry their cousins.

Tsing-kiang-heh, or black tribe of Tsing-kiang, wear silver ornaments, and the young folk select their own partners.

Lu-ku-heh, or Black Miau of Pa-chai and Tsing-kiang, are pastoral, but dwell in houses, their cattle below. They are diligent farmers. Their dead are kept in coffius for a period, and all the accumulated dend are then interred.

Pa-kchai-heh, or the black tribes of the eight cantonments of the Ta-yun-fu district, are violent. They fringe their sleeves with flowered cloth. They erect a 'Malang' or hall, at which the unmarried assemble and pair off.

Heh shan, or tribes of the black hills of Tai-kung in Tsing-kiang, live in the recesses of the mountains, and are predatory.

Heh-sang-miau, black subdued tribes of Tsing-kiang, are highly predatory.

Kau-po-miau, or Crown Board Miau, are usually black. They cultivate on the higher plateaux.

Yu-fah-miau of Sien-tien in Kwei-ting, at marriages and solemn periods sacrifice dogs. The men wear short petticoats, the women short bodices and long petticoats, and fasten their hair with a long bodkin.

Tsing-chung-miau live in Tai-kung-ting. The men are notoriously predatory, and ransom their captives ; their women plough and weave.

Li-min-tsze of Ta-ting-fu, Kien-si-chau, Kwei-yang-fu, Ngan-shun-fu, etc., are traders, and rear cattle and sheep, spin and weave. They are the most civilised of all the Miau tribes.

Peh'rh-tsze, or the Whites, live in Wei-ning-chau, rear cattle and horses.

Peh-lung-kia, or White Dragon families, live in the district of Ping-yuen in Ta-ting-fu. They dress in white, and collect lac and forest produce. They are a moral race.

Peh-chung-kia live in Li-po-ting, and are agricultural. The men wear a fox-tail on their heads. The women are small but fair and well made, and wear blue-dyed clothes.

Tu-kih-lau live in Ka-ning-chau, and plait grass into clothing. They are labourers to the Ko-lo people.

Che-chai-miau, or 600 wild Miau families in $\mathrm{Ku}$-chauting, are descendants of 600 soldiers of the army of Ma-san-Pau, who took refuge there in the time of Tai-tsung of the Tang dynasty. The men are variously occupied. The unmarried arrange their own weddings.

Si-ki-miau live in the Tien-chu district. The women have green cloth wound round their thighs, with petticoats reaching to the knees. The young people select their own partners, and after the birth of a child a marriage present of a cow is given.

Hu-lu of Lo-kuk, in the Ting-pwan-chau district, are violent and predatory, despising agriculture.

Hung-chau-miau of Li-ping-fu are agricultural, and the women spin and weave cotton cloths and grass-cloth. The Hung grass-cloth is famed.

Heh-lau-miau of Tsin-kiang-ting dwell on the plateau. They have a town hall where public matters are discussed.

Heh-kioh, or Black-leg Miau of Tsin-kiang-ting, are predatory, carrying spears and knives. Before an expedition, they draw omens from the fighting of two crabs. A peaceful man could not get a wife.

Twan-kwau-miau, dwelling in Ta-yan-fu. The men have short dresses and broad trousers. The women wear petticoats, and have their body exposed from 
the waist upwards. They are very intemperate. They collect and sell a red grass.

Narrow-headed Miau of Yang are agricultural, the women taking their share in the field work. Both men and women dress their hair into a peak. The first day of the 11th month is held as a festival.

Lang-tsze-miau of Wei-ning follow the couvade practice. On the birth of a child, the husband takes to bed, and the wife cooks food for the husband, and goes to work in the field, and suckles the child. Only after a month the husband goes abroar. When a parent dies, so soon as life is extinct, they twist the head round backwards, so that, as they say, he can see who is behind him.

Lo-han-miau live in Tau-kinng and Pa-chai-ting, and are Buddhists, making offerings on the third day of the third month. The men let their hair fall loose behind, and wear a fox-tail on their heads.

Luh-tung-i, or the Six-valley Barbarians, live in Liping-fu, and are able to read and write. The women spin and weave, wear many-coloured clothes, and bind their legs with cloths in lieu of buskins. Unmarried persons exchange portions of their dresses, and, on a fortunate day, the spinsters, each carrying a blue umbrella, convey the bride to her father's home, where the bridegroom privately visits nightly, until the first child is born, on which the bride is taken to her husband's home.

Crow-miau live in Kwei-yang; they fringe the edges of their clothes and sleeves with white cloth. They dwell on the higher hills, and cultivate millets, and bury their dead on the summits of the hills.

Other tribes mentioned by Mr. Colquhoun are the Ching-pao or Ka-Khyen, the Lao, Laos, Pai, Thai or Shan, Po-Loung, Pou-La, and Yeou.-A.R. Colquhoun; Cooper: See China.

\section{MICA.}

Kobub-ul-arz,

Arab. Glimmer, DA., DUT., Ger

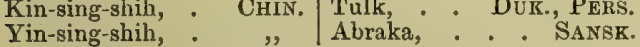

Mica is one of the constituents of granite, gneiss, and mica-slate, and gives to the latter its laminated structure. It also occurs in granular limestove. It is found abundantly in India and other parts of the world. The principal mica mines of Behar are on the northern face of the Vindhya Hills, where the three districts of Beliar, Monghir, and Ramgarh meet. The most westerly mine is situated 37 miles in a S.E. direction from Gya, and is in the district of Behar; the most easterly mine is about 60 miles distant in Zillah Monghir; the whole of the intermediate 60 miles being more or less productive of the mineral. The mica reaches the surface in three different states, viz. the good, hard, and serviceable mineral; the soft, wet, and flimsy mineral; and the chipped and powdered mineral. The tests as to whether the mica is good for anything, or whether, as the natives say, 'it is alive,' are its firmness, specific gravity, and the power of reflecting the countenance free of contortions; the latter test showing the perfect parallelism of its individual plates, and consequent likelihood to split well ; the heavier the mineral and the more perfect the reflection, the more valuable is the mineral considered; all the plates not standing the necessary test, or of a soft and flimsy nature without any of the brilliant sparkle of the better sort, the natives call 'dead mica,' and it appears to be in a state of decay. The plates of the superior kind are used in all the large Gangetic cities and towns by the native draftsmen, whose beautiful productions in body colours must be familiar to most people; by the lamp and toy-makers; by the Muhammadans for ornamenting their tazia or tabut, as well as for ornamenting umbrellas and boats, and for making artificial flowers. The second and third sorts are pounded and used for ornamenting toys, pottery, the inside of houses, for sprinkling over clothes and turbands at feasts, the sparkle from which by torch-light resembles diamonds; but the great consumption of the inferior mineral takes place during the Holi festival, during which period the abir of pounded mica, mixed with the flour of the small grain Kodu, Paspalum stoloniferum, Linn., and coloured with some red-colouring matter, is freely sprinkled over the votaries of those bacchanalian oryies. Mica is the soft sbining scaly part of granite, and is very liable to decay from constant damp; it passes into a greasy or soapy earth or loam. Mica is mixed with lime to form a beautiful glistening plaster for native buildings.

In Russia it is used as a substitute for glass, and hence it is called Muscovy glass. The very thin laminæ are employed for examining objects under the microscope. Slips of mica afford a convenient substitute for platinum foil in chemical experiments on the effect of heat on organic bodies, and they are useful for covering photographs. It readily splits into transparent, elastic flakes. It consists of nearly equal parts of silica and magnesia, and about 6 per 100 of lime. Mica has been used as a substitute for glass; in the taking of collodion pictures, the collodion film adheres to it very firmly. On it negatives can be as easily carried, without injury, in a portfolio, as on paper, and positives backed with colour and a plain varnish can be pasted, without risk of deterioration, in a book. The mica being attached to a piece of glass by its back being moistened, may be then coated, exposed, and developed, after which it may be detached and fixed. Upwards of 1000 maunds, or nearly 40 tons, are sent to Calcutta annually, of the value of Rs. 7500 at Rs. $7 \frac{1}{2}$ per maund.-Capt. Sherwill, Beng. As. Soc. Jour., 1851; Cat. Ex., 1862; O'Shaughnessy.

MICHAEL or Mikail, according to Muhammadan belief, the angel who has charge of heavenly bodies, of breathing creatures, and of the angels tenanted in the seventh paradise.

MICHELBORNE, SIR EDWARD, obtained from James I. of England, in 1606, a licence to trade to Cathay, China, Japau, and Cambaya. On arrival in the east, he plundered the native traders among the islands of the Archipelago. He obtained considerable booty, but brought great disgrace on the English name, which interfered with the English Company's trade at Bantam.

MICHELIA, a genus of plants of the order Magnoliaceæ, some of which furnish useful woods. M. kisopa, Buch., is a tree of the forests of Nepal. M. aurantiaca, Wall., Sa-ga, BurM., of Pegu, has large orange - coloured, fragrant flowers. M. doltsopa, Buch., of the forests of Nepal; wood fragrant, excellent, used for house-building. M. excelsa, $B l$., Magnolia excelsa, Wall., is a Nepal and Darjiling tree; yields valuable timber, of a fine texture, at first greenish, but soon changing into a pale yellow. M. lanuginosa, a Magnolia of the Himalayas. M. oblonga, Wall., a tree of Khassya. M. suaveolens, the Champaca of Java ; its small flowers are in much esteem by the Chinese women. Mr. Gamble notices M. Cathcartii, Nilagirica, and Punduana. M. fuscata, $B l$. 
the Magnolia fuscata, Andr. B. Repos., a tree of China. Flowers largish, cream-coloured, purpleedged, dark, and fragrant. Flowers in March and April, and fruits in October.-Bennett ; Voigt.

\section{MICHELIA CHAMPACA. Linn.}

Champaka, . BENG. Bongas jampacca, Malay. Champa, . : ", Sappoo, . SINGH. Sa-ga, : : BüM. Shembugha, : ТАM. Sumpaghy, : . CAN. Champakamu, : TEL. Chen-poo-kia, : CHIN, Kanchanamu, URIYA.

A large tree of most parts of the $\mathrm{E}$. Indies and China. It grows in the Panjab at Kalka and Kangra, and at Chamba at 2000 to 3000 feet. Those at Chamba attain to 7 or 8 feet in girth, and are 60 or 70 feet high. Ploughshares are occasionally made of the wood. In Ceylon it is used for drums, carriages, palanquins, and in buildings; it is prized for well-works, verandah posts, and also for furniture, as it polishes well, though it is apt to warp. It flowers and fruits nearly all the year, and has large, deep yellow, intensely fragrant flowers. In China, its bark is used with that of other Magnoliaceæ to adulterate ciunamon.

The beautiful golden-coloured flower is held in high estimation by the Hindus, by whom it is dedicated to Krishna, and is one of five with which the Hindu Kama, god of love, ornaments his arrow. When Vasant'ha, the personified spring time, is preparing the bow and shafts for his friend,-

'He bends the luscious cane, and twists the string

With bees, how sweet! but oh! how keen their sting! He with fine flowerets tips the ruthless darts,

Which through five senses strike enraptured hearts :

Strong Chumpa, rich in odorous gold;

Warm Amer, nursed in heavenly mould;

Dry Nag-Kesur, in silver smiling;

Hot Kittikum, our sense beguiling;

And last, to kindle fierce the scorching flame,

Love-shaft which gods bright Bela name.'

Sir William Jones says its aromatic scent is so strong as to be offensive to bees, which never alight upon it. Rheede informs us that the powder of the bark of the root of this tree is given to excite the flow of the menses. The aromatic Sumpunghee oil of Madras is obtained from this tree. It is one of the few Indian trees embalmed in English soug,-

'The maid of India, blest again to hold

GIn her full lap, the Champac's leaves of gold,

Thinks of the time when, by the Ganges' flood,

Her little playmates scattered many a bud

Upon her long dark hair.'

Its rich orange, exquisitely fragrant blossoms are used by Burmese maidens to adorn their long black hair. The bark is bitter and aromatic, and appeared to Dr. O'Shaughnessy to possess the properties attributed to the Magnolia glauca. It may be given in powder in intermittent fevers, in doses of from 10 to 30 grains.

MICHELIA NILAGIRICA. W. Ic., Zenk. M. Pulneyensis, Wight.

Pila champa, - HIND. Shembugha maram, TAM. Walsa-pu, . SINGH. Sampanghy maram, ",

Var. a. Ovalifolia, Wight; petalis cum sepalis sæpissime 9.

Var. b. Walkeri, H. f. et T. (M. Walkeri and M. glauca, Wight); petalis cum sepalis sæpissime 12.

This large tree grows in the Central Province of Ceylon up to elevations of 3000 to 8000 feet. It is rare in the Walliar forests, being alpine in its tendencies, and is common on the Neilgherries.
Its wood is strong, close, fine - grained, and straight; a pretty olive-coloured mottled wood, not heavy, but too highly hygrometrical to be useful in other form than rafters or beams, it could be turned to account in house-building, and might with advantage be creosoted. In Ceylon, the most typical form of this plant is that called M. Walkeri by Dr. Wight. Its beautiful goldencoloured flowers are held in high estimation by the Hindus; the bark of the root of the tree is used medicinally in some female complaints. At the Madras Exhibition of 1855 , a plank from this tree, contributed by Captain Cunningham of the Mysore Commission, had the extraordinary dimensions, - length $11 \frac{1}{2}$ feet, breadth $4 \frac{1}{2}$ feet, thickness 3 inches. The specimen was apparently from a tree of very great age.-Thuaites; Wight; Beddome; M. E. J.R.

MICO, a vegetable butter prepared in Japan from the Dolichos bean. - Simmonds.

MICROLENA SPECTABILIS? a tree growing at the foot of the Himalaya, which yields fibres for rope-making. It is one of the most numerous timber trees of Pegu, but the Burmese do not make use of it.-Royle; $M^{6}$ Clelland.

MICROLONCHUS DIVARICATA. - ?

Biramdandi, . PaNJab, / Rathomandi, . PanjaB.

Used in special diseases to purify the blood.Powell, i. p. 357.

MICROMELUM INTEGERRIMUM. W. and A. Bergera integerrima, Buch., a shrub which grows on the banks of the Megna river. It has small greenish-white, fragrant flowers. M. hirsutum and M. pubescens are also known.-Roxb. ii. p. 376 ; Voigt, p. 149.

MICROMERIA MALCOLMIANA, Dalz, used as a carminative, equal to peppermint.-Dalzell.

MICRONESIA, a designation proposed by Mr. Logan for part of the Indo-Pacific islands, peopled by the Negrito. The Indo-Pacific islands he names Oceanica.

MICRORHYNCHUS SARMENTOSUS ? a sand-binding plant, growing on the shores of the Bay of Bengal.

MIDDLETON, SIR HENRY, an officer in the Maritime Service of the English E. I. Company, who commanded in their sixth voyage in 1610. Sent out for the sixth voyage to carry on a legitimate trade, he converted the expedition into a marauding one ; in short, turned pirate. By plundering the trading vessels passing to and from the Red Sea, he obtained large quantities of goods, with which he proceeded to the Moluccas, where he died. See Lancaster.

MIDNAPUR, a town and a district in the Bardwan division of Bengal. The district lies between lat. $21^{\circ} 37^{\prime}$ and $22^{\circ} 57^{\prime} \mathrm{N}$, and long. $86^{\circ} 45^{\prime}$ and $88^{\circ}$ $14^{\prime} \mathrm{E}$. It is one of the most important districts of Bengal. Its chief rivers are the Hoogly and its three tributaries, the Rupnarayan, the Haldi, and the Rasulpur. The aboriginal tribes belong chiefly to the hills of Chutia Nagpur and Bankura, and $d$ well for the most part in the west and south-west of the district; the most numerous of them are Santals and Bhumij.-Imp. Gaz.

\section{MIDSUMMER ROOT.}

Sang-pwan-hia, . CHIN. | Fa-pwan-hia, . . CHIN.

In China, Pinellia tuberifera, Arisæma ternatum, Arum macrorum, and other aroids are gathered in the middle of summer, and have received this name. Their poisonous properties 
are exhausted by frequent soaking and drying, and are then powdered and used as sulphate of potash. -Smith.

MIGI, a tribe dwelling to the north of the Aka, north of the Assam valley. They and the Aka intermarry; they are the more powerful; they rarely visit the plains except to support the Aka in mischief.-Dalton, p. 37.

MIGNAN, CAPTAIN R, author of a Winter Journey through Russia, the Caucasian Alps, and Georgia, and thence into Kurdistan.

MIGNONETTE, Reseda odorata, is a general favourite in all countries, and grows in great luxuriance on the plains of India during the cold months.

MIGRATION of birds to and from Southern Asia, says Mr. Hodgson, seems to take place across the mountains of Nepal. The wading and natatorial birds, generally, make a mere stage of the valley on their way to and from the vast plains of India and Tibet, the valley being too small, dry, open, and populous for their taste, especially that of the larger ones. Some, however, stay for a longer or shorter time in their vernal and autumnal migrations ; and some, again, remain throughout that large portion of the year in which the climate is congenial to their habits. Of all of them, the. seasons of arrival both from the north and from the south are marked with precision. They all arrive in the valley of Nepal, from the north, towards and at the close of the rains; and all as regularly reappear from the south upon, or soon after, the cessation of the hot weather.

The jackdaw, Corvus monedula, of Europe, Siberia, Barbary, West Asia, Peshawur valley, and Kashmir, may be seen in flocks in winter in the northern frontier of the Panjab, associated with the Cornish chough and the rook. The first two come from Kashmir, where they are found in great abundance during the summer; but the rook, if ever seen in Kashmir, is only a coldweather visitor, and seems to come from the west, inasmuch as it is said to be common in Afghanistan. It appears at Rawal Pindi in flocks about the beginning of September; it is found in winter as far south as Lahore, and disappears entirely in March. The hooded crow has been brought from Northern Afghanistan, and is mentioned by Lieutenant Wood in his travels as common in Kunduz, but it is not found in Kashmir or in the Panjab. The chimney swallow makes its appearance in October, and leaves again for the straw-built sheds of Kashmir, where it breeds and spends the summer months. The white-rumped martin and sand martin are both likewise migratory, and repair to Kashmir and Ladakh in summer. The black and alpine swifts remain longer, and may be seen careering about during the summer evenings, especially after a shower of rain. The ringdove is a resident on the Sub-Himalaya. The common starling is plentiful in the north as elsewhere in Hindustan. The lapwing, Vanellus cristatus, arrives in flocks in the beginuing of November, and departs for the west early in spring; its summer residence has not been found out, but it must be common in certain parts of Persia and Afghanistan. The common and jack snipe, with a few painted snipe, appear in the Rawal Pindi district in February and March.

Nearly all the water-fowl met with in the rivers and marshes of the north-west come from the Tartarian lakes, where they breed.

The numerous wild-fowl of Tibet, swimmers and waders, migrate from India in March and April, and return in October and November. They all breed on the lakes and rivers of the country, and are very numerous; the eggs are found in great quantities; the people who live by gathering and selling these eggs never rob a nest of all its contents, but take about half the number.

After a sultry day it is usual to see the wiretailed swallow skimming over the plains, and by the side of pools and streams a solitary green sandpiper, Totanus ochropus, is not rare. The brown-backed heron, Ardeola leucoptera, also occurs in such situations. The black ibis (G. papillosus), with its red crown, is seen during the cold months flying along with the rooks and European jackdaws; and besides, on the marshes about, the great and little bitterns, with the spotted tail, are not uncommon. Of the other European birds may be noticed the short-cared owl, moor buzzard, the pale harrier, Circus Swainsonii, the commorant, ruff, and smew, all coming and departing with the winter months.

Migration of Fishes. - The fishes inhabiting the fresh waters of India, Burma, and Ceylon may be divided into those which enter from the sea for breeding or predaceous purposes, and such as more or less pass their lives without descending to the salt water. Of the spiny-rayed or Acanthopterygian order, we have nineteen genera, the members of which are most numerous in the maritime districts and deltas of large rivers, while their numbers decrease as we proceed inland. Few are of much economic importance, if we except the common goby, spined-eels (Mastacembelidæ), the snake-headed walking-fishes (Ophiocephalidæ), and the labyrinthiciform climbing-perch and its allies.

The anadromous fishes, as the salmon and shad of Europe, and the hilsa fish, the Clupea palasah of India, migrate from the sea to the fresh waters to deposit their eggs in suitable localities.

The migratory hill tishes coinprise various species of large barbels (Barbus), termed mahaseer or big-heads of India. In the Himalaya they ascend the main rivers, but turn into the side streams to breed. On the less elevated Neilgherry mountains, they deposit their ova in the main streams, because such are small. Occasionally the fish are too large to ascend these mountain rivers, and such breed at the base of the hills, but they ascend to other feeding graunds when the rivers are in flood, and after spawning, as the water of the river diminishes, they keep dropping gently down stream. They are thus separated from and are prevented eating the young fish. In the following season the fry descend to the larger rivers.

Many of the carps of the plains are migratory, and make great efforts to reach the heads of the rivers, leaping weirs and other obstructions raised to catch them.

The Ophiocephalidæ of India are known as walking or the snake-headed fishes. They and other amphibious types are monogamous. Some of them reside in ponds; others prefer rivers, where they take up their residence in deserted holes which crabs have excavated in the banks. The pond species delight in lying at the grassy margins, where they respire atmospheric air 
direct. The striped Ophiocephalus constructs a nest with its tail among the vegetation, and bites off the ends of the water-weeds. Here the ova are deposited, the male keeping guard; but should he be killed or captured, the vacant post is filled by his partner.

The hissar, Callichthys, of S. America, is likewise monogamous, constructing a nest, which it also defends. It is migratory.

Fishes which migrate in shoals for breeding purposes, as the mackerel, herrings, and some species of carp, are all polygamous.

The salmon, the shad, and the siluroid Ariinæ do not appear to feed during the period of depositing their spawn. The Clupea palasah is an anadromous shad of India. It is known to the English as the pullah and hilsa or ilisha sablefish, to the Tamil as the ulum, and to the Teling race as the palasah, while the Burmese call it nga-tha-louk. In Sind they ascend the Indus in February to spawn, descending in September. In the Cauvery river, when the first burst of the June monsoon fills the river, - they pass up and continue to do so for the next four months. The Kistna river also fills in June, but it is a more rapid river, and the hilsa defers making the ascent until September or beginning of October, when the waters are subsiding. In the Godavery, a less rapid river, they ascend most numerously from July to September, and in the Hoogly and Irawadi they continue ascending throughout the June monsoon. The main bodies of these fish ascend the large rivers of India and Burma generally when the S.W. monsoon begins in June, but not always at the same period, dependent apparently on the rapidity of the current and other causes. That it is not solely due to the presence of rain-water flooding the rivers is evident, because those of the Indus and Irawadi are mainly caused by melting snows at this period, and likewise in the latter river these fishes push on to Upper Burma, to which country the monsoon scarcely extends, but where the inundations are due to snow floods. Shad are excellent eating up to the period when they have deposited their eggs, subsequent to which they become thin, flabby, and positively unwholesome. Fresh-water fishes do not appear to be so deleteriously affected by breeding. Dr. Day counted 1,023,645 eggs in an Indian shad, and 410,500 in a barbel (Barbus sarana), and in a walking-fish (Ophiocephalus) 4700.

The gar fish (Belone) and the flying-fish (Exocetus) have filaments springing from their eggs for the purpose of attachment to contiguous objects. Among some of the marine siluroids (Ariinæ) the male carries about the larger eggs in its mouth until hatched, or it may be only removes them in that manner from one place to another. Dr. Day netted many along the seacoast of India with from 10 to 12 eggs in their mouths, and in one there were young fry just hatched.

The Sind fishermen float down the Indus resting upon a gourd or hollow earthen pot, while the net is let down beneath them; as a hilsa fish ascends up the muddy and rapid stream, it strikes against the dependent net, which is made to contract like a purse by means of a string that the fisherman holds in his hand.-Day.

Migration of Races.-Besides the instances of the Samaritans and Jews transplanted under the Assyrians and Babylonians, history shows the deportation of whole tribes, expressly termed

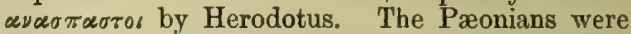
removed to Phrygia, the Barcæans from Africa to Bactria, the Milesians to Ampe near the Tigris, Egyptians to Susa, Eretrians from Euboea to Ardericca and to Gordeyn, and Antiochians to Mahuza.

Pastoral nomade tribes compose the great bulk of the inhabitants of Turkish Arabia, of Persia, Baluchistan, and they migrate twice a year to their summer and winter pastures.

Muhammad Taghalaq during his reign (A.D. 1325 to 1351 ) removed the whole of the inhabitants of Dehli to Deogiri, to which he gave the name it still retains of Dowlatabad. After this, the people were twice permitted to return to Dehli, and twice compelled, on pain of death, to leave it. These movements were attended with ruin and distress to thousands, but one of them in particular was made during a famine, and caused a prodigious loss of life.

When Ahmad, the grandson of the apostate Jaka, better known in history under his Muhammadan name of Wujeh-ul-Mulk, determined to immortalize himself by a new capital, the site he chose was the residence of a Bhil community, whose marauding exploits were the terror of the country. In order to commemorate its extirpation, he disregarded its local disadvantages, and the city rose upon an uninteresting, unhealthy, low flat, on the banks of the Sabarmati. Not content with transporting the materials of Chandravati, he resolved that its soul as well as body should migrate, that the population should follow the spoils of the temples and the dwellings. Another general migration was once attempted by Mahmud, the Ghilji, who resolved that Dehli should take root on the Vindya Hills, but Mandoo and A hmadabad shared the like fate.

Bokhara has a considerable number of Persians, and Persian captives were formerly brought to it in small parties. But the majority of this race were transplanted from Merv in the reign of Amir Said, when that city fell under his sway. With a view of weakening it, he ordered 40,000 families to be transported from Merv to the neighbourhood of Samarcand. They are easily distinguished by their regular features and their bushy black hair.

When Nadir Shah overran Herat and Kandahar, he is said to have deported 18,000 Ghilzai with their families to Teheran, and to have distributed the lands of Kandahar amongst his Persian followers.

Shah Abbas established in Andkhui the Persian tribe of Afshar, who form three-fourths of the population.

After the British mission had left Herat, the vizir Yar Muhammad pressed Ibrahim Khan of Gour, who had 7000 families of Taemuni under his rule, and, after having completely devastated the country which they occupied, Yar Muhammad removed them to Herat, where he established some in the city and the remainder in the suburbs. Subsequently to this, in the beginning of 1846 , when Yar Muhammad marched with his army in the direction of the Murghab, on the banks of which river some Hazara Zeidnat were encamped, they decamped into the Persian territory, and 
Asof-ud-Dowla gave them the village of Karez on the frontier of Herat. After the removal of Asof-ud-Dowla, however, at the close of 1846 , Yar Muhammad marched against the small Uzbak khanates in the north of Khorasan, and attacked and defeated the Hazara chief Karim Dad Khan, in the open country of Killah-nun. Yar Muhammad encamped upon the field of battle, and in the space of eight days collected 10,000 families of the Hazara Zeidnat, whom he removed from their native soil to that part of the district of Herat reaching from Obeh to Goian, where he settled them on the banks of the Hari-Rud. $\mathrm{By}$ these forced migrations of the Taemuni and Hazara, the Herat principality became more populous than it had been previously to the siege of Herat in 1838, and Yar Muhammad obtained the further advantage of keeping under his eye the most turbulent inhabitants of his dominions. He made excellent soldiers of these Eimak, and by their amalgamation with the Afghans it became almost impossible for the former to betray him.

Baron de Bode met an Iliyat tribe belonging to a Lur stem, which had been transplanted into Fars from Luristan Kuchuk by Aga Nuhammad Khan, uncle of Fat'h Ali Khan. After his death many returned to their prior encampments in the Zagros chain.

A memorable instance of voluntary migration occurred at the close of the 18th century, when 100,000 families of a Kalmuk tribe left the Black Sea, and, forcing their way through all opposition to the Dasht-i-Kipchak, north of the Jaxartes (Syr Darya), at length reached the original seat of their ancestors at Yarkand and Eela. They advanced with their herds and flocks, occupying in the breadth of the advancing column a distance of no less than three days' journey.

About the year 1880, the Government of Russia resolved to transfer 25,000 families of Cossacks to the Amur territory, in the district lying between Vladivostock and the Chinese frontier, to check the colonizing efforts of the Chinese. But the curious spectacle has been witnessed of Chinese immigrants appearing in such numbers as often to defeat the Cossacks, to march into Russian territory, and settle down upon it, whether Russia liked it or not. A large proportion of the population of the Amur is composed of Chinese.

About the year 1860, the exodus from the independent Shan States to British Burma of a large body of Shans was brought to public notice. Quarrelling among themselves, and oppressed by the Burmese, they fled for protection and peace to British territories. Several thousands formed - I settlement a few miles from Tounghoo, where they built themselves houses and commenced agriculture. They were mostly all of the Saga tribe, the Tsau-bwa of whorn, or chieftain, Kwoon Nay, arrived in Rangoon in the train of the Deputy-Commissioner. Some of the very imperfectly described tribes on the eastern side of the Irawadi, to the north of the Karen-ni, viz. the Za-baing, Ka-Khyen, etc., may belong to the older immigration; but the Mon is the only remnant within the ancient Karen province.

In the winter of 1863-64, when the Circassians, finally overcome, resolved to quit their country, they moved in great bodies into the Turkish dominions, and it was supposed that above 300,000 would so arrive.

VOL. II.
Perhaps all known instances of migration in ancient or modern times, voluntary or otherwise, have been thrown into the shade by the voluntary departures from Ireland to America, from among the races, largely Celtic, occupying that country.

MIHRAB. ARAB. The raised steps in a mosque from which the sermon is spoken.

MIHTAR. HIND. A sweeper.

MIH-TSZE, a Chinese philosopher who lived in the interval between Confucius and Mencius, and wrote on ethics. Seun-tsze and Han-yii also wrote on ethics. Seun-tsze held that the nature of man is bad, but Mencius held, jin-che-choosing-pun-shen, that man has originally a good moral nature.-Edkins.

MIKADO, a title of the emperor of Japan. The first historic emperor, Jimmu, succeeded to the throne of Japan about B.c. 660 . His father was reputed to be a god. Hence his descendants the Mikados trace their descent from the gods, and have a sanctity attached to them. Books describe the Mikado as the sacred, and the Tycoon as the secular king. Such was indeed the result of what was really a usurpation, the Tycoon being nominally only the Mikado's chief executive officer. During a period of 1000 years, successive Mikados were reduced to a state of insignificance, while the history of the country is made up of bloody contests of powerful houses for the office of Thogun or commander-in-chief, afterwards styled Taikun or Tycoon. After the ascent of the Tokugawa dynasty to power in the beginning of the 17th century, there was not a battle on Japanese soil for 250 years. The intervention of the European powers in the affairs of Japan led to the reigning Mikado (instigated by the enemies of the predominant Thogun dynasty) denouncing the concessions made to the foreigner. Internecine troubles further weakened the power of the Thogunate, until Kieki, who succeeded to that office in 1866, resigned, and restored the government into the hands of the Mikado. He repented of his decision, and marched to remove from the emperor his bad counsellors; but Keiki was overthrown, and finally, in 1868 , he submitted to the imperial power. Since that time the Mikado's Government has been re-establishing itself on a European basis. A cabinet of ministers formed upon European models, the abolition of torture, the reform of the coinage, the introduction of railways, telegraphs, the postal system, and of Government schools, both male and female, are among the most remarkable innovations adopted by this, formerly most conservative, now most receptive, nation.

MIKIR, a hill race in the Nowgong district of Assam, at the foot of the Naga Hills. Their clans extend across the Naga Hills from Nowgong into Cachar. According to their own legend, they were driven by the Cachari from what is called Tolaram or Senapatis country, between Nowgong and Cachar, and sought refuge in Jaintia; but, not being satisfied with their reception, they piaced themselves under the rajas of Assam, and have ever since peaceably occupied the hill country in which they are now settled. The houses vary in size according to the number of families residing under one roof. Some are 30 , some 40 feet long, and 20 feet wide, with the grass roof brought down almost to the platform.
30 
The whole building consists of one large room; they keep their grain in baskets in the room, and up to 30 families of men, women, and children all lie down together on their respective mats in their allotted places. Unlike most hill tribes, the Mikir seem devoid of anything approaching to a martial spirit. They are a quiet, industrious race of cultivators, and the only weapons used by them are the spear and dao hand-bill for cutting down jungle. The Mikir take up fresh land every two or three years, and remove their dwellings to different parts of the hills, cultivating in the jhum or kumari mauner.

They are very like the Khasiya race in countenance, but inferior to them in physique. They will eat of almost any animal food except the cow, which they affect to reverence; they have in dislike to milk. Marriages are not contracted till the parties are adult. There is no ceremony, but a feast is given in honour of the event; also when a child is born. Polygamy is discountenanced, and widows are allowed to re-marry. They worship a being whom they call Hempatim.Butler; Latham; Dalton.

MIL, a sharp lancet-shaped surgical instrument, which is used for blinding a person ; it is run redhot into the eyes. The small lance used by orientals for dyeing their eyelashes with kohl (the dust of black ironstone) is also called mil.Vambery, Bokhara, p. 233.

MILCH BUFFALOES are fed in the Panjab with mala patra, the dried and bruised leaves of the wild ber, which much increases the quantity of ghi ; green wheat and mustard and maize, green with the ears on, and joar, also increase the quantity of milk. Cows that have lately calved, and whose milk is deficient, get milk mixed with gur (molasses); and also wheat and barley made by boiling into a kind of caudle, called kunji.Powell's Panj. p. 151.

MILDEW, Puccinia graminis, a fungus attacking corn in Europe, the spores of which appear to enter the grass, not by the roots, but by the stomata. - Hassal.

MILIUSA VELUTINA. Roxb.

Uvaria velutina, Duval. | U. villosa, Roxb.

Tha-boo-kyee, . BURr. | Pedda chilka dudagu, TeI.

This tree grows in the Godavery forests, on the Circar mountains, in Bengal and Behar, at the foot of the Himalayas, and in Burma. It yields a strong yellow wood, which is said not to warp; unseasoned, it weighs 62 to $65 \mathrm{lbs}$. the cubic foot, and 50 lbs. when seasoned; sp. gr. 800 . In the Godavery districts it is used for house-building, for poles of carts, harrows, yokes, spear-shafts, and oars. Other known species are M. Indica, macrocarpa, Nilagirica, Roxburghiana, and sclerocarpa.-Beddome, Fl. Sylv.

MILK. ARab. Possession, property. Mälik, owner, king ; Malikāh, queen ; Mamlūk, possessed. MILK.

Halib, 。 ARAB, HeB, |Musu,

Halib, ${ }^{-}$ARAB., HeB, Nusu, , . MALEAL

Niu-ju, Niu-nai, . Chin. Shir, . . . Pers,

Lait, . . Fr. Leite, . . PORT

Milch, . . . GER. Moloko, . . RUS

Dud'h, . . Hind. Ellakerrie, . SINGH.

Latte, : . . IT. Leche, . . . . SP.

Lac,. . . LAT. Mjolk, . . . Sw

Susu, Ayar susu, Malay. Pal, Palu, : TAM., TeL,

Except among the Hindus, the fresh milk of cows, goats, etc., is little used as an article of diet in Southern and Eastern Asia. It may even be said that aversion to fresh milk as an article of food obtains among nearly all the Chinese, IndoChinese, and Malay races, including specifically the Kbasiya, Mikir, etc., of the eastern frontier of British India, the Garo and Naga, the Burmese, the Sumatran races, the Javanese, and Chinese. The Brahui and Baluch nomades in the Peshin valley, though they will give milk in exchange for other commodities, yet they consider it a disgrace to make money by it. With the Arabs the term labban (milk-seller) is an opprobrium and a disgrace. They, too, will give or exchange, but not sell milk. Possibly the origin of the sentimeut may be the recognising of a traveller's guest-right to call for milk gratis. No one will sell milk even at Mecea, except Egyptians, a people supposed to be utterly without honour. Camel's milk is consumed by millions in Asia to this day, as it has been from time immemorial, - milk and its products forming, indeed, the main means of subsistence of various tribes. The Jews probably used it from their earliest times, as 30 milch camels were amongst the cattle Jacob presented to his brother Esau (Genesis xxxii. 15). Milk is not used fresh by the Chinese of Canton, but is curdled and eaten at night with sugar and vinegar. In the northern parts of China, and especially in Mongolia, milch cows are in great numbers, and milk is used there fresh, also made into butter and cheese. Milk of mares is largely used by the Mongol. They extract from it a spirituous liquor, which they call koumiss. Mare's milk used by the Tartars for making koumiss has -17 per cent. of solid matter, and 8 per cent. of sugar of milk, which renders it very liable to undergo alcoholic fermentation. It was in use in China during the Han dynasty. The Tartars make other drinks from whey and butter-milk. Mare's milk and cow's milk are used by the Kalmuk Tartars. They boil it on being drawn, and let it sour, and make it undergo various fermentations, and use it largely in summer for inebriation. All their preparations of milk are called Tchigan. The drinks prepared from pure milk of mares (the koumiss of the Tartars) are named Gunna Tchigan or Horse Tchigan; those in which mare's and cow's milk enter are called Besiek; some cow's milk is named Airek, and all kinds of fresh milk Ussoun. The milk intended for distillation is only allowed to remain 24 hours in summer in the skin bottles to sour, but in the cold weather of winter it is left for 2 or 3 days. The spirit is several times distilled; it is drank warm, but before drinking, libations are poured out to the spirit of the air.

Milk of the domesticated buffalo is richer than that of the cow, and is supposed to yield more butter. In British India a mixture of buffalo's and cow's milk is often used in making butter. The fluid refuse of arrack distilleries is largely drank by horned cattle, and is supposed to increase their milk. In Tibet, Mongolia, and parts of the Chinese empire, the zebu (Bos Indicus) and the yak (Bos grunniens) supply milk. The Akit, used by the Arabs as a refreshing drink, is known by the name of Mazir, as well as Iqt (a corruption of Akit). When very sour it is called Saribah, and when dried without boiling, Jamidah. The Arabs make it by evaporating the serous part of the milk; the remainder is then formed into cakes or lumps with the hands, and spread upon hair- 
clath to dry. They eat it with clarified butter, and drink it dissolved in water. It is considered by the Arab a cooling and refreshing beverage, but boasts few attractions to the stranger. The Baluchi and wild Sindian tribes call this preparation of milk Krut or Kurut, and make it in the same way as the Bedouins. It is perhaps the source of the English word curds. The Negroes of Abeokuta, on the W. coast of Africa, abstain from it, and the Portuguese on both coasts of Africa avoid it. Milk is frequently mentioned in Scripture. Milk of goats, Proverbs xxvii. 27; of cows, Deuteronomy xxxii. 14, 1 Samuel vi. 7 ; milk clotted, Genesis xviii. 8 . The following analyses of several kinds of milk is by MM. O. Henry and Chevallier, in 100 parts :-

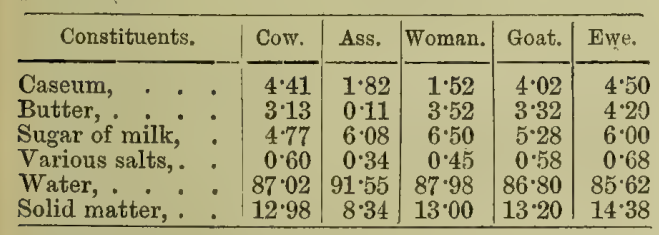

-O'Sh.; Moor; Yule's Mission; Burton's Mecca, i. p. 362 ; Wall. i. p. 42 ; Gray; Jam. Ed. J., 1830, p. 360 .

MILK-BUSH, milk-hedge, Seir, Teg, Mahr., is the Euphorbia tirucalli, Linn.

MILK OF PALM NUTS is a popular term for the albumen of the seed when in a liquid. state; and which, when the fruit is quite ripe, appears as a solid white or yellowish mass, and is then termed the kernel. This albuminous fluid or water, when the nut is taken from the tree early in the morning, and whilst the dew is still upon it, is a cool and delicious draught. It is, however, very seldom used in this fluid condition. - Seeman. See Copra.

MILK TREES, Arbol de leche, Palo de vaca, Arbre de la vache. Milk - yielding plants occur chiefly amongst the Euphorbiaceæ, Urticaceæ, and Apocyneæ, but nearly all their milky secretions contain acrid and deleterious principles. The genera Euphorbia and Asclepias, however, contain species said to yield a mild and innocuous milky juice. Amongst these are the Euphorbia balsamica of the Canaries. In Ceylon is found the Gymnema lactifera.

The Tabayla dolce or Euphorbia balsamifera of South America should be introduced into India. It grows chiefly in the valley of Caucagua in the neighbourhood of Valencia. It was seen by Humboldt and Bonpland on the 1st March 1800, during their expedition to the valley of Aragua, and these authors describe the milk as used freely by the Negroes. On making an incision into the bark of the Palo de vaca, there issues a glutinous and somewhat thick milk, free from all acridness, and possessing a balsamic odour. The travellers partook of it freely at bed-time, and found no ill effects from it in the morning, and they were assured that the Negro slaves and the freemen used it abundantly, and fattened on it.

Caoutchouc is the dried juice of several plants, the Hevea Guyanensis, Vahea gummifera of Madagascar, Siphonia cahuchu, Siphonia elastica, the Haucornia speciosa of Brazil, the Jatropha elastica, the Urceola elastica of Sumatra, the Willughbeia edulis of the East Indies. In A.D. 1736, La
Condamine directed attention to the caoutchouc from the Siphonia elastica. Fremeau discovered the Hevea at Cayenne, and mentioned that longitudinal or oblique incisions were made through the bark, and the fluid, white-coloured sap directed by an inserted leaf to an earthen pot below.Marion, pp. 49, 138.

MILKY WAY of the heavens is the Suraj-ulasma of the Arabs.

MILL, JAMES, a political economist and historiau. In 1818, he published a History of British India, in 6 vols. 8 vo, which led to his appointment in the correspondence department of the East India House of the revenue branch. He died in 1836. His work was continued by Professor Horace Hayman Wilson, in vols. 7 and 8 , London 1858.

MILL. The cereal grains, millets, and pulses are usually ground by hand-mills and by women; sometimes a single woman, sometimes two sit opposite. This has been the eastern custom from ancient times. Isaiah xlvii. 2, Matthew xxiv. 41, make mention of 'two women grinding at the mill.' The Hindus grind their flour by turning one stone round upon another with the hand. It is not uncommon to see two women engaged in this work.

A form of mill frequently to be seen is that of the pestle and mortar, the latter sometimes of wood, sometimes of stone, and used for expressing oil from oil-seeds. Wooden mills for pressing sugar-cane, consisting of wooden rollers, are generally used in the Bardwan district, and also in the Hoogly, Kishengarh, and Baraset districts, and around Calcutta. In Furridpur a kind of mill is used, made with rollers on the endless screw principle, which is very effective. A mill on the same principle is used in Cuttack, and also in Ganjam and various other parts of the Madras Presidency. In Ganjam the rollers are made of wood of the toughest and hardest kind obtainable, and which will not impart any bad taste to the juice. The wood of Albizzia odoratissima is preferred, being remarkably hard, tough, and durable. The wood of the Schleichera trijuga is largely used.

MILLANOWE, a race on the N.E. of the Sarawak territory. They are of a fair complexion, and are occupied with agriculture, trade, and peaceful pursuits.

MILLEPORA, a genus of the coral reef building polypifer. The coral they construct is in thick vertical plates, intersecting each other at various angles, and forming an exceedingly strong honeycombed mass, which generally assumes a circular form, the marginal plates alone being alive. Between these plates, and in the protected crevices in the reef, a multitude of branching zoophytes and other productions flourish, but the porites and millepora alone seem able to resist the fury of the breakers on its upper and outer edge; at the depth of a few fathoms, other kinds of stony corals live. The corals of the porites and millepora invariably compose the outer margin. M. alcicornis, M. complanata, M. corymbosa are known species; M. pocillifera at the Mauritius. See Coral ; Madrepore.

MILLER'S TRUST, a Persian proverb, originating in the treacherous slaughter of Yezdejird, in A.D. 651 , by a miller to whom his secret had been confided. 
MILLET.

Dukhn, .

Navonay, . ARAB. Navaria, . Maleal. Liang, Kau-liang, : ChIN. Milho, Mindoo, : Port. Cay khe, . Coch.-Chin. Prosso, . . . Rus. Hirse, . . DAN., Ger. Kangu, Priyangu, SANsk. Ral, Rala, : 'DukH, Tana-hal,. . SINGH, Gierst,. . . Dut. Mijo, . . . . SP. Kang, : GuJ., Hinu. Tenny, : : TaM. Higlio, : . . Ir. Koraloo, . : TEL

The millets belong to the natural order Panicaceæ. Various kinds are met with in the hottest parts of Africa, in the south of Europe, in Asia Minor, and in the East Indies. In India they hold a rank second to rice alone, and those chiefly cultivated for food are as follows:-

Eleusine coracana, Gcertner, Marwa.

E. stricta, Roxb., Ragi.

Oplismenus frumentaceus, Roxb., Damra Shama.

Panicum Italicum, $L$., Kangoo.

P. miliaceum, little millet, Sawee Cheena.

Paspalum stoloniferum, Linn., Kodu.

Penicillaria spicata, Willd., Bajra.

Poa Abyssinica, Ait., teff bread plant.

Setaria Germanica, Beauv., German millet.

Sorghum bicolor, Willde, Kala Deb-dhan.

S. cernuum, Willde.

S. saccharatum, Pers., Sada Deb-dhan.

S. vulgare, Pers., Jowari, great millet.

Millets are known as petit mais, or tropical crops. In India, they form a great part of the food of the labouring people everywhere but on sea-board, in the valleys, and on the banks of rivers, perhaps as much as rice, and more than wheat, and in Egypt, perhaps, surpass all other crops in importance. In Western Africa they are the staff of life. In China, the Setaria Italica, the S. glauca, the Panicum miliaceum, Sorghum vulgare, and $\mathrm{S}$. saccharatum are all cultivated. Turkey abounds in small grains. Panicum miliaceum, P. frumentaceum, and P. glaucum are all grown in the East Indies and China. The Setaria Germanica, German millet plants, are readily increased by division of the roots or by seed, and will grow in any common soil. The West Indian species are Panicum fasciculatum and $P$. oryzoides.

In Southern India, there are three kinds of sorghum, white, green, and red; their straw is of great bulk and goodness, and furnishes good provender for cattle, being preferable to that of rice. It is, however, given dried, as the green plant is injurious. Among culmiferous plants and legumes used in the east are the Panicum Italicum, Eleusine coracana (the meal of which is baked and eaten in India and Ceylon under the name of Corakan flour), and Paspalum of several varieties. Sorghum vulgare, a principal grain of Southern Asia, is cultivated throughout Western Hindustan, and in most parts of the Western Dekhan, between the Nerbadda and the Godavery.

In the United States, Setaria Germanica is grown for hay, being found a good substitute for clover and the ordinary grasses. The plant flourishes well on rather thin soils, and it grows so fast that when it is up and well set it is seldom much affected by drought. Half a bushel or more of seed to the acre is the usual quantity sown, broadcast and harrowed in. The ordinary yield of crops may be put at from a ton to a ton and a half of hay to the acre. It should be cut as soon as it is out of blossom; if it stand later, the stems are liable to become too hard to make good hay. It grows ordinarily to the height of about 3 feet, with compact heads from 6 to 9 inches in length, bearing yellow seed. The subvarieties of this are the white and purple-seeded. The Italian millet, Panicum Italicum, is larger than German millet, reaching the height of 4 feet in tolerable soil, and its leaves are correspondingly larger and thicker. The heads are sometimes a foot or more in length, and are less compact than the German, being composed of several spikes slightly branching from the main stem.

Sorghum vulgare, great Indian millet, is the Andropogon sorghum of Roxburgh. It is grown in must tropical countries. In the West Indies it is chiefly raised for feeding poultry, and is called Guinea corn. In Egypt it is known as Dharra, in Hindustan and Bengal as Jowari, in the Tamil country as Cholum. It is harvested in December and January, requires a light soil, and is usually grown after Eleusine coracana. The red kind ripens a month earlier than the rest, or about four months from the time of sowing, at the close of May or early in June. A gallow and a third of seed is sown per acre, and the produce averages 16 bushels. For the great bulk and goodness of its straw, which grows usually to the height of 8 or 10 feet, it is sometimes sown for fodder in the beginning of April, and is ready to cut in July. This grain is frequently fermented to form the basis, in combination with gur or half-made sugar, of arrack, and in the hills is fermented into a kind of beer or sweet wort, and drank warm.

Penicillaria spicata is cultivated throughout India. From one to four seers are sown on a bigha of land, and the yield is about four maunds per acre. It is sown after the heavy rains commence, and the plough serves to cover the seed. The crop is ripe in three months, and the ears only are taken off at first. Afterwards the straw is cut down close to the surface of the soil, to be used for thatching, for it is not much in request as fodder. Being a grain of small price, it is a common food of the poorer class of natives, and really yields a sweet palatable flour. It is also excellent as a fattening grain for poultry.

Poa Abyssinica is one of the bread corns of Abyssinia. The bread made from it is called teff, and is the ordinary food of the country, that made from wheat being only used by the richer classes. The way of manufacturing it is by allowing the dough to become sour, when, generating carbonic acid gas, this serves instead of yeast. It is then baked in circular cakes, which are white, spongy, and of a hot acid taste, but easy of digestion. This bread, carefully toasted, and left in water for three or four days, furnishes the boza or common beer of the country, similar to the quas of Russia.

MILLINGTONIA, a genus of plants of the sub-order Millingtonieæ. Drs. Roxburgh, Wallich, Royle, and Wight have described several species. M. pinnata, Roxb., a tree of Sylhet, M. pungens, Wall., a tree of the Neilgherries, Khassya, and Nepal, and M. simplicifolia, Roxb., are the generally recognised species.

M. simplicifolia grows in Madura, Nepal, the Khassya Hills, and is found in the forests of the Pegu valley, but scarce. Its properties as a timber are valuable from its weight and strength. Wood white colour, and adapted for every purpose of house-building.-Roxb.; Royle; $D r$. $M$ 'Clelland. 
MILUM, a glacier in the W. Himalaya, 8 to 10 miles in length, and 3000 feet broad.

MILVUS, a genus of birds of the sub-family Milvinæ or kites. The common European kite (Milvus regalis) was numerous in England in the days of the Tudors, and was protected by law, as it formerly performed the duties of scavenger in London and other cities, as indeed M. atu does now in Constantinople and in Egypt. M. melanotis is of China, and M. affinis and M. parasiticus are of Australia and Africa respectively.

Milvus govinda, Sykes.

M. cheele, Jerdon.

M. Indicus, Hodgs.

Hal, lineatus, Gray.

Pariah kite, . . ENG. Paria prandu, . TAM. Chil, . . : Hind. Malla gedda, . TEL.

This is the scavenger kite, and is seen throughout India up to 8000 feet. They pick up garbage of all kinds, along with crows and dogs. When gorged, this bird delights to sit on the entablature of buildings, exposing its back to the hottest rays of the sun, placing its breast against the wall, and stretching out its wings exactly as the Egyptian hawk is represented on monuments.Jerdon; Tennent's Ceylon.

MIMANSA, a scbool of philosopby which investigates the doctrine and practices of the Vedas. The Hindus have six different schools or systems of metaphysical philosophy. They are called the Purva Mimansa, Uttara Mimansa or Vedanta, the Sankhya, the Patanjala, the Nyayika, and the Vaisheshika. These, although some of them offer irreconcilable contradictions to essential doctrines of their religious belief, are recognised by the Brahmans as orthodox, and attributed to authors of . saintly reputation; while the Charraka, Buddhist, and Jain schools, although in some respects not wore at variance with received opinions than the preceding, are stigmatized with the reproach of infidelity and atheism. The cause of this distinction is that the orthodox schools of philosophy do not disparage the authority of the Vedas, and they do not dissuade the celebration of the acts of formal devotion which the Vedas or Puranas enjoin, although they argue their utter inefficacy as means of final and permanent felicity. They recoinmend their performance, however, as conducive to that frame of mind in which abstract contemplation may be safely substituted for devotional rites, and even admit of external observances after the mind is in pursuit of true knowledge, so long as such ceremonies are practised from no interested motive, so long as they are observed because they are enjoined, and not because any benefit is either to be expected or desired from their practice. Again, the writings of the orthodox philosophers do not meddle with existing institutions, and least of all do they urge or insinuate any consideration to detract from the veneration, or trespass upon the privileges, of the Brahmans. So long as these precautions were observed, the Brahmans did not, nor would they now, object to any form of doctrine having in view the establishment of merely abstract propositions. The case was very different with the heterodox schools. They went from abstractions to things. The Charvaka condemned all ceremonial rites, ridiculed even the Srad'ha, and called the authors of the Vedas fools, knaves, and buffoons. The Buddhjots and Jains denied the inspiration of the
Vedas and the sanctity of the Brahmanical character, abrogated the distinction of caste, invented a set of deities for themselves, whom they placed above those of the Hindu pantheon, and organized a regular hierarchy, a priesthood, and a pontiff, - an institution still subsisting in the trans-Indian countries, of which the Grand Lama of Tibet is the head; and Burma and Siam have their respective pontiffs, presiding over the Buddhist hierarchy. It is a remarkable historical fact that this organization was found too feeble to oppose, in India, the apparently loose and incoherent, the undisciplined, the anarchical authority of the Brahmans. It had, however, the effect of exciting their apprehensions and their hatred to such an extent that it became proverbial with them to say, "If your only alternative be to encounter a heretic or a tiger, throw yourself before the latter; better be devoured by the animal than contaminated by the man.' There may be a few of the Charraka sect in India, but their opinions are unavowed. The Jains have numbers and influence in the west of India, but Buddhists are little heard of in India, though numerous in Ceylon, Tibet, Burma, Siam, Cambodia, Cochin-China, China, and Japan.

Besides the above acknowledged schools or systems of philosophy, there is the Pauranik. It is not considered one of the number of regular schools, and does not claim the character of a system, but it presents a peculiar scheme of doctrine on metaphysical subjects, and exercises more influence over popular opinion than any of the rest. It may also be termed the Eclectic school, as it has evidently derived its principles from different systems, and formed them into a miscellaneous combination of its own contrivance. It is not put forward as a new scheme, but is subsidiary to the popularization of particular objects of worship for which the Puranas seem to have been composed. The Vedas are authority for the existence of a Divine Being, supreme over the universe, and existing before all worlds. 'In the beginning,' it is said, 'this all (this universe) was in darkness, $\mathrm{He}$ (the supreme) was alone without a second. He reflected, I am one, I will become many.' Will was conceived in divine mind, and creation ensued. This being the doctrine of the Vedas, is also that of the Vedantas, the purport of which school is declared to be the same as that of the Vedas, their end (anta) or aim. The Vedanta is called also the Uttara Mimansa, - subsequent or supplementary investigation. There is also, however, a Purva Mimansa, or prior school of investigation, the object of which is to teach the art of reasoniug, with the express purpose of aiding the interpretation of the Vedas not only in the speculative but the practical portion. As far as concerns the former, it of course adopts the same monotheistic principles. The Patanjala school teaches also the being of a God, the Nyayika and Vaisheshika teach the existence of one Supreme Soul, - the seat of knowledge, and the maker of all things, and the Pauranik or Eclectic school maintain the same doctrine. The Sankhya denies the existence of a Supreme Being, although it recognises a twofold distribution of the universe as matter and spirit. Of these six ancient schools of philosoply recognised among the Hindus, some are avowedly inconsistent with the religious doctrines of the 
Brabmans, and others, though deemed perfectly orthodox, advance opinions not stated in the Vedas. The six schools were enumerated in the following order by Mr. Colebrooke:-

The prior Mimansa, founded by Jaimani.

The latter Mimansa or Vedanta, attributed to Vyasa. The Nyaya, or logical school of Gautama.

The Atomic school of Kanada.

The Atheistical school of Kapila.

The Theistical school of Patanjali.

The two last schools agree in many points, and are included in the common name of Sankhya. Mimansa-darsana and Mimansa-vartikka are works on the Mimansa philosophy, the latter by Kumarila Bhatta.-Wilson's Opinions of the Hindus, p. 44 ; Elphinstone.

MIMOSA, a genus of plants of the natural order Fabaceæ. The leaves of some of the species are remarkable for being sensitive to the touch. The pink and yellow flowers of one of the small shrubby kinds are particularly beautiful in the rains; they readily grow from seed in any soil. Many plants formerly placed by botanists in this genus have been referred to other genera, chiefly to the acacia, albizzia, caillea, dichrostachys, entada, inga, and vachellia.

MIMOSA PUDICA. Linn. Sensitive plant. Najuk, . . . BENG. Tota vadi, . TAM. Hte-ka-yung, . BURM. Attapatti, . . TRL. Lajuk, Lajwanti, . HINn. Pedda nidra kanti, . ,"

This plant has small purple or pale pink flowers, and its leaves fall on the slightest touch. It is common in gardens, and grows readily from seed.

MIMOSA RUBICAULIS. Lam.

Arlu, Kikri of . . BEA8. Didriar of . . . RAvi. Kochee-kanta, . BENG. Alla, . : SuTLEJ.

$\begin{array}{ll}\text { Ral, Riaul, . PANJAB. } & \text { Undra, Ventra, . Tel } \\ \text { Deo-khadir, . . , } & \end{array}$

Deo-khadir,

TEL.

A very prickly shrub (M. octandra, $R_{0} x b$.), with small purple flowers, gradually becoming whitish. It grows over India, and is a valuable hedge plant.

MIMOSA SENSITIVA. Linn. P'a-yang-hwa, Chin. A native of Brazil, has small purple flowers. The leaflets are sensitive to touch. It will grow in almost any situation and soil, raised easily from seeds. It is cultivated by the Burmese, and is quite naturalized.-Mason; Roxb.

MIMULUS CARDINALIS, Monkey flower. Thubbæ, BurM. Ornamental plants, well suited for flower borders; the colours are chiefly blue, red, and yellow. It takes its name from Mimo, an ape, the seed bearing some resemblance to the face of a monkey.-Riddell.

MIMUSOPS ELENGI. Linn. Bakula tree. Kya-ya, . . . Burm. Kesura, ... . SANSK. Mugali mara, . CAN. Moone mal-gass, SINGH. Taindu, . . DuкH. Maghadam maram, TAM. Mulsari, Bakula, HIND. Pogada manu, . . TeL. Elengi, . . MALeaL.

This ornamental flowering tree grows in Ceylon, India, Burma, and the Moluccas. It has dark, evergreen, oblong, alternate leaves, and small pale brown or white, sweet-smelling, fragrant flowers, of moderate size, from which an oil is distilled. Its fragrant aromatic flowers are celebrated in the Puranas, and even placed amongst the flowers of the Hindu paradise. Krishna is said to have fascinated the milkmaids of Brindaban, on the banks of the Jumua, by playing on his flute beneath a bakula tree. The wood is strong, very hard and durable for any ordinary purpose, serviceable for houses, but not used in ships or boats. The berries are eaten sometimes by the poor. The seeds yield an abundance of oil, which is used by painters. Burmese ladies value its small, delicate, sweet-scented blossoms, which they string in chaplets for the head. A cubic foot weighs 61 lbs.

MIMUSOPS INDICA. A. D. $C ., W . I c$.

Paloo-gass, . . Srngr. | Palava maram, . TAM.

This valuable tree grows very abundantly in the hot, dxier parts of the island of Ceylon. The timber is extremely hard and strong, and very durable. It grows in Tinnevelly. It is in large demand by the Madras Ordnance Department for making gun-stocks.

MIMUSOPS LITTORALIS, Kurz. A timber tree of the Andamans.

MINA. An Assyrian weight $=7 \cdot 747$ grains. The average man of Baghdad and Shiraz is $14^{\circ} 0$, that of Tabreez and Bushire, 6.985.

MINA. HIND. Enamel; rods of coloured glass used in ornamenting glass bracelets. Minakari, the process of enamelling. Vitreous masses of colours for enamels are employed by the minakar, enameller on silver, etc. The colours used are principally green and blue, salts of iron and copper diffused through vitreous matter; a yellowish colour also is produced by litharge. The manufacture consists in taking a silver or metal vase, having the pattern of leaves or flowers worked on it in relief, and filling the hollows with enamel in a melted state. The colours exhibited are blue, green, and red. The art of making this material is known at Lahore, Multan, Jeypore, and other places.

Mina, in Persian means a glass vase, a blue glass; it is also applied to the deep blue sky, and hence to the blue vitreous enamel which is the commoner sort. Mina bazar amongst the Mahratta race is any exhibition. The enamels of Jeypore rank before all others, and three forms of emanelling are followed there. Two of these are comparatively modern. The third (by incrustation) is very ancient. The Japanese practise a fourth form of enamelling. The art is probably. Turaniau; it is practised everywhere in India. It was, according to the Chinese, introduced into China by the Yueche, and was carried as early, if not earlier, into India. From Assyria it probably passed into Egypt, and thence to Europe.-Powell's Handbook.

MINABAN, Burm., the Moulmein lancewood, is useful for handles of tools, but it is not equal to lancewood in elasticity. It is liable to the attacks of insects.

MINAGARA, a historical city on the Indus river, the chief site of the dominions of the Parthian kings of the Panjab. Captain Balfour, I.N., is of opinion that it was situated on the Baggaur branch of the Indus, which flows from the inain stream a few miles south of Tatta, and disembogues through the Gharra near Kurachee, and at some remote period had been the main stream of the river, but is now open only during the inundation period. On Sind being conquered by Omar, general of the khalif Al-Mansur, the name of Minagara was changed to Mansura, 'une ville celebre sur le rivage droit du Sind ou Mehran, Ptolemee fait aussi mention de cette ville; mais en la deplacant,' etc. D'Anville places it about $26^{\circ}$, but not so high as Ulug Beg, 
whose tables make it $26^{\circ} 40^{\prime}$. General Cunningham has little doubt that Minagara, handed down to us by the author of the Periplus, was the Sami Nagara of the Yadu Jhareja, whose chronicles claim Seistan as their ancient possession, and in all probability was the stronghold (nagara) of Sambus, the opponent of Alexander, and he is inclined to place it on the site of Sehwan. Vincent, in his translation of the Periplus, enters fully upon this point, citing Arrian, Ptolemy, AlBiruni, Edrisi, D'Anville, and De la Rochette. He has a note $(26$, p. 386, i.) which is conclusive, could he have applied it,- 'Al-Birun (equidistant) between Debeil and Mansura.' D'Anville also says: 'De Mansora a la ville nommée Birun, la distance est indiquée de quinze parasanges dans Abulfeda,' who fixes it, on the authority of Abu-Rehan (surnamed Al-Biruni from his birthplace), at $26^{\circ} 40^{\prime}$. - Cunningham, Anc. Geog. p. 288.

MINAHASSA. Menado and Kama, in the province of Minahassa, lie directly opposite each other on the W. and E. sides of the N.E. peninsula of the island of Celebes, and are open to foreign trade. Menado is the capital of Minahassa, and is situated on a large and beautiful bay on the W. side of the northerly promontory of Celebes, in lat. $1^{\circ} 30^{\prime} \mathrm{N}$., and long. $124^{\circ} 56^{\prime} \mathrm{E}$. The people of Minahassa differ much from all the other people in the Archipelago, with the usual long, straight, jet-black hair of the Malays. They are of a light brown or yellow tint, often approaching the fairuess of a European, of a rather short stature, stout, and well made, of an open and pleasing countenance, but disfigured as age advances with projecting cheek-bones. The coast people, where there has been intermixture, are coarse; but in inland villages, where the race is pure, both men and women are remarkably handsome. They are quiet and gentle, submissive to authority, and easily adopt the habits of civilised life. They seem capable of acquiring a considerable amount of intellectual education, and they are clever mechanics.

MINAR. PERs. A minaret of a mosque or other building. Char-minar, a building inside Hyderabad city. Minara, boundary pillars.

MINBASHI. TURK. A commander of 1000 horsemen.

MINBOO, near here, opposite Magway in Burma, are mud volcanoes.

MINCOPI occupy the Andaman Islands, and are perbaps the least civilised race in the world, being nearer to a state of nature than any people we read of. They are in the very lowest and most abject state of human society, without fixed dwellings, unclad, and unacquainted with the meanest of the useful arts. They have been isolated from unknown times; and when the British settled on their islands in 1858 , they were found in the lowest condition in which human beings can exist. They go quite naked, the women wearing ouly at times a kind of tassel or fringe round the middle, which is intended merely as ornament, as they do not betray any signs of bashfulness when seen without it. The men are cumning, crafty, and revengeful, and frequently express their aversion to strangers in a loud and threatening tone of voice, exhibiting various signs of defiance, and expressing their contempt by the most indecent gestures. At other times they appeared quiet and docile, with the most insidious intent. They are small in stature, seldom rising in height over 5 feet. The height of the men was found to average 4 feet 11 inches, and that of the women 4 feet $7 \frac{1}{2}$ inches. The minima and maxima observed were, of the men 4 feet $5 \frac{3}{4}$ inches and 5 feet $4 \frac{1}{4}$ inches, and of the women 4 feet 4 inches and 4 feet $11 \frac{1}{2}$ inches, but these maxima were quite exceptional. They are of a squat, thick-set figure, skin intensely black and glossy; that of the men has deep scars on it, produced by cuts of flint or glass chips, this form of tattooing being performed by the women. The head is round, smaller than neighbouring Asiatics, and eyes prominent, even projecting. Depressions exist in the temporal region of the head. The teeth are nearly white, but often so irregular as to seem in double rows. They are muscular, and are deficient in the roundness and fullness which give such symmetry of form to other races. Their aspect uncouth, their limbs are ill-formed and slender, their bellies prominent, and, like the Africans, they have woolly heads, thick lips, and flat noses. They may be culled hunters and fishermen, hunting game in their own wilds and jungles, using the bow and arrow, with which they are expert, and employing the bark of a tree for fishing - lines. In disposition they are shy, unsocial, and mischievous. They are skilful in shooting fish, manage their canoes well, and are fond of singing and dancing. They take little pains to cultivate the soil, and are ignorant of the art of working in metals. They make their canoes by hollowing out the trunks of trees by means of fire.

The area of the Andaman Islands is 1746 square miles, that of the Great Coco 11 square miles, the Little Coco 2 square miles, the three main Andaman Islands 1353 square miles, and others smaller 380 square miles.

MINDANAO is in lat. $5^{\circ} 39^{\prime} \mathrm{N}$., long. $125^{\circ} 18^{\prime}$ E. Mindanao, Palawang, and the Sulu group of islets, forming the southern limits of the Philippine Archipelago, contain many nations and tribes speaking many languages. The interior is said to be inhabited by many small tribes of Papuans, but those only who reside near the north-east, where there are several Spanish settlements, are known to Europeans. The chief tribes of the north are called respectively Dumaga, Tagabaloy, Malano, and Manabo, and, in common with the other mountain Papuans of Mindanao, they are comparatively inoffensive.

MINDORO, an island lying immediately adjacent to the S.W. coast of Luçon, being separated only by a narrow strait. The Mindoro Sea is bounded on the S.W. side by the N.E. coast of Borneo. It is much resorted to by British sperm whalers, who obtain entire cargoes there. Mindoro Strait is 27 to 33 miles wide. The sea is so clear and transparent that the spotted corals are plainly visible under 25 fathoms water.

The Negrito race in this island are congregated in a mountainous district called Bengan, where they live on friendly terms with the Manguianes or wild tribes of the brown race, by whom they are surrounded, although very little intercourse subsists between them. The Manguianes are a mild people, little advanced in civilisation.-Bikmore; Crawford; Earl; Wallace.

MINDRA, in a Hindu temple, is the cella.

MINERALOGY is a science which deals with 
the description and classification of the chemically distinct substances which form the material of the globe. Mineral substances, useful in the arts, and applicable for personal ornament, are very numerous in South-Eastern Asia, and under their respective headings will be found noticed,--agate, alum, amber, amethyst, antimony, arsenic, asbestos, avanturine, barytes, beryl, bismuth, bloodstone, building stones, cairngorm, calcedony, cat's - eye, cinnamon stone, clays, coal, copper ores, coral, cornelian, corundum, diamond, earths, emerald, fire-clay, fuller's earth, galena, garnet, gold, graphite, gypsum, iron, jacynth, jade, kankar, kaolin, kyanite, lapis-lazuli, lead, lime, limestones, lithographic stone, manganese, marbles, meerschaum, mercury, mica, millstones, molybdenum, mother - of - pearl, ochres, onyx, pearls, peat, petroleum, plaster of Paris, platinum, prase, plumbago, pumice, red earth, rock-crystal, ruby, salt, saltpetre, sapphire, selenite, serpentine, silver, slate, soda, spinel, sulphur, talc, tin, topaz, tourmaline, turquoise, zinc, zircon.

Mineralogists arrange these substances according to their chemical composition, as those consisting exclusively of native elements; also the compounds of arsenoid metals, the compounds of metals with halogen elements, compounds of elements with oxygen, and organic compounds.

The result of the study of rocks and of their component minerals has been to show that the great mass of the earth's crust is formed of aggregations of minerals belonging to a very small number of the types that have been determined by the mineralogist. The ores furnish metals essential to the needs and happiness of man. Numerous minerals furnish products important in daily life. Materials for construction and architectural ornamentation, for pigments, mordants, and bleaching processes, the phosphates for manures, the alkalies, and the materials for the manufacturing of acids, are all dependent on the mineral resources of the earth.

Of the above, the coal seams, the salt mines, the ores of iron, tin, galena, gold, antimony, and salt are the most valuable.

Valuable tin ores exist in the Tenasserim Provinces, and still more valuable beds of salt in the Panjab. Coal abounds, and in several parts of British India iron ores occur plentifully, but are worked chiefly by the natives in the rudest and most unthrifty manner. Galena and copper ores occur, but not in large quantities, and gold is found in many places, but has not been to any extent worked with scientific skill. Of the precious stones, rubies, sapphires, emeralds, and others are found in Ceylon, Independent Burma, Siam, and in countries N.IV. of the Himalaya. In British India the other stones now procured for jewellery are diamonds, garnets, agates, cornelians, and other forms of quartz. The coarse sapphire of corundum is found in some places associated with jade. Mewar is rich in metals. Mysore has iron ore and corundum in abundance.

Baluchistan is rich in mineral productions; copper, lead, iron, antimony, sulphur, and alum abound in various parts, while common salt is too plentiful to be advantageous to vegetation. On the high road from Kalat to Cutch Gandava is a range of hills from which red salt is extracted. Sulphur and alum are to be had at the same place. Ferrier saw quantities of white and grey marble in the mountains to the westward of Nooshky, but it does not seem to be at all prized by the Baluch. Marbles abound in S.E. Asia.

Chinese authors assert that there are between four and five hundred mountains in the empire which produce copper, and that there are upwards of three thousand which produce iron. Gold and silver mines abound, but the policy of that Government discourages their being worked. The mines of the province of Kwei-chu supply all the mercury used for the manufacture of vermilion, and there are mines producing lead, tin, and calamine scattered all over the country. Coal was used very early in China as fuel; it is mentioned by Du Halde as black stones dug out of the mountains, which stones burn when kindled, and are used by many persons in preference to wood, of which there is abundauce. It is found in the north and in the south, and probably might be had in nearly every province in the empire. At Shanghai it has been used on board Government steamers; in this district it resembles cannel coal. It is to be had also at Canton. Le Compte assures us that there is not any country better supplied with coal than China, and he particularizes the provinces of Shan-si, Shen-si, and Chi-li._Sirr's China, i. $424 ; M . E . J . R$.

MINERAL SPRINGS exist in many parts of the south and east of Asia. The districts richest in mineral waters appear to be the Tenasserim Provinces; a district around Hazaribagh, stretching in almost every direction for about 130 miles, in many places literally teeming with hot springs; the upper part of the Jalandbar Doab, or rather the hills beyoud its northern boundary, the Salt Range, and Northern and Western Sind; next to these is the Konkan, and, though not to be compared with any of the foregoing, the springs in the peninsula of Gujerat. The known springs are found at every elevation from within high-water mark to a height of 12,000 feet.

The most frequent of all appear to be the hot springs without any very strong mineral impregnation, which are so abundant in the Tenasserim Provinces, and in the Hazaribagh districts, in some parts of the Himalaya, in the Konkan, also in Sind, where, as in many other places, an impregnation with carbonate of lime is common. One or two such have been found in Rajputana and the Dekhan.

Sulphurous springs appear to be pretty equally diffused: several in Hazaribagh, some in the Nerbadda, some in the Konkan and Gujerat, some in Sind and the Salt Range, many at the base of the Himalaya, and in the upper part of the Jalandhar Doab. The great majority of them are thermal.

The saline springs are chiefly found in Sind and in the higher portion of the Panjab ; they usually contain common salt with some sulphate of soda and small quantities of other salts, when they are not simply brine. Traces of iodine are found near Kangra. Throughout Rajputana and in some parts of the Panjab, the wells are abundantly impregnated with soda. Some of the springs in Kamaon contain mineral impregnations, but scarcely to an extent to be considered saline. Scarcely any strong saline ones are thermal. The few thermal salines are chiefly calcareous, and one or two silicious.

There appears to be a general deficiency of chalybeates, and there is no one district in which 
they have been found more frequently than another, unless in the outer ranges of the Hirnalaya. Wells in the Neilgherries are said often to have a trace of iron. None of the Indian chalybeates are thermal, and none of those known, except that at the beautiful spot Nagconda, appear to be strong ones. Some of the thermal springs, as the Seeta Kund at Monghir, the water of which is highly prized, and often carried on long voyages, are probably slightly carbonated.

Dr. Buist, in Trans. Bombay Geogr. Society, collected a large list of thermal springs. In the great majority of instances they have only been regarded by the natives of the country as emanations of the deity, and as objects of worship. Wherever there is a hot spring, there is pretty sure to be a temple, visited by pilgrims. Many have been used medicinally; and those which appear to be most resorted to for their healing virtues are the springs at Malacca, also at Sona, near Dehli, where considerable buildings have been erected for the convenience of bathers, at Munnikarn, and at the Lukki pass. All of them are thermal, and except Munnikarn are sulphuretted. Natives have undoubtedly faith in them in certain cases, and they might easily at a small expense be made more extensively useful. Mr. Ludlow in 1826 suggested that the wells at Sona should be made use of for European soldiers. Dr. Murray attempted in $1843-44$ to employ the sulphuretted and chalybeate springs in the valley below Landour for the benefit of the invalids at that sanatorium, but the situation of the springs, at the bottom of a hot and confined though picturesque valley, was an obstacle to success. The absence, at most seasons of the year, of a bracing climate, at the generality of the thermal springs in India, diminishes the chance of their ever proving of utility to Europeans. Perhaps the climate of Hazaribagh, which is 1500 feet above the level of the sea, alone offers something of an exception to this remark.

The sulphuretted spring at Chaunch is prettily situated, not far from the Pachete Hills. But there is a much more abundant and hotter one, called Tanloie, on the banks of the Damuda, two or three miles off. Those at Bum Buklesir, about fifteen miles from Mungulpur and Suri, are more powerful and abundant. The hot spring at Lakarakunda is not far off, and there is said to be another near at Kisshun. The elevation of all of them may be about 300 feet above the sea-level.

Bum Buklesir is a pretty spot situated in a well-cultivated country. It is one mile from the large town of Tantipara, on the banks of a small nullah called the Buklesir. There are five or six hot springs, the whole group called Bum Buklesir. The hot wells that have been surrounded with masonry walls are immediately on the north or right bank of the nullah. There are numerous hot springs in the bed of the nullah, only to be seen in the dry season, giving out sulphuretted hydrogen, with which the air is tainted. Near the hot springs there are several cold ones, all flowing from a tough gneiss rock. The hot and cold springs are only separated by a few feet from each other. The body of water ejected from the hottest well is about 120 cubit feet per minute; it runs from innumerable small orifices in an accumulation of mud, the rock being nowhere visible within the masonry of the tank. In the hottest water, $162^{\circ}$, a green shining conferva thrives. Another spring is $128^{\circ}$, and the coolest $83^{\circ}$. Some 300 or 400 feet from the bank of the river, among the dilapidated temples, there is a large tank which is supplied by two springs, one hot and the other cold; so that at one end the water is warm, at the other cold, and in the centre tepid. The stream of the nullah is about 50 yards across, with a brisk current, and it retains its heat below the springs for a considerable distance; its temperature was $83^{\circ}$ in the month of December, when the temperature of the air was in the shade $77^{\circ}$. The sand of the stream some little way from the spring, and at the depth of six inches, is intolerably hot to the hand. Extending for about 200 yards along the right bank of the stream, are 320 small brick and mortar vihara or temples, built by various pilgrims, each containing a lingam emblem of Siva Mahadeo. Numerous attendant Brahmans loiter. about the temples, engaged in bathing in the hot stream, or watching the cremation of dead bodies, which is constantly being carried on.

The Panjah mineral springs are either in the hills or in submontane districts. There are hot springs, also saline and sulphurous waters, and in limestone districts petrifying streams are not uncommon. Kangra district has four mineral waters, -at Koballa, Beshisht Kooloo, Munnikarn Kooloo, and the Jowallaji, Amte, and Bassa springs, also at Bohun.

The higher portion of the Jalandhar is a tract abounding in mineral wells of all descriptions, where the icy stream of the Parbati, close to the boiling fountain of Munnikarn, which rises in a jet at an elevation of 5587 feet, could furnish Russian baths, if they were desired, and where the immediate vicinity of a chalybeate is not to be forgotten; where some are reported to contain iodine or bromine, and possess the advantage of an almost European climate. In this district, on the banks of the Beas, is Beshisht, at an elevation of 6681 feet, with an ample thermal sulphuretted source. Gerard says there are a few mineral springs impregnated with salt, iron, and alum, and at the famous wells of Zungsum, at the meeting of the Spiti and Parati rivers, four miles north of Shealkhur, inscriptions in the Tartar language on tablets of stone describe the particular virtues of each spring.

The Jawala Mukhi springs are situated all within a distance of about 30 miles near the base of the hills, on their south-westerly face, looking towards the Beas; all contain chloride of sodium, common salt, and iodide of potassium in considerable quantity. In the Jawala Mukhi valley, naturally formed by an elbow of the Beas near Nadaun, the salt ioduretted springs are placed in the following order : - Koopera, Jawala (two springs), Jawala Mukhi, Nageah, and Kanga Bassa. All the water from these five springs, after having undergone slight concentration by being exposed only for a few hours to the open air, is purchased by the Banyas at one anna per seer, or exchanged for the same value in flour, etc. The livelihood of the natives living in the vicinity of these springs is chiefly earned by this trade. They are convinced, and tell all who question them, that the water contains an efficacious principle which promotes the cure of the goitre. 'The sulphuretted hydrogen spring at Danera is considered sacred 
by the natives, who resort to it for cure in goitre and other diseases. The spring is not a thermal one. A small wayside spring in the lills near Dalhousie has a strong chalybeate taste, and deposits the reddish precipitate indicative of iron. The temperature of Beshisht spring is $102^{\circ}$ Fahr., that of the principal spring at Munnikarn $202^{\circ}$ Fahr.

Mineral waters occur at Deori and Kosunghat and Surar and Kudra near Jubbulpur; their waters bubble up, and are drank during convalescence to restore the appetite.

The mineral water of Sonachur does not bubble up, but produces a good deal of water; the villagers drink it daily. Comes out of black earth.

Mineral waters occur at Kooslee, Churgaon, Bumbee Boomba, and Nurgur Moha.

Mineral water of a spring walled in at Kudjora in Jessore is a carbonated, calcareous, and magnesian water, with a slight proportion of iron in the state of carbonate, and held in solution in the water.

Mineral water of Sosonea, north of Hazaribagh, is a carbonated and slightly chalybeate spring, with a little muriate and carbonate of soda, also in solution.

Sind abounds in mineral waters.

There is a mineral spring in the Singpho country at Khouang in Assam.

In China the springs of mineral waters are generally thermal or solfataras, yielding sulphurous gases, steam, and warm water, and their warm character gives them their Chinese names Wants'iuen, Wan-t'ang, and Fuh-ts'iuen. The hot sulphur mines of Tung-t'ang, about 50 miles from Chefoo, resemble those of Atami in Japan, and are useful in skin diseases and the contractions and pains of rheumatism and other diseases. Twenty miles N.N.W. from Macao is the island of Hiang-shan, in which the hot springs Yung-mah occur, with a temperature of $170^{\circ}$. The waters contain salt, sulphate of soda, chloride of calcium, and are useful in skin diseases. In the gypsum districts of the division of Ying-ching, in Hu-peh, are several warm medicinal springs, resorted to by the sick. Large quantities of salt and fibrous gypsum come from these places in Ying-ching. Hwang-shan, a hill to the west of Hwui-chau-fu city, in Ngan-hwui, has cinnabar springs which are reddened at times, and are hot enough to make tea. A clear, hot spring, Yuh-shih-tsiuen, is met with at Li-shan, near Si-ngan-fu (Shen-si). At the Lu-shan, near Kill-kiang (Kiang-si), are warm springs, once much vaunted for their efficacy in syphilitic, leprous, and exanthematous disorders. At Li-hien, in Shen-si, is a carbonated spring called Li-ts'iuen or Kan-ts'iuen, whose sweet waters were deemed to encourage vegetation and to prolong life, and to be cooling, stomachic, and corrective. To the S.E. of the city of Hoh-king-chau, in Li-kiang-fu (Yun-nan), are warm mineral springs, esteemed in the treatment of abdominal tumours. There is the celebrated well of A-yih, at a place about 60 li to the N.E. of the district city of Yang-ku, in Kwanchau-fu (Shan-tung), anciently called O-yih or A-yih. The well is 70 Chinese feet deep, and its water's have a gelatinous principle like the waters of Bareges in France. The water is evaporated, and produces a gelatine called 0 'kiau or asses' glue.

In Formosa, at its northern end, 1750 feet above the sea, are sulphur pits, in the rocky gorge of a mountain, and 85 miles east of Tamoui, and clouds of steam and sulphureous vapour issue from rents in the rocks. There are several hot springs and pools, and a miniature geyser throws intermitting jets of boiling water to a height of 50 or 60 feet. Another solfatara is near the village of Kim-pao-li, some seven or eight miles to the N.W. of Kelung. In Japan similar solfataras occur, in the department of Satsuma, in the island of Kiu-siu. The ground is volcanic and impregnated with sulphur. At the southern end of Satsuma is the burning sulphur island of Ivoosima.

\section{Sulphuretted Mineral Springs.}

Malacea, thermal.

27 miles N. from Hazaribagh, thermal.

Bum Buklesir, thermal, 16 miles W. and S. of Suri, in Birbhum.

Jorya Buri, not far from Chaunch, near meeting of Barakur and Damuda rivers, thermal.

Tantloie, on other side Damuda, thermal.

Tata Pani, Sirguja, Chutia Nagpur, thermal.

N. base of Maha-deo mountains, Nerbadda, thermal. Well at Gwalior.

At Sona, 30 miles from Dehli, thermal.

At Lousa, in Nurpur.

At Beshisht, in Kullu, thermal.

In the Bukh Ravine, Salt Range, thermal.

At Jubba, in Salt Range, 10 miles $\mathbf{E}$. of Indus.

Chihalee, W. bank of Indus, below Kalibagh.

Mitta, near Esa Khail, W. bank of Indus.

Pir Mangal and Ghazi Pir, in Sind, thermal.

Within high-water mark in Kattyawar.

Temple of Somnath, in Gujerat.

Arowlee, in the Konkan, thermal,

Bhadrachellum, on the Godavery, thermal.

At Chittur, slightly thermal.

\section{Saline.}

Several springs at Surujkund, near Belcuppee and Burkutta, Grand Trunk Road.

Teva, in Kangra district.

Mukhdur Rashid, in Multan.

Shahpur, near Jhung.

Lahard Khad, on Sutlej, above Rupur.

Universal throughout Salt Range.

Sumundur and Kullur Khar lakes, in Salt Range?

Duzikustuck, Sind, thermal.

Ooch, Sind.

Hyderabad, Dekhan.

Saline and sulphurous springs in Lukki pass.

Sambhar lake.

a. Brine.

Brine springs in Bikanir and Jeysulmir.

Cachar Hills.

\section{b. Alkaline.}

Lunar lake, 50 miles from Jaulna.

At Mian Mir, and other places in Panjab.

Kairi soda water wells in Ajmir.

Well at Jawala Mukhi?

c. Aluminous.

Well below at Landour, thermal.

$$
\text { d. Iodine. }
$$

Traces of iodine in well at Jawala Mukhi, at Arlun in Kangra and Thunga Bara near Hurripur; though bronchocele is very common in the district, the inhabitants of Jawala are exempt from it.

$$
\text { e. Lime. }
$$

Many in Murree Hills, above Rawal Pindi.

Peeth, in Hala mountains, thermal.

Kye, in Kala mountains, thermal.

Near Sunjabundia, Kurnool, thermal, temperature de. creasing.

f. Silicious.

Burrare and Bhim Bhand, Kurruckpur Hills, thermal.

$$
\text { 3. Chalybeate. }
$$

At Dalhousie, Chamba.

Rhotas, near Jhelum. 
Bakh Ravine, in Salt Range.

At Nagconda, Simla Hills.

Below Landour.

On Ranjit river, Darjiling.

Rungnu river, 4 miles $\mathrm{E}$. by $\mathrm{N}$. of Darjiling:

Ramandrug Hill, near Bellary?

Near old town of Attaran, Moulmein, thermal?

4. Thermal Springs with no important ingredients.

Hot springs at Cannea, in Ceylon, temperature variable?

Hot water fountains at Tavoy and Lunkyen and Sienli, and near Kaline Aurig, Martaban.

On Attaran river, Tenasserim.

On the Palouk river and at Pee, between Mergui and Tavoy, some sulphuretted.

Springs at Numyan, near Prome.

Between Meeaday and the Arakan Hills.

Seeta Kund, near Chittagong.

Uttir, 30 miles from Purie.

Kaljhurnee, Maharu, Hatbullea, Noubhil, between Rajamahal and Suri.

Saugur taluk, Nuggur division of Mysore.

At Darjiling, the water of the Minchu spring is a carbonated and sulphuretted chalybeate, containing its iron in the state in which it is found in the Bath waters.

At Kudjora, in Jessore, is a carbonated, calcareous, and magnesian water, with a slight proportion of carbonate of iron, held in solution in the water.

At Sosonea, N. of Hazaribagh, is a slightly chalybeate spring, with a little muriate and carbonate of soda also in solution.

At Mujoolee, 30 miles S.E. of Rhotas.

Lacarakunda, 21 miles S.W. of Suri in Birbhum.

At Katkamsandi, old Benares road.

Pinarkoon, Ramgur.

Sitakund, Monghir.

Paharpur, Kurruckpore Hills.

Rajeer and Guriuk, N. by E. of Gya.

On Ranjit river.

Near Bagin river, in Pana district, Bundelkhand.

Alwar country, one 15 miles W. by $\mathrm{S}$. from Alwar, one 20 miles N.E. of Jeypore.

Mineral springs at Machery?

At Sitabari, in Harowtee, also cold springs.

Jumnotri, Gungootri, Kedarnath, and Badrinath, in Garhwal.

Near Nutpa, Bukti, and Jauri, valley of Sutlej.

Opposite Soni, banks of Sutlej.

Hot spring at Silol, Kangra.

Mnnnikarn, in Kullu, and hot spring farther up the Parbati. The water where it issues from its source is $207^{\circ} \mathrm{Fahr}$. - one of the hottest known springs. Geysers, $180^{\circ}$; Surajkund, $190^{\circ}$; the Petersquelle, in the Caucasus, $195^{\circ}$; spring on Paluk river, $196^{\circ}$; and Guanaxuata, in Mexico, $207^{\circ}$. The boiling point of water at the elevation of Munnikarn is much below that point. Rice is cooked in the spring at Jumnotri $194^{\circ}$, at about 11,000 feet above the sea, and in many others of inferior temperature. Kulat, in Kullu.

Suliman mountains.

Pir Muggen, Alligator Tank, 13 miles from Kurachee. Juggen and Deyra, N. Sind.

At the base of the Hala mountains, Sind.

Oonee, central range of Kattyawar, variable.

Oonopdeen and Sunupdeen, in Satpura Range.

From near Surat to Rajapur many hot springs, at Mahar, Ratnagherry, Mat, etc., more than 12 in number.

At Byora, Kair, and Urjumna, Dekhan.

\section{Petroleum.}

Arakan, Paidong, 5 miles from Ramri.

Island of Cheduba.

Assam, at Jeypore and five other places.

Sylhet.

Kafir Kot, Algud ravine, W. bank of Indus.

Jubba, N. side of Salt Range, 10 miles E. of the Indus. Jawala Mukhi

Three springs in Dulu, eastward of Gogra.

MINERY, an artificial lake in Ceylon, 20 miles in circumference. A charming sylvan spot.

MING, a dynasty of China of A.D. 1370-1650.
Choo Yuen-chang, the first of the dynasty, was the son of a labouring man. In his youth he had been a servant in a monastery, but joined the insurgents who overthrew the Mongols. He speedily obtained the leadership of a large army, with which he established a new Chinese dynasty, over the thirteen provinces of the empire. His military genius was as undoubted as his political sagacity was great. No sooner had he reached the throne than one of his first acts was to issue an edict in which he justified his recent rebellion, by claiming a beavenly mission, in strict imitation of the usurper T'ang (B.C. 1766), who published a like manifesto in explanation of his having overthrown the last emperor of the Hea dynasty. He further followed the example of preceding founders of dynasties, in leaving at their posts all officials who were willing to acknowledge his sovereignty, and in giving every encouragement to the national literature, and thus succeeded in establishing his rule in the affections of the people. During Ming rule there was great literary activity, considerable refinement in manners, and material civilisation; the exquisite blue pottery was brought to great perfection. The Portuguese obtained Macao, the Jesuit fathers came from Rome, and but for the quarrels between the Jesuits, Franciscans, and the Dominicans, Buddhism, Taoism, and Confucianism would have disappeared. The Jesuit missionary Matteo Ricci acquired an unrivalled knowledge of the book language, and the style of his metaphysical and theological and scientific treatises commands the admiration of the Chinese. Hsii Kuang-ch'-i, a scholar and statesman, was his intimate friend, and wrote a defence of the Jesuits. About this time there appeared the Encyclopædia of 22,000 books, with about $1,100,000$ pages; also the Chinese Herbal, and the imperial library had 1,000,000 books. The dynasty was overthrown by a popular rising, and a Manchu leader selected.

MINGAL, a tribe of rude and predatory habits, who occupy the southern hills of Jhalawan, from Khozdar to Bela in Las. They have two great divisions, the Shahi-zai and Phailwan-zai. The Bizunju, of which are two great divisions, the Amalari and Tanbarari, are west, but on the same hills as the Mingal. They are a violent people, and rauch addicted to rapine. The Zigger Mingal and Rakshani, who inhabit Nushki, have no proper towns or villages, but reside in tents, and are not migratory. Their river, the Kaisar, is useless for irrigation, and is lost amongst the sands. They cultivate wheat at the skirt of the hill ranges supporting the plateau of Saharawan. Snow seldom falls. The Zigger Mingal at one time occupied the Dasht-i-Guran near Kalat, but their increasing numbers compelled them to migrate into Nushki, dispossessing the Raksbani, of whom two tomans or clans still reside at Nushki. They have a good breed of horses, called Tarji. Their flocks are very numerous. Saharawan and Las are on a great mountain range or table-land that runs N. and S. Jhalawan, with less elevation than Saharawan, is held by Brahui tribes, amongst whom are the Mingal, Bizunju, and Samalari in the hills. The fixed population in their little towns does not exceed 10,000, and are greatly exceeded by the pastoral tribes, the great tribes of Mingal and Bizunju giving them the preponderance. 
MINGULA-THOOT of the Burmese is supposed to be the Mangula Sutra, meaning the auspicious or fortunate discourse. It is a beatitude sermon of Gautama, containing 38 rules of life or a summary of beatitude. It is one of the first lessons taught to a Burmese youth.-Yule, p. 96. See Mangala.

MINHAJ-ud-DIN, author of Tabakat-i-Nasiri, a general history from the earliest times up to A.H. 658, A.D. 1259. His name was Abu-Umar Minhaj-ud-Din Usman-bin-Siraj-ud-Din alJurjani. In A.D. 624 , A.D. 1227 , he came from Ghor to Sind, Uchh, and Multan, and served under Sultan Shams-ud-Din Altamsh, the Sultana Razia, Bahram Shah. After the last was slain (A.H. 639), Minhaj-us-Siraj visited Lakhnauti, and in 642 returned to Dehli, where he was appointed president of the Nasiriya College. Honours were heaped upon him, and he was entitled Sadr-iJahan. The date of his death is not known.H. Elliot.

MINIUM, Red oxide of lead.

Suranj of . Avicenna. Menning rothes

Yuen-tan, Tan-fen, CHIN. bleioxyd, . . GER Chu-fen, Hung-tan, , Sundoor, : . HIND. Oxide rouge de plomb, Fr. Minio, . . . . . IT. Mining,. . . . GER.

Red lead is a brilliant red-coloured tri-plumbic oxide of lead. Massicot and minium may be produced at pleasure, by continuing the calcination of the metal first into litharge or massicot, the monoxide, and then into the red tri-plnmbic tetroxide. It is largely prepared by Hindu chemists. It is used for purifying concentrated acetic acid, also to adulterate, or in lieu of, vermilion, and by glass-makers and painters. The Hindus smear it largely on their idols, or on stones to convert them into a deity. -Smith; Royle.

\section{MINT, Mentha sativa.}

Hibbuk, . . . ARAB. Pudina, Nana, . . Hind. Pa-ho,. : CHIN. Menta romanna, . IT. Baume verte, : FR. Menta, . : SP. Frauen murze, : GER. Widda, : : : TAM.

Dried mint is esteemed as a medicine by the natives of India, and is prescribed by Muhammadan practitioners in dyspeptic complaints, and to stop vomiting. The cornmon sorts are three, spear-mint, pepper-mint, and penny-royal, also Mentha hirsuta, M. crispa, and M. Canadensis. The first is generally used for culinary purposes. It may be propagated by layers or cuttings or parting of the roots; it requires a moderate proportion of water. In the rains a small black caterpillar attacks the leaves, and will destroy the whole bed if not removed by hand or by flooding the beds, when the insect becomes detached from the leaves, and is easily destroyed. The mints are domestic medicines, carminative, antispasmodic, stomachic, astringent, sudorific, and alexipharmic. Dogs refuse to sleep on rugs beneath which mint has been placed, and this simple plant thus affords a good means of ensuring cleanliness. -Riddell; Powell; Smith.

MINTO, EARL OF, was Governor-General of India from the 31st July 1807 to 4 th October 1813. In that time he prohibited the three eminent missionaries, Marshman, Ward, and Carey, from circulating tracts against Muhammadanism or Hinduism, and prohibited preaching in bazars. A sepoy mutiny occurred at Vellore in 1809 , which was put down. The European officers of the Madras army mutinied, and the Earl of Minto went there to support the local government, of which Sir George Barlow was the president. He sent an expedition to capture Bourbon and the Mauritius, and he accompanied the expedition which conquered Java. He sent Sir Charles Metcalfe to Ranjit Singh, with whom a treaty was concluded. He returned to England, but died at Stevenage on the 21 st June 1814. His Indian career was written by his grand-niece the Countess of Minto, 1880.

MINTRA, a wild tribe in the Malay Peninsula, with numerous superstitions. They clear a small piece of ground in March, in July they set fire to the trees, which are then sufficiently dried, and at the beginning of September they plant paddy, cludy, etc. 'I'hey are very partial to the Hesh of monkeys. They use the sumpitan, which is a bamboo from 6 to 8 feet long; the arrows are slips of bamboo 10 inches long, with a piece of light wood at the bottom, shaped to the bore of the tube, which they propel by blowing hard, the point of the arrow being anointed with a prepared poison called tlipoh. After two or three minutes the smaller animals vomit and fall dead. Large animals are generally able to run, after having been wounded, to a distance. These savages seldom miss their aim, but will shoot with their arrows monkeys seated on trees 70 or 80 feet high. - Jour. Ind. Arch., 1851.

MIR. Hind., Pers. A chief, a president of an assembly, a title of any Syud, as Mir Akbar Ali, Mir Kasim Ali, Mir Mohib Ali; largely employed in compounding titular words, as Mirmunshi, head munshi ; Mir-saman, head steward; Mir-Akhor, master of the horse; Mir-Babr, harbour - master, a fisher tribe of Sind; MirBakshi, paymaster; Mir-dah, head peon, head of ten.

MIRA BAI, wife of Lakha, the rana of Udaipur, capital of Mewar. She was a daughter of the Rahtor of Mairta; the first of the clans of Marwar; and was celebrated for her beauty and her romantic piety. She was a poetess, and some of her odes and hymns to Krishna are yet admired, and supposed to equal in merit those of Jayadeva. She visited all the shrines of Krishna from the Jumna to Gujerat. There was a difference between her and her mother-in-law on some religious matters, and she therefore separated from her husband, and led a religious life. She left the effusions of her piety in the poems and odes which constitute the ritual of the theistic sects, especially those of Nanak and Kabir.

MIRABAU, a Penang wood of a light red colour ; much used for ship-building, furniture, etc.

MIRABILIS JALAPA. $L$. Marvel of Peru. Zahr-ul-ajl, . . ARAB. Rambut-poluKrishna keli, : BENG. kampat, . MALAY. Zjibb-ul-ajl,. : EGYPr. Sandal mulam, . MALEAL Gul baji, : . HIND, Sendrikka, . SINGH. Gul abbas, : : ", Badraksha, : 'TAM., TEL,

Cultivated as an ornament in most gardens; root considered as an aperient by the native doctors, etc. Its roots were long considered as the source of the true jalap; their taste is acrid and nauseous, and they abound in starch; the seeds also contain this principle. M. dichotoma and M. longifiora are reputed to possess similar properties. The flowers are of various colours, 
red, white, and yellow, also variegated red and white, yellow and white. It becomes in a short time quite a weed in a garden.

MIRAGE.

Bahr-bi la-ma, . . AR. | Namaish-i-ab, . PERs. Si-kot, Chitram, Hind. Sahr-ab,

This phenomenon is the unreal waters alluded to in Jeremiah xv. 18; the parched ground of Isaiah xxxy. 7. It is said that beasts are never deceived by the mirage. But, to man, the distress occasioned in Arabia by a deficiency of water is frequently increased by the tantalizing appearance presented by the mirage. The light refracted in the rarefied air immediately above the heated ground gives rise to the resemblance of an extensive lake, and the thirsty traveller advancing towards it finds the flattering delusion recede before him. In the early part of the morning, while some dew remains on the ground, the perception is remarkably strong; every object is then also magnified, so that shrubs appear as trees, and under them frequently appear their images inverted, as if reflected from the surface of water. On the west of Jacobabad, in the Kalat territory, is a place famed for this deceitful appearance. It is there called the Lumpani $A b$, or the shining of the minstrel's water. Dr. Bellew on the 8th January 1872 sighted two lofty mounds set together in the midst of the hard, dry clay desert, with shrubby bushes at their bases fringing pools of water, all remarkably clear and distinct. But as he approached near, the illusion disappeared, and the semblance dissolved to the reality,- -two heaps of clay on the sides of a dry well-shaft, a few scattered salt-worts, and a patch of soda efflorescence. The tradition which gives this particular place its name is that a Lum or travelling minstrel, when crossing this desert, deceived by the appearance of so much water, emptied the cruse under whose weight he was toiling, and perished in the desert from thirst.

In the desert of Dhat and Umra-Sumra, where the shepherds pasture flocks, and especially where the alkaline plant is produced, the stratification is very horizontal, and produces much of the mirage. It is this illusion to which the inspired writer refers, when he says, "The mock pool of the desert shall become real water.' The inhabitants of the desert term it Chitram, literally the picture, by no means an unhappy designation. This optical deception is well known to the Rajputs; is called See-kot or winter castles, because chiefly visible in the cold season; hence possibly originated the equally illusory and delightful Château en Espagne, so well known in Europe.

It is to be seen in every part of British India, just as Eothen describes (p. 271) the likeness of a fresh-water lake, "like a broad sheet of calm water that stretches far towards the south, stretching deep into winding creeks, and hemmed in by jutting promontories, and shelving smooth off towards the sluallow side. On its bosom the reflected fire of the sun lay playing, and seeming to float upon waters deep and still."

'Though,' says he, 'I knew of the cheat, it was not till the spongy foot of my camel had almost trodden in the seeming waters that I could undeceive my eyes, for the shore-line was quite true and natural. I soon saw the cause of the phantasm. A sheet of water, heavily impregnated with salts, had filled this great hollow, and when dried up by evaporation had left a white saline deposit that exactly marked the space which the waters had covered, and thus sketched a true shore-line. The minute crystals of the salt sparkled in the sun, and so looked like the face of a lake that is calm and smooth.'

The refraction of the atmosphere in the Eastern Archipelago is often marked. Dr. Bennett relates (ii. p. 72) that the ship's boats, while floating on a calm sea, at a distance from the ship, were magnified to a great size. The crew, standing up in them, appeared as masts or trees, and their arms in motion as the wings of windmills; while the neighbouring islands (especially at their low and tapered extremities) seemed to be suspended in the air some feet above the ocean-level. On another occasion the setting sun assumed the form of the hull of a ship, and in a few moments changed to $a_{0}$ perfectly square shape-Bennett's Whaling Voyage; Eothen; Burton's Mecca, iii. 23 ; Tod's Rajasthan, i. 18 ; Col. Chesney, i. 57\%.

MIRAJ-i-MAHOMED, or Laddu-i-Mahomed, is a Muhammadan festival held on the 27th Rajab, in commemoration of the ascent to heaven of Mahomed. It is alluded to in the 17 th chapter of the Koran, and Katib al-IVakidi says it occurred on the 17th Ramzan. On the occasion the angel Gabriel mounted Mahomed on the horse Burak, and conveyed him to heaven. Miraj is from the root Urj.

MIR ALAM, the prime minister of the Nizam of Hyderabad. He died 1808.

MIRANZAI. In continuation of the Kohat valley, there runs the valley of Hungu or Hangu, 20 miles long by 2 or 3 broad, which opens into the plain of Miravzai. This latter plain, about 9 miles square, and bounded on the south-west by the Kuram river, scarcely 20 miles distant from where it emerges into the Bannu plain, is held by 7 fortified villages. The Zymosht Afghan are a small but brave tribe, numbering about 5000 fighting men, some of whom are well mounted. They inhabit a valley leading from Western Miranzai onward towards the crest of a range called the Pewar Kothul, over which General Roberts led a British Indian army in his advance on Kābul.

MIRAS. ARAB., TAM. Inheritance; any inherited property, patrimony. Mirasidar, the holder of a hereditary estate. In Benares the Mirasi is a class of Muhammadans who teach girls singing and dancing. Their women are also employed as jesters in the presence of native ladies, in zananas or female apartments of large houses. In Sind the Mirasi is a bard, who accompanied his chief to the field, and sang the Shair or war-song during the combat. In India he is often the same as the Nai, a musician, barber, and astrologer combined. Usually it means any hereditary right or office.

Mirasi is a revenue term introduced into India by the Muhammadans. It means that which is inherited, and seems to have been substituted for the Tamil term Kaniachi, or right of ownership by inheritance. The term Mirasidar corresponds to that of the Tamil Kaniachi-karan, and means a person exercising mirasi rights. In the mirasi tenure of lands of the S. of India villages a certain number shared the land, democratic republicans among themselves, and regarding all others as servants. 
Mirasidar is a revenue term in use in Bombay, signifying a hereditary occupant of land, whom Government cannot displace so long as he pays the appointed assessment on his field. The emperor Akbar, however, claimed all land as the property of the state.-Campbell; Sherring.

MIRA SALICIFOLIA is the Maire or sandalwood timber tree of New Zealand.

India.

MIRDA, migratory shepherds in the south of

MIR-DAH. PERS. Literally a master of ten, the chief of peons; also a land measurer, who must measure with a standard yard or gaz, with the seal of the principal town of the district affixed to it. The Illahi gaz, as fixed by Akbar, is the one used.-Malcolm's Central India, ii. p. 30 .

MIRDUNG. Hind. A drum which is an accompaniment to the kunchnee ka taefa.

MIRGIA, a variety of the elephant in Cachar.

MIRI, of the Assam borders, occupy the country from the Sisi district to the Dihang river, S. and E. of the Dophla, and on lower land, stretching to the east, all along the north bank of the Brahmaputra, up to the Dihang river; they also settle at times on the south bank of the Brahmaputra river. The Miri and Abor tribes are expert bowmen, and use poisoned arrows.

The Tanae Miri dwell in a fertile valley of the Sundri river, N.W. of the hill Miri. They have fifteen large villages, and cultivate rice. They tattoo their faces, from which the Assam people. call them Anka-Miri.

The Ghy-ghasi Miri dwell west of the Dirjmo ; the Sarak Miri are on both banks of the Subansiri in its hill course; and the Pani-botia Miri and Tar-botia Miri are near.

Miri of the plains are offshoots from Abor, and are claimed by that people as runaway slaves. But there are various clans of them, differing in external appearance. The Saiengya and Arengya clans crop their hair like the Abor.

MIR IZZAT ALLAH, author of Travels in Central Asia in the years 1812-13, translated by Captain Henderson, 1872.

MIR JAFAR, a nawab of Bengal, whom the English East India Company's Council raised to that office after the defeat at Plassey of Suraj-udDowla. On the outbreak of war between Great Britain and France, Clive took possession of the French factory of Chandernagar on the Hoogly, which Suraj-ud-Dowla resented as an aggression. Clive with 1000 Europeans and 2000 sepoys met Suraj-ud-Dowla's army at Plassey, 70 miles from Calcutta, overthrew Suraj-ud-Dowla there on the $23 \mathrm{~d}$ June 1757 , and put aside Suraj-udDowla in favour of Mir Jafar, for whom authority was obtained from the Moghul court. Mir Jafar, as the reward, was asked to pay a kror of rupees to the E. I. Company, and 85 lakhs to the naval squadron and the inhabitants of Calcutta, and $12,80,000$ to Mr. Drake, the Governor, to Colonel Clive, Mr. Becker, Mr. Walls, and Major Kilpatrick; the total amount demanded being Rs. 2,69,77,500. But the nawab could only provide one-half of the asked amount, and even of the reduced amount one-third had to be accepted in jewels and plate. But, at the same time, Mir Jafar granted to the Company the zamindari of the Twenty - four Parganas around Calcutta, an area of 882 square miles, and in 1759 the Dehli emperor bestowed on Clive the right to receive the land tax. Clive was raised to the rank of mansabdar of 6000 foot and 5000 horse, and received as jaghir a large allotment of land near Calcutta. Subsequently, after a ten years' tenure, Clive's jaghir reverted to the E. I. Company. In 1761 Mir Jafar was set aside, and replaced by his son-in-law Mir Kasim.

Suraj-ud-Dowla's forces at the battle of Plassey numbered 35,000 infantry, 15,000 cavalry, and 50 cannon.

MIR JUMLA, minister of Abdullah Kutub Shah of Hyderabad during the 17 th century. He was originally a diamond merchant, and was known and respected throughout the Dekhan for his wealth and respectability before he was made minister. His son Muhammad Amin was a dissolute and violent young man, who involved his father in a dispute with the court, and Mir Jumla applied to Shah Jahan and Aurangzeb. Shah Jahan haughtily ordered Abdullah Kutub Shah to redress Mir Jumla's grievances, which interference was resented, and Aurangzeb treacherously seized Hyderabad, reduced the fortress of Golconda, and rendered Abdullah tributary. Mir Jumla took service with the Moghul, attained the highest offices at the capital, and afterwards became the chosen counsellor of Aurangzeb, and one of the most useful instruments of his ambitious designs. He was imprisoned (supposed to be a pretence) in Dowlatabad by Aurangzeb, for a brief period, but joined Aurangzeb a day or two before his defeat of Shuja, on the 15th January 1659 , and was second in command on that occasion. He drove Shuja into Arakan, where that prince disappeared. Mir Jumla was afterwards employed in the conquest of Koch-Bahar and Assam, but was forced by the rains to withdraw, and he died at Dacca on the 6th January 1663 (A.H. 6 Jamadius-Sani 1073), worn out by the fatigues which, though far in years, he had encountered equally with the humblest soldier. Aurangzeb immediately raised his son Muhammad Amin to the rank and to all the honours his father had held. -Elph. pp. $519-541$.

MIR-KHOND was the literary title of Muhammad-bin-Khavand Shah-bin-Mahmud. He was born in 1432, flourished at the court of Husain Mirza at Herat. After many years of disappointment from want of patronage, he was at length befriended by the munificent minister Ali Shir Beg, who obtained him a suitable dwelling near Herat, and assisted him in collecting materials for his History of the Early Kings of Pensia, from Kaiomars to the Conquest of Iran by Alexander the Great, and down to A.D. 1471. Mir-Khond died in 1498, and his son Khondamir wrote an abridgment of his father's work, which he called Khalasat - al - Akhbar. Texeira, a Portuguese traveller, published a translated abstract of MirKhond's book, and there is an English translation of Texeira by Stephens; but the best translation of that portion of Mir-Khond's work which relates to the history of Timur's conquests, was published in Major David Price's Muhammadan History, in 18:1. There is also a translation of Mir-Khond's History of the Early Kings of Iran, published by David Shea in 1832. He wrote his book in the cancahalo-culasya caravansary built by the vizir Mir Ali Shir, to whom he dedicated his work, which he entitled Rauzat-us-safa fi sirat al-anbia, o ul muluc, o ul kulafa; which signifies the Garden of Pleasure, touching the lives of the 
prophets, kings, and khalifs. The preface treats of the science or art of chronological history.History of Genghiz Can, p. 429; Ouseley's Tr. ii. p. 392 : Markham's Embassy, p. 33.

MIR MOHANNA, a celebrated pirate who ravaged the Persian Gulf. His stronghold was Bandar Reg, which the Persians and English took and razed.

MIR MUHAMMAD MASUM, author of Tarikhus-Sind, a history of the conquest of Sind by the Arabs, and down to the time of Akbar. He took the takhallus of Nami. He was born at Bhakkar in Sind, and wrote A.D. 1600.-Elliot's India.

MIRPUR. Eastward of Hyderabad in Sind is Mirpur, the stronghold of a former chieftain of the Talpur house; still farther towards the desert was Omarkot, noted as the birthplace of the illustrious Akbar. This was long looked upon as the depository of the accumulated wealth of the Kalora and Talpur rulers, and the point in which the chiefs would make $a$ stand in case of an invasion of their country.

MIRRORS are in use in every household of the Muhammadan and Hindu races, also amongst the Chinese, Japanese, and Malay. They are sometimes of polished metal. With the Japanese, the bronze mirror with its stand holds a prominent position. This mirror is usually circular, from 3 to 12 inches in diameter, made of bronze, and with a bronze handle covered with bamboo. The reflecting face is generally more or less convex, polished with a mercury amalgam, and the back is beautifully ornamented with a gracefully-executed raised design. Some for the rustic population have. also polished letters. Japan belief is, that as the sword was "the soul of the Samouri," so is the mirror the 'soul of woman.' It therefore constitutes the most valuable of all her possessions, and two mirrors form part of the trousseau of every Japanese bride. The characteristic qualities of the mirror must, it is believed, be in accordance with the constitution of the possessor, and second sight is resorted to in the selection of a mirror. The fortune-teller, instead of looking at a girl's palm, regards the reflection in a mirror. Instead of referring to the book of the recording angel, the Japanese Plato brings before the boatman his evil deeds reflected in a mirror.

MIR TAHIR MUHAMMAD, NASYANI, son of Syed Hasan of Tatta, is the author of the historical work Tarikh-i-Tahiri. He left Kandahar when it was beleaguered by the Persians, for Tatta, A.D. 1606, A.H. 1015, and he wrote his book A.D. 1621.-Elliot's Hist. of India.

MIRWARI, a Brahui tribe located in Mushki, Jhow, and Kolwah. The Brahui entered from the west, and point to Khozdar as the capital prior to occupying Kalat. See Kalat.

MIRZA. Pers. An honorary title, from two Persian words, Amir-zadah, nobly born; when prefixed to a name, as Mirza Abdul Baki Khan, it means a secretary, a munshi; when suffixed, as Abbas Mirza, it means prince Abbas.

MIRZA KHAN, styled Khan Khanan, son of Bahram Khan, was the second of Akbar's generals. He made the Persian translation now extant of Baber's Memoirs, from the Turki, in which Baber wrote.-Elph. p. 468.

MIRZAPUR, a town and district in the N.W. Provinces of British India, the district lying between lat. $23^{\circ} 51^{\prime} 30^{\prime \prime}$ and $25^{\circ} 31^{\prime} \mathrm{N}$., and between long. $82^{\circ} 9^{\prime} 15^{\prime \prime}$ and $83^{\circ} 36^{\prime} \mathrm{E}$. Area, 5217 square miles. It has grown and prospered under the British rule since the latter part of the 18th century, and, as a mart of trade, ranks next to Calcutta and Bombay. The grains, cotton, and the dyes of one-sixth of India are sold here. Mirzapur has risen purely from commercial causes, unconnected with religion or the auspices of royalty. In Mirzapur is seen the most beautiful market-place or chauk of all India. Four miles from Mirzapur is the temple of Bindachul.

MIRZA SALIM, the Jahangir of Indian history, was son of the emperor Akbar. He was born near the abode of Moin-ud-Din, Chisti. They show to this day the little roof of tiles, close to the original little dingy mosque of the old hermit, where the empress gave birth to Jahangir. There is not a greater among Muhammadan saints than the wali Moin-ud-Din, who was a Persian of Chist, but whose holy dust remains in Ajmir. The empress happened to be pregnant about the time, and remained in the vicinity of the old man's hermitage till the promised boy was born. He reigned A.D. 1605-1627.-Tr. Hind. ii. p. 4 .

MISCHODON ZEYLANICUS. D.C., Thu. This is the Tamana of the Singhalese. It is a fine large tree, common in Ceylon, near Colombo and Kandy. The young leaves are of a beautiful red colour. The timber is excellent. It seeds abundantly ; is most readily propagated from seed.Beddome.

MISHMI, of the Assam borders, dwell between the north and the east branches of the Brahmaputra river. They have several subdivisions, of which the Chul-katta or crop-haired are the chief. Some of the Abor and some Bor Khamti are mixed with them. Their colonies sweep round to the east of the Dapha Bhum mountain, and then up the valley of the Brahmaputra proper to the confines of Tibet. They extend west to the Digaru river (lat. $27^{\circ} 40^{\prime}$ to $28^{\circ} 40^{\prime} \mathrm{N}$, and long. $96^{\circ}$ to $97^{\circ} 30^{\prime}$ E.). They are a short, sturdy race, of fair complexion for Asiatics, well-knit figures, and active as monkeys; they vary much in feature. The clans best known in the plains are the Tain; the Maro are to the south of the Brahmaputra. The most eastern known to the British are the Mizha; they are perhaps connected with the Miautze, the aborigines of $Y$ un-nan and other provinces of China.

MISHTI KHEL, a dependent section of the Orakzai clan, with about 3000 fighting men. They occupy the hills from the exit of the Kobat river to Kasha. - N.W. Frontier.

MISKAL. ARAB., Hind. A measure of weight of $63 \frac{1}{2}$ troy grains. $-W$.

MISKAT-ul-MUSABIH, literally the niche for lamps; a collection of the most reliable of Muhammadan traditions, according to Sunni views. It was translated in 1809 by Captain A. N. Mathews, Calcutta.

MISR. In the districts of Gorakhpur, Azimgarh, and Benares is an agricultural tribe who call themselves Bhuin-har or Bhun-har. They claim to be Brahmans, and take the titles of Thakur, Misr, and Tewari ; the raja of Benares belongs to them. Misr or Misra is also a surname given to a Brahman of the Kanoujia tribe, and especially. to the members of two of the subdivisions, got, or families belonging to it, those of the Sandal and Katyayana or Viswamitra got. The term Misr has been conjectured to have been connected with the 
ancient name of Egypt Misr, as if some of the Brahmans had come from that country; it is more probably of affinity to Misra, mixed, indicating some mixture of race or family, the tradition of which has perished.-Wilson.

MISSI. ARAB., HIND. A powder made from gall-nuts, sulphate of copper, steel filings, mirobalans, and the pods or gum of the kikur acacia. Hindu and Muhammadan women use it as a vitriolic dentifrice to dye the teeth black. It is rubbed into the roots of the teeth. The colour is between rust and verdigris, and the appearance unnatural and offensive; and it is probably a custom resembling that of Japan, and, like that of the Kyan of Prome, adopted to destroy the natural attractiveness of the married woman, for it is only applied to married women's teeth.

Safed-missi is an oxide of zinc; to make white missi, take safaid surum (crystallized carbonate of lime, double refracting spar) and cinnamon; pound together. It is used as tooth-powder.

Kala-missi or Missi-siah is an oxide of manganese.

Hira-kassis is a dry persulphate of iron, used in dyeing, in making ink, blackening leather, used in medicine, and made into missi to apply to the teeth. To make black missi, take of hira-kassis, chaipal harra, chuni-gond, lila tutiya, iron filings, kuth, equal parts, pound and mix.

Sada-kassis is an impure sulphate of iron, the refuse from the manufactory of the sulphate of copper.-Herklots; Gen.Med.Top.; Burton's Scinde.

MISSIONARIES. The south and east of Asia has been a scene of proselytizing labour from remote times. The earliest recorded missions in India were of the Buddhists, who sent agents to every country around, and forms of their faith still prevail in Tibet, in Ceylon, Burma, Siam, Cochin-China, Java, China, and Japan. No sooner had Sakya left the scene of bis labours in Northern India than councils were held; and while members of it were sent into Bactria, others advocated their faith by their writings. The intercourse between China and India was kept up by missionaries, two of whom, Fa Hian and Hiwen Thsang, of the 5th and 7th centuries, have left behind them histories of their travels. Pilgrims from China to the present day continue to visit India; Banyiu Nanjio and Kasawara, monks from Japan, have sought for information as to their religion in the library of Oxford University ; and the monasteries in Ceylon, aided from Siam, are putting forth violent polemical tracts in support of their own faith, and attacking Christianity. Ancient Buddhist writings are in two forms, - the Pali canon as preserved in Ceylon, Burma, and Siam, and the Sanskrit canon, preserved partially in the libraries of Nepal, but far more fully represented in Chinese, Tibetan, and Mongolian translations. The Yueh-chi, Parthia, Khoten, Kābul, Bukhara, and Tibet all drew on India for their sacred literature. In A.D. 65 , the Chinese emperor Ming-ti sent eighteen commissioners to India, and they returned to China to preach Buddhism, A.D. 67. The names are now known of forty missionaries who have been engaged in translating from Sanskrit into Chinese. In the early part of the 4 th century, a descendant of Sakya's family, named Budhabhadra, settled in China to help in the translation of the sacred canon which contained the teaching of his great ancestor. The collections containing the canonical books of the southern Buddhists are called the Tripitaka, and the Udanavarga is the northern Buddhist version of Dhammapada.

Buddhism prevailed in parts of India from B.C. 350 to the close of the 12 th century A.D. It was prevalent along with, and intervened between, two forms of religion which the Aryan Hindus have practised, those of the ancient Vedic creed and the Puranic polytheism of the moderns. Since the latter form has been current, the Aryan Hindus, believers in Siva, or in Vishnu, or in any of the many incarnations of the latter deity, and of their sakti or female energies, have striven to bring over to their views the aboriginal Turanian races whom they found preoccupying the country, and their conversions of the hill and forest indigenes is by whole tribes. Their missionaries are continuously converting them. From about A.D. 700 an almost unbroken succession of gifted men have been proclaiming modern Hinduism. There will be found notices of their lives under their respective names, - Sankaracharya, Kumarila Bhatta, Madhavacharya, Chaitanya, and Valabha Swami; with Kabir, the weaver; Nam Deo, the tailor; Ram Das, the tanner; Dudu, the cotton cleaner; Krishna, the founder of the Manbhow sect; and Tuka Ram, the cultivator.

It has been the policy of the East Aryan Brahmans to regard all who do not follow their teachings as immeasurably their inferiors in the social scale. Even those who follow caste rules, if of other than Brahmanical descent, are deemed to be greatly their inferiors. Repeated efforts to throw down this caste barrier have been made by reformers, both of Aryan and non-Aryan descent, but the learning, ability, knowledge of official business, and unanimity of the Brahman race, have enabled them to hold their undoubtedly high position, and many of the non-Aryan tribes welcome the Hindu missionaries, influenced by the desire of being nearer the high-caste Braliman. But the craving of the Hindu races for a monotheistic creed is incessant, and many reformers have appeared who gained converts. The Sikh religionists are one of these, the Sad'hs are another, as also in a Hindu form are the Lingaet, the Baishnab, and the Satani. Ram Singh, the Kuka, carpenter, in the space of ten years counted his followers by hundreds of thousands. Dudu Mehan, a Bengali Musalman, was a weaver, and his followers may still be counted by thousands.

The sects who accept Siva or Vishnu strive to inculcate the view that the object worshipped by them is the one true God. In the early years of the 19 th century, a great monotheistic movement was effected by Ram Mohun Roy, a Brahman of Bengal. Under the name of Brahmoism, it has become a theistic system, solely based on natural religion, exhibiting all the characteristics of a practical cultus, with its temples, priests, and worshippers. They have unpaid missionaries throughout the whole of India. They are seeking to fuse all the creeds of the world in a religious synthesis resting on the universal revelations of the conscience and reason. The views of Ram Mohun Roy have been expanded by several eminent men,-Dwarkanath Tagore, Debendra Nath Tagore, and Keshub Chunder Sen. It was Ram Mohun Roy who founded the Brahmo Somajj or Society of God, which was based on the 
unity of God as revealed in the Vedas. He was succeeded as a leader by Debendra Nath Tagore, who had previously founded the Tattva Bodhini Sabha, which merged in the Brahmo Somāj; and later on, Keshub Chunder Sen claimed for the sect the position of followers of a revealed, in contradistinction to philosophical, deism. Before his death in 1884 he became a visionary.

Since the beginning of the Christian era, Christian missionaries of every sect have striven to win the many races to a belief in Jesus. There are at present in British India, Burma, CochinChina, and China, missionaries from many of the numerous sects of Christians in Great Britain, Germany, France, Portugal, Spain, America, and Italy; but in British India, in 1881, the numbers of Christians were under two millions:

American Church, . 737 Lutherans, . . 29,577 Armenian, 1,308 Other Protestants, 107,886 Church of England 353,713 Roman Catholics, 963,058 $\begin{array}{ll}\text { Church of Scotland, 20,034 } & \text { Syrians, . : }: 304,410 \\ \text { Episcopalians, . 20,135 } & \text { Others,. . } 60,833\end{array}$ Greeks, . . . 834

Ever since the Portuguese came to India, missionaries have been labouring in the southern districts of the Peninsula. The earliest were of the Romish persuasion, - St. Francis Xavier (1542), Robert de Nobilibus (1606-1660), John de Britto, who was martyred in Madura by the Senapati in 1693; Father Beschi, the eminent Tamil scholar $(1746)$; and the Abbé Dubois of the closing years of the 18th century. Of Protestant missionaries in the south of India there have been Ziegenbalg and Plutshau (1705), followed by Schultze (1725), Schwartz (1750-1798), Kiernander (1758), followed by Fabricius, Klein, Jaenicke, Rottler, Kohloff, Rhenius (1820), Schmid (1820), Sargent and Caldwell still (1884) working. Bombay had John Wilson. Two Christian missionaries named Joseph Taylor, father and son, occupied districts of the Bombay Presidency. The son founded the Christian village community of Borsad in Gujerat. Bengal has had Carey, Marshman, Ward, and Alexander Duff. In Burma, Judson, Bennet, Wade, Boardman, Mason, Abbot, and Bishop Bigandet have made many converts. These missionaries have offered education and equality, and have established schools open to all.

The number of Christians in China is estimated at 800,000 . It seems to have been early preached in China. Arnobius, writing about A.D. 300 , makes mention of the Christian deeds done in India, and among the Seres, Persians, and Medes. There were Christian monks in China in the time of the emperor Justinian, and two of them brought the eggs of the silk-worm in a bollow cane to Constantinople, A.D. 552. Salibaz-acha, a Nestorian patriarch, created the metropolitan sees of Sina and Samarcand, A.D. 714-727. A monument with a Syriac inscription of the Nestorian missionaries was discovered at Singan $\mathrm{Fu}$, in the N.W. of China, in A.D. 1625, and seems to have been erected A.D. 635. Native scholars regard it as a most valuable specimen of the caligraphy and composition of the age of the Tang dynasty. In the days of Marco Polo there were in Yun-nan many Nestorian Christians, none of which sect now remain.

The Romish form of Christianity is called by the Chinese Teen-Choo-Keaou. Their missionaries, one of the most famed of whom was

VOL. II.
Père Ricci, have made great progress; and since the middle of the 19 th century the Protestant missionaries of Great Britain and America have extended it. Many of the Chinese have become imbued with a knowledge of the Christian doc: trines. Tae-ping-Wang, an unsuccessful leader of a great rebellion in China, with many of his followers, were believers in the Old and New Testaments. It was a great movement of fanatic Christians from near Canton.

In the north of Asia, the Greek Church is making great efforts in Irkutsk, the Trans-Baikal province, and the Altai. In 1879, the great Manchu Lama, Tapchin-Nag-bu-Mangolaiev, at Chita and at Verniudinsk, was present in 1878 at episcopal celebrations, which produced upon him a profound impression, and in the waters of Lake Baikal he received baptism.

Jews seem to have been in China B.C. 258. They call themselves the Tiau-kin-Kiau, 'the sect which plucks out the sinew,' alluded to in Genesis xxxii. 32, 'the children of Israel ate not of the sinew which shrank.' The Jewish monuments of China are at Kai-fung-foo. About 200 is the remnant of all the colonies.

The Muhammadan faith was propagated partly by forcible conversion, but largely in Persia, Sind, British India, Ceylon, Sumatra, and the Archipelago, by zealous, devout men. Their numbers in these countries may be about three hundred millions, principally converts from the West Aryans or Iranians in Persia, and from Turanian and Mongolian races in the East Indies. Comparatively few of the East Aryans have accepted Islam. The conversions among the Rajputs of Northern India, among the Jat of Hindustan, Sind, and the Panjab, have been in whole tribes; in Lower Bengal and amongst the Malays of Acheen, in whole nations. Muhammadans largely use the Arabic Koran, and that language is taught in the schools attached to the mosques. Great conversions have also been effected amongst the races in Northern Africa.

Muhammadans in China are supposed by $\mathrm{Mr}$. Edkins (p. 178) to be of the Persian and Turk races. They entered China between the 11th and 17 th centuries, but principally in the time of the Sung and Ming dynasties. They are most numerous in $\mathrm{N}$. China, where in some parts they form a third of the population. Their mosques are called Tsing-chin-sze, pure and true temple. The name of their sect is Hwei Hwei, which is derived from Uigur. They call God Choo, Lord, or Chinchoo, true Lord. In some northern cities they place over their doors the words Hwei Hwei, Muhammadan, or Kiau-mun, religious sect.

MISTLETOE. Lih-huh, CHIN.; Tung-tsing, MANCHU. Viscum album.

MISW AK. HIND. A substitute in India for a tooth-brush, made from a twig of the margosa, the rough Achyrantes, Careya arborea, Phyllanthus multiflorus, and the palmyra, or any soft wood chewed at one end.

MITAKSHARA. This is a book by Vijnaneswara Bhatta, who flourished in the 10th century of the Christian era. It is a commentary on the law book of Yajnavalkya, which again is an abbreviation of Menu, composed in the 4 th or 5th century, and more suited to modern requirements than the older work. The Mitakshara is still the chief authority in all parts of India on 
civil contracts and the law of inheritance, and a good edition and translation are much to be desired. The little work of Stenzler (Berlin 1849) contains a clear edition of the text and faithful translation of Yajnavalkya's couplets.

MITANLI, in Persia, a sect of freethinkers, who deny everything they cannot prove by reason.-Chesney; MacGregor, iv. p. 134.

MITE, a species of Acarus. The Acarus coffeæ or coffee mite is so small as to be hardly perceptible to the naked eye. It is closely allied to the red spider of the hothouses of Europe. Nearly all the year round, but chiefly from November to April, it feeds on the upper side of the coffee leaves, giving them a brownish sunburnt appearance. Individual trees suffer from its attacks, but the aggregate damage from it is not great. Scarlet mite or red spider, the Aoarus telarius or Gamasus telarius insect, envelops the leaves of a plant in a delicate, closely-woven web, which so checks the respiration that the plant becomes dry and withered. See Insects.

MITHAI. HiND. Sweetmeats of India are of many kinds, but they are chiefly formed of sugar, clarified butter (ghi), and wheat flour, or milk and sugar, or with various pulps of fruits and sugar. The bazar sweetmeats are not palatable to Europeans.

MTTHA-LONARI. MAHR. A caste who make salt from inland saline deposits or marshes.

MITHA-NIRAKH. MAHR. Salt heaps. After manufacture, salt is heaped. Earth mounds 2 to 3 feet high are made, on which, after manufacture, salt is heaped, and protected from the rain by a thatch or mud cover. If left uncovered, some of the salt melts, but a thick hard coating is soon formed which protects the remainder of the heap.

MITHANKOT, a municipal town in Dehra Ghazi Khan district, Panjab, once situated on the high bank of the Indus a short distance below its confluence with the Panjnad, 12 miles south of Rajanpur, and 85 from Dehra Ghazi Khan.

MITHILA, a historical country north of the Ganges, between the Gandak and Kosi rivers, comprebending the modern provinces of Puraniya and Tirhut. The remains of the capital founded by Janaka, and thence termed Janakapur, according to Buchanan, are still to be seen on the northern frontier, at the Janickpur of the maps. Nearly coeval in point of time with Ayodhya was Mithila, founded by Mithila, grandson of Icshwaca. The name of Janika, son of Mithila, eclipsed that of the founder, and became the patronymic of this branch of the Solar race. These are the two chief capitals of the kingdoms of the Solar line described in the early ages, though there were others of a minor order, such as Rotas, Champapur, etc., all founded previously to Rama.

But Mithila, according to Elphinstone (p. 215), seems to have been the capital of a sovereignty in Rama's time, and to have endured till A.D. 1325. It was the capital of the father of Sita, wife of Rama. It is little mentioned in history, but it was famous for a school of law, and has given its name to one of the Indian languages. By the numerous dynasties of the Lunar race of Budha many kingdoms were founded. Much has been said of the antiquity of Purag, yet the first capital of the Indu or Lunar race appears to have been founded by Sehesra Arjuna of the Hihya tribe. This was Mahesvati on the Nerbadda, still existing in Maheswar. The rivalry between the Lunar race and that of the Surya race of Ayodhya, in whose aid the priesthood armed and expelled Sehesra Arjuna from Mahesvati, has been mentioned. A small branch of these ancient Hihya, until the early years of the 19 th century, were still existing in the line of the Nerbadda, near the very top of the valley at Sohagpur, in Baghelcund, aware of their ancient lineage, and, though few in number, were still celebrated for their valour. Kusust'hulli Dwaraka, the capital of Krishna, was founded prior to Purag, to Surpur, or Mathura. The Bhagavat attributes the foundation of the city to Anirt, the brother of Icshwaca, of the Solar race, but states not how or when the Yadu race became possessed thereof. The ancient anuals of the Jeysulmir family of the Yadu stock give the priority of foundation to Purag, next to Mathura, and last to Dwaraka.-Tod's Rajasthan, i. p. 39 ; Wilson's Hindu Theatre, i. p. 298; Elphinstone.

MITHRA or Mithras, the sun, the object of worship of the ancient Aryans, the Bactrian sungod. Mithra is not mentioned in the Gatha of Zoroaster. In the Vedas he is rarely invoked alone, but generally along with (Ouranos) Varuna, the heavenly vault. In the later Iranian religion, Mithra is included as one of the Yayata, and in the Mithra prayers he addresses Ahura-mazda. It appears that there were two forms of worship in Vedic India, - the one domestic, universal, celebrated three times a day, the other rare and exceptional, but both blended by a compromise into one incongruous whole. The worship of the elements was clearly the national faith, with its offerings of the fruits of the earth, soma juice, barley, milk, and butter. Animal sacrifice came from without, corrupted more and more, and at last losing sight altogether of its original import. Indra and fire-worship was the later form on Indian ground. The aboriginal tribes to the present day sacrifice buffaloes and other animals, and there is no trace of fire-worship among them. On the other hand, the Viswamitra or Agnisara claim the honour of having been the first to introduce the worship both of Agni and Indra in various sakta of the Veda. Viswat Mithra, however, was the name of a body of immigrants; Viswamitra, the men or people of Mitbra.

Agastya, a native of Tibet, is a Maha Muni, of great celebrity in the legends of Southern India. He methodized the Tamil language, and is the chief Tamil medical authority. $\mathrm{He}$ is estimated to have lived in the 6th century B.C. According to Hindu legend, Agastya was the son of Mithra and Varuna conjointly, and born in a water-jar along with Vasisht'ha. Having commanded the Vindhya mountain to lie prostrate till his return, he repaired to the south of India, to Kolhapur, where he continued to reside, and appears to have been mainly instrumental in introducing the Hiudu religion into the Peninsula. —Wilson's Hind. Theat. i. p. 313 ; Rev. W. Taylor; Dr. Caldwell; As. Soc. Trans, ii. p. 213.

MITHRIDATES. The disruption of the empire of Eucratides enabled Mithridates I., a Parthian monarch, to seize upon a large part of his territories; and he made a successful invasion of India about B.C. 140 , and there is reason to believe that satraps (chatrapati) or governors were left by him in possession of the Panjab, where coins of Parthian princes have been found, 
the dates of which are placed between the years 90 and 60 B.c.-History of the Panjab, i. p. 57.

MITHRIDATUM, the Theriaca Andromachi or T. Damocratis of the ancients, represented in India by the Tariak faruk of the bazars.

MITRA. Sansk. A friend, from Mid, love. Mitra-caca, a crow, so named from her friendly disposition. Mitra-vinda, from Mitra, a friend, and Vid, to obtain.

MITRAGUPTA, son of Chandragupta, was known to the Greeks by the name of Allitro. Diamachus was an ambassador from the Greeks of Babylon to Mitragupta.

MITRA-MISRA, author of the law book Vira Mitradaya.

MITRA-VARUNA, a name of the Hindu god Ila, the analogue of Neptune.

MITREPHORA GRANDIFLORA. Bedd. A large and very handsome tree in the South Canara ghat forests, growing at an elevation of about 2000 feet. When in full flower it is very beautiful, its large flowers giving it at the distance more the appearance of a magnoliaceous than an anonaceous tree. The three inner petals are mitriform, are early deciduous, but the three outer ones subsequenty increase in size, and turn from pure white to yellow; the timber is very tough.-Beddome, Fl. Sylv. p. 75.

MITREPHORA HEYNEANA. Blume. Orophea Heyneana, $H . f$. et $T$. A middle-sized tree, growing at Haragam and other places on the lower Badulla road from Kandy, up to an elevation of 1500 feet. $-T h w$. Zeyl. p. 8.

MI-YO-PHA-LA. BURM. Hereditary descent from father to son.

MIZZ, ARAB., in colloquial Arabic Misd, are tight - fitting inner slippers of soft Cordovan leather, worn as stockings inside the slipper. They are always clean, so they may be retained in the mosque or on the divan.-Burton's Mecca, ii. 34.

MOALLAKAT. ARAB. Poetic compositions, which the ancient Arabs were accustomed to suspend in competition with other poets; the word means suspended. Several of them continue to be much admired. Of these may be mentioned the two poems of the Mantle,-one recited by Kaab, son of Zoheyr, in the presence and in praise of the prophet Mahomed in the ninth year of the Hijira; and the other written 600 years later by El-Busiri, and still, after six centuries more, renowned through all the kingdoms of Islam, inscribed on amulets, and chanted in sickness and over the dead.

MOASHUR. HIND. A variety of magic squares.

MOAWIYAH-ibn-ABI SOFIAN was governor of Syria, but renounced allegiance to Ali, and proclaimed himself khalif of the Western Provinces. Moawiyah (A.D. 671-678) for seven successive summers renewed the endeavour to take Constantinople, at length felt himself under the necessity of sending envoys to sue for peace from the emperor Constantine Pogonatus. The latter agreed, and sent the patrician Joannes Petrigaudius (the Yen-yo of the Chinese) to Damascus to conduct the negotiation with the Arabs. The result was that the latter pledged themselves to a 30 years' peace, and to pay to the empire every year 3000 pieces of gold, 50 slaves, and 50 horses. -Yule, Cathay, i. p. 60.

MOCHA, a town in Arabia. It had its origin about A.D. 1430 , by the people flocking around the learned Shaikh Ali Shaduli-ibn-Oman. About the beginning of the 17th century, the English and Dutch E. I. Companies established factories there, and carried on a lucrative commerce with the Indian ports. At this time the revenues amounted to Rs. 75,000 per annum; ships from all parts of the east anchored in its roadstead, and caravans from Egypt and Syria, and from the eastern nations of Europe, flocked to its markets. In the beginning of the 18 th century the French established a factory at Mocha, which was then at the height of its prosperity. In the early years of the 19th century its condition had changed. In 1836 it was half in ruin, and the trade had been deoreasing for many years, the result of misgovernment by the Turks or Arabs (it was plundered by the latter twice). The country around Mocha is a barren plain.-Playfair, Aden. MOD. MAHR. The broken or cursive or running handwriting used by the Mahrattas on ordinary occasions.

MODERA is about 25 miles in length, lying to the N.N.E. of the Great Ki, distant about 60 miles, and is the south-westernmost of a group of high islands which, until lately, were considered as forming a part of New Guinea. The inhabitants are Papuans. The sea is unfathomable at a short distance from the island, but there are several indifferent anchorages on the north side.

MODI. HIND. A chandler, a grocer. Modi khana, the shop; amongst the Mahratta race, the Army Supply Department, the commissariat.

MODI, Mora, or Mudi, in the Bombay Presidency, a land measure of 45 gunta of 33 feet square each $=4900.5$ square feet, or $1 \frac{18}{100}$ of an acre. In Mercara and the Padinalkanad taluks of Mysore, it contains 30 linga raja poles in length, and 4 in breadth $=3414$ square yards.

MOFUSSIL. PERs. In British India, any district outside of Calcutta, Madras, or Bombay.

MOGGILANA and Sariputra, the most distinguished of the earlier converts by Buddha and his companions; relics of them were found in the Bhilsa topes.

MOGHI, Bagri, Bhil, Sondi, and Bhilala, in the 18 th century had been for many years the worst euemies to the prosperity of Central India. The Bagri and Moghi came to Central India originally from the western parts of India, chiefly from the neighbourhood of Chitore. The Moghi hardly passed the Chambal, but the Bagri settled in the eastern parts of Malwa in considerable numbers; and about the beginning of the 19th century the Solunki Rajputs introduced 400 of them to garrison the small fort of Sattambari in Bersia, in which district, and others in its vicinity, there had been for a long period many settlers of this tribe. The Bagri are a very brave race. Their favourite pursuits were thieving and plundering. They were also mercenary soldiers. They were foot soldiers, but jamadars or leaders were usually mounted. Whenever they settled they remained in colonies, and even when three or four families fixed on a small village, they lived distinct from the other inbabitants. There were not more than 1200 in the countries of Bagur and Kantul, and their immediate vicinity. The Meena and Gujar who settled in Central India also distinguished themselves as expert thieves and robbers.-Malcolm's Central India, ii. p. 185. 
MOGHUL, a term derived from Mongol. As a title it was especially applied to the sovereigns of Dehli of the house of Timur, although they were equally at least of Turk descent, and presented in their appearance entirely Turkish characteristics. But Hindus apply this term, as also Turk, to all Muhammadans except the Afghans, whom they designate Pathans; and Moghulai is used to distinguish Muhammadan laws and territories from those of the Hindus and the British. Each of the successive emperors of Hindustan was known to Europe as the Grand Moghul; nevertheless the father of Baber, the founder of the dynasty, was a Chaghtai Turk, who spoke and wrote in Chaghtai Turki, and never alluded to the Moghuls but with contempt and aversion. His mother is said to have been a Moghulani. $\mathrm{He}$ said the horde of Moghuls have uniformly been the authors of every kind of mischief and devastation. With the Portuguese, the northern part of Hindustan, held by the Moghul sovereigns, was styled Mogor, and Goa and the western coast of the Peninsula was to them India, just as the British now designate as India all their possessions in Hindustan and the two Peninsulas, and as with the Dutch, India means Java, Sumatra, and the Netherland possessions in the Archipelago.

Moghul, in India, is at present applied to, and is indifferently used by, persons of Persian or Turk descent, though the former race assume also the title of Mirza, while the descendants of the civilians and soldiery from High Asia, whom Baber and others brought into India, have the tribal title of Beg, also that of Agha or Aka. Moghulani, a female attendant on a lady, a lady'smaid.

MOHAMMERA, a town in the Persian Gulf, at which the British Indian army landed in 1855, when attacking Persia.

MOHANA, a fisherman race in Sind, who appear to be converted Hindus, but they claim to be of Arab descent from the town of Arlitah. They have five claus, - the Bundri, Karācha, Lana, Jhabar, and Wungara. They fish in the creeks and channels. They profess Muhammadanism. The Jhabar eat the porpoise and crocodile, and are deemed unclean. The Mohana features are peculiar, and the complexion very dark; some of the women are handsome when young, but hardship, exposure, and other causes soon deprive them of their charms. They are to be found chiefly about the lakes of Manchar, Maniyar, and Kinjur. At the last place are some ruins of a palace built by Jam Tamachi, one of the rulers of Sind, who married Nuren, the beautiful daughter of a fisherman. The event is celebrated in the legends of the country, and the poet Shah Bhetao has given it a Sindi immortality in one of his Sufi effusions. The Mohana are not a moral people. Their language is gross in the extreme, and chastity seems to be unknown to them. The men are hardy and industrious, but addicted to bhang, opium, and other kinds of intoxication. They are admirable swimmers; children begin that exercise almost as soon as they can walk. They keep up regular mosques and places of worship, with Pir, Mullah, and all the appurtenances of devotion. The river Indus is adored by them under the name of Khajah Khizr, and is periodically propitiated by'a caste offering of rice, in earthen pots covered with red cloth. Their caste disputes are settled by the headmen, who are called Changa Mursa, and invested with full powers to administer justice to those who consult them.

MOHANI, in Hinduism, a celestial songstress; 10 in heaven and 34 on earth.

MOHARI. HIND. A cornelian or agate point mounted on an iron handle, for polishing work.

MOHINI. Sansk. From Mooh, to be infatuated. In Hindu mythology, the female form of Vishnu with whom Siva associated, and Mohini brought forth Ayenar.

MOHMAND, a tribe of Pathans inhabiting the hilly country to the N.W. of Peshawur, between the Kābul and Swat rivers. Their clans are the Tarakzai, Alamzai, Baizai, Khwaizai, Utmanzai, and Dawezai. They could turn out 16,000 or 17,000 fighting men. Their country is rugged and unfruitful. In 1873, about 272 were in the British Native army. In 1851, a force under Sir Colin Campbell was moved against them; in 1854 , another force was sent against them under Colonel Boileau, and in 1864 one under Colonel Macdonald. The Pendiali Mohmand worried the border for the first eleven years of British rule. The Mohmand subdivision of the Peshawur district is immediately south of Peshawur, and contained in 1808 a population of 40,443 , Syud, Mohmand, Kashmiri, and Khatri. The chief of all the Mohmands bas the title of Arbab.H. A., N.W.F.; MacGregor, iii. 4. See Momund. MOHRCHAL. HIND. A fly-flapper of peacocks' feathers.

MOHSIN FANI, author of the Dabistan.

MOHTUR or Pat, the Mahratta custom of widow re-marriage.

MOHUR or Ashruffi, a gold coin of India, now rarely seen, of 15 rupees value, so called from having had the sun's image.

MOI, Di-ditish, Nguon, Ro-moi, and Ke-moi are rude tribes occupying the mountain ranges between Tonkin and Cochin-China, and between Cochin-China and Cambodia. The Moi or Kamoi, on the opposite side of the Mei-kong, occupy the broad expansion of the Annam chain towards Cambodia, and appear to extend northwards along these mountains, marching with the Lau on the westward. They are said to be black savages, with Negro features. The Cambodians style them Kha-men; they are the Kho-men of Leyden and the Kha-men of Gutzlaff.

MOINEE, an order of Hindu devotees who vow perpetual silence. They go almost naked, and smear their bodies with cow-dung. - Cole. Myth. Hind. p. 389.

MOIRA, EARL, afterwards Marquis of Hastings, Governor-General of India from 1813 to 1821 . During his incumbency, the third Mahratta war occurred, in which the British were successful, and the power of the Peshwas finally overthrown.

MOI-'IAL, or Ka-the, a tribe in lat. $21^{\circ} 15^{\prime} \mathrm{N}$., and long. $94^{\circ} \mathrm{E}$, south of Munipur, with the Komnaga in the S. W., the Lahooppa naga in the N.E., and the Cachari on the west.

MOIZ-ud-DIN ALLAH, the fourth khalif of Barbary, and the first king of Egypt of the Fatimate dynasty, A.D. 952-976. He subdued all Northern Africa, and built Cairo.

MOKANNA. Hashim-bin-Hekiam was his proper name. He was a native of Gheze, in the district of Merv. He early distinguished himself 
by the keenness of his intellect, and enjoyed the reputation of being acquainted with secret arts. His father had filled the post of a sarbang or general under Abu Jafar Revaneki Balkhi, and Mokanna at first served in the same capacity under Abu Muslim. But on Abu Muslim's death, Mokanna openly proclaimed his religious views. He was seized and sent as a prisoner to Baghdad. How long he remained there is uncertain, but he came back from Baghdad, as did Bāb in more modern days, strengthened in his delusions of a prophetic mission. In Merv he collected the remains of his former secret adherents, and proclaimed his doctrines with all the greater zeal.Vambery, Bokhara.

MOKSH or Moksha, in Buddhism, final annibilation, equivalent to the Buddhist and Hindu Nirvana. See Nirvana.

MOLAVE, a valuable wood of the Philippines, equal to teak. It is largely exported to China.

MOLLUGO CERVIANA. Ser., $W$. and $A$. Pharnaceum cerviana, Linn. | Parpadagum, . TAM. Ghimshak, . . BENG. Parpataka, . TEL.

This plant grows in Peninsular India, where it is employed in medicine. M. spergula, Linn., is Gyen-ga of the Burmese.

MOLLUSCA or Molluscs.

Sadaf, . . . ARAB. Sipi,

Fils assamak, Pesce de nicchio, : "Fr. Conchudo, Concha, SP. Pescado, . . GER. Kilinjil, Matti, . TAM. Malakia, : : GR. Silakalu, . : TEL.

Mollusc is a term derived from the Greek word

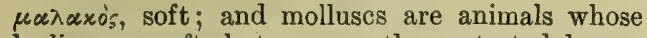
bodies are soft, but are mostly protected by an external shell.

The mollusca are related to the zoopbytes by the affinity of their simpler forms, and the higher classes of them to the fishes.

Distribution.-The ocean mollusca of the East Indies have an uninterrupted area from the Red Sea and east coast of Africa to Easter Island in the Pacific, and from Australia to Japan. They have some peculiar shells, but the genera throughout are in many instances identical ; even a considerable number of the same species have been found throughout the region, and their general character is the same. Mr. Cuming obtained more than 100 species from the east coast of Africa identical with those collected by himself at the Philippines. Of the numerous mollusca of the Red Sea, only. a very few are common to the Mediterranean, from which it would seem that these seas have communicated since the first appearance of some existing shells. Meleagrina margaritifera, or the pearl oyster, Avicula, occurs in the Persian Gulf, on the Madagascar coast, in the Straits of Menaar, Torres Straits, at the Society Islands and Philippines.

Surgeon-General Balfour, when forming the Government Central Museum at Madras, and the Mysore Museum at Bangalore, arranged the mollusca and the catalogue of them in accordance with Mr. S. P. Woodward's Manual, a fourth edition of which was published by Mr. Tate in 1880. The shells in the Madras Museum were collected from every part of the Indian Ocean, the Arabian Archipelago, and Australasian seas. Dr. Traill in Journal Indian Archipelago, and Dr. Cuthbert Collingwood in Rambles of a Naturalist, have furnished useful information.
Mr. Benson of the Bengal Civil Service has been a large contributor to scientific journals, and he described Dr. Cantor's Chusan shells. Since then the mollusca of the East Indies has been treated in Lieut.-Colonel H. H. Godwin-Austen's Land and Fresh - water Mollusca of India; Geoffroy Nevill gave a Hand List of the Mollusca in the Calcutta Museum; Mr. Theobald printed a Catalogue of the Recent Shells in the Bengal Asiatic Society's Museum; Mr. Theobald and Mr. Hanley's Conchologia Indica, and Mr. Theobald's Catalogue of the Land and Freshwater Shells of British India, have been the most important works for the Indian area. Lovell Reeve's work on the Mollusca extended to twenty volumes; and as a recent general work, Mr. S. P. Woodward's Manual of the Mollusca is of great value.

Writing in 1850, Mr. Woodward said that at least 15,000 fossil species of molluscous animals and 12,000 recent were then known. The numbers of living species have since been estimated at 16,792, viz. Cephalopoda, 190; Gasteropoda, 13,146; Pteropoda, 79; Brachiopoda, 75 ; Conchifera, 3150 ; Tunicata, 150 . Of these 5200 are animal feeders, 3255 vegetable feeders, 3376 infusorial feeders, and 4960 pulmonifera.

Propagation.-For the continuance of these creatures, the sexes are distinct in the most highlyorganized (or diøecious) mollusca; they are united in the (monœcious) land-snails, pteropods, opisthobranchs, and in some of the conchifers. The monocious land-snails require reciprocal union; the limneidæ unite in succession, forming floating chains. In a few species of gasteropods, a kind of viviparous reproduction happens through the retention of the eggs in the oviduct until the young attain a considerable growth.

The egg clusters of the Teuthidæ, calamaries, or squids, have been estimated to contain 40,000 eggs. The Ianthina ocean-snail secretes a raft from its foot, which serves to float its egg-capsules. The spawn of some species consists of large numbers of eggs adhering together in masses, or spread out in the shape of a strap or ribbon, upon which the eggs are arranged in rows. This ribbon is sometimes coiled up like a watch-spring, and attached by one of its edges. The Ianthinæ are gregarious in the open sea, and feed on the small blue acalephæ (Velella). In rough weather, their floats are broken and detached, and the beach is then strewed with the shells. When handled, a violet fluid exudes from beneath the margin of the mantle. The egg-raft is too large to be withdrawn within the shell, and their eggs are attached to its under-surface.

Little is known as to the longevity of molluses, but from the size of some of the bivalves, and from the partitions in the shell of the large nautilus, some of them must have many years of life. An Oyster Culture Company in England have verified oysters up to twenty years. At the age of two years oysters begin to give out spat, which assumes a calcareous covering in about a fortnight, and by the time they are a year old, the shells are about $1 \frac{1}{2}$ inches across. Neither has it been ascertained for how long the oyster continues to produce. Semicircular rings on the convex back of the oyster shell indicate repetitions of growth, but seemingly not annual growth. On one occasion the spat of one oyster was counted, 
and found to number $1,740,000$, but the quantities of spat are not continuous. In 1857, 1858 , and 1859, the oysters on the British coast produced spat in great abundance, and it is supposed that this was in some relation with the warmer temperature of the water. The great enemy of the oyster is the star-fish. It spreads itself over the convex surface of the shell, and by some mechanical process or chemical action bores through to the animal within. The dog-whelk, and also Murex erinaceus or sting-winkle, also destroy many by boring through the shell; and barnacles likewise destroy much of the young spat. The starfish swallow the smaller bivalve entire, and dissolve the animal out of its shell.

Defence.-To protect themselves from enemies, many gasteropods withdraw within their covering shell, and close the opening by a horny or shelly lid. Most spiral shells are provided with this means of sheltering themselves. Bivalve shells, as the oyster and mussel, close their valves. The cephalopods are provided with an ink-bag, from which it ejects a black pigment to cloud the water and facilitate its escape. This was formerly used for writing, and in the preparation of sepia, but Indian ink and sepia are now made of lamp-smoke or of prepared charcoal. In cold and temperate climates, the mollusca are subject to hybernation; also æstivation when the heat is great. In these changes they cover themselves with leaves, or hide in the mud; the limneidæ frequently glide beneath the surface of the water, and hybernate or æestivate in the mud. There are various other defences. The olives or rice-shell molluses are very active animals, and can turn over when laid on their back; as the tide retires, they may be seen gliding about or burrowing in the sands. Conus aulicus, one of the cones (Conidæ), sometimes bites when handled. The solen or razor-fish, if taken from its burrow, can quickly re-bury itself.

Alimentary.-Molluscs are eaten by most races. Amongst these are the loligo, the oyster, mussel, cockle, periwinkle, the haliotis, scallops, and whelks; the arms of the cuttle-fish are eaten by the Neapolitans and Chinese.

Helix pomatia, the grand escargot or applesnail, is eaten in France during Lent. They are reared and fattened in snail gardens. This was a culture of the ancient Romans.

Fusus antiquus (Chrysodomus antiquus), the red whelk, is largely dredged in Britain for food. Applied to the ear, a sound as of the sea may always be heard in it, from which it is named the roaring buckie. The common whelk of Britain, Buccinum undatum, is eaten by the people, and used as bait by fishermen. It is dredged for, and is also taken in baskets, baited with dead fish.

Anotber edible molluse is the common periwinkle, Littorina littorea. Besides these, the mussel scallop, Pecten maximus, which is served up broiled, and the razor-fish (Solen maximus), the cockle (Cardium edule), the limpet (Patella vulgata), are all eaten. The mussels are full grown in a year, and from some unascertained cause they are at times extremely deleterious. They are largely used for bait.

The poor of India use as food species of Cyclas, Cerithium, Nerita, and Corbicula, one species found within tidal influence, and two others in fresh water. Also Velorita cyprinoides, Gray, of the family Cyrenidæ, Unio, Limnea stagnalis,
Ampullaria glauca, $L$., Planorbis Indicus, P. Coromandelicus, and Paludina Bengalensis.

Ommastrephes sagittatus is the principal food of the dolphin and cachalots, as well as of the albatross and larger petrels, and is extensively used in the cod fishery off Newfoundland. Sailors call them sea arrows, also flying squids, from their habit of leaping out of the water, often to fall on the ship's deck. The pteropods swarm in all seas. In high latitudes they are the principal food of the whale, and also of many sea birds. The mussel, the limpet, the whelk, and the calamary are all used as bait in the fisheries.

Economy.-Many shells consist of two layers, an upper or outer, which is rough, and more or less developed, and an inner layer, called nacre, which is smooth. The nacre consists of a series of delicate layers one over the other in an imbricated manner, with their edges presenting a series of lines with waved margins. The brilliancy of the colours reflected from this iridescent surface depends on the thinness of the laminæ or layers of the nacre; where the layers are thick, like those in the oyster, only a dull white appearance is presented, but, as in the ear-shell and motherof-pearl shell, the iridescent colours reflected from the thin layers are beautiful ; they are used for the ornamentation of papier-maché work, and for other ormamental purposes. As seen in cabinets, the outer rough layer is always removed, and the hard layer below polished. The beautiful pearl, so largely used for ornament, the name of which is synonymous with purity, is the produce of various species of molluscs. The nacre is secreted by a part of the mollusc known as the mantle, and a pearl is the result of the nacreous matter being secreted by the mantle around some nucleus lying loose in the body of the shell, generally a grain of sand or some loose particle of nacre. The largest pearls are obtained near Ceylon in the Persian Gulf, and in the Persian Gulf on the coast of Arabia, from the pearl oyster, the Avicula margaritifera, in eastern seas from A. fimbriata of California. The shells are opened, and the pearls picked out, and the shells are used for their nacre which is called mother-of-pearl, almost as valuable as the pearl, being, with that of the Haliotis splendens, extensively employed in ornamenting papiermaché work.

Smaller-sized pearls are obtained from the common oyster, the British river mussel (Margaritana margaritifera), also in the Anodonta cygnea, the Pinna nobilis, the Mytilus edulis or common European mussel, in the Perna and Spondylus gæderopus. In these they are generally of a green or rose colour; the pearls found in Arca noæ are violet, and Anomia cepa purple. They are similar in structure to the shell, and likc it consist of three layers; what is the innermost layer in the shell is placed on the outside in the pearl. The mother-of-pearl shell is extensively fished for in the straits and seas south of Singapore; the diving-bell is utilized, and the divers are natives of the Pacific islands.

Cameo ornaments are obtained by carving shells. The inner strata of porcellanous shells are differently coloured from the exterior, and the makers of shell cameos avail themselves of this difference to produce white or rose-coloured figures on a dark ground. Cameos are used as brooches, pins, bracelets, etc., and the most 
beautiful are cut on a large species of Cassis (C. rufa), known as the bull's-mouth, and found in the Mediterranean; but any shell can be made into a cameo, the term meaning any small carving on a solid object. The queen-conch or helmet-shell, Cassis Madagascariensis, and other large species of Cassis, also species of Chama, are used in the manufacture of the shell cameos. Strombus gigas, $I_{\text {., }}$ the fountain-shell, is imported in immense quantities into Europe from the Bahamas, for the manufacture of shell cameos. Stone cameos are cut from the onyx, agate, and jaspers, and cost up to $£ 40$; a shell cameo, $£ 2$ to $£ 4$.

The shells of nearly all the Turbinidæe are brilliantly pearly when the epidermis and outer layer of shell are removed. Many of them are used in this state for ornamental purposes. The Chinese carve a variety of patterns in the outer opaquelayer of the nautilus shell, relieved by the pearly ground beneath. Species of the genera Trochus and Phasianella are used as beads. Cypræa tigris, which is prettily spotted with black, is frequently made into snuff-boxes in England. The mantle is so large as to cover all the shell, on the back of which there is often a longitudinal line which marks where its two folds meet. This membrane continually secretes an abundance of viscid fluid which lubricates the shell, and preserves the beautiful polish which has procured for them the name of porcelain shells.

The shells of species of Nautilus and Carinaria are prized for ornamental purposes. The beautiful paper Nautilus, Argonauta argo, is admired by all who see it for its graceful form, delicate structure, and pure colour. The argonaut or paper sailor is thin and translucent. A. hyans, Solander, is still living in the China seas, and fossil in the sub-Apennine tertiaries of Piedmont. The earshells, species of Haliotis, are largely used for ornament and inlaying. When polished, they present varied and beautiful tints, with motherof-pearl lustre. Cone-shells are also ornamental, as also are species of Tellina,Murex, and Buccinum.

The money cowrie, Cypræa moneta, of eastern seas, is used as small change throughout British India, and on the east coast of tropical Africa. It is also largely utilized in the ornamentation of horse and elephant trappings. C. annulus is used by the Asiatic islanders to adorn their dress, to weight their fishing-lines, and for barter. The smaller cypræa are made into clasps, buttons, earrings, bracelets, etc. The larger species were consecrated by the Greeks at Cnidos in the temple of Venus. At the present day Muhammadans of India suffering from guinea-worm make as a charm a string of human hair, to which they attach the eye of a peacock's feather, a piece of the root of Amomum zerumbet, and a cowrie. The cypræa, cones, olives, and ovulus are called love-shells.

Many species of Purpura secrete a fluid which gives a dull crimson dye; it may be obtained by pressing on the operculum.

Murex brandaris and M. trunculus are supposed to be the species of the Gasteropoda from which the Tyrian purple dye was obtained, but Purpura patula and others have also been indicated. The Ianthina also yields a colour.

The calcareous internal shell (Sepiostaire) of the Sepiidæ is the cuttle-bone in use by painters as pounce, also in casting counterfeits. It was formerly used in medicine as an antacid. That of a Chinese species of sepia attains $1 \frac{1}{2}$ feet in length.

Potamides telescopium (Terebralia telescopium) is so abundant near Calcutta as to be made into lime after exposure to the sun to kill the animals. The dead and living shells of species of the Conchiferæ are largely converted into lime at Nadras, for the beautiful plaster called chunam.

The great Tridacna gigas of the Indian Ocean, China seas, and Pacific is a marvel to behold. A pair of valves may weigh $500 \mathrm{lbs}$, and the animal, about $20 \mathrm{lbs}$. in weight, is good to eat. Some Christian churches, as in St. Sulspice in Paris, use them as benetiers. If a man were to put his hand inside and the animal shut its valves, he would be unable to withdraw it.

The chank-shell of the Indian Ocean and Bay of Bengal, Turbinella pyrum, long the war trumpet of the ancient Hindu races, is still represented in the hand of their deity Vishnu and other of their gods, and it is used as a trumpet in the Hindu temples and in their funeral processions. The Australasian and Polynesian islanders utilize the Triton tritonis similarly. The Buccinum whelk, employed similarly, bas its Latin name from Buccina, a trumpet or triton's shell. At Dacca, in Bengal, chanks are cut into necklaces, bracelets, armlets, and anklets, often of several hundred rupees value. Veneration is paid all over India to the large chanks, but especially those with the spiral line and mouth turned to the left. Chanks are used for beetling fine cloths; also as oil lamps in Hindu temples. In some years, above four millions of chank-shells are obtained in the Gulf of Manaar, of the value of $£ 10,000$.

Some shells are frequently found reversed, among others, Pyrula perversa, many species of pupa, and the entire genera clausilia, physa, and triphoris; also the whelk and the garden snail are sometimes reversed, and Bulimus citrinus is as often sinistral as dextral.

Injurious.-There are several boring-shells; the ship-worm or teredo and some allied genera perforate timber, whilst the pholas bores into stones, chalk, clay. A piece of serpentine found on the Madras beach was bored with the pholas. The pholas shell is rough like a file. Other boring shells are lithodomus, gastrochæna, saxicava, and ungulina.

The Teredo navalis is ordinarily a foot long, sometimes $2 \frac{1}{2}$ feet. It destroys soft wood rapidly, and teak and oak do not escape.

Teredo corniformis, Lam., is found burrowing in the husks of cocoanuts and other woody fruits floating in tropical seas.

The bivalves obtain their food by filtering water through their gills. They do not feed upon prey caught between their valves. Whatever particles the current brings are collected on the surface of the breathing organ and conveyed to the mouth. It is in this manner that they help to remove the impurities of turbid water.

Some of the gasteropoda attach themselves by glutinous threads; litiopa and rissoa parva anchor themselves to seaweeds, and cerithidea and Indian land-snail, Cyclostoma suspensum, suspend themselves. The mussel, pearl oyster, and other of the bivalves habitually spin a byssus, by which they attach themselves to objects. This they can detach and renew, and the mussel is essentially 
migratory. The byssus of the pinna of the Mediterranean attains to $1 \frac{1}{2}$ feet in length, and at Palermo has been woven into gloves and stockings as a fancy work.

The injury caused by the teredo has been noticed above. Nearly all the land molluscs are vegetable feeders. They commit great ravages on the crops of the farmers, particularly on the pea tribe and cabbage tribe; but they hold white mustard in abhorrence, and they fast or shift their quarters while that crop is on the ground. Snails are destroyed by salt, but dilute lime-water and very weak alkaline solutions are still more fatal to them. Slugs feed chiefly on decaying vegetable and animal matter. One of them, the Limax noctilucus, Fer., of Teneriffe, has a luminous pore in the posterior border of the mantle.

The mouth of the cephalopoda has two strong horny mandibles, something like the beak of a parrot, and it is surrounded by long fleshy arms, called tentacles, provided with numerous suckers, by means of which the animal grasps tightly whatever comes in its way. In some of the cephalopods the tentacles are long and powerful. Banks and Solander, in Cook's first voyage, met with a dead cephalopod in the Pacific, which was estimated to have been 6 feet long when perfect. It was the Enoploteuthis unguiculata; an arm of it is in the London College of Surgeons Museum.

Some species of loligo or pen-fish have been seen to leap out of the sea like the flying fish.

Fossils.-The window-shell, Placuna placenta, is at present living in the China seas, but is found fossil in abundance all round the coasts of India, from Sind to Singapore, and in the Peninsula of India and in China is largely used as a substitute for window glass. Of the genera and speeies of shells discovered in the black clay underlying Madras, the chief are :-

Rotella, A. granosa

Ranella tubercu-Anomia. lata.

Cerithi Natica helvacea. Venus. tera. C. palustre. C. telescopium. Turritella.

Eburna spirata.

Bullia vittata.

Ampullaria globosa.

Solarium.

Arca disparilis. N. maculosa. N mamilla Tapes ramosa. Donax scortum. Purpura carinifera Mactra. Oliva utriculus. Meroe. O. irisans. Cytherea. Nassa crenulata. Sanguinolaria N. clathrata. diphos. N. Jacksonianum. Tellina N. thirsites Nucula. Ostrea. Pullastra

The Pecten Jacobæus or St. James' shell was worn by the former pilgrims to the Holy Land, and became the badge of several orders of knighthood.

Amussium Japonicum is a large scallop of Japan. The Japanese call it Tsuki-hi-kai, and the sun and moon shell, from its presenting a yellow disc on one side and a white one on the other.

The genus Pecten or scollop shell possesses greater power of locomotion than most bivalves. The movements of the lima or file shell, when in the water, are graceful, the two valves being used as fins, by means of which it swims with considerable rapidity; the shell is less curved than the scallop, and generally white; the valves do not entirely close.

Living. - The following are genera of the salt-water mollusca living in all the eastern seas :- acmea.

anatina. anatinella. ancillaria.

anomia.

artemis. aspergillum. bankivia. broderipia buccinum.

bulla.

bullia.

cancellaria.

cardilia.

cardita.

cardium.

cassis.

cerithium.

chæna.

chama.

chamostrea.

circe.

cithara.

clavella.

clavigella.

clementia.

columbella.

conus.

corbula.

crassatella.

crenella.

crepidula.

cuculæa.

cultellus.

cyclena.

cylindra.

cyllene.

cypraa.

cypricardia.

cytherea.

delphinula.

dentalium.

diplodonta.

dolabella.

dolium.

donax.

eburna.

elenchus.

fasciolaria,

fissurella,

fusus.

gena.

haliotis.

harpa.

hemicardium.

hemipecten.

hippopus.

imbricaria.

imperator.

\begin{tabular}{|c|c|}
\hline $\begin{array}{l}\text { isocardia. } \\
\text { jouannetia. } \\
\text { limax. } \\
\text { limopsis. } \\
\text { linteria. } \\
\text { liotia. } \\
\text { littorina. } \\
\text { lucina. } \\
\text { lutraria. } \\
\text { macroschisma. } \\
\text { mactra. } \\
\text { magilus. } \\
\text { malleus. } \\
\text { mangelia. } \\
\text { margarita. } \\
\text { martesia. } \\
\text { meleagrina. } \\
\text { melo. } \\
\text { meroe. } \\
\text { mesodesma. } \\
\text { mitra. } \\
\text { monodonta. } \\
\text { monoptygma. } \\
\text { murex. } \\
\text { myadora. } \\
\text { myochama. } \\
\text { mytilus. } \\
\text { natica. } \\
\text { nautilus. } \\
\text { nerita. } \\
\text { neritopsis. } \\
\text { nucula. } \\
\text { octopus. } \\
\text { odostomia. } \\
\text { oliva. } \\
\text { onychoteuthis. } \\
\text { ovulum. } \\
\text { paludinella. } \\
\text { pandora. } \\
\text { panopæa. } \\
\text { parmophorus. } \\
\text { patella. } \\
\text { pecten. } \\
\text { pectunculus. } \\
\text { pedum. } \\
\text { perna. } \\
\text { peronia. } \\
\text { petricola. } \\
\text { phasianella. } \\
\text { phorus. } \\
\text { phos. } \\
\text { pileopsis. } \\
\text { pilidium. } \\
\text { pinnoctopus. } \\
\text { pisania. } \\
\text { placuna. } \\
\text { placunomia. } \\
\text { planaxis. } \\
\text { pleurotoma. }\end{array}$ & $\begin{array}{l}\text { plicatula. } \\
\text { psammobia. } \\
\text { pteroceras. } \\
\text { purpura. } \\
\text { pyramidella. } \\
\text { pyrula. } \\
\text { pythina. } \\
\text { quoyia. } \\
\text { radius. } \\
\text { ranella. } \\
\text { ricinula. } \\
\text { rimella. } \\
\text { rimula. } \\
\text { ringicula. } \\
\text { risella. } \\
\text { rostellaria. } \\
\text { rotella. } \\
\text { sanguinolaria. } \\
\text { saxidomus. } \\
\text { scalaria. } \\
\text { scutellina. } \\
\text { semele. } \\
\text { sepia. } \\
\text { sepiola. } \\
\text { septifer. } \\
\text { seraphs. } \\
\text { sigaretus. } \\
\text { siliquaria. } \\
\text { siphonaria. } \\
\text { solecurtus. } \\
\text { solen. } \\
\text { solenella. } \\
\text { spirula. } \\
\text { spondylus. } \\
\text { stomatella. } \\
\text { stomatia. } \\
\text { strombus. } \\
\text { strutbiolaria. } \\
\text { syndosmya. } \\
\text { tapes. } \\
\text { tectarius. } \\
\text { tellina. } \\
\text { terebra. } \\
\text { terebratella. } \\
\text { terebratulina. } \\
\text { tricotropis. } \\
\text { tridacna. } \\
\text { trigonia. } \\
\text { triphoris. } \\
\text { triton. } \\
\text { trochus. } \\
\text { turbinella. } \\
\text { turritella. } \\
\text { velutina. } \\
\text { venerupis. } \\
\text { Venus. } \\
\text { verticordia. } \\
\text { voluta. } \\
\text { vulsella. } \\
\text { sala }\end{array}$ \\
\hline
\end{tabular}

The following are the genera of the land and fresh-water molluses of Eastern and Southern Asia; a few of them are peculiar to the region :achatina. acicula. alasmodon. allisa.

amnicola. amphibola. ampullaria. ancylus. anodon. arca. ariophanta. assinuinea. aulopoma. auricula. balen.

bithynia. bulimulus. bulimus. camptoceras. cataulus. cerithidium.

$\begin{array}{ll}\text { clausilia. } & \text { leptopoma. } \\ \text { conovulus. } & \text { limax. } \\ \text { corbicula. } & \text { limnæa. } \\ \text { cyclas. } & \text { megalomastoma. } \\ \text { cyclophorus. } & \text { meghimatium. } \\ \text { cyclostoma. } & \text { melampus. } \\ \text { cyclotus. } & \text { melanatria. } \\ \text { cyrena. } & \text { melania. } \\ \text { diplomatina. } & \text { mogatina. } \\ \text { electrina. } & \text { nanina. } \\ \text { Gibbus. } & \text { navicella. } \\ \text { glaucomya. } & \text { nematura. } \\ \text { helicarion. } & \text { neritina. } \\ \text { helicina. } & \text { novaculina. } \\ \text { helix. } & \text { omphalotropis. } \\ \text { hemimitra. } & \text { oncidium. } \\ \text { hypostoma. } & \text { otopoma. } \\ \text { incilaria. } & \text { paludina. } \\ \text { janella. } & \text { paludomus. } \\ \text { lampania. } & \text { parmacella. } \\ \text { latia, } & \text { paxillus. }\end{array}$

clausilia

cyclas.

cyclophorus

cyclotus.

cyrena.

electrina.

Gibbus.

helicina. 
peronia. pholas. physa.

pirenia. pisidium. planorbis. platycloster.

polydonta.
-Balfour's Cat. Mad. Mus. ; Phipson's Minute Life; Dr. Traill in Journ. Ind. Archip.; Woodward's Manual, Mollusca.

MOLOSSUS TIBETANUS, the Tibetan mastiffs, fierce-looking animals.

MOLUCCAS, or Spice Islands, are terms often applied to all the groups of islands lying between Celebes and New Guinea, although politically this name is restricted to the Dutch Spice Islands. The groups are under three Dutch Residencies, viz.-1. The Ternate Islands, including the Moluccas proper, comprising Ternate, Gilolo, Batchian, Obi, Mortui, and the Kaiva Islands; 2. The Amboyna Islands, including Amboyna, Cerain, Bouru, Goram, Amblau, and some smaller islands; and 3. The Banda Islands, 10 in number, including Great Banda or Lonthoir, Banda Neira, Pulo Run, Pulo Ai, Gunong A pi, Rosengyn, Kapal, Pisang Sjethan, and Vroumen. Rearrangements of the groups are made from time to time to meet altering conditions of the administration. The islands are mostly small, volcanic, unproductive in grain, but fertile in fine spices. Ternate, Tidore, Motir, and Makian are only trachytic cones standing on the same great fissure of the earth. The clove tree grows spontaneously on Ternate, Tidore, Motir, Makian, and Bachian. It begins to bear at 15 years, and is in full perfection at 20 , and the average yield is 5 lbs. Ternate is the most northerly of a chain of islands off the W. coast of Gilolo, in lat. $0^{\circ} 48^{\prime} \mathrm{N}$., and long. $127^{\circ} 16^{\prime} \mathrm{E}$. Ternate is merely a high volcano, with its base beneath the ocean. Its circumference around its shore is 6 miles, and its height is 5480 feet. Severe and destructive eruptions took place in $1608,1635,1653 ; 1673$, and next on the 26th February 1838, then on the 25th March 1839, and on 2d February 1840. In that of 1673 a considerable quantity of ashes was carried to Amboyna. In that of $2 \mathrm{~d}$ February 1840 , for 15 hours the solid ground rolled like the sea; but the heaviest ground wave was at 10 A.M. of the 15th February, and the people then took to their boats. In this interval were great eruptions of ashes and hot stones, which fell like hail. Lava poured from the crater into the sea. For ten days clouds of black smoke poured out. About midnight of the 14th the shocks were more violent, and before half-past three A.M. every house was levelled. Fissures formed in the earth, out of which hot water rose for a moment, and then the earth closed again to re-open at another place. The lower part of the mountain behind the town is covered with fruit trees,-the dorian and mango, lansat, mangosteen. When Drake visited Ternate in A.D. 1579, the Portuguese had been driven out of the island by the sultan. It was taken by the Dutch in 1607 . The people are of three well-marked races, - the Ternate Malay, the Orang Sirani, and the Dutch. The first are the descendants of the intruding Malay, who drove out the indigenes (who were no doubt the same as those of the adjacent mainland of Gilolo), and established a monarchy. The Sirani are the
Christian descendants of Portuguese. Ternate town is at the foot of the mourtains.

Makian Island is 50 miles from Ternate, and consists of a single grand volcano. In 1646 there was a violent eruption, which blew up the whole top of the mountain, leaving a truncated jagged summit, and vast gloomy crater valley. It was said to have been as lofty as Tidore before this calamity. On the 29 th December 1862 another eruption of the vast mountain took place, in which all the villages and crops were destroyed, and many of the inhabitants killed. The sand and ashes fell so far that crops at Ternate were destroyed, and it was so dark at Ternate that lamps had to be lighted at noon.

Gilolo north end is in about lat. $2^{\circ} 23^{\prime} \mathrm{N}$. It has a long mountainous coast, bigh bold land, with three remarkable peaks. The northern peninsula of Gilolo and the great island of Ceram are inhabited by the Alfura.

The Galela race are natives of a district in the extreme north of Gilolo, but they are great wanderers over the archipelago. They are remarkably energetic and industrious, of light complexion, tall, and with Papuan features, coming near to the drawings and descriptions of the true Polynesians of Tahiti and Owyhee. They build large and roomy prahus with outriggers, and settle on any coast or island they take a fancy for. They are an industrious and enterprising race; cultivating rice and vegetables, and indefatigable in their search after game, fish, trepang, pearls, and tortoise-shell. Professor Bikmore, however, states that they are strictly of the Malay type, and have not the dark skin and frizzly hair of the Alfura of Ceram and Buru, though representatives of that people may exist in Gilolo.

Tidore, on the west coast of Gilolo, is about 6 miles long. A mountain on the N.E. end of the island is in lat. $0^{\circ} 40^{\prime} \mathrm{N}$, and long. $127^{\circ} 22^{\prime} 30^{\prime \prime}$ E. Tidore is over 4000 feet high. Tidore, like Ternate,-from which it is two or three leagues distant, -is formed in its southern part of lofty hills. The soil is of great fecundity, and plentifully watered by streams from the peaks. The people have an aptitude for agricultural occupation.

Batchian is about 52 miles long by 20 , and is separated from Gilolo only by a narrow strait. It is the largest of the chaplet of isles surrounding Gilolo, and is as fertile as Tidore, but with a sparse, poor, indolent population. The soil is volcanic, and below the active crater springs of sulphureous water break from the ground in the most picturesque situations. Here, as in Amboyna, the Christian converts are the most inert. The situation and aspect of the island are beautiful. Monkeys are to be found nowhere else in the Molucca Archipelago.

Amboyna is about 32 miles long by 10 in breadth. Amboyna and Banda are-supposed to have been discovered by Antonio d'Abreu, a Portuguese captain, who left Malacca in 1511; but Ludovica Barthema (Vartoma) of Bologua claims to have been there in 1506. The Amboynese are of a middling height, and well formed. They make good mounted and foot soldiers, are gentle, brave, very sober, and easily managed. A considerable number have embraced Christianity. 
Ceram.-The cluster of islets lying at the S.E extremity of the island of Seran as it is called by the natives, or Ceram as it is laid down in the maps, are situated in lat. $30^{\circ} 55^{\prime} \mathrm{S}$., and in long. $133^{\circ} \mathrm{E}$. Ceram is the second in size of the Moluccas, having an estimated area of about 10,000 square miles. It is 162 miles long, but its greatest breadth is only 42 miles. The island is one long mountain chain that sets off transverse spurs, and some of the peaks are 5000 or 6000 feet in height, sending down innumerable streams to the sea. The vegetation is everywhere luxuriant, and the trees gigantic. The several islets which compose the Ceram group produce fruit trees in considerable abundance, - the dorian, mangosteen, the wild nutmeg, and the cocoanut and sago palm, the latter supplying to the natives the chief article of subsistence. Cloves and nutmegs grow wild. The Alfura of Papuan race are the predominant type in the island of Ceram. The people of Ceram approach nearer to the Papuan type than those of Gilolo. They are darker in colour, and a number of them have the frizzly Papuan hair; their features are harsh and prominent, and the women are far less engaging than those of the Malay race. The Papua or Alfura man of Ceram gathers his frizzly hair into a flit circular knot over the left temple, and places cylinders of wood, as thick as one's fingers and coloured red at the ends, in the lobes of the ears. They are very nearly in a state of nature, and go almost naked; but armlets and anklets of woven grass or of silver, with necklaces of beads or small fruit, complete their attire. The women have similar ornaments, but wear their hair loose. Ceram has on its western side the three islands, Bonoa, Kelang, and Manipa. The commercial products from the islands consist of tortoiseshell, mother-o'-pearl shell, beche-de-mer, wild cinnamon, wild nutmegs, and birds of paradise. The Greater and the Lesser Keffing, however, S.E. of Ceram, are well peopled by Muhammadan Malays, and sprinkled with houses of traders engaged in traffic with the Nassau, the $\mathrm{Ki}$, and the Tenimber Isles, where they sell the produce of their fishery, tortoise and trepang. The isles are low, but remarkably picturesque.

Bouro Island is one of the Moluccas, and is about 200 miles in circumference. The island is high, and has a semicircular mountain on its N.W. part. Bouro has two races; the larger number are Malays of the Celebes type, often exactly similar to the Tomore people of $\mathbf{E}$. Celebes, who are settled in Batchian, but the other race resemble the Alfura of Ceram. The bulk of the inhabitants are a comparatively fair people, very closely resembling the native of Amboyna.

Banda belongs to a group of ten small but high volcanic islands, situated between lat. $3^{\circ} 50^{\prime}$ and $4^{\circ} 40^{\prime} \mathrm{S}$. The largest is Lontar or Great Banda, it is erescent-shaped; and Pulo Pisang, Banana Island, and Pulo Kapal, Ship Island, lie in the hollow of the crescent, and form the arc of a circle. Within this arc are three other islands, the highest of which is Gunong Api, next Banda, Neira, N.E. of which is Pulo Krakka or Old Woman's Island. The nutmeg, the excellent maritime position, the superb roadstead, and the fertile soil of Banda, render it conspicuous among the Spice Islands; but, unlike Amboyna, it is unhealthy, and exposed to constant danger from the Gunong Api volcano, which has many times burst in eruption, devastating the neighbouring region, and blasting it with showers of scorching ashes. The base of this volcano, called by the French the Grenade of Banda, occupies the whole surface of the islet. Its height is about 2000 feet, covered with magnificent vegetation, commencing at the line where the waves cease to beat, and continuing upwards to the point where the lava ceases to flow. The isle is inhabited only by a few emigrants from Timor. For nearly 100 years the Portuguese monopolized the trade. In 1609 the Dutch attempted to take these islands, but the war lasted 18 years, and the natives fled to the neighbouring islands. The Dutch had to cultivate the islands with slaves, and when slavery was abolished, with convicts. The water is so transparent that living corals and minute objects are seen below. Almost all Banda Island is covered with nutmeg trees, grown under the shade of the Canarium commune. About three-fourths of the inhabitants are mixed races,-Malay, Papuan, Arab, Portuguese, and Dutch. When first discovered by Europeans, the inhabitants had made considerable advance in civilisation, but one still much inferior to that of the Malays and Javanese.

Rosingain, near Banda, was almost abandoned after the extirpation of its spice trees, its people emigrating to the neighbouring islands in search of a livelihood. The people are of the Malayan race, short, squat, and darker in complexion than the Malays or Javanese.

Land manmals are few in number. The only one of the quadrumana is Cynopithecus nigrescens, at Batchian; the Viverra tangalunga, Rusa hippelaphus, var. babirusa, Sorex myosurus; the flying opossum, Belideus ariel, a beautiful little marsupial animal like a flying squirrel; and three species of Cuscus, opossum-like animals, with long prehensile tails, small heads, large eyes, with a covering of woolly fur; their flesh is everywhere eaten. There are, however, 265 species of birds known. Amongst them the large red-crested cockatoo, 2 species of the Eclectus parrot, and 5 of the beautiful crimson lories, 21 species of pigeons, 16 species of kingfishers, and the moundmaking megapodii, for M. Wallacei inhabits Gilolo, Ternate, and Bouro.

The insects are very numerous and very beautiful,-Pieridæ, Danaidæ, Ornithoptera priamus, helena, and remus, Papilio ulysses, deiphobus, and gambrisius; Iphias leucippe, one of the Pieridæ; also Hestra idea of the Danaidæ; two large Nymphalidæ, Diadema pandarus and Charaxus euryalus; and amongst the beetles Enchirus longimanus and Xenocerus semiluctuosus.-Bikmore; Crawfurd; Hogendorp; Horsburgh; Keppel; Kolff; Logan; St. John; Temminck; Wallace.

MOLUNGHI. BeNG., URIYA, A salt manufacturer.

MOMBAZA, Mombassa, or Mombas, a small island on the E. coast of Africa. Castle in lat. $4^{\circ} 4^{\prime} \mathrm{S}$., and long. $39^{\circ} 43^{\prime} 9^{\prime \prime} \mathrm{E}$. The Indian colony here comprises Bohra, Sindi, Khojah, and Hindus. Of these, the Bohra are the most numerous, as well as the longest established; they came from Surat and Cambay. The Sindi, who arrived much later, numbered 30 houses in 1873 , and holding, as they do, the Sunni doctrines, are stated to have fewer sympathies with the British Government than either of the other 
Indian Muslim sects. The Hindus are the least numerous of the Mombassa traders, and while scattered everywhere at the ports, are only largely represented, like the rest of the Indian races, at Zanzibar alone. The trade of Mombassa is increasing, and none but free men of the place are . engaged on the caravans sent into the interior in quest of ivory and other produce. The annual export of ivory, much of which is shipped direct to Bombay, does not exceed 70,000 doilars. The tax levied by the Sultan on this article amounts at Mombassa to 3 dollars per 35 lbs. Copal pays the heavy tax of 15 per cent. on arrival at Zanzibar. Rhinoceros horns and wax pay each 1 dollar per 35 lbs. Only grain and oil-seeds are allowed to pass free.

MOMtaI. PERs.

Hajar-ul-musa, . . ARAb. Shih ts'ih, . . . CHin. Shih-lan-yu, : CHIN.

This name is applied in Persia and Central Asia to several forms of asphalte, mineral pitch, Jew's pitch, maltha. Near the Straits of Tang-i-Teko, from whence the Kurdistan river issues into the plain, and not far from the village of Peshker, is a fissure high up in the mountains, out of which runs a black substance resembling pitch, which is gathered by the natives, and is much esteemed in Persia for its healing qualities, especially for bruises and fractures. It is called Mumia or Mumia-i-Nai, from the village Nai-deh at its bottom. Shiraz sustained the shock of an earthquake about the year 1810 , when this fissure was enlarged, and the momiai has since flowed out more copiously. The excessive esteem in which it was held by the Persians may be judged by mentioning that Ali Murad Khan sent about an ounce of momiai enclosed in a gold box to the empress of Russia. It is alluded to also in the Ajaib-ul-Makhlukat and the Jahan Numa. Baron de Bode surmises that this is the Sarcocolla of Dioscorides, iii. p. 99, which is described as obtained from Persia, and to possess wonderfully healing properties. Sir William Ouseley states that the momiai of Darabjird is alone reckoned genuine. The Persian momiai is deemed a certain specific in fractured bones. It is a solid, hard, heavy, black, glistening mass, withont any particular odour. In all eastern bazars may be found, under the name of Persian mumiai, a compound resembling the genuine in appearance. According to Dr. Seligmann, Mum in Persia signifies wax; Iai or Ayu is the name of the village in the vicinity of which the spring of water containing mumiai or mumiajin is found.

MOMIN, a town 90 miles from Bamo. It seems to be under the Pan-thay Muhammadans. From Momin to Bamo the road runs through Shan and Chinese territory.

MONIN. ARAB. A Muhammadan believer. In Berar, weaver's and sellers of native cloths, the saree, susi, rarban, khodi. They profess Muhammadanism. Amir-ul-Mominin, commander of the faithful, a title of the early khalifs.

MOMINABAD, also known as Amba Jogi, a walled town in the Hyderabad territory. It has some Brahmanical and Jaina caves. It is a military cantonment of the Hyderabad contingent.-Ferg. and Burg. p. 425.

MOMIRA, or Manuran, or Mamiran, small cylindrical roots, brown externally, with a yellow peditullium; very much valued by natives as an astringent application to the eyes in chronic ophthalmia. One kind, Momira Chini, is said to come from Yarkand. The Makhsan-ul-Adwiya says there are three kinds,-Hindi, Khorasani, and Chini. Hindi is blackish-yellow in colour; Chini is dull yellow; Khorasani is dark and greenish.-Powell.

MOMORDICA, a genus of plants belonging to the natural order Cucurbitaceæ. The best known species are M. balsamina, M. charantia, M. charantia, var, muricata, M. Cochin-Chinensis, M. dioeca, M. ovifera.

MOMORDICA BALSAMINA. Linn.

Mokah, .. . ARAB. Balsam apple, . ENG. Kokah,
Kai-pu-t'an, : : : : CHAN.

This bears a bitter oblong fruit. When ripe, of a beautiful red colour, and eventually bursts. When green, it is carefully washed in warm water, and cooked and eaten by the Chinese, but has purgative properties. In Sind used in pickles.Smith, Ch. M. M.; Murray.

MOMORDICA CHARANTIA. Linn. Var. M. muricata, Willde., Roxb., $W$. and $A$.

Kyet-hen-kha, . . Burm. Karawila, . . . Singh. Karela, . . HIND., PERS. Pandi pavel, . Malead. Kakara, . . TEL。

This vegetable is very commonly cultivated in India and Burma at the commencement of the rains. The fruit is from 10 to 14 inches long, and from 2 to 4 in diameter; the edges are curiously notched and ridged; the flavour is bitter. When ripe, it is of a beautiful deep red and yellow. The natives fry and eat them, but they are principally used in curries. They require to be soaked in salt and water before dressing.

A variety, with oblong fruit,

Lamba karela, . DUKH. Comboo pagulkai, . TAM. Pandy pavel, HoRT., MAL. Commoo kakakaia, TEL. Deerga karavulli, SANSK.

is a very valuable, pleasant-tasted, and wholesome vegetable, though perbaps a little too bitter. It is about 4 or 5 inches long, and of a wrinkled and seabrous appearance outside. The natives sometimes make curry of it, but prefer it fried. In some parts of the country the Tamil name is pronounced Kombu-pawa-kai. Another fruit, called Nerree pavay-kai, belonging to the Cucurbitacer, is sold in the bazars.-Roxb.; Voigt; Jaffiey.

MOMORDICA COCHIN-CHINENSIS. Spr. \begin{tabular}{l|l} 
Muricia Cochin-Chinensis, & $\begin{array}{l}\text { M. mixta, Roxb. } \\
\text { Gour. }\end{array}$
\end{tabular}

Gol-kakra, . . BENG.

This is grown in Bengal. Has large creamcoloured flowers. The fruit is large, red, and thorny, contains a yellow insipid pulp, is totally inert as a medicine, and is indeed occasionally used for food in Bengal.-O'Sh.

MOMORDICA DIOECA. Roxb.

Sa-byet, . . Burm. Palu paghel, . . . TA3r. Dhar-karela, : : HrND. Potu-agakara, : : TEL. Kirars,. : RAVI. Potu kakara, . : ", Tumba karawilla, SiNGH.

A small round-fruited species of Momordica, much cultivated by the natives for their curries. The powder or the infusion of the fruit, when introduced into the nostrils, produces a powerful errhine effect.

MOMUND, an Afghan tribe, partly in British territory, partly semi-independent. The Upper or Hill Momund country stretches from the southwestern districts of Swat to the hills north of the 
Khaibar, and includes both banks of the river Käbul, Lalpura, the capital town, being situated on its left bank, just beyond the north-western extremity of the Khaibar. The Doaba between the Kābul and Lundi rivers overlooks British territory, and at one point is only 25 miles distant from Peshawur. The Lower Momunds inhabit lands within the British frontier, although doubtless of the same family originally. Four clans of this tribe at the least have come into collision with the British Government. These are the Pindi Ali Momunds, whose country extends westwards from the right bank of the Lundi, and in naturally a very strong position; the Alamzai Momunds, to the south of the former, who are also in possession of estates in British Doaba, which are let out for the most part to tenants; the Lalpura Momunds on the Kābul river; and the Michni Momunds, a portion of whose territory is attached to the Peshawur district. They hold a jaghir at the junction of the Käbul and Lundi rivers, a fertile tract, partly cultivated by themselves, and partly by members of various tribes on the plains, who are tenants. This jaghir was once more extensive than it is now, but was considerably diminished by reason of their murder of Lieutenant Bullenois, of the Engineers, at the end of 1852. That officer had, for the sake of amusemient, ridden to a very short distance into the lower hills among their lands, when he was seized and killed, and his head was sent as a trophy to Lalpura. Also they withheld the payment of two years' tribute. At last retribution was dealt out. In the autumn of 1854 a force was sent against them, which destroyed some of their villages, and brought the refractory Michuis to order. They have a few large villages, such as Lalpura, Kaumeh, and Goshteh, but the people generally live in very small hamlets. They originally acquired their present possession by conquest from the Delazaks on occasion of the Afghans from the west invading this part of the country. See Mohmund.

MON is the native name of the people of Pegu. The Burmese call them Talaing. The Siamese appellation is Ming-mon. Part of this population dwell on the delta of the Irawadi, in Moulmein, Amherst, and Martaban. Their alphabet, like that of the Thay and Burmese, is of Indian origin, being essentially that of the Pali form of speech, and, like all alphabets of this kind, it embodies a Buddhist literature. The Mon language is quite unintelligible to a Burmese or Siamese. The Mon long successfully contested with the Burmans the sway over the busin of the Irawadi. They were annexed to Burma in the middle of the 16th century, butagain threw off the yoke in the beginning of the 18th century, and subjugated all Burma. Their range embraces the delta of the Sa-luen, where Moutama or Martaban was their chief port. They long preceded the Siamese in the Tenasserim Provinces, and the languages of the Semang and Binua of the Malay Peninsula retain deep traces of their ancient influence to the south. A colony is also found in the basin of the Menam. Before the great southern movement of the Lau, the Mon appear to have occupied that basin also, and to have marched and intermixed with the closelyallied Cambodians of the Lower Mei-kong. They seem to have been at one time the chief traders eastward of the Bay of Bengal. No trace of the
Mon is now left along the Yuma range,-tribes of the Karen family being the exclusive holders of its inner valleys. Some of the very imperfectlydescribed tribes on the eastern side of the Irawadi, to the north of the Karen-ni, viz. the Za-baing, Ka-Khyen, etc., may belong to the older immigration. But the Mon is the only remuant within the ancient Karen province, and its earlier preservation is doubtless owing to the same causes, its arts, civilisation, and wealth, which have enabled it to hold its own against the Tibeto. Burman horde of the Irawadi. The Mon or Teling language has the intonations characteristic of the Chinese family, but to a much less extent than the Chinese itself, the Tai, or the Karen. The roots are principally monosyllabic; but this language is remarkable for its numerous compound consonants. Like all other Indo-Chinese languages, grammatical distinctions are made by particles prefixed or suffixed. In its vocables, it is the most isolated language in Further India, but it has a radical affinity with the language of the Ho or Kol. This is the view of Mr. J. R. Logan as quoted by Colonel Phayre, in his paper on the History of the Burma race. He considers the radical identity of the relative pronouns, definitives, and numerals of the Kol with those of the Mon-Annam group as established. Both groups in their glossarial basis are branches of one formation much more akin to Tibetan-Burman than to Dravidian.-Dalton, Ethnol. of Bengal, p. 119.

MONAL, a pheasant of the Himalaya, Lophophorus impeyanus.

MONAS, a tributary to the Brahmaputra. It rises in the Himalaya range, in lat. $28^{\circ} 20^{\prime} \mathrm{N}$., and long. $91^{\circ} 18^{\prime}$ E. ; runs S. 40 miles, S.W. 110 miles, S.W. into Brahmaputra. Length, 189 miles. It receives the Dimri, of greater length than itself. The Monas is the largest river of Bhutan, which state is almost drained by it.

\section{MONASTERY.}

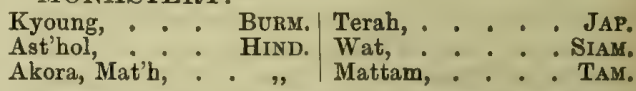

Monasticism is an essential feature in Buddhism. In the Brahmanical religion, it is only so far connected with the popular worship that several of the sects are ascetics, and the chiefs or gurus of most of the Hindu temples are also ascetics. Christianity also has several sects whose priests, as in the Romish persuasion, are monks. The Burmese monk is termed Phoungye. Their ranks comprise - (1) the Shin, a novice or postulant; (2) the Pyit-Shin or Pyin-Sin, a full menuber of the order; (3) the Sayah, always a Phoungye, the head of a kyoung; (4) the Geingoke, the provincial over the monasteries of a district; and (5) the Sadaw or royal teacher or vicar-general of the order, who manages the affairs of all Burma, British and Independent. The most learned and most famous Sadaw must go forth every morning to beg his daily food, even when tottering, old, and decrepit. In every monastery of Burma, the Kappee-dayaka has a stock of money, which is given in charity to the poor.

In Burma, the Shin or Shin-pyoo, probationer in a Buddhist monastery or kyoung, is admitted by baptism, Shin-pyoo-thee, to become a believer, usually from 12 years of age. The head is shaved and washed, and the yellow robe assumed, some- 
times only for 24 hours, others all Lent. Monks of Burma and Siam, as they go round every morning, with a begging-bowl strapped around the neck, accept meekly, without word of thanks or glance thrown to the right or left, the food poured in by the pious. About 8 in the morning, they set out in orderly procession in Indian file. On returning they present what they have received to the Buddha.

Lent is a periodical abstaining rite in the religions of Christians, Muhammadans, and Buddhists. With the first of these, the abstinence is only from certain diet articles, for a period of 40 days; Muhammadans, for a lunar month, call Ramadan or Ramzan, between sunrise and sundown, fast and are continent; but Burmese have a Lenten period of nearly three months' duration. See Myenmo.

Literature. - The Burmese Buddhist's sacred book is the Beetaghat. The IVee nee contains the whole duty of the Burmese monk. The young Buddhists of Burma learn the Payeht gyee and the Payah Shekho, Pali sermons and forms of worship, also the Mingola Thoht, Buddhist Beatitudes. Later on they pore over the Abidhamma Konitgyan, the seven books of the most difficult parts of the Beetaghat, with the Thing-yoh and Thaddah. Their lay literature consists of beast tales, fables of animals, with the Nataka or drama, from Nata, a dancer, or the Pooay or Pwe, a dramatic performance. Amusement usually winds up with a dramatic performance, called a pwe or pooay.

Burmese Buddhists have ten commandments, five of them obligatory on all Buddhists at all times, viz. Do not take any life; nor steal; nor commit adultery; nor lie; nor drink intoxicating liquor. And five incumbent on laymen only on sacred days and Lent, viz. Do not eat after midday; not to sing, dance, or play on any musical instrument; not to use cosmetics, or colour the face; not to sit, stand, or sleep on platforms or elevated places not proper for them; and not to touch gold or silver.

Monks of Burma use rosaries of Canna Indica, which they believe sprang from Shin Gautama's blood. Hermits of Burma, called Ya-theht, are not numerous, though the cells in the rocks above Nyoung Oo near Pagahon, near Old Mandalay Hill, and at other parts of the Irawadi, continue to receive occupants.

In Burma, within the enclosing parawoon or wooden rail of the Burmese kyoung all is sacred, and the laity, when they enter, take off their shoes and carry them in their hands. This applies to the highest in the land; and when a prince or Min-gyee arrives on an elephant, he dismounts at the monastery gate, and enters reverently barefooted. Mandalay Hill is held sacred, and rescued fowls are sent to it. There are great turtle in a tank at the Arakan pagoda. They are held sacred, and are fed by the pious. In March 1879 the tank dried up, and many died before water could be brought from the river. The circumstance was supposed to be an indication of the displeasure of the Nats, at the shedding of the royal blood in February by king Thebaw.

The Thihadaw monastery is on a small island in the middle of the third and lowest defile of the Irawadi. Large numbers of half-tamed dog-fish are in the waters around the island, great fivefeet-long, gape-mouthed creatures, which are fed by the pious. All the monastic tanks of Burma have such fish, more or less tame. The Nga-dan or butter-fish at the Kyeiklat monastery are summoned by beating the bank and calling Tit, tit, tit, and fed by the Ya-han and young Ko-yin. The Nga-dan allow their heads to be stroked and to have gold-leaf affixed. There is a peak 3650 feet high, on the crest of the main dividing range between the rivers Tsit-toung and Salwin, in British Burma. Its most remarkable features are the numerous gravitoid boulders scattered about the summit, some being balanced in a marvellous manner on the most prominent rocks. On the more striking of these, pagodas have been built, among which the Kyaik-hti-yo-ge-le and the Kyaik - hti - yo are the principal. The latter, about 15 feet high, is built on a huge egg-shaped boulder, perched on the apex of a shelving and tabular rock, which it actually overhangs by nearly one-half. Pious Buddhists believe that the pagoda is retained in its position solely by the power of the hair of Buddha or Gautama enshrined in it. This relic is fabled to have been given to a hermit living on the mountain by Buddha himself.

The gurus of most of the Hindu sects are monks, and several of the sects are ascetics, who recruit their numbers by adoption. The gurus or priors reside in the mat'h or monasteries. They are not numerous with Hindus, and asceticism and monasticismamong the Muhammadan sects is very rare.

Monasticism, among Christians, first took its rise in Egypt; and the Coptic monasteries of St. Anthony and St. Paul claim to be founded on the spots where the first hermits established their cells on the shores of the Red Sea. Next in point of antiquity are the monasteries of Nitria in the neighbourhood of the Natron lakes, which are situated in the desert to the N.W. of Cairo, on the western side of the Nile. Of these monasteries authentic accounts are extant, dated as far back as the middle of the second century, when Fronto retired to the valleys of the Natron lakes with 70 brethren in his company.

The Abba Ammon and the Abba Bischoi betook themselves to this desert in the beginning of the 4 th century, the latter founding the monastery still called after his name, Isaiah or Esa, to which the Copts prefix the article B or P. St. Macarius first retired into the Thebaid A.D. 335 , and about 373 establisbed himself in a solitary cell on the borders of the Natron lakes. He died A.D. 394, after 60 years' residence in various deserts. Numerous anchorites followed his example. $\mathrm{He}$ was the founder of the monastic order which, as well as the monastery still existing on the site of his cell, was called after his name. After the time of Macarius the number of ascetic monks increased to a surprising amount. Rufinus, who visited them in the year 372 , mentions 50 of their convents. Palladius, who was there in the year 387 , reckons the devotees at 5000. St. Jerome also visited them, and their number seems to have been kept up without diminution for several centuries.-Quarterly Review.

MONEGAR, in the south of India, a superintendent or head of a village or temple, or subordinate revenue officer.-Wilson.

MONEGAR CHOULTRY, a charitable institution in Madras, comprising a poorhouse, a foundling hospital, an hospital for native sick, and a leper 
hospital. It was founded in the early part of the 19th century by the E. I. Company, the nawab of the Carnatic, and the general public, and in 1808 Surgeon Underwood was the original founder of the infirmary. Since then, Mr. John de Monte, Lord William Bentinck, Arnachellum Chetty, the maharaja of Vizianagram, Gajapati Rao, Sir Albert David Sassoon, the rajas of Pittapur and Colastry, have largely aided it. Lord Napier and $\mathrm{Mr} . \mathrm{R}$. Ellis subscribed for the erection of a school for the children of the paupers, foundlings, and of those in the neigbbourhood. In 1856 the average cost of maintenance of each pauper was 1 anna $4 \frac{9}{16}$ pice per diem; in 1863 the rate was 1 anna $5 \frac{1}{2}$ pies in the idiot asylum, and a little higher in the hospital; in 1871 the cost in the pauper choultry was 1 anna 5 pies.

MONEY.

Naqd, Tankah,

Monnaie, .

Geld,

ARAB. Moneta, Danaro,

FR. Zar-o-sim

GER. Moneda,

IT

Rupai, Paise,

Hind. Para, Akcha,

PORT., SP.

The Greeks, the inventors of the use of money, were imbued with the only true theory as to its character of real merchandise, and in no one of the Greek writers of the autonomous period is there any trace of the theory which treats gold and silver coins merely as conventional signs of value, subject to the will of the sovereign or of the state. The Greek coinage was, as a rule, excellent. Its metal was pure, its weight exact, and its real value corresponded to its nominal value, except in the case of the small change, which was everywhere more or less fiduciary. All the members of the community exercised a constant supervision over the operations of the mint.

The magistrates to whom was confided the duty of supervising the currency at Athens, were three in number, two being annual, the third changed about every month. The signatures of all three upon the Athenian tetradrachws warranted the excellence of the coin. In some other cities the chief political magistrate signed the coins, as the Prytanis at Smyrna, the Archon at Taba in Caria, the priest of Actian Apollo at Leucas, etc. At Rome in republican times the regular magistrates appointed to look after the coinage were called tresviri monetales. They were not finally abolished until the time of Aurelian, although from the commencement of the empire only the copper money remained under their administration. In ancient as in mediæval times, e.g. Venice and Florence, republics were by the very principles of their constitution far better secured than monarchies against the adulteration of money. In the Hellenic world there is hardly any bad money to be found which does not bear the stamp of a king or a tyrant. The Flaminian law, passed when Hannibal was at the gates of Rome, was the first which gave to money a conventional value which it could not command as merchandise. This temporary measure, adopted in a time of pressure to recruit an exhausted treasury, was the fatal precedent upon which was based the false theory that a legislative decision was sufficient to fix the value of the metallic specie. This theory henceforth became one of the dogmas of the new aristocratic party, and against it the democrats protested in vain. Marius Gratidianus, in the eyes of this party, committed a heinous crime in assailing the right of the state to depreciate the currency, and on this account Sulla visited him with cruel retribution.

The Cæsarean despotism restored for a time the public credit by issuing good money; but Augustus and his successors had absolute control over the gold and silver coinage, and before many years adulteration commenced, and went on growing until the systematic alterations in the coinage by imperial orders produced such confusion as was scarcely equalled in the most disastrous years of the 14 th century.

Ever since Alexander visited Western India, all dynasties have coined money as a royal right. But the current and convenient principal coin of the Malay and Philippine Archipelago has long been the hard Spanish dollar, the peso duro of the Spaniards; and that with globes and pillars, containing 3709 grains of pure silver, and worth in sterling money about 51.79 pence, has a universal preference. The British rupee and Dutch guilder are but of local currency there, and always more or less at a discount. The dollar, the Malays usually call a real, which is no doubt an abbreviation of the Spanish real de a ocho, or a piece-of-eight. The common name with the Javanese is ring git, which literally means scenic figure. A great variety of small coins of brass, copper, tin, and zinc are in circulation throughout all the islands. The most frequent of these is the Dutch doit, of which about 300 ought to go to a Spanish dollar. The intrinsic values of all such coins, however, have no relation to their assumed one, and being usually over-issued, they are generally at a heavy discount. The small coins of Palembang, Acheen, Bantam, and Queda are of tin. Those of the latter place go under the name of tra, which is, however, only the word stamp or impression. Of these 160 are filed on a filament of rattan, of which 8 strings or 1280 coins are considered equivalent to a hard dollar. In Bali and Lombok, the currency consists of Chinese zinc coins, with a hole in the middle for filing them on a string, each string having 200 . and five of these are called a siah, that is one thousand, being the highest denomination of money in the reckoning of the inhabitants of these islands. Their value rises and falls in the market according to the supply, like any ordinary article of merchandise; so that a Spanish dollar will sometimes buy 800 of them, but often as few as 500 only. All these small coins are generally known by the Javanese name of pichis, corrupted pitis by the Malays, a name which had extended to the Philippines. The only native country of the Archipelago in which a coin of the precious metals seems ever to have been coined, is Acheen. This is of gold, of the weight of nine grains, and of about the value of $14 \mathrm{~d}$. sterling; to which European traders have given the name of a mace, a corruption of the Malay mas, itself a corruption of the Sanskrit masha, the name of an Indian weight. All the coins of this description that have been seen are inscribed with Arabic characters, and bear the names of the sovereigns under whom they were struck, so that they are comparatively modern. The Javanese appear to have coined some of their own money, as we find from many examples excavated from old temples and other places.

Money seems to have been coined in China, in gold and silver and lead, so early as the time 
of Confucius, but money payments are still made in kind or by pieces of silver. Most of their calculations are made by a reckoning board. There is no coined money in China, except the brass pieces with a hole in the centre. Silver is sold by the weight, and an ounce is the equivalent of from 1700 to 1800 of these brass coins, which are called sapek by Europeans; they have some pieces of brass called tsian, and in Mongol tchos, of which the inhabitants of Siberia make Tchok and Tchek; they are of less value than a copec. A kind of notes are in circulation among private persons.

In British India, it was enacted that from the 1st September 1835 there should be coined a rupee (with doubles, halves, and quarters) to be called the Company's rupee, which should contain 165 grains (11-12ths) pure silver, and 15 grains (1-12th) alloy. This new rupee, which was made a legal tender in all payments, is nearly equal to the former Farrakhabad, Madras, aud Bombay rupees, and is received as an equivalent by them and for the Sonat rupee, and for 15-16ths of the Calcutta Sicca rupee. It is worth, reckoning silver at $56 \mathrm{~d}$. an ounce, $1 \mathrm{~s}$. $11 \mathrm{~d}$. and $2 \mathrm{~s} .0 \frac{1}{2} \mathrm{~d}$. stg., its nominal value being 2s. This current rupee bore on the one side the head of the reigning sovereign of Great Britain, and on the obverse the words E. I. Co., and the designation of the coin in English and Persian. It was also enacted that from the 1st September 1835, no gold coins shall be coined at any mint in India, except gold mohurs or 15 rupee pieces (with the subdivisions), containing each 165 grains (11-12ths) pure gold, and 15 grains (1-12th) alloy. Such mohurs were consequently worth $29 \mathrm{~s}$. 2d. each. These coins were marked in the same way as the new rupees, but they were not a legal tender.

About the year 1882, Sir Richard Temple, at a meeting of the Institute of Bankers in the London Institution, Finsbury Circus, gave a short account of the varied native coinages of India before the regulation of 1793 . He pointed out that up to 1835 Indir had in effect a double standard or a system of bi-metallism. Referring to the practice of hoarding on the part of the natives, he stated that in addition to silver, gold, and precious stones, they now held notes to the extent of several millions sterling and Government securities to the value of about 20 millions, and both notes and scrip were to some extent hoarded. He said the best opinions put the amount of silver coin in actual circulation in 1850 at 150 millions sterling; the best opinions would put it now at 200 millions. The coins issued from the Indian mints during a period of 35 years averaged 11 rupees per head of the whole population. That would amount to 220 millions sterling, but a deduction of 20 millions was to be made for the money withdrawn from circulation for hoarding. The total amount of the precious metals in India he put at 333 millions sterling in silver and 122 millions in gold, or 455 millions sterling. Of this, 255 millions of silver and three millions of gold had been coined by the British mints; but this total, while exceeding by 58 millions the highest estimate of the amount in circulation, was 197 millions less than the quantity of the precious metals possessed by the people of India. In estimating the probable absorption of silver as coin in India, an analysis of the mint returns since
18355 supplied the best criterion. The amount coined during that period gave an average of about 51-3 millions annually. In quiet years the amount coined varied from two to three millions, and in brisk years from 10 to 15 millions.

There are at present two mints in British India, one at Calcutta, the other at Bombay; and in the ten years 1874 to 1883 , the amounts coined yearly have ranged between $£ 2,229,241$ in 1882 and $£ 16,344,553$ in 1878 ,-in gold, mostly all in Calcutta, averaging $£ 14,195$; in silver, largely in Bombay, $£ 6,268,070$; and in copper, $£ 77,583$, about the same in the two mints. The average value of the British Indian currency notes, in the ten years, in circulation, has ranged from $£ 10,670,407$ in 1875 to $£ 15,180,711$ in 1883 .

Persian coins are of gold, silver, and copper, each metal being struck in almost its pure state. The gold coins are called toman; one of which in intrinsic value may now be equal to $10 \mathrm{~s}$. English. They were worth more formerly; but during the last fifty years their size and weight have gradually decreased. There are two sorts of silver money; the highest in value is the real, eight of which amount to a toman. The smaller silver coin is called the white; eight of these being equal to a real. The copper money has the name of black, siabi ; and twenty-four of them amount to one real. Tomans are coined in almost every great province; but they differ much in actual value, though all pass current for the same number of real.

Payments are made in the Turkish dominions in piastres and Spanish dollars, fifteen of the former being equal to one of the latter. The piastre is divided into forty para. A pound sterling is worth seventy to one hundred piastres.-Prinsep's Tibet; Craufured's Dict.; La Monnaie dans l'Antiquite, par F. Lenormant; Statistical Abstract.

MONG or Mung, a village in the Gujerat district of the Panjab, identified by General Cunningham with the city of Nikæa, built by Alexander the Great upon the site of his battle with Porus, after the passage of the river Jhelum. It stands in lat. $32^{\circ} 39^{\prime} \mathrm{N}$., and long. $73^{\circ} 33^{\prime} \mathrm{E}$., on an old ruined mound, the modern houses being built of large aucient bricks. Greek and Indo-Scythian coins occur among the ruins, many of them bearing the monogram NIK. Tradition assigns the origin of the mound to raja Moga, whom General Cunningham identifies with the Moa or Mauas of the coins.-Imp. Gaz.

MONGHIR, a town in Bengal on the S. bank of the Ganges, in lat. $25^{\circ} 22^{\prime} 32^{\prime \prime}$ N., long. $86^{\circ}$ $30^{\prime} 21^{\prime \prime} \mathrm{E}$. It is a pretty town in a charming. green valley, with the broad river washing it on two sides and hills in the background. Monghir was captured on the 10 th October 1763 . The town is celebrated for its iron manufactures. The entire process of iron manufacture, from smelting the ore to hammering out delicate ornaments, is carried on in the district. Fire-arms, swords, and iron articles of every kind are produced in abundance. A serviceable double-barrel gun can be obtained for $£ 2$, and a large double-barrel pistol for $£ 1$. The art of inlaying sword-hilts and other articles with gold or silver affords employment to about twenty families. The population, chiefly Hindus, is above 50,000. There are aboriginal and hill tribes, and semi-Hinduized aborigines inhabit the jungles in the southern 
parts of the districts. Among high castes are the Babhans, who follow Rajput and Brahman customs. In the Begu Sarai subdivision, to the north of the Ganges, they are twice as numerous as the whole Muhammadan community, and form a fifth part of the entire population. Among the lower castes, the Goala are cattle-breeders, herdsmen, and dairymen. It has a monument to Pir Shah Lohouni, a Muhammadan saint of great repute. The hot spring called Sitakund, the well of Sita, wife of Rama, is five miles distant.-Hooker, Him. Jour. p. 87; Tr. of Hind. i. p. 107; Imp. Gaz.

MONGOLIA, in the east of Asia, stretches from Siberia in the north, towards the Great Wall of China in the south, and from Dauria and Manchuria in the east, to the Altai and the sources of the Irtish, Tian Shan, and Eastern Turkestan in the west. In the centre of this region is the desert of Gobi, called Sha-mo or Sand Sea by the Chinese. The country north of the Gobi, from the Altai, Tungnu, and the Saian mountains in the west, to Manchuria in the east, is called Kalka, comprising as its chief districts, Urga (Kurd), Uliasutai, and Kobdo. In a N.W. direction from Gobi, between Tian Shan and the Altai, is Sungaria. Population, 2,000,000; area, 1,400,000 square miles. Mongolia populations extend in the south over the Great Wall, to the basin of the Koko Nor or Blue Lake, and thence range due west over Tangut and the northern border of Tibet. There are Mongol likewise in Turkestan, in the territories of Semeryetshensk, Alatan, and Semi-palatinsk, in the south of the province of Tomsk, with a more populous region due north to Siberia, round the Baikal lake.

This is a prolific region, and has given forth the warriors who extinguished Christianity in Asia and Africa, and nearly also in Europe, who conquered China and India, and held Russia for nigh two hundred years. They have been known to Europe as the Hun, Turk, Tartar or Tata, Kitan, Mongol, and Manchu. As known in Asia, the branches of the race comprise the Buriat, Char Aimak, Hazara, Kalmuk, Kazak, Kerait, Kipchak, Koshod or Eleuth. But, as a whole, the race may be classed as East and West Mongols and Buriat.

The East Mongols are divided into the Kalka, also the Shara Mongols, south of the Gobi, along the Great Wall north-eastward to Manchuria; and lastly, the Shiraigol in Tangut and Northern Tibet.

The West Mongol clans are the Kalmuk, Oelod, Oirad or Dorbon Oirad.

The Dorbon Oirad clans are the Sungar, Torgod, Khoshod, and Dorbod.

The ruthless conqueror Temuchin, afterwards known as Chengiz Khan, was a Mongol, born on the banks of the Onon, A.D. 1162.

The Mongol are called Kalmuk in Herat and Afghanistan. Those of Kābul and Persia are the Char Aimak and the Hazara. Aimak is a Mongolian, Manchu, and Turk word, meaning tribe. They dwell to the north of Herat and Kābul, in a country which in some places assumes a mountainous, in others a hilly character, and in some parts is well watered, in others bleak and rough, forming a watershed of two natural divisions, from the west of which flow the Murghab, the Tajend, and the Farrah-Rud, and from the east, the Helmand, the south-eastern feeders of year. Asia.

the Oxus, and the north-western feeders of the Kābul river.

The Tibetan and Nepalese are a Mongol race. The Dharma race, occupying the Dharma pass leading into Garhwal, are said to be the descendants of a body of Mongol whom Timur left behind him in Kamaon. They practise divination, taking their omens from the warm liver of the sacrificed sheep. They eat the yak and the cow, inter their dead for a time, and then, in the month Kartik, they exhume and burn them.

The great aboriginal stock of the inhabitants of the mountains, east of the river Kali, as in Nepal, is Mongol. The fact is inscribed in plain characters upon their faces, forms, and languages.

Ethnologists give to the race very extended possessions. Mongol is said to be from Mung, brave. It was softened by the Persians into Moghul, under which term, as known to Europe, Timur's descendants ruled in Northern India from the 16 th to the 18 th centuries.

Dr. Latham regards the indigenous Americans as Mongols who have emigrated direct from Eastern

About two or three millions of the population of Mongolia are directly under Chinese rule, but among Mongoloid races under that empire ethnologistr include also the people of Formosa, the Chinese, the Manchu, Tibetans, Tungus, and Uzbak.

Alexander Castren arranges them into Mongol proper, Tungus, Turk, Finn, and Samoyed.

Peschel, adopting the opinions of Moritz Wagner, Dr. Latham, and Mr. A. R. Wallace, designates the following nations as Mongoloid, viz. :-

$$
\text { A. Malay races, viz. }
$$

Polynesian Malays.

Asiatic Malays, viz.

Sunda.

Tagala.

Bisaya.

Bisaya. Macassar

Javanese.

B. S. Asiatics, with monosyllabic languages-

Races in Tibet and

Himalayas.

Burmese.

Siamese.

Micronesians.

Madagascar.

Formosa.

Batta.

Bugis.

Laos.

Annamite.

Chinese.

\section{Coreans, Japanese.}

D. Old World, Northern Mongoloid nations.

Ural Altaic race, viz.

a. Tungus branch.

b. Mongolian branch, viz.

Eastern Mongolian,

Kalmuk, Buriat, and Hazara.

c. Turkish branch, viz. Basian, Karakalpak, Kirghiz, Kumuk, Nogay, Osmanli, Turkoman, Uigur, Uzbak, and Yakrit.

\section{$E$. Northern Asiatics, doubtful. F. Behring's Straits tribes. $G$. American Aborigines.}

The Aleutian Islands are a volcanic band rumning in a regular course between Alaska and Kamtschatka. Their inhabitants are a Mongoloid race, and their children are married in their tenth 
MONGOOS, written also Mungoose, is an AngloIndian name applied to species of Herpestes, viz. :-

H. brachyurus of Java.

$\mathrm{H}$. exilis of Archipelago.

II. fuscus, Neilgherry brown mongoos.

$H$. griseus, Geoff $r$, Madras mongoos.

H. Javanicus, Genffir., of Java, Sumatra.

H. Jerdoni.

H. Mralaccensis, $\boldsymbol{F}$. Cuv., Bengal mongoos.

H. monticollis, W. Elliot, long-tailed mongoos.

H. Nepalensis, Gray, gold-spotted mongoos, Nepal.

H. nyula, Hodgs, nyul or neyool of the Terai.

H. Smithii, Gray, ruddy mongoos.

H. vitticollis, Bennet, stripe-necked mongoos of S, India and Ceylon.

One species, called by the Singhalese hotambeya, is believed by them not to prey upon serpents, but to live near rivers and mud brooks, the adjacent thickets affording them shelter, and aquatic reptiles, crabs, and mollusca their food. The ichneumon of the Egyptians is the Herpestes ichneumon, a quadruped celebrated for destroying serpents and crocodiles. It was also called Ichneumon pharaonis. 'The mongoos are all of active habits, and of bold and sanguinary dispositions. The Madras mongoos is spread through most parts of India up to the Panjab. It hunts for and eats the eggs of birds that lay on the ground, kills lizards, rats, and small snakes, and is very destructive to poultry.

The prevailing notion in India is that the cobra poison makes no impression on it. In the year 1863, at Trichinopoly, Major Macauly repeatedly placed cobras and the mongoos in the same room, and was satisfied that the cobra poison is innocuous to the mongoos. On one occasion, in the presence of himself and two brother officers, the mongoos was fairly struck at least once; this was distinctly seen by the three; the cobra fixed on the mongoos, then they grappled and rolled over and over together. On that occasion, the mongoos never showed the least fear during the whole contest; he would sometimes brush by the cobra within easy distance of being struck, but on these occasions the cobra simply remained on the defensive, erect and watchful; it was only when the mongoos advanced with the intention of fixing on him that the cobra struck at him. When the mongoos got the cobra's head fairly in his jaws, and gave it a good crunch, he quickly let it go again and foamed at the mouth considerably, and went running round shaking out the froth from his mouth as a dog does when he has bitten a frog; nevertheless it did not deter him from going in at him again and again till he had fairly munched the head and killed his enemy. He had the mongoos tied up immediately after the contest, to prevent him from obtaining that wonderful herb which he is said to eat. He examined the jaws of the cobra after death, one fang was plainly visible; the bead was considerably smashed, which accounted for the other one not being detected. The cobra measured 3 feet $3 \frac{1}{4}$ inches, spectacles beautifully marked; he was a particularly lively snake.

The Bengal mongoos is of similar habits to that of Madras, and is found in Bengal, Assam, Burma, and Malay Peninsula. The long-tailed mongoos is found in the Eastern Ghats of the Peninsula of India, as also is the ruddy mongoos. The goldspotted mongoos occurs from the Panjab, along the Himalaya, through Bengal to the Malay Penin- sula. The Neilgherry brown mongoos is restricted to the Neilgherries. $H$. vitticollis occurs along the western side of India from Dharwar through Travancore to Ceylon. H. nyula, Hodgs., in Nepal, lives in burrows of its own making.-Horsfield; Tennent; Blyth; Jerdon.

MONITOR. This name is given to a family of reptiles, the Monitoridx of naturalists, comprising the genera Empagusia, Monitor, Odatria, and Varanus, some transferred to the Varanidæ.

Monitor dracæna, Gray.

Lacerta dracæna, Linn. | T. cepidianus, Daud.

Stellio salveguardia, Laur. T. Bengalensis, Daud.

Tapinambis Indicus, Daud. Varanis dracæna, $L$.

Varanus guttatus, Indian monitor.

\begin{tabular}{l|l} 
Varanus argos, Merrem. & V. gemmatus, Guerin.
\end{tabular} \begin{tabular}{l|l} 
V. punctatus. & Talla-goya, . SINGH.
\end{tabular}

Brown, black-spotted, or yellow-eyed when young. Nostrils central, scales over the eyes Hat, small, sub-equal; of the head rather large. It is a native of India.

Kabara goya, SingH., is a larger species than M. dracæua, partial to marshy ground, and when disturbed upon land will take refuge in the nearest water.

Monitor Gouldii, Schlegel. Hydrosaurus Gouldii, Gray. Neck with two yellow streaks on the side; scales over the eyes small, granular; of forehead larger. Ventral shields small, longer than broad. N.W. Australia. See Reptiles; Varanidæ.

MONKEY, Ape, Baboon, Gibbon.

Kird, Maimūn, . Arab. Cephus, . . Lat. Sadān, : : Etrior. Kaki, Kubbi, : : Pers.
Ceph,. : SIsGH. Kephos, Kepos, . GR. Mono, : : : . SP. Koph, : : HEB. Korangu, : : TAM. Bandr, . HrNd. Kothi, . . TeL. Scimia, Bertuccia, . IT. Māymūn, : : TURK.

The monkeys are arranged by zoologists into two great groups, which are as distinct in their anatomical characters as they are in their geographical distribution:

1. The monkeys of the eastern hemisphere (Catarrhinæ), inhabiting Africa, Arabia, India, Japan, China, Ceylon, and the islands of the Indian Archipelago.

2. The monkeys of the western hemisphere (Platyrrhinæ), inhabiting the warmer portions of Central and Southern America.

The Catarrhinæ are characterized by nostrils which converge at their lower extremity, and are there only separated by a very narrow cartilage. Their dentition is the same as in man, consisting of eight incisor teeth, four canines, and twenty molars.

Monkeys of the Old World may also be divided into-(1) Apes, without a tail, to which the orangs and gibbons belong; (2) Monkeys properly so called; and (3) Baboons.

The apes, sub-fam. Simianæ, comprise the chimpanzee and gorila of Africa, and the orangs of Borneo and Sumatra. The gibbons are peculiar to the Indo-Chinese countries, and Malayana, Sylhet, Cachar, Assam, Khassya, Tenasserim, Malay Peninsula, and Archipelago.

The various kinds of ape seem to have been made known to the Hebrews, Greeks, and Romans by specimens brought from Africa and India; those of the Hebrews probably from India, the Hebrew name Koph being almost the same as the Sanskrit Kapi. Apes, gold, and ivory could, however, have been got from wany parts of Africa, 
as well as from the south and east of Asia, and their Sanskrit, Ethiopian, Hebrew, Greek, and Persian names,-Kapi, Ceph, Koph, Kephos or Kepos, Keibi, and Kubbi,-are identical, and show that the apes may have been brought from any of those regions; the Singhalese, Tamil, and Telugu names, Kaki, Korangu, and Kothi, are less similar. Had the Hebrew ships visited the isles in the Malay Peninsula, Sumatra, Java, or Borneo, they would have known of the Simia satyrus, the orang-utang of Malacea and Sumatra, the Mia of Borneo, or have seen the Siamanga syndactyla, the long arms of which measure 5 feet 6 inches across in an adult about 3 feet high. Mr. A. Russell Wallace has given the names for monkey in thirty-three languages of the Eastern Archipelago, none of which have any resemblance to the Kapi, Kubbi, or Koph of the Sanskrit, Egyptian, and Hebrew, but one of them, the Kurango of Balanghitam in N. Celebes, is almost identical with the Tamil Korangu. The names are:-

Aruka of Morella, Amboyna.

Babah of Sanguir, Siau.

Balanghitam of $\mathrm{N}$. Celebes.

Bohen of Menado.

Budess, Javanese.

Dare of Bouton.

Kesi of Camarian, and Teluti in Ceram.

Kess of Amblaw, and of Cajeli, Wayapo, and Massaratty in Bouro and Batumerah.

Kessi of Cajeli.

Kurango in N. Celebes.

Lebi of Matabello.

Lek of Teor, and Gah in Ceram.

Luka and Lukar of Teluti, Ahtiago, and Tobo of Coram.

Meiram of the Alfura, Ahtiago in Ceram.

Mia of the Sulu Islands, Tidore and Galela of Gilolo.

Miunyeet, Malay.

Mondo of the Baju.

Nok of Gani, Gilolo.

Roke of Bouton, Celebes.

Rua of Larike and Saparua.

Salayer of S. Celebes.

Sia of Liang in Amboyna.

Yakiss of Wahai in Ceram.

The ancient Egyptians are said to have worshipped monkeys. Some of them in India are still worshipped, and where thus protected, they are very troublesome, often even dangerous.

Raja Krishna Chunder Roy is said to have procured monkeys from Gooptiparah, and to have married them at Krishuuggur, and on the occasion to have invited pandits from Naddya, Gooptiparah, Ula, and Santipur. The expenses of the nuptials cost about half a lakh of rupees.

Monkeys appear to frequent regions exceeding 11,000 feet in height, the Presbytis schistaceus, Hodgs., ascending higher than others. These langur have been frequently seen, more especially in Garhwal and Simla, at the height of 11,000 feet, 'leaping and playing about at this elevation,' as Captain Hutton says, "while the fir trees among which they sported were loaded with snowwreaths.' The Macacus rhesus, Audeb., is met with as well in India (particularly in Bengal and Assam) as in the Himalaya, where it frequents heights of about 8000 feet. Turner mentions having seen a large troop of these animals in Bhutan, which are in Ceylon held in great veneration; but in Western Tibet, and farther to the north, no monkeys have yet been found.

Cynopitecus nigrescens is the black baboon monkey of Celebes.

In Ceylon there are five species of monkeys, four of which belong to one group, the Wanderoos, and the other is the little graceful, grimacing rilawa (Macacus pileatus, Shaw and Desmarest), which is the universal pet and favourite of both natives and Europeans. The Tamil conjurors teach it to dance.-Tr. of a Hind.v. i. p. 19. See Mammalia, p. 836.

MONOGAMY, amongst the Hebrew people, so far back as the time of Abraham, was recognised as the only legitimate state of things. The elevated conception of marriage presented in the record of the creation testifies to a most profound sense of the sacredness of monogamy as the most intimate possible union of two persons. The Canticle is a song of wedded love and fidelity. Polygamy was not prohibited amongst the Hebrews, but there is nothing to warrant the horrible seraglio customs depicted in Judges, and instituted by David and Solomon as regal. The great bulk of the Hindu races are monogamic, and their laws and practice are in accordance with their belief.-Bunsen, i. p. 177.

MONOTHEISM is the primary doctrine of the Vedas, and the great craving of the Hindu mind is to turn to the worship of one God. Most perhaps believe that the idol or deity whom they worship is the one dread Being.

MONRO, SIR THOMAS, K.C.B., born in 1762 , a Madras infantry officer, who rose to the rank of Major-General. He was Collector of the Ceded Districts and of the Bara Mahal, and commanded a division of the Madras army in the third Mahratta war. He took Sholapur, and settled the whole of the country between the Ceded Districts and the Southern Mahratta country. While Governor of Madras, he died of cholera near Ghooty, at Puttecondah, 6th July 1827, aged 65. He was an able administrator. A statue by Chantrey, in which he is seated on a horse in still life, has been erected in Madras to his memory. He entered the Madras army in 1779. His successful occupation of all the southern country, about 700 miles long, belonging to the Mahrattas, has been famed in history. Starting with 500 or 600 soldiers, amongst whom were a few Europeans, he took possession of the country which had been ceded by the treaty of Poona. Nine forts were surrendered to him or taken by assault on the way, and at the end of a silent and scarcely observed progress, he emerged from districts hitherto ruled by the hostile Mahratta race with an accession instead of a diminution of forces.

Under British rule three land tenures are known, the zamindari or permanent settlement, made in 1792 by Lord Cornwallis, of Bengal proper, and since then extended to Behar and Orissa, in which the lands are divided amongst middlemen, who pay a quit-rent to Government.

Under the ryotwari tenure in Madras, recognised by $\operatorname{Sir} \mathrm{T}$. Monro, the cultivators are the co-owners of the soil, and pay direct to Government. A modification of this has been introduced into Bombay.

The pattadari tenure was established by $\mathrm{Mr} . \mathrm{R}$. Martius Bird in the North-West Provinces, and it has since been extended to the Panjab. In this, Government deal direct with village communities, who are jointly responsible for the assessment.

In Bombay and Madras, Goverument transacts its revenue business direct with the cultivating ryot 
orfarmer, who is regarded as the feuar or proprietor, paying a feu-duty; and so long as that is paid he cannot be dispossessed. Neither in Bombay nor Madras is there any middleman. In Bengal, however, the British took up the zamindar system, who, under Muhammadan rule, had been partly a rent collector and partly a landed proprietor, and elected him to be owner, to the exclusion in many cases of the rights of the cultivators. Subsequently the Government, to the exclusion of the real owner, elected the tenant or the village community. In Bengal and Oudh the land tax is still levied on estates; in Northern India, on villages and proprietary holdings, and on individual fields. But in Madras and Bombay the tax is levied on the blocks of 10 or 12 acres, according to the convenience of the occupiers. Sir Thomas Monro was the strongest advocate of the ryotwari tenure.

MONSOON.

Mausam,. . . ARAB. | Etesiæ, GREeK, from हैros.

In Hindustan the people usually arrange the year into three periods, - the Choumasa or Burk'ha, which is the rainy season of four months' duration after which is the Siala or Jara or Mohasa, the cold season; followed by the Dhūp-kala or K'hursa, or hot season. This division indicates generally the course of the seasons in British India, though in one locality the rains or the hot or the cold seasons may be somewhat more prolonged than in another. In the Indian Ocean, and generally throughout India, the winds blow from certain quarters periodically, and are known as the southwest and north-east monsoons, these being their directions at sea. These monsoons prevail in the Indian Ocean, between Sumatra and the African coast, and between lat. $3^{\circ} \mathrm{S}$. to the Asiatic coast, including the Arabian Sea, the Gulf of Bengal, and between the island of Madagascar and coast of Africa. Both of them bring rain, and that from the south-west prevails from the latter part of May till the middle of September, and is chiefly felt on the west coasts of India and Burma, and northwards towards the Himalaya. The north-east monsoon prevails from about the middle of October till the middle of December, and in British India its force is chiefly felt on the eastern coast of the Peninsula. It gathers up its waters in the Australian seas and the Archipelago, where the sun in its southern course increases the evaporation.

The north-east monsoon mostly prevails in the entrance of Malacca Strait, between Acheen Head and the Nicobar Islands, from November to May, the October and November winds being variable. On the Coromandel coast it sets in, on the average, on the 19th October, being very rarely ten days earlier or later. Its force lasts till the 10th December, and milder until the middle of February. When the north-east monsoon sets in, a current flows from the north, and by the 1st - November it runs past Madras at the rate of three miles an hour. From that date it decreases till the 10th December, when it amounts to a small fraction of a mile.

The south-west monsoons, coming from the sea, carry into the interior rains for the great watershed of India. They bear with them an immense volume of vapour, as is shown by the rivers, and confirmed by the rainfall of Cherrapunji, and at 126 other stations. Cherrapunji is 4500 feet above the sea-level. It reaches quite up to the cloud region, and receives a precipitation of $537 \frac{1}{3}$ inches during the south-west monsoon, from May to August inclusive. Colonel Sykes reported to the British Association, at its meeting in 1852, the rainfall at 127 places, between the parallels of $20^{\circ}$ and $34^{\circ}$ in India; and according to this report the south-west monsoons pour down during the three summer months upon this area $29 \frac{3}{4}$ inches of rain.

The south-west monsoon generally commences in the China Sea about the middle or end of April, and continues to the beginning or middle of October. It sets in rather sooner about the Gulf of Siam and Tonquin, and along the western coasts, than over to the eastward in the open sea, near the coast of China, or near the coasts of Palawan and Luconia. It also continues longer to the south of Cape Padaran and Pulo Sapata, and along the coast of Palawan, in the southern part of the China Sea, than it does more to the northward, for southerly winds frequently prevail between the Straits of Singapore and Pulo Sapata until the 8th or 15th of October, when the north-east and easterly winds are blowing in the northern part of that sea. Between Acheen Head and the Nicobar Islands the south-west monsoon generally begins about the end of April or rather early in May, and abates in October. In September, and in the greater part of October, the winds off the north extremity of Borneo and the west end of Palawan generally blow strong from the S.W., with dark cloudy weather and much rain. In that region the S.W. monsoon is strongest and least variable in June, July, and August; but from May to August sudden hard squalls blow sometimes out of the Gulf of Siam, as far as Pulo Condore and Pulo Sapata. From the Gulf of Siam to Cape Padaran the S.W. monsoon blows along the coast nearly parallel to it, though land and sea breezes are felt close to the land on the coast of Cochin-China, from Cape Padaran northward to the Tonquin Gulf. In June, July, and part of August there is in general much rain and cloudy weather all over the China Sea. On the S. coast of China the winds during the S.W. monsoon prevail frequently at S. and S.S.E. At the autumnal equinox, storms and typhoons are very liable to occur. The N.E. monsoon, in the northern part of the China Sea, opens about the end of September or beginning of October. In the southern part of this sea it usually does not set in steadily until November. In February the strength of the N.E. monsoon abates; during this month and in March it blows moderately, with steady weather all over the China Sea.

The countries and islands of South-Eastern Asia have thus a wet and a dry side. The S.W. monsoon drops much of its rain on the Western Ghats of the Peninsula of India, and moisture brought by the N.E. monsoon is deposited principally on the eastern side of the Peninsula. The south side of an island in the S.W. monsoon has one continuous shower, but as the clouds spend their rain on the central mountains, the $N$. coast is quite dry. In the N.E. monsoon this is reversed.

In British India the S.W. monsoons commence at the north, and back down, or work their way towards the south. Thus they set in earlier at 
Calcutta than they do at Ceylon, and earlier in Ceylon than they do at the equator. The average rate of travel, or backing down to the south, as seamen express it, is from 15 to 20 miles a day. It takes the S.W. monsoons 6 or 8 weeks to back down from the tropic of Cancer to the equator. During this period there is a sort of barometric ridge in the air over this region, which may be called the monsoon-wave. In this time it passes from the northern to the southern edge of the monsoon belt, and as it rolls along in its invisible but stately march, the air beneath its pressure flows out from under it both ways, on the polar side as the S.W. monsoon, on the equatorial as the N.E.

As the vernal equinox approaches, the heat of the sun begins to play upon the steppes and deserts of Asia, with power enough to rarefy the air, and cause an uprising sufficient to produce an indrought thitherward from the surrounding region. The air that is now about to set off to the south as the N.E. monsoon is thus arrested, turned back, and drawn into this place of low barometer as the S.W. monsoon. These plains become daily more and more heated, the sun more and more powerful, and the ascending columns more and more active ; the are of inrushing air, like a circle on the water, is winded, and thus the S.W. monscons, backing down towards the equator, drive the N.E. monsoons from the land, replace them, and gradually extend themselves out to sea.

The S.IW. monsoon commences to change at Calcutta, in lat. $22^{\circ} 34^{\prime} \mathrm{N}$., in February, and extends thence out to sea at the rate of 15 or 20 miles a day; yet these winds do not gather vapour enough for the rainy season of Cherrapunji, in lat. $25^{\circ} 16^{\prime} \mathrm{N}$., to commence with until the middle or last of April, though this station, of all others in the Bengal Presidency, seems to be most favourably situated for wringing the clouds. Selecting from Colonel Sykes' Report of the Rainfall of India, those places which happen to be nearest the same meridian, and about $2^{\circ}$ of latitude apart, the following statement is made, with the view of showing, as far as such data can show, the time at which the rainy season commences in the interior :-

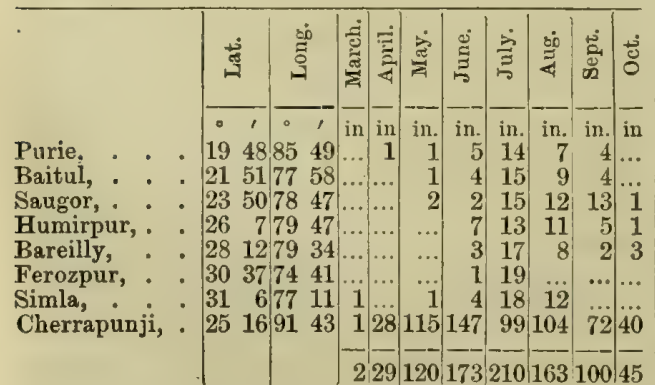

The course of the local monsoons is determined by the existence of alternately high and low atmospheric pressure over the country. This centre of minimum pressure is, as it were, a point upon which the wind turns, or it is the goal towards which the wind blows, while the place of greatest pressure is the point from which the winds diverge. As the determination of these points gives the general character to the monsoon in each locality, so the irregularities, the exceptions to the rule, give a distinctive character to each season. For example, in 1868, a local depression in the north-west of the Bay of Bengal diverted the moisture-laden winds from Central and Northern India, and attracted an excessive rainfall towards Bengal, west of the delta, and the northern part of Orissa. In 1869 the frontiers of Bengal were surrounded by a belt of low atmospheric pressure which shut in the rainfall, threatening to afflict the north-west with a second drought, until an egress was found for the imprisoned clouds during September and October in a rise of pressure about Hazaribagh. Such local atmospheric irregularities throw out calculation. Probably the most striking evidence of this is their misleading effects upon the determination of heights by the barometer. Thus the difference of Cuttack and Saugor Islands, which is known to be only 74 feet, appeared from the barometric readings of 1868 to be 205 feet, and from those of another year 166 feet. The track of cyclones also, though not their occurrence, is influenced in a considerable degree by local depressions.

MONTEITH, COLONLL IV., of the Madras Engineers, author of Description of the Tribes and States on the Frontier of Persia and Russia; on the Boundary between Persia and Russia; Latitude and I.ongitude and Revenues of Azerbijan: Routes from Bushahr to Shiraz.

MONTGOMERY, a town which gives its name to the north-eastern district of the Multan division of the Panjab. It was named after Sir Robert Montgomery, K.C.B., a distinguished civil officer of the Bengal Government. The district occupies a wide extent of the Bari.Doab, and stretches across the Ravi into the Rechna Doab. From time immemorial, the Rechna Doab has formed the home of a wild race of pastoral Jat. At the time of Alexander's invasion, the Kathreans held the northern portion of the modern district, while the Malli, with their capital at Multan, had possession of the southern tract. The population of the district consists largely of the Jat, with their subdivisions Khattia, the turbulent Kharral, together with the Fatehana, Murdana, Vainiwal, Baghela, Wattu, and Johea, and Hindus of the Arora, Rajput, Brahman, Kshatriya, and Gujar, with Syud, Moghul, Pathan, Baluch Muhammadans. Many of the Jat, Gujar, and Rajput have adopted the Sikh and the Muhammadan religions. Sir Robert Montgomery distinguished himself during the Indian revolt of 1857 , and afterwards served as Lieutenant-Governor of the Panjab. During his administration, there were steady and progressive measures of improvement. He subsequently became a member of the India Council to assist the Secretary of State for India.

\section{MONTH.}

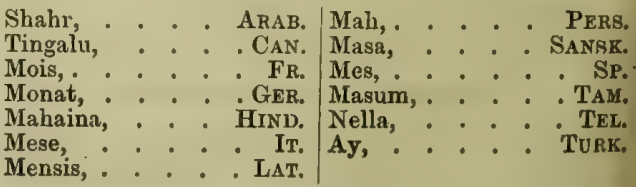

In the south and east of Asia, the races occupying the various countries divide the year into months, but some reckon by the lunar periods and some by the solar changes, The Hindus 
further divide the month in to two portions, called pukh, or fortnights. The first is termed badi, reckoning from the 1st to the 15 th, which day of partition is called amavus, answering to the ides of the Romans, and held by the Hindus, as it was by the Jews, in great sanctity. The last division is termed Sudi, the bright half of the month from new to full moon, and they recommence with the initial numeral, thence to the 30th or completion, called poonum; thus, instead of the $16 \mathrm{th}, 17 \mathrm{th}$, etc., of the month, they say Sudi ekum (1st), Sudi doag (2d). The Muhammadans of Arabia, Persia, and India, following the lunar changes, divide their year into twelve montbs, viz. :-

Mal arram.

Safar.

Rabi-ul-awal.

Rabi-ul-akhir or

Rabi-us-sani.
Jamadi-ul-awal. Jamadi-ul-akhir or Jamadi-us-sani Rajab. Shaban.
The Muhammadans, like most others, have weeks of seven days, called shambah. The following are the Persian uames of the days :-

Ek-shambah, . Sunday. Panj-shambah, . Thurs. Do-shambah, : Monday. Aduna or Jummah,Friday. Si-shambah, Tuesday. Shambah, . . Satur. Char-shambah, Wednes.

The Arabs distinguish their days or yom as first, second, third, etc., and the Muhammadans in British India use terms partly of Arabic, partly of Persian, and partly of Sanskrit origin :-

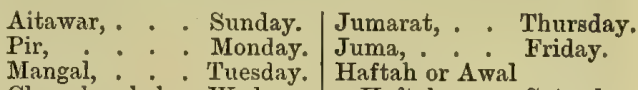
Char-shambah, Wednes. Haftah, Saturday.

Several of the Hindu races designate the months of the year by terms derived from one source :-

\begin{tabular}{|c|c|c|c|c|c|c|c|}
\hline English. & Singhalese. & Sanskrit. & Canarese. & Gujerati. & Hindi. & Telugu. & Tamil, \\
\hline $\begin{array}{l}\text { April. } \\
\text { May. }\end{array}$ & $\begin{array}{l}\text { Bak-masse. } \\
\text { Wesak-masse. }\end{array}$ & $\begin{array}{l}\text { Chaitra. } \\
\text { Baisakh. }\end{array}$ & $\begin{array}{l}\text { Chitra. } \\
\text { Vaishkha. }\end{array}$ & $\begin{array}{l}\text { Chaitr. } \\
\text { Vaisak'h or } \\
\text { Vaishak'h. }\end{array}$ & $\begin{array}{l}\text { Chait. } \\
\text { Byshakh. }\end{array}$ & $\begin{array}{l}\text { Chaitr. } \\
\text { Vaishakh. }\end{array}$ & $\begin{array}{l}\text { Chytram. } \\
\text { Vyasei. }\end{array}$ \\
\hline $\begin{array}{l}\text { June. } \\
\text { July. } \\
\text { August. } \\
\text { September. } \\
\text { October. }\end{array}$ & $\begin{array}{l}\text { Peson-masse. } \\
\text { Essele-masse. } \\
\text { Nikini-masse. } \\
\text { Binnere-masse. } \\
\text { Wak-masse. }\end{array}$ & $\begin{array}{l}\text { Jyest'h. } \\
\text { Asar'h. } \\
\text { Shraban. } \\
\text { Bhadra. } \\
\text { Ashwin. }\end{array}$ & $\begin{array}{l}\text { Jeshta. } \\
\text { Ashdadha. } \\
\text { Shrawana. } \\
\text { Bhadrapada. } \\
\text { Ashvina. }\end{array}$ & $\begin{array}{l}\text { Jet'h. } \\
\text { Ashad or Asad. } \\
\text { Shrawan. } \\
\text { Bhadariso. } \\
\text { Ashwan, Asho, } \\
\quad \text { Ashwin. }\end{array}$ & $\begin{array}{l}\text { Jeth. } \\
\text { Asar'h. } \\
\text { Sawan. } \\
\text { Bhacun. } \\
\text { Asan. }\end{array}$ & $\begin{array}{l}\text { Jyesth. } \\
\text { Ashad'h. } \\
\text { Shrawan. } \\
\text { Bhadrapad. } \\
\text { Ashwin. }\end{array}$ & $\begin{array}{l}\text { Ani. } \\
\text { Adi. } \\
\text { Avani. } \\
\text { Paratasi. } \\
\text { Arpasi. }\end{array}$ \\
\hline $\begin{array}{l}\text { November. } \\
\text { December. }\end{array}$ & $\begin{array}{l}\text { Il-masse. } \\
\text { Oondoowak-masse. }\end{array}$ & $\begin{array}{l}\text { Kartik. } \\
\text { Agrahayan or } \\
\text { Maraga-sirsha. }\end{array}$ & $\begin{array}{l}\text { Kartika. } \\
\text { Margashira. }\end{array}$ & $\begin{array}{l}\text { Kartik, Kartak } \\
\text { Magashar, } \\
\text { Margashirsh. }\end{array}$ & $\begin{array}{l}\text { Kartik. } \\
\text { Aghan. }\end{array}$ & $\begin{array}{l}\text { Kartik. } \\
\text { Magashirsh. }\end{array}$ & $\begin{array}{l}\text { Kartiga. } \\
\text { Margali. }\end{array}$ \\
\hline $\begin{array}{l}\text { January. } \\
\text { February. } \\
\text { March. }\end{array}$ & $\begin{array}{l}\text { Doorootoo-masse. } \\
\text { Navan-masse. } \\
\text { Meddin-dinne. }\end{array}$ & $\begin{array}{l}\text { Paush. } \\
\text { Magh. } \\
\text { Phalguna. }\end{array}$ & $\begin{array}{l}\text { Pushya. } \\
\text { Magha. } \\
\text { Phalguna. }\end{array}$ & $\begin{array}{l}\text { Posh, } \\
\text { Magh, Maha. } \\
\text { Fagan. }\end{array}$ & $\begin{array}{l}\text { Pas. } \\
\text { Magh. } \\
\text { Phagan. }\end{array}$ & $\begin{array}{l}\text { Paush. } \\
\text { Magh. } \\
\text { Phalgun. }\end{array}$ & $\begin{array}{l}\text { Tye. } \\
\text { Mausi. } \\
\text { Punguni. }\end{array}$ \\
\hline
\end{tabular}

MONTIFITSH, a Bedouin tribe in Irak or Turkish Arabia. They are fishermen, and breed horses. MOON, Luna.

Kamr, . . ARAB. Chandra, . . SANSK. Mond, Monat, : Ger. Nellah, : : TAM. Chand, . . H H HND. Vennil, : : : TEL. Bulan, : : MALAY. Aii, . : : TURK. Mah, . Pers., Turk.

In Hindu mythology, Chandra, the moon, is fabled to have been married to the twenty-seven daughters of the patriarch Daksha, who are in fact persouifications of the lunar asterisms. His favourite amongst them was Rohini, to whom he so wholly devoted himself as to neglect the rest. They complained to their fatber, and Daksha repeatedly interposed, till, finding his remonstrances vain, he denounced a curse upon his sonin - law, in consequence of which he became affected by consumption, and remained childless. The wives of Chandra having interceded in his behalf with their father, Daksha modified an imprecation which he could not recall, and pronounced that the decay should be periodical only, and that it should alternate with periods of recovery. Hence the successive wane and increase of the moon. Rohini, in Hindu astronomy, is the fourth lunar mansion, containing five stars, the principal of which is Aldebaran. Hindus have long been aware of the astronomical facts of the moon's deriving its light from the sun, and by its positions forming the days of the lunar month on which particular ceremonies are to be observed. In the latter case it is supposed to move in the Mandala, the sphere or orbit of the sun, and when in conjunction, as at the new moon or Amavasya, funeral obsequies are especially to be celebrated. According to their mythological notions, also, the moon is the grand receptacle and storehouse of amrit or ambrosia, which it supplies during the fortnight of its wane to the gods, and on the last day to the Pitri or deified progenitors. Also as personified, in Hinduism, the moon is the father of Budha and grandfather of Pururavas. The half-moon is worn by Siva upon his forehead. With the Rajputs, as with the Scandinavians, the moon is a male divinity. The Tatar nation also considered him a male divinity, like Adonis. The moon has, in many nations, been considered to exercise an influence on the body, producing and modifying diseases, and has played an important part in the development of the character of nations, and in determining the destinies of the human race. "The sun shall not smite thee by day, nor the moon by night' (Psalm cxxi. 6). Eastern races believe firmly in the evil effects of moonlight upon the human frame. New moons, and full moons, and moonless heavens at the conjunction, have been kept with ceremonies or fastings. Eclipses, whether of the sun or moon, have been looked on as evidences of divine displeasure; the influence of the moon on marriage and child-bearing was considered great. According to Egede, the Greenlanders believe that the moon visits their wives now and then; and that staring long at it when at its full will make a maid pregnant. Amongst the Jews, according to Rabbi Abravanel, the full moon was believed to be lucky, and the other phases disastrous, and the belief of the Greeks and Romans was similar. 
The day of the full moon was by the Greeks the best for marriage. Hesiod, Aristotle, Lucilius, Horace, Pliny, Galen, Lord Bacon, and others have all made similar notices.-Winslow on Light; Hindu Theatre; Tod's Rajasthan.

MOON. JAP. A crest or arms, of which the Japanese are as proud as any European noble. It is worn on their dresses, on their armour, before their gateways, and wherever it can be seen. Before the Government House there is generally spread a grass tree or linen cloth, which means 'No admittance except on business.' The crest on it has much the appearance of a clover leaf, and is the 'moon' of government.-Hodgson's Nagasaki, pp. 16, 22.

MOON, ALEXANDER, author of a Catalogue of Indigenous and Exotic Plants growing in Ceylon. It is a bare list of names. Colombo 1824. It is

MOON - FLOWER, Calonyction grandiflorum.

'the white moon-flower, such as shows

On Serendib's high crags to those

Who near the isle at evening sail,

Scenting her clove trees in the gale.'-Mason.

MOONSTONE, a felspathic mineral, is a partially decomposed orthoclase of little value. Some of the cat's-eyes that are brought for sale by the Ceylonese are made of moonstone, and in Europe moonstone is often sold for opal.

Adularia is very abundant in some parts of the interior of Ceylon, particularly in the neighbourhood of Kandy, where it is occasionally the predominating ingredient of the rock,-Mason.

MOOR, a term by which the Muhammadans of the south of India were known all through the 18 th and to the middle of the 19 th century. In the Hindustani dictionary by Captain Roebuck in 1813 , that language was styled the jargon of the Moors. It is still used in Ceylon to designate the Muhammadans there. The Tamil and Teling people of the Peninsula call them Turk, Turkakara, Turka-vadu. The term Moor seems to have been handed down from the early Portuguese.

Moor-man is the designation in Ceylon for a race believed to be of Arab descent. The establishment of a Muhammadan colony before the close of the 7 th century is alluded to by the autbor Beladeri in a Chronicle of the Arab Conquests in Europe and Asia. In their funerals, the corpse, after being washed and sprinkled with powder of sandal-wood, is borne in a coffin without a bottom (its place being supplied by plaited tapes), and carried on a bier decorated with flowers, which are afterwards planted on the grave. The procession is accompanied by mourners.

The Moor-man of Ceylon seem of similar origin with the Moplah of Malabar and the Labbai of the south of the Peninsula. Throughout the Peninsula, the uneducated of the European community continue to designate every Muhammadan as a Moor-man.-Tennent's Christianity, p. 35.

MOOR, MAJOR, an officer of the Bombay army, who was present at Seringapatam. He wrote Oriental Fragments, Hindu Pantheon, Hindu Infanticide, Narrative of the Operations of Capt. Little's Detachment and of the Mahratta Army against Tipu Sultan.

MOORCROFT, WILLIAM, a Veterinary Surgeon of the Bengal army, who travelled in Central Asia, and after some days' illness died at Andkhui.
He lies interred outside the walls of Balkh. Author of Journey to Lake Manasarovara, in Little Tibet. His first attempt was made by way of Chinese Tartary, and was described in the Asiatic Researches. In this journey he made his way to the great plain between that and the Kouen Lun chain, the situation of the sources of the Indus and the Sutlej, and of the two remarkable lakes of Ravan and Manasarovara.

After traversing the mountains, Moorcroft and his party arrived safely at Leh, by a route on which no European had preceded them, and on his way he first determined the direction of the upper parts and the sources of two of the three great rivers of the Panjab, - the Beyah, Vipasa or Hyphasis, and the Chandrabhaga or Chenab, also the Acesines or Ab-i-sin. A very small portion of this tract, or the southern part of the hill states of Kahalur, Sukhet, and Kotoch, were crossed by Forster, but in a condition of personal restraint and danger which left him little leisure for observation. About two centuries earlier (1624), the Jesuit missionary Andrada appears to have made his way from Srinuggur to the north of the Himalaya into either Ladakh, and in the beginning of the 18th century (1715) the missionary Desideri entered Kashmir by the Pir Panjal pass, and thence proceeded to Lhassa through Ladakb. The route from Käbul to Bokhara was, at the time when it was travelled by Moorcroft, new to European investigation. Goez, who travelled from Kābul to Kashgar, and thence to China, in 1603 , passed over a portion of it, but his account is concise and imperfect. 'Before I quit Turkestan,' Moorcroft writes from Bokhara, 'I mean to penetrate into that tract which contains probably the best horses in Asia, but with which all intercourse has been suspended during the last five years. The experiment is full of hazard, but le jeu vaut bien la chandelle.' His life fell a sacrifice to his zeal. At Andkhui, where he spent some days in effecting purchases, he was taken ill with fever, and died.

Mr. Trebeck, the last of Moorcroft's unfortunate party, expired at Mazar. A Haji attended him on his death-bed, and he is laid in a small buryingground westward of the town, under a mulberry tree.-Travels in the Himalayan Provinces.

MOORIES are blue cloths, principally manufactured in the districts of Nellore and at Cunatur in the Chingleput collectorate of Madras. They are 2 cubits in breadth and 28 long, and sold at from Rs. 2 to 7 each, according to their sizes. They are largely exported to the Straits of Malacca. MOPEN, a chief of the Kardar race of the Animallay Hills.

MOP-GHA, a tribe who occupy the range of bills between Thouk-ye-khat and Kannie creeks, skirting the Bghai race on the west. See Karen.

MOPLA, an energetic and prosperous race in considerable numbers in the south of India; in a large portion of Malabar they form half the populations, and in the Malabar district their total number by census is not short of half a million; they are also numerous in Travancore and Canara. They are a good-looking race, sturdy, intelligent, and educated. They are perhaps, in industrious habits, not second to any population to be found any where in India. They have comfortable, neat two-storeyed houses and homesteads; they have most of the trade of the western coast in their 
hands, and are rapidly acquiring a larger and larger share in the land. They do not often seek public service. The name is supposed to be derived from the Maleala word Mapilla, literally mother's son. The intercourse with the Muhammadan merchants and seamen and Arab women of Western India seems to have been from the most ancient times. Abuzaid, writing A.D. 916, mentions that the more devout merchants of Siraf, when young men were on board, avoided sending their ships to Ceylon, as the women were very licentious; and merchants would, when newly arrived, make advances to the daughter of a king, and she, with the knowledge of her father, would go to meet him in some woody place.

The Mopla of North Malabar follow the rule, as to property, of the Marumakkatayam, having in this respect conformed to Hindu usage in the times of the ascendency of the Hindus. The Mopla also take the wife of a deceased brother. The Mopla are sometimes called Jonakan Mapilla (from Yavana, GrEEK), to distinguish them from the Nasrani (Nazarene) Mapilla, the Nestorian Christians of Malabar. On the south-east parts of the Peninsula they receive and accept the honorary designation of Labbai, from their habit of using in conversation the Arabic word Labek, 'May it please you,' 'I beg your pardon,' when not apprehending a remark.

Other titular names of the Mopla of Travancore are Gurukal, Marakar, and Kowtan. The Chulia Mopla or Labbai of the south-east of the Peniusula are called by the Teling, Jonangi, Jonagar, Jonakari. The Mopla wear a beard and moustache, cut tolerably close, and little or no hair on the head. A linen skull-cap, covered by a variedcoloured topi, protects the crown; and with the richer members of the sect, a white and gold pagri is wound around the head also. A loose flowing chemise, with gold or coloured threads worked round the borders, and a jacket of pink, blue, or elaborately-embroidered cloth of gold, with an under garment of scarlet or blue cloth, loose and short white cotton trousers, and wooden sandals, more or less handsomely decorated, complete the Mopla's costume. He invariably carries a China folding umbrella, and wears a bunch of keys suspended by a string from his neck. In his hand, flung over his shoulder, or tied round his waist, a smart Madras cotton handkerchief is always to be seen. The Mopla are generally cleanly and well attired when they appear out of their houses and bazars. Their women dress in blue and white cotton cloths, and on feast days are sometimes gorgeous to behold, with rings of brass, silver, and copper, bracelets of blue, red, and black glass, tinselled wood and white metal, ear-rings of lead, silver, and pinchbeck, and necklaces of a variety of materials.

The Mopla in N. Malabar write Malealam with the Arabic character, but with additional vowel marks for e, o, di, and some of the consonants have additional dots. In S. Malabar they use the old Tamil character called vattezhuttu.

On several occasions since the west part of India came into the possession of Great Britain, the Mopla have required to be coerced. They are known to possess much religious zeal; but agrarian disputes have been a prominent cause of their outbursts. Hindu landlords kept the land in their own hands, or leased it out to the Mopla at high rents, and then took advantage of legal rights to turn them out.

Small numbers of them with agrarian grievances, and sustained by religious fanaticism, have taken up arms, their favourite weapon being a knife. In 1849 , after a series of oppressions inflicted on Hindus, the Moplas seized the pagoda of Munjerry, near Calicut, and slew a Brahman priest at the very altar itself. Madras infantry were sent to dislodge them. Mr. Wyse and others who kept close to him were killed, and the 94th Queen's came from Cannanore. The Moplas, 64 in number, fought with the greatest fury, leaving their bodies on the field, for not one man escaped.

In 1851, at Kallatur, a burst of religious zeal led to the murder of Hindus, and they were attacked in their stronghold by Madras sepoys. The 94th had to be again summoned. But outrages took place in several other places at the same time, and a wealthy Hindu and a Nair fell victims to Mopla attacks. They have had an Arab, called Tangul, as their religious leader.

MOR. HIND. A coronet. On two occasions the Rajput chieftain wears the mor or coronet,on his marriage, and when going to die in battle, symbolic of his nuptials with the Apsara, or 'fair of heaven.'-Tod's Rajasthan.

MORADABAD, a town in the N.W. Provinces of British India, the headquarters of a revenue district, lying between lat. $28^{\circ} 13^{\prime} 45^{\prime \prime}$ and $29^{\circ}$ $45^{\prime} 45^{\prime \prime} \mathrm{N}$., and long. $78^{\circ} 7^{\prime}$ and $79^{\circ} 2^{\prime} 45^{\prime \prime} \mathrm{E}$. It is on the great Gangetic plain. Gold is obtained in the sands of the river Beas, in those of the Gumti river, at Jompole, and in sand in the Moradabad district. Moradabad was founded by Rustum Khan, who governed Sumbul under Shah Jahan. He named it Rustumnuggur, but this offending the emperor, he altered it to Moradabad, after prince Morad, to whom, however, he was opposed in the famous action on the Chambal in A.D. 1658, in which he lost his life.Elliot.

MORANG, a large building in which the unmarried hillmen of Assam reside. Amongst the Abor, that at Membu was 200 feet long, and had 16 or 17 fireplaces. It is occupied nightly by all bachelors in the village, both freemen and slaves, and with them a certain proportion of the married men are nightly on duty, so as to constitute together a sufficient available force for any contingency of attack, fire, or other public emergency.

MORAR, headquarters of the Gwalior division of the Bengal army, situated in the state of Gwalior, Central India, in lat. $26^{\circ} 13^{\prime} 40^{\prime \prime} \mathrm{N}$., and long. $78^{\circ} 16^{\prime} 30^{\prime \prime} \mathrm{E}$, , on an affluent of the Chambal river. The battlefield of Panniar is to the south of Gwalior, and that of Maharajpur to the north.

MORARI RAO, a Mahratta commander of 6000 soldiers, who came to the assistance of Clive when besieged in Arcot.

MORCHELLA, the Morel.

Ti-rh,Mu-rh, . . CHIN. Khat-karwa, . . HIND. Sama-rogh,. : HiND. Kanha-bichu, . "

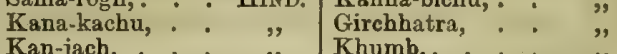

Kan-jach, : : ", Khumb,. : : "

One of the fungi or mushrooms, some of which, belonging to the genera Agaricus, Morchella, and Tuber, are edible. T. cebarium is the truffle. 
The morel plants of the N.W. Himalaya are M. esculenta, Linn., and the M. semilibera. Morels are abundant in and near Kashmir, from which considerable quantities are, after drying, exported to the plains. Dr. Stewart noticed the morel growing fresh, at 6000 feet, near Chamba. It is much eaten by natives, both fresh and dry, and is said to be preferred by them to the mushroom. Dried, it is a not unsatisfactory addition to a stew even for a European taste. A morel is found abundantly in the desert about Jhang, etc., and is said to be got near Hoshiarpur, etc., but the name of the species is not known. It is considered a great dainty by natives, and relished by Europeans. The morels which are brought from the Hazara country are large. The wholesome sorts of mushroom are said to be readily distinguished by being of a pink or flesh colour in the gills, changing to darker colour as they get older; they have also a peculiar sweet smell; and another criterion of their being edible is the outer skin peeling off easily. With some temperaments, however, mushrooms are always poisonous. M. deliciosa, $F r_{\text {. }}$, is the M. gigaspora, Cooke. In the N.W. Provinces it is called Kharaira, Khooma, Khumba, Khumbur, Gumbir.-Powell ; Jaffrey; Hogg; Voigt ; Stewart.

MORDECAI. Hamadan, a town in Persia, is the ancient Ecbatana. It is impossible to conceive a more charming situation, a country better suited to live happily in, than Hamadan and its neighbourhood. The country is undulating, the soil rich, the water good, the climate singularly clear, bealthy, and bracing; with picturesque mountains at hand for retirement during the heats of summer. In the centre of Hamadan is the tomb of $\mathrm{Bu} \mathrm{Ali}$ Bin Sina, and not far from it are those of Esther and Mordecai, which are held in great veneration by the Jews of the town, and kept in a perfect state of repair. On the dome over these tombs is an inscription to the effect that Elias and Samuel, sons of Kachan, finished building this temple over the tombs of Mordecai and Esther on the 15th of the month Adhar 4474. The tombs are made of hard black wood, which has suffered little from the effects of time during the $11 \frac{1}{2}$ centuries they have existed. They are covered with Hebrew inscriptions, still very legible, of which Sir John Malcolm has given the following translation: "At that time there was in the palace of Suza a certain Jew of the name of Mordecai; he was the son of Jair of Shimei, who was the son of Kish, a Benjamite, for Mordecai the Jew was the second of that name under the king Ahasuerus, a man much distinguished among the Jews, and enjoying great consideration among his own people, anxious for their welfare, and seeking to promote the peace of all Asia.' The traveller, unless told, would never recognise them as tombs. The entry is by a low door, and the tombs occupy the whole of the internal space to the ceiling, leaving only a very narrow passage for walking round the huge stone-like construction in the middle. Literally not an inch is left on the whitewashed wall on which the Jewish pilgrims of a thousand years have not inscribed their names.-Malcolm's Persia ; Ferrier's Journ.; Porter's Tr.

MORE or Mudi. KARN. A land measure, said to be of 45 gant'ha, each of 33 feet square, or about $1 \frac{13}{100}$ th of an acre.
MOREA CHINENSIS. Linn., Thunb.

Ixia Chinensis, $L . \quad$ | Pardanthus Chinensis, Ker. Dusbaha, .. Being. Belameanda sholarmani, Dusbichundi,. : "

A native of India and China. The root is ground and applied to any part bitten by a cobra, and believed by the people of Southern: India to prevent fatal consequences. The leaves are given to cattle that have eaten poisonous vegetables.Hortus Malabaricus.

MORESBY, CAPTAIN R., of the Indian navy, between 1828 and 1840 surveyed many islands in the Arabian Sea, and drew up a splendid series of charts of the Maldive"Islands. Between 183034 he made an admirable survey of the Red Sea, assisted by Captain Elwon, with their officers, Haines, Carless, Grieves, Jones, Barker, and others, who subsequently surveyed other parts of the coasts of India.

MORETON ISLAND is 19 miles in length, and $4 \frac{1}{2}$ in greatest breadth; its timber consists of Eucalypti, Banksiæ, etc., with abundance of the cypress-pine (Callitris arenaria), a wood much prized for ornamental work. Moreton'Bay chestnut is the Castanospermum Australe. Among its other plants are three which merit notice, from their efficacy in binding down the drift-sand by their long trailing stems, viz. Ischæmum Rottboellioide; a handsome pink-flowered convolvulus (Ipomæa maritima), one stem of which measured 15 yards in length; and Hibbertia volubilis, a plant with large yellow blossoms. Among the marine animals of Moreton Bay are two cetacea of great interest. One of these is the Australian dugong (Halicore australis), which was at one time the object of a regular fishery, on account of its valuable oil. It frequents the Brisbane river and the mud flats of the harbour, and is harpooned by the natives, who know it under the name of Yung-un. The other is an undescribed porpoise.-Macgillivray.

MORIER, JAMES, author of a Journey through Persia, Armenia, and Asia Minor to Constantinople in 1808-9; also of a Second Journey, between 1810 and 1816; and an Account of the lliyats of Persia.

MORINDA, a genus of plants of the natural order Cinchonaceæ, section Guettardeæ. The following species are the principal known to occur in the East Indies :-

Morinida angustifolia, Roxb., Chittagong.

M. bracteata, Roxb., Ganjam, Andaman, E. Archipelago. M. citrifolia, $L$., Peninsula, Pegu, Moluccas, CochinChina.

M. exserta, Roxb., Bun, Uch, Bengal.

M. multiflora, Roxb., Berar.

M. persicæfolia, Buch., Pegu.

M. pubescens, Sm., British India, Mauritius.

M. squarrosa, Buch., Kamrup.

M. tinctoria, $R o x b$, Uch, all India.

M. tomentosa, Heyne, Dekhan.

M. umbellata, $L$, Courtallum, S. Konkan.

M. vagans, Wall., China.

The bark and root of M. tinctoria and M. citrifolia in India, and M. exserta in Burma, and the root of M. ternifolia in Mysore, are employed to form a very valuable red dye, which is fixed with alum. Most of the red turbands of Madras are dyed with the root of the M. umbellata. The Karen prepare their red dyes most usually from the roots of two or three species. M. citrifolia is cultivated by the Burmese for a dye, but the Karen more commonly 
use M. exserta, the indigenous species. The colour, though not brilliant, is far more permanent than many other colours.

In many parts the roots of the M. umbellata are employed instead of chay-root in dyeing cotton yarn red, but the colour is neither so bright nor so durable. Dr. Heyne thus describes the process: Take $3 \frac{1}{2} \mathrm{lbs}$. of white cotton yarn, and soak it in $1 \frac{1}{2} \mathrm{lbs}$. of gingelly oil, a strong lye made of the ashes of the milk-hedge, and the yarn steeped in it for four nights being dried in the sun during the day, it is then washed in brackish water and dried in the sun.

Five seers (kutcha, $13 \frac{1}{2}$ lbs.?) of togara root finely powdered are put into a pot of water together with the yarn, and kept all night over a fire of cow-dung. In the morning it is taken out and dried in the sun; the same process is repeated for two successive days and nights, which completes the process. It is probable that a superior dye might be obtained if the same niceties were observed as in dyeing with chayroot. In Sumatra, the outward parts of the root, being dried, pounded, and boiled in water, afford a red dye, for fixing which the ashes procured from the stalks of the fruit and midribs of the leaves of the cocoanut are employed. Sometimes the bark or wood of the sahang tree is mixed with these roots. Marsden says that a species with broader leaves does not yield any colouring matter, but is commonly planted in the Malayan Peninsula and in Pulo Penang as a support to the pepper vine.-Roxl.; Heyne; Royle; Marsden; Williams; Ure; Tomlinson.

MORINDA BRACTEATA. Roxb. i. p. 544.

Rouch,. . . BeNG. / Yaiyoe? Mhan-bin, BurM.

A small tree with large shining leaves, native of Ganjam, the Andamans, the Philippines, Moluccas, common throughout Pegu, and cultivated about Phoungye houses. Its wood, of a bright yellow colour, is found in the Bengal bazars under the name of rouch, and is valuable as affording a bright yellow dye.-M'Clelland; Voigt.

MORINDA CITRIFOLIA, Linn.

Yai-yoe, Mhan-bin, BurM. Ahu-gaha, . . SINGH. Nie-pa-hsæ, Nyahgyee, ,, Manja pavattay, TAM. Al, Ach, Ak, . HIND. Nuna maram, : " Bengado, - . JAP. Maddi, Mulugu, : TEL. Bartondi, . . MAHR. Toguru, . . . ", Kada pilva, . MaLEAL.

This small tree grows in many parts of British India, and in the islands of the Archipelago, both wild and cultivated, and its bark and root bark are used to dye red. It is grown in the N.W. Provinces only in the black soils called Kabar and Mar. It is not productive till the third year of its growth. When ripe, the roots are dug out of the ground with narrow pickaxes, every care being taken to save from injury the small roots, the bark or skin of which yields the most valuable portion of the dye; the roots when dug up are sorted into three kinds, according to the fineness of the fibres.

The colouring matter resides principally in the bark of the roots, which are long and sleuder, and the small pieces are the best, fetching $8 \mathrm{~s}$. to 10s. a maund. It is exported in large quantities from Malabar to Gujerat and the northern parts of Hindustan, but seldom finds its way to Europe. Most of the Madras red turbands are dyed with this substance.
The produce of the Mysore country and Bundelkhand are most prized. It is employed also to assist more expensive dyes in giving a red colour to yarn and cloth; the red thread used in carpetmaking is entirely dyed with it. It is not an exhausting crop, and is usually followed by grain. The small white flowers have a very sweet scent, and the tree would thrive well and be ornamental in compounds. It is usually grown as a prop and shade for the pepper vine and coffee tree. The wood is of a deep brownish-yellow, is easily worked, is common, and little, if at all, inferior to Nauclea cordifolia. It makes tolerable planks, but appears never to be so used on the Bombay side, except for door-shutters and such like. It must be borne in mind that the use of mineral mordant in'the native process is unknown, and, with the exception of weak lye made from the ashes of some of the plants of the jungles, no other application is made beyond the simple solution of the extract from the wood itself.-Drs. Wight, Roxb., Voigt, Gibson; Mr. Rohde.

\section{MORINDA EXSERTA. Roxb.}

Bun-uch, . . Beng. |Mogilli,

Mhan-bin? * BENG. Mogilli, . . . TEL Myau, Nya?

A small tree of the Circars, of Bengal, Berar, and Burma; its yellow wood, hard and useful, is fit for fancy work, and does not warp. M. bracteata and this are only found about Phoungye houses in a cultivated state. - Roxb.; Voigt; Beddome.

MORINDA MULTIFLORA. Roxb.

Achmal of . Berar. | Al of . . NAGPUR.

Much cultivated for its dye about Nagpur, through Rajputana, principally near Kotah, and all over Harowtee. The plant is allowed to remain three years in the ground, and then the roots are taken up and dried. The dye is a fine turkey red. It is very plentiful. One maund costs 16 rupees. - Roxb.; Mr. Rohde; Irvine.

MORINDA TINCTORIA. Roxb.

Al, Uch, Ach, . . Hind. Mulugu chettu, . TEL. Uchyuta, . . SANSK. Luagru, Tagaru, : ., Maddi chettu,. : TEL.

A small tree, supposed by Colonel Beddome to be the same as $M$. citrifolia in its wild state. Extreme height 36 feet, circumference $2 \frac{1}{2}$ feet. Height from ground to the intersection of the first branch, 10 feet. Its green fruit is pickled or eaten in curries. It is in flower and fruit the greater part, if not the whole, of the year. It is pretty common in every part of India, is largely cultivated at Ganjam, Gumsur, Bundi, Kotah, Gurgaon, Philibeet, and Mewar. Its root-bark is used as a red dye, and its wood for gun-stocks. In the Circars the dyers use the bark of the fresh roots bruised and gently boiled in water for a short time. The cloth or yarn is prepared in a cold infusion of the powdered gall of Terminalia chebula in milk and water. It is then dried and moistened with alum water, and again dried, and receives from the above decoction a pretty bright but fugitive red. The woods of all the species of morinda are beautiful, hard, and durable, and excellent for gun-stocks. That of this species possesses all these qualities, is variegated and white, and is employed for gun-stocks in preference to all other kinds. The flowers are very fragrant.-Drs. Roxb., Irvine, Voigt. 
MORINDA TOMENTOSA. Heyne. M. mudia, Ham. Manjanati, Maleal. A very common Travancore tree, attaining a height of 20 to 30 feet. Its timber is of a yellow colour, and is used for various economical purposes. The inner wood of the older trees furnishes a dye.-Useful Plants.

MORINDA UMBELLATA. Linn.

\section{M. padavara, Juss. | M. scandens, Roxb.}

Nya, . . . Burm. Kliba, . . . SANsK.

Patangi vrikshs, : CAN. Nuna maram, : TAM. Chota al, . . Dukr. Mulu-gudu, . . TEL. Mang-kudu, : MaLAT.

A trailing creeping plant which grows in the western parts of the Peninsula of India, at Courtallum, in Malabar, and in the S. Konkan.

MORINGA APTERA. O'Sh. The Yessur of the Arabs, a native of Sennaar, Cairo, and Palestine. The seed yields the oil of ben, much used by perfumers and by watchmakers, as it neither grows rancid nor freezes readily; seeds acrid, and used as a rubefacient. They are also said to be purgative and emetic in small quantities.O'Shaugh.

MORINGA PTERYGOSPERMA. Gærtn. Hyperanthera moringa, Vahl.

Moriaben, Ban, ARAB. Sainga, Saigut, Marr. Mub-ul-ban (seed), ," Murinna, ? MALEAL. Sohanjana, . BENG. Sajna, . : PERs. Da-tha-lwon, . . BURM. Sigru, . . . SANSK. Dha-ne eha, " San murangay, SINGH. Nugga, Nugge-gida, C̈AN. Murungai maram,. TAM. Mungay-ki-jhar, . DUKH. Munaga chettu, . TEL.

This is the horse-radish tree, very abundant all over British India, Burma, and the Malay Peninsula. The leaves, flowers, and seed-vessels are used in curries. The roots bave precisely the flavour of horse-radish, and in India are substituted for it. The gum and bark are used in native medicine; the oil is aperient, and is much used by the native doctors in gout and rheumatism; and they prescribe the green root as a stimulant in paralysis and in intermittents, in scruple doses, and use it also in epilepsy and hysteria. The seeds are also used internally for their pungent and stimulating virtues. In Jamaica the wood is used for dyeing a blue colour. An oil is obtained from the seeds, possessed of the same qualities as the oil of beu, the product of the M. aptera. The delicate perfumes of flowers are often retained by the ben oil, by pouring it over the flowers, or strewing layers of the flowers for about four hours over cotton soaked in the oil. In the West Indies it is used as a salad oil. A compound infusion of Sohanjana represents a similar infusion of horse-radish. A compound spirit of Sohanjana is stimulant in a dose of from two to four fluid drachms in water. Its gum is obtained in large quantity, does not dissolve in water, resembles in some respects gum - tragacanth, for which it may probably be substituted. It exudes freely whenever an incision is made in the bark. It is used by the natives in headache, mixed with milk and rubbed on the temples, and is also employed as a local application for pains in the limbs.-Royle; Ainslie; Roxb.; Mason; Stewart.

MOR-MORAH, a religious sect located in Siam. - Captain Hannay.

MOROCARPUS LONGIFOLIUS. Blume.

Debregeasia velutina, $G$. | Urtica verrucosa, Moon. Conocephalus niveus, $W$. U. longifolia, Burm. Gass-dool, SINGH.
Common in the Central Province of Ceylon, at an elevation of 1000 to 3000 feet, and called gass-dool. The Singhalese make fishing-lines of its bark.-Thw. p. 261.

MOROCARPUS WALLICHIANUS. Thw. Debregeasia Wallichiana. | Urtica leucophylla, Wall.

A tree of 15 to 20 feet high, grows at Hantani, in the Central Province.-Thu. En. Pl. Zeyl.

MOROCCO or Marocca, the Marakash of the Arabs, a country of 300,000 square miles, at the N.W. extremity of Africa. The dominant race are Moors. Berber, Shellok, Arab, Negro, Christians, and Jews are numerous. All the mercantile and artisan transactions are carried on by Jews. These reside in the Mellah quarter, and are obliged to wear black clothes. It is the ancient Mauritania, and has been successively under the sway of the Romans, Vandals, Greeks, and Arabs. In the 11th century it fell under the Fatimite khalifs, and in the 16 th century under the sherifs, descendants of Mahomed, who are still reigning. It has a population of about eight millions, but Behm and Wagner only estimate $6,140,000,-$

Berber, . . 2,300,000 Jew, . . 340,000 Shellok, : : 1,450,000 Negro and Abid, 120,000 Moor, . . 3,550,000 Christians, . . 300 Arab, : : 740,000 Renegades, . : . 200

The Arabs of Morocco are the Moors of Spain, the Saracens of France, tall graceful sons of the Arabian desert, courteous, brave, hospitable, and confiding,--descendants of the conquerors who, in the first ages of the Hijira, propagated the religion of Mahomed, crossed the Straits of Gibraltar, destroyed the Gothic chivalry, reigned in Spain for 700 years, invaded France, devastated Italy, and pillaged the suburbs of imperial Rome. When the last Arab king submitted to Ferdinand and Isabella, and the Moorish palaces of Grenada were surrendered to the Christians, the old conquerers went back to Africa and resumed their nomade life. In Tripoli, the Arab has monopolized the country. In Tunis the native reappears in a smaller proportion, and in Morocco he is very scarce. The Berber and Shellok are untamed warlike tribes dwelling in the mountains; when possible, rovers of the sea, claiming fanciful origins, but impatient of any subjection. They are the same race whom the French call Kabyle and Zouave. The Moor are little idle men, who grow fat from indolence. They are lowlanders, traders, dwellers in cities, avaricious, perfidious, cowardly, cringing, and insolent. The Riff dwellers of Kalhya, Cape Tres Forcas, correspond to the Arab Sabali on the Red Sea coast, the name Riff being evidently from Ripa, a bank. The towns of Mequenez on the north, and Morocco on the south, are the chief cities.-Catafago.

\section{MOROCCO LEATHER.}

Maroquin, . . . Fr. Safian, . . . Rus. Saffiam, : : : GER. Marroqui, : : . SP. Marrocchino, . . IT.

A fine kind of leather prepared of skins of goats in the Levant, Barbary, Spain, etc. It is of various colours, and is used for lining carriages, chairs, in the binding of books, etc.-M'Culloch's Dict. p. 809.

MORRHUA VULGARIS, the common cod. In New England the intestines are cut into ribbon isinglass. In Iceland also the cod is said to yield 
isinglass, so also the ling (Lota molva); but Mr. Yarrell informed Mr. Royle that he had no reason to believe that isinglass is so prepared. See Airbladder; Fish ; Isinglass; Sounds.

MORRIESON. In the years 1812-1818, that portion of the Sunderbans lying between the Hoogly river and the Bara Punga was surveyed by two young brothers, lieutenants in the Honourable Company's army. Their names were Hugh Morrieson, of the 4th Regiment Native Infautry, who is supposed to have died of jungle fever at Jessore, contracted whilst surveying in this unhealthy tract, and W. E. Morrieson, of the Bengal Engineers, who was killed by a grape shot upon the $3 \mathrm{~d}$ of January 1815 , at a place called Jitghur, in an unsuccessful attack upon the Gurkhas.-Cal. Review, p. 15.

MORRISON, father and son, eminent Chinese scholars. The father wrote a Chinese Dictionary, the son a Compendious Description of Chinese Products. The father, Robert Morrison, was born at Morpeth on the 5th January 1782, and up to 1798 was a boot-tree maker with his father. In 1801 he began to learn Latin, in 1803 he commenced the study of theology, and the following year he joined the London Missionary Society. In January 1807 he was ordained a missionary to China, for which he embarked on the 31st of that month by way of America. He dressed and ate like the Chinese, and in 1809 was appointed Chinese translator to the E.I. Company. His Anglo-Chinese Dictionary was published by the E. I. Company at an expense of $£ 12,000$. He died at Canton on the 1st August 1834, in his 53d year. He completed a Dictionary and a Grammar of the Chinese language, and a version of the Bible in the Chinese torigue. He was buried at Macao. His son succeeded him as interpreter to the British, and did not long survive his father.

MORTY ISLAND, close to the N.E. point of Gilolo, has about 56 species of land birds, among which are the kingfisher, Tanysiptera doris; the honeysucker, Tropidorrhyncus fuscicapillus; and Lycocorax morotensis, a large crow-like starling, not yet found on Gilolo, only 25 miles distant. Wall. ii. p. 5; Horsburgh; Bikmore.

MORUNG, the Nepal name for the Terai, west of the Mechi river.

MORUS, a genus of plants belonging to the natural order Urticaceæ. The chief $\mathrm{E}$. Indian species known:-

Morus alba, $L$., all Southern Asia.

M. atropurpurea, Roxb., China, India.

M. bifaria, Wall.?

M. Cashmeriana, Royle, Kashmir.

M. Indica, $L_{\text {. }}$, Bengal.

M. lævigata, Wall., Nepal, Saharunpur.

M. multicaulis, Perottet, China.

M, nigra, $L$., Persia, Egypt.

M. paniculata, Roxb., Moluccas.

M. rubra, $L$, introduced into India, Bengal.

M. scandens, Wall., China.

II. serrata, Roxb., China.

M. tatarica, Pall, cultivated in British India.

M. viridis, Buch., Patna.

Several species are cultivated on account of their fruit, but still more for their leaves as food for the silk-worm. The bark of the white mulberry seems from very early times to have been made into paper in China. Marco Polo informs us that 'the Grand Khan causes the bark to be stripped from these mulberry trees, the leaves of which are used for feediug silk-worms, and takes from it that thin rind which lies between the coarse bark and the wood of the tree. This being steeped, and afterwards pounded in a mortar until reduced to a pulp, is made into paper, resembling that which is made from cotton.' The bush cultivation of the mulberry in Bengal, for feeding silk-worms, consists in planting cuttings, which, as they grow, are cut down about four times in the year, in order to produce young leaves for the successive broods of silk - worms. The bark separates when the cut stems are steeped in water, and when pounded up, the greater part of the mucilaginous matter passes off, leaving a mass having much of the good qualities of linen rag half-stuff. In China, although the leaf of the common mulberry is the principal object of its culture, the fruit is eaten, and the wood burned for the lamp-black used in making ink. Morus alba and M. nigra grow equally well in the Dekhan; the white, growing to a very large tree, shedding its leaves before the hot season. The red mulberry bears fruit in the rains, as well as the black. Silk-worms may be fed on its young fresh leaves, although the leaves of the white are preferred. It grows from seed or cuttings. M. alba, atropurpurea, Indica, nigra, rubra, and tatarica are all grown in China, but M. alba and M. nigra are the general favourites, and many varieties have been obtained by cultivation; the shan-sang or hill mulberry, the kin-sang or golden mulberry, the ki-sang or fowl mulberry, and the i-sang or Morus tatarica, are all grown. The white species produces little fruit. An epiphyte grows on the mulberry tree in China. It is called sang-shangki-sang, and its woody branches are highly prized as a medicine in the pregnant and puerperal states. M. alba, Cashmeriana, Indica, lævigata, and tatarica grow in the hills up to Kashmir, 5000 feet, where they abound, and to 7000 feet on the Chenab. Thomson mentions it in parts of Tibet at over 9000 feet. From the accounts by Dr. Bellew and others, nine or ten kinds would appear to abound in parts of Afghanistan. Some of the trees attain to large size; specimens of 10 and 12 feet girth are not very uncommon, and Dr. Stewart noted one of 16 feet in the Salt Range. The wood of old trees is strong and useful, and is much employed for construction, implements, etc., in parts where the tree is common. About Peshawur it is the staple ordinary timber. The fresh twigs are in Kashmir used for tying loads.

The Japanese make abundance of a paper as well for writing and printing as for tapestry, handkerchiefs, packing cloths for goods, etc. It is of different qualities, and some of it is as soft and flexible as our cotton cloth. Indeed, that used for handkerchiefs might be mistaken for cloth, so far as toughness and flexibility are concerned. The materials of which it is made is the bark of Morus papyrifera, now transferred to the genus Broussonetia. In December, after the tree has shed its leaves, they cut off the branches about three feet in length, and tie them up in bundles. They are then boiled in a lye of ashes in a covered kettle, till the bark is so shrunk that half an inch of the wood may be seen projecting at either end of the branch. When they have become cool, the bark is stripped off and soaked in water three or four hours until it becomes soft, when the fine black skin is scraped off with a knife. 
The coarse bark is then separated from the fine. The new branches make the finest paper. The bark is then boiled again in fresh lye, continually stirred with a stick, and fresh water from time to time is added. It is then put in a sieve and taken to a brook, and. here the bark is incessantly stirred until it becomes a fine pulp. It is then thrown into water, and separates in the form of meal. This is put into a small vessel with a decoction of rice and a species of Hibiscus, and stirred uutil it has attained a tolerable consistence. It is then poured into a large vessel, from whence it is taken out and put in the form of sheets on mats or layers of grass straw. These sheets are laid one upon another with straw between, and pressed to force the water out. After this they are spread upon boards in the sun, dried, cut, and gathered into bundles for sale. This paper will better endure folding, and last longer than that of Europe. - American Expedition; O'Sh.; Royle; Williams; Riddell; Smith; Slewart; Thomson; Bellew.

MORUS ALBA. Limn.

Safed-tut, . Beng., Hind. | Tukhlu, . . Kashmik. Tut, Shahtut,

Cultivated in Europe, and in all the south and east of Asia, for its leaves, which are plucked to feed the silk-worm. M. alba has many forms, which have received specific names, viz.-

Byzantina, Sieb.

Chinensis, Bert.

Indica, Linn.

Italica, Poir.

Japonica, Nois.

latifolia, Poir.

macrophylla, Morett.

M. Indica yields a black fruit. It has been very extensively planted in California ; an acre supporting 700 to 1000 trees, producing; when five years old, $5000 \mathrm{lbs}$. of leaves fit for food. On this quantity 140,000 worms can be raised, from which ova, at a net profit ranging from $£ 80$ to $\mathfrak{£ 2 4 0}$ per acre, will be obtained by the work of one person.-Roxb.; Voigt; Ton Mueller.

\section{MORUS ATROPURPUREA. Roxb.}

\section{M, rubra, Linn. | Shatoot, . . DUkH.}

This species of mulberry from China produces a very agreeable and valuable black berry, 2 inches long, in great quantities.-Roxb.; Mason.

\section{MORUS INDICA. Linn.}

Po-sa, . . Burm. | Toota, . . SAnsk. Toot, . Dukr., Hind, Rata-ombilla, SINGH. Babisaram, . MALAX. Cumble-pullum, TAM.

A small tree with long tapering leaves sometimes lobed ; fruit dark-red, used for making tarts ; is found in Southern India; is largely cultivated in Bengal to feed silk-worms; has a delightful fruit, considered by the natives as cooling and aperient.-Roxb.; Riddell; Ainslie.

MORUS LAVIGATA. Wall. Tut, HIND. Grows in Nepal and Saharunpur. Attains a large size ; wood excellent.-Wall.

MORUS MULTICAULIS. Perottet. M. cucullata, Bonafons. Grows in China, the Philippine Archipelago, and in India, to which it has been introduced. It will probably soon displace the white mulberry for feeding silk-worms. The cultivation of M. multicaulis and $M$. Sinensis has been largely extended in the Panjab. - Voigt; Stewart.
MORUS NIGRA. Linn. The black mulberry tree of S. Russia and Persia, yields a pleasant fruit and leaves for silk-worms. M. atropurpurea, Roxb., is an allied variety. - Von Mueller.

MORUS PARVIFOLIA. Royle.

Ful, Kurun, . . . PANJ. | Tut, Tutri, . . PANJ.

This small tree is found in the Sutlej valley between Rampur and Sungnam at an elvation of 4000 to 7000 feet; it occurs wild in the plains of the Eastern Panjab, and grows up to 5000 feet in Kashmir, etc. Its fruit does not appear to be valued. Wood highly esteemed. It is cultivated; foliage prized for cattle.-Stewart; Cleghorn.

MORUS SERRATA. Roxb, Wall.

Krun, Krum, Chun, Hind. | Chimu, Kimu, Soa, Surles.

This tree is common in many parts of the Panjab, Darjiling, Himalaya, from 2500 to 9000 feet. It grows to a large size, trees of 10 and 12 feet girth being not uncommon. Dr. Stewart had seen several over 20 feet; and at Barmoor, in Chamba, he saw a magnificent specimen of 28 feet girth. Its fruit is not much valued. Its wood is yellow and strong, but is subject to the attacks of worms. It is used in construction, and for ploughs, troughs, toys, etc. The twigs are in some parts largely lopped for fodder.-Stewart; Brandis.

MOSCHID E, a genus of mammals of the order Ungulata. Moschus memimna is the musk deer of Ceylon.

MOSCHUS MOSCHIFERUS. Linn.

M. saturatus, Hodgson.

M. chrysogaster, Hodgs.

M. leucogaster, Hodgson.

Honde, Baikal-Tungus. Saiga, . . Lake Baikal. Dsehija, Ceuta-Tungus. Bjos, ... Ostiak. Xe, Che hiang, . . Chin. Gifar, Toorgo, . TArtar. Kastura, . : Hind, Lag, Lawa, . TIB. Kudari, - KalmuK. Glao, Altah, TIB.-TangoT Bena, . Kanawak. Kaborga, Yenisei-Russ. Rouz, : : Kastmir. Tsanja, YeniseI-Tungus. Ribjo, . . LADAKH.

The musk deer is found from Siberia through Central Asia to the Himalaya. In these mountains it is found at great elevations, in summer rarely below 8000 feet, and as high as the limits of the forest. It is solitary, living in retired spots near rocks, or in the depths of the forest. It is easily traced by the heaps of dung on its runs, for it is partial to localities, and both in habits and general appearance has a great affinity to the hare. Adams sometimes found it by following up its trail through the ccpse across the grassy glade into a little dell, where the indifferent creature might have been seen feeding within a few yards. The mode of its progression is remarkable, and comprises a series of spasmodic leaps, while now and then it stops to reconnoitre, or, walking a few feet, resumes these fantastic movements. The musk is most sought after during the rutting season in autumn. Adams repeatedly examined the contents of the glands at other seasons, but except a rank, offensive odour from the dark pigmentary substance contained in them, he could not discover a trace of musk.

Moquin Tandon describes the glands as consisting of two oval pyriform sacs of unequal size, which open into the preputial groove by two large orifices. Those of the adult male are from 3 to 5 inches in length; those of the female are somewhat less developed. In the living animal the 
castoreum is an almost fluid substance of a strong, penetrating, and nearly fetid odour. When dried, the sacs have a dark-brown colour and wrinkled appearance. The market value of each bag is from $£ 1$ to $£ 1,10 \mathrm{~s} .-$ Adams' Naturalist in India; Jerdon's Mammals.

MOSEILAMA, an opponent of Mahomed. He wrote suggesting a combined action and division of the conquests: "Moseilama the apostle of God, to Mahomed the apostle of God - Now let the earth be half mine and half thine?' The reply was: 'Mahomed the apostle of God, to Moseilama the liar - The earth is God's, he giveth it to such of his servants as he pleaseth, and they who fear him shall prosper.' He was killed at the battle of Yemaina.

MOSES, a leader of the Hebrew race, known amongst Muhammadans as the prophet Musa or Hazrat Musa, also as the Kalam-Allah or mouthpiece of God, and as the author of the fire books which they style Taurait. His Egyptian name means Son of the Water. He was brought up in the neighbourhood of Heliopolis, the chief seat of Egyptian philosophy. On leaving the city of the Sun, called in Coptic Rameses, in Greek Heliopolis, he fled to the desert. Moses subsequently led the Israelites out of Egypt. - Sharpe's Egypt.

MOSES OF CHORENE wrote a little after A.D. 440 , and probably drew from earlier authors. He speaks of Jenasdan (i.e. Chinistan or China land) as a great plain country east of Scythia, at the extremity of the known world, and occupied by a wealthy and civilised people of character so eminently pacific as to deserve to be called not merely friends of peace, but friends of life. Their country then furnished an abundance of silk, insomuch that silk dresses, so rare and costly in Armenia, were there common to all classes.Yule, Cathay, i. p. 83.

MOSLIM, properly Muslim, a term by which Muhammadans in Asia designate themselves; it is derived from the Arabic word Salam, he gave safety, peace; and hence Muslim, a person who is saved, the plural of which is Muslimin, ordinarily written Musalman, and for the feminine Musalmani.

MOSQUE, the place of public worship amongst Muhammadans. The Janma Masjid is the chief mosque of the city, where general service is held every Friday. The word is derived from the Arabic Masjid or Masgid. It is generally a square, with three walls so built that looking to the back wall the worshipper faces Mecca. The Kazi or other preacher stands on a mimbar, a small dais with three steps built against the back wall. The first mosque of the Mubammadans was erected by Mahomed at Medina; shortly afterwards, when he entered Mecca as a conqueror, he destroyed the idols of the Arab pantheon, and purified that venerable building of its abominations. He had probably observed in Syria the two forms appropriated by the Christians to their places of worship, the cross and the basilica; he therefore preferred a square to a parallelogram, some authors say with, others without, a cloister, for the prayers of the saving faith. At length, in the reign of $\mathrm{El}$ WValid (about A.H. 90), the cupola, the niche, and the minaret made their appearance, and what is called the Saracenic style became the order of the Muhammadan world.
Several of the mosques of India are of large dimensions. One in Bombay would hold 4000 worshippers. The mosque at Constantinople was originally the St. Sophia Church of the Christians. It is the largest building in the world. One in the Ahmadabad collectorate was built by Balol Khan Kazi at an expense of 1 lakh of rupees, about the 13th century. The Khan Masjid, built about the 12th century, and the Jama Masjid, each cost about 2 lakhs. The Jama Masjid at Champanir, in Gujerat, is said to have been built by Mubammad Shah A.D. 148t. It is of white sandstone, beautifully cut and set.

The mosque at Ajmir was commenced A.D. 1200, and completed by Altamsh 1210-1236, and is called the Arhai din ka jhompra. It was constructed from a Jaina temple. Its courtyard has a screen of seven inches, on which Cufic and Togra inscriptions are interwoven with architectural decorations. A nere mention must be made of the tomb at Sipri near Gwalior; and that of Sher Shah near Sasseran in Shahabad; at Jaunpore (Jonpur), the Jama Masjid and I,al Darwaza Masjid; at Alımadabad, the Jama Masjid and other mosques; and tombs and mosques at Sirkej and Butwa; the Jama Masjid at Cambay, erected A.D. 1325, in the time of Mahmud Shah Ghori; the tomb of Mahmud Begurra near Kaira; at Mandu, the great mosque, the Dharmsala, the Jahaz Mahal; in Bengal, the Kadam Rasul mosque, the Minar at Gaur, and the Adina mosque at Malda.

In Egypt, mosques are matted or carpeted, and over is spread the chandni, a carpet of white cotton cloth. In India, the ordinary flooring is of stone slabs, and usually the sole object to be seen is a small pulpit niche, the mihrab, and near to it the mimbar or three steps built on the wall next to Mecca, on or near which the Kazi, Mulvi, or Imam stand. There is nothing to distract the worshipper's attention, and every one seems absorbed in devotion. The Rev. Norman M'Leod, D.D. (Eastward, p. 67), alludes to this, and says that the whole service imparts the impression of worship to an unseen God. It is perhaps something in their character, either original or acquired, or in their faith, or perhaps to their being accustomed to a more out-of-door life, that enables them so entircly to abstract themselves from their ordinary arocations, and to engage with such reverent earnestness in prayer. But every traveller in the east will see Muhammadans spread their carpets on the ground, or place their staff or sword in front of them, and bend their knee in lowly homage to their Maker, and, in all the bustle of a crowded bazar, or on ship board, remain apparently as much abstracted as if in a desert. Muhammadanism, adds the reverend author, owes its origin to Judaism and Christianity: like them is derived from Abraham, and is the worship of the one God; and Christians, he thinks, are apt to undervalue the good obtained from its divinely-reflected beams, which in some degree irradiate spots that would otherwise be in outer darkness. Muhammadanism was perhaps seen in its brighter aspects at Baghdad during the khalifat, and at Cordova, to which Christians repaired for a liberal education. But, in India, it has ever been a mere ritualistic worship, with certain dogmatic formulæ in Arabic words, the meanings of which are known to very few even of those 
acquainted with the words themselves.

Khayyam says, -

'Pagodas are like mosques, true houses of prayer, 'Tis prayer that church bells waft upon the air; Kaaba and temple, rosary and cross,

Are but divers tongues of world-wide prayer.'

There is a curious resemblance in this verse to the words of Abul Fazl, the minister of the emperor Akbar, words in which the poet is supposed to represent his royal master's views as well as his own, -

'If it be a mosque, people murmur the holy prayer;

If it be a Christian church, people ring the bell from love to thee.'

MOSQUITO.

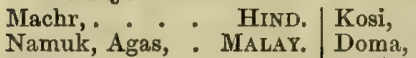

a, TEL

gih, . . " " Sivri-sinek, . . TuRK,

Species known are Culex laniger, C. fuscanus, $\mathrm{C}$. circumvolens, and C. regius. These insects chiefly abound near stagnant water and near the great rivers. Along the banks of the Irawadi, every Burman sleeps under a mosquito curtain, the insects are so numerous. Their passage from a river or tank is intercepted by trees, and at Kimmendyne myriads hang about the trees. The mosquito has three stages of existence, in two of which it is a water insect, in the third the wellknown winged one. On a 6 th May, at 6 A.M. Dr. W. Gilchrist observed several mosquitoes on the surface of some stagnant water, each in close proximity to a yellowish substance, which, when viewed through a microscope, proved to be a collection of eggs that the mosquitoes were depositing; each collection, though consisting of not fewer than 100 eggs, did not exceed 3-20ths of an inch in length, and about 1-20th of an iuch in breadth. These eggs were arranged in lines, standing on end, and were each about 1-40th of an inch long; the lower end being larger than the upper, so that the upper surface of the collection was somewhat concave. A few of these collections of ova were carefully introduced, with some of the water on which they floated, into a tumbler, and placed under a glass shade. Excepting a change of colour, from a yellow to a dark brownish-grey, which occurred within six hours after being put into the tumbler, no visible alteration took place till two days and a half, when the water was found to swarm with animalculæ. The shells of the ova were still adherent, as when first observed. On examining one minutely, the larger or under end was found to have opened, like a lid, to allow the insect to escape into the water. A lady's thimble, furnished with a lid, would resemble exactly the appearance of what is being described. The design of having the lids placed at the bottom is evidently to allow the newly-hatched animalculæ immediate exit from the shell into the water; and the concavity of the whole collection, above alluded to, effectually tends to retain the large ends undermost. Had the ova been arranged promiscuously, as to the large and small ends being upwards and downwards, it is evident that the newly-hatched insects, under the former arrangement, would have some difficulty in reaching the water, a difficulty that most probably would amount to an impossibility், 一one which, at all events, is effectually prevented by the concave form of the collection. In the newly-hatched insect, the chest or thorax (the heart is seen, obscurely however, the body being only semi-transparent) is furnished with four projections; from this organ two blood-vessels proceed down the centre of. the body, to the end of the elongation, the extreme termination of which is to be seen just above the surface of the water, where the insect lives for the most part; the body being suspended, as it were, from this, head lowermost. Between the heart, in the thorax, and the extremity of this singular elongation, an active sanguiferous circulation is to be observed; in all probability, therefore, it is the seat of the lungs or gills, and it would appear that a comparatively large supply of air is essential to the existence of the insect, as it lives as much as possible in this pendulous position at the surface, with the extremity of the elongation rising just above. Its motion, which is quick, is effected by a rapid bending of its whole body, so that the head and tail (tbe latter consisting of a bundle of delicate filaments) approximate alternately on either side of the body. It always goes tail foremost, so that the head is dragged along behind. When in search of food, it throws out, in advance of its mouth, a couple of delicate brushes, the individual filaments of which are of microscopic size. Each of these is put in rapid circular. motion, whereby a double kind of whirlpool is occasioned. Whatever food comes within the sphere of these vortices is speedily devoured. The food appears to be principally decomposing vegetable matter, some of which he put into the tumbler, as the vessel in which the ova were discovered contained it; on this they fed voraciously. They did not, however, entirely confine themselves to a vegetable diet. He was much amused with one, when in a drop of water, under the microscope; in these confined limits its appetite did not forsake it, and the only article of food it found was the head of one of its own species. So soon as this came within the vortex, it was ravenously seized, but, being apparently too large a morceau, it was let go, after sundry futile attempts at swallowing. It frequently came within the whirlpool again, and was as often seized, but with no better success. They, however, eat the shells they had recently quitted. Some that were kept in clean water, without food, died on the third day. In this stage of their existence the insects were lively, and grew apace. At the termination of 21 days, during which the water was thrice changed, they had attained three or four twentieths of an inch in length. On attaining this size or age, they underwent a second metamorphosis. Most likely they cast their former envelope, for the hairs, so conspicuous on the former insect, were not to be seen on the present. The shape, it will be remarked, has materially altered, but the most remarkable change is that which occurs with respect to the seat of the lungs or gills. These organs are now situate in the thorax, their former seat has disappeared, and the channel of communication now between them and the air are two small tubes on the top of the chest. In this stage of their existence the insects are much less active than during the former one. A still greater contrast, however, is that now they do not require food, and have no mouth; in this respect resembling the chrysalis stage of the butterfiy tribe. But the demand for air appears increased; they 
rarely leave the surface of the water, and when they do descend, they take down a supply of air, small globules of which are distinctly to be observed at the end of the tube. Their descent is accomplished by striking the water with their body, but, being specifically lighter than that fluid, they rise without any effort to the surface, though in case of despatch can impel themselves upwards by the same means as they descended. However, as has been remarked, they seldom leave the surface, and, having done so, speedily return to it. The insects remain about 48 hours in this stage, towards the termination of which the legs and proboscis of the winged mosquito can be distinctly seen through the thin membrane that surrounds it. This in due course bursts, when the winged mosquito draws itself out, stands on the surface of the water a few minutes to dry and expand its wings, on which it presently proceeds to a dry situation. If the mosquito, when in either of the first two stages, be taken out of the water, it speedily dies, and it is as speedily deprived of life if immersed in that fluid immediately after becoming the winged insect. We learn from the above that the mosquito is a most prolific insect, and that, as stagnant water, such as that of tanks, etc., is necessary to its propagation, all such ought to be kept as distant as possible. Next to the torture which Culex laniger inflicts, its most annoying peculiarities are the booming hum of its approach, its cunning, its audacity, and the perseverance with which it renews its attacks, however frequently repulsed. Various substances are employed by the Chinese to drive them away. In India they are smoked out of a room by burning chips. A few sprigs of wormwood placed about the pillow will generally protect the sleeper from their attacks; or rub the wormwood gently over the forehead and wrists the last thing at night, and neither mosquitoes nor other noxious insects will give annoyance.

Captain Elphinstone Erskine also mentions that whenever the mosquitoes were uncommonly numerous in Rewa (which was five miles from Niuque), he always used to be told that the boys had been disturbing the akau ni namu. This tree was completely covered with mosquitoes, and so thick were they, that one could easily have taken a capful from any branch at one scoop. Every part of the tree, from the very top to the root, and in the same manner the branches, appeared to be one solid trunk, composed of mosquitoes. $\mathrm{He}$ was told by Thakonau that it had been so since he was a boy; that it was the property of the tree to attract the mosquitoes; and that, if never disturbed, the country would be entirely free from these troublesome insects. See Insects.

MOSQUITO BLIGHT, or Tea Bug, the Helopeltis Antonii, Wood-Mason, injures the tea-leaf. Other known species are H. braconiformis and nigra from Waigiou; theiovora of Assam, Collaris pellucida, and podagrica. The tea mite or red spider of the planter is the Tetranychus buculatus, Wood-Mason. It lives in societies, and punctures the leaves.

MOSQUITO TOBACCO of China are pastilles made of the sawdust of juniper and other resinous woods. The mixture is of jumiper or pine-tree sawings (pih heang fun or sung shoo), artemisia leaves reduced to powder (nai-hai), tobacco leaves (can fun), a small portion o arsenic (pe-za), and a mineral called nu-wang. To thirty pounds of the pine or juniper sawings, about twenty of artemisia, five of tobacco, and a small quantity of arsenic were added. Each article was well beaten up with water, then the whole mixed together, and in the form of a thick paste rolled on a slip of bamboo, and dried. The sticks are somewhat like the common joss-sticks of the country, or about the thickness and length of a light walking-cane. Another substance is in long narrow bags of paper, - say half an inch in diameter, and two feet long,-which are filled with the following substances, namely, the sawings of pine or juniper mixed with a small portion of nu-wang and arsenic. The proportions are thirty pounds of sawings, two ounces of nu-wang, and one ounce of arsenic. This mixture is not made up in the form of a paste like the latter, but simply well mixed, and then run into the bags in a dry state. Each bag being filled, is closed at the mouth, and then coiled up like a rope, and fastened in this position with a bit of thread. Various species of wormwood are likewise employed for the same purpose. The stems and leaves of these plants are twisted and dried, and probably dipped in some preparation to make them burn. The mosquito has a mortal aversion to all these substances, and wherever they are burning, there the little tormentors will not come. MOSS.

Mousse, . . . Fr. $\mid$ Musco, Muschio, . IT. Moos, Sumpf, : GER. Moho o musgo, : Sp. The order Musci of botanists, small plants with very delicate tripled roots and a simple branched stem. The musci are arranged into two tribes, viz. the Andreæ, which comprises the genera Andræa, and Acroschisma, and the Bryeæ, with the genera Bryum, Mnium, Polytrichum, and Sphagnum. Club-moss belongs to the order Lycopodiaceæ, with the genera Lycopodium, Selaginella. The very fine powder discharged from the spore cases of lycopodium, called vegetable brimstone, is highly inflammable, but burns with such rapidity that it does not set fire to bodies with which it is in contact. Iceland moss is the Cetraria Icelandica, and a decoction of it forms, when cold, a thick jelly. On the Upper Chenab a beverage is prepared from the thick rhizomoid roots and lower leaves (mingled with moss, etc.) of a small herbaceous plant, with scabrous leaves. This plant, in Tibetan, is called Sbangja. In commerce several useful food plants are called moss, Australian moss, Eucheuma speciosum.

Ceylon moss, Plocaria candida.

Chinese moss, Plocaria tenax.

Corsican moss, Gracillaria helminthocorton and Laurencia obtusa.

Irish moss, Chondrus crispus and Gigartina mamillosa. -Hogg; Powell. See Algæ; Sbangja. MOSUL, a walled city of Asiatic Turkey, in the pashalik of Baghdad, lat. $36^{\circ} 51^{\prime} \mathrm{N}$., long. $43^{\circ}$ $5^{\prime}$ E., situated on the west bank of the Tigris, opposite to the spot where Ninereh stood; population 35,000 , of whom 9000 are Christians, 1500 Jews, and the rest Arabs, Turk, and Kurd. The city is so close to the river as to be often flooded. Near there are beds of granular gypsum, and of sulphuretted springs. On the left bank, both above and below Mosul, are the ruins of Nineveh, the walls of which city extended about 3100 yards along the river, and nearly the same distance towards the interior. At about 28 miles 
by the river, and 20 miles in direct distance south, long. $12^{\circ} \mathrm{E}$., below Nineveh, is the celebrated bund or dyke of solid masonry, called Zikr-ulAwaz or Nimrud, which crosses the bed of the river; and at 7 miles lower there is a dyke, called Zikr Ismail, similar to the former, but in a more dilapidated state. Mosul is the Mes-Plyæ of Xenophon. Here the Tigris rarely exceeds 250 yards, and its population and trade have greatly diminished since the time, prior to the discovery of the Cape passage, when it was the thoroughfare for the caravans between Europe and India. It formerly enjoyed a high reputation for the manufacture which derives its name from the town, and is known in France as moussiline, and in English as muslin. At a short distance is the mound and village of Nebbi Yunus, in which is a mosque which covers the supposed tomb of the prophet Jonah.-Col. Chesney's Euphrates and Tigris.

MOT. HiND. A leathern bucket open at both ends, used with the pe-cottah lever for raising water.

MOTHER.

Am, Walidab, - ARAB. Ai, MAHR. Mère, - : . Fr. Mādar, : : . Pers. Mutter, : : Gr. Ger. Amma, . : SP., TAM.
Mater, : . TAM. Ma, : : : Hind Tilli, : : : Té. Madre, : : : Ir., SP. Ana, Nine, : 'Tunk.

The ancients loved to personify nature, as distinct from the world, and Universal Mother was a term by which it was often styled. Eastern nations deem the term mother to be one of the most reverential that can be used towards a woman; and the expressions big mother, little mother, are acceptable to all, aged women or spinsters. Genesis xxiv. relates how, in blessing Rebekah, they said unto her, 'Thou art our sister; be thou the mother of thousands of millions, 'etc. Similar addresses to a daughter, when she is going from her father's house to live with her husband, are very common among the Hindus; such as, 'Be thou the mother of a son;' 'Be thou the wife of a king,' etc. 'I remember,' says Colonel Tod, 'in my subaltern days and wanderings through countries then little known, one of my Rajput soldiers at the well, impatient for water, asked a woman for the rope and bucket by the uncivil term of Rand, meaning widow. "Myn Rajputni che," "I am a Rajputni," she replied in the Hara dialect, to which tribe she belonged, "aur Rajput ki ma cho," "and the mother of Rajputs." At the indignant reply the hands of the brave Kulian were folded, and he asked her forgiveness by the endearing and respectful epithet of mother. It was soon granted, and, filling his brass vessel, she dismissed him with the epithet of son, and a gentle reproof. Kulian was himself a Rajput, and a bolder lived not.' This was in 1807, and in 1817 he gained his sergeant's knot as one of the thirty-two firelocks of Colonel Tod's guard, who led the attack, and defeated a camp of 1500 Pindaras.-Tod's Rajas. than, i. pp. 641,642 .

MOTHER OF CITIES, or Amu-balad, a name of Balkh. The river Oxus is known as the Amu Darya.

MOTHER OF HEAVEN, a goddess known as Mylitta, Astarte, Aphrodite, Isis, Mata, and Venus. The eminences consecrated to her worship were of a conical or pyramidal shape.
MO'THER-OF-PEARL, Nacre.

Perlemoor, . . DAN. Madre perla, . IT., SP. Parelmoer, - . DUT. Indung mutigara, MaLAY. Perlen-mutter, : GER. Madre-perola, . PORT. Chip, . . . GuJ. Perlo-mutr,. . Rus. Sipi chip, : . Hind. Perlemor, . . . Sw.

Mother-of-pearl, or nacre, is the hard, silvery, internal layer of several kinds of shells; and the large varieties in the Indian seas secrete this coat of sufficient thickness to render the shell an object of commerce. Pearls are found in the shells round the coasts of Ceylon, near Ormus, in the Persian Gulf, at Cape Comorin, and in some of the Archipelagic and Australian seas. Fine large shells of a dead white are supplied by Singapore ; varieties come from Valparaiso with jet-black edges. South Sea pearl-shells are common with white edges. The beautiful dark-green pearl-shells, called ear-shells or sea-ears, are more concave than the others, and have small holes round the margin; they are the coverings of the haliotis, which occurs in the Californian, South African, and East Indian seas. In the Indian collection of the Great Exhibition, specimens of the finest mother-of-pearl shells were shown, such as the Meleagrina margaritifera, Haliotis gigas, H. iris, and a large species of Turbo, which shells are known in commerce as flat-shells, ear-shells, green snailshells, buffalo-shells. The beautiful tints of mother-of-pearl depend upon its structure, the surface being covered with a multitude of minute grooves which decompose the reflected light. It is in consequence of this lamellar structure that mother-of-pearl shells admit of being split into laminæ for the handles of knives, for counters, and for inlaying. Splitting, however, is liable to spoil the shell, and different parts are selected as nearly as possible to suit the required purposes, the excess of thickness being got rid of at the grindstone. Mother-of-pearl shell is obtained on the Australian bank. The mother-of-pearl shells of the Aru Islands and Sulu sell at $\mathfrak{E} 3,2$ s. 6 d. per $133 \frac{1}{3}$ lbs. avoirdupois. The mother-of-pearl from the Red Sea is taken to Jerusalem, and there made into chaplets, saints' figures, and crucifixes for Christian pilgrims. At Mecca it is worked into rosaries for the pilgrims. In Europe and China it is made into buttons, in ornamentation of the papier-maché work, cabinet and ornamental work, which cause a considerable demand for it. Mother-of-pearl shells and tortoiseshell are brought to China from the Archipelago and the islands of the Pacific, but a large part is re-exported in the shape of buttons, combs, and other productions of Chinese skill. The shells of the pearl-oyster are of almost as much value as the pearls, the nacre of these shells being exteusively employed in manufactures for useful and ornamental purposes. Other shells, however, have a large nacreous surface. One kind, called silverlipped, is imported to Liverpool ; another kind, called black-lipped, is brought from Manilla, and a smaller shell from Panama. Coral and motherof-pearl in India, and all the quartzose gems, are held in but little esteem by the people, who value a stone for its intrinsic price, not for the workman's skill expended in shaping it, in which the chief value of all the inferior gems consists. -Ouseley's Tr., 1868; Tomlinson's Cat. Ex. 1862 ; Burton's Mecca; Williams. See Mollusca. MOTI-TALAO, or Lake of Pearls, is a large 
tank in Mysore district, Mysore, formed by a dam carried across the gorge where several hill streams unite, in lat. $13^{\circ} 10^{\prime} \mathrm{N}$., and long. $78^{\circ} 25^{\prime}$ E. The tank, if full, would contain two years' supply for this area ; but in recent years, the level of the water has rarely risen as high as the mouth of the channel.-Imp. Gaz.

MOUAT, FREDERIC JOHN, a medical officer of the Bengal army, to which he was appointed in 1839. He published a paper on the Nosological Arrangements of the Bengal Medical Returns; an Atlas of Anatomy in folio, with descriptive letterpress in Hindustani and English. Author of Rough Notes of a Trip to Reunion, and Account of the Andamans.

MOULMEIN, a large town, in lat. $16^{\circ} 30^{\prime} \mathrm{N}$., and long. $97^{\circ} 38^{\prime} \mathrm{E}$.; built on the left bank of the Moulmein river, inmediately below the junction of the Gyne and the Attaran, on a small peninsula formed by the Salwin and Attaran. It is the chief town of the Tenasserim division of British Burma. The Moulmein river is also called the Martaban river, and is the Salwin river in its lower course. The entrance is 9 miles broad from the end of Pelew Gewen Island and Amherst point. The adjacent country consists of alluvial plains, through which flow the Salwin, Gyne, and Attaran, with several abrupt crags, that at Trouba rising 2600 feet. The population in 1881 was 53,107 souls, chiefly Burmese, Arakanese, Talaing, Shan, Chinese, Hindus, Europeans, natives of Mladras and Bengal, with a few Jervs and Parsees, Karen, and Khyeng. ralia.

MOUND BIRD, Megapodus tumulus of Aus-

MOUNG-KHUNG, the Ka-du, a race scattered over the country between Kyun-Dung and MoungKhung, a space of nearly two degrees. They are said to be a race of different origin from the Burmans. See India.

\section{MOUNTAINS.}

Jabl, Gabl, . . ARAB. Koh,

Mont, Montagne, . Fr. Roh,

GER. Khas, ... . SIAM.

Pahar, . . . HrNd. Monte, Montana, . SP.

Monte, Montagna, . IT. Droog, . . . TAM., TEL.

Mons, . . LAT. Rig,. . . TIB.

Gunong, : Malar. Dagh, : . :Turk.

The continent of Asia is crossed by a great desert, extending from the Caspian almost to the gates of Pekin and the Yellow Sea. To the south of this wilderness lies a region divided into northern and southern parts by the great chain of the Himalaya and the lofty Nanling mountains, which run from its western extremity to the shores of the Pacific, opposite the island of Formosa. To the north of this mountain wall are Tibet and China, separated by the Yunling mountains; to the south of the same barrier are the plains of Hindustan and the valleys of the Indo-Chinese countries, these two geographical areas being separated by the hills of Arakan. Beyond the Trans-Gangetic Peninsula there is a third region, the Malay Archipelago. Tibet is a vast expanse of plains, hills, and valleys, rising from a tableland of 15,000 feet in elevation. Its lowest elevation seems to be at its south-eastern corner, where it joins the Indo-Chinese countries, and whence they expand in long mountain ranges, which spread out like the ribs of a fan as they approach the Pacific.
The Altai Mountains divide the Chinese and Russian empires. This series is connected with the Himala-Tibetan mountains by the Pamir on the west and the Yunling-Irshan chains on the east. The whole forms a mountain girdle enclosing Central Asia or Mongolia and Tibet.

The mountain mass of Asia sinks to the westward of Afghanistan, rising again only in isolated peaks ; and hence the Himalaya is rather ideally than really connected with the mountains south of the Caspian; and so with the Caucasian Alps on the one hand, and those of Asia Minor on the other. The Afghan mountains form a meridional chain from the western extremity of the Himalaya, descending parallel to the Indus, with a gradually decreasing elevation from above 15,000 feet, to the level of the ocean, at the Arabian Sea. The Ava and Malayan mountain chain is given off from the snow-clad mountains of East Tibet, and is continued uninterruptedly almost to the equator. The Vindhya chain crosses the Peninsula from the Gulf of Cambay to the Ganges. The Aravalli mountains extend from Hansi and Dehli to Gujerat. In the Peninsula of British India the Sahyadri or Western Ghats extend from the Tapti river to Cape Comorin. This peninsular chain forms a continuous watershed throughout its length of upwards of 900 miles, scarcely deviating from a straight line, which is parallel and close to the west coast of the Peninsula, and perpendicular to the direction of the monsoon. This chain divides the Peninsula of India unequally into two portions, marked by different climates, - a narrow. western one, including Malabar, Travancore, and the Konkan; and a broad eastern one, traversed by several great rivers, and including the Carnatic, Mysore, and the Dekhan.

Between India and Tartary, the broad mountain range has the Himalaya forming the southern crest, and the Kouen Lun the northern. The interior has some lovely valleys, among which Kashmir is pre-eminent, but it is more usually broken into rocky ravines, through which the Indus, Ganges, and their affluents force their way towards the plains; or else stretches away in those vast treeless uplands which are one of the chief characteristics of the range through its whole extent. The ascent from Yarkand and Kashgar, westward to the table-land of Pamir, is almost imperceptible; and when that lofty position is gained, where the average elevation is probably as much as 15,000 feet above the sea, a lofty plateau stretches across the head-streams of the Oxus to the top of the Chitral valley. This plateau may be 700 or 800 miles in extent. It is varied by lakes, and from it descend great river systems. The Naryn and Syr (Jaxartes) belong to the Altai mountains. Only the Oxus and the Tarim come from Pamir. The Naryn, which is the main stream of the Jaxartes, runs through a long, luxuriant valley, between the culminating ridge and outer range of the Tian Shan, and drains all the northern range of the plateau. The Oxus, rising in the Sir-i-Kul or Yellow Lake of Pamir, at least 300 miles to the south of the Jaxartes, receives from its right bank a multitude of small streams, which run to the south through rugged valleys, on the western face of the Pamir uplands. The western face of Pamir between the Jaxartes and the Oxus 
is far more precipitous than the eastern. Ridges run out as far as Samarcand and Karshi, and the streams from the upland which twine amongst these ridges form the Zar-afshan and Karshi part of the water system of the Oxus, though before they reach that river they are entirely consumed in irrigation.

The Kouen Lun mountain chain, as seen from Sumgal in Turkestan, is in lat. $36^{\circ} 8^{\prime} \mathrm{N}$, and long. $78^{\circ} 5^{\prime} \mathrm{E}$., and 13,215 feet above the sea. The Kouen Lun is the northern crest of the great range which bounds the high table-land of Tibet. This range has been supposed by some writers to be the true watershed between India and Central Asia, the Murus Ussu or Yang-tze absorbing all the streams which flow from the southern slopes of the range, while the northern rivers which form the Kara Kush force their way through or round the outer barrier of the Kouen Lun, and wend northward to the Gobi or Sandy Desert. The Kouen Lun is unknown between Khoten and Chardam. In the Kouen Lun, all passes above 15,000 feet are closed in wiuter by the heavy snowfall.

The most westerly of the passes belongs to the Kara-korum mountains; it is called in Balti the pass of the Mustagh, and lies at the source of the right branch of the Shigar river, a stream which joins the Indus opposite the town of Iskardo. The road over this pass to Yarkand was frequented by merchants, but for many years was disused, the reason assigned being the danger of plunder by the hordes of robbers. As described by persons who have crossed it, the snow is reached after ten days' journey from Iskardo, and continues during three marches.

The second pass, also over Kara-korum, is at the head of a considerable tributary which joins the Shayuk river opposite Khapalu. The enormous glacier over which this road runs was described by Vigne. Dr. Thomson did not, while in Tibet, meet with any one who had crossed it, and he was assured by the inhabitants of Nubra that they were not acquainted with any road from the upper part of their valley, either towards Khapalu or towards Yarkand.

The third pass, and the only one now frequented, is also over the Kara-korum, an extremely easy though very elevated one. It is by this pass that Eastern Turkestan communicates with Tibet and India.

The most easterly pass of which there is any notice, occurs on the road between Ruduk and Khoten. It was visited by Mr. Johnson, and a native explorer traversed another route fartber east.

The Tian Shan, or Celestial Mountain chain, has three characteristic divisions, from the meridian of Kucha, long. $82^{\circ} 48^{\prime} \mathbf{E}$., to its intersection with the Bolor. To the east, from the transverse course of the Aksu to Kucha, the Celestial Mountains rise in a towering ridge, covered with perpetual snows, which feed enormous glaciers, and are therefore called the Muzart or -Icy Mountains. There is only one pass through the Muzart mountains, which is called by the Chinese 'the pass of Glaciers,' and by Humboldt Djeparle. Through this pass there is a road leading from Kuldja, in lat. $45^{\circ} 54^{\prime} \mathrm{N}$., and long. $80^{\circ} 58^{\prime} \mathrm{E}$., to Aksu.

Bolor Mountains. - The mountains of Balti extend for 300 miles, from the sources of the Gilgit and Yasin rivers, from long. $73^{\circ}$ to $77^{\circ} \mathrm{E}$., the source of the Nubra river. The Bolor mountains are called Altai by the Audijans. They are precipitous and inaccessible on their western face, and form on the east a high, cold plateau, visited only in the summer by the Kirghiz. There is ouly one caravan road over the Bolor, which passes through Badakhshan. The road through Badakhshan to Yarkand leads to Khulm, thence to Bokhara, Balkh, and Kābul ; caravans requiring sixty-five days to reach Bokhara by this route.

The Pamir is intersected by roads well trodden by the Kirghiz, all of which lead to the khanate of Kokan, or to Karatagin.

Eastern Turkestan is enclosed by mountains on three sides: by the Tian Shan on the northern, the Pamir on the western, and Kouen Lun on the southern. These mountains belong to the highest ranges of Central Asia, and form the natural limits of the western portion of the Chinese empire. The actual boundary, however, runs along the line of pickets stretching through the outlying lower ranges on the Chinese side; beyond this frontier the territory is occupied by roaming Kirghiz. To the eastward, Eastern Turkestan is bounded by the uninhabited sandy deserts of the Makhai and Hami Gobi. It occupies consequently a plain between lat. $36^{\circ}$ and $43^{\circ} \mathrm{N}$, and long. $70^{\circ}$ and $90^{\circ} \mathrm{E}$. from the meridian of Paris. Eastern Turkestan occupies the centre of the table-land of Eastern Asia.

Continental India.-Its primary divisions are four,-Hindustan, in the widest sense of that term, including the whole Western Peninsula and the Gangetic plain to the base of the Himalaya; 2 . The Himalaya, which rises abruptly from the Gangetic plain, and is connected with the mountain mass of Tibet to the north, and beyond India; 3. India ultra Ganges, including British Burma, the kingdoms of Burma and Siam, Cambodia, Annam, the French acquisitions, and the Malayan Peninsula; 4. Afghanistan. These divisions are marked out by great mountain barriers and by the ocean.

Himalaya. - The two sections of the Himalaya present almost insurmountable physical obstacles to communication between the countries which they divide, thereby separating the Bhoti or people of Tibet from the Hindu family of India. The distinction of climate is not less positively marked by the lines of demarcation between the cold and dry climate of Tibet with its dearth of trees, and the warm and humid climate of India with its luxuriance of vegetable productions.

To the north of the Eastern Himalaya, in Tibet, lies a vast little known tract, in which rise the head-waters of the Yang-tze-kiang, the Lantsan or Cambodia river, and the $\mathrm{Nu}$ or Salwin, which is identified by Chinese geographers with the Nu-king.

Western Tibet is a highly mountainous region lying on both sides of the river Indus, with its longer axis directed, like that river, from southeast to north-weet. It is bounded on the northeast by the Kouen I,un chain of mountains, by which it is separated from the plains of Yarkand. On the south-east its boundary is formed by the ridge which separates the waters of the Indus from those of the San-pu. To the north-west and south-west its boundaries include the whole of the valley of the Indus and its tributaries down to about 6000 feet above the level of the sea 
a cousiderable portion of the upper course of the Sutlej down to between 9000 and 10,000 feet, and small portions of the upper course of the Chenab, of the Ganges (Jahnavi), and of the Gogra. Every part of Tibet is traversed by ranges of mountains which have their origin either in the Kouen Luu on the north, or in the Trans-Sutlej Himalaya on the south.

The Himalaya mountains are nowhere under 15,000 feet, usually exceeding 17,000 and 18,000 feet, and rise in isolated peaks or groups of peaks from 21,000 to 29,000 feet. The name in Sanskrit signifies the abode of snow; and Pliny (Hist. Nat. vi. p. 17) was aware of the signification of the name, for he says, Imaus incolarum lingua nivorum significaus. To the south of the great Kashmir valley are a varied series of hills running off from the Panjal mountains, and forming the elevated country between the Chenab and Jhelum, including Rajauri. The Panjal mountains are the continuation of the culminating summits that form the Southern Himalaya. Beyond the Jhelum we have a continuation southward of that l long mountain series which forms the Himalayan wall of the Kaghan valley. On this is situated the hill station of Murree; this range may be taken as almost the limit of the Himalaya. Beyond this we have the whole hill country of Hazara up to the Indus. Besides these ranges, there are endless subordinate though important divisions.

In the Western Himalaya, the average elevation of Kashmir valley is between 5000 and 6000 feet above the sea. Huramuk Mount, 13,000; Pir Panjal, 15,000; average of the valley of Indus (N. of Kashmir vale), 6000 to 7000 feet. Mountains on each side rising from 6000 to 8000 feet higher.

The Bara Lacha range is a part of the Northern Himalaya; it was regarded by Alexander Cunningham as the western continuation of the Himalaya. The Bara Lacha separates the Indus river from its first affluents, as the Eastern Himalaya separates the Tshang-po from the Ganges.

The Khatak range continues the boundary to the Indus, maintaining an average height of from 3000 to 5000 feet.

The Salt Range is a well-defined group of hills, varying from 2000 to 5000 feet at extreme elevations; it is remarkably scant of vegetation. The name has been given by geographers from its productiveness of rock-salt at the mines of Kheura and other places. But the range is known to natives by a variety of names. There are peaks called Karuli, Kundal, Sardi, Tilla, Bhulla, Kheura, Kas Gabhir, Kas Soj, Sangli and Chitta Hills, with many others both of the Shahpur and Jhelum districts. The Salt Range generally is called Khawa. The range runs across the SindSagur Doab between the Jhelum and the Indus, crossing it from east to west, between the parallels of lat. $32^{\circ} 22^{\prime}$ and $33^{\circ} \mathrm{N}$, and long. $71^{\circ} 30^{\prime}$ and $73^{\circ} 30^{\prime} \mathrm{E}$. It starts with three spurs or prongs, one on the east bank of the Jhelum, and two on the right; both continue separate as far as the Buna Nalla, which joins the Jhelum river at Darapur and Rasul, and then unite into one range, which continues up to Kalabagh on the Indus.

The main range of the Western Himalaya includes the great peak (20,000 feet) of Dayamar or Nanga Parbat. Here the range is intersected by the Indus river, beyond which the snowy peaks extend westward between Swat and Chitral. At this point also the two ranges which enclose the Kaghan valley (traversed down the centre by the Nainsukh river) strike off in a S.E. direction. The southern range of the West Himalaya runs nearly parallel to the Indus, and some distance south of it. The provinces which it bounds are Kanawar and Spiti, Lahoul, Kishtwar, Kasbmir, and near the Indus the tract of hill country represented by Hazara and Marri. The most remarkable pendant to this central chain is the vast chain of mountains which, starting off near the 76 th parallel of longitude at the Sheshanag peak, runs round, enclosing an irregular elliptical space, and rejoins the original range midway between the 75 th and 76 th parallels. The amphitheatre thus formed is the Kashmir valley; the mountain ranges enclosing it, which form as it were a loop depending from the main line, are known by the name of the Panjal, or the Pir Panjal, the Snowy Paujal, the Panjal of Banihal. This chain of hills separates Kashmir from Kishtwar on the east, and from Hazara on the west. The eastern portion of the central range has another range parallel to it on the south, enclosing the Chandra Bhaga or Chenab, and forming the valley of that river which runs among them. First, then, there is the Cis-Sutlej Himalaya, which runs downward towards the plains separating the Ganges basin from the valley of the Beas, including the Suket and Mandi territory. Beyond this comes the Dhauladhar range (in which are Dharmsala and other well-known places), separating the valley of the Beas from Chamba and the valley of the Ravi; and then a system, rather than a definite chain, of hills separating the Ravi from the Chenab.

The Siwalik is a Sub-Himalayan range of the later or tertiary formation, named from Siva, a Hindu deity. What is strictly called the Siwalik extends in a north-western direction from the right bank of the Ganges, and runs parallel to the Himalayan range, forming the boundary of the Doab between the Ganges and Jumna; beyond this it skirts the Ambala and Ludhiana districts, and comes to its termination in the Hoshiarpur district. Though this portion alone, restrictedly, receives the name of Siwalik, Dr. Royle had shown that hills of a precisely similar nature can be traced all along below the Himalaya from the Indus, as far as the foot of the Sikkim Hills. The Siwaliks are merely the detritus of the Himalaya, and seldom reach 3000 feet, while the Himalaya rise nearly to 30,000 feet. At Hardwar the Siwalik Hills form the gorge at which the Ganges issues into the plains of Hindustan. The breadth of this range is at its widest part about ten miles when it approaches the Sutlej river, and towards its termination beyond that river the range assumes the form of little more than sandhills. The highest part of the range is about Hardwar; and to the south of Garhwal, beyond Sirmur, some of the peaks are as high as 3000 or 3500 feet above the sea-level. Dr. Falconer, on his first visit to the Siwalik Hills, inferred that they were of a tertiary age, and analogous to the molasse of Switzerland. Subsequent research by other geologists has not altered that determination, although the exact knowledge of the formation has been greatly extended. About the end of 1834, Lieutenants Baker and Durand discovered 
the great fossiliferous deposit of the Siwalik, near the valley of Markanda, westward of the Jumna, and below Nahun. The range is all alluvial, in many places consisting of beds of gravel and rolled stones, fragments of the older formations of the Himalayan range above, consisting of granites, limestone, clayslate, gueiss, mica-schists, etc. Besides these there are beds of loose-grained sandstone, with much mica interposing. There are also beds of calcareous conglomerate and subordinate beds of clay. It is the clay and sand-beds of these ranges that are fossiliferous. Shells of the tertiary miocene period abound, but the chief characteristic fossils are the remains of gigantic mammalia, among which may be mentioned the Sivatherium, a huge creature somewhat similar to the tapir of modern days.

Two ranges cross the base of the Peninsula from east to west, the Vindhya north of the Nerbadda, the Satpura to the south of that river. The Vindhya rise abruptly from the Nerbadda, and the Salamber ranges on the slopes from the Malwa plateau connect the Vindhya with the Aravalli.

The Satpura range runs between the Nerbadda and the Tapti, and on its eastern edge is the Amarkantak plateau, rising 4500 feet. A mountainous plateau, in continuation of the Satpura, extends as far as the Ganges, terminating there in the Rajmahal Hills. This high land is bounded by the Sone on its N.W. face, and is divided by the river from the Kymore range. The S.E. slope of the plateau is towards the Bay of Bengal, and it is drained by the Mahanadi, Brahmany, Byturni, Sabunreka, and Damuda rivers.

The Aravalli chain of hills is connected by lower ranges with the western extremity of the Vindhya mountains on the borders of Gujerat, and stretches from S.W. to N.E. up to a considerable distance beyond Ajmir, in the direction of Dehli. The range divides Rajputana into two nearly equal parts, forming the division between the desert on the west and the Malwa table-land. It would be more correct to say the level of the desert, for the south-eastern portion, including Jodhpur, is a fertile country. The Aravalli chain divides the tributaries of the Indus from those of the Ganges, and may hence be regarded as a continuation of the Cis-Sutlej chain of the Himalaya, which terminates to all appearance in the plains near Nahun in Sirmur. In like manner, the peninsula of Kattyawar may be considered as the southern termination of the Aravalli, though separated from it by an alluvial plain, being the continuation of the watershed, and dividing the streams flowing to the Gulf of Cutch or the delta of the Indus from those that flow into the Gulf of Cambay.

The Dehli, Shekhawati, and Kalayana series of low hills furnish the mineral wealth of Dehli, Gurgaon, and Hissar; they appear to be spurs and offshoots of the extremity of the Aravalli range. The principal hills are the Dehli Hills, in the south-west of the district of the same name, and the Shekhawati Hills in Gurgaon, etc., and the Kalayana Hill at Dadri, which yields the flexible sandstone and the grey Narnaul marble. Among the hills in the Dehli district, a white clay, supposed to be kaolin, is produced. In Gurgaon, several clays-white, red, and yellow-and mica occur; also hematite and ironstone. and also copper, both at Singhana and in Hissar. Balla- garh yields white and red sandstones, and the mottled red and white and blackish of the new red group.

Mount Abu, says Mr. Fergusson (p. 234), rises from the desert as abruptly as an island from the ocean up to 5650 feet high, and presents on almost every side inaccessible scarps, the summit being reached only by ravines that cut into its sides. When the summit is reached, it opens out into a lovely valley six or seven miles long by two or three miles in width, with the little Nakhi Talao or Pearl Lake, and near to it, at Delwara, the Jains selected a site for their pilgrimage or tirth. During Jaina supremacy it was adorned with several temples, two of which are of white marble. The more modern of these was built by the two brothers Tejpala and Vastupala, who erected a triple temple at Girnar (A.D. 1197-1247), and for minute delicacy of carving and beauty of details it stands almost unrivalled. The other, built also by a merchant, Vimala Sah, about A.D. 1032, is simpler and bolder, and is the oldest and must complete example of a Jaina temple. It is dedicated to Parswanatha, who is seated within.

The term Sahyadri is applied to the entire system of the Western Ghats (q.v.) from the Tapti river to Cape Comorin. The range consists to the northward of nearly horizontal strata of basalt and similar rocks steeply scarped on the western side. The highest summits, such as Mahahales. war, 4717 feet, are perfectly flat-topped, and are undenuded remnants of a great elevated plain. The southern portion of the Sabyadri range is entirely separated by a broad gap (the Palghat, q.v.), through which the railway from Madras to Beypur passes.

The Neilgherries, a mountain offshoot from the Western Ghats, are situated between lat. $10^{\circ}$ and $12^{\circ} \mathrm{N}$, and long. $76^{\circ}$ and $77^{\circ} \mathrm{E}$. The brse of these mountains, including that of the Kunda Hills, covers a circumference of 200 miles. Their greatest length is from E. to W. 46 miles, and medium breadth 15 miles. The surface is composed of ridges of different elevations. The country is divided into three Naad, viz. Peringa, Malka, and Todawar Naad. The first two are mountainous, but the third is of sloping hills, and a gently undulating surface of table-land. Dodabetta is 8700 feet above the level of the sea. The people occupying these Naad are the Todawar, Badagar, Kotar, and Kurambar. The Neilgherries, and its various branches of the Kunda, Sispara, and Kotagherry, are the mountain system of greatest absolute elevation in India proper, and exceed at several points 8000 feet.

The Travancore mountains present a striking analogy to the island of Ceylon. They are loftiest at the extreme north of the district, where they stretch east and west for 60 or 70 miles, separating the districts of Dindigul and Madura.

The Pulney or Palnai mountains are west of Dindigul.

The Animallay, south of Coimbatore; the Shevaghiri mountains, south-west of Madura; and ranges are near Courtallum.

The Trans-Gangetic Peninsula mountain system may be compared to an open fan or to an outstretched hand, of which the thumb represents the hills of Arakan, the fore-finger the ridge which terminates in Malacca, the little finger the Nanling chain, running through Southern China, 
north of Canton; and the wrist the depressed edge of the table-land of Tibet, from which its waters are poured down into the Pacific, through valleys corresponding to the openings of the outstretched palm. One range prolonged through Arakan balts at Point Negrais, to reappear through the Andamans and Nicobars, and, after extending along the S.W. coast of Sumatra, passes eastward through Java and the Lesser Sunda Islands, terminating at its S.E. point. Another runs along the Malay Peninsula, is lost for a time, but appears again in the high peak of Lingin, and terminates in Banca and Billiton, and a branch from this separates at Pulo Timoan, on the east coast of the Peninsula, and ends at Carimata, in the strait between Billiton and Borneo. Two parallel ranges traverse Cambodia and Cochin-China in the same direction. Between the Cambodian range and the mountains at Sarawak, on the north-west extremity of Borneo, the Natunas Islands and Pulo Condor form the connecting link. This range, after traversing the western part of Borneo, terminates on the south coast a little to the eastward of Kotaringin. The Annam or Cochin-Chinese range can be traced most distinctly across the Archipelago to Australia.

The Yoma Mountains are the central chain of Burma proper. Yoma means a chain of mountains, as the parallel ranges of Arakan Yoma and the Pegu Yoma. They extend into Pegu, and form the spine, as it were, of the province, with the valley of the Irawadi on the east, and the several minor valleys lying between the off shoots by which the chain is terminated on the south, as the valley of the Zamayee or Pegu river, the valley of the Hlaine river, together with the intermediate valley of the Phoungye river or Paizundoung creek, lying between the Hlaine and Pegu rivers. One of the most southern points of the Yoma lies between the Hlaine and Paizundoung, of which the Pagoda Hill at Rangoon may be considered the last elevation, marking the direction of the chain or line of local disturbance. The most elevated portion of the Yoma chain appears to be that from whence these southern branches radiate, where the Oakkan and Thoun-zai Choungs derive their source, falling into the Hlaine river on the east and south. This part of the chain Dr. M'Clelland estimates at about 2000 feet above the sea on the west, and the Zamayee and the Phamgye rivers presenting steep and inaccessible declivities.

The productiveness of the tin mines of the Malay Peninsula and of Banca is well known. The Cambodian range is also rich in minerals, especially the Borneon part of it. Iron, coal, gold, and diamonds are obtained. The volcanic islands of the Archipelago also contain metals, gold-dust being found at the bottoms of many of the mountain streams.

Snow.- In the Himalaya the lowest height at which snow has fallen in winter is about 2500 feet; but such cases are extremely rare, having occurred in Kamaon and Garhwal ouly twice (in 1817 and 1849) since the British took possession of the country. At an elevation of 5000 feet scarcely one year in ten passes by without snowfall; but at this height the snow disappears after a few days, and sometimes even hours. 'It snows, but one does not see it,' said the natives of Kbatmandu ( 4354 feet), meaning that the rare nightly hoar-frosts are melted away by the earliest rays of the sun. 6000 feet may be assigned as the limit where snow regularly falls in winter with a probability of remaining some time upon the ground.

In Western Tibet and in the Kara-korum the general elevation of the country is so great even in its lowest regions, that no part lies below the limit of hibernal snowfall.

In the Kouen Lun, even on its southern slope, a greater amount of snow is precipitated than on the northern side of the Kara-korum, while its Turkestan (northern) slopes differ still more from the Kora-korum in this respect.

The values obtained for the height of the snow line on the three mountain chains of High Asia are-
a. Himalaya--
Southern (Indian) slopes, . . 16,200 feet.
Northern (Tibetan) slopes,
17,400
b. Kara-korum-
Southern (Tibetan) slopes,
Northern (along the Turkestani plateau),
19,400
18,600
c. Kouen Lun-
Southern (facing mountainous ramifications),
Northern (facing the Turkestani plain), 15,100 ",

In the Himalaya the truly temperate vegetation supersedes the subtropical above 4600 feet, and the elevation at which this change takes place corresponds roughly with that at which the winter is marked by an annual fall of snow. This phenomenon varies extremely with the latitude, longitude, humidity, and many local circumstances. In Ceylon and the Madras Peninsula, whose mountains attain 8000 feet, and where considerable tracts are elevated above 6000 to 8000 feet, snow has never been known to fall. On the Khassya mountain, which attains 7000 feet, and where a great extent of surface is above 5000 feet, snow seems to be unknown. In Sikkim snow annually falls at about 6000 feet elevation; in Nepal at 5000 feet, in Kamaon and Garbwal at 4000 , and in the extreme West Himalaya lower still. In the mountains of Ceylon, on the Neilgherries, and on the Khassya Hills, the temperate forms of plants are more numerous than upon the Himalaya. Violent winds sweep over the broad grassy undulating tops of the Khassya Hills, and hundreds of species common to the Sikkim Himalaya and to the Khassya ascend higher in the warm, forest-clad, and sheltered Himalayan valleys at 5700 feet in Sikkim, than they do in the Khassya Hills.

Heights,-The following heights of well-known places may be interesting :-

In the Himalaya.

Gaurisankar, 29,002 feet. Singoleelah, 12,329 feet. Sihsur, . . 27,799, Tendon, . 8,662," Dhoulagiri, .26,826" "Tonglu, : 10,079", Yassa, . . 26,680", Darjiling, . . 7,165 ", Jib-jibia, : 26,306" "Julla Pahar, 7,452",

Massuri Bazar, 6,719 ", Barathor, . 26,069 ",

" Church, 7,369 ", Yangma, . 26,000",

Landour ," 7,369 ", Nanda Devi, . 25,749 ",

\begin{tabular}{r|l} 
Kanchinjinga, 28,808 ", & Ibi Gamin, .25,550 ,"
\end{tabular}

Jumru, . . 25,311 ", Jannoo, : . 25,304 ",

Kabroo, : .24,004 ", Lebong, : . 6,039 ",

Pandim, : 22,015 ", Senchal, : : 8,606"

Narsing, . . 19,139 ", Punkabarry, . 4,600? ",

In the Kara-korum.

Dapsang, . . 28,278 feet. Masheribrum, 25,626 feet. Diamer, : .26,629," 
In the Kouen Lun the peaks seem not to exceed 22,000 feet.

Neilgherries.

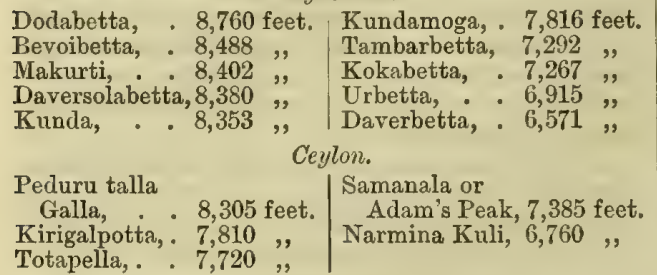

Central India.

Parasnath, . 4,469 feet. Kalsubai, . . 5,410 feet. Abu, : : 5,650 ", Dhorup, : : 4,745 ",

Rajmirgarh, . 3,753 ", Varada, . . 4,655 ",

Bubul, . . 3,353 ", Torna, . . 4,619 ",

Dekhan.

Putta, . . 4,569 feet. Aunda, . . 4,339 feet. Ikhara, . 4,482, Mandvi, . . 4,123,

The heights of the following localities have been ascertained :-

Aksae Chin, . 16,620 feet. Upper Tsomo-

Tso Gyagar, . 15,693 , $\quad$ gnalari, .

, Karor Khauri

Talau, . 15,684,

Mure Tso, : 15,517,

Kiuk Kiol, : 15,460,",

Mansaraur or

To Mapan, . 15,250,

Rakus Tal or

Tso Lanag, . 15,250

Tsomoriri, . 15,130,"

Nima Kar, . 15,100

Hanle, . . 14,600,"

Tso Gam, : 14,580",

, Rul, . . 14,400,

"Mitleal, . 14,167,

Lower Tsomo-

gnalari, . 14,010

Jumnotra,

Nepal, . 25,500,

Dhailun, do., 24,740 ,

Peak in Nepal Valley, . 24,625,

Petcha in

Tartary, . 15,000,

Sumunang, . 14,000,

Ghassa, . 13,080 ,

Ophir, Sum-

atra, . . 13,840,

The inhabitants of the Himalaya occupy the valleys of its rivers, and carry on traffic and intercourse over the passes of the mountains, of which the following heights above the sea may be mentioned :-

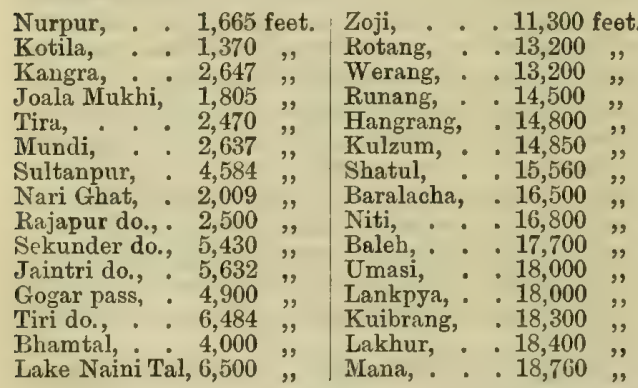

18,760

The Himalaya population comprise numerous tribes, mostly of the Bhot race. The names of the chief of their clans are as follows :-

\begin{tabular}{l|l|l|l|} 
Abor. & Dogra. & Koli. & Murmi or \\
Awalia. & Dunghar. & Kumba. & Tamar. \\
Awan. & Gaddi. & Kus, Khas, & Newar. \\
Bahoa. & Gakkar. & or Kbasi. & Pallas. \\
Bamba. & Garhwali. & Kusund. & Palpa. \\
Bhutia. & Gurung. & Kuswar. & Pa-lu-sen. \\
Bhramu. & Hayu. & Lahuli. & Rajivaru. \\
Bodo. & Janjob. & Lepcha or & Rajput. \\
Boksa. & Kahka. & Deun jong- & Rawat. \\
Bor. & Kanait. & maro. & Rongbo. \\
Chepang. & Kanet. & Lhopa. & Serpa. \\
Chibh. & Khatir. & Limbu. & Sunwar. \\
Dafla. & Khombo. & Magar. & Thaksya. \\
Dahi or Dari. & Kichak. & Mewar. & Tharu. \\
Dardu. & Kiranti. & Miri. & Thumba. \\
Dhenwar. & Koch'h. & Mishmi. & Yakhu. \\
Dhimal. & &
\end{tabular}

In the Himalaya, the number of inhabited places is comparatively insignificant; while the population reaches its maximum in the rich belt of life rising from 3000 to 8000 feet, the traces of man and his dwelling-place begin rapidly to disappear at 11,000 feet, and even before.

In some provinces, especially in Nepal, Kamaon, and Garhwal, many villages are deserted in winter, though, as far as regards their elevation and the solid construction of the houses, they might very well be inhabited throughout the year. The natives, however, prefer removing to villages less elevated, where they spend the colder months. Chalets (Alpenhutten) are as little used in the Himalaya as tents in the Alps. The pasture grounds, Karik, for sheep and bovine cattle are for the most part in low elevations, and at no great distance from the village. In the frontier country bordering Tibet, herds of sheep and goats are used for the transport of merchandise. They are driven over the passes to Tibet, laden with grain (a full-grown sheep carrying about seven pounds), and return at the end of the summer with salt and borax.

Of the sanatoria, Simla is 7156 feet, Darjiling 6905 , Mussoori 6849 feet, etc. They are at present confined to the outer ranges, at a distance of 40 or 50 miles from the foot of the mountains. Chini, a most salubrious place in Kanawar (9096 feet). Srinuggur, the capital of the valley of Kashmir (5146 feet).

Tigers ascend to 11,000 feet in the Himalaya; they are not, however, seen in Western Tibet, or the Kouen Lun. Leopards may be met with in the Himalaya and in Western Tibet even at 13,000 or 14,000 feet; on the Kedar-kanta $(12,430$ feet). The domestic cat is common in Tibet. Domestic animals, such as sheep, goats, tame yaks, horses, and dogs, follow man across the highest passes (18,000 feet), between Turkestan and Tibet the two-humped Bactrian camel even being used as a beast of burden. When without a load, no difficulty is experienced in bringing these camels even over the steeper passes of the Himalaya.

Jackals are found in the Kara-korum, between 16,000 and 17,000 feet. Hodgson mentions two species of foxes in Eastern Tibet. Wolves are not known to frequent the Himalaya proper, but they are found in Western Tibet, and close to the Kara-korum pass $(18,345$ feet).

The wild yak and the kiang, several species of wild sheep and goats, hares and mice, are found as high as 16,000 to 17,000 feet. The number of species of snakes and frogs rapidly decrease with height, but lizards remain nearly the same between 1000 to 15,000 feet.

Butterflies are found in the Himalaya to 13,000 feet, in Western Tibet and Turkestan even 16,000 feet, as localities of permanent habitation. The upper limit of mosquitoes is at about 8500 feet, and with the peepsa make themselves very troublesome in the Eastern Himalaya during the rainy season as high as 13,000 feet. As in the Alps, the new fields of the glaciers are often covered with the remains of insects carried up by the ascending current to 18,000 and even 19,000 feet.

Mountains are famed in the mythologies of many races. Mount Olympus was the fabled seat of the epic deities of Greece and Rome. Mount Sinai 
was the mountain of legislation for the Hebrews. Govardhan is the mountain where the scenes of Krishna's reforming efforts are painted. The Bedouin Arabs take off their shoes when they enter the stone circle on the heights of Serbals, and the adjacent Jabal Munadshat is called by the Arabs the Hill of the Dialogue, viz, of Moses and Jehovah. Mount Meru, a fabulous Himalayan mountain, is supposed by Hindus to be the centre of the earth and the heaven of their Vedic god Indra. Mount Kailasa, or Gana Parvata, in the Himalaya, north of Lake Manasa, is the paradise of Siva and the abode of Kuvera. Vaikuntha or Vaibhra is the paradise of Vishnu, and is sometimes supposed to be on Mount Meru.

Five mountains are considered sacred by the Jains, viz. Girnar, Palitana, and Talijah in Saurashtra, near Deesa, and Sakar, about whose locality there exists much doubt; the Jains themselves speak of it as to the westward.Trelawney Saunders in Geng. Mag., July 1877; also Mountains and River Basins, Beng. As. Soc. Journ. See Parses.

MOUNT ABU. The peaks which crown this mountain, according to Tod, are six. The most elevated is that of Gorakhnath, having on its summit an area of only ten feet in diameter, and surrounded by a shrine dedicated to Gorakhnath; each of the other peaks has its shrine. On a small table-land on the mountain, about 600 feet below its summit, is the ancient palace of Khengur and numerous Jain temples.

MOUNT ARAFAT, near Mecca, is visited by the pilgrims, as Muhammadans have a tradition that Adam, conducted by the angel Gabriel, here rejoined Eve, after a separation of 200 years, in consequence of their disobedience in Paradise, and from here he carried her to Ceylon.Catafago.

MOUNT ARARAT. In the last volume of Cosmos, Humboldt records the height of Demavend at 19,715 feet, which is 1785 feet under the height attributed to it, and Ararat 17,112 feet high. The Ararat of modern geographers, in the province of Erivan, is the Mons Macis of the ancients. At a distance, it has a resemblance to a ship, and is called by the Persians, Mountain of Noah, Aghri-dagh being the name given to it by the Turks. Arabs call it Jabl-ul-Judi, and the Armenians Massis Sinsar, or Mountain of the Ark. All unite in revering it as the haven of the great ship which preserved Noah from the waters of the deluge. It was reported that some planks of the ark remained on this hill at the date of the accession of the Abbasside khalifs, A.D. 749, and the people still assert their presence.

MOUNT DILLI, a hill on the Malabar coast, a conspicuous headland, visible 24 to 27 miles at sea. The small fort on its outer extreme headland is in lat. $12^{\circ} 2^{\prime} \mathrm{N}$., and long. $75^{\circ} 0^{\prime} 30^{\prime \prime} \mathrm{E}$. The hill rises 850 feet above the sea. It is also called Yelli-pand. It was styled by Ptolemy Purrbus Mons, or Mountain of Yarasa Rama.

MOUNT EVEREST, 29,003 feet in height, lies to the west of Kanchinjinga, and is the highest mountain of the world at present known. According to the brothers Schlagentweit, the Nepalese call it Gaurisankar, but the Tibetans to the north call it Chingopanmari.

MOUNT GOVARDHAN, the Hindu Parnassus, the age of seven, he uplifted Govardhan on the tip of his little finger, to shelter the Gopa and Gopi from the wrath of Indra, the Jupiter Pluvius of the Hindu pantheon, who, enraged with jealousy at the diminution of his votaries and sacrifices, consequent on the adoration of Krishna, attempted to destroy them by a partial deluge. This story is represented in the Matsya Purana, whence Sir W. Jones introduced it in his hymn to Indra. The bard

... "warbling in a softer mode,

Sang the red lightning, hail, and whelming rain, O'er Gokal green, and Vraja's nymph-lov'd plain, By Indra hurl'd, whose altars ne'er had glow'd Since infant Krishna rul'd the rustic train

Now thrill'd with terror. Them, the heavenly child Call'd, and with looks ambrosial smil'd :

Then, with one finger rear'd the vast Goverdhan, Beneath whose rocky burden,

On pastures dry, maids and herdsmen trod :

The lord of thunder felt a mightier god.'

In pictures of this miracle, Krishna is always represented as a man, attended by his favourite mistress Radha, and sometimes by a multitude of shepherds and shepherdesses; the former with poles, steadying the uplifted sheltering mountain, a shower of rain and fire falling vainly on its summit. The legend seems to mean that Krishna had departed from the Vedic worship of Indra, from which persecutions arose.

MOUNT HERMON, the modern Jabl-us-Shaikb, the southern parts of Anti-Libanus.

MOUNT IMAUS, the Koh-i-Kaf of the Persians, according to oriental cosmographers, surrounded the world; but since geography has made some progress in the east, the name has been confined to Mount Imaus to the east, and Mount Atlas to the west. Jan or genii, a race intermediate between angels and men, produced of fire, are supposed to have inhabited the earth for several ages before the birth of Adam, and to have been governed by kings, all of whom were called Suleiman (Solomon). They fell into a general state of depravity, and were driven into remote places by Eblis (the fallen angel), and such as remained in the time of Kaiumeras, the first of the Pesdadian dynasty of Persia, were by him driven to Mount Kaf,-Journ. Ind. Arch. v. p. 548.

MOUNT KAILAS. Here, according to Hindu mythology, lies the city of Kuvera, the Indian Plutus; also the habitation of the god Siva. It is the Kailas range or Gangri range of mountains in the N.IV. Himalaya. The range has six passes, at heights from 15,000 to 18,105 feet. Kailas means crystalline or icy, and is possibly the source of the Latin, French, German, and Danish words for ice and glass, - glesum, glace, gler, glas, glass, - and is itself a compound term derived from $\mathrm{Ke}$, water, and Las, to shine.

MOUNT LEBANON, a mountain in Palestine, occupied by the Druse race, who are likewise spread over the Hauran, S.E. of Damascus. Zahle, seven hours from Balbec, belongs to the Druse territory. Half an hour from Zahle, on the south side of the village of Kerak, is a tomb shown as that of Noah. In Lebanon, about 18 miles east of Tripoli, is the Maronite convent of Kozhaia, in which the monks exorcise demons.

MOUN'I MAHABAN, or the Black Mountain, is supposed by some to be the Aornos of the At Greeks. It is in the Pir Panjal, and is 40 miles 999 
up the Indus from Attock. It is at least 50 miles in circuit, and from 7000 to 10,000 feet high. Aornos was fabled in the Greek camp to have thrice defied Heracles himself. See Khaibar; Mahaban. MOUNT MANDAR, an isolated hill, visible from Bhagulpur on the Ganges, famed as a place of Hindu pilgrimage.

MOUNT MERU, in Hindu legends, a sacred mountain, supposed to have been in the N.W. Himalaya.

MOUNT NEBO. From the top of this, on their return from Egypt, the Israelites first beheld the land of promise, and there their illustrious leader breathed his last._Robinson's $T r$.

MOUNT OF OLIVES, a hill on the east of Jerusalem; its highest summit is 2400 feet above the level of the sea.

MOUNT OHOD, the burial-place of Aaron, is shown over the summit of Mount Hor.

MOUNT OPHIR, in lat. $0^{\circ} 5^{\prime} \mathrm{N}$., long. $100^{\circ}$ $\mathrm{E}$, on the west coast of Sumatra, 9459 feet above the sea. It is 24 miles inland, appears by itself like an obtuse cone separated from the chain of other mountains, and may be seen from a distance of 110 miles in clear weather.

MOUNT SINAI, on the eastern shore of the Gulf of Suez, 150 miles south of Suez, is famed in the history of the Hebrew nation as the district whence laws for their guidance were communicated to Moses, their leader. It is surrounded by desert, which the wandering Bedouins occupy. At the foot of the mountain is the Greek convent of St. Catherine, founded in 1331 by William Bowldesell, the monks of which are kept almost prisoners by the Bedouins. The Arabs call Sinai, Jabl-u-Tur. Dr. Beke supposes Mount Sinai to be the mountain called Barghir, which is also called Jabal-un-Nur or Mountain of Light, and that whereon the Almighty spoke with Moses. -Burkhardt's $T r$.

MOUSTACHE. In British India, amongst Hindus and Muhammadans, passing the hand over the moustache is a signal both of defiance and self-gratulation.-Tod's Rajasthan, i. p. 353.

MOU-TAN. CHIN. The mou-tan or tree peony, Poonia moutan, is abundant in China, and bears the title of hwawang, or king of flowers. 'The skill of the Chinese gardeners has made many varieties. Tree peonies are brought in large quantities about the month of January from the northern provinces. They flower soon after they arrive, and are rapidly bought up by the Chinese to ornament their houses, after which they are thrown away, as they do not thrive well so far south as Canton or Macao, and will not flower a second season. They are sold according to the number of flower-buds they may have upon them, many of them fetching rather bigh prices. Williams' Middle Kingdom; Fortune's Wanderings.

MOUZAH. ArAB. A village. Mouzadar, in Bengal, one of the village authorities.

MOWALI, a Bedouin tribe of the northern desert. They came from Hejaz, and their shaikh claims descent from the Abbassi khalifs. For 50 years the Shammar and the Mowali fought for the present Mowali district.

MOWAMARIA, Muttuck, or Moran, a tribe of Assam, subject to one chief, called Bar Senapati. They are Vaishnava Hindus.

MOW CHOK. CHIN. The most beautiful bamboo in the world,
Central and Eastern Provinces of China it is largely cultivated, particularly on the sides of mountains where the soil is rich, and in the vicinity of temples and other monastic buildings. Its stems are straight, smooth, and clean; the joints are small. It grows to the height of from 60 to 80 feet. 20 to 30 feet of the lower part of its stem are generally free from branches. These are produced on the upper portion of the tree. They are so light and feathery that they do not affect the cleanness of the main stem. It is therefore of great value in the arts, owing to the smoothness and fineness of its structure, and is used in the making of sieves for the rolling mauipulation of tea, baskets of all kinds, ornamental inlaid works, and other purposes for which the bamboos of India are unsuitable. It perfects its growth in a few months. A healthy plant generally grows about 2 or $2 \frac{1}{2}$ feet in the 24 hours, and the greatest rate of growth is during the night. The young shoots, just as they peep out of the ground, are esteemed as food, split up, boiled, dished by themselves, used in soup like cabbage, and form an ingredient of an excellent omelette.

MOZAMBIQUE is a coral island, very low and narrow, and $1 \frac{1}{2}$ miles long, first seen by Vasco da Gama on the 1st March 1498. Alvares Cabral visited it in 1500, and Vasco da Gama returned to it in 1502, and in 1505 it was declared a Portuguese province.

MOZDAK, a pretended prophet in the time of Kobad of Persia, who preached the doctrine of a community of women and possessions.

MOZOME ANGAMI, a rude pagan tribe on the hills of Assam, on the eastern frontier of the Mikir and Cachar. See Naga.

MRICH'CHHA-KATI, or the Toy Cart, a drama in ten acts, by king Sudraka, supposed to have been written in the 1 st or $2 \mathrm{~d}$ century A.D., and to be the oldest Sanskrit drama extant. There are several editions of the text, and translations into French.-Dowson.

MRIG-SAL or Mirg-sal, the husbandman or cultivator's year. It commences at the end of Vaisakh or beginning of Jyesakh (May-June), when the grain is sown.

MRIGUENA, or the Fawn-Eyed, a Gujarani princess who was married to Maun Singh, the great Tamara raja of Gwalior, in the beginning of the 16th century. The raja was fond of music, especially of the sankirna rag or mixed modes, of which Mriguena was a great genius. Four specimens of her composition are yet extant, and called after her name, Gujari, Bahul Gujari, Mal Gujari, and Mangal Gujari. It was supposed that the Hindu musician Tan Sen, attracted by her songs, went to Gwalior, where he is buried.

MRITTIKA, the earth deity of the Hindus, is worshipped in several forms. One of these is in the Nagapanchami festival, during which a snake of clay is worshipped; a second form is as the Gokul-ashtami, when a clay image of the infant Krishna is worshipped; and a third form is in the earth or clay figure of Ganesa, on the fourth of the mouth Bhadrapad, about the beginning of September, during which Ganesa is brought to the homes with much ceremony, and finally thrown into the sea or into water. Also, numerous temples are erected on the banks of the Ganges, in honour of the goddess Ganga, in which clay images are set up and worshipped. 
MRITTYU. SANsk. Death, from Mri, to die. Mrityunjava, vanquisher of death, a name of Siva, from Mrittyu, death, and Jee, to overcome: Mrita-sanjivini, to restore to life.-Dowson.

MRU or Tung Mru, a tribe in the Koladyn valley. The number of the Mru in Arakan is about 2800. At one time a Mru chief was chosen king of Arakan, and the dominion was Mru when the Rakbeng conqueror invaded the country. 'They seem of the same lineage as the Myamina. The Mru dwelt on the Koladyn river and its feeders, but, having been driven out by the Kami, now occupy hills on the border between Arakan and Chittagong, at the source of the Moree river, which disembogues in lat. $21^{\circ} 40^{\prime} \mathrm{N}$., south of Kutabudea Island.-Dr. Latham's Ethnology.

MRU, an arm of the sea in Arakan, from 3 to 4 miles broad at its mouth, and running inland more than 50 miles.-Imp. Gaz.

MRUNG of Arakan dwell with the Doing-Nuk in the upper basin of the Mayu, and also, it is said, amongst the hills on the eastern border of the Chittagong district. They are said to be the desceudants of a race whom, several generations back, Arakan kings carried away from Tiperah, but also a colony imported from the Bodo country by the kings of Arakan, at the period when their conquests extended far up Eastern Bengal.

M'TEPE. ARAB. A sailing ship of Zanzibar.

$\mathrm{MU}$, in the weights of Burma, is the one-tenth part of a kyat or tikal.

MUALLAKAT. ARAB. Poetic pieces of the Arabs about the time of Mabomed, which they were accustomed to string together and suspend on the wall at the entrance of the Kaba. Those approved of were written in letters of gold.

MUANG, a race who inhabit the mountains on the west of the Tonquinese province of Than-Hoanoi, and stretch into China. They are an extension of the aboriginal or uncivilised Lau of Yun-nan. The name is the Burmese and Lau term for town or village which is scattered over so large a portion of the Chinese maps of $Y$ un-nan, indicating the present limits of Lau in that province.

MUANG THAI is the kingdom of Siam, i.e. the land Thai. In their books it is found with this epithet, Krom Thep Pramma haa Ikoon (Circuitus visitationis Deorum), the circuit of the visitation of the gods. Malay and Peguaus call it Tziam, from whence comes the European name Siam.-Thun. Japan, i. p. 25.

MUASI, a tribe of the Central Provinces of British India. Their chief objects of worship are the sun and the moon. They also worship at the shrine of Sultan Sakada, whom they suppose to have been a king among them in former times. The Muasi of Barar and in the western tributary estates of Chutia Nagpur worship Bhavani, a name of Durga, and Gansam or Ghanasyama.Dalton's Bengal.

MUAWIYA, governor of Syria, was proclaimed khalif of Damascus, on which Ali declared war.

MUAZZAN, the servant of the Muhammadan mosques who calls the Azan or summons to prayers. The words of his summons are-

i. Allahu Akbar, Allahu Akbar! God is most great! God is most great.

ii. Ashhaduan la ilaha il Allaho, Ashhaduan la ilaha il Allaho; I bear witness there is no deity but God, I bear witness there is no deity but God. iii. $\mathbf{O}$ ashaduanna Mahomed-ur-Rasul Allahe, $\mathbf{O}$ ashaduanna Mahomed-ur-Rasul Allahe; and I bear witness that Mahomed is the apostle of God, and $I$ bear witness that Mahomed is the apostle of God.

iv. Hy-ul-us-salwat, Hy-ul-us-salwat; come to prayers. v. Hy-ul-al-fallah, Hy-ul-al-fallah; come to security.

vi. Us - sallato - khair - un-min - nun - nowm, Us-sallatokhair-un-min-nun-nown; prayer is better than sleep.

vii. Allahu Akbar, Allahu Akbar! God is most great. viii. La ilaha il Allahu, there is no deity but God.

MUBARAK. AraB. Blessed. Mubārak bād, May it be blessed, a congratulatory salutation.

MUBARAK, father of Abul Fazl and Faizi. $\mathrm{He}$ is supposed to have been a native of Nagor, and had at one time taught a college or school of law and divinity at Agra. He was at first a Sunni, but turned Shiah, and afterwards took to reading the philosophical works of the ancients, and became a freethinker, or, according to his enemies, an atheist. So great a persecution was raised against him on this account, that he was constrained to give up his school, and fly with his family from Agra. His sons Abul Fazl and Faizi conformed in all respects to the Muhammadan religion.-Elph. p. 468.

MUCHALKA. ARAB. A bond, a deed, a written obligation or agreement, a penal recognisance:

MUCHI, a Hindu caste, shoemakers, painters, bookbinders, saddlers, etc.

MUCHI-RAS. Hind. Gum from several plants,-Salmalia Malabarica and Moringa pterygosperma, also a gall from the Areca catechu.

MUCUNA, a genus of plants belonging to the order Fabaceæ, climbing herbs or shrubs, with pinnately-trifoliate leaves and axillary racemes, which hang down when bearing fruit. Species of Mucuna produce the cowhage. In the East Indies are-

Mucuna atropurpúrea, D.C., Courtallum, Konkan, Travancore.

M. bracteata, D.C., Chittagong.

M. capitata, $W$. and $A$., cultivated.

M. gigantea, D.C., Peninsula of India, Sunderbans,

M. hirsuta, $W$. and $A$., Pen. of India, Sunderbans.

M. imbricata, D.C., Sylhet.

I. monosperma, D.C., all British India.

M. novea, Buch., Bengal.

M. pruritas, Hook., S.E. Asia, Archipelago.

M. utilis, Wall., Australia, Mauritius.

Cowhage consists of the hairs found upon the pods of different species. They are exceedingly slender, brittle, and easily detached, and the fragments readily stick into the skin, and produce an intolerable itching; hence they are at times employed for mischievous purposes. Cow-itch is also used medicinally as a vermifuge, by being mixed with syrup till of the consistence of honey, and given in doses of two or three teaspoonfuls. The species are found in hedges, thickets, on the banks of rivers, and about watercourses, in the East and West Indies, and in America within the tropics. M. urens and M. pruriens usually furnish the substance; but that from M. monosperma is said to exceed the others in the irritating burning property of its hairs. Dr. Roxburgh states that M. pruxiens was one of the plants formerly used in India to poison wells; but it is less hurtful than was supposed. M. imbricata, D.C., a climber of Darjiling, Terai, and Chanda. M. utilis, the Mauritius black bean, is cultivated in India and Ceylon.-Roxb.; Voigt; Br. Par. Ex. 1878. 
MUCUNA ATROPURPUREA.

MUCUNA ATROPURPUREA. D.C. Oarpopogon atropurpureum, $R o x b$.

Gede dulagondi, . TeL. | Tella kada, . . TeL. It has large dark purple flowers.

MUCUNA COCHIN-CHINENSIS. Bentham. Macranthus Coch., Loureiro, a elimbing plant; pods cooked as vegetables, like kidney beans.Johnson.

MUCUNA GIGANTEA. D.C.

Dolichos giganteum, Willd. | Stizolobium giganteum, Carpopogon giganteum, $R$. Spring.

Kakavalli, . Malear. Pedda dulagondi, . TEL. Enuga-dulagondi, . TEL.

This climbing plant grows on the coasts of Peninsular India. It is employed in medicine.

MUCUNA PRURITA. Hook, W. and $A$. Carpopogon pruriens, Roxb. Dolichos pruriens, Roxb.? Mucuna pruriens, Wall.?

Alkushi,. . . Beng. / Gunch-gaji, . . PANJ. Khwæ-læ, : . BurM. Copikachu, . . SANsK.

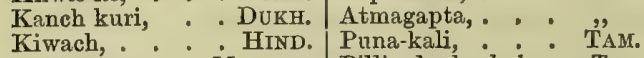
Nai karana, . Maleal. Pillia-dughu-kaia, Tel,

Kanaucha, . PANJ. Dulagondi, . . ",

Grows all over British India and in the Moluccas. It has large purple flowers. Sir W. Hooker distinguished the E. Indian plant M. prurita from M. pruriens, which is indigenous in the West Indies. The pods when ripe are of a brownish colour, and covered with innumerable sharp pricklelike hairs, which penetrate into and irritate the skin. The strigose hairs, as well as those of Rottlera tinctoria, are used in India as an anthelmintic. They dispel lumbrici and ascarides by sticking into their bodies, when pressed against the intestines, and thus irritating and dislodging them. The pods being dipped into treacle or honey, have the hairs scraped off until they have the consistency of an electuary, when a tablespoonful may be given to adults, and a teaspoonful to children, followed by a purgative of castor-oil, etc. They have been applied externally for paralysis, and produce much itching.Roxb.; Voigt; Porvell; Royle; O'Sh.; Ains.

MUCUNDA. During the lifetime of the emperor Akbar, many Hindus believed him to have been a Hindu in a former birth; that he enclosed in his body the soul of a devout Brahman, who had in a past age borne the name of Mucunda, and had taken a fancy to become the emperor of India. In nine months after Mucunda's death, he was permitted to generate in the womb of sultana Hamida Banu, and to take his birth at Amerkot in the character of Akbar. Indeed, there were some grounds for the Hindus to claim Akbar as a prince of their race. That emperor had a Hindu wife, the princess Jodh Bai; had a Hindu daughterin-law, the Marwari wife of Jahangir; had a Hindu general, the raja Man Singh; had a Hindu financier, the raja Todar Mull; had a Hindu favourite, the raja Beerbul ; had a Hindu songster, Tansen; had many Hindu officers and Hindu pandits always about him; much in his court savoured of the Hindu, and he had in a manner Hinduized himself by his ardent devotedness to the cause of Hindu welfare.-Tr. of Hind. $i$. p. 311 .

MUDALI. TAM. Mudliar, plural. Literally, first man, first men, honorific terms applied usually to the men of the Vallalar or agricultural race amongst the Tamil people. The term Pillai is
MUDHOL.

similarly applied to the Idayan or shepherd race dwelling in the Tamil country. It is generally used in the plural form of Mudliar; it is also conceded to the Kucheler, a weaver race of the Madras Presidency. It is an official designation in Ceylon, seemingly similar to the Mandal, village headman of Bengal.

MUDANI, a Muhammadan sect founded by Mudan, a Sufi. They admit the divine mission of Mahomed, but disclaim his title to particular veneration. The Mudani go nearly naked, braiding the hair and smearing the body with ashes, and wearing iron chains round their waists and necks.

MUDAR. HiND. Calotropis gigantea, the gigantic swallow-wort, a plant which is widely diffused throughout the Southern Provinces of the Peninsula of India, where it grows wild, preferring poor soil near the sea. It is replaced in the Bellary district by $\mathrm{C}$. procera, which is equally common, and in Northern India by C. Hamiltonii. To obtain the fibre, the branches are gathered and dried in the sun from twenty-four to thirty-six hours, then they are taken up, the bark peeled from the woody parts, and the fibres gathered. If placed out in the dew for a night, they lose their greenish tint, and become white. The sap of the Mudar plant is applied externally as a rubefacient; dried, it is mixed with croutchouc. See Madar.

MUDARI, an order of the fakirs or darvesh of India.

MUDAWIR. ARAB, A circle, implying repetition, from the Arabic word Daur.

MUD BAY or Muddy Bay is the commercial port of Alleppie, in Travancore, 36 miles $\mathrm{S}$. of Cochin, remarkable for the singular natural breakwater formed in the open sea, consisting of a long and wide bank of mud, the effect of which is so completely to break the waves, that ships of all sizes can securely anchor even at the stormiest season of the year in the open roads, where the water is perfectly calm. The origin of this deposition of mud has never been satisfactorily accounted for. It imparts a dirty colour to the water, and makes it thick and slimy. It has shifted within the last century, but not to any great extent. A similar deposit exists at Narrakul, about 29 miles north of Cochin, and the advantage of this latter place, as a natural open harbour for shipping, has been brought to the notice of the British Government. $-H . D$.

MUDDIKPOR, Kili-katr, or Kotaboo, are wandering minstrels. Other names have been given to this people who dwell in the Southern Mahratta country. Kablgira or ferryman, Koli and Barkur, are the terms most usually employed, but Muddikpor is the designation they apply to themselves. They are generally tall and powerful men, with an olive-yellow complexion, and are numerous throughout that part of India; they say that their original locality was the village of Talicot, near the town of Shorapur, and that all classes speak the Mahratta tongue.

MUDHOL, a Native State in the Southern Mahratta country, lying between lat. $16^{\circ} 6^{\prime} 50^{\prime \prime}$ and $16^{\circ} 26^{\prime} 45^{\prime \prime} \mathrm{N}$., and between long. $75^{\circ} 4^{\prime} 21^{\prime \prime}$ and $75^{\circ} 31^{\prime} 56^{\prime \prime} \mathrm{E}$. The Mudhol chiefs were of the Ghorpara family; they were the most determined opponents of Sivaji during his early conquests, but on the overthrow of the Muham- 
madan power, they joined the Mahrattas, and accepted military cornmand from the Peshwa. The chief enjoys an estimated gross yearly revenue of $£ 14,647$, and pays a tribute of $£ 217$ to the British Government.-Imp. Gaz.

MUDKI or Moodkee, a village in the Ferozpur district, Panjab, memorable for a battle fought on 18th December 1845 , between the Sikhs and the British. It is in lat. $30^{\circ} 47^{\prime} \mathrm{N}$., and long. $74^{\circ} 55^{\prime} 15^{\prime \prime} \mathrm{E}$., on a plain 26 miles south of the Sutlej. Two days before the battle, which inaugurated the first Sikh war, the enemy crossed the boundary river at Ferozpur. They were met by a much smaller British force at Mudki, and driven from their position, with the loss of 17 guns, after a hard contest, in which the British lost a large proportion of officers. Monuments have been erected on the battlefield in honour of those who fell.-1mp. Gaz.

MUDRA. HIND. A round prickly seed worn by the Hindu ascetics in ear-rings. The Kan Phatta Jogi wear a large metal ear-ring.

MUDRA. SANSK. A position of the hands amongst Buddhists and Hindus in attitudes of teaching. Ait-mudra is the attitude of bestowing a blessing. Bhumisparsa-mudra is the attitude of the hand pointing to the earth; Jnana mudra, the attitude of abstraction; Dharma chakra mudra, the attitude of teaching.

MUDRA RAKSHASA, or Signet of the Minister, a Sanskrit drama by Visakha Datta, perhaps of the 11 th or 12 th century A.D. The events dramatized relate to the history of Chandragupta, the Sandracottus of the Greeks. Rakshasa was the minister of Nanda, and afterwards of Chandragupta. In one scene Viradha Gupta visits Rakshasa, and a conversation ensues which relates to historical events-

' Rak. What news from Pashpapur?

Vir. I have not much to tell, sir; where shall I commence?

Rak. With Chandragupta's entry in the city

Whate'er my agents since have done, inform me.

Vir. You will remember, sir, when in close league, United by Chanakya, Parvateswara

And Chandragupta in alliance, led

Their force against our city, - a wild multitude

Of Sakas, Yavanas, and mountaineers,

The fierce Kambojas, with the tribes who dwell

Beyond the western streams, and Persia's hosts

Poured on us like a deluge ...'

In the Mudra Rakshasa, Chandragupta is frequently named Vrishala, a term said to be equivalent to Sudra; and Nanda himself was the son of a Sudra woman. There can be little doubt that the celebrated Maurya family were of Sudra extraction.

MUFASSAL. Arab., Hind. In Hindustan, a subordinate or separate district, the provinces or stations in the interior of the country, in contradistinction to the sadr or principal station or town. All outside of Calcutta, Madras, or Bombay is mufassal. $-W$.

MUFTI. In British India, an officer of a law court, from Fatwa, ARAB, a sentence.

MUGA. HIND. One of the silk-worm moths of British India. The two principal indigenous varieties of silk are the muga and the eri. A dress made of muga silk is prized beyond all others by the Assamese. A plant grows wild in the southern part of the Chittagong district, on which the moth lives.

MUGGAR-TALAO, crocodile ponds, lie to the north-west of Kurachee, also known as Magar Pir and Pir Mangho. The greater pond is about 300 yards in circumference, and contains many little grassy islands, on which the majority of the crocodiles (Crocodilus palustris) bask; some are seen asleep on its slimy sides, other halfsubmerged in the muddy water, while now and then a huge monster raises himself upon his diminutive legs, and, waddling for a few paces, falls flat on his belly. The water in the pool feels cold, although fed from two hot springs, one of which has too high a temperature to retain the hand in it; yet animal life exists ; for where the water bubbles up from its sandy bottom, and in the little lake running to the tank, is an abundance of a small black spiral shell, very like Melania pyramis, an allied species of which frequents the river Jordan. The crocodiles dig deep in the sand under the neighbouring date trees and there deposit their eggs. Quantities of deciduous teeth of various sizes are strewn along the slimy sides of the pond. A guide, taking piece after piece of flesh, dashed it on the bank, uttering a low growling sound, at which the whole tank became in motion, and crocodiles splashed through the shallow water, struggling which should seize the prize. The shore was literally covered with scaly monsters, snapping their jaws at one another. They seize their food with the side of the mouth, and toss the head backward, in order that it may fall into the throat.-Adams.

MUGH. PERS. A follower of Zoroaster, a fire-worshipper, applied by the Arabs and Muhammadans similarly to Gabr (Guebre) and Kafir. The term is applied by the people of Bengal to all the Arakanese, and to a race in the Chittagong district, who call themselves Rajbansi in Bengali, and Myam-ma-gyee or Great Myam-ma in Burmese, doubtless offspring of Bengali women by Burmese; their dress and language is Bengali, but some are of Buddhist faith. This race form six-tenths of the native population of Arakan, one-tenth being Burmese, and the remainder Hindu. Professor H. H. Wilson says the term Mugh, which the British have given to the Arakanese, by that people is restricted to the descendants of Arakanese by Bengali mothers. Colonel Dalton says that in personal appearance the Mugh resemble the Chinese; the cheek-bone is high and broad, the nose flat, and the eyes oblique. Though short, they are a well-made people, hardy, muscular, and athletic. The hair both of men and women is generally very beautiful, and of a glossy black; both sexes pride themselves on its fine quality. The dress of the women consists of a cloth tightly bound round the bosom, and flowing to the feet, and a large outer dress thrown over the whole person, and reaching to the knees. The unmarried women wear a jacket, which is assumed by girls when marriageable, and abandoned when they become wives. It is again adopted upon widowhood. The dress of the men is composed of a cloth round the middle, and one thrown over the shoulders. Although somewhat slothful in disposition, they are very fond of hunting, and delight in manly exercises, such as wrestling and boxiug; and a game peculiar to 
the country called Kilome, which is somewhat similar to battledore and shuttlecock, only instead of the hands the feet are employed. They are very partial to boat-racing.-Wilson's Glossary; Dalton's Ethnol. of Bengal, p. 111.

MUGHSI or Maghazzi have been noticed under the latter spelling at p. $767, q . v$. The Rind are settled in Cutch Gandava, to which fertile plain they have emigrated at different periods from the province of Mekran, and have become incorporated with the Jat or cultivators of the soil, as the subjects of the Khan of Kalat; a few likewise reside in the bills to the N.E. of Cutch Gandava and skirts of the deserts north of Kalat. The subdivision of the Brahui tribes amount to about ten, and those of the Rind and Mughsi each amount to double that number.

MUGIL, the mullet genus of fish, belonging to the Mugilidæ of the order Acanthopterygii; about 34 species are known in the seas of the south and east of Asia. A species of mullet is very common in Tenasserim, and is often seen on the tables of Europeans, by whom it is highly esteemed.

Mugil cephalotus, Cuv, and $\mathrm{Val}$. Mugil our, Forskal. M. cephalus, Russell.

Boutali, TAM., Russell.

Sole bhauggan, Ham. Jumpul, . MALAY.

Total length, 2 feet. It inhabits Penang, Malayan Peninsula, Singapore, Macao, Lancary, Chusan, Madura, Coromandel, Bay of Bengal, Gangetic estuaries, Malabar. The air-vessel is large, elongated; its parietes very thin, pearl coloured. M. corsula is a fish of the Bay of Bengal. It is a surface swimmer. See Mullet.

MUGUT, also Kirita, also Toop. SANsk. Terms for the high cap figured on the head of Vishnu as Narayana.

MUHAMMERAH is situated near the junction of the Jerahi or Tab with the Karūn river. It affords vessels sailing up the Persian Gulf facilities for landing goods without going on to Basra, which lies higher up the stream of the Shatt-ulArab. See Mahamra.

MUHAQQIQ. ARAB. A very learned doctor in one or two sciences.

MUHAR or Muhr. Hind, Pers. A seal, a gold coin of value 16 rupees. $-W$.

MUHARRAM. ARAB. Sacred, unlawful, prohibited. The first month of the Muhammadan year, in which it was held unlawful to make war. Among the Shiah Muhammadaus this month is held in peculiar veneration, as being the month in which Hasan and Husain, the sons of Ali, were killed. Their deaths are the subject of public mourning during the first ten days, when fasting and self-denial are also enjoined. The educated of the Sunni Mubammadans also regard these days as days for solemn thoughts. The uneducated regard the period as a time for a carnival. See Ali.

MUHTAJ. In the Parsee religion, on the 26th day of the 12th month, the Muhtaj commences; the souls of deceased relatives revisit the houses of their descendants. Four or five days before, all the house is cleaned with water and whitewashed, and on the 25 th day one room is purified and set apart, a white sheet is put on the ceiling, flowers and fruits are put in pure water in vessels, prayers offered, and a fire lit there by the Mobeds. This is continued for ten days, after which the room is closed for four days and re-opened for a two days' repetition of the cleaning till the Khordad sal, at the dawn of which the souls of the departed take flight to their original dwelling-place.

MUIN - ud - DIN, CHISHTI, who is buried at Ajmir, was born A.D. 1142, died A.D. 1236, aged 97 lunar years. The inside of his mausoleum is magnificent yet solemn.

MUIR, JOHN, C.I.E., D.C.L., LL.D., Ph.D., a Bengal Civil Servant, an eminent Sanskrit scholar, author and translator of many Sanskrit writings. In 1879 be published Metrical Translations from Sanskrit Writers, with an introduction, ProseVersions, and Parallel Passages from Classical Authors; and he had previously published a small volume of Religious and Moral Sentiments metrically rendered from Sanskrit. In 1831 he put forth the first part of his Christa Sangita or Life of Christ, in Sanskrit verse. After completing this work, which excited much curiosity and gained considerable favour among learned Hindus, he followed it up with a Life of St. Paul. Then he published the Mata Pariksha or Examination of Religions, which set forth a sketch of the argu-. ment for Christianity, and combated some of the leading points of Hinduism. These were all composed in verse, -in the form most familiar to Brahmans. The last of them excited so much interest as to call forth some replies. All of these have been reproduced in the vernacular languages. Amongst his other works may be mentioned Arguments for Christianity, 1839 ; Missionary Operations in Northern India, 1852; Reasons for a Sanskrit Chair, 1860; Original Sanskrit Texts, 1858,1868 . In 1862 , he founded the Chair of Sanskrit and Comparative Philology in the Ediuburgh University, and he instituted the Muir Lectures on Comparative Religion.

MUIR, SIR WILLIAM, K.C.S.I., LL.D. of the Universities of Edinburgh and Glasgow, and D.C.L. of Oxford, born 27th April 1819, a Bengal Civil Servant of the middle of the 19 th century, 1837-1876, who held the high offices of Foreign Secretary to Government, Member of the Council of the Governor-General, Lieutenant-Governor N.W. Provinces, and Financial Minister of India, and afterwards a member of the Council of H.M. Secretary of State for India. Author of Life of Mahomed and History of Islam, 1858 and 1877 ; The Early Caliphate and Rise of Islam, 1881; The Koran, its Composition and Teaching, and the Testimony it bears to the Holy Scriptures, 1877 ; Extracts from the Koran, with English Renderings, 1880 ; Rise and Decline of Islam, 1882-1883. In 1882, he translated from the Arabic, the Apology for Christianity by Abd-ulMasib ibn Ishaq-al-Kindi; Annals of the Early Caliphate from Original Sources, 1883.

MUJALLIBAH, also called Maklouba, ruins on the east or left bank of the Euphrates, $4 \frac{1}{4}$ miles N.N.W. from the bridge of Hillah, and $1 \frac{1}{2}$ N. of the Amram Hill. Maklouba means overturned. The Mujallibah is a solid quadrangular mound, the sides of which face the cardinal points. Its height is not more than 90 or 100 feet in the loftiest part; but Sir R. Porter assigns to it that of 140 feet. It is called by the natives El-Mujallibah, the overturned; also Haroot and Maroot, from a tradition handed down, with little deviation, from time immemorial. This solid mound is regarded as the remains of the tower of Babel, an opinion 
adopted by Major Rennell. Near the Mujallibah, and to the south of it, are remains of the Kasr, as well as those of the hanging gardens; and at rather more than six miles from Hillah, standing amidst and crowning the summit of extensive masses of ruin, is the Birs or Bars Nimrud. This has been considered by Niebuhr, Rich, and others to be the celebrated temple of Belus, and, according to Herodotus, it was separated from the palace by the river (lib. i. clxxx.): L'un (des quartiers) est remarquable par le palais du roi, et l'autre par le lieu consacre à Jupiter Belus. The Kasr ruins near Hillah are 750 yards from Amram Hill. Still farther south is the hill of Amram; a more extensive, though less lofty mass than the last, which must comprise the relics of many and important edifices. To the E.N.E., at the distance of six miles from the Mujallibah, is an insulated and lofty conical mound, named Al-Heimer; and, lastly, a considerable conical mound, called the Tuebo, and by some considered to be the N.E. angle of the ancient city, stands about 15 miles to the north of those just enumerated. There are, besides, a vast number of inferior heaps, some of which indicate the courses of canals that irrigated the country, or supplied distant quarters of the city with water, and some are the remaius of ramparts which probably enclosed and defended the principal edifices.-Rennell; Mignan's Tr.; Herodotus.

MUJAWAR, a servant who attends the tomb, hermitage, or spot consecrated to a Muhammadan saint or person of rank.

MUJMIL, a Persian version of an Arabic translation from Sanskrit, written in the year 1026 A.D., by Abul Hasan of Jorjan, near the Caspian. It gives a description of the Maldives.

MUJOUS. PERS. The priests of the Persians, from Mugh, an infidel priest; generally applied to the priests of the Zoroastrian Guebres, but sometimes to Christians. This word is sometimes used in Persian poetry to signify a tavern-keeper. This is, however, only a metaphorical application of the term.-Malcolm's Persia, i. p. 200.

MUJZUB or Majzub. ARAB. Lit. abstracted, a class of fakirs.

MUKADDAM. ARAB. A chief, a leader, the headman of a village, the superintendent of a gang.

MUKAT, a tinsel crown worn at weddings. See Mor; Mugut.

MUKÁVAN. MaL. A tribe of fishermen in Malabar. See Mukkawa.

MUKESH. Hind. Gold wire flattened for embroidery of a heavy kind. Mukesh bati-hui, twisted tinsel. Mukesh gokru, waved mukesh, made by crimping mukesh bati-hui with iron tongs. Mukesh-ki-tand, wire for making mukesh.

MUKHASA, a portion of land or a village assigned to an individual, either rent-free or at a low quit-rent, on condition of service, or for service rendered. Mukbasadar, one holding a mukhasa.

MUKHIA, in Bengal, one of the village authorities; also a comptroller, appointed to collect tribute to Hindu idols. Such sacred offerings were held in high estimation by the nations of antiquity. Herodotus observes that these were transmitted from the remotest nations of Scythia to Delos in Greece; but that range is far less extensive than the offerings to the dewal or temple of Krishna in Mewar. Tod relates that in his time the spices of the isles of the Indian Archipelago; the balmy spoils of Araby the Blest; the nard or frankincense of Tartary; the raisins and pistachios of Persia; every variety of saccharine preparation, from the sacarcand (sugar-candy) of the Celestial Empire, with which the god sweetens his evening repast, to that more common sort which enters into the pera of Mathura, the fond of his infancy; the shawls of Kashmir, the silks of Bengal, the scarfs of Benares, the brocades of Gujerat,

$$
\text { 'the flower and choice }
$$

Of many provinces from bound to bound,'

-all contribute to enrich the shrine of Nat'hdwara in Mewar. But it is with the votaries of the maritime provinces of India that he has most reason to be satisfied; in the commercial cities of Surat, Cambay, Muscat, Mandavi, etc. etc., the Mukhia or comptrollers deputed by the high priest reside to collect the benefactions, and transmit them as occasion requires. A deputy resides on the part of the high priest at Multan, who invests the distant worshippers with the initiative cordon and necklace. Even from Samarcand the pilgrims repair with their offerings; and a sum, seldom less than 10,000 rupees, is aunually transmitted by the votaries from the Arabian ports of Muscat, Mocha, and Jedda, which contribution is probably augmented not only by the votaries who dwell at the mouths of the Volga, but by the Samoyede of Siberia. There is not a petty retailer professing the Vishnu creed who does not carry a tithe of his trade to the stores; and thus caravans of 30 and 40 cars, double-yoked, pass twice or thrice annually by the upper road to Nat'hdwara. These pious bounties are not allowed to moulder in the bindar: the apparel is distributed with a liberal hand as the gift of the deity to those who evince their devotion; and the edibles enter daily into the various food prepared at the shrine.-Tod's Rajasthan, i. p. 527.

MUKHTAR. ARAB. An agent, an attorney. Mukhtar nama, a power of attorney.

MUKKAWA, a race in Travancore, supposed to have immigrated from Ceylon. A tribe of tishermen in Malabar; those of North Malabar follow the rule of descent a matrice, but those in the south permit of descent of property to sons.

MUKNA. Hind. An elephant without tusks.

MUKSHA, SANSK., from Mooch, to liberate. The Hindu theologic opinion, known as nirvana, is one species of muksha or liberation, as koivulya is another; they both mean absorption, excluding every idea of separate identity.-Ward's Hindoos, iv. p. 364.

MUKTAD, a Parsee ceremony in honour of the dead, performed at the end of the Parsee year, before a pile of metal vessels filled with water, and raised from the ground on iron stools.

MULA, in Mysore, a rain commencing between 12th-25th December. Cumin, coriandar, tobacco, and other seeds are sown at this time.

MULA, a river of Baluchistan, about 150 miles long, rises a few miles south of Kalat, runs southeasterly about 80 miles, north - easterly, and easterly, and is ultimately absorbed in the desert of Shikarpur. Along its course winds the Mula pass or Gandava pass of Cutch Gandava, from lat. $28^{\circ} 10^{\prime}$ to $28^{\circ} 24^{\prime} \mathrm{N}$., and long. $66^{\circ} 12^{\prime}$ to $67^{\circ} 27^{\prime}$ E. It is about 100 miles long; it has open spaces 
connected by defiles. Bapow is 5250 feet; Peesee Bhent, 4600; Nurd, 2850; Bent-i-Jah, 1850; Kullar, 750 feet. Descent, 4650 feet; average, 46 feet per mile. Water abundant. It is practicable for artillery. In 1839, a British-Indian detachment marched through it. It is preferable to the Bolan pass in a military point of view, and it is the southern pass by which access is gained from Cutch Gandava to the table-land of Jbalawan. It has three entrances-(1) at Pir Chatta, 9 miles from Kotri ; (2) the Taphoi entrance leading from Jhal, 9 miles south of Kotri ; and (3) the Gatti entrance, a very difficult road.

MULA, pronounced properly Maula, a judge, the magistrate of a large city, hence the word Maulawi or Maulvi, judicial, belonging to a judge or magistrate, but applied in India to a Muhammadan learned in Arabic. It takes the place of Alim, plural Ulema, of the Turks. In Egypt, the Ulema and men of religion and letters in general wear a turband particularly wide and formal, called a mukleh. El-Melik-el-Ashraf-Shaaban, a sultan of Egypt (A.D. 1362-1376), was the first who ordered the sherifs (or descendants of the prophet) to distinguish themselves by the green turband and dress. In Egypt these descendants are addressed as Sherif, noble, and Seyd or Seyyid (master or lord), whatever be his station. Anotber word is Maulana, Maulana as Sultan, our lord the Sultan. Maulana Jalal-ud-Din-er Rumi, founder of the Mawlavi darveshes.

MULA ABDUL KADIR, BADAUNI, also called Kadiri, was the author of the Muntakhabut-Tawarikh, also known as the Tarikh-i-Badauni. It is a general history of India from the time of the Ghaznivides to the fortieth year of Akbar's reign, and notices Akbar in a prevalent tone of censure and disparagement. $\mathrm{He}$ was born at Badaun A.H. 947 or 949 . He was an eminently pious man, and excelled in music, history, and astronomy.

MULA KHEL, a section of the Orakzai clan on the outer spurs of the Samanagarh, S.W. of Hangu. They could muster 700 fighting men.H. A., N.W. F. p. 496.

MULANA AHMAD, with other writers, were authors of the Tarikh-i-Alfi. He was also author of the Khulasat-ul-Hayat, the Essence of Life (A.H. 990), and was son of the Kazi of Tatta. It was finished A.H. 1000; hence its name Alf.

MULA ZAKKI, the founder of a school of philosophy whose followers, in the early part of the 19th century, when Mountstuart Elphinstone visited Kābul, were said to take the full advantage of their release from the fear of hell and the awe of a Supreme Being, and to be dissolute and unprincipled profligates.-Elphinstone's Caubul.

MULBERRY.

Mure, :- :

Fr. Tut, .

Ger. Mora,

HIND. their fruit. In the Panjab there are white mulberries, and two sorts of each colour; one is a small oval, being rather sweet, but a most miserable fruit. The other, called shahtut, is a very long, narrow fruit, looking almost like a caterpillar, either greenish-yellow or red-black in colour; this fruit is somewhat better than the first kind; it is very sweet, but has no flavour. The shahtut, or royal mulberry of Kashmir, is a fine large subacid fruit; it is dried and made into flour; the bread from it is nutritious and fattening. The hill mulberry, or kimu, is the Morus serrata.

Tut or karun is the Morus Indica, a tree of fast growth, attaining its full size in 20 years, when it becomes useful.

The leaves of the red and white mulberry trees form the food of the Bombyx mori, yielding the silk of commerce. The Philippine mulberry is the Morus multicaulis of botanists. In Birbhum, mulberry gardens are innumerable, dotting the country in patches of a dark-green colour.

The white species in China bears but little fruit. The Chinese recommend the dung of fowls and ducks as a manure to produce abundant foliage for silk-worms. Species of mulberry have been cultivated for long ages in China. Morus Indica, M. atropurpurea, M. rubra, M. alba, M. tartarica, and M. nigra are all grown, and many varieties have been produced by cultivation, such as the hill mulberry, the golden mulberry, and the fowl mulberry.

Mulberry trees constitute the wealth of the Druse, Maronite, Mutawali, Ansari, and other tribes of Syria.

In the United States of America it is considered that an acre should support 700 to 1000 trees, producing when four years old, 5000 lbs. of leaves fit for silk-worm food. On this quantity of leaves, 140,000 worms can be reared, from which eggs at a net profit ranging from $£ 80$ to $£ 240$ per acre will be obtained by the work of one person. Mulberry trees have been largely cultivated in California ; in 1870 , to 7 or 8 millions, and in one year $£ 700$ were cleared from $3 \frac{1}{2}$ acres, the working expenses having been $\mathfrak{f} 90$.

Mulberry bark, the Sang-ken-peh-p' of the Chinese ; a silky fibre is extracted from the bark.

Mulberry epiphyte. Sang-shang-ki - sang, Chin. An epiphyte so called grows on the mulberry trees of China, the woody branches of which are highly prized by the Chinese, and highly adulterated in consequence.

Mulberry paper. Pi-chi, CHIN.-Smith, M. M. Ch. ; Von Mueller.

MULE. The Chinese possess a handsome and docile race, mostly like the mule of Egypt, but some resembling the dim-coloured breed of the Volterra. Mules seldom go so few as 30 miles in a day. They will carry a load of about $3 \mathrm{cwt}$., passing over such kotals or passes as would appal even a Spanish muleteer.

MULI or Moola. Hind, A radish, Raphanus sativus; any root. To call a Muhammadan a garden root, as Tum kon si bagh ki mooli ho? What garden root are you? is very offensive.

MULK. ARAB. A kingdom, the third title amongst Indian Muhammadans, as Saraj-ul-Mulk, Sharf-ul-Mulk, Mukhtar-ul-Mulk.

MULLAI. MAHR. Rich ground along the banks of some rivers, formed by alluvial deposits a field of garden or meadow land.

MULLAVELLY, a town in the Masulipatam collectorate. It is a diamond locality, and tho Hyderabad Government reserved it when ceding the Northern Circars. Sandstone conglomerate extends from Banaganapilly to Condapilly and Mullavelly, in all which localities diamonds are found. See Diamonds.

MULLER. Frederick Max-Müller, Member of the Institute of France, Knight of the Ordre 
pour le Mérite, Member of the Reale Accademia del Lincei of Rome, and LL.D. of Cambridge and Edinburgh, is a learned German who settled in England. He was born on the 6th December 1823 at Dessau, the capital of the small Duchy of Anhalt Dessau. His father was Wilhelm Müller, a celebrated poet of Germany. In 1843 he took the degree of Ph.D. at the University of Leipzig, after which, in 1845 , he went to Paris, and in 1846 to England. He undertook to superintend the printing of the Rig Veda at the charge of the E. I. Company, at Oxford, where he held the Chairs of Taylorian Professor of European Languages (1850 and 1854), Comparative Philology (1868). In 1844 he translated the Hitopadesa into German, and printed it at Leipzig; which he translated and republished in London. In 1847 he translated Kalidasa's poem, the Megha-duta, from the German into English. In 1847 he read an essay on the Relations of the Bengali to the Aryan and Aboriginal Languages of India. In 1853 he wrote to Chevalier Bunsen a letter on the Classification of the Turanian Languages. In 1854 he submitted proposals for a missionary alphabet; in 1859 the History of Ancient Sanskrit Literature; in 1861, 1864, and 1873, Lectures on the Science of Language, which up to 1878 had gone through nine editions, and have been translated into French, German, Italian, and Russian; and his Science of Religion, False Analogies in Comparative Philology, and the Philosophy of Mythology, have also been translated into the principal Continental languages. His Chips from a German Workshop, and Sayanacharya's Commentary on the Rig Veda, Lectures on Missions, have also been translated; and he undertook to edit The Sacred Books of the East, of which, up to the end of 1884,24 volumes have appeared. In 1873 he delivered, in Westminster Abbey, a lecture on the Religions of the World; in 1878 , in the Chapter House of Westminster, he gave a course of lectures on the Origin and Growth of Religion, as illustrated by the Religions of India; in 1882 he lectured on India, at Cambridge College. In 1880 and 1881, with the help of Sanskrit manuscripts from Japan, he published the Sanskrit text of several Buddhist texts; his principal essays have been collected in his four volumes of Chips from a German Workshop and two volumes of Selected Essays. His published works have been numerous beyond those of any writer of his time, and have chiefly relation to the races and literature of India and Southern and Eastern Asia.-The Leisure Hour, July 1878.

MULLET FISH, Mugil, $s p$.

Arabi mutehi, . DUKH. | Puthin,

- HIND.

The mullets spawn largely in estuaries, and apparently nowhere else. The seer, Cybrium Commersonii, seems to spawn very near the mouths of the estuaries, while others appear to ascend nearly as high as the tidal influence for the purpose. The muilet lives largely on shrimps and sand-worms. A small plot of some 4 or 5 acres in the Mangalore backwaters was therefore buoyed off to be left undisturbed for shrimps to breed in. The Tenasserim seas have large-eyed mullet, valuable for the table, and common in Calcutta, but distinguished by its small head, smaller scales, and goggle eyes, which appear to be starting out of its head. Mugil subviridis, Valenciennes, a small mullet often found in great numbers in the river near Moulmein ; many of the Burmese regard it as the young of $M$. cepsalotus, but it is a distinct species.-Ainslie; Mason; Thomas. See Mugil.

MULTAN, a city in the Panjab, which gives its name to a revenue division and district. The city is in lat. $30^{\circ} 12^{\prime} \mathrm{N}$., and long. $71^{\circ} 30^{\prime} 45^{\prime \prime} \mathrm{E}$., and is now 4 miles from the present left bank of the Chemab. Cunningham thinks it is the Kasyapapura of Ptolemy, and that it was situated on the bank of the Ravi in the $2 \mathrm{~d}$ century A.D.

At the capture of Multan by Chach, in the middle of the 7 th century, the waters of the Ravi were still flowing under the walls of the fortress; but in A.D. 713, when the citadel was besieged by Muhammad-bin-Kasin, it is stated by Biladuri that the city was supplied with water by a stream flowing from the river. Muhammad cut off the water, and the inhabitants, pressed by thirst, surrendered at discretion.

The population in 1881 was 68,674 . Multan division lies between lat. $29^{\circ} 1^{\prime}$ and $32^{\circ} 4^{\prime} \mathrm{N}$., and between long. $70^{\circ} 33^{\prime}$ and $74^{\circ} 10^{\prime} 30^{\prime \prime} \mathrm{E}$., and comprises the four districts of Multan, Jhang, Montgomery, and Muzaffargurh. The Multan district is, on the whole, an arid, sandy country, about 110 miles in length, and 70 in its greatest breadth. Multan town has had its name repeatedly changed. It is supposed to be the capital of the Malli of Alexander's historians, the place where Alexander was wounded. At an interval of 1300 years, two conquerors, Alexander and Mahmud, were opposed by a race of this name. In A.D. 1000 , Mahmud entered Hindustan, but in the course of eight years he made no farther progress than Multan. The Malli and Catheri (that is the Khatry or Rajput tribe) of Alexander must have preserved their ancient spirit, to be able to oppose, for so long a time, such formidable armies, headed by so furious an enthusiast as Mahmud.

Multan city was conquered by Shahab-ud-Din in 1171. After the invasion of Timur, it fell into the hands successively of an Afghan, of the Arghuns of Sind, of the Moghul emperors of Iudia, of Nadir Shah, of the Sikhs, and now of the British. Its local name is still Mallithan. Multan fortress, with Mulraj and garrison, after a prolonged siege, surrendered unconditionally to the investing Indian army on the 22d January 1849.

Multan and Tatta were the ancient seats of the Balla or Balli-ka-putra race, and to the present the blessing or byrd of the bards is TattaMultan-ka-Rao.

There are in the Multan and Dehrajat divisions 42 castes returned as Jat, in number about 100,000 souls, engaged in gardening and otber trades, Arain, bazigar, bhatiara, Baluch, charhoa, Chubra, darzi, dhobi, Dum, fakir, Gujar, julaha, jogi, kallal, kamāngar, Kahar, kutana, khoja, kumhar, Labana, lohar, machhi, mali, mahar, mochi, mujawar, Moghul, mallah, mirasi, Pathan, paoli, pungar, qassab, qazi, Qureshi, Rajput, Shaikh, saiklgar, Tarkhan, teli, zargar. Multan town in 1881 had Hindus, 29,962; Muhammadans, 36,294 ; Sikh, 661 ; Jain, 46 ; unspecified, 174. The city of Multan forms the great commercial centre of the district, but there are also bazars at Shujabad, Kahrur, Sarai Sidhu, Tulamba, Lodhran, Jalalpur, and other smaller towns.

Turkestan, and especially the city of Bokhara, supplies Multau with silk of three kinds, namely, 
Lab-i-abi, Charkhi, and Hoshkari. These are purchased in Bokhara from 7, 9, to 12 rupees per seer, and sold in Multan from 10, 12, to 15 rupees. One camel-load of the first kind of silk, which is equal to $6 \frac{1}{2}$ maunds in weight, costs at Bokhara 440 tila, or 2837 rupees 8 annas. Each tila makes 6 Nanakshai rupees and 6 or 7 annas. The trade of Bokhara to Multan is generally conducted by the Lohani and Shikarpuri on camels. Multan indigo is of good colour.

In the citadel is the shrine of Baha-u-Din, Rukn-i-Alam. North of the city is the shrine of the martyr Shams Tabreezi. Burton states that the people of Multan murdered Shams of Tabreez, a celebrated Murshid or spiritual teacher, in order to bury him in their town. The Afghan Hazara, he says, made a point of killing and burying in their own country, any stranger who is indiscreet enough to commit a miracle or show any particular sign of sanctity.

MULTANIA THUG, a class of Thugs who were all Muhammadans, and assumed the character of Banjaras, trading in grain, and travelling with their families, but putting most of their female children to death. They strangled travellers with their bullock ropes; they were considered among the ancient Thugs.

MULVI, in India the pronunciation of the Arabic Mula or Maula, a learned Muhammadan, one learned in the Muhammadan law. Formerly, in British India, a mulvi was attached to each court of justice, but latterly learned Muhammadan and other subordinate judges have been styled Amin and Sadr-Amin. See Mula.

MUMMURTI, the Hindu triad, Brahma, Vishnu, and Siva, literally three forms, from Mur, three, and Mur't, forms.

MUMMY, the Egyptians believed in the reoccupation of the body by the soul, and their object in so preserving the body was to have it ready for the re-entry of the soul after completing its period of migrations. The mummy cases of Egypt were made of the wood of Cordia myxa. In 1881, 39 mummies of royal and priestly persons were discovered at Deir-el-Bahari near Thebes. They were mostly found wrapped in shrouds of fine linen, enclosed in three wooden mummy cases, each disclosing the form of the body, and fitting in one another like a nest of boxes, the arms crossed upon the breast, the right hand grasping the crux ansata, the urœi serpents gilt, the head-dress exquisitely carved; written texts on the mummy cases, in yellow, orange, and green, festoons and wreaths of flowers in marvellous preservation, and papyri of value.

Ramses II. is the Pharaoh of Jewish history.

King Raskenen, 17 th dynasty.

King Aahmes I. (Amosis), founder of 18th dynasty.

Queen Aahmes Nofert Ari, wife of Aahmes I.

Queen Ar-hotep, daughter of Aahmes I.

Prince Sa Ammon, son of

Princess Sat Ammon, daughter of ",

King Amenhotep I. (Amenophis), 2d of 18th dynasty.

King Thotmes I, second king of 18th dynasty.

King Thotmes II., third

King Thotmes III. the Great, fourth king of 18th dynasty.

Queens Hont-ta-me-hou, Au, and Selka of the 18th dynasty.

King Ramses I., founder of the 19th dynasty.

King Seti I., second of ",

King Ramses II., third of " " "

Queen Noutjent, of 21st dynasty.

High priest Pinotem, of ",
Queen Ra-ma-ka, of 21st dynasty.

King Pinotem, of

Queen Hon-ta-taoui, daughtter of king Pinotem.

High priest Ma-sahata, relative of

Queen Ast-em-jeb, daughter of

Princess Nessi Kon sou, daughter of
2

"
-Times, 28th August 1881.

MUMTAZ MAHAL, the title of Arjamand Banu Begum, queen of Shah Jahan, emperor of Dehli. She was the daughter of Abul Hasan, son of Itimad-ud-Dowla, prime minister of the emperor Jahangir. She was twenty years married to Shah Jahan, and bore him a child almost every year. Bernier says the emperor loved her so passionately that bis conjugal fidelity was never impeached while she lived. The death of the Begum on the 18th July 1631 was occasioned by her giving birth to a daugbter, who is fabulously said to have been heard crying in the womb by herself and her other daughters. The sultana died in two hours after the birth of the princess. Her husband, Shah Jahan, erected over her remains a magnificent tomb, known to Europeans as the Taj Mahal, a corruption of Mumtaz Mahal. Travernier says that in building the Taj 20,000 workmen were employed for 22 years in its erection, and he states it was erected by a Frenchman of the name of Austin de Bordeaux. The brick scaffolding is said to have cost as much as the building itself. The marble had been presented by the raja of Jeypore, and was brought from its quarries, a distance of 140 miles, upon wheeled carriages. The mausoleum stands on a marble terrace over the Jumna, is flanked at a moderate distance by two mosques, and is surrounded by extensive gardens. The building itself on the outside is of white marble, with a high cupola and four minarets. In the centre of the interior is a lofty hall of a circular form under a dome, in the middle of which is the tomb, enclosed within an open screen of elaborate tracery formed of marble and mosaics. The walls are of white marble, with borders of a running pattern of flowers in mosaic. The graceful flow, the harmonious colours, and, above all, the sparing use of this rich ornament, with the mild lustre of the marble on which it is displayed, form the peculiar charm of the building, and distinguish it from any other in the world. The materials are the inferior gems, lapis-lazuli, jasper, heliotrope or bloodstone, a sort of golden stone (not well understood), with calcedony, agates, jade, and various stones of the same description. Voysey (As. Res. v. p. 434) says a single flower in the screen contains 100 stones, each cut to the exact shape necessary, and highly polished; and yet, says Bishop Heber, though everything is finished like an ornament for a drawing-room chimney-piece, the general effect produced is rather solenin and iropressive than gaudy. In the minute beauties of execution, however, these flowers are by no means equal to those on tables and other small works in Pietra Dura at Florence. It is the taste displayed in the outline and application of this ornament, combined with the lightness and simplicity of the building, which gives it so prodigious an advantage over the gloomy panels of the chapel of the Medici. The mosaics of the Taj are said, with great probability, to have been the workmanship of Italians. Her husband died in A.D. 1666. In the middle of the apart- 
ment, underneath the great cupola, are the cenotaphs of the royal pair. They lie side by side, the empress to the left. Her name, Mumtaz Mahal, Banu Begum, and the date of her death, 1631, are read on the slab. That of her husband, and the date of his death, 1666, are also inscribed upon the other tomb.-Tr. Hind. i. p. 413 ; Elphinstone, p. 531 .

MUND. Mahr. A lot of land. Mundwahik, the cultivator of a mund or lot; from Mund, head, principal, stipulated sum or quantity, and Wahik, to cultivate. Munda, a headman. - W.

MUNDA. Maleal. In Malabar, a cloth worn by both sexes around the waist. Mundasa, a cloth worn by the poorer classes in Dharwar,

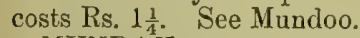

MUNDAH, a race occupying the eastern and southern parts of Chutia Nagpur. The Mundah, Ho, and Oraon are all divided into families, called khel or clan, and may not take to wife a girl of their own khel. Manki is the name applied to the Mundah chiefs in the southern parts of Chutia Nagpur. The Nanki have acquired considerable estates. The Mundah and Ho houses are more isolated, with better accommodation than those of the Oraon, with verandahs, and separate apartments for the married and unmarried members. Every Mundah village has its own dancingplace. The Mundah comprise about two-thirds of the population of the five parganas of Silli, Tamar, Baranda, Rabey, and Bundu, all others being recent settlers. But many of the Mundah Kol have been dispossessed of their ancestral lands by middlemen, Brahmans and Rajputs. The Mundah settlements are chiefly in the eastern and southern parts of Chutia Nagpur. Mundah features are flat and broad. The extreme features of this race are high cheek-bones, small eye orbits, often with an oblique setting, flat faces, without much beard or whisker, and in colour from brown to tawny-yellow. The richer people of the Mundah wear the poita, reverence Brabmans, and worship Kali, but the mass continue in their original faith. The great propitiatory sacrifices to the local deities are carousals, at which they ent, drink, sing, dance, and make love, and the Hindus settled in the province propitiate the local deities. The Mundal country is arranged into purha or divisions, each consisting of twelve or more villages under a chief, and the chiefs meet at times for consultation.

Many of the Oraon, and some of the Mundah clans or khel, are called after animals, - the eel, hawk, crow, heron, etc.; and the clans do not eat the animal whose name they bear.

Mundah were estimated by Colonel Dalton as under half a million.

The Ho or Larka of Singbhum, and the Mundah of the southern parganas, are finer as races than the Bhumij or the Santal.

The Mundah and the Ho keep the Magh Parab or Desauli Bonga festival, a period of licentious debauchery; but while with the Ho it lasts for a month, the Mundah restrict it to the full of the moon in Magh. At this the Mundah dance the Jadura dance-it is like the Hoja of Chutia Nagpur-round a branch of the Karam tree planted in the Akhra or dancing-place. The licentiousness these two indulge in at their great festival is a great defect in their character, and the elders drink heavily of their illi or beer.

VOL. II.
The Mundah are less truthful and open, less manly and honest, than the Ho.

In the Mundah marriages the bride is always adult, and 5 or 7 rupees are paid for her. The couple are first married to two trees, the bride to the mahwa tree (Bassia latifolia), and the groom to the mango (Mangifera Indica), which they touch with sandur (red lead), and then clasp in their arms. They then stand on a curry-stone together, touch each other's forehead with sandur, when water is poured over them. This necessitates a change of clothes, for which they retire to a hut, and do not emerge until morning.

The dead of the Mundah and Ho are placed in a coffin along with all the clothes and ornaments used, and all the money the deceased had, and all burned. The larger bones are preserved till a large monumental stone can be obtained, and the bones interred below it,-the Ho near the houses, the Oraon separate from the village. They are taken to the tomb in a procession, with young girls bearing empty and partly broken pitchers, which they reverse from time to time to show that they are empty. The collection of these massive grave-stomes under the fiue old tamarind trees is a remarkable feature in Kol villages. The stones are sometimes so large that the men of sereral villages are required to move them. The bones are put with some rice into a new earthen vessel, deposited into the cavity prepared for them, and covered with the big stone. The Mundah and Oraon races are fond of field sports, and all game, large and small, disappear from near them. They form great hunting parties. Fishing and cockfighting are also resorted to. 'The Mundah and Ho have a shamanite religion. They have no worship of material idols, but Singbongu, the sun, is the supreme being, the creator and preserver, a beneficent deity. 'They have secondary gods, all invisible, and generally malevolent. Sacrifices to Singbongu are made of fowls, pigs, white goat, ram, and buffalo.

The Oraon worship the sun under the name of Dbarmi, as the creator and the preserver, and offer white animals to him in sacrifice.

Manki is the name applied to the Mundah chiefs on the southern parts of Chutia Nagpur.

Every Mundah village has its own dancingplace. General Cunningham suggests, pp. 505, 507 , that the Mundah are the ancient Murunda.Major Dalton, pp. 76-196; Mr. (Sir) G. Camphell.

MUNDA-PHORA. GUJ. A Muhammadan mendicant in the west of India, who, to extort charity, draws blood from his own head or other parts of his body; from Moonda, the head, Phorna, to break.

MUNDAVER. In the Animallay Hills are the Kader, Mundaver, and Pullar. The latter are wild-looking men, with long bair. They live on jungle products, mice, and other small animals. The Mundaver have no fixed dwellings, but wander over the innermost bills with their cattle, sheltering themselves in caves, or under little leaf sheds, and seldom remaining in one spot more than a year.

The Kader, Lords of the Hills, are a thicklipped, small-bodied race, who live by the chase, and wield some influence over the ruder forest folk.

These hills have many kistraens and dolmens.

MUNDEE. This ancient Rajput principality came into the control of the British Government 
by the Lahore Treaty of the 9th March 1846. Area, 1080 square miles; population, 139,259; revenue, Rs. $3,00,000$; tribute, Rs. $1,00,000$. Full sovereignty was conceded to the raja Bulbeer Sein, his heirs, and those of his brothers, according to seniority, unless specially set aside by Government for incapacity or misconduct. The right of adoption has been conferred on the raja by sunnud. It furnishes rock-salt.-Aitcheson's Treaties, etc. p. 374.

MUNDEL, a cloth of cotton and gold, obtainable in Cutch, costs Rs. 8.4.11. An article of dress.

MUNDHATA, an island in the Nerbadda, famed for its Saiva, Hindu, and Jaina temples. Between it and the south bank is a deep, silent pool, with many crocodiles and large fish. On the south bank, the shrine of Amareswara has one of the 12 lingams which existed in India at the time of Mahmud's invaision. Up to the year 1824 worshippers sacrificed themselves to Kal Bhairava and his consort Kal Devi by precipitating themselves over the Birkbala rocks, at the eastern end of the island, at the rocks of the river's brink, where the terrible deity presided. The statues and figures of the deities have all been mutilated by the Mubammadan rulers. $-P$. and $I$. vii.

MUND-MALA. HIND. A necklace of human heads which is suspended from the necks of Siva and some of his avatars, as Bhairava, and of Parvati as Kal and Kali.

MUNDOO. Maleal. A cloth given to a Nair woman betrothed to a single man.

MUNDUM or Mundwa, a temporary open shed or hall, adorned with flowers, and erected on festive occasions, as at marriages, etc. Also an open temple consecrated to a Hindu deity.

MUNDUN. HIND. A Muhammadan rite of shaving the child's head on the 6th or 40th day after birth.-Herklots.

MUNG. HIND. Phaseolus mungo, green gram. This is grown throughout British India, but more in the upper part of Hindustan; it is eaten by the natives dressed in various ways. It is used as Dal, and considered the third best among Dals. The dry leaves are given to cattle. - Jaffrey.

MUNGALA, or Kartikeya, in Hinduism, the leader of the celestial armies, is the Mars of the Hindus. $\mathrm{He}$ is one of the planets, and is of the Khettri caste. He was produced from the sweat of Siva's brow ; and is painted of a red or flame colour, with four arms, holding in his bands a trident, a club, a lotus, and a spear. His vahan is a ram.

MUNGNEE. TEL. A chlorite? slate; when freshly quarried, it is comparatively soft, and easily workable, but by long weathering becomes highly indurated, black, and bright. It comes from the hill state of Nilgiri, in Orissa, where extensive quarries are said to exist. This stone is used principally for the manufacture of various utensils. Idols are also made of it ; and the Aroon Khumba, a polygonal column of considerable grace and beauty, now standing before the principal entrance of the Puri temple, also the elaborately carved and figured slabs that adorned the top and sides of the doorways of the old temple of the Luwat-Kanarac (temple of the sun) in the same district, and the gigantic figures of native deities of Jeypore, in the Cuttack district, are of this stone.-Cal. Cat. Ex. 1862, 1872.
MUNGY PATTUN, a town in the Dekhan, anciently called Dhank.

MUNH-BOLA-BHAI. HIND. An adopted brother; a custom amongst Muhammadan women of adopting a person as a brother; the Hindu men have it in the Bel-Bandhar, and the Rajput women in the Rakhi. See Bel-Bandhar; Brother-making; Rakhi.

MUNI, in Hinduism, a sage, ancient, holy, or learned men, styled also Rishi, to whom great deeds and the sacred books are ascribed. The siccation or drying up of the vale of Kashmir and of the Nepal valley are ascribed to two Muni. See Brahmadica; Hindu; Lords of Created Beings; Prajapati.

MUNI BEGUM, a European lady of Akbar's harem. The emperor survived his Lusitanian mistress, and showed his affection for her memory by erecting over her remains a handsome tomb at Secundra. In this tomb was located for many years the Press of the Church Mission Society, and its premises afforded shelter to 300 orphans in the famine of 1838. - Tr. of Hind. ii. p. 17.

MUNJ. HiNd. Saccharum sara and S. munja, also Eriophorum comosum, very useful grasses; common in many parts of $\mathrm{N}$. India, and known under several names. The boatmen of the Indus employ the munj as a towing rope, and for the rigging of their vessels, in all places above Sukkur. It is possessed of great tenacity, twoinch ropes, often 50 fathoms in length, made of its fibres, being sufficient for dragging the largest or 1200 -maund boats up the Indus. The rope is also possessed of lightness, so advantageous for rigging, and is capable also of bearing, without injury, alternate exposure to wet and to subsequent drying. Plants growing beyond the range of the overflowings of the river, or of the intluence of the tides, are possessed of the greatest strength. The upper leaves, about a foot or so in length, are preferred and collected. When required for twisting into rope, they are first moistened in water; two men then, sitting opposite to each other, take one of those moist bundles and beat it alternately with mallets, until the loose cellular are separated from the fibrous parts. These are then ready for twisting into ropes. It would form an ample supply of half-stuff for paper makers.-Royle.

MUNJA BYTHNA, sitting in state, a Muhammadan marriage ceremony.

MUNJAN. HIND. A tooth-powder made of burnt almond shells, common charcoal, or charcoal made from myrobalans or betel-nuts, or of frankincense and alum; any tooth-powder.Herklots.

MUNJIRA, or Jhanjh. Hind. Small cymbals in the shape of cups, struck against each other, and accompanying most bands.

MUNJITH. GUJ., HrNo. Rubia cordifolia, Indian madder, grows in various parts of India, Central Asia, Persia, etc. It is applied to the same purposes in dyeing as Europe madder. The roots are long, about the thickness of a quill, with a smell somewhat resembling liquorice-root. Munjith is largely imported into Bombay from the Persian Gulf and Kurachee. The imports vary,-
1881-82,
1882-83,
8,241 cwt.
Rs. 92,445
1883-84,
17,096
$1,44,013$

MUNKIR (Mankar) and Nakir, according to 
Muhammadan belief, two angels who examine the spirits of the departed in the tomb. See Jibril.

MUNRO, SIR HECTOR, an oflicer serving the East Indian Company, who took Mahé in $\mathbf{1 7 6 1 .}$ On the 23d October 1764 he defeated the wazir of Oudh at Buxar. This victory broke the forces of Shuja-ud-Dowla, and placed the emperor of Dehli under the protection of the East Indian Company.

MUNRO, Sir THOMAS, BARONET, K.C.B., entered the service of the East Indian Company as a cadet of infantry in 1780 , and rose to be Governor of Madras. He died of cholera at Putticondah, near Ghooty, on the evening of 6th July 1827. He was long employed in the revenue department, and it was chiefly his influence that obtained the establishment in the Madras Presidency of the ryotwari system. In the last Mahratta war he rejoined the military department, took command of his own regiment, and added a handful of half-armed and halfdisciplined men. He moved with these to the west, settling the region in his progress, and by his influence and promises inducing the Ghorpara chiefs of Sandur and Akalkot to remain quiet. He was simple and straightforward in his habits, capable of severe labour, bodily and mental. His life was written by Mr. Gleig. See Ryotwari.

MUNSHI, in Persia, a secretary; in India, a Muhammadan teacher of languages, usually the Urdu or Hindustani and the Persian.

MUNSIF. ARAB. An officer of a law court, a judge with limited jurisdiction.

MUNZERABAD, a district of Mysore, in which coffee-planting by Europeans is largely carried on.

MURA, a small fly in Garhwal, the Sarju valley, and Kamaon, which hovers a while in the air before alighting on the skin, to which it remains attached a considerable time. Its bite is at first painless, but after a short time a troublesome itching is felt, and a small round black spot of effused blood appears on the place where it has inflicted its bite. The black spot continues distinct for about a fortnight, and a traveller's hands, if unprotected, are very soon spotted all over. It is supposed to be the pipsa of Darjiling.

MURABBA. ARAB. A kind of magic square.

MURAJAT. ARAB. Conducting a distinguished guest on his return road. In all countries it is customary for a host to advance to receive a guest or visitor, and to accompany the visitor a short way on leaving. With Muhammadans, Istaqbāl is the advancing to receive a guest or visitor, and Murajāt is the conveying a visitor to the door or on his road.

MURALI, a name of Krishna in his Apollonic character. By the sounds of his pipe (Murali) he captivated the shepherdesses as he attended the kine in the pastoral Surasen. See Krishna; Murli.

MURARI MISRA, author of the Anargha Raghava, a drama in seven acts, of little merit, written in the 13 th or 14 th century. Raghava or Rama is the hero of the piece.-Ward,iv. p. 376 ; Dowson.

MURASAKAR. HIND. A jeweller working gold and gems.

MURCH'HUL. HIND, A fan for driving away flies, especially of peacocks' feathers. A club-like fan, made of peacocks' feathers, used by the great.-Herklots.

MURCHUNG. HiND. Jew's-harp.
MURDAH. Hind. A dead body. Murdahfarosh, a person who removes the dead. Murdargosht, flesh of animals that have died. Murdahsho or Ghassala, HIND, persons who wash the bodies of the dead. $-W$.

MURDANNIA SCAPIFLORA. Ruyle.

Aneilema tuberosa, Ham. | Commelyna scapiflora, $R$.

Grows in the Panjab and in the Southern Konkans. Its tubers are used medicinally.Pouell; Drury.

MURFA, a drum like a d'hol, covered at both ends with leather, but played upon only on one side with a stick.

MURGHAB, a river of Afghanistan, which rises in the Koh-i-Baba mountains and Western Safed Koh, about lat. $35^{\circ}$ N., and long. $66^{\circ}$ E., and, flowing W. and N.W. past Merv, is lost in a lake or swamp in the sands of the Kara Kum desert, 50 miles N.W. of Merv, after running 450 miles. It is the Margus or Epardus of the Greeks.Ferrier's Journey, p. 195 ; Collett's Khiva.

MURIATIC ACID.

Hydrochloric acid, . ENG. Luna rasa, . . Singr. Chlorwasser, . . Ger. Ooppu dravagam, TAM. Stoffsaure, . . ", Lavana dravakum, . TEL. Namak ka tezab, HIND.

This acid is a solution of the gas in water. The Hindus know it by a name equivalent to spirit or sharp water of salt. The commercial acid is always of a yellow colour. It is prepared by pouring the oil of vitriol of commerce on common salt in earthen or iron vessels.

MURICIA COCHIN-CHINENSE. Lindley. Muh-pieh-tsze, CHIN. A cucurbitaceous plant of China and Cochin-China, with a fruit containing 30 to 40 flat seeds. Berry large, reddish-purple, scentless, insipid. Seeds and leaves aperient, and used by the Chinese in obstructions of the liver, tumours, malignant ulcerations, etc.; externally employed in fractures and in dislocations.Lindley; O'Sh.; Smith.

MURID or Mureed. ARAB. Amongst Muhammadans, a disciple, a pupil, particularly a pupil of a murshid or head of an order of the darvesh. Those who crave for aids to salvation seek the spiritual advice of a holy man, who is reckoned a pir or religious teacher, and by certain secret words and signs are initiated as his murid or disciples. Others, even men of rank, adopt the darvesh or fakir life of the religious mendicant devotee, often attended with solemn rites of investiture, and followed by the severest of ascetic rites; but the bulk of these mendicants are, in India, idle, dissipated men, and a few are of very degraded habits. They arrange themselves into the followers of certain pir or spiritual guides, and those usually met with in India are the Kadria or Banawa, Chastia, Shutaria, Tabqatia or Madaria, Mallang, Rafai or Gurz-mar, Jalalia, Sohagia, Naksh-bandia, and Bawa Piray. All these have their own rules and customs; some of them are ascetic devotees, eating if given to eat, but never begging; some largely use intoxicating fluids and vegetable substances; some, as the Salik, have wives; the Majzub and Azad have no wives; and some of the Calandars marry, and some do not. The Muhammadan rite of making a murid is performed in the presence of others, or alone in a closet by the murshid or religious teacher.

MURILLO VELARDE, P. P., anthor of a 
History of the Philippines from A.D. 1616 to 1716 , printed at Manilla, 1749.

MURKI KHEL. In former times fire-worship prevailed in Afghanisten, pyrethræ or fire-altars still crowning the crests of hills at Gard-dez, at Bamian, at Seghan, and at other places. Near Bamian is a cavern containing enormous quantities of human bones, apparently a common receptacle of the remains of Gabar corpses. At Murki Khel, also in the valley of Jalalabad, and under the Safed Koh, human bones are so abundant on the soil that walls are made of them. There is every reason to suppose it a sepulchral locality of the ancient Gabar. Coins are found in some number there.

MURLI. MAHr. A girl devoted to the Hindu gods, being married to some idol, to a knife, a dagger, a tree, and who may remain a virgin, but is usually common in India. Hereditary prostitutes are married to the plants togore, kund, goluncha or kulka, and sephalika, which are male. All other plants are female. The Murli of the Mahratta people is identical in character with the Jogini and the Basavi of the Teling people. Basava is a name of the vahan bull or conveyauce of the god Siva. The Linga Basavi are women who have been dedicated to the lingam. The Garuda Basavi have been dedicated to Garuda, the eagle vahan of Vishnu, but they are alike common. There are few instances of the Brahman, the Kshatriya, Vaisya, or Sudra races so devoting their children, but amongst the non-Aryan races in the large towns it is commonly done as a means of prostitution without shame. The Dhangar, Mhar, Dher or Pariah, Mang or Chakili, Koli, and Manurwara, and oceasionally even the higher Hindu castes, under various vows, devote their girls to the gods. The deity to whom the girl is more frequently vowed is some incarnation of Siva and his consorts. On the western side of India, Kandoba is the usual Siva avatar to whom the girls are devoted, and his chief shrines are at Jejuri, Khanapur, near Beder, and at Malligaon. The ordinary people believe that from time to time the shadow of the god comes on the devotee (deo ki chaya ati ang par), and possesses the devotee's person (Murli ki ang ko bhar deta). These devotees are called Murli in Mahratta, Jogni or Jognidani in Canarese, and Basava in Telugu. They at times affect to be possessed, perhaps are really hysterical, during which they rock the body, and people occasionally make offerings to them as to an oracle or soothsayer, laying money at their feet, and await the possessing, to hear a decision enunciated. The female deity to whom those near the Bhima river are devoted is Yellamah; the Bhui-koli race devote their Murli to Mata ; boys also are devoted, and styled Waghia, from Wag, a tiger. Near Amraoti it is to Amba and to Kandoba that the Murli and the Waghia are devoted. The Waghia does not associate with the Murli. Occasionally the girl is taken to the idol, in some parts to a dagger, to whom she is married by a ceremony, and the deity is supposed to take possession of her. In Berar, at Amraoti, the people say that Kandoba particularly moves on Sunday, and selects a clean tree (clean Murli), whose body be fills. This idea of the visits of the gods pervades Hindu society. It is not the belief that their visits are restricted to these devoted women, but that all women are liable to be selected by the deity, the visitor assuming the appearance of the husband. A comely Hindu woman is married, but without offspring, is supposed to be the subject of such supernatural visitation. So of old, when Demaratus, says Herodotus, had spoken to his mother, the mother answered him in this manner: 'Son, because you so earnestly desire me to speak the truth, I shall conceal nothing from you. The third night after Ariston bad conducted me home to his house, a phantom, entirely like him in shape, entered my chamber, and, having lain with me, put a crown on my head, and went out again.' Similarly in the Bacchæ of Euripides, the hero says, -

' For that the sisters of my mother (least

Becomes it them) declared that not from Jove

I sprung, but pregnant by some mortal's love ;

That Semele on Jove had falsely charged

Her fault, the poor device of Cadmus.'

In British history, Merlin and Arthur himself were both the sons of bhoots (Vide Geoffrey's History, book vi. chap. xviii., and book viii. chap. xix.), to the former of which cases Spenser thus alludes, -

'And soothe men say that he was not the sonne

Of mortal sire or other living wighte,

But wondrously begotten and begonne,

By false illusion of a guileful sprite

On a faire ladye nun.?

In Scotland, the story of the Lady of Drummelziar and the Spirit of the Tweed is related in Note M., Lay of the Last Minstrel. In India, the cases of Sheeladitya, of Usa and Anirud, and of Kamala Kunwari are similar; and Captain Westmacott relates another in an article on Chardwar in Assam, in the Journal Bengal Asiatic Society, iv. p. 187 et seq. Butler thus satirically alludes to these stories, -

' Not as the ancient heroes did,

Who, that their base births might be hid

(Knowing that they were of doubtful gender,

And that they came in at a windore),

Made Jupiter himself, and others

$O$ ' th' gods, gallants to their own mothers,

To get on them a race of champions,

of which old Homer first made lampoons.'

But this satirist's scornful remarks, however applicable to a civilised people, are not so to races like those of India, whose belief in spirits is their chief cult.-Hudibras, v. 211-218; Rasamala.

MURLIDAR, or the Tuneful, a name of Krishna represented playing on his flute.

MURMARI, a village 10 miles from Bandara; its viliagers worship at the tomb of an English lady. Similarly, at Assaye, the villagers worship at the grave of a French artillery officer who was killed during the battle.

MURMI, a Buddhist tribe bordering between Nepal and Sikkim. They appear to be a pastoral branch of the Bhutia. They are Mongolian in appearance, Buddhist in religion, and speak a language which Colonel Dalton supposed to be a Bhutia dialect. They live in houses built of stone, on mountain tops at an elevation of from 4000 to 6000 feet. They are found in all parts of Nepal, from the Gandak river to the Mechi, and in smaller numbers in the Sikkim country. They are divided into several families or clans. The Murmi, like the Bhutia, burn their dead.-Dalton's Ethnol. of Bengal, p. 105.

MURRAIN. From their constapt exposure at all 
seasons, the cattle of the $\mathrm{E}$. Indies, both those employed in agriculture and for carriage, are subject to devastating murrains that sweep them away by thousands. So frequent is the recurrence of these calamities, and so extended their ravages, that they reduce the facilities of agriculture at critical periods of harvest. A disorder, probably peripneumonia, frequently carries off the cattle in Assam and other hill countries on the continent of India; and there, as also in Ceylon, the inflammatory symptoms in the lungs and throat, and the internal derangement and external eruptive appearances, seem to indicate that the disease is attributable to neglect and exposure in a moist and variable climate, and that its prevention might be hoped for, and the cattle preserved, by the simple expedient of more humane and considerate treatment, especially by affording them cover at night.-Tennent's Ceylon, p. 50.

MURRAYA EXOTICA. Linn. China box.

Chaleas paniculata, Mant.

Camminum Sinense, Rumph.

Marsana buxifolia, Sonnerat.

Kamini, . . BEng. | Bibzar, Koontie, Hind.

Tha-nat kha, : BurM. Murchob of . KamaON. May kay, . . . . ,, Attaireya gass, . SINGH. Cosmetic box, . ENG. Naga golunga, . . TEL.

A bush of all India, Ceylon, the Andamans, and China. The delightful fragrance of its delicate white flowers has procured for it the name of the honey-bush. M. exotica, M. paniculata, and the Aglaia odorata, are cultivated in China as very fragrant shrubs. A variety grows in Ceylon in gardens, and another variety is common in the warmer parts of the island, and up to an elevation of 3000 feet. M. exotica is an ornamental shrub, with beautiful dark green leaves; flowers white, and fragrant in the evening, and is easily grown by layers or cuttings.

Murraya paniculata, indigenous in Burma above Rangoon. It is a small, ornamental, fragrant flowering shrub, with pinnate leaves; flowers white aud fragrant, appear in December and January ; fruit reddish. Its fragrant bark is more used for a cosmetic than sandal-wood.-Mason.

MURREE, a sanatorium situated on the summit of a ridge at the western extremity of the Himalaya, overhanging the plateau of Rawal Pindi, from which it is 40 miles distant. Its position is lat. $33^{\circ} 54^{\prime} 30^{\prime \prime} \mathrm{N}$., and long. $73^{\circ} 26^{\prime} 30^{\prime \prime}$ E. On the southern slope the vegetation presents the ordinary features of the Western Himalaya. The forest-clad range of hills on which the sanatoriurn is built consists of a series of sandstone spurs, culminating in peaks some 8000 feet above sea-level, and stretching onward into Hazara, till they finally blend with the snowy ranges which enclose the Kashmir valley. They form a series of lateral spurs of the Himalayan system, running down from the main Kashmir and Hazara chain at right angles towards the plains, with a general direction from north-east to south-west. Thence they stretch down to the Murree ridge itself, whose highest portion, the Kashmir Point, has an elevation of 7507 feet above sea-level. Pindi Point is 7266 feet in height. - Imp. Gaz.

MURREE and Bugti tribes dwell in the hills forming a conterminous boundary of Sind and the Panjab. Near Harrund, the great Sulimani range having run in almost a straight line paralle to the Indus for 300 miles, approaches its termination and joins the Mara Mount, which leads on to the Murree Hills, behind which lies the tableland, where Kaliun, the capital of the Murree tribe, is situated. But in front of these Murree ranges there rises a series of sterile rocky hills, which run towards the Indus, and form themselves into an apex near the Gundheree peak, approaching to within a few miles of the river bank. It is at this point (Shawulla) that the conterminous boundary of Sind and the Panjab has been marked off. These last-named bills, projecting into the Lower Dehrajat, opposite Asnee, are crossed by passes leading towards the Murree Hills, and are claimed partly by the Murree and partly by the Bugti, whose bills lie farther to the south. A part of the Murree in Cutch Gandava were notorious for their lawless habits, and made frequent inroads on the plains. They and the Maghzi seem to have emigrated from Mekran to Cutch Gandava at different periods, and to have become incorporated with the Jat cultivators. A peaceful and obedient portion of the tribe are in the hills west of the province below Jell. A large portion are at Ada Murree, on the south-eastern frontier of Sind. The Doda Murree occupy Kahun. The Murree are a brave race.

MURREL. HIND. Species of the Ophiocephalidæ or snake-headed fish.

MURRHINE CUP. The fragments of a murrbine cup, the little Cambay stone cup still made in Cambay, were exhibited in the theatre of Nero; as if, adds Pliny, they had been the ashes of 'no less than Alexander the Great himself !' Seventy thousand sesterces was the price of one of these little Cambay cups in Rome in the days of Pompey. The price in Bombay ranges from 18 to 35 and 75 rupees. Nero paid $1,000,000$ sesterces for a cup, a fact, remarks Pliny, "well worthy of remembrance, that the father of his country should have drunk from a vessel of such a costly price.'

MURSHID. ARAB. A religious teacher of the Muhammadans of India and Persia, a guide to the right path. Amongst the Sunni Mubammadans, this person is a religious instructor in a family. Amongst the Shiah sect there are reckoned 12 imāms, Ali and his eleven descendants. The Murshid or Pir of the Sunni Mubammadans initiates disciples, styled Murid, into his sect, after repeating the astafghar or renunciation and the five sections of the Muhammadan creed.

MURSHIDABAD, a city in Bengal, in lat. $24^{\circ}$ $11^{\prime} 5^{\prime \prime} \mathrm{N}$., and loug. $88^{\circ} 18^{\prime} 50^{\prime \prime} \mathrm{E}$., situated on the left bank of the Bhagirathi river, and gives its name to a revenue district lying between lat. $23^{\circ} 43^{\prime} 15^{\prime \prime}$ and $24^{\circ} 52^{\prime} \mathrm{N}$., and long. $87^{\circ} 43^{\prime}$ and $88^{\circ} 47^{\prime} \mathrm{E}$., which is divided into two parts by the Bhagirathi. It was originally called Maksudabad, and is said by Tieffenthaler to have been founded by Akbar. Murshidabad was 5 miles long and $2 \frac{1}{2}$ miles broad in 1759 , only two years after the battle of Plassey, when it had already attained its greatest magnitude.

Murshidabad was ruled by a dynasty founded by Murshid Kuli Khan, a converted Brahman, and is still the residence of the titular nawab. The area of the district is 2462 square miles. The Mal, Kaibartha, and Goala are numerous, and there are many Nat vagrants. A raft festival is 
celebrated at Murshidabad in honour of Khwaja Khizr.

The Moti Jhil, or Pearl Lake, is about two miles south of Murshidabad. A palace was built by Suraj-ud-Dowla of materials brought from the ruins of Gaur, and a few arches are still left. It was from Moti jhil that Suraj-ud-Dowla, in 1757, marched out for the battle of Plassey; it was in the palace here that Colonel Clive placed Mir Jafar on the musnud; and at Moti jhil, Lord Clive, in 1766, as dewan of Bengal, Behar, and Orissa, held the first British Punya. Mir Jafar fixed his residence on the farther side of the river. To the north-east of Moti jhil, and immediately outside the city of Murshidabad, is the Kuttara, containing the tomb of Murshid Kuli Khan.- $T r$. of Hind. i. p. 71.

MURUKEA, formerly one of the many kinds of slaves in Assam, distinguished by distinct appellations. The Murukea is a kind of Chapunea, neither servant, slave, nor equal, but partaking of all. The master provides the Murukea with a pair of bullocks and a plough, and he tills his master's land for two days. On the third day the Murukea may plough bis own ground with his master's bullocks and plough.-Butler's Assam, p. 228.

MURUT, a race occupying the inland parts of Borneo. The Murut are the only existing race of head-hunters north of the capital, but this savagery is disappearing. The Dusun and Kadyan, although formerly head-hunters, have now taken to agricultural pursuits, and are well fed and prosperouis compared to the Muruts, who, although they clear and plant the land around their immensely long pile dwellings, still depend much on their skill in hunting wild pig, deer, and other game for food. The Dyaks of Sarawak are now peaceful and industriously engaged in seafaring or agricultural pursuits. The Kayan are still warlike, and are a fine race of straight-limbed, powerful people. They formerly inhabited the country inland near the Limbang, and used to plunder the villages of the Muruts and Sabayans, killing the men and taking the women and children into slavery. Of late years, however, they have migrated farther south, and their headquarters are now on the Baram river.

Borneo population is 3 to 4 million. The languages of the interior are Murut, Dusun, and Brunei. The chief tribes are the Dyak, Kayan, Murut, Kadyan, Dusun, Lanun, Baju, Balagnini, and Sulu. The last-named four inhabit the northern part of Borneo and the islands to the N.E. The Murut highly prize old skulls as trophies. They are expert with the sumpitan.Burbidge, p. 148.

MURVI. The thakur of Murvi is a Jhareja, was the first in Colonel Walker's time to abandon infanticide. He has possessions in Cutch. He visited England in 1884.

MURWUT, an agricultural and pastoral race within the British territories, stout, active men. Their country is sandy and arid, divided by ranges of hills. It depends entirely on rain for cultivation, and in many parts the inhabitants are even obliged to carry water for several miles to supply their families. Their country is about 35 miles square, stretching from Bannu to Muckelwand, and from near the foot of the Sulimani mountains to the short range of hills which separates Saugor from the Indus. Damān proper, which lies to the south of the Murwut, and extends along the foot of the Sulimani mountains, is inhabited by the Waziri, Sheorani, and Zimurree, and is of equal length with Muckelwand, but of various breadth, from 8 or 10 miles to 30 and upwards. It is inhabited by the Dowlutkhail and Gundelpuray; the Mean-khail, Babur, and Sturiauni tribes, with the exception of the Gundehpur, are included in the general designation of Lohani. The Esau-khail, Murwut, and Khyssore, also, are comprehended under this denomination.-Elphinstone's Caubul; Recordls of the Government of India.

MURWY KOLI, one of the Balotta, and found in every village in the Northern Konkan. In Bombay families they are employed as palanquin bearers. Some Koli are settled in Angriah Kolaba, at Bombay, Kolaba, and Bassein, employing themselves as fishermen and seamen. At their meetings, whether for congratulation or condolence, they consume large quantities of spirits.

MUSA. Arab. Moses, the prophet, to whom Muhammadans apply the epithet Kālam-ullah, he who spoke with God, or the mouthpiece of God. The Wells of Moses, the Ayun Musa, are eight miles down the Red Sea from Suez on the eastern shore. Ain (Ayun, plural) is a natural spring, and differs from the Ber or Bir, a cistern to hold rain-water. Jacob's Well, Bir Yakub, or Bir-usSamaria, is 9 feet broad, and more than 70 fect deep. In 1855 it still had a stone over its mouth.

MUSA, a genus of the Musaceæ, the banana or plantain tribe of plants. Natives of South America, China, Madagascar, Mauritius, and the East Indies, about 20 species.

$$
\begin{gathered}
\text { a. Heliconiex, A. Rich. } \\
\text { Heliconia buccinata, Roxb., Moluocas. } \\
\text { b. Ravenalex. }
\end{gathered}
$$

Musa paradisiaca, $L$., all the tropics.

IN, rotacea, Jacq., Chittagong, Mauritius.

II. superba, Roxb., Dindigul.

M. Nepalensis, Wall., Nepal.

M. glauca, Roxb., Pegu.

M. textilis, Nees, Philippines.

M. Cavendishii, Lamb, China.

M. coccinea, Andr., China.

M. corniculata, Rumph., Archipelago.

M. ensete, Gmelin, Abyssinia.

I. simiarum, Rumph., Malacca.

M. rubra, Wall., Irawadi.

M. Chinensis, Swt., China.

M. maculata, Jacq., Mauritius.

M. balbisiana, Culla, Amboyna.

M. acuminata, Culla, Amboyna.

M. verteroniana, Culla, Moluccas.

M. textilis, Nees, Manilla.

M. ornata, Roxb., Chittagong.

The fruits of several species of musa, the plantain or banana, are used as food and for dessert, but the most esteemed is M. paradisiaca, $L$. The plantain is the muz or mauz of the Arabian writers, whence the Latin term musa. The plantain was known by description both to the Greeks and Romans. Theophrastus, among the plants of India, describes one as having fruit which serves as food for the wise men, and which was remarkable both for its sweetness and for its size, as one would suffice for four men, - referring most probably to a bunch of plantains. Pliny, evidently describing the same plant, informs us that its name was Pala, and in Malealam it is Vella, and in Tamil Valle. In the 
Indian Archipelago, the edible species extend northwards as far as Japan; in China are found M. coccinea and M. Cavendishii; also along the Malayan Peninsula to Chittagong,-M. glauca being indigenous in the former, and M. ornata in the latter locality. In the valleys of the soutb of the Peninsula of India and of the Dindigul mountains, M. superba is found.

No Burma or Karen house is to be found without a plantation of plantains. As the Karen leave their abodes, at least every three years, in order to migrate to fresh localities, they leave their plantain gardens behind them, and these may be found growing luxuriantly in many uninhabited places, until they become choked up by the growth of the more vigorous jungle. Natives of Bengal generally prefer the large and coarsefruited kinds, while the smaller and more delicately-tasted fruit is alone esteemed by Europeans. All of that growing in Nepal has been called M. Nepalensis, and a similar wild species may be seen growing below the Mussoori range, as well as near Nabu. The fruit, however, in all these situations consists of little else than the hard, dry seeds; a variety having seeds surrounded with a gummy substance, instead of fruit-like pulp, was found by Dr. Finlayson, on Pulo Ubi, near the southern extremity of Cambodia. In Batavia, also, there is stated to be a variety full of seeds, which is called Pisang batu, or Pisang bidju,that is, seed plantain. In Kamaon and Garhwal the plantain is cultivated at an elevation of 4000 and 5000 feet above the sea, and has been seen as far north as the Chamba range at an equal elevation. Major Munro has seen a wild plantain at 7000 feet above the sea, in the Konda slopes of the Neilgherries.

Mr. R. Brown thinks that nothing has been advanced to prevent all the cultivated varieties being derived from one species. Plantains and bananas are extensively cultivated in various parts of S. America, and at an elevation of 3000 feet in the Caraccas, and they are abundant in the W. India Islands, as well as at considerable elevations in Mexico. To the Negroes in the West Indies the plantain is invaluable; and in Guiana, Demerara, Jamaica, Trinidad, and other principal colonies, many thousand acres are planted with the plantain.

Dr. Roxburgh described the small-sized M. ornata, the On-ang-chok-cheel of the Chinese, and Ramanigi-kula of Bengal. It resembles the banana and plantain in habit and in its perennial root. It was introduced into India. His description of the M. glauca, Roxb., is that it is a very stately, elegant, perfectly-distinct, strongly-marked species, a native of Pegu, and from thence introduced by the discoverer, Mr. F. Carey, into the Botanic Garden at Calcutta.Royle, Bot. and Fib. Plants; Roxb.; Helfer; Mason; Voigt ; Hogg; Drury.

MUSA CAVENDISHII. Lambert.

M. regia, Rumph.

M. nana, Loureir.

M. Chinensis, Sweet.

The Chinese banana stem attains 5 or 6 feet, has a profuse yield of fruit, 200 to 300 fruits in a spike; ripens in Madeira and Florida.

MUSA COCCINEA. Ait. A dwarf ornamental species of China.-Von Mueller.

MUSA CORNICULATA. Rumph. A plant of the Archipelago; fruits as large as a goodsized cucumber; skin thin; pulp reddish-white, firm, dry, sweet, excellent for cooking.

The

Lubang variety is of enormous size.-Kurz.

MUSA ENSETE, Gmelin, is a magnificent plant of Abyssinia, attaining to 30 feet in height, with leaves 20 feet long and 3 feet broad. The body of the stem for several feet high is esculent. But so soon as the stalk appears perfect and full of leaves, it turns hard and fibrous, and is no longer eatable; before, it is the best of vegetables. When boiled it has the taste of the best new wheat-bread not perfectly baked. The fruit is not eatable.-Bruce's Abyssinia.

MUSA FEIHI, the Fei or mountain plantain tree of Tahiti. Its fruit is cooked and mixed with arrow-root.

\section{MUSA PARADISIACA. Linn.} Musa sapientum, Roxb.

Maoz, . ARAB., HiNd, Kadali, . . SANSK. Kach-kula, . . BENG. Anawalu-kesul, . SINGH. Huget-pyau, : BURM.
Banana, Plantain, ENel-khang, : : 'MAM. Banana, Plantain, ENG.
Kela, . . . Hali pallum, : . TAM.
Ariti pandu, : TEL. Godang, : : : JAV. Ananti, Anati, : ", Pesang, : : MaLAY. Anti chettu, : " " Vella, Valati, . MALEAL. Kommu ariti, . ',

There is a great variety of this delicious fruit in the East Indies, where this species is largely cultivated for its fruit. The natives eat them with milk and sugar, as Europeans do strawberries. Europeans also fry the fruit with butter, and eat it dusted with sugar. A dye is obtainable from the skin of the fruit. Its stem and leaves afford a fibre suited for certain purposes, but inferior in point of strength to Manilla hemp, the fibre of the Musa textilis. The stem is placed on a board, and the pulpy mass scraped out with a blunt knife, whilst clean water is poured on to wash away the remains of the pulp; the fibres are then dried in the sun. Each stem will give about $4 \mathrm{lbs}$. of raw fibre and 50 lbs. of fruit yearly. The fibre is fine, white, and silky, long, light, and strong. The quality depends on the mode of cultivation and treatment, but it is not so valuable as Manilla hemp. The stem seldom exceeds 7 or 8 inches in diameter and 12 feet in height, bears but one bunch of fruit, and dies, but it throws off new plants. The leaves, when young; are beautiful, expanding, with a smooth surface aud vivid green, to 6 feet in length, and 2 or more in breadth, but, soon after attaining full size, the edges become torn by the wind. The flower is very large, purple, and shaped like an ear of Indian corn. At the root of the outer leaf, a double row of the fruit comes out half round the stalk or cob. The stalk then elongates a few inches, and another leaf is deflected, revealing another double row. Thus the stalk grows on, leaving a leaf of the flower and a bunch of the fruit every few inches, till there come to be 25 or 30 bunches, containing about 150 or 180 plantains, and weighing from 60 to $80 \mathrm{lbs}$. The weight bends over the end of the stalk, and when ripe it hangs within reach. Like the palms, it has no branches. In the East Indies, it is for the fruit, as a dessert, that this plantain is cultivated; but Humboldt calculated that $33 \mathrm{lbs}$. of wheat and $99 \mathrm{lbs}$. of potatoes require the same surface of ground that will produce $4000 \mathrm{lbs}$. of ripe plantains, which is to potatoes as 44 to 1 , and to wheat as 133 to 1 . Banana is a West Indian and tropical American term. In India the term plantain alone is given. 
The edible varieties extend through the Indian Archipelago, northwards as far as Japan, while in China are found M. coccinea and M. Cavendishii. M. glauca is indigenous along the Malayan Peninsula. Dr. Helfer mentions that 20 varieties are found in the Tenasserim Provinees, and M. ornata grows in Chittagong. The Malays reckon 40 varieties of the cultivated banana, and the Philippine Islanders carry them to 57, both people having a distinctive epithet for each variety. The qualities are as various as those of apples and pears in Europe, the ordinary sorts being very indifferent fruit. In Khassya the name of the wild plautain is Kairem, and the cultivated Kakesh.-Ainslie; Malcom's Travels; Hooker's Him. Jour.; Royle's Fib. Pl.; Crawfurd's Dict.

MUSA SIMIARUM. Rump $\pi$.

M. acuminata, Cull. | M. corniculata, tour.

Grows from Malacea to the Sunda Islands. It has about 50 varieties. It has fruit sometimes two feet long.-Kurz; Von Mueller.

MUSA TEXTILIS. Nees.

Pissang-utan, - MALAY, | Abaca brava,

Koffo, Kola-abbal. : ' T'A

TAG.

A plant of the Philippines, said also to grow wild on the Western Ghats of the Peninsula of India, from Cape Comorin northward. In the northern slopes of the ghats, the plant does not reach a height fitted to afford a fibre of more than two feet in length. Its strength is well known to the ghat people, who employ it occasionally for domestic purposes, in rope-making, as well as the stem for food. Professor Bikmore states (p. 340) that in Minahassa this plant is raised from seed, and in the Philippines its fibre is called Bandala, the plant itself receiving the naine of Abaca. The plant grows freely at Singapore, from which it was introduced into Madras by Colonel (Sir George) Balfour, C.B., of the Madras Artillery, but seems to have succeeded only in the Wynad, where it bas been grown since 1864 , and its value is fully recognised. Its fibre is largely imported from Manilla into Great Britain. See Manilla Hemp.

1877, 332,304 cwt. $£ 488,069$ 1881, 353,770 cwt. $£ 691,186$ $1878,421,160,, \quad 551,856 \quad 1882,373,231, \quad 830,033$

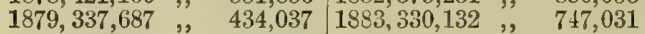
$1880,407,431,, 622,776$

and is there made into ropes for yacht rigging and clothes-lines. It is a native of the Philippines, also of some of the more northerly of the Molucca Islands. On account of its fibres, it is extensively cultivated in the first of these, particularly in the provinces of Camarines, and Albay in the great island of Luçon, and in several of the Bisaya Islands, a range lying south and east of it. It is grown extensively in Manilla, where 250,000 acres are planted with this staple; it has hitherto been treated only by hand, the natives preparing about $12 \mathrm{lbs}$. weight of fibre per day, and receiving one-half its value for the work, the waste being so great that only about $1 \mathrm{lb}$. of fibre is obtained from each tree. Yet, notwithstanding this, the exports have amounted to 35,000 tons annually. Manilla hemp is imported into Europe and America for rope-making only, and is worth $£ 20$ to $\mathfrak{E 6 0}$ per ton, according to quality; the crop may be taken at from $10 \mathrm{cwt}$. to 2 tons per acre, according to successful treatment.
MUSA TROGLODYTARUM. Lim. The M. uranoscopos of Rumph. A plant of the Fiji Islands, has an upright fruit-stalk, as also has the dwarf Chinese M. coccinea, Ait.-V. Mueller.

MUSA - bin - MAIMUN, known to Western Europe as Mainonides, was called by the Jews the Eagle of the Doctors. He was born A.D. 1131 or 1133, at Cordova in Spain, of an illustrious family. He studied philosophy and medicine under Averrhoes, and he was learned in Arabic, Hebrew, Chaldee, and Turkish. He was a voluminous writer on theology. He settled at Cairo, where he opened a school, to which numerous pupils came from Greece and Alexandria.

MUSAFAHAH. ARAB. The Arab fashion of joining hauds. They apply the palms of the right hands flat to each other, without squeezing the fingers, and then raise the hand to the forehead. Among polite people the right hand is placed on the breast, or the lips and forehead or turband touched by the same hand. This action is called Tcymeeneh.

MUSAHIR, in the Terai, an aboriginal race. They are employed as woodmen; they eat the flesh of the lesser civet-cat, Viverra Malaccensis.

MUSA-ibn-NASIR, a celebrated Arab conqueror, who, A.D. 707, was Governor of Mauritania, and overran all the north of Africa. In 710 he crossed into Spain, and returned with much plunder. In 711 he despatched bis general Tarik into Spain, who defeated and killed Roderick, the Gothic king, took Toledo and other cities. In 712 Musa landed at Algesiras, and reduced Seville, Beja, and Merida, and arlvanced on Toledo, where he displaced Tarik, and even flogged him; but Tarik was replaced by the khalif Walid, who ordered both Musa and Tarik to Syria. Tarik at once obeyed, but Musa required a reiterated order, and then, A.D. 715 , took with bim thousands of captives, among whom were 400 of the Spanish nobility, aud a long train of camels laden with spoil. The khalif received Musa coldly, and the succeeding kbalif, Suliman, cast Musa into prison, and fined him 200,000 pieces of gold, put one of his sons to death, and his head was brought to Musa by Suliman himself, who asked him if he knew it. The afflicted parent replied, 'Cursed be he who has slain a better man than himself.' Musa died in poverty, A.D. 717 ; born 640 .-Catafago.

MUSA-KHEL, lat. $32^{\circ} 43^{\prime} \mathrm{N}$., long. $71^{\circ} 39^{\prime} \mathrm{E}$., in the Panjab, western part of the Salt Range, S.E. of Kalabagh. Mean height of the plain, 706 feet.-Flem.

MUSAL, in lat. $36^{\circ} 21^{\prime} \mathrm{N}$, a town on the right bank of the Tigris, in the province of Musal, sturrounded by a stone wall. Its population, estimated at from 20,000 to 45,000 souls, Turks, Kurds, Jews, Armenians, Nestorians, and Arabs, the Christiaus being 6000. It was formerly famed for its muslins. Near it are several warm sulphurous springs. The plague has repeatedly devasted it.-MacGregor. See Mosul.

MUSA MMAT. Arab., Hind., Pers. An honorific prefix to the names of women of rank, equivalent to lady.- $W$.

MUSAN. Hind. The place where Hindus burn their dead; it is called in Tamil Soodookadoo, and in Telugu Pinigalloo-kalsi-tagaloo.

MUSA RIVER at Hyderabad is a tributary of 
the Kistna river. It skirts the city wall on its northern face.

MUSA SOHAG, the founder of a sect of Hindu devotees.

MUSCARDINE, a disease which in Europe attacks silk-worms; it is from the fungus Botrytis bassiana, the spores of which enter the bodies of the caterpillars and destroy them. The still more fatal pebrine disease is produced by a minute vibrio-like organism.- $V$. Mueller.

MUSCAT, in lat. $23^{\circ} 28^{\prime} \mathrm{N}$., long. $59^{\circ} 19^{\prime} \mathrm{E}$., is surrounded by bare rugged rocks. The town is built close to the water's edge, but its supply of water is brought by an aqueduct from a well half a mile distant. The arid hills protect, by almost encircling, a cove at the extremity of which is a small plain crowded with high houses, which form the town of Muscat. This emporium to the trade of the Persian Gulf is defended by batteries, which command the narrow entrance, as well as by fortifications that cover every part of the uneven and misshapen hills and crags around it.

In summer the heat is intolerable. Shut out by the hills from every breeze except that which blows direct into the narrow entrance of the cove, there is seldom a breath of air, and the reflection of the sun from the bare rocks and white fortifications which overhang the town and harbour, produce a temperature which is described by a Persian poet as giving a panting sinner a lively anticipation of his future destiny.

The Governor-General of India in Council claims power and jurisdiction over native Indian subjects of Her Majesty within the coast-line from Gwadur westward to the Persian Gulf, all the shores of the Persian Gulf and the Gulf of Oman, with the islands situated in these gulfs and the territories of the Sultan of Muscat in Arabia.

MUSEUM is derived from a Greek term signifying a temple of the muses, but, as used in Great Britain and in British India, it designates an institution in which are arranged specimens of the animal, vegetable, and mineral kingdoms, and those illustrative of economic geology. The probability is that there were many students of natural history in ancient times ; for in Pompeii, destroyed in A.D. 79 by lava, in the room of a painter, a large collection of shells was found, comprising a great variety of Mediterranean species, in as good a state of preservation as if they had remained for the same number of years in a inuseum. We know, moreover, that on the revival of science in Western Europe, after the fall of the Constantinopolitan empire, the princes and nobles formed collections of relics of art, of specimens of natural objects, and other productions, constituting cabinets and museums. The discovery of busts, statues, bas-reliefs, inscriptions, and other antiquities of various kinds, led to the formation of many museums in Italy earlier than in other countries; the Medici, Dukes of Florence, particularly signalizing themselves by the liberality and magniticence they displayed in procuring relics of antiquities and valuable manuscripts and works of art. In Europe, in the 17 th and 18th centuries, numerous museums, some exclusively appropriated to objects relating to one science only, and others of a more miscellaneous nature, were formed; not by kings and princes only, but by numbers of private persons. In England, John Tradescant collected curiosities of various kinds, and his museum constituted the nucleus or foundation of the Ashmolean Museum at Oxford. James Petiver, a London apothecary, formed a cabinet of natural history ; in Holland, Albert Seba distinguished himself as a collector of similar curiosities; and John Swammerdan devoted much time and labour to the study of the natural history of the insect tribes, and to tho formation of a valuable museum. The Ashmolean Museum was presented in 1836 to the University of Oxford by Elias Ashmole, an eminent herald and antiquary. It comprised originally specimens to illustrate natural history, and various artificial curiosities, especially Roman antiquities; and since its establishment numerous additions bave been made to it. Among the most celebrated collectors in England during the 18th century may be reckoned Richard Mead, an cminent physician, who accumulated a valuable cabinet of coins and medals, besides otber interesting objects; Dr John Woodward, who applied himself especially, but not exclusively, to the collection and illustration of British minerals and fossil remains; and Sir Hans Sloane bequeathed to Government a magnificent musuem and library, in the formation of which he had expended upwards of fifty thousand pounds. This formed the foundation of the British Museum, to which has since been added the donations of many eminent men, and has been aided by large annual grants from the Imperial Parliament. There are in London, Edinburgh, and Dublin, indeed in nearly every large town in Britain, other musenms which have attained a considerable size. On the continent of Europe, picture galleries, sculpture galleries, and collections of natural history are to be met with in all the principal towns; and in the United States of America the collections that have been made rival those of the Old World.

The oldest museum in India was that of the Asiatic Society of Bengal, which included a Museum of Natural History and a Museum of Economic Geology, of which Mr. Blyth and Mr. Piddington for many years had been the respective curators.

The Asiatic Society of Bombay possessed a museum to which Dr. Carter, Dr. Buist, and Dr. Impey contributed; and the Madras Literary Society had a small collection of interest. In 1851, Surgeon (Surgeon-General) Edward Balfour formed the Goverument Central Museum at Madras, and in 1865 he founded the Mysore Museum at Bangalore; and in 1855, to that at Madras he added a zoological collection, which was subsequently transferred to the People's Park.

The Madras Museum is free to the public, who formed it by their liberal donations; the number of visitors amounted in the year 1855 to 201,987 , and in the year $1856,542,866$; and the highest number since then was 709,009 in 1876 . The visitors to the British Museum in 1878 were only 611,612. The Madras Museum embraces economic geology, all the branches of natural history, a public library, and collections of coins and antiquities. Calcutta got since an Imperial Museum.

The East Indian Company, from an early part of their career, had a museum in the India Ottice, at Leadenhall Street, and afterwards in Westminster, which was transferred to the South Kensington Museum, of which it became a section. There is now a museum at Agra, one 
at Nagpur, another at Calcutta, one at Bombay, and one at Trevandrum.

MUSHAFI, whose name was Shaikh Ghulam Hamadani, was born at Amroha, in the Moradabad district, Rohilkhand. He lived for a time in Agra, then in Lucknow, where he closed his life about A.D. 1830. He wrote six diwans and two lives of the poets.

M USHA I KH. ARAB. Properly written Mashaikh. A patriarch or devout man, a religious teacher. Shaikh is applied to a learned man or a reputed saint. Shaikh is also a religious chief; also the shaikh of an order of darveshes is called the occupant of the sajjadeh, or prayer carpet, of the founder of the order. Candidates for admission into it vow that they take the shaikh as their shaikh and guide unto God. Shaikh-ulIslam, the dignity of shaikh of Muhammadanism. Mashyakhat, seniors, princes, presidents.

MÚSHATA. Hind. A female jester.

MUSHKI, a western division of Baluchistan. Mushki has several towns and castles, and is occupied by the Mehmasani, the Nushirwani and Merwari tribes. The Merwari Brahui are located in Mushk, Jhow, and Kolwah. The Brahui entered from the west, and point to Khozdar as the capital prior to occupying Kalat. See Kalat.

MUSHRIK, ARAB. One who gives a companion to the Almighty; a term used by Mahomed in the Koran to designate Christians.

\section{MUSHROOM.}

Kamat, . . ARAB, Kamba, Moksha, Hind, Hiang-kwang, : . CHIN, Kukur-mutta, . ", Champignons, : Fr. Kudrati, Pad-behera," Schwamme, . GER. Funghi, . . IT. Guchi, . : Hind. Kharere, . Pushtu. Kama-guchu, : ", Samarogh, : : ,

The Agaricaceæ or mushroom tribe of plants comprise mushrooms, puff-balls, and mildews. They grow on the earth, and on decayed animal and vegetable substances, scarcely ever on living bodies of either kingdom, in which respect they differ from lichens, which commonly grow on the living bark of trees. Dr. Royle's collections in the Himalaya amounted to about 40 specimens. There are 5000 recognised species of mushroom, of which only a few can be safely eaten. The poisonous properties vary with climate and the season of the year and locality, and some individuals, by idiosyncrasy, are liable to be affected even by species which other people eat with inpurity.

Agaricus campestris, the common mushroom, various species of the Helvella or morel, and of the tuber or truffle are useful as food, but there is great difficulty experienced in distinguishing the poisonous from the edible kinds. Such as are poisonous or suspicious have a cap very thin in proportion to the gills; have the stalk growing from one side of the cap; have the gills all of equal length; have a milky juice; deliquesce, that is, run speedily into a dark watery liquid; or the collar that surrounds the stalk resembles a spider's web. The Kudrati mushroom is found throughout the Dekhan in the rainy season. Mushrooms are often seen in the Tenasserim bazar, and the Karens have names for 64 different species of mushrooms and the allied fungi. They distinguish the edible from the poisonous kinds, they say, by touching them with the lime that they eat with the betel. If the fungus turn red when touched, it is regarded as poisonous. But they are so careless or ignorant, that sickness and death often ensue after eating them. A new mushroom, collected from the stumps of trees, Agaricus (Pleurotus) subocreatus, is a dendrophytal species, drying readily, is employed in the Straits Settlements as an article of food, and is nearly allied to the British Agaricus ulmarius, from which it is separated by the volva, remains of which may be traced at the base of the stem.

Hydnum coralloides, Scop., the Koho khur mushroom of Kashmir, where it is cooked and eaten, its taste being excellent. It grows in the hollow trunks of the Pinus Webbiana tree. Mr. Powell says there are three edible kinds of fungi in the Panjab, viz. the mushroom (Agaricus campestris, the Samarak or Samarugh of the Panjab), also the morel, Morchella esculenta (Phallus esculentus), and the truffle, Tuber cibarium, or allied species, called khumba and khambur. The Agaricus campestris is usually called pad bahera; and the morel, guchi or kama-guchu. Dr. Henderson mentions that in Shahpur and other districts, where there is kalr in the soil, the morel, and mushroom are both abundant, the former in August and September, the latter in the end of the cold season, after heavy falls of rain. Muhammadans eat only the morel, and consider the mushroom as harām or unlawful food. The Hindus there say that every mushroom having a pleasant smell and taste is wholesome. In the Jhang district, an underground morel, called phahor, is found in fields of Sorghum vulgare; and Edgeworth, in the Florula Mallica, mentions an esculent morel, which he calls bănphăl, literally wild fruit. Quantities of the morel are brought from Kashmir to Amritsar. The khumba of Muzaffargarh is of a pure white colour, with a powdery surface, and destitute of gills ; it is very common in the rains, and is much esteemed as an article of food. Fried in the ordinary way, they are equal in flavour to English mushrooms.

General MacGregor says (p. 42) that mushrooms are largely used by the Afghan nomades and poorer classes to supply the place of meat. The Chinese in every province eat large quantities of fungi, but prefer the polypori or boleti to the agarics. The Ti-kai are edible agarics; the Muh-rh are parasitic fungi growing on trees, and much eaten.

In Japan the best edible species are called Matushake and Shu-take. The latter are largely cultivated; they are almost tasteless when raw, but when dried have an extremely fine flavour. They grow on the decayed trunk of the Shu tree. They are largely exported. In France, in Italy, and especially in Russia, a useful aliment is afforded by a great variety of species which, although very common in Britain, it would be extremely dangerous to eat; even the dangerous Agaricus muscarius is used in Kamtschatka. The Asiatic physicians still employ the A. muscarius in their medicinal practice, long discarded from the European pharinacopoeias. - Royle ; Riddell; Honig.; Mason; O'Sh.; Powell; Murray.

MUSHRU. HiND. A stuff of silk and cotton; satins, the back or warp of which consists of cotton. Value, 2 to 4 rupees per yard. Kimkhab, hemru, luppa, tas are all of the same order of manufacture, gold, or gold and silver, and silk. In the kimkhab, metal predominates, whereas in 
the hemru the silk predominates. Another of the latter's characteristics is that the design is generally a diaper or buta. Affixes of single and double are also made use of to designate one colour or several, such as ekowdu hemru and bewdu hemru. In Surat it is known as kamjurno aleeacha, which means that there is only a small quantity of gold thread used in it. Luppa is all gold or silver, that is, the metal only is visible. Tas is much thinner, but manufactured in the same manner. Mushru and hemru are not used for tunics, but for the trousers of men and women, and for women's skirts; as also for covering bedding and pillows; they are very strong and durable fabries, wash well, and preserve their colour, however long worn or roughly used; but they can hardly be compared with English satins, which, however, if more delicate in colour and texture, are unfitted for the purposes to which the Indian fabrics are applied. For example, a labada or dressing-gown was worn for 20 years, was washed over and over again, and subjected to all kinds of rough usage, yet the satin continued unfrayed, and the colour and gloss as bright as ever.

MUSIC. Amongst the Hindus of early ages music appears to have attained a theoretical precision at a period when even Greece was little removed from barbarism. The Arab system of music is derived partly from Greek, Persian, and Indian treatises,-Musika, their general name for music, and the uames of several musical instruments, being from the Greek; while most of the technical terms used by the Arab musicians are borrowed from the Persian and Indian languages. The inspirations of the bards of the Vedic Aryans of the first ages were all set to music; the children of the most powerful potentates sang the episodes of the great epics of Valmiki and Vyasa.

Music appears to have been cultivated largely by the Hindus, even after Vedic times, and the writings of many ancient authors are still extant. They fixed all their svara or notes within the compass of 3 octaves. Leaving the eighth note, they called the diapason a saptaka or heptachord, the seven notes being sharja, rishabha, gandhara, madhyama, panchama, dhaibhata, and nishada. Hindu music has 84 modes, of which 36 are in general use. They are named from the seasons of the year and the hours of the day and night, and are each considered to possess some quality appropriate to the time, and each is supposed to have a peculiar expression and the power of moving some particular sentiment or affection. The Hindu modes are formed partly by giving the lead to one or other of the twelve sounds recognised in Europe, and varying seven different ways the position of the semitones. This gives the number 84 .

In Sanskrit, harmony is termed Sruti, and melody Raga. While the reading of the Vedas, Puranas, and other religious books was monopolized by the Vydika, religious men, and poetry, rhetoric, and kindred branches of learning became the hobby of the Lokika, or men of the world, music, left without any place and protection, took refuge in Hindu brothels. The religious Brahmans went so far as to hurl their thunders against those who practised it, and said 'Gayata na thayam' (that we should not give them anything). Much attention has not, however, been paid to this injunction, and it has often been violated.

In British India, instrumental music is chiefly cultivated by professionals, and while it is common for men to perform on instruments, and those in a great variety, women do so comparatively to a small extent, and only use few and simple instruments. Amongst the Hindus, professional musicians form a distinct tribe or caste called Kathaks, and with these the gift or inspiration of music is supposed to be hereditary. The sitar is a favourite with amateurs. It is made from a hollow gourd. Usually it has three wire strings, whence its name, but sometimes it has six, or even nine, and is played with the first finger of the right hand alone, on which is placed a little steel wire frame, called a misrab, with which the strings are struck; the left hand stops the notes in the frets, but only those of the first string, while the other notes in the manner in which they are tuned produce a sort of pedal sound. The saringi is in appearance somewhat like a violin, and is played with a bow; the tabla is a sinall drum with only one opening, the part opposite to this being concave and made of wood. The drum rests upon the ground, the covered opening being uppermost, and is struck rapidly and sharply by the fingers. Sometimes two such drums are played by the right and left hand together. The dhol is more like an English drum; it is usually 1 foot 2 inches long, and 8 inches in diameter, but sometimes larger, with both ends covered with leather, and is played on with the hands. The tanpoora is another kind of drum, while the turri and sunkh are two varieties of trumpets.

The Muhammadans of India have the following instruments, viz. :-

Algoa, a small flageolet, a span Iong.

Banka is the Turri, with the upper piece turned from the performer, forming it into the shape of the letter $\mathrm{S}$.

Banslee, or flute.

Been or Vina, a sort of sitar, but having two dried hollow pumpkins (Cucurbita melopepo, Willd.) fixed to the end of it, with five or seven steel strings.

Chukara, a kind of violin.

Daeera, a tambourine, played upon with a stick.

Dhol, a large drum, both sides covered with leather, and played upon with the hands. D'holuk, smaller, and only one side covered with leather.

Doroo, a small double-headed hand-drum.

Duff or Duffra, the tambour de basque; tympanum, according to Gentius, Sadi Resar. Polit. p. 303. A sort of bass tambourine, played upon with a stick.

Dunka, a bass kettle-drum, middle size, between the nugara and tukkoray.

Ghugree, one or two hollow rings with pebbles in them, worn on one or both thumbs.

Goonghroo, little bells fastened round the wrists and ankles.

Keenggree has three or four pumpkins, and only two steel strings, generally used by Hindus.

Khunjuree, a small tambourine, played upon with the fingers.

Meerdung, a kind of drum which is an accompaniment to the kunchnee ka taefa.

Munjeera or Jhanjh, a kind of small cymbals in the shape of cups, struck against each other, and accompanying most bands.

Murchung, or Jew's-harp.

Murfa, a drum like a dhol, covered at both ends with leather, but played upon only on one side with a stick.

Nugara or Nakārā, a kettle-drum.

Pukhawaj, a kind of drum, a timbrel. 
Qanoon, a species of dulcimer or harp.

Qurna, a straight or curved horn, twelve feet long.

Ragmala, a piano.

Rubah, a kind of violin, a rebec.

Saringi, like a fiddle, played upon with a bow.

Shuhnaee, a clarionet, a cubit long, and having a leaf mouthpiece, commonly called Soornaee.

Sitara, sometimes it has nine or eleven steel wires, but generally three; whence its name, Si, three, and Tara, string or wire.

Sunkh, the chank shell, is the trumpet of the Hindu temples, frequently used by devotees, also as an accompaniment to the tumkee. Sometimes they play trios and quartettos on the chank shells alone.

Sur, a bass or drone to the shuhnaee.

Surod, guitar (or sitar) having catgut or silk strings.

Tabla, a couple of drums, played upon at the same time, one with each hand.

Tabul, an enormously large drum, used in the field of battle.

Tal, cymbals used by devotees, and frequently as an accompaniment to the taefa.

Tasa or Tasha-murfa, $n$ drum of a semicircular shape, played upon with two sticks, and invariably accompanied by the murfa.

Taus or Mayuri, a modern instrument formed out of the sitar and saringi, derives its name from the figure of a peacock at its base. It is generally used to accompany the female voice.

Tukkoray, kettle-drums; one is called zayr, the other bum.

Tumboora, a sitar having catgut strings instead of wire.

Tumkee, a small circular brass plate, played on with a piece of wood, having a knob at the end.

Turri or Turturi, commonly denominated by Europeans collery horn, consists of three pieces fixed into one another, of a semicircular shape.

Those in use by the Tamil musicians are drums, one of thern called malum murathangam or mathaluma; large and small flageolets; the mogoveni; cymbals; and the thoothe, somewhat like a bagpipe-this comprises the entire skin of a sheep or goat, freed of hair, and having all the openings closed, excepting two pipes of reed, one of which is inserted in the neck, and the other at one of the extremities, one to blow with, and the otber through which the air issues, producing a low, moaning sound. They sometimes have a clarionet, violin, tambourine, and guitar, but these are innovations of late introduction.

With the Burmese, the tunes Tay-dat, A-poodeik, Lon-gyin, etc., are as familiar as 'God save the Queen,' to an Englishman. The Kayah-than is of modern origin. In their acknowledged national airs it is difficult to get a definite rhythm, the music being almost invariably a mere succession of recitative.

Of the Burmese musical instruments, the chief in size and power is the patshaing, a drum harmonicon. It consists of a circular tub-like frame, about 30 inches bigh, and $4 \frac{1}{2}$ feet in diameter. This frame is formed of separate wooden staves fancifully carved, and fitting by tenon into a hoop, which keeps them in place. Round the interior of the frame are suspended vertically some 18 or 20 drums, or tom-toms, graduated in tone, and in size from about $2 \frac{1}{2}$ inches diameter up to 10 . In tuning, the tone of each drum is modified as required, by the application of a little moist clay with a sweep of the thumb in the centre of the parchment. The whole system then forms a sort of harmonicon, on which the performer, squatted in the middle, plays with the natural plectra of his fingers and palms, and with great dexterity and musical effect.

Another somewhat similar instrument has a frame about 4 feet in diameter, and 14 inches high. The player sits within the inner circle, and strikes the gongs with small drum-sticks. This instrument is one of singular sweetness and melody.

The harp of Burma is held across the lap when played, the curved horn being to the left, and the right hand passed round and over the strings, instead of being kept upright like the Welsh harp. Tasselled cords attached to the ends of the strings, and twisted round the curved head, serve for tuning. This is done by pushing them up or down, so that the curvature of the head increases or diminishes the tension. These cords are at the same time ornamental appendages to the harp. This harp is a pleasing instrument by itself, but it is usually only an accompaniment to unmelodious chants of intolerable prolixity.

Other musical instruments are the pattala harmonicon, the meegyoung harps, the puloay or pynay flutes, the patma drum, the seing-weing drum harmonicon, the Soung harp, the Wah-Jekroht castanets, and the ya-gwin and thanlwin cymbals.

The bamboo harmonicon or staccato is used throughout Burma and the Eastern Archipelago. In Java they have a number of such instruments, made in wood and metal, and only slightly differing from one another, though distinguished by different names. In that of Burma, 18 to 20 slips of bamboo, about an inch and a half broad, and of graduated length, are strung upon a double string, and suspended in a catenary over the mouth of a trough-like sounding box. The roundish side of the bamboo is uppermost, and whilst the extremities of the slips are left of their origival thickness, the middle part of each is thinned and hollowed out below. The tuning is accomplished partly by the regulating of this thinning of the middle part. The scale so formed is played with one or two drum-sticks, and the instrunent is one of very mellow and pleasing tone. Though the materials are of no value, a good old harmonicon is prized by the owner like a good old cremona, and he can rarely be inducer to part with it. Other musical instruments of Java are the bonang, kromo, and gambang.

Chinese musical instruments, -

The great bell, with the Chinese the regulator of the harmonic scale and giver of the fundamental note was used in the adjustment of weights and mea sures. In size it did not surpass the keun or standard of measure, in weight the shih or standard of Teight; the concert pitch, the measuring rod, the standard of capacity, were all derived from this.

Cha-keo or horn consists of a stem and a crook expanding into a bell. There are two kinds, a larger and smaller; both utter grave sounds.

Chih-teih, or in the Canton dialect teem-tek, often called sew, is the flute or vocal reed in its most primitive form. It is pierced with five holes.

Haou-tung, sometimes called heang-teik, on the principle of the trombone. It is made of thin copper, a conical bell with a ball at the top.

Kin-chin, the scholar's lute, was the instrument played upon by Confucius and ancient scholars, and is held sacred by men of letters. It is made from the woo-tung wood, Dryandria cordifolia. The strings are of silk.

Koo or drum, the ta-koo or big drum, resembles a kettle-drum. The King-foo or pillar-drum. The Yung, a smaller kind of pillar-drum. Pe-koo or low drum, with its yoke-fellow in a chorus called the Pang-koo.

Lo, the gong of the Javanese, of two kinds, both round, 
one large and flat, used on shipboard at eventide in place of prayer and praise.

Pepa, the balloon-shaped guitar, made of woo-tung. It corresponds exactly to the harp of Pythagoras in the outline.

Sang, a collection of tubes of varied length so as to utter sounds at barmonic intervals with each other. There are two kinds, one called chaou or bird's nest, the other ho or sweet concord.

San-heen, three-stringed guitar, is made of the swanche wood, covered with the skin of the tan-snake. It is played as an accompaniment to the pepa.

Urh-heen, the two-stringed:fiddle, the rebec of the Chinese, a very cheap instrument, on the principle of the violin, but consists of a stick of bamboo passing through a hollow cylinder of the same material.

Yue-kin, or Full Moon guitar, with four strings, is made of the swan-che wood, and has a perfectly circular body ; it is never varnished.

Japanese musical instruments are the ko-to, ko-yu, and sa-mi-sen.-Sir W. Jones, As. Res.

MUSICAL FISH, or Drum Fish, a sea fish near the Pearl River near Macao. Every evening they assemble around a ship and continue their musical humming till about midnight. The noise rises and falls, or suddenly ceases at times, as they quit the ship in search of food.

Dr. Buist, writing in the Bumbay Times of January 1847, mentioned that a party, while crossing from the promontory in Salsette called the Neat's Tongue to near Sewree, about sunset, heard long distinct sounds like a long-drawn-out musical note, and the boatmen intimated that the sounds were produced by fish abounding in the muddy creeks aud shoals around Bombay and Salsette. The boatmen next day produced specimens of the fish, a creature closely resembling in size and shape the fresh-water perch of the north of Europe. It is supposed that the fish are confined to particular localities,-shallows, estuaries, and muddy creeks. 'The Bombay Times of 13 th February 1849 contained a communication from Vizagapatam relative to 'musical sounds like the prolonged notes on the harp ' having been heard to proceed from under water at that station. Several fish utter sounds.-Adams, p. 63. MUSIRIS, a port known to the Greeks on the coast of Malabar, probably Mangalore. It is alluded to in the Periplus of the Erythræan Sea (supposed to have been written by Arrian, to whom we are indebted for the earliest mention of the peninsula of the Dekhan); and we are informed of Hippalus, the commander of a vessel in the Indian trade, having the hardihood to stretch out to sea, from the mouth of the Arabian Gulf, and practically test the more theoretical observations of his predecessors. This experiment was successful, and he found himself carried by the south-west monsoon to Musiris. This bold adventure gained for him the honour of having his name attached to the wind by which he was enabled to perform this novel voyage.-Ind. in 15th Century.

\section{MUSK.}

Kado

shie-hiang,

Kasturi,

Burm. | D'ed'es, Rasi, . MALay.

Musk of commerce is a secretion of the muskdeer, the Moschus moschiferus of the Himalaya, Siberia, Tonquin, and Cochin-China. In the year $1879-80$, India exported 3224 ounces, value 90,039 rupees.

The musk-bag is at the end of the renis. globular, about $1 \frac{1}{2}$ inches in diameter, and hairy, with a hole in the centre about the size of a lead pencil, from which the secretion can be squeezed. The orifice of the urethra lies near this, a little posteriorly. Round the margin of the opening of the gland is a circle of small glandular-looking bodies. In the living musk-deer the musk has the consistence of honey, is of a brownish-red colour, and has a strong odour. When dry, this musk is almost solid, granular, and of a darkbrown colour. It feels unctuous and fatty, has a bitter aromatic taste, and its smell is powerful. Good musk is in irregular, nnctuous, light, dry, reddish-black, or dark-purple grains, concreted in a slightly oval bag, about $1 \frac{1}{2}$ inches in diameter, hairy on one side and not on the other. They weigh from 200 to 250 grains a-piece. The small dark bags with the greyish hairs arranged evenly around the centre are the best.

The trace when rubbed on paper is a lively yellow, and no grittiness is felt or, residue left. It is sometimes adulterated with dried blood or catechu. If the former be present, agitation with distilled water will often form a solution, coagulated by heat. The latter is detected by adding a solution of muriate of iron to the water in which the musk was diffused. A deep black colour is produced if catechu be present. Globules of lead are often fraudulently introduced into the sacs; the best test is the strength of the alcoholic solution.

Three other deer are said to yield musk, viz. the Napu or Moschus Javanicus, Raffes, found in the woods of Java and Sumatra; the Kranchil or M. Kranchil, Raffles; and the Chevrotain of the Altai, the M. Altaicus, Esch.-Sinith's M. M. C.

MUSK-MELON, Cucumis melo; Musk-okro or Musk-bibiscus; Abelmoschus moschatus; Musk shrew, Sorex cærulescens, Shau:

MUSK-RAT of Canada is the Ondatra Americana, Tiedemann; Castor Zibethicus, Linn.; Fiber Zithicus, Cuv.; Ondatra, Lacep.; the musquash of the Cree Indians, little beaver. The tails of the ondatra form a considerable article of import into India, being regarded by some races as aphrodisiac. The tails are covered with a thin sleek coat of short hairs, have a pleasing odour of musk, and are greatly prized in Russia and the Maldive Islands. The musquash is easily tamed, soon becomes attached, and is cleauly and playful. There are three varieties, the black, the pied, and the white.-Eng. Cyc.

MUSK-ROO'T is the root of the Euryangium sumbal, Kaufman, a plant of Central Asia, and brought to England from Russia and Persia. The root exhales a powerful smell of musk, and has been used in medicine as a substitute for that substauce. Its tissues are full of starch.-Eng. Cyc.

MUSK-TVOD of Tasmania and New South Wales (Eurybia argophylla, Cass.) is close-grained, and takes a good polish; it is useful in cabinetwork.

MUSLI. HIND, Medicinal substances in use among the Indian practitioners. They are roots, and supposed of several plants. There were three sorts represented in the Panjab Exhibition. Musli sembal from Bombax heptaphyllum, Musii safaid, apparently an immature specimen of satawar (Asparagus adscendens), and Musli siah. Musli sembal was a light, woody, fibrous root of a 021 
brownish colour, with thin epidermis, easily detached, and a very fibrous thick tuber. It acts as a stimulant and tonic, and some consider it in large doses emetic.

White musli.

Safed musli, . . HIND. Tannir-vittang.

Tsullaghedalu, : TEL. $\mid$ kalangu, .

TAY.

The root is long, fleshy, and whitish; is used powdered in the form of a thick mucilage with water, and answers admirably as a nutritious demulcent for convalescents. It is supposed, when taken in this form, to have the effect of filling the small-pox, and preventing the confluent disease. Asparagus sarmentosus root is offered for sale as the white musli, which is said to be the rootlets of Salmalia Malabarica. It was supposed by Ainslie to be from Curculigo orchioides. Birdwood thinks it is from Murdannia scapiflora, Royle, or from a species of Tradescantia. The Asparagus filicinus and Aneilema tuberosa are also named.

Black musli

Tal muli,

Kali musli,

BENG. Warahi musali, . SANsk. . Hind. Nelepanny kalangu, Tar. Siah musli, . PERS. Nalla taty gudda, TEL.

is a tuberous and wrinkled root about four inches long, slightly bitter and mucilaginous to the taste, and reckoned among those medicines which purify the blood; it also possesses tonic properties; is considered stimulant, and used as an aphrodisiac. It is procurable in most bazars throughout India. Musli siah is supposed to be the product of Curculigo brevifolia and C. nigra?-Ainslie; Royle; Irvine; Birdwood; Powell.

MUSLIM. ARAB. A follower of the Islam faith, a Muhammadan. Its plural form is Muslimin. Muslim and Nas-Muslim are applied in India to a convert to that faith.

\section{MUSLIN.}

Neteldoek, . . Dut. Moussolina, . . . IT. Mousseline, : :Fr. Sana sella, : 'PoL. Musselin, . . GER. Kissea, . . Rus. Nesseltuch, : : ", Moselina, : . . SP. Malmal, Saila, : HuNo.

A fine cotton fabric, extensively manufactured in India, in Europe, and America. There are in commerce a great variety of kinds and qualities, as book-muslin, cambric - muslin, mull-muslin, etc. Until the middle of the 19 th century, from the earliest times India was famed for the delicacy of its cotton fabrics. The work of its looms was of a splendour unknown to European weavers. The gold and white, gold and purple, white and silver muslins, for colour, taste, and delicacy of arrangement, were artistic triumphs. Some of them, of gossamer transparency, were used for the dresses of the Indian princes, and of their families.

After the conquests of Alexander, Greek art undoubtedly exercised an influence on oriental architecture and sculpture, perhaps on oriental imagery generally, more particularly that of Persia. But the Indian textile splendours are of oriental origin, and the Greeks adopted the beautiful combinations and fabrics after they got a hold on Asia Minor; and as imperial Rome adopted the arts of Greece, and absorbed every clement of luxury that the world could offer, the light and transparent textiles of India found their way to the wardrobes of the patricians, and the

way in which men as well as women adopted such transparent draperies in open day became a theme for the strictures of moral writers of thetime.

The muslins made in Dacca in Bengal, and Arnee in Chingleput, were long celebrated, Dacca especially, for its webs of woven wind employed thousands of hands; but it was with great difficulty that the specimens of the fabrics sent to the Great Exhibition of 1851 were procured. The kind of cotton (which is very short in the staple) employed was little grown, and scarcely a loom then existed which was fit for the finest fabrics. Dacca muslin was made from cotton grown in the vicinity, the thread from which does not swell.

Chicacole and Upada, a few miles north of Cocanada, formerly produced fine muslins.

At Maderpak in N. Arcot, the thread used in weaving muslin of the finest kind is spun from a peculiar kind of cotton, known by the vernacular name of $\mathrm{Pu} P$ arthi. The weavers purchase this thread ready spun from a colony of Pariahs who have settled in the neighbourhood, and who have the speciality of its preparation. After the cotton is carefully cleaned and picked, it is laid by in cloth bundles for two or three years, when it is rolled in plantain bark and then wound off.

For the exceedingly fine Dacca muslins, the Ab-rawan or running water, and Shab-nam or night-dew, there is now no demand. The native nobility of India do not patronize the finest sort, and there is no market for them elsewhere. In 1862 there was only a single family of weavers in Dacca who could manufacture the very finest quality; and it took them six months to make up one piece, but even for this piece they got no orders. Besides, the particular kind of cotton, supposed to be finer than the finest New Orleans staple, from which alone the thread was spun, is now never grown. The principal varieties of muslins manufactured at Dacca are Malmal Khas, Ab-rawan, Shab-nam, Khasa, Jhuna Circar Ali, Tan-zeb, Alabullee, Nynsook, Buddun Khas, Turandam, Sarbuti, and Sarbund,-names which denote fineness, beauty, or transparency of texture, or the uses to which they are put. There were exhibited also-

\section{Charkhana.}

Junglelchassa.

Striped or Dooria.

Spotted or Bootee.

Jamdanee, figured

muslin.

The famous Arnee muslins, of which bookmuslins are an imitation, are prepared at Arnee in the Chingleput district. They sell according to quality. At the 1851 and 1862 Exhibitions, Dacca muslins stood successful in comparison with those of Europe, and the Industrial Museum at London had a piece 20 yards $\times 1$ yard, weighing only $7 \frac{1}{2} \mathrm{oz}$. An excellent specimen of Dacca manufacture, shown in 1851, proved to be of No. $357 \mathrm{~s}$. yarn, and that of $1862,380 \mathrm{~s}$. Some machinemade muslin in the 1851 and 1862 Exhibitions was superior in point of fineness, according to the mode of computation adopted.

MUSS ENDA CORYMBOSA.Roxb. A small tree of Sylhet, Malabar, and Ceylon, with middlesized bright orange flowers. Its white floral leaves are sometimes eaten.-Roxb.; Voigt. 
MUSS无NDA FRONDOSA. Linn.

M. flavescens, Roxb.

Sarwad, . . Bombay.| Bebina, . . . Hind. Bhooteasse, . . , Belila, . ' MALEAt. Sanchout, . . , $\mid$ Vella-ellay,. . . TAM.

Grows in most parts of British India, Nepal, and Ceylon. Its white leaf contrasts with its deep golden-coloured flower. There are many varieties of it. Its root and the juice of its leaves and fruit are used in native medicine.$R o x b$.

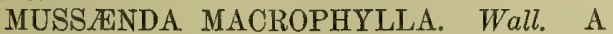
plant of Nepal with deep orange flowers. Dr. Mason notices, under the name of M. Wallichii, a species with corymbs of orange-coloured flowers, and a single sepal expanded into a large white leaf. It is abundant in Tenasserim forests. In Calcutta an allied species is cultivated in the gardens.-Roxb. i. p. 556 ; Mason; Voigt.

MUSSELS are molluscous animals, of the family Mytilidæ. Mussels are caught in small cylindrical basket traps, attached to a single rope, and floated with the tide near the bottom.

MUSSOI, a medicinal bark of the Archipelago, largely an article of trade.

MUSSOORI or Masuri, a town and sanatorium in the Dehra Doon district of the N.W. Provinces of India, in lat. $30^{\circ} 27^{\prime} 30^{\prime \prime} \mathrm{N}$., long. $78^{\circ} 6^{\prime} 30^{\prime \prime}$ E. It stands on the crest of a Himalayan peak, among beautiful and varied mountain scenery, and forms practically one station with Landaur. Elevation above sea-level, 7433 feet. It has many visitors during the summer months, but contains a large number of permanent residents. The thermometer has a range from $27^{\circ}$ to $80^{\circ}$.

Banog, a hill to the west, has been ascertained to be 7545 feet above the sea. The river Jumna flows around the northern face of Banog, and Badray bounds Mussoori on the west. Mussoori houses are built upon heights varying from 6400 to 7200 feet. The view of the Snowy Mountains to the north, and of the valley of the Dhoon, spread out like a painted map at the foot of the hill to the south, is greatly admired. The rains set in in June, cease on or before the 18th of September, and are succeeded by an agreeable season, which lasts till Christmas, and sometimes till the middle or end of January. The temperature gradually sinks from $64^{\circ}$ in the shade, in the begioning of October, into that of sharp winter, the frost becoming strong in the course of November. In January and February the weather is wintry, always with frost more or less intense, and occasional falls of snow.

MUSSULMAN. ARab. Properly Musalmin, a person of the Muhammadan religion; it is the plural form of the Arabic Muslim. A woman is called Mussulmani, and the creed Islam. There are in British India about $50,121,585$ of this faith, many of Arab, Persian, and Moghul descent, with many converts from Hinduism, however, particularly in Lower and Eastern Bengal. A large portion of the people of Turkey in Europe, most of the people of Northern Africa, the majority of those of Turkey in Asia, Arabia, Central and Southern Asia up to the Indus river, a fourth part of the population of British India and Ceylon, with a sprinkling in Sumatra, the Archipelago, and China, are of this faith. They are chiefly of two sects, Sunni and Shiah, Arabia, Syria, Asiatic Turkey, Central Asia, Egypt, and Af- ghanistan are largely Sunni. In European Turkey the Muhammadans form about a sixth part of the population. The Afghans are Mussulmans chiefly of the Sunni sect. The Parsivan and Aimak, who are subject to the Afghans, profess the Shiah form of Islam, but some of them are Ali-Illahi. Mussulman sects are numerous, one of them is the Wahabee. The Wahabee calls himself a Muwahhid or Unitarian, in opposition to Musbrik-Polytheist, - any other sect but his own. The founder of this sect was Abdul Wahab, a native of Aijaene, a town in the district of ElAred. This man in his youth first studied at home those sciences which are chiefly cultivated in Arabia. He afterwards spent some time at Basra, and made several journeys to Baghdad and through Persia. After his return to his native place, he propagated his opinions among bis countrymen, and succeeded in converting several independent Shaikhs, whose subjects consequently became followers of this leader.Ferrier's Afghans; Jahan Numa, 523; Wellsted's Tr.; Burton's Mecca; Niebuhr's Tr.; Palgrave.

MUST. Hind. Mudda, Singh. A period of great excitement to which male elephants are subject in the rutting season, and during which it is not safe even for the mahout or driver to approach them.

MUSTAGH, a name of the Kouen Lun mountain chain. Aksu, a city of Chinese Tartary, lies to the south of the glacier pass over the Mustagh, in lat. $78^{\circ} 58^{\prime} \mathrm{N}$., long. $41^{\circ} 9^{\prime} \mathrm{E}$. It contained 1200 houses. It stands at the confluence of the rivers Aksu (white water) and Kokshal. It is the central point of the Chinese trade, and from it diverge all the great routes towards China, the Ili country, and the cities both of Eastern and Western Turkestan.-Yule, Cathay, ii. p. 572. MUSTARD SEED.

Khardal, . . ARAB. | Sirshaff, . . . Pers, Kung-nyen, : : BURM. Sirsun, Rajika, 'SANSK. Kadi-tsai, . . CHIN. Gan-aba,. . . SINGH.

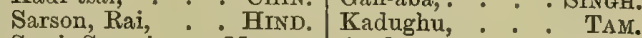
Sawi, Sasavi, : MaLAY. Avalu, : : TEL.

Mustard is from the two Latin words, Mustum and Ardens, and is in varied forms in European tongues. Black mustard is indigenous in almost every part of Europe and S. Asia; its seeds are small and roundish. A mustard seed was the Buddhist unit of long measure. Mustard seed is used as a condiment. The seeds are crushed between rollers, and then pounded in mortars and sifted. The residue in the sieve is called dressings or siftings; what passes through by a secoud sifting yields pure flour of mustard; by pressure, the dressings yield a fixed oil, which is used for mixing with rape and other oils. Immense quantities of wheaten flour are employed in the adulteration of mustard.

Mustard oil is expressed in various parts of India from the seeds of different species of Sinapis, especially from the black mustard seed. S. glauca, S. bichotoma, S. toria, S. racemosa, and S. juncea are also extensively cultivated in the east for their oil, and S. alba, S. arvensis, S. nigra are also grown. The oil is used in most parts of India in cookery, and is considered superior to all other oils for anointing the body, which it is supposed to invigorate. The seeds of the $\mathrm{S}$. alba yield by expression 36 per cent. of a bright yellow, pleasant-tasted, edible oil, having a strong 
smell and slight taste of mustard. The seeds of S. nigra yield only 28 per cent. of an oil in all respects similar to the above.

MUSTARD TREE of Scripture, according to Dr. Royle, is the Salvadora Persica, a native of the East Indies. But this is not generally accepted.

MUSTELID王, a family of mammals belonging to the tribe Semi-plantigrada. They include the weasels and martens; and in S.E. Asia there are about five known species of the former, and twelve of the lattcr. See Mammals, p. 8:8.

MUSTER. ANGLo-Indian. A pattern, from Portuguese Mostro.

MUSTIKA, an amulet, which amongst the Malays of Java is always some very scarce substance, and is worn about the person to act as a talisman and ward off evil. The Mustika Kerbo or buffalo amulct is quite white, and round like marble, nearly an inch in diameter, and semitransparent; it is stated to be found at Panggul. The Mustika Waringin, a calcareous concretion, is found at Ngadi Rejo; it is quite black, and a little smaller than the Mustika Kerbo. Amulets are, however, worn by almost all eastern nations. They are especially prized by Mubammadaus, and both young and old wear them. They-are usually put on the young to ward off disease and to protect from the evil eye, and consist of figures with numbers on pieces of paper, or Arabic words, often extracts from the Koran, engraved on potstone or silver or gold, and worn from the neck. They are also put over the door porch, or on the house wall.-Jour. Ind. Archip., 1853.

MUSTUNG, an extensive valley of Baluchistan, to the south of the valleys of Quetta and Kanhee. It extends from about lat. $29^{\circ} 30^{\prime}$ to near $30^{\circ} \mathrm{N}$., and its eastern boundary is nearly defined by the $67^{\circ}$ of E. long. It is therefore about 40 miles in length, and varies in breadth from 5 to 8 miles, spreading out towards its upper end, and being gradually constricted towards its lower or southern extrenity. It is bounded by parallel ranges running N.N.E. by S.S.W., of height from 500 to 800 feet. The range to the eastward is pierced by a pass leading to the Dasht-i-be-Daulat. Mustung has a healthy climate and fertile soil. It contains no Afghans; the fixed inhabitants are Delswar, mixed with the Raisani, Sherwani, Muhammad Shahi, Baugulzai, Lari, and Sirpherra tribes of Brahui. The Bangulzai exclusively occupy Isprinji, but reside also at Shal and Mustung, and in winter repair to Talli near Lehri.

MU-SUH or Muk-suk. PERs. Sweet clover or lucerne, upon which the horses of Farghana were pastured.

MUT, also Muter, Hind., Carex Indica, grows at a great altitude; is used to form those parts of the suow-shoes in Pangi and Lahoul which are most liable to be torn.-Povell, Handbook, i. 521.

MUTA. HrND. Muhammadans of the Shiah sect marry by the Muta form. This may be for a mutually recognised temporary period, or a permanent marriage with a person of inferior rank in life.

MUTARFA. ARAB. A tax in the Madras Presidency on houses, trades, and professions. It was abolished 5th November 1856 . In 1848, discriminating duties on goods carried in foreign vessels were abolished, and in 1850 the coasting trade was thrown open to all nations.
MUTAWALI. ARAB. The trustee of any religious building, a trustee of a mosque.

MUTHI. HIND. A handful, a right granted to religieuses to take a handful at harvest.

MUTHIA THUG, a class of Thugs who resided chiefly in Rajpur and Dinajpur, usually following the business of weavers, said to be so termed from giving their leaders a handful (Muthi) of rupees from each man's share, in addition to their own.

MUTH-THU or Mut'ha, 'TAM., TEL., incorrectly written Mutah and Mootah, the subdivision of a district; in the Northern Circars, a large estate, including several villages, and corresponding with a zamindari in Bengal.

MUTHUNKA PIILOO. TAM. Grass corn. It grows wild, but was first cultivated in Chittur by Miss Pereira. It produces abundantly, and the grain is cooked in the same way as paddy and ragi. $-M, E . J . R$.

MUTHYAN-jo-ZOR, a popular exercise in Sind, of placing the fists on the ground, and raising up a boy or a man who stands upon them. Chambo Wathan, another feat, consists of interlacing the fingers, and trying to disengage them from the grasp of the adversary. Pera to Uthan, squatting on the hams, lifting one leg off the ground, and then slowly rising up by means of the other; no easy task. Kakk Khanan, here the gymnast, in the squatting position with both arms behind the back, picks up with the lips a bit of straw placed on the ground before him. Burton's scinde, p. 290.

MUTIALAMMA, one of the non-Hindu goddesses of the Peninsula of India. See Ammun; Hindu.

MUTILLA ANTIGUENSIS. Linn. Mutilla occidentalis, the Beer buti, is a beautiful scarlet velvet coloured insect, about the size of a large pea, commonly found in rainy weather throughout British India. These insects are kept by the druggists, and native doctors use them against snake-bites, and in colic of horses. The family Mutillidx is a genus of insects of the order Hymenoptera, comprising two genera, Mutilla and Tiphia.-Honigberger. See Insects.

MUTINY has occurred amongst the British Indian army on several occasions. In January 1766, double batta was abolished. It had been granted to the E. I. Company's army by Mir Jafar, in gratitude for their services. But on its abolition both officers and men mutinied, and it was only put down in fifteen days by the severe measures which Clive adopted.

In May 1764, Major (afterwards Sir Hector) Munro, on joining the army at Patna, found the European and Native soldiers extremely mutinous, and, on part of them deserting to the enemy, they were overtaken and brought back, and 24 of them blown away from guns. On that occasion four of the grenadiers stepped forward, and begged, as they had always had the post of honour, to be allowed to be fixist blown away.

In 1795, the European ofticers of the Bengal army broke out into open rebellion. Its cause was Lord Cornwallis' abolition of all oflices of gain in the military branch of the service. The revolt was settled by the concession which Sir John Shore made to them.

Disaffection sprang up amongst the European officers of the Madras amy, in the early 
part of the 19 th century, with whom a few regiments of sepoys sympathized, but it was quickly subdued.

In 1806, the native soldiers in the garrison of Vellore mutinied and massacred all their officers and the other Europeans, but in the early part of the same day, Colonel Gillespie galloped from Arcot and suppressed the rising. After the fall of Seringapatar in 1799, the family of Tipu Sultan were detained at Vellore, but, as they were supposed to have instigated the revolt, they were removed to Bengal.

On the 1st November 1824, a mutiny occurred at Barrackpur in the 47th Regiment Bengal Native Infantry, part of the 26th and $62 \mathrm{~d}$ Regiments, when ordered to Burma. The commander-in-chief ordered them to be fired upon by artillery, attacked by the cavalry of the body-guard and British troops, and 440 of them were destroyed. Their ostensible grievance was that they could not obtain cattle for carriage, and that they ought to receive double batta when proceeding to Burma.

In 1857 the greater part of the native army of Bengal and several regiments of the Bombay army revolted. The first signs occurred near Calcutta, but the revolt continued by the outbreak of the native cavalry at Meerut on the 10th May 1857, and before the end of 1858 nearly all the Bengal army was swept away; but before this could be done, many of the predatory tribes and numbers of the civil population engaged in the rising, and a rebellion of nearly all Upper India was the result.

This revolt has been described by many writers, but chiefly by Sir John Kaye, who wrote a History of the Sepoy War, also by Colonel Malleson in his History of the Indian Mutiny, and by Mr. T. R. C. Holmes in his History of the Indian Mutiny, and of the disturbances which accompanied it among the civil population. The first overt acts were shown at Barrackpur, where the native soldiery planued to burn the houses, and then proceed to Calcutta to seize the fortress there, and take possession of the treasury.

The 19th Regiment sepoys refused to take the percussion-caps that were served out to them, and they were at once disbanded. The disgraced soldiers brought their colours to the front, piled their arms, stripped off their accoutrements, and, retaining their uniforms and taking their pay, marched off under an escort to Chinsurah, cheering as they went. A few days after, a sepoy of the 34th Bengal Native army, named Mungal Pandy, cut down his officer in the presence of the guard, without a finger being uplifted to prevent him.

At Meerut, on the 10th May, the sepoys broke into open mutiny. They threw open the jail, rushed through the cantonment, cutting down every European whom they met, and streamed off to stir up the native soldiery at Dehli. A rallying centre was given to the revolt by the possession of this historical city, and ali that the Europeans could do before leaving Dehli was to blow up the arsenal. Throughout the cantonments of the N.W. Provinces of British India the sepoys revolted, usually without warning, sometimes after protestations of fidelity. The Europeans were massacred, occasionally also the women and children. The jails were broken open, and the mutineers marched to the centres of the revolt. In the Panjab, Sir John (Lord) Lawrence and his civil and military officers, Montgomery, Macleod, Edwards, Nicholson, repressed and disarmed the sepoys serving there, but the Sikhs and Afghans remained loyal, and furnished an army for the recovery of Dehli.

The population of Oudh and Rohilkhand rose en masse, and with the soldiery occupied Sir Colin Camplell through two campaigns. The nawab of Bareilly and the begum of Oudh joined the mutineers. The crisis here was prolonged. But the centres of the conflict were at Dehli, Cawnpur, and Lucknow. The Cawnpur troops mutinied on the 6th June, and Dandhu Punt, the adopted son of Peshwa Baji Rao, styled Nana Rao and Nana Sahib, was proclaimed Peshwa of the Mahrattas. The Europeans, trusting a safe conduct from Dandbu Punt as far as Allababad, evacuated Cawnpur, but all but a single boat's crew were destroyed; and on the 15th July, when General Havelock's army was near, 125 women and children were cruelly massacred.

The siege of Dehli began on the 8th June 1857. The rebels were 30,000 strong, and the British army never exceeded 8000 men. On the 14th September the assadult was delivered. A little party of 2 lieutenants, 2 sergeants, a corporal, a bugler, 14 native and 10 Panjab sappers and miners, in broad daylight, under a shower of bullets from every loop-hole and from the wicket-gate in front of them, went forward with powder bags to blow up the Kashmir gate. Their destruction seemed certain, but with the loss of two, who were killed, and four wounded, one mortally, they accomplished their object, which is one of the noblest deeds on record in military history. Dehli was then entered in four columns of assault, but not until five days were the whole of the defences taken.

From the 14th to the 17 th of September, the church, the cutcherry, the college, the kotwalli, the magazine, and the Dehli Bank house were one after the otber carried and recovered. On the 18th the line of communication between the magazine and the Kābul gate was completed. On the 19th the Burn bastion, near the Lahore gate, was taken possession of by a surprise.

The old king of Dehli, Suraj-ud-Din Hyder Shah, Ghazi, and two of his sons, were captured, and the two latter shot by Captain Hodson of the Bengal army; while the king, who on the 11th May 1857 had proclaimed himself emperor of India, was sent prisoner to Rangoon, where be died in 1862. The mutineers who fled from Dehli moved upon Agra in a formidable-mass, followed by a flying column under Colonel Greathed, who defeated a body of them at Bulundshahr, destroyed the fort of Malagarh, and scattered a body at Aligarh. Finally, Lucknow was relieved, and its garrison strengthened by Sir James Outram and General Havelock, until, in the month of March 1858, Sir Colin Campbell advanced on that city, after severe fighting, and made himself master of the southeastern suburbs, inflicting great loss on the mutineers, 2000 of them having fallen at the fight at the walled garden called the Sekundar Bagh. On the 2d July, Sir Henry Lawrence, Commissioner of Oudl, had occupied the Residency at Lucknow, and two days later he was mortally 
wounded by a shell. The garrison was relieved on the 25th September by Havelock and Outram, but it was re-invested by fresh swarms of rebels, till Sir Colin Campbell (Lord Clyde) withdrew the garrison, 16th November 1857, and Lucknow was again re-occupied in March 1858.

Sir Hugh Rose (Lord Strathnairn), with an army from Bombay, fought his way from the Southern Mahratta country to Central India. Among his opponents were the rani of Jhansi and Tantia Topi; the former died fighting at the head of her troops in June 1858.

When the rebellion in Central India was extinguished, when Saugor was relieved; and Ratgarh as well as Shahgarh captured, and when Chanderee, Kalpee, and Jhansi had fallen, and Gwalior re-occupied by its chief, the maharaja Sindia restored to his capital, and with the final relief of Lucknow, the mutiny may be said to have been extinguished. On the 30th November 1858 the last body of rebels surrendered or passed the Nepal frontier. The last who made a stand was Dandhu Punt, Nana Rao. He was surprised and attacked in the vicinity of Bankee, and was driven through a jungle, which he tried to defend, and finally into and across the Rapti, from which date he has not been heard of.

The Indian Mutiny is one of the greatest dramas in the history of the world. Rome in all her might never contended with a greater peril, nor was ever arrayed against a mightier host. The successful manner in which the British met and sustained it will ever be quoted to the renown and glory of the military successes of Great Britain. The contest for supremacy was severe and long continued.

In May 1857 there were in India 45,000 European soldiers, 244,000 native soldiers, and 80,000 semi-military police.

About 250,000 native soldiery were arrayed against the British power in 1857. Of the British forces were 45,000 Europeans, and about 60,000 reliable native soldiery. These last were, before the end of 1857 , increased to about 150,000 native soldiers, by the addition of the Sikh army fram the Panjab, and before July 1858 there were over 80,000 British soldiers in India. After that revolt the native army began to be reduced, and by November 1866 it fell to 135,000 men, with only 12 guns, against 150 in 1857 .

Claims were advanced by the European soldiers of the E. I. Company's army on the 2d May 1859, which resulted in about 10,000 soldiers taking their discharge. They had been enlisted to serve the E. I. Company, and when, in 1858, India was attached to the British sovereign, they claimed that the agreement was annulled, and this view was admitted to be correct.-Oriental Herald, 1825.

MUTLAH RIVER is a branch of the Ganges next to the eastward, and second in importance to the Hoogly branch. Canning town was attempted to be built there.

MUTTRA or Mathura, in lat. $27^{\circ} 30^{\prime} 13^{\prime \prime} \mathrm{N}$., and long. $77^{\circ} 43^{\prime} 45^{\prime \prime} \mathrm{E}$., the beadquarters town of a district in the N.W. Provinces of British India. The town is on the right or western bank of the Jumna. The district comprises an irregular strip of territory lying on either side of the river. The central portion of the district for $84 \cos$ around Gokal and Brindaban is called Brij
Mandal. It is one of the most sacred spots in the mythology of the Hindus of the earliest Aryan times, connected with the towns of Govardhan, Gokal, Mahaban, and Brindaban. It was here that Krishna and Bala Rama pastured their herds. It is famous in the legendary history of Krishna as the stronghold of his enemy raja Kansa; and it is noticed by Arrian, on the authority of Megasthenes, as the capital of the Suraseni. Surasena was the grandfather of Krishna, and from him Krishna and his descendants, who held Mathura after the death of Kansa, were called the Suraseni. Arrian says the Suraseni possessed two great cities, Methora and Klisobora, and the navigable river Jobares flowed through their territories. Pliny names this river Jomanes, that is, the Jumna, and says that it passed between the towns of Methora and Klisobora. Ptolemy mentions only Mathura, under the form of Modura, Modoúpa, to which he

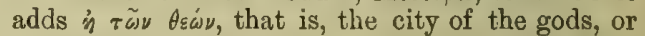
holy city.

The Greeks are said to have seen the Hindus worship Bacchus in ancient Methora. This may possibly refer to a Greek-clad statue, which, with his portly carcase, drunken lassitude, and vinewreathed forehead, is considered to be the wellknown wine-bibbing Silenus. The statue was discovered along with a Bacchic altar in 1836. Any Buddhist or Greek god has long ceased to be worshipped in Muttra. The most farourite local deity now is Krishna, who is adored in nearly all the temples, abounding in the town which owns his exclusive jurisdiction. Taking Muttra as a centre, the circle described by a radius of 84 miles would give the extent of ancient Vrij, the seat of all that was refined in Hinduism, and the language of which, Vrij-boli, was the purest and the most melodious dialect of India. In all Vrij the most classic spot is Briudaban. As the birthplace of Krishna, Muttra is as sacred to the Vishnavites as Bethlehem is to the Christians. The most sacred spot in all Muttra is the Bisramghat, where Krishna and Baldeo rested from their labours of slaying Kansa, and dragging his corpse to the river side. At the Bisramghat is annually held a great bathing mela or assembly, called Jumna-ki-Burki, on which occision the gathering of men from near and remote parts of India exceeds more than 100,000 . To the Chowbay race the occasion proves a great harvest of gain. The pittances offered to the images of Krishna and Baldeo at the ghat sometimes amount to 30,000 or 40,000 rupees.

During the Buddhist period Muttra became a centre of that faith. In Hiwen Thsang's time there were only five Brahmanical temples in Muttra; in the middle of the 19 th century there was only one Jain temple in Brindaban. $\mathrm{Fa}$ Hian and his companions halted at Muttra for a whole month, during which time the Buddhist clergy held a great assembly, and discoursed upon the law. After the meeting they proceeded to the stupa of Sariputra, to which they made an offering of all sorts of perfumes, and before which they kept lamps burning the whole night. In Hiwen Thsang's time the number of towers and monasteries was the same, but that of the monks had been reduced to 2000 . The king and his ministers were all zealous Buddhists. In the 7th century Muttra was the capital of a large kingdom, which is said to bave been $5000 \mathrm{li}$, or 
833 miles, in circuit. After the invasion of Mahmud of Ghazni, Muttra city fell into insignificance. During the 18th century the district was held by the Jat of Bhurtpur, but in 1757 , during Ahmad Shah's invasion, Sirdar Jahan Khan plundered the city, and massacred all the inbabitants. The principal surviving edifices include the Sati-burj (or Tower of the Faithful Widow), built by raja Bhagwan Das in 1570 . The city is surrounded by numbers of high mounds, the remains of extensive buildings, which, having been dug over for ages in search of bricks, are now mere heaps of brick-dust and broken bricks. Contiguous to Muttra are those great sandstone quarries, which for ages have furnished materials to the architects of Upper India for building the houses, shops, temples, and ghats of its principal cities. In Muttra the ghats are light and graceful; in Benares they are severe and simple.-Cunningham's Ancient Geography of India, p. 373 ; Tr. of Hind. ii. p. 22.

MUTTUK, also called Moran, also Mowa Moria, are tribes in Upper Assam, subject to a chief styled Bar Senapati. The Muttuk dwell N.E. of the Singpho, to the S. of the Lohit or Brahmaputra. They are a branch of the Singpho group, the others being the Singpho and Khamti. The Bar Senapati in May 1826 acknowledged the supremacy of the British, and bound himself to supply 300 soldiers in time of war. The management of the country was left in his own hands, except as regards capital offences. In January 1835 the obligation to supply troops was commuted to a money payment of Rs. 1800 a year. In 1826 similar agreements were made with the Khamti chief of Suddeya, but in 1839 they attacked the town of Suddeya, and many persons, as also Colonel White, the Political Agent, were slain. Agreements were also made in May 1836 with the Singpho tribes who were implicated in the Khamti rising in 1839 , but they were allowed to surrender under conditions. Many of the Singpho clans have become extinct, and the main body have left Assam for Hukong-in Upper Burma.-Aitcheson's Treaties, etc.

MUTUWAKKAL is the title of the tenth khalif of the house of Abbas. His name was Abu-1-Fazal Jafar. He became khalif A.D. 847 , A.H. 232. Mutuwakkal was very intolerant, especially towards Jews and Christians, but he also forbade the pilgrimage to Karbala, and razed the graves there of Husain and the other martyrs.

MUZAFFARGHAR, a small town in the Multan division of the Panjab, built on the right bank of the Chenab, in lat. $30^{\circ} 4^{\prime} 30^{\prime \prime} \mathrm{N}$., and long. $71^{\circ} 14^{\prime} \mathrm{E}$. The district occupies the extreme southern aspect of the Sagor Doab, and has an area of 2954 square miles, and a population of 295,547 souls, mostly Muhammadans, with Arora, Brahmans, Baluch, Jat, Pathan, Rajput, and Sikhs. MUZAFFARNAGAR, in the Meerut division of the North-West Provinces, is built on the left bank of the West Kali Nadi, in lat. $29^{\circ} 18^{\prime} 10^{\prime \prime} \mathrm{N}$., and long. $77^{\circ} 44^{\prime} \mathrm{E}$., and 900 feet above the sea. The central portion of the district consists of an elevated plateau, cut into three portions by the Hindan and Kali Nadi. The division lying close along the bank of the Ganges is covered in its northern part by one continuous swamp, caused by the overflow of the little river Solani and percolation from the Ganges Canal. South of this marshy tract stretches the Khadar or lowlying valley of the Ganges, over which the stream runs freely, frequently changing its course, and rendering cultivation hazardous or impracticable. The greater part is densely covered by coarse grasses, interspersed with occasional clumps of tamarisk. - Imp). Gaz.

MUZARI, a tribe of Baluch, on the western bank of the Indus, near Shikarpur. They were formerly predatory, and rode mares in their chupaos or forays. They formerly dwelt in the hills, but migrated to the plains, where they have since remained. Their headquarters are at Rojha, below Mithunkote, and near the confines of Sind. When Mithunkote was conquered by the Sikhs, they harassed the newcomers, and laid waste the acquisition. A strong Sikh force moved against them, and thus the lower extremity of the Dehrajat, down to Shawullee, was then added to the Silkh dominions, and at annexation became included in British territory.

MUZIRIS. Cranganore, on the Malabar coast, in lat. $10^{\circ} 12^{\prime} \mathrm{N}$., is built on the Cranganore or Aycotta river. Cranganore seems to have been one of the most ancient capitals of Malabar, and in some of the ancient copper deeds appears to be called Muyiri-Kodu, which a writer in the Madras Journal indicates as perhaps identifying it with the classical Muziris? Gibbon says every year about the summer solstice a fleet of 120 vessels sailed from Myas Hormus, a port of Egypt on the Red Sea. The coast of Malabar or the island of Ceylon was the usual limit of their navigation, and it was in those markets that the merchants from the more remote parts of Asia expected their arrival. In classical days the extremity of the Peninsula was the entrepot of commerce between the east and the west. During the reign of Claudius, a fleet of ships left Myas Hormus for India, to the Malabar coast or Ceylon. They sailed about the time of the summer solstice, and returned the following December or January, bringing silk, pearls, and spices.-Cunningham's Sikhs; Horsburgh; Yule, Cathay. See Musiris.

MYAL trees of Australia are species of Acacia, viz. A. acuminata, pendula, and stenophylla.A. Cunn.; Ton Mucller.

MYAM-MA. Burm. The Burman race. This word is the source of the European name.

MYEN-MO. Buim. In Burmese cosmology, the great mountain Maha-Meru, surrounded by its seven concentric and graduated ranges, in the centre of this Sakwala or mundane system, which again is encompassed by a circular wall of rock called the Sakwalagala. One of the Burmese feasts, at the termination of their Wa or Lent, is called Tsee-mee-myen-mo, or Myen-mo, lamp lights. The streets are illuminated, and in them are exhibited high round structures, to represent Mount Myen-mo, covered with little figures of its spiritual inhabitants. This mythical central moun tain is several millions of miles high, around which, according to the Burmese theory of the solar system, are firmly fixed four great islands, on the southern of which Asia and Europe are situated, the sun which lights them revolving round the central mountain. Myen-mo mountain forms the centre of the Sakwara or Sekhya system of cosmogony. One of the four great islands which surround it is Jambu-dipa, the world we live in. - Yule, p. 172 . 
MYGALE, Mason Spiders, Crab Spiders. M. avicularia builds a strong white web, and Mr. Bates found two finches involved in it, one dead, the other dying. Madame Merian, in a work on the inscets of Surinam, published in 1705 , figured the M. avicularia in the act of devouring a hummingbird. M. fasciata is a well-known Ceylon spider. By day, it remains concealed in its den, whence it issues at night to feed on larvæ and worms, cockroaches and their pupa, its food consisting of soft insects and annelids. It makes its nest in walls, trees, or sheltered by stones. It is lined throughout with a tubular silk tapestry, so fine and closely woven as to be water-tight, and at its mouth is a little platform stayed by braces. In the rainy season the platform is extended so as to form an awning. Mygale fasciata is sluggish in its habits, and disgusting in its form and dimensions. Its colour is a gloomy brown, interrupted by irregular blotches and faint bands (whence its name); it is sparingly sprinkled with hairs, and its limbs, when expanded, stretch over an area of 6 to 8 inches in diameter. Furopeans in Ceylon have given it the name, and ascribed to it the fabulous propensities, of the tarantula. This hideous creature does not weave a broad web or skin or net, like other spiders, but nevertheless it forms a comfortable mansion in the wall of a neglected building, the hollow of a tree, or under the eave of an overhanging stone.-Tennent's Ceylon; Bates' Nat. on the Amazons.

MYHERE, a Feudatory State, originally a dependency of Rewah. On the occupation of Bundelkhand, thakur Durjun Singh was confirmed in his possession on his executing a deed of allegiance. The area of Myhere is about 400 square miles, the population 70,000 , and the revenue Rs. 74,200 .

MYLABRIS, a genus of insects of the order Coleoptera, possessing properties identical with those of the blistering beetle Cantharis vesicatoria. The ancients chiefly employed two species of Mylabris, one of which, the M. Cichorii, the Telini of the Hindus, has been used for ages, and is so at present by the European and native physicians of India and China. The blistering flies of India are chiefly the M. Cichorii, the Cantharis gigas, and the C. violacea. M. Cichorii is about an inch long, and one-third broad; the elytræ or wing coverts are marked with six cross stripes of deep blue and russet brown. The Buprestis of ancient writers is met with in the bazars under the name of the golden fly (sona-makhi). The Cantharis violacea is often mixed with specimens of Mylabris in the bazars. The Telini fly, if procured before the mites have commenced its destruction, yields on an average one-third more of cantharidine than the Spanish fly of the European shops. The blue fly is of uncertain strength. M. trianthema, so called from its being usually found on the plant named Trianthema decandra (Biscopra, Hind.), was described by Dr. Fleming. Some prejudice exists against the article on account of its alleged excessive severity of action. Mylabris pustulata and M. punctum are found in large quantities at certain seasons all over Southern India. The officinal blistering fly bas had a variety of names. It was called Meloe vesicatorius by Linnæus, Lytta vesicatoria by Fabricius, and Cantharis vesicatoria by Geoffroy, and now by the Pharmacopoias. The name xaytupss was applied by the Greeks to a species of coleopterous insect which possessed the properties of the officinal blistering beetle, but it was distinguished by yellow transverse bands. This is the characteristic of species of Mylabris, one of which, M. Fusseleni, occurs in the south of Europe, and another, M. Cichorii, throughout the east. In India it is called Telee or Telini, and Teli makhi, or the oily fly, from the oil-like exudation which the insects of this genus give out from the articulations of their legs when seized.

MYLABRIS CICHORII. Linn.

Pan mau, . . . ChIn. | Telini, . . Hind.

Teli makhi, : H Hovd. Meloe telini, : LAT.

Blistering beetle of Southern Europe, Egypt, Southern and Eastern Asia, is obtainable from June till December in the granite district of the Nizam's territories, and can be gathered for a rupee a pound. Abounds in Bengal, Behar, Hyderabad, and Oudh, particularly in the rainy season, during which period, almost everywhere, it is seen feeding on the flowers of cucurbitaceous plants. In Cbiva they are met with on species of faba, dolichos, euonymus, silene, and other plants. It is considered in China useful in scrofula, renal ailments, syphilis, and hydrophobia.-Smith; Honigberger; Ains.

MYLABRIS SCHONHERII. - ? Tsau-mau, Chin. Occurs in China, and is found on the zizyphus.-Smith.

MYLABRIS TRIANTHEMA is frequently found in fields overrun with the Trianthema decandra, Willd. It is now much used as a safe and efficacious epispastic. Its peculiar qualities were discovered by Dr. Adan Burt, Superintending Surgeon of the Bengal Establishment, in 1809. He first noticed the insect in fields around Muttra. It, however, abounds in every part of the Doab, and in the districts on the right bank of the Jumna.-Ainslie's Mat. Med. p. 297.

MYLAPUR, or Saint Thomé, a suburb of the city of Madras. A legend relates that Mylapur formed the scene of the labours of the Apostle St. Thomas. The shrine, regarded as the tomb of the apostle, was visited by various travellers in the 13th and 14th centuries. It attracted the Portuguese to this spot, and gave the Portuguese name to it. A relic stated to be that of the apostle is shown in the cathedral.-Imp. Gaz.

MYLAY, a word prefixed to the names of coins in the south of India, as Mylay fanam.

MYLITTA, the goddess of the Babylonians, at whose temple every woman had once in her life to sacrifice, as the necessary preliminary to marriage.

MYLITTA AUSTRALIS, of Tasmania, one of the Panicaceæ. Its root is called native bread, weighs from 1 to $11 \mathrm{lbs}$.

MYIITTA LAPIDESCENS. Smith. Lui-hwan, Fuh-ling, Chrs. This fungus of China resembles the truffle and the fruit of the Gynocardia odorata. They are dug up from the ground. They are similar to the vegetable substance dug up out of the chalk beds in the mountains separating Travancore from Tinnevelly.-Smith, M.M.C.

MYMENSING, a district in the Dacca division of Bengal, between lat. $23^{\circ} 56^{\prime}$ and $25^{\circ} 25^{\prime} \mathrm{N}$., and long. $89^{\circ} 43^{\prime}$ and $91^{\circ} 18^{\prime} \mathrm{E}$. The district furnishes the best sunn (Crotalaria juncea), and the best pat or jute (Corchorus olitorius), and maestee pat(Hibiscus cannabinus)grown in Bengal. The most numerous race are the semi-Hinduized 
Chandal, who are fishermen, cultivators, day labourers; they are greatly despised. Their touch of food or drinking water is deemed to render it impure. The Hajang and the Garo are also in the district. The Kaibartta are agriculturists, and Brahmans and Kayasths make up the population.

MYNA, a name given by the Muhammadans of India to the species of several genera of birds of the Sturnidæ (or starling family). The grackles (commonly known as hill mainas) are very different from the saliks (or common house maina and its congeners, genus Acridotheres); and both again from the Gulabi maina of the Bengalis (Pastor roseus), or the starling-like ablaka (Sturnopastor contra), the true starlings (Sturuus), the Pawes (Temenuchus), and others.

Telia maina, Sturnus vulgaris.

Ablak maina, Sturnopastor contra.

Common maina, Acridotheres tristis.

Java maina, A. Javanicus.

Gingi maina, A. ginginianus,

Pahari maina, A. fuscus.

A. cristatellus of China.

Bahmani maina, Temenuchus pagodarun.

Grey-headed maina, T. Malabaricus.

White-headed maina, T. Blythii.

Gulabi maina, Pastor roseus.

Konkani or southern hill maina, Eulabes religiosa.

Nepal or southern hill maina, E. intermedia.

Acridotheres tristis is often domesticated, and will follow its master about the house like a dog. It soon learns to pick up words and sentences. A. fuscus has similar habits.

MYNPAT, a table-land about 30 miles S.E. from Sirguja town, and about 3000 or 3500 feet above the sea. On the S.W. frontier of Bengal are Chutia Naopur, Sirouja, Palemow, Ramgarh, Hazaribagh, Mynpat, and Amarkantak. The elevation of Chutia Nagpur is 3000 feet, with hills running $\mathbf{E}$. and W., but of little height. Sirguja is mountainous, rising 600 to 700 feet above the level of Chutia Nagpur. Palemow district is very mountainous. Hazaribagh town, lat. $24^{\circ} \mathrm{N}$., long. $85^{\circ} 54^{\prime} \mathrm{E}$., 1750 feet. Slope of country to $\mathrm{S}$, towards Sumbulpur; N. and E. parts of district very mountainous, but level and even depressed towards the Mahanadi. Sumbulpur town only 400 feet. Orissa table-land then rises on the southern side of the Mahanadi, in some places to 1700 feet, backed by the chain of E. Ghats. Amarkantak, jungly table-land, lat. $22^{\circ} 40^{\prime} \mathrm{N}$., long. $81^{\circ} 5^{\prime} \mathrm{E}$., 3500 feet. The soil in the plains is generally fertile, producing abundant crops of wheat, barley, rice, pulse, excellent regetables, cotton, and sugar-cane. The uncultivated parts are overrun with a coarse grass.

MYNPURY, a town and district in the Agra division of the N.W. Provinces. The district lies between lat. $26^{\circ} 52^{\prime} 30^{\prime \prime}$ and $27^{\circ} 30^{\prime} \mathrm{N}$., and long. $78^{\circ} 27^{\prime} 45^{\prime \prime}$ and $79^{\circ} 28^{\prime} 30^{\prime \prime} \mathrm{E}$. ; area, 1696 square miles. The town is on the banks of the Esun, 111 miles N.W. from Cawupur, in lat. $27^{\circ} 14^{\prime}$ N., and long. $79^{\circ} 4^{\prime}$ E., 620 feet above the sea; population, 21,177. Of the Hindu religionists, the Rajput thakur land proprietors are a very important race; besides these are Brahman and Banya and Jain religionists; the Ahir, Chamar, Kachhi, Lodha, Gadarya, Kahar, and some $\mathrm{Mu}$ hammadans, mostly poor. The Chauhan Rajputs, and the Phatta, Ahir, and other races, were largely guilty of infanticide. In 1843 there was not a single female child amongst the Chauhan. The Infanticide Act of 1870 was introduced, and in 1875,276 villages were under it.

MYY. BUlM. A district, a town, a township. Myo-obe, a native officer, head of a township possessing civil, criminal, and revenue jurisdiction.

MYOPORACE E. Lindl. An order of plants comprising two species of Myoporum. Myoporum tenuifolium is the Naiho tree of the Sandwich Islands; the heart-wood is fragrant, but less so than sandal-wood, and is less esteemed in the China market.-Bennett.

MYOSOTIS ARVENSIS. Sibthorpe. A plant of the borage tribe, of Europe, Asia, Africa, and N. America. M. palustris, great water scorpiongrass, or forget-me-not, is a native throughout Europe, and also of Asia and North America. In Great Britain it is found in humid meadows, bogs, banks of rivers, rivulets, and ditches. This plant has a large bright blue corolla, with a yellow eye. It is a beautiful plant, and when once seen will be seldom forgotten. Its common name is forget-me-not. Amongst the young it is regarded as emblematical of true affection.-Eng. Cyc.

MYRICACEA, Lindl. The Gale tribe of plants, comprising in India the genera Myrica and Putranjiva. Dr. Wight gives Myrica integrifolia and M. Nilagirica, and Fortune says the yang-mae of China appears to be a species of Myrica, allied to the Himalayan M. sapida. He believes the Chinese have both varieties, but use the Indian one as a stock for grafting upon. The fine variety of yang-mae is grafted upon the wild kind, which the Chinese call the san or hill variety of M. sapida. The fruits of M. integrifolia and M. sapida are eaten. M. cerifera, the wax myrtle, abounds in the Bahama Islands, and might be introduced into India. The shrub produces a small green berry, which, like the hog plum, puts out from the trunk and larger limbs. Much patient labour is required in gathering these berries, and from them is obtained a beautiful green wax, which burns very nearly, if not fully, as well as the spermaceti or composition candles. The method of procuring this wax is by boiling the berries in a copper or brass vessel for some time. Iron pots are found to darken and cloud the wax. The vessel after a sufficient time is take from the fire, and when cool, the hardened wax, floating on the top of the water, is skimmed off. M. cordifolia, the wax tree of Louisiana, contains immense quantities of wax. -Fortune; Wight.

MYRICA GERMANICA. Desf.

Kathi, . . Chenab. Hambukh, . Kangra. Bis, : : JHELUM. Joaraktse, : LADAKH. Shalakal, : : KangRA. Humbu,. : : SUTLEJ.

Not uncommon in various parts of the basins of the Jhelum, Chenab, and Sutlej, and in Spiti and Ladakh, from 6000 to over 16,000 feet.J. L. Stewart, M.D.

MYRICA INTEGRIFOLIA, Roxburgh, $\mathrm{Fl}$. Ind. iii. p. 765 , from the N.E. frontier and Khassya mountain; seems to be different from $M$. sapida ; its fruit, kai-phal, is acid, and used for pickling.-O'Sh.

MYRICA SAPIDA. Wall. Box-myrtle.

Kai-phal, . . HrND. | Kai-daryamu, . TEL。

This tree occurs in different parts of the Him. alaya, from the Sutlej to Nepal and Sylhet. The 
same, or a nearly allied species, is found in China and Japan. The fruit is edible, with a sweetishbitter taste; it ripens in June. In the Himalaya it is generally met with at an altitude of from 4000 to 6000 feet. On the Lower Sutlej it is conmon, and a few trees may be seen at from 3200 to 6000 feet up to the Ravi. Its bark is exported to the plains as a dye and as medicine. It is aromatic and stimulant, and a favourite native medicine. The fruit has not much flesh, but is a pleasant sour-sweet, and is mostly used in sherbets.

MYRICARIA ELEGAN.S. Royle.

Humbu, Umbu, of . . LADAKH, SUTLEJ.

This is one of the Tamaricaceæ. Dr. Stewart found it at 9000 feet sparingly on the Sutlej, and it grows from 10,000 feet on the Upper Chenab to 15,000 in Ladakh. The leaves are often covered with a saline efflorescence; in Lahoul its leaves are applied to bruises, etc. The twigs are in Ladakh browsed by sheep and goats.

MYRIOGYNE MINUTA. Less.

Cotula minuta, Willde.

C. cuneifolia, Willde.

Artemisia minima, Thunb.

Grangea cuneifolia, Poir. Dicrocebala minuta, $L$ ' $H$.

G. minuta, Poir:

Nak-chikni,

HIND.

India, Madagascar, Japan, New Holland. Considered by natives a hot and dry medicine, useful in paralysis, pains in joints, and special diseases, also as a vermifuge. It promotes sneezing; hence its vernacular name.-Roxb.; Powell; Voigt.

MYRIOPHYLI,UM VERTICILLATUM. $L$. Water-milfoil, . . ENG. | Punatsu, . . . TEL.

A small aquatic plant, the flowers of which become detached and swim on the surface of the water. Sugar-refiners cover their moist sugar with the plant, as clay was used in the West Indies. Willdenow describes M. Indicum, and Roxburgh notices M. tetrandrum and M. tuberculatum; the latter grows on the borders of lakes and other moist places near Calcutta, and is in blossom most part of the year.

MYRISTICACE $A$, Lindl., the nutmeg tribe of plants, are trees of the Moluccas, Cochin-China, Java, Ceylon, the ultra-Gangetic Peninsula of India, the intra-Gangetic Peninsula of India, S. America, Madagascar, Aleppo, Mauritius, Chittagong; the Khassya mountains, and New Holland. The nutmeg of the shops is the seed of Myristica officinalis. Other species bear fruit that may be employed as a substitute, but they are all inferior to the real oriental myristica. The better known species of the E. Indies are-

Myristica moschata, Thunb., Moluccas.

M. Horsfieldii, Sprenger, Ceylon, Java.

M. tomentosa, Thunb., Moluccas, Malabar.

MI. peltata, Roxb., Moluccas.

MI. amygdalina, Wall., Moulmein.

M. spicata, Roxb., Moluccas.

M. parviflora, $R o x b$., Moluccas.

II. sphærocarpa, Wall., Martaban.

M. sylvestris, Telf., Mauritius.

M. irya, Goertner, Apdamans.

MYRISTICA AMYGDALINA Wall TOUngsa-ga, BurM. A Tenasserim tree. The fruit has none of the aroma of the nutmeg; the timber is large, and is used by the natives in house-carpentry.

MYRISTICA CINEREA. Wight, Gibson. Ran jai-phal,. . MAHR. Jadakaia chettu, Sandikai maram, . TAM. Tadikaia chettu,
A tall and straight tree, usually with a clean bole, found in the Bombay green-wood jungles or raees, above and below the ghats. It is not sufficiently common, nor found generally in situations easy of access, so as to allow of its being used for household or agricultural purposes.

\section{MYRISTICA CORTICOSA. Lour.}

M. globularia, Lam.

\begin{tabular}{l|l} 
M. glabuca, Bl. & M. missionis, Wall. \\
M. angustifolia, Roxb.
\end{tabular}

Knema corticosa, Lour.

A lofty, very large, erect, and handsome tree, common in all the western moist forests of the Peninsula of India, up to 3000 feet elevation, from South Canara down to South Travancore, very abundant about the foot of the Neilgherries west side (near Nellicuta), and about the Tinnevelly ghats. It grows also in the east part of Bengal, Burma, the Malay Peninsula, Java, Borneo, and Cochin-China.-Beddome, Fl. Sylv.

MYRISTICA FARQUHARIANA. Wall. Pindee, CAN. Is a very abundant tree in the dense moist forests in the plains and ghats of $\mathrm{S}$. Canara and Coorg, up to an elevatior of 1500 or 2000 feet. It is also found on the Tambercherry ghat in the Wynad.-Beddome, Fl. Sylv.

MYRISTICA FATUA. Hout. The wild nutmeg tree of commerce, a native of Banda. Its nuts are often substituted for the true nutmeg. M. fatua, Swz., is a native of Guiana, W. Indies, and Surinam.

MYRISTICA LAURIFOLIA. $H . F$.
M. Ceylonica, $D, C$.
M. laurifolia, $D, C$.

M. diospyrifolia, $D, C$.

This is a very handsome tree. It is the commonest wild nutmeg tree in the Madras Presidency, and is to be found in all the western forests of the Peninsula up to 5000 feet, and it is common in Ceylon. Its nutmeg and mace are of no value. -Beddome, $\mathrm{Fl}$. Sylv.

MYRISTICA MAGNIFICA, Bedd., is a conspicuous tree, with a lofty, straight trunk, and is one of the most magnificent trees in the southern parts of the Madras Presidency. In Travancore it is abundant in the dense moist forests, quite in the plains not far from the foot of the ghats round about Mimuti, near Colatoorpalay. Every sapling is furnished with large roots, proceeding from the base of the trunk up to 6 or 8 feet from the ground, and these form immense buttresses in the old trees, many of which are much over 100 feet high, with a perfectly erect trunk of 80 or 90 feet in length, and of great girth.-Bedd.

MYRISTICA MALABARICA. Roxb. Kanagi, CAN. A rather small but very elegant tree, very common in the dense moist forests in the plains of S. Canara and N. Malabar, not far from the ghats.-Beddome; Brandis.

MYRISTICA MOSCHATA. Thun. Nutmeg. II. fragrans, Hout.

M. aromatica, Lam.

Jowz-ut-teib, . . ARAB. Jowz-bewa, . . Pers. Za-te-pho, . : BurM. Jatapala, . SANsK. Jaephal, . HIND. Jadikaia, . TAM. Pala, Buwahpala, Maxur. Jadikaia, Jaji kaia, Ter. The Mace.

Buzbas, Bisbaseh, Arab. | Bunga-pala, . MALAY. Jytree, : . BNNG. Jatiputri, . . SANSK. Jae-putri, : : DUKH.

A tree with small, pale yellow, and inodorous flowers, successfully cultivated in Sumatra, Bencoolen, and Penang. The girth is 6 to 10 inches 
a foot above the ground. It branches like the laurel, and its loftiest sprays are frequently 50 feet high. The fruit when ripening resembles a peach, and on removing the epicarp or fleshy outer rind is seen a spherical nut, black, clasped by a fine branching aril, of a vermilion colour, which is the mace of commerce. When ripe, the fruit is picked, the outer part removed, the mace taken off and dried in shallow baskets in the sun. The nut contains a volatile as well as a fixed oil. Nutmeg butter is prepared by beating up the nutmegs, enclosing the paste in a bag, and exposing it to the vapour of water, and afterwards expressing the fat by means of heated plates. The nutmeg tree is moncecious as well as dicecious, but no means is known of discovering the sexes before the period of inflorescence. Upon an average, the nutmeg tree fruits at the age of 7 years, increases in produce till the 15 th year, and is said to continue prolific for 60 or 80 years. Seven months in general elapse between the appearance of the blossom and the ripening of the fruit; and the produce of one bearing tree with another, under good cultivation, in the 15th year, may be calculated at $5 \mathrm{lbs}$. of nutmegs and $1 \frac{1}{4} \mathrm{lbs}$. of mace. It bears all the year round, but more plentifully in some months than others, and generally yields more abundantly every other year. It is necessary that the roots of the trees during their growth should be kept well covered with mould, for they have a tendency to seek the surface. The growth of the lateral branches is to be alone encouraged, and all suckers, or dead and unproductive branches, are to be removed with the pruning knife, and the lower shoots lopped off, with the view of establishing an unimpeded circulation of air.

The aril, arillus, or mace, is thick, between horny and fleshy. The smell and taste of the arillus are peculiarly fragrant and agreeable. It softens, but does not dissolve in the mouth. Beneath the arillus is found a bony shell, which covers the almond or kernel; this shell encloses the nutmeg of commerce.

The odour of the nutmeg is most agreeably aromatic; its taste hot, and analogous to the smell. The nut readily divides under the teeth, and is partially soluble in the saliva.

MYRISTICA TOMENTOSA. Thunb.

M. Malabarica, Lam. | Male nutmeg tree, ENG.

A tree of the Moluccas, Malabar, S: Konkan, with small yellowish flowers. The fruit is downy, its substance fleshy, solid, and firm. The kernel is covered by a hard shell provided with a pale arillus; the kernel is $1 \frac{1}{2}$ to 2 inches long, elliptical; the parenchyme devoid of marbling. Its odour is weak, flavour disagreeable. Its mace is distinguished from the true mace by being formed of three or four regular bands united at the summit. The oils are so inferior that the male nutmeg is but of little commercial value. - O'Sh.

MYRMECODIA, $s p$, a parasitic plant on low jungle trees of Borneo. The young seedlings when about an inch in height are punctured by an ant, from which the stem enlarges and eventually becomes hollow, and the ants then shelter themselves within, but rush out and resent any attack on their nest.-Burbidge, p. 11.

MYRMELEON, a genus of the ant-lions of India. Ceylon seems to have four species peculiar to the island, viz. Palpares contrarius,
Walker, Myrmeleon gravis, Walker, M. dirus, Walker, M. barbarus, Walker. The form of the larvæ at the lower part resembles that of a spider, but the head is armed with a sharp, strong pair of claws. They form, in fields, gardens, and roadways, small cup-shaped cavities, with exquisitely smooth edges and sides, at the bottom of which they lurk, so that any insect approaching near immediately falls below to the ambush, and is seized and destroyed. Their excavations are usually carried on at night, and in the process they throw up the sand and gravel to a considerable beight and distance, the soil around their cups being very level. They often throw up a particle of sand towards any adhering insect, which, by moving the mass, brings down the insect with it. One of the large black ants was seen to fall into one of the cups, and was seized by the ant-lion, but its comrades adhered to the captive to release it.-Walker, in Tennent's Ceylon.

MYROBALANS of commerce, yielded by the Terminalia chebula and T. bellerica, are called also gall-nuts. They are oval fruits of a dingy yellow colour, containing much tannin; hence they are useful to the tanner as well as to the dyer. With alum, this fruit yields a good durable yellow; and with salts of iron, a black colour, little inferior to that produced by oak-galls. The trees grow throughout India, Further India, and in parts of the Archipelago. Their dried fruits, the myrobalans, are largely exported from India, but in varying quantities, -

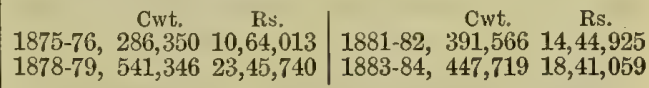

When ripe, the fruit is pear-shaped, deeply wrinkled, of a brownish - yellow colour, and weighs from 70 to 100 grains. The husk contains the whole of the astringent matter, some mucilage, and a brownish-yellow colouring substance, which is used in India for dyeing yellow. The husk is usually separated by bruising the nut, which it encloses. The tannin of myrobalans differs slightly from that of galls. Gallic acid is present in rather large proportion.

Belleric myrobalan.

Heleyluj, . . Araв. Kadondong, . MaLay. \begin{tabular}{l|l} 
A-mo-loh-kia-kwo, CHIn. & Belelah, Beleylah, . PErs.
\end{tabular} Bella, . DuKr. Behira, Vibitaka, SANSK. Beheyra, Bida, : HIND. Booloo, Bulu, SINGH. Malaka, . . ." Tanikai, . . . TAM.

The belleric myrobalan is the fruit of the Terminalia bellerica; in its dried state, is little larger than a gall-nut, but not so regular in shape, of a dirty brown colour and astringent taste. It is supposed to be similar in its properties to the chebulic myrobalan, but in a much weaker degree. It is much used in India as the basis of several colours, and also in medicine. It is sometimes used by the natives, in its dried state, in cases requiring slight astringents.

Chebulic myrobalan.

Heliluj kabuli, . ARAB. Helilah, . . PERs. A-mo-loh-kia-kwo, CHIN. Haritaka, : SANSK. Huldah, Humbether, GUJ., Hind. Kadukai, : . . TAM. Hurda, Har, . . Hind.

This is the fruit of the Terminalia chebula. In its dried state it is about the size of a large Spanish olive, of an oblong ovate shape, yellowbrown colour, and is marked with edges and 
furrows alternately. The tree is common in the Mysore country, Bengal, and in some parts of the Bombay ${ }_{i}$ Presidency. This fruit is very astringent, and is extensively used by the natives of India in their arts and manufactures. It is more astringent than the Aleppo galls. This myrobalan, well rubbed in conjunction with galls and catechu, is considered by the Vyteans as an excellent external application in the apthous affections of children and adults.

Six kinds of chebulic myrobalans, all known as Helileh, are used in India,-

Helilah-Zira, the fruit is dried when just formed, and the size of a cumin seed or zira.

H.-i-Jawi, the fruit dried when the size of a jao or barley-corn.

H.-i. Zingi, the fruit dried when of a larger size, and black like a negro.

H.-i-Chini, larger than H.-i-Zingi, and greenish.

H.-i-Asfar, the fruit near maturity, and yellow (Asfar).

H.-i-Kābuli, the fruit at full maturity.

Mature Kābul myrobalans sell for a rupee a piece in the Bombay market, under the name of Sarwar-i-Hindi.

MYROSPERMUM, a genus of plants belonging to the natural order Amyridacex. This species are trees with dotted leaves. M. Peruiferum, the Myroxylon Peruiferum, Linn., is a tree of Central America, and supposed to yield the balsam of Peru. The article known in commerce as white balsam, or myrrh seed or quiniquino, is made from this tree and from M. pubescens. The stem has a thick, smooth, straight trunk with a grey, coarse bark, which is filled with resin. This, by distillation with water, yields a volatile oil; by exposure to the air it hardens, and it is then termed Opobalsamum siccum. The true balsam of Tolu is also sometimes called opobalsamum. It is the M. Toluiferum.

MYRRH.

\begin{tabular}{|c|c|}
\hline & $\begin{array}{l}\text { Bol, Hirabol, } \\
\text { Mirra, IT, PoRT., SP. } \\
\text { Mur, : MALAY, PERs. } \\
\text { Manisan lebah, : : T", } \\
\text { Valati-polam, : : TAM. } \\
\text { Palendra-bo-lum, : " } \\
\text { Villey-bolum, : : T" } \\
\text { Bolintra-bolum, : TEL. }\end{array}$ \\
\hline
\end{tabular}

The myrrh of commerce is believed to be one produced from the Balsamodendron myrrha, Nees $a b$ Esen., a tree of Abyssinia, and it is said also of Arabia. Myrrh is mentioned in Genesis xxxvii. 25, and in Exodus xxx. 23, by the name of Mor or Mur. In the Periplus of the Red Sea, Arrian mentions myrrh with olibanum as exported from the coast of Barbaria, that is, the modern Berbera. Bruce learned that it as well as frankincense was produced in the country behind Azab, or in that of the Dankali. The embassy to Abyssinia under Major Harris met with it on the bills, in the comparatively flat country which extends from Abyssinia to the Red Sea, near the straits of Bab-ul-Mandab, or from the Doomi valley to the banks of the Hanwash. Mr. Johnston (Trav. i. p. 249) met with it in nearly the same locality. Both anthors describe the myrrh as exuding from wounds made in the bark, and say that it is collected in January and March, but chiefly in July and August, and in small quantities at other times of the year, and exchanged for tobacco with the merchants who proceed to Berbera, etc., whence it is exported to the coast of Arabia.

Myrrh reaches Europe chiefly from Bombay, having been imported there from the Arabian and Persian Gulfs. It used formerly to be obtained also from Turkey. Ehrenberg and Hemrich found a small tree in Arabia near Gison, on the borders of Arabia Felix, from off which they collected some very fine myrrh. The resin of Balsamodendron mukul, Hooker, of India, is the bdellium of commerce; B. pubescens, Stocks, yields the googul resin; B. Gileadense, Kunth, furnishes the balm of. Gilead; and Boswellia papyrifera, Hock, the frankincense and olibanum.

MYRSINACE $Æ$. Lindl. An order of plants comprising species of Egiceras, Myrsine, Badula, Ardisia, Embelia, Chorepetalum, Reptonia, Samara, Mrsa, Oncinus. Most of them inhabit the Himalaya, the mountains of Assam, the Khassya, Circars, Neilgherries, Malayana, and Java.

\section{MYRSINE AFRICANA.}

Bui-baring, . ARAB. Bimak-kabuli, , HIND.

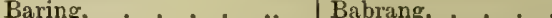

A plant of Kaghan, one of the Myrsinacer. Its gum is considered by Hindu practitioners to be a warn remedy, used for dysmenorrhæa.-Cleghorn; Powell, i. p. 369.

MYRSINE CAPITELLATA. Wall, Roxb. ii. p. 295. A very common tree on the Neilgherries, particularly about Ootacainund, also throughout the western mountains of the Peninsula, and in Ceylon up to the highest altitudes. Its timber is hard and durable, and used for various purposes. The fruit is eaten.-Beddome, $F l$. Sylv.

MYRTACE E, the myrtle tribe of plants or myrtle blooms, comprises 45 genera, with about 1300 species, principally belonging to $\mathrm{S}$. America, Australia, the South Sea Islands, and the E. Indies. The more important species of the $S$. and $E$. of Asia and Australasia plants are species of the genera baekia, Barringtonia, careya, decaspermum, eucalyptus, eugenia, melaleuca, myrtus, planchonia, psidium, rhodamnia, rhodomyrtus, tristania.

\section{MYRTUS COMMUNIS. $L_{\bullet}, D . C ., R o x b$.}

\section{Ass, Asbiri, Murad, ARAB.|Barg-i-murad}

Isbar, Ismar, Isferem, , (leaves), . . PERs.

Mursine, : . GR. Hab'hul, Hab'-ul-as

Vilaiti mendi, : Hind. (fruit), . . , ,

The unyrtle is a native of Asia Minor and S. of Europe; it assumes the shrubby or arborescent form according to the latitude. The plant in all its parts is most agreeably perfumed; $10 \mathrm{lbs}$. of the leaves afford about a drachm of yellow essential oil of most delightful fragrance. The berries were employed by the Romans as a spice. The Tuscans still use them, and they also prepare from the berries a kind of wine called Myrtidanum. A distilled water prepared from all parts of the plant is employed as a cosmetic, and called Eau d'ange by the French perfumers. The leaves are given in cerebral affections, for flatulence, diarrhœa, internal ulcerations, and rheumatism. The hab'-ul-as, though nominally always the fruit of myrtle, appears at times to be the small fruit of some other plants not yet identified with certainty. The myrtle grows well by layers, and even cuttings, but requires careful pruning, and after the rains all the leaves on which insects have deposited larvæ must be removed, or the plant will lose its verdure and beauty by the destructiveness of the young caterpillars. - Roxb. ; Lindley; Riddell; Jaffrey; Steurart. 
MYRTUS TOMENTOSA. Aiton. M. canescens, Lour. A showy plant of China, Cochin-China, Neilgherries, Penang, Singapore. Flowers large, rose-coloured, with crimson filaments. Berries edible.-Roxb. ii. p. 498; Voigt; Eng. Cyc.

MYSORE, a city in the south of the Peninsula of India, in lat. $12^{\circ} 18^{\prime} 24^{\prime \prime} \mathrm{N}$., and long. $76^{\circ} 41^{\prime}$ $48^{\prime \prime}$ E., 10 miles S. by W. of Seringapatam. This city gives its name to a principality lying between lat. $11^{\circ} 38^{\prime}$ and $15^{\circ} 2^{\prime} \mathrm{N}_{\text {, }}$, and long. $74^{\circ}$ $42^{\prime}$ and $78^{\circ} 36^{\prime} \mathrm{E}$., surrounded on all sides by British territory. The state has an area of 24,723 . square miles, and in 1881 had a population of $4,186,188$, the census of 1871 having shown $5,055,412$. It is an undulating and much broken table-land, elevated from 1800 to 3000 feet above the sea, and the general elevation of the country increases from about 2000 feet above sea-level, along the northern and southern frontiers, to about 3000 feet at the central water-parting which separates the basin of the Krishna from that of the Cauvery. The hill country called the Malnad is confined to the tracts bordering or resting on the Western Ghats. The Nuggur division to the $\mathrm{N}$. of Astagram possesses an elevation generally from 2000 to 2400 feet above the level of the sea. A marked feature of the country is the number of isolated hills called Drug, on the most inaccessible of which former chiefs built forts, afterwards in many instances strengthened and improved by Hyder and Tipu, and still in good preservation, but now without guns. The most remarkable are Shivaganga, Savandrug (4024 feet), Nundidrug (4810 feet), and Chittuldrug, Coalidrug, and Karbaldrug, the last of which obtained an evil fame as a state prison. The eight highest peaks in Mysore areMulaina Giri (6317 feet), Kuduri-mukha (6215 feet), Baba Booden Giri (6214 feet), Kalhatti (6155 feet), Rudra Giri (5692 feet), Pushpa Giri (5626 feet), Merti Gudda (5451 feet), Woddin Gudda (5006 feet). Five of these hills are in the Baba Booden or Chandradrona range, a magnificent cluster in the shape of a horse-shoe, in the centre of which is a rich but pestiferous valley called Jagar.

The geological structure of Mysore is mainly hypogene schists, penetrated and broken up by plutonic and trappean rocks in every form of intrusion, and overlaid with occasional patches of laterite and the kankar calcareous deposit. The gneissic rock about Bangalore possesses great economic value, being easily quarried from the surface. Gold is found betwixt Anicul and Punganur, near Baitmangalam and Ooscotta, and near the Batterine Hills, but not in remunerative quantities.

Rivers.-The Tunga and Bhudra rise in the N.T. of Mysore, and, uniting, form the Tumbudra, which flows northwards and westwards till it joins the Krishna below Kurnool. The banks of the 'Tumbudra are too high for irrigation purposes. The Cauvery rises in Coorg, and passes through and out of Mysore in a south-easterly direction, after receiving the Hemawati, the Lokani, the Shimsha, and the Arkavati from the north, and the Lachmantirth and the Kabbani from the south. The Cauvery and its tributaries supply numerous irrigation channels and tanks. The Peunar or Pennér, the Palar, and Southern Pennar or Poniar, rise in the eastern part of Mysore, in their short course through which their waters are detained and converted into chains of tanks. The Sharavatty, on the N.IV., runs to the west, and hurls itself, by a sheer descent of 900 feet, down the ghats in the magnificent falls of Gersoppa. None of these rivers are suitable for navigation. There are no natural lakes in Mysore; but there are 37,682 artificial reservoirs, some of which are of considerable magnitude; that of Sulekére is 40 miles in circumference.

The principal forests are found clothing the sides of the western mountains. They abound in teak, black-wood, and other valuable kinds of timber.

The climate, though pleasant, is not generally salubrious. That of Bangalore is favourable to Europeans. The thermometer rarely rises above 90 degrees, and the nights all the year round are cool and refreshing. The elevation of the Chittuldrug or N.E. division is somewhat less than that of Bangalore. In climate it is similar, but its hills are feverish. The S.E. division, called Astagram, in its southern and western parts is covered with fine jungle extending to the slopes of the Western Ghats on the one side, and to the base of the Neilgherry Hills on the other. Fever prevails during some seasons of the year, but on the whole the climate is generally a healthy one.

The earliest historical dynasty of Mysore was the Kadamba, whose capital, Banawasi, is mentioned by Ptolemy. The dynasty, after 14 centuries of rule, fell to the Chalukya, and the Chera or Kongu seized the southern districts. The Ballala fell to the Vijayanagar rulers, who again yielded to the Adal Shahi kings of Bijapur. For a time it formed part of the dominions of the Adal Shahi dynasty of Bijapur, and the year after the fall of that dynasty it was taken by Aurangzeb's general, Kasim Khan, and the city of Mysore sold to Chik Deo Raj for 3 lakhs of rupees. But several polygar chiefs continued almost if not wholly independent. The most important of these were the Wodeyar of Mysore in the south, the Nayak of Keladi in the north, the Nayak of Balam (Maujarabad) in the west, and the Beder chiefs of Chittuldrug and Tarikere. In 1610, the Raj Wodeyar of Mysore seized the fortress of Seringapatam, and thus laid the foundation of the present Mysore state. Wodeyar is a plural or honorific form of Odeya, a Canarese word meaning lord or master. Hyder Ali, in the middle of the 18th century, brought Mysore proper, Coorg, with the Carnatic and much of the Dekhan, under subjection, and he was at the height of his successes when Chum Raj, the titular ruler, died. Till then Hyder Ali had professed to rule Mysore in behalf of the Hindu raja, and, every Dassara, Chum Raj appeared before the people in the state balcony, scented on an ivory throne, Hyder Ali being present as his commander-in-chief and minister, and he selected a successor, also named Chum Raj, from amongst the collateral relations, but Hyder continued to rule in reality until his death on the 7 th December 1782. The Carnatic rulers, aided latterly by the British, the Mahrattas, and the Hyderabad state, were frequently at war with Hyder Ali and his son Tipu Sultan. When Hyder died in 1782 , peace was finally concluded with Tipu in 1784 , on the basis of a mutual restitution of all conquests. But in seven years war was again declared, and Lord Cornwallis in 1791 took cummand, and on 
the 21st March captured Bangalore. On the 13th May, Tipu opposed him at Arikera, and was completely routed, but Lord Cornwallis was obliged to retreat. In August, however, Lord Cornwallis captured several difficult forts, and on the 5th February 1792 he encamped before Seringapatam, and drove the enemy into the fort, on which Tipu came to terms, delivering up half his kingdom, and three kror of rupees, with two of his sons as hostages.

The taking of Bangalore from Tipu Sultan, on the 21st March 1791, gave the British a permanent position in Mysore; but eight years later, on the 4th May 1799 , when Seringapatam was stormed, the whole country came under British supremacy, by the replacement on the throne of the descendant of former Hindu rulers. The genealogy of this family is traced from the $\mathrm{Yadu}$ line of Chandravansa, but the first in authentic history was Timma Raja Wodeyar, son of Betta, A.D. 1530 , and the dynasty ruled until A.D. 1767, when Hyder Ali put aside the raja Chama Raja Wodeyar. Krishna Raja Wodeyar was restored by the British in 1799, on the fall of Tipu at the storm of Seringapatam, and, after he came of age, ruled the country till 1831, but during Lord W. Bentinck's administration, owing to frequent insurrections, commissioners were appointed for its management. The raja died childless in the beginning of 1868 , but had adopted as his successor the third child of Chikka Krishna Arasu of the Bettada Kote branch of the royal house, the new sovereign being installed under the title of Chama Rajendra Wodeyar. The date of the rendition was 25 th March 1881. The British Government conferred the country on the maharaja and his heirs for ever, prohibited building or repairing of forts, increase of military beyond a fixed maximum, the introduction of separate coinage, and the employment of Europeans without the previous sanction of the Indian Government. Provision was made for establishing British cantonments in Mysore wherever and whenever required, the constructing and working of railways and telegraphs, respecting and continuing the existing laws, the revenue settlement and the existing system of administration, and prohibiting or limiting the manufacture of salt or opium. The maharaja renounced his jurisdiction over the Bangalore cantonment, and surrendered his jurisdiction over European British subjects. The present annual tribute, amounting to 24 lakhs, or about $\frac{1}{5}$ th of the gross revenue, is to be increased by 10 lakbs; but this clause was not to come into operation witbout the mature consideration of the mabaraja. An infant princess, born a few days before the installation, was named Jaya Lukshmi, Jaya, in compliment to the Queen-Empress Victoria.

Rain.-The soil is tolerably fertile, but the rainfall is scant and uncertain; it ranges from 29.22 to $47 \cdot 65$ in the different parts of the country. This is often a cause of dearth, at times of famine. There was scarcity in $1824,1831,1833$, and 1865 ; there was also scant rain in 1851 and 1860 . The drought which affected all Southern India in 1876-78, fell with especial severity upon Mysore. From October 1875 to October 1877, four successive monsoons failed to bring their full supply of rain. The harvest of 1875 was generally below the average, and remissions of revenue were found necessary; but it was not till towards the close of
1876 that famine was recognised to be abroad in the land. The crops of that year, in some parts, had yielded only $\frac{1}{8}$ th: and even in the less stricken dictricts of Hasan and Shimoga, under the Western Ghats, only half of a fair harvest was gathered. On the other hand, grain was poured into Bangalore by the Madras railway; but the means for bringing the food to the hungry mouths were inadequate. During the whole twelve months of 1877, famine was at work. In October of that year, the S.W. monsoon broke with a fair rainfall, and cultivation at last became possible. It is calculated that the loss of population in $1876-78$ must have been in excess of the number as estimated by the Famine Commissioners, namely, $1,172,548$; for the total population in 1871 was $5,055,412$, that of 1881 was $4,186,188$, or 869,224 less than the total in 1871 . The area under cultivation in $1880-81$ was $4,280,674$ acres, against $3,996,206$ in the previous year.

From 1831 the British authorities had conducted the administration to $1880-81$, the last year of the Goveriment administration previous to its being handed over to the present maharaja. Large reductions had been made since 1878-79. The civil charges had been reduced by $£ 1,423,000$; the expenditure on the local fund by $£ 31,000$; public works by $£ 775,000$. The condition of the state funds at the period of rendition was as follows :- Ordinury expenditure, $£ 8,585,000$; civil expenditure, $£ 754,000$; local military forces, $£ 1,070,000$; in all, $£ 10,409,000$. Nearly all the European civil and military officers had been displaced by natives of India on smaller salaries. The great bulk of the population follow some form of Hinduism, but the aborigines are numerous; there are 200,484 Muhammadans, and a considerable number of Christians. The village officers are the Gowda, the Talawar or watchman, the Madiga, the Baraka or Kalawadi, whose office is that of the Totti of the Tamil villages; the Shambogue or accountant, Badega or carpenter.

The majority of Mysore Brahmans belong to one or other of the Pancha Dravida or five southern tribes, viz.-(1) Karnataka; (2) Telinga or Andhra; (3) Dravida or Tamil; (4) Mahratta; and (5) Gujerati. These names indicate the countries from which the various sects originally came; and they still use their native languages as their house-tongue. The Brahmans are of three sects, the Smartta, Madhava, and Sri Vaishnava. The first of these hold to the Adwaita (non-dual) philosophy; the Madhava are of the dwaita (dual) school; and the Sri Vaishnava entertain the Vasisht-adwaita belief.

The most numerous cultivators are the Wakaliga; they numbered 695,215 at the census of 1881. They are divided into more than $50 \mathrm{sub}-$ classes; they form the backbone of the population, and for skill and industry are unsurpassed by any agriculturists of India. Other cultivators are the Reddi $(54,593)$, and some of the Gaudaru. The more prominent castes are as under :-

Aradhyaru, 5,912 Chitragar, . 679 Gujerati, . . 82 Arasu, . 5,266 Christiaus, 30,249 Halo Paika, 63,246 Ayagalu, 33,932 Coorgs, . . . 33 Holaya, . 447,421 Banajiga, 93,037 Dasari, . : 693 Irular, . . 1,229 Beda, 171,269 Doomar, : 2,787 Jain, : 10,760 Besta, : 65,826 Gauliga, : 6,681 Jetti, : . 1,440 Bhatraj, 1,320 Gaudaru, 259,110 Kama, : : 7,663 Brahman, 162,652 Gollar, 102,633 Komati, 25,985 Byragi, . 277 Gosain, - 446|Kshatriya, 13,251 
Kunchign, 82,474!Marwari, . Kurubar, 291,965 Mudali and Ladar, - 1,415 Pilli, . Lingaet, 470,269 Muhammada
Lumbani, 31,442 Madiga, 174,824 Multani, $\begin{array}{ll}\text { Mahrati, } & 41,239 \\ \text { Mala, Nagartaru, } & \text { 7,943. U pparu, } \\ \end{array}$ Maleali,. . . 21 Panchala, '91,423'

235 Rangare, Reddi, 10,002 Saligeya, dans, Satani, Soliga,

\section{The right-hand castes of Mysore are-}

The Banajiga, trader.

Wakaliga, farmer.

Ganiga, oilman, who yokes only one bullock to the - mill.

Rangari, dyer.

Lada, Mahratta trader.

Gujerati, merchant.

Kamati, labourer.

Jaina.

Buddhist.

Kuruba or shepherd. Kumbara, potter. Agasa, washerman.

Besta, fisher, palki-bearer. Padmasale, weaver. Nainda, barber. Uppara, saltmaker. Chitriga, painter. Golla, cowherd. Holaya.

The tradition is that the goddess Kali at Conjeveram placed certain castes on her right hand, and others on her left, and ever since these have contended for precedence.

The left-hand castes are Panchala, five artisans; Bheri, traders of the Nagarat caste; Devanga, weavers; Hegganiga, oilmen using two bullocks at the mill; Golla or Dhanapala; Beda, hunters ; Wakalu, farmer; Palli or Tiglar; Madiga, leather workers.

Betta or Hill Kurubar live in the woods in small communities called hadis, in sheds made of branches of trees. They are credited with possessing magical powers. They are dark in colour, and short in stature. The women are rarely seen, and do not work with the men. The Jenu (Honey) Kurubar subsist almost entirely on forest products, and occupy themselves in collecting honey in the jungle. Their features are coarse and irregular, and their hair hanging in a dishevelled mass. The other Kurubar named are the Kada or wild; the Halu or milk; the Handi or swineherd; and Kamli Kuruba or weaver. In the Malnad, the aboriginal Holayaru (from the Canarese word Hola, a field) are rural serfs, attached to the farms of the feudal headmen. The Munnalu (from Munna, land, and Alu, a slave) used to be sold with the land, and were specified in the leases.

Honnalu (from Hona, gold) were transferable with or without the soil. The price of a man and wornan was from $£ 4$ to $£ 5$; and it was calculated that these, with a pair of bullocks, could cultivate 10 acres of land. Their owner maintained them, giving them 2 lbs. of rice daily, with double this amount on feast-days, and an annual supply of clothes andblankets, to which were added presents on marriage. Children belonged to the lord of the soil. The Holayaru live in huts in the neighbourhood of the farms, and generally possess small gardens for kitchen produce. They are a stout and healthy race, with broad features and flat faces, and generally carry about with them a wood knife.

The Koracha $(16,591)$ have mat huts, and are notorious thieves. They associate with the Lumbani, whom they join in dacoity and burglary. They know Tamil and Telugu, but have also their own language. Their women bang round their necks, and falling over their bosoms, numerous strings of small white and red beads.

The Soliga (1596 in number) live in the dense forests of the Bilikalrangam Hills, where there are besides themselves only wild animals. They are in small communities of six or seven huts, and cultivate with the hoe small patches of ground with plantain, vegetables, and a little ragi, which with forest produce and wild animals form their food. They avoid civilised men.

The Holeya $(225,348)$ are regarded by the Hindus as unclean. They are in the Canaresespeaking country in the same position as the Dher of the Dekhan, the Mhar of the Mahratta country, the Mala of Telingana, and the Parayan of the Tamil provinces. A Holeya having to deliver anything to a Brahman, places it on the ground, and retires to a distance. When meeting in a street or road, the Holeya moves as far as possible away from the path of his superior.

The Madaga are leather dressers like the Tamil Chakili, the Mahratta Mhar, and Northern Chamar.

Religion.-681,745 of the aboriginal population have not yet accepted Hinduism. They comprise the Doomar, Holeya, Irular, Jogi, Koracha, Kurubar, Lumbani, Madaga, Mala, and Soliga. Besides these are the non-Hindu Muhammadans, 200,484; Christians, 30,249; Jains, 10,760. Buddhist emissaries appear to have visited the country in the $3 \mathrm{~d}$ century B.c.; while the Jains established their supremacy here, and maintained it during many successive ages, leaving behind them several richly-wrought temples, and other memorials.

The language spoken throughout Mysore, except in Kolar and the eastern side of Chittuldrug, is Canarese, which is the vernacular of 9 millions of people $(8,335,859)$ in different parts of India. There are three dialects of Canarese-(1) Purvada Hale Kannada, or the archaic Canarese of inscriptions earlier than the end of the 7 th century; (2) Hale Kannada, or old Canarese, up to the end of the 14th century, in which were written the older sacred books of the Jains and the majority of the Mysore stone inscriptions; and (3) Hosa Kannada, the existing language. The Kannada speakers, 3,095,647; Telugu, 637,230; Tamil, 130,569; Tulu, 8941; Maleali, 332 ; and Kodaga, 21.

MYTHOLOGY. Aryan races have a complicated mythology. The Semitic races had El, strong; Bel or Baal, lord; Adonis, lord; Shet, master; Moloch, king; Ram and Rimmon, the exalted; and other similar terms for their deities. Vedic Aryans, on the contrary, had Zeus, the sky; Phobus, Apollo, the sun; Neptune, the sea; Mars, war; Venus, beauty; etc.

Aryans of India are worshipping deified beroes, non-Aryans have numerous fetish, and both races have many elemental deities. The Chinese, too, have many of the latter, and have also deified many of their illustrious men and women, and all Hindus and Chinese are essentially spiritworshippers. The Muhammadans, the Ali Ilahi sect, credit continuous incarnations from Ali, whom they believe to be deity. Hindus of the Saiva sect have Mount Kailasa as the paradise of Siva, and those of the Vaishnava sect have Vaikuntha, on Mount Meru, for their supreme god Vishnu. Swarga is the heaven of Indra, and the Vishnu Purana (ii. p. 214) enumerates twenty-one hells.

Hindu mythology accords precisely with the Greek in sending the souls of the dead to receive judgment, and, according to the sentence of their judge, they are thence conveyed to Naraka 
or Swarga, each according to their evil or good deeds. The Jaina sect also have their temples on Abu, Govardhan, and other hills, and Hindus and Jains make pilgrimages there.

But in modern Hindu mythology, the guardians of the world are eight deities, who now rank next below the Hindu triad. They are-Indra; Agni, or fire; Surya, the sun; Chandra, the moon; Pavana, the wind; Yama, the god of justice and lord of the infernal regions; Varuna, the god of water; and Kuvera, the god of wealth. The eight regents of the winds of the Hindus corlespond with those on the temple of winds at Athens.

Amongst the Hindus, mythology is all-pervading. Their history, legends, science, literature, arts, customs, and conversation are replete with mythological allusions. A respectable knowledge of their pantheon is consequently an almost indispensable preparatory acquirement to the study and comprehension of nearly everything which relates to them. The subject of the original home of the Aryans has been engaging the attention of the most eminent philologists ever since Bopp published his Comparative Grammar. Latham, Benfey, Lazar Geiger, Fr. Müller, Cuno, Peschel, Pösche, Dr. Schrader, and Karl Penka all have discussed the hypothesis that their early home was in Northern Europe, and the last-named writer points to Scandinavia as their original dwelling-place. The mythology of India has done much to explain that of ancient Greece and Scandinavia. This will be seen by the following list of the principal of the Hindu deities of the present day, and their principal analogues. It is taken from the Pantheum Mysticum of Pomeg, which formerly belonged to Sir IVilliam Jones, and is referred to by him in his Dissertation on the Gods of Greece, Italy, and India :-

Agni $=$ Vulcan, fire, ignis .

Ahi, the Greek Echidna.

Anna Purna = Anna Perenna.

Aruna $=$ Aurora

Aswiculapa $=$ Esculapius = Genii.

Aswini-Kumara = Castor and Pollux.

Ata-Devi or Atava-Devi = Diana.

Bala Rama $=$ Bacchus as the inventor of the use of wine.

Bhawani $=$ Venus.

Brahma $=$ Saturnus.

Chandra = Lunus, the moon.

Durga is the analogue of Juno.

Dyaus = Zeus, Dyaushpitar, Diespiter.

Dyava-Prithivi, a dual god = Ouranos and Graia.

Ganesa = a male Minerva, Janus.

Gopyah.Vilyah $=$ Musæ.

Hanuman, the monkey god, son of Pavana $=$ Pan.

Harit $=$ the Charites.

Ileracula, an Indian deity $=$ Hercules.

Indra = Jupiter, god of the firmament.

Kali or Durga = Proserpine.

Kama = Cupid, Eros, god of love.

Kartikeya or Skanda = Mars, the god of war.

Krishna $=$ Apollo.

Kuvera $=$ Plutus, god of riches.

Lakshmi or Sri = Ceres.

Narada, god of music = Mercury.

Pavana $=$ Pan.

Prithivi $=$ Cybele, goddess of earth.

Rama, god of wine = Bacchus, the Grecian Dionysius.

Remb'ha $=$ Venus.

Sabala $=$ Kerberos.

Sarameya $=$ Ermeias.

Saraswati $=$ Minerva.

Siva $=$ Indra, Jupiter.

Skanda $=$ Mars.
Sni $=$ Ceres.

Surya or Arka $=$ Sol, the sun.

Swaha, wife of Agni = Vesta.

Ushasa $=$ Aurora.

Varuna $=$ Neptune, god of the water, the Greek Ouranos.

Viraja or Vaitarini $=$ the river Styx.

Viswakarma $=$ Vulcan, architect of the gods.

Yama or Dharmaraja $=$ Minos, the Grecian Pluto.

Many of the Hindu deities, however, belong to a bygone age, and ceased to be worshipped more than 2000 years ago. Perhaps Agni, Chandra, Indra, Saraswati, Surya, and Yama, among the the old myths, are all that are now renowned; the other Vedic deities have yielded to Bhawani, Durga, Ganesa, Hanuman, Kali, Krishna, Lakshmi, Prithivi, Rama, Siva, and Vishnu, with many gods of local fame.

The deities of the ancient Greeks were exceedingly numerous and dissimilar in their character. In Greece and Asia Minor, each of the deities was the paternal god of some city or race, having not only separate rites, but a form of worship widely different. Each deity had his favourite abode and local attachment: to some valley, or grove, or town, the power and presence of the divinity especially belonged; and hence in Bœotian Thrace we trace the orgies of Bacchus; in Northern Thessaly, the worship of Apollo; on the Corinthian shores, the rites of Neptune; in Argos, the temples of Juno; and in Ephesus, the worship of Diana. Though acknowledged to be divine out of their own peculiar domains, yet their worshippers were rather averse to proselytism, fearing lest, by an extended conmunication, the local influence of the deity should be weakened. The sacred object of Ephesian worship was carefully preserved, from the period of its first formation, through the ages which intervened, till the demolition of pagan temples, which followed upon the rise of Christianity. The image consisted of a large block of wood of beech or elm, but, according to some, of ebony or vine, shaped into a likeness of the goddess, and evidencing its remote antiquity by the rudeness of its workmanship. The first statues were unshaped blocks and stones; and hence the word columı was generally used by the Greeks to denote a statue. The Greeks identified Baal with Zeus as they did Astarte with Venus. The heaven-fallen idol of Ephesus was not a representation of the elegant huntress of classic fable, but an Egyptian hieroglyphic, a personification of nature. In this character she was pictured as a woman having a number of breasts, to denote, according to Jerome, that, as nature, she was the nurse, the supporter and life of all living creatures.

Similarly, at the present day, amongst the Hindus and other idol-worshippers of British India, shapeless stones and pieces of wood are worshipped in every village. The three famed idols at Jaganath are three shapeless masses of wood, and similar pieces of wood are used as deities on the left bank of the Bhima river. Also every village has its own local deity, and the idol worshipped at Tripati is quite dissimilar from that at Srirangain.

The two gods Indra and Agni, rain and fire, were the chief deities worshipped by the Vedic Aryans. The sovereign of the gods, Indra, the most powerful of the Vedic deities, was the god of the firmament, the hurler of the thunderbolt, who 
smote the rain-cloud, and brought down waters, who delighted in the soma juice, in eating, drinking, and war, strong and drunk with wine.

Indra, according to Bunsen (iii. 587, iv. 459) is the prototype of Zeus, and was a personification of ether; soma was offered to him in sacrifice as the regent of the east, identical with Devandra, the king of the Devas. The Erythrina fulgens, the Pari-jata, or fairy locks, is supposed to bloom in Indra's gardens, and an episode in the Puranas relates the quarrelling of Rukmini and Satyabhama, the two wives of Krishna, as to the exclusive possession of this flower which Krishna had stolen from the garden. The Gandharra, in Hindu mythology, a shade, a spirit, a ghost, a celestial musician, are demigods or angels who inhabit Indra's heaven, and form the orchestra at the banquets of the gods. They are described as witnesses of the actions of men, and are 60 millions in number.

Agni, the personification of fire, was worshipped as the destroyer of forests, as useful in the sacrifice and in the household.

"When generated from the rubbing of sticks, the radiant Agni bursts forth from the wood like a fleet courser.

"When excited by the wind, he rushes amongst the trees like a bull, and consumes the forest as a raja destroys his enemies.

'Such as thou art, Agni, men preserve thee constantly kindled in their dwellings, and offer upon thee abundant food.' (Rig Veda, i. 73.)

Varuna was the Vedic god of the waters, and god of the ocean, but the name was sometimes applied to the suu and sometimes used as a personification of day. As with other gods, when addressed, he was regarded as supreme, and capable of forgiving sin,-

'Let me not yet, $\mathrm{O}$ Varuna, enter the house of clay ; have mercy, Almighty, have mercy!

'If I go along trembling, like a cloud driven by the wind; have mercy, Alnighty, have mercy!

"Thirst came upon the worshipper, though be stood in the midst of waters; have mercy, Almighty, have mercy.'

Surya, or the sun, called also Savitra, Mitra, Aryaman, and other names, was a Vedic god, who continues to be worshipped down to the present day, by Brahmans and Zoroastrians. The Solar race of Kshatriya, who appear in the Ramayana, derive their origin from the sun; but, in the higher spirit, the sun is regarded as divine, as pervading all things, as the soul of the world and supporter of the universe. In a verse of the Rig Veda (iii. 62, v. 10) this idea is supposed to be indicated. It is $O^{\prime} \mathrm{m}$ ! Bhürbhuvăssuvăhā, O'm ! Tatsa vit'hru varennyăm, B'hargo devassyă dhimahi dhiyo yonaha pracho dăyāth: O'm! earth, air, beaven, O'm! Let us meditate on the supreme splendour of the divine Sun ; may he illuminate our minds.' And, at the present day, the enlightened Brahmans regard this verse as an invocation to the several deities who are implored by the worshipper to aid his intellect in the apprehension and adoration of God.

In connection with the sun are the 12 Aditya, sons of Aditi, the universe. In the latter Vedic age, they were identified with the 12 signs of the zodiac, or the sun in its 12 successive signs.

Soma, also Chandra, the moon, is chiefly cele- brated in the Vedas in connection with the soma plant; but in the Mahabharata, Soma is the mythical progenitor of the great Lunar race of Bharata.

The Aswini, apparently a personification of light and moisture as sons of the sun, also as the sun's rays, and noticed as the physicians of the gods. They are described as young and handsome, and riding on horses.

I ayu, or the air, and the Maruts as winds, are personified and invoked. The Maruts are depicted as roaring amongst the forests, and compared to youthful warriors bearing lances on their shoulders, delighting in the soma juice, like Indra, and, like him, the bestowers of benefits on their worshippers.

Ushas, or the dawn, the early morning, the first pale flush of light. Ushas is compared to a mother awakening her children; to a lovely maiden awakening a sleeping world; to a young married maiden, 'like a youthful bride before her husband, thou uncoverest thy bosom with a smile.' As a goddess, she is styled (Rig Veda, i. 23, v. 2) the mighty, the giver of light; 'from on high she beholds all things; ever youthful, ever reviving, she comes first to the invocation.'

Perhaps the most wonderful circumstance of all connected with the ancient Hindu literature, is the completeness with which its effects have passed away from the people of the land. The Veda, in modern Hinduism, is a mere name, - a name of high authority, and highly reverenced,-but its language is unintelligible, and its gods and rites are things of the past. The modern system is quite at variance with the Vedic writings out of which it grew, and the descendant bears but few marks of resemblance to its remote ancestor. The key to this modern Hinduism is to be found in the literature of the Puranas; but before this literature began to assume a definite shape, the point had been already reached which marked the complete divergence of Hindu from European thought. We have to go back to the genuine Vedic ages for conceptions of visible and invisible things analogous to those which determined the course of Greek thought, and, through this, of the thought of the whole western world. Of history, in the true sense, it possesses next to nothing. Of the old poets, philosophers, grammarians, and astronomers, many were beyond doubt men of great genius, and some were possessed of powers as remarkable as any which the world has seen in her most gifted children; but the incidents of their lives can be related generally in a few lines, and. not much space is needed to give a tolerably adequate outline of their philosophical systems. - Williams' Story of Nala; Cole. Myth. Hind.; Calcutta Review; Ins. of Menu; Wilson's Hindu Theatre; Rig Veda, v. 10; Bunsen; Sir W. Jones; Moor's Pantheon; Hymm to Indra; Jacob Grimm, Mythology; Dowson's Classical Dictionary; Lubbock's Origin of Civil. ; Milner's Seven Churches of Asia.

MYTILUS, the mussel genus of molluses, of the family Mytilidæ. The mussel is abundant on most rocky coasts, where the species are to be found moored by their coarse filamentous byssus, generally to such rocks or other submarine bodies as are exposed at some periods of the tide where tides exist, and covered by the sea at high water. The species are numerous, and most of them are used as food; but illness and even death have issued from a meal made on some of them. The 
byssus, or beard, as it is popularly called, should be carefully cleared away, and they should be particularly avoided when cholera is about, or even when diarrhoea is prevalent. The common edible mussel, M. edulis, is found in extensive beds below low-water mark, and also at a greater depth. Rocks and stones between high - water marks are also covered with them. When freed from the epidermis and polished, the undersurface of the external parts of the shell is exposed, and is of a deep blue. See Mollusca.

MYXA, or Egyptian plum of Pliny, is supposed to be the Cordia latifolia.

\section{$\mathrm{N}$}

$\mathrm{N}$, the fourteenth letter of the English alphabet, is a nasal consonant, and its sound is obtained by placing the tongue against the palate, with a vocalized expulsion of the breath. Its principal sound is that heard in bun, done, moon; but when followed by $\mathrm{g}$ or $\mathbf{k}$, it takes other sounds, as in singer, finger, brink. When final after $m$, it is silent, condemn. In the Nagari alphabet there are four symbols for $\mathrm{n}$, the sounds of all of which occur in the English, although not represented in it by separate letters, chiefly caused by the preceding or following letter. There is an $\mathrm{n}$ in the Tamil tongue with a dental nasal sound; and in Hindustani, Gujerati, and Mahrati, there is a nasal, usually a final, although sometimes a medial, which is scarcely sounded, although it gives a nasal sound to the preceding vowel. $\mathrm{N}$ amongst the Baluch becomes $\mathrm{m}$, so that Nila, blue, is made into Miloh.

NA, also Sna. TIB. A wild sheep of Ladakh. Vigne calls it of the size of an ordinary sheep, of a dull brownish $-g r e y$ colour, with curved, smooth, and four-sided horns. It is called by De Koros a large sheep-like deer. Major Cunningham supposes it the same as the Nahur of Nepal, the Ovis nahur.

NAAF, the Anouk-ngay of the Burmese, lat. $20^{\circ} 45^{\prime} \mathrm{N}$., long. $92^{\circ} 30^{\prime} \mathrm{E}$., an arm of the Bay of Bengal, forming a portion of the western boundary of Akyab district. It is about 31 miles long, and 3 miles broad at its mouth. The island of Shahpuri protects its entrance to some extent from the S.W. monsoon. In September 1823, a small British detachment, then occupying the island, was attacked by the Arakanese troops under the raja of Ramri, which led to the first war with Burma.-Imp. Gaz.

NABHA, one of the Cis-Sutlej States under the pulitical control of the Government of the Panjab, lying between lat. $30^{\circ} 17^{\prime}$ and $30^{\circ} 40^{\prime} \mathrm{N}$., and between long. $75^{\circ} 50^{\prime}$ and $76^{\circ} 20^{\prime} \mathrm{E}$. Area, 863 square miles; estimated population in 1876 , 226,155 . The ruling family is descended from Tiloka, the eldest son of Phul, a Sidhu Jat, who founded a village in the Nabha territory. The raja of Jhind is descended from the same branch, and the raja of Patiala is descended from Rama, second son of Phul. These three families are accordingly known as the Phulkian bouses. By a sunnud of May 5, 1860, it was provided that, in a case of failure of male heirs to any one of the three Phulkian houses, a successor should be chosen from among the descendants of Phul, by the two other chiefs and the representative of the British Government. The family behaved ill in the Sikh war of $1845-46$, but did well in the revolt of 1857 , and were rewarded by a grant of land out of the Jhujjur territory. The troops formed part of the Native Contingents which held the Khaibar and Kuram country during the operations in Afghanistan in 1879.

NABHAGADISHTA, a son of Menu who, whilst a student, was deprived of his inheritance. $\mathrm{He}$ subsequently became wealthy by teaching spiritual knowledge.-Dow:son.

NABHAJI, a disciple of Ramanand, author of the Bhaktamala.-As. Res. p. 8.

NABI. Arab., Pers. A prophet, but particularly applied to Mahomed.

NABLUS, a corruption of Neapolis or New Town, the Shechem of the Old Testament, and the Sychar of the New, one of the oldest cities of Palestine, and at one time the capital of Samaria, the imperial city of the ten tribes. It is situated in a narrow valley between Mount Ebal and Mount Gerizim. The present village, called Sabouste, is small, and its inhabitants poor.

NABONASSAR or Nabu-Natsir, a king of Babylon, under whose reign astronomical studies were much advanced in Chaldea. He is known to the Arabs and in Muhammadan literature as Bakht-un-Nasr. The first day of the era which he established was Wednesday the 26th February 747 B.c. Its year was of 365 days, without any intercalary day on the fourth year. Oriental historians, and particularly the Persians, also style him Raham, also Gudarz.-D'Herbelot, iii. p. 1 ; Mignan's $T r$.p. 254; G. Smith.

NABOPOLASSAR or Nabu-pal-Uzur, the father of Nebuchadnezzar, the Nabu-kudur-Uzur, of the Babylonians. Nabopolassar became the Assyrian satrap of Babylon B.c. 626. He made himself independent, and in alliance with the Medes checked the career of empire of the Assyrians, and raised Babylon into the seat of empire of IVestern Asia. The Medes had revolted, and Sardanapalus, king of Assyria, commanded Nabopolassar to march against them, but instead of doing so, he made an alliance with Cyaxares, and marched with him against Nineveh, which was destroyed B.C. 606 . Sardanapalus burned himself in his palace, and ended the Assyrian empire; and from that time Babylon became independent.-G. Smith; Bunsen.

NACHIKETAS, in Hindu mythology, son of Aruni or Vaja-sravasa, who, having angered bis father, departed to the abodes of death, and, after staying there three nights, Yama granted him permission to see his father again, and instructed him in a true knowledge of the soul.-Douson.

NACHRAVALI, TAM., Asees, Hind, is a form of Hindu benediction, only bestowed by women and priests. It is performed by clasping both hands over the person's head, and waving over him a piece of silver or other valuable, which is bestowed in charity. The Tamil people similarly wave a fowl or sheep's head around a sick man. This is a very ancient ceremony. Colonel Tod frequently had a large salver filled with silver coin waved over his head, which was handed for distribution amongst his attendants. It is most appropriate from the ladies, from whom also he had this performed by their proxies, the family priest or female attendants. It is also a Muham- 
madan rite.-Tod's Rajasthan, i. p. 618. See Balain Lena; Sacrifice.

NACRE. Fr. Mother-of-pearl or mother-o'pearl. The nacre in shell is more especially observed in their interior, and is distinguished by the iridescence produced by the action of light. It consists of layers or folds of membranous shell substance. This lustre has been successfully imitated on engraved steel buttons.

NAD, also written Naad or Nadu, KarN., Maleal., Tel, and Nat, Maleal., Tam., a province, a district of a country, as Mulnad, Wynad. The plateau of the Neilgherry Hills is arranged into three naad, the Peringa-naad, Malka-naad, and Thodawar-naad. Mulnad means a hilly country.

NADI or Nari. BENG. A caste who make ornaments of lac for Mubammadan women.

NADIR. ARab. Wonderful, an epithet to describe the Almighty. Nadir Kuli, the slave of the wonderful (i.e. God).

NADIR SHAH, a native of Khorasan, was one of the greatest warriors whom Persia has ever produced. His name was Nadir Kuli, but he has also been known as Tahmasp Kuli. According to Mirza Mahdi, his historiographer, Nadir was descended from the Karakli branch of the tribe of Afshar, or Aushar, according to the pronunciation of the Turkomans, meaning one who holds together. The Afshar was one of the seven Turkish tribes that had attached themselves to the family of the Suffavean dynasty, moved from Turkestan into Iran during the dominion of the Mongols, and settled in Azerbijan. In the time of Shah Ismail Safi, they emigrated to Khorasan, where they dwelt in Yap Kopken, which belonged to Abiverd, and is situated twenty farsakbs to the north-west of Meshed. Here, on the border of the steppe, Nadir was born, A.D. 1687.

At seventeen he was taken prisoner by the Uzbak, but four years afterwards he escaped and returned to his native country, and subsequently accepted service with the king of Khorasan. He successfully commanded an army against the Tartars, but, being ill rewarded, he left and became predatory.

After the abdication of Shah Husain in favour of Mahmud, chief of the Ghilji, A.D. 1722, when Isfahan yielded to that Ghilji chief, Tahmasp, son of Shah Husain, escaped. He had fled from Isfahan, and had remained under the protection of the Kajar tribe on the shore of the Caspian, where he was joined by Nadir Kuli.

He captured Meshed, and recovered Khorasan from the Abdali and Muhammad Khan of Seistan, and in a succession of battles broke down and dispersed the Ghilji, most of whom were killed or perished in the desert on their attempting to return home. Ashraf, son of Mahmud, was murdered by a Baluch chief (January 1729) between Kirman and Kandahar. Nadir next marched against the Turks, from whom he recovered Tabreez, opposed a rising of the Abdali, took Herat, and gained over the Abdali to his views. Shortly after this he adopted the Sunni religion, and the Abdali became the most devoted of his followers. Shah Tahmasp had begun to exercise the prerogatives of royalty, but Nadir replaced him by his infant son. This was virtually the commencement of Nadir's own reign, but it was not till he gained many victories over the
Turks, recovered the whole of the territories which that nation and the Russians had seized, and made peace with both powers, that he formally assumed the title of king of Persia. He repaired with his army to the plain of Moghan, to which place he summoned the civil and military functionaries. They assembled to the number of 100,000 persons, and unanimously offered him the crown (A.D. 1736), which he accepted on the condition that the Sunni religion should be established throughout Persia. He was crowned at 20 minutes past 8 A.M., 26th February 1736 A.D., or Shawal 1148 A.II. His next military effort was to seize Kandahar from the Ghilji, and restore it to the Persian monarchy. He set out with an army of 80,000 men, but, though aided by the Abdali, it was not till after a close investment for nearly a twelvemonth that Nadir ventured an assault, and even then he was more than once repulsed before Kandahar fell into his hands (March 1738). While carrying on the siege, he settled the greater part of the surrounding country, and at the same time his son Razza Kuli Mirza, who had marched from Meshed against the Uzbaks, not only conquered the province of Balkh, but gained a victory on the Oxus (Amu Darya) over the king of Bokhara in person (Malcolm's Hist. of Persia, ii. p. 68 ; Hanway, ii. p. 335 ; Sir W. Jones, Nadir Namah). His treatment of the Ghilji was Inoderate; he regarded them like his other subjects, and admitted many of them into his army, but he removed a portion of them from their lands around Kandahar, which he made over to the Abdali, and particularly to that part of them which had been settled about Nishapur in the west of Khorasan.

After a little he advaneed and occupied Ghazni and Kābul (May A.D. 1738, A.H. Safr 1151). The court of Dehli being at this time occupied by the Mahrattas, his messages to the Indian Government were neglected, and one of his messengers was cut off by the Afghans (October A.D. 1738, A.H. Shaban 1151). He therefore advanced through the mountains (November A.D. 1738, A.H. Ramzan 1151), defeated a small force under one of their governors, threw a bridge across the Indus, advanced through the Panjab, and met with no real hindrance till he approached the Jumna, within 100 miles of Dehli, when he found himself in the veighbourhood of the Indian army. The armies closed at Karnal, and the battle (12th February 1739, 15th Zikaida 1151) cnded in the complete rout of the Indian army. Khan-i-Daoran, the commander-in-chief, was killed. Sadat Khan, viceroy of Oudh, was taken prisoner, and Mubaminad Shah, the enperor, sent Asof Jah to tender his submission, and himself repaired with a few attendants to the Persian camp. The two kings marched towards Dehli, which they reached in the beginning of March 1739 , and took up their residence in the palace. Nadir stationed his troops about the town, to preserve order and protect the people. But, on the second day of the occupation, a report spread that Nadir was dead, on which the Indians fell on all the Persians within their reach, and from their isolated positions about 700 were sacrificed. Nadir exerted himself personally to suppress the insurrection, but he was soon assailed with stones, arrows, and firearms from the houses, and one of his chiefs was killed at his side by a shot aimed at 
himself. On this he ordered a general massacre of the Indians (Fraser's Nadir Namah, p. 183). The slaughter raged from sunrise until the day was far advanced. It was attended with all the horrors that could be inspired by rapine, lust, and thirst of vengeance. The city was set on fire in several places, and was soon involved in one scene of destruction, blood, and terror. At length Nadir ordered it to be stopped, and his order was at once obeyed. 30,000 are stated by the anthor of the Nadir Namah to have been slain, but the numbers killed have been given at 120,000 to 150,000 . Nadir afterwards seized the imperial treasures, also the celebrated peacock throne; and every inhabitant was forced to disclose the amount of his property, and pay accordingly. Torture and murder were employed to enforce payment. Nadir concluded a treaty with Muhammad Shah, by which all the country west of the Indus was cerled to Persia, his son was married to a daughter of the house of Timur, and he reseated Mubammad on the throne, invested him with the ornaments and crown with his own hands, and commanded all the nobles to obey him, on pain of his future vengeance. At length he marched from Dehli, after a residence of 58 days, carrying with him a treasure in money amounting at the lowest computation to eight or nine kror of rupees, besides, to the value of several kror or millions sterling, in gold and silver plate, valuable furniture, and rich stuffs of every description, and jewels of inestimable price. He also carried off many elephants, horses, camels, and led away several hundred of the most skilful workmen and artisans.

Up to the taking of Dehli, he was perhaps less sanguinary than the generality of Asiatic monarchs. He had been a rigorous though not unjust master; but after the sack of Dehli he gradually became a cruel and capricious tyrant. The first years after his return from India were occupied in the conquest of the kingdoms of Khorasan, Khiva, and Bokhara, which he subdued and evacuated. He attempted to reduce the hill tribe of Lezgi, and led three campaigns against the Turks; but he became doubtful of the Persians, all of whom continued Shiahs at heart, and was especially jealous of his eldest son, Razza Kuli, In the belief that a wound he had received in a forest when hunting had been inflicted by an emissary, he put out his son's eyes. His remorse, instead of softening his heart, exasperated his fury, and he taunted all who entreated him for mercy with their failure to intercede when his own son was in danger. His cruelties and extortions led to revolts, which drew on fresh enormities; whole cities were depopulated, and piles of heads raised to consummate their ruin; eyes were torn out, tortures inflicted, and no man could count for a moment on his exemption from death in torments. During the last two years of his life, his rage was increased by bodily sickness, until it partook of frenzy. On the day before his death, while labouring under a feeling of impending evil, he leaped on his horse in the midst of his camp, and was on the point of flying from his own army, to take refuge in a fortress. But he calmed down, and sent for the Afghan chiefs in his service, appealed to their fidelity for the preservation of his life, and ordered them to displace his Persian guards, and seize on the principal nobles.
These orders became known, and his death was resolved on. A number of conspirators, among whom were the captain of his guard and the chief of his own tribe of Afshar, entered his tent at midnight. They involuntarily drew back when challenged by that deep voice at which they had so often trembled, but they soon recovered their courage. One of them made a blow at the king with a sabre, and brought hin to the ground; he endeavoured to raise himself, and attempted to beg his life, but the conspirators redoubled their blows until he expired. He had been the boast, the terror, and the execration of his country (A.D. Sunday, 10th May 1747, A.H. 10th Jamadi-ul-A wal 1160). The Afghans, about 4000 in number, led by Alumad Khan Abdali, unaware of their master's death, on the next morning made an attack on the Persians, in the hope of being still in time to rescue the Shah. In this Ahmad Khan Abdali was joined by the Uzbaks, but they were worsted and compelled to retreat to their own country, which they did in good order.

Nadir Shah's plunder destroyed the Moghul empire. The Mahrattas, the nawab of the Carnatic, the Asof Jahi family of Hyderabad, the subahdars of Bengal and Oudh, and the Jat of Bhurtpur, all declared for independence, and set the imperial power at defiance.

One of Nadir Shah's features of policy was the colonization of the countries he conquered, and in pursuance thereof he encouraged settlement in Af ghanistan by the various tribes of the vast Persian empire. At the time of his death, numbers, under such intention, had reached Meshed, and were subsequently invited to come by Ahmad Shah. Hence at Kābul, at this day, are found Juanshir, Kurd, Rika, Afshar, Bakhtiari, Shah Sewan, Talish, Baiyat, in short, representatives of every Persian tribe. Under Ahmad Shah and his successors they formed the principal portion of the ghulam khana, or household troops.

Ouseley mentions that one of the attendants, who at a levee presented to him pipes and coffee, was a grandson or great-grandson of the mighty Nadir Shab. - Elphinstone's India; Tr. of a Hindu; Rennell's Memoir; Ouseley's Tr.; Cunningham's Sikhs; Père Bazin, Lettres Edifiantes; Balfour's Memoirs of Hazin; Elliot's India; Sair-i-Mutakkhirin; Vambery; Baillie; Fraser in Tr. R. Geog. Soc.; Oriental Biography.

NADIYA, a small town on the west bank of the Bhagirathi, in lat. $23^{\circ} 24^{\prime} 55^{\prime \prime} \mathrm{N}$., long. $88^{\circ}$ $25^{\prime} 3^{\prime \prime} \mathrm{E}$., which gives its name to a district of Bengal. Nadiya is at the head of the Gangetic delta. Along the entire north-eastern boundary flows the wide stream of the Padma, which is now the main channel of the Ganges; and all the remaining rivers of the district are offshoots of the great river. The Bhagirathi on the - eastern border, and the Jalangi and the Matabhanga meandering through the centre of the district, are the chief of these offshoots, and are called distinctively the Nadiya rivers. But the whole surface of the country is interlaced with a network of minor streams, communicating with one another by side channels. The Jalangi flows past the civil station of Krishmagar, and falls into the Bhagirathi opposite the old town of Nadiya.

Of Plassey, the memorable scene of Clive's victory over Suraj-ud-Dowla, on the $23 \mathrm{~d}$ June 1757 , only a small fragment now remains. The Bhagirathi, on 
whose left, or east, bank the battle of Plassey was fought, has eaten away the scene of the strife, as the Jalangi river, in the same district, has eaten away the city of Nadiya. As early as 1801, the river had eaten away the actual field of battle; and a traveller recorded in that year that ' $a$ few miserable huts, literally overhanging the water, are the only remains of the celebrated Plassey.' The neighbourhood relapsed into jungle, and was long a favourite haunt of river dacoits. Part of the site is now covered by the waters of the Bhagirathi, the rest stretches out as a richly cultivated plain, and the solitary surviving tree of the historic mango grove is held sacred by the Mulammadans.

It was the capital of Lakshman Sen, the last independent Hindu king of Bengal. It is the birtliplace of Chaitanya, a great Hindu religious reformer in the end of the 15th century. The descendant of the rajas of Nadiya resides at Krishnagar. The family is of great antiquity and sanctity. They trace descent in direct line from Bhattanarayan, the chief of the five Brahmans imported from Kanouj by Adisur, king of Bengal.

The aboriginal races are Chamar, Bagdi, Chandal, and Muchi. When Clive, in 1757, defeated the nawab Suraj-ud-Dowla, Maharaja Krishna Chandra Raya aided the British. He was the Mecænas of his age.

Nadiya is famous for its Sanskrit schools or tol. Nyaya Sastra or logic, and Smriti or jurisprudence, have been always sedulously and successfully cultivated here. Soon after the foundation of Nadiya, Abdihodh Yogi migrated there from the Upper Provinces. $\mathrm{He}$ was the first to set up a school of logic, for the cultivation of which the city has since been famous. His principal disciples were Sankar Tarkabagis and Baypti Siromani, both of whom wrote several works on logic.

Vasu Deva Sarbwabhauma was the founder of another chatuspati, or regular school for logic, in the village of Vidyanagara, in the vicinity of Nadiya. Of the numerous students who matriculated at the clatuspati, the most distinguished were Raghu Rama and Raghunatha Siromani. Raghu Rama's commentaries have earned for him a conspicuous place among Hindu jurisconsults. Raghunatha Siromani has left a commentary on the Gautama Sutra, which, for profound knowledge of Nyaya and the subtlety of dialectics, and for felicity of illustration, challenges the admiration of the oriental world.

Raghunatha was the author of another work exposing the errors of the Chintamani, a standard treatise on the Nyaya Sastras, written by Ganges Upadhyaya. The work is entitled Didhiti, or a Ray of Light. Professing to be a critique and a commentary on Chintamani, it is one of the most exhaustive treatises on the Nyaya Sastras. Raghunatha proceeded to Mithila, and held a literary controversy with the pandits there. He carried away the palm, and his intellectual victory conferred on Nadiya the power of bestowing degrees on successful students. It gave an unprecedented impetus to the progress of philosophical studies. Students flocked there from all parts of the country. Several of them ripened into profound and distinguished pandits, and the works produced by them are considered of the highest authority. Among these works may be mentioned the Sabdasaktiprakasika, by Jagadis Tarkalankar ; the Saktipad and Muktipad, by Gadadhar Bhattachariya; and the annotations on Siromani, by Jagadis and by Gadadhar; and the Siddhanta Muktabali of Viswanatha Nyayapanchanan.

The decadence of learning in Nadiya attracted the attention of the British Government as early as 1811. On the 16th March of that year, Lord Minto recorded a minute advocating the establishment of Sanskrit colleges in Nadiya and Tirhut.Calcutta Review, No. 109, p. 97.

NADOL, a town in the Jodhpur State in Rajputana. Its raja, Rao Lakha, a Chauhan, was one of the princes who opposed Malimud when advancing against Somnath. It has a temple of Mahavira, the last of the 24Jain apostles, a fine piece of architecture, with vaulted roof, in the most aucient style of dome in the east. The stones are placed by a gradual projection one over the other, the apex being closed by a circular keystone. The toran in front of the altar is exquisitely sculptured, as well as several statues of marble, discovered about A,D, 1700 in the bed of the river, when it changed its course. It is famed also for its Channa Baoli, an immense reservoir.

NADOLI. HrND. A stone engraved with a verse of the Koran, and suspended as a charm round the necks of children.-Herklots.

NA-DOUNG. BURMr. Ear ornaments, ear tubes, cylinders of gold $1 \frac{1}{2}$ inches long, $\frac{3}{4}$ inch diameter, introduced into the lobe of the ear of the Burmese men and women. The image of Gautama is always found with long pendent ear lobes, reaching to his shoulders.

NAF, the navel. Naf-talna or Naf-ukharna, meaning a disease caused by the shifting of the navel, by Muhammadans an imaginary removal from its place of the navel cord, umbilical vein or cœliac artery.-Gloss.

NA-FARMAN. HIND. Delphinium ajacis. $\mathrm{Na}$-farmani, a blue, lilac, or mauve colour from the flower of Cheiranthus annuum.

NAFIS-bin-IWAS, author of an Arabic commentary on Ala-ud-Din Ali's commentary on Aristotle's book on the Principles of Medicine. He styled it Hull-i-Mujiz-ul-Qanun.

NAFR. Pers., Hind, A servant, a man, an individual. In the west of Bengal the Nafr and his offspring were slaves, transferable and saleable. In Purneya the Nafr was sometimes a domestic slave, sometimes an agricultural slave. In the native cavalry of India the term is applied to a horse-keeper or groom, also, though rarely, to a person who is hired to ride a horse, equivalent to assami.

NAGA, in Hindu mythology, a demigod, with the face of a man, the tail of a serpent, and the expanded hood of the cobra di capello, created by Kadra, wife of Kasyapa, to people Patala, where they reign in great splendour. Hence their other name Kadà-veya. The snake-gods were worshipped in Kashmir, and the cobra snakes continue to be worshipped throughout India by all Hindus.-As. Res. xv. 10, 94.

NAGA, a Scythic race who appear to have occupied part of India prior to the appearance of the Aryans. In the mythology of India they are described as true snakes. In the Persepolitan inscription, Xerxes calls himself Nagua or Nuka, the Greek Anax, and some writers have surmised that this may be the true meaning of the Naga 
dynasties of Kashmir and Magadha. A Naga race seem to have ruled in Magadha until dispossessed by the Aryan Pandava. Whether they came from the N.E., whilst the Aryan race advanced from the N.W., is not known. But the races seem to have come in contact in the lands where the Jumna joins the Ganges, at a time when the Aryans were divided as to the object of their worship between Indra, Siva, and Vishnu. One of the opening scenes of the Mahabharata describes the destruction of the forest of Khanduva, and a great sacrifice of serpents; and though the application of the term Nag or Naga has come to be taken literally, there can be no doubt that the descriptions in the Mahabharata, and as to Krishna's exploits against snakes, relate to the opposing Naga race. In India the term Nag or Naga is applied to the cobra serpent, and the race who were so designated are believed to have paid their devotions to that reptile, or took it as their emblem. They are mentioned in the Mahabharata (B.C. 1200) as causing the death of Parikshit, which led to their great slaughter by Janemajaya. But a Naga dynasty was still dominant B.C. 691, likewise when (B.C. 623) Sakya, a prince of the Solar race, was born, and it was this race who placed Buddhism on a secure basis in India, and led to its adoption by Asoka as the state religion.

A Naga dynasty ruled over Magadha at the date of Alexander's invasion, and the reigning prince bore the name of Nanda. His minister Chandragupta, the Sandracottus of the Greeks, - assassinated the Naga prince, and seized upon the throne for himself; and a Naga dynasty, tributary to the Gupta, were ruling to the south of the Jumna during the first three centuries of the Christian era. A Naga race are said also to have occupied Ceylon, on the northern and western coasts, before the Christian era.

Colonel Tod shows; in the annals of Marwar, that the Rahtor race conquered Nagore, or Nagadrug (the Serpent's Castle), from the Mohil, who held 1440 villages so late as the fifteenth century. So many of the colonies of Agnicula bestowed the name of serpent on their settlements, that he was convinced all were of the Tak, Taksbak; or Nagvansa race from Sakadwipa, who, six centuries anterior to Vik ramaditya, under their leader Sehesnaga, conquered India, and whose era must, he thinks, be the limit of Agnicula antiquity.

The Nagbansi chieftains of Ramgarh Sirguja have the lunettes of their serpent ancestor engraved on their signets in token of their lineage. The Manipur rulers were also Scythic, and most of the Manipur people continued to worship snakes till the beginning of the 19th century, as indeed is still the custom amongst all Aryan and nonAryan tribes throughout the Peninsula of India.

Naga and Takshak are Sanskrit names for a snake or serpent, the emblem of Budha or Mercury. The races who dwelt in India prior to the advent of the Aryans are alluded to in ancient books as Naga, Rakshasa, Dasya, Asura. The whole of the Seythiau race are mythically descended from a being half-snake and half-woman, who bore three sons to Heracles (Herod. iv. 9, $10)$, the meaning of which probably is that the ancestral pair were of two races, and the offspring took the snake as their emblem, similarly to the Numri or Lumri Baluch of the present day, who are foxes, and the Cuch'hwaha Rajputs, who are tortoises. The snake race seem to have spread into North America. Abbé Domenech mentions an Indian race there who traced their origin from the snakes of Seythia. The serpents who invaded the kingdom of the Lydians just before the downfall of Croesus, were probably the Scythian Naga (Herod.) race.

The Naga race were so numerous in Ceylon that it was called Nagadwipo, as Rhodes and Cyprus received the designation of Ophiusa, from their being the residence of the Ophites, who introduced snake-worship into Greece. According to Byrant, Euboea is from Oubaia, and means serpent island. Strabo calls the people of Phrygia and the Hellespont the Ophio or serpent races.-Tod's Rajasthan.

NAGA. All Hindu sects have followers to whom this designation was applied. The Naga in all essential points were of the same description as the Viragi or Sanyasi, but in their zeal they used to leave off every kind of covering and go naked, and were the most worthless and profligate members of the Hindu religion. They always travelled with weapons, usually a matchlock, a sword, and shield, and sanguinary conflicts have occurred between Naga mendicants of opposite sects. The Saiva Naga were the leading actors in the bloody fray at Hardwar in 1790 , which excluded the Vaishnava from the great fair there until the country came under the sway of the British. On that occasion 18,000 Viragi were left dead on the field. A party of them attacked Colonel Goddard's troops in their march between Dorawal and Herapur, and on a critical occasion 6000 of them aided Sindia. The Saiva Sanyasi smear their bodies with ashes, allow their hair, beards, and whiskers to grow, and wear the projecting braid of hair called the jata; like the Viragi Naga, they used to carry arms, and wander about in bodies soliciting alms or levying contributions. The Saiva Naga were generally the refuse of the Dandi and Atit orders, or men who have no inclination for a life of study or business. When weary of the vagrant and violent habits of the Naga, they re-entered one of the better-disposed classes which they had originally quitted.

Naga is also applied to a class of the Dadu Panthi Hindu sect, who carried arms and served Hindu princes, making good soldiers. A sect of the Gosain are likewise termed Naga, because they perform their ablutions (Sth'nanam) in a state of nudity. These Gosain profess asceticism, but wellinformed Hindus believe that almost all of them originally adopt the tenets of the sect with the object of securing a living without labour, and that few, not more than one in a hundred, live as celibates; and the personal appearance of these men, sleek, with well-covered muscles, supports this view. They wander to very distant places, begging for their mat'h or monastery, and have very scanty clothing, only a small strip of eloth between their thighs. Immoralities, when detected, are punished by fine. The ascetic Gosain can withdraw from the monastery on payment of a fine, can marry and engage in business. Only the Brahman, Kshatriya, and Vaisya are admitted as Gosains. The head of the mat'h is styled mahant. In the 19th century, under the settled rule of the British Government, the Naga migrants have greatly disappeared, especially from the towns, seats of busy commerce. 
NAGA, also Nag. Hind. The term by which, in the Hindi tongue, the Naia snake is designated, known to Europeans as the cobra, also cobra di capello, the Naia genus of venomous colubrine snakes of the family Elapidæ. There is only one species, the Naia tripudians, Merr., which has a moderate body, with rather short tail. There are several varieties. It has a small or moderate eye, with a round pupil, a poison fang in front of the maxillary, which is but little moveable or erectile, and only one tooth behind. The anterior ribs are elongate and erectile, and the skin of the neck is dilatable.

NAGA HILLS are in the S.E. corner of Assam, between lat. $25^{\circ} \cdot 13^{\prime}$ and $26^{\circ} 32^{\prime} \mathrm{N}$., and long. $93^{\circ}$ and $94^{\circ} 13^{\prime} \mathrm{E}$. It is a mountainous border-land between the settled district of Nowgong, in the Brahmaputra valley, and the Feudatory State of Munipur. It is inhabited by tribes termed Naga, who, in 1875 , treacherously murdered Lieutenant Holcombe and his follower's, and in 1879 killed Mr. Damant, the deputy-commissioner.

In 1870 the numbers of the races in the hills were estimated at 82,444, viz. Assamese, 705 ; Aitanya, 355 ; Cachari, 3505; Mikir, 90 ; Kuki, 2524 ; and Naga, 66,535. The several Naga families dwell in one house.

They are a large number of virtually independent tribes of the Indo-Chinese race, and speaking different dialects, who occupy the hill country from the northern boundary of Cachar to the banks of the Dihang river; in the extreme east of Assam. The British portion is occupied by the Angami Naga, the Kacha, and the Rongina Naga. The last are a small and inoffensive clan, engaged in traffic. The other Nagas are brave and martial, but vindictive and treacherous. The Angami, from $185 \pm$ to 1865 , made 19 raids into the plains, and killed 236 people.

The dress of the Angami Naga consists of a blue or black kilt, prettily ornamented with cowrie shells; and a coarse brown cloth made of the bark of the nettle plant is loosely thrown over the shoulders. The warrior wears a collar round the neck, reaching to the waist, made of goat's hair, dyed red, intermixed with long flowing locks of hair of the persons he bas killed, and ornamented with cowrie shells. The relations of a murdered person instantly, if possible, spear the murderer, without reference to the council of elders, unless the delinquent take refuge in another village, when he may escape for years; but years after he may be surprised and killed. If a man's wife is seduced, the husband will surely spear the seducer on the first opportunity. The Angami Naga imagine there are good and evil spirits residing in their hills. To one they offer up sacrifices of cows and mithum; to another, dogs; and to a third, cocks and spirituous liquor. At sixteen years of age a youth puts on ivory or wooden armlets or red-coloured cane collars round his neck, puts brass ear-rings in his ears, and wears the black kilt. If a man has killed another in war, he wears three or four rows of cowries round the kilt, and ties up his hair with a cotton band. He is entitled, also, to wear one feather of the dhune bird stuck in his hair, one feather being added for every man he has killed, and these feathers are also fastened to their shields. They also use coloured plaited cane leggings, wear the war sword, spear, shield, and choonga or tube for carrying panjies. They also attach to the top of the shield two pieces of wood in the shape of buffalo horns, with locks of hair of human beings killed in action hanging from the centre.

Colonel Dalton says (p. 39) it was the custom of some of the Naga clans to allow matrimony to those only who had their faces elaborately tattooed. To this rite of disfiguration they are not admitted till they have taken a human scalp or a skull, or shared in some of their expeditions. Scalps need not be trophies of honourable warfare, nor even be taken from the bodies of declared enemies. A skull may be acquired by the blackest treachery, but so long as the victim was not a member of the clan, it is accepted.

The Naga do not consume milk, and cattle are not used for tilling the ground, but are kept chiefly for sacrifices and feasts. They eat every kind of flesh. That of the elephant is highly esteemed; they are not averse to tiger's flesh. Their houses are gable-ended, and about 30 or 40 feet long by 12 or 16 feet wide. Each house is divided off into one or two rooms; the pigs, fowls, wife, and children are all huddled together with the grain in large bamboo baskets five feet high, and four feet in diameter, in the same room. In a large building called Rangkee or the Dakachang, all the boys of the village reside until they are married. The building is about 60 feet long, and 20 high, with gable-ends. The inside of the house consists of one large room, in the centre of which a wood fire is kept burning on the ground, and wooden stools are arranged in rows for the boys to sleep upon. At one end a small room is partitioned off for the accommodation of an elderly man, who is superintendent of the establishment. The Hilokee (a building of similar dimensions and construction with the Rangkee) is devoted entirely to the use or residence of the girls of the village, who live in it altogether, in the same manner as the boys, until the day of their marriage. The damsels are all decently attired. A large sheet with coloured stripes is worn round the waist, extending to the knees; a blue cloth is folded over the breast under the arms; a profusion of glass bead necklaces adorn their necks, with a number of brass ear-rings of all sizes. An old woman superintends the establishment, and the utmost order prevails in both the Rangkee and the Hilokee. The boys and girls take their meals with their parents, work for them during the day, and at night retire to their respective asylums. All the youths see the girls during the day without the smallest restraint, and they select their own wives, and are married by the consent of their parents. The Naga of Cachar have several graceful dances, in which the sexes mingle.

The Tun-khul or Luhuppa, a Naga tribe of the N.E. frontier, shave the sides of their heads, leaving only a ridge of hair on the top about five inches broad, with a small knotted pig-tail behind. On the eldest son of a family marrying; he takes possession of the entire property, houses, fields, etc., of his parents, who quit their home, and they are thus displaced by successive sons' settlements. The men have only a narrow piece of cloth round the waist, one end of which hangs in front, and they dispense with it when engaged in any hard work. The men also put the prepuce 
and glaud in a ring of deer horn or ivory. It is removed for micturition and at night, but worn from puberty till death, and they appear and work and sit in women's presence with this sole covering. - Dr. Broun; Fytche, ii. p. 350 ; Butler's Assam; Wilson; Mr. Hodgson; B. As. S. J., 1865; Latham's Ethri.; Rep. Brit. Ass.; Dalton's Ethn.

NAGA-LEKA-BALJIWANLU, or the Chippegiree, are worshippers of Siva, in the form of a cobra. The Siva Chippaga wanlu are worshippers of Siva; they are found in the Bellary collectorate of the Madras Ceded Districts.

NAGA-LOKA. SANSK. Patala, the residence of the Naga.-Douson.

NAGA-NANDAVA, a Buddhist drama in five acts, by Sri Harsha Deva. Mr. Boyd translated it.

NAGA-PANCHAMI is a festival held on the fifth day of the first or bright half of the lunar month S'ravana, which generally corresponds with August of the Christian year. S'ravana is a month in which the Hindus generally have some vrata or ceremony to perform every day, and sometimes more than one festival occurs on one and the same day. The fifth day of the month is considered sacred to the Naga or serpent. On this day, early in the morning, each family brings an earthen or clay representation of a serpent, or paints a family of five, seven, or nine serpents with rubbed sandal-wood or turmeric. If there be a Naga temple in the village, every one goes there to perform worship. The women proceed to snakes? holes, circle round hand in hand, prostrate themselves, and pray for blessings. Offerings are then made to snakes of milk, grain, and other articles poured into holes. Battisa-S'iralen is a town in Satara collectorate, in lat. $16^{\circ} 57^{\prime} \mathrm{N}$, and long. $74^{\circ} 15^{\prime} \mathrm{E}$., famous as a place of serpent-worship. Here, at the present day, the snakes called Nagakuli, said to be not very poisonous, are actually caught on the day of the Naga-panchami, and kept either in earthen pots or covered bamboo baskets. They are fed with milk and edibles, and worshipped in other respects like the snake images and drawings of snakes. The day after the Naga-panchami they are taken back to the jungles and set free. There is at this town a curious tradition in connection with the Gorakhachincha tree (Adansonia digitata) or the tamarind of Gorakha. Tradition ascribes this tree to be the result of a miracle performed by a saint called Gorakhanatha or Gorakshanatha. A Naga temple, dedicated to the goddess Naga Tambiran, exists in the island of Nainatavoe, S.W. of Jaffna, in which consecrated serpents are reared by the pandarams, and daily fed at the expense of the worshippers. Such temples are to be seen in many places in the south of India. There are several in the town of Madras, and one of great extent at Vasarapad, a suburban village on its north, where crowds of Brahman women come every Sunday morning to worship. The priests are the wild Yenadi.

NAGAPATANA, a town in the district of Tanjore, with a celebrated temple of Naga-natha. Inside the temple, near the idol of Naganatha, there is a white ant hill, to which large offerings are made in honour of the serpent-god.

NAGAR, HIND, from Nagara, a town, any town, as Nagar, Ahmadnagar, Vizianagram. Hindus have seven sacred nagara, viz. Ayodhya,
Mathura, Maya (Gaya), Kasi or Benares, Kanchi or Conjeveram, Avanti or Avantika, the modern Ujjaini, and Dwaraka or Dwaravati-Douson. See Kapilavastu.

NAGAR, or Bednur, a town which gives its name to a division of Mysore, conprising the districts of Shimoga, Kadur, and Chittuldrug. The Nagar district is to the north of Coory. It consists of table-topped hills, 4000 to 5000 feet in mean elevation; the Baba Booden Hills are 5700 feet, and some parts are 6000 feet. Coffee is largely grown; its climate and vegetation appear to be identical with that of Malabar. As with all other parts of the western chain, the climate of the western parts is excessively humid. The rains at the town of Nagar or Bednur, elevated 4000 feet on a spur to the westward of the chain, are said to last for nine months, during six of which they are heavy. It belonged to the ancient Chalukya dynasty. It was taken by Hyder Ali, and he found in it many kror of rupees.-Hooker and Thomson.

NAGAR or Nagore, a small town on the Coromandel coast, in lat. $10^{\circ} 49^{\prime} 30^{\prime \prime} \mathrm{N}$., and long. $79^{\circ} 53^{\prime} 24^{\prime \prime} \mathrm{E}$., three miles N. from Negapatam. It is a seaport town in the Tanjore district, chiefly inlabited by Muhammadans of the Labbai race. It is the ancient Thellyr. It has a celebrated mosque, with a beautiful minaret 90 feet high, more resembling a Chinese pagoda than the minar of India. It is an excellent landmark. - Horsburgh.

NAGARAHARA, or Jalalabad, is the Nanggo-lo-ho-lo of the Chinese Buddhist pilgrin Hiwen Thsang of the 7 th century A.D. Its capital was at Hidda, the Hi-lo of the Chinese, and it was the Nagara or Dionysopolis of Ptolemy. 'The natural boundaries of the district are the Jagdalak pass on the west, and the Khaibar pass on the east, with the Kābul river to the north, and the Safed Koh or Snowy Mountains to the south. Within these limits the direct measurements on the map are about 75 by 30 miles, which in actual road distance would be about the same as the numbers stated by Hiwen Thsang. The position of the capital would appear to have been at Begran, about two miles to the west of Jalalabad, and five or six miles to the W.N.W. of Hidda, which every inquirer has identified with the Hi-lo of the Chinese Pilgrims. The town of $\mathrm{Hi}$-lo was only four or fiveli, or about three-quarters of a mile, in circuit; but it was celebrated for its possession of the skullbone of Buddha, which was deposited in a stupa or solid round tower, and was only exhibited to pilgrims on payment of a piece of gold. Hidda is a small village five miles to the south of Jalalabad, but it is well known for its large collection of Buddhist stupas, tumuli, and caves, which were explored by Masson.-Cunningham's Ancient Geography, p. 44.

NAGARCOIL, a small town in the State of Travancore, near Cape Comorin, in lat. $8^{\circ} 11^{\prime} \mathrm{N}$., and long. $77^{\circ} 28^{\prime} 41^{\prime \prime} \mathrm{E}$. Its name means snaketemple, and it is one of the centres of this worship. The principal image of Naga Amman or the Snake Mother, of copper-gilt, and in the form of a serpent, is, like other idols, carried in procession in a car once a year. Inside the temple and without are numerous stone images of snakes. People assemble on Sundays and other special days from many quarters, bringing milk, sugar, and cocoanuts to worship the serpent-goddess, and for the 
living cobras. The priests keep up the report that within a circuit of a mile from the temple no snake-bite will be mortal; and daily some sand from the seashore is distributed from the temple as a charm. The principal seat of the serpentworship in Travancore is at Manarchala in Kartigapalli district. The Rev. Mr. Mateer mentions that a family in the Cochin country made a household god of a cobra. It dwelt on their premises, and was served with daily offerings of food by each member of the family. A girl about ten years of age was bitten by it, and Dr. Doran approached the house just as she had breathed her last, and he asked them if they had killed the snake, but the child's mother replied, 'Sir, if we were to kill the cobra all the other nembers of the family would die likewise." At Warkkala several members of a family of llavars having been attacked one after another with leprosy, a sorcerer told them that they had failed to pay due homage to Naga Raja, and should erect a domicile for him to reside in, and make special offerings to pacify his wrath. A large quantity of rice, cocoanuts, and other provisions was accordingly offered.-Mateer's Travancore, p. 326.

NAGARI. Hind. Relating to a town or city, applied especially to the alphabet of the Sanskrit language, and its modifications in Hindi, Mahrati, etc., sometimes with deva (divine) prefixed, as Deva Nagari. At the present day the Hindi and Mahrati tongues are written in Deva Nagari character, the Burmese in the Pali; the Tamil, Telugu, Canarese, Malealam, Bengali, Gujerati, Uriya, and others have each their own separate character. The four varieties of the Nagari character are the Gurmukhi, that used by the Dogra Rajputs, the Lundi used by mercantile firms, and the Thakuri of the Kangra district. In 1881 the numbers speaking Mahrati were 16,966,665; Panjabi, 14,246,881.-C'ust.

NAGARI NOSE, a peak of the Nagari Hills, in the North Arcot district, Madras, in lat. $13^{\circ} 22^{\prime} 53^{\prime \prime}$ N., and long. $79^{\circ} 39^{\prime} 22^{\prime \prime}$ E., 2824 feet above the sea, and 50 miles inland. It is visible from the sea in fine weather, and is a recognised landmark.

NAGARJUNA, a Buddhist innovator, founder of the Mahayana school.

NAGARJUNA CAVE, one of the Behar caves, in the neighbourhood of Rajagriba. The Nagarjuna cave and Haft Khaneh or Satgarh group are situated in the southern arm of the hill at some little distance from the Brahman Girl and Milkmaid's Cave. Another group is the neighbouring Karna Chapara and Lomas Rishi caves. See Architecture.

NAGAR KOT, an ancient town in the Kangra district. Near it is the temple of Jwala Mukhi.

NAGASAKI, a chief seaport town in Japan. Porcelain made at Nagasaki is solid, and at the same time elegant. Exquisitely-worked basket cups of the thin porcelain are bound by a fine network of cane or young bamboo, so neatly woven that the meshes are imperceptible. The origin of this beautiful texture was, no doubt, a protection to the fingers of tea-drinkers; and many are so well done that they appear to have been painted on the cup.-Frere, Antipodes.

NAGBANSI, a ruling race in Chutia Nagpur and in Jashpur, also styled Nagesar. Their faces are of an exaggerated Turanian type. The nose is low, scarcely rising at all between the eye, very broad across the nostrils, and looks as if it had been there sliced off. The lips are very full and prominent, and the chin receding. Their faces generally present a Chinese flatness of surface; eyes on a level with the cheeks and frontal bones, but straight; complexion tawny to brown. The term is also applied to a race of cultivators known as the Kisan, but who do not claim to be clansmen of the Chutia Nagpur rajas, who are the head of the Nagbansi or Nags. These Kisan cultivate on the skirts of the forest.Dalton's Ethn. p. 136.

NAGINA, a town in the Bijnor district of the N.W. Provinces, celebrated for its manufacture of gun-barrels, ebony carvings, glassware, ropes, and matchlocks. - Imp. Gaz.

NAGKESUR. HiND. Flower-buds of Calysaccion longifolium, also of Mesua ferrea. The root of the Mesua ferrea tree is considered astringent and refrigerant. One tola is taken internally, and it is applied externally in cynanche. The flower-buds of $\mathrm{C}$. longifolium are used for dyeing silk. They have the fragrance of violets.-Genl. Med. Top. p. 147.

NAGODE, or Ucheyra, a State in Baghelcund. Like Koti, the state of Ucheyra was originally included as one of the feudatories of Punnah in the sunnud granted to raja Kishore Singh. The raja rendered good service during the mutinies, and was rewarded with the grant of a jaghir from the confiscated estate of Bijiragogarb. $\mathrm{He}$ also received the right of adoption. The area of this petty state is 450 square miles, and the population 70,000. The revenues are Rs. 72,400 . Nagode State is ruled by a Parihar Rajput.

NAGPORE or Nagpur is the name of a town and a district in the Central Provinces. The Nagpur district is between lat. $20^{\circ} 36^{\prime}$ and $21^{\circ} 43^{\prime}$ $\mathrm{N}$, , and long. $78^{\circ} \cdot 17^{\prime}$ and $79^{\circ} 42^{\prime} \mathrm{E}$, and lies immediately below the great table-land of the Satpura range. The province lapsed to the British in 1853, through the death of the raja, Raghoji Bhonsla III., without heirs. Its area is 3786 square miles, comprising the districts of Nagpur, Bhandara, Chanda, Wardha, Balaghat, and Upper Godavery. The aboriginal population were Gond, but many Hindu castes have settled in it for centuries, largely Mahratta Kunbi and their cognates, with the Dher, Chamar, and Mbang, and other semi-Hinduized races. The first rulers are said to have been Gauli or Abir chieftains, whose exploits yet live in the songs of the villagers. The historical knowledge, however, begins with the 16th century, when the district formed part of the Gond kingdom of Deogarh. The Bhonsla rajas of Nagpur commenced in 1734, when Raghoji Bhonsla was nominated Sena Sahib Suba, or general of the Mahratta confederacy. Raghoji Bhonsla was the son of Bimbaji, the third son of Bapuji, the brother of Parsoji. In 1739 and again in 1743 he was called in to aid the Gond family, and on the latter occasion he remained, taking advantage of the difficulties in which the Peshwa found himself placed ; in 1744 Raghoji obtained for himself a sumnud, conferring upon him the right of collecting all revenue and contributions from Lucknow, Patna, and Lower Bengal, including Behar, and vesting him with the sole authority to levy tribute from the whole territory from Berar 
to Cuttack. Bold and decisive in action, he was the perfect type of a Mahratta leader. He saw in the troubles of other states only an opening for his own ambition; he did not wait even for a pretext for plunder and invasion. Though he was unscrupulous in his dealings with his neighbours, yet he was liked and admired by his countrymen. With him occurred the great influx of Mahrattas, which resulted in the spread of the Kunbi and cognate Mahratta tribes over the entire district. And in this there was deep policy, as the Bhonslas would be seen holding the Nagpur territory from the Gonds, and not subject to the paramount power at Poona, and thus deriving a position superior to that of other military chiefs of the Mahratta empire, who owed their elevation to the Peshwa, and held their fiefs by his favour. Raghoji, as a leader of predatory expeditions, had, at the time of his death in 1755 , established the Mahratta supręmacy over the country between the Nerbadda and the Godavery, from the Adjunta Hills eastward to the sea. He was succeeded by his eldest son Janoji, who adopted as his heir his nephew Raghoji II., but was put aside by Madhoji, a brother of Janoji. Madhoji died 1788 . Raghoji II. then resumed, and lived till 1816. During his reign he joined with Sindia; their united armies were overthrown at Assaye and Argaum, and Raghoji lost nearly a third of his dominions. Raghoji was succeeded by his only son, Pursoji. This prince being incapacitated for government by a complication of diseases, a regency was formed under Madhoji Bhonsla, better known as Appa Sahib, Pursoji's cousin. In 1817 Pursoji died suddenly, having been murdered, as was afterwards discovered, by Appa Sahib. Soon after his succession, Appa Sahib had made common cause with the Peshwa, who was then inciting all the Mahrattas to unite against the British. After an unsuccessful attempt to regain his hold of Nagpur, he fled to Hindustan in February 1819, and he died at Jodhpur in 1840. On the deposition of Appa Sahib, a grandson of Raghoji by his daughter was placed in power on 26th June 1818, and in 1826 he attained his majority, and was entrusted with the administration. A treaty was made with him, by which he ceded for ever territories to pay the cost of the subsidiary force, and assigned lands as a guarantee for the payment of the troops which he was bound to maintain, and which were thenceforth to be uuder British control. Raghoji retained the administration of affairs till his death, 11th December 1853. He died without a son, without any heir whatever, and without any adopted child, and it was determined to incorporate Nagpur State with the British territories. In 1855 the surviving widows of the late raja adopted as their son and heir Janoji Bhonsla, a collateral relation of the raja in the female live. In consideration of the loyalty of the family during the rebellion of 1857 , the title of Raja Bahadur of Deor, and the lands of Deor in the distriet of Satara, were conferred in perpetuity on Janoji and his heirs, whether by blood or by adoption. The family received pensions. The zamindars with whom written engagements were contracted were those of Chatisgarb, Chanda, and Deogarh or Chindwara. The Ch'hattisgarh zamindars, including the raja of Bustar, with whom a separate treaty had been concluded, and the rajas of Kharond and Kakair, were 27 in number, and paid an annual tribute of Rs. 1,28,032. In Chanda there were 18 petty Gond zamindars, paying altogether a tribute of only Rs. 420. The Gond zamindars of Deogarh were 14 in number, who usually paid only a trifling quit-rent. Besides these there were 32 zamindars in the Wainganga districts, who paid a total tribute of Rs. 1,41,594, but with whom no written engagements were formed.

The Nagpur territory and the Saugor and Nerbadda territory have since been formed into a separate administration under a Chief Commissioner, to which have been added Sumbulpur and its dependencies. The territories under the jurisdiction of the Chief Commissioner are now known as the Central Provinces. The principal chiefs in the Central Provinces are the rajas of Bustar, Kharond, and Mukrai, to all of whom the right of adoption has been conceded. The raja of Bustar pays an annual tribute of Rs. 4000 . The Kharond chief pays Rs. 4500 . The revenues of Bustar and Kharond are respectively Rs. 25,870 and Rs. 29,878 , and the population about 80,000 in each state.

Nagpur town is large and straggling, about 7 miles in circuit; it is 85 miles to the north of Chanda. It is the headquarters of the Chief Commissioner. The British military cantonment of Kamptee is in its neighbourhood. Nagpur is situated in an extensive plain, and is, strictly speaking, an open city. A rampart in the usual native style, with occasional round towers, had on some former occasion been commenced, but had in no place been carried to a greater height than 8 feet, and is in general less. The extent of the city, as defined by this unfinished rampart, is scarcely 3 miles, but the suburbs, which run close up to the city wall, are not less than 7 miles in circumference, extending chiefly on the north and east sides, and not exceeding 400 yards in depth on the west and south. The language is a mixture of Hindi and Mahrati. The bulk of the population worship Siva as Mahadeva. The agriculturists are chiefly the Kunbi, Mahratta, Pardesi, Teli, Lodhi, Mali, Barhai, and Pardhan, of whom the Kunbi is the best and the most numerous.

NAGUNI, in the Hinduism of Rajputana, figures half-serpent, half-woman. The gras is the griffin of Rajputana. At Barolli, the gras and naguni are represented in a highly-finished sculpture.-Rajasthan, ii. p. 716 .

NAHAR. ARAB. A river, a canal. Nahri, watered land. Naharaina or Nahrain, the Neharajim of the Scriptures. In Syriac, Nahrim is a pure Semitic word, signifying the country between the two rivers, the Mesopotamia of the Greeks, the Jazirah or island of the Arabs, and the Doab of India. Mawar-un-Nahr is the country between the Oxus and Jaxartes.

NAHUSHA, son of Ayus, the eldest son of Pururavas, father of Yagati. In Hindu mythology, it is said by austerity he acquired the dominion over three worlds, but lost it again through a want of virtuous humility. He touched with his feet the great Agastya, who cursed him, and he became a serpent, but was subsequently restored by the influence of Yudishthra.-Dowson.

NAI, Hind., signifies a reed, pipe, etc., and Anban or Anbana, a bag made of the skin taken entire off a sheep. It is a musical instrument 
not often seen in Persia beyond the Garm-sair, about Bushahr. In sound, as in make, it resembles the bagpipe; which is expressed by its name, Nai ambana, or, according to the usual pronunciation here, Nai amboonah. - Ouseley's Travels, i. p. 241.

NAI. Hind. Also called Napit, a barber who combines also surgical practice, and is a genealogist. The Nai are pure in Bengal, impure in Behar. In some places they have certain priestly functions assigned to them (originating probably in the inportance attached to the operation of shaving on some occasions), and are respected - accordingly.--Dalton, Ethnol.; Hindu Castes.

NAIA TRIPUDIANS. Merr. The cobra di capello snake, common in all parts of British India, Ceylon, the Malay Peninsula. It is a genus of the Elapidæ. There are two varieties, and its synonyms are N. atra, Cantor, N. Kaonthia, Less., N. larvata, Cantor, N. lutescens, Lour., and N. sputatrix, Rein. When the cobra rises in play or for amusement, it spreads out the skin of the neck, from which it gets the Spanish name of cobra di capello, in English the hooded-snake. The spectacled or bin-ocellate variety of the cobra has its neck, on the steel-brown skin, marked with a white, blackedged $₫$ or $\varangle$, enclosing at either extremity a black ocellus, which is only seen when the hood is expanded. It is found in Southern India and in Burma? It grows to $5 \frac{1}{2}$ feet. The monocellate, or one-marked cobra, has a plain white ocellus, with black centre and margin, and grows to $4 \frac{1}{2}$ feet in length. It is the cobra of Central India and Burma. The cobra is worshipped by all the races following Hinduism, and by nearly all the non-Aryan races in British India, and its form, as an idol, with one, three, or nine heads, in stone or brass, may be everywhere seen. It is generally represented bending over the idol of the lingam. The cobra sometimes swims out to sea. It is said that the poison can be combated by injecting potash into the veins, but, owing to the rapidity of the poison's action, this, even if true, is valueless. Notwithstanding this, the natives of Ceylon do not kill the cobra when caught, but enclose it in a mat bag with some boiled rice for food, and place it thus in a flowing stream. In Gujerat the Hindus do not.kill this or any other snake. See Cobra; Naga ; Reptiles; Serpent.

NAIB. Arab., Hind., Pers. A deputy, a representative. Its Arabic plural is nawab, a title given to the viceroys of the Dehli empire; corruptly nabob of Europeans.

NAICHA or Necha. Hind. The monthpiece and drawing tube of a hookah.

NAIDU, a division of the Teling Sudra race, the plural of Naik, an honorific term applied to masters, or chiefs of tribes.

NAIK, a chief, a military leader, a head of police under the Vijayanagar dynasty. A division of the Teling Sudras, conmonly styled Naidu, as Lutchmana Naidu. Also the titulary distinction of the Bhil chieftains. In Cuttack this title was applied to the headman of a village. In the south of India, some of those known as Polygars were so called, and many of the Naiks held lands on military tenure. The leader of a tanda of Binjaras takes the title of Naik, in the British Indian army a rank equivalent to a corporal.
In Telingana the titles more frequently met with are Nayakan, Nayaka, Naik, Naeker, Naidu, and Reddi, applied to the Balaja and the Kamavar tribes. These eat together, but do not intermarry. They are classed as Sudra Hindus originally. In the beginning of the 16 th century, A.D. 1532, the great Hindu state of Vijayanagar established a Naik dynasty, in the person of Viswanatha Naik, under its protection, at Madura. When the Vijayanagar sovereignty fell, the Naik dynasty of Madura coutinued to be dominant. The founder of this dynasty, Viswanatha, was the son of an officer of the king of Vijayanagar. He established himself as king of Madura in 1559, and subjugated Trichinopoly soon afterwards. The greater portion of the fort of Trichinopoly, and most of the city itself, were built in his reign. The Naiks ruled Trichinopoly and Madura from 1559 to 1740. The greatest of them was the famous Tirumala Nayakkan, who died in 1659. His graudson, Choka Nayakkan, removed the capital of the kingdom from Madura to Trichinopoly, where he raised the building known as the Nawab's Palace. Its last ruler, a queen, was first aided and then betrayed by Chanda Sahib of Tanjore.

NAIKASHEYA or Nikashatmaja, in Hindu mythology, carnivorous imps descended from Nikasha, mother of Ravana.-Douson.

NAI-KUDE, a Gond tribe inhabiting the jungles on both banks of the Pain Ganga, especially in the tract between Digaras and Umarkher, and found about Aparawapet and as far as Nirmul. They have adopted the Hindu dress, and will not eat beef; but they live by the chase, cut wood and grass, and are a terror to their neighbourhood by their depredations.

NAIMISHA, an aranya or forest near the river Gumti, in which the Mahabharata was rehearsed by Sauti to the assembled Rishi.-Dowson .

NAINI TAL, a sanatorium in Kamaon, in the outer ranges of the Himalaya, and 6409 feet above the sea, in lat. $29^{\circ} 22^{\prime} \mathrm{N}$., and long. $79^{\circ} 29^{\prime} 35^{\prime \prime} \mathrm{E}$. It has a picturesque lake, and the houses of the Europeans were placed on the slope. of the mountain ; but on the 18th September 1881, two landslips overwhelmed several houses, and about thirty-eight Europeans, civil and military officers, and soldiers. The lake is a mile long and 400 yards wide, between the points Sherku Danda and Luria Kanta. It has good fish. The Naini Tal valley is in the heart of the mountains, two miles long by one broad, all but enclosed, and mostly occupied by the beautiful lake, 6350 feet above the level of the sea. The mountains, composed of igneous rocks, covered with slate, limestone, and shale, with a light friable surface soil, are well wooded with ilex, pine, rhododendra, cypress, and ash; at certain times luxuriantly carpeted with andromedas, potentillas, violets, anemonies, and rare orchids; and tower majestically 2000 feet over the head of the lake, but gradually taper away where the water debouches into the plains. Geologically, the mountains differ, one side made up of argillaceous schists, the other of black limestone. Free perflation of air is always maintained throughout the valley. The greatest leugth of the lake is 4702 feet; its width, at the narrowest part 792, to 1518 at the broadest; its depth ranges from 20 to 93 feet; the circumference 2 miles; superficial area 120 acres.-Schlagent. Macnamara. 
NAIN SINGH, known to geographers as the Pandit. He was employed with Robert Schlagentweit, under Major Montgomerie and others, in the middle of the 19th century, in exploring the Himalaya. He was born about the year 1825, and was Robert Schlagentweit's assistant. After the murder of his master, he settled down as a schoolmaster in his native village. From this retirement he was called in the year 1863 to become one of the staff of trained native explorers under the orders of Colonel Montgomerie of the Trigonometrical Survey. In 1866 he determined the true position of Lhassa; in 1867 he visited the celebrated gold mines of Thok Jalung; and seven years later he began his most celebrated tour of all, that through Tibet from west to east. During this he visited the capital of the Dalai Lama, took numerous observations, and threw much fresh light on the question of the Sanpu river, and whether its lower course is the Brahmaputra or not. He left $\mathrm{J}$,eh in July 1874 , and succeeded in crossing the Tibetan frontier, in the disgnise of a Lama or Buddhist priest. Passing about 15 miles to the north of Rudokh, he travelled nearly due east for a distance of more that 800 miles, over a new line of country, separated from the valley of the Tsampo, or Great River of Tibet, by an almost continuous range of spur mountains, which trends eastwards from the Gangri peaks, in long. $81^{\circ}$ E., up to the Thangla peaks, south of the great Tengri Nur lake, in long. $90^{\circ} 30^{\prime} \mathrm{E}$. His road lay, throughout, over an extensive table-land ranging in height from 13,900 to nearly 16,000 feet above the sea-level, a region containing some gold fields, and numerous lakes and streams, and almost covered with rich pastures. The inhabitants are bands of nomades, who dwell in tents, and regulate their movements by the supply of grass and water available for their flocks and herds. The Pandit struck the Tengri Nur lake at its N.W. corner, and travelled along the northern coast of the lake-a distance of nearly 50 miles-to the opposite corner, whence he turned southwards to Lbassa. He had spent three months at Lhassa on the occasion of his first visit, without being discovered to be a British employé. On the present occasion, one of the first men he met was a Muhammadan merchant, whose acquaintance he had made at Leh. Fearing that he might be betrayed, he hurried away at once. He followed the Tsampo (or Brahmaputra) river for a distance of 30 miles, in a portion of its course through Tibet about 50 miles lower down than the lowest which had been reached by previous explorers, and his observations enabled the course of the river to be laid down approximately for a farther distance of about 100 miles, so that the part which still remains unknown is now materially reduced. He crossed the Bhutan Hills by the route from Chetang via Tawang into Assam, which lies nearly north and south on the meridian of $92^{\circ}$. And finally he brought his work to a close at the town of Odalguri in British territory, and, going down the Brahmaputra river by steamer, reached Calcutta on the 11th March 1875. This exploit closed Nain Singh's public career. He was awarded the Royal medal by the Royal Geographical Society, and the Indian Government granted him a small estate, where lie died towards the end of January 1880.
NAINSUKH, also written Nainsook and Nainu, sprigged inuslin or other fabric.

NAINSUKH, a valley in Kaghan famous for ghi, which is quite solid, and cuts like cheese.Cleghorn, Pan. Rep. p. 178.

NAIQUE, a non-commissioned rank in the native army equal to a corporal. See Naik.

NAIR, a race on the Malabar coast, following the Hindu religion, and claiming to be of the Sudra caste. They are designated Maleala Sudras. The royal family of Travancore are of this race. The whole of the Nair race and other races there follow the rule of female descent, and from this custom results the practice that a man's heirs are not his own, but his sister's, children. The Kasia, the Koc'ch, and the Nair races, as also the artisans, the Teer or Teeyeer race, and some of the Moplah Muhammadans of Malabar, have this custom. Among the Buntar in Tulava, also, a man's property does not descend to his own children, but to those of his sister. Most of the people of Malabar, notwithstanding the same diversity of caste as in other provinces, agree in the usage of transmitting property through females only. It is the custom in Travancore among all the races except Ponan and the Namburi Brahmans. The Nair marry before they are ten years of age, but the husband never associates with his wife. Such a circumstance, indeed, would be considered as very indecent. She lives in her mother's house, or, after her parents' death, with her brothers, and cohabits with any person that she chooses, of an equal or higher rauk than her own. If detected in associating with any low man, she becomes an outcaste. It is no kind of reflection on a woman's character to say that she has formed the closest intimacy with many persons; on the contrary, Nair women are proud of reckoning among their favoured lovers many Brahmans, rajas, or other persons of high birth. In consequence of this manner of propagating the species, no Nair knows his father, no father knows his son, and every man looks upon his sister's children as his heirs. He, indeed, looks upon them with the same fondness that fathers in other parts of the world have for their own children; and he would be considered as an unnatural monster were he to show such signs of grief at the death of a child, which, from long cohabitation and love with its mother, he might suppose to be his own, as he did at the death of a child of his sister. A man's mother manages his family, and after her death his eldest sister assumes the direction. Brothers almost always live under the same.roof; but if one of the family separate from the rest, he is always accompanied by his favourite sister. Even cousins, to the most remote degree of kindred, in the female line, generally live together in greatharmony; for in this part of the country, love, jealousy, or distrust never can disturb the pence of a Nair family. A man's moveable property, after his death, is divided equally among the sons and daughters of all his sisters. His land estate is managed by the eldest male of the family, but each individual has a right to a share of the income. In case of the eldest male being unable, from infirmity or incapacity, to manage the affairs of the family, the next in rank does it in the name of his senior. Under these social rules it is not easy to see the inducement to the Nair to marry. The Nair family is undivided, and by theory the ancestral 
property is impartible, though it sometimes is divided by consent. The Nair people of the Malaya and Tulava countries are frequently educated, and are good accountants. They hold many public offices, and compete for office employments with the Brahmans. The Nairs are a good-sized, wellfeatured race, but rather dark. The Nairs of Malabar were formerly accustomed to duelling. The practice was called Ankam, but hired champions were often substituted.

Nair or Nayar is a title added to nearly all the names of the race, and it is, like Mister and Esquire, assumed as a birthright by any respectable member of the race who has no other. The Kiriyathil, Valta-Kaden, and At'hi-Kuruthi also assume the title. The Kiriyatbil Nair, called also Kuruppu, Keimmal, and Menon, are the offspring of temple women by Brahmans. Men are not accustomed to cover the body above the waist; so also females when in the house, but when going out they cover the bosom with a piece of light white cloth, which is sometimes a costly article, having a border of gold thread. They wear many ornaments, and the hair clone up in a kind of chignon on the left side of the head.

Picart quotes Oviedo as stating that the Nair women regard association with men to be an institution so holy that they believe virgins to be secluded from paradise; but this seems merely an excuse put forward by some one of the race who has been ashamed of this social custom. A Nair writer observes that the Teyettee or Teey eer women are notorious harlots, and become the concubines of strangers of any caste or religion, and this without the least prejudice to their own caste or any loss of esteem in society; on the other band, any such act proved against any females of the other castes, subjects the person to excommunication from caste, banishment from society, and all religious advantages. The Teeyeer females of South Malabar, however, do not, so readily as those of the North, yield themselves to this practice.

Nair women of Malabar are said by Pietro Pellerino (II. letter vii.) 'De Malavaro poi solo sentii de notabile che le loro donne negli atti venerei per usauza far loro recevuta, ed universale, non vogliono mai soggiacere agli nomini.'

These Nair customs are alluded to by Van Linschoten in the 16th, Fryer in the 17th, and Buchanan and Day in the 19th century. The Zamorin of Calicut is a Nair. Among the Limboo tribe in N.E. India, near Darjiling, the boys become the property of the father on his paying the mother a small sum of money when the child is named, and enters his father's tribe; girls remain with the mother, and belong to their mother's tribe. Among the Batta of Sumatra, the succession to the chiefships does not go, in the first instance, to the son of the deceased, but to the nephew, by a sister. The same rule, with respect to the property in general, prevails also amongst the Maliys of that part of the island, and even in the neighbourhood of Padang.Tennent's Ceylon; As. Researches; Mateer's Iravancore; Buchanan, Mysore.

NAIRITTI or Niritti, the dread earth-goddess, of whom terror and deprecation were the only worship. She seems thrust by fear, rather than adopted, into the Vedic pantheon, the gopin of the Kali goddesses and Bhawani. A god named Nairitta, of a fierce and evil nature, is said to have been worshipped by the Sakæ. In Hindu mythology, Nairitta is the regent of the south quarter; a goblin ; a rakshasa.

NAISHADHA-CHARITA or Naishadhya, a history written by Sri Harsha, of the life of Nala, king of Nishadha. It is one of the six MahaKarya of the Hindu literature. See Sri Harsha.

NAI VEDYA. HiND. Food offered to a Hindu god; a meat-offering, belonging to the puja or worship of a Hindu deity or idol. It is offered and distributed.

NAJAB-ud-DIN MUHAMMAD UMAR was a native of Samarcand, but his era is not precisely known. He wrote the Asbab-wa-Ilamat in Arabic, on the Causes, Signs, and Remedies of Disease. A commentary of it, also in Arabic, entitled Sharh-ul-Asbab-wa-Ilamat, was written by Nafisbin-Iwaz, and dedicated to Timur's grandson, Sultan Ulugh Beg, who ruled at Samarcand from his early youth up to 1447 , when he succeeded to the throne of his father Shah Rukh. A translation into Persian of the Sharh-ul-Asbab was made by Muhammad Akbar Arzani, physician to the emperor Aurangzeb (A.D. 1658-1707), to whom it was dedicated, and named the Tibb-i-Akbari.

NAJAFGARH, a village in Cawnpur district, North-Western Provinces, in lat. $26^{\circ} 18^{\prime} \mathrm{N}$., and long. $80^{\circ} 36^{\prime} \mathrm{E}$. The Najafgarh jhil is a large straggling lake or marsh in the Gurgaon and Dehli districts, lying between lat. $28^{\circ} 26^{\prime} 30^{\prime \prime}$ and $28^{\circ} 34^{\prime} \mathrm{N}$., and between long. $76^{\circ} 56^{\prime}$ and $77^{\circ} 4^{\prime}$ $30^{\prime \prime} \mathrm{E}$. Its various branches measure in all 46 miles, and when full in October it submerges about 27,000 acres.

NAJD, a province of Arabia.

NAJRAN, a town in the north of Yemen. It was once filled with Christians. Dzu Newas obtained possession of it by treachery, and gave it up to plunder. Large pits were dug in the neighbourhood, and filled with burning fuel, and all who refused to abjure their faith, amounting to many thousands, were committed to the flames.

NAKARAH. HiND. A drum, a kettle-drum. Nakarah khanah, from Nakarah, a small brazenbodied drum, and Khanah, a house, is generally used to express an assemblage of military or ficld musicians, whose instruments are loud, harsh, and disagreeable; long brazen trumpets, called Karrena, the sounds of which may be compared to the braying: of asses, and two Surna, in appearance not unlike clarionets, but sending forth notes such as might be expected from two discordant bagpipes without a drone. The Sitara, the Kamancheh, and other string-instruments, produce with good voices in chamber concerts very soft and pleasing melody. - Onseley's Travels.

NAKATIYA. SInGH. An astrologer. The practice of astrology at the present day in Ceylon, and the preparation of the ephemeris predicting the weather and other particulars of the forthcoming year, appears to have undergone little or no.change since this custom of the inhabitants of India was described by Arrian and Strabo. But in latter times the Brahmans and the Buddhists have superadded to that occupation the casting of nativities and the composition of horoscopes for individuals, from which the Sophistre described by Arrian abstained. It is practised alike by the highest and most humble castes of Singhalese and Buddhist, from the Vellala or agricultural aristocracy to the beaters of tom-toms, who have 
thus acquired the title of Nakatiya or astrologers. The attendance on particular ceremonies, however, called Bali, which are connected with divination, belongs exclusively to the latter class. Amongst the Muhammadans of British India, astrology is almost unheard of, though they keep their calendar or Jantri, and the Hindu Joshi calculates the ephemeris. The Hindus also have their calendar or Panjangam, but they all practise divination from books, of which the Chintamini pastakam is in use in the south of India.

NAKD. ARAB., Hind, Coin. Nakdi, ready money. It has various combinations.

NAKED. The practice of appearing naked is alluded to in Deut. xxviii. 48 , in Job xxii. 6 , and xxiv. 7, in Ezekiel xviii. 7 and 16, Matthew xxv. 36 and 44,2 Corinthians xi. 27 , and James ii. 15. The word Arom, rendered naked in the English Bible, in many places has the meaning in Job $\mathrm{i}$. 21, Ecclesiastes v. 15, Micah i. 8, Amos ii. 16. In other places it means one who is ragged or poorly clad (John xxi. 7, Isaiah lviii. 7), which does not indeed differ from the familiar application of the word.

NAKHIS, religious ascetic mendicants amonyst the Hindus, who live by begging. They resemble the Urddha-bahu and Akas-mukhi.

NAKHODA, from Nao, a vessel, and Khoda, lord and master, a ship captain.

NAKHONG-VAT or Nakon-Wat and NakonHluang, two famous Buddhist temples in Cambodia. In Cambodia serpent-worship by the Buddhists reached its utmost splendour. The great temple of Nakhon-Vat, wholly devoted to this cultus, is even in its ruins one of the noblest buildings in the world. First discovered in 1858 and 1860 by M. Mouhot, they have since been photographed by Mr. J. Thomson. It exhibits architecture of the utmost splendour, and of a style curiously resembling the Roman form of Doric. Six hundred feet square at the base, the building rises in the centre to the height of 180 feet, while every part is covered with carvings in stone, generally beautiful in design, and always admirably adapted to their situation. Every.angle of the roof, every cornice, every entablature, bears the seven-headed serpent; and instead of the Greek cella, with the statue of the genius loci, there are courts containing tanks in which (we are compelled to infer) the living serpents dwelt and were adored. The date of this marvellous structure must be somewhere about the tenth century of our era, at all events before the fourteenth. When the Siamese conquered Cambodia, the cities of the serpent-worshippers were deserted, and Buddhism was established.

NAKIR and Munkir, according to Muhammadan belief, are two angels who question the dead on their interment as to their good and bad actions in life.

NAKL-us-SHAITAN, Arab, or Devil's Date Palm, a dwarf-giant of palms, grows near Zanzibar. It has no trunk, but the midrib of each branch is as thick as a man's thigh. Eccentric in foliage and frondage, it projects over the waves its gracefully-curved arms, sometimes thirty and forty feet long.-Black. Mag., March 1858.

NAKSHA-i-DILKHUSHA, by Babu Janmejaya Mitra, father of Babu Rajendralala Mitra ; a list of Muhammadan poetesses.

NAKSHATRA. SANSK. Lunar asterisms, mansions of the moon, formerly 27 in number. In Hindu mythology, they are fabled to be daughters of Daksha, a son of Brahma. In Hindu astrology, Sherring says the Nakshatra are regarded as heavenly bodies, which have great influence on mankind, not only at the time of their birth, but during the whole course of their life on earth. In astrology, that portion of a Nakshatra which is deemed unlucky is called Varjya, and the period of its duration is the Tyajya (wrongly spelt Thyajum and Thyagum). It is called Devi when it occurs at day time, and Ravi when at night. It is therefore an astrological element, but is nevertheless registered every day in the Hindu ephemerides, where the instant of its commencement is registered. Its mean duration is about 4 guddia (1h. 36' European time), so that the beginning being known, the end may be supported, with sufficient accuracy for practical purposes, without actual computation. Nakshatri-Mala, a garland of 27 pearls, the number of the Nakshatra or lunar mansions.-Warren; Hind. 'Theat. ii. 66. NAKSH-BANDI. HIND. A sect of the Muhammadan fakirs or darvesh, characterized by carrying a lighted lamp in one hand, and going about singing verses in honour of the prophet, etc. They derive their institution and name from KLaja Baha-ud-Din of Naksh-band. See Khaja.

NAKSH-i-RUSTUM. On cliffs near Persepolis are the sculptured tombs of the Achæmenids and the monuments of the Sassanians, the latter being carved lower down on the same rocks. The rocks on which the bas-reliefs of Naksh-i-Kustum are sculptured bear the name of Koh-i-Husain. They form the continuation of the ridge lying south of the valley of Kamin, and serve for a northern boundary to the district of Hafrek. They are rugged cliffs of white and yellowish marble, with hardly any slope towards the plain. The more ancient sculptures are known as royal tombs. These are seven in number, of which four are at Naksh-i-Rustum, and three in the rocks. of Rahmat, at Takht-i-Jamshid. The former are supposed to contain the four Persian monarchs who immediately followed Cyrus, namely, Cambyses, Darius I., Xerxes, and Artaxerxes I. The remaining three kings of the Achæmenid race are supposed to have been interred in the three other tombs in the rock of Rahmat, at Takht-i-Jamshid. Ardeshir (Artaxerxes), a grandson of Sassan, in three great battles overthrew the Parthian king Artabanus. Artabanus was slain, and the Arsacid empire, which had lasted 476 years, replaced by the Sassanide. Ardeshir caused a bas-relief to be sculptured on the rock at Naksh-i-Rustum, representing himself on horseback trampling on the prostrate figure of Artabanus, close to the portrait of Darius, his reputed ancestor. The inscription is triliteral, in the Pahlavi of E. and W. Iran, with a Greek translation. His son, Shahpur I. (A.D. 241-272), recorded his victory over the Romans on the same rock,-Shahpur on horseback, and Valerian kneeling before him as a suppliant. Shahpur I. has also left his effigy on the rock at Naksh-i-Rajab, near Persepolis, and in the cave at Haji-abad. Some of the monuments of Persepolis and other ancient sites in Persia were erected by the Achrmenian princes,-Darius, the son of Hystaspes, and his successors, - and the inscriptions on them were in three different systems of cuneiform writing. These were placed side by 
side, and were addressed to the three chief populations of the Persian empire. One of them is in the ancient Persian language, and has 40 distinct characters.

The clue to the successful decipherment of the cuneiform inscriptions was discovered by Grote, and Rawlinson followed. Naksh-i-Rustum has an inscription by Darius giving a list of Persian satrapies. There is a long inscription of Darius on the rock of Behistun, which was discovered by Sir Henry Rawlinson.-Baron C. A. De Bode's Travels in Luristan and Arabistan, p. 97.

NAKUH. ARAB. A steep acclivity on a low sandstone hill, facing the coast of the Gulf of Suez. It is about 10 miles from Tor in Sinai, and is covered with coarse sand, the movement of which produces a hollow sound, at first like that of an Eulian haxp; probably Nakus, in Arabic, a bell.-Jam. Ed. Journ., 1830 , p. 74.

NAKULA, the fourth of the Pandu princes, was the twin son of Madri, the second wife of Pandu. He was taught by Drona to train and manage horses, and became Master of the Horse of Virata. By his wife Karenu-mati, a princess of Chedi, he had a son named Nir-Amitra. ${ }^{\circ} \mathrm{He}$ is fabled to have been begotten by the elder of the Aswini.-Dowson.

NAL. Hind. Arundo donax; also Amphidonax karka; also a hollow reed or cane, a tube, a pipe. The reeds used as pens or kalm, for writing in the Persian character. The best are red without, white within, and hard as stone. Nal also means a tube, whence the nal-gola, a kind of arquebuse; a ball propelled by whatever force from a tube; a term used by the old martial poets of India for a warlike engine long before gunpowder was known in Europe. A single-barrelled gun is ek-nalli-ka-banduq, and do-nali-ka-banduq is a double-barrel. It also means a blow-pipe and a weaver's shuttle.-Tod's Travels, p. 25.

NALA, Hivd, is a term applied to a mountain stream, from Nal, a defile, indicating that the course of a stream always presents some mode of penetrating into mountainous regions. Vulg. a nullah, a watercourse or stream; often a long: inlet from one of the great rivers, and receiving the drainage of the country, but not having any origin in a spring or snow bed, as rivers and streams have; usually a rivulet, a channel cut in the soil by rain-water or watercourse; an aqueduct.

NALA and Damayanti, a story of ancient Hindu life, in the later Vedic period preceding Brahmanism. Nala inbabited Nishada, in the Bhil country, and Damayanti was the only daughter of the Vidarbha, in the modern Berar. The raja of Jeypore claims to have sprung from the ancient raja Nala of romantic memory. The story is told as an episode in the Mahabharata, and also in the Nalodaya, said to be by Kalidasa. Being a domestic story, it is better fitted than battles to the Hindu genius, and is a model of beautiful simplicity. Damayanti chose Nala at her Swayamvara, and they lived happily for some time, a son and daughter being born to them. But Nala was lured on to gamble with Pushkara, who used charmed dice, and Nala lost kingdom, wife, and children, and he wandered off in want, and at length forsook his wife. After various fortunes, he and Damayanti again met. He had learned how to play with dice, and challenged Pushkara, from whom he recovered all he had lost, and Nala was restored to his kingdom.-Dowson.

NALA, a monkey chief in the service of Rama. He built the stone bridge called Rama or Nalasetu, from the Peninsula to Ceylon.-Dowson.

NALANDA, a celebrated. Buddhist vihara or monastery, 7 miles $\mathrm{N}$. of the old capital of Rajagriha, and 34 miles S. of Patna. During the first 500 years of the Christian era it was to Central India the depository of all true learning, from which it spread over all the other Buddhist lands. Hiwen Thsang was a student here for five years. Religion and philosophy were taught from 100 chairs, and in his time there were 10,000 priests and neophytes. It was the most famous Buddhist monastery in all India.-Cunninghum's Ancient Geog. of India, p. 15; Fergusson, pp. 136, 137.

NALAYIRA PIRAPANTAM, 4000 stanzas by 7 Vaishnava AIvars, or chief devotees. The last part, Iyarpa, is said to have been written before the commencement of the Kali Yugam; the third part, 4900 years ago ; the other two portions at a later period. No part is probably older than the 12th century. It is sometimes called the Tamil Veda. The work is divided into four books. Part i., Sacred Words, relates the story of Krishna's childhood, and contains hymns in praise of temples. Part ii., called the Great Sacred Words, is chiefly about Vaishnara temples. Part iii. is termed Words of the Sacred Mouth. The divinity of Vishnu, how to meditate on him, a message sent to God by a bird, duty of men to God, are some of the subjects. In part iii. is an invocation to Vishnu: 'Why dost thou not help me, thou, the Great One, my Lord, my Ambrosia, my Father, and my Ruler.' Part iv. contains prayers to Vishnu, meditations, etc.

NALDRUG, a fortress in the western part of the Hyderabad dominions, 27 miles E. from Sholapur. It is built on a bare knoll of greenstone rock, overlooking the ravine in which the river Bori runs southwards, and across which a bridge is thrown. It is supposed to have been built prior to the Chalukya rule, and to have belonged successively at times to the Bahmani, the Adal Shahi, and the Nizam Shahi dynasties, as now to the Asof Jahi. In 1853 it was assigned for a short time to the British with the Raichore Doab.

NALLA. ANGLo-Hind. A bed of a rivulet, or the rivulet itself, the nala of the Urdu tongue. The Arabo-Spanish arroya, a word almost naturalized by the Anglo-Americans, exactly corresponds with the Italian fiumara and the Indian nullah.

NALLA MALLA, a chain of mountains, between lat. $14^{\circ} 43^{\prime}$ and $15^{\circ} 14^{\prime} \mathrm{N}$., long. $78^{\circ} 43^{\prime}$ and $78^{\circ} 58^{\prime}$ E., 16 miles broad, which separate the Ceded Districts from the littoral tracts bordering the Bay of Bengal. Twelve passes lead across them. Their highest points are situated between Cummum, in the Cuddapah district, and Amrabad, a Hyderabad town north of the Kistna, and vary in height from 2000 to 3055 feet above the level of the sea. Sandstone breccia is seen in all parts of the Nalla Malla mountains at various depths from the surface. In one instance, at a depth of 50 feet, the upper strata being sandstone, clayslate, and slaty limestone. A stratum of breccia is 2 feet in thickness, and immediately above it lies a stratum of pudding-stone, composed of quartz and hornstone pebbles, cemented by calcareous clay and grains of sand. It is thought 
likely that this stratum would be found productive in diamonds, and that the gems found at present in the bed of the Kistna are washed down from these, their native beds, during the rainy season.

At Banaganapilly, about 12 miles west of Nandial the breccia is found under a compact sandstone rock, differing in no respect from that which is found in other parts of the main range. It is composed of a beantiful mixture of red and yellow jasper, quartz, chalcedony, and hornstone of various colours, cemented together by a quartz paste. It passes into a pudding-stone composed of rounded pebbles of quartz hornstone, etc. The miners sift and examine the old rubbish of the mines, from an opinion which prevails among them, and which is also common to the searchers for diamonds in Hindustan, and to those on the banks of the Kistna, at Parteala, Malavelly, etc., viz. that the diamond is always growing, and that the chips and small pieces rejected by former searchers actually increase in size, and in process of time become large diamonds. The only rock of this formation in which the diamond is found is the sandstone breccia.

The wild races occupying the hills are the Chenchuar and Yanadi, but the ruins of extensive fortifications, stone wells, pagodas, the Purvut pagoda called Sri Sailam, with tanks and small fortresses, show that the range was formerly largely occupied. It is now very sickly, and wild beasts infest the jungles. The inner valleys contain a large number of lakes, or, as they are termed, Lankas. All these lankas or lakes are connected with fabulous tales. There are five plateaux on these hills. The highest peak is Gundla Brahmeshwaram, 3050̃ feet above sea-level, said to have been the seat of the great Muni (Saint) Jamadagni. The four principal passes are the Nandikanama, Jotikanama, Mantralamakanama, and Kortikanama.

NALODAYA, the rise of Nala, a poem supposerl to be by Kalidasa; it relates the story of king Nala and his wife Damayanti.- $D$.

NAL-SAHIB. HIND. (Lit. Mr. Horse-shoe.) An ālam or standard of Muhammadans; a man who, in the Maharram festival, runs as fast as he can, carrying a horse-shoe standard, typical of the horse of Husain.

NAMA. Hind. A name; applied to the marks which the sects of Hindus place on their foreheads. The term is usually applied to the trident-shaped mark which the Vaishnava sect place on their foreheads. The Vaishnava sect have perpendicular lines, with or without a dot or circle between them, or have a chakra or discus, or a triangle, shield cone, heart-shaped, or any similar form having its apex pointed downwards. It is called Tirunama or holy name. It is a representation of the trident of Vishnu, closely resembling the Hebrew character Shin. It consists of three perpendicular lines, the central one red, the other two white. The name is given also to the white clay used for making the marks. The namam mark of the Ramanuja sect consists of two perpendicular white lines, drawn from each root of the hair to the commencement of the eyebrow, and connected by a transverse streak across the root of the nose. In the centre is a perpendicular streak of red, made with red sanders or with roli, a preparation of turmeric and lime. They hare also patches of Gopi chandana, with a central red streak on the breast and each upper arm. The marks are supposed to represent the Sankh (shell), Chakra (discus), Gada (club), and Padma (lotus).

The Saiva sectarian marks are white horizontal lines, two or more, with or without a dot below or above the lines, or on the middle line, or with or without the oval or half oval, also by a triangle or any other pointed or arched form having its apex or convex ends upward.-Birdwood's Arts; Wilson.

NAMADUS, of Ptolemy, the Nerbadda river.

NAMAKARANA, SANSK., from Nama, a name, and Kree, to make, a Hindu ceremony of naming a child. On the 11th day, Punyahavachanam, or the purification rite for the mother and house, is performed. It is then that the child receives its name, - that of some one of its grand or great-grand parents, - by the father writing it three times, with a golden ring, in unhusked rice, spread on a plate. This is the Namakaranarn, and is followed by the guests bestowing blessings on the young one as they scatter rice, coloured with turmeric, over it and the mother, who are seated in the midst of the assembly. The father then distributes money to the poor, and entertains relatives and friends. On this night, for the first time, the child is put into the cradle by the fernale guests, some of whom sing religious songs, while others rock the little one, and at the close the assembly are dismissed, after being presented with betel-nut, plantains, and boiled pigeon-pea, Cajanus Indicus. The Namakarana may be on the 10 th, 11th, 12th, or 101 st day.

NAMAK DALLA. HIND. A salt of soda, a natron salt from the waters of the lake of Lonar. It is used in dyeing, in medicine, and the arts.

NAMA KIRTANA. In the Hindu religion, the constant repetition of any of the names of the deity.

NAMA SIVAYA. SANSK. Salutation to Siva! is the five-lettered mantra or mystic prayer of the Saiva sect of Hindus. Namaskara is a respectful Hindu salutation to an idol or a Brahman. See Salutation.

NAMAZ. Hind., Pers. Prayer. The Muhammadan prayer time occurs five times daily. The Koran mentions four periods of prayer in Suratur-Rum (xxx. 17), viz. glorify God when it is evening (masa), and at morning (subh), and to him be praise in the heavens and in the earth; and at afternoon (ashr), and at noontide (zuhr); but masa is recognised as including sunset and after sunset. It is preceded by ablution (wazu), and summoned to by the Azan and Iqamat. Amongst the Muhaninadans in India there are recognised-

Fajar-ki-namaz, morning prayer. Zuhar-ki-namaz, mid-day prayer Asar-ki-namaz, afternoon prayer. Maghrib-ki-namaz, sunset prayer. Aysha-ki-namaz, evening prayer.

Namaz ishraq, at $7.30 \mathrm{A.M}$.

Namaz chasht, at 9 A.M.

Namaz tahajjoor, after 12 P.M.

Namaz taraweeh, after 8 A.M., a particular form of prayer not of divine command.

Namaz-i-janaza, the funeral service.

Namaz gah or Eedgah, place of public prayer.

In order to catch a blessing from heaven, at the close of the whole set of their prayers, they 
raise their handș, offer up their (manājāt) supplications, and draw the hands over their face in order to transfer it to every part of their body. The prayers of Muhammadans are a ritual that must be said in the Arabic, and admit of no change or variety.

\section{'Ta dỉl bā mihnat dāūīm, \\ Dar bahr-i-fikr uftädim, \\ Chun dar namaz istādīm, \\ Kuwat ämad ānderim.'}

-Yule, Cathay, ii. p. 499.

NAMBUDARI, commonly pronounced and written Namburi. Maleal., Tam. A Brahman tribe of Malabar who make high claims to sanctity, look down on all other Brahmans, and are regarded by the other castes almost as sacred. They are said, however, to be descendants from a fisher race. According to the legend of the Hindus, the country of Kerala, which includes Malabar and Canara, was (together with the Konkan) miraculously gained from the sea by Parasu Rama, the conqueror of the Kshatriya, and as miraculously peopled by him with Brahmans who emigrated into this province, and introduced their religion amougst the inhabitants. The province was divided by them into 64 districts, which were governed by an ecclesiastical senate presided over by a Brahman every three years. But on the arrival of the Portuguese in 1498, they found a Hindu ruler, designated Zamorin, ruling over one of the most important of the principalities into which the country had been divided in the 9th century. Kerala is also called Parasu Ram Kshetrom, and is a long narrow strip of country stretching from Cape Comorin to Gokurnom. Of this, the tract of country below the ghats, from the river Canjarote pooya, the original southern boundary of Canara, to Travancore, inclusive, is now called Malealam or the Malabar coast. Kerala, from about B.C. 68 to A.D. 352 , was ruled by 37 Perumal or viceroys from the Chera or Salem rulers, and after them by the ancestors of the present nominal raja.

None of them reside in South Travancore, which is only visited by them from time to time, for the celebration of religious festivals and ceremonies for the kings and temples. They are large landed proprietors, and to preserve their properties intact, it is usual only for the eldest son of a family to marry; the younger sons associate with the Nair women, and their daughters often remain unmarried. The landlords are designated Janami in the Malealam country, and their numbers are greatest in the fastnesses of the mountains.

A Namburi Brahman of Malabar is always the Rawal or chief priest of the temple of Badarinath in the Mana pass of the Himalaya. When the Namburi Brahman women are guilty of connection with inferior castes, they are often sold by their relatives, and chiefly to the Muhammadan Mapilla. Under the terms head-price and breastprice, the princes of Malabar, in granting certain lands to the Christians in A.D. 316, allowed them the revenues derived from the sale of males and females for serious caste offences, a practice which the Namburi continue.-Mateer's Travancore.

NAMCUL, near Salem, a fortified detached hill with a pretty large town at the foot. The hill is steep but not high; its rocks are syenitic, in which white quartz and felspar prevail. In some places it contains garnets in hornblende, and a greenstone which possesses the characters of felspar, and is composed of the sime constituents; the latter compound seemed to prevail particularly in the lower country. The sand in the nullas and in some part of the road was mostly an aggregate of small garnets and hornblende.

NAMDAH. Hind., Pers. A thick felt used by the nomade races of Persia and Afghanistan for their tents; hence the term nomade. The Namdah and the Pankhi felts are also largely used as a sleeping rug, blankets, and for carpeting. See Nammad.

NAMES of Europenn Christians, of the Rajputs, Mahrattas, and Brahmans of India, and of the Chinese, are hereditary. Those of the Rajputs are, however, so diffused as to be almost impossible to apply except in the most general way, for every one of this race knows whether he is of a Puar, a Chauhan, a Rahtor, Grahilot, Kachwaha, Yadu, Pramara, Paribara, or Chalukya family. In the sonth of India, Brahmans have confined themselves to intellectual employments, and every one knows the got or family to which he belongs; and amoug the Mahrattas, the Bhonsla, Gaekwar, Holkar, and Sindia are well-known patronymies. In China, the family names are only a little over 400 , but they are carefully remembered, because that race are strictly exogamic, and do not narry women with their own family names. In all races, whether or not possessing family names, there are personal names applicable to the individual. Captain R. C. Temple has given notices of over 4000 names of the people of India, and they are largely those of their deities, and animals and plants familiar to them.

The habit of distinguishing families by epithets derived from objects in the animal or vegetable creation, has prevailed in every land, and many a name, which receives our homage from blending phonetic dignity with historical recollections, traces its origin to some humble and often ludicrous incident, as that watchword of chivalry, Plantagenet, derived from the lowly broom. The names of animals, plants, and things inanimate all furnish symbolic appellations. In Scripture we have the fly, the bee, the ram, to describe the princes of Egypt, Assyria, and Macedonia. Amongst the ancient as well as the present races in India, we have the snake, the horse, the monkey, the fox, the tortoise, the wolf, the boar, the nag or snake race being the Takshak, the rhinoceros, the tiger.

Before Islamism had thoroughly taken root amongst the Turks, it was by no means uncommon to designate grave and distinguished personages by the names of animals. Boghra, or more properly Bokra or Bokhra, means in Eastern Turkish a male camel. The Gurgiani tribe of the Brahui take their title from Gurg, the Persian for a wolf; the Numri or Lumri tribe from the fox; and Landgha, wolf, also gives its name. Among the Rajput clans are the Rahtor or the spine, the Kachwaha and Sessodia from the tortoise and hare. In India, the names of Muhammadan men are usually associated with some attribute of the Almighty, or with the name of some reverenced person.

Among Muhammadan men's names are Abbas, stern of countenance; Abd-u-Rahman, servant of the merciful; Abubakr, father of the maiden 
(Ayasha); Chengiz, from Zin in Moghul, great, gis or ghis, the superlative-Zingis is applied to the ocean; Eldoz means star; Fazil, excellent; Gbalib, overcoming; Haidar, Hirsuma, Asad, and Lais, all mean lion; Hamd, part of an Arabic verb, meaning he did praise-from this all the names Ahmad and Hamid, the most praised, the same, Mahmud and Muhammad, praised; Hashim, a breaker, from Hashm, he broke; Hasan, beautiful; Husain, a little beauty; Jafar, a little stream; Kasim, divided; Malik, master; Obeid is the diminutive of Abd, servant. The titles Sultan, Khan, and Agha Sultan are of frequent occurrence. Tahir, ARAB, pure. The Tahir dynasty became independent in the $3 \mathrm{~d}$ century of the Hijira. The founder was ambidexter, and styled Zu-l-yamanin, possessor of two right hands. Takin or Taquin in Turki, a warrior, as Alpetgin, whose slave Sabaktagin was father of Mahmud; Tayib, good, delicate; Togrul, Turki, a falcon.

Among Muhammadan ladies' names are $\mathrm{Ak} \mathrm{Be}-$ gum, white lady; Amina, mother of Mahomed, means tranquillity; Fakhr-un-Nissa, glory of women. Akbar's mother's titular name was Hazrat MariamMakani, Hamida Bana Begum. Khanum for a Moghul lady, and Begum, a Turki lady, are the feminines of Kbau and Beg; Mahomed's wives were Khadija, Fatima, Ayasha, Asya, Miriam or Mary, Hind or Hinda, Zainab, Maimana, Safiya. Nur Banu, lady of light; Nur Mahal, light of the palace; Mihr, the sun; Rakya, enchantment; Shahar, the moon; Zainab, ornament, the Zenobia of the Europeans ; Zobeida, wife of Harun-uRashid; Zohra, the blooming, a name of Venus.

Timur got his name in an unusual manner. He was born 25th Shaban A.H. 736 (7th May A.D. 1336), at a small village 40 miles to the south of Samarcand in Kesh, a province of Independent Tartary. He says that his father related to him the following circumstances connected with his name. "Soon after your birth, I took your virtuous mother to pay our respects to the celebrated saint, Shaikh Shams-ud-Din. When we entered his apartment he was reading aloud the 67 th chapter of the Koran, and was repeating this verse, "Are you sure that $\mathrm{He}$ who dwelleth in heaven will not cause the earth to swallow you up, and behold it shall shake (tamurū)." The Shaikh then stopped, and said, We have named your son Timur.' There is a legend that his mother was with child before her marriage, and that she said to her father that while she was lying on her couch, a sunbeam covered her with a mantle of light, and at the same time seemed affectionately to caress her.

Amongst the servant and haram women of the Muhammadans, the usual names relate to some personal or mental peculiarity, as Jamila, Kali, Nek-Kadam, Rahat Afza, Dil Aram; or the name of some flower is given, as Chambeli, Nargis, Gulab, Yasmin.

Names of Hindus of the present day in the south of India are often those of some deity, of some beast, of some devout man, or relate to the complexion. Those of their wives are of some goddess, or of some flowering plant.

Amongst the Hindus of Madras, names common to men and women are Adakalam, Arokeum, Chintadri, Chittaray, Kasi, Kuppu, Manikum, Parenjody, Pollyam, Ruthuum, Tulsi, Tunyasam. Many of the Hindu men's names are those of
Hindu deities, as Rama, Kistna, Ranga, Narain, with the added title Swami.

Muhammadan ladies have evinced a wish to associate their names with inhabited places, and there is many a Begum Pet in India. The names also of distinguished officers of the Indian Government have been given to towns and hamlets. Malcolm Pet, a small village on the Mahabaleswar Hills, recalls the Sir John Malcolm who was Governor of Bombay in 1828. Another Pet or Petta or town is named in Mysore after Mr. L. B. Bowring, a former Chief Commissioner. Colonel Dalton, almost. a model commissioner amongst wild tribes, gave his name to the headquarters of Palamau, a subdivision in the chief district of the S. W. Agency. Sir Herbert Edwardes, as well as that of the heir of Ranjit Singh, survive in the district of Bannu, at a place known variously as Edwardesabad and Dhulip-nagar. The fort there is associated with the maharaja, and the bazar with the accomplished soldier-civilian, who could win a battle with raw levies, write a good despatch, and sketch an oriental landscape. The market-place at Etah, N.W. Provinces, commemorates the name and services of Mr. F. 0 . Mayne. The first Political Agent in Coorg changed the name of a place from Kushalnagara to Fraser Pet. Some enterprising gentlemen, named the four Morell brothers, converted a jungly tract on the edge of the Sunderbans into a rice-growing plain, dotted with thriving villages, on the bank of a noble river, and the port is now known, locally and officially, as Morellganj. Sir R. Montgomery, Lieutenant-Governor of the Panjab and a member of the Indian Council, has a district named after him, with its administrative headquarters. It is usual with Muhammadans to apply some rhyming alliteration to their famous cities, and they add the words Dar-ul-Karar to Kandahar, and Farkhunda banyad to Hyderabad. A tribe in India give daily names. If born on Sunday, the child is called Adya; on Monday, Somburu; on Tuesday, Mangada ; on Wednesday, Budu; on Thursday, Lakya; on Friday, Sukku ; and on Saturday, Sanya. These names of the days of the week are the same as those among the Telugu and Uriya people,-Telugu Adivaram, Somavaram, Mangalavaram, Buduvaram, Laksmanavaram, Sukravaram, and Sanivaram. Hindu women will not pronounce their husband's names, and a Muhammadan will not summon his wife by her name. The Japanese wife calls her husband Tei-shiu (Tei-shi), meaning master.

In Behar, amongst all castes of Hindus, when a man's elder children die, he gives to subsequent offspring names signifying something unpleasant, and bores the septa of their noses.

In Sumatra, the father in many parts of the country, particularly in Passumma, is distinguished by the name of his first child, as $\mathrm{Pa}$-Ladin, $\mathrm{Pa}$ Rindu ( $\mathrm{Pa}$ forbapoa, signifying the father of), and loses, in this acquired, his own proper name. They have adopted this from the Arabs, who speak of a man and wife as the father and mother. -Dowson's Ancient India; Elphinstone's History of India; Captain Temple.

NAMI, a root of the form of a large potato, which grows in Mindoro, cultivated also in Timor and in the Moluccas. It is said to be the manioc or cassava of South America.

NAM-NAM. MaLAY. An acid apple-like fruit 
of the Malay Peninsula, growing on a small tree. -M'Nair, p. 63.

NAMO-NAMA. SANSK.? MAHR. A respectful salutation to Brahmans.

NAMOONE-KULE, a mountain near Badulla in Ceylon, nearly 7000 feet high.

NAM-PHRIK, a sauce used by all classes in Siam; it is prepared by bruising a quantity of red pepper in a mortar, to which are added kapi (paste of shrimps or prawns), black pepper, garlic, and onions. These being thoroughly mixed, a small quantity of brine and citron juice is added. Ginger, tamarinds, and gourd seeds are also employed. The nam-phrik is a most appetite-exciting condiment.-Bowring's Siam, i. p. 108.

NAMRUD. 9 miles from Baghdad is the small Akarkouf; the ground around the ruined pile is called Tall Namrud by the Arabs, and by the Turks Namrud Tapassi. Both these terms mean the hill, not the tower, of Nimrud; and the term Akarkouf or Agargouf, given by the Arabs, is intended to signify the ground only around it.

NAMSANG, a rude pagan tribe on the hills of Assam, on the eastern frontier of the Mikir and Cachar. See Naga.

NAMZAD BAZI. Pers., Pushtu. An Afghan custom of allowing an engaged couple to see each other.

NAN, a dependency of Siam, N.E. of Bankok. Its capital is in a fertile valley. Lu, one of the Laos tribes, were often at war with Nan.

NANA FARNAVIS, a distinguished civil administrator of the Mahrattas, as Karkun of the Peshwa Madhu Rao, from 1769 till his death on 13th March 1800 . He was present at the battle of Paniput, but was amongst the first of the fugitives from the field. See Baji Rao.

NANA ISHTAR of the Chaldees, the planet Venus, the Phoenician Astarte, the Hebrew Ashtoreth; in Babylonia, called Nana. She had many appellations, was seemingly the Nanæa of Maccabees, i. 13-15, and the Nani of the modern Syriaus.

NANAK, the founder of the Sikh religion, is often styled Nanak Shah by the Sikl historians, who likewise designate him Baba Nanak, also Nanak Narinkar, or Nanak the Omnipotent. Nanak was a Hindu of the Kshatriya caste and Bedi tribe. He was born A.D. 1469, at the sinall village of Talwandi (since become a town, and now called Rayapur), on the banks of the Beas, in the district of Bhatti and province of Lahore. He was son of a grain factor at Talwandi, but in early life he deserted the humble shop of his father to seek, in study and retirement, a more genial occupation for a naturally reflective mind. The tenets of the Hindu and Muhammadan of that day alike dissatisfied him; and, after prolonged travel in search of truth, he returned to his family and passed his life in calling upon men to worship the one invisible God, to live virtuously, and to be tolerant to the failings of others. He began to teach A.D. 1490. For the gross polytheism of Hindu mythology, he substituted what may be defined a high philosophic deism, and succeeded in collecting together a large body of followers, whom he called Sikh or disciples; and these he organized under a theocratic form of polity, being himself recognised as their guru or teacher. For many years this rapidly-increasing body of con- verts continued to lead a peacuful meditative life, absorbed in the study of their sacred book, the Grant'h, which contained all the recorded dogmas of their founder. They gradually spread over other parts of India, and a. college of tbem existed so far south as Patna. But in the beginning of the 17th century, Govind Singh, the tenth guru, gave a new character to this religious community. He was a man of a naturally warlike spirit and ambitious views, and, thirsting to be revenged for domestic wrongs, soon converted the hitherto contemplative Sikhs into a band of warriors. These were the men who a century afterwards formed the flower of Ranjit Singh's army, and who presented so formidable an array against the British on the different battlefields during the Sutlej and Panjab campaigns. Nanak's biographical history is contained in the Janam-Sakbi. Stories of his miraculous gifts are still current; the tree where he lay concealed, the shops where he used to trade, the weights which he used, are still shown; travellers at Hasan Abdul may look on the impression of a hand in marble religiously believed to be his. Of his real goodness, of the purity of his motives, of the excellence of his life, and of the moral effect of his teaching, there can be no question. Nanak's view of the omnipresence of the Deity has been told in pointed terms. The Sikh reformer was reproved at Mecca by zealous Muhammadans for daring to turn his feet towards the Kaba or sanctuary where God is. 'Turn them if you can,' was the immediate answer, "where God is not.' He died A.D. 1539 .

Of the distinguishing features of their respective teachers, it may be said that Nanak disengaged his little society of worshippers from Hindu idolatry and Muhaumadan superstition, and placed them free on a broad basis of religious and moral purity. Umar Das preserved the infant community from declining into a sect of quietists and ascetics. Arjun gave his increasing followers a written rule of conduct and a civil organization. Har Govind added the use of arms and a military system, and Govind Singh bestowed upon them a distinct political existence, and inspired them with the desire of being socially free and nationally independent.

Angad, the second guru, wrote some of the sacred books. He died A.D. 1552, followed by Umar Das, who died 1574.

The fourth guru, Ram Das, founded Amritsar. A piece of land was presented by Akbar to Rau Das, within which a pool or reservoix was dug, since well known as Amritsar, or the Pool of Immortality; but the temples and the surrounding huts were at first named Ram-Das-pur, from its founder. Arjun, his son and successor, was the first who really understood the pure doctrines of Nanak, and made Amritsar the seat of his followers. This Arjun was the fifth guru of the Sikhs, was born A.D. 1553. He compiled the Adi Grant'h in the Gurmukhi dialect. He died a prisoner at Lahore, 1606.

Har Govind, son of Arjun, the sixth guru of the Sikhs, was the first of them who becarne a military leader, as well as spiritual teacher. This impulse effectually removed the Sikhs from the possibility of becoming ascetic monks or mendicants. He became a follower of the emperor Jahangir. After a tumultuous life, during which 
he was often engaged in repulsing attacks made upon him, he died at Keritpur on the Sutlej in A.D. 1645 .

The ninth guru, Tegh Bahadur, was beheaded at Dehli in 1675 .

Govind, son of Tegh Bahadur, was the tenth guru of the Sikhs. He introduced the Khalsa. He was born A.D. 1662, and was killed in his 48th year by two Pathans, in 1708, at Nander, on the left bank of the Godavery. A Sikh college is still kept up there. He remodelled the Sikh government. He composed the Grant'h in the Gurmukbi dialect, instituted the Singh initiations, and took service with the imperialists.

Banda, a Byragi ascetic, succeeded Govind as the guru of the Sikhs; he was a gloomy man, and in 1715 was tortured to death at Dehli, in the reign of Ferokhsir, son of Bahadur Shab. After which the direction of the Sikhs passed to the Akali and the confederate Jat sirdars. In 1764, they occupied Lahore, and from 1797 to 1839 were ruled by Ranjit Singh. Between 1708 and 1774, the country became infested by predatory bands, when Nan Singh extended his rule, and died in 1792. 'I'he most famed of the Sikhs, however, was Ranjit Singh, born 1780 , who in 1805 established the Lahore independency; but the Sikh government, after his death, became torn by internal convulsions, was checked by Lord Hardinge, and inally closed in the time of Lord Dalhousie.

Of the Sikh religionists, the highest class are the Bedi. Like the Syud race, who claim a priority over all Muhammadans as being lineal descendants of Mahomed, a section of the Bedi rank first among the Sikh as being descended from Nanak, the founder of their sect. They are to be found in all parts of the Panjab: in the districts lying at the base of the Kangra Hills, at Gujranwalla in the middle of the Rechna Doab, at Gogaira on the Ravi, and at Shahpur on the Jhelum, and a few at Rawal Pindi. They are also occasionally to be met with to the south of the Sutlej. But their home and stronghold is at a town named after their founder, Derah Baleæ Nanak, on the Ravi, near Buttalla.

But there are Bedi still of that original tribe who are not descendants of the Guru, nor, indeed, Sikhs at all. The crime of infanticide among the descendants of Nanak has been so notorious, that a Bedi was generally known by the opprobrious title of Kori Mar, or daughter-slayer. With these men, pride, and pride alone, prompted to the crime. The fear of poverty arising from marriage expenditure would have little weight with them, as, unlike the impoverished Rajputs, they were generally men of wealth and affluence. They held fertile jaghirs, and their priestly coffers were well filled with the offerings and dues of their race. But in defence of the unnatural custom, which they did not attempt to deny, they, like the Rajput races, were ready with a traditionary obligation laid upon them by an indignant ancestor. The story given by Major Herbert Edwardes is that when a bridegroom and his party were departing, the two sons of Dharm Chand accompanied them to give them rooksat. The weather was hot, the party out of temper, and they took it malicious pleasure in taking the young Bedi farther than etiquette required. When the lads returned home footsore, Dharm Chand asked if the Khutra had not bid them to turn back sooner. The boys said 'No ;' and it was then that the old man, indignant at all the insults which the bridal of his daughter had brought down upon him from an inferior class, laid the inhuman injunction on his descendants that in future 'no Bedi should let a daughter live.' The boys were horror-stricken at so unnatural a law, and with clasped hands represented to their father that to take the life of a child was one of the greatest sins in the Shastras. But Dharm Chand replied, "that if the Bedi remained true to their faith, and abstained from lies and strong drink, Providence would reward them with none but male children, but at any rate let the burden of the crime be upon his neck, and no one else's.' And from that time forth Dharm Chand's head fell forward upon his chest, and he evermore walked as one who bore an awful weight upon his shoulders. With consciences thus relieved, the race of Bedi continued for 300 years to murder their infant daughters: and if any Bedi, out of natural feeling, preserved a girl, he was excommunicated by the rest, and treated as a common sweeper.

In 1794 , a religious war was proclaimed against the Muhammadans of Maler Kotla by the Bedi Sahib Singh, the lineal descendant of Nanak. This man, who was half-fanatic and half-impostor, inflamed the Sikhs against the coiw-killers of Maler Kotla, and a great many Sikh sirdars joined him. The nawab and his troops were defeated in a pitched battle, and compelled to flee to the capital, where they were closely besieged by the fanatical Bedi. His ally of Patiala sent troops to help him, and the Bedi was induced to withdraw across the Sutlej by the offer of a sum of money by the Patiala raja.-MacGregor's Sikhs, i. p. 44; Major H. Edwardes' Jalandhar Report; Browne's Indian Infanticide, p. 115; Hist. of the Panjab, i. p. 79 .

NANAK SHAHI, a sect of religious devotees, followers of Nanak. The Nanak Shahi are classed under seven distinctions, all recognising Nanak as their primitive instructor, and all professing to follow his doctrines, but separated from each other by variations of practice, or by a distinct and peculiar teacber. In the west of the Peninsula, they are a low order of mendicants. About Benares they wear the ochrey red or gerua vastra cloth; they do not marry, but have no Naga or naked mendicants like the Udasi; their sacred book is the Grant'h of Nanak, but they will partake of food in the houses of all Hindus. Other followers of Nanak are the Udasi, the Nirmali, the Naga, Ganj Bakhshi, Ram Rayi, Sutra Shahi, and Govind Singhi.

NANAK-SHAHI, a rupee coin of the Sikh State; it had a pipal leaf on one side.

NANA RAO, or the Nana Sabib of Bithur, an adopted son of Baji Rao, the last Mahratta Peshwa. His name was Dandhu Punt. He was infamous for his cruel outrages at Cawnpur in 1857 against helpless men, women, and children. He joined early in the revolt of 1857-58. The three most notorious and distinguished characters among the rebels in 1857 were Tantia Topi, once a shroff in the Oudh bazar, and subsequently servant of Nana Rao at Bithur; Jwalla Pershad, the Kotwal of Cawnpur, subsequently commanderin-chief of Nana Rao's army ; and Khan Bahadur Khau of Bareilly, an old servant and pensioner of 
the British Government, and long the successful leader of revolt in his district, - all three were hanged. Mummu Khan, a low menial whom the passions of the Begum of Lucknow raised from the kennel to power, was transported to the Andamans. His paramour and her son Brijis Kadr, who claimed the throne of Oudh, went to Katminndu under the care of the Nepalese, where the Rani Chanda of Lahore, a Messalina of Indian history, had long found an asylum. Bala Rao, brother of Nana Rao; Azeemullah, whom, once a khidınatgar, he sent to London as his agent, and who was his confidant throughout the revolt, and Nana Rao himself, are said to have died in the Dookurh valley of fever. Firoz Shah, the aspirant to the succession of Dehli, and the companion of 'Tuntia Topi, was never captured. The three claimants for power in India were Nana Rao, Brijis Kadr, and Firoz Shah. The claim of the first was as Peshwa of the Mahrattas, that of the second was to Oudh, and of the third to Dehli.

NANAIVATI, amongst the Afridi, an assembly to discuss public affairs.

NANCOWRY, one of the Nicobar Islands, in lat. $8^{\circ} \mathrm{N}$.

NANDA, a person not of princely extraction, who successfully rebelled against Pinga-makha, the last of the Sisunaga kings of Magadha, captured Patalipura, and ascended the throne B. C. 378. His younger brother? was dethroned and killed by Chandragupta, B.C. 313 . Nauda and his sons ruled from B.C. 378 to $313 .-B$. iii p. 541 .

NANDA, the cow-keeper foster-father of Krishna, in whose house Krishna grew up. See Gokul.

NANDA DEVI, a snow-clad mountain peak in the Kamaon district of the N.W. Provinces, lat. $30^{\circ} 22^{\prime} \mathrm{N}$., and long. $80^{\circ} 1^{\prime} \mathrm{E}$. (Thornton); elevation above sea-level, 25,661 feet. It is one of the higher Himalayan summits. Almost conical in shape, the summit is inaccessible; but a religious fair is held every twelfth year at the highest point to which pilgrims can climb. The Hindus regard the cloud which usually rests on the peak as smoke from the kitchen of the goddess Nanda. - Imp. Gaz.

NANDAIR, lat. $19^{\circ} 9^{\prime} \mathrm{N}$., and long. $77^{\circ} 20^{\prime} \mathrm{E}$. in the Dekhan, on the left bank of the Godavery. Level of the Godavery here is 1152 feet. The mean height of the village, 1276 feet. There is a college of the Sikhs here-C Cull. See Nanak.

NANDAN SAK, in Kashmir, a small lake on the north side of the Pir Panjal range. The source of the Haripur river. It is a place of Hindu pilgrimage, and is in lat. $32^{\circ} 37^{\prime} \mathrm{N}$., and long. $74^{\circ} 40^{\prime} \mathrm{E}$. There are four other small lakes near.

NANDAVANAM. SANSK. The grove of Indra; in $\mathrm{S}$. India, any garden. $-W$.

NANDGAON, a small Feudatory State in the Raipur district of the Central Provinces, with a population of 148,454 . The chief is an ascetic Byragi, and the succession is by adoption. In 1877, the mahant had a supposed gross revenue of $£ 9874$, and paid tribute of $£ 4600$. His military force consisted of 7 elephants, 100 horses, 5 camels, and 500 infantry.-Imp. Gaz.

NANDI, a snow-white bull, the attendant and favourite vehicle (Vahan) of Siva. The Hindus make stone images of Nandi, some of them of huge size. The bull is represented on a pedestal, crouching, in front of Saiva temples, the head turned towards the small door of the shrine, or towards a lingam. Nandi is also called Salankayana; also Nandi-deha and Tandava-talika; also Basavi and Rishaba. The sacred bull of Mahadeva or Siva by some is described as the emblem of justice. In the Institutes of Menu, ch. 8, vol. 16, the divine form of justice is represented as Vrisha, or a bull; and the gods consider him who violates justice as a Vrishala, or one who slays a bull.

NANDIAL, a town in the Kurnool district, in lat. $15^{\circ} 29^{\prime} 30^{\prime \prime} \mathrm{N}$., and long. $78^{\circ} 31^{\prime} 40^{\prime \prime} \mathrm{E}$. There is a forest race in the district called Chenchwar. They speak Telugu, with a harsh and peculiar pronunciation. Brahmans say they formerly were shepherds of the Yerra Golla caste. They have large dogs, and a few are employed as hill police in the pass from the Cumbum to Badwail. The Nandial Chenchwar have no images. They are polygamists; they bury their dead, but sometimes burn, and carry the deceased's weapons to the grave. They have the spear, hatchet, the matchlock. and a bamboo bow and reed arrow tipped with iron. They look on weaving and other manufacturing arts with contempt, and they have in general only a rag for covering. They are patient and docile. It is suggested by Mr. Logan that the Chenchwar are a continuation of the wild forest Surah of the mountainous tracts farther north in the line of the Eastern Ghats. Vocabularies of six of the non-Aryan tonguesthe Kond, Savara, Gadaba, Yerukala, Chentsu, and another-are given at p. 39 of $1856 \mathrm{vol}$. of Bengal As. Soc. Jour. - Newbold in R. As. Soc. J., 1845; Logan in J. Ind. Arch.

NANDIDRUG, a fortified hill with precipitous sides in the Kolar district of Mysore, 31 miles north of Bangalore, in lat. $13^{\circ} 22^{\prime} 17^{\prime \prime} \mathrm{N}$., and long. $77^{\circ} 43^{\prime} 38^{\prime \prime} \mathrm{E}$., with an elevation of 4810 feet above the sea. The plateau on the summit is extensive, and has a tank fed by perennial springs. A forest with an area of 7 square miles surrounds the mountains. It was taken by storm by the British army under Lord Cornwallis in 1791. At its N.E. base is the village of Nandi, where an annual cattle fair is held during the Siva ratri festival, and the best bullocks bred in the country are brought here for sale, to the number of 10,000 . As much as $£ 100$ is sometimes offered for a pair of draught bullocks. The earliest fortifications were erected by the Chikballahpur chiefs; but the extensive works whose ruins now crown the summit, were constructed by Hyder Ali and Tipu Sultan. A cliff is still pointed out as Tipu's Drop, from which prisoners are said to have been hurled.

NANDINA DOMESTICA. Thbg. A tree of Japan, with red berries. It is called by the Chinese the Tein-chok or sacred bamboo. Large quantities of its branches are brought in from the country, and hawked about the streets. Each of these branches is crowned with a large bunch of red berries, not very unlike those of the holly, and, when contrasted with the dark shining leaves, are singularly ornamental. It is used chiefly in the decoration of altars, not only in the temples, but also in private dwellings and in boats,- - for here every house and boat has its altar, -and hence the name of sacred bamboo which it bears. -Fortune, p. 122; Roxb. ii. p. 184; Voigt, p. 27. 
NANDINI, in Hindu legend, a cow of plenty, belonging to the sage Vasishtha, said to have been born of Surabhi, the cow of plenty produced at the churning of the ocean.-Dowson.

NAND KUMAR, a wealthy banker of Calcutta, who held the office of foujdar of Hoogly in the reign of the Nawab Jâfar Ali Khan. He was convicted of forgery by the British Court of Justice, and hanged at Calcutta 5th August 1775. His execution caused great grief to the Hindus.

NANDUS MARMORANTHUS and N. Malabaricus are fish of the rivers of Malabar, which build nests among the rushes at the margin of the water, deposit their eggs therein, and keep guard over them like the stickleback. Similarly the Ophiocepbalus striatus, $O$. marubus, and $O$. diplogramme exhibit parental affection, swimming always close below their offspring, and attacking everything that comes near them. This they do till the fry are about three inches long, when they turn on and eat them themselves if they do not disperse. Some fish spawn in the sand, in the gravel, and even on rock. Others prey on their brethren, and others again are omnivorous, and none more so than the mahseer. Some fish seem to be almost entirely herbivorous, and they find an ample supply of fresh-water weeds on all the rocks in the rivers. Six different sorts of Podostemaceæ have been gathered in flower and seed, but the names of only two of them have been ascertained; these are Moriopsis Hookeriana and Dalzellia pedunculosa.-Mr. Thomas.

NANEH GHAT, in the Dekhan, has a cave chamber with an inscription in old Pali of date B.C. in the old Lat character. The inscription is in a chamber cut in the rock overlooking the Konkan in a pass which was evidently the highroad from Ajunta, Ellora, Junir to Kalian, and the cave temples in Salsette. The inscription relates to the Buddhist religion, and has the words Glory to Dharma, Indra, the Lords of Sakra, sun and moon, sanctified saints, Yama, Varuna, and spirits of the air, and Lokapala, or upholders of the world. It mentions the young prince Rakesa, the great warrior Tunakayiko, prince Hakusaro, connected with the house of Amara Pala.

NANESHWER, a subordinate incarnation of Vishnu, described by Major Moor as having taken place at Alundy, near Poona, about, as some state, 700, or, according to others, 1200 years ago. He is stated to have been a religious ascetic, and to have been buried alive at Alundy, where his tomb is seen under a splendid temple, and where he yet appears (for, although buried, he is not dead) to pious, if at the same time wealthy, visitors.-Cole. Myth. Hind. p. 390.

NANG. Pers. Shame, honour. NangPukhtana, honour of a Patban.

NANGAL, a village, generally inhabited by the Hindu Sad'h sect. Their body is left naked, except the lower part, which is covered by a jiece of coarse clotl. They wear wooden shoes, and commonly do penance in the Himalaya mountains. Their hair is exceedingly long, and made brown by ashes.-Mohun Lal's Travels, 19.

NANGA PARBAT, a peak of a mountain in the W. Hinalaya in Kashmir, rising 26,629 feet above the sea. It has a glacier on its lower slope. - Drew, The Northern Barrier.

NAN-HUA, CHin., also called Nan-hwa-king, the works of Chuang-tsze, a Chinese philosopher of the Taoist sect. Tsze means a venerable teacher, and Chuang-tsze was a follower of Laou-tsze, the founder of Taoism. He lived about 200 years after Laou-tsze.

NANING, an inland territory in the Malay Peninsula, in length about 40 , and in breadth about 10 miles, to the north of the old Portuguese capital. It is an undulating district, composed of jungly knolls and round valleys, inhabited chiefly by Malays. They dwell in rudely built villages. Nazing has a hot sulphur spring near Sabang, and yields tin.-St. John's Archipelago, ii. p. 91.

NANJA. TAM. Soil suited for rice cultivation, admitting of artificial irrigation, in contradistinction to punja.- $W$.

NANJANGUD, a town in Mysore, in lat. $12^{\circ} 7^{\prime} 20^{\prime \prime}$ N., and long. $76^{\circ} 44^{\prime} \mathrm{E}$., celebrated for the temple of Siva, under his name of Nanjandeswara. It is 385 feet long by 160 feet broad, and supported by 147 columns. A car festival, held at the end of March, is attended by thousands. The name means the town of the swallows.Imp. Gaz.

NANKA, a silk fabric worn by people of Kābul, etc.

NANKA ISLANDS are three in number, and are situated about four or five miles from the Banca shore, in the Straits of Bauca. The tidal waves from the China and Java seas meet near these islands.-Horsburgh.

NANKAR. There were two kinds of recognised perquisites which landholders enjoyed in Oudh, and in most other parts of India, the nankar and the seer land. The nankar was a portion of the recognised rent-roll, acknowledged by the ruler to be due to the landholder for the risk, cost, and trouble of management, and for his perquisite as hereditary proprietor of the soil when the management is confided to another. It may be 10,20 , or 100 per cent. upon the rent-roll of the estate, which is recognised in the public accounts, as the holder happens to be an object of fear or of favour, or otherwise ; and the real rentroll may be more or less than that which is recognised in the public accounts. The seer lands are those which the landholders and their families till thernselves, or by means of their servants or hired cultivators. Generally they are not entered at all in the rent-rolls, and when they are entered it is at less rates than are paid for the other lands. The difference between the no rent, or less rates, and the full rates, is part of their perquisites. These lands were generally shared out among the members of the family as hereditary possessions. Nankar is a compound Persian phrase of Nan, bread, and Kar, work, meaning support for service. Qu. Nankhwah, gratuity. - Slecman's Journey, iii. pp. 23, 26; Malcolm's Central India, i. p. 8.

NANKEEN, also Nankin.

Nankings linnen, . DUT. | Nanquino, . . . . IT. Toile-de-nankin, : .Fr. Langking, : MALAY. Nanking, . . : GR. Nanquina, : . .SP,

A Chinese cotton cloth, either of white, blue, or brownish-yellow colour. In point of strength and durability, it was unrivalled by any of the cotton fabrics of Europe. In some of the southern parts of Europe, the warmer parts of America, and the British settlements in Africa, it was formerly worn all the year round. This cloth was named from Nanking, where the reddish 
threads were originally made. Nankins were also manufactured in Canton and other parts of the empire, but of an inferior quality.

NANKING, or, according to the court pronunciation, Nan-chang, is the Chinese name of the old metropolis of the empire, and means southern capital, just as Pekin (in the court pronunciation Pei-ching) means northern capital. King, in Chinese, means an imperial capital, as in Pekin, Nanking; $\mathrm{Tu}$, in Chinese, is a court or imperial residence, as Taitu, Shangtu; Fu, in Chinese, is a city of the first class, or rather the department of which it is the head; Cheu is a city of the second class, or the district of which it is the head. The great porcelain tower at Nanking, in the province of Kiang-nan, was built by the emperor Yong-lo, and is called by the Chinese the temple of gratitude. The tower is ereeted upon a pile of bricks, and is formed upon a most substantial timber framework. It stands about 200 feet high, and is of an octangular shape.Meadow's Desultory Notes, p. 10 ; Yule's Cathay, ii. p. 262 ; Sirr's China and the Chinese, ii. p. 426.

NANNAYA BHATTA or Nanappa, a Brahman, whose book is the oldest extant work on the Telugu grammar. He lived about the 12th century, in the reign of Vishnu Vardhana, a king of the Kalinga branch of the Chalukya family, who reigned at Rajamundry.

NAN-NUL, a High Tamil grammar of great excellence by Pavananti. There have been several editions printed, and it has been partly translated into English. The poetical vocabularies of the Tamil were all written by Jaina scholars, and must be placed a little later than the Chintamani, but yet anterior to the Chola conquest of the Pandiya country, which took place in the 11th century.

NAN-SHOK-THEE. BURM. To sniff up a scent. See Kissing.

NAO. Hind. A ship, a boat. Nao-khuda, a shipmaster; written Nakhuda and Nacoda.

NAO-AIT, a small unwarlike race, who, but for a slightly zanthous tinge, would have an almost English fairness. They are called Nao-ait, newcomers, and are said to have emigrated from Arabia about 300 years ago, and are now to be found in considerable numbers in Southern India. They are slender, fair men, with very fair, handsome women, and are engaged in civil arocations, never becoming soldiers. Their history is variously given. But the term is literally new-comers. They are supposed to be of Persian origin. But in the beginuing of the 8th century, the governor of Siak drove some members of the house of Hashim into exile. They embarked with their families and effects, in the Persian Gulf, and landed some on the west side of the Peninsula of India, in the Konkan, and others to the eastward of Cape Comorin. The descendants of the former are the Nao-aits, and those of the latter the Labbai. The Labbai thus claim a common origin with the Nao-aits, though their colour and other physical features are not Persian but Assyrian. This supports the account of the Naoaits, who maintain that the Labbai are descendants of their domestic slaves. By avoiding marriages with the Indians, and even with the highest Muhammadan families, the Nao-aits have preserved the original purity of their blood, and there are still some ainongst them with com- plexions as fair as those of Englishmen. They were famed, at the Muhammadan courts of the Carnatic, for uniting the qualities of the soldier and the gentleman. In the present day the Nao-ait are a class engaged in civil life. The Naoait, the Labbai, the Moplah of Southern India, the Moormen of Ceylon, and the Arab settlers of . Sumatra, are direct from Arabia and Persia.

NAOBAT. Hind, PERs. A martial drum, on which the watches of the day are sounded. At native courts the use of it is a royal prerogative. and can only be assumed by permission of the sovereign. Rulers have a Naobat-khana, or guard-room, where the beaters stay and the drums are kept. See Nakarah.

NAO-ROZ. The Parsees of India have a New Year's day in March. The Muhammadans of Persia reckon the year from their Nao-roz or New Year's day, the day on which the sun enters Aries; but the Muhammadans of India follow the lunar montbs, and have no intercalary periods, so that their anniversaries and festivals make, continuously, circuits of the seasons. The Hindus of India follow the lunar months, but every twenty-fifth year insert an intercalary month to adjust.

\section{NAPHTHA.}

Neft, . . . ARAB. Kesoso no abra, . JAV Mang-ho-yu, : : CHIN. Minak tanah, MALAY. Bitume de judi, : . Fr. Bhumi tailum,. . SANSK. Naphte, . : : TAM. Nuk-tel, : GUJ., HiNo. Manti tylum, : TrL. Mitti-ka-tel,

The term naphtha is usually limited to the thinner and purer varieties of rock oil, and petroleum to the darker and more viscid liquids. Naphtha, rock oil, or petroleum, are mixtures of various hydrocarbons; but in its purest form naphtha may be said to consist of $\mathrm{C}_{5} \mathrm{H}_{6}$, and yielding a vapour of the density of $2 \cdot 8$. Such a hydrocarbon is obtained as a natural product at Baku on the shores of the Caspian, where the soil is a clayey marl impregnated with naphtha. The pits are generally from 210 to 490 feet deep. The first 210 feet cost about $£ 2$ a foot to sink the tubes. Refiners buy crude oil at 2 copecs per $36 \mathrm{lbs}$. Locally refined oil or kerosene is sold at from 27 to 30 copecs per $36 \mathrm{lbs}$. At St. Petersburg it fetches from 1 rouble 80 copecs to 2 roubles the $36 \mathrm{lbs}$. The flaming soil or everlasting (as it is called) fire of Baku is the attraction to pilgrims, and is not less famous than its naphtha springs. When mixed with earth or ashes as fuel, naphtha is used both for fuel and light by the inhabitants of Baku, on the Caspian. The vapour is made to pass through earthen tubes, and is inflamed as it passes out, and used in cooking. Naphtha springs and rich mineral deposits have been discovered in the Tekke oasis, and the land is being rapidly purchased by mining speculators.

In the peninsula of Abcheran, on the western shore of the Caspian, naphtha rises through a marly soil in vapour, and is collected by sinking pits several yards in depth, into which the naphtha flows.

After the Tigris has succeeded in forcing its way through the Hamrin Hills, at a spot called El-Fattha, on the left bank, there is an abundant supply of sulphur, and, directly opposite, naphtha rises in great quantities from the bed of the river.

Naphtha is obtained in the Bakhtiari mountains, between Shuster and Ram Hormuz; also near the 
village of Dilaki in Fars. Major Porter saw a fountain of white naphtba at the foot of the mountains of Bakhtiari, half-way between the city of Shuster and the valley of Ram Hormuz. In Irak Arabi and the Lower Kurdistan, the most productive are in the vicinity of Kirkook, Mendali, and Hit, on the banks of the Euphrates.

The naphtha pits near Kifri, in the province of Baghdad, five or six in number, are in the pass through which the $\mathrm{Ak}-\mathrm{su}$ penetrates to the plains. The hills are about a mile S.E. of the town of Tuzkurmatti, close to the gypseous hills of Kifri, and the pit, being in the bed of the torrent, is sometimes overflowed by it, and for a time, spoilt. The pit is about 1 f feet deep, and, to the height of 10 feet, filled with water, on the surface of which black oil of naphtha floats, small air-bubbles continually rising to the surface. They skim off the naphtha, and ladle out the water into a channel, which distributes it into a set of oblong, shallow compartments, made in the gravel, where they allow it to crystallize, when it becomes very good salt, of a fine, white, brilliant grain, without any intermixture of bitterness. The Kifri naphtha supplies Baghdad; the Kirkook naphtha supplies Kurdistan.

Naphtha springs occur at Ayer-i-Nosh. Naphtha holding in solution a bituminous matter was obtained by Vigne near Deraband in the Suliman mountains. In Burma, on one of the branches of the Irawadi, there are upwards of 500 naphtha and petroleum wells, which afford annually 412,000 hogsheads. The Burma petroleum contains the compound paraffine. Petroleum is used as lampoil in Burma.

Naphtha may be obtained by the distillation of petroleum; it is also one of the results of the destructive distillation of coal; it often passes with the gas to the distant parts of the apparatus, and may be found in gas-meters and gas-meter tanks, and even in the mains. Carefully-rectified naphtha, whether from natural or artificial sources, appears to possess similar properties. The sp. gr. of the purest Persian and Italian naphtha is said to vary from 750 to 760 , while that of coal naphtha may be 820 , or higher. The odour of the natural naphtha is bituminous but not unpleasant; that of coal is penetrating and disagreeable. It does not congeal at zero. It ignites readily, and burns with a voluminous sooty flame. It is not soluble in water, although it communicates its odour to that fluid. It dissolves in absolute alcohol, in ether and the oils. The boiling-point varies in different specimens from $320^{\circ}$ to $365^{\circ}$. Naphtha is employed for preserving the metals of the alkalies, potassium and sodium, which cannot be kept in contact with any substance containing oxygen. It is used for the purpose of diminishing the friction of machinery as a substitute for sperm oil. It dissolves the greater number of the essential oils and the resins, and is extensively used for dissolving caoutchouc to render cloth waterproof; with certain vegetable oils, it forms a good varnish, and for this purpose is sometimes substituted for turpentine.

NAPIER, LORD FRANCIS, of Merchistoun and Ettrick, was Governor of Madras from 1866 to 1871. He was Viceroy and Governor-General of India from the 23d February to the 3d May 1872. an officer of the Bengal Engineers, who rose to the rank of General, was engaged in the wars against the Sikhs, and was styled the Bayard of the Panjab. Subsequently he was engaged in the wars of the mutiny in $1857-58$, in the second China war, was a member of the Viceroy's Council, was Commander-in-Chief of Bombay, and commanded the expedition to Abyssinia, into which he led successfully a mixed army of natives of India and Europeans through the mountains of Abyssinia to the storm of Magdala, the capital of the emperor Theodore of Abyssinia. Theodore destroyed himself at the gateway. The march to and from Magdala has not been surpassed since Hannibal crossed the Alps. Officiated as Viceroy and Governor-General from the 21 st November to the 2d December 1863. As Military Engineer to the Board of Administration, Colonel Napier planned the defences of the Panjab frontier, and drew up schemes for bridging the Indus. Colonel Napier joined in more than one expedition against the border tribes. He was subsequently Governor of Gibraltar.

NAPIER, SIR CHARLES, an officer of the British army, who served in India under the E. I. Company. He commanded at the battles of Meanee and Dubbee and Hyderabad, against great odds, and conquered Sind. His march to Imam-Ghar was one of the most remarkable military feats ever known to be performed. His victories added to British India the territory on both banks of the Indus river, from Sukkur to the sea, which was annexed on the 24th March 1843. He was a humorist, and it has been said reported his conquest of Sind with the single Latin word 'peccavi." He was afterwards Commander-in-Chief of India, which office he resigned in consequence of differences with Lord Dalhousie. He died 29th August 1853. A statue has been erected at Trafalgar Square, London.

NAPIT. HIND. A barber, a shaver, who usually acts also as a surgeon; the village barber and barber-surgeon. Along with the original term, the dialects have various modifications of the word, as nai, Hind.; naida, nainda, napig, Karn. ; nau and nhawi, MAHR.

NAR. Tay. Nara, Maleal. Any fibre.

NARA, man; the original eternal man. Nara and Narayana, in Hindu legend, sons of Dharma and Ahinsa, who deroted themselves to ascetic exercises which alarmed the gods, and Indra sent Kama and Vasanta, or love and spring, with the nymphs of heaven, to inflame the sages with passion, and thus end their penance. Narayana observing the gambols of the party, suspected their purpose. He invited them to approach, and treated them with so much civility, that they thought their object was attained. The sage, however, taking up a flower-stalk, placed it on his thigh, when a beautiful nymph appeared, the superiority of whose charms covered the nymphs of heaven with shame. Narayana then told them to return to Indra, and bear him a proof he needed not the company of beauty, in the present he made him of the new-born nymph, who accompanied the Apsarasas to Swarga, and was called Urvasi, from Uru, a thigh (Vamana Purana). A commentator on the drama says Nara and Narayana were avataras, descents, or incarnations of Arjuna and Krishua.-Wilson's Hindu Theatre; The Hero and the Nymph, 
NARA. HIND. The tape or band for the trousers; a rope used by tight-rope dancers. $-W$. NARA, or Kim-purusha. SANSK. In Hindu mythology, beings with human bodies and the limbs of horses, created by Brahma, - the analogue of the Greek Centaur.

NARA. HIND. A sliding cord bridge in Kashmir.

NARA. In Sind, the Eastern Nara and the Western Nara are two large and important water channels. The former rises in the Bahawulpur State, and runs southwards through the Rohri, the Khairpur, and the Thar and Parkar districts. It has been improved by a channel from the Indus. The Western Nara has its rise from the Indus, and, after a course of 138 miles to the south, falls into Lake Manchhar. In the valleys of the Eastern Nara are 400 lakes and several canals. After the opening of the supply channel at Rohri, much of the flood-water was expended in filling up the numerous depressions called dandhs or kolabs, which line the eastern bank of the Nara throughout the greater part of its course. They are very deep, and extend some miles into the desert. To prevent this supply from being lost, strong embankments were thrown across the feeding channels leading to the dandhs, and the water was thus forced into the plain. It was, however, in a few years found that this annual flooding caused great damage, by converting the country into a jungly swamp; and, to correct this, excavations were made in the bed of the Nara itself, so as to facilitate the flow of the water southwards.

NARADA PANCHA RUTRA, a ritualistic book of the Vaishnava sect.

NARADA PURANA and Brihan Naradiya, sectarian Vaishnara books, enjoining the doctrine of Bhakti or faith in Vishnu.-Dowson.

NARAINA, 40 miles from Jeypore, the chief site of the Dadu Panthi sect.

NARAIN RAO, Peshwa of the Mahrattas, was the third son of Balaji Rao Peshwa, and in November 1770 succeeded his brother Madhu Rao. On the afternoon of the 30th August 1773, Somer Singh and Muhammad Yusuf led a band of mutinous soldiers to the palace, and, aided by Truleea Powar, a domestic, gained admission to the private apartments, where Somer Singh and Truleea Powar assassinated Narain Rao. Several years afterwards, Truleea Powar was beheaded for the murder, by order of Nana Farnavis.

NARAKA, the Hindu Tartarus, the hell of the Hindus, the abode of the wicked. Menu enumerates 21 divisions or abodes, and the Vishnu Purana 28. They are said to be situated beneath the earth and beneath the waters. Below Naraka is Patala, a terrific region of deep gloom, fear, and great terror. Below Patala are Krimbhojana and Krimisa.

NARAKAL, a small seaport town in the state of Cochin, in lat. $10^{\circ} 2^{\prime} 30^{\prime \prime} \mathrm{N}$, and long. $76^{\circ} 12^{\prime}$ E. It is sheltered by a mud bank, $2 \frac{1}{2}$ miles seaward, and 4 miles long, within which vessels can run in the worst weather.

NARAKARU, part of the inferior village servants of India; they are similar to the menials of the ballota system.

NARA-PARAMATMA. SANSK. The waters of the world were the first productions of God in creation.
NARAPATI, the Chola dynasty of Karnata, Dravira, and the southern portion of the Peninsula of India, embraced a period of 534 years, during which 27 rajas reigned, from A.D. 266 to A.D. 800 . After the overthrow of the Narapati dynasty, Karnata and Dravira seem to have been separated from the southern districts, in which the Chera, Chola, and Pandava lines were at first united under one sovereignty. Thereafter, 13 maharajas of Madura, Tanjore, and Coimbatore reigned 239 years, after which follow the Belal rajas of the Karnata, and the petty polygar dynasties of Madura, etc.-Prinsep, p. 275.

NARA-SINGHA, or Man-lion avatar of Visbuu, in which he took the form of a monster to punish the wickedness of Hiranya-kasipa, a profane and unbelieving monarch, the brother of the gigantic demon mentioned in the third avatar, and his successor on the throne, who also refused to do homage to Vishnu. Quarrelling with his son Pralhaud, the king boasted that he himself was Lord of the Universe, and asked wherein Vishnu was greater than himself. Pralhaud replied that Vishuu was supreme over all, and was everywhere. Is he, cried Hiranya-kasipa, in this pillar? striking it at the same moment with his sceptre; if he be, let him appear. In an instant the magnificent column was rent in twain, and Vishnu, in the form of a man with the head of a lion, issued from it, and tore Hiranya-kasipa in pieces. Nara-singhi is a name of Lakshmi, as the sakti of Vishnu in the Nara-singh avatar.-Coleman, Myth. Hind. p. 390.

NARAYANA, the son of Nara, the original man, and often identified or coupled with Nara; also the creator Brahma; also, in Hindu belief, the Spirit of God, Bralim. By the Vaishnava sect, Narayana is identified with Vishnu, but in the Saiva theogony, Narayana and Siva coalesce. In the Ins. of Menu, c. 1. v. 10, the waters are called Nara, because they were the first production of Nara, or the Supreme Spirit; and since they were his first ayana, or place of motion, he is thence named Narayana, or Moving on the Waters, The name is found for the first time in the Satapatha Brahmana. As commonly used in Southern India, it applies to Vishnu, and is that under which he was first worshipped. In Hindu mythology, the beverage of immortality drank by the gods, Narayan's gem and other gifts to man, are fabled to have been produced by churning the ocean. Chitra-ratha describes in song how

'Whilom from the troubled main

The sov'reign elephant Airavan sprang;

The breathing shell, that peals of conquest rang;

The patient cow, whom none implores in vain;

The milk-white steed; the bow with deaf'ning clang ;

The goddesses of beauty, wealth, and wine;

Flow'rs, that unfading shine;

Narayan's gem; the moonlight's tender languish ;

Blue venom, source of anguish ;

The solemn leech, slow moving o'er the strand,

A vase of long-sought Amrit in his hand.-

To soften human ills, dread Siva drank

The pois'nous food that stain'd his azure neck;

The rest, thy mansions deck,

High Swerga, stor'd in many a blazing rank.'

-Moor, pp. 79, 399 ; As. Res. vii., Arts. viii. and ix., by $\mathbf{M r}$. Colebrooke; Dowson.

NARAYANI, a name usually applied to Lakshmi as the sakti of Vishnu, but may also be applied to Parvati and Saraswati. See Lakshmi; Sakti. 
NARBADA, a river of India, which rises on the plateau of Amarkantak, and disembogues in the Gulf of Cambay. It is also written Nerbadda, and is the Namadus of Ptolemy and Namnadius of the Periplus. It rises on the Amarkantak Hill, lat. $22^{\circ} 41^{\prime} \mathrm{N}$, long. $81^{\circ} 49^{\prime} \mathrm{E}$, and, after a westward course of 800 miles, falls into the sea below Broach, in lat. $21^{\circ} 38^{\prime} \mathrm{N}$., long. $72^{\circ} 30^{\prime} \mathrm{E}$. Amarkantak is a massive flat-topped hill. All round lies a wild and desolate country; but Hindus have reared their temples in the middle of these solitudes, to guard the sources of the sacred river. The Narbadit bubbles up gently in a small tank in one of the undulating glades on the summit of the mountain. Then, for about three miles, it meanders through green meadows, receiving the waters of countless springs, till it reaches the edge of the Amarkantak plateau, where it falls over the black basaltic cliff in a glistening cascade of 78 feet, called Kapila-Dhara.

From Haran Pal, or the Deer's Leap gorge, to the temple of Sulpani Mahadeva, a distance of some 70 miles, there occurs the main barrier of the Narbada. Here the Narbada displays all her terrors. Thereafter the Narbada enters on the rich plains of Broach, which border on the sea, and in this section it is navigated by country craft. Rising in the highest land of Central India, 5000 feet above the sea, and pursuing a serpentine westerly course for 750 miles through a hilly tract, which runs parallel to and borders closely both its banks, this river may be said to flow through a longitudinal cleft rather than a distinct valley, and to present the general characters of a mountain stream more than anything else. No great depth of water can ever be expected in it, from the nature of its tributaries, except in the monsoon; neither could it be retained, owing to the great declivity of the river bed, which from Jhansi Ghat, near Jubbulpur, to the sea, falls 1200 feet in 500 miles. The falls of Kapiladhara and Dudhdhara are near its source, the former of 78 feet. The next is at Umaria, in the Narsingpur district, and is about 10 feet. At Mandhar, 90 miles below Hoshangabad, and about 25 below Handia, there is a fall of 40 feet; at Dadri, near Punasa, 25 miles below Mandhar, there is another fall of 40 feet. The aboriginal races which prevail most among the agricultural population of the Narbada valley are the Gujar, the Jat, the Kaonra, the Kirar ; the Kurmi are numerous; then follow the Lodhi, Chamar, Gond, Brahman, A hir, Banya, Rajput, etc.

As a sacred river, the Narbada, in Hindu estimation, is only inferior to the Ganges. According to the Rewa Purana, the sanctity of the Ganges will cease in the Samvat year 1951 (A.D. 1895), while the purifying virtue of the Narbada will continue the same throughout all the ages of the world. So holy is the water, that the very pebbles in its bed are worn into the shape of the emblem of Siva. Few Hindus would dare to forswear themselves, standing in the Narbada with a garland of red flowers round the neck and some water in the right hand. The most meritorious act that a pilgrim can perform is to walk from the sea up to the source at Amarkantak, and then back along the opposite bank. This pilgrimage, called parikram or pradakshana, is chiefly undertaken by devotees from Gujerat and the Dekhan, and takes from one year to two years in accomplishment.
In Broach district the most sacred spots areSukaltirth, with its ancient banian tree; the site near Broach eity where Raja Bali performed the ten-horse sacrifice; and the temples at Karod and Bhadbat. The coal-measures extend along the southern side of the valley, with some interruptions, from Baitul and Sewne to the neighbourhood of Jubbulpur. They consist of a series of slightly micaceous sandstones, shales, and coalseams, and are quite destitute of iron ore. They form a long narrow strip resembling an old seabeach, extending along the base of the Puchmurry Hills, which consist of a great thickness of conglomerates and sandstones, overlaid by an unconformable series of rocks. Limestone occurs everywhere, much of it crystalline. The iron ores of Baug and Ladgaon are brown iron ore and limonite; Burwa and the Muchuk river, brown iron ore and compact hematite; Changhur and the Powah river, compact hematite; Tendukera, calcareous hematite; Hutnapur, silicious hydrate, and micaceous specular ore occurs in Dhurumpura, Agaria, Partabgarh, and Jowli. In some of these sites, as in Tendukera, the ore has been worked for ages._-1mp. Gaz.; J. H. Blackwell, Report to Government, No. xliv., 1857.

NARCISSUS. From the habit of planting the narcissus upon tombs and shrines, it has acquired a certain sacredness of character. The Hindus have few tombs. They have shrines, however, many of which have been occupied by the Muhammadans. The narcissus is common in the Panjab. The narcissus flowers are of easy culture in a light soil ; though they throw out a profusion of leaves, they rarely blossom.-Ben. As. Soc. Jour., 1854 ; Riddell.

NARCOTICS in use among eastern nations are opium, bhang, madad, majum, ganja, charas. The use of these by orientals can be traced to times of high antiquity. Almost every race has its own peculiar intoxicant.

NARDOSTACHYS GRANDIFLORA has a glabrous stem, oblong glabrous leaves, with solitary terminal flowers. The capsule is downy, and the lobes of the calyx evidently denticulated. It is a native of Nepal and Kamaon,-Lindley, $\mathrm{Fl}$. Med.; Eng. Cyc.

NARDOSTACHYS JATAMANSI. $W$. Valeriana jatamansi, Roxb. | Nardus Indike, Diosc. Am-ul-tibi,. . . ARAB. Bekh-i-sumbul, . Pers. Sumbul, , ARAB., HiNd. Mu-i-giah, . . " Balchari, Jatamansi, ,

A dwarf herbaceous plant of Bengal, W. India, Nepal, the Panjab, Himalaya, up to 10,000 feet. Dr. Royle says that its hairy top-root is the spikenard of the ancients, mentioned in the Song of Solomon (Cant. i. 12) and in Saint Mark, ch. xiv. 3, and John, ch. xiii. 3, Horace promised Virgil a whole cadus, about thirty quarts of wine, for a small onyx box of spikenard. Dioscorides says the ointment was a compound of amomum, balsamum, costus, myrrha, nardus, and schœenus, in nut oil. Other nards, Celtic, Mountain, and Syriac, are mentioned. The term nard was in use amongst the ancients to designate any Indian essence, as attar (otto) is now used. Dioscorides (I. i. c. 6) describes three kinds of nard, of the first and principal of which there are two varieties, Syrian and Indian; the latter was also called Gangites, from the river Ganges, near which, flowing by a mountain, it is produced. The 
second kind is called Celtic, and the third is Mountain nard.-Murray.

NAREDA, in Hindu mythology, is a son of Brahma and Saraswati, usually regarded as one of the ten Rishi or Prajapati, first created by Brahma, and called his sons. He is described as a celebrated lawgiver, and as the inventor of the vina or lute, and is mentioned in Menu i. 34, 35, as one of the ten lords of created beings, eminent in holiness. In the Hindu plays Nareda usually acts as a kind of messenger of the gods, frequently going on errands. See Vikramorvasi, end of Act v.; and Sakuntala, end of Act vi. He is constantly employed in giving good counsel. It was Nareda who declares to king Harischandra the benefit of having a son. He is the analogue of the Grecian Orpheus. His musical talents were so great that he became presumptuous, and, emulating the divine strains of Krishna, he was punished by having his vina placed in the paws of a bear, whence it emitted sounds far sweeter than the minstrelsy of the mortified musician. In a picture of this joke, Krishna is forcing his reluctant friend to attend to his rough-visaged rival, who is ridiculously touching the chords of poor Nareda's vina, accompanied by a brother Bruin on the cymbals. To this day Nareda is represented in the Hindu Jatra under a long grizzled beard.-Williams' Stor'y'of Nala, p. 167; Cole.'s Myth. Hind. p. 7; Tr. of Hind. i. p. 269.

NAREGAMIA ALATA. $W$. and $A$.

Turroa alata, Wight. | Nela-narœgam, MALEAL.

A pretty garden plant of the Travancore forests, used in medicine.

NARGIS. HrND. Narcissus tazetta. Honigberger states that the roots of this are officinal, being brought from Kashmir. Nargis, also GoolNargis, is the Hemerocallis fulva.-Stewart, Panjab Plants, p. 235.

NARI, Nari-Khorsum, Gnari, or Mnah-ris, the Tibetan names for the north-western part of Tibet, a Tibetan Chinese province connected with British India by the five Bhot passes in Garhwal and Kamaon. The Chinese viceroys are Tibetans, with Mangol or Turk troops, or perhaps Manchu Tartars, as they are said to use horseflesh, which no Tibetan and no Chinese would do. It is enormously lofty, utterly barren, and almost uninhabited, except on the lowest part of the ravine of the Indus. -H. f. et T. p. 225 .

NARRI - KOMBOO. SINGH. A projecting process on the frontal bone of the jackal. It is called the jackal's horn, which Hindus say only grows on the head of the leader of the pack. The Singhalese and the Tamil races regard it as a talisman, and believe that its fortunate, possessor can command by its instrumentality the realization of every wish, and that, if stolen or lost by him, it will invariably return of its own accord. It is the popular belief that the fortunate discoverer of a jackal's horn becomes thereby invincible in every law-suit, and must irresistibly triumph over every opponent. In the Museum of the College of Surgeons, London, is a cranium of a jackal which exhibits an osseous process on the super-occipital boue, and Sir J. E. Tennent placed along with it a specimen of the horny sheath, which was presented to him by Mr. Lavalliere, District Judge of Kandy. - Tennent's Ceylon, p. 36.

NARSAPUR, a seaport town at the extreme south of the Godavery district, situated on the ashista branch of the Godavery, about 6 miles from its mouth, in lat. $16^{\circ} 26^{\prime} 20^{\prime \prime} \mathrm{N}$., long. $81^{\circ}$ $44^{\prime} 30^{\prime \prime} \mathrm{E}$.

NARSIA, a Hindu deity, a contraction of Narasingha, the man-lion or fourth avatar of Vishnil.

NARSIPUR (known as Tiruma-Kadalu, or 'The most Holy Union'), a municipal village in Mysore district, Mysore, in lat. $12^{\circ} 12^{\prime} 40^{\prime \prime} \mathrm{N}$., and long. $76^{\circ} 57^{\prime} 21^{\prime \prime}$ E. A sacred spot, containing two ancient temples, one dedicated to Vishnu, under his name of Gunja Narasinha; the other situated between the junction of the two rivers, and dedicated to Agasteswara.-Imp. Gaz.

NASAFI, the surname of Najm-ud-Din Abu Hafs Umar-bin-Muhammad, died A.D. 1142, a celebrated doctor, and author of the Akaid-al-Nasifi. in Arabic, containing the fundamental principlea of the Muhammadan religion. It is greatly esteemed by Muhammadans.

NASAFI or Al-Nasafi, commonly called Hafiz-ud-Din al-Nasaf, author of a law-book called Wafi, and of its commentary called Kafi. $\mathrm{He}$ is also the author of Kanz-ul-Dakaik. Obiit A.D. 1310 .

NASALIS LARVATUS.

Kahan of . . BORNEO. | Bangkatan of . LABUAN.

The proboscis monkey of Labuan and Borneo. Its glossy coat is richly coloured. It is shy.

NASASALAR, Parsee corpse-bearers who can enter the Tower of Silence. They are undean. Khandhia, also, are corpse-bearers.

NASIK, a town near the source of the Godavery, supposerl the ancient Pancharati. It is in lat. $19^{\circ} 59^{\prime} 45^{\prime \prime} \mathrm{N}$., long. $73^{\circ} 49^{\prime} 50^{\prime \prime} \mathrm{E}$. It gives its name to a revenue district of the Bombay Presidency of 8116 square miles, and in 1871 it had near a million souls, chiefly Hindus; the hill tribes being Bhil, Koli, Kathodi, Thakur, and Warli, mostly poor cultivators. Nasik is considered by Hindus a very holy town. It is built on the right bank of the Godavery, with about 27,070 inhabitants.

Nasik has a chaitya cave. An inscription over its gateway states it to have been the gift of a citizen. Another inscription on the pillars states it to have been excavated in honour of Badrakaraka, who was a king of the Sunga dynasty.

Nasik lies for the most part on a table-land, and for administrative purposes it is divided into 12 districts, while two great natural divisions mark off the cultivable from the uncultivable region. These latter are called Dang and Desh; and while the former is a bare and barren expanse of country, with tracts of absolute desert, the latter is thickly wooded in parts, and cultivated throughout by an industrious population. The Koli are more generally eugaged in agriculture than the rest; the Bhil subsist chiefly by gathering and selling forest produce; the Thakur and Warli cultivate a little by the hoe. The Kathodi, or catechu makers, are the poorest.

Nasik diamond, taken in the Dekhan war, originally valued at $£ 30,000$, was sold to Lord Westminster for $£ 7000$.-Fergusson.

NASIKH, whose name was Shaikh Imam Bakhsh, was the son of a tent-maker, and was born at Faizabad. He never had a teacher, but was a genius, and wrote several books. Dila! Shair goi uthi Lucknow sé, gives the date of his death.

NASIRABAD, a cantonment in Ajmir-Mhairwara district, Rajputana, situated in lat. $26^{\circ} 18^{\prime} 45^{\prime \prime}$ 
N., and long. $74^{\circ} 47^{\prime} \mathrm{E}$, on a bleak, open plain. -Imp. Gaz.

NASIRI, nomade Afghans, who occupy the Tohki and Hotuki countries in summer, and the Daman or skirts of the Suliman range in winter. In their migrations they appoint a Chahlwasti or captain of forty, and a Khan or director-general.

NASIR JUNG was the second son of Nizamul-Mulk, on whose death, in 1748 , the son assumed the subahship of the Dekhan. He took part with Muhammad Ali and the British against Chanda - Sahib and the French. After varied fortunes, he dwelt at Arcot in an indolent and voluptuous manner. In 1750 , however, he again took the field against the French, but was killed by the Pathan nawab of Cuddapah, and three of the conspirators to his death fell in one day. His death gave great relief to Dupleix, Chanda Sahib, and Pondicherry.-Orme.

NASIR-ud-DIN-ABDALLAH - bin - OMAR-alBAIZAVI. Baizavi was the literary takhallus. He died in the year 1286, Hijira 685, at Tabreez, but the date is disputed. His book is in Persian, entitled Nizam-ut-Tuarikh, which signifies the Order of Chronological Histories. He was a kazi or judge. He has treated of most of the Asian monarchs, and particularly of the ancient Moghuls. - History of Genghiz Can, p. 413. See Baizawi.

NASIR-ud-DIN MAHMUD, emperor of India from A.D. 1246 till February 1266. He followed Razia Begum, the daughter of Altamsh. His private life was that of a darvesh. He defrayed all his personal expenses by copying books; his fare was of the humblest description, and was cooked by the queen, to whom he allowed no female servant, and he had no concubines. $-E l p h$. p. 327.

NASIR-ud-DIN, TAUSI, a famed philosopher and astronomer, who was ernployed by Hulaku, grandson of Chengiz Khan, to form the Il Khani tables; born at Taus A.D. 1201, died 1274. He was one of the best and certainly the most universal scholar that Persia ever produced. $\mathrm{He}$ was a voluminous writer. It was he who advised Hulaku to march against Baghdad.

NASR. Arab. An eagle; an idol of the ancient Arabs. An nasr-u-tayir, the soaring eagle, a mystical name of the religion of the Ansariah, signifying mystically the sun, as the eagle is an emblem of the sun and light. The priucipal remaining part of the temple of the sun at Balbec contains tablets in the form of lozenges, on which is represented Jupiter sitting on his eagle. There is also the figure of a soaring bird sculptured on both the gates of the temple of the sun at Balbec and Palmyra, and its crooked beak, large claws, and the caduceus it bears, seem to represent an eagle, the soaring eagle consecrated to the sun.Catafagu.

NASRANI, a term applied to the Christians of India and Persia, and used by the Muhammadans in a derogatory sense. It plural is Nassāra, i.e. Nazarenes. It is prefixed to the names of the Nestorian Christians of Malabar.

NASTIKA. SANSK. An atheist, one who denies the authority of the Vedas.

NASTURTIUM, the water-cress genus of plants, of the order Brassicacez. N. officinale, the Lutputiah of India, is cultivated in gardens. It has been found at various elevations in the Panjab, Himalaya, and Afghanistan.
NAT. Bury. Spirit. The Burmese and Kahhyens have many of these, all requiring to be propitiated on commencing or carrying on any undertaking or war, with offerings of animals, articles of food and clothing. The Nat are supposed to have been objects of Burmese worship in pre-Buddhistic times. They correspond to the devata of the Hindus, whose place they take in the Burman Buddhist system. The Burmese kings on dying are said to ascend to the Nat's village, Nat-yua-tsan-thee. Nat-tha-nay, fairy children. Nat-pan, a devil dance, literally possessing spirit. Nat-worshippers in Burma number 143,581.-Yule, p. 17.

NAT or Nut, in Bengal, a wandering tribe, who are dancers, actors, athletæ. They are called also Nut Sirki bash (dwellers under mats); those in the Dekhan are not distinguishable from Dher.

NATA. MaL., TAM., TEL. A country, relating to the country; used to form many compound words - Wils.

NATA-KOTHIAR, a race in the south of the Peninsula who speak Tamil and follow Hinduism. They are large merchants, and all of them have the marked African protruding lips, and noses sharply cut at the forehead.

NA'TAL, on the coast of Africa, extends 12\% miles between the Umsimkulu and the Tugela rivers. It was discovered and uamed by Vasco da Gama on Christmas day 1497. It has about 200 miles of sea-coast, and became a British colony on 12th May 1843.-Findlay.

NATH or Nat'ha. SANSK. Lord; hence Jaganatha, vernacularly Jagannath or Juggernath, lord of the world, a name especially applied to Krisbna in the form in which he is worsbipped in the temple of Jaganath at Puri in Orissa. A name borne by some classes of religious mendicants. See Kala-Priya-Nath.

NATHDWARA, a town in the Rajput State of Mewar. It is the most celebrated of the fanes of Krishna. Its etymology is the portal (Dwara) of the god (Nath), of the same import as lis more ancient shrine of Dwaraka at the world's end. Nathdwara is 22 miles N.X.E. of Udaipur, on the right bauk of the Banas. It owes its celebrity entirely to an image of Krishna, said to be the same that had been worshipped at Mathura ever since his deification, between 1100 and 1200 years before Christ. When Aurangzeb (Alamgir I.) endeavoured to root out the worship of Krishua at Mathura, rana Raj Singh of Udaipur obtained permission to bring the idol to Mewar, and it was escorted with vast pomp by the route of Kotah and Rampura; but in Mewar, at a place called Siarh in Delwara, the chariot wheel stuck fast, on which the rao of Delwara, one of the 16 great nobles of Mewar, declared it an omen of the god's wish to remain there, and conferred on Nath-ji all the lands of the village. A temple was erected for the idol, and around it has grown the present Nathd wara. Rich offerings are sent here from all parts of India. From the little ridge on the east, to the banks of the Banas on the west, precincts of the god, has always been a sanctuary, within which no blood can be shed, no arrest made, and the criminal is free from pursuit. Nathdwara is one of the most frequented places of pilgrimage, though it must want that attraction to the classical Hindu which the caves of Gaya, the shores of the distant Dwaraka, or the pastoral Vrij, the place 
of the nativity of Krishna, present to his imagination.-Tod's Rajasthan, i. p. 521.

NATIVE is the ordinary term by which the idolworshipping people and Muhammadans of British India are at present known. The peoples to whom it is applied are only now fusing, under the firm sway of the British rule, and never before had, nor could have had, one common designation. Natives of India first sat on the petty jury on the 25th July 1828 .

NATIVE BREAD of Australia, used by the aborigines, is Mylitta Australis. Native cat of Australia is the Dasyurus viverrinus. Native companion, the egret.

NATIVE STATES is a term in general use for designating the dominions ruled by princes in alliance with the British, and the term occasionally is loosely applied to the frontier states of Kashmir, Nepal, and Bhutan, as well as to the territories of the king of Burma. The principalities of all grades have already been detailed under the heading British India, and the following is a mere summary of the British Indian Provinces and of the states under Native rule:-

\section{British Provinces.}

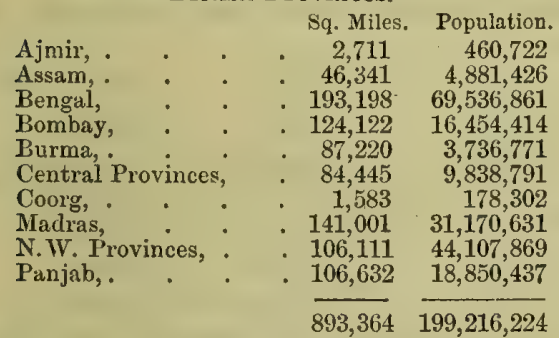

\section{Native States.}

Bombay Feudatory States, 73,753 Central Provinces do. do., 28,834 N.W. Provinces do. do., 5,125 Panjab do. do., . • 35,817 Baroda, : : 8,570 Central India, : . 75,079 Cochin,. . . . 1,361 Hyderabad, : : 81,807 Berar, : : : 17,711 Mysore, : . 24,723 Rajputana, . . . 129,750 Travancore, . . . 6,730

489,260

$6,941,249$

$1,709,720$

741,750

$3,861,683$

$2,185,005$

$9,261,907$

600,278

$9,845,594$

$2,672,673$

$4,186,188$

$10,268,392$

$2,401,158$

$54,675,597$

The more important States of Central India are Bhopal, Dewas, Dhar, Gwalior, Indore, and Rewah. Those of Rajputana are Bhurtpur, Bikanir, Bundi, Dholpur, Jeypore, Kerrowlee, Kishengarh, Kotah, Marwar, Mewar, Tonk, and Ulwar. In the Panjab are Busahir, Bahawulpur, Bilaspur, Kashmir, Jheend, Kapurthala, Keonthal, Maler Kotla, Nabha, Patiala, and Sirmur.

In Bombay the more important are Baroda, Cambay, Cutch, Janjira, Khairpur, Kolhapur, Mahikanta, Rewakanta, and Sawuntwari.

In the Madras side, Banaganapilly, Cochin, Hyderabad, Mysore, Puducottah, Sundur, Travancore.

The Kashmir ruler by treaty annually contributes six male and six female shawl goats, and three pairs of Kashmir shawls.

The maharaja maintains an army of 25,000 infantry, 1400 cavalry, and 160 guns. His dominions comprise the Kashmir valley, also Ladakh, and lead in the Gilgit valley towards the Hindu Kush. The army is recruited among Dogra Rajputs and hillmen, and the artillery guns are of excellent native manufacture. It holds the salient angle of the British position with regard to Afghanistan and Central Asia.

The subjects of the Mahratta States of Baroda, Gwalior, and Indore are largely of the aboriginal non-Aryan races, who, at most, have only become semi-Hinduized. Their populations number $6,250,000$; their State revenues, $£ 3,300,000$; and they maintain standing armies of a total of 59,000 men, and 115 guns.

The Hindu States, chiefly of Rajputana, Central India, with populations of 27,000,000, and revenue of $£ 8,000,000$, have armies with a total of $188,476 \mathrm{men}$, and 3096 guns.

Kashmir, with a population of $1,500,000$, and a revenue of $£ 600,000$, has 27,000 men, and 160 guns.

The Muhammadan States of Hyderabad, Bhopal, etc., have a population of $14,300,000$, a revenue of $\$ 5,240,000$, and standing armies of 74,760 men, with 865 pieces of artillery.

Thus Feudatory India, with a total population of $54,675,597$, with a revenue of $£ 17,140,000$, is maintaining armies of $349,835 \mathrm{men}$, and an artillery of 4237 guns.

N.W. Frontier:-Between British Indian territory and Afghanistan in the north, and British India and Baluchistan in the south, independent Pathan tribes hold the Sulairnan range from Abbotabad to Kaclı'hi, and they number their fighting men at 150,000 . But they have no cohesion; their government is essentially democratic.

Baluchistan has an estimated area of 80,000 square miles, and a population of 350,000 , with an annual revenue of 5 lakhs of rupees, or $£ 50,000$. With this income, the Khan maintains 3000 armed men; and his principal dependent, the Jam of Las, has about 1000 more. Two regiments of the British Indian arny have been raised from the Baluchistan tribes, and they make excellent soldiers.

Nepal is an Independent State ruling over numerous tribes, the more powerful being the dominant Gurkha, who in 1767 succeeded the Newar. At the close of a war with the British in 1814-15, Sir David Ochterlony made a treaty in which most of the Gurkha conquests and the Terai were ceded to the British. Since then there have been great dynastic convulsions, which ended in the minister Jung Bahadur becoming the ruler. His family are still dominant. The population is about 3 millions. Its army is about 100,000 strong, well armed, raised amongst the Gurkha tribes, with whom also the British India Government has formed a brigade of 5000 men.

Bhutan, geographically, is within the area of British India. It is an Independent State, under a ruler styled the Deb Raja, and in 1772 and 1866 has been at war with the Indian Government. On the first occasion, the plains of KochBahar were successfully defended; and on the secoud, the fertile Dwar districts were ceded to the British, and the Bhutanese subjects are now restricted to the remote recesses of their mountainous region, where their immoral systen, based on their practice of polyandry, has effectually prevented all national development. The Bhutau country is a fertile region in one-half of it, and in the other half contains some of the grandest scenery along the Himalaya. 
Munipur, a Hill State on the north-east frontier of British India, lying south of Assam, and touching on its southern side territory, which, though nominally Burmese, is really inbabited by independent tribes. The maharaja rules from his capital of Imphal, 125,000 subjects, who occupy territory described as being 12,500 square miles. His revenue does not exceed 6 lakhs annually, but the people also give military service, and his army consists of 500 artillery, 400 cavalry, and 4400 infautry. On several occasions this force has co-operated with the British troops in repressing the turbulent tribes on the south, and the maharaja has been uniformly friendly.

NATRON, Kien, Chin., a native carbonate of soda, is brought into China from Tibet and Mongolia by way of Kalgan. The Chinese confuse natron and nitre, as other nations have often done. Natron is abundant in the vicinity of Ava, where it is used by the Burmese instead of soap, and they call it earth-soap. It occurs in the lake of Lunar._Smith; Mason.

NATTAM, as in Alada-Nattam, is a Tamil term to designate a village inhabited by Sudra Hindus. It is also employed to denote the village lands on which the houses of the proprietors (mirasdar) are erected. It is distinguished from a Brahman village or Agrahara.

NATTAMAKAN, also Nattamakkal and Nattamar. TAM. A subdivision of the Vallala tribe, husbandmen, farmers.

NATURAL HISTORY is a description of the earth and of the plants and animals that have inhabited the earth, or are still dwellers therein. Its branches are geology, mineralogy, zoology, and botany. It is the province of geology to trace and correlate in historical sequence the physical changes that the earth's crust has undergone under the influence of volcanic forces, and the strains resulting from the contraction of the globe, as well as of the not less potent agrency of water in its various phases of rain and river, sea and ice. Mineralogy deals with the nature and characteristics of the materials that undergo these changes. It classifies the separate substances that are mingled and massed together to form a rock, or that may be met with in an isolated condition in cavities or veins, or as transported bodies. Substances of this kind, which, when isolated, are homogeneous and definite in their composition and character, are minerals, and when submitted to analysis are shown by the chemist to be composed of elements, not mingled as are the minerals in a rock, but united according to the laws of chemical combination. The result of the study of rocks, and of their component minerals, has been to show that the great mass of the earth's crust is formed of aggregations of minerals belonging to a very small number of the types that have been determined by the mineralogist.

The geological formations in Peninsular India are arrauged as-

Recent and post-tertiary.

Cenozoic-

Tertiary.

Mesozoic-

Dekhan trap series.

Marine cretaceous rocks.

Marine jurassic rocks.

Golidwana system.
Palceozoic.

Azoic-

Vindhyan series.

Transition or sub-metamorphic rocks.

Metamorphic or gneissic.

Minerals of the British Museum are arranged in five principal divisions:-

I. Native elements.

II. Compounds of metals, with

(i.) Elements of the arsenic group (the arsenoids, viz. bismuth, antimony, and arsenic).

(ii.) Elements of the sulphur group (the thionids, viz. tellurium, selenium, and sulphur).

(iii.) and (iv.) Elements of both the arsenic and sulphur groups.

III. Compounds of metals with elements of the chlorine group (the halogen elements-iodine, bromine, chlorine, and fluorine).

IV. Compounds of elements with oxygen.

V. Organic compounds.

The biological sciences deal with the forms of life that have existed or still exist on the globe. As a whole, they are designated the Animal Kingdom. Its primary divisions, according to Huxley (1869), Herr Carus and Gerstaeker (1868), and British Museum (1883), have been given as under :-

$$
\text { Huxley. } \begin{gathered}
\text { Carus and } \\
\text { Gerstaeker. British Museum. }
\end{gathered}
$$

1. Protozoa. $\}$ 1. Protozoa. 1. Protozoa.

3. Colenterata. 2. Colenterata. 2. Colenterata.

4. Annuloida, 3. Echinodermata. 3. Echinodermata.

5. Annulosa. \{4. Vermes. 4. Annulosa.

6. \{5. Arthropoda. 5. Arthropoda.

7. Mollusca. 7 . Mollusca. $\}$. Mollusca.

8. Vertebrata. 8. Vertebrata. 7. Vertebrata.

The science of botany treats of everything relating to plants whether in a living or a fossil state. Since the 17 th century, there have been several classifications proposed by eminent men, prominent among whom are Linnæus, whodied 8th January 1778 , whose arrangement was based on the sexes of plants. Subsequently, Antoine Laurent de Jussieu put forward a system, which is known as the natural classification; he died in 1836, but his son Adrian adopted his father's views. The next great botanist was De Candolle, whose system is a modification of that of Jussieu; and at the present day, De Candolle's Prodromus and Lindley's Vegetable Kingdom are largely accepted as guides in systematic botany, according to the natural system. The names of the classes, such as acrogen, endogen, exogen, are derived from Greek words.

Neither the Buddhist nor the Brahmanical nor the non-Aryan races of India have ever directed their attention to these sciences. The two known works of Arabia, Persia, and India are the Ajaib-ul-Makhlu-qat wa Ghraib-ul-Maujudat, the Wonders of Creation and the Marvels of Things Existing, written in Arabic by Zakariya-binMuhammad-bin-Mahmud, and which he completed A.D. 1363. In A.D. 1535-1557, in the reign of Ibrahim Adal Shah, it was translated into Persian, and in 1865 this was printed in lithograph. It was subsequently translated into Urdu, and printed by Maulana Muhammad Husain, and again in Persian in 1869. All the editions are illustrated, but the figures of monsters are imaginary. It is, however: a work of great merit for the 14th century. The other work is the Jahān Numā. 
That the Hindus have no work on natural history is remarkable, seeing that they have before their eyes much to excite their curiosity, their wonder, and their fear; and while the stratified rocks of their country contain the remains of many huge extinct creatures of bygone ages, the elephant yet roams wild in the forest tracts, crocodiles infest the river banks, the lion, tiger, panther, leopard, wolf, and wild dog destroy great numbers of other creatures, and many human beings fall victims to the bites of poisonous snakes.

There are 13 known species of fossil elephants, 9 of which occur in India. The Elephas ganesa of the Siwalik Hills has tusks $10 \frac{2}{2}$ feet long. It is one of the largest of the fossil elephants. The great sabre - toothed tiger, Machairodus latidens, which has been found in Europe and S. America, occurs also in the Upper Miocene fresh-water limestones of the Siwalik Hills of India. The Mastodon Perimensis and extinct Dinotherium have been found in Europe and in Perim Island in the Gulf of Cambay. The threetoed miocene ancestor of the horse, one of the Ungulata or hoofed animals, Hipparion or Hippotherium, occurs fossil in the Siwalik Hills, and also extinct species of hippopotamus. Two species of pigs, now extinct, the Sus giganteus and Sus hysudricus, have been found in India; and extinct camels in the Siwalik.

The Siwalik Hills of India and the rocks of China have also furnished the huge Sivatherium ; and from there also have been obtained two species of Chalicotherium, also fossil oxen and antelopes; while of fossil birds the Siwalik have furnished the Struthio Asiaticus and Argala Falconeri. Remains of many species of alligators, crocodiles, and gavials have been found in the tertiary rocks of India. The extinct Colossochelys atlas, from the Siwalik Hills, is one of several gigantic land tortoises which still inhabit islands of the Indian and Pacific Oceans. Of all these, Hindu literature makes no mention, though these religionists utilize, medicinally and in the arts, many minerals and plants and animals; and they reverence the cow, and even worship the Hanuman monkey, Presbytis entellus, the cobra snake, and the tulsi plant.

The Chinese students of natural history have been fairly successful in their botanical writings. They can show the Nanfang-tsao-mu-Chuang, by Ki-han, so early as the time of the Tsin dynasty, A.D. $265-410$; and since then, the Pun-tsao of Li Shi Chin, A.D. 1590, and many others, have appeared. But in other branches of natural science they entertain very childish notions. Remusat, writing in 1828 , mentioned that one of the strangest errors among them relates to the transformation of beings into each other. This delusion has arisen from their following popular fallacies, and learned absurdities have beeu added to puerile prejudices. That which the vulgar have believed, the learned have attempted to explain. They point to fossils as proving that animate beings can become inanimate; they believe that ice, if kept long in the earth, becomes rock-crystal ; that lead, in time, becomes cinnabar, tin, and silver; that in spring the rat changes to a quail, and in the eighth month, from a quail to a rat.

Even, however, to those who make natural history a life's study, the multitude of current synonyms offer hindrances to the acquisition of all branches of this science. The Bengal leopard cat, for instance, has been called the Felis Bengalensis by Desmoulins, F. Sumatrana by Horsfield, the F. Javanensis by Jerdon and Horsfield, F. minuta by Temminck, F. undulata by Schinz, F. Nepalensis and F. pardichrous by Hodgson; and Dr. Gray gave it four names, Leopardus Chinensis, L. Reevesii, L. Elliotti, and Chaus servalinus.

Another instance, amongst birds, the bearded eagle, Gypaetos barbatus, has had twelve names given to it, in the genera falco, gypaetos, phene, and vultur. The Scops aldrovandi, Ray, has eleven synonyms, of the genera ephialtes, otus, scops, and strix. Herodias bubulcus has twelve specific synonyms. Leptoptilos argala, the great adjutant bird of Europeans, has six synonyms, of the genera ardea, argala, ciconea, and leptoptilos.

Among reptiles, the Crocodilus palustris has five synonyms. Euprepes rufescens, the common Indian skink, has nine synonyms of the genera euprepes, lacerta, plestrodon, scincus, and tiliqua. Bungarus cærulius has eight.

In 'Pfeiffer's monograph of the Helicidæ, a family containing 17 genera, no less than 330 generic synonyms are enumerated. One very common estuary shell of Europe has been named Arenaria plana by Megerle, Lutraria compressa by Lamarck, Mactra Listeri by many authors, Mya Hispanica by Chemnitz, Scrobicularia piperata by Grelin, Trigonella plana by Da Costa, and Venus borealis by Pennant.

Similarly with most fishes. The small barbel of India has 11 synonyms,-Barbus caudimarginatus, deliciosus, Duvaucelli, gardonides, sarana, and Russellii, Cyprinus kunnamoo, M'Clellandi, and sarana, Systomus chrysostomus and immaculatus; and to curtail this part of the subject, it must suffice to say that the synonyms of plants are even more numerous.

This multiplication of names has often resulted from a genus or species being described by more than one person, in ignorance of each other's labours; but occasionally has occurred from the desire of giving new designations to old and familiar objects, and from fresh views as to classification. In botany, with the knowledge of new lands and their varied flora, the numbers of names may be expected to grow indefinitely. At the present time it may be thought a safe estimate to say that there are probably not less than half a million distinct species of vegetable organisms on land and in the water dispersed over the globe. The plants of India alone are reckoned at 12,000 to 13,000 .

The oriental region, for its fauna, has been arranged into four sub-regions, viz. Hindustan, Ceylon and South India, the Himalayan or IndoChinese sub-region, and Indo-Malaya.

Mr. W. T. Blanford, in the Bengal Asiatic Society's Journal for 1881, has given the following estimate of the land and fresh-water animals in British India, Baluchistan, and the Mergui Archipelago:-

\begin{tabular}{|c|c|c|}
\hline $\begin{array}{l}\text { a. Vertebrata } \\
\text { Cammals, viz, } \\
\text { adrumana, : } \\
\text { aures, } \\
\text { iroptera, : } \\
\text { ectivora, : }\end{array}$ & & $\begin{array}{l}\text { Carnivora, } \\
\text { Cetacea, } \\
\text { Rodentia, } \\
\text { Ungulata, } \\
\text { Sirenia, } \\
\text { Edentata, }\end{array}$ \\
\hline
\end{tabular}


1681 Birds, viz.-

149 Raptores-

Accipitres, .

.$\quad .97$

1182 . . 52

1182 Insessores, viz.--

Psittaci,

Picariz,

Passeres,

72 liasores, viz. -

Pteroclidx,

Grallæ,

Otididx,

Limicolæ,

Gruidæ,

Rallid $x$,

Ciconida,

Ardeidæe,

Tantalidx,

Plataleidæe,

Ibididæ,

97 Natatores, viz.

Phonicopteridæ,

Anseres,

Podicipida,

Procellaridæ,

Laridre,

Phaëtonidæ,

Sulidæ,

Attagenidæ,

Pelacanidæ,

Graculidæ, .

514 Reptiles, viz.-

Chelonia,

Crocorlilia, .

182 Lacertilia, viz.-

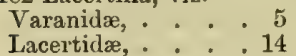

Zonuridx, · . 11

Scincidæ, . . 48

Geckotidæ, : : . 59
Agamidæ, . 54

Agamidæ,

274 Ophidia, viz.-

Typhlopidæ,

10

135 Grallatores, viz

Tortricidæ,

Xenopeltidæ,,$\cdot 2$

Uropeltidæ, : : 41

Calamaridæ, . . 11

Oligodontidæ, . . 27

Colubridæ, . . . 57

Homalopsidæ, . 10

Acontiophidx, . . 1

Psammophidæ, , , 3

Dendrophidæe,

Dryiophidæ,

Dipsadidæ,

Lycodontidæ, . . 10

Amblycephalidæ, . 5

Pythonidx,

Erycidæ,

Acrochordidæ,

Elapidæ,

Hydridæ,

Crotalidx, .

Viperidæe,

100 ? Amphibia.

1357 Fishes, viz. -

Acanthopterygii,. 705

Acanthini, . : . 43

Physostomi, . . 485

Lophobranchii, . . 15

Plectognathi, . . 44

Chondropterygii,. . 65

b. Invertebrata.

1000 Mollusca, viz. -

Gasteropoda,

Lamellibrancheata, 100

12,370 Arthropoda, viz.-

Insecta.

Coleoptera,

Hymenoptera,

4780

Lepidoptera, . . 4620

Diptera, . . 500

Khynchota, . ?650

Neuroptera, . . 350

Myriopoda,

Arachnida,

Crustacea,

.50

120

-A.R. Wallace; W. T. Blanford.

NATURE-TWORSHIP or Totemism is a cult in which natural objects, trees, lakes, stones, animals, etc., are worshipped. According to Bunsen, the earliest Bactrian faith was a pure nature-worship, as recorded in the Vedas. That was superseded by an ethical faith, when light and darkness, sunshine and storm, became represented by good and evil; but in the change, Zoroaster denotes the spirits of evil by the term Deva, common to the old Aryan divinities. The Bactrian religion continued unchanged amongst the Aryan emigrants until they reached the Panjab. Amongst Aryan Hindus, non-Aryans, and the Parsees, spirit-worship has almost displaced the natureworship of the Vedas. But Hindus recognise in Prithivi, an earth-goddess, the mother of all beings. Her worship among the Asiatic races has been associated with sanguinary and licentious rites. It was to her that to the present day the Kaudhs of the Orissa mountains have been sacrificing the Meriah victims. In Phœnicia and the adjacent parts of Syria, the worship of Ashtoreth was from the first accompanied with licentious rites. As at Babylon, so in Phoenicia and Syria, -at Byblus, at Ascalon, at Aphaca, at Hierapolis, --the cult of the great nature-goddess tended to encourage dissoluteness in the relations between the sexes, and even to sanctify impurities of the most abominable description. Even in Africa, where an original severity of morals had prevailed, and Tauith had been worshipped as a virgin with martial attributes, and with severe, not licentious, rites, corruption gradually crept in: and by the time of Augustine the Carthaginian worship of the celestial goddess was characterized by the same impurity as that of Ashtoreth in Phonicia and Syria. The Babylonian Anat or Nana, the Assyrian Istar, the Phœnician Astarte, the Cypriote Venus, and the Ephesian Artemis, are all developments of the Asiatic mothergoddess, whose worship spread from Babylon to A sia Minor and Greece. A bas-relief in a corridor at the ancient Carchemish, the capital of the Hittites, represents her worship. The figure is nude, full face, and winged, the feet close together, and the slender curves of the figure recall the terra-cotta votive figures of Anat found in the temples in Chaldæa. The hands support the breasts, as the nutrice of all created nature. The Ephesian Artemis represented the goddess manybreasted, as the mother of nature. Nannoea or Bibi Nani, the Babylonian Venus, has a statue shrine in the Hazara country on the top of a gigantic scarped rock, from the base of which flows the source of the Kurnuk. Her worship was introduced into Bactria from Syria, and is frequently indicated on Indo-Scythic coins.Rawlinson's Religions, p. 175.

NAU. Hind, SANSK. Nine. Nau-naga, nineheaded snake. Nau, Naua, in Persian and Hindi, also mean 'new.'

NAU-AIT, in the south of India, a class of Muhammadans engaged in civil life, who came from Persia to Gujerat. The words mean newcomers. They are fair men.

NAUBAT. Hind, Pers. A drum, a kettledrum.

NAUCLEA CADAMBA. Roxb.

Kaddam, BENG, Hind. Halamba-gass, . Sinot. Maoo-ka-doon, . BurM. Kadamba, - TAM. Kudda-vailoo, . . CAN. Kadapa, . . . TEL.

This is a noble ornamental tree of British India and Burma. It is common in Ceylon up to an elevation of 2000 feet; it is found in Travancore and in the Dekhan. It has orange-coloured flowers, collected into heads the size of a small apple. Makaranda says, -

'Thick on the hill's broad bosom the Kadamba Shows bright with countless blossoms.'

It attains a height of 70 to 80 feet, with a girth of from 6 to 15 feet, and a stem of 32 feet to the nearest branch. It is made into boats; its flowers are offered to the Hindu deities; it is used for various kinds of furniture. The wood is of a deep yellow colour, but loose-grained. A cubic foot weighs $37 \mathrm{lbs}$. It sells in Burma at 8 annas per cubic foot, is suitable for furniture, and is used for building purposes. A spirit was formerly distilled from its fruit. According to Hindu mythology, this is one of the four shady trees that grow on Mount Meru, the others being the Eugenia, the Ficus Indica, and E. religiosa. The corollets of the flower are numerous, forming a large, perfectly globular, beautiful orange-coloured head, with the large white clubbed stigmas projecting. Delight, according to the Hindus, gives a bristly eleration to the down of the body, and is thus alluded to in the Hindu Theatre:-

'How chances it

That one so free from passion should betray,

Without apparent cause, this agitation,

And blossom like the round Kadamba flower?"

—Roxb.; 'Ihw.; Hindu Theatre; Beddome. 
NAUCLEA COADUNATA. Roxb. Bakmeegass, Singh. Common in the warmer parts of Ceylon.-Thw.

NAUCLEA CORDIFOLIA. Roxl. Keli kadam, . BENG. Adumbay,

Thay, . TAQ. H'nau, * BurM. Manja karamba, . TAM. Hedde, Ye:tay-ga, CAN. Bandaru, Daduga,. TEL. Hurdu, Haldu, Hind. Paspu karami, . TiB. Kolong, . . SINGH. Holondho, - URIYA. This large tree grows in the hot, drier parts of Ceylon, and abundantly in the mountainous districts of the Peninsula of India; it is a common tree in the coast forests of the Bombay Presidency, but never found inland. Its wood is light chestnutcoloured, firm, close-grained, and much in use for building, gun-stocks, and various other purposes ; it requires to be kept dry, as it soon rots if exposed to wet. The leaves are used as fodder. At one time there were great forests of this tree in Kamaon, but these have been thinned. The tree rises with a clear stem of 30 to 40 feet, and has a girth of 6 to 12 feet. When growing singly it throws out branches close to the ground, and gives support to itself by projecting large buttresses from the bole.-Drs. Roxb., Stewart, Cleghorn, Thw., Wight, Gibson.

NAUCLEA PARVIFLORA. Roxb.

N. orientalis, Gertn. | Cephalanthus pilulifer, $L$. Kalham, BEAS, Rivi. Kuddum, . MAHR. H'tein,. : BurM, Kalam, Karam, Panjab. Hedu, Kongu, : C CAN. Helembe, . SINGH. Yetega, Yetegal, : ", Nir kuddembay, TAM. Kyen, . . ' HIND. Botta kadapa chettu, , Haldu, : KaMAON. Buta karamee, . TEL.

This large tree is found in the Western and Northern Provinces of Ceylon, in the bot, drier parts of the island, where its close-grained hard timber is used for common honse-building purposes. Dr. Wight says in Coimbatore it has a strong fine-grained timber, sustaining $400 \mathrm{lbs}$., and yielding considerable beams, dark-coloured, but that it soon rots if exposed to wet. From the fineness of its grain it seems well fitted for cabinet purposes, and has the advantage of being easily worked. On the western coast it is valued for yielding flooring planks, packing-boxes, etc. It is worshipped by the Oraons. In the Bombay Presidency the wood is valuable for gun-stocks, for flooring of houses, and house beams. It is found in the Nullamallay, and a cubic foot weighs 43 lbs. The leaves are given as fodder.-Drs. Roxb., Wight, Gibson, Siterart, Cleghorn, Thw., Pouell.

NAUCLEA PEDUNCULARIS. Wall. Cat. N. triflora, Moon's Cat. I N. purpurea, Roxb., var.

A moderate-sized tree of Ceylon in the Saffragam and contiguous districts, up to an elevation of 1000 feet, not uncommon in the Central Province.-Thw. ii. p. 137.

NAUCLEA ROTUNDIFOLIA. Roxb. tree of Burma and the Andamans, the Bin-gah of the Burmese; its wood is close and even graiued, moderately hard, and of a yellowish-brown colour. - Gamble.

NAUCLEA TUBULOSA. Thw. A small tree of Ceylon; one variety very abundant in the Kokulcorle. Another variety in the hot, drier parts of the island.-Thw. Enum. Pl. Zeyl.

NAUCLEA UNDULATA. Wall. Ma-u lettan, Burm. A soft, useless wood in British Burma, decays in less than a year. Breaking weight, 80 to 120 lbs. A cubic foot weighs 22 to
34 lbs. In a full-grown tree on good soil the average length of the trunk to the first branch is 100 feet, and average girth mensured at 6 feet from the ground is 15 feet. It sells at 2 annas per cubic foot.-Dr. Brandis, Cal. Cat. Ex. of 1862 .

NAUCRATES, the pilot-tish genus of fishes, belonging to the family Scombridre. The species Naucrates ductor usually accompanies the shark; its ordinary length is from 4 to 8 inches.

NAU RATN. HIND. Nine gems ; an ornament worn on the arm, which indicates the only jewels that are esteemed as precious; they are, diamoud, ruby, emerald, sapphire, topaz, pearls, coral, hyacinth, carbuncle. The others, and also the inferior gems, agates, bloodstone, etc., are mostly in use for signet rings, in the art of engraving which natives of India are extremely skilful.

Triratna, or triple gems, in the Buddhist religion are Buddha, Dharma, and the Church.

NAU RATN, nine learned men at the court of Vikrama, supposed to have been Vikramaditya, B.C. 56 ; their names were Amara Sinha, Dhanwantari, Ghata - karpara, Kalidasa, Kshapanaka, Sanku, Varaha - mibira, Vararuchi, and Vetalabhatta.-Douson.

NAU RATRI, a Hindu festival lasting nine days, three of them in honour of Saraswati, and six for Siva's consort.

NAUTCH. HIND. A dance; a Hindustani nautch-girl does not dance like Taglioni and Cerito, but by a movement of her feet to music. The dancing of nautch-girls on public occasions is always decorous. The dances are, to a European, dreary; not only not graceful, but monotonous, wearisome.-Kaye's Christianity in India, 309.

NAUTILID正, a family of cephalopodous molluscs. The genus Nautilus is the type of this family. There are three or four species in the seas of warm climates, especially those of Asia and Africa, and their islands, Amboyna, Zanzibar, and New Guinea, and the Pacitic and Australian Oceans. G. Bennett mentions (pp. 374, 385) $\mathrm{N}$. macromphalus, N. pompilius, and N. umbilicus in the seas of the Eastern Archipelago and $\mathrm{S}$. Pacific. The shell of the pearly nautilus, $N$. pompilius, is heavy, dense, and chambered. It is made into cups and vases, and the natives of the New Hebrides and other groups eat the animal. Montgomery tells how,

"Light as a fiake of foam upon the wind,

Keel upward, from the deep emerged a shell ;

The native pilot of this little barque

Puts out a tier of oars on either side,

Spreads to the wafting breeze a two-fold sail,

And mounted up and glided down the billow.

NAVA-KHANDA, or Nine-divisions, is the title of an account of India, which was first described by the astronomers Parasara and Varaha-Mihira, although it was probably older than their time, and was afterwards adopted by the authors of several of the Puranas. According to this arrangement, Panchala was the chief district of the central division, Magadha of the east, Kalinga of the south-east, Avanta of the south, Anarta of the south-west, Sindhu-Sauvira of the west, Harahaura of the north-west, Madra of the north, and Kauninda of the north-east. The division of India into five great provinces would appear to have been the most popular one during the early centuries of the Christian era, as it was adopted by the Chinese Pilgrims, and from them by all 
Chinese writers. According to the Vishnu Purana, the centre was occupied by the Kuru and Panchala; in the east was Kamarupa or Assam; in the south were the Pandua, Kalinga, and Magadha; in the west were the Saurashtra, Sura, Abhira, Arbuda, Karusha, Malava, Sauvira, and Saindhava ; and in the north the Huna, Salwa, Sakala, Rama, Ambashta, and Parasika._Cunningham's Ancient India, p. 5.

NAVAKIRE, near Putoor, 21 miles from Jaffna, in Ceylon, has a remarkable well, which rises and falls once every twelve hours, and retains the same quantity of water however drawn. It is alluded to in Sinbad's travels.

NAVANDGARH or Naondgarh is a ruined fort from 250 to 300 feet square at top, and 80 feet in height. It is situated close to the large village of Lauriya, 15 miles to the N.N.W. of Bettia, and 10 miles from the nearest point of the Gandak river. The ancient remains consist of a handsome stone pillar, surmounted by a lion, and inscribed with Asoka's edicts, and of three rows of earthen barrows or conical mounds of earth, of which two rows lie from north to south, and the third from east to west. The stupas usually met with are built either of stone or of brick; but the earliest stupas were mere mounds of earth, of which these are the most remarkakle specimens that General Cunningham had seen. He believes that they are the sepulchral monuments of the early kings of the country prior to the rise of Buddhism, and that their date may be assumed as ranging from 600 to 1500 B.C. Every one of these barrows is called simply 'bhisa' or mound, but the whole are said to have been the kots or fortified dwellings of the ministers and nobles of Raja Uttanpat, while the fort of Navandgarh was the king's own residence.-Cunningham's An. Geog. p. 448 .

NAVARATN, a nine-pinnacled Hindu temple.

NAVARETTE. Father Navarette, a Spanish Dominican, who visited the east about the middle of the $17 \mathrm{th}$ century, and left an elaborate account of his pilgrimage. - He was sent out by his order in $1646^{\circ}$ to control its missions, which were then very extensive in China and Manilla. He taught for some time in the College of St. Thomas at Manilla, but, finding that the field was too limited for his missionary zeal, he passed over to the mainland, and applied himself with great success to the study of Chinese, and to the mastery of the Confucian religion. His Account of China, Historical, Political, Moral, and Religious, which was translated into English in the beginning of the 18th century, displays a surprising mastery of the history and religion of the Chinese. An important part of the volume is devoted to the discussion of the controversial points debated by the Catholic missionaries and the Chinese literati. On his return to Europe in 1673, Navarette was well received at Rome, and his views of the Chinese disputes were adopted by the Pope. On his way to Europe he landed at Madras, about the year 1669-70, and visited the shrines at the Little Mount and St. Thomas Mount, the Luz and St. Thomé.

NAVASHT. PERS. Writing. Navasht-waKhand, reading and writing. Khush Navis, an elegant writer.

NAVNE. Hind. A jar in which rose-water is held. The rose oil or atr (otto) rises to the top, and is skimmed off.
NAVY. During the rule of the English East India Company, the first application of ships in war was to suppress piracy along the coast of Malabar. The fleet was named the Bombay Marine, but about 1833 was changed to the Indian Navy. In 1850 the fleet consisted of 32 steam vessels, with 72 guns; also of 14 sailing vessels, with crews numbering 737 , and 89 guns. This navy was abolished about the year 1860 , but was re-established in 1884 in a modified form.

NAWAB. ARAB. Plural of Naib, a sovereign, a viceroy, corruptly Nabob; also the highest honorary title under a Muhammadan sovereign in India. The Muhammadan titular distinctions are Bahadur, Khan, Dowla, Umra, Jah, Nawab. The emperors of Dehli granted this title to the viceroys of the empire, these viceroys again to their Muhammadan officers. It was a prefix to the names or other titles. The nawabs of the Carnatic granted the title to the female members of their families, and the successive Begums ruling at Bhopal have assumed it.

NAWAB-NAZIM, the title of the descendant of Mir Jafar, held in succession until Syud Mansur Ali retired from the position in 1883, and renounced all rights in consideration of an annual stipend of $£ 10,000$, the payment to him of 10 lakhs of rupees in settlement of various claims, and a suitable provision for his four children born in England. The title of nawab of Murshidabad was conferred on the eldest son, and the title of Nawab-Nazim became extinct.

NAWANAGAR, a Native State on the southern shore of the Gulf of Cutch, with an area of 3395 square miles. Its ruler, the Jam, is a Jhareja Rajput. Until the year 1812 the Jhareja race were notoriously addicted to killing their female children. Nawanagar is a flourishing town, in lat. $22^{\circ} 26^{\prime} 30^{\prime \prime} \mathrm{N}$., and long. $70^{\circ} 16^{\prime} 30^{\prime \prime} \mathbf{E}$. North of the town are some beds of pearl oysters. The Jharejas entered Kattyawar from Cutch, and dispossessed the ancient family of Jetwas (Parbandar) then established at Ghumli. It is said that Nawanagar was founded in 1442 . The Muhammadans called it Islamnagar, but the Jams have restored the original nawe. The Jams are of the same family as the Raos of Cutch. The chief of Dhrol State claims to be descended from a brother of Jam Rawal, founder of the Nawanagar line; and Rajkot is also an offshoot from this state.-Imp. Gaz.

NAWARA, written Nowarrah, a large boat, a barge, a flotilla. $-W$.

NAWERA ELLIA, in lat. $7^{\circ} 3^{\prime} \mathrm{N}$., and long. $81^{\circ} 52^{\prime} \mathrm{E}$., a sanatorium in the interior of Ceylon.

NAYADI, corruptly Naiade. MaL. A low easte tribe, found only in the northern parts of Cochin. They are the most degraded of all the low tribes. The many low castes of Travancore are Parayan or Pariah, labourers and basketmakers ; the Pulayan, slave labourers; the Nayadi, beggars; Ulladan, woodcutters; and, of the hills, the Vedan ; Kaniyan, hunters; Kuruban or Kuravan or Kurumban; and Mala Arayan, hill cultivators.-Mateer's Travancore, p. 32.

NAYAKA. TEL. This is an honorific appellation used variously amongst some of the races in the south of India, under the pronunciations Naik, Naikan, and in the plural Naidu. It is in use in the native army of British India as the designation of a non-commisioned ofticer, equivalent to a corporal. 
Amongst the people speaking Telugu it is a title of several hill chiefs, and is applied to a militia holding lands on military tenure. A Naik dynasty ruled in Tanjore immediately prior to the Maharattas. The Bhil chieftains have this title.

NAYUTA, or Munja, i.e. presents carried in state, a Muhammadan ceremony.

NAZARETH, a small village of Palestine, 50 miles from Jerusalem, in a valley of the same name. Its population is about 3000 .- Catafago.

NAZARITE. Numbers vi. 18 : 'The Nazarite shall shave the head.' The Hindus, after a vow, cease to cut their hair a during the term of the vow : at the expiration of which time they shave it off at the place where the vow was made. It is a very ancient form of votive offering. It is uncertain (Acts xviii. 18; Romans xvi. 1) whether Paul or Aquila, or both, shaved their heads at Cenchrea. It is probable that Paul had become a Nazaræus votivus, and consequently had bound himself to serve the law of the Nazarites for a certain time. The Nazaræi votivi (Numbers vi.) were required to abstain from wine, grapes, and all inebriating liquors during the time of their separation. They were also to let their hair grow without cutting till the days of their vow were fulfilled; then it was to be shaved off, and the appointed sacrifice to be offered in the temple. Consecrating the hair, in times of danger, etc., to the heathen divinities, Lucian represents as of frequent occurrence, and he himself had complied with the custom. The emperor Nero is said, by Suetonius, to have cut off his first beard, and to have devoted it to Jupiter Capitolinus, placing it in a golden box, set with jewels. Nazaritism was partly a religious institution, and partly civil and prudential. Its laws were promotive of the strictest sanctity, and calculated to preserve the health, sobriety, and temperance of the community. Hence we read, 'Her Nazarites were purer than snow, they were whiter than milk.' (Lamentations iv. 7.) Samson, Samuel, John the Baptist, and, according to the rabbins, Absalom, were Nazarites, and Joseph is said to have been Nazir echaiv, which we translate 'separated from his brethren,' but which the Vulgate renders 'Nazaræi inter fratres suos.' Persons recovering from sickness, or preserved from danger, frequently took upon them the vow. At the present time in Persia, if a Muhammadan child be sick, the mother frequently makes a vow that the razor shall not come upon his head for a certain time, and sometimes for life, as in 1 Samuel i. 11. When the time that is limited expires, the child's head is shaved, money is collected from the relatives, and sent as nazr or offerings to the mosque, and consecrated. Homer speaks of parents dedicating to some deity the hair of their children which was cut off when they came to mauhood, and consecrated to the gods. Achilles cut off his golden locks at the funeral of Patroclus, and threw them into the river, his father having dedicated them to the river-god Sperchius. In the south of India, at the sacred hill of Triputty, thousands of both sexes annually cut off their hair, and leave it as a votive offering.-Milner's Seven Churches, p. 110; Iliad, xxiii. 149, etc. ; Aneid, i. 698.

NAZIM, under the native rulers of India, the chief local revenue and executive officer of a division or nizamat. He was either a salaried officer collecting the revenue for the Government under the amani or trust system, or he was a farmer or contractor or jjaradar, taking a lease of the revenue of the district at so much per annum. It is also a Muhammadan official name for a eunuch.

NAZM. ARAB. Order, arrangement; poetry, as distinguished from Nasr, prose.-Wils.

NAZR. Arab. A present, a fine or fee paid to the state. An offering from an inferior to a superior. Nuzzerana, a fee for investiture, a succession fee; Nuzzerana, or relief, marks the original emanation of a grant, and in Mewar was fixed at one year's revenue of the state. Nuzzur-o-Niaz, vows and oblations.

Nazr or Nazzr is an offering from an inferior to a superior, a present. It is the present sent before, as in the time of (Genesis xxxii. 18) Jacob and Esau, when the servants said it is a present sent unto my lord Esau. Also 1 Samuel ix. 7: 'Then said Saul to his servant, But, behold, if we go, what shall we bring the man? for the bread is spent in our vessels, and there is not a present to bring to the man of God: what have we?' When Xenophon on bis retreat reached the country of Senthes, and agreed to attach his corps to the service of the Thracian, his officers, on introduction, presented their gifts of homage; but Xenophon presented his sword. This eastern custom is continued. Up to the present day, the native officers of the Indian army, on introduction to a superior, present to him their swords, and, in taking leave, a drop of rose essence is allowed to fall on the half-drawn blade. It is a very effective, interesting rite. The Viceroy and GovernorGeneral of India at his receptions receives the nazrs of all the princes in the form of coins. It is very common in British India for a person, who is desirous of asking a favour from a superior, to take a present of fruits or sweetmeats in his hand. If not accepted, the feelings of the offerer are greatly wounded. There are periodical occasions in Persia at which all who are admitted to stand in the presence of its monarch are expected to appear before him with a present. Of these, the chief is the Nao-Roz or new year, which occurs about the end of March or beginning of April.Traser's Khorasan, p. 214; Tod's Travels, p. 486.

NAZUL. Hind. Property belonging to Government, usually in charge of district local fund committees; the property is chiefly houses, gardens, or plots of land in cities. In the Panjab the various nazul gardens (i.e. Government property) are generally planted with mangoes, as well as other trees; and the right to the fruit is sold on contract by auction at the beginning of the season. The property of a large garden, like that of Shalimar at Lahore, is something very considerable.-Powell, p. 279.

NBAN MAI. This seed is made into oil for lamp and other household use. One basket will give 65 viss of oil.-Local Committee, Monlmein.

NEARCHUS, a general whom Alexander the Great commissioned to survey the Southern Asiatic coast, from the mouth of the Indus to that of the Tigris. He sailed along the coast. His journal is incorporated in Arrian's History of Alexander. - Ind. in 15th Century.

NEBO, Pisgah, and Peor are parts of the

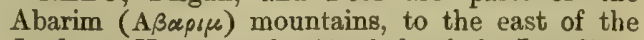
Jordan. Here was the 41 st balt of the Israelites, and Moses died here-Catafago.

NEBONG or Nibong. MALAY. The Oneo, 
sperma filimentosum, a tall, thin, but straight tree ; wood used for railiogs. Its cabbage is edible.

NEBUCHADNEZZAR, king of Babylou, B.C. 598-562. He was the son of Nabopolassar, who had combined with Cyaxares, king of Media, and a king of Egypt, for the overthrow of Ninevel. After the fall of Assyria, the Median provinces and the north of Assyria, as far as Cilicia, fell to Cyaxares of Media, the south of Assyria and part of Arabia fell to Babylon, the western boundary of Nabopolassar being the Upper Euphrates. All west of Carchemish and south of Cilicia was joined to Egypt. Babylon, by the successes of Nabopolassar and his son Nebuchadnezzar, became for a brief period mistress of Western Asia. B.c. 605, Nabopolassar sent his son Nebuchadnezzar against Necho II., king of Egypt, who was defeated near Carchemish, and all Syria fell to him. Palestine revolted about B.c. 602, he swept down on it, attacking Tyre on the way, and overran Judah, deposed Jehoiachin, and raised his uncle Zedekiah to the throne, carrying Jehoiachin to Babylon. But Zedekiah also revolted, and, B.c. 589 , Nehuchadnezzar sent an army to Palestine under his general Nebuzaradan, and B.C. 587 Jerusalem fell. The city was destroyed, the temple burned, its sacred vessels and treasures carried off, Zedekiah's sons put to death, and then Zedekiah's eyes put out, plundering other cities of Judah, and carrying their people into captivity. He followed this up, B.c. 586, by the siege of Tyre, which is said to have been taken B.c. 573. The Jews again revolted, and murdered Gedaliah, the Chaldæan governor, which led in 582 to Judah being again ravaged, and the last of its captives sent to Babylon. About this time Nebuchadnezzar repressed the tribes on the borders of the desert east of Palestine, and his army penetrated far into Arabia.

In B.C. 572, Nebuchadnezzar, in personal command of his army, invaded Egypt, defeated the army of Hophra, overran the country, and pluudered it of all its wealth. Hophra was deposed, and was replaced by a general named Ahmes or Amasis. The Babylonian empire was at this time at its greatest. It seems to have comprised Elam or Khuzistan on the east, and parts north of this, including Zimri and the region as far as the Zagros mountains, taking in all the best parts of Assyria, and probably all the districts south of the Merdin Rocks, south to the shores of the Persian Gulf, and westwards to Cilicia, where the boundary touched the Mediterranean; all Syria, as far as the Mediterranean, was included; all the northern parts of Arabia aud Egypt, with part of Lybia, southwards to the Lybian desert, the cataracts of the Nile.

In Nebuchadnezzar's reign a great commerce was carried on with India. The great temple of Babylon, called Seggal, which was dedicated to Bel-Merodach, he rebuilt, and richly adorned with gold, silver, and precious stones, and here he once more raised the head of the Ziggurrat or tower called T'emin-sami-irtsiti, the foundation of heaven and earth. The sanctuary of Bel he roofed with cedar brought from the mountains of Lebanon, and overlaid with gold; the temples of Birbir and Ziru, dedicated to Bel and Rubat, the temple of the Sun, the temple of the Moon-god, the temple of $\mathrm{Vul}$, the atmospheric god, the temple of the goddess Gula, the temple of Venus, and other buildings, he constructed and beautified. He formed the celebrated hanging gardens, consisting of arched terraces covered with earth, which was planted with trees and flowering shrubs. He rebuilt the great walls of Babylon; on the other side of the Euphrates he rebuilt the temple of Nebo, and some smaller shrines. Here was a celebrated ruined temple in the form of a truncated pyramid or ziggurrat, 70 feet $(42$ cubits) high, and this Nebuchadnezzar rebuilt in the form of a temple of seven stages, each stage being dedicated to one of the planetary bodies. He rebuilt the principal temples at all the cities of Babylonia, but in Babylon he lavished his wealth, and the richer classes followed his exanıle, and the noblest youths from conquered provinces served in the presence of the king and courtiers. According to the writings of Daniel, during the latter part of his reign the king became insane. $\mathrm{He}$ died B.c. 562, and was succeeded by his son Amil-Maruduk, the Evil Merodach of the Hebrew Scriptures. The name Nebuchadnezzar is written in many ways in the Bisutun inscription, - we have Nabokliodrossor, Nabukhadrachar, and Nabukhudrachar. In pure Babylonian inscriptions it undergoes even more numerous changes. In Daniel he is called Nebuchadnezzar or Nabuchodonosor, in Ezekiel (xxvi. 7) the name is written Nebuchadrezzar. The first component of the word, Nebo, was the name of a Babylonian divinity (Isaiah xlvi. 1). The Muhammadans call him Bakht-un-Nasr.Smith's Babylonia; Layard's Nineveh, ii. p. 177 ; Bunsen. See Babylon.

NECHO II., a king of Egypt who reigned about 600 years B.c. He was desirous of joining the Red Sea with the Nile. He is also said by Herodotus to have sent a fleet of triremes under Phœenicians from the Red Sea, round the Cape of Good Hope, to the Mediterranean, a voyage which they accomplished in two years. Necho (like his predecessor Rameses Sesostris) and his successors Darius (son of Hystaspes) and Ptolemy Philadelphus, had in view the diversion of the Red Sea trade exclusively to Egypt, and for that account the canal which they endeavoured to construct was cut, not from the Mediterranean, but from the Nile, between Memphis and the Red Sea.

\section{NECKLACE.}

Collier, . . . Fr. Monile, . . . . IT. Nalsband, : : GER. Collar, : : : SP. Kanthi, Mala, : Hind.

Necklaces of precious stones, of the precious metals, of shells, seeds, etc., are worn by all races of British India, by men and women amongst Hindus, by women amongst Muhammadans. A string of beads, usually of the quartzose minerals, is worn by Muhammadan takirs; also head-necklaces of seeds by the heads of Hindu religious establishments, as a mark of dignity; and wood and seed necklaces by Hindu mendicants and ascetics.

NEDDIAVATTAM, a hamlet on the Neilgherry Hills, at 5800 feet elevation.

NEEDLES.

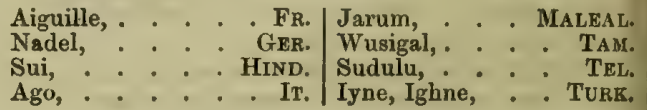

The ancient Egyptians were skilled in needlework. Joseph's dyed coat of many colours is, 
however, the first mention (B.C. 1705) of this art amongst the Hebrews, and the only elaborate description of needle-work in the Bible is of that made by the Hebrew women to decorate the tabernacle and the priests' dresses. At the period of the building of the tabernacle, the priests' ephods were to be made of 'gold, of blue, and of purple, of scarlet, and fine twined linen, with cunning work.' 'And beneath upon the hem of it, thou shalt make pomegranates of blue, and of purple, and of scarlet, round about the hem thereof; and bells of gold between them round about. . ... And thou sbalt embroider the coit of fine linen, and thou shalt make the mitre of fine linen, and thou shalt make the girdle of needle-work. And for Aaron's sons thou shalt make coats, and thou shalt make for them girdles, and bonnets shalt thou make for them, for glory and for beauty' (Exodus xxviii. $33,39,40)$. "Moreover, thou shalt make the tabernacle with ten curtains of fine twined linen, and blue, and purple, and scarlet: with cherubim of cunning work shalt thou make them ' (Exodus xxvi. 1). This curtain is elsewhere more particularly described as being of linen entirely, on which the most skilful of the Hebrew ladies - embroidered cherubims with scarlet, purple, light blue, and gold thread, which was solid bullion, beaten out so fine that it could be even woven. The women had devoted their bracelets and other gold ornaments to the purpose, and every one who had cloth of the beautiful dyes named also made an offering of it. Besides this, 'all the women that were wise hearted did spin with their hands, and brought that which they had spun, both of blue, and of purple, and of scarlet, and of fine linen. And all the women whose hearts stirred them up in wisdom spun goat's hair.' The linen embroidered made the inner covering of the temple. The spun goat's hair was the second covering, and above were skins, such as the Arabs still use for their tents. Embroidered work was executed in India, and exported from it in very remote ages, and the use of needles is very frequently referred to.-Leisure Hour. See Embroidery.

NEGAPATAM, a seaport town on the Coromandel coast, in lat. $10^{\circ} 4 \tilde{o}^{\prime} 30^{\prime \prime} \mathrm{N}$., long. $79^{\circ} 53^{\prime} 30^{\prime \prime}$ $\mathrm{E}$., in the Tanjore district. The town has a considerable coasting trade; is near one of the mouths of the Cauvery. It was taken from the Portuguese by the Dutch in 1660 , and became the headquarters of the Dutch trade on the Coromandel coast. It was taken by the British in 1781. It has an ancient brick tower 70 feet high, supposed of Buddhist or Jaina origin; it is called Gangondram. 20 per cent. of the population consist of Labbai Nuhammadans. Negapatam is the terminus of the Great S. of India Railway. It has a Jesuit college, a Wesleyan mission establishment, and two large Hindu temples.Cal. Rev.

NEGRAIS, an island, a river, and a cape of this name. The cape is in lat. $16^{\circ} 2^{\prime} 30^{\prime \prime} \mathrm{N}$., long. $94^{\circ} 13^{\prime} \mathrm{E}$.; is the south-west land of the coast of Ava. A river of the same name is navigable inland by a channel on each side of the island.

NEGRITO, a short-statured race of Negroes in several islands of the Eastern Archipelago.

NEGRO RACES. The existence of a Negro race in the Indian Archipelago seems to have been known to Ptolemy the geographer, who flourished soon after the commencement of the Christian era. In the last map of his volume, that which contains the Aurea Chersonesus and the Jabados Insulæ, supposed to have meant respectively the Malayan Peninsula and Sumatra and Java Islands, he places a country far to the eastward of the Aurea Chersonesus, under the equinoctial line, which he states to be occupied by AEthiopes Icthyophagi. The country alluded to was apparently New Guinea, and Ethiopes was the appellation by the Romans for the black, woolly-haired Africans, to distinguish them from Mauritani and other races on the coast.

Ethnologists are of opinion that Africa has had an important influence in the colonization of Southern Asia, of India, and of the Eastern Islands, in times prior to authentic history or traditions. The marked African features of some of the people in the extreme south of the Peninsula of India, the Negro and Negrito races of the Andamans and Great Nicobar, the Semang, Bila, and Jakun of the Maliy Peninsula, and the Negrito and Negro, Papuan and Malagasi races of the islands of the Indian Archipelago, Australia, and Polynesia, indicate the extent which characterizes their colonization.

A Negro race occupies the hills in the Dandilli district of N. Canara. Their origin has not been traced; but since the Muhammmadans of Arab, Afghan, Moghul, and Turk origin have been invading India, almost all the dynasties have retained large bodies of Africans, either of the large-lipped, curly-haired Negro type, or of the softer-featured Abyssinian, and one ruling family of Abyssinians was the Habshi or Sidi of Janjirah near Bombay. The Negro sailors of the Sidi continued up to the 18th century the most ruthless pirates on the west coast of India. The Adal Shahi and Nizam Shah Bhairi dynasties, who ruled in Bijapur and Ahmadnaggur in the 15th and 16th centuries, had considerable bodies of Negro soldiers as their household troops. The Talpur Amirs of Sind had, till the latest hour of their rule, bodies of African Negroes around them; the nawabs of the Carnatic had a small body of the Negro race as their housebold slaves. The Negro race are numerous in Las and Mekran, and they still form part both of the regular and irregular troops of the nizam of the Dekhan.

Mr. Logan thinks that Southern Asia has always been occupied as at present with several races, tribes, and languages, and that S.W. Asia and Asianesia have been contemporaneously occupied by-1. Archaic Indo-Australian; 2. Papuan; 3. Tibeto-Chinese or Ultra-Indian; 4. Dravidian; 5. Scythic; 6. Iranian; 7. Semitic races; and the spiral-haired Negro race seems to have preceded the lank-haired brown race. But, according to Mr. Logan, the oldest races of India, Ultra-India, and Asianesia were of a variable African type, the two principal forms being Australo-Tamilian or quasi-Semitic and Negrito, followed in Asianesia by the Malagasi. He is of opinion that the present prevalent Ultra-Indian races entered the region from the north-east, and at a very remote period spread, on the one side, over Ultra-India and the basins of the Brahmaputra and Ganges, and partly into Southern India; and, on the other, were diffused by a long succession of movements all over Asianesia. Throughout these 
regions they came in contact with more ancient races, and have in some places variously blended with them, and in some dislodged or exterminated them, while in others the old tribes have been able to maintain a certain degree of independence and purity. In Southern India, the ancient element was preserved in some degree, owing apparently to a civilisation early received from partially allied Semitico-African and Semitic nations. In the Andamans, the interior of the Great Nicobar, the jungles of the Malay Peninsula, in Australia, and in the various Papuan and partially Papuan islauds, the African element has been maintained from the comparative isolation of the tribes. In the Gangetic province, as in the greater portion of Ultra-India, including the Malay Peninsula, the intrusive race appears to have been recruited by the entrance of new tribes from the north-east, and to have ultimately assimilated the native race, although the influence of the latter is still slightly perceptible. He remarks that when we consider the position of India, between the two great Negro provinces, that on the west being still mainly Negro, even in most of its improved races, and that on the east preserving the ancient Negro basis in points so near India as the Andamans and Kedah, it becomes highly probable that the African element in the population of the Peninsula has been transmitted from an archaic period before the Semitic, Turanian, and Iranian races entered India, and when the Indian Oceau had Negro tribes along its northern as well as its eastern and western shores. The basis of the present population of the Dekhan, he says, was of an African character, which was partially improved by Turanians or Irano-Turanians and Semitico-Turanians from the N.W., and afterwards by more advanced ancient N.E. African and Semitic settlers. Perhaps all the original population of Southern Arabia, and even of the Semitic lands generally, was once African; and the Semitic race had descended on them from a tribe located in the mountains at the head of the Euphrates.

From the time when the adjacent shores of the Indian Ocean began to be the seats of general commercial and maritime nations, the Peninsula must have been exposed to the regular influx of foreign traders and adventurers. From the antiquity of the Egyptian civilisation, it is probable that the earliest commercial visitors were Africans from Eastern Africa or Southern Arabia. It is certain that the subsequent Semitic navigators of Arabia at an early date established that intercourse with India which they have maintained to the present day. The trade between India and the west appears to have been entirely in their hands for about 3000 years. During that period, the Arab navigators not only remained for some months in the Indian ports between the outward and home voyages, but many settled in them as merchants: and, under the name of Moormen in Ceylon, and as Moplah and Labbai in the Peninsula, their descendants are active, thriving members of the communities.

Mr. Logan thinks that the influence of African and Arabic blood must have preceded that of the Aryan in the southern part of the Peninsula. In after ages, the Aryan ingredient in the Peninsular population became considerable, but it has not modified the native races in the sanie degree as it has done the Bengali. The languages are still essentially distinct, and the non-Aryan physical element remains strong. In Southern India are languages of one formation, which is broadly distinguished from the Aryan or Sanskrit on the one side, and from Tibetan and Ultra-Indian on the other. Physically, the population of Southern India is one of the most variable and mixed which any ancient archaic province displays, the number of varieties amongst the people being too great to allow of their being referred to a single race of pure blood. Some are exceedingly Iranian, more are Semitico-Iranian, some are Semitic, others Australian; some remind us of Egyptians, while others again have Malayo-Polynesian and even Semang and Papuan features. The strong Africanism of some of the lower South Indian castes is believed to be the remnant of an archaic formation of a more decided African character. In certain of the classes of Southern India in which the complexion is fairer, an Egyptian style of features is not unfrequently observable. In this, the nose is not indented at the root. It is long and slightly curved; the eyes almond-shaped and slightly oblique, and the chin is short. In general, the physiognomy is more the Iranian than the East African and Egyptian. Where the Aryan or Semitic crossing is not striking, the person is generally rather small and slender, the legs in particular being very thin, compared with those of the Gangetic race. The colour varies from black to different degrees of brown and yellowish-brown, in general contrasting strongly with the Ultra-Indian and Indonesian races. There is a tendency to certain peculiar physical traits, neither Ultra-Indian, Tibetan, nor Aryan, but seem to be East African. The typical East African head is removed both from the exaggerated prognathous form, prevalent amongst the Guinea Negroes, and the highly Semitic form characteristic of tribes that have been deeply crossed by Arab blood, and is in some respects intermediate between the Iranian and Turanian, while it has specialities of its own. The cheek-bones are often much more prominent than in the Iranian, and less so than in the typical Turanian, the projection being frequently anterior more than lateral. The lips are full or turgid, and turned out, frequently with sharp edges. Slightly prognathous heads are not infrequent. In the South Indian population as a whole, the bridge of the nose is generally less prominent than in the Iranian, and much more so than in the Turanian. Even where the root of the nose, between the eyes, sinks in, the upper line as a whole is much more thrown out from the face than in the Turanian head, so as to render the point comparatively sharp and prominent. The alæ have an upward expansion, leaving the upper part of the septum exposed, and the elongated nares open and conspicuous. This is a Semitico-African trait. The AfricoPapuan pyramidal nose, with a deep and sharp sinking in at the root, is common, particularly in some of the lower castes, in which the colour is nearly black. Mr. Logan thinks it probable that at one period this lower and apparently the more normal southern type characterized the whole population of India. Even yet amongst the Vindhyans, some tribes are found who seem to approximate to it, such as the little ill-favoured 
Tamariah, the neighbours of the Ho, and the short and jet black Saura, who are spread for 200 miles from the hilly southern side of the basin of the Ganges along the eastern face of the ghats to the Godavery, who are much in person, in civilisation, akin to the Gangetic population. The Chensuar, who occupy the western portions of the continuation of the ghats between the Penuar and the Kistna, are described by Captain Newbold as being between a Teling and Jakun of the Malay Peninsula, and the Jakun of the Malay Peninsula is the most African and prognathous of the lankhaired Indianesian tribes. The Chensuar live in beehive-shaped huts like the African, Nicobarian, and unany of the ruder Asianesian tribes.

The sequestered tribes of Southern India in some cases approximate to the more TuranianAfrican type, in which the wose is flatter, the beard scanty, and the person shorter. There is so considerable a difference between this type and the more Semitic, that, whatever may be the original relationship of the two, it is necessary to recognise both as cxisting in India at the earliest era which ethnology can descry. A similar phenomenon presents itself on the western side of the Indian Ocean, and, what is still more important witb reference to India, it is found also in the Negro population of the eastern side. Many of the East African tribes are very short and sleuder, small-eyed, flat-faced, and beardless, while others are middle-sized and even tall and robust, with the Semitico-African beards, aquiline or pyramidal noses, raised nares, and large eyes of the other archaic types of Southern India. Both types preserve a black complexion, alike in Africa, India, the Audamans, the Malay Peninsula, the Malayo-Polynesian Islands, and Australia, although modifications of colour also occur throughout this area. Mr. Logan thinks that little weight is to be attached to the present absence of spiral hair in S. India, for some of the spiral-haired Papuan tribes of New Guinea and Torres Straits are often more Africo-Semitic and S. Indian in their physiognomy, than the Australians, while the latter have the fine hair of S. Indians and some MidAfrican nations, and a linguistic formation which resembles the $\mathrm{S}$. Indian more than any in the world.

In Further India, in the extreme S.E. of Asia, are two marked types of the human family. These are the lank-haired Malay and brown races, and the curly-haired races to whom the terms Negro, Negrito, Papuan, Alfura, etc., have been applied. The Ultra-Indian races in their fundamental characters, physical and mental, and in all their social and national developments, from the lowest or most barbarous stage in which any of their tribes now exist, to the highest civilisation which they have attained in Burma, Pegu, Siam, and Cambodia, are intimately connected with the predominant Oceanic races. The tribes of the Nita Polynesian family, who appear to have preceded those of the Malayan, resemble the finer type of the Mon, Burman, and the allied Indian and Himalayan tribes. The Malayan family, according to Mr. Logan, approximates closely to the ruder or more purely Mongolian type of Ultra-India, and the identity in person and character is accompanied by a close agreement in habits, customs, institutions, and arts, so as to place beyond doubt that the lank-baired populations of the islands have been received from the Gangetic and Ultra-Indian races. The influx of this population closed the long era of Papuan predominance, and gave rise to the new or modified forms of language which now prevail.

The opinions of other eminent writers merit notice. In the Archipelago, there seemed to Mr. Crawfurd to be four races of man, the Malays proper, the Semang or dwarf Negro of the Malay Peninsula, the Negrito or Aeta of the Philippines, the larger Negro race or Papua of New Guinea, and a race whom Crawfurd styles the Negro-Malay, intermediate between the Papuan and Malay.

Both Mr. Earl and Mr. Alfred Wallace have shown that the Archipelago is divisible into an Asiatic and an Australian portion, that the flora and fama differ, and that all the peoples of the various islands can be grouped either with the Malay or the Papuan, two radically distinct races, who differ in every physical, mental, and moral character; and Mr. Wallace states his belief that under these two forms, as types, the whole of the peoples of the Malay Archipelago and Polynesia can be classed. He considers that a line can be drawn which shall so divide the islands as to indicate the one-half which truly belongs to Asia, while the other no less certainly is allied to Australia; and he designates these respectively the Indo-Malayan and the AustroMalayan divisions. Mr. Wallace gives to Mr. Earl the credit of having been the first to indicate the division of the Archipelago into an Australian and Asiatic region. All the wide expanse of sea which divides Java, Sumatra, and Borneo from each other, and from Malacca and Siam, rarely exceeds 40 fathoms in depth, and the seas north to the Philippine Islands and Bali, east of Java, are not 100 fathoms deep; and he is of opinion that these islands have been separated from the continent and from each other by subsidence of the intervening tracts of land. In the IndoMalayan Islands of Sumatra and Borneo are the elephant and tapir; and the rhinoceros of Sumatra and the allied species of Java, the wild cattle of Borneo, and the species long supposed to be peculiar to Java, all inhabit some part or other of Southern Asia. Of the birds and insects, every family, and almost every genus, of the groups found in any of the islands, occur also on the Asiatic continent, and in a great number of cases the species are exactly identical. The resemblance in the natural productions of Java, Sumatra, and Borneo with those of the adjacent parts of the continent, lead to the conclusion that at a very recent geological epoch the continent of Asia extended far beyond its present limits in a southeasterly direction, including the islands of Java, Sumatra, and Borneo, and probably reaching as far as the present 100 fathom line of soundings. The Philippine Islands agree in some respect with Asia and the other islands, but present some anomalies which seem to indicate that they were separated at an earlier period, and have since been subject to many revolutions in their physical geography.

On the other hand, all the islands from Celebes and Lombok eastward exhibit almost as close a resemblance to Australia and New Guinea as the western islands do to Asia. Australia in its natural productions differs from Asia more than any of the four ancient quarters of the world differ 
from each other, and all its striking peculiarities are found also in those islands which form the Austro-Malayan division of the Archipelago. The contrast between the Asiatic or Indo-Malayan forms and those of the Austro-Malayan is abruptly exhibited in passing from the island of Bola to that of Lombok, though the strait is only 15 miles wide; and in travelling from Java or Borneo to Celebes or the Moluccas the difference is still more striking, leaving the only inference that the whole of the islands eastwards beyond Java and Borneo do essentially form a part of a former Australian or Pacific continent, although it may never have actually been joined to it, and it may have been broken up before the western islands were separated from Asia, and probably before the extreme south-eastern part of Asia was raised above the waters of the ocean.

The numbers of Negroes in Africa are vaguely estimated at 20 millions, including the Hottentot and Kafir offshoots from the great family. The race on the American continent are now fewer than the whites. But they are prolific; and Professor Gilliam estimates that by the year 1984 the black population of the Southern States will be 192 millions, while the white will be only 96 millions. Their numbers on the Asiatic continent, on the shores of the Red Sea and Persian Gulf, and in the Malay Peninsula, may not exceed half a million; but from the Andaman Islands eastwards to the races in the Pacific, of the people generally classed as Negroes there are at least 12 varieties, differing from each other in physical appearance, some being pigmies under five feet, and others large and powerful men of near six feet. Some of these will now be noticed.

The Mincopi Negroes of the Andamans are in the very lowest and most abject state of human society, without fixed dwellings, unclad, and unacquainted with the meanest of the useful arts of life. In disposition they are unsocial and mischievous. They seem to have been isolated for an unknown period; and when the British last settled on their islands, in 1858 , they were found in the lowest condition to which human beings can fall. They are not cannibals, as was long supposed, but live on pork, fish, grains, roots, cocoanut, and other fruits, and broil the flesh of their animals before eating it. They may be called hunters and fishermen, hunting game in their own wilds and jungles, using the bow and arrow, with which they are expert, and employ the bark of a tree for fishing-lines. They have no clothing, but go entirely naked, and seem unconscious of that feeling of shame which guides the other races in the world to cover their persons. They construct huts, but of the rudest character. They were intensely averse to the intrusion of strangers. They are small in stature, seldom rising in height over five feet. The head is small, and depressions exist in the temporal region. The teeth are nearly white, but often so irregular as to seem in double rows. They are muscular. Their bodies are scarified all over with broken glass, which gives the skin a bead-like appearance, the lines running longitudinally down the arms and bust. When pleased with anything to which their attention is drawn, they gently bite with their teeth the lower edge of the palm of the right hand, and then smartly strike the left shoulder. They also contract the lips as in kissing, and make a hissing noise like that of grooms in cleaning horses. When they speak to one another their pronunciation is so indistinct as to resemble a chatter, but they are sharp in catching words and sounds. In dancing, they hop on one foot, beating it down smartly in regular time, keeping both hands raised above the head. They change feet, keeping cadence with the song, work the head, bow the body, and thus spring and jump till the dance is closed.

Semang, Bila. - Further eastward, in the nortbern portion of the Malay Peninsula, within the Kedah, Perak, Pahang, and Tringanu territories, is a Negro race known to the Malays under the names of Semang and Bila. Their complexion is black or sooty, the hair woolly, the features approaching to the African, and the stature dwarfish. An adult Semang male, of the mean height of this people, was found to be only four feet nine inches high. Some of the Semang or Bila have fixed habitations, and practise a rude agriculture, but the majority lead an erratic life, gathering the rude products of the forest to exchange with the Malays for the necessaries of life, or substituting those of the chase.

The average height of the adults of a party of Semang Bukit on the Ijan, a feeder of the Krian, was four feet eight inches, the highest four feet ten inches. Head small, ridged, that is, rising above the forehead in an obtuse wedge shape, the back rounded and markedly narrower than the zygomatic or middle zone; the face generally narrower and smaller than the Malay; eyebrows very prominent, standing out from the forehead and projecting over the ocular furrow which extends across the face, the root of the nose sinking into it and forming a deep angle with the base of the superciliary ridge. The nose short and somewhat sharp at the point, and often turned up, but the alæ spreading; eyes fine, middle-sized, and straight; iris large, piercing ; conjunctiva membrane yellow; the upper eyelashes, owing to the deep ocular depression or prominent ridges, are compressed or folded, the roots of the hair being hidden. The cheek-bones generally broad, but in some cases not remarkably prominent, save with reference to the narrow forehead. Mouth large or wide, but lips not thick or projecting; the lower part of the face oval or round, but not square. The deep depression at the eyes, and sinking in at the root of the nose, give a very remarkable character to the head, compared with the Malay. The projecting brow is in a vertical line with the nose, mouth, and chin, and the upper jaw is not projecting or prognathous. The person is slender, the belly protuberant, owing to their animal life in the jungle and precarious food. This induces them to cram themselves whenever they can, and the skin of the abdomen thus becomes flaccid and expansible like that of an ape. The skin generally is fine and soft, although of ten disfigured by seurf, and the colour is a dark brown, but in some cases lighter and approaching to the Malay. The more exposed hordes are black. The Semang of Tringanu are not of such a jet black glossy colour as the Kedah tribe. The hair is spiral, not woully, and grows thickly on the head in tufts. They have thick moustaches, the growth being much stronger than in the Malay race. The lead is neither Mongolian nor Negro of the Guinea type; it is Papua-Tamulian. The expression of the face is mild, simple, and stupid. 
The voice is soft, low, nasal, and hollow or cerebral. A line of tattooing extends from the forehead to the cheek-bones. The right ear is pierced, the orifice being large. The hair is cropped, save a ring or fringe round the forehead.

Semangs are found in all the rivers of Perak, and are classed as the Semang Paya, who frequent the low and marshy alluvium between the sea and the hill, the Semang Bukit, who wander in the forests of the bills, and the Saki, who are confined to the mountains of the interior. There are said to be numbers of Semangs in the interior of Patani, T'ringanu, Kedah, and Perak, wherever the country is covered with forest, and there are few or no Malays. Semang tribes of Kedah and Perak have a language mainly dissyllabic like other Asianesian ones. The people of Kedah more often approximate to the eastern Negro type than in Southern Malaya, and Mr. Logan was particularly struck with the repeated occurrence of the deep nasal depression of the Semangs, the Australians, and Papuans. Small heads, with all the features as it were contracted or compressed, were common.

The Papuan race are to be found in the islands of Floris, Sumba or Handana, Adenara, Solor, Lombata, Rutar, Ombay, Wetter, Rotte, Servatty, Babbar, Timor, Timor Laut, Larat, Tenember, part of Bourou, part of Ternate, the Ki Islands, Ceram, Ceram Laut, Banda, Amboyna, Batchian, Oby, Gilolo, Morty, Aru, Vorkai, New Guinea, Myfore, Johi, Mysol, Waigiou, Salwatty, Ansus, Bo, Geby, Goram, Hoek, Luçon, Mindanao, Mindoro, Moluccas, Mysol, Negros, New Guinea, Patani, Poppo, Sumba Islands, New Caledonia, New Ireland, Otaheite, Polynesia, and Fiji. Tana Papua, or land of the Papua, is a term applied by the Malays not only to New Guinea, but to all the adjacent islands which are occupied by the frizzly-haired race.

The Malayan term for crisped or woolly hair is rambut pua-pua. Hence the term pua-pua, or papua (crisped), has come to be applied to the entire race, and expresses their most striking peculiarity.

The features of the Papuans have a decided Negro character: broad nose, thick and prominent lips, receding forehead and chin, and that turbid colour of what should be the white of the eye, which is apt to give the countenance a sinister expression. Their natural complexion is almost universally a chocolate colour, sometimes closely approaching to black, but certainly some shades lighter than the deep black which is often met with among the Negro tribes of Africa. The Papuans, when placed in circumstances favourable for the development of their powers, are physically superior to other races of South-Eastern Asia. Some of the New Guinea tribes would bear a comparison, in point of stature and proportions, with the races of Europe, were it not for a deficiency about the lower extremities. Even the more diminutive mountain tribes are remarkable for energy and agility, qualities which had led to their being in great demand as slaves anong their more civilised neighbours. With regard to mental capacity, also, they are certainly not inferior to the brown races; but their impatience of control while in an independent state, utterly precludes that organization which would enable them to stand their ground against encroachment, and they inrariably fall under the influence of the
Malayans whenever the two races are brought into contact.

Within the geographical limits of the Indian Archipelago, the Papuans only appear, as inhabitants of the sea-coast, in New Guinea and the islands immediately adjacent. In other parts of this region they are found only among the mountain fastnesses, maintaining an unequal struggle with the brown races by whom they are surrounded. In some of the Spice Islands, the group nearest to New Guinea, their extirpation is matter of history, as observed by Mr. Crawfurd (History of the Indian Archipelago, i. p. 18). In Ceram and Gilolo a few scattered remnants of the race still exist; but they hold little or no intercourse with their more civilised neighbours, flying into the thickets, which afford them shelter and concealment, on the first appearance of a stranger, experience having taught them that death or captivity will be their fate if they fall into the hands of their natural enemies. The characteristics of the mountain Papuans must therefore be sought in those islands where their numerical strength permits them to lead a life more fitted for buman beings than that of their hunted brethren. It is an error to suppose that these poor creatures disappear before civilisation. Their chief destroyers are the wild and warlike liunting tribes of the brown race; and, excepting the case of the Moluccas, wherever European civilisation has been introduced, the Papuans are more numerous than elsewhere. In the Philippines, for example, according to an intelligent modern traveller, their number in the year 1842 amounted to 25,000 souls (M. Mallat, Les Philippines, etc., i. p. 97, Paris 1846). The large island of Mysol, or Mræsual, which lies nearly midway between the north-western extreme of New Guinea and Ceram, is said to have been occupied exclusively by Papuans when this region was first visited by Europeans, and they still form the bulk of the inland population, but the villages of the coast are occupied by a mixed race, in which, however, the Papuan element prevails. The islands of Goram, Ceram Laut, Bo, Poppo, Geby, Patani, Hoek, and the south-eastern extremity of Gilolo, are also occupied by people of the mixed race, who are remarkable for their maritime activity, and for their friendly disposition towards European strangers. The woolly-haired tribes are more numerous in the Philippines than in any other group of the Indian Archipelago, with the exception of New Guinea. The island on which they were first seen was named by Magellan, Isla dos Negros, to distinguish it from the adjacent island Zebu, where his ships remained for some months. Negros Island still contains a large population of Papuans, while Zebu is altogether free from them, and no record exists of their having ever been found there. Samar and Leyte are similarly situated with Zebu.

Mr. Wallace (ii.p. 280) believes that the numerous intermediate forms which occur among the countless islands of the Pacific are not merely the result of an intermixture of these races, but are to some extent truly intermediate or transitional, and that the brown and the black, the Papuan, the natives of Gilolo and Ceram, the Fijian, the native iuhabitants of the Sandwich Islands, and those of New Zealand, are all varying forms of one great Oceanic or Polynesian race. Professor Huxley, 
however, is of opinion that the Papuans are more nearly allied to the Negroes of Africa than to any other race. The whole of the great island of New Guinea, the $\mathrm{Ki}$ and Aru Islands, with Mysol; Salwatty, and Waigiou, are inhabited almost exclusively by the typical Papuan, and the same Papuan race extends over the islands east of New Guinca as far as the Fiji Islands. The people on the coast of New Guinea are in some places mixed with the browner races of the Moluccas. In the typical Papuan, the colour of the body somewhat varies; generally it is a deep sooty-brown or black, somewhat approaching, but never quite equalling, the jet black of some Negro races, but it is occasionally a dusky brown. The hair is harsh, dry, and frizzly, growing in little tufts or curls, which in youth are very short and compact, but afterwards grow out to a considerable length, forming the compact frizzled mop which is the Papuan's pride and glory. The face has a beard of the same frizzly hair, and the arms, legs, and breast are also more or less clothed with hair of a similar kind. In stature, the Papuan is superior to the Malay, and the equal or superior of the average European. The legs are long and thin, and the hands and feet larger than those of the Malay. The face is somewhat elongated; the forehead flattish, the brows very prominent; the nose is large, rather arched and high, the base thick, the nostrils broad, and the aperture hidden, owing to the tip of the nose being clongated; the mouth is large, the lips thick and protuberant. He is impulsive and demonstrative in speech and action; his emotions and passions express themselves in shouts and laughter, in yells and frantic leapings; women and children take their share in every discussion. The Papuan has much vital energy. In the Moluccas, Papuan slaves were often promoted to places of considerable trust. He decorates his canoe, his house, his domestic utensils, with elaborate carving. They are often violent and cruel towards their children. The Dutch, since the early years of the 19th century, have formed settlements on New Guinea, and on the 6th November 1884, Great Britain proclaimed its protection east of long. $141^{\circ}$. If the tide of Europeon civilisation turn towards New Guinea, the Papuan, like the true Polynesian of the farthest isles of the Pacific, will no doubt become extinct. A warlike and energetic people, who will not submit to national dependence or to domestic servitude, must disappear before the white man. A race identical in all its chief features with the Papuan, is found in all the islands as far east as the Fiji.

Mysol and Waigiou are Papuan, mixed, partly from Gilolo, partly from New Guinea.

The larger Papuans are more remarkable for their strength than for their symmetry. They have broad shoulders and deep chests, but a deficiency is generally found about their lower extremities, the splay feet and curved shins of Western Africa being equally or even more common among those whom Mr. Earl calls the gigantic Papuans. The independent Papuans are invariably treacherous and revengeful. The tribes on the N.E. coast of New Guinea, for instance, are never to be depended on. 'They retain an unextinguishable hatred towards all who attempt to settle in their territory, and this is probably the cause of their being found in the interior of islauds where mountains exist, and their utter externination in all the islands where there are no fastnesses to which they could retire.

Papuans never tattoo their skins, but they raise the skin over the shoulders, breast, thighs, and buttocks into cicatrices, of ten as large as the finger.

A Negro race occurs in the island of Flores, and in the great island of New Guinea they form the whole native or aboriginal population, as they also do of the islets near its coasts. In New Guinea the many Papuan tribes are generally in a state of warfare with each other, and return from their warlike expeditions with heads. The New Guinea people worship a wooden deity called Karwar, 18 inches high, whom they consult on all occasions. A widow remains in the family of her deceased husband. The Negroes of New Guinea are in various states of civilisation. Some of the rudest dwell in miserable huts, and scek a bare subsistence by the chase, or the spontaneous productions of the forest. There are, however, other Negro tribes living on the coast who have made some advance in civilisation. These dwell by whole tribes in huge barn-like houses raised on posts, like those of the wild inhabitants of Borneo, but ruder.

In Dori the Papuans are called Myfore. They are about 5 feet 3 inches high, few attain 5 feet 6 inches. They wear their crisped hair its full length, and generally uncared for, which gives them a wild, scared appearance. The men, not the women, wear a comb. The beard is crisp. The forehead is high and narrow; eyes large, dark brown or black; nose flat and broad; mouth large, lips thick, and teeth good; few have regular features, and most are apathetic. The ordinary men wear a waist-cloth made of the bark of a tree, called mar, which is wrapped round the waist, and passed between the legs. Women wear a short sarong to the knee, generally of blue cloth. Men and women tattoo their bodies on occasions, by pricking the skin with a fish-bone, and rubbing in lamp-black. The Dori people are a seafaring people, and are expert swimmers and divers. Their prahus have outriggers, and are excavated from the trunk of a single tree. Their food consists of millet, obi, maize, a little rice, fish and hog's flesh, and fruits. Sago is imported in small quantities. Theft is considered a grave offeuce. They are chaste, and marry one wife.

The Aru Islands extend 100 miles from north to south. Inland are many fresh-water swamps, with thick, impenetrable jungle in other places. Their produce is pearls, mother-of-pearl, tortoiseshell, birds of paradise, and trepang. The timber of the islands is much praised. Aru islanders have much intercourse with strangers. They are fond of arrack, and purchase from the Bugis the Papuan slaves brought from New Guinea, who are then employed in diving for pearls and in the beche-de-mer fishery. The Aru islanders are impoverished by their excessive use of intoxicating liquors, imported from Java and Macassar. In personal appearance the people are between the Malayan and Polynesian Negro. They are not many degrees further advanced in civilisation than the natives of the north coast of Australia, to whom many of them bear considerable personal resemblance. In stature they surpass the civilised 
natives of Celebes. The dress of the men is a piece of matting or cloth gircled round the loivs, and drawn tight between the thighs, and a salendan' or shawl. No fillet is worn round the head. The hair is woolly, and frizzled out like that of the Papua. The men are of a jealous disposition, and easily roused to anger by abuse of their women or ancestors; otherwise they are mild of disposition. The women wear a mat in front and one behind. Some are Muhammadans. Christianity was introduced many years ago by the Dutch of Amboyna, and nearly all the principal people profess this creed. The Aru Papuan ormament their houses with brazen trays, dulam or talam, and elephants teeth, which are broken up when the owner dies.

The Kei group of ten islands adjoin the Aru Islands. Ke, Kei, or $\mathrm{Ki}$ is prefixed to the names of all their villages. The Great Kei is about the size of Tanakeka, an island near Macassar. The men profess Muhammadanism, but eat hog's flesh. The Papuan women of $\mathrm{Ki}$ are not secluded; the children are merry, noisy, and have the nigger grin, and amongst the men is a noisy confusion of tongues and excitement on every occasion. The Ki group form the northern of the south-easterly islands. The islands are covered with luxuriant forests. Maratigo and Banyaro woods are well adapted for masts. The islands are occupied by two races, one of them the Papuau, who malse cocoanut oil, build boats, and make wooden bowls. Their boats are from small planked canoes to prahus of 20 to 30 tons burden. They build the skin first, and fit on the knees and bends and ribs. Money is not used, but every trausaction is in kind. The Papuan wear a waistcloth of cotton or bark. The other race are Muhammadans, who were driven out of Banda. They wear cotton clothing. They are probably a brow.1 race, more allied to Malays, but their mixed descendants have great varieties of hair, colour, and features, graduating between the Malay and Papuan tribes.

Ceram is the largest island of the Moluceas. It is 162 miles long, but its greatest breadth is only 42 miles. The island is one long mountain chaiu that sets off transverse spurs, and some of the peaks are 5000 or 6000 feet in height. The people of Ceram approach nearer to the Papuan type than those of Gilolo. They are darker in colour, and a number of them have the frizzly Papuan hair; their features are harsh and prominent, and the women are far less engaging than those of the Malay race. The Papua or Alfuro man of Ceram gathers his frizzly liair into a flat circular knot over the left temple, and places cylinders of wood as thick as one's fingers, and coloured red at the ends, in the lobes of the ears. They are very nearly in a state of nature, and gro almost naked, but armlets and anklets of woven grass or of silver, with necklaces of beads or small fruits, complete their attire. The women have similar ornaments, but wear their hair loose. All are tall, with a dark brown skin, and wellmarked Papuan physiognomy. The Alfuro or Papuan race are the predominant type in the island.

In Celebes, the Trans-Javan or Timorian baud, and the Moluccas, is a large and important class of Indonesians, who graduate between tbe Annam type, the Burman, and the Negrito. The most prevalent head, or that of the predominant, is ovoid, but it is somewhat Burman or Indo-Burman in nose, eye, and colour. Celebes is intersected by the equator, leaving a small portion of it in the northern and the mass in the southern hemisphere. Its greatest length is about 500 miles, but its greatest breadth does not exceed 100 ; and in some places it is hardly one-third of this width. Celebes may be considered to be the focus of an original and independent civilisation, which probably sprang up amongst the most advanced of the nations which occupy it, called by themselves Wugi, and by the Malays, and after them by Europeans, Bugi. In material civilisation the Bugi are equal to the Malays.

Philippines.-The woolly-haired tribes are more numerous in the Philippines than in any other group of the Indian Archipelago. They are smaller, more slightly built, and less dark in colour, than the Negroes of Africa, and have features less marked by the Negro characteristics, but have woolly instead of lank hair. The name bestowed on them by the Spaniards is Negritos, or little Negroes, but that of Ita or Aheta, so pronounced but written Ajeta, seems to be their usual appellation among the planters and villagers of the plains. They are ebony black, well-formed, and sprightly, but rarely exceed $4 \frac{1}{2}$ feet in height.

Of the central group of the Philippines, consisting of Panag, Negros, Samar, Leyte, Masbate, Bohol, and Zebu, the two former are the only islands in which Negrito tribes exist to the present day; and even as regards Panag, the fact must be considered doubtful. Negros Island, however, contains a considerable Negrito population, the crest of the mountain range, which extends throughout the length of the island, a distance of 120 miles, being almost exclusively. occupied by scattered tribes.

Waigiou.-The inhabitants of the islands of Waigiou, lying between New Guinea and Gilolo, one of the Moluccas, are Negroes. M. Du Perry represents them as having more regular features.

Gebbe.-M. Freycinet has described the Negroes of Gebbe, an island also between New Guinea and Gilolo, and not far from the latter. The nose is flat, the lips thick and projecting, the complexion a dark olive, the eyes deep-seated, and on average the facial angle $77^{\circ}$, but as high as $81^{\circ}$. In Gebbe, Waigiou, and some parts also of the coast of New Guinea, the Malayan race may have become intermixed with the Negro, as the complexion is lighter, and the peculiar texture of the Negro hair altered or obliterated.

All the islands extending from New Guinea up to the Fiji group appear to be inhabited by Negroes. But they differ greatly in physical appearance in New Ireland, Malicollo, one of the great Cyclades, Tanna and New Caledonia in the New Hebrides. A Papuan or Timorese is darker, and with more frizzly hair than the Polynesian, New Zealander, or Otaheitan, but their features are aimost identical.

Australian Papuans is a term employed by Peschel (p. 338) to designate the iuhabitants of New Guinea, the Pelew Islands, Tombara (New Irelaud), Birara, the Solomon group, the New Hebrides, New Caledonia, with the adjacent Loyalty Islands, and, lastly, those of the Fiji Archipelago. The distinctive characters of the race are preserved in greatest purity in New Guinea, although even there, especially in the western half, intermixtures with the Asiatic 
Malays have recently taken place. In the other islands mentioned, the Polynesians liave intruded themselves among the older populations, and have materially influenced the language and manners, but their influence upon the physical characters has been much less, so that the inhabitants of the Pelew and Fiji groups, as well as of New Caledonia, may be unhesitatingly reckoned among the Papuan race. In the Carolines and Mariannes or Ladrones, Polynesian and Papuan blood is intermingled, but the former predominates, so that, as hybrids, these so-called Micronesians are more correctly placed in the Polynesian group of Mongoloid races.

Fiji. - The Papuan race improves as it recedes from the continent of Asia and advances into the Pacific. The people of Fiji are the aristocracy of their race, are polite and polished in couversation, and have a strong feeling of national pride. But the Papuans of New Guinea, New Caledonia, and the Fiji Islands were addicted to camnibalism.

The Papuan of Fiji have a tufted matting of the bair like the Koin Koin or Hottentots and the San or Bushman of S. Africa, and the narrow shape of the skull common to both. Also among the Papuan women dwelling on the shores of the Utenata river in New Guinea, there is the same tendency to fatty cushions as the women of the Hottentot and Bushman. The Papuans of New Guinea and the smaller islands are praised for their chastity and morality, for their respect to parents, and their brotherly affection.-Crawfurd's Malay Grammar and Dictionary, and in Jo. Ind. Arch.; Logan in Journ. Ind. Arch., 1848-1850; Newbold in Journ. R. As. Soc, and in Madras Lit. Soc.; Earl's Papuans; Spreewenberg in Journ. Ind. Arch.; Wallace's Archipelago; Peschel.

NEIBUHR, M. CARSTEN. In A.D. 1762, an expedition was organized by king Frederick v. of Denmark, for the exploration of Arabia, but more particularly of the province of Yemen. It was under the charge of the learned M. Carsten Neibuhr, with whom were associated Professor Von Hanen as linguist; Professor Forskal and Dr. Cramer as naturalists; and M. Baurenfeind as draughtsman. They arrived in Yemen in the end of December 1762. Von Hanen died at Mokha on the 25th May 1763, Forskal died at Yereem on the 17th July following, M. Baurenfeind expired at sea, near the island of Socotra, on the 29th August, and Dr. Cramer at Bombay on the 11th February 1764.-Playfair's Aden.

NEILL, GeNeral Sir J A MES, K.C.B., an officer of the Madras Fusiliers, who served in the second Burmese war, and distinguished himself during the mutiny, where he commanded his regiment. $\mathrm{He}$ took possession of the railway to reach and save Benares, and he then advanced to Allahabad. He was the first to stem the rebellion.

NEJD or Najd occupies nearly the centre of, and is the largest province in, Arabia, being in its greatest limits 640 miles from north to south, and 750 miles from east to west. On the east is the long strip of El-Hassa, or Hajar, on the north that part of Arabia Deserta called Tauf, the Hijaz on the west, with a part of Yemen on the south, and the desert of Ahkaf on the south-east. The surface, as the name implies, is elevated, but it is diversified with mountains, valleys, and plains. Some writers consider the mountainous district of
Nejd Arad as a separate province, for Nejd has been defined by various writers in various ways. The Turks, in their offeial documents, include, for political reasons, all the former territories of the Wahabee empire in that name, giving to their new conquest on the seaboard of El-Hassa the title of 'Our Vilayet of Nejd.' The fact is that Nejd is a purely geographical expression, in no sense political, and in Arabia means all the highlying district included within the Nefuds.

The existence of a fresh-water lake at El-Hassa, and of several in Nejd, as ascertained by Captain Sadleir, has established the fidelity of Strabo in this particular. There are others, but of small size, in Arabia Felix, in Tehameh, and in Oman, and one called Salome in Ahkaf. The Anezi, in the time of Burkhardt, were the most powerful Arab nation in the vicinity of Syria, and if their brethren in Nejd be added, they are the most considerable body of Bedouins in the Arabian deserts.-Tr. Bom. Lit. Soc.; Niebuhr's Tr.; Ches.

NELLORE, a town on the right bank of the Pennar river, in lat. $14^{\circ} 26^{\prime} 38^{\prime \prime} \mathrm{N}$., and long. $80^{\circ}$ $1^{\prime} 27^{\prime \prime} \mathrm{E}$, on the eastern side of the Peninsula of India, which gives its name to a revenue district of 8462 square miles, and in $1871,1,376,811$ inbabitants. The name is from the nelli plant, Phyllanthus emblica, and Ur, a town. It is surrounded S.W. by North Arcot, W. and N.W. by Cuddapah, and N. by Guntur. It lies partly in Central Carnatic, and partly in the Northern Carnatic; was acquired by treaty in 1801, and includes Ongole, and part of the Western Pollams or zamindaries, vi\%. Venkatagiri, Choondy, Mootialpad, and Kallistry. The chief towns are Doorgaraz-Patnam, or Armegon, in lat. $13^{\circ} 59^{\prime} \mathrm{N}$., 55 miles north of Madras. It was the site of the first settlement of the $\mathbf{E}$. I. Co. on the Coromandel coast. Its rivers are the Pennar, Suvarnamukhi, and Gundlakama, and a salt-water creek runs several miles inland near Joo-ul-Dinna. Copper ore occurs in the Kallistry zamindari, and one block of $20 \mathrm{cwt}$. yielded 9 cwt. of copper. Red, yellow, purple, brown, and grey sandstones occur in the Podelay, Panoor, and Pedda Reddapully taluks, and at Pullaybootoo, fine-grained sandstones.

The Nellore horned cattle are celebrated, and are largely exported. Bos Indicus is there in a wild state. There are two uncivilised homeless races, the Yenadi and Yerkala, but the bulk of the people are Hindu Sudras, speaking Telugu. The Yenadi race in the Nellore district are estimated to number 20,000 .

NELLY of sailors, or Green Bill, is the Diomedea spadicea.

NELU. SINGH. The honey plant of the Horton plains, Ceylou. The flowers emit a fragrant perfume resembling that of new honey. It flowers once in eight years, and bees then cluster on the blossoms.-Sirr's Ceylon.

NELUMBIUM SPECIOSUM. Willde. The-kyah, . Burm, |Bakla kubti, . Pers. Kamala, Padma, Hind. Pubbun, . PInd. Nilofar, . . PERS. Tamara, : TAM, TEL,

The lotus, sacred, Egyptian, or Pythagorean bean, has two varieties-( $\alpha)$ rubrum, the Raktopadmo of Bengal, with rose-coloured flowers, and $(\beta)$ album, the Shwet-padmo, with white flowers. It grows throughout the East Indies, also in Persia, Tibet, China, North Australia, and Japan. 
The leaves and flowers of the plants spring from beneath the waters, and in Kashmir the broad leaves form a verdant carpet, over which the water-hen runs. In the hot weather, the stalks are very commonly eaten by the poorer classes, and boiled in their curries. The flowers are a favourite offering at the Hindu and Burmese pagodas. The fruit is believer to have been the Egyptian bean of Pythagoras, and the flower that mystic lotus which so often occurs on the monuments of Egypt and India. The stalks are, in Hindi, called Kanwal kukri, Kanwal gatha, and Nalru bheng. The long fine filaments contained within the cells of the stem are drawn out, and the thread spun from the filament is used as the wicks of the lamps in pagodas. The lotus is highly venerated by the Hindus, but it is the more immediate attribute of Vishnu from being the prime of aquatic vegetables, and he a personification of water. It is also peculiarly sacred to Lakshmi, the wife of Vishnu, who is sometimes called Kamala, or lotus-like; it is, moreover, an emblem of female beauty. The new-blown flowers of the rose-coloured lotus have an agreeable fragrance; those of the white and yellow bave less odour. In China, the nelumbium covers extensive marshes in the Eastern and Northern Provinces, otherwise unsightly and barren. The root is two or three feet long, and pierced longitudinally with several holes; when boiled, it is of a yellowish colour and sweetish taste, not unlike turnip. Its boiled roots are eaten in Kashmir as a pot-herb by the natives; in Lahore they are called $\mathrm{Pe}$, in Kashmir Nadru. Taro is there used less than the nelumbium, and so are the watercaltrops and water-chestnuts; the broad leaves are used as dishes to eat from, and the flowers as offerings.

N. cæruleum, Fisch., the blue-flowered sacred bean, grows in Lower Egypt and in Sind. It was held sacred in Egypt. It is a variety of Nelumbium speciosum.-Murray.

NEMI, a name of Krishna; he is called Arishta Nemi, the black Nemi, from his complexion. Krishna worshipped his great ancestor Budha, and his temple at Dwaraka rose over the ancient shrine of the latter, which yet stands. In an inscription from the cave of Gaya, their characters are conjoined,-Heri, who is Budha. According to western mythology, Apollo and Mercury ex. changed symbols, the caduceus for the lyre; so likewise in India, their characters intermingle; and even the Saiva sectarian propitiates Heri as the mediator and disposer of the divine spark (jote) to its reunion with the parent flame; thus, like Mercury, he may be said to be the conveyer of the souls of the dead. Accordingly, in funeral lamentation, his name only is invoked, and Heri-bol! Heri-bol! is emphatically pronounced by those conveying the corpse to its final abode. The vahan (qu. the Saxon van?) or celestial car of Krishna, in which the souls (ansa) of the just are conveyed to Surya-Mandal, the mansion of the sun, is painted like himself, blue (indicative of space); Nem-nath and Sham-nath have the same personal epithets derived from their dark complexions, the first being familiarly called Arishta Nemi, the black Nemi, the other Sham and Krishna, both also meaning dark-coloured.

NEMINATH, a deified saint of the Jains. It was to counteract a fervour towards women that the Jains of Western India set up their image of Neminath, a fact communicated in confidence to Colonel T'od by one of the sect.-Tr. of H. ii. 45 .

NEMI-TIRTHA, a ghat, sacred to the memory of Chaitanya for his having halted and bathed here in the course of his wanderings. $-\mathrm{Tr}$. of Hind. i. p. 8.

NEMNOOK. MAHr. Village fees, in which all the commune officers share.

NEMOOKA ROOT. HIND. Roots of several species of Cissampelos, efficient substitutes for Pareira._O'Sh.

NEMORHCEDUS, a genus of mammals of the sub-family Caprinæ, $q . \imath$. N. bubalina, Jerd., the Sarao, Serou, or Sarrowa is of the Himalaya central ranges, from Kashmir to Sikkim, at 6000 to 12,000 feet. It is the serow or forest goat of sportsmen. Its appearance is between an ass and the tahir (Hemitragus jemlaica), with long, stout legs and a strong neck. It is very bold, and will keep the wild dog at bay.

$\mathrm{N}$. goral, Jerd., the gural or Himalayan chamois of sportsmen, inhabits the whole range of the Himalaya, from Kashmir to Sikkim, at from 3000 to 8000 feet. Its horns are from 6 to 9 inches long, and have 20 to 25 annuli.

N. rubida, Blyth, inhabits the mountains of Arakan. N. Sumatrensis, in the Malay Peninsula and Sumatra, and N. Swinhoii, Gray, is of China.-Jerdon's Mammals.

NECERA LAPIDA. Cramer. The Limacodes graciosa, Werter. A moth common on the western side of Ceylon, with dark brown wings. It is produced from a caterpiliar that feeds on the carissa, and stings with virulence.

\section{NEOPHRON PERCNOPTERUS. Lim.}

\begin{tabular}{l|l} 
Vultur gingianus, Daud. & Percnopterus Egyptiacus,
\end{tabular} V. stercorarius, Lapey. $\quad$ Steph. \begin{tabular}{l|ll} 
Kal-murgb, & Mind. & Manju tiridi, : : TAr. \\
Sungra, Sunda, : SIND. & Tella borawa, : TEL.
\end{tabular} Pitri-gedda, . . TAM. Sind'ho of the "WAGREe,

This bird, the Egyptian vulture, dung bird, Pharaoh's chicken, scavenger vulture, one of the Neophroninæ, inhabits Europe, Africa, and Asia, is common in the Peninsula and in Central and Northern India, but is not known in Bengal. A single pair has been known to stray beyond its ordinary haunt so far as Britain. Its chief food is refuse of all kinds. A second species of this genus, the N. pileatus, inhabits Africa only.

NEPAL. The southern escarpment of the plateau of Central Asia is divided into two mountain ranges, the Himalaya on the east and the Hindu Kush on the west, and the valleys in this escarpment are occupied, in succession from west to east, by the alpine states and districts of Afghanistan, Kashmir, Garhwal, Kamaon, Nepal, Sikkim, and Bhutan. The Nepal State, between Kamaon on the west and Sikkim in the east, is made up of the valleys of the head-waters of three tributaries of the Ganges, the Gogra, Gandak, and Kosi, and of a corresponding portion of the Terai.

Between the valleys of the Gogra and the Kosi flows the Bhagamuttee, past the capital Khatmandu, through the beautiful central valley, 4200 to 4700 feet above the sea. In summer the thermometer seldom rises over $80^{\circ}$ in the shade, in winter it does not fall below $20^{\circ}$, and at the latter season the air is clear and braciug. The views of the Snowy Range obtainable from the 
valley and from the hills are unrivalled in extent and unagnificence.

Nepal is an Independent State in treaty with British India. It is between British India and Tibet on the north, with Sikkim and Darjiling on its east; on its south, Purniah, Bhagulpur, Sarun, Tirhut, Gorakhpur, and Busti ; on its south-west, Oudh and Bareilly; and Kamaon on its west. It extends from lat. $26^{\circ} 25^{\prime}$ to $30^{\circ} 17^{\prime} \mathrm{N}$., and long. $80^{\circ} 15^{\prime}$ to $88^{\circ} 15^{\prime} \mathrm{E}$., is 500 miles long from east to west, and 16 miles in breadth. Area, 54,500 square miles. Population variously estimated at $2,000,000$ to $3,000,000$.

The surface of Nepal generally consists of valleys varying from 3000 to 6000 feet above the Bengal plains. The capital of Khatmandu is in an ovalshaped valley, 12 miles long from north to south, and from east to west 10 miles, lat. $27^{\circ} 42^{\prime} \mathrm{N}$., and long. $85^{\circ} 18^{\prime}$ E., and 4628 feet above the sea. A tradition is current that the valley of Khatmandu was at some former period a lake; it is now throughout its whole extent well watered, and is almost unrivalled in fertility. To the extreme west of Nepal lies Almora, a hill station wrested from the Nepalese in the wars of 1814-15; to the extreme east is Darjlling, another hill station, used as a sanatorium. The breadth of the mountainous belt immediately north and east of Khatmandu is estimated at from 30 to 40 miles, and its higher parts rise to the level of perpetual snow. Among its lofty summits is Mount Everest, the bighest known peak in the world $(29,002$ feet). On the south is the Terai belt of low level land. The word signifies marshy lands, and is sometimes applied to the flats lying below the hills in the interior of Nepal, as well as to the level tract bordering immediately on the British frontier.

The legendary history of Nepal, like that of Kashmir, commences with the desiccation of the valley, for ages full of water, by Naia Muni, whence the name of the country Naipala, whose descendants swayed the country 500 years. The first authentic history is B.C. 844 . Then the Kerrat tribe of eastern mountaineers, B.C. 646. Then the Suryavansa race of rulers B.C. 178., The Ahir began in A.D. 43. The Neverit dynasty was restored in A.D. 470 , and one of this dynasty, Raghoba deva, in A.D. 880, introduced the use of the Samvat era into Nepal. In the Newar year 731, A.D. 1600, Jaya Eksba Mall (or Jye Kush Mull) divided Patan, Khatmandu, Banepa, and Bhatgaon between his daughter and three sons, and Ranjit Malla, one of the Bhatgaon dynasty, in A.D. 1721 formed an alliance with the Gurkha, which ended in his own subversion, and finally in that of all Nepal. The Gurkhali, descended from the Udaipur Rajputs, had occupied Kamaon and Noa kot for six or eight centuries prior to their conquest of Nepal in A.D. 1768.

British political relations with it date from the invasion of the valley by the Gurkha race, under Raja Prithi Narain. In 1767, the Newar raja of Khatmandu, being hard pressed by the Gurkha, applied for assistance to the British Government. Aid was granted, and Captain Kinloch was despatched with a small force in the middle of the rainy season. He was, however, compelled by the deadly climate of the Terai to retire. The Gurkha chief, meeting but a feeble resistance, overran Nepal, and extinguished the Newar dynasty, and was eventually recognised by the
British Government as raja of Nepal. For several years previous to 1792 , the Gurkha power had been extending their conquests in the direction of Tibet. They had advanced as far as Digarchi, the Lama of which place was spiritual father to the emperor of China. Incensed by the plunder of the sacred temples of Digarchi, the emperor of China despatehed an army to punish the Nepal raja, and when within a few miles of their capital the Gurkha submitted uneonditionally to the Chinese commander, who imposed a tribute and triennial mission to Pekin, besides restitution of all the booty taken at Teeshu Lumbu, and he took hostages for the performance of these stipulations. The raja of Sikkim was at the same time taken under Chinese protection. Checked towards the east by these events, the Gurkha extended their dominion westward, subjugating Kamaon, Srinuggur, and all the hill country to the Sutlej. When Lord Hastings commenced his administration, their dominion extended as far as the river Tista to the east, and westward to the Sutlej, thus occupying the whole of the strong country in the mountainous tract which stretches on the northern borders of India, between that and the highlands of Tartary. They had acquired these territories, during the preceding 50 years, from many disunited hill chiefs whom they dispossessed, exterminating the families as each raja fell before them.

Muhammadan invaders began the conquest of Hindustan in the 11th century, from which date up to the middle of the 18 th century many Hindu chiefs with their followers sought refuge in Nepal, and intermarried with the Newar, Gurung, and Magar. The descendants of these marriages are styled the Khas; they claim to be considered of the Kshatriya caste; they are the military nobility of Nepal. The Gurkha had a small Hindu State, existing from the 10th or 12th centuries, to the westward of Khatmandu, and claiming descent from the maharana of Udaipur. In 1768, Jye Kush, the 6th king of the Mall dynasty of Nepal, during troubles in his kingdom, called in the aid of Prithi Narain, the Gurkha chief, who conquered the three kings of Bhatgaon, Khatmandu, and Lalita Patan. From that time up to the year 1814, the Gurkha continued aggressive, annexing all the surrounding states; and in consequence of inroads on British territory, war between the Gurkha and the British was formally declared on 1st November 1814. In an arduous campaign, in which the Gurkhas fought most bravely, the British were unsuccessful, and General Gillespie fell at a hill fort; but the Nepalese were subsequently defeated by Sir David Ochterlony, and by the convention of Almora Nepal ceded all the conquests they had made to the west of the Kali branch of the Gogra. Previous to this war the Gurkhas had extended their conquests westwards as far as the Sutlej. By the 5th article of the treaty of 1815 , the Nepalese renounced all claim to the countries west of the Kali, and the British were left in possession of the whole tract of hills from the Gogra to the Sutlej. Kamaon and the Dehra Doon were annexed to the British dominions, and the rest of the territory, with the exception of Subathu, Raengarb, Sundoch, and a few other military posts, was restored to the hill rajas from whom it had been conquered by the Nepalese.

Towards the close of the 18th century the kings of Nepal had fallen into a titular position, the 
government being carried on by the ministers, who had assumed the character of the Maire du Palais. Towards the middle of the 19th century, Jung Bahadur rose to power. On the 18th of May 1845, Mataber Singh, the minister, was summoned to an audience with the king at the palace. On entering the room where he expected to find the king, he was killed by a rifle shot fired from the zanana gallery at the end of the room. His bodywas then thrown out of the window, and dragged away by an elephant to the banks of the Bhagmuttee at Pashupati. Next morning Jung Bahadur reported the circunstance officially to the Resident. Subsequently it appeared that Nataber Singh had been killed by Jung Bahadur at the instigation of the queen.

On the 15th of September 1846, the Resident (Mr. Colvin) was surprised by a visit at midnight from the king, who informed him that a fearful tragedy had been enacted in the city. The rani, after the murder of Mataber Singh, may be said to have been the actual ruler of the country. In the coalition ministry she had one especial friend, Guggun Singh. This noble, on the night of the 14th of September, was shot in his own house while he was in the act of performing his devotions in a private room. The rani then insisted on the king assembling all the ministers and nobles in council to find out the assassin. Fath Jung and his colleagues hurried to the place of meeting at the kot,near the palace. Here were assembled the rani, Jung Bahadur, his band of brothers, and his bodyguard, armed with rifles. The queen's party was carefully arranged and heavily armed, whereas the members of council came as they were summoned, in a hurry, each from his own house, and with no weapons but their swords. In a few minutes 32 of the nobles and upwards of 100 of the lower ranks were shot down. The king, alarmed by the noise of the struggle, mounted his horse and rode off to the Residency. On his return, within an hour, he found the gutters around the kot filled with the blood of his ministers, and what little power he possessed in the state was gone for ever. On the $2 d$ of November, 13 more of the sirdars were put to death, and in December the king fled from the country to Benares. Jung Bahadur became virtually ruler of the country, and he visited England in 1850. The assassination of Guggun Singh, and the massacre of the influential chiefs, in 1846, had paved the way for the rise of Jung Bahadur to the office of prime minister; he was created maharaja of Nepal, and invested with the perpetual sovereignty of two provinces. $\mathrm{He}$ effected the marriage of $\mathrm{a}$ son and two daughters into the royal family of Nepal.

By the treaty of 1815 , a British officer was to reside at the capital, and some of the ablest and most conciliatory servants of the Indian Government have since been there. Mr. Gardener, 1816-1829; Brian Hodgson, 1831-1843 ; Sir Henry Lawrence, 1843-1847 ; Mr. J. R. Colvin, Major Ramsay, 1849-1863; and Drs. Wright and Oldfield have been Residency surgeons.

All through the Afghan war of 1838-43, the darbar at Khatmandu was in constant communication with that of Lahore, and with the Sind sirdars and Mahratta chiefs. Between 1838 and 1840,23 secret missions from Khatmandu to Lahore and other parts of India were intercepted, through the exertions of Sir George Clerk at
Ambala, and Mr. Hodgson at Khatmandu. But on Sir Jung Bahadur succeeding to power, he ruled Nepal with great ability and success, until his death, suddenly, in the Terai in the spring of 1877. During the mutiny of 1857 , and the subsequent campaigns, Jung Bahadur assisted the British in the re-occupation of Gorakhpur, the re-capture of Lucknow, and the subsequent capture of the rebels who infested the Terai. In consideration of these services he was created a Knight of the Grand Cross of the Bath, and under a treaty (No. I.V.), concluded on the 1st November 1860 , the tract of territory on the Oudh frontier, which had been ceded to the British Government in 1816, was restored to Nepal.

The population consists of Mongoloid tribes who have immigrated from the Tibetan border, and of Aryan refugees from the plains of India. West of the Kali river, almost all the inhabitants claim a descent from Hindu colonists. They accordingly consist principally of Brahmans and Kshatriyas, with their various subdivisions. East of the Kali, the Magar occupied the lower hills in the western parts, and are at present enlisted by the Gurkha sovereigns, composing a great majority of their troops; the Gurung, a pastoral tribe; the Jariyas; the Newars, an industrious people, following agriculture and commerce, and more advanced in the mechnnical arts than the other mountain tribes; the Dhenwars and Mhanjis, the husbandmen and fishers of the western districts ; the Bhutias; the Bhanras, which branched off from the Newars; and to the eastward, some districts of the Nepal dominions are inhabited by the Limbuas and Nacarkuti tribes.

Mr. Hunter gives the Nepal races as under:-

Nepal, East to West.-Serpa, Sunwar, Gurung, Murmi, Magar, Khaksya, Pakhya, Newar, Limbu. The language of the Magar, Gurung, and Newar. is chiefly Tibetan.

Kiranti Group, East Nepal._-Kiranti, Rodong, Rungchenbung, Chhingtangya, Nach-hereng, Waling, Yakua, Chourasya, Kulungya, Thulungya, Babingya, Lohorong, Limbichhong, Balali, Sangpang, Dumi, Khaling, Dungmali.

Broken tribes of Nepal.-Darhi, Dhenwar, Pahri, Chepang, Brahmu, Vayu, Kuswar, Kusunda, Tharoo.

The martial classes are the Khas, Magar, and Gurung, each comprising a very numerous clan or race variously subdivided.

Khas, Khus, or Kus is the usual title of the dominant race, and Sah or Sahi, the tribal title of the royal family. They are descendants of immigrant Hindu Rajputs with Nepal women. The Khas possess a pre-eminently masculine energy of character and love of enterprise, and have a free, sometimes a noble carriage. The Khas form one of the martial classes, and hold jaghir lands on military tenure. This and other two tribes take the name of Gurkha, which the Chinese pronounce Ku-ru Ka-li. It is derived from the eponymous deity of the royal family, Gorakhshanath or Gorkhanath, whom Brahmans claim to be a form of Siva. Gorkha town, the original seat of the Khas, is 60 miles W.N.W. of Khatmandu. They have 13 divisions, and 116 clans.

In the west of Nepal dwell the Gurung and Magar tribes, small, with features of an extreme Mongolian type, full of martial ardour and energy. In feature and figure, the true Gurkha are al ways 
remarkable, from their broad Chinese or Tartarlike physiognomy, the small eyes, flat nose, and meagre whiskers, as well as the stout, square make and sturdy limbs. The Magar have peopled the lower Gogra valley. The men are of great bodily and mental vigour. The Gurung are an energetic and pastoral race. It has been calculated that there are in Nepal no less than 30,000 Dakhriah, or soldiers off the roll by rotation, belonging to the Khas, Magar, and Gurung tribes. Their energy of character, love of enterprise, and freedom from the shackles of caste, are conspicuous, and, in the opinion of competent judges, they are by far the best soldiers of India. The Government of British India since 1840 has been employing them in their native army.

The Newar belong to the Indo-Tibetan stock, and profess Buddhism. They are confined almost to the valley of Nepal. They are divided into several orders, according to trades and occupations. They are peaceable agriculturists, and skilful workers in iron, copper, brass, and bell-metal; the chief seats of industry being Lalita Patan and Bhatgaon. Their copper, brass, and bellmetal vessels are exported to Tibet. Newar women, as well as the men of the hill tribe of Magars, weave two sorts of cotton cloth, partly for home use and partly for exportation. Those who are not very poor wear woollen blankets, which are manufactured by the Bhutias, who wear nothing else.

The Bhama are a sort of separatists from the Newar, supposed to amount to 5000 . They shave their heads like the Bhutia, observe many of the religious rites as well as civil customs of the latter, in a dialect of whose language they are said to preserve their sacred writings. The lands of Nepal proper are cultivated almost without exception by Newars. The Parbatya tribe, called Dherwara, cultivates the western lands at Nurkale, etc. The Dherwar and Margi are the husbandmen of the western districts. Parbatya is a general name given in India to the mountain Hindus of Nepal, and to their language.

The Elthariah are the descendants, more or less pure, of Rajputs and other Kshatriyas of the plains, who sought refuge in these mountains from the Muslim, or merely military service, as adventurers. The Elthariah speak only the Khas language.

The Murmi or Tamar are a very numerous tribe of Tibetan origin, dwelling in all parts of the Nepal mountains, from the Gandak river, 20 miles IV. of Khatmandu, to the Mechi river. When in smaller numbers they are to be met with in the Sikkim country as far east as the Tista. The great bulk of the tribe, however, is to be found between the valley of Nepal and the Dood Kosi. Murmi are taller, coarser in their feature, and more Tibetan in their temperament, than the remaining tribes, and appear to be Tibetan, or more Tibetan than Gangetic. Mr. Hodgson thinks that they do not notably exceed the Gangetic stature. Of all the tribes on the S. side of Himalaya, they have least changed in habits. They settle on the mountains at elevations of 4000 to 6000 feet, living in cottages made of stone and thatched with grass. They are altogether a pastoral and agricultural people, rearing flocks of sheep and goats near the snows, and cultivating Indian corn and murwa (Eleusine coracana) at the greatest elevations capable of producing them. They arc Buddbists of the Bhutia and Lepcha Lama sect. Their priests are not restricted to celibacy. They have several families or clans. They bury their dead on the tops of mountains, and raise tombs of earth and stones, covered by a slab of stone, on which the name is engraved.

The Kiranti and Limbu occupy the Nepalese districts of the great valley (the basin of the Kosi). The Kiranti, Kirata, or Kichak are the classical Cirrhatæ. They are said to be also called Khombo. The Kiranti are of ten included in the Limbu, whom they much resemble in appearance.

The Jarya tribe are south of the Gurung, with whom they intermarry. They are Hindu in creed and manners.

The Hainu, the Chepang, and the Kusundu are three Bhot tribes who dwell amid the dense forests of the central region of Nepal, to the westward of the great valley. They have no apparent affinity with the civilised races of that country, but live in huts rnade of the branches of trees, subsisting on wild fruits and the produce of the chase, snaring wild animals. They are constantly migratory. They are all darker and more slender than the tribes around them, and in form and colour greatly resemble some of the races in the plains, particularly the Kol.

In Central Nepal also are the Pahri, the Darahi or Dorhi, Denerar, and Paksya.

The Thakuri are descendants from former princes.

Sood, in Nepal, along the northern frontier of British India, and in the Panjab, are a mercantile body, dry grocers. They do not eat beef, but use other animal food, game, and fish.

Sumwar or Sanwar, a tribe in Nepal, dwelling below the mountain peaks of Gosainthan, to the north of the Magar and Gurung, and near and among the cis-nivean Bhutia race, dwelling in the central and temperate parts of the mountains. They are among the principal alpine tribes of the Sub-Himalayas, between the Kali, where the aboriginal tongues are merged into the Prakrit, and the Dhansri, where they begin to pass into monosyllabic-tongued races of Indo-Chinese origin.

Thuroo, a migratory forest race in Nepal and along the base of the Himalaya mountains, between Chumparun and Khatmandu, as far west as the river Gandak, which they occupy along with the Boksa at the foot of, but quite external to, the Himalaya. They cultivate a little, and live and thrive in the most malarious situations, and are invaluable in effecting forest clearances.

Just as the Tharoo inhabit the Terai, the Kuswar and Bhutia, called the Manjhi, the Kumha, Bhramu, Denwar, and Durre, inhabit with impunity the lowest and hottest and most malarious valleys of Nepal, dwelling in small villages or in scattered cottages, following the arocation of potters, agriculturists, fishermen, and ferrymen. They have dark-coloured skins, slender forms, oval faces, elevated features, and peculiar dialects.

The Dharmi, a dancer caste of Nepal, attend at the annual festival at which buffaloes are sacrificed, and drink copious draughts of the warm blond of the victims.

The Dherwar and Margi, the husbaudmen and fishermen in the western districts. The Dherwar cultivate the western lands at Nurkale, etc. Yakha, Mungar, Brahman, Khumbu, Nimbu, 
chiefly cultivators. The Gallia rear buffaloes chiefly; the Kami, blacksmiths; the Sarki, tanners; and the Domai, tailors (Dome).

The Brahmans of Nepal have 94 tribes. Eastward of Nepal, some districts are oocupied by the Limbu, the Naggankot, and others. The Limbu are also called Yakthumba.

About four-fifths of the people are professing Buddhists, and the remainder Hindus; but Hinduism has succeeded in materially corruptivg the purity of the numerically predominant creed. Nepal presents the curious spectacle of Buddhism, with castes, distinctly polytheistic, addicted to bloody sacrifices, and, in part at least, practising the obscenities of the Tantrika system. There are about 2000 Buddhist temples in Nepal.

Languages.-About 40 tribes, with as many different languages, inhabit Nepal, Sikkim, and Bhutan. In Nepal is a perfect maze of dialects. Beginning from the Singhaleela range, we find Limbu or Kirauta, which goes west as far as the Dood Kosi river, in long. $86^{\circ} 44^{\prime}$ E. Sherwill found the Gurung in the higher parts of Singhaleela, closely connected with whom are the Murmi. Along the lower hills are the Magar, who extend to the west as far as Palpa. In Central Nepal are the Newar, Pahri, and Brahmo, a dialect of Magar, also the Darahi or Dorhi, Denwar, and Paksya. The Parbatya or Paharia dialect of Hindi is spoken all over Nepal, and is the court language. West of this again comes the Palpa, then the Thaksya, Sunwar, and Sarpa, the dialects of Kamaon and Garhwal, which carry us ou to the Milchan of Kanawar; the Hundisi and Tibarskad, north of it, speak the Kbas language. The language of the Magar, Gurung, and Newar is chiefly Tibetan.

The Gurkha had a language of their own until they adopted Brahmanism, when they partially adopted the Hindi, with which their own language became mixed.

Produce.-The mountainous parts of Nepal are rich in mines of iron and copper. The copper is of a superior kind. I Lead mines, yielding a proportion of silver, are in Moulk. Small quantities of gold-dust are found in the Gandak. In addition to the sal timber trees and Bechiacouri pine, are the sissoo, the Setti-sal, the Phullamical, an ironwood, the Kalikset, a black wood, the Sajk, Burra, Sunni, Moolta, and a small quantity of ebony. These woods constitute in a great measure the commercial wealth of Nepal. Wood merchants congregate at the southernmost point of the forest, near the river Gandak, because of the facility presented by that river of floating the timber to Calcutta. The bark of Photina dubia or Mespilus Bengalensis is used for dyeing scarlet.-London Times; Smith's Nepal; Kirkpatrick's Nepal; Bogle's Tibet; Oldfield's Sketches of Nepal; Munshi Shew Shunker. Sing Pandit Shri-Gunänand's History; Dr: A. Camplell in J. A. Soc.; Thomas' Prinsep.

NEPENTHACE E. Lindl. The pitcher-plant tribe, a natural order of exogenous plants inhabiting the damper and warmer parts of S.E. Asia, and having, in the place of leaves, large hollow bodies furnished with a lid, and containing water secreted from a peculiar glandular apparatus with which they are lined. These bodies, or pitchers, as they are called, appear at the end of a leafy tendril-like expansion of the bark, and are con- sidered to be a hollow state of the apex of the petiole of a leaf, while the lid that closes them is regarded as the blade. The inner surface of the pitcher is glandular, and, during active vegetation, secretes the fluid, in which insects are frequently drowned. Some species of Borneo bear pitchers 12 inches long, and 6 inches in diameter, large enough to hold two quarts of water (N. Rajah, Hooker, of Borneo); Nepenthes Edwardsiana is 18 inches long, and 2 to 3 inches in diameter. Other known species are N. Northiana, Hooker, of Borneo, N. distillatoria, $L ., \mathrm{N}$. lævis, N. phyllamphora, N. gymnamphora, of Java, gracilis, hirsuta, Lowii, Veitchii, and villosa. N. ampullacea, Jack, and N. Rafflesiana, Jack, grow in Singapore. One species grows in Ceylon. The Dutch call this plant Kannekens kruyd, or the can-fruit, from its singular form. They are insectivorous plants. The urns of one species are armed with two sharp and strong spines. Its pitchers always contain insects of various kinds, and the spines prevent birds and insect-hunting animals, such as the tarsier, from removing these insects from the urns.

NEPENTHES of Homer (Odyss. iv. 1. 221), supposed by some to have been hemp, Cannabis sativa. Opium has also been supposed.-Powell, i. p. 321.

\section{NEPETA CILIARIS. Benth.}

N. leucophylia, $B l$. Zufa vabis, . . PANJ. It occurs in the Panjab Himalaya at from 4000 to 8000 feet, and is given in sherbet for fever and cough. $-D r . J$. L. Stewart.

NEPH, the divine spirit, a god of the Egyptians. See Osiris.

NEPHELIUM, a genus of plants of the natural order Sapindaceæ. Under the Canarese and Mahratta names Andgeree and Yaroo, Dr. Gibson mentions a nephelium tree growing in Canara and Sunda, above the ghat, chiefly at the Nilcoond and southern jungles. Wood said to be serviceable in house-building. Mr. Thwaites notices in Ceylon N. bifoliatum, Thw:, a moderate-sized tree ou the Lower Badulla road from Kandy, at no great elevation, which flowers in April. N. eximium, a large tree of the Central Province, at an elevation of 1000 to 2000 feet, flowers in May and fruits in July; and N. erectum, Thw., also of the Central Province, up to an elevation of 3000 feet. N. hypoleucum, Kurz, and N. rubescens, Hiern., are trees of Burma. Three species are celebrated for their fruits, viz. N. litchi, Don, the litchi of S.E. Asia; N. longanum, the longan of China; and $N$. lappaceum, the rambutan of the Malay Peninsula. Dr. Mason mentions a small inferior Tenasserim fruit as the red nephelium, eaten by the natives only, though bearing its fruit in bunches like the lichi. One of the indigenous nephelium trees of Tenasserim bears a fruit whose subacid is very agreeable to the palate, and much resembles that of the rambutan so famous at Malacca. Malays say it is the wild rambutan. Other species known are $\mathrm{N}$. rimosum, rubrum, verticillatum, and variabile. N. stipulaceum, Bedc., a handsome middlingsized tree, rather rare in the moist forests in Malabar and on the Animallays; the wood is strong and serviceable.-Mason; Thu. i. p. 57; Voigt; Gibson.

NEPHELIUM LAPPACEUM. Lim. The rambutan fruit is produced in bunches terminally. The pulp, which surrounds a seed of the 
size and flavour of a cob-nut, is transparent, and of a delicate sweetish-acid flavour. It is in appearance not much unlike the fruit of the arbutus, but larger, of a brighter red, and covered with coarser hair or soft spines, from whence it derives its name. The part eaten is a gelatinous and almost transparent pulp surrounding the kernel, of rich and pleasant acid. - Low's Sarawak, p. 73 ; Marsden's Sumatra, p. 101.

NEPHELIUM LITCHI. $W$. and $A$.

Dimocarpus lichi, Lour. | Euphoria lichi, Desf.

Scytalia lichi, Roxb.

Kayet mouk, . . Bunм. | Kaleng ken, Lichi, MaLAY. Tan-li, Lichi, . CHIN.

This native of China is an evergreen, and grows to a large size. The fruit is of a dark brown colour, and contains a glutinous, yellow, sweet sort of pulp. In British India it is not much prized, perhaps from its inferior quality to the Chinese fruit, which is much esteemed. The fruit ripens in March and April. The sun-dried fruits are largely exported from Foh-kien and Canton provinces, being in demand as a marriage present or dessert at feasts.-Riddell; Smith.

NEPHELIUM LONGANA. Camb.

Dimocarpus longan, Roxb. Scytalia longana, Roxb. Euphoria longana, Lamk.

Ashphal,. . . Beng. Longan, . . Malay. Kayet mouk, : Burm. Puna,. : : MaleaL Mal ahcota, . . CAN. Morre, . . Singh Lung yen, - . Chin. Puvati, : : TAr. Wumb, MAHR

A moderate-sized tree of the Peninsula of India, the Khassya Hills, the Malay Peninsula, Cochin-China, and China, having a straight trunk and fine globular head. It occurs in Coimbatore, is rare in the Bombay Presidency, being confined to their raee or greenwood jungles. In China it grows in Foh-kien, Kwang-tung, and Kwang-si. It is more easily grown than the litchi. The fruit is globular; it is not equal to the litchi. The wood is white, hard, and close-grained.Wight; Gibson; Voigt; Smith; Gamble.

NEPHRITE, jade, or axe-stone, the Yashm or Sang-i-yashm, so much valued in China, is found in Central Asia, New Zealand, Western America, Corsica, the Hartz mountain, and Egypt. It is the yu of the Chinese. It is highly prized by the Maori race, whose choicest weapons and ornaments are carved out of it by means of friction of flint and wet sand, while the holes are generally pierced by a drill of a pointed piece of hard wood. The following is an analysis by Kastner :-Silica, 50.50 ; alumina, 10.00 ; magnesia, 31.00 ; oxide of iron, 5.50 ; oxide of chromium, 0.05 ; water, 2.75 . In China it is carved into images, and worn as a charm. It was supposed to be good in diseases of the kidney; hence its Chinese name.-Smith.

NEREOCYSTIS LUTKEANA, one of the algæ, formas dense marine forests in Norfolk Bay and all about Sitcha. Its stem resembles whipcord, and is often 300 feet long, and terminates in a large air-vessel 6 or 7 feet long, and crowned with a bunch of dichotomous leaves, each 30 or 40 feet in length. The sea-otter when fishing rests on the colossal air-vessels of this giant seaweed, and its stems furnish fishing-tackle-Hartwig.

NERIUM (from unpós, humid, the habitat of the species), a genus of plants belonging to the natural order Apocynaceæ or dogbanes. whole fanily are poisonous.
NERIUM ODORUM, Solander. Oleander. Kanér, Kharuba, HIND. Arali, . . . . TАM. Jovana arali, "MALEAL. Ghenneru kusturiKhar-zahrib, . Pers. patte, . . TEL. Karavera, . SANSk, Gandera, TRANS-INDUs.

A sweet-scented oleander, grows throughout India, Sind, Baluchistan, Afghanistan, Siwalik Hills, and the Himalaya, and is often confounded with the $\mathrm{N}$. oleander. Its varieties have flowers of a red, crimson, and rose colour, and are double and single. The root and root-bark are used medicinally, but need great care, as they are virulently poisonous. The leaves also are used. In the Dekhan the double red and white grow wild on the banks of rivers, bearing both white and red flowers; and by budding the red colour on the opposite one in several parts of the same stalk, a very pretty appearance may be given to the shrub. Amongst Hindus its flowers are sacred to Siva. The single white is called in Hindi safaid-kurpud, the single rose-coloured lalkurpud, and the beantiful large double rose variety is called padma-kurpud. The yellow congener is called the exile, and was introduced from America. The root contains a yellow poisonous resin, tannic acid, wax, and sugar, but no alcoholoid or volatile poison. The bark and flowers contain the same poisonous resin, which is most abundant in the liber or inner bark; it is very soluble in carbonate of soda, and, though not volatile, is carried over mechavically when the plant is distilled with water. The root is so frequently resorted to for the purpose of selfdestruction by the women of India when tormented with jealousy, that it is proverbial among the females of the hills, when quarrelling, to bid their opponent go and eat of the root of Kaner. A man about 35 years old swallowed an ounce of the expressed juice, and immediately fell senseless on the floor. He did not recover, even by vigorous treatment, from a state of collapse, under 40 hours, and during that time had constant spasmodic seizures of the whole body. Cainels eat it, but nearly all die. The stalks are said to be used as hookah tubes. The powder of the dried leaves is given in colic, and used as an errhine. A wash is made from the bark, which is used in itch and for destroying vermiu. Externally the leaves and bark have been used (and sometimes even internally) as a remedy in herpes and itch. The rasped wood is employed as ratsbane. The wood itself is used by some eastern nations as a material for gunpowder charcoal. - Roxb. ; Pouell ; Eng. Cyc.; Riddell; Irvine; Ainslie; Honig.; O'Sh.; Mason.

NERIUM OLEANDER, Limn, Kiah-chuht'-au, CHIN.; Nnproy Pododsvòpov; Pododxфvn; Kharzahra. Oleander, rose bay, spurge laurel, a plant of the Levant, is equally poisonous with $N$. odorum.

NESA KULA. KARN. A. caste of fowlers, bird-catchers.

NEST.

Ghonsala, Ghar, Hind. Nido, . . . . SP. Nido, Nidio, Nidiata, IT. Y Yiwah, : TEL, Turk.

The nests of birds greatly vary. Those of the weaver bird, tailor bird, honey-sucker, and oriole are made with much art. The edible nest of the colocalia swallow is formed of inspissated saliva in caverns; swallows, swifts, bee-eaters, and weaverbirds build in companies; certain ducks breed on cliffs or trees, and they must carry their young to 
the water, though this has not been observed. The Megapodidae gallinaceous birds, found in Australia, its surrounding islands, and as far as the Philippines and the N.W. of Borneo, bury their egg's in sand, earth, or rubbish, and leave them to be hatched by the sun or by fermentation. They have large feet and long curved claws, and most of them rake together rubbish, dead leaves, sticks, and stones, earth and rotten wood, until they form a mound often 6 feet high and 12 feet across, in the middle of which they bury their eggs. The eggs are as large as those of a swan, and of a brick-red colour, and are considered a great delicacy. The natives are able to say whether eggs be in the mound, and they rob them eagerly. It is said that a number of these birds unite to make a mound, and lay their eggs in it, and 40 or 50 are found in one heap. The mounds are found in dense thickets. The species of the Megapodidx in Lombok is as large as a hen, and entirely of a dark hue, with brown tints. It eats fallen fruits, earth-worms, snails, and centipedes, but the flesh is white, and when properly cooked well flavoured.

Mr. Allan Hume says the nests of the white scarenger vulture (Neophron ginginianus) of India are clumsy, ragged stick structures,-platforms slightly depressed towards the centre, loosely put together, and liued with any soft substance they can most readily meet with. Old rags are a great stand-by. In many parts of the country, wayfarers as they pass particular trees have a semi-religious custom of tearing a strip off their clothes to hang thereon. The tree (usually a babul) soon becomes loaded with rags and tatters. These are a perfect godsend to the Neophrons of the neighbourhood, who rob these rural shrines of their trophies by the score. Sometimes the rags of various colours are laid out neatly in the nest, as if an attempt had been made to please the eye; sometimes they are irregularly jumbled up with the materials of the nest. Cottonwool, old and dirty, - stolen perhaps from the old rizais, or padded coverlids, thrown with halfburnt dead bodies into the river,-occurs occasionally in great lumps in the nest. And he had several times found nests lined entirely with masses of human hair, which, in a country where near relatives shave their heads as a part of the funeral ceremonies, often lies thick in the environs of 7illages and towns. Sometimes the birds line their nests with green leaves, much as Eutolmactus. Bonelli and many other eagles do. In size the nests vary from 2 feet to 3 feet in diameter, and from 4 inches to 10 inches in depth. Nominally they lay two eggs, but he had repeatedly found birds incubating a single egg; twice he found three eggs in the same nest, but in each of these latter cases one of the three egg's was much smaller and feebler-coloured than the other two.-Wallace, pp. 154, 156.

NESTORIUS. A Christian sect in Kurdistan and Mesopotamia is said to be called from Nestorius, who was Bishop of Constantinople in the 5th century, and whose doctrines were spread with much zeal through Syria, Egypt, Persia, India, Tartary, and China. They number about 200,000 in Persia, Turkey, and Kurdistan. They do not accept the view that describes them to be followers of the creed of Nestorius, and claim to be Kaldi, descendants of the Chaklreaus, and state that their name is derived from Nassara (Nazarene) or Nazareth. Turks and other orientals call them Nasrani.

Colonel Yule, in Cathay and the Way Thither, says that so late as the 14 th century a Nestorian bishopric existed in the neighbourhood of the modern Hazrati Turkestan, north of Samarcand, and that the sect had been established in that district since the 4 th century. In Persia the sect inhabit the district of Urumia, in Azerbijan, and the mountains to the south, occupying the Hakkian chain in Kurdistan. In Upper Mesopotamia there are many Nestorians, some of whom have become Roman Catholics, and Jacobite as well as Roman Catholic Syrians. Their priests are styled Kieshish and Abuna, and are hereditary office-holders. Their patriarch is designated, he says (p. 272), Mar Shumun? He dwelt at Kojamis, near Julamerk, in the heart of the Kurd mountains. They live amongst the Kurds, and are wild, brave, and grasping. The Kurds, about the year 1870 , attacked and massacred a large body of the Christians. Nestorian Tiyari women and girls bathe unrestrained in the presence of men in the streams that pass their doors.

Nestorius was patriarch of Constantinople, and in 431 was expelled and denounced as a heretic by the Council of Ephesus, for refusing to call the Virgin Mother of God, and sundry other so-called heresies. Nestorian doctrines are more like those of the Protestant Church than other Eastern Christian systems. They have no image or relics, no convents or nunneries; they acknowledge no purgatory, no transubstantiation, no auricular confession; and their notions of the divinity of the Saviour are scriptural and accurate.

The Nestorian faith, after being condemned in the west during the first half of the 5th century, spread rapidly in the east, and prevailed in Persia and Asia Minor. American missionaries have established themselves at Urumia on the frontier of that region, and are now zealously employed in educating and instructing many of the younger members of this Christian sect. Colonel Chesney; Wagner; Yule; Layard, i. p. 196; MacGregor, iv. p. 343 ; Vambery, p. 61 ; Grant.

\section{NET.}

Rets, Filets, . . Fr. Pukat, Panauk, MaLAX. Netz, : : GER, Red, . . . SP. Jhal, Jala, : HrNd Agh, : . : : Tunk. Rete, Reticella, Ragma, IT.

Net-making is the art in which the fabric is required to be transparent, but in which the fibres are decussated and retained in their places by knots, that the interstices may retain their form and size, and prevent objects from escaping; it seems to have been known in the earliest ages in Egypt, and is practised with the greatest skill throughout the East Indies in great variety, their nets being from a few to 50 fathoms in length. Those of Singapore are made with cotton, and others with the fibre, which is very similar to, if not identical with, that forming the so-called China grass; rami fibre, trap fibre, cotton, and hemp being all employed in net-making. Nets are woven also of hempen thread, and boiled in a solution of gambier (Uncaria gambier) to preserve them from rotting. The fishing-smacks which swarm along the Malay coast go out in pairs, partly that the crews may afford mutual relief and protection, but chiefly to join in dragging the uet fastened to their boats. 
In the shallows of rivers, rows of heavy poles are driven down, and nets secured to them, which are examined and changed at every tide. Those who attend these nets, moreover, attach to their boats scoops or drag-nets, so loaded that they will sink and gather the sole, ray, and other fish feeding near the bottom. Lifting nets, 20 feet square, are suspended from poles elevated and depressed by a hawser worked by a windlass on shore; the nets are baited with the whites of eggs spread on the meshes. There are also casting-nets and sievenets. In hunting and fowling, also, nets are in use to a considerable extent, and the clap-net seen in use in Sind and elsewhere is identical with that depicted on the Egyptian monuments for catching wild-fowl. Job xix. 6 ; Psalm cxl. 5 ; Isaiah li. 20 .

For sea-fishing in Sind a suitable net costs $£ 40$ or $£ 50$, and does not last above a year. A seagoing fishing-boat costs about $£ 100$, and ought to be serviceable for several seasons. Stake-nets are extensively constructed off the coasts of Sind, Bombay, and the Malay Peninsula. In Sind and Bombay the stakes are usually the trunks of some species of palin trees, and by joining are made up to 100 feet in length. Those near land are placed at right angles to the shore, and pressed perpendicularly into the mud to a depth of 12 feet or more, and 25 feet apart. Nets of a bag or funnel shape, often 40 yards long, are attached to them, and the currents sweep the fish into the bag. But the banks far out at sea are similarly utilized, the fishermen attending at each change of the tide to empty the capture, and reverse the funnel-net. The dip-net is worked from a framework fixed on the bank of a tidal river, or from a boat or platform. The purse-net, lave-net, and bag-net are fixed on bamboo frames, and dragged up narrow or shallow pieces of water. The cast-net is easily carried from place to place, and, being thrown horizontally with a centrifugal motion, it spreads out over a considerable surface. Several of these are occasionally joined together to form a dragnet. Cones and traps made of bamboo are in much request. The Chinese nets are the bag, casting, flat sluice, trawl, and stake nets, and the sieve; also nets for shrimps and shell-fish.-Royle, Arts, etc., of India, p. 505.

NETHERLAND INDIA. Netherland is a name in use for the European country called Holland, occupier by the Dutch people, who have large possessions in the Eastern Archipelago, which are the empire of Netherland India. In 1596 the Dutch, under Houtmamn, first arrived off Bantam, and found the native king at war with the Portuguese. They lent him aid, on condition of having land allotted for a factory. In 1610 the Dutch - fortified the village of Jakatra, which they named Batavia. In 1619 this was destroyed, but it was then rebuilt by Mr. Bolt, the Dutch GovernorGeneral, and this was the beginning of the present town of Batavia. Java up to the 13th century was partly Hindu, partly Buddbist, partly Muhammadan; but in the 15 th century Muhammadanism took the lead, and in 1475 a Muhammadan prince took the throne on the overthrow of the great kingdom of Majapahit, which had dominion over the whole of Java and the eastern parts of Sumatra. In 1635 they occupied Formosa ; in 1640 they took Malacca from the Portuguese; in 1647 they were trading at Sadras, on the east coast of the Indian Peninsula; in 1651 they founded a colony at the Cape of Good Hope; in 1652 they built a factory at Palakollu, on the Madras coast; in 1658 they captured Jaffnapatam from the Portuguese in Ceylon; in 1664 they wrested from the Portuguese all their earlier settlements on the pepper-bearing coast of Malabar; and in 1669 they expelled the Portuguese from St. Thomé and Macassar. In 1749 the reigning prince abdicated in favour of the Dutch East Indian Company. Seven years prior to that event the sovereignty had been divided into a spiritual head, the Susunan or object of adoration, whose descendants now reside at Surakarta, near Solo, and a second prince who was styled Sultan, and whose descendants reside at Jokyokarta, all of them highly pensioned. Clive, in $17 \overline{5} 8$, attacked the Dutch at Chinsura both by land and water. In 1811, when France overran Holland, the flag of France was hoisted at Batavia, but in the same year the British captured it, only to restore it on the 19th August 1816, and exchanged Sumatra for Malacca in 1824. From this time the Dutch ceased to have territory on the continent of Asia, and have been extending their great island empire.-Imp. Gaz.; Bikmore, pp. 22, 26. See Dutch ; Holland.

NE'TSUKE. JAPAN. Curiosities, trinkets, charms, attached to the silken cord by which the Japanese fasten their tobacco pouch or tiny medicine-box to their girdles.-Galatea.

NETTAPUS COROMANDELIANUS. Gmelin. The white-bodied goose teal, or cotton teal, of British India, Ceylon, Burma, and Malayana. It is a pretty little goslet, it is unwary and familiar, frequents weedy and grassy. tanks, flies with rapidity, and utters a cackling call. It breeds in holes of old trees, ruined houses, temples, chimneys, and lays eight or ten small white eggs. It is the Berviclea girra of Gray and Dendrocygnus affinis of Jerdon, and is 13 or 14 inches long. See Birds.

NETTLE is a name applied to plants which, when touched, inpart a stinging sensation. They are classed by botanists under the natural order Urticaceæ of Endlicher. Of the species of the genus Urtica, of which there are known about 20, many sting, as also do those of Boehmeria. The Urticaceæ are widely diffused throughout both tropical and temperate climates. They grow to a gigantic size in the hot moist parts of Asia, and extend from its warm tropical islands all along the Malayan Peninsula to the foot of the Himalayas, along which, and in its valleys, they flourish even near to the banks of the Sutlej. Species are also found around the Neilgherries, and along the Malabar coast to the Konkan. Though the flowers of all are inconspicuous, some of the species (as Urtica pulcherrima) are remarkable for the beauty of their foliage. One of them (U. tuberosa) is distinguished by its tuberous root-stock, which is eaten by some of the natives of India, either in its raw or cooked state. The great characteristic, however, of the nettles is their sting. Some of the Indian species are remarkable, even among nettles, for this quality; as, for instance, $U$. crenulata and U. heterophylla. The latter is called the Neilgherry nettle; it is the most widely diffused of the large Indian nettles, being found in South Konkan, along the Malabar coast, Mysore, the Neilgherries, the vallays of the Himalaya, in 
Assam, and Burma. It is an annual plant, the sting of it produces intense pain, the bark abounds in fine white glossy silk-like fibres; but these probably differ with the locality in which the plant is grown. Dr. Wight describes those of the Neilgherries as a fine soft flax-like fibre, and fitted to compete with flax in the manufacture of even very fine textile fabrics. The Toda extract it by boiling the plant, and use it as a material for making thread. Mr. Dickson passed it through his machine and liquid, which rendered it like a beautiful, soft, silky kind of flax. He calls it a wonderful fibre, of which the tow would be useful for mixing with wool, as has been done with China grass. It is very like fine wool, brings $£ 45$ to $£ 50$ a ton in the rough state, and prime warp £100 a ton. It grows wild all over the Neilgherry Hills. The fibre from the bark of old wood is steeped in cold water for about six days. For the bark of the young wood 24 hours suffice for the fibre to separate readily from the pulp. The fibre bleaches readily, is of great length and good quality and colour, the plant attaining a height of 8 to 12 feet; length of staple, however, is of very little consequence in jute, bemp, or flax plants, as one of the first parts of the process of applying them to manufacturing purposes is to cut them into lengths of 12 or 15 inches, to prevent them from getting entangled in the machinery. The Neilgherry nettle grows very abundant as a weed, yields a large percentage of fibre, and its cultivation could very easily be extended. By boiling for a short while, the stinging property of the nettle is destroyed.

The great shrubby nettle (Urtica crenulata) is common at Chakung in Sikkim. This plant, called Mealum-ma, attains 15 feet in height; it has broad glossy leaves, and, though apparently without stings, is held in so great dread, that Dr. Hooker had difficulty in getting help to cut it down. He gathered many specimens without allowing any part to touch his skin; still the scentless effluvium was so powerful, that mucous matter poured from his eyes and nose all the rest of the afternoon in such abundance, that he had to hold bis head over a basin for an hour. The sting is very virulent, producing inflammation; and to punish a child with Mealum-ma is the severest Lepcha threat. Violent fevers and death have been said to ensue from its sting; but this he very much doubts. The stinging hairs are microscopic, and confined to the young shoots, leaf, and flowerstalks. Leschenault de la Tour describes being stung by this nettle, on three fingers of his hand only, at the Calcutta Botanical Gardens, and the subsequent sneezing and running at the nose, followed by tetanic symptoms and two days'suffering, nor did the effects disappear for nine days. It is, says Dr. Hooker, a remarkable fact that the plant stings violently only at this season. I frequently gathered it with impunity on subsequent occasions, and suspected some inaccuracy in my observations; but in Sylhet both Dr. Thomson and I experienced the same effects in autumn. Endlicher (Lindley's Vegetable Kingdom) attributes the causticity of nettle-juice to bicarbonates of ammonia, which Dr. Thomson and I ascertained was certainly not present in this species.-Royle; Hooker, Him. Jour. ii. p. 188.

NEUERA ELIA, a mountain summit in Ceylon, taking its name from Nuwara, SiNeH., an imperial residence, and Elia, light. It was first visited by British officers in 1826, and in 1829 Sir Edward Barnes opened it as a sanatorium. It is 6222 feet about the sea, and, on its north, mountains rise 2000 feet higher still. Its temperature ranges from $36^{\circ}$ to $81^{\circ}$, with a mean daily variance of $11^{\circ}$, the average at noon being $62^{\circ}$, and the highest observation of the unexposed thermometer $70^{\circ}$. The quantity of rain falling has perceptibly decreased of late years, probably owing to the extensive clearing of the surrounding forests to prepare them for coffee-planting. Its highest peak is . Peduru-talla-galla, 8280 feet in elevation, which derives its name from the plants which grow there amongst the rocks (galla), and are substituted for the (talla) leaves in making mats (peduru). It is a favourite place of resort from the commencement of January to the middle of May. At that time the rainy season commences, and visitors rapidly disappear.-Baker's Rifle, p. 32; Tennent's Ceylon.

NEUROPTERA (from vẽupoy, a nerve, and $\pi \tau$ זsón, a wing), one of the orders into which the insect class is divided. It may be illustrated by the Libellula or dragon-fly, Ephemera or Mayfly, and Phryganea or alder-fly.

NEIV BOLD, CaPTAin T. J., an infantry officer of the 12th Regiment of the Madras Presidency, a voluminous and accurate writer on varied branches of science. Ob. 1850. He wrote on the Beryl Mine in Coimbatore, in Ediv. New Phil, Jl, xx. 241 ; Valley of Sondoor, Mad. Lit. Trans., 1838 ; Temperature of the Springs, Wells, and Rivers in India and Egypt, Phil. Trans., and republished Edin. New Phil. Jl., 1845-46; Geological Notes on the Southern Mahratta Country, in Bl. As. Trans., 1845; Osseous Breccia and Deposits in the Caves of Billa Soorgum, Southern India, ibid., 1844; Visit to the Bitter Lakes, Istlimus of Suez, in Lond. As. Traus., 1845; Geological Notes from Masulipatam to Goa; on the Alpine Glacier, Iceberg, Diluvial, and Wave Translation Theories, with reference to the Deposits of Southern India, in Bl. As. Trans, ibid. v., xiv. part 1, 217 ; Geological Notes across the Peninsula of Southern India, from Kistapatam, ibid., 398 ; History of the Persian Poets, in Mad. Lit. Trans. ii. 245 ; Summary of the Geology of Southern India, in Lond. As. Trans, 1845 ; Essays on the Metrical Compositions of the Persian Poets, with a Notice of their Poetry, Mad. Lit. Trans. iii. 113, 232 ; on the Code and Historical MSS. of the Siamese; on the Progress of Buddhism to the Eastward, ibid. vi. 117 ; Recent Fresh-water Deposits near Kurnool, in Bl. As. Trans., 1844, xiii. 213 ; Account of the Muhammadan Kings of Acheen, ibid. iv. 117; Notice of Malayan Code, ibid. 390; Political and Statistical Account of the British Settlements in the Straits of Malacca, 2 vols. 8vo; Site of $\mathrm{Hai}$ or Ai, Royal City of the Canaanites, in Bom. Geo. Trans. viii. 335.Bombay Times, May $1850 ;$ Dr. Buist's Catalogue.

NEIV BRITAIN, a chain of large islands which stretch between the parallels of $4^{\circ}$ and $6 \frac{1}{2}^{\circ} \mathrm{S}$. from near the N.E. part of New Guinea and the S.W. part of New Ireland, and having Dampin Channel to their westward, and St. George's Channel to the eastward of them. In the New Britain group the Papuan girls of six or eight years old are shut up for some five years in cages made of palmleaves, out of which they are never allowed to 
come till they are to be married. The cages are placed inside large houses, with old women to watch them. The girls are taken out once a day to wash, but they never leave the house. Mr. Wallace says that they do not seem to suffer in health.

NEW CALEDONIA is surrounded by a great reef. It was colonized by the French in 1855 . Its southern extremity is in lat. $22^{\circ} 24^{\prime} \mathrm{S}$., and long. $166^{\circ} 55^{\prime} \mathrm{E}$. The Isle of Pines lies to the east, in lat. $22^{\circ} 42^{\prime}$ S., and long. $167^{\circ} 31^{\frac{3}{4}}{ }^{\prime} \mathrm{E}$. Port St. Vincent, a beautiful and extensive harbour, is formed by islands, three miles within the coral reef that extends, with a few breaks, along the whole S. W. coast of New Caledonia. It fronts the shore at the distance of four to eight miles. It is steep to seaward, level with the water's edge. Loyalty Islands form a large range to the eastward of New Caledonia. Its soil is of volcanic origin, and its flora almost exclusively arborescent, Proteaceæ, gigantic ferns, and casuarineæ.

NEW GUINEA, or Tana Papua, is an island on the eastern border of the Eastern Archipelago. Its north coast is generally high; towards the sea there is low land, but a little way inland a chain of mountains extends paraliel to the coast, and elevated in some places 4000 or 5000 feet above the sea, and there are said to be mountains 17,000 feet high, covered with snow; Mount Owen Stanley being 13,000 feet. Near Dori the loftier mountains retire a little backward, and seem to reach their greatest altitude in the Arfak range, which the officers of the Coquille ascertained to have an elevation of 9500 feet. It is 1500 miles long, and 410 in breadth, with an area of 224,000 square miles. It may be said to consist of a great central mass about the size of the Austrian einpire, and two tapering peninsulas, one at the north-west, or Dutch, the other at the south-east, or British end. Mountain ranges exist in these peninsulas, but little is known of the country inland. Signor D'Albertis, who ascended the Fly river for about 500 miles into the interior, alone has seen anything of it.

The Portuguese (Jorge de Meneses) stumbled on it in 1526, and the Spaniard (Luiz Vaez de Torres), in 1606, formally took possession of it in the name of the king of Spain, and with it 20 natives, so that, to use his own words, "with them we might be able to give a better account to your Majesty.' The Dutch Commissioner Van Delden, in a proclamation dated August 24, 1828, annexed to the crown of Holland that portion of New Guinea and the lands lying therein, beginning with the 141st degree of longitude east of Greenwich on the S. coast, and from thence W.N.IW. and N. as far as the Cape of Good Hope, situated on the north coast. The climate was found to be too unhealthy, and in 1835 the settlement was abandoned. But in 1848 , by resolution of the Governor-General (dated the 30th July), the Netherlands territory was determined to extend from the Cape Bonplanc in $140^{\circ} 17^{\prime} \mathrm{E}$. on the $\mathrm{N}$. coast, along the shores of Geelvinks Bay to the Cape of Good Hope, and, further, towards the W., S., and S.E. as far as $140^{\circ} \mathrm{E}$. on the S. coast. On this portion, posts, provided with the Netherland arms, and with the inscription New Guinea, were set up in 1850 . The surface thus under Netherlands rule, together with that of the island iucluded, amounts to 3210 square geographical miles (Dutch), with a population estimated at about 200,000 souls.

The British connection with it began with Captain Bligh, of Bounty fame, who sighted New Guinea in 1792 , and he took possession in the King's name of 'everything he saw' on his voyage through Torres Straits. According to a despateh from the Adniralty to the Colonial Office, dated 14th October 1873, New Guinea was formally taken possession of by Lieutenant Yule, of Her Majesty's ship Bramble, in 1846, at a point named by him Cape Possession, about 300 miles westward of Captain Moresby's subsequent discoveries. Captain Moresby, in the Basilisk, in 1874 circumnavigated the island, and found an archipelago of about 60 islands, with many fine harbours. On the 24th April 1874, he landed his ship's company on Hayter Island, and, in the Queen's name, took possession of it, as well as of Moresby and Basilisk Islands, together with various groups of detached islets. On the 6th November 188t, Great Britain proclaimed the British Protectorate over all the southern coasts to the eastward of the 141st meridian of east longitude. The area of annexed territory is about 175,000 square miles. The races are untouched by civilisation, and for the most part are perfect strangers to the white man.

The villages are small and scattered, but all are independent, and recognise no central authority. A large and powerful village is feared by the smaller ones, and will plunder and oppress them, but there is no chieftainship over an entire district. The promulgation of laws and the exercise of justice are alike unknown. They are all predatory, and given to thieving. The men, when they have killed an enemy, are tattooed. The women wear a kilt, and are all tattooed.

The London Missionary Society have established a mission at Port Moresby, Boera, Samoa, and other places; but the climate of New Guinea is such as to render European colonization hazardous. Experience scarcely warrants the hope that healthy districts will be found.

The rainfall in the wet season averages 34 inches, whilst the heat at Port Moresby ranges from $73.5^{\circ}$, the average minimum night temperature, to $90.43^{\circ}$ in the shade during February, which is the hottest month.

New Guinea has several varieties of the Negro race, the tall Papuan, the small Negrito, and the Maori form, and the people on the coast are in some places mixed with the browner races of the Moluccas. The darker type of Papuans struck D'Albertis as identical with the true Negro of Africa, insomuch that on his return home he felt sure that were some of the Somali men, among whom he was shipwrecked in the Red Sea, transported to New Guinea, they might be mistaken for natives of that island, having the same receding forehead, aquiline nose, and moderately thick lips, with curly but not woolly hair. This is what he called the Arab type when speaking of Moatta and Tawan, distinct in many respects from the Negroes of Central and Southern Africa. The skulls 'collected by him exhibit specimens both of the extreme prognathous type, and of the round or brachycephalic, generally identified with the Polynesian race. The skin is black in the natives of the west, while from Redscar Bay eastward it is light brown. 
In the interior, again, the people in the mountains are intermediate in colour, and are quite distinct in habits.

It is the great seat of the Papuan race. The names by which the island is known to Europeans and Asiatics, New Guinea and Tanna Papua, both distinctly refer to the leading peculiarity of the race by which the coasts are inhabited.

This island, and also the $\mathrm{Ki}$ and Aru Islands, with Mysol, Salwatty, and Waigiou, are occupied almost exclusively by varieties of the Papuan, and a Negro variety extends over the islands east of New Guinea as far as the Fiji group, though they differ greatly in physical appearance in New Ireland, Malicollo, one of the great Cyclades, Tanna and New Caledonia in the New Hebrides.

The Papuan variety about the Fly river in New Guinea has an intensely dark brown skin, but not nearly black, are taller and more warlike, Captain Moresby says, than those of the E. Peninsula, also less intelligent, but better wood-carvers. They are said to be cannibals. On the 7 th of March 1879, the missionaries were attacked by the natives at Kato, in the district of Port Moresby, Hulu, and four of them, with two of their wives, four children, and two servants, were killed.

The tribes on its E. Peninsula vary in colour from light yellowish-brown to rich coffee-brown. They have many tribes, and seem to be of PapuaMalay descent.

The Rev. IV. G. Lawes described the villages round Hood Bay as inhabited by a fine industrious race, but they have martial proclivities, and carry on hostilities against each other. Their women seem to be better treated than with most savages. They are excellent sailors, make capital pottery, are bold hunters, and skilful fishermen. The Koitapu and Koiari aborigines of the part of New Guinea about Port Moresby (lat. $9^{\circ} 30^{\prime} \mathrm{S}$., long. $147^{\circ} 10^{\prime} \mathrm{E}$.) differ in physique, language, ornaments, modes of cooking, weapons, and manufactures from the coast tribes or Motu. They have frizzy, not woolly hair, and are rather small in stature. The number of separate tribes and races on the S.E. coast of New Guinea is very great, 25 different dialects and languages having come under notice in 300 miles of coast. Its S.W. part is known to native traders as Papua-kowiyee and Papua-Onen; it is inhabited by the most treacherous and bloodthirsty tribes, and up to the present time traders continue to be murdered there. The Papuans of Mysol, Salwatty, Waigiou, and some parts of the adjacent coast, have become peaceable. On the S.W. coast of New Guinea, however, and in the large island of Jobi, the Papuan race are in a very barbarous condition, and take every opportunity to rob and murder. The tribe in the interior of Dori are called Arfak. They are savages. Not a single Malay, or Bugis, or Ceramese settlement exists on New Guinea, though several are scattered over the outlying islands, the principal being at Salwatty, a large island forming the apparent N.W. extremity of New Guinea, from which it is separated by a very narrow strait.

The flora and fauna are to a great extent Australian. Some districts are hungry and barren, while in others food is plentiful. Areca palm, breadfruit, wild mango, and chestnut, pandanus, crotons of variegated leaf, crimson dracænæ, orchids, creepers, and ferns flourish near watercourses and rivers, or in gorges and ravines of the hills. Bananas are plentiful, and a few yams are grown. Taro is abundant in some places; and sugar-cane, pumpkins, melons, wild mango, and cucumber are found to flourish in others. A great deal of sago, too, is made from the sago-palm, and the native dietary is eked out not only by cocoanuts, but by shell-fish, lizards, beetles, and, writes Mr. Wallace, almost every kind of large insect, eaten either raw or cooked, so that the people are never half-starved like the Australians. The coasts are rich in mother-of-pearl shell, tortoise-shell, pearl oysters, trepang, and fish.

The flora is rich in Filices, Scitamineæ, Aroideæ with edible roots, Convolvulaceæ and Solanaceæ. The Gramineæ furnish saccharum, milium, oryza, zea, the beautiful Phalaris arundinacea. Amongst the fruit trees are seen the Carica papaya, Musa paradisiaca, Bromelia ananas, Citrus aurantium in great quantity, Canarium commune, Terminalia catappa and Myristica moschata. Along the shore there are Rhizophora, Myrobalanus, Mangium, Avicennia, Barringtonia, Elæocarpus, Xanthoxylum, Celastrineæ, Ficus, Ricinus, Artocarpus, Calamus, Flagellaria, Bambusa, Acacia, and Casuarina. More than 150 kinds of insects, Scarabei, Buprestides, Curculionides, and also beautiful Lepidopteres and Hemipteres. This country is also rich in beautiful coloured Arachnides. Amongst the birds there are found Psittacus galeritus, Phlyctolaphus sulphureus, Psittacus aterrimus, and species of Buceros. Of the birds of paradise are the brown-feathered with beautiful white and orange-coloured feathers on the sides; the wholly black with long tail and large bent beak; a small yellow kind with orange-coloured breast; another kind, red with two pens projecting from the tail, with a small green-coloured curled bunch of feathers at the ends. Epimachus magnus, a bird of the coasts of New Guinea, is the Upupa inagna, Gm., and U. superba, Lath. Its tail is three feet long, and its head-feathers are lustrous steel-blue. The maminiferous animals are few in number. Some wild hogs, and a species of marsupial, Perameles doryanus, about the size of a rat, with scanty reddish hair like bristles, an extended pointed snout, short tail, and a pocket on the belly in which it carries its young ones; the cuscus, flying phalanger, and the echidua or prickly ant-eater. There is no elephant, leopard, or tiger.-Saturday Review; Moresby in J. R. Geog. Soc.; D'Albertis' New Guinea; Voyage of the Triton, 1828 ; Bikmore, $\mathrm{p}$. 204; A. R. Wallace; Mr.W. G. Laues.

NEIV HEBRIDES, islands in the Pacific Ocean, lying between lat. $14^{\circ} 29^{\prime}$ and $20^{\circ} 1^{\prime} \mathrm{S}$., and long. $166^{\circ} 41^{\prime}$ and $170^{\circ} 21^{\prime} \mathrm{E}$. In Taua, the colour of the native skins is a shiny black, and their bodies covered thinly with hair, or a kind of down. Some have black or brown crisp hair; and that of the greater number is twisted and tied up into an immense number of thin cords, the ends being frizzled out about two inches from the extremity, where the colour is a sandy red. The nose is generally rather flat, and the eyes of a chocolate colour; the ears of almost all being pierced, and flat rings of tortoise-shell and other trinkets hanging from them. The men wear the wrapper, the end of it being, in many 'cases, tied up by a narrow band of some kind of plait, passing round 
the hips, and producing a much stronger effect of indecency, according to European notions, than the total absence of clothing would do, the more so that this scant garment serves as a pocket wherein to deposit a pipe, piece of tobacco, or any such article that they may obtain by traffic. Women dress in a petticoat reaching to the knees. Some skulls exhibited in 1876 at the Anthropological Society from Malicollo had their forehead artificially depressed. The Conus textilis, Linn., found at $\Lambda$ neityum, bites and injects a poisonous acrid fluid into the wound, occasioning the part to swell, and often endangering life.-Captain Elphinstone Erskine; Western Pacific.

NEIV IRELAND is a narrow island upwards of 200 miles long. Its southern part and the east end of New Britain form the east side of St. George's Channel. Its Cape St. George is in lat. $4^{\circ} 51^{\prime} \mathrm{S}$, and long. $152^{\circ} 48^{\prime} \mathrm{E}$. Captain Keppel mentions that the water where he anchored was so beautifully clear that in forty fathoms deep the coral shells and seaweed growing at the bottom could be distinctly seen, and gave it all the appearance of a beautiful submarine garden.-Keppel's Ind. Arch. ii. p. 208.

NEWSPAPER. The oldest newspaper in the world is the King-Pau, or Capital-Sheet, published in Pekin, and, since the 4 th of June, issued in a new form preseribed by special edict of the reigning emperor Quang-soo. It first appeared A.D. 911, but came out only at irregular intervals; since the year 1351, however, it has been published weekly, and of uniform size. Until its reorganization by Imperial decree, it contained nothing but Orders in Council and Court news, was published about midday, and cost two cash, or something less than a halfpenny. Now, however, it appears in three editions daily. The first, issued early in the morning, and printed on yellow paper, is called Hsing-Pau (Business-Sheet), and contains trade prices, exchange quotations, and all manner of commercial intelligence. Its circulation is a little over 8000 . The second edition, which comes out during the forenoon, also printed upon yellow paper, is devoted to official announcements, fashionable intelligence, and general news. Besides its ancient title of King-Pau it owns another designation, that of Shuen-Pau, or Official-Sheet. The third edition appears late in the afternoon, is printed on red paper, and bears the name of Tilani-Pau (Country-Sheet). It consists of extracts from the earlier editions, and is largely subscribed for in the provinces. All three issues of the King-Pau are edited by six members of the Hau-Lin Academy of Sciences, appointed and salaried by the Chinese State. The total number of copies printed daily varies between 13,000 and 14,000 . About the year 1880 , the Chinese at Shanghai bad three daily papers, and the ShuenPau circulation was 16,000 daily. Japan has several newspapers.

The Hindu and Mubammadun courts of India, from the most ancient times, kept news-writers at towns of importance, but in British India the first vernacular newspaper of the kind familiar to Europeans was the Sumachar Durpun, issued by Mr. Marshman, who was also for many years the editor of The Friend of India. The next newspaper was the Cowmoody, of which Raja Ram Mohun Roy was one of the editors.

The first newspaper of British India in the Eng- lish language appeared in Bengal on the 29th January 1780. It assumed a great latitude of expression, and the Government of India established a censorship, supported by penalties, which was continued for nearly 30 years, and at times great restrictions were put upon it. Comments were forbidden on the acts of the higher authorities, and the press for a long time was a mere receptacle for advertisements. About the year 1820, however, Mr. James Silk Buckingham cominenced to write freely, and as the Marquis of Hastings, then Governor-General, avowed that good government had nothing to fear from the light, Mr. Buckingham commented freely on the acts of the Government; but succeeding Governor-Generals stringently applied the existing penal rules, and deported Mr. Buckingham. Subsequently Loril Amherst and Lord William Bentinck again permitted freedom of discussion; and during Sir Charles Metcalfe's administration, supported by Mr. Thomas Babington Macaulay, the press was declared free, and it continued so until the beginning of 1878 , when a censorship of the native presz was re-established.

The Vernacular Press Act (Act 9 of 1878) empowered the provincial Governments to take repressive measures against such vernacular journals as might transgress certain very wide canons of loyal conduct and of political criticism; but the orders of the Supreme Government of India, approved by the Secretary of State, further required that no repressive measures should be instituted under the Act without the previous sanction of the Supreme Government in each case. In 1872 there were in India about 300 newspapers published in the various vernacular languages,-chiefly in Bengali, Urdu, Mabrati, Gujerati, Tamil, and Telugu ; in English 142, vernacular 223, in English and vernacular 66 ; total, 431. There are also nearly 20 journals published in English, of which the chief are those of Calcutta, Bombay, Madras, Allahabad, and Lahore.

NEIV TESTAMENT, a sacred book of the Christians, called Anjil by Muhammadans.

NEW YEAR of the Chinese falls on the first day of the new moon after the sun enters Aquarius. The Muhammadans of India have a year of lunar months, and their New Year's day is the first of the month of Maharram. See Nao-roz.

NEIV ZEALAND, in the South Pacific Ocean. between Australia and North America, consists of two large and several small islands, lying between lat. $34 \frac{1}{2}^{\circ}$ and $47 \frac{1}{2}^{\circ} \mathrm{S}$., and long. $166 \frac{1}{2}^{\circ}$ and $178 \frac{3}{4}^{\circ}$ E., 800 miles long from north to south, and 120 miles broad, with an area of 99,969 English square miles. It was discovered in 1642 by the Dutch seaman Abel Tasman, four of whose crew were killed and eaten, and on the 6th October 1769 by Captain Cook, a British navigator, who had with him Solander and Joseph Banks as naturalists, and in his second voyage the Forsters.

The Middle island is the largest, and has fewer tribes of aborigines than the north. The South island is very small, and not fit for agriculture or grazing, owing to the severe cold and thick bush. It is but thinly populated, and the chief occupation of its inhabitants is turning to account the whales and seals which abound on its coast. Down the middle of the North island runs a high range of mountains, of which Ruarahu, 9000 feet above the sea, is the highest. From the main range 
some high spurs run down to the sea, but most of the range finishes off in low hills, valleys, and plains, highly in request for agricultural and grazing purposes.

Amongst these hills are several active volcanoes, with many that have become extinct. In the higher ranges are many fresh-water lakes. The hot springs on Lake Taupo are one of the great sights of this colony. From these lakes and this mountain tract spring many streams and rivers, some of which are navigable for some distance inlaud. The rivers of New Zealand are all subject to sudden rises, from the melting of the snow, or from heavy falls of rain; the mountains from their abrupt formation rapidly throwing off the surplus waters. In the Middle island the main range of mountains runs chiefly down the west coast, and on that side there is little land suitable for agricultural or grazing purposes; but on the eastern coast this formation gives room for large plains and fertile valleys. Of this range, called the Southern Alps, Mount Cook attains an elevation of 13,000 feet, and from it to the sea runs the largest glacier in New Zealand. There are many other glaciers in the region of perpetual suow, but this one is of great extent.

On the east coast of both islands there are some splendid harbours, especially the Bay of Islands, Auckland, and Akarva. The principal towns, Wellington, Christ Churcb, Dunedin, and the Bluff, have harbours. Some other towns on both coasts have open roadsteads safe only with offshore winds.

Wellington is now the capital of New Zealand. The great gold-digging towns Auckland and Dunedin have the largest population.

The aborigines are the Maori. In stature they are almost equal to Englishmen, the average height of the men being 5 feet $6 \frac{1}{4}$ inches. The females are less bandsome than the men, although the young are invariably pleasing. 87 per cent. have brown skins, with black, straight, and waving hair; 10 per cent. have reddish-brown skins, with short frizzly or long straight hair, having a rusty-red tinge in it; and 3 per cent. have black skins, with dark frizzly hair, which does not, however, spread over the head as in Negroes, but grows in tufts which, if allowed to join, twist round each other and form spiral ringlets. Among some tribes the black and reddish men are more numerous than among others. Chiefs are generally brown-coloured, occasionally reddish, rarely black. Every tribe, however, comprises the three varieties; all speak the same language.

Tattooing is a Polynesian word signifying a repetition of taps. In the language of the New Zealanders, moko is the general term for the tattooing on the face, and whakairo for that on the body. Dampier in 1691 brought to England the first tattooed South Sea islander, a man who was well known in London as the painted prince, at which place he died of small-pox. New Zealand men tattoo their faces, hips, and thighs; and the women their lips, chins, eyelids; and occasionally straight lines, the offspring of each woman's fancy, are drawn on their bodies. Every line has a name, and among distant tribes the tattoo marks are alike, although the figures tattooed are not made up of the same number of lines. And among the New Zealanders it is a mark of rank to have the streaks of a fish carefully cut on their bodies.

When first discovered, New Zealand possessed, of mammalia, only dogs and rats. The islands had 15 species of the wingless apteryx birds; the Dinornis giganteus, now extinct, was about $9 \frac{1}{2}$ feet high, and the D. elephantopus; the Palapteryx ingens, $6 \frac{1}{2}$ feet high. While left to themselves, the Maori became skilful hunters and fishermen, and good agriculturists. They learned to carve, to weave, and to tan. They built up an elaborate mythology. Their cannibalism was associated with a belief that the better qualities of the victim were transferred to his devourer. Captain Elphinstone Erskine heard it asserted that there did not exist in 1845 many New Zealand males of twenty years of age who had not, in their childhood, tasted of human flesh. The race is fast disappearing. In 1840 their number was 100,000 ; in $1856,65,000$; in 1874 , 45,000 ; and in 1882, only 40,000 in North Island, and 200 in South Island. The Maoris themselves scent their approaching fate: "As the white man's rat has extirpated our rat, as the European fly is driving out our fly, as the foreign clover is killing our ferns, so the Maori himself will disappear before the white man.' Everywhere, from the Australian aborigines to the New Zealand Maori, the native races are depicted as fading away before the white man, like the native rat and even the native grasses. Its principal timber trees are species of dacrydium, metrosideros, and podocarpus.

NGARI or Gnari, a territory which embraces the whole of the upper valley of the Sutlej, from the Manasarowara lake to the crest of the Porgyal mountain.

NG TSOCK, in Cbina, undress and wash and re-clothe the dead. They are deemed unclean, are not permitted to worship in the temples, their sons are not allowed to become candidates for literary degrees; they resemble the pollinctores of the ancient Romans.-Gray, p. 280.

NHARUI. The races occupying Baluchistan are divided into two great classes, severally known by the appellation of Baluch and Brahui, and these again are subdivided into a number of tribes, who take their names from the chief under whom they serve, the district or country to which they belong, or the traditions whence they derive their descent. The contour of the people of the two classes is as unlike, in most instances, as their languages, provided they be descendants of a regular succession of ancestors of either; but the frequent intermarriages which take place amongst them have tended in some degree so to blend together the peculiar characteristics of both, that in inany families, and even whole tribes, they haveceased to exist. The Baluch branch, in the first instance, form the original class of that name, subdivided into three principal tribes, called Nharui, Rindi, and Mughsi. The Nharui principally inhabit that portion of Baluchistan which lies to the W. of the desert, and there are likewise khels of them at Nooshky and in Seistan. The Baluchi partakes considerably of the idiom of the Persian, and at least one-half of its words are borrowed from that language, but greatly disguised under a corrupt and unaccountable pronunciation. The Brahuiki is dissimilar in sound and formation, not in any way approaching to the idion of the 
Persian. It contains a portion of ancient Hindu words.

NIAMAT-ULLA-author of the Makhzan-iAfghani and of the Tarikb-i-Khan-Jahan Lodi, essentially the same books. He was the Wakia navis or news-writer at the court of the emperor Jahangir.-Elliot.

NLAN. BHoT. Ovis ammon, the wild sheep of Ladakh. It is fleet and agile and graceful.

NIARIYA, a Hindu caste about Benares who purchase and sift the sweepings of goldsmiths' shops.

NIAZI, a tribe of Afghans, British subjects, who are settled in the Bannu district. They are descended from Niaz Kban, second son of Lodi, king of Ghor, by his second wife Takia. Lodi was the Lohani chief who in A.H. 955 invaded Hindustan, and, conquering the Daman, apportioned the lands amongst his sons. The fertile districts of Isa Khel fell to the lot of Niaz Khan, whose descendants are settled there to this day. Their four agricultural sections are about 16,000 souls, the great majority being settled in the Bannu and in the Trans-Indus districts. The Povindah subdivision trade only between Khorasan and the Dehrajat, encamping in the cold weather on the west of the Indus, and, when in Khorasan, wander in the Pana district. They have five clans, with about 1000 fighting men. The route they follow is the Ghwalarai, though they sometimes go to Kābul by Dawar and Khost, but this route is seldom followed on account of the difficulties of transit through the -Turni country.

NIBONG. MaLAY. A palm of the Malacca districts, said to be the Oncosperma filamentosum? Its stem is split into lathes, and used for flooring and other house-building purposes.

NIBUTTI of the Buddhists is identical with the uivertti or moksham of the Brahmans, and possibly analogous to the apolutrosis and exanastasis of St. Paul. Nibutti or nirvana means the release from re-appearance in a material body.-Taylor.

NICANDRA INDICA. Kaknaj, HIND. Winter cherry. Said to be diuretic and purgative, useful in ulcerations of the bladder.-Powell, i. p. 364 .

NICANDRA PHYSALODES. Gærtn. Atropa physalodes, Linn. It is said to be diuretic.-O'Sh. p. 460 .

NICANOR, a lientenant of Antigonus (B.C. 305), who seized the whole of Media, Parthia, Asia, and all the countries as far as the Indus.

NICARAGUA WOOD, or Peach wood.

Bloed-haut, . . Dut. Blutholtz, . . GEr. Bois de sang, : . Fr. Legno sanguigno, . IT. Bojs de Nicarague, . , Palo de sangre, . SP. Nicaragaholz, 'GER. Pao sanguinho, : PoRT. $-M^{\prime} C$. Com. Dict. p. 851.

NICHOLSON. A medical officer of the Bombay service, who wrote an Account of the Kooree, or eastern branch of the Indus, showing the probable changes of its course, and the manner in which the old channels have been blocked up, in Bom. Geo. Trans. vi. p. 111; Account of the Island of Perim, in Bom. As. Trans. i. p. 10; of the Submerged City of Balabhipura, in Lond. As. Trans., 1852 .

NICHOLSON, JOHN, a Bengal military officer who rose to the rank of lieutenant-colonel. He was a Deputy-Commissioner in the Panjab Civil Commission. He had more influence with his subordinates than perhaps any native of Great Britain in the east has ever had. One class of natives actually termed themselves "The Nicholsani or Nikar Singhi Fakirs.' A native speaking of him said, "The sounds of his horse's hoofs were heard from Attock to the Khaibar.' In an official report of the Panjab Government, this sentence occurs, 'Nature makes but few such men, and the Panjab is happy to have had oue.' He was employed in the Afghan war of 1838 to 1842 , and fell at the re-taking of Dehli.-Tr. of Hind. ii. 368.

NICKEL, a brilliant white metal resembling silver; ductile and malleable, and capable of receiving a high polish. It is usually procured from speise, a compound of the metal with arsenic, found associated with cobalt in Germany. Alloyed with copper, it forms argentan or German silver, and is besides used in making mariners' compasses, and for other purposes. Nickel and cobalt occur near Saffragam, in Ceylon.-Waterstone; Faulkner.

NICOBAR, Sambalang, or Nine Islands, in the Bay of Bengal, between lat. $6^{\circ} 40^{\prime}$ and $9^{\circ} 20^{\prime} \mathrm{N}$., have an area of 735 square miles. The Danes formed a settlement on this group in 1756, but abandoned it twelve years after. In 1864, Captain Steem Bille, the commander of a Danish corvette, reported to his Government their unhealthy character, and that Government finally abandoned them. The Indian Government, on the 15th July 1872, annexed the Andamans, the Great and Little Cocos, and the Nicobar Islands, the islands of Car Nicobar and Great Nicobar, with those lying between them, including Tillanchong. The Nicobars are not more than 120 miles distant from the west end of Sumatra. The population is about 6000 . Those of Malay origin are of a sallow copper colour, with small oblique eyes, the whites of which have a yellowish tinge ; their noses are flat, their mouths large, their lips thick their persons are well proportioned but short, their hair coarse and black, and little or no beard. The back of their heads is extremely flat, it being made so by compression in infancy. They are lazy, cowardly, drunken, indolent, and apathetic; in a rude state of society, and unacquainted with any of the ordinary arts. Agriculture is unknown, their industry being confined to fishing, raising a few roots, fruits, and palms, and rearing the hog, dog, and common fowl. The people are supposed to have cut off many sailing ships. There are many wild cattle from a breed introduced by the Danes. The many dialects of the Nicobars have been supposed to be allied to those of the browncomplexioned people of the Archipelago. They suppose that the soul of the dead stays for a time in the neighbourhood in which it lived. Burials are conducted with great solemnity, and over each body a post is erected, on which are placed the utensils daily used by the deceased. Calœenas Nicobaricus, the Nicobar pigeon, is of great size and splendour; its appearance and habits exhibit a near approach, to the gallinaceous birds. It lives chiefly on the ground, runs with great swiftness, and flies up into a tree when disturbed. Its nest is of the rude platform construction usual among the pigeon family; one of them found was built in a tree about ten feet from the ground, and contained a single white egg.Crawfurd; As. Res.; J. Ind. Arch.; Rec. Govt. Ind. ; MacGillivray; Horsburgh. 
NICOLO-di-CONTI, or in Latin De Comitibus, a Venetian of noble family, who resided as a merchant in the city of Damascus about A.D. 1419. He passed through Persia, sailed along the coast of Malabar, visited Bengal, Cambay, Vizianagar, Palconda, St. Thomé, Ceylon, Sumatra, Tenasserim, Ava, Java, thence returned to Quilon, Cochin, Calicut, Socotra, and homeward. On his return passed along the coasts of Ethiopia, sailed up the Red Sea, crossed the desert, and reached Cairo, where he lost his wife and two children, and returned to Venice in 1444, after twenty-five years' absence. As a penance for having apostatized to the Muhanmadan religion, the Pope Eugene IV. required him to relate his adventures to Poggio Bracciolini, the Pope's secretary, and the original Latin appeared in the fourth book of Poggio's treatise, de Varietate Fortuni, libri quatuor, Paris 1723. He speaks highly of what he saw about Gujerat. $\mathrm{H}_{e}$ found the banks of the Ganges (or perhaps the Megna) covered with towns amidst beautiful gardens and orchards, and be passed four cities before he reached Maarazia, which he described as a powerful city filled with gold, silver, and precious stones.-Ind. in 15th Century; Ramusio, i. p. 359 ; Elph. p. 427.

NICOTIANA, the tobacco genus of plants, belonging to the order Solanaceæ, mostly herbs. The following are the better known species:-

Nicotiana angustifolia, Ruiz and Pav., Chili.

N. Bonariensis, Lehm., Buenos Ayres.

N. fruticosa, $L$, the $N$. frutescens, Cav., India.

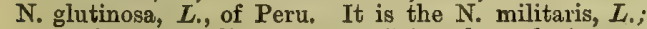
Tabacus viridis, Monch; Sairanthus glutinosus, G. Don.

N. latissima, Miller (N. macrophylla, Lehm.), yielding largely the Chinese, Orinoco, and Maryland tobacco.

N. multivalvis, Lindley, Columbia river.

N. nana, - ? Rocky Mountains.

N. paniculata, Linn., N. viriditlora, Cav., Peru.

N. Persica, Lind., Persia, Shiraz tobacco.

N. plumbaginifolia, Viv., the N. cerinthoides, Vittm., Rio Grande.

N. quadrivalvis, Pursh., N. America, Missouri.

$\mathrm{N}$. repanda, Willde, Cuba, Havannah tobacco.

N. rotundifolia, Lindley, Swan river.

N. rustica, Linn., Europe, Asia, Afriea, America, English tobacco, Godavery tobacco, Syrian tobacco.

N. tabacum, Linn., the N. Havanensis, Lag., America

Most of these yield tobacco leaves for smoking, and many of them are cultivated in the gardens of Europe. The name Nicotiana was given to these plants after Jean Nicot of Nimes, in Languedoc, who was an agent of the king of France at Portugal, and in 1560 procured the seeds of the tobacco from a Dutchman who had obtained them in Florida. Tobacco was the name nsed by the Caribbees for the pipe in which it was smoked, and this word was transferred by the Spaniards to the herb itself. Tobacco leaves when properly dried have a greenish-yellow colour, a strong, pleasant smell, and acrid taste; taken into the stomach by persons not habituated to its effects, violent vomiting, diarrhoea, and collapse are occasioned. N. quadrivalvis has capsules with four valves; it grows near the Missouri river, and is there smoked by the natives. N. multivalvis has capsules with many valves; it is cultivated by the Indians on the Columbia river for smoking. It is a fetid plant, and the calyx, the most fetid part, is selected by the Indians for smoking. N. nana, a small species, a native among the Rocky Mountains of North America, is smoked by the Indians. N. repanda, a native of Cuba, is said to furnish the tobacco for making the small cigars known as Queen's. The Macuba tobacco, which grows in Martinique, is deemed the finest, and next to it in esteem is the Cuba tobacco. N. macrophylla, or Orinoco tobacco, is a herbaceous plant with ovate-acute leaves clasping the stem; throat of corolla inflated, segments short-pointed; the stem rising from 5 to 7 feet high. It is a native of America, and is frequently used for smoking; the milder Havannah cigars are said to be made from it. The Havannah, Persian, Manilla, and Maryland tobaccos have been extensively introduced into the Peninsula of India. The British smoke more of the strongest tobacco than any nation in the world.

Nicotiana Persica, Shiraz tobacco, is a herbaceous plant, clothed with clammy down, with the leaves of the root oblong, those of the stem acuminate and sessile; corolla salver-shaped, with a long tube, and rather unequal segments. This tobacco is milder than that produced by the N. tabacum.

Nicotiana rustica, Lim.

Kakkar-tamaku, CHENAB. | Bauerm-tabak, - GER. Tseang, . . . CHIN. Tabac-comaroso, . . SP. Tabac-pausse, . . FR.

This plant is grown in Europe, Asia, Africa, and America, and in India is highly valued. It is the English, Syrian, Salonica, Godavery, Turkish, Latakia, Tamaku, Kandahari tamaku, Kalkatti tamaku. It has a herbaceous square stem, with petiolate-ovate quite entire leaves; tube of corolla cylindrical, longer than the calyx; segments of the limbs roundish, obtuse. It was the first species that was introduced into Britain for growth from America. It grows very well in that climate, and in some places is almost naturalized. From the extensive range of climate and difference of situation which this plant occupies, its characters suffer considerable change; hence a number of varieties have been described. The yellow Chinese Tseang tobacco is cultivated in East Tibet and in West China. It resembles in flavour the finest Syrian tobacco, and is most agreeable when the smoke is passed through the nose. Under various names, it is cultivated at many places in British India.

Nicotiana tabacum, Linn. N. Havanensis, Lag. Bujjir bhang, . . ARAB. Dhumra-patra, .SANSK. T'sha, . : BURM. Doon-kola, . . SINGH Tamakhu, : HIND. Poghei, : : TAM. Tumbaku, . MAleal. Poghaku, . . TeL Sahastra-patra, . SANSK,

This species is the common tobacco, Virginian tobacco, Herbe-à-la-reine, sweet-scented tobacco, Orinoco and Maryland; it is herbaceous, with acuminated oblong-lanceolate sessile leaves, lower ones decurrent; throat of corolla inflated, segments of the limb pointed. This plant is a native of the West Indies, where it first became known to the Spaniards, and of Virginia, where the English first became acquainted with its properties. Of the various species, it is that which is most commonly cultivated in gardens as an ornament. It is largely cultivated in Europe for the purpose of smoking. It is grown over all the plains of the E. Indies, on the Himalaya up to 7400 feet at least, on the Chenab to 11,000 feet. This species is the one most commonly employed for making tobacco and cigars. Dr. Royle mentions that it 
was introduced into India in A.H. 1014 (A.D. 1605), towards the end of the reign of Akbar. He quotes the authority of Pallas, Loureiro, and Rumphius, who think tobacco was nsed in China at a period anterior to the discovery of the New World. N. tabacum is much imported into T'ibet, where it is called Tumma (probably a corruption of the Persian Tamakhu).-Eng. Cyc.; Mason; Hooker, Him. Jour.; Von Mueller; O'Sh.; Dr.J. L. Stevart. See Tobacco.

NICOTRIS, the queen-mother of the king of Babylon. She is said to have counselled resistence against Cyrus, but after a siege of two years, Cyrus drained the Euphrates into the trenches which he had dug around the city, and his soldiers entered it through the bed of the river, and opened the gates for the rest of his army, A.D. 539. Belshazzar was killed in the attack.

NIDANA, SANSK., Nosology, also Nidana Sthana, medical treatises of the Hindus. Some of these, along with the writings of Charaka and Susruta, were translated and studied by the Arabs in the times of Harun-ur-Rashid and Mansur. Nidana, in Buddhism, indicates twelve conditions of existence,-ignorance, karmam or acts, consciousness, individuality, sensibility, objects of sense, sensation, desire or thirst, clinging to existence, birth, old age, and death or suffering.Barth, p. 110.

NIEBUHR, a Danish traveller on the shores of the Red Sea, and between Bombay and Abushahr. Niebuhria linifolia, Linn., and N. oblongifolia, D.C., of the natural order Capparidaceæ, bear his name. They are of the Peninsula of India.-Voy. en Arab. (Amst. 1780). See Neibuhr.

NIGELLA SATIVA. Limu. Var. Indica, D.C.

Shoonez, Hub-sindi, ArAB. Siah-dana, . . PERs Sa-mung-net, . . BurM. Krishna jirakæ, SANsK. Small fennel flower, ENG. Kaloo-dooroo, . . SingH. Kala-jira, . . HIND. Karin siragum, . TAM Magrila, : . . ", Nalla jilakara,. . TEL.

This is the small feunel flower of the south of Europe, Egypt, Barbary, and the Caucasus, and extensively cultivated in India. It is the M M $\varepsilon \lambda_{\alpha \nu}$ $\theta 6 \nu$ of Hippocrates, Steril, 675 , and of Dioscorides, and the Githex of Pliny. The seeds, resembling coarse gunpowder, are triangular, black externally, internally of a greenish-white hue. They have a strong aromatic odour, and a flavour resembling sassafras or cubebs, due to an essential oil, of which the seeds yield from 5 to 10 per cent. They are chiefly employed by the Indian hakim and baid, as aromatic adjuncts to purgative or bitter remedies. In eruptions of the skin, the seeds, reduced to powder and mixed with sesamum oil, are much used as an external application. The tincture is a useful, warm stimulant. In Bengal they are given to nurses, in the belief that they increase the secretion of milk; mixing the powdered seed with curry, to which, however, it communicates a very heavy and disagreeable flavour. To prevent injury to furs, feathers, books, papers, and clothes that are lodged in trunks, bookcases, etc., it is useful to place along with them small packets of camphor, or little cups of camphor dissolved in alcohol, and packets of Nigella sativa. Pieces of the roots of the Aconitum ferox, Ati Singeea bish, or bishnak of the bazars, may also be used, but its highly poisonous effects on avimal life require its use to be had recourse to with the greatest precaution.
Cups of carbolic acid are useful. The oil from N. sativa seeds is clear and colourless, but rather viscid. It is employed principally as a medicine. It is called jungle jira oil in Mysore- $-R o x b$. ii. p. $646 ; O^{\prime}: S h$.

NIGHASAN, a pargana in the Kheri district of Oudh. Bounded on the north by Khairigarh, from which it is separated by the river Sarju, the Chauka river marking the south boundary. The banks of these rivers have a broad fringe of khair, shisham, and gular trees, and the forests along the Sarju swarm with wild hog, deer, nil-gai, and antelopes, which do great injury to the crops. Tigers are seldom found, but leopards are numerous.-Imp. Gaz.

NIGHTINGALE is the bulbul of the Persians, in whose country it occurs. It is a species of Luscinia or Sylvia, and is the true nightingale. The bulbuls of the Muhammadans of British India are short-legged thrushes, the Brachy podidæ, and sub-families Pycnonotinæe and Phyllornithinæ. See Birds ; Bulbul.

NIGHT OF POIVER. Amongst Hindus, the seventh night of the seventh month of the seventyseventh year of a man's age is termed Bbima Ratri, or Night of Power! and is considered the end of his natural life. After that a Hindu is considered exempt from all instituted observances. - Wils. Gloss. See Lailat-ūl-Kadr.

NIHANG, a Sikh sect who believe in Nanak, but their manners and dress are quite different from those of other Sikbs. The Nihang sect were careless of their own lives, and consequently of those of others.-Mohun Lal's Journeys, p. 9 .

NIK $A A$, on the Hydaspes, a city mentioned by Alexander, supposed to be the present Mong or Mung. Mong is six miles to the east of Jalalpur, and the same distance to the south of Dilawar. It is said to have been founded by Raja Moga or Muga, also called Raja Sankhar, meaning king of the Sakas or Sacæ.-Cunningham, India, p. 178 .

NIKAH. ARAB. Marriage, amongst Muhammadans; Nikah namah, the marriage certificate. In Arabia, Egypt, and Persia, the nikah is the principal part of the marriage ceremony. In India, a marriage confined to the nikah is deemed disreputable, or it is with some person of inferior rank. In the case of a spinster of equal rank, the shadi or rejoicings lasting for five days, put all the religious ceremonial of the nikah into the shade. The nikah engagement, though inferior to the shadi form of marriage, is still respectable. It is common where the condition of the parties is too unequal to admit of one more public. Nikah and shadi are often in India used synonymously, as meaning the marriage or the marriage ceremonial of the Mulammadans. The nikah, however, is the form of words used by the Kazi in uniting the couple, and the shadi or rejoicings are all additional, and may be lengthened or curtailed at the will of the relatives. About Dehli, the ceremony of nikah would appear to be styled Burat. The shadi ceremonial in India is generally used only where the bride is a spinster and of equal rank with the bridegroom.

NIKARI. BENG. A fish-dealer, a fisherman; in Behar is a mullan or machua. A nikari is not the class which catches fish, but the caste which takes it from the fisherman and sells it in the market. 
NIKUMBHA, in Hindu mythology, a rakshasa who fought against Rama. Also an Asura king of Shatpuri, who carried off the daughters of Brahmadatta, the friend of Krishna. Krishna slew him, and gave Shatpura to Brahmadatta.Dox'son.

NILAKANTHA, a name of Siva, from his having a blue throat, in consequence of having drank the poison produced at the churning of the ocean.-Cole. p. 390.

NILA KANTHA BHATTA, author of the Mahratta law-book Vyavahara Mayukha.

NIL DARPAN, a Bengali play; it means the Mirror of Indigo, Indigo Factory, and became the subject of a trial in Calcutta.-Imp. Gaz.

NILE, the great river of Egypt, is formed by the Bahr-ul-Abiad or White River, and Bahr-ulAzrak or Blue River, and flowing northwards, it disembogues into the Mediterranean Sea. In 1846, the brothers Abbadie believed they had discovered its sources south of Abyssinia, in lat. $7^{\circ} 49^{\prime} \mathrm{N}$., and long. $34^{\circ} 38^{\prime} \mathrm{E}$, but subsequent travellers have shown that the brothers had given this title to the Uma, one of its affluents; that the true sources were greatly farther south, and the great I,ake Ukereve or Nyanza, which Captains Speke and Grant explored in 1862, is undoubtedly one source of the supply of the Nile waters. The Nile traverses Nubia, fertilizing Halfay, Chendy, Damer (where it receives on its right bank the Takazza or Athara), Chakye, Dongola, Mahas, Sukhot, Hajar, and Barabras. It enters Egypt at Assouan, in lat. $24^{\circ} \mathrm{N}$., and runs almost directly from $\mathrm{S}$. to $\mathrm{N}$. to lat. $30^{\circ} 12^{\prime} \mathrm{N}$., where it divides into two branches, that of Rosetta on the west near Alexandria, and that of Damietta on the east, and both of which have seven distinct mouths. It has six cataracts in its course, but the only one of consequence is that of the ancient Philoe, the modern El-Birhe near Assouan, at the boundary of Egypt and Nubia. About the summer solstice the rise of the Nile is observed to commence above the last cataract. This rise becomes apparent at Cairo in the first days of July, and its progressive increase there is indicated by the Nilometer, which has been established at the extremity of the isle of Roda. For the first six or eight days its rise is almost insensible. Soon, however, its daily increase becomes more rapid. Towards the 15th August it has attained to half its highest rise, which it usually attains about the 20 th or 30 th September. When it has reached this stage, it remains nearly stationary for about 15 days, after which it begins to fall, but much more gently than it rose. By the 10th November it has fallen to half the height to which it had risen, and it continues to subside till the 20th of May of the following year, from which date there are no sensible changes until its rise recommences at the ordinary time of the year. The causes of its rise are now well known. During the hot months of the year, rain falls every day in Habbesh or Abyssinia, and all that rain-water is collected into the Nile, which, from its entrance into Egypt till it reaches the sea, runs through a wide vale. It does not rise alike high through all Egypt. In Upper Egypt the rise is about 30 feet, and at the Nilometer on Roda Island, at Cairo, the full height is 24 feet above its ordinary level. At Rosetta and Damietta it is only four feet. At Cairo, the Nile being confined to one channel, between high banks, must necessarily rise to a much greater height than nearer the sea, where it is divided into two streams, after running over so much barren ground, and forming so many lakes. The branch upon which Rosetta stands is only 650 feet broad; and that by Damietta, not more than 100. Between the dyke of the canal of Cairo and the Nile, a pillar of earth is raised, nearly of the height to which the waters of the rivers are expected to rise. This pillar is called Arūs, or the bride, and serves as a sort of Nilometer, for the use of the common people. When the waters enter the canal, this bride is carried away by the current. A like custom, which prevailed among the ancient Egyptians, has subjected them to the imputation of sacrificing every year a virgin to the Nile. Nukta signifies, in Arabic, both a drop and the time of the sun's entering the sign of Cancer, at which season the great rains fall in Abyssinia, which occasion the swelling of the Nile. The rise of the Nile, as shown by the Roda Island Nilometer, is daily proclaimed in the streets of the metropolis, from its commencement, about the beginning of July (the Coptic month Baooneh), until it has attained the sixteenth cubit of the Nilometer. The Wifa-un-Nil (the completion or abundance of the Nile) is then proclaimed, generally between the 6th and 16th of August (or 1st and 11th of the Coptic month Mesra). Un the day following, the Nile is admitted into the canal which traverses the city, and thereafter only the increase of the river above 16 cubits is notified. On the date the river reaches its greatest height, usually on the last days of September, the public cry of the river's state ceases, and the shaikh of the Nilometer becomes entitled to a fee from the Government for every digit of the river's increase.

NIL-GAI or Nil-gao. Portax pictus, $J$.

Damalis rizia, $H$. Smith. Antilope pictus, Pallas.

Tragelaphus hippelaphus, A. tragocamelus, Pall., Ogilby.

Maravi, . . . CAN. Roz, Rogh, Nil, Lil, Hind. Gurayi, Guriya,: Gond. Manu potu, . . TEL.

Is one of the largest and most magnificent of known antelopes, being upwards of four feet high at the shoulder. It is found throughout India, from the Panjab and foot of the Himalaya to the south of Mysore, being most abundant in Central India, frequenting thin forests, low jungles, and bushy, open plains. The male is about $6 \frac{1}{2}$ to 7 feet long, and height at the shoulder $4 \frac{1}{1}$ to $4 \frac{1}{2}$ feet. Its horns 8 to 10 inches long, and tail 18 to 21 inches; ear 7 inches, and very broad. It is of a grey slatyblue with a white abdomen, and gives the name Nil-gao or blue bull. The cow is smaller, and of a dun colour. They rove in small herds of half-adozen or thereabouts, and sometimes the bull is found alone, and is occasionally ridden down and speared by British sportsmen. The skin of the bull is very thick and tough, and in demand as furnishing, from the neck and chest, an excellent material for the manufacture of native shields. It runs with a lumbering, ungainly pace. It is supposed to be the hippelaphus of Aristotle. It breeds in the Zoological Gardens of London, the female producing two calves at a birth.

NILGIRI or Neilgherry, a Native State in the Bengal Province of Orissa, lying between lat. $21^{\circ} 18^{\prime} 50^{\prime \prime}$ and $21^{\circ} 37^{\prime} \mathrm{N}$., and between , long. $86^{\circ} 29^{\prime}$ and $86^{\circ} 51^{\prime} 30^{\prime \prime}$ E. Area, 278 
square miles, and a population in 1872 of 33,944 . It has valuable quarries of a black stone, from which are made cups, bowls, platters, etc. The aboriginal population is mainly composed of the Bhumij race.

NILGIRI or Neilgherry Hills are a mountain mass in the S. of the Peninsula of India, Madras Presidency. The district comprises two distinct tracts of mountainous country, between lat. $11^{\circ}$ $12^{\prime}$ and $11^{\circ} 37^{\prime} \mathrm{N}$., and long. $76^{\circ} 18^{\prime}$ and $77^{\circ} 51^{\prime}$ E. One of these tracts is the Neilgherries proper, and the other the Kundas. The total area of the Neilgherry district is 957 square miles. The surface of the Neilgherries proper is undulating, and not much wooded, and the fall to the plains sudden and abrupt. The Kundas are in the south-west angle of the Neilgherries. They are a mass of mountains, which throw off spurs to the south almost as far as the Ponany river, and the innumerable valleys between the spurs have a rich, fertile soil. In the elevated land to the N. and W. of the Pykara river, on the whole of the Kundas, and the N.E. portion of the plateau called Kodanaad, are extensive forests. The highest mountain on the Neilgherries is Dodabetta, and from it to the E. foot of the Kundas the land falls continuously. The highest peaks are -Dodabetta, 8760 feet; Kudiakad, 8502; Bevobetta or Beroyabetta, 8488; Makurti, 8402 ; Davarsolabetta, 8380; Kunda, 8353; Kundamoge, 7816 ; Ootacamund, 7361; Tambrabetta, 7292; Hokabbetta, 7267 ; Urbetta,-6915; Kodanad, 6815; Davebetta, 6571; Kotagherry, 6571; Kundabetta, 6555 ; Dimhatti, 6330; Coonoor, 5886 ; and Rangasawmi peak, 5948. The area of the district is 978 square miles. The ghats or passes leading up to the plateau are the Coonoor, Segur, Gudalur, Sispara, Kotagherry, and Sundapatti.

The general elevation of the table-land differs a little in the three principal divisions. That of the Kunda range may be estimated at 7600 feet. The central portion at 7100 or 7200 , and the Kotagherry division at 6000 . The Kunda range forms the seaward bank of the Neilgherries with a very steep slope towards the Malabar coast. It attains at its higher parts an elevation of 7500 to 8000 feet above the sea. The Kunda or Sispara ghat or pass which leads to Calicut is 6742 feet above the sea. The Kundas rise abruptly from the plain, bordered by several precipices of great height, and accessible only at one or two points. The upper surface is intersected by narrow, deep valleys, thickly dotted with wood, and presenting some most picturesque scenery. A prolongation of the Kundas to the north is called the Neddimulla range, and forms a narrow ridge, shooting up into sharp peaks, and bordered by lofty precipices on the west. On the inner side, the Kundas sink into a lower range of table-land, formed by a succession of low, rounded hills and valleys, less richly wooded, and bounded to the east by the great central range of Dodabet, running completely across from north to south. This is the highest point of the hills, being 8730 feet above the sea. On the west side of the Dodabet range, immediately below the highest summit, is Ootacamund, situated in a basin surrounded on all sides by high hills. At the northern extremity of the range is Coonoor, from which a magnificent gorge descends to the plain of Coimbatore. A corresponding fissure on the north, but much less deep and not so picturesque, is the Segur ghat, which gives access to the hills from Mysore and the north. After crossing the Dodabet range, the country sinks considerably, and is covered with Badaga villages and cultivation for some miles, when it again rises into long grassy ranges like the Kundas, but without the lofty peaks which distinguish the latter. At the commencement of the rise is situated Kotagherry, and a little to the north a deep valley running east and west descends abruptly into the low country, and is known as the Orange Valley, from containing a number of wild orange trees. It also contains a picturesque waterfall of some height. The descent from the table-land of Kotagherry, though less abrupt than that of the Kundas, is sufficiently sudden-to present a bold and imposing aspect when viewed from below. About the middle of the east face, nearly opposite the Guzzelhutty pass, which ascends into Mysore, is the old Jackanairy pass (5659 feet), which for many years was the only practicable access to any part of them. The views on the Kundas are bold and magnificent. Those towards and near Ootacamund, more pastoral ; and in the vicinity of Kotagherry, richer and more agricultural. Several considerable streams unite to form the Bowani river, which, descending by a succession of beautiful falls into a most romantic gorge, forces its way through the southern edge of the table-land. where it makes an abrupt turn to the east, and flows along the whole southern aspect of the hills till it meets the Moyar, descending in a similar manner, and with sinilar accompaniments of scenery, from the northern face.

The mean annual temperature of Ootacamund is $58^{\circ}$ to $68^{\circ}$. The annual range is considerable, being equal in some years to $38^{\circ}$, the highest observed temperature in the shade being $77^{\circ}$, and the lowest $39^{\circ}$. The mean daily range is $17^{\circ}$. The hygrometrical state of the atmosphere varies from intense dryness (from January to May) to saturation, with moisture, during the monsoon, and evaporation is in almost direct ratio with the dryness of the air. January, February, and the half of March are uniformly fair, clear, and dry. The nights are very cold, and hoar-frost is almost always to be found in valleys and sheltered situations towards morning, disappearing as the sun acquires power. The air in the shade is always cold, but the rays of the sun are very powerful. Rain seldom occurs before the end of March, when the air becomes milder, and there are generally a few heavy showers. April and May are mild, pleasant months, with frequent heavy showers and thunderstorms. In June the S.W. monsoon sets in; in general 10 or 14 days later than on the Malabar coast. At first the rain is pretty constant and heavy, but during the whole continuance of the monsoon, that is, till the middle or end of September, there are frequent intervals of most delightful weather. October is an uncertain month, being occasionally blustery and showery, occasionally very fine and dry, according as the N.E. monsoon occurs, early or late. November is showery and unpleasant, but after the occurrence of some heavy fogs in the early part of December, the frost sets in, and the weather becomes dry, cold, and bracing. The seasons are subject to great fluctuations, almost as much so as in Europe. The climates of Kotagherry and 
Coonoor are considerably milder than that of Otacamund, and there is also some difference in the seasons, the S.W. monsoon being comparatively light at both these stations, while the N.E. is heavier.

The Neilgherries had been traversed by a party of pioneers under Captain Bevan and Dr. Ford in 1809 , and were partially surveyed under the direction of Colonel Morrison in 1812. About the year 1819, they were ascended by Messrs. Whish and Kindersley in pursuit of a band of smugglers, and their report led to Mr. Sullivan establishing himself there, and ultimately to their being selected as a convalescent station. The remains of two forts are still to be seen, each of which was used as a state prison, and was occupied by a small garrison in the time of Hyder Ali and Tipu Sultan. The Neilgherries have been occupied since 1826, and European settlers are now established in some numbers. In $1881^{\circ}$ the population was 91,034. The mountain races, Badaga, Irular, Kotar, Kurumbar, and Todawar have hamlets and villages in different parts of the hills, but the European stations are Ootacamund, Wellington or Jackatalla, Coonoor, and Kotagherry. Ootacamund has no accommodation for troops. Wellington is almost exclusively a military station. Kotagherry is 16 miles and Coonoor 10 miles distant from Ootacamund. Dimhati is between Kotagherry and the Orange Valley.

Ootacamund is picturesquely situated in the basin formed by the central chain of Dodabet, from which two considerable spurs run in a semicircular direction to the west, and completely enclose it on all sides except the W.N.W. On the subordinate hills and interjacent valleys, houses are perched at the summit or sheltered in the nooks, and the terre-plaine of the valley is advantageously occupied by a long narrow lake, formed by an artificial dam, which closes it to the west, and retains all the waters of the basin. Kotagherry is preferred by those who, from long residence in India or natural delicacy of constitution, are unpleasantly affected by the suddenness of the transition from the low country. This remark applies still more strongly to Coonoor, the climate of which is a shade milder than Kotagherry.

The rainfall, which is excessive to the westward, is much diminished before reaching the axis of the chain; at Dodabetta it is 100 inches, and at Ootacamund only 64 inches.

European settlers are chiefly engaged in coffeeplanting, tea-planting, and cinchona-planting. The Toda are the oldest of the inbabitants. Their language is partly derived from the Hala or ancient Canarese. Each mund or village has a separate and somewhat larger house set apart, and sacred, as a dairy, into which women are not allowed to enter. They subsist by the produce of their herds, receiving also a ground-rent in kind from the Badaga and Kota, who acknowledge them as the lords of the soil. They are polyandric, the brothers of the family having only one wife in common; female infanticidelong prevailed. They slaughter buffaloes at funerals, attended with some ceremonies. They appear to be decreasing in number. Females number about 3 to every 5 males. Their sole occupation is cattle-herding and dairy work. The Toda worship their dairy buffaloes, the buffalo bell, and several deities.
The Badaga or Vadaga, by far the most numerous race on the hills, some time in the middle of the 16 th century quitted their original location in Mysore to escape from oppression. They are almost entirely employed in cultivation, but they keep large flocks and herds of cattle, and readily act as labourers, etc. They are industrious; their numbers are increasing, and their villages are populous and thriving.

The Kota race have habits like the Chucklers below. They are looked down upon by the Badaga from their eating offal, but they are industrious, and are the artisans of the hills, making and repairing ploughshares and other agricultural impleinents, as also the silver ornaments worn by the Toda and Badaga women and children.

Kota (properly Gauhatar, from the Sanskrit Gau, a cow, and Hata, slaying, i.e. cow-killers), are well made. They worship two silver plates, which they regard as husband and wife; they have no other deity.

The Irular (or benighted ones, from the Tamil word Iral, darkness) live on the lowest slopes and forests extending from the base of the Neilgherries to the plains, and are not, strictly speaking, inhabitants of the hills.

The Irular and the Mula-Kurumbar inhabit the wildest recesses of the jungles on the skirts of the hills, where they erect wretched huts, surrounded by a little wretched cultivation. The other inhabitants attribute to the Kurumbar every piece of ill-luck that befalls their cattle or themselves. In the year 1835, after a severe murrain had prevailed among the cattle, the Kurumbar to the number of 50 or 60 were assembled to a feast, and in the height of their merriment were cruelly massacred by the Toda race, scarcely one escaping. Massacres have since then repeatedly occurred, and in 1882 a whole family were destroyed. The Irular are fowlers, and subsist on forest produce. The Kurumbar are taking to labour on the estates.

Dr. Jerdon records 118 species of birds, residents of or visitors to the hills, mostly of tropical genera.

A large number of rude stone monuments -cairns, barrows, kistvaens, and cromlechs-are found all over the plateau. The cairns consist of circles of stones, some of them in their inside faced with slabs, others outside surrounded by heaped stones. The kistvaens are found below Kotagherry. They contain pottery with a rich red glaze, and clay figures with a high Tartar headdress. These remains are not claimed by any race now on the hills. The most numerous are the cairns and barrows, which resemble each other, and which are found most often in groups and on the tops of hills and ridges.-Imp. Gaz.; Dr. Benza in M. L. S.J.; Harkness' Neilgherries; Birch's Neilgherries ; Baikie's Neilgherries.

NILHO. SINGH. A Ceylon plant. When its blossom fades, the seed forms a sweet little kernel, with the flavour of a nut. The bees now leave the country, and the jungles suddenly swarm, as though by magic, with pigeons, jungle-fowl, and rats. At length the seed is shed, and the nilho dies.-Baker's Rifle, p. 305 .

NIL-KHENT, a small village of Nepal, situated at the base of Mount Sheopuri. Its inhabitants are liable to be attacked with a pendulous tumour of the ear. 
NILOMETER, Mikyas.

Nilometre, . . Fr. / Neilometrion, . Gr. Niloscope.

Neiloscopion,

Apparatus for measuring the rise of the Nile has been in use from the most ancient times; the portable instruments were entrusted to the priests of the god Serapis, who alone were permitted to use them, and who kept them religiously in their temple; but the kings of Egypt created fixed instruments at different parts of the river, and are noticed by Herodotus, who travelled through Egypt, and resided at Thebes, Heliopolis, Memphis. Strabo travelled in Egypt in the early years of the Christian era, and, when speaking of the island of Elephantina, he says that it had a town with a temple to Cneph and a Nilometer. Millet, p. 21 ; Sharpe's Egypt; Niebuhr's Travels.

NIMACH or Neemuch, a village and British cantonment in the Gwalior territory, part of the possessions of the Maharaja Sindia, in lat. $24^{\circ}$ $27^{\prime} 38^{\prime \prime}$ N., and long. $74^{\circ} 54^{\prime} 15^{\prime \prime}$ E., and 1476 feet,above the sea. It is near the western boundary of Malwa, adjoining the Mewar territory.Imp. Ga:

\section{NIMA QUASSIOIDES. Hamilton.}

Simaruba quassioides, Don.

Bera, Puthorin, Chenab. Pesho, Birjo, Mathu, Mont, . ." Khashbar, . . ," Berning, . . . Kavi.

A tall, straggling plant, common in places in the Panjab Himalaya from the Sutlej to the Chenab, at from 3000 to 9000 feet. It it browsed by goats and sheep, and in Chamba the leaves are applied to itch. In some parts the red fruit is eaten. The wood is light-coloured and very bitter, and has long been used for killing insects; latterly recommended in fever by M. Macardieu. - Stewart.

NIMAR is the most westerly district in the Central Provinces of British India, between lat. $21^{\circ} 4^{\prime}$ and $22^{\circ} 26^{\prime} \mathrm{N}$., and long. $75^{\circ} 50^{\prime}$ and $77^{\circ} 1^{\prime}$ E., with an area of 3340 square miles, and a population in 1872 of 211,176 . Its average elevation is about 1000 feet. It consists of the valleys of the Tapti and Nerbadda, separated by a rauge of mountains. It has often changed hands since the 10th century A.D., and is still a border-land. It has had successively as rulers, the Tak, the Asir, Chauhan, the Muhammadans, the Mahrattas, the Hyderabad dynasty, and now the British. The poet Chand mentions the Ahir as leaders in the Hindu armies, battling in Northern India against the Mubammadan invaders. Between the 9 th and the 12 th centuries, the Jain religion was paramount, and numerous remains of their finely-carved temples, etc., yet remain at Wun, Barwani, and other places in Prant Nimar, and at Khandwa, and near Mandhata. Tigers, leopards, bears, wolves, sambur (Rusa Aristotelis), spotted deer, bison (Bos frontalis), nil-gai (Portax pictus), and wild hog abound in the district and in the upper part of the valley of the Tapti.

NIMBU. HIND. Citrus acida, C. bergamia, Risso. Bajauri nimbu, Citrus medica. Mitha nimbu is Citrus limetta. Ward says (ii. p. 12) the nimbu tree supplies the intages of Vishnu in his different forms, also of Durga, Radha, Lakshmi, Siva, Garuda, Chaitanya, etc. Wooden images are not kept in private houses, but in separate temples. They are generally from one to three cubits in height.

NIMBUS, or gloire, or circular disc, is sculptured at the back of the heads of the figures on the Jamalgiri and Amraoti sculptures. The glory surrounding the heads of Tibetan deities is alluded to by Erinann, who recognises in it the Nimbus of the ancients, used to protect the heads of statues from the weather, and from being soiled by birds; and adds that the glory of the ancient masters in painting was no doubt introduced into the Byzantine school from the Buddlist.

NIM-CHAH, a half-breed race, on the southern slope of the Indian Cancasus, between the Afghans and the higher peaks. They speak a language related to the Indian tongues, but possessing a curious affinity to Latin. In the lower country, the people near the debouchure of the Kashgar river speak a mixed tongue called Lughmani.Campbell, p. 146.

NIMCHAK. HIND. A well-curb; curved pieces of wood used as the foundation of the circular masonry of a well.

NIMI, son of Ikshwaku, and founder of the dynasty of Mithila.-Dou'son.

NIMKHAR or Nimsar, a town in the Sitapur district of Oudh, situated on the left bank of the Gumti. It is a place of great sanctity, with numerous tanks and temples. A legend relates that it was in one of these holy tanks that Rama washed away his sin of having slain a Brahman in the person of Ravana, the demon king of Ceylon, who had carried off his wife Sita.-Imp. Gaz,

NIMROD or Nimrud, a chief mentioned in Genesis x. 8-12, as a mighty hunter ruling in Babel, Erech, Accad, and Calneh, in the land of Shinar, and Resen between Nineveh and Calah. George Smith supposed him to be Izdhubar, a local Babylonian chief, ruling at Erech, the modern Warka, over the country from the Armenian mountains to the Persian Gulf. Professor Sayce says (Fresh Light, p. 51) that his name has not yet been discovered in the cuneiform records. A mound about 9 miles from Baghdad, a ponderous mass of ruin, is called by the Arabs Tull Akerkouf, and by the Turks Nimrud Tapasi, both which appellations signify the mound of Nimrud. The ruined city near the mouth of the Upper Zab, now usually known by the name of Nirmod, is called Ashur by the Arabic geographers, and in Athur we recognise the old vame of Assyria, which Dio Cassius writes Atyria, remarking that the barbarians changed the Sigma into Tau. Xenophon, in bis account of the Retreat of the 10,000 , makes mention of a pyramid in a town called by him Larissa. It is probable that the mound marks the site of that place, which the Turks generally believe to have been Nimrod's own city ; and one or two of the better informed with whom Rich conversed at Mosul, said it was Al-Athur or Ashur, from which the whole country was denominated. Assyriologists, however, mention Calah as a large city about 20 miles south of Nineveh, now represented by the mounds of Nimrud Resen, a city lying between Calah and Nineveh, supposed to be represented by the modern Salamiyah. Professor Sayce says (Fresh Light, p. 50 ) a few miles to the south of Nineveh, on the site now known as Nimrud, was Calah, a town built by Shalmaneser I., who lived B.C. 1300. Calah subsequently fell into 
ruins, but was rebuilt in the 9th century B.C.-Mignan's Tr.p. 102.

NIM-SIM. HIND. Boundaries of lands; a grant on copper-plate enumerating revenues (basil), contributions (burar), taxes, dues (lagut be lagut), trees, shrubs, foundations, and boundaries (nim-sim): the sovereign can only alienate the revenues (hasil), and not the soil. The nimsim is almost as powerful an expression as the old grant to the Rawdons:- 'From earth to heaven, from heaven to hell, for thee and thine therein to dwell.'-Tod's Rajasthan, p. 564 .

NINEVEH, an ancient historical city, frequently mentioned in the Hebrew Bible. It was built on the eastern bank of the Tigris, opposite the ınodern town of Mosul. It was 8 miles round, was well fortified, and contained a large population and numerous merchants (Nahum iii. 16). It was long the capital of the Assy rians, a Semitic race, and seems to have been a populous city in the 19 th century B.c. It was finally overthrown, B.C. 606 , by the confederate armies of Nabopolassar of Babylon, Necho of Egypt, Cyaxares of Media, and the king of Armenia, and in the assault its monarch Assur Ebil-lli set fire to his palace, and perished in the flames. The Assyrians worshipped Assur, Nebo and his consort Urmitu, Merodach and his wife Zirratbanit, Ishtar (Astarte), Nirgal, Ninip, Vul, Anu, and Hea. They had many libraries of clay tablets in cuneiform characters. Their religion, science, literature, and method of writing were derived from Babylon.

Mr. George Smith estimated that there were over 10,000 inscribed tablets in the royal library at Nineveh. By far the greater number of the tablets brought to Europe from there belong to the age of Sardanapalus, who reigned over Assyria B.C. 670 .

When visited by Jonas, who was sent thither by Jeroboam, king of Israel, it was three days' journey in circumference. Diodorus Siculus, who has given the dimensions of Nineveh, says that it was 480 stadia, or 47 miles, in circuit; that it was surrounded by a wall and towers, the former 100 feet in height, and so broad that three chariots might drive on it abreast; and the towers 200 feet high, and amounting in number to 1500 . The numerous mounds indicate great vicissitudes; and so utter was its destruction, that though in B.C. 400 Xenophon must have passed within a few miles of its site, he makes no mention of it; and Lucian, a native of Samasata, near the Euphrates, living between A.D. 90 and 180 , states that its site could not then be pointed out. Mr. Rich, however, in 1820, detected it in the mounds opposite Mosul; and M. Botta in 1843 , and $\mathrm{Mr}$. Layard in 1845 , obtained numerous sculptures from it. Sir Henry Rawlinson and George Smith have also been discoverers.-Kinneir's Geographical Memoir; Layard's Nineveh; Bunsen; Chesney.

NINGPO lies in lat. $29^{\circ} 45^{\prime} \mathrm{N}$., and long. $121^{\circ} 22^{\prime} \mathrm{E}$.; is situated on the banks of the river Yung or Tae-hae, and in the province of Chekiang. Ningpo is about 12 miles distant from the sea, being in a westward direction from the cluster of the Chusan islands. Over the river is a bridge constructed in a most ingenions manner. Ningpo was taken 13th October 1841 by the British. It is the point of convergence of an extensive river and canal system, and occupies a commanding position with reference to the Chusan Archipelago.-Sirr's China.

NIPA FRUTICANS. Roxb.

\begin{tabular}{l|l} 
Cocos nypa, Lour. & Do-ni, . . . . BUrM.
\end{tabular} Gabra, Gulga, : BENG. Atap, : : MALAT.

A stemless palm, very abundant in the tidal waters of the Sunderbans, in Tenasserim, the Malay Peninsula, and Eastern Archipelago, throwing up pale yellow-green tufts of feathery leaves from $a$ short, thick, creeping stem, and bearing at the base of the leaves its great head of nuts, which float on the waters and vegetate in the mud. Nuts of a similar plant abound in the tertiary formations at the mouth of the Thames, buried deep in the salt and mud that now forms the island of Sheppey. Like other palins, it yields a wine by the usual process, and in some parts of the Archipelago, particularly in the Philippines, it is cultivated for its wine. Its principal use, however, is for the leaf, usually called Atap, the common term for thatch among the Malays, but specially applied to the leaves of this palm, because among that people it is almost the only material used for that purpose. But the nipa leaf is also used for the fabrication of coarse mats. The small, insipid, pulpy kernels (buah atop) are sometimes preserved as sweetmeats. The tuba, or juice, is extracted from the tree whilst in its flowering state, in the same way as that of the cocoanut tree, and afterwards distilled by a similar process : but it is more spirituous, from six to six and a half jars being sufficient to yield one of wine. It is convertible into syrup, sugar, vinegar, yeast, and a strong spirit.

NIPUR, or Calneh of Hebrew Scripture, is the modern Niffer. It was founded under the second ruling dynasty of Berosus, to which is assigned the date of B.C. 2286 .

NIRADI-MOOTOO, TAM., of Ainslie, is the seed of Hydnocarpus inebrians, W. and A. The oil was sent to the Madras Exhibition under the various names of Niradi-mootoo, jungle almond, Maroty, Tamana, Maravetti, Nirvetti, and Soorty. It is in great repute as a medicine amongst native practitioners, and the kernel enters largely into their prescriptions. It much resembles almond oil, but is rather thicker.

NIRANG. HIND. The liquid excreta of the cow; largely used by the Hindus in their purificatory rites, and in houses, and taken internally.

NIR-ANJAN. BENG. The Hindu rite of casting an image into the water after a festival dedicated to its worship.

NIRBISI, Hind., is sometimes said to be the root of a species of aconite, but is generally supposed identical with jadwar or zadwar, the zedoaria of old writers. Curcuma zedoaria, Roxb., also Kyllingia monocephala. Bara nirbisi is the Scirpus glomeratus. In Sirmur the root of Delphinium pauciflorum is also called Nirbisi.

NIRGUNA. In Hindu metaphysics there are three Guna,-Satya-guna, or property of truth, the source of purity and wisdom; the Rajo-guna, or property of foulness, the source of passion and error; and the Tamo-guna, or property of darkness, the source of inertness and ignorance. Deity, abstractedly, is Nirguna, or without any of the three properties.-Wilson.

NIRIKH. HIND. A price list, a fixed rate for labour or prodnce supplies. It was in operation 
in British India until the early part of the 19th century, but has been steadily put down.

NIRMALI, nude ascetics of the Sikh sect, who dedicate themselves exclusively to a religious life. They are nearly naked. Sherring describes the Nirmali as of a Vaishnava sect of Benares, who devote all their time to the one purpose of keeping themselves clean. They bathe many times, and wash their hands 108 times daily. They do not separate themselves from their families, but they refrain from touching even their children, lest they should be defiled. They are very careful not to take the life of any creature. Women as well as men belong to this sect.-Sherring's Hindu Tribes, p. 263.

NIR-MASOR, an antidote for opium, sent from the Panjab to the Exhibition in London in $\mathbf{1 8 6 2 .}$

NIRRITI. SANsk. Death, decay; death personified as a goddess, the wife or the daughter of Adharma. The Hindus of Shikarpur, on the Indus, in August 1884 prepared a huge hideous image of an earthen deity representing fear. The image wore a dreadful appearance. About 7000 people celebrated the death of this god. An old woman sat by the image, representing the mother of the dreaded deity. A circle about 50 feet in diameter was formed round the image, in the midst of which moved hundreds of spectators, men and women, crying at the top of their voice, 'Fear is dead!' 'Fear is dead!' The old woman near the image, on hearing of the death of her son, broke out into lamentable strains, mourning the loss of her beloved son, the god of fear. Some women, again, reverently approached the idol, kissed its feet, and scattered fullahs upon it to propitiate its anger.-Dowson.

NIRUKTA, in Sanskrit grammar, etymology. That of Yaska is a model of method and conciseness, but it is far surpassed by that of Panini, which was compiled in the 4 th century B.C., about 4000 short rules in eight books. Panini also compiled a list of 1700 roots (dhatu) or elements. Sayce, i. p. 42.

NIRVANA or Nigban is the Tibetan Nyangan; in Buddhism, final emancipation, a Buddhist idea of anvihilation, or the spirit's absorption. Bunsen asserts it to mean the absence of desire in this life, inward peace; but M. St. Hilaire, M. Eugene Burnouf, and Prof. Max Muller identify Nirvana with absolute annihilation, the pure not-being, in which there is no absorption in the higher life of the uncreated essence, no consciousness of peace and freedom from evil, but the loss of being and consciousness at once, - a blown-out candle. This doctrine is shadowed forth in the despair of Job and Jeremiah, in the deep melancholy of Ecclesiastes, in the choruses of Sophocles, the Apologia of Plato, and in the soliloquy of Hamlet; yet this has nowhere led to suicide as the path to Nirvana, but to fasting, prayer, almsgiving, and self-sacrifice. But the doctrine was offered to people who held to the belief of a natural immortality and metempsychosis, to whom death brought no sure deliverance, but might lead to ills greater than in this world, new forms of human or brute life more miserable than what they had passed through. The life of self-sacrifice of Buddha, his voluntary acceptance of poverty, his proclamation of a universal brotherhood, and his making war on the caste system, are remarkable features of his career. But after him Brahmanism rose triumphant, and drove Buddhism into other lands, and the region of Sakya Muni's birth and labours became a place of pilgrimage to peoples from distant countries. The Nirvana of Sakya Muni, according to the Rajguru of Assam, occurred in the 18th year of Ajatra Satru, and 196 years before Chandragupta, the contemporary of Alexander, which may agree thus: $348+196=544 .-B u n s e n$, God in Hist. i. p. 5.

NIRWA. GUJ. Lands held in commune in the Kaira and Ahmadabad districts.

NISEA, the Nisaia of Ptolemy, called also Nisa and Nisæa, a city on the Upper Oxus, was the chief town of the district in Northern Parthia famous for its breed of horses, bordering on Hyrkania and Margiana. The fourth settlement of the Aryans.-Bunsen.

NISAETUS BONELLI. Temm.

Aquilaintermedia, Bonelli. | Nisaetus niveus, Jerd.

M'hor-angah, . HIND. Rajali, . . TAM. M'hor-angi, : "

This crestless hawk eagle is about 27 inches long, and is found throughout India, in the hilly and jungly districts. It preys on game birds and peafowl, ducks, herons, and water-fowl.

NISARNA. HiNd. To blossom; the blossom. ing of sugar-cane is thought very unlucky.

NISHADA of the Sanskrit writers, a race who seem to have been occupants of part of India prior to, and opponents of, the Aryans; wild, barbarous forest and mountain tribes. It is applied in the Vedas to the ancient aborigines of India, and Professor Max Muller proposed to use the words Nishada languages to all the non-Aryan tongues.-Wils.

NISHAPUR, a district of Khorasan, in Persia, to the west of Meshid. Nishapur town is in lat. $36^{\circ} 12^{\prime} 20^{\prime \prime} \mathrm{N}$., and long. $58^{\circ} 49^{\prime} 27^{\prime \prime} \mathrm{E}$. It was built by Tapamur or Taimuras, a prince of the Peshdadian dynasty, who called it Abarshahr. It was taken and destroyed by Alexander, was again taken by the Arabs, the Turkomans took it; and in 1220 , Kuli Khan, son of Chengiz Khan, took it and massacred about two millions of people of the adjoining territory; since which date, Mongol, Turkoman, and Uzbak have repeatedly plundered it. A glen 40 miles west of Nishapur is celebrated for its turquoise mines. The hills are of porphyritic conglomerates, claystone porphyry, and other porphyritic rocks of various colours. There are six mines from which the turquoise is obtained. Some of the mines are in the centre hill of the range, another near the summit, and the Kamari mines are pits sunk in a similar rock.

NISHKRAMANAM, a domestic ceremony of the Hindus, at which the child, when three months old, is taken out of doors and shown the moon in the third light fortnight.

NISHNI-NOVGOROD, a Russian town on the Volga, 250 miles from Moscow, celebrated for the large concourse of people resorting to its fair. The Asiatics at the Nishni market are mostly Russian subjects; Caucasians, Armenians, Tartars, and inhabitants of Tashkend are numerous. Among the Asiatics not subject to Russia, Persians and Bokharians are most frequent. A few Chinese are sometimes seen. Of the few visitors from Western Europe, 95 per cent. at least are Germans. Mixed with them are Polish Jews, among them many wealthy dealers in costly furs.

NISIBIS, a fort situated between the Tigris and Euphrates, the possession of which was contested 
by the Romans and Persians. It was taken after Shahpur had subdued Armenia. Persian authors term this fort Nisibyn and Nisibi. It has long been celebrated for its white roses.-Malcolm's Persia; Catafago.

NISUNG. Scotch farmers plait the first corn cut threefold, and fix it over the chimney-piece till next harvest, when it is renewed. The Tartars of Nisung use three ears of barley, which they paste outside above the door. At Nisung there was not a house in the village but was ornamented in this way. The Tartars are called by the Kanawar inbabitants of the lowest parts, Zhad, Bhotia or Bootuntee, and their country is often named Bhot and Bootunt.

NITI, a pass in Garhwal district, in lat. $30^{\circ} 46^{\prime}$ $10^{\prime \prime} \mathrm{N}$., long. $79^{\circ} 51^{\prime} 50^{\prime \prime} \mathrm{E}$.; the crest is 16,570 feet; village of Niti, 11,464 feet. It is open from the end of June to October. Niti is considered the best pass between Kamaon and Tibet, and is one of the principal channels of trade between Chinese Tartary and Hindustan.

NITIKIN, ATHANASIUS, a Russian traveller who visited India in the 15 th century. He started from 'Twer in 1468, and descended the Volga to Astracan, and on to Baku, thence to Bokhara? He then returned to Masandaran and southwards to Hormuz, from which he crossed the Arabian Sea to Muscat, sailing from thence to Gujerat and Cambay. He seems to have visited Junir, Beder, Kulburga. He re-embarked from Dabyl (Dabul) for Hormuz, from which he proceeded through Shiraz, Isfahan, Tabreez, to 'Trebizond, crossed the Black Sea to Caffa or Theodosia in 1474. He describes the commerce and products of Hormuz, Cambay, Dabyl, Calicut, Ceylon, Beder, and Bijanagar.

NITI-SASTRA. SANsk. Works on morals and polity.-Dowson.

NITRARIA TRIDENTA, a plant of Tunis, the true lotus of the lotophagi; this and Nitraria scoberi, the berry of which is the chief luxury of the tribes of the Caspian desert, might be introduced into India.

NITRATE OF SODA, or cubic nitre, is being imported into Great Britain in iucreasing quantities.
1881,
1882 ,
$1,080,512 \mathrm{cwt}$.
$1,915,138$,
$£ 789,949$
$1,270,352$
$1,168,088$

NITRIC ACID, Aquafortis.

Maulabker, . ARAB. Arak-i-shora, . .PERS. Acide nitrique, : Fr. Aqua forte, : PORT. Salpeter saure, - GER. Vedi-lunu-rasa, SINGH. When pure it is colourless, but as met with in commerce it is yellowish, owing to its containing nitrous acid in solution; besides which it is often highly diluted, and mixed with sulphuric and muriatic acids. It is exceedingly corrosive, and its taste is sour and acid. It is employed in metallurgy and assaying, for etching on iron and copper, in dyeing and in medicine. It is made in Lahore, by acting on pure nitrate of soda with a quantity of sulphuric acid. This sort is used for the purification of silver, and the formation of the nitrate. A less pure kind is made by the action of Kahi (impure sulphate of iron) on nitre, but this is rather a mixture of nitric and hydrochloric acids, and will dissolve gold-leaf.-Royle; Faulkner; Poucll.
NITRO-MURIATIC ACID, Aqua regia. Eau regale,. . . Fr. | Konigswasser, . GER.

The Acidum nitro-muriaticum, Acidum nitrohydrochloricum, is of a golden-yellow colour, with the suffocating odour of chlorine, and the irritant corrosive properties of the strong acids. The manufacturers mix gradually in a cooled vessel, and where the fumes can easily escape, nitric acid 1 part, muriatic acid 2 parts (both by measure). They keep the mixture in a well-closed bottle in a cool, dark place. The resulting acid is not a mere mixture of the two acids, for both become decomposed. It is distinguished by the property of dissolving gold.-Royle.

NITYANAND, a disciple of Chaitanya, who resided at Khardah, in Bengal, on the left bank of the Hoogly river. His descendants are regarded as gurus. It is a place of Vaishnava pilgrimage. The name is from Nitya, constant, and Ananda, joy.

NI-WO-SON, JAP. (lit. two honoured kings), are two figures placed under the Niomon or gateway of Buddhist temples in Japan, the guardians of the right and left. They are erect figures, with flowing robes on. Yo, on the right, represents the male principle of Chinese philosophy ; it is red, and its mouth is open. That on the left is green, with mouth closed, and is In, the female principle. Small prints of these are pasted on the beams over the entrances of houses to protect them from thieves. The Chinese names are Yin-Yang.-Sir J. E. Reid.

NIZAM, an Arabic word meaning order, disposition, arrangement, constitution, and variously applied. Nizam-i-jadid, the new system of government introduced into Turkey by Sultan Mahmud II. in 1826, particularly the employment of regularly disciplined troops. Nizam has become, in common parlance, a title of the sovereign of Hyderabad in the Dekban, being part of the original title, Nizam-ul-Mulk, bestowed on the founder of the Asof Jahi dynasty now ruling there.

NIZAMANI, a Baluch tribe in Sind, following settled pursuits. They take their name from Nizam, a common ancestor, though now subdivided into separate clans or houses. They are well educated in Persian, Sindi, and Arabic.

NIZAMI, the literary title of Nizam-ud-Din, Ganjawi, a celebrated Persian poet who resided at the court of Babram, a distinguished patron of letters. He died in A.H. 576 or A.D. 1180 , but 1194 and 1209 are also stated. He compiled his Sikandar Namah, or History of Alexander, from Jewish, Christian, and Pehlavi records, by which we may suppose him to mean Hebrew, Greek or Latin, and old Persian manuscripts. It is one of the most celebrated romances of the east. He also is the author of the Makhsan-ul-Asrar, Laili-wa-Majnun, Khusru-wa-Shirin, and the Haft Paikar.-Ouseley's Travels, ii. p. 362.

NIZAM SHAHI, a Muhammadan dynasty that ruled at Ahmadnaggur A.D. 1490-1607. Ahmad Nizam Shah, the founder, was a Brahman of Bijapur, who was taken prisoner and sold as a slave to the Babmani king of the Dekban, where he became a convert to the Muhammadan faith. At its greatest extent, the kingdom of Ahmadnaggur comprehended all the subah of Aurangabad, all the west of that of Berar, and a portion of the seacoast in the Konkan between the tracts belonging to Gujerat and Bijapur. Duels were common under this dynasty. In one invasion of Bijapur, 
600 guns were lost, amongst them a brass gun now on the ramparts there. It is the largest brass gun in the world.

\begin{tabular}{|c|c|c|c|c|c|c|}
\hline & & A.D. & A.H. & & & A.D. $\mid$ A. \\
\hline Ahmad, & & 1490 & 896 & Ismail, . . & & 1588 \\
\hline Burhan, & & .1508 & 914 & Burhan II., & - & .1590 \\
\hline Husain, & & .1553 & 961 & Ibrahim, . & - & . 1594$]$ \\
\hline Murtazza, & & .1565 & 972 & Ahmad II., & - & 1594 \\
\hline & & .1588 & & & & \\
\hline
\end{tabular}

NIZAM-ud-DIN AHMAD, BAKHSHI, author of the Tabakat-i-Akbar Shahi. His father lived under the emperors Humayun and Akbar, and Nizam-ud-Din under Akbar. His book is also known as the Tarikh-i-Nizami. It was completed A.D. 1590. It is one of the most celebrated histories of India, and was abridged by Badauni under the name of Mantakhab-ut-Tawarikh. Nizam-ud-Din was eminently upright, and at one time was Bakhshi or commander-in-chief of the army in Gujerat. It contains a short account of the independent kings of Bengal from A.D. 1338 to 1538 . He died 28th October 1594.-Elliot.

NIZAM-ud-DIN, AULIA, a very celebrated Muhammadan saint of India, styled Sultan-ulMushaikh. He died at Dehli, 3d April 1325, and his tomb at Ghayaspur is a place of pilgrimage.

NIZAM-ul-MULK, an officer of the emperor of Dehli, who assumed independence as a ruler in the Dekhan. He was of a Turk family. His name was Chin Kilich Khan, son of Ghaziud-Din, an officer of Aurangzeb, under whom both father and son served. Chin Kilich Khan maintained his dignity during the depression of the nobility by the mistress of Jahandār Shah. He was made viceroy of Malwa, but during the rule of the Syuds he revolted, and marched to the Dekhan. Dilawar Khan, a Syud of Bara, was sent in pursuit, but was defeated and slain at Burhanpur; and at Balapur in Berar, Chin Kilich Khan defeated Alam Ali, A.D. 1720. The following year (1721) he was raised to the dignity of wazir of the empire, and took possession of the oftice at Dehli. He was sent against Hyder Kuli, governor of Gujerat, which he recovered, and returned to Dehli; but, dissatisfied with his position at court, he again, in 1723 , marched off to the Dekhan, where he defeated and slew Mubāraz Khan (1726), and fixed his residence at Hyderabad. His title had been Nizam-ul-Mulk, but that of Asof Jah was now given to him, from which his family, still ruling at Hyderabad, are known as the Asof Jahi.

In 1737 and 1738 he was employed by the Dehli emperor against the Peshwa, Baji Rao, but was unsuccessful. He was at Dehli in 1739 when Nadir Shah arrived, and was employed to negotiate terms of peace. He was recalled to the Dekhan in 1741 by the rebellion of his son Nazir Jung, and while there he died (1748), at the age of 77. He was the Pagri Baddal Bhai or turbandexchanged brother of the Hara prince. He left five sons, - Ghazi-ud-Din, Nazir Jung, Salabat Jung, Nizam Ali, and Basalat Jung, of whom the second son, Nazir Jung, succeeded. His successors down to 1884 have been-

Nazir Jung, . . ob, 1750 | Secunder Jah, • ob. 1829 Muzaffar Jung, . , 1751 Nasir-u-Dowla, ., 1857 Salabat Jung, . , 1762 Afzal-u-Dowla, . , 1868 Nizam Ali, : ", 1803 Mahbub Ali Khan, reigning

The tbree immediate successors of Asof Jah died violent deaths. Nazir Jung was shot by a rebellious noble. Within a year Muzaffar Jung shared his fate. Salabat Jung ruled the Dekhan for ten years, during the greater part of which he had a French army near his capital, nominally as his allies. The overthrow of the French in the Carnatic was accompanied by the withdrawal of all French interest from the Dekhan, and laid Salabat Jung open to the intrigues of his brother Nizam Ali, to which he fell a victim about 1762 . Nizam Ali, in the beginning of his reign, came into conflict with the British respecting the Northern Circars. The emperor at that time was Shah Alam II., who had already become little more than a pensioner of the British. Clive obtained from him a grant of the Northern Circars, which then formed part of the territories of the Nizam. In return the Nizam invaded the Carnatic, and in a treaty the British agreed to pay a rent for the possession of the coveted territory; but for many years afterwards the British occupation of the Northern Circars was a sore point with the Nizam. The two great events which brought Nizam Ali and the British into contact and collision were the warsagainst Mysore and against the Mahrattas.

NIZAM-ut-TUARIKH, a historical work by Baizavi on the Asian monarchies, a general history of the Ghaznivide rulers. Two authors are known as Baizavi, to each of whom this book is attributed. One of them, Nasir-ud-Din, died at Tabreez, A.D. 1286 or 1292, wrote the Tafsir Baizavi, a commentary on the Koran; the other, Abu Said Abdulla, lived about the year 1275 .

N'MO-N'MA, a salutation in Western India between Brahmans.

NOACOLI,Y or Noakhāli or Sudharm, a town which gives its name to the district in Bengal lying between lat. $20^{\circ} 22^{\prime}$ and $23^{\circ} 17^{\prime} 30^{\prime \prime} \mathrm{N}$., and between long. $90^{\circ} 43^{\prime}$ and $91^{\circ} 40^{\prime} \mathrm{E}$., with an area of 1852 square miles, and about a million of inhabitants, chiefly the Kaibartta and Kayasth, Hindus and Muhammadans. It is an alluvial tract, broken up into several islands, Sandwip, Hatia, Sibnath, and others, at the mouth of the Megna. The Portuguese occupied the islands in the 16 th century, but were addicted to piracy, and the Muhammadan population also continued pirates down to a comparatively recent date. The Portuguese leader in the beginning of the 17 th century was Gonzalez, who was defeated in 1616 by the raja of Arakan, and Sandwip taken. In 1664, Slıaista Khan, Governor of Bengal, induced the Portuguese to aid him in a war against the Arakan raja. Chittagong was taken in 1666 , and the Portuguese settled at Dacca; but the Portuguese were subsequently reduced to a dependent position, and their descendants in dress and customs have sunk to the level of natives, though retaining their Christianity and the old Portuguese names.-Imp. Gaz. See Megna.

NOAH. His tomb is shown by the people of Balbec in the plain of Bekaa, or Cœlo-Syria, two miles from Zable, on the south side of the village of Kerak. It is a tombstone about ten feet long, three broad, and two high, plastered all over. Over this is a long structure, measuring nearly 60 feet. It is a place of pilgrimage. Four miles from Noah's tomb is the ruined temple of Hermes Nicha, the Mercury of the Greeks and Romans. The Noah of Bible history is known to Mubammadans as Nuh. The Babylonian or Chaldrean 
Xisuthrus or Sisuthros of Berosus has the listory of the Biblical Noah, the Iydian Maues, the Phrygian Noe, and the Greek Deucalion. In the Chaldæan account of the deluge, discovered by Mr. George Smith, as in Genesis of the Hebrew Bible, Sisuthros, the Accadian Noah, is saved from destruction on account of his piety, the rest of mankind being drowned as a punishment for their sins. The land of Nizir, in which the vessel of Sisuthros rested, was among the mountains of Pir Mam, to the N.E. of Babylonia. Rowandiz, the highest peak in this part of Asia, rises a little to the north of the Pir Mam.-Catafago ; Sayce, - Fresh Limht, pp. 32-40.

NOBILI. Robert de Nobili or De Nobilibus, a Portuguese missionary of the Society of Jesus, who founded a mission at Madura A.D. 1624, during the reign of Tirumala Naik. He was supported by the College of Rome de propaganda fide, founded in 1622 by Pope Gregory xv. He was called by the Hindus, Tatwa Bodnagar, $-A s$. lies. xiv. 30, 59.

NOBUT. HiNd. A kettle-drum. The use of this amongst the Malays is confined to royalty, and even theu they are used only on occasions of state. In the regulations for the government of Malacca, in the 11th Annal, it is laid down that when it is necessary for the Laksmana to be in attendance, the nobuts ought to be present; the term, to confer nobuts, means to give one the government of a country with the rights of royalty. The nobut-khanalı or saloon for the martial or royal band is usually placed over an arched gateway. Amongst the Muhammadan rulers of British India the right to the nobut is granted to their 1:obles.-Jour. Ind. Arch., 1851.

NOCTUA. $\Lambda$ species of this insect attacks the maturing coffee-plant in February and March in lower Bengal.

NODDY, a sea-bird, Sterna stolida. The sooty tern is St. tenuirostris, $7^{\prime} \mathrm{cmm}$. The small grey norddy is the Anous cinereus of Norfolk and Nepean Islands.

NOGAI, a Tartar race settled in the city of Bokhara, who migrated from Russian territory.

NOLE-COLE or Knol Khol, a vegetable sown exactly as cabbage, broccoli, etc. It comes in early, and remains in season until April. If watered during the hot weather and taken care of, it will, when the rains commence, throw out sprouts on the old stalk, which may either be used or slipped off and planted. They will not be so fine as those raised from seed, yet are fit for use.-Jufficy.

NOMADE. The pastoral tribes of Central and Southern Asia migrate from place to place at seasons of the year, to obtain forage for their flocks. The Persian word numud or felt, of which the tents of the wandering tribes of Central Asia are composed, has supplied the root to the word yopecossxos. In British India there are many small migratory tribes living in tents of mats or cloth, encamping in the outskirts of towns, all of them poor and mostly predatory; and there are fowler, hunter, and forest races who move from place to place within a recognised area; and the movements of the more settled, Dhangar and Ahir or cowherd races of the Peninsula of India, are restricted to the forest and open tracts. But the nomades of S. Asia move for some hundred miles to their Garm-sair and Sard-sair lands.
The summer station is also called Eilauk, and the winter station Kishlauk, words which the Afghans and Persians have borrowed from the Tartars. Residents of British India who have witnessed a large Banjara camp migrating, will have seen a true picture of the nomade life of Central Asia. The principal feature in which the Western Afghans differ from the Eastern, is formed by the numerous pastoral tribes. 'The tent used among the Afghans and Persians is of coarse black camlet. It is called Kizhdi in the Afghan language, Siah-chadar in Persian, and Karra-ooee in Turkish, meaning black tent. The tents of the tribes that move little are larger and better than those of the very migratory. The latter have often fine tents, which they leave at the stations where the climate is most severe, carrying lighter ones on their journeys to the places where shelter is less required. Much land is wasted in this mode of life. A nomadic family of Upper A sia requires for its support 300 head of cattle, for which not less is necessary than one-sixth of a geographical square mile of pasture. A tribe of 10,000 requires 200 or 300 square miles of pasture land.

The nomade Turkoman tribes are the representatives of a family which has existed from times anterior to history, and are occupying at the present day the immense steppes of Tartary. The Turkoman, out of whom the Turks of the towns and cities of Southern and Western Asia sprung, were apparently those of the Persian frontier, the ancestors of the present Yamud, Goklan, Tekke, and Ersan tribes, who lie along: the frontier of Persia, from the Caspian to the south-western feeders of the Oxus. Except on the valley of the Attrak, where they have developed an imperfect agriculture more akin to gardening than to farming, they are nomades, with no towns, with more tents than houses, and with pre-eminently predatory habits, as the Persiaus of Khorasan and Asterabad know to their cost. Unrivalled riders, with a breed of horses that will endure any hardship, they have been infamous for their forays; and as they have a great robbing-ground to the south, where the occupants are other than Turk, they are more incorrigible plunderers than even the central Kirghiz and Uzbak. When settled in more favourable localities, they are slow to lay aside their origiual habits. So far as they are mixed in blood, it is the Persian element that has mixed. Such are the Turkomans. A true picture of Iliyat nomade life is expressed in Isaiah xl. 11: 'He shall feed his flock like a shepherd: he shall gather the lambs with his arm, and carry them in his bosom, and shall gently lead those that are with young.' As the Iliyat move along, the women are seen with their spinning-wheels on their shoulders, some twisting woollen yarn, others bent forward, and advancing slowly with their children astride on their backs, clasping their little arms around their mother's neck, and twisting their little legs round her waist. The smaller ones are usually tied up in a bag behind the back, while infant babies, together with their clumsy cradles, are hoisted on the heads or shoulders of their foud mothers, sinking under the weight. The word Iliyat or Ilat is derived from Eel, a tribe. It is also expressed by Zem or Zim, which Ibn Haukal explains by the equivalent Arabic, Kabilah. The whole of the Turk 
races, the Iliyats of Persia, and the great bulk of the Afghan races, and of the independent nations between Afghanistan and British India, are migratory at seasons. An Iliyat tribe whom Baron de Bode met belonged to a Lur stem, which had been transplanted into Fars by Aga Muhammad Khan, the uncle of Fat'h Ali Shah, from Luristan Kuchuk. After his death, many of them returned to their primitive encampments in the Zagros chain. When Nadir Shah overran Herat and Kandahar, he is said to have deported 18,000 Ghilzai with their families to Teheran, and to have distributed the lands of Kandahar amongst his Persian followers. Many nomades met with by Vigne were of a sickly complexion, attributed to the pernicious alkaline quality of the water. The diseases to which they were most subject were fevers, cutaneous and nervous disorders, and especially blindness. It is the peculiar character of the seasons that compels these distant migrations of Asiatic tribes in the lands they occupy, as in the Eastern Archipelago tribes of seafarers, the Ryot Laut or people of the sea, shift from the weather to the leeward sides of the islands with the changes of the monsoons.Lieut.-Col. MacGregor, p. 61 ; De Bode's Travels, pp. 118, 255; Ouseley's Tr. i. p. 307 ; Vigne, p. 83. NOMEN HAN. TIB. A prince of the religious law, an equivalent of the Sanskrit Dharma raja.

NON-ARYAN, a term in use in India to designate the races whom the Axyans found in the country. Some of the Dravidian non-Aryans, as the Tamil, Teling, Canarese, and Gond, are in great nationalities and civilised; but the hills and forests of Central India are occupied by tribes, many of whom differ widely from those of the plains. They are small, black, and slender, but active, with peculiar features and a quick and restless eye. They wear few clothes, in the case of the wilder Bhils are armed with bows and arrows, and, unless the government is strong, are always at war with their neighbours. They live in scattered and sometimes moveable hamlets, are divided into small communities, and allow great power to their chiefs. They subsist on the produce of their own imperfect cultivation, and on what they obtain by exchanges. Besides one or two of the Hindu gods, they have many of their own, who dispense particular blessings or calamities. The one who presides over the small-pox is, in most places, looked on with particular awe. The early history of all these tribes is uncertain. In the Dekhan they were in their present state at the time of the Hindu invasion. The great tract of forest called Gondwana, lying between the rich countries of Berar and Cuttack, and occasionally broken in upon by patches of cultivation, gives a clear idea of the original state of the Dekhan and the progress of its improvement.

They sacrifice fowls, pour libations before eating, are guided by inspired magicians, and not by priests, and bury their dead. They are all much addicted to spirituous liquors, and most of them kill and eat oxen. Their great abode is the Vindhya mountains, which run east and west from the Ganges to Gujerat, and also the broad tract of forest which extends north and south, from the neighbourhood of Allahabad to the latitude of Masulipatam, and with interruptions almost to Cape Comorin. In some places the forest has been encroached on by eultivation, and their inhabitants have remained in the plains as village watchmen, hunters, and other trades suited to their habits. In a few places their devastatious have restored the clear country to the forest, and the remains of villages are seen among the haunts of wild beasts. There are other tribes of mountaineers in the north-eastern bills and the lower branches of the Himalaya, who partake more of the features and appearance of the nations between them and China. No separate mention is made of the mountain tribes by the Greeks, but Pliny more than once speaks of such communities. NORFOLK ISLAND PINE, Araucaria excelsa. Norfolk Island grass tree, Freycinetia baueriana.

NORIMON, an oblong box, used in Japan as the palanquins in India, carried by means of poles passed through iron loops on either side. There are many kinds of norimon, with decisive marks which distinguish the norimon of the great from the kako of the humble. The norimon in Japan, if for a big man, is covered with curtains. A common hack norimon is left in its naked ugliness and discomfort. The occupant must sit crosslegged, and even then can hardly raise his head.Hodgson's Naqasaki; Frere's Antipodes.

NORMAN, Lieutenant-General Sir HENRY, K.C.B., C.I.E., an officer of the Bengal army. While still an ensign, he was Brigade-Major to the expeditionary forces in the Peshawu valley, and as a lieutenant was Adjutant-General to the troops in the field under Lord Clyde. While Acting Adjutant-General of the Bengal army, before Dehli, both pen and sword were ever in his hand; and to those who knew him then, and fought beside him, his name will be inseparably connected with Metcalfe's ruined home, and that intrenched position on the heights commanding Dehli where Hindu Rao once lived. Sir John (Lord) Lawrence writing of him said, "There is a young officer now at headquarters, who, though young in years, has seen much service, and proved himself an excellent soldier. I allude to Captain Norman, of the Adjutant-General's office. Sir Colin Campbell (Lord Clyde) had the highest opinion of his judgment, and when he left Peshawur, it was considered a public loss.' After the mutiny of 1857-58, the Indian Government reorganized its native army. His plan of establishing a Staff Corps was partially followed, and the immediate pressure was removed, but the real difficulties of the situation were increased tenfold, and after many years of, for an army, demoralization and anxiety, only in 1867 was some conclusion come to. In 1883 he was appointed to be Governor of Jamaica.-Thurlow, p. 26 ; Smith's Lord Lawrence, ii. p. 31.

NORTHBROOK, LoRD, G.C.S.I., was Viceroy and Governor-General of India from the $3 d$ May 1872 to the 12th April 1876. He resigned office on the ground that the British ministry resolved on waging war with the Amir of Afghanistan.

NORTHCOTE, SrR STAFFORD H., an enlightened statesman of Great Britain, for many years Secretary of State for India. He gave every support to the progress of railways, canals, channels of irrigation, and sanitation.

NORTHERN CIRCARS, a designation of four districts of the Madras Presidency, on the eastern side of the Peninsula of India. These comprise a narrow tract of land extending between lat. 
$16^{\circ}$ and $20^{\circ} \mathrm{N}$., and from the sea-coast to the Eastern Ghats, by which it is separated from the great table-land. It is a tolerably level region, with occasional spurs from the ghats approaching the sea-coast; has little or no natural wood, except towards the ghats. On the dissolution of the Moghul empire, the Northern Circars passed into the possession of the Nizam of Hyderabad. During the disputed succession which ensued on the death of the first Nizam, the French rendered such essential services in placing Salabat Jung on the throne, that he presented to them the four Circars of Mustafauagar, Ellore, Rajamundry, and Chicacole. M. Bussy himself assumed the government; and during one of his campaigns, besieged and took Bobbili, an event which has been commemorated in ballads that are sung to this day. The Gajapati Vijiaram Raju of Vizianagram, at feud with Raja Rao, raja of Bobbili, induced M. Bussy to attack Bobbili. When Raja Rao and his followers perceived that resistance was vain, they put to death all the women and children in the fort, and then died fighting sword. in hand, refusing every offer of quarter. An infant son of Raja Rao was alone rescued from this scene of slaughter. Four of his retainers, seeing their chief fall, rowed to arenge his death. Having secreted themselves in the jungle for some time, they penetrated to Vijiaram Raju's tent by night, and assassinated him.- Imp. Gaz.

NORTH-WESTER, a term applied to sudden tempestuous squalls in the lower part of Bengal and in the Straits of Malacca. In the latter locality they occur shortly after the N.E. monsoon sets in, and whirlwinds and waterspouts are not rare, but they occur in Lower Bengal, in March and April, accompanying most refreshing: falls of rain. The season of the north-westers is, above all others, that which requires the most attention and care by voyagers on the Ganges. The north-westerly squalls in the Straits of Malacca do not prevail so much as the Sumatras. They are most common in the northern part of the strait between Acheen Head and the Arroa Islands; they sometimes blow through it to the Carimons or even through Singapore Strait to Pedro Branco.-Hursb.; Neubold, i. p. 3 ; Rennell's Memoir, p. 361.

NORTH-TVEST PROVINCES, an administrative province of British India, Iying between lat. $23^{\circ} 51^{\prime} 30^{\prime \prime}$ and $31^{\circ} 5^{\prime} \mathrm{N}$, and long. $77^{\circ} 3^{\prime}$ and $84^{\circ} 43^{\prime} 30^{\prime \prime} \mathrm{E}$. Area, 111,236 square miles. Between the census of 1872 and 1882 , Oudh and the N.W. Provinces were placed under one Lieutenant-Governor; and the 1881 figures show $11,407,625$ souls for Oudh, and $32,699,436$ for the N.W. Provinces, giving a total of $44,849,611$ souls. These provinces are bounded on the north by the Chinese empire, on the north-east by Nepal, on the east by Bengal, on the south by Chutia Nagpur, Rewa, the Bundelkband States, and the Central Provinces, and on the west by Sindia's dominions, Rajputana, and the Panjab. Its revenue divisions are-Agra, Allahabad, Benares, Jhansi, Kamaon, Meerut, Rohilkhand. The Native States are-Garhwal or Tehri, with 4180 square miles, and 150,000 people; and Rampur, 945 square miles, and 507,013 inhabitants. The family domains of the maharaja of Benares are of 986 square miles, and 392,415 inhabitants. Its physical character is seen in the N.W. Himalayas, in Garhwal, the Siwalik on the south of the Himalayas, the Doab of the Ganges and Jumna, the poor tract of Bundelkhand, and the triangular plain of Rohilkhand.

Its rivers are the Ganges, the Jumna, and the Gogra, two Kali Naddi, Hindan, Chambal, Betwa, Ken, Ramganga, Gumti, and Rapti. The ancient historical 'cities were Hastinapur and Ayodhya. In 1881, the prominent castes in the population were :-

Christians, . . 47,673 Lohar, . . . . 497,242 Muhammadans, 6,232,900 Gujar, : : : : 269,838 Sikls, . . : 3,644 Mali,. : : : 257,234

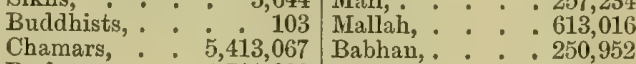
Brahmans, : 4,711,890 Gadaria, : : 866,990

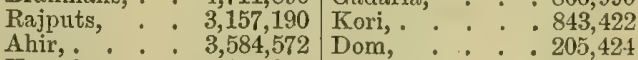
Kurmi, : : 2,110,345 Kalwar, : : $: 345,751$ Banya, : : 1,213,471 Bhangi, . : 435,633 Jat, : : : 674,547 Lonia, : : : 378,619 Teli, : : : 687,672 Bhurji, : : : 304,844 Kachhi, : : 1,959,514 Ahar, : : : 272,863 Kayasth, : : 519,982 Bhuinhar, : : : 188,151 Pasi, . : i 1,034,602 Khatak, : : . 152,030 Kahar, : : 1,225,420 Bhat, : : 130,402 Kumbar, : : 639,380 Gosain, : : : 120,641 Nai, . : : 644,142

Its modern cities are-Agra, Aligarh, Allahabad, Bareilly, Benares, Cawnpur, Farrakhabad, Gorakhpur, Hardwar, Mirzapur, Moradabad, Muttra, with the hill sanatoria of Landaur, Mussoori, and Naini Tal.

Places of interest in the provinces are the sacred Hindu town of Hardwar ; the ruined sites of Kanouj and Hastinapur; the deserted Moghul capital of Futtehpur Sikri; and the ancient temples and fortresses of Mahoba and Kolinjar; and for irrigation the British have formed the Ganges, the Eastern Ganges, the Jumna, the Dun, and the Agra canals; also the Bijnour canals and the Bundelkhand lakes.

The region of the N.W. Provinces and Oudh is that in which all invaders from the N.W. have formed governments. That portion of the Panjab which surrounds the upper waters of the Saraswati river is still regarded by the Aryan Hindus as one of the most sacred spots of Hindu pilgrimage; and their earliest traditions of the N.W. Provinces clister round the city of Hastinapur, the ancient metropolis of the Pandava. But the earliest empire in this portion of Upper India of which any certain monuments remain, was that of the Buddhist dynasty of Magadha. It was at Kapila, B.C. 598, that Sakya, the founder of the Buddhist creed, was born, and he died at Kassia, in the Gorakhpur district, in 543. When Alexander the Great invaded the Panjab in B.C. 327, he heard of the great Naga empire of Magadha, whose capital lay at Palibothra, the modern Patna. The reigning prince at the date of Alexander's invasion bore the name of Nanda. His minister Chandragupta, the Sandracottus of the Greeks, assassinated the Naga prince, and seized upon the throne for himself. Seleucus, the successor of Alexander in his easternmost dominions, marched with a large army. into the Ganges basin, and endeavoured to annex the provinces to his own kingdom, but Chandragupta succeeded in so far as to preserve his territory intact, and received the Greek philosopher Megasthenes as ambassador from Seleucus at his court in Palibothra. Under his grandson Asoka, B.C. 260, 
the whole of Hindustan and the Panjab, together with portions of the Dekhan and the nortlwestern mountain country, formed parts of the Magadha empire. The pillar and rock edicts containing the inscriptions of Asoka, are still to be seen at Peshawur, at Allababad, at Dehli, in the Dehra Doon, also on the shores of the Bay of Bengal and in Gujerat; and he established Buddhism as the State religion throughout his wide dominions.

Little is known of the history of this region for the next 1500 years, during which it was overrun by Tartar, Rajput, and Jat clans, whose last effort against the advaueing Muhammadans failcd under the leadership of Prithi-raj. Muhammad Ghori, who overthrew the Ghaznivide dynasty, was the founder of the Musalman power iu Hindustan. Subsequently, in 1398, ' 'imur, crossing the Indus at Attock, marched through the Panjab to Dehli, under the walls of which he defeated Mulsammad Taghalaq, and then entered the imperial capital in state.

NORTON, JUHN BRUCE, born 1815, a barrister practising in Madras from 1842 to 1871 , and who held the office of Advocate-General, and was a member of the Legislative Council. He wrote on all the events of the period. His chief literary works were entitled the Administration of Justice in British India, and the Law of Evidence. He died in London in 1883.

NOSE-RUBBING is a salutation in China, New Zealand, and amongst the Lapland Alps. As a parting salutation, it is practised among the Macassars, the Papuaus of New Caledonia, the Australians, the New Zealanders, and the Marquesas islanders. - Max Multer's C'hips.

NOSHERA, a town on the left bank of the $\mathrm{K}$ abul river, the scene of a great battle between the Sikhs under Ranjit Singh and the Afghans under Azim Khan, who, however, himself held back from the battle, and ultimately fled, and the Afghans were defeated with great slaughter.

NOSH-i-JAN. PERs. A Persian congratulatory salutation, meaning, May it be a drink of life to you.

NOSTOE (edule? collenum?), a shower of this fell in Booudika, a little beyond the Begari canal, in the Shikarpur collectorate. It is used in China as food.

NOTATION. The decimal system of notation has been shown by Woepcke to have entered Europe from India through the Arabs. Mr. Burnell supposes the cypher represents the large cowrie used by Indian astronomers in the decimal places in the very ancient method of calculation by cowries.

NOTELAEA LONGIFOLIA, one of the ironwoods of Norfolk Island; is used in all wheelwright's work, and is very hard and durable. It is also used for cabinet work, and when French polished it is not excelled by any of the fancy woods.-Keppel's Ind. Arch. ii. p. 283.

NOTONIA GRANDIFLORA, D.C., the Cacalia grandifolia, Wall, one of the Matricariaceæ, is a shrub of Travancore and the Neilgherries. Its flower-heads are largish. It was supposed by Dr.". Alexander Gibson to be specific in hydrophobia. N. crassessima is a shrub of Burma. N. corymbosa, D.C., was also recommended by Dr. Gibson in hydrophobia.

NOTOPIERUS KAPIRAT, an edible fish of the rivers of the S.E. of Asia. It is ngly in appearance, but good eating.

NOTT, Sir WILLIAM, a general of the Bengal army who conducted an army against Kābul.

NOURATRI, a Hindu festival occupying the period from the first to the ninth of the moonlight half of Asoj, consecrated to the family goddess, or to Durga, the consort of Siva. Colonel Tod gives an interesting account of the Mewar manner of celebrating this annual festival. On the 1st of Asoj, the rana of Mewar, after fasting, ablution, and prayer on the part of the prince and his household, has the double-edged khanda removed from the hall of arms (awad-sala), and having received the homage (puja) of the court, it is carried in procession to the Kishenpol (gate of Kishen), where it is delivered to the Raj-Jogi, the mahants, and band of Jogi assembled in front of the temple of Devi, the goddess, adjoining the portal of Kishen. By these, the monastic militant adorers of Heri, the god of battle, the brand, emblematic of the divinity, is placed on the altar before the image of his divine consort. At three in the afternoon, the nakarra, or grand kettledrums, proclaim from the tripolia the signal for the assemblage of the chiefs with their retainers; and the rana and his cavalcade proceed direct to the stables, when a buffalo is sacrificed in honour of the war-horse. Thence the procession moves to the temple of Devi, where the Raja Krishen (Godi) has preceded. Upon this, the rana seats himself close to the Raj-Jogi, presents two pieces of silver and a cocoanut, performs homage to the sword (kharga), and returns. On the $2 d$ of Asoj, in similar state, he proceeds to the Chougan, their Champ de Mars, where a buffalo is sacrificed; and on the same day another buffalo victim is felled by the nervous arm of a Rajput, near the Torunpol, or triumphal gate. In the evening, the rana goes to the temple of Anba Mata, the universal mother, when several goats and buffaloes bleer to the goddess. On the $3 \mathrm{~d}$, five buffaloes and two rams are sacrificed to Harsid Mata.

On the 4 th, as on every one of the nine days, the first visit is to the Champ de Mars: the day opens with the sacrifice of a buffalo. The rana proceeds to the temple of Devi, where he worships the sword and the standard of the Raj-Jogi, to whom, as the high priest of Siva, the god of war, he pays homage and makes offering of sugar' and a garland of roses. A buffalo having been previously fixed to a stake near the temple, the rana sacrifices him with his own hand, by piercing him from his travelling throne (raised ou men's shoulders, and surrounded by his vassals) with an arrow. On the 5th; after the usual sacrifice at the Chougan, and an elephant fight, the procession marches to the temple of A sapurna (Hope); a buffalo and a ram are offered to this goddess, adored by all the Rajputs and the tutelary divinity of the Chauhan tribe. On this day, the lives of some victims are spared, at the intercession of the Nuggur-Set'b, or chief magistrate, and those of his faith, the Jains. On the 6th, the rana visits the Chougan, but makes no sacrifice. In the afternoon, prayers and victims to Devi, and in the evening the raua visits Bikbiari Nat'h, the chief of the Kanphata Jogi, or split-ear ascetics. The 7 th, after the daily routine at the Chougan, and sacrifices to Devi (the goddess of destruction), the chief equerry is commanded to adorn the 
steeds with their new caparisons, and lead them to be bathed in the lake. At night, the sacred fire (hom) is kindled, and a buffalo and a ram are sacrificed to Devi; the Jogi are called up, and feasted on boiled rice and sweetmeats. On the conclusion of this day, the rana and his chieftains visited the hermitage of Sukria Baba, an anchorite of the Jogi sect. 8th, there is the homa, or fire-sacrifice in the palace. 9th, at three in the afternoon, the nakarras laving thrice sounded, the whole state insignia, under a select band, proceed to mount Matachil, and bring home the sword. Then its arrival in the court of the palace is announced, the rana advances and receives it with due homage from the hands of the Raj-Jogi, who is presented with a kelat; while the mahant who bas performed all the austerities during the nine days, has his patera filled with gold and silver coin. The whole of the Jogi are regaled, and presents are made to their chiefs. The elephants and horses again receive homage, and the sword, the shield, and spear are worshipped within the palace. The 10 th, or Dussera, is a festival respected in India by all classes, although entirely military. Being commemorative of the day on which the deified Rama commenced his expedition to Lanka for the recovery of Sita, the tenth of Asoj is consequently deemed by the Rajput a fortunate day for warlike enterprise. The day commences with a visit from the prince or chieftain to his spiritual guide. Tents and carpets are prepared at the Chougan or Matachil mount, where the artillery is sent; and in the afternoon, the rana, his chiefs aud their retainers, repair to the field of Mars, worship the kaijri tree, liberate the niltach or jay, as sacred to Rama, and return amidst a discharge of guns. On the 11th, in the morning, the rana, with all the state insignia, the kettledrums sounding in the rear, proceeds towards the Matachil mount, and takes the muster of his troops, amidst discharges of cannon, tilting, and display of horsemanship. And while every chief or vassal is at liberty to leave his ranks, and ' witch the world with noble horsemanship,' there is nothing tumultuous in their mirth. The steeds purchased since the last festival are named, and as the cavalcade returns, their grooms repeat the appellation of each as the word is passed by the master of the horse, as Baj Raj, the royal steed; Hymor, the chief of horses; Manika, the gem; Bajra, the thunderbolt, etc. On returning to the palace, gifts are presented by the rana to his chiefs. The Chauhan chief of Kotario claims the apparel which his prince wears on this day, in token of the fidelity of his ancestor to the minor Oody Singh in Akbar's wars. To others, a fillet or balabaud for the turband is presented; but all such compliments are regulated by precedent or immediate merit. Thus terminates the nouratri festival, sacred to the god of war, which in every point of view is analogous to the autumnal festival of the Scythic warlike nations, when these princes took the muster of their armies, and performed the same rites to the great celestial luminary. If we look westward from the central land of earliest civilisation to Dacia, Thracia, Pannonia, the seats of the Thyssagetæ or the Western Getes, we find the same form of adoration addressed to the emblem of Mars, as mentioned by Xenophon in his memorable Retreat, and prac- tised by Alaric and his Goths, centuries afterwards, in the Acropolis of Athens. If we transport ourselves to the shores of Scandinavia, amongst the Cimbri and Getes of Jutland, to the Ultima Thule, wherever the name of Gete prevails, we shall find the same adoration was paid by the Getic warrior to his sword.-Tod's Rajasthan, i. p. 582; Forbes' Rasamala; Hindu Annals.

NOUROZ, New Year's day. This celebrated festival of the ancient and modern Persians originated in the time of Jamshid. It falls generally on the 21st of March, is coeval with the vernal equinox, and with the Makar Sakarant of the Hindus. This day is observed by the modern Persian, Arab, Turk, Parsee, and several other Asiatic nations, for the computation of the solar year, and for state purposes, such as the collection of the revenue and the arrangement of the agricultural operations of the year. In Persia, the festival is kept up for several days with unusual pomp by all the inhabitants, but in India, among the Parsees, it is simply a day of rejoicing. On the Nouroza festival the Great Moghul used to slay a camel with his own hand, which was distributed and eaten by the court favourites. Akbar named it Khoosh roz,-Tod, Rajasthan, i. p. 72.

NOUSHERIVAN, surnaned Adil or the Just, is the Chosroes of the Greeks. He was the son of Kubad, king of Persia, at whose death, A.D. 531 , he ascended the throne of that kingdom. The accounts given by eastern and western authors of the successes of this king in his invasions of the Roman empire, differ but very little. Some eastern historians have asserted that he took an emperor of the Romans prisoner; and they have all passed over the few reverses which his arms sustained. But the disgraceful peace which the emperor Justinian purchased at the commencement of the reign of Nousherwan, the subsequent war, the reduction of all Syria, the capture of Antioch, the unopposed progress of the Persian monarch to the shores of the Mediterranean, his conquest of Iberia, Calchos, and the temporary establishment of his power on the banks of the Phasis, and on the shores of the Euxine, are facts not questioned by his opponents. They, however, assert that his success as a military leader, even when his fortune was at the highest, was cbecked by Belisarius, who was twice sent to oppose his progress, and whose success, considering his want of means, and the character of the court he served, was certainly wonderful. In all the negotiations which took place between the emperor Justinian and Nousherwan, the latter assumed the tone of a superior. His lowest servants were treated, at the imperial court, in a manner calculated to inflame the pride of an arrogant nation, and the agreement of the Roman emperor to pay 30,000 pieces of gold showed the monarch of the western world in the rank of one of Nousherwan's tributaries. In a second war with the Roman emperors Justin and Tiberius, Nousherwan, who, though 80 years of age, still led his armies, experienced some reverses of fortune; but the perseverance of the aged sovereign were ultimately rewarded by the conquest of Dara and the plunder of Syria, A.D. 572. He died, after a prosperous reign of 48 years, about the year 579 A.D., and was succeeded by his son, Hurmuz IV.

Nahomed, who was born durivg the reign of 
Nousherwan, A.D. 571, used to boast of his fortune in being born when so just a king reigned. This is great praise, and from a source that cannot be suspected of flattery. Various Persian authors, quoted by Sir John Malcolm, assert that this monarch earried his arms into Ferghana on the north, and Sind and India on the east; and as they are supported in the first assertion by Chinese records, there seems no reason to distrust them in the second. Sir Henry Pottinger (though without stating his authority) gives a minute and probable account of Nousherwan's march along the sea-coast of Mekran to Sind, and, as Vallabi was close to Sind, we may easily believe him to have destroyed that city.

The Vallabhi prince Goha was married to the daughter of Nousherwan. She was granddaughter of Maurice, emperor of Constantinople, and from her are descended the present maharanas of Udaipur, capital of Mewar, who thus represent Rama of the Solar race, the Sassanian kings of Persia, and the Crass of Rome. The maharanas of Udaipur are always represented in their portraits with an aureole round their heads. Perhaps the current story of the descent claimed for the maharanas of Mewar from Nousherwan may have some connection with their being driven into their present seats by that monarch. Nousherwan was surnamed 'the Just,' and was distinguished for equity, wisdom, and munificence. He erected many colleges, caravansaries, and other buildings of public benefit, and gave great encouragement to learning and philosophy. In his time the fables of Bidpai were translated into Pehlavi. - Pottinger's Beluchistan, p. 386 ; Elphinstone's Hist. of India, i. p. 401; Beale's Biographical Dictionary.

NOUSherWANI. Malay. A tribe in Baluchistan.

NOWBUT. HIND. An instrument of music sounded at the gate of a great nan at certain intervals. See Nobut.

NOWGONG or Naogaon, a British cantonment in Bundelkhand, in Central India, situated between the British district of Hamirpur and the native state of Ch'hatarpur. The Rajkumar College, opened at Nowgong in 1875-76, was established by the native chiefs of Bundelkhand in memory of Lord Mayo.

NOWGONG, a revenue district of Assam, lying between lat. $25^{\circ} 45^{\prime}$ and $26^{\circ} 40^{\prime} \mathrm{N}$., and long. $92^{\circ}$ and $93^{\circ} 50^{\prime} \mathbf{E}$., with an area of 3415 square miles. It presents the appearance of a wide plain, intersected by numerous rivers and streams, and dotted with shallow marshes, and with the Kamakhya Hills, 1500 feet high, near the Brahmaputra. On the hills is a temple to Durga, which is associated with the founder of the Koch-Bahar dynasty. The most numerous tribe is the Koch, descendants of a people once dominant throughout the country, and identical with the Rajbansis of Bengal. In Assam, the appellation of Koch is held in comparative honour. The Doms in Assam lay claim to exclusive purity of caste, but accept Kolitas as their spiritual guides in preference to Brahmans. The Mikir, Lalang, and Cachari are other tribes.-Imp. Gaz.

NOWSARI, in Gujerat, the city of the Parsee priests, whence numbers are sent every year to Bombay to minister to the Parsee population of that city.-Parsecs.
NRI. SANsk. A man. Nri-medha, a human sacrifice; Nri-singha, the man-lion avatar.

NUBIA, between lat. $11^{\circ}$ and $24^{\circ} \mathrm{N}$., and long. $28^{\circ}$ and $29^{\circ} \mathrm{E}$, a country of East Africa, enclosed between Egypt, the Nile, Abyssinia, and the Red Sea ; area with Kordofau, 300,000 square miles. The Nile runs through it, on the banks of which it is fruitful, but in other places barren, sandy, and destitute of water. It derives its name from Noub, gold. The immediate banks of the Nile are rendered fertile by laborious irrigation by wheels, but all the rest of Nubia consists of sandy and rocky deserts, as the Nile here seldom overflows its banks. The population is estimated at 400,000 , and up to 1821 , when it was conquered by Ibrahim Pasha, it was under a number of chiefs. It is covered with many magnificent remains of antiquity.-Catafago.

NUBRA, the north-western district of Ladakb, on the Shayuk river, in the North-west Himalaya, is in lat. $35^{\circ}$ to $36^{\circ} \mathrm{N}$., and long. $77^{\circ}$ to $78^{\circ} \mathrm{E}$. The Sassar pass is 17,753 feet above the sea. The Nubra, Pangong, and Rodok districts, in the basin of the Shayuk river and its affluents, lie on the S. flank of the Kouen Lun, from Balti to Nari, and have Ladakh as their southern boundary. With the exception of Nari, this is the most lofty and sterile part of Tibet, the axis of the Kouen Lun being probably upwards of 18,500 feet, the valleys 16,000 or 17,000 feet, and numerous peaks rise 20,000 or 23,000 feet. The Karakorum pass is 18,300 feet, the salt Pangong lakes 13,400 feet. The villages of Lower Nubra are not numerous, but some of them possess very extensive cultivation. From Kashmir eastwards, all the easily accessible portions of the Himalaya are occupied by Aryan Hindus as far as the eastern border of Kamaon and the Kali river separating Kamaon from Nepal, the Tibetans being here confined to the valleys about and beyoud the snow. People of Tibetan blood have migrated into Nepal, throughout its whole length, and have formed mixed tribes, whose appearance and language is more Tibetan than Indian, but whose religion and manners are Hindu. East of Nepal, in Sikkim and Bhutan, the Hindu element almost disappears, and the Tibetans are altogether dominant. Eastward of Kashmir are the Bhot race in Balti and Ladakh. Balti includes Hasora, Rongdo, Rong-yul, Shagar, Skardo, Balti, Parkuta, Tolti, Kartaksho, Kiris, Khaybalu, and Chorbat, Ladakh or the Botpa includes Spiti, Zangskar, Purik, Suru, Hembako (Dras), Ladakh proper or Leh, Nubra, Rong, Rupshu, and Hanle. The language of the Bhotias of Tibet, the Bhutia or Tibetan, is also that of Bhutan, and is a connecting link between the polysyllabic and monosyllabic languages. Garhwal is to a large extent Bhot.-Thomson's Tr. p. 199; Hooker and Thomson, p. 22.

NUKA. HIND. Land on the ridges or banks left by the dry course of a running river.

NUL, Nulkhagra. BENG. Amphidonax karka, the grass of which the Durma mats are made, formed of the stalks split open.

NULLIPORID艮 of the Corallinaceæ belong to one of the lowest classes of the vegetable kingdom. One species is of a beautiful bright peach-blossom colour; its branches as thick as crow quilis, slightly flattened and knobbed at the 
extremities. The extremities only are alive and brightly coloured. Other two species are of a dirty purplish-white, and one of them is extremely hard and cylindrical.-Darwin.

NULU-CHAMPOO. SANSK. From Nulu, the name of a king, and Champoo, a particular kind of composition, in which the same subject is maintained in all the varieties of prose and verse.

NUMBER. This English word has been added to all the languages of British India. The number seven is used frequently in Scripture, not to signify a definite, but a large and sufficient quantity; hence Daubuz states its Hebrew etymology to signify fulness and perfection, and Philo and Cyprian call it the completing number. 'The barren hath borne seven,' said Hannah in her song, meaning a great number. The victims under the Jewish law bled by sevens; the golden candlestick $\mathrm{h}$ id seven branches, bearing seven golden lamps; the mercy-seat was sprinkled seven times with the blood of the atonement; and to sacrifice by səvens was a characteristic of great solemnity in putriarchal times. The key to this rite, says Horsley, is the institution of the Sabbath, the observance of the seventh day being the sacrament of the ancient church. The numbering by seven was doubtless taken from the phases of the moon. With the Indian Mubammadans, sât-āt, 7,8 represent a small number. The number ten also is often used in Scripture to denote frequency and abundance, and is evidently taken from the ten fingers on the hands. "Thou hast changed my wages ten times,' Genesis xxxi. 7, 41 ; 'Those men have tempted me now these ten times,' Numbers xiv. 22 ; 'These ten times have ye reproached me,' Job xix. 3 ; 'He found them ten times better than all the magicians,' Daniel i. 20. The ten days are again interpreted as indicating the shortness of the persecution, in the same sense as they are employed by Terence: 'Decem dierum vix mibi est familia,' I have enjoyed my family but a short time. There is in India a very remarkable use of seventy-four, in epistolary correspondence. It is an almost universal practice in India to write this number on the outside of letters, it being intended to convey the meaning that nobody is to read the letter but the person to whom it is addressed. The practice was originally Hindu, but has been adopted by the Muhammadans.

The Roman system of using letters to indicate figures is followed by all Muhammadans. The death of Karim Khan, Zend, is commemorated in the sentence-

'Ai va'e Karim Khan mūrd.'

'Woe and alas! Karim Khan is dead.'

The numeral values of the letters composing these few words, being added up, give 1193, the year of the Hijira, corresponding with A.D. 1779, in which this good king died.

Nadir Shah was assassinated in his tent at Meshed in Khorasan, on the 8th June 1747, and his fate was thus recorded-

$$
\text { 'Nadir b' dūzakh raft.' }
$$

These letters give A.H. 1161, which corresponds with A.D. 1747.

A famous glee-maiden of Hyderabad, at the closing years of the 18 th century, built a mosque near Maul Ali Hill, and, seeking a date for it, a learned man proposed the satirical couplet-

'Pesh-i-īn mihrāāb sajūd-i-khas-o-ām ast, Falk guft īn bait-ūl-Harām ast.

-Tod's Rajasthan; Elliot's Supp.; Milner's Seven Churches, pp. 23, 205.

NUMIDA PTILORHYNA. The guinea-fowl is believed to be descended from the Numida ptilorhyna of the hot arid parts of East Africa, but it has become wild in Jamaica and St. Domingo, and is small with black legs. The guinea-fowl is the Bohemian of the barn-yard. They are hardy and prolific, and are valuable in gardens, as they rarely scratch the ground, are eager in their search for insects, and, with a scraping motion of their bill, gather the seeds of grasses. Their value in India in checking the increase of snakes cannot be too highly praised.-Darwin.

NUMMULITE, the Shudnaj udsee of the Arabs, officinal with the natives of India. They are lentil-shaped greyish pebbles of various sizes, consisting of carbonate of lime and iron, with a nucleus of calcareous crystals. The hakims administer them in eye diseases and ulcers. The rocks around Cairo are a soft fine-grained nummulite, abounding in many sorts of marine, with some land, remains. The most abundant is the multilocular shell which gives them their name, and believed by the Egyptians to be the money of the Jews cursed and turned into stone. A similar tradition to this, in reference to nummulites, prevails in Cutch. A holy man who had been refused charity by a miser, cursed his money, and it became stone at once, so that it is now found in the rocks. A transverse section of this little shell very closely resembles a coin.-Royle; Honigberger.

NUMRI or Lumri, a people of Luz, a dependency of Kalat, with about 1600 fighting men. They are Muhammadans. Numri of the Kurachee collectorate claim descent from a Rajputni who had nine sons, from which the tribe are named Nao Mardi, and the twenty-four branches in which the tribe are now divided have all sprung from these sons.

NUN. Buddhism assumed a distinct form in the middle of the $3 \mathrm{~d}$ century B.C., and became powerful during the Greek connection with India. Women embracing Buddhism became prominent. They not only began to frequent places of public worship, but came forward to join the clerical body, and were admitted as nuns. Maha Prajapati was the first female admitted to the order. The daughter of Asoka, Sanghamitta, also entered the church, taking the usual vow of celibacy. She went to Ceylon to ordain the princesses, in compliance with the request of her brother Mahendra, who had been sent there to propagate the religion, he being of opinion that a male priest could not ordain a female. Gautama had 500 women admitted into the order. The nuns were, however, restricted in their liberty in holding communication with priests. Women of rank, such as the Maha Maya, the mother of Gautama and Misaka, were moving freely in society, while other classes of females not only moved from place to place, but carried on discussions with men, and took part in secessions. There are several notices of educated females. Visakha, a most celebrated Buddhist lady, resided in Sakita or Ayodhya. Nevertheless Buddha's 
personal opinion as to females leading the religious life was: 'Be careful; do not permit females to enter upon my law and become Sramans.' He said, 'What is named woman is sin,' and 'it is better for a priest to embrace the flame than to approach a woman, however exalted her rank.' Mendicants and novices were not permitted to look at a womau. Priests were not allowed to visit widows, grown-up virgins, or women whose husbands were abroad. If a woman had a fall, and required to be lifted up by the hand, no Buddha would help her, because it was considered sinful to touch a woman, whether she lived or died. The Patimokhan forbids not only 'the contact with the person of a woman,' but 'impure conversation with a woman,' sitting on the same seat with her, reclining with her on the same place, beivg alone with a woman, accompanying her on a journey, and preaching more than five or six sentences to a woman, except in the presence of a man who understood what was said. And yet, according to Hinao, Buddha accepted the invitation of Ambasali, the celebrated courtesan of Vaisali, "who took her seat on one side of him.' The Buddhist women of that day were clad in robes. The king of Kosala presented to each of his 500 wives 'a splendid robe.' The Bhilsa monument shows the Buddhist female drapery, - 'a long flowing vest resembling that which is seen in Grecian sculpture. Fa Hian, who came here in A.D. 399, says that 'the females were kept down, and ordered to follow certain precepts.' He cites the instance of brothers marrying non-uterine sisters, in the case of the sons of one of the kings of Patala settled near the hermitage of Kapila. As to caste, he says that although the principle in the selection of the chief of religion was the moral merit, inasmuch as Sakya was a Kshatriya, and his successor a Vaisya, and his successor a Sudra, yet the son of the king of Kapila, by the daughter of a slave, was not admitted into the church. When he entered, the cry was, "The son of a slave dares to enter and be seated here.' In the drawings of the excavated temples of Ajunta ' there are groups of women in various attitudes, particularly in the one of performing tapasya on the Asan siddha;" and also 'of a female worshipper of Buddha' surrounded by a group, and a Brahman among them whom she is teaching. There are, at present, in Buddhist Tibet, many nums, and the Buddhists and Taosts of China have nuns, but they are not much respected. Christians, Jains, and Manbhaos also have nuns.-Cal. Rev. No. 109.

NUN, also Nuna. Hind. Salt. Nunia, a saltmaker. Nun-dāb, from Nun or Loon, salt, and Dabna, to dip, bespatter, or sprinkle, a custom among the Rajput races of dipping the hand in the salt. The Nun-dāb is the most sacred pledge of good faith. It is had recourse to, to increase the solemnity of an occasion, and to banish all suspicion of treachery, as well as to extinguish ancient feuds, and reconcile chiefs who had never met but in hostility.-Tod's Rajasthan, ii. p. 409. See Manwar Piala.

NUNDO KUMAR, commonly written Nundcomar, a Hindu who was condemned to death and executed for forgery. The trial at Calcutta, before Sir Elijah Inpey, lasted more than two days. The accused was defended by able counsel. His original offence was backed up on his trial by perjury, and the blameless Sir Robert Chambers, the friend of Johnson, Gibbon, and Burke, was one of the full bench that rejected a legal plea in bar of punishment, on full deliberation, after sentence had been pronounced.

NUR. ARAB. Light, splendour. Nur-ul Iman, Light of the faith. Kitab Nur-ul-Anwaran-Nuraniyah, or Book of the brilliant and luminous lights, is a religious book of the Shamsin worshippers of the sun. It asserts that the sun is God the creator, has been from all eternity, is the true God of nature. The author puts forth as a creed, La illahā jllulahō wa as Shams arash illahì, Kadūs! Kadūs! Kadūs! There is no deity but God, and the sun is the throne of God, holy! boly! holy! The book is in elegant language, and contains many beautiful hymns in honour of the sun.-Catafayo.

NUREH. ARab., Pers. Quicklime, also a depilatory made of yellow arsenic $(1 \mathrm{oz}$.$) , pounded$ and mixed with quicklime $(4 \mathrm{oz}$.) till the con:pound assumes a uniform yellowish tinge. It is applied to the skin in a paste made with warm water, and must be washed off after a minute or two, as it burns as well as stains. This admirable invention is ascribed by eastern authors to the ingenious Soliman, who could not endure to see the state of Bilkis of Sheba's bare legs.-Burton's Scinde, i.p. 278; Lane.

NUR JAHAN was first the wife of Sher Afghan Khan, and was afterwards married by the emperor Jahangir. Her name was Mihr-un-Nissa. Her grandfather was a native of Teheran, and held a high civil office under the Government of Persia ; but his son Mirza Ghaias was reduced to poverty, and emigrated to India with his wife, two sons, and a daughter. At Kandahar his wife gave birth to Nur Jahan, but the family were in such poverty that they exposed the new-born child on the road. A merchant in the caravan, however, found the infant, and adopted her, and her mother was employed as its nurse. The merchant took an interest in the family, gave them employment, and introduced them to the emperor Akbar, who gave the husband employment. Nur Jahan and her mother often visited Akbar's haram, and Akbar recommended that she should be married, in order to withdraw her from the notice of his son Salim. She was accordingly wedded to Sher Afghan, a young Persian, to whom Akbar gave a jaghir in Bengal. When Kutub-ud-Din, Salim's fosterbrother, went there as viceroy, Sher Afghan took alarm, and threw up his employ under the emperor. The viceroy visited the part of the country in which Sher Afghan lived, and invited his attendance. At the interview, Sher Afghan, insulted by the proposals, killed the viceroy with his dagger, was himself immediately despatched by the attendants, and Nur Jahan was sent prisoner to Dehli. For some time she refused Jahangir's offers of marriage, but at length yielded, and under her influence his conduct improved, his barbarous cruelties ceased, and he drank only at night, and in bis private apartments. She increased the magnificence of his court, yet lessened the expenses. She was facile in composing extempore verses, and is said to have taught the manufacture of otto of roses. Her niece, daughter of Asof Khau, was married to Prince Kurranu, afterwards Shah Jahan, and her own daughter by Sher Afghan was married to Prince Shahriar, the emperor's 
youngest son. She remained with her husband when he was made prisoner by Muhabbat Khan, on the banks of the Hydaspes, while on his way to Käbul, in March A.D. 1626 (Jamadi-ul-Akhir $1035)$, and procured her husband's and her brother's release. She used all her powers to prevent Shah Jahan succeeding his father, and to secure the throne for her son-in-law, Prince Shahriar, but on the 28th October 1627 (A.H. 28th Safar 1037) her husband, in the 60th year of his age, died of asthma while on his way for change of air from Kashmir to Lahore, and all her influence expired with her husband's life. Shahriar was absent in Lahore, her brother Asof Khan took the side of Shah Jahan, put Nur Jahan under restraint, and marched against and defeated Shahriar. Shah Jahan arrived at Agra, and was proclaimed emperor on the 26th January 1628 (A.II. 7th Jamadi-ul-Akhir 1037). From that time, although she lived till A.D. 1646 (A.H. 1055), her name is never again mentioned in history. She was treated with respect, and allowed a yearly stipend of $£ 250,000$. She wore no colour but white after Jahangir's death, abstained from all entertainments, and appeared to devote her life to his memory. She was buried at Lahore in a tomb she herself had erected close to that of Jahangir. -Khafi Khan; Elphin. p. 483.

NURMA and Nustoo, a male and a female deity of the Garo race.

NURPUR. This town derives its name from the celebrated Nur Jahan, the wife of the emperor Jahangir. Its original name was Dahmari, or Dahmala, or, as Abul Fazl writes, Dahmahri. The people pronounce the name as if written Dahmeri. It is also called Pat'baniya. Nurpur is at the entrance of the Western Himalaya, where they rise from the plain of the Panjab, and contains about 15,000 people, principally Kashmirians engaged in the shawl trade. It is on the great road through which Kashmir, Chenab, and Ladakh are attainable._Cunningham's India, p. 143.

NURTIUNG, a town in the Jaintia Hills. Its people erect stone pillars, which Lieutenant (Colonel) Yule supposed to be connected with their religion. He says that in the Khassya upright stones are raised as memorials of great events, or of men, whose ashes are not necessarily, though frequently, buried or deposited in hollow stone sarcophagi near them, and sometimes in an urn placed inside a sarcophagus, or under horizontal slabs. The usual arrangement is a row of five, seven, or more, erect, oblong blocks with round heads (the highest being placed in the middle), on which are often wooden discs and cones; more rarely pyramids are built. Broad slabs for seats are also common by the wayside. Lieutenant (Colonel) Yule mentions one 32 feet by 15 , and 2 feet in thickness; and states that the sarcophagi (which, however, are rare) formed of four slabs resemble a drawing in Bell's Circassia aud descriptions in Irby and Mangles' Travels in Syria. He adds that many villages derive their names from these stones, mau signifying stone: thus mausmai is the stone of oath, because, as his native informant said, 'there was war between Churra and Mausmai, and when they made peace, they swore to it, and placed a stone as a witness.' Mamloo is the stone of salt, eating salt from a sword's point being the Khassya form of oath; mauflong is the grassy stone, etc. In the south of England, maen, man, or men is the Druidical name for a stone, whence penmaenmawr, for the hill of the big stone; maen-hayr, for the standing stones of Brittany, and dolmen, the table stone of a cromlech.-Hooker's Him. Jour.; The Khassya Mountains, by Licut. H. Yule. NUR-ud-DIN LUTF-ULLAH, better known as Hafiz Abru, was born in the town of Herat, but was educated at Hamadan, and travelled extensively in Asia. He was much esteemed by Timur, and after Timur's death he attended the court of Shah Rukh, to whom he dedicated bis great work Zabdat-ut-Tawarikh Baisanghari, which contains a complete history of the world, and an account of the institutions and religions of different people down to A.H. 829 (A.D. 1425). His work is generally known as the Tarikh-i-Hafiz Abru. $\Lambda$ large part of the work is copied from older historians, Tabari, Rashid-ud-Din, and the Zafar Nama.Elliot's Hist. of India.

NUR-ul-HAQQ, styled Al Mashrahi, Al Dehlini, Al Bokhari, son of Abd-ul-Haqq, author of the Zabdat-ut-Tawarikh. His father had written a literary history, which Nur-ul-Haqq continued to the close of Akbar's reign. He gives a history of the kings of Bengal, the Dekhan, Dehli, Gujerat, Juanpur, Kashmir, Malwa, Sind, and Tatta. - Elliot.

NUSHKI, a western subdivision of Baluchistan. The Zigger Minghal and Rakshani, who inhabit Nushki, have no proper towns or villages, but reside in tents, though not migratory. Their river, the Kassar, is useless for irrigation, and is lost amongst the sands. They cultivate wheat at the skirts of the hill ranges supporting the plateau of Saharawan. Snow seldom falls. The Zigger Minghal at one time occupied the Dasht-i-Giran, near Kalat, but their increasing numbers compelled them to migrate into Nushki, dispossessing the Rakshani, of whom two tomans or clans still reside at Nushki. They have a much-valued breed of horses, called Tarji. Their flocks are very numerous. The original seats of the Yusufzai were about Garra and Nushki, the last of which places is on the borders of Dasht-i-Loot, or Great Salt Desert, and now held by the Baluch under Kalat-i-Nusseer.

NUSSUL or Nasl, an elephant variety in Cachar, between the Kumirah and the Mirgia.

NUT, in India, a wandering tribe, who are dancers, actors, athletæ, called also Sirki bash (dwellers under mats). Those met with in the Dekhan are not distinguishable from Dher. The Bazigur and Nut have each a language understood only by themselves. They live principally by fortune-telling (by palmistry and other means), and are alike addicted to thieving. The Nut leader is the nardar bouthah. They appear to be equally indifferent on the subject of religion, and in no respect particular in their food. The Bazigur are subdivided into seven clans, viz. the Charee, At'bhyee'a, Bynsa, Purbuttee, Kalkoor, Dorkinee, and Gungwar ; but they live together and intermarry. They practise the Muhammadan rite of circumcision. They regard Tan-Sin as their tutelar deity. They play on various instruments, sing, dance, and are athletes; the two latter accomplishments are peculiar to the women. Their songs are beautifully simple.-Cole. Myth. Hind: p. 313.

NUTCRACKER, a genus of birds, comprising Nucifraga caryocatactes and $\mathrm{N}$. hemispila from the Himalayan mountains. N. caryocatactes of 
the pine forests of Europe and Siberia, is replaced by $\mathrm{N}$. hemispila in those of the Himalaya generally, and by N. multimaculata about Kashmir.-Eng. Cyyc.

NUT GRASS, Agrostis linearis.

NUT'H, the nose-jewel worn by Hindu women; even to mention this is considered a breach of delicacy. But Colonel Tod states that, as a token of the full confidence reposed in him, he was told that, 'Should you even send to the queen's apartment and demand her necklace or nutna, it shall be granted.'-Tod's Rajasthan, i. p. 431.

\section{NUTMEG.}

Jowz-ul-teib, Za te pha,

Juh-tau-k'au,

ARAB. Jowz bewa,

Juh-kwo, Yuh-kwo, , Jadikai, .

Jaiphul,. . . HINn. Jajikaia,

Buah pala,. . MaLAY. Jevizi,

Pers. SANSK. SINGH. TAM.

TEL。

TURK.

The nutmeg of commerce is from the Myristica moschata, a tree from 20 to 25 feet high, but other species produce aromatic fruits, supposed to be mixed with the true nutmeg; amongst which may be named the M. tomentosa, Thunb., M. parviflora, M. peltata, and M. spicata, Roxb. M. moschata is the only one of which the nut or mace is of any value, and its geographical limits are comprehended between long. $126^{\circ}$ and $135^{\circ} \mathrm{E}$., and lat. $3^{\circ} \mathrm{N}$. and $7^{\circ} \mathrm{S}$. It is, or has been, found wild in the proper Moluccas, in Gilolo, Ceram, Amboyna, Boeroe, Damma, the N. and S. sides of the Western Peninsula of New Guinea, and in all its adjacent islands. It certainly does not exist in its wild state in any of the islands W. of these, nor in any of the Philippines. Wherever the soil and climate are suitable for its growth, the aromatic nutmeg is raised with great facility. It is even transported to remote parts, and two species of pigeon, Columba perspicillata and C. ænea, which prey on the nutmeg (as the wood-pigeons on the acorn), feed on the mace, and drop the nut, have spread it from the Moluccas to New Guinea.

The clove plant has been spread over Asia, Africa, and the West Indies, but the nutmeg tree rarely flourishes out of the Malay Archipelago, except as an exotic, all attempts to introduce it largely into other tropical countries having decidedly failed. The island of Ternate, which is in about the same latitude as Singapore, is said to have been the spot where it was truly indigenous, but no doubt the tree is to be found on most of the Moluccas. The Dutch, in 1632, removed the plantations from Ternate to the Banda Isles for better surveillance, where they still remain and flourish. It was cultivated in Penang with little success, and is to be found in Ceylon and the west coast of India. In the Banda Isles no further attention is paid to its cultivation than setting out the plants in parks, under the shade of large forest trees, with long horizontal branches, called Canari by the natives. There it attains a height of 50 feet and upwards.

In its native country the nutmeg tree comes into full bearing in its ninth year, and lives to 75 . In shape and size, the ripe fruit resembles a nectarine. It consists, first, of an outer fleshy covering called the pericarp, which, when mature, separates into nearly equal longitudinal parts or valves; secondly, of the aril or mace, which, when recent, is of a bright scarlet colour; and, thirdly, of the seed proper or nutmeg. This is enclosed in a shell, which is made of two coats ; the outer is hard and smooth, the inner, thin, closely invests the seed, sending off prolongations which enter the substance of the seed, and which, being coloured, impart the marbled or mottled appearance characteristic of nutmeg.

The mace amounts to about one-fifth part of the weight of the whole dried fruit. These two articles, the nut and mace, constitute the spices which for so many ages have been in request among the nations of Europe and Asia, although never used as a condiment by the inhabitants of the countries that produce it. It is a dicecious plant, having the male pale yellow flowers upon one tree, and female or fertile flowers upon another.

In the Banda Islauds the principal gathering is in July or August, the second in November, and the third in March or April. The fruit is gathered by means of a barb attached to a long stick; the mace is separated from the nut, and separately cured. On account of their liability to the attacks of the nutmeg insect, they should be dried in their shells, as they are then secure from the insect. They are placed on hurdles, and smoke-dried over a slow wood fire for about two months. In the Banda Islands they are first dried in the sun for a few days. When the operation of drying is complete, the nuts rattle in their shells; these are cracked with mallets, and the damaged, shrivelled, or worm-eaten nuts removed. To prevent the attacks of the insect, the nuts are frequently limed. The Dutch lime them by dipping them into a thick mixture of lime and water, but this process is considered to injure their flavour. Others lime them by rubbing them with recently prepared, well-sifted lime. This process is sometimes practised in London. For the British market, however, the brown or unlimed nutmegs are preferred.

The extremely limited consumption of nutmegs and mace, and of the latter especially, over the world, perhaps ever will check any permanently large progressive increase of these spices. The Dutch confined the cultivation of the nutmey, when they got possession of the Moluccas from the Portuguese in the end of 1598 , to Lonthoir or Great Banda, Banda Neira, and Pulo Aye. The produce has ever been subject to great fluctuations, owing to various causes, the most prominent of which were the eruptions of volcanoes and earthquakes. In 1772 a hurricane nearly annihilated the plantations, and in 1811 a severe storm destroyed much fruit. High winds frequently diminish the crops greatly, and sulphureous vapours sometimes blast the trees.

The wild nutmeg from the M. tomentosa has scarcely any flavour or odour. The seeds of $M$. fatua are about balf as long again as the true or round nutmeg; they are paler and less aromatic. At the Madras Exhibition of 1855 . fine samples of nutmegs were sent by General Cullen from his gardens, Velley Malay, near Oodagherry, south of Travancore, 1890 feet above the sea. Two sorts of nutmegs were exhibited by C. S. Vernede, Esq. commercial agent to the Cochin Government. A wild or spurious nutmeg was also forwarded from the Baba Booden Hills, Mysore, and from Canara ; it is much used as a substitute for the true spice, but is almost wholly devoid of aroma, and of no interest. A wild nutmeg grows in Damma, Am- 
ooyna, Ceram, Obi, New Guinea, Gilolo, of an elliptical shape, 1 inch or $1 \frac{1}{4}$ inch long. Acrodilidium camara, Schomb., yields a fruit known as the Camara, also Ackani nutmeg of Guiana; the clove nutmeg and the Brazil nutmeg. The calabash nutmeg is from the Moreodora myistica. Pyrrhosia Horsfieldii, Blume, also yields wild nutmeg.

NUTMEG BUTTER

Taphul ka tel, . HIND. Jadipootrie tailum, TAM. Adeps myristic , LAT. Jajikarra noona,. . TkL. s obtained by expression from the nutmeg. It has an aromatic smell from the volatile oil it contains. The nutmegs are beaten into a paste, which is enclosed in a bag, steamed, and pressed oetween hot plates. It is imported in oblong cakes, wrapped in flag-leaves or. leaves of the oanana, and weighing about three-quarters of a pound. 'It is of an orange or reddish-brown colour, and of a fragrant odour. It is liable to much adulteration, and so also is the volatile oil, with which turpentine is frequently mixed. The article called expressed oil of mace is obtained from the nutmeg, and should bear its name. Nutmeg butter, according to Playfair, consists of three fatty substances, two of which are soluble in alcohol, and the third almost insoluble in that fuid. The third substance has been termed myristine, and from this myritic acid is prepared. NUTMEG, MALE, a native of the Moluccas, is covered with a hard shell, and provided with a pale arillus. It is $1 \frac{1}{2}$ to 2 inches long; elliptical, the parenchyma devoid of marbling. Its odour is weak, and flavour disagreeable. Its properties are analogous to that of the true nutmeg, but the oil is so inferior in proportion, that is but of little commercial value. It is thought that it might, however, be greatly improved by cultivation. They are procurable in most Indian vazars.-Faulkner.

NUTS, ACHEEN, are the betel-nut, boiled, of very inferior quality, chiefly used by the lower classes in the south of India, and are in no lemand at Madras; sold from 35 to 50 rupees a aindy.

NUTS, COLUMBO, are raw betel-nuts, chiefly used by the Kayala Muhammadans.

NUX VOMICA, Strychnos nux vomica.

Falus Mahi, . ARAB. Izaraki,

Jaoz-ul-kai ? " .", Veshamosti bejum, ",

nla-tsien-tsze, . . , Yetti cottay, . . TAM.

I'oison nut, Dogbane, ÉNG. Mustighenza musadi

Noix vomique, . FR.

Kuchla,. : HrND.

The nux vomica is the nut of Strychnos nux vomica, a moderate-sized tree of Southern India, 13urma, Siam, and China, also Australia. The pulp I:as a bitter taste, and acts as a poison to man, from the strychuine and brucine it contains, but Joxburgh mentions that it is eaten by some birds. The seeds of the fruit contain two alkalies, sirychnia and brucia, united with igasuric acid. Strychnine also occurs in the bark of the tree and in the bark and root of several other species of the genus. Nux vomica was early used as a medicine by the Hindus, by whom its properties must have been investigated long before it could be known to foreign nations.-Murray.

NYAD. HIND. A term applied to converts to
Muhammadanism. The western Nyad from the Rajput or other Hindu tribes are Zjhut, Rajur, Umra, Sumra, Mair or Mer, Mor or Mohor, Baluch, Lumria or Looka, Sumaicha, Mangulia, Baggreah, Dabya, Jobya, Kairooee, Jangurea, Undur, Beromee, Bawuri, Tawuri, Chrendea, Khossa, Sudani, Lohana. These converts are ferocious and intolerant. The word means newcomers.

NYA-PEE or Gna-pee. BurM. The Balachang of the Malays, a compound of several kinds of small fish. Putrescent fish, in some shape or other, is a condiment among all the races from the mountains of Sylhet to the isles of the Archipelago.

NYASA, in Hindu worship, a form of ejaculation, made with a short and mystic prayer, to the heart, the head, the crown of the head, and the eye, as Om! Sirase Namah! Om! salutation to the head, with the addition of the Kavacha, the armour, or syllable Phat, and the Astra, the weapon, or syllable Hum. The entire mantra, the prajer or incantation, is then, Om ! Sirase Namah, Hum, Phat. The Nyasa is performed at the time of worship (puja), and consists of a number of curious, minute, and almost undefinable motions of the hands and fingers (while the person repeats prayers), such as touching the eyes, ears, shoulders, mouth, nose, head, breast, etc., doubling and twisting the hands, fingers, etc.-Hin. Th. ii. 53.

NYAYA, a system of philosophy of the Hindus, a syllogism; Nyaya means going into, or analysis. This school of philosophy, or logical system of Gautama, considers, by means of subtle and logical argument, the true mode of inquiring after truth; and it has surveyed the whole field of this argument more exactly and completely than any other of the Hindu systems.

The first inquiry of this system is what is the way to attain perfect beatitude? and the answer given is, that deliverance is only to be secured by a knowledge of the truth.

It then proceeds to examine what instruments are best adapted for the acquisition of that deliverance, and comes to the conclusion that they are four in number, namely, perception, inference, comparison, and testimony.

It then minutely examines the various objects of knowledge which are required to be proved and known, which objects are twelve in number, soul, body, sense, object, knowledge, the mind, activity, fault, transmigration, fruit, pain, and beatitude.

The Nyaya system is one of six ortbodox philosophical schools of the Hindus. Of these philosophical schools, the Nyaya seems analogous to the Peripatetic of Greece, or to the dialectal school of Xenophanes; the second, sometimes called Vaisishica or Vaiseshka, to the Ionic; the two Mimansa - the Mimansa of Jaimini and the Mimansa or Vedant of Vyasa (the second of which being often distinguished by the name of Vedanta) - to the Platonic; the first Sanchya to the Italic, and the second, or Patanjala, to the Stoic philosophy. So that Gautama corresponds with Aristotle, Kanada with Thales, Jaimini with Socrates, Vyasa with Plato, Kapila with Pythagoras, and Patanjali with Zeno; but an accurate comparison between the Grecian and Indian schools would require a considerable volume. The original works of those philosophers are very succinct; but, 
like all the other shastras, they are explained or obscured by Upadarsana, or commentaries, without end. The Veda, Upa Veda, Vedanga, Purana, Dharma, and Darsana are their six great shastras, in which all knowledge, divine and human, is supposed to be comprehended. The word shastra, derived from a root signifying to ordain, means generally an ordinance, and particularly a sacred ordinance, delivered by inspiration; properly, therefore, the word is applied only to sacred literature. The Sudras, or fourth class of Hindus, are not permitted to study the six proper shastras before mentioned; but an ample field remains for them in the study of profane literature, comprised in a multitude of popular books, which correspond with the several shastras. All the tracts on medicine must, indeed, be studied by the Vaidyas, or hereditary physicians, who have often more learning, with far less pride, than any of the Brahmans ; they are usually poets, grammarians, rhetoricians, moralists, and may be esteemed, in general, the most virtuous and amiable of the Hindus. See Darsana; Veda; Vidya.

NYCTANTHES ARBOR-TRIS'IS. Linn.

Scabrita scabra, Vahl. | Parilium arbor-tristis,

S. triflora, L., Mart.

Kuri of . . BEAs. Pahar-butti,. . MAHR. Shioli, Singahar, - Beng. Manjapu-maram, Maleal. Hseik-ba-lu, . Burir. Pakura, . . Ravi. Hursing, Hursinghar,CAN. Sephalica, . . SANSK. Laduri, Ludika, ChENAB. Sepala, . . Singh. Hung-moh-li, . CHIN. Paghalamalli, . TAs. Keysur, . DukH. Poghadamullay, 'TEL. Birjat, Sital, . . Hind.

The sorrowful nyctanthes, tree of mourning, is a charming little tree, with rough scabrous leaves, well known for the delicious though evanescent perfume of its flowers. The tubes of their corollas, called in Hindi Kesru Dundee, are of a fine rich yellow colour, and are employed alone or in conjunction with the Parasam flowers (Butea frondosa) in preparing a beautiful though transient bright yellow dye, much sought after by the Mubammadans for dyeing their turbands, and used for dyeing silks especially ; it produces a good yellow colour, and compounds with reds into a pleasing series of flame, salmon, and orange colours. The flowers, Dunda poo, TEL., are used for giving a scent to cloths. Buchanan mentions the product as the powder scattered at the Holi feast. In Ajmir, the tubes of the corolla are used under the name of Kesru, to dye buff or orange colour. This plant is very abundant, wild, at the foot of the Vindhya range, where the green tough stalks are used to make large grain baskets of. It is as great a favourite in India as in South America. Its delicate orange and white blossoms pour the most delicious fragrance on the evening air, and then fall in showers, bedewing the earth's cold bosom with sweetness. Its flower is held sacred to Siva.

NYCTERIBIA, a genus of insects, large parasites, found only on bats, and often associated on these animals with fleas and mites. It has loug claws like a spider, and insinuates itself among the fur. It is a singular parasitic creature, which appears to have neither head, antennæ, eyes, nor mouth. It moves by rolling itself rapidly along, rotating like a wheel on the extremities of its spokes, or like the clown in a pantomime, hurling himself forward on hands and feet alternately. It was first discovered only on a few
European bats. Joinville figured one which he found on the large rousette or flying-fox, and says he had seen another on a bat of the same family. Dr. Templeton observed them in Ceylon in great abundance on the body of the Scotophilus Coromandelicus.-Tennent's Ceylon, p. 20.

NYMPHACE $A$, or Water-lily tribe, are all floating plants, dispersed through most warm parts of the world. Their stems are bitter and astringent, and contain a considerable quantity of frecula, which may be used as food. The gencra and species are as under :-

Euryale ferox, Salisb., North India, Bengal.

Nymphæa pubescens, $L$., British India.

N. rubra, Roxb., British India.

N. rubra, var. rosea, Roxb., Bengal.

N. rubra, var. major, the N. cyanea, $R$., Bengal.

N. versicolor, Roxb., Bengal.

N. edulis, D.C., Bengal.

N. stellata, Willd., Peninsula of India.

NYMPHAA EDULIS. D.C.

Nymphæa esculenta, Roxb. | Castalia edulis, Salisb.

Choto sundhi, . . BeNG. Kotika, . . . . TeL. Edible lotus, . . ENG. Kalharamu, . . . ,

The edible water-lily, a native of the-East Indies, in wet, fenny districts. Like all the species, it has large pear-shaped roots, which contain an abundance of starch, and they are consequently used as articles of diet.-Roxb.; Voigt.

NYMPH EA GIGANTEA, of Eastern and Northern Australia, has large blue flowers, which measure 12 inches across. The rhizome and seeds are eaten by the aborigines; the flower-stalks of the unexpanded flowers, deprived of their fibre, are also eatable.

NYMPH庄A PUBESCENS. Willd. Lotus. N. lotus, Burm., Roxb. ii. p. 577.

Kyrob, . . . Assam. Kooni, . . . Sind. Buro-shaluk, : Beng. Juda-tel-olu, : SINGH. Kya-phyu, : : BurM. Tella-kaluva, : . TEL. Koi, Kumul, . . HrND. Kaki-kaluva, . . . , Nilofar,. . : Pers. Alli-kalung, : : ',

A native of Africa, of all the $\mathrm{E}$. Indies, and of Java. It was venerated by the Egyptians, and is held sacred by the Hindus, being regarded as an emblem of fertility. It has large white flowers, with sepals. The root is large, tuberous, and eatable.

NYMPHÆA PYGMIA, a diminutive waterlily. Its flower is no larger than a half-crown; grows on the Khassya Hills, in China and Siberia. -Hooker's Journ. ii. p. 312.

NYMPHAA RUBRA. Roxb. Water-lily.

Kya-nee, . . BurM. Ruta-tel-olu, . Sтngr. Rakta kamala, : Hind. Erra kaluwa, : . TEL Rakto-sanduka, . SANSK,

This water-lily grows in tanks in the Peninsulas of India and in Bengal. Its flowers appear at the close of the rains, are of an intense red or dark crimson colour.

Var. $\beta$. Nymphæa rosea.

Ch'hoto-rukto kumul, BEN. | Rakta kamala, . HIND,

This has large rose-coloured flowers. It is cultivated in tanks, but grows wild. - Roxb.

NYMPH无A STELLATA. Willd. Blue lotus. Ch'hoto nil-padma, BENG. Nal-tel-olu, . . . SINGH. Soondi, . . . ", Indivara, . . TrL。 Kahlara, Indevara,SANSK. Nalla-kaluwa, . . ", Nilumbo-janma,

Grows common in ponds and tanks in the 


\section{DETAILED INDEX OF THE ARTICLE 'INDIA, VOL, II. Pp. 151-331.}

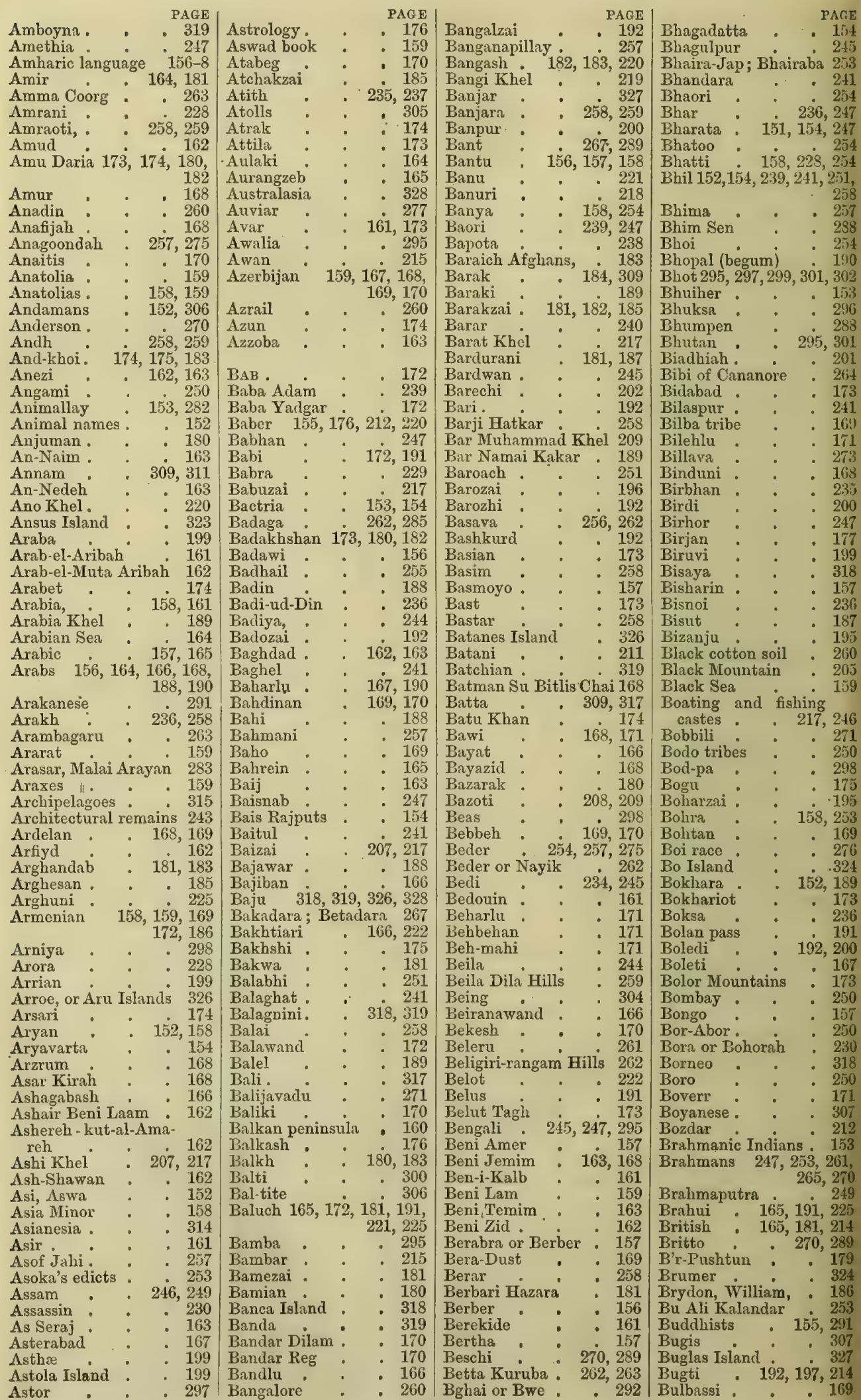


DETAILED INDEX OF THE ARTICLE 'INDIA,' VOL. II. Ip. 151-331.

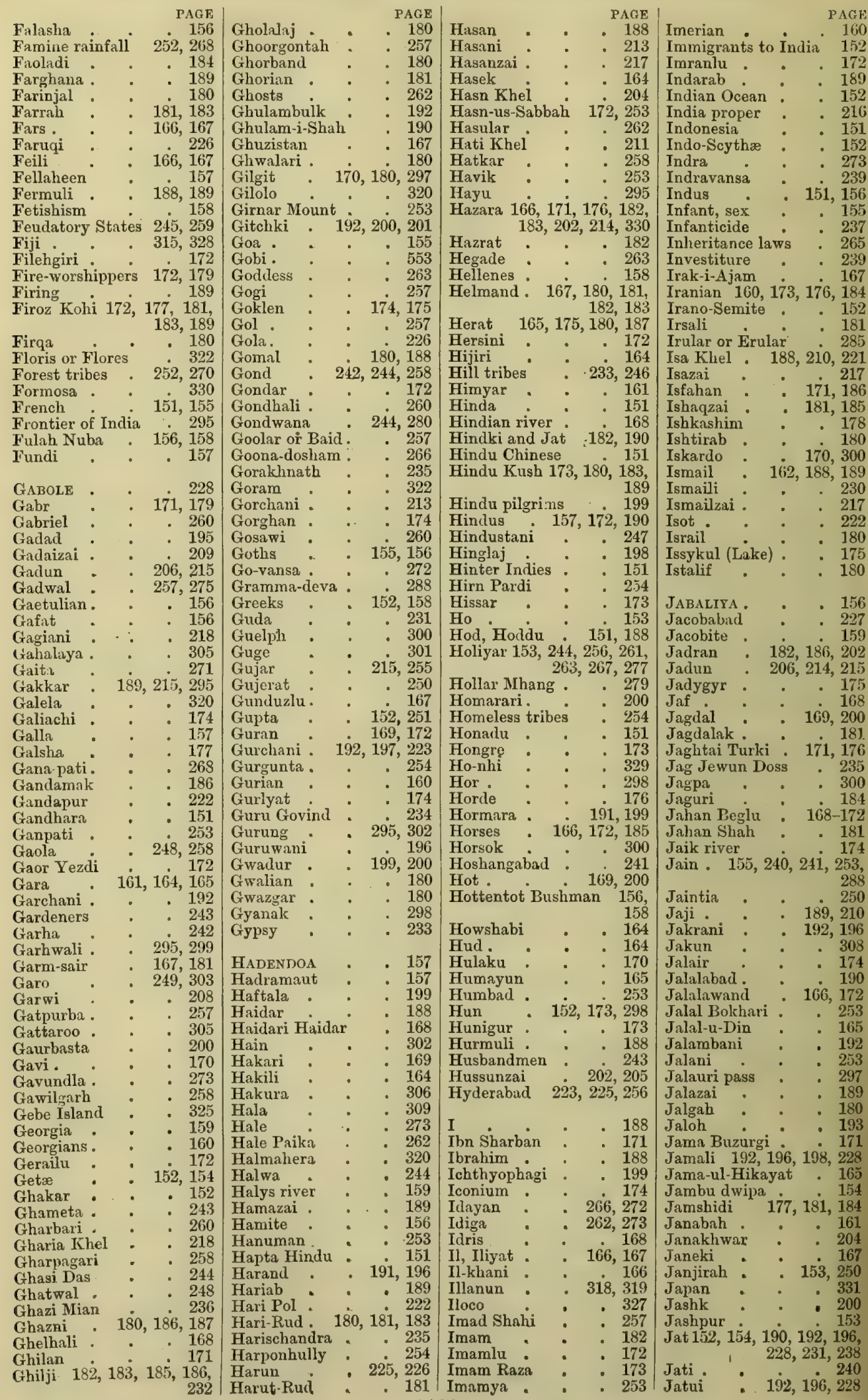


DETAILED INDEX OF THE ARTICLE 'INDIA,' VOL. II. Pp. 151-331.

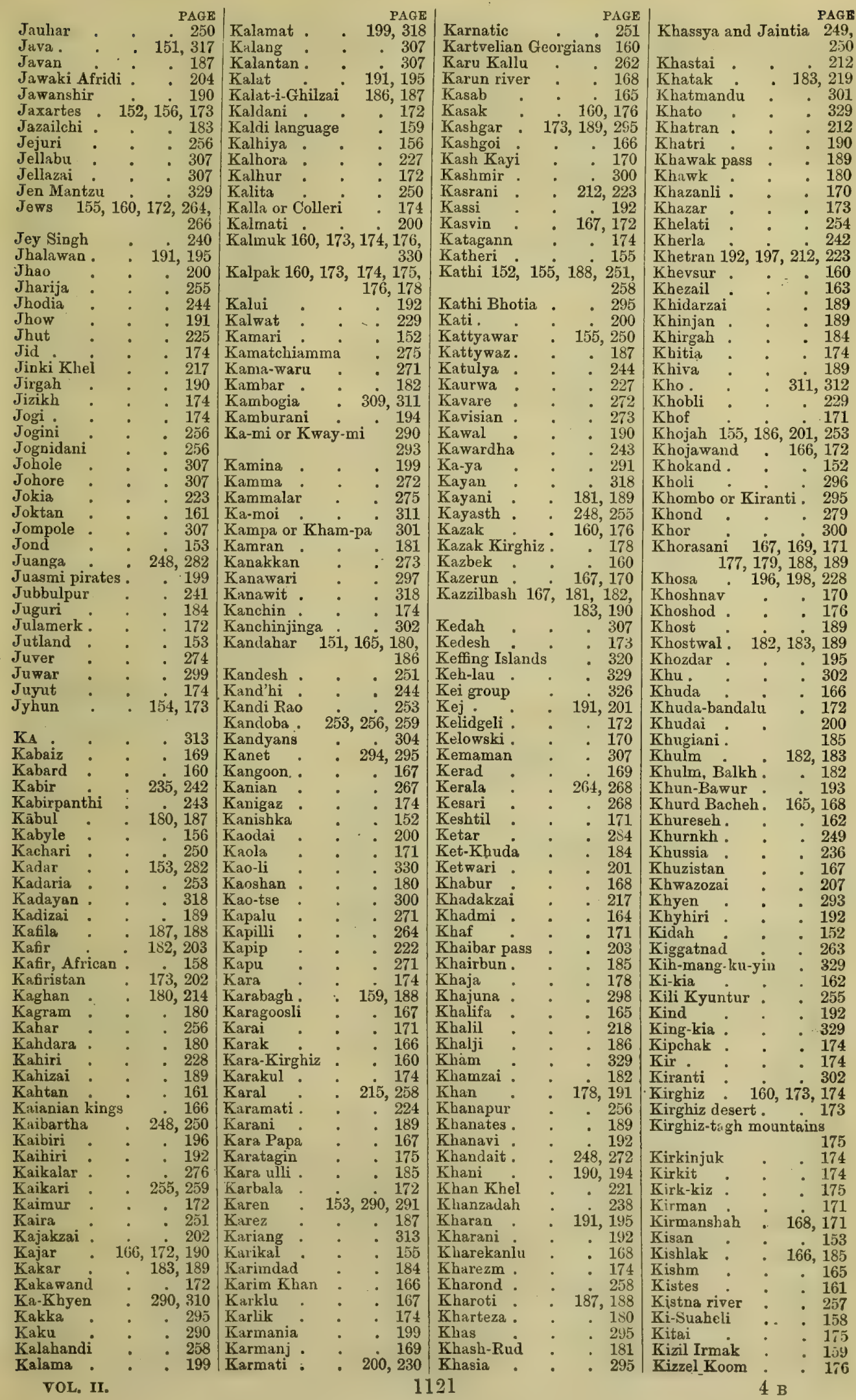


DETAILED INDEX OF THE ARTICLE 'INDIA,' VOL. II. Pp. 151-331.

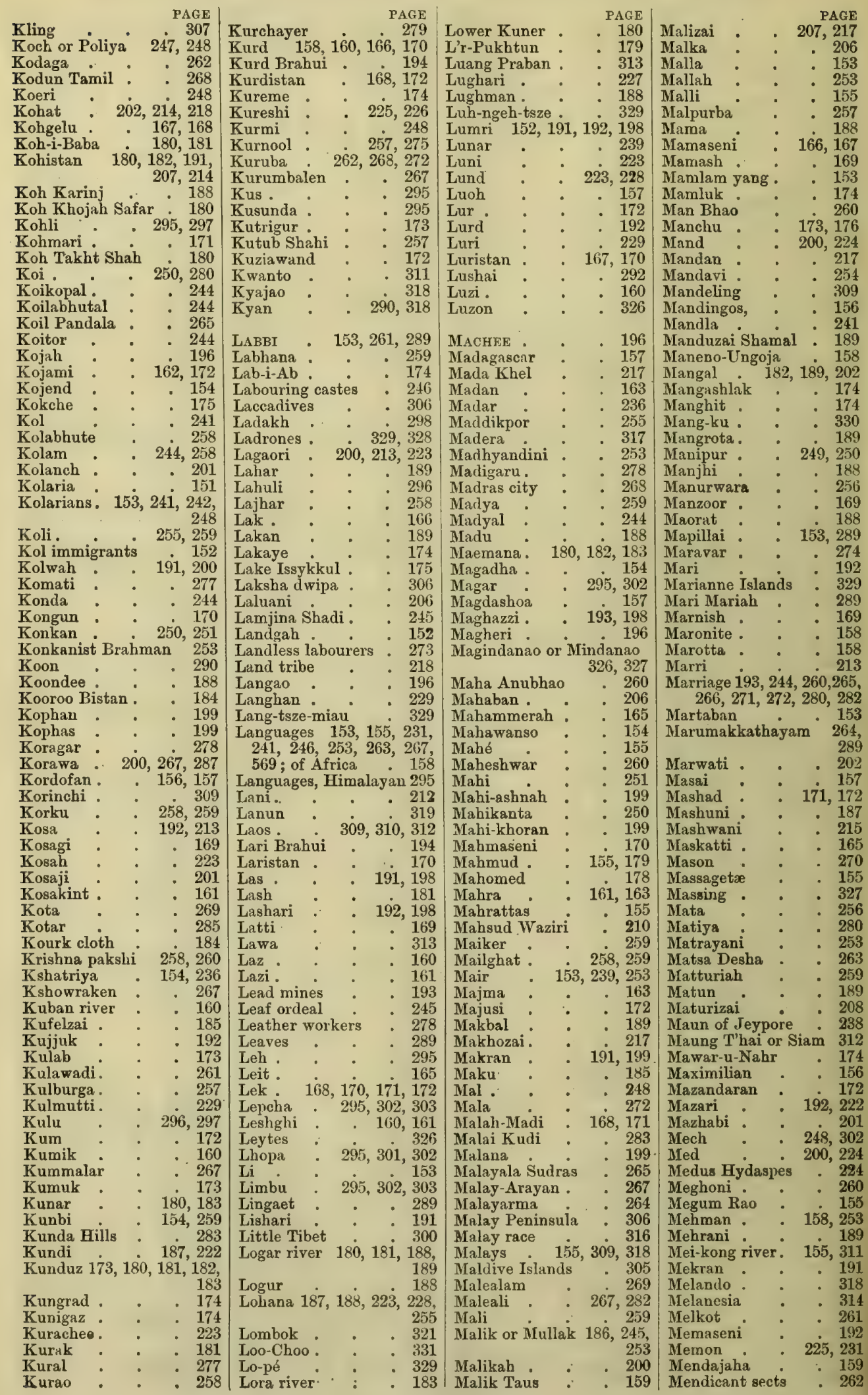


DETAILED INDEX OF THE ARTICLE 'INDIA,' VOL. II. Pp. 151-331.

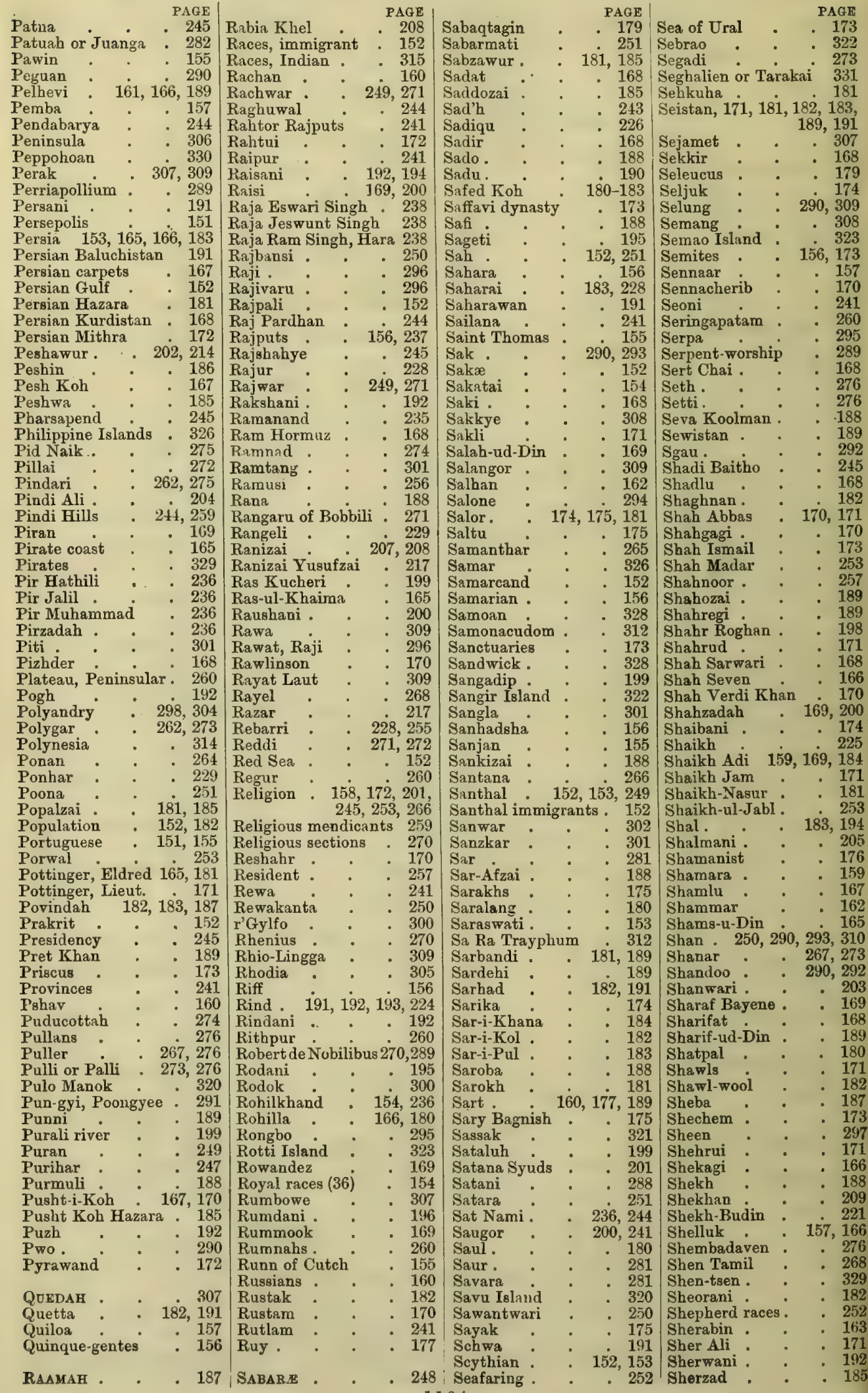


DETAILED INDEX OF THE ARTICLE 'INDIA,' VOL. II. Pp. 151-331.

\begin{tabular}{|c|c|c|c|c|c|c|c|c|c|c|c|c|}
\hline & & & PAGE & & & PAGE & & & PAGE & & & $A G E$ \\
\hline Shet. & Hills & & - $\quad 276$ & Sufehwand & - & - 172 & Tat : & 160,1 & 170,177 & Tungistan & - & 167 \\
\hline ibrgham & & s. & 180,182 & $\begin{array}{l}\text { Suti . } \\
\text { Suimanial. }\end{array}$ & $\dot{5}$ & $\begin{array}{l}\cdot 172 \\
\cdot \quad 169\end{array}$ & $\begin{array}{l}\text { 1a Ia } \\
\text { Tatao }\end{array}$ & - & $\begin{array}{l}330 \\
318\end{array}$ & $\begin{array}{l}\text { Tungstar : } \\
\text { Tungus }\end{array}$ & : & $\begin{array}{r}175 \\
176,330\end{array}$ \\
\hline & & . & - 178 & Suiva & : & . 156 & Tauri : & & 170 & Tura & & 174 \\
\hline & & . & 224,225 & Sujah Vaksan & . & . 166 & Tchernie Koblu & luki & 175 & Turan & & 173 \\
\hline & & & - 298 & yt. & - & 296 & Tebula . & - & 301 & Turanian imm & nigran & nts 152 \\
\hline nki & & - & . 168 & ania & . & $\begin{array}{r}169 \\
\end{array}$ & Teda & . & 156 & Turanian race & es. 1 & 153,241 \\
\hline nwari & - & . & 183,187 & n Khel & - & 186,187 & Tedzen & - & 166 & Turbat Haidas & & 171 \\
\hline $\operatorname{ani}$ & - & - & . 211 & an range & & . 180 & Teeag . & & 240 & Turbet & 1 & 176,201 \\
\hline & & - & 188 & a Sanjar & . & $\therefore \quad 181$ & Teera, Teyar, or & or Tis & 267 & Turget & & . 176 \\
\hline hivagang & & - & . 274 & - & - & 319,327 & Teheran & . & 168 & Turi & 183 & 208,210 \\
\hline & & - & 274 & uluk , & - & - 318 & Teki . & & - 185 & Turk & & 168,170 \\
\hline apur & & 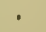 & 251 & aicha. & . & - 228 & Teling . & - & 271,272 & & 173 & 189,298 \\
\hline bak & & 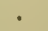 & . 183 & Sumatra . & - & 225,316 & Telugu & - & - 269 & Turkey in Asi & & - 158 \\
\hline & & - & 253 & wa. & & . 321 & Tenizai & . & 189 & Turkhani . & & 225 \\
\hline $\operatorname{man}$ & & - & . 173 & ulpur & . & - 241 & Tereki . & - & 186 & Turki . & & 165 \\
\hline & & & . 197 & $\mathrm{na}$. & . & 224,226 & $\mathbf{k}$ river & - & - 160 & Turkish carpe & ets & . 167 \\
\hline & & - & - 185 & a & - & $\therefore \quad 224$ & Ternate . & - & 319 & Turkish Kurd & distan & \\
\hline Toh & & & 180,183 & Sund & & 257,275 & Tezin & - & 186 & & & 169 \\
\hline osh & & 170 & 183,202 & Sunjie & . & - 307 & bet & - & 162 & Turk Karae & & 171 \\
\hline & & $\cdot$ & 309,312 & Sunni & $\cdot$ & - 201 & Thal. & - & - 180 & Turkolani & & 187 \\
\hline & & - & $\begin{array}{l}\text { - } 322 \\
153\end{array}$ & - & : & 2505 & Thammuz & - & 245 & Turkoman 1 & 108, & 160,166 , \\
\hline dra book & & $\dot{.}$ & $\begin{array}{l}\cdot 153 \\
: \quad 159\end{array}$ & $\begin{array}{l}\text { Surat } \\
\text { Sur Das }\end{array}$ & : & $\begin{array}{r}250,251 \\
. \quad 235\end{array}$ & $\begin{array}{l}\text { Thar } \\
\text { Tharu }\end{array}$ & : & $\begin{array}{l}224 \\
237\end{array}$ & 178 & & $\begin{array}{l}187 \\
155\end{array}$ \\
\hline & & & - 313 & Surjabea : & . & - 172 & $\mathrm{~Tb}$ & : & : 293 & rnak & $\dot{0}$ & . 181 \\
\hline & & 299 & 300,329 & Surl & - & 206 & Thian Shan & . & . 176 & $z$ & . & 171 \\
\hline & & & . 167 & Sur & . & . 190 & Thoki . & . & - 186 & Tutamdarra & . & - \\
\hline & & 155 , & 234,259 & alley & . & . 249 & Thotyal . & - & ․ 244 & $\mathrm{ng} \quad \cdot$ & - & 318 \\
\hline kim & & $\cdot$ & 295,302 & nsa & - & $\therefore \quad 239$ & Thundan . & 2 & 267,273 & Tu & . & 168 \\
\hline Silal & & - & . 167 & - & & 153,297 & r $\quad$. & - & - 225 & $\mathrm{Ty}$ & . & \\
\hline & - & - & - 174 & Svar & - & . 160 & Tia & - & 159 & Ty & - & 151,187 \\
\hline & & & $\therefore \quad 151$ & Swartz & - & - 270 & Tibbes & & 177 & Tru. & - & - 329 \\
\hline 166 & & 225 , & 245,250 & Swat . & & 206,214 & Tibbu & & $\therefore \quad 156$ & & & \\
\hline & . & . & - 151 & Swetambara & - & - 240 & Tibet & - & 295,298 & UBUL KHAIR & KHAI & \\
\hline & & . & - 228 & Syr & . & 158 & Tidore & 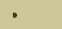 & - 319 & Udai . & . & - 308 \\
\hline river & & - & 154 & - & - & 173 & Tigre & - & - 156 & Uig & - & 173,17 \\
\hline & & - & 151 & Syrian & & 156 & Tigris : & - & 159,168 & Ujong & - & - 307 \\
\hline alese & & - & 304,305 & Syuds & . & 225 & Tileh Kobi & - & - 171 & Ulatan & - & $\therefore 176$ \\
\hline & & - & - 243 & & & & Timor & & & Ultra-India & & 151,20 \\
\hline & - & - & - 250 & ТАAFAH & & . 169 & Timur & 55,16 & 65,173 & Ulu . . . & . & . 307 \\
\hline injani & - & - & - 172 & Tab . & & 167 & & & 183,185 & Ulus & & 190 \\
\hline & - & & - 169 & Tabakat-i-Nasi & & 165 & erah Hills & - & . 246 & Umar, Khalif & - & 155 \\
\hline & & 204, & 208,209 & -Ghayn & & $\therefore 171$ & Tipu Sultan & - & 260 & Umarari . & - & 195 \\
\hline 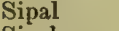 & . & . & - 297 & Tabriz . & & 159,170 & Tirah . & - & 180 & Umas & . & . \\
\hline era & & . & . 194 & Taemuni . & 77,1 & 181,183 & Tirai , & - & 203 & Ums & . & - \\
\hline , Siss & sodya & & - 152 & & & 189 & Tirthankara & - & 253 & Umrani & & 192 \\
\hline au & & & - 241 & Taemuri & 71 & 177,181 & Tista river & - & 302 & Ung . & - & 174 \\
\hline lo or & Iska & ardo & 300 & & & & Titles . & - & . 184 & Ungachit . & & 174 \\
\hline laves & & 175, & 184,231 & Taga or Tyagia & & - 236 & Tiyar . & . & 267,273 & Ung & - & 157 \\
\hline es of 2 & Zanzi & zibar & - 158 & Tagala . & & 326,327 & Tobedanie & - & . 157 & Upper Sind & & $\therefore 224$ \\
\hline & - & - & 309 & - & - & - 180 & Tochari & - & 224 & Ural. . & . & 174,176 \\
\hline & . & - & . 281 & Taghai & - & 188 & Toda & - & 283 & 1 Altaic & . & . 158 \\
\hline & - & - & 226,227 & Taifah & & . 180 & Toddy-drawers & & 262 & Ur-bhoi-wanlu & u. & 271 \\
\hline iana & - & . & - 152 & 160,17 & 77,1 & 182,188 & $\operatorname{mah}$ & . & . & .. & . & . \\
\hline & - & - & 299 & & & 189 & Toka & - & 162 & - & - & - \\
\hline -po & - & - & 298 & Tak, Tak-pa & - & 302 & nyris . & - & - & aun & - & - \\
\hline & & - & 175 & keh & & 181 & daman & - & - & $\mathrm{Ux}$ & - & . \\
\hline & & . & 167 & 'akht-i-Sulima & & 183 & To & - & 221 & nia & - & \\
\hline & • & - & 330 & e & & 174,175 & Tor & - & - & Us & & 168, \\
\hline & - & . & 262 & shak & & 152,154 & Corsang-raj & . & 299 & $\mathrm{i}$. & . & 169,17 \\
\hline & • & - & 322 & - & 153, & 290,293 & in. & - & - 186 & rana & & . \\
\hline & & . & 157 & in . & . & - 312 & Totti & & 264,279 & & & \\
\hline & & . & 253 & han. & & $\therefore 182$ & & - & - 293 & ali . & 173 & $3,174-78$ \\
\hline & & - & 253 & 1 & 160, & 171,172 & Baluch . & - & - 181 & zai . & . & . 18 \\
\hline & Tiy: & & 273 & $\mathrm{~T}$ & . & . 188 & castes & & 245,252 & lu. & . & \\
\hline & . & . & 257 & & . & 227 & [ndia & & . 151 & Uta & & 192 \\
\hline & - & - & 175 & & - & 195 & ontar & & $\therefore 167$ & Utman Khel & 187,1 & 189,209 \\
\hline & • & . & 222 & higt & & 156 & Travan & & 263,265 & Utm & 182,21 & 211,215 \\
\hline & & - & 157 & p . & - & . 165 & izond & & 159 & & & \\
\hline & & & $\therefore 281$ & & 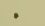 & . 304 & Tre & - & 260 & Uttara & & \\
\hline $\operatorname{sh}$ Ir & ndies & & 151,155 & a-parni & . & 304 & Triu & . & 307 & Uzbak 166,1 & 173,18 & 181, \\
\hline & err & ory & . 326 & Tar & & $\therefore 153$ & le deity. & & 160 & 183 & 184,1 & 187,18 \\
\hline & & - & i. 186 & & & 214,215 & podgir . & . & 176 & Uzoi . & . & . \\
\hline & & pers & 245,289 & Tangistani & & . 166 & a-Lung & & 176 & & & \\
\hline & & . & - 307 & $\operatorname{Tan}$ & & - 188 & & & 156 & EN, Oolla & aden & \\
\hline & & & 299 & a Papua & - & - 324 & Tubal & & 18 & $a$ & - & \\
\hline & . & . & $\begin{array}{r}199 \\
-\therefore\end{array}$ & obane & - & - 304 & Tuda or Tudava & ara & . & an & . & \\
\hline & & & 152,224 & & & - 251 & & & 26 & hi & . & . \\
\hline & & & . 156 & & & 331 & Tulsi Das. . & & - 235 & tuvar & - & - \\
\hline i of $\mathbf{P}$ & Pliny & & 281 & $\mathrm{Ta}$ & & 185,196 & Tulu, Tuju, or ' & Tula & V8 264 & $\mathrm{Vs}$ & . & . \\
\hline & & & 156 & & & $\therefore 187$ & & & 26 & $\mathrm{ra}$ & . & 274 \\
\hline & & & 164 & Tartars 160 , & & 174,176 & Tum & fur & 17 & cha & & \\
\hline & e ban & & 314 & & & 187 & Tum & - & 257 & Vannian & & \\
\hline dra & - & & - & Tashkand. & - & 154 & Tung & - & 329 & Varaha & & \\
\hline
\end{tabular}


DETAILED INDEX OF THE ARTICLE 'INSECTS,' VOL. II. Pp. 350-366.

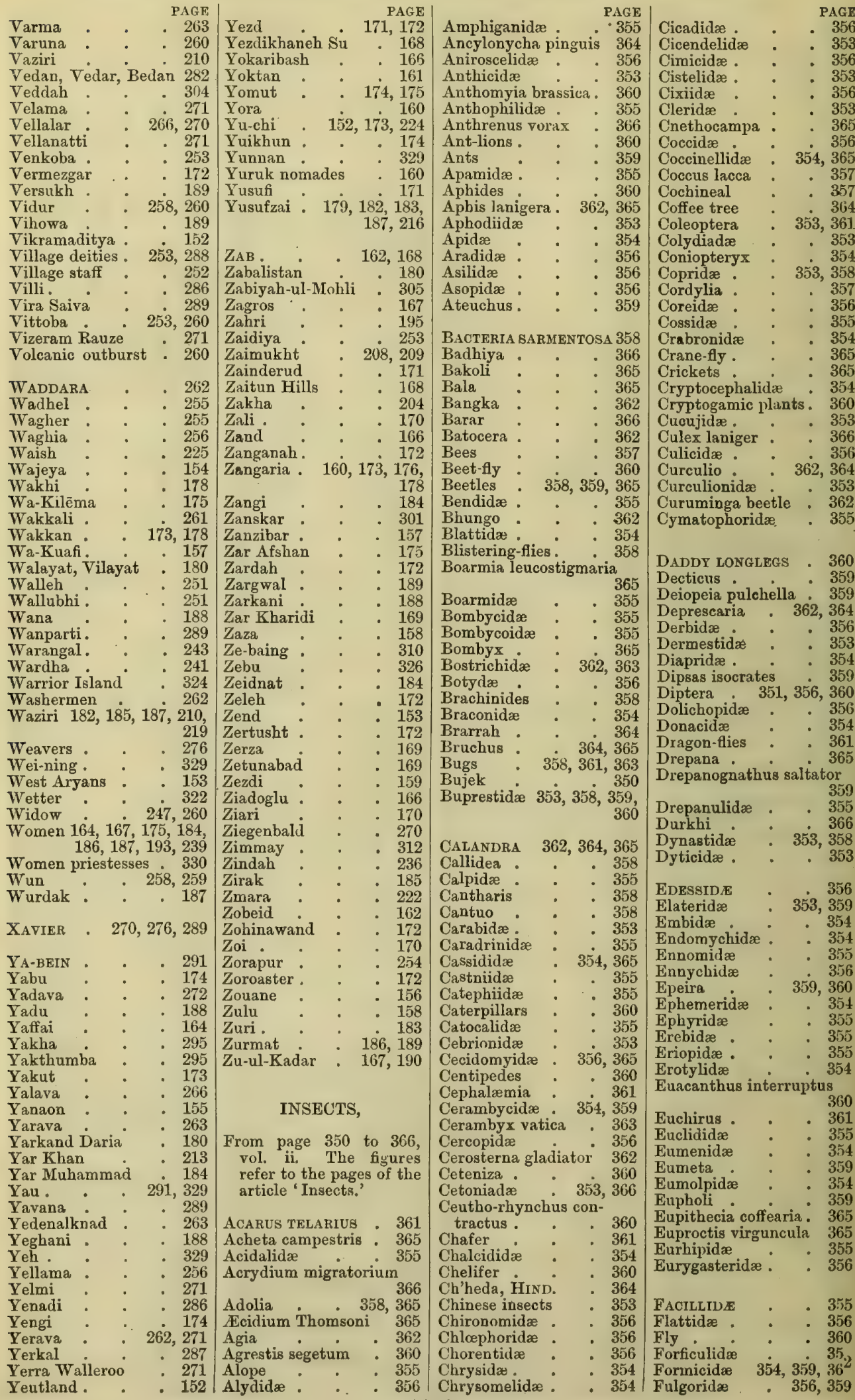


DETAILED INDEX OF THE ARTICLE 'MAMMALIA,' VOL. II. Pp. 819-835.

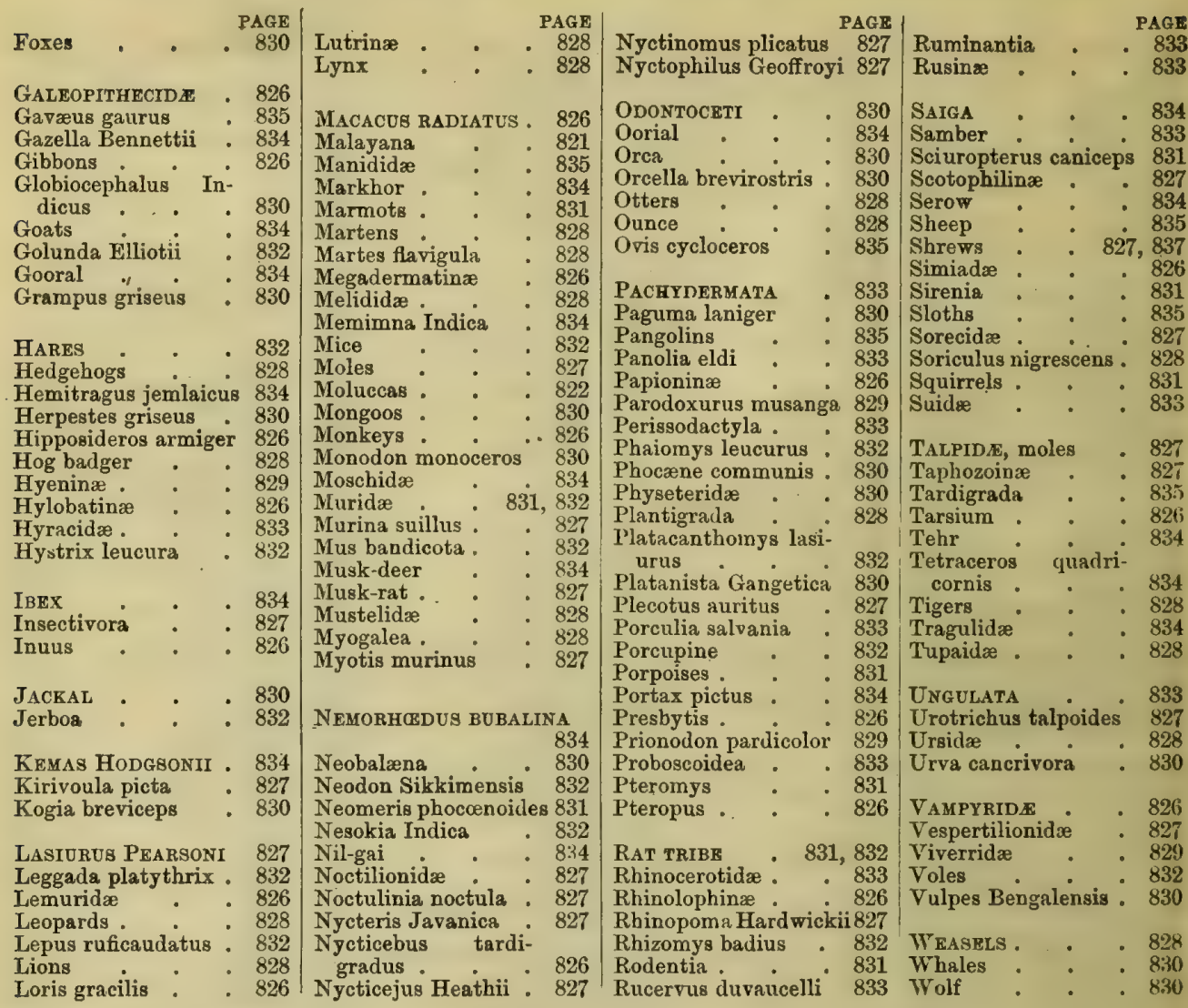

END OF VOL. II. 


